1. NAME OF COMMITTEE (in full, type or print)

\title{
Friends of Herman Cain
}

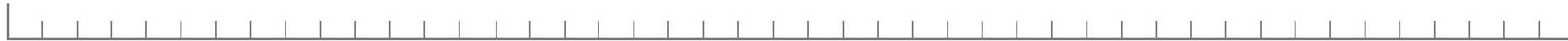

ADDRESS (number and street)) Post Office Box 2158

Check if different

than previously

reported. (ACC

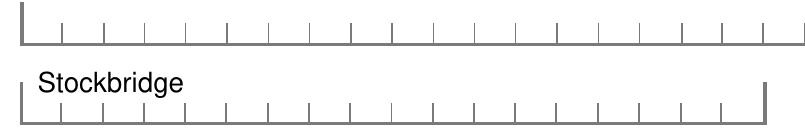

\section{CITY}

\section{FEC IDENTIFICATION NUMBER $>$ C C00496067}

Check here if this is a Termination Report (TER)

\section{Monthly Reports:}

Quarterly Reports:

April 15 (Q1) X October 15 (Q3)

July 15 (Q2) January 31 Year-End Report (YE)

Thirtieth day report following the General Election

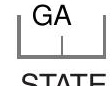

STATE
$30281-$

ZIP CODE
3. THIS REPORT IS FOR Primary $X$ or General $\mathbf{X}$

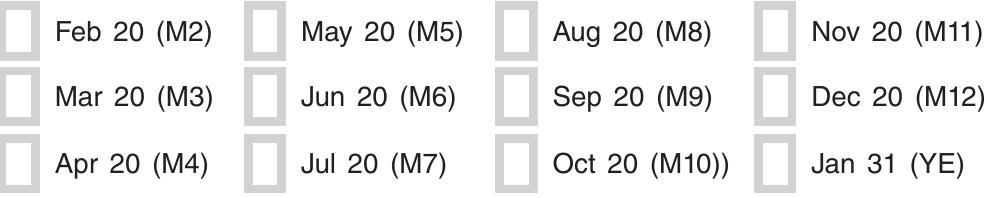

Twelfth day report preceding

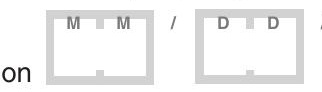
election

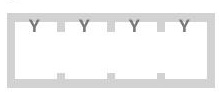

in the State of

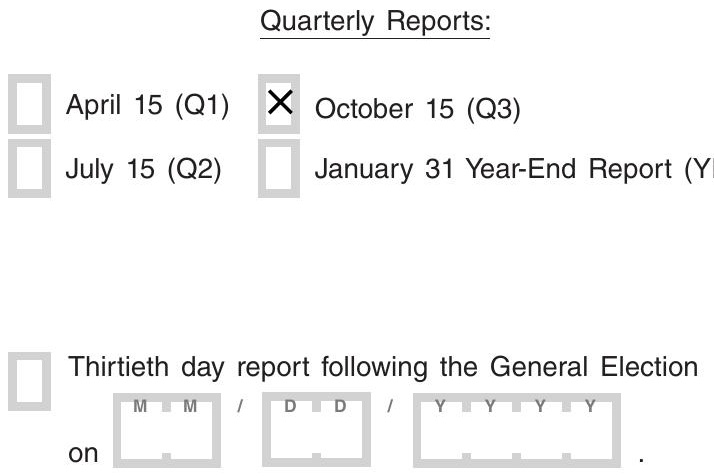

4. TYPE OF REPORT (Choose One)

Is this Report an Amendment?

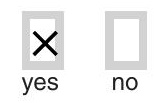

\section{Covering Period

\begin{tabular}{|c|c|c|c|c|}
\hline 07 & 1 & 01 & I & $\begin{array}{ccc}Y & Y & Y \\
& Y & Y \\
& & Y\end{array}$ \\
\hline
\end{tabular} \\ through

$0^{\mathrm{M}}$ \\ 30 \\ 2011}

I certify that I have examined this Report and to the best of my knowledge and belief it is true, correct and complete.

Type or Print Name of Treasurer

Mark Block

Signature of Treasurer

Mark Block

[Electronically Filed]

Date

\begin{tabular}{|c|c|c|c|c|}
\hline $04^{\mathrm{M}}$ & 1 & 12 & & $\begin{array}{l}Y Y \\
2012\end{array}$ \\
\hline
\end{tabular}

NOTE: Submission of false, erroneous, or incomplete information may subject the person signing this Report to the penalties of 2 U.S.C. §437g. All previous versions of this form are obsolete and should no longer be used.

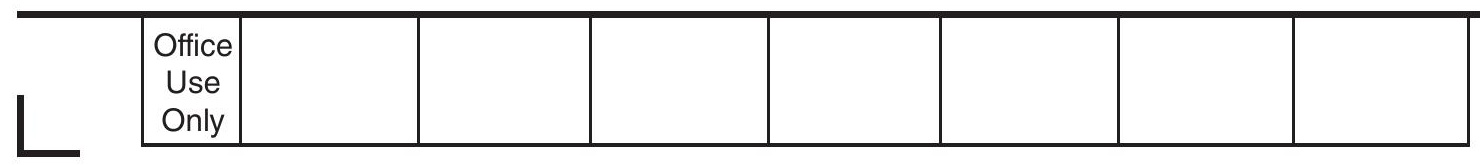


FEC Form 3P (Rev. 03/2011)

Write or Type Committee Name

\section{Friends of Herman Cain}

\begin{tabular}{|c|c|c|c|c|c|c|c|}
\hline Report Covering the Period: & From: & 07 & $\begin{array}{c}\mathrm{D} \\
01\end{array}$ & I & $\begin{array}{l}Y \\
Y \\
2011\end{array}$ & To: & 09 \\
\hline
\end{tabular}

\section{SUMMARY}

6. CASH ON HAND AT BEGINNING OF REPORTING PERIOD

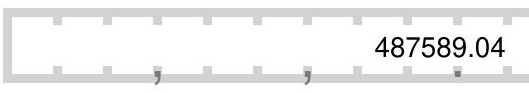

7. TOTAL RECEIPTS THIS PERIOD

(From Line 22, Column A, Page 3)

8. SUBTOTAL

(Lines 6 and 7)

3314589.76

9. TOTAL DISBURSEMENTS THIS PERIOD

(From Line 30, Column A, Page 2)

1980711.20

10. CASH ON HAND AT CLOSE OF THE REPORTING PERIOD

(Subtract Line 9 from 8

11. DEBTS AND OBLIGATIONS OWED TO THE COMMITTEE

(Itemize All on Schedule C-P or Schedule D-P).

12. DEBTS AND OBLIGATIONS OWED BY THE COMMITTEE (Itemize All on Schedule C-P or Schedule D-P)...

13. EXPENDITURES SUBJECT TO LIMIITATION

4007188.27

\section{NET ELECTION CYCLE-TO-DATE CONTRIBUTIONS AND EXPENDITURES}

14. NET CONTRIBUTIONS (Other than Loans)

(Subtract Line 28d, Column B from 17e, Column B, Page 2)

15. NET OPERATING EXPENDITURES

(Subtract Line 20a, Column B from 23, Column B, Page 2). 
FEC Form 3P (Rev. 03/2011)

NAME OF COMMITEE (in Full)

Friends of Herman Cain

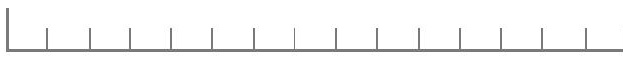

Report Covering the Period: From:

\begin{tabular}{|c|c|c|c|c|}
\hline${ }^{\mathrm{M}} 07^{\mathrm{M}}$ & 1 & ${ }^{\mathrm{D}} 0{ }^{\mathrm{D}}$ & 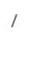 & $\begin{array}{cccc}Y & Y & Y & Y \\
& 2011\end{array}$ \\
\hline
\end{tabular}

To:

$09^{M}$

30

${ }^{Y} 2011^{Y}{ }^{Y}$

\section{RECEIPTS}

COLUMN A Total This Period

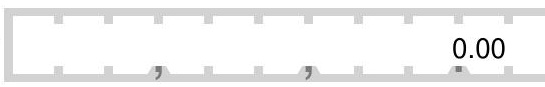

17. CONTRIBUTIONS (other than loans) FROM:

(a) Individuals/Persons Other Than Political Committees

(i) itemized ......

(ii) unitemized

(iii) Total contributions

(b) Political Party Committees

(c) Other Political Committees

(d) The Candidate.

(e) TOTAL CONTRIBUTIONS (other than loans) (Add 17(a), 17(b), 17(c) and 17(d)) ....

18. TRANSFERS FROM OTHER AUTHORIZED COMMITTEES.

19. LOANS RECEIVED:

(a) Loans Received From or Guaranteed by Candidate.

(b) Other Loans.

(c) TOTAL LOANS (Add 19(a) and 19(b)

20. OFFSETS TO EXPENDITURES

(Refunds,Rebates, etc.):

(a) Operating.

(b) Fundraising...

(c) Legal and Accounting

(d) TOTAL OFFSETS TO EXPENDITURES (Add 20(a), 20(b) and 20(c))

21. OTHER RECEIPTS (Dividends, Interest, etc.).

22. TOTAL RECEIPTS

(Add 16, 17(e), 18, 19(c), 20(d) and 21)
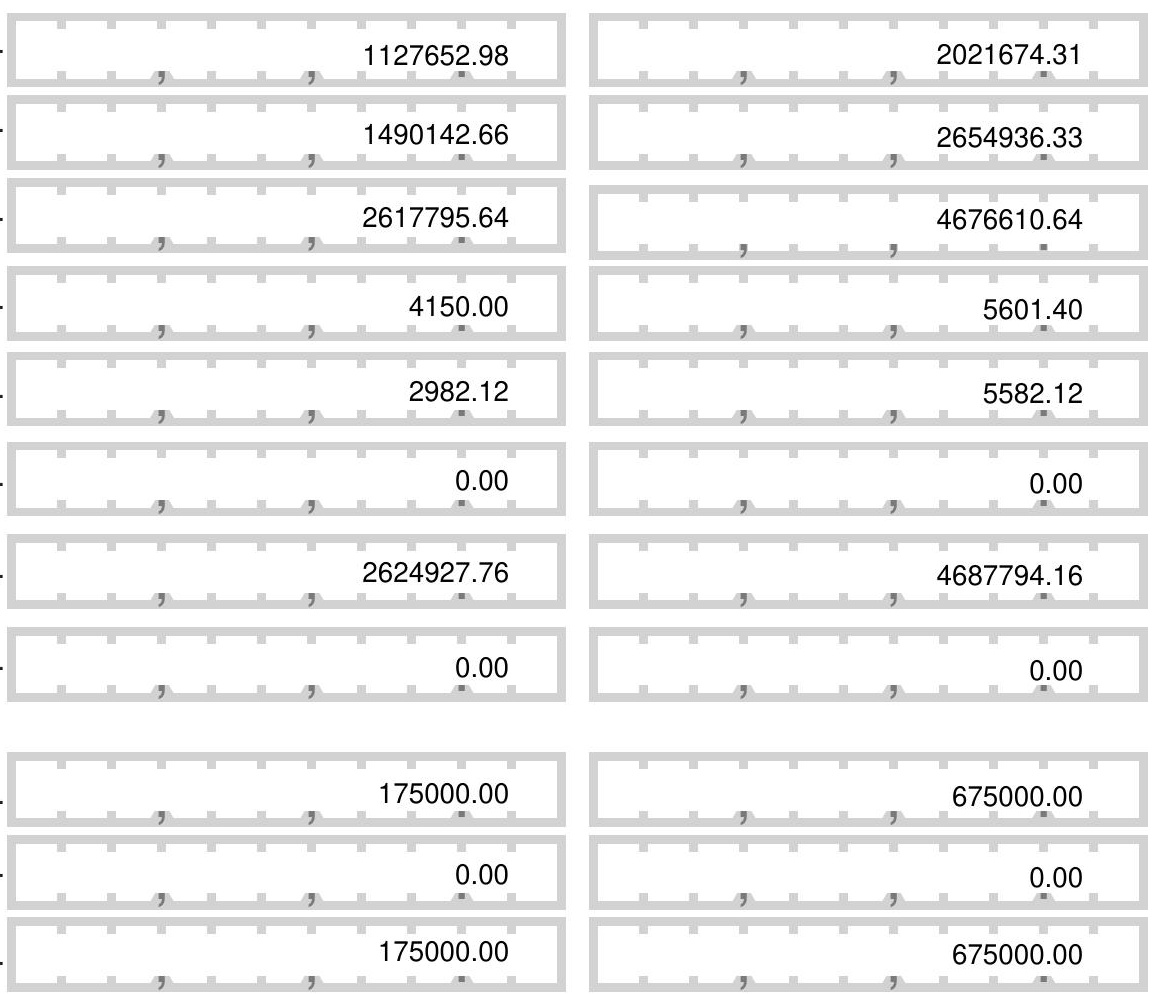

\section{Election Cycle-to-Date}

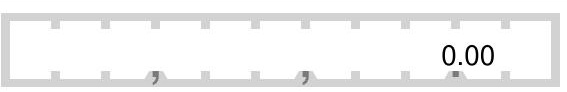


NAME OF COMMITEE (in Full)

Friends of Herman Cain

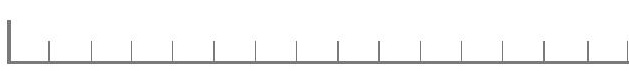

Report Covering the Period: From:

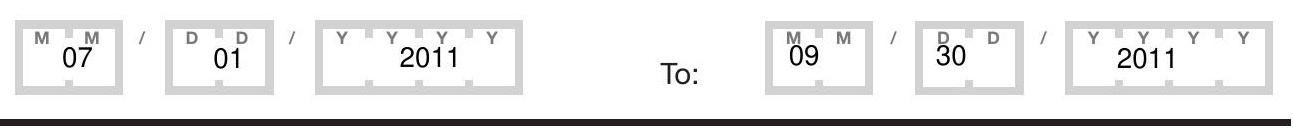

\section{DISBURSEMENTS}

\section{COLUMN A} Total This Period
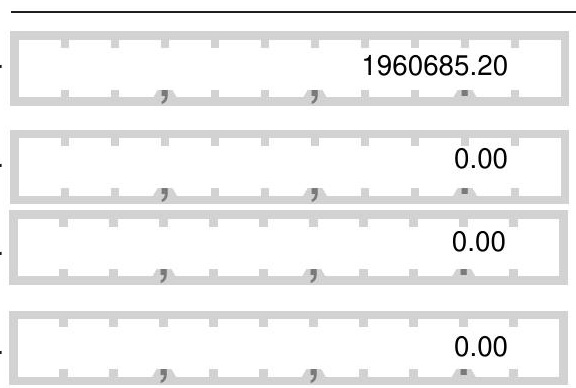

0.00 ACCOUNTING DISBURSEMENTS

27. LOAN REPAYMENTS MADE:

(a) Repayments of Loans made or Guaranteed by Candidate......

(b) Other Repayments

(c) TOTAL LOAN REPAYMENTS MADE (Add 27(a) and 27(b)) .

28. REFUNDS OF CONTRIBUTIONS TO:

(a) Individuals/Persons Other Than Political Committees

(b) Political Party Committees

(c) Other Political Committees

(d) TOTAL CONTRIBUTION REFUNDS (Add 28(a), 28(b) and 28(c))

29 OTHER DISBURSEMENTS .

30. TOTAL DISBURSEMENTS

(Add 23, 24, 25, 26, 27(c), 28(d) and 29)
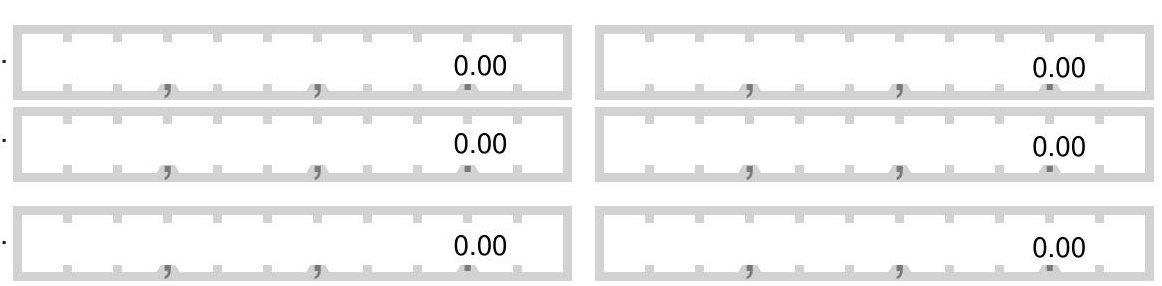

Calendar Year-to-Date

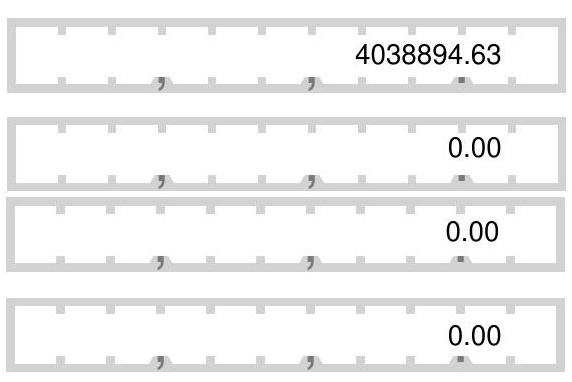

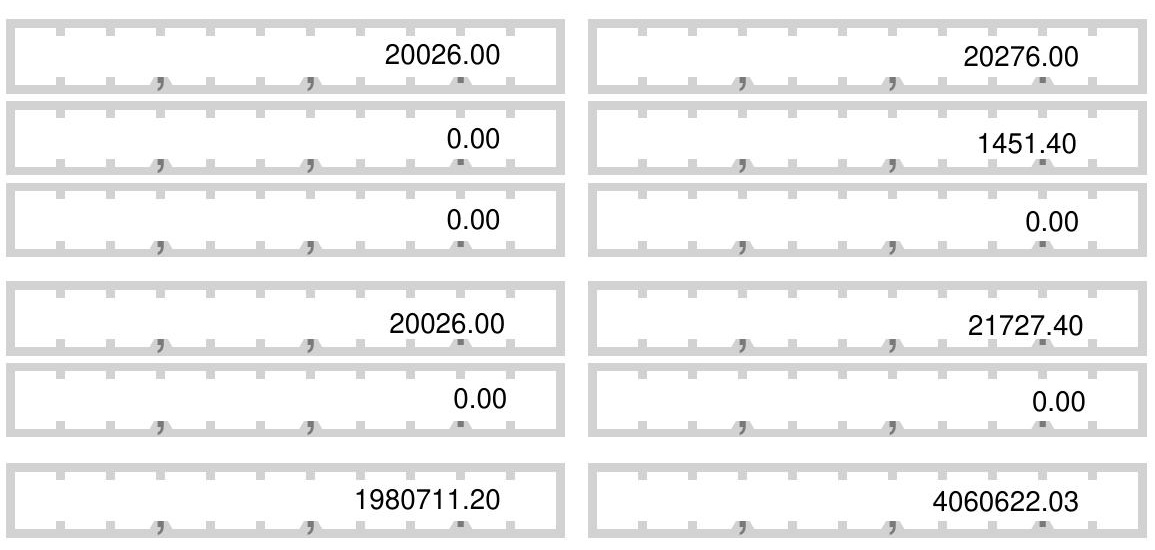

\section{CONTRIBUTED ITEMS (Stock, Art Objects, Etc.)}

31. ITEMS ON HAND TO BE LIQUIDATED (Attach List)

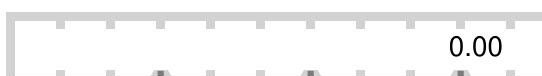


FEC FORM 3P,

Federal Election Commission 999 E Street, N.W.

Washington, D.C. 20463
ALLOCATION OF PRIMARY EXPENDITURES BY STATE FOR

A PRESIDENTIAL CANDIDATE

(Used Only by Primary Committees Receiving or Expecting To Receive Federal Funds)

1. NAME OF COMMITTEE (in full, type or print)

2. FEC IDENTIFICATION NUMBER

C $\quad 00496067$

\section{Friends of Herman Cain}

ADDRESS (number and street) Post Office Box 2158

\section{Stockbridge}

CITY

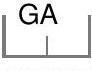

STATE
30281ZIP CODE

3. NAME OF CANDIDATE

\section{ALLOCATION BY STATE}

STATE

ALLOCATION This Period

TOTAL ALLOCATION To Date

\begin{tabular}{|c|c|c|}
\hline Alabama & 0.00 &,$\quad 0.00$ \\
\hline Alaska &,$\quad 0.00$ &,$\quad 0.00$ \\
\hline Arizona & 0.00 & 0.00 \\
\hline Arkansas &,$\quad 0.00$ &,$\quad 0.00$ \\
\hline California &,$\quad 0.00$ &,$- \quad 0.00$ \\
\hline Colorado & 0.00 & 1 \\
\hline Connecticut &,$\quad 0.00$ &,$\quad 0.00$ \\
\hline Delaware & $, \quad, \quad 0.00$ & $-\quad 0.00$ \\
\hline District of Columbia &,$\quad 0.00$ &,$+ \quad 0.00$ \\
\hline Florida &,$\quad 0.00$ & $-\quad 0.00$ \\
\hline Georgia & 0.00 & $-\quad 0.00$ \\
\hline Hawaii &,$\quad 0.00$ & 0.00 \\
\hline Idaho & 0.00 & -0.00 \\
\hline Illinois & 0.00 & 0.00 \\
\hline
\end{tabular}




\begin{tabular}{|c|c|c|}
\hline Indiana & 0.00 &,$\quad 0.00$ \\
\hline lowa & 0.00 &,$\quad 0.00$ \\
\hline Kansas & 0.00 & 0.00 \\
\hline Kentucky &,$\quad 0.00$ &,$\quad 0.00$ \\
\hline Louisiana &,$\quad 0.00$ &,$- \quad 0.00$ \\
\hline Maine & $, \quad, \quad 0.00$ & $, \quad, \quad 0.00$ \\
\hline Maryland &,$- \quad 0.00$ & $-\quad 0.00$ \\
\hline Massachusetts &,$\quad 0.00$ &,$\quad 0.00$ \\
\hline Michigan &,$+ \quad 0.00$ &,$+ \quad 0.00$ \\
\hline Minnesota & $, \quad, \quad 0.00$ & 0.00 \\
\hline Mississippi & , & 0.00 \\
\hline Missouri &,$\quad 0.00$ &,$\quad 0.00$ \\
\hline Montana &,$\quad 0.00$ &,$+ \quad 0.00$ \\
\hline Nebraska &,$\quad 0.00$ &,$\quad 0.00$ \\
\hline Nevada &,$\quad 0.00$ & 0.00 \\
\hline New Hampshire &,$\quad 0.00$ & - \\
\hline New Jersey &,$\quad 0.00$ & $=0.00$ \\
\hline New Mexico & 0.00 & 0.00 \\
\hline New York &,$+ \quad 0.00$ &,$- \quad 0.00$ \\
\hline North Carolina & 0.00 & 0.00 \\
\hline North Dakota &,$+ \quad 0.00$ & , \\
\hline Ohio & 0.00 &,$\quad 0.00$ \\
\hline Oklahoma & $, \quad, \quad 0.00$ & $=0.00$ \\
\hline Oregon & 0.00 & 0.00 \\
\hline Pennsylvania & 0.00 & , $\quad 0.00$ \\
\hline
\end{tabular}




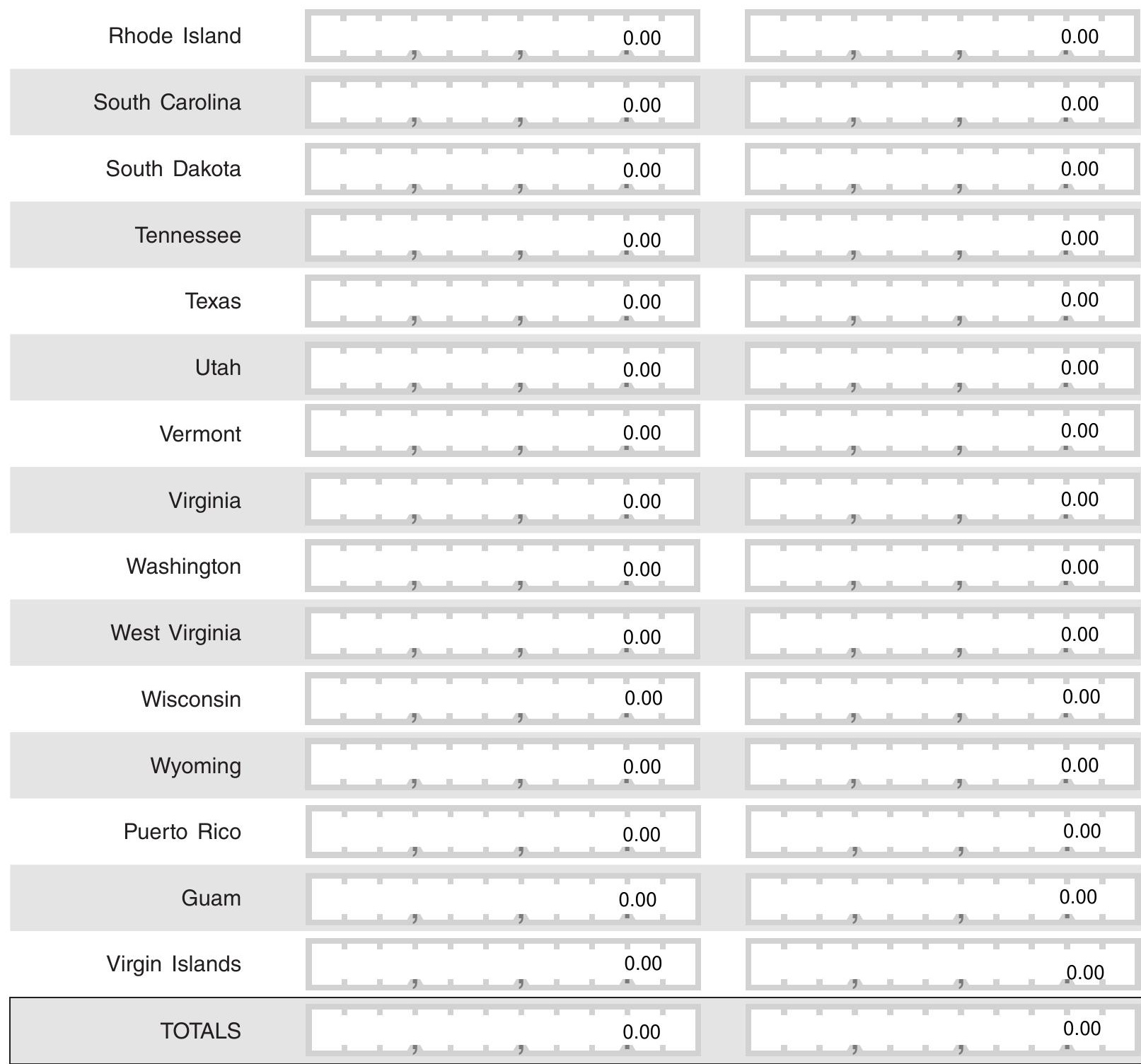


Form/Schedule: F3PA

Transaction ID :

Our committees procedures are in compliance with the best efforts and donor identification provisions cited in your letter. As an initial matter, all committee solicitations request the donors first name, middle initial, and last name; notify the donor that the Committee is required to report occupation and employer information; and request that the donor provide such information. For those donors who choose not to provide the occupation and employer information, the Committee, within thirty days of receiving the contribution, sends the required follow-up letter, which asks the donor again to provide the information, and again advises the donor of the Committees obligation to report the information. Finally, all such information received, including the contributors address, is reported. Any additional information received subsequent to the filing of the original report will be included on amendments to be filed by the Committee. All unacceptable employer and occupation entries contained in the original report have been corrected in this amendment. It is our understanding that when itemizing reimbursements to individuals the regulations do not require that a committee include memo entries with the specifics of the original vendor. Hence, for these reimbursements we have provided purposes that have been deemed acceptable by the commission. The petty cash disbursements were for office furniture and event change. No further itemization is required.

Form/Schedule:

Transaction ID: 
SCHEDULE A-P ITEMIZED RECEIPTS
Use separate schedule(s) for each category of the Detailed Summary Page
FOR LINE NUMBER: (check only one)

\begin{tabular}{|c|c|c|c|c|c|c|}
\hline & & & & & & \\
\hline 16 & $\times 1$ & $17 a$ & $17 b$ & $17 c$ & $17 d$ & 18 \\
\hline $19 a$ & & $19 b$ & $20 \mathrm{a}$ & $20 \mathrm{~b}$ & $20 \mathrm{c}$ & 21 \\
\hline
\end{tabular}

Any information copied from such Reports and Statements may not be sold or used by any person for the purpose of soliciting contributions or for commercial purposes, other than using the name and address of any political committee to solicit contributions from such committee.

NAME OF COMMITTEE (In Full)

\section{Friends of Herman Cain}

A. Full Name (Last, First, Middle Initial)

Kim Johnson

Mailing Address p.o. box 7164

\begin{tabular}{lcc}
\hline City & State & Zip Code \\
Auburn & CA & $95604-7164$
\end{tabular}

FEC ID number of contributing federal political committee.

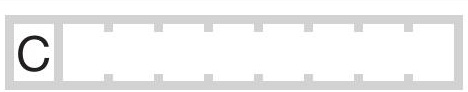

Name of Employer
Information Requested
Receipt For: 2012
X Primary
Other (specify) General

Occupation Information Requested

Election Cycle-to-Date

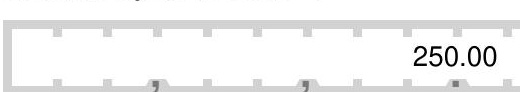

B. Full Name (Last, First, Middle Initial)

Michael Welsh

Mailing Address 2211 Marina Drive

\begin{tabular}{lcc}
\hline City & State & Zip Code \\
Naples & FL & $34102-7629$ \\
\hline
\end{tabular}

FEC ID number of contributing

federal political committee.

C

Name of Employer
Information Requested
Receipt For: 2012
X Primary
Other (specify)

Occupation

Information Requested

Election Cycle-to-Date

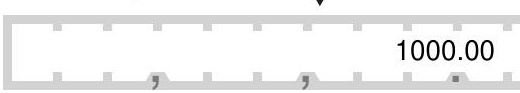

Transaction ID : A41D55FDA26014357A37

Date of Receipt

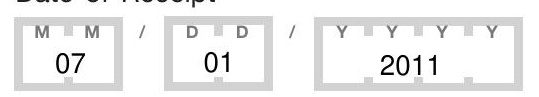

Amount of Each Receipt this Period

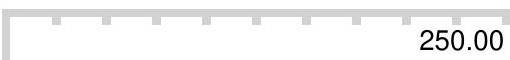

C. Full Name (Last, First, Middle Initial)

Gina Skinner

Mailing Address 110 W Greenbriar Lane

\begin{tabular}{lcc}
\hline City & State & Zip Code \\
Colleyville & TX & $76034-8619$
\end{tabular}

FEC ID number of contributing

federal political committee.

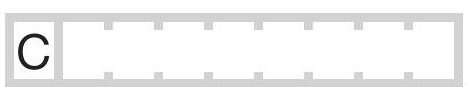

Name of Employer
None
Receipt For: 2012
Х Primary $\quad \square$ General
Other (specify)

Occupation

Retired

Election Cycle-to-Date

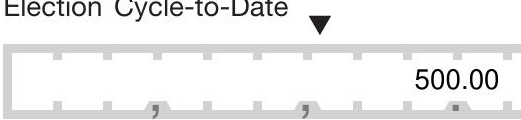

Transaction ID : ADA53DDEB8FC94DF4BFC Date of Receipt

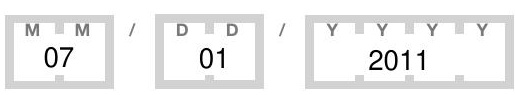

Amount of Each Receipt this Period

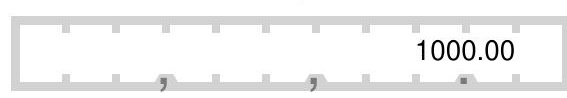

Transaction ID : A5D3D01493B50417197D

Date of Receipt

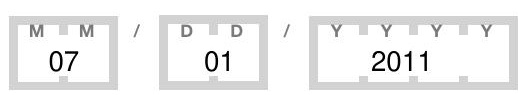

Amount of Each Receipt this Period

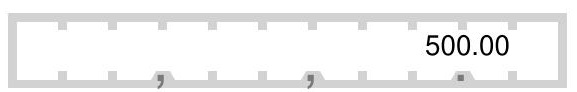

\section{Subtotal Of Receipts This Page (optional)}

Total This Period (last page this line number only) 


\section{SCHEDULE A-P} ITEMIZED RECEIPTS
Use separate schedule(s)

for each category of the

Detailed Summary Page
FOR LINE NUMBER: (check only one)
PAGE $10 / 1572$

\begin{tabular}{|c|c|c|c|c|c|}
\hline & & & & & \\
\hline 16 & $\begin{array}{l}\mathbf{X} \\
17 a\end{array}$ & $17 b$ & $17 c$ & $17 d$ & 18 \\
\hline $19 a$ & $19 \mathrm{~b}$ & $20 \mathrm{a}$ & $20 \mathrm{~b}$ & $20 \mathrm{c}$ & 21 \\
\hline
\end{tabular}

Any information copied from such Reports and Statements may not be sold or used by any person for the purpose of soliciting contributions or for commercial purposes, other than using the name and address of any political committee to solicit contributions from such committee.

NAME OF COMMITTEE (In Full)

\section{Friends of Herman Cain}

A. Full Name (Last, First, Middle Initial)

Katherine Sproul

Mailing Address 2600 Golden Gate Parkway

\begin{tabular}{lcc}
\hline City & State & Zip Code \\
Naples & FL & $34105-3227$
\end{tabular}

FEC ID number of contributing

federal political committee.

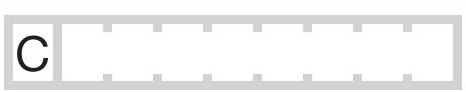

Name of Employer
Information Requested
Receipt For: 2012
X Primary $\quad \square$ General
Other (specify)

Occupation

Information Requested

Election Cycle-to-Date

500.00

B. Full Name (Last, First, Middle Initial)

Barry Cole

Mailing Address 1601 S Grove St

\begin{tabular}{lcc}
\hline City & State & Zip Code \\
Wichita & KS & $67211-4634$ \\
\hline
\end{tabular}

FEC ID number of contributing

federal political committee.

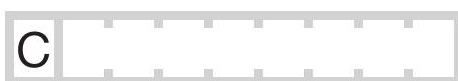

Name of Employer
National Radar
Receipt For: 2012
X Primary
Other (specify)

\section{Occupation}

Sales

Election Cycle-to-Date

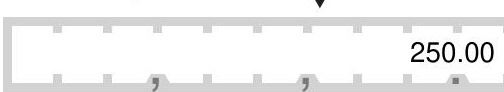

Transaction ID : AOD7E9EB9FF1B4C0EA49

Date of Receipt

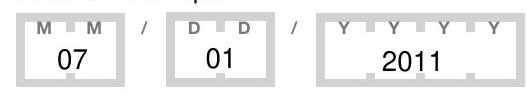

Amount of Each Receipt this Period

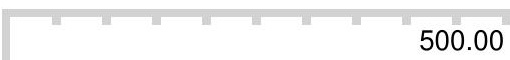

C. Full Name (Last, First, Middle Initial)

Carol Burke

Mailing Address 180 W Benton Ave Unit 303

\begin{tabular}{lcc}
\hline City & State & Zip Code \\
Naperville & IL & $60540-4587$
\end{tabular}

FEC ID number of contributing

federal political committee.

C

Name of Employer
None
Receipt For: 2012
X Primary $\quad \square$ General
Other (specify)

\section{Occupation}

Homemaker

Election Cycle-to-Date

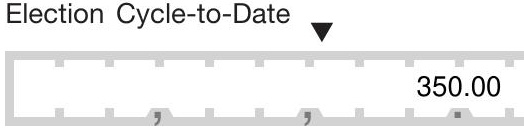

Amount of Each Receipt this Period

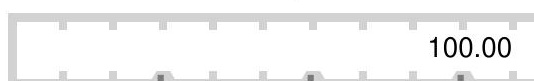

Transaction ID : A283AB6ACB0CD443FA84 Date of Receipt

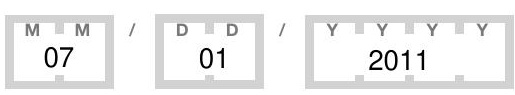

Transaction ID : A26467F9C789349E19DA Date of Receipt

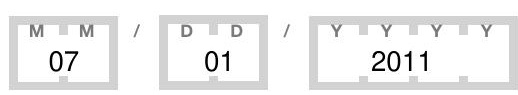

Amount of Each Receipt this Period

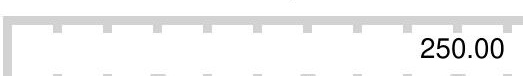

\section{Subtotal Of Receipts This Page (optional)}

Total This Period (last page this line number only) 


\section{SCHEDULE A-P} ITEMIZED RECEIPTS
Use separate schedule(s)

for each category of the

Detailed Summary Page
FOR LINE NUMBER: (check only one)
PAGE $11 / 1572$

\begin{tabular}{|c|c|c|c|c|c|}
\hline & & & & & \\
\hline 16 & $\begin{array}{l}\mathbf{X} \\
17 a\end{array}$ & $17 b$ & $17 c$ & $17 d$ & 18 \\
\hline $19 a$ & $19 \mathrm{~b}$ & $20 \mathrm{a}$ & $20 \mathrm{~b}$ & $20 \mathrm{c}$ & 21 \\
\hline
\end{tabular}

Any information copied from such Reports and Statements may not be sold or used by any person for the purpose of soliciting contributions or for commercial purposes, other than using the name and address of any political committee to solicit contributions from such committee.

NAME OF COMMITTEE (In Full)

\section{Friends of Herman Cain}

A. Full Name (Last, First, Middle Initial)

\section{Lamar Gable}

Mailing Address 2600 Golden Gate Parkway

\begin{tabular}{lcc}
\hline City & State & Zip Code \\
Naples & FL & $34105-3227$
\end{tabular}

FEC ID number of contributing federal political committee.

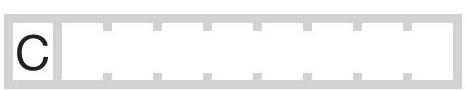

Name of Employer
Information Requested
Receipt For: 2012
X Primary
Other (specify) General

Occupation Information Requested

Election Cycle-to-Date

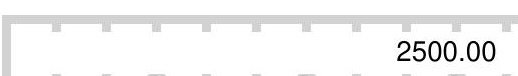

Transaction ID : A4506A3D359104C0C954

Date of Receipt

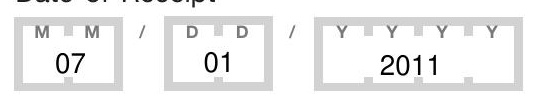

Amount of Each Receipt this Period

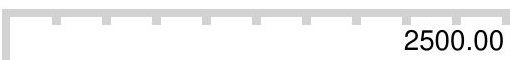

B. Full Name (Last, First, Middle Initial)

Herbert C Jardine

Mailing Address 1451 Summer Oaks Ct

\begin{tabular}{lcc}
\hline City & State & Zip Code \\
Marietta & GA & $30062-6155$ \\
\hline
\end{tabular}

FEC ID number of contributing

federal political committee.

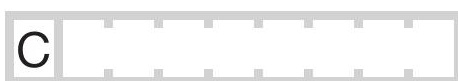

Name of Employer
None
Receipt For: 2012
X Primary
Other (specify)

\section{Occupation}

Retired

Election Cycle-to-Date

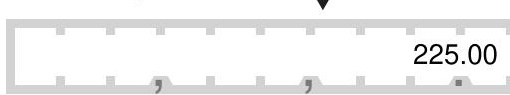

C. Full Name (Last, First, Middle Initial)

Joan Virag

Mailing Address 307 Worthing Lane

\begin{tabular}{lcc}
\hline City & State & Zip Code \\
McDonough & GA & $30253-4244$
\end{tabular}

FEC ID number of contributing federal political committee.

C

C

Name of Employer

Information Requested

Occupation

Information Requested

Receipt For: 2012

Х $\begin{aligned} & \text { Primary } \square \text { General } \\ & \text { Other (specify) }\end{aligned}$

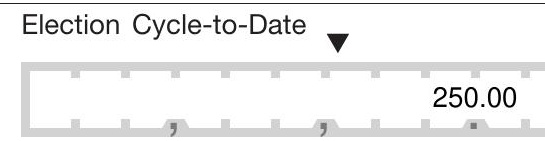

Transaction ID : A07FC030D8C084715B78

Date of Receipt

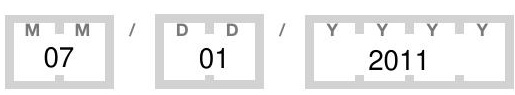

Amount of Each Receipt this Period

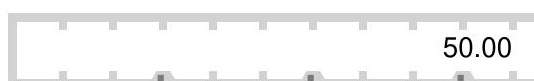

Transaction ID : A8559904384314DB795C

Date of Receipt

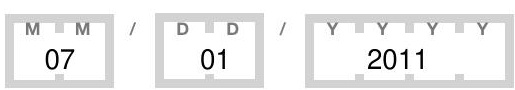

Amount of Each Receipt this Period

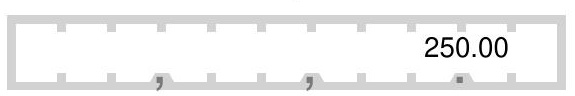

2800.00

.

Total This Period (last page this line number only)

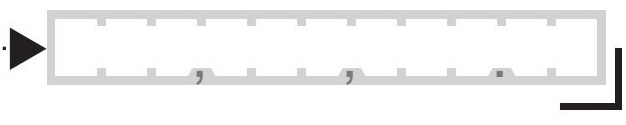

FEC Schedule A-P (Form 3P) (Rev. 03/2011) 
SCHEDULE A-P ITEMIZED RECEIPTS
Use separate schedule(s) for each category of the Detailed Summary Page
FOR LINE NUMBER: (check only one)

\begin{tabular}{|c|c|c|c|c|c|}
\hline & & & & & \\
\hline 16 & $\begin{array}{ll}X & 17 a \\
\end{array}$ & $17 \mathrm{~b}$ & $17 c$ & $17 d$ & 18 \\
\hline $19 a$ & $19 b$ & $20 \mathrm{a}$ & $20 \mathrm{~b}$ & $20 c$ & 21 \\
\hline
\end{tabular}

Any information copied from such Reports and Statements may not be sold or used by any person for the purpose of soliciting contributions or for commercial purposes, other than using the name and address of any political committee to solicit contributions from such committee.

NAME OF COMMITTEE (In Full)

\section{Friends of Herman Cain}

A. Full Name (Last, First, Middle Initial) James Dowling

Mailing Address 2234 Meadowbrook Rd.

\begin{tabular}{lcc}
\hline City & State & Zip Code \\
Benton Harbor & MI & $49022-9605$ \\
\hline
\end{tabular}

FEC ID number of contributing federal political committee.

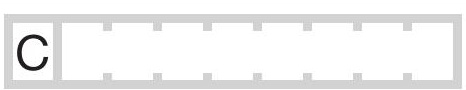

Name of Employer
Not Employed
Receipt For: 2012
X Primary $\quad$ General
Other (specify)

Occupation Not Employed Election Cycle-to-Date

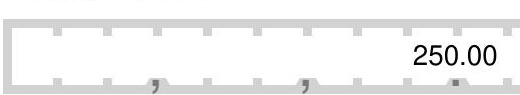

B. Full Name (Last, First, Middle Initial) Robert Shive

Mailing Address 1080 Cherry Tree Rd.

\begin{tabular}{lcc}
\hline City & State & Zip Code \\
Saint Augustine & FL & $32086-5028$ \\
\hline
\end{tabular}

FEC ID number of contributing

federal political committee.

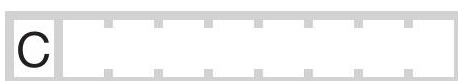

Name of Employer
None
Receipt For: 2012
X Primary
Other (specify)

\section{Occupation}

Retired

Election Cycle-to-Date

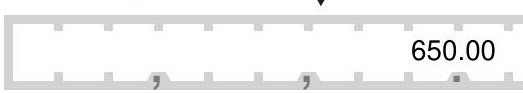

Transaction ID : A8BCB79197353402FA85

Date of Receipt

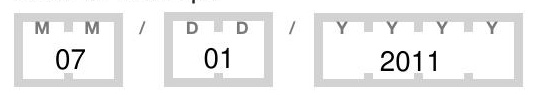

Amount of Each Receipt this Period

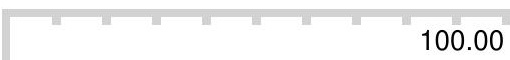

Transaction ID : A10187FFD304A4D2A8D7 Date of Receipt

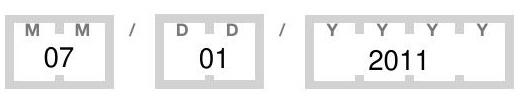

Amount of Each Receipt this Period

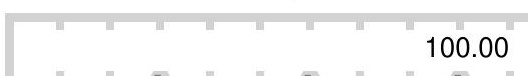

Transaction ID : A3B72D715FB534D97AEF Date of Receipt

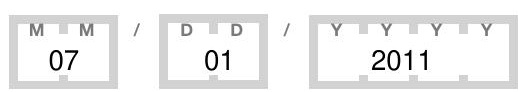

Amount of Each Receipt this Period

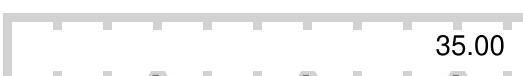

Name of Employer

Contrary Mary's Greenhouse

Receipt For: 2012

Х $\begin{aligned} & \text { Primary } \square \text { General } \\ & \text { Other (specify) }\end{aligned}$

$\begin{array}{cc}\text { State } & \text { Zip Code } \\ \text { GA } & 30281-5651\end{array}$

C

\section{Occupation}

Owner

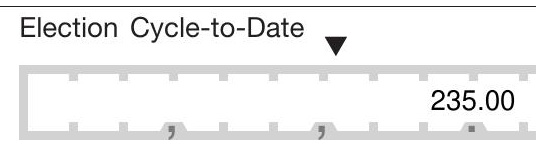

Subtotal Of Receipts This Page (optional)

235.00

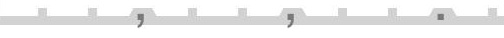

Total This Period (last page this line number only)

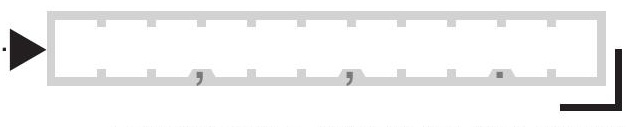

FEC Schedule A-P (Form 3P) (Rev. 03/2011) 
SCHEDULE A-P ITEMIZED RECEIPTS
Use separate schedule(s) for each category of the Detailed Summary Page
FOR LINE NUMBER: (check only one)

\begin{tabular}{|c|c|c|c|c|c|}
\hline & & & & & \\
\hline 16 & $\begin{array}{ll}X & 17 a \\
\end{array}$ & $17 \mathrm{~b}$ & $17 c$ & $17 d$ & 18 \\
\hline $19 a$ & $19 b$ & $20 \mathrm{a}$ & $20 \mathrm{~b}$ & $20 c$ & 21 \\
\hline
\end{tabular}

Any information copied from such Reports and Statements may not be sold or used by any person for the purpose of soliciting contributions or for commercial purposes, other than using the name and address of any political committee to solicit contributions from such committee.

NAME OF COMMITTEE (In Full)

\section{Friends of Herman Cain}

A. Full Name (Last, First, Middle Initial)

\section{Dexil Rold}

Mailing Address 1509 W. Courtland

\begin{tabular}{lcc}
\hline City & State & Zip Code \\
Spokane & WA & $99205-2608$
\end{tabular}

FEC ID number of contributing federal political committee.

Name of Employer
Retired
Receipt For: 2012
X Primary $\quad$ General
Other (specify)

B. Full Name (Last, First, Middle Initial)

Charles Adams

Mailing Address 5230 ACR 2202

\begin{tabular}{lcc}
\hline City & State & Zip Code \\
Palestine & TX & 75803 \\
\hline
\end{tabular}

FEC ID number of contributing

federal political committee.

Name of Employer
Univ. of Texas Medical Branch
Receipt For: 2012
Primary
Other (specify)

C. Full Name (Last, First, Middle Initial)

Mary McCane

Mailing Address 3389 East Fairview Rd.

\begin{tabular}{l|ll}
\hline $\begin{array}{l}\text { City } \\
\text { Stockbridge }\end{array}$ & $\begin{array}{c}\text { State } \\
\text { GA }\end{array}$ & $\begin{array}{c}\text { Zip Code } \\
30281-5651\end{array}$ \\
\hline $\begin{array}{l}\text { FEC ID number of contributing } \\
\text { federal political committee. }\end{array}$ & C & \\
\hline $\begin{array}{l}\text { Name of Employer } \\
\text { Contrary Mary's Greenhouse }\end{array}$ & $\begin{array}{l}\text { Occupation } \\
\text { Owner }\end{array}$ \\
\hline $\begin{array}{l}\text { Receipt For: } 2012 \\
\text { Primary } \\
\text { Other (specify) }\end{array}$ & Election Cycle-to-Date & \\
\hline
\end{tabular}

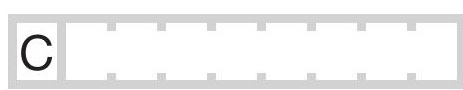

C

Transaction ID : A2464828B56064F4CB4E

Date of Receipt

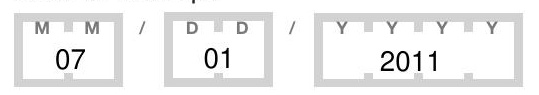

Amount of Each Receipt this Period

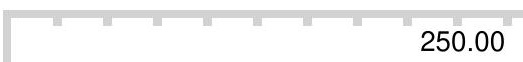

Occupation

Election Cycle-to-Date

250.00

Occupation

Physician

Election Cycle-to-Date

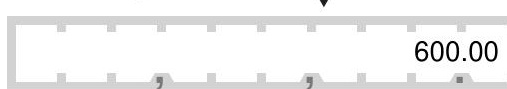

Transaction ID : AOA7B17B8870949719E9

Date of Receipt

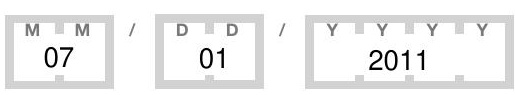

Amount of Each Receipt this Period

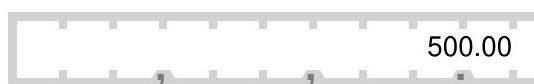

\section{Subtotal Of Receipts This Page (optional)}

800.00

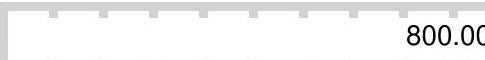

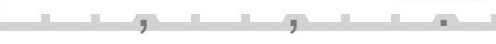

Total This Period (last page this line number only)
Amount of Each Receipt this Period

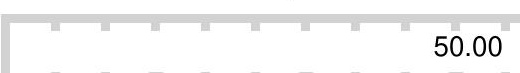

Transaction ID : AB46EF118F6E04A638DB Date of Receipt
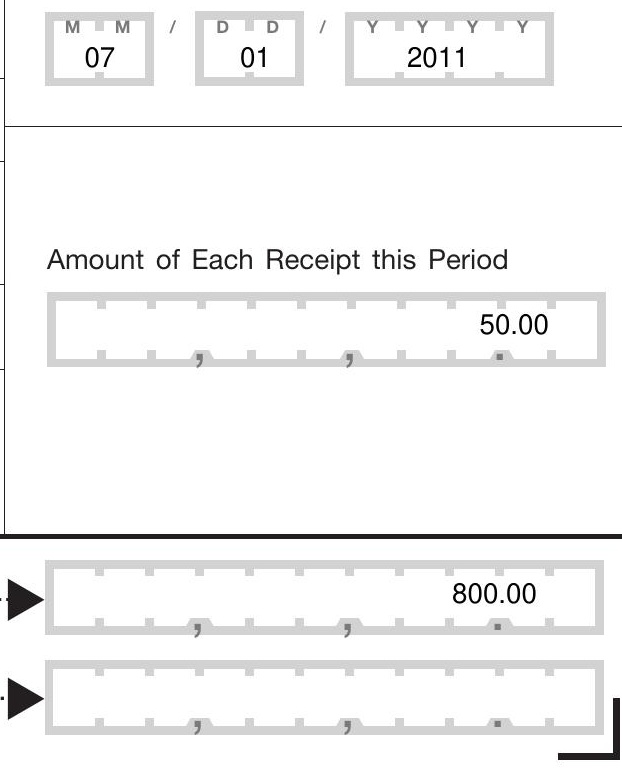

FEC Schedule A-P (Form 3P) (Rev. 03/2011) 
SCHEDULE A-P ITEMIZED RECEIPTS
Use separate schedule(s) for each category of the Detailed Summary Page
FOR LINE NUMBER: (check only one)

\begin{tabular}{|c|c|c|c|c|c|}
\hline & & & & & \\
\hline 16 & $\begin{array}{ll}X & 17 a \\
\end{array}$ & $17 \mathrm{~b}$ & $17 c$ & $17 d$ & 18 \\
\hline $19 a$ & $19 b$ & $20 \mathrm{a}$ & $20 \mathrm{~b}$ & $20 c$ & 21 \\
\hline
\end{tabular}

Any information copied from such Reports and Statements may not be sold or used by any person for the purpose of soliciting contributions or for commercial purposes, other than using the name and address of any political committee to solicit contributions from such committee.

NAME OF COMMITTEE (In Full)

\section{Friends of Herman Cain}

A. Full Name (Last, First, Middle Initial)

Richard Harper

Mailing Address 176 Rainbow Dr \#7626

\begin{tabular}{lcc}
\hline City & State & Zip Code \\
Livingston & TX & $77399-1076$ \\
\hline
\end{tabular}

FEC ID number of contributing federal political committee.

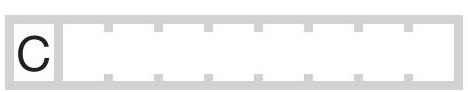

Name of Employer
Not Employed
Receipt For: 2012
X Primary $\quad$ General
Other (specify)

Occupation Retired

Election Cycle-to-Date

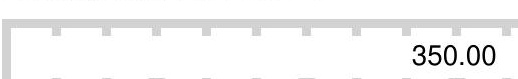

B. Full Name (Last, First, Middle Initial)

Ralph Davis

Mailing Address 6300 Browns Bridge Rd.

\begin{tabular}{lcc}
\hline City & State & Zip Code \\
Cumming & GA & $30041-4761$ \\
\hline
\end{tabular}

FEC ID number of contributing

federal political committee.

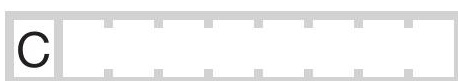

Name of Employer
RAD Enterprizes inc
Receipt For: 2012
X Primary
Other (specify)

\section{Occupation} Manger

Election Cycle-to-Date

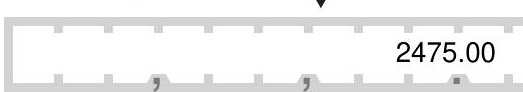

Transaction ID : AD92E3301FC264005856

Date of Receipt

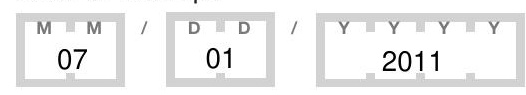

Amount of Each Receipt this Period

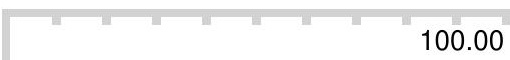

Amount of Each Receipt this Period

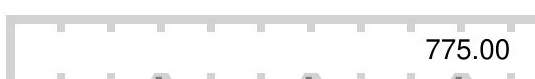

C. Full Name (Last, First, Middle Initial)

Ron Allen

Mailing Address 3605 Taurus Drive

\begin{tabular}{lcc}
\hline City & State & Zip Code \\
Racine & WI & $53406-1333$
\end{tabular}

FEC ID number of contributing federal political committee.

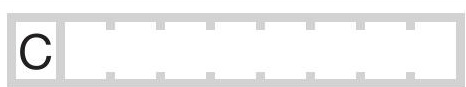

Name of Employer

Self Employed

Occupation

Self Employed

Surgeon

Transaction ID : A71DA3902D0BF42378BB

Date of Receipt

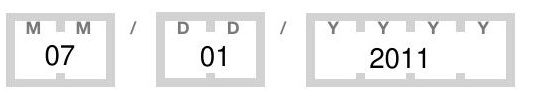

Receipt For: 2012

Х $\begin{aligned} & \text { Primary } \square \text { General } \\ & \text { Other (specify) }\end{aligned}$

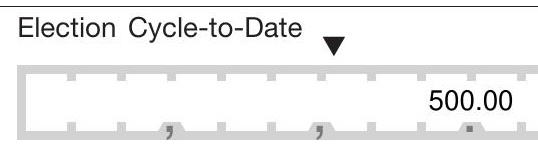

Amount of Each Receipt this Period

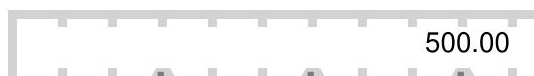

Transaction ID : AA6C699C89B8241CDB18 Date of Receipt

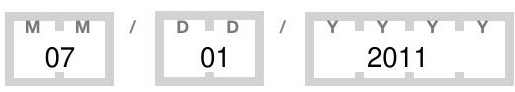

Subtotal Of Receipts This Page (optional)

Total This Period (last page this line number only) 


\section{SCHEDULE A-P} ITEMIZED RECEIPTS
Use separate schedule(s)

for each category of the

Detailed Summary Page
FOR LINE NUMBER: (check only one)
PAGE $15 / 1572$

\begin{tabular}{|c|c|c|c|c|c|}
\hline & & & & & \\
\hline 16 & $\begin{array}{l}\mathbf{X} \\
17 a\end{array}$ & $17 b$ & $17 c$ & $17 d$ & 18 \\
\hline $19 a$ & $19 \mathrm{~b}$ & $20 \mathrm{a}$ & $20 \mathrm{~b}$ & $20 \mathrm{c}$ & 21 \\
\hline
\end{tabular}

Any information copied from such Reports and Statements may not be sold or used by any person for the purpose of soliciting contributions or for commercial purposes, other than using the name and address of any political committee to solicit contributions from such committee.

NAME OF COMMITTEE (In Full)

\section{Friends of Herman Cain}

A. Full Name (Last, First, Middle Initial)

Daniel Agius

Mailing Address 426 Federal Road

\begin{tabular}{lcc}
\hline City & State & Zip Code \\
Brookfield & CT & $06804-2018$
\end{tabular}

FEC ID number of contributing

federal political committee.

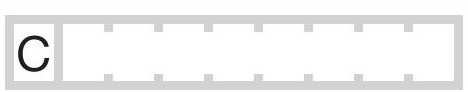

Name of Employer
nordex
Receipt For: 2012
X Primary $\quad$ General
Other (specify)

Occupation

Executive

Election Cycle-to-Date

500.00

B. Full Name (Last, First, Middle Initial)

Haburn Arnold

Mailing Address 10510 Rivertown Rd

\begin{tabular}{lcc}
\hline City & State & Zip Code \\
Fairburn & GA & $30213-2169$ \\
\hline
\end{tabular}

FEC ID number of contributing

federal political committee.

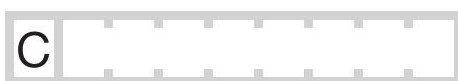

Name of Employer
Bruske Products Inc.
Receipt For: 2012
X Primary
Other (specify)

Occupation

Factory Rep.

Election Cycle-to-Date

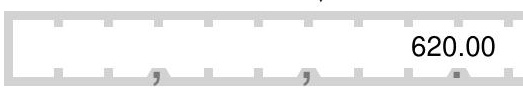

C. Full Name (Last, First, Middle Initial)

Mr. Howard Bowser

Mailing Address PO Box 26767

\begin{tabular}{lcc}
\hline City & State & Zip Code \\
Jacksonville & FL & $32226-6767$
\end{tabular}

FEC ID number of contributing federal political committee.

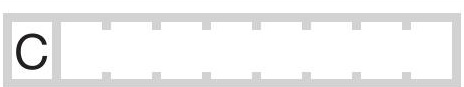

Name of Employer

Information Requested

\section{Occupation}

Information Requested

Receipt For: 2012

Х $\begin{aligned} & \text { Primary } \square \text { General } \\ & \text { Other (specify) }\end{aligned}$

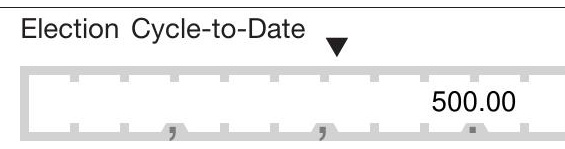

Amount of Each Receipt this Period

Transaction ID : A848E8FF3B7294887B00

Date of Receipt

Date of Receipt

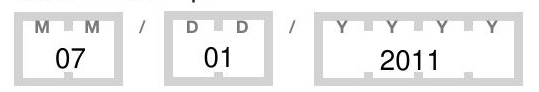

Amount of Each Receipt this Period
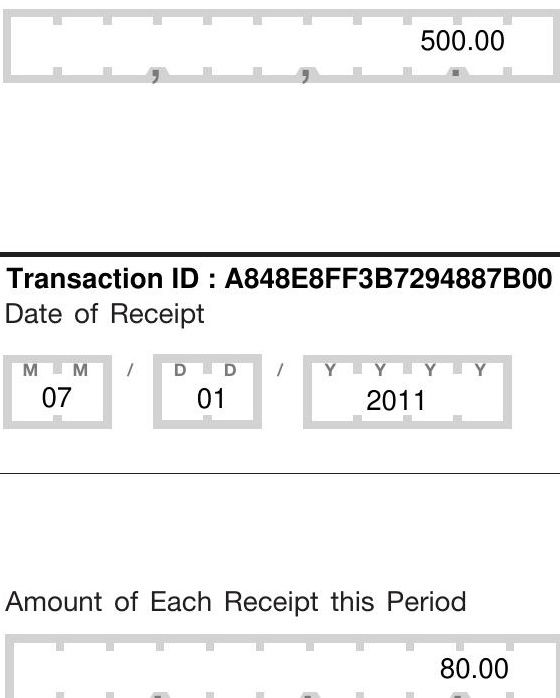

Transaction ID : A41AB3AC6457343FB8A8 Date of Receipt

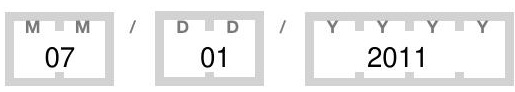

Amount of Each Receipt this Period

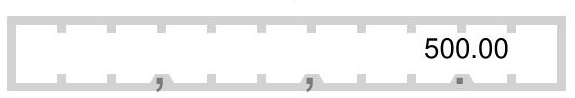

Subtotal Of Receipts This Page (optional).

1080.00

Total This Period (last page this line number only) 


\section{SCHEDULE A-P} ITEMIZED RECEIPTS
Use separate schedule(s)

for each category of the

Detailed Summary Page
FOR LINE NUMBER: (check only one)
PAGE $16 / 1572$

\begin{tabular}{|c|c|c|c|c|c|}
\hline & & & & & \\
\hline 16 & $\begin{array}{l}\mathbf{X} \\
17 a\end{array}$ & $17 b$ & $17 c$ & $17 d$ & 18 \\
\hline $19 a$ & $19 \mathrm{~b}$ & $20 \mathrm{a}$ & $20 \mathrm{~b}$ & $20 \mathrm{c}$ & 21 \\
\hline
\end{tabular}

Any information copied from such Reports and Statements may not be sold or used by any person for the purpose of soliciting contributions or for commercial purposes, other than using the name and address of any political committee to solicit contributions from such committee.

NAME OF COMMITTEE (In Full)

Friends of Herman Cain

A. Full Name (Last, First, Middle Initial)

Darren Magness

Mailing Address 30559 Meadow Run Place

\begin{tabular}{lcc}
\hline City & State & Zip Code \\
Menifee & CA & $92584-8942$
\end{tabular}

FEC ID number of contributing

federal political committee.

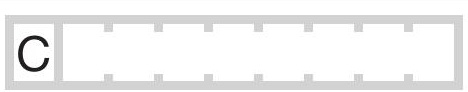

Name of Employer
Self Employed
Receipt For: 2012
X Primary
$\square$ Other (specify) General

Occupation

Healthcare Consultant

Election Cycle-to-Date

350.00

B. Full Name (Last, First, Middle Initial)

Lavigne Kirkpatrick

Mailing Address 420 Widgeon Pt

\begin{tabular}{lcc}
\hline City & State & Zip Code \\
Naples & FL & $34105-2434$
\end{tabular}

FEC ID number of contributing

federal political committee.

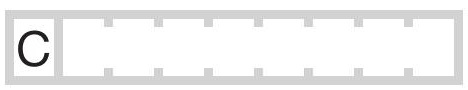

Name of Employer
Avow Hospice
Receipt For: 2012
X Primary
Other (specify) General

\section{Occupation}

$\mathrm{RN}$

Election Cycle-to-Date

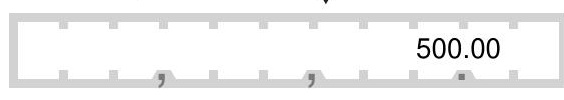

Transaction ID : A9B814C068ADB445FAD9

Date of Receipt

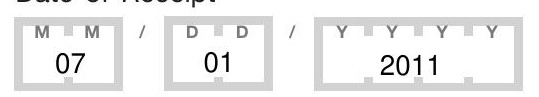

Amount of Each Receipt this Period

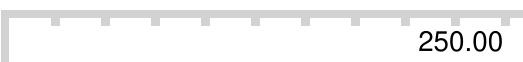

Amount of Each Receipt this Period

Transaction ID : A9C30E663937B4C6AAC6

Date of Receipt
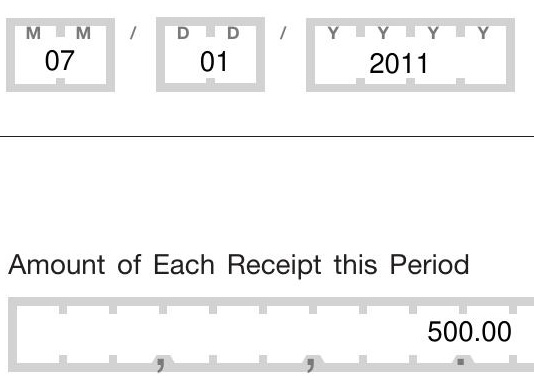

Transaction ID : A553C5C7DBDA745BE9CA Date of Receipt

steven dyke

Mailing Address 400 Wyldewood Dr

\begin{tabular}{lcc}
\hline City & State & Zip Code \\
McDonough & GA & $30253-4776$
\end{tabular}

FEC ID number of contributing

federal political committee.

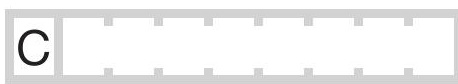

Name of Employer
Delta Air Lines
Receipt For: 2012
X Primary $\quad \square$ General
Other (specify)

Occupation

Machinist

Election Cycle-to-Date

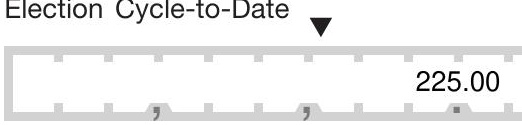

Subtotal Of Receipts This Page (optional)

Amount of Each Receipt this Period

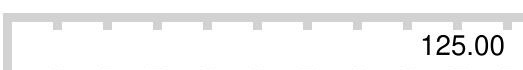

Total This Period (last page this line number only)

875.00

in a r a

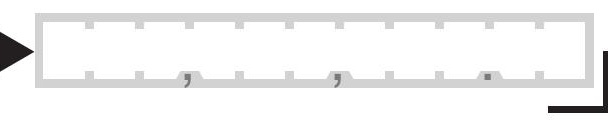

FEC Schedule A-P (Form 3P) (Rev. 03/2011) 
SCHEDULE A-P ITEMIZED RECEIPTS
Use separate schedule(s) for each category of the Detailed Summary Page
FOR LINE NUMBER: (check only one)

\begin{tabular}{|c|c|c|c|c|c|c|}
\hline & & & & & & \\
\hline 16 & $\times 1$ & $17 a$ & $17 b$ & $17 c$ & $17 d$ & 18 \\
\hline $19 a$ & & $19 b$ & $20 \mathrm{a}$ & $20 \mathrm{~b}$ & $20 \mathrm{c}$ & 21 \\
\hline
\end{tabular}

Any information copied from such Reports and Statements may not be sold or used by any person for the purpose of soliciting contributions or for commercial purposes, other than using the name and address of any political committee to solicit contributions from such committee.

NAME OF COMMITTEE (In Full)

\section{Friends of Herman Cain}

A. Full Name (Last, First, Middle Initial)

\section{Patricia Daman}

Mailing Address 9108 S Water Tower Rd

\begin{tabular}{lcc}
\hline City & State & Zip Code \\
Fort Worth & TX & $76179-5148$
\end{tabular}

FEC ID number of contributing federal political committee.

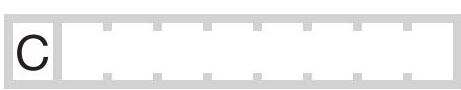

Name of Employer
n/a
Receipt For: 2012
X Primary $\quad$ General
Other (specify)

Occupation Retired

Election Cycle-to-Date

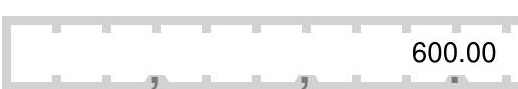

Transaction ID : A1A5C79B31A5840BE90F

Date of Receipt

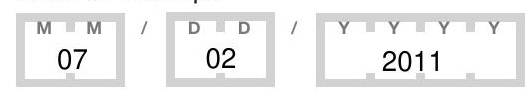

Amount of Each Receipt this Period

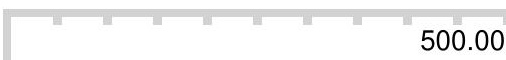

B. Full Name (Last, First, Middle Initial)

Matthew Marston

Mailing Address 90 Beacon St

\begin{tabular}{lcc}
\hline City & State & Zip Code \\
Boston & MA & $02108-3324$ \\
\hline
\end{tabular}

FEC ID number of contributing

federal political committee.

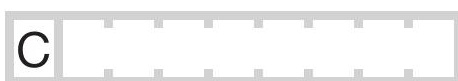

Name of Employer
FourTier Strategies
Receipt For: 2012
X Primary
Other (specify)

\section{Occupation}

Partner

Election Cycle-to-Date

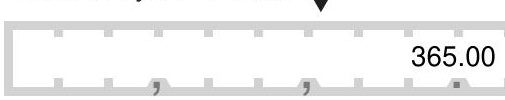

Amount of Each Receipt this Period

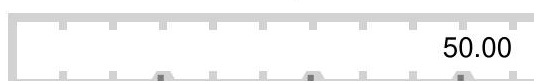

C. Full Name (Last, First, Middle Initial)

Myra Grosbach

Mailing Address 1393 Hayton Ave

\begin{tabular}{lcc}
\hline City & State & Zip Code \\
Deland & FL & $32724-7361$
\end{tabular}

FEC ID number of contributing federal political committee.

C

32724-7361

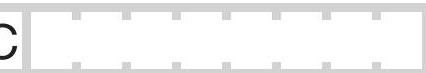

Name of Employer
None
Receipt For: 2012
X Primary $\quad \square$ General
Other (specify)

\section{Occupation}

Homemaker

Election Cycle-to-Date

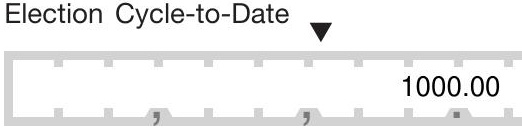

Transaction ID : A47DF745393BB4F65975

Date of Receipt

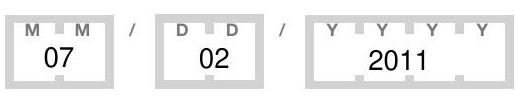

Transaction ID : A130AC9E99D8844CDBF0 Date of Receipt

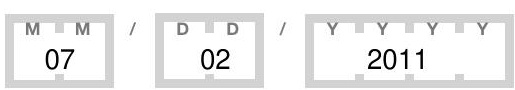

Amount of Each Receipt this Period

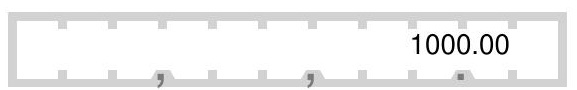

1550.00

(1)

Total This Period (last page this line number only)

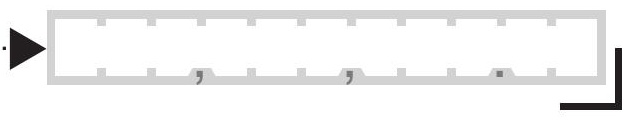

FEC Schedule A-P (Form 3P) (Rev. 03/2011) 


\section{SCHEDULE A-P} ITEMIZED RECEIPTS
Use separate schedule(s)

for each category of the

Detailed Summary Page
FOR LINE NUMBER: (check only one)
PAGE $18 / 1572$

\begin{tabular}{|c|c|c|c|c|c|}
\hline & & & & & \\
\hline 16 & $\mathbf{X} 17 \mathrm{a}$ & $17 \mathrm{~b}$ & $17 c$ & $17 d$ & 18 \\
\hline $19 a$ & $19 b$ & $20 a$ & $20 \mathrm{~b}$ & $20 c$ & 21 \\
\hline
\end{tabular}

Any information copied from such Reports and Statements may not be sold or used by any person for the purpose of soliciting contributions or for commercial purposes, other than using the name and address of any political committee to solicit contributions from such committee.

NAME OF COMMITTEE (In Full)

Friends of Herman Cain

A. Full Name (Last, First, Middle Initial)

MARK LOPEZ

Mailing Address 1830 BREA BLVD \#3

\begin{tabular}{lcc}
\hline City & State & Zip Code \\
Fullerton & CA & $92835-3944$
\end{tabular}

FEC ID number of contributing

federal political committee.

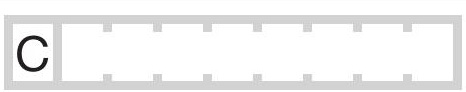

Name of Employer
BECKMAN COULTER INC
Receipt For: 2012
X Primary $\quad \square$ General
Other (specify)

Occupation

SW Engineer

Election Cycle-to-Date

500.00

B. Full Name (Last, First, Middle Initial)

john credico

Mailing Address $200 \mathrm{~s}$ cousino road

\begin{tabular}{lcc}
\hline City & State & Zip Code \\
Oregon & OH & $43616-5827$
\end{tabular}

FEC ID number of contributing

federal political committee.

C

Name of Employer
self
Receipt For: 2012
Primary
Other (specify)

Occupation

Physician

Transaction ID : A9D5259633090421FAC5

Date of Receipt

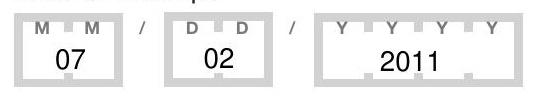

Amount of Each Receipt this Period

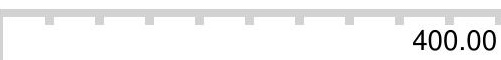

400.00

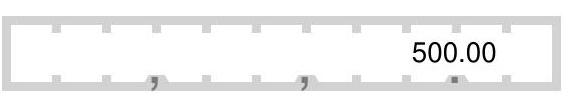

Transaction ID : A26EFAFEBE6E84495AB1

Date of Receipt

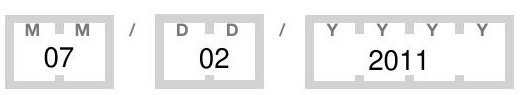

Amount of Each Receipt this Period

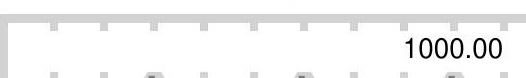

Election Cycle-to-Date

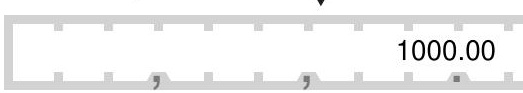

C. Full Name (Last, First, Middle Initial)

Linda Siffring

Mailing Address 5502 Farnam Street

\begin{tabular}{lcc}
\hline City & State & Zip Code \\
Omaha & NE & $68132-3424$
\end{tabular}

FEC ID number of contributing

federal political committee.

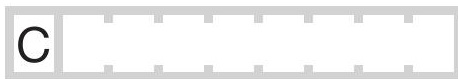

Name of Employer
homemaker
Receipt For: 2012
X Primary
Other (specify) General

\section{Occupation}

Attorney

Election Cycle-to-Date

Transaction ID : AF212B22F233A49A0ABD Date of Receipt

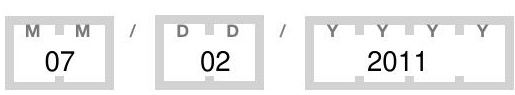

Amount of Each Receipt this Period

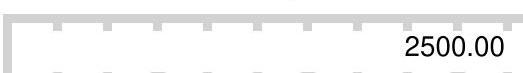

2500.00

\section{Subtotal Of Receipts This Page (optional)}

3900.00

a

Total This Period (last page this line number only) 
SCHEDULE A-P ITEMIZED RECEIPTS
Use separate schedule(s) for each category of the Detailed Summary Page
FOR LINE NUMBER: (check only one)

\begin{tabular}{|c|c|c|c|c|c|}
\hline & & & & & \\
\hline 16 & $\begin{array}{ll}X & 17 a \\
\end{array}$ & $17 \mathrm{~b}$ & $17 c$ & $17 d$ & 18 \\
\hline $19 a$ & $19 b$ & $20 \mathrm{a}$ & $20 \mathrm{~b}$ & $20 c$ & 21 \\
\hline
\end{tabular}

Any information copied from such Reports and Statements may not be sold or used by any person for the purpose of soliciting contributions or for commercial purposes, other than using the name and address of any political committee to solicit contributions from such committee.

NAME OF COMMITTEE (In Full)

\section{Friends of Herman Cain}

A. Full Name (Last, First, Middle Initial)

Joe Kerola

Mailing Address 420 Ravine Dr

\begin{tabular}{lcc}
\hline City & State & Zip Code \\
Hubbard & OH & $44425-2269$ \\
\hline
\end{tabular}

FEC ID number of contributing federal political committee.

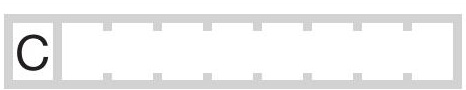

Name of Employer
P.I\&I. Motor Express
Receipt For: 2012
X Primary $\quad \square$ General
Other (specify)

Occupation

Executive

Election Cycle-to-Date 250.00
B. Full Name (Last, First, Middle Initial)

CAROLYN BRAUN

Mailing Address 46 W 14 RD

\begin{tabular}{lcc}
\hline City & State & Zip Code \\
Broad Channel & NY & $11693-1139$
\end{tabular}

FEC ID number of contributing

federal political committee.

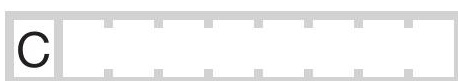

Name of Employer
self
Receipt For: 2012
X Primary
Other (specify)

\section{Occupation}

COPYWRITER

Election Cycle-to-Date

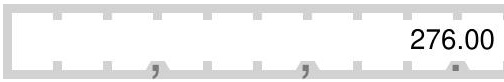

C. Full Name (Last, First, Middle Initial)

Ralph Korpman

Mailing Address P O Box 6406

\begin{tabular}{lcc}
\hline City & State & Zip Code \\
San Bernardino & CA & $92412-6406$
\end{tabular}

FEC ID number of contributing federal political committee.

C

Name of Employer
Self Employed
Receipt For: 2012
X Primary $\quad \square$ General
Other (specify)

Occupation

Physician

Election Cycle-to-Date

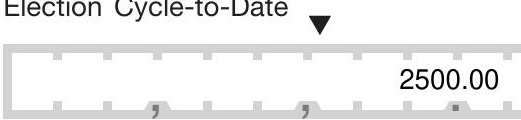

Transaction ID : A903F893F63E44C3B9C3

Date of Receipt

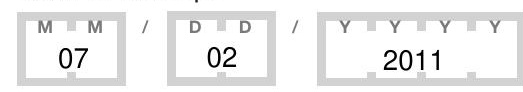

Amount of Each Receipt this Period

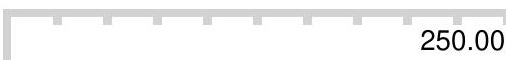

250.00

Transaction ID : A9167C9B5024346A8A3A

Date of Receipt

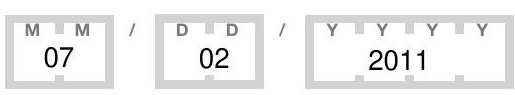

Amount of Each Receipt this Period

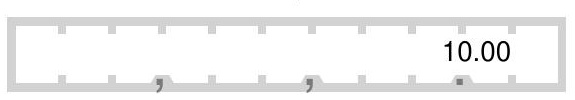

Transaction ID : AB4D83529038F4AA1B8B Date of Receipt

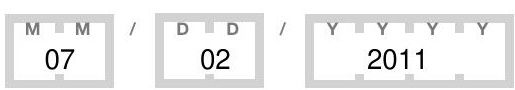

Amount of Each Receipt this Period

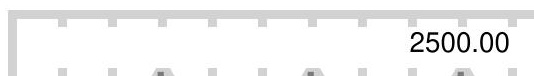

2760.00

Subtotal Of Receipts This Page (optional)

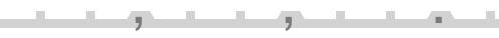

Total This Period (last page this line number only) 
SCHEDULE A-P ITEMIZED RECEIPTS
Use separate schedule(s) for each category of the Detailed Summary Page
FOR LINE NUMBER: (check only one)

\begin{tabular}{|c|c|c|c|c|c|c|}
\hline & & & & & & \\
\hline 16 & $\times 1$ & $17 a$ & $17 b$ & $17 c$ & $17 d$ & 18 \\
\hline $19 a$ & & $19 b$ & $20 \mathrm{a}$ & $20 \mathrm{~b}$ & $20 \mathrm{c}$ & 21 \\
\hline
\end{tabular}

Any information copied from such Reports and Statements may not be sold or used by any person for the purpose of soliciting contributions or for commercial purposes, other than using the name and address of any political committee to solicit contributions from such committee.

NAME OF COMMITTEE (In Full)

\section{Friends of Herman Cain}

A. Full Name (Last, First, Middle Initial)

Stacy Taylor

Mailing Address 4704 Chestfield Dr

\begin{tabular}{lcc}
\hline City & State & Zip Code \\
Greensboro & NC & $27407-6152$ \\
\hline
\end{tabular}

FEC ID number of contributing federal political committee.

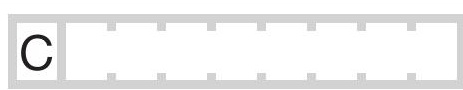

Name of Employer
Cone Health
Receipt For: 2012
X Primary $\quad$ General
Other (specify)

B. Full Name (Last, First, Middle Initial)

Wade Harrison

Mailing Address 1368 Mar Del Dr

\begin{tabular}{lcc}
\hline City & State & Zip Code \\
Greenville & OH & $45331-2412$ \\
\hline
\end{tabular}

FEC ID number of contributing

federal political committee.

\begin{tabular}{l} 
Name of Employer \\
Whirlpool \\
Receipt For: 2012 \\
X Primary \\
\hline Other (specify)
\end{tabular}

C. Full Name (Last, First, Middle Initial)

Stephen Prior

Mailing Address 9606 Atom Rd.

\begin{tabular}{lcc}
\hline City & State & Zip Code \\
Clinton & MD & $20735-2903$
\end{tabular}

FEC ID number of contributing federal political committee.

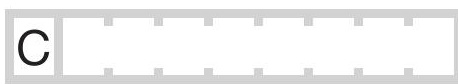

Name of Employer
US Navy
Receipt For: 2012
X Primary $\quad \square$ General
Other (specify)

Occupation

Administrative Assistant

Election Cycle-to-Date 250.00

$\begin{aligned} & \text { Occupation } \\ & \text { Management Analyst }\end{aligned}$
Election Cycle-to-Date

Transaction ID : A23EA7A25B6CC4BD38DF

Date of Receipt

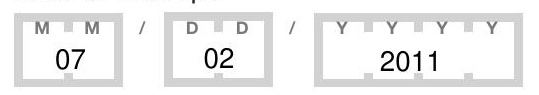

Amount of Each Receipt this Period

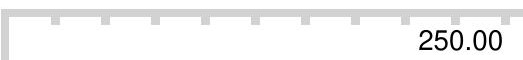

C
Amount of Each Receipt this Period

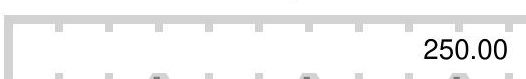

Transaction ID : A060DF310F9804FEF823 Date of Receipt

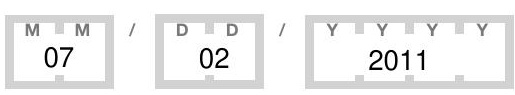

Occupation

Engineer

Election Cycle-to-Date

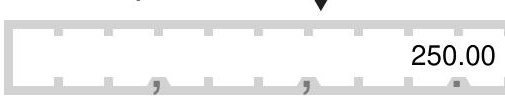

Transaction ID : A439F7940F3E34BD7A41

Date of Receipt

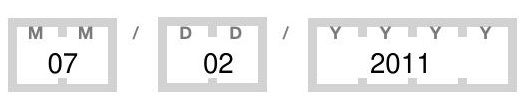

Amount of Each Receipt this Period

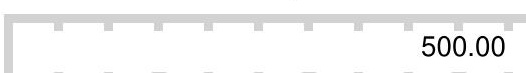

500.00

\section{Subtotal Of Receipts This Page (optional)}

Total This Period (last page this line number only) 


\section{SCHEDULE A-P} ITEMIZED RECEIPTS
Use separate schedule(s)

for each category of the

Detailed Summary Page
FOR LINE NUMBER: (check only one)

\begin{tabular}{|c|c|c|c|c|c|c|}
\hline & & & & & & \\
\hline 16 & $\times 1$ & $17 a$ & $17 b$ & $17 c$ & $17 d$ & 18 \\
\hline $19 a$ & & $19 b$ & $20 \mathrm{a}$ & $20 \mathrm{~b}$ & $20 \mathrm{c}$ & 21 \\
\hline
\end{tabular}

Any information copied from such Reports and Statements may not be sold or used by any person for the purpose of soliciting contributions or for commercial purposes, other than using the name and address of any political committee to solicit contributions from such committee.

NAME OF COMMITTEE (In Full)

\section{Friends of Herman Cain}

A. Full Name (Last, First, Middle Initial)

Wayne Ray

Transaction ID : A3A183F13BE5340F4922

Mailing Address 10325 Willeo Creek Trce

\begin{tabular}{lcc}
\hline City & State & Zip Code \\
Roswell & GA & $30075-2751$
\end{tabular}

FEC ID number of contributing federal political committee.

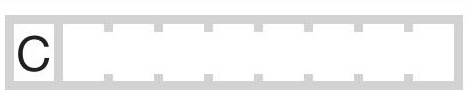

Name of Employer
Retired
Receipt For: 2012
X Primary $\quad$ General
Other (specify)

Occupation Information Requested

Election Cycle-to-Date

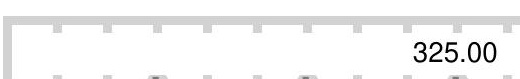

B. Full Name (Last, First, Middle Initial) carol sloan

Mailing Address 11150 N. 1940 road

\begin{tabular}{lcc}
\hline City & State & Zip Code \\
Elk City & OK & $73644-2324$
\end{tabular}

FEC ID number of contributing

federal political committee.

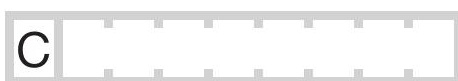

Name of Employer

high plains wireline services inc.

Occupation

Receipt For: 2012

Х Primary $\square$ General

OWNER

Date of Receipt

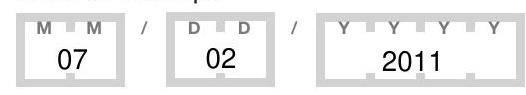

Amount of Each Receipt this Period

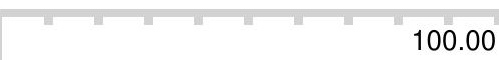

100.00

Transaction ID : AE4EC71D335244885957

Date of Receipt

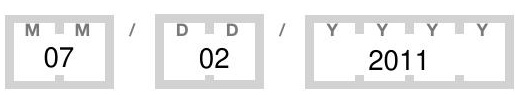

Amount of Each Receipt this Period

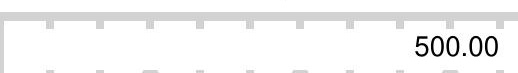

Election Cycle-to-Date

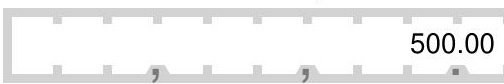

C. Full Name (Last, First, Middle Initial)

Nancy Kittles

Mailing Address 158 Sharon Lane

\begin{tabular}{lcc}
\hline City & State & Zip Code \\
Athens & GA & $30607-2798$
\end{tabular}

FEC ID number of contributing

federal political committee.

C

Name of Employer

Gwinnett Medical Center Lawrenceville

Receipt For: 2012

Х $\begin{aligned} & \text { Primary } \square \text { General } \\ & \text { Other (specify) }\end{aligned}$

Occupation

Registered Nurse

Election Cycle-to-Date

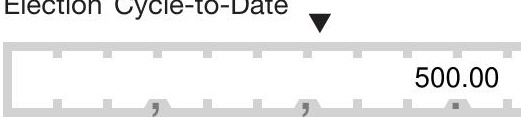

Transaction ID : A88C3FA2C9B194E96AF3 Date of Receipt

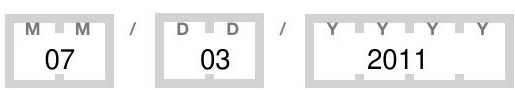

Amount of Each Receipt this Period

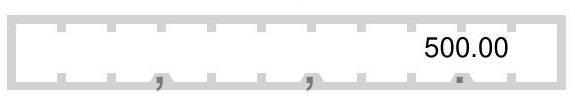

\section{Subtotal Of Receipts This Page (optional)}

Total This Period (last page this line number only) 
SCHEDULE A-P ITEMIZED RECEIPTS
Use separate schedule(s) for each category of the Detailed Summary Page
FOR LINE NUMBER: (check only one)

\begin{tabular}{|c|c|c|c|c|c|c|}
\hline & & & & & & \\
\hline 16 & $\times 1$ & $17 a$ & $17 b$ & $17 c$ & $17 d$ & 18 \\
\hline $19 a$ & & $19 b$ & $20 \mathrm{a}$ & $20 \mathrm{~b}$ & $20 \mathrm{c}$ & 21 \\
\hline
\end{tabular}

Any information copied from such Reports and Statements may not be sold or used by any person for the purpose of soliciting contributions or for commercial purposes, other than using the name and address of any political committee to solicit contributions from such committee.

NAME OF COMMITTEE (In Full)

\section{Friends of Herman Cain}

A. Full Name (Last, First, Middle Initial)

William Lamkin

Mailing Address 12858 N Nancy Jane Ln

\begin{tabular}{lcc}
\hline City & State & Zip Code \\
Phoenix & AZ & $85022-5714$ \\
\hline
\end{tabular}

FEC ID number of contributing federal political committee.

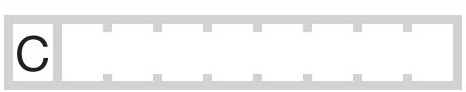

Name of Employer
Glendale Community College
Receipt For: 2012
X Primary
Other (specify) General

Occupation college teacher

Election Cycle-to-Date

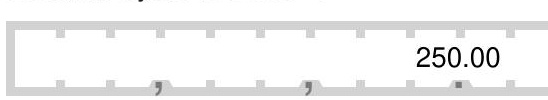

B. Full Name (Last, First, Middle Initial)

David Northrup

\section{Mailing Address P.O. Box 82}

\begin{tabular}{lcc}
\hline City & State & Zip Code \\
New Ulm & TX & $78950-0082$
\end{tabular}

FEC ID number of contributing

federal political committee.

C

Name of Employer

Richardson \& Dunn Inc.

Occupation

Receipt For: 2012

$\searrow \begin{aligned} & \text { Primary } \\ & \text { Other (specify) }\end{aligned}$

Superintendent

Election Cycle-to-Date

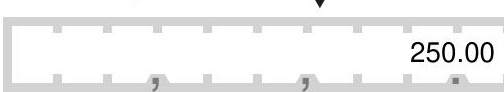

C. Full Name (Last, First, Middle Initial)

Susan Dopkowski

Mailing Address 8 Bayside Drive

\begin{tabular}{lll}
\hline $\begin{array}{l}\text { City } \\
\text { Dundalk }\end{array}$ & $\begin{array}{c}\text { State } \\
\text { MD }\end{array}$ & $\begin{array}{c}\text { Zip Code } \\
21222-4912\end{array}$ \\
\hline $\begin{array}{l}\text { FEC ID number of contributing } \\
\text { federal political committee. }\end{array}$ & C \\
\hline $\begin{array}{l}\text { Name of Employer } \\
\text { Legg Mason }\end{array}$ & $\begin{array}{l}\text { Occupation } \\
\text { Telecommunications Specialist }\end{array}$ \\
$\begin{array}{l}\text { Receipt For: } 2012 \\
\text { Xrimary } \\
\text { Other (specify) }\end{array}$ & Election Cycle-to-Date & \\
\hline
\end{tabular}

Transaction ID : A6C77B1DEEC32457D8EC Date of Receipt

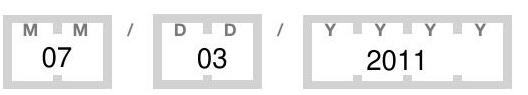

Amount of Each Receipt this Period

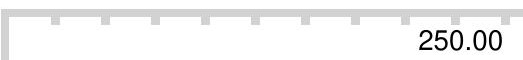

Date of Receipt
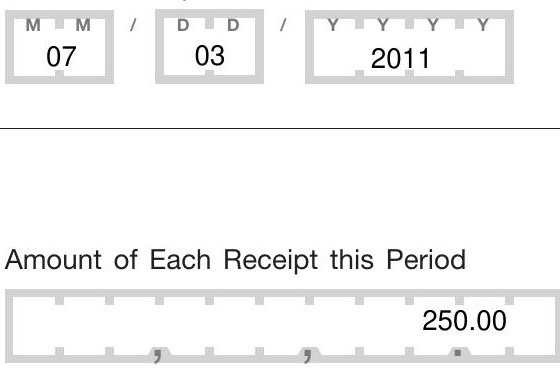

Amount of Each Receipt this Period

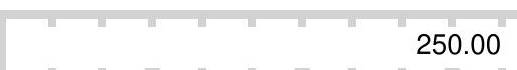

Amount of Each Receipt this Period

Transaction ID : A82290EE6434849A1A6C Date of Receipt
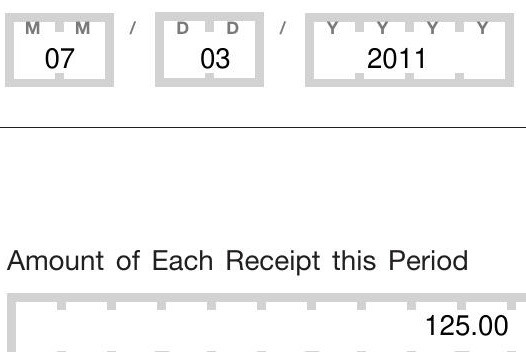

Subtotal Of Receipts This Page (optional)

625.00

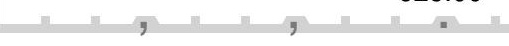

Total This Period (last page this line number only)

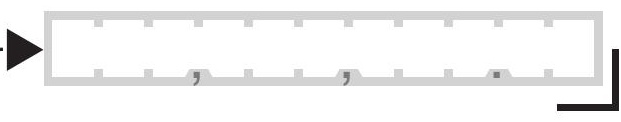

FEC Schedule A-P (Form 3P) (Rev. 03/2011) 
SCHEDULE A-P ITEMIZED RECEIPTS
Use separate schedule(s) for each category of the Detailed Summary Page
FOR LINE NUMBER: (check only one)

\begin{tabular}{|c|c|c|c|c|c|}
\hline & & & & & \\
\hline 16 & $\begin{array}{ll}X & 17 a \\
\end{array}$ & $17 \mathrm{~b}$ & $17 c$ & $17 d$ & 18 \\
\hline $19 a$ & $19 b$ & $20 \mathrm{a}$ & $20 \mathrm{~b}$ & $20 c$ & 21 \\
\hline
\end{tabular}

Any information copied from such Reports and Statements may not be sold or used by any person for the purpose of soliciting contributions or for commercial purposes, other than using the name and address of any political committee to solicit contributions from such committee.

NAME OF COMMITTEE (In Full)

\section{Friends of Herman Cain}

A. Full Name (Last, First, Middle Initial) John LaRosa

Mailing Address 273 Roslindale Ave.

\begin{tabular}{lcc}
\hline City & State & Zip Code \\
Roslindale & MA & $02131-3339$ \\
\hline
\end{tabular}

FEC ID number of contributing federal political committee.

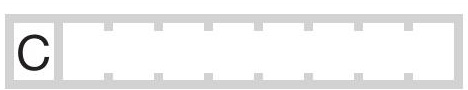

Name of Employer
self
Receipt For: 2012
X Primary $\quad$ General
Other (specify)

Occupation Consulting

Election Cycle-to-Date

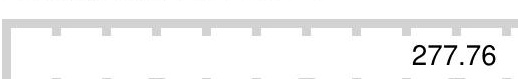

B. Full Name (Last, First, Middle Initial)

Susan McHugh

Mailing Address 114 Indian Pipe Ln

\begin{tabular}{lcc}
\hline City & State & Zip Code \\
Concord & MA & $01742-4766$ \\
\hline
\end{tabular}

FEC ID number of contributing

federal political committee.

C

Name of Employer
Not Employed
Receipt For: 2012
Xrimary
Other (specify)

Occupation

Not Employed

Election Cycle-to-Date

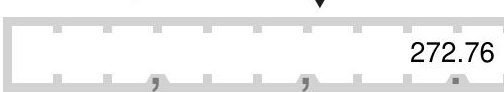

Transaction ID : AE5C41AAE5F9F4FA6B48

Date of Receipt

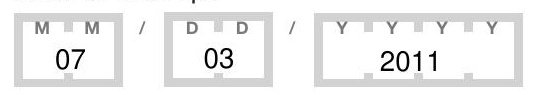

Amount of Each Receipt this Period

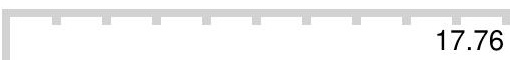

17.76

C. Full Name (Last, First, Middle Initial)

Laurence Berg

Mailing Address 151 Fairway Ct

\begin{tabular}{lcc}
\hline City & State & Zip Code \\
Onalaska & WI & $54650-8713$
\end{tabular}

FEC ID number of contributing federal political committee.

C

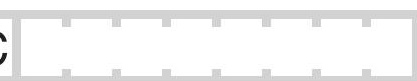

Name of Employer
Physician
Receipt For: 2012
X Primary $\square$ General
Other (specify)

\section{Occupation}

Gundersen Lutheran Med Ctr

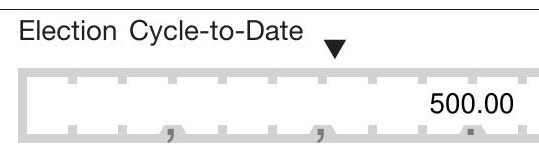

Transaction ID : ABD04E0BFBE3A4BA4BE9 Date of Receipt

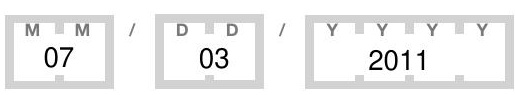

Amount of Each Receipt this Period

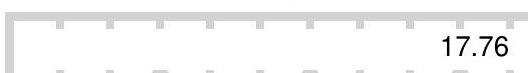

Transaction ID : A3BA98762670943C7BBD Date of Receipt

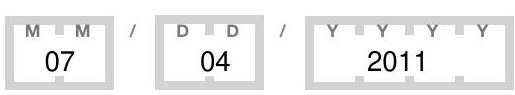

Amount of Each Receipt this Period

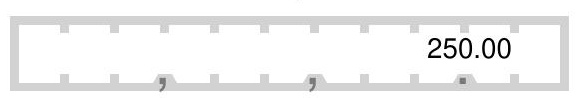

\section{Subtotal Of Receipts This Page (optional)}

Total This Period (last page this line number only) 
SCHEDULE A-P ITEMIZED RECEIPTS
Use separate schedule(s) for each category of the Detailed Summary Page
FOR LINE NUMBER: (check only one)

\begin{tabular}{|c|c|c|c|c|c|}
\hline & & & & & \\
\hline 16 & $\begin{array}{ll}X & 17 a \\
\end{array}$ & $17 \mathrm{~b}$ & $17 c$ & $17 d$ & 18 \\
\hline $19 a$ & $19 b$ & $20 \mathrm{a}$ & $20 \mathrm{~b}$ & $20 c$ & 21 \\
\hline
\end{tabular}

Any information copied from such Reports and Statements may not be sold or used by any person for the purpose of soliciting contributions or for commercial purposes, other than using the name and address of any political committee to solicit contributions from such committee.

NAME OF COMMITTEE (In Full)

\section{Friends of Herman Cain}

A. Full Name (Last, First, Middle Initial)

\section{Brian Mulhern}

Mailing Address 14948 Vireo Court

\begin{tabular}{lcc}
\hline City & State & Zip Code \\
Woodbridge & VA & 22193-1899 \\
\hline
\end{tabular}

FEC ID number of contributing federal political committee.

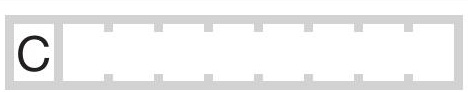

Name of Employer
Lockheed Martin
Receipt For: 2012
X Primary $\quad$ General
Other (specify)

Occupation

System Engineer

Election Cycle-to-Date

B. Full Name (Last, First, Middle Initial)

Bradie Burson

Mailing Address 2615 Bluefield Avenue

\begin{tabular}{lcc}
\hline City & State & Zip Code \\
Nashville & TN & $37214-2810$
\end{tabular}

FEC ID number of contributing

federal political committee.

C

Name of Employer

Vanderbilt Stallworth Rehabilitation C

Occupation

Receipt For: 2012

X Primary $\square$ General Other (specify) $\nabla$

$\mathrm{RN}, \mathrm{MSN}$

Transaction ID : A34261C8ECD2041328C4

Date of Receipt

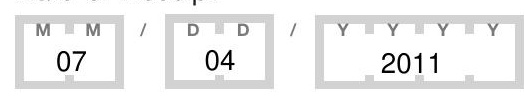

Amount of Each Receipt this Period

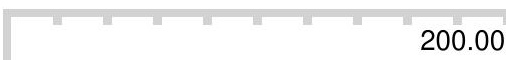

200.00

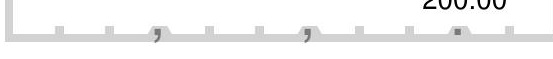

300.00

Transaction ID : A15605FFF6D024B3790A

Date of Receipt

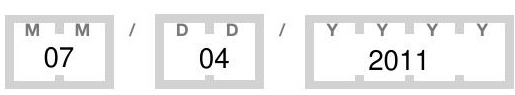

Amount of Each Receipt this Period

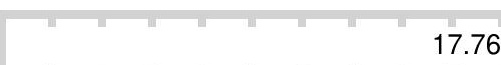

Election Cycle-to-Date

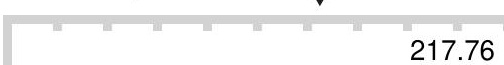

217.76

C. Full Name (Last, First, Middle Initial)

Judith Neville

Mailing Address 4817 W Yoosooni Dr.

\begin{tabular}{lcc}
\hline City & State & Zip Code \\
New River & AZ & $85087-3074$
\end{tabular}

FEC ID number of contributing

federal political committee.

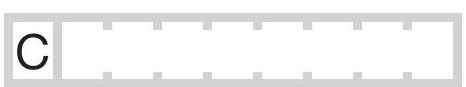

$\begin{aligned} & \text { Name of Employer } \\ & \text { self }\end{aligned}$
Receipt For: 2012
X Primary $\square$ General
Other (specify)

Occupation

Consultant

Amount of Each Receipt this Period

Transaction ID : A7D10C0DF0E3B43EC8F8

Date of Receipt
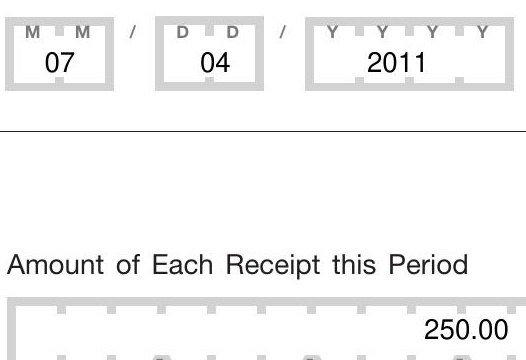

Subtotal Of Receipts This Page (optional).

250.00

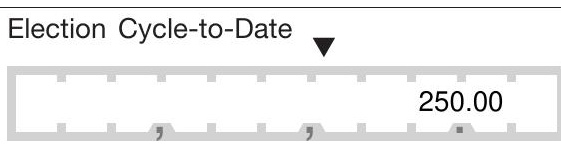

Total This Period (last page this line number only)

$-\quad 467.76$

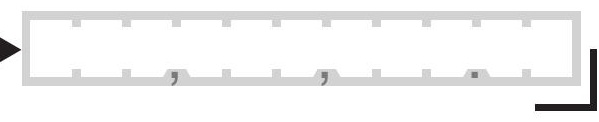

FEC Schedule A-P (Form 3P) (Rev. 03/2011) 
SCHEDULE A-P ITEMIZED RECEIPTS
Use separate schedule(s) for each category of the Detailed Summary Page
FOR LINE NUMBER: (check only one)

\begin{tabular}{|c|c|c|c|c|c|c|}
\hline & & & & & & \\
\hline 16 & $\times 1$ & $17 a$ & $17 b$ & $17 c$ & $17 d$ & 18 \\
\hline $19 a$ & & $19 b$ & $20 \mathrm{a}$ & $20 \mathrm{~b}$ & $20 \mathrm{c}$ & 21 \\
\hline
\end{tabular}

Any information copied from such Reports and Statements may not be sold or used by any person for the purpose of soliciting contributions or for commercial purposes, other than using the name and address of any political committee to solicit contributions from such committee.

NAME OF COMMITTEE (In Full)

\section{Friends of Herman Cain}

A. Full Name (Last, First, Middle Initial)

\section{Mr. Nick Edwards}

Mailing Address 3820 River Rd.

\begin{tabular}{lcc}
\hline City & State & Zip Code \\
Wimberley & TX & $78676-5141$
\end{tabular}

FEC ID number of contributing federal political committee.

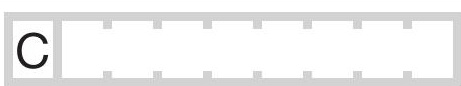

Name of Employer
Information Requested
Receipt For: 2012
X Primary
Other (specify) General

Occupation Information Requested

Election Cycle-to-Date

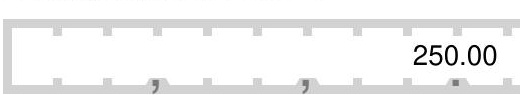

B. Full Name (Last, First, Middle Initial)

Mr. Donald S. Simpson

Mailing Address 18543 Ravenwood Dr.

\begin{tabular}{lcc}
\hline City & State & Zip Code \\
Saratoga & CA & $95070-5649$
\end{tabular}

FEC ID number of contributing

federal political committee.

C

Name of Employer
Information Requested
Receipt For: 2012
X Primary
Other (specify)

\section{Occupation}

Information Requested

Election Cycle-to-Date

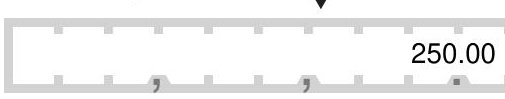

Transaction ID : A56293ACCC1634E57BA0

Date of Receipt

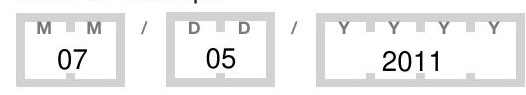

Amount of Each Receipt this Period

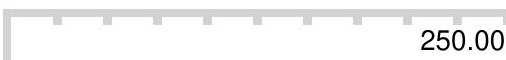

Transaction ID : A1B1D7454D9404ED99D1

Date of Receipt

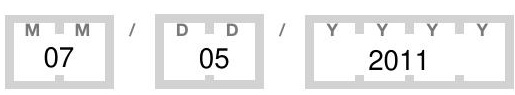

Amount of Each Receipt this Period

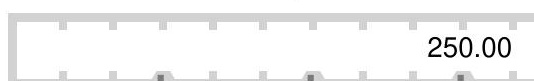

Transaction ID : A9F6B5510401643EAAE1 Date of Receipt

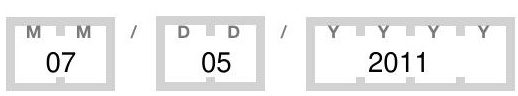

Amount of Each Receipt this Period

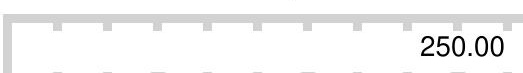

C. Full Name (Last, First, Middle Initial)

Bruce-Radar Radford

Mailing Address PO Box 10408

\begin{tabular}{lcc}
\hline City & State & Zip Code \\
Burke & VA & $22009-0408$
\end{tabular}

FEC ID number of contributing federal political committee.

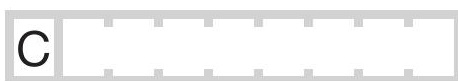

\section{Name of Employer}

Self Employed

entrepr

Receipt For: 2012

Х $\begin{aligned} & \text { Primary } \\ & \text { Other (specify) }\end{aligned}$

Subtotal Of Receipts This Page (optional)

Total This Period (last page this line number only)
750.00

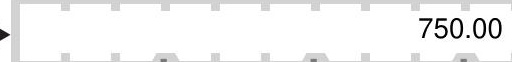

a 1 ,

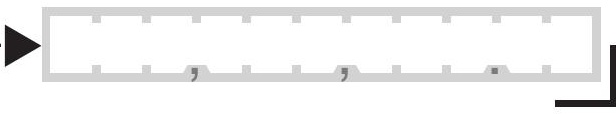

FEC Schedule A-P (Form 3P) (Rev. 03/2011) 
SCHEDULE A-P ITEMIZED RECEIPTS
Use separate schedule(s) for each category of the Detailed Summary Page
FOR LINE NUMBER: (check only one)

\begin{tabular}{|c|c|c|c|c|c|c|}
\hline & & & & & & \\
\hline 16 & $\times 1$ & $17 a$ & $17 b$ & $17 c$ & $17 d$ & 18 \\
\hline $19 a$ & & $19 b$ & $20 \mathrm{a}$ & $20 \mathrm{~b}$ & $20 \mathrm{c}$ & 21 \\
\hline
\end{tabular}

Any information copied from such Reports and Statements may not be sold or used by any person for the purpose of soliciting contributions or for commercial purposes, other than using the name and address of any political committee to solicit contributions from such committee.

NAME OF COMMITTEE (In Full)

\section{Friends of Herman Cain}

A. Full Name (Last, First, Middle Initial)

Norman Goldstein

Mailing Address 10200 Stafford Lane

\begin{tabular}{lcc}
\hline City & State & Zip Code \\
Ellicott City & MD & $21042-5862$ \\
\hline
\end{tabular}

FEC ID number of contributing

federal political committee.

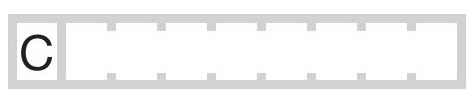

Name of Employer
Information Requested
Receipt For: 2012
X Primary $\quad \square$ General
Other (specify)

Occupation

Information Requested

Election Cycle-to-Date

250.00

B. Full Name (Last, First, Middle Initial)

steven kimball

Mailing Address 2224spininngwheel lane

\begin{tabular}{lcc}
\hline City & State & Zip Code \\
Cincinnati & OH & 45244 \\
\hline
\end{tabular}

FEC ID number of contributing

federal political committee.

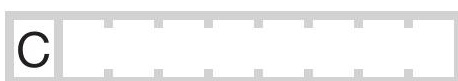

Name of Employer
Emersion Design
Receipt For: 2012
X Primary $\quad$ General
Other (specify)

\section{Occupation}

CEO

Election Cycle-to-Date

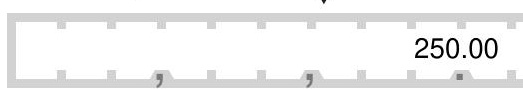

Transaction ID : A86877E9DED074EBFA90

Date of Receipt

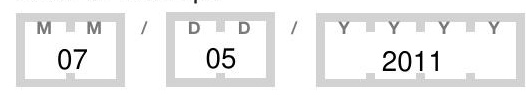

Amount of Each Receipt this Period

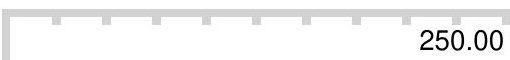

C. Full Name (Last, First, Middle Initial)

Mr Dennis B Lazzari

Mailing Address 1211 N Diamond Bar Blvd

\begin{tabular}{lcc}
\hline City & State & Zip Code \\
Diamond Bar & CA & $91765-1151$
\end{tabular}

FEC ID number of contributing

federal political committee.

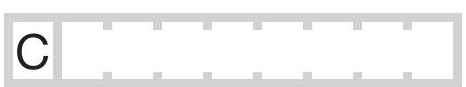

Name of Employer
Los Angeles Cnty
Receipt For: 2012
X Primary
Other (specify) General

Occupation

Retired

Election Cycle-to-Date

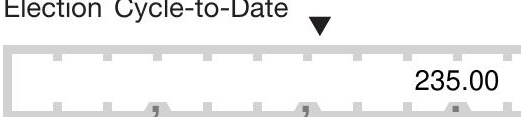

Amount of Each Receipt this Period

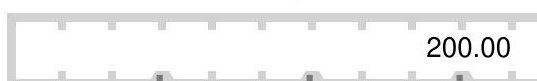

Transaction ID : A061EFC34325F46D0803

Date of Receipt

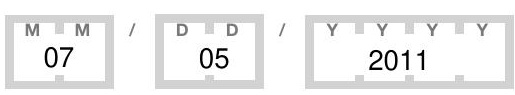

Transaction ID : A02D3BB45F2D141C8AFA Date of Receipt

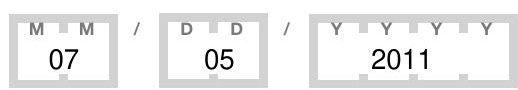

Amount of Each Receipt this Period

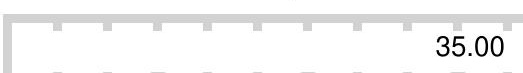

\section{Subtotal Of Receipts This Page (optional)}

485.00

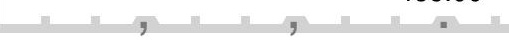

Total This Period (last page this line number only)

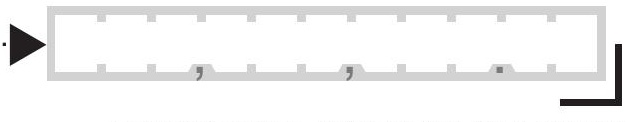

FEC Schedule A-P (Form 3P) (Rev. 03/2011) 
SCHEDULE A-P ITEMIZED RECEIPTS
Use separate schedule(s) for each category of the Detailed Summary Page
FOR LINE NUMBER: (check only one)

\begin{tabular}{|c|c|c|c|c|c|}
\hline & & & & & \\
\hline 16 & $\begin{array}{ll}X & 17 a \\
\end{array}$ & $17 \mathrm{~b}$ & $17 c$ & $17 d$ & 18 \\
\hline $19 a$ & $19 b$ & $20 \mathrm{a}$ & $20 \mathrm{~b}$ & $20 c$ & 21 \\
\hline
\end{tabular}

Any information copied from such Reports and Statements may not be sold or used by any person for the purpose of soliciting contributions or for commercial purposes, other than using the name and address of any political committee to solicit contributions from such committee.

NAME OF COMMITTEE (In Full)

\section{Friends of Herman Cain}

A. Full Name (Last, First, Middle Initial)

John Tafel

Mailing Address 7369 Central Ave

\begin{tabular}{lcc}
\hline City & State & Zip Code \\
Glenside & PA & 19038
\end{tabular}

FEC ID number of contributing

federal political committee.

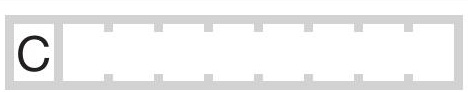

Name of Employer
Information Requested
Receipt For: 2012
X Primary $\quad \square$ General
Other (specify)

Occupation

Information Requested

Election Cycle-to-Date

500.00

B. Full Name (Last, First, Middle Initial)

Sunny Park

Mailing Address 3835 Presidential Parkway 200

\begin{tabular}{lcc}
\hline City & State & Zip Code \\
Atlanta & GA & $30340-3724$
\end{tabular}

FEC ID number of contributing

federal political committee.

C

Name of Employer
Information Requested
Receipt For: 2012
X Primary
Other (specify)

Occupation

Information Requested

Election Cycle-to-Date

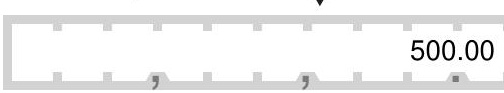

Transaction ID : A4AFA2D6EB8274964B7F

Date of Receipt

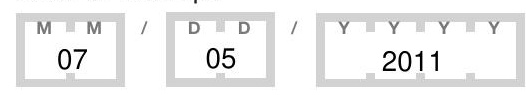

Amount of Each Receipt this Period

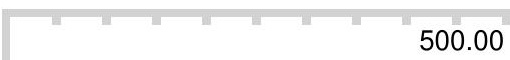

C. Full Name (Last, First, Middle Initial)

Ms Lenora H Pusta

Mailing Address 138 W Sunflower Dr

\begin{tabular}{lcc}
\hline City & State & Zip Code \\
Payson & AZ & $85541-6152$ \\
\hline
\end{tabular}

FEC ID number of contributing

federal political committee.

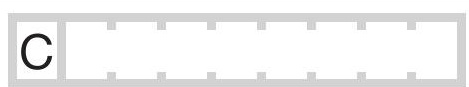

Name of Employer
None
Receipt For: 2012
Х Primary $\quad \square$ General
Other (specify)

Occupation

Retired

Election Cycle-to-Date

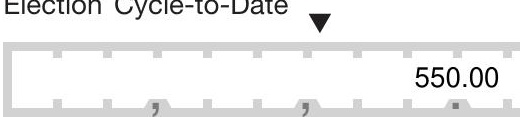

Transaction ID : A6A20C15682C844EBBFC Date of Receipt

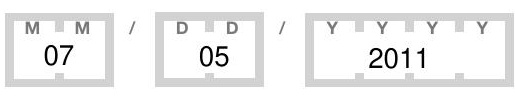

Amount of Each Receipt this Period

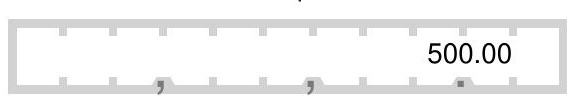

Transaction ID : AE4EF704EEB8848C99AA Date of Receipt

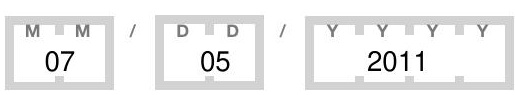

Amount of Each Receipt this Period

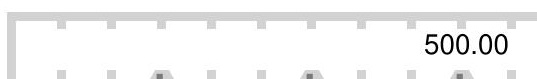

\section{Subtotal Of Receipts This Page (optional)}

Total This Period (last page this line number only) 
SCHEDULE A-P ITEMIZED RECEIPTS
Use separate schedule(s) for each category of the Detailed Summary Page
FOR LINE NUMBER: (check only one)

\begin{tabular}{|c|c|c|c|c|c|c|}
\hline & & & & & & \\
\hline 16 & $\times 1$ & $17 a$ & $17 b$ & $17 c$ & $17 d$ & 18 \\
\hline $19 a$ & & $19 b$ & $20 \mathrm{a}$ & $20 \mathrm{~b}$ & $20 \mathrm{c}$ & 21 \\
\hline
\end{tabular}

Any information copied from such Reports and Statements may not be sold or used by any person for the purpose of soliciting contributions or for commercial purposes, other than using the name and address of any political committee to solicit contributions from such committee.

NAME OF COMMITTEE (In Full)

\section{Friends of Herman Cain}

A. Full Name (Last, First, Middle Initial)

Mrs. Peter Van Dyk Berg

Mailing Address 301 Michigan Rd.

\begin{tabular}{lcc}
\hline City & State & Zip Code \\
New Canaan & CT & $06840-2230$
\end{tabular}

FEC ID number of contributing federal political committee.

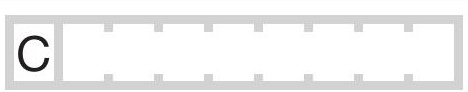

Name of Employer
Information Requested
Receipt For: 2012
X Primary
Other (specify) General

Occupation Information Requested

Election Cycle-to-Date

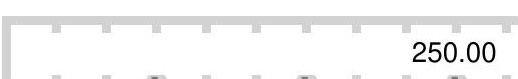

B. Full Name (Last, First, Middle Initial)

Miss Patricia Bonaparte

Mailing Address 775 Johnston St

\begin{tabular}{lcc}
\hline City & State & Zip Code \\
Half Moon Bay & CA & $94019-1958$
\end{tabular}

FEC ID number of contributing

federal political committee.

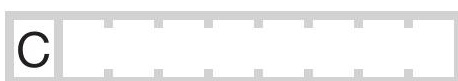

Name of Employer
Self Employed
Receipt For: 2012
X Primary
Other (specify)

\section{Occupation}

Accountant

Election Cycle-to-Date

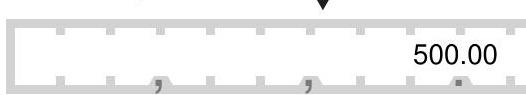

Transaction ID : A8A48DF99E0B94F29BC8

Date of Receipt

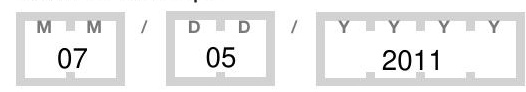

Amount of Each Receipt this Period

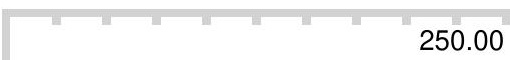

250.00

C. Full Name (Last, First, Middle Initial)

Richard Thoms Crowder

Mailing Address 501 Slaters Ln Apt 1219

\begin{tabular}{lcc}
\hline City & State & Zip Code \\
Alexandria & VA & $22314-1139$
\end{tabular}

FEC ID number of contributing federal political committee.

C

22314-1139

Name of Employer

Information Requested

Occupation

Receipt For: 2012

Х $\begin{aligned} & \text { Primary } \square \text { General } \\ & \text { Other (specify) }\end{aligned}$

Information Requested

Election Cycle-to-Date

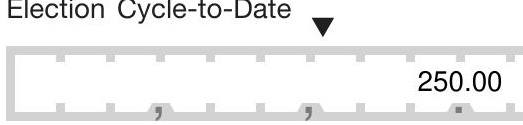

Amount of Each Receipt this Period

Transaction ID : ACBE39B03146949A1923

Date of Receipt
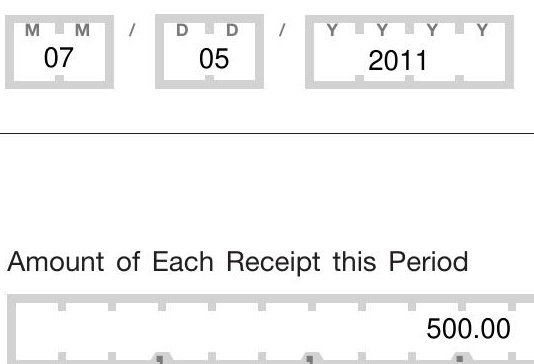

Transaction ID : A728335E4D9B64FA682B

Date of Receipt

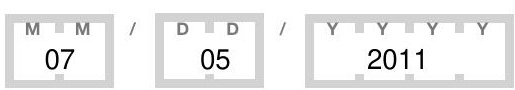

Amount of Each Receipt this Period

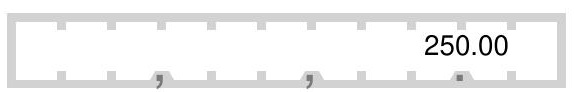

Subtotal Of Receipts This Page (optional).

1000.00

Total This Period (last page this line number only) 
SCHEDULE A-P ITEMIZED RECEIPTS
Use separate schedule(s) for each category of the Detailed Summary Page
FOR LINE NUMBER: (check only one)
PAGE 29 / 1572

\begin{tabular}{|c|c|c|c|c|c|}
\hline & & & & & \\
\hline 16 & $\begin{array}{lll}X & 17 a \\
\end{array}$ & $17 \mathrm{~b}$ & $17 c$ & $17 d$ & 18 \\
\hline $19 a$ & $19 b$ & $20 a$ & $20 \mathrm{~b}$ & $20 c$ & 21 \\
\hline
\end{tabular}

Any information copied from such Reports and Statements may not be sold or used by any person for the purpose of soliciting contributions or for commercial purposes, other than using the name and address of any political committee to solicit contributions from such committee.

NAME OF COMMITTEE (In Full)

\section{Friends of Herman Cain}

A. Full Name (Last, First, Middle Initial) James Stewart

Mailing Address 3560 E. Via Colonia del Sol

\begin{tabular}{lcc}
\hline City & State & Zip Code \\
Tucson & AZ & $85718-6065$
\end{tabular}

FEC ID number of contributing federal political committee.

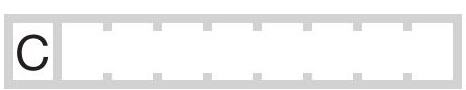

Name of Employer
Information Requested
Receipt For: 2012
X Primary
Other (specify) General

Occupation Information Requested Election Cycle-to-Date 568.00

B. Full Name (Last, First, Middle Initial)

Craig M Gradick

Mailing Address 4410 Village Oaks Trail

\begin{tabular}{lcc}
\hline City & State & Zip Code \\
Atlanta & GA & $30338-5726$ \\
\hline
\end{tabular}

FEC ID number of contributing

federal political committee.

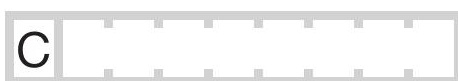

Name of Employer
PGE
Receipt For: 2012
X Primary
Other (specify)

\section{Occupation}

Engineer

Election Cycle-to-Date

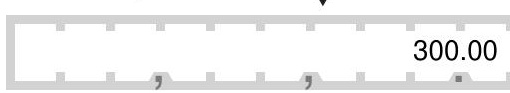

C. Full Name (Last, First, Middle Initial)

Terrence Diefenbacher

Mailing Address 5570 Yeatman Road

\begin{tabular}{lcc}
\hline City & State & Zip Code \\
Cincinnati & OH & $45252-1444$
\end{tabular}

FEC ID number of contributing federal political committee.

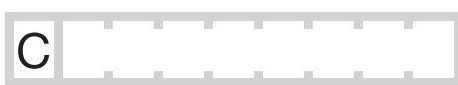

Name of Employer

Cincinnati Christian Schools

Receipt For: 2012

Х $\begin{aligned} & \text { Primary } \square \text { General } \\ & \text { Other (specify) }\end{aligned}$

Occupation

School Administrator

Election Cycle-to-Date
Transaction ID : AFC57F7C69A40400782D

Date of Receipt

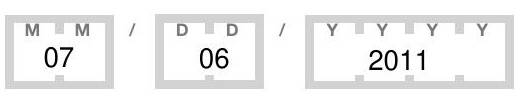

Amount of Each Receipt this Period

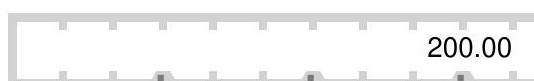

Transaction ID : AD0E24448B4D741F5B57 Date of Receipt

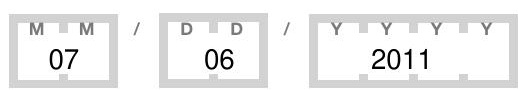

Amount of Each Receipt this Period

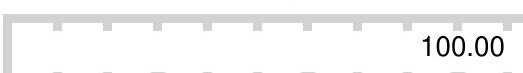

\section{Subtotal Of Receipts This Page (optional)}

Total This Period (last page this line number only) 
SCHEDULE A-P ITEMIZED RECEIPTS
Use separate schedule(s) for each category of the Detailed Summary Page
FOR LINE NUMBER: (check only one)

\begin{tabular}{|c|c|c|c|c|c|}
\hline & & & & & \\
\hline 16 & $\begin{array}{ll}X & 17 a \\
\end{array}$ & $17 \mathrm{~b}$ & $17 c$ & $17 d$ & 18 \\
\hline $19 a$ & $19 b$ & $20 \mathrm{a}$ & $20 \mathrm{~b}$ & $20 c$ & 21 \\
\hline
\end{tabular}

Any information copied from such Reports and Statements may not be sold or used by any person for the purpose of soliciting contributions or for commercial purposes, other than using the name and address of any political committee to solicit contributions from such committee.

NAME OF COMMITTEE (In Full)

\section{Friends of Herman Cain}

A. Full Name (Last, First, Middle Initial)

Lance Wilson

Mailing Address 200 Riverside Blvd. Apt. 23 E

\begin{tabular}{lcc}
\hline City & State & Zip Code \\
New York & NY & $10069-0901$
\end{tabular}

FEC ID number of contributing

federal political committee.

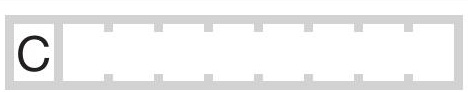

Name of Employer
Oppenheimer \& Company
Receipt For: 2012
X Primary $\quad \square$ General
Other (specify)

Occupation banker

Election Cycle-to-Date

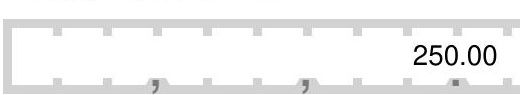

B. Full Name (Last, First, Middle Initial)

Anne Fesler-Butts

Mailing Address $295 \mathrm{~N}$ Val Vista Rd

\begin{tabular}{lcc}
\hline City & State & Zip Code \\
Apache Junction & AZ & $85119-8854$ \\
\hline
\end{tabular}

FEC ID number of contributing

federal political committee.

C

Name of Employer
Information Requested
Receipt For: 2012
X Primary
Other (specify)

Occupation

Information Requested

Election Cycle-to-Date

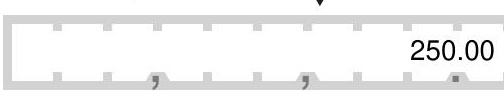

Transaction ID : ACD952F3C5B7C4440A1C

Date of Receipt

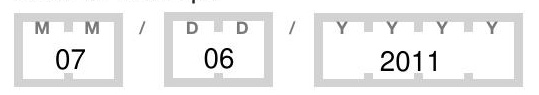

Amount of Each Receipt this Period

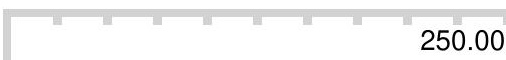

Amount of Each Receipt this Period

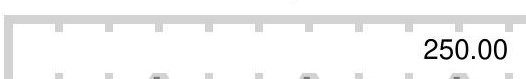

C. Full Name (Last, First, Middle Initial)

Mrs. Mary D. Hinton

Mailing Address 5207 Lakedale Dr

\begin{tabular}{lcc}
\hline City & State & Zip Code \\
Durham & NC & $27713-6088$
\end{tabular}

FEC ID number of contributing

federal political committee.

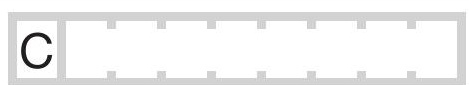

Name of Employer

Occupation

Credit Sousse

Computer Programmer

Receipt For: 2012

Х $\begin{aligned} & \text { Primary } \square \text { General } \\ & \text { Other (specify) }\end{aligned}$

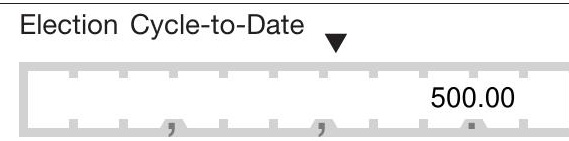

Amount of Each Receipt this Period

Transaction ID : AB1F0BABBFCB344C89E9 Date of Receipt
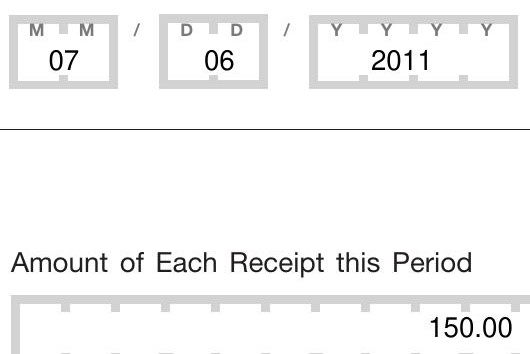

Subtotal Of Receipts This Page (optional)

650.00

Total This Period (last page this line number only) 
SCHEDULE A-P ITEMIZED RECEIPTS
Use separate schedule(s) for each category of the Detailed Summary Page
FOR LINE NUMBER: (check only one)

\begin{tabular}{|c|c|c|c|c|c|}
\hline & & & & & \\
\hline 16 & $\begin{array}{ll}X & 17 a \\
\end{array}$ & $17 \mathrm{~b}$ & $17 c$ & $17 d$ & 18 \\
\hline $19 a$ & $19 b$ & $20 \mathrm{a}$ & $20 \mathrm{~b}$ & $20 c$ & 21 \\
\hline
\end{tabular}

Any information copied from such Reports and Statements may not be sold or used by any person for the purpose of soliciting contributions or for commercial purposes, other than using the name and address of any political committee to solicit contributions from such committee.

NAME OF COMMITTEE (In Full)

\section{Friends of Herman Cain}

A. Full Name (Last, First, Middle Initial)

\section{Beatrice A Santelli}

Mailing Address 7342 Firefly Court

City

Hoschton

FEC ID number of contributing

federal political committee.

Name of Employer
self
Receipt For: 2012
X Primary
$\square$ Other (specify)

B. Full Name (Last, First, Middle Initial)

Arthur Stone

Mailing Address 1810 Reavis Mtn Rd

\begin{tabular}{lcc}
\hline City & State & Zip Code \\
Ball Ground & GA & $30107-2752$ \\
\hline
\end{tabular}

FEC ID number of contributing

federal political committee.

C

Name of Employer
Information Requested
Receipt For: 2012
X Primary
Other (specify)

C. Full Name (Last, First, Middle Initial)

Glen Ebbing

Mailing Address 1400 Huntleigh Rd

\section{City}

Quincy

FEC ID number of contributing

federal political committee.

Name of Employer
ColorMaster Pain Inc
Receipt For: 2012
X Primary
Other (specify) General

Information Requested

Election Cycle-to-Date
Occupation

Psychotherapist

Election Cycle-to-Date

275.00
Transaction ID : A4493E42C7C2C4F60A22

Date of Receipt

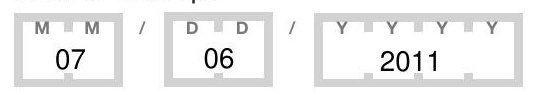

Amount of Each Receipt this Period

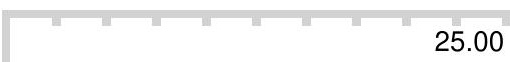

25.00

Amount of Each Receipt this Period

Transaction ID : A8D5484E829134F98B1E

Date of Receipt
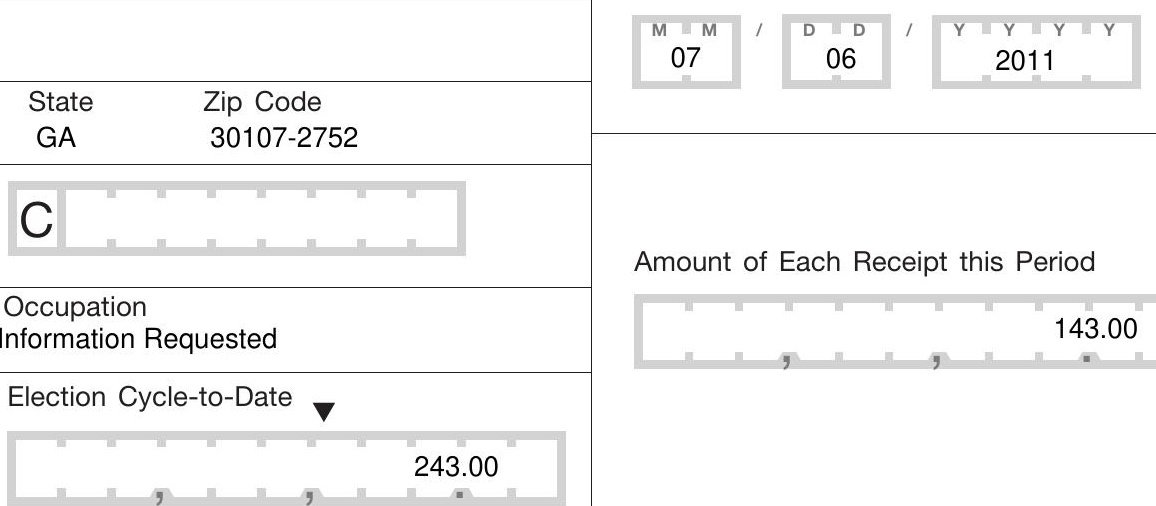

243.00

Transaction ID : A5BE0237432EB4B5B825

Date of Receipt

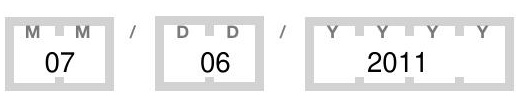

Amount of Each Receipt this Period

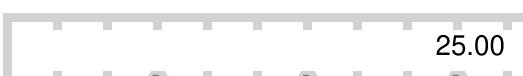

228.00

Subtotal Of Receipts This Page (optional)

193.00

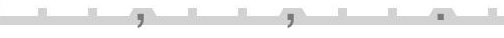

Total This Period (last page this line number only)

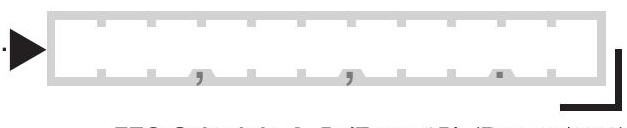

FEC Schedule A-P (Form 3P) (Rev. 03/2011) 
SCHEDULE A-P ITEMIZED RECEIPTS
Use separate schedule(s) for each category of the Detailed Summary Page
FOR LINE NUMBER: (check only one)

\begin{tabular}{|c|c|c|c|c|c|}
\hline & & & & & \\
\hline 16 & $\begin{array}{ll}X & 17 a \\
\end{array}$ & $17 \mathrm{~b}$ & $17 c$ & $17 d$ & 18 \\
\hline $19 a$ & $19 b$ & $20 \mathrm{a}$ & $20 \mathrm{~b}$ & $20 c$ & 21 \\
\hline
\end{tabular}

Any information copied from such Reports and Statements may not be sold or used by any person for the purpose of soliciting contributions or for commercial purposes, other than using the name and address of any political committee to solicit contributions from such committee.

NAME OF COMMITTEE (In Full)

\section{Friends of Herman Cain}

A. Full Name (Last, First, Middle Initial)

\section{Susan Walter}

Mailing Address P.O. Box 690

\begin{tabular}{lcc}
\hline City & State & Zip Code \\
Sautee Nacoochee & GA & $30571-0690$ \\
\hline
\end{tabular}

FEC ID number of contributing federal political committee.

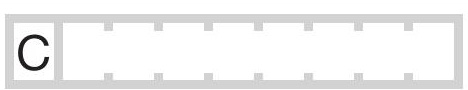

Name of Employer
None
Receipt For: 2012
X Primary $\quad$ General
Other (specify)

Occupation Retired

Election Cycle-to-Date

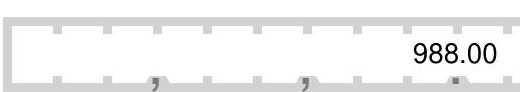

B. Full Name (Last, First, Middle Initial)

Kate C Thompson

Mailing Address PO Box 221

\begin{tabular}{lcc}
\hline City & State & Zip Code \\
Port Washington & OH & $43837-0221$ \\
\hline
\end{tabular}

FEC ID number of contributing

federal political committee.

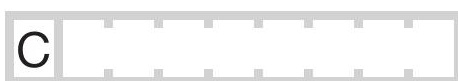

Name of Employer
Retired
Receipt For: 2012
X Primary
Other (specify)

\section{Occupation}

Retired

Election Cycle-to-Date

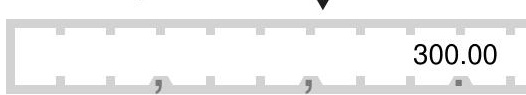

Transaction ID : AB128A9F4F3C441A497C

Date of Receipt

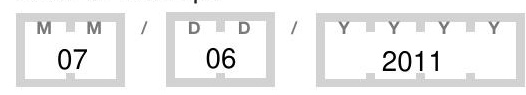

Amount of Each Receipt this Period

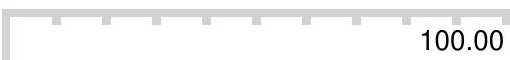

Amount of Each Receipt this Period

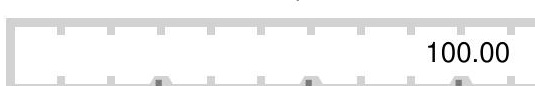

C. Full Name (Last, First, Middle Initial)

James $\mathrm{R}$ Thompson

Mailing Address 4018 Keeneland Court

\begin{tabular}{lcc}
\hline City & State & Zip Code \\
Duluth & GA & $30096-5419$
\end{tabular}

FEC ID number of contributing federal political committee.

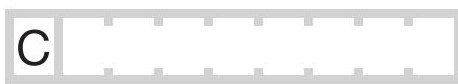

Name of Employer

Information Requested

Occupation

Information Requested

Receipt For: 2012

Х $\begin{aligned} & \text { Primary } \square \text { General } \\ & \text { Other (specify) }\end{aligned}$

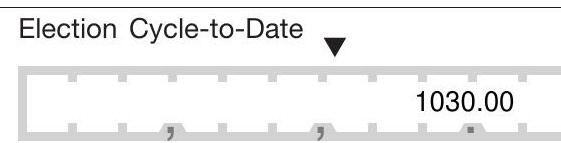

Amount of Each Receipt this Period

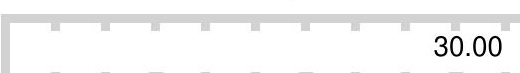

Transaction ID : ADF9ECF3929CB4B79A1E Date of Receipt

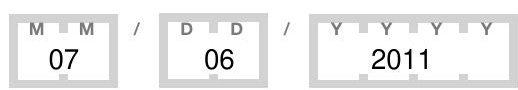

Subtotal Of Receipts This Page (optional)

Total This Period (last page this line number only) 
SCHEDULE A-P ITEMIZED RECEIPTS
Use separate schedule(s) for each category of the Detailed Summary Page
FOR LINE NUMBER: (check only one)

\begin{tabular}{|c|c|c|c|c|c|}
\hline & & & & & \\
\hline 16 & $\begin{array}{ll}X & 17 a \\
\end{array}$ & $17 \mathrm{~b}$ & $17 c$ & $17 d$ & 18 \\
\hline $19 a$ & $19 b$ & $20 \mathrm{a}$ & $20 \mathrm{~b}$ & $20 c$ & 21 \\
\hline
\end{tabular}

Any information copied from such Reports and Statements may not be sold or used by any person for the purpose of soliciting contributions or for commercial purposes, other than using the name and address of any political committee to solicit contributions from such committee.

NAME OF COMMITTEE (In Full)

\section{Friends of Herman Cain}

A. Full Name (Last, First, Middle Initial)

Mr Edward L Reed

Mailing Address 1337 Briarcliff Dr

\begin{tabular}{lcc}
\hline City & State & Zip Code \\
Rantoul & IL & $61866-1701$
\end{tabular}

FEC ID number of contributing federal political committee.

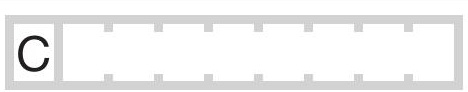

Name of Employer
Retired
Receipt For: 2012
X Primary $\quad$ General
Other (specify)

Occupation Retired

Election Cycle-to-Date

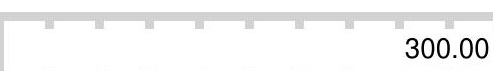

B. Full Name (Last, First, Middle Initial)

Thomas Piper

Mailing Address 1704 RAINIER sT.

\begin{tabular}{lcc}
\hline City & State & Zip Code \\
Idaho Falls & ID & $83402-2533$
\end{tabular}

FEC ID number of contributing

federal political committee.

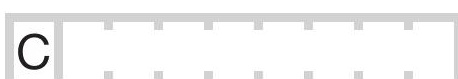

Name of Employer
Retired
Receipt For: 2012
X Primary
Other (specify)

\section{Occupation}

Retired

Election Cycle-to-Date

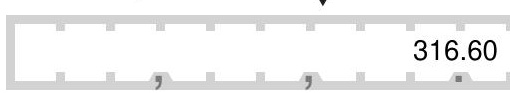

Transaction ID : AF03042BA9E3E4961AC8

Date of Receipt

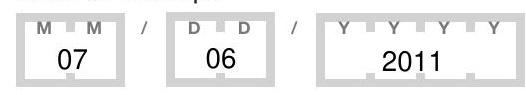

Amount of Each Receipt this Period

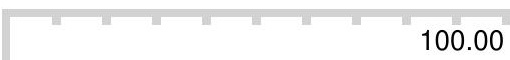

C. Full Name (Last, First, Middle Initial)

Van P Cunningham

Mailing Address 111 Barkwood Dr

\begin{tabular}{lcc}
\hline City & State & Zip Code \\
Dahlonega & GA & $30533-4641$
\end{tabular}

FEC ID number of contributing federal political committee.

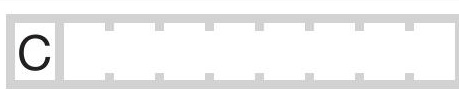

Name of Employer
None
Receipt For: 2012
Х Primary $\quad \square$ General
Other (specify)

Occupation

Retired

Election Cycle-to-Date

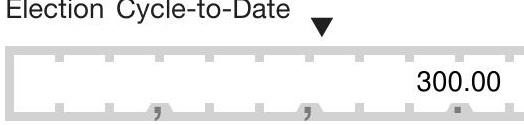

Transaction ID : A22C8D1D0006B4BACB2C Date of Receipt

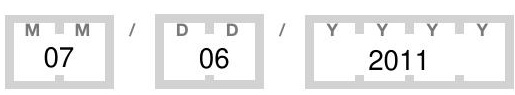

Amount of Each Receipt this Period

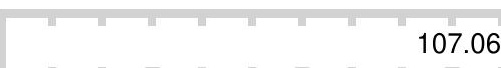

Transaction ID : A5A75649A4C4E4465A44 Date of Receipt

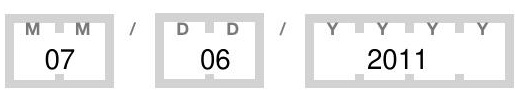

Amount of Each Receipt this Period

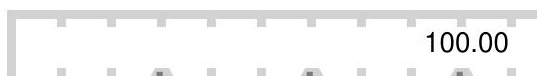

\section{Subtotal Of Receipts This Page (optional)}

307.06

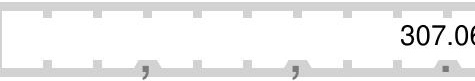

Total This Period (last page this line number only)

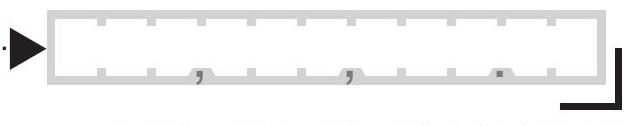

FEC Schedule A-P (Form 3P) (Rev. 03/2011) 
SCHEDULE A-P ITEMIZED RECEIPTS
Use separate schedule(s) for each category of the Detailed Summary Page
FOR LINE NUMBER: (check only one)

\begin{tabular}{|c|c|c|c|c|c|}
\hline & & & & & \\
\hline 16 & $\begin{array}{ll}X & 17 a \\
\end{array}$ & $17 \mathrm{~b}$ & $17 c$ & $17 d$ & 18 \\
\hline $19 a$ & $19 b$ & $20 \mathrm{a}$ & $20 \mathrm{~b}$ & $20 c$ & 21 \\
\hline
\end{tabular}

Any information copied from such Reports and Statements may not be sold or used by any person for the purpose of soliciting contributions or for commercial purposes, other than using the name and address of any political committee to solicit contributions from such committee.

NAME OF COMMITTEE (In Full)

\section{Friends of Herman Cain}

A. Full Name (Last, First, Middle Initial)

William Donohue

Mailing Address 7 Vicksburg Ct.

\begin{tabular}{lcc}
\hline City & State & Zip Code \\
Madison & WI & $53718-3154$
\end{tabular}

FEC ID number of contributing federal political committee.

Name of Employer
State Farm Insurance Co.
Receipt For: 2012
X Primary
Other (specify) General

B. Full Name (Last, First, Middle Initial)

Richard Van Dresser

Mailing Address 602 Maple Ave

\begin{tabular}{lcc}
\hline City & State & Zip Code \\
Pueblo & CO & $81005-1716$ \\
\hline
\end{tabular}

FEC ID number of contributing

federal political committee.

C

Name of Employer
ABC Rail Corp.
Receipt For: 2012
X Primary $\square$ General
Other (specify)

C. Full Name (Last, First, Middle Initial)

Kamau Bakari

Mailing Address 1584 Spring Rain Rd.

\begin{tabular}{lcc}
\hline City & State & Zip Code \\
Las Vegas & NV & $89142-7900$ \\
\hline
\end{tabular}

FEC ID number of contributing federal political committee.

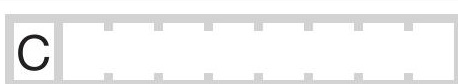

Name of Employer
Kemet Electric LLC
Receipt For: 2012
X Primary $\quad \square$ General
Other (specify)

Occupation

Election Cycle-to-Date

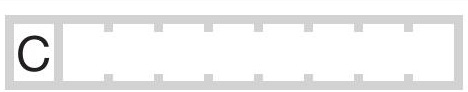

Occupation

Retired

Election Cycle-to-Date

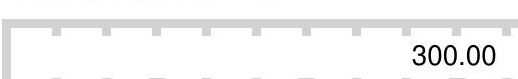

\section{Occupation}

Retired

Election Cycle-to-Date

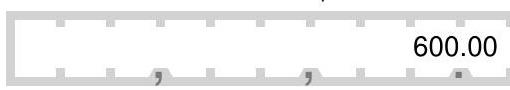

Transaction ID : A51F8A2ABAACC4EB8A66

Date of Receipt

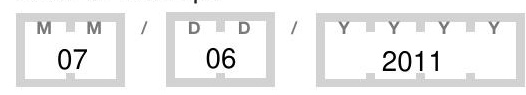

Amount of Each Receipt this Period

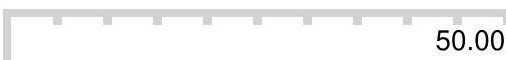

50.00

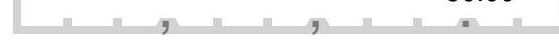

Transaction ID : A3A2227A85A664CE685B

Date of Receipt

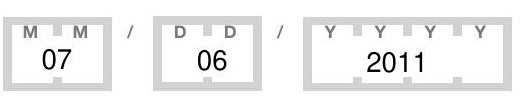

Amount of Each Receipt this Period

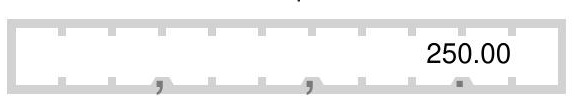

Transaction ID : A1AE7BF53D5A54D51B1B Date of Receipt

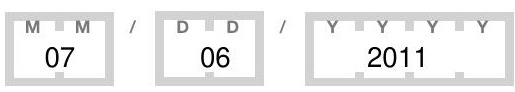

Amount of Each Receipt this Period

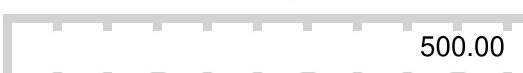

1250.00
Subtotal Of Receipts This Page (optional)

800.00

a

Total This Period (last page this line number only)

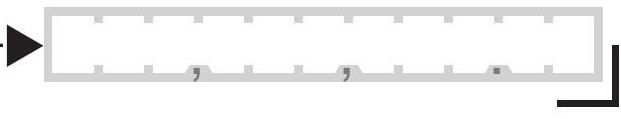

FEC Schedule A-P (Form 3P) (Rev. 03/2011) 
SCHEDULE A-P ITEMIZED RECEIPTS
Use separate schedule(s) for each category of the Detailed Summary Page
FOR LINE NUMBER: (check only one)

\begin{tabular}{|c|c|c|c|c|c|}
\hline & & & & & \\
\hline 16 & $\begin{array}{ll}X & 17 a \\
\end{array}$ & $17 \mathrm{~b}$ & $17 c$ & $17 d$ & 18 \\
\hline $19 a$ & $19 b$ & $20 \mathrm{a}$ & $20 \mathrm{~b}$ & $20 c$ & 21 \\
\hline
\end{tabular}

Any information copied from such Reports and Statements may not be sold or used by any person for the purpose of soliciting contributions or for commercial purposes, other than using the name and address of any political committee to solicit contributions from such committee.

NAME OF COMMITTEE (In Full)

\section{Friends of Herman Cain}

A. Full Name (Last, First, Middle Initial)

\section{Carol Czechowski}

Mailing Address PO Box 190

\begin{tabular}{lcc}
\hline City & State & Zip Code \\
Good Hope & GA & $30641-0190$
\end{tabular}

FEC ID number of contributing federal political committee.

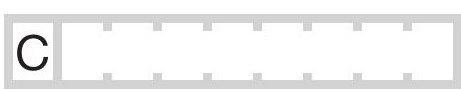

Name of Employer
Self Employed
Receipt For: 2012
X Primary $\quad$ General
Other (specify)

B. Full Name (Last, First, Middle Initial) James Dooley

\section{Mailing Address 17 Redfern Ct}

\begin{tabular}{lcc}
\hline City & State & Zip Code \\
Lincroft & NJ & $07738-1830$
\end{tabular}

FEC ID number of contributing

federal political committee.

C

Name of Employer

Stone Harbor Investment Partners

Receipt For: 2012

X Primary $\square$ General Other (specify) $\nabla$
Occupation

Cast Glass Mfg.

Election Cycle-to-Date

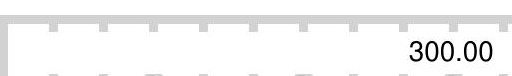

Transaction ID : AB373727621AF4412896

Date of Receipt

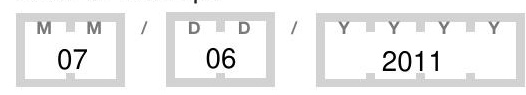

Amount of Each Receipt this Period

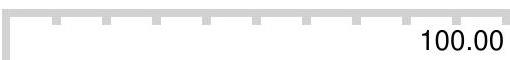

100.00
Amount of Each Receipt this Period

Occupation
Manager
Election Cycle-to-Date

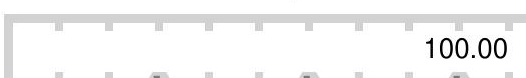

C. Full Name (Last, First, Middle Initial)

Stephen H Perry

Mailing Address 517 Carilion Ln

\begin{tabular}{lcc}
\hline City & State & Zip Code \\
Greenville & SC & $29617-7914$
\end{tabular}

FEC ID number of contributing federal political committee.

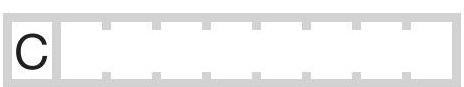

Name of Employer
Information Requested
Receipt For: 2012
X Primary $\quad \square$ General
Other (specify)

\section{Occupation}

Information Requested

Election Cycle-to-Date

Transaction ID : A1CC68AEECB3A47379EC Date of Receipt

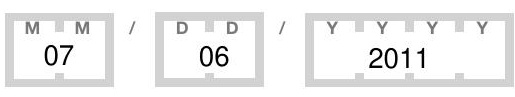

Transaction ID : ABFE33751E9C340478BE Date of Receipt

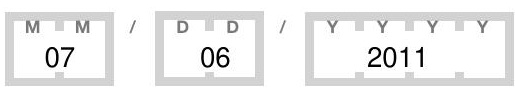

Amount of Each Receipt this Period

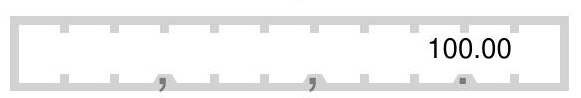

405.00

\section{Subtotal Of Receipts This Page (optional)}

Total This Period (last page this line number only) 


\section{SCHEDULE A-P} ITEMIZED RECEIPTS
Use separate schedule(s)

for each category of the

Detailed Summary Page
FOR LINE NUMBER: (check only one)
PAGE $36 / 1572$

\begin{tabular}{|c|c|c|c|c|c|}
\hline & & & & & \\
\hline 16 & $\mathbf{X} 17 \mathrm{a}$ & $17 \mathrm{~b}$ & $17 c$ & $17 d$ & 18 \\
\hline $19 a$ & $19 b$ & $20 a$ & $20 \mathrm{~b}$ & $20 c$ & 21 \\
\hline
\end{tabular}

Any information copied from such Reports and Statements may not be sold or used by any person for the purpose of soliciting contributions or for commercial purposes, other than using the name and address of any political committee to solicit contributions from such committee.

NAME OF COMMITTEE (In Full)

\section{Friends of Herman Cain}

A. Full Name (Last, First, Middle Initial)

Boyztown Restoration, LLC

Mailing Address 504 Creekside Way

\begin{tabular}{lcc}
\hline City & State & Zip Code \\
Peachtree City & GA & 30269 \\
\hline
\end{tabular}

FEC ID number of contributing

federal political committee.

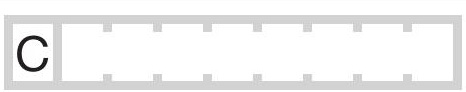

Name of Employer
Receipt For: 2012
P Primary $\quad \square$ General
Other (specify)

Occupation

Election Cycle-to-Date

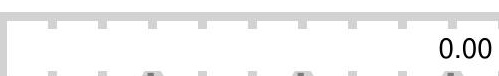

B. Full Name (Last, First, Middle Initial)

marilyn Sensney

Mailing Address 19528 Creekside Ct

\begin{tabular}{lcc}
\hline City & State & Zip Code \\
Salinas & CA & $93908-1245$
\end{tabular}

FEC ID number of contributing

federal political committee.

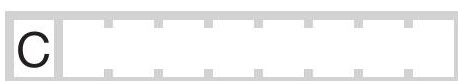

Name of Employer
Monerey School District
Receipt For: 2012
Xrimary
Other (specify)

Occupation

Teacher

Election Cycle-to-Date

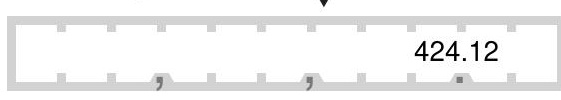

Transaction ID : A310E30EBFC904FB78B8

Date of Receipt

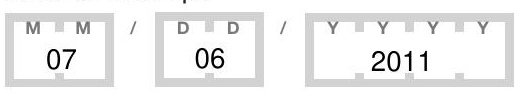

NSF

Amount of Each Receipt this Period

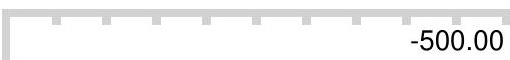

C. Full Name (Last, First, Middle Initial)

Mr. Carl L Franklin

Mailing Address 2179 N. Forest Trail

\begin{tabular}{lcc}
\hline City & State & Zip Code \\
Atlanta & GA & $30338-5826$ \\
\hline
\end{tabular}

FEC ID number of contributing

federal political committee.

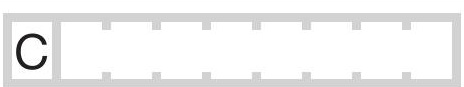

Name of Employer

Franklin Diamonds

\section{Occupation}

Owner

Receipt For: 2012

Х $\begin{aligned} & \text { Primary } \square \text { General } \\ & \text { Other (specify) }\end{aligned}$

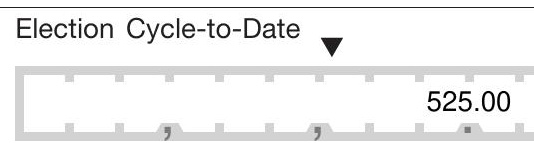

Amount of Each Receipt this Period

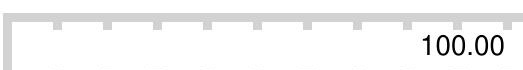

Amount of Each Receipt this Period

Transaction ID : ABE61C5B685C14A50B6E Date of Receipt

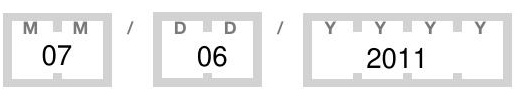

Transaction ID : AA32F24255D624674897

Date of Receipt

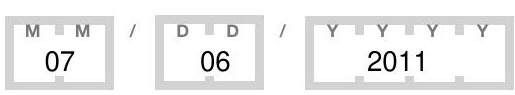

\section{Subtotal Of Receipts This Page (optional)}

$-375.00$

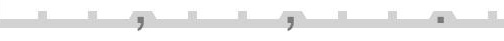

Total This Period (last page this line number only)

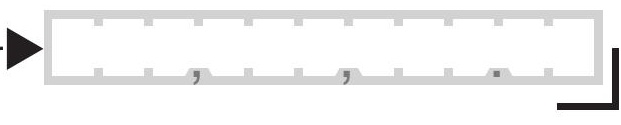

FEC Schedule A-P (Form 3P) (Rev. 03/2011) 
SCHEDULE A-P ITEMIZED RECEIPTS
Use separate schedule(s) for each category of the Detailed Summary Page
FOR LINE NUMBER: (check only one)

\begin{tabular}{|c|c|c|c|c|c|}
\hline & & & & & \\
\hline 16 & $\begin{array}{ll}X & 17 a \\
\end{array}$ & $17 \mathrm{~b}$ & $17 c$ & $17 d$ & 18 \\
\hline $19 a$ & $19 b$ & $20 \mathrm{a}$ & $20 \mathrm{~b}$ & $20 c$ & 21 \\
\hline
\end{tabular}

Any information copied from such Reports and Statements may not be sold or used by any person for the purpose of soliciting contributions or for commercial purposes, other than using the name and address of any political committee to solicit contributions from such committee.

NAME OF COMMITTEE (In Full)

\section{Friends of Herman Cain}

A. Full Name (Last, First, Middle Initial)

\section{Richard Van Dresser}

Mailing Address 602 Maple Ave

\begin{tabular}{lcc}
\hline City & State & Zip Code \\
Pueblo & CO & $81005-1716$ \\
\hline
\end{tabular}

FEC ID number of contributing federal political committee.

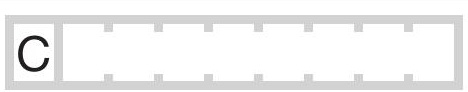

Name of Employer
ABC Rail Corp.
Receipt For: 2012
X Primary $\quad$ General
Other (specify)

B. Full Name (Last, First, Middle Initial)

Raymond A Hallenbeck

Mailing Address 5389 Bear Bluff Drive

\begin{tabular}{lcc}
\hline City & State & Zip Code \\
Conway & SC & $29526-7447$
\end{tabular}

FEC ID number of contributing

federal political committee.

C

Name of Employer
Retired
Receipt For: 2012
X Primary $\quad$ General
Other (specify)

\section{Occupation}

Retired

Election Cycle-to-Date

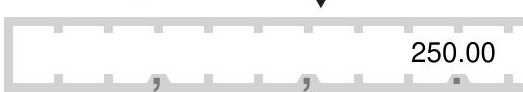

Transaction ID : AB9682F2322D04944ABD

Date of Receipt

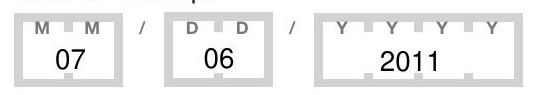

Amount of Each Receipt this Period

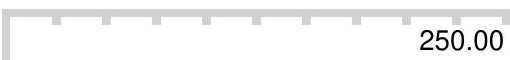

250.00

C. Full Name (Last, First, Middle Initial)

William Perez

Mailing Address 1320 N State Parkway 14 A

\begin{tabular}{lcc}
\hline City & State & Zip Code \\
Chicago & IL & $60610-2455$
\end{tabular}

FEC ID number of contributing federal political committee.

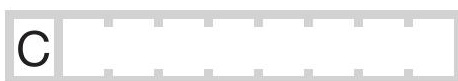

Name of Employer
Greenhul
Receipt For: 2012
X Primary $\quad \square$ General
Other (specify)

\section{Occupation}

Senior Advisor

Election Cycle-to-Date

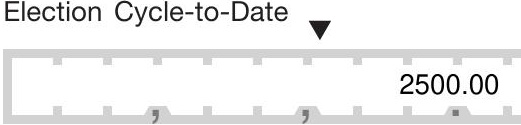

Transaction ID : A956670576AF04723806

Date of Receipt

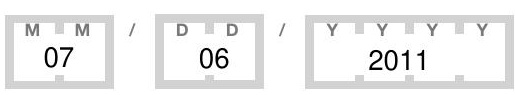

Amount of Each Receipt this Period

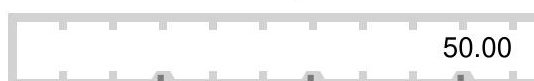

Transaction ID : A898A2EB5F4864DBB8A5 Date of Receipt

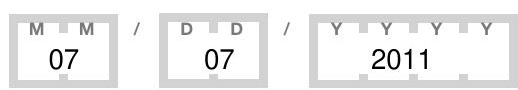

Amount of Each Receipt this Period

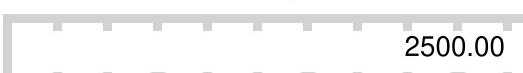

2500.00
Subtotal Of Receipts This Page (optional)

2800.00

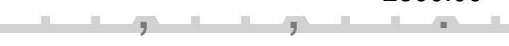

Total This Period (last page this line number only)

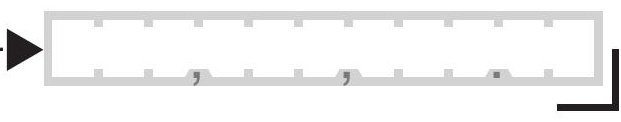

FEC Schedule A-P (Form 3P) (Rev. 03/2011) 


\section{SCHEDULE A-P} ITEMIZED RECEIPTS
Use separate schedule(s)

for each category of the

Detailed Summary Page
FOR LINE NUMBER: (check only one)
PAGE $38 / 1572$

\begin{tabular}{|c|c|c|c|c|c|}
\hline & & & & & \\
\hline 16 & $\begin{array}{l}\mathbf{X} \\
17 a\end{array}$ & $17 b$ & $17 c$ & $17 d$ & 18 \\
\hline $19 a$ & $19 \mathrm{~b}$ & $20 \mathrm{a}$ & $20 \mathrm{~b}$ & $20 \mathrm{c}$ & 21 \\
\hline
\end{tabular}

Any information copied from such Reports and Statements may not be sold or used by any person for the purpose of soliciting contributions or for commercial purposes, other than using the name and address of any political committee to solicit contributions from such committee.

NAME OF COMMITTEE (In Full)

\section{Friends of Herman Cain}

A. Full Name (Last, First, Middle Initial)

Denver Jones

Mailing Address 1271 Owego road

\begin{tabular}{lcc}
\hline City & State & Zip Code \\
Owego & NY & $13827-2532$
\end{tabular}

FEC ID number of contributing federal political committee.

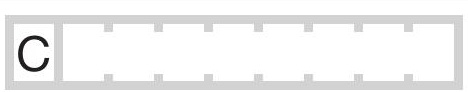

Name of Employer
Information Requested
Receipt For: 2012
X Primary
Other (specify) General

Occupation Information Requested

Election Cycle-to-Date

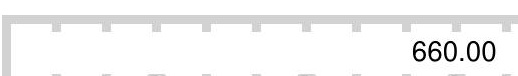

B. Full Name (Last, First, Middle Initial)

Mr Louis C Dietz

Mailing Address 33126 Forest West St

\begin{tabular}{lcc}
\hline City & State & Zip Code \\
Magnolia & TX & $77354-6844$
\end{tabular}

FEC ID number of contributing

federal political committee.

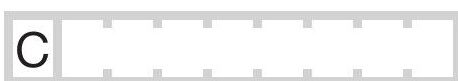

Name of Employer
CYFAIR HOSPITAL
Receipt For: 2012
X Primary
Other (specify)

\section{Occupation}

$\mathrm{RN}$

Election Cycle-to-Date

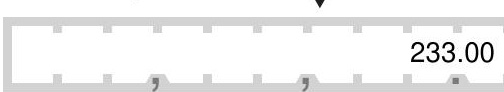

Transaction ID : AB316E4975CB84B5085E

Date of Receipt

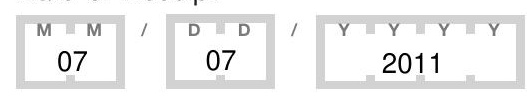

Amount of Each Receipt this Period

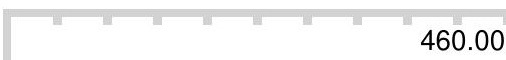

Amount of Each Receipt this Period

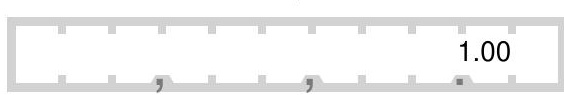

C. Full Name (Last, First, Middle Initial)

Joseph Phillips

Mailing Address PO Box 872

\begin{tabular}{lcc}
\hline City & State & Zip Code \\
Norwich & VT & $05055-0872$
\end{tabular}

FEC ID number of contributing federal political committee.

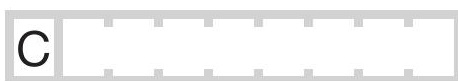

Name of Employer

Information Requested

Occupation

Receipt For: 2012

Х $\begin{aligned} & \text { Primary } \square \text { General } \\ & \text { Other (specify) }\end{aligned}$

Information Requested

Election Cycle-to-Date

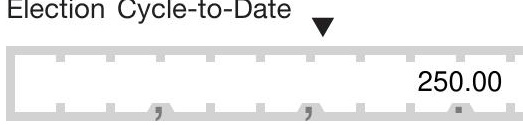

Transaction ID : A7A9C4000C1CC445ABF9

Date of Receipt

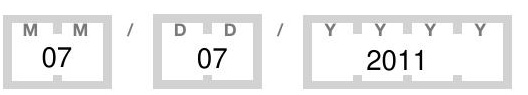

Transaction ID : A8D26A77997064D8498F

Date of Receipt

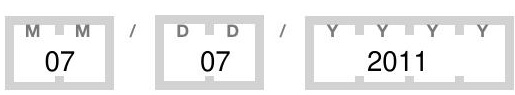

Amount of Each Receipt this Period

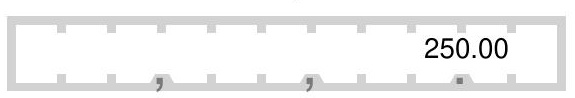

Subtotal Of Receipts This Page (optional).

711.00

Total This Period (last page this line number only) 
SCHEDULE A-P ITEMIZED RECEIPTS
Use separate schedule(s) for each category of the Detailed Summary Page
FOR LINE NUMBER: (check only one)

\begin{tabular}{|c|c|c|c|c|c|}
\hline & & & & & \\
\hline 16 & $\begin{array}{ll}X & 17 a \\
\end{array}$ & $17 \mathrm{~b}$ & $17 c$ & $17 d$ & 18 \\
\hline $19 a$ & $19 b$ & $20 \mathrm{a}$ & $20 \mathrm{~b}$ & $20 c$ & 21 \\
\hline
\end{tabular}

Any information copied from such Reports and Statements may not be sold or used by any person for the purpose of soliciting contributions or for commercial purposes, other than using the name and address of any political committee to solicit contributions from such committee.

NAME OF COMMITTEE (In Full)

\section{Friends of Herman Cain}

A. Full Name (Last, First, Middle Initial)

Andrew Roeska

Mailing Address W55N193 Woodmere Ct. \#3

\begin{tabular}{lcc}
\hline City & State & Zip Code \\
Cedarburg & WI & $53012-2833$
\end{tabular}

FEC ID number of contributing federal political committee.

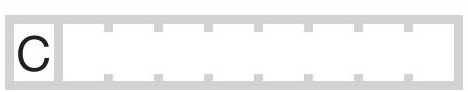

Name of Employer
Information Requested
Receipt For: 2012
X Primary
Other (specify) General

Occupation Information Requested

Election Cycle-to-Date 2400.00

B. Full Name (Last, First, Middle Initial)

Robert J Muller Sr.

Mailing Address 16-13 Split Rock Rd

\begin{tabular}{lcc}
\hline City & State & Zip Code \\
Fair Lawn & NJ & $07410-4401$
\end{tabular}

FEC ID number of contributing

federal political committee.

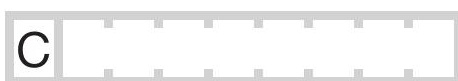

Name of Employer
None
Receipt For: 2012
X Primary
Other (specify)

\section{Occupation}

Retired

Election Cycle-to-Date

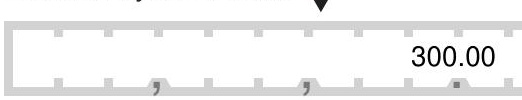

Transaction ID : A25D8AE1813144F92A93

Date of Receipt

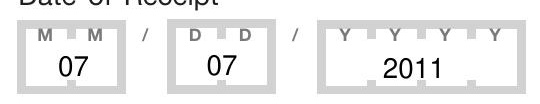

In-kind:Graphic Design

Amount of Each Receipt this Period

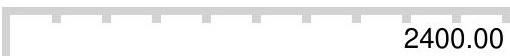

2400.00

C. Full Name (Last, First, Middle Initial)

James Thompson

Mailing Address 1214 Tulip Tree Lane

City

West Des Moines

FEC ID number of contributing

federal political committee.

Name of Employer

Stoney Creek Hospitality Corp.

Receipt For: 2012

Х $\begin{aligned} & \text { Primary } \square \text { General } \\ & \text { Other (specify) }\end{aligned}$

$\begin{array}{cc}\text { State } & \text { Zip Code } \\ \text { IA } & 50266-6666\end{array}$

C

\section{Occupation}

Executive

Election Cycle-to-Date

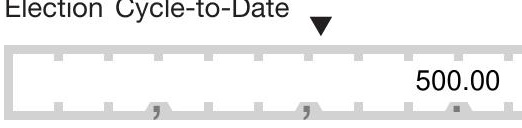

Transaction ID : A09BA1383157F4510884

Date of Receipt

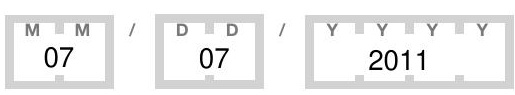

Amount of Each Receipt this Period

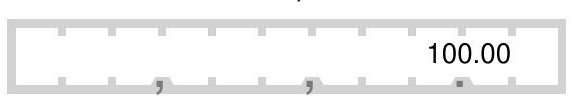

Transaction ID : ABF5F3B8B8FC04A22B3A Date of Receipt

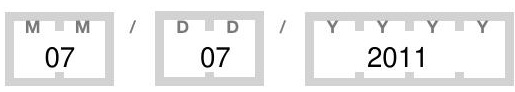

Amount of Each Receipt this Period

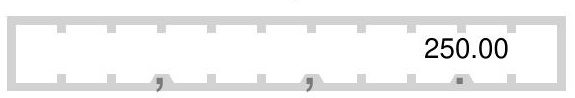

\section{Subtotal Of Receipts This Page (optional)}

2750.00

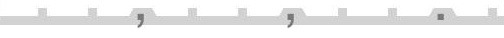

Total This Period (last page this line number only)

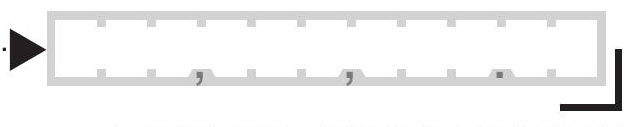

FEC Schedule A-P (Form 3P) (Rev. 03/2011) 
SCHEDULE A-P ITEMIZED RECEIPTS
Use separate schedule(s) for each category of the Detailed Summary Page
FOR LINE NUMBER: (check only one)

\begin{tabular}{|c|c|c|c|c|c|c|}
\hline & & & & & & \\
\hline 16 & $\times 1$ & $17 a$ & $17 b$ & $17 c$ & $17 d$ & 18 \\
\hline $19 a$ & & $19 b$ & $20 \mathrm{a}$ & $20 \mathrm{~b}$ & $20 \mathrm{c}$ & 21 \\
\hline
\end{tabular}

Any information copied from such Reports and Statements may not be sold or used by any person for the purpose of soliciting contributions or for commercial purposes, other than using the name and address of any political committee to solicit contributions from such committee.

NAME OF COMMITTEE (In Full)

\section{Friends of Herman Cain}

A. Full Name (Last, First, Middle Initial)

\section{Roger Gatewood}

Mailing Address 123 Bay Point Drive NE

\begin{tabular}{lcc}
\hline City & State & Zip Code \\
Askov & MN & 55704 \\
\hline
\end{tabular}

FEC ID number of contributing federal political committee.

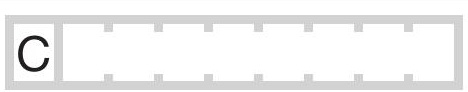

Name of Employer
Information Requested
Receipt For: 2012
X Primary
Other (specify) General

Occupation Information Requested

Election Cycle-to-Date

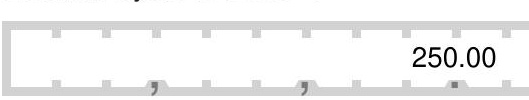

B. Full Name (Last, First, Middle Initial)

Rose Mare Distefano

Mailing Address 2881 Jonesboro Rd

\begin{tabular}{lcc}
\hline City & State & Zip Code \\
Hampton & GA & $30228-2730$ \\
\hline
\end{tabular}

FEC ID number of contributing

federal political committee.

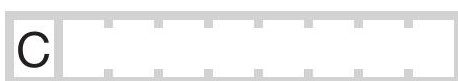

Name of Employer
None
Receipt For: 2012
X Primary
Other (specify)

Occupation

Retired

Election Cycle-to-Date

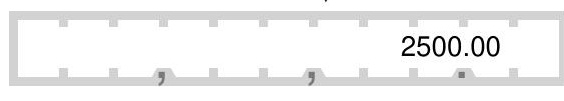

Transaction ID : A2B47FBB645FA45BCBB8

Date of Receipt

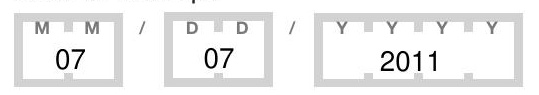

Amount of Each Receipt this Period

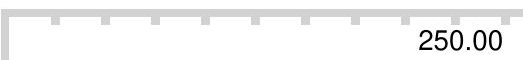

C. Full Name (Last, First, Middle Initial)

Ted Kirkpatrick

Mailing Address 11434 Huntsman Dr

\begin{tabular}{lcc}
\hline City & State & Zip Code \\
Manassas & VA & $20112-2761$
\end{tabular}

FEC ID number of contributing federal political committee.

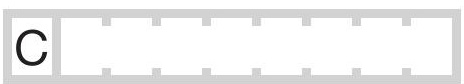

Name of Employer

Ardaiolo Bausman and Associates

Receipt For: 2012

Х $\begin{aligned} & \text { Primary } \\ & \text { Other (specify) }\end{aligned}$

Occupation

Financial Advisor

Election Cycle-to-Date

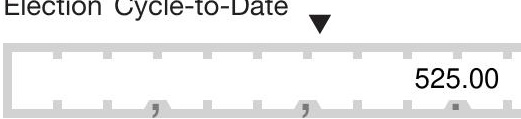

Amount of Each Receipt this Period

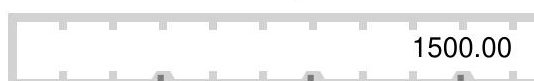

Transaction ID : A5BB5CDB7D74B46778BF Date of Receipt

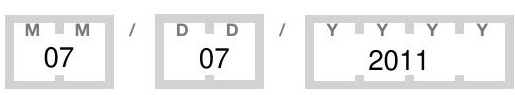

Transaction ID : A8D2B50BD96514CA08D9 Date of Receipt

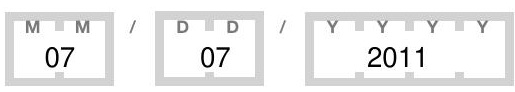

Amount of Each Receipt this Period

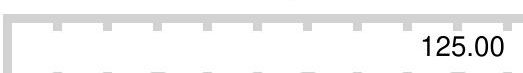

\section{Subtotal Of Receipts This Page (optional)}

Total This Period (last page this line number only) 


\section{SCHEDULE A-P} ITEMIZED RECEIPTS
Use separate schedule(s)

for each category of the

Detailed Summary Page
FOR LINE NUMBER: (check only one)
PAGE $41 / 1572$

\begin{tabular}{|c|c|c|c|c|c|}
\hline & & & & & \\
\hline 16 & $\mathbf{X} 17 \mathrm{a}$ & $17 \mathrm{~b}$ & $17 c$ & $17 d$ & 18 \\
\hline $19 a$ & $19 b$ & $20 a$ & $20 \mathrm{~b}$ & $20 c$ & 21 \\
\hline
\end{tabular}

Any information copied from such Reports and Statements may not be sold or used by any person for the purpose of soliciting contributions or for commercial purposes, other than using the name and address of any political committee to solicit contributions from such committee.

NAME OF COMMITTEE (In Full)

\section{Friends of Herman Cain}

A. Full Name (Last, First, Middle Initial)

Waldo Shank Jones

Mailing Address 465 4th Ave Condo \#5

\begin{tabular}{lcc}
\hline City & State & Zip Code \\
Chula Vista & CA & $91910-4474$ \\
\hline
\end{tabular}

FEC ID number of contributing federal political committee.

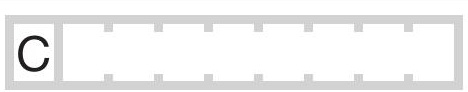

Name of Employer
Not Employed
Receipt For: 2012
X Primary $\quad$ General
Other (specify)

Occupation Not Employed

Election Cycle-to-Date

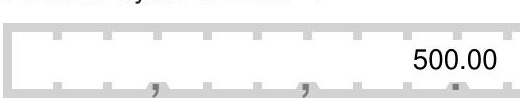

B. Full Name (Last, First, Middle Initial)

Charles King Sewell

Mailing Address 8 Woodlawn Dr NE

\begin{tabular}{lcc}
\hline City & State & Zip Code \\
Marietta & GA & $30067-4712$ \\
\hline
\end{tabular}

FEC ID number of contributing

federal political committee.

C

\begin{tabular}{l} 
Name of Employer \\
Information Requested \\
Receipt For: 2012 \\
X Primary \\
\hline Other (specify)
\end{tabular}

Occupation

Information Requested

Election Cycle-to-Date

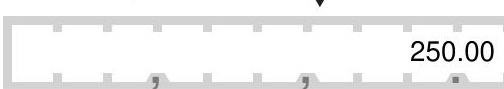

Transaction ID : A13D459D2050A4AFD9B4

Date of Receipt

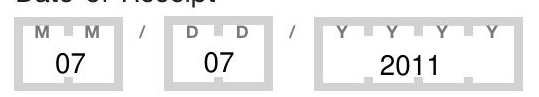

Amount of Each Receipt this Period

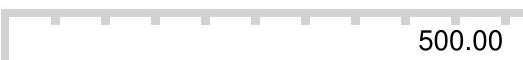

Transaction ID : A6D1C7399703840E3BD7

Date of Receipt

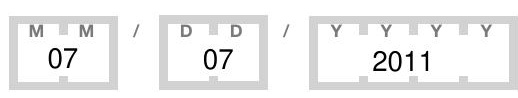

Amount of Each Receipt this Period

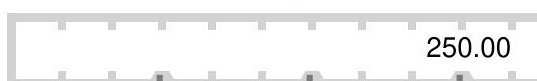

Transaction ID : AC81B029716C349698C2

Date of Receipt

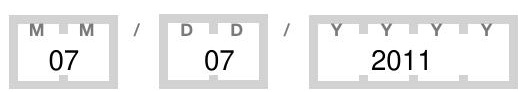

Amount of Each Receipt this Period

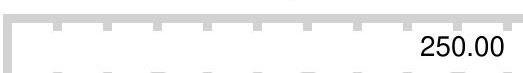

$\begin{array}{cc}\text { State } & \text { Zip Code } \\ \text { FL } & 32726-5687\end{array}$

C

Occupation

Information Requested

Election Cycle-to-Date

Receipt For: 2012

Х $\begin{aligned} & \text { Primary } \square \text { General } \\ & \text { Other (specify) }\end{aligned}$

250.00

Subtotal Of Receipts This Page (optional).

1000.00

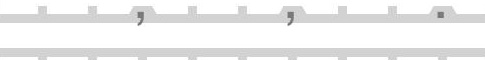

Total This Period (last page this line number only) 


\section{SCHEDULE A-P} ITEMIZED RECEIPTS
Use separate schedule(s)

for each category of the

Detailed Summary Page
FOR LINE NUMBER: (check only one)

\begin{tabular}{|c|c|c|c|c|c|c|}
\hline & & & & & & \\
\hline 16 & $\times 1$ & $17 a$ & $17 b$ & $17 c$ & $17 d$ & 18 \\
\hline $19 a$ & & $19 b$ & $20 \mathrm{a}$ & $20 \mathrm{~b}$ & $20 \mathrm{c}$ & 21 \\
\hline
\end{tabular}

Any information copied from such Reports and Statements may not be sold or used by any person for the purpose of soliciting contributions or for commercial purposes, other than using the name and address of any political committee to solicit contributions from such committee.

NAME OF COMMITTEE (In Full)

Friends of Herman Cain

A. Full Name (Last, First, Middle Initial)

ROGER COWELL

Mailing Address P.O. BOX 1092

\begin{tabular}{lcc}
\hline City & State & Zip Code \\
Fayetteville & TN & $37334-1092$
\end{tabular}

FEC ID number of contributing

federal political committee.

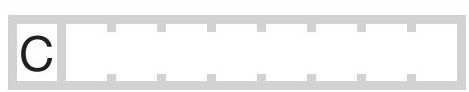

Name of Employer
Information Requested
Receipt For: 2012
X Primary $\quad \square$ General
Other (specify)

Occupation

Information Requested

Election Cycle-to-Date

500.00

B. Full Name (Last, First, Middle Initial)

Linus Pottebaum

Mailing Address 4501 Lindell Terrace \#10G

\begin{tabular}{llc}
\hline City & State & Zip Code \\
Saint Louis & MO & $63108-2052$ \\
\hline
\end{tabular}

FEC ID number of contributing

federal political committee.

C

Name of Employer
Retired
Receipt For: 2012
Primary
$\square$ Other (specify)

Occupation

Retired (Military)

Election Cycle-to-Date

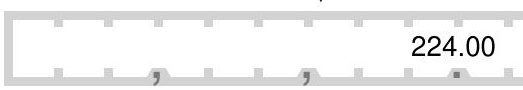

Transaction ID : A25928C9E4A364131B11

Date of Receipt

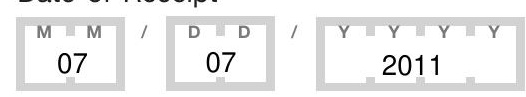

Amount of Each Receipt this Period

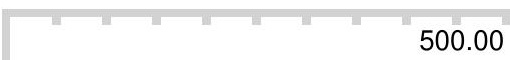

Amount of Each Receipt this Period

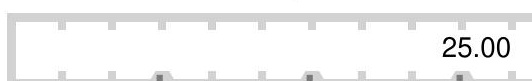

C. Full Name (Last, First, Middle Initial)

Larry Weiss

Mailing Address 2112 Pleasantview Ct

\begin{tabular}{lcc}
\hline City & State & Zip Code \\
New Albany & IN & $47150-9670$
\end{tabular}

FEC ID number of contributing

federal political committee.

C

$\begin{aligned} & \text { Name of Employer } \\ & \text { self }\end{aligned}$
Receipt For: 2012
Primary
Other (specify) General

Occupation

Insurance Agent

Election Cycle-to-Date

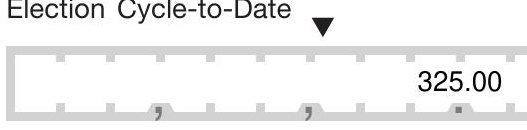

Transaction ID : A4002D3A98C7E41F3A43

Date of Receipt

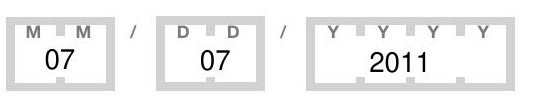

Transaction ID : A107853F3D88F4B96A97

Date of Receipt

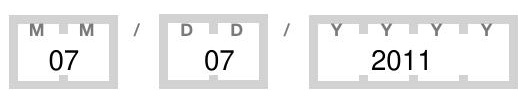

Amount of Each Receipt this Period

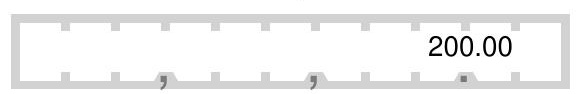

Subtotal Of Receipts This Page (optional).

725.00

Total This Period (last page this line number only) 
SCHEDULE A-P ITEMIZED RECEIPTS
Use separate schedule(s) for each category of the Detailed Summary Page
FOR LINE NUMBER: (check only one)

\begin{tabular}{|c|c|c|c|c|c|}
\hline & & & & & \\
\hline 16 & $\begin{array}{ll}X & 17 a \\
\end{array}$ & $17 \mathrm{~b}$ & $17 c$ & $17 d$ & 18 \\
\hline $19 a$ & $19 b$ & $20 \mathrm{a}$ & $20 \mathrm{~b}$ & $20 c$ & 21 \\
\hline
\end{tabular}

Any information copied from such Reports and Statements may not be sold or used by any person for the purpose of soliciting contributions or for commercial purposes, other than using the name and address of any political committee to solicit contributions from such committee.

NAME OF COMMITTEE (In Full)

\section{Friends of Herman Cain}

A. Full Name (Last, First, Middle Initial)

Mr. Philip H. Ray

Mailing Address 5953 Feather Wind Way

\begin{tabular}{lcc}
\hline City & State & Zip Code \\
Fort Worth & TX & $76135-5386$
\end{tabular}

FEC ID number of contributing

federal political committee.

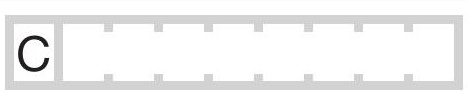

Name of Employer
None
Receipt For: 2012
X Primary $\quad$ General
Other (specify)

Occupation

Retired

Election Cycle-to-Date

244.00

B. Full Name (Last, First, Middle Initial)

Kate C Thompson

Mailing Address PO Box 221

\begin{tabular}{lcc}
\hline City & State & Zip Code \\
Port Washington & OH & $43837-0221$ \\
\hline
\end{tabular}

FEC ID number of contributing

federal political committee.

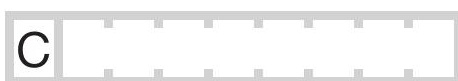

Name of Employer
Retired
Receipt For: 2012
X Primary
Other (specify)

\section{Occupation}

Retired

Election Cycle-to-Date

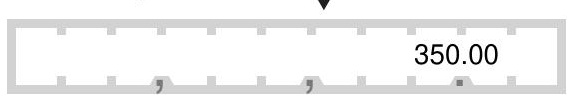

C. Full Name (Last, First, Middle Initial)

Earl Williams

Mailing Address 13505 Peseta Ct

\begin{tabular}{l|ll}
\hline $\begin{array}{l}\text { City } \\
\text { Corpus Christi }\end{array}$ & $\begin{array}{c}\text { State } \\
\text { TX }\end{array}$ & $\begin{array}{c}\text { Zip Code } \\
78418-6932\end{array}$ \\
\hline $\begin{array}{l}\text { FEC ID number of contributing } \\
\text { federal political committee. }\end{array}$ & C \\
$\begin{array}{l}\text { Name of Employer } \\
\text { Retired }\end{array}$ & $\begin{array}{l}\text { Occupation } \\
\text { Information Requested }\end{array}$ \\
$\begin{array}{l}\text { Receipt For: } 2012 \\
\text { Xrimary } \\
\text { Other (specify) }\end{array}$ & Election Cycle-to-Date & \\
\end{tabular}

Transaction ID : A49F3CA218FE342CDA57

Date of Receipt

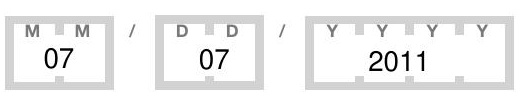

Amount of Each Receipt this Period

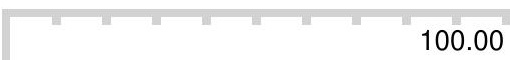

Date of Receipt
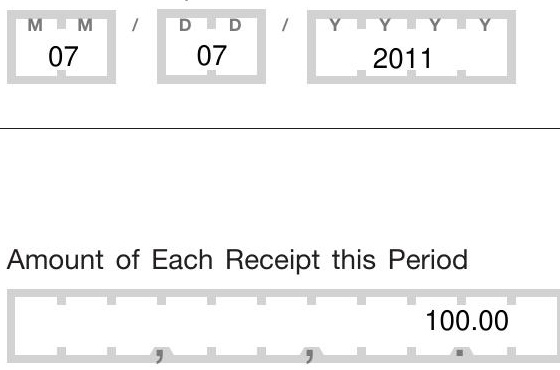

Amount of Each Receipt this Period

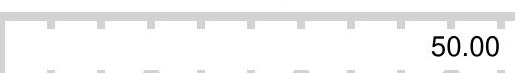

Amount of Each Receipt this Period

Transaction ID : A193FF04463D5469DB1A Date of Receipt
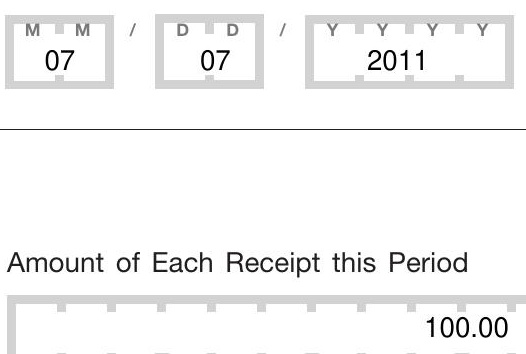

Subtotal Of Receipts This Page (optional)

250.00

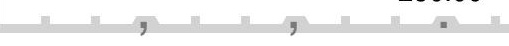

Total This Period (last page this line number only)

FEC Schedule A-P (Form 3P) (Rev. 03/2011) 
SCHEDULE A-P ITEMIZED RECEIPTS
Use separate schedule(s) for each category of the Detailed Summary Page
FOR LINE NUMBER: (check only one)

\begin{tabular}{|c|c|c|c|c|c|c|}
\hline & & & & & & \\
\hline 16 & $\times 1$ & $17 a$ & $17 b$ & $17 c$ & $17 d$ & 18 \\
\hline $19 a$ & & $19 b$ & $20 \mathrm{a}$ & $20 \mathrm{~b}$ & $20 \mathrm{c}$ & 21 \\
\hline
\end{tabular}

Any information copied from such Reports and Statements may not be sold or used by any person for the purpose of soliciting contributions or for commercial purposes, other than using the name and address of any political committee to solicit contributions from such committee.

NAME OF COMMITTEE (In Full)

\section{Friends of Herman Cain}

A. Full Name (Last, First, Middle Initial)

\section{Glenwood Grunder}

Mailing Address 4429 M-66 SE

\begin{tabular}{lcc}
\hline City & State & Zip Code \\
Kalkaska & MI & 49646
\end{tabular}

FEC ID number of contributing federal political committee.

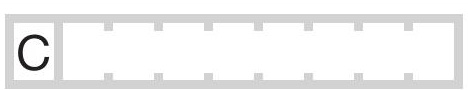

\begin{tabular}{l} 
Name of Employer \\
None \\
Receipt For: 2012 \\
X Primary $\quad$ General \\
\hline Other (specify)
\end{tabular}

Occupation Retired

Election Cycle-to-Date

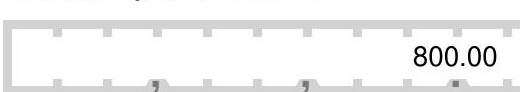

B. Full Name (Last, First, Middle Initial) Rex Holloway

Mailing Address 7119 Miltondale Rd

\begin{tabular}{lcc}
\hline City & State & Zip Code \\
Macclenny & FL & $32063-5538$ \\
\hline
\end{tabular}

FEC ID number of contributing

federal political committee.

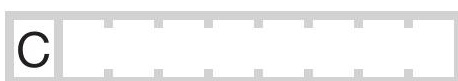

Name of Employer
Retired
Receipt For: 2012
X Primary
Other (specify)

\section{Occupation}

Retired

Election Cycle-to-Date

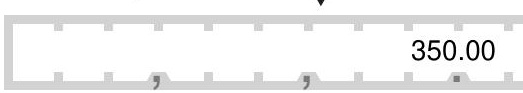

Transaction ID : A7ADD0E2151EB4910800

Date of Receipt

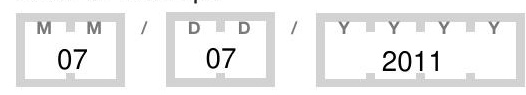

Amount of Each Receipt this Period

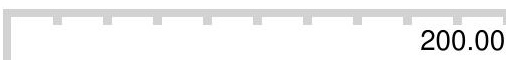

200.00

C. Full Name (Last, First, Middle Initial)

Stephen Losee

Mailing Address 17778 HWY 416E

\begin{tabular}{lcc}
\hline City & State & Zip Code \\
Henderson & KY & $42420-9495$
\end{tabular}

FEC ID number of contributing federal political committee.

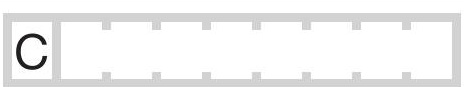

Name of Employer
Sysco
Receipt For: 2012
X Primary $\square$ General
Other (specify)

\section{Occupation}

driver

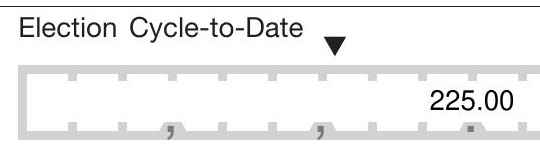

Transaction ID : A601060D76E5F4C73946

Date of Receipt

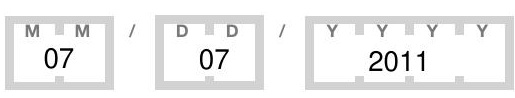

Amount of Each Receipt this Period

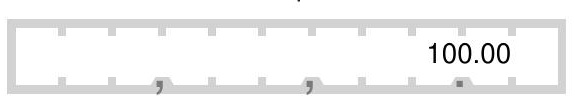

Transaction ID : A2CF5C50BC9F543BAB5E Date of Receipt

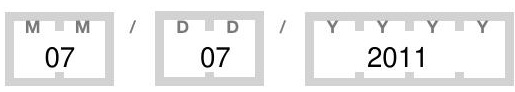

Amount of Each Receipt this Period

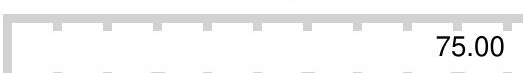

\section{Subtotal Of Receipts This Page (optional)}

375.00

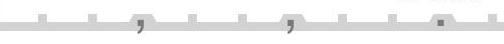

Total This Period (last page this line number only)

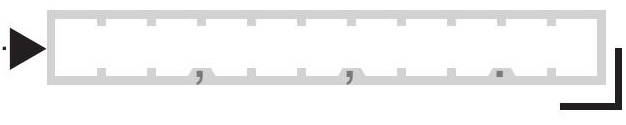

FEC Schedule A-P (Form 3P) (Rev. 03/2011) 


\section{SCHEDULE A-P} ITEMIZED RECEIPTS
Use separate schedule(s)

for each category of the

Detailed Summary Page
FOR LINE NUMBER: (check only one)
PAGE 45 / 1572

\begin{tabular}{|c|c|c|c|c|c|}
\hline & & & & & \\
\hline 16 & $\mathbf{X} 17 \mathrm{a}$ & $17 \mathrm{~b}$ & $17 c$ & $17 d$ & 18 \\
\hline $19 a$ & $19 b$ & $20 a$ & $20 \mathrm{~b}$ & $20 c$ & 21 \\
\hline
\end{tabular}

Any information copied from such Reports and Statements may not be sold or used by any person for the purpose of soliciting contributions or for commercial purposes, other than using the name and address of any political committee to solicit contributions from such committee.

NAME OF COMMITTEE (In Full)

\section{Friends of Herman Cain}

A. Full Name (Last, First, Middle Initial)

Mr. James Burger

Mailing Address 2303 Choto Rd

\begin{tabular}{lcc}
\hline City & State & Zip Code \\
Knoxville & TN & $37922-6106$
\end{tabular}

FEC ID number of contributing federal political committee.

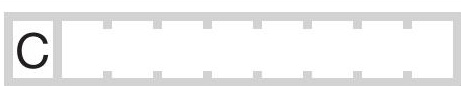

Name of Employer
Information Requested
Receipt For: 2012
X Primary
Other (specify) General

Occupation Information Requested

Election Cycle-to-Date

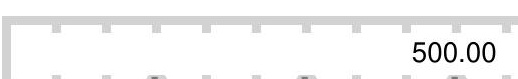

B. Full Name (Last, First, Middle Initial) James Saleska

Mailing Address 1777 Valley Road

\begin{tabular}{lcc}
\hline City & State & Zip Code \\
West Bend & WI & $53090-8929$
\end{tabular}

FEC ID number of contributing

federal political committee.

C

Name of Employer
Information Requested
Receipt For: 2012
Xrimary
Other (specify)

Occupation

Information Requested

Election Cycle-to-Date

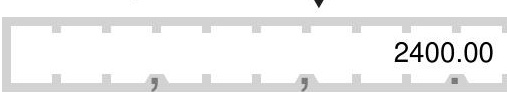

C. Full Name (Last, First, Middle Initial)

james lorence

Mailing Address 6424 Hidden Holw

\begin{tabular}{lcc}
\hline City & State & Zip Code \\
Holland & MI & $49423-7901$
\end{tabular}

FEC ID number of contributing

federal political committee.

C

Name of Employer

J. lorence \& assoc.

Occupation

Receipt For: 2012

Х $\begin{aligned} & \text { Primary } \square \text { General } \\ & \text { Other (specify) }\end{aligned}$

investment advisor

Election Cycle-to-Date

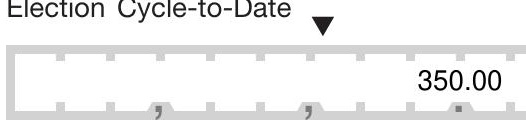

Transaction ID : AF39C56AD2B5646FB988

Date of Receipt

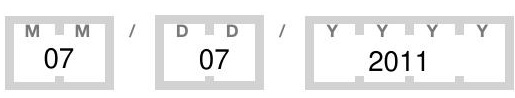

In-kind:Graphic Design

Amount of Each Receipt this Period

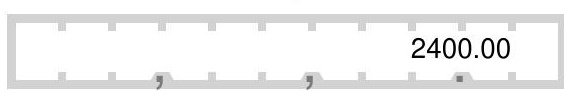

Amount of Each Receipt this Period

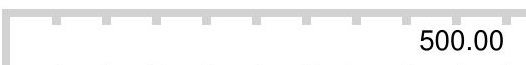

Date of Receipt

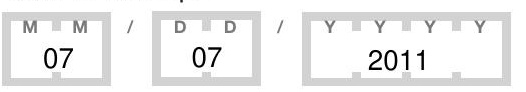

\section{9}


SCHEDULE A-P ITEMIZED RECEIPTS
Use separate schedule(s) for each category of the Detailed Summary Page
FOR LINE NUMBER: (check only one)

\begin{tabular}{|c|c|c|c|c|c|c|}
\hline & & & & & & \\
\hline 16 & $\times 1$ & $17 a$ & $17 b$ & $17 c$ & $17 d$ & 18 \\
\hline $19 a$ & & $19 b$ & $20 \mathrm{a}$ & $20 \mathrm{~b}$ & $20 \mathrm{c}$ & 21 \\
\hline
\end{tabular}

Any information copied from such Reports and Statements may not be sold or used by any person for the purpose of soliciting contributions or for commercial purposes, other than using the name and address of any political committee to solicit contributions from such committee.

NAME OF COMMITTEE (In Full)

\section{Friends of Herman Cain}

A. Full Name (Last, First, Middle Initial)

Marty Smith

Mailing Address 504 TIger Lily Ct

\begin{tabular}{lcc}
\hline City & State & Zip Code \\
Franklin & TN & $37064-6187$
\end{tabular}

FEC ID number of contributing federal political committee.

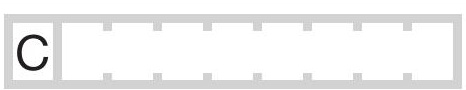

Name of Employer
FedEx Kinkos
Receipt For: 2012
X Primary $\quad \square$ General
Other (specify)

Occupation Pilot

Election Cycle-to-Date

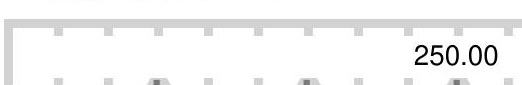

B. Full Name (Last, First, Middle Initial)

Angela Pope

Mailing Address 104 Niagara Drive

\begin{tabular}{lcc}
\hline City & State & Zip Code \\
Watkinsville & GA & $30677-2477$
\end{tabular}

FEC ID number of contributing

federal political committee.

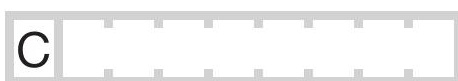

Name of Employer
self
Receipt For: 2012
Primary
Other (specify)

Occupation

Attorney

Election Cycle-to-Date

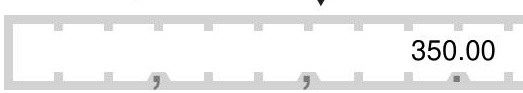

Transaction ID : A701F441B6D1945D0B4B

Date of Receipt

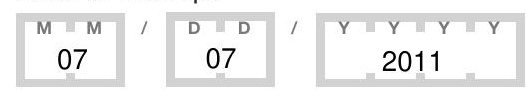

Amount of Each Receipt this Period

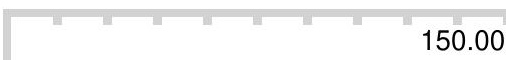

C. Full Name (Last, First, Middle Initial)

Leah K Lovett

Mailing Address 3914 Union Pacific Dr W

\begin{tabular}{lcc}
\hline City & State & Zip Code \\
Jacksonville & FL & $32246-7626$
\end{tabular}

FEC ID number of contributing federal political committee.

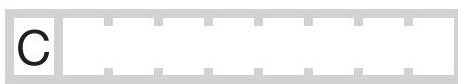

Name of Employer
GEDC
Receipt For: 2012
X Primary
Other (specify) General

\section{Occupation}

Dentist

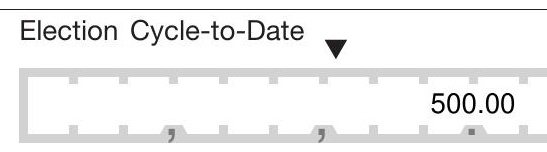

Transaction ID : A05654820B2DE4239A97

Date of Receipt

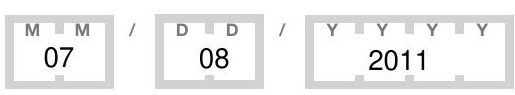

Amount of Each Receipt this Period

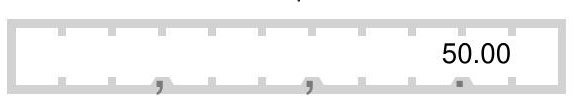

Transaction ID : A133A36B9B5E94A11BF7 Date of Receipt

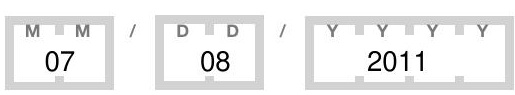

Amount of Each Receipt this Period

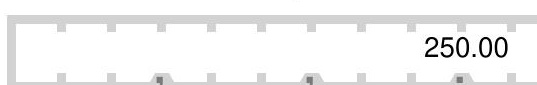

\section{Subtotal Of Receipts This Page (optional)}

Total This Period (last page this line number only) 
SCHEDULE A-P ITEMIZED RECEIPTS
Use separate schedule(s) for each category of the Detailed Summary Page
FOR LINE NUMBER: (check only one)

\begin{tabular}{|c|c|c|c|c|c|}
\hline & & & & & \\
\hline 16 & $\begin{array}{ll}X & 17 a \\
\end{array}$ & $17 \mathrm{~b}$ & $17 c$ & $17 d$ & 18 \\
\hline $19 a$ & $19 b$ & $20 \mathrm{a}$ & $20 \mathrm{~b}$ & $20 c$ & 21 \\
\hline
\end{tabular}

Any information copied from such Reports and Statements may not be sold or used by any person for the purpose of soliciting contributions or for commercial purposes, other than using the name and address of any political committee to solicit contributions from such committee.

NAME OF COMMITTEE (In Full)

\section{Friends of Herman Cain}

A. Full Name (Last, First, Middle Initial)

Fay Kist

Mailing Address 5292 Shenstone Cir

\begin{tabular}{lcc}
\hline City & State & Zip Code \\
Virginia Beach & VA & $23455-3214$
\end{tabular}

FEC ID number of contributing federal political committee.

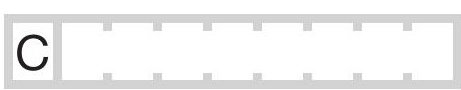

Name of Employer
Information Requested
Receipt For: 2012
X Primary
Other (specify) General

Occupation Information Requested

Election Cycle-to-Date

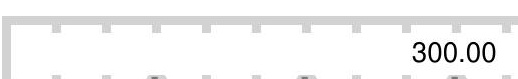

B. Full Name (Last, First, Middle Initial)

Edward J Phelan

Mailing Address 1049 Pecan Grive Place

\begin{tabular}{lcc}
\hline City & State & Zip Code \\
Lawrenceville & GA & $30046-5517$
\end{tabular}

FEC ID number of contributing

federal political committee.

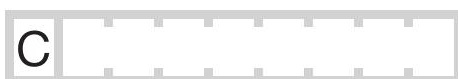

Name of Employer
None
Receipt For: 2012
X Primary
Other (specify)

\section{Occupation}

Retired

Election Cycle-to-Date

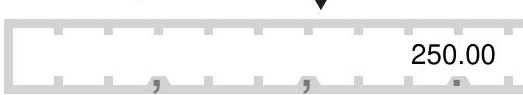

Transaction ID : A55967A3B73354EEC8FE

Date of Receipt

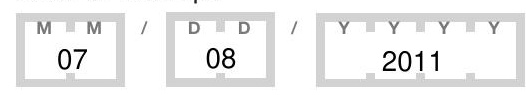

Amount of Each Receipt this Period

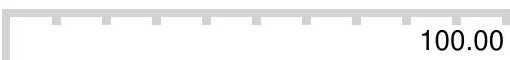

Transaction ID : A27A2111DECD94B81B90 Date of Receipt

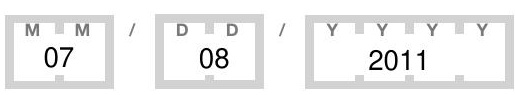

Amount of Each Receipt this Period

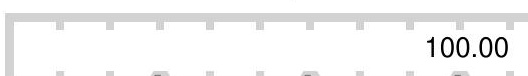

Transaction ID : AC9C3096C36D14224B55

Date of Receipt

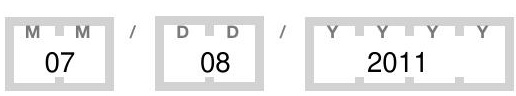

Amount of Each Receipt this Period

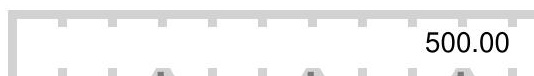

$\begin{array}{cc}\text { State } & \text { Zip Code } \\ \text { NJ } & 07666-6627\end{array}$

C

Occupation

Retired

Election Cycle-to-Date

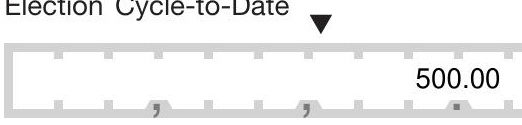

Subtotal Of Receipts This Page (optional)

$+\quad 700.00$

Total This Period (last page this line number only)

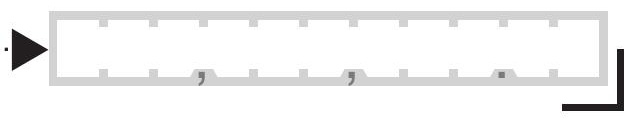

FEC Schedule A-P (Form 3P) (Rev. 03/2011) 


\section{SCHEDULE A-P} ITEMIZED RECEIPTS
Use separate schedule(s)

for each category of the

Detailed Summary Page
FOR LINE NUMBER: (check only one)
PAGE 48 / 1572

\begin{tabular}{|c|c|c|c|c|c|}
\hline & & & & & \\
\hline 16 & $\mathbf{X} 17 \mathrm{a}$ & $17 \mathrm{~b}$ & $17 c$ & $17 d$ & 18 \\
\hline $19 a$ & $19 b$ & $20 a$ & $20 \mathrm{~b}$ & $20 c$ & 21 \\
\hline
\end{tabular}

Any information copied from such Reports and Statements may not be sold or used by any person for the purpose of soliciting contributions or for commercial purposes, other than using the name and address of any political committee to solicit contributions from such committee.

NAME OF COMMITTEE (In Full)

\section{Friends of Herman Cain}

A. Full Name (Last, First, Middle Initial)

Mr. Richard C Wade

Mailing Address 133 Wormsloe Way

\begin{tabular}{lcc}
\hline City & State & Zip Code \\
Eatonton & GA & $31024-5436$ \\
\hline
\end{tabular}

FEC ID number of contributing federal political committee.

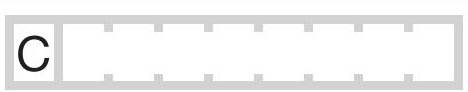

Name of Employer
None
Receipt For: 2012
X Primary $\quad$ General
Other (specify)

Occupation

Retired

Election Cycle-to-Date

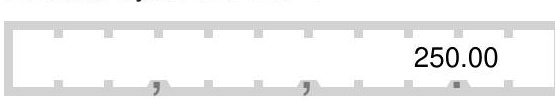

B. Full Name (Last, First, Middle Initial)

Ms Bobbye Harris

Mailing Address 135 Windsor Dr

\begin{tabular}{lcc}
\hline City & State & Zip Code \\
Calhoun & GA & $30701-2055$
\end{tabular}

FEC ID number of contributing

federal political committee.

C

Name of Employer
Information Requested
Receipt For: 2012
X Primary
Other (specify)

Occupation

Retired

Election Cycle-to-Date

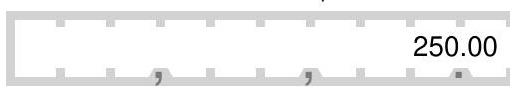

Transaction ID : AF9B97B86D15E4457AB9

Date of Receipt

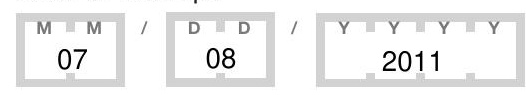

Amount of Each Receipt this Period

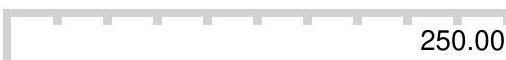

Transaction ID : AD52FD969A49A453492E

Date of Receipt

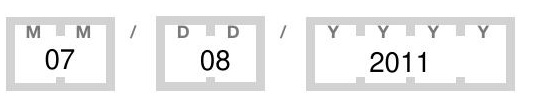

Amount of Each Receipt this Period

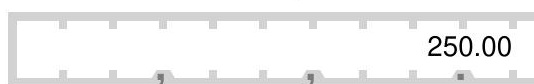

Transaction ID : AD9DA60E316C74B57B44 Date of Receipt

Don Mark Williamson

Mailing Address P.O Box 356

\begin{tabular}{lcc}
\hline City & State & Zip Code \\
Brittany & LA & $70718-0356$
\end{tabular}

FEC ID number of contributing federal political committee.

C

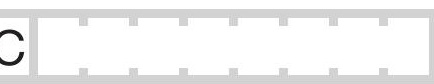

Name of Employer

State of Louisiana

Occupation

Investigator III

Receipt For: 2012

Х $\begin{aligned} & \text { Primary } \square \text { General } \\ & \text { Other (specify) }\end{aligned}$

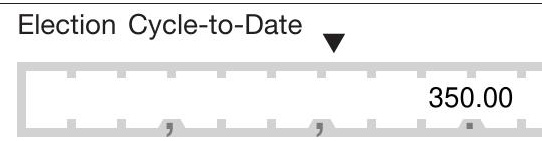

Amount of Each Receipt this Period

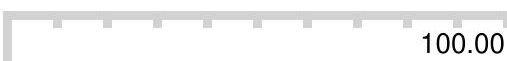

100.00

600.00

Subtotal Of Receipts This Page (optional)

Total This Period (last page this line number only) 
SCHEDULE A-P ITEMIZED RECEIPTS
Use separate schedule(s) for each category of the Detailed Summary Page
FOR LINE NUMBER: (check only one)

\begin{tabular}{|c|c|c|c|c|c|c|}
\hline & & & & & & \\
\hline 16 & $\times 1$ & $17 a$ & $17 b$ & $17 c$ & $17 d$ & 18 \\
\hline $19 a$ & & $19 b$ & $20 \mathrm{a}$ & $20 \mathrm{~b}$ & $20 \mathrm{c}$ & 21 \\
\hline
\end{tabular}

Any information copied from such Reports and Statements may not be sold or used by any person for the purpose of soliciting contributions or for commercial purposes, other than using the name and address of any political committee to solicit contributions from such committee.

NAME OF COMMITTEE (In Full)

\section{Friends of Herman Cain}

A. Full Name (Last, First, Middle Initial)

\section{Susan Walter}

Mailing Address P.O. Box 690

\begin{tabular}{lcc}
\hline City & State & Zip Code \\
Sautee Nacoochee & GA & $30571-0690$ \\
\hline
\end{tabular}

FEC ID number of contributing federal political committee.

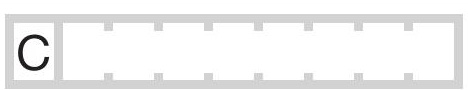

Name of Employer
None
Receipt For: 2012
X Primary $\quad$ General
Other (specify)

Occupation Retired

Election Cycle-to-Date

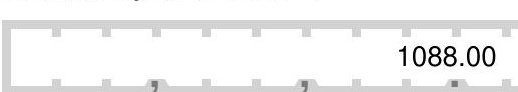

B. Full Name (Last, First, Middle Initial)

Mr Robert L Rankin

Mailing Address 701 Mercer Rd

\begin{tabular}{lcc}
\hline City & State & Zip Code \\
Butler & PA & $16001-1841$
\end{tabular}

FEC ID number of contributing

federal political committee.

C

Name of Employer
self
Receipt For: 2012
X Primary
Other (specify)

Occupation

Engineer

Election Cycle-to-Date

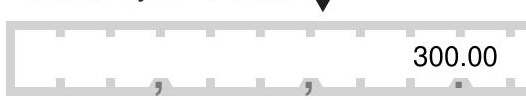

Transaction ID : A47C7E441B13A4EF7865

Date of Receipt

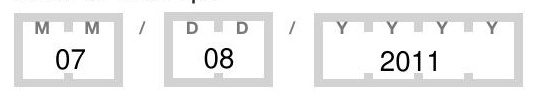

Amount of Each Receipt this Period

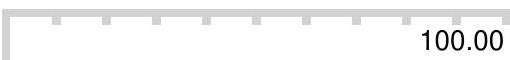

Transaction ID : A9A08043A8F0A433C97A

Date of Receipt

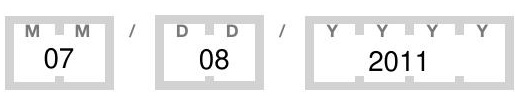

Amount of Each Receipt this Period

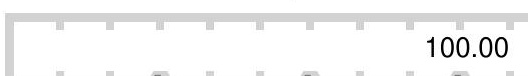

Transaction ID : A21D81A94ABE2417CA30 Date of Receipt

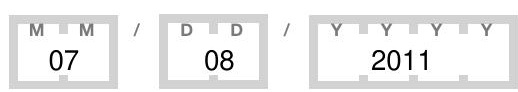

Amount of Each Receipt this Period

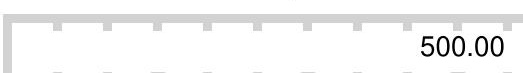

$\begin{array}{cc}\text { State } & \text { Zip Code } \\ \text { GA } & 30326-1021\end{array}$

C

\section{Occupation}

Owner

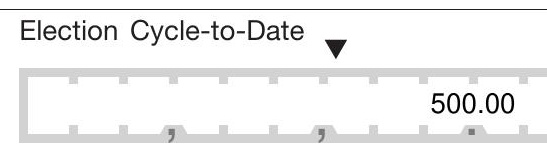

Subtotal Of Receipts This Page (optional)

$-\quad 700.00$

Total This Period (last page this line number only)

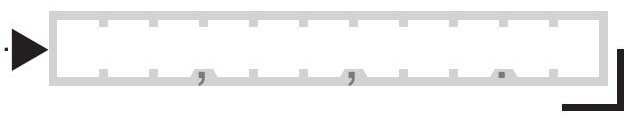

FEC Schedule A-P (Form 3P) (Rev. 03/2011) 
SCHEDULE A-P ITEMIZED RECEIPTS
Use separate schedule(s) for each category of the Detailed Summary Page
FOR LINE NUMBER: (check only one)

\begin{tabular}{|c|c|c|c|c|c|}
\hline & & & & & \\
\hline 16 & $\begin{array}{ll}X & 17 a \\
\end{array}$ & $17 \mathrm{~b}$ & $17 c$ & $17 d$ & 18 \\
\hline $19 a$ & $19 b$ & $20 \mathrm{a}$ & $20 \mathrm{~b}$ & $20 c$ & 21 \\
\hline
\end{tabular}

Any information copied from such Reports and Statements may not be sold or used by any person for the purpose of soliciting contributions or for commercial purposes, other than using the name and address of any political committee to solicit contributions from such committee.

NAME OF COMMITTEE (In Full)

\section{Friends of Herman Cain}

A. Full Name (Last, First, Middle Initial) Jackie White

Mailing Address 6161 Acorn Drive

\begin{tabular}{lcc}
\hline City & State & Zip Code \\
Memphis & TN & $38134-4601$
\end{tabular}

FEC ID number of contributing federal political committee.

C

Name of Employer

Ave Maria Nursing Home

Occupation

Receipt For: 2012

Х Primary $\square$ General

Registered Nurse

Election Cycle-to-Date

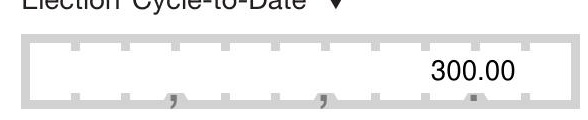

B. Full Name (Last, First, Middle Initial)

Joseph Phillips

Mailing Address PO Box 872

\begin{tabular}{lcc}
\hline City & State & Zip Code \\
Norwich & VT & $05055-0872$ \\
\hline
\end{tabular}

FEC ID number of contributing

federal political committee.

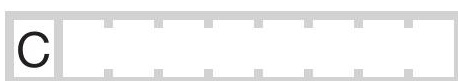

Name of Employer
Information Requested
Receipt For: 2012
X Primary
Other (specify)

Occupation

Information Requested

Election Cycle-to-Date

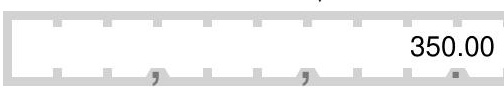

Transaction ID : A595E400F5C5E4FE6952

Date of Receipt

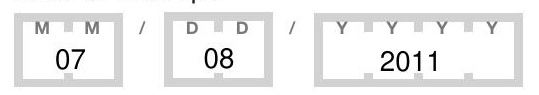

Amount of Each Receipt this Period

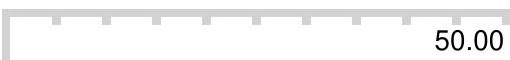

50.00

C. Full Name (Last, First, Middle Initial)

Eleanor Goodwin

Mailing Address 1759 Dunridge Court

\begin{tabular}{lcc}
\hline City & State & Zip Code \\
Atlanta & GA & $30338-3501$
\end{tabular}

FEC ID number of contributing

federal political committee.

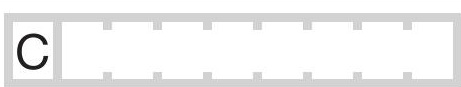

Name of Employer
NA
Receipt For: 2012
Х Primary $\quad \square$ General
Other (specify)

Occupation

homemaker

Election Cycle-to-Date

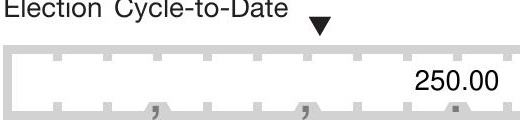

Transaction ID : A1B153E09E15447889B0

Date of Receipt

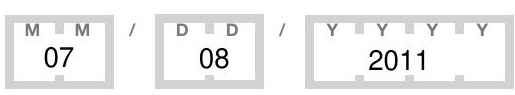

Amount of Each Receipt this Period

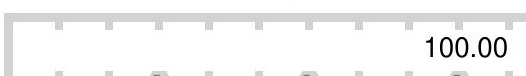

Transaction ID : A75F7E9A8942B464D914

Date of Receipt

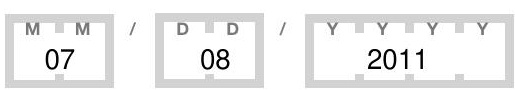

Amount of Each Receipt this Period

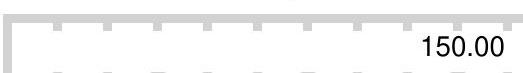

150.00

\section{Subtotal Of Receipts This Page (optional)}

Total This Period (last page this line number only) 


\section{SCHEDULE A-P} ITEMIZED RECEIPTS
Use separate schedule(s)

for each category of the

Detailed Summary Page
FOR LINE NUMBER: (check only one)

\begin{tabular}{|c|c|c|c|c|c|c|}
\hline & & & & & & \\
\hline 16 & $\times 1$ & $17 a$ & $17 b$ & $17 c$ & $17 d$ & 18 \\
\hline $19 a$ & & $19 b$ & $20 \mathrm{a}$ & $20 \mathrm{~b}$ & $20 \mathrm{c}$ & 21 \\
\hline
\end{tabular}

Any information copied from such Reports and Statements may not be sold or used by any person for the purpose of soliciting contributions or for commercial purposes, other than using the name and address of any political committee to solicit contributions from such committee.

NAME OF COMMITTEE (In Full)

\section{Friends of Herman Cain}

A. Full Name (Last, First, Middle Initial)

\section{Renee Brown}

Mailing Address 170 Sutallee Ridge Way

\begin{tabular}{lcc}
\hline City & State & Zip Code \\
White & GA & $30184-3236$ \\
\hline
\end{tabular}

FEC ID number of contributing federal political committee.

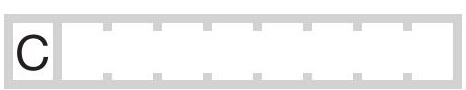

Name of Employer
Cherokee Co. Bd. of Ed.
Receipt For: 2012
X Primary
Other (specify) General

Occupation Bus Driver

Election Cycle-to-Date

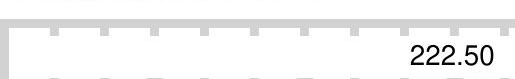

B. Full Name (Last, First, Middle Initial)

Sally A Hayes

Mailing Address 927 NW 40th Drive

\begin{tabular}{lcc}
\hline City & State & Zip Code \\
Gainesville & FL & $32605-4746$
\end{tabular}

FEC ID number of contributing

federal political committee.

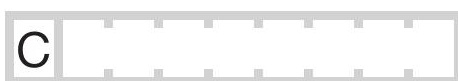

Name of Employer
self
Receipt For: 2012
X Primary
Other (specify)

\section{Occupation}

homemaker

Election Cycle-to-Date

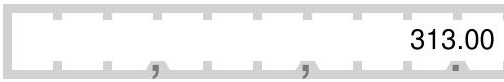

C. Full Name (Last, First, Middle Initial)

Ms Wilma Miller

Mailing Address P. O. Box 434

\begin{tabular}{lcc}
\hline City & State & Zip Code \\
Washington & OK & $73093-0434$
\end{tabular}

FEC ID number of contributing federal political committee.

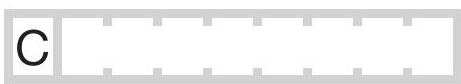

Name of Employer
Kenneth Sturgell
Receipt For: 2012
X Primary
Other (specify) General

\section{Occupation}

File Clerk

Election Cycle-to-Date

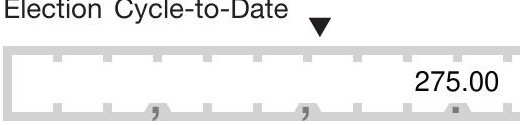

Transaction ID : A6CC6461EB5844754978

Date of Receipt

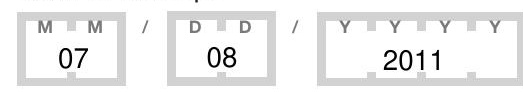

Amount of Each Receipt this Period

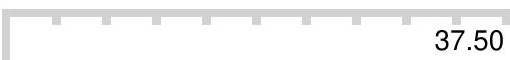

37.50

Transaction ID : A1B8C20CC77FD442AB59

Date of Receipt

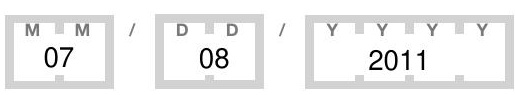

Amount of Each Receipt this Period

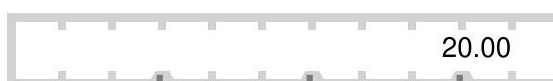

Transaction ID : ADBF4A31AD805400C841 Date of Receipt

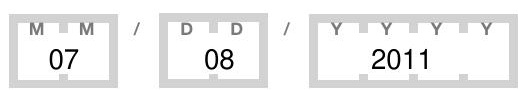

Amount of Each Receipt this Period

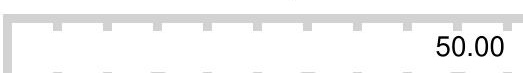

50.00

\section{Subtotal Of Receipts This Page (optional)}

107.50

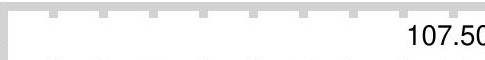

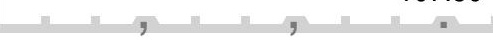

Total This Period (last page this line number only)

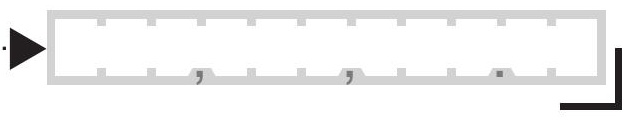

FEC Schedule A-P (Form 3P) (Rev. 03/2011) 


\section{SCHEDULE A-P} ITEMIZED RECEIPTS
Use separate schedule(s)

for each category of the

Detailed Summary Page
FOR LINE NUMBER: (check only one)
PAGE 52 / 1572

\begin{tabular}{|c|c|c|c|c|c|}
\hline & & & & & \\
\hline 16 & $\mathbf{X} 17 \mathrm{a}$ & $17 \mathrm{~b}$ & $17 c$ & $17 d$ & 18 \\
\hline $19 a$ & $19 b$ & $20 a$ & $20 \mathrm{~b}$ & $20 c$ & 21 \\
\hline
\end{tabular}

Any information copied from such Reports and Statements may not be sold or used by any person for the purpose of soliciting contributions or for commercial purposes, other than using the name and address of any political committee to solicit contributions from such committee.

NAME OF COMMITTEE (In Full)

Friends of Herman Cain

A. Full Name (Last, First, Middle Initial)

Mrs Beverly Redgwick

Mailing Address PO Box 51879

\begin{tabular}{lcc}
\hline City & State & Zip Code \\
Pacific Grove & CA & $93950-6879$ \\
\hline
\end{tabular}

FEC ID number of contributing federal political committee.

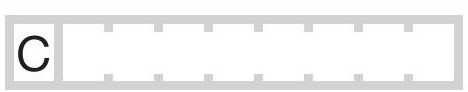

Name of Employer
Information Requested
Receipt For: 2012
X Primary
$\square$ Other (specify)

Occupation

Information Requested

Election Cycle-to-Date

500.00

B. Full Name (Last, First, Middle Initial)

Barbara Delorge

Mailing Address 9611 Halkirk St.

\begin{tabular}{lcc}
\hline City & State & Zip Code \\
Spring & TX & $77379-4385$
\end{tabular}

FEC ID number of contributing

federal political committee.

C

Name of Employer
Information Requested
Receipt For: 2012
X Primary
Other (specify)

Occupation

Information Requested

Election Cycle-to-Date

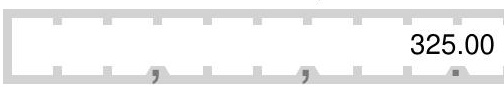

Transaction ID : A0C809A0B445542BC8CE

Date of Receipt

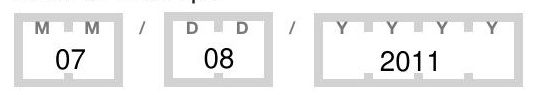

Amount of Each Receipt this Period

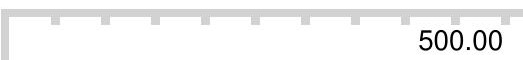

C. Full Name (Last, First, Middle Initial)

Mr James T Howell

Mailing Address 5716 Fairley Hall Ct

\begin{tabular}{lcc}
\hline City & State & Zip Code \\
Norcross & GA & $30092-1425$
\end{tabular}

FEC ID number of contributing federal political committee.

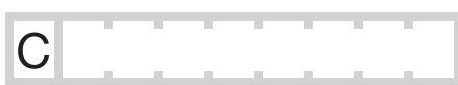

Name of Employer

Information Requested

\section{Occupation}

Information Requested

Receipt For: 2012

Х $\begin{aligned} & \text { Primary } \square \text { General } \\ & \text { Other (specify) }\end{aligned}$

Amount of Each Receipt this Period

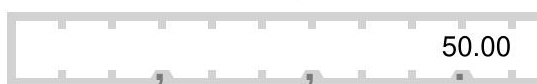

Transaction ID : A57F5DEEB513D44AFB3B Date of Receipt

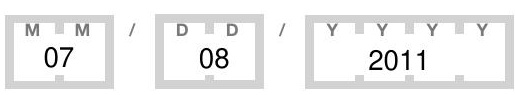

Transaction ID : AAFCC71C04AFE424EB77 Date of Receipt

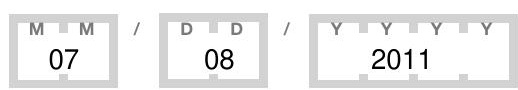

Amount of Each Receipt this Period

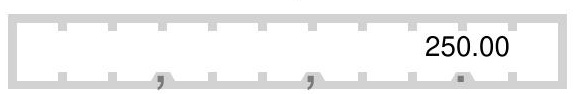

250.00
Subtotal Of Receipts This Page (optional)

800.00

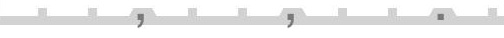

Total This Period (last page this line number only)

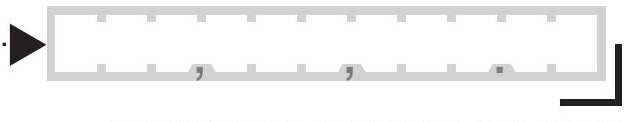

FEC Schedule A-P (Form 3P) (Rev. 03/2011) 
SCHEDULE A-P ITEMIZED RECEIPTS
Use separate schedule(s) for each category of the Detailed Summary Page
FOR LINE NUMBER: (check only one)

\begin{tabular}{|c|c|c|c|c|c|}
\hline & & & & & \\
\hline 16 & $\begin{array}{ll}X & 17 a \\
\end{array}$ & $17 \mathrm{~b}$ & $17 c$ & $17 d$ & 18 \\
\hline $19 a$ & $19 b$ & $20 \mathrm{a}$ & $20 \mathrm{~b}$ & $20 c$ & 21 \\
\hline
\end{tabular}

Any information copied from such Reports and Statements may not be sold or used by any person for the purpose of soliciting contributions or for commercial purposes, other than using the name and address of any political committee to solicit contributions from such committee.

NAME OF COMMITTEE (In Full)

\section{Friends of Herman Cain}

A. Full Name (Last, First, Middle Initial)

Barry Camp

Mailing Address 305 Pandora St.

\begin{tabular}{lcc}
\hline City & State & Zip Code \\
Lafayette & LA & $70506-5238$ \\
\hline
\end{tabular}

FEC ID number of contributing federal political committee.

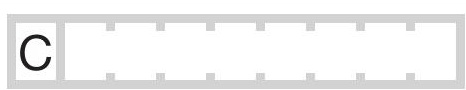

Name of Employer
Information Requested
Receipt For: 2012
X Primary
Other (specify) General

Occupation Information Requested

Election Cycle-to-Date

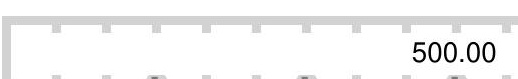

B. Full Name (Last, First, Middle Initial)

Robert Lapotaire

Mailing Address 344 E Woodstone Ct

\begin{tabular}{lcc}
\hline City & State & Zip Code \\
Baton Rouge & LA & $70808-5142$ \\
\hline
\end{tabular}

FEC ID number of contributing

federal political committee.

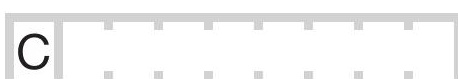

Name of Employer
$\mathrm{CCH}$
Receipt For: 2012
X Primary
$\square$ Other (specify)

\section{Occupation}

Sales

Election Cycle-to-Date

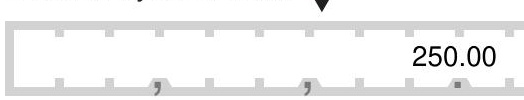

Transaction ID : A2022305B456F4837B8A

Date of Receipt

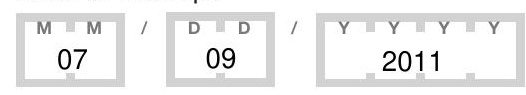

Amount of Each Receipt this Period

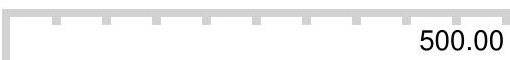

C. Full Name (Last, First, Middle Initial)

Daniel Stone

Mailing Address 4417 Sterling Pointe $\mathrm{Dr}$

\begin{tabular}{lcc}
\hline City & State & Zip Code \\
Kennesaw & GA & $30152-7348$
\end{tabular}

FEC ID number of contributing federal political committee.

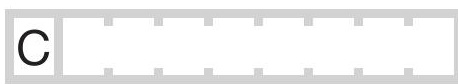

Name of Employer
INVISTA S.a.r.I.
Receipt For: 2012
X Primary $\quad \square$ General
Other (specify)

Occupation

VP - Business Analysis

Election Cycle-to-Date

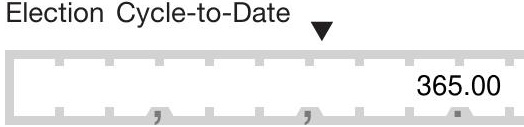

Transaction ID : AA036824C33CE49B7A17 Date of Receipt

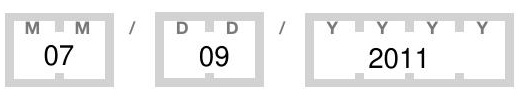

Amount of Each Receipt this Period

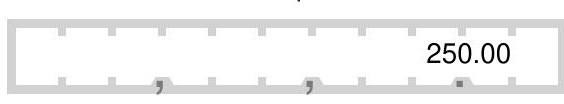

Transaction ID : AEE4092C9F056403E99C Date of Receipt

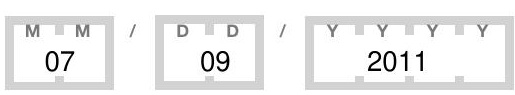

Amount of Each Receipt this Period

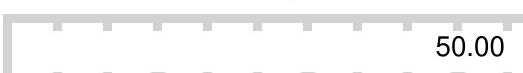

\section{Subtotal Of Receipts This Page (optional)}

800.00

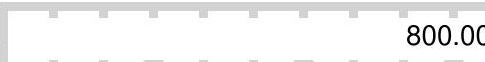

ㄱ․․

Total This Period (last page this line number only)

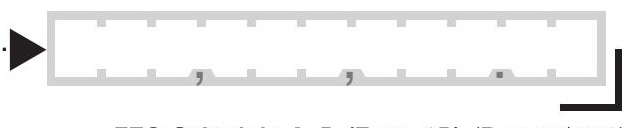

FEC Schedule A-P (Form 3P) (Rev. 03/2011) 
SCHEDULE A-P ITEMIZED RECEIPTS
Use separate schedule(s) for each category of the Detailed Summary Page
FOR LINE NUMBER: (check only one)

\begin{tabular}{|c|c|c|c|c|c|c|}
\hline & & & & & & \\
\hline 16 & $\times 1$ & $17 a$ & $17 b$ & $17 c$ & $17 d$ & 18 \\
\hline $19 a$ & & $19 b$ & $20 \mathrm{a}$ & $20 \mathrm{~b}$ & $20 \mathrm{c}$ & 21 \\
\hline
\end{tabular}

Any information copied from such Reports and Statements may not be sold or used by any person for the purpose of soliciting contributions or for commercial purposes, other than using the name and address of any political committee to solicit contributions from such committee.

NAME OF COMMITTEE (In Full)

\section{Friends of Herman Cain}

A. Full Name (Last, First, Middle Initial)

Joe Billion

Mailing Address 32 Kean Drive

\begin{tabular}{lcc}
\hline City & State & Zip Code \\
Bozeman & MT & $59718-8706$
\end{tabular}

FEC ID number of contributing federal political committee.

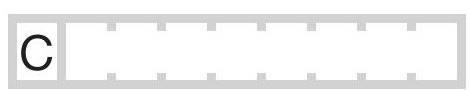

Name of Employer
J C Billion Inc
Receipt For: 2012
X Primary $\quad$ General
Other (specify)

Occupation Auto Sales

Election Cycle-to-Date

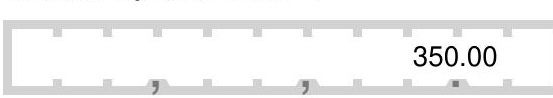

B. Full Name (Last, First, Middle Initial)

Walter Knight

Mailing Address 335 E Big Beaver

\begin{tabular}{lcc}
\hline City & State & Zip Code \\
Troy & MI & $48083-1235$
\end{tabular}

FEC ID number of contributing

federal political committee.

C

Name of Employer
Knight \& Firth PC
Receipt For: 2012
Primary
Other (specify)

Occupation

Attorney

Election Cycle-to-Date

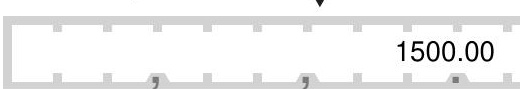

C. Full Name (Last, First, Middle Initial)

Elizabeth wickham

Mailing Address po box 15

\begin{tabular}{lcc}
\hline City & State & Zip Code \\
Palm Springs & CA & $92263-0015$
\end{tabular}

FEC ID number of contributing federal political committee.

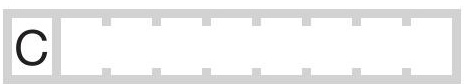

Name of Employer
Merrill Lynch
Receipt For: 2012
X Primary $\quad \square$ General
Other (specify)

\section{Occupation}

Financial Advisor

Election Cycle-to-Date

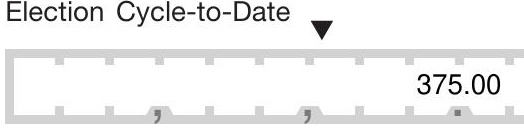

Transaction ID : A4BC780A14E5145EBA6B

Date of Receipt

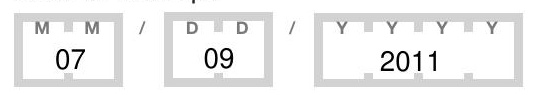

Amount of Each Receipt this Period

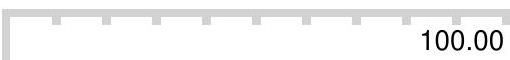

100.00

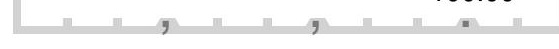

Transaction ID : AC005F756F4C2498BBF3

Date of Receipt

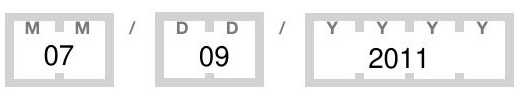

Amount of Each Receipt this Period

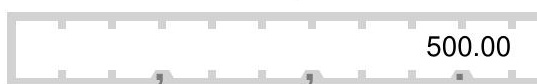

Transaction ID : A8091AF2FA5524E64AC8 Date of Receipt

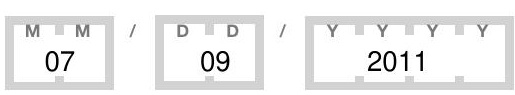

Amount of Each Receipt this Period

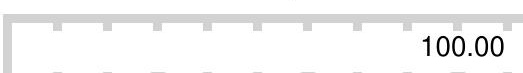

100.00

Subtotal Of Receipts This Page (optional)

Total This Period (last page this line number only) 
SCHEDULE A-P ITEMIZED RECEIPTS
Use separate schedule(s) for each category of the Detailed Summary Page
FOR LINE NUMBER: (check only one)

\begin{tabular}{|c|c|c|c|c|c|}
\hline & & & & & \\
\hline 16 & $\begin{array}{ll}X & 17 a \\
\end{array}$ & $17 \mathrm{~b}$ & $17 c$ & $17 d$ & 18 \\
\hline $19 a$ & $19 b$ & $20 \mathrm{a}$ & $20 \mathrm{~b}$ & $20 c$ & 21 \\
\hline
\end{tabular}

Any information copied from such Reports and Statements may not be sold or used by any person for the purpose of soliciting contributions or for commercial purposes, other than using the name and address of any political committee to solicit contributions from such committee.

NAME OF COMMITTEE (In Full)

\section{Friends of Herman Cain}

A. Full Name (Last, First, Middle Initial)

\section{Fleet Davis}

Mailing Address 5376 Harbor Court Dr

\begin{tabular}{lcc}
\hline City & State & Zip Code \\
Alexandria & VA & $22315-3946$ \\
\hline
\end{tabular}

FEC ID number of contributing federal political committee.

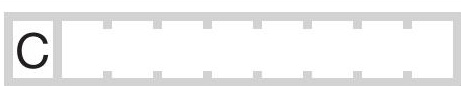

Name of Employer
Information Requested
Receipt For: 2012
X Primary $\quad \square$ General
Other (specify)

Occupation Information Requested

Election Cycle-to-Date

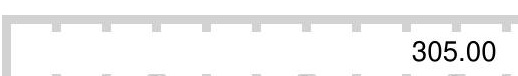

B. Full Name (Last, First, Middle Initial)

Fleet Davis

Mailing Address 5376 Harbor Court Dr

\begin{tabular}{lcc}
\hline City & State & Zip Code \\
Alexandria & VA & $22315-3946$ \\
\hline
\end{tabular}

FEC ID number of contributing

federal political committee.

C

Name of Employer
Information Requested
Receipt For: 2012
X Primary
Other (specify)

Occupation

Information Requested

Election Cycle-to-Date

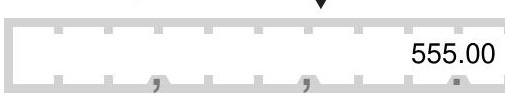

Transaction ID : A20AABF4932C74934B34

Date of Receipt

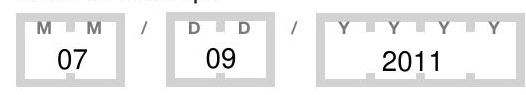

Amount of Each Receipt this Period

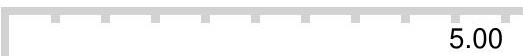

C. Full Name (Last, First, Middle Initial)

Cynthia Lalas

Mailing Address 13428 Valerie $\mathrm{Dr}$

\begin{tabular}{lcc}
\hline City & State & Zip Code \\
Pensacola & FL & $32507-8767$
\end{tabular}

FEC ID number of contributing

federal political committee.

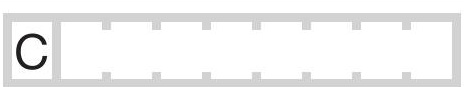

Name of Employer
NA
Receipt For: 2012
Х Primary $\quad \square$ General
Other (specify)

Occupation

Retired

Election Cycle-to-Date

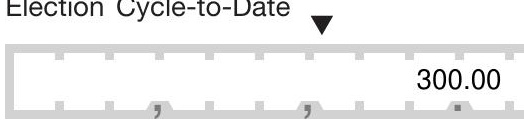

Transaction ID : ADDDF1C002D4347E9B08 Date of Receipt

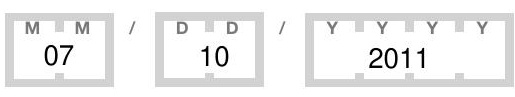

Amount of Each Receipt this Period

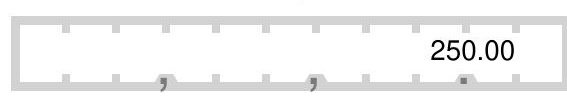

Transaction ID : A8EFD9BD9376E41D19C5 Date of Receipt

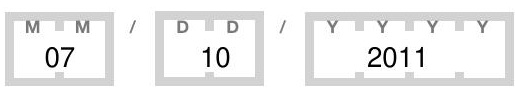

Amount of Each Receipt this Period

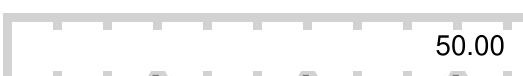

\section{Subtotal Of Receipts This Page (optional)}

305.00

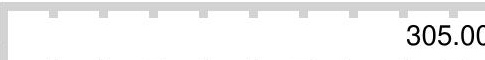

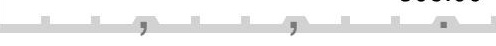

Total This Period (last page this line number only)

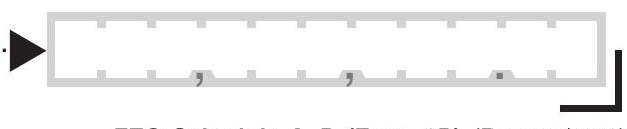

FEC Schedule A-P (Form 3P) (Rev. 03/2011) 
SCHEDULE A-P ITEMIZED RECEIPTS
Use separate schedule(s) for each category of the Detailed Summary Page
FOR LINE NUMBER: (check only one)

\begin{tabular}{|c|c|c|c|c|c|}
\hline & & & & & \\
\hline 16 & $\begin{array}{ll}X & 17 a \\
\end{array}$ & $17 \mathrm{~b}$ & $17 c$ & $17 d$ & 18 \\
\hline $19 a$ & $19 b$ & $20 \mathrm{a}$ & $20 \mathrm{~b}$ & $20 c$ & 21 \\
\hline
\end{tabular}

Any information copied from such Reports and Statements may not be sold or used by any person for the purpose of soliciting contributions or for commercial purposes, other than using the name and address of any political committee to solicit contributions from such committee.

NAME OF COMMITTEE (In Full)

\section{Friends of Herman Cain}

A. Full Name (Last, First, Middle Initial)

Mary Watkins

Mailing Address 1870 Bridle Ridge Trce

\begin{tabular}{lcc}
\hline City & State & Zip Code \\
Roswell & GA & $30075-2151$
\end{tabular}

FEC ID number of contributing federal political committee.

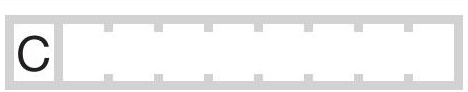

Name of Employer
n/a
Receipt For: 2012
X Primary $\quad$ General
Other (specify)

Occupation Homemaker

Election Cycle-to-Date

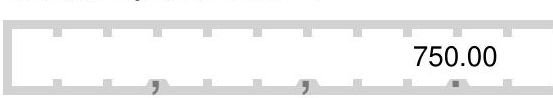

B. Full Name (Last, First, Middle Initial)

Mr. Baron F. Newton

Mailing Address 3260 Sutcliffe Rdg NW

\begin{tabular}{lcc}
\hline City & State & Zip Code \\
Marietta & GA & $30064-1736$ \\
\hline
\end{tabular}

FEC ID number of contributing

federal political committee.

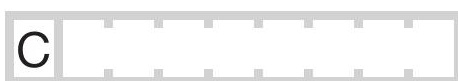

Name of Employer
Lockheed Marietta
Receipt For: 2012
X Primary $\quad$ General

Occupation

CNC Machinist

Election Cycle-to-Date

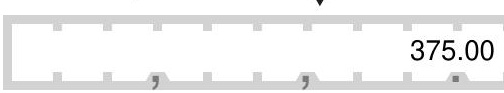

Transaction ID : A55BB58D322684975A16

Date of Receipt

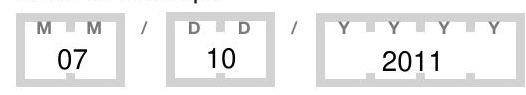

Amount of Each Receipt this Period

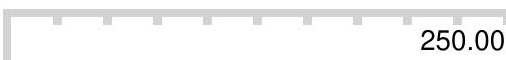

Amount of Each Receipt this Period

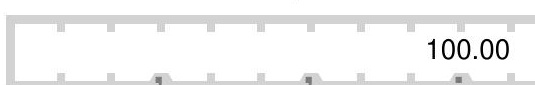

C. Full Name (Last, First, Middle Initial)

James Stewart

Mailing Address 3560 E. Via Colonia del Sol

\begin{tabular}{lcc}
\hline City & State & Zip Code \\
Tucson & AZ & $85718-6065$
\end{tabular}

FEC ID number of contributing federal political committee.

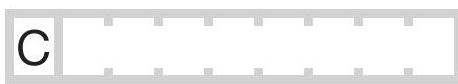

Name of Employer

Information Requested

Occupation

Information Requested

Receipt For: 2012

Х $\begin{aligned} & \text { Primary } \\ & \text { Other (specify) }\end{aligned}$

Election Cycle-to-Date

618.00

Transaction ID : A9A4C6FB74B1642C487F

Date of Receipt

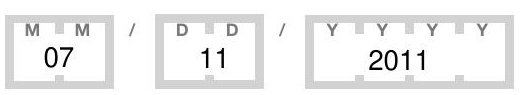

Transaction ID : AECE2F6BE808D47BAA9A Date of Receipt

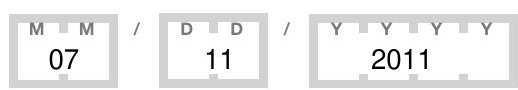

Amount of Each Receipt this Period

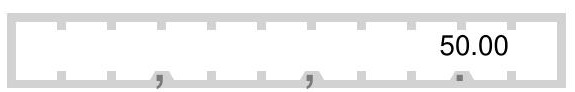

Subtotal Of Receipts This Page (optional).

400.00

Total This Period (last page this line number only) 
SCHEDULE A-P ITEMIZED RECEIPTS
Use separate schedule(s) for each category of the Detailed Summary Page
FOR LINE NUMBER: (check only one)

\begin{tabular}{|c|c|c|c|c|c|}
\hline & & & & & \\
\hline 16 & $\begin{array}{ll}X & 17 a \\
\end{array}$ & $17 \mathrm{~b}$ & $17 c$ & $17 d$ & 18 \\
\hline $19 a$ & $19 b$ & $20 \mathrm{a}$ & $20 \mathrm{~b}$ & $20 c$ & 21 \\
\hline
\end{tabular}

Any information copied from such Reports and Statements may not be sold or used by any person for the purpose of soliciting contributions or for commercial purposes, other than using the name and address of any political committee to solicit contributions from such committee.

NAME OF COMMITTEE (In Full)

Friends of Herman Cain

A. Full Name (Last, First, Middle Initial) albert caddis

Mailing Address POB 9

\begin{tabular}{lcc}
\hline City & State & Zip Code \\
Duncanville & AL & $35456-0009$
\end{tabular}

FEC ID number of contributing federal political committee.

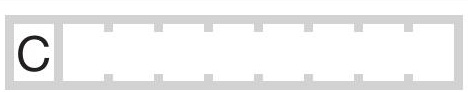

Name of Employer
Central Alabama Transport
Receipt For: 2012
X Primary
$\square$ Other (specify)

Occupation truck driver

Election Cycle-to-Date

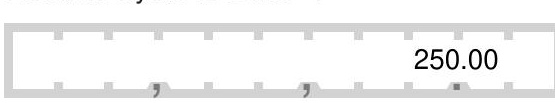

B. Full Name (Last, First, Middle Initial) John Tollett

Mailing Address 258 Riverdale Rd

\begin{tabular}{lcc}
\hline City & State & Zip Code \\
Severna Park & MD & $21146-1334$
\end{tabular}

FEC ID number of contributing

federal political committee.

C

Name of Employer
Constellation Energy
Receipt For: 2012
Primary
Other (specify)

Occupation

Controlroom Operator

Election Cycle-to-Date

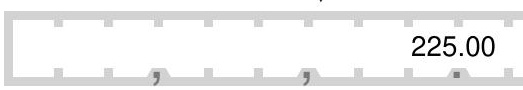

C. Full Name (Last, First, Middle Initial)

Marianne Mason

Mailing Address 30 Tall Oaks Trail

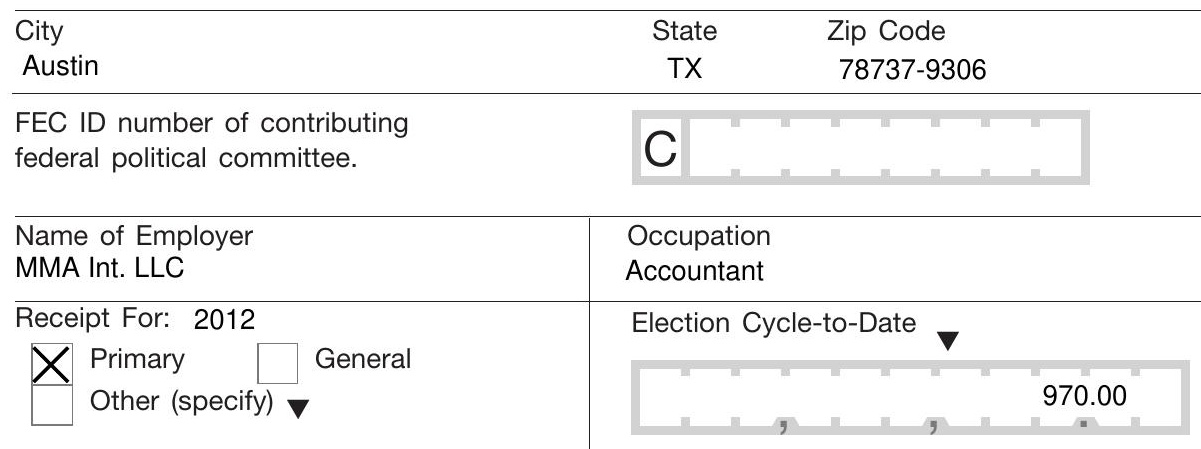

Transaction ID : A9DB0E21824884656A17

Date of Receipt

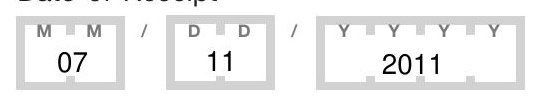

Amount of Each Receipt this Period

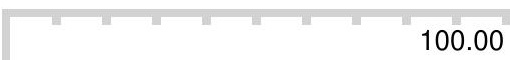

Transaction ID : AEFE1CCBDFD1A4E6CB74 Date of Receipt

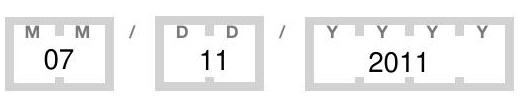

Amount of Each Receipt this Period

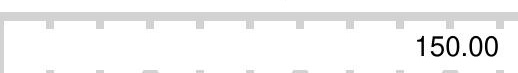

Amount of Each Receipt this Period

Transaction ID : A5B2066BA17FE41559E2 Date of Receipt
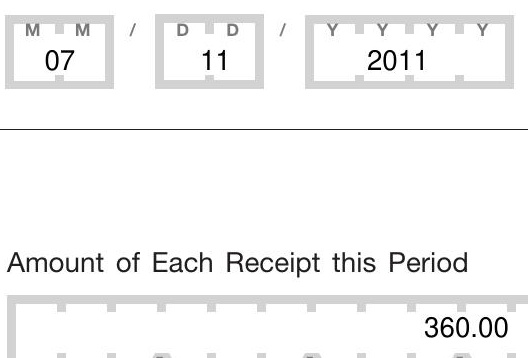

360.00

Subtotal Of Receipts This Page (optional).

610.00

Total This Period (last page this line number only) 
SCHEDULE A-P ITEMIZED RECEIPTS
Use separate schedule(s) for each category of the Detailed Summary Page
FOR LINE NUMBER: (check only one)

\begin{tabular}{|c|c|c|c|c|c|}
\hline & & & & & \\
\hline 16 & $\begin{array}{ll}X & 17 a \\
\end{array}$ & $17 \mathrm{~b}$ & $17 c$ & $17 d$ & 18 \\
\hline $19 a$ & $19 b$ & $20 \mathrm{a}$ & $20 \mathrm{~b}$ & $20 c$ & 21 \\
\hline
\end{tabular}

Any information copied from such Reports and Statements may not be sold or used by any person for the purpose of soliciting contributions or for commercial purposes, other than using the name and address of any political committee to solicit contributions from such committee.

NAME OF COMMITTEE (In Full)

\section{Friends of Herman Cain}

A. Full Name (Last, First, Middle Initial)

\section{Susan Walter}

Mailing Address P.O. Box 690

\begin{tabular}{lcc}
\hline City & State & Zip Code \\
Sautee Nacoochee & GA & $30571-0690$ \\
\hline
\end{tabular}

FEC ID number of contributing federal political committee.

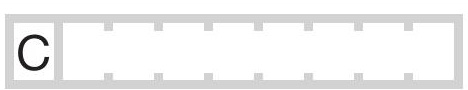

Name of Employer
None
Receipt For: 2012
X Primary $\quad$ General
Other (specify)

Occupation Retired

Election Cycle-to-Date

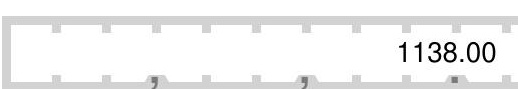

B. Full Name (Last, First, Middle Initial)

Cheryl Lenhart

Mailing Address 4200 E. Skelly Dr. \#610

\begin{tabular}{lcc}
\hline City & State & Zip Code \\
Tulsa & OK & $74135-3255$ \\
\hline
\end{tabular}

FEC ID number of contributing

federal political committee.

C

Name of Employer
None
Receipt For: 2012
X Primary
Other (specify)

\section{Occupation} Homemaker

Election Cycle-to-Date

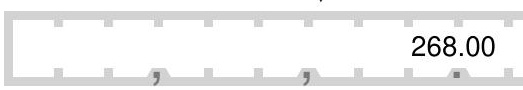

Transaction ID : A24A7EFB29B584C81975

Date of Receipt

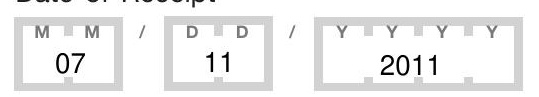

Amount of Each Receipt this Period

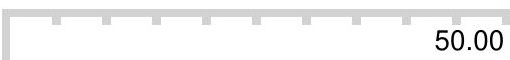

50.00

C. Full Name (Last, First, Middle Initial)

claire mencke

Mailing Address 5 tudor city place apt 305

\begin{tabular}{lcc}
\hline City & State & Zip Code \\
New York & NY & $10017-6858$
\end{tabular}

FEC ID number of contributing federal political committee.

C

$10017-6858$

Name of Employer

buckingham research group

Receipt For: 2012

Х $\begin{aligned} & \text { Primary } \\ & \text { Other (specify) }\end{aligned}$

\section{Occupation}

research assoc

Election Cycle-to-Date

Transaction ID : AA26ACAAF8B7B4B9096A Date of Receipt

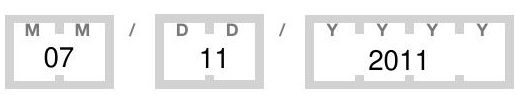

Amount of Each Receipt this Period

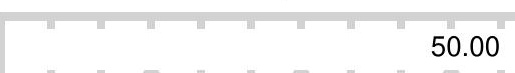

Transaction ID : A1A66832921DC40FAB95

Date of Receipt

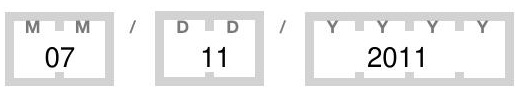

Amount of Each Receipt this Period

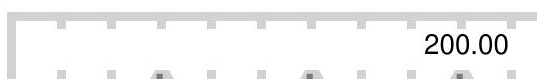

500.00

\section{Subtotal Of Receipts This Page (optional)}

Total This Period (last page this line number only) 
SCHEDULE A-P ITEMIZED RECEIPTS
Use separate schedule(s) for each category of the Detailed Summary Page
FOR LINE NUMBER: (check only one)

\begin{tabular}{|c|c|c|c|c|c|}
\hline & & & & & \\
\hline 16 & $\begin{array}{ll}X & 17 a \\
\end{array}$ & $17 \mathrm{~b}$ & $17 c$ & $17 d$ & 18 \\
\hline $19 a$ & $19 b$ & $20 \mathrm{a}$ & $20 \mathrm{~b}$ & $20 c$ & 21 \\
\hline
\end{tabular}

Any information copied from such Reports and Statements may not be sold or used by any person for the purpose of soliciting contributions or for commercial purposes, other than using the name and address of any political committee to solicit contributions from such committee.

NAME OF COMMITTEE (In Full)

\section{Friends of Herman Cain}

A. Full Name (Last, First, Middle Initial) John Ellery

Mailing Address 2488 Old Fork Rd

\begin{tabular}{lcc}
\hline City & State & Zip Code \\
Gainesville & GA & $30506-1124$
\end{tabular}

FEC ID number of contributing federal political committee.

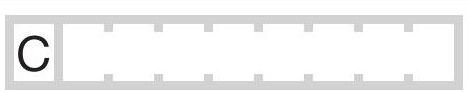

Name of Employer
Automatic IT Corp
Receipt For: 2012
X Primary
Other (specify) General

Occupation

IT Consultant

Election Cycle-to-Date

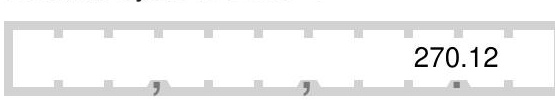

B. Full Name (Last, First, Middle Initial)

Calvin Nickal

Mailing Address 6511 Monarch Dr.

\begin{tabular}{lcc}
\hline City & State & Zip Code \\
Cheyenne & WY & $82009-5777$ \\
\hline
\end{tabular}

FEC ID number of contributing

federal political committee.

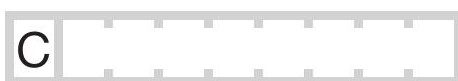

Name of Employer
self
Receipt For: 2012
Primary
Other (specify)

Occupation

rancher

Election Cycle-to-Date

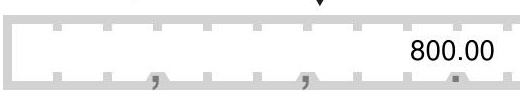

Transaction ID : AFAA813CDABE849B19C9

Date of Receipt

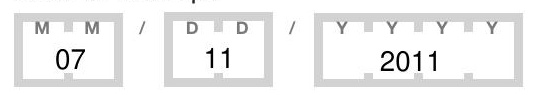

Amount of Each Receipt this Period

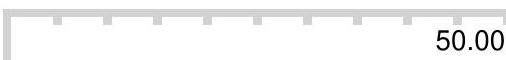

50.00

C. Full Name (Last, First, Middle Initial)

Bianca Beary

Mailing Address 10451 Grandoaks Ln

\begin{tabular}{lcc}
\hline City & State & Zip Code \\
Montgomery & OH & $45242-5033$
\end{tabular}

FEC ID number of contributing federal political committee.

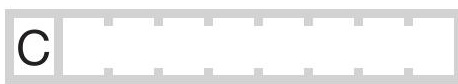

Name of Employer

Information Requested

Occupation

Information Requested

Receipt For: 2012

Х $\begin{aligned} & \text { Primary } \\ & \text { Other (specify) }\end{aligned}$

Election Cycle-to-Date

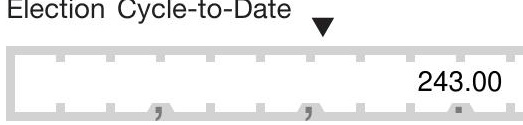

Amount of Each Receipt this Period

Transaction ID : A7380B4C7B92E44F4B1D

Date of Receipt
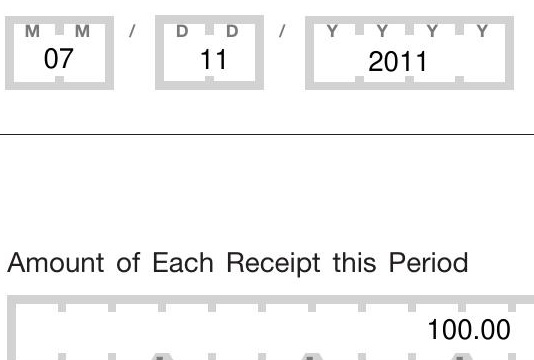

Transaction ID : AE5597B26506A4C89919

Date of Receipt

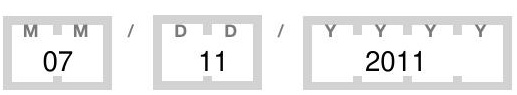

Amount of Each Receipt this Period

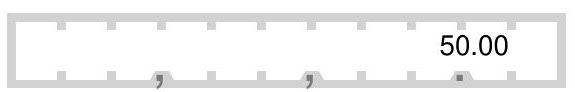

Subtotal Of Receipts This Page (optional).

200.00

Total This Period (last page this line number only) 
SCHEDULE A-P ITEMIZED RECEIPTS
Use separate schedule(s) for each category of the Detailed Summary Page
FOR LINE NUMBER: (check only one)

\begin{tabular}{|c|c|c|c|c|c|}
\hline & & & & & \\
\hline 16 & $\begin{array}{ll}X & 17 a \\
\end{array}$ & $17 \mathrm{~b}$ & $17 c$ & $17 d$ & 18 \\
\hline $19 a$ & $19 b$ & $20 \mathrm{a}$ & $20 \mathrm{~b}$ & $20 c$ & 21 \\
\hline
\end{tabular}

Any information copied from such Reports and Statements may not be sold or used by any person for the purpose of soliciting contributions or for commercial purposes, other than using the name and address of any political committee to solicit contributions from such committee.

NAME OF COMMITTEE (In Full)

\section{Friends of Herman Cain}

A. Full Name (Last, First, Middle Initial) Jeanne Downer

Mailing Address 6007 N Kansas AVe

\begin{tabular}{lcc}
\hline City & State & Zip Code \\
Kansas City & MO & $64119-2115$
\end{tabular}

FEC ID number of contributing federal political committee.

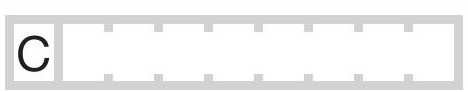

Name of Employer
WNB Architects
Receipt For: 2012
X Primary $\quad$ General
Other (specify)

Occupation Office Manager

Election Cycle-to-Date

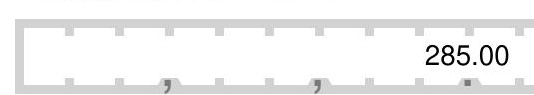

B. Full Name (Last, First, Middle Initial) Sharon Waite

Mailing Address 8301 W Business Highway 83

\begin{tabular}{lcc}
\hline City & State & Zip Code \\
Mission & TX & $78572-9445$
\end{tabular}

FEC ID number of contributing

federal political committee.

C

Name of Employer
Self Employed
Receipt For: 2012
X Primary
Other (specify)

Occupation Agriculture

Election Cycle-to-Date

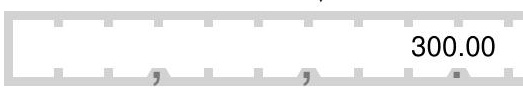

Transaction ID : AC1E8835488E34C87AA7

Date of Receipt

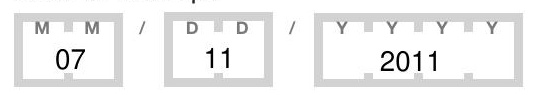

Amount of Each Receipt this Period

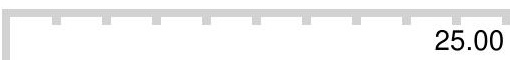

25.00

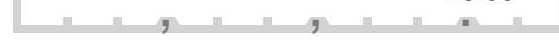

Transaction ID : AA9988D93F00A44A8957

Date of Receipt

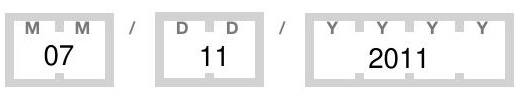

Amount of Each Receipt this Period

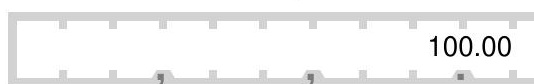

Transaction ID : A8DFBD174657C4597825

Date of Receipt

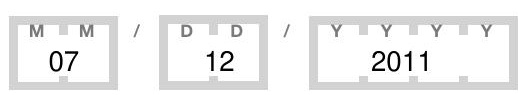

Amount of Each Receipt this Period

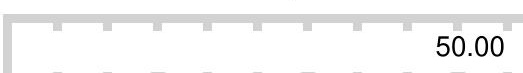

Name of Employer

Nebraska Plastics Inc.

Receipt For: 2012

Х $\begin{aligned} & \text { Primary } \\ & \text { Other (specify) }\end{aligned}$

$\begin{array}{cc}\text { State } & \text { Zip Code } \\ \text { NE } & 69130-0045\end{array}$

C

Occupation

CEO

Election Cycle-to-Date

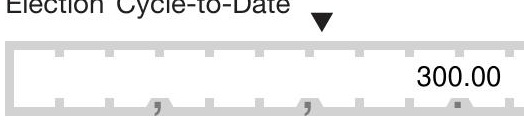

Subtotal Of Receipts This Page (optional).

175.00

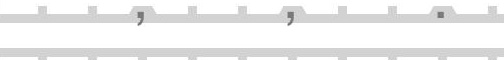

Total This Period (last page this line number only) 


\section{SCHEDULE A-P} ITEMIZED RECEIPTS
Use separate schedule(s)

for each category of the

Detailed Summary Page
FOR LINE NUMBER: (check only one)
PAGE $61 / 1572$

\begin{tabular}{|c|c|c|c|c|c|}
\hline & & & & & \\
\hline 16 & $\mathbf{X} 17 \mathrm{a}$ & $17 \mathrm{~b}$ & $17 c$ & $17 d$ & 18 \\
\hline $19 a$ & $19 b$ & $20 a$ & $20 \mathrm{~b}$ & $20 c$ & 21 \\
\hline
\end{tabular}

Any information copied from such Reports and Statements may not be sold or used by any person for the purpose of soliciting contributions or for commercial purposes, other than using the name and address of any political committee to solicit contributions from such committee.

NAME OF COMMITTEE (In Full)

\section{Friends of Herman Cain}

A. Full Name (Last, First, Middle Initial)

Diane Weissman

Mailing Address 8632 Titleist Circle

\begin{tabular}{lcc}
\hline City & State & Zip Code \\
Las Vegas & NV & $89117-5843$
\end{tabular}

FEC ID number of contributing

federal political committee.

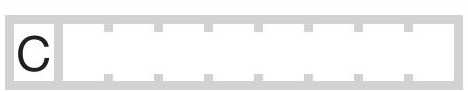

Name of Employer
Information Requested
Receipt For: 2012
X Primary
Other (specify) General

Occupation

Information Requested

Election Cycle-to-Date

1000.00

B. Full Name (Last, First, Middle Initial)

Mr Paul A Brock

Mailing Address 11 Juliana Ct

\begin{tabular}{lcc}
\hline City & State & Zip Code \\
Ellenwood & GA & $30294-2835$ \\
\hline
\end{tabular}

FEC ID number of contributing

federal political committee.

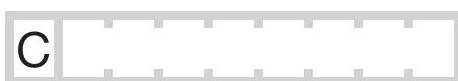

Name of Employer
None
Receipt For: 2012
X Primary
Other (specify)

Occupation

Retired

Election Cycle-to-Date

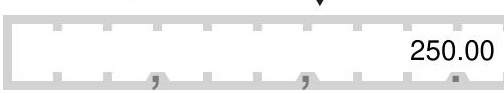

Transaction ID : AE39D4FA8CC974711A88

Date of Receipt

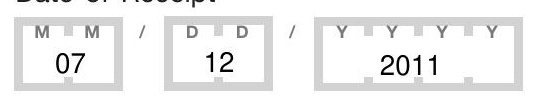

Amount of Each Receipt this Period

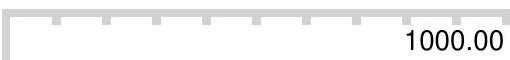

1000.00

C. Full Name (Last, First, Middle Initial)

James Scheffel

Mailing Address 3704 Carrollwood Place Circle APT

\begin{tabular}{lcc}
\hline City & State & Zip Code \\
Tampa & FL & $33624-3080$
\end{tabular}

FEC ID number of contributing federal political committee.

C

33624-3080

Name of Employer

Information Requested

\section{Occupation}

Information Requested

Receipt For: 2012

Х $\begin{aligned} & \text { Primary } \square \text { General } \\ & \text { Other (specify) }\end{aligned}$

Transaction ID : A0BC51E30EB7A456AA9B

Date of Receipt

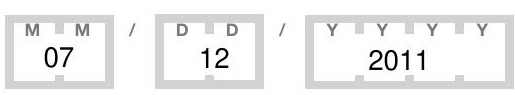

Amount of Each Receipt this Period

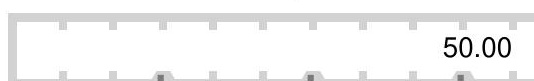

Transaction ID : A77E6261C8C454D1D89A Date of Receipt

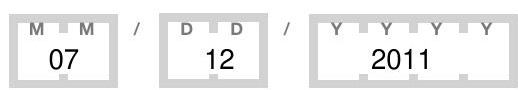

Amount of Each Receipt this Period

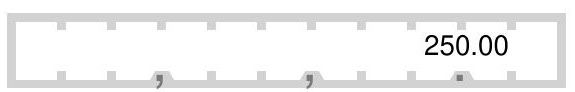

250.00

\section{Subtotal Of Receipts This Page (optional)}

Total This Period (last page this line number only) 
SCHEDULE A-P ITEMIZED RECEIPTS
Use separate schedule(s) for each category of the Detailed Summary Page
FOR LINE NUMBER: (check only one)

\begin{tabular}{|c|c|c|c|c|c|c|}
\hline & & & & & & \\
\hline 16 & $\times 1$ & $17 a$ & $17 b$ & $17 c$ & $17 d$ & 18 \\
\hline $19 a$ & & $19 b$ & $20 \mathrm{a}$ & $20 \mathrm{~b}$ & $20 \mathrm{c}$ & 21 \\
\hline
\end{tabular}

Any information copied from such Reports and Statements may not be sold or used by any person for the purpose of soliciting contributions or for commercial purposes, other than using the name and address of any political committee to solicit contributions from such committee.

NAME OF COMMITTEE (In Full)

\section{Friends of Herman Cain}

A. Full Name (Last, First, Middle Initial)

\section{Tim Cunningham}

Mailing Address 88 main St

\begin{tabular}{lcc}
\hline City & State & Zip Code \\
Southampton & NY & $11968-4834$
\end{tabular}

FEC ID number of contributing federal political committee.

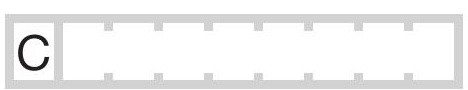

Name of Employer
Cunningham Insurance
Receipt For: 2012
X Primary
$\square$ Other (specify)

B. Full Name (Last, First, Middle Initial) Conrad Weibler

Mailing Address 10307 Wilde Lake Ter

\begin{tabular}{lcc}
\hline City & State & Zip Code \\
Columbia & MD & $21044-2503$ \\
\hline
\end{tabular}

FEC ID number of contributing

federal political committee.

C

Name of Employer
Retired
Receipt For: 2012
X Primary
Other (specify)

C. Full Name (Last, First, Middle Initial) John LaRosa

Mailing Address 273 Roslindale Ave.

\begin{tabular}{lcc}
\hline City & State & Zip Code \\
Roslindale & MA & $02131-3339$
\end{tabular}

FEC ID number of contributing federal political committee.

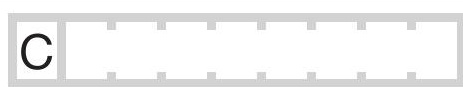

Name of Employer
self
Receipt For: 2012
Primary
Other (specify) General

\section{Occupation} Pres.

Election Cycle-to-Date 300.00
Transaction ID : A048648D55ED448B9AA1

Date of Receipt

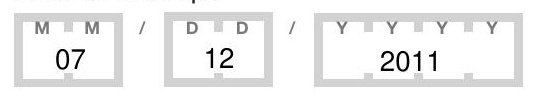

Amount of Each Receipt this Period

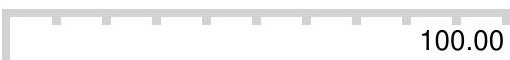

Amount of Each Receipt this Period

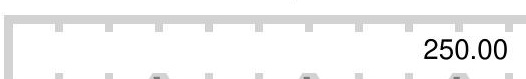

Amount of Each Receipt this Period

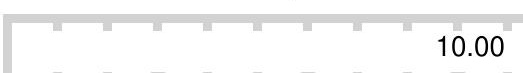

\section{Subtotal Of Receipts This Page (optional)}

360.00 Consulting

Election Cycle-to-Date 287.76

Transaction ID : ACCA46D333B2A4C0D900 Date of Receipt

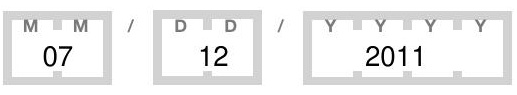

Total This Period (last page this line number only) 
SCHEDULE A-P ITEMIZED RECEIPTS
Use separate schedule(s) for each category of the Detailed Summary Page
FOR LINE NUMBER: (check only one)

\begin{tabular}{|c|c|c|c|c|c|}
\hline & & & & & \\
\hline 16 & $\begin{array}{ll}X & 17 a \\
\end{array}$ & $17 \mathrm{~b}$ & $17 c$ & $17 d$ & 18 \\
\hline $19 a$ & $19 b$ & $20 \mathrm{a}$ & $20 \mathrm{~b}$ & $20 c$ & 21 \\
\hline
\end{tabular}

Any information copied from such Reports and Statements may not be sold or used by any person for the purpose of soliciting contributions or for commercial purposes, other than using the name and address of any political committee to solicit contributions from such committee.

NAME OF COMMITTEE (In Full)

\section{Friends of Herman Cain}

A. Full Name (Last, First, Middle Initial)

Nathan Kirkes

Mailing Address 4025 Jamaica Dr

\begin{tabular}{lcc}
\hline City & State & Zip Code \\
Jonesboro & GA & $30236-5466$
\end{tabular}

FEC ID number of contributing federal political committee.

Name of Employer
Information Requested
Receipt For: 2012
X Primary
Other (specify) General

B. Full Name (Last, First, Middle Initial)

\section{Edward Lozick}

Mailing Address 29425 Chagrin Blvd Ste 201

\begin{tabular}{lcc}
\hline City & State & Zip Code \\
Cleveland & OH & $44122-4602$
\end{tabular}

FEC ID number of contributing

federal political committee.

C

Name of Employer
Swagelok Company
Receipt For: 2012
X Primary
Other (specify)

C. Full Name (Last, First, Middle Initial)

Kathy Hoellen

Mailing Address 471 Swift Creek Cv

\begin{tabular}{lcc}
\hline City & State & Zip Code \\
Clover & SC & $29710-5500$
\end{tabular}

FEC ID number of contributing federal political committee.

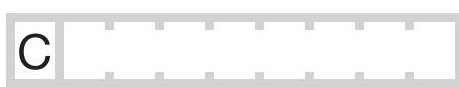

Name of Employer

York Technical College

Receipt For: 2012

Х $\begin{aligned} & \text { Primary } \\ & \text { Other (specify) }\end{aligned}$

\section{Occupation}

education

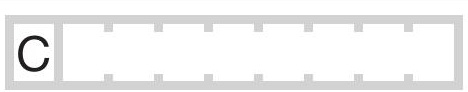

Occupation Information Requested

Election Cycle-to-Date

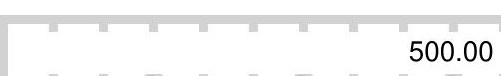

\section{Occupation}

Chairman Of The Board

Election Cycle-to-Date

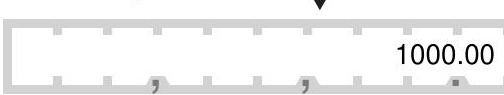

Transaction ID : A33E64CA64E6340B4B2A

Date of Receipt

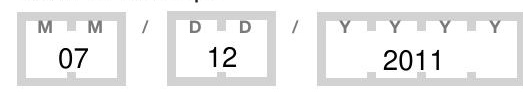

Amount of Each Receipt this Period

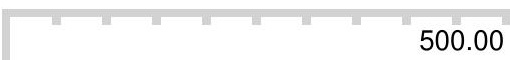

500.00

Transaction ID : A03C35E9029874A94A05

Date of Receipt

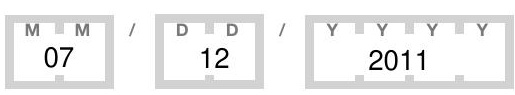

Amount of Each Receipt this Period

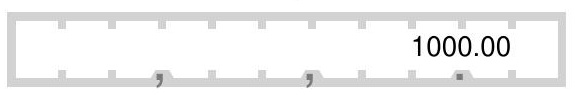

Transaction ID : A5FEDDEA6421A44A8A2E Date of Receipt

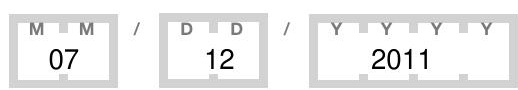

Amount of Each Receipt this Period

100.00
Subtotal Of Receipts This Page (optional)

1600.00

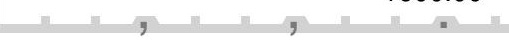

Total This Period (last page this line number only)

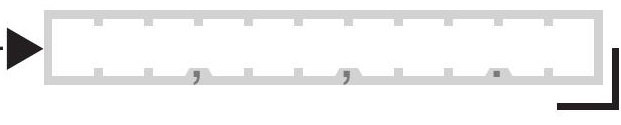

FEC Schedule A-P (Form 3P) (Rev. 03/2011) 
SCHEDULE A-P ITEMIZED RECEIPTS
Use separate schedule(s) for each category of the Detailed Summary Page
FOR LINE NUMBER: (check only one)

\begin{tabular}{|c|c|c|c|c|c|}
\hline & & & & & \\
\hline 16 & $\mathbf{X} 17 a$ & $17 b$ & $17 c$ & $17 d$ & 18 \\
\hline $19 a$ & $19 b$ & $20 \mathrm{a}$ & $20 \mathrm{~b}$ & $20 \mathrm{c}$ & 21 \\
\hline
\end{tabular}

Any information copied from such Reports and Statements may not be sold or used by any person for the purpose of soliciting contributions or for commercial purposes, other than using the name and address of any political committee to solicit contributions from such committee.

NAME OF COMMITTEE (In Full)

\section{Friends of Herman Cain}

A. Full Name (Last, First, Middle Initial)

Harold Deas

Mailing Address 2225 Dinsmore Road

\begin{tabular}{lcc}
\hline City & State & Zip Code \\
Alpharetta & GA & $30004-2730$
\end{tabular}

FEC ID number of contributing

federal political committee.

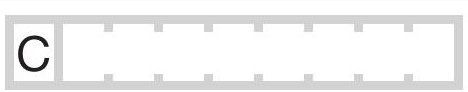

Name of Employer
Information Requested
Receipt For: 2012
X Primary $\quad \square$ General
Other (specify)

Occupation

Information Requested

Election Cycle-to-Date

250.00

Transaction ID : A36ADF866F6C34300943

Date of Receipt

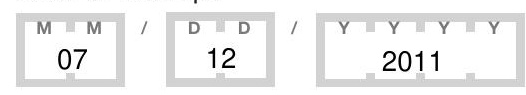

Amount of Each Receipt this Period

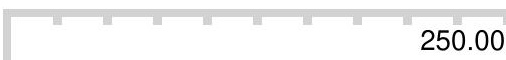

B. Full Name (Last, First, Middle Initial)

Fred D Backer Jr

Mailing Address 18 Narry Ln

\begin{tabular}{lcc}
\hline City & State & Zip Code \\
Mount Morris & NY & $14510-1519$ \\
\hline
\end{tabular}

FEC ID number of contributing

federal political committee.

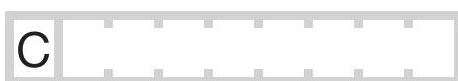

Name of Employer
None
Receipt For: 2012
X Primary
Other (specify)

Occupation

Retired

Election Cycle-to-Date

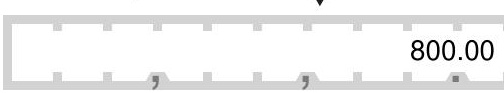

Transaction ID : A4326C645014844B8B8A

Date of Receipt

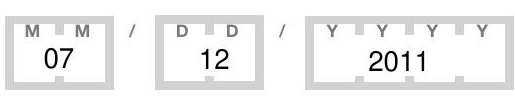

Amount of Each Receipt this Period

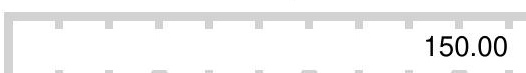

Transaction ID : A6FFB70E5FF5C4819BF5 Date of Receipt

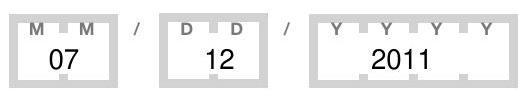

Amount of Each Receipt this Period

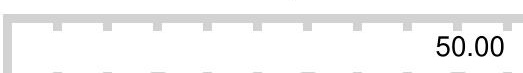

\section{Occupation}

project mgr

Election Cycle-to-Date

Receipt For: 2012

Х $\begin{aligned} & \text { Primary } \square \text { General } \\ & \text { Other (specify) }\end{aligned}$

\section{State Zip Code \\ 92011-3226}

C

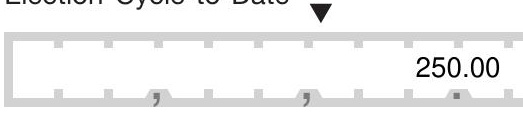

Subtotal Of Receipts This Page (optional)

450.00

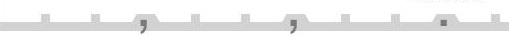

Total This Period (last page this line number only)

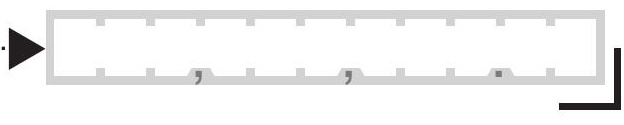

FEC Schedule A-P (Form 3P) (Rev. 03/2011) 
SCHEDULE A-P ITEMIZED RECEIPTS
Use separate schedule(s)

for each category of the

Detailed Summary Page
FOR LINE NUMBER: (check only one)

\begin{tabular}{|c|c|c|c|c|c|}
\hline & & & & & \\
\hline 16 & $\begin{array}{ll}X & 17 a \\
\end{array}$ & $17 \mathrm{~b}$ & $17 c$ & $17 d$ & 18 \\
\hline $19 a$ & $19 b$ & $20 \mathrm{a}$ & $20 \mathrm{~b}$ & $20 c$ & 21 \\
\hline
\end{tabular}

Any information copied from such Reports and Statements may not be sold or used by any person for the purpose of soliciting contributions or for commercial purposes, other than using the name and address of any political committee to solicit contributions from such committee.

NAME OF COMMITTEE (In Full)

\section{Friends of Herman Cain}

A. Full Name (Last, First, Middle Initial)

Mr Paul A Brock

Mailing Address 11 Juliana Ct

\begin{tabular}{lcc}
\hline City & State & Zip Code \\
Ellenwood & GA & $30294-2835$
\end{tabular}

FEC ID number of contributing federal political committee.

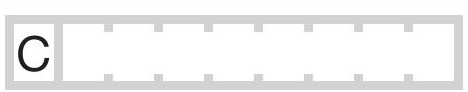

\begin{tabular}{l} 
Name of Employer \\
None \\
Receipt For: 2012 \\
X Primary $\quad$ General \\
\hline Other (specify)
\end{tabular}

Occupation

Retired

Election Cycle-to-Date

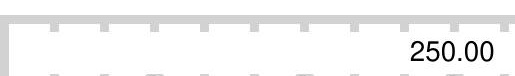

B. Full Name (Last, First, Middle Initial)

lois edgerly

Mailing Address 32 highland street

\begin{tabular}{lcc}
\hline City & State & Zip Code \\
Cambridge & MA & $02138-2210$
\end{tabular}

FEC ID number of contributing

federal political committee.

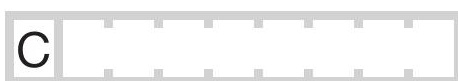

Name of Employer
Retired
Receipt For: 2012
X Primary $\quad$ General
Other (specify)

\section{Occupation}

Retired

Election Cycle-to-Date

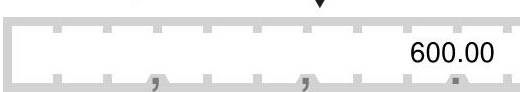

C. Full Name (Last, First, Middle Initial)

Glen Ebbing

Mailing Address 1400 Huntleigh Rd

\begin{tabular}{lcc}
\hline City & State & Zip Code \\
Quincy & IL & $62305-6017$
\end{tabular}

FEC ID number of contributing

federal political committee.

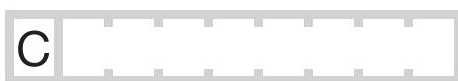

Name of Employer
ColorMaster Pain Inc
Receipt For: 2012
X Primary $\quad \square$ General
Other (specify)

Occupation

sales representative

Election Cycle-to-Date
Transaction ID : A5985736AF03A469C827

Date of Receipt

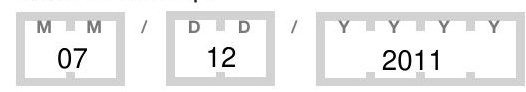

Amount of Each Receipt this Period

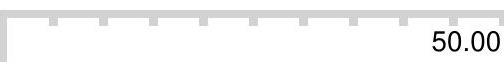

50.00
Amount of Each Receipt this Period

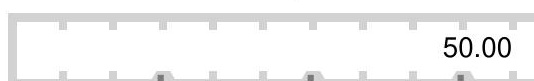

Transaction ID : A6E3356B4C258400283F

Date of Receipt

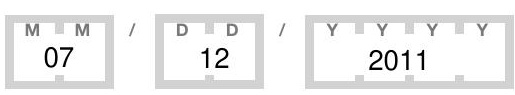

Transaction ID : AC812C3ADBF6A4D1E9C2 Date of Receipt

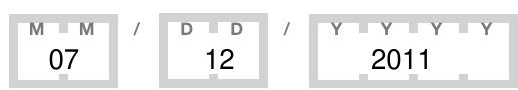

Amount of Each Receipt this Period

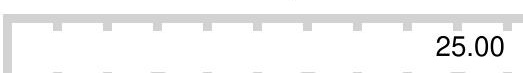

\section{Subtotal Of Receipts This Page (optional)}

Total This Period (last page this line number only) 
SCHEDULE A-P ITEMIZED RECEIPTS
Use separate schedule(s)

for each category of the

Detailed Summary Page
FOR LINE NUMBER: (check only one)

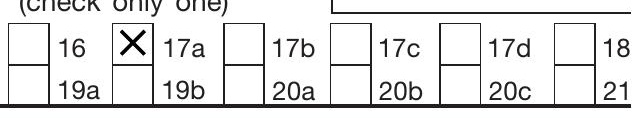

Any information copied from such Reports and Statements may not be sold or used by any person for the purpose of soliciting contributions or for commercial purposes, other than using the name and address of any political committee to solicit contributions from such committee.

NAME OF COMMITTEE (In Full)

\section{Friends of Herman Cain}

A. Full Name (Last, First, Middle Initial)

John Rose

Mailing Address 446 Horseshoe Way, Apt\# H203

\begin{tabular}{lcc}
\hline City & State & Zip Code \\
Dalton & GA & $30721-1677$
\end{tabular}

FEC ID number of contributing

federal political committee.

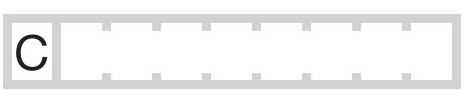

Name of Employer
Shaw Transport
Receipt For: 2012
X Primary
Other (specify) General

Occupation

Transportation

Election Cycle-to-Date

225.00

B. Full Name (Last, First, Middle Initial)

Janis Bourassa

Mailing Address PO Box 130

\begin{tabular}{lcc}
\hline City & State & Zip Code \\
Mesa & CO & $81643-0130$
\end{tabular}

FEC ID number of contributing

federal political committee.

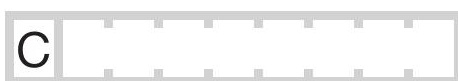

Name of Employer
Self-Employed
Receipt For: 2012
X Primary
Other (specify)

Occupation

Treasurer

Election Cycle-to-Date

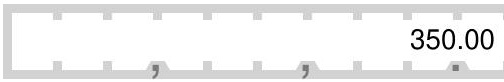

C. Full Name (Last, First, Middle Initial)

Diane Vinson

Mailing Address 461 McKinney Road

\begin{tabular}{lcc}
\hline City & State & Zip Code \\
Wexford & PA & $15090-8539$
\end{tabular}

FEC ID number of contributing

federal political committee.

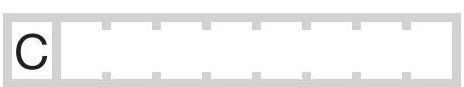

Name of Employer

Information Requested

Occupation

Information Requested

Receipt For: 2012

Х $\begin{aligned} & \text { Primary } \\ & \text { Other (specify) }\end{aligned}$

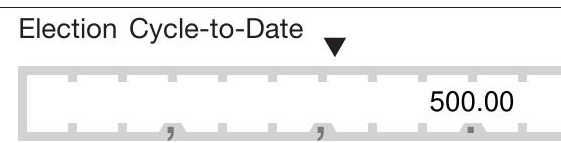

Amount of Each Receipt this Period

Transaction ID : AD81FAD9F37DA40419D5

Date of Receipt
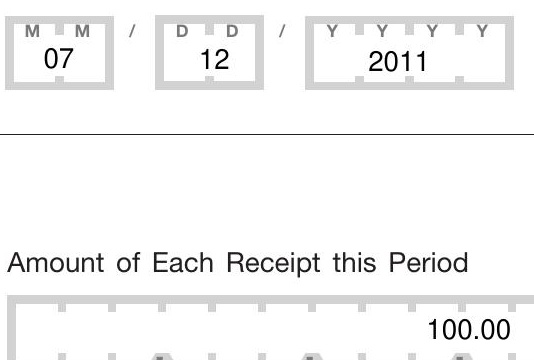

Transaction ID : A9E37BA219B654969BB1 Date of Receipt

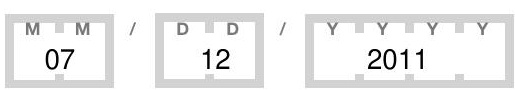

Amount of Each Receipt this Period

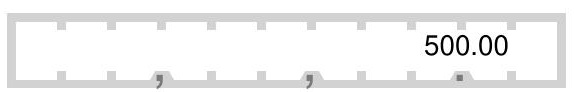

Subtotal Of Receipts This Page (optional)

650.00

Total This Period (last page this line number only) 
SCHEDULE A-P ITEMIZED RECEIPTS
Use separate schedule(s) for each category of the Detailed Summary Page
FOR LINE NUMBER: (check only one)

\begin{tabular}{|c|c|c|c|c|c|c|}
\hline & & & & & & \\
\hline 16 & $\times 1$ & $17 a$ & $17 b$ & $17 c$ & $17 d$ & 18 \\
\hline $19 a$ & & $19 b$ & $20 \mathrm{a}$ & $20 \mathrm{~b}$ & $20 \mathrm{c}$ & 21 \\
\hline
\end{tabular}

Any information copied from such Reports and Statements may not be sold or used by any person for the purpose of soliciting contributions or for commercial purposes, other than using the name and address of any political committee to solicit contributions from such committee.

NAME OF COMMITTEE (In Full)

\section{Friends of Herman Cain}

A. Full Name (Last, First, Middle Initial)

Richard Baumgardner

Mailing Address P.O. Box 263

\begin{tabular}{lcc}
\hline City & State & Zip Code \\
Madison & ME & $04950-0263$
\end{tabular}

FEC ID number of contributing federal political committee.

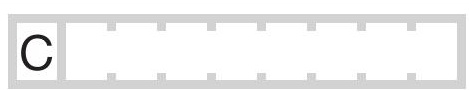

Name of Employer
n/a
Receipt For: 2012
X Primary $\quad$ General
Other (specify)

Occupation Retired

Election Cycle-to-Date

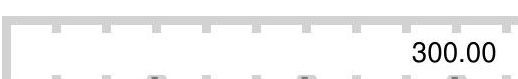

B. Full Name (Last, First, Middle Initial)

Terry Chick

Mailing Address 13650 N Heritage Canyon Dr

\begin{tabular}{lcc}
\hline City & State & Zip Code \\
Marana & AZ & $85658-4073$
\end{tabular}

FEC ID number of contributing

federal political committee.

C

Name of Employer

Retired

Receipt For: 2012

$\bigotimes \begin{aligned} & \text { Primary } \square \text { General } \\ & \text { Other (specify) } \nabla\end{aligned}$

C. Full Name (Last, First, Middle Initial)

Judy Phillips

Mailing Address PO Box 872

\section{City}

Norwich

FEC ID number of contributing federal political committee.

Name of Employer

Fmr. Self (currently NA)

Receipt For: 2012

Х $\begin{aligned} & \text { Primary } \square \text { General } \\ & \text { Other (specify) }\end{aligned}$

\section{Occupation}

Retired

Election Cycle-to-Date

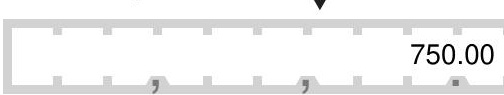

Transaction ID : ABFDEFC9549BA40E28CA

Date of Receipt

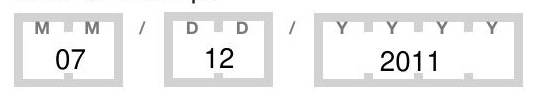

Amount of Each Receipt this Period

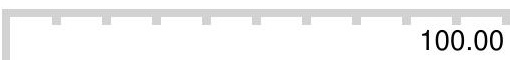

Amount of Each Receipt this Period

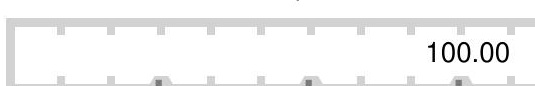

Transaction ID : A680EDDDDEBEE48EC86F Date of Receipt

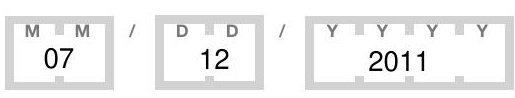

Transaction ID : A3232AD2D659D4B22ABE Date of Receipt

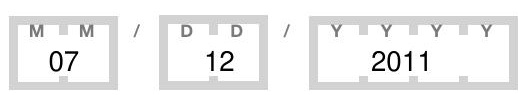

Amount of Each Receipt this Period

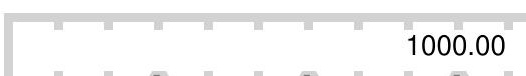

\section{Subtotal Of Receipts This Page (optional)}

1200.00

Public Finance - Analyst

Election Cycle-to-Date

1250.00

Total This Period (last page this line number only) 
SCHEDULE A-P ITEMIZED RECEIPTS
Use separate schedule(s)

for each category of the

Detailed Summary Page
FOR LINE NUMBER: (check only one)

\begin{tabular}{|c|c|c|c|c|c|}
\hline & & & & & \\
\hline 16 & $\begin{array}{ll}X & 17 a \\
\end{array}$ & $17 \mathrm{~b}$ & $17 c$ & $17 d$ & 18 \\
\hline $19 a$ & $19 b$ & $20 \mathrm{a}$ & $20 \mathrm{~b}$ & $20 c$ & 21 \\
\hline
\end{tabular}

Any information copied from such Reports and Statements may not be sold or used by any person for the purpose of soliciting contributions or for commercial purposes, other than using the name and address of any political committee to solicit contributions from such committee.

NAME OF COMMITTEE (In Full)

Friends of Herman Cain

A. Full Name (Last, First, Middle Initial)

KURT HOGAN

Mailing Address 3156 DOCKSIDE DR

\begin{tabular}{lcc}
\hline City & State & Zip Code \\
Gainesville & GA & $30501-1470$ \\
\hline
\end{tabular}

FEC ID number of contributing

federal political committee.

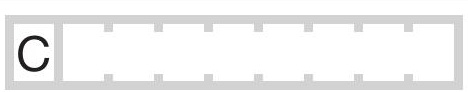

Name of Employer
BOLT EXPO LLC
Receipt For: 2012
X Primary $\quad \square$ General
$\square$ Other (specify)

Occupation

FASTENER DISTRIBUTOR

Election Cycle-to-Date $\boldsymbol{\nabla}$

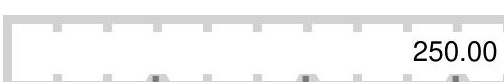

B. Full Name (Last, First, Middle Initial)

Arlene Rouse

Mailing Address 4655 E 58th St

\begin{tabular}{lcc}
\hline City & State & Zip Code \\
Tulsa & OK & $74135-4319$ \\
\hline
\end{tabular}

FEC ID number of contributing

federal political committee.

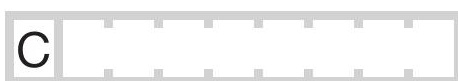

Name of Employer
Dillards
Receipt For: 2012
X Primary $\quad$ General
Other (specify)

\section{Occupation}

Sales

Election Cycle-to-Date

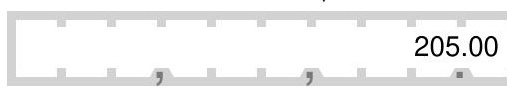

Transaction ID : A2AA4FF1B51FF4B4CAF3

Date of Receipt

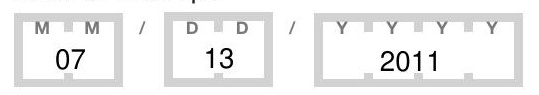

Amount of Each Receipt this Period

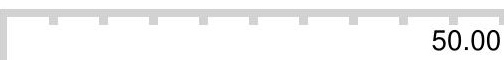

50.00

C. Full Name (Last, First, Middle Initial)

Nancy Gunsallus

Mailing Address 3461 Donegal Way

\begin{tabular}{lcc}
\hline City & State & Zip Code \\
Snellville & GA & $30039-8635$
\end{tabular}

FEC ID number of contributing

federal political committee.

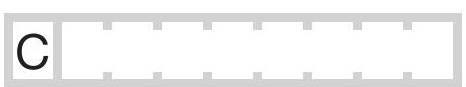

Name of Employer

American Shutter Components LLC

Receipt For: 2012

Х $\begin{aligned} & \text { Primary } \square \text { General } \\ & \text { Other (specify) }\end{aligned}$

\section{Occupation}

co-owner

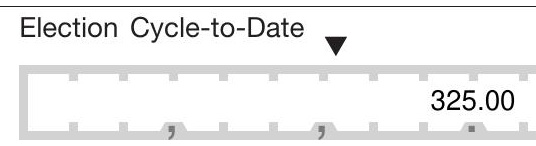

Transaction ID : AD70604E4B5294154BB5

Date of Receipt

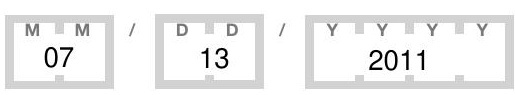

Amount of Each Receipt this Period

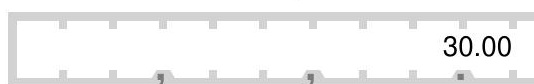

Transaction ID : A22181D3387094B54900

Date of Receipt

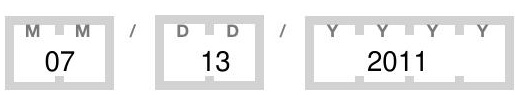

Amount of Each Receipt this Period

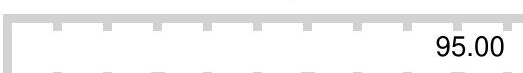

\section{Subtotal Of Receipts This Page (optional)}

175.00

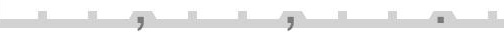

Total This Period (last page this line number only)

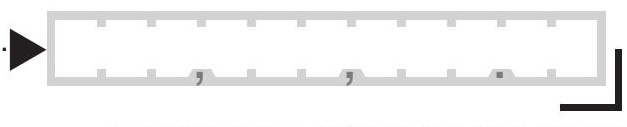

FEC Schedule A-P (Form 3P) (Rev. 03/2011) 
SCHEDULE A-P ITEMIZED RECEIPTS
Use separate schedule(s)

for each category of the

Detailed Summary Page
FOR LINE NUMBER: (check only one)

\begin{tabular}{|c|c|c|c|c|c|}
\hline & & & & & \\
\hline 16 & $\begin{array}{ll}X & 17 a \\
\end{array}$ & $17 \mathrm{~b}$ & $17 c$ & $17 d$ & 18 \\
\hline $19 a$ & $19 b$ & $20 \mathrm{a}$ & $20 \mathrm{~b}$ & $20 c$ & 21 \\
\hline
\end{tabular}

Any information copied from such Reports and Statements may not be sold or used by any person for the purpose of soliciting contributions or for commercial purposes, other than using the name and address of any political committee to solicit contributions from such committee.

NAME OF COMMITTEE (In Full)

\section{Friends of Herman Cain}

A. Full Name (Last, First, Middle Initial)

Mr. Phillip Mullinax

Mailing Address 965 Oak Grove Rd

\begin{tabular}{lcc}
\hline City & State & Zip Code \\
Dahlonega & GA & $30533-4840$
\end{tabular}

FEC ID number of contributing federal political committee.

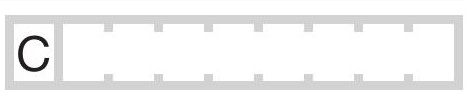

Name of Employer
self
Receipt For: 2012
X Primary $\quad$ General
Other (specify)

Occupation entrepreneur

Election Cycle-to-Date

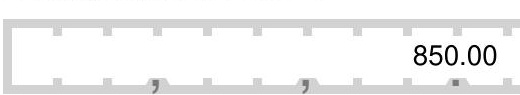

B. Full Name (Last, First, Middle Initial) EDWARD MURPHY

Mailing Address 214 CAMINO VISTA REAL

\begin{tabular}{lcc}
\hline City & State & Zip Code \\
Chula Vista & CA & $91910-6326$
\end{tabular}

FEC ID number of contributing

federal political committee.

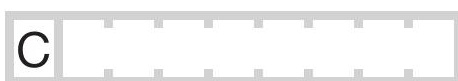

Name of Employer
navy exchange
Receipt For: 2012
Primary
Other (specify)

Occupation

Retired

Election Cycle-to-Date

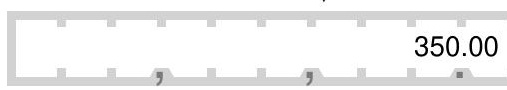

Transaction ID : A0A26A3F135BB4A5FB2A

Date of Receipt

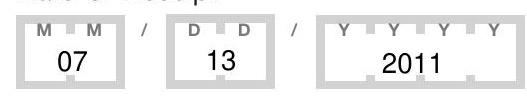

Amount of Each Receipt this Period

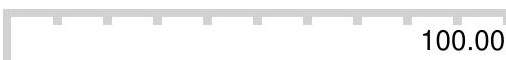

Transaction ID : A832F1594913B4B2CA83

Date of Receipt

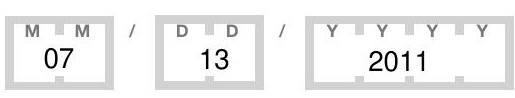

Amount of Each Receipt this Period

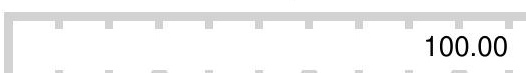

C. Full Name (Last, First, Middle Initial)

Paul Jones

Mailing Address 33922 Wadsworth St

\begin{tabular}{lcc}
\hline City & State & Zip Code \\
Livonia & MI & $48150-1534$
\end{tabular}

FEC ID number of contributing federal political committee.

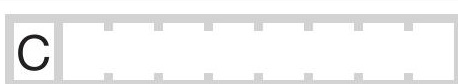

Name of Employer
Retired
Receipt For: 2012
X Primary $\quad \square$ General
Other (specify)

Occupation

Retired

Election Cycle-to-Date

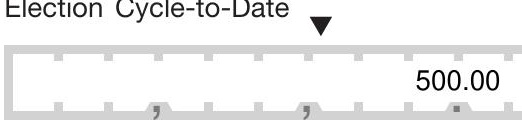

Subtotal Of Receipts This Page (optional)

450.00

Amount of Each Receipt this Period

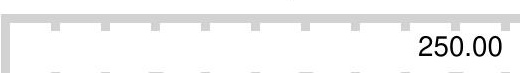

Total This Period (last page this line number only)

Transaction ID : A3F86D02FC5DC40D898D Date of Receipt

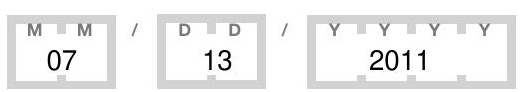


SCHEDULE A-P ITEMIZED RECEIPTS
Use separate schedule(s) for each category of the Detailed Summary Page
FOR LINE NUMBER: (check only one)

\begin{tabular}{|c|c|c|c|c|c|c|}
\hline & & & & & & \\
\hline 16 & $\times 1$ & $17 a$ & $17 b$ & $17 c$ & $17 d$ & 18 \\
\hline $19 a$ & & $19 b$ & $20 \mathrm{a}$ & $20 \mathrm{~b}$ & $20 \mathrm{c}$ & 21 \\
\hline
\end{tabular}

Any information copied from such Reports and Statements may not be sold or used by any person for the purpose of soliciting contributions or for commercial purposes, other than using the name and address of any political committee to solicit contributions from such committee.

NAME OF COMMITTEE (In Full)

\section{Friends of Herman Cain}

A. Full Name (Last, First, Middle Initial)

\section{Fred A Beach}

Mailing Address 4695 Arden Dr

\begin{tabular}{lcc}
\hline City & State & Zip Code \\
Buford & GA & $30518-3543$
\end{tabular}

FEC ID number of contributing federal political committee.

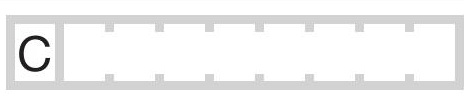

Name of Employer
self
Receipt For: 2012
X Primary $\quad$ General
Other (specify)

B. Full Name (Last, First, Middle Initial)

Clifford Cash

Mailing Address W172N7888 Shady Ln

\begin{tabular}{lcc}
\hline City & State & Zip Code \\
Menomonee Falls & WI & $53051-4172$
\end{tabular}

FEC ID number of contributing

federal political committee.

C

Name of Employer
Unemployed
Receipt For: 2012
X Primary
Other (specify)

\section{Occupation} architect

Election Cycle-to-Date

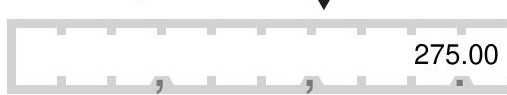

Election Cycle-to-Date 900.00
Transaction ID : AB17EE2B262874C7DB75

Date of Receipt

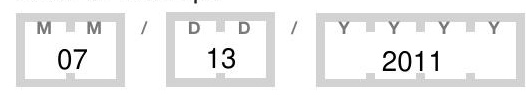

Amount of Each Receipt this Period

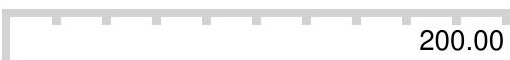

C. Full Name (Last, First, Middle Initial)

Heather Luther

Mailing Address 1000 Greystone Manor Pkwy

\begin{tabular}{lcc}
\hline City & State & Zip Code \\
Chesterfield & MO & $63005-4941$
\end{tabular}

FEC ID number of contributing federal political committee.

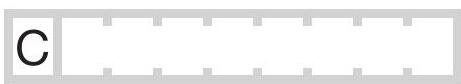

\section{Name of Employer}

ICL Performance Products LP

Receipt For: 2012

Х $\begin{aligned} & \text { Primary } \square \text { General } \\ & \text { Other (specify) }\end{aligned}$

\section{Occupation}

Lawyer

Election Cycle-to-Date

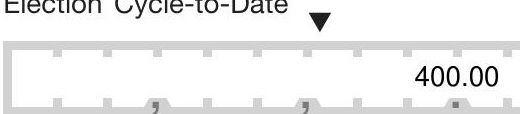

Transaction ID : AFB848D52E6F64FC6B31

Date of Receipt

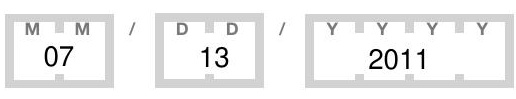

Amount of Each Receipt this Period

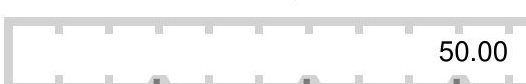

Transaction ID : A830FF208E4F147AAA0C Date of Receipt

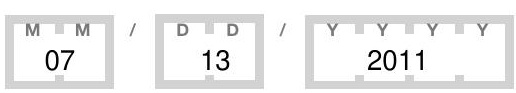

Amount of Each Receipt this Period

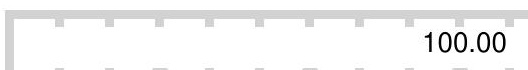

\section{Subtotal Of Receipts This Page (optional)}

Total This Period (last page this line number only) 
SCHEDULE A-P ITEMIZED RECEIPTS
Use separate schedule(s) for each category of the Detailed Summary Page
FOR LINE NUMBER: (check only one)

\begin{tabular}{|c|c|c|c|c|c|}
\hline & & & & & \\
\hline 16 & $\begin{array}{ll}X & 17 a \\
\end{array}$ & $17 \mathrm{~b}$ & $17 c$ & $17 d$ & 18 \\
\hline $19 a$ & $19 b$ & $20 \mathrm{a}$ & $20 \mathrm{~b}$ & $20 c$ & 21 \\
\hline
\end{tabular}

Any information copied from such Reports and Statements may not be sold or used by any person for the purpose of soliciting contributions or for commercial purposes, other than using the name and address of any political committee to solicit contributions from such committee.

NAME OF COMMITTEE (In Full)

\section{Friends of Herman Cain}

A. Full Name (Last, First, Middle Initial)

Donald Johnston

Mailing Address 6147 West 76th Street

\begin{tabular}{lcc}
\hline City & State & Zip Code \\
Los Angeles & CA & $90045-1637$ \\
\hline
\end{tabular}

FEC ID number of contributing

federal political committee.

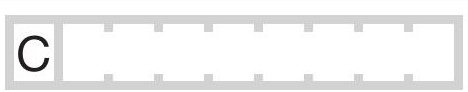

Name of Employer
Information Requested
Receipt For: 2012
X Primary $\quad \square$ General
Other (specify)

Occupation

Information Requested

Election Cycle-to-Date

250.00

B. Full Name (Last, First, Middle Initial)

Jeanne Downer

Mailing Address $6007 \mathrm{~N}$ Kansas AVe

\begin{tabular}{llc}
\hline City & State & Zip Code \\
Kansas City & MO & $64119-2115$ \\
\hline
\end{tabular}

FEC ID number of contributing

federal political committee.

C

Name of Employer
WNB Architects
Receipt For: 2012
X Primary
Other (specify) General

Occupation

Office Manager

Election Cycle-to-Date

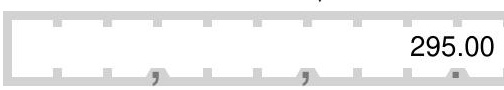

Transaction ID : AC574ED77923F45DE905

Date of Receipt

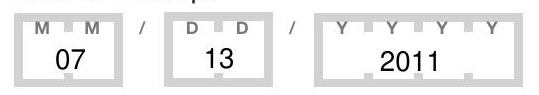

Amount of Each Receipt this Period

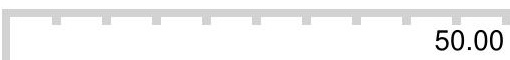

50.00

C. Full Name (Last, First, Middle Initial)

Leighton Wells

Mailing Address 717 Edgemont Way

\begin{tabular}{lcc}
\hline City & State & Zip Code \\
Springfield & OR & $97477-3607$
\end{tabular}

FEC ID number of contributing

federal political committee.

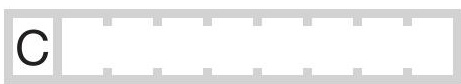

Name of Employer
n/a
Receipt For: 2012
X Primary $\square$ General
Other (specify)

Occupation

Retired

Election Cycle-to-Date

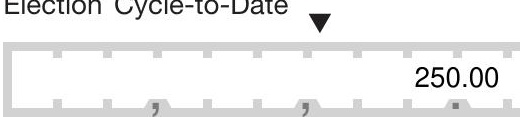

Transaction ID : A44B387351B0B4227BA4

Date of Receipt

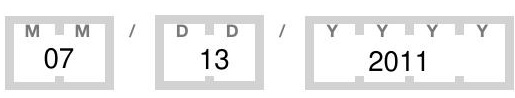

Amount of Each Receipt this Period

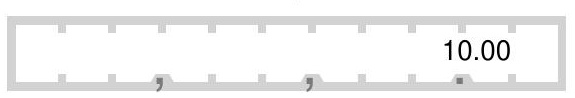

Transaction ID : ABFDA31B415E846678B6 Date of Receipt

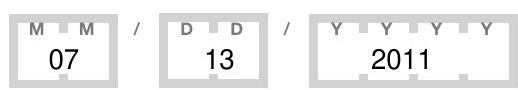

Amount of Each Receipt this Period

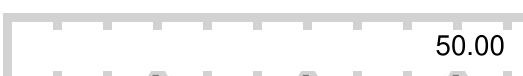

\section{Subtotal Of Receipts This Page (optional)}

110.00

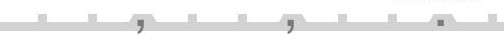

Total This Period (last page this line number only)

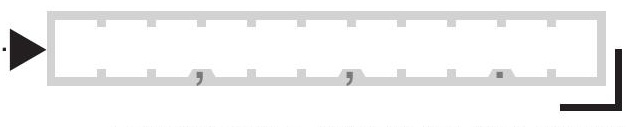

FEC Schedule A-P (Form 3P) (Rev. 03/2011) 


\section{SCHEDULE A-P} ITEMIZED RECEIPTS
Use separate schedule(s)

for each category of the

Detailed Summary Page
FOR LINE NUMBER: (check only one)
PAGE 72 / 1572

\begin{tabular}{|c|c|c|c|c|c|}
\hline & & & & & \\
\hline 16 & $\mathbf{X} 17 \mathrm{a}$ & $17 \mathrm{~b}$ & $17 c$ & $17 d$ & 18 \\
\hline $19 a$ & $19 b$ & $20 a$ & $20 \mathrm{~b}$ & $20 c$ & 21 \\
\hline
\end{tabular}

Any information copied from such Reports and Statements may not be sold or used by any person for the purpose of soliciting contributions or for commercial purposes, other than using the name and address of any political committee to solicit contributions from such committee.

NAME OF COMMITTEE (In Full)

\section{Friends of Herman Cain}

A. Full Name (Last, First, Middle Initial)

Rebecca Marsh

Mailing Address 262 Kings Row NE

\begin{tabular}{lcc}
\hline City & State & Zip Code \\
Marietta & GA & $30067-4104$
\end{tabular}

FEC ID number of contributing federal political committee.

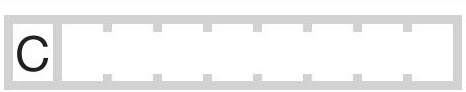

Name of Employer
Southern Company Services
Receipt For: 2012
X Primary
Other (specify) General

Occupation

Accounting Manager

Election Cycle-to-Date

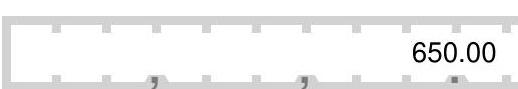

B. Full Name (Last, First, Middle Initial)

ELAINE POWERS

Mailing Address QT CONTRACTING INC 200 TIGER WAY

\begin{tabular}{lcc}
\hline City & State & Zip Code \\
Peachtree City & GA & $30269-1679$ \\
\hline
\end{tabular}

FEC ID number of contributing

federal political committee.

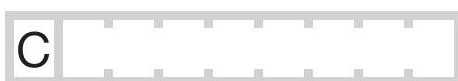

Name of Employer
Powers Heating \& Air
Receipt For: 2012
X Primary
Other (specify)

\section{Occupation}

HVAC

Election Cycle-to-Date

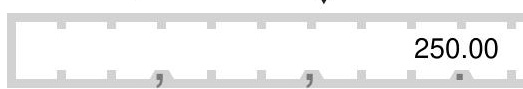

C. Full Name (Last, First, Middle Initial)

David Cabell

Mailing Address Box 7173

\begin{tabular}{lcc}
\hline City & State & Zip Code \\
Beaumont & TX & $77726-7173$
\end{tabular}

FEC ID number of contributing federal political committee.

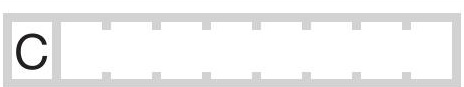

Name of Employer

Information Requested

\section{Occupation}

Information Requested

Receipt For: 2012

Х $\begin{aligned} & \text { Primary } \square \text { General } \\ & \text { Other (specify) }\end{aligned}$

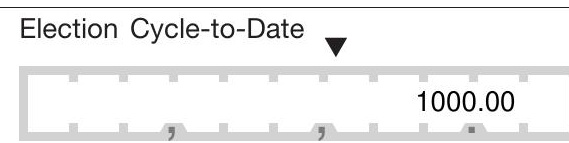

Amount of Each Receipt this Period

Transaction ID : A0F0CD743338C4387AA8

Date of Receipt

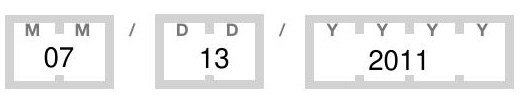

Amount of Each Receipt this Period
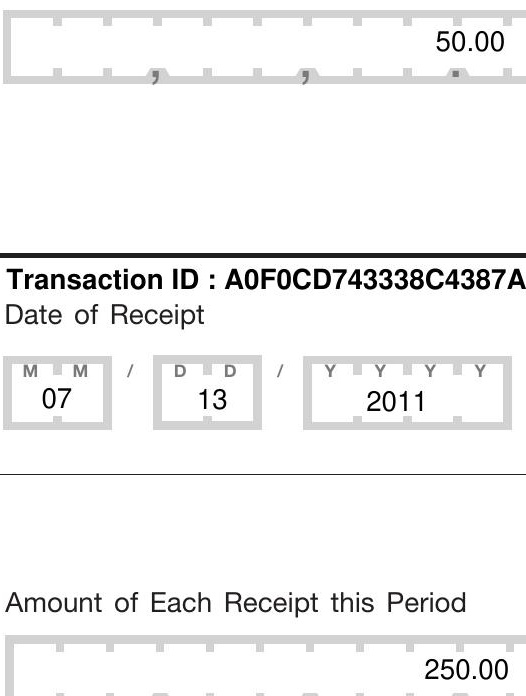

Transaction ID : A758079EAA5FF445EA4F Date of Receipt

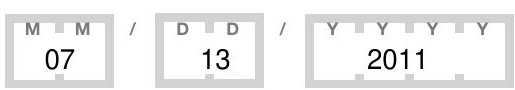

Amount of Each Receipt this Period

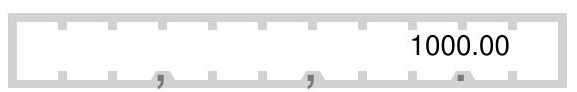

Subtotal Of Receipts This Page (optional)

1300.00

Total This Period (last page this line number only) 
SCHEDULE A-P ITEMIZED RECEIPTS
Use separate schedule(s) for each category of the Detailed Summary Page
FOR LINE NUMBER: (check only one)

\begin{tabular}{|c|c|c|c|c|c|}
\hline & & & & & \\
\hline 16 & $\begin{array}{ll}X & 17 a \\
\end{array}$ & $17 \mathrm{~b}$ & $17 c$ & $17 d$ & 18 \\
\hline $19 a$ & $19 b$ & $20 \mathrm{a}$ & $20 \mathrm{~b}$ & $20 c$ & 21 \\
\hline
\end{tabular}

Any information copied from such Reports and Statements may not be sold or used by any person for the purpose of soliciting contributions or for commercial purposes, other than using the name and address of any political committee to solicit contributions from such committee.

NAME OF COMMITTEE (In Full)

\section{Friends of Herman Cain}

A. Full Name (Last, First, Middle Initial)

Derek Simmons

Mailing Address 62 Avenida Cristal

\begin{tabular}{lcc}
\hline City & State & Zip Code \\
San Clemente & CA & $92673-6843$
\end{tabular}

FEC ID number of contributing

federal political committee.

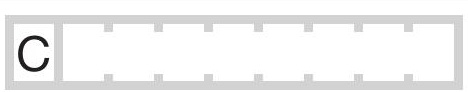

Name of Employer
Information Requested
Receipt For: 2012
X Primary $\quad \square$ General
Other (specify)

Occupation

Information Requested

Election Cycle-to-Date

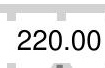

B. Full Name (Last, First, Middle Initial)

Debra Gilliam

Mailing Address 1807 Rockybranch Pass

\begin{tabular}{lcc}
\hline City & State & Zip Code \\
Marietta & GA & $30066-8014$
\end{tabular}

FEC ID number of contributing

federal political committee.

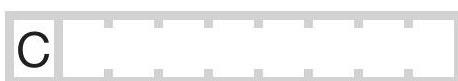

Name of Employer
Information Requested
Receipt For: 2012
X Primary
Other (specify)

\section{Occupation}

Information Requested

Election Cycle-to-Date

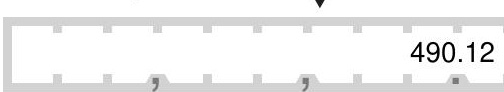

Transaction ID : A3D42AD09727F43ACA72

Date of Receipt

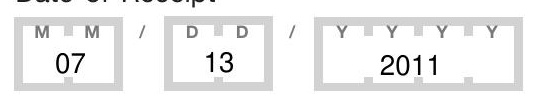

Amount of Each Receipt this Period

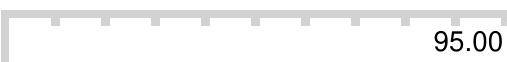

95.00

C. Full Name (Last, First, Middle Initial)

Gary Locke

Mailing Address 2602 Booger Hill Road

\begin{tabular}{lcc}
\hline City & State & Zip Code \\
Danielsville & GA & $30633-6102$
\end{tabular}

FEC ID number of contributing

federal political committee.

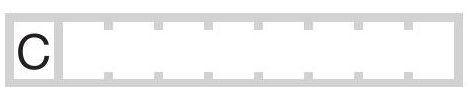

Name of Employer
None
Receipt For: 2012
X Primary $\quad \square$ General
Other (specify)

Occupation

Retired

Election Cycle-to-Date

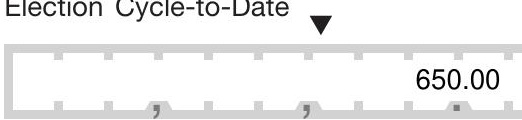

Transaction ID : A238F831D68E841BCADA Date of Receipt

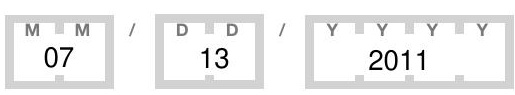

Amount of Each Receipt this Period

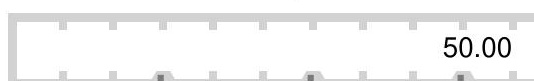

Transaction ID : A00553A3EA52F4AAC84C Date of Receipt

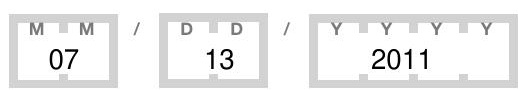

Amount of Each Receipt this Period

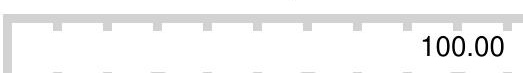

\section{Subtotal Of Receipts This Page (optional)}

245.00

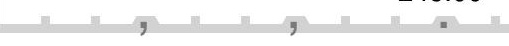

Total This Period (last page this line number only)

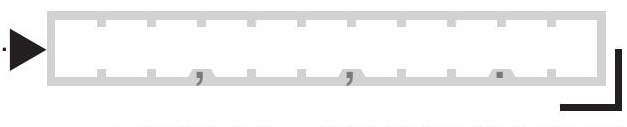

FEC Schedule A-P (Form 3P) (Rev. 03/2011) 
SCHEDULE A-P ITEMIZED RECEIPTS
Use separate schedule(s) for each category of the Detailed Summary Page
FOR LINE NUMBER: (check only one)

\begin{tabular}{|c|c|c|c|c|c|}
\hline & & & & & \\
\hline 16 & $\begin{array}{ll}X & 17 a \\
\end{array}$ & $17 \mathrm{~b}$ & $17 c$ & $17 d$ & 18 \\
\hline $19 a$ & $19 b$ & $20 \mathrm{a}$ & $20 \mathrm{~b}$ & $20 c$ & 21 \\
\hline
\end{tabular}

Any information copied from such Reports and Statements may not be sold or used by any person for the purpose of soliciting contributions or for commercial purposes, other than using the name and address of any political committee to solicit contributions from such committee.

NAME OF COMMITTEE (In Full)

\section{Friends of Herman Cain}

A. Full Name (Last, First, Middle Initial)

WILLIAM MORAN

Transaction ID : AFF5FDDBE796A4FECB88

Mailing Address 6601 Ladera Norte

\begin{tabular}{lcc}
\hline City & State & Zip Code \\
Austin & TX & $78731-2619$
\end{tabular}

FEC ID number of contributing federal political committee.

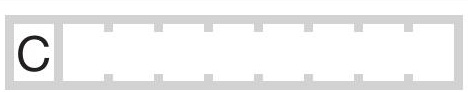

Name of Employer
Information Requested
Receipt For: 2012
X Primary
Other (specify) General

Occupation Information Requested

Election Cycle-to-Date

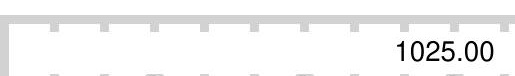

B. Full Name (Last, First, Middle Initial)

Donald Frenzl

Mailing Address 2895 Buck Grove Road

\begin{tabular}{lcc}
\hline City & State & Zip Code \\
Brandenburg & KY & $40108-6331$ \\
\hline
\end{tabular}

FEC ID number of contributing

federal political committee.

C

Name of Employer
Information Requested
Receipt For: 2012
X Primary
Other (specify)

Occupation

Information Requested

Election Cycle-to-Date

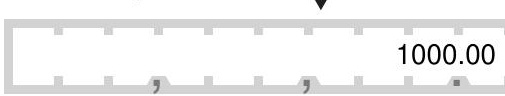

C. Full Name (Last, First, Middle Initial)

Stephen Arnold

Mailing Address 2719 Bay Ridge Dr.

\begin{tabular}{lcc}
\hline City & State & Zip Code \\
Loganville & GA & $30052-3706$
\end{tabular}

FEC ID number of contributing

federal political committee.

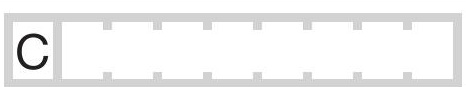

Name of Employer

Peachtree Pest Control Co. Inc.

Receipt For: 2012

Х $\begin{aligned} & \text { Primary } \square \text { General } \\ & \text { Other (specify) }\end{aligned}$

Occupation

pest Control

Election Cycle-to-Date

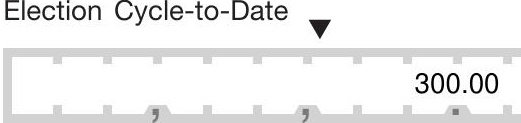

Date of Receipt

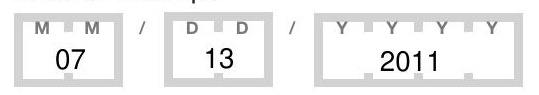

Amount of Each Receipt this Period

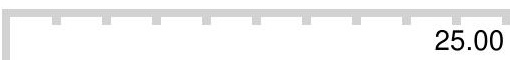

25.00

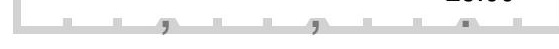

Transaction ID : AFC61B60FF8AB435587D

Date of Receipt

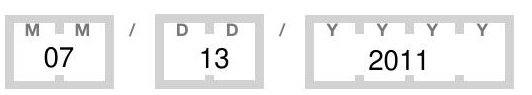

Amount of Each Receipt this Period

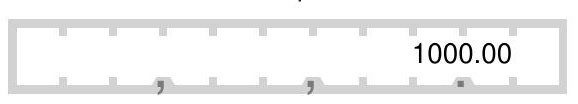

Transaction ID : A030F044C03D247D1A7C Date of Receipt

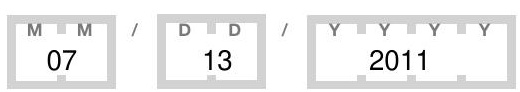

Amount of Each Receipt this Period

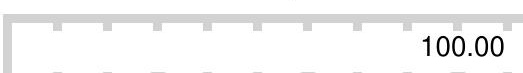

100.00

\section{Subtotal Of Receipts This Page (optional)}

Total This Period (last page this line number only) 
SCHEDULE A-P

ITEMIZED RECEIPTS
Use separate schedule(s)

for each category of the

Detailed Summary Page
FOR LINE NUMBER: (check only one)

\begin{tabular}{|c|c|c|c|c|c|}
\hline & & & & & \\
\hline 16 & $\begin{array}{ll}X & 17 a \\
\end{array}$ & $17 \mathrm{~b}$ & $17 c$ & $17 d$ & 18 \\
\hline $19 a$ & $19 b$ & $20 \mathrm{a}$ & $20 \mathrm{~b}$ & $20 c$ & 21 \\
\hline
\end{tabular}

Any information copied from such Reports and Statements may not be sold or used by any person for the purpose of soliciting contributions or for commercial purposes, other than using the name and address of any political committee to solicit contributions from such committee.

NAME OF COMMITTEE (In Full)

\section{Friends of Herman Cain}

A. Full Name (Last, First, Middle Initial)

Barbara Williams

Mailing Address 149 Four Diamond Dr

\begin{tabular}{lcc}
\hline City & State & Zip Code \\
Seven Devils & NC & $28604-8991$
\end{tabular}

FEC ID number of contributing

federal political committee.

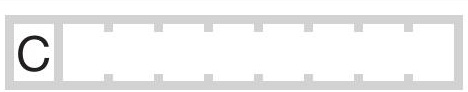

Name of Employer
None
Receipt For: 2012
X Primary $\quad$ General
Other (specify)

Occupation

Retired

Election Cycle-to-Date

\subsection{0}

B. Full Name (Last, First, Middle Initial)

Christine Preble

Mailing Address 3847 Monument Rd.

\begin{tabular}{lcc}
\hline City & State & Zip Code \\
Jasper & GA & $30143-2402$ \\
\hline
\end{tabular}

FEC ID number of contributing

federal political committee.

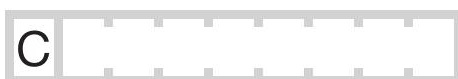

Name of Employer

Occupation

Retired

RN Childbirth Educator

Receipt For: 2012

Х $\begin{aligned} & \text { Primary } \square \text { General } \\ & \text { Other (specify) } \boldsymbol{\nabla}\end{aligned}$

Election Cycle-to-Date

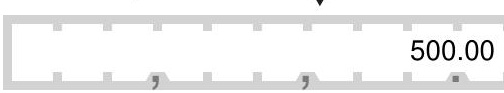

C. Full Name (Last, First, Middle Initial)

Daniel Cox

Mailing Address 980 N. Halifax Dr.

\begin{tabular}{lcc}
\hline City & State & Zip Code \\
Ormond Beach & FL & $32176-4169$
\end{tabular}

FEC ID number of contributing

federal political committee.

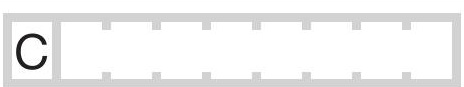

Name of Employer

Information Requested

Occupation

Information Requested

Receipt For: 2012

Х $\begin{aligned} & \text { Primary } \square \text { General } \\ & \text { Other (specify) }\end{aligned}$

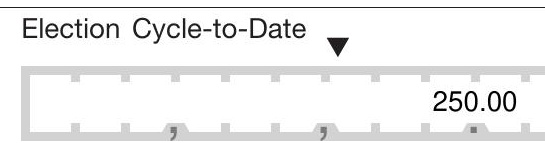

Amount of Each Receipt this Period

Transaction ID : A43C3E6322E5049BD97E

Date of Receipt

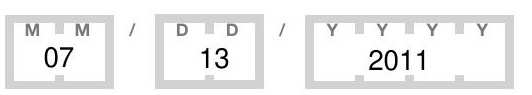

Amount of Each Receipt this Period

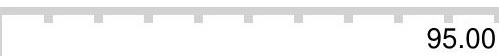

95.00

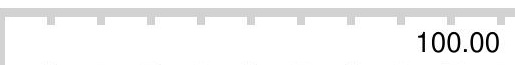

Transaction ID : A40AE80605C5B40CFBE9

Date of Receipt

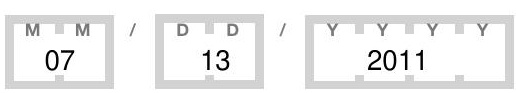

Amount of Each Receipt this Period

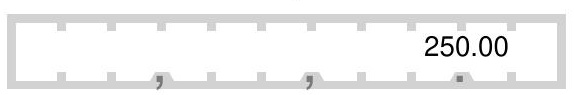

Subtotal Of Receipts This Page (optional).

445.00

Total This Period (last page this line number only) 


\section{SCHEDULE A-P} ITEMIZED RECEIPTS
Use separate schedule(s)

for each category of the

Detailed Summary Page
FOR LINE NUMBER: (check only one)
PAGE $76 / 1572$

\begin{tabular}{|c|c|c|c|c|c|}
\hline & & & & & \\
\hline 16 & $\begin{array}{l}\mathbf{X} \\
17 a\end{array}$ & $17 b$ & $17 c$ & $17 d$ & 18 \\
\hline $19 a$ & $19 \mathrm{~b}$ & $20 \mathrm{a}$ & $20 \mathrm{~b}$ & $20 \mathrm{c}$ & 21 \\
\hline
\end{tabular}

Any information copied from such Reports and Statements may not be sold or used by any person for the purpose of soliciting contributions or for commercial purposes, other than using the name and address of any political committee to solicit contributions from such committee.

NAME OF COMMITTEE (In Full)

\section{Friends of Herman Cain}

A. Full Name (Last, First, Middle Initial)

Karen McMillan

Mailing Address 6594 Meadowbrook Ln

\begin{tabular}{lcc}
\hline City & State & Zip Code \\
Morrow & GA & $30260-2439$
\end{tabular}

FEC ID number of contributing

federal political committee.

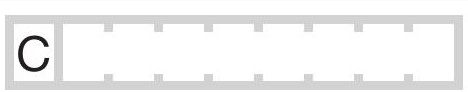

Name of Employer
Information Requested
Receipt For: 2012
X Primary $\quad \square$ General
Other (specify)

Occupation

Information Requested

Election Cycle-to-Date

225.00

B. Full Name (Last, First, Middle Initial)

Susan Walter

Mailing Address P.O. Box 690

\begin{tabular}{lcc}
\hline City & State & Zip Code \\
Sautee Nacoochee & GA & $30571-0690$
\end{tabular}

FEC ID number of contributing

federal political committee.

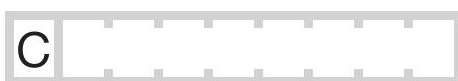

Name of Employer
None
Receipt For: 2012
X Primary
Other (specify)

Occupation

Retired

Election Cycle-to-Date

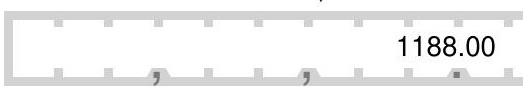

Transaction ID : A62F4C86AE2FA43E2AC8

Date of Receipt

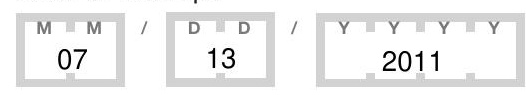

Amount of Each Receipt this Period

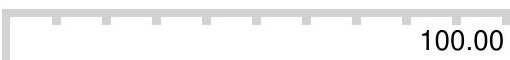

Transaction ID : A25D1986F07EE41A2BD8

Date of Receipt

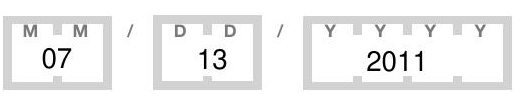

Amount of Each Receipt this Period

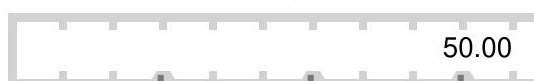

Transaction ID : AA331D45F329E40F2820

Date of Receipt

\section{James Scandle}

Mailing Address 3836 Winters Hill Dr

\begin{tabular}{lcc}
\hline City & State & Zip Code \\
Atlanta & GA & $30360-133$
\end{tabular}

FEC ID number of contributing federal political committee.

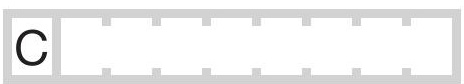

Name of Employer

Ernst \& Young LLP

Occupation

Sales and Operations leader

Receipt For: 2012

Х $\begin{aligned} & \text { Primary } \square \text { General } \\ & \text { Other (specify) }\end{aligned}$

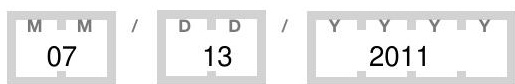

Amount of Each Receipt this Period

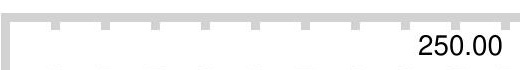

\section{Subtotal Of Receipts This Page (optional)}

400.00

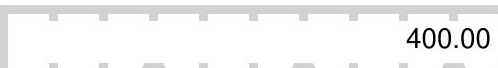

Total This Period (last page this line number only)

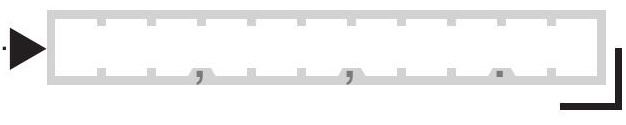

FEC Schedule A-P (Form 3P) (Rev. 03/2011) 
SCHEDULE A-P ITEMIZED RECEIPTS
Use separate schedule(s) for each category of the Detailed Summary Page
FOR LINE NUMBER: (check only one)

\begin{tabular}{|c|c|c|c|c|c|}
\hline & & & & & \\
\hline 16 & $\begin{array}{ll}X & 17 a \\
\end{array}$ & $17 \mathrm{~b}$ & $17 c$ & $17 d$ & 18 \\
\hline $19 a$ & $19 b$ & $20 \mathrm{a}$ & $20 \mathrm{~b}$ & $20 c$ & 21 \\
\hline
\end{tabular}

Any information copied from such Reports and Statements may not be sold or used by any person for the purpose of soliciting contributions or for commercial purposes, other than using the name and address of any political committee to solicit contributions from such committee.

NAME OF COMMITTEE (In Full)

\section{Friends of Herman Cain}

A. Full Name (Last, First, Middle Initial)

Rodney Heltzel

Mailing Address 219 S Main

\begin{tabular}{lcc}
\hline City & State & Zip Code \\
Jacksboro & TX & $76458-2319$
\end{tabular}

FEC ID number of contributing federal political committee.

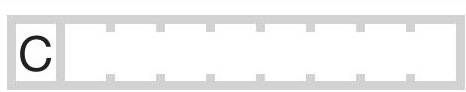

Name of Employer
JMSALP
Receipt For: 2012
X Primary $\quad$ General
Other (specify)

B. Full Name (Last, First, Middle Initial) ELAINE POWERS

Mailing Address 258 MATTHEWS RD

\begin{tabular}{lcc}
\hline City & State & Zip Code \\
Fayetteville & GA & $30215-3044$
\end{tabular}

FEC ID number of contributing

federal political committee.

C

Name of Employer
Information Requested
Receipt For: 2012
X Primary
Other (specify)

\section{Occupation}

Information Requested

Election Cycle-to-Date

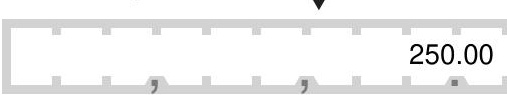

Transaction ID : A548EEB5DA7DF4CAD876

Date of Receipt

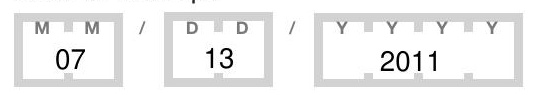

Amount of Each Receipt this Period

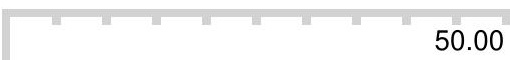

50.00

C. Full Name (Last, First, Middle Initial) richard clampitt

Mailing Address 7261 ashington dr

\begin{tabular}{lcc}
\hline City & State & Zip Code \\
Dallas & TX & $75225-1704$ \\
\hline
\end{tabular}

FEC ID number of contributing federal political committee.

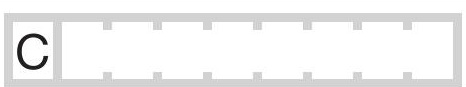

Name of Employer
red river paper
Receipt For: 2012
Primary
Other (specify) General

\section{Occupation}

Executive

\section{Election Cycle-to-Date}

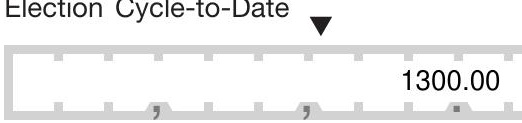

Transaction ID : AB328E64B7A2F44388D3 Date of Receipt

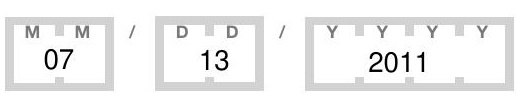

Amount of Each Receipt this Period

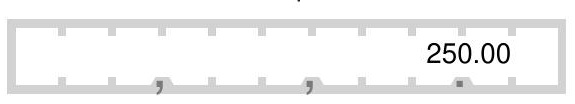

Transaction ID : A71C04EA952E84284BD6 Date of Receipt

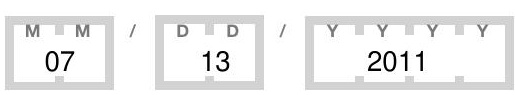

Amount of Each Receipt this Period

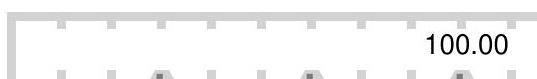

\section{Subtotal Of Receipts This Page (optional)}

400.00

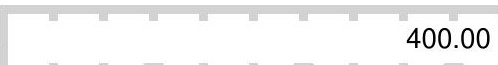

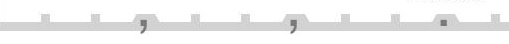

Total This Period (last page this line number only)

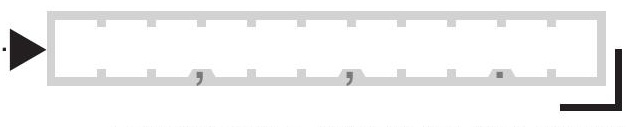

FEC Schedule A-P (Form 3P) (Rev. 03/2011) 
SCHEDULE A-P ITEMIZED RECEIPTS
Use separate schedule(s) for each category of the Detailed Summary Page
FOR LINE NUMBER: (check only one)

\begin{tabular}{|c|c|c|c|c|c|c|}
\hline & & & & & & \\
\hline 16 & $\times 1$ & $17 a$ & $17 b$ & $17 c$ & $17 d$ & 18 \\
\hline $19 a$ & & $19 b$ & $20 \mathrm{a}$ & $20 \mathrm{~b}$ & $20 \mathrm{c}$ & 21 \\
\hline
\end{tabular}

Any information copied from such Reports and Statements may not be sold or used by any person for the purpose of soliciting contributions or for commercial purposes, other than using the name and address of any political committee to solicit contributions from such committee.

NAME OF COMMITTEE (In Full)

\section{Friends of Herman Cain}

A. Full Name (Last, First, Middle Initial)

Mary Daniel

Transaction ID : ACD18740E677547B2862

Mailing Address 131 South End Street

\begin{tabular}{lcc}
\hline City & State & Zip Code \\
Saint Augustine & FL & $32095-6821$
\end{tabular}

FEC ID number of contributing federal political committee.

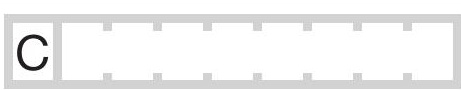

Name of Employer
The Shannon Group
Receipt For: 2012
X Primary
Other (specify)

Occupation medical management

Election Cycle-to-Date

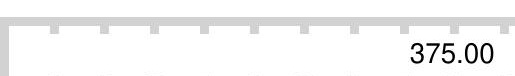

B. Full Name (Last, First, Middle Initial)

Marilyn Seidler

Mailing Address 700 Shore Rd Apt 31

\begin{tabular}{lcc}
\hline City & State & Zip Code \\
Long Beach & NY & $11561-4715$ \\
\hline
\end{tabular}

FEC ID number of contributing

federal political committee.

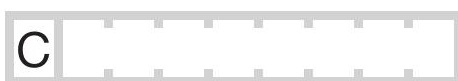

Name of Employer
Retired
Receipt For: 2012
X Primary $\quad$ General
Other (specify)

\section{Occupation}

Retired

Election Cycle-to-Date

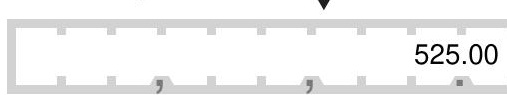

C. Full Name (Last, First, Middle Initial)

Mr. Roger W. Cain

Mailing Address 1496 Cotaco Florette Rd

\begin{tabular}{l|ll}
\hline $\begin{array}{l}\text { City } \\
\text { Somerville }\end{array}$ & $\begin{array}{c}\text { State } \\
\text { AL }\end{array}$ & $\begin{array}{c}\text { Zip Code } \\
35670-6926\end{array}$ \\
\hline $\begin{array}{l}\text { FEC ID number of contributing } \\
\text { federal political committee. }\end{array}$ & C & \\
\hline $\begin{array}{l}\text { Name of Employer } \\
\text { None }\end{array}$ & $\begin{array}{l}\text { Occupation } \\
\text { Retired }\end{array}$ \\
\hline $\begin{array}{l}\text { Receipt For: } 2012 \\
\text { Primary } \\
\text { Other (specify) }\end{array}$ & Election Cycle-to-Date & \\
\hline
\end{tabular}

Transaction ID : AE344DA0250084312859

Date of Receipt

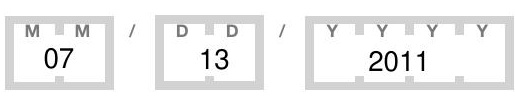

Amount of Each Receipt this Period

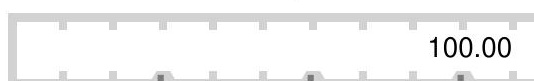

Amount of Each Receipt this Period

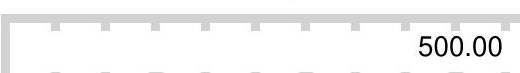

Transaction ID : A17ABDA25490E45B28F7 Date of Receipt

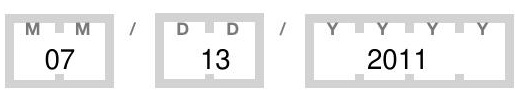

\section{Subtotal Of Receipts This Page (optional)}

Total This Period (last page this line number only) 
SCHEDULE A-P ITEMIZED RECEIPTS
Use separate schedule(s) for each category of the Detailed Summary Page
FOR LINE NUMBER: (check only one)

\begin{tabular}{|c|c|c|c|c|c|c|}
\hline & & & & & & \\
\hline 16 & $\times 1$ & $17 a$ & $17 b$ & $17 c$ & $17 d$ & 18 \\
\hline $19 a$ & & $19 b$ & $20 \mathrm{a}$ & $20 \mathrm{~b}$ & $20 \mathrm{c}$ & 21 \\
\hline
\end{tabular}

Any information copied from such Reports and Statements may not be sold or used by any person for the purpose of soliciting contributions or for commercial purposes, other than using the name and address of any political committee to solicit contributions from such committee.

NAME OF COMMITTEE (In Full)

\section{Friends of Herman Cain}

A. Full Name (Last, First, Middle Initial) James Burton

Mailing Address 2012 Armstrong Mill Rd

\begin{tabular}{lcc}
\hline City & State & Zip Code \\
Franklin & GA & $30217-3751$ \\
\hline
\end{tabular}

FEC ID number of contributing federal political committee.

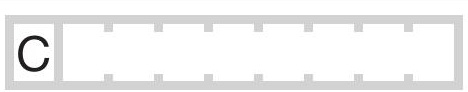

Name of Employer
University of West GA
Receipt For: 2012
X Primary
Other (specify) General

Occupation Professor Election Cycle-to-Date

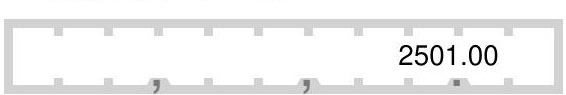

B. Full Name (Last, First, Middle Initial)

Thomas Ward

Mailing Address 6630 Richardson Rd

\begin{tabular}{lcc}
\hline City & State & Zip Code \\
Houston & TX & $77069-1730$
\end{tabular}

FEC ID number of contributing

federal political committee.

C

Name of Employer
Retired
Receipt For: 2012
X Primary
Other (specify) General

\section{Occupation}

Retired

Election Cycle-to-Date

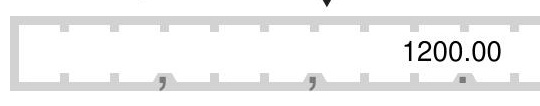

C. Full Name (Last, First, Middle Initial)

Patricia Brooks

Mailing Address 2375 E. Tropicana Ave. \#747

\begin{tabular}{lcc}
\hline City & State & Zip Code \\
Las Vegas & NV & $89119-6564$
\end{tabular}

FEC ID number of contributing federal political committee.

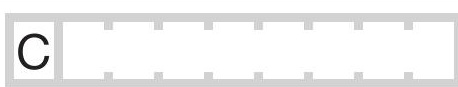

Name of Employer
Information Requested
Receipt For: 2012
X Primary $\quad \square$ General
Other (specify)

Transaction ID : A7F5E4BD5EEEC43A19E5

Date of Receipt

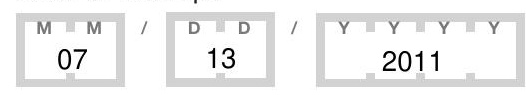

Amount of Each Receipt this Period

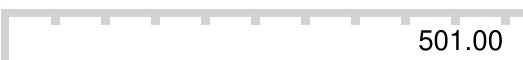

501.00
Amount of Each Receipt this Period

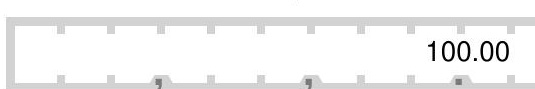

Transaction ID : AB8216067CD424FCEA03 Date of Receipt

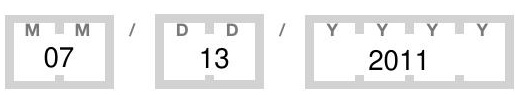

Transaction ID : A7C3B579AFE07415AA8A Date of Receipt

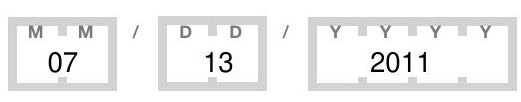

Amount of Each Receipt this Period

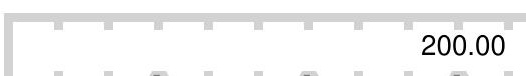

Subtotal Of Receipts This Page (optional)

801.00

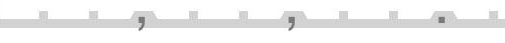

Total This Period (last page this line number only) 
SCHEDULE A-P ITEMIZED RECEIPTS
Use separate schedule(s) for each category of the Detailed Summary Page
FOR LINE NUMBER: (check only one)

\begin{tabular}{|c|c|c|c|c|c|}
\hline & & & & & \\
\hline 16 & $\begin{array}{ll}X & 17 a \\
\end{array}$ & $17 \mathrm{~b}$ & $17 c$ & $17 d$ & 18 \\
\hline $19 a$ & $19 b$ & $20 \mathrm{a}$ & $20 \mathrm{~b}$ & $20 c$ & 21 \\
\hline
\end{tabular}

Any information copied from such Reports and Statements may not be sold or used by any person for the purpose of soliciting contributions or for commercial purposes, other than using the name and address of any political committee to solicit contributions from such committee.

NAME OF COMMITTEE (In Full)

\section{Friends of Herman Cain}

A. Full Name (Last, First, Middle Initial)

Nancy McConnell

Mailing Address 500 23rd Ave N

\begin{tabular}{lcc}
\hline City & State & Zip Code \\
Saint Petersburg & FL & $33704-4318$ \\
\hline
\end{tabular}

FEC ID number of contributing federal political committee.

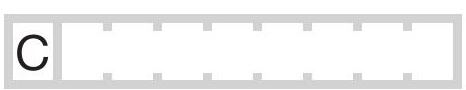

Name of Employer
Self Employed
Receipt For: 2012
X Primary $\quad$ General
Other (specify)

\section{Occupation} CPA

Election Cycle-to-Date

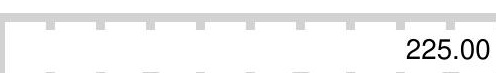

B. Full Name (Last, First, Middle Initial)

James Stewart

Mailing Address 3560 E. Via Colonia del Sol

\begin{tabular}{lcc}
\hline City & State & Zip Code \\
Tucson & AZ & $85718-6065$
\end{tabular}

FEC ID number of contributing

federal political committee.

C

Name of Employer
Information Requested
Receipt For: 2012
X Primary
Other (specify)

Occupation

Information Requested

Election Cycle-to-Date

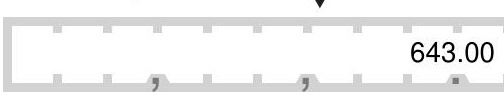

Transaction ID : AFB13D22291F741859FF

Date of Receipt

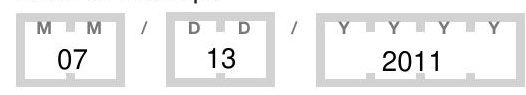

Amount of Each Receipt this Period

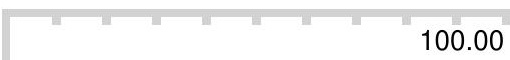

C. Full Name (Last, First, Middle Initial)

Mr Thomas Hanley

Mailing Address N2752 Summerville Park Rd

\begin{tabular}{lcc}
\hline City & State & Zip Code \\
Lodi & WI & $53555-9642$ \\
\hline
\end{tabular}

FEC ID number of contributing federal political committee.

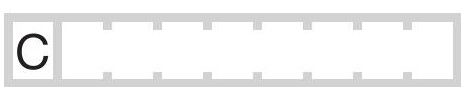

Name of Employer
None
Receipt For: 2012
Х Primary $\quad \square$ General
Other (specify)

Occupation

Retired

Election Cycle-to-Date

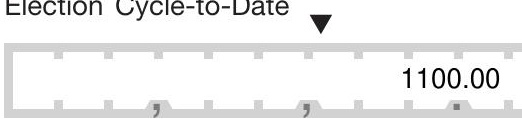

Amount of Each Receipt this Period

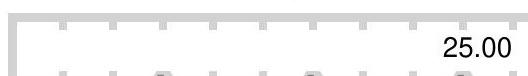

Transaction ID : A6D757221550747E0948

Date of Receipt

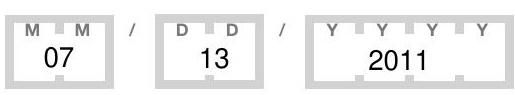

Transaction ID : A88AF0FF6718943878A1 Date of Receipt

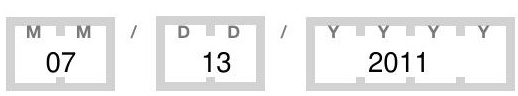

Amount of Each Receipt this Period

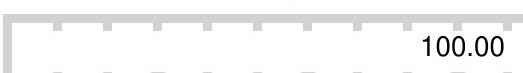

\section{Subtotal Of Receipts This Page (optional)}

Total This Period (last page this line number only) 
SCHEDULE A-P ITEMIZED RECEIPTS
Use separate schedule(s) for each category of the Detailed Summary Page
FOR LINE NUMBER: (check only one)

\begin{tabular}{|c|c|c|c|c|c|}
\hline & & & & & \\
\hline 16 & $\begin{array}{ll}X & 17 a \\
\end{array}$ & $17 \mathrm{~b}$ & $17 c$ & $17 d$ & 18 \\
\hline $19 a$ & $19 b$ & $20 \mathrm{a}$ & $20 \mathrm{~b}$ & $20 c$ & 21 \\
\hline
\end{tabular}

Any information copied from such Reports and Statements may not be sold or used by any person for the purpose of soliciting contributions or for commercial purposes, other than using the name and address of any political committee to solicit contributions from such committee.

NAME OF COMMITTEE (In Full)

\section{Friends of Herman Cain}

A. Full Name (Last, First, Middle Initial)

\section{Donna Odar}

Mailing Address 13712 Winding Oak Circle \#202

\begin{tabular}{lcc}
\hline City & State & Zip Code \\
Centreville & VA & $20121-4759$
\end{tabular}

FEC ID number of contributing federal political committee.

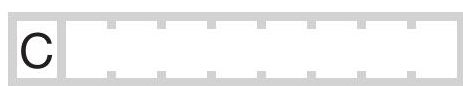

Name of Employer
n/a
Receipt For: 2012
X Primary $\quad$ General
Other (specify)

Occupation Retired

Election Cycle-to-Date

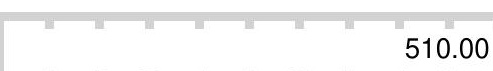

B. Full Name (Last, First, Middle Initial)

Lynn Zody

Mailing Address 708 Callaway $\mathrm{Dr}$

\begin{tabular}{lcc}
\hline City & State & Zip Code \\
Graniteville & SC & $29829-4054$
\end{tabular}

FEC ID number of contributing

federal political committee.

C

Name of Employer
Stix \& Co. Inc.
Receipt For: 2012
X Primary
Other (specify) General

Occupation

FOOD SERVICE

Election Cycle-to-Date

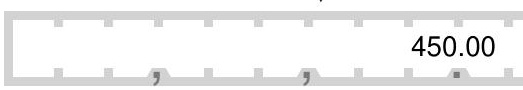

Transaction ID : A4C8FBA9A013A4F60950

Date of Receipt

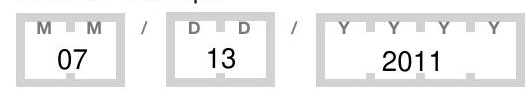

Amount of Each Receipt this Period

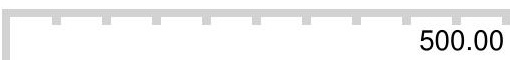

Amount of Each Receipt this Period

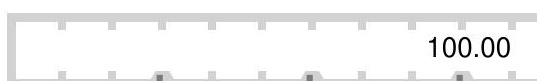

C. Full Name (Last, First, Middle Initial)

Theodore Zampetis

Mailing Address 125 Wakefield Run Blvd

\begin{tabular}{lcc}
\hline City & State & Zip Code \\
Hinckley & OH & $44233-9224$
\end{tabular}

FEC ID number of contributing federal political committee.

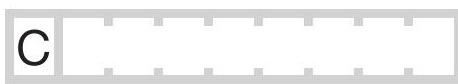

Name of Employer

Shiloh Industries, Inc.

Occupation

Receipt For: 2012

Х $\begin{aligned} & \text { Primary } \square \text { General } \\ & \text { Other (specify) }\end{aligned}$

President \& CEO

Election Cycle-to-Date

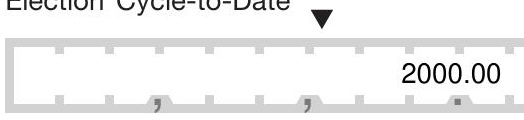

Transaction ID : A407F2FAF918641AB9B4

Date of Receipt

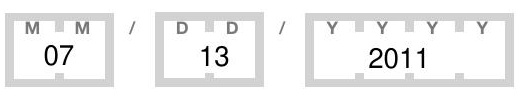

Transaction ID : AA60C2449DEC045D19C2 Date of Receipt

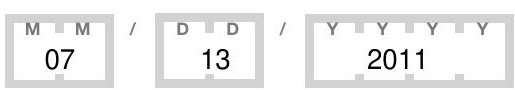

Amount of Each Receipt this Period

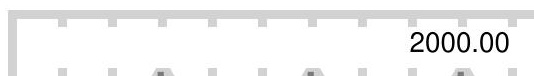

2600.00

Subtotal Of Receipts This Page (optional)

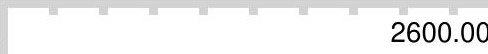

Total This Period (last page this line number only) 
SCHEDULE A-P ITEMIZED RECEIPTS
Use separate schedule(s) for each category of the Detailed Summary Page
FOR LINE NUMBER: (check only one)

\begin{tabular}{|c|c|c|c|c|c|}
\hline & & & & & \\
\hline 16 & $\begin{array}{ll}X & 17 a \\
\end{array}$ & $17 \mathrm{~b}$ & $17 c$ & $17 d$ & 18 \\
\hline $19 a$ & $19 b$ & $20 \mathrm{a}$ & $20 \mathrm{~b}$ & $20 c$ & 21 \\
\hline
\end{tabular}

Any information copied from such Reports and Statements may not be sold or used by any person for the purpose of soliciting contributions or for commercial purposes, other than using the name and address of any political committee to solicit contributions from such committee.

NAME OF COMMITTEE (In Full)

\section{Friends of Herman Cain}

A. Full Name (Last, First, Middle Initial)

Timothy Hicks

Mailing Address 1145 Hawthorne Ridge Dr

\begin{tabular}{lcc}
\hline City & State & Zip Code \\
Brookfield & WI & $53045-4514$
\end{tabular}

FEC ID number of contributing

federal political committee.

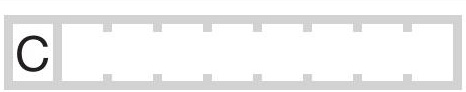

Name of Employer
Ardur LLC
Receipt For: 2012
X Primary $\quad$ General
Other (specify)

Occupation

Manager

Election Cycle-to-Date

300.00

B. Full Name (Last, First, Middle Initial)

Robert Porter

Mailing Address 5710 Grand Reunion Dr

\begin{tabular}{lcc}
\hline City & State & Zip Code \\
Hoschton & GA & $30548-4045$ \\
\hline
\end{tabular}

FEC ID number of contributing

federal political committee.

C

Name of Employer
Information Requested
Receipt For: 2012
X Primary
Other (specify)

Occupation

Information Requested

Election Cycle-to-Date

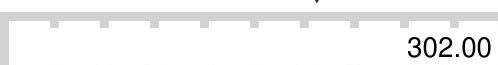

Transaction ID : A0256CBF2EA5D435296B

Date of Receipt

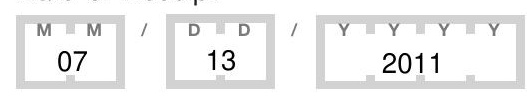

Amount of Each Receipt this Period

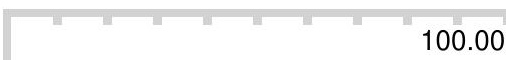

Transaction ID : A0A28A06C7F254614A82

Date of Receipt

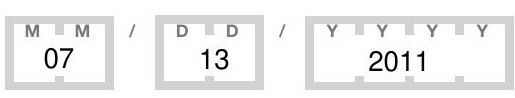

Amount of Each Receipt this Period

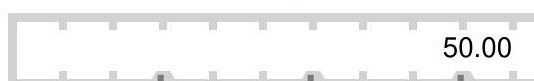

Transaction ID : A1DFDC528070B4E8196D Date of Receipt

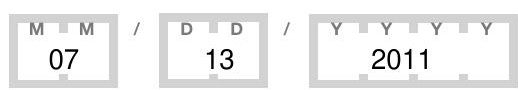

Amount of Each Receipt this Period

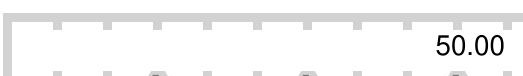

$\begin{array}{cc}\text { State } & \text { Zip Code } \\ \text { GA } & \text { 30062-1342 }\end{array}$

C

Occupation

Information Requested

Election Cycle-to-Date

Receipt For: 2012

Х $\begin{aligned} & \text { Primary } \\ & \text { Other (specify) }\end{aligned}$

400.00

Subtotal Of Receipts This Page (optional).

200.00

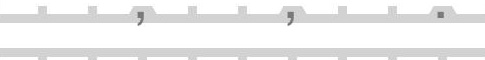

Total This Period (last page this line number only) 
SCHEDULE A-P ITEMIZED RECEIPTS
Use separate schedule(s) for each category of the Detailed Summary Page
FOR LINE NUMBER: (check only one)

\begin{tabular}{|c|c|c|c|c|c|}
\hline & & & & & \\
\hline 16 & $\begin{array}{ll}X & 17 a \\
\end{array}$ & $17 \mathrm{~b}$ & $17 c$ & $17 d$ & 18 \\
\hline $19 a$ & $19 b$ & $20 \mathrm{a}$ & $20 \mathrm{~b}$ & $20 c$ & 21 \\
\hline
\end{tabular}

Any information copied from such Reports and Statements may not be sold or used by any person for the purpose of soliciting contributions or for commercial purposes, other than using the name and address of any political committee to solicit contributions from such committee.

NAME OF COMMITTEE (In Full)

\section{Friends of Herman Cain}

A. Full Name (Last, First, Middle Initial)

Brandon Crain

Mailing Address 2895 Milano Lane

\begin{tabular}{lcc}
\hline City & State & Zip Code \\
League City & TX & $77573-3273$ \\
\hline
\end{tabular}

FEC ID number of contributing federal political committee.

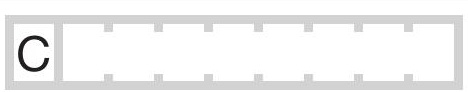

Name of Employer
E.J. Reynolds company
Receipt For: 2012
X Primary
Other (specify) General

Occupation General Manager

Election Cycle-to-Date

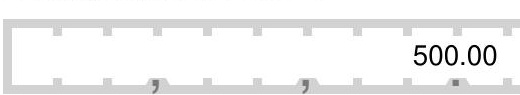

B. Full Name (Last, First, Middle Initial)

NEIL PFEIFFER

Mailing Address 23921 Stringtown Rd

\begin{tabular}{lcc}
\hline City & State & Zip Code \\
Clarksburg & MD & $20871-9211$
\end{tabular}

FEC ID number of contributing

federal political committee.

Name of Employer
Not Employed
Receipt For: 2012
X Primary
Other (specify)

Transaction ID : ADEBFD237A8D04BB6AC0

Date of Receipt

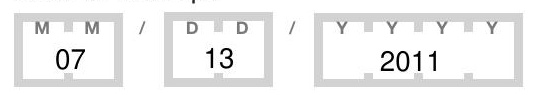

Amount of Each Receipt this Period

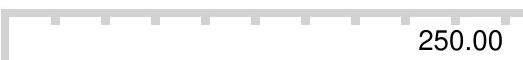

C
Occupation

Not Employed

Election Cycle-to-Date

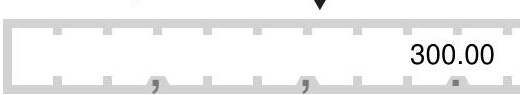

Transaction ID : A8491E562C4B344BF864

Date of Receipt

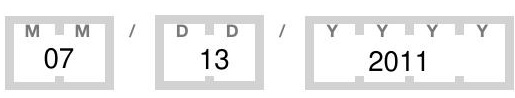

Amount of Each Receipt this Period

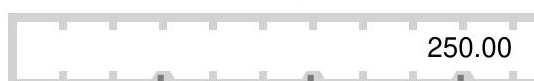

Transaction ID : AB4FDD4E99FBC46E7A72 Date of Receipt

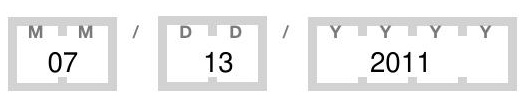

Amount of Each Receipt this Period

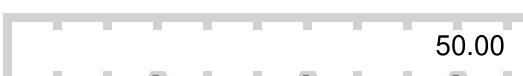

Real Estate Investor

Election Cycle-to-Date

275.00

$\begin{array}{cc}\text { State } & \text { Zip Code } \\ \text { GA } & 30009-7115\end{array}$

C

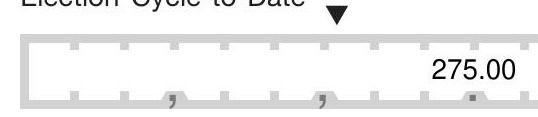

Name of Employer

CMR Residential Properties LLC

Receipt For: 2012

Х $\begin{aligned} & \text { Primary } \square \text { General } \\ & \text { Other (specify) }\end{aligned}$
Subtotal Of Receipts This Page (optional)

550.00

Total This Period (last page this line number only)

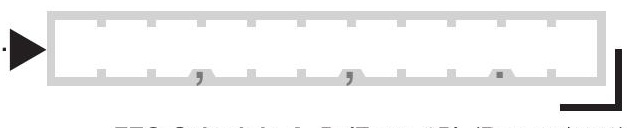

FEC Schedule A-P (Form 3P) (Rev. 03/2011) 
SCHEDULE A-P ITEMIZED RECEIPTS
Use separate schedule(s) for each category of the Detailed Summary Page
FOR LINE NUMBER: (check only one)

\begin{tabular}{|c|c|c|c|c|c|}
\hline & & & & & \\
\hline 16 & $\begin{array}{ll}X & 17 a \\
\end{array}$ & $17 \mathrm{~b}$ & $17 c$ & $17 d$ & 18 \\
\hline $19 a$ & $19 b$ & $20 \mathrm{a}$ & $20 \mathrm{~b}$ & $20 c$ & 21 \\
\hline
\end{tabular}

Any information copied from such Reports and Statements may not be sold or used by any person for the purpose of soliciting contributions or for commercial purposes, other than using the name and address of any political committee to solicit contributions from such committee.

NAME OF COMMITTEE (In Full)

\section{Friends of Herman Cain}

A. Full Name (Last, First, Middle Initial)

Neil Hobart

Mailing Address 219 N Barry Avenue

\begin{tabular}{lcc}
\hline City & State & Zip Code \\
Mamaroneck & NY & $10543-2827$
\end{tabular}

FEC ID number of contributing

federal political committee.

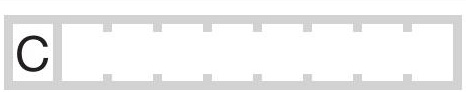

Name of Employer
None
Receipt For: 2012
X Primary $\quad \square$ General
Other (specify)

Occupation unemployed

Election Cycle-to-Date

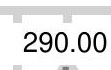

B. Full Name (Last, First, Middle Initial)

Diane E Becker

Mailing Address 2010 Gallagher Ave

\begin{tabular}{lcc}
\hline City & State & Zip Code \\
Deltona & FL & $32725-3278$ \\
\hline
\end{tabular}

FEC ID number of contributing

federal political committee.

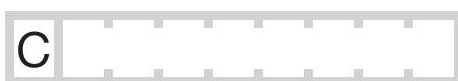

Name of Employer
None
Receipt For: 2012
X Primary
Other (specify)

\section{Occupation}

Retired

Election Cycle-to-Date

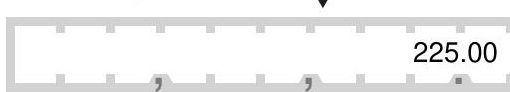

Transaction ID : AD68F4534889848A8BFB

Date of Receipt

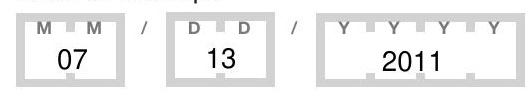

Amount of Each Receipt this Period

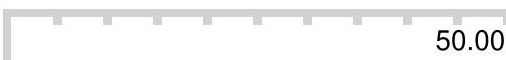

50.00

C. Full Name (Last, First, Middle Initial)

Cathie Serrano

Mailing Address 5641 Shadow View Dr

\begin{tabular}{lcc}
\hline City & State & Zip Code \\
Stone Mountain & GA & $30087-2953$
\end{tabular}

FEC ID number of contributing

federal political committee.

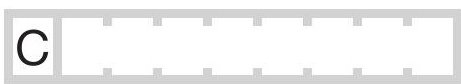

Name of Employer
n/a
Receipt For: 2012
X Primary $\square$ General
Other (specify)

Occupation

Retired

Election Cycle-to-Date

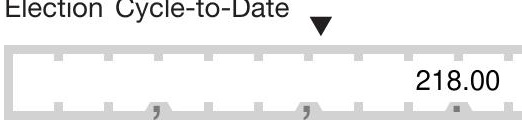

Transaction ID : AC8F99240C9AE48C7A72

Date of Receipt

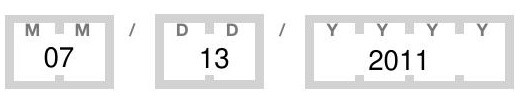

Amount of Each Receipt this Period

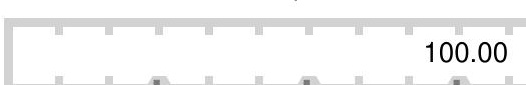

Transaction ID : A4B50529768D64A47855

Date of Receipt

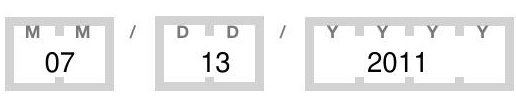

Amount of Each Receipt this Period

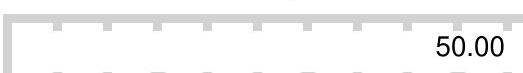

\section{Subtotal Of Receipts This Page (optional)}

Total This Period (last page this line number only) 
SCHEDULE A-P ITEMIZED RECEIPTS
Use separate schedule(s) for each category of the Detailed Summary Page
FOR LINE NUMBER: (check only one)

\begin{tabular}{|c|c|c|c|c|c|}
\hline & & & & & \\
\hline 16 & $\begin{array}{ll}X & 17 a \\
\end{array}$ & $17 \mathrm{~b}$ & $17 c$ & $17 d$ & 18 \\
\hline $19 a$ & $19 b$ & $20 \mathrm{a}$ & $20 \mathrm{~b}$ & $20 c$ & 21 \\
\hline
\end{tabular}

Any information copied from such Reports and Statements may not be sold or used by any person for the purpose of soliciting contributions or for commercial purposes, other than using the name and address of any political committee to solicit contributions from such committee.

NAME OF COMMITTEE (In Full)

\section{Friends of Herman Cain}

A. Full Name (Last, First, Middle Initial) John Wheelock

Mailing Address 2031 State St.

\begin{tabular}{lcc}
\hline City & State & Zip Code \\
New Orleans & LA & $70118-6253$ \\
\hline
\end{tabular}

FEC ID number of contributing federal political committee.

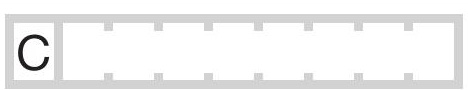

Name of Employer
Information Requested
Receipt For: 2012
X Primary
Other (specify) General

Occupation Information Requested

Election Cycle-to-Date

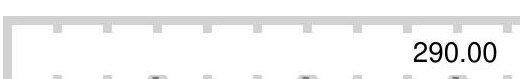

B. Full Name (Last, First, Middle Initial)

Peaches Kavanaugh

Mailing Address 216 Monty Manor

\begin{tabular}{lcc}
\hline City & State & Zip Code \\
Yorktown & VA & $23693-4414$ \\
\hline
\end{tabular}

FEC ID number of contributing

federal political committee.

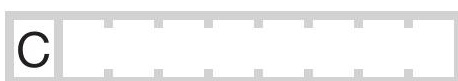

Name of Employer
Air Force
Receipt For: 2012
X Primary
$\square$ Other (specify) General

Occupation

Retired

Election Cycle-to-Date

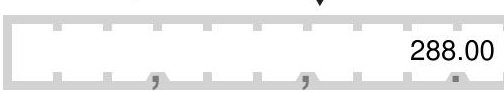

Transaction ID : AC4860A7327D64EC7BF0

Date of Receipt

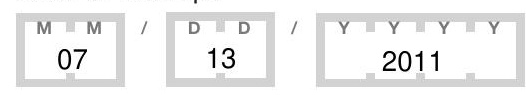

Amount of Each Receipt this Period

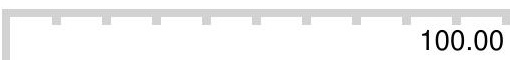

Transaction ID : A3026C7961C7D41E9AD2

Date of Receipt

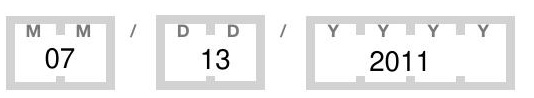

Amount of Each Receipt this Period

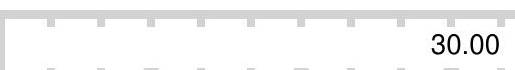

Transaction ID : ACACE81A357534579A27 Date of Receipt

Lynn Weidner

Mailing Address 9711 Orient Express Court

\begin{tabular}{lcc}
\hline City & State & Zip Code \\
Las Vegas & NV & $89145-8702$ \\
\hline
\end{tabular}

FEC ID number of contributing federal political committee.

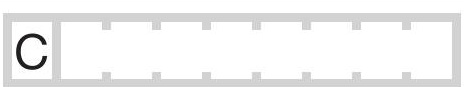

Name of Employer

Occupation

Information Requested

Information Requested

Receipt For: 2012

Х $\begin{aligned} & \text { Primary } \\ & \text { Other (specify) }\end{aligned}$

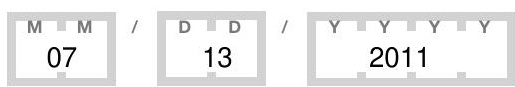

Amount of Each Receipt this Period

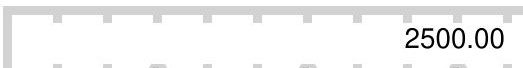

\section{Subtotal Of Receipts This Page (optional)}

Total This Period (last page this line number only) 


\section{SCHEDULE A-P} ITEMIZED RECEIPTS
Use separate schedule(s)

for each category of the

Detailed Summary Page
FOR LINE NUMBER: (check only one)
PAGE $86 / 1572$

\begin{tabular}{|c|c|c|c|c|c|}
\hline & & & & & \\
\hline 16 & $\mathbf{X} 17 \mathrm{a}$ & $17 \mathrm{~b}$ & $17 c$ & $17 d$ & 18 \\
\hline $19 a$ & $19 b$ & $20 a$ & $20 \mathrm{~b}$ & $20 c$ & 21 \\
\hline
\end{tabular}

Any information copied from such Reports and Statements may not be sold or used by any person for the purpose of soliciting contributions or for commercial purposes, other than using the name and address of any political committee to solicit contributions from such committee.

NAME OF COMMITTEE (In Full)

\section{Friends of Herman Cain}

A. Full Name (Last, First, Middle Initial)

Lynn Weidner

Mailing Address 9711 Orient Express Court

\begin{tabular}{lcc}
\hline City & State & Zip Code \\
Las Vegas & NV & $89145-8702$ \\
\hline
\end{tabular}

FEC ID number of contributing

federal political committee.

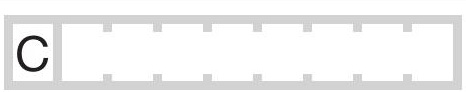

\begin{tabular}{l} 
Name of Employer \\
Information Requested \\
Receipt For: 2012 \\
$\square$ Primary \\
\hline Other (specify)
\end{tabular}

Occupation

Information Requested

Election Cycle-to-Date

5000.00

B. Full Name (Last, First, Middle Initial)

Stephen Northington

Mailing Address 1915 Landfall Pass NW

\begin{tabular}{lcc}
\hline City & State & Zip Code \\
Kennesaw & GA & $30152-7736$ \\
\hline
\end{tabular}

FEC ID number of contributing

federal political committee.

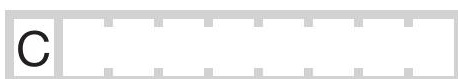

Name of Employer
Group Insurance Solutions LLC.
Receipt For: 2012
X Primary
Other (specify)

Occupation

Sales Director

Election Cycle-to-Date

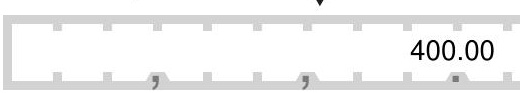

Transaction ID : ADBF0AC341C0042D4974

Date of Receipt

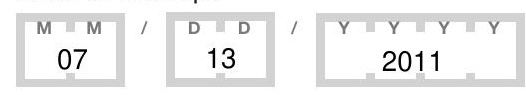

Amount of Each Receipt this Period

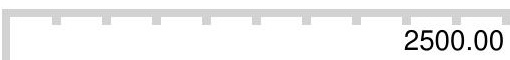

2500.00

C. Full Name (Last, First, Middle Initial)

Allison Ficken

Mailing Address 5601 Queensborough Drive

\begin{tabular}{lcc}
\hline City & State & Zip Code \\
Atlanta & GA & $30338-2619$
\end{tabular}

FEC ID number of contributing

federal political committee.

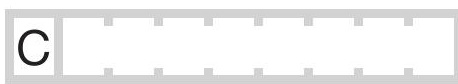

Name of Employer

Dovin Malkin \& Ficken

\section{Occupation}

Attorney

Receipt For: 2012

Х $\begin{aligned} & \text { Primary } \\ & \text { Other (specify) }\end{aligned}$

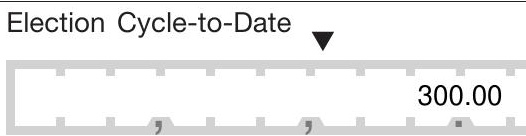

Amount of Each Receipt this Period

Transaction ID : ACAB8A886F6DE4C4097D Date of Receipt
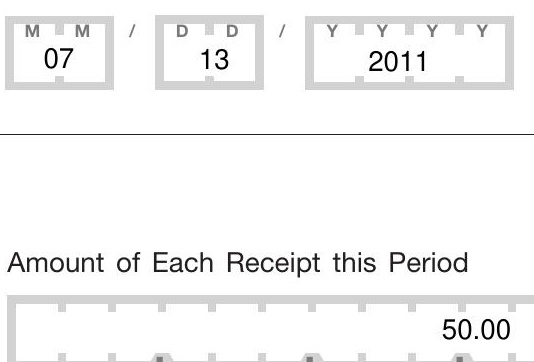

Transaction ID : AC068AE0E468146328CC

Date of Receipt

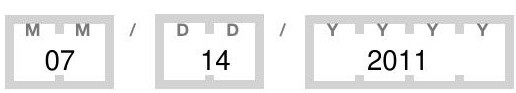

Amount of Each Receipt this Period

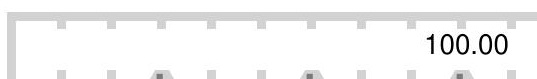

2650.00

Subtotal Of Receipts This Page (optional)

Total This Period (last page this line number only) 


\section{SCHEDULE A-P} ITEMIZED RECEIPTS
Use separate schedule(s)

for each category of the

Detailed Summary Page
FOR LINE NUMBER: (check only one)
PAGE 87 / 1572

\begin{tabular}{|c|c|c|c|c|c|}
\hline & & & & & \\
\hline 16 & $\begin{array}{l}\mathbf{X} \\
17 a\end{array}$ & $17 b$ & $17 c$ & $17 d$ & 18 \\
\hline $19 a$ & $19 \mathrm{~b}$ & $20 \mathrm{a}$ & $20 \mathrm{~b}$ & $20 \mathrm{c}$ & 21 \\
\hline
\end{tabular}

Any information copied from such Reports and Statements may not be sold or used by any person for the purpose of soliciting contributions or for commercial purposes, other than using the name and address of any political committee to solicit contributions from such committee.

NAME OF COMMITTEE (In Full)

Friends of Herman Cain

A. Full Name (Last, First, Middle Initial)

Stephen Northington

Mailing Address 1915 Landfall Pass NW

\begin{tabular}{lcc}
\hline City & State & Zip Code \\
Kennesaw & GA & $30152-7736$ \\
\hline
\end{tabular}

FEC ID number of contributing

federal political committee.

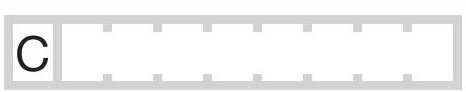

Name of Employer

Group Insurance Solutions LLC.

Receipt For: 2012

Х $\begin{aligned} & \text { Primary } \square \text { General } \\ & \text { Other (specify) }\end{aligned}$

Occupation

Sales Director

Election Cycle-to-Date

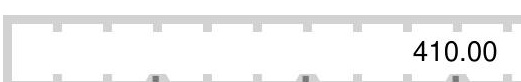

B. Full Name (Last, First, Middle Initial)

Don Mark Williamson

\section{Mailing Address P.O Box 356}

\begin{tabular}{lcc}
\hline City & State & Zip Code \\
Brittany & LA & $70718-0356$ \\
\hline
\end{tabular}

FEC ID number of contributing

federal political committee.

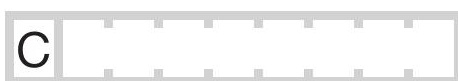

Name of Employer
State of Louisiana
Receipt For: 2012
X Primary
Other (specify)

Occupation

Investigator III

Election Cycle-to-Date

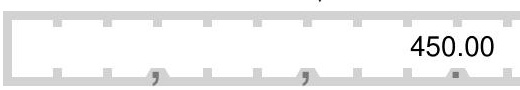

Transaction ID : AF929012AC0634B4B9EA

Date of Receipt

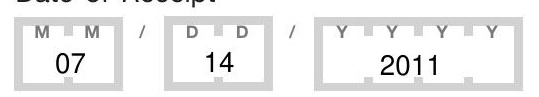

Amount of Each Receipt this Period

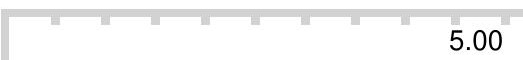

Amount of Each Receipt this Period

Transaction ID : A6D1891DCBAEE4E0EB34 Date of Receipt
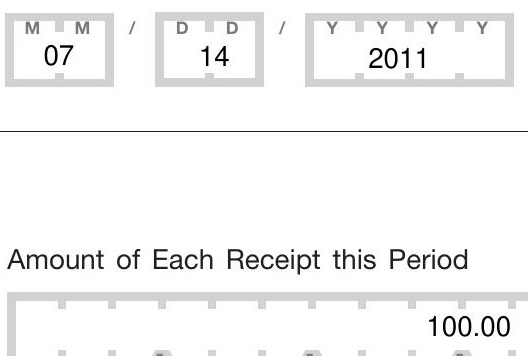

Transaction ID : AE9CA2241CD044507A2B Date of Receipt

Dan Spengler

Mailing Address 5400 Stanford Drive

\begin{tabular}{lcc}
\hline City & State & Zip Code \\
Nashville & TN & $37215-4236$
\end{tabular}

FEC ID number of contributing federal political committee.

C

Name of Employer
Information Requested
Receipt For: 2012
X Primary
Other (specify) General

\section{Occupation}

Information Requested

Election Cycle-to-Date

Subtotal Of Receipts This Page (optional).

Amount of Each Receipt this Period

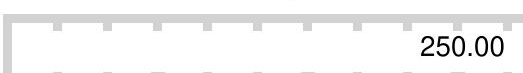

Total This Period (last page this line number only)

355.00

,

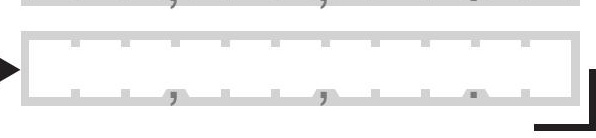

FEC Schedule A-P (Form 3P) (Rev. 03/2011) 
SCHEDULE A-P ITEMIZED RECEIPTS
Use separate schedule(s) for each category of the Detailed Summary Page
FOR LINE NUMBER: (check only one)

\begin{tabular}{|c|c|c|c|c|c|c|}
\hline & & & & & & \\
\hline 16 & $\times 1$ & $17 a$ & $17 b$ & $17 c$ & $17 d$ & 18 \\
\hline $19 a$ & & $19 b$ & $20 \mathrm{a}$ & $20 \mathrm{~b}$ & $20 \mathrm{c}$ & 21 \\
\hline
\end{tabular}

Any information copied from such Reports and Statements may not be sold or used by any person for the purpose of soliciting contributions or for commercial purposes, other than using the name and address of any political committee to solicit contributions from such committee.

NAME OF COMMITTEE (In Full)

\section{Friends of Herman Cain}

A. Full Name (Last, First, Middle Initial)

Bianca Beary

Mailing Address 10451 Grandoaks Ln

\begin{tabular}{lcc}
\hline City & State & Zip Code \\
Montgomery & OH & $45242-5033$
\end{tabular}

FEC ID number of contributing

federal political committee.

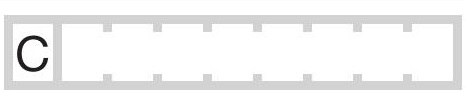

Name of Employer
Information Requested
Receipt For: 2012
X Primary $\quad \square$ General
Other (specify)

Occupation

Information Requested

Election Cycle-to-Date

293.00

B. Full Name (Last, First, Middle Initial)

CAROLYN BRAUN

Mailing Address 46 W 14 RD

\begin{tabular}{lcc}
\hline City & State & Zip Code \\
Broad Channel & NY & $11693-1139$
\end{tabular}

FEC ID number of contributing

federal political committee.

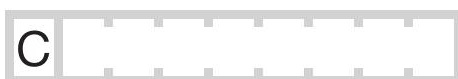

Name of Employer
self
Receipt For: 2012
X Primary
Other (specify)

\section{Occupation}

COPYWRITER

Transaction ID : A2B566CF9FA7B47D8919

Date of Receipt

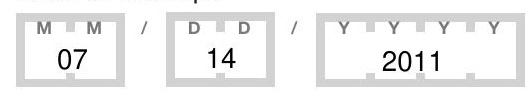

Amount of Each Receipt this Period

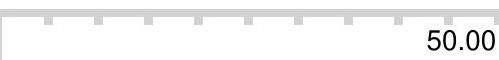

50.00

(n)

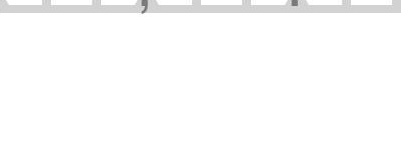

Transaction ID : A31BE9F88165241B3814

Date of Receipt

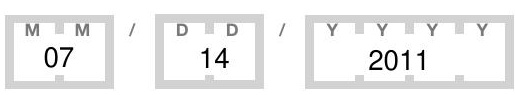

Amount of Each Receipt this Period

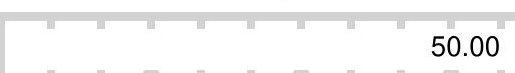

Election Cycle-to-Date

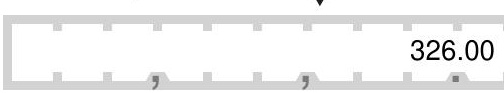

C. Full Name (Last, First, Middle Initial)

Daren Kaiser

Mailing Address 215 Wisteria Drive

\begin{tabular}{lcc}
\hline City & State & Zip Code \\
Oxford & GA & $30054-4040$
\end{tabular}

FEC ID number of contributing

federal political committee.

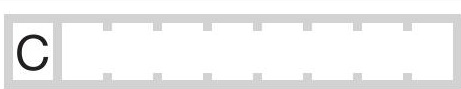

Name of Employer

Occupation

Information Requested

Information Requested

Receipt For: 2012

Х $\begin{aligned} & \text { Primary } \\ & \text { Other (specify) }\end{aligned}$

Transaction ID : A17294875D6FA4F54971

Date of Receipt

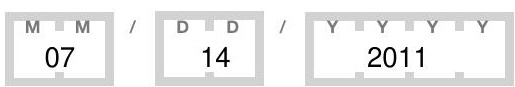

Amount of Each Receipt this Period

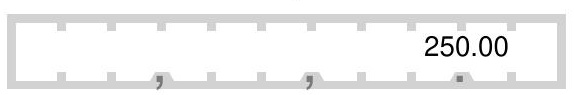

250.00
Subtotal Of Receipts This Page (optional)

350.00

(1)

Total This Period (last page this line number only)

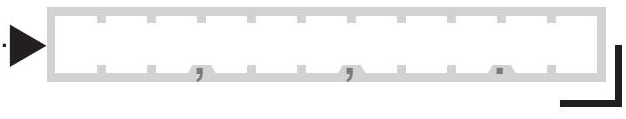

FEC Schedule A-P (Form 3P) (Rev. 03/2011) 
SCHEDULE A-P ITEMIZED RECEIPTS
Use separate schedule(s) for each category of the Detailed Summary Page
FOR LINE NUMBER: (check only one)

\begin{tabular}{|c|c|c|c|c|c|c|}
\hline & & & & & & \\
\hline 16 & $\times 1$ & $17 a$ & $17 b$ & $17 c$ & $17 d$ & 18 \\
\hline $19 a$ & & $19 b$ & $20 \mathrm{a}$ & $20 \mathrm{~b}$ & $20 \mathrm{c}$ & 21 \\
\hline
\end{tabular}

Any information copied from such Reports and Statements may not be sold or used by any person for the purpose of soliciting contributions or for commercial purposes, other than using the name and address of any political committee to solicit contributions from such committee.

NAME OF COMMITTEE (In Full)

Friends of Herman Cain

A. Full Name (Last, First, Middle Initial)

Mary Romans

Mailing Address 5012 Trinity Landing Dr W

\begin{tabular}{lcc}
\hline City & State & Zip Code \\
Fort Worth & TX & $76132-3736$
\end{tabular}

FEC ID number of contributing

federal political committee.

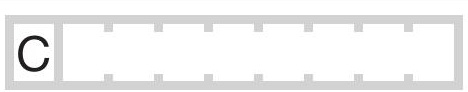

Name of Employer
Self Employed
Receipt For: 2012
X Primary $\quad$ General
Other (specify)

Occupation

Physician

Election Cycle-to-Date

350.00

B. Full Name (Last, First, Middle Initial)

Stephen Northington

Mailing Address 1915 Landfall Pass NW

\begin{tabular}{lcc}
\hline City & State & Zip Code \\
Kennesaw & GA & $30152-7736$ \\
\hline
\end{tabular}

FEC ID number of contributing

federal political committee.

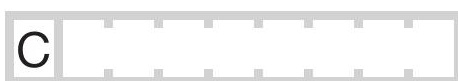

Name of Employer
Group Insurance Solutions LLC.
Receipt For: 2012
X Primary
Other (specify)

Occupation

Sales Director

Election Cycle-to-Date

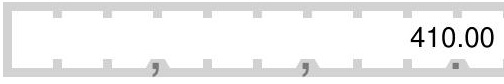

C. Full Name (Last, First, Middle Initial)

Thomas Park

Mailing Address 26614 Country Crk Ln

\begin{tabular}{lcc}
\hline City & State & Zip Code \\
Calabasas & CA & $91302-3587$
\end{tabular}

FEC ID number of contributing federal political committee.

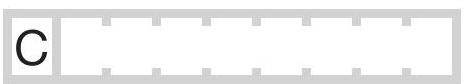

Name of Employer

Information Requested

\section{Occupation}

Information Requested

Receipt For: 2012

Х $\begin{aligned} & \text { Primary } \square \text { General } \\ & \text { Other (specify) }\end{aligned}$

Transaction ID : A33614D4661374314820

Date of Receipt

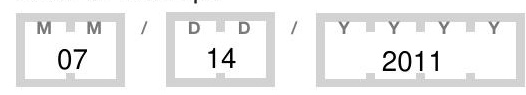

Amount of Each Receipt this Period

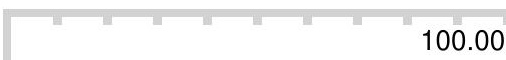

100.00

Amount of Each Receipt this Period

Transaction ID : A9491D2F95BFC4353912

Date of Receipt
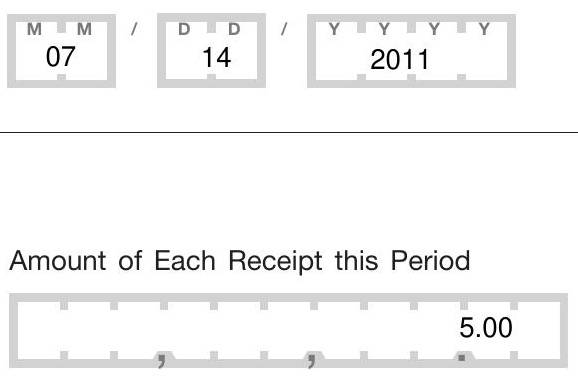

Transaction ID : AB072A65CAECE4833AC4 Date of Receipt

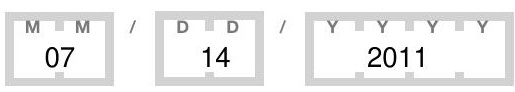

Amount of Each Receipt this Period

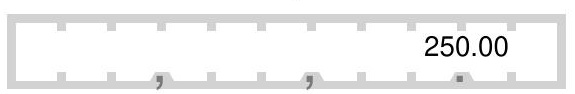

250.00

\section{Subtotal Of Receipts This Page (optional)}

Total This Period (last page this line number only) 
SCHEDULE A-P ITEMIZED RECEIPTS
Use separate schedule(s) for each category of the Detailed Summary Page
FOR LINE NUMBER: (check only one)

\begin{tabular}{|c|c|c|c|c|c|c|}
\hline & & & & & & \\
\hline 16 & $\times 1$ & $17 a$ & $17 b$ & $17 c$ & $17 d$ & 18 \\
\hline $19 a$ & & $19 b$ & $20 \mathrm{a}$ & $20 \mathrm{~b}$ & $20 \mathrm{c}$ & 21 \\
\hline
\end{tabular}

Any information copied from such Reports and Statements may not be sold or used by any person for the purpose of soliciting contributions or for commercial purposes, other than using the name and address of any political committee to solicit contributions from such committee.

NAME OF COMMITTEE (In Full)

\section{Friends of Herman Cain}

A. Full Name (Last, First, Middle Initial)

\section{Diane E Becker}

Mailing Address 2010 Gallagher Ave

\begin{tabular}{lcc}
\hline City & State & Zip Code \\
Deltona & FL & $32725-3278$ \\
\hline
\end{tabular}

FEC ID number of contributing federal political committee.

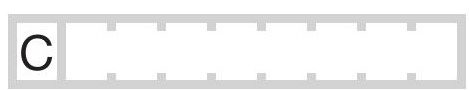

Name of Employer
None
Receipt For: 2012
X Primary $\quad$ General
Other (specify)

Occupation Retired

Election Cycle-to-Date

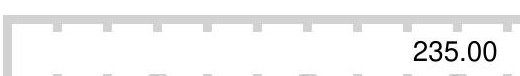

B. Full Name (Last, First, Middle Initial)

Deborah Robinson

Mailing Address 1807 Cool Springs Drive

\begin{tabular}{lcc}
\hline City & State & Zip Code \\
Alexandria & VA & $22308-1631$
\end{tabular}

FEC ID number of contributing

federal political committee.

C

Name of Employer
None
Receipt For: 2012
X Primary
$\quad$ Other (specify)

\section{Occupation}

Homemaker

Election Cycle-to-Date

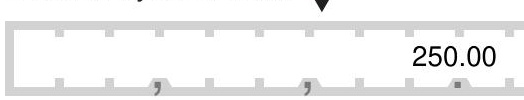

Transaction ID : ADB9E22C6D9E74D4B875

Date of Receipt

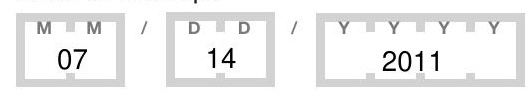

Amount of Each Receipt this Period

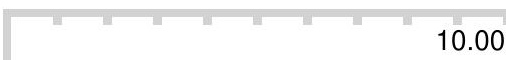

10.00

C. Full Name (Last, First, Middle Initial)

heather fowler

Mailing Address 205 Grogans Lake Pt

\begin{tabular}{lcc}
\hline City & State & Zip Code \\
Atlanta & GA & $30350-3120$
\end{tabular}

FEC ID number of contributing federal political committee.

C

GA

Name of Employer
capital city orthopaedics
Receipt For: 2012
X Primary
Other (specify) General

\section{Occupation}

housewife

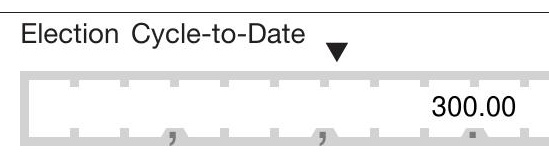

Transaction ID : AD56890E16BA0430FA22

Date of Receipt

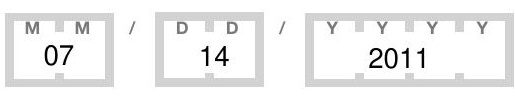

Amount of Each Receipt this Period

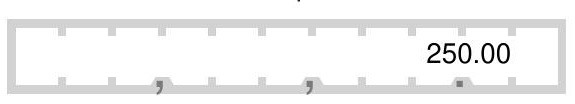

Transaction ID : A01CCDFF44D80406EA9E Date of Receipt

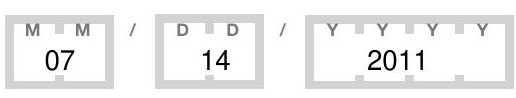

Amount of Each Receipt this Period

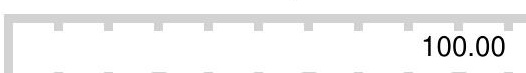

100.00

\section{Subtotal Of Receipts This Page (optional)}

Total This Period (last page this line number only) 
SCHEDULE A-P ITEMIZED RECEIPTS
Use separate schedule(s) for each category of the Detailed Summary Page
FOR LINE NUMBER: (check only one)

\begin{tabular}{|c|c|c|c|c|c|}
\hline & & & & & \\
\hline 16 & $\begin{array}{ll}X & 17 a \\
\end{array}$ & $17 \mathrm{~b}$ & $17 c$ & $17 d$ & 18 \\
\hline $19 a$ & $19 b$ & $20 \mathrm{a}$ & $20 \mathrm{~b}$ & $20 c$ & 21 \\
\hline
\end{tabular}

Any information copied from such Reports and Statements may not be sold or used by any person for the purpose of soliciting contributions or for commercial purposes, other than using the name and address of any political committee to solicit contributions from such committee.

NAME OF COMMITTEE (In Full)

\section{Friends of Herman Cain}

A. Full Name (Last, First, Middle Initial)

Dennis Casey

Mailing Address 1318 5th Street

\begin{tabular}{lcc}
\hline City & State & Zip Code \\
Rapid City & SD & $57701-3729$ \\
\hline
\end{tabular}

FEC ID number of contributing federal political committee.

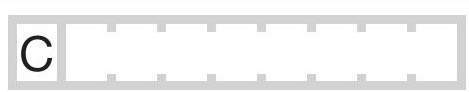

Name of Employer
Casey's Auto
Receipt For: 2012
X Primary
Other (specify) General

Occupation

Owner / Operator

Election Cycle-to-Date

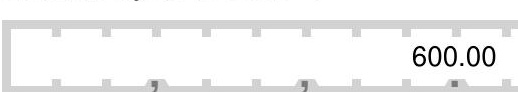

B. Full Name (Last, First, Middle Initial)

Marianne Mason

Mailing Address 30 Tall Oaks Trail

\begin{tabular}{lcc}
\hline City & State & Zip Code \\
Austin & TX & $78737-9306$ \\
\hline
\end{tabular}

FEC ID number of contributing

federal political committee.

C

Name of Employer
MMA Int. LLC
Receipt For: 2012
X Primary
Other (specify)

Occupation

Accountant

Election Cycle-to-Date

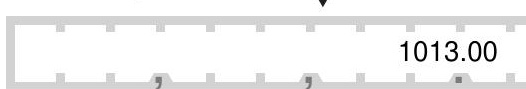

Transaction ID : ADC33D68965214534B97

Date of Receipt

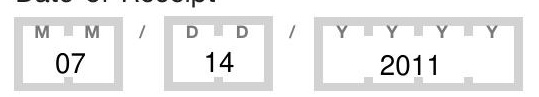

Amount of Each Receipt this Period

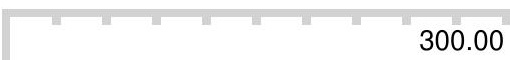

300.00

C. Full Name (Last, First, Middle Initial)

L Sims

Mailing Address 214 Emery St

\begin{tabular}{lcc}
\hline City & State & Zip Code \\
Mulvane & KS & $67110-1609$
\end{tabular}

FEC ID number of contributing federal political committee.

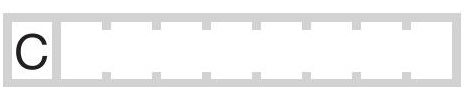

Name of Employer

Information Requested

\section{Occupation}

Information Requested

Receipt For: 2012

Х $\begin{aligned} & \text { Primary } \square \text { General } \\ & \text { Other (specify) }\end{aligned}$

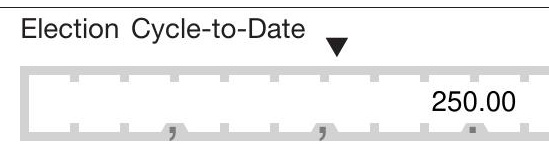

Amount of Each Receipt this Period

Transaction ID : A9B5A4E8DB4FF489CAB3 Date of Receipt
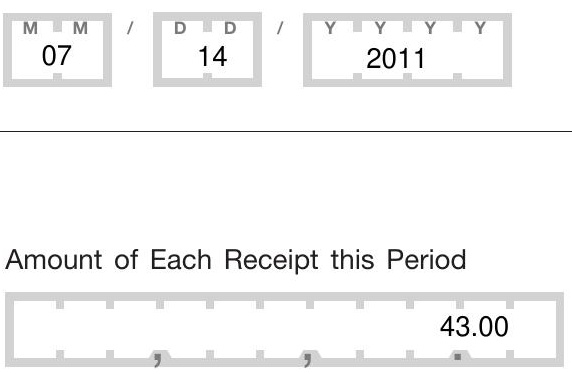

Transaction ID : AF4ABF06494FB4DB2BB8 Date of Receipt

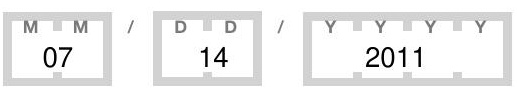

Amount of Each Receipt this Period

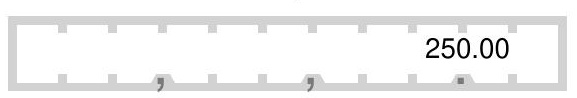

\section{Subtotal Of Receipts This Page (optional)}

Total This Period (last page this line number only) 
SCHEDULE A-P ITEMIZED RECEIPTS
Use separate schedule(s) for each category of the Detailed Summary Page
FOR LINE NUMBER: (check only one)

\begin{tabular}{|c|c|c|c|c|c|}
\hline & & & & & \\
\hline 16 & $\begin{array}{ll}X & 17 a \\
\end{array}$ & $17 \mathrm{~b}$ & $17 c$ & $17 d$ & 18 \\
\hline $19 a$ & $19 b$ & $20 \mathrm{a}$ & $20 \mathrm{~b}$ & $20 c$ & 21 \\
\hline
\end{tabular}

Any information copied from such Reports and Statements may not be sold or used by any person for the purpose of soliciting contributions or for commercial purposes, other than using the name and address of any political committee to solicit contributions from such committee.

NAME OF COMMITTEE (In Full)

\section{Friends of Herman Cain}

A. Full Name (Last, First, Middle Initial)

\section{Bruce Best}

Mailing Address PO Box 303

\begin{tabular}{lcc}
\hline City & State & Zip Code \\
Everett & WA & $98206-0303$
\end{tabular}

FEC ID number of contributing federal political committee.

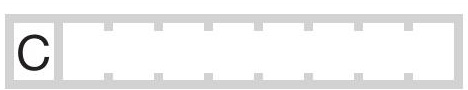

Name of Employer
Kimberly Clark
Receipt For: 2012
X Primary $\quad$ General
Other (specify)

Occupation

Paper maker

Election Cycle-to-Date

B. Full Name (Last, First, Middle Initial)

Colleen V Wynne

Mailing Address 221 Woodland Rd

\begin{tabular}{lcc}
\hline City & State & Zip Code \\
Gatlinburg & TN & $37738-5886$ \\
\hline
\end{tabular}

FEC ID number of contributing

federal political committee.

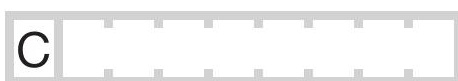

Name of Employer
Park Liquor
Receipt For: 2012
X Primary
$\square$ Other (specify)

\section{Occupation} clerk

Election Cycle-to-Date

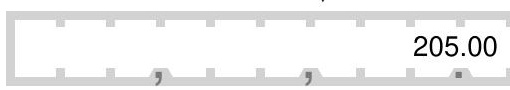

Transaction ID : A6BBFBB8A7C7944F2AD4

Date of Receipt

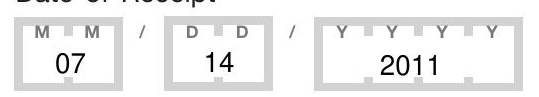

Amount of Each Receipt this Period

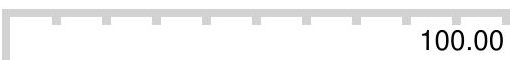

100.00

\subsection{2}

C. Full Name (Last, First, Middle Initial)

Jeff Frederiksen

Mailing Address PO BOX 844

\begin{tabular}{lcc}
\hline City & State & Zip Code \\
Pahrump & NV & $89041-0844$
\end{tabular}

FEC ID number of contributing federal political committee.

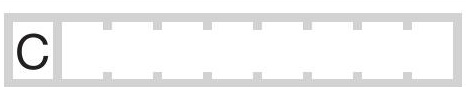

Name of Employer
n/a
Receipt For: 2012
X Primary $\square$ General
Other (specify)

Occupation

Retired

Election Cycle-to-Date

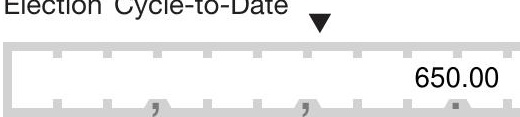

Transaction ID : AB7328A804B614995A95

Date of Receipt

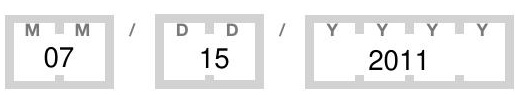

Amount of Each Receipt this Period

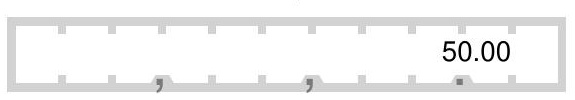

Transaction ID : A0B9B1FFD5339409D876

Date of Receipt

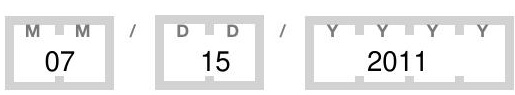

Amount of Each Receipt this Period

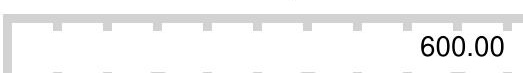

\section{Subtotal Of Receipts This Page (optional)}

Total This Period (last page this line number only) 
SCHEDULE A-P ITEMIZED RECEIPTS
Use separate schedule(s) for each category of the Detailed Summary Page
FOR LINE NUMBER: (check only one)

\begin{tabular}{|c|c|c|c|c|c|}
\hline & & & & & \\
\hline 16 & $\begin{array}{ll}X & 17 a \\
\end{array}$ & $17 \mathrm{~b}$ & $17 c$ & $17 d$ & 18 \\
\hline $19 a$ & $19 b$ & $20 \mathrm{a}$ & $20 \mathrm{~b}$ & $20 c$ & 21 \\
\hline
\end{tabular}

Any information copied from such Reports and Statements may not be sold or used by any person for the purpose of soliciting contributions or for commercial purposes, other than using the name and address of any political committee to solicit contributions from such committee.

NAME OF COMMITTEE (In Full)

\section{Friends of Herman Cain}

A. Full Name (Last, First, Middle Initial)

\section{Eleanor Ahern}

Mailing Address 6105 Elton Avenue

\begin{tabular}{lcc}
\hline City & State & Zip Code \\
Las Vegas & NV & $89107-2537$
\end{tabular}

FEC ID number of contributing federal political committee.

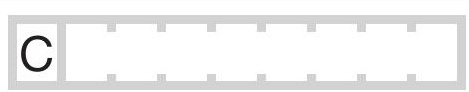

Name of Employer
Information Requested
Receipt For: 2012
X Primary
Other (specify) General

Occupation Information Requested

Election Cycle-to-Date

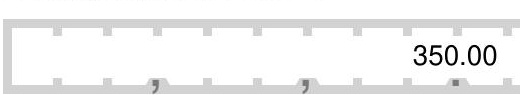

B. Full Name (Last, First, Middle Initial)

Hans Bergstrom

Mailing Address 2612 SW 15th street

\begin{tabular}{lcc}
\hline City & State & Zip Code \\
Deerfield Beach & FL & $33442-6051$
\end{tabular}

FEC ID number of contributing

federal political committee.

C

Name of Employer
Information Requested
Receipt For: 2012
X Primary
Other (specify)

\section{Occupation}

Information Requested

Election Cycle-to-Date

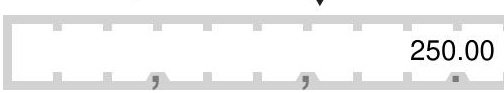

Transaction ID : A012CE2E8E18D4D1FA4E

Date of Receipt

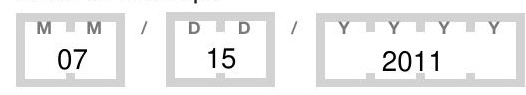

Amount of Each Receipt this Period

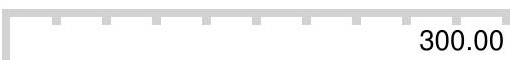

C. Full Name (Last, First, Middle Initial)

Mr Alfred Igler

Mailing Address 2457 Care Dr

\begin{tabular}{lcc}
\hline City & State & Zip Code \\
Tallahassee & FL & $32308-3501$
\end{tabular}

FEC ID number of contributing federal political committee.

C

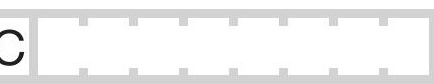

Name of Employer

Occupation

Information Requested

Information Requested

Receipt For: 2012

Х $\begin{aligned} & \text { Primary } \\ & \text { Other (specify) }\end{aligned}$

Transaction ID : A52EC344FE10D4397A3A

Date of Receipt

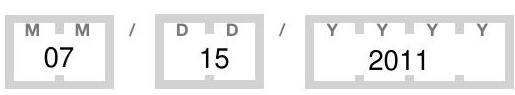

Amount of Each Receipt this Period

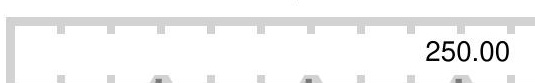

Transaction ID : AA60B71E799CD497CA17 Date of Receipt

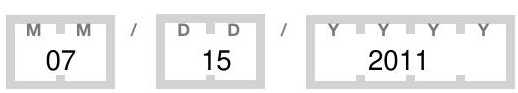

Amount of Each Receipt this Period

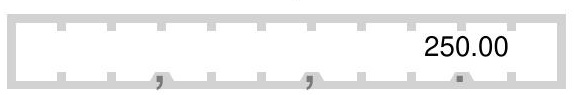

250.00
Subtotal Of Receipts This Page (optional)

800.00

a l

Total This Period (last page this line number only)

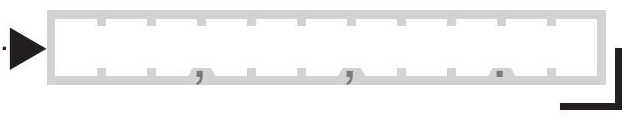

FEC Schedule A-P (Form 3P) (Rev. 03/2011) 
SCHEDULE A-P ITEMIZED RECEIPTS
Use separate schedule(s) for each category of the Detailed Summary Page
FOR LINE NUMBER: (check only one)

\begin{tabular}{|c|c|c|c|c|c|}
\hline & & & & & \\
\hline 16 & $\begin{array}{ll}X & 17 a \\
\end{array}$ & $17 \mathrm{~b}$ & $17 c$ & $17 d$ & 18 \\
\hline $19 a$ & $19 b$ & $20 \mathrm{a}$ & $20 \mathrm{~b}$ & $20 c$ & 21 \\
\hline
\end{tabular}

Any information copied from such Reports and Statements may not be sold or used by any person for the purpose of soliciting contributions or for commercial purposes, other than using the name and address of any political committee to solicit contributions from such committee.

NAME OF COMMITTEE (In Full)

\section{Friends of Herman Cain}

A. Full Name (Last, First, Middle Initial)

\section{Diane Briscoe}

Mailing Address 117 Marten Ct

\begin{tabular}{lcc}
\hline City & State & Zip Code \\
Waleska & GA & $30183-4685$
\end{tabular}

FEC ID number of contributing federal political committee.

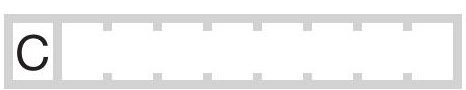

\section{Name of Employer}

Phoenix Aviation Managers, Inc.

Receipt For: 2012 Х $\begin{aligned} & \text { Primary } \\ & \text { Other (specify) }\end{aligned}$

Occupation

Accounting

Election Cycle-to-Date

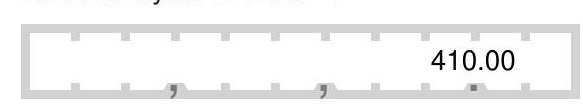

B. Full Name (Last, First, Middle Initial)

Lewis Lester

Mailing Address 7715 Harbour Walk

\begin{tabular}{lcc}
\hline City & State & Zip Code \\
Cumming & GA & $30041-2221$
\end{tabular}

FEC ID number of contributing

federal political committee.

C

Name of Employer
Information Requested
Receipt For: 2012
X Primary
Other (specify)

Occupation

Information Requested

Election Cycle-to-Date

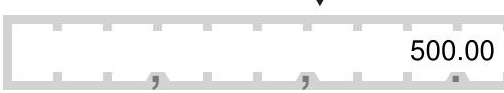

Transaction ID : A47A10E29035448A79C0

Date of Receipt

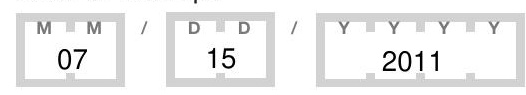

Amount of Each Receipt this Period

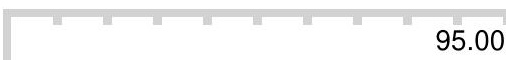

95.00

C. Full Name (Last, First, Middle Initial)

David Morris

Mailing Address 7921 E 46th Street

\begin{tabular}{lcc}
\hline City & State & Zip Code \\
Indianapolis & IN & $46226-3931$
\end{tabular}

FEC ID number of contributing

federal political committee.

C

$46226-3931$

Name of Employer
Precision Dry Wall Inc.
Receipt For: 2012
Primary
Other (specify) General

\section{Occupation}

Construction

Election Cycle-to-Date

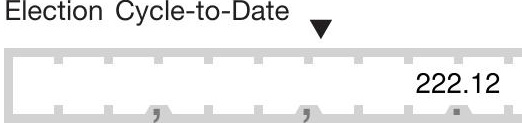

Transaction ID : A0012F14A68654302B40

Date of Receipt

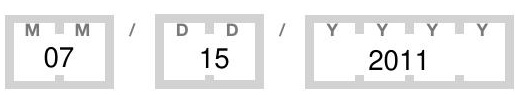

Amount of Each Receipt this Period

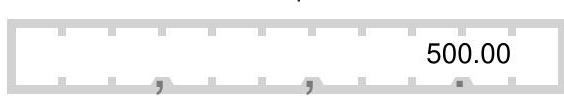

Transaction ID : A56379AE55DF145AEA57 Date of Receipt

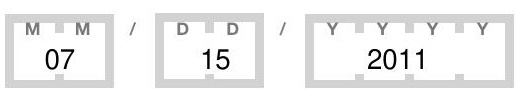

Amount of Each Receipt this Period

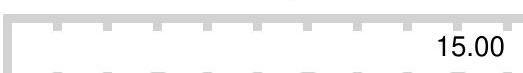

15.00

\section{Subtotal Of Receipts This Page (optional)}

Total This Period (last page this line number only) 
SCHEDULE A-P ITEMIZED RECEIPTS
Use separate schedule(s) for each category of the Detailed Summary Page
FOR LINE NUMBER: (check only one)

\begin{tabular}{|c|c|c|c|c|c|}
\hline & & & & & \\
\hline 16 & $\begin{array}{ll}X & 17 a \\
\end{array}$ & $17 \mathrm{~b}$ & $17 c$ & $17 d$ & 18 \\
\hline $19 a$ & $19 b$ & $20 \mathrm{a}$ & $20 \mathrm{~b}$ & $20 c$ & 21 \\
\hline
\end{tabular}

Any information copied from such Reports and Statements may not be sold or used by any person for the purpose of soliciting contributions or for commercial purposes, other than using the name and address of any political committee to solicit contributions from such committee.

NAME OF COMMITTEE (In Full)

\section{Friends of Herman Cain}

A. Full Name (Last, First, Middle Initial)

\section{Carole Harris}

Mailing Address 20115 E. Trimmer Springs Rd

\begin{tabular}{lcc}
\hline City & State & Zip Code \\
Sanger & CA & $93657-9006$
\end{tabular}

FEC ID number of contributing federal political committee.

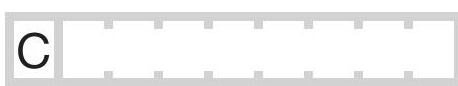

Name of Employer
Harris Farms Inc
Receipt For: 2012
X Primary
Other (specify) General

Occupation OWNER

Election Cycle-to-Date

B. Full Name (Last, First, Middle Initial) Jackie Jenkins

Mailing Address 4700 Balley Shannon Drive

\begin{tabular}{lcc}
\hline City & State & Zip Code \\
Mableton & GA & $30126-1752$
\end{tabular}

FEC ID number of contributing

federal political committee.

C

Name of Employer
MedSolutions
Receipt For: 2012
X Primary
Other (specify)

Occupation

medical management

Election Cycle-to-Date

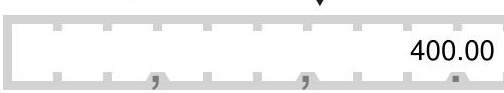

Transaction ID : A707284B1044F4C87BA0

Date of Receipt

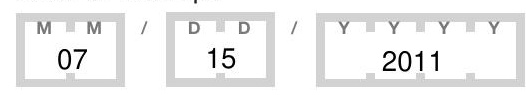

Amount of Each Receipt this Period

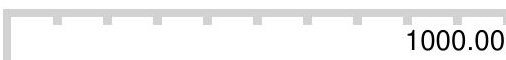

1000.00

C. Full Name (Last, First, Middle Initial)

Susan Walter

Mailing Address P.O. Box 690

\begin{tabular}{lcc}
\hline City & State & Zip Code \\
Sautee Nacoochee & GA & $30571-0690$
\end{tabular}

FEC ID number of contributing federal political committee.

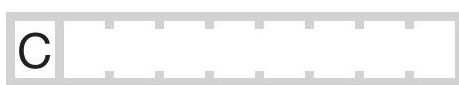

Name of Employer
None
Receipt For: 2012
X Primary $\quad \square$ General
Other (specify)

\section{Occupation}

Retired

Election Cycle-to-Date

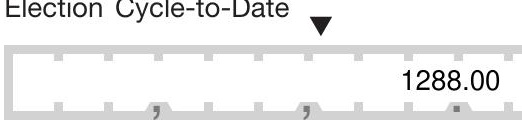

Transaction ID : A94E47062201241778E0

Date of Receipt

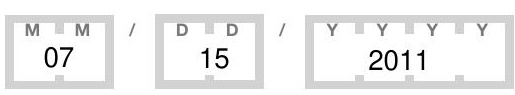

Amount of Each Receipt this Period

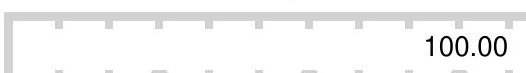

Transaction ID : AA00E25760F0146528C3

Date of Receipt

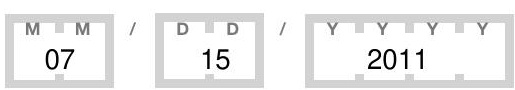

Amount of Each Receipt this Period

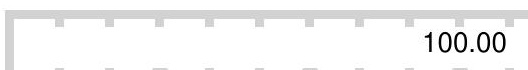

\section{Subtotal Of Receipts This Page (optional)}

Total This Period (last page this line number only) 


\section{SCHEDULE A-P} ITEMIZED RECEIPTS
Use separate schedule(s)

for each category of the

Detailed Summary Page
FOR LINE NUMBER: (check only one)
PAGE 96 / 1572

\begin{tabular}{|c|c|c|c|c|c|}
\hline & & & & & \\
\hline 16 & $\mathbf{X} 17 \mathrm{a}$ & $17 \mathrm{~b}$ & $17 c$ & $17 d$ & 18 \\
\hline $19 a$ & $19 b$ & $20 a$ & $20 \mathrm{~b}$ & $20 c$ & 21 \\
\hline
\end{tabular}

Any information copied from such Reports and Statements may not be sold or used by any person for the purpose of soliciting contributions or for commercial purposes, other than using the name and address of any political committee to solicit contributions from such committee.

NAME OF COMMITTEE (In Full)

Friends of Herman Cain

A. Full Name (Last, First, Middle Initial)

Michael Marchman

Mailing Address 1625 E 72nd St STE 700 PMB 224

\begin{tabular}{lcc}
\hline City & State & Zip Code \\
Tacoma & WA & $98404-5455$
\end{tabular}

FEC ID number of contributing

federal political committee.

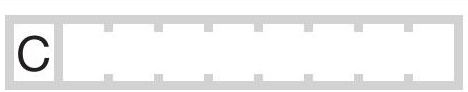

\section{Name of Employer}

U.S. Customs and Border Protection

Receipt For: 2012 Х Primary $\square$ General

Occupation CBP Officer

Election Cycle-to-Date 600.00

B. Full Name (Last, First, Middle Initial)

Mr George W Jackson

Mailing Address 4155 Pittman Rd

\begin{tabular}{lcc}
\hline City & State & Zip Code \\
Atlanta & GA & $30349-1440$
\end{tabular}

FEC ID number of contributing

federal political committee.

C

Name of Employer
TC1 of Alabama LLC
Receipt For: 2012
X Primary
Other (specify)

Occupation

BUSINESS OWNER

Election Cycle-to-Date

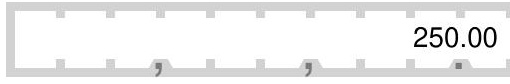

C. Full Name (Last, First, Middle Initial)

Siegfried Juckinies

Mailing Address 273 Winchester

\begin{tabular}{l|lc}
\hline $\begin{array}{l}\text { City } \\
\text { Tuscola }\end{array}$ & $\begin{array}{c}\text { State } \\
\text { TX }\end{array}$ & $\begin{array}{c}\text { Zip Code } \\
\text { 79562-3937 }\end{array}$ \\
\hline $\begin{array}{l}\text { FEC ID number of contributing } \\
\text { federal political committee. }\end{array}$ & C \\
\hline $\begin{array}{l}\text { Name of Employer } \\
\text { Information Requested }\end{array}$ & $\begin{array}{l}\text { Occupation } \\
\text { Information Requested }\end{array}$ \\
$\begin{array}{l}\text { Receipt For: } 2012 \\
\text { X } \begin{array}{l}\text { Primary } \\
\text { Other (specify) }\end{array}\end{array}$ & Election Cycle-to-Date & 250.00 \\
\hline
\end{tabular}

Transaction ID : A462C796C888041D1A82

Date of Receipt

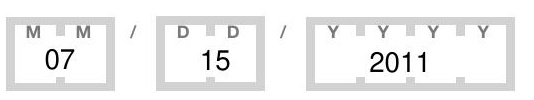

Amount of Each Receipt this Period

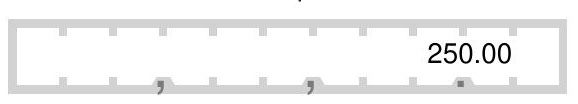

Amount of Each Receipt this Period

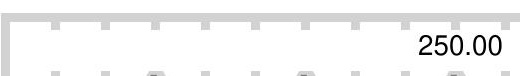

Transaction ID : A2C3900567A014637B79

Date of Receipt

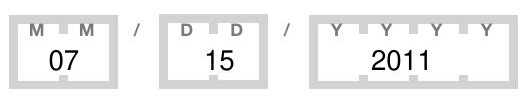

Subtotal Of Receipts This Page (optional).

Total This Period (last page this line number only) 
SCHEDULE A-P ITEMIZED RECEIPTS
Use separate schedule(s) for each category of the Detailed Summary Page
FOR LINE NUMBER: (check only one)

\begin{tabular}{|c|c|c|c|c|c|}
\hline & & & & & \\
\hline 16 & $\begin{array}{ll}X & 17 a \\
\end{array}$ & $17 \mathrm{~b}$ & $17 c$ & $17 d$ & 18 \\
\hline $19 a$ & $19 b$ & $20 \mathrm{a}$ & $20 \mathrm{~b}$ & $20 c$ & 21 \\
\hline
\end{tabular}

Any information copied from such Reports and Statements may not be sold or used by any person for the purpose of soliciting contributions or for commercial purposes, other than using the name and address of any political committee to solicit contributions from such committee.

NAME OF COMMITTEE (In Full)

\section{Friends of Herman Cain}

A. Full Name (Last, First, Middle Initial)

Debra Warden

Mailing Address 74 Skinner Street

\begin{tabular}{lcc}
\hline City & State & Zip Code \\
East Hampton & CT & $06424-1741$
\end{tabular}

FEC ID number of contributing federal political committee.

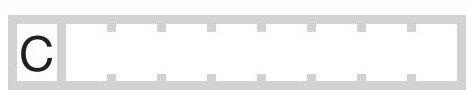

Name of Employer
State of CT/Judicial
Receipt For: 2012
X Primary
Other (specify) General

Occupation

Administrative Assistant

Election Cycle-to-Date

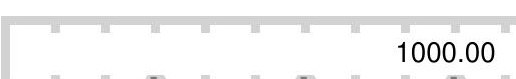

B. Full Name (Last, First, Middle Initial)

\section{Todd Nesley}

Mailing Address 406 headgate dr

\begin{tabular}{lcc}
\hline City & State & Zip Code \\
Augusta & GA & $30907-3306$ \\
\hline
\end{tabular}

FEC ID number of contributing

federal political committee.

C

Name of Employer
Nurse Anesthetist
Receipt For: 2012
Primary
Other (specify)

C. Full Name (Last, First, Middle Initial)

Matthew Clements

Mailing Address 122 Asbury Rd

\begin{tabular}{lcc}
\hline City & State & Zip Code \\
Winchester & VA & $22602-7900$
\end{tabular}

FEC ID number of contributing federal political committee.

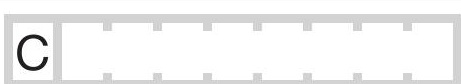

Name of Employer
AWC
Receipt For: 2012
X Primary $\square$ General
Other (specify)

\section{Occupation}

Todd Nesley

Election Cycle-to-Date

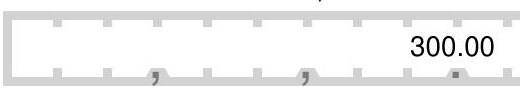

Occupation
Engineer
Election Cycle-to-Date

Transaction ID : A6CD869C3D5A14CFB9BF

Date of Receipt

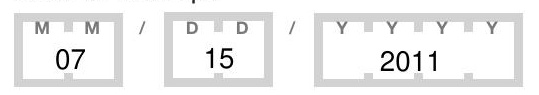

Amount of Each Receipt this Period

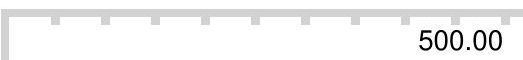

Amount of Each Receipt this Period

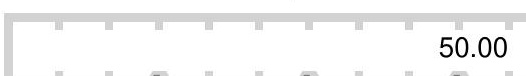

Transaction ID : ACDA429A12FA64370A71 Date of Receipt

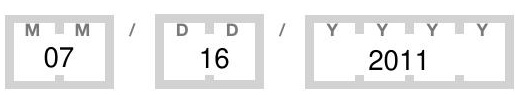

Transaction ID : AAA72E49C8707497AAB1 Date of Receipt

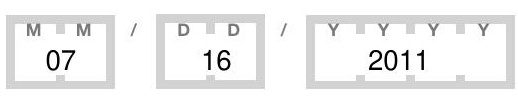

Amount of Each Receipt this Period

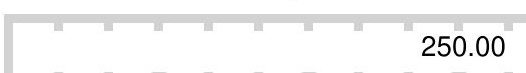

250.00

\section{Subtotal Of Receipts This Page (optional)}

800.00

a

Total This Period (last page this line number only)

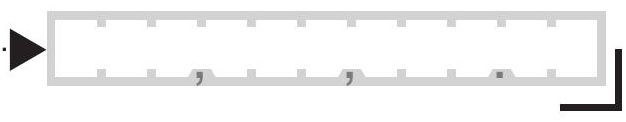

FEC Schedule A-P (Form 3P) (Rev. 03/2011) 


\section{SCHEDULE A-P} ITEMIZED RECEIPTS
Use separate schedule(s)

for each category of the

Detailed Summary Page
FOR LINE NUMBER: (check only one)
PAGE 98 / 1572

\begin{tabular}{|c|c|c|c|c|c|}
\hline & & & & & \\
\hline 16 & $\mathbf{X} 17 \mathrm{a}$ & $17 \mathrm{~b}$ & $17 c$ & $17 d$ & 18 \\
\hline $19 a$ & $19 b$ & $20 a$ & $20 \mathrm{~b}$ & $20 c$ & 21 \\
\hline
\end{tabular}

Any information copied from such Reports and Statements may not be sold or used by any person for the purpose of soliciting contributions or for commercial purposes, other than using the name and address of any political committee to solicit contributions from such committee.

NAME OF COMMITTEE (In Full)

Friends of Herman Cain

A. Full Name (Last, First, Middle Initial)

Peggy Catha

Mailing Address 4595 Valley Pky. Apt. B

\begin{tabular}{lcc}
\hline City & State & Zip Code \\
Smyrna & GA & $30082-4986$ \\
\hline
\end{tabular}

FEC ID number of contributing federal political committee.

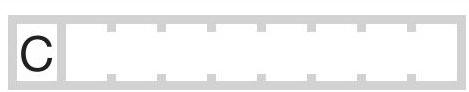

Name of Employer
Officemax Inc.
Receipt For: 2012
X Primary $\quad$ General
Other (specify)

Occupation

Furniture Sales

Election Cycle-to-Date

1100.00

B. Full Name (Last, First, Middle Initial)

KENNETH BROLIN

Mailing Address 6019 rose arbor court

\begin{tabular}{lcc}
\hline City & State & Zip Code \\
Chester & VA & $23831-8704$ \\
\hline
\end{tabular}

FEC ID number of contributing

federal political committee.

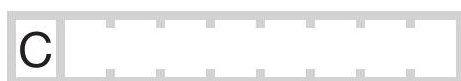

Name of Employer

TSS Photography in Central Virginia

Occupation

Receipt For: 2012

$\chi \begin{aligned} & \text { Primary } \\ & \text { Other (specify) } \boldsymbol{\nabla}\end{aligned}$ General

Executive

Election Cycle-to-Date

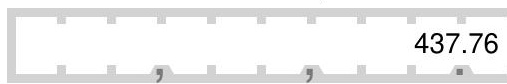

C. Full Name (Last, First, Middle Initial)

christina lipsey

Mailing Address 1219 libby rd

\begin{tabular}{lcc}
\hline City & State & Zip Code \\
Heber Springs & AR & $72543-8985$
\end{tabular}

FEC ID number of contributing

federal political committee.

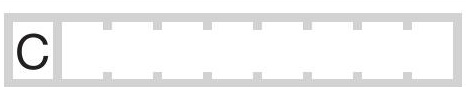

Name of Employer
little rock scool distrct
Receipt For: 2012
X Primary
Other (specify) General

Occupation

Teacher

Election Cycle-to-Date

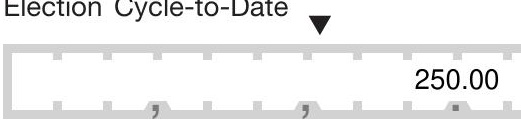

Transaction ID : A34CF94B9B3E84698B30

Date of Receipt

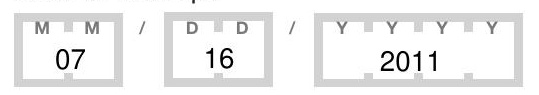

Amount of Each Receipt this Period

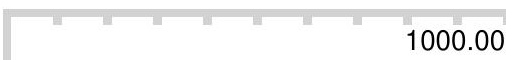

1000.00

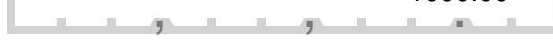

Transaction ID : A7B6C01DAA28048D8833

Date of Receipt

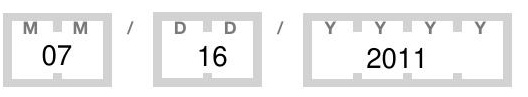

Amount of Each Receipt this Period

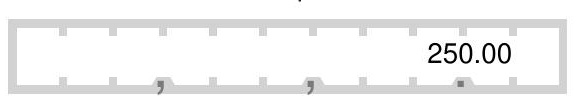

Transaction ID : A61768ECC88B74D74856

Date of Receipt

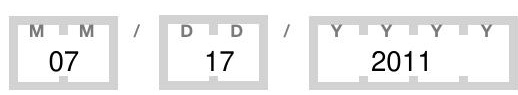

Amount of Each Receipt this Period

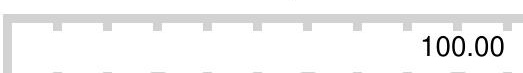

100.00

Subtotal Of Receipts This Page (optional).

1350.00

Total This Period (last page this line number only) 
SCHEDULE A-P ITEMIZED RECEIPTS
Use separate schedule(s) for each category of the Detailed Summary Page
FOR LINE NUMBER: (check only one)

\begin{tabular}{|c|c|c|c|c|c|c|}
\hline & & & & & & \\
\hline 16 & $\times 1$ & $17 a$ & $17 b$ & $17 c$ & $17 d$ & 18 \\
\hline $19 a$ & & $19 b$ & $20 \mathrm{a}$ & $20 \mathrm{~b}$ & $20 \mathrm{c}$ & 21 \\
\hline
\end{tabular}

Any information copied from such Reports and Statements may not be sold or used by any person for the purpose of soliciting contributions or for commercial purposes, other than using the name and address of any political committee to solicit contributions from such committee.

NAME OF COMMITTEE (In Full)

\section{Friends of Herman Cain}

A. Full Name (Last, First, Middle Initial)

Letty Goodman Lutzker MD

Mailing Address 408 S 2nd St

\begin{tabular}{lcc}
\hline City & State & Zip Code \\
Bangor & PA & $18013-2514$ \\
\hline
\end{tabular}

FEC ID number of contributing federal political committee.

Name of Employer
Self Employed
Receipt For: 2012
X Primary $\quad$ General
Other (specify)

B. Full Name (Last, First, Middle Initial)

Brian Mulhern

Mailing Address 14948 Vireo Court

\begin{tabular}{lcc}
\hline City & State & Zip Code \\
Woodbridge & VA & $22193-1899$ \\
\hline
\end{tabular}

FEC ID number of contributing

federal political committee.

Name of Employer
Lockheed Martin
Receipt For: 2012
X Primary
$\square$ Other (specify) General

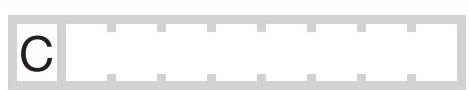

Occupation Physician Election Cycle-to-Date

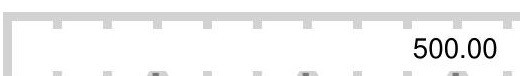

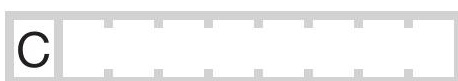

Occupation

System Engineer

Election Cycle-to-Date

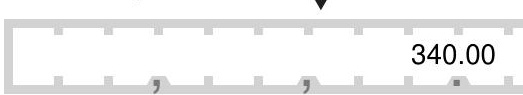

Transaction ID : AAFE68E3C35214413AFD

Date of Receipt

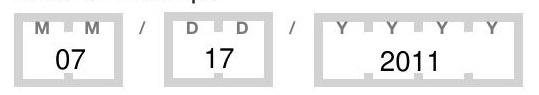

Amount of Each Receipt this Period

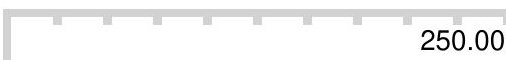

250.00

Transaction ID : A59227C98E1184EAA818

Date of Receipt

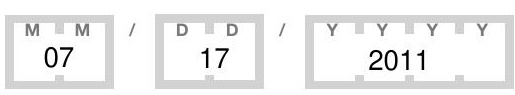

Amount of Each Receipt this Period

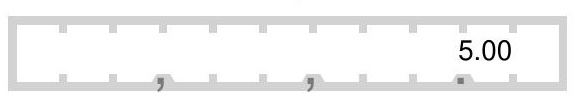

Transaction ID : AD2C7F30EECB94635AD3 Date of Receipt

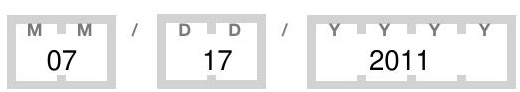

Amount of Each Receipt this Period

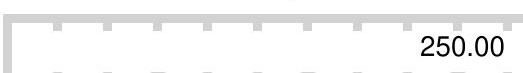

Air Contioniong Contractor

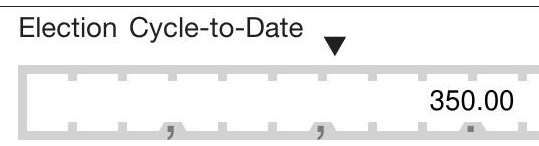

Subtotal Of Receipts This Page (optional).

505.00

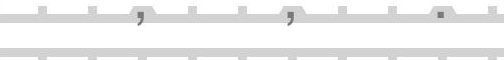

Total This Period (last page this line number only) 


\section{SCHEDULE A-P} ITEMIZED RECEIPTS
Use separate schedule(s)

for each category of the

Detailed Summary Page
FOR LINE NUMBER: (check only one)

PAGE $100 / 1572$

\begin{tabular}{|c|c|c|c|c|c|}
\hline & & & & & \\
\hline 16 & X $17 a$ & $17 b$ & $17 c$ & $17 d$ & 18 \\
\hline $19 a$ & $19 b$ & $20 \mathrm{a}$ & $20 \mathrm{~b}$ & $20 \mathrm{c}$ & 21 \\
\hline
\end{tabular}

Any information copied from such Reports and Statements may not be sold or used by any person for the purpose of soliciting contributions or for commercial purposes, other than using the name and address of any political committee to solicit contributions from such committee.

NAME OF COMMITTEE (In Full)

Friends of Herman Cain

A. Full Name (Last, First, Middle Initial)

Dave Sauter

Mailing Address 5927 Almeda Rd Unit 21505

\begin{tabular}{lcc}
\hline City & State & Zip Code \\
Houston & TX & $77004-7992$ \\
\hline
\end{tabular}

FEC ID number of contributing

federal political committee.

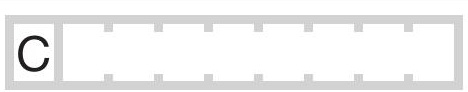

Name of Employer
MD Anderson Cancer Centre
Receipt For: 2012
X Primary
$\square$ Other (specify)

Occupation

Accelerator Maintenance Technician

Election Cycle-to-Date $\mathbf{\nabla}$

250.00

B. Full Name (Last, First, Middle Initial)

Jan Hamil

Mailing Address 2207 CR 34250

\begin{tabular}{lcc}
\hline City & State & Zip Code \\
Sumner & TX & $75486-5206$ \\
\hline
\end{tabular}

FEC ID number of contributing

federal political committee.

C

Name of Employer
Information Requested
Receipt For: 2012
Primary
Other (specify)

Occupation

Information Requested

Election Cycle-to-Date

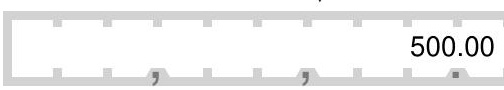

Transaction ID : A1EC402E9A75B446285C

Date of Receipt

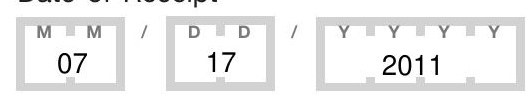

Amount of Each Receipt this Period

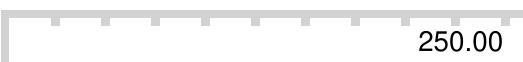

250.00

C. Full Name (Last, First, Middle Initial)

Randolph White

Mailing Address 3265 Hembree Court

\begin{tabular}{lcc}
\hline City & State & Zip Code \\
Marietta & GA & $30062-4219$ \\
\hline
\end{tabular}

FEC ID number of contributing

federal political committee.

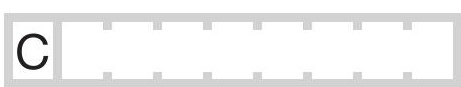

Name of Employer

Automationdirect.com

\section{Occupation}

technical writer

Receipt For: 2012

Х $\begin{aligned} & \text { Primary } \\ & \text { Other (specify) }\end{aligned}$

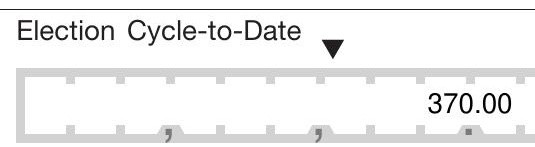

Amount of Each Receipt this Period

Transaction ID : A0524EC72F037405CB90

Date of Receipt
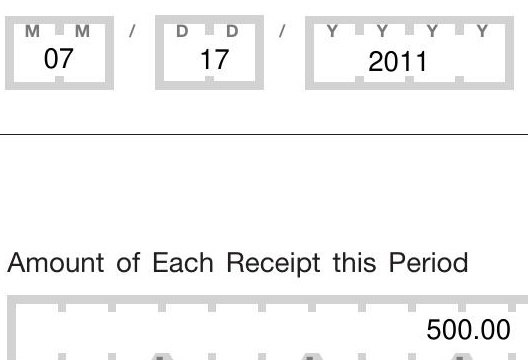

Transaction ID : AB31AC9A371A34547834

Date of Receipt

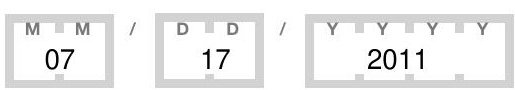

Amount of Each Receipt this Period

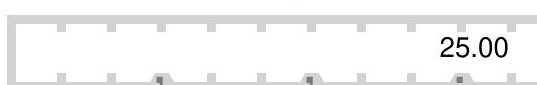

775.00

Subtotal Of Receipts This Page (optional)

Total This Period (last page this line number only) 


\section{SCHEDULE A-P} ITEMIZED RECEIPTS
Use separate schedule(s) for each category of the Detailed Summary Page

FOR LINE NUMBER:
(check only one)

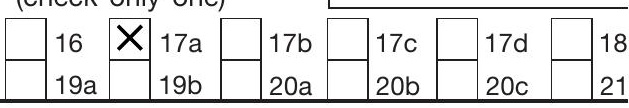

Any information copied from such Reports and Statements may not be sold or used by any person for the purpose of soliciting contributions or for commercial purposes, other than using the name and address of any political committee to solicit contributions from such committee.

NAME OF COMMITTEE (In Full)

\section{Friends of Herman Cain}

A. Full Name (Last, First, Middle Initial)

David VanNederynen

Mailing Address 804 Waltham St \# A

\begin{tabular}{lcc}
\hline City & State & Zip Code \\
Metairie & LA & $70001-5050$ \\
\hline
\end{tabular}

FEC ID number of contributing federal political committee.

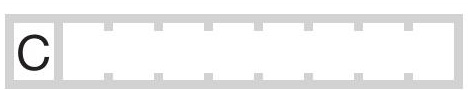

Name of Employer
DM Petroleum
Receipt For: 2012
X Primary
$\square$ Other (specify) General

Occupation

Supervisor Configuration Data Manageme

Election Cycle-to-Date

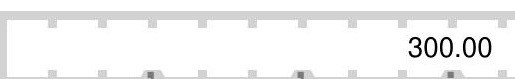

B. Full Name (Last, First, Middle Initial)

Robert Durst

Mailing Address 1706 SW 10th Ave

\begin{tabular}{lcc}
\hline City & State & Zip Code \\
Topeka & KS & $66604-1306$ \\
\hline
\end{tabular}

FEC ID number of contributing

federal political committee.

C

Name of Employer
Dermatology PA
Receipt For: 2012
X Primary
Other (specify)

Occupation

Physician

Election Cycle-to-Date

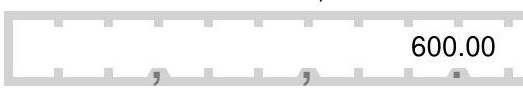

Transaction ID : A3AA073FD8DF44CCFBE4

Date of Receipt

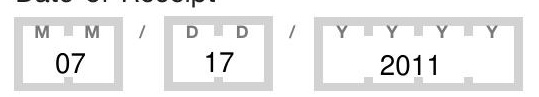

Amount of Each Receipt this Period

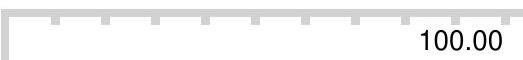

Transaction ID : A1F009A290ECC41BFA36 Date of Receipt

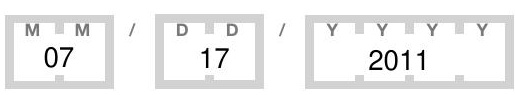

Amount of Each Receipt this Period

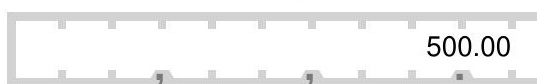

Transaction ID : A3428D943E8D24BBD9D4 Date of Receipt

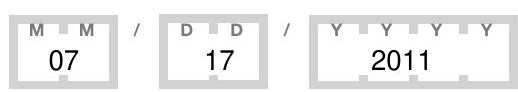

Amount of Each Receipt this Period

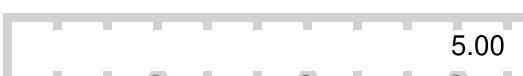

$\begin{array}{cc}\text { State } & \text { Zip Code } \\ \text { VA } & \text { 22193-1899 }\end{array}$

C

Occupation

System Engineer

Election Cycle-to-Date

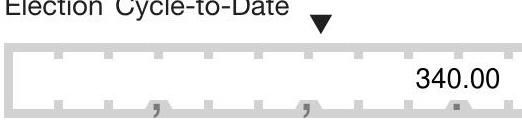

Subtotal Of Receipts This Page (optional)

605.00

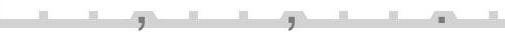

Total This Period (last page this line number only)

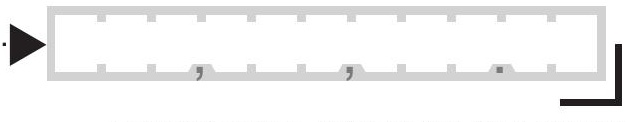

FEC Schedule A-P (Form 3P) (Rev. 03/2011) 
SCHEDULE A-P ITEMIZED RECEIPTS
Use separate schedule(s) for each category of the Detailed Summary Page
FOR LINE NUMBER: (check only one)

PAGE 102 / 1572

\begin{tabular}{|c|c|c|c|c|c|}
\hline & & & & & \\
\hline 16 & $\begin{array}{l}\mathbf{X} \\
17 a\end{array}$ & $17 b$ & $17 c$ & $17 d$ & 18 \\
\hline $19 a$ & $19 \mathrm{~b}$ & $20 \mathrm{a}$ & $20 \mathrm{~b}$ & $20 \mathrm{c}$ & 21 \\
\hline
\end{tabular}

Any information copied from such Reports and Statements may not be sold or used by any person for the purpose of soliciting contributions or for commercial purposes, other than using the name and address of any political committee to solicit contributions from such committee.

NAME OF COMMITTEE (In Full)

\section{Friends of Herman Cain}

A. Full Name (Last, First, Middle Initial)

Paul Engleson

Mailing Address 5877 Pontiac Dr.

\begin{tabular}{lcc}
\hline City & State & Zip Code \\
Woodbridge & VA & $22193-3801$
\end{tabular}

FEC ID number of contributing

federal political committee.

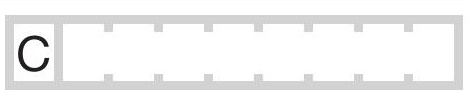

Name of Employer
GWS
Receipt For: 2012
X Primary $\quad$ General
Other (specify)

Occupation

bench marking

Election Cycle-to-Date

275.00

B. Full Name (Last, First, Middle Initial)

Thomas Johnson III

Mailing Address 10005 Autumn Valley Lane

\begin{tabular}{lcc}
\hline City & State & Zip Code \\
Knoxville & TN & $37922-4254$ \\
\hline
\end{tabular}

FEC ID number of contributing

federal political committee.

C

Name of Employer
Information Requested
Receipt For: 2012
X Primary
Other (specify)

Occupation

Information Requested

Election Cycle-to-Date

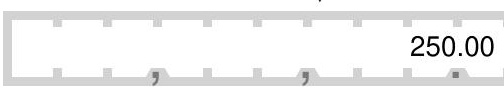

Transaction ID : A1F92FC66E1394B7DBD7

Date of Receipt

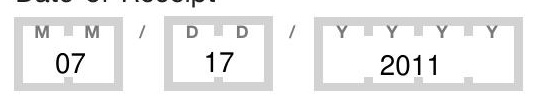

Amount of Each Receipt this Period

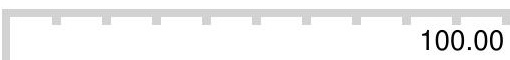

Transaction ID : ACFD648D3B9A7476094B

Date of Receipt

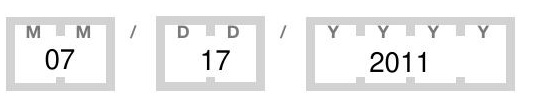

Amount of Each Receipt this Period

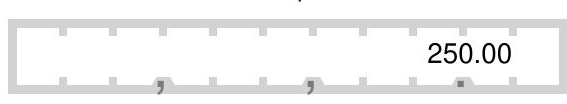

C. Full Name (Last, First, Middle Initial)

Karen Duddlesten

Mailing Address 1000 Uptown Park Blvd \#164

\begin{tabular}{lcc}
\hline City & State & Zip Code \\
Houston & TX & $77056-3248$
\end{tabular}

FEC ID number of contributing

federal political committee.

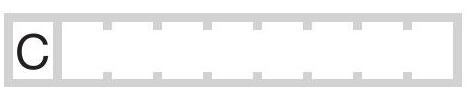

Name of Employer

Information Requested

Occupation

Information Requested

Receipt For: 2012

Х $\begin{aligned} & \text { Primary } \\ & \text { Other (specify) }\end{aligned}$

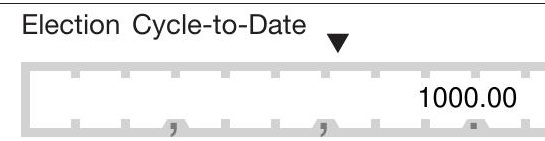

Amount of Each Receipt this Period

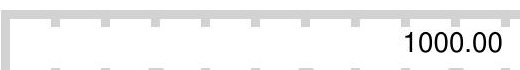

Transaction ID : AF710061DE5B84093AC6

Date of Receipt

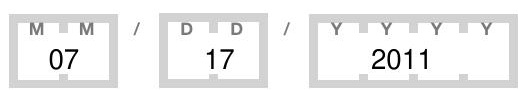

Subtotal Of Receipts This Page (optional)

1350.00

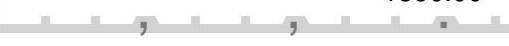

Total This Period (last page this line number only)

FEC Schedule A-P (Form 3P) (Rev. 03/2011) 
SCHEDULE A-P ITEMIZED RECEIPTS
Use separate schedule(s) for each category of the Detailed Summary Page
FOR LINE NUMBER: (check only one)

PAGE $103 / 1572$

\begin{tabular}{|c|c|c|c|c|c|c|}
\hline & & & & & & \\
\hline 16 & $\lambda$ & $17 \mathrm{a}$ & $17 \mathrm{~b}$ & $17 \mathrm{c}$ & $-17 d$ & -18 \\
\hline $19 a$ & & $19 b$ & $20 a$ & $20 \mathrm{~b}$ & $20 \mathrm{c}$ & 21 \\
\hline
\end{tabular}

Any information copied from such Reports and Statements may not be sold or used by any person for the purpose of soliciting contributions or for commercial purposes, other than using the name and address of any political committee to solicit contributions from such committee.

NAME OF COMMITTEE (In Full)

\section{Friends of Herman Cain}

A. Full Name (Last, First, Middle Initial)

\section{Brian Mulhern}

Mailing Address 14948 Vireo Court

\begin{tabular}{lcc}
\hline City & State & Zip Code \\
Woodbridge & VA & $22193-1899$
\end{tabular}

FEC ID number of contributing federal political committee.

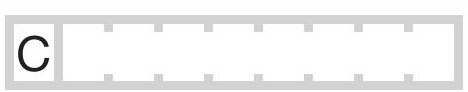

Name of Employer
Lockheed Martin
Receipt For: 2012
X Primary $\quad$ General
Other (specify)

Occupation

System Engineer

Election Cycle-to-Date

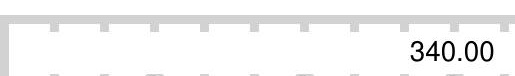

B. Full Name (Last, First, Middle Initial)

Alan Nelsen

Mailing Address 1925 Via Vineda

\begin{tabular}{lcc}
\hline City & State & Zip Code \\
San Antonio & TX & $78258-4518$ \\
\hline
\end{tabular}

FEC ID number of contributing

federal political committee.

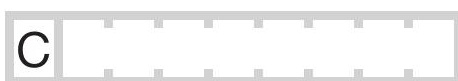

Name of Employer
Humana Inc.
Receipt For: 2012
X Primary
Other (specify)

Occupation

Physician

Election Cycle-to-Date

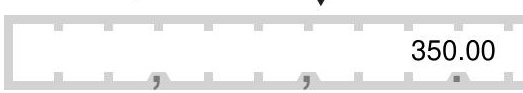

Transaction ID : A8BA49E8D0C3645F68C1

Date of Receipt

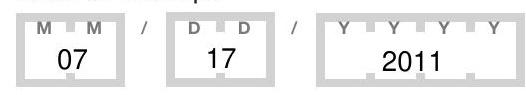

Amount of Each Receipt this Period

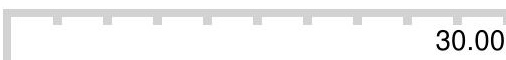

30.00

C. Full Name (Last, First, Middle Initial)

James Rouch

Mailing Address 1107 Belgrade Ct

\begin{tabular}{lcc}
\hline City & State & Zip Code \\
Plattsmouth & NE & $68048-4299$
\end{tabular}

FEC ID number of contributing federal political committee.

C

$68048-4299$

Name of Employer

Information Requested

Occupation

Receipt For: 2012

Х $\begin{aligned} & \text { Primary } \square \text { General } \\ & \text { Other (specify) }\end{aligned}$

Information Requested

Election Cycle-to-Date

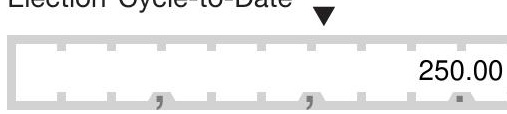

Transaction ID : A7D2E495E0E7C4F578A0

Date of Receipt

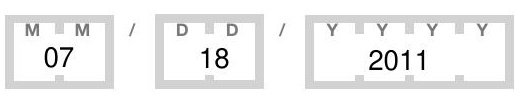

Amount of Each Receipt this Period

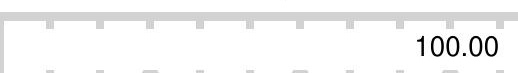

Transaction ID : AE14646816F044EDD96D

Date of Receipt

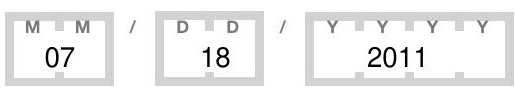

Amount of Each Receipt this Period

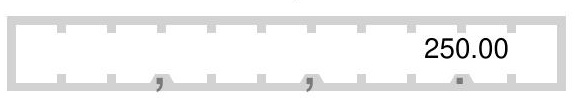

Subtotal Of Receipts This Page (optional)

380.00

Total This Period (last page this line number only) 
SCHEDULE A-P ITEMIZED RECEIPTS
Use separate schedule(s) for each category of the Detailed Summary Page
FOR LINE NUMBER: (check only one)

PAGE 104 / 1572

\begin{tabular}{|c|c|c|c|c|c|c|}
\hline & & & & & & \\
\hline 16 & $\lambda$ & $17 \mathrm{a}$ & $17 \mathrm{~b}$ & $17 \mathrm{c}$ & $-17 d$ & -18 \\
\hline $19 a$ & & $19 b$ & $20 a$ & $20 \mathrm{~b}$ & $20 \mathrm{c}$ & 21 \\
\hline
\end{tabular}

Any information copied from such Reports and Statements may not be sold or used by any person for the purpose of soliciting contributions or for commercial purposes, other than using the name and address of any political committee to solicit contributions from such committee.

NAME OF COMMITTEE (In Full)

\section{Friends of Herman Cain}

A. Full Name (Last, First, Middle Initial)

David Fortin

Mailing Address 9012 SR 17

\begin{tabular}{lcc}
\hline City & State & Zip Code \\
Plymouth & IN & $46563-9477$
\end{tabular}

FEC ID number of contributing federal political committee.

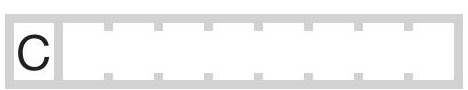

Name of Employer
Information Requested
Receipt For: 2012
X Primary
Other (specify) General

Occupation Information Requested

Election Cycle-to-Date

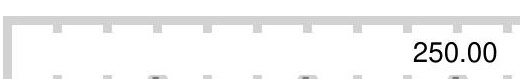

B. Full Name (Last, First, Middle Initial)

Mark Montgomery

Mailing Address 2229 Regal Way

\begin{tabular}{lcc}
\hline City & State & Zip Code \\
Naples & FL & $34110-1020$
\end{tabular}

FEC ID number of contributing

federal political committee.

C

Name of Employer
Information Requested
Receipt For: 2012
X Primary
Other (specify)

Occupation

Information Requested

Election Cycle-to-Date

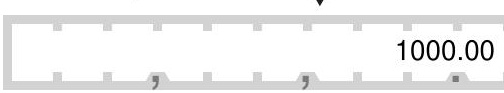

Transaction ID : A2AB00399577A492897E

Date of Receipt

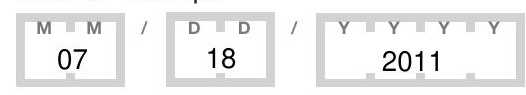

Amount of Each Receipt this Period

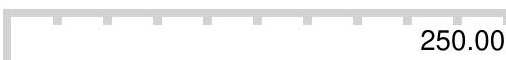

250.00

C. Full Name (Last, First, Middle Initial)

christina lipsey

Mailing Address 1219 libby rd

\begin{tabular}{lcc}
\hline City & State & Zip Code \\
Heber Springs & AR & $72543-8985$
\end{tabular}

FEC ID number of contributing federal political committee.

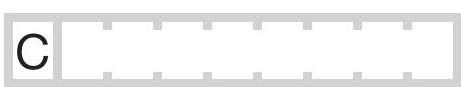

Name of Employer
little rock scool distrct
Receipt For: 2012
X Primary
Other (specify) General

\section{Occupation}

Teacher

Election Cycle-to-Date

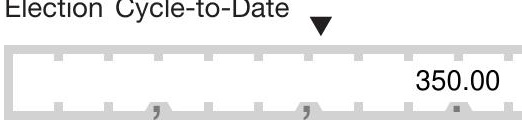

Transaction ID : AF5C636B803F24C0C960

Date of Receipt

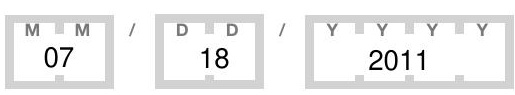

Amount of Each Receipt this Period

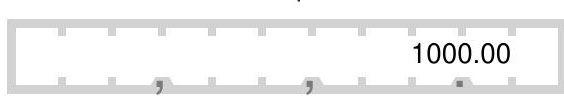

Transaction ID : AD6457E02042A4FF0B93 Date of Receipt

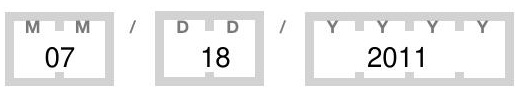

Amount of Each Receipt this Period

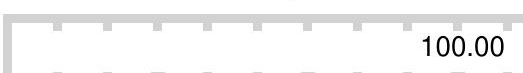

100.00

\section{Subtotal Of Receipts This Page (optional)}

Total This Period (last page this line number only) 
SCHEDULE A-P ITEMIZED RECEIPTS
Use separate schedule(s) for each category of the Detailed Summary Page
FOR LINE NUMBER: (check only one)

PAGE $105 / 1572$

\begin{tabular}{|c|c|c|c|c|c|c|}
\hline & & & & & & \\
\hline 16 & $\lambda$ & $17 \mathrm{a}$ & $17 \mathrm{~b}$ & $17 \mathrm{c}$ & $-17 d$ & -18 \\
\hline $19 a$ & & $19 b$ & $20 a$ & $20 \mathrm{~b}$ & $20 \mathrm{c}$ & 21 \\
\hline
\end{tabular}

Any information copied from such Reports and Statements may not be sold or used by any person for the purpose of soliciting contributions or for commercial purposes, other than using the name and address of any political committee to solicit contributions from such committee.

NAME OF COMMITTEE (In Full)

\section{Friends of Herman Cain}

A. Full Name (Last, First, Middle Initial)

Michael Burgess

Mailing Address 22865 Redwood Dr

\begin{tabular}{lcc}
\hline City & State & Zip Code \\
Lawrenceburg & IN & $47025-7433$
\end{tabular}

FEC ID number of contributing federal political committee.

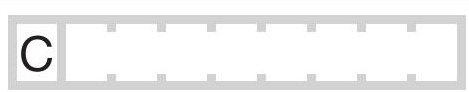

Name of Employer
Dearborn County Indiana
Receipt For: 2012
X Primary $\quad \square$ General
Other (specify)

Occupation

Veterans Service Officer

Election Cycle-to-Date $\boldsymbol{\nabla}$

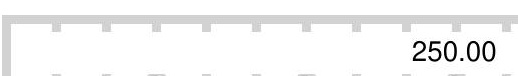

B. Full Name (Last, First, Middle Initial) STEPHEN DAVIS

Mailing Address $124821 \mathrm{Rd}$

\begin{tabular}{lcc}
\hline City & State & Zip Code \\
Grand Junction & CO & $81505-9381$
\end{tabular}

FEC ID number of contributing

federal political committee.

C

Name of Employer
Information Requested
Receipt For: 2012
X Primary
Other (specify)

Occupation

Information Requested

Election Cycle-to-Date

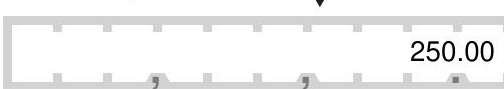

Transaction ID : A65CCA105F8724DF5B64

Date of Receipt

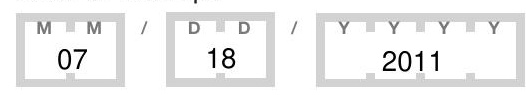

Amount of Each Receipt this Period

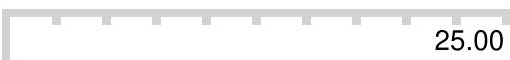

25.00

C. Full Name (Last, First, Middle Initial)

JOhn Berggreen

Mailing Address 101 Timmons Ranch Rd.

\begin{tabular}{lcc}
\hline City & State & Zip Code \\
Etna & CA & $96027-9774$
\end{tabular}

FEC ID number of contributing

federal political committee.

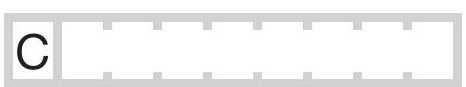

Name of Employer
PERS
Receipt For: 2012
Х Primary $\square$ General
Other (specify)

Occupation

Retired

Election Cycle-to-Date

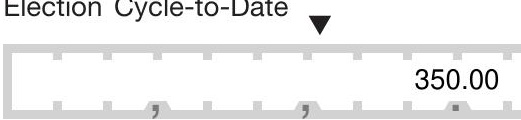

Transaction ID : A678E1864239C4A47B91

Date of Receipt

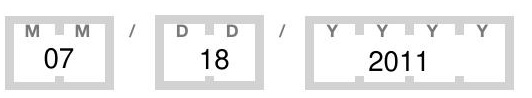

Amount of Each Receipt this Period

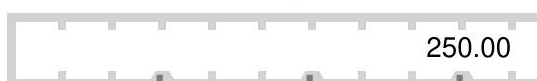

Transaction ID : AAC911E01FDEF483BA39

Date of Receipt

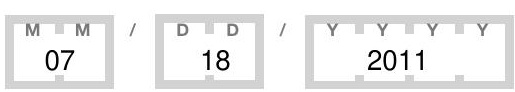

Amount of Each Receipt this Period

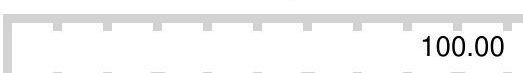

Subtotal Of Receipts This Page (optional).

375.00

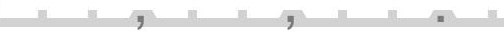

Total This Period (last page this line number only)

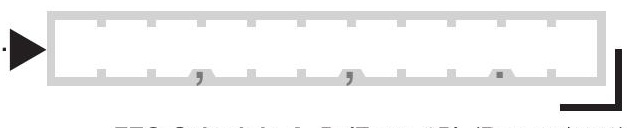

FEC Schedule A-P (Form 3P) (Rev. 03/2011) 
SCHEDULE A-P ITEMIZED RECEIPTS
Use separate schedule(s) for each category of the Detailed Summary Page
FOR LINE NUMBER: (check only one)

PAGE $106 / 1572$

\begin{tabular}{|c|c|c|c|c|c|c|}
\hline & & & & & & \\
\hline 16 & $\lambda$ & $17 \mathrm{a}$ & $17 \mathrm{~b}$ & $17 \mathrm{c}$ & $-17 d$ & -18 \\
\hline $19 a$ & & $19 b$ & $20 a$ & $20 \mathrm{~b}$ & $20 \mathrm{c}$ & 21 \\
\hline
\end{tabular}

Any information copied from such Reports and Statements may not be sold or used by any person for the purpose of soliciting contributions or for commercial purposes, other than using the name and address of any political committee to solicit contributions from such committee.

NAME OF COMMITTEE (In Full)

\section{Friends of Herman Cain}

A. Full Name (Last, First, Middle Initial)

\section{Fred Baker}

Mailing Address 629 Driftwood Dr

City

Woodstock

FEC ID number of contributing

federal political committee.

Name of Employer
AT\&T
Receipt For: 2012
X Primary $\quad \square$ General
$\square$ Other (specify)

B. Full Name (Last, First, Middle Initial)

JAMES BRANDEL

Mailing Address 5713 JACK ROAD

\begin{tabular}{lcc}
\hline City & State & Zip Code \\
Jacksonville & FL & $32277-2429$
\end{tabular}

FEC ID number of contributing

federal political committee.

C

Name of Employer
Information Requested
Receipt For: 2012
X Primary
Other (specify)

Name of Employer

Information Requested

Receipt For: 2012

Х $\begin{aligned} & \text { Primary } \square \text { General } \\ & \text { Other (specify) }\end{aligned}$

C. Full Name (Last, First, Middle Initial)

Douglas Gesso

Mailing Address 402 Blue Bird Dr

\begin{tabular}{lcc}
\hline City & State & Zip Code \\
Grayson & KY & $41143-8177$
\end{tabular}

FEC ID number of contributing federal political committee.

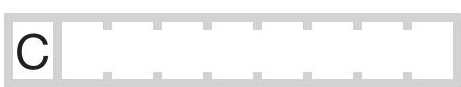

Name of Employer
Unemployed
Receipt For: 2012
X Primary $\quad \square$ General
Other (specify)

Occupation contractor

Election Cycle-to-Date 250.00
Information Requested

Election Cycle-to-Date

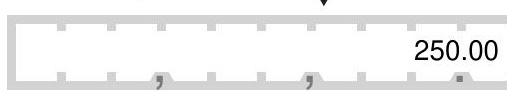
Occupation
Civil Engineer
Election Cycle-to-Date

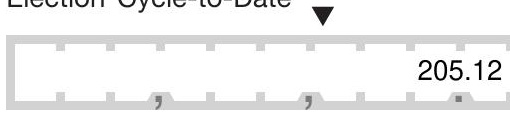

Transaction ID : AB6354018F15947F5BA4

Date of Receipt

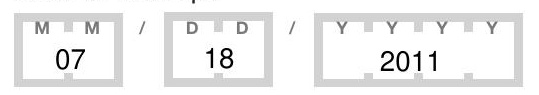

Amount of Each Receipt this Period

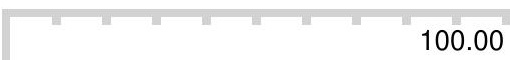

100.00

Amount of Each Receipt this Period

Transaction ID : AE331817FA5924B358C9

Date of Receipt
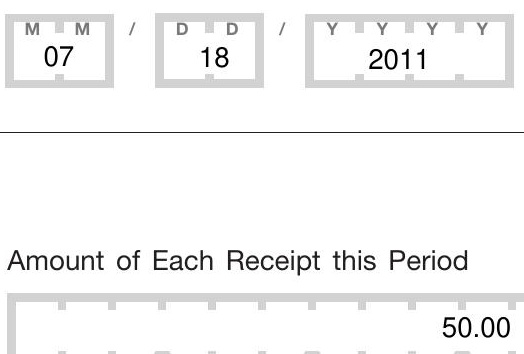

Transaction ID : AFA15AFFF7DF34E75BA5 Date of Receipt

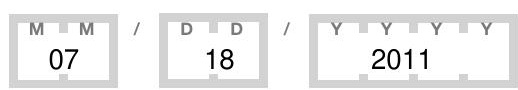

Amount of Each Receipt this Period

Subtotal Of Receipts This Page (optional)

200.00

a l

Total This Period (last page this line number only)

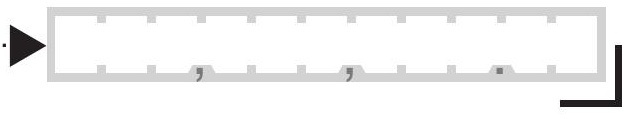

FEC Schedule A-P (Form 3P) (Rev. 03/2011) 
SCHEDULE A-P ITEMIZED RECEIPTS
Use separate schedule(s) for each category of the Detailed Summary Page
FOR LINE NUMBER: (check only one)

PAGE 107 / 1572

\begin{tabular}{|c|c|c|c|c|c|}
\hline & & & & & \\
\hline 16 & $\begin{array}{l}\mathbf{X} \\
17 a\end{array}$ & $17 b$ & $17 c$ & $17 d$ & 18 \\
\hline $19 a$ & $19 \mathrm{~b}$ & $20 \mathrm{a}$ & $20 \mathrm{~b}$ & $20 \mathrm{c}$ & 21 \\
\hline
\end{tabular}

Any information copied from such Reports and Statements may not be sold or used by any person for the purpose of soliciting contributions or for commercial purposes, other than using the name and address of any political committee to solicit contributions from such committee.

NAME OF COMMITTEE (In Full)

\section{Friends of Herman Cain}

A. Full Name (Last, First, Middle Initial)

Richard Scotti

Mailing Address 2563 Golden Bay Ct

\begin{tabular}{lcc}
\hline City & State & Zip Code \\
Henderson & NV & $89052-2943$
\end{tabular}

FEC ID number of contributing

federal political committee.

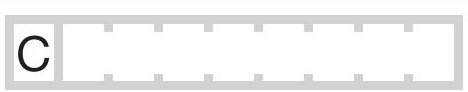

Name of Employer
Information Requested
Receipt For: 2012
X Primary
Other (specify) General

Occupation

Information Requested

Election Cycle-to-Date

1000.00

B. Full Name (Last, First, Middle Initial)

Christopher bent

Mailing Address 150 3rd Ave N

\begin{tabular}{lcc}
\hline City & State & Zip Code \\
Naples & FL & $34102-8408$ \\
\hline
\end{tabular}

FEC ID number of contributing

federal political committee.

C

Name of Employer
Information Requested
Receipt For: 2012
X Primary
Other (specify)

Occupation

Information Requested

Election Cycle-to-Date

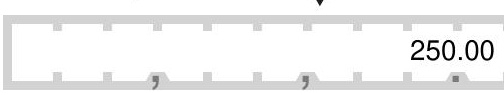

Transaction ID : A7B63AED2B2DC4A369F3

Date of Receipt

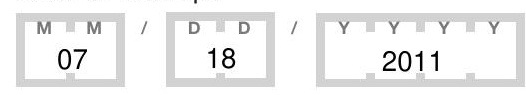

Amount of Each Receipt this Period

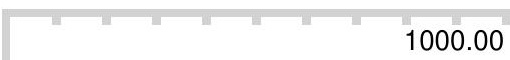

C. Full Name (Last, First, Middle Initial)

Mr John Murray

Mailing Address 27 Clearview $\mathrm{Dr}$

\begin{tabular}{lcc}
\hline City & State & Zip Code \\
Cartersville & GA & $30121-2249$
\end{tabular}

FEC ID number of contributing

federal political committee.

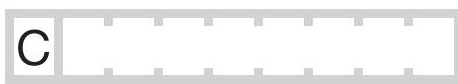

Name of Employer
None
Receipt For: 2012
X Primary $\quad \square$ General
Other (specify)

Occupation

Retired

Election Cycle-to-Date

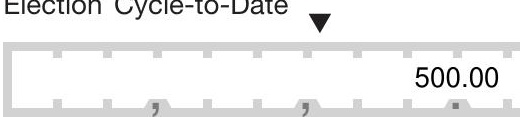

Amount of Each Receipt this Period

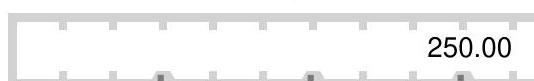

Transaction ID : AEB0CE28180054B9E8AB

Date of Receipt

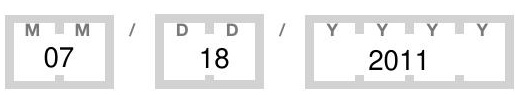

Transaction ID : AB6CF8C87F57B4A44A0A Date of Receipt

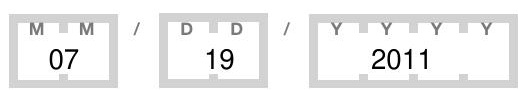

Amount of Each Receipt this Period

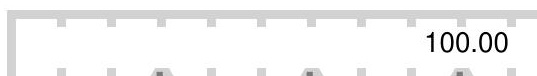

\section{Subtotal Of Receipts This Page (optional)}

Total This Period (last page this line number only) 
SCHEDULE A-P ITEMIZED RECEIPTS
Use separate schedule(s) for each category of the Detailed Summary Page
FOR LINE NUMBER: (check only one)

PAGE $108 / 1572$

\begin{tabular}{|c|c|c|c|c|c|}
\hline & & & & & \\
\hline 16 & $\begin{array}{l}\mathbf{X} \\
17 a\end{array}$ & $17 b$ & $17 c$ & $17 d$ & 18 \\
\hline $19 a$ & $19 \mathrm{~b}$ & $20 \mathrm{a}$ & $20 \mathrm{~b}$ & $20 \mathrm{c}$ & 21 \\
\hline
\end{tabular}

Any information copied from such Reports and Statements may not be sold or used by any person for the purpose of soliciting contributions or for commercial purposes, other than using the name and address of any political committee to solicit contributions from such committee.

NAME OF COMMITTEE (In Full)

\section{Friends of Herman Cain}

A. Full Name (Last, First, Middle Initial) Jack Gano

Mailing Address 606 Edgewood Drive

\begin{tabular}{lcc}
\hline City & State & Zip Code \\
Boone & IA & $50036-5216$
\end{tabular}

FEC ID number of contributing federal political committee.

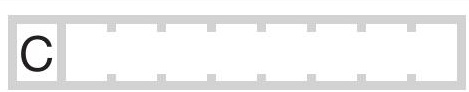

Name of Employer
Information Requested
Receipt For: 2012
X Primary
Other (specify) General

Occupation Information Requested

Election Cycle-to-Date

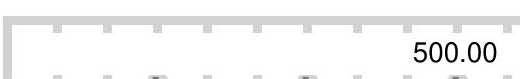

B. Full Name (Last, First, Middle Initial)

Ms Wilma Miller

Mailing Address P. O. Box 434

\begin{tabular}{lcc}
\hline City & State & Zip Code \\
Washington & OK & $73093-0434$ \\
\hline
\end{tabular}

FEC ID number of contributing

federal political committee.

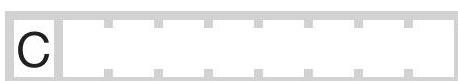

Name of Employer
Kenneth Sturgell
Receipt For: 2012
X Primary
Other (specify)

\section{Occupation}

File Clerk

Election Cycle-to-Date

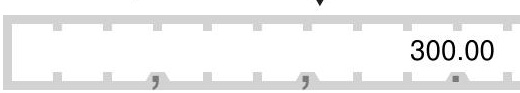

Transaction ID : A32BA0D65DFDD4696A13

Date of Receipt

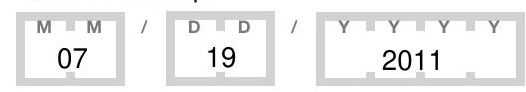

Amount of Each Receipt this Period

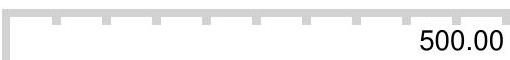

Amount of Each Receipt this Period

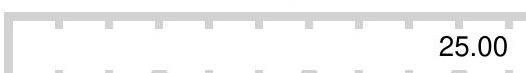

C. Full Name (Last, First, Middle Initial)

Stephen H Perry

Mailing Address 517 Carilion Ln

\begin{tabular}{lcc}
\hline City & State & Zip Code \\
Greenville & SC & $29617-7914$
\end{tabular}

FEC ID number of contributing federal political committee.

C

Name of Employer
Information Requested
Receipt For: 2012
X Primary
Other (specify) General

Occupation

Information Requested

Election Cycle-to-Date
Transaction ID : AD2FB244EE11941F4964

Date of Receipt

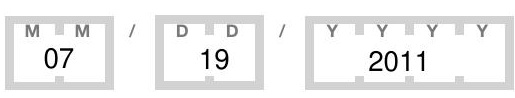

Transaction ID : A6863C9DC144F416BA14 Date of Receipt

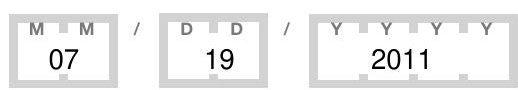

Amount of Each Receipt this Period

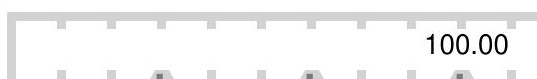

505.00

\section{Subtotal Of Receipts This Page (optional)}

625.00

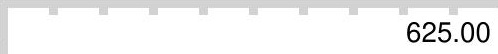

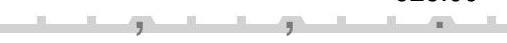

Total This Period (last page this line number only)

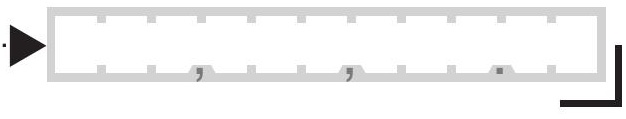

FEC Schedule A-P (Form 3P) (Rev. 03/2011) 
SCHEDULE A-P ITEMIZED RECEIPTS
Use separate schedule(s) for each category of the Detailed Summary Page
FOR LINE NUMBER: (check only one)

PAGE $109 / 1572$

\begin{tabular}{|c|c|c|c|c|c|}
\hline & & & & & \\
\hline 16 & $\begin{array}{l}\mathbf{X} \\
17 a\end{array}$ & $17 b$ & $17 c$ & $17 d$ & 18 \\
\hline $19 a$ & $19 \mathrm{~b}$ & $20 \mathrm{a}$ & $20 \mathrm{~b}$ & $20 \mathrm{c}$ & 21 \\
\hline
\end{tabular}

Any information copied from such Reports and Statements may not be sold or used by any person for the purpose of soliciting contributions or for commercial purposes, other than using the name and address of any political committee to solicit contributions from such committee.

NAME OF COMMITTEE (In Full)

\section{Friends of Herman Cain}

A. Full Name (Last, First, Middle Initial)

\section{Lawrence Bollinger}

Mailing Address 122 Seminole Lane

\begin{tabular}{lcc}
\hline City & State & Zip Code \\
Loudon & TN & $37774-2112$
\end{tabular}

FEC ID number of contributing federal political committee.

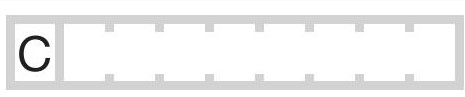

Name of Employer
Retired
Receipt For: 2012
X Primary $\quad$ General
Other (specify)

B. Full Name (Last, First, Middle Initial)

Randy Weidner

Mailing Address 2518 Stonequist Ave.

\begin{tabular}{lcc}
\hline City & State & Zip Code \\
Henderson & NV & $89052-2338$ \\
\hline
\end{tabular}

FEC ID number of contributing

federal political committee.

Name of Employer
Walgreens
Receipt For: 2012
X Primary
Other (specify)

C. Full Name (Last, First, Middle Initial)

James Dunn

Mailing Address P.O. Box 150155

\begin{tabular}{lcc}
\hline City & State & Zip Code \\
Alexandria & VA & $22315-0155$ \\
\hline
\end{tabular}

FEC ID number of contributing federal political committee.

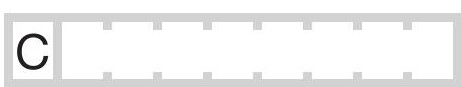

Name of Employer

Information Requested

Receipt For: 2012

Х $\begin{aligned} & \text { Primary } \\ & \text { Other (specify) }\end{aligned}$
Occupation

Retired

Election Cycle-to-Date

300.00
Information Requested

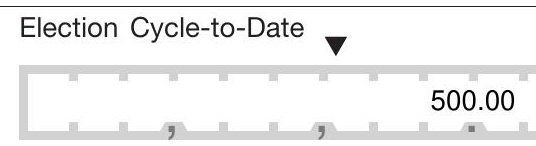

Transaction ID : A14A081C53C1C40DF8DA

Date of Receipt

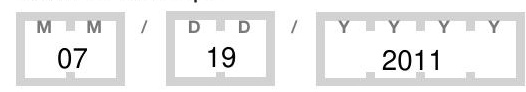

Amount of Each Receipt this Period

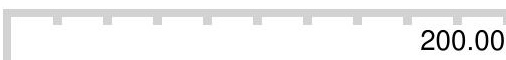

C
Amount of Each Receipt this Period

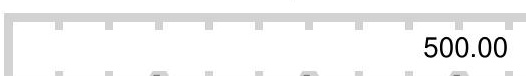

Transaction ID : AE952EEDB9A30467E8E1 Date of Receipt

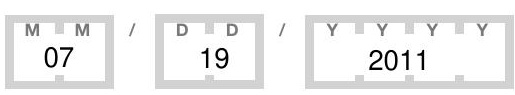

Occupation

Pharmacist

Election Cycle-to-Date

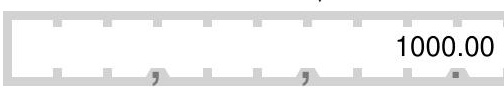

Transaction ID : A102EB6BB56364469A36

Date of Receipt

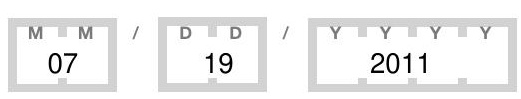

Amount of Each Receipt this Period

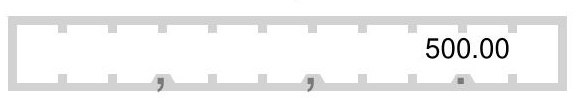

Subtotal Of Receipts This Page (optional)

1200.00

a 1 ,

Total This Period (last page this line number only)

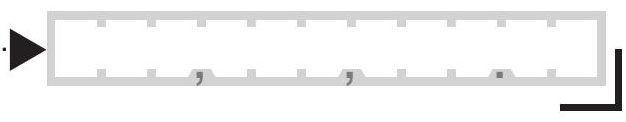

FEC Schedule A-P (Form 3P) (Rev. 03/2011) 
SCHEDULE A-P ITEMIZED RECEIPTS
Use separate schedule(s) for each category of the Detailed Summary Page
FOR LINE NUMBER: (check only one)

PAGE $110 / 1572$

\begin{tabular}{|c|c|c|c|c|c|}
\hline & & & & & \\
\hline 16 & $\begin{array}{l}\mathbf{X} \\
17 a\end{array}$ & $17 b$ & $17 c$ & $17 d$ & 18 \\
\hline $19 a$ & $19 \mathrm{~b}$ & $20 \mathrm{a}$ & $20 \mathrm{~b}$ & $20 \mathrm{c}$ & 21 \\
\hline
\end{tabular}

Any information copied from such Reports and Statements may not be sold or used by any person for the purpose of soliciting contributions or for commercial purposes, other than using the name and address of any political committee to solicit contributions from such committee.

NAME OF COMMITTEE (In Full)

\section{Friends of Herman Cain}

A. Full Name (Last, First, Middle Initial)

\section{Scott Karosa}

Mailing Address 9065 S Pecos Rd, \#200

\begin{tabular}{lcc}
\hline City & State & Zip Code \\
Henderson & NV & $89074-6606$
\end{tabular}

FEC ID number of contributing federal political committee.

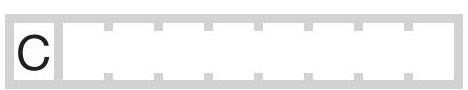

Name of Employer
Information Requested
Receipt For: 2012
X Primary
Other (specify) General

Occupation Information Requested

Election Cycle-to-Date

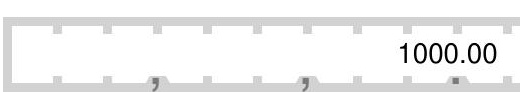

B. Full Name (Last, First, Middle Initial)

David Bryant

Mailing Address 2265 Sussex Court

\begin{tabular}{lcc}
\hline City & State & Zip Code \\
Snellville & GA & $30078-3120$ \\
\hline
\end{tabular}

FEC ID number of contributing

federal political committee.

C

Name of Employer
Information Requested
Receipt For: 2012
Xrimary
Other (specify)

Occupation

Information Requested

Election Cycle-to-Date

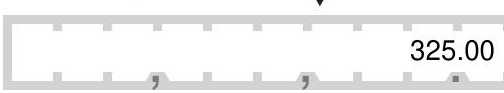

Transaction ID : A391F8EB65E7746FD967

Date of Receipt

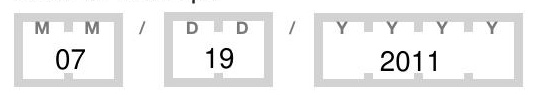

Amount of Each Receipt this Period

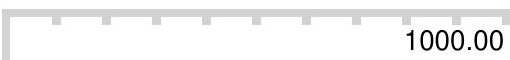

1000.00

C. Full Name (Last, First, Middle Initial)

Kamau Bakari

Mailing Address 1584 Spring Rain Rd.

\begin{tabular}{lcc}
\hline City & State & Zip Code \\
Las Vegas & NV & $89142-7900$
\end{tabular}

FEC ID number of contributing federal political committee.

C

Name of Employer
Kemet Electric LLC
Receipt For: 2012
X Primary $\quad \square$ General
Other (specify)

Occupation

Electrician

Election Cycle-to-Date

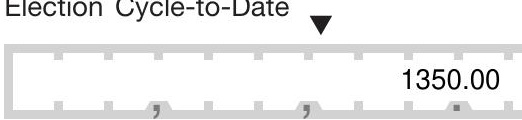

Transaction ID : A056839221B8B4EC289E

Date of Receipt

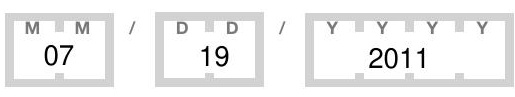

Amount of Each Receipt this Period

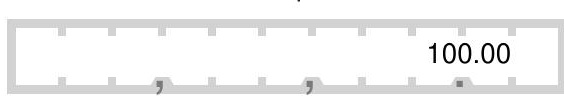

Transaction ID : A8D5FA7E00F0C40CAB19 Date of Receipt

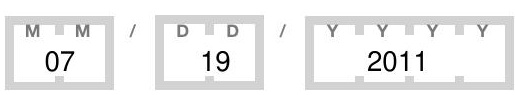

Amount of Each Receipt this Period

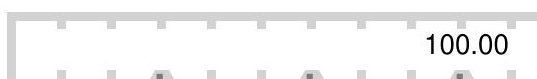

\section{Subtotal Of Receipts This Page (optional)}

Total This Period (last page this line number only) 
SCHEDULE A-P ITEMIZED RECEIPTS
Use separate schedule(s) for each category of the Detailed Summary Page

FOR LINE NUMBER:
(check only one)

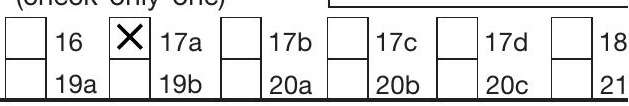

Any information copied from such Reports and Statements may not be sold or used by any person for the purpose of soliciting contributions or for commercial purposes, other than using the name and address of any political committee to solicit contributions from such committee.

NAME OF COMMITTEE (In Full)

\section{Friends of Herman Cain}

A. Full Name (Last, First, Middle Initial) Joyce Luster

Mailing Address 305 Martin Drive

\begin{tabular}{lcc}
\hline City & State & Zip Code \\
Bellevue & NE & $68005-4726$
\end{tabular}

FEC ID number of contributing federal political committee.

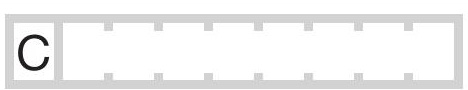

Name of Employer
n/a
Receipt For: 2012
X Primary $\quad$ General
Other (specify)

Occupation Retired Election Cycle-to-Date

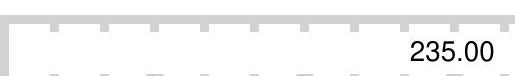

B. Full Name (Last, First, Middle Initial) John Seaman

Mailing Address 9050 W Tropicana Ave. Unit 1149

\begin{tabular}{lcc}
\hline City & State & Zip Code \\
Las Vegas & NV & $89147-8190$ \\
\hline
\end{tabular}

FEC ID number of contributing

federal political committee.

C

Name of Employer
Information Requested
Receipt For: 2012
X Primary
Other (specify)

Occupation

Information Requested

Election Cycle-to-Date

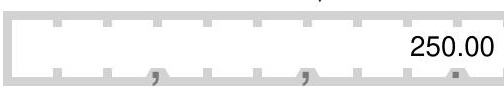

Transaction ID : A2E415220251B4D84BEA

Date of Receipt

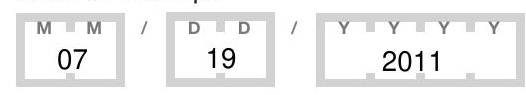

Amount of Each Receipt this Period

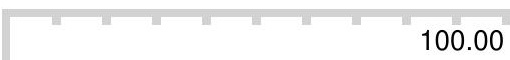

Amount of Each Receipt this Period

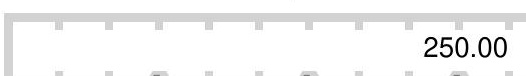

C. Full Name (Last, First, Middle Initial)

Marilyn Gubler

Mailing Address P.O. Box 371330

\begin{tabular}{lcc}
\hline City & State & Zip Code \\
Las Vegas & NV & $89137-1330$
\end{tabular}

FEC ID number of contributing federal political committee.

C

Name of Employer
Information Requested
Receipt For: 2012
X Primary
Other (specify) General

Occupation

Information Requested

Election Cycle-to-Date
Transaction ID : A4EC2A84EB02F4CAFAB4 Date of Receipt

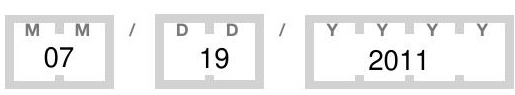

Transaction ID : A3A85A693241944FD838 Date of Receipt

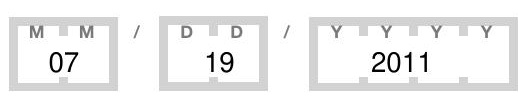

Amount of Each Receipt this Period

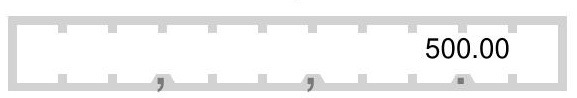

500.00

\section{Subtotal Of Receipts This Page (optional)}

Total This Period (last page this line number only) 
SCHEDULE A-P ITEMIZED RECEIPTS
Use separate schedule(s) for each category of the Detailed Summary Page
FOR LINE NUMBER: (check only one)

PAGE 112 / 1572

\begin{tabular}{|c|c|c|c|c|c|}
\hline & & & & & \\
\hline 16 & $\begin{array}{l}\mathbf{X} \\
17 a\end{array}$ & $17 b$ & $17 c$ & $17 d$ & 18 \\
\hline $19 a$ & $19 \mathrm{~b}$ & $20 \mathrm{a}$ & $20 \mathrm{~b}$ & $20 \mathrm{c}$ & 21 \\
\hline
\end{tabular}

Any information copied from such Reports and Statements may not be sold or used by any person for the purpose of soliciting contributions or for commercial purposes, other than using the name and address of any political committee to solicit contributions from such committee.

NAME OF COMMITTEE (In Full)

\section{Friends of Herman Cain}

A. Full Name (Last, First, Middle Initial)

Billy Atwood

Mailing Address PO Box 849

\begin{tabular}{lcc}
\hline City & State & Zip Code \\
Kosciusko & MS & $39090-0849$
\end{tabular}

FEC ID number of contributing federal political committee.

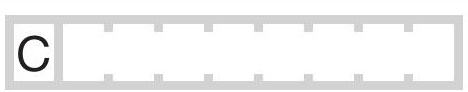

Name of Employer
Information Requested
Receipt For: 2012
X Primary
Other (specify) General

Occupation Information Requested

Election Cycle-to-Date

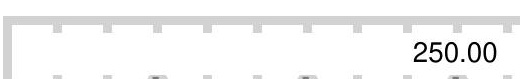

B. Full Name (Last, First, Middle Initial) Joseph Prigge

Mailing Address 210 coventry court

\begin{tabular}{lcc}
\hline City & State & Zip Code \\
Elgin & IL & $60123-5081$ \\
\hline
\end{tabular}

FEC ID number of contributing

federal political committee.

C

Name of Employer
William Prigge
Receipt For: 2012
X Primary
Other (specify)

Occupation

Geotechnical Technician

Election Cycle-to-Date

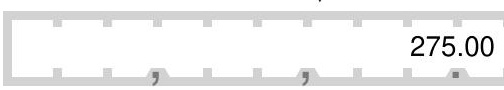

Transaction ID : A6112C2948010487F8EC

Date of Receipt

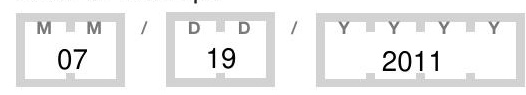

Amount of Each Receipt this Period

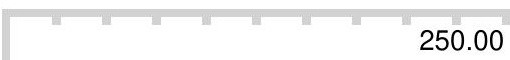

250.00

C. Full Name (Last, First, Middle Initial)

Mr. James S Parsons, Jr.

Mailing Address 2427 Fairway Drive

\begin{tabular}{lcc}
\hline City & State & Zip Code \\
Winston Salem & NC & $27103-3508$
\end{tabular}

FEC ID number of contributing federal political committee.

C

27103-3508

Name of Employer

Womble Carlyle Sandridge \& Rice

Receipt For: 2012

Х $\begin{aligned} & \text { Primary } \square \text { General } \\ & \text { Other (specify) }\end{aligned}$

\section{Occupation}

Attorney

Election Cycle-to-Date

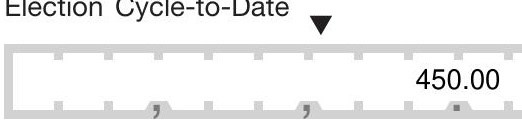

Transaction ID : A946038397CEA4E8A903

Date of Receipt

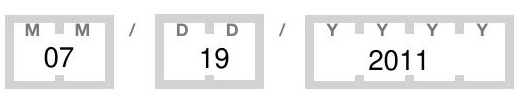

Amount of Each Receipt this Period

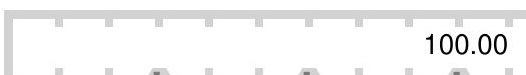

Transaction ID : A2C0E49A27AE34C5E880 Date of Receipt

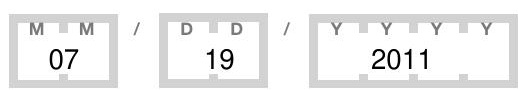

Amount of Each Receipt this Period

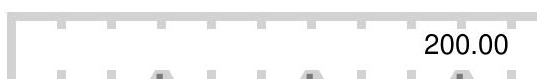

\section{Subtotal Of Receipts This Page (optional)}

Total This Period (last page this line number only) 
SCHEDULE A-P ITEMIZED RECEIPTS
Use separate schedule(s) for each category of the Detailed Summary Page
FOR LINE NUMBER: (check only one)

PAGE $113 / 1572$

\begin{tabular}{|c|c|c|c|c|c|}
\hline & & & & & \\
\hline 16 & $\begin{array}{lll}X & 17 a \\
\end{array}$ & $17 \mathrm{~b}$ & $17 c$ & $17 d$ & 18 \\
\hline $19 a$ & $19 b$ & $20 a$ & $20 \mathrm{~b}$ & $20 c$ & 21 \\
\hline
\end{tabular}

Any information copied from such Reports and Statements may not be sold or used by any person for the purpose of soliciting contributions or for commercial purposes, other than using the name and address of any political committee to solicit contributions from such committee.

NAME OF COMMITTEE (In Full)

\section{Friends of Herman Cain}

A. Full Name (Last, First, Middle Initial)

Debbie A Barry

Mailing Address 21 Hewey St

\begin{tabular}{lcc}
\hline City & State & Zip Code \\
Lisbon Falls & ME & $04252-1912$
\end{tabular}

FEC ID number of contributing federal political committee.

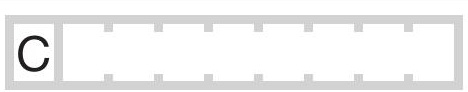

Name of Employer
None
Receipt For: 2012
X Primary $\quad \square$ General
Other (specify) $\nabla$

Occupation Retired

Election Cycle-to-Date

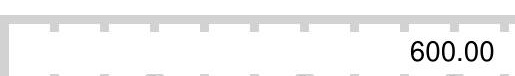

B. Full Name (Last, First, Middle Initial)

DONOVAN E MCLAURIN

\section{Mailing Address 7085 MAIN ST \# 1}

\begin{tabular}{lcc}
\hline City & State & Zip Code \\
Wade & NC & $28395-9767$
\end{tabular}

FEC ID number of contributing

federal political committee.

C

Name of Employer
McLaurin Company, Inc
Receipt For: 2012
X Primary
Other (specify)

\section{Occupation}

Lumber Manufacturing

Election Cycle-to-Date

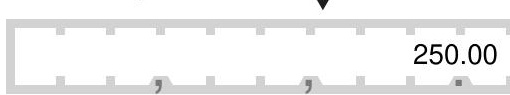

Transaction ID : A9BE1C27BD9CE417D886

Date of Receipt

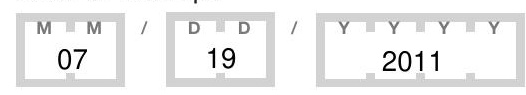

Amount of Each Receipt this Period

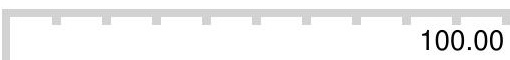

Amount of Each Receipt this Period

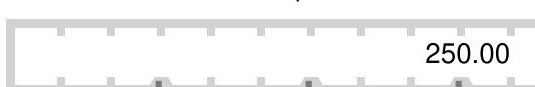

C. Full Name (Last, First, Middle Initial)

Jayne D Wayson

Mailing Address 400 E Colonial Dr Apt 402

\begin{tabular}{lcc}
\hline City & State & Zip Code \\
Orlando & FL & $32803-4530$
\end{tabular}

FEC ID number of contributing federal political committee.

C

Name of Employer
Information Requested
Receipt For: 2012
X Primary
Other (specify) General

Occupation

Information Requested

Election Cycle-to-Date

Transaction ID : ADC7376C830FD4B01BCF Date of Receipt

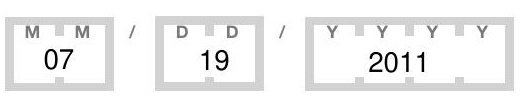

Transaction ID : AFB675F2F04DB4B1C85F Date of Receipt

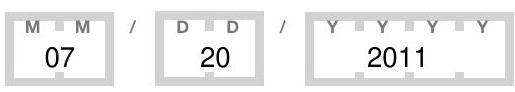

Amount of Each Receipt this Period

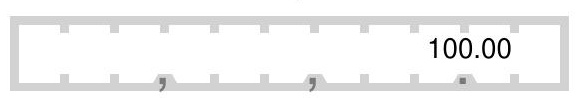

243.00

\section{Subtotal Of Receipts This Page (optional)}

Total This Period (last page this line number only) 
SCHEDULE A-P ITEMIZED RECEIPTS
Use separate schedule(s) for each category of the Detailed Summary Page
FOR LINE NUMBER: (check only one)

PAGE 114 / 1572

\begin{tabular}{|c|c|c|c|c|c|}
\hline & & & & & \\
\hline 16 & $\begin{array}{l}\mathbf{X} \\
17 a\end{array}$ & $17 b$ & $17 c$ & $17 d$ & 18 \\
\hline $19 a$ & $19 \mathrm{~b}$ & $20 \mathrm{a}$ & $20 \mathrm{~b}$ & $20 \mathrm{c}$ & 21 \\
\hline
\end{tabular}

Any information copied from such Reports and Statements may not be sold or used by any person for the purpose of soliciting contributions or for commercial purposes, other than using the name and address of any political committee to solicit contributions from such committee.

NAME OF COMMITTEE (In Full)

\section{Friends of Herman Cain}

A. Full Name (Last, First, Middle Initial)

\section{Anna Nataros}

Mailing Address 1600 E Hanley Blvd. Suite 128

\begin{tabular}{lcc}
\hline City & State & Zip Code \\
Tucson & AZ & $85737-9180$
\end{tabular}

FEC ID number of contributing federal political committee.

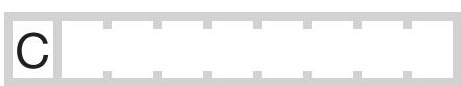

Name of Employer
Information Requested
Receipt For: 2012
X Primary
Other (specify) General

Occupation Information Requested

Election Cycle-to-Date

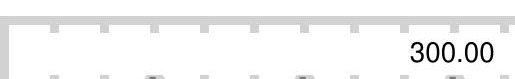

B. Full Name (Last, First, Middle Initial)

KENNETH BROLIN

Mailing Address 6019 rose arbor court

\begin{tabular}{lcc}
\hline City & State & Zip Code \\
Chester & VA & $23831-8704$ \\
\hline
\end{tabular}

FEC ID number of contributing

federal political committee.

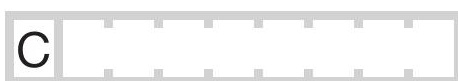

Name of Employer

TSS Photography in Central Virginia

Occupation

Receipt For: 2012

$\chi \begin{aligned} & \text { Primary } \\ & \text { Other (specify) }\end{aligned}$

Executive

Transaction ID : A8FB0250766A34247B0B

Date of Receipt

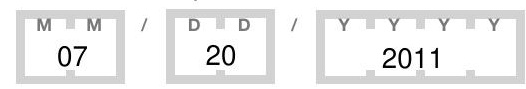

Amount of Each Receipt this Period

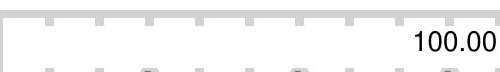

Transaction ID : AB080EDFE2E7842309E2

Date of Receipt

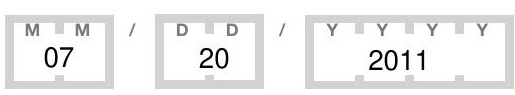

Amount of Each Receipt this Period

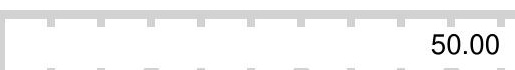

Election Cycle-to-Date

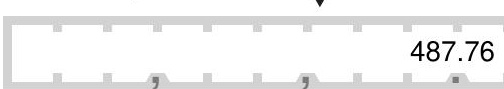

C. Full Name (Last, First, Middle Initial)

Frank Smith

Mailing Address Po box 70971

\begin{tabular}{lcc}
\hline City & State & Zip Code \\
Salt Lake City & UT & $84170-0971$
\end{tabular}

FEC ID number of contributing

federal political committee.

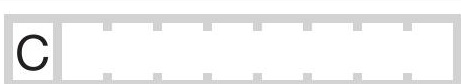

Name of Employer

Occupation

Pride Transport

truck driver

Receipt For: 2012

Х $\begin{aligned} & \text { Primary } \\ & \text { Other (specify) }\end{aligned}$

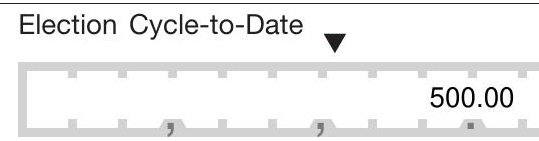

Amount of Each Receipt this Period

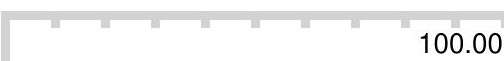

100.00

Subtotal Of Receipts This Page (optional)

250.00

Total This Period (last page this line number only) 


\section{SCHEDULE A-P} ITEMIZED RECEIPTS
Use separate schedule(s)

for each category of the

Detailed Summary Page
FOR LINE NUMBER: (check only one)

PAGE $115 / 1572$

\begin{tabular}{|c|c|c|c|c|c|}
\hline & & & & & \\
\hline 16 & X $17 a$ & $17 b$ & $17 c$ & $17 d$ & 18 \\
\hline $19 a$ & $19 b$ & $20 \mathrm{a}$ & $20 \mathrm{~b}$ & $20 \mathrm{c}$ & 21 \\
\hline
\end{tabular}

Any information copied from such Reports and Statements may not be sold or used by any person for the purpose of soliciting contributions or for commercial purposes, other than using the name and address of any political committee to solicit contributions from such committee.

NAME OF COMMITTEE (In Full)

Friends of Herman Cain

A. Full Name (Last, First, Middle Initial)

Sandra Shackelford

Mailing Address 130 Middling Lane

City State Zip Code

Fayetteville

GA 30214-3767

FEC ID number of contributing

federal political committee.

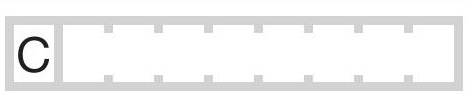

Name of Employer
Delta Airlines
Receipt For: 2012
X Primary
$\square$ Other (specify) General

Occupation

Enterprise Document Mgmt

Election Cycle-to-Date

675.00

B. Full Name (Last, First, Middle Initial)

Eugene Adamson

Mailing Address 412 The Falls of Cherokee Dr

\begin{tabular}{lcc}
\hline City & State & Zip Code \\
Canton & GA & $30114-8142$ \\
\hline
\end{tabular}

FEC ID number of contributing

federal political committee.

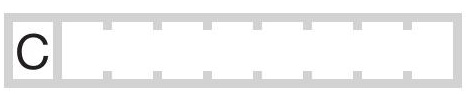

Name of Employer
CKI Service
Receipt For: 2012
X Primary
Other (specify)

Occupation

OWNER

Election Cycle-to-Date

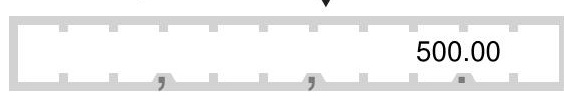

Transaction ID : A330263553B65448E9A9

Date of Receipt

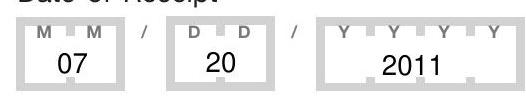

Amount of Each Receipt this Period

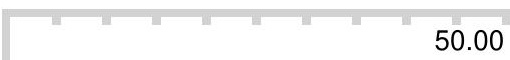

C. Full Name (Last, First, Middle Initial)

CARLOS URUCHURTU SR Sr.

Mailing Address 33150 PAUBA RD

\begin{tabular}{lll}
\hline $\begin{array}{l}\text { City } \\
\text { Temecula }\end{array}$ & $\begin{array}{c}\text { State } \\
\text { CA }\end{array}$ & $\begin{array}{c}\text { Zip Code } \\
92592-9264\end{array}$ \\
\hline $\begin{array}{l}\text { FEC ID number of contributing } \\
\text { federal political committee. }\end{array}$ & C \\
\hline $\begin{array}{l}\text { Name of Employer } \\
\text { GEORGE CHEVROLET }\end{array}$ & $\begin{array}{l}\text { Occupation } \\
\text { VP/GM }\end{array}$ \\
$\begin{array}{l}\text { Receipt For: } 2012 \\
\text { Xrimary } \\
\text { Other (specify) }\end{array}$ & Election Cycle-to-Date & 300.00 \\
\hline
\end{tabular}

Transaction ID : AE139AF4FBE384C2D9EF Date of Receipt

Amount of Each Receipt this Period

Transaction ID : AB4FFE09004EA409EADD Date of Receipt
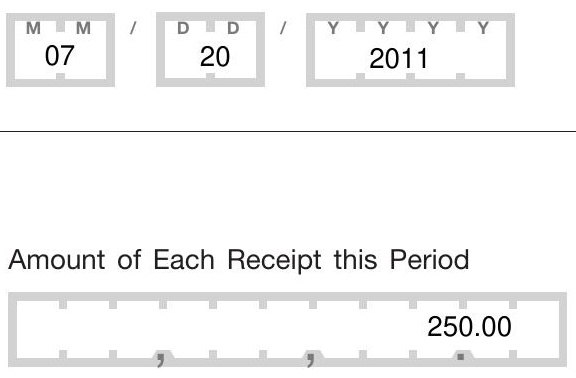

Amount of Each Receipt this Period
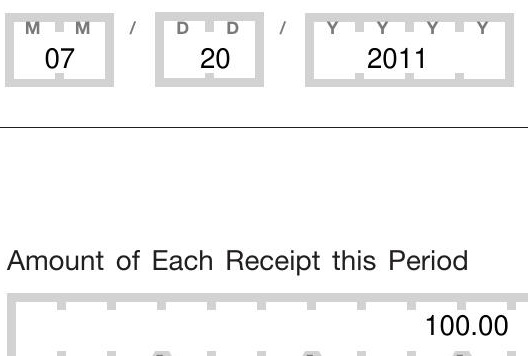

Subtotal Of Receipts This Page (optional)

400.00

Total This Period (last page this line number only) 
SCHEDULE A-P ITEMIZED RECEIPTS
Use separate schedule(s) for each category of the Detailed Summary Page
FOR LINE NUMBER: (check only one)

PAGE $116 / 1572$

\begin{tabular}{|c|c|c|c|c|c|}
\hline & & & & & \\
\hline 16 & $\begin{array}{l}\mathbf{X} \\
17 a\end{array}$ & $17 b$ & $17 c$ & $17 d$ & 18 \\
\hline $19 a$ & $19 \mathrm{~b}$ & $20 \mathrm{a}$ & $20 \mathrm{~b}$ & $20 \mathrm{c}$ & 21 \\
\hline
\end{tabular}

Any information copied from such Reports and Statements may not be sold or used by any person for the purpose of soliciting contributions or for commercial purposes, other than using the name and address of any political committee to solicit contributions from such committee.

NAME OF COMMITTEE (In Full)

\section{Friends of Herman Cain}

A. Full Name (Last, First, Middle Initial)

Mr. Jose R Soberon Jr.

Mailing Address 3613 Ridgeway Drive

\begin{tabular}{lcc}
\hline City & State & Zip Code \\
Metairie & LA & $70002-1832$
\end{tabular}

FEC ID number of contributing

federal political committee.

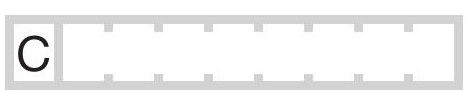

Name of Employer
Ochsner Clinic Foundation
Receipt For: 2012
X Primary $\quad \square$ General
Other (specify)

Occupation

Physician

Election Cycle-to-Date

600.00

B. Full Name (Last, First, Middle Initial)

CHris Guarino

Mailing Address 2665 Ball Ground Hwy

\begin{tabular}{lcc}
\hline City & State & Zip Code \\
Canton & GA & $30114-7439$ \\
\hline
\end{tabular}

FEC ID number of contributing

federal political committee.

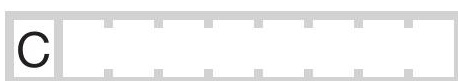

Name of Employer
Asset Technology Group
Receipt For: 2012
X Primary
Other (specify)

Occupation

BUSINESS OWNER

Election Cycle-to-Date

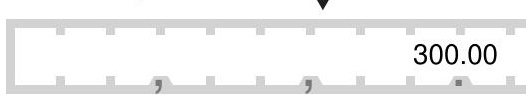

C. Full Name (Last, First, Middle Initial)

Wendell Parkey

Mailing Address 2404 S.W. Ave. E

\begin{tabular}{l|ll}
\hline $\begin{array}{l}\text { City } \\
\text { Seminole }\end{array}$ & $\begin{array}{c}\text { State } \\
\text { TX }\end{array}$ & $\begin{array}{c}\text { Zip Code } \\
79360\end{array}$ \\
\hline $\begin{array}{l}\text { FEC ID number of contributing } \\
\text { federal political committee. }\end{array}$ & C \\
\hline $\begin{array}{l}\text { Name of Employer } \\
\text { Self Employed }\end{array}$ & $\begin{array}{l}\text { Occupation } \\
\text { Physician }\end{array}$ \\
\hline $\begin{array}{l}\text { Receipt For: } 2012 \\
\text { Xrimary } \\
\text { Other (specify) }\end{array}$ & Election Cycle-to-Date \\
\hline
\end{tabular}

Transaction ID : A3D56BCFA76994A8297E

Date of Receipt

Amount of Each Receipt this Period

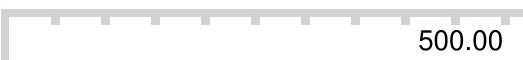

Date of Receipt
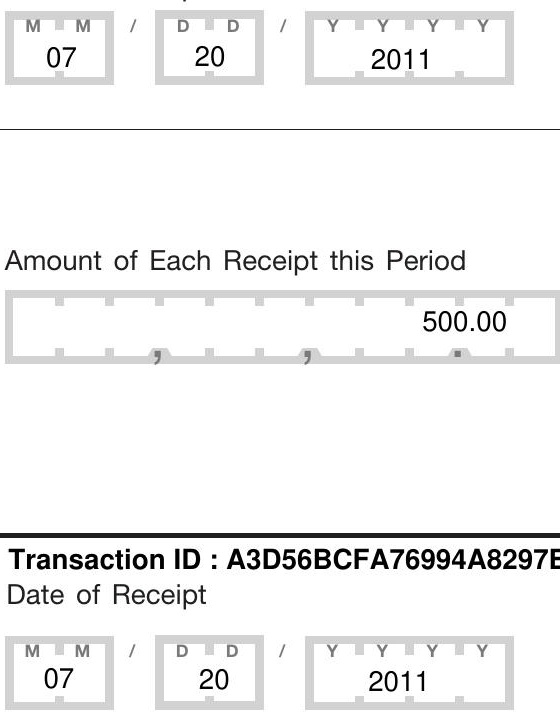

Amount of Each Receipt this Period

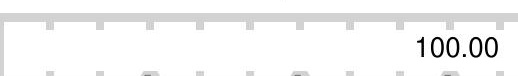

Amount of Each Receipt this Period

Transaction ID : A23103DCF175740D586B

Date of Receipt
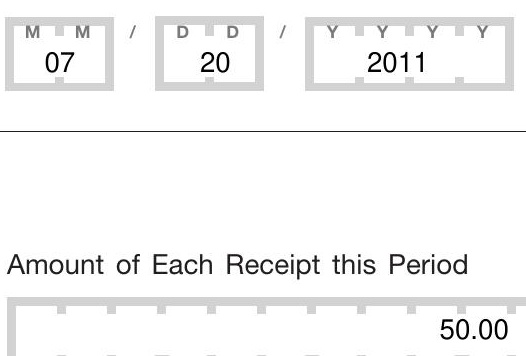

50.00

650.00

Subtotal Of Receipts This Page (optional)

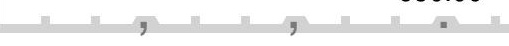

Total This Period (last page this line number only)

FEC Schedule A-P (Form 3P) (Rev. 03/2011) 
SCHEDULE A-P ITEMIZED RECEIPTS
Use separate schedule(s) for each category of the Detailed Summary Page
FOR LINE NUMBER: (check only one)

PAGE $117 / 1572$

\begin{tabular}{|c|c|c|c|c|c|}
\hline & & & & & \\
\hline 16 & $\begin{array}{l}\mathbf{X} \\
17 a\end{array}$ & $17 b$ & $17 c$ & $17 d$ & 18 \\
\hline $19 a$ & $19 \mathrm{~b}$ & $20 \mathrm{a}$ & $20 \mathrm{~b}$ & $20 \mathrm{c}$ & 21 \\
\hline
\end{tabular}

Any information copied from such Reports and Statements may not be sold or used by any person for the purpose of soliciting contributions or for commercial purposes, other than using the name and address of any political committee to solicit contributions from such committee.

NAME OF COMMITTEE (In Full)

\section{Friends of Herman Cain}

A. Full Name (Last, First, Middle Initial)

Kay Trettin-Benson

Mailing Address 11 Meadow Cove Drive

\begin{tabular}{lcc}
\hline City & State & Zip Code \\
Spring & TX & $77381-3323$ \\
\hline
\end{tabular}

FEC ID number of contributing federal political committee.

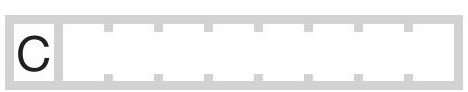

Name of Employer
Not Employed
Receipt For: 2012
X Primary $\quad$ General
Other (specify)

Occupation Not Employed

Election Cycle-to-Date

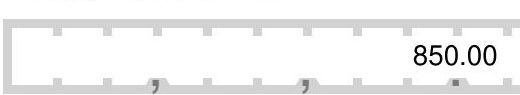

B. Full Name (Last, First, Middle Initial)

David Herman

Mailing Address 118 Greer Lane

\begin{tabular}{lcc}
\hline City & State & Zip Code \\
Toccoa & GA & $30577-3096$ \\
\hline
\end{tabular}

FEC ID number of contributing

federal political committee.

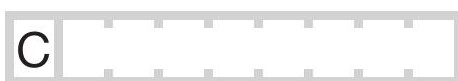

Name of Employer
Air Tran
Receipt For: 2012
X Primary
$\square$ Other (specify) General

\section{Occupation}

Pilot

Election Cycle-to-Date

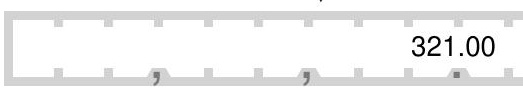

Transaction ID : A15217D1799F9435C998

Date of Receipt

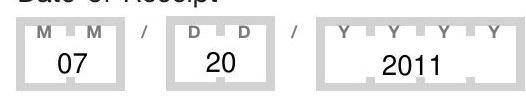

Amount of Each Receipt this Period

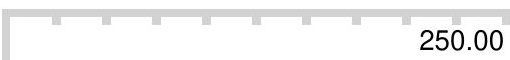

C. Full Name (Last, First, Middle Initial)

eugene wordehoff

Mailing Address 692 Solano Ct

\begin{tabular}{lcc}
\hline City & State & Zip Code \\
Marco Island & FL & $34145-1928$
\end{tabular}

FEC ID number of contributing

federal political committee.

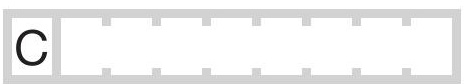

Name of Employer

Self Employed

Occupation

Receipt For: 2012

Х $\begin{aligned} & \text { Primary } \square \text { General } \\ & \text { Other (specify) }\end{aligned}$

Consultant

Transaction ID : A77C85B32AC7B4427BD4

Date of Receipt

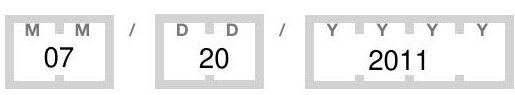

Amount of Each Receipt this Period

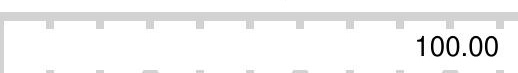

Transaction ID : A67B39EB5FEE14A2DB40 Date of Receipt

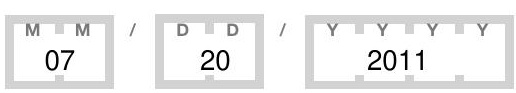

Amount of Each Receipt this Period

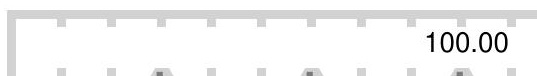

Subtotal Of Receipts This Page (optional)

300.00

Election Cycle-to-Date

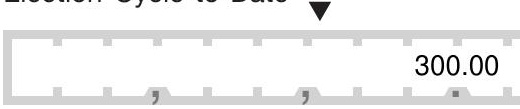

Total This Period (last page this line number only)

$+\quad 450.00$

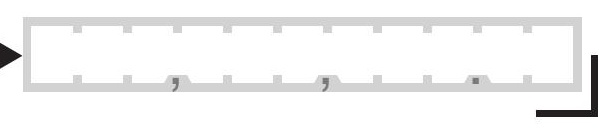

FEC Schedule A-P (Form 3P) (Rev. 03/2011) 


\section{SCHEDULE A-P} ITEMIZED RECEIPTS
Use separate schedule(s) for each category of the Detailed Summary Page

FOR LINE NUMBER:
(check only one)

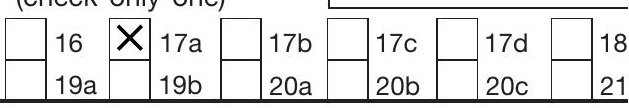

Any information copied from such Reports and Statements may not be sold or used by any person for the purpose of soliciting contributions or for commercial purposes, other than using the name and address of any political committee to solicit contributions from such committee.

NAME OF COMMITTEE (In Full)

\section{Friends of Herman Cain}

A. Full Name (Last, First, Middle Initial)

Carlotta Monningh

Mailing Address 70 Seabolt Dr

\begin{tabular}{lcc}
\hline City & State & Zip Code \\
Locust Grove & GA & $30248-2143$ \\
\hline
\end{tabular}

FEC ID number of contributing federal political committee.

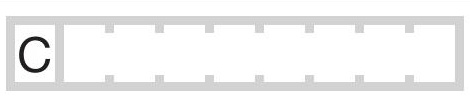

Name of Employer
Coldwell Banker Bullard Rlty
Receipt For: 2012
X Primary
Other (specify)

Occupation

Realtor

Election Cycle-to-Date

300.00

B. Full Name (Last, First, Middle Initial)

Kendall Collier

Mailing Address 500 Rock Springs Road

\begin{tabular}{lcc}
\hline City & State & Zip Code \\
Atlanta & GA & $30324-5104$ \\
\hline
\end{tabular}

FEC ID number of contributing

federal political committee.

C

Name of Employer

A Divine Event

Occupation

Receipt For: 2012

$\chi \begin{aligned} & \text { Primary } \\ & \text { Other (specify) }\end{aligned}$

Special Event Producer

Election Cycle-to-Date

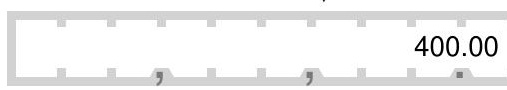

Transaction ID : A98125814BA124D9EBF4

Date of Receipt

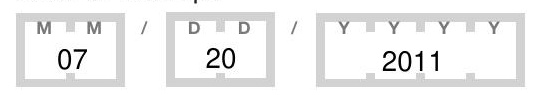

Amount of Each Receipt this Period

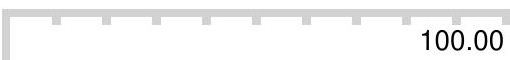

100.00
Amount of Each Receipt this Period

Transaction ID : A53A9EC753FDF45459BA

Date of Receipt
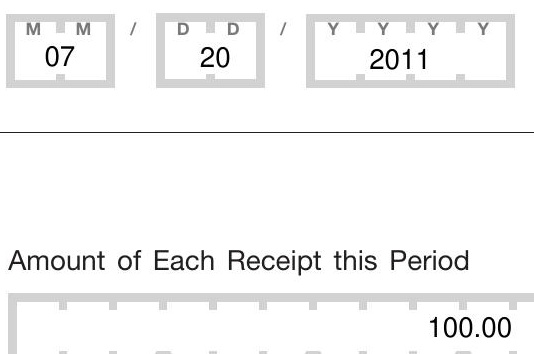

C. Full Name (Last, First, Middle Initial)

Harvey Coombs

Mailing Address PO Box 189

\begin{tabular}{lcc}
\hline City & State & Zip Code \\
Whites Creek & TN & $37189-0189$
\end{tabular}

FEC ID number of contributing federal political committee.

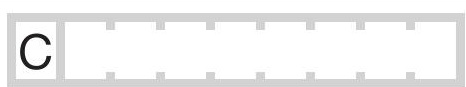

Name of Employer

Information Requested

\section{Occupation}

Information Requested

Receipt For: 2012

Х $\begin{aligned} & \text { Primary } \square \text { General } \\ & \text { Other (specify) }\end{aligned}$

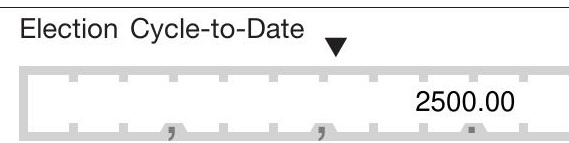

Transaction ID : AF50361B85154421AB09

Date of Receipt

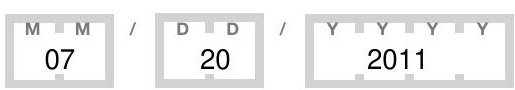

Amount of Each Receipt this Period

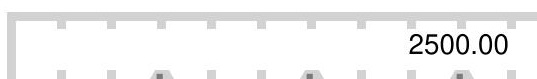

2700.00

Subtotal Of Receipts This Page (optional)

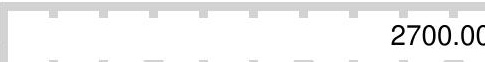

Total This Period (last page this line number only) 
SCHEDULE A-P ITEMIZED RECEIPTS
Use separate schedule(s) for each category of the Detailed Summary Page
FOR LINE NUMBER: (check only one)

PAGE $119 / 1572$

\begin{tabular}{|c|c|c|c|c|c|}
\hline & & & & & \\
\hline 16 & $\begin{array}{l}\mathbf{X} \\
17 a\end{array}$ & $17 b$ & $17 c$ & $17 d$ & 18 \\
\hline $19 a$ & $19 \mathrm{~b}$ & $20 \mathrm{a}$ & $20 \mathrm{~b}$ & $20 \mathrm{c}$ & 21 \\
\hline
\end{tabular}

Any information copied from such Reports and Statements may not be sold or used by any person for the purpose of soliciting contributions or for commercial purposes, other than using the name and address of any political committee to solicit contributions from such committee.

NAME OF COMMITTEE (In Full)

\section{Friends of Herman Cain}

A. Full Name (Last, First, Middle Initial)

Robert Jones

Mailing Address 5600 Trail Blvd Ste 5

\begin{tabular}{lcc}
\hline City & State & Zip Code \\
Naples & FL & $34108-2860$ \\
\hline
\end{tabular}

FEC ID number of contributing federal political committee.

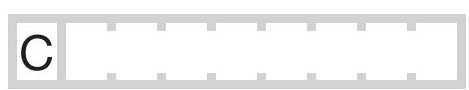

Name of Employer
Information Requested
Receipt For: 2012
X Primary
Other (specify) General

Occupation Information Requested

Election Cycle-to-Date

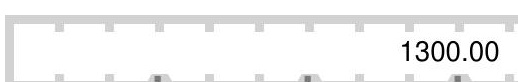

B. Full Name (Last, First, Middle Initial)

\section{Tom Wozniak}

Mailing Address 2350 chandler ct

\begin{tabular}{lcc}
\hline City & State & Zip Code \\
Aurora & IL & $60502-1312$ \\
\hline
\end{tabular}

FEC ID number of contributing

federal political committee.

C

Name of Employer
railroad
Receipt For: 2012
X Primary
Other (specify)

\section{Occupation}

railroad employee

Election Cycle-to-Date

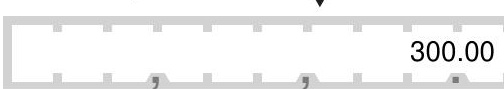

Transaction ID : A581D5B008B40463C860

Date of Receipt

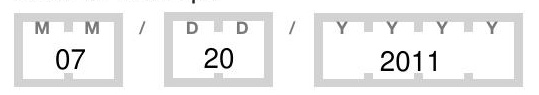

Amount of Each Receipt this Period

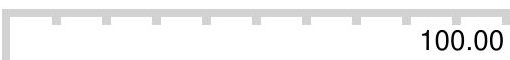

Transaction ID : AC7395DA4F51340919FD

Date of Receipt

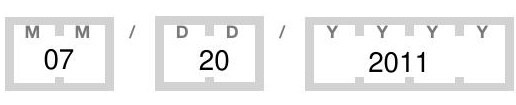

Amount of Each Receipt this Period

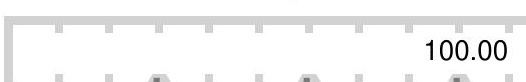

C. Full Name (Last, First, Middle Initial)

Maryanne Metcalfe

Mailing Address 1610 Wood Pointe Ln Apt 1

\begin{tabular}{lcc}
\hline City & State & Zip Code \\
Midland & MI & $48642-3380$
\end{tabular}

FEC ID number of contributing

federal political committee.

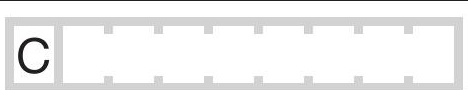

Name of Employer
None
Receipt For: 2012
Х Primary $\quad \square$ General
Other (specify)

Occupation

Retired

Election Cycle-to-Date

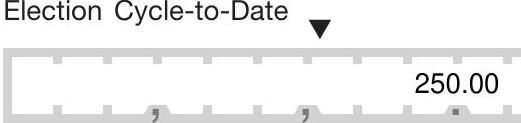

Subtotal Of Receipts This Page (optional)

250.00

Amount of Each Receipt this Period
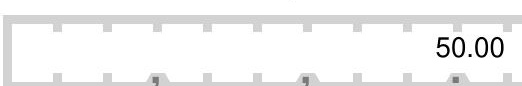

Total This Period (last page this line number only)

Transaction ID : A434A004B71E74A7BA19 Date of Receipt
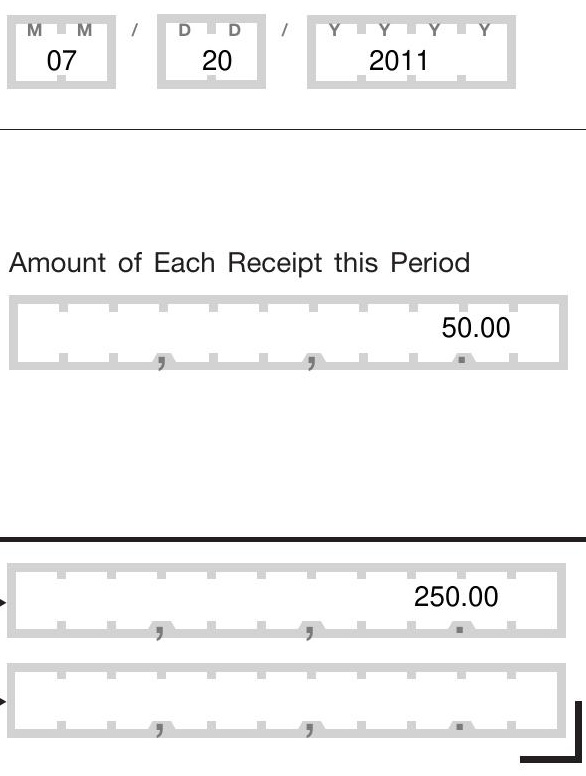
SCHEDULE A-P ITEMIZED RECEIPTS
Use separate schedule(s) for each category of the Detailed Summary Page
FOR LINE NUMBER: (check only one)

PAGE $120 / 1572$

\begin{tabular}{|c|c|c|c|c|c|c|}
\hline & & & & & & \\
\hline 16 & $\lambda$ & $17 \mathrm{a}$ & $17 \mathrm{~b}$ & $17 \mathrm{c}$ & $-17 d$ & -18 \\
\hline $19 a$ & & $19 b$ & $20 a$ & $20 \mathrm{~b}$ & $20 \mathrm{c}$ & 21 \\
\hline
\end{tabular}

Any information copied from such Reports and Statements may not be sold or used by any person for the purpose of soliciting contributions or for commercial purposes, other than using the name and address of any political committee to solicit contributions from such committee.

NAME OF COMMITTEE (In Full)

\section{Friends of Herman Cain}

A. Full Name (Last, First, Middle Initial)

Samuel Sylvester

Mailing Address 701 S. University Blvd. Apt. 312

\begin{tabular}{lcc}
\hline City & State & Zip Code \\
Mobile & AL & $36609-7801$
\end{tabular}

FEC ID number of contributing

federal political committee.

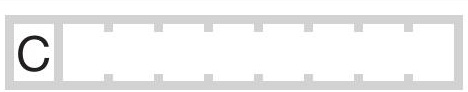

Name of Employer
The SSI Group
Receipt For: 2012
X Primary
Other (specify) General

Occupation

R\&D Programmer

Election Cycle-to-Date

420.00

B. Full Name (Last, First, Middle Initial)

Richard Gauthier

Mailing Address 14310 Clearview Lane

\begin{tabular}{lcc}
\hline City & State & Zip Code \\
Urbandale & IA & $50323-2083$ \\
\hline
\end{tabular}

FEC ID number of contributing

federal political committee.

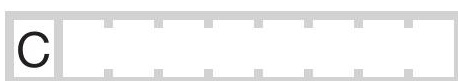

Name of Employer
The Cheesecake Factory
Receipt For: 2012
X Primary
Other (specify)

\section{Occupation}

General Manager

Election Cycle-to-Date

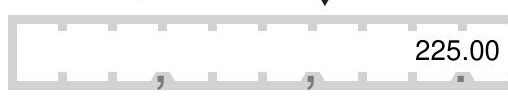

Transaction ID : A5EC8D8B4618C4B71876

Date of Receipt

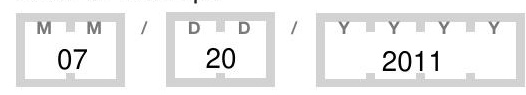

Amount of Each Receipt this Period

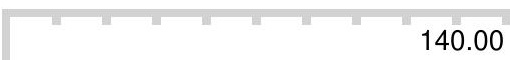

C. Full Name (Last, First, Middle Initial)

Gary Stubblefield

Mailing Address 2001 Raymond Ave

\begin{tabular}{lcc}
\hline City & State & Zip Code \\
Signal Hill & CA & $90755-5930$
\end{tabular}

FEC ID number of contributing

federal political committee.

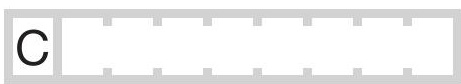

Name of Employer
Retired
Receipt For: 2012
X Primary $\quad \square$ General
Other (specify)

Occupation

Retired

Election Cycle-to-Date

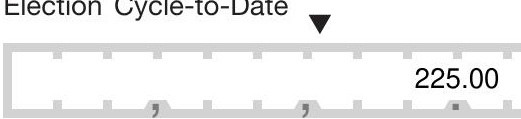

Amount of Each Receipt this Period

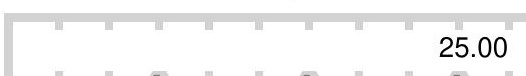

Transaction ID : AE6C613975EB9412DAC3

Date of Receipt

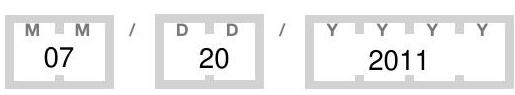

Transaction ID : A03542808202B4996954

Date of Receipt

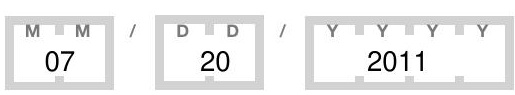

Amount of Each Receipt this Period

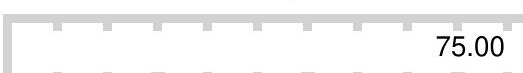

\section{Subtotal Of Receipts This Page (optional)}

240.00

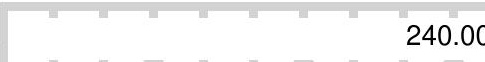

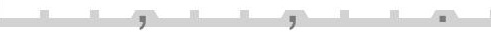

Total This Period (last page this line number only)

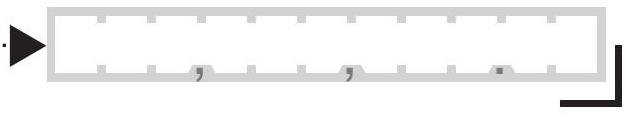

FEC Schedule A-P (Form 3P) (Rev. 03/2011) 


\section{SCHEDULE A-P} ITEMIZED RECEIPTS
Use separate schedule(s)

for each category of the

Detailed Summary Page
FOR LINE NUMBER: (check only one)

PAGE $121 / 1572$

\begin{tabular}{|c|c|c|c|c|c|}
\hline & & & & & \\
\hline 16 & X $17 a$ & $17 b$ & $17 c$ & $17 d$ & 18 \\
\hline $19 a$ & $19 b$ & $20 \mathrm{a}$ & $20 \mathrm{~b}$ & $20 \mathrm{c}$ & 21 \\
\hline
\end{tabular}

Any information copied from such Reports and Statements may not be sold or used by any person for the purpose of soliciting contributions or for commercial purposes, other than using the name and address of any political committee to solicit contributions from such committee.

NAME OF COMMITTEE (In Full)

Friends of Herman Cain

A. Full Name (Last, First, Middle Initial)

Carl A Voigtsberger

Mailing Address 7249 Manhattan Lane

\begin{tabular}{lcc}
\hline City & State & Zip Code \\
Cheyenne & WY & 82009-2003 \\
\hline
\end{tabular}

FEC ID number of contributing federal political committee.

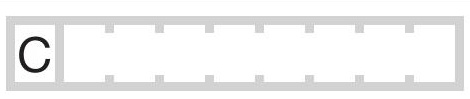

Name of Employer
None
Receipt For: 2012
X Primary $\square$ General
$\square$ Other (specify)

Occupation

Retired

Election Cycle-to-Date

250.00

B. Full Name (Last, First, Middle Initial)

Donald Henager

Mailing Address 9222 E. Chirco PI.

\begin{tabular}{lcc}
\hline City & State & Zip Code \\
Tucson & AZ & $85710-3131$ \\
\hline
\end{tabular}

FEC ID number of contributing

federal political committee.

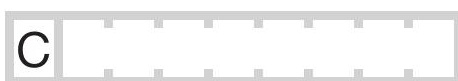

Name of Employer
SAIC
Receipt For: 2012
X Primary
Other (specify)

Occupation

Training Specialist

Election Cycle-to-Date

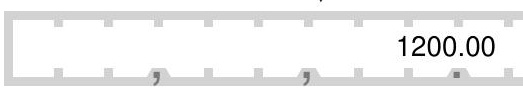

Transaction ID : A883FAEC8CE304B40850

Date of Receipt

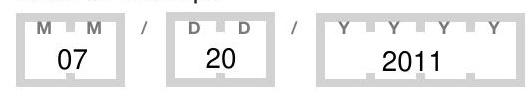

Amount of Each Receipt this Period

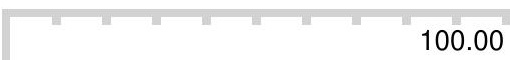

C. Full Name (Last, First, Middle Initial)

Mr. David W Anderson

Mailing Address 579 Audubon St.

\begin{tabular}{lcc}
\hline City & State & Zip Code \\
New Orleans & LA & $70118-4949$
\end{tabular}

FEC ID number of contributing federal political committee.

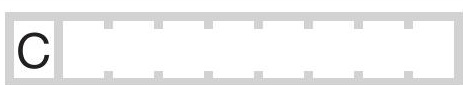

Name of Employer

Information Requested

Occupation

Information Requested

Receipt For: 2012

Х $\begin{aligned} & \text { Primary } \\ & \text { Other (specify) }\end{aligned}$

Election Cycle-to-Date

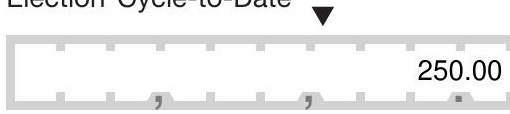

Transaction ID : AEB1EBB48A8C74D7D82C Date of Receipt

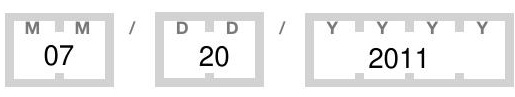

Amount of Each Receipt this Period

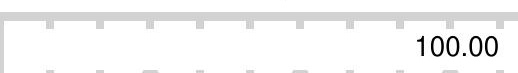

Transaction ID : AD7F38BD53C894BE7931 Date of Receipt

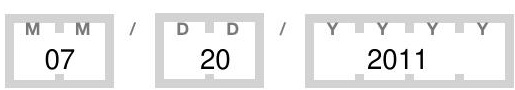

Amount of Each Receipt this Period

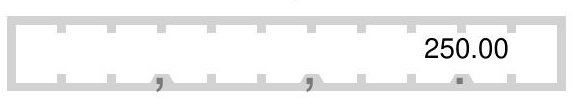

Subtotal Of Receipts This Page (optional)

450.00

Total This Period (last page this line number only) 
SCHEDULE A-P ITEMIZED RECEIPTS
Use separate schedule(s) for each category of the Detailed Summary Page
FOR LINE NUMBER: (check only one)

PAGE 122 / 1572

\begin{tabular}{|c|c|c|c|c|c|c|}
\hline & & & & & & \\
\hline 16 & $\lambda$ & $17 \mathrm{a}$ & $17 \mathrm{~b}$ & $17 \mathrm{c}$ & $-17 d$ & -18 \\
\hline $19 a$ & & $19 b$ & $20 a$ & $20 \mathrm{~b}$ & $20 \mathrm{c}$ & 21 \\
\hline
\end{tabular}

Any information copied from such Reports and Statements may not be sold or used by any person for the purpose of soliciting contributions or for commercial purposes, other than using the name and address of any political committee to solicit contributions from such committee.

NAME OF COMMITTEE (In Full)

\section{Friends of Herman Cain}

A. Full Name (Last, First, Middle Initial) Joseph Anderson

Mailing Address 376 Louisville Rd

\begin{tabular}{lcc}
\hline City & State & Zip Code \\
Grovetown & GA & $30813-4105$
\end{tabular}

FEC ID number of contributing federal political committee.

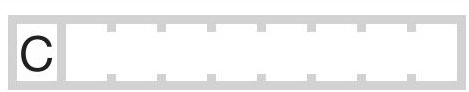

Name of Employer
Not Employed
Receipt For: 2012
X Primary $\quad$ General
Other (specify)

Occupation Not Employed Election Cycle-to-Date

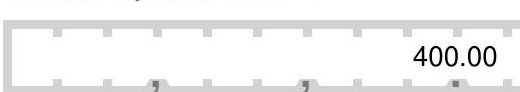

B. Full Name (Last, First, Middle Initial)

Ronny Shiflet

Mailing Address 924 Pine Cir

\begin{tabular}{lcc}
\hline City & State & Zip Code \\
Woodstock & GA & $30189-1418$ \\
\hline
\end{tabular}

FEC ID number of contributing

federal political committee.

C

Name of Employer
Information Requested
Receipt For: 2012
X Primary
Other (specify)

Occupation

Information Requested

Election Cycle-to-Date

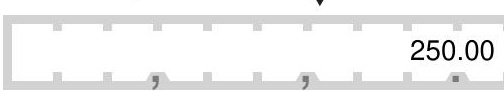

Transaction ID : A986F3907098447E8B55

Date of Receipt

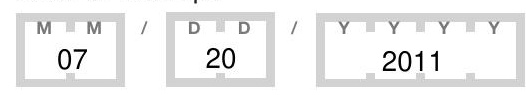

Amount of Each Receipt this Period

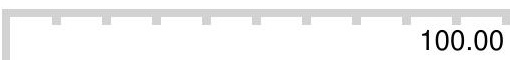

100.00

C. Full Name (Last, First, Middle Initial)

Christopher Gregerson

Mailing Address 1116 S. Esplanade

\begin{tabular}{lcc}
\hline City & State & Zip Code \\
Leavenworth & KS & $66048-3522$
\end{tabular}

FEC ID number of contributing federal political committee.

C

66048-3522

Name of Employer

\section{Occupation}

Booz Allen Hamilton Inc

Consultant

Receipt For: 2012

Х $\begin{aligned} & \text { Primary } \\ & \text { Other (specify) }\end{aligned}$

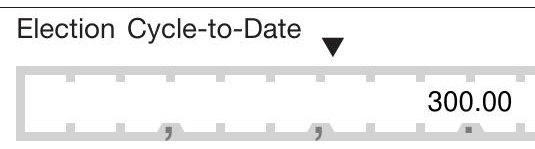

Amount of Each Receipt this Period

Transaction ID : A460D1566FF4D4695B27

Date of Receipt
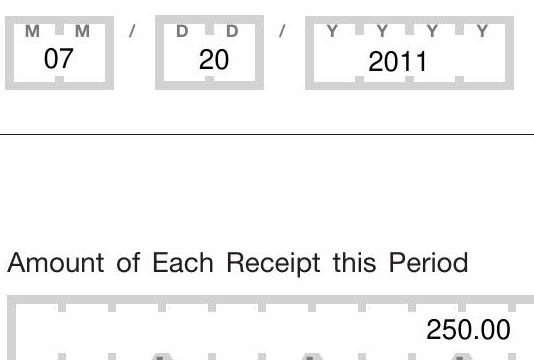

Transaction ID : A45368A49CDD443AF9C9 Date of Receipt

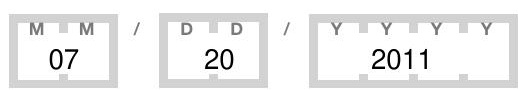

Amount of Each Receipt this Period

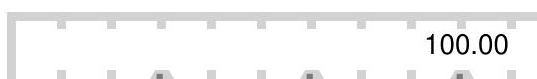

450.00

Subtotal Of Receipts This Page (optional)

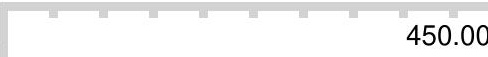

Total This Period (last page this line number only) 
SCHEDULE A-P ITEMIZED RECEIPTS
Use separate schedule(s) for each category of the Detailed Summary Page
FOR LINE NUMBER: (check only one)

PAGE $123 / 1572$

\begin{tabular}{|c|c|c|c|c|c|}
\hline & & & & & \\
\hline 16 & $\begin{array}{lll}X & 17 a \\
\end{array}$ & $17 \mathrm{~b}$ & $17 c$ & $17 d$ & 18 \\
\hline $19 a$ & $19 b$ & $20 a$ & $20 \mathrm{~b}$ & $20 c$ & 21 \\
\hline
\end{tabular}

Any information copied from such Reports and Statements may not be sold or used by any person for the purpose of soliciting contributions or for commercial purposes, other than using the name and address of any political committee to solicit contributions from such committee.

NAME OF COMMITTEE (In Full)

Friends of Herman Cain

A. Full Name (Last, First, Middle Initial) James Reardon

Mailing Address 414 Country Village Dr.

\begin{tabular}{lcc}
\hline City & State & Zip Code \\
Smyrna & TN & $37167-5571$
\end{tabular}

FEC ID number of contributing federal political committee.

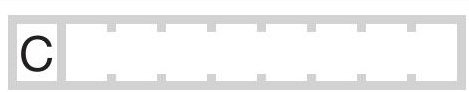

Name of Employer
Alive Hospice Inc
Receipt For: 2012
X Primary $\quad$ General
Other (specify)

Occupation Registered Nurse

Election Cycle-to-Date 250.00

B. Full Name (Last, First, Middle Initial) George Williams

Mailing Address 15560 Dogwood Rd.

\begin{tabular}{lcc}
\hline City & State & Zip Code \\
Bay Minette & AL & $36507-8568$
\end{tabular}

FEC ID number of contributing

federal political committee.

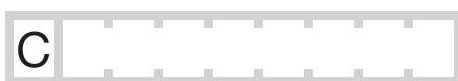

Name of Employer
Information Requested
Receipt For: 2012
X Primary
Other (specify)

Occupation

Information Requested

Election Cycle-to-Date

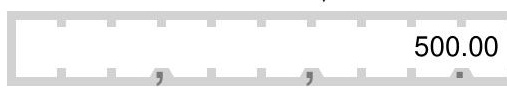

C. Full Name (Last, First, Middle Initial)

Mary Garofalo Rudd

Mailing Address 1306 Layor Court

\begin{tabular}{lcc}
\hline City & State & Zip Code \\
Peachtree City & GA & $30269-1876$
\end{tabular}

FEC ID number of contributing federal political committee.

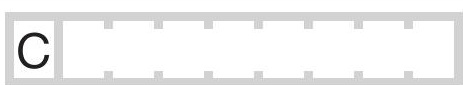

Name of Employer

Information Requested

\section{Occupation}

Information Requested

Receipt For: 2012

Х $\begin{aligned} & \text { Primary } \\ & \text { Other (specify) }\end{aligned}$

Transaction ID : A8F350FED0AFE4F619E2

Date of Receipt

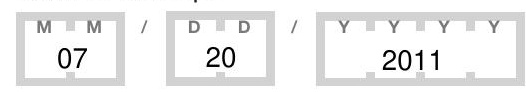

Amount of Each Receipt this Period

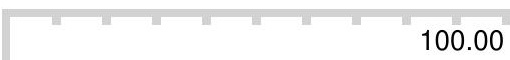

100.00
Transaction ID : A8DBC52760AD248AEB71 Date of Receipt

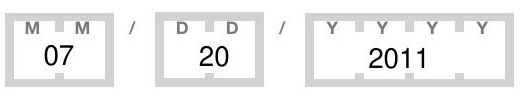

Amount of Each Receipt this Period

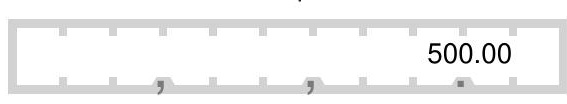

Transaction ID : AAC9478D64B1047DAA22 Date of Receipt

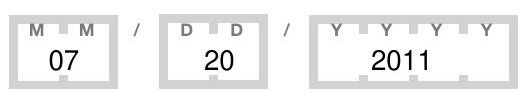

Amount of Each Receipt this Period

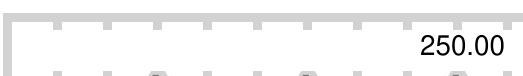

\section{Subtotal Of Receipts This Page (optional)}

Total This Period (last page this line number only) 
SCHEDULE A-P ITEMIZED RECEIPTS
Use separate schedule(s) for each category of the Detailed Summary Page
FOR LINE NUMBER: (check only one)

PAGE 124 / 1572

\begin{tabular}{|c|c|c|c|c|c|}
\hline & & & & & \\
\hline 16 & $\begin{array}{l}\mathbf{X} \\
17 a\end{array}$ & $17 b$ & $17 c$ & $17 d$ & 18 \\
\hline $19 a$ & $19 \mathrm{~b}$ & $20 \mathrm{a}$ & $20 \mathrm{~b}$ & $20 \mathrm{c}$ & 21 \\
\hline
\end{tabular}

Any information copied from such Reports and Statements may not be sold or used by any person for the purpose of soliciting contributions or for commercial purposes, other than using the name and address of any political committee to solicit contributions from such committee.

NAME OF COMMITTEE (In Full)

\section{Friends of Herman Cain}

A. Full Name (Last, First, Middle Initial) James Weidner

Mailing Address 9711 Orient Express Ct.

\begin{tabular}{lcc}
\hline City & State & Zip Code \\
Las Vegas & NV & $89145-8702$
\end{tabular}

FEC ID number of contributing federal political committee.

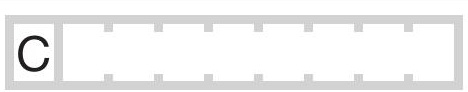

Name of Employer
Information Requested
Receipt For: 2012
X Primary
Other (specify) General

Occupation Information Requested

Election Cycle-to-Date

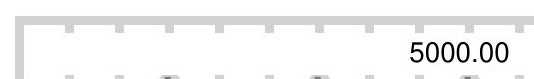

B. Full Name (Last, First, Middle Initial)

Alvin Baumer

Mailing Address 2424 Edenborn Ave. Ste. 510

\begin{tabular}{lcc}
\hline City & State & Zip Code \\
Metairie & LA & $70001-6445$ \\
\hline
\end{tabular}

FEC ID number of contributing

federal political committee.

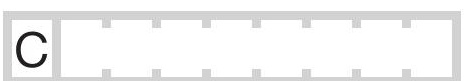

Name of Employer
Baumer Foods
Receipt For: 2012
X Primary $\quad$ General
Other (specify)

\section{Occupation} CEO

Election Cycle-to-Date

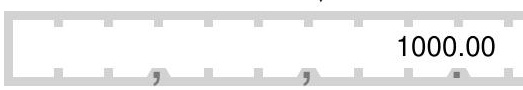

C. Full Name (Last, First, Middle Initial)

Donna Van Dries

Mailing Address 11515 Autumn Chase

\begin{tabular}{lcc}
\hline City & State & Zip Code \\
Houston & TX & $77065-4927$
\end{tabular}

FEC ID number of contributing federal political committee.

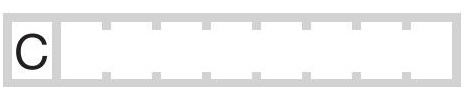

Name of Employer

State of Texas

Receipt For: 2012

Х $\begin{aligned} & \text { Primary } \square \text { General } \\ & \text { Other (specify) }\end{aligned}$

\section{Occupation}

Retired

Election Cycle-to-Date
Transaction ID : ACB748E74FB4340C0BC0

Date of Receipt

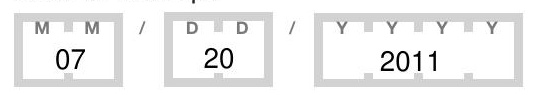

Amount of Each Receipt this Period

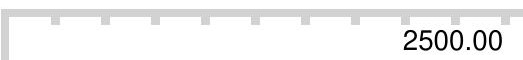

Amount of Each Receipt this Period

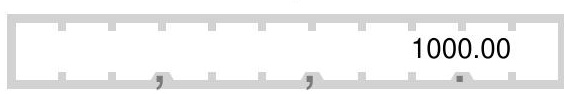

Subtotal Of Receipts This Page (optional).

3600.00

a

Total This Period (last page this line number only)
Amount of Each Receipt this Period

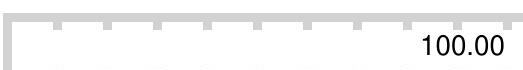

Transaction ID : AF9C44BF6EE034A4D886 Date of Receipt
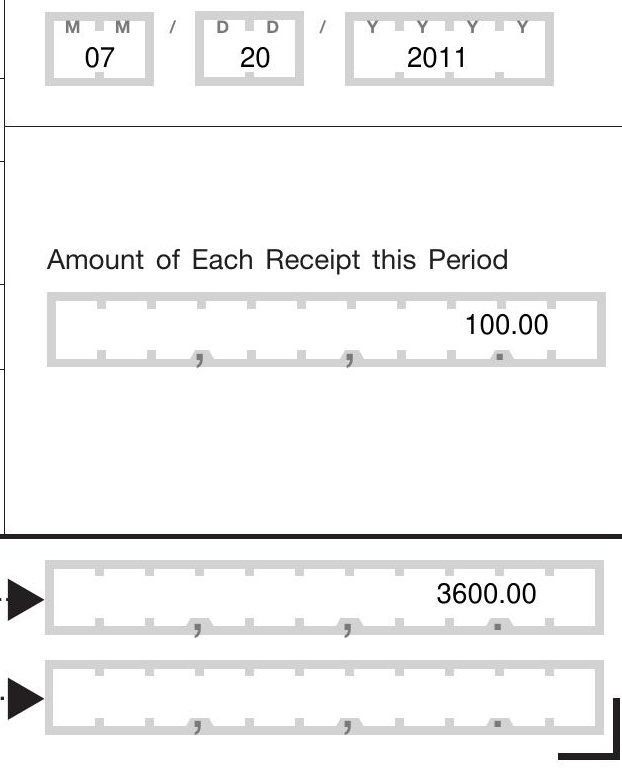

FEC Schedule A-P (Form 3P) (Rev. 03/2011) 
SCHEDULE A-P ITEMIZED RECEIPTS
Use separate schedule(s) for each category of the Detailed Summary Page
FOR LINE NUMBER: (check only one)

PAGE $125 / 1572$

\begin{tabular}{|c|c|c|c|c|c|}
\hline & & & & & \\
\hline 16 & $\begin{array}{l}\mathbf{X} \\
17 a\end{array}$ & $17 b$ & $17 c$ & $17 d$ & 18 \\
\hline $19 a$ & $19 \mathrm{~b}$ & $20 \mathrm{a}$ & $20 \mathrm{~b}$ & $20 \mathrm{c}$ & 21 \\
\hline
\end{tabular}

Any information copied from such Reports and Statements may not be sold or used by any person for the purpose of soliciting contributions or for commercial purposes, other than using the name and address of any political committee to solicit contributions from such committee.

NAME OF COMMITTEE (In Full)

\section{Friends of Herman Cain}

A. Full Name (Last, First, Middle Initial) Joseph Daniell

Mailing Address 805 Streamside Dr.

\begin{tabular}{lcc}
\hline City & State & Zip Code \\
McDonough & GA & $30252-9035$ \\
\hline
\end{tabular}

FEC ID number of contributing federal political committee.

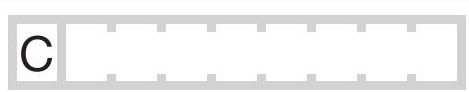

Name of Employer
Dynamac Corp.
Receipt For: 2012
X Primary
Other (specify) General

Occupation

Sr. Project Mgr

Election Cycle-to-Date

Transaction ID : A415AE3230DCD4FEBBD0

Date of Receipt

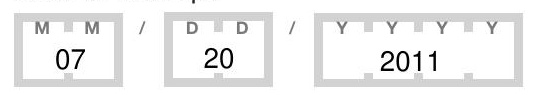

Amount of Each Receipt this Period

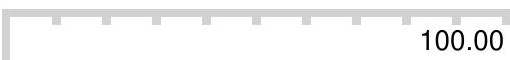

100.00

750.00

B. Full Name (Last, First, Middle Initial)

Mr Louis C Dietz

Mailing Address 33126 Forest West St

\begin{tabular}{lcc}
\hline City & State & Zip Code \\
Magnolia & TX & $77354-6844$ \\
\hline
\end{tabular}

FEC ID number of contributing

federal political committee.

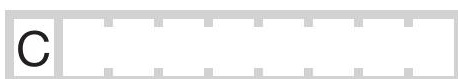

Name of Employer
CYFAIR HOSPITAL
Receipt For: 2012
X Primary
Other (specify)

\section{Occupation}

$\mathrm{RN}$

Election Cycle-to-Date

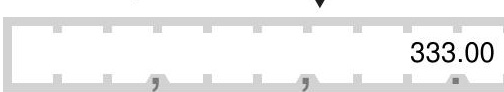

C. Full Name (Last, First, Middle Initial)

Wayne Fogel

Mailing Address 7140 SE 172nd Hazelwood Loop

\begin{tabular}{lcc}
\hline City & State & Zip Code \\
The Villages & FL & $32162-5359$
\end{tabular}

FEC ID number of contributing federal political committee.

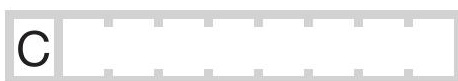

Name of Employer
None
Receipt For: 2012
Х Primary $\quad \square$ General
Other (specify)

\section{Occupation}

Retired

Election Cycle-to-Date

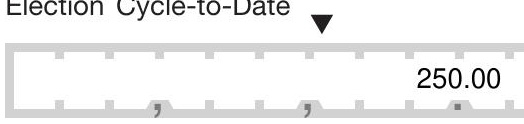

Transaction ID : AD54B3911A3A84D6FBDF Date of Receipt

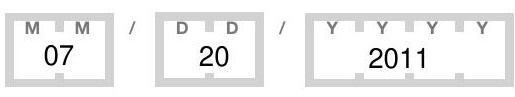

Amount of Each Receipt this Period

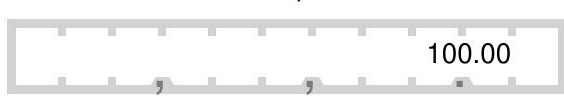

Transaction ID : ACD0FCCF91217457FA9B Date of Receipt

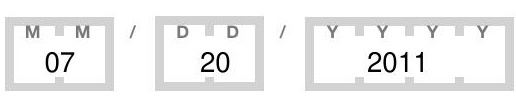

Amount of Each Receipt this Period

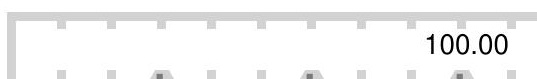

\section{Subtotal Of Receipts This Page (optional)}

300.00

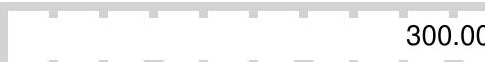

Total This Period (last page this line number only)

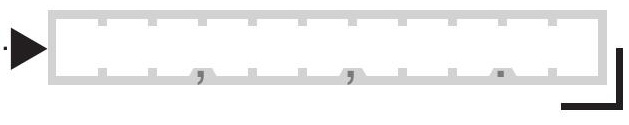

FEC Schedule A-P (Form 3P) (Rev. 03/2011) 
SCHEDULE A-P ITEMIZED RECEIPTS
Use separate schedule(s) for each category of the Detailed Summary Page
FOR LINE NUMBER: (check only one)

PAGE $126 / 1572$

\begin{tabular}{|c|c|c|c|c|c|}
\hline & & & & & \\
\hline 16 & $\begin{array}{lll}X & 17 a \\
\end{array}$ & $17 \mathrm{~b}$ & $17 c$ & $17 d$ & 18 \\
\hline $19 a$ & $19 b$ & $20 a$ & $20 \mathrm{~b}$ & $20 c$ & 21 \\
\hline
\end{tabular}

Any information copied from such Reports and Statements may not be sold or used by any person for the purpose of soliciting contributions or for commercial purposes, other than using the name and address of any political committee to solicit contributions from such committee.

NAME OF COMMITTEE (In Full)

\section{Friends of Herman Cain}

A. Full Name (Last, First, Middle Initial)

\section{Paul Besse}

Mailing Address 48 Duffy St.

\begin{tabular}{lcc}
\hline City & State & Zip Code \\
Westwego & LA & $70094-2152$
\end{tabular}

FEC ID number of contributing federal political committee.

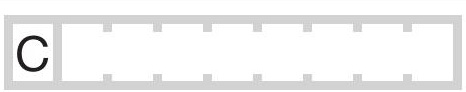

Name of Employer
Gibbs \& Cox
Receipt For: 2012
X Primary
Other (specify) General

Occupation Engineer

Election Cycle-to-Date

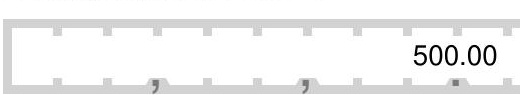

B. Full Name (Last, First, Middle Initial)

William Holloway

Mailing Address 10222 Old Stagecoach Rd

\begin{tabular}{lcc}
\hline City & State & Zip Code \\
Chappell Hill & TX & $77426-6032$ \\
\hline
\end{tabular}

FEC ID number of contributing

federal political committee.

C

Name of Employer
self
Receipt For: 2012
X Primary
Other (specify)

Occupation

plumbing contractor

Election Cycle-to-Date

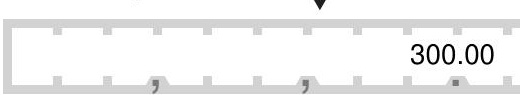

Transaction ID : AFE9EDB275B5A44C2B54

Date of Receipt

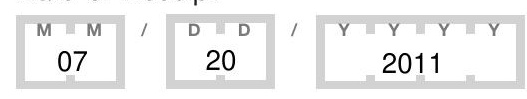

Amount of Each Receipt this Period

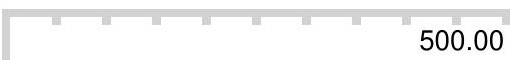

Amount of Each Receipt this Period

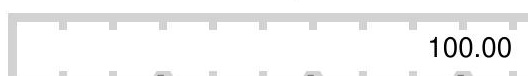

C. Full Name (Last, First, Middle Initial)

Douglas Buchanan

Mailing Address 9811 Ascot

\begin{tabular}{lcc}
\hline City & State & Zip Code \\
Omaha & NE & $68114-3847$
\end{tabular}

FEC ID number of contributing federal political committee.

C

Name of Employer
renze display
Receipt For: 2012
X Primary
Other (specify) General

Occupation

President

Election Cycle-to-Date
Transaction ID : A2CAB45B093854BE1B05

Date of Receipt

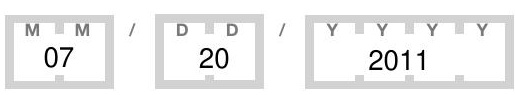

Transaction ID : AB0046C66ADA2437DA5E Date of Receipt

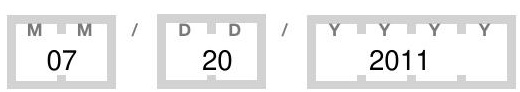

Amount of Each Receipt this Period

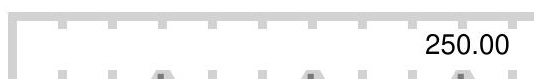

1000.00

\section{Subtotal Of Receipts This Page (optional)}

Total This Period (last page this line number only) 
SCHEDULE A-P ITEMIZED RECEIPTS
Use separate schedule(s) for each category of the Detailed Summary Page
FOR LINE NUMBER: (check only one)

PAGE 127 / 1572

\begin{tabular}{|c|c|c|c|c|c|c|}
\hline & & & & & & \\
\hline 16 & $\lambda$ & $17 \mathrm{a}$ & $17 \mathrm{~b}$ & $17 \mathrm{c}$ & $-17 d$ & -18 \\
\hline $19 a$ & & $19 b$ & $20 a$ & $20 \mathrm{~b}$ & $20 \mathrm{c}$ & 21 \\
\hline
\end{tabular}

Any information copied from such Reports and Statements may not be sold or used by any person for the purpose of soliciting contributions or for commercial purposes, other than using the name and address of any political committee to solicit contributions from such committee.

NAME OF COMMITTEE (In Full)

\section{Friends of Herman Cain}

A. Full Name (Last, First, Middle Initial)

Toby Nelson

Mailing Address 811 2nd Street

\begin{tabular}{lcc}
\hline City & State & Zip Code \\
Milford & NE & $68405-9609$
\end{tabular}

FEC ID number of contributing federal political committee.

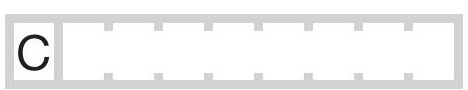

Name of Employer
Nelson Contracting LLC
Receipt For: 2012
X Primary $\quad \square$ General
Other (specify)

Occupation contractor

Election Cycle-to-Date

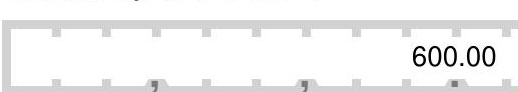

B. Full Name (Last, First, Middle Initial)

Carl A Voigtsberger

Mailing Address 7249 Manhattan Lane

\begin{tabular}{llc}
\hline City & State & Zip Code \\
Cheyenne & WY & $82009-2003$
\end{tabular}

FEC ID number of contributing

federal political committee.

C

Name of Employer
None
Receipt For: 2012
X Primary $\quad$ General
Other (specify)

C. Full Name (Last, First, Middle Initial)

Larry Klipp

Mailing Address PO Box 279

\begin{tabular}{lcc}
\hline City & State & Zip Code \\
Belle Fourche & SD & $57717-0279$
\end{tabular}

FEC ID number of contributing federal political committee.

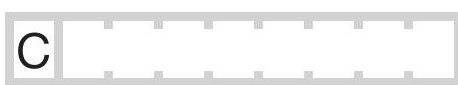

Name of Employer
None
Receipt For: 2012
X Primary $\quad \square$ General
Other (specify)

\section{Occupation}

Retired

Election Cycle-to-Date

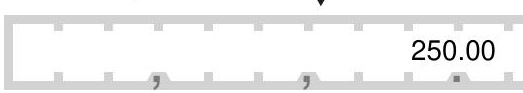

Retired (Military)
Transaction ID : AE9D47BA9228F426A8B4

Date of Receipt

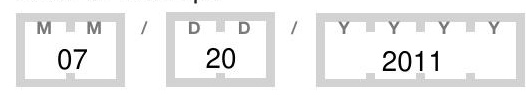

Amount of Each Receipt this Period

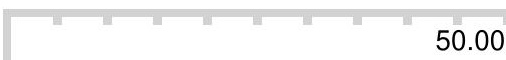

50.00
Transaction ID : A6B1EDADAF899405096F Date of Receipt

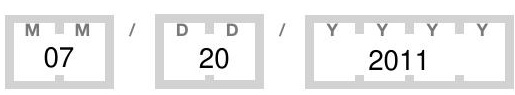

Amount of Each Receipt this Period

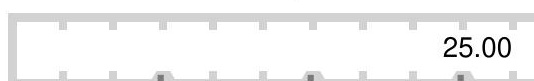

Transaction ID : A152F715A38EE4743A1A Date of Receipt

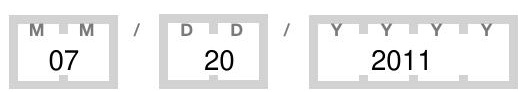

Amount of Each Receipt this Period

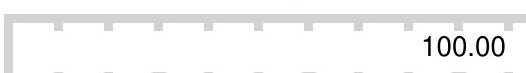

\section{Subtotal Of Receipts This Page (optional)}

175.00

Election Cycle-to-Date

300.00

Total This Period (last page this line number only) 
SCHEDULE A-P ITEMIZED RECEIPTS
Use separate schedule(s) for each category of the Detailed Summary Page
FOR LINE NUMBER: (check only one)

PAGE $128 / 1572$

\begin{tabular}{|c|c|c|c|c|c|}
\hline & & & & & \\
\hline 16 & $\begin{array}{l}\mathbf{X} \\
17 a\end{array}$ & $17 b$ & $17 c$ & $17 d$ & 18 \\
\hline $19 a$ & $19 \mathrm{~b}$ & $20 \mathrm{a}$ & $20 \mathrm{~b}$ & $20 \mathrm{c}$ & 21 \\
\hline
\end{tabular}

Any information copied from such Reports and Statements may not be sold or used by any person for the purpose of soliciting contributions or for commercial purposes, other than using the name and address of any political committee to solicit contributions from such committee.

NAME OF COMMITTEE (In Full)

\section{Friends of Herman Cain}

A. Full Name (Last, First, Middle Initial)

\section{Howard Edwards}

Mailing Address 16823 Cold Harbour Avenue

\begin{tabular}{lcc}
\hline City & State & Zip Code \\
Baton Rouge & LA & $70817-2560$
\end{tabular}

FEC ID number of contributing federal political committee.

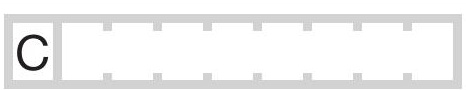

Name of Employer
The Shaw Group
Receipt For: 2012
X Primary
Other (specify) General

Occupation

Piping Designer

Election Cycle-to-Date

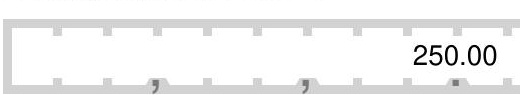

B. Full Name (Last, First, Middle Initial)

John Taylor

Mailing Address 92 Jackson Meadows Dr.

\begin{tabular}{lcc}
\hline City & State & Zip Code \\
Hoschton & GA & $30548-6345$
\end{tabular}

FEC ID number of contributing

federal political committee.

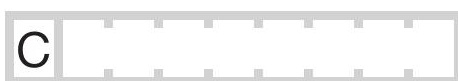

Name of Employer
Self Employed
Receipt For: 2012
X Primary
Other (specify)

\section{Occupation}

Musician

Election Cycle-to-Date

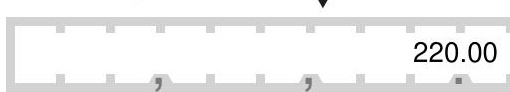

Transaction ID : A278728353FB7483EAOD

Date of Receipt

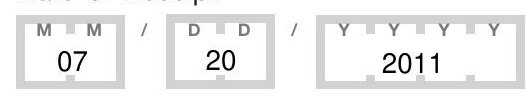

Amount of Each Receipt this Period

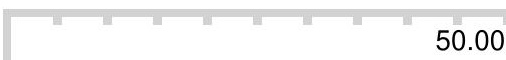

50.00

C. Full Name (Last, First, Middle Initial)

Kyle France

Mailing Address 720 Elise Ave.

\begin{tabular}{lcc}
\hline City & State & Zip Code \\
Metairie & LA & $70003-3837$
\end{tabular}

FEC ID number of contributing federal political committee.

C

70003-3837

Name of Employer

Information Requested

Occupation
Information Requested

Receipt For: 2012

Х $\begin{aligned} & \text { Primary } \square \text { General } \\ & \text { Other (specify) }\end{aligned}$

Election Cycle-to-Date

Transaction ID : A6C3CF526E9E84BB3866

Date of Receipt

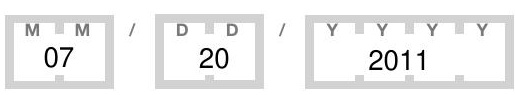

Amount of Each Receipt this Period

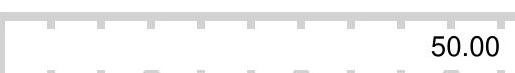

Transaction ID : A45E7C926DB144D908BA Date of Receipt

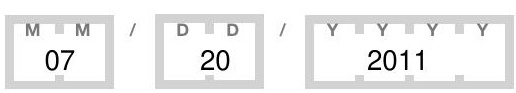

Amount of Each Receipt this Period

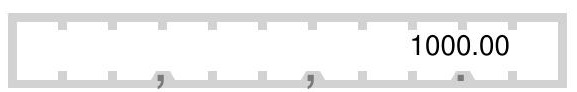

1000.00

\section{Subtotal Of Receipts This Page (optional)}

Total This Period (last page this line number only) 
SCHEDULE A-P ITEMIZED RECEIPTS
Use separate schedule(s) for each category of the Detailed Summary Page
FOR LINE NUMBER: (check only one)

PAGE 129 / 1572

\begin{tabular}{|c|c|c|c|c|c|}
\hline & & & & & \\
\hline 16 & $\begin{array}{l}\mathbf{X} \\
17 a\end{array}$ & $17 b$ & $17 c$ & $17 d$ & 18 \\
\hline $19 a$ & $19 \mathrm{~b}$ & $20 \mathrm{a}$ & $20 \mathrm{~b}$ & $20 \mathrm{c}$ & 21 \\
\hline
\end{tabular}

Any information copied from such Reports and Statements may not be sold or used by any person for the purpose of soliciting contributions or for commercial purposes, other than using the name and address of any political committee to solicit contributions from such committee.

NAME OF COMMITTEE (In Full)

\section{Friends of Herman Cain}

A. Full Name (Last, First, Middle Initial)

\section{Don Deal}

Mailing Address 238 Midvale Drive NE

City

Atlanta

FEC ID number of contributing

federal political committee.

Name of Employer
Delphix
Receipt For: 2012
X Primary
$\square$ Other (specify) General

B. Full Name (Last, First, Middle Initial)

Matthew Marston

Mailing Address 90 Beacon St

\begin{tabular}{lcc}
\hline City & State & Zip Code \\
Boston & MA & $02108-3324$
\end{tabular}

FEC ID number of contributing

federal political committee.

Name of Employer
FourTier Strategies
Receipt For: 2012
X Primary
Other (specify)

C. Full Name (Last, First, Middle Initial)

Brent Barby

Mailing Address Rt. 2 Box 94

\begin{tabular}{l|ll}
\hline $\begin{array}{l}\text { City } \\
\text { Beaver }\end{array}$ & $\begin{array}{c}\text { State } \\
\text { OK }\end{array}$ & $\begin{array}{c}\text { Zip Code } \\
73932-9662\end{array}$ \\
\hline $\begin{array}{l}\text { FEC ID number of contributing } \\
\text { federal political committee. }\end{array}$ & C \\
\hline $\begin{array}{l}\text { Name of Employer } \\
\text { self }\end{array}$ & $\begin{array}{l}\text { Occupation } \\
\text { Rancher }\end{array}$ \\
\hline $\begin{array}{l}\text { Receipt For: } 2012 \\
\text { X } \begin{array}{l}\text { Primary } \\
\text { Other (specify) }\end{array}\end{array}$ & Election Cycle-to-Date & 300.00 \\
\hline
\end{tabular}

C

Transaction ID : A4351CA5C807D49E8A2E

Date of Receipt

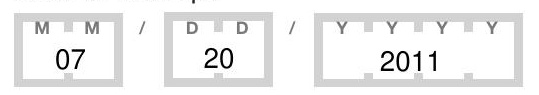

Amount of Each Receipt this Period

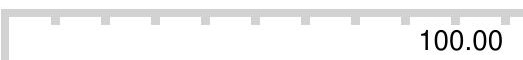

Software Engineer

Election Cycle-to-Date

300.00

Occupation

Partner

Election Cycle-to-Date

370.00

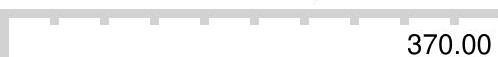

Transaction ID : AE7EF5A74FE7A4EFB9DB Date of Receipt

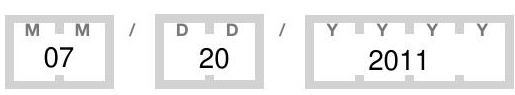

Amount of Each Receipt this Period

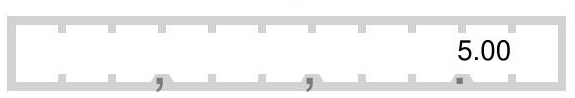

Amount of Each Receipt this Period

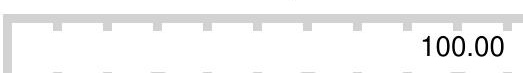

Transaction ID : A6174BD48CFEF4627B01 Date of Receipt

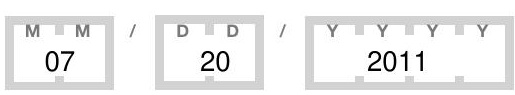

Subtotal Of Receipts This Page (optional).

Total This Period (last page this line number only) 
SCHEDULE A-P ITEMIZED RECEIPTS
Use separate schedule(s) for each category of the Detailed Summary Page
FOR LINE NUMBER: (check only one)

PAGE $130 / 1572$

\begin{tabular}{|c|c|c|c|c|c|}
\hline & & & & & \\
\hline 16 & $\mathbf{X} 17 a$ & $17 b$ & $17 c$ & $17 d$ & 18 \\
\hline $19 a$ & $19 b$ & $20 \mathrm{a}$ & $20 \mathrm{~b}$ & $20 \mathrm{c}$ & 21 \\
\hline
\end{tabular}

Any information copied from such Reports and Statements may not be sold or used by any person for the purpose of soliciting contributions or for commercial purposes, other than using the name and address of any political committee to solicit contributions from such committee.

NAME OF COMMITTEE (In Full)

\section{Friends of Herman Cain}

A. Full Name (Last, First, Middle Initial)

\section{Sharon Rodgers}

Mailing Address 1447 Glenover Circle

\begin{tabular}{lcc}
\hline City & State & Zip Code \\
Marietta & GA & $30062-2151$
\end{tabular}

FEC ID number of contributing federal political committee.

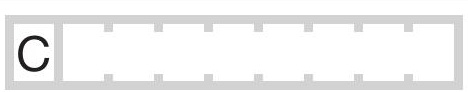

Name of Employer
Rutherfoord
Receipt For: 2012
X Primary $\quad$ General
Other (specify)

Occupation sales/service

Election Cycle-to-Date

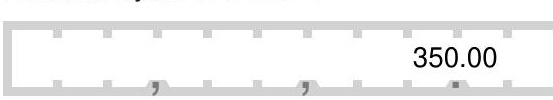

B. Full Name (Last, First, Middle Initial) James Weidner

Mailing Address 9711 Orient Express Ct.

\begin{tabular}{lcc}
\hline City & State & Zip Code \\
Las Vegas & NV & $89145-8702$ \\
\hline
\end{tabular}

FEC ID number of contributing

federal political committee.

C

Name of Employer
Information Requested
Receipt For: 2012
$\begin{aligned} & \square \text { Primary } \\ & \text { Other (specify) }\end{aligned}$

Occupation

Information Requested

Election Cycle-to-Date

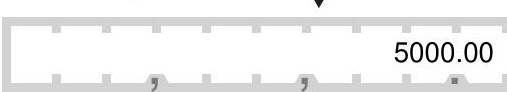

Transaction ID : A344B87EFFD4C4BC8B14

Date of Receipt

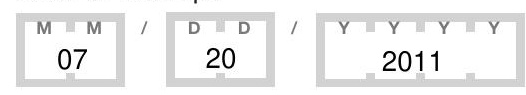

Amount of Each Receipt this Period

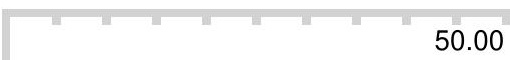

50.00

C. Full Name (Last, First, Middle Initial)

jesse ada

Mailing Address 340 7th st

\begin{tabular}{lcc}
\hline City & State & Zip Code \\
Marietta & $\mathrm{OH}$ & 45750
\end{tabular}

FEC ID number of contributing federal political committee.

C

Name of Employer
Information Requested
Receipt For: 2012
X Primary $\quad \square$ General
Other (specify)

Occupation

Information Requested

Election Cycle-to-Date

Transaction ID : A1917CDA2CAC74D11B28 Date of Receipt

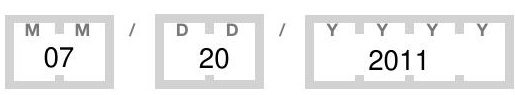

Amount of Each Receipt this Period

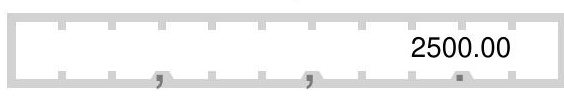

Transaction ID : A66EB9C08E40E43FB9E6 Date of Receipt

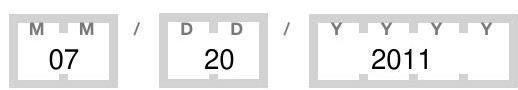

Amount of Each Receipt this Period

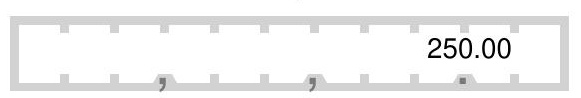

250.00

\section{Subtotal Of Receipts This Page (optional)}

Total This Period (last page this line number only) 
SCHEDULE A-P ITEMIZED RECEIPTS
Use separate schedule(s) for each category of the Detailed Summary Page
FOR LINE NUMBER: (check only one)

PAGE $131 / 1572$

\begin{tabular}{|c|c|c|c|c|c|c|}
\hline & & & & & & \\
\hline 16 & $\lambda$ & $17 \mathrm{a}$ & $17 \mathrm{~b}$ & $17 \mathrm{c}$ & $-17 d$ & -18 \\
\hline $19 a$ & & $19 b$ & $20 a$ & $20 \mathrm{~b}$ & $20 \mathrm{c}$ & 21 \\
\hline
\end{tabular}

Any information copied from such Reports and Statements may not be sold or used by any person for the purpose of soliciting contributions or for commercial purposes, other than using the name and address of any political committee to solicit contributions from such committee.

NAME OF COMMITTEE (In Full)

\section{Friends of Herman Cain}

A. Full Name (Last, First, Middle Initial)

James McClymond

Mailing Address 15914 Wild Holly Ln.

\begin{tabular}{lcc}
\hline City & State & Zip Code \\
Poway & CA & $92064-2140$ \\
\hline
\end{tabular}

FEC ID number of contributing

federal political committee.

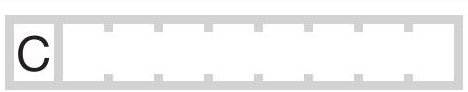

Name of Employer
Information Requested
Receipt For: 2012
X Primary
Other (specify) General

Occupation

Information Requested

Election Cycle-to-Date

1000.00

B. Full Name (Last, First, Middle Initial)

Anthony Babiak

Mailing Address 3415 E Barrington Dr

\begin{tabular}{lcc}
\hline City & State & Zip Code \\
Orange & CA & $92869-2579$
\end{tabular}

FEC ID number of contributing

federal political committee.

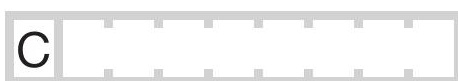

Name of Employer
V \& M Plating Co
Receipt For: 2012
X Primary
Other (specify)

Occupation

Corp. Executive

Election Cycle-to-Date

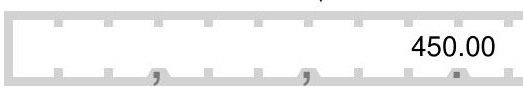

C. Full Name (Last, First, Middle Initial)

richard hughes

Mailing Address 808 bayshore dr.

\begin{tabular}{l|ll}
\hline $\begin{array}{l}\text { City } \\
\text { Miramar Beach }\end{array}$ & $\begin{array}{c}\text { State } \\
\text { FL }\end{array}$ & $\begin{array}{c}\text { Zip Code } \\
32550-3927\end{array}$ \\
\hline $\begin{array}{l}\text { FEC ID number of contributing } \\
\text { federal political committee. }\end{array}$ & C & \\
\hline $\begin{array}{l}\text { Name of Employer } \\
\text { Richard J. Hughes MD PA }\end{array}$ & $\begin{array}{l}\text { Occupation } \\
\text { Physician }\end{array}$ \\
\hline $\begin{array}{l}\text { Receipt For: } 2012 \\
\text { Xrimary } \\
\text { Other (specify) }\end{array}$ & Election Cycle-to-Date & 300.00 \\
\hline
\end{tabular}

Transaction ID : A047037D8F6EE4F26A7A

Date of Receipt

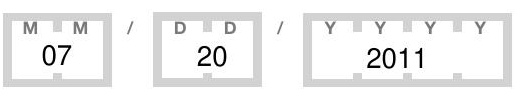

Amount of Each Receipt this Period

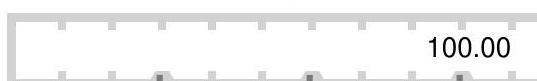

Subtotal Of Receipts This Page (optional).

1200.00

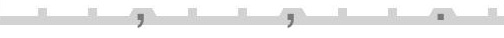

Total This Period (last page this line number only)
Amount of Each Receipt this Period

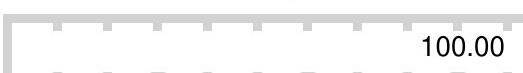

Transaction ID : AE916F88761B14C408A2 Date of Receipt
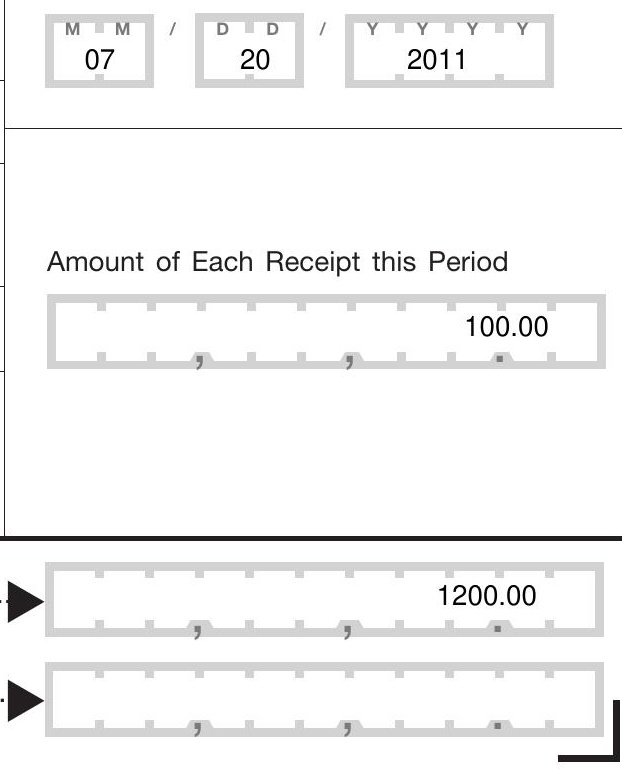

FEC Schedule A-P (Form 3P) (Rev. 03/2011) 
SCHEDULE A-P ITEMIZED RECEIPTS
Use separate schedule(s) for each category of the Detailed Summary Page
FOR LINE NUMBER: (check only one)

PAGE 132 / 1572

\begin{tabular}{|c|c|c|c|c|c|c|}
\hline & & & & & & \\
\hline 16 & $\lambda$ & $17 \mathrm{a}$ & $17 \mathrm{~b}$ & $17 \mathrm{c}$ & $-17 d$ & -18 \\
\hline $19 a$ & & $19 b$ & $20 a$ & $20 \mathrm{~b}$ & $20 \mathrm{c}$ & 21 \\
\hline
\end{tabular}

Any information copied from such Reports and Statements may not be sold or used by any person for the purpose of soliciting contributions or for commercial purposes, other than using the name and address of any political committee to solicit contributions from such committee.

NAME OF COMMITTEE (In Full)

\section{Friends of Herman Cain}

A. Full Name (Last, First, Middle Initial)

Roger Case

Mailing Address 1621 NE 6th Ave

\begin{tabular}{lcc}
\hline City & State & Zip Code \\
Oak Harbor & WA & $98277-4326$
\end{tabular}

FEC ID number of contributing federal political committee.

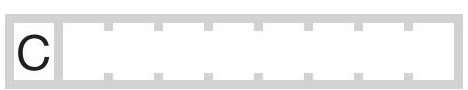

Name of Employer
Retired
Receipt For: 2012
X Primary $\quad$ General
Other (specify)

Occupation Physician Election Cycle-to-Date

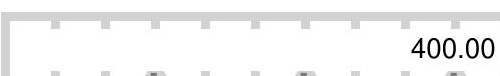

B. Full Name (Last, First, Middle Initial) John Shoup

\section{Mailing Address PO Box 56757}

\begin{tabular}{lcc}
\hline City & State & Zip Code \\
New Orleans & LA & $70156-6757$
\end{tabular}

FEC ID number of contributing

federal political committee.

C

\begin{tabular}{l} 
Name of Employer \\
Information Requested \\
Receipt For: 2012 \\
X Primary \\
\hline Other (specify)
\end{tabular}

Occupation

Information Requested

Election Cycle-to-Date

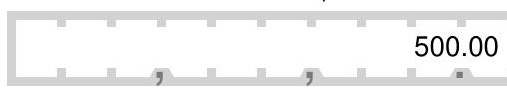

Transaction ID : A5590A06D7F75472A9A5

Date of Receipt

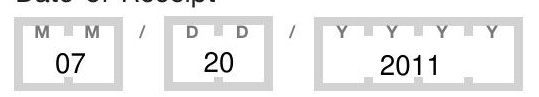

Amount of Each Receipt this Period

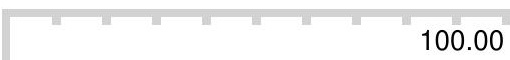

Amount of Each Receipt this Period

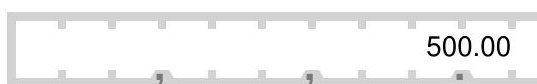

C. Full Name (Last, First, Middle Initial) thomas mims

Mailing Address 1655 Banks St

\begin{tabular}{lcc}
\hline City & State & Zip Code \\
Houston & TX & $77006-6021$
\end{tabular}

FEC ID number of contributing federal political committee.

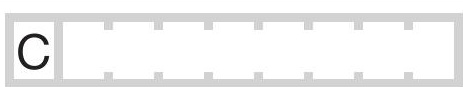

\section{Name of Employer}

Self Employed

Occupation

Receipt For: 2012

Х $\begin{aligned} & \text { Primary } \square \text { General } \\ & \text { Other (specify) }\end{aligned}$

Physician

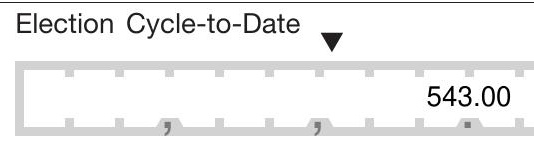

Transaction ID : A9AA3AC6A9F3049AA9A1 Date of Receipt

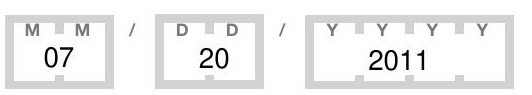

Transaction ID : AD853FC51A07A4C55AA8 Date of Receipt

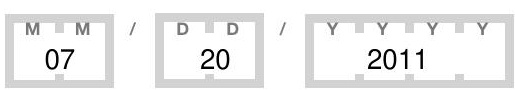

Amount of Each Receipt this Period

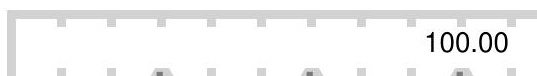

Subtotal Of Receipts This Page (optional).

Total This Period (last page this line number only) 
SCHEDULE A-P ITEMIZED RECEIPTS
Use separate schedule(s) for each category of the Detailed Summary Page
FOR LINE NUMBER: (check only one)

PAGE $133 / 1572$

\begin{tabular}{|c|c|c|c|c|c|}
\hline & & & & & \\
\hline 16 & $\begin{array}{lll}X & 17 a \\
\end{array}$ & $17 \mathrm{~b}$ & $17 c$ & $17 d$ & 18 \\
\hline $19 a$ & $19 b$ & $20 a$ & $20 \mathrm{~b}$ & $20 c$ & 21 \\
\hline
\end{tabular}

Any information copied from such Reports and Statements may not be sold or used by any person for the purpose of soliciting contributions or for commercial purposes, other than using the name and address of any political committee to solicit contributions from such committee.

NAME OF COMMITTEE (In Full)

\section{Friends of Herman Cain}

A. Full Name (Last, First, Middle Initial)

\section{Eileen Million}

Mailing Address 252 Vine Cliff Drive

\begin{tabular}{lcc}
\hline City & State & Zip Code \\
Harvest & AL & $35749-5816$
\end{tabular}

FEC ID number of contributing federal political committee.

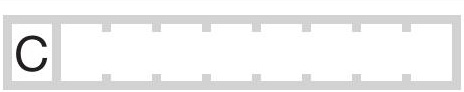

Name of Employer
None
Receipt For: 2012
X Primary $\quad$ General
Other (specify)

Occupation Homemaker

Election Cycle-to-Date

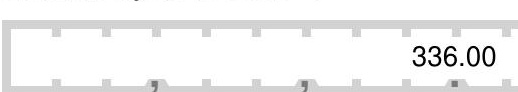

B. Full Name (Last, First, Middle Initial)

Tommy Morgan

Mailing Address 1811 McDaniel Mill Road, SW

\begin{tabular}{lcc}
\hline City & State & Zip Code \\
Conyers & GA & $30094-6023$
\end{tabular}

FEC ID number of contributing

federal political committee.

C

Name of Employer
Information Requested
Receipt For: 2012
X Primary
Other (specify)

Occupation

Information Requested

Election Cycle-to-Date

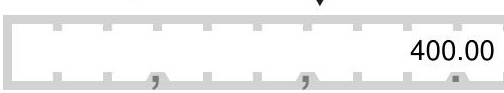

Transaction ID : A57B387DFC24448918C1

Date of Receipt

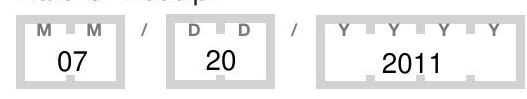

Amount of Each Receipt this Period

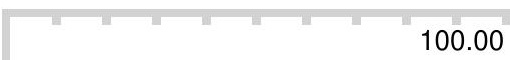

Transaction ID : A39161A70DDFF41F38DE Date of Receipt

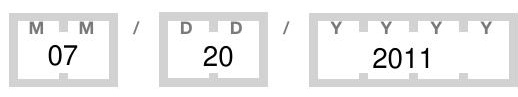

Amount of Each Receipt this Period

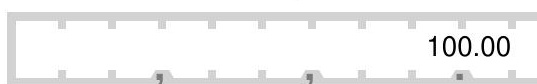

Transaction ID : ABBAF883CA6714F4D957 Date of Receipt

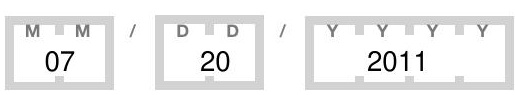

Amount of Each Receipt this Period

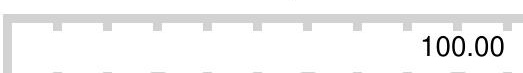

$\begin{array}{cc}\text { State } & \text { Zip Code } \\ \text { NC } & 28303-2883\end{array}$

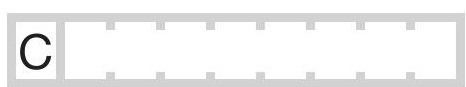

\section{Occupation}

Officer

Election Cycle-to-Date

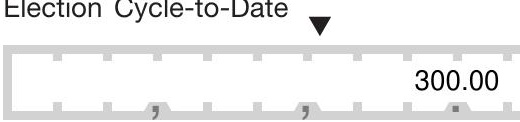

Subtotal Of Receipts This Page (optional)

300.00

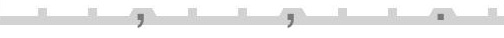

Total This Period (last page this line number only)

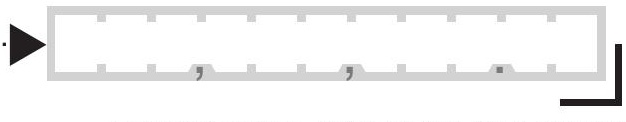

FEC Schedule A-P (Form 3P) (Rev. 03/2011) 
SCHEDULE A-P ITEMIZED RECEIPTS
Use separate schedule(s) for each category of the Detailed Summary Page
FOR LINE NUMBER: (check only one)

PAGE 134 / 1572

\begin{tabular}{|c|c|c|c|c|c|}
\hline & & & & & \\
\hline 16 & $\begin{array}{l}\mathbf{X} \\
17 a\end{array}$ & $17 b$ & $17 c$ & $17 d$ & 18 \\
\hline $19 a$ & $19 \mathrm{~b}$ & $20 \mathrm{a}$ & $20 \mathrm{~b}$ & $20 \mathrm{c}$ & 21 \\
\hline
\end{tabular}

Any information copied from such Reports and Statements may not be sold or used by any person for the purpose of soliciting contributions or for commercial purposes, other than using the name and address of any political committee to solicit contributions from such committee.

NAME OF COMMITTEE (In Full)

\section{Friends of Herman Cain}

A. Full Name (Last, First, Middle Initial) John Ellery

Mailing Address 2488 Old Fork Rd

\begin{tabular}{lcc}
\hline City & State & Zip Code \\
Gainesville & GA & $30506-1124$
\end{tabular}

FEC ID number of contributing federal political committee.

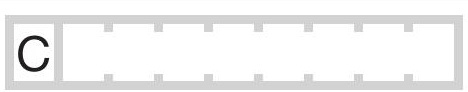

Name of Employer
Automatic IT Corp
Receipt For: 2012
X Primary
Other (specify) General

Occupation

IT Consultant

Election Cycle-to-Date

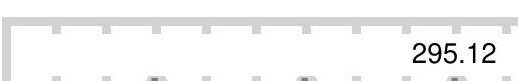

B. Full Name (Last, First, Middle Initial)

Mrs. Barbara C. Mathews

Mailing Address 2367 LAvista Road

\begin{tabular}{lcc}
\hline City & State & Zip Code \\
Atlanta & GA & $30329-3346$ \\
\hline
\end{tabular}

FEC ID number of contributing

federal political committee.

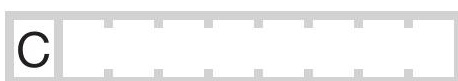

Name of Employer
None
Receipt For: 2012
X Primary $\quad$ General
Other (specify)

\section{Occupation}

Retired

Election Cycle-to-Date

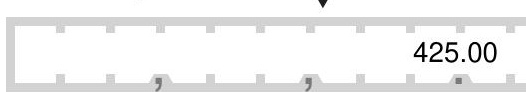

Transaction ID : A6D9A27CEA09D427DB3E

Date of Receipt

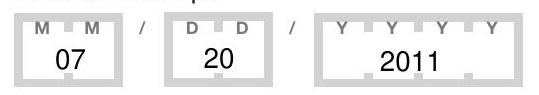

Amount of Each Receipt this Period

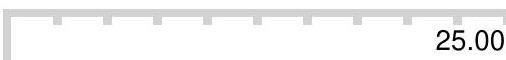

25.00

C. Full Name (Last, First, Middle Initial)

Durward Pridgen

Mailing Address 1806 Silver Maple Drive

\begin{tabular}{lcc}
\hline City & State & Zip Code \\
North Augusta & SC & $29860-8440$
\end{tabular}

FEC ID number of contributing

federal political committee.

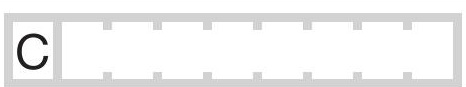

Name of Employer

Occupation

Veterans Administration

Physician

Receipt For: 2012

Х $\begin{aligned} & \text { Primary } \\ & \text { Other (specify) }\end{aligned}$

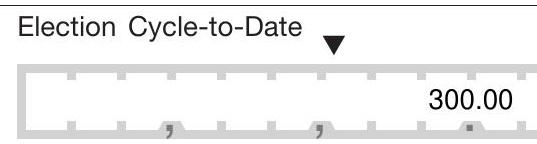

Amount of Each Receipt this Period

Transaction ID : A2A44A8E732504C7687C

Date of Receipt
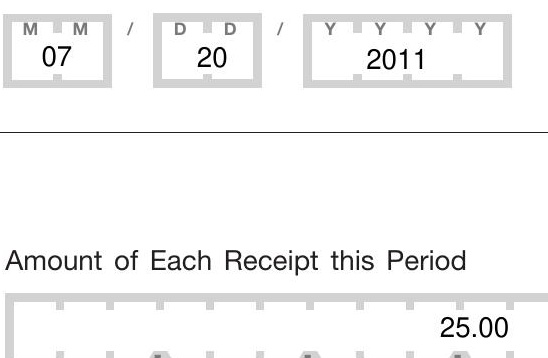

Transaction ID : AAD1FFCAB9F214569A36

Date of Receipt

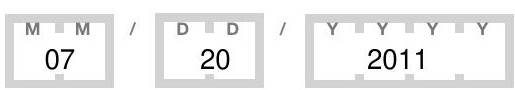

Amount of Each Receipt this Period

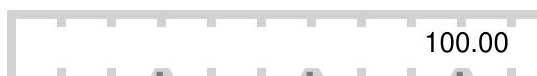

150.00

Subtotal Of Receipts This Page (optional)

Total This Period (last page this line number only) 
SCHEDULE A-P ITEMIZED RECEIPTS
Use separate schedule(s) for each category of the Detailed Summary Page
FOR LINE NUMBER: (check only one)
PAGE $135 / 1572$

\begin{tabular}{|c|c|c|c|c|c|}
\hline & & & & & \\
\hline 16 & $\begin{array}{lll}X & 17 a \\
\end{array}$ & $17 \mathrm{~b}$ & $17 c$ & $17 d$ & 18 \\
\hline $19 a$ & $19 b$ & $20 a$ & $20 \mathrm{~b}$ & $20 c$ & 21 \\
\hline
\end{tabular}

Any information copied from such Reports and Statements may not be sold or used by any person for the purpose of soliciting contributions or for commercial purposes, other than using the name and address of any political committee to solicit contributions from such committee.

NAME OF COMMITTEE (In Full)

\section{Friends of Herman Cain}

A. Full Name (Last, First, Middle Initial)

\section{Leslie Olson}

Mailing Address 24218 SE 42 PI

\begin{tabular}{lcc}
\hline City & State & Zip Code \\
Issaquah & WA & $98029-7516$
\end{tabular}

FEC ID number of contributing federal political committee.

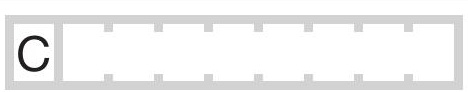

Name of Employer
LifeCenter NW
Receipt For: 2012
X Primary $\quad$ General
Other (specify)

Occupation Surgical Organ Recovery Specialist Election Cycle-to-Date

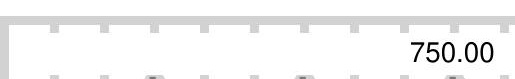

B. Full Name (Last, First, Middle Initial)

Robert Haugen

Mailing Address 445 Iron King

\begin{tabular}{lcc}
\hline City & State & Zip Code \\
Durango & CO & $81301-9418$ \\
\hline
\end{tabular}

FEC ID number of contributing

federal political committee.

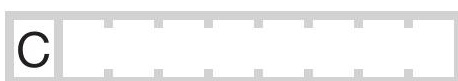

Name of Employer
Haugen Custom Financial System
Receipt For: 2012
Xrimary
Other (specify)

\section{Occupation}

Finance

Election Cycle-to-Date

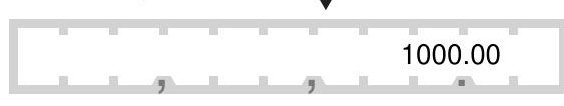

Transaction ID : AB28CEA8391EC4AF6993

Date of Receipt

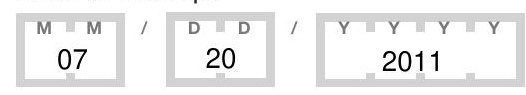

Amount of Each Receipt this Period

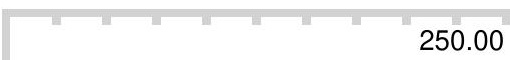

C. Full Name (Last, First, Middle Initial)

Donald Anderson

Mailing Address 3360 hwy 112

\begin{tabular}{lcc}
\hline City & State & Zip Code \\
Camilla & GA & $31730-4736$
\end{tabular}

FEC ID number of contributing federal political committee.

C

GA $31730-4736$

Name of Employer
Information Requested
Receipt For: 2012
X Primary
$\square$ Other (specify) General

\section{Occupation}

Information Requested

Election Cycle-to-Date

Transaction ID : A53D10A1AB46F4535A83

Date of Receipt

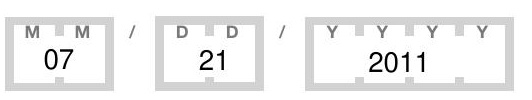

Amount of Each Receipt this Period

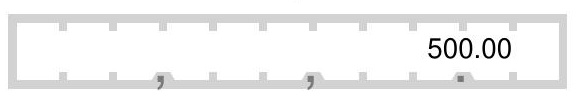

Transaction ID : A6F6F4C9A93FC474797E Date of Receipt

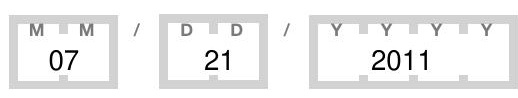

Amount of Each Receipt this Period

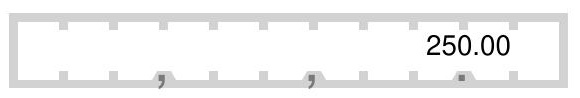

250.00

\section{Subtotal Of Receipts This Page (optional)}

Total This Period (last page this line number only) 
SCHEDULE A-P ITEMIZED RECEIPTS
Use separate schedule(s) for each category of the Detailed Summary Page
FOR LINE NUMBER: (check only one)

PAGE $136 / 1572$

\begin{tabular}{|c|c|c|c|c|c|}
\hline & & & & & \\
\hline 16 & $\begin{array}{l}\mathbf{X} \\
17 a\end{array}$ & $17 b$ & $17 c$ & $17 d$ & 18 \\
\hline $19 a$ & $19 \mathrm{~b}$ & $20 \mathrm{a}$ & $20 \mathrm{~b}$ & $20 \mathrm{c}$ & 21 \\
\hline
\end{tabular}

Any information copied from such Reports and Statements may not be sold or used by any person for the purpose of soliciting contributions or for commercial purposes, other than using the name and address of any political committee to solicit contributions from such committee.

NAME OF COMMITTEE (In Full)

\section{Friends of Herman Cain}

A. Full Name (Last, First, Middle Initial)

\section{Gerald Camiener}

Mailing Address 7022 Green Tree Drive

\begin{tabular}{lcc}
\hline City & State & Zip Code \\
Naples & FL & $34108-7525$ \\
\hline
\end{tabular}

FEC ID number of contributing federal political committee.

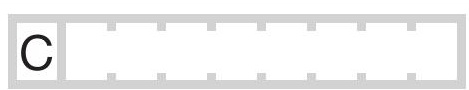

Name of Employer
n/a
Receipt For: 2012
X Primary $\quad$ General
Other (specify)

Occupation Retired

Election Cycle-to-Date

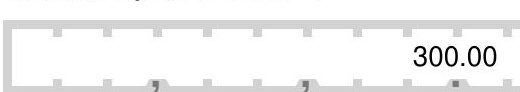

B. Full Name (Last, First, Middle Initial)

\section{Susan Krechel}

Mailing Address blackhorsefarm@myway.com

\begin{tabular}{lcc}
\hline City & State & Zip Code \\
Jonesburg & MO & 63351
\end{tabular}

FEC ID number of contributing

federal political committee.

C

Name of Employer
None
Receipt For: 2012
X Primary
Other (specify)

C. Full Name (Last, First, Middle Initial)

Oliver Krechel

Mailing Address 474 Hwy FF

\begin{tabular}{lcc}
\hline City & State & Zip Code \\
Jonesburg & MO & $63351-2204$
\end{tabular}

FEC ID number of contributing federal political committee.

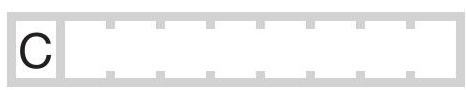

Name of Employer
n/a
Receipt For: 2012
X Primary $\quad \square$ General
Other (specify)

\section{Occupation}

Retired

Election Cycle-to-Date

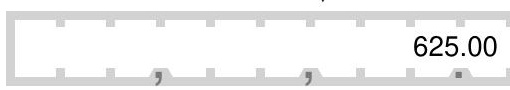

$\begin{aligned} & \text { Occupation } \\ & \text { Retired }\end{aligned}$
Election Cycle-to-Date

Transaction ID : A0D62A555D2464AFDA0C

Date of Receipt

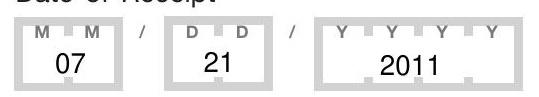

Amount of Each Receipt this Period

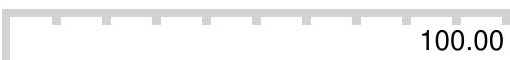

Amount of Each Receipt this Period

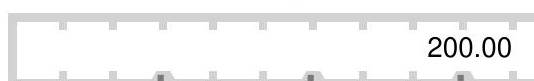

Transaction ID : ACF292D9E17C94E0981F Date of Receipt

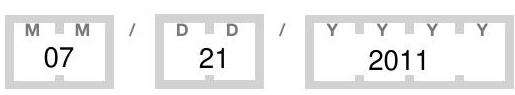

Transaction ID : A67992726AC2849B19E7 Date of Receipt

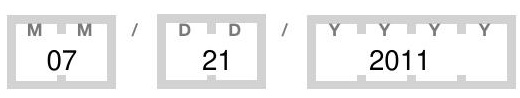

Amount of Each Receipt this Period

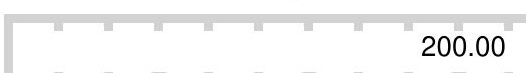

200.00

\section{Subtotal Of Receipts This Page (optional)}

Total This Period (last page this line number only) 
SCHEDULE A-P

ITEMIZED RECEIPTS
Use separate schedule(s)

for each category of the

Detailed Summary Page
FOR LINE NUMBER: (check only one)

\begin{tabular}{|c|c|c|c|c|c|}
\hline & & & & & \\
\hline 16 & $\begin{array}{ll}X & 17 a \\
\end{array}$ & $17 \mathrm{~b}$ & $17 c$ & $17 d$ & 18 \\
\hline $19 a$ & $19 b$ & $20 \mathrm{a}$ & $20 \mathrm{~b}$ & $20 c$ & 21 \\
\hline
\end{tabular}

Any information copied from such Reports and Statements may not be sold or used by any person for the purpose of soliciting contributions or for commercial purposes, other than using the name and address of any political committee to solicit contributions from such committee.

NAME OF COMMITTEE (In Full)

\section{Friends of Herman Cain}

A. Full Name (Last, First, Middle Initial)

HARRY BEARDSLEY

Mailing Address PO BOX 8457

\begin{tabular}{lcc}
\hline City & State & Zip Code \\
Warner Robins & GA & $31095-8457$
\end{tabular}

FEC ID number of contributing

federal political committee.

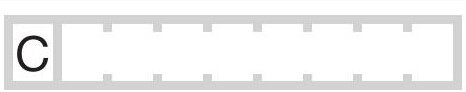

Name of Employer
Information Requested
Receipt For: 2012
X Primary $\quad \square$ General
Other (specify)

Occupation

Information Requested

Election Cycle-to-Date

250.00

B. Full Name (Last, First, Middle Initial)

steven kimball

Mailing Address 2224spininngwheel lane

\begin{tabular}{lcc}
\hline City & State & Zip Code \\
Cincinnati & OH & 45244 \\
\hline
\end{tabular}

FEC ID number of contributing

federal political committee.

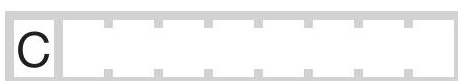

Name of Employer
Emersion Design
Receipt For: 2012
X Primary
Other (specify)

\section{Occupation}

CEO

Election Cycle-to-Date

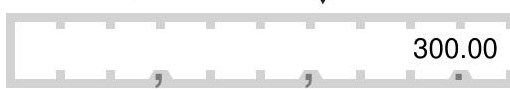

Transaction ID : A1AB710E6814A47509E3

Date of Receipt

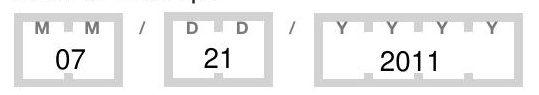

Amount of Each Receipt this Period

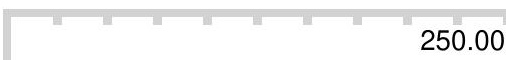

Amount of Each Receipt this Period

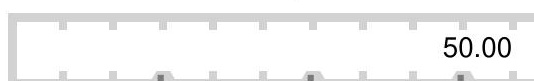

C. Full Name (Last, First, Middle Initial)

RUFUS SMITH

Mailing Address 9990 SADLER CIRCLE

\begin{tabular}{lcc}
\hline City & State & Zip Code \\
Loveland & $\mathrm{OH}$ & $45140-1867$
\end{tabular}

FEC ID number of contributing federal political committee.

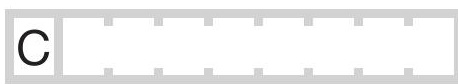

Name of Employer

Information Requested

Occupation

Receipt For: 2012

Х $\begin{aligned} & \text { Primary } \\ & \text { Other (specify) }\end{aligned}$

Information Requested

Election Cycle-to-Date

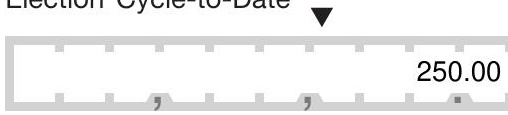

Transaction ID : AF27FE13207DE419B99F

Date of Receipt

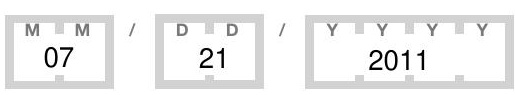

Transaction ID : A97DEDCF44C7646C184E Date of Receipt

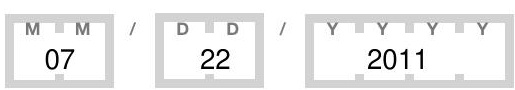

Amount of Each Receipt this Period

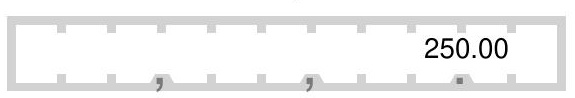

Subtotal Of Receipts This Page (optional)

550.00

Total This Period (last page this line number only) 
SCHEDULE A-P ITEMIZED RECEIPTS
Use separate schedule(s) for each category of the Detailed Summary Page
FOR LINE NUMBER: (check only one)

PAGE $138 / 1572$

\begin{tabular}{|c|c|c|c|c|c|}
\hline & & & & & \\
\hline 16 & $\begin{array}{l}\mathbf{X} \\
17 a\end{array}$ & $17 b$ & $17 c$ & $17 d$ & 18 \\
\hline $19 a$ & $19 \mathrm{~b}$ & $20 \mathrm{a}$ & $20 \mathrm{~b}$ & $20 \mathrm{c}$ & 21 \\
\hline
\end{tabular}

Any information copied from such Reports and Statements may not be sold or used by any person for the purpose of soliciting contributions or for commercial purposes, other than using the name and address of any political committee to solicit contributions from such committee.

NAME OF COMMITTEE (In Full)

\section{Friends of Herman Cain}

A. Full Name (Last, First, Middle Initial)

Florence Attridge

Mailing Address 2820 Habersham Rd

\begin{tabular}{lcc}
\hline City & State & Zip Code \\
Atlanta & GA & $30305-2959$ \\
\hline
\end{tabular}

FEC ID number of contributing

federal political committee.

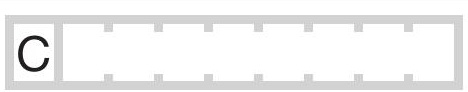

Name of Employer
Information Requested
Receipt For: 2012
X Primary
Other (specify) General

Occupation

Information Requested

Election Cycle-to-Date

275.00

B. Full Name (Last, First, Middle Initial)

Stevan Gilmore

Mailing Address 2437 Bay Area Blvd \# 163

\begin{tabular}{lcc}
\hline City & State & Zip Code \\
Houston & TX & $77058-1519$ \\
\hline
\end{tabular}

FEC ID number of contributing

federal political committee.

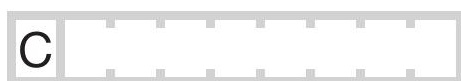

Name of Employer
Emcare
Receipt For: 2012
X Primary
Other (specify)

\section{Occupation}

Physician

Transaction ID : A2B67B9ECCBBE46CC8B2

Date of Receipt

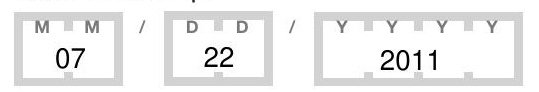

Amount of Each Receipt this Period

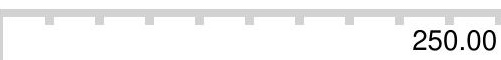

250.00

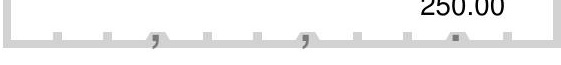

Transaction ID : A077DBC72D2ED4E7F9C4

Date of Receipt

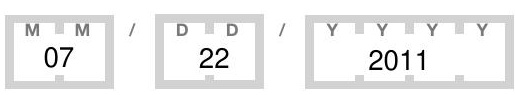

Amount of Each Receipt this Period

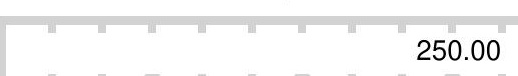

Election Cycle-to-Date

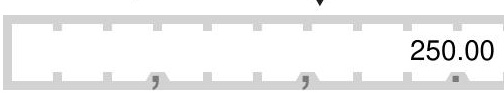

C. Full Name (Last, First, Middle Initial)

Kevin George

Mailing Address PO Box 88

\begin{tabular}{lcc}
\hline City & State & Zip Code \\
Burleson & TX & $76097-0088$
\end{tabular}

FEC ID number of contributing

federal political committee.

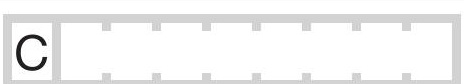

Name of Employer
Expro
Receipt For: 2012
X Primary $\quad \square$ General
Other (specify)

Occupation

Enginnering Manager

Election Cycle-to-Date

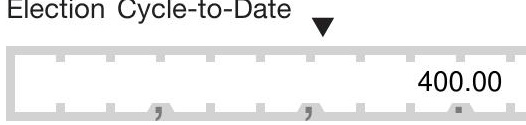

Amount of Each Receipt this Period

Transaction ID : A1D55FC94644A4FDF8E4 Date of Receipt
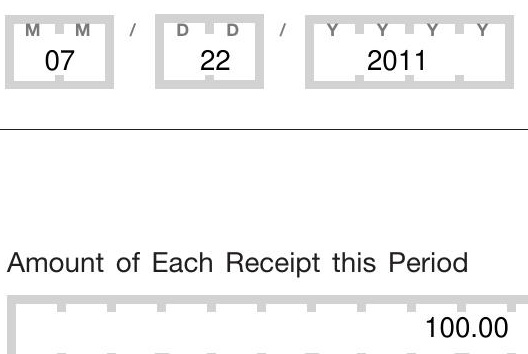

100.00

Subtotal Of Receipts This Page (optional)

600.00

Total This Period (last page this line number only) 
SCHEDULE A-P ITEMIZED RECEIPTS
Use separate schedule(s) for each category of the Detailed Summary Page
FOR LINE NUMBER: (check only one)

PAGE $139 / 1572$

\begin{tabular}{|c|c|c|c|c|c|}
\hline & & & & & \\
\hline 16 & $\begin{array}{l}\mathbf{X} \\
17 a\end{array}$ & $17 b$ & $17 c$ & $17 d$ & 18 \\
\hline $19 a$ & $19 \mathrm{~b}$ & $20 \mathrm{a}$ & $20 \mathrm{~b}$ & $20 \mathrm{c}$ & 21 \\
\hline
\end{tabular}

Any information copied from such Reports and Statements may not be sold or used by any person for the purpose of soliciting contributions or for commercial purposes, other than using the name and address of any political committee to solicit contributions from such committee.

NAME OF COMMITTEE (In Full)

\section{Friends of Herman Cain}

A. Full Name (Last, First, Middle Initial) Jody Harshman

Mailing Address 5908 THistledown Dr

\begin{tabular}{lcc}
\hline City & State & Zip Code \\
Pasco & WA & $99301-3118$
\end{tabular}

FEC ID number of contributing federal political committee.

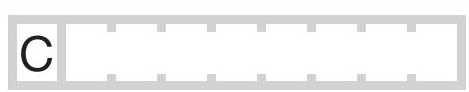

Name of Employer
Independent Contractor
Receipt For: 2012
X Primary $\quad \square$ General
Other (specify)

Occupation technician

Election Cycle-to-Date

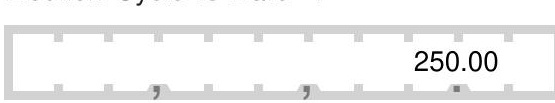

B. Full Name (Last, First, Middle Initial)

Mr Thomas Duke

Mailing Address 3315 Beauclerc Rd

\begin{tabular}{lcc}
\hline City & State & Zip Code \\
Jacksonville & FL & $32257-4907$
\end{tabular}

FEC ID number of contributing

federal political committee.

C

Name of Employer
Information Requested
Receipt For: 2012
X Primary
Other (specify)

Occupation

Information Requested

Election Cycle-to-Date

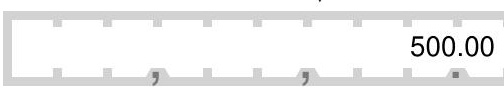

Transaction ID : AE0ADC3A2FF194CE4A99

Date of Receipt

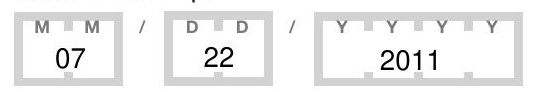

Amount of Each Receipt this Period

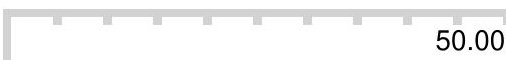

50.00

C. Full Name (Last, First, Middle Initial)

Tania De La Fuente Herman

Mailing Address 5121 Windward Way

\begin{tabular}{lcc}
\hline City & State & Zip Code \\
Edmond & OK & $73013-8644$
\end{tabular}

FEC ID number of contributing federal political committee.

C

73013-8644

Name of Employer

Information Requested

Occupation

Receipt For: 2012

Х $\begin{aligned} & \text { Primary } \square \text { General } \\ & \text { Other (specify) }\end{aligned}$

Information Requested

Election Cycle-to-Date

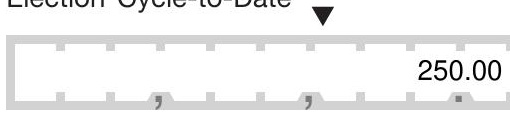

Amount of Each Receipt this Period

Transaction ID : AF923F0ECA58145AF983

Date of Receipt
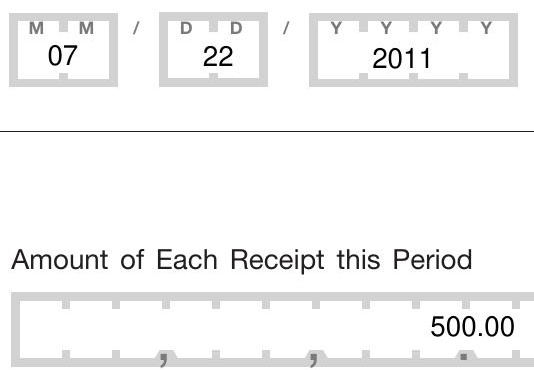

Transaction ID : AF04D4967A6784262B29

Date of Receipt

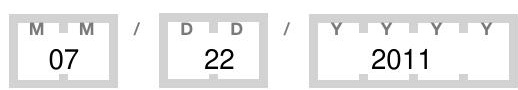

Amount of Each Receipt this Period

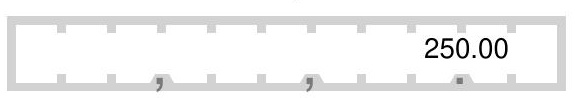

Subtotal Of Receipts This Page (optional).

800.00

Total This Period (last page this line number only) 
SCHEDULE A-P ITEMIZED RECEIPTS
Use separate schedule(s) for each category of the Detailed Summary Page
FOR LINE NUMBER: (check only one)

PAGE $140 / 1572$

\begin{tabular}{|c|c|c|c|c|c|}
\hline & & & & & \\
\hline 16 & $\begin{array}{l}\mathbf{X} \\
17 a\end{array}$ & $17 b$ & $17 c$ & $17 d$ & 18 \\
\hline $19 a$ & $19 \mathrm{~b}$ & $20 \mathrm{a}$ & $20 \mathrm{~b}$ & $20 \mathrm{c}$ & 21 \\
\hline
\end{tabular}

Any information copied from such Reports and Statements may not be sold or used by any person for the purpose of soliciting contributions or for commercial purposes, other than using the name and address of any political committee to solicit contributions from such committee.

NAME OF COMMITTEE (In Full)

\section{Friends of Herman Cain}

A. Full Name (Last, First, Middle Initial)

Diane Speedling

Mailing Address 2927 Sand Pine Rd

\begin{tabular}{lcc}
\hline City & State & Zip Code \\
Miramar Beach & FL & $32550-7835$
\end{tabular}

FEC ID number of contributing

federal political committee.

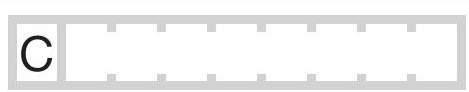

Name of Employer
Self Employed
Receipt For: 2012
X Primary $\quad$ General
Other (specify)

Occupation

Anesthesiologist

Election Cycle-to-Date

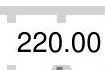

B. Full Name (Last, First, Middle Initial)

claire mencke

Mailing Address 5 tudor city place apt 305

\begin{tabular}{lcc}
\hline City & State & Zip Code \\
New York & NY & $10017-6858$
\end{tabular}

FEC ID number of contributing

federal political committee.

C

Name of Employer
buckingham research group
Receipt For: 2012
Primary
Other (specify)

Occupation

research assoc

Election Cycle-to-Date

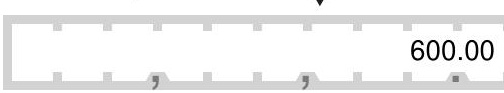

Transaction ID : A31C2E8536AAA4FB6B6D

Date of Receipt

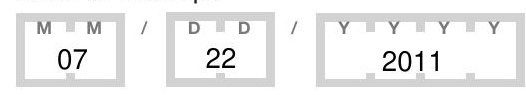

Amount of Each Receipt this Period

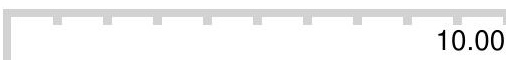

10.00

C. Full Name (Last, First, Middle Initial)

Joann Hohmann

Mailing Address 7595 Shadburn Ferry Rd

\begin{tabular}{lcc}
\hline City & State & Zip Code \\
Cumming & GA & $30041-8156$
\end{tabular}

FEC ID number of contributing

federal political committee.

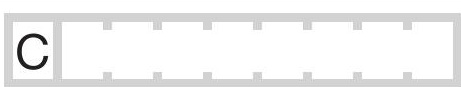

Name of Employer
None
Receipt For: 2012
Х Primary $\quad \square$ General
Other (specify)

Occupation

Homemaker

Election Cycle-to-Date

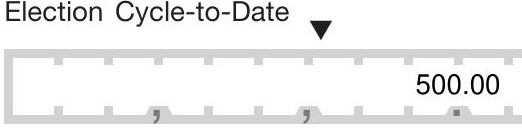

Transaction ID : A1C0B5B598D3F439BA78

Date of Receipt

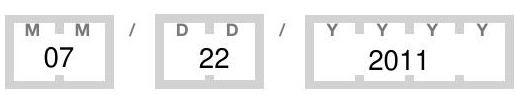

Amount of Each Receipt this Period

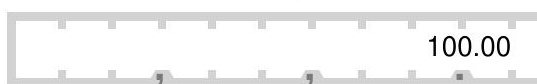

Transaction ID : A6AC6CB8B3144489A95B Date of Receipt

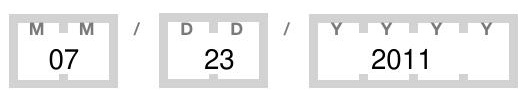

Amount of Each Receipt this Period

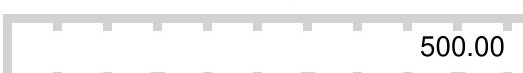

\section{Subtotal Of Receipts This Page (optional)}

Total This Period (last page this line number only) 
SCHEDULE A-P ITEMIZED RECEIPTS
Use separate schedule(s) for each category of the Detailed Summary Page

FOR LINE NUMBER:
(check only one)

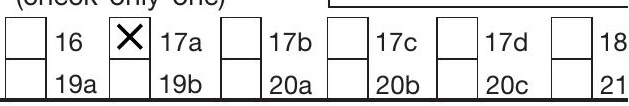

Any information copied from such Reports and Statements may not be sold or used by any person for the purpose of soliciting contributions or for commercial purposes, other than using the name and address of any political committee to solicit contributions from such committee.

NAME OF COMMITTEE (In Full)

\section{Friends of Herman Cain}

A. Full Name (Last, First, Middle Initial)

Thomas Carter

Mailing Address 645 Mission Bay Drive

\begin{tabular}{lcc}
\hline City & State & Zip Code \\
Satellite Beach & FL & $32937-5701$
\end{tabular}

FEC ID number of contributing federal political committee.

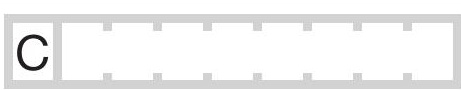

Name of Employer
Information Requested
Receipt For: 2012
X Primary
Other (specify) General

\section{Occupation} Information Requested

Election Cycle-to-Date

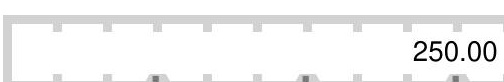

B. Full Name (Last, First, Middle Initial) scott cooper

Mailing Address 5175 saddlebred lane

\begin{tabular}{lcc}
\hline City & State & Zip Code \\
Cumming & GA & $30028-7919$ \\
\hline
\end{tabular}

FEC ID number of contributing

federal political committee.

C

Name of Employer

Medical Associates of North Georgia

Receipt For: 2012

Х $\begin{aligned} & \text { Primary } \square \text { General } \\ & \text { Other (specify) } \boldsymbol{\nabla}\end{aligned}$

\section{Occupation}

Neurologist

Election Cycle-to-Date

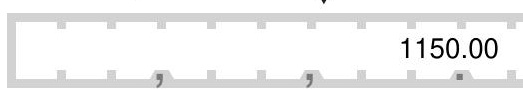

Transaction ID : A308923E3E3E745A6BAB

Date of Receipt

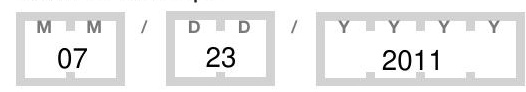

Amount of Each Receipt this Period

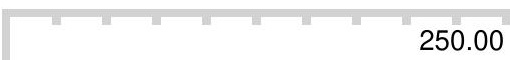

250.00
Amount of Each Receipt this Period

C. Full Name (Last, First, Middle Initial)

Michael Ribelin

Mailing Address 2900 McKinnon 2408

\begin{tabular}{lcc}
\hline City & State & Zip Code \\
Dallas & TX & $75201-1099$ \\
\hline
\end{tabular}

FEC ID number of contributing federal political committee.

C

Name of Employer
Retired
Receipt For: 2012
X Primary $\quad \square$ General
Other (specify)

\section{Occupation}

Retired

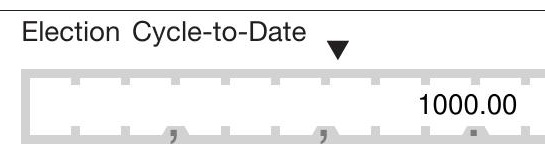

Transaction ID : AB919792EA0A345F9A20

Date of Receipt
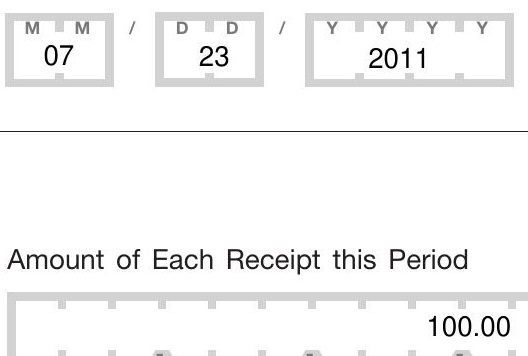

Transaction ID : A31BA348C483942C9B76 Date of Receipt

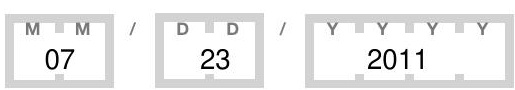

Amount of Each Receipt this Period

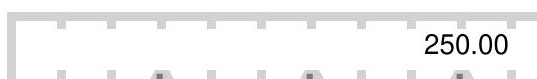

\section{Subtotal Of Receipts This Page (optional)}

600.00

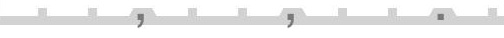

Total This Period (last page this line number only)

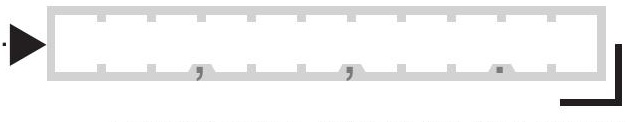

FEC Schedule A-P (Form 3P) (Rev. 03/2011) 
SCHEDULE A-P ITEMIZED RECEIPTS
Use separate schedule(s) for each category of the Detailed Summary Page
FOR LINE NUMBER: (check only one)

PAGE 142 / 1572

\begin{tabular}{|c|c|c|c|c|c|}
\hline & & & & & \\
\hline 16 & $\begin{array}{l}\mathbf{X} \\
17 a\end{array}$ & $17 b$ & $17 c$ & $17 d$ & 18 \\
\hline $19 a$ & $19 \mathrm{~b}$ & $20 \mathrm{a}$ & $20 \mathrm{~b}$ & $20 \mathrm{c}$ & 21 \\
\hline
\end{tabular}

Any information copied from such Reports and Statements may not be sold or used by any person for the purpose of soliciting contributions or for commercial purposes, other than using the name and address of any political committee to solicit contributions from such committee.

NAME OF COMMITTEE (In Full)

\section{Friends of Herman Cain}

A. Full Name (Last, First, Middle Initial) Jesse Hines

Mailing Address 13 Gainsborough Place

\begin{tabular}{lcc}
\hline City & State & Zip Code \\
Newport News & VA & $23608-2007$
\end{tabular}

FEC ID number of contributing federal political committee.

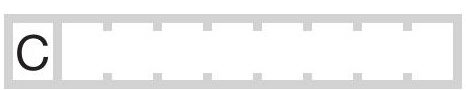

Name of Employer
First Colony Pizza Inc.
Receipt For: 2012
X Primary
Other (specify) General

Occupation pizza delivery driver Election Cycle-to-Date

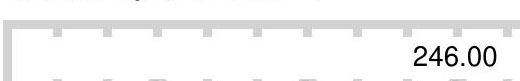

B. Full Name (Last, First, Middle Initial)

Norman Ennis

Mailing Address 720 2nd St

\begin{tabular}{lcc}
\hline City & State & Zip Code \\
Humble & TX & $77338-3825$ \\
\hline
\end{tabular}

FEC ID number of contributing

federal political committee.

C

Name of Employer
Information Requested
Receipt For: 2012
X Primary
Other (specify)

\section{Occupation}

Information Requested

Election Cycle-to-Date

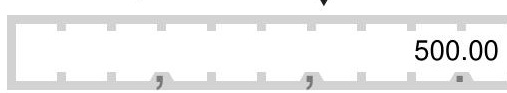

Transaction ID : A72F9BB7F21174C649D5

Date of Receipt

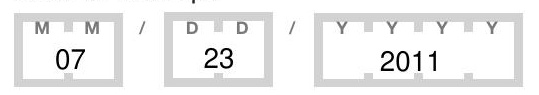

Amount of Each Receipt this Period

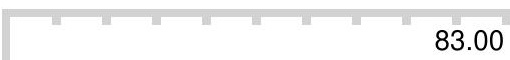

83.00

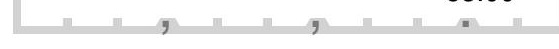

Transaction ID : A95D05C6463B445AEB96

Date of Receipt

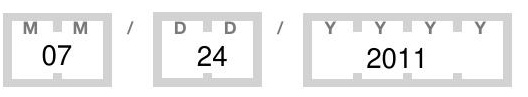

Amount of Each Receipt this Period

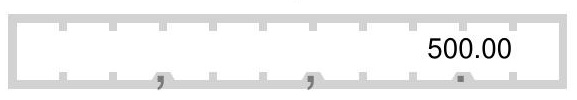

Transaction ID : A17F0A007F016476BADD Date of Receipt

\section{Robert Porter}

Mailing Address 5710 Grand Reunion Dr

\begin{tabular}{lcc}
\hline City & State & Zip Code \\
Hoschton & GA & $30548-4045$
\end{tabular}

FEC ID number of contributing federal political committee.

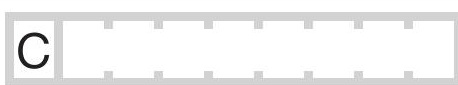

Name of Employer
Information Requested
Receipt For: 2012
X Primary $\quad \square$ General
Other (specify)

Occupation

Information Requested

Election Cycle-to-Date

Subtotal Of Receipts This Page (optional).

Amount of Each Receipt this Period

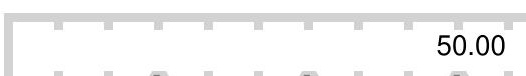

Total This Period (last page this line number only)

633.00

a

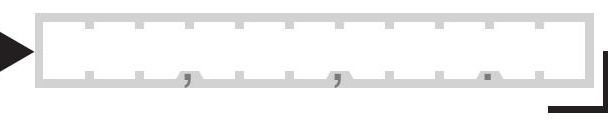

FEC Schedule A-P (Form 3P) (Rev. 03/2011) 
SCHEDULE A-P ITEMIZED RECEIPTS
Use separate schedule(s) for each category of the Detailed Summary Page
FOR LINE NUMBER: (check only one)

PAGE $143 / 1572$

\begin{tabular}{|c|c|c|c|c|c|}
\hline & & & & & \\
\hline 16 & $\begin{array}{lll}X & 17 a \\
\end{array}$ & $17 \mathrm{~b}$ & $17 c$ & $17 d$ & 18 \\
\hline $19 a$ & $19 b$ & $20 a$ & $20 \mathrm{~b}$ & $20 c$ & 21 \\
\hline
\end{tabular}

Any information copied from such Reports and Statements may not be sold or used by any person for the purpose of soliciting contributions or for commercial purposes, other than using the name and address of any political committee to solicit contributions from such committee.

NAME OF COMMITTEE (In Full)

\section{Friends of Herman Cain}

A. Full Name (Last, First, Middle Initial) Linda Luce

Mailing Address 3604 Maple Forge Ln

\begin{tabular}{lcc}
\hline City & State & Zip Code \\
Gainesville & GA & $30504-5763$
\end{tabular}

FEC ID number of contributing federal political committee.

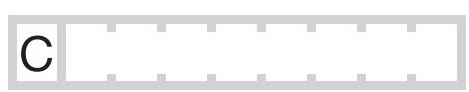

\section{Name of Employer}

Northeast Georgia Medical Center

Occupation

Medical Technologist

Receipt For: 2012

X Primary $\square$ General Other (specify)

Election Cycle-to-Date

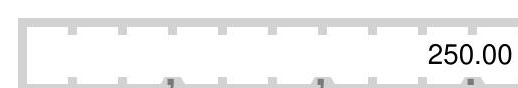

B. Full Name (Last, First, Middle Initial)

THOMAS MCPETERS

Mailing Address 6451 N. SILVERSMITH PLACE

\begin{tabular}{lcc}
\hline City & State & Zip Code \\
Tucson & AZ & $85750-1086$ \\
\hline
\end{tabular}

FEC ID number of contributing

federal political committee.

C

Name of Employer

McPETRS MCALEARNEY SHIMOFF \&

$H \Delta T T$

Receipt For: 2012

Х Primary $\square$ General

$\triangle$ Other (specify)

Occupation

Attorney

Election Cycle-to-Date

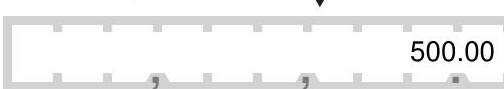

Transaction ID : A4E57E9AF06C34A7FB9A

Date of Receipt

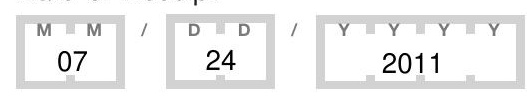

Amount of Each Receipt this Period

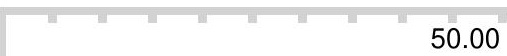

50.00

C. Full Name (Last, First, Middle Initial)

Richard E Hull

Mailing Address 1634 N.W. 10TH ST.

\begin{tabular}{lcc}
\hline City & State & Zip Code \\
Oklahoma City & OK & $73106-4824$
\end{tabular}

FEC ID number of contributing federal political committee.

C

73106-4824

Name of Employer

Nabholz Corp

Receipt For: 2012

Х $\begin{aligned} & \text { Primary } \\ & \text { Other (specify) }\end{aligned}$

\section{Occupation}

Construction

Election Cycle-to-Date

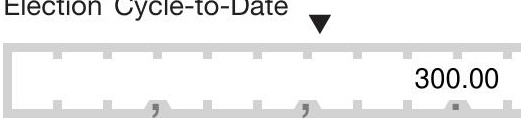

Transaction ID : A72BAA65A89F04CC7B64 Date of Receipt

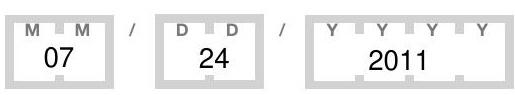

Amount of Each Receipt this Period

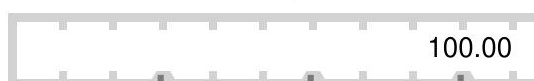

Transaction ID : A13E2383BBD8E468CB7E Date of Receipt

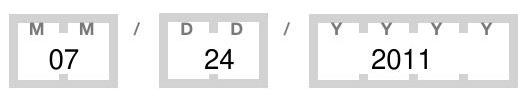

Amount of Each Receipt this Period

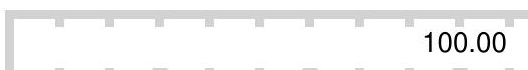

100.00

\section{Subtotal Of Receipts This Page (optional)}

Total This Period (last page this line number only) 
SCHEDULE A-P ITEMIZED RECEIPTS
Use separate schedule(s) for each category of the Detailed Summary Page
FOR LINE NUMBER: (check only one)

\begin{tabular}{|c|c|c|c|c|c|c|}
\hline & & & & & & \\
\hline 16 & $\times 1$ & $17 a$ & $17 b$ & $17 c$ & $17 d$ & 18 \\
\hline $19 a$ & & $19 b$ & $20 \mathrm{a}$ & $20 \mathrm{~b}$ & $20 \mathrm{c}$ & 21 \\
\hline
\end{tabular}

Any information copied from such Reports and Statements may not be sold or used by any person for the purpose of soliciting contributions or for commercial purposes, other than using the name and address of any political committee to solicit contributions from such committee.

NAME OF COMMITTEE (In Full)

\section{Friends of Herman Cain}

A. Full Name (Last, First, Middle Initial)

Laura A Hay

Mailing Address 231 Burke Circle

\begin{tabular}{lcc}
\hline City & State & Zip Code \\
McDonough & GA & $30253-2012$
\end{tabular}

FEC ID number of contributing federal political committee.

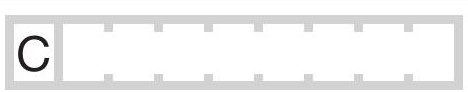

Name of Employer
Retired
Receipt For: 2012
X Primary $\quad$ General
Other (specify)

\section{Occupation} N/A

Election Cycle-to-Date

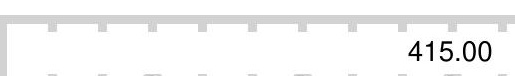

B. Full Name (Last, First, Middle Initial) John Hester

Mailing Address 3882 Glen meadow Dr

\begin{tabular}{lcc}
\hline City & State & Zip Code \\
Norcross & GA & $30092-1912$
\end{tabular}

FEC ID number of contributing

federal political committee.

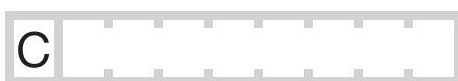

Name of Employer
Turner Broadcasting
Receipt For: 2012
X Primary
Other (specify)

\section{Occupation}

Engineer

Election Cycle-to-Date

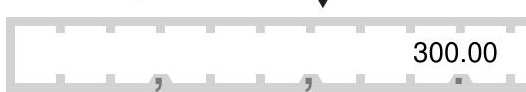

C. Full Name (Last, First, Middle Initial)

Patricia Durham

Mailing Address 205 Saint Elizabeth Ter

\begin{tabular}{lcc}
\hline City & State & Zip Code \\
Stockbridge & GA & $30281-9701$
\end{tabular}

FEC ID number of contributing federal political committee.

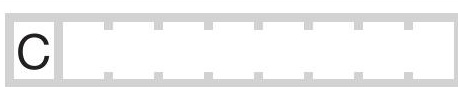

Name of Employer
Henry Medical Center
Receipt For: 2012
X Primary
Other (specify) General

\section{Occupation}

$\mathrm{RN}$

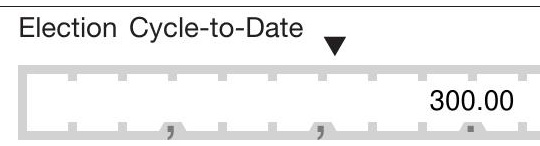

Transaction ID : A42EA9A1ACD2542719FE

Date of Receipt

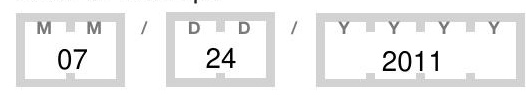

Amount of Each Receipt this Period

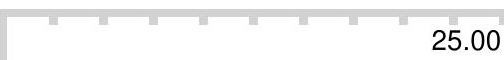

25.00

Transaction ID : A9924C2301FFC43B48B1

Date of Receipt

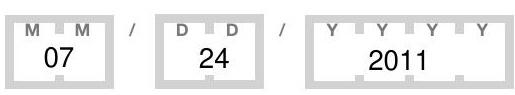

Amount of Each Receipt this Period

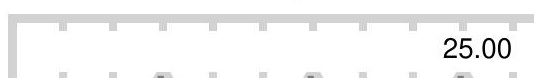

Transaction ID : A6F058F29D7EF4E608A1

Date of Receipt

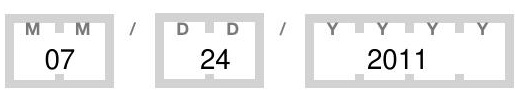

Amount of Each Receipt this Period

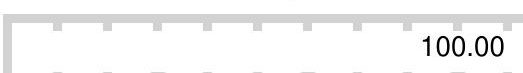

100.00

Subtotal Of Receipts This Page (optional)

Total This Period (last page this line number only) 
SCHEDULE A-P ITEMIZED RECEIPTS
Use separate schedule(s) for each category of the Detailed Summary Page
FOR LINE NUMBER: (check only one)

PAGE $145 / 1572$

\begin{tabular}{|c|c|c|c|c|c|}
\hline & & & & & \\
\hline 16 & $\begin{array}{l}\mathbf{X} \\
17 a\end{array}$ & $17 b$ & $17 c$ & $17 d$ & 18 \\
\hline $19 a$ & $19 \mathrm{~b}$ & $20 \mathrm{a}$ & $20 \mathrm{~b}$ & $20 \mathrm{c}$ & 21 \\
\hline
\end{tabular}

Any information copied from such Reports and Statements may not be sold or used by any person for the purpose of soliciting contributions or for commercial purposes, other than using the name and address of any political committee to solicit contributions from such committee.

NAME OF COMMITTEE (In Full)

\section{Friends of Herman Cain}

A. Full Name (Last, First, Middle Initial)

Harry Nolan

Mailing Address P.O. Box 421428

\begin{tabular}{lcc}
\hline City & State & Zip Code \\
Atlanta & GA & $30342-8428$ \\
\hline
\end{tabular}

FEC ID number of contributing federal political committee.

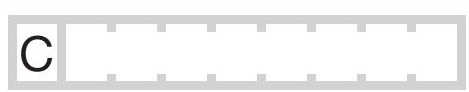

Name of Employer
MAS
Receipt For: 2012
X Primary $\quad$ General
Other (specify)

Occupation Consultant

Election Cycle-to-Date

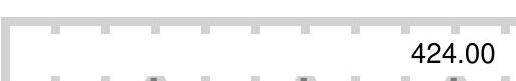

B. Full Name (Last, First, Middle Initial)

Martha Shaw

Mailing Address 1478 IDLEWILD DR

\begin{tabular}{lcc}
\hline City & State & Zip Code \\
Marysville & OH & $43040-7078$ \\
\hline
\end{tabular}

FEC ID number of contributing

federal political committee.

C

Name of Employer
Honda of America
Receipt For: 2012
X Primary
Other (specify) General

Occupation

Autoworker

Election Cycle-to-Date

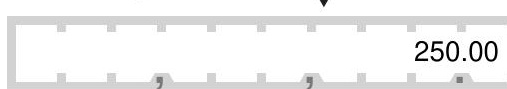

Transaction ID : AB5F367C669344ADD879

Date of Receipt

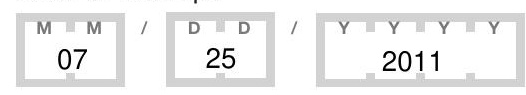

Amount of Each Receipt this Period

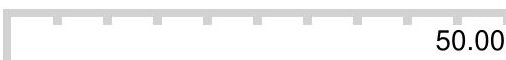

50.00

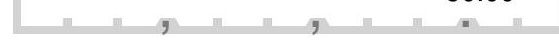

Transaction ID : A535FD93155CC4F06803

Date of Receipt

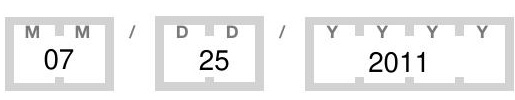

Amount of Each Receipt this Period

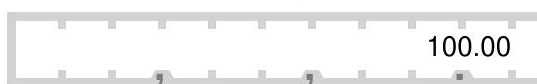

Transaction ID : AF3FF8F52D7FA4518895

Date of Receipt

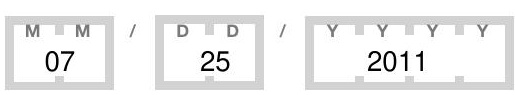

Amount of Each Receipt this Period

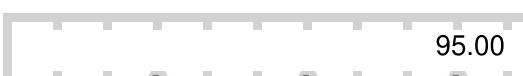

Information Requested

Election Cycle-to-Date

Receipt For: 2012

Х $\begin{aligned} & \text { Primary } \square \text { General } \\ & \text { Other (specify) }\end{aligned}$

345.00
Subtotal Of Receipts This Page (optional)

245.00

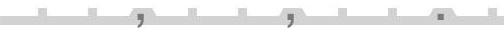

Total This Period (last page this line number only)

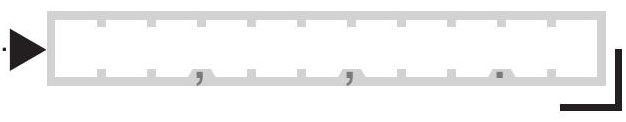

FEC Schedule A-P (Form 3P) (Rev. 03/2011) 
SCHEDULE A-P ITEMIZED RECEIPTS
Use separate schedule(s) for each category of the Detailed Summary Page
FOR LINE NUMBER: (check only one)

PAGE $146 / 1572$

\begin{tabular}{|c|c|c|c|c|c|}
\hline & & & & & \\
\hline 16 & $\begin{array}{l}\mathbf{X} \\
17 a\end{array}$ & $17 b$ & $17 c$ & $17 d$ & 18 \\
\hline $19 a$ & $19 \mathrm{~b}$ & $20 \mathrm{a}$ & $20 \mathrm{~b}$ & $20 \mathrm{c}$ & 21 \\
\hline
\end{tabular}

Any information copied from such Reports and Statements may not be sold or used by any person for the purpose of soliciting contributions or for commercial purposes, other than using the name and address of any political committee to solicit contributions from such committee.

NAME OF COMMITTEE (In Full)

\section{Friends of Herman Cain}

A. Full Name (Last, First, Middle Initial) John C Bridge

Mailing Address 43 Estates Dr Apt 2

\begin{tabular}{lcc}
\hline City & State & Zip Code \\
Manchester & ME & $04351-3655$
\end{tabular}

FEC ID number of contributing federal political committee.

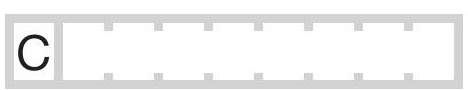

Name of Employer
None
Receipt For: 2012
X Primary $\quad$ General
Other (specify)

Occupation Retired Election Cycle-to-Date

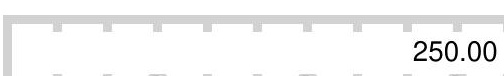

B. Full Name (Last, First, Middle Initial)

Mr Wayne Ryan

Mailing Address 1606 S 187th Cir

\begin{tabular}{lcc}
\hline City & State & Zip Code \\
Omaha & NE & $68130-2809$
\end{tabular}

FEC ID number of contributing

federal political committee.

C

Name of Employer
Information Requested
Receipt For: 2012
Primary
Other (specify)

Occupation

Information Requested

Election Cycle-to-Date

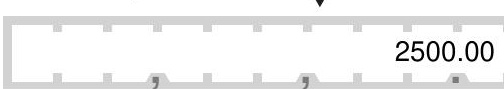

C. Full Name (Last, First, Middle Initial)

Brenda Eidson

Mailing Address 454 Furys Ferry Rd.

\begin{tabular}{lcc}
\hline City & State & Zip Code \\
Martinez & GA & $30907-9506$
\end{tabular}

FEC ID number of contributing federal political committee.

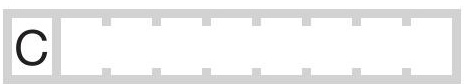

Name of Employer

Information Requested

\section{Occupation}

Information Requested

Receipt For: 2012

Х $\begin{aligned} & \text { Primary } \square \text { General } \\ & \text { Other (specify) }\end{aligned}$

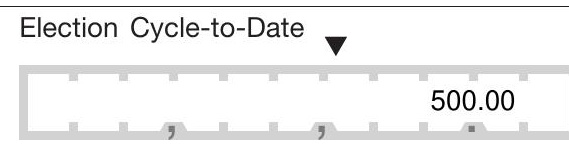

Amount of Each Receipt this Period

Transaction ID : A0CB7BF5277D3484E894

Date of Receipt

Date of Receipt

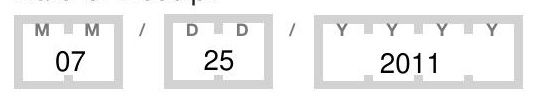

Amount of Each Receipt this Period

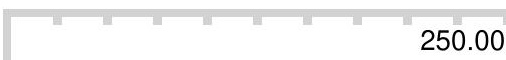

250.00
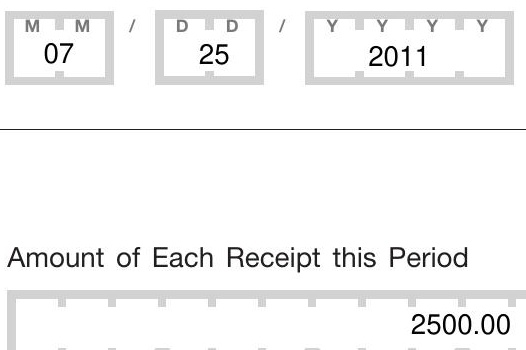

Transaction ID : A906B86195DB74E8E82C Date of Receipt

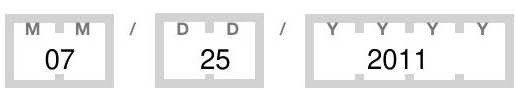

Amount of Each Receipt this Period

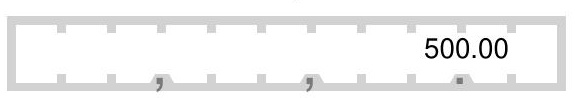

Subtotal Of Receipts This Page (optional).

Total This Period (last page this line number only) 
SCHEDULE A-P ITEMIZED RECEIPTS
Use separate schedule(s) for each category of the Detailed Summary Page
FOR LINE NUMBER: (check only one)

PAGE 147 / 1572

\begin{tabular}{|c|c|c|c|c|c|}
\hline & & & & & \\
\hline 16 & $\begin{array}{l}\mathbf{X} \\
17 a\end{array}$ & $17 b$ & $17 c$ & $17 d$ & 18 \\
\hline $19 a$ & $19 \mathrm{~b}$ & $20 \mathrm{a}$ & $20 \mathrm{~b}$ & $20 \mathrm{c}$ & 21 \\
\hline
\end{tabular}

Any information copied from such Reports and Statements may not be sold or used by any person for the purpose of soliciting contributions or for commercial purposes, other than using the name and address of any political committee to solicit contributions from such committee.

NAME OF COMMITTEE (In Full)

Friends of Herman Cain

A. Full Name (Last, First, Middle Initial)

Mr Solon P Patterson

Mailing Address 2660 Peachtree Rd NW Apt 22E

\begin{tabular}{lcc}
\hline City & State & Zip Code \\
Atlanta & GA & $30305-3678$ \\
\hline
\end{tabular}

FEC ID number of contributing federal political committee.

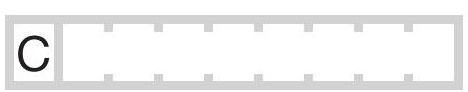

Name of Employer
Information Requested
Receipt For: 2012
X Primary
$\square$ Other (specify)

Occupation

Retired

Election Cycle-to-Date

250.00

B. Full Name (Last, First, Middle Initial)

David Stewart

Mailing Address 10740 Stargate Lane

\begin{tabular}{lcc}
\hline City & State & Zip Code \\
Cincinnati & OH & $45240-3532$ \\
\hline
\end{tabular}

FEC ID number of contributing

federal political committee.

C

Name of Employer
Casco Manufacturing Solutions
Receipt For: 2012
Xrimary
Other (specify)

Occupation

Customer Service/Sales

Election Cycle-to-Date

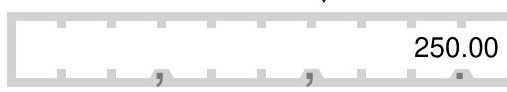

C. Full Name (Last, First, Middle Initial)

Fred D Backer Jr

Mailing Address 18 Narry Ln

\begin{tabular}{lcc}
\hline City & State & Zip Code \\
Mount Morris & NY & $14510-1519$
\end{tabular}

FEC ID number of contributing federal political committee.

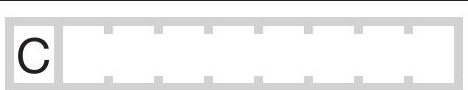

Name of Employer
None
Receipt For: 2012
Х Primary $\quad \square$ General
Other (specify)

\section{Occupation}

Retired

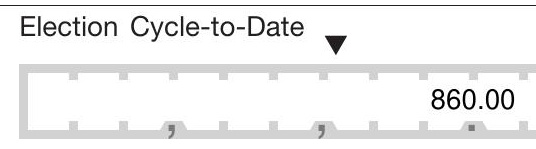

Transaction ID : A6998C178E5C946E49DD

Date of Receipt

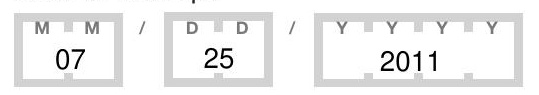

Amount of Each Receipt this Period

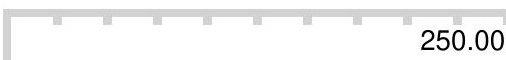

Amount of Each Receipt this Period

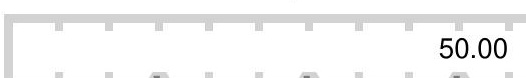

Transaction ID : AD7BBC9A7C0FA4AE999A Date of Receipt

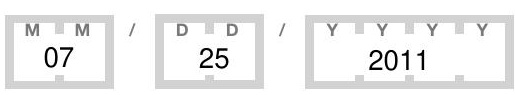

Transaction ID : A12E1446E5C294534ACA Date of Receipt

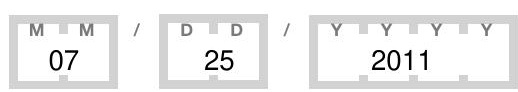

Amount of Each Receipt this Period

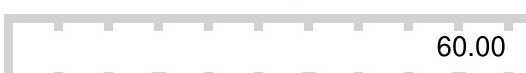

Subtotal Of Receipts This Page (optional).

$+, \quad 360.00$

Total This Period (last page this line number only)

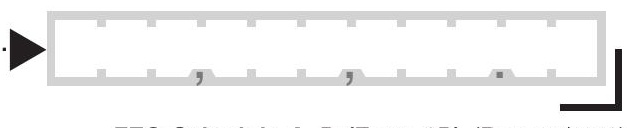

FEC Schedule A-P (Form 3P) (Rev. 03/2011) 
SCHEDULE A-P ITEMIZED RECEIPTS
Use separate schedule(s) for each category of the Detailed Summary Page
FOR LINE NUMBER: (check only one)

PAGE $148 / 1572$

\begin{tabular}{|c|c|c|c|c|c|}
\hline & & & & & \\
\hline 16 & $\begin{array}{l}\mathbf{X} \\
17 a\end{array}$ & $17 b$ & $17 c$ & $17 d$ & 18 \\
\hline $19 a$ & $19 \mathrm{~b}$ & $20 \mathrm{a}$ & $20 \mathrm{~b}$ & $20 \mathrm{c}$ & 21 \\
\hline
\end{tabular}

Any information copied from such Reports and Statements may not be sold or used by any person for the purpose of soliciting contributions or for commercial purposes, other than using the name and address of any political committee to solicit contributions from such committee.

NAME OF COMMITTEE (In Full)

\section{Friends of Herman Cain}

A. Full Name (Last, First, Middle Initial)

Mary J Roddey

Mailing Address 12971 Highway 1

\begin{tabular}{lcc}
\hline City & State & Zip Code \\
Oil City & LA & $71061-9122$ \\
\hline
\end{tabular}

FEC ID number of contributing federal political committee.

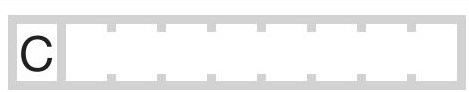

Name of Employer
Heard McElroy \& Vestal CP
Receipt For: 2012
X Primary $\quad \square$ General
Other (specify)

\section{Occupation}

CPA

Election Cycle-to-Date

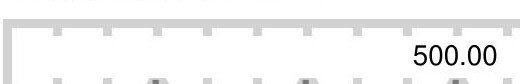

B. Full Name (Last, First, Middle Initial)

Laura Depoe

Mailing Address 2794 Emerald Dr.

\begin{tabular}{lcc}
\hline City & State & Zip Code \\
Jonesboro & GA & $30236-5302$ \\
\hline
\end{tabular}

FEC ID number of contributing

federal political committee.

C

\begin{tabular}{l} 
Name of Employer \\
DePoe Eye Center \\
Receipt For: 2012 \\
Primary \\
\hline Other (specify) General
\end{tabular}

Occupation

Physician

Election Cycle-to-Date

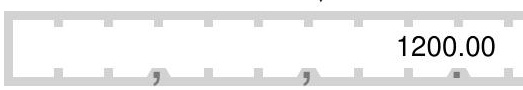

Transaction ID : ABEC2BE194B954FA8AA5

Date of Receipt

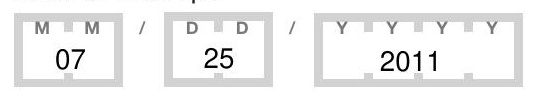

Amount of Each Receipt this Period

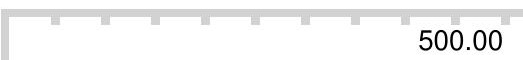

C. Full Name (Last, First, Middle Initial)

Brenda McLaughlin

Mailing Address 1418 Lynnview Dr

\begin{tabular}{lcc}
\hline City & State & Zip Code \\
Houston & TX & $77055-3426$
\end{tabular}

FEC ID number of contributing federal political committee.

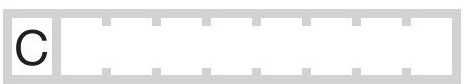

Name of Employer

Information Requested

\section{Occupation}

Information Requested

Receipt For: 2012

Х $\begin{aligned} & \text { Primary } \square \text { General } \\ & \text { Other (specify) }\end{aligned}$

Transaction ID : A808AA94CBC244749A2D

Date of Receipt

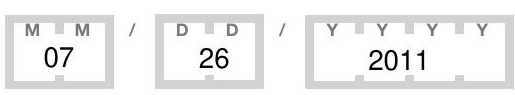

Amount of Each Receipt this Period

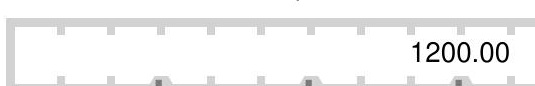

Transaction ID : A57B79ADAE00948A394B Date of Receipt

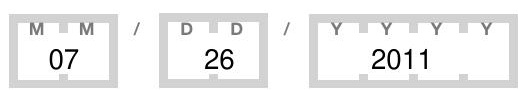

Amount of Each Receipt this Period

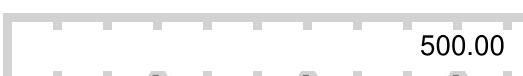

500.00

\section{Subtotal Of Receipts This Page (optional)}

Total This Period (last page this line number only) 
SCHEDULE A-P ITEMIZED RECEIPTS
Use separate schedule(s) for each category of the Detailed Summary Page
FOR LINE NUMBER: (check only one)

PAGE $149 / 1572$

\begin{tabular}{|c|c|c|c|c|c|}
\hline & & & & & \\
\hline 16 & $\begin{array}{l}\mathbf{X} \\
17 a\end{array}$ & $17 b$ & $17 c$ & $17 d$ & 18 \\
\hline $19 a$ & $19 \mathrm{~b}$ & $20 \mathrm{a}$ & $20 \mathrm{~b}$ & $20 \mathrm{c}$ & 21 \\
\hline
\end{tabular}

Any information copied from such Reports and Statements may not be sold or used by any person for the purpose of soliciting contributions or for commercial purposes, other than using the name and address of any political committee to solicit contributions from such committee.

NAME OF COMMITTEE (In Full)

\section{Friends of Herman Cain}

A. Full Name (Last, First, Middle Initial)

\section{Susan Walter}

Mailing Address P.O. Box 690

\begin{tabular}{lcc}
\hline City & State & Zip Code \\
Sautee Nacoochee & GA & $30571-0690$ \\
\hline
\end{tabular}

FEC ID number of contributing federal political committee.

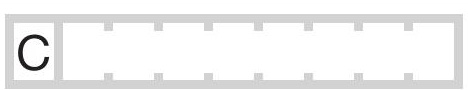

\begin{tabular}{l} 
Name of Employer \\
None \\
Receipt For: 2012 \\
X Primary $\quad$ General \\
\hline Other (specify)
\end{tabular}

Occupation Retired

Election Cycle-to-Date

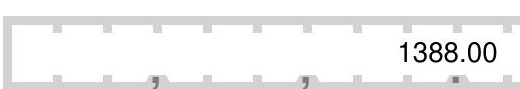

B. Full Name (Last, First, Middle Initial)

Ada Cook

Mailing Address 1400 Ortega St.

\begin{tabular}{lcc}
\hline City & State & Zip Code \\
San Francisco & CA & $94122-4436$
\end{tabular}

FEC ID number of contributing

federal political committee.

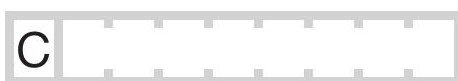

Name of Employer
Self-Employed
Receipt For: 2012
X Primary $\quad$ General
Other (specify)

\section{Occupation} NURSE

Election Cycle-to-Date

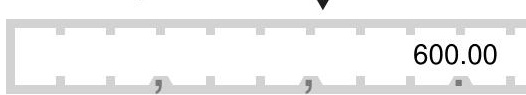

Transaction ID : AF15AF365388242B89BF

Date of Receipt

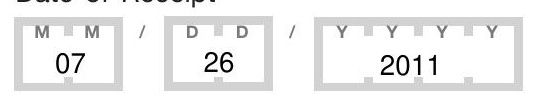

Amount of Each Receipt this Period

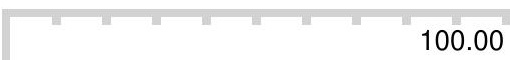

Transaction ID : AE045A6D202FD46648A0

Date of Receipt

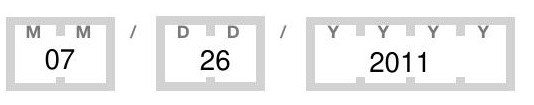

Amount of Each Receipt this Period

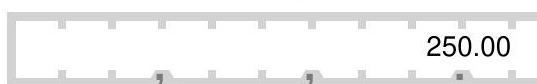

Transaction ID : AABD393356B91453BB00 Date of Receipt

Christy Williams

Mailing Address Po Box 672373

\begin{tabular}{lcc}
\hline City & State & Zip Code \\
Marietta & GA & $30006-0040$
\end{tabular}

FEC ID number of contributing federal political committee.

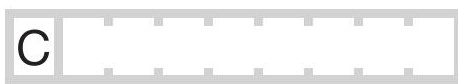

Name of Employer
Self Employed
Receipt For: 2012
X Primary $\quad \square$ General
Other (specify)

\section{Occupation}

Tac Consultant

Election Cycle-to-Date

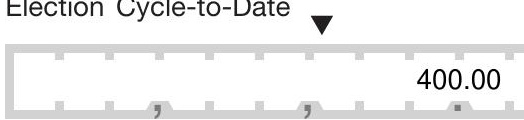

Subtotal Of Receipts This Page (optional)

Amount of Each Receipt this Period

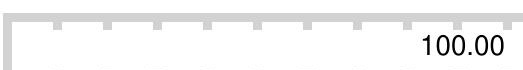

Total This Period (last page this line number only)

450.00

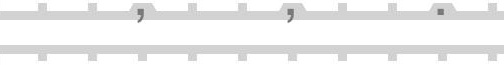

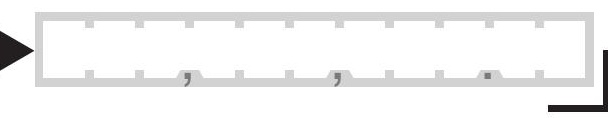

FEC Schedule A-P (Form 3P) (Rev. 03/2011) 
SCHEDULE A-P ITEMIZED RECEIPTS
Use separate schedule(s) for each category of the Detailed Summary Page
FOR LINE NUMBER: (check only one)

PAGE $150 / 1572$

\begin{tabular}{|c|c|c|c|c|c|}
\hline & & & & & \\
\hline 16 & $\begin{array}{l}\mathbf{X} \\
17 a\end{array}$ & $17 b$ & $17 c$ & $17 d$ & 18 \\
\hline $19 a$ & $19 \mathrm{~b}$ & $20 \mathrm{a}$ & $20 \mathrm{~b}$ & $20 \mathrm{c}$ & 21 \\
\hline
\end{tabular}

Any information copied from such Reports and Statements may not be sold or used by any person for the purpose of soliciting contributions or for commercial purposes, other than using the name and address of any political committee to solicit contributions from such committee.

NAME OF COMMITTEE (In Full)

\section{Friends of Herman Cain}

A. Full Name (Last, First, Middle Initial)

\section{Gordon Hamrick}

Mailing Address P.O. Box 1060

\section{City}

Shelby

FEC ID number of contributing federal political committee.

Name of Employer
Information Requested
Receipt For: 2012
X Primary
Other (specify)

B. Full Name (Last, First, Middle Initial)

Ted Frey

Mailing Address 5292 Fairfield W.

\begin{tabular}{lcc}
\hline City & State & Zip Code \\
Dunwoody & GA & $30338-3203$ \\
\hline
\end{tabular}

FEC ID number of contributing

federal political committee.

C

Name of Employer
Information Requested
Receipt For: 2012
Primary
Other (specify)

Name of Employer

Information Requested

Receipt For: 2012

Other (specify)

$\begin{array}{cc}\text { State } & \text { Zip Code } \\ \text { NC } & 28151-1060\end{array}$

C

Occupation

Information Requested

Election Cycle-to-Date

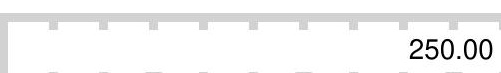

Transaction ID : ABD38D128EC5248B18F1

Date of Receipt

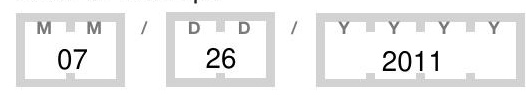

Amount of Each Receipt this Period

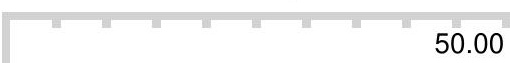

Transaction ID : A9EFEB59F640345C083C

Date of Receipt

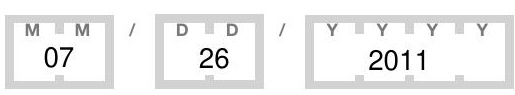

Amount of Each Receipt this Period

Occupation

Information Requested

Election Cycle-to-Date

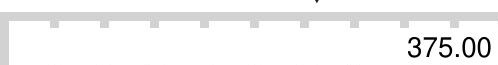

C. Full Name (Last, First, Middle Initial)

Mary Williams

Mailing Address 1224 McIntosh Woods Rd

\begin{tabular}{lcc}
\hline City & State & Zip Code \\
Florence & SC & $29501-4579$
\end{tabular}

FEC ID number of contributing

federal political committee.

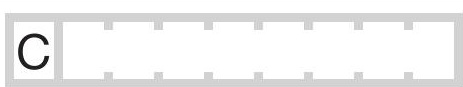

Name of Employer
None
Receipt For: 2012
X Primary $\quad \square$ General
Other (specify)

Occupation

Retired

Election Cycle-to-Date

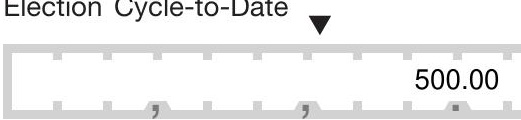

Subtotal Of Receipts This Page (optional)

925.00

Amount of Each Receipt this Period
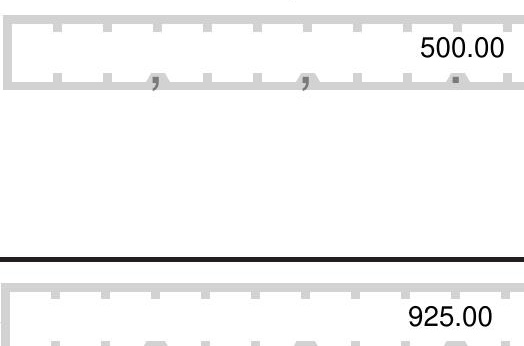

Total This Period (last page this line number only)

Transaction ID : A20677BED06C44826B69

Date of Receipt

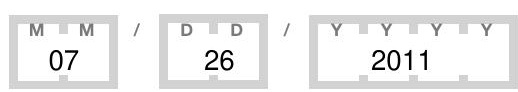

a 1 , L

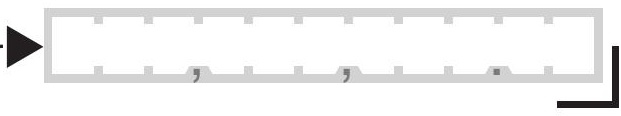




\section{SCHEDULE A-P} ITEMIZED RECEIPTS
Use separate schedule(s)

for each category of the

Detailed Summary Page
FOR LINE NUMBER: (check only one)

PAGE $151 / 1572$

\begin{tabular}{|c|c|c|c|c|c|}
\hline & & & & & \\
\hline 16 & X $17 a$ & $17 b$ & $17 c$ & $17 d$ & 18 \\
\hline $19 a$ & $19 b$ & $20 \mathrm{a}$ & $20 \mathrm{~b}$ & $20 \mathrm{c}$ & 21 \\
\hline
\end{tabular}

Any information copied from such Reports and Statements may not be sold or used by any person for the purpose of soliciting contributions or for commercial purposes, other than using the name and address of any political committee to solicit contributions from such committee.

NAME OF COMMITTEE (In Full)

Friends of Herman Cain

A. Full Name (Last, First, Middle Initial)

Mark Slepin

Mailing Address 638 Masters Way

\begin{tabular}{lcc}
\hline City & State & Zip Code \\
Palm Beach Gardens & FL & $33418-8493$
\end{tabular}

FEC ID number of contributing

federal political committee.

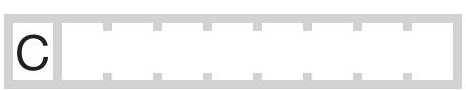

Name of Employer
Information Requested
Receipt For: 2012
X Primary $\quad \square$ General
Other (specify)

Occupation

Information Requested

Election Cycle-to-Date

300.00

B. Full Name (Last, First, Middle Initial)

robert schwartz

Mailing Address 65293 East Rocky

\begin{tabular}{lcc}
\hline City & State & Zip Code \\
Tucson & AZ & 85739 \\
\hline
\end{tabular}

FEC ID number of contributing

federal political committee.

C

Name of Employer
Information Requested
Receipt For: 2012
Primary
Other (specify)

Occupation

Information Requested

Election Cycle-to-Date

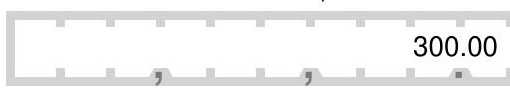

Transaction ID : AB4851A6E24EF4639ACF

Date of Receipt

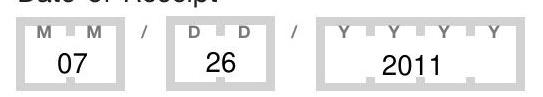

Amount of Each Receipt this Period

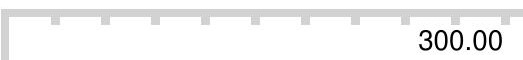

C. Full Name (Last, First, Middle Initial)

George Gardner

Mailing Address PO Box 38

\begin{tabular}{lcc}
\hline City & State & Zip Code \\
Carlisle & PA & $17013-0038$
\end{tabular}

FEC ID number of contributing

federal political committee.

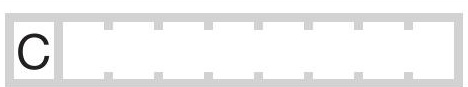

Name of Employer
Retired
Receipt For: 2012
X Primary $\quad \square$ General
Other (specify)

Occupation

Retired

Election Cycle-to-Date

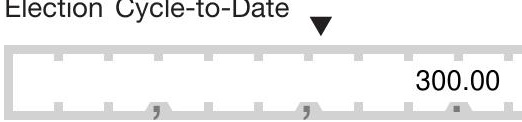

Transaction ID : AB38D537A01E14AB7B14 Date of Receipt

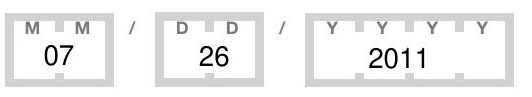

Amount of Each Receipt this Period

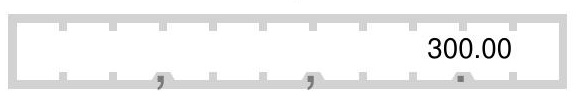

Transaction ID : A3F71ACAB1EF148D78E7 Date of Receipt

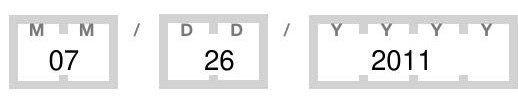

Amount of Each Receipt this Period

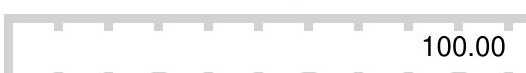

\section{Subtotal Of Receipts This Page (optional)}

Total This Period (last page this line number only) 
SCHEDULE A-P ITEMIZED RECEIPTS
Use separate schedule(s) for each category of the Detailed Summary Page
FOR LINE NUMBER: (check only one)

PAGE 152 / 1572

\begin{tabular}{|c|c|c|c|c|c|}
\hline & & & & & \\
\hline 16 & $\begin{array}{l}\mathbf{X} \\
17 a\end{array}$ & $17 b$ & $17 c$ & $17 d$ & 18 \\
\hline $19 a$ & $19 \mathrm{~b}$ & $20 \mathrm{a}$ & $20 \mathrm{~b}$ & $20 \mathrm{c}$ & 21 \\
\hline
\end{tabular}

Any information copied from such Reports and Statements may not be sold or used by any person for the purpose of soliciting contributions or for commercial purposes, other than using the name and address of any political committee to solicit contributions from such committee.

NAME OF COMMITTEE (In Full)

\section{Friends of Herman Cain}

A. Full Name (Last, First, Middle Initial)

Dianne B Chin

Mailing Address P O Box 962812

\begin{tabular}{lcc}
\hline City & State & Zip Code \\
Riverdale & GA & $30296-6928$ \\
\hline
\end{tabular}

FEC ID number of contributing federal political committee.

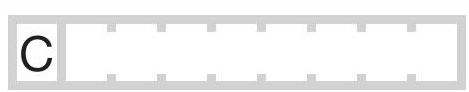

Name of Employer

Auto Auction Services Corp.

Occupation

Receipt For: 2012

X Primary $\square$ General Other (specify)

software engineer

Election Cycle-to-Date

400.00

B. Full Name (Last, First, Middle Initial)

Rick Papandrea

Mailing Address N28W30628 Red Fox Court

\begin{tabular}{lcc}
\hline City & State & Zip Code \\
Pewaukee & WI & $53072-4292$ \\
\hline
\end{tabular}

FEC ID number of contributing

federal political committee.

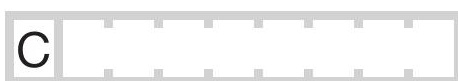

Name of Employer
self
Receipt For: 2012
X Primary
Other (specify)

Occupation

Doctor

Election Cycle-to-Date

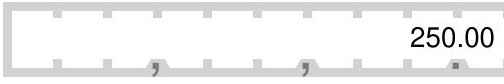

C. Full Name (Last, First, Middle Initial)

Irving Hopkins

Mailing Address 3428 Hill Valley Street

\begin{tabular}{lcc}
\hline City & State & Zip Code \\
Las Vegas & NV & 89129 \\
\hline
\end{tabular}

FEC ID number of contributing

federal political committee.

C

Name of Employer
Information Requested
Receipt For: 2012
X Primary
Other (specify) General

Occupation

Information Requested

Election Cycle-to-Date
Transaction ID : A8474FD99F71D4D1D897

Date of Receipt

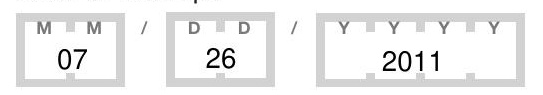

Amount of Each Receipt this Period

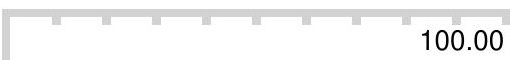

Amount of Each Receipt this Period

Transaction ID : A5E5EFADFD7354A0FAEE Date of Receipt
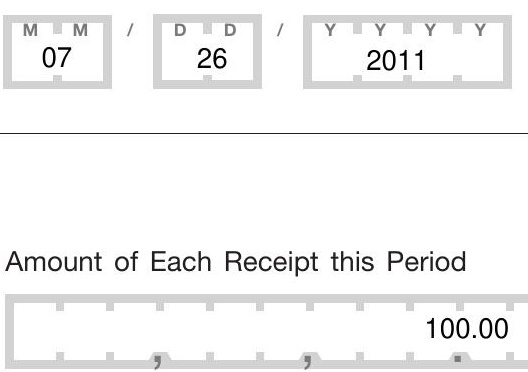

Transaction ID : AA943B0D0F5BA4FD8BDD Date of Receipt

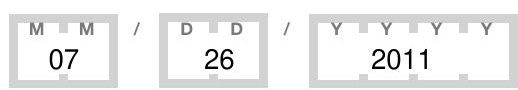

Amount of Each Receipt this Period

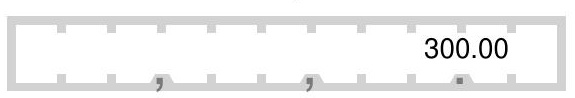

300.00

\section{Subtotal Of Receipts This Page (optional)}

Total This Period (last page this line number only) 
SCHEDULE A-P ITEMIZED RECEIPTS
Use separate schedule(s) for each category of the Detailed Summary Page
FOR LINE NUMBER: (check only one)
PAGE $153 / 1572$

\begin{tabular}{|c|c|c|c|c|c|}
\hline & & & & & \\
\hline 16 & $\begin{array}{lll}X & 17 a \\
\end{array}$ & $17 \mathrm{~b}$ & $17 c$ & $17 d$ & 18 \\
\hline $19 a$ & $19 b$ & $20 a$ & $20 \mathrm{~b}$ & $20 c$ & 21 \\
\hline
\end{tabular}

Any information copied from such Reports and Statements may not be sold or used by any person for the purpose of soliciting contributions or for commercial purposes, other than using the name and address of any political committee to solicit contributions from such committee.

NAME OF COMMITTEE (In Full)

\section{Friends of Herman Cain}

A. Full Name (Last, First, Middle Initial)

Larry Smead

Mailing Address 164 Belden Street

\begin{tabular}{lcc}
\hline City & State & Zip Code \\
Falls Village & CT & $06031-1124$
\end{tabular}

FEC ID number of contributing

federal political committee.

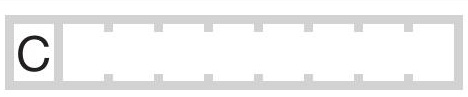

Name of Employer
Information Requested
Receipt For: 2012
X Primary
Other (specify) General

Occupation

Information Requested

Election Cycle-to-Date

300.00

B. Full Name (Last, First, Middle Initial)

Robin Andrews

Mailing Address 5880 Huddersfield Rd

\begin{tabular}{lcc}
\hline City & State & Zip Code \\
Macon & GA & $31210-2061$
\end{tabular}

FEC ID number of contributing

federal political committee.

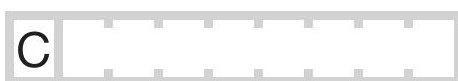

Name of Employer
Ear Dynamics
Receipt For: 2012
X Primary
Other (specify)

\section{Occupation}

Audiologist

Election Cycle-to-Date

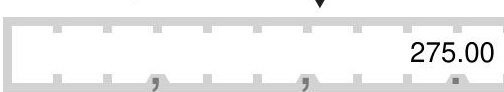

Transaction ID : A87CAD8AEAA3E4188B02

Date of Receipt

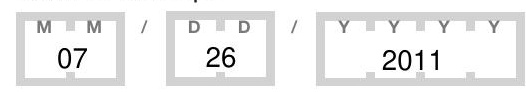

Amount of Each Receipt this Period

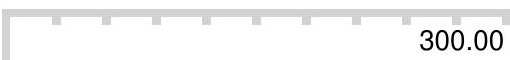

Transaction ID : A12453797C160487A805

Date of Receipt

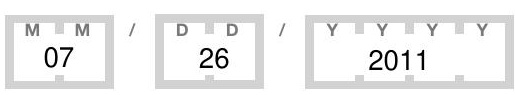

Amount of Each Receipt this Period

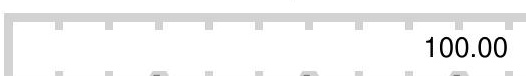

Transaction ID : A71B4184548C345DC970 Date of Receipt

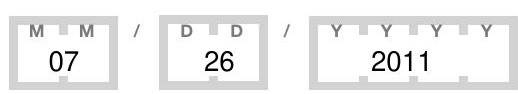

Amount of Each Receipt this Period

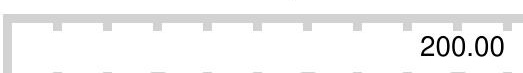

$\begin{array}{cc}\text { State } & \text { Zip Code } \\ \text { NC } & 28151-1060\end{array}$

C

Occupation

Information Requested

Election Cycle-to-Date

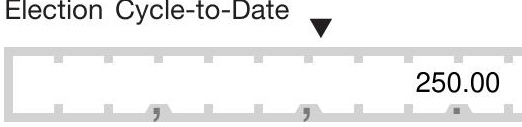

Subtotal Of Receipts This Page (optional)

600.00

a 1 ,

Total This Period (last page this line number only)

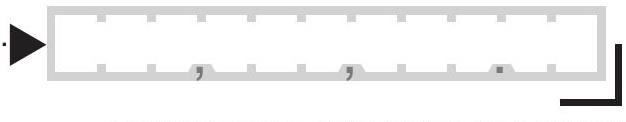

FEC Schedule A-P (Form 3P) (Rev. 03/2011) 
SCHEDULE A-P ITEMIZED RECEIPTS
Use separate schedule(s) for each category of the Detailed Summary Page
FOR LINE NUMBER: (check only one)
PAGE 154 / 1572

\begin{tabular}{|c|c|c|c|c|c|}
\hline & & & & & \\
\hline 16 & $\begin{array}{lll}X & 17 a \\
\end{array}$ & $17 \mathrm{~b}$ & $17 c$ & $17 d$ & 18 \\
\hline $19 a$ & $19 b$ & $20 a$ & $20 \mathrm{~b}$ & $20 c$ & 21 \\
\hline
\end{tabular}

Any information copied from such Reports and Statements may not be sold or used by any person for the purpose of soliciting contributions or for commercial purposes, other than using the name and address of any political committee to solicit contributions from such committee.

NAME OF COMMITTEE (In Full)

\section{Friends of Herman Cain}

A. Full Name (Last, First, Middle Initial)

\section{Doug Eames}

Mailing Address 1385 West Coach Rd. DO NOT MAIL

City

Boulder

FEC ID number of contributing federal political committee.

Name of Employer
self
Receipt For: 2012
X Primary
Other (specify) General

B. Full Name (Last, First, Middle Initial)

Lee Vliet

Mailing Address PO Box 64507

\begin{tabular}{lcc}
\hline City & State & Zip Code \\
Tucson & AZ & $85728-4507$
\end{tabular}

FEC ID number of contributing

federal political committee.

C

Name of Employer
Information Requested
Receipt For: 2012
Primary
Other (specify)

C. Full Name (Last, First, Middle Initial)

Barbara Marks

Mailing Address P.O. Box 31377

\begin{tabular}{l} 
City \\
Laughlin \\
\hline FEC ID number of contributing \\
federal political committee.
\end{tabular}

Name of Employer

Information Requested

Receipt For: 2012

Х $\begin{aligned} & \text { Primary } \\ & \text { Other (specify) }\end{aligned}$

Information Requested

Election Cycle-to-Date

Zip Code

NV 89028-1377

Occupation

Announcer

Election Cycle-to-Date 400.00
Transaction ID : A4F88EF52EBE148AF968

Date of Receipt

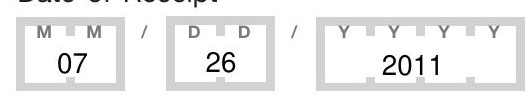

Amount of Each Receipt this Period

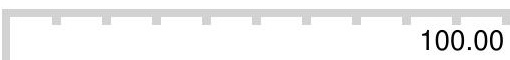

100.00

Amount of Each Receipt this Period

Transaction ID : A56D068B5CE9B4EAD846 Date of Receipt
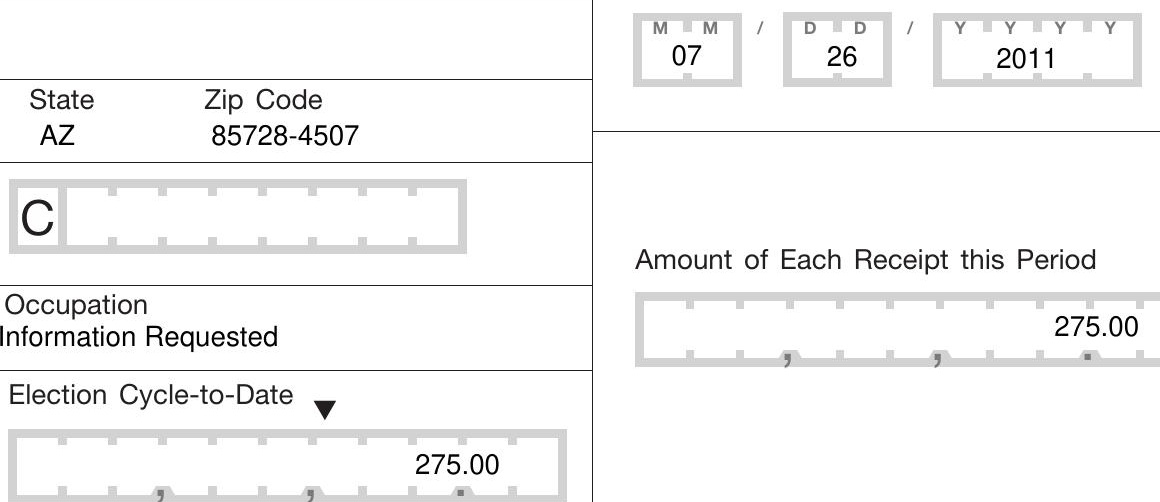

Transaction ID : AD84999CF248B4EC3B5D Date of Receipt

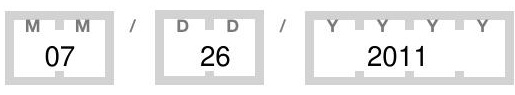

Amount of Each Receipt this Period

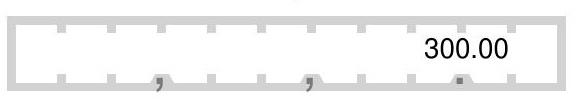

$$
\begin{aligned}
& \begin{array}{l}
\text { Occupation } \\
\text { Information Requested }
\end{array} \\
& \text { Election Cycle-to-Date } \\
&
\end{aligned}
$$

Subtotal Of Receipts This Page (optional)

Total This Period (last page this line number only) 
SCHEDULE A-P ITEMIZED RECEIPTS
Use separate schedule(s) for each category of the Detailed Summary Page
FOR LINE NUMBER: (check only one)
PAGE 155 / 1572

\begin{tabular}{|c|c|c|c|c|c|}
\hline & & & & & \\
\hline 16 & $\begin{array}{lll}X & 17 a \\
\end{array}$ & $17 \mathrm{~b}$ & $17 c$ & $17 d$ & 18 \\
\hline $19 a$ & $19 b$ & $20 a$ & $20 \mathrm{~b}$ & $20 c$ & 21 \\
\hline
\end{tabular}

Any information copied from such Reports and Statements may not be sold or used by any person for the purpose of soliciting contributions or for commercial purposes, other than using the name and address of any political committee to solicit contributions from such committee.

NAME OF COMMITTEE (In Full)

\section{Friends of Herman Cain}

A. Full Name (Last, First, Middle Initial)

\section{Barbara Marks}

Mailing Address P.O. Box 31377

\begin{tabular}{lcc}
\hline City & State & Zip Code \\
Laughlin & NV & $89028-1377$
\end{tabular}

FEC ID number of contributing federal political committee.

Name of Employer
Information Requested
Receipt For: 2012
X Primary
Other (specify) General

B. Full Name (Last, First, Middle Initial)

Glen Ebbing

Mailing Address 1400 Huntleigh Rd

\begin{tabular}{lcc}
\hline City & State & Zip Code \\
Quincy & IL & $62305-6017$
\end{tabular}

FEC ID number of contributing

federal political committee.

Name of Employer
ColorMaster Pain Inc
Receipt For: 2012
X Primary
Other (specify)

C. Full Name (Last, First, Middle Initial)

Herbert $C$ Jardine

Mailing Address 1451 Summer Oaks Ct

\begin{tabular}{l|ll}
\hline $\begin{array}{l}\text { City } \\
\text { Marietta }\end{array}$ & $\begin{array}{c}\text { State } \\
\text { GA }\end{array}$ & $\begin{array}{c}\text { Zip Code } \\
\text { 30062-6155 }\end{array}$ \\
\hline $\begin{array}{l}\text { FEC ID number of contributing } \\
\text { federal political committee. }\end{array}$ & C & \\
\hline $\begin{array}{l}\text { Name of Employer } \\
\text { None }\end{array}$ & $\begin{array}{l}\text { Occupation } \\
\text { Retired }\end{array}$ \\
\hline $\begin{array}{l}\text { Receipt For: } 2012 \\
\text { Primary } \\
\text { Other (specify) }\end{array}$ & Election Cycle-to-Date & \\
\hline
\end{tabular}

Information Requested

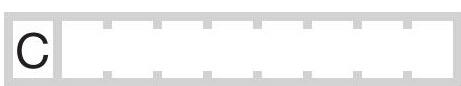

C

Transaction ID : A2BE348575E4E4E34B66

Date of Receipt

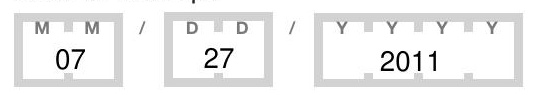

Amount of Each Receipt this Period

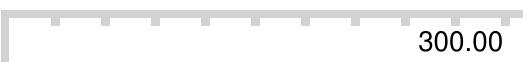

Election Cycle-to-Date

600.00

Occupation

sales representative

Election Cycle-to-Date

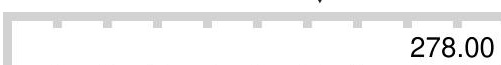

Transaction ID : AF15DEBD5ECA143BA9D8 Date of Receipt

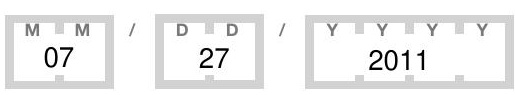

Amount of Each Receipt this Period

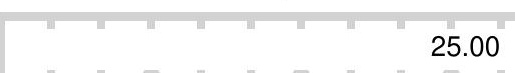

Amount of Each Receipt this Period

Transaction ID : A270832A9298C4F78926

Date of Receipt
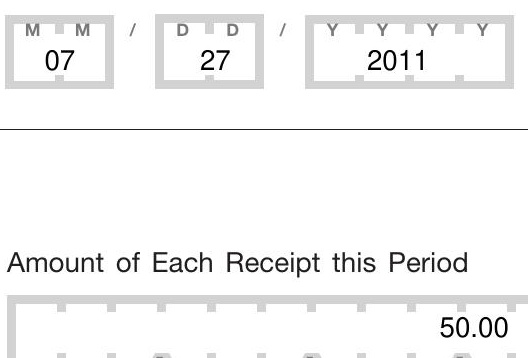

50.00

375.00

Subtotal Of Receipts This Page (optional)

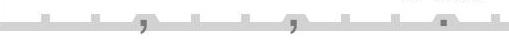

Total This Period (last page this line number only)

FEC Schedule A-P (Form 3P) (Rev. 03/2011) 
SCHEDULE A-P ITEMIZED RECEIPTS
Use separate schedule(s) for each category of the Detailed Summary Page
FOR LINE NUMBER: (check only one)
PAGE $156 / 1572$

\begin{tabular}{|c|c|c|c|c|c|}
\hline & & & & & \\
\hline 16 & $\begin{array}{lll}X & 17 a \\
\end{array}$ & $17 \mathrm{~b}$ & $17 c$ & $17 d$ & 18 \\
\hline $19 a$ & $19 b$ & $20 a$ & $20 \mathrm{~b}$ & $20 c$ & 21 \\
\hline
\end{tabular}

Any information copied from such Reports and Statements may not be sold or used by any person for the purpose of soliciting contributions or for commercial purposes, other than using the name and address of any political committee to solicit contributions from such committee.

NAME OF COMMITTEE (In Full)

\section{Friends of Herman Cain}

A. Full Name (Last, First, Middle Initial)

Martha Duggan

Mailing Address 302 East Carlisle Road

\begin{tabular}{lcc}
\hline City & State & Zip Code \\
Thousand Oaks & CA & $91361-5303$
\end{tabular}

FEC ID number of contributing

federal political committee.

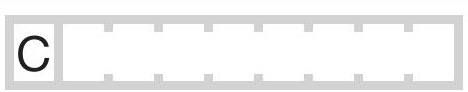

Name of Employer
Information Requested
Receipt For: 2012
X Primary $\quad \square$ General
Other (specify)

Occupation

Information Requested

Election Cycle-to-Date

400.00

B. Full Name (Last, First, Middle Initial)

Susan Walter

Mailing Address P.O. Box 690

\begin{tabular}{lcc}
\hline City & State & Zip Code \\
Sautee Nacoochee & GA & $30571-0690$
\end{tabular}

FEC ID number of contributing

federal political committee.

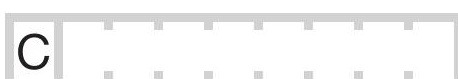

Name of Employer
None
Receipt For: 2012
X Primary
Other (specify)

Occupation

Retired

Election Cycle-to-Date

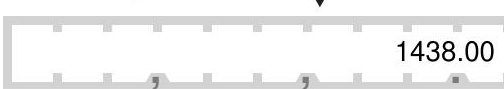

Transaction ID : A242FFB34A3D745DCA47

Date of Receipt

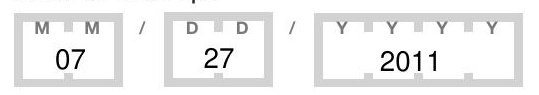

Amount of Each Receipt this Period

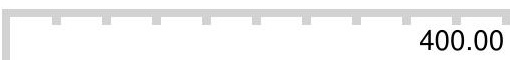

C. Full Name (Last, First, Middle Initial)

Heather Luther

Mailing Address 1000 Greystone Manor Pkwy

\begin{tabular}{lcc}
\hline City & State & Zip Code \\
Chesterfield & MO & $63005-4941$
\end{tabular}

FEC ID number of contributing

federal political committee.

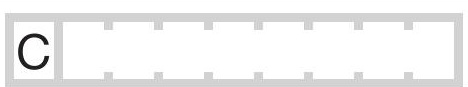

Name of Employer

ICL Performance Products LP

Receipt For: 2012

Х $\begin{aligned} & \text { Primary } \\ & \text { Other (specify) }\end{aligned}$

Occupation

Lawyer

Election Cycle-to-Date

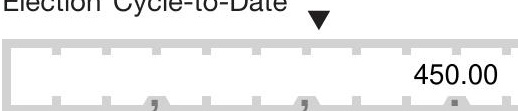

Amount of Each Receipt this Period

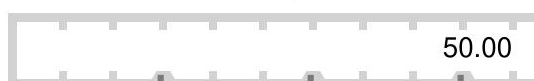

Transaction ID : ACA6247BE9AE84E4AB4E Date of Receipt

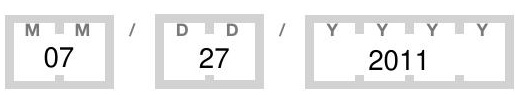

Transaction ID : A18AFDE9582B04DCBB8B Date of Receipt

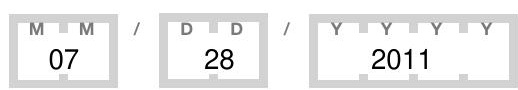

Amount of Each Receipt this Period

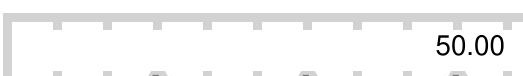

\section{Subtotal Of Receipts This Page (optional)}

Total This Period (last page this line number only) 
SCHEDULE A-P ITEMIZED RECEIPTS
Use separate schedule(s) for each category of the Detailed Summary Page
FOR LINE NUMBER: (check only one)

PAGE 157 / 1572

\begin{tabular}{|c|c|c|c|c|c|}
\hline & & & & & \\
\hline 16 & $\begin{array}{l}\mathbf{X} \\
17 a\end{array}$ & $17 b$ & $17 c$ & $17 d$ & 18 \\
\hline $19 a$ & $19 \mathrm{~b}$ & $20 \mathrm{a}$ & $20 \mathrm{~b}$ & $20 \mathrm{c}$ & 21 \\
\hline
\end{tabular}

Any information copied from such Reports and Statements may not be sold or used by any person for the purpose of soliciting contributions or for commercial purposes, other than using the name and address of any political committee to solicit contributions from such committee.

NAME OF COMMITTEE (In Full)

\section{Friends of Herman Cain}

A. Full Name (Last, First, Middle Initial)

Sarajane Jablinske

Mailing Address 95 Cartis Parker Road

\begin{tabular}{lcc}
\hline City & State & Zip Code \\
Alexander & NC & $28701-9772$ \\
\hline
\end{tabular}

FEC ID number of contributing

federal political committee.

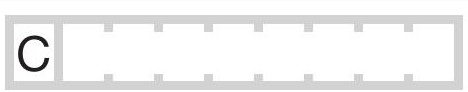

Name of Employer
Retired
Receipt For: 2012
X Primary $\quad$ General
Other (specify)

Occupation

Retired

Election Cycle-to-Date

400.00

B. Full Name (Last, First, Middle Initial)

Thomas Ward

Mailing Address 6630 Richardson Rd

\begin{tabular}{lcc}
\hline City & State & Zip Code \\
Houston & TX & $77069-1730$ \\
\hline
\end{tabular}

FEC ID number of contributing

federal political committee.

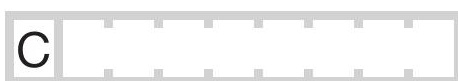

Name of Employer
Retired
Receipt For: 2012
X Primary
Other (specify)

\section{Occupation}

Retired

Election Cycle-to-Date

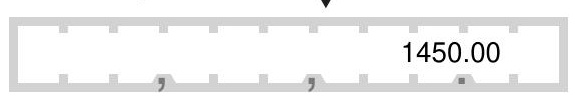

C. Full Name (Last, First, Middle Initial)

Scott Vaughn

Mailing Address 1107 61st Ct

\begin{tabular}{lcc}
\hline City & State & Zip Code \\
Meridian & MS & $39305-1230$
\end{tabular}

FEC ID number of contributing

federal political committee.

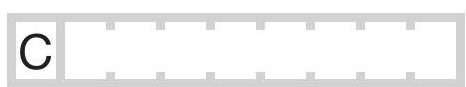

Name of Employer

Occupation

Self Employed

Restaurant Owner

Receipt For: 2012

Х $\begin{aligned} & \text { Primary } \square \text { General } \\ & \text { Other (specify) }\end{aligned}$

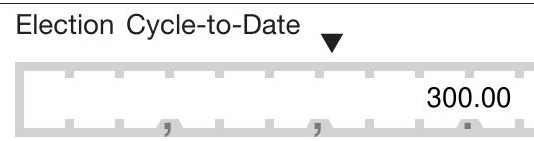

Transaction ID : AAC58929672A546C1B42

Date of Receipt

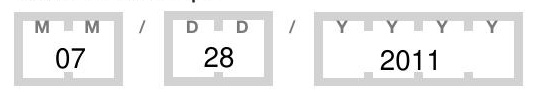

Amount of Each Receipt this Period

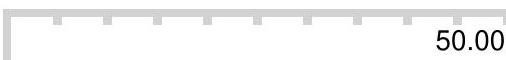

50.00

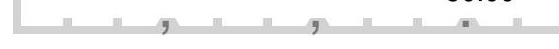

Transaction ID : ACCE10BD7C257480EA41

Date of Receipt

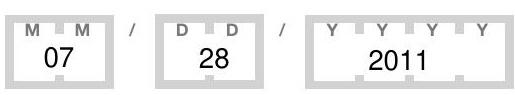

Amount of Each Receipt this Period

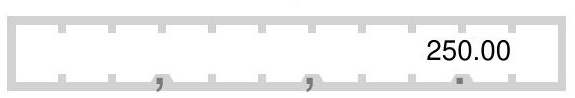

Transaction ID : AF70225DFF4F748EAB1D Date of Receipt

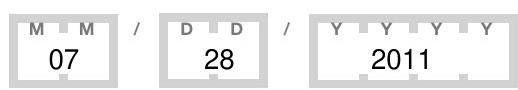

Amount of Each Receipt this Period

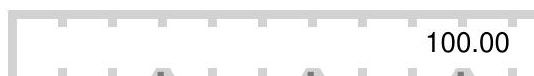

400.00

Subtotal Of Receipts This Page (optional)

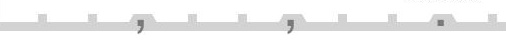

Total This Period (last page this line number only) 
SCHEDULE A-P ITEMIZED RECEIPTS
Use separate schedule(s) for each category of the Detailed Summary Page
FOR LINE NUMBER: (check only one)
PAGE $158 / 1572$

\begin{tabular}{|c|c|c|c|c|c|}
\hline & & & & & \\
\hline 16 & $\begin{array}{lll}X & 17 a \\
\end{array}$ & $17 \mathrm{~b}$ & $17 c$ & $17 d$ & 18 \\
\hline $19 a$ & $19 b$ & $20 a$ & $20 \mathrm{~b}$ & $20 c$ & 21 \\
\hline
\end{tabular}

Any information copied from such Reports and Statements may not be sold or used by any person for the purpose of soliciting contributions or for commercial purposes, other than using the name and address of any political committee to solicit contributions from such committee.

NAME OF COMMITTEE (In Full)

\section{Friends of Herman Cain}

A. Full Name (Last, First, Middle Initial)

Geoffrey Hollick

Mailing Address 3315 Highland Laurels Dr.

\begin{tabular}{lcc}
\hline City & State & Zip Code \\
Kingwood & TX & $77345-1162$ \\
\hline
\end{tabular}

FEC ID number of contributing

federal political committee.

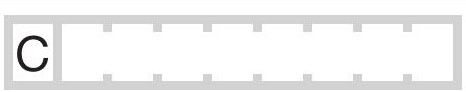

Name of Employer
Information Requested
Receipt For: 2012
X Primary $\quad \square$ General
Other (specify)

Occupation

Information Requested

Election Cycle-to-Date

250.00

B. Full Name (Last, First, Middle Initial)

Robert Bolling

Mailing Address 2109 Freeman Rd

\begin{tabular}{lcc}
\hline City & State & Zip Code \\
Jonesboro & GA & $30236-6711$
\end{tabular}

FEC ID number of contributing

federal political committee.

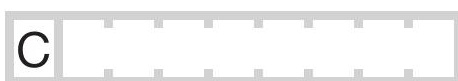

\begin{tabular}{l} 
Name of Employer \\
self \\
Receipt For: 2012 \\
X Primary $\square$ General \\
\hline Other (specify)
\end{tabular}

Occupation

contractor

Election Cycle-to-Date

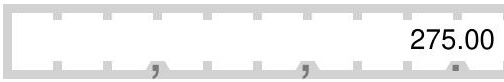

Transaction ID : A5EA830376AFF4446859

Date of Receipt

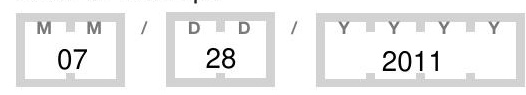

Amount of Each Receipt this Period

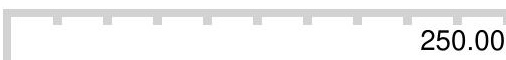

C. Full Name (Last, First, Middle Initial)

Allen Field

Mailing Address P O Box 5706

\begin{tabular}{lcc}
\hline City & State & Zip Code \\
Atlanta & GA & $31107-0706$
\end{tabular}

FEC ID number of contributing federal political committee.

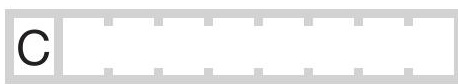

Name of Employer
Pomeroy IT
Receipt For: 2012
X Primary
Other (specify) General

Occupation

Area Manager

Election Cycle-to-Date

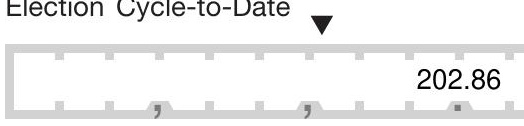

Amount of Each Receipt this Period

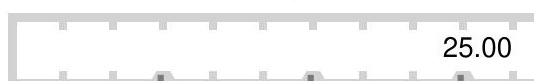

Transaction ID : ADD09301E67F447B0AF8

Date of Receipt

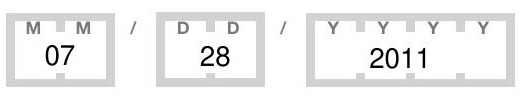

Transaction ID : A11BFB88B210A47CD841 Date of Receipt

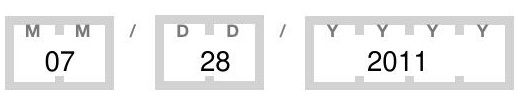

Amount of Each Receipt this Period

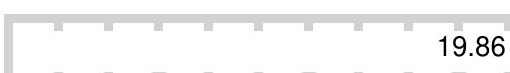

\section{Subtotal Of Receipts This Page (optional)}

294.86

(n)

Total This Period (last page this line number only)

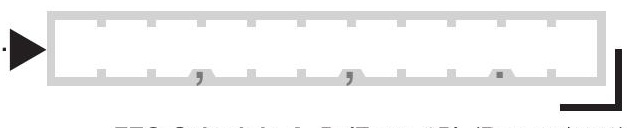

FEC Schedule A-P (Form 3P) (Rev. 03/2011) 
SCHEDULE A-P ITEMIZED RECEIPTS
Use separate schedule(s) for each category of the Detailed Summary Page
FOR LINE NUMBER: (check only one)

PAGE 159 / 1572

\begin{tabular}{|c|c|c|c|c|c|}
\hline & & & & & \\
\hline 16 & $\begin{array}{l}\mathbf{X} \\
17 a\end{array}$ & $17 b$ & $17 c$ & $17 d$ & 18 \\
\hline $19 a$ & $19 \mathrm{~b}$ & $20 \mathrm{a}$ & $20 \mathrm{~b}$ & $20 \mathrm{c}$ & 21 \\
\hline
\end{tabular}

Any information copied from such Reports and Statements may not be sold or used by any person for the purpose of soliciting contributions or for commercial purposes, other than using the name and address of any political committee to solicit contributions from such committee.

NAME OF COMMITTEE (In Full)

\section{Friends of Herman Cain}

A. Full Name (Last, First, Middle Initial)

Margaret Jones

Mailing Address 1451 Bannister Dr

\begin{tabular}{lcc}
\hline City & State & Zip Code \\
Anchorage & AK & $99508-3927$
\end{tabular}

FEC ID number of contributing federal political committee.

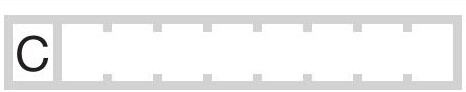

Name of Employer
Guess \& Rudd P.C.
Receipt For: 2012
X Primary
Other (specify) General

Occupation Attorney

Election Cycle-to-Date

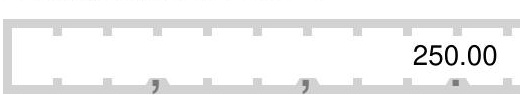

B. Full Name (Last, First, Middle Initial)

Terry Chick

Mailing Address 13650 N Heritage Canyon Dr

\begin{tabular}{lcc}
\hline City & State & Zip Code \\
Marana & AZ & 85658-4073 \\
\hline
\end{tabular}

FEC ID number of contributing

federal political committee.

C

Name of Employer
Retired
Receipt For: 2012
Primary
Other (specify)

Occupation

Retired

Election Cycle-to-Date

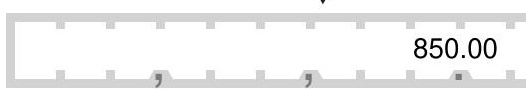

Transaction ID : A26BC7F52266546FAB8C

Date of Receipt

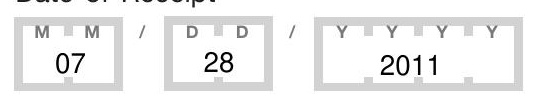

Amount of Each Receipt this Period

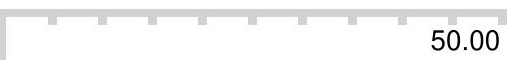

50.00

C. Full Name (Last, First, Middle Initial)

Kathryn Collier

Mailing Address 1075 Byrnwyck Trail

\begin{tabular}{lcc}
\hline City & State & Zip Code \\
Atlanta & GA & $30319-1670$
\end{tabular}

FEC ID number of contributing federal political committee.

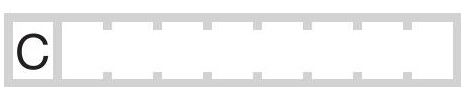

Name of Employer

Information Requested

\section{Occupation}

Information Requested

Receipt For: 2012

Х $\begin{aligned} & \text { Primary } \square \text { General } \\ & \text { Other (specify) }\end{aligned}$

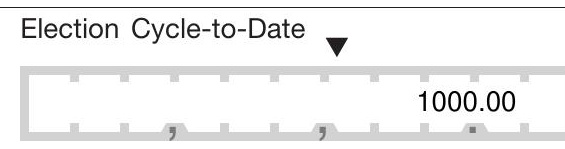

Amount of Each Receipt this Period

Transaction ID : AE50FE3FF16A24886985

Date of Receipt
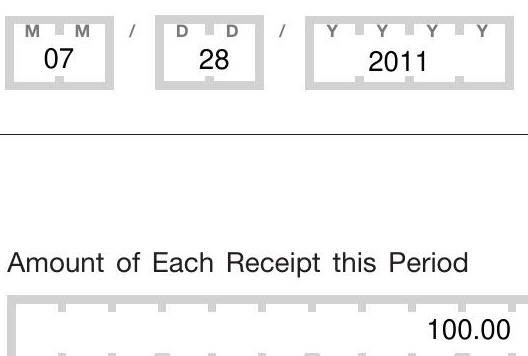

Transaction ID : AED241BE9F576400BB15 Date of Receipt

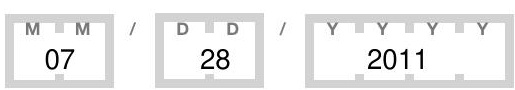

Amount of Each Receipt this Period

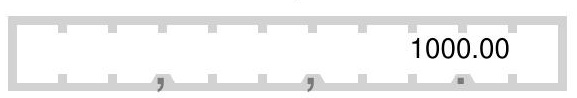

Subtotal Of Receipts This Page (optional).

1150.00

Total This Period (last page this line number only) 
SCHEDULE A-P ITEMIZED RECEIPTS
Use separate schedule(s) for each category of the Detailed Summary Page
FOR LINE NUMBER: (check only one)

PAGE $160 / 1572$

\begin{tabular}{|c|c|c|c|c|c|c|}
\hline & & & & & & \\
\hline 16 & $\lambda$ & $17 \mathrm{a}$ & $17 \mathrm{~b}$ & $17 \mathrm{c}$ & $-17 d$ & -18 \\
\hline $19 a$ & & $19 b$ & $20 a$ & $20 \mathrm{~b}$ & $20 \mathrm{c}$ & 21 \\
\hline
\end{tabular}

Any information copied from such Reports and Statements may not be sold or used by any person for the purpose of soliciting contributions or for commercial purposes, other than using the name and address of any political committee to solicit contributions from such committee.

NAME OF COMMITTEE (In Full)

\section{Friends of Herman Cain}

A. Full Name (Last, First, Middle Initial)

Laura A Hay

Mailing Address 231 Burke Circle

\begin{tabular}{lcc}
\hline City & State & Zip Code \\
McDonough & GA & $30253-2012$
\end{tabular}

FEC ID number of contributing federal political committee.

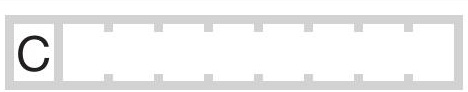

Name of Employer
Retired
Receipt For: 2012
X Primary $\quad$ General
Other (specify)

\section{Occupation}

N/A

Election Cycle-to-Date

\subsection{0}

B. Full Name (Last, First, Middle Initial)

Martha R Boland

Mailing Address 1833 W Water St Apt 33

\begin{tabular}{lcc}
\hline City & State & Zip Code \\
Elmira & NY & $14905-1837$ \\
\hline
\end{tabular}

FEC ID number of contributing

federal political committee.

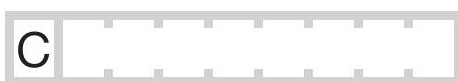

Name of Employer
Retired
Receipt For: 2012
X Primary
Other (specify)

\section{Occupation}

Retired

Election Cycle-to-Date

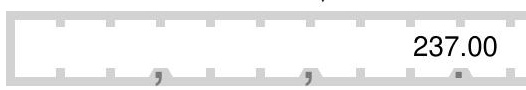

C. Full Name (Last, First, Middle Initial)

Donna Odar

Mailing Address 13712 Winding Oak Circle \#202

\begin{tabular}{lcc}
\hline City & State & Zip Code \\
Centreville & VA & $20121-4759$
\end{tabular}

FEC ID number of contributing federal political committee.

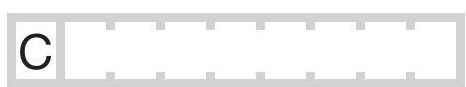

Name of Employer
n/a
Receipt For: 2012
X Primary $\square$ General
Other (specify)

\section{Occupation}

Retired

Election Cycle-to-Date
Transaction ID : A25BD3B950557428F85F

Date of Receipt

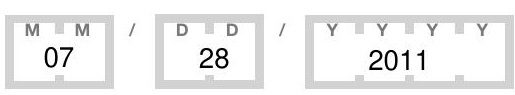

Amount of Each Receipt this Period

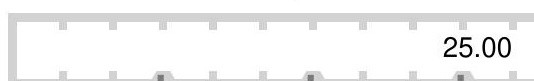

Transaction ID : A159F1226837C4E00942

Date of Receipt

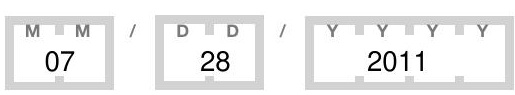

Amount of Each Receipt this Period

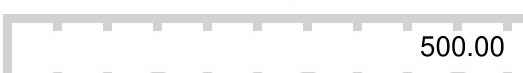

\section{Subtotal Of Receipts This Page (optional)}

Total This Period (last page this line number only) 
SCHEDULE A-P ITEMIZED RECEIPTS
Use separate schedule(s) for each category of the Detailed Summary Page

FOR LINE NUMBER:
(check only one)

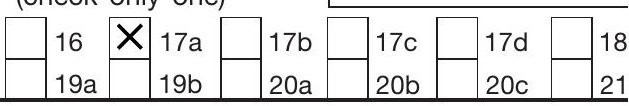

Any information copied from such Reports and Statements may not be sold or used by any person for the purpose of soliciting contributions or for commercial purposes, other than using the name and address of any political committee to solicit contributions from such committee.

NAME OF COMMITTEE (In Full)

\section{Friends of Herman Cain}

A. Full Name (Last, First, Middle Initial) James Stewart

Mailing Address 3560 E. Via Colonia del Sol

\begin{tabular}{lcc}
\hline City & State & Zip Code \\
Tucson & AZ & $85718-6065$
\end{tabular}

FEC ID number of contributing federal political committee.

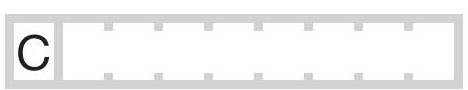

Name of Employer
Information Requested
Receipt For: 2012
X Primary
$\square$ Other (specify)

Occupation

Election Cycle-to-Date

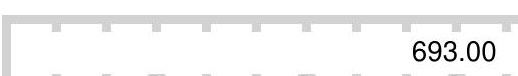
Information Requested

B. Full Name (Last, First, Middle Initial) Susan Weston

Mailing Address P.O. Box 111704

\begin{tabular}{lcc}
\hline City & State & Zip Code \\
Anchorage & AK & $99511-1704$
\end{tabular}

FEC ID number of contributing

federal political committee.

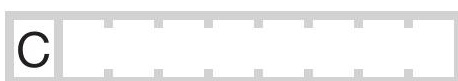

Name of Employer
self
Receipt For: 2012
Primary
Other (specify)

\section{Occupation} Writer

Election Cycle-to-Date

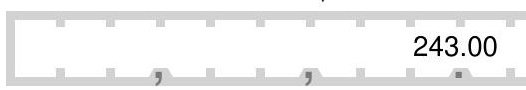

Transaction ID : A7381726CF93B4835B5D

Date of Receipt

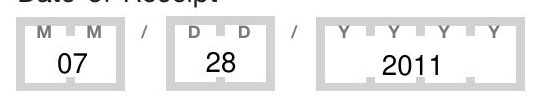

Amount of Each Receipt this Period

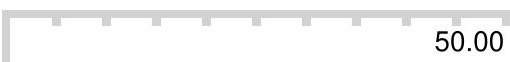

Transaction ID : A6CAB1685625F4A40919

Date of Receipt

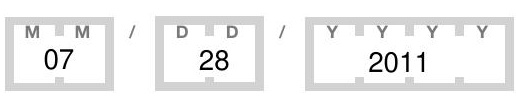

Amount of Each Receipt this Period

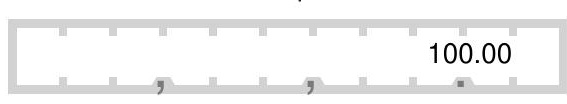

Transaction ID : AF9361AC851134EF1BC6 Date of Receipt

Nancy Gunsallus

Mailing Address 3461 Donegal Way

\begin{tabular}{l|ll}
\hline $\begin{array}{l}\text { City } \\
\text { Snellville }\end{array}$ & $\begin{array}{c}\text { State } \\
\text { GA }\end{array}$ & $\begin{array}{c}\text { Zip Code } \\
30039-8635\end{array}$ \\
\hline $\begin{array}{l}\text { FEC ID number of contributing } \\
\text { federal political committee. }\end{array}$ & C & \\
\hline $\begin{array}{l}\text { Name of Employer } \\
\text { American Shutter Components LLC }\end{array}$ & $\begin{array}{l}\text { Occupation } \\
\text { co-owner }\end{array}$ \\
\hline $\begin{array}{l}\text { Receipt For: } 2012 \\
\text { Xrimary } \\
\text { Other (specify) }\end{array}$ & Election Cycle-to-Date & 425.00 \\
\hline
\end{tabular}

Amount of Each Receipt this Period

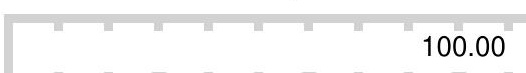

\section{Subtotal Of Receipts This Page (optional)}

Total This Period (last page this line number only) 
SCHEDULE A-P ITEMIZED RECEIPTS
Use separate schedule(s) for each category of the Detailed Summary Page
FOR LINE NUMBER: (check only one)
PAGE 162 / 1572

\begin{tabular}{|c|c|c|c|c|c|}
\hline & & & & & \\
\hline 16 & $\begin{array}{lll}X & 17 a \\
\end{array}$ & $17 \mathrm{~b}$ & $17 c$ & $17 d$ & 18 \\
\hline $19 a$ & $19 b$ & $20 a$ & $20 \mathrm{~b}$ & $20 c$ & 21 \\
\hline
\end{tabular}

Any information copied from such Reports and Statements may not be sold or used by any person for the purpose of soliciting contributions or for commercial purposes, other than using the name and address of any political committee to solicit contributions from such committee.

NAME OF COMMITTEE (In Full)

\section{Friends of Herman Cain}

A. Full Name (Last, First, Middle Initial)

Colleen V Wynne

Mailing Address 221 Woodland Rd

\begin{tabular}{lcc}
\hline City & State & Zip Code \\
Gatlinburg & TN & $37738-5886$
\end{tabular}

FEC ID number of contributing federal political committee.

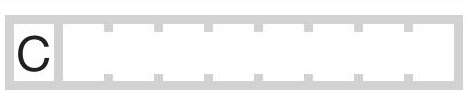

Name of Employer
Park Liquor
Receipt For: 2012
X Primary $\quad$ General
Other (specify)

Occupation clerk

Election Cycle-to-Date

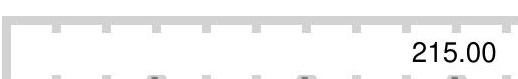

B. Full Name (Last, First, Middle Initial) richard craig

Mailing Address p.o. box 899

\begin{tabular}{lcc}
\hline City & State & Zip Code \\
Edwards & CO & $81632-0899$ \\
\hline
\end{tabular}

FEC ID number of contributing

federal political committee.

C

Name of Employer
Information Requested
Receipt For: 2012
X Primary
Other (specify)

Occupation

Information Requested

Election Cycle-to-Date

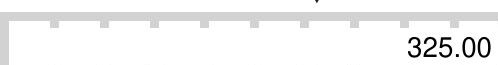

Transaction ID : A788D5ABEF1364CAB9B2

Date of Receipt

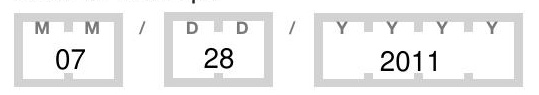

Amount of Each Receipt this Period

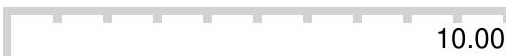

Transaction ID : A193689C37F0F472A887

Date of Receipt

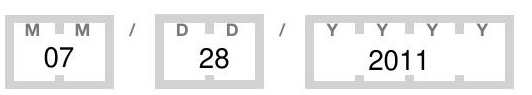

Amount of Each Receipt this Period

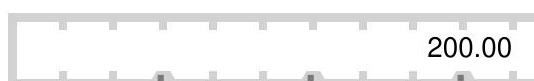

Transaction ID : A5920BCFC56E24294BF1 Date of Receipt

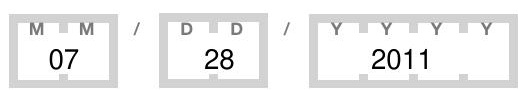

Amount of Each Receipt this Period

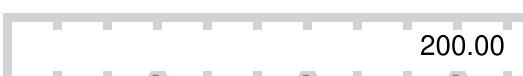

$\begin{array}{cc}\text { State } & \text { Zip Code } \\ \text { CO } & 80018-1687\end{array}$

C

Occupation

Information Requested

Election Cycle-to-Date

Receipt For: 2012

Х $\begin{aligned} & \text { Primary } \\ & \text { Other (specify) }\end{aligned}$

230.00

Subtotal Of Receipts This Page (optional).

410.00

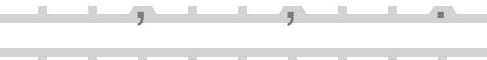

Total This Period (last page this line number only) 
SCHEDULE A-P ITEMIZED RECEIPTS
Use separate schedule(s) for each category of the Detailed Summary Page
FOR LINE NUMBER: (check only one)

\begin{tabular}{|c|c|c|c|c|c|}
\hline & & & & & \\
\hline 16 & $\begin{array}{ll}X & 17 a \\
\end{array}$ & $17 \mathrm{~b}$ & $17 c$ & $17 d$ & 18 \\
\hline $19 a$ & $19 b$ & $20 \mathrm{a}$ & $20 \mathrm{~b}$ & $20 c$ & 21 \\
\hline
\end{tabular}

Any information copied from such Reports and Statements may not be sold or used by any person for the purpose of soliciting contributions or for commercial purposes, other than using the name and address of any political committee to solicit contributions from such committee.

NAME OF COMMITTEE (In Full)

\section{Friends of Herman Cain}

A. Full Name (Last, First, Middle Initial)

\section{Susan Walter}

Mailing Address P.O. Box 690

\begin{tabular}{lcc}
\hline City & State & Zip Code \\
Sautee Nacoochee & GA & $30571-0690$ \\
\hline
\end{tabular}

FEC ID number of contributing federal political committee.

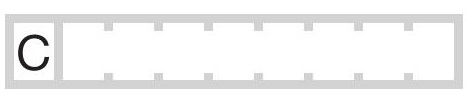

Name of Employer
None
Receipt For: 2012
Primary $\quad$ General
Other (specify)

Occupation Retired

Election Cycle-to-Date

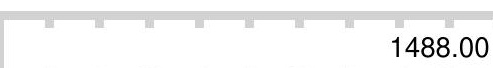

B. Full Name (Last, First, Middle Initial)

Corinne Wray

Mailing Address 512 W 1st

\begin{tabular}{lcc}
\hline City & State & Zip Code \\
Larned & KS & $67550-3805$ \\
\hline
\end{tabular}

FEC ID number of contributing

federal political committee.

C

Name of Employer
Information Requested
Receipt For: 2012
Primary
Other (specify)

\section{Occupation}

Information Requested

Election Cycle-to-Date

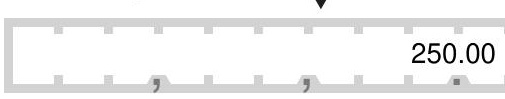

Transaction ID : A2202ED632AC04D989ED

Date of Receipt

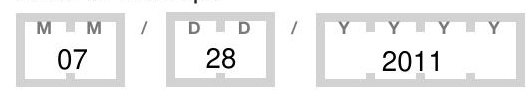

Amount of Each Receipt this Period

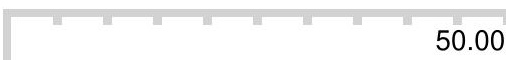

50.00

C. Full Name (Last, First, Middle Initial)

David C. Rowe

Mailing Address 3325 Piedmont Rd NE

\begin{tabular}{lcc}
\hline City & State & Zip Code \\
Atlanta & GA & $30305-1889$
\end{tabular}

FEC ID number of contributing federal political committee.

C

30305-1889

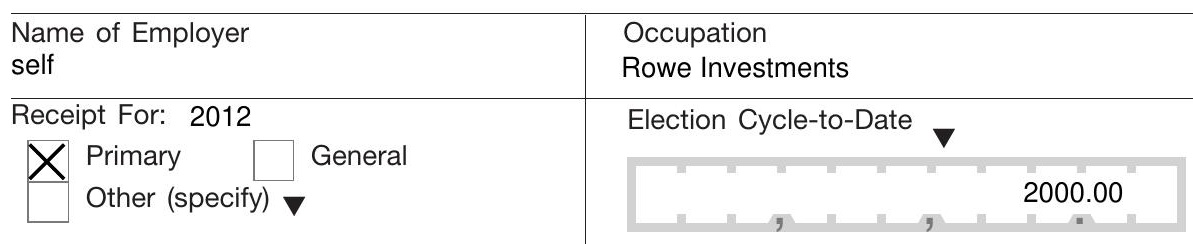

Amount of Each Receipt this Period

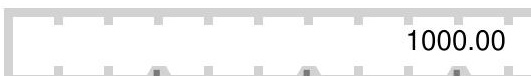

\section{Subtotal Of Receipts This Page (optional)}

Total This Period (last page this line number only) 
SCHEDULE A-P ITEMIZED RECEIPTS
Use separate schedule(s) for each category of the Detailed Summary Page
FOR LINE NUMBER: (check only one)
PAGE 164 / 1572

\begin{tabular}{|c|c|c|c|c|c|}
\hline & & & & & \\
\hline 16 & $\begin{array}{l}\mathbf{x} 17 a \\
\end{array}$ & $17 b$ & $17 c$ & $17 d$ & 18 \\
\hline $19 a$ & $19 b$ & $20 a$ & $20 b$ & $20 c$ & 21 \\
\hline
\end{tabular}

Any information copied from such Reports and Statements may not be sold or used by any person for the purpose of soliciting contributions or for commercial purposes, other than using the name and address of any political committee to solicit contributions from such committee.

NAME OF COMMITTEE (In Full)

\section{Friends of Herman Cain}

A. Full Name (Last, First, Middle Initial)

ROBERT PARROTT

Mailing Address PO BOX 798

\begin{tabular}{lcc}
\hline City & State & Zip Code \\
Ruston & LA & $71273-0798$
\end{tabular}

FEC ID number of contributing federal political committee.

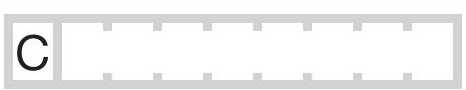

Name of Employer
Information Requested
Receipt For: 2012
X Primary
Other (specify) General

Occupation Information Requested

Election Cycle-to-Date

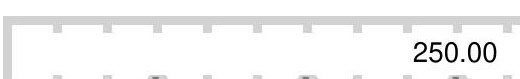

B. Full Name (Last, First, Middle Initial) Jayne D Wayson

Mailing Address 400 E Colonial Dr Apt 402

\begin{tabular}{lcc}
\hline City & State & Zip Code \\
Orlando & FL & $32803-4530$ \\
\hline
\end{tabular}

FEC ID number of contributing

federal political committee.

C

Name of Employer
Information Requested
Receipt For: 2012
X Primary
Other (specify)

Occupation

Information Requested

Election Cycle-to-Date

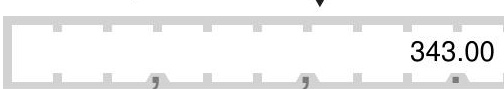

Transaction ID : A31C30691574641C1A84

Date of Receipt

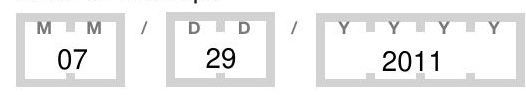

Amount of Each Receipt this Period

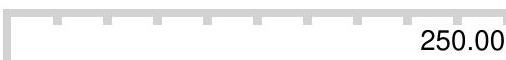

C. Full Name (Last, First, Middle Initial)

Ross Delash

Mailing Address 515 Mask Rd

\begin{tabular}{lcc}
\hline City & State & Zip Code \\
Brooks & GA & $30205-2214$
\end{tabular}

FEC ID number of contributing federal political committee.

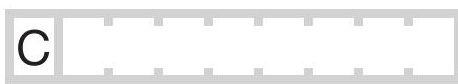

Name of Employer

Atlantic Southeast Airlines

Receipt For: 2012

Х $\begin{aligned} & \text { Primary } \\ & \text { Other (specify) }\end{aligned}$

\section{Occupation}

Pilot

Election Cycle-to-Date

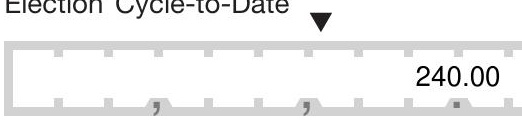

Amount of Each Receipt this Period

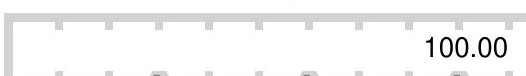

Transaction ID : A908F245D316841A1A0B

Date of Receipt

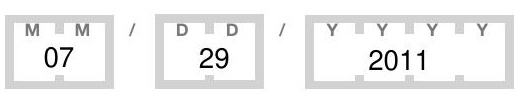

Transaction ID : A4875576F789D4A2E887

Date of Receipt

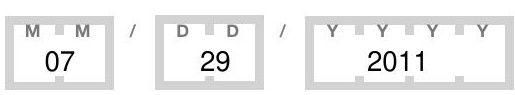

Amount of Each Receipt this Period

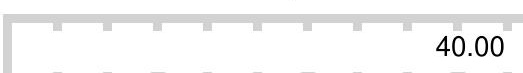

\section{Subtotal Of Receipts This Page (optional)}

Total This Period (last page this line number only) 
SCHEDULE A-P ITEMIZED RECEIPTS
Use separate schedule(s)

for each category of the

Detailed Summary Page
FOR LINE NUMBER: (check only one)

Any information copied from such Repor or for commercial purposes, other than using the name and address of any political committee to solicit contributions from such committee.

NAME OF COMMITTEE (In Full)

\section{Friends of Herman Cain}

A. Full Name (Last, First, Middle Initial)

Mr. Dudney A Harris

Mailing Address 1801 Sugar Creek Trl

\begin{tabular}{lcc}
\hline City & State & Zip Code \\
Buckhead & GA & $30625-2517$
\end{tabular}

FEC ID number of contributing

federal political committee.

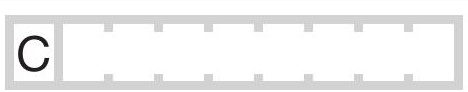

\begin{tabular}{l} 
Name of Employer \\
None \\
Receipt For: 2012 \\
X Primary $\quad$ General \\
\hline Other (specify)
\end{tabular}

Occupation

Retired

Election Cycle-to-Date

1700.00

B. Full Name (Last, First, Middle Initial)

Eric Teringer

Mailing Address 435 Ridgetop Dr NW

\begin{tabular}{lcc}
\hline City & State & Zip Code \\
Acworth & GA & $30102-8104$
\end{tabular}

FEC ID number of contributing

federal political committee.

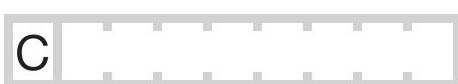

Name of Employer
Courier Express
Receipt For: 2012
X Primary
Other (specify)

\section{Occupation}

courier

Election Cycle-to-Date

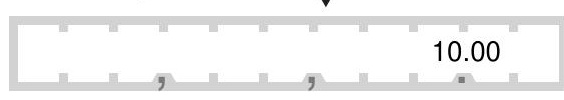

Transaction ID : A9D40BE65EE624BD2BBD

Date of Receipt

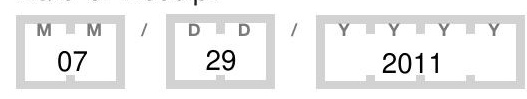

Amount of Each Receipt this Period

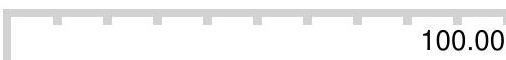

100.00

C. Full Name (Last, First, Middle Initial)

David Morris

Mailing Address 7921 E 46th Street

\begin{tabular}{lcc}
\hline City & State & Zip Code \\
Indianapolis & IN & $46226-3931$
\end{tabular}

FEC ID number of contributing

federal political committee.

C

$46226-3931$

Name of Employer
Precision Dry Wall Inc.
Receipt For: 2012
X Primary
Other (specify) General

\section{Occupation}

Construction

Election Cycle-to-Date

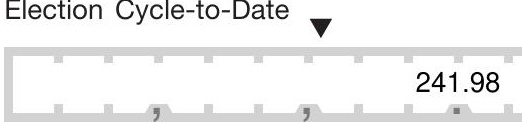

Transaction ID : A09BC16E2F9914586830

Date of Receipt

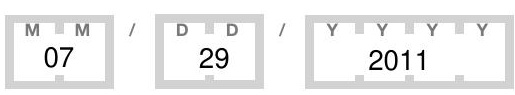

NSF

Amount of Each Receipt this Period

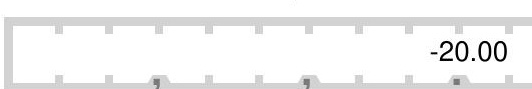

Transaction ID : A74F83D006A704F72956

Date of Receipt

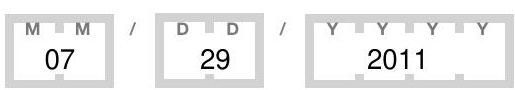

Amount of Each Receipt this Period

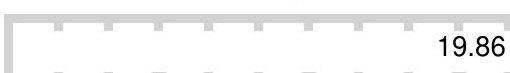

19.86

\section{Subtotal Of Receipts This Page (optional)}

99.86

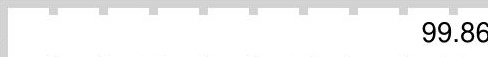

ㄱ․․

Total This Period (last page this line number only)

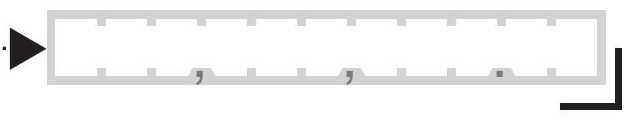

FEC Schedule A-P (Form 3P) (Rev. 03/2011) 
SCHEDULE A-P ITEMIZED RECEIPTS
Use separate schedule(s)

for each category of the

Detailed Summary Page
FOR LINE NUMBER: (check only one)

\begin{tabular}{|c|c|c|c|c|c|}
\hline & & & & & \\
\hline 16 & $\begin{array}{ll}X & 17 a \\
\end{array}$ & $17 \mathrm{~b}$ & $17 c$ & $17 d$ & 18 \\
\hline $19 a$ & $19 b$ & $20 \mathrm{a}$ & $20 \mathrm{~b}$ & $20 c$ & 21 \\
\hline
\end{tabular}

Any information copied from such Reports and Statements may not be sold or used by any person for the purpose of soliciting contributions or for commercial purposes, other than using the name and address of any political committee to solicit contributions from such committee.

NAME OF COMMITTEE (In Full)

Friends of Herman Cain

A. Full Name (Last, First, Middle Initial)

Roberto Eaton

Mailing Address 12640 W 66th Place

\begin{tabular}{lcc}
\hline City & State & Zip Code \\
Arvada & CO & $80004-2213$ \\
\hline
\end{tabular}

FEC ID number of contributing

federal political committee.

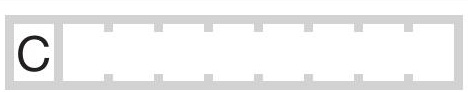

Name of Employer
Maintenance Manager
Receipt For: 2012
X Primary $\quad \square$ General
Other (specify)

Occupation

Manager

Election Cycle-to-Date

225.00

B. Full Name (Last, First, Middle Initial)

Mrs. Jane $P$ Bath

Mailing Address 2430 Snows Mill Rd

\begin{tabular}{lcc}
\hline City & State & Zip Code \\
Bogart & GA & $30622-2713$ \\
\hline
\end{tabular}

FEC ID number of contributing

federal political committee.

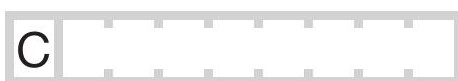

Name of Employer
None
Receipt For: 2012
X Primary $\quad$ General
Other (specify)

Occupation

Retired

Election Cycle-to-Date

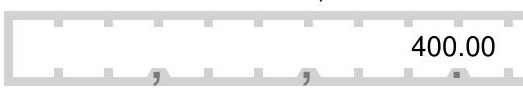

Transaction ID : A7D580409B9204893A36

Date of Receipt

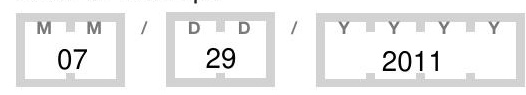

Amount of Each Receipt this Period

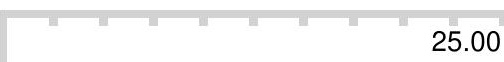

25.00

C. Full Name (Last, First, Middle Initial)

Arlene Rouse

Mailing Address 4655 E 58th St

\begin{tabular}{lcc}
\hline City & State & Zip Code \\
Tulsa & OK & $74135-4319$
\end{tabular}

FEC ID number of contributing federal political committee.

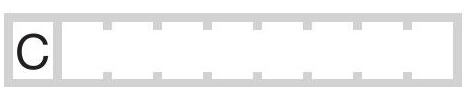

Name of Employer
Dillards
Receipt For: 2012
X Primary $\square$ General
Other (specify)

\section{Occupation}

Sales

Election Cycle-to-Date

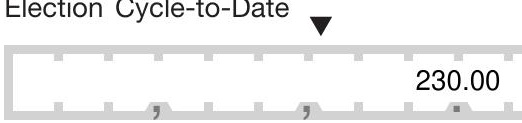

Transaction ID : A77F5C2E2EF8F459A948

Date of Receipt

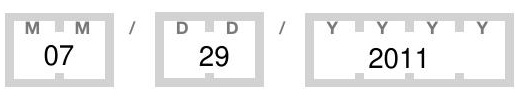

Amount of Each Receipt this Period

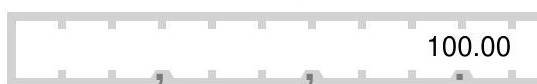

Transaction ID : ABD3858A365B54FFC959 Date of Receipt

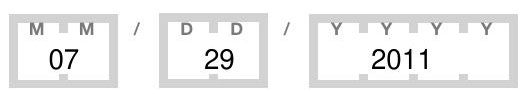

Amount of Each Receipt this Period

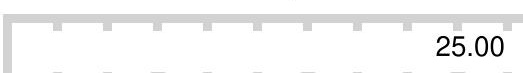

\section{Subtotal Of Receipts This Page (optional)}

Total This Period (last page this line number only) 
SCHEDULE A-P ITEMIZED RECEIPTS
Use separate schedule(s) for each category of the Detailed Summary Page
FOR LINE NUMBER: (check only one)
PAGE 167 / 1572

\begin{tabular}{|c|c|c|c|c|c|}
\hline & & & & & \\
\hline 16 & $\begin{array}{lll}X & 17 a \\
\end{array}$ & $17 \mathrm{~b}$ & $17 c$ & $17 d$ & 18 \\
\hline $19 a$ & $19 b$ & $20 a$ & $20 \mathrm{~b}$ & $20 c$ & 21 \\
\hline
\end{tabular}

Any information copied from such Reports and Statements may not be sold or used by any person for the purpose of soliciting contributions or for commercial purposes, other than using the name and address of any political committee to solicit contributions from such committee.

NAME OF COMMITTEE (In Full)

Friends of Herman Cain

A. Full Name (Last, First, Middle Initial)

Donald Gallo

Mailing Address 6342 Puma Point Way

\begin{tabular}{lcc}
\hline City & State & Zip Code \\
Golden & CO & $80403-8005$ \\
\hline
\end{tabular}

FEC ID number of contributing federal political committee.

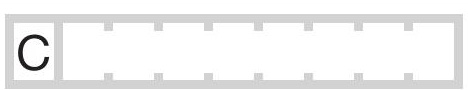

Name of Employer
Towers Watson
Receipt For: 2012
X Primary
$\square$ Other (specify) General

Occupation

Management Consultant

Election Cycle-to-Date $\boldsymbol{\nabla}$

225.00

B. Full Name (Last, First, Middle Initial)

Mrs. Susan K. McLaurine

Mailing Address 114 La Encinal Court

\begin{tabular}{lcc}
\hline City & State & Zip Code \\
Clayton & CA & $94517-1750$
\end{tabular}

FEC ID number of contributing

federal political committee.

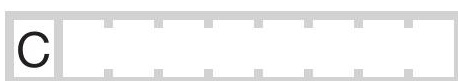

Name of Employer
Vantage Consulting LLC
Receipt For: 2012
X Primary
Other (specify)

Occupation

Business Consul

Election Cycle-to-Date

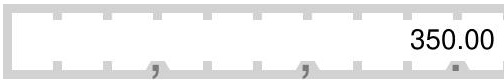

C. Full Name (Last, First, Middle Initial)

John Algee

Mailing Address $32 \mathrm{~N}$. Tenney Drive

\begin{tabular}{lll}
\hline $\begin{array}{l}\text { City } \\
\text { Buckhannon }\end{array}$ & $\begin{array}{c}\text { State } \\
\text { WV }\end{array}$ & $\begin{array}{c}\text { Zip Code } \\
26201-8538\end{array}$ \\
\hline $\begin{array}{l}\text { FEC ID number of contributing } \\
\text { federal political committee. }\end{array}$ & C \\
$\begin{array}{l}\text { Name of Employer } \\
\text { Information Requested }\end{array}$ & $\begin{array}{l}\text { Occupation } \\
\text { Information Requested }\end{array}$ \\
$\begin{array}{l}\text { Receipt For: } 2012 \\
\text { Xrimary } \\
\text { Other (specify) }\end{array}$ & Election Cycle-to-Date & \\
\hline
\end{tabular}

Transaction ID : A421425628E964D739AA

Date of Receipt

Amount of Each Receipt this Period
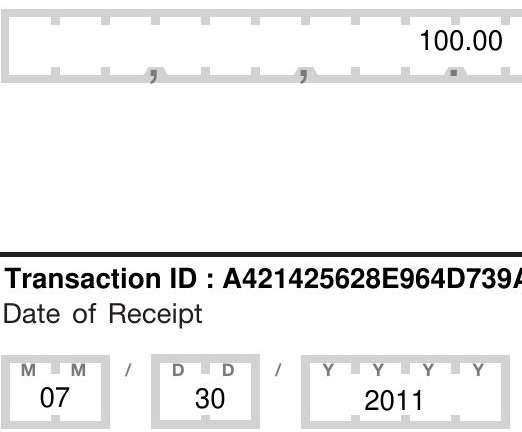

Amount of Each Receipt this Period

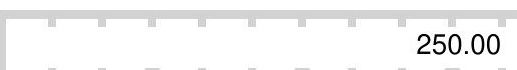

Amount of Each Receipt this Period

Transaction ID : A2FE8B23105914D8486D

Date of Receipt
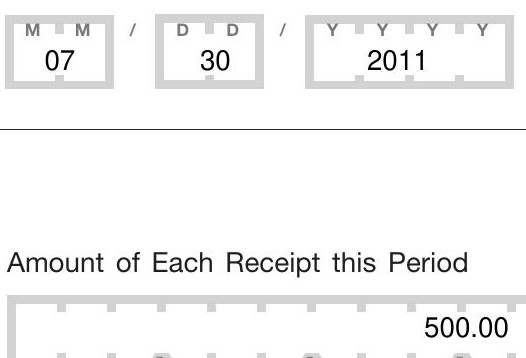

500.00

Subtotal Of Receipts This Page (optional)

850.00

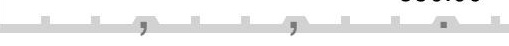

Total This Period (last page this line number only)

FEC Schedule A-P (Form 3P) (Rev. 03/2011) 
SCHEDULE A-P ITEMIZED RECEIPTS
Use separate schedule(s)

for each category of the

Detailed Summary Page
FOR LINE NUMBER: (check only one)

Any information copied from such Repor or for commercial purposes, other than using the name and address of any political committee to solicit contributions from such committee.

NAME OF COMMITTEE (In Full)

\section{Friends of Herman Cain}

A. Full Name (Last, First, Middle Initial)

Mr. John Furbush

Mailing Address 45 Orrills Hill Rd

\begin{tabular}{lcc}
\hline City & State & Zip Code \\
Lebanon & ME & $04027-3910$
\end{tabular}

FEC ID number of contributing federal political committee.

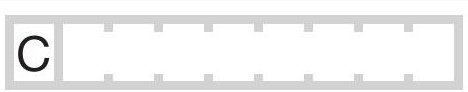

Name of Employer
Global Tecnology Talent
Receipt For: 2012
X Primary $\quad \square$ General
Other (specify)

Occupation

Project Manager

Election Cycle-to-Date

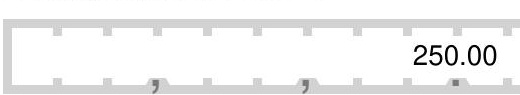

B. Full Name (Last, First, Middle Initial)

hollis curtis

Mailing Address 6314 Carbonton Rd

\begin{tabular}{lcc}
\hline City & State & Zip Code \\
Sanford & NC & $27330-3027$ \\
\hline
\end{tabular}

FEC ID number of contributing

federal political committee.

C

Name of Employer

$\mathrm{h} \mathrm{r}$ curtis plumbing contractor

Occupation

Receipt For: 2012

Х ${ }_{\text {Other (specify) }}^{\square}$ General

plumbing contractor

Election Cycle-to-Date

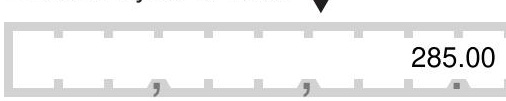

C. Full Name (Last, First, Middle Initial)

claire mencke

Mailing Address 5 tudor city place apt 305

\begin{tabular}{lcc}
\hline City & State & Zip Code \\
New York & NY & $10017-6858$
\end{tabular}

FEC ID number of contributing

federal political committee.

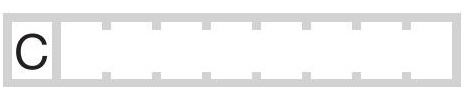

Name of Employer

buckingham research group

Receipt For: 2012

X Primary $\square$ General

\section{Occupation}

research assoc

Election Cycle-to-Date

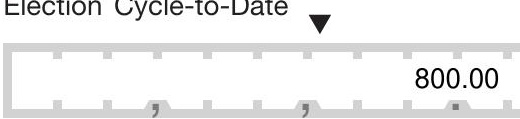

Transaction ID : ABC2FE9CA6DF8433A97D

Date of Receipt

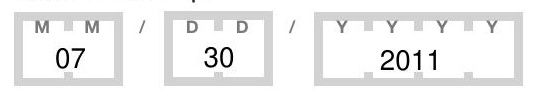

Amount of Each Receipt this Period

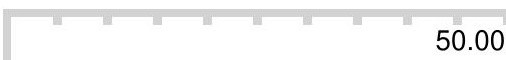

50.00
Amount of Each Receipt this Period

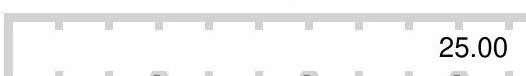

Transaction ID : A4B847A543C044318B22 Date of Receipt

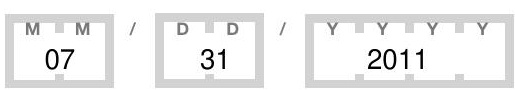

Amount of Each Receipt this Period

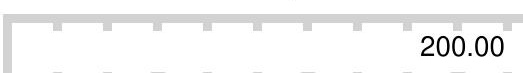

\section{Subtotal Of Receipts This Page (optional)}

Total This Period (last page this line number only) 
SCHEDULE A-P ITEMIZED RECEIPTS
Use separate schedule(s)

for each category of the

Detailed Summary Page
FOR LINE NUMBER: (check only one)

Any information copied from such Repor or for commercial purposes, other than using the name and address of any political committee to solicit contributions from such committee.

NAME OF COMMITTEE (In Full)

\section{Friends of Herman Cain}

A. Full Name (Last, First, Middle Initial)

Cliff Beveridge

Mailing Address 1216 Gotier Trace Rd.

\begin{tabular}{lcc}
\hline City & State & Zip Code \\
Paige & TX & $78659-4400$ \\
\hline
\end{tabular}

FEC ID number of contributing

federal political committee.

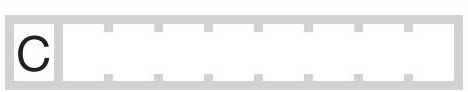

Name of Employer
Ultra Electronics-ATS
Receipt For: 2012
X Primary $\quad \square$ General
Other (specify)

Occupation

Senior Software Engineer

Election Cycle-to-Date $\boldsymbol{\nabla}$

700.00

B. Full Name (Last, First, Middle Initial)

John Reece

Mailing Address 184 Manor Hills Road

\begin{tabular}{lcc}
\hline City & State & Zip Code \\
Lillington & NC & $27546-8449$ \\
\hline
\end{tabular}

FEC ID number of contributing

federal political committee.

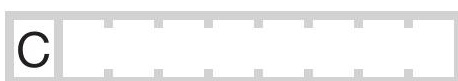

Name of Employer
Retired
Receipt For: 2012
X Primary $\quad$ General
Other (specify)

Occupation

Retired

Election Cycle-to-Date

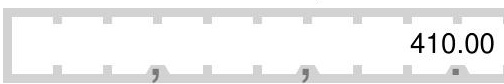

C. Full Name (Last, First, Middle Initial)

Susan Walter

Mailing Address P.O. Box 690

\begin{tabular}{lcc}
\hline City & State & Zip Code \\
Sautee Nacoochee & GA & $30571-0690$
\end{tabular}

FEC ID number of contributing

federal political committee.

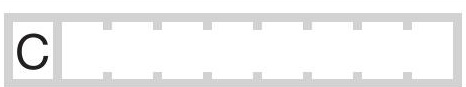

Name of Employer
None
Receipt For: 2012
X Primary $\quad \square$ General
Other (specify)

Occupation

Retired

Election Cycle-to-Date

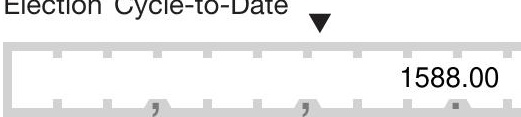

Transaction ID : A1E695DDEC12D4639A99

Date of Receipt

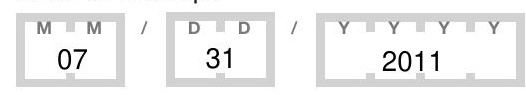

Amount of Each Receipt this Period

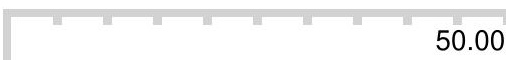

50.00

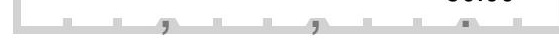

Transaction ID : A7309E46F7E904460B86

Date of Receipt

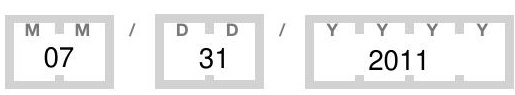

Amount of Each Receipt this Period

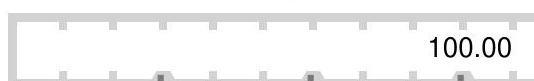

Transaction ID : A04C1646BE4A74AAE853 Date of Receipt

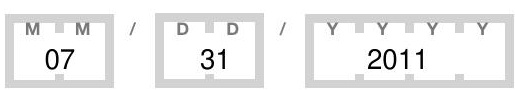

Amount of Each Receipt this Period

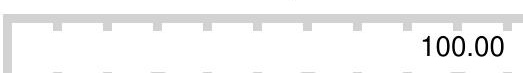

100.00

\section{Subtotal Of Receipts This Page (optional)}

Total This Period (last page this line number only) 
SCHEDULE A-P ITEMIZED RECEIPTS
Use separate schedule(s) for each category of the Detailed Summary Page
FOR LINE NUMBER: (check only one)

PAGE $170 / 1572$

\begin{tabular}{|c|c|c|c|c|c|}
\hline & & & & & \\
\hline 16 & $\begin{array}{l}\mathbf{X} \\
17 a\end{array}$ & $17 b$ & $17 c$ & $17 d$ & 18 \\
\hline $19 a$ & $19 \mathrm{~b}$ & $20 \mathrm{a}$ & $20 \mathrm{~b}$ & $20 \mathrm{c}$ & 21 \\
\hline
\end{tabular}

Any information copied from such Reports and Statements may not be sold or used by any person for the purpose of soliciting contributions or for commercial purposes, other than using the name and address of any political committee to solicit contributions from such committee.

NAME OF COMMITTEE (In Full)

\section{Friends of Herman Cain}

A. Full Name (Last, First, Middle Initial) richard willman

Mailing Address 5501 NW 65th St

\begin{tabular}{lcc}
\hline City & State & Zip Code \\
Warr Acres & OK & $73132-7758$
\end{tabular}

FEC ID number of contributing federal political committee.

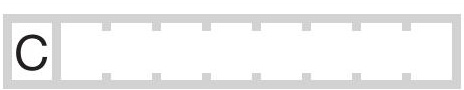

Name of Employer

Raytheon Technical Services

Occupation

Receipt For: 2012

X Primary $\square$ General Other (specify)

Air Traffic Control Instructor

Election Cycle-to-Date

450.00

B. Full Name (Last, First, Middle Initial)

Edward J Phelan

Mailing Address 1049 Pecan Grive Place

\begin{tabular}{lcc}
\hline City & State & Zip Code \\
Lawrenceville & GA & $30046-5517$
\end{tabular}

FEC ID number of contributing

federal political committee.

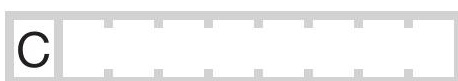

Name of Employer
None
Receipt For: 2012
X Primary
Other (specify)

Occupation

Retired

Election Cycle-to-Date

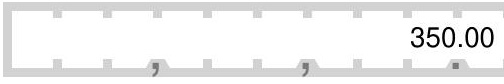

C. Full Name (Last, First, Middle Initial)

Robert Osborn

Mailing Address 255 Lakemont $\mathrm{Dr}$

\begin{tabular}{lcc}
\hline City & State & Zip Code \\
Fayetteville & GA & $30215-8137$
\end{tabular}

FEC ID number of contributing federal political committee.

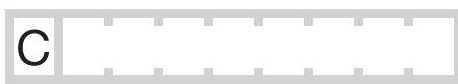

Name of Employer
HR Select Consultants
Receipt For: 2012
X Primary $\quad \square$ General
Other (specify)

Occupation

Robert Osborn

Election Cycle-to-Date

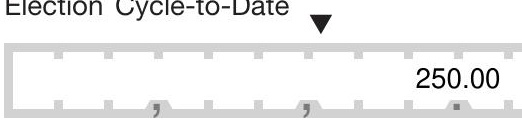

Transaction ID : A34BFA6E17D034FB2B83

Date of Receipt

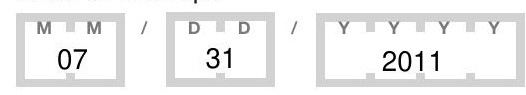

Amount of Each Receipt this Period

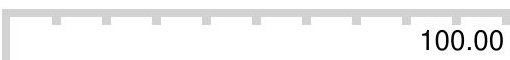

100.00

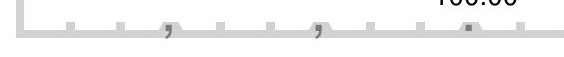

Transaction ID : A75DA7E504AAF428DBAF Date of Receipt

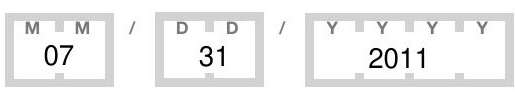

Amount of Each Receipt this Period

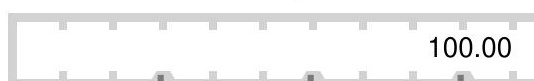

Transaction ID : A56EAE8928EE743E7BCD Date of Receipt

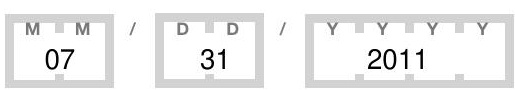

Amount of Each Receipt this Period

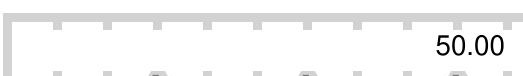

50.00

Subtotal Of Receipts This Page (optional)

Total This Period (last page this line number only) 
SCHEDULE A-P ITEMIZED RECEIPTS
Use separate schedule(s) for each category of the Detailed Summary Page
FOR LINE NUMBER: (check only one)

PAGE $171 / 1572$

\begin{tabular}{|c|c|c|c|c|c|c|}
\hline & & & & & & \\
\hline 16 & $\lambda$ & $17 \mathrm{a}$ & $17 \mathrm{~b}$ & $17 \mathrm{c}$ & $-17 d$ & -18 \\
\hline $19 a$ & & $19 b$ & $20 a$ & $20 \mathrm{~b}$ & $20 \mathrm{c}$ & 21 \\
\hline
\end{tabular}

Any information copied from such Reports and Statements may not be sold or used by any person for the purpose of soliciting contributions or for commercial purposes, other than using the name and address of any political committee to solicit contributions from such committee.

NAME OF COMMITTEE (In Full)

\section{Friends of Herman Cain}

A. Full Name (Last, First, Middle Initial) Jonathan Conwell

Mailing Address 104 Township Road 1343

\begin{tabular}{lcc}
\hline City & State & Zip Code \\
South Point & OH & $45680-7917$
\end{tabular}

FEC ID number of contributing federal political committee.

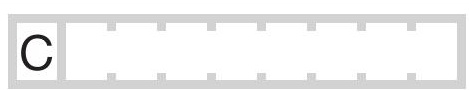

Name of Employer
Federal Government
Receipt For: 2012
X Primary
Other (specify) General

Occupation IT Specialist

Election Cycle-to-Date

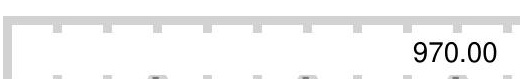

B. Full Name (Last, First, Middle Initial) Jo Ann Paschal

Mailing Address 701 Fox Valley Dr.

\begin{tabular}{lcc}
\hline City & State & Zip Code \\
Longwood & FL & $32779-2507$ \\
\hline
\end{tabular}

FEC ID number of contributing

federal political committee.

C

Name of Employer
FIS
Receipt For: 2012
X Primary
$\quad$ Other (specify)

Occupation

Business Analyst

Election Cycle-to-Date

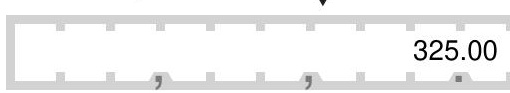

Transaction ID : A88C9416BA9C348BE92E

Date of Receipt

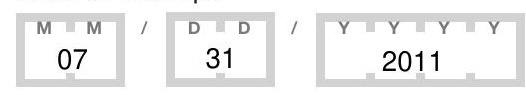

Amount of Each Receipt this Period

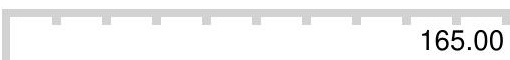

165.00

C. Full Name (Last, First, Middle Initial)

Mr. Larry Hochhalter

Mailing Address 24528 Madewood Ave

\begin{tabular}{lcc}
\hline City & State & Zip Code \\
Leesburg & FL & $34748-7879$
\end{tabular}

FEC ID number of contributing federal political committee.

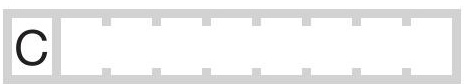

Name of Employer
None
Receipt For: 2012
Х Primary $\quad \square$ General
Other (specify)

Occupation

Retired

Election Cycle-to-Date

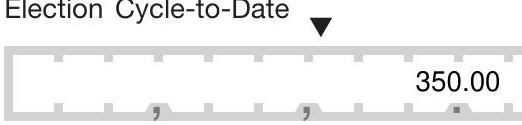

Transaction ID : A824A3AE053EA41FFAB1 Date of Receipt

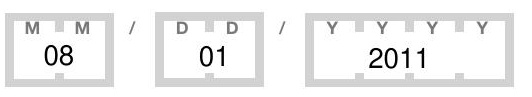

Amount of Each Receipt this Period

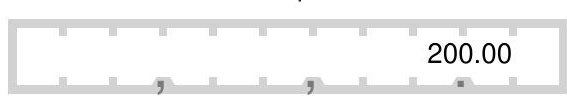

Transaction ID : A3D8781F7CC794646AED Date of Receipt

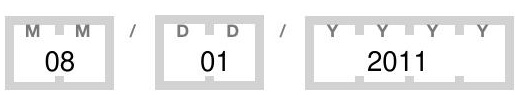

Amount of Each Receipt this Period

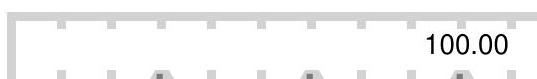

\section{Subtotal Of Receipts This Page (optional)}

Total This Period (last page this line number only) 
SCHEDULE A-P ITEMIZED RECEIPTS
Use separate schedule(s) for each category of the Detailed Summary Page
FOR LINE NUMBER: (check only one)

PAGE 172 / 1572

\begin{tabular}{|c|c|c|c|c|c|}
\hline & & & & & \\
\hline 16 & $\begin{array}{l}\mathbf{X} \\
17 a\end{array}$ & $17 b$ & $17 c$ & $17 d$ & 18 \\
\hline $19 a$ & $19 \mathrm{~b}$ & $20 \mathrm{a}$ & $20 \mathrm{~b}$ & $20 \mathrm{c}$ & 21 \\
\hline
\end{tabular}

Any information copied from such Reports and Statements may not be sold or used by any person for the purpose of soliciting contributions or for commercial purposes, other than using the name and address of any political committee to solicit contributions from such committee.

NAME OF COMMITTEE (In Full)

\section{Friends of Herman Cain}

A. Full Name (Last, First, Middle Initial)

Sylvia Downey

Mailing Address 134 S Hawk Dr

\begin{tabular}{lcc}
\hline City & State & Zip Code \\
Rainbow City & AL & $35906-3608$ \\
\hline
\end{tabular}

FEC ID number of contributing federal political committee.

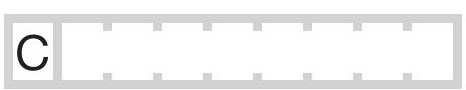

\begin{tabular}{l} 
Name of Employer \\
None \\
Receipt For: 2012 \\
X Primary $\quad$ General \\
\hline Other (specify)
\end{tabular}

Occupation

Retired

Election Cycle-to-Date

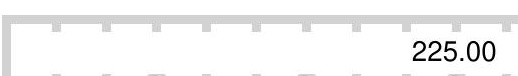

B. Full Name (Last, First, Middle Initial)

William Donohue

Mailing Address 7 Vicksburg Ct.

\begin{tabular}{lcc}
\hline City & State & Zip Code \\
Madison & WI & $53718-3154$ \\
\hline
\end{tabular}

FEC ID number of contributing

federal political committee.

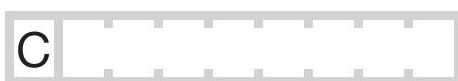

Name of Employer
State Farm Insurance Co.
Receipt For: 2012
X Primary
Other (specify)

\section{Occupation}

Retired

Election Cycle-to-Date

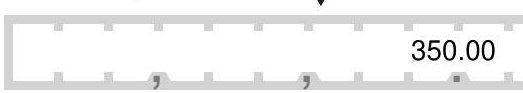

Transaction ID : AF0F7C85D5110428EB43

Date of Receipt

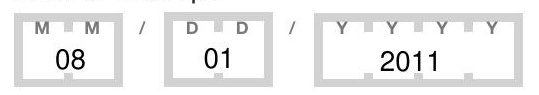

Amount of Each Receipt this Period

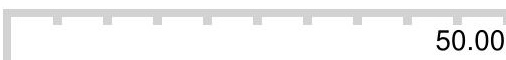

50.00

C. Full Name (Last, First, Middle Initial)

Kelli Richard

Mailing Address 12777 Cijon St

\begin{tabular}{lcc}
\hline City & State & Zip Code \\
San Diego & CA & $92129-3024$
\end{tabular}

FEC ID number of contributing federal political committee.

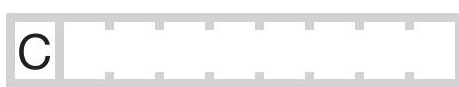

Name of Employer
Life Technologies
Receipt For: 2012
X Primary $\quad \square$ General
Other (specify)

\section{Occupation}

Accountant

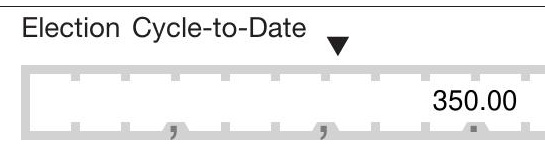

Transaction ID : A90BCEB1B25E8402AA16 Date of Receipt

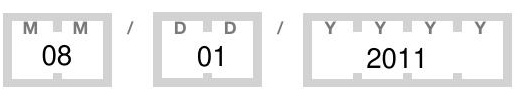

Amount of Each Receipt this Period

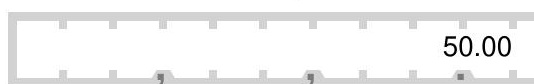

Transaction ID : A79C01D94F937411B9D1 Date of Receipt

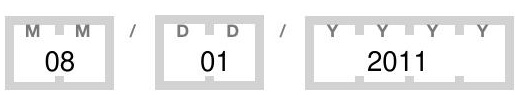

Amount of Each Receipt this Period

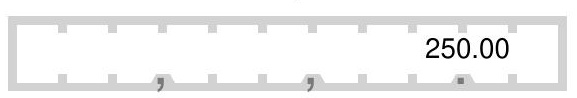

\section{Subtotal Of Receipts This Page (optional)}

Total This Period (last page this line number only) 
SCHEDULE A-P ITEMIZED RECEIPTS
Use separate schedule(s) for each category of the Detailed Summary Page
FOR LINE NUMBER: (check only one)

PAGE $173 / 1572$

\begin{tabular}{|c|c|c|c|c|c|}
\hline & & & & & \\
\hline 16 & $\begin{array}{lll}X & 17 a \\
\end{array}$ & $17 \mathrm{~b}$ & $17 c$ & $17 d$ & 18 \\
\hline $19 a$ & $19 b$ & $20 a$ & $20 \mathrm{~b}$ & $20 c$ & 21 \\
\hline
\end{tabular}

Any information copied from such Reports and Statements may not be sold or used by any person for the purpose of soliciting contributions or for commercial purposes, other than using the name and address of any political committee to solicit contributions from such committee.

NAME OF COMMITTEE (In Full)

\section{Friends of Herman Cain}

A. Full Name (Last, First, Middle Initial)

Demetrios Logothetis

Mailing Address 677 Long Cove Court

\begin{tabular}{lcc}
\hline City & State & Zip Code \\
Riverwoods & IL & $60015-3850$
\end{tabular}

FEC ID number of contributing

federal political committee.

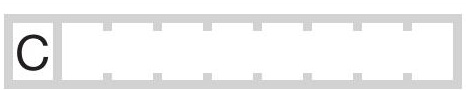

Name of Employer
Information Requested
Receipt For: 2012
X Primary $\quad \square$ General
Other (specify)

Occupation

Information Requested

Election Cycle-to-Date

500.00

B. Full Name (Last, First, Middle Initial)

Susan Walter

Mailing Address P.O. Box 690

\begin{tabular}{lcc}
\hline City & State & Zip Code \\
Sautee Nacoochee & GA & $30571-0690$
\end{tabular}

FEC ID number of contributing

federal political committee.

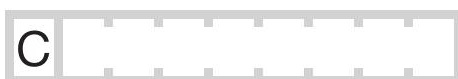

Name of Employer
None
Receipt For: 2012
X Primary
Other (specify)

Occupation

Retired

Election Cycle-to-Date

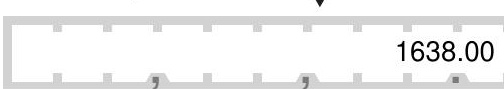

Transaction ID : AA565DCD728344974A1A

Date of Receipt

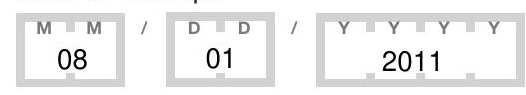

Amount of Each Receipt this Period

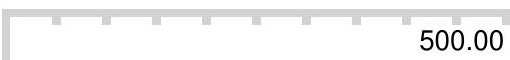

C. Full Name (Last, First, Middle Initial)

Fred D Backer Jr

Mailing Address 18 Narry Ln

\begin{tabular}{lcc}
\hline City & State & Zip Code \\
Mount Morris & NY & $14510-1519$
\end{tabular}

FEC ID number of contributing federal political committee.

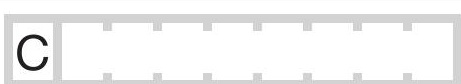

Name of Employer
None
Receipt For: 2012
X Primary $\quad \square$ General
Other (specify)

Occupation

Retired

Election Cycle-to-Date

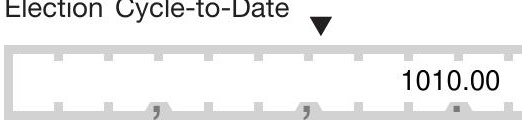

Amount of Each Receipt this Period

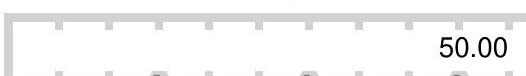

Transaction ID : A0F7F4C9D8A4B4523A11

Date of Receipt

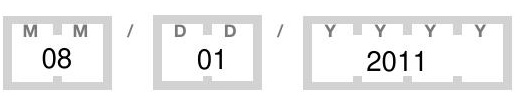

Transaction ID : A1C7964C5E0F84EE4B8E Date of Receipt

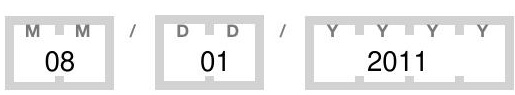

Amount of Each Receipt this Period

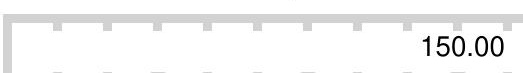

150.00

\section{Subtotal Of Receipts This Page (optional)}

Total This Period (last page this line number only) 
SCHEDULE A-P ITEMIZED RECEIPTS
Use separate schedule(s) for each category of the Detailed Summary Page
FOR LINE NUMBER: (check only one)

PAGE 174 / 1572

\begin{tabular}{|c|c|c|c|c|c|}
\hline & & & & & \\
\hline 16 & $\begin{array}{l}\mathbf{X} \\
17 a\end{array}$ & $17 b$ & $17 c$ & $17 d$ & 18 \\
\hline $19 a$ & $19 \mathrm{~b}$ & $20 \mathrm{a}$ & $20 \mathrm{~b}$ & $20 \mathrm{c}$ & 21 \\
\hline
\end{tabular}

Any information copied from such Reports and Statements may not be sold or used by any person for the purpose of soliciting contributions or for commercial purposes, other than using the name and address of any political committee to solicit contributions from such committee.

NAME OF COMMITTEE (In Full)

\section{Friends of Herman Cain}

A. Full Name (Last, First, Middle Initial)

earl hays

Mailing Address 866 mount tabor road

\begin{tabular}{lcc}
\hline City & State & Zip Code \\
Oxford & GA & $30054-4530$
\end{tabular}

FEC ID number of contributing federal political committee.

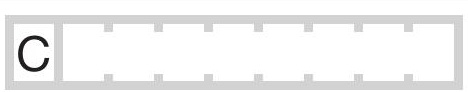

Name of Employer
mcnaughton-mckay
Receipt For: 2012
X Primary
Other (specify) General

Occupation General Manager

Election Cycle-to-Date

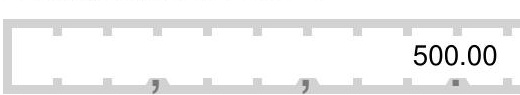

B. Full Name (Last, First, Middle Initial)

Mr. Baron F. Newton

Mailing Address 3260 Sutcliffe Rdg NW

\begin{tabular}{lcc}
\hline City & State & Zip Code \\
Marietta & GA & $30064-1736$ \\
\hline
\end{tabular}

FEC ID number of contributing

federal political committee.

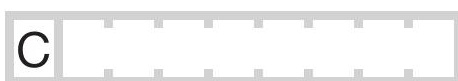

Name of Employer
Lockheed Marietta
Receipt For: 2012
X Primary
Other (specify)

Occupation

CNC Machinist

Election Cycle-to-Date

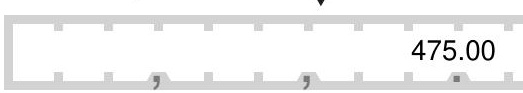

Transaction ID : ADBC5B72CE0AE4B4E938

Date of Receipt

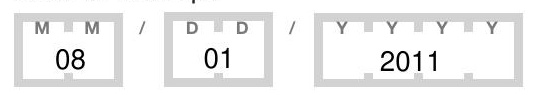

Amount of Each Receipt this Period

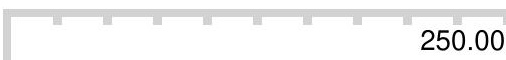

250.00

C. Full Name (Last, First, Middle Initial)

David Sondheimer

Mailing Address 2810 Hiwall Count

\begin{tabular}{lcc}
\hline City & State & Zip Code \\
Castle Rock & CO & 80109 \\
\hline
\end{tabular}

FEC ID number of contributing federal political committee.

C

Name of Employer
Information Requested
Receipt For: 2012
X Primary
Other (specify) General

\section{Occupation}

Information Requested

Election Cycle-to-Date

Transaction ID : A84F6A5A410764FB6A07

Date of Receipt

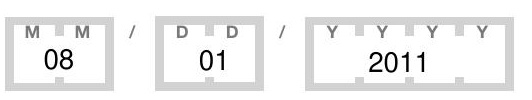

Amount of Each Receipt this Period

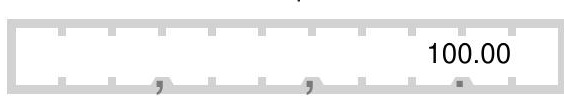

Transaction ID : A2501452FDFDC442C9CE Date of Receipt

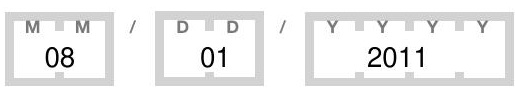

Amount of Each Receipt this Period

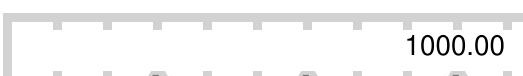

1000.00

\section{Subtotal Of Receipts This Page (optional)}

Total This Period (last page this line number only) 
SCHEDULE A-P ITEMIZED RECEIPTS
Use separate schedule(s) for each category of the Detailed Summary Page
FOR LINE NUMBER: (check only one)

PAGE $175 / 1572$

\begin{tabular}{|c|c|c|c|c|c|}
\hline & & & & & \\
\hline 16 & $\begin{array}{l}\mathbf{X} \\
17 a\end{array}$ & $17 b$ & $17 c$ & $17 d$ & 18 \\
\hline $19 a$ & $19 \mathrm{~b}$ & $20 \mathrm{a}$ & $20 \mathrm{~b}$ & $20 \mathrm{c}$ & 21 \\
\hline
\end{tabular}

Any information copied from such Reports and Statements may not be sold or used by any person for the purpose of soliciting contributions or for commercial purposes, other than using the name and address of any political committee to solicit contributions from such committee.

NAME OF COMMITTEE (In Full)

\section{Friends of Herman Cain}

A. Full Name (Last, First, Middle Initial)

\section{Stephen Govaker}

Mailing Address 4515 Rfd

\begin{tabular}{lcc}
\hline City & State & Zip Code \\
Long Grove & IL & $60047-9733$ \\
\hline
\end{tabular}

FEC ID number of contributing federal political committee.

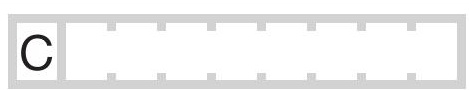

Name of Employer
Information Requested
Receipt For: 2012
X Primary
Other (specify) General

Occupation Information Requested

Election Cycle-to-Date

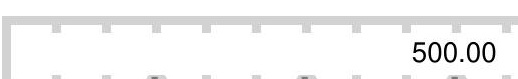

B. Full Name (Last, First, Middle Initial)

Christopher Blair

Mailing Address 21 8th Ave

\begin{tabular}{lcc}
\hline City & State & Zip Code \\
Milford & CT & $06460-5328$
\end{tabular}

FEC ID number of contributing

federal political committee.

C

Name of Employer
AKUSTIKS
Receipt For: 2012
X Primary
Other (specify)

\section{Occupation} consultant

Election Cycle-to-Date

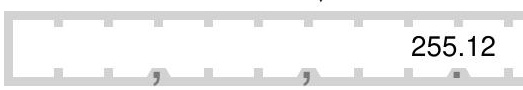

Transaction ID : ABAF460DBCD274A5DA28

Date of Receipt

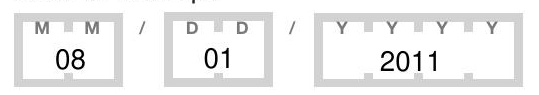

Amount of Each Receipt this Period

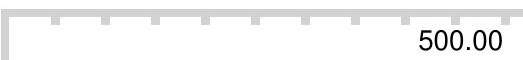

C. Full Name (Last, First, Middle Initial)

Peaches Kavanaugh

Mailing Address 216 Monty Manor

\begin{tabular}{lcc}
\hline City & State & Zip Code \\
Yorktown & VA & $23693-4414$
\end{tabular}

FEC ID number of contributing federal political committee.

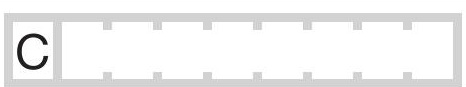

Name of Employer
Air Force
Receipt For: 2012
X Primary
Other (specify) General

\section{Occupation}

Retired

Election Cycle-to-Date

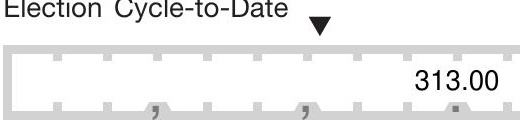

Amount of Each Receipt this Period

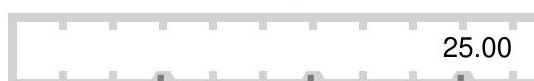

Transaction ID : AD57E1D0E7557455BB2B Date of Receipt

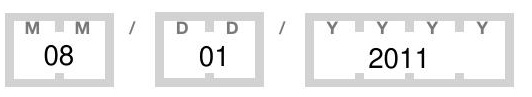

Transaction ID : A988433D2A5CC49D2BA1 Date of Receipt

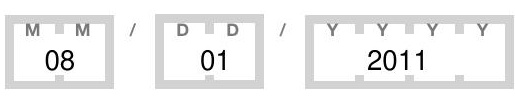

Amount of Each Receipt this Period

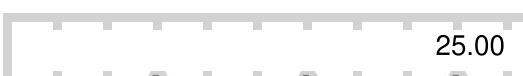

\section{Subtotal Of Receipts This Page (optional)}

Total This Period (last page this line number only) 
SCHEDULE A-P ITEMIZED RECEIPTS
Use separate schedule(s) for each category of the Detailed Summary Page
FOR LINE NUMBER: (check only one)

PAGE $176 / 1572$

\begin{tabular}{|c|c|c|c|c|c|}
\hline & & & & & \\
\hline 16 & $\begin{array}{l}\mathbf{X} \\
17 a\end{array}$ & $17 b$ & $17 c$ & $17 d$ & 18 \\
\hline $19 a$ & $19 \mathrm{~b}$ & $20 \mathrm{a}$ & $20 \mathrm{~b}$ & $20 \mathrm{c}$ & 21 \\
\hline
\end{tabular}

Any information copied from such Reports and Statements may not be sold or used by any person for the purpose of soliciting contributions or for commercial purposes, other than using the name and address of any political committee to solicit contributions from such committee.

NAME OF COMMITTEE (In Full)

\section{Friends of Herman Cain}

A. Full Name (Last, First, Middle Initial)

Brian E Whitehead

Mailing Address 14604 S Oak Ct

\begin{tabular}{lcc}
\hline City & State & Zip Code \\
Glenpool & OK & $74033-3712$ \\
\hline
\end{tabular}

FEC ID number of contributing federal political committee.

Name of Employer
Campbell Wholesale
Receipt For: 2012
X Primary $\quad \square$ General
Other (specify)

B. Full Name (Last, First, Middle Initial)

Jane Hyman

Mailing Address 17460 lh 35 N Ste 160-107

\begin{tabular}{lcc}
\hline City & State & Zip Code \\
Schertz & TX & $78154-1243$
\end{tabular}

FEC ID number of contributing

federal political committee.

Name of Employer
None
Receipt For: 2012
X Primary
Other (specify)

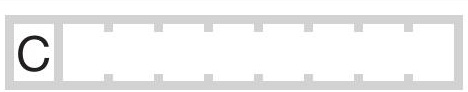

Occupation

Accountant

Election Cycle-to-Date

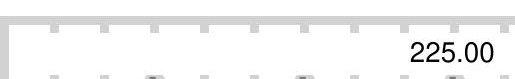

C
Occupation

Retired

Election Cycle-to-Date

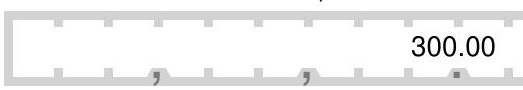

Transaction ID : A7098C3E657F1461394D

Date of Receipt

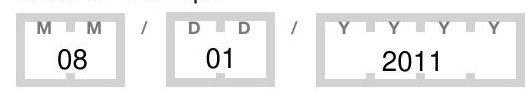

Amount of Each Receipt this Period

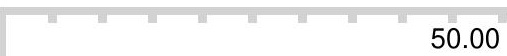

50.00

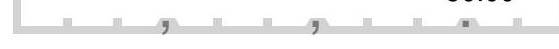

Transaction ID : A5D3073A1B10A41B0916

Date of Receipt

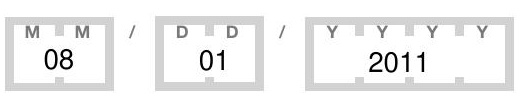

Amount of Each Receipt this Period

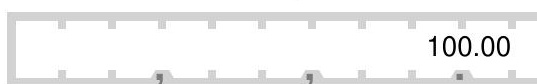

Transaction ID : A9311C04AAC2849C68A2 Date of Receipt

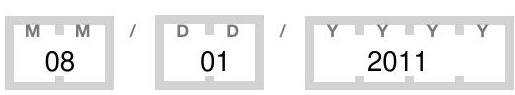

Amount of Each Receipt this Period

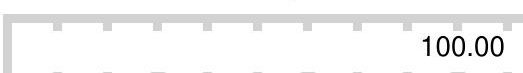

Attorney

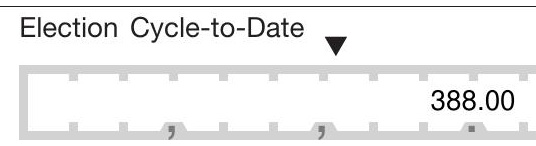

Subtotal Of Receipts This Page (optional)

250.00

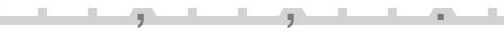

Total This Period (last page this line number only)

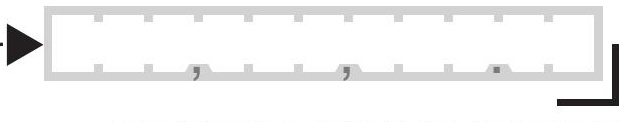

FEC Schedule A-P (Form 3P) (Rev. 03/2011) 
SCHEDULE A-P ITEMIZED RECEIPTS
Use separate schedule(s) for each category of the Detailed Summary Page
FOR LINE NUMBER: (check only one)

PAGE 177 / 1572

\begin{tabular}{|c|c|c|c|c|c|}
\hline & & & & & \\
\hline 16 & $\begin{array}{l}\mathbf{X} \\
17 a\end{array}$ & $17 b$ & $17 c$ & $17 d$ & 18 \\
\hline $19 a$ & $19 \mathrm{~b}$ & $20 \mathrm{a}$ & $20 \mathrm{~b}$ & $20 \mathrm{c}$ & 21 \\
\hline
\end{tabular}

Any information copied from such Reports and Statements may not be sold or used by any person for the purpose of soliciting contributions or for commercial purposes, other than using the name and address of any political committee to solicit contributions from such committee.

NAME OF COMMITTEE (In Full)

\section{Friends of Herman Cain}

A. Full Name (Last, First, Middle Initial)

H. Legare Coleman

Mailing Address 683 Faulkner Dr.

\begin{tabular}{lcc}
\hline City & State & Zip Code \\
Mount Pleasant & SC & $29466-8347$
\end{tabular}

FEC ID number of contributing

federal political committee.

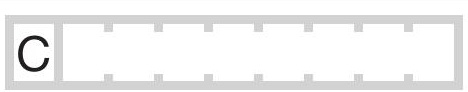

Name of Employer
Information Requested
Receipt For: 2012
X Primary
Other (specify) General

Occupation

Information Requested

Election Cycle-to-Date

300.00

B. Full Name (Last, First, Middle Initial)

don weidler

Mailing Address 912 Woodland Trl SE

\begin{tabular}{lcc}
\hline City & State & Zip Code \\
Smyrna & GA & $30080-1536$ \\
\hline
\end{tabular}

FEC ID number of contributing

federal political committee.

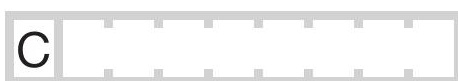

Name of Employer
Self Employed
Receipt For: 2012
X Primary
Other (specify)

\section{Occupation}

courier

Election Cycle-to-Date

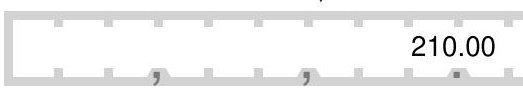

Transaction ID : AABD7CFC5D6EA47B4A3F

Date of Receipt

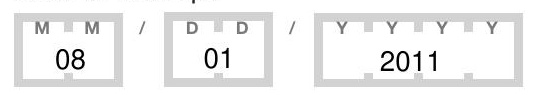

Amount of Each Receipt this Period

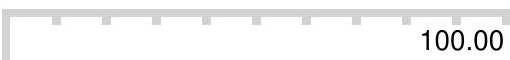

C. Full Name (Last, First, Middle Initial)

Don Mark Williamson

Mailing Address P.O Box 356

\begin{tabular}{lcc}
\hline City & State & Zip Code \\
Brittany & LA & $70718-0356$
\end{tabular}

FEC ID number of contributing federal political committee.

C

Name of Employer
State of Louisiana
Receipt For: 2012
X Primary
Other (specify) General

Occupation

Investigator III

Election Cycle-to-Date

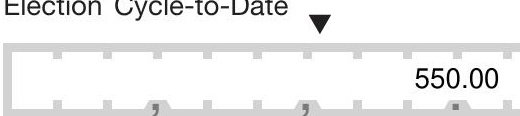

Amount of Each Receipt this Period

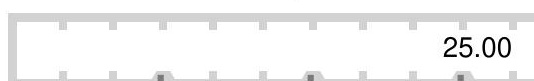

Transaction ID : AB02D178A45E8437C8BB Date of Receipt

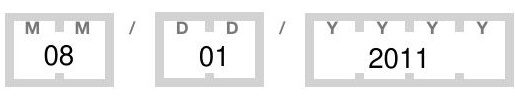

Transaction ID : A58D37BD5CB7E48B0A5E Date of Receipt

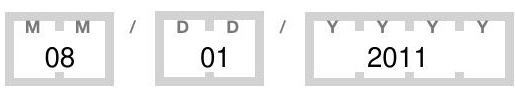

Amount of Each Receipt this Period

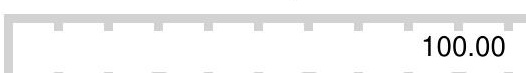

\section{Subtotal Of Receipts This Page (optional)}

Total This Period (last page this line number only) 
SCHEDULE A-P ITEMIZED RECEIPTS
Use separate schedule(s) for each category of the Detailed Summary Page
FOR LINE NUMBER: (check only one)

PAGE $178 / 1572$

\begin{tabular}{|c|c|c|c|c|c|}
\hline & & & & & \\
\hline 16 & $\begin{array}{l}\mathbf{X} \\
17 a\end{array}$ & $17 b$ & $17 c$ & $17 d$ & 18 \\
\hline $19 a$ & $19 \mathrm{~b}$ & $20 \mathrm{a}$ & $20 \mathrm{~b}$ & $20 \mathrm{c}$ & 21 \\
\hline
\end{tabular}

Any information copied from such Reports and Statements may not be sold or used by any person for the purpose of soliciting contributions or for commercial purposes, other than using the name and address of any political committee to solicit contributions from such committee.

NAME OF COMMITTEE (In Full)

\section{Friends of Herman Cain}

A. Full Name (Last, First, Middle Initial) Jody Harshman

Mailing Address 5908 THistledown Dr

\begin{tabular}{lcc}
\hline City & State & Zip Code \\
Pasco & WA & $99301-3118$ \\
\hline
\end{tabular}

FEC ID number of contributing federal political committee.

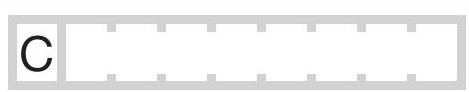

Name of Employer
Independent Contractor
Receipt For: 2012
X Primary $\quad \square$ General
Other (specify)

Occupation technician

Election Cycle-to-Date

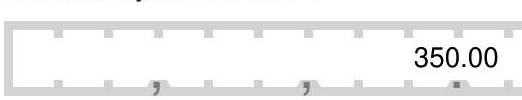

B. Full Name (Last, First, Middle Initial)

Anne Holliday

Mailing Address P.O. Box 311

\begin{tabular}{lcc}
\hline City & State & Zip Code \\
Easley & SC & $29641-0311$
\end{tabular}

FEC ID number of contributing

federal political committee.

C

Name of Employer

Sunbelt Human Advancement Resources In

Occupation

Receipt For: 2012

Х Primary $\square$ General

Dept. Director

Election Cycle-to-Date

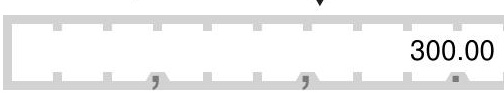

C. Full Name (Last, First, Middle Initial)

WILLIAM ROBSON

Mailing Address 7000 SCIOTO ROAD

\begin{tabular}{lcc}
\hline City & State & Zip Code \\
Dublin & OH & $43017-9319$
\end{tabular}

FEC ID number of contributing federal political committee.

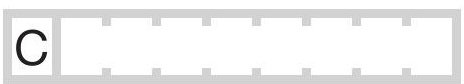

Name of Employer

Information Requested

\section{Occupation}

Information Requested

Receipt For: 2012

Х $\begin{aligned} & \text { Primary } \square \text { General } \\ & \text { Other (specify) }\end{aligned}$

Transaction ID : A64DB88379C1340268D5

Date of Receipt

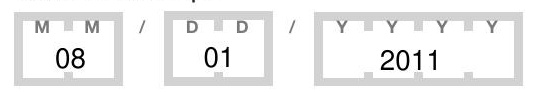

Amount of Each Receipt this Period

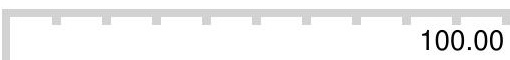

Amount of Each Receipt this Period

Transaction ID : A071A4D10648946D39F8

Date of Receipt
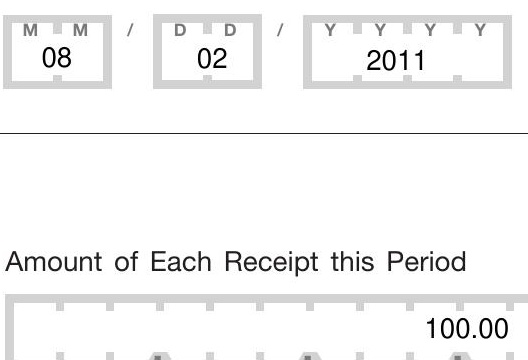

Transaction ID : AB7D6CE4E16514276BC8 Date of Receipt

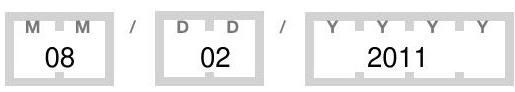

Amount of Each Receipt this Period

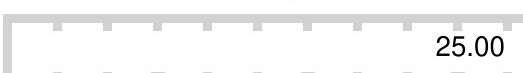

225.00

Subtotal Of Receipts This Page (optional).

Total This Period (last page this line number only) 
SCHEDULE A-P ITEMIZED RECEIPTS
Use separate schedule(s) for each category of the Detailed Summary Page
FOR LINE NUMBER: (check only one)

PAGE $179 / 1572$

\begin{tabular}{|c|c|c|c|c|c|}
\hline & & & & & \\
\hline 16 & $\begin{array}{l}\mathbf{X} \\
17 a\end{array}$ & $17 b$ & $17 c$ & $17 d$ & 18 \\
\hline $19 a$ & $19 \mathrm{~b}$ & $20 \mathrm{a}$ & $20 \mathrm{~b}$ & $20 \mathrm{c}$ & 21 \\
\hline
\end{tabular}

Any information copied from such Reports and Statements may not be sold or used by any person for the purpose of soliciting contributions or for commercial purposes, other than using the name and address of any political committee to solicit contributions from such committee.

NAME OF COMMITTEE (In Full)

\section{Friends of Herman Cain}

A. Full Name (Last, First, Middle Initial)

Colie Whitaker III

Mailing Address 5245 Abbey Park Ln.

\begin{tabular}{lcc}
\hline City & State & Zip Code \\
Mableton & GA & $30126-5609$
\end{tabular}

FEC ID number of contributing

federal political committee.

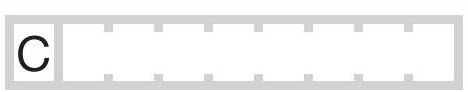

Name of Employer
Whitaker Oil Co.
Receipt For: 2012
X Primary
Other (specify) General

Occupation BUSINESS OWNER

Election Cycle-to-Date 2500.00

B. Full Name (Last, First, Middle Initial) Robert Fash

Mailing Address 13002 Leader Twonhouse 907

\begin{tabular}{lcc}
\hline City & State & Zip Code \\
Houston & TX & 77072 \\
\hline
\end{tabular}

FEC ID number of contributing

federal political committee.

C

Name of Employer
Selene Finance
Receipt For: 2012
Primary
Other (specify)

\section{Occupation}

Accountant

Election Cycle-to-Date

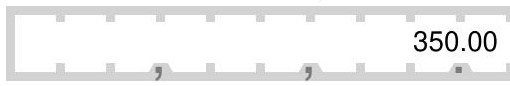

C. Full Name (Last, First, Middle Initial)

Eric Renz

Mailing Address 514 Huffer Rd.

\begin{tabular}{lcc}
\hline City & State & Zip Code \\
Hilton & NY & $14468-9575$
\end{tabular}

FEC ID number of contributing federal political committee.

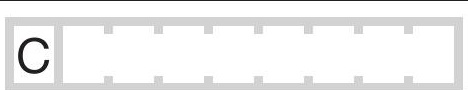

Name of Employer
Retired
Receipt For: 2012
Х Primary $\square$ General
Other (specify)

Occupation

Retired

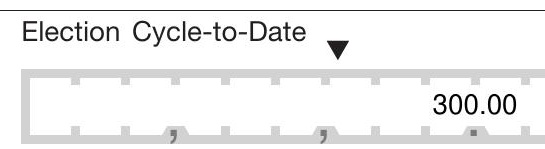

Transaction ID : A89F8342A3A3D48C3BF3

Date of Receipt

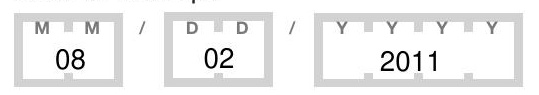

Amount of Each Receipt this Period

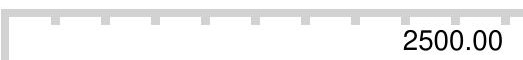

2500.00

Transaction ID : A401C8A0880C54682BA6

Date of Receipt

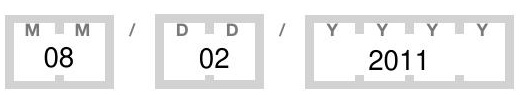

Amount of Each Receipt this Period

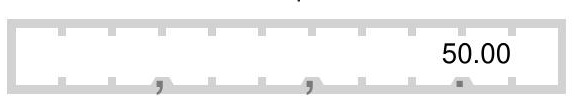

Transaction ID : A5D1CD5DAAB7F49098B7 Date of Receipt

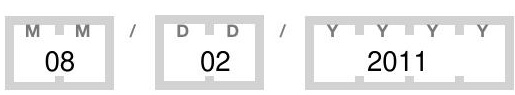

Amount of Each Receipt this Period

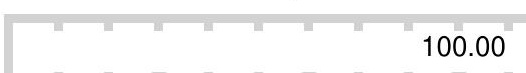

100.00

\section{Subtotal Of Receipts This Page (optional)}

2650.00

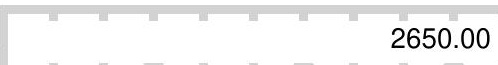

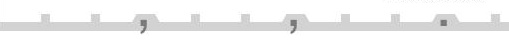

Total This Period (last page this line number only)

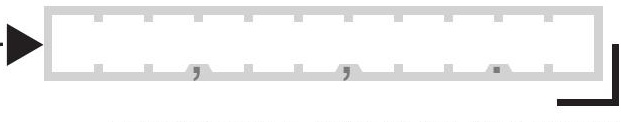

FEC Schedule A-P (Form 3P) (Rev. 03/2011) 
SCHEDULE A-P ITEMIZED RECEIPTS
Use separate schedule(s) for each category of the Detailed Summary Page
FOR LINE NUMBER: (check only one)

\begin{tabular}{|c|c|c|c|c|c|}
\hline & & & & & \\
\hline 16 & $\begin{array}{ll}X & 17 a \\
\end{array}$ & $17 \mathrm{~b}$ & $17 c$ & $17 d$ & 18 \\
\hline $19 a$ & $19 b$ & $20 \mathrm{a}$ & $20 \mathrm{~b}$ & $20 c$ & 21 \\
\hline
\end{tabular}

Any information copied from such Reports and Statements may not be sold or used by any person for the purpose of soliciting contributions or for commercial purposes, other than using the name and address of any political committee to solicit contributions from such committee.

NAME OF COMMITTEE (In Full)

\section{Friends of Herman Cain}

A. Full Name (Last, First, Middle Initial)

Thomas Parrott

Mailing Address 6153 Stadium Ct

\begin{tabular}{lcc}
\hline City & State & Zip Code \\
Norcross & GA & $30092-2340$ \\
\hline
\end{tabular}

FEC ID number of contributing

federal political committee.

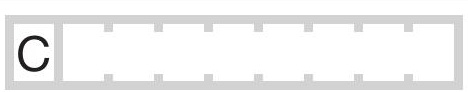

Name of Employer
IBM
Receipt For: 2012
X Primary $\quad$ General
Other (specify)

Occupation

Sales

Election Cycle-to-Date

350.00

B. Full Name (Last, First, Middle Initial)

Gary Arnold

Mailing Address 3160 Francis Road

\begin{tabular}{lcc}
\hline City & State & Zip Code \\
Alpharetta & GA & $30004-0921$
\end{tabular}

FEC ID number of contributing

federal political committee.

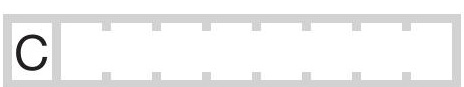

\begin{tabular}{l} 
Name of Employer \\
Canine Assistants \\
Receipt For: 2012 \\
X Primary \\
\hline Other (specify) General
\end{tabular}

\section{Occupation} CEO

Election Cycle-to-Date

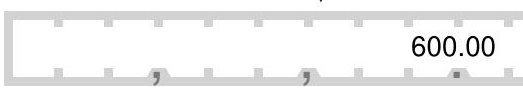

Transaction ID : A7C56F707BA21475386D

Date of Receipt

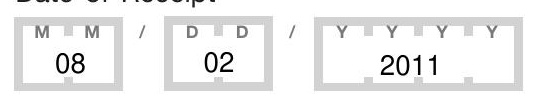

Amount of Each Receipt this Period

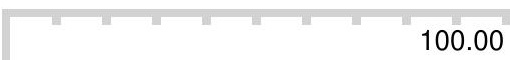

Transaction ID : AF654E239E2B44136965

Date of Receipt

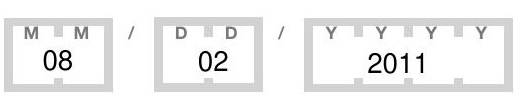

Amount of Each Receipt this Period

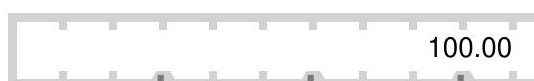

Transaction ID : A618A01F6F04C4505A3C Date of Receipt

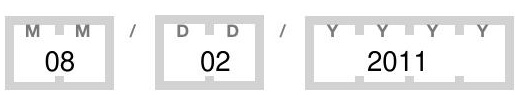

Amount of Each Receipt this Period

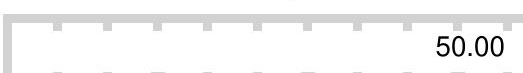

\section{Subtotal Of Receipts This Page (optional)}

Total This Period (last page this line number only) 


\section{SCHEDULE A-P} ITEMIZED RECEIPTS
Use separate schedule(s)

for each category of the

Detailed Summary Page
FOR LINE NUMBER: (check only one)

PAGE $181 / 1572$

\begin{tabular}{|c|c|c|c|c|c|}
\hline & & & & & \\
\hline 16 & $\begin{array}{l}\mathbf{X} \\
17 a\end{array}$ & $17 b$ & $17 c$ & $17 d$ & 18 \\
\hline $19 a$ & $19 \mathrm{~b}$ & $20 \mathrm{a}$ & $20 \mathrm{~b}$ & $20 \mathrm{c}$ & 21 \\
\hline
\end{tabular}

Any information copied from such Reports and Statements may not be sold or used by any person for the purpose of soliciting contributions or for commercial purposes, other than using the name and address of any political committee to solicit contributions from such committee.

NAME OF COMMITTEE (In Full)

Friends of Herman Cain

A. Full Name (Last, First, Middle Initial)

Robert Porter

Mailing Address 5710 Grand Reunion Dr

\begin{tabular}{lcc}
\hline City & State & Zip Code \\
Hoschton & GA & $30548-4045$
\end{tabular}

FEC ID number of contributing

federal political committee.

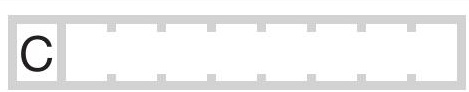

Name of Employer
Information Requested
Receipt For: 2012
X Primary $\quad \square$ General
Other (specify)

Occupation

Information Requested

Election Cycle-to-Date

387.00

B. Full Name (Last, First, Middle Initial)

John Ellery

Mailing Address 2488 Old Fork Rd

\begin{tabular}{lcc}
\hline City & State & Zip Code \\
Gainesville & GA & $30506-1124$
\end{tabular}

FEC ID number of contributing

federal political committee.

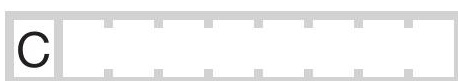

Name of Employer
Automatic IT Corp
Receipt For: 2012
X Primary
Other (specify) General

Occupation

IT Consultant

Election Cycle-to-Date

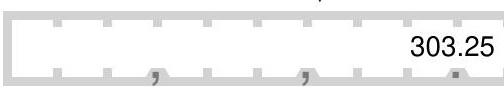

Transaction ID : AC61835012B9B492CA80

Date of Receipt

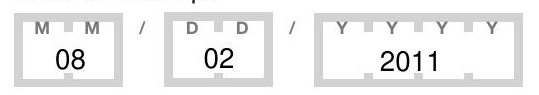

Amount of Each Receipt this Period

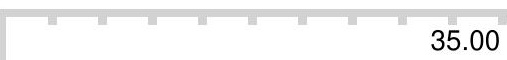

C. Full Name (Last, First, Middle Initial)

Arlene Rouse

Mailing Address 4655 E 58th St

\begin{tabular}{lcc}
\hline City & State & Zip Code \\
Tulsa & OK & $74135-4319$
\end{tabular}

FEC ID number of contributing federal political committee.

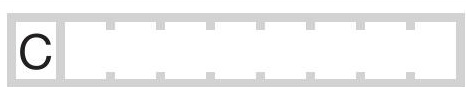

Name of Employer
Dillards
Receipt For: 2012
X Primary $\square$ General
Other (specify)

\section{Occupation}

Sales

Election Cycle-to-Date

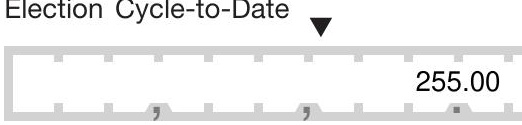

Amount of Each Receipt this Period

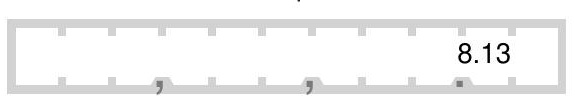

Transaction ID : A8CDD3A5905AA4C31B5D Date of Receipt

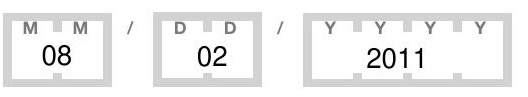

Transaction ID : A2BB26A066C1846E08F6 Date of Receipt

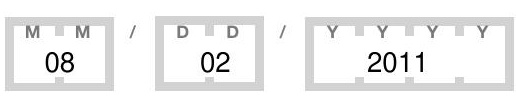

Amount of Each Receipt this Period

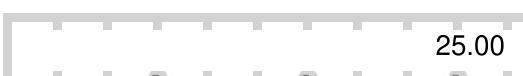

\section{Subtotal Of Receipts This Page (optional)}

Total This Period (last page this line number only)
68.13

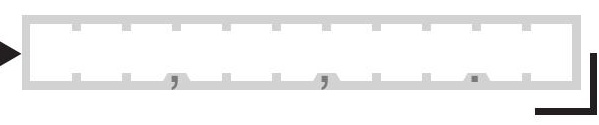

FEC Schedule A-P (Form 3P) (Rev. 03/2011) 
SCHEDULE A-P ITEMIZED RECEIPTS
Use separate schedule(s) for each category of the Detailed Summary Page
FOR LINE NUMBER: (check only one)

PAGE 182 / 1572

\begin{tabular}{|c|c|c|c|c|c|c|}
\hline & & & & & & \\
\hline 16 & $\lambda$ & $17 \mathrm{a}$ & $17 \mathrm{~b}$ & $17 \mathrm{c}$ & $-17 d$ & -18 \\
\hline $19 a$ & & $19 b$ & $20 a$ & $20 \mathrm{~b}$ & $20 \mathrm{c}$ & 21 \\
\hline
\end{tabular}

Any information copied from such Reports and Statements may not be sold or used by any person for the purpose of soliciting contributions or for commercial purposes, other than using the name and address of any political committee to solicit contributions from such committee.

NAME OF COMMITTEE (In Full)

\section{Friends of Herman Cain}

A. Full Name (Last, First, Middle Initial)

Douglas Horgen

Mailing Address 230 Etowah Trace

\begin{tabular}{lcc}
\hline City & State & Zip Code \\
Fayetteville & GA & $30214-5912$ \\
\hline
\end{tabular}

FEC ID number of contributing

federal political committee.

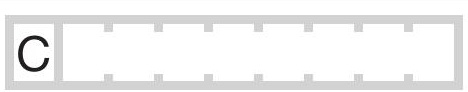

Name of Employer
Information Requested
Receipt For: 2012
X Primary $\quad \square$ General
Other (specify)

Occupation

Information Requested

Election Cycle-to-Date

500.00

B. Full Name (Last, First, Middle Initial)

Philip Dobbs

Mailing Address 216 Pine Branch Drive

\begin{tabular}{lcc}
\hline City & State & Zip Code \\
Stockbridge & GA & $30281-6023$
\end{tabular}

FEC ID number of contributing

federal political committee.

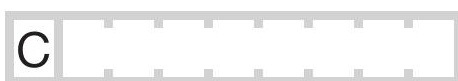

Name of Employer
Ga Municipal Assoc
Receipt For: 2012
X Primary
Other (specify)

\section{Occupation}

Graphics Manager

Election Cycle-to-Date

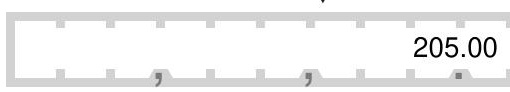

C. Full Name (Last, First, Middle Initial)

Donna Odar

Mailing Address 13712 Winding Oak Circle \#202

\begin{tabular}{lcc}
\hline City & State & Zip Code \\
Centreville & VA & $20121-4759$
\end{tabular}

FEC ID number of contributing

federal political committee.

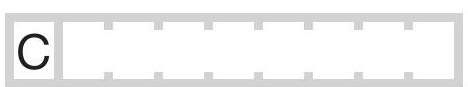

Name of Employer
n/a
Receipt For: 2012
X Primary $\square$ General
Other (specify)

Occupation

Retired

Election Cycle-to-Date

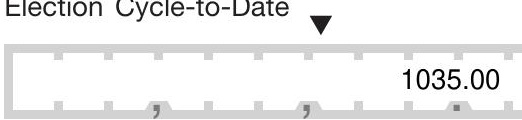

Transaction ID : A9813F9FFD50C42268E9

Date of Receipt

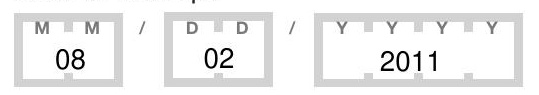

Amount of Each Receipt this Period

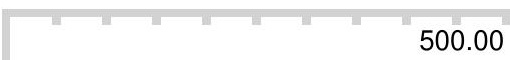

500.00

Transaction ID : A0E10DA62DCAA4077BA6

Date of Receipt

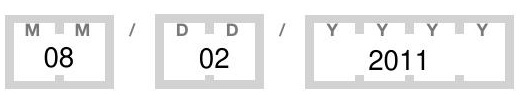

Amount of Each Receipt this Period

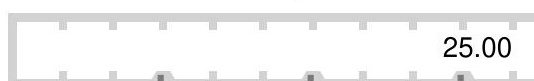

Transaction ID : A2780A49932CB485593F

Date of Receipt

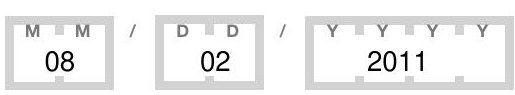

Amount of Each Receipt this Period

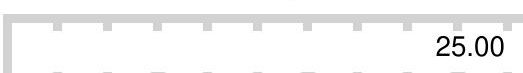

\section{Subtotal Of Receipts This Page (optional)}

Total This Period (last page this line number only) 
SCHEDULE A-P ITEMIZED RECEIPTS
Use separate schedule(s) for each category of the Detailed Summary Page
FOR LINE NUMBER: (check only one)

PAGE $183 / 1572$

\begin{tabular}{|c|c|c|c|c|c|}
\hline & & & & & \\
\hline 16 & $\begin{array}{lll}X & 17 a \\
\end{array}$ & $17 \mathrm{~b}$ & $17 c$ & $17 d$ & 18 \\
\hline $19 a$ & $19 b$ & $20 a$ & $20 \mathrm{~b}$ & $20 c$ & 21 \\
\hline
\end{tabular}

Any information copied from such Reports and Statements may not be sold or used by any person for the purpose of soliciting contributions or for commercial purposes, other than using the name and address of any political committee to solicit contributions from such committee.

NAME OF COMMITTEE (In Full)

Friends of Herman Cain

A. Full Name (Last, First, Middle Initial)

Tamela McKemie

Mailing Address 596 Inglis Drive

\begin{tabular}{lcc}
\hline City & State & Zip Code \\
Marietta & GA & $30067-6710$
\end{tabular}

FEC ID number of contributing

federal political committee.

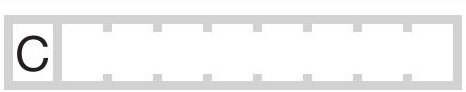

Name of Employer
Troutman Sanders
Receipt For: 2012
X Primary
Other (specify) General

Occupation

Secretary

Election Cycle-to-Date

335.00

B. Full Name (Last, First, Middle Initial)

Glen Ebbing

Mailing Address 1400 Huntleigh Rd

\begin{tabular}{lcc}
\hline City & State & Zip Code \\
Quincy & IL & $62305-6017$ \\
\hline
\end{tabular}

FEC ID number of contributing

federal political committee.

C

Name of Employer
ColorMaster Pain Inc
Receipt For: 2012
X Primary
Other (specify)

Occupation

sales representative

Election Cycle-to-Date

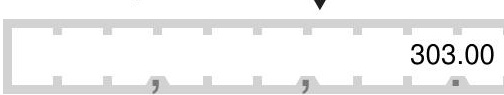

Transaction ID : A3F1CC9CFA28B433EB4C

Date of Receipt

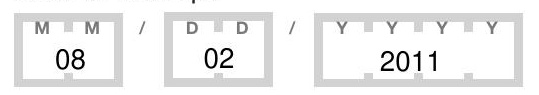

Amount of Each Receipt this Period

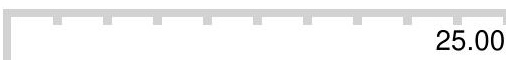

25.00

C. Full Name (Last, First, Middle Initial)

Larry Weiss

Mailing Address 2112 Pleasantview Ct

\begin{tabular}{lcc}
\hline City & State & Zip Code \\
New Albany & IN & $47150-9670$
\end{tabular}

FEC ID number of contributing

federal political committee.

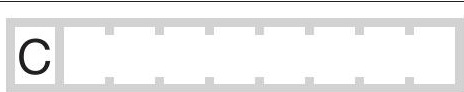

$\begin{aligned} & \text { Name of Employer } \\ & \text { self }\end{aligned}$
Receipt For: 2012
X Primary $\square$ General
Other (specify)

\section{Occupation}

Insurance Agent

Election Cycle-to-Date

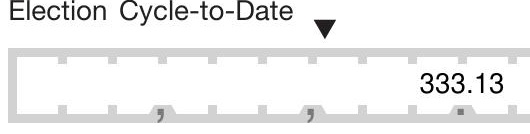

Amount of Each Receipt this Period

Transaction ID : ACA5B6F0AD2D447249FF

Date of Receipt
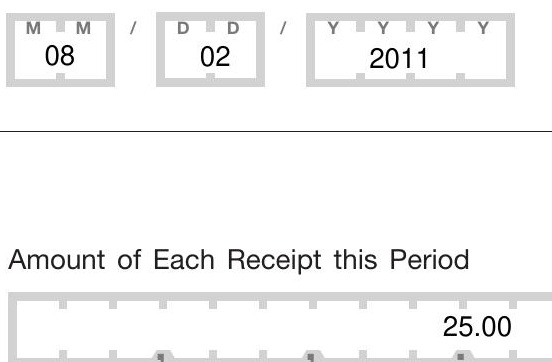

Transaction ID : A4EF4823C1C104DDB99D Date of Receipt

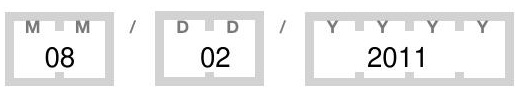

Amount of Each Receipt this Period

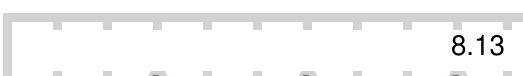

Subtotal Of Receipts This Page (optional).

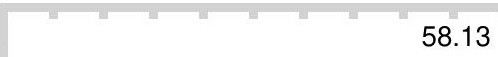

Total This Period (last page this line number only) 
SCHEDULE A-P ITEMIZED RECEIPTS
Use separate schedule(s) for each category of the Detailed Summary Page
FOR LINE NUMBER: (check only one)
PAGE 184 / 1572

\begin{tabular}{|c|c|c|c|c|c|}
\hline & & & & & \\
\hline 16 & $\begin{array}{lll}X & 17 a \\
\end{array}$ & $17 \mathrm{~b}$ & $17 c$ & $17 d$ & 18 \\
\hline $19 a$ & $19 b$ & $20 a$ & $20 \mathrm{~b}$ & $20 c$ & 21 \\
\hline
\end{tabular}

Any information copied from such Reports and Statements may not be sold or used by any person for the purpose of soliciting contributions or for commercial purposes, other than using the name and address of any political committee to solicit contributions from such committee.

NAME OF COMMITTEE (In Full)

\section{Friends of Herman Cain}

A. Full Name (Last, First, Middle Initial)

Todd Nesley

Mailing Address 406 headgate dr

\begin{tabular}{lcc}
\hline City & State & Zip Code \\
Augusta & GA & $30907-3306$
\end{tabular}

FEC ID number of contributing federal political committee.

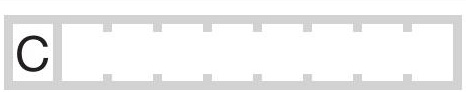

Name of Employer
Nurse Anesthetist
Receipt For: 2012
X Primary $\quad$ General
Other (specify)

Occupation Todd Nesley

Election Cycle-to-Date

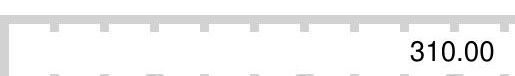

B. Full Name (Last, First, Middle Initial)

Alyn Holt

Mailing Address 10 Hessian Way

\begin{tabular}{lcc}
\hline City & State & Zip Code \\
Cherry Hill & NJ & $08003-2615$
\end{tabular}

FEC ID number of contributing

federal political committee.

C

Name of Employer
inTEST Corp
Receipt For: 2012
X Primary
Other (specify)

Occupation

Executive

Election Cycle-to-Date

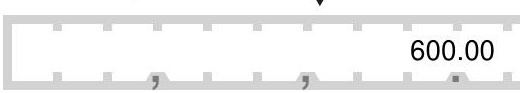

Transaction ID : AD26E5684D6694AFAB64

Date of Receipt

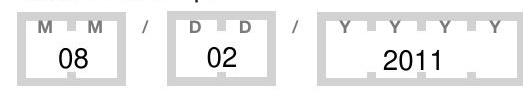

Amount of Each Receipt this Period

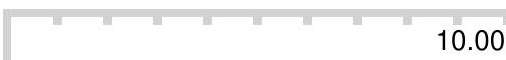

10.00

C. Full Name (Last, First, Middle Initial)

Don Lewis

Mailing Address 166 Merion

\section{City}

Saint Simons Island

FEC ID number of contributing federal political committee.

Name of Employer

Sea Island Company

Receipt For: 2012

Х $\begin{aligned} & \text { Primary } \square \text { General } \\ & \text { Other (specify) }\end{aligned}$

\section{State Zip Code \\ GA 31522-2415}

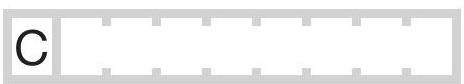

Occupation

Realtor

Election Cycle-to-Date

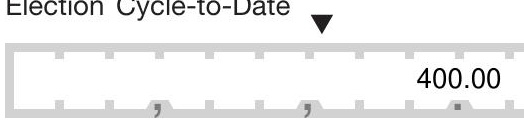

Transaction ID : A46C61895BB434B66AAF Date of Receipt

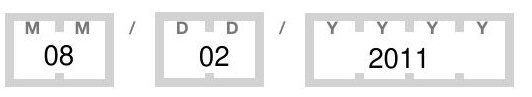

Amount of Each Receipt this Period

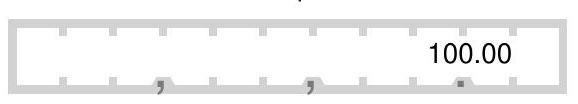

Transaction ID : ABAD2FCAAC00C418C83E Date of Receipt

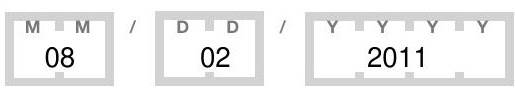

Amount of Each Receipt this Period

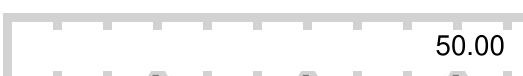

50.00

\section{Subtotal Of Receipts This Page (optional)}

160.00

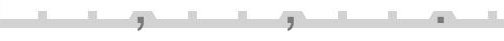

Total This Period (last page this line number only)

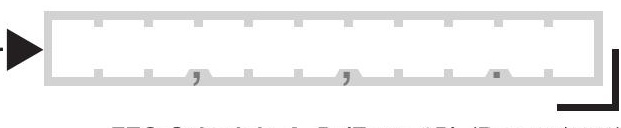

FEC Schedule A-P (Form 3P) (Rev. 03/2011) 
SCHEDULE A-P ITEMIZED RECEIPTS
Use separate schedule(s) for each category of the Detailed Summary Page
FOR LINE NUMBER: (check only one)
PAGE $185 / 1572$

\begin{tabular}{|c|c|c|c|c|c|}
\hline & & & & & \\
\hline 16 & $\begin{array}{lll}X & 17 a \\
\end{array}$ & $17 \mathrm{~b}$ & $17 c$ & $17 d$ & 18 \\
\hline $19 a$ & $19 b$ & $20 a$ & $20 \mathrm{~b}$ & $20 c$ & 21 \\
\hline
\end{tabular}

Any information copied from such Reports and Statements may not be sold or used by any person for the purpose of soliciting contributions or for commercial purposes, other than using the name and address of any political committee to solicit contributions from such committee.

NAME OF COMMITTEE (In Full)

\section{Friends of Herman Cain}

A. Full Name (Last, First, Middle Initial) marilyn Sensney

Mailing Address 19528 Creekside Ct

\begin{tabular}{lcc}
\hline City & State & Zip Code \\
Salinas & CA & $93908-1245$
\end{tabular}

FEC ID number of contributing federal political committee.

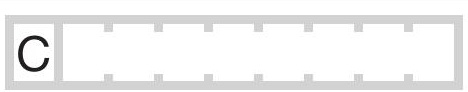

Name of Employer
Monerey School District
Receipt For: 2012
X Primary $\quad \square$ General
Other (specify)

Occupation Teacher Election Cycle-to-Date

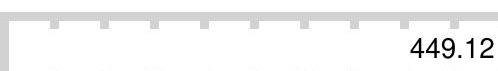

B. Full Name (Last, First, Middle Initial)

Richard Leder

Mailing Address 3674 Lower Tanners Bridge Rd.

\begin{tabular}{lcc}
\hline City & State & Zip Code \\
Monroe & GA & $30656-8549$ \\
\hline
\end{tabular}

FEC ID number of contributing

federal political committee.

C

Name of Employer
Information Requested
Receipt For: 2012
X Primary
Other (specify)

\section{Occupation}

Information Requested

Election Cycle-to-Date

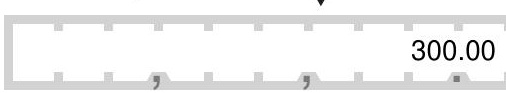

Transaction ID : AC11723701C404D73B25

Date of Receipt

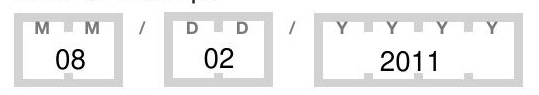

Amount of Each Receipt this Period

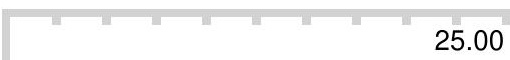

C. Full Name (Last, First, Middle Initial)

Clete Kelly

Mailing Address 5640 Manuel Place

\begin{tabular}{lcc}
\hline City & State & Zip Code \\
Buford & GA & $30518-5602$
\end{tabular}

FEC ID number of contributing

federal political committee.

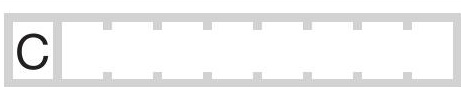

Name of Employer

Exhibits South Corp.

\section{Occupation}

VP/Owner

Transaction ID : AA7DBC7FFC7004A8ABA5 Date of Receipt

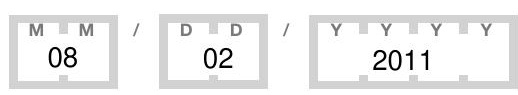

Amount of Each Receipt this Period

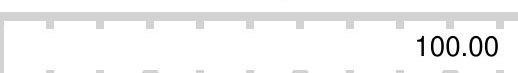

Transaction ID : A29EEF03CD2D543429B9 Date of Receipt

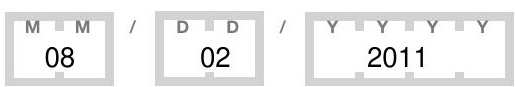

Amount of Each Receipt this Period

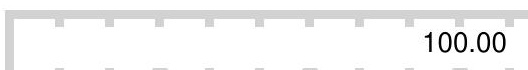

650.00

\section{Subtotal Of Receipts This Page (optional)}

Total This Period (last page this line number only) 
SCHEDULE A-P ITEMIZED RECEIPTS
Use separate schedule(s) for each category of the Detailed Summary Page
FOR LINE NUMBER: (check only one)
PAGE $186 / 1572$

\begin{tabular}{|c|c|c|c|c|c|}
\hline & & & & & \\
\hline 16 & $\begin{array}{l}\mathbf{x} 17 a \\
\end{array}$ & $17 b$ & $17 c$ & $17 d$ & 18 \\
\hline $19 a$ & $19 b$ & $20 a$ & $20 b$ & $20 c$ & 21 \\
\hline
\end{tabular}

Any information copied from such Reports and Statements may not be sold or used by any person for the purpose of soliciting contributions or for commercial purposes, other than using the name and address of any political committee to solicit contributions from such committee.

NAME OF COMMITTEE (In Full)

\section{Friends of Herman Cain}

A. Full Name (Last, First, Middle Initial)

Elin Carlson

Mailing Address 17553 Lanark St.

\begin{tabular}{lcc}
\hline City & State & Zip Code \\
Northridge & CA & $91325-4317$
\end{tabular}

FEC ID number of contributing federal political committee.

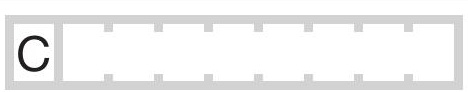

Name of Employer
self
Receipt For: 2012
X Primary $\quad$ General
Other (specify)

Occupation professional singer

Election Cycle-to-Date

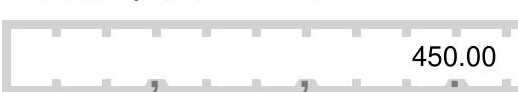

B. Full Name (Last, First, Middle Initial)

Mary Daniel

Mailing Address 131 South End Street

\begin{tabular}{lcc}
\hline City & State & Zip Code \\
Saint Augustine & FL & $32095-6821$
\end{tabular}

FEC ID number of contributing

federal political committee.

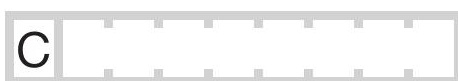

Name of Employer
The Shannon Group
Receipt For: 2012
X Primary
Other (specify)

Occupation

medical management

Election Cycle-to-Date

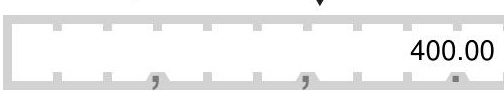

Transaction ID : A446E0A3D54EF476AB75

Date of Receipt

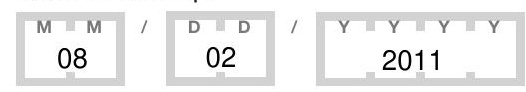

Amount of Each Receipt this Period

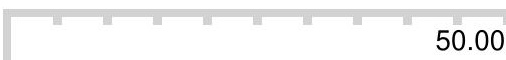

C. Full Name (Last, First, Middle Initial)

David Morris

Mailing Address 7921 E 46th Street

\begin{tabular}{lcc}
\hline City & State & Zip Code \\
Indianapolis & IN & $46226-3931$
\end{tabular}

FEC ID number of contributing

federal political committee.

C $46226-3931$

Name of Employer
Precision Dry Wall Inc.
Receipt For: 2012
X Primary
Other (specify) General

\section{Occupation}

Construction

Election Cycle-to-Date

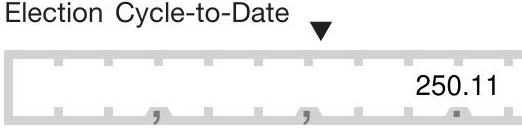

Transaction ID : ADA08C7DF350D4D13A7F Date of Receipt

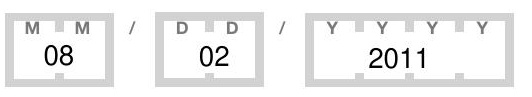

Amount of Each Receipt this Period

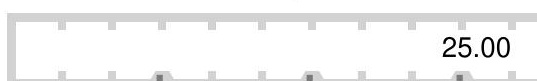

Transaction ID : A4FD5029961AD4BDFB46 Date of Receipt

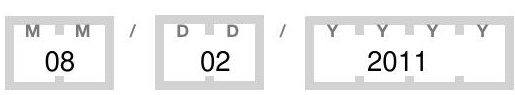

Amount of Each Receipt this Period

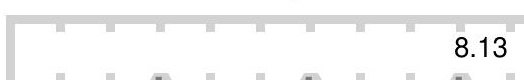

8.13

Subtotal Of Receipts This Page (optional).

Total This Period (last page this line number only) 
SCHEDULE A-P ITEMIZED RECEIPTS
Use separate schedule(s) for each category of the Detailed Summary Page
FOR LINE NUMBER: (check only one)
PAGE 187 / 1572

\begin{tabular}{|c|c|c|c|c|c|}
\hline & & & & & \\
\hline 16 & $\begin{array}{lll}X & 17 a \\
\end{array}$ & $17 \mathrm{~b}$ & $17 c$ & $17 d$ & 18 \\
\hline $19 a$ & $19 b$ & $20 a$ & $20 \mathrm{~b}$ & $20 c$ & 21 \\
\hline
\end{tabular}

Any information copied from such Reports and Statements may not be sold or used by any person for the purpose of soliciting contributions or for commercial purposes, other than using the name and address of any political committee to solicit contributions from such committee.

NAME OF COMMITTEE (In Full)

\section{Friends of Herman Cain}

A. Full Name (Last, First, Middle Initial)

Arthur Ferguson

Mailing Address 3900 Wedgewood Ct.

\begin{tabular}{lcc}
\hline City & State & Zip Code \\
Arlington & TX & $76013-1065$ \\
\hline
\end{tabular}

FEC ID number of contributing

federal political committee.

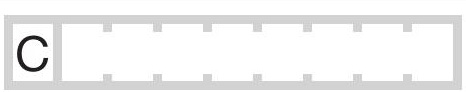

Name of Employer
American Airlines
Receipt For: 2012
X Primary $\quad$ General
Other (specify)

Occupation

Retired

Election Cycle-to-Date

300.00

B. Full Name (Last, First, Middle Initial)

Carl Bell

Mailing Address 2897 Watchmans Walk NW

\begin{tabular}{lcc}
\hline City & State & Zip Code \\
Marietta & GA & $30064-1295$ \\
\hline
\end{tabular}

FEC ID number of contributing

federal political committee.

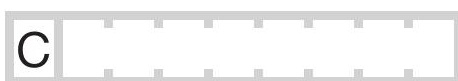

Name of Employer
Retired
Receipt For: 2012
X Primary $\quad$ General
Other (specify)

\section{Occupation}

Retired

Election Cycle-to-Date

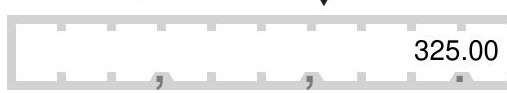

C. Full Name (Last, First, Middle Initial)

Edward Logue

Mailing Address 5205 Saint Regis PI

\begin{tabular}{lcc}
\hline City & State & Zip Code \\
Belle Isle & FL & $32812-1033$
\end{tabular}

FEC ID number of contributing

federal political committee.

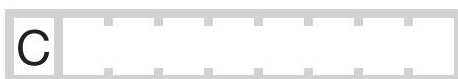

Name of Employer

Computer Sciences Corporation

Receipt For: 2012

Х $\begin{aligned} & \text { Primary } \\ & \text { Other (specify) }\end{aligned}$

Occupation

Program Manager

Election Cycle-to-Date

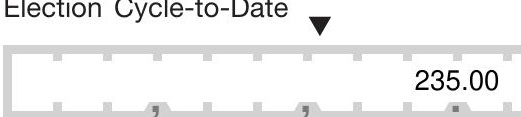

Transaction ID : AB41AAF20C9B94F539A5

Date of Receipt

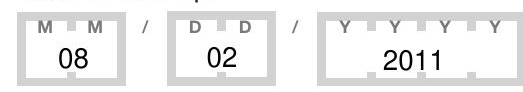

Amount of Each Receipt this Period

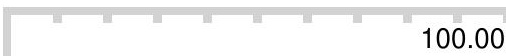

100.00

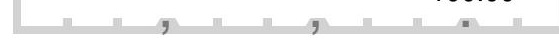

Transaction ID : A66CA7DCD733B4F2AA05

Date of Receipt

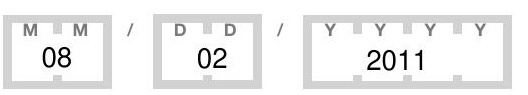

Amount of Each Receipt this Period

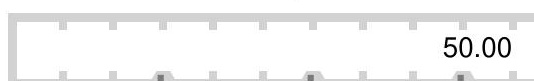

Transaction ID : A90358143B65B44B4BBE Date of Receipt

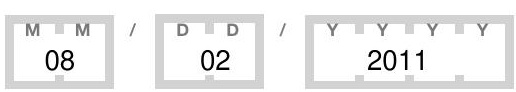

Amount of Each Receipt this Period

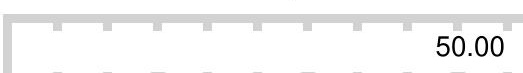

50.00

\section{Subtotal Of Receipts This Page (optional)}

200.00

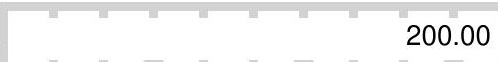

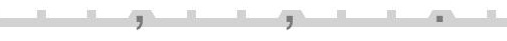

Total This Period (last page this line number only) 
SCHEDULE A-P ITEMIZED RECEIPTS
Use separate schedule(s) for each category of the Detailed Summary Page
FOR LINE NUMBER: (check only one)
PAGE $188 / 1572$

\begin{tabular}{|c|c|c|c|c|c|}
\hline & & & & & \\
\hline 16 & $\begin{array}{l}\mathbf{x} 17 a \\
\end{array}$ & $17 b$ & $17 c$ & $17 d$ & 18 \\
\hline $19 a$ & $19 b$ & $20 a$ & $20 b$ & $20 c$ & 21 \\
\hline
\end{tabular}

Any information copied from such Reports and Statements may not be sold or used by any person for the purpose of soliciting contributions or for commercial purposes, other than using the name and address of any political committee to solicit contributions from such committee.

NAME OF COMMITTEE (In Full)

Friends of Herman Cain

A. Full Name (Last, First, Middle Initial)

Jackie Stonecipher

Mailing Address 1060 Olde Towne Lane

\begin{tabular}{lcc}
\hline City & State & Zip Code \\
Woodstock & GA & $30189-8187$
\end{tabular}

FEC ID number of contributing

federal political committee.

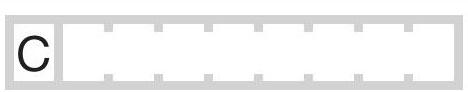

Name of Employer
Quick Weight Loss
Receipt For: 2012
X Primary
Other (specify) General

Occupation

Management

Election Cycle-to-Date

390.00

B. Full Name (Last, First, Middle Initial)

Mr Dennis B Lazzari

Mailing Address 1211 N Diamond Bar Blvd

\begin{tabular}{lcc}
\hline City & State & Zip Code \\
Diamond Bar & CA & $91765-1151$
\end{tabular}

FEC ID number of contributing

federal political committee.

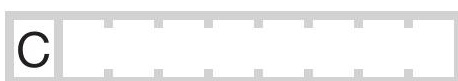

Name of Employer
Los Angeles Cnty
Receipt For: 2012
X Primary
Other (specify)

Occupation

Retired

Election Cycle-to-Date

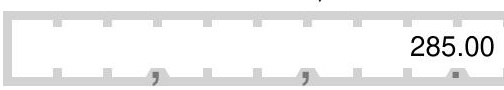

Transaction ID : A921CD74426CC47A2B67

Date of Receipt

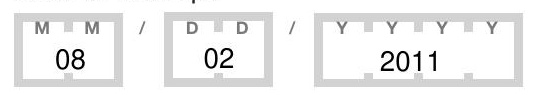

Amount of Each Receipt this Period

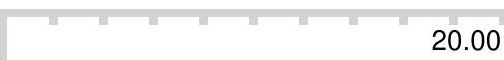

20.00

C. Full Name (Last, First, Middle Initial)

EDWARD MURPHY

Mailing Address 214 CAMINO VISTA REAL

\begin{tabular}{lcc}
\hline City & State & Zip Code \\
Chula Vista & CA & $91910-6326$
\end{tabular}

FEC ID number of contributing

federal political committee.

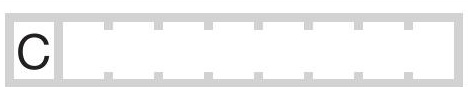

Name of Employer

navy exchange

Receipt For: 2012

Х $\begin{aligned} & \text { Primary } \square \text { General } \\ & \text { Other (specify) }\end{aligned}$

\section{Occupation}

Retired

Election Cycle-to-Date

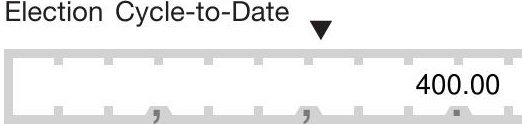

Transaction ID : AD3A54759017E4A8A97D

Date of Receipt

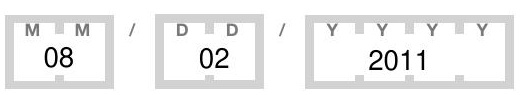

Amount of Each Receipt this Period

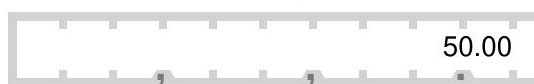

Transaction ID : A8609038B064C432281B

Date of Receipt

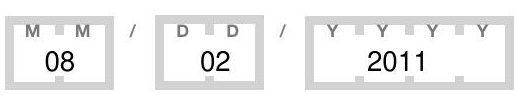

Amount of Each Receipt this Period

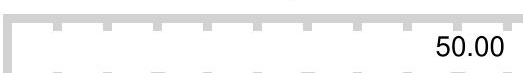

\section{Subtotal Of Receipts This Page (optional)}

120.00

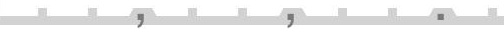

Total This Period (last page this line number only)

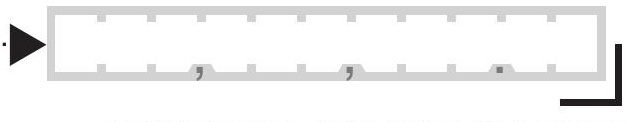

FEC Schedule A-P (Form 3P) (Rev. 03/2011) 
SCHEDULE A-P ITEMIZED RECEIPTS
Use separate schedule(s) for each category of the Detailed Summary Page
FOR LINE NUMBER: (check only one)

PAGE $189 / 1572$

\begin{tabular}{|c|c|c|c|c|c|c|}
\hline & & & & & & \\
\hline 16 & $\lambda$ & $17 \mathrm{a}$ & $17 \mathrm{~b}$ & $17 \mathrm{c}$ & $-17 d$ & -18 \\
\hline $19 a$ & & $19 b$ & $20 a$ & $20 \mathrm{~b}$ & $20 \mathrm{c}$ & 21 \\
\hline
\end{tabular}

Any information copied from such Reports and Statements may not be sold or used by any person for the purpose of soliciting contributions or for commercial purposes, other than using the name and address of any political committee to solicit contributions from such committee.

NAME OF COMMITTEE (In Full)

\section{Friends of Herman Cain}

A. Full Name (Last, First, Middle Initial)

\section{Carol Bockhorn}

Mailing Address 1816 Chincoteague Way

\begin{tabular}{lcc}
\hline City & State & Zip Code \\
Round Rock & TX & $78681-7100$
\end{tabular}

FEC ID number of contributing federal political committee.

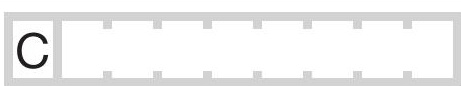

Name of Employer
Immanuel Lutheran Church
Receipt For: 2012
X Primary
Other (specify)

Occupation

Pre-School Teacher

Election Cycle-to-Date

B. Full Name (Last, First, Middle Initial)

Georgia White

Mailing Address 4050 Norton PI SE

\begin{tabular}{lcc}
\hline City & State & Zip Code \\
Smyrna & GA & $30082-3963$ \\
\hline
\end{tabular}

FEC ID number of contributing

federal political committee.

C

Name of Employer

Retired

Occupation

Receipt For: 2012

$\chi \begin{aligned} & \text { Primary } \\ & \text { Other (specify) }\end{aligned}$

finance executive

Election Cycle-to-Date

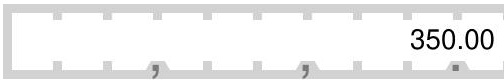

C. Full Name (Last, First, Middle Initial)

Erik Anhaus

Mailing Address 6395 Queens Court Trce

\begin{tabular}{lcc}
\hline City & State & Zip Code \\
Mableton & GA & $30126-7242$
\end{tabular}

FEC ID number of contributing

federal political committee.

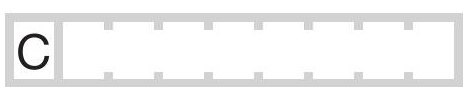

Name of Employer

Ameriprise Financial

Occupation

Financial Advisor

Receipt For: 2012

Х $\begin{aligned} & \text { Primary } \\ & \text { Other (specify) }\end{aligned}$

Transaction ID : A35B928557D254907AB6

Date of Receipt

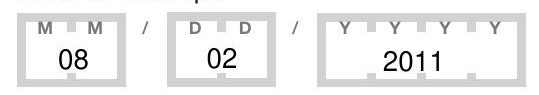

Amount of Each Receipt this Period

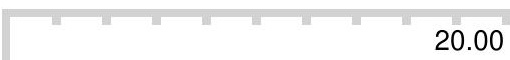

20.00

Amount of Each Receipt this Period

Transaction ID : A86E4AE688EA24956AAE Date of Receipt
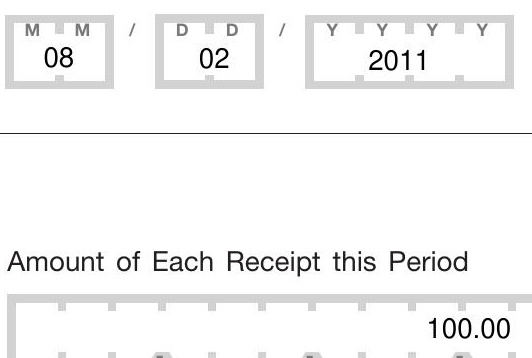

Transaction ID : A754EF77185DD4AF9A48 Date of Receipt

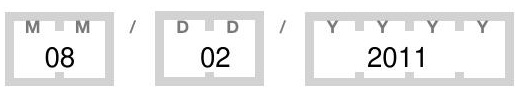

Amount of Each Receipt this Period

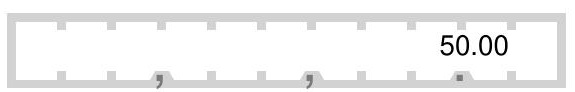

218.00

\section{Subtotal Of Receipts This Page (optional)}

Total This Period (last page this line number only) 
SCHEDULE A-P ITEMIZED RECEIPTS
Use separate schedule(s) for each category of the Detailed Summary Page
FOR LINE NUMBER: (check only one)

PAGE $190 / 1572$

\begin{tabular}{|c|c|c|c|c|c|c|}
\hline & & & & & & \\
\hline 16 & $\lambda$ & $17 \mathrm{a}$ & $17 \mathrm{~b}$ & $17 \mathrm{c}$ & $-17 d$ & -18 \\
\hline $19 a$ & & $19 b$ & $20 a$ & $20 \mathrm{~b}$ & $20 \mathrm{c}$ & 21 \\
\hline
\end{tabular}

Any information copied from such Reports and Statements may not be sold or used by any person for the purpose of soliciting contributions or for commercial purposes, other than using the name and address of any political committee to solicit contributions from such committee.

NAME OF COMMITTEE (In Full)

\section{Friends of Herman Cain}

A. Full Name (Last, First, Middle Initial) steven kimball

Mailing Address 2224spininngwheel lane

\begin{tabular}{lcc}
\hline City & State & Zip Code \\
Cincinnati & OH & 45244
\end{tabular}

FEC ID number of contributing federal political committee.

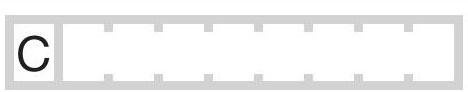

Name of Employer
Emersion Design
Receipt For: 2012
X Primary $\quad$ General
Other (specify)

\section{Occupation} CEO

Election Cycle-to-Date

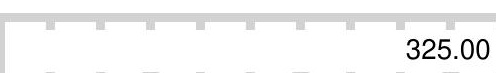

B. Full Name (Last, First, Middle Initial)

Barbara Delorge

Mailing Address 9611 Halkirk St.

\begin{tabular}{lcc}
\hline City & State & Zip Code \\
Spring & TX & $77379-4385$ \\
\hline
\end{tabular}

FEC ID number of contributing

federal political committee.

C

Name of Employer
Information Requested
Receipt For: 2012
Primary
Other (specify)

Occupation

Information Requested

Election Cycle-to-Date

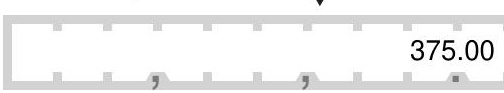

Transaction ID : AAC14D31582484C64B7E

Date of Receipt

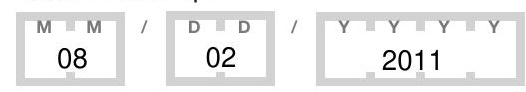

Amount of Each Receipt this Period

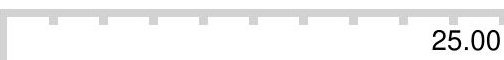

25.00

C. Full Name (Last, First, Middle Initial)

William Wardley

Mailing Address 243 W Main St

\begin{tabular}{lcc}
\hline City & State & Zip Code \\
Saint Paris & OH & $43072-9515$
\end{tabular}

FEC ID number of contributing federal political committee.

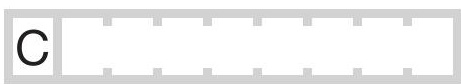

Name of Employer
Retired
Receipt For: 2012
X Primary $\quad \square$ General
Other (specify)

\section{Occupation}

Retired

Election Cycle-to-Date

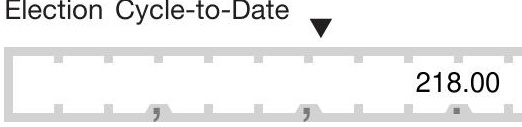

Transaction ID : A515824A009124A81B00

Date of Receipt

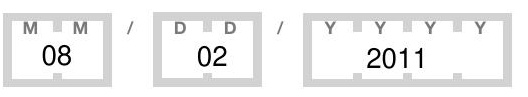

Amount of Each Receipt this Period

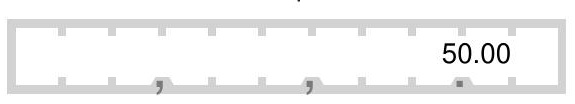

Transaction ID : A650F9C67C3A54D0F94D Date of Receipt

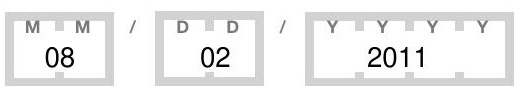

Amount of Each Receipt this Period

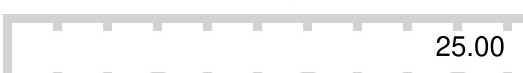

\section{Subtotal Of Receipts This Page (optional)}

100.00

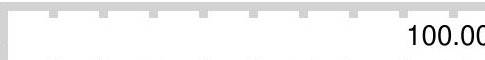

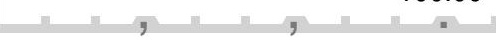

Total This Period (last page this line number only)

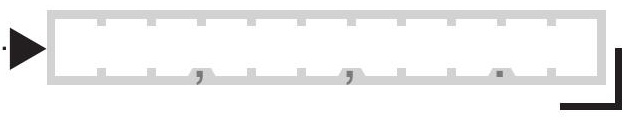

FEC Schedule A-P (Form 3P) (Rev. 03/2011) 
SCHEDULE A-P ITEMIZED RECEIPTS
Use separate schedule(s) for each category of the Detailed Summary Page
FOR LINE NUMBER: (check only one)
PAGE $191 / 1572$

\begin{tabular}{|c|c|c|c|c|c|}
\hline & & & & & \\
\hline 16 & $\begin{array}{lll}X & 17 a \\
\end{array}$ & $17 \mathrm{~b}$ & $17 c$ & $17 d$ & 18 \\
\hline $19 a$ & $19 b$ & $20 a$ & $20 \mathrm{~b}$ & $20 c$ & 21 \\
\hline
\end{tabular}

Any information copied from such Reports and Statements may not be sold or used by any person for the purpose of soliciting contributions or for commercial purposes, other than using the name and address of any political committee to solicit contributions from such committee.

NAME OF COMMITTEE (In Full)

Friends of Herman Cain

A. Full Name (Last, First, Middle Initial)

Ron Pomeroy

Mailing Address PO Box 703

\begin{tabular}{lcc}
\hline City & State & Zip Code \\
Belle Plaine & KS & $67013-0703$
\end{tabular}

FEC ID number of contributing

federal political committee.

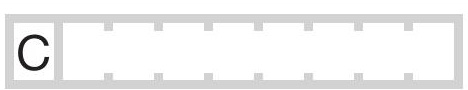

Name of Employer
Kansas Castings Inc
Receipt For: 2012
X Primary
Other (specify) General

Occupation

Metalcasting

Election Cycle-to-Date

325.00

B. Full Name (Last, First, Middle Initial)

Robert Eidson

Mailing Address 2076 Old Grandview Road

\begin{tabular}{lcc}
\hline City & State & Zip Code \\
Jasper & GA & $30143-2726$
\end{tabular}

FEC ID number of contributing

federal political committee.

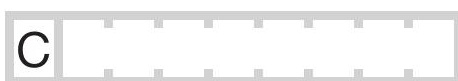

Name of Employer

Aztec-Energy Partners a Danfoss compan

Receipt For: 2012

Х $\begin{aligned} & \text { Primary } \\ & \text { Other (specify) }\end{aligned}$

Occupation

Energy Conservation

Transaction ID : AB7ED9404EDBB41C08F8

Date of Receipt

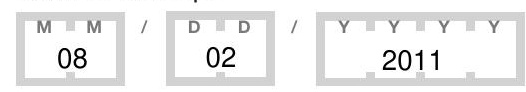

Amount of Each Receipt this Period

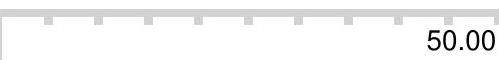

50.00

(n)

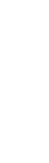

Transaction ID : A57A0CF338E4C485AB5D

Date of Receipt

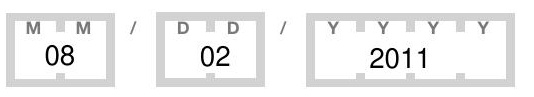

Amount of Each Receipt this Period

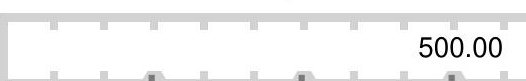

Election Cycle-to-Date

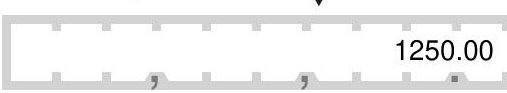

C. Full Name (Last, First, Middle Initial)

Mr Robert L Rankin

Mailing Address 701 Mercer Rd

\begin{tabular}{lcc}
\hline City & State & Zip Code \\
Butler & PA & $16001-1841$
\end{tabular}

FEC ID number of contributing

federal political committee.

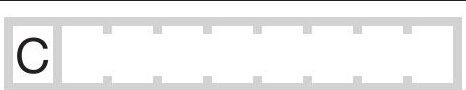

$\begin{aligned} & \text { Name of Employer } \\ & \text { self }\end{aligned}$
Receipt For: 2012
X Primary
Other (specify) General

\section{Occupation}

Engineer

Election Cycle-to-Date

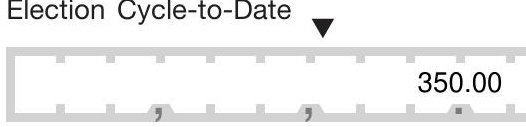

Amount of Each Receipt this Period

Transaction ID : ACC55537DBC854E23944

Date of Receipt
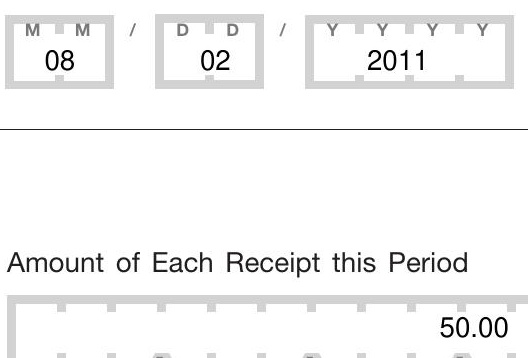

50.00

Subtotal Of Receipts This Page (optional).

600.00

Total This Period (last page this line number only) 
SCHEDULE A-P ITEMIZED RECEIPTS
Use separate schedule(s) for each category of the Detailed Summary Page
FOR LINE NUMBER: (check only one)

PAGE 192 / 1572

\begin{tabular}{|c|c|c|c|c|c|c|}
\hline & & & & & & \\
\hline 16 & $\lambda$ & $17 \mathrm{a}$ & $17 \mathrm{~b}$ & $17 \mathrm{c}$ & $-17 d$ & -18 \\
\hline $19 a$ & & $19 b$ & $20 a$ & $20 \mathrm{~b}$ & $20 \mathrm{c}$ & 21 \\
\hline
\end{tabular}

Any information copied from such Reports and Statements may not be sold or used by any person for the purpose of soliciting contributions or for commercial purposes, other than using the name and address of any political committee to solicit contributions from such committee.

NAME OF COMMITTEE (In Full)

\section{Friends of Herman Cain}

A. Full Name (Last, First, Middle Initial)

\section{Susan Walter}

Mailing Address P.O. Box 690

\begin{tabular}{lcc}
\hline City & State & Zip Code \\
Sautee Nacoochee & GA & $30571-0690$
\end{tabular}

FEC ID number of contributing federal political committee.

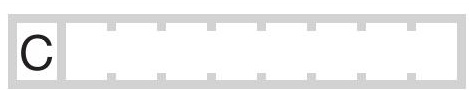

Name of Employer
None
Receipt For: 2012
X Primary $\quad$ General
Other (specify)

Occupation Retired

Election Cycle-to-Date

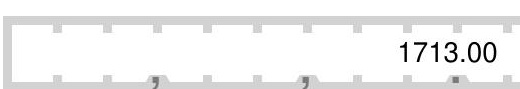

B. Full Name (Last, First, Middle Initial)

Debra Gilliam

Mailing Address 1807 Rockybranch Pass

\begin{tabular}{lcc}
\hline City & State & Zip Code \\
Marietta & GA & $30066-8014$
\end{tabular}

FEC ID number of contributing

federal political committee.

C

Name of Employer
Information Requested
Receipt For: 2012
X Primary
Other (specify)

Occupation

Information Requested

Election Cycle-to-Date

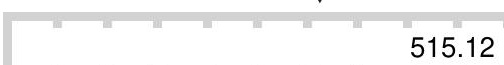

Transaction ID : A192C3706700343B5AD0

Date of Receipt

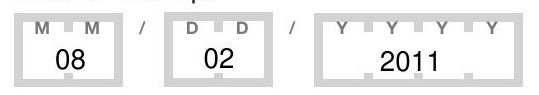

Amount of Each Receipt this Period

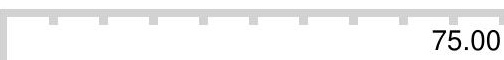

75.00

C. Full Name (Last, First, Middle Initial)

Wayne Thomas

Mailing Address 1533 Clark Avenue

\begin{tabular}{lcc}
\hline City & State & Zip Code \\
Cottage Grove & OR & $97424-1891$
\end{tabular}

FEC ID number of contributing

federal political committee.

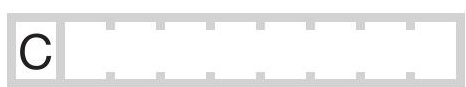

Name of Employer

PeaceHealth Laboratories

Receipt For: 2012

Х $\begin{aligned} & \text { Primary } \square \text { General } \\ & \text { Other (specify) }\end{aligned}$

\section{Occupation}

courier

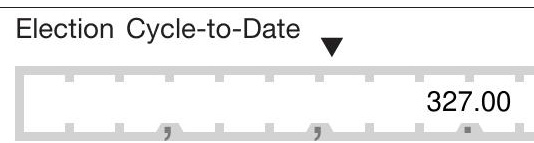

Transaction ID : A2047BD976D404334816

Date of Receipt

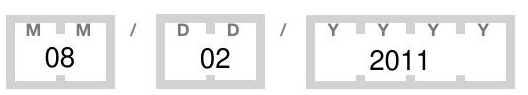

Amount of Each Receipt this Period

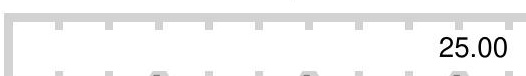

Transaction ID : A019913B4ED764A64B6F

Date of Receipt

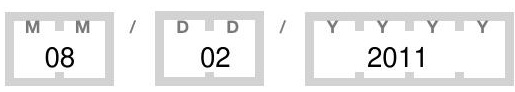

Amount of Each Receipt this Period

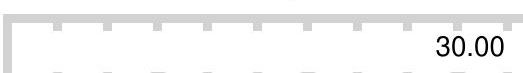

\section{Subtotal Of Receipts This Page (optional)}

Total This Period (last page this line number only) 
SCHEDULE A-P ITEMIZED RECEIPTS
Use separate schedule(s) for each category of the Detailed Summary Page
FOR LINE NUMBER: (check only one)

PAGE $193 / 1572$

\begin{tabular}{|c|c|c|c|c|c|c|}
\hline & & & & & & \\
\hline 16 & $\lambda$ & $17 \mathrm{a}$ & $17 \mathrm{~b}$ & $17 \mathrm{c}$ & $-17 d$ & -18 \\
\hline $19 a$ & & $19 b$ & $20 a$ & $20 \mathrm{~b}$ & $20 \mathrm{c}$ & 21 \\
\hline
\end{tabular}

Any information copied from such Reports and Statements may not be sold or used by any person for the purpose of soliciting contributions or for commercial purposes, other than using the name and address of any political committee to solicit contributions from such committee.

NAME OF COMMITTEE (In Full)

\section{Friends of Herman Cain}

A. Full Name (Last, First, Middle Initial)

Kathy Hoellen

Mailing Address 471 Swift Creek Cv

\begin{tabular}{lcc}
\hline City & State & Zip Code \\
Clover & SC & $29710-5500$
\end{tabular}

FEC ID number of contributing federal political committee.

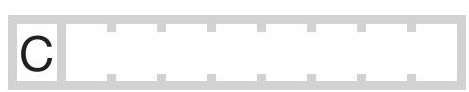

Name of Employer
York Technical College
Receipt For: 2012
X Primary $\quad \square$ General
Other (specify)

Occupation education

Election Cycle-to-Date

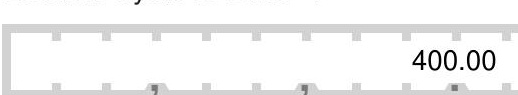

B. Full Name (Last, First, Middle Initial)

Mrs. Audrey P. Chambers

Mailing Address 121 Robson $\mathrm{Trl}$

\begin{tabular}{lcc}
\hline City & State & Zip Code \\
McDonough & GA & $30252-4208$ \\
\hline
\end{tabular}

FEC ID number of contributing

federal political committee.

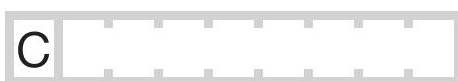

Name of Employer
None
Receipt For: 2012
X Primary $\quad$ General
Other (specify)

\section{Occupation}

Retired

Election Cycle-to-Date

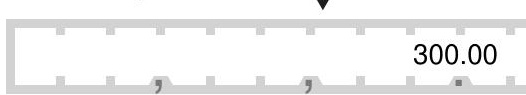

Transaction ID : AF137D1F5070F484FA16

Date of Receipt

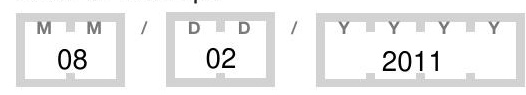

Amount of Each Receipt this Period

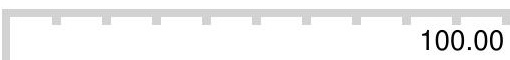

Transaction ID : A9213D73D837C4B079E4

Date of Receipt

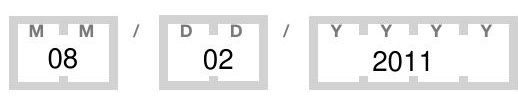

Amount of Each Receipt this Period

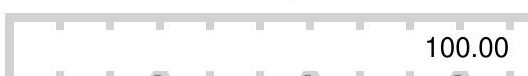

C. Full Name (Last, First, Middle Initial)

Gary Locke

Mailing Address 2602 Booger Hill Road

\begin{tabular}{lcc}
\hline City & State & Zip Code \\
Danielsville & GA & $30633-6102$
\end{tabular}

FEC ID number of contributing

federal political committee.

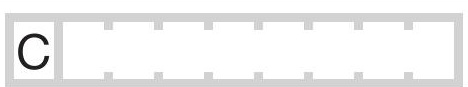

Name of Employer
None
Receipt For: 2012
Х Primary $\quad \square$ General
Other (specify)

Occupation

Retired

Election Cycle-to-Date

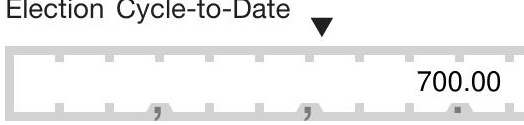

Subtotal Of Receipts This Page (optional)

250.00

Amount of Each Receipt this Period
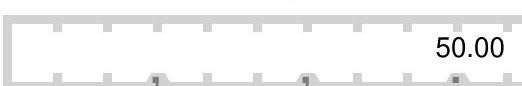

Total This Period (last page this line number only)

Transaction ID : AD135833A7B364DDFACF Date of Receipt

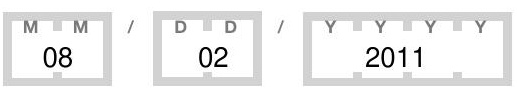


SCHEDULE A-P ITEMIZED RECEIPTS
Use separate schedule(s)

for each category of the

Detailed Summary Page
FOR LINE NUMBER: (check only one)

Any information copied from such Reports and Statementer por the purpose of soliciting contributions or for commercial purposes, other than using the name and address of any political committee to solicit contributions from such committee.

NAME OF COMMITTEE (In Full)

\section{Friends of Herman Cain}

A. Full Name (Last, First, Middle Initial)

Robert Bolling

Mailing Address 2109 Freeman Rd

\begin{tabular}{lcc}
\hline City & State & Zip Code \\
Jonesboro & GA & $30236-6711$
\end{tabular}

FEC ID number of contributing

federal political committee.

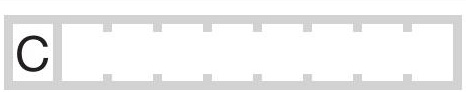

Name of Employer
self
Receipt For: 2012
X Primary $\quad$ General
Other (specify)

Occupation contractor

Election Cycle-to-Date

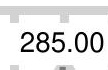

B. Full Name (Last, First, Middle Initial)

James Fincher

Mailing Address 1881 Calvin Drive

\begin{tabular}{lcc}
\hline City & State & Zip Code \\
Duluth & GA & $30097-5123$ \\
\hline
\end{tabular}

FEC ID number of contributing

federal political committee.

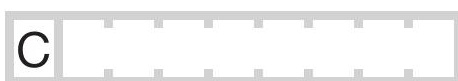

Name of Employer
Self Employed
Receipt For: 2012
X Primary
Other (specify)

Occupation

RE Developer

Election Cycle-to-Date

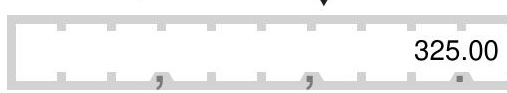

Transaction ID : A3621F0C453F24CD08CD

Date of Receipt

Amount of Each Receipt this Period

10.00
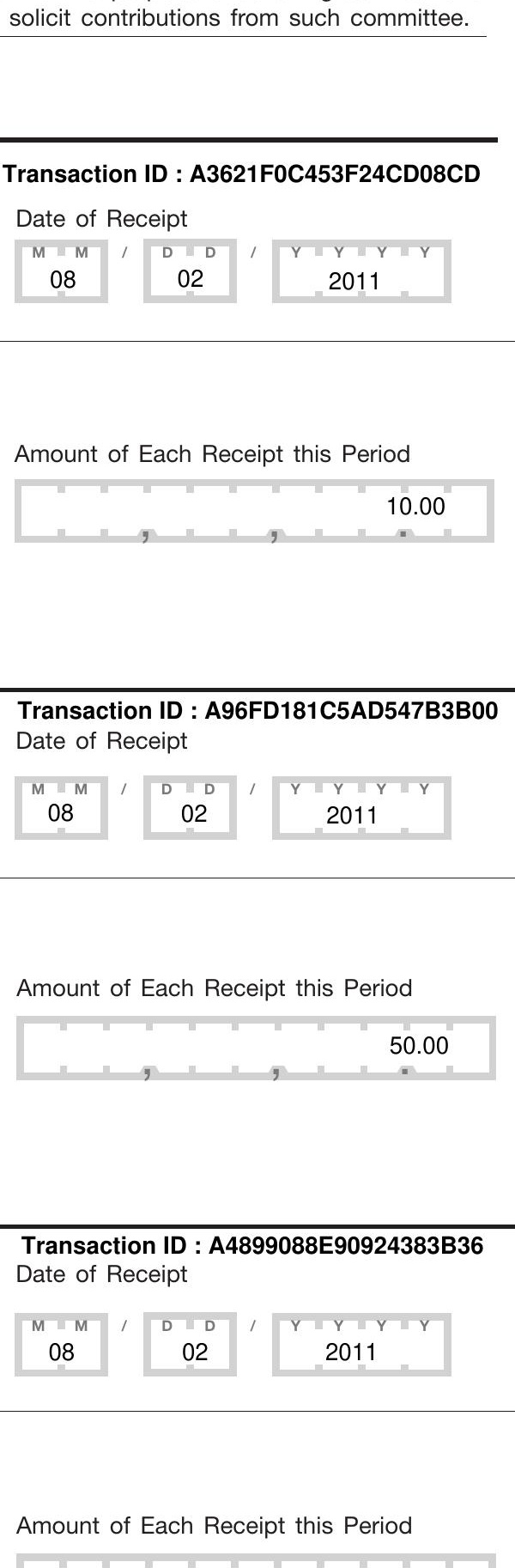

C. Full Name (Last, First, Middle Initial)

James Roberts

Mailing Address 1016 BAYVIEW OVERLOOK

\begin{tabular}{lcc}
\hline City & State & Zip Code \\
Stafford & VA & $22554-5235$ \\
\hline
\end{tabular}

FEC ID number of contributing

federal political committee.

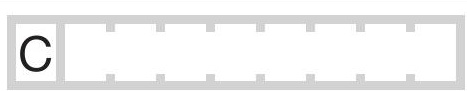

Name of Employer

ManTech Intl.

Occupation

Proposal Manager

Receipt For: 2012

Х $\begin{aligned} & \text { Primary } \square \text { General } \\ & \text { Other (specify) }\end{aligned}$

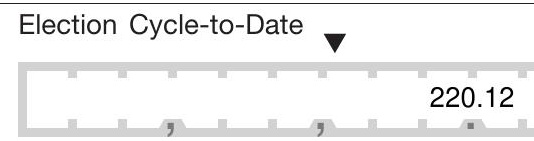

Amount of Each Receipt this Period

Transaction ID : A96FD181C5AD547B3B00

Date of Receipt
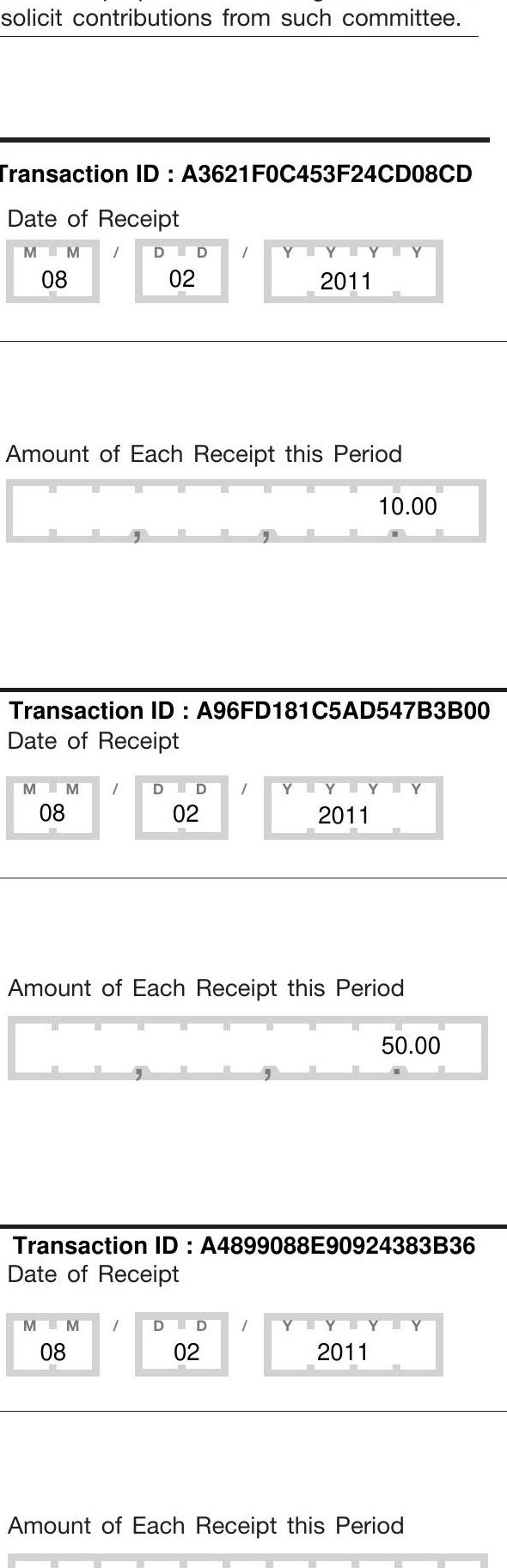

Transaction ID : A4899088E90924383B36

Date of Receipt

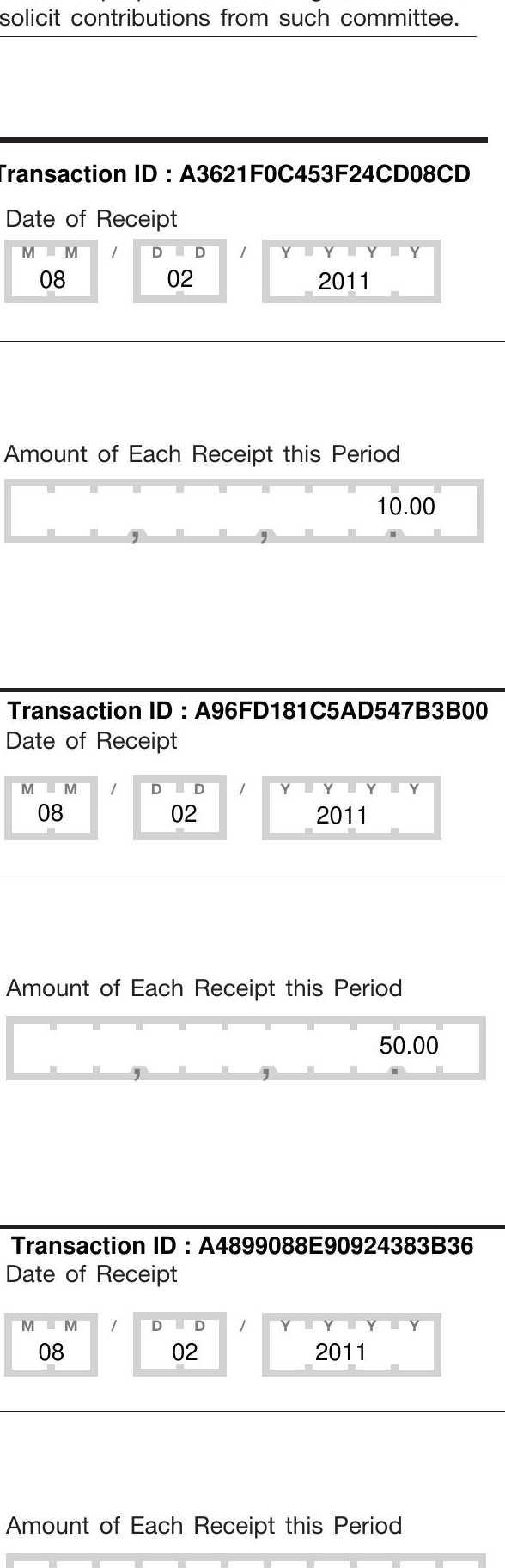

Amount of Each Receipt this Period

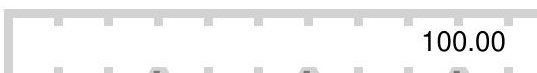

Subtotal Of Receipts This Page (optional)

160.00

Total This Period (last page this line number only) 
SCHEDULE A-P ITEMIZED RECEIPTS
Use separate schedule(s) for each category of the Detailed Summary Page
FOR LINE NUMBER: (check only one)
PAGE $195 / 1572$

\begin{tabular}{|c|c|c|c|c|c|}
\hline & & & & & \\
\hline 16 & $\begin{array}{l}\mathbf{x} 17 a \\
\end{array}$ & $17 b$ & $17 c$ & $17 d$ & 18 \\
\hline $19 a$ & $19 b$ & $20 a$ & $20 b$ & $20 c$ & 21 \\
\hline
\end{tabular}

Any information copied from such Reports and Statements may not be sold or used by any person for the purpose of soliciting contributions or for commercial purposes, other than using the name and address of any political committee to solicit contributions from such committee.

NAME OF COMMITTEE (In Full)

\section{Friends of Herman Cain}

A. Full Name (Last, First, Middle Initial)

Robby Lawson

Mailing Address 9622 Vermilion Dr

\begin{tabular}{lcc}
\hline City & State & Zip Code \\
Knoxville & TN & 37922-5821 \\
\hline
\end{tabular}

FEC ID number of contributing federal political committee.

C

Name of Employer

ABF Freight System, Inc.

Occupation

Receipt For: 2012 Х $\begin{aligned} & \text { Primary } \square \text { General } \\ & \text { Other (specify) }\end{aligned}$ operations supervisor

Election Cycle-to-Date

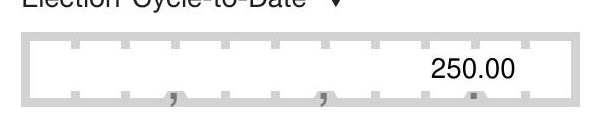

B. Full Name (Last, First, Middle Initial)

Sandra Shackelford

Mailing Address 130 Middling Lane

\begin{tabular}{lcc}
\hline City & State & Zip Code \\
Fayetteville & GA & $30214-3767$
\end{tabular}

FEC ID number of contributing

federal political committee.

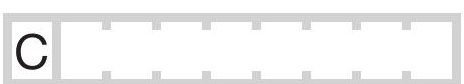

Name of Employer
Delta Airlines
Receipt For: 2012
X Primary
$\square$ Other (specify) General

Occupation

Enterprise Document Mgmt

Election Cycle-to-Date

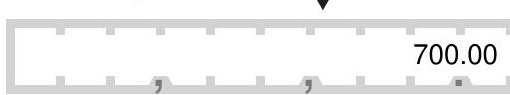

Transaction ID : AB28A2C6387784B96B4D

Date of Receipt

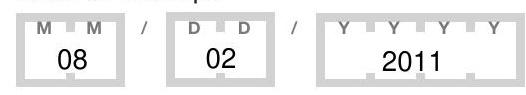

Amount of Each Receipt this Period

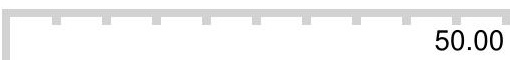

50.00

C. Full Name (Last, First, Middle Initial)

amy peil

Mailing Address 4410 Highgrove Pte

\begin{tabular}{lcc}
\hline City & State & Zip Code \\
Atlanta & GA & 30319 \\
\hline
\end{tabular}

FEC ID number of contributing

federal political committee.

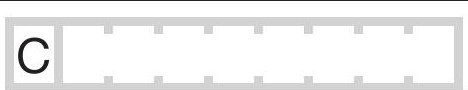

$\begin{aligned} & \text { Name of Employer } \\ & \text { self }\end{aligned}$
Receipt For: 2012
X Primary $\quad \square$ General
Other (specify)

Occupation

Decorator/Home staging

Election Cycle-to-Date
Transaction ID : A0CB7F5CCB9C848D4932

Date of Receipt

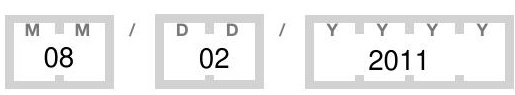

Amount of Each Receipt this Period

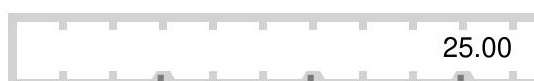

Transaction ID : A0747FC532BF84AA0AFA Date of Receipt

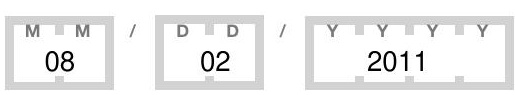

Amount of Each Receipt this Period

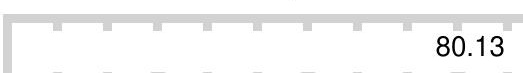

\section{Subtotal Of Receipts This Page (optional)}

Total This Period (last page this line number only) 
SCHEDULE A-P ITEMIZED RECEIPTS
Use separate schedule(s) for each category of the Detailed Summary Page
FOR LINE NUMBER: (check only one)

PAGE $196 / 1572$

\begin{tabular}{|c|c|c|c|c|c|c|}
\hline & & & & & & \\
\hline 16 & $\lambda$ & $17 \mathrm{a}$ & $17 \mathrm{~b}$ & $17 \mathrm{c}$ & $-17 d$ & -18 \\
\hline $19 a$ & & $19 b$ & $20 a$ & $20 \mathrm{~b}$ & $20 \mathrm{c}$ & 21 \\
\hline
\end{tabular}

Any information copied from such Reports and Statements may not be sold or used by any person for the purpose of soliciting contributions or for commercial purposes, other than using the name and address of any political committee to solicit contributions from such committee.

NAME OF COMMITTEE (In Full)

\section{Friends of Herman Cain}

A. Full Name (Last, First, Middle Initial) Jeff Hatfield

Mailing Address 770 N Greenwich Rd

\begin{tabular}{lcc}
\hline City & State & Zip Code \\
Belle Plaine & KS & $67013-8251$
\end{tabular}

FEC ID number of contributing federal political committee.

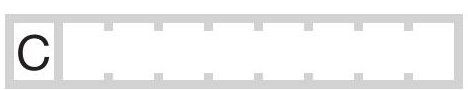

Name of Employer
self
Receipt For: 2012
X Primary $\quad$ General
Other (specify)

Occupation Farmer/Rancher Election Cycle-to-Date

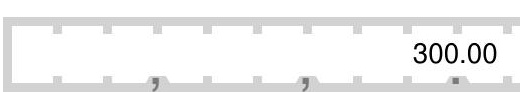

B. Full Name (Last, First, Middle Initial) John Johnson

\section{Mailing Address 2645 dellwood Ave}

\begin{tabular}{lcc}
\hline City & State & Zip Code \\
Jacksonville & FL & $32204-3527$
\end{tabular}

FEC ID number of contributing

federal political committee.

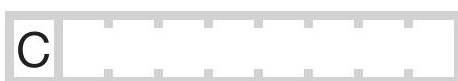

\begin{tabular}{l} 
Name of Employer \\
$\mathrm{n} / \mathrm{a}$ \\
\hline Receipt For: 2012 \\
Primary \\
Other (specify)
\end{tabular}

\section{Occupation}

Retired

Election Cycle-to-Date

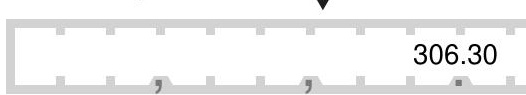

Transaction ID : AAD1165C2253B42A884A

Date of Receipt

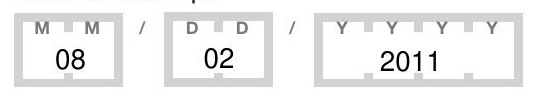

Amount of Each Receipt this Period

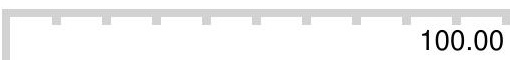

Transaction ID : A589147A88A7C4374B61

Date of Receipt

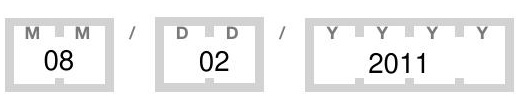

Amount of Each Receipt this Period

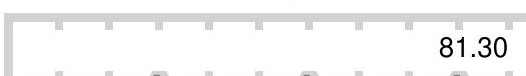

Transaction ID : A44C486E75FB34CEBB40 Date of Receipt

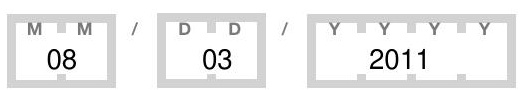

Amount of Each Receipt this Period

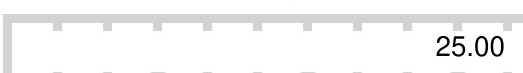

$\begin{array}{cc}\text { State } & \text { Zip Code } \\ \text { GA } & 30080-1536\end{array}$

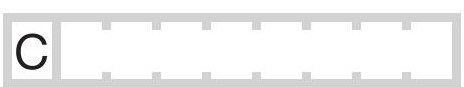

\section{Occupation}

courier

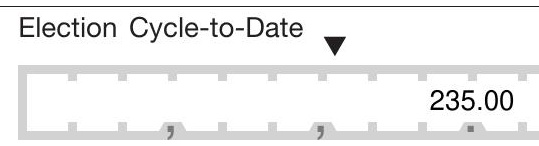

Subtotal Of Receipts This Page (optional).

206.30

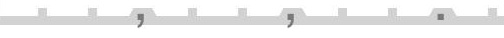

Total This Period (last page this line number only)

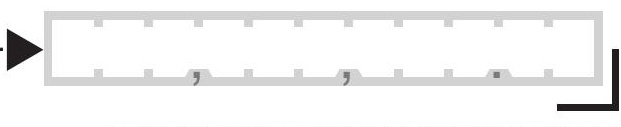

FEC Schedule A-P (Form 3P) (Rev. 03/2011) 
SCHEDULE A-P ITEMIZED RECEIPTS
Use separate schedule(s)

for each category of the

Detailed Summary Page
FOR LINE NUMBER: (check only one)

PAGE $197 / 1572$

\begin{tabular}{|c|c|c|c|c|c|}
\hline & & & & & \\
\hline 16 & $\begin{array}{l}\mathbf{X} \\
17 a\end{array}$ & $17 b$ & $17 c$ & $17 d$ & 18 \\
\hline $19 a$ & $19 \mathrm{~b}$ & $20 \mathrm{a}$ & $20 \mathrm{~b}$ & $20 \mathrm{c}$ & 21 \\
\hline
\end{tabular}

Any information copied from such Reports and Statements may not be sold or used by any person for the purpose of soliciting contributions or for commercial purposes, other than using the name and address of any political committee to solicit contributions from such committee.

NAME OF COMMITTEE (In Full)

\section{Friends of Herman Cain}

A. Full Name (Last, First, Middle Initial)

\section{Susan Euart}

Mailing Address 2612 Parkside Dr.

\begin{tabular}{lcc}
\hline City & State & Zip Code \\
Atlanta & GA & $30305-3734$
\end{tabular}

FEC ID number of contributing federal political committee.

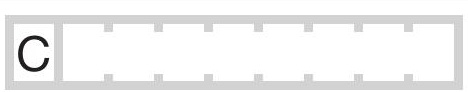

Name of Employer
self
Receipt For: 2012
X Primary $\quad$ General
Other (specify)

\section{Occupation}

Photographer

Election Cycle-to-Date

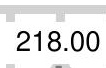

B. Full Name (Last, First, Middle Initial)

Mary Watkins

Mailing Address 1870 Bridle Ridge Trce

\begin{tabular}{lcc}
\hline City & State & Zip Code \\
Roswell & GA & $30075-2151$
\end{tabular}

FEC ID number of contributing

federal political committee.

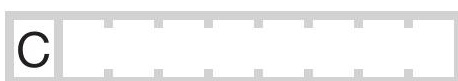

Name of Employer
n/a
Receipt For: 2012
X Primary
Other (specify)

\section{Occupation}

Homemaker

Election Cycle-to-Date

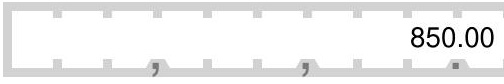

C. Full Name (Last, First, Middle Initial)

Geoey Cook

Mailing Address 136 Flora Ave

\begin{tabular}{lcc}
\hline City & State & Zip Code \\
Atlanta & GA & $30307-2714$ \\
\hline
\end{tabular}

FEC ID number of contributing federal political committee.

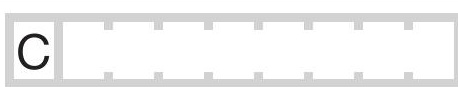

\section{Name of Employer}

Smart Marketer

Receipt For: 2012

Х $\begin{aligned} & \text { Primary } \square \text { General } \\ & \text { Other (specify) }\end{aligned}$

\section{Occupation \\ Online Marketing Superhero}

Election Cycle-to-Date

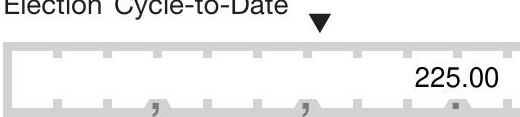

Transaction ID : A8093FBDAE6414E7EAD1

Date of Receipt

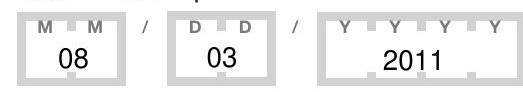

Amount of Each Receipt this Period

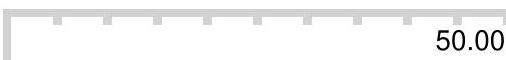

50.00

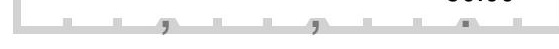

Transaction ID : A9441E8BD2D3F45D48B8

Date of Receipt

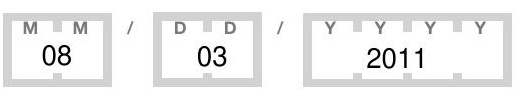

Amount of Each Receipt this Period

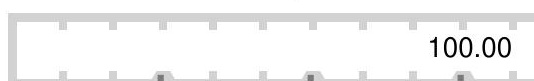

Transaction ID : ACD822BA295A94E8EBC8 Date of Receipt

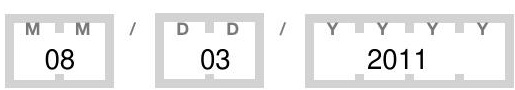

Amount of Each Receipt this Period

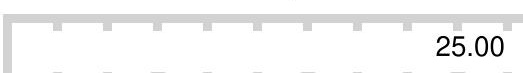

25.00

\section{Subtotal Of Receipts This Page (optional)}

175.00

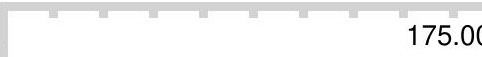

(2)

Total This Period (last page this line number only)

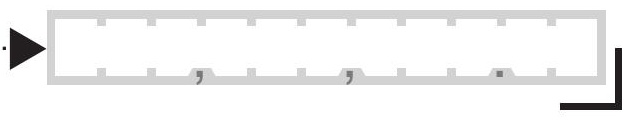

FEC Schedule A-P (Form 3P) (Rev. 03/2011) 
SCHEDULE A-P ITEMIZED RECEIPTS
Use separate schedule(s) for each category of the Detailed Summary Page
FOR LINE NUMBER: (check only one)

PAGE $198 / 1572$

\begin{tabular}{|c|c|c|c|c|c|c|}
\hline & & & & & & \\
\hline 16 & $\lambda$ & $17 \mathrm{a}$ & $17 \mathrm{~b}$ & $17 \mathrm{c}$ & $-17 d$ & -18 \\
\hline $19 a$ & & $19 b$ & $20 a$ & $20 \mathrm{~b}$ & $20 \mathrm{c}$ & 21 \\
\hline
\end{tabular}

Any information copied from such Reports and Statements may not be sold or used by any person for the purpose of soliciting contributions or for commercial purposes, other than using the name and address of any political committee to solicit contributions from such committee.

NAME OF COMMITTEE (In Full)

\section{Friends of Herman Cain}

A. Full Name (Last, First, Middle Initial)

\section{Carl Durk}

Mailing Address 206 w maple

\begin{tabular}{lcc}
\hline City & State & Zip Code \\
Pocatello & ID & $83201-5147$ \\
\hline
\end{tabular}

FEC ID number of contributing federal political committee.

Name of Employer
Self Employed
Receipt For: 2012
X Primary $\quad$ General
Other (specify)

B. Full Name (Last, First, Middle Initial) Lance Hickel

Mailing Address 240 Goose Creek Rd

\begin{tabular}{lcc}
\hline City & State & Zip Code \\
Raphine & VA & $24472-2318$
\end{tabular}

FEC ID number of contributing

federal political committee.

Name of Employer
Retired
Receipt For: 2012
X Primary $\quad$ General
Other (specify)

C. Full Name (Last, First, Middle Initial) Jean Warner

Mailing Address 2740 Briarfield Way

\begin{tabular}{l|ll}
\hline $\begin{array}{l}\text { City } \\
\text { Lawrenceville }\end{array}$ & $\begin{array}{c}\text { State } \\
\text { GA }\end{array}$ & $\begin{array}{c}\text { Zip Code } \\
\text { 30043-6801 }\end{array}$ \\
\hline $\begin{array}{l}\text { FEC ID number of contributing } \\
\text { federal political committee. }\end{array}$ & C \\
$\begin{array}{l}\text { Name of Employer } \\
\text { n/a }\end{array}$ & $\begin{array}{l}\text { Occupation } \\
\text { Home Maker }\end{array}$ \\
\hline $\begin{array}{l}\text { Receipt For: } 2012 \\
\text { Xrimary } \\
\text { Other (specify) }\end{array}$ & Election Cycle-to-Date & \\
\end{tabular}
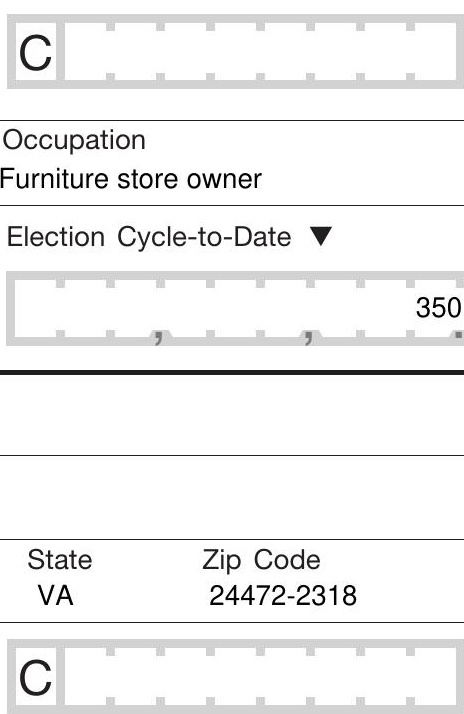

Transaction ID : A6A0EAC379D1B47719F7

Date of Receipt

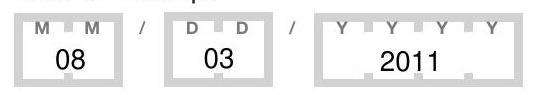

Amount of Each Receipt this Period

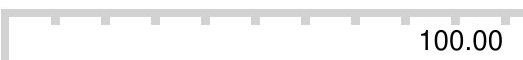

Furniture store owner

Election Cycle-to-Date

350.00

\section{Occupation}

$\mathrm{N} / \mathrm{A}$

Election Cycle-to-Date

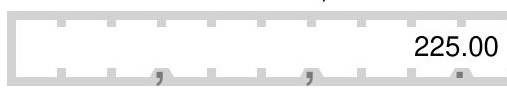

Transaction ID : AF5B0F02A16D34882837

Date of Receipt

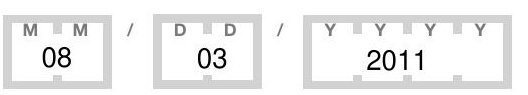

Amount of Each Receipt this Period

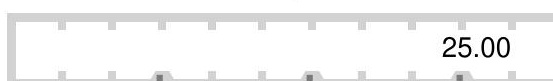

Amount of Each Receipt this Period

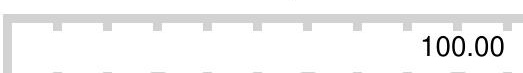

Transaction ID : A59921B86955242CFA16 Date of Receipt

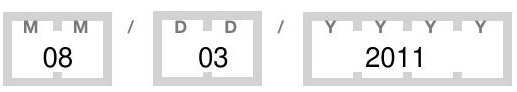

Subtotal Of Receipts This Page (optional).

Total This Period (last page this line number only) 
SCHEDULE A-P ITEMIZED RECEIPTS
Use separate schedule(s) for each category of the Detailed Summary Page
FOR LINE NUMBER: (check only one)

PAGE $199 / 1572$

\begin{tabular}{|c|c|c|c|c|c|c|}
\hline & & & & & & \\
\hline 16 & $\lambda$ & $17 \mathrm{a}$ & $17 \mathrm{~b}$ & $17 \mathrm{c}$ & $-17 d$ & -18 \\
\hline $19 a$ & & $19 b$ & $20 a$ & $20 \mathrm{~b}$ & $20 \mathrm{c}$ & 21 \\
\hline
\end{tabular}

Any information copied from such Reports and Statements may not be sold or used by any person for the purpose of soliciting contributions or for commercial purposes, other than using the name and address of any political committee to solicit contributions from such committee.

NAME OF COMMITTEE (In Full)

\section{Friends of Herman Cain}

A. Full Name (Last, First, Middle Initial)

Beth Solomon

Mailing Address 3333 N St. NW \#1

\begin{tabular}{lcc}
\hline City & State & Zip Code \\
Washington & DC & $20007-2812$
\end{tabular}

FEC ID number of contributing

federal political committee.

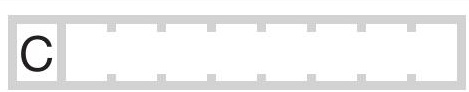

Name of Employer
Information Requested
Receipt For: 2012
X Primary
$\square$ Other (specify)

Occupation

Information Requested

Election Cycle-to-Date

1000.00

B. Full Name (Last, First, Middle Initial)

michael schneider

Mailing Address 307 bidwell rd.

\begin{tabular}{lcc}
\hline City & State & Zip Code \\
Coldwater & MI & $49036-9238$ \\
\hline
\end{tabular}

FEC ID number of contributing

federal political committee.

C

Name of Employer
Walmart
Receipt For: 2012
X Primary
Other (specify)

\section{Occupation}

Maintenance Supervisor

Election Cycle-to-Date

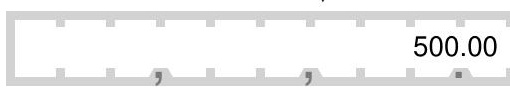

C. Full Name (Last, First, Middle Initial)

Fernande Silvers

Mailing Address 5850 Birch Ridge $\mathrm{Tr}$

\begin{tabular}{lcc}
\hline City & State & Zip Code \\
Cumming & GA & $30028-3410$
\end{tabular}

FEC ID number of contributing

federal political committee.

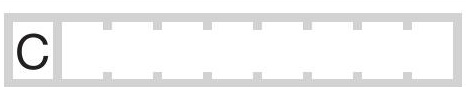

Name of Employer

Spielman \& Hicks. LLC

Occupation

Paralegal

Receipt For: 2012

Х $\begin{aligned} & \text { Primary } \square \text { General } \\ & \text { Other (specify) }\end{aligned}$

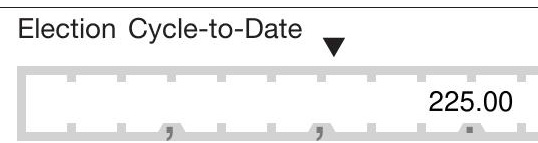

Transaction ID : AFFE16567641542C19F0

Date of Receipt

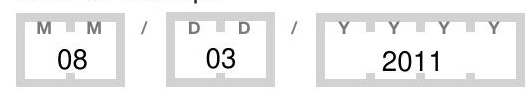

Amount of Each Receipt this Period

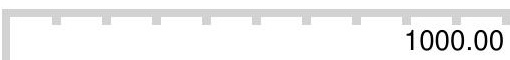

1000.00

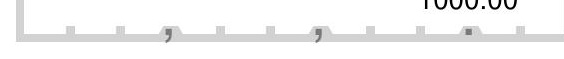

Transaction ID : AA05FBD8961F54CD3BE7

Date of Receipt

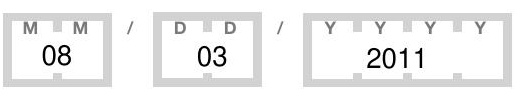

Amount of Each Receipt this Period

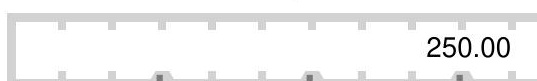

Transaction ID : A2175CE1078674669A98

Date of Receipt

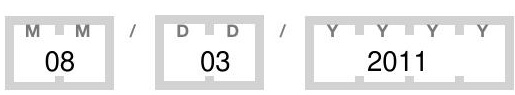

Amount of Each Receipt this Period

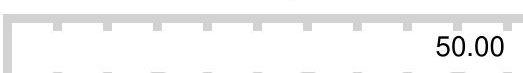

50.00
Subtotal Of Receipts This Page (optional)

1300.00

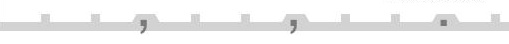

Total This Period (last page this line number only)

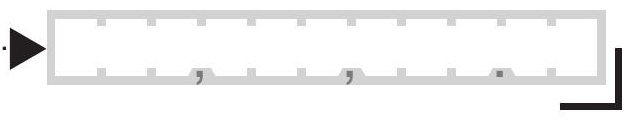

FEC Schedule A-P (Form 3P) (Rev. 03/2011) 


\section{SCHEDULE A-P} ITEMIZED RECEIPTS
Use separate schedule(s)

for each category of the

Detailed Summary Page
FOR LINE NUMBER: (check only one)

PAGE $200 / 1572$

\begin{tabular}{|c|c|c|c|c|c|}
\hline & & & & & \\
\hline 16 & $\begin{array}{l}\mathbf{X} \\
17 a\end{array}$ & $17 b$ & $17 c$ & $17 d$ & 18 \\
\hline $19 a$ & $19 \mathrm{~b}$ & $20 \mathrm{a}$ & $20 \mathrm{~b}$ & $20 \mathrm{c}$ & 21 \\
\hline
\end{tabular}

Any information copied from such Reports and Statements may not be sold or used by any person for the purpose of soliciting contributions or for commercial purposes, other than using the name and address of any political committee to solicit contributions from such committee.

NAME OF COMMITTEE (In Full)

Friends of Herman Cain

A. Full Name (Last, First, Middle Initial)

klaus schoening Sr.

Mailing Address 205 Waverly Hall Ln

\begin{tabular}{lcc}
\hline City & State & Zip Code \\
Simpsonville & SC & $29681-5287$
\end{tabular}

FEC ID number of contributing

federal political committee.

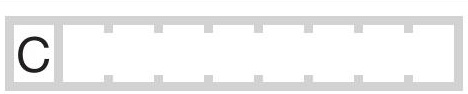

Name of Employer
self
Receipt For: 2012
X Primary $\quad \square$ General
Other (specify)

Occupation

Financial Advisor

Election Cycle-to-Date

350.00

B. Full Name (Last, First, Middle Initial)

Michele Beranek

Mailing Address 891 Trail Ridge Rd.

\begin{tabular}{lcc}
\hline City & State & Zip Code \\
Aiken & SC & $29803-7734$ \\
\hline
\end{tabular}

FEC ID number of contributing

federal political committee.

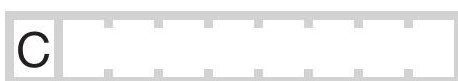

Name of Employer
Retired
Receipt For: 2012
X Primary
Other (specify)

\section{Occupation}

Retired

Election Cycle-to-Date

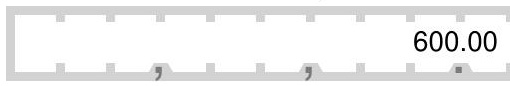

C. Full Name (Last, First, Middle Initial)

Lee Bates

Mailing Address 777 Celia Drive SE

\begin{tabular}{l|ll}
\hline $\begin{array}{l}\text { City } \\
\text { Hartselle }\end{array}$ & $\begin{array}{c}\text { State } \\
\text { AL }\end{array}$ & $\begin{array}{c}\text { Zip Code } \\
35640-3321\end{array}$ \\
\hline $\begin{array}{l}\text { FEC ID number of contributing } \\
\text { federal political committee. }\end{array}$ & $\mathrm{C}$ & \\
\hline $\begin{array}{l}\text { Name of Employer } \\
\text { self }\end{array}$ & $\begin{array}{l}\text { Occupation } \\
\text { programmer }\end{array}$ \\
$\begin{array}{l}\text { Receipt For: } 2012 \\
\text { Xrimary } \\
\text { Other (specify) }\end{array}$ & Election Cycle-to-Date & \\
\hline
\end{tabular}

Subtotal Of Receipts This Page (optional)

300.00

Transaction ID : AE01DF614EDB14FDEAA7 Date of Receipt

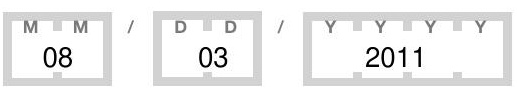

Amount of Each Receipt this Period

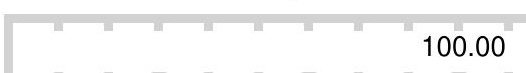

100.00

Total This Period (last page this line number only)

FEC Schedule A-P (Form 3P) (Rev. 03/2011) 
SCHEDULE A-P ITEMIZED RECEIPTS
Use separate schedule(s) for each category of the Detailed Summary Page
FOR LINE NUMBER: (check only one)

PAGE $201 / 1572$

\begin{tabular}{|c|c|c|c|c|c|}
\hline & & & & & \\
\hline 16 & $\begin{array}{l}\mathbf{X} \\
17 a\end{array}$ & $17 b$ & $17 c$ & $17 d$ & 18 \\
\hline $19 a$ & $19 \mathrm{~b}$ & $20 \mathrm{a}$ & $20 \mathrm{~b}$ & $20 \mathrm{c}$ & 21 \\
\hline
\end{tabular}

Any information copied from such Reports and Statements may not be sold or used by any person for the purpose of soliciting contributions or for commercial purposes, other than using the name and address of any political committee to solicit contributions from such committee.

NAME OF COMMITTEE (In Full)

\section{Friends of Herman Cain}

A. Full Name (Last, First, Middle Initial)

\section{Leann L Davis}

Mailing Address 602 W 4th St

\begin{tabular}{lcc}
\hline City & State & Zip Code \\
Delavan & IL & $61734-9689$ \\
\hline
\end{tabular}

FEC ID number of contributing federal political committee.

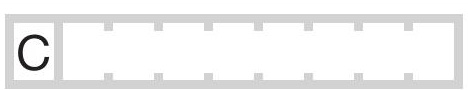

Name of Employer
self
Receipt For: 2012
X Primary $\quad$ General
Other (specify)

\section{Occupation} landscape designer

Election Cycle-to-Date 350.00

B. Full Name (Last, First, Middle Initial)

Jim Eure Jr.

Mailing Address PO Box 156

\begin{tabular}{lcc}
\hline City & State & Zip Code \\
Dahlonega & GA & $30533-0003$
\end{tabular}

FEC ID number of contributing

federal political committee.

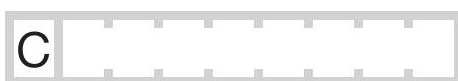

Name of Employer
Protex Security Systems
Receipt For: 2012
X Primary
Other (specify)

\section{Occupation}

Owner

Election Cycle-to-Date

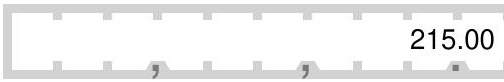

C. Full Name (Last, First, Middle Initial)

Richard Knoch

Mailing Address P.O. Box 2041

\begin{tabular}{lcc}
\hline City & State & Zip Code \\
Lake Ozark & MO & $65049-2041$
\end{tabular}

FEC ID number of contributing federal political committee.

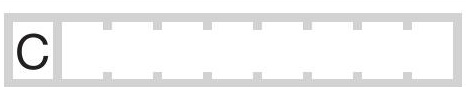

Name of Employer

CompuLink Ltd.

Occupation

Receipt For: 2012

Х $\begin{aligned} & \text { Primary } \square \text { General } \\ & \text { Other (specify) }\end{aligned}$

Software Developer

Election Cycle-to-Date

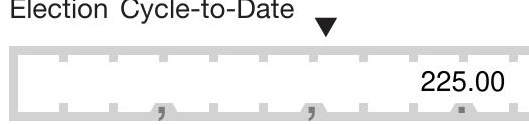

Transaction ID : A3FCF7EAA85F7456DA27

Date of Receipt

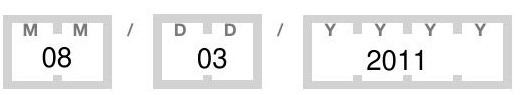

Amount of Each Receipt this Period

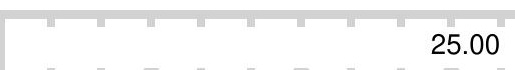

Transaction ID : AFB7C3499B64D49588AE Date of Receipt

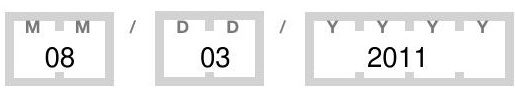

Amount of Each Receipt this Period

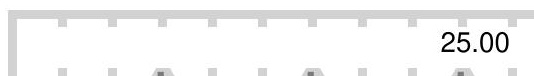

Subtotal Of Receipts This Page (optional)

$+\quad 100.00$

Total This Period (last page this line number only)

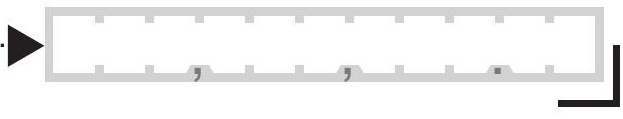

FEC Schedule A-P (Form 3P) (Rev. 03/2011) 
SCHEDULE A-P ITEMIZED RECEIPTS
Use separate schedule(s) for each category of the Detailed Summary Page
FOR LINE NUMBER: (check only one)

PAGE 202 / 1572

\begin{tabular}{|c|c|c|c|c|c|}
\hline & & & & & \\
\hline 16 & $\begin{array}{l}\mathbf{X} \\
17 a\end{array}$ & $17 b$ & $17 c$ & $17 d$ & 18 \\
\hline $19 a$ & $19 \mathrm{~b}$ & $20 \mathrm{a}$ & $20 \mathrm{~b}$ & $20 \mathrm{c}$ & 21 \\
\hline
\end{tabular}

Any information copied from such Reports and Statements may not be sold or used by any person for the purpose of soliciting contributions or for commercial purposes, other than using the name and address of any political committee to solicit contributions from such committee.

NAME OF COMMITTEE (In Full)

\section{Friends of Herman Cain}

A. Full Name (Last, First, Middle Initial)

\section{Doug Friedrichsen}

Mailing Address 12535 Wedd Street

\begin{tabular}{lcc}
\hline City & State & Zip Code \\
Overland Park & KS & $66213-1845$
\end{tabular}

FEC ID number of contributing federal political committee.

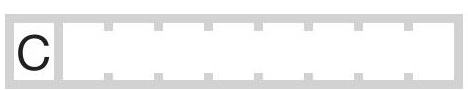

Name of Employer
self
Receipt For: 2012
X Primary $\quad$ General
Other (specify)

\section{Occupation}

Accountant

Election Cycle-to-Date

\subsection{0}

B. Full Name (Last, First, Middle Initial)

Marilyn Seidler

Mailing Address 700 Shore Rd Apt 3I

\begin{tabular}{lcc}
\hline City & State & Zip Code \\
Long Beach & NY & $11561-4715$ \\
\hline
\end{tabular}

FEC ID number of contributing

federal political committee.

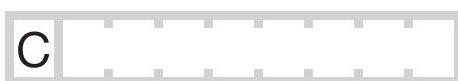

Name of Employer
Retired
Receipt For: 2012
X Primary
Other (specify)

\section{Occupation}

Retired

Election Cycle-to-Date

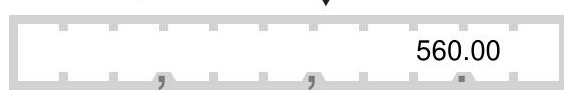

Transaction ID : ABD938F68BE7E4D9381B

Date of Receipt

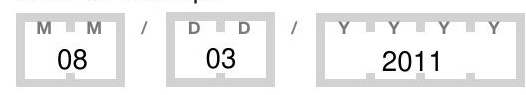

Amount of Each Receipt this Period

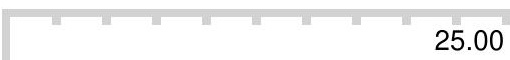

25.00

C. Full Name (Last, First, Middle Initial)

Marilyn Seidler

Mailing Address 700 Shore Rd Apt 3I

\begin{tabular}{lcc}
\hline City & State & Zip Code \\
Long Beach & NY & $11561-4715$
\end{tabular}

FEC ID number of contributing

federal political committee.

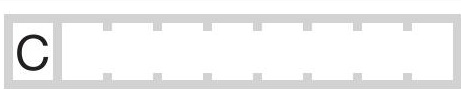

Name of Employer
Retired
Receipt For: 2012
X Primary $\quad \square$ General
Other (specify)

Occupation

Retired

Election Cycle-to-Date

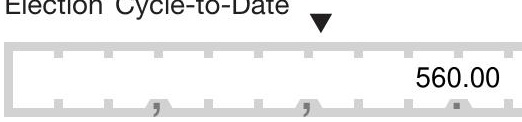

Transaction ID : A45C69E79B6E440F2873

Date of Receipt

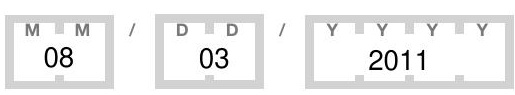

Amount of Each Receipt this Period

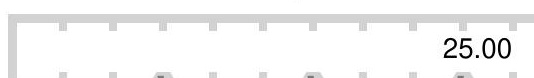

Transaction ID : A201C81C46BD349BD96E Date of Receipt

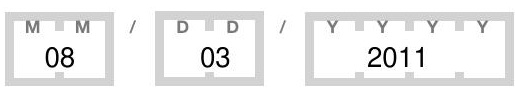

Amount of Each Receipt this Period

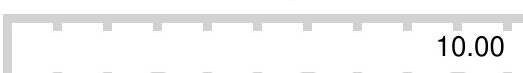

\section{Subtotal Of Receipts This Page (optional)}

Total This Period (last page this line number only) 
SCHEDULE A-P ITEMIZED RECEIPTS
Use separate schedule(s) for each category of the Detailed Summary Page
FOR LINE NUMBER: (check only one)

PAGE $203 / 1572$

\begin{tabular}{|c|c|c|c|c|c|}
\hline & & & & & \\
\hline 16 & $\begin{array}{l}\mathbf{X} \\
17 a\end{array}$ & $17 b$ & $17 c$ & $17 d$ & 18 \\
\hline $19 a$ & $19 \mathrm{~b}$ & $20 \mathrm{a}$ & $20 \mathrm{~b}$ & $20 \mathrm{c}$ & 21 \\
\hline
\end{tabular}

Any information copied from such Reports and Statements may not be sold or used by any person for the purpose of soliciting contributions or for commercial purposes, other than using the name and address of any political committee to solicit contributions from such committee.

NAME OF COMMITTEE (In Full)

\section{Friends of Herman Cain}

A. Full Name (Last, First, Middle Initial)

\section{Eleanor Goodwin}

Mailing Address 1759 Dunridge Court

\begin{tabular}{lcc}
\hline City & State & Zip Code \\
Atlanta & GA & $30338-3501$
\end{tabular}

FEC ID number of contributing federal political committee.

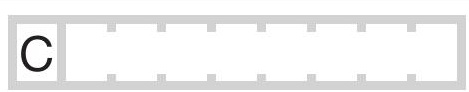

Name of Employer
NA
Receipt For: 2012
X Primary $\quad$ General
Other (specify)

\section{Occupation} homemaker

Election Cycle-to-Date

\subsection{0}

B. Full Name (Last, First, Middle Initial)

Richard Butler

Mailing Address 177 Blue Sky Dr

\begin{tabular}{lcc}
\hline City & State & Zip Code \\
Marietta & GA & $30068-3812$ \\
\hline
\end{tabular}

FEC ID number of contributing

federal political committee.

C

Name of Employer
Associates Express nlnc
Receipt For: 2012
X Primary
Other (specify)

\section{Occupation}

truck driver

Election Cycle-to-Date

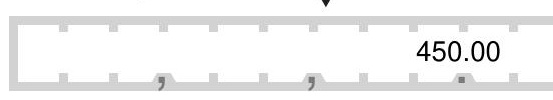

Transaction ID : AF0642829B0704F59A2C

Date of Receipt

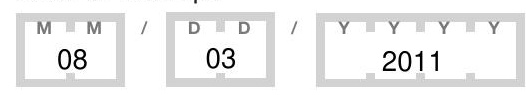

Amount of Each Receipt this Period

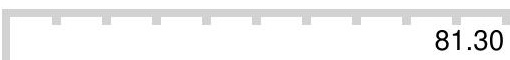

81.30

C. Full Name (Last, First, Middle Initial)

Lee Bossert

Mailing Address 5564 Gustavo Madrid Ln

\begin{tabular}{lcc}
\hline City & State & Zip Code \\
El Paso & TX & $79934-3177$
\end{tabular}

FEC ID number of contributing

federal political committee.

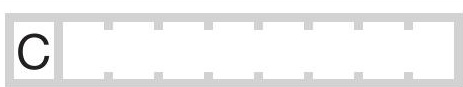

\section{Name of Employer}

Self-Employed

\section{Occupation}

missionary

Receipt For: 2012

Х $\begin{aligned} & \text { Primary } \square \text { General } \\ & \text { Other (specify) }\end{aligned}$

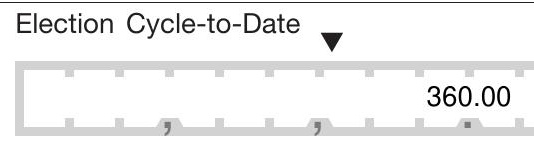

Amount of Each Receipt this Period

Transaction ID : AA981756F20624D7D94B

Date of Receipt
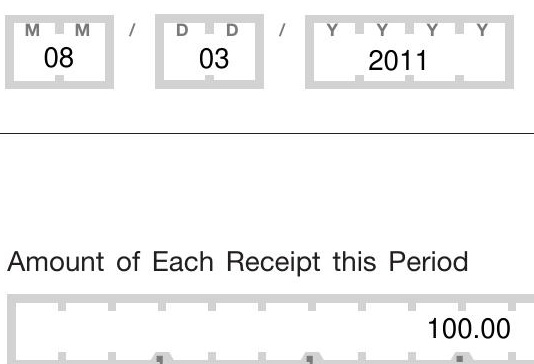

Transaction ID : AD92662DC61F24817ACC Date of Receipt

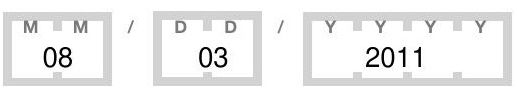

Amount of Each Receipt this Period

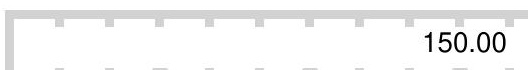

150.00

Subtotal Of Receipts This Page (optional)

331.30

Total This Period (last page this line number only) 
SCHEDULE A-P ITEMIZED RECEIPTS
Use separate schedule(s) for each category of the Detailed Summary Page
FOR LINE NUMBER: (check only one)

PAGE 204 / 1572

\begin{tabular}{|c|c|c|c|c|c|}
\hline & & & & & \\
\hline 16 & $\begin{array}{l}\mathbf{X} \\
17 a\end{array}$ & $17 b$ & $17 c$ & $17 d$ & 18 \\
\hline $19 a$ & $19 \mathrm{~b}$ & $20 \mathrm{a}$ & $20 \mathrm{~b}$ & $20 \mathrm{c}$ & 21 \\
\hline
\end{tabular}

Any information copied from such Reports and Statements may not be sold or used by any person for the purpose of soliciting contributions or for commercial purposes, other than using the name and address of any political committee to solicit contributions from such committee.

NAME OF COMMITTEE (In Full)

\section{Friends of Herman Cain}

A. Full Name (Last, First, Middle Initial)

Michael Burgess

Mailing Address 22865 Redwood Dr

\begin{tabular}{lcc}
\hline City & State & Zip Code \\
Lawrenceburg & IN & $47025-7433$
\end{tabular}

FEC ID number of contributing

federal political committee.

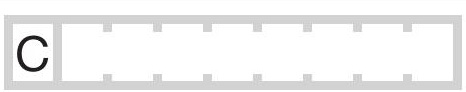

Name of Employer
Dearborn County Indiana
Receipt For: 2012
X Primary $\quad \square$ General
Other (specify)

Occupation

Veterans Service Officer

Election Cycle-to-Date $\boldsymbol{\nabla}$

275.00

B. Full Name (Last, First, Middle Initial)

Cheryl Monaghan

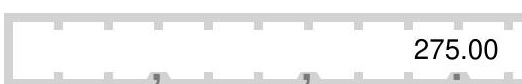

Mailing Address 41303 North River Bend Road

\begin{tabular}{lcc}
\hline City & State & Zip Code \\
Phoenix & AZ & $85086-5803$ \\
\hline
\end{tabular}

FEC ID number of contributing

federal political committee.

C

\begin{tabular}{l} 
Name of Employer \\
Information Requested \\
Receipt For: 2012 \\
X Primary \\
\hline Other (specify)
\end{tabular}

Occupation

Information Requested

Election Cycle-to-Date

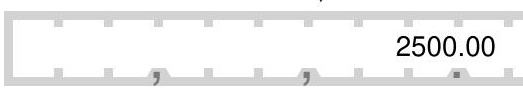

Transaction ID : A97E130C224BC4B90852

Date of Receipt

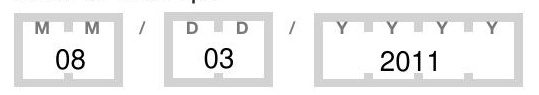

Amount of Each Receipt this Period

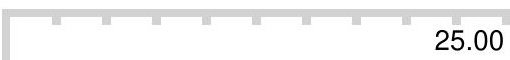

25.00

C. Full Name (Last, First, Middle Initial)

Patricia Duvall

Mailing Address 19 Lullwater Estate Road

\begin{tabular}{lcc}
\hline City & State & Zip Code \\
Atlanta & GA & 30307 \\
\hline
\end{tabular}

FEC ID number of contributing

federal political committee.

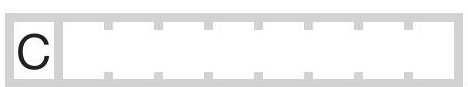

Name of Employer

American Settlement Corp.

Receipt For: 2012

Х $\begin{aligned} & \text { Primary } \square \text { General } \\ & \text { Other (specify) }\end{aligned}$

\section{Occupation}

Case Manager

Election Cycle-to-Date

Transaction ID : AB0E985AADC2E43D9B27 Date of Receipt

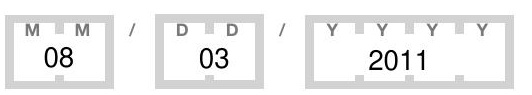

Amount of Each Receipt this Period

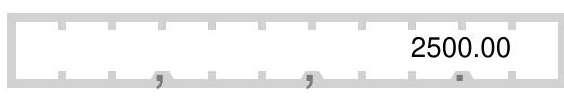

Transaction ID : A43E59C3D57994A8FA2D Date of Receipt

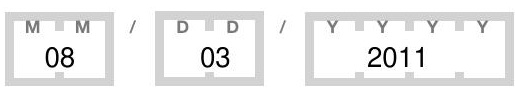

Amount of Each Receipt this Period

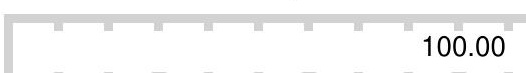

300.00

\section{Subtotal Of Receipts This Page (optional)}

Total This Period (last page this line number only) 
SCHEDULE A-P ITEMIZED RECEIPTS
Use separate schedule(s) for each category of the Detailed Summary Page
FOR LINE NUMBER: (check only one)

PAGE $205 / 1572$

\begin{tabular}{|c|c|c|c|c|c|}
\hline & & & & & \\
\hline 16 & $\begin{array}{l}\mathbf{X} \\
17 a\end{array}$ & $17 b$ & $17 c$ & $17 d$ & 18 \\
\hline $19 a$ & $19 \mathrm{~b}$ & $20 \mathrm{a}$ & $20 \mathrm{~b}$ & $20 \mathrm{c}$ & 21 \\
\hline
\end{tabular}

Any information copied from such Reports and Statements may not be sold or used by any person for the purpose of soliciting contributions or for commercial purposes, other than using the name and address of any political committee to solicit contributions from such committee.

NAME OF COMMITTEE (In Full)

\section{Friends of Herman Cain}

A. Full Name (Last, First, Middle Initial)

Michael Grillot

Mailing Address 5919 S. Farm Road 183

\begin{tabular}{lcc}
\hline City & State & Zip Code \\
Rogersville & MO & $65742-8235$ \\
\hline
\end{tabular}

FEC ID number of contributing federal political committee.

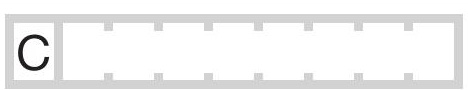

Name of Employer

Orthopaedic Specialists of Springfield

Occupation

Physician

Receipt For: 2012

X Primary $\square$ General Other (specify)

Election Cycle-to-Date

275.00

B. Full Name (Last, First, Middle Initial)

Mr. Michael Slocum

Mailing Address 4303 O'Brien Rd.

\begin{tabular}{lcc}
\hline City & State & Zip Code \\
Vassar & MI & $48768-8929$
\end{tabular}

FEC ID number of contributing

federal political committee.

C

Name of Employer
None
Receipt For: 2012
Primary
Other (specify)

Occupation

Retired

Election Cycle-to-Date

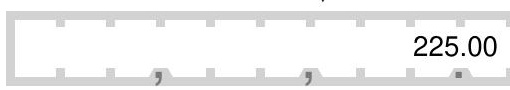

Transaction ID : AAA9A9B13F0F04838AEF

Date of Receipt

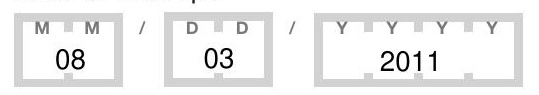

Amount of Each Receipt this Period

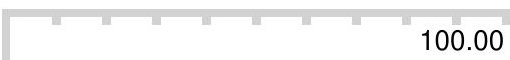

Transaction ID : ACBD948BD6B1646DC9AE Date of Receipt

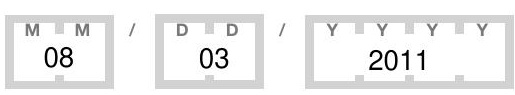

Amount of Each Receipt this Period

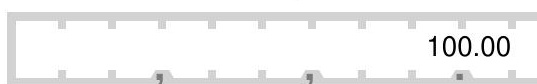

Transaction ID : AE81C35A511D54494855

Date of Receipt

Phyllis Fine

Mailing Address 266 Trailwood Lane

\begin{tabular}{lcc}
\hline City & State & Zip Code \\
Northbrook & IL & $60062-1031$
\end{tabular}

FEC ID number of contributing federal political committee.

C

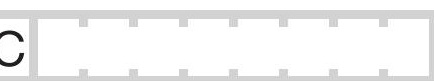

Name of Employer
homemaker
Receipt For: 2012
X Primary $\square$ General
Other (specify)

Occupation

Homemaker

Election Cycle-to-Date

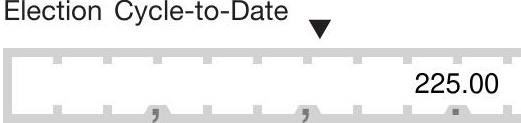

Subtotal Of Receipts This Page (optional)

225.00

Amount of Each Receipt this Period

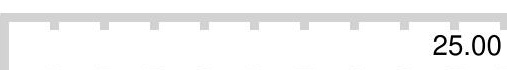

Total This Period (last page this line number only) 
SCHEDULE A-P ITEMIZED RECEIPTS
Use separate schedule(s) for each category of the Detailed Summary Page
FOR LINE NUMBER: (check only one)

PAGE 206 / 1572

\begin{tabular}{|c|c|c|c|c|c|}
\hline & & & & & \\
\hline 16 & $\begin{array}{l}\mathbf{X} \\
17 a\end{array}$ & $17 b$ & $17 c$ & $17 d$ & 18 \\
\hline $19 a$ & $19 \mathrm{~b}$ & $20 \mathrm{a}$ & $20 \mathrm{~b}$ & $20 \mathrm{c}$ & 21 \\
\hline
\end{tabular}

Any information copied from such Reports and Statements may not be sold or used by any person for the purpose of soliciting contributions or for commercial purposes, other than using the name and address of any political committee to solicit contributions from such committee.

NAME OF COMMITTEE (In Full)

\section{Friends of Herman Cain}

A. Full Name (Last, First, Middle Initial) richard craig

Mailing Address p.o. box 899

\begin{tabular}{lcc}
\hline City & State & Zip Code \\
Edwards & CO & $81632-0899$
\end{tabular}

FEC ID number of contributing federal political committee.

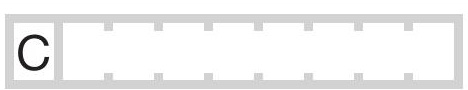

Name of Employer
Information Requested
Receipt For: 2012
X Primary
Other (specify) General

Occupation Information Requested

Election Cycle-to-Date

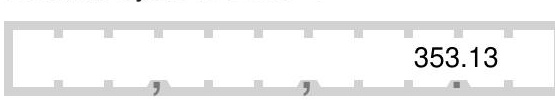

B. Full Name (Last, First, Middle Initial)

Bonnie Jones

Mailing Address 15373 Mansfield Way

\begin{tabular}{lcc}
\hline City & State & Zip Code \\
Warsaw & MO & $65355-5908$ \\
\hline
\end{tabular}

FEC ID number of contributing

federal political committee.

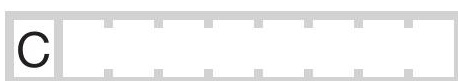

Name of Employer
Warsaw Health and Rehab
Receipt For: 2012
X Primary
Other (specify)

\section{Occupation}

$\mathrm{RN}$

Election Cycle-to-Date

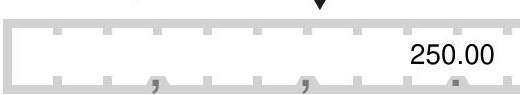

C. Full Name (Last, First, Middle Initial)

James Hogsed

Mailing Address 6750 Saint Ives Ct.

\section{City}

Fort Myers

FEC ID number of contributing federal political committee.

$\begin{aligned} & \text { Name of Employer } \\ & \text { self }\end{aligned}$
Receipt For: 2012
X Primary $\square$ General
Other (specify)

Transaction ID : A4123D2D49D564271A1D

Date of Receipt

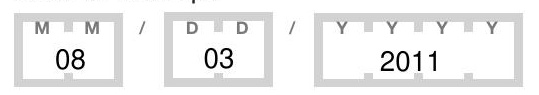

Amount of Each Receipt this Period

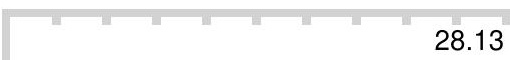

28.13
Amount of Each Receipt this Period

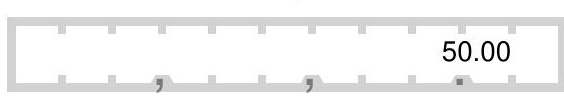

Transaction ID : A8A90A4E2A5CE41D4A61 Date of Receipt

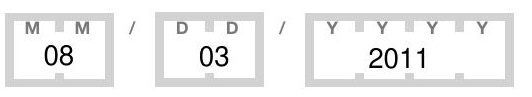

Transaction ID : AC64D849B5B28483B98D Date of Receipt

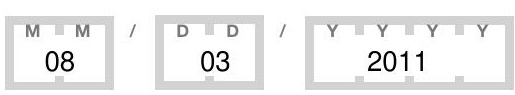

Amount of Each Receipt this Period

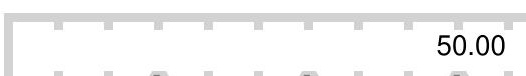

\section{Subtotal Of Receipts This Page (optional)}

Total This Period (last page this line number only) 
SCHEDULE A-P ITEMIZED RECEIPTS
Use separate schedule(s) for each category of the Detailed Summary Page
FOR LINE NUMBER: (check only one)

PAGE $207 / 1572$

\begin{tabular}{|c|c|c|c|c|c|}
\hline & & & & & \\
\hline 16 & $\begin{array}{l}\mathbf{X} \\
17 a\end{array}$ & $17 b$ & $17 c$ & $17 d$ & 18 \\
\hline $19 a$ & $19 \mathrm{~b}$ & $20 \mathrm{a}$ & $20 \mathrm{~b}$ & $20 \mathrm{c}$ & 21 \\
\hline
\end{tabular}

Any information copied from such Reports and Statements may not be sold or used by any person for the purpose of soliciting contributions or for commercial purposes, other than using the name and address of any political committee to solicit contributions from such committee.

NAME OF COMMITTEE (In Full)

\section{Friends of Herman Cain}

A. Full Name (Last, First, Middle Initial)

Michael McGraw

Mailing Address 2621 Darlington Ct.

\begin{tabular}{lcc}
\hline City & State & Zip Code \\
Conyers & GA & $30013-4916$ \\
\hline
\end{tabular}

FEC ID number of contributing federal political committee.

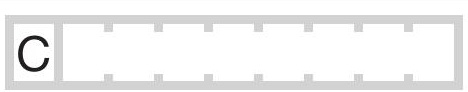

Name of Employer
n/a
Receipt For: 2012
X Primary $\quad$ General
Other (specify)

Occupation

Retired

Election Cycle-to-Date

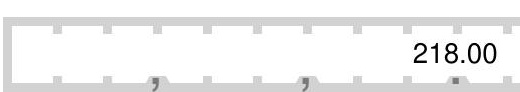

B. Full Name (Last, First, Middle Initial)

Jim McGuinness

Mailing Address 1010 Briardale Court

\begin{tabular}{lcc}
\hline City & State & Zip Code \\
McKinney & TX & $75069-1592$
\end{tabular}

FEC ID number of contributing

federal political committee.

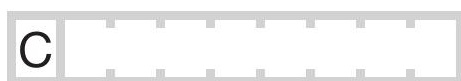

Name of Employer
Self-Employed
Receipt For: 2012
X Primary
Other (specify)

\section{Occupation}

Consultant

Election Cycle-to-Date

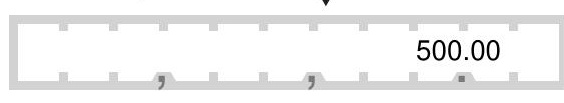

Transaction ID : A332E015ADE9D4E199E6

Date of Receipt

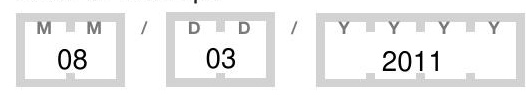

Amount of Each Receipt this Period

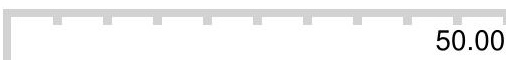

50.00

C. Full Name (Last, First, Middle Initial)

SHERRILL WILLIAMS

Mailing Address 1121 KAIMOKU PLACE

\begin{tabular}{lcc}
\hline City & State & Zip Code \\
Honolulu & HI & $96821-1440$
\end{tabular}

FEC ID number of contributing

federal political committee.

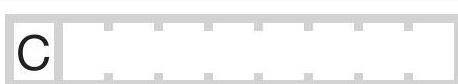

Name of Employer

Information Requested

Occupation

Information Requested

Receipt For: 2012

Х $\begin{aligned} & \text { Primary } \\ & \text { Other (specify) }\end{aligned}$

Election Cycle-to-Date

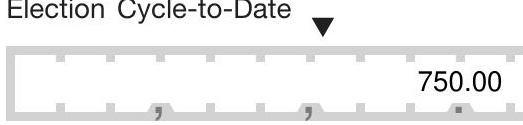

Amount of Each Receipt this Period

Transaction ID : A673E30B2912F4C3F992

Date of Receipt
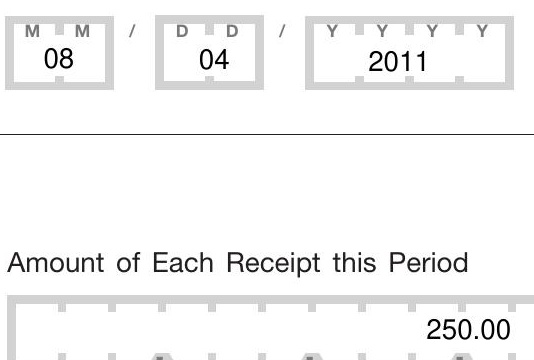

Transaction ID : A880336C4C9B149579EC

Date of Receipt

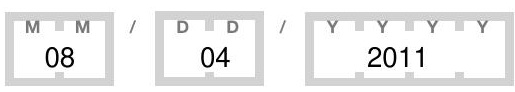

Amount of Each Receipt this Period

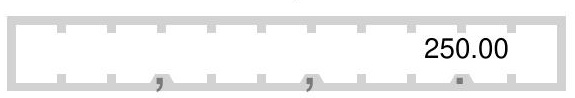

Subtotal Of Receipts This Page (optional)

550.00

Total This Period (last page this line number only) 
SCHEDULE A-P ITEMIZED RECEIPTS
Use separate schedule(s) for each category of the Detailed Summary Page
FOR LINE NUMBER: (check only one)

PAGE $208 / 1572$

\begin{tabular}{|c|c|c|c|c|c|}
\hline & & & & & \\
\hline 16 & $\begin{array}{l}\mathbf{X} \\
17 a\end{array}$ & $17 b$ & $17 c$ & $17 d$ & 18 \\
\hline $19 a$ & $19 \mathrm{~b}$ & $20 \mathrm{a}$ & $20 \mathrm{~b}$ & $20 \mathrm{c}$ & 21 \\
\hline
\end{tabular}

Any information copied from such Reports and Statements may not be sold or used by any person for the purpose of soliciting contributions or for commercial purposes, other than using the name and address of any political committee to solicit contributions from such committee.

NAME OF COMMITTEE (In Full)

\section{Friends of Herman Cain}

A. Full Name (Last, First, Middle Initial)

Walter Carter

Mailing Address 926 Ridge Rd

\begin{tabular}{lcc}
\hline City & State & Zip Code \\
Dadeville & AL & $36853-4933$
\end{tabular}

FEC ID number of contributing federal political committee.

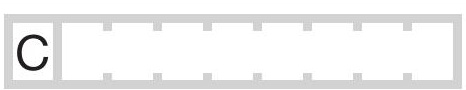

Name of Employer
Carter \& Carter Construction
Receipt For: 2012
X Primary
Other (specify) General

Occupation

Construction Management

Election Cycle-to-Date

300.00

B. Full Name (Last, First, Middle Initial)

Sarajane Jablinske

Mailing Address 95 Cartis Parker Road

\begin{tabular}{lcc}
\hline City & State & Zip Code \\
Alexander & NC & $28701-9772$ \\
\hline
\end{tabular}

FEC ID number of contributing

federal political committee.

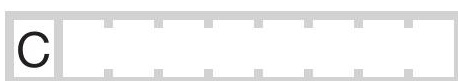

Name of Employer
Retired
Receipt For: 2012
X Primary $\quad$ General
Other (specify)

\section{Occupation}

Retired

Election Cycle-to-Date

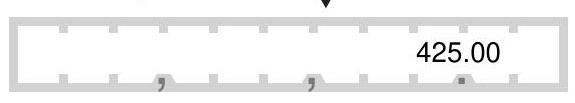

C. Full Name (Last, First, Middle Initial)

John Kerber

Mailing Address 6900 NorthGlenn Way

\begin{tabular}{lcc}
\hline $\begin{array}{l}\text { City } \\
\text { Johnston }\end{array}$ & State & Zip Code \\
& IA & $50131-1234$ \\
\hline
\end{tabular}

FEC ID number of contributing federal political committee.

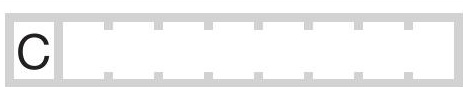

Name of Employer
Information Requested
Receipt For: 2012
X Primary
Other (specify) General

\section{Occupation}

Information Requested

Election Cycle-to-Date
Transaction ID : AC28AF12C35B9452391A

Date of Receipt

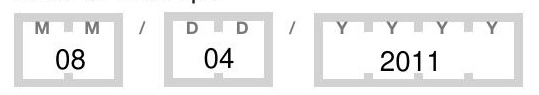

Amount of Each Receipt this Period

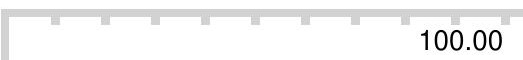

Amount of Each Receipt this Period

Transaction ID : A209BF4249E394FD69BC

Date of Receipt
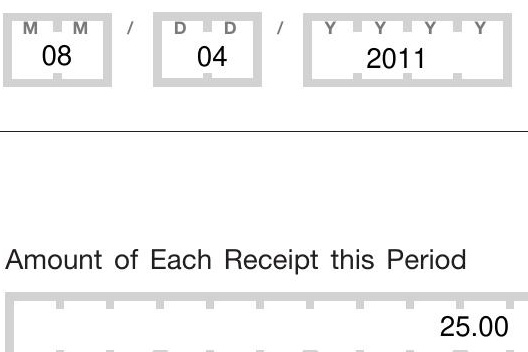

Transaction ID : A5A7FBE163E104926B41

Date of Receipt

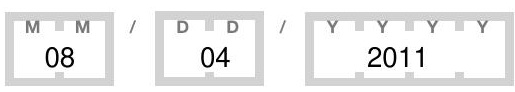

Amount of Each Receipt this Period

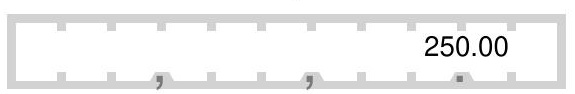

250.00

\section{Subtotal Of Receipts This Page (optional)}

Total This Period (last page this line number only) 
SCHEDULE A-P ITEMIZED RECEIPTS
Use separate schedule(s) for each category of the Detailed Summary Page
FOR LINE NUMBER: (check only one)

PAGE 209 / 1572

\begin{tabular}{|c|c|c|c|c|c|}
\hline & & & & & \\
\hline 16 & $\begin{array}{l}\mathbf{X} \\
17 a\end{array}$ & $17 b$ & $17 c$ & $17 d$ & 18 \\
\hline $19 a$ & $19 \mathrm{~b}$ & $20 \mathrm{a}$ & $20 \mathrm{~b}$ & $20 \mathrm{c}$ & 21 \\
\hline
\end{tabular}

Any information copied from such Reports and Statements may not be sold or used by any person for the purpose of soliciting contributions or for commercial purposes, other than using the name and address of any political committee to solicit contributions from such committee.

NAME OF COMMITTEE (In Full)

\section{Friends of Herman Cain}

A. Full Name (Last, First, Middle Initial)

Karen Narramore

Mailing Address 26437 N Lewisburg Rd

\begin{tabular}{lcc}
\hline City & State & Zip Code \\
North Lewisburg & OH & $43060-9608$
\end{tabular}

FEC ID number of contributing

federal political committee.

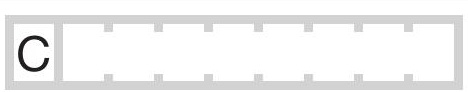

Name of Employer
Information Requested
Receipt For: 2012
X Primary $\quad \square$ General
Other (specify)

Occupation

Information Requested

Election Cycle-to-Date

340.00

B. Full Name (Last, First, Middle Initial)

Denver Jones

Mailing Address 1271 Owego road

\begin{tabular}{lcc}
\hline City & State & Zip Code \\
Owego & NY & $13827-2532$ \\
\hline
\end{tabular}

FEC ID number of contributing

federal political committee.

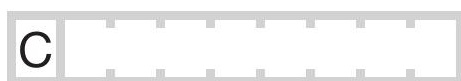

Name of Employer
Information Requested
Receipt For: 2012
X Primary
Other (specify)

Occupation

Information Requested

Election Cycle-to-Date

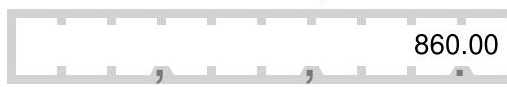

C. Full Name (Last, First, Middle Initial)

Robert Protzman

Mailing Address 230 ash park jefferson city mo 230

\begin{tabular}{lcc}
\hline City & State & Zip Code \\
Jefferson City & MO & 65109 \\
\hline
\end{tabular}

FEC ID number of contributing federal political committee.

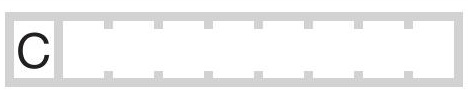

Name of Employer
retired dentist
Receipt For: 2012
X Primary
Other (specify) General

\section{Occupation}

Retired

Election Cycle-to-Date

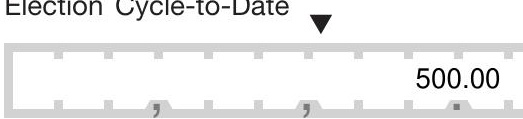

Transaction ID : A1FE2900166F540018B5

Date of Receipt

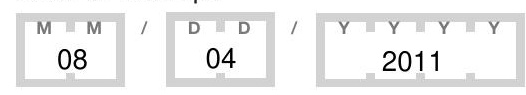

Amount of Each Receipt this Period

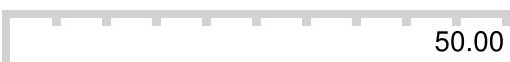

50.00

Transaction ID : A5B07230FBC8941C1A0F

Date of Receipt

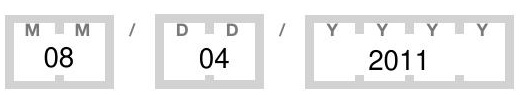

Amount of Each Receipt this Period

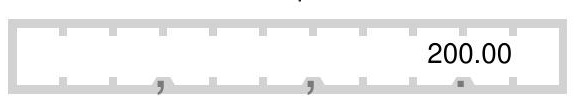

Transaction ID : A0BA10C16BCB94B43842 Date of Receipt

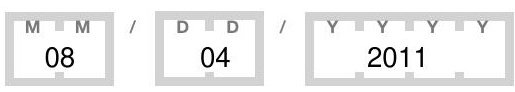

Amount of Each Receipt this Period

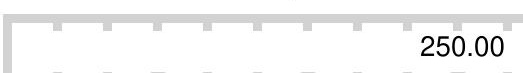

\section{Subtotal Of Receipts This Page (optional)}

Total This Period (last page this line number only) 
SCHEDULE A-P ITEMIZED RECEIPTS
Use separate schedule(s) for each category of the Detailed Summary Page
FOR LINE NUMBER: (check only one)

PAGE $210 / 1572$

\begin{tabular}{|c|c|c|c|c|c|c|}
\hline & & & & & & \\
\hline 16 & $\lambda$ & $17 \mathrm{a}$ & $17 \mathrm{~b}$ & $17 \mathrm{c}$ & $-17 d$ & -18 \\
\hline $19 a$ & & $19 b$ & $20 a$ & $20 \mathrm{~b}$ & $20 \mathrm{c}$ & 21 \\
\hline
\end{tabular}

Any information copied from such Reports and Statements may not be sold or used by any person for the purpose of soliciting contributions or for commercial purposes, other than using the name and address of any political committee to solicit contributions from such committee.

NAME OF COMMITTEE (In Full)

\section{Friends of Herman Cain}

A. Full Name (Last, First, Middle Initial) John Reece

Mailing Address 184 Manor Hills Road

\begin{tabular}{lcc}
\hline City & State & Zip Code \\
Lillington & NC & $27546-8449$
\end{tabular}

FEC ID number of contributing federal political committee.

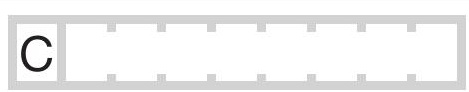

Name of Employer
Retired
Receipt For: 2012
X Primary $\quad$ General
Other (specify)

Occupation Retired

Election Cycle-to-Date

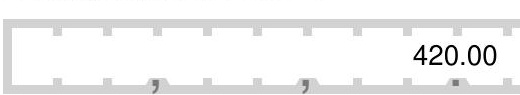

B. Full Name (Last, First, Middle Initial)

David White

Mailing Address 3689 Wentworth Lane

\begin{tabular}{lcc}
\hline City & State & Zip Code \\
Lilburn & GA & $30047-2256$ \\
\hline
\end{tabular}

FEC ID number of contributing

federal political committee.

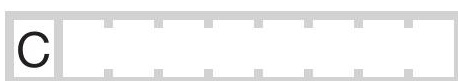

Name of Employer
Delta Airlines
Receipt For: 2012
X Primary $\quad$ General
Other (specify)

Occupation

Aviation Maintenance

Election Cycle-to-Date

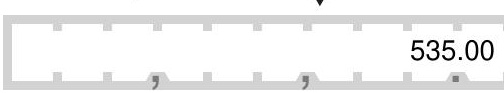

Transaction ID : AC6818132153A4B439C2

Date of Receipt

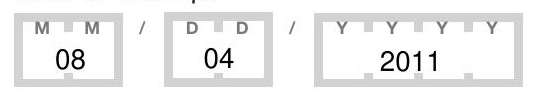

Amount of Each Receipt this Period

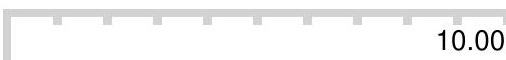

Transaction ID : A4AAD774E43B34469AC9

Date of Receipt

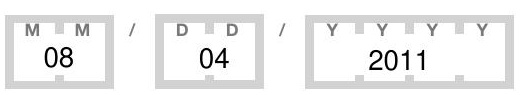

Amount of Each Receipt this Period

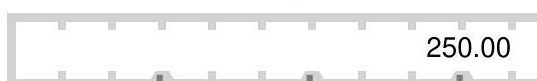

Transaction ID : A04392BF4733345ADB60

Date of Receipt

James Brown

Mailing Address 3305 Pebble Ridge Lane

\begin{tabular}{lcc}
\hline City & State & Zip Code \\
Buford & GA & $30519-7231$ \\
\hline
\end{tabular}

FEC ID number of contributing federal political committee.

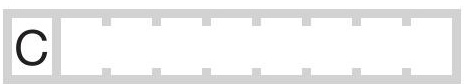

Name of Employer
USDA Forest Service
Receipt For: 2012
X Primary
Other (specify) General

Occupation

Retired

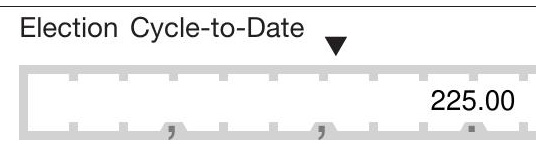

Subtotal Of Receipts This Page (optional)

Amount of Each Receipt this Period

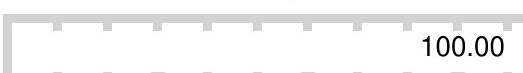

Total This Period (last page this line number only)

$\quad 360.00$

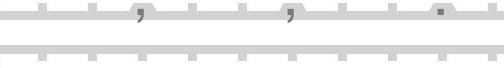

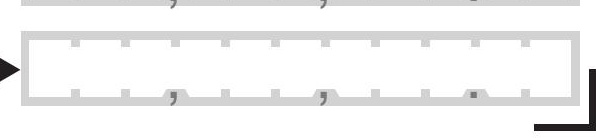

FEC Schedule A-P (Form 3P) (Rev. 03/2011) 
SCHEDULE A-P ITEMIZED RECEIPTS
Use separate schedule(s) for each category of the Detailed Summary Page
FOR LINE NUMBER: (check only one)

PAGE $211 / 1572$

\begin{tabular}{|c|c|c|c|c|c|c|}
\hline & & & & & & \\
\hline 16 & $\lambda$ & $17 \mathrm{a}$ & $17 \mathrm{~b}$ & $17 \mathrm{c}$ & $-17 d$ & -18 \\
\hline $19 a$ & & $19 b$ & $20 a$ & $20 \mathrm{~b}$ & $20 \mathrm{c}$ & 21 \\
\hline
\end{tabular}

Any information copied from such Reports and Statements may not be sold or used by any person for the purpose of soliciting contributions or for commercial purposes, other than using the name and address of any political committee to solicit contributions from such committee.

NAME OF COMMITTEE (In Full)

\section{Friends of Herman Cain}

A. Full Name (Last, First, Middle Initial)

John Inwright

Mailing Address 2866 North Star Road

\begin{tabular}{lcc}
\hline City & State & Zip Code \\
Columbus & $\mathrm{OH}$ & $43221-2959$
\end{tabular}

FEC ID number of contributing

federal political committee.

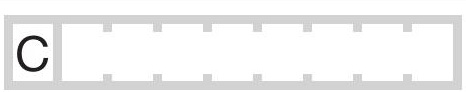

Name of Employer
Information Requested
Receipt For: 2012
X Primary
Other (specify) General

Occupation

Information Requested

Election Cycle-to-Date

500.00

B. Full Name (Last, First, Middle Initial)

Cheryl Lenhart

Mailing Address 4200 E. Skelly Dr. \#610

\begin{tabular}{lcc}
\hline City & State & Zip Code \\
Tulsa & OK & $74135-3255$
\end{tabular}

FEC ID number of contributing

federal political committee.

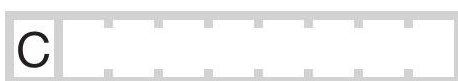

Name of Employer
None
Receipt For: 2012
X Primary
Other (specify)

\section{Occupation}

Homemaker

Transaction ID : A80B45079708D420D884

Date of Receipt

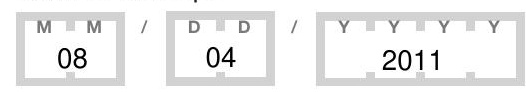

Amount of Each Receipt this Period

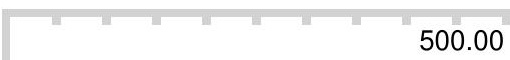

500.00

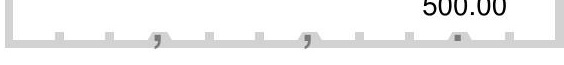

Transaction ID : A9BE76B1F34C4459C8CA

Date of Receipt

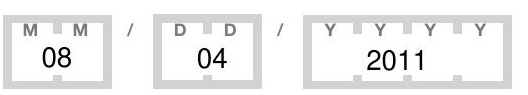

Amount of Each Receipt this Period

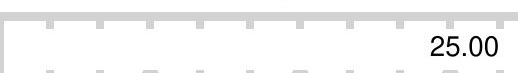

Election Cycle-to-Date

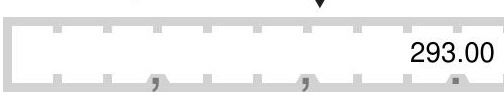

C. Full Name (Last, First, Middle Initial)

David Ford

Mailing Address 5162 Anton Dr Apt 308

\begin{tabular}{lcc}
\hline City & State & Zip Code \\
Fitchburg & WI & $53719-1717$
\end{tabular}

FEC ID number of contributing

federal political committee.

C

53719-1717

Name of Employer

University of Wisconsin Hospital

Receipt For: 2012

Х $\begin{aligned} & \text { Primary } \\ & \text { Other (specify) }\end{aligned}$

Occupation

Registered Nurse

Election Cycle-to-Date

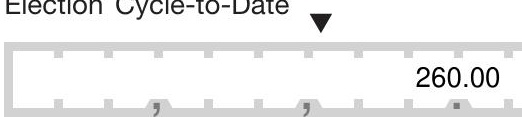

Transaction ID : A274FC4BB8D804593A42 Date of Receipt

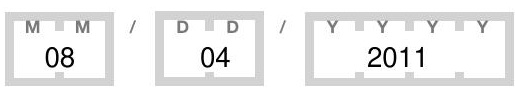

Amount of Each Receipt this Period

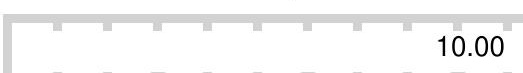

\section{Subtotal Of Receipts This Page (optional)}

Total This Period (last page this line number only) 
SCHEDULE A-P ITEMIZED RECEIPTS
Use separate schedule(s) for each category of the Detailed Summary Page
FOR LINE NUMBER: (check only one)

PAGE 212 / 1572

\begin{tabular}{|c|c|c|c|c|c|}
\hline & & & & & \\
\hline 16 & $\begin{array}{l}\mathbf{X} \\
17 a\end{array}$ & $17 b$ & $17 c$ & $17 d$ & 18 \\
\hline $19 a$ & $19 \mathrm{~b}$ & $20 \mathrm{a}$ & $20 \mathrm{~b}$ & $20 \mathrm{c}$ & 21 \\
\hline
\end{tabular}

Any information copied from such Reports and Statements may not be sold or used by any person for the purpose of soliciting contributions or for commercial purposes, other than using the name and address of any political committee to solicit contributions from such committee.

NAME OF COMMITTEE (In Full)

\section{Friends of Herman Cain}

A. Full Name (Last, First, Middle Initial)

Tim Freeman

Mailing Address 22911 Bland Circle

\begin{tabular}{lcc}
\hline City & State & Zip Code \\
West Linn & OR & $97068-9217$ \\
\hline
\end{tabular}

FEC ID number of contributing federal political committee.

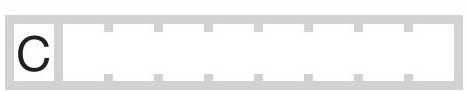

Name of Employer
Effective Marketing, Inc.
Receipt For: 2012
X Primary $\quad \square$ General
Other (specify)

Occupation

Consultant

Election Cycle-to-Date

294.86

B. Full Name (Last, First, Middle Initial)

Audrey Matisa

Mailing Address 6 Colonial Ridge Drive

\begin{tabular}{lcc}
\hline City & State & Zip Code \\
Yardley & PA & $19067-3110$ \\
\hline
\end{tabular}

FEC ID number of contributing

federal political committee.

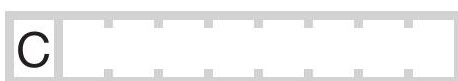

Name of Employer
n/a
Receipt For: 2012
X Primary
Other (specify)

Occupation

Retired

Election Cycle-to-Date

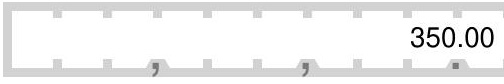

C. Full Name (Last, First, Middle Initial)

Patricia Durham

Mailing Address 205 Saint Elizabeth Ter

\begin{tabular}{lcc}
\hline City & State & Zip Code \\
Stockbridge & GA & $30281-970$
\end{tabular}

FEC ID number of contributing federal political committee.

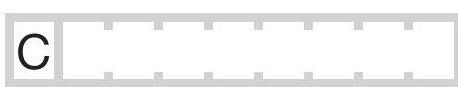

Name of Employer
Henry Medical Center
Receipt For: 2012
X Primary
Other (specify) General

\section{Occupation}

$\mathrm{RN}$

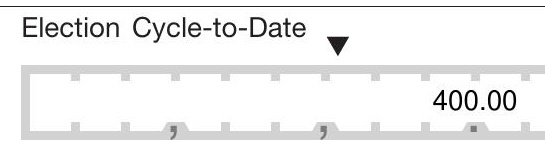

Transaction ID : A6988C2CF32704C9E9FE

Date of Receipt

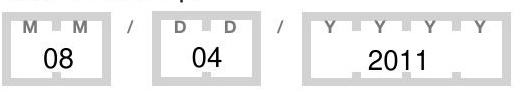

In-kind:Event Catering

Amount of Each Receipt this Period

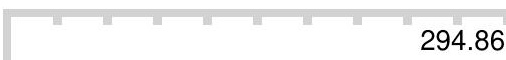

294.86

Transaction ID : AA9C53159D2D64D559F5

Date of Receipt

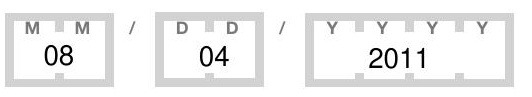

Amount of Each Receipt this Period

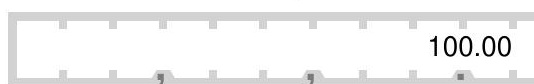

Transaction ID : A1C519FA15373477AA05

Date of Receipt

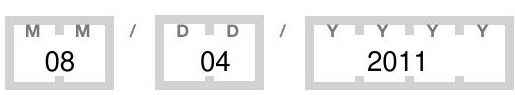

Amount of Each Receipt this Period

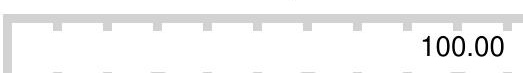

100.00

\section{Subtotal Of Receipts This Page (optional)}

494.86

(n)

Total This Period (last page this line number only)

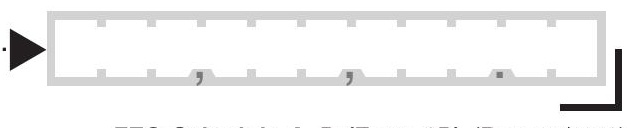

FEC Schedule A-P (Form 3P) (Rev. 03/2011) 
SCHEDULE A-P ITEMIZED RECEIPTS
Use separate schedule(s) for each category of the Detailed Summary Page
FOR LINE NUMBER: (check only one)

\begin{tabular}{|c|c|c|c|c|c|}
\hline & & & & & \\
\hline 16 & $\begin{array}{ll}X & 17 a \\
\end{array}$ & $17 \mathrm{~b}$ & $17 c$ & $17 d$ & 18 \\
\hline $19 a$ & $19 b$ & $20 \mathrm{a}$ & $20 \mathrm{~b}$ & $20 c$ & 21 \\
\hline
\end{tabular}

Any information copied from such Reports and Statements may not be sold or used by any person for the purpose of soliciting contributions or for commercial purposes, other than using the name and address of any political committee to solicit contributions from such committee.

NAME OF COMMITTEE (In Full)

\section{Friends of Herman Cain}

A. Full Name (Last, First, Middle Initial)

\section{Susan Walter}

Mailing Address P.O. Box 690

\begin{tabular}{lcc}
\hline City & State & Zip Code \\
Sautee Nacoochee & GA & $30571-0690$ \\
\hline
\end{tabular}

FEC ID number of contributing federal political committee.

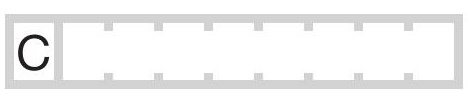

\begin{tabular}{l} 
Name of Employer \\
None \\
Receipt For: 2012 \\
X Primary $\quad$ General \\
\hline Other (specify)
\end{tabular}

Occupation Retired

Election Cycle-to-Date

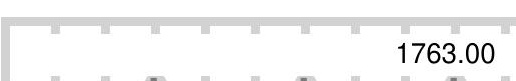

B. Full Name (Last, First, Middle Initial)

Mrs. Barbara C. Mathews

Mailing Address 2367 LAvista Road

\begin{tabular}{lcc}
\hline City & State & Zip Code \\
Atlanta & GA & $30329-3346$ \\
\hline
\end{tabular}

FEC ID number of contributing

federal political committee.

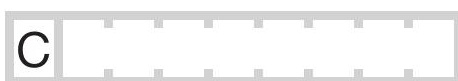

Name of Employer
None
Receipt For: 2012
X Primary
Other (specify)

\section{Occupation}

Retired

Election Cycle-to-Date

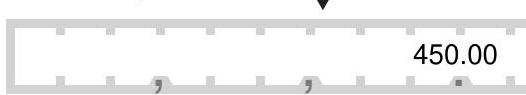

Transaction ID : A91E9E67CF36C4F62B69

Date of Receipt

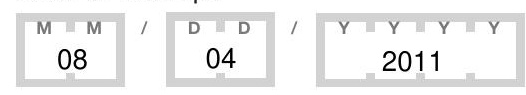

Amount of Each Receipt this Period

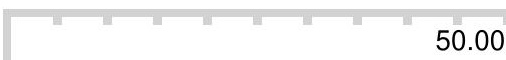

50.00

C. Full Name (Last, First, Middle Initial)

Vikki Brown

Mailing Address 391 Leeches Rd

\begin{tabular}{lcc}
\hline City & State & Zip Code \\
Ellijay & GA & $30540-7354$ \\
\hline
\end{tabular}

FEC ID number of contributing federal political committee.

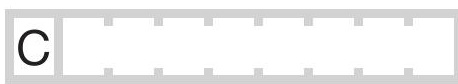

Name of Employer
AT\&T
Receipt For: 2012
X Primary $\quad \square$ General
Other (specify)

Occupation

Intellectual Property Specialist

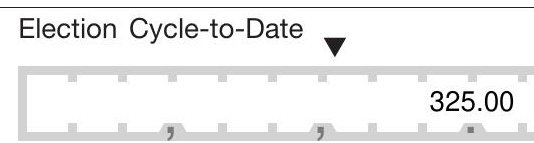

Transaction ID : AE250160A9A4447D38F5

Date of Receipt

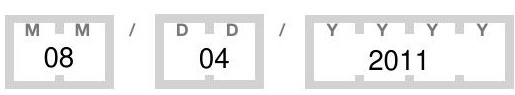

Amount of Each Receipt this Period

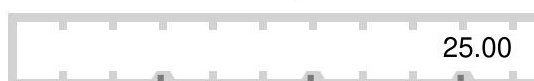

Transaction ID : A376AFA380BBE46B6A8A Date of Receipt

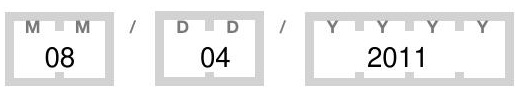

Amount of Each Receipt this Period

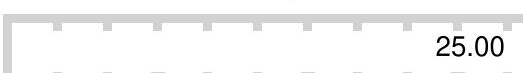

\section{Subtotal Of Receipts This Page (optional)}

100.00

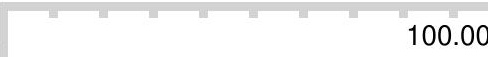

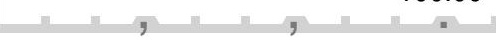

Total This Period (last page this line number only)

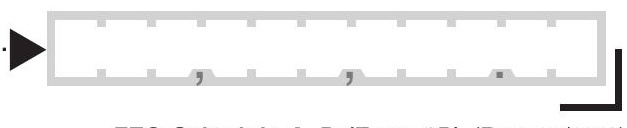

FEC Schedule A-P (Form 3P) (Rev. 03/2011) 
SCHEDULE A-P ITEMIZED RECEIPTS
Use separate schedule(s) for each category of the Detailed Summary Page
FOR LINE NUMBER: (check only one)

PAGE 214 / 1572

\begin{tabular}{|c|c|c|c|c|c|}
\hline & & & & & \\
\hline 16 & $\begin{array}{l}\mathbf{X} \\
17 a\end{array}$ & $17 b$ & $17 c$ & $17 d$ & 18 \\
\hline $19 a$ & $19 \mathrm{~b}$ & $20 \mathrm{a}$ & $20 \mathrm{~b}$ & $20 \mathrm{c}$ & 21 \\
\hline
\end{tabular}

Any information copied from such Reports and Statements may not be sold or used by any person for the purpose of soliciting contributions or for commercial purposes, other than using the name and address of any political committee to solicit contributions from such committee.

NAME OF COMMITTEE (In Full)

\section{Friends of Herman Cain}

A. Full Name (Last, First, Middle Initial)

\section{Bruce Eberle}

Mailing Address 1449 Montague Dr.

\begin{tabular}{lcc}
\hline City & State & Zip Code \\
Vienna & VA & $22182-1440$
\end{tabular}

FEC ID number of contributing federal political committee.

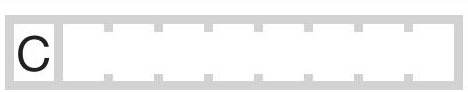

Name of Employer
Eberle Communications Group Inc.
Receipt For: 2012
X Primary $\quad \square$ General
Other (specify)

Occupation

Direct Marketing

Election Cycle-to-Date

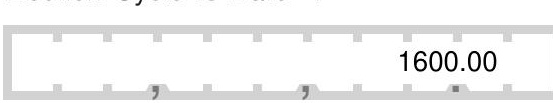

B. Full Name (Last, First, Middle Initial)

Paula Sandell

Mailing Address 16619 Sunlight Way

\begin{tabular}{lcc}
\hline City & State & Zip Code \\
Houston & TX & $77058-2243$
\end{tabular}

FEC ID number of contributing

federal political committee.

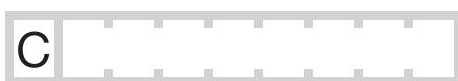

Name of Employer
None
Receipt For: 2012
X Primary
Other (specify)

Occupation

Retired

Election Cycle-to-Date

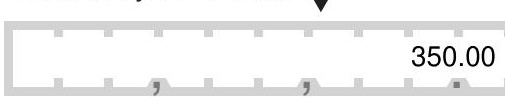

Transaction ID : A02530B4CCCAB4F80BC6

Date of Receipt

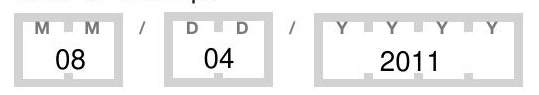

Amount of Each Receipt this Period

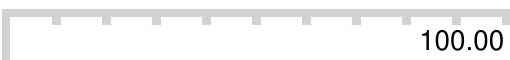

100.00

C. Full Name (Last, First, Middle Initial)

Gary Metzer

Mailing Address 3 Rustic View Ct.

\begin{tabular}{lcc}
\hline City & State & Zip Code \\
Spring & TX & $77381-3838$
\end{tabular}

FEC ID number of contributing

federal political committee.

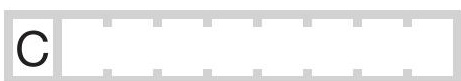

Name of Employer

Southwestern Energy Company

Receipt For: 2012

Х $\begin{aligned} & \text { Primary } \square \text { General } \\ & \text { Other (specify) }\end{aligned}$

\section{Occupation}

Engineer

Election Cycle-to-Date
Transaction ID : A87D1A8B3A82D44F49B5

Date of Receipt

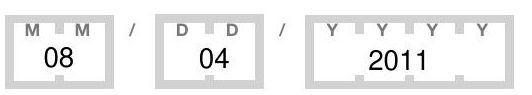

Amount of Each Receipt this Period

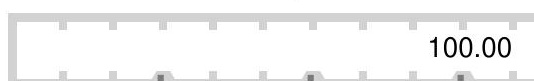

Amount of Each Receipt this Period

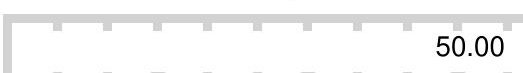

Transaction ID : A8CBD4814DAB8405EBC3 Date of Receipt

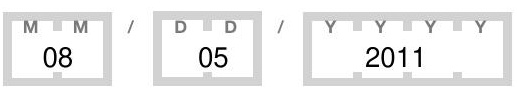

\section{Subtotal Of Receipts This Page (optional)}

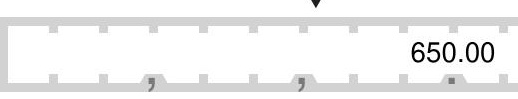

(1)

Total This Period (last page this line number only) 
SCHEDULE A-P ITEMIZED RECEIPTS
Use separate schedule(s) for each category of the Detailed Summary Page
FOR LINE NUMBER: (check only one)

PAGE $215 / 1572$

\begin{tabular}{|c|c|c|c|c|c|c|}
\hline & & & & & & \\
\hline 16 & $\lambda$ & $17 \mathrm{a}$ & $17 \mathrm{~b}$ & $17 \mathrm{c}$ & $-17 d$ & -18 \\
\hline $19 a$ & & $19 b$ & $20 a$ & $20 \mathrm{~b}$ & $20 \mathrm{c}$ & 21 \\
\hline
\end{tabular}

Any information copied from such Reports and Statements may not be sold or used by any person for the purpose of soliciting contributions or for commercial purposes, other than using the name and address of any political committee to solicit contributions from such committee.

NAME OF COMMITTEE (In Full)

\section{Friends of Herman Cain}

A. Full Name (Last, First, Middle Initial)

Betsy Trapp

Mailing Address 3051 Deanna Way

\begin{tabular}{lcc}
\hline City & State & Zip Code \\
Lawrenceville & GA & $30044-5764$
\end{tabular}

FEC ID number of contributing federal political committee.

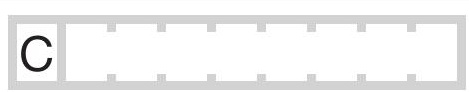

Name of Employer
Gwinnett Public Schools
Receipt For: 2012
X Primary $\quad \square$ General
Other (specify)

Occupation

Special Education

Election Cycle-to-Date

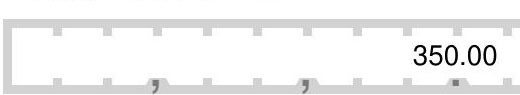

B. Full Name (Last, First, Middle Initial)

Karen Hatke

Mailing Address 75 Hibiscus Court

\begin{tabular}{lcc}
\hline City & State & Zip Code \\
Lafayette & IN & $47909-6302$ \\
\hline
\end{tabular}

FEC ID number of contributing

federal political committee.

C

Name of Employer
self
Receipt For: 2012
Primary
Other (specify)

Occupation

Freelance Writer

Election Cycle-to-Date

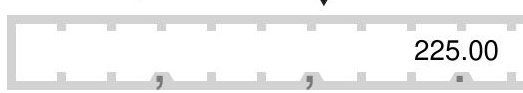

Transaction ID : A04EB658840984179BB1

Date of Receipt

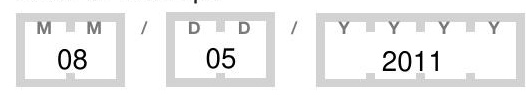

Amount of Each Receipt this Period

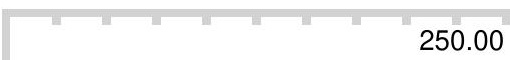

250.00

C. Full Name (Last, First, Middle Initial)

Thomas J Humphrey

Mailing Address 12902 W Mesa Verde Dr

\begin{tabular}{lcc}
\hline City & State & Zip Code \\
Sun City West & AZ & $85375-3226$
\end{tabular}

FEC ID number of contributing

federal political committee.

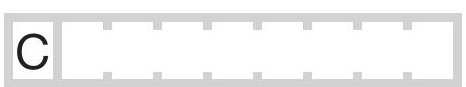

Name of Employer
None
Receipt For: 2012
Х Primary $\quad \square$ General
Other (specify)

Occupation

Retired

Election Cycle-to-Date

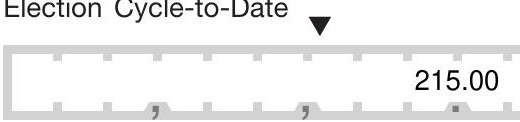

Transaction ID : AAFA860C5D12C4E6EAA2 Date of Receipt

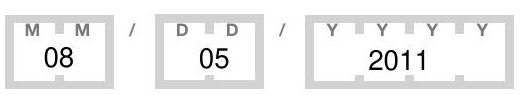

Amount of Each Receipt this Period

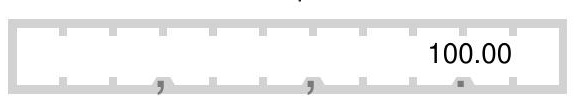

Transaction ID : A13C8BACD0A464B86A6D Date of Receipt

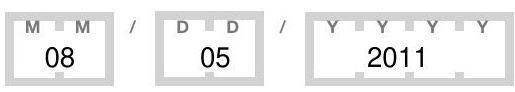

Amount of Each Receipt this Period

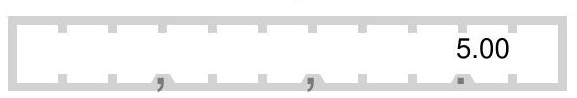

\section{Subtotal Of Receipts This Page (optional)}

Total This Period (last page this line number only) 


\section{SCHEDULE A-P} ITEMIZED RECEIPTS
Use separate schedule(s)

for each category of the

Detailed Summary Page
FOR LINE NUMBER: (check only one)

PAGE $216 / 1572$

\begin{tabular}{|c|c|c|c|c|c|}
\hline & & & & & \\
\hline 16 & X $17 a$ & $17 b$ & $17 c$ & $17 d$ & 18 \\
\hline $19 a$ & $19 b$ & $20 \mathrm{a}$ & $20 \mathrm{~b}$ & $20 \mathrm{c}$ & 21 \\
\hline
\end{tabular}

Any information copied from such Reports and Statements may not be sold or used by any person for the purpose of soliciting contributions or for commercial purposes, other than using the name and address of any political committee to solicit contributions from such committee.

NAME OF COMMITTEE (In Full)

Friends of Herman Cain

A. Full Name (Last, First, Middle Initial)

Robbie McCormick

Mailing Address 607 Winged Foot

\begin{tabular}{lcc}
\hline City & State & Zip Code \\
Carlsbad & NM & $88220-9205$ \\
\hline
\end{tabular}

FEC ID number of contributing federal political committee.

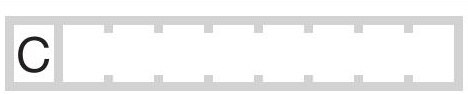

Name of Employer
Information Requested
Receipt For: 2012
X Primary
$\square$ Other (specify)

Occupation

Information Requested

Election Cycle-to-Date

250.00

B. Full Name (Last, First, Middle Initial)

Jeanne Downer

Mailing Address $6007 \mathrm{~N}$ Kansas AVe

\begin{tabular}{llc}
\hline City & State & Zip Code \\
Kansas City & MO & $64119-2115$ \\
\hline
\end{tabular}

FEC ID number of contributing

federal political committee.

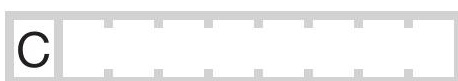

Name of Employer
WNB Architects
Receipt For: 2012
X Primary
Other (specify)

Occupation

Office Manager

Election Cycle-to-Date

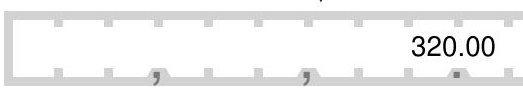

C. Full Name (Last, First, Middle Initial)

JOHN HARRINGTON

Mailing Address 19 Norwood Hts

\begin{tabular}{lcc}
\hline City & State & Zip Code \\
Gloucester & MA & $01930-1212$
\end{tabular}

FEC ID number of contributing

federal political committee.

C

Name of Employer
None
Receipt For: 2012
X Primary $\quad \square$ General
Other (specify)

Occupation

Retired

Election Cycle-to-Date

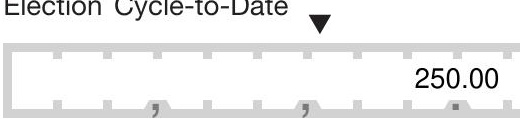

Transaction ID : A295E4092F2FB4B13AE4

Date of Receipt

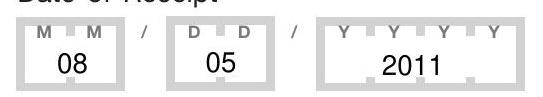

Amount of Each Receipt this Period

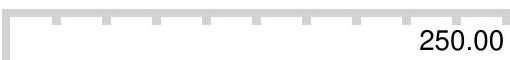

250.00
Amount of Each Receipt this Period

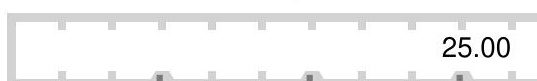

Transaction ID : A0ACAA9FE53F540C1864 Date of Receipt

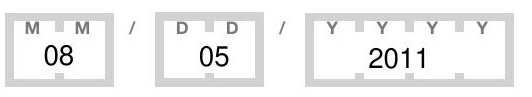

Transaction ID : ACBBCA93FB9324020B5D Date of Receipt

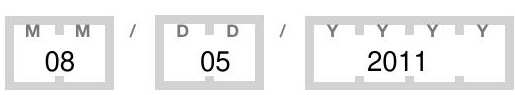

Amount of Each Receipt this Period

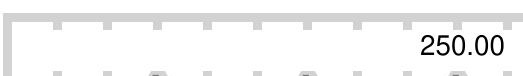

Subtotal Of Receipts This Page (optional).

Total This Period (last page this line number only) 
SCHEDULE A-P ITEMIZED RECEIPTS
Use separate schedule(s) for each category of the Detailed Summary Page
FOR LINE NUMBER: (check only one)

PAGE 217 / 1572

\begin{tabular}{|c|c|c|c|c|c|}
\hline & & & & & \\
\hline 16 & $\begin{array}{l}\mathbf{X} \\
17 a\end{array}$ & $17 b$ & $17 c$ & $17 d$ & 18 \\
\hline $19 a$ & $19 \mathrm{~b}$ & $20 \mathrm{a}$ & $20 \mathrm{~b}$ & $20 \mathrm{c}$ & 21 \\
\hline
\end{tabular}

Any information copied from such Reports and Statements may not be sold or used by any person for the purpose of soliciting contributions or for commercial purposes, other than using the name and address of any political committee to solicit contributions from such committee.

NAME OF COMMITTEE (In Full)

Friends of Herman Cain

A. Full Name (Last, First, Middle Initial)

David Dunnavant Jr

Mailing Address 29415 Lakeview Dr

\begin{tabular}{lcc}
\hline City & State & Zip Code \\
Ardmore & AL & $35739-7747$
\end{tabular}

FEC ID number of contributing

federal political committee.

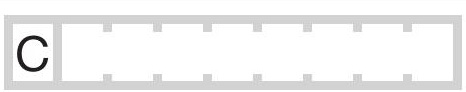

Name of Employer
Information Requested
Receipt For: 2012
X Primary $\quad \square$ General
Other (specify)

Occupation

Information Requested

Election Cycle-to-Date

1075.00

B. Full Name (Last, First, Middle Initial)

Thomas J Humphrey

Mailing Address 12902 W Mesa Verde Dr

\begin{tabular}{lcc}
\hline City & State & Zip Code \\
Sun City West & AZ & 85375-3226
\end{tabular}

FEC ID number of contributing

federal political committee.

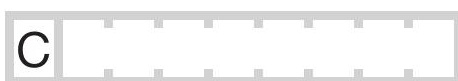

Name of Employer
None
Receipt For: 2012
X Primary
Other (specify)

Occupation

Retired

Election Cycle-to-Date

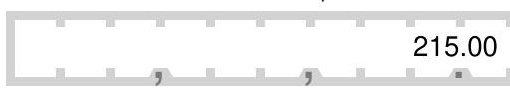

Transaction ID : AD455D4DAABA04D48B4C

Date of Receipt

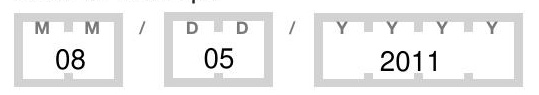

Amount of Each Receipt this Period

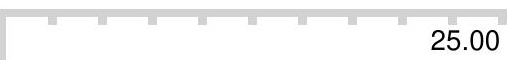

25.00

C. Full Name (Last, First, Middle Initial)

Thomas J Humphrey

Mailing Address 12902 W Mesa Verde Dr

\begin{tabular}{lcc}
\hline City & State & Zip Code \\
Sun City West & AZ & $85375-3226$
\end{tabular}

FEC ID number of contributing

federal political committee.

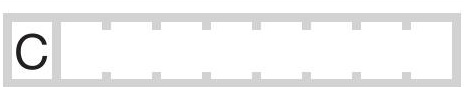

Name of Employer
None
Receipt For: 2012
Х Primary $\quad \square$ General
Other (specify)

Occupation

Retired

Election Cycle-to-Date

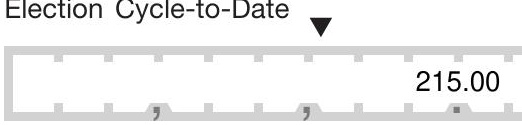

Transaction ID : A198714FD3A4B4ED2B89

Date of Receipt

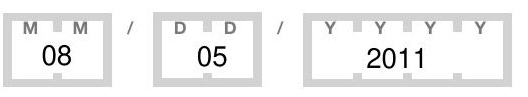

Amount of Each Receipt this Period

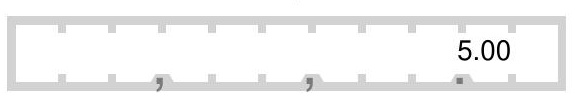

Transaction ID : A02B7249327F74CF8B3E

Date of Receipt

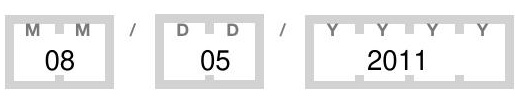

Amount of Each Receipt this Period

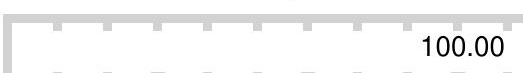

Subtotal Of Receipts This Page (optional).

130.00

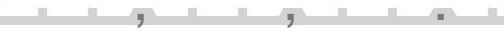

Total This Period (last page this line number only)

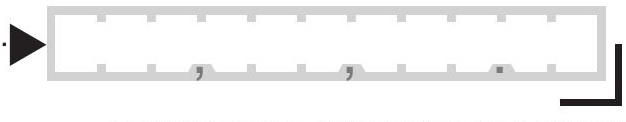

FEC Schedule A-P (Form 3P) (Rev. 03/2011) 
SCHEDULE A-P ITEMIZED RECEIPTS
Use separate schedule(s) for each category of the Detailed Summary Page
FOR LINE NUMBER: (check only one)

PAGE $218 / 1572$

\begin{tabular}{|c|c|c|c|c|c|}
\hline & & & & & \\
\hline 16 & $\begin{array}{l}\mathbf{X} \\
17 a\end{array}$ & $17 b$ & $17 c$ & $17 d$ & 18 \\
\hline $19 a$ & $19 \mathrm{~b}$ & $20 \mathrm{a}$ & $20 \mathrm{~b}$ & $20 \mathrm{c}$ & 21 \\
\hline
\end{tabular}

Any information copied from such Reports and Statements may not be sold or used by any person for the purpose of soliciting contributions or for commercial purposes, other than using the name and address of any political committee to solicit contributions from such committee.

NAME OF COMMITTEE (In Full)

Friends of Herman Cain

A. Full Name (Last, First, Middle Initial)

Mrs. Dama L Curtright

Mailing Address P.O. Box 1350

\begin{tabular}{lcc}
\hline City & State & Zip Code \\
Jefferson & OR & $97352-1350$
\end{tabular}

FEC ID number of contributing federal political committee.

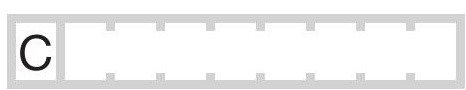

Name of Employer

Ames Research Laboratory, Inc.

Occupation

Co-Owner

Receipt For: 2012

X Primary $\square$ General Other (specify)

Election Cycle-to-Date $\boldsymbol{\nabla}$

5000.00

B. Full Name (Last, First, Middle Initial)

Thomas J Humphrey

Mailing Address 12902 W Mesa Verde Dr

\begin{tabular}{lcc}
\hline City & State & Zip Code \\
Sun City West & AZ & $85375-3226$
\end{tabular}

FEC ID number of contributing

federal political committee.

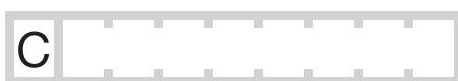

Name of Employer
None
Receipt For: 2012
X Primary
Other (specify)

\section{Occupation}

Retired

Election Cycle-to-Date

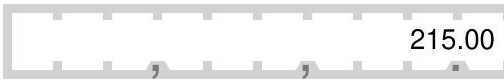

C. Full Name (Last, First, Middle Initial)

Mr. David J Carie

Mailing Address 5024 E. Otterbein Ln.

\begin{tabular}{lcc}
\hline City & State & Zip Code \\
Olney & IL & $62450-543$
\end{tabular}

FEC ID number of contributing federal political committee.

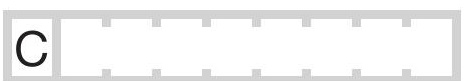

Name of Employer
Information Requested
Receipt For: 2012
X Primary
Other (specify) General

\section{Occupation}

Information Requested

Election Cycle-to-Date
Transaction ID : AA3C10565C7494C3FAE4

Date of Receipt

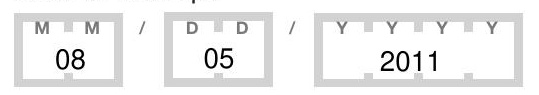

Amount of Each Receipt this Period

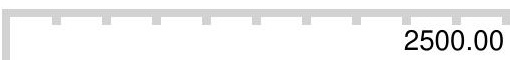

2500.00

Amount of Each Receipt this Period

Transaction ID : A18A959D6329E40C0997

Date of Receipt
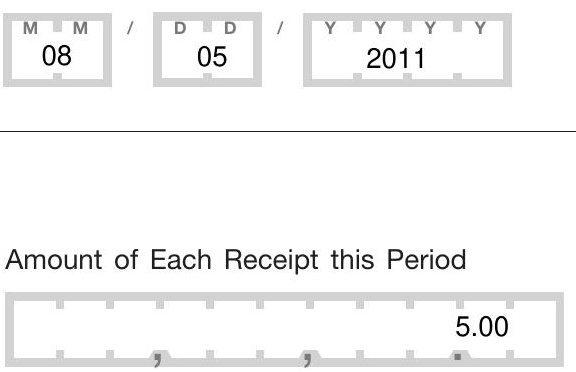

Transaction ID : AAA85E968EF464B1BB08 Date of Receipt

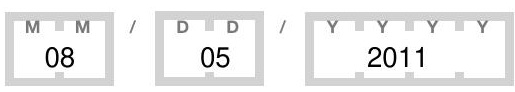

Amount of Each Receipt this Period

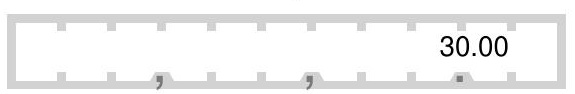

230.00

\section{Subtotal Of Receipts This Page (optional)}

Total This Period (last page this line number only) 
SCHEDULE A-P ITEMIZED RECEIPTS
Use separate schedule(s) for each category of the Detailed Summary Page
FOR LINE NUMBER: (check only one)

PAGE $219 / 1572$

\begin{tabular}{|c|c|c|c|c|c|}
\hline & & & & & \\
\hline 16 & $\begin{array}{l}\mathbf{X} \\
17 a\end{array}$ & $17 b$ & $17 c$ & $17 d$ & 18 \\
\hline $19 a$ & $19 \mathrm{~b}$ & $20 \mathrm{a}$ & $20 \mathrm{~b}$ & $20 \mathrm{c}$ & 21 \\
\hline
\end{tabular}

Any information copied from such Reports and Statements may not be sold or used by any person for the purpose of soliciting contributions or for commercial purposes, other than using the name and address of any political committee to solicit contributions from such committee.

NAME OF COMMITTEE (In Full)

\section{Friends of Herman Cain}

A. Full Name (Last, First, Middle Initial)

\section{Christine Preble}

Mailing Address 3847 Monument Rd.

\begin{tabular}{lcc}
\hline City & State & Zip Code \\
Jasper & GA & $30143-2402$
\end{tabular}

FEC ID number of contributing federal political committee.

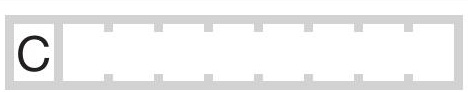

Name of Employer
Retired
Receipt For: 2012
X Primary $\quad$ General
Other (specify)

Occupation

RN Childbirth Educator

Election Cycle-to-Date

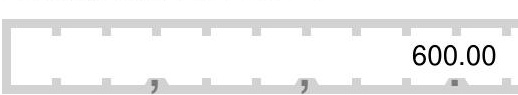

B. Full Name (Last, First, Middle Initial)

George Dangler

Mailing Address P.O. Box 254

\begin{tabular}{lcc}
\hline City & State & Zip Code \\
Blairsville & GA & $30514-0254$
\end{tabular}

FEC ID number of contributing

federal political committee.

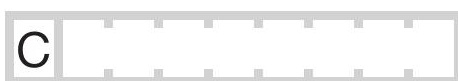

$\begin{aligned} & \text { Name of Employer } \\ & \text { self }\end{aligned}$
Receipt For: 2012
X Primary
Other (specify)

\section{Occupation}

Motorcycle Dealer

Election Cycle-to-Date

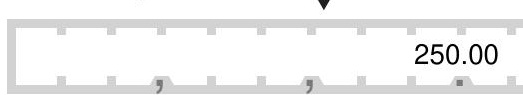

Transaction ID : A807D75D209DA45BBA3E

Date of Receipt

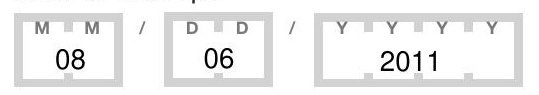

Amount of Each Receipt this Period

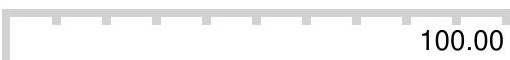

Transaction ID : A3F7979DAA0D84AE697E

Date of Receipt

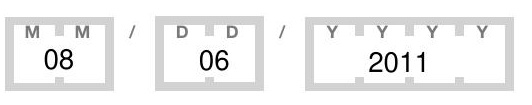

Amount of Each Receipt this Period

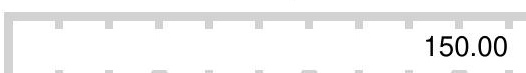

Transaction ID : AEEC4665D0CD94042A66 Date of Receipt

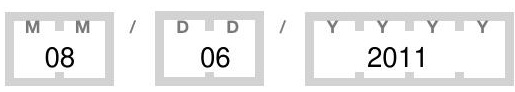

Amount of Each Receipt this Period

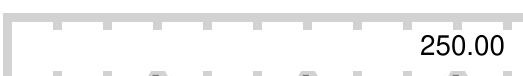

$\begin{array}{cc}\text { State } & \text { Zip Code } \\ \text { OR } & 97034-0108\end{array}$

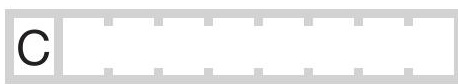

Occupation

Information Requested

Election Cycle-to-Date

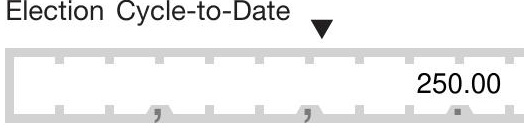

Subtotal Of Receipts This Page (optional)

500.00

,

Total This Period (last page this line number only) 


\section{SCHEDULE A-P} ITEMIZED RECEIPTS
Use separate schedule(s)

for each category of the

Detailed Summary Page
FOR LINE NUMBER: (check only one)

PAGE $220 / 1572$

\begin{tabular}{|c|c|c|c|c|c|}
\hline & & & & & \\
\hline 16 & X $17 a$ & $17 b$ & $17 c$ & $17 d$ & 18 \\
\hline $19 a$ & $19 b$ & $20 \mathrm{a}$ & $20 \mathrm{~b}$ & $20 \mathrm{c}$ & 21 \\
\hline
\end{tabular}

Any information copied from such Reports and Statements may not be sold or used by any person for the purpose of soliciting contributions or for commercial purposes, other than using the name and address of any political committee to solicit contributions from such committee.

NAME OF COMMITTEE (In Full)

Friends of Herman Cain

A. Full Name (Last, First, Middle Initial)

Will Olschewski

Mailing Address 1732 South Congress Avenue \#265

\begin{tabular}{lcc}
\hline City & State & Zip Code \\
Palm Springs & FL & $33461-2140$
\end{tabular}

FEC ID number of contributing

federal political committee.

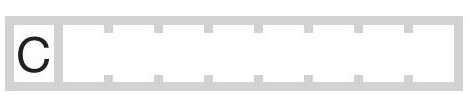

Name of Employer
Information Requested
Receipt For: 2012
X Primary $\quad \square$ General
Other (specify)

Occupation

Information Requested

Election Cycle-to-Date

2400.00

B. Full Name (Last, First, Middle Initial)

Betty Roberts

Mailing Address 530 Sutton St SW

\begin{tabular}{lcc}
\hline City & State & Zip Code \\
Abingdon & VA & $24210-3030$
\end{tabular}

FEC ID number of contributing

federal political committee.

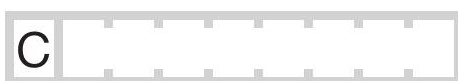

Name of Employer
Self Employed
Receipt For: 2012
X Primary
Other (specify) General

Occupation

Physician

Election Cycle-to-Date

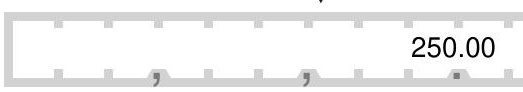

C. Full Name (Last, First, Middle Initial)

Lori Simmons

Mailing Address 10101 Wenonga Ln

\begin{tabular}{lcc}
\hline City & State & Zip Code \\
Leawood & KS & $66206-2444$
\end{tabular}

FEC ID number of contributing

federal political committee.

C

Name of Employer
None
Receipt For: 2012
X Primary

Other (specify) General

\section{Occupation}

Homemaker

Election Cycle-to-Date

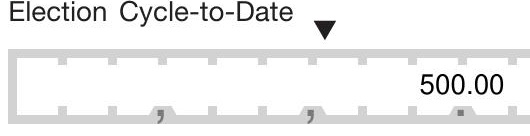

Transaction ID : A65FD39D0834E4792B8F

Date of Receipt

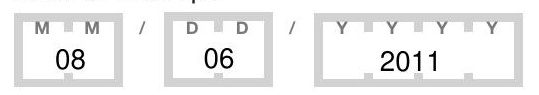

Amount of Each Receipt this Period

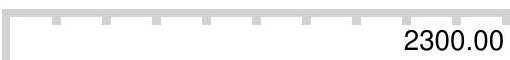

2300.00

Transaction ID : AD4C344925DB4413AB52

Date of Receipt

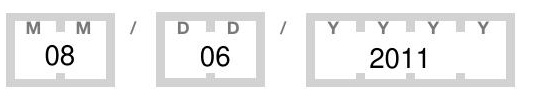

Amount of Each Receipt this Period

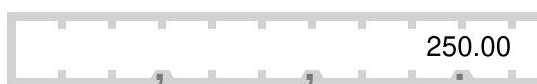

Transaction ID : AEBED014E901643D58B4

Date of Receipt

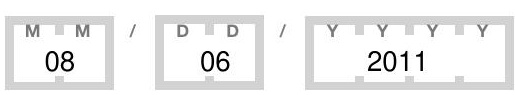

Amount of Each Receipt this Period

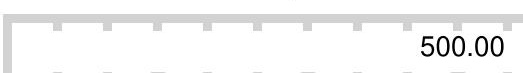

500.00

Subtotal Of Receipts This Page (optional)

Total This Period (last page this line number only) 
SCHEDULE A-P ITEMIZED RECEIPTS
Use separate schedule(s) for each category of the Detailed Summary Page
FOR LINE NUMBER: (check only one)

PAGE $221 / 1572$

\begin{tabular}{|c|c|c|c|c|c|c|}
\hline & & & & & & \\
\hline 16 & $\lambda$ & $17 \mathrm{a}$ & $17 \mathrm{~b}$ & $17 \mathrm{c}$ & $-17 d$ & -18 \\
\hline $19 a$ & & $19 b$ & $20 a$ & $20 \mathrm{~b}$ & $20 \mathrm{c}$ & 21 \\
\hline
\end{tabular}

Any information copied from such Reports and Statements may not be sold or used by any person for the purpose of soliciting contributions or for commercial purposes, other than using the name and address of any political committee to solicit contributions from such committee.

NAME OF COMMITTEE (In Full)

\section{Friends of Herman Cain}

A. Full Name (Last, First, Middle Initial)

Susan McHugh

Mailing Address 114 Indian Pipe Ln

\begin{tabular}{lcc}
\hline City & State & Zip Code \\
Concord & MA & $01742-4766$
\end{tabular}

FEC ID number of contributing federal political committee.

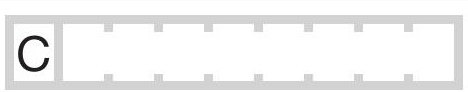

Name of Employer
Not Employed
Receipt For: 2012
X Primary $\quad$ General
Other (specify)

Occupation Not Employed

Election Cycle-to-Date

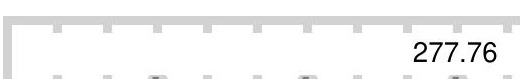

B. Full Name (Last, First, Middle Initial)

Brian Mulhern

Mailing Address 14948 Vireo Court

\begin{tabular}{lcc}
\hline City & State & Zip Code \\
Woodbridge & VA & $22193-1899$ \\
\hline
\end{tabular}

FEC ID number of contributing

federal political committee.

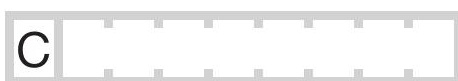

Name of Employer
Lockheed Martin
Receipt For: 2012
X Primary $\quad$ General

Occupation

System Engineer

Election Cycle-to-Date

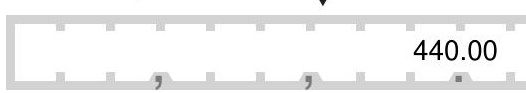

Transaction ID : A537ED13B4E9443DFB73

Date of Receipt

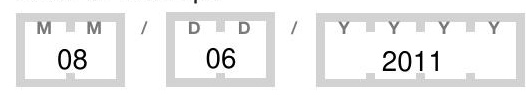

Amount of Each Receipt this Period

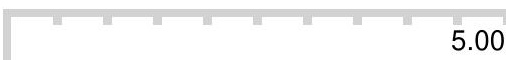

Transaction ID : A351299F31AA94A3E899

Date of Receipt

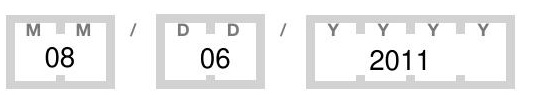

Amount of Each Receipt this Period

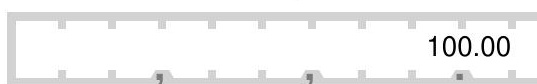

Transaction ID : A575B094823FE41D4AB2 Date of Receipt

Randi Helgeson

Mailing Address 16485 Ellerdale Lane

\begin{tabular}{lcc}
\hline City & State & Zip Code \\
Eden Prairie & MN & $55346-1431$
\end{tabular}

FEC ID number of contributing federal political committee.

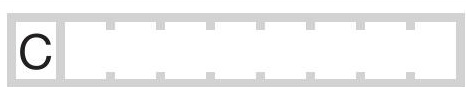

Name of Employer
Retired
Receipt For: 2012
X Primary $\quad \square$ General
Other (specify)

\section{Occupation}

CPA

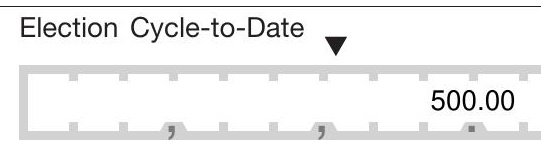

Subtotal Of Receipts This Page (optional)

Amount of Each Receipt this Period

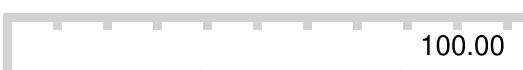

Total This Period (last page this line number only)

205.00

(2)

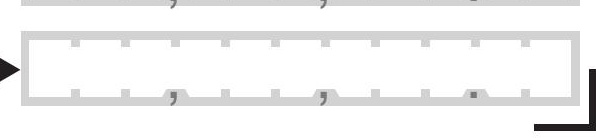

FEC Schedule A-P (Form 3P) (Rev. 03/2011) 
SCHEDULE A-P ITEMIZED RECEIPTS
Use separate schedule(s) for each category of the Detailed Summary Page
FOR LINE NUMBER: (check only one)

PAGE 222 / 1572

\begin{tabular}{|c|c|c|c|c|c|}
\hline & & & & & \\
\hline 16 & $\begin{array}{l}\mathbf{X} \\
17 a\end{array}$ & $17 b$ & $17 c$ & $17 d$ & 18 \\
\hline $19 a$ & $19 \mathrm{~b}$ & $20 \mathrm{a}$ & $20 \mathrm{~b}$ & $20 \mathrm{c}$ & 21 \\
\hline
\end{tabular}

Any information copied from such Reports and Statements may not be sold or used by any person for the purpose of soliciting contributions or for commercial purposes, other than using the name and address of any political committee to solicit contributions from such committee.

NAME OF COMMITTEE (In Full)

\section{Friends of Herman Cain}

A. Full Name (Last, First, Middle Initial)

Randolph White

Mailing Address 3265 Hembree Court

\begin{tabular}{lcc}
\hline City & State & Zip Code \\
Marietta & GA & $30062-4219$
\end{tabular}

FEC ID number of contributing

federal political committee.

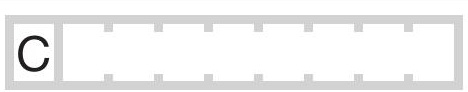

Name of Employer
Automationdirect.com
Receipt For: 2012
X Primary $\quad \square$ General
Other (specify)

Occupation

technical writer

Election Cycle-to-Date

395.00

B. Full Name (Last, First, Middle Initial)

Lynn Zody

Mailing Address 708 Callaway $\mathrm{Dr}$

\begin{tabular}{lcc}
\hline City & State & Zip Code \\
Graniteville & SC & $29829-4054$
\end{tabular}

FEC ID number of contributing

federal political committee.

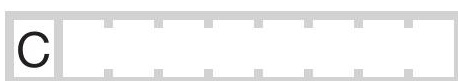

Name of Employer
Stix \& Co. Inc.
Receipt For: 2012
X Primary
Other (specify)

Occupation

FOOD SERVICE

Election Cycle-to-Date

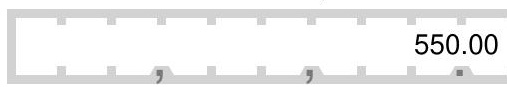

C. Full Name (Last, First, Middle Initial)

Cathie Serrano

Mailing Address 5641 Shadow View Dr

\begin{tabular}{lcc}
\hline City & State & Zip Code \\
Stone Mountain & GA & $30087-2953$
\end{tabular}

FEC ID number of contributing

federal political committee.

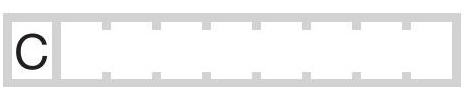

Name of Employer
n/a
Receipt For: 2012
X Primary $\square$ General
Other (specify)

Occupation

Retired

Election Cycle-to-Date

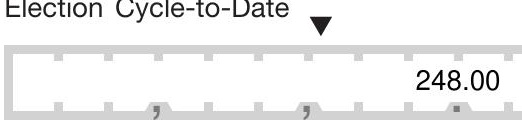

Transaction ID : AB6F78E2BCFBD4E37804

Date of Receipt

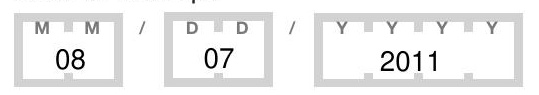

Amount of Each Receipt this Period

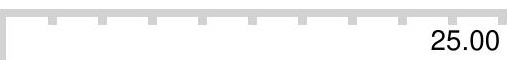

25.00

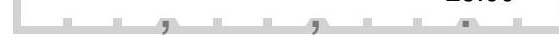

Transaction ID : A1FBF0CCE526E4912B5E

Date of Receipt

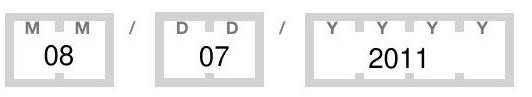

Amount of Each Receipt this Period

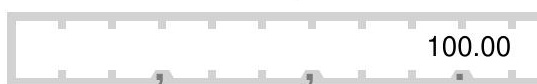

Transaction ID : A93817381CE3D4C0B9BA Date of Receipt

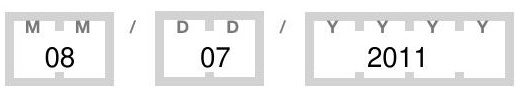

Amount of Each Receipt this Period

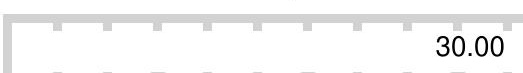

\section{Subtotal Of Receipts This Page (optional)}

155.00

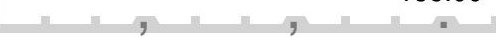

Total This Period (last page this line number only)

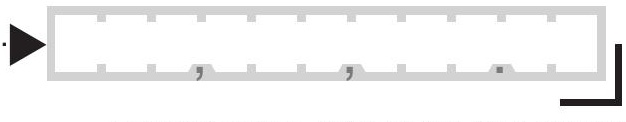

FEC Schedule A-P (Form 3P) (Rev. 03/2011) 
SCHEDULE A-P ITEMIZED RECEIPTS
Use separate schedule(s) for each category of the Detailed Summary Page
FOR LINE NUMBER: (check only one)

PAGE 223 / 1572

\begin{tabular}{|c|c|c|c|c|c|}
\hline & & & & & \\
\hline 16 & $\begin{array}{l}\mathbf{X} \\
17 a\end{array}$ & $17 b$ & $17 c$ & $17 d$ & 18 \\
\hline $19 a$ & $19 \mathrm{~b}$ & $20 \mathrm{a}$ & $20 \mathrm{~b}$ & $20 \mathrm{c}$ & 21 \\
\hline
\end{tabular}

Any information copied from such Reports and Statements may not be sold or used by any person for the purpose of soliciting contributions or for commercial purposes, other than using the name and address of any political committee to solicit contributions from such committee.

NAME OF COMMITTEE (In Full)

\section{Friends of Herman Cain}

A. Full Name (Last, First, Middle Initial)

Maria Honaski

Mailing Address 15414 Escapade St

\begin{tabular}{lcc}
\hline City & State & Zip Code \\
Corpus Christi & TX & $78418-6433$ \\
\hline
\end{tabular}

FEC ID number of contributing

federal political committee.

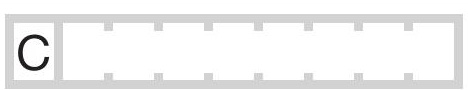

Name of Employer
Spohn
Receipt For: 2012
X Primary $\quad$ General
Other (specify)

Occupation healthcare

Election Cycle-to-Date 550.00

B. Full Name (Last, First, Middle Initial) JoAnn Aniol

Mailing Address 1346 Hueco Springs Loop Rd.

\begin{tabular}{lcc}
\hline City & State & Zip Code \\
New Braunfels & TX & $78132-3001$
\end{tabular}

FEC ID number of contributing

federal political committee.

C

Name of Employer
Information Requested
Receipt For: 2012
X Primary
Other (specify)

\section{Occupation}

Information Requested

Election Cycle-to-Date

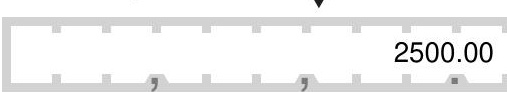

Transaction ID : A4E61ACAF30EE41A1A57

Date of Receipt

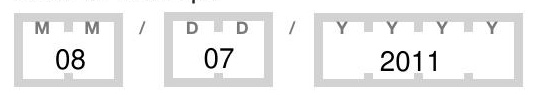

Amount of Each Receipt this Period

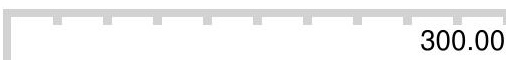

Amount of Each Receipt this Period

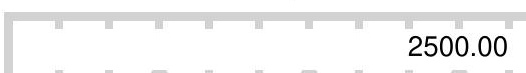

C. Full Name (Last, First, Middle Initial)

James Stewart

Mailing Address 3560 E. Via Colonia del Sol

\begin{tabular}{lcc}
\hline City & State & Zip Code \\
Tucson & AZ & $85718-6065$
\end{tabular}

FEC ID number of contributing federal political committee.

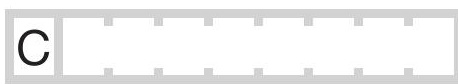

Name of Employer

Information Requested

Occupation

Information Requested

Receipt For: 2012

Х $\begin{aligned} & \text { Primary } \\ & \text { Other (specify) }\end{aligned}$

Election Cycle-to-Date

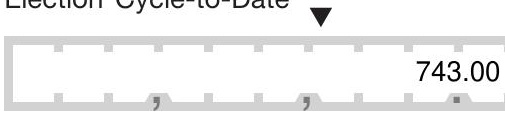

Transaction ID : A813B6681C00740AA942

Date of Receipt

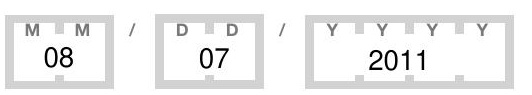

Transaction ID : AB061C1A50C2F4F4DB4E Date of Receipt

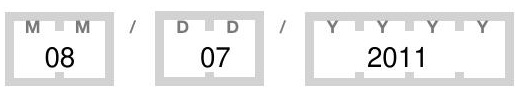

Amount of Each Receipt this Period

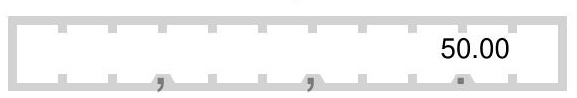

Subtotal Of Receipts This Page (optional)

Total This Period (last page this line number only) 
SCHEDULE A-P ITEMIZED RECEIPTS
Use separate schedule(s) for each category of the Detailed Summary Page
FOR LINE NUMBER: (check only one)

PAGE 224 / 1572

\begin{tabular}{|c|c|c|c|c|c|}
\hline & & & & & \\
\hline 16 & $\begin{array}{l}\mathbf{X} \\
17 a\end{array}$ & $17 b$ & $17 c$ & $17 d$ & 18 \\
\hline $19 a$ & $19 \mathrm{~b}$ & $20 \mathrm{a}$ & $20 \mathrm{~b}$ & $20 \mathrm{c}$ & 21 \\
\hline
\end{tabular}

Any information copied from such Reports and Statements may not be sold or used by any person for the purpose of soliciting contributions or for commercial purposes, other than using the name and address of any political committee to solicit contributions from such committee.

NAME OF COMMITTEE (In Full)

\section{Friends of Herman Cain}

A. Full Name (Last, First, Middle Initial)

Susan Sykes

Mailing Address 171 Dogwood Meadows

\begin{tabular}{lcc}
\hline City & State & Zip Code \\
Wetumpka & AL & $36093-3860$
\end{tabular}

FEC ID number of contributing

federal political committee.

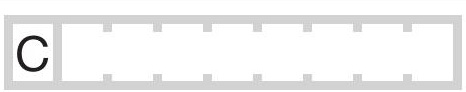

Name of Employer
Information Requested
Receipt For: 2012
X Primary $\quad \square$ General
Other (specify)

Occupation

Information Requested

Election Cycle-to-Date

1000.00

B. Full Name (Last, First, Middle Initial)

Marianne Mason

Mailing Address 30 Tall Oaks Trail

\begin{tabular}{lcc}
\hline City & State & Zip Code \\
Austin & TX & 78737-9306 \\
\hline
\end{tabular}

FEC ID number of contributing

federal political committee.

C

Name of Employer
MMA Int. LLC
Receipt For: 2012
X Primary
Other (specify)

\section{Occupation}

Accountant

Transaction ID : AF44E74AF426B4A529BF

Date of Receipt

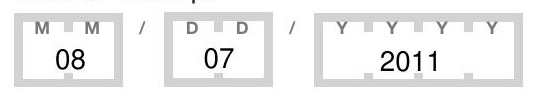

Amount of Each Receipt this Period

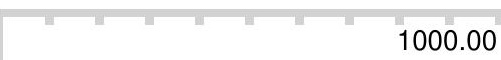

1000.00

Transaction ID : A65DD1DCB7B5C49248FF

Date of Receipt

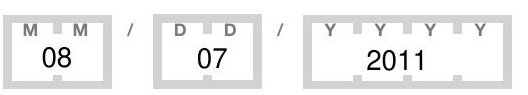

Amount of Each Receipt this Period

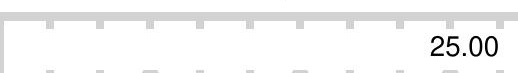

Election Cycle-to-Date

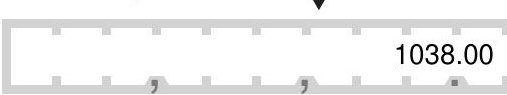

C. Full Name (Last, First, Middle Initial)

Margaret Metzger

Mailing Address 763 Glen Rd

\begin{tabular}{lcc}
\hline City & State & Zip Code \\
Jenkintown & PA & $19046-1528$
\end{tabular}

FEC ID number of contributing federal political committee.

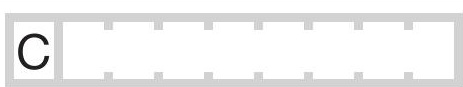

$\begin{aligned} & \text { Name of Employer } \\ & \text { self }\end{aligned}$
Receipt For: 2012
X Primary $\quad \square$ General
Other (specify)

\section{Occupation}

Homemaker

Election Cycle-to-Date

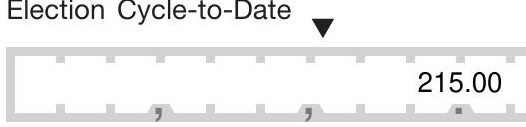

Subtotal Of Receipts This Page (optional)

Transaction ID : A369DCE54FB6B47E6865 Date of Receipt

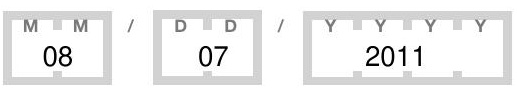

Amount of Each Receipt this Period

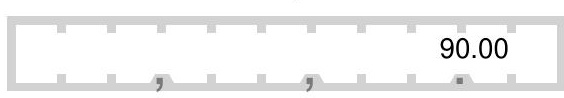

Total This Period (last page this line number only)

1115.00

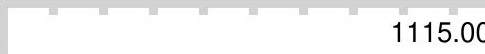

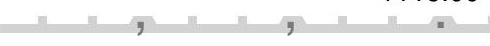
L

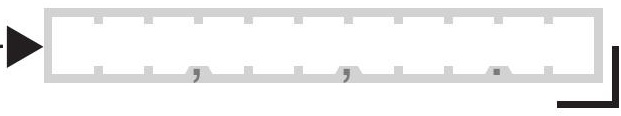


SCHEDULE A-P ITEMIZED RECEIPTS
Use separate schedule(s) for each category of the Detailed Summary Page
FOR LINE NUMBER: (check only one)

PAGE 225 / 1572

\begin{tabular}{|c|c|c|c|c|c|}
\hline & & & & & \\
\hline 16 & $\begin{array}{l}\mathbf{X} \\
17 a\end{array}$ & $17 b$ & $17 c$ & $17 d$ & 18 \\
\hline $19 a$ & $19 \mathrm{~b}$ & $20 \mathrm{a}$ & $20 \mathrm{~b}$ & $20 \mathrm{c}$ & 21 \\
\hline
\end{tabular}

Any information copied from such Reports and Statements may not be sold or used by any person for the purpose of soliciting contributions or for commercial purposes, other than using the name and address of any political committee to solicit contributions from such committee.

NAME OF COMMITTEE (In Full)

\section{Friends of Herman Cain}

A. Full Name (Last, First, Middle Initial)

Bianca Beary

Mailing Address 10451 Grandoaks Ln

\begin{tabular}{lcc}
\hline City & State & Zip Code \\
Montgomery & OH & $45242-5033$
\end{tabular}

FEC ID number of contributing

federal political committee.

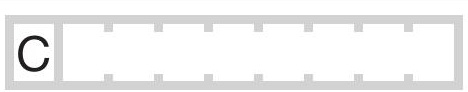

Name of Employer
Information Requested
Receipt For: 2012
X Primary
Other (specify) General

Occupation

Information Requested

Election Cycle-to-Date

343.00

B. Full Name (Last, First, Middle Initial)

Vickie Mitchell

Mailing Address PO Box 795

\begin{tabular}{lcc}
\hline City & State & Zip Code \\
Douglasville & GA & $30133-0795$ \\
\hline
\end{tabular}

FEC ID number of contributing

federal political committee.

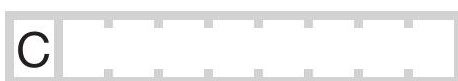

Name of Employer
Mitchell Appliance Co.
Receipt For: 2012
X Primary
Other (specify)

Occupation

Retail Sales

Transaction ID : A8129FC33EDD94F4D83F

Date of Receipt

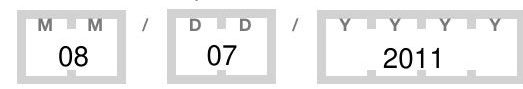

Amount of Each Receipt this Period

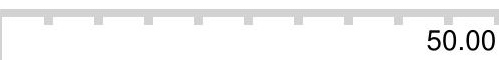

50.00

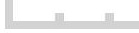

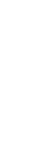

Transaction ID : A85FD070D675D4EC2B5A

Date of Receipt

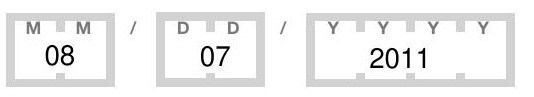

Amount of Each Receipt this Period

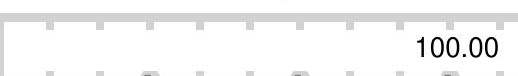

Election Cycle-to-Date

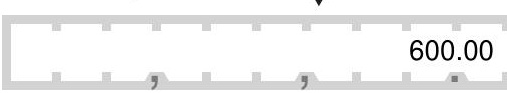

C. Full Name (Last, First, Middle Initial)

Marv Kuhn

Mailing Address 6122 FM 723 Rd.

\begin{tabular}{lcc}
\hline City & State & Zip Code \\
Richmond & TX & $77406-9751$
\end{tabular}

FEC ID number of contributing

federal political committee.

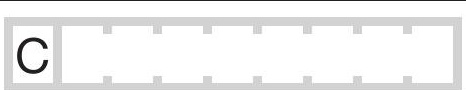

Name of Employer

Mustang Delivery Service

Receipt For: 2012

Х $\begin{aligned} & \text { Primary } \\ & \text { Other (specify) }\end{aligned}$

\section{Occupation}

Owner

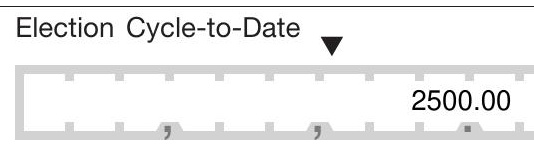

Transaction ID : AB95508669F9E4DC8AE4 Date of Receipt

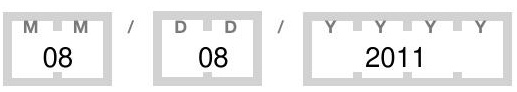

Amount of Each Receipt this Period

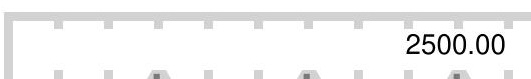

2650.00

Subtotal Of Receipts This Page (optional)

Total This Period (last page this line number only) 
SCHEDULE A-P ITEMIZED RECEIPTS
Use separate schedule(s) for each category of the Detailed Summary Page
FOR LINE NUMBER: (check only one)

PAGE 226 / 1572

\begin{tabular}{|c|c|c|c|c|c|}
\hline & & & & & \\
\hline 16 & $\begin{array}{l}\mathbf{X} \\
17 a\end{array}$ & $17 b$ & $17 c$ & $17 d$ & 18 \\
\hline $19 a$ & $19 \mathrm{~b}$ & $20 \mathrm{a}$ & $20 \mathrm{~b}$ & $20 \mathrm{c}$ & 21 \\
\hline
\end{tabular}

Any information copied from such Reports and Statements may not be sold or used by any person for the purpose of soliciting contributions or for commercial purposes, other than using the name and address of any political committee to solicit contributions from such committee.

NAME OF COMMITTEE (In Full)

\section{Friends of Herman Cain}

A. Full Name (Last, First, Middle Initial)

Robert Sullentrup

Mailing Address 140 Hunters Ridge

\begin{tabular}{lcc}
\hline City & State & Zip Code \\
Saint Charles & MO & $63301-0427$ \\
\hline
\end{tabular}

FEC ID number of contributing

federal political committee.

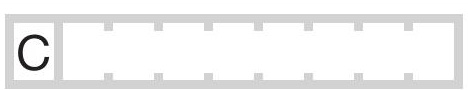

Name of Employer
Fiserv
Receipt For: 2012
X Primary $\quad$ General
Other (specify)

Occupation

Computer Specialist

Election Cycle-to-Date

\subsection{0}

B. Full Name (Last, First, Middle Initial)

JIM MANLEY

Mailing Address 5115 S. 122ND EAST AVE

\begin{tabular}{lcc}
\hline City & State & Zip Code \\
Tulsa & OK & $74146-6017$
\end{tabular}

FEC ID number of contributing

federal political committee.

C

Name of Employer
Information Requested
Receipt For: 2012
X Primary
Other (specify)

Occupation

Information Requested

Election Cycle-to-Date

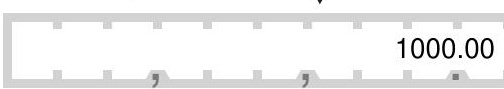

Transaction ID : A101B2A652B914F1EAA6

Date of Receipt

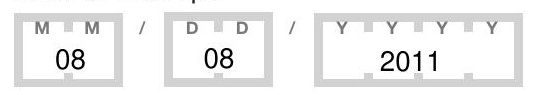

Amount of Each Receipt this Period

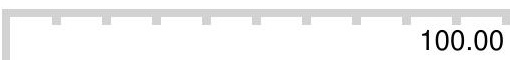

Transaction ID : A749112F17EC2437EBBF

Date of Receipt

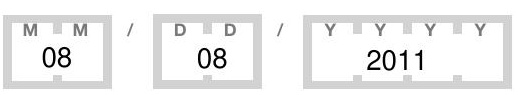

Amount of Each Receipt this Period

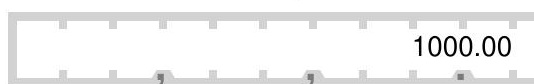

Transaction ID : A1989C6DD50694040942

Date of Receipt

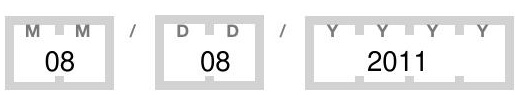

Amount of Each Receipt this Period

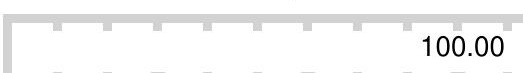

$\begin{array}{cc}\text { State } & \text { Zip Code } \\ \text { WA } & 98033-7649\end{array}$

C

\section{Occupation}

Retired

Election Cycle-to-Date

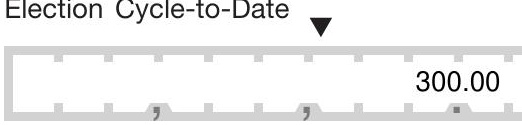

Subtotal Of Receipts This Page (optional)

1200.00

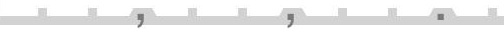

Total This Period (last page this line number only)

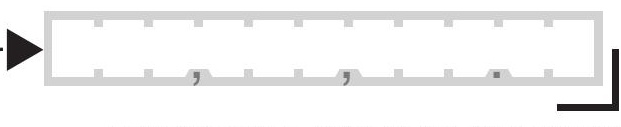

FEC Schedule A-P (Form 3P) (Rev. 03/2011) 
SCHEDULE A-P ITEMIZED RECEIPTS
Use separate schedule(s) for each category of the Detailed Summary Page
FOR LINE NUMBER: (check only one)

PAGE 227 / 1572

\begin{tabular}{|c|c|c|c|c|c|}
\hline & & & & & \\
\hline 16 & $\begin{array}{l}\mathbf{X} \\
17 a\end{array}$ & $17 b$ & $17 c$ & $17 d$ & 18 \\
\hline $19 a$ & $19 \mathrm{~b}$ & $20 \mathrm{a}$ & $20 \mathrm{~b}$ & $20 \mathrm{c}$ & 21 \\
\hline
\end{tabular}

Any information copied from such Reports and Statements may not be sold or used by any person for the purpose of soliciting contributions or for commercial purposes, other than using the name and address of any political committee to solicit contributions from such committee.

NAME OF COMMITTEE (In Full)

\section{Friends of Herman Cain}

A. Full Name (Last, First, Middle Initial)

Robert Bradstreet

Mailing Address 209 Pennfield Trl.

\begin{tabular}{lcc}
\hline City & State & Zip Code \\
Battle Creek & MI & 49017
\end{tabular}

FEC ID number of contributing federal political committee.

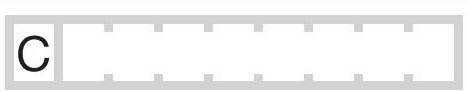

Name of Employer
Allen Pattern of Michigan
Receipt For: 2012
X Primary
Other (specify) General

Occupation

Pattern Maker

Election Cycle-to-Date

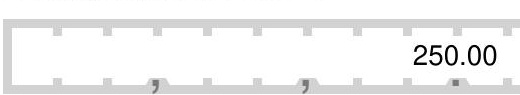

B. Full Name (Last, First, Middle Initial) Jennifer Major

Mailing Address 4010 Jenkins Ct

\begin{tabular}{lcc}
\hline City & State & Zip Code \\
Alpharetta & GA & $30009-7115$ \\
\hline
\end{tabular}

FEC ID number of contributing

federal political committee.

C

Name of Employer

CMR Residential Properties LLC

Occupation

Receipt For: 2012

Х Primary $\square$ General

Real Estate Investor

Election Cycle-to-Date

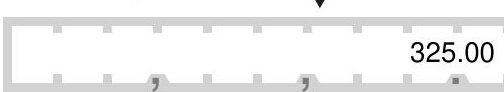

C. Full Name (Last, First, Middle Initial)

Debra Gilliam

Mailing Address 1807 Rockybranch Pass

\begin{tabular}{lcc}
\hline City & State & Zip Code \\
Marietta & GA & $30066-8014$
\end{tabular}

FEC ID number of contributing

federal political committee.

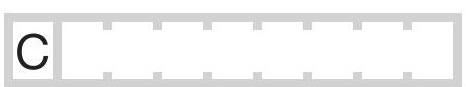

Name of Employer

Information Requested

Occupation

Information Requested

Receipt For: 2012

Х $\begin{aligned} & \text { Primary } \square \text { General } \\ & \text { Other (specify) }\end{aligned}$

Transaction ID : A6A36F4408B0F469D8FA

Date of Receipt

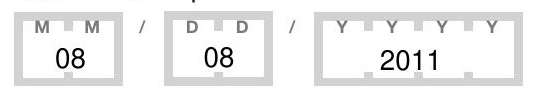

Amount of Each Receipt this Period

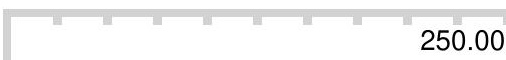

250.00
Amount of Each Receipt this Period

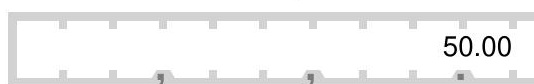

Transaction ID : A280655B4C1FC46E29F6 Date of Receipt

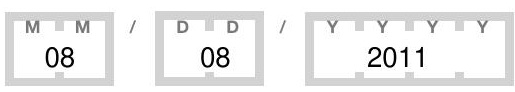

Amount of Each Receipt this Period

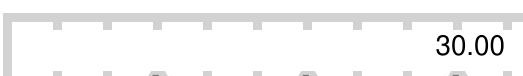

\section{Subtotal Of Receipts This Page (optional)}

Total This Period (last page this line number only) 
SCHEDULE A-P ITEMIZED RECEIPTS
Use separate schedule(s) for each category of the Detailed Summary Page
FOR LINE NUMBER: (check only one)

\begin{tabular}{|c|c|c|c|c|c|c|}
\hline & & & & & & \\
\hline 16 & $\times 1$ & $17 a$ & $17 b$ & $17 c$ & $17 d$ & 18 \\
\hline $19 a$ & & $19 b$ & $20 \mathrm{a}$ & $20 \mathrm{~b}$ & $20 \mathrm{c}$ & 21 \\
\hline
\end{tabular}

Any information copied from such Reports and Statements may not be sold or used by any person for the purpose of soliciting contributions or for commercial purposes, other than using the name and address of any political committee to solicit contributions from such committee.

NAME OF COMMITTEE (In Full)

\section{Friends of Herman Cain}

A. Full Name (Last, First, Middle Initial)

E. Kuhn

Mailing Address 6122 FM 723 Rd.

\begin{tabular}{lcc}
\hline City & State & Zip Code \\
Richmond & TX & $77406-9751$ \\
\hline
\end{tabular}

FEC ID number of contributing federal political committee.

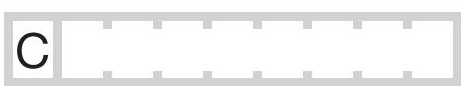

Name of Employer
Not Employed
Receipt For: 2012
X Primary $\quad$ General
Other (specify)

Occupation Not Employed

Election Cycle-to-Date

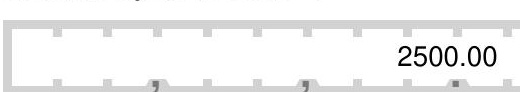

B. Full Name (Last, First, Middle Initial)

Allen Simon

Mailing Address 1383 N Criss St

\begin{tabular}{lcc}
\hline City & State & Zip Code \\
Chandler & AZ & $85226-1307$
\end{tabular}

FEC ID number of contributing

federal political committee.

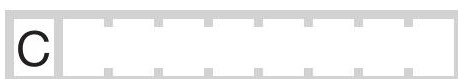

Name of Employer
Retired
Receipt For: 2012
X Primary
Other (specify)

Occupation

Retired

Election Cycle-to-Date

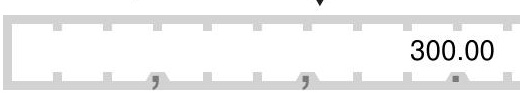

Transaction ID : A4FA216B630E242AFB7B

Date of Receipt

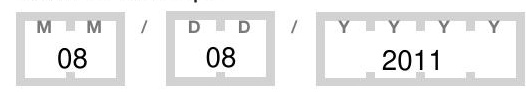

Amount of Each Receipt this Period

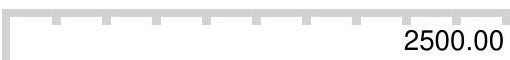

C. Full Name (Last, First, Middle Initial)

amos slater

Mailing Address 23180 harper avenue

\begin{tabular}{lcc}
\hline City & State & Zip Code \\
Punta Gorda & FL & $33980-2903$
\end{tabular}

FEC ID number of contributing

federal political committee.

C

33980-2903

Name of Employer
Disabled
Receipt For: 2012
X Primary $\square$ General
Other (specify)

Occupation

Disabled

Election Cycle-to-Date

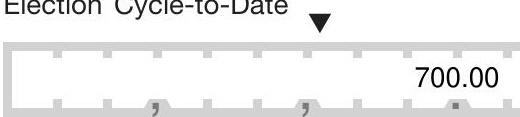

Transaction ID : A8195015D4EF047ECB3F

Date of Receipt

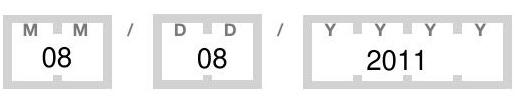

Amount of Each Receipt this Period

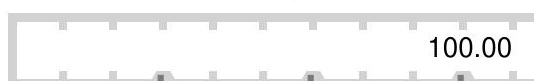

Transaction ID : A03F63395C74342B3B79

Date of Receipt

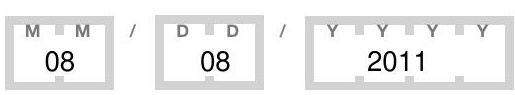

Amount of Each Receipt this Period

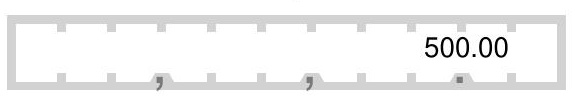

\section{Subtotal Of Receipts This Page (optional)}

3100.00

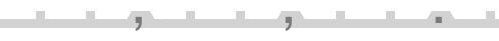

Total This Period (last page this line number only)

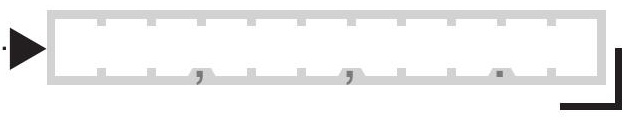

FEC Schedule A-P (Form 3P) (Rev. 03/2011) 
SCHEDULE A-P ITEMIZED RECEIPTS
Use separate schedule(s)

for each category of the

Detailed Summary Page
FOR LINE NUMBER: (check only one)

\begin{tabular}{|c|c|c|c|c|c|}
\hline & & & & & \\
\hline 16 & $\begin{array}{ll}X & 17 a \\
\end{array}$ & $17 \mathrm{~b}$ & $17 c$ & $17 d$ & 18 \\
\hline $19 a$ & $19 b$ & $20 \mathrm{a}$ & $20 \mathrm{~b}$ & $20 c$ & 21 \\
\hline
\end{tabular}

Any information copied from such Reports and Statements may not be sold or used by any person for the purpose of soliciting contributions or for commercial purposes, other than using the name and address of any political committee to solicit contributions from such committee.

NAME OF COMMITTEE (In Full)

Friends of Herman Cain

A. Full Name (Last, First, Middle Initial)

\section{George Gardner}

Mailing Address PO Box 38

\begin{tabular}{lcc}
\hline City & State & Zip Code \\
Carlisle & PA & $17013-0038$
\end{tabular}

FEC ID number of contributing federal political committee.

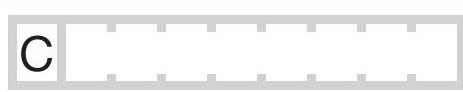

Name of Employer
Retired
Receipt For: 2012
X Primary $\quad$ General
Other (specify)

B. Full Name (Last, First, Middle Initial) JARROD FRIEDMAN

Mailing Address 2519 north ocean blvd apt. 401

\begin{tabular}{lcc}
\hline City & State & Zip Code \\
Boca Raton & FL & $33431-7823$
\end{tabular}

FEC ID number of contributing

federal political committee.

C

Name of Employer
friedman spine and pain clinic
Receipt For: 2012
Primary
Other (specify)

Occupation

Doctor

Election Cycle-to-Date

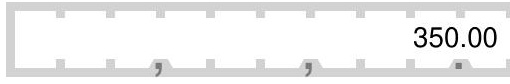

Retired

Election Cycle-to-Date
Transaction ID : A3CB128F0E62B4902A3B

Date of Receipt

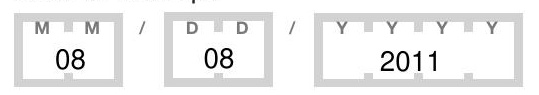

Amount of Each Receipt this Period

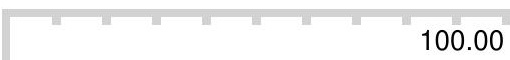

C. Full Name (Last, First, Middle Initial)

Benton Pittman

Mailing Address 9 Todd Terrace

\begin{tabular}{lcc}
\hline City & State & Zip Code \\
Danville & IN & $46122-1043$
\end{tabular}

FEC ID number of contributing federal political committee.

C

Name of Employer
None
Receipt For: 2012
Х Primary $\quad \square$ General
Other (specify)

Occupation

Retired

Election Cycle-to-Date
Transaction ID : A26F87C063F07410AA4E Date of Receipt

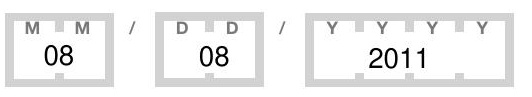

Amount of Each Receipt this Period

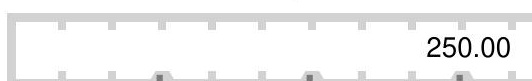

Transaction ID : A205F5E808AA04546950 Date of Receipt

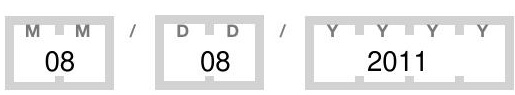

Amount of Each Receipt this Period

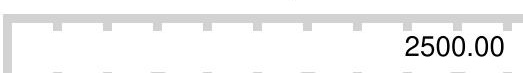

Subtotal Of Receipts This Page (optional).

Total This Period (last page this line number only) 
SCHEDULE A-P ITEMIZED RECEIPTS
Use separate schedule(s) for each category of the Detailed Summary Page
FOR LINE NUMBER: (check only one)

PAGE $230 / 1572$

\begin{tabular}{|c|c|c|c|c|c|}
\hline & & & & & \\
\hline 16 & $\begin{array}{l}\mathbf{X} \\
17 a\end{array}$ & $17 b$ & $17 c$ & $17 d$ & 18 \\
\hline $19 a$ & $19 \mathrm{~b}$ & $20 \mathrm{a}$ & $20 \mathrm{~b}$ & $20 \mathrm{c}$ & 21 \\
\hline
\end{tabular}

Any information copied from such Reports and Statements may not be sold or used by any person for the purpose of soliciting contributions or for commercial purposes, other than using the name and address of any political committee to solicit contributions from such committee.

NAME OF COMMITTEE (In Full)

\section{Friends of Herman Cain}

A. Full Name (Last, First, Middle Initial)

Lisa Fred

Mailing Address 9102 Drumaldry Dr.

\begin{tabular}{lcc}
\hline City & State & Zip Code \\
Bethesda & MD & 20817-3341
\end{tabular}

FEC ID number of contributing

federal political committee.

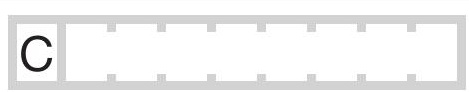

Name of Employer
Dr. Stephen Fred
Receipt For: 2012
X Primary
Other (specify) General

Occupation

Dental Hygienist

Election Cycle-to-Date

250.00

B. Full Name (Last, First, Middle Initial)

Richard Gauthier

Mailing Address 14310 Clearview Lane

\begin{tabular}{lcc}
\hline City & State & Zip Code \\
Urbandale & IA & $50323-2083$ \\
\hline
\end{tabular}

FEC ID number of contributing

federal political committee.

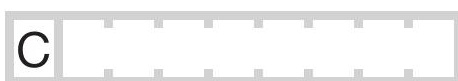

Name of Employer
The Cheesecake Factory
Receipt For: 2012
X Primary
Other (specify)

\section{Occupation}

General Manager

Election Cycle-to-Date

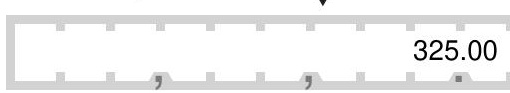

Transaction ID : AD316EB14C4A049288DE

Date of Receipt

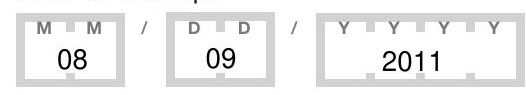

Amount of Each Receipt this Period

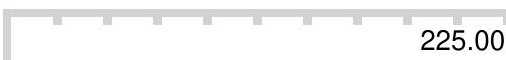

225.00

C. Full Name (Last, First, Middle Initial)

Mr John Murray

Mailing Address 27 Clearview $\mathrm{Dr}$

\begin{tabular}{lcc}
\hline City & State & Zip Code \\
Cartersville & GA & $30121-2249$
\end{tabular}

FEC ID number of contributing

federal political committee.

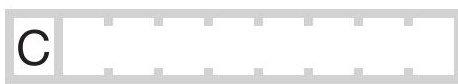

Name of Employer
None
Receipt For: 2012
X Primary $\quad \square$ General
Other (specify)

Occupation

Retired

Election Cycle-to-Date

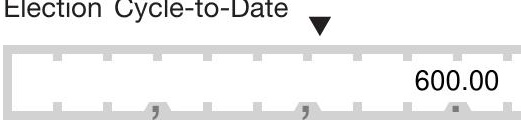

Transaction ID : A02A2EB2CC2014C94857

Date of Receipt

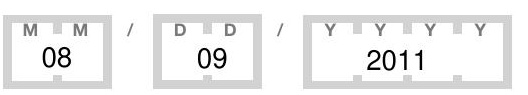

Amount of Each Receipt this Period

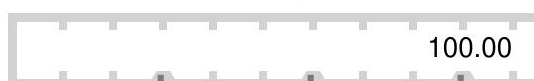

Transaction ID : ABD10ABC91FC341FF8A3 Date of Receipt

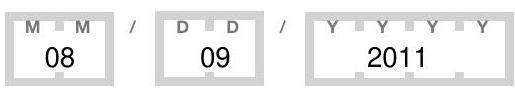

Amount of Each Receipt this Period

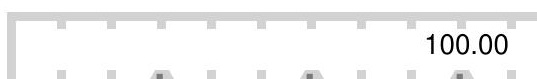

\section{Subtotal Of Receipts This Page (optional)}

425.00

(1)

Total This Period (last page this line number only)

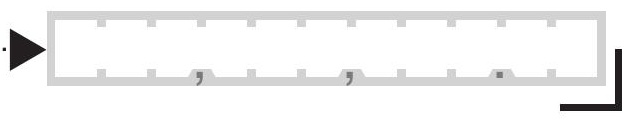

FEC Schedule A-P (Form 3P) (Rev. 03/2011) 
SCHEDULE A-P ITEMIZED RECEIPTS
Use separate schedule(s) for each category of the Detailed Summary Page
FOR LINE NUMBER: (check only one)

PAGE $231 / 1572$

\begin{tabular}{|c|c|c|c|c|c|}
\hline & & & & & \\
\hline 16 & $\begin{array}{l}\mathbf{X} \\
17 a\end{array}$ & $17 b$ & $17 c$ & $17 d$ & 18 \\
\hline $19 a$ & $19 \mathrm{~b}$ & $20 \mathrm{a}$ & $20 \mathrm{~b}$ & $20 \mathrm{c}$ & 21 \\
\hline
\end{tabular}

Any information copied from such Reports and Statements may not be sold or used by any person for the purpose of soliciting contributions or for commercial purposes, other than using the name and address of any political committee to solicit contributions from such committee.

NAME OF COMMITTEE (In Full)

\section{Friends of Herman Cain}

A. Full Name (Last, First, Middle Initial)

Mr Robert D Long

Mailing Address 47 Savannah Trl

\begin{tabular}{lcc}
\hline City & State & Zip Code \\
Hilton Head Island & SC & 29926-2693 \\
\hline
\end{tabular}

FEC ID number of contributing

federal political committee.

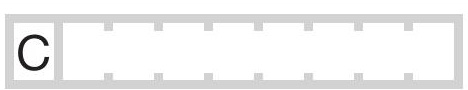

Name of Employer
None
Receipt For: 2012
X Primary $\quad$ General
Other (specify)

Occupation

Retired

Election Cycle-to-Date

250.00

B. Full Name (Last, First, Middle Initial)

Donald J Neseth

Mailing Address NO ADDRESS

\begin{tabular}{lll}
\hline City & State & Zip Code
\end{tabular}

FEC ID number of contributing

federal political committee.

C

Name of Employer
Information Requested
Receipt For: 2012
Primary
Other (specify)

Occupation

Information Requested

Election Cycle-to-Date

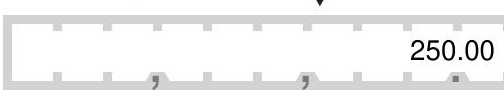

Transaction ID : A49813A2CEB5F4A1F8DA

Date of Receipt

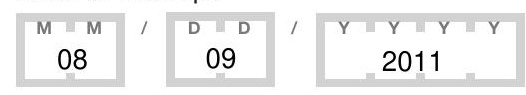

Amount of Each Receipt this Period

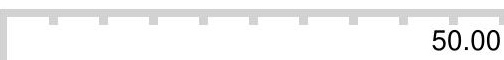

50.00

C. Full Name (Last, First, Middle Initial)

Ed Chickanis

Mailing Address 4340 Doncaster Drive

\begin{tabular}{lcc}
\hline City & State & Zip Code \\
Ellicott City & MD & $21043-6782$
\end{tabular}

FEC ID number of contributing

federal political committee.

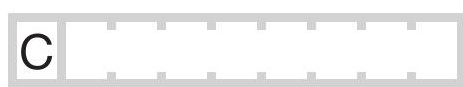

Name of Employer

Information Requested

Occupation

Information Requested

Receipt For: 2012

Х $\begin{aligned} & \text { Primary } \\ & \text { Other (specify) }\end{aligned}$

Election Cycle-to-Date

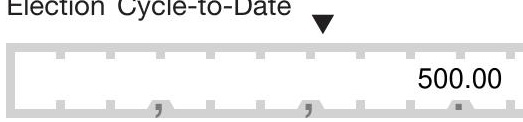

Amount of Each Receipt this Period

Transaction ID : A7871262E7CAD4530ADC

Date of Receipt
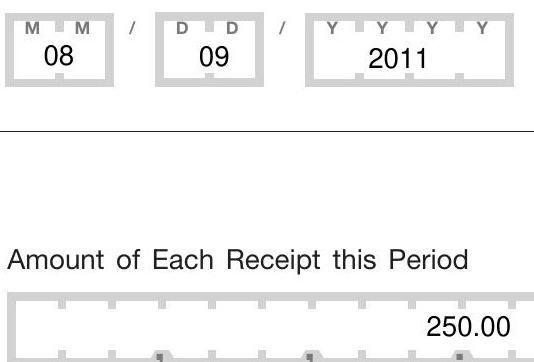

Transaction ID : A7C2D2BB44F90444F869

Date of Receipt

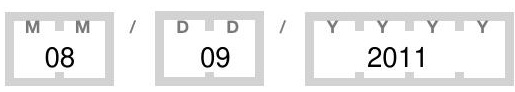

Amount of Each Receipt this Period

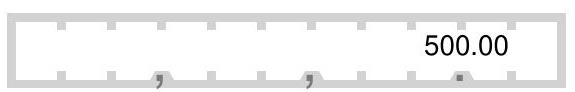

Subtotal Of Receipts This Page (optional)

800.00

Total This Period (last page this line number only) 


\section{SCHEDULE A-P} ITEMIZED RECEIPTS
Use separate schedule(s)

for each category of the

Detailed Summary Page
FOR LINE NUMBER: (check only one)

PAGE 232 / 1572

\begin{tabular}{|c|c|c|c|c|c|}
\hline & & & & & \\
\hline 16 & X $17 a$ & $17 b$ & $17 c$ & $17 d$ & 18 \\
\hline $19 a$ & $19 b$ & $20 \mathrm{a}$ & $20 \mathrm{~b}$ & $20 \mathrm{c}$ & 21 \\
\hline
\end{tabular}

Any information copied from such Reports and Statements may not be sold or used by any person for the purpose of soliciting contributions or for commercial purposes, other than using the name and address of any political committee to solicit contributions from such committee.

NAME OF COMMITTEE (In Full)

Friends of Herman Cain

A. Full Name (Last, First, Middle Initial)

Beverly K Olson

Mailing Address 200 Idle Hour Dr

\begin{tabular}{lcc}
\hline City & State & Zip Code \\
Macon & GA & $31210-4702$
\end{tabular}

FEC ID number of contributing

federal political committee.

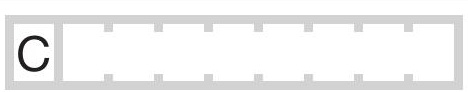

Name of Employer
Information Requested
Receipt For: 2012
X Primary $\quad \square$ General
Other (specify)

Occupation

Information Requested

Election Cycle-to-Date

350.00

B. Full Name (Last, First, Middle Initial)

Jay Woodworth

Mailing Address 2090 Ridge Point Drive

\begin{tabular}{lcc}
\hline City & State & Zip Code \\
Lake Oswego & OR & $97034-7572$ \\
\hline
\end{tabular}

FEC ID number of contributing

federal political committee.

C

Name of Employer
Information Requested
Receipt For: 2012
X Primary
Other (specify)

Occupation

Information Requested

Election Cycle-to-Date

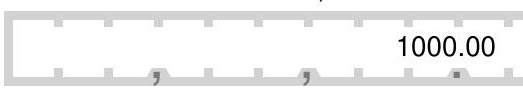

C. Full Name (Last, First, Middle Initial)

Lynn Harden

Mailing Address 17851 Westview Dr.

\begin{tabular}{lcc}
\hline City & State & Zip Code \\
Lake Oswego & OR & $97034-7330$
\end{tabular}

FEC ID number of contributing

federal political committee.

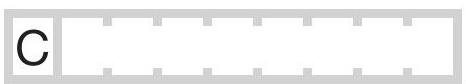

Name of Employer

Information Requested

Occupation

Information Requested

Receipt For: 2012

Х $\begin{aligned} & \text { Primary } \square \text { General } \\ & \text { Other (specify) }\end{aligned}$

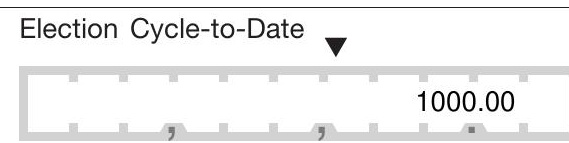

Amount of Each Receipt this Period

Transaction ID : A3453EA9F187C4F9A920

Date of Receipt

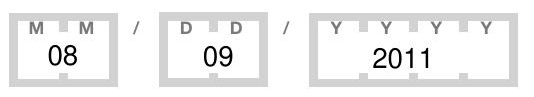

Amount of Each Receipt this Period
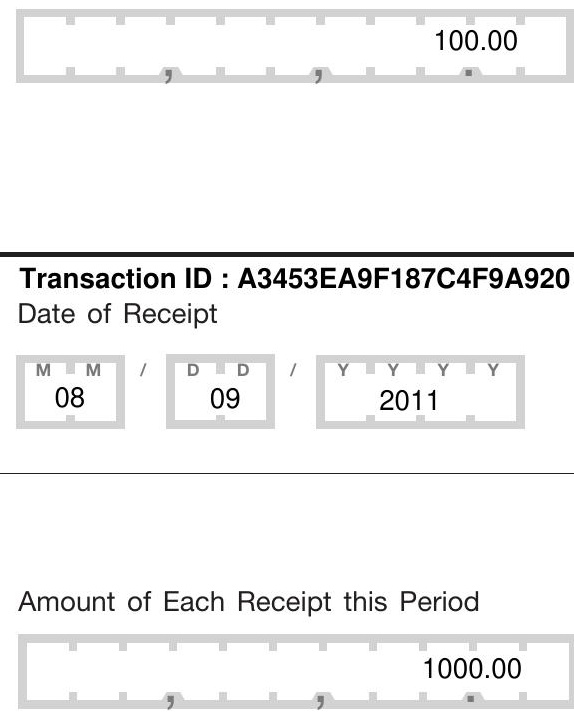

Transaction ID : A67120A6A29E9436E8C3

Date of Receipt

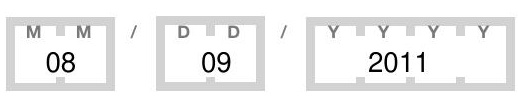

Amount of Each Receipt this Period

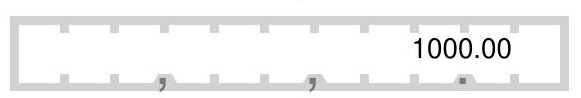

Subtotal Of Receipts This Page (optional).

2100.00

Total This Period (last page this line number only) 
SCHEDULE A-P ITEMIZED RECEIPTS
Use separate schedule(s) for each category of the Detailed Summary Page
FOR LINE NUMBER: (check only one)

\begin{tabular}{|c|c|c|c|c|c|}
\hline & & & & & \\
\hline 16 & $\begin{array}{ll}X & 17 a \\
\end{array}$ & $17 \mathrm{~b}$ & $17 c$ & $17 d$ & 18 \\
\hline $19 a$ & $19 b$ & $20 \mathrm{a}$ & $20 \mathrm{~b}$ & $20 c$ & 21 \\
\hline
\end{tabular}

Any information copied from such Reports and Statements may not be sold or used by any person for the purpose of soliciting contributions or for commercial purposes, other than using the name and address of any political committee to solicit contributions from such committee.

NAME OF COMMITTEE (In Full)

\section{Friends of Herman Cain}

A. Full Name (Last, First, Middle Initial)

Herb Koss

Mailing Address 2643 South Shore Blvd.

\begin{tabular}{lcc}
\hline City & State & Zip Code \\
Lake Oswego & OR & $97034-5763$
\end{tabular}

FEC ID number of contributing federal political committee.

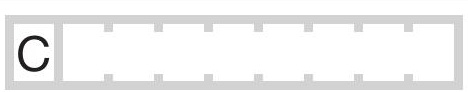

Name of Employer
Self-Employed
Receipt For: 2012
X Primary $\quad \square$ General
Other (specify)

Occupation Real Estate

Election Cycle-to-Date

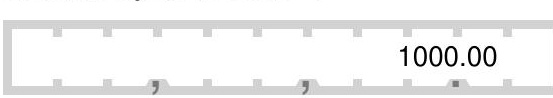

B. Full Name (Last, First, Middle Initial)

Reece V Morris

Mailing Address 7555 Maysville Rd

\begin{tabular}{lcc}
\hline City & State & Zip Code \\
Maysville & GA & $30558-3529$ \\
\hline
\end{tabular}

FEC ID number of contributing

federal political committee.

C

Name of Employer
None
Receipt For: 2012
Primary
Other (specify)

Occupation

Retired

Election Cycle-to-Date

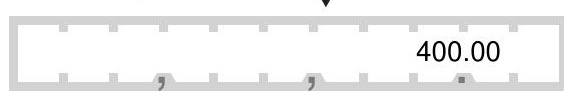

Transaction ID : A2A59A087416D4045822

Date of Receipt

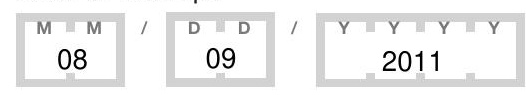

Amount of Each Receipt this Period

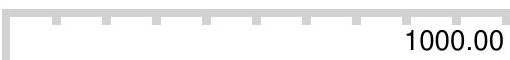

Transaction ID : A5218BB43C4A742F1968

Date of Receipt

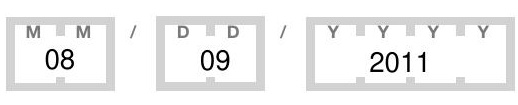

Amount of Each Receipt this Period

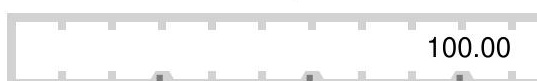

Transaction ID : A46AF2DCFF1CB463291D Date of Receipt

Charles Watkins

Mailing Address 43 Aquinas Street

\begin{tabular}{lcc}
\hline City & State & Zip Code \\
Lake Oswego & OR & $97035-1203$
\end{tabular}

FEC ID number of contributing federal political committee.

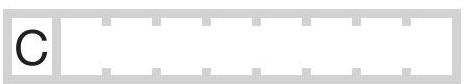

Name of Employer
Core Innovations
Receipt For: 2012
X Primary $\quad \square$ General
Other (specify)

Occupation

Programmer

Election Cycle-to-Date

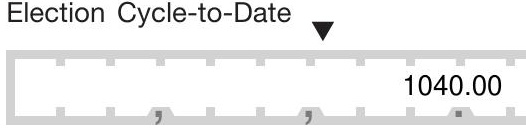

Subtotal Of Receipts This Page (optional)

Amount of Each Receipt this Period

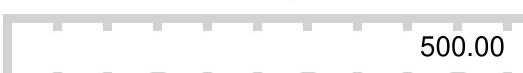

Total This Period (last page this line number only)

1600.00

a

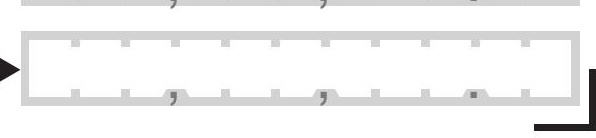

FEC Schedule A-P (Form 3P) (Rev. 03/2011) 
SCHEDULE A-P ITEMIZED RECEIPTS
Use separate schedule(s) for each category of the Detailed Summary Page
FOR LINE NUMBER: (check only one)

\begin{tabular}{|c|c|c|c|c|c|}
\hline & & & & & \\
\hline 16 & $\begin{array}{ll}X & 17 a \\
\end{array}$ & $17 \mathrm{~b}$ & $17 c$ & $17 d$ & 18 \\
\hline $19 a$ & $19 b$ & $20 \mathrm{a}$ & $20 \mathrm{~b}$ & $20 c$ & 21 \\
\hline
\end{tabular}

Any information copied from such Reports and Statements may not be sold or used by any person for the purpose of soliciting contributions or for commercial purposes, other than using the name and address of any political committee to solicit contributions from such committee.

NAME OF COMMITTEE (In Full)

\section{Friends of Herman Cain}

A. Full Name (Last, First, Middle Initial)

Mrs Carolyn Malion

Mailing Address 8264 Nc Highway $130 \mathrm{E}$

\begin{tabular}{lcc}
\hline City & State & Zip Code \\
Fairmont & NC & $28340-7812$ \\
\hline
\end{tabular}

FEC ID number of contributing

federal political committee.

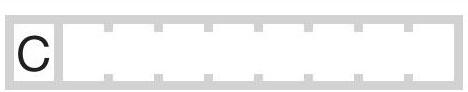

Name of Employer
Information Requested
Receipt For: 2012
X Primary $\quad \square$ General
Other (specify)

Occupation

Information Requested

Election Cycle-to-Date

300.00

B. Full Name (Last, First, Middle Initial)

Gerald W Gray

Mailing Address PO Box 5506

\begin{tabular}{lcc}
\hline City & State & Zip Code \\
Incline Village & NV & $89450-5506$ \\
\hline
\end{tabular}

FEC ID number of contributing

federal political committee.

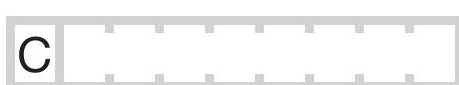

Name of Employer
None
Receipt For: 2012
X Primary
Other (specify)

Occupation

Retired

Election Cycle-to-Date

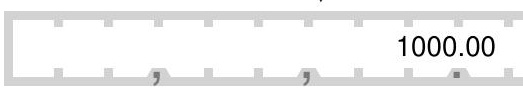

C. Full Name (Last, First, Middle Initial)

Leighton Wells

Mailing Address 717 Edgemont Way

\begin{tabular}{lcc}
\hline City & State & Zip Code \\
Springfield & OR & $97477-3607$
\end{tabular}

FEC ID number of contributing

federal political committee.

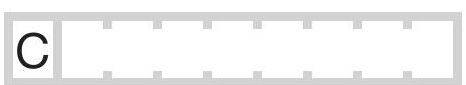

Name of Employer
n/a
Receipt For: 2012
X Primary $\square$ General
Other (specify)

Occupation

Retired

Election Cycle-to-Date

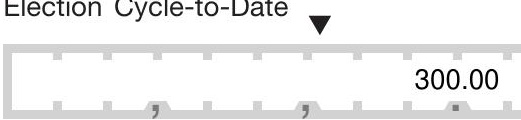

Transaction ID : AD4FEF166FC48409485B

Date of Receipt

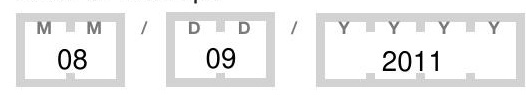

Amount of Each Receipt this Period

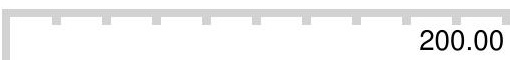

200.00

Transaction ID : A8F7C0EB12B3E4EBFBB0 Date of Receipt

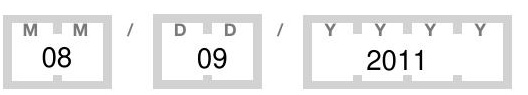

Amount of Each Receipt this Period

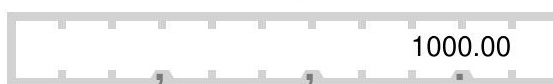

Transaction ID : A5239E642A74A46D2910

Date of Receipt

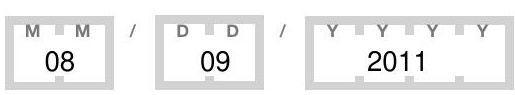

Amount of Each Receipt this Period

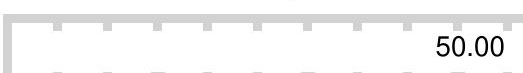

50.00

\section{Subtotal Of Receipts This Page (optional).}

Total This Period (last page this line number only) 
SCHEDULE A-P ITEMIZED RECEIPTS
Use separate schedule(s) for each category of the Detailed Summary Page

FOR LINE NUMBER:
(check only one)

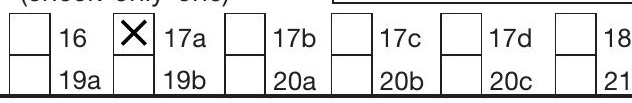

Any information copied from such Reports and Statements may not be sold or used by any person for the purpose of soliciting contributions or for commercial purposes, other than using the name and address of any political committee to solicit contributions from such committee.

NAME OF COMMITTEE (In Full)

\section{Friends of Herman Cain}

A. Full Name (Last, First, Middle Initial)

Dwight Patel

\begin{tabular}{l} 
Mailing Address 10125 Colesville Road \\
Ste 215 \\
\hline City
\end{tabular}

Silver Spring

State

Zip Code

MD

20901-2457

FEC ID number of contributing

federal political committee.

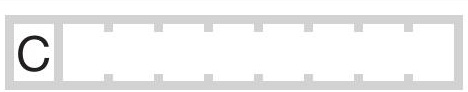

Name of Employer
Information Requested
Receipt For: 2012
X Primary
Other (specify) General

Occupation

Information Requested

Election Cycle-to-Date

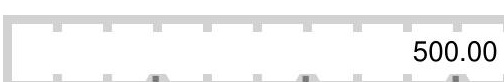

B. Full Name (Last, First, Middle Initial)

Rebecca Helman

Mailing Address 10842 Nantucket Ter.

\begin{tabular}{lcc}
\hline City & State & Zip Code \\
Potomac & MD & 20854-4424 \\
\hline
\end{tabular}

FEC ID number of contributing

federal political committee.

C

Name of Employer
Information Requested
Receipt For: 2012
X Primary
Other (specify)

Occupation

Information Requested

Election Cycle-to-Date

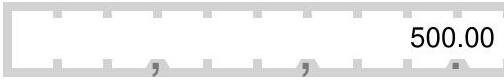

C. Full Name (Last, First, Middle Initial)

JOSHUA THADEN

Mailing Address 4089 S 84th St \# 185

\begin{tabular}{lcc}
\hline City & State & Zip Code \\
Omaha & NE & $68127-1701$
\end{tabular}

FEC ID number of contributing

federal political committee.

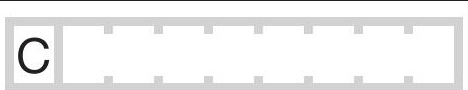

Name of Employer

Information Requested

Occupation

Information Requested

Receipt For: 2012

Х $\begin{aligned} & \text { Primary } \square \text { General } \\ & \text { Other (specify) }\end{aligned}$

Election Cycle-to-Date

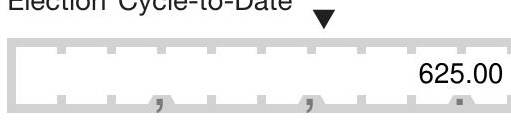

Transaction ID : A9B523F69DAD04923869

Date of Receipt

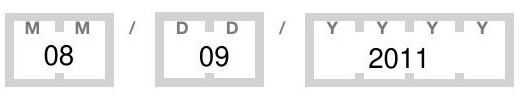

Amount of Each Receipt this Period

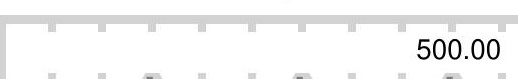

Transaction ID : A00CF2D017EBE454BBAF Date of Receipt

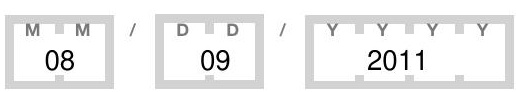

Amount of Each Receipt this Period

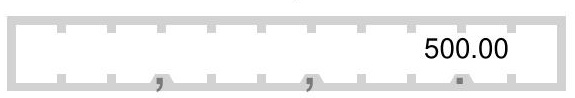

Subtotal Of Receipts This Page (optional)

1500.00

Total This Period (last page this line number only) 
SCHEDULE A-P ITEMIZED RECEIPTS
Use separate schedule(s) for each category of the Detailed Summary Page
FOR LINE NUMBER: (check only one)

PAGE 236 / 1572

\begin{tabular}{|c|c|c|c|c|c|}
\hline & & & & & \\
\hline 16 & $\begin{array}{l}\mathbf{X} \\
17 a\end{array}$ & $17 b$ & $17 c$ & $17 d$ & 18 \\
\hline $19 a$ & $19 \mathrm{~b}$ & $20 \mathrm{a}$ & $20 \mathrm{~b}$ & $20 \mathrm{c}$ & 21 \\
\hline
\end{tabular}

Any information copied from such Reports and Statements may not be sold or used by any person for the purpose of soliciting contributions or for commercial purposes, other than using the name and address of any political committee to solicit contributions from such committee.

NAME OF COMMITTEE (In Full)

Friends of Herman Cain

A. Full Name (Last, First, Middle Initial)

Wayne Thomas

Mailing Address 1533 Clark Avenue

\begin{tabular}{lcc}
\hline City & State & Zip Code \\
Cottage Grove & OR & $97424-1891$ \\
\hline
\end{tabular}

FEC ID number of contributing federal political committee.

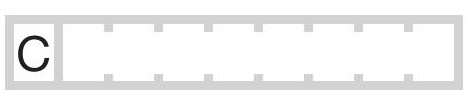

Name of Employer
PeaceHealth Laboratories
Receipt For: 2012
X Primary
Other (specify)

Occupation courier

Election Cycle-to-Date

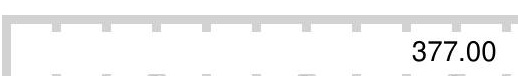

B. Full Name (Last, First, Middle Initial)

George Steele III

Mailing Address 80 Wagon Wheel Ct SE

\begin{tabular}{lcc}
\hline City & State & Zip Code \\
Marietta & GA & $30067-4238$ \\
\hline
\end{tabular}

FEC ID number of contributing

federal political committee.

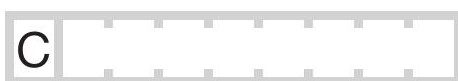

Name of Employer
GA Dept Com Health
Receipt For: 2012
X Primary
Other (specify)

Occupation

Director Reimb

Election Cycle-to-Date

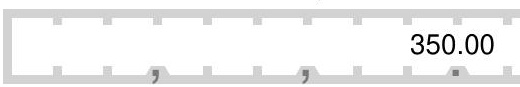

C. Full Name (Last, First, Middle Initial)

Joanne Talbert

Mailing Address 3421 Turner Road

\begin{tabular}{lcc}
\hline City & State & Zip Code \\
West Linn & OR & $97068-8601$
\end{tabular}

FEC ID number of contributing

federal political committee.

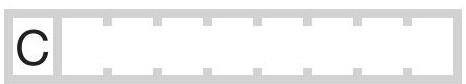

Name of Employer

Self-Employed

Occupation

Receipt For: 2012

Х $\begin{aligned} & \text { Primary } \\ & \text { Other (specify) }\end{aligned}$

Real Estate

Election Cycle-to-Date

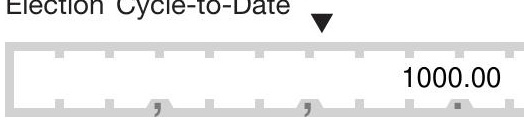

Transaction ID : AE76A1F161F6D4C6D9BF

Date of Receipt

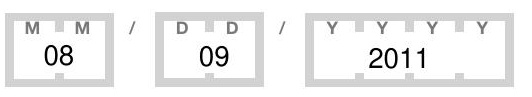

Amount of Each Receipt this Period

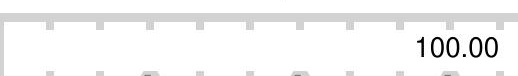

Transaction ID : A6CD7B81025364CBD88F Date of Receipt

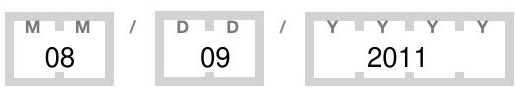

Amount of Each Receipt this Period

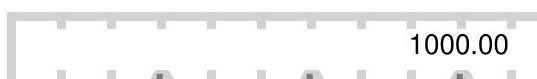

1150.00

Subtotal Of Receipts This Page (optional)

Total This Period (last page this line number only) 
SCHEDULE A-P ITEMIZED RECEIPTS
Use separate schedule(s) for each category of the Detailed Summary Page
FOR LINE NUMBER: (check only one)

PAGE 237 / 1572

\begin{tabular}{|c|c|c|c|c|c|}
\hline & & & & & \\
\hline 16 & $\begin{array}{l}\mathbf{X} \\
17 a\end{array}$ & $17 b$ & $17 c$ & $17 d$ & 18 \\
\hline $19 a$ & $19 \mathrm{~b}$ & $20 \mathrm{a}$ & $20 \mathrm{~b}$ & $20 \mathrm{c}$ & 21 \\
\hline
\end{tabular}

Any information copied from such Reports and Statements may not be sold or used by any person for the purpose of soliciting contributions or for commercial purposes, other than using the name and address of any political committee to solicit contributions from such committee.

NAME OF COMMITTEE (In Full)

\section{Friends of Herman Cain}

A. Full Name (Last, First, Middle Initial)

Neil Bates

Mailing Address 5333 Likini 1506

\begin{tabular}{lcc}
\hline City & State & Zip Code \\
Honolulu & HI & $96818-1767$ \\
\hline
\end{tabular}

FEC ID number of contributing federal political committee.

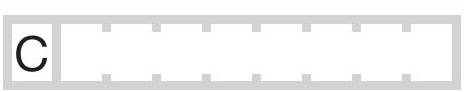

Name of Employer
Pearl Harbor Naval Shipyard
Receipt For: 2012
X Primary
Other (specify) General

Occupation

Engineer

Election Cycle-to-Date

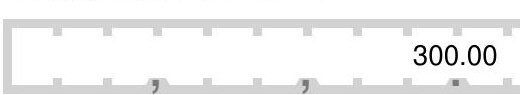

B. Full Name (Last, First, Middle Initial)

Jon Kimmett

Mailing Address 2116 NE 28th Ave

\begin{tabular}{lcc}
\hline City & State & Zip Code \\
Portland & OR & $97212-5036$ \\
\hline
\end{tabular}

FEC ID number of contributing

federal political committee.

C

Name of Employer
Self Employed
Receipt For: 2012
Xrimary
Other (specify)

Occupation

Real Estate Investor

Election Cycle-to-Date

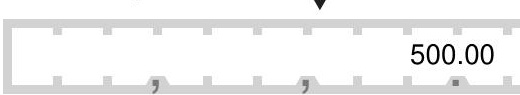

Transaction ID : A4AC3EB8AB4F84E2D923

Date of Receipt

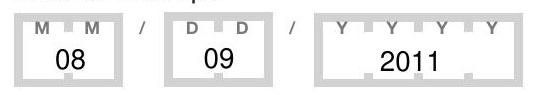

Amount of Each Receipt this Period

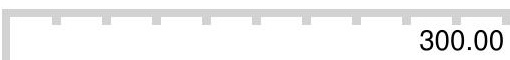

C. Full Name (Last, First, Middle Initial)

Basil Kelley

Mailing Address 22025 Airport Rd. NE

\begin{tabular}{lcc}
\hline City & State & Zip Code \\
Tualatin & OR & 97062 \\
\hline
\end{tabular}

FEC ID number of contributing

federal political committee.

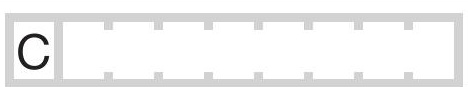

Name of Employer
Loti Corporation
Receipt For: 2012
X Primary $\quad \square$ General
Other (specify)

\section{Occupation}

PRESIDENT

Election Cycle-to-Date
Amount of Each Receipt this Period

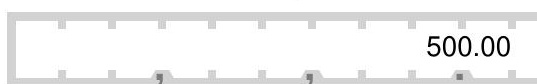

Transaction ID : A6396592BD0A341EF9CF Date of Receipt

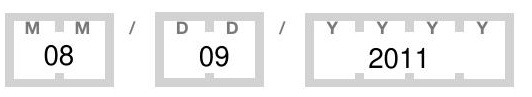

Transaction ID : A73CB3EDEC1264DEEB5B Date of Receipt

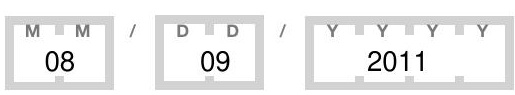

Amount of Each Receipt this Period

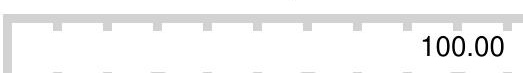

\section{Subtotal Of Receipts This Page (optional)}

900.00

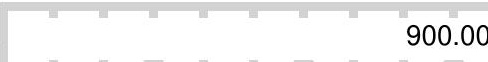

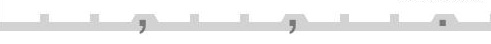

Total This Period (last page this line number only)

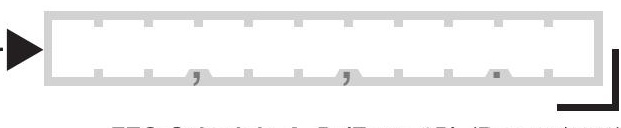

FEC Schedule A-P (Form 3P) (Rev. 03/2011) 
SCHEDULE A-P ITEMIZED RECEIPTS
Use separate schedule(s) for each category of the Detailed Summary Page
FOR LINE NUMBER: (check only one)

PAGE $238 / 1572$

\begin{tabular}{|c|c|c|c|c|c|}
\hline & & & & & \\
\hline 16 & $\begin{array}{l}\mathbf{X} \\
17 a\end{array}$ & $17 b$ & $17 c$ & $17 d$ & 18 \\
\hline $19 a$ & $19 \mathrm{~b}$ & $20 \mathrm{a}$ & $20 \mathrm{~b}$ & $20 \mathrm{c}$ & 21 \\
\hline
\end{tabular}

Any information copied from such Reports and Statements may not be sold or used by any person for the purpose of soliciting contributions or for commercial purposes, other than using the name and address of any political committee to solicit contributions from such committee.

NAME OF COMMITTEE (In Full)

\section{Friends of Herman Cain}

A. Full Name (Last, First, Middle Initial)

Charles Watkins

Mailing Address 43 Aquinas Street

\begin{tabular}{lcc}
\hline City & State & Zip Code \\
Lake Oswego & OR & $97035-1203$ \\
\hline
\end{tabular}

FEC ID number of contributing federal political committee.

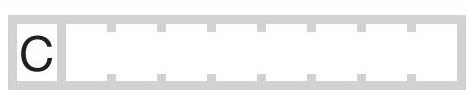

Name of Employer
Core Innovations
Receipt For: 2012
X Primary $\quad$ General
Other (specify)

Occupation

Programmer

Election Cycle-to-Date

1040.00

B. Full Name (Last, First, Middle Initial)

Diane Briscoe

Mailing Address 117 Marten Ct

\begin{tabular}{lcc}
\hline City & State & Zip Code \\
Waleska & GA & $30183-4685$ \\
\hline
\end{tabular}

FEC ID number of contributing

federal political committee.

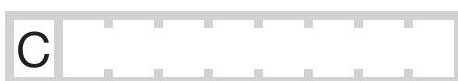

Name of Employer

Phoenix Aviation Managers, Inc.

Occupation

Receipt For: 2012

Х $\begin{aligned} & \text { Primary } \\ & \text { Other (specify) }\end{aligned}$

Accounting

Transaction ID : A851B7EBA46FF47A78FB

Date of Receipt

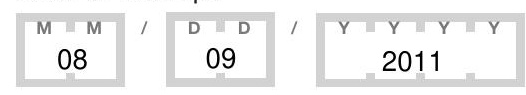

Amount of Each Receipt this Period

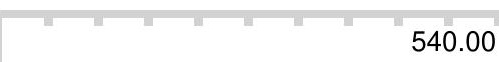

540.00

Transaction ID : A790604603141482982E

Date of Receipt

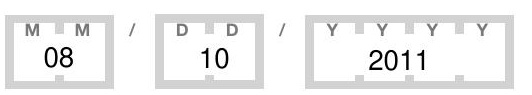

Amount of Each Receipt this Period

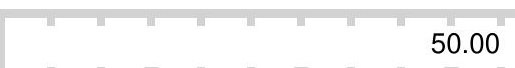

Election Cycle-to-Date

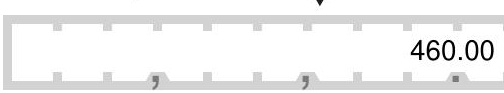

C. Full Name (Last, First, Middle Initial)

$\mathrm{Mr}$ Thomas Dean

Mailing Address PO Box 35

\begin{tabular}{lcc}
\hline City & State & Zip Code \\
Sunny Side & GA & $30284-0035$
\end{tabular}

FEC ID number of contributing

federal political committee.

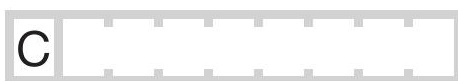

Name of Employer

Information Requested

Occupation

Information Requested

Receipt For: 2012

Х $\begin{aligned} & \text { Primary } \\ & \text { Other (specify) }\end{aligned}$

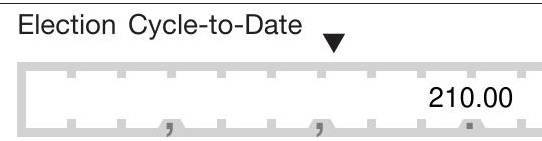

Amount of Each Receipt this Period

Transaction ID : ABF3BFDD9FCBF465496E Date of Receipt
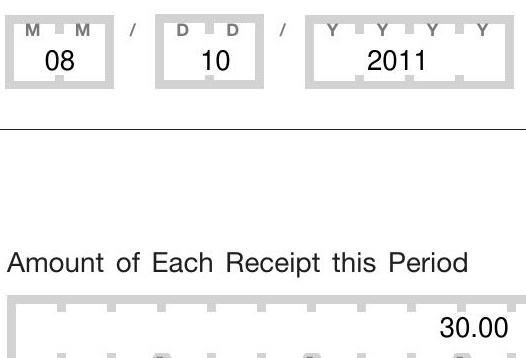

Subtotal Of Receipts This Page (optional)

620.00

Total This Period (last page this line number only)

FEC Schedule A-P (Form 3P) (Rev. 03/2011) 
SCHEDULE A-P ITEMIZED RECEIPTS
Use separate schedule(s) for each category of the Detailed Summary Page
FOR LINE NUMBER: (check only one)

PAGE 239 / 1572

\begin{tabular}{|c|c|c|c|c|c|}
\hline & & & & & \\
\hline 16 & $\begin{array}{l}\mathbf{X} \\
17 a\end{array}$ & $17 b$ & $17 c$ & $17 d$ & 18 \\
\hline $19 a$ & $19 \mathrm{~b}$ & $20 \mathrm{a}$ & $20 \mathrm{~b}$ & $20 \mathrm{c}$ & 21 \\
\hline
\end{tabular}

Any information copied from such Reports and Statements may not be sold or used by any person for the purpose of soliciting contributions or for commercial purposes, other than using the name and address of any political committee to solicit contributions from such committee.

NAME OF COMMITTEE (In Full)

\section{Friends of Herman Cain}

A. Full Name (Last, First, Middle Initial)

Jill Davis

Mailing Address 998 E Elizabeth St

\begin{tabular}{lcc}
\hline City & State & Zip Code \\
Pasadena & CA & $91104-2408$
\end{tabular}

FEC ID number of contributing

federal political committee.

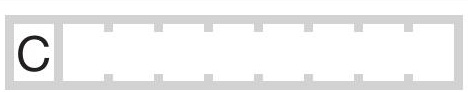

Name of Employer
Information Requested
Receipt For: 2012
X Primary
Other (specify) General

Occupation

Information Requested

Election Cycle-to-Date

350.00

B. Full Name (Last, First, Middle Initial)

David Bryant

Mailing Address 2265 Sussex Court

\begin{tabular}{lcc}
\hline City & State & Zip Code \\
Snellville & GA & $30078-3120$
\end{tabular}

FEC ID number of contributing

federal political committee.

C

Name of Employer
Information Requested
Receipt For: 2012
X Primary
Other (specify)

Occupation

Information Requested

Election Cycle-to-Date

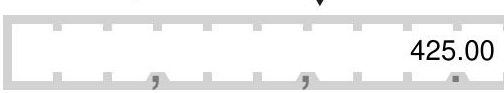

Transaction ID : A880B6F5D9265476EAD8

Date of Receipt

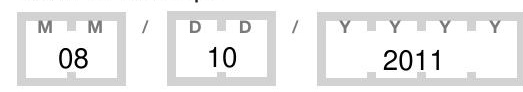

Amount of Each Receipt this Period

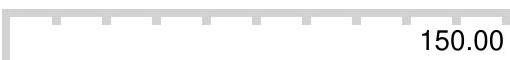

150.00

C. Full Name (Last, First, Middle Initial)

Michael Desiderio

Mailing Address 1115 Wilderness Trail

\begin{tabular}{lcc}
\hline City & State & Zip Code \\
Downingtown & PA & $19335-4047$
\end{tabular}

FEC ID number of contributing federal political committee.

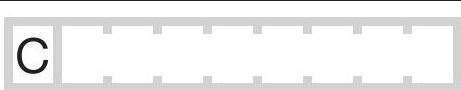

Name of Employer

Information Requested

Occupation

Information Requested

Receipt For: 2012

Х $\begin{aligned} & \text { Primary } \\ & \text { Other (specify) }\end{aligned}$

Election Cycle-to-Date

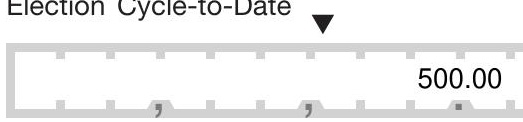

Amount of Each Receipt this Period

Transaction ID : A2A740558229B41FB917

Date of Receipt
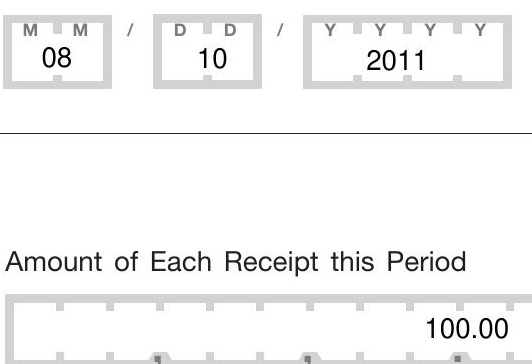

Transaction ID : A5491F9D7C4CF498A95E

Date of Receipt

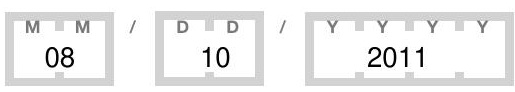

Amount of Each Receipt this Period

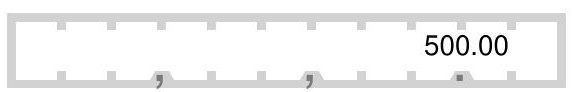

Subtotal Of Receipts This Page (optional).

750.00

Total This Period (last page this line number only) 


\section{SCHEDULE A-P} ITEMIZED RECEIPTS
Use separate schedule(s)

for each category of the

Detailed Summary Page
FOR LINE NUMBER: (check only one)

PAGE 240 / 1572

\begin{tabular}{|c|c|c|c|c|c|}
\hline & & & & & \\
\hline 16 & X $17 a$ & $17 b$ & $17 c$ & $17 d$ & 18 \\
\hline $19 a$ & $19 b$ & $20 \mathrm{a}$ & $20 \mathrm{~b}$ & $20 \mathrm{c}$ & 21 \\
\hline
\end{tabular}

Any information copied from such Reports and Statements may not be sold or used by any person for the purpose of soliciting contributions or for commercial purposes, other than using the name and address of any political committee to solicit contributions from such committee.

NAME OF COMMITTEE (In Full)

Friends of Herman Cain

A. Full Name (Last, First, Middle Initial)

Ernest Swible Jr. Jr.

Mailing Address PO Box 561108

\begin{tabular}{lcc}
\hline City & State & Zip Code \\
Orlando & FL & $32856-1108$
\end{tabular}

FEC ID number of contributing

federal political committee.

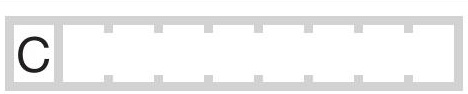

Name of Employer
Charles Rutenberg Realty
Receipt For: 2012
X Primary $\quad \square$ General
Other (specify)

Occupation

Realtor

Election Cycle-to-Date

477.00

B. Full Name (Last, First, Middle Initial)

Mr Thomas Dean

Mailing Address PO Box 35

\begin{tabular}{lcc}
\hline City & State & Zip Code \\
Sunny Side & GA & $30284-0035$ \\
\hline
\end{tabular}

FEC ID number of contributing

federal political committee.

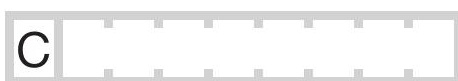

Name of Employer
Information Requested
Receipt For: 2012
X Primary
Other (specify)

Occupation

Information Requested

Election Cycle-to-Date

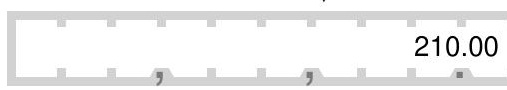

Transaction ID : A14E3D454FBA74E3EA66

Date of Receipt

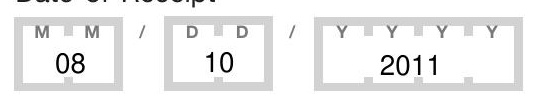

Amount of Each Receipt this Period

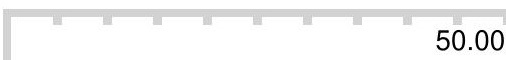

50.00

C. Full Name (Last, First, Middle Initial)

Mr Dennis Dunn

Mailing Address 4817 Lake Washington Blvd NE

\begin{tabular}{lcc}
\hline City & State & Zip Code \\
Kirkland & WA & $98033-7649$
\end{tabular}

FEC ID number of contributing

federal political committee.

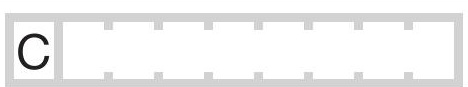

Name of Employer
None
Receipt For: 2012
Х Primary $\quad \square$ General
Other (specify)

\section{Occupation}

Retired

Election Cycle-to-Date

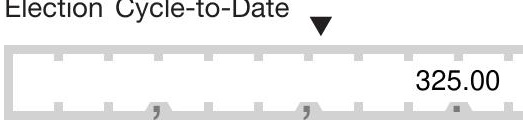

Transaction ID : AE1D16222310B42D09ED

Date of Receipt

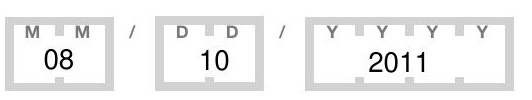

Amount of Each Receipt this Period

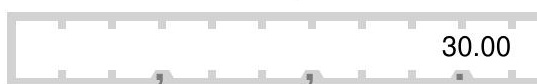

Transaction ID : A26111216EE8D45D298B

Date of Receipt

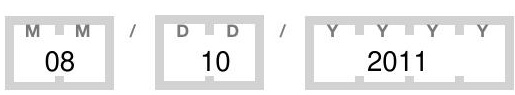

Amount of Each Receipt this Period

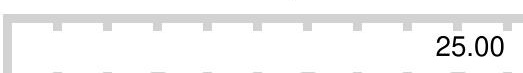

\section{Subtotal Of Receipts This Page (optional)}

105.00

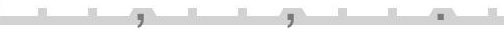

Total This Period (last page this line number only)

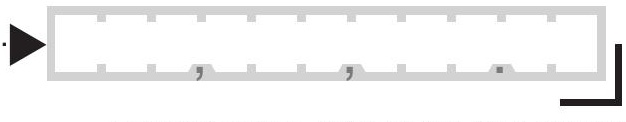

FEC Schedule A-P (Form 3P) (Rev. 03/2011) 
SCHEDULE A-P ITEMIZED RECEIPTS
Use separate schedule(s) for each category of the Detailed Summary Page
FOR LINE NUMBER: (check only one)

\begin{tabular}{|c|c|c|c|c|c|}
\hline & & & & & \\
\hline 16 & $\begin{array}{ll}X & 17 a \\
\end{array}$ & $17 \mathrm{~b}$ & $17 c$ & $17 d$ & 18 \\
\hline $19 a$ & $19 b$ & $20 \mathrm{a}$ & $20 \mathrm{~b}$ & $20 c$ & 21 \\
\hline
\end{tabular}

Any information copied from such Reports and Statements may not be sold or used by any person for the purpose of soliciting contributions or for commercial purposes, other than using the name and address of any political committee to solicit contributions from such committee.

NAME OF COMMITTEE (In Full)

\section{Friends of Herman Cain}

A. Full Name (Last, First, Middle Initial)

\section{Bruce Hall}

Mailing Address 24213 Valley St

\begin{tabular}{lcc}
\hline City & State & Zip Code \\
Newhall & CA & $91321-3526$
\end{tabular}

FEC ID number of contributing federal political committee.

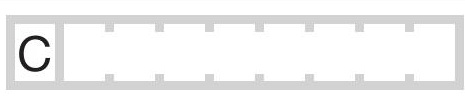

Name of Employer
Information Requested
Receipt For: 2012
X Primary
Other (specify) General

B. Full Name (Last, First, Middle Initial)

Thomas Tamulewicz

Mailing Address 1335 Stony Hill Road

\begin{tabular}{lcc}
\hline City & State & Zip Code \\
Hinckley & OH & $44233-9540$
\end{tabular}

FEC ID number of contributing

federal political committee.

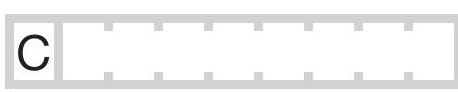

Name of Employer
Oil Associates
Receipt For: 2012
X Primary
Other (specify)

\section{Occupation}

Sales

Election Cycle-to-Date

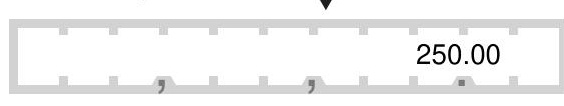

C. Full Name (Last, First, Middle Initial)

Steve Lyle

Mailing Address 320 WCR 3460

\begin{tabular}{|c|c|}
\hline $\begin{array}{l}\text { City } \\
\text { Hawkins }\end{array}$ & $\begin{array}{cc}\text { State } & \text { Zip Code } \\
\text { TX } & 75765\end{array}$ \\
\hline $\begin{array}{l}\text { FEC ID number of contributing } \\
\text { federal political committee. }\end{array}$ & $\mathrm{C}$ \\
\hline $\begin{array}{l}\text { Name of Employer } \\
\mathrm{CCH} \text { of Tyler }\end{array}$ & $\begin{array}{l}\text { Occupation } \\
\text { RN }\end{array}$ \\
\hline $\begin{array}{l}\text { Receipt For: } 2012 \\
\text { X Primary }\end{array}$ & Election Cycle-to-Date $\boldsymbol{\nabla}$ \\
\hline $\begin{array}{l}\text { X } \\
\text { Other (specify) }\end{array}$ & 350.00 \\
\hline
\end{tabular}

Subtotal Of Receipts This Page (optional)

Total This Period (last page this line number only)
Transaction ID : A2670272DBC7D446899E

Date of Receipt

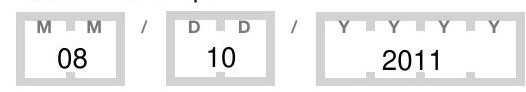

Amount of Each Receipt this Period

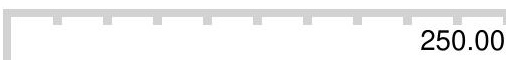

250.00
Transaction ID : AABF56BFF14B14BA98DF Date of Receipt

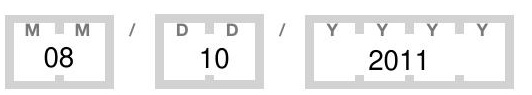

Amount of Each Receipt this Period

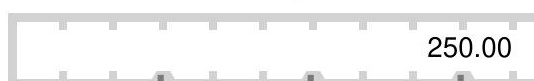

Amount of Each Receipt this Period

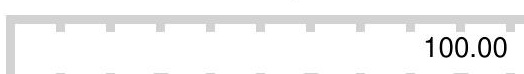

Transaction ID : A6128D2215A174B6E83F

Date of Receipt

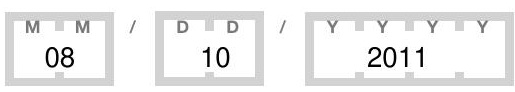

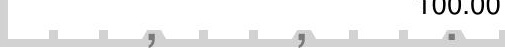

600.00

.

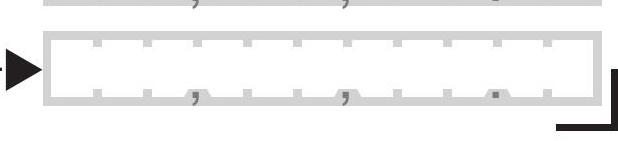

FEC Schedule A-P (Form 3P) (Rev. 03/2011) 
SCHEDULE A-P ITEMIZED RECEIPTS
Use separate schedule(s) for each category of the Detailed Summary Page
FOR LINE NUMBER: (check only one)

PAGE 242 / 1572

\begin{tabular}{|c|c|c|c|c|c|}
\hline & & & & & \\
\hline 16 & $\begin{array}{l}\mathbf{X} \\
17 a\end{array}$ & $17 b$ & $17 c$ & $17 d$ & 18 \\
\hline $19 a$ & $19 \mathrm{~b}$ & $20 \mathrm{a}$ & $20 \mathrm{~b}$ & $20 \mathrm{c}$ & 21 \\
\hline
\end{tabular}

Any information copied from such Reports and Statements may not be sold or used by any person for the purpose of soliciting contributions or for commercial purposes, other than using the name and address of any political committee to solicit contributions from such committee.

NAME OF COMMITTEE (In Full)

\section{Friends of Herman Cain}

A. Full Name (Last, First, Middle Initial)

Dr. John Moore

Mailing Address 11050 Presbyterian Dr Apt 1008

\begin{tabular}{lcc}
\hline City & State & Zip Code \\
Indianapolis & IN & $46236-2982$
\end{tabular}

FEC ID number of contributing federal political committee.

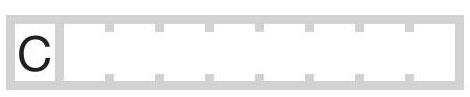

Name of Employer
Retired
Receipt For: 2012
X Primary $\quad$ General
Other (specify)

Occupation Librarian

Election Cycle-to-Date

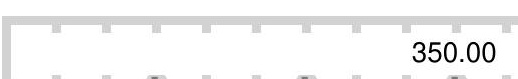

B. Full Name (Last, First, Middle Initial)

Thomas Cole

Mailing Address 9 Parks Ave

\begin{tabular}{lcc}
\hline City & State & Zip Code \\
Newnan & GA & $30263-1561$
\end{tabular}

FEC ID number of contributing

federal political committee.

C

Name of Employer

Henry Cole Construction (self)

Receipt For: 2012

$\chi \begin{aligned} & \text { Primary } \square \text { General } \\ & \text { Other (specify) } \nabla\end{aligned}$

C. Full Name (Last, First, Middle Initial)

Mr. Philip H. Ray

Mailing Address 5953 Feather Wind Way

City

Fort Worth

FEC ID number of contributing

federal political committee.

Name of Employer
None
Receipt For: 2012
X Primary
Other (specify) General

\section{Occupation}

Retired

\section{Occupation}

Home Builder

Election Cycle-to-Date

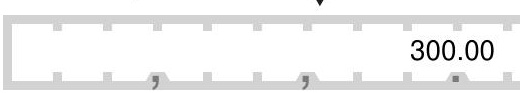

Transaction ID : A0F7DF7948B614CABB3D

Date of Receipt

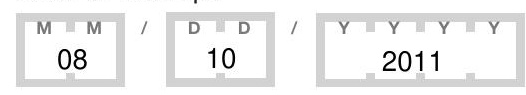

Amount of Each Receipt this Period

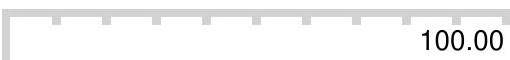

Amount of Each Receipt this Period

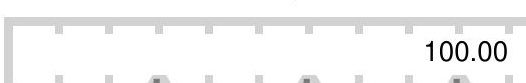

Transaction ID : A742F73ABBD574E518F0 Date of Receipt

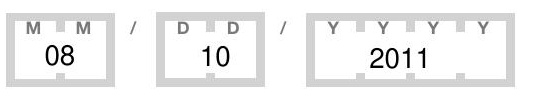

Transaction ID : A9135B7C806E44745BCA Date of Receipt

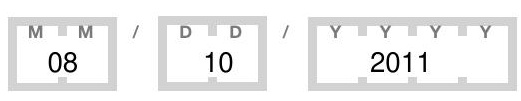

Amount of Each Receipt this Period
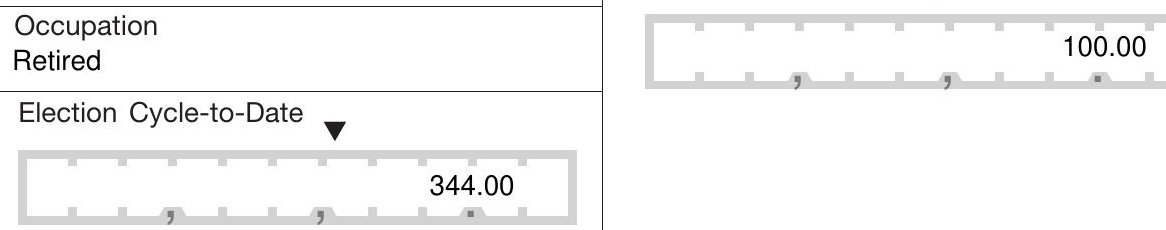

Subtotal Of Receipts This Page (optional)

300.00

a 1 ,

Total This Period (last page this line number only)

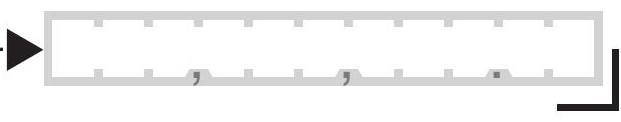

FEC Schedule A-P (Form 3P) (Rev. 03/2011) 
SCHEDULE A-P ITEMIZED RECEIPTS
Use separate schedule(s) for each category of the Detailed Summary Page
FOR LINE NUMBER: (check only one)

PAGE $243 / 1572$

\begin{tabular}{|c|c|c|c|c|c|}
\hline & & & & & \\
\hline 16 & $\begin{array}{l}\mathbf{X} \\
17 a\end{array}$ & $17 b$ & $17 c$ & $17 d$ & 18 \\
\hline $19 a$ & $19 \mathrm{~b}$ & $20 \mathrm{a}$ & $20 \mathrm{~b}$ & $20 \mathrm{c}$ & 21 \\
\hline
\end{tabular}

Any information copied from such Reports and Statements may not be sold or used by any person for the purpose of soliciting contributions or for commercial purposes, other than using the name and address of any political committee to solicit contributions from such committee.

NAME OF COMMITTEE (In Full)

\section{Friends of Herman Cain}

A. Full Name (Last, First, Middle Initial)

Suzanne Pope

Mailing Address Box 120

\begin{tabular}{lcc}
\hline City & State & Zip Code \\
Kearsarge & $\mathrm{NH}$ & $03847-0120$
\end{tabular}

FEC ID number of contributing federal political committee.

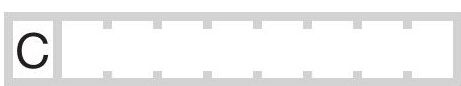

Name of Employer
Information Requested
Receipt For: 2012
X Primary
Other (specify) General

B. Full Name (Last, First, Middle Initial) James Flynn

Mailing Address 1800 Crown Way

\begin{tabular}{lcc}
\hline City & State & Zip Code \\
Orlando & FL & $32804-5101$
\end{tabular}

FEC ID number of contributing

federal political committee.

C

Name of Employer
Information Requested
Receipt For: 2012
Xrimary
Other (specify)

\section{Occupation}

Information Requested

Election Cycle-to-Date

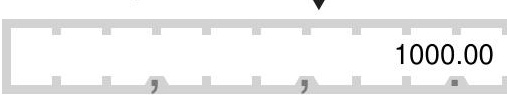

\subsection{0}

Transaction ID : A41B3DD11671F4C0BB27

Date of Receipt

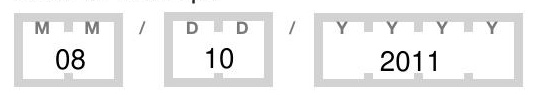

Amount of Each Receipt this Period

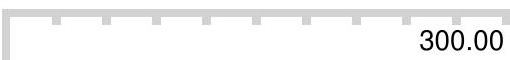

C. Full Name (Last, First, Middle Initial)

Allen Field

Mailing Address P O Box 5706

\begin{tabular}{lcc}
\hline City & State & Zip Code \\
Atlanta & GA & $31107-0706$
\end{tabular}

FEC ID number of contributing federal political committee.

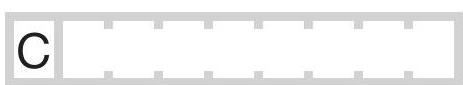

Name of Employer

Pomeroy IT

\section{Occupation}

Area Manager

Receipt For: 2012

Х $\begin{aligned} & \text { Primary } \square \text { General } \\ & \text { Other (specify) }\end{aligned}$

Transaction ID : A6B23B19109954941A97

Date of Receipt

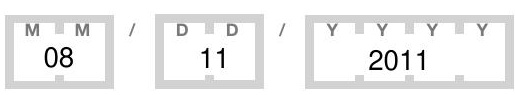

Amount of Each Receipt this Period

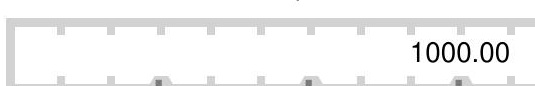

Transaction ID : A4DCE1D189CB64BBCAF0 Date of Receipt

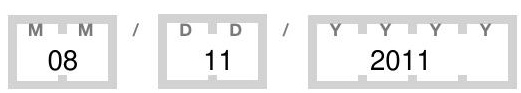

Amount of Each Receipt this Period

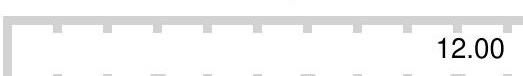

\section{Subtotal Of Receipts This Page (optional)}

Total This Period (last page this line number only) 
SCHEDULE A-P ITEMIZED RECEIPTS
Use separate schedule(s) for each category of the Detailed Summary Page
FOR LINE NUMBER: (check only one)

\begin{tabular}{|c|c|c|c|c|c|}
\hline & & & & & \\
\hline 16 & $\begin{array}{ll}X & 17 a \\
\end{array}$ & $17 \mathrm{~b}$ & $17 c$ & $17 d$ & 18 \\
\hline $19 a$ & $19 b$ & $20 \mathrm{a}$ & $20 \mathrm{~b}$ & $20 c$ & 21 \\
\hline
\end{tabular}

Any information copied from such Reports and Statements may not be sold or used by any person for the purpose of soliciting contributions or for commercial purposes, other than using the name and address of any political committee to solicit contributions from such committee.

NAME OF COMMITTEE (In Full)

\section{Friends of Herman Cain}

A. Full Name (Last, First, Middle Initial) John Lehman

Mailing Address PMB 311 - 1133 Bal Harbor Blvd.

\begin{tabular}{lcc}
\hline City & State & Zip Code \\
Punta Gorda & FL & $33950-6577$
\end{tabular}

FEC ID number of contributing federal political committee.

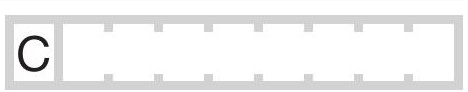

Name of Employer
self
Receipt For: 2012
X Primary
$\square$ Other (specify)

Occupation

Sales

Election Cycle-to-Date

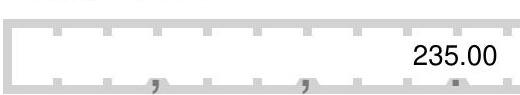

B. Full Name (Last, First, Middle Initial)

Susan Sewald

Mailing Address 25025 E 4th PI

\begin{tabular}{lcc}
\hline City & State & Zip Code \\
Aurora & CO & $80018-1687$
\end{tabular}

FEC ID number of contributing

federal political committee.

C

Name of Employer
Information Requested
Receipt For: 2012
Primary
Other (specify)

Occupation

Information Requested

Election Cycle-to-Date

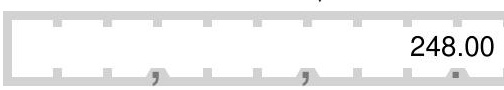

Transaction ID : AAAB505531D21401DA8C

Date of Receipt

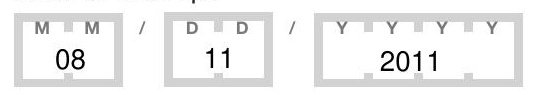

Amount of Each Receipt this Period

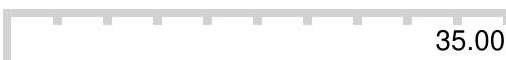

C. Full Name (Last, First, Middle Initial)

Gene Richardson

Mailing Address PO Box 1619

\begin{tabular}{lcc}
\hline City & State & Zip Code \\
Lindale & TX & $75771-1619$
\end{tabular}

FEC ID number of contributing federal political committee.

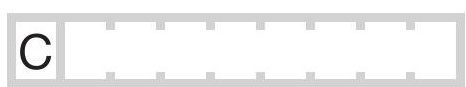

Name of Employer
None
Receipt For: 2012
Х Primary $\quad \square$ General
Other (specify)

\section{Occupation}

Retired

Election Cycle-to-Date

Transaction ID : A948F7E3CB1E2482CBBC Date of Receipt

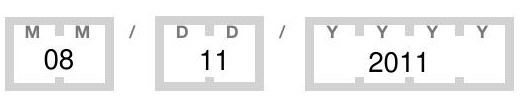

Amount of Each Receipt this Period

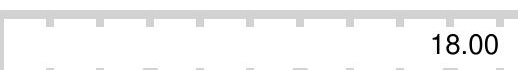

Transaction ID : A38696C27CB0F40E1AD9 Date of Receipt

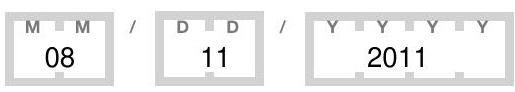

Amount of Each Receipt this Period

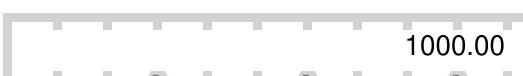

1000.00

\section{Subtotal Of Receipts This Page (optional)}

Total This Period (last page this line number only) 


\section{SCHEDULE A-P} ITEMIZED RECEIPTS
Use separate schedule(s)

for each category of the

Detailed Summary Page
FOR LINE NUMBER: (check only one)

PAGE 245 / 1572

\begin{tabular}{|c|c|c|c|c|c|}
\hline & & & & & \\
\hline 16 & X $17 a$ & $17 b$ & $17 c$ & $17 d$ & 18 \\
\hline $19 a$ & $19 b$ & $20 \mathrm{a}$ & $20 \mathrm{~b}$ & $20 \mathrm{c}$ & 21 \\
\hline
\end{tabular}

Any information copied from such Reports and Statements may not be sold or used by any person for the purpose of soliciting contributions or for commercial purposes, other than using the name and address of any political committee to solicit contributions from such committee.

NAME OF COMMITTEE (In Full)

Friends of Herman Cain

A. Full Name (Last, First, Middle Initial)

Mr. James S Parsons, Jr.

Mailing Address 2427 Fairway Drive

\begin{tabular}{lcc}
\hline City & State & Zip Code \\
Winston Salem & NC & $27103-3508$ \\
\hline
\end{tabular}

FEC ID number of contributing federal political committee.

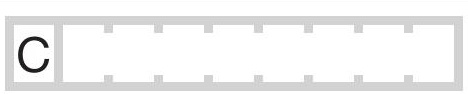

Name of Employer

Womble Carlyle Sandridge \& Rice

Occupation

Attorney

Receipt For: 2012

X Primary $\square$ General Other (specify)

Election Cycle-to-Date

550.00

B. Full Name (Last, First, Middle Initial)

Michael Frentz

Mailing Address 8730 Cardinal Forest Cir

\begin{tabular}{lcc}
\hline City & State & Zip Code \\
Laurel & MD & $20723-1256$ \\
\hline
\end{tabular}

FEC ID number of contributing

federal political committee.

C

Name of Employer
Information Requested
Receipt For: 2012
X Primary
Other (specify)

Occupation

Information Requested

Election Cycle-to-Date

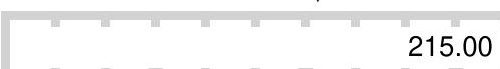

Transaction ID : AB3F449120DFB4C0BBF2

Date of Receipt

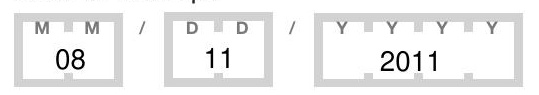

Amount of Each Receipt this Period

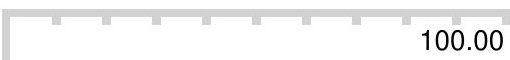

100.00

C. Full Name (Last, First, Middle Initial)

Allen Field

Mailing Address P O Box 5706

\begin{tabular}{lcc}
\hline City & State & Zip Code \\
Atlanta & GA & $31107-0706$
\end{tabular}

FEC ID number of contributing federal political committee.

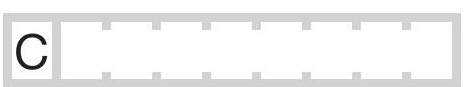

Name of Employer

Pomeroy IT

\section{Occupation}

Area Manager

Receipt For: 2012

Х $\begin{aligned} & \text { Primary } \\ & \text { Other (specify) }\end{aligned}$

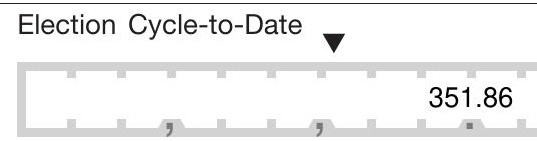

Amount of Each Receipt this Period

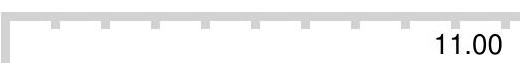

Subtotal Of Receipts This Page (optional)....

Total This Period (last page this line number only) 
SCHEDULE A-P ITEMIZED RECEIPTS
Use separate schedule(s) for each category of the Detailed Summary Page
FOR LINE NUMBER: (check only one)

PAGE 246 / 1572

\begin{tabular}{|c|c|c|c|c|c|}
\hline & & & & & \\
\hline 16 & $\begin{array}{l}\mathbf{X} \\
17 a\end{array}$ & $17 b$ & $17 c$ & $17 d$ & 18 \\
\hline $19 a$ & $19 \mathrm{~b}$ & $20 \mathrm{a}$ & $20 \mathrm{~b}$ & $20 \mathrm{c}$ & 21 \\
\hline
\end{tabular}

Any information copied from such Reports and Statements may not be sold or used by any person for the purpose of soliciting contributions or for commercial purposes, other than using the name and address of any political committee to solicit contributions from such committee.

NAME OF COMMITTEE (In Full)

\section{Friends of Herman Cain}

A. Full Name (Last, First, Middle Initial)

Larry Ray Stone

Mailing Address 381 E Salzburg Rd

\begin{tabular}{lcc}
\hline City & State & Zip Code \\
Bay City & MI & $48706-9770$ \\
\hline
\end{tabular}

FEC ID number of contributing

federal political committee.

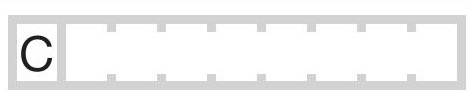

Name of Employer
US Navy
Receipt For: 2012
X Primary $\quad$ General
Other (specify)

Occupation

Retired

Election Cycle-to-Date

500.00

B. Full Name (Last, First, Middle Initial)

Mr Curtis D Krehbiel

Mailing Address 2602 W Dengar Ave

\begin{tabular}{lcc}
\hline City & State & Zip Code \\
Midland & TX & $79705-6325$
\end{tabular}

FEC ID number of contributing

federal political committee.

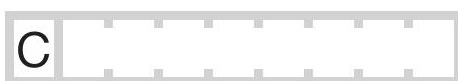

Name of Employer
None
Receipt For: 2012
X Primary
Other (specify)

Occupation

Retired

Election Cycle-to-Date

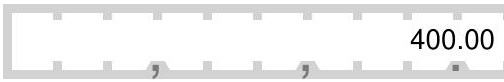

C. Full Name (Last, First, Middle Initial)

Jim Eure Jr.

Mailing Address PO Box 156

\begin{tabular}{lcc}
\hline City & State & Zip Code \\
Dahlonega & GA & $30533-0003$
\end{tabular}

FEC ID number of contributing federal political committee.

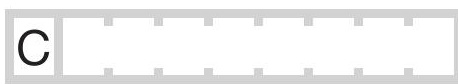

Name of Employer

Occupation

Protex Security Systems

Owner

Receipt For: 2012

Х $\begin{aligned} & \text { Primary } \square \text { General } \\ & \text { Other (specify) }\end{aligned}$

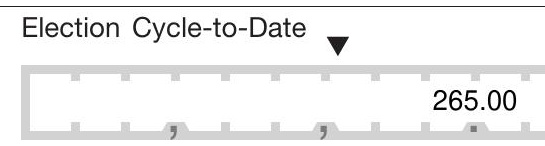

Amount of Each Receipt this Period

Transaction ID : A32E0F0C2A85C4163BDB

Date of Receipt

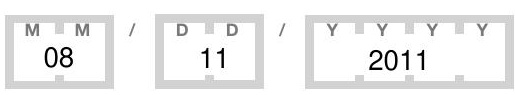

Amount of Each Receipt this Period

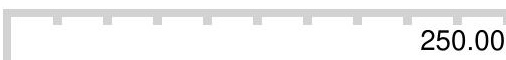

250.00

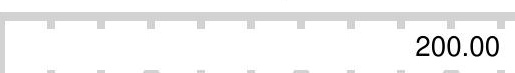

Transaction ID : AF484D7212C7C4E9995A

Date of Receipt

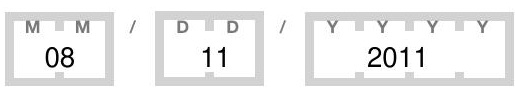

Amount of Each Receipt this Period

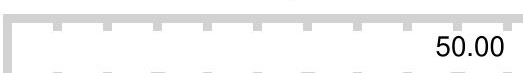

Subtotal Of Receipts This Page (optional)

500.00

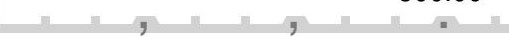

Total This Period (last page this line number only)

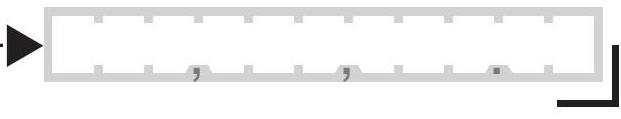

FEC Schedule A-P (Form 3P) (Rev. 03/2011) 
SCHEDULE A-P ITEMIZED RECEIPTS
Use separate schedule(s) for each category of the Detailed Summary Page
FOR LINE NUMBER: (check only one)

PAGE 247 / 1572

\begin{tabular}{|c|c|c|c|c|c|}
\hline & & & & & \\
\hline 16 & $\begin{array}{l}\mathbf{X} \\
17 a\end{array}$ & $17 b$ & $17 c$ & $17 d$ & 18 \\
\hline $19 a$ & $19 \mathrm{~b}$ & $20 \mathrm{a}$ & $20 \mathrm{~b}$ & $20 \mathrm{c}$ & 21 \\
\hline
\end{tabular}

Any information copied from such Reports and Statements may not be sold or used by any person for the purpose of soliciting contributions or for commercial purposes, other than using the name and address of any political committee to solicit contributions from such committee.

NAME OF COMMITTEE (In Full)

\section{Friends of Herman Cain}

A. Full Name (Last, First, Middle Initial)

\section{Arvin Rolfs}

Mailing Address 4201 Lakeside Ave N

Apt 202

\begin{tabular}{lcc}
\hline City & State & Zip Code \\
Minneapolis & MN & $55429-3822$
\end{tabular}

FEC ID number of contributing federal political committee.

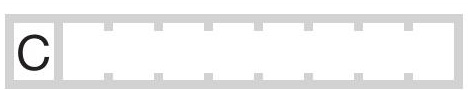

Name of Employer
None
Receipt For: 2012
X Primary $\quad$ General
Other (specify)

B. Full Name (Last, First, Middle Initial)

Mr Alan Weldon

Mailing Address $651 \mathrm{~S}$ Roosevelt St

\begin{tabular}{lcc}
\hline City & State & Zip Code \\
Wichita & KS & $67218-2035$ \\
\hline
\end{tabular}

FEC ID number of contributing

federal political committee.

C

Name of Employer
USD 259
Receipt For: 2012
X Primary
Other (specify)

C. Full Name (Last, First, Middle Initial)

Mr Shawn Burns

Mailing Address 139 E Mount Kirk Ave

\begin{tabular}{lcc}
\hline City & State & Zip Code \\
Norristown & PA & $19403-1140$
\end{tabular}

FEC ID number of contributing federal political committee.

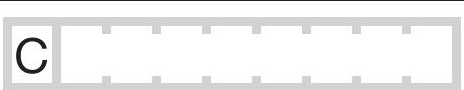

Name of Employer

The Rees Co. Inc.

Receipt For: 2012

Х $\begin{aligned} & \text { Primary } \square \text { General } \\ & \text { Other (specify) }\end{aligned}$
Occupation

Retired

Election Cycle-to-Date

300.00
Occupation

RISK MANAGEMENT

Election Cycle-to-Date

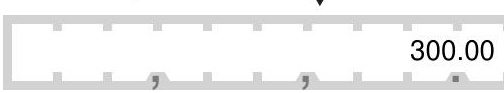

\section{Occupation}

VP

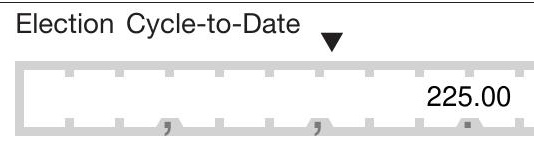

Transaction ID : A8E0EF574CA0E44DAB48

Date of Receipt

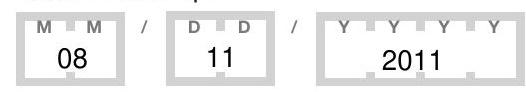

Amount of Each Receipt this Period

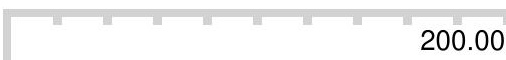

Amount of Each Receipt this Period

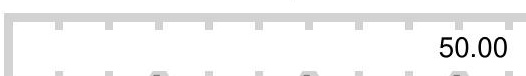

Transaction ID : AD7055C9363614F7A89F

Date of Receipt

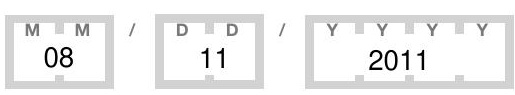

Transaction ID : AD26107E209B14224BCC Date of Receipt

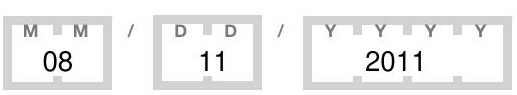

Amount of Each Receipt this Period

Subtotal Of Receipts This Page (optional)

400.00

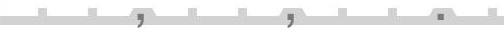

Total This Period (last page this line number only) 
SCHEDULE A-P ITEMIZED RECEIPTS
Use separate schedule(s) for each category of the Detailed Summary Page
FOR LINE NUMBER: (check only one)

PAGE 248 / 1572

\begin{tabular}{|c|c|c|c|c|c|}
\hline & & & & & \\
\hline 16 & $\begin{array}{l}\mathbf{X} \\
17 a\end{array}$ & $17 b$ & $17 c$ & $17 d$ & 18 \\
\hline $19 a$ & $19 \mathrm{~b}$ & $20 \mathrm{a}$ & $20 \mathrm{~b}$ & $20 \mathrm{c}$ & 21 \\
\hline
\end{tabular}

Any information copied from such Reports and Statements may not be sold or used by any person for the purpose of soliciting contributions or for commercial purposes, other than using the name and address of any political committee to solicit contributions from such committee.

NAME OF COMMITTEE (In Full)

\section{Friends of Herman Cain}

A. Full Name (Last, First, Middle Initial)

Terrence Diefenbacher

Mailing Address 5570 Yeatman Road

\begin{tabular}{lcc}
\hline City & State & Zip Code \\
Cincinnati & OH & $45252-1444$
\end{tabular}

FEC ID number of contributing federal political committee.

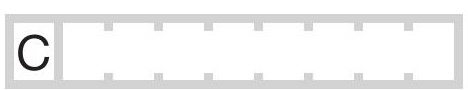

Name of Employer
Cincinnati Christian Schools
Receipt For: 2012
X Primary $\quad \square$ General
Other (specify)

Occupation

School Administrator

Election Cycle-to-Date

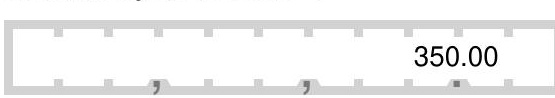

B. Full Name (Last, First, Middle Initial)

David Morris

Mailing Address 7921 E 46th Street

\begin{tabular}{lcc}
\hline City & State & Zip Code \\
Indianapolis & IN & $46226-3931$ \\
\hline
\end{tabular}

FEC ID number of contributing

federal political committee.

C

Name of Employer

Precision Dry Wall Inc.

Occupation

Receipt For: 2012

Х Primary $\square$ General

Construction

Election Cycle-to-Date

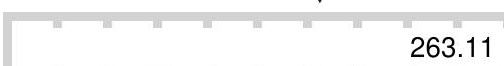

C. Full Name (Last, First, Middle Initial)

Allen Field

Mailing Address P O Box 5706

\section{City}

Atlanta

FEC ID number of contributing

federal political committee.

Name of Employer
Pomeroy IT
Receipt For: 2012
X Primary
Other (specify) General

Transaction ID : A9A7374EA2DF44304B85

Date of Receipt

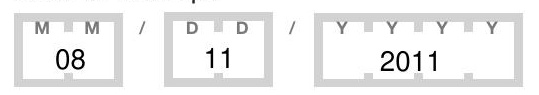

Amount of Each Receipt this Period

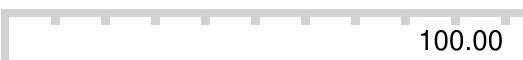

Transaction ID : A47566B4498AA4D9F8F6

Date of Receipt

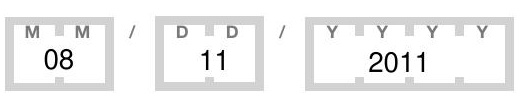

Amount of Each Receipt this Period

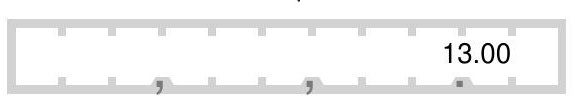

Transaction ID : A83901C48CF45443383D

Date of Receipt

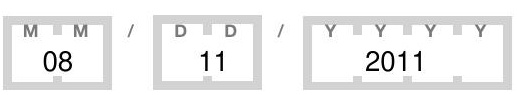

Amount of Each Receipt this Period

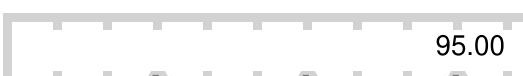

Area Manager

Election Cycle-to-Date

351.86

Subtotal Of Receipts This Page (optional).

208.00

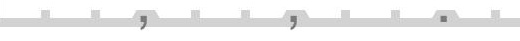

Total This Period (last page this line number only)

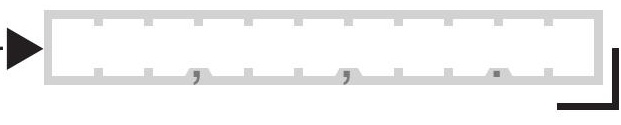

FEC Schedule A-P (Form 3P) (Rev. 03/2011) 
SCHEDULE A-P ITEMIZED RECEIPTS
Use separate schedule(s) for each category of the Detailed Summary Page
FOR LINE NUMBER: (check only one)

PAGE 249 / 1572

\begin{tabular}{|c|c|c|c|c|c|}
\hline & & & & & \\
\hline 16 & $\begin{array}{l}\mathbf{X} \\
17 a\end{array}$ & $17 b$ & $17 c$ & $17 d$ & 18 \\
\hline $19 a$ & $19 \mathrm{~b}$ & $20 \mathrm{a}$ & $20 \mathrm{~b}$ & $20 \mathrm{c}$ & 21 \\
\hline
\end{tabular}

Any information copied from such Reports and Statements may not be sold or used by any person for the purpose of soliciting contributions or for commercial purposes, other than using the name and address of any political committee to solicit contributions from such committee.

NAME OF COMMITTEE (In Full)

\section{Friends of Herman Cain}

A. Full Name (Last, First, Middle Initial)

\section{Gilbert T Pallen}

Mailing Address 710 Mount Tabor Rd

\begin{tabular}{lcc}
\hline City & State & Zip Code \\
Oxford & GA & $30054-4503$
\end{tabular}

FEC ID number of contributing federal political committee.

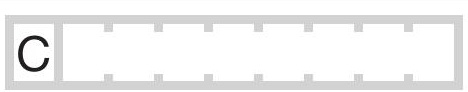

Name of Employer
None
Receipt For: 2012
X Primary $\quad$ General
Other (specify)

Occupation Retired

Election Cycle-to-Date

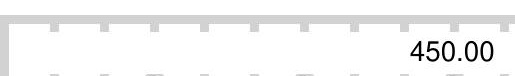

B. Full Name (Last, First, Middle Initial)

Susan Walter

Mailing Address P.O. Box 690

\begin{tabular}{lcc}
\hline City & State & Zip Code \\
Sautee Nacoochee & GA & $30571-0690$ \\
\hline
\end{tabular}

FEC ID number of contributing

federal political committee.

C

Name of Employer
None
Receipt For: 2012
X Primary
Other (specify)

C. Full Name (Last, First, Middle Initial)

Scott McEachin

Mailing Address 7032 East 100th Street

City

Tulsa

FEC ID number of contributing federal political committee.

Name of Employer

Scott William McEachin PC

Receipt For: 2012

Х $\begin{aligned} & \text { Primary } \square \text { General } \\ & \text { Other (specify) }\end{aligned}$

\section{Occupation}

Retired

Election Cycle-to-Date

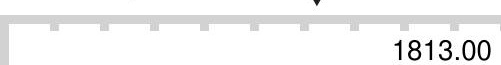

Transaction ID : AB1664F5291684E05A1A

Date of Receipt

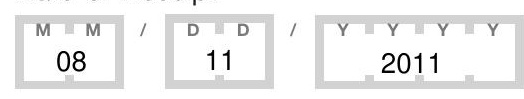

Amount of Each Receipt this Period

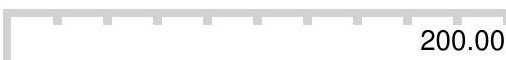

200.00
Amount of Each Receipt this Period

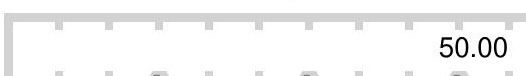

Transaction ID : A370AEFBB106B49EA977 Date of Receipt

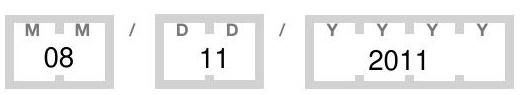

Transaction ID : A54A3472ED09E4F468CC Date of Receipt

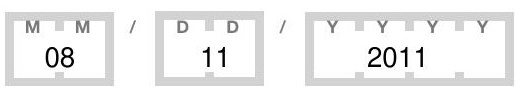

Amount of Each Receipt this Period

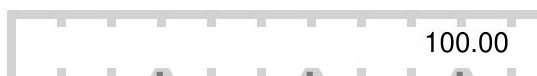

\section{Subtotal Of Receipts This Page (optional)} Attorney

Election Cycle-to-Date

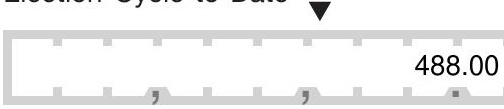

Total This Period (last page this line number only)

$-\quad 350.00$

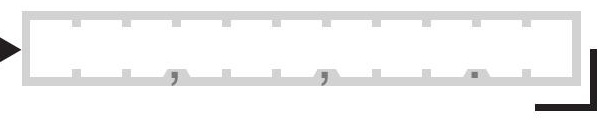

FEC Schedule A-P (Form 3P) (Rev. 03/2011) 
SCHEDULE A-P ITEMIZED RECEIPTS
Use separate schedule(s) for each category of the Detailed Summary Page
FOR LINE NUMBER: (check only one)

PAGE $250 / 1572$

\begin{tabular}{|c|c|c|c|c|c|}
\hline & & & & & \\
\hline 16 & $\begin{array}{l}\mathbf{X} \\
17 a\end{array}$ & $17 b$ & $17 c$ & $17 d$ & 18 \\
\hline $19 a$ & $19 \mathrm{~b}$ & $20 \mathrm{a}$ & $20 \mathrm{~b}$ & $20 \mathrm{c}$ & 21 \\
\hline
\end{tabular}

Any information copied from such Reports and Statements may not be sold or used by any person for the purpose of soliciting contributions or for commercial purposes, other than using the name and address of any political committee to solicit contributions from such committee.

NAME OF COMMITTEE (In Full)

Friends of Herman Cain

A. Full Name (Last, First, Middle Initial)

Nancy Gunsallus

Mailing Address 3461 Donegal Way

\begin{tabular}{lcc}
\hline City & State & Zip Code \\
Snellville & GA & $30039-8635$
\end{tabular}

FEC ID number of contributing federal political committee.

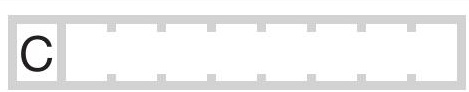

Name of Employer

American Shutter Components LLC

Receipt For: 2012

X Primary $\square$ General Other (specify)
Occupation

co-owner

Election Cycle-to-Date
B. Full Name (Last, First, Middle Initial)

Allen Field

Mailing Address P O Box 5706

\begin{tabular}{lcc}
\hline City & State & Zip Code \\
Atlanta & GA & $31107-0706$ \\
\hline
\end{tabular}

FEC ID number of contributing

federal political committee.

C

\begin{tabular}{l} 
Name of Employer \\
Pomeroy IT \\
Receipt For: 2012 \\
X Primary \\
\hline Other (specify)
\end{tabular}

Occupation

Area Manager

Election Cycle-to-Date

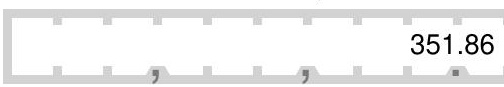

Transaction ID : ABF5D1538F2D740DCBF7

Date of Receipt

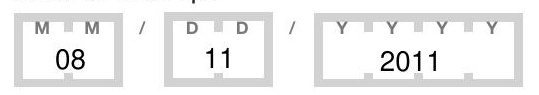

Amount of Each Receipt this Period

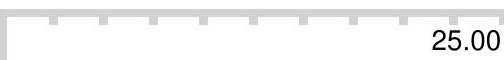

25.00

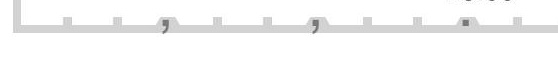

Transaction ID : A09B4ED2403E74980AAA

Date of Receipt

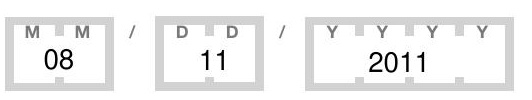

Amount of Each Receipt this Period

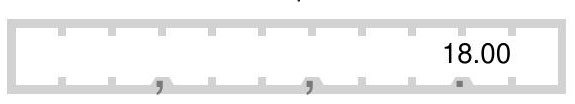

Transaction ID : AD05E224DC6EC42F5B37 Date of Receipt

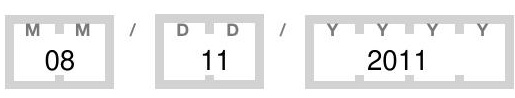

Amount of Each Receipt this Period

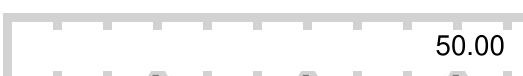

Occupation

\begin{tabular}{l|l}
\hline Receipt For: 2012 & Election Cycle-to-Date
\end{tabular}

Х $\begin{aligned} & \text { Primary } \\ & \text { Other (specify) }\end{aligned}$

300.00
Subtotal Of Receipts This Page (optional)

93.00

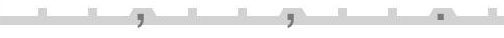

Total This Period (last page this line number only)

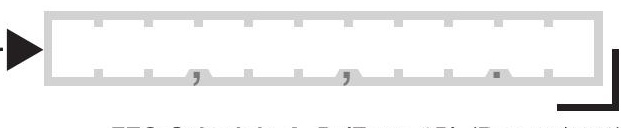

FEC Schedule A-P (Form 3P) (Rev. 03/2011) 
SCHEDULE A-P ITEMIZED RECEIPTS
Use separate schedule(s) for each category of the Detailed Summary Page
FOR LINE NUMBER: (check only one)

PAGE $251 / 1572$

\begin{tabular}{|c|c|c|c|c|c|}
\hline & & & & & \\
\hline 16 & $\begin{array}{l}\mathbf{X} \\
17 a\end{array}$ & $17 b$ & $17 c$ & $17 d$ & 18 \\
\hline $19 a$ & $19 \mathrm{~b}$ & $20 \mathrm{a}$ & $20 \mathrm{~b}$ & $20 \mathrm{c}$ & 21 \\
\hline
\end{tabular}

Any information copied from such Reports and Statements may not be sold or used by any person for the purpose of soliciting contributions or for commercial purposes, other than using the name and address of any political committee to solicit contributions from such committee.

NAME OF COMMITTEE (In Full)

\section{Friends of Herman Cain}

A. Full Name (Last, First, Middle Initial) Jerry Glenn

Mailing Address 54 Fairway Dr.

\begin{tabular}{lcc}
\hline City & State & Zip Code \\
Southgate & KY & $41071-3025$ \\
\hline
\end{tabular}

FEC ID number of contributing federal political committee.

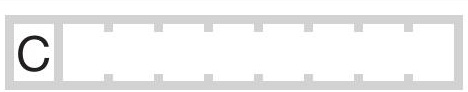

Name of Employer
Retired
Receipt For: 2012
X Primary $\quad$ General
Other (specify)

Occupation Retired

Election Cycle-to-Date

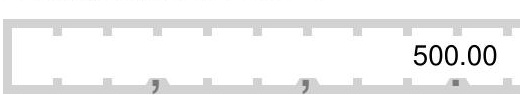

B. Full Name (Last, First, Middle Initial) James Gillespie

Mailing Address 965 Windsor Place Circle

\begin{tabular}{lcc}
\hline City & State & Zip Code \\
Grayson & GA & $30017-4914$ \\
\hline
\end{tabular}

FEC ID number of contributing

federal political committee.

C

Name of Employer
Retired
Receipt For: 2012
X Primary
Other (specify)

Occupation

Retired

Election Cycle-to-Date

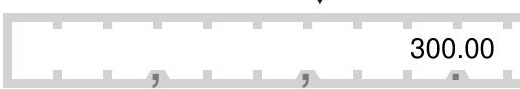

Transaction ID : A8B21DFB84EC64C549C3

Date of Receipt

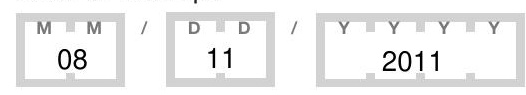

Amount of Each Receipt this Period

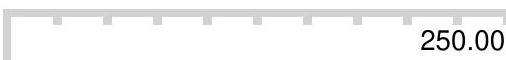

C. Full Name (Last, First, Middle Initial)

Mr. Ronald W Crosby

Mailing Address 17508 Oak Mount PI

\begin{tabular}{lcc}
\hline City & State & Zip Code \\
Dallas & TX & $75287-7529$
\end{tabular}

FEC ID number of contributing federal political committee.

C

75287-7529

Name of Employer
wynn crosby
Receipt For: 2012
Primary
Other (specify) General

Occupation

Engineer

Election Cycle-to-Date

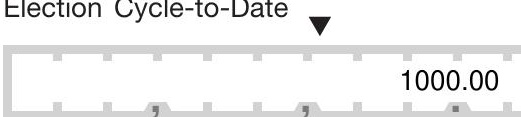

Amount of Each Receipt this Period

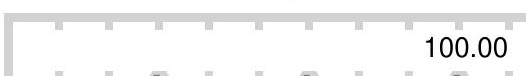

Transaction ID : A2D186539961A4FE5890

Date of Receipt

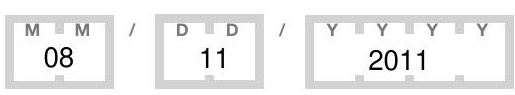

Transaction ID : A0C21A9535D8A45DE99F Date of Receipt

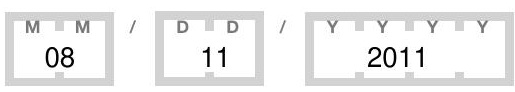

Amount of Each Receipt this Period

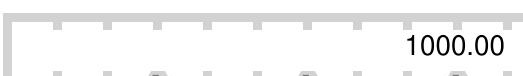

\section{Subtotal Of Receipts This Page (optional)}

Total This Period (last page this line number only) 
SCHEDULE A-P ITEMIZED RECEIPTS
Use separate schedule(s) for each category of the Detailed Summary Page
FOR LINE NUMBER: (check only one)

PAGE 252 / 1572

\begin{tabular}{|c|c|c|c|c|c|}
\hline & & & & & \\
\hline 16 & $\begin{array}{l}\mathbf{X} \\
17 a\end{array}$ & $17 b$ & $17 c$ & $17 d$ & 18 \\
\hline $19 a$ & $19 \mathrm{~b}$ & $20 \mathrm{a}$ & $20 \mathrm{~b}$ & $20 \mathrm{c}$ & 21 \\
\hline
\end{tabular}

Any information copied from such Reports and Statements may not be sold or used by any person for the purpose of soliciting contributions or for commercial purposes, other than using the name and address of any political committee to solicit contributions from such committee.

NAME OF COMMITTEE (In Full)

\section{Friends of Herman Cain}

A. Full Name (Last, First, Middle Initial) Julie Waddle

Mailing Address 711 Arnold Mill Road

\begin{tabular}{lcc}
\hline City & State & Zip Code \\
Woodstock & GA & $30188-3010$ \\
\hline
\end{tabular}

FEC ID number of contributing federal political committee.

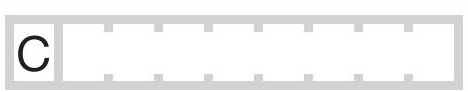

Name of Employer
n/a
Receipt For: 2012
X Primary $\quad$ General
Other (specify)

Occupation Homemaker

Election Cycle-to-Date

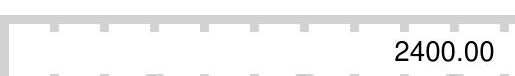

B. Full Name (Last, First, Middle Initial)

Florence Attridge

Mailing Address 2820 Habersham Rd

\begin{tabular}{lcc}
\hline City & State & Zip Code \\
Atlanta & GA & $30305-2959$ \\
\hline
\end{tabular}

FEC ID number of contributing

federal political committee.

C

Name of Employer
Information Requested
Receipt For: 2012
X Primary
Other (specify)

Occupation

Information Requested

Election Cycle-to-Date

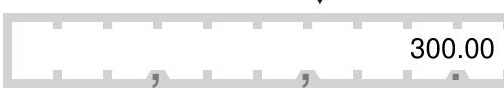

Transaction ID : AB07EB5C7813A4CD28B0

Date of Receipt

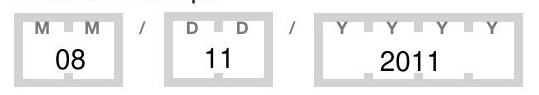

Amount of Each Receipt this Period

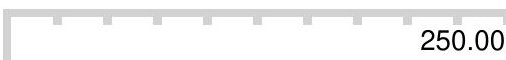

Amount of Each Receipt this Period

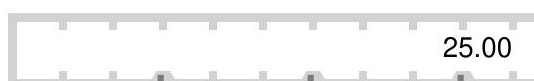

C. Full Name (Last, First, Middle Initial)

Rebecca Marsh

Mailing Address 262 Kings Row NE

\begin{tabular}{lcc}
\hline City & State & Zip Code \\
Marietta & GA & $30067-4104$
\end{tabular}

FEC ID number of contributing

federal political committee.

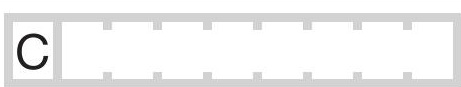

Name of Employer

Southern Company Services

Receipt For: 2012

Х $\begin{aligned} & \text { Primary } \square \text { General } \\ & \text { Other (specify) }\end{aligned}$

Occupation

Accounting Manager

Election Cycle-to-Date
Transaction ID : A4B10DB60B4B64B8F9F2

Date of Receipt

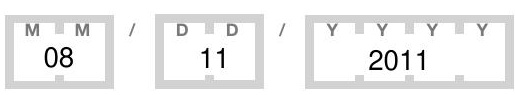

Transaction ID : A9867B5C1A6BF4D0A9B0 Date of Receipt

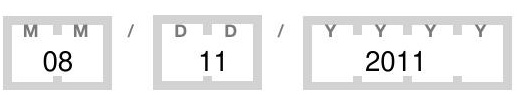

Amount of Each Receipt this Period

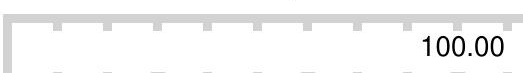

750.00

Subtotal Of Receipts This Page (optional)

375.00

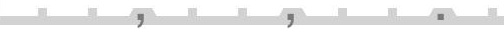

Total This Period (last page this line number only)

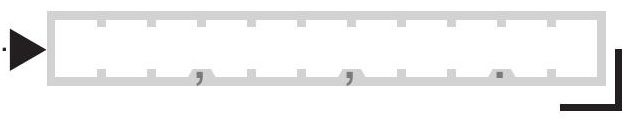

FEC Schedule A-P (Form 3P) (Rev. 03/2011) 
SCHEDULE A-P ITEMIZED RECEIPTS
Use separate schedule(s) for each category of the Detailed Summary Page
FOR LINE NUMBER: (check only one)

PAGE $253 / 1572$

\begin{tabular}{|c|c|c|c|c|c|}
\hline & & & & & \\
\hline 16 & $\begin{array}{lll}X & 17 a \\
\end{array}$ & $17 \mathrm{~b}$ & $17 c$ & $17 d$ & 18 \\
\hline $19 a$ & $19 b$ & $20 a$ & $20 \mathrm{~b}$ & $20 c$ & 21 \\
\hline
\end{tabular}

Any information copied from such Reports and Statements may not be sold or used by any person for the purpose of soliciting contributions or for commercial purposes, other than using the name and address of any political committee to solicit contributions from such committee.

NAME OF COMMITTEE (In Full)

\section{Friends of Herman Cain}

A. Full Name (Last, First, Middle Initial)

Sylvia Downey

Mailing Address 134 S Hawk Dr

\begin{tabular}{lcc}
\hline City & State & Zip Code \\
Rainbow City & AL & $35906-3608$
\end{tabular}

FEC ID number of contributing

federal political committee.

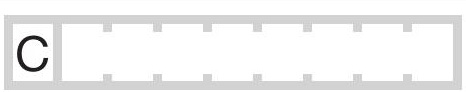

\begin{tabular}{l} 
Name of Employer \\
None \\
Receipt For: 2012 \\
X Primary $\quad$ General \\
\hline Other (specify)
\end{tabular}

Occupation

Retired

Election Cycle-to-Date

325.00

B. Full Name (Last, First, Middle Initial)

Maryann Westfall

Mailing Address 3620 Shadow Creek Dr.

\begin{tabular}{lcc}
\hline City & State & Zip Code \\
Cumming & GA & $30041-6643$ \\
\hline
\end{tabular}

FEC ID number of contributing

federal political committee.

C

Name of Employer
Information Requested
Receipt For: 2012
X Primary
Other (specify)

Occupation

Information Requested

Election Cycle-to-Date

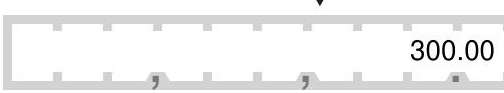

Transaction ID : A866185BCE9B04DB69D5

Date of Receipt

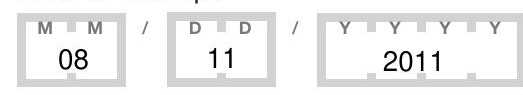

Amount of Each Receipt this Period

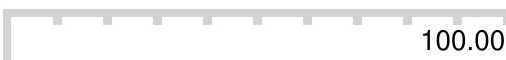

Transaction ID : A1419F5B9911A43DA833

Date of Receipt

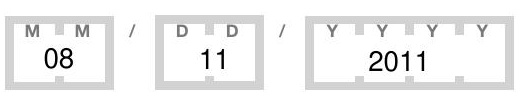

Amount of Each Receipt this Period

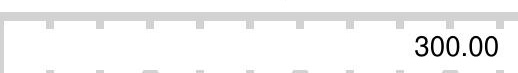

Transaction ID : A34E062580DAE4A4BAF5 Date of Receipt

\section{John M Corothers}

Mailing Address 47617 181s Street

\begin{tabular}{lcc}
\hline City & State & Zip Code \\
Clear Lake & SD & 57226
\end{tabular}

FEC ID number of contributing federal political committee.

C

Name of Employer
None
Receipt For: 2012
Х Primary $\quad \square$ General
Other (specify)

Occupation

Retired

Election Cycle-to-Date

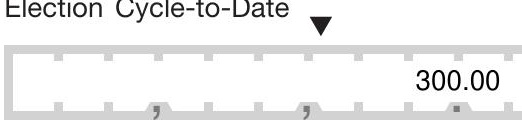

Subtotal Of Receipts This Page (optional)

Amount of Each Receipt this Period

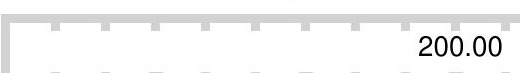

Total This Period (last page this line number only)

600.00

a

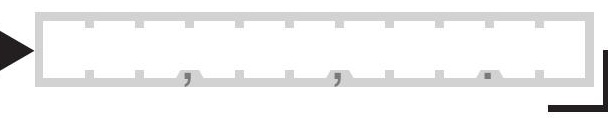

FEC Schedule A-P (Form 3P) (Rev. 03/2011) 
SCHEDULE A-P ITEMIZED RECEIPTS
Use separate schedule(s) for each category of the Detailed Summary Page
FOR LINE NUMBER: (check only one)

PAGE 254 / 1572

\begin{tabular}{|c|c|c|c|c|c|}
\hline & & & & & \\
\hline 16 & $\begin{array}{l}\mathbf{X} \\
17 a\end{array}$ & $17 b$ & $17 c$ & $17 d$ & 18 \\
\hline $19 a$ & $19 \mathrm{~b}$ & $20 \mathrm{a}$ & $20 \mathrm{~b}$ & $20 \mathrm{c}$ & 21 \\
\hline
\end{tabular}

Any information copied from such Reports and Statements may not be sold or used by any person for the purpose of soliciting contributions or for commercial purposes, other than using the name and address of any political committee to solicit contributions from such committee.

NAME OF COMMITTEE (In Full)

\section{Friends of Herman Cain}

A. Full Name (Last, First, Middle Initial)

Jayne D Wayson

Mailing Address 400 E Colonial Dr Apt 402

\begin{tabular}{lcc}
\hline City & State & Zip Code \\
Orlando & FL & $32803-4530$
\end{tabular}

FEC ID number of contributing federal political committee.

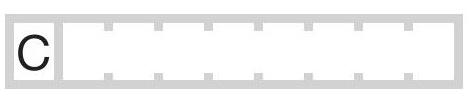

Name of Employer
Information Requested
Receipt For: 2012
X Primary
$\square$ Other (specify)

Occupation Information Requested

Election Cycle-to-Date

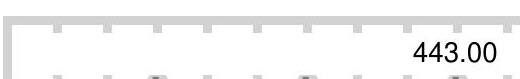

B. Full Name (Last, First, Middle Initial)

Ben W. Keeler

Mailing Address 4160 Summit Dr.

\begin{tabular}{lcc}
\hline City & State & Zip Code \\
Marietta & GA & $30068-4150$
\end{tabular}

FEC ID number of contributing

federal political committee.

C

Name of Employer
Information Requested
Receipt For: 2012
Primary
Other (specify)

Occupation

Information Requested

Election Cycle-to-Date

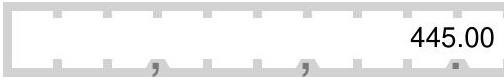

C. Full Name (Last, First, Middle Initial)

Douglas McKissack

Mailing Address 7 Bitterroot Ln

\begin{tabular}{lcc}
\hline City & State & Zip Code \\
Savannah & GA & $31419-9507$
\end{tabular}

FEC ID number of contributing federal political committee.

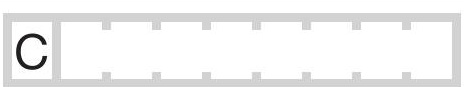

Name of Employer
Gulfstream Aerospace
Receipt For: 2012
X Primary $\quad \square$ General
Other (specify)

\section{Occupation}

Engineer

Election Cycle-to-Date

Transaction ID : A25EB4EC4B70647A4985

Date of Receipt

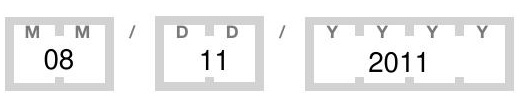

Amount of Each Receipt this Period

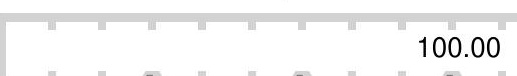

Transaction ID : A1A9A91BC1B8D46B0BCC Date of Receipt

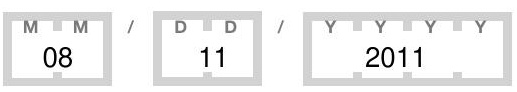

Amount of Each Receipt this Period

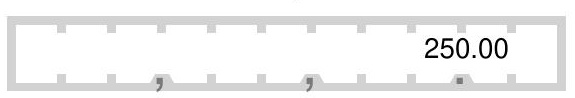

500.00

\section{Subtotal Of Receipts This Page (optional)}

Total This Period (last page this line number only) 
SCHEDULE A-P ITEMIZED RECEIPTS
Use separate schedule(s) for each category of the Detailed Summary Page
FOR LINE NUMBER: (check only one)

PAGE 255 / 1572

\begin{tabular}{|c|c|c|c|c|c|}
\hline & & & & & \\
\hline 16 & $\begin{array}{l}\mathbf{X} \\
17 a\end{array}$ & $17 b$ & $17 c$ & $17 d$ & 18 \\
\hline $19 a$ & $19 \mathrm{~b}$ & $20 \mathrm{a}$ & $20 \mathrm{~b}$ & $20 \mathrm{c}$ & 21 \\
\hline
\end{tabular}

Any information copied from such Reports and Statements may not be sold or used by any person for the purpose of soliciting contributions or for commercial purposes, other than using the name and address of any political committee to solicit contributions from such committee.

NAME OF COMMITTEE (In Full)

\section{Friends of Herman Cain}

A. Full Name (Last, First, Middle Initial)

\section{Allen Field}

Mailing Address P O Box 5706

\begin{tabular}{lcc}
\hline City & State & Zip Code \\
Atlanta & GA & $31107-0706$ \\
\hline
\end{tabular}

FEC ID number of contributing federal political committee.

Name of Employer
Pomeroy IT
Receipt For: 2012
X Primary $\quad$ General
Other (specify)

B. Full Name (Last, First, Middle Initial)

Theodore Bruegel

Mailing Address 2179 Amadeus Drive

\begin{tabular}{lcc}
\hline City & State & Zip Code \\
Clarksville & TN & $37040-7505$ \\
\hline
\end{tabular}

FEC ID number of contributing

federal political committee.

Name of Employer
n/a
Receipt For: 2012
X Primary
Other (specify)

C. Full Name (Last, First, Middle Initial)

Travis Burgess

Mailing Address 905 North Elm

\begin{tabular}{|c|c|c|}
\hline $\begin{array}{l}\text { City } \\
\text { Red Cloud }\end{array}$ & $\begin{array}{l}\text { State } \\
\text { NE }\end{array}$ & $\begin{array}{l}\text { Zip Code } \\
68970-2133\end{array}$ \\
\hline $\begin{array}{l}\text { FEC ID number of contributing } \\
\text { federal political committee. }\end{array}$ & C & \\
\hline $\begin{array}{l}\text { Name of Employer } \\
\text { US Postal Service }\end{array}$ & $\begin{array}{l}\text { Occup } \\
\text { Letter } \mathrm{C}\end{array}$ & \\
\hline Receipt For: 2012 & Electio & to-Date $\nabla$ \\
\hline $\begin{array}{l}\text { X } \\
\text { Other (specify) } \\
\end{array}$ & & 300.00 \\
\hline
\end{tabular}

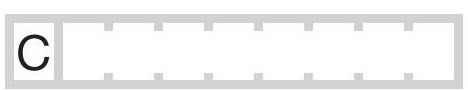

C

Transaction ID : AEF0712772D194147AC5

Date of Receipt

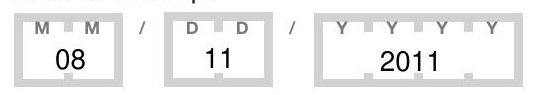

Amount of Each Receipt this Period

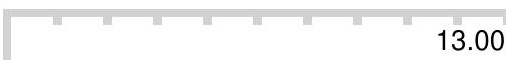

Area Manager

Election Cycle-to-Date

351.86

Occupation

Retired

Election Cycle-to-Date

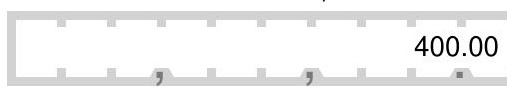

Transaction ID : A499B2AA2FEE94065832

Date of Receipt

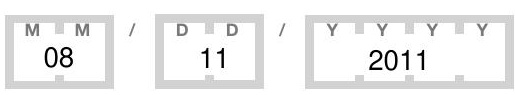

Amount of Each Receipt this Period

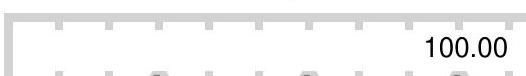

Amount of Each Receipt this Period

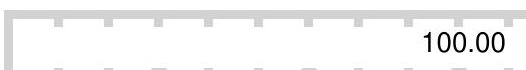

Transaction ID : AD0D9E98020474FAE942 Date of Receipt

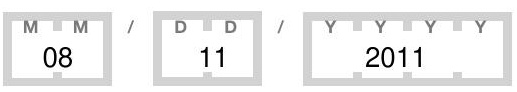

\section{Subtotal Of Receipts This Page (optional)}

Total This Period (last page this line number only) 
SCHEDULE A-P ITEMIZED RECEIPTS
Use separate schedule(s) for each category of the Detailed Summary Page
FOR LINE NUMBER: (check only one)

PAGE 256 / 1572

\begin{tabular}{|c|c|c|c|c|c|}
\hline & & & & & \\
\hline 16 & $\begin{array}{l}\mathbf{X} \\
17 a\end{array}$ & $17 b$ & $17 c$ & $17 d$ & 18 \\
\hline $19 a$ & $19 \mathrm{~b}$ & $20 \mathrm{a}$ & $20 \mathrm{~b}$ & $20 \mathrm{c}$ & 21 \\
\hline
\end{tabular}

Any information copied from such Reports and Statements may not be sold or used by any person for the purpose of soliciting contributions or for commercial purposes, other than using the name and address of any political committee to solicit contributions from such committee.

NAME OF COMMITTEE (In Full)

\section{Friends of Herman Cain}

A. Full Name (Last, First, Middle Initial)

Mr. John C. Thomas

Mailing Address 4756 Martins Crossing West Dr

\begin{tabular}{lcc}
\hline City & State & Zip Code \\
Flowery Branch & GA & $30542-5703$
\end{tabular}

FEC ID number of contributing

federal political committee.

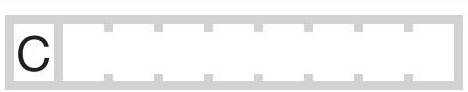

Name of Employer
Universal Resources Inc.
Receipt For: 2012
X Primary
Other (specify) General

Occupation

Recruiter

Election Cycle-to-Date

450.00

B. Full Name (Last, First, Middle Initial)

Joseph T. Freitas III

Mailing Address PO Box 677

\begin{tabular}{lcc}
\hline City & State & Zip Code \\
La Pine & OR & $97739-0677$
\end{tabular}

FEC ID number of contributing

federal political committee.

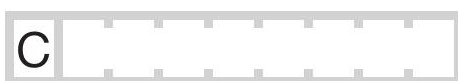

Name of Employer
None
Receipt For: 2012
X Primary
Other (specify)

\section{Occupation}

Retired

Election Cycle-to-Date

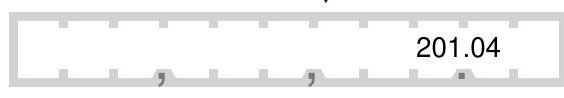

C. Full Name (Last, First, Middle Initial)

William Wieger

Mailing Address 112 Gayven Drive

\begin{tabular}{lcc}
\hline City & State & Zip Code \\
Ball & LA & $71405-4903$ \\
\hline
\end{tabular}

FEC ID number of contributing federal political committee.

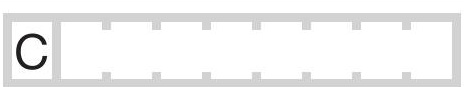

Name of Employer
Information Requested
Receipt For: 2012
X Primary $\quad \square$ General
Other (specify)

Occupation

Information Requested

Election Cycle-to-Date

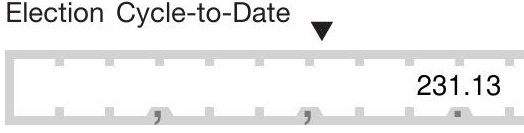

Transaction ID : ACB83C354FCD4418DAA0

Date of Receipt

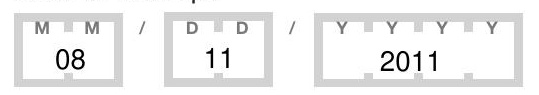

Amount of Each Receipt this Period

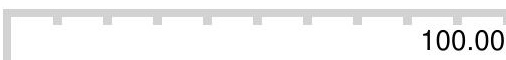

100.00
Amount of Each Receipt this Period

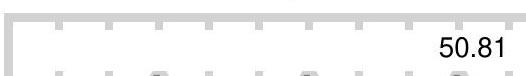

Transaction ID : A9941DAD46F724433857

Date of Receipt

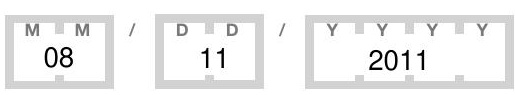

Transaction ID : ADA8B585CBA71452EA10 Date of Receipt

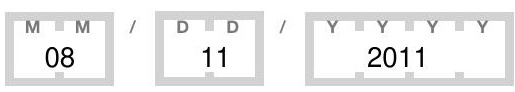

Amount of Each Receipt this Period

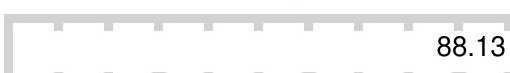

\section{Subtotal Of Receipts This Page (optional)}

Total This Period (last page this line number only) 
SCHEDULE A-P ITEMIZED RECEIPTS
Use separate schedule(s) for each category of the Detailed Summary Page
FOR LINE NUMBER: (check only one)

PAGE 257 / 1572

\begin{tabular}{|c|c|c|c|c|c|}
\hline & & & & & \\
\hline 16 & $\begin{array}{l}\mathbf{X} \\
17 a\end{array}$ & $17 b$ & $17 c$ & $17 d$ & 18 \\
\hline $19 a$ & $19 \mathrm{~b}$ & $20 \mathrm{a}$ & $20 \mathrm{~b}$ & $20 \mathrm{c}$ & 21 \\
\hline
\end{tabular}

Any information copied from such Reports and Statements may not be sold or used by any person for the purpose of soliciting contributions or for commercial purposes, other than using the name and address of any political committee to solicit contributions from such committee.

NAME OF COMMITTEE (In Full)

Friends of Herman Cain

A. Full Name (Last, First, Middle Initial)

Mr Carl H Powell

Mailing Address 700 North Ave Apt 314

\begin{tabular}{lcc}
\hline City & State & Zip Code \\
Battle Creek & Ml & $49017-3267$
\end{tabular}

FEC ID number of contributing

federal political committee.

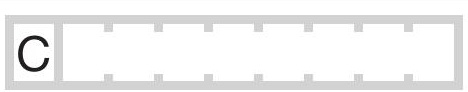

Name of Employer
Retired
Receipt For: 2012
X Primary $\quad \square$ General
$\square$ Other (specify)

Occupation

Medical Doctor

Election Cycle-to-Date

400.00

B. Full Name (Last, First, Middle Initial)

Brian Mullaney

Mailing Address 1579 Monroe Drive, NE Suite F-336

\begin{tabular}{lcc}
\hline City & State & Zip Code \\
Atlanta & GA & $30324-5039$ \\
\hline
\end{tabular}

FEC ID number of contributing

federal political committee.

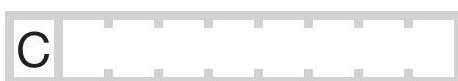

Name of Employer
Information Requested
Receipt For: 2012
X Primary
Other (specify)

Occupation

Information Requested

Election Cycle-to-Date

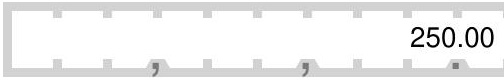

C. Full Name (Last, First, Middle Initial)

Marianne Mason

Mailing Address 30 Tall Oaks Trail

\begin{tabular}{lcc}
\hline City & State & Zip Code \\
Austin & TX & $78737-9306$
\end{tabular}

FEC ID number of contributing federal political committee.

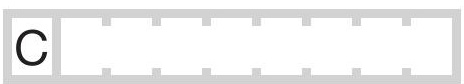

Name of Employer
MMA Int. LLC
Receipt For: 2012
Х Primary $\quad \square$ General
Other (specify)

Occupation

Accountant

Election Cycle-to-Date
Transaction ID : A82A1A1912E474FEF91A

Date of Receipt

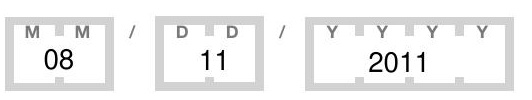

Amount of Each Receipt this Period

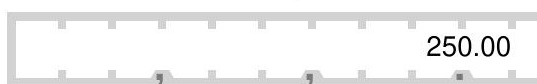

Transaction ID : A46821D26A2BB48D08C0 Date of Receipt

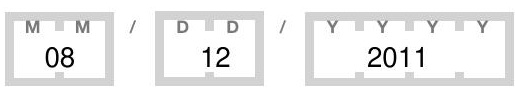

Amount of Each Receipt this Period

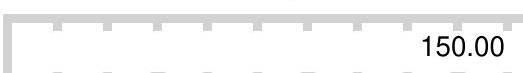

Subtotal Of Receipts This Page (optional).

600.00

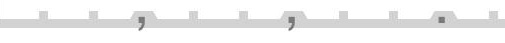

Total This Period (last page this line number only)
Transaction ID : A7E7AABC304D64B499FB

Date of Receipt

Amount of Each Receipt this Period

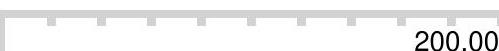


SCHEDULE A-P ITEMIZED RECEIPTS
Use separate schedule(s) for each category of the Detailed Summary Page
FOR LINE NUMBER: (check only one)

PAGE $258 / 1572$

\begin{tabular}{|c|c|c|c|c|c|}
\hline & & & & & \\
\hline 16 & $\begin{array}{l}\mathbf{X} \\
17 a\end{array}$ & $17 b$ & $17 c$ & $17 d$ & 18 \\
\hline $19 a$ & $19 \mathrm{~b}$ & $20 \mathrm{a}$ & $20 \mathrm{~b}$ & $20 \mathrm{c}$ & 21 \\
\hline
\end{tabular}

Any information copied from such Reports and Statements may not be sold or used by any person for the purpose of soliciting contributions or for commercial purposes, other than using the name and address of any political committee to solicit contributions from such committee.

NAME OF COMMITTEE (In Full)

\section{Friends of Herman Cain}

A. Full Name (Last, First, Middle Initial) James Brown

Mailing Address 3305 Pebble Ridge Lane

\begin{tabular}{lcc}
\hline City & State & Zip Code \\
Buford & GA & $30519-7231$
\end{tabular}

FEC ID number of contributing federal political committee.

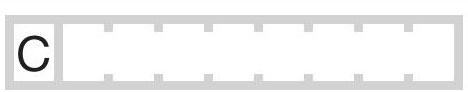

Name of Employer
USDA Forest Service
Receipt For: 2012
X Primary
Other (specify) General

Occupation Retired Election Cycle-to-Date

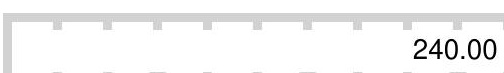

B. Full Name (Last, First, Middle Initial) James Scandle

Mailing Address 3836 Winters Hill Dr

\begin{tabular}{lcc}
\hline City & State & Zip Code \\
Atlanta & GA & $30360-1331$
\end{tabular}

FEC ID number of contributing

federal political committee.

C

Name of Employer
Ernst \& Young LLP
Receipt For: 2012
X Primary
Other (specify)

Occupation

Sales and Operations leader

Election Cycle-to-Date

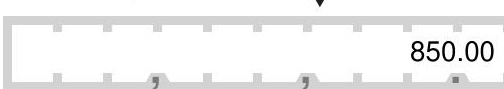

Transaction ID : A30F4A84E07F541949A5

Date of Receipt

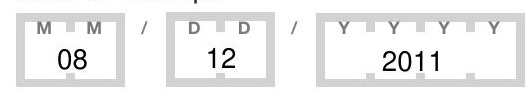

Amount of Each Receipt this Period

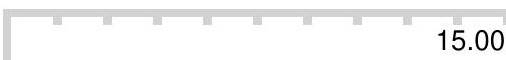

15.00

C. Full Name (Last, First, Middle Initial)

Joseph Nicholson

Mailing Address 1952 Huntington Hall Ct

\begin{tabular}{lcc}
\hline City & State & Zip Code \\
Atlanta & GA & $30338-5713$
\end{tabular}

FEC ID number of contributing

federal political committee.

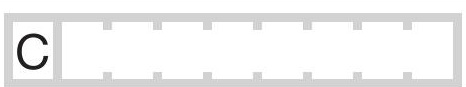

Name of Employer
$\mathrm{n} / \mathrm{a}$
Receipt For: 2012
X Primary
Other (specify) General

Occupation

Retired

Election Cycle-to-Date

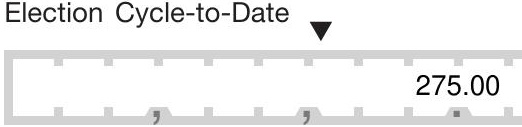

Transaction ID : A59B9053ADC474EC6822

Date of Receipt

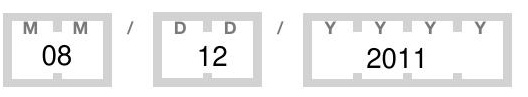

Amount of Each Receipt this Period

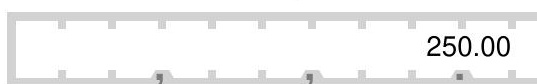

Transaction ID : AF14E6089CB2541BC90F Date of Receipt

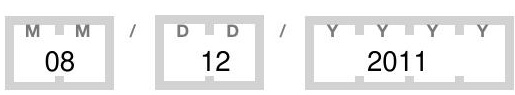

Amount of Each Receipt this Period

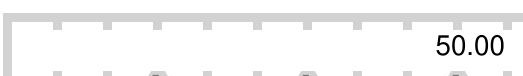

\section{Subtotal Of Receipts This Page (optional)}

Total This Period (last page this line number only) 
SCHEDULE A-P ITEMIZED RECEIPTS
Use separate schedule(s)

for each category of the

Detailed Summary Page
FOR LINE NUMBER: (check only one)

Any information or for commercial purposes, other than using the name and address of any political committee to solicit contributions from such committee.

NAME OF COMMITTEE (In Full)

Friends of Herman Cain

A. Full Name (Last, First, Middle Initial)

Ms Myra Asplundh

Mailing Address PO Box 11

\begin{tabular}{lcc}
\hline City & State & Zip Code \\
Bryn Athyn & PA & $19009-0011$ \\
\hline
\end{tabular}

FEC ID number of contributing

federal political committee.

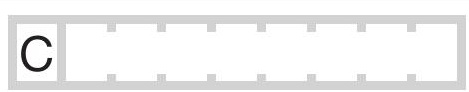

Name of Employer
None
Receipt For: 2012
X Primary $\quad \square$ General
Other (specify)

Occupation

Retired

Election Cycle-to-Date

750.00

B. Full Name (Last, First, Middle Initial)

John Edwards

Mailing Address 29 Governors Road

\begin{tabular}{lcc}
\hline City & State & Zip Code \\
Hilton Head Island & SC & $29928-3028$ \\
\hline
\end{tabular}

FEC ID number of contributing

federal political committee.

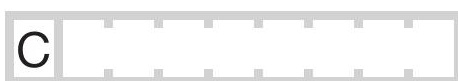

Name of Employer
None
Receipt For: 2012
X Primary
Other (specify)

\section{Occupation}

Retired

Election Cycle-to-Date

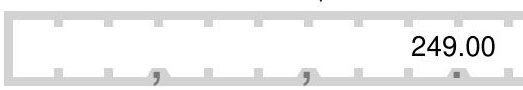

C. Full Name (Last, First, Middle Initial)

James Myette

Mailing Address 70 Silva St

\begin{tabular}{lcc}
\hline City & State & Zip Code \\
Carver & MA & $02330-1336$
\end{tabular}

FEC ID number of contributing

federal political committee.

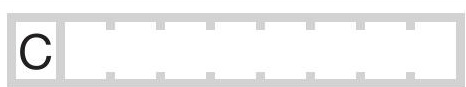

Name of Employer

Wind River Environmental

Receipt For: 2012

Х $\begin{aligned} & \text { Primary } \square \text { General } \\ & \text { Other (specify) }\end{aligned}$

Occupation

truck driver

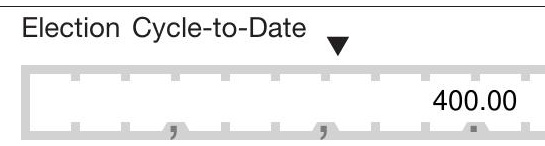

Transaction ID : A0FD40BEB0DD740B3B99

Date of Receipt

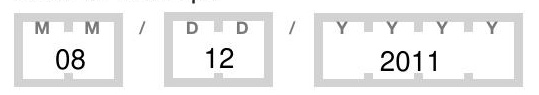

Amount of Each Receipt this Period

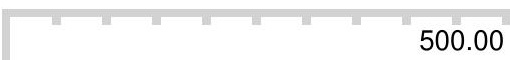

Amount of Each Receipt this Period

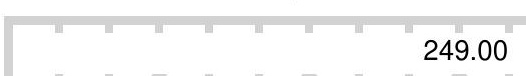

Transaction ID : ADFDFCAB2408C433DBC3 Date of Receipt

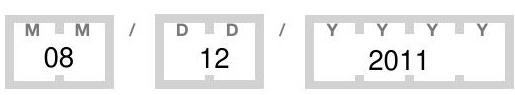

Subtotal Of Receipts This Page (optional).

849.00

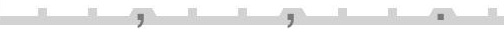

Total This Period (last page this line number only)
Amount of Each Receipt this Period

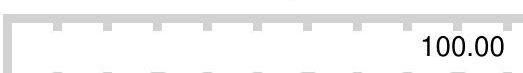

Transaction ID : AF39E41C5921946A3B0F Date of Receipt
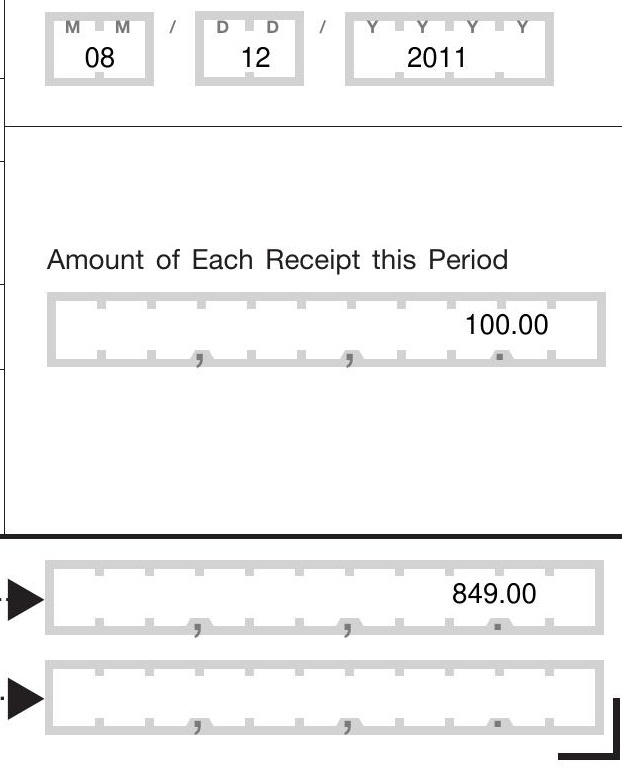

FEC Schedule A-P (Form 3P) (Rev. 03/2011) 
SCHEDULE A-P ITEMIZED RECEIPTS
Use separate schedule(s) for each category of the Detailed Summary Page
FOR LINE NUMBER: (check only one)

PAGE $260 / 1572$

\begin{tabular}{|c|c|c|c|c|c|}
\hline & & & & & \\
\hline 16 & $\begin{array}{l}\mathbf{X} \\
17 a\end{array}$ & $17 b$ & $17 c$ & $17 d$ & 18 \\
\hline $19 a$ & $19 \mathrm{~b}$ & $20 \mathrm{a}$ & $20 \mathrm{~b}$ & $20 \mathrm{c}$ & 21 \\
\hline
\end{tabular}

Any information copied from such Reports and Statements may not be sold or used by any person for the purpose of soliciting contributions or for commercial purposes, other than using the name and address of any political committee to solicit contributions from such committee.

NAME OF COMMITTEE (In Full)

\section{Friends of Herman Cain}

A. Full Name (Last, First, Middle Initial)

Lorine Schocknmyer

Mailing Address po box 12970

\begin{tabular}{lcc}
\hline City & State & Zip Code \\
Ogden & UT & $84412-2970$ \\
\hline
\end{tabular}

FEC ID number of contributing federal political committee.

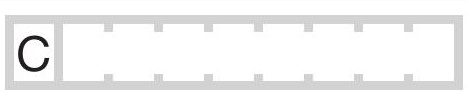

Name of Employer
Self Employed
Receipt For: 2012
X Primary $\quad$ General
Other (specify)

Occupation truck driver

Election Cycle-to-Date 285.00

B. Full Name (Last, First, Middle Initial) Mr Paul A Brock

Mailing Address 11 Juliana Ct

\begin{tabular}{lcc}
\hline City & State & Zip Code \\
Ellenwood & GA & $30294-2835$ \\
\hline
\end{tabular}

FEC ID number of contributing

federal political committee.

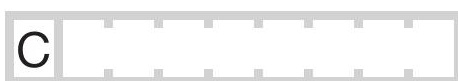

Name of Employer
None
Receipt For: 2012
X Primary $\quad$ General
Other (specify)

\section{Occupation}

Retired

Election Cycle-to-Date

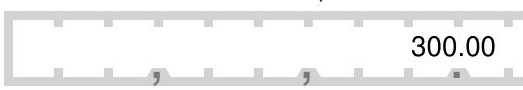

Transaction ID : AE1E46DA1684C4FEC966

Date of Receipt

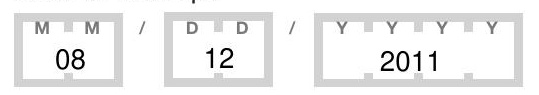

Amount of Each Receipt this Period

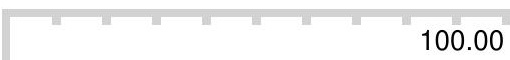

Transaction ID : A2367862A01DD4CE48CB

Date of Receipt

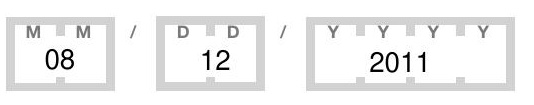

Amount of Each Receipt this Period

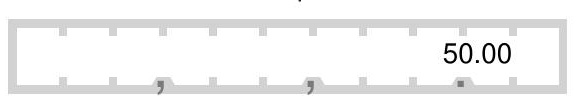

Transaction ID : A84FC3AC6CB1540FA85F Date of Receipt

christina lipsey

Mailing Address 1219 libby rd

\begin{tabular}{lcc}
\hline City & State & Zip Code \\
Heber Springs & AR & $72543-8985$
\end{tabular}

FEC ID number of contributing federal political committee.

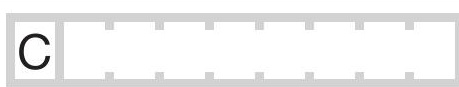

Name of Employer
little rock scool distrct
Receipt For: 2012
X Primary
Other (specify) General

Occupation

Teacher

Election Cycle-to-Date

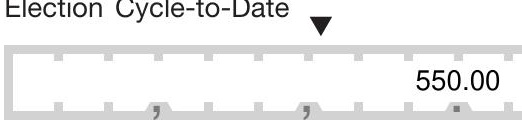

Subtotal Of Receipts This Page (optional)

350.00

Amount of Each Receipt this Period

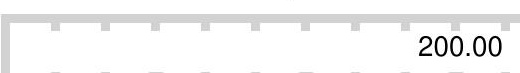

Total This Period (last page this line number only) 


\section{SCHEDULE A-P} ITEMIZED RECEIPTS
Use separate schedule(s) for each category of the Detailed Summary Page

\begin{tabular}{|c|c|c|c|c|c|}
\hline \multicolumn{3}{|c|}{$\begin{array}{l}\text { FOR LINE NUMBER: } \\
\text { (check only one) }\end{array}$} & \multicolumn{3}{|c|}{ PAGE 261 / 1572} \\
\hline 16 & $X$ 17a & $17 b$ & $17 \mathrm{c}$ & $17 d$ & 18 \\
\hline $19 a$ & $19 \mathrm{~b}$ & $20 a$ & $20 \mathrm{~b}$ & $20 c$ & 21 \\
\hline
\end{tabular}

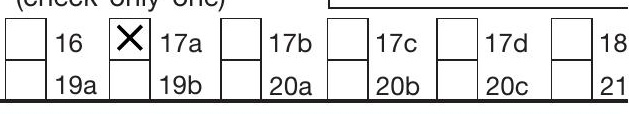

Any information copied from such Reports and Statements may not be sold or used by any person for the purpose of soliciting contributions or for commercial purposes, other than using the name and address of any political committee to solicit contributions from such committee.

NAME OF COMMITTEE (In Full)

\section{Friends of Herman Cain}

A. Full Name (Last, First, Middle Initial) CHANNING FREDERICK

Mailing Address 2485 HIGHWAY $460 \mathrm{E}$

\begin{tabular}{lcc}
\hline City & State & Zip Code \\
West Liberty & KY & $41472-8248$ \\
\hline
\end{tabular}

FEC ID number of contributing federal political committee.

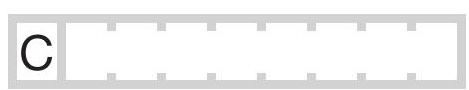

Name of Employer
FOOTHILLS CONTRACTING LLC
Receipt For: 2012
X Primary
Other (specify)

Occupation FOOTHILLS CONTRACTING LLC

Election Cycle-to-Date $\boldsymbol{\nabla}$

\subsection{0}

B. Full Name (Last, First, Middle Initial)

Richard Adelizzi

Mailing Address 291 Glendale Rd

\begin{tabular}{lcc}
\hline City & State & Zip Code \\
Upper Darby & PA & $19082-4017$
\end{tabular}

FEC ID number of contributing

federal political committee.

C

Name of Employer
Information Requested
Receipt For: 2012
Primary
Other (specify)

Occupation

Information Requested

Election Cycle-to-Date

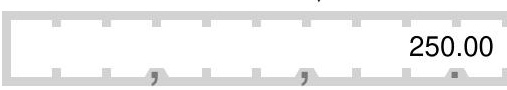

C. Full Name (Last, First, Middle Initial)

Martha Perrine

Mailing Address 170 Shady Oak Lane SW

\begin{tabular}{lcc}
\hline City & State & Zip Code \\
Cartersville & GA & $30120-7465$
\end{tabular}

FEC ID number of contributing federal political committee.

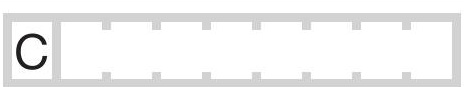

Name of Employer

Information Requested

\section{Occupation}

Information Requested

Receipt For: 2012

Х $\begin{aligned} & \text { Primary } \\ & \text { Other (specify) }\end{aligned}$

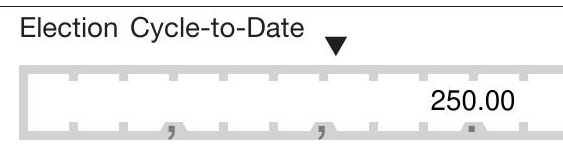

Amount of Each Receipt this Period

Transaction ID : A08DF8F4630034414883

Date of Receipt

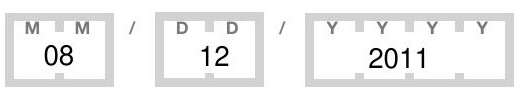

Amount of Each Receipt this Period
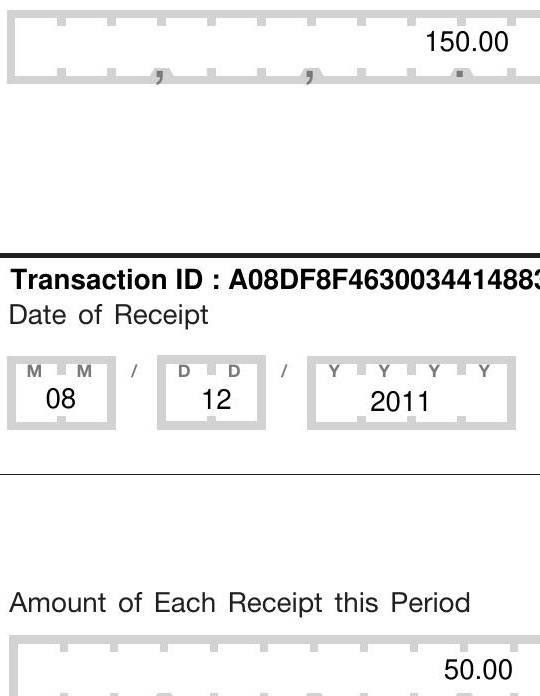

Transaction ID : AC6DB713B703B49DB8ED Date of Receipt

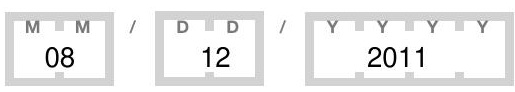

Amount of Each Receipt this Period

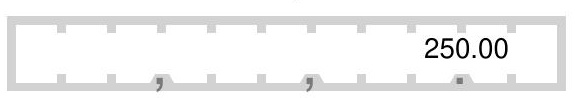

Subtotal Of Receipts This Page (optional).

450.00

Total This Period (last page this line number only) 
SCHEDULE A-P ITEMIZED RECEIPTS
Use separate schedule(s) for each category of the Detailed Summary Page
FOR LINE NUMBER: (check only one)

PAGE 262 / 1572

\begin{tabular}{|c|c|c|c|c|c|}
\hline & & & & & \\
\hline 16 & $\begin{array}{l}\mathbf{X} \\
17 a\end{array}$ & $17 b$ & $17 c$ & $17 d$ & 18 \\
\hline $19 a$ & $19 \mathrm{~b}$ & $20 \mathrm{a}$ & $20 \mathrm{~b}$ & $20 \mathrm{c}$ & 21 \\
\hline
\end{tabular}

Any information copied from such Reports and Statements may not be sold or used by any person for the purpose of soliciting contributions or for commercial purposes, other than using the name and address of any political committee to solicit contributions from such committee.

NAME OF COMMITTEE (In Full)

\section{Friends of Herman Cain}

A. Full Name (Last, First, Middle Initial)

Gary Locke

Mailing Address 2602 Booger Hill Road

\begin{tabular}{lcc}
\hline City & State & Zip Code \\
Danielsville & GA & $30633-6102$
\end{tabular}

FEC ID number of contributing federal political committee.

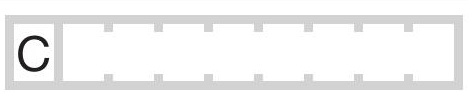

Name of Employer
None
Receipt For: 2012
X Primary $\quad$ General
Other (specify)

Occupation

Retired

Election Cycle-to-Date

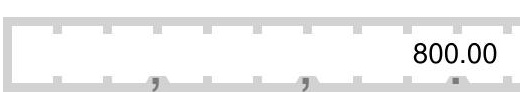

B. Full Name (Last, First, Middle Initial)

Jody Lepore

Mailing Address 6293 S. 2525 W.

\begin{tabular}{lcc}
\hline City & State & Zip Code \\
Salt Lake City & UT & $84129-7260$
\end{tabular}

FEC ID number of contributing

federal political committee.

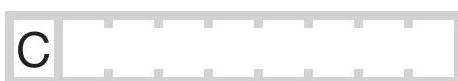

Name of Employer
Not Employed
Receipt For: 2012
X Primary
Other (specify)

\section{Occupation}

Not Employed

Election Cycle-to-Date

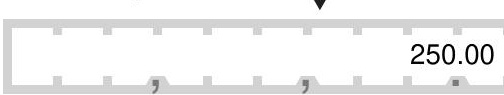

C. Full Name (Last, First, Middle Initial)

David Kilcy

Mailing Address 119 Maximillian Ct SW

\begin{tabular}{lcc}
\hline City & State & Zip Code \\
Leesburg & VA & $20175-2711$
\end{tabular}

FEC ID number of contributing federal political committee.

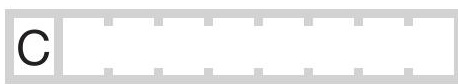

Name of Employer

Transaction Network Services Inc

Receipt For: 2012

Х $\begin{aligned} & \text { Primary } \\ & \text { Other (specify) }\end{aligned}$

Occupation

Senior Systems Developer

Election Cycle-to-Date
Transaction ID : A4D52B93C09604250AE6

Date of Receipt

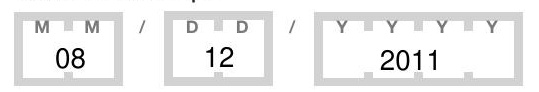

Amount of Each Receipt this Period

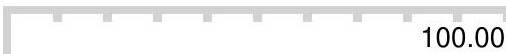

100.00

Amount of Each Receipt this Period

Transaction ID : AE9F7B972B33147A390D

Date of Receipt
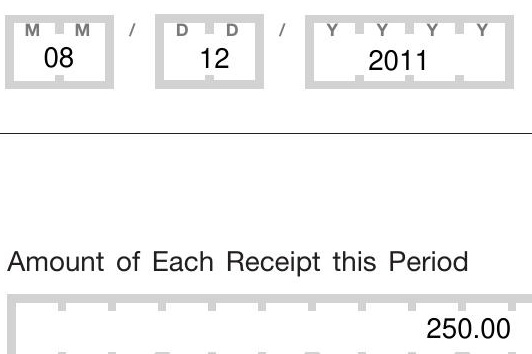

Transaction ID : A37B8BFEADA4B400B8ED Date of Receipt

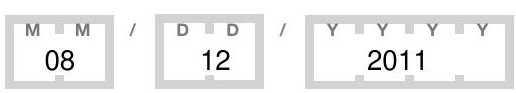

Amount of Each Receipt this Period

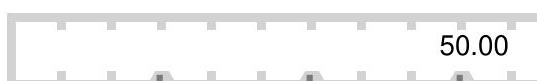

245.00

Subtotal Of Receipts This Page (optional)

400.00

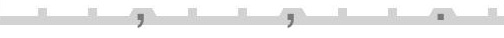

Total This Period (last page this line number only)

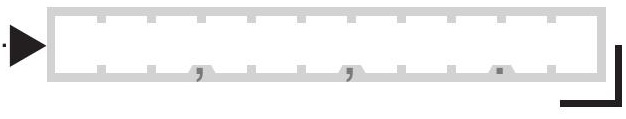

FEC Schedule A-P (Form 3P) (Rev. 03/2011) 
SCHEDULE A-P ITEMIZED RECEIPTS
Use separate schedule(s) for each category of the Detailed Summary Page
FOR LINE NUMBER: (check only one)

PAGE 263 / 1572

\begin{tabular}{|c|c|c|c|c|c|}
\hline & & & & & \\
\hline 16 & $\mathbf{X} 17 a$ & $17 b$ & $17 c$ & $17 d$ & 18 \\
\hline $19 a$ & $19 b$ & $20 \mathrm{a}$ & $20 \mathrm{~b}$ & $20 \mathrm{c}$ & 21 \\
\hline
\end{tabular}

Any information copied from such Reports and Statements may not be sold or used by any person for the purpose of soliciting contributions or for commercial purposes, other than using the name and address of any political committee to solicit contributions from such committee.

NAME OF COMMITTEE (In Full)

\section{Friends of Herman Cain}

A. Full Name (Last, First, Middle Initial)

Claudia Tavares

Mailing Address 1085 Fieldstone Rd

\begin{tabular}{lcc}
\hline City & State & Zip Code \\
Grovetown & GA & $30813-4821$
\end{tabular}

FEC ID number of contributing federal political committee.

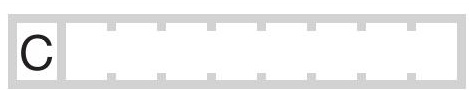

Name of Employer
Retired
Receipt For: 2012
X Primary $\quad$ General
Other (specify)

Occupation Retired

Election Cycle-to-Date

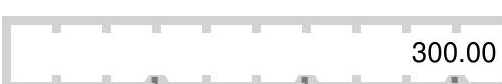

B. Full Name (Last, First, Middle Initial)

Mary Romans

Mailing Address 5012 Trinity Landing Dr W

\begin{tabular}{lcc}
\hline City & State & Zip Code \\
Fort Worth & TX & $76132-3736$
\end{tabular}

FEC ID number of contributing

federal political committee.

C

Name of Employer
Self Employed
Receipt For: 2012
X Primary
Other (specify)

Occupation

Physician

Election Cycle-to-Date

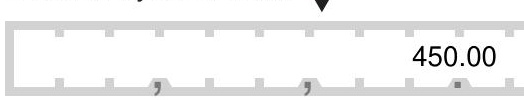

Transaction ID : A1BC0EE942F6D4B34AEA

Date of Receipt

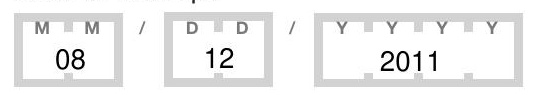

Amount of Each Receipt this Period

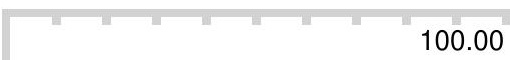

Amount of Each Receipt this Period

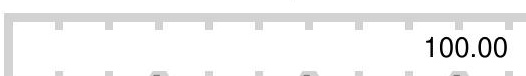

C. Full Name (Last, First, Middle Initial)

Cathy Spivey

Mailing Address 5041 Liberty Rd

\begin{tabular}{lcc}
\hline City & State & Zip Code \\
Villa Rica & GA & $30180-3187$
\end{tabular}

FEC ID number of contributing federal political committee.

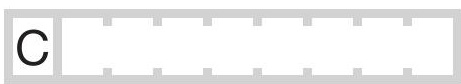

Name of Employer
self
Receipt For: 2012
X Primary $\quad \square$ General
Other (specify)

Occupation

Real Estate Appraiser

Election Cycle-to-Date
Transaction ID : AA701B777491E4B4CB2D Date of Receipt

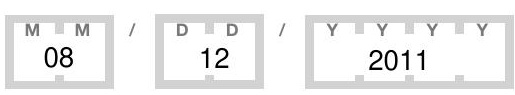

Amount of Each Receipt this Period

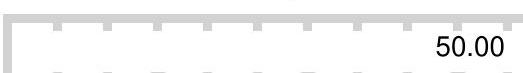

Subtotal Of Receipts This Page (optional)

Transaction ID : A043EF0391E8C445EB08 Date of Receipt

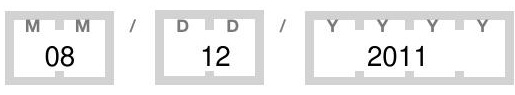

Total This Period (last page this line number only)

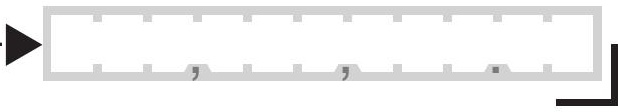


SCHEDULE A-P ITEMIZED RECEIPTS
Use separate schedule(s) for each category of the Detailed Summary Page
FOR LINE NUMBER: (check only one)

PAGE 264 / 1572

\begin{tabular}{|c|c|c|c|c|c|}
\hline & & & & & \\
\hline 16 & $\begin{array}{l}\mathbf{X} \\
17 a\end{array}$ & $17 b$ & $17 c$ & $17 d$ & 18 \\
\hline $19 a$ & $19 \mathrm{~b}$ & $20 \mathrm{a}$ & $20 \mathrm{~b}$ & $20 \mathrm{c}$ & 21 \\
\hline
\end{tabular}

Any information copied from such Reports and Statements may not be sold or used by any person for the purpose of soliciting contributions or for commercial purposes, other than using the name and address of any political committee to solicit contributions from such committee.

NAME OF COMMITTEE (In Full)

\section{Friends of Herman Cain}

A. Full Name (Last, First, Middle Initial)

Patricia Dabbs

Mailing Address 1406 Reidsboro Rd

\begin{tabular}{lcc}
\hline City & State & Zip Code \\
Williamson & GA & $30292-3463$
\end{tabular}

FEC ID number of contributing federal political committee.

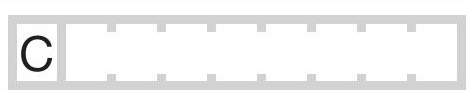

Name of Employer
Information Requested
Receipt For: 2012
X Primary
Other (specify) General

Occupation Information Requested

Election Cycle-to-Date

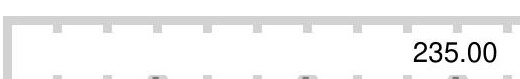

B. Full Name (Last, First, Middle Initial) John Hammond

Mailing Address 32490 River Road

\begin{tabular}{lcc}
\hline City & State & Zip Code \\
Millsboro & DE & $19966-2551$
\end{tabular}

FEC ID number of contributing

federal political committee.

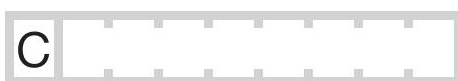

Name of Employer
Retired
Receipt For: 2012
X Primary
Other (specify)

\section{Occupation}

Retired

Election Cycle-to-Date

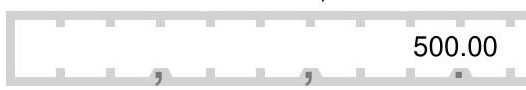

Transaction ID : A5F519BF24CAC49CCB61

Date of Receipt

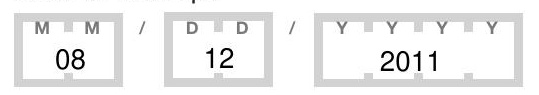

Amount of Each Receipt this Period

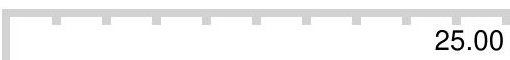

25.00

C. Full Name (Last, First, Middle Initial)

PHILLIP GRANQUIST

Mailing Address $13105 \mathrm{~W}$ Berridge Ct

\begin{tabular}{lcc}
\hline City & State & Zip Code \\
Litchfield Park & AZ & $85340-7328$
\end{tabular}

FEC ID number of contributing federal political committee.

C

Name of Employer
Retired
Receipt For: 2012
Х Primary $\square$ General
Other (specify)

Occupation

Retired

Election Cycle-to-Date

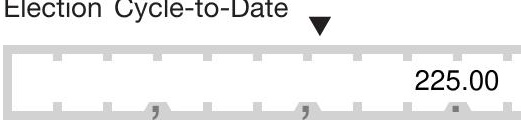

Transaction ID : A000E90BE5A044B42A72

Date of Receipt

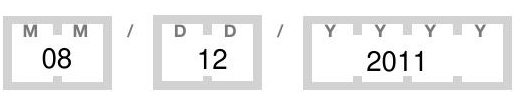

Amount of Each Receipt this Period

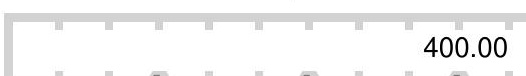

Transaction ID : A1166649513444760907

Date of Receipt

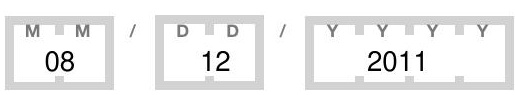

Amount of Each Receipt this Period

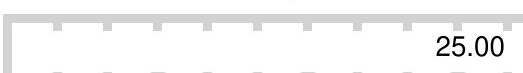

\section{Subtotal Of Receipts This Page (optional)}

Total This Period (last page this line number only) 
SCHEDULE A-P ITEMIZED RECEIPTS
Use separate schedule(s) for each category of the Detailed Summary Page
FOR LINE NUMBER: (check only one)

PAGE 265 / 1572

\begin{tabular}{|c|c|c|c|c|c|}
\hline & & & & & \\
\hline 16 & $\begin{array}{l}\mathbf{X} \\
17 a\end{array}$ & $17 b$ & $17 c$ & $17 d$ & 18 \\
\hline $19 a$ & $19 \mathrm{~b}$ & $20 \mathrm{a}$ & $20 \mathrm{~b}$ & $20 \mathrm{c}$ & 21 \\
\hline
\end{tabular}

Any information copied from such Reports and Statements may not be sold or used by any person for the purpose of soliciting contributions or for commercial purposes, other than using the name and address of any political committee to solicit contributions from such committee.

NAME OF COMMITTEE (In Full)

\section{Friends of Herman Cain}

A. Full Name (Last, First, Middle Initial)

\section{Brian Cox}

Mailing Address 4932 S Cherokee Ave

\begin{tabular}{lcc}
\hline City & State & Zip Code \\
Sierra Vista & AZ & $85650-8931$
\end{tabular}

FEC ID number of contributing federal political committee.

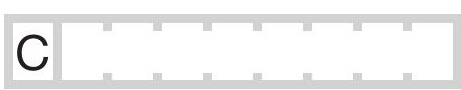

Name of Employer
Information Requested
Receipt For: 2012
X Primary
Other (specify) General

B. Full Name (Last, First, Middle Initial) John Bertel

Mailing Address 343 Vincent Ave

\begin{tabular}{lcc}
\hline City & State & Zip Code \\
Metairie & LA & $70005-4419$ \\
\hline
\end{tabular}

FEC ID number of contributing

federal political committee.

Name of Employer
Hayes Dockside Inc
Receipt For: 2012
X Primary
Other (specify)

C. Full Name (Last, First, Middle Initial)

Linda Smith

Mailing Address 133 Equinox $\mathrm{Dr}$

\begin{tabular}{lcc}
\hline City & State & Zip Code \\
Castle Rock & CO & $80108-9038$
\end{tabular}

FEC ID number of contributing federal political committee.

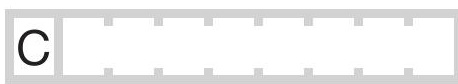

Name of Employer
Information Requested
Receipt For: 2012
X Primary $\quad \square$ General
Other (specify)

C

\section{Occupation} Information Requested

Election Cycle-to-Date

\section{Occupation}

Business Executive

Election Cycle-to-Date

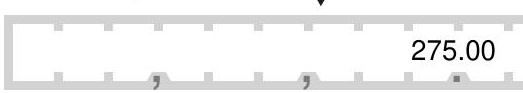

400.00
Information Requested

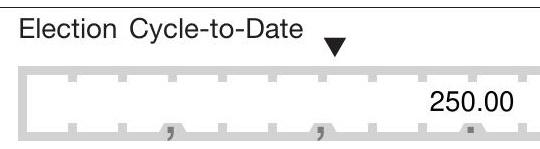

Transaction ID : AB719BA2D455F4677963

Date of Receipt

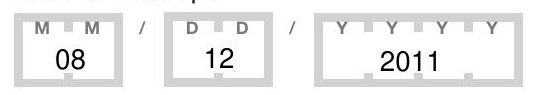

Amount of Each Receipt this Period

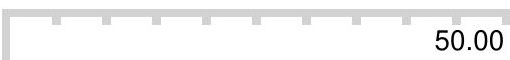

Transaction ID : A64931AC5F0724FE491F

Date of Receipt

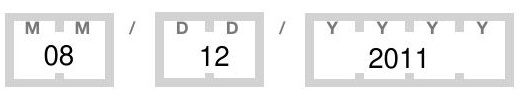

Amount of Each Receipt this Period

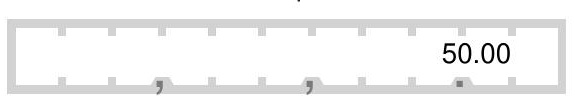

Transaction ID : A5129C6C73B2041C688B Date of Receipt

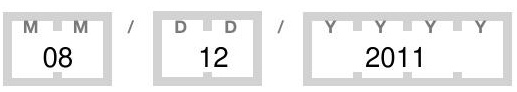

Amount of Each Receipt this Period

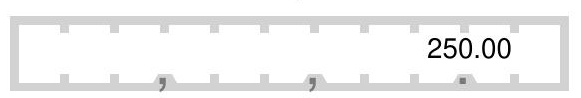

Subtotal Of Receipts This Page (optional)

350.00

a

Total This Period (last page this line number only)

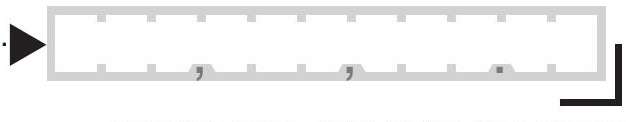

FEC Schedule A-P (Form 3P) (Rev. 03/2011) 
SCHEDULE A-P ITEMIZED RECEIPTS
Use separate schedule(s) for each category of the Detailed Summary Page
FOR LINE NUMBER: (check only one)

PAGE 266 / 1572

\begin{tabular}{|c|c|c|c|c|c|}
\hline & & & & & \\
\hline 16 & $\begin{array}{l}\mathbf{X} \\
17 a\end{array}$ & $17 b$ & $17 c$ & $17 d$ & 18 \\
\hline $19 a$ & $19 \mathrm{~b}$ & $20 \mathrm{a}$ & $20 \mathrm{~b}$ & $20 \mathrm{c}$ & 21 \\
\hline
\end{tabular}

Any information copied from such Reports and Statements may not be sold or used by any person for the purpose of soliciting contributions or for commercial purposes, other than using the name and address of any political committee to solicit contributions from such committee.

NAME OF COMMITTEE (In Full)

\section{Friends of Herman Cain}

A. Full Name (Last, First, Middle Initial)

Roy Rapp III

Mailing Address 2494 Leonard Rd

\begin{tabular}{lcc}
\hline City & State & Zip Code \\
Martinsville & IN & $46151-7759$
\end{tabular}

FEC ID number of contributing

federal political committee.

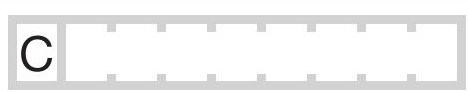

Name of Employer
Information Requested
Receipt For: 2012
X Primary $\quad \square$ General
$\square$ Other (specify)

Occupation

Information Requested

Election Cycle-to-Date

250.00

B. Full Name (Last, First, Middle Initial)

Robert Porter

Mailing Address 5710 Grand Reunion Dr

\begin{tabular}{lcc}
\hline City & State & Zip Code \\
Hoschton & GA & $30548-4045$
\end{tabular}

FEC ID number of contributing

federal political committee.

C

Name of Employer
Information Requested
Receipt For: 2012
X Primary
Other (specify)

Occupation

Information Requested

Election Cycle-to-Date

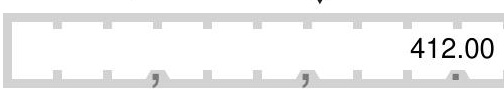

Transaction ID : A857EA109AF4D4A128B6

Date of Receipt

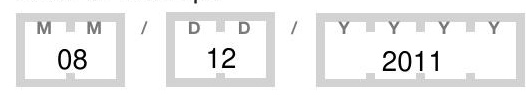

Amount of Each Receipt this Period

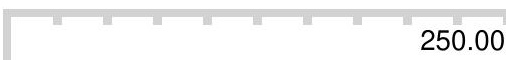

250.00

C. Full Name (Last, First, Middle Initial)

Clifford Cash

Mailing Address W172N7888 Shady Ln

\begin{tabular}{lcc}
\hline City & State & Zip Code \\
Menomonee Falls & WI & $53051-4172$
\end{tabular}

FEC ID number of contributing

federal political committee.

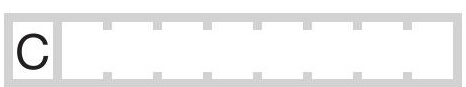

Name of Employer
Unemployed
Receipt For: 2012
X Primary $\quad \square$ General
Other (specify)

\section{Occupation}

architect

Election Cycle-to-Date

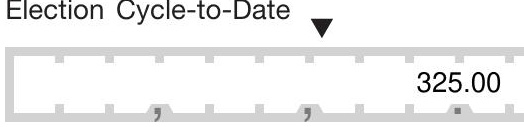

Transaction ID : A4493638E37D84339891

Date of Receipt

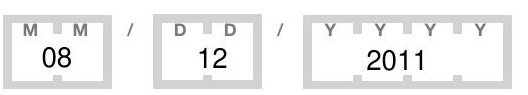

Amount of Each Receipt this Period

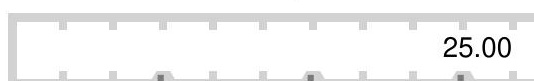

Transaction ID : AC1D49EE9CC864108973

Date of Receipt

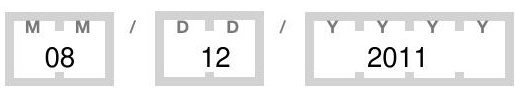

Amount of Each Receipt this Period

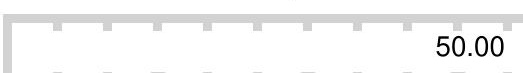

\section{Subtotal Of Receipts This Page (optional)}

Total This Period (last page this line number only) 
SCHEDULE A-P ITEMIZED RECEIPTS
Use separate schedule(s) for each category of the Detailed Summary Page
FOR LINE NUMBER: (check only one)

PAGE 267 / 1572

\begin{tabular}{|c|c|c|c|c|c|}
\hline & & & & & \\
\hline 16 & $\begin{array}{l}\mathbf{X} \\
17 a\end{array}$ & $17 b$ & $17 c$ & $17 d$ & 18 \\
\hline $19 a$ & $19 \mathrm{~b}$ & $20 \mathrm{a}$ & $20 \mathrm{~b}$ & $20 \mathrm{c}$ & 21 \\
\hline
\end{tabular}

Any information copied from such Reports and Statements may not be sold or used by any person for the purpose of soliciting contributions or for commercial purposes, other than using the name and address of any political committee to solicit contributions from such committee.

NAME OF COMMITTEE (In Full)

\section{Friends of Herman Cain}

A. Full Name (Last, First, Middle Initial)

Sylvia D Barnes

Mailing Address 75495 Road 436

\begin{tabular}{lcc}
\hline City & State & Zip Code \\
Lexington & NE & $68850-5638$ \\
\hline
\end{tabular}

FEC ID number of contributing federal political committee.

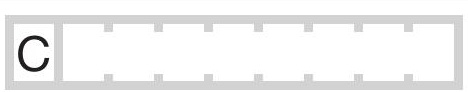

Name of Employer
None
Receipt For: 2012
X Primary $\quad$ General
Other (specify)

Occupation

Retired

Election Cycle-to-Date

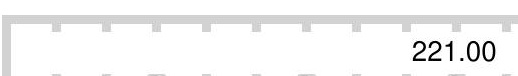

B. Full Name (Last, First, Middle Initial) richard clampitt

Mailing Address 7261 ashington dr

\begin{tabular}{lcc}
\hline City & State & Zip Code \\
Dallas & TX & $75225-1704$ \\
\hline
\end{tabular}

FEC ID number of contributing

federal political committee.

C

Name of Employer
red river paper
Receipt For: 2012
Primary
Other (specify)

Occupation

Executive

Election Cycle-to-Date

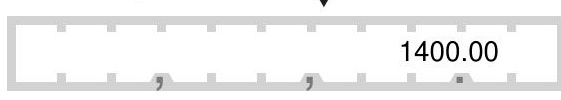

Transaction ID : A3AA3676B26AC4E34927

Date of Receipt

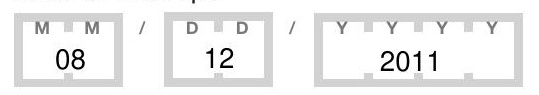

Amount of Each Receipt this Period

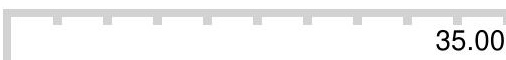

35.00

C. Full Name (Last, First, Middle Initial)

Tony Grady

Mailing Address 3364 Kingwood Forest Ln

\begin{tabular}{lcc}
\hline City & State & Zip Code \\
Beavercreek & OH & $45440-3648$
\end{tabular}

FEC ID number of contributing federal political committee.

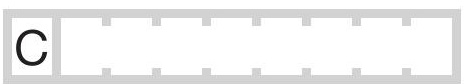

Name of Employer

Information Requested

\section{Occupation}

Information Requested

Receipt For: 2012

Х $\begin{aligned} & \text { Primary } \square \text { General } \\ & \text { Other (specify) }\end{aligned}$

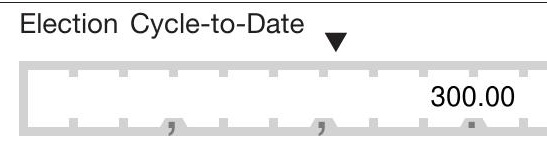

Amount of Each Receipt this Period

Transaction ID : AF26C51639E094D2C85A

Date of Receipt
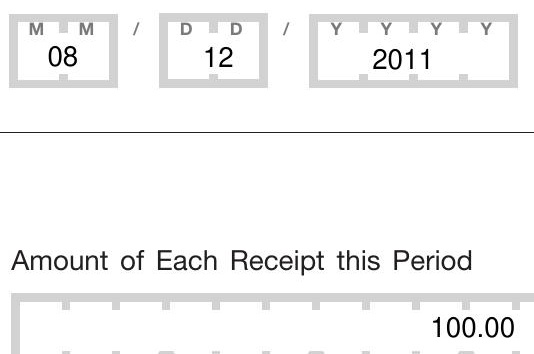

Transaction ID : A1529DF5DFA28400AAB0 Date of Receipt

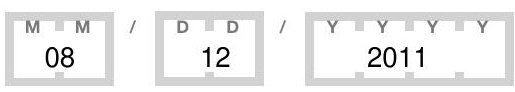

Amount of Each Receipt this Period

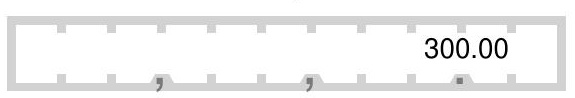

\section{Subtotal Of Receipts This Page (optional)}

Total This Period (last page this line number only) 
SCHEDULE A-P ITEMIZED RECEIPTS
Use separate schedule(s) for each category of the Detailed Summary Page
FOR LINE NUMBER: (check only one)

PAGE $268 / 1572$

\begin{tabular}{|c|c|c|c|c|c|}
\hline & & & & & \\
\hline 16 & $\begin{array}{l}\mathbf{X} \\
17 a\end{array}$ & $17 b$ & $17 c$ & $17 d$ & 18 \\
\hline $19 a$ & $19 \mathrm{~b}$ & $20 \mathrm{a}$ & $20 \mathrm{~b}$ & $20 \mathrm{c}$ & 21 \\
\hline
\end{tabular}

Any information copied from such Reports and Statements may not be sold or used by any person for the purpose of soliciting contributions or for commercial purposes, other than using the name and address of any political committee to solicit contributions from such committee.

NAME OF COMMITTEE (In Full)

\section{Friends of Herman Cain}

A. Full Name (Last, First, Middle Initial)

Taz Anderson Jr

Mailing Address 2931 Paces Ferry Rd SE

\begin{tabular}{lcc}
\hline City & State & Zip Code \\
Atlanta & GA & $30339-3732$
\end{tabular}

FEC ID number of contributing federal political committee.

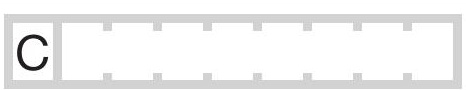

Name of Employer
Taz Anderson Realty Co
Receipt For: 2012
X Primary
Other (specify)

Occupation

Real Estate Developer

Election Cycle-to-Date

350.00

B. Full Name (Last, First, Middle Initial)

Sharon Terrell

Mailing Address 11471 Brown Bridge Road

\begin{tabular}{lcc}
\hline City & State & Zip Code \\
Monroe & GA & 30655 \\
\hline
\end{tabular}

FEC ID number of contributing

federal political committee.

C

Name of Employer

Athens Regional Medical Center

Occupation

Receipt For: 2012

Х $\begin{aligned} & \text { Primary } \\ & \text { Other (specify) }\end{aligned}$

Registered Nurse

Election Cycle-to-Date

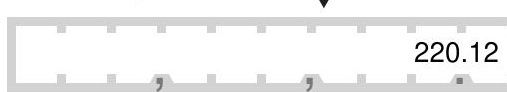

C. Full Name (Last, First, Middle Initial)

Gail L Crane

Mailing Address 4205 Oren Ave

\begin{tabular}{lcc}
\hline City & State & Zip Code \\
Corning & CA & $96021-9647$
\end{tabular}

FEC ID number of contributing federal political committee.

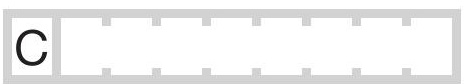

Name of Employer

Walgreens Infusion Services

Receipt For: 2012

Х $\begin{aligned} & \text { Primary } \square \text { General } \\ & \text { Other (specify) }\end{aligned}$

Occupation

Administrative Assistant

Election Cycle-to-Date
Transaction ID : AB94B960CB1A34542B9C

Date of Receipt

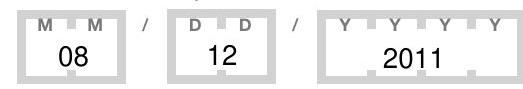

Amount of Each Receipt this Period

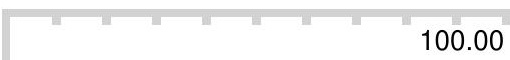

100.00

Transaction ID : A15446CD55876445CA7A

Date of Receipt

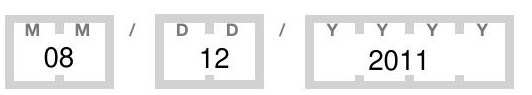

Amount of Each Receipt this Period

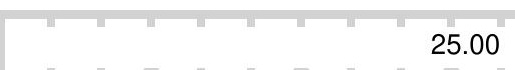

Transaction ID : A64D99733D178498F8FE

Date of Receipt

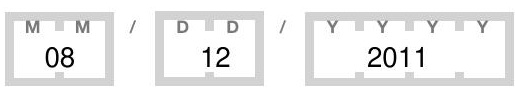

Amount of Each Receipt this Period

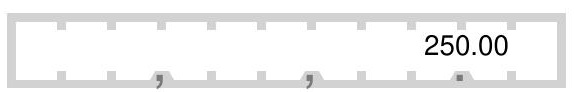

250.00

Subtotal Of Receipts This Page (optional)

Total This Period (last page this line number only)
375.00

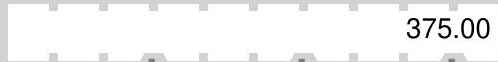

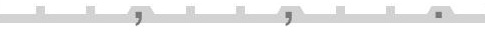

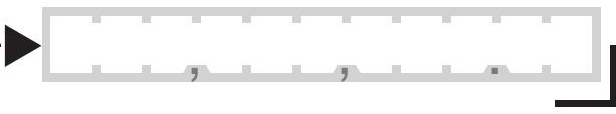

FEC Schedule A-P (Form 3P) (Rev. 03/2011) 
SCHEDULE A-P ITEMIZED RECEIPTS
Use separate schedule(s)

for each category of the

Detailed Summary Page
FOR LINE NUMBER: (check only one)

Any information copied from such Repor or for commercial purposes, other than using the name and address of any political committee to solicit contributions from such committee.

NAME OF COMMITTEE (In Full)

\section{Friends of Herman Cain}

A. Full Name (Last, First, Middle Initial)

Robert Weeks

Mailing Address 13900 60th Ave N

\begin{tabular}{lcc}
\hline City & State & Zip Code \\
Minneapolis & MN & $55446-3522$
\end{tabular}

FEC ID number of contributing

federal political committee.

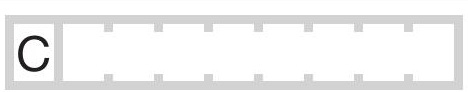

Name of Employer
Information Requested
Receipt For: 2012
X Primary $\quad \square$ General
Other (specify)

Occupation

Information Requested

Election Cycle-to-Date

250.00

B. Full Name (Last, First, Middle Initial)

Glen Ebbing

Mailing Address 1400 Huntleigh Rd

\begin{tabular}{lcc}
\hline City & State & Zip Code \\
Quincy & IL & $62305-6017$
\end{tabular}

FEC ID number of contributing

federal political committee.

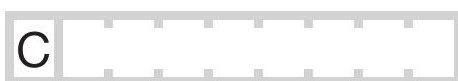

Name of Employer
ColorMaster Pain Inc
Receipt For: 2012
X Primary
Other (specify)

Occupation

sales representative

Election Cycle-to-Date

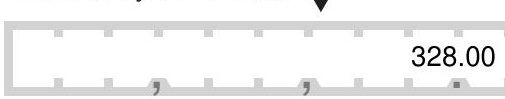

C. Full Name (Last, First, Middle Initial)

pamela bensen

Mailing Address 132 egret lane

\begin{tabular}{lcc}
\hline City & State & Zip Code \\
Buffalo Junction & VA & $24529-3505$
\end{tabular}

FEC ID number of contributing federal political committee.

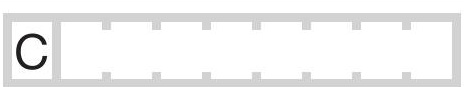

Name of Employer

Information Requested

\section{Occupation}

Information Requested

Receipt For: 2012

Х $\begin{aligned} & \text { Primary } \square \text { General } \\ & \text { Other (specify) }\end{aligned}$

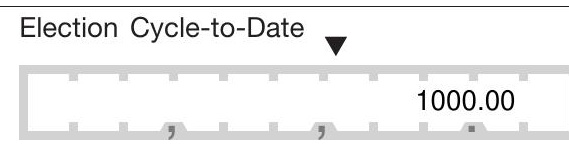

Amount of Each Receipt this Period

Transaction ID : AD5FCEABA497443BC83C Date of Receipt

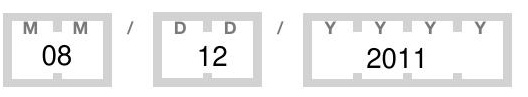

Amount of Each Receipt this Period
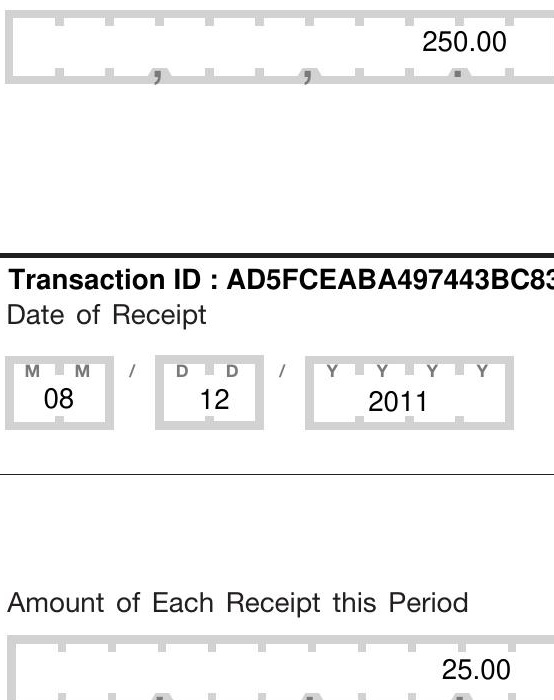

Transaction ID : AAF749066557B4EEB827

Date of Receipt

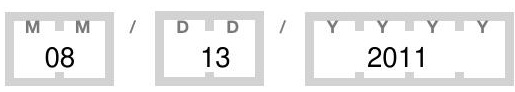

Amount of Each Receipt this Period

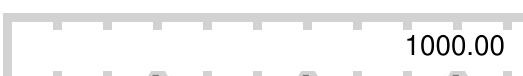

1275.00

Subtotal Of Receipts This Page (optional)

Total This Period (last page this line number only) 
SCHEDULE A-P ITEMIZED RECEIPTS
Use separate schedule(s) for each category of the Detailed Summary Page
FOR LINE NUMBER: (check only one)

PAGE $270 / 1572$

\begin{tabular}{|c|c|c|c|c|c|}
\hline & & & & & \\
\hline 16 & $\begin{array}{l}\mathbf{X} \\
17 a\end{array}$ & $17 b$ & $17 c$ & $17 d$ & 18 \\
\hline $19 a$ & $19 \mathrm{~b}$ & $20 \mathrm{a}$ & $20 \mathrm{~b}$ & $20 \mathrm{c}$ & 21 \\
\hline
\end{tabular}

Any information copied from such Reports and Statements may not be sold or used by any person for the purpose of soliciting contributions or for commercial purposes, other than using the name and address of any political committee to solicit contributions from such committee.

NAME OF COMMITTEE (In Full)

\section{Friends of Herman Cain}

A. Full Name (Last, First, Middle Initial)

Vikki Brown

Mailing Address 391 Leeches Rd

\begin{tabular}{lcc}
\hline City & State & Zip Code \\
Ellijay & GA & $30540-7354$ \\
\hline
\end{tabular}

FEC ID number of contributing federal political committee.

Name of Employer
AT\&T
Receipt For: 2012
X Primary $\quad$ General
Other (specify)

B. Full Name (Last, First, Middle Initial)

Kelly Keener

Mailing Address 2888 OShields Ct

\begin{tabular}{lcc}
\hline City & State & Zip Code \\
Marietta & GA & $30060-6378$ \\
\hline
\end{tabular}

FEC ID number of contributing

federal political committee.

Name of Employer
Information Requested
Receipt For: 2012
X Primary
Other (specify)

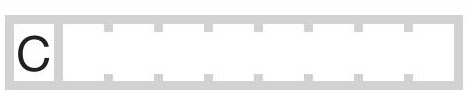

\section{Occupation}

Intellectual Property Specialist

Election Cycle-to-Date $\boldsymbol{\nabla}$

\subsection{0}

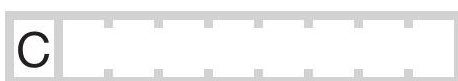

\section{Occupation}

Information Requested

Election Cycle-to-Date

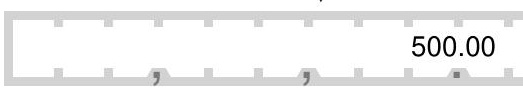

Transaction ID : AE7C742C3C83E4D889C2

Date of Receipt

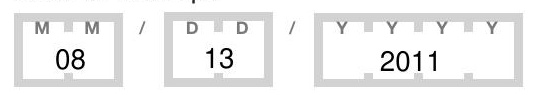

Amount of Each Receipt this Period

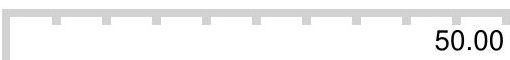

50.00

Transaction ID : A83483719FE694BB1926

Date of Receipt

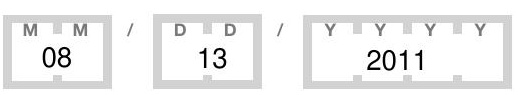

Amount of Each Receipt this Period

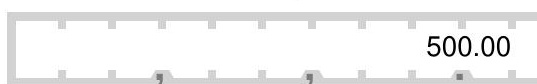

Transaction ID : A3F0FFEAD702B407A85F Date of Receipt

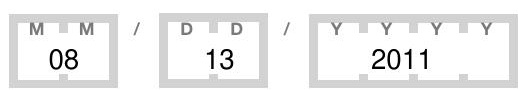

Amount of Each Receipt this Period

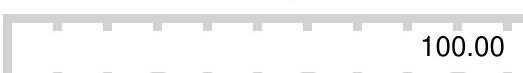

Computer Programmer

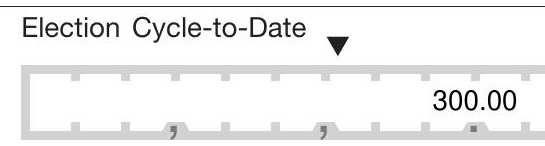

Subtotal Of Receipts This Page (optional)

650.00

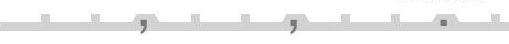

Total This Period (last page this line number only)

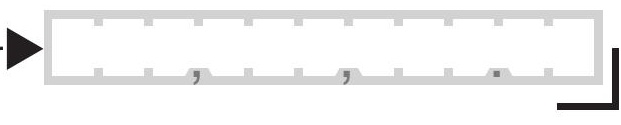

FEC Schedule A-P (Form 3P) (Rev. 03/2011) 
SCHEDULE A-P ITEMIZED RECEIPTS
Use separate schedule(s) for each category of the Detailed Summary Page
FOR LINE NUMBER: (check only one)

PAGE $271 / 1572$

\begin{tabular}{|c|c|c|c|c|c|}
\hline & & & & & \\
\hline 16 & $\begin{array}{l}\mathbf{X} \\
17 a\end{array}$ & $17 b$ & $17 c$ & $17 d$ & 18 \\
\hline $19 a$ & $19 \mathrm{~b}$ & $20 \mathrm{a}$ & $20 \mathrm{~b}$ & $20 \mathrm{c}$ & 21 \\
\hline
\end{tabular}

Any information copied from such Reports and Statements may not be sold or used by any person for the purpose of soliciting contributions or for commercial purposes, other than using the name and address of any political committee to solicit contributions from such committee.

NAME OF COMMITTEE (In Full)

\section{Friends of Herman Cain}

A. Full Name (Last, First, Middle Initial)

\section{Susan Walter}

Mailing Address P.O. Box 690

\begin{tabular}{lcc}
\hline City & State & Zip Code \\
Sautee Nacoochee & GA & $30571-0690$
\end{tabular}

FEC ID number of contributing federal political committee.

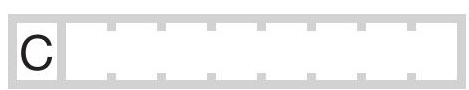

\begin{tabular}{l} 
Name of Employer \\
None \\
Receipt For: 2012 \\
X Primary $\quad$ General \\
\hline Other (specify)
\end{tabular}

Occupation Retired

Election Cycle-to-Date

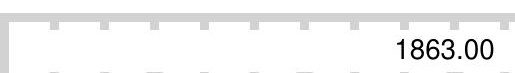

B. Full Name (Last, First, Middle Initial)

Tim Blevins

Mailing Address 3432 Conley Downs Drive

\begin{tabular}{lcc}
\hline City & State & Zip Code \\
Powder Springs & GA & $30127-1199$ \\
\hline
\end{tabular}

FEC ID number of contributing

federal political committee.

C

Name of Employer
The Coca-Cola Company
Receipt For: 2012
X Primary
Other (specify)

Occupation

Learning \& Development

Election Cycle-to-Date

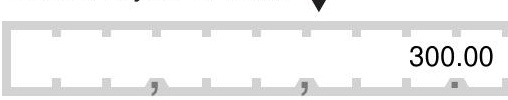

Transaction ID : AE34D44667F804B0FA67

Date of Receipt

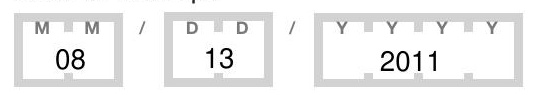

Amount of Each Receipt this Period

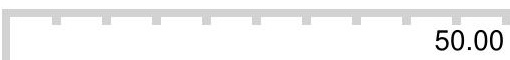

50.00

C. Full Name (Last, First, Middle Initial)

William Tuxhorn

Mailing Address 3132 Maginn $\mathrm{Dr}$

\begin{tabular}{lcc}
\hline City & State & Zip Code \\
Beavercreek & $\mathrm{OH}$ & $45434-5863$
\end{tabular}

FEC ID number of contributing federal political committee.

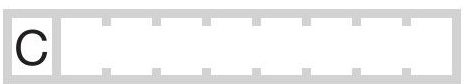

Name of Employer
Not Applicable
Receipt For: 2012
X Primary $\quad \square$ General
Other (specify)

\section{Occupation}

Retired

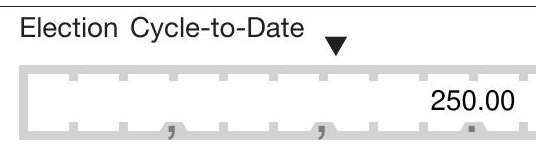

Transaction ID : AE42EC37DEAB5420E913 Date of Receipt

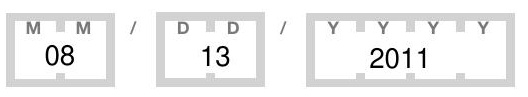

Amount of Each Receipt this Period

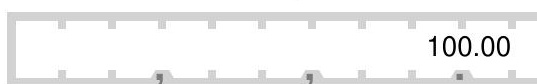

Transaction ID : A382885ABF5334EE2A11 Date of Receipt

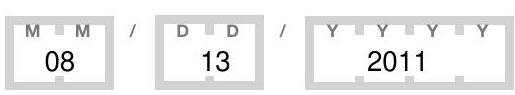

Amount of Each Receipt this Period

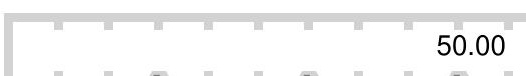

\section{Subtotal Of Receipts This Page (optional)}

Total This Period (last page this line number only) 
SCHEDULE A-P ITEMIZED RECEIPTS
Use separate schedule(s) for each category of the Detailed Summary Page
FOR LINE NUMBER: (check only one)

PAGE 272 / 1572

\begin{tabular}{|c|c|c|c|c|c|}
\hline & & & & & \\
\hline 16 & $\begin{array}{l}\mathbf{X} \\
17 a\end{array}$ & $17 b$ & $17 c$ & $17 d$ & 18 \\
\hline $19 a$ & $19 \mathrm{~b}$ & $20 \mathrm{a}$ & $20 \mathrm{~b}$ & $20 \mathrm{c}$ & 21 \\
\hline
\end{tabular}

Any information copied from such Reports and Statements may not be sold or used by any person for the purpose of soliciting contributions or for commercial purposes, other than using the name and address of any political committee to solicit contributions from such committee.

NAME OF COMMITTEE (In Full)

\section{Friends of Herman Cain}

A. Full Name (Last, First, Middle Initial)

\section{Dennis Friend}

Mailing Address 1716 W Lake Dr

\begin{tabular}{lcc}
\hline City & State & Zip Code \\
Gladewater & TX & $75647-3210$ \\
\hline
\end{tabular}

FEC ID number of contributing federal political committee.

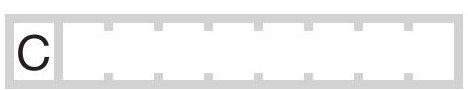

Name of Employer

Maverick Technical Systems, Inc.

Occupation

Engineer

Receipt For: 2012

X Primary $\square$ General Other (specify)

Election Cycle-to-Date

250.00

B. Full Name (Last, First, Middle Initial)

Sarajane Jablinske

Mailing Address 95 Cartis Parker Road

\begin{tabular}{lcc}
\hline City & State & Zip Code \\
Alexander & NC & $28701-9772$
\end{tabular}

FEC ID number of contributing

federal political committee.

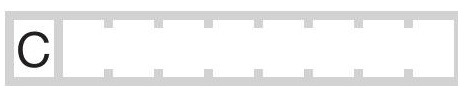

Name of Employer
Retired
Receipt For: 2012
X Primary
Other (specify)

\section{Occupation}

Retired

Election Cycle-to-Date

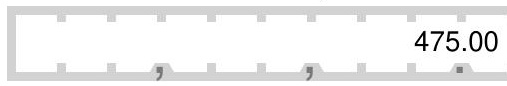

C. Full Name (Last, First, Middle Initial)

Robert Shive

Mailing Address 1080 Cherry Tree Rd.

\begin{tabular}{l|ll}
\hline $\begin{array}{l}\text { City } \\
\text { Saint Augustine }\end{array}$ & $\begin{array}{c}\text { State } \\
\text { FL }\end{array}$ & $\begin{array}{c}\text { Zip Code } \\
32086-5028\end{array}$ \\
\hline $\begin{array}{l}\text { FEC ID number of contributing } \\
\text { federal political committee. }\end{array}$ & C & \\
\hline $\begin{array}{l}\text { Name of Employer } \\
\text { None }\end{array}$ & $\begin{array}{l}\text { Occupation } \\
\text { Retired }\end{array}$ \\
\hline $\begin{array}{l}\text { Receipt For: } 2012 \\
\text { X } \begin{array}{l}\text { Primary } \\
\text { Other (specify) }\end{array}\end{array}$ & Election Cycle-to-Date & 700.00
\end{tabular}

Transaction ID : A8845A5B0558B4ACC817 Date of Receipt

Amount of Each Receipt this Period

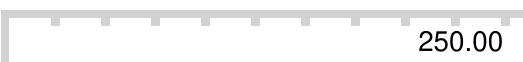

Date of Receipt
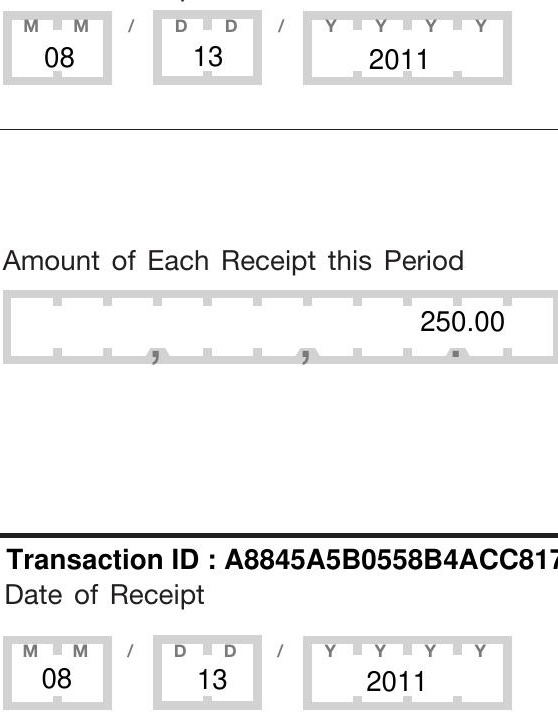

Amount of Each Receipt this Period

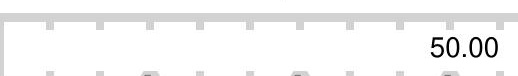

Amount of Each Receipt this Period

Transaction ID : A78CEA1E28FFC4D0BBDF Date of Receipt
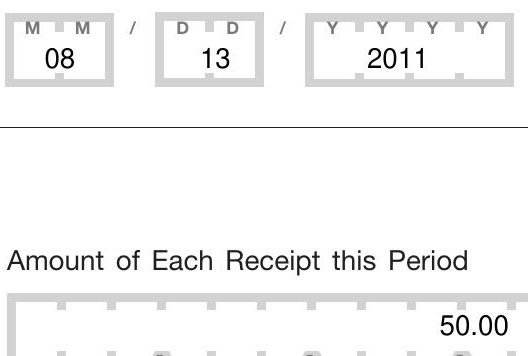

50.00

Subtotal Of Receipts This Page (optional)

Total This Period (last page this line number only) 
SCHEDULE A-P ITEMIZED RECEIPTS
Use separate schedule(s) for each category of the Detailed Summary Page
FOR LINE NUMBER: (check only one)

PAGE $273 / 1572$

\begin{tabular}{|c|c|c|c|c|c|c|}
\hline & & & & & & \\
\hline 16 & $\lambda$ & $17 \mathrm{a}$ & $17 \mathrm{~b}$ & $17 \mathrm{c}$ & $-17 d$ & -18 \\
\hline $19 a$ & & $19 b$ & $20 a$ & $20 \mathrm{~b}$ & $20 \mathrm{c}$ & 21 \\
\hline
\end{tabular}

Any information copied from such Reports and Statements may not be sold or used by any person for the purpose of soliciting contributions or for commercial purposes, other than using the name and address of any political committee to solicit contributions from such committee.

NAME OF COMMITTEE (In Full)

\section{Friends of Herman Cain}

A. Full Name (Last, First, Middle Initial)

Betty McRae

Mailing Address 8101 N 47th Street

\begin{tabular}{lcc}
\hline City & State & Zip Code \\
Paradise Valley & AZ & $85253-2907$ \\
\hline
\end{tabular}

FEC ID number of contributing federal political committee.

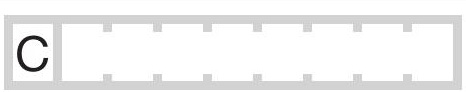

Name of Employer
Information Requested
Receipt For: 2012
X Primary
Other (specify) General

Occupation Information Requested

Election Cycle-to-Date

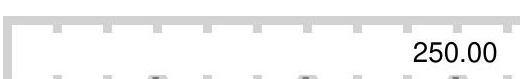

B. Full Name (Last, First, Middle Initial)

mary grech

Mailing Address 1984 lower bellbrook rd

\begin{tabular}{lcc}
\hline City & State & Zip Code \\
Xenia & OH & $45385-9313$ \\
\hline
\end{tabular}

FEC ID number of contributing

federal political committee.

C

Name of Employer
Information Requested
Receipt For: 2012
X Primary
Other (specify)

Occupation

Information Requested

Election Cycle-to-Date

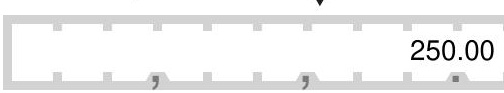

Transaction ID : A9A35633CDAC9474F911

Date of Receipt

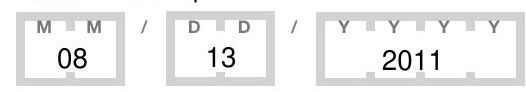

Amount of Each Receipt this Period

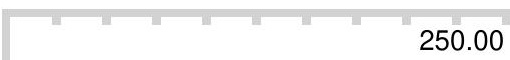

C. Full Name (Last, First, Middle Initial)

Debra ABney

Mailing Address 5829 Dekker Road

\begin{tabular}{lcc}
\hline City & State & Zip Code \\
Castle Hayne & NC & $28429-5227$
\end{tabular}

FEC ID number of contributing federal political committee.

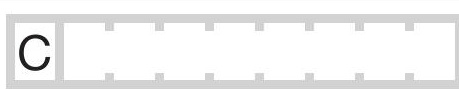

Name of Employer
None
Receipt For: 2012
X Primary $\quad \square$ General
Other (specify)

Occupation

Homemaker

Election Cycle-to-Date

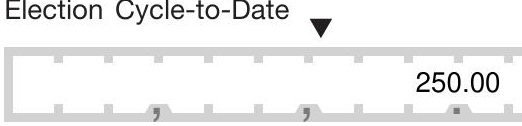

Amount of Each Receipt this Period

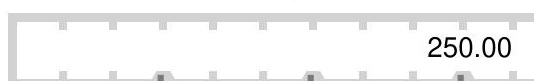

Transaction ID : A1ECA5124DE804BC298D Date of Receipt

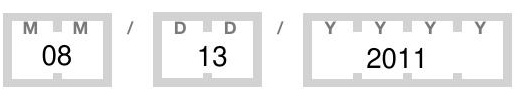

Transaction ID : AD748008A3A664D66904 Date of Receipt

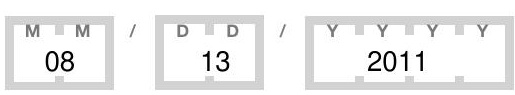

Amount of Each Receipt this Period

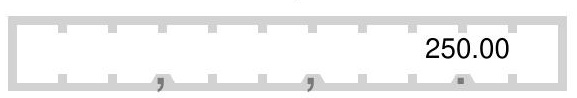

\section{Subtotal Of Receipts This Page (optional)}

Total This Period (last page this line number only) 
SCHEDULE A-P ITEMIZED RECEIPTS
Use separate schedule(s) for each category of the Detailed Summary Page
FOR LINE NUMBER: (check only one)

PAGE 274 / 1572

\begin{tabular}{|c|c|c|c|c|c|}
\hline & & & & & \\
\hline 16 & $\begin{array}{l}\mathbf{X} \\
17 a\end{array}$ & $17 b$ & $17 c$ & $17 d$ & 18 \\
\hline $19 a$ & $19 \mathrm{~b}$ & $20 \mathrm{a}$ & $20 \mathrm{~b}$ & $20 \mathrm{c}$ & 21 \\
\hline
\end{tabular}

Any information copied from such Reports and Statements may not be sold or used by any person for the purpose of soliciting contributions or for commercial purposes, other than using the name and address of any political committee to solicit contributions from such committee.

NAME OF COMMITTEE (In Full)

\section{Friends of Herman Cain}

A. Full Name (Last, First, Middle Initial)

Loretta Twiford

Mailing Address 215 MacGregor Drive

\begin{tabular}{lcc}
\hline City & State & Zip Code \\
Blue Ridge & VA & 24064-1566 \\
\hline
\end{tabular}

FEC ID number of contributing

federal political committee.

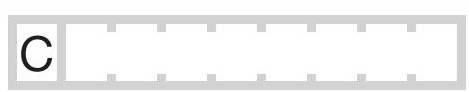

Name of Employer
n/a
Receipt For: 2012
X Primary $\quad$ General
Other (specify)

Occupation

Retired

Election Cycle-to-Date

245.00

B. Full Name (Last, First, Middle Initial)

John Gallagher

Mailing Address 3678 Janiero Rd

\begin{tabular}{lcc}
\hline City & State & Zip Code \\
Arapahoe & NC & $28510-9532$
\end{tabular}

FEC ID number of contributing

federal political committee.

C

Name of Employer
Pamlico Community College
Receipt For: 2012
X Primary
Other (specify)

Occupation

Teacher

Election Cycle-to-Date

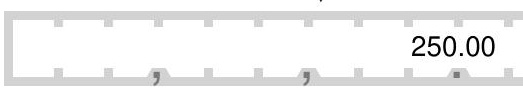

Transaction ID : A905F217861AB4016877

Date of Receipt

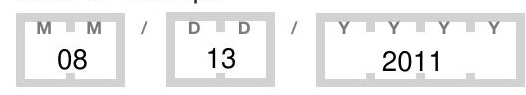

Amount of Each Receipt this Period

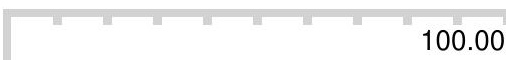

Amount of Each Receipt this Period

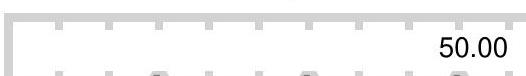

C. Full Name (Last, First, Middle Initial)

Joe Knoll

Mailing Address 2510 10th Ave

\begin{tabular}{lcc}
\hline City & State & Zip Code \\
Canyon & TX & $79015-5404$ \\
\hline
\end{tabular}

FEC ID number of contributing

federal political committee.

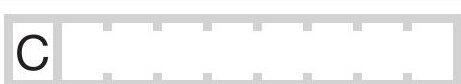

Name of Employer

AAA Electric Company

Occupation

Electrician

Receipt For: 2012

Х $\begin{aligned} & \text { Primary } \\ & \text { Other (specify) }\end{aligned}$

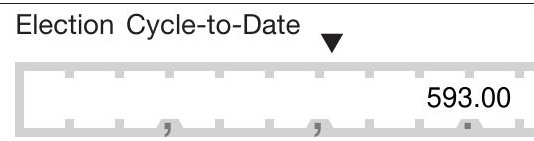

Amount of Each Receipt this Period

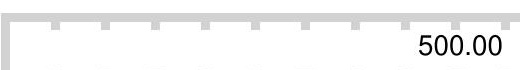

Transaction ID : A3A2B549093A4425BA06

Date of Receipt

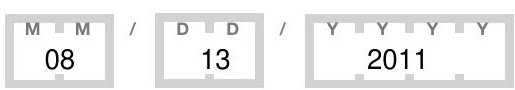

Subtotal Of Receipts This Page (optional)

650.00

Total This Period (last page this line number only) 
SCHEDULE A-P ITEMIZED RECEIPTS
Use separate schedule(s) for each category of the Detailed Summary Page
FOR LINE NUMBER: (check only one)

PAGE 275 / 1572

\begin{tabular}{|c|c|c|c|c|c|}
\hline & & & & & \\
\hline 16 & $\begin{array}{l}\mathbf{X} \\
17 a\end{array}$ & $17 b$ & $17 c$ & $17 d$ & 18 \\
\hline $19 a$ & $19 \mathrm{~b}$ & $20 \mathrm{a}$ & $20 \mathrm{~b}$ & $20 \mathrm{c}$ & 21 \\
\hline
\end{tabular}

Any information copied from such Reports and Statements may not be sold or used by any person for the purpose of soliciting contributions or for commercial purposes, other than using the name and address of any political committee to solicit contributions from such committee.

NAME OF COMMITTEE (In Full)

\section{Friends of Herman Cain}

A. Full Name (Last, First, Middle Initial) James Moyers

Mailing Address 2554 Reins Rd

\begin{tabular}{lcc}
\hline City & State & Zip Code \\
Beaumont & TX & $77713-3983$ \\
\hline
\end{tabular}

FEC ID number of contributing federal political committee.

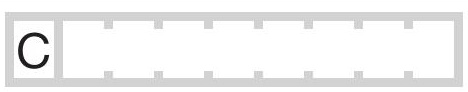

Name of Employer
Retired
Receipt For: 2012
X Primary $\quad \square$ General
$\square$ Other (specify)

Occupation Retired

Election Cycle-to-Date

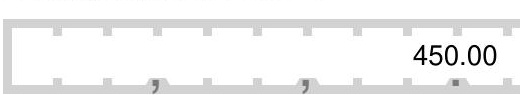

B. Full Name (Last, First, Middle Initial)

David Morris

\section{Mailing Address 7921 E 46th Street}

\begin{tabular}{lcc}
\hline City & State & Zip Code \\
Indianapolis & IN & $46226-3931$ \\
\hline
\end{tabular}

FEC ID number of contributing

federal political committee.

C

Name of Employer
Precision Dry Wall Inc.
Receipt For: 2012
X Primary
Other (specify)

\section{Occupation}

Construction

Election Cycle-to-Date

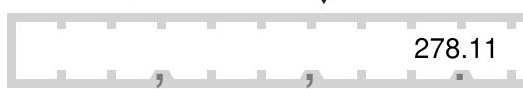

C. Full Name (Last, First, Middle Initial)

OTTO Lehrack

Mailing Address 11 Ridgeland Lane

\begin{tabular}{lcc}
\hline City & State & Zip Code \\
Asheville & NC & $28805-0001$
\end{tabular}

FEC ID number of contributing federal political committee.

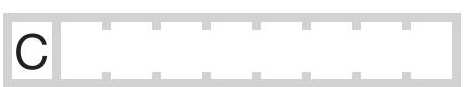

Name of Employer
None
Receipt For: 2012
Х Primary $\quad \square$ General
Other (specify)

Occupation

Retired

Election Cycle-to-Date

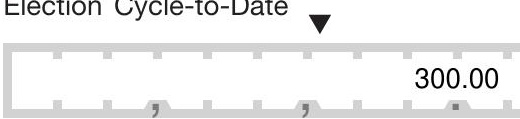

Transaction ID : AD46666D171904972B1D

Date of Receipt

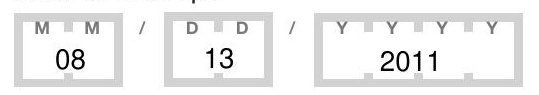

Amount of Each Receipt this Period

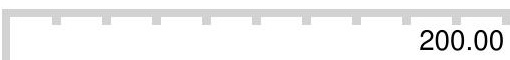

200.00
Amount of Each Receipt this Period

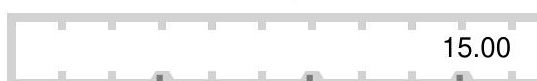

Transaction ID : A791EA4C4119C440086E Date of Receipt

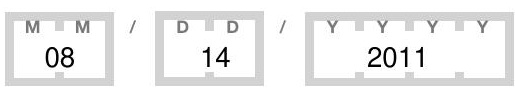

Amount of Each Receipt this Period

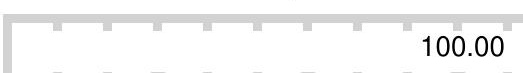

Transaction ID : AA78D3EB21E054FFE84E Date of Receipt
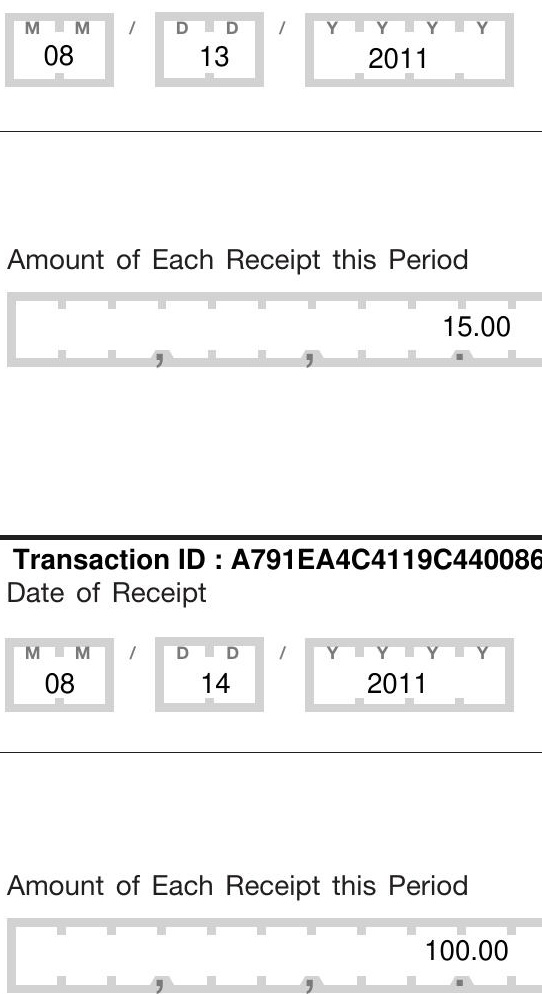

\section{Subtotal Of Receipts This Page (optional)}

315.00

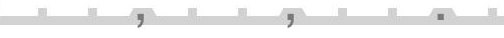

Total This Period (last page this line number only)

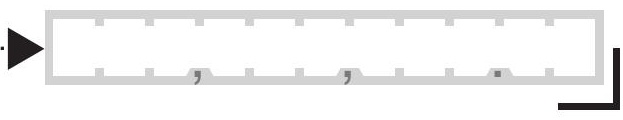


SCHEDULE A-P ITEMIZED RECEIPTS
Use separate schedule(s) for each category of the Detailed Summary Page
FOR LINE NUMBER: (check only one)

PAGE 276 / 1572

\begin{tabular}{|c|c|c|c|c|c|}
\hline & & & & & \\
\hline 16 & $\begin{array}{l}\mathbf{X} \\
17 a\end{array}$ & $17 b$ & $17 c$ & $17 d$ & 18 \\
\hline $19 a$ & $19 \mathrm{~b}$ & $20 \mathrm{a}$ & $20 \mathrm{~b}$ & $20 \mathrm{c}$ & 21 \\
\hline
\end{tabular}

Any information copied from such Reports and Statements may not be sold or used by any person for the purpose of soliciting contributions or for commercial purposes, other than using the name and address of any political committee to solicit contributions from such committee.

NAME OF COMMITTEE (In Full)

\section{Friends of Herman Cain}

A. Full Name (Last, First, Middle Initial)

Bob Hill

Mailing Address 12147 Caminito Mira Del Mar

\begin{tabular}{lcc}
\hline City & State & Zip Code \\
San Diego & CA & $92130-2302$ \\
\hline
\end{tabular}

FEC ID number of contributing

federal political committee.

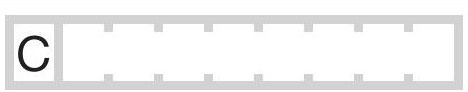

Name of Employer
Retired
Receipt For: 2012
X Primary $\quad$ General
Other (specify)

Occupation the man in charge

Election Cycle-to-Date 300.00

B. Full Name (Last, First, Middle Initial)

Gary Shawver

Mailing Address 551 Excelsior Lane

\begin{tabular}{lcc}
\hline City & State & Zip Code \\
Waterloo & IA & $50701-4967$ \\
\hline
\end{tabular}

FEC ID number of contributing

federal political committee.

C

Name of Employer

Shawver Well Co. Inc

Occupation

Receipt For: 2012

Х Primary $\square$ General

Water well contractor

Election Cycle-to-Date

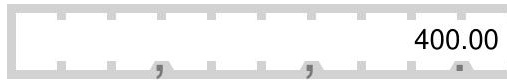

C. Full Name (Last, First, Middle Initial)

Christy Williams

Mailing Address Po Box 672373

\begin{tabular}{lcc}
\hline City & State & Zip Code \\
Marietta & GA & $30006-0040$
\end{tabular}

FEC ID number of contributing

federal political committee.

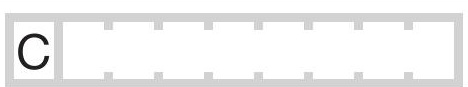

Name of Employer

Self Employed

Occupation

Tac Consultant

Receipt For: 2012

X Primary $\square$ General

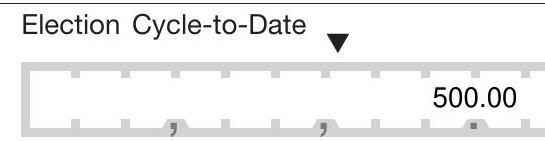

Transaction ID : A0089363BCA6A4E749CE

Date of Receipt

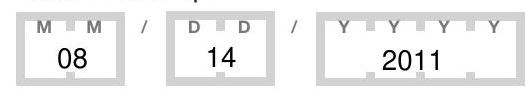

Amount of Each Receipt this Period

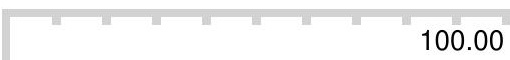

100.00

Transaction ID : A60D9A53DF83549339BE

Date of Receipt

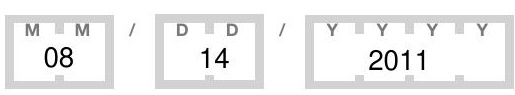

Amount of Each Receipt this Period

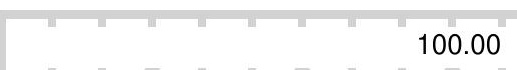

Transaction ID : A3DBA19076D8B46FAA20 Date of Receipt

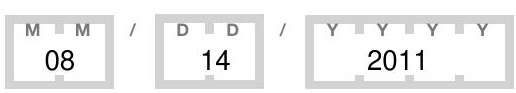

Amount of Each Receipt this Period

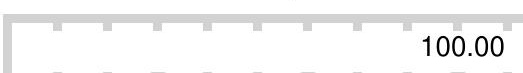

100.00
Subtotal Of Receipts This Page (optional)

300.00

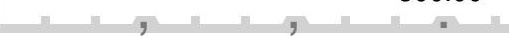

Total This Period (last page this line number only)

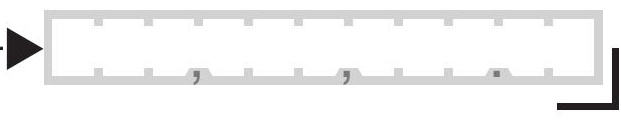

FEC Schedule A-P (Form 3P) (Rev. 03/2011) 
SCHEDULE A-P ITEMIZED RECEIPTS
Use separate schedule(s) for each category of the Detailed Summary Page
FOR LINE NUMBER: (check only one)

PAGE 277 / 1572

\begin{tabular}{|c|c|c|c|c|c|}
\hline & & & & & \\
\hline 16 & $\begin{array}{l}\mathbf{X} \\
17 a\end{array}$ & $17 b$ & $17 c$ & $17 d$ & 18 \\
\hline $19 a$ & $19 \mathrm{~b}$ & $20 \mathrm{a}$ & $20 \mathrm{~b}$ & $20 \mathrm{c}$ & 21 \\
\hline
\end{tabular}

Any information copied from such Reports and Statements may not be sold or used by any person for the purpose of soliciting contributions or for commercial purposes, other than using the name and address of any political committee to solicit contributions from such committee.

NAME OF COMMITTEE (In Full)

\section{Friends of Herman Cain}

A. Full Name (Last, First, Middle Initial)

MARK LOPEZ

Mailing Address 1830 BREA BLVD \#3

\begin{tabular}{lcc}
\hline City & State & Zip Code \\
Fullerton & CA & $92835-3944$
\end{tabular}

FEC ID number of contributing

federal political committee.

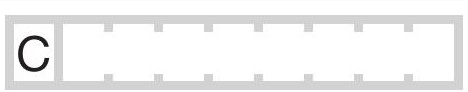

Name of Employer
BECKMAN COULTER INC
Receipt For: 2012
X Primary $\quad \square$ General
Other (specify)

Occupation

SW Engineer

Election Cycle-to-Date

600.00

B. Full Name (Last, First, Middle Initial)

Judith Walker

Mailing Address 3079 Spring Hill Dr

\begin{tabular}{lcc}
\hline City & State & Zip Code \\
Monroe & GA & $30656-4093$ \\
\hline
\end{tabular}

FEC ID number of contributing

federal political committee.

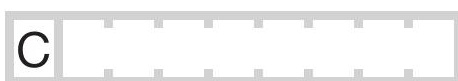

Name of Employer
FOOD LION
Receipt For: 2012
X Primary
Other (specify)

\section{Occupation}

Pharmacist

Transaction ID : A82B813AB01C1401C9A7

Date of Receipt

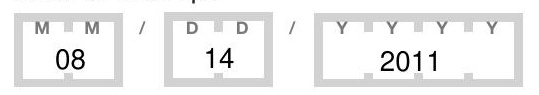

Amount of Each Receipt this Period

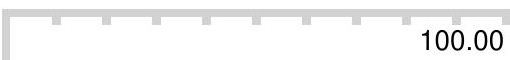

100.00

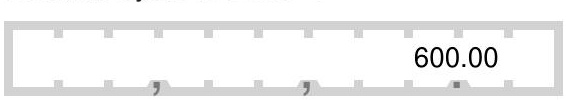

Transaction ID : AA5DB0D61BD364E1C99A

Date of Receipt

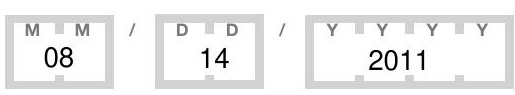

Amount of Each Receipt this Period

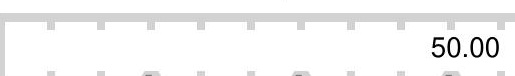

Election Cycle-to-Date

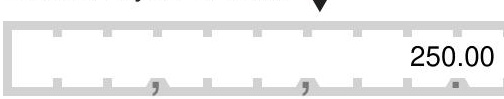

C. Full Name (Last, First, Middle Initial)

James Thompson

Mailing Address 1214 Tulip Tree Lane

City

West Des Moines

State Zip Code

IA 50266-6666

FEC ID number of contributing

federal political committee.

C

Name of Employer
Stoney Creek Hospitality Corp.
Receipt For: 2012
X Primary
Other (specify) General

Occupation

Executive

Election Cycle-to-Date

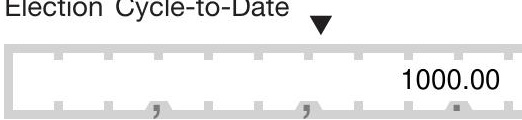

Transaction ID : A27FDC093FA7041128B8 Date of Receipt

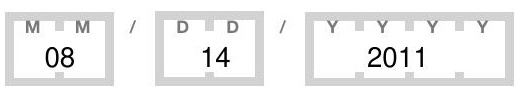

Amount of Each Receipt this Period

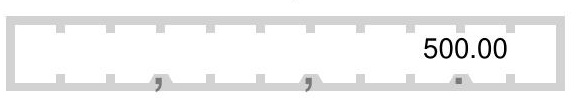

\section{Subtotal Of Receipts This Page (optional)}

650.00

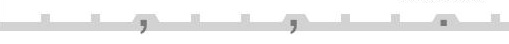

Total This Period (last page this line number only)

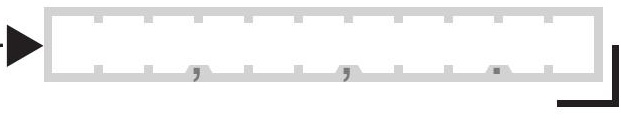

FEC Schedule A-P (Form 3P) (Rev. 03/2011) 
SCHEDULE A-P ITEMIZED RECEIPTS
Use separate schedule(s) for each category of the Detailed Summary Page
FOR LINE NUMBER: (check only one)

PAGE $278 / 1572$

\begin{tabular}{|c|c|c|c|c|c|}
\hline & & & & & \\
\hline 16 & $\begin{array}{l}\mathbf{X} \\
17 a\end{array}$ & $17 b$ & $17 c$ & $17 d$ & 18 \\
\hline $19 a$ & $19 \mathrm{~b}$ & $20 \mathrm{a}$ & $20 \mathrm{~b}$ & $20 \mathrm{c}$ & 21 \\
\hline
\end{tabular}

Any information copied from such Reports and Statements may not be sold or used by any person for the purpose of soliciting contributions or for commercial purposes, other than using the name and address of any political committee to solicit contributions from such committee.

NAME OF COMMITTEE (In Full)

\section{Friends of Herman Cain}

A. Full Name (Last, First, Middle Initial)

Peaches Kavanaugh

Mailing Address 216 Monty Manor

\begin{tabular}{lcc}
\hline City & State & Zip Code \\
Yorktown & VA & $23693-4414$
\end{tabular}

FEC ID number of contributing federal political committee.

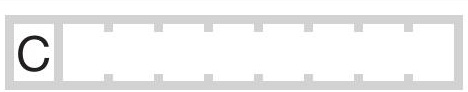

Name of Employer
Air Force
Receipt For: 2012
X Primary $\quad$ General
Other (specify)

Occupation Retired

Election Cycle-to-Date

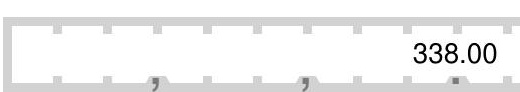

B. Full Name (Last, First, Middle Initial) claire mencke

Mailing Address 5 tudor city place apt 305

\begin{tabular}{lcc}
\hline City & State & Zip Code \\
New York & NY & $10017-6858$
\end{tabular}

FEC ID number of contributing

federal political committee.

C

Name of Employer
buckingham research group
Receipt For: 2012
Primary
Other (specify)

Occupation

research assoc

Election Cycle-to-Date

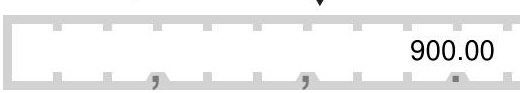

Transaction ID : AA3DBEC90E25F4F2E9A3

Date of Receipt

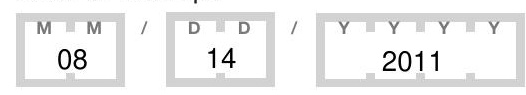

Amount of Each Receipt this Period

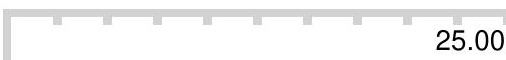

25.00

C. Full Name (Last, First, Middle Initial)

Samuel Brian Goodrich

Mailing Address 9620 Callaway Ct

\begin{tabular}{lcc}
\hline City & State & Zip Code \\
Denton & TX & $76207-5602$
\end{tabular}

FEC ID number of contributing federal political committee.

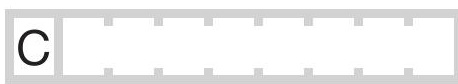

Name of Employer
None
Receipt For: 2012
Х Primary $\quad \square$ General
Other (specify)

Occupation

Retired

Election Cycle-to-Date

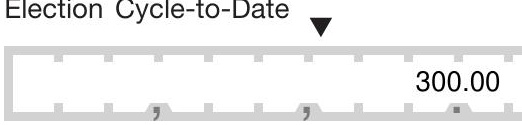

Transaction ID : A85B596E993244E43AA0

Date of Receipt

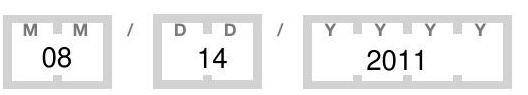

Amount of Each Receipt this Period

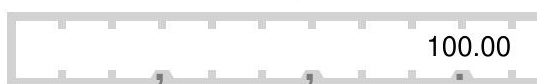

Transaction ID : A4B357568F53340C48EC Date of Receipt

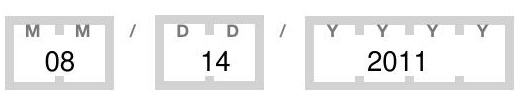

Amount of Each Receipt this Period

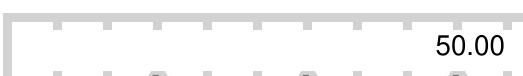

\section{Subtotal Of Receipts This Page (optional)}

175.00

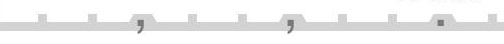

Total This Period (last page this line number only)

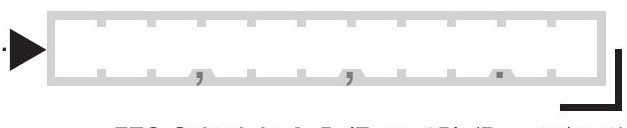

FEC Schedule A-P (Form 3P) (Rev. 03/2011) 
SCHEDULE A-P ITEMIZED RECEIPTS
Use separate schedule(s)

for each category of the

Detailed Summary Page
FOR LINE NUMBER: (check only one)

PAGE 279 / 1572

\begin{tabular}{|c|c|c|c|c|c|}
\hline & & & & & \\
\hline 16 & $\begin{array}{l}\mathbf{X} \\
17 a\end{array}$ & $17 b$ & $17 c$ & $17 d$ & 18 \\
\hline $19 a$ & $19 \mathrm{~b}$ & $20 \mathrm{a}$ & $20 \mathrm{~b}$ & $20 \mathrm{c}$ & 21 \\
\hline
\end{tabular}

Any information copied from such Reports and Statements may not be sold or used by any person for the purpose of soliciting contributions or for commercial purposes, other than using the name and address of any political committee to solicit contributions from such committee.

NAME OF COMMITTEE (In Full)

\section{Friends of Herman Cain}

A. Full Name (Last, First, Middle Initial)

\section{Donald Eboch}

Mailing Address 3716 Princwe William Drive

\begin{tabular}{lcc}
\hline City & State & Zip Code \\
Fairfax & VA & $22031-3865$
\end{tabular}

FEC ID number of contributing federal political committee.

C

Name of Employer

Elite Technical Services Inc

Receipt For: 2012

X Primary $\square$ General Other (specify)

Occupation

IT Contractor

Election Cycle-to-Date

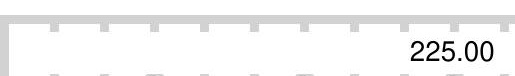

B. Full Name (Last, First, Middle Initial)

Wayne Fogel

Mailing Address 7140 SE 172nd Hazelwood Loop

\begin{tabular}{lcc}
\hline City & State & Zip Code \\
The Villages & FL & $32162-5359$
\end{tabular}

FEC ID number of contributing

federal political committee.

C

Name of Employer
None
Receipt For: 2012
X Primary
Other (specify)

Occupation

Retired

Election Cycle-to-Date

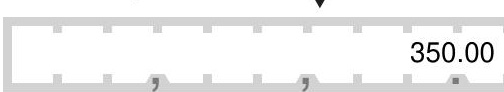

Transaction ID : ADDF14895FC344D8AB13

Date of Receipt

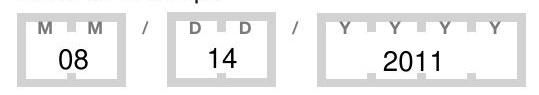

Amount of Each Receipt this Period

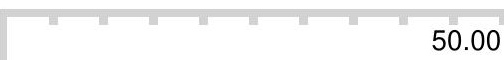

50.00

C. Full Name (Last, First, Middle Initial)

Tim Landis

Mailing Address 2202 SE 20th PL

\begin{tabular}{lcc}
\hline City & State & Zip Code \\
Cape Coral & FL & $33990-3107$
\end{tabular}

FEC ID number of contributing

federal political committee.

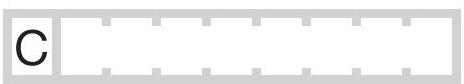

Name of Employer

Information Requested

\section{Occupation}

Information Requested

Receipt For: 2012

Х $\begin{aligned} & \text { Primary } \square \text { General } \\ & \text { Other (specify) }\end{aligned}$

Transaction ID : A1181B570332C4212B95

Date of Receipt

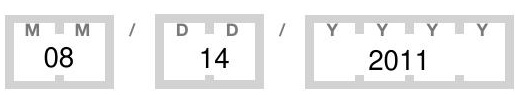

Amount of Each Receipt this Period

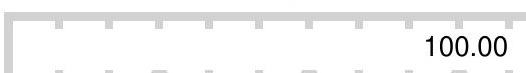

Transaction ID : A4D0FF35787ED4906B8F

Date of Receipt

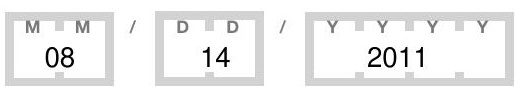

Amount of Each Receipt this Period

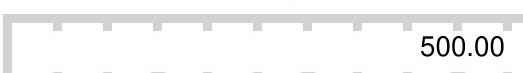

500.00

\section{Subtotal Of Receipts This Page (optional)}

Total This Period (last page this line number only) 
SCHEDULE A-P ITEMIZED RECEIPTS
Use separate schedule(s) for each category of the Detailed Summary Page
FOR LINE NUMBER: (check only one)

PAGE $280 / 1572$

\begin{tabular}{|c|c|c|c|c|c|}
\hline & & & & & \\
\hline 16 & $\begin{array}{l}\mathbf{X} \\
17 a\end{array}$ & $17 b$ & $17 c$ & $17 d$ & 18 \\
\hline $19 a$ & $19 \mathrm{~b}$ & $20 \mathrm{a}$ & $20 \mathrm{~b}$ & $20 \mathrm{c}$ & 21 \\
\hline
\end{tabular}

Any information copied from such Reports and Statements may not be sold or used by any person for the purpose of soliciting contributions or for commercial purposes, other than using the name and address of any political committee to solicit contributions from such committee.

NAME OF COMMITTEE (In Full)

\section{Friends of Herman Cain}

A. Full Name (Last, First, Middle Initial)

Terry Chick

Mailing Address 13650 N Heritage Canyon Dr

\begin{tabular}{lcc}
\hline City & State & Zip Code \\
Marana & AZ & $85658-4073$
\end{tabular}

FEC ID number of contributing federal political committee.

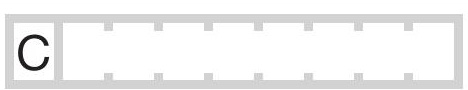

Name of Employer
Retired
Receipt For: 2012
X Primary $\quad$ General
Other (specify)

Occupation Retired

Election Cycle-to-Date

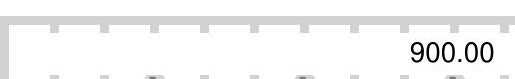

B. Full Name (Last, First, Middle Initial)

Colleen V Wynne

Mailing Address 221 Woodland Rd

\begin{tabular}{lcc}
\hline City & State & Zip Code \\
Gatlinburg & TN & $37738-5886$ \\
\hline
\end{tabular}

FEC ID number of contributing

federal political committee.

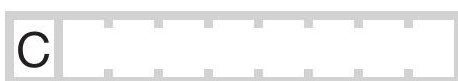

Name of Employer
Park Liquor
Receipt For: 2012
X Primary
Other (specify)

\section{Occupation} clerk

Election Cycle-to-Date

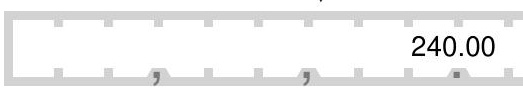

Transaction ID : A408FBAE810E24D54A1F

Date of Receipt

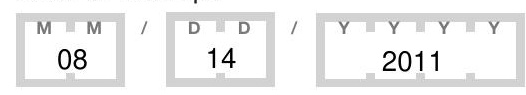

Amount of Each Receipt this Period

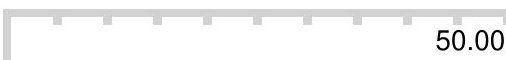

C. Full Name (Last, First, Middle Initial)

Tom Crook

Mailing Address 180 Freedom Ave

\begin{tabular}{lcc}
\hline City & State & Zip Code \\
Murfreesboro & TN & $37129-6926$
\end{tabular}

FEC ID number of contributing federal political committee.

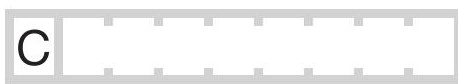

Name of Employer
RFE
Receipt For: 2012
Х Primary $\quad \square$ General
Other (specify)

\section{Occupation}

Chair

\section{Election Cycle-to-Date}

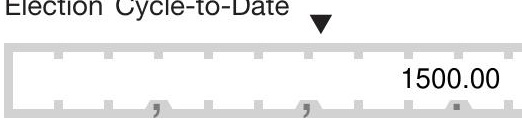

Amount of Each Receipt this Period

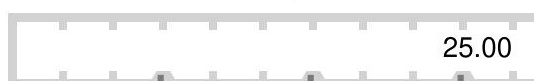

Transaction ID : AB94D3E633DFD48E0AD1 Date of Receipt

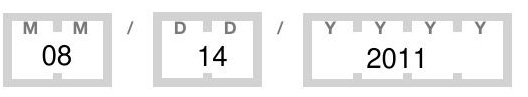

Transaction ID : A365192080CC644B296E Date of Receipt

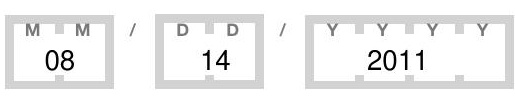

Amount of Each Receipt this Period

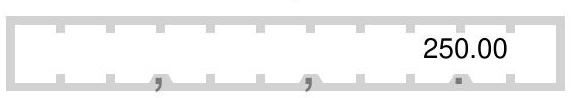

\section{Subtotal Of Receipts This Page (optional)}

Total This Period (last page this line number only) 


\section{SCHEDULE A-P} ITEMIZED RECEIPTS
Use separate schedule(s)

for each category of the

Detailed Summary Page
FOR LINE NUMBER: (check only one)

PAGE $281 / 1572$

\begin{tabular}{|c|c|c|c|c|c|}
\hline & & & & & \\
\hline 16 & X $17 a$ & $17 b$ & $17 c$ & $17 d$ & 18 \\
\hline $19 a$ & $19 b$ & $20 \mathrm{a}$ & $20 \mathrm{~b}$ & $20 \mathrm{c}$ & 21 \\
\hline
\end{tabular}

Any information copied from such Reports and Statements may not be sold or used by any person for the purpose of soliciting contributions or for commercial purposes, other than using the name and address of any political committee to solicit contributions from such committee.

NAME OF COMMITTEE (In Full)

Friends of Herman Cain

A. Full Name (Last, First, Middle Initial)

Thomas McArdle

Mailing Address 4104 Couts St

\begin{tabular}{lcc}
\hline City & State & Zip Code \\
San Diego & CA & $92103-1550$ \\
\hline
\end{tabular}

FEC ID number of contributing federal political committee.

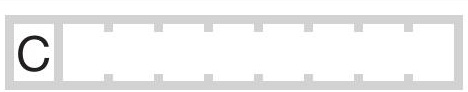

Name of Employer
Information Requested
Receipt For: 2012
X Primary
Other (specify) General

Occupation

Information Requested

Election Cycle-to-Date

\subsection{0}

B. Full Name (Last, First, Middle Initial)

William Swan

Mailing Address 302 Woodlake Drive

\begin{tabular}{lcc}
\hline City & State & Zip Code \\
Athens & GA & $30606-3361$
\end{tabular}

FEC ID number of contributing

federal political committee.

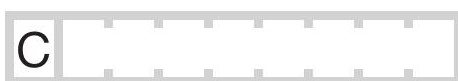

Name of Employer
None
Receipt For: 2012
X Primary
Other (specify)

Occupation

Retired

Election Cycle-to-Date

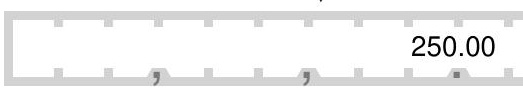

C. Full Name (Last, First, Middle Initial)

Dianne Sula

Mailing Address 6 E. Walker Ave.

\begin{tabular}{lcc}
\hline City & State & Zip Code \\
Temple & TX & $76501-1724$
\end{tabular}

FEC ID number of contributing

federal political committee.

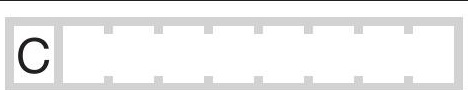

Name of Employer

Occupation

US Postal Service

mail processor

Receipt For: 2012

Х $\begin{aligned} & \text { Primary } \square \text { General } \\ & \text { Other (specify) }\end{aligned}$

Election Cycle-to-Date

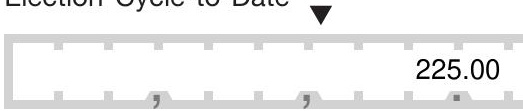

Transaction ID : A81C9CAE1D9E546088FF

Date of Receipt

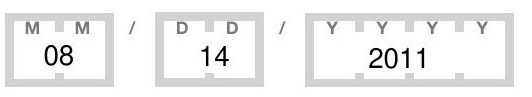

Amount of Each Receipt this Period

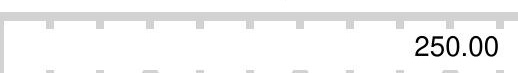

Transaction ID : AC406CE982F714D729B1

Date of Receipt

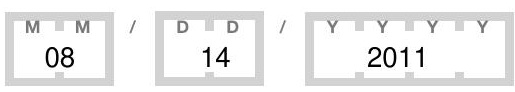

Amount of Each Receipt this Period

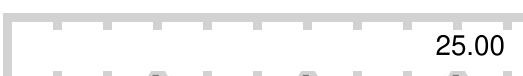

Subtotal Of Receipts This Page (optional)

375.00

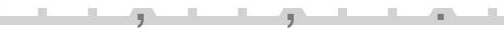

Total This Period (last page this line number only)

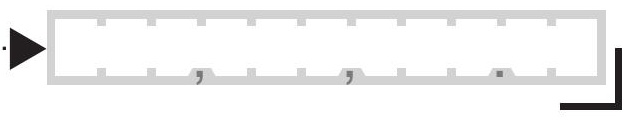

FEC Schedule A-P (Form 3P) (Rev. 03/2011) 
SCHEDULE A-P ITEMIZED RECEIPTS
Use separate schedule(s) for each category of the Detailed Summary Page
FOR LINE NUMBER: (check only one)

PAGE 282 / 1572

\begin{tabular}{|c|c|c|c|c|c|}
\hline & & & & & \\
\hline 16 & $\begin{array}{l}\mathbf{X} \\
17 a\end{array}$ & $17 b$ & $17 c$ & $17 d$ & 18 \\
\hline $19 a$ & $19 \mathrm{~b}$ & $20 \mathrm{a}$ & $20 \mathrm{~b}$ & $20 \mathrm{c}$ & 21 \\
\hline
\end{tabular}

Any information copied from such Reports and Statements may not be sold or used by any person for the purpose of soliciting contributions or for commercial purposes, other than using the name and address of any political committee to solicit contributions from such committee.

NAME OF COMMITTEE (In Full)

\section{Friends of Herman Cain}

A. Full Name (Last, First, Middle Initial)

Ted Kirkpatrick

Mailing Address 11434 Huntsman Dr

\begin{tabular}{lcc}
\hline City & State & Zip Code \\
Manassas & VA & $20112-2761$
\end{tabular}

FEC ID number of contributing federal political committee.

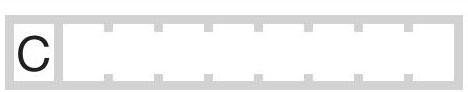

Name of Employer

Ardaiolo Bausman and Associates

Occupation

Receipt For: 2012

Х Primary $\square$ General

Financial Advisor

Election Cycle-to-Date

625.00

B. Full Name (Last, First, Middle Initial)

Clete Kelly

Mailing Address 5640 Manuel Place

\begin{tabular}{lcc}
\hline City & State & Zip Code \\
Buford & GA & $30518-5602$ \\
\hline
\end{tabular}

FEC ID number of contributing

federal political committee.

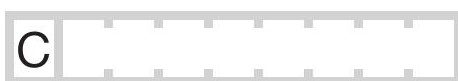

Name of Employer
Exhibits South Corp.
Receipt For: 2012
X Primary
Other (specify)

Occupation

VP/Owner

Transaction ID : A91B87265D6E74B1D82B

Date of Receipt

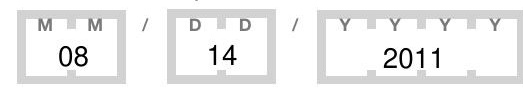

Amount of Each Receipt this Period

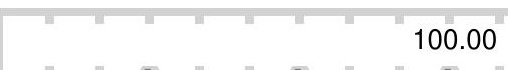

Transaction ID : AE9D96C5EE9394E859FA

Date of Receipt

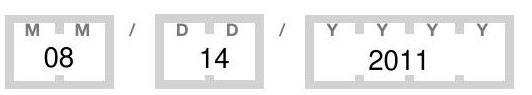

Amount of Each Receipt this Period

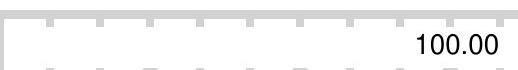

Election Cycle-to-Date

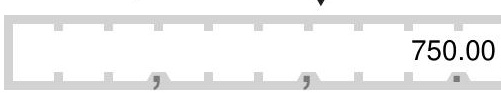

C. Full Name (Last, First, Middle Initial)

Rick Papandrea

Mailing Address N28W30628 Red Fox Court

\begin{tabular}{lcc}
\hline City & State & Zip Code \\
Pewaukee & WI & $53072-4292$
\end{tabular}

FEC ID number of contributing

federal political committee.

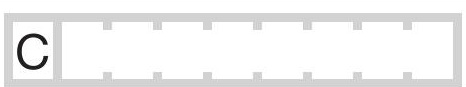

$\begin{aligned} & \text { Name of Employer } \\ & \text { self }\end{aligned}$
Receipt For: 2012
X Primary
Other (specify) General

Occupation

Doctor

Election Cycle-to-Date

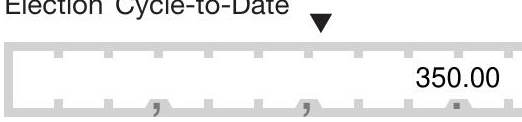

Subtotal Of Receipts This Page (optional)

300.00

Amount of Each Receipt this Period
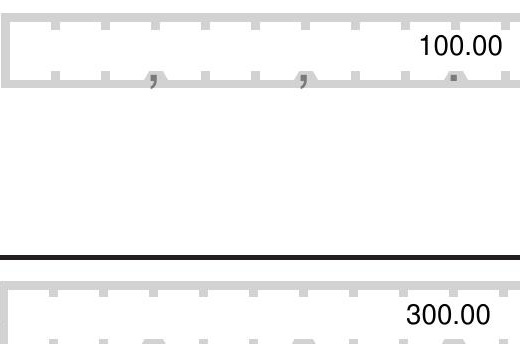

Total This Period (last page this line number only)

Transaction ID : AAE28733BE73240E2B3D Date of Receipt

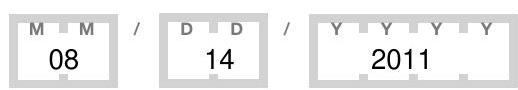

a L 
SCHEDULE A-P ITEMIZED RECEIPTS
Use separate schedule(s) for each category of the Detailed Summary Page
FOR LINE NUMBER: (check only one)

PAGE 283 / 1572

\begin{tabular}{|c|c|c|c|c|c|}
\hline & & & & & \\
\hline 16 & $\begin{array}{l}\mathbf{X} \\
17 a\end{array}$ & $17 b$ & $17 c$ & $17 d$ & 18 \\
\hline $19 a$ & $19 \mathrm{~b}$ & $20 \mathrm{a}$ & $20 \mathrm{~b}$ & $20 \mathrm{c}$ & 21 \\
\hline
\end{tabular}

Any information copied from such Reports and Statements may not be sold or used by any person for the purpose of soliciting contributions or for commercial purposes, other than using the name and address of any political committee to solicit contributions from such committee.

NAME OF COMMITTEE (In Full)

\section{Friends of Herman Cain}

A. Full Name (Last, First, Middle Initial) JRobert Love

Mailing Address 2065 Old Dominion Road

\begin{tabular}{lcc}
\hline City & State & Zip Code \\
Atlanta & GA & $30350-4620$
\end{tabular}

FEC ID number of contributing federal political committee.

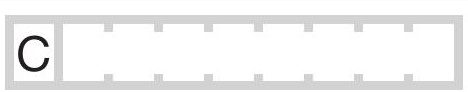

Name of Employer
Simpson Housing
Receipt For: 2012
X Primary $\quad$ General
Other (specify)

Occupation CEO

Election Cycle-to-Date

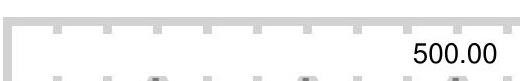

B. Full Name (Last, First, Middle Initial)

jeff dayton

Mailing Address 360 Fetterhoff Hollow Rd

\begin{tabular}{lcc}
\hline City & State & Zip Code \\
Montoursville & PA & $17754-7846$
\end{tabular}

FEC ID number of contributing

federal political committee.

C

Name of Employer
Self Employed
Receipt For: 2012
X Primary
Other (specify)

Occupation antique dealer

Election Cycle-to-Date

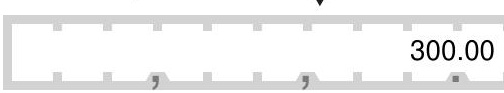

Transaction ID : AEE498E47AA57486FA5B

Date of Receipt

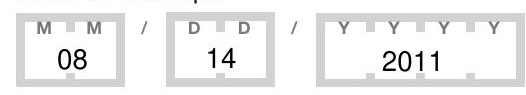

Amount of Each Receipt this Period

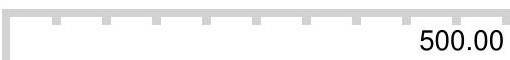

C. Full Name (Last, First, Middle Initial)

lois edgerly

Mailing Address 32 highland street

\begin{tabular}{lcc}
\hline City & State & Zip Code \\
Cambridge & MA & $02138-2210$
\end{tabular}

FEC ID number of contributing federal political committee.

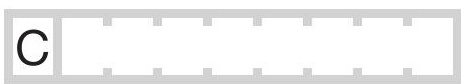

Name of Employer
Retired
Receipt For: 2012
X Primary $\quad \square$ General
Other (specify)

\section{Occupation}

Retired

Election Cycle-to-Date

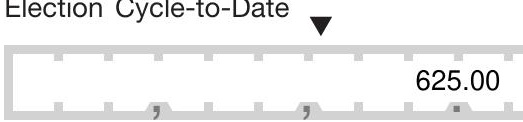

Amount of Each Receipt this Period

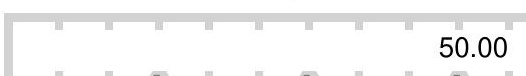

Transaction ID : A6583A84DA7F84F9B904

Date of Receipt

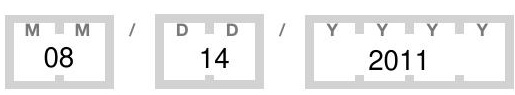

Transaction ID : A37D0AEA8332B4144A10 Date of Receipt

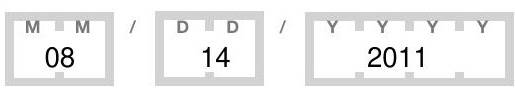

Amount of Each Receipt this Period

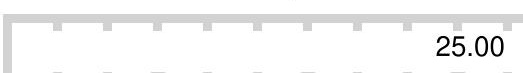

\section{Subtotal Of Receipts This Page (optional)}

Total This Period (last page this line number only) 
SCHEDULE A-P ITEMIZED RECEIPTS
Use separate schedule(s) for each category of the Detailed Summary Page
FOR LINE NUMBER: (check only one)

\begin{tabular}{|c|c|c|c|c|c|}
\hline & & & & & \\
\hline 16 & $\begin{array}{ll}X & 17 a \\
\end{array}$ & $17 \mathrm{~b}$ & $17 c$ & $17 d$ & 18 \\
\hline $19 a$ & $19 b$ & $20 \mathrm{a}$ & $20 \mathrm{~b}$ & $20 c$ & 21 \\
\hline
\end{tabular}

Any information copied from such Reports and Statements may not be sold or used by any person for the purpose of soliciting contributions or for commercial purposes, other than using the name and address of any political committee to solicit contributions from such committee.

NAME OF COMMITTEE (In Full)

\section{Friends of Herman Cain}

A. Full Name (Last, First, Middle Initial)

William Edwards

Mailing Address 8885 SW 196th Terrace Rd

\begin{tabular}{lcc}
\hline City & State & Zip Code \\
Dunnellon & FL & $34432-2624$
\end{tabular}

FEC ID number of contributing federal political committee.

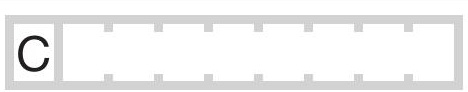

Name of Employer
None
Receipt For: 2012
X Primary $\quad \square$ General
Other (specify)

Occupation

Retired

Election Cycle-to-Date

400.00

B. Full Name (Last, First, Middle Initial) Judy Williams

Mailing Address 12679 Biscayne Ct

\begin{tabular}{lcc}
\hline City & State & Zip Code \\
Naples & FL & $34105-4935$ \\
\hline
\end{tabular}

FEC ID number of contributing

federal political committee.

C

Name of Employer
Eli Lilly \& Company
Receipt For: 2012
X Primary
Other (specify)

Occupation

Assoc Consultant - Clinical Trial Mana

Election Cycle-to-Date

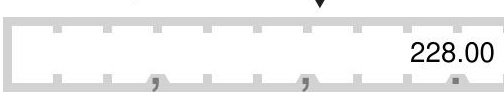

Transaction ID : A8504D33C4C944415A95

Date of Receipt

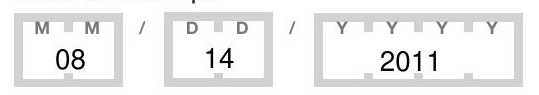

Amount of Each Receipt this Period

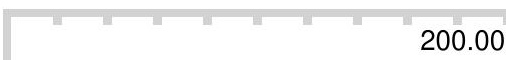

Amount of Each Receipt this Period

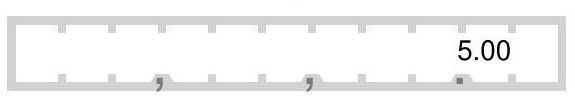

C. Full Name (Last, First, Middle Initial)

Sharon Waite

Mailing Address 8301 W Business Highway 83

\begin{tabular}{lcc}
\hline City & State & Zip Code \\
Mission & TX & $78572-9445$
\end{tabular}

FEC ID number of contributing

federal political committee.

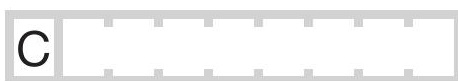

Name of Employer

Occupation

Self Employed

Agriculture

Receipt For: 2012

Х $\begin{aligned} & \text { Primary } \\ & \text { Other (specify) }\end{aligned}$

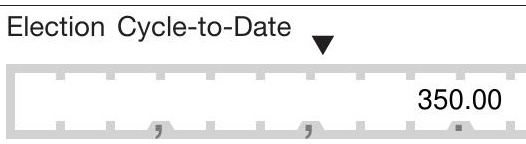

Amount of Each Receipt this Period

Transaction ID : A84D628AD89E74043AF5

Date of Receipt
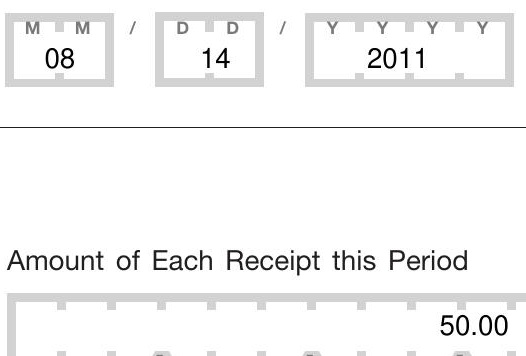

50.00

Subtotal Of Receipts This Page (optional)

255.00

Total This Period (last page this line number only) 
SCHEDULE A-P ITEMIZED RECEIPTS
Use separate schedule(s) for each category of the Detailed Summary Page
FOR LINE NUMBER: (check only one)

PAGE $285 / 1572$

\begin{tabular}{|c|c|c|c|c|c|}
\hline & & & & & \\
\hline 16 & $\begin{array}{l}\mathbf{X} \\
17 a\end{array}$ & $17 b$ & $17 c$ & $17 d$ & 18 \\
\hline $19 a$ & $19 \mathrm{~b}$ & $20 \mathrm{a}$ & $20 \mathrm{~b}$ & $20 \mathrm{c}$ & 21 \\
\hline
\end{tabular}

Any information copied from such Reports and Statements may not be sold or used by any person for the purpose of soliciting contributions or for commercial purposes, other than using the name and address of any political committee to solicit contributions from such committee.

NAME OF COMMITTEE (In Full)

\section{Friends of Herman Cain}

A. Full Name (Last, First, Middle Initial)

Mary Daniel

Mailing Address 131 South End Street

\begin{tabular}{lcc}
\hline City & State & Zip Code \\
Saint Augustine & FL & $32095-6821$
\end{tabular}

FEC ID number of contributing federal political committee.

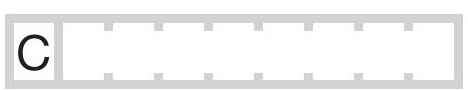

Name of Employer
The Shannon Group
Receipt For: 2012
X Primary
Other (specify) General

Occupation medical management

Election Cycle-to-Date

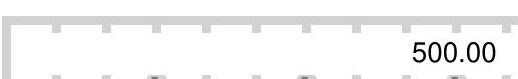

B. Full Name (Last, First, Middle Initial) Judy Williams

Mailing Address 12679 Biscayne Ct

\begin{tabular}{lcc}
\hline City & State & Zip Code \\
Naples & FL & $34105-4935$ \\
\hline
\end{tabular}

FEC ID number of contributing

federal political committee.

C

Name of Employer
Eli Lilly \& Company
Receipt For: 2012
X Primary
Other (specify)

Occupation

Assoc Consultant - Clinical Trial Mana

Election Cycle-to-Date

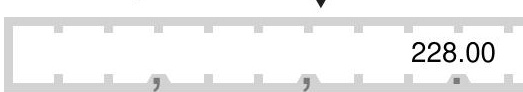

Transaction ID : ADA4D438CC81448068C4

Date of Receipt

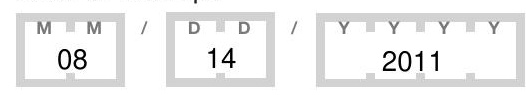

Amount of Each Receipt this Period

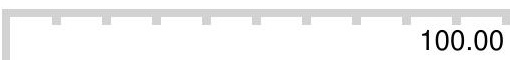

100.00

C. Full Name (Last, First, Middle Initial)

Scott Vaughn

Mailing Address 1107 61st Ct

\begin{tabular}{lcc}
\hline City & State & Zip Code \\
Meridian & MS & $39305-1230$
\end{tabular}

FEC ID number of contributing federal political committee.

C

$39305-1230$

Name of Employer

Self Employed

Occupation

Receipt For: 2012

Х $\begin{aligned} & \text { Primary } \square \text { General } \\ & \text { Other (specify) }\end{aligned}$

Restaurant Owner

Election Cycle-to-Date

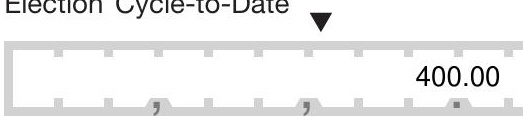

Amount of Each Receipt this Period

Transaction ID : ADD5CE623908447259C2

Date of Receipt
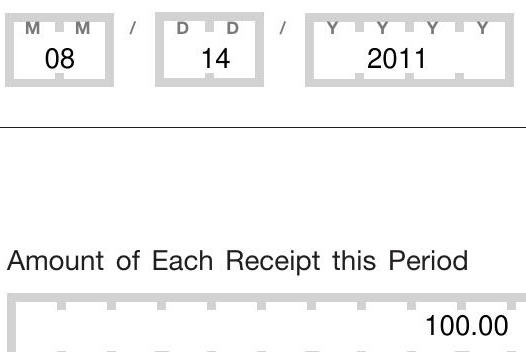

Transaction ID : A408E9B8EE5CD4ECD926

Date of Receipt

Amount of Each Receipt this Period

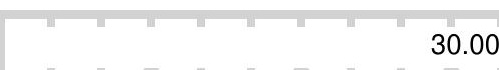

Subtotal Of Receipts This Page (optional)

Total This Period (last page this line number only) 
SCHEDULE A-P ITEMIZED RECEIPTS
Use separate schedule(s) for each category of the Detailed Summary Page
FOR LINE NUMBER: (check only one)

PAGE 286 / 1572

\begin{tabular}{|c|c|c|c|c|c|}
\hline & & & & & \\
\hline 16 & $\begin{array}{l}\mathbf{X} \\
17 a\end{array}$ & $17 b$ & $17 c$ & $17 d$ & 18 \\
\hline $19 a$ & $19 \mathrm{~b}$ & $20 \mathrm{a}$ & $20 \mathrm{~b}$ & $20 \mathrm{c}$ & 21 \\
\hline
\end{tabular}

Any information copied from such Reports and Statements may not be sold or used by any person for the purpose of soliciting contributions or for commercial purposes, other than using the name and address of any political committee to solicit contributions from such committee.

NAME OF COMMITTEE (In Full)

\section{Friends of Herman Cain}

A. Full Name (Last, First, Middle Initial)

Jim Eure Jr.

Mailing Address PO Box 156

\begin{tabular}{lcc}
\hline City & State & Zip Code \\
Dahlonega & GA & $30533-0003$ \\
\hline
\end{tabular}

FEC ID number of contributing federal political committee.

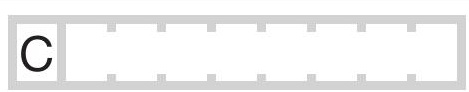

Name of Employer
Protex Security Systems
Receipt For: 2012
X Primary $\quad$ General
Other (specify)

Occupation

Owner

Election Cycle-to-Date

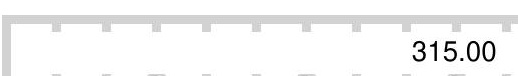

B. Full Name (Last, First, Middle Initial)

David Kilcy

Mailing Address 119 Maximillian Ct SW

\begin{tabular}{lcc}
\hline City & State & Zip Code \\
Leesburg & VA & $20175-2711$ \\
\hline
\end{tabular}

FEC ID number of contributing

federal political committee.

C

Name of Employer

Transaction Network Services Inc

Occupation

Receipt For: 2012

X Primary $\square$ General Other (specify)

Senior Systems Developer

Election Cycle-to-Date

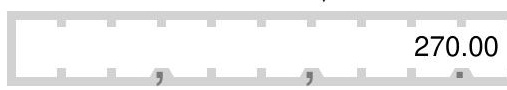

C. Full Name (Last, First, Middle Initial)

Gertrude Gatto

Mailing Address 222 Clark Drive

\begin{tabular}{lcc}
\hline City & State & Zip Code \\
Johnstown & OH & $43031-8902$ \\
\hline
\end{tabular}

FEC ID number of contributing federal political committee.

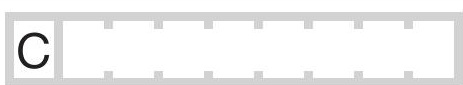

Name of Employer

Berkeley Park at New Albany LLC

Receipt For: 2012

Х $\begin{aligned} & \text { Primary } \square \text { General } \\ & \text { Other (specify) } \boldsymbol{\nabla}\end{aligned}$

Occupation

Office Assistant

Election Cycle-to-Date

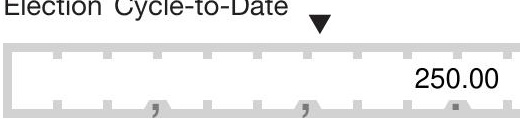

Transaction ID : A1E87AA291DF44476B6C

Date of Receipt

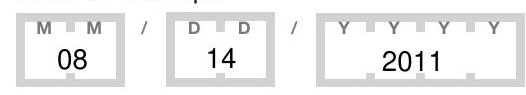

Amount of Each Receipt this Period

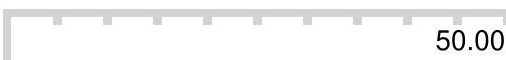

50.00

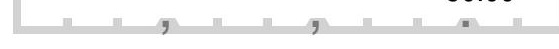

Transaction ID : A8EC92497D2B64E9B8C1

Date of Receipt

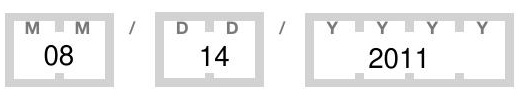

Amount of Each Receipt this Period

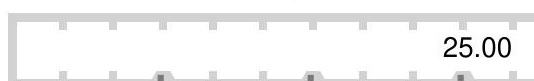

Transaction ID : AB25F5FD644C94E69BBE Date of Receipt

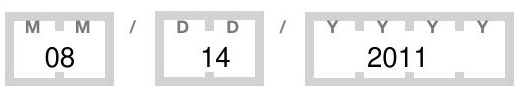

Amount of Each Receipt this Period

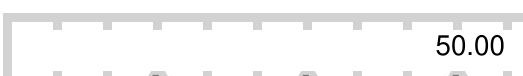

50.00

Subtotal Of Receipts This Page (optional)

Total This Period (last page this line number only) 
SCHEDULE A-P ITEMIZED RECEIPTS
Use separate schedule(s) for each category of the Detailed Summary Page
FOR LINE NUMBER: (check only one)

PAGE 287 / 1572

\begin{tabular}{|c|c|c|c|c|c|}
\hline & & & & & \\
\hline 16 & $\begin{array}{l}\mathbf{X} \\
17 a\end{array}$ & $17 b$ & $17 c$ & $17 d$ & 18 \\
\hline $19 a$ & $19 \mathrm{~b}$ & $20 \mathrm{a}$ & $20 \mathrm{~b}$ & $20 \mathrm{c}$ & 21 \\
\hline
\end{tabular}

Any information copied from such Reports and Statements may not be sold or used by any person for the purpose of soliciting contributions or for commercial purposes, other than using the name and address of any political committee to solicit contributions from such committee.

NAME OF COMMITTEE (In Full)

\section{Friends of Herman Cain}

A. Full Name (Last, First, Middle Initial)

hollis curtis

Mailing Address 6314 Carbonton Rd

\begin{tabular}{lcc}
\hline City & State & Zip Code \\
Sanford & NC & $27330-3027$
\end{tabular}

FEC ID number of contributing federal political committee.

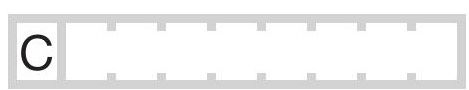

Name of Employer

$\mathrm{h} r$ curtis plumbing contractor

Occupation

plumbing contractor

Receipt For: 2012

X Primary $\square$ General Other (specify)

Election Cycle-to-Date

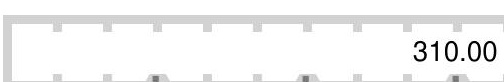

B. Full Name (Last, First, Middle Initial)

Oren Gruber

Mailing Address 2015 Darien Park Drive

\begin{tabular}{lcc}
\hline City & State & Zip Code \\
Roswell & GA & $30076-4294$ \\
\hline
\end{tabular}

FEC ID number of contributing

federal political committee.

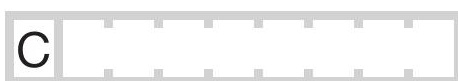

Name of Employer

Ecologix Environmental Systems

Occupation

Receipt For: 2012

Х $\begin{aligned} & \text { Primary } \\ & \text { Other (specify) }\end{aligned}$

Project Manager

Election Cycle-to-Date

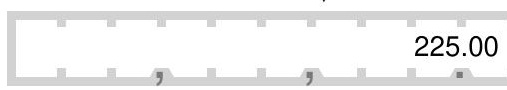

C. Full Name (Last, First, Middle Initial)

William Hester Jr.

Mailing Address 5015 Gravelbrook Dr

\begin{tabular}{lcc}
\hline City & State & Zip Code \\
Richmond & VA & $23234-4627$
\end{tabular}

FEC ID number of contributing

federal political committee.

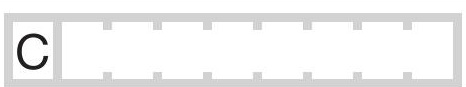

Name of Employer

Hester Process Service

Occupation

President

Receipt For: 2012

Х $\begin{aligned} & \text { Primary } \\ & \text { Other (specify) }\end{aligned}$

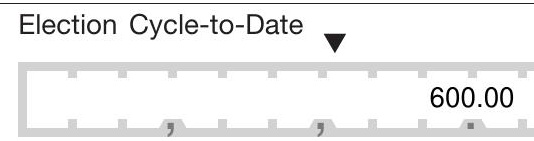

Transaction ID : AE521E295DC624EC2A85

Date of Receipt

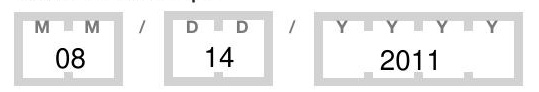

Amount of Each Receipt this Period

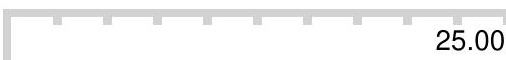

25.00

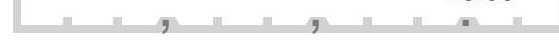

Transaction ID : A926DE070B94F4191A47

Date of Receipt

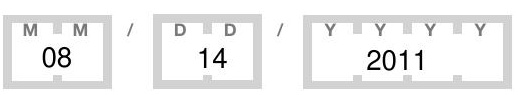

Amount of Each Receipt this Period

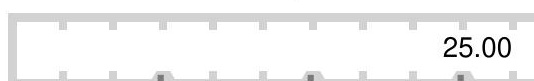

Transaction ID : ACD16B27EE8734F9C9A4 Date of Receipt

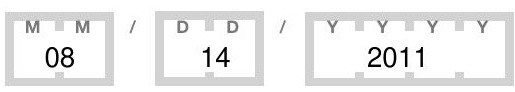

Amount of Each Receipt this Period

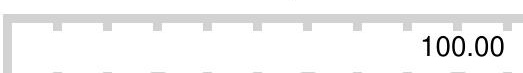

100.00

Subtotal Of Receipts This Page (optional).

Total This Period (last page this line number only) 
SCHEDULE A-P ITEMIZED RECEIPTS
Use separate schedule(s) for each category of the Detailed Summary Page
FOR LINE NUMBER: (check only one)

PAGE $288 / 1572$

\begin{tabular}{|c|c|c|c|c|c|}
\hline & & & & & \\
\hline 16 & $\begin{array}{l}\mathbf{X} \\
17 a\end{array}$ & $17 b$ & $17 c$ & $17 d$ & 18 \\
\hline $19 a$ & $19 \mathrm{~b}$ & $20 \mathrm{a}$ & $20 \mathrm{~b}$ & $20 \mathrm{c}$ & 21 \\
\hline
\end{tabular}

Any information copied from such Reports and Statements may not be sold or used by any person for the purpose of soliciting contributions or for commercial purposes, other than using the name and address of any political committee to solicit contributions from such committee.

NAME OF COMMITTEE (In Full)

\section{Friends of Herman Cain}

A. Full Name (Last, First, Middle Initial)

Robert Wiggins

Mailing Address 296 Country Lake Drive

\begin{tabular}{lcc}
\hline City & State & Zip Code \\
McDonough & GA & $30252-8405$ \\
\hline
\end{tabular}

FEC ID number of contributing federal political committee.

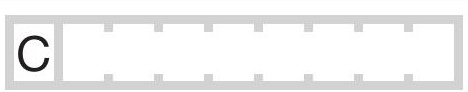

Name of Employer
The Itlalian Oven
Receipt For: 2012
X Primary
Other (specify) General

Occupation

Restaurant Manager

Election Cycle-to-Date

350.00

B. Full Name (Last, First, Middle Initial)

Fred Baker

Mailing Address 629 Driftwood Dr

\begin{tabular}{lcc}
\hline City & State & Zip Code \\
Woodstock & GA & $30189-5405$ \\
\hline
\end{tabular}

FEC ID number of contributing

federal political committee.

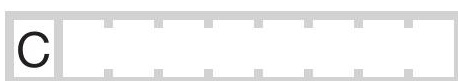

Name of Employer
AT\&T
Receipt For: 2012
X Primary
Other (specify)

Occupation

contractor

Election Cycle-to-Date

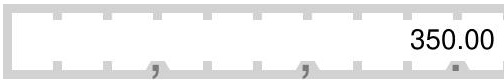

C. Full Name (Last, First, Middle Initial)

Mr Terence J Mortenson

Mailing Address 502 Sunnyside Ave

\begin{tabular}{lcc}
\hline City & State & Zip Code \\
Aurora & IN & $47001-1548$
\end{tabular}

FEC ID number of contributing federal political committee.

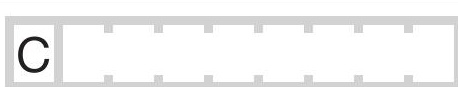

Name of Employer
answers in genesis
Receipt For: 2012
X Primary
Other (specify) General

\section{Occupation}

Lecturer

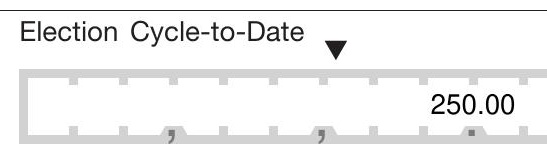

Transaction ID : A5CCF0F9B01704D90B84

Date of Receipt

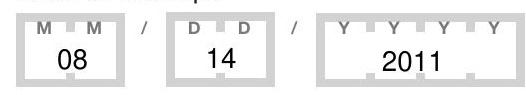

Amount of Each Receipt this Period

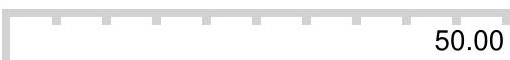

50.00
Amount of Each Receipt this Period

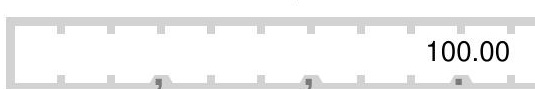

Transaction ID : A8E360B095B154CF0816 Date of Receipt

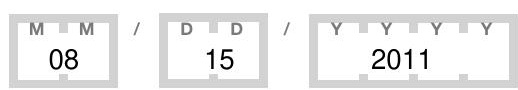

Amount of Each Receipt this Period

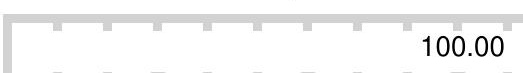

\section{Subtotal Of Receipts This Page (optional)}

Total This Period (last page this line number only) 
SCHEDULE A-P ITEMIZED RECEIPTS
Use separate schedule(s) for each category of the Detailed Summary Page
FOR LINE NUMBER: (check only one)

PAGE 289 / 1572

\begin{tabular}{|c|c|c|c|c|c|}
\hline & & & & & \\
\hline 16 & $\begin{array}{l}\mathbf{X} \\
17 a\end{array}$ & $17 b$ & $17 c$ & $17 d$ & 18 \\
\hline $19 a$ & $19 \mathrm{~b}$ & $20 \mathrm{a}$ & $20 \mathrm{~b}$ & $20 \mathrm{c}$ & 21 \\
\hline
\end{tabular}

Any information copied from such Reports and Statements may not be sold or used by any person for the purpose of soliciting contributions or for commercial purposes, other than using the name and address of any political committee to solicit contributions from such committee.

NAME OF COMMITTEE (In Full)

\section{Friends of Herman Cain}

A. Full Name (Last, First, Middle Initial)

Mr. Richard M. Callahan

Mailing Address 4465 Buchanan Hwy

\begin{tabular}{lcc}
\hline City & State & Zip Code \\
Buchanan & GA & $30113-2123$
\end{tabular}

FEC ID number of contributing federal political committee.

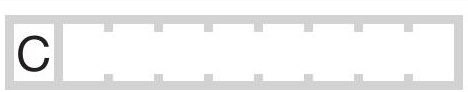

\begin{tabular}{l} 
Name of Employer \\
None \\
Receipt For: 2012 \\
X Primary $\quad$ General \\
\hline Other (specify)
\end{tabular}

Occupation

Retired

Election Cycle-to-Date

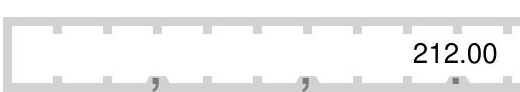

B. Full Name (Last, First, Middle Initial)

Dennis Callewaert

Mailing Address 301 N 5th Ave

\begin{tabular}{lcc}
\hline City & State & Zip Code \\
Redgranite & WI & $54970-9801$
\end{tabular}

FEC ID number of contributing

federal political committee.

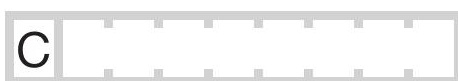

Name of Employer
Not Employed
Receipt For: 2012
X Primary
Other (specify)

Occupation

Retired

Election Cycle-to-Date

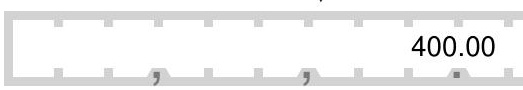

C. Full Name (Last, First, Middle Initial) richard craig

Mailing Address p.o. box 899

\begin{tabular}{lcc}
\hline City & State & Zip Code \\
Edwards & CO & $81632-0899$
\end{tabular}

FEC ID number of contributing federal political committee.

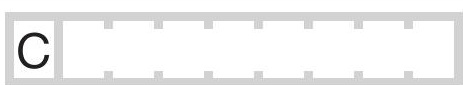

Name of Employer
Information Requested
Receipt For: 2012
X Primary $\quad \square$ General
Other (specify)

\section{Occupation}

Information Requested

Election Cycle-to-Date
Transaction ID : AEB587AF3FCC74A9E8CD

Date of Receipt

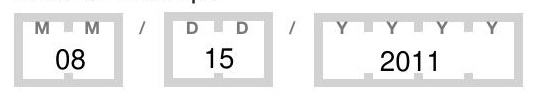

Amount of Each Receipt this Period

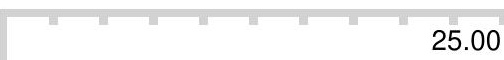

25.00

Amount of Each Receipt this Period

Transaction ID : AF2399A31058648BAA13

Date of Receipt
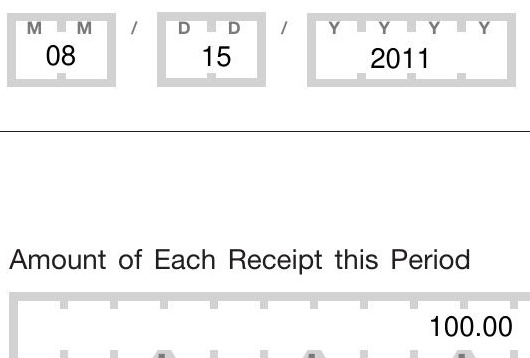

Transaction ID : A886B0CCD567845A0A12 Date of Receipt

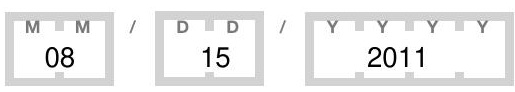

Amount of Each Receipt this Period

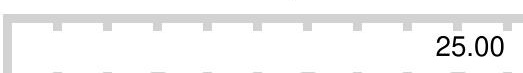

378.13

Subtotal Of Receipts This Page (optional)

150.00

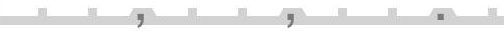

Total This Period (last page this line number only)

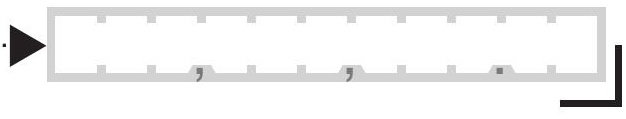

FEC Schedule A-P (Form 3P) (Rev. 03/2011) 
SCHEDULE A-P ITEMIZED RECEIPTS
Use separate schedule(s) for each category of the Detailed Summary Page
FOR LINE NUMBER: (check only one)

PAGE $290 / 1572$

\begin{tabular}{|c|c|c|c|c|c|}
\hline & & & & & \\
\hline 16 & $\begin{array}{l}\mathbf{X} \\
17 a\end{array}$ & $17 b$ & $17 c$ & $17 d$ & 18 \\
\hline $19 a$ & $19 \mathrm{~b}$ & $20 \mathrm{a}$ & $20 \mathrm{~b}$ & $20 \mathrm{c}$ & 21 \\
\hline
\end{tabular}

Any information copied from such Reports and Statements may not be sold or used by any person for the purpose of soliciting contributions or for commercial purposes, other than using the name and address of any political committee to solicit contributions from such committee.

NAME OF COMMITTEE (In Full)

\section{Friends of Herman Cain}

A. Full Name (Last, First, Middle Initial) James Richard

Mailing Address PO Box 118

\begin{tabular}{lcc}
\hline City & State & Zip Code \\
East Otis & MA & $01029-0118$
\end{tabular}

FEC ID number of contributing federal political committee.

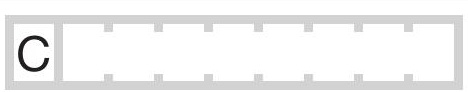

Name of Employer
Information Requested
Receipt For: 2012
X Primary
Other (specify) General

Occupation Information Requested

Election Cycle-to-Date

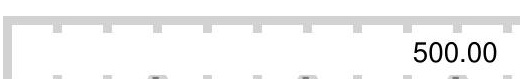

B. Full Name (Last, First, Middle Initial)

Kelli Richard

Mailing Address 12777 Cijon St

\begin{tabular}{lcc}
\hline City & State & Zip Code \\
San Diego & CA & $92129-3024$
\end{tabular}

FEC ID number of contributing

federal political committee.

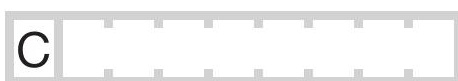

\begin{tabular}{l} 
Name of Employer \\
Life Technologies \\
Receipt For: 2012 \\
X Primary \\
\hline Other (specify) General
\end{tabular}

\section{Occupation}

Accountant

Election Cycle-to-Date

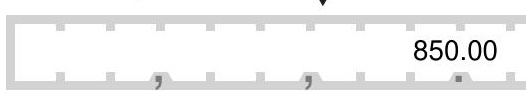

Transaction ID : A6897E1 AE96A34D4FBE6

Date of Receipt

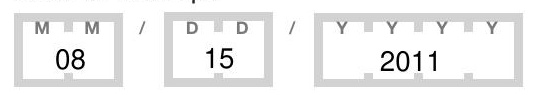

Amount of Each Receipt this Period

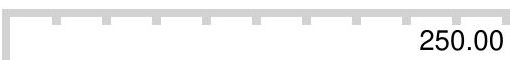

C. Full Name (Last, First, Middle Initial)

Robert Bolling

Mailing Address 2109 Freeman Rd

\begin{tabular}{lcc}
\hline City & State & Zip Code \\
Jonesboro & GA & $30236-6711$
\end{tabular}

FEC ID number of contributing federal political committee.

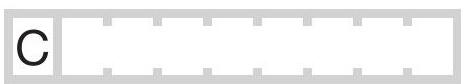

Name of Employer
self
Receipt For: 2012
X Primary $\quad \square$ General
Other (specify)

\section{Occupation}

contractor

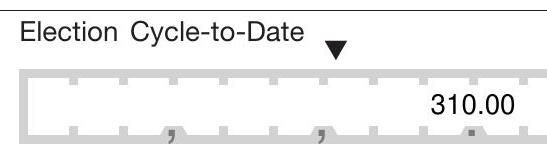

Amount of Each Receipt this Period

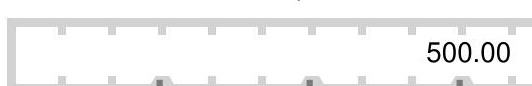

Transaction ID : A20DE349F62A741B190A

Date of Receipt

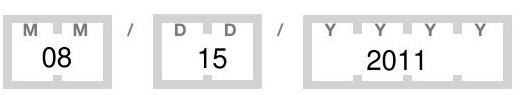

Transaction ID : A331989A1C228489AB44 Date of Receipt

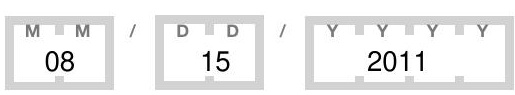

Amount of Each Receipt this Period

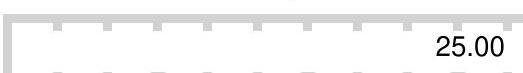

\section{Subtotal Of Receipts This Page (optional)}

775.00

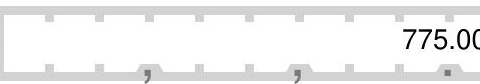

Total This Period (last page this line number only)

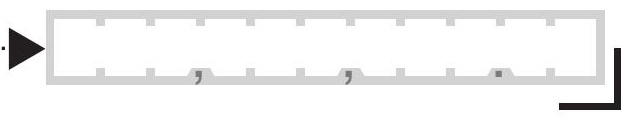

FEC Schedule A-P (Form 3P) (Rev. 03/2011) 


\section{SCHEDULE A-P} ITEMIZED RECEIPTS
Use separate schedule(s)

for each category of the

Detailed Summary Page
FOR LINE NUMBER: (check only one)

PAGE $291 / 1572$

\begin{tabular}{|c|c|c|c|c|c|}
\hline & & & & & \\
\hline 16 & X $17 a$ & $17 b$ & $17 c$ & $17 d$ & 18 \\
\hline $19 a$ & $19 b$ & $20 \mathrm{a}$ & $20 \mathrm{~b}$ & $20 \mathrm{c}$ & 21 \\
\hline
\end{tabular}

Any information copied from such Reports and Statements may not be sold or used by any person for the purpose of soliciting contributions or for commercial purposes, other than using the name and address of any political committee to solicit contributions from such committee.

NAME OF COMMITTEE (In Full)

Friends of Herman Cain

A. Full Name (Last, First, Middle Initial)

JAMES BRANDEL

Mailing Address 5713 JACK ROAD

\begin{tabular}{lcc}
\hline City & State & Zip Code \\
Jacksonville & FL & $32277-2429$
\end{tabular}

FEC ID number of contributing

federal political committee.

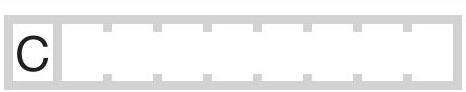

Name of Employer
Information Requested
Receipt For: 2012
X Primary $\quad \square$ General
Other (specify)

Occupation

Information Requested

Election Cycle-to-Date

290.00

B. Full Name (Last, First, Middle Initial)

Anthony Acosta

Mailing Address 663 Avenue C

\begin{tabular}{lcc}
\hline City & State & Zip Code \\
Redondo Beach & CA & $90277-4840$
\end{tabular}

FEC ID number of contributing

federal political committee.

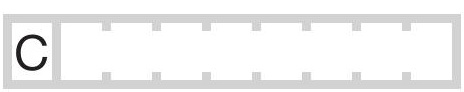

Name of Employer
northrop grumman
Receipt For: 2012
Primary
Other (specify) General

Occupation

MATHEMATICIAN

Election Cycle-to-Date

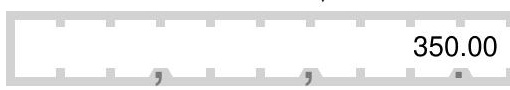

C. Full Name (Last, First, Middle Initial)

Aileen Hatcher

Mailing Address 1 Brookhaven Dr NE Apt 204

\begin{tabular}{lcc}
\hline City & State & Zip Code \\
Atlanta & GA & $30319-3057$ \\
\hline
\end{tabular}

FEC ID number of contributing

federal political committee.

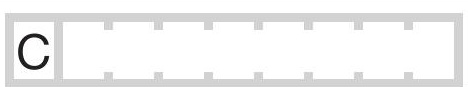

Name of Employer

Information Requested

Occupation

Information Requested

Receipt For: 2012

Х $\begin{aligned} & \text { Primary } \square \text { General } \\ & \text { Other (specify) }\end{aligned}$

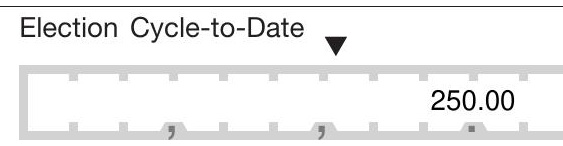

Amount of Each Receipt this Period

Transaction ID : AF082D32C0FD14C64906

Date of Receipt

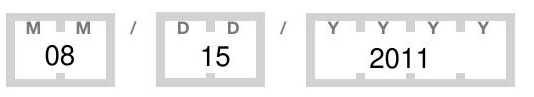

Amount of Each Receipt this Period

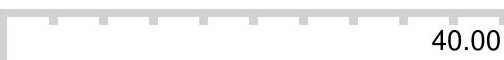

40.00

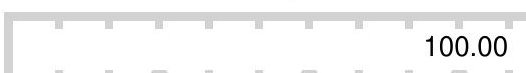

Transaction ID : A3824F9CCE24B4810843

Date of Receipt

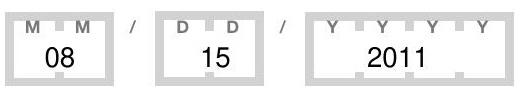

Amount of Each Receipt this Period

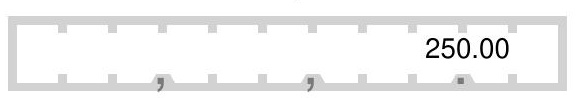

Subtotal Of Receipts This Page (optional).

390.00

Total This Period (last page this line number only) 
SCHEDULE A-P ITEMIZED RECEIPTS
Use separate schedule(s) for each category of the Detailed Summary Page
FOR LINE NUMBER: (check only one)

PAGE 292 / 1572

\begin{tabular}{|c|c|c|c|c|c|}
\hline & & & & & \\
\hline 16 & $\begin{array}{l}\mathbf{X} \\
17 a\end{array}$ & $17 b$ & $17 c$ & $17 d$ & 18 \\
\hline $19 a$ & $19 \mathrm{~b}$ & $20 \mathrm{a}$ & $20 \mathrm{~b}$ & $20 \mathrm{c}$ & 21 \\
\hline
\end{tabular}

Any information copied from such Reports and Statements may not be sold or used by any person for the purpose of soliciting contributions or for commercial purposes, other than using the name and address of any political committee to solicit contributions from such committee.

NAME OF COMMITTEE (In Full)

\section{Friends of Herman Cain}

A. Full Name (Last, First, Middle Initial)

Barbara Williams

Mailing Address 149 Four Diamond Dr

\begin{tabular}{lcc}
\hline City & State & Zip Code \\
Seven Devils & NC & $28604-8991$
\end{tabular}

FEC ID number of contributing

federal political committee.

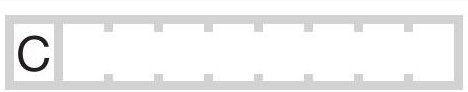

Name of Employer
None
Receipt For: 2012
X Primary $\quad$ General
Other (specify)

Occupation

Retired

Election Cycle-to-Date

345.00

B. Full Name (Last, First, Middle Initial)

michele bosack

Mailing Address 175 new philadelphia rd

\begin{tabular}{lcc}
\hline City & State & Zip Code \\
Orwigsburg & PA & $17961-9023$ \\
\hline
\end{tabular}

FEC ID number of contributing

federal political committee.

C

Name of Employer
Information Requested
Receipt For: 2012
X Primary
Other (specify)

Occupation

Information Requested

Election Cycle-to-Date

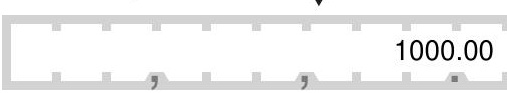

Transaction ID : A51FC44DB12804F3F884

Date of Receipt

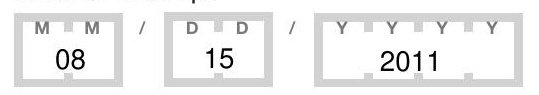

Amount of Each Receipt this Period

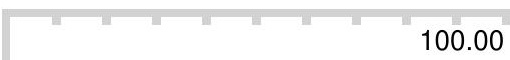

100.00

C. Full Name (Last, First, Middle Initial)

Ed Fry

Mailing Address 14722 Fishers Cove

\begin{tabular}{lcc}
\hline City & State & Zip Code \\
Pinehurst & TX & $77362-1928$
\end{tabular}

FEC ID number of contributing

federal political committee.

C

$77362-1928$

\section{Name of Employer}

FaithSearch Partners Inc.

Receipt For: 2012

Х $\begin{aligned} & \text { Primary } \square \text { General } \\ & \text { Other (specify) }\end{aligned}$

\section{Occupation}

Consultant

\section{Election Cycle-to-Date}

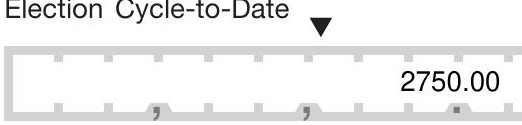

Transaction ID : AB1A503E8A80E4A33936

Date of Receipt

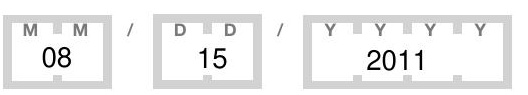

Amount of Each Receipt this Period

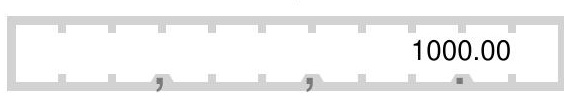

Transaction ID : ABE1EF9B865264BC6B39 Date of Receipt

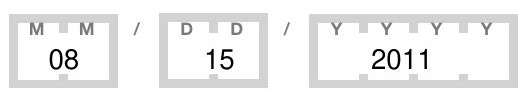

Amount of Each Receipt this Period

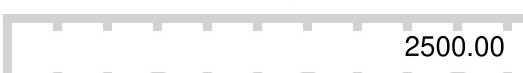

2500.00
Subtotal Of Receipts This Page (optional)

3600.00

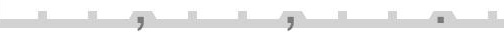

Total This Period (last page this line number only)

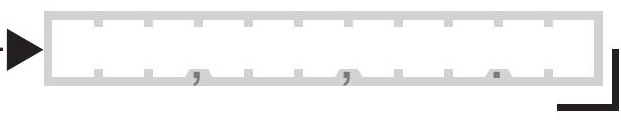

FEC Schedule A-P (Form 3P) (Rev. 03/2011) 
SCHEDULE A-P ITEMIZED RECEIPTS
Use separate schedule(s) for each category of the Detailed Summary Page
FOR LINE NUMBER: (check only one)

PAGE $293 / 1572$

\begin{tabular}{|c|c|c|c|c|c|}
\hline & & & & & \\
\hline 16 & $\begin{array}{l}\mathbf{X} \\
17 a\end{array}$ & $17 b$ & $17 c$ & $17 d$ & 18 \\
\hline $19 a$ & $19 \mathrm{~b}$ & $20 \mathrm{a}$ & $20 \mathrm{~b}$ & $20 \mathrm{c}$ & 21 \\
\hline
\end{tabular}

Any information copied from such Reports and Statements may not be sold or used by any person for the purpose of soliciting contributions or for commercial purposes, other than using the name and address of any political committee to solicit contributions from such committee.

NAME OF COMMITTEE (In Full)

\section{Friends of Herman Cain}

A. Full Name (Last, First, Middle Initial)

Edward Douglas

Mailing Address 1804 Eagle Dr

\begin{tabular}{lcc}
\hline City & State & Zip Code \\
League City & TX & $77573-5129$ \\
\hline
\end{tabular}

FEC ID number of contributing federal political committee.

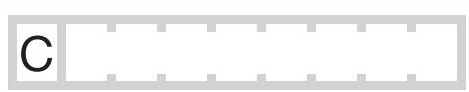

Name of Employer
City of Pasadena Texas
Receipt For: 2012
X Primary
Other (specify) General

Occupation

Police Officer

Election Cycle-to-Date

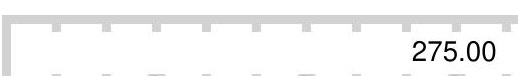

Transaction ID : A47E98BA65E024B16842

Date of Receipt

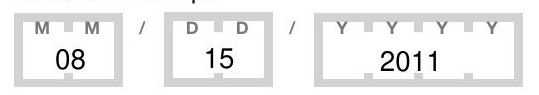

Amount of Each Receipt this Period

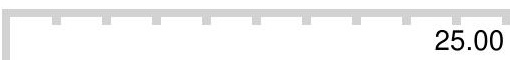

25.00
B. Full Name (Last, First, Middle Initial) scott debates

Mailing Address 22398 burr oak circle

\begin{tabular}{lcc}
\hline City & State & Zip Code \\
Gretna & NE & $68028-4858$
\end{tabular}

FEC ID number of contributing

federal political committee.

C

Name of Employer
Information Requested
Receipt For: 2012
X Primary
Other (specify)

Occupation

Information Requested

Election Cycle-to-Date

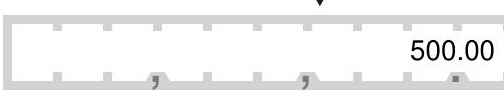

C. Full Name (Last, First, Middle Initial)

frederick moser

Mailing Address 15421 Brodick Dr

\section{City}

Austin

FEC ID number of contributing

federal political committee.

Name of Employer

True World Services

Receipt For: 2012

Х $\begin{aligned} & \text { Primary } \square \text { General } \\ & \text { Other (specify) }\end{aligned}$

$\begin{array}{cc}\text { State } & \text { Zip Code } \\ \text { TX } & 78717-3923\end{array}$

C

\section{Occupation}

Sales Rep

Election Cycle-to-Date

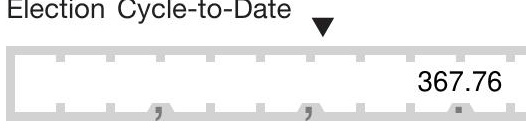

Transaction ID : AB66B14B2973E46DAAF6 Date of Receipt

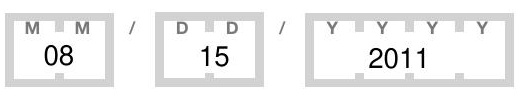

Amount of Each Receipt this Period

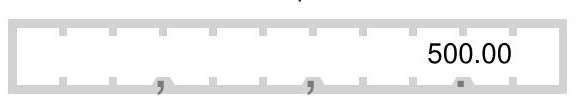

Transaction ID : A8237D0332B184EDEADF Date of Receipt

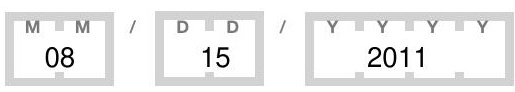

Amount of Each Receipt this Period

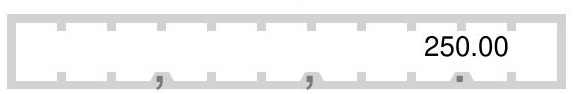

775.00

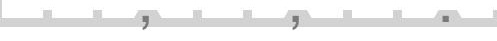

Total This Period (last page this line number only)

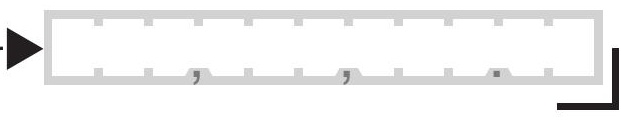

FEC Schedule A-P (Form 3P) (Rev. 03/2011) 
SCHEDULE A-P ITEMIZED RECEIPTS
Use separate schedule(s) for each category of the Detailed Summary Page
FOR LINE NUMBER: (check only one)

\begin{tabular}{|c|c|c|c|c|c|c|}
\hline & & & & & & \\
\hline 16 & $\times 1$ & $17 a$ & $17 b$ & $17 c$ & $17 d$ & 18 \\
\hline $19 a$ & & $19 b$ & $20 \mathrm{a}$ & $20 \mathrm{~b}$ & $20 \mathrm{c}$ & 21 \\
\hline
\end{tabular}

Any information copied from such Reports and Statements may not be sold or used by any person for the purpose of soliciting contributions or for commercial purposes, other than using the name and address of any political committee to solicit contributions from such committee.

NAME OF COMMITTEE (In Full)

\section{Friends of Herman Cain}

A. Full Name (Last, First, Middle Initial)

Gary Locke

Mailing Address 2602 Booger Hill Road

\begin{tabular}{lcc}
\hline City & State & Zip Code \\
Danielsville & GA & $30633-6102$
\end{tabular}

FEC ID number of contributing

federal political committee.

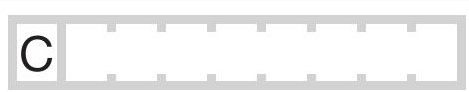

Name of Employer
None
Receipt For: 2012
X Primary $\quad$ General
Other (specify)

Occupation

Retired

Election Cycle-to-Date

900.00

B. Full Name (Last, First, Middle Initial)

marilyn Sensney

Mailing Address 19528 Creekside Ct

\begin{tabular}{lcc}
\hline City & State & Zip Code \\
Salinas & CA & $93908-1245$
\end{tabular}

FEC ID number of contributing

federal political committee.

Name of Employer
Monerey School District
Receipt For: 2012
X Primary $\quad$ General
Other (specify)

Transaction ID : A0A66469D40C34A70A48

Date of Receipt

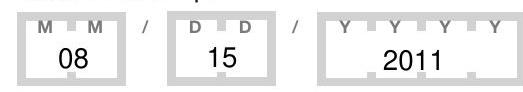

Amount of Each Receipt this Period

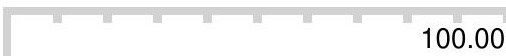

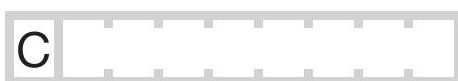

\section{Occupation}

Teacher

Election Cycle-to-Date

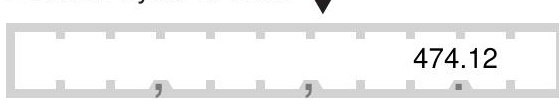

Transaction ID : AC47CB42525104428882

Date of Receipt

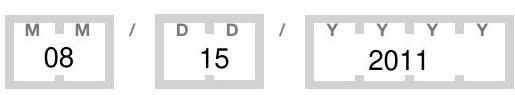

Amount of Each Receipt this Period

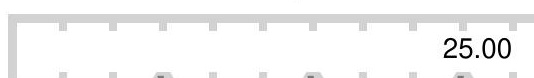

Transaction ID : AEFBCE57FE7C44B57997 Date of Receipt

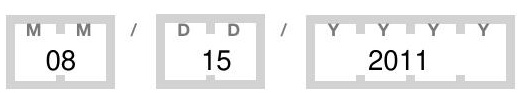

Amount of Each Receipt this Period

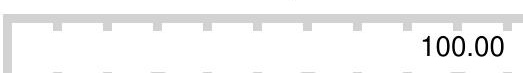

Occupation

Election Cycle-to-Date

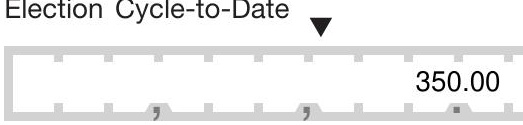

Subtotal Of Receipts This Page (optional)

225.00

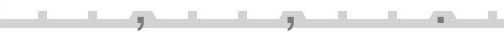

Total This Period (last page this line number only)

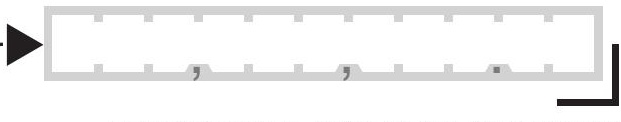

FEC Schedule A-P (Form 3P) (Rev. 03/2011) 
SCHEDULE A-P ITEMIZED RECEIPTS
Use separate schedule(s) for each category of the Detailed Summary Page
FOR LINE NUMBER: (check only one)

PAGE $295 / 1572$

\begin{tabular}{|c|c|c|c|c|c|}
\hline & & & & & \\
\hline 16 & $\begin{array}{l}\mathbf{X} \\
17 a\end{array}$ & $17 b$ & $17 c$ & $17 d$ & 18 \\
\hline $19 a$ & $19 \mathrm{~b}$ & $20 \mathrm{a}$ & $20 \mathrm{~b}$ & $20 \mathrm{c}$ & 21 \\
\hline
\end{tabular}

Any information copied from such Reports and Statements may not be sold or used by any person for the purpose of soliciting contributions or for commercial purposes, other than using the name and address of any political committee to solicit contributions from such committee.

NAME OF COMMITTEE (In Full)

\section{Friends of Herman Cain}

A. Full Name (Last, First, Middle Initial)

mary nestlerode

Mailing Address 26191 roymor dr

\begin{tabular}{lcc}
\hline City & State & Zip Code \\
Calabasas & CA & $91302-1045$
\end{tabular}

FEC ID number of contributing federal political committee.

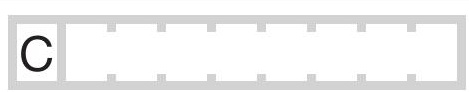

Name of Employer
Retired
Receipt For: 2012
X Primary $\quad$ General
Other (specify)

Occupation Retired

Election Cycle-to-Date

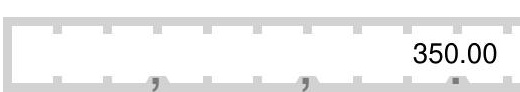

B. Full Name (Last, First, Middle Initial)

Michael Rountree

Mailing Address 55 Hawthorn Glen Trl

\begin{tabular}{lcc}
\hline City & State & Zip Code \\
Beavercreek & OH & $45440-3547$
\end{tabular}

FEC ID number of contributing

federal political committee.

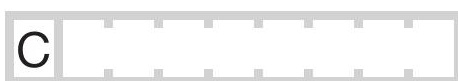

Name of Employer
None
Receipt For: 2012
X Primary $\quad$ General
Other (specify)

\section{Occupation}

Retired

Election Cycle-to-Date

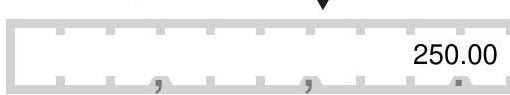

Transaction ID : ADB5E5F0E23DA44A0921

Date of Receipt

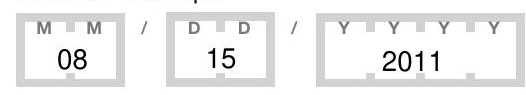

Amount of Each Receipt this Period

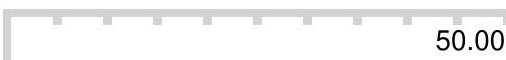

Transaction ID : A1407341DFD8A406DB5E

Date of Receipt

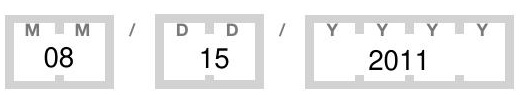

Amount of Each Receipt this Period

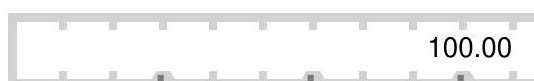

Transaction ID : A26B99961A4ED4A08B6A Date of Receipt

Gabrielle Manigault

Mailing Address 832 Greenough Rd.

\begin{tabular}{lcc}
\hline City & State & Zip Code \\
Recluse & WY & 82725 \\
\hline
\end{tabular}

FEC ID number of contributing federal political committee.

C

Name of Employer
Information Requested
Receipt For: 2012
X Primary
Other (specify) General

Occupation

Information Requested

Election Cycle-to-Date

Subtotal Of Receipts This Page (optional).

Amount of Each Receipt this Period

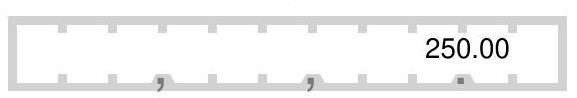

Total This Period (last page this line number only)

400.00

a 12.

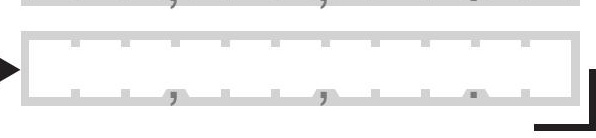

FEC Schedule A-P (Form 3P) (Rev. 03/2011) 
SCHEDULE A-P ITEMIZED RECEIPTS
Use separate schedule(s) for each category of the Detailed Summary Page
FOR LINE NUMBER: (check only one)

PAGE $296 / 1572$

\begin{tabular}{|c|c|c|c|c|c|}
\hline & & & & & \\
\hline 16 & $\begin{array}{l}\mathbf{X} \\
17 a\end{array}$ & $17 b$ & $17 c$ & $17 d$ & 18 \\
\hline $19 a$ & $19 \mathrm{~b}$ & $20 \mathrm{a}$ & $20 \mathrm{~b}$ & $20 \mathrm{c}$ & 21 \\
\hline
\end{tabular}

Any information copied from such Reports and Statements may not be sold or used by any person for the purpose of soliciting contributions or for commercial purposes, other than using the name and address of any political committee to solicit contributions from such committee.

NAME OF COMMITTEE (In Full)

\section{Friends of Herman Cain}

A. Full Name (Last, First, Middle Initial) James Wright

Mailing Address 7175 Gaston Avenue \#2121

\begin{tabular}{lcc}
\hline City & State & Zip Code \\
Dallas & TX & $75214-6140$
\end{tabular}

FEC ID number of contributing federal political committee.

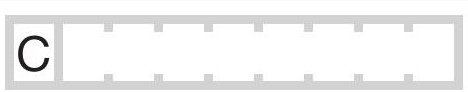

Name of Employer
The Leaves
Receipt For: 2012
X Primary
Other (specify) General

Occupation Director

Election Cycle-to-Date

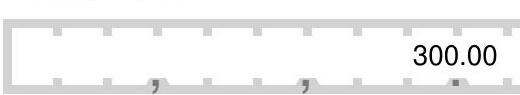

B. Full Name (Last, First, Middle Initial) James D Young

Mailing Address 1270 Allendale Dr

\begin{tabular}{lcc}
\hline City & State & Zip Code \\
Cumming & GA & $30041-8645$ \\
\hline
\end{tabular}

FEC ID number of contributing

federal political committee.

C

Name of Employer
Andrew Systems Inc.
Receipt For: 2012
X Primary
Other (specify)

Occupation

Telecommunications

Election Cycle-to-Date

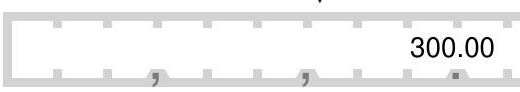

Transaction ID : A19FF5CDEE1D94664866

Date of Receipt

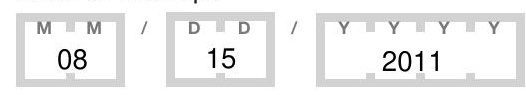

Amount of Each Receipt this Period

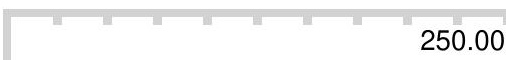

C. Full Name (Last, First, Middle Initial)

Carol Czechowski

Mailing Address PO Box 190

\begin{tabular}{lcc}
\hline City & State & Zip Code \\
Good Hope & GA & $30641-0190$
\end{tabular}

FEC ID number of contributing federal political committee.

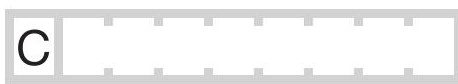

Name of Employer
Self Employed
Receipt For: 2012
X Primary $\quad \square$ General
Other (specify)

\section{Occupation}

Cast Glass Mfg.

Election Cycle-to-Date

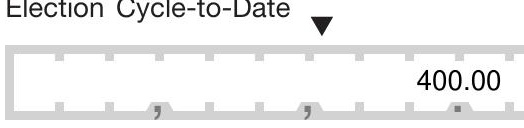

Amount of Each Receipt this Period

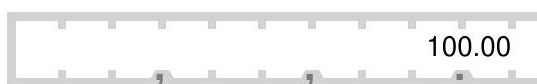

Transaction ID : AA16BF91EC36E4CBA88B Date of Receipt

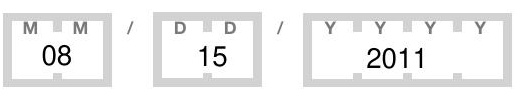

Transaction ID : A5FD6A2407DBF4A85AC5 Date of Receipt

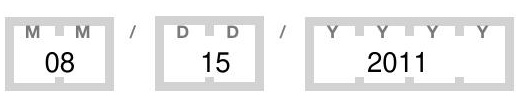

Amount of Each Receipt this Period

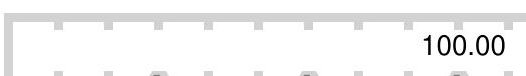

\section{Subtotal Of Receipts This Page (optional)}

Total This Period (last page this line number only) 
SCHEDULE A-P ITEMIZED RECEIPTS
Use separate schedule(s) for each category of the Detailed Summary Page
FOR LINE NUMBER: (check only one)

PAGE 297 / 1572

\begin{tabular}{|c|c|c|c|c|c|}
\hline & & & & & \\
\hline 16 & $\begin{array}{l}\mathbf{X} \\
17 a\end{array}$ & $17 b$ & $17 c$ & $17 d$ & 18 \\
\hline $19 a$ & $19 \mathrm{~b}$ & $20 \mathrm{a}$ & $20 \mathrm{~b}$ & $20 \mathrm{c}$ & 21 \\
\hline
\end{tabular}

Any information copied from such Reports and Statements may not be sold or used by any person for the purpose of soliciting contributions or for commercial purposes, other than using the name and address of any political committee to solicit contributions from such committee.

NAME OF COMMITTEE (In Full)

\section{Friends of Herman Cain}

A. Full Name (Last, First, Middle Initial)

Newell Atkinson

Mailing Address 1117 Zuni PI

\begin{tabular}{lcc}
\hline City & State & Zip Code \\
El Paso & TX & $79925-3409$
\end{tabular}

FEC ID number of contributing federal political committee.

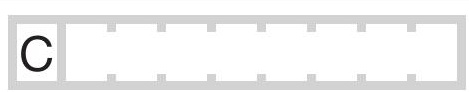

Name of Employer
Commodity Central Inc.
Receipt For: 2012
X Primary $\quad \square$ General
Other (specify)

Occupation Management

Election Cycle-to-Date

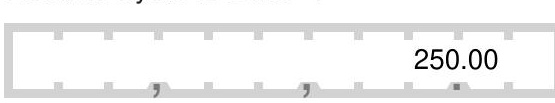

B. Full Name (Last, First, Middle Initial) James Moates

Mailing Address 1410 Old Bethany Rd

\begin{tabular}{lcc}
\hline City & State & Zip Code \\
Greensboro & GA & $30642-4212$ \\
\hline
\end{tabular}

FEC ID number of contributing

federal political committee.

C

Name of Employer
Parsons-Brinckerhoff
Receipt For: 2012
X Primary
Other (specify)

Occupation

Engineering Consultant

Election Cycle-to-Date

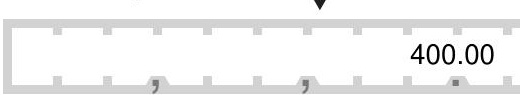

Transaction ID : AB5E9F3C9149445578C6

Date of Receipt

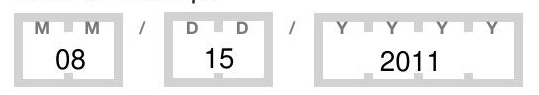

Amount of Each Receipt this Period

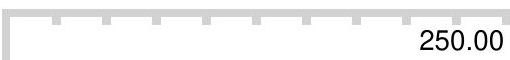

Transaction ID : A85F922494D3340BB832

Date of Receipt

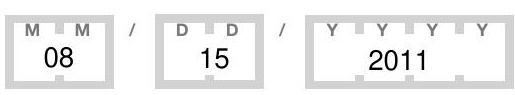

Amount of Each Receipt this Period

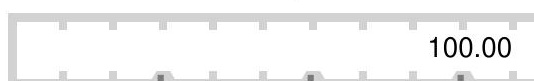

Transaction ID : A6FE9AC2796D94D61BB7 Date of Receipt

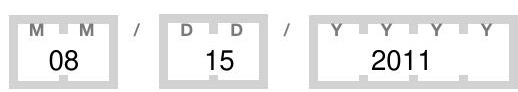

Amount of Each Receipt this Period

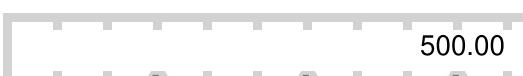

$\begin{array}{cc}\text { State } & \text { Zip Code } \\ \text { GA } & 30349-2342\end{array}$

C

$\begin{aligned} & \text { Occupation } \\ & \text { Information Requested }\end{aligned}$
Election Cycle-to-Date

Subtotal Of Receipts This Page (optional)

850.00

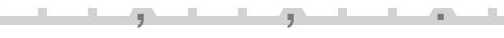

Total This Period (last page this line number only)

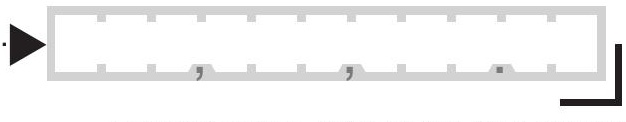

FEC Schedule A-P (Form 3P) (Rev. 03/2011) 
SCHEDULE A-P ITEMIZED RECEIPTS
Use separate schedule(s) for each category of the Detailed Summary Page
FOR LINE NUMBER: (check only one)

PAGE $298 / 1572$

\begin{tabular}{|c|c|c|c|c|c|}
\hline & & & & & \\
\hline 16 & $\begin{array}{l}\mathbf{X} \\
17 a\end{array}$ & $17 b$ & $17 c$ & $17 d$ & 18 \\
\hline $19 a$ & $19 \mathrm{~b}$ & $20 \mathrm{a}$ & $20 \mathrm{~b}$ & $20 \mathrm{c}$ & 21 \\
\hline
\end{tabular}

Any information copied from such Reports and Statements may not be sold or used by any person for the purpose of soliciting contributions or for commercial purposes, other than using the name and address of any political committee to solicit contributions from such committee.

NAME OF COMMITTEE (In Full)

\section{Friends of Herman Cain}

A. Full Name (Last, First, Middle Initial)

Anthony Chuck

Mailing Address 571 Windhaven Ct

\begin{tabular}{lcc}
\hline City & State & Zip Code \\
Suwanee & GA & $30024-7096$
\end{tabular}

FEC ID number of contributing federal political committee.

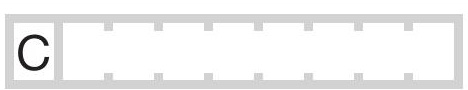

Name of Employer
OrtusTech Inc.
Receipt For: 2012
X Primary
Other (specify) General

Occupation CEO

Election Cycle-to-Date

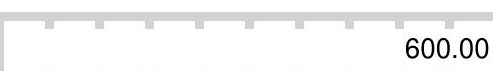

B. Full Name (Last, First, Middle Initial)

Mary Causey

Mailing Address 189 Lamplighter Lane

\begin{tabular}{lcc}
\hline City & State & Zip Code \\
Ponte Vedra Beach & FL & $32082-1951$ \\
\hline
\end{tabular}

FEC ID number of contributing

federal political committee.

C

Name of Employer
Dat'l Do-It Inc.
Receipt For: 2012
X Primary
Other (specify)

Occupation

Small Business Owner

Election Cycle-to-Date

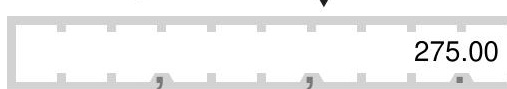

Transaction ID : A4079513EFE7B46E29A7

Date of Receipt

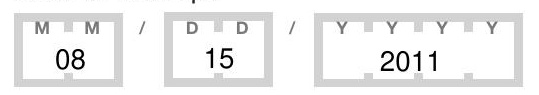

Amount of Each Receipt this Period

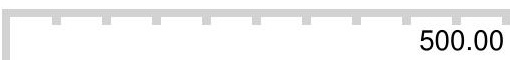

C. Full Name (Last, First, Middle Initial)

Steve Thomas

Mailing Address 6369 Pittman Cr.

\begin{tabular}{lcc}
\hline City & State & Zip Code \\
Casper & WY & $82604-3632$ \\
\hline
\end{tabular}

FEC ID number of contributing federal political committee.

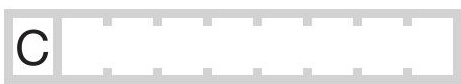

Name of Employer
john deere
Receipt For: 2012
X Primary $\square$ General
Other (specify)

Occupation

Mechanic

Election Cycle-to-Date

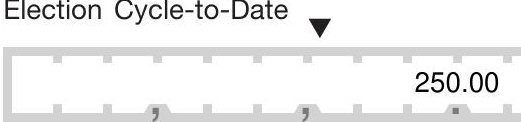

Transaction ID : AD3F4713C750F437BA50

Date of Receipt

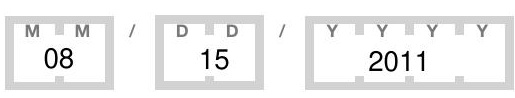

Amount of Each Receipt this Period

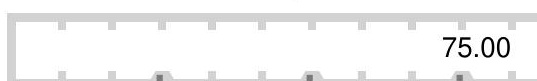

Transaction ID : A1FC3A9F2E2724EDA90B Date of Receipt

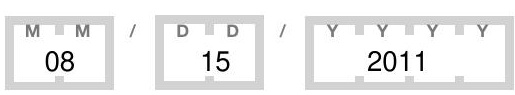

Amount of Each Receipt this Period

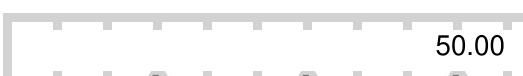

\section{Subtotal Of Receipts This Page (optional)}

Total This Period (last page this line number only) 
SCHEDULE A-P ITEMIZED RECEIPTS
Use separate schedule(s)

for each category of the

Detailed Summary Page
FOR LINE NUMBER: (check only one)

Any information or for commercial purposes, other than using the name and address of any political committee to solicit contributions from such committee.

NAME OF COMMITTEE (In Full)

\section{Friends of Herman Cain}

A. Full Name (Last, First, Middle Initial)

Joy Reider

Mailing Address 2534 Ridgewood Ter NW

\begin{tabular}{lcc}
\hline City & State & Zip Code \\
Atlanta & GA & $30318-1321$
\end{tabular}

FEC ID number of contributing

federal political committee.

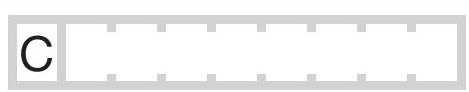

Name of Employer
Information Requested
Receipt For: 2012
X Primary
Other (specify) General

Occupation

Information Requested

Election Cycle-to-Date

500.00

B. Full Name (Last, First, Middle Initial)

Jean M Redding

Mailing Address 1151 Brookhaven Ct NE

\begin{tabular}{lcc}
\hline City & State & Zip Code \\
Atlanta & GA & $30319-2867$
\end{tabular}

FEC ID number of contributing

federal political committee.

C

Name of Employer
Information Requested
Receipt For: 2012
X Primary
Other (specify)

Occupation

Information Requested

Election Cycle-to-Date

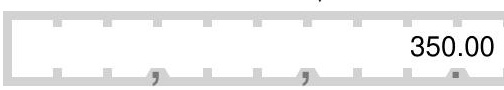

Transaction ID : A43586DA5178143339EB

Date of Receipt

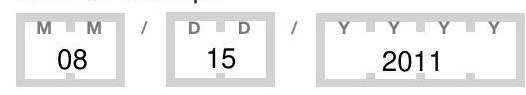

Amount of Each Receipt this Period

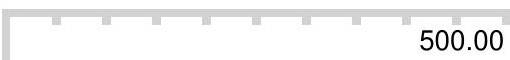

Transaction ID : A303692D53E1E43C9B0F

Date of Receipt

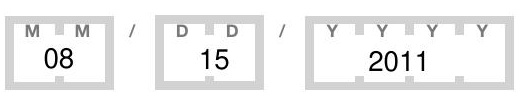

Amount of Each Receipt this Period

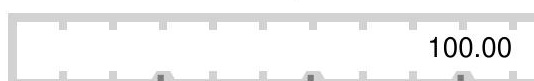

Transaction ID : AC992DBD9ACD649B5B1D Date of Receipt

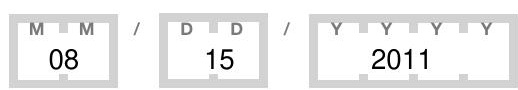

Amount of Each Receipt this Period

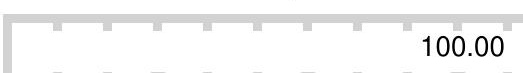

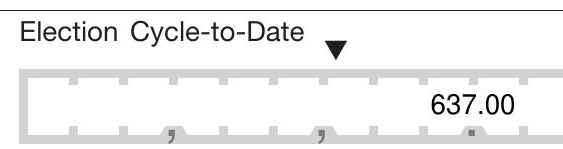

C. Full Name (Last, First, Middle Initial)

Michael Elliot

Mailing Address 3914 E. Brookhaven

\begin{tabular}{lcc}
\hline City & State & Zip Code \\
Atlanta & GA & $30319-2808$
\end{tabular}

FEC ID number of contributing federal political committee.

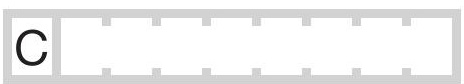

Name of Employer
real estate
Receipt For: 2012
Xrimary
Other (specify) General

Investments

Occupation 
SCHEDULE A-P ITEMIZED RECEIPTS
Use separate schedule(s) for each category of the Detailed Summary Page
FOR LINE NUMBER: (check only one)

PAGE $300 / 1572$

\begin{tabular}{|c|c|c|c|c|c|}
\hline & & & & & \\
\hline 16 & $\begin{array}{l}\mathbf{X} \\
17 a\end{array}$ & $17 b$ & $17 c$ & $17 d$ & 18 \\
\hline $19 a$ & $19 \mathrm{~b}$ & $20 \mathrm{a}$ & $20 \mathrm{~b}$ & $20 \mathrm{c}$ & 21 \\
\hline
\end{tabular}

Any information copied from such Reports and Statements may not be sold or used by any person for the purpose of soliciting contributions or for commercial purposes, other than using the name and address of any political committee to solicit contributions from such committee.

NAME OF COMMITTEE (In Full)

\section{Friends of Herman Cain}

A. Full Name (Last, First, Middle Initial)

Edward Scott

Mailing Address 2261 Sidney Dr

\begin{tabular}{lcc}
\hline City & State & Zip Code \\
Gainesville & GA & $30506-1168$
\end{tabular}

FEC ID number of contributing federal political committee.

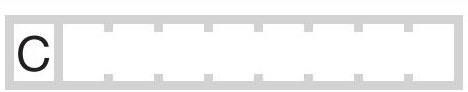

Name of Employer
Information Requested
Receipt For: 2012
X Primary
Other (specify) General

Occupation Information Requested

Election Cycle-to-Date 250.00

B. Full Name (Last, First, Middle Initial) Herbert $C$ Jardine

Mailing Address 1451 Summer Oaks Ct

\begin{tabular}{lcc}
\hline City & State & Zip Code \\
Marietta & GA & $30062-6155$ \\
\hline
\end{tabular}

FEC ID number of contributing

federal political committee.

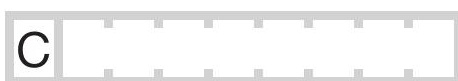

Name of Employer
None
Receipt For: 2012
X Primary
Other (specify)

\section{Occupation}

Retired

Election Cycle-to-Date

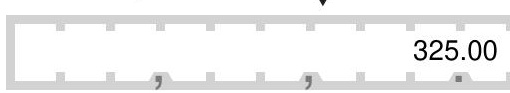

Transaction ID : AC4DD29AEDB184237958

Date of Receipt

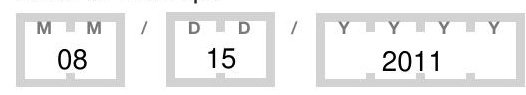

Amount of Each Receipt this Period

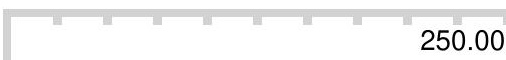

Amount of Each Receipt this Period

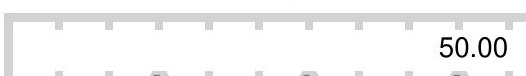

C. Full Name (Last, First, Middle Initial)

Igor Tsalyuk

Mailing Address 39 Coral PI

\begin{tabular}{lcc}
\hline City & State & Zip Code \\
Greenwood Village & CO & $80111-3461$
\end{tabular}

FEC ID number of contributing federal political committee.

C

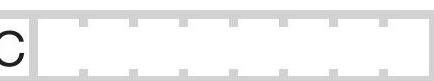

Name of Employer

Occupation

Arrow Electronics

Software Engineer

Receipt For: 2012

Х $\begin{aligned} & \text { Primary } \square \text { General } \\ & \text { Other (specify) }\end{aligned}$

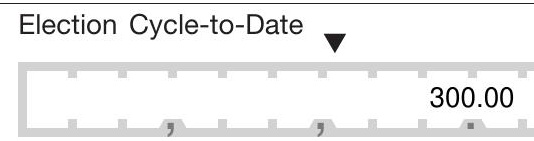

Amount of Each Receipt this Period

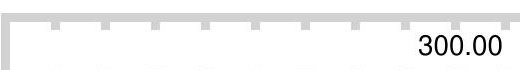

Transaction ID : AB22D32297FA14F38A40

Date of Receipt

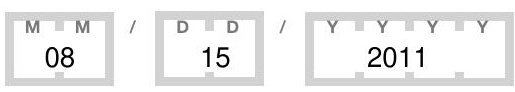

Subtotal Of Receipts This Page (optional)

600.00

Total This Period (last page this line number only) 
SCHEDULE A-P ITEMIZED RECEIPTS
Use separate schedule(s) for each category of the Detailed Summary Page
FOR LINE NUMBER: (check only one)

PAGE $301 / 1572$

\begin{tabular}{|c|c|c|c|c|c|}
\hline & & & & & \\
\hline 16 & $\begin{array}{l}\mathbf{X} \\
17 a\end{array}$ & $17 b$ & $17 c$ & $17 d$ & 18 \\
\hline $19 a$ & $19 \mathrm{~b}$ & $20 \mathrm{a}$ & $20 \mathrm{~b}$ & $20 \mathrm{c}$ & 21 \\
\hline
\end{tabular}

Any information copied from such Reports and Statements may not be sold or used by any person for the purpose of soliciting contributions or for commercial purposes, other than using the name and address of any political committee to solicit contributions from such committee.

NAME OF COMMITTEE (In Full)

\section{Friends of Herman Cain}

A. Full Name (Last, First, Middle Initial)

\section{Geoey Cook}

Mailing Address 136 Flora Ave

\begin{tabular}{lcc}
\hline City & State & Zip Code \\
Atlanta & GA & $30307-2714$
\end{tabular}

FEC ID number of contributing federal political committee.

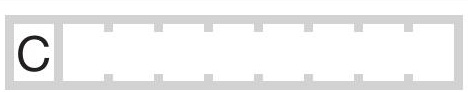

Name of Employer
Smart Marketer
Receipt For: 2012
X Primary $\quad$ General
Other (specify)

Occupation

Online Marketing Superhero

Election Cycle-to-Date

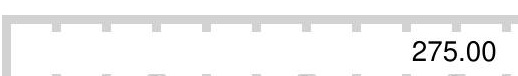

B. Full Name (Last, First, Middle Initial)

John C Houghton

Mailing Address 7145 Potomac Place

\begin{tabular}{lcc}
\hline City & State & Zip Code \\
Gilroy & CA & $95020-6326$
\end{tabular}

FEC ID number of contributing

federal political committee.

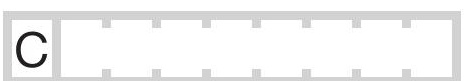

Name of Employer
The Energy House
Receipt For: 2012
Primary
Other (specify) General

\section{Occupation}

Sales

Election Cycle-to-Date

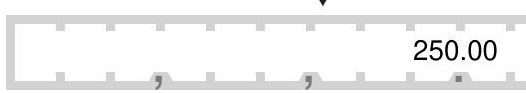

Transaction ID : A29FAC283A6BF464FB80

Date of Receipt

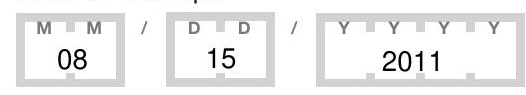

Amount of Each Receipt this Period

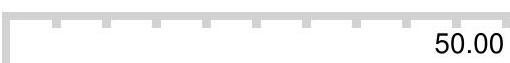

50.00

C. Full Name (Last, First, Middle Initial)

Thomas Park

Mailing Address 26614 Country Crk Ln

\begin{tabular}{lcc}
\hline City & State & Zip Code \\
Calabasas & CA & $91302-3587$
\end{tabular}

FEC ID number of contributing federal political committee.

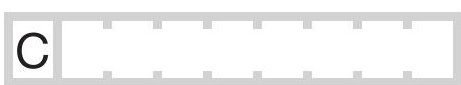

Name of Employer

Information Requested

\section{Occupation}

Information Requested

Receipt For: 2012

Х $\begin{aligned} & \text { Primary } \square \text { General } \\ & \text { Other (specify) }\end{aligned}$

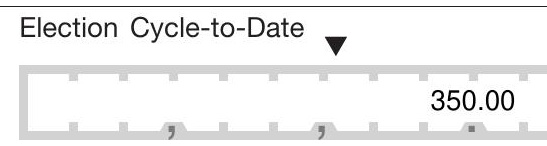

Amount of Each Receipt this Period

Transaction ID : AE9A255C307FF480CB02

Date of Receipt
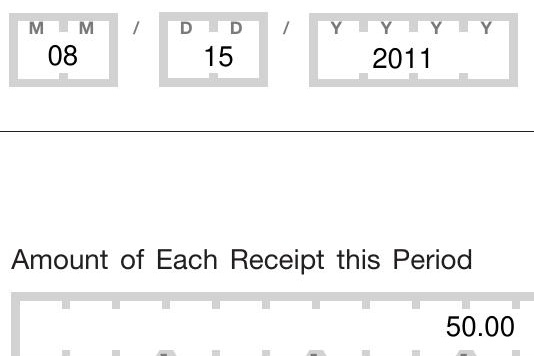

Transaction ID : AB92289983CA14679B66

Date of Receipt

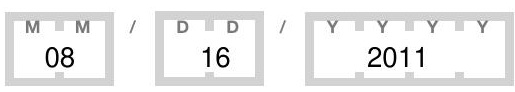

Amount of Each Receipt this Period

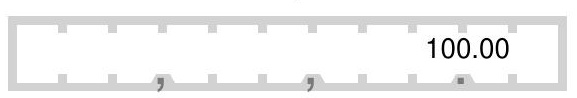

Subtotal Of Receipts This Page (optional).

200.00

Total This Period (last page this line number only) 
SCHEDULE A-P ITEMIZED RECEIPTS
Use separate schedule(s) for each category of the Detailed Summary Page
FOR LINE NUMBER: (check only one)

PAGE 302 / 1572

\begin{tabular}{|c|c|c|c|c|c|}
\hline & & & & & \\
\hline 16 & $\begin{array}{l}\mathbf{X} \\
17 a\end{array}$ & $17 b$ & $17 c$ & $17 d$ & 18 \\
\hline $19 a$ & $19 \mathrm{~b}$ & $20 \mathrm{a}$ & $20 \mathrm{~b}$ & $20 \mathrm{c}$ & 21 \\
\hline
\end{tabular}

Any information copied from such Reports and Statements may not be sold or used by any person for the purpose of soliciting contributions or for commercial purposes, other than using the name and address of any political committee to solicit contributions from such committee.

NAME OF COMMITTEE (In Full)

\section{Friends of Herman Cain}

A. Full Name (Last, First, Middle Initial)

THOMAS MCPETERS

Mailing Address 6451 N. SILVERSMITH PLACE

\begin{tabular}{lcc}
\hline City & State & Zip Code \\
Tucson & AZ & $85750-1086$
\end{tabular}

FEC ID number of contributing federal political committee.

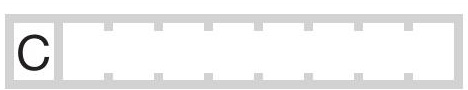

Name of Employer
McPETRS MCALEARNEY SHIM
Receipt For: 2012
X Primary
Other (specify) General

Occupation

Attorney

Election Cycle-to-Date

B. Full Name (Last, First, Middle Initial)

Alyn Holt

Mailing Address 10 Hessian Way

\begin{tabular}{lcc}
\hline City & State & Zip Code \\
Cherry Hill & NJ & $08003-2615$
\end{tabular}

FEC ID number of contributing

federal political committee.

C

Name of Employer
inTEST Corp
Receipt For: 2012
X Primary
Other (specify)

\section{Occupation}

Executive

Election Cycle-to-Date

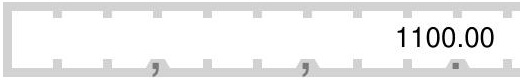

Transaction ID : A08F2702CC9F145DDB05

Date of Receipt

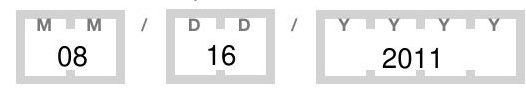

Amount of Each Receipt this Period

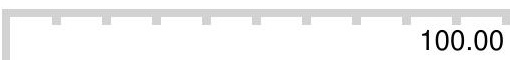

100.00

C. Full Name (Last, First, Middle Initial)

James Renfro

Mailing Address 150 Swansea Lane

\begin{tabular}{lcc}
\hline City & State & Zip Code \\
Fayetteville & GA & $30214-7429$
\end{tabular}

FEC ID number of contributing

federal political committee.

C

C

Name of Employer

Occupation

Information Requested

Information Requested

Receipt For: 2012

Х $\begin{aligned} & \text { Primary } \\ & \text { Other (specify) }\end{aligned}$

Transaction ID : AA82EBE7D09594A44AF4

Date of Receipt

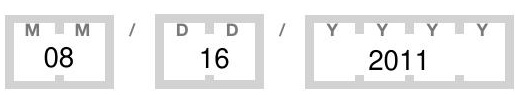

Amount of Each Receipt this Period

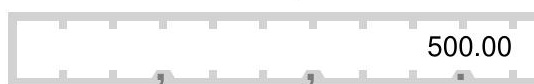

Transaction ID : A3FFC8455E6484229AA9

Date of Receipt

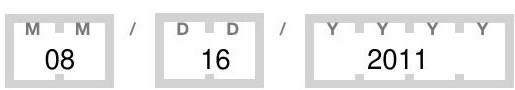

Amount of Each Receipt this Period

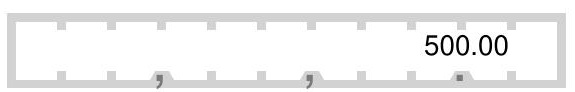

500.00

\section{Subtotal Of Receipts This Page (optional)}

Total This Period (last page this line number only) 
SCHEDULE A-P ITEMIZED RECEIPTS
Use separate schedule(s) for each category of the Detailed Summary Page
FOR LINE NUMBER: (check only one)

PAGE $303 / 1572$

\begin{tabular}{|c|c|c|c|c|c|}
\hline & & & & & \\
\hline 16 & $\begin{array}{l}\mathbf{X} \\
17 a\end{array}$ & $17 b$ & $17 c$ & $17 d$ & 18 \\
\hline $19 a$ & $19 \mathrm{~b}$ & $20 \mathrm{a}$ & $20 \mathrm{~b}$ & $20 \mathrm{c}$ & 21 \\
\hline
\end{tabular}

Any information copied from such Reports and Statements may not be sold or used by any person for the purpose of soliciting contributions or for commercial purposes, other than using the name and address of any political committee to solicit contributions from such committee.

NAME OF COMMITTEE (In Full)

\section{Friends of Herman Cain}

A. Full Name (Last, First, Middle Initial) James Stewart

Mailing Address 3560 E. Via Colonia del Sol

\begin{tabular}{lcc}
\hline City & State & Zip Code \\
Tucson & AZ & $85718-6065$
\end{tabular}

FEC ID number of contributing federal political committee.

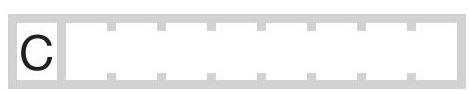

Name of Employer
Information Requested
Receipt For: 2012
X Primary
Other (specify) General

Occupation Information Requested

Election Cycle-to-Date

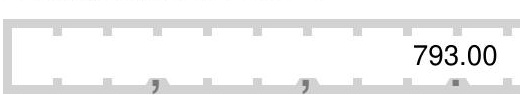

B. Full Name (Last, First, Middle Initial)

Margaret Schrader

Mailing Address 10624 S. Eastern Ave A-336

\begin{tabular}{lcc}
\hline City & State & Zip Code \\
Henderson & NV & 89052-2982 \\
\hline
\end{tabular}

FEC ID number of contributing

federal political committee.

C

Name of Employer
Large Marge Trucking Co
Receipt For: 2012
X Primary
Other (specify)

Occupation

Owner operator

Election Cycle-to-Date

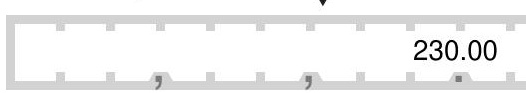

C. Full Name (Last, First, Middle Initial)

Deborah Medel

Mailing Address 5709 SE Morrison

\begin{tabular}{lcc}
\hline City & State & Zip Code \\
Portland & OR & $97215-1854$
\end{tabular}

FEC ID number of contributing federal political committee.

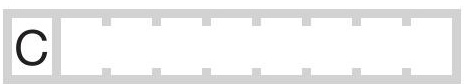

Name of Employer

ADP Dealer Services

Occupation

Receipt For: 2012

Х $\begin{aligned} & \text { Primary } \\ & \text { Other (specify) }\end{aligned}$

Computer Programmer

Election Cycle-to-Date

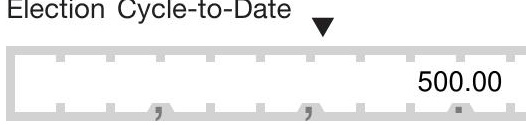

Transaction ID : A90540CF83A8549A58F6

Date of Receipt

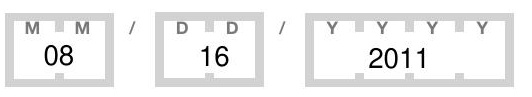

Amount of Each Receipt this Period

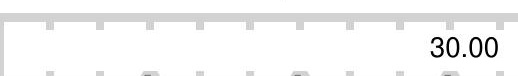

Transaction ID : A64FDECDFD9E94F589C6 Date of Receipt

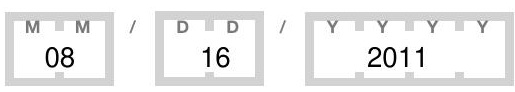

Amount of Each Receipt this Period

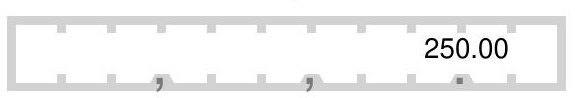

Subtotal Of Receipts This Page (optional).

330.00

Total This Period (last page this line number only) 
SCHEDULE A-P ITEMIZED RECEIPTS
Use separate schedule(s) for each category of the Detailed Summary Page
FOR LINE NUMBER: (check only one)

PAGE 304 / 1572

\begin{tabular}{|c|c|c|c|c|c|}
\hline & & & & & \\
\hline 16 & $\begin{array}{l}\mathbf{X} \\
17 a\end{array}$ & $17 b$ & $17 c$ & $17 d$ & 18 \\
\hline $19 a$ & $19 \mathrm{~b}$ & $20 \mathrm{a}$ & $20 \mathrm{~b}$ & $20 \mathrm{c}$ & 21 \\
\hline
\end{tabular}

Any information copied from such Reports and Statements may not be sold or used by any person for the purpose of soliciting contributions or for commercial purposes, other than using the name and address of any political committee to solicit contributions from such committee.

NAME OF COMMITTEE (In Full)

\section{Friends of Herman Cain}

A. Full Name (Last, First, Middle Initial)

Paul Hubert

Mailing Address 5225 Schuyler Dr

\begin{tabular}{lcc}
\hline City & State & Zip Code \\
Carmichael & CA & $95608-0527$
\end{tabular}

FEC ID number of contributing federal political committee.

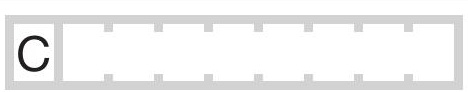

Name of Employer
State of California
Receipt For: 2012
X Primary
$\square$ Other (specify) General

Occupation

Retired

Election Cycle-to-Date

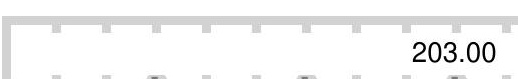

B. Full Name (Last, First, Middle Initial)

Ms Wilma Miller

Mailing Address P. O. Box 434

\begin{tabular}{lcc}
\hline City & State & Zip Code \\
Washington & OK & $73093-0434$ \\
\hline
\end{tabular}

FEC ID number of contributing

federal political committee.

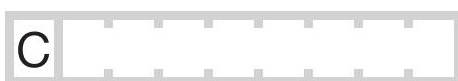

Name of Employer
Kenneth Sturgell
Receipt For: 2012
X Primary
Other (specify)

Occupation

File Clerk

Election Cycle-to-Date

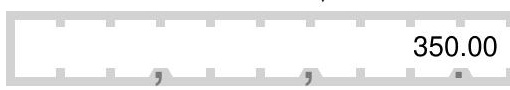

C. Full Name (Last, First, Middle Initial)

Judith McKenney

Mailing Address 220 Schooley Lane

\begin{tabular}{lcc}
\hline City & State & Zip Code \\
Silverton & OR & $97381-2435$
\end{tabular}

FEC ID number of contributing

federal political committee.

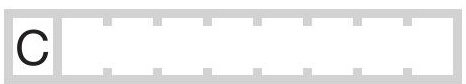

Name of Employer
None
Receipt For: 2012
Х Primary $\quad \square$ General
Other (specify)

Occupation

homemaker

Election Cycle-to-Date

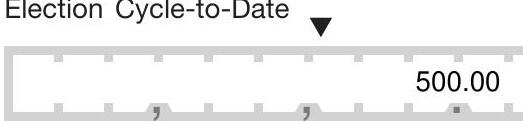

Transaction ID : ABE22483E3DBA4215BCE

Date of Receipt

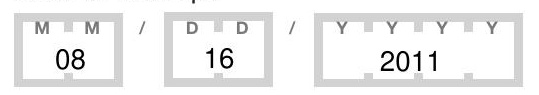

Amount of Each Receipt this Period

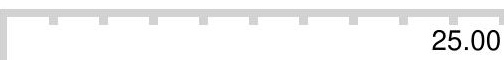

25.00

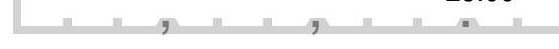

Transaction ID : A00B796F98BAB40798F2

Date of Receipt

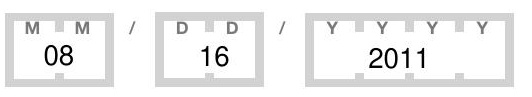

Amount of Each Receipt this Period

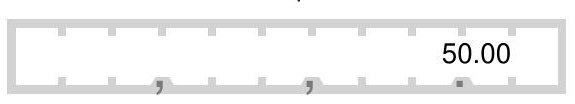

Transaction ID : A8AD2AD3BD94C41E0B09 Date of Receipt

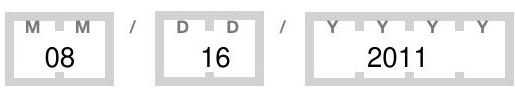

Amount of Each Receipt this Period

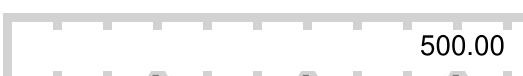

500.00

\section{Subtotal Of Receipts This Page (optional)}

575.00

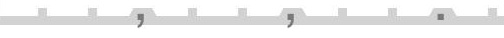

Total This Period (last page this line number only)

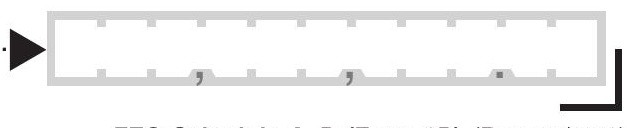

FEC Schedule A-P (Form 3P) (Rev. 03/2011) 
SCHEDULE A-P ITEMIZED RECEIPTS
Use separate schedule(s) for each category of the Detailed Summary Page
FOR LINE NUMBER: (check only one)

PAGE $305 / 1572$

\begin{tabular}{|c|c|c|c|c|c|}
\hline & & & & & \\
\hline 16 & $\begin{array}{l}\mathbf{X} \\
17 a\end{array}$ & $17 b$ & $17 c$ & $17 d$ & 18 \\
\hline $19 a$ & $19 \mathrm{~b}$ & $20 \mathrm{a}$ & $20 \mathrm{~b}$ & $20 \mathrm{c}$ & 21 \\
\hline
\end{tabular}

Any information copied from such Reports and Statements may not be sold or used by any person for the purpose of soliciting contributions or for commercial purposes, other than using the name and address of any political committee to solicit contributions from such committee.

NAME OF COMMITTEE (In Full)

\section{Friends of Herman Cain}

A. Full Name (Last, First, Middle Initial)

Ada Hagan

Mailing Address 103 Creekwood Dr

\begin{tabular}{lcc}
\hline City & State & Zip Code \\
Brunswick & GA & $31523-9743$ \\
\hline
\end{tabular}

FEC ID number of contributing federal political committee.

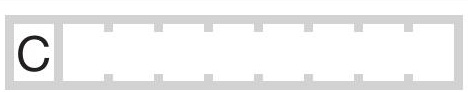

Name of Employer
Information Requested
Receipt For: 2012
X Primary
Other (specify) General

Occupation Information Requested

Election Cycle-to-Date

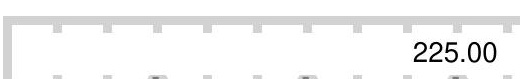

B. Full Name (Last, First, Middle Initial)

Lauri Hein

Mailing Address 5915 Burma Rd.

\begin{tabular}{lcc}
\hline City & State & Zip Code \\
Lake Oswego & OR & $97035-3239$
\end{tabular}

FEC ID number of contributing

federal political committee.

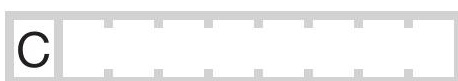

Name of Employer
Self-Employed
Receipt For: 2012
X Primary
Other (specify)

Occupation

property management

Election Cycle-to-Date

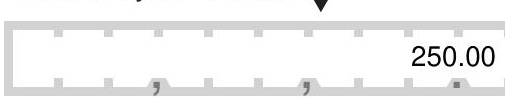

C. Full Name (Last, First, Middle Initial)

Loraine Whitehead

Mailing Address PO Box 218869

\begin{tabular}{lcc}
\hline City & State & Zip Code \\
Houston & TX & $77218-8869$
\end{tabular}

FEC ID number of contributing federal political committee.

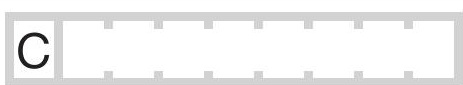

Name of Employer
ConocoPhillips
Receipt For: 2012
X Primary $\quad \square$ General
Other (specify)

\section{Occupation}

Analyst

Election Cycle-to-Date

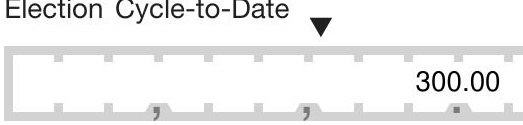

Transaction ID : A0F98199F02844249825

Date of Receipt

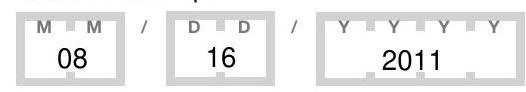

Amount of Each Receipt this Period

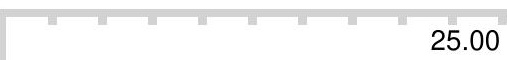

25.00

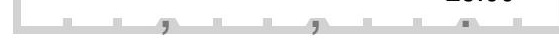

Transaction ID : ABCCB26CA37A04961892

Date of Receipt

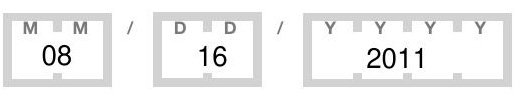

Amount of Each Receipt this Period

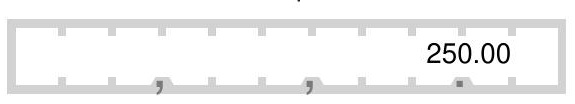

Transaction ID : A0D6DDE7A937D4E99BFB Date of Receipt

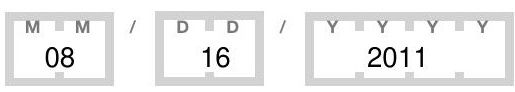

Amount of Each Receipt this Period

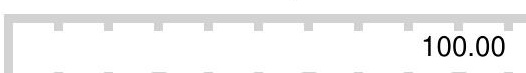

100.00

\section{Subtotal Of Receipts This Page (optional)}

375.00

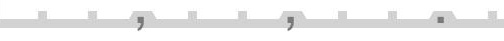

Total This Period (last page this line number only)

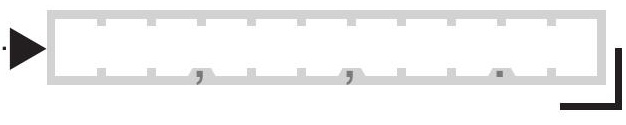

FEC Schedule A-P (Form 3P) (Rev. 03/2011) 
SCHEDULE A-P ITEMIZED RECEIPTS
Use separate schedule(s) for each category of the Detailed Summary Page
FOR LINE NUMBER: (check only one)

PAGE $306 / 1572$

\begin{tabular}{|c|c|c|c|c|c|}
\hline & & & & & \\
\hline 16 & $\begin{array}{l}\mathbf{X} \\
17 a\end{array}$ & $17 b$ & $17 c$ & $17 d$ & 18 \\
\hline $19 a$ & $19 \mathrm{~b}$ & $20 \mathrm{a}$ & $20 \mathrm{~b}$ & $20 \mathrm{c}$ & 21 \\
\hline
\end{tabular}

Any information copied from such Reports and Statements may not be sold or used by any person for the purpose of soliciting contributions or for commercial purposes, other than using the name and address of any political committee to solicit contributions from such committee.

NAME OF COMMITTEE (In Full)

\section{Friends of Herman Cain}

A. Full Name (Last, First, Middle Initial) Jeremy Jackson

Mailing Address 2261B N Main St

\begin{tabular}{lcc}
\hline City & State & Zip Code \\
Danville & VA & $24540-2415$
\end{tabular}

FEC ID number of contributing federal political committee.

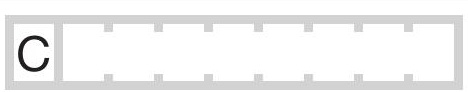

Name of Employer
Areva
Receipt For: 2012
X Primary $\quad$ General
Other (specify)

Occupation

Field Service Rep

Election Cycle-to-Date

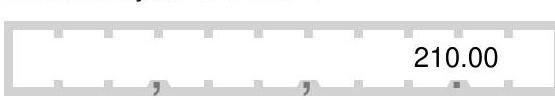

B. Full Name (Last, First, Middle Initial)

Doug Friedrichsen

Mailing Address 12535 Wedd Street

\begin{tabular}{lcc}
\hline City & State & Zip Code \\
Overland Park & KS & $66213-1845$ \\
\hline
\end{tabular}

FEC ID number of contributing

federal political committee.

C

Name of Employer
self
Receipt For: 2012
Primary
Other (specify)

Occupation

Accountant

Election Cycle-to-Date

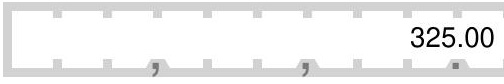

C. Full Name (Last, First, Middle Initial)

Leighton Wells

Mailing Address 717 Edgemont Way

\begin{tabular}{lcc}
\hline City & State & Zip Code \\
Springfield & OR & $97477-3607$
\end{tabular}

FEC ID number of contributing

federal political committee.

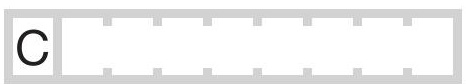

Name of Employer
n/a
Receipt For: 2012
X Primary $\square$ General
Other (specify)

Occupation

Retired

Election Cycle-to-Date

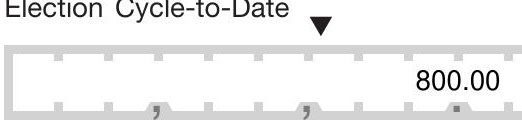

Transaction ID : A00367BE434804CE6BFE

Date of Receipt

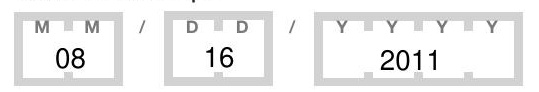

Amount of Each Receipt this Period

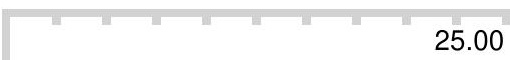

25.00

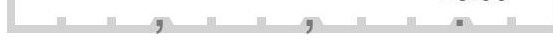

Transaction ID : AD63273D6CEAE4ADFA48 Date of Receipt

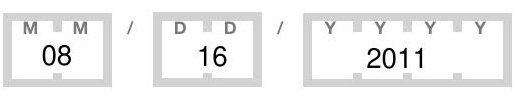

Amount of Each Receipt this Period

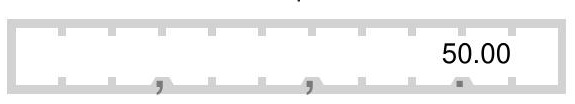

Transaction ID : AD808DE4490444AD3B79 Date of Receipt

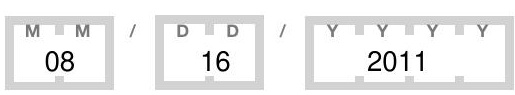

Amount of Each Receipt this Period

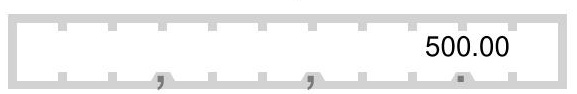

575.00

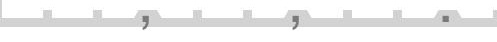

Total This Period (last page this line number only)

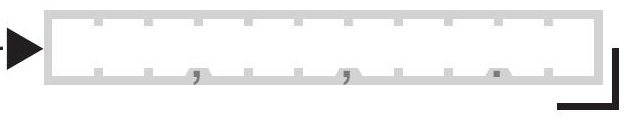

FEC Schedule A-P (Form 3P) (Rev. 03/2011) 
SCHEDULE A-P ITEMIZED RECEIPTS
Use separate schedule(s) for each category of the Detailed Summary Page
FOR LINE NUMBER: (check only one)
PAGE 307 / 1572

\begin{tabular}{|c|c|c|c|c|c|}
\hline & & & & & \\
\hline 16 & $\begin{array}{lll}X & 17 a \\
\end{array}$ & $17 \mathrm{~b}$ & $17 c$ & $17 d$ & 18 \\
\hline $19 a$ & $19 b$ & $20 a$ & $20 \mathrm{~b}$ & $20 c$ & 21 \\
\hline
\end{tabular}

Any information copied from such Reports and Statements may not be sold or used by any person for the purpose of soliciting contributions or for commercial purposes, other than using the name and address of any political committee to solicit contributions from such committee.

NAME OF COMMITTEE (In Full)

\section{Friends of Herman Cain}

A. Full Name (Last, First, Middle Initial)

Sylvia D Barnes

Mailing Address 75495 Road 436

\begin{tabular}{lcc}
\hline City & State & Zip Code \\
Lexington & NE & $68850-5638$
\end{tabular}

FEC ID number of contributing federal political committee.

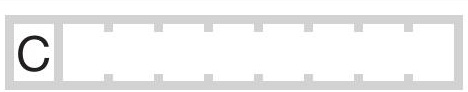

\begin{tabular}{l} 
Name of Employer \\
None \\
Receipt For: 2012 \\
X Primary $\quad$ General \\
\hline Other (specify)
\end{tabular}

Occupation

Retired

Election Cycle-to-Date

241.00

B. Full Name (Last, First, Middle Initial)

Jeffrey Odem

Mailing Address 1053 Stillhouse Creek Drive

\begin{tabular}{lcc}
\hline City & State & Zip Code \\
Ellijay & GA & $30540-0291$ \\
\hline
\end{tabular}

FEC ID number of contributing

federal political committee.

C

Name of Employer
Information Requested
Receipt For: 2012
X Primary
Other (specify)

Occupation

Information Requested

Election Cycle-to-Date

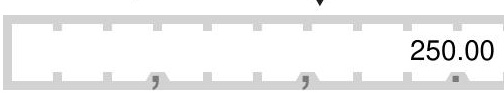

Transaction ID : A7E21D4367E344E6986A

Date of Receipt

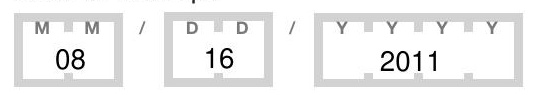

Amount of Each Receipt this Period

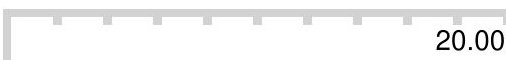

20.00

C. Full Name (Last, First, Middle Initial)

Randy Lamartiniere

Mailing Address 723 Place Saint Etienne

\begin{tabular}{lcc}
\hline City & State & Zip Code \\
Covington & LA & $70433-8141$
\end{tabular}

FEC ID number of contributing

federal political committee.

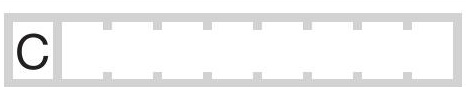

Name of Employer
Ochsner Clinic
Receipt For: 2012
X Primary $\quad \square$ General
Other (specify)

Occupation

Physician

Election Cycle-to-Date

Transaction ID : AD05B5DAB3EE84F7C921

Date of Receipt

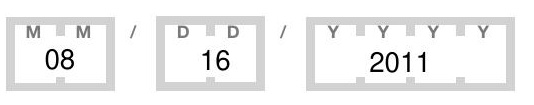

Amount of Each Receipt this Period

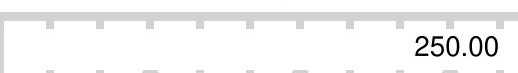

Transaction ID : A5441B9E4952943F3910

Date of Receipt

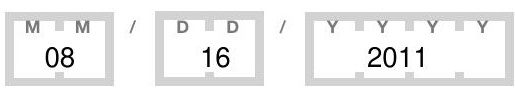

Amount of Each Receipt this Period

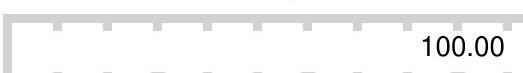

300.00

\section{Subtotal Of Receipts This Page (optional)}

370.00

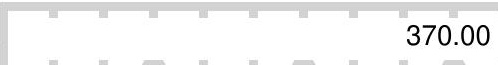

(1)

Total This Period (last page this line number only)

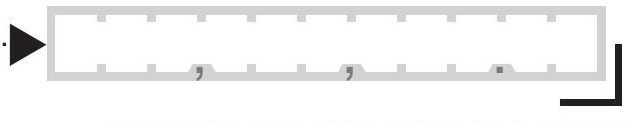

FEC Schedule A-P (Form 3P) (Rev. 03/2011) 
SCHEDULE A-P ITEMIZED RECEIPTS
Use separate schedule(s) for each category of the Detailed Summary Page
FOR LINE NUMBER: (check only one)

PAGE $308 / 1572$

\begin{tabular}{|c|c|c|c|c|c|}
\hline & & & & & \\
\hline 16 & $\begin{array}{l}\mathbf{X} \\
17 a\end{array}$ & $17 b$ & $17 c$ & $17 d$ & 18 \\
\hline $19 a$ & $19 \mathrm{~b}$ & $20 \mathrm{a}$ & $20 \mathrm{~b}$ & $20 \mathrm{c}$ & 21 \\
\hline
\end{tabular}

Any information copied from such Reports and Statements may not be sold or used by any person for the purpose of soliciting contributions or for commercial purposes, other than using the name and address of any political committee to solicit contributions from such committee.

NAME OF COMMITTEE (In Full)

\section{Friends of Herman Cain}

A. Full Name (Last, First, Middle Initial)

Alison Nommay

Mailing Address 7502 E. Lakewood Dr. -92

\begin{tabular}{lcc}
\hline City & State & Zip Code \\
Roanoke & IN & 46783 \\
\hline
\end{tabular}

FEC ID number of contributing

federal political committee.

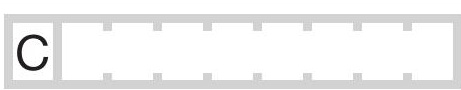

Name of Employer
Information Requested
Receipt For: 2012
X Primary
Other (specify) General

Occupation

Information Requested

Election Cycle-to-Date

500.00

B. Full Name (Last, First, Middle Initial)

Rose Mare Distefano

Mailing Address 2881 Jonesboro Rd

\begin{tabular}{lcc}
\hline City & State & Zip Code \\
Hampton & GA & $30228-2730$ \\
\hline
\end{tabular}

FEC ID number of contributing

federal political committee.

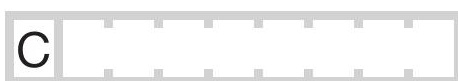

Name of Employer
None
Receipt For: 2012
X Primary
Other (specify)

Occupation

Retired

Election Cycle-to-Date

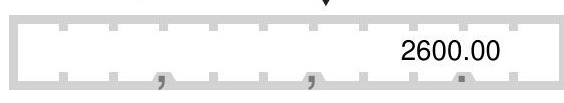

Transaction ID : AB46A8CB033B74FEA9F1

Date of Receipt

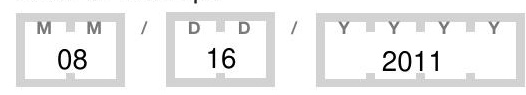

Amount of Each Receipt this Period

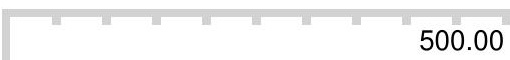

C. Full Name (Last, First, Middle Initial)

Susan Walter

Mailing Address P.O. Box 690

\begin{tabular}{lcc}
\hline City & State & Zip Code \\
Sautee Nacoochee & GA & $30571-0690$
\end{tabular}

FEC ID number of contributing

federal political committee.

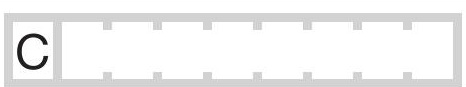

Name of Employer
None
Receipt For: 2012
X Primary $\quad$ General
Other (specify)

Occupation

Retired

Election Cycle-to-Date

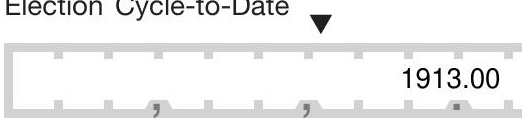

Amount of Each Receipt this Period

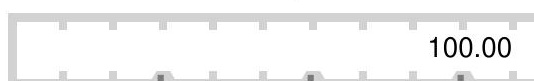

Transaction ID : A07F9C1F5B4AD492993D

Date of Receipt

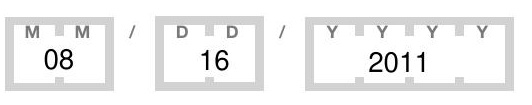

Transaction ID : A26A1497BD54B4F9DB27 Date of Receipt

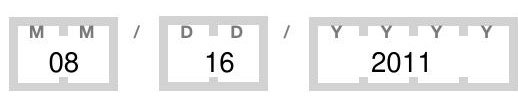

Amount of Each Receipt this Period

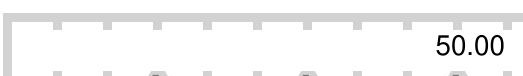

\section{Subtotal Of Receipts This Page (optional)}

650.00

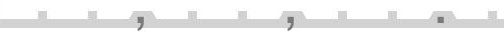

Total This Period (last page this line number only)

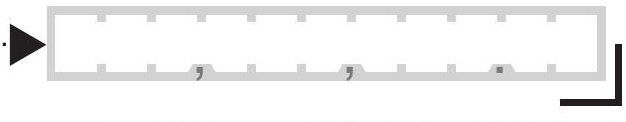

FEC Schedule A-P (Form 3P) (Rev. 03/2011) 
SCHEDULE A-P ITEMIZED RECEIPTS
Use separate schedule(s) for each category of the Detailed Summary Page
FOR LINE NUMBER: (check only one)

PAGE 309 / 1572

\begin{tabular}{|c|c|c|c|c|c|}
\hline & & & & & \\
\hline 16 & $\begin{array}{l}\mathbf{X} \\
17 a\end{array}$ & $17 b$ & $17 c$ & $17 d$ & 18 \\
\hline $19 a$ & $19 \mathrm{~b}$ & $20 \mathrm{a}$ & $20 \mathrm{~b}$ & $20 \mathrm{c}$ & 21 \\
\hline
\end{tabular}

Any information copied from such Reports and Statements may not be sold or used by any person for the purpose of soliciting contributions or for commercial purposes, other than using the name and address of any political committee to solicit contributions from such committee.

NAME OF COMMITTEE (In Full)

\section{Friends of Herman Cain}

A. Full Name (Last, First, Middle Initial)

W.H. Brandt

Mailing Address 3490 NW Circle Blvd.

\begin{tabular}{lcc}
\hline City & State & Zip Code \\
Corvallis & OR & $97330-1760$
\end{tabular}

FEC ID number of contributing federal political committee.

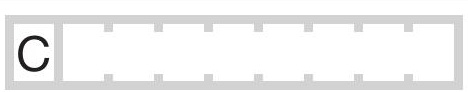

Name of Employer
None
Receipt For: 2012
X Primary $\quad$ General
Other (specify)

Occupation

Retired

Election Cycle-to-Date

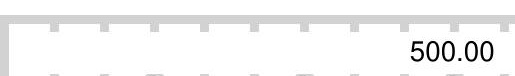

B. Full Name (Last, First, Middle Initial)

Vicki Murphy

Mailing Address 4110 E. 17th Avenue

\begin{tabular}{lcc}
\hline City & State & Zip Code \\
Denver & CO & $80220-1013$
\end{tabular}

FEC ID number of contributing

federal political committee.

C

Name of Employer
Information Requested
Receipt For: 2012
X Primary
Other (specify)

Occupation

Information Requested

Election Cycle-to-Date

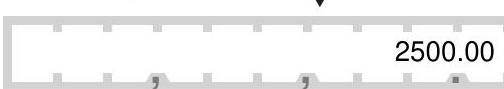

Transaction ID : A9BCC4FFE384A4D779B1

Date of Receipt

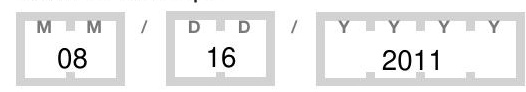

Amount of Each Receipt this Period

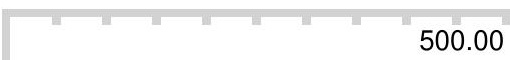

C. Full Name (Last, First, Middle Initial)

WILLIAN FIELDS

Mailing Address 139 APRIL POINT DRIVE NORTH

\begin{tabular}{lcc}
\hline City & State & Zip Code \\
Montgomery & TX & $77356-5832$ \\
\hline
\end{tabular}

FEC ID number of contributing federal political committee.

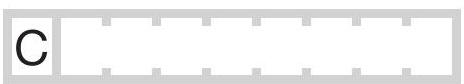

Name of Employer

Information Requested

Occupation

Receipt For: 2012

Х $\begin{aligned} & \text { Primary } \square \text { General } \\ & \text { Other (specify) }\end{aligned}$

Information Requested

Election Cycle-to-Date

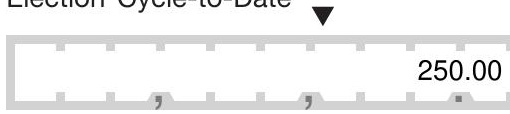

Amount of Each Receipt this Period

Transaction ID : A34B6DD16C9374C7EBF7 Date of Receipt
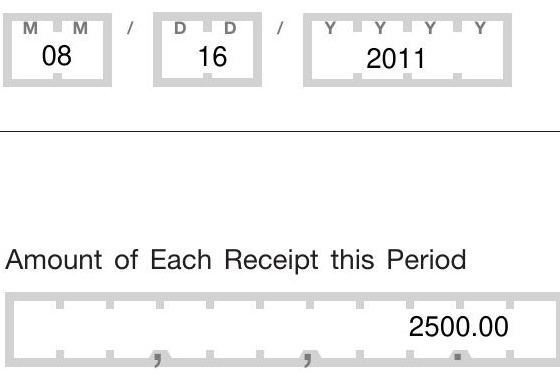

Transaction ID : ABDF5909D101E48B4945 Date of Receipt

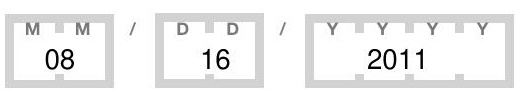

Amount of Each Receipt this Period

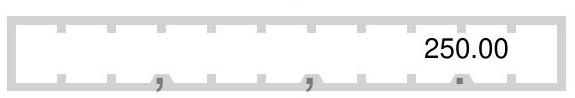

Subtotal Of Receipts This Page (optional)

Total This Period (last page this line number only) 
SCHEDULE A-P ITEMIZED RECEIPTS
Use separate schedule(s) for each category of the Detailed Summary Page
FOR LINE NUMBER: (check only one)

PAGE $310 / 1572$

\begin{tabular}{|c|c|c|c|c|c|}
\hline & & & & & \\
\hline 16 & $\begin{array}{l}\mathbf{X} \\
17 a\end{array}$ & $17 b$ & $17 c$ & $17 d$ & 18 \\
\hline $19 a$ & $19 \mathrm{~b}$ & $20 \mathrm{a}$ & $20 \mathrm{~b}$ & $20 \mathrm{c}$ & 21 \\
\hline
\end{tabular}

Any information copied from such Reports and Statements may not be sold or used by any person for the purpose of soliciting contributions or for commercial purposes, other than using the name and address of any political committee to solicit contributions from such committee.

NAME OF COMMITTEE (In Full)

\section{Friends of Herman Cain}

A. Full Name (Last, First, Middle Initial)

Glen Ebbing

Mailing Address 1400 Huntleigh Rd

\begin{tabular}{lcc}
\hline City & State & Zip Code \\
Quincy & IL & $62305-6017$
\end{tabular}

FEC ID number of contributing federal political committee.

Name of Employer
ColorMaster Pain Inc
Receipt For: 2012
X Primary $\quad \square$ General
Other (specify)

B. Full Name (Last, First, Middle Initial) Laura A Hay

Mailing Address 231 Burke Circle

\begin{tabular}{lcc}
\hline City & State & Zip Code \\
McDonough & GA & $30253-2012$ \\
\hline
\end{tabular}

FEC ID number of contributing

federal political committee.

Name of Employer
Retired
Receipt For: 2012
X Primary $\square$ General
Other (specify)

C. Full Name (Last, First, Middle Initial)

Mr. Carl L Franklin

Mailing Address 2179 N. Forest Trail

\section{City}

Atlanta

FEC ID number of contributing federal political committee.

Name of Employer
Franklin Diamonds
Receipt For: 2012
X Primary
Other (specify) General

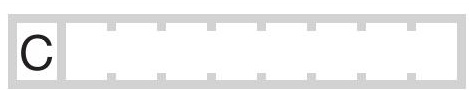

Occupation sales representative Election Cycle-to-Date $\mathbf{\nabla}$

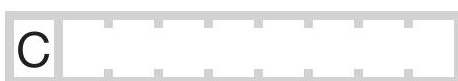

Transaction ID : A38B99E5B4EED4CFC8D7

Date of Receipt

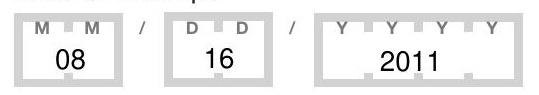

Amount of Each Receipt this Period

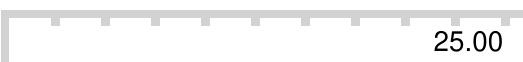

25.00

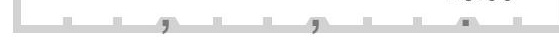

353.00

Transaction ID : A03A0343EE0934121850

Date of Receipt

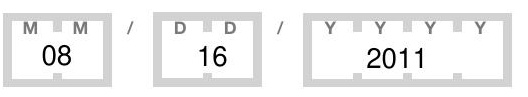

Amount of Each Receipt this Period

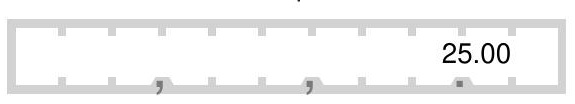

\section{Occupation}

$\mathrm{N} / \mathrm{A}$

Election Cycle-to-Date

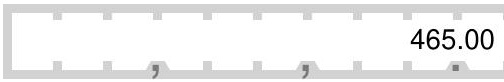

Transaction ID : AB3755FFA46C149979EC

Date of Receipt

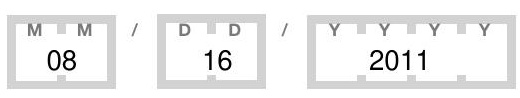

Amount of Each Receipt this Period

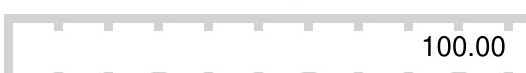

625.00

Subtotal Of Receipts This Page (optional).

Total This Period (last page this line number only)

150.00

a

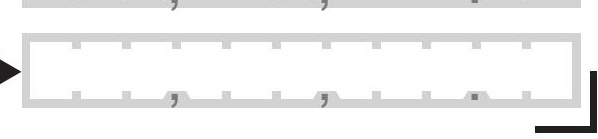

FEC Schedule A-P (Form 3P) (Rev. 03/2011) 
SCHEDULE A-P ITEMIZED RECEIPTS
Use separate schedule(s) for each category of the Detailed Summary Page
FOR LINE NUMBER: (check only one)

PAGE $311 / 1572$

\begin{tabular}{|c|c|c|c|c|c|c|}
\hline & & & & & & \\
\hline 16 & $\lambda$ & $17 \mathrm{a}$ & $17 \mathrm{~b}$ & $17 \mathrm{c}$ & $-17 d$ & -18 \\
\hline $19 a$ & & $19 b$ & $20 a$ & $20 \mathrm{~b}$ & $20 \mathrm{c}$ & 21 \\
\hline
\end{tabular}

Any information copied from such Reports and Statements may not be sold or used by any person for the purpose of soliciting contributions or for commercial purposes, other than using the name and address of any political committee to solicit contributions from such committee.

NAME OF COMMITTEE (In Full)

\section{Friends of Herman Cain}

A. Full Name (Last, First, Middle Initial)

Karon Baumann

Mailing Address 3333 SE 38th ST

\begin{tabular}{lcc}
\hline City & State & Zip Code \\
Ocala & FL & $34480-8454$
\end{tabular}

FEC ID number of contributing federal political committee.

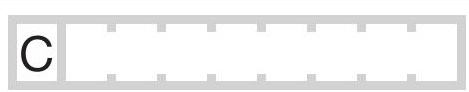

Name of Employer
Marion County School Board
Receipt For: 2012
X Primary $\quad \square$ General
Other (specify)

Occupation

Teacher

Election Cycle-to-Date

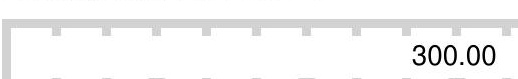

B. Full Name (Last, First, Middle Initial)

Diane Speedling

Mailing Address 2927 Sand Pine Rd

\begin{tabular}{lcc}
\hline City & State & Zip Code \\
Miramar Beach & FL & $32550-7835$
\end{tabular}

FEC ID number of contributing

federal political committee.

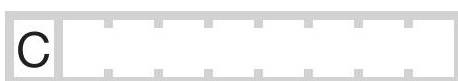

Name of Employer
Self Employed
Receipt For: 2012
X Primary
Other (specify)

Occupation

Anesthesiologist

Election Cycle-to-Date

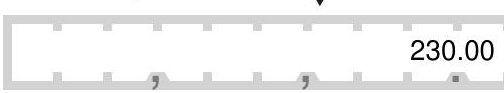

Transaction ID : A447193EFCBC04418B7C

Date of Receipt

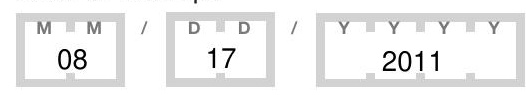

Amount of Each Receipt this Period

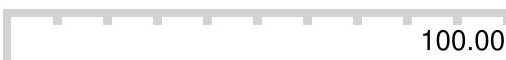

Transaction ID : A447911610C62479D826

Date of Receipt

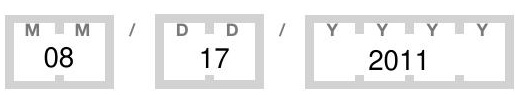

Amount of Each Receipt this Period

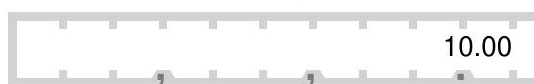

Transaction ID : A9644234E497943C38F8

Date of Receipt

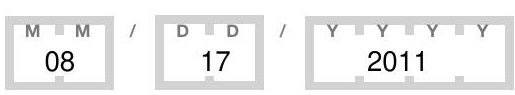

Amount of Each Receipt this Period

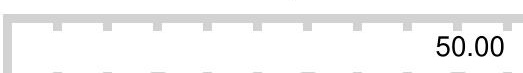

$\begin{array}{cc}\text { State } & \text { Zip Code } \\ \text { NV } & 89109-4610\end{array}$

C

\section{Occupation}

BUSINESS OWNER

Election Cycle-to-Date

Receipt For: 2012

Х $\begin{aligned} & \text { Primary } \square \text { General } \\ & \text { Other (specify) }\end{aligned}$

250.00

Subtotal Of Receipts This Page (optional)

160.00

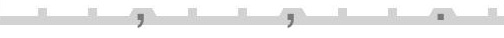

Total This Period (last page this line number only)

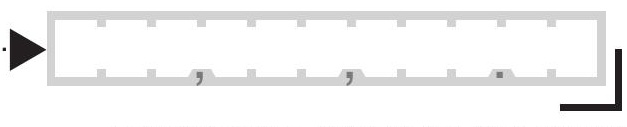

FEC Schedule A-P (Form 3P) (Rev. 03/2011) 
SCHEDULE A-P ITEMIZED RECEIPTS
Use separate schedule(s) for each category of the Detailed Summary Page
FOR LINE NUMBER: (check only one)

PAGE 312 / 1572

\begin{tabular}{|c|c|c|c|c|c|c|}
\hline & & & & & & \\
\hline 16 & $\lambda$ & $17 \mathrm{a}$ & $17 \mathrm{~b}$ & $17 \mathrm{c}$ & $-17 d$ & -18 \\
\hline $19 a$ & & $19 b$ & $20 a$ & $20 \mathrm{~b}$ & $20 \mathrm{c}$ & 21 \\
\hline
\end{tabular}

Any information copied from such Reports and Statements may not be sold or used by any person for the purpose of soliciting contributions or for commercial purposes, other than using the name and address of any political committee to solicit contributions from such committee.

NAME OF COMMITTEE (In Full)

\section{Friends of Herman Cain}

A. Full Name (Last, First, Middle Initial)

Mr Louis C Dietz

Mailing Address 33126 Forest West St

\begin{tabular}{lcc}
\hline City & State & Zip Code \\
Magnolia & TX & $77354-6844$ \\
\hline
\end{tabular}

FEC ID number of contributing

federal political committee.

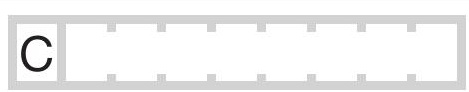

Name of Employer
CYFAIR HOSPITAL
Receipt For: 2012
X Primary $\quad \square$ General
Other (specify)

Occupation

$\mathrm{RN}$

Election Cycle-to-Date

433.00

B. Full Name (Last, First, Middle Initial)

Gary Stubblefield

Mailing Address 2001 Raymond Ave

\begin{tabular}{lcc}
\hline City & State & Zip Code \\
Signal Hill & CA & $90755-5930$
\end{tabular}

FEC ID number of contributing

federal political committee.

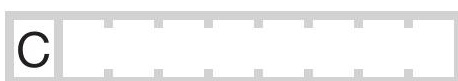

Name of Employer
Retired
Receipt For: 2012
X Primary
Other (specify)

\section{Occupation}

Retired

Election Cycle-to-Date

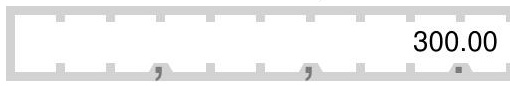

C. Full Name (Last, First, Middle Initial)

Roger Case

Mailing Address 1621 NE 6th Ave

\begin{tabular}{lcc}
\hline City & State & Zip Code \\
Oak Harbor & WA & $98277-4326$
\end{tabular}

FEC ID number of contributing

federal political committee.

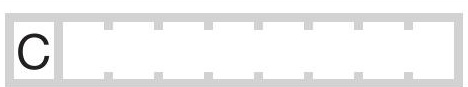

Name of Employer
Retired
Receipt For: 2012
X Primary $\quad \square$ General
Other (specify)

\section{Occupation}

Physician

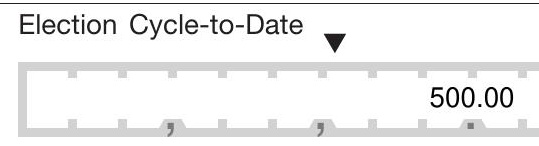

Transaction ID : A986E2A497CAB472A98E

Date of Receipt

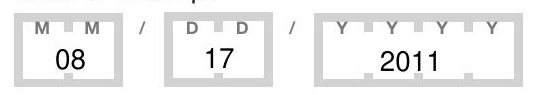

Amount of Each Receipt this Period

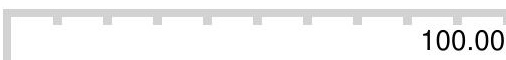

100.00

Transaction ID : ADF49A382F818424C930

Date of Receipt

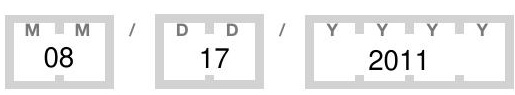

Amount of Each Receipt this Period

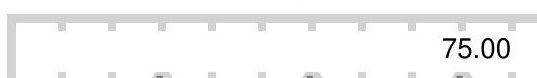

Transaction ID : AA8BBD29F2E1D435899A

Date of Receipt

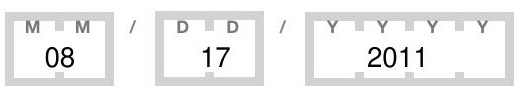

Amount of Each Receipt this Period

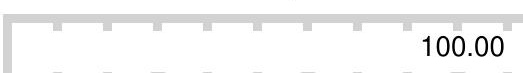

100.00

\section{Subtotal Of Receipts This Page (optional)}

275.00

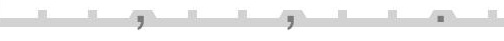

Total This Period (last page this line number only) 
SCHEDULE A-P ITEMIZED RECEIPTS
Use separate schedule(s) for each category of the Detailed Summary Page
FOR LINE NUMBER: (check only one)

PAGE $313 / 1572$

\begin{tabular}{|c|c|c|c|c|c|}
\hline & & & & & \\
\hline 16 & $\begin{array}{lll}X & 17 a \\
\end{array}$ & $17 \mathrm{~b}$ & $17 c$ & $17 d$ & 18 \\
\hline $19 a$ & $19 b$ & $20 a$ & $20 \mathrm{~b}$ & $20 c$ & 21 \\
\hline
\end{tabular}

Any information copied from such Reports and Statements may not be sold or used by any person for the purpose of soliciting contributions or for commercial purposes, other than using the name and address of any political committee to solicit contributions from such committee.

NAME OF COMMITTEE (In Full)

\section{Friends of Herman Cain}

A. Full Name (Last, First, Middle Initial)

Mark Racheau

Mailing Address 10400 White Rabbit Rd

\begin{tabular}{lcc}
\hline City & State & Zip Code \\
North Chesterfield & VA & $23235-2600$
\end{tabular}

FEC ID number of contributing

federal political committee.

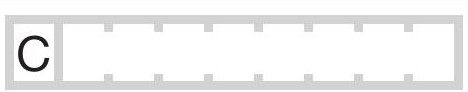

Name of Employer
Information Requested
Receipt For: 2012
X Primary
Other (specify) General

Occupation

Information Requested

Election Cycle-to-Date

250.00

B. Full Name (Last, First, Middle Initial)

judy kapke

Mailing Address 1819 rolling river dr.

\begin{tabular}{lcc}
\hline City & State & Zip Code \\
Lilburn & GA & $30047-4520$
\end{tabular}

FEC ID number of contributing

federal political committee.

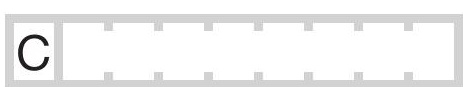

Name of Employer
Emory Healthcare
Receipt For: 2012
X Primary
$\square$ Other (specify) General

\section{Occupation}

$\mathrm{RN}$

Election Cycle-to-Date

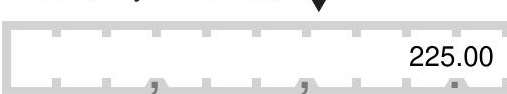

Transaction ID : AE32BBF70204B4E4CB74

Date of Receipt

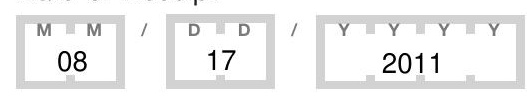

Amount of Each Receipt this Period

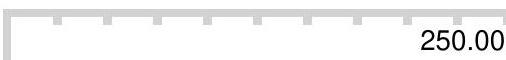

C. Full Name (Last, First, Middle Initial)

steven miller

Mailing Address 6200 bradford hills dr

\begin{tabular}{lcc}
\hline City & State & Zip Code \\
Nashville & TN & $37211-7921$
\end{tabular}

FEC ID number of contributing

federal political committee.

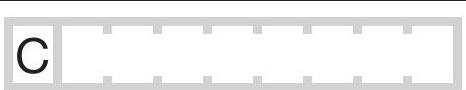

Name of Employer
pharmmd
Receipt For: 2012
X Primary
Other (specify) General

Occupation

Pharmacist

Election Cycle-to-Date
Amount of Each Receipt this Period

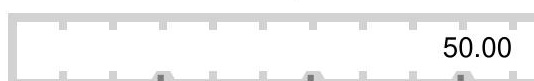

Transaction ID : A05FC13C473B84A678E1

Date of Receipt

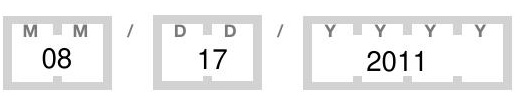

Transaction ID : A415A383B1CA54F48B6A Date of Receipt

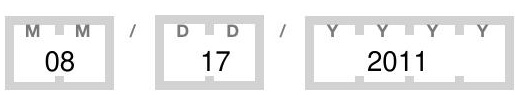

Amount of Each Receipt this Period

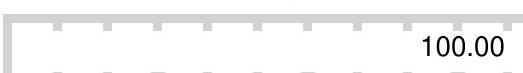

\section{Subtotal Of Receipts This Page (optional)}

400.00

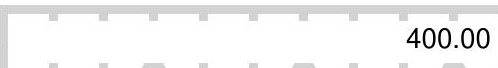

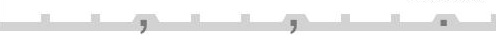

Total This Period (last page this line number only)

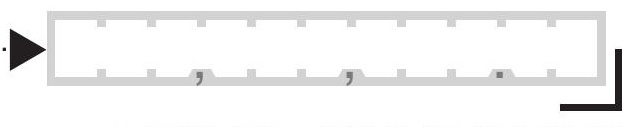

FEC Schedule A-P (Form 3P) (Rev. 03/2011) 
SCHEDULE A-P ITEMIZED RECEIPTS
Use separate schedule(s) for each category of the Detailed Summary Page
FOR LINE NUMBER: (check only one)

PAGE 314 / 1572

\begin{tabular}{|c|c|c|c|c|c|}
\hline & & & & & \\
\hline 16 & $\begin{array}{l}\mathbf{X} \\
17 a\end{array}$ & $17 b$ & $17 c$ & $17 d$ & 18 \\
\hline $19 a$ & $19 \mathrm{~b}$ & $20 \mathrm{a}$ & $20 \mathrm{~b}$ & $20 \mathrm{c}$ & 21 \\
\hline
\end{tabular}

Any information copied from such Reports and Statements may not be sold or used by any person for the purpose of soliciting contributions or for commercial purposes, other than using the name and address of any political committee to solicit contributions from such committee.

NAME OF COMMITTEE (In Full)

\section{Friends of Herman Cain}

A. Full Name (Last, First, Middle Initial)

Durward Pridgen

Mailing Address 1806 Silver Maple Drive

\begin{tabular}{lcc}
\hline City & State & Zip Code \\
North Augusta & SC & $29860-8440$ \\
\hline
\end{tabular}

FEC ID number of contributing

federal political committee.

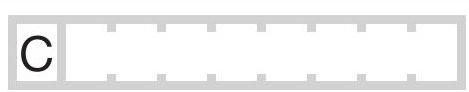

Name of Employer
Veterans Administration
Receipt For: 2012
X Primary $\quad \square$ General
Other (specify)

Occupation

Physician

Election Cycle-to-Date

400.00

B. Full Name (Last, First, Middle Initial)

Dwight Watson

Mailing Address 502 Maple St Ste C

\begin{tabular}{lcc}
\hline City & State & Zip Code \\
Murray & KY & $42071-2586$ \\
\hline
\end{tabular}

FEC ID number of contributing

federal political committee.

C

Name of Employer
Information Requested
Receipt For: 2012
X Primary
Other (specify)

Occupation

Information Requested

Election Cycle-to-Date

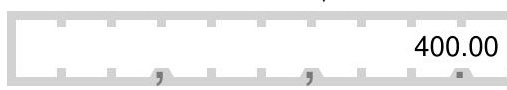

Transaction ID : AC7F2DBA5D9904BC8B6E

Date of Receipt

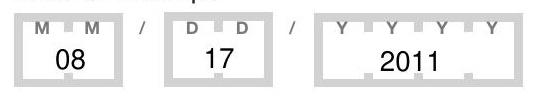

Amount of Each Receipt this Period

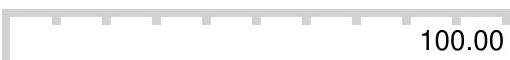

Transaction ID : ADBB0E9184FB44418B39

Date of Receipt

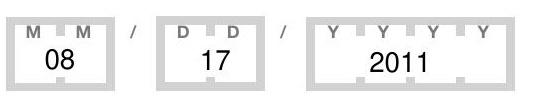

Amount of Each Receipt this Period

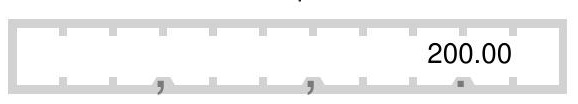

C. Full Name (Last, First, Middle Initial)

Larry Williams

Mailing Address 5907 Wesleyan Dr N

\begin{tabular}{lcc}
\hline City & State & Zip Code \\
Macon & GA & $31210-6011$
\end{tabular}

FEC ID number of contributing

federal political committee.

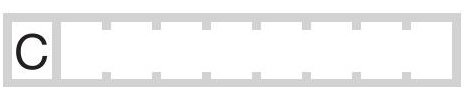

Name of Employer

Occupation

U. S. Air Force

Engineer

Receipt For: 2012

Х $\begin{aligned} & \text { Primary } \square \text { General } \\ & \text { Other (specify) }\end{aligned}$

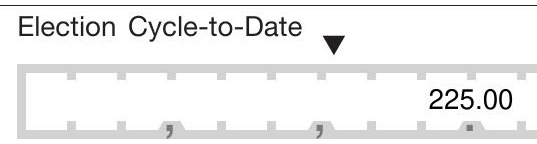

Amount of Each Receipt this Period

Transaction ID : A6D3852656EDE4D06B0F

Date of Receipt
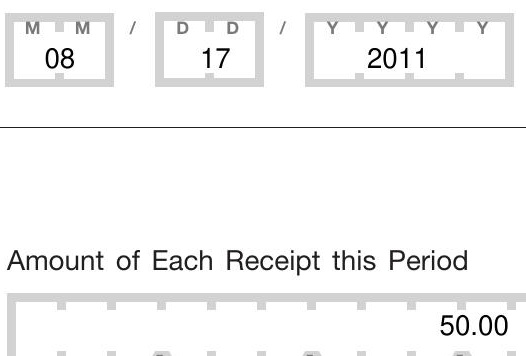

50.00

350.00

Subtotal Of Receipts This Page (optional)

Total This Period (last page this line number only) 
SCHEDULE A-P ITEMIZED RECEIPTS
Use separate schedule(s) for each category of the Detailed Summary Page
FOR LINE NUMBER: (check only one)

PAGE $315 / 1572$

\begin{tabular}{|c|c|c|c|c|c|}
\hline & & & & & \\
\hline 16 & $\begin{array}{l}\mathbf{X} \\
17 a\end{array}$ & $17 b$ & $17 c$ & $17 d$ & 18 \\
\hline $19 a$ & $19 \mathrm{~b}$ & $20 \mathrm{a}$ & $20 \mathrm{~b}$ & $20 \mathrm{c}$ & 21 \\
\hline
\end{tabular}

Any information copied from such Reports and Statements may not be sold or used by any person for the purpose of soliciting contributions or for commercial purposes, other than using the name and address of any political committee to solicit contributions from such committee.

NAME OF COMMITTEE (In Full)

Friends of Herman Cain

A. Full Name (Last, First, Middle Initial)

Douglas Buchanan

Mailing Address 9811 Ascot

\begin{tabular}{lcc}
\hline City & State & Zip Code \\
Omaha & NE & $68114-3847$
\end{tabular}

FEC ID number of contributing federal political committee.

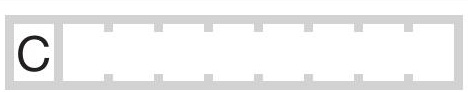

Name of Employer
renze display
Receipt For: 2012
X Primary
Other (specify) General

Occupation

President

Election Cycle-to-Date

1250.00

B. Full Name (Last, First, Middle Initial)

KENNETH BROLIN

Mailing Address 6019 rose arbor court

\begin{tabular}{lcc}
\hline City & State & Zip Code \\
Chester & VA & $23831-8704$ \\
\hline
\end{tabular}

FEC ID number of contributing

federal political committee.

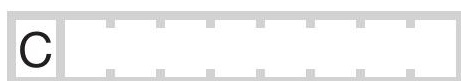

Name of Employer

TSS Photography in Central Virginia

Occupation

Receipt For: 2012

Х $\begin{aligned} & \text { Primary } \\ & \text { Other (specify) }\end{aligned}$

Executive

Election Cycle-to-Date

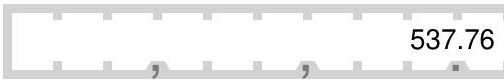

C. Full Name (Last, First, Middle Initial)

Tom Brown

Mailing Address 1566 Ridley Road

\begin{tabular}{lcc}
\hline City & State & Zip Code \\
Dahlonega & GA & $30533-1972$
\end{tabular}

FEC ID number of contributing

federal political committee.

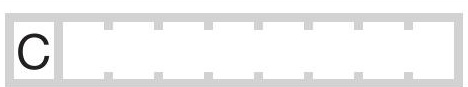

Name of Employer
None
Receipt For: 2012
X Primary $\quad \square$ General
Other (specify)

Occupation

Retired

Election Cycle-to-Date

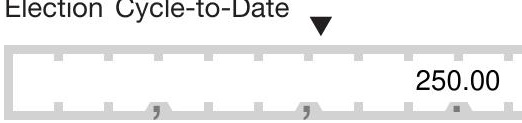

Transaction ID : A31351E868A2F4E8BA6F

Date of Receipt

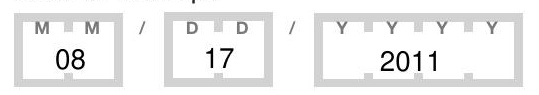

Amount of Each Receipt this Period

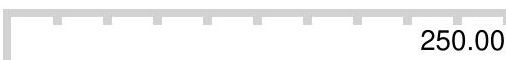

250.00
Amount of Each Receipt this Period

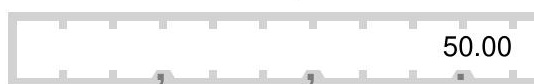

Transaction ID : AB4AC5B55340D49E3896 Date of Receipt

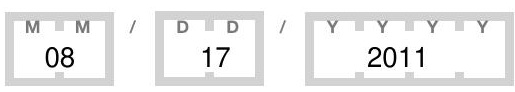

Amount of Each Receipt this Period

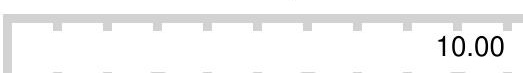

\section{Subtotal Of Receipts This Page (optional)}

Total This Period (last page this line number only) 
SCHEDULE A-P ITEMIZED RECEIPTS
Use separate schedule(s) for each category of the Detailed Summary Page
FOR LINE NUMBER: (check only one)

PAGE $316 / 1572$

\begin{tabular}{|c|c|c|c|c|c|}
\hline & & & & & \\
\hline 16 & $\begin{array}{l}\mathbf{X} \\
17 a\end{array}$ & $17 b$ & $17 c$ & $17 d$ & 18 \\
\hline $19 a$ & $19 \mathrm{~b}$ & $20 \mathrm{a}$ & $20 \mathrm{~b}$ & $20 \mathrm{c}$ & 21 \\
\hline
\end{tabular}

Any information copied from such Reports and Statements may not be sold or used by any person for the purpose of soliciting contributions or for commercial purposes, other than using the name and address of any political committee to solicit contributions from such committee.

NAME OF COMMITTEE (In Full)

\section{Friends of Herman Cain}

A. Full Name (Last, First, Middle Initial)

\section{David Girault}

Mailing Address 512 S. Casa Linda St.

\begin{tabular}{lcc}
\hline City & State & Zip Code \\
McAllen & TX & $78501-9003$
\end{tabular}

FEC ID number of contributing federal political committee.

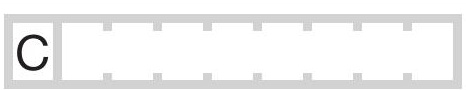

Name of Employer
Royal Freight LP
Receipt For: 2012
X Primary
Other (specify) General

Occupation Legal \& Finance

Election Cycle-to-Date

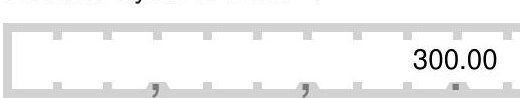

B. Full Name (Last, First, Middle Initial) eugene wordehoff

Mailing Address 692 Solano Ct

\begin{tabular}{lcc}
\hline City & State & Zip Code \\
Marco Island & FL & $34145-1928$
\end{tabular}

FEC ID number of contributing

federal political committee.

C

Name of Employer
Self Employed
Receipt For: 2012
X Primary
Other (specify)

\section{Occupation}

Consultant

Election Cycle-to-Date

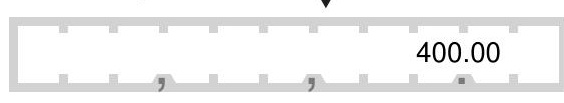

Transaction ID : AFA4E1B82F9E94A6E8E7

Date of Receipt

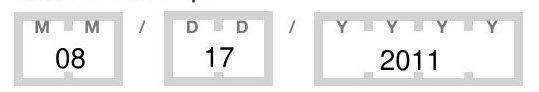

Amount of Each Receipt this Period

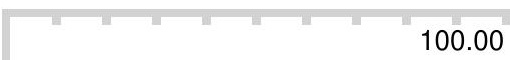

100.00

C. Full Name (Last, First, Middle Initial)

Wendell Parkey

Mailing Address 2404 S.W. Ave. E

\begin{tabular}{l|ll}
\hline $\begin{array}{l}\text { City } \\
\text { Seminole }\end{array}$ & $\begin{array}{c}\text { State } \\
\text { TX }\end{array}$ & $\begin{array}{c}\text { Zip Code } \\
79360\end{array}$ \\
\hline $\begin{array}{l}\text { FEC ID number of contributing } \\
\text { federal political committee. }\end{array}$ & C & \\
\hline $\begin{array}{l}\text { Name of Employer } \\
\text { Self Employed }\end{array}$ & $\begin{array}{l}\text { Occupation } \\
\text { Physician }\end{array}$ \\
\hline $\begin{array}{l}\text { Receipt For: } 2012 \\
\text { Xrimary } \\
\text { Other (specify) }\end{array}$ & Election Cycle-to-Date & \\
\hline
\end{tabular}

Amount of Each Receipt this Period

Transaction ID : A3B932F682D8A4340A11

Date of Receipt
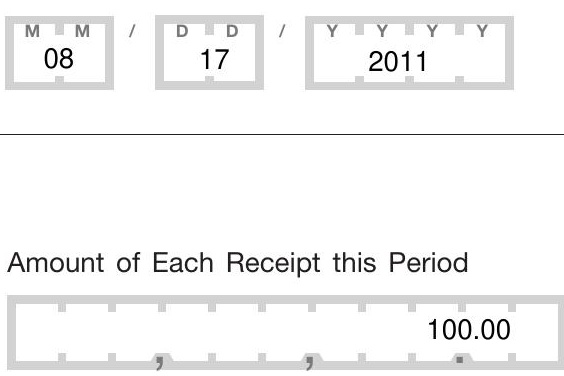

Amount of Each Receipt this Period

Transaction ID : A0120EF9E9A394C8B8FA Date of Receipt
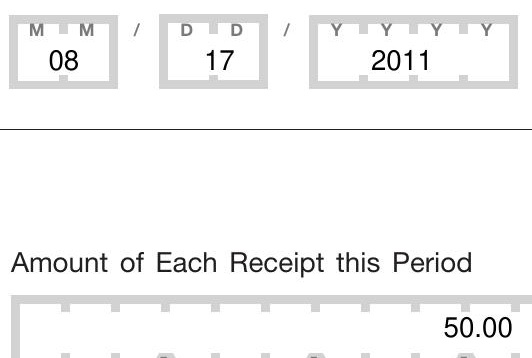

Subtotal Of Receipts This Page (optional)

Total This Period (last page this line number only) 
SCHEDULE A-P ITEMIZED RECEIPTS
Use separate schedule(s) for each category of the Detailed Summary Page
FOR LINE NUMBER: (check only one)

PAGE $317 / 1572$

\begin{tabular}{|c|c|c|c|c|c|}
\hline & & & & & \\
\hline 16 & $\begin{array}{l}\mathbf{X} \\
17 a\end{array}$ & $17 b$ & $17 c$ & $17 d$ & 18 \\
\hline $19 a$ & $19 \mathrm{~b}$ & $20 \mathrm{a}$ & $20 \mathrm{~b}$ & $20 \mathrm{c}$ & 21 \\
\hline
\end{tabular}

Any information copied from such Reports and Statements may not be sold or used by any person for the purpose of soliciting contributions or for commercial purposes, other than using the name and address of any political committee to solicit contributions from such committee.

NAME OF COMMITTEE (In Full)

\section{Friends of Herman Cain}

A. Full Name (Last, First, Middle Initial)

\section{Edward Knowlton}

Mailing Address 200 W Sahara Ave Unit 3304

\begin{tabular}{lcc}
\hline City & State & Zip Code \\
Las Vegas & NV & $89102-5089$
\end{tabular}

FEC ID number of contributing federal political committee.

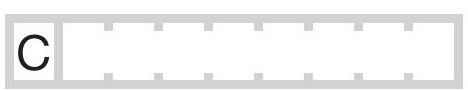

Name of Employer
None
Receipt For: 2012
X Primary $\quad$ General
Other (specify)

\section{Occupation}

Retired Physician

Election Cycle-to-Date

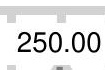

B. Full Name (Last, First, Middle Initial)

Paul Lawrenz

Mailing Address 2632 Thorngrove Ct

\begin{tabular}{lcc}
\hline City & State & Zip Code \\
Fayetteville & NC & 28303-2883 \\
\hline
\end{tabular}

FEC ID number of contributing

federal political committee.

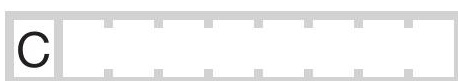

Name of Employer
US Air Force
Receipt For: 2012
X Primary
Other (specify)

\section{Occupation}

Officer

Election Cycle-to-Date

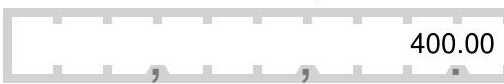

C. Full Name (Last, First, Middle Initial)

Joan Postell

Mailing Address 3925 Merriweather Woods

\begin{tabular}{lcc}
\hline City & State & Zip Code \\
Alpharetta & GA & $30022-7172$
\end{tabular}

FEC ID number of contributing federal political committee.

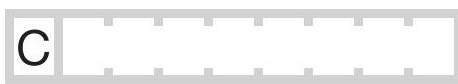

Name of Employer

Information Requested

Occupation

Information Requested

Receipt For: 2012

Х $\begin{aligned} & \text { Primary } \square \text { General } \\ & \text { Other (specify) }\end{aligned}$

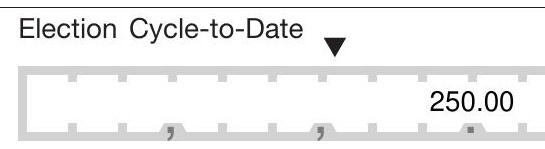

Amount of Each Receipt this Period

Transaction ID : A0918D039B59D4803BF6

Date of Receipt

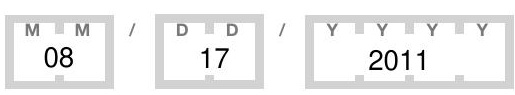

Amount of Each Receipt this Period

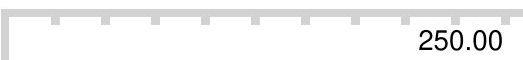

250.00

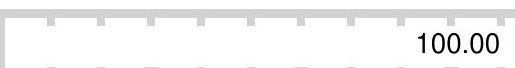

Transaction ID : A1C822F0FF0C245369CD

Date of Receipt

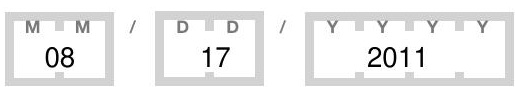

Amount of Each Receipt this Period

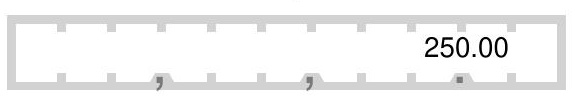

Subtotal Of Receipts This Page (optional)

600.00

Total This Period (last page this line number only) 


\section{SCHEDULE A-P} ITEMIZED RECEIPTS
Use separate schedule(s)

for each category of the

Detailed Summary Page
FOR LINE NUMBER: (check only one)

PAGE $318 / 1572$

\begin{tabular}{|c|c|c|c|c|c|}
\hline & & & & & \\
\hline 16 & X $17 a$ & $17 b$ & $17 c$ & $17 d$ & 18 \\
\hline $19 a$ & $19 b$ & $20 \mathrm{a}$ & $20 \mathrm{~b}$ & $20 \mathrm{c}$ & 21 \\
\hline
\end{tabular}

Any information copied from such Reports and Statements may not be sold or used by any person for the purpose of soliciting contributions or for commercial purposes, other than using the name and address of any political committee to solicit contributions from such committee.

NAME OF COMMITTEE (In Full)

\section{Friends of Herman Cain}

A. Full Name (Last, First, Middle Initial)

Keith Lacey

Mailing Address 445 11th Street

\begin{tabular}{lcc}
\hline City & State & Zip Code \\
Marion & IA & $52302-4414$
\end{tabular}

FEC ID number of contributing federal political committee.

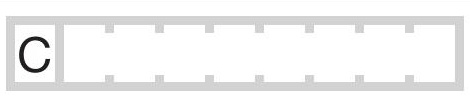

Name of Employer
Godfather"s Pizza
Receipt For: 2012
X Primary
$\square$ Other (specify)

Occupation PRESIDENT

Election Cycle-to-Date

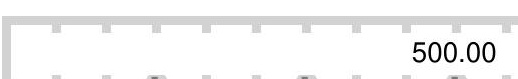

B. Full Name (Last, First, Middle Initial)

Ron Highburger

Mailing Address 745 SW 56th Street

\begin{tabular}{lcc}
\hline City & State & Zip Code \\
Corvallis & OR & $97333-2915$
\end{tabular}

FEC ID number of contributing

federal political committee.

C

Name of Employer
Information Requested
Receipt For: 2012
Primary
Other (specify)

Occupation

Information Requested

Election Cycle-to-Date

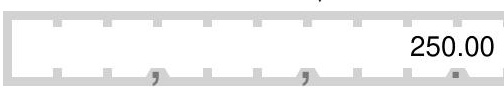

Transaction ID : A412EC6808D1848978CA

Date of Receipt

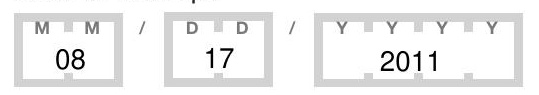

Amount of Each Receipt this Period

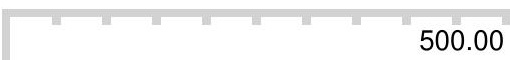

C. Full Name (Last, First, Middle Initial) Judy Williams

Mailing Address 12679 Biscayne Ct

\begin{tabular}{lcc}
\hline City & State & Zip Code \\
Naples & FL & $34105-4935$
\end{tabular}

FEC ID number of contributing federal political committee.

C

Name of Employer
Eli Lilly \& Company
Receipt For: 2012
X Primary
Other (specify) General

Occupation

Assoc Consultant - Clinical Trial Mana

Election Cycle-to-Date

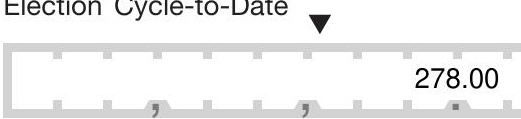

Amount of Each Receipt this Period

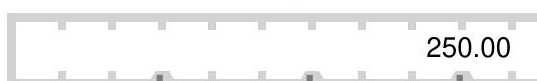

Transaction ID : A38833981586141368CF

Date of Receipt

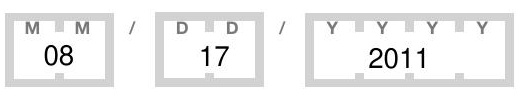

Transaction ID : A828728D95CDF45449B2 Date of Receipt

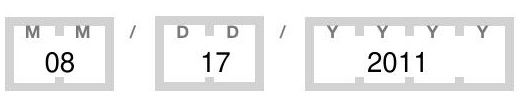

Amount of Each Receipt this Period

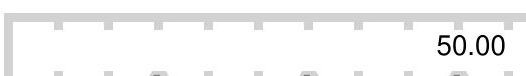

\section{Subtotal Of Receipts This Page (optional)}

800.00

a

Total This Period (last page this line number only)

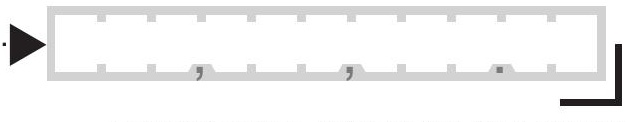

FEC Schedule A-P (Form 3P) (Rev. 03/2011) 
SCHEDULE A-P ITEMIZED RECEIPTS
Use separate schedule(s) for each category of the Detailed Summary Page
FOR LINE NUMBER: (check only one)

PAGE $319 / 1572$

\begin{tabular}{|c|c|c|c|c|c|}
\hline & & & & & \\
\hline 16 & $\begin{array}{l}\mathbf{X} \\
17 a\end{array}$ & $17 b$ & $17 c$ & $17 d$ & 18 \\
\hline $19 a$ & $19 \mathrm{~b}$ & $20 \mathrm{a}$ & $20 \mathrm{~b}$ & $20 \mathrm{c}$ & 21 \\
\hline
\end{tabular}

Any information copied from such Reports and Statements may not be sold or used by any person for the purpose of soliciting contributions or for commercial purposes, other than using the name and address of any political committee to solicit contributions from such committee.

NAME OF COMMITTEE (In Full)

\section{Friends of Herman Cain}

A. Full Name (Last, First, Middle Initial)

Dianne B Chin

Mailing Address P O Box 962812

\begin{tabular}{lcc}
\hline City & State & Zip Code \\
Riverdale & GA & $30296-6928$
\end{tabular}

FEC ID number of contributing federal political committee.

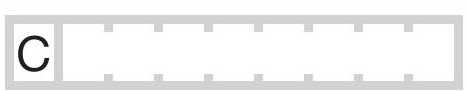

Name of Employer

Auto Auction Services Corp.

Receipt For: 2012

X Primary $\square$ General Other (specify)

Occupation software engineer

Election Cycle-to-Date

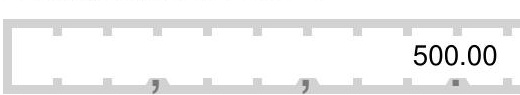

B. Full Name (Last, First, Middle Initial)

Kendall Collier

Mailing Address 500 Rock Springs Road

\begin{tabular}{lcc}
\hline City & State & Zip Code \\
Atlanta & GA & $30324-5104$ \\
\hline
\end{tabular}

FEC ID number of contributing

federal political committee.

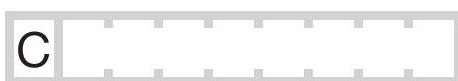

Name of Employer
A Divine Event
Receipt For: 2012
Xrimary
Other (specify) General

Occupation

Special Event Producer

Election Cycle-to-Date

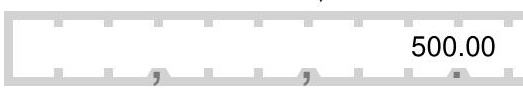

Transaction ID : AE9CB80CE6F4748F5B73

Date of Receipt

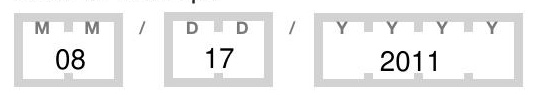

Amount of Each Receipt this Period

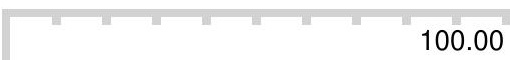

Transaction ID : AC1D14B85569D4527851

Date of Receipt

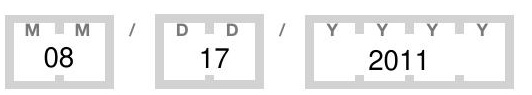

Amount of Each Receipt this Period

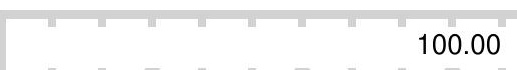

Transaction ID : ADDF90E924E004AA4BD4 Date of Receipt

Anna Nataros

Mailing Address 1600 E Hanley Blvd. Suite 128

\begin{tabular}{lcc}
\hline City & State & Zip Code \\
Tucson & AZ & $85737-9180$
\end{tabular}

FEC ID number of contributing federal political committee.

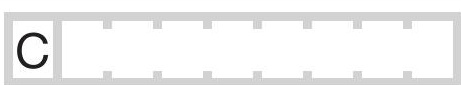

Name of Employer

Information Requested

Occupation

Information Requested

Receipt For: 2012

Х $\begin{aligned} & \text { Primary } \\ & \text { Other (specify) }\end{aligned}$

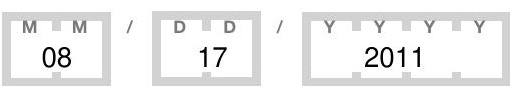

Amount of Each Receipt this Period

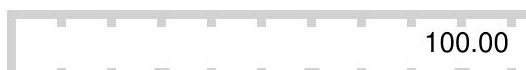

\section{Subtotal Of Receipts This Page (optional)}

300.00

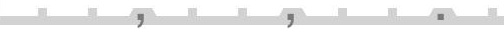

Total This Period (last page this line number only)

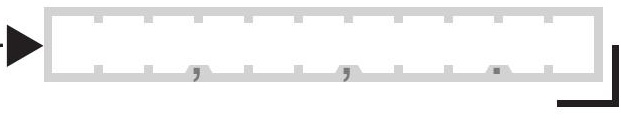

FEC Schedule A-P (Form 3P) (Rev. 03/2011) 
SCHEDULE A-P ITEMIZED RECEIPTS
Use separate schedule(s) for each category of the Detailed Summary Page
FOR LINE NUMBER: (check only one)

PAGE $320 / 1572$

\begin{tabular}{|c|c|c|c|c|c|}
\hline & & & & & \\
\hline 16 & $\begin{array}{l}\mathbf{X} \\
17 a\end{array}$ & $17 b$ & $17 c$ & $17 d$ & 18 \\
\hline $19 a$ & $19 \mathrm{~b}$ & $20 \mathrm{a}$ & $20 \mathrm{~b}$ & $20 \mathrm{c}$ & 21 \\
\hline
\end{tabular}

Any information copied from such Reports and Statements may not be sold or used by any person for the purpose of soliciting contributions or for commercial purposes, other than using the name and address of any political committee to solicit contributions from such committee.

NAME OF COMMITTEE (In Full)

\section{Friends of Herman Cain}

A. Full Name (Last, First, Middle Initial)

Larry Klipp

Mailing Address PO Box 279

\begin{tabular}{lcc}
\hline City & State & Zip Code \\
Belle Fourche & SD & $57717-0279$ \\
\hline
\end{tabular}

FEC ID number of contributing federal political committee.

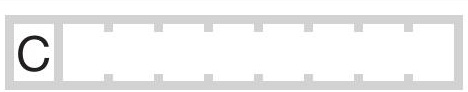

\begin{tabular}{l} 
Name of Employer \\
None \\
Receipt For: 2012 \\
X Primary $\quad$ General \\
\hline Other (specify)
\end{tabular}

Occupation

Retired (Military)

Election Cycle-to-Date

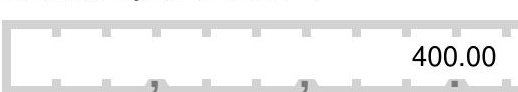

B. Full Name (Last, First, Middle Initial) charles murphy

Mailing Address 299 cherokee drive

\begin{tabular}{lcc}
\hline City & State & Zip Code \\
Harrisburg & IL & $62946-3798$ \\
\hline
\end{tabular}

FEC ID number of contributing

federal political committee.

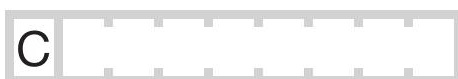

Name of Employer
murphy homes inc
Receipt For: 2012
Primary
Other (specify) General

\section{Occupation} homebuilder

Election Cycle-to-Date

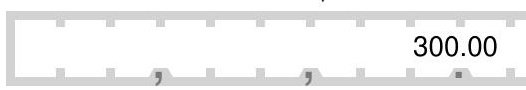

C. Full Name (Last, First, Middle Initial)

christina lipsey

Mailing Address 1219 libby rd

\begin{tabular}{lcc}
\hline City & State & Zip Code \\
Heber Springs & AR & $72543-8985$
\end{tabular}

FEC ID number of contributing federal political committee.

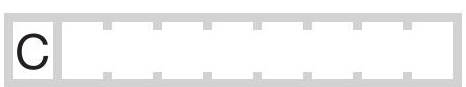

Name of Employer
little rock scool distrct
Receipt For: 2012
X Primary
Other (specify) General

Occupation

Teacher

Election Cycle-to-Date
Transaction ID : A8A64C2FE643342A5995

Date of Receipt

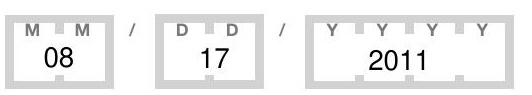

Amount of Each Receipt this Period

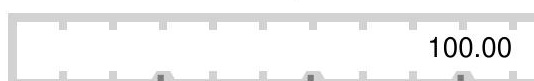

Transaction ID : AF34BD54F13F9481FB49

Date of Receipt

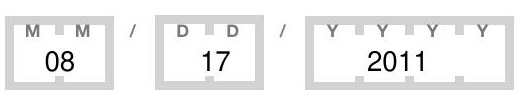

Amount of Each Receipt this Period

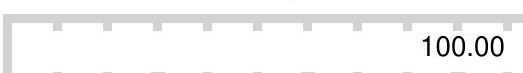

\section{Subtotal Of Receipts This Page (optional)}

Total This Period (last page this line number only) 
SCHEDULE A-P ITEMIZED RECEIPTS
Use separate schedule(s) for each category of the Detailed Summary Page
FOR LINE NUMBER: (check only one)

PAGE $321 / 1572$

\begin{tabular}{|c|c|c|c|c|c|c|}
\hline & & & & & & \\
\hline 16 & $\lambda$ & $17 \mathrm{a}$ & $17 \mathrm{~b}$ & $17 \mathrm{c}$ & $-17 d$ & -18 \\
\hline $19 a$ & & $19 b$ & $20 a$ & $20 \mathrm{~b}$ & $20 \mathrm{c}$ & 21 \\
\hline
\end{tabular}

Any information copied from such Reports and Statements may not be sold or used by any person for the purpose of soliciting contributions or for commercial purposes, other than using the name and address of any political committee to solicit contributions from such committee.

NAME OF COMMITTEE (In Full)

\section{Friends of Herman Cain}

A. Full Name (Last, First, Middle Initial)

Matthew Marston

Mailing Address 90 Beacon St

\begin{tabular}{lcc}
\hline City & State & Zip Code \\
Boston & MA & $02108-3324$
\end{tabular}

FEC ID number of contributing federal political committee.

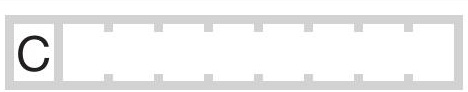

Name of Employer
FourTier Strategies
Receipt For: 2012
X Primary
Other (specify) General

Occupation

Partner

Election Cycle-to-Date

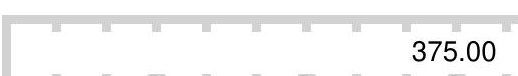

B. Full Name (Last, First, Middle Initial)

David Herman

Mailing Address 118 Greer Lane

\begin{tabular}{lcc}
\hline City & State & Zip Code \\
Toccoa & GA & $30577-3096$ \\
\hline
\end{tabular}

FEC ID number of contributing

federal political committee.

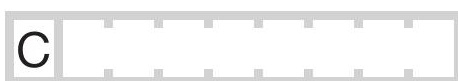

Name of Employer
Air Tran
Receipt For: 2012
X Primary
Other (specify)

\section{Occupation}

Pilot

Election Cycle-to-Date

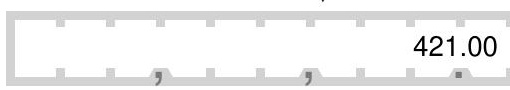

Transaction ID : AF725595CBC04483594B

Date of Receipt

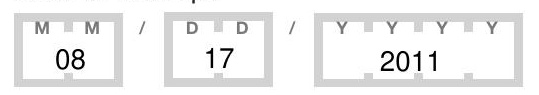

Amount of Each Receipt this Period

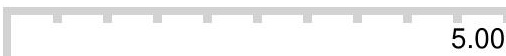

Amount of Each Receipt this Period

Transaction ID : A28F0F7609E564EAAACA Date of Receipt
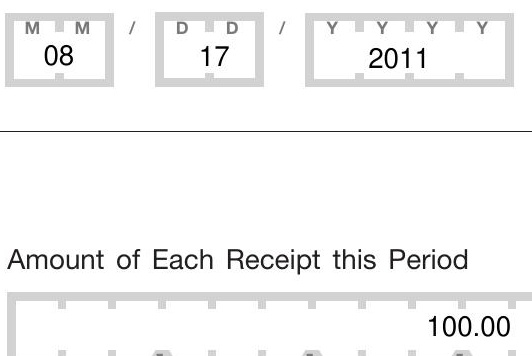

Transaction ID : A1172A0EC5D1A486F975 Date of Receipt

Tommy Morgan

Mailing Address 1811 McDaniel Mill Road, SW

\begin{tabular}{lcc}
\hline City & State & Zip Code \\
Conyers & GA & $30094-6023$
\end{tabular}

FEC ID number of contributing federal political committee.

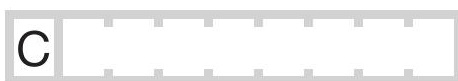

Name of Employer
Information Requested
Receipt For: 2012
X Primary $\quad \square$ General
Other (specify)

\section{Occupation}

Information Requested

Election Cycle-to-Date
Amount of Each Receipt this Period

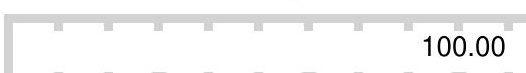

\section{Subtotal Of Receipts This Page (optional)}

205.00

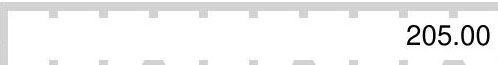

Total This Period (last page this line number only)

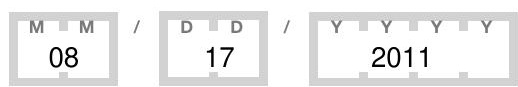


SCHEDULE A-P ITEMIZED RECEIPTS
Use separate schedule(s) for each category of the Detailed Summary Page
FOR LINE NUMBER: (check only one)

PAGE 322 / 1572

\begin{tabular}{|c|c|c|c|c|c|c|}
\hline & & & & & & \\
\hline 16 & $\lambda$ & $17 \mathrm{a}$ & $17 \mathrm{~b}$ & $17 \mathrm{c}$ & $-17 d$ & -18 \\
\hline $19 a$ & & $19 b$ & $20 a$ & $20 \mathrm{~b}$ & $20 \mathrm{c}$ & 21 \\
\hline
\end{tabular}

Any information copied from such Reports and Statements may not be sold or used by any person for the purpose of soliciting contributions or for commercial purposes, other than using the name and address of any political committee to solicit contributions from such committee.

NAME OF COMMITTEE (In Full)

\section{Friends of Herman Cain}

A. Full Name (Last, First, Middle Initial)

Eugene Adamson

Mailing Address 412 The Falls of Cherokee Dr

\begin{tabular}{lcc}
\hline City & State & Zip Code \\
Canton & GA & $30114-8142$
\end{tabular}

FEC ID number of contributing federal political committee.

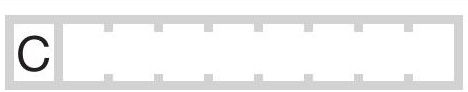

Name of Employer
CKI Service
Receipt For: 2012
X Primary $\quad$ General
Other (specify)

Occupation OWNER

Election Cycle-to-Date

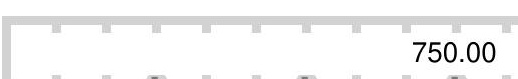

B. Full Name (Last, First, Middle Initial)

Sandra Shackelford

Mailing Address 130 Middling Lane

\begin{tabular}{lcc}
\hline City & State & Zip Code \\
Fayetteville & GA & $30214-3767$ \\
\hline
\end{tabular}

FEC ID number of contributing

federal political committee.

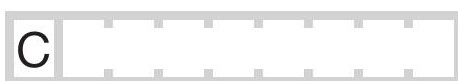

Name of Employer
Delta Airlines
Receipt For: 2012
X Primary
Other (specify)

Occupation

Enterprise Document Mgmt

Election Cycle-to-Date

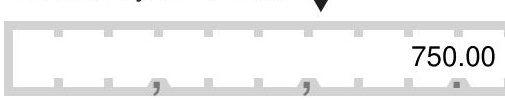

C. Full Name (Last, First, Middle Initial)

Basil Kelley

Mailing Address 22025 Airport Rd. NE

\begin{tabular}{lcc}
\hline City & State & Zip Code \\
Tualatin & OR & 97062
\end{tabular}

FEC ID number of contributing

federal political committee.

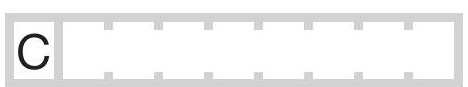

Name of Employer

Loti Corporation

\section{Occupation}

PRESIDENT

Receipt For: 2012

Х $\begin{aligned} & \text { Primary } \\ & \text { Other (specify) }\end{aligned}$

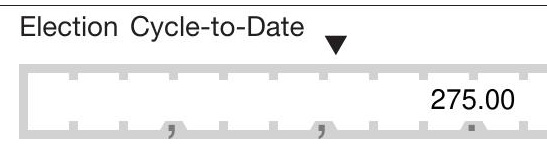

Amount of Each Receipt this Period

Transaction ID : AA4CC22828ECD4B019CE Date of Receipt

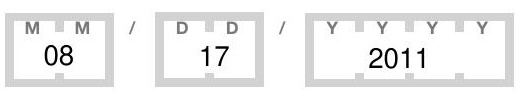

Amount of Each Receipt this Period
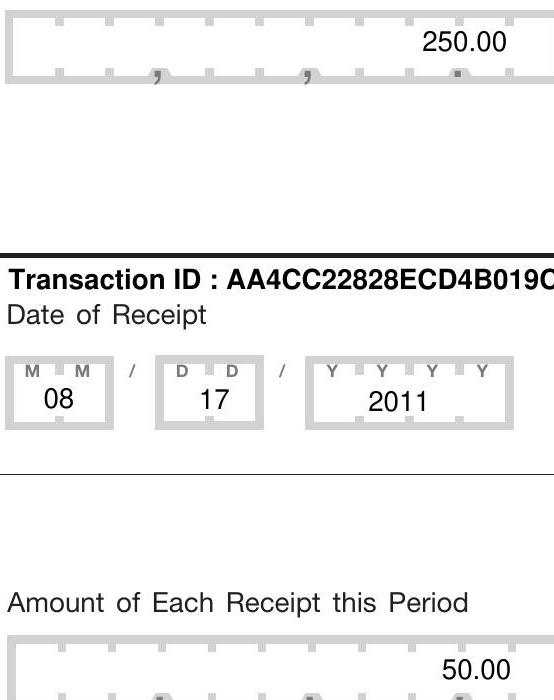

Transaction ID : AF6497D78D89B42FBA9D Date of Receipt

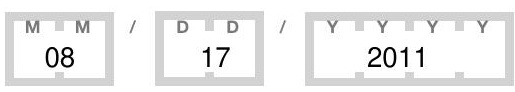

Amount of Each Receipt this Period

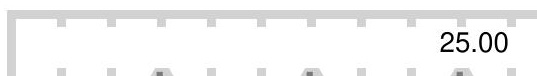

Subtotal Of Receipts This Page (optional)

325.00

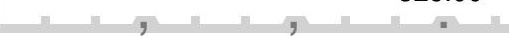

Total This Period (last page this line number only)

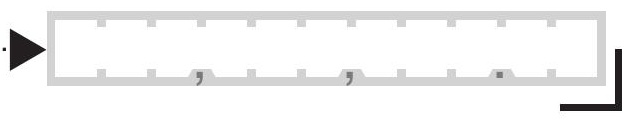

FEC Schedule A-P (Form 3P) (Rev. 03/2011) 
SCHEDULE A-P ITEMIZED RECEIPTS
Use separate schedule(s) for each category of the Detailed Summary Page
FOR LINE NUMBER: (check only one)

\begin{tabular}{|c|c|c|c|c|c|}
\hline & & & & & \\
\hline 16 & $\begin{array}{ll}X & 17 a \\
\end{array}$ & $17 \mathrm{~b}$ & $17 c$ & $17 d$ & 18 \\
\hline $19 a$ & $19 b$ & $20 \mathrm{a}$ & $20 \mathrm{~b}$ & $20 c$ & 21 \\
\hline
\end{tabular}

Any information copied from such Reports and Statements may not be sold or used by any person for the purpose of soliciting contributions or for commercial purposes, other than using the name and address of any political committee to solicit contributions from such committee.

NAME OF COMMITTEE (In Full)

\section{Friends of Herman Cain}

A. Full Name (Last, First, Middle Initial)

Ms Lenora H Pusta

Mailing Address 138 W Sunflower Dr

\begin{tabular}{lcc}
\hline City & State & Zip Code \\
Payson & AZ & $85541-6152$ \\
\hline
\end{tabular}

FEC ID number of contributing federal political committee.

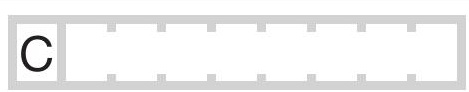

\begin{tabular}{l} 
Name of Employer \\
None \\
Receipt For: 2012 \\
X Primary $\quad$ General \\
\hline Other (specify)
\end{tabular}

Occupation Retired

Election Cycle-to-Date

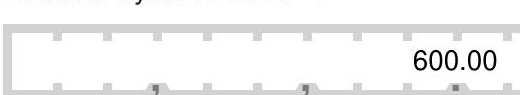

B. Full Name (Last, First, Middle Initial)

Anthony Babiak

Mailing Address 3415 E Barrington Dr

\begin{tabular}{lcc}
\hline City & State & Zip Code \\
Orange & CA & $92869-2579$ \\
\hline
\end{tabular}

FEC ID number of contributing

federal political committee.

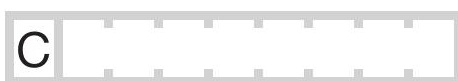

Name of Employer
V \& M Plating Co
Receipt For: 2012
X Primary
Other (specify)

Occupation

Corp. Executive

Election Cycle-to-Date

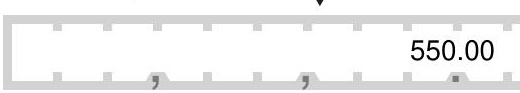

Transaction ID : A2F2E9668E10742F7ADE

Date of Receipt

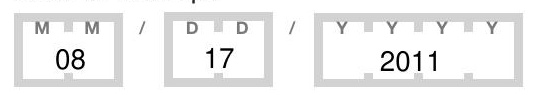

Amount of Each Receipt this Period

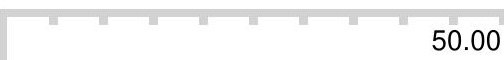

50.00

C. Full Name (Last, First, Middle Initial)

Tom Brown

Mailing Address 1566 Ridley Road

\begin{tabular}{lcc}
\hline City & State & Zip Code \\
Dahlonega & GA & $30533-1972$
\end{tabular}

FEC ID number of contributing federal political committee.

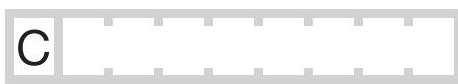

Name of Employer
None
Receipt For: 2012
Х Primary $\quad \square$ General
Other (specify)

Occupation

Retired

Election Cycle-to-Date

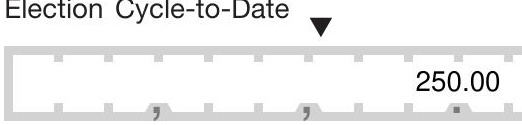

Transaction ID : A017A1DE5531340E0B0D

Date of Receipt

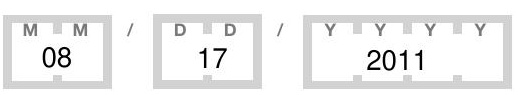

Amount of Each Receipt this Period

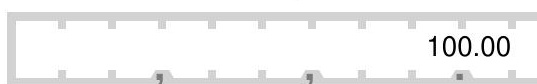

Transaction ID : A6E13818A65974D91992

Date of Receipt

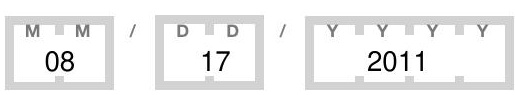

Amount of Each Receipt this Period

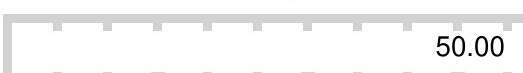

\section{Subtotal Of Receipts This Page (optional)}

Total This Period (last page this line number only) 
SCHEDULE A-P ITEMIZED RECEIPTS
Use separate schedule(s) for each category of the Detailed Summary Page
FOR LINE NUMBER: (check only one)

PAGE 324 / 1572

\begin{tabular}{|c|c|c|c|c|c|}
\hline & & & & & \\
\hline 16 & $\begin{array}{l}\mathbf{X} \\
17 a\end{array}$ & $17 b$ & $17 c$ & $17 d$ & 18 \\
\hline $19 a$ & $19 \mathrm{~b}$ & $20 \mathrm{a}$ & $20 \mathrm{~b}$ & $20 \mathrm{c}$ & 21 \\
\hline
\end{tabular}

Any information copied from such Reports and Statements may not be sold or used by any person for the purpose of soliciting contributions or for commercial purposes, other than using the name and address of any political committee to solicit contributions from such committee.

NAME OF COMMITTEE (In Full)

\section{Friends of Herman Cain}

A. Full Name (Last, First, Middle Initial)

Nathan Moore

Mailing Address 1513 ocean breeze Ln

\begin{tabular}{lcc}
\hline City & State & Zip Code \\
Gulf Breeze & FL & $32563-9222$
\end{tabular}

FEC ID number of contributing federal political committee.

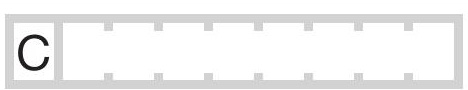

Name of Employer
self
Receipt For: 2012
X Primary $\quad$ General
Other (specify)

Occupation Carpenter

Election Cycle-to-Date 275.00

B. Full Name (Last, First, Middle Initial) Carlotta Monningh

Mailing Address 70 Seabolt Dr

\begin{tabular}{lcc}
\hline City & State & Zip Code \\
Locust Grove & GA & $30248-2143$ \\
\hline
\end{tabular}

FEC ID number of contributing

federal political committee.

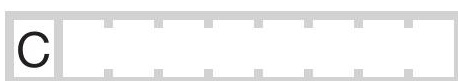

Name of Employer
Coldwell Banker Bullard Rlty
Receipt For: 2012
X Primary
Other (specify)

Occupation

Realtor

Election Cycle-to-Date

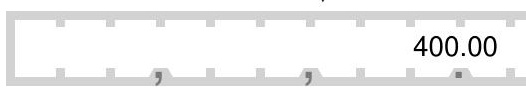

C. Full Name (Last, First, Middle Initial)

Kay Trettin-Benson

Mailing Address 11 Meadow Cove Drive

\begin{tabular}{lcc}
\hline City & State & Zip Code \\
Spring & TX & $77381-3323$ \\
\hline
\end{tabular}

FEC ID number of contributing federal political committee.

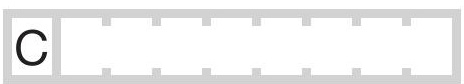

Name of Employer
Not Employed
Receipt For: 2012
X Primary $\quad \square$ General
Other (specify)

\section{Occupation}

Not Employed

Election Cycle-to-Date

Transaction ID : A6CAED5E2FD81406E800 Date of Receipt

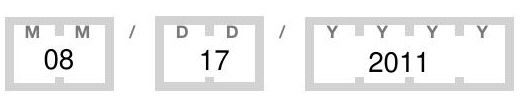

Amount of Each Receipt this Period

Amount of Each Receipt this Period

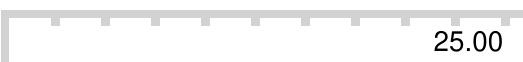

25.00

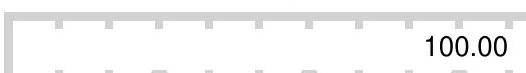

Transaction ID : A44A3BF6FE4BB4110A7E Date of Receipt

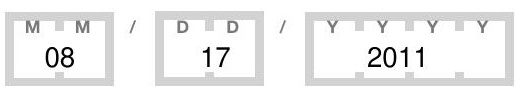

Amount of Each Receipt this Period

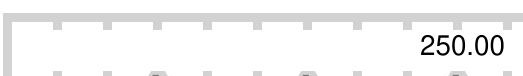

1100.00

\section{Subtotal Of Receipts This Page (optional)}

Total This Period (last page this line number only) 
SCHEDULE A-P ITEMIZED RECEIPTS
Use separate schedule(s) for each category of the Detailed Summary Page
FOR LINE NUMBER: (check only one)

PAGE $325 / 1572$

\begin{tabular}{|c|c|c|c|c|c|}
\hline & & & & & \\
\hline 16 & $\begin{array}{l}\mathbf{X} \\
17 a\end{array}$ & $17 b$ & $17 c$ & $17 d$ & 18 \\
\hline $19 a$ & $19 \mathrm{~b}$ & $20 \mathrm{a}$ & $20 \mathrm{~b}$ & $20 \mathrm{c}$ & 21 \\
\hline
\end{tabular}

Any information copied from such Reports and Statements may not be sold or used by any person for the purpose of soliciting contributions or for commercial purposes, other than using the name and address of any political committee to solicit contributions from such committee.

NAME OF COMMITTEE (In Full)

\section{Friends of Herman Cain}

A. Full Name (Last, First, Middle Initial)

Eileen Million

Mailing Address 252 Vine Cliff Drive

\begin{tabular}{lcc}
\hline City & State & Zip Code \\
Harvest & AL & $35749-5816$
\end{tabular}

FEC ID number of contributing federal political committee.

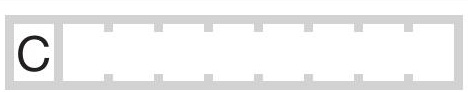

Name of Employer
None
Receipt For: 2012
X Primary $\quad$ General
Other (specify)

Occupation Homemaker

Election Cycle-to-Date 436.00

B. Full Name (Last, First, Middle Initial) Joseph Daniell

Mailing Address 805 Streamside Dr.

\begin{tabular}{lcc}
\hline City & State & Zip Code \\
McDonough & GA & $30252-9035$ \\
\hline
\end{tabular}

FEC ID number of contributing

federal political committee.

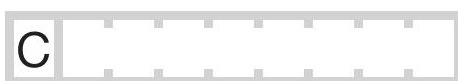

Name of Employer
Dynamac Corp.
Receipt For: 2012
X Primary
Other (specify)

\section{Occupation}

Sr. Project Mgr

Election Cycle-to-Date

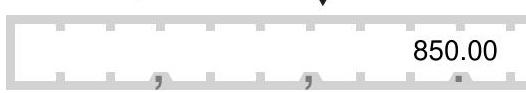

C. Full Name (Last, First, Middle Initial)

CHris Guarino

Mailing Address 2665 Ball Ground Hwy

\begin{tabular}{lcc}
\hline City & State & Zip Code \\
Canton & GA & $30114-7439$ \\
\hline
\end{tabular}

FEC ID number of contributing federal political committee.

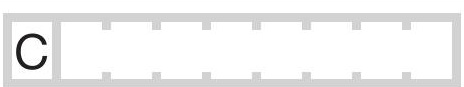

Name of Employer

Asset Technology Group

Receipt For: 2012

Х $\begin{aligned} & \text { Primary } \square \text { General } \\ & \text { Other (specify) }\end{aligned}$

\section{Occupation}

BUSINESS OWNER

Election Cycle-to-Date
Transaction ID : AB5F2889064BD4890BD3

Date of Receipt

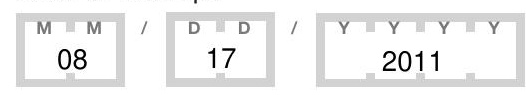

Amount of Each Receipt this Period

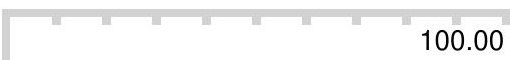

Amount of Each Receipt this Period

Transaction ID : A2A6B6DD73AA64AA6AE1 Date of Receipt
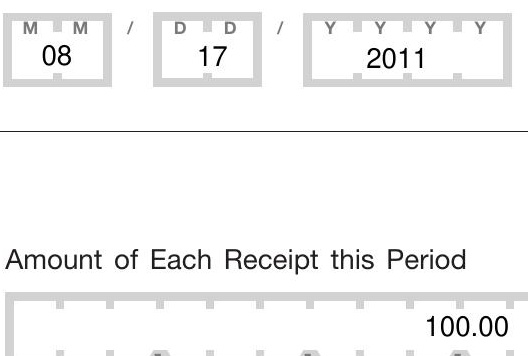

Transaction ID : AFEFE169C43CA46CB9C5 Date of Receipt

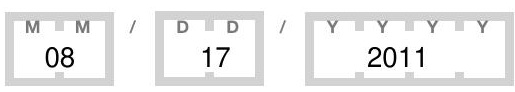

Amount of Each Receipt this Period

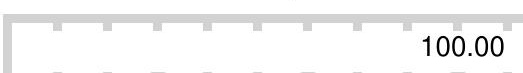

400.00

\section{Subtotal Of Receipts This Page (optional)}

Total This Period (last page this line number only) 
SCHEDULE A-P ITEMIZED RECEIPTS
Use separate schedule(s) for each category of the Detailed Summary Page
FOR LINE NUMBER: (check only one)

PAGE 326 / 1572

\begin{tabular}{|c|c|c|c|c|c|}
\hline & & & & & \\
\hline 16 & $\begin{array}{l}\mathbf{X} \\
17 a\end{array}$ & $17 b$ & $17 c$ & $17 d$ & 18 \\
\hline $19 a$ & $19 \mathrm{~b}$ & $20 \mathrm{a}$ & $20 \mathrm{~b}$ & $20 \mathrm{c}$ & 21 \\
\hline
\end{tabular}

Any information copied from such Reports and Statements may not be sold or used by any person for the purpose of soliciting contributions or for commercial purposes, other than using the name and address of any political committee to solicit contributions from such committee.

NAME OF COMMITTEE (In Full)

\section{Friends of Herman Cain}

A. Full Name (Last, First, Middle Initial) robert swartz

Mailing Address 4001 n. new braunfels ave

\begin{tabular}{lcc}
\hline City & State & Zip Code \\
San Antonio & TX & $78209-6349$
\end{tabular}

FEC ID number of contributing federal political committee.

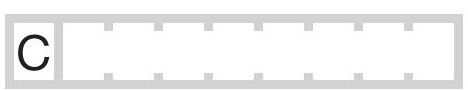

Name of Employer
None
Receipt For: 2012
X Primary $\quad \square$ General
Other (specify)

Occupation Retired Election Cycle-to-Date

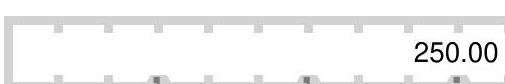

B. Full Name (Last, First, Middle Initial)

CARLOS URUCHURTU SR Sr.

Mailing Address 33150 PAUBA RD

\begin{tabular}{lcc}
\hline City & State & Zip Code \\
Temecula & CA & $92592-9264$ \\
\hline
\end{tabular}

FEC ID number of contributing

federal political committee.

C

Name of Employer
GEORGE CHEVROLET
Receipt For: 2012
X Primary
Other (specify)

\section{Occupation}

VP/GM

Election Cycle-to-Date

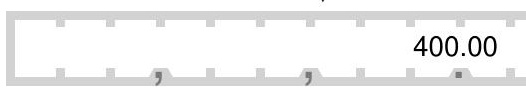

Transaction ID : A60C3BCDB66C246F3B71

Date of Receipt

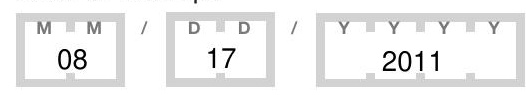

Amount of Each Receipt this Period

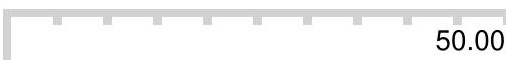

C. Full Name (Last, First, Middle Initial)

Erica Daniell

Mailing Address 805 Streamside Dr

\begin{tabular}{lcc}
\hline City & State & Zip Code \\
McDonough & GA & $30252-9035$
\end{tabular}

FEC ID number of contributing federal political committee.

C

C

Name of Employer
Chevy's Diner
Receipt For: 2012
Primary
Other (specify) General

\section{Occupation} OWNER

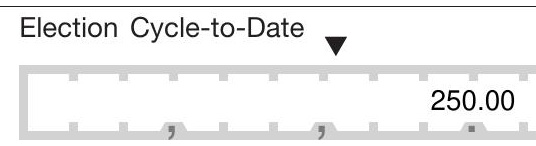

Transaction ID : AF15C6AABC80C4C3F893 Date of Receipt

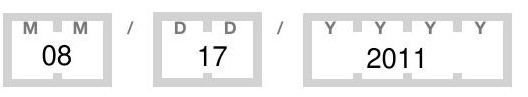

Amount of Each Receipt this Period

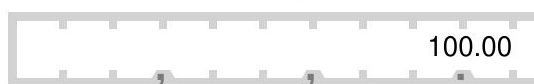

Transaction ID : A1F14B7F910D143338D5

Date of Receipt

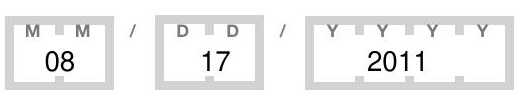

Amount of Each Receipt this Period

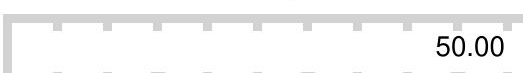

50.00

\section{Subtotal Of Receipts This Page (optional)}

200.00

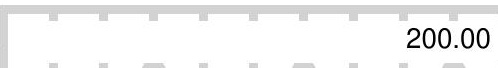

Total This Period (last page this line number only)

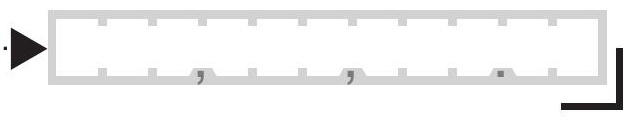

FEC Schedule A-P (Form 3P) (Rev. 03/2011) 
SCHEDULE A-P ITEMIZED RECEIPTS
Use separate schedule(s) for each category of the Detailed Summary Page
FOR LINE NUMBER: (check only one)

PAGE 327 / 1572

\begin{tabular}{|c|c|c|c|c|c|}
\hline & & & & & \\
\hline 16 & $\begin{array}{l}\mathbf{X} \\
17 a\end{array}$ & $17 b$ & $17 c$ & $17 d$ & 18 \\
\hline $19 a$ & $19 \mathrm{~b}$ & $20 \mathrm{a}$ & $20 \mathrm{~b}$ & $20 \mathrm{c}$ & 21 \\
\hline
\end{tabular}

Any information copied from such Reports and Statements may not be sold or used by any person for the purpose of soliciting contributions or for commercial purposes, other than using the name and address of any political committee to solicit contributions from such committee.

NAME OF COMMITTEE (In Full)

\section{Friends of Herman Cain}

A. Full Name (Last, First, Middle Initial)

\section{Steve fish}

Mailing Address 15975 manor club dr

\begin{tabular}{lcc}
\hline City & State & Zip Code \\
Alpharetta & GA & $30004-8849$
\end{tabular}

FEC ID number of contributing federal political committee.

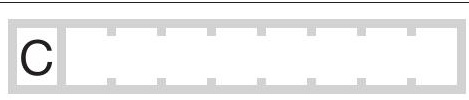

Name of Employer
dewolff boberg \& associates
Receipt For: 2012
X Primary
Other (specify) General

B. Full Name (Last, First, Middle Initial)

Don Deal

Mailing Address 238 Midvale Drive NE

\begin{tabular}{lcc}
\hline City & State & Zip Code \\
Atlanta & GA & $30342-3327$ \\
\hline
\end{tabular}

FEC ID number of contributing

federal political committee.

Name of Employer
Delphix
Receipt For: 2012
X Primary
Other (specify)

C. Full Name (Last, First, Middle Initial)

Samuel Sylvester

Mailing Address 701 S. University Blvd. Apt. 312

\begin{tabular}{lcc}
\hline City & State & Zip Code \\
Mobile & AL & $36609-780$
\end{tabular}

FEC ID number of contributing federal political committee.

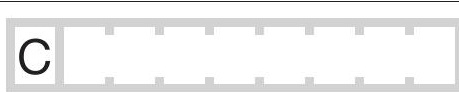

Name of Employer
The SSI Group
Receipt For: 2012
X Primary
Other (specify) General

\section{Occupation} Consultant Election Cycle-to-Date

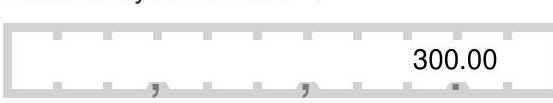

\section{R\&D Programmer}

Election Cycle-to-Date

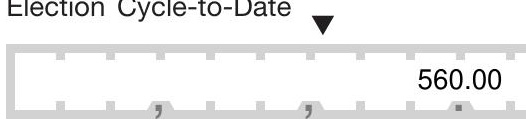

Transaction ID : A5D9E12E37B444DA9878

Date of Receipt

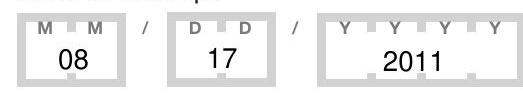

Amount of Each Receipt this Period

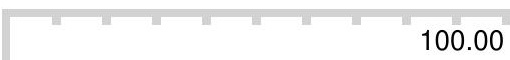

C
Amount of Each Receipt this Period

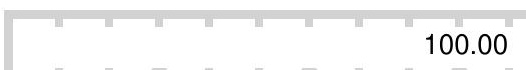

Transaction ID : AF66C0F767BFC4BD1B99 Date of Receipt

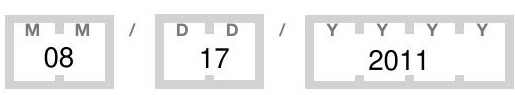

Software Engineer

Election Cycle-to-Date

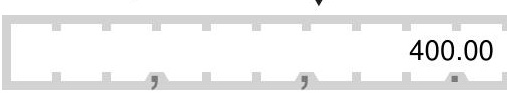

Amount of Each Receipt this Period

Transaction ID : A6EB2B345910F4EEF98C Date of Receipt
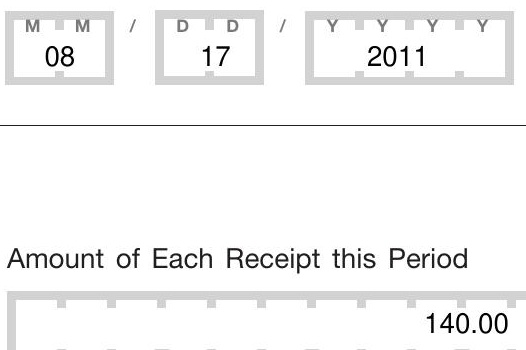

Subtotal Of Receipts This Page (optional)

Total This Period (last page this line number only) 
SCHEDULE A-P ITEMIZED RECEIPTS
Use separate schedule(s) for each category of the Detailed Summary Page
FOR LINE NUMBER: (check only one)

PAGE $328 / 1572$

\begin{tabular}{|c|c|c|c|c|c|}
\hline & & & & & \\
\hline 16 & $\begin{array}{l}\mathbf{X} \\
17 a\end{array}$ & $17 b$ & $17 c$ & $17 d$ & 18 \\
\hline $19 a$ & $19 \mathrm{~b}$ & $20 \mathrm{a}$ & $20 \mathrm{~b}$ & $20 \mathrm{c}$ & 21 \\
\hline
\end{tabular}

Any information copied from such Reports and Statements may not be sold or used by any person for the purpose of soliciting contributions or for commercial purposes, other than using the name and address of any political committee to solicit contributions from such committee.

NAME OF COMMITTEE (In Full)

\section{Friends of Herman Cain}

A. Full Name (Last, First, Middle Initial)

Mary-Anne Mahaffy

Mailing Address 532 Lower Georges Valley Rd

\begin{tabular}{lcc}
\hline City & State & Zip Code \\
Spring Mills & PA & $16875-8200$
\end{tabular}

FEC ID number of contributing

federal political committee.

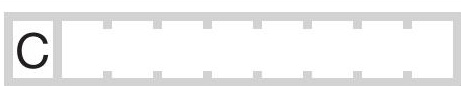

Name of Employer
Information Requested
Receipt For: 2012
X Primary
Other (specify) General

Occupation

Information Requested

Election Cycle-to-Date

300.00

B. Full Name (Last, First, Middle Initial)

James Reardon

Mailing Address 414 Country Village Dr.

\begin{tabular}{lcc}
\hline City & State & Zip Code \\
Smyrna & TN & $37167-5571$ \\
\hline
\end{tabular}

FEC ID number of contributing

federal political committee.

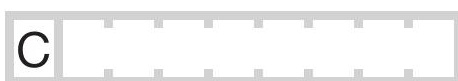

Name of Employer
Alive Hospice Inc
Receipt For: 2012
X Primary
Other (specify)

Occupation

Registered Nurse

Election Cycle-to-Date

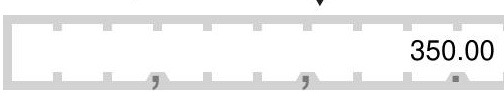

Transaction ID : A2F5E70D3ACFB441E8B4

Date of Receipt

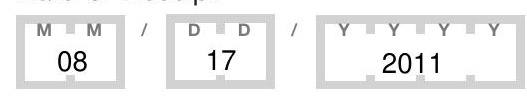

Amount of Each Receipt this Period

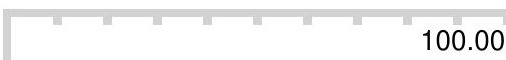

Transaction ID : A10A2022A3EA14B2C9AA

Date of Receipt

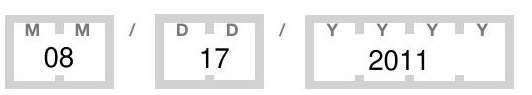

Amount of Each Receipt this Period

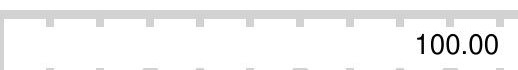

Transaction ID : A408384F6551847BE972

Date of Receipt

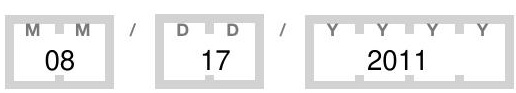

\begin{tabular}{lcc}
\hline City & State & Zip Code \\
Houston & TX & $77065-4927$
\end{tabular}

FEC ID number of contributing

federal political committee.

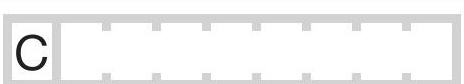

Name of Employer

State of Texas

Occupation

Retired

Receipt For: 2012

Х $\begin{aligned} & \text { Primary } \\ & \text { Other (specify) }\end{aligned}$

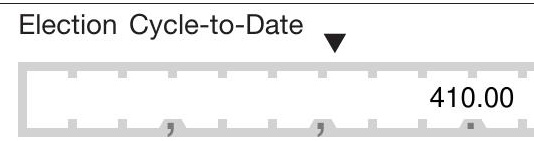

Amount of Each Receipt this Period

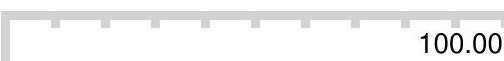

100.00

Subtotal Of Receipts This Page (optional)

300.00

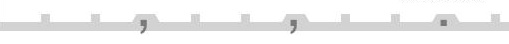

Total This Period (last page this line number only)

FEC Schedule A-P (Form 3P) (Rev. 03/2011) 
SCHEDULE A-P ITEMIZED RECEIPTS
Use separate schedule(s)

for each category of the

Detailed Summary Page
FOR LINE NUMBER: (check only one)

\begin{tabular}{|c|c|c|c|c|c|}
\hline & & & & & \\
\hline 16 & $\begin{array}{ll}X & 17 a \\
\end{array}$ & $17 \mathrm{~b}$ & $17 c$ & $17 d$ & 18 \\
\hline $19 a$ & $19 b$ & $20 \mathrm{a}$ & $20 \mathrm{~b}$ & $20 c$ & 21 \\
\hline
\end{tabular}

Any information copied from such Reports and Statements may not be sold or used by any person for the purpose of soliciting contributions or for commercial purposes, other than using the name and address of any political committee to solicit contributions from such committee.

NAME OF COMMITTEE (In Full)

Friends of Herman Cain

A. Full Name (Last, First, Middle Initial)

Sharon Rodgers

Mailing Address 1447 Glenover Circle

\begin{tabular}{lcc}
\hline City & State & Zip Code \\
Marietta & GA & $30062-2151$ \\
\hline
\end{tabular}

FEC ID number of contributing

federal political committee.

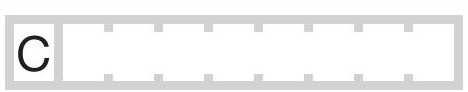

Name of Employer
Rutherfoord
Receipt For: 2012
X Primary $\quad$ General
Other (specify)

Occupation

sales/service

Election Cycle-to-Date

400.00

B. Full Name (Last, First, Middle Initial)

Stephen Arnold

Mailing Address 2719 Bay Ridge Dr.

\begin{tabular}{lcc}
\hline City & State & Zip Code \\
Loganville & GA & $30052-3706$ \\
\hline
\end{tabular}

FEC ID number of contributing

federal political committee.

C

Name of Employer

Peachtree Pest Control Co. Inc.

Occupation

pest Control

Receipt For: 2012

$\chi \begin{aligned} & \text { Primary } \\ & \text { Other (specify) } \boldsymbol{\nabla}\end{aligned}$ General

Election Cycle-to-Date

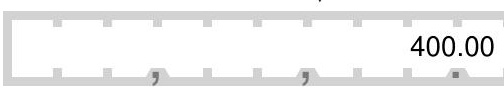

C. Full Name (Last, First, Middle Initial)

thomas mims

Mailing Address 1655 Banks St

\begin{tabular}{lcc}
\hline City & State & Zip Code \\
Houston & TX & $77006-6021$
\end{tabular}

FEC ID number of contributing

federal political committee.

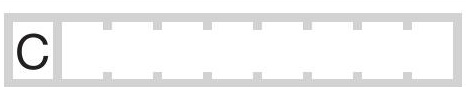

Name of Employer

Self Employed

Occupation

Receipt For: 2012

Х $\begin{aligned} & \text { Primary } \square \text { General } \\ & \text { Other (specify) }\end{aligned}$

Physician

Election Cycle-to-Date

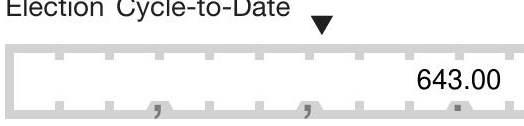

Transaction ID : A6717BFAC090342CABC1

Date of Receipt

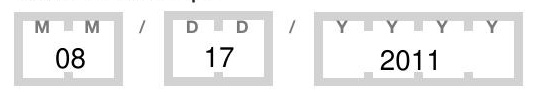

Amount of Each Receipt this Period

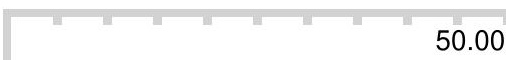

50.00

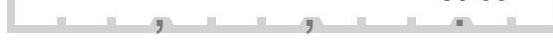

Transaction ID : AC21758C6CB0441719EA

Date of Receipt

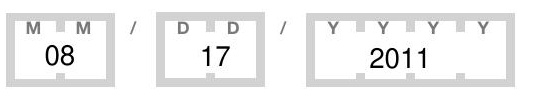

Amount of Each Receipt this Period

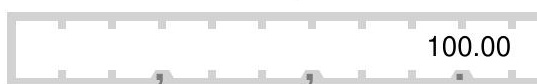

Transaction ID : A92CF8A894831438C956

Date of Receipt

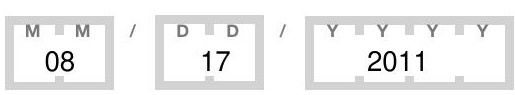

Amount of Each Receipt this Period

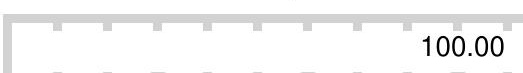

100.00

\section{Subtotal Of Receipts This Page (optional)}

Total This Period (last page this line number only) 
SCHEDULE A-P ITEMIZED RECEIPTS
Use separate schedule(s) for each category of the Detailed Summary Page
FOR LINE NUMBER: (check only one)

PAGE $330 / 1572$

\begin{tabular}{|c|c|c|c|c|c|}
\hline & & & & & \\
\hline 16 & $\begin{array}{l}\mathbf{X} \\
17 a\end{array}$ & $17 b$ & $17 c$ & $17 d$ & 18 \\
\hline $19 a$ & $19 \mathrm{~b}$ & $20 \mathrm{a}$ & $20 \mathrm{~b}$ & $20 \mathrm{c}$ & 21 \\
\hline
\end{tabular}

Any information copied from such Reports and Statements may not be sold or used by any person for the purpose of soliciting contributions or for commercial purposes, other than using the name and address of any political committee to solicit contributions from such committee.

NAME OF COMMITTEE (In Full)

\section{Friends of Herman Cain}

A. Full Name (Last, First, Middle Initial)

Margaret Sorrells

Mailing Address 2394 Bold Springs Road

\begin{tabular}{lcc}
\hline City & State & Zip Code \\
Monroe & GA & $30656-4000$
\end{tabular}

FEC ID number of contributing

federal political committee.

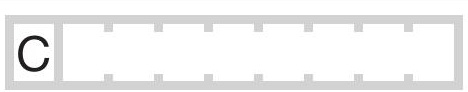

Name of Employer
Walton County Schools
Receipt For: 2012
X Primary $\quad \square$ General
Other (specify)

Occupation

Educator

Election Cycle-to-Date

250.00

B. Full Name (Last, First, Middle Initial)

John Taylor

Mailing Address 92 Jackson Meadows Dr.

\begin{tabular}{lcc}
\hline City & State & Zip Code \\
Hoschton & GA & $30548-6345$
\end{tabular}

FEC ID number of contributing

federal political committee.

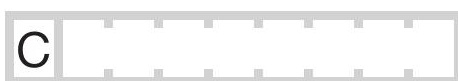

Name of Employer
Self Employed
Receipt For: 2012
X Primary
Other (specify)

\section{Occupation}

Musician

Transaction ID : AFEED4AF2A59340DE98C

Date of Receipt

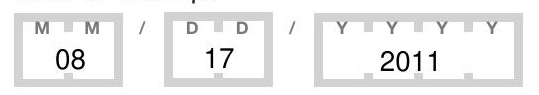

Amount of Each Receipt this Period

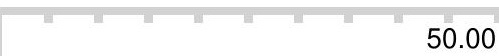

50.00

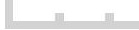

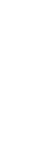

Transaction ID : A6562FF2BEB91411FA75

Date of Receipt

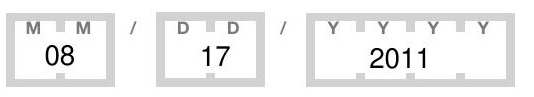

Amount of Each Receipt this Period

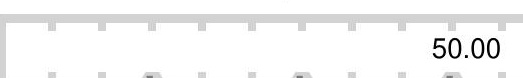

Election Cycle-to-Date

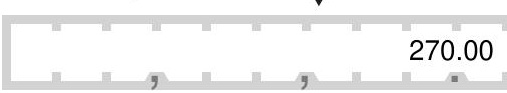

C. Full Name (Last, First, Middle Initial)

Maryanne Metcalfe

Mailing Address 1610 Wood Pointe Ln Apt 1

\begin{tabular}{lcc}
\hline City & State & Zip Code \\
Midland & MI & $48642-3380$
\end{tabular}

FEC ID number of contributing

federal political committee.

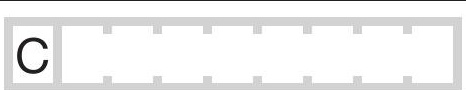

Name of Employer
None
Receipt For: 2012
Х Primary $\quad \square$ General
Other (specify)

Occupation

Retired

Election Cycle-to-Date

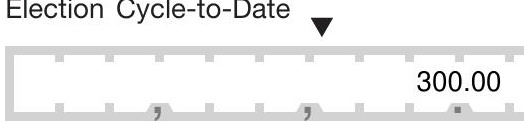

Subtotal Of Receipts This Page (optional)

150.00

Amount of Each Receipt this Period
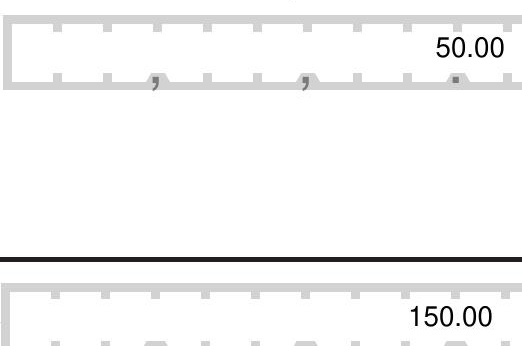

Total This Period (last page this line number only)

Transaction ID : AFB872C66D65642DC97A Date of Receipt

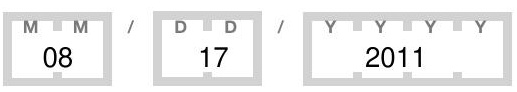

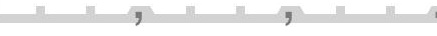
L

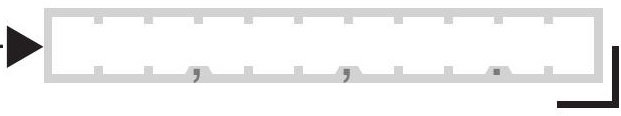


SCHEDULE A-P ITEMIZED RECEIPTS
Use separate schedule(s) for each category of the Detailed Summary Page
FOR LINE NUMBER: (check only one)

\begin{tabular}{|c|c|c|c|c|c|}
\hline & & & & & \\
\hline 16 & $\begin{array}{ll}X & 17 a \\
\end{array}$ & $17 \mathrm{~b}$ & $17 c$ & $17 d$ & 18 \\
\hline $19 a$ & $19 b$ & $20 \mathrm{a}$ & $20 \mathrm{~b}$ & $20 c$ & 21 \\
\hline
\end{tabular}

Any information copied from such Reports and Statements may not be sold or used by any person for the purpose of soliciting contributions or for commercial purposes, other than using the name and address of any political committee to solicit contributions from such committee.

NAME OF COMMITTEE (In Full)

\section{Friends of Herman Cain}

A. Full Name (Last, First, Middle Initial)

\section{Leslie Olson}

Mailing Address 24218 SE 42 PI

\begin{tabular}{lcc}
\hline City & State & Zip Code \\
Issaquah & WA & $98029-7516$ \\
\hline
\end{tabular}

FEC ID number of contributing federal political committee.

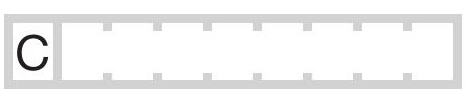

Name of Employer
LifeCenter NW
Receipt For: 2012
X Primary
$\quad$ Other (specify) General

Occupation Surgical Organ Recovery Specialist Election Cycle-to-Date

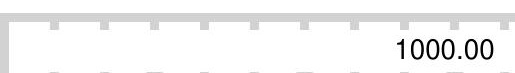

B. Full Name (Last, First, Middle Initial)

Robert Jones

Mailing Address 5600 Trail Blvd Ste 5

\begin{tabular}{lcc}
\hline City & State & Zip Code \\
Naples & FL & $34108-2860$
\end{tabular}

FEC ID number of contributing

federal political committee.

C

Name of Employer
Information Requested
Receipt For: 2012
X Primary
Other (specify)

\section{Occupation}

Information Requested

Election Cycle-to-Date

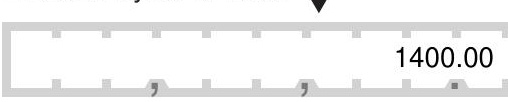

Transaction ID : A366A4427953B40B78F8

Date of Receipt

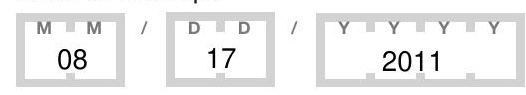

Amount of Each Receipt this Period

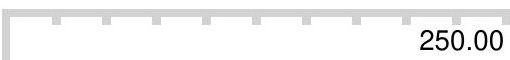

250.00

C. Full Name (Last, First, Middle Initial)

Brent Barby

Mailing Address Rt. 2 Box 94

\begin{tabular}{lcc}
\hline City & State & Zip Code \\
Beaver & OK & $73932-9662$ \\
\hline
\end{tabular}

FEC ID number of contributing federal political committee.

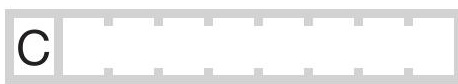

$\begin{aligned} & \text { Name of Employer } \\ & \text { self }\end{aligned}$
Receipt For: 2012
X Primary $\quad \square$ General
Other (specify)

\section{Occupation}

Rancher

Election Cycle-to-Date

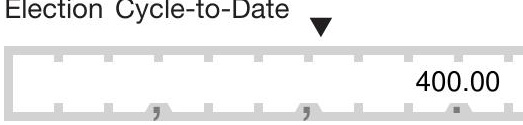

Transaction ID : A2FCC02136B3643819D6

Date of Receipt

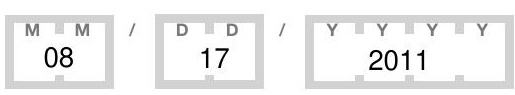

Amount of Each Receipt this Period

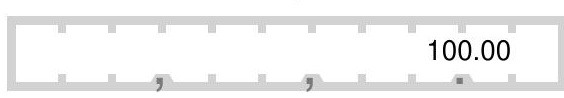

Transaction ID : A93D7B0A69E5A430E8D3 Date of Receipt

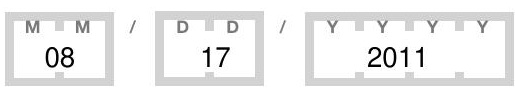

Amount of Each Receipt this Period

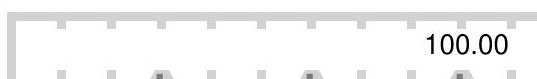

\section{Subtotal Of Receipts This Page (optional)}

Total This Period (last page this line number only) 
SCHEDULE A-P ITEMIZED RECEIPTS
Use separate schedule(s) for each category of the Detailed Summary Page
FOR LINE NUMBER: (check only one)

PAGE 332 / 1572

\begin{tabular}{|c|c|c|c|c|c|c|}
\hline & & & & & & \\
\hline 16 & $\lambda$ & $17 \mathrm{a}$ & $17 \mathrm{~b}$ & $17 \mathrm{c}$ & $-17 d$ & -18 \\
\hline $19 a$ & & $19 b$ & $20 a$ & $20 \mathrm{~b}$ & $20 \mathrm{c}$ & 21 \\
\hline
\end{tabular}

Any information copied from such Reports and Statements may not be sold or used by any person for the purpose of soliciting contributions or for commercial purposes, other than using the name and address of any political committee to solicit contributions from such committee.

NAME OF COMMITTEE (In Full)

\section{Friends of Herman Cain}

A. Full Name (Last, First, Middle Initial) Joseph Kassler

Mailing Address 4810 Smokey Rd

\begin{tabular}{lcc}
\hline City & State & Zip Code \\
Newnan & GA & $30263-4941$ \\
\hline
\end{tabular}

FEC ID number of contributing federal political committee.

Name of Employer
Level 5
Receipt For: 2012
X Primary $\quad$ General
Other (specify)

B. Full Name (Last, First, Middle Initial)

Nathan Moore

Mailing Address 1513 ocean breeze Ln

\begin{tabular}{lcc}
\hline City & State & Zip Code \\
Gulf Breeze & FL & $32563-9222$ \\
\hline
\end{tabular}

FEC ID number of contributing

federal political committee.

Name of Employer
self
Receipt For: 2012
X Primary
Other (specify)

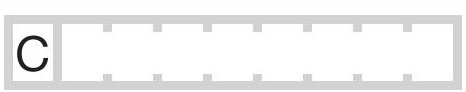

Occupation

Election Cycle-to-Date

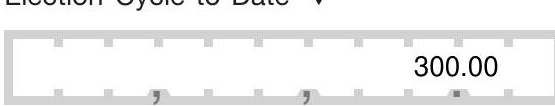

Own a Business

C
Occupation

Carpenter

Election Cycle-to-Date

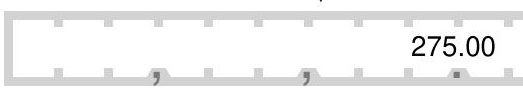

Transaction ID : A0AD527BD1CD7418581F

Date of Receipt

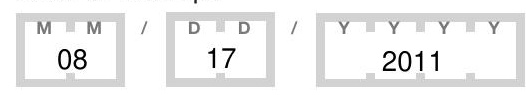

Amount of Each Receipt this Period

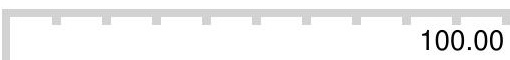

100.00

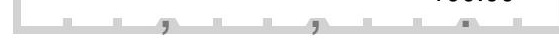

Transaction ID : A3EBE70261CE64318883

Date of Receipt

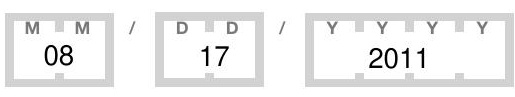

Amount of Each Receipt this Period

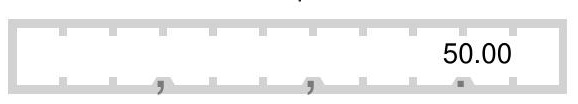

Transaction ID : A27F4A3ACB6D14F10852 Date of Receipt

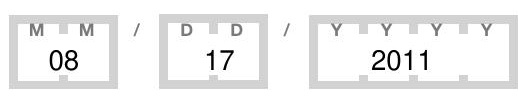

Amount of Each Receipt this Period

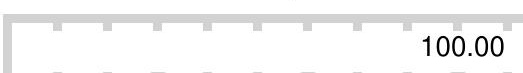

Training Specialist

Election Cycle-to-Date

1300.00
Subtotal Of Receipts This Page (optional).

250.00

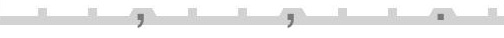

Total This Period (last page this line number only)

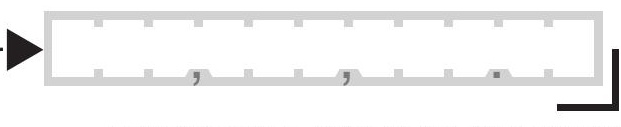

FEC Schedule A-P (Form 3P) (Rev. 03/2011) 
SCHEDULE A-P ITEMIZED RECEIPTS
Use separate schedule(s) for each category of the Detailed Summary Page
FOR LINE NUMBER: (check only one)

\begin{tabular}{|c|c|c|c|c|c|}
\hline & & & & & \\
\hline 16 & $\begin{array}{ll}X & 17 a \\
\end{array}$ & $17 \mathrm{~b}$ & $17 c$ & $17 d$ & 18 \\
\hline $19 a$ & $19 b$ & $20 \mathrm{a}$ & $20 \mathrm{~b}$ & $20 c$ & 21 \\
\hline
\end{tabular}

Any information copied from such Reports and Statements may not be sold or used by any person for the purpose of soliciting contributions or for commercial purposes, other than using the name and address of any political committee to solicit contributions from such committee.

NAME OF COMMITTEE (In Full)

\section{Friends of Herman Cain}

A. Full Name (Last, First, Middle Initial)

Frank Smith

Mailing Address Po box 70971

\begin{tabular}{lcc}
\hline City & State & Zip Code \\
Salt Lake City & UT & $84170-0971$
\end{tabular}

FEC ID number of contributing federal political committee.

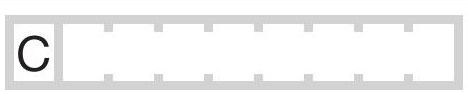

Name of Employer
Pride Transport
Receipt For: 2012
X Primary
Other (specify) General

Occupation truck driver

Election Cycle-to-Date

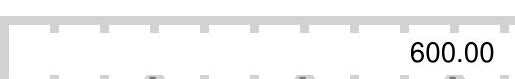

B. Full Name (Last, First, Middle Initial)

$\mathrm{H}$ Harris

Mailing Address 2551 Crestview Dr

\begin{tabular}{lcc}
\hline City & State & Zip Code \\
Newport Beach & CA & $92663-5624$
\end{tabular}

FEC ID number of contributing

federal political committee.

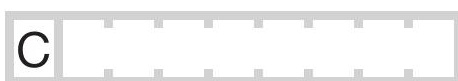

Name of Employer
Better Beverages
Receipt For: 2012
X Primary
$\square$ Other (specify) General

\section{Occupation}

Sales

Election Cycle-to-Date

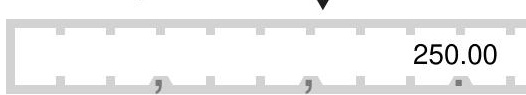

Transaction ID : A8BD9FEB45F174256A6C

Date of Receipt

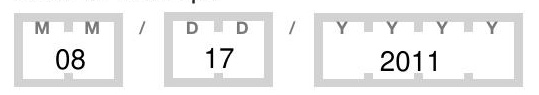

Amount of Each Receipt this Period

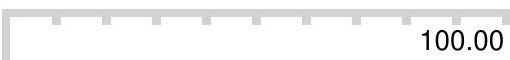

C. Full Name (Last, First, Middle Initial)

richard hughes

Mailing Address 808 bayshore dr.

\begin{tabular}{l|ll}
\hline $\begin{array}{l}\text { City } \\
\text { Miramar Beach }\end{array}$ & $\begin{array}{c}\text { State } \\
\text { FL }\end{array}$ & $\begin{array}{c}\text { Zip Code } \\
32550-3927\end{array}$ \\
\hline $\begin{array}{l}\text { FEC ID number of contributing } \\
\text { federal political committee. }\end{array}$ & C \\
\hline $\begin{array}{l}\text { Name of Employer } \\
\text { Richard J. Hughes MD PA }\end{array}$ & $\begin{array}{l}\text { Occupation } \\
\text { Physician }\end{array}$ \\
\hline $\begin{array}{l}\text { Receipt For: } 2012 \\
\text { Xrimary } \\
\text { Other (specify) }\end{array}$ & Election Cycle-to-Date & \\
\hline
\end{tabular}

Transaction ID : A03C45EE89D944CA7BB6 Date of Receipt

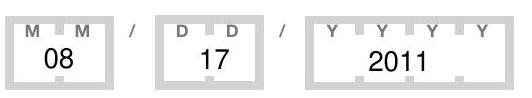

Amount of Each Receipt this Period

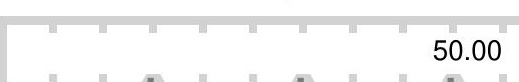

Amount of Each Receipt this Period

Transaction ID : AFC252E924492490DA5E

Date of Receipt
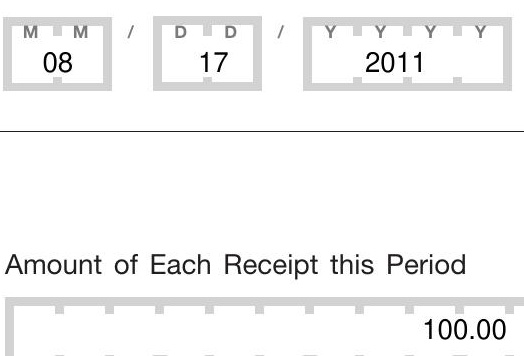

Subtotal Of Receipts This Page (optional)

Total This Period (last page this line number only) 
SCHEDULE A-P ITEMIZED RECEIPTS
Use separate schedule(s) for each category of the Detailed Summary Page
FOR LINE NUMBER: (check only one)

PAGE 334 / 1572

\begin{tabular}{|c|c|c|c|c|c|}
\hline & & & & & \\
\hline 16 & $\begin{array}{l}\mathbf{X} \\
17 a\end{array}$ & $17 b$ & $17 c$ & $17 d$ & 18 \\
\hline $19 a$ & $19 \mathrm{~b}$ & $20 \mathrm{a}$ & $20 \mathrm{~b}$ & $20 \mathrm{c}$ & 21 \\
\hline
\end{tabular}

Any information copied from such Reports and Statements may not be sold or used by any person for the purpose of soliciting contributions or for commercial purposes, other than using the name and address of any political committee to solicit contributions from such committee.

NAME OF COMMITTEE (In Full)

\section{Friends of Herman Cain}

A. Full Name (Last, First, Middle Initial)

Matthew Phillips

Mailing Address 776 Streamview Lane

\begin{tabular}{lcc}
\hline City & State & Zip Code \\
Vineland & NJ & $08360-2479$
\end{tabular}

FEC ID number of contributing federal political committee.

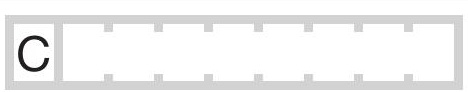

Name of Employer

Public Service Enterpise Group

Receipt For: 2012

X Primary $\square$ General Other (specify)

Occupation

Engineer

Election Cycle-to-Date

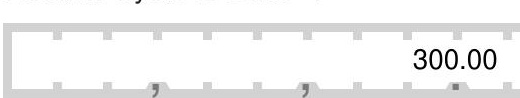

B. Full Name (Last, First, Middle Initial)

Stephen Northington

Mailing Address 1915 Landfall Pass NW

\begin{tabular}{lcc}
\hline City & State & Zip Code \\
Kennesaw & GA & $30152-7736$ \\
\hline
\end{tabular}

FEC ID number of contributing

federal political committee.

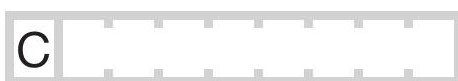

Name of Employer

Group Insurance Solutions LLC.

Occupation

Receipt For: 2012

Х $\begin{aligned} & \text { Primary } \\ & \text { Other (specify) }\end{aligned}$

Sales Director

Election Cycle-to-Date

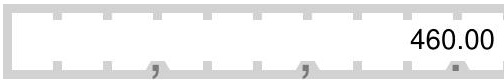

C. Full Name (Last, First, Middle Initial)

Harpel Keller

Mailing Address 13221 SW 68th Parkway

\begin{tabular}{lcc}
\hline City & State & Zip Code \\
Portland & OR & $97223-8328$
\end{tabular}

FEC ID number of contributing

federal political committee.

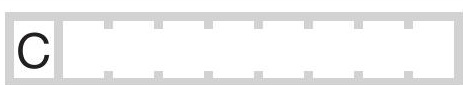

Name of Employer

Total Assets Management

Receipt For: 2012

Х $\begin{aligned} & \text { Primary } \square \text { General } \\ & \text { Other (specify) }\end{aligned}$

Occupation

investment advisor

Election Cycle-to-Date

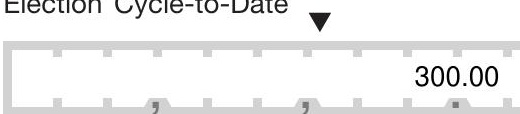

Transaction ID : A5BB42A99A0D34339943

Date of Receipt

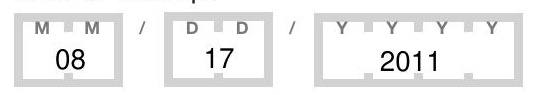

Amount of Each Receipt this Period

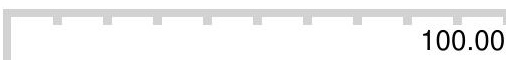

100.00
Amount of Each Receipt this Period

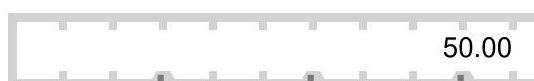

Transaction ID : A442C7EACC56C47C3AB5 Date of Receipt

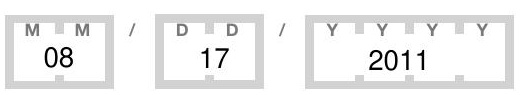

Transaction ID : AC85CAFAF6E104251B4D Date of Receipt

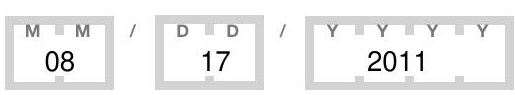

Amount of Each Receipt this Period

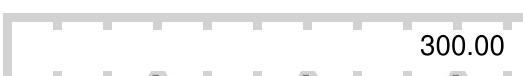

\section{Subtotal Of Receipts This Page (optional)}

Total This Period (last page this line number only) 
SCHEDULE A-P ITEMIZED RECEIPTS
Use separate schedule(s) for each category of the Detailed Summary Page
FOR LINE NUMBER: (check only one)

PAGE $335 / 1572$

\begin{tabular}{|c|c|c|c|c|c|}
\hline & & & & & \\
\hline 16 & $\begin{array}{l}\mathbf{X} \\
17 a\end{array}$ & $17 b$ & $17 c$ & $17 d$ & 18 \\
\hline $19 a$ & $19 \mathrm{~b}$ & $20 \mathrm{a}$ & $20 \mathrm{~b}$ & $20 \mathrm{c}$ & 21 \\
\hline
\end{tabular}

Any information copied from such Reports and Statements may not be sold or used by any person for the purpose of soliciting contributions or for commercial purposes, other than using the name and address of any political committee to solicit contributions from such committee.

NAME OF COMMITTEE (In Full)

\section{Friends of Herman Cain}

A. Full Name (Last, First, Middle Initial)

Christopher Gregerson

Mailing Address 1116 S. Esplanade

\begin{tabular}{lcc}
\hline City & State & Zip Code \\
Leavenworth & KS & $66048-3522$
\end{tabular}

FEC ID number of contributing federal political committee.

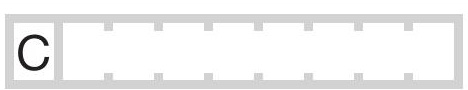

Name of Employer
Booz Allen Hamilton Inc
Receipt For: 2012
X Primary $\quad \square$ General
Other (specify)

Occupation

Consultant

Election Cycle-to-Date

400.00
Transaction ID : A1E3DB8FE3A3744019EC

Date of Receipt

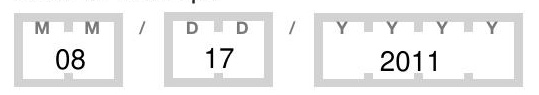

Amount of Each Receipt this Period

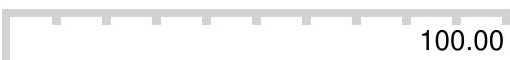

B. Full Name (Last, First, Middle Initial)

Mr Ray P Oden Jr

Mailing Address 702 Thora Blvd

\begin{tabular}{lcc}
\hline City & State & Zip Code \\
Shreveport & LA & $71106-1824$
\end{tabular}

FEC ID number of contributing

federal political committee.

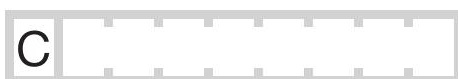

Name of Employer
Retired
Receipt For: 2012
\begin{tabular}{l}
$\square$ Primary \\
\hline Other (specify)
\end{tabular}

\section{Occupation}

Retired

Election Cycle-to-Date

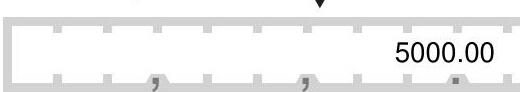

C. Full Name (Last, First, Middle Initial)

Alan Segal

Mailing Address 9700 Hillside Dr

\begin{tabular}{lcc}
\hline City & State & Zip Code \\
Roswell & GA & $30076-2827$
\end{tabular}

FEC ID number of contributing federal political committee.

C

Name of Employer
Advanced Ent.
Receipt For: 2012
X Primary
Other (specify) General

Occupation

Audiologist

Election Cycle-to-Date

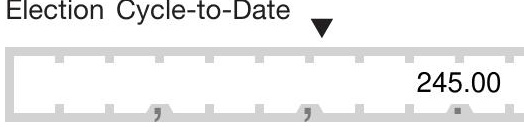

Transaction ID : AACC2B0158F8D408781A

Date of Receipt

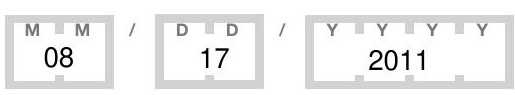

Amount of Each Receipt this Period

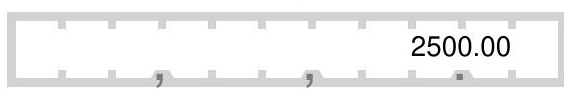

Transaction ID : AFBCEF177976B4F0C92E Date of Receipt

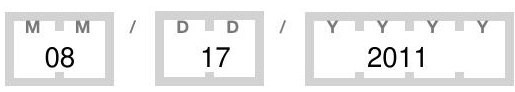

Amount of Each Receipt this Period

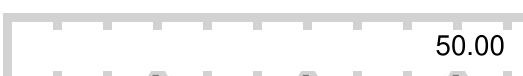

50.00

\section{Subtotal Of Receipts This Page (optional)}

Total This Period (last page this line number only) 
SCHEDULE A-P ITEMIZED RECEIPTS
Use separate schedule(s) for each category of the Detailed Summary Page
FOR LINE NUMBER: (check only one)

PAGE $336 / 1572$

\begin{tabular}{|c|c|c|c|c|c|}
\hline & & & & & \\
\hline 16 & $\begin{array}{l}\mathbf{X} \\
17 a\end{array}$ & $17 b$ & $17 c$ & $17 d$ & 18 \\
\hline $19 a$ & $19 \mathrm{~b}$ & $20 \mathrm{a}$ & $20 \mathrm{~b}$ & $20 \mathrm{c}$ & 21 \\
\hline
\end{tabular}

Any information copied from such Reports and Statements may not be sold or used by any person for the purpose of soliciting contributions or for commercial purposes, other than using the name and address of any political committee to solicit contributions from such committee.

NAME OF COMMITTEE (In Full)

\section{Friends of Herman Cain}

A. Full Name (Last, First, Middle Initial)

Thomas Kershaw

Mailing Address 84 Beacon St.

\begin{tabular}{lcc}
\hline City & State & Zip Code \\
Boston & MA & $02108-3421$
\end{tabular}

FEC ID number of contributing federal political committee.

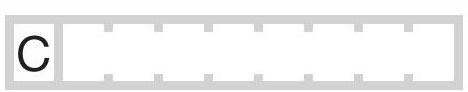

\begin{tabular}{l} 
Name of Employer \\
Hampshire House Corp. \\
Receipt For: 2012 \\
$\square$ Primary \\
\hline Other (specify)
\end{tabular}

Occupation

Owner

Election Cycle-to-Date

3500.00

B. Full Name (Last, First, Middle Initial)

Mr. Thomas $\mathrm{H}$. Jones

Mailing Address 2301 Knollwood Dr.

\begin{tabular}{lcc}
\hline City & State & Zip Code \\
Leesburg & FL & $34748-9561$ \\
\hline
\end{tabular}

FEC ID number of contributing

federal political committee.

C

Name of Employer
Leesburg-Ocala Heart
Receipt For: 2012
X Primary
Other (specify)

Occupation

Physician Assistant

Election Cycle-to-Date

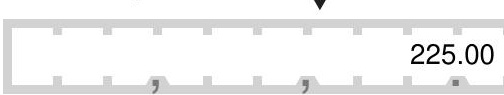

C. Full Name (Last, First, Middle Initial)

Toby Nelson

Mailing Address 811 2nd Street

\begin{tabular}{lcc}
\hline City & State & Zip Code \\
Milford & NE & $68405-9609$
\end{tabular}

FEC ID number of contributing federal political committee.

C

Name of Employer
Nelson Contracting LLC
Receipt For: 2012
X Primary $\quad \square$ General
Other (specify)

\section{Occupation}

contractor

Election Cycle-to-Date

Transaction ID : A94EBA744FF6D420E977

Date of Receipt

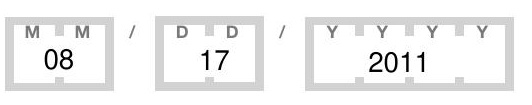

Amount of Each Receipt this Period

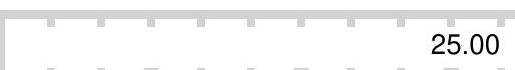

Transaction ID : A6153B429F3C74FD8B3D Date of Receipt

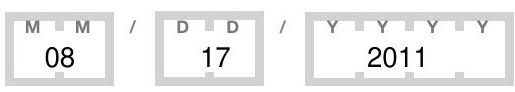

Amount of Each Receipt this Period

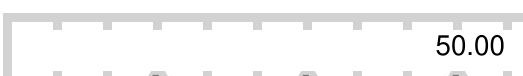

650.00

\section{Subtotal Of Receipts This Page (optional)}

Total This Period (last page this line number only) 
SCHEDULE A-P ITEMIZED RECEIPTS
Use separate schedule(s) for each category of the Detailed Summary Page
FOR LINE NUMBER: (check only one)

PAGE $337 / 1572$

\begin{tabular}{|c|c|c|c|c|c|}
\hline & & & & & \\
\hline 16 & $\begin{array}{l}\mathbf{X} \\
17 a\end{array}$ & $17 b$ & $17 c$ & $17 d$ & 18 \\
\hline $19 a$ & $19 \mathrm{~b}$ & $20 \mathrm{a}$ & $20 \mathrm{~b}$ & $20 \mathrm{c}$ & 21 \\
\hline
\end{tabular}

Any information copied from such Reports and Statements may not be sold or used by any person for the purpose of soliciting contributions or for commercial purposes, other than using the name and address of any political committee to solicit contributions from such committee.

NAME OF COMMITTEE (In Full)

\section{Friends of Herman Cain}

A. Full Name (Last, First, Middle Initial)

Nancy McKee

Mailing Address 339 Springhill Road

\begin{tabular}{lcc}
\hline City & State & Zip Code \\
Huntsville & AL & $35806-1735$
\end{tabular}

FEC ID number of contributing federal political committee.

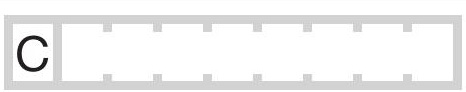

Name of Employer

The Aussie Pouch Company Inc.

Occupation

BUSINESS OWNER

Receipt For: 2012

X Primary $\square$ General Other (specify)

Election Cycle-to-Date

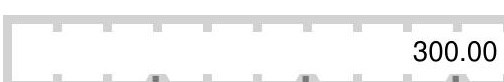

B. Full Name (Last, First, Middle Initial)

Ronald Coffey

Mailing Address 155 Millcreek Ln

\begin{tabular}{lcc}
\hline City & State & Zip Code \\
Chagrin Falls & OH & $44022-1266$ \\
\hline
\end{tabular}

FEC ID number of contributing

federal political committee.

C

Name of Employer
Information Requested
Receipt For: 2012
Primary
Other (specify)

Occupation

Information Requested

Election Cycle-to-Date

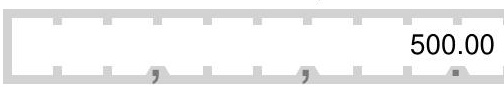

Transaction ID : AC3AAAD6B9A854655856

Date of Receipt

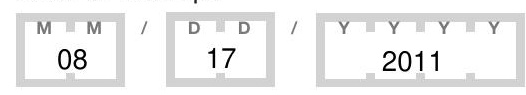

Amount of Each Receipt this Period

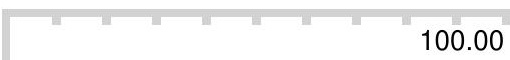

100.00

C. Full Name (Last, First, Middle Initial)

Randi Helgeson

Mailing Address 16485 Ellerdale Lane

\begin{tabular}{lcc}
\hline City & State & Zip Code \\
Eden Prairie & MN & $55346-1431$
\end{tabular}

FEC ID number of contributing

federal political committee.

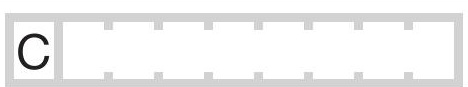

Name of Employer
Retired
Receipt For: 2012
X Primary $\quad \square$ General
Other (specify)

\section{Occupation}

CPA

Election Cycle-to-Date

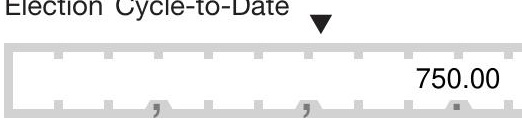

Transaction ID : A6D11417FEEEB4420ABC Date of Receipt

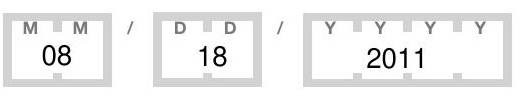

Amount of Each Receipt this Period

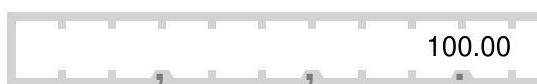

Transaction ID : A055C8F4C03604B919EC

Date of Receipt

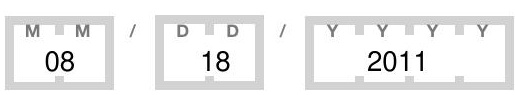

Amount of Each Receipt this Period

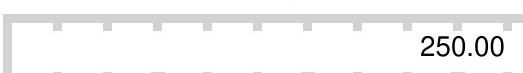

\section{Subtotal Of Receipts This Page (optional)}

Total This Period (last page this line number only) 


\section{SCHEDULE A-P} ITEMIZED RECEIPTS
Use separate schedule(s)

for each category of the

Detailed Summary Page
FOR LINE NUMBER: (check only one)

PAGE $338 / 1572$

\begin{tabular}{|c|c|c|c|c|c|}
\hline & & & & & \\
\hline 16 & X $17 a$ & $17 b$ & $17 c$ & $17 d$ & 18 \\
\hline $19 a$ & $19 b$ & $20 \mathrm{a}$ & $20 \mathrm{~b}$ & $20 \mathrm{c}$ & 21 \\
\hline
\end{tabular}

Any information copied from such Reports and Statements may not be sold or used by any person for the purpose of soliciting contributions or for commercial purposes, other than using the name and address of any political committee to solicit contributions from such committee.

NAME OF COMMITTEE (In Full)

Friends of Herman Cain

A. Full Name (Last, First, Middle Initial) bruce mcclaren

Mailing Address suite 26201 e ogden ave

\begin{tabular}{lcc}
\hline City & State & Zip Code \\
Hinsdale & IL & $60521-3651$
\end{tabular}

FEC ID number of contributing federal political committee.

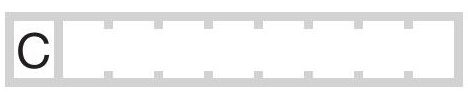

Name of Employer
Information Requested
Receipt For: 2012
X Primary $\quad \square$ General
Other (specify)

Occupation Information Requested

Election Cycle-to-Date

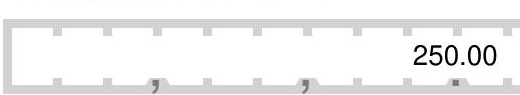

B. Full Name (Last, First, Middle Initial) John Vander Haag

Mailing Address 408 Sunrise Ave PO Box 550

\begin{tabular}{lcc}
\hline City & State & Zip Code \\
Sanborn & IA & $51248-0550$ \\
\hline
\end{tabular}

FEC ID number of contributing

federal political committee.

C

Name of Employer
Information Requested
Receipt For: 2012
Primary
Other (specify)

Occupation

Information Requested

Election Cycle-to-Date

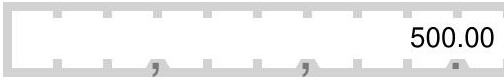

C. Full Name (Last, First, Middle Initial)

Karen Miller

Mailing Address 70 Lambets Way

\begin{tabular}{lcc}
\hline City & State & Zip Code \\
Alpharetta & GA & $30005-3903$
\end{tabular}

FEC ID number of contributing federal political committee.

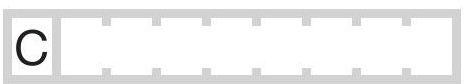

Name of Employer

Occupation

SunTrust Bank

Bank Employee

Receipt For: 2012

Х $\begin{aligned} & \text { Primary } \square \text { General } \\ & \text { Other (specify) }\end{aligned}$

Election Cycle-to-Date

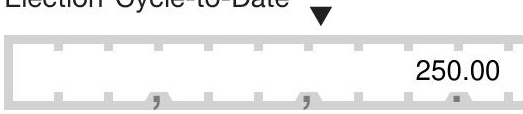

Transaction ID : AB116DFD529994732BCF

Date of Receipt

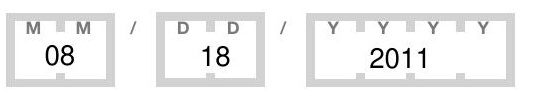

Amount of Each Receipt this Period

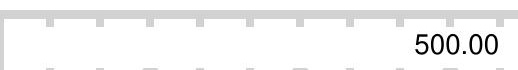

Transaction ID : AA5F3228C0E4E4045B67

Date of Receipt

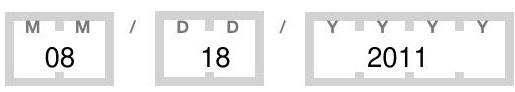

Amount of Each Receipt this Period

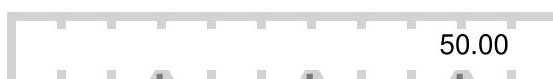

800.00

Subtotal Of Receipts This Page (optional)

Total This Period (last page this line number only) 
SCHEDULE A-P ITEMIZED RECEIPTS
Use separate schedule(s) for each category of the Detailed Summary Page
FOR LINE NUMBER: (check only one)

PAGE $339 / 1572$

\begin{tabular}{|c|c|c|c|c|c|}
\hline & & & & & \\
\hline 16 & $\begin{array}{l}\mathbf{X} \\
17 a\end{array}$ & $17 b$ & $17 c$ & $17 d$ & 18 \\
\hline $19 a$ & $19 \mathrm{~b}$ & $20 \mathrm{a}$ & $20 \mathrm{~b}$ & $20 \mathrm{c}$ & 21 \\
\hline
\end{tabular}

Any information copied from such Reports and Statements may not be sold or used by any person for the purpose of soliciting contributions or for commercial purposes, other than using the name and address of any political committee to solicit contributions from such committee.

NAME OF COMMITTEE (In Full)

Friends of Herman Cain

A. Full Name (Last, First, Middle Initial)

Richard Knoch

Mailing Address P.O. Box 2041

\begin{tabular}{lcc}
\hline City & State & Zip Code \\
Lake Ozark & MO & $65049-2041$
\end{tabular}

FEC ID number of contributing federal political committee.

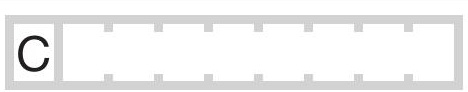

Name of Employer
CompuLink Ltd.
Receipt For: 2012
X Primary
$\square$ Other (specify)

Occupation

Software Developer

Election Cycle-to-Date

275.00

B. Full Name (Last, First, Middle Initial)

Susan Walter

Mailing Address P.O. Box 690

\begin{tabular}{lcc}
\hline City & State & Zip Code \\
Sautee Nacoochee & GA & $30571-0690$
\end{tabular}

FEC ID number of contributing

federal political committee.

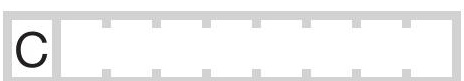

Name of Employer
None
Receipt For: 2012
X Primary
Other (specify)

Occupation

Retired

Election Cycle-to-Date

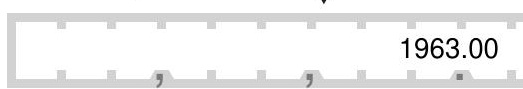

C. Full Name (Last, First, Middle Initial)

Steven Bane

Mailing Address 33322 N 71st Street

\begin{tabular}{lcc}
\hline City & State & Zip Code \\
Scottsdale & AZ & $85266-7194$
\end{tabular}

FEC ID number of contributing federal political committee.

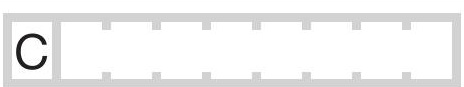

Name of Employer

Bane O'Leary Financial Group

Receipt For: 2012

Х $\begin{aligned} & \text { Primary } \square \text { General } \\ & \text { Other (specify) }\end{aligned}$

Occupation

Financial Advisor

Election Cycle-to-Date

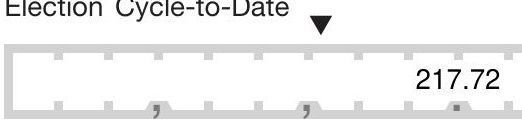

Transaction ID : A76350834AD0D497AABC

Date of Receipt

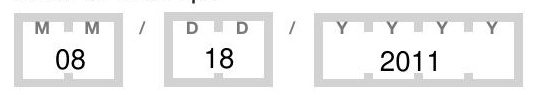

Amount of Each Receipt this Period

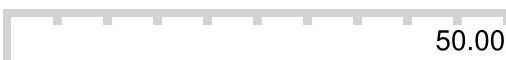

50.00

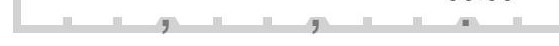

Transaction ID : A2228B3E79F9740D2BC2

Date of Receipt

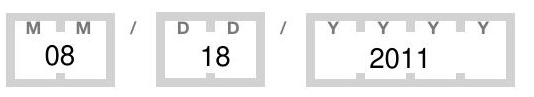

Amount of Each Receipt this Period

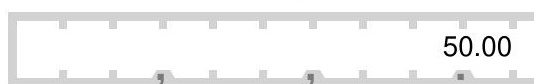

Transaction ID : AD88874C56C3E4B2C9D4 Date of Receipt

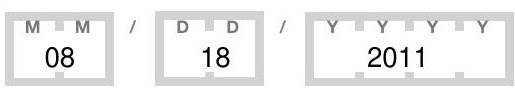

Amount of Each Receipt this Period

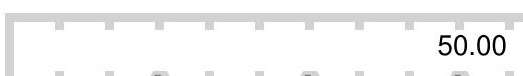

50.00

Subtotal Of Receipts This Page (optional).

Total This Period (last page this line number only) 
SCHEDULE A-P ITEMIZED RECEIPTS
Use separate schedule(s) for each category of the Detailed Summary Page
FOR LINE NUMBER: (check only one)

PAGE $340 / 1572$

\begin{tabular}{|c|c|c|c|c|c|}
\hline & & & & & \\
\hline 16 & $\begin{array}{l}\mathbf{X} \\
17 a\end{array}$ & $17 b$ & $17 c$ & $17 d$ & 18 \\
\hline $19 a$ & $19 \mathrm{~b}$ & $20 \mathrm{a}$ & $20 \mathrm{~b}$ & $20 \mathrm{c}$ & 21 \\
\hline
\end{tabular}

Any information copied from such Reports and Statements may not be sold or used by any person for the purpose of soliciting contributions or for commercial purposes, other than using the name and address of any political committee to solicit contributions from such committee.

NAME OF COMMITTEE (In Full)

\section{Friends of Herman Cain}

A. Full Name (Last, First, Middle Initial)

Leonard Magers

Mailing Address 2053 Isla de Palma Circle

\begin{tabular}{lcc}
\hline City & State & Zip Code \\
Naples & FL & $34119-3405$
\end{tabular}

FEC ID number of contributing federal political committee.

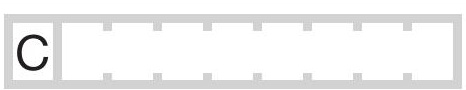

Name of Employer
Naples Community Hospital
Receipt For: 2012
X Primary $\quad \square$ General
Other (specify)

Occupation

Pharmacist

Election Cycle-to-Date

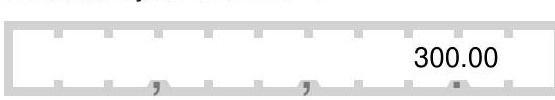

B. Full Name (Last, First, Middle Initial)

Robert Gover

Mailing Address 3837 E Fernwood Ave

\begin{tabular}{lcc}
\hline City & State & Zip Code \\
Orange & CA & $92869-5317$
\end{tabular}

FEC ID number of contributing

federal political committee.

C

Name of Employer
None
Receipt For: 2012
X Primary
Other (specify)

\section{Occupation}

Retired

Election Cycle-to-Date

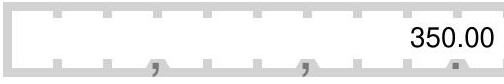

Transaction ID : AC3DC2E94DF5A4B6CB59

Date of Receipt

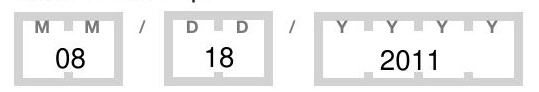

Amount of Each Receipt this Period

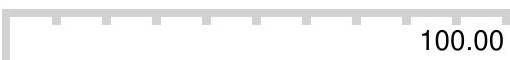

100.00

C. Full Name (Last, First, Middle Initial)

Robert Cooper

Mailing Address 4472 Sandleworth Circle

\begin{tabular}{lcc}
\hline City & State & Zip Code \\
Orlando & FL & 32826 \\
\hline
\end{tabular}

FEC ID number of contributing

federal political committee.

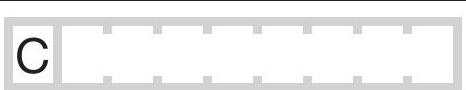

Name of Employer
Team Health
Receipt For: 2012
X Primary $\quad \square$ General
Other (specify)

Occupation

Physician

Election Cycle-to-Date

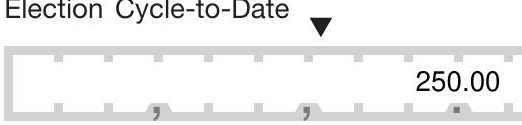

Transaction ID : AA9DF560878D24B24A62

Date of Receipt

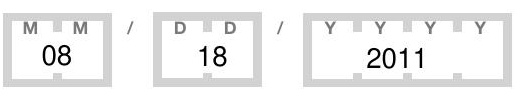

Amount of Each Receipt this Period

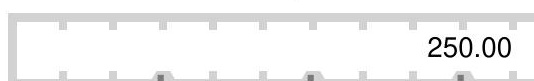

Transaction ID : A06EC3E4818944053A32

Date of Receipt

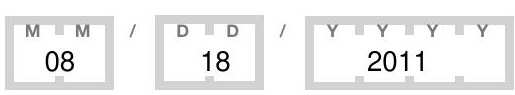

Amount of Each Receipt this Period

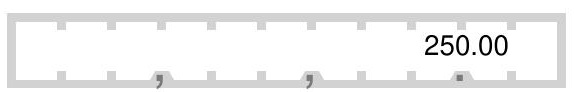

\section{Subtotal Of Receipts This Page (optional)}

600.00

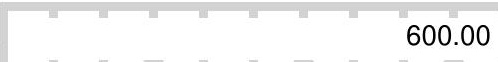

‥

Total This Period (last page this line number only)

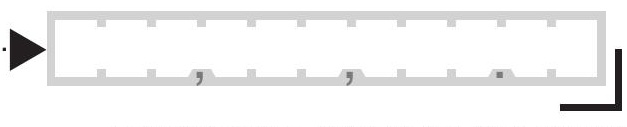

FEC Schedule A-P (Form 3P) (Rev. 03/2011) 
SCHEDULE A-P ITEMIZED RECEIPTS
Use separate schedule(s) for each category of the Detailed Summary Page

FOR LINE NUMBER:
(check only one)

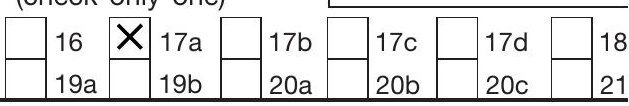

Any information copied from such Reports and Statements may not be sold or used by any person for the purpose of soliciting contributions or for commercial purposes, other than using the name and address of any political committee to solicit contributions from such committee.

NAME OF COMMITTEE (In Full)

\section{Friends of Herman Cain}

A. Full Name (Last, First, Middle Initial) Jan Petersen

Mailing Address 8951 Lake Dr Apt 503

\begin{tabular}{lcc}
\hline City & State & Zip Code \\
Cape Canaveral & FL & $32920-5504$
\end{tabular}

FEC ID number of contributing federal political committee.

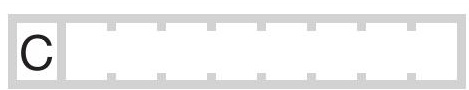

Name of Employer
Information Requested
Receipt For: 2012
X Primary $\quad \square$ General
Other (specify)

Occupation Information Requested Election Cycle-to-Date 500.00

B. Full Name (Last, First, Middle Initial) Stephen Ray

Mailing Address 1611 Cameron Landing Drive

\begin{tabular}{lcc}
\hline City & State & Zip Code \\
Stockbridge & GA & $30281-6863$
\end{tabular}

FEC ID number of contributing

federal political committee.

C

Name of Employer
Delat Air Lines
Receipt For: 2012
X Primary
Other (specify) General

\section{Occupation}

Maintenance Coodinator

Election Cycle-to-Date

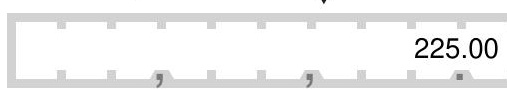

Transaction ID : A29E6423D0C0947D0A2F

Date of Receipt

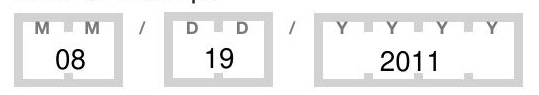

Amount of Each Receipt this Period

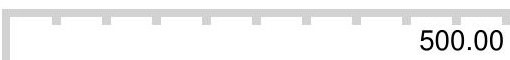

C. Full Name (Last, First, Middle Initial)

Deborah Robinson

Mailing Address 1807 Cool Springs Drive

\begin{tabular}{lcc}
\hline City & State & Zip Code \\
Alexandria & VA & $22308-1631$
\end{tabular}

FEC ID number of contributing federal political committee.

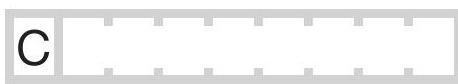

Name of Employer
None
Receipt For: 2012
X Primary $\quad \square$ General
Other (specify)

\section{Occupation}

Homemaker

Election Cycle-to-Date

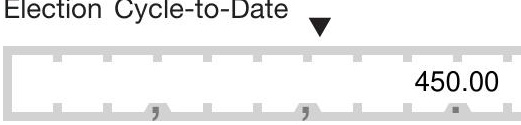

Amount of Each Receipt this Period

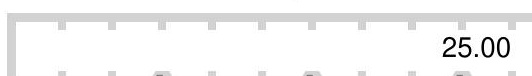

Transaction ID : A3BC90400A1A74740A99

Date of Receipt

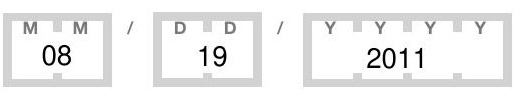

Transaction ID : AC24A80103B544E669D8 Date of Receipt

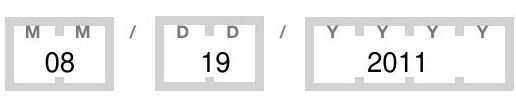

Amount of Each Receipt this Period

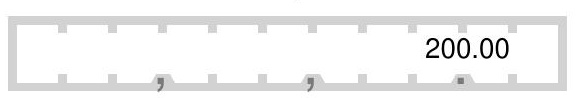

\section{Subtotal Of Receipts This Page (optional)}

Total This Period (last page this line number only) 
SCHEDULE A-P ITEMIZED RECEIPTS
Use separate schedule(s) for each category of the Detailed Summary Page
FOR LINE NUMBER: (check only one)

PAGE 342 / 1572

\begin{tabular}{|c|c|c|c|c|c|}
\hline & & & & & \\
\hline 16 & $\begin{array}{l}\mathbf{X} \\
17 a\end{array}$ & $17 b$ & $17 c$ & $17 d$ & 18 \\
\hline $19 a$ & $19 \mathrm{~b}$ & $20 \mathrm{a}$ & $20 \mathrm{~b}$ & $20 \mathrm{c}$ & 21 \\
\hline
\end{tabular}

Any information copied from such Reports and Statements may not be sold or used by any person for the purpose of soliciting contributions or for commercial purposes, other than using the name and address of any political committee to solicit contributions from such committee.

NAME OF COMMITTEE (In Full)

\section{Friends of Herman Cain}

A. Full Name (Last, First, Middle Initial)

Mr. Thomas A Sweat II

Mailing Address 3080 Dowry Dr

\begin{tabular}{lcc}
\hline City & State & Zip Code \\
Lawrenceville & GA & $30044-2672$
\end{tabular}

FEC ID number of contributing federal political committee.

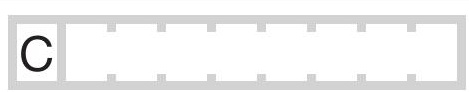

Name of Employer
None
Receipt For: 2012
X Primary $\quad$ General
Other (specify)

Occupation

Retired

Election Cycle-to-Date

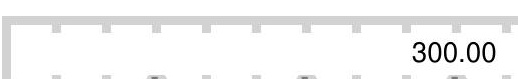

B. Full Name (Last, First, Middle Initial)

Steven Solum

Mailing Address 222 Crystal Springs Road

\begin{tabular}{lcc}
\hline City & State & Zip Code \\
Lexington & SC & $29073-8018$ \\
\hline
\end{tabular}

FEC ID number of contributing

federal political committee.

C

Name of Employer
Information Requested
Receipt For: 2012
X Primary
Other (specify)

\section{Occupation}

Information Requested

Election Cycle-to-Date

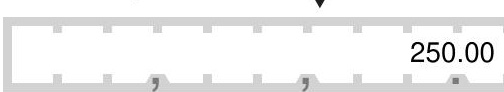

Transaction ID : A423CFBC9E4B54DC5888

Date of Receipt

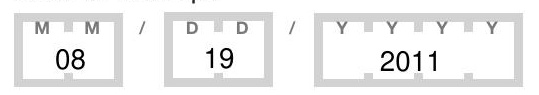

Amount of Each Receipt this Period

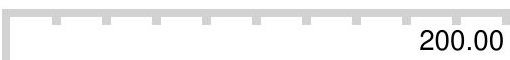

Amount of Each Receipt this Period

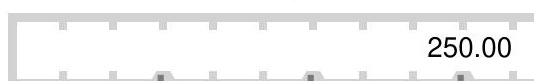

C. Full Name (Last, First, Middle Initial)

Earl Williams

Mailing Address 13505 Peseta Ct

\begin{tabular}{lcc}
\hline City & State & Zip Code \\
Corpus Christi & TX & $78418-6932$
\end{tabular}

FEC ID number of contributing

federal political committee.

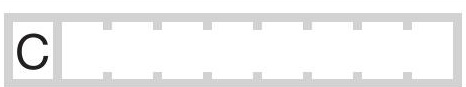

Name of Employer

Retired

Receipt For: 2012

Х $\begin{aligned} & \text { Primary } \\ & \text { Other (specify) }\end{aligned}$

Occupation

Information Requested

Election Cycle-to-Date
Transaction ID : AC51F2CC93D0F43EC99A

Date of Receipt

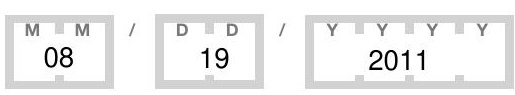

Transaction ID : AB6982E688DE34564B78 Date of Receipt

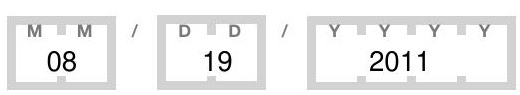

Amount of Each Receipt this Period

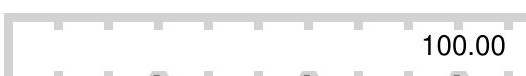

500.00

Subtotal Of Receipts This Page (optional)

550.00

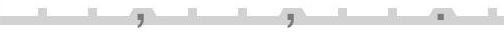

Total This Period (last page this line number only)

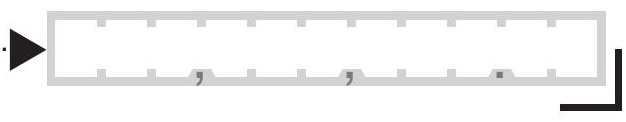

FEC Schedule A-P (Form 3P) (Rev. 03/2011) 
SCHEDULE A-P ITEMIZED RECEIPTS
Use separate schedule(s) for each category of the Detailed Summary Page
FOR LINE NUMBER: (check only one)

PAGE $343 / 1572$

\begin{tabular}{|c|c|c|c|c|c|c|}
\hline & & & & & & \\
\hline 16 & $\lambda$ & $17 \mathrm{a}$ & $17 \mathrm{~b}$ & $17 \mathrm{c}$ & $-17 d$ & -18 \\
\hline $19 a$ & & $19 b$ & $20 a$ & $20 \mathrm{~b}$ & $20 \mathrm{c}$ & 21 \\
\hline
\end{tabular}

Any information copied from such Reports and Statements may not be sold or used by any person for the purpose of soliciting contributions or for commercial purposes, other than using the name and address of any political committee to solicit contributions from such committee.

NAME OF COMMITTEE (In Full)

\section{Friends of Herman Cain}

A. Full Name (Last, First, Middle Initial)

GABRIEL THOMAS

Mailing Address 15056 BEACON RIDGE DR.

\begin{tabular}{lcc}
\hline City & State & Zip Code \\
Seneca & SC & $29678-1300$ \\
\hline
\end{tabular}

FEC ID number of contributing federal political committee.

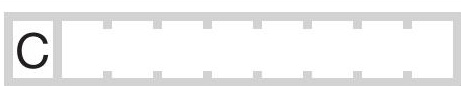

Name of Employer
Information Requested
Receipt For: 2012
X Primary
Other (specify) General

Occupation Information Requested

Election Cycle-to-Date 500.00

B. Full Name (Last, First, Middle Initial)

Douglas Gesso

Mailing Address 402 Blue Bird Dr

\begin{tabular}{lcc}
\hline City & State & Zip Code \\
Grayson & KY & $41143-8177$
\end{tabular}

FEC ID number of contributing

federal political committee.

C

Name of Employer
Unemployed
Receipt For: 2012
X Primary
Other (specify) General

Occupation

Civil Engineer

Election Cycle-to-Date

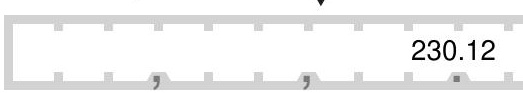

Transaction ID : A107BD9F8382745E8894

Date of Receipt

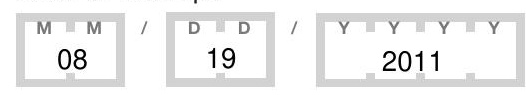

Amount of Each Receipt this Period

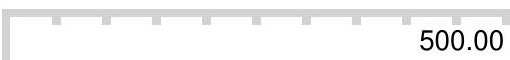

C. Full Name (Last, First, Middle Initial)

Gary Stanford

Mailing Address 387 N. 5th Street

\begin{tabular}{lcc}
\hline City & State & Zip Code \\
Woodburn & OR & $97071-4637$
\end{tabular}

FEC ID number of contributing federal political committee.

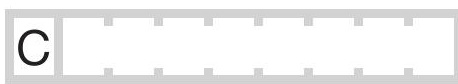

Name of Employer
Self Employed
Receipt For: 2012
X Primary $\quad \square$ General
Other (specify)

Occupation

Physician

Election Cycle-to-Date

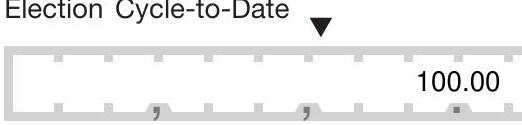

Amount of Each Receipt this Period

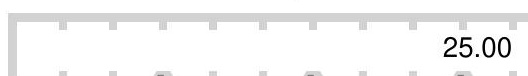

Transaction ID : A44930AEA9F8548C5993

Date of Receipt

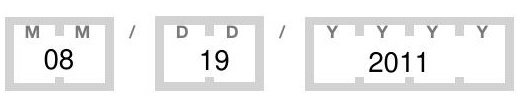

Transaction ID : A145DC1E832904E72933

Date of Receipt

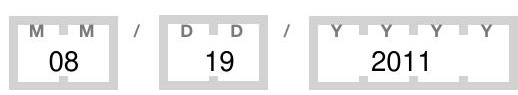

Amount of Each Receipt this Period

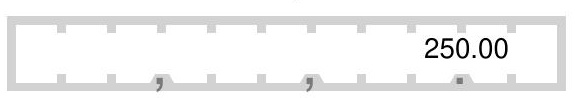

\section{Subtotal Of Receipts This Page (optional)}

Total This Period (last page this line number only)
$-775.00$

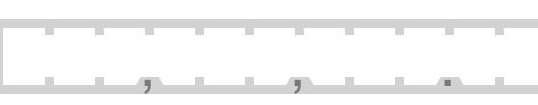

FEC Schedule A-P (Form 3P) (Rev. 03/2011) 
SCHEDULE A-P ITEMIZED RECEIPTS
Use separate schedule(s) for each category of the Detailed Summary Page
FOR LINE NUMBER: (check only one)

PAGE 344 / 1572

\begin{tabular}{|c|c|c|c|c|c|}
\hline & & & & & \\
\hline 16 & $\begin{array}{l}\mathbf{X} \\
17 a\end{array}$ & $17 b$ & $17 c$ & $17 d$ & 18 \\
\hline $19 a$ & $19 \mathrm{~b}$ & $20 \mathrm{a}$ & $20 \mathrm{~b}$ & $20 \mathrm{c}$ & 21 \\
\hline
\end{tabular}

Any information copied from such Reports and Statements may not be sold or used by any person for the purpose of soliciting contributions or for commercial purposes, other than using the name and address of any political committee to solicit contributions from such committee.

NAME OF COMMITTEE (In Full)

Friends of Herman Cain

A. Full Name (Last, First, Middle Initial)

Michael Huntington

Mailing Address P.O.Box 130

\begin{tabular}{lcc}
\hline City & State & Zip Code \\
Duluth & GA & $30096-0003$
\end{tabular}

FEC ID number of contributing federal political committee.

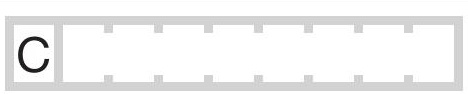

Name of Employer
Information Requested
Receipt For: 2012
X Primary
$\square$ Other (specify)

Occupation

Information Requested

Election Cycle-to-Date

1000.00

B. Full Name (Last, First, Middle Initial)

Brian E Whitehead

Mailing Address 14604 S Oak Ct

\begin{tabular}{lcc}
\hline City & State & Zip Code \\
Glenpool & OK & $74033-3712$ \\
\hline
\end{tabular}

FEC ID number of contributing

federal political committee.

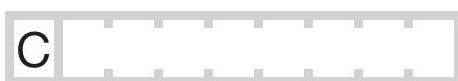

Name of Employer
Campbell Wholesale
Receipt For: 2012
X Primary $\quad$ General
Other (specify)

Occupation

Accountant

Election Cycle-to-Date

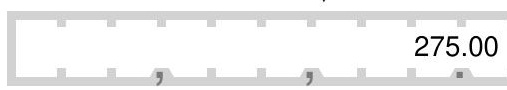

Transaction ID : AC6B3F8D8DD874E53BD3

Date of Receipt

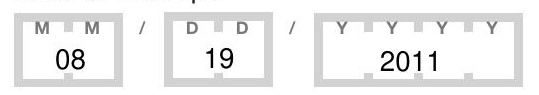

Amount of Each Receipt this Period

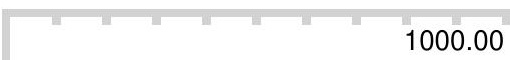

1000.00

C. Full Name (Last, First, Middle Initial)

Fred D Backer Jr

Mailing Address 18 Narry Ln

\begin{tabular}{lcc}
\hline City & State & Zip Code \\
Mount Morris & NY & $14510-1519$
\end{tabular}

FEC ID number of contributing federal political committee.

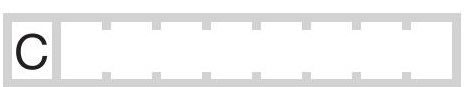

Name of Employer
None
Receipt For: 2012
Х Primary $\quad \square$ General
Other (specify)

Occupation

Retired

Election Cycle-to-Date

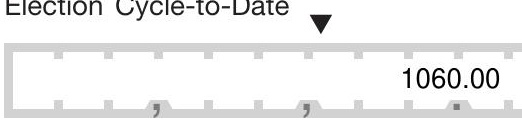

Transaction ID : ADD7F13427E1D43D895A

Date of Receipt

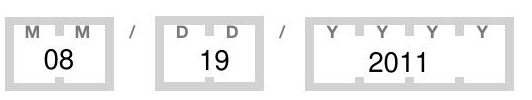

Amount of Each Receipt this Period

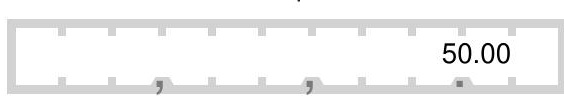

Transaction ID : A47077D691C80434FAE6 Date of Receipt

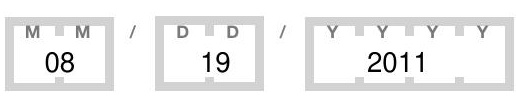

Amount of Each Receipt this Period

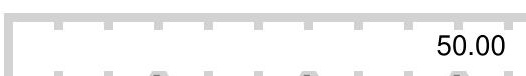

\section{Subtotal Of Receipts This Page (optional)}

Total This Period (last page this line number only) 
SCHEDULE A-P ITEMIZED RECEIPTS
Use separate schedule(s) for each category of the Detailed Summary Page
FOR LINE NUMBER: (check only one)

PAGE $345 / 1572$

\begin{tabular}{|c|c|c|c|c|c|}
\hline & & & & & \\
\hline 16 & $\begin{array}{l}\mathbf{X} \\
17 a\end{array}$ & $17 b$ & $17 c$ & $17 d$ & 18 \\
\hline $19 a$ & $19 \mathrm{~b}$ & $20 \mathrm{a}$ & $20 \mathrm{~b}$ & $20 \mathrm{c}$ & 21 \\
\hline
\end{tabular}

Any information copied from such Reports and Statements may not be sold or used by any person for the purpose of soliciting contributions or for commercial purposes, other than using the name and address of any political committee to solicit contributions from such committee.

NAME OF COMMITTEE (In Full)

\section{Friends of Herman Cain}

A. Full Name (Last, First, Middle Initial)

Sally Sidman

Mailing Address 21 Coachlight Drive

\begin{tabular}{lcc}
\hline City & State & Zip Code \\
Danville & IL & $61832-8240$
\end{tabular}

FEC ID number of contributing federal political committee.

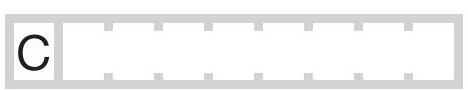

Name of Employer
Ascension Health
Receipt For: 2012
X Primary
Other (specify) General

Occupation Health Care

Election Cycle-to-Date 250.00

B. Full Name (Last, First, Middle Initial)

Mrs. Barbara C. Mathews

Mailing Address 2367 LAvista Road

\begin{tabular}{lcc}
\hline City & State & Zip Code \\
Atlanta & GA & $30329-3346$ \\
\hline
\end{tabular}

FEC ID number of contributing

federal political committee.

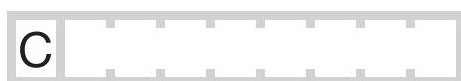

Name of Employer
None
Receipt For: 2012
X Primary
Other (specify)

\section{Occupation}

Retired

Election Cycle-to-Date

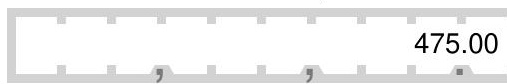

C. Full Name (Last, First, Middle Initial)

Jody Harshman

Mailing Address 5908 THistledown Dr

\begin{tabular}{lcc}
\hline City & State & Zip Code \\
Pasco & WA & $99301-3118$
\end{tabular}

FEC ID number of contributing federal political committee.

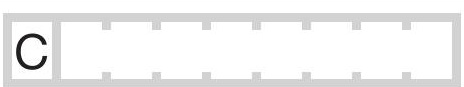

Name of Employer
Independent Contractor
Receipt For: 2012
X Primary $\quad \square$ General
Other (specify)

\section{Occupation}

technician

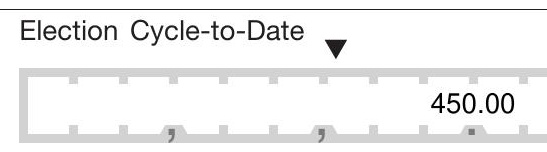

Transaction ID : AE898E90D400541DCBFA

Date of Receipt

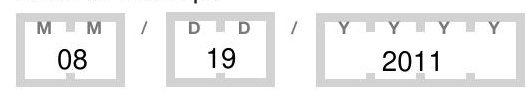

Amount of Each Receipt this Period

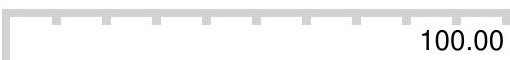

100.00

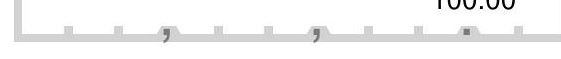

Transaction ID : A33F8125A58134059B10

Date of Receipt

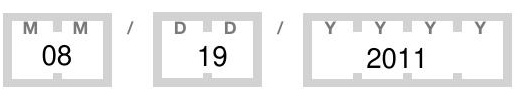

Amount of Each Receipt this Period

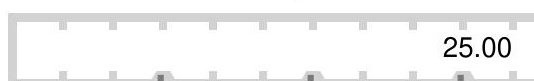

Transaction ID : AA862659945B847D3B0D Date of Receipt

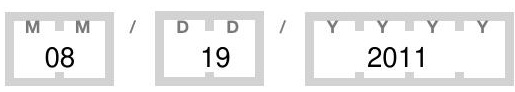

Amount of Each Receipt this Period

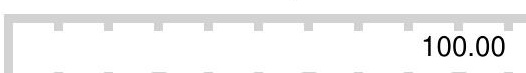

100.00

Subtotal Of Receipts This Page (optional)

Total This Period (last page this line number only) 
SCHEDULE A-P ITEMIZED RECEIPTS
Use separate schedule(s) for each category of the Detailed Summary Page
FOR LINE NUMBER: (check only one)

PAGE 346 / 1572

\begin{tabular}{|c|c|c|c|c|c|}
\hline & & & & & \\
\hline 16 & $\begin{array}{l}\mathbf{X} \\
17 a\end{array}$ & $17 b$ & $17 c$ & $17 d$ & 18 \\
\hline $19 a$ & $19 \mathrm{~b}$ & $20 \mathrm{a}$ & $20 \mathrm{~b}$ & $20 \mathrm{c}$ & 21 \\
\hline
\end{tabular}

Any information copied from such Reports and Statements may not be sold or used by any person for the purpose of soliciting contributions or for commercial purposes, other than using the name and address of any political committee to solicit contributions from such committee.

NAME OF COMMITTEE (In Full)

\section{Friends of Herman Cain}

A. Full Name (Last, First, Middle Initial)

Bianca Beary

Mailing Address 10451 Grandoaks Ln

\begin{tabular}{lcc}
\hline City & State & Zip Code \\
Montgomery & OH & $45242-5033$
\end{tabular}

FEC ID number of contributing

federal political committee.

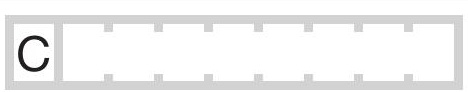

Name of Employer
Information Requested
Receipt For: 2012
X Primary $\quad \square$ General
Other (specify)

Occupation

Information Requested

Election Cycle-to-Date

393.00

B. Full Name (Last, First, Middle Initial)

BENJAMIN HEAD

Mailing Address PO Box 731

\begin{tabular}{lcc}
\hline City & State & Zip Code \\
San Marcos & TX & $78667-0731$
\end{tabular}

FEC ID number of contributing

federal political committee.

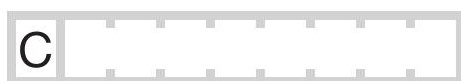

Name of Employer
None
Receipt For: 2012
X Primary
Other (specify)

Occupation

Retired

Election Cycle-to-Date

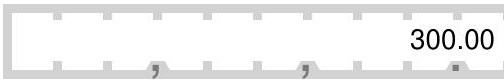

C. Full Name (Last, First, Middle Initial)

Louis J Bayer

Mailing Address 120 Lost Cove $\mathrm{Dr}$

\begin{tabular}{lcc}
\hline City & State & Zip Code \\
Spicewood & TX & $78669-4111$
\end{tabular}

FEC ID number of contributing

federal political committee.

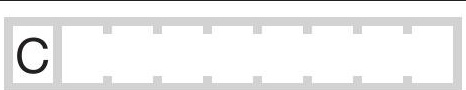

Name of Employer
None
Receipt For: 2012
Х Primary $\quad \square$ General
Other (specify)

Occupation

Retired

Election Cycle-to-Date

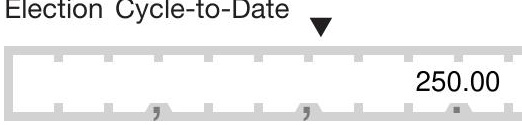

Transaction ID : ABA4DEAD8EF5142EF9CB

Date of Receipt

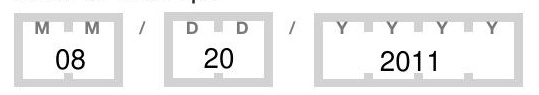

Amount of Each Receipt this Period

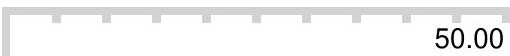

50.00
Amount of Each Receipt this Period

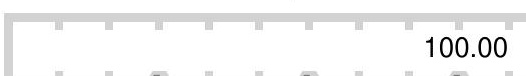

Transaction ID : A2EB7BE1596B7413EB99 Date of Receipt

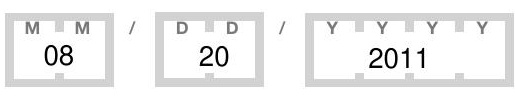

Transaction ID : ADC8F2372F0134460BD0 Date of Receipt

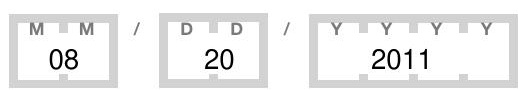

Amount of Each Receipt this Period

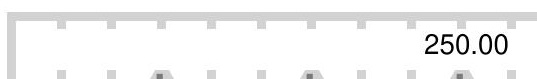

\section{Subtotal Of Receipts This Page (optional)}

400.00

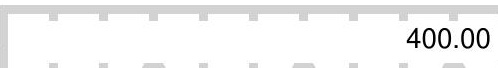

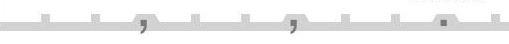

Total This Period (last page this line number only)

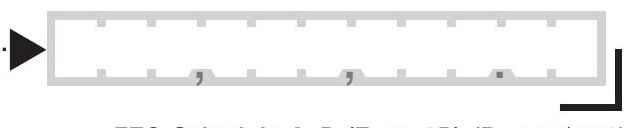

FEC Schedule A-P (Form 3P) (Rev. 03/2011) 
SCHEDULE A-P ITEMIZED RECEIPTS
Use separate schedule(s) for each category of the Detailed Summary Page
FOR LINE NUMBER: (check only one)

PAGE 347 / 1572

\begin{tabular}{|c|c|c|c|c|c|}
\hline & & & & & \\
\hline 16 & $\begin{array}{l}\mathbf{X} \\
17 a\end{array}$ & $17 b$ & $17 c$ & $17 d$ & 18 \\
\hline $19 a$ & $19 \mathrm{~b}$ & $20 \mathrm{a}$ & $20 \mathrm{~b}$ & $20 \mathrm{c}$ & 21 \\
\hline
\end{tabular}

Any information copied from such Reports and Statements may not be sold or used by any person for the purpose of soliciting contributions or for commercial purposes, other than using the name and address of any political committee to solicit contributions from such committee.

NAME OF COMMITTEE (In Full)

\section{Friends of Herman Cain}

A. Full Name (Last, First, Middle Initial) Conrad Weibler

Mailing Address 10307 Wilde Lake Ter

\begin{tabular}{lcc}
\hline City & State & Zip Code \\
Columbia & MD & $21044-2503$
\end{tabular}

FEC ID number of contributing federal political committee.

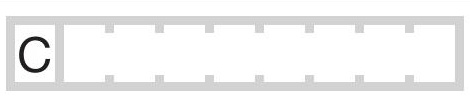

Name of Employer
Retired
Receipt For: 2012
X Primary $\quad \square$ General
$\square$ Other (specify)

Occupation Retired

Election Cycle-to-Date

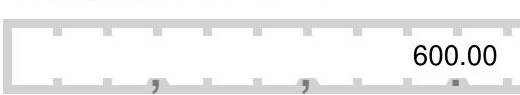

B. Full Name (Last, First, Middle Initial)

Glen Dasher

Mailing Address 613 Perkins Mill Road

\begin{tabular}{lcc}
\hline City & State & Zip Code \\
Claxton & GA & $30417-6453$ \\
\hline
\end{tabular}

FEC ID number of contributing

federal political committee.

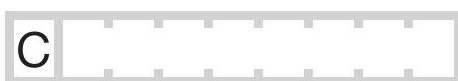

Name of Employer
Tri-Care Family Medicine
Receipt For: 2012
X Primary
Other (specify)

Occupation

Physician

Election Cycle-to-Date

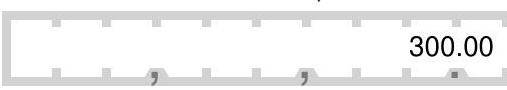

C. Full Name (Last, First, Middle Initial)

yvonne roberts

Mailing Address 4415C Constitution Ln \#223

\begin{tabular}{lcc}
\hline City & State & Zip Code \\
Marianna & FL & $32448-4472$
\end{tabular}

FEC ID number of contributing

federal political committee.

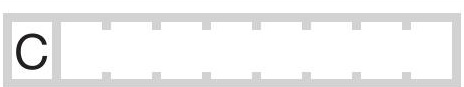

Name of Employer

Information Requested

\section{Occupation}

Information Requested

Receipt For: 2012

Х $\begin{aligned} & \text { Primary } \square \text { General } \\ & \text { Other (specify) }\end{aligned}$

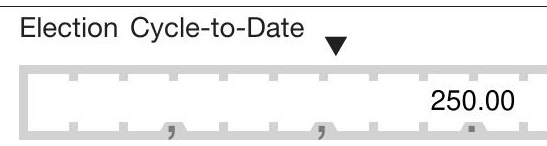

Amount of Each Receipt this Period

Transaction ID : AD73CAF4F9C9043F7B55

Date of Receipt

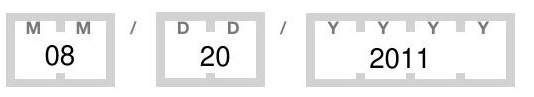

Amount of Each Receipt this Period

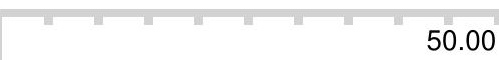

50.00

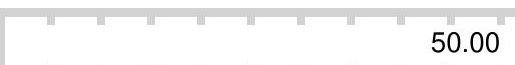

Transaction ID : A885D89B209F647EEB9E

Date of Receipt

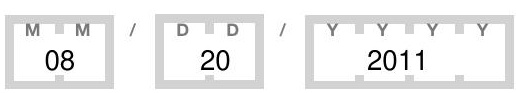

Amount of Each Receipt this Period

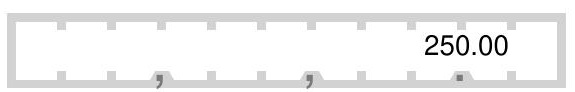

Subtotal Of Receipts This Page (optional)

350.00

Total This Period (last page this line number only) 
SCHEDULE A-P ITEMIZED RECEIPTS
Use separate schedule(s) for each category of the Detailed Summary Page
FOR LINE NUMBER: (check only one)

PAGE $348 / 1572$

\begin{tabular}{|c|c|c|c|c|c|}
\hline & & & & & \\
\hline 16 & $\begin{array}{l}\mathbf{X} \\
17 a\end{array}$ & $17 b$ & $17 c$ & $17 d$ & 18 \\
\hline $19 a$ & $19 \mathrm{~b}$ & $20 \mathrm{a}$ & $20 \mathrm{~b}$ & $20 \mathrm{c}$ & 21 \\
\hline
\end{tabular}

Any information copied from such Reports and Statements may not be sold or used by any person for the purpose of soliciting contributions or for commercial purposes, other than using the name and address of any political committee to solicit contributions from such committee.

NAME OF COMMITTEE (In Full)

\section{Friends of Herman Cain}

A. Full Name (Last, First, Middle Initial)

Jerry Miller

Mailing Address 125 South Mill Street

\begin{tabular}{lcc}
\hline City & State & Zip Code \\
Mansfield & OH & $44904-9571$
\end{tabular}

FEC ID number of contributing

federal political committee.

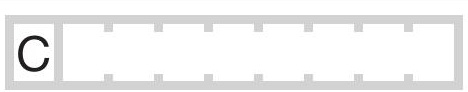

Name of Employer
M\&M Hi Tech Fab LLC
Receipt For: 2012
X Primary $\quad \square$ General
Other (specify)

Occupation

self

Election Cycle-to-Date

550.00

B. Full Name (Last, First, Middle Initial)

Herrmann Glockler

Mailing Address 3265 Sierra Crest Way

\begin{tabular}{lcc}
\hline City & State & Zip Code \\
Reno & NV & $89519-8041$ \\
\hline
\end{tabular}

FEC ID number of contributing

federal political committee.

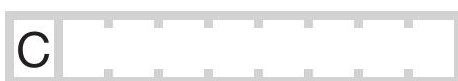

Name of Employer
Retired
Receipt For: 2012
X Primary
Other (specify)

\section{Occupation}

Engineer

Transaction ID : A8E5685975A8B4412B37

Date of Receipt

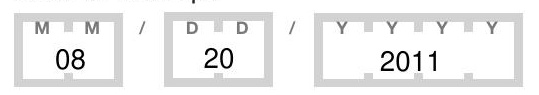

Amount of Each Receipt this Period

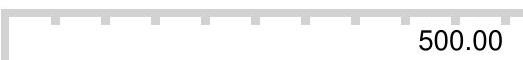

500.00

Transaction ID : AD67FD217F76A4319983

Date of Receipt

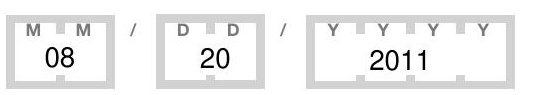

Amount of Each Receipt this Period

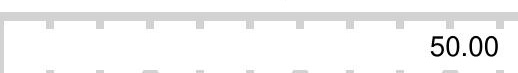

Election Cycle-to-Date

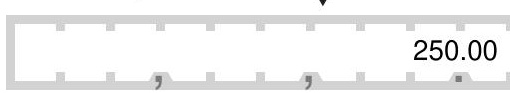

C. Full Name (Last, First, Middle Initial)

Irene Wyckoff

Mailing Address 1002 Thrid St. \#209

\begin{tabular}{lcc}
\hline City & State & Zip Code \\
Bowling Green & $\mathrm{OH}$ & 43402 \\
\hline
\end{tabular}

FEC ID number of contributing

federal political committee.

C

Name of Employer
Information Requested
Receipt For: 2012
X Primary
Other (specify) General

Occupation

Information Requested

Election Cycle-to-Date

Transaction ID : A7268D8E743B14C63B0E

Date of Receipt

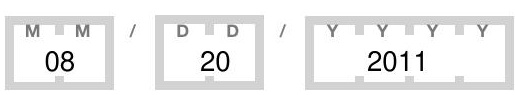

Amount of Each Receipt this Period

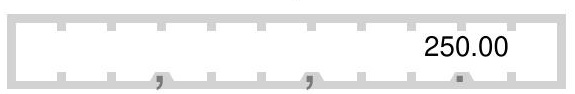

250.00

\section{Subtotal Of Receipts This Page (optional)}

800.00

a 1 ,

Total This Period (last page this line number only)

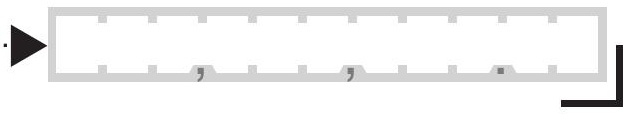

FEC Schedule A-P (Form 3P) (Rev. 03/2011) 
SCHEDULE A-P ITEMIZED RECEIPTS
Use separate schedule(s) for each category of the Detailed Summary Page
FOR LINE NUMBER: (check only one)

PAGE 349 / 1572

\begin{tabular}{|c|c|c|c|c|c|}
\hline & & & & & \\
\hline 16 & $\begin{array}{l}\mathbf{X} \\
17 a\end{array}$ & $17 b$ & $17 c$ & $17 d$ & 18 \\
\hline $19 a$ & $19 \mathrm{~b}$ & $20 \mathrm{a}$ & $20 \mathrm{~b}$ & $20 \mathrm{c}$ & 21 \\
\hline
\end{tabular}

Any information copied from such Reports and Statements may not be sold or used by any person for the purpose of soliciting contributions or for commercial purposes, other than using the name and address of any political committee to solicit contributions from such committee.

NAME OF COMMITTEE (In Full)

\section{Friends of Herman Cain}

A. Full Name (Last, First, Middle Initial)

Richard Grady

Mailing Address PO BOX 4241

\begin{tabular}{lcc}
\hline City & State & Zip Code \\
Pahrump & NV & $89041-4241$
\end{tabular}

FEC ID number of contributing federal political committee.

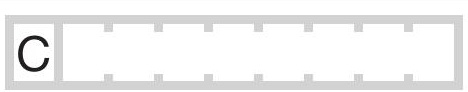

Name of Employer
Information Requested
Receipt For: 2012
X Primary
Other (specify) General

Occupation Information Requested

Election Cycle-to-Date

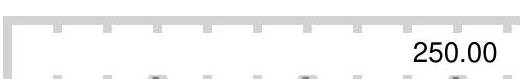

B. Full Name (Last, First, Middle Initial)

Susan Walter

Mailing Address P.O. Box 690

\begin{tabular}{lcc}
\hline City & State & Zip Code \\
Sautee Nacoochee & GA & $30571-0690$
\end{tabular}

FEC ID number of contributing

federal political committee.

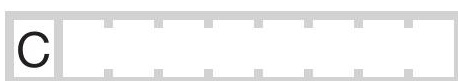

Name of Employer
None
Receipt For: 2012
X Primary
Other (specify)

Occupation

Retired

Election Cycle-to-Date

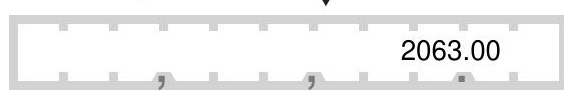

Transaction ID : AE8B7142DD5054167A56

Date of Receipt

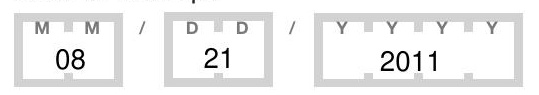

Amount of Each Receipt this Period

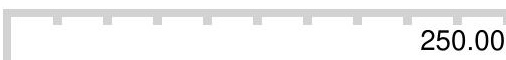

Amount of Each Receipt this Period

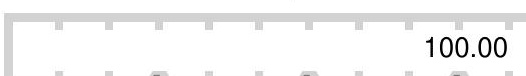

C. Full Name (Last, First, Middle Initial)

Diane Briscoe

Mailing Address 117 Marten Ct

\begin{tabular}{lcc}
\hline City & State & Zip Code \\
Waleska & GA & $30183-4685$
\end{tabular}

FEC ID number of contributing federal political committee.

C

Name of Employer
Phoenix Aviation Managers, Inc.
Receipt For: 2012
X Primary
Other (specify) General

Occupation

Accounting

Election Cycle-to-Date

Transaction ID : A640C5C1E0FCA499887F

Date of Receipt

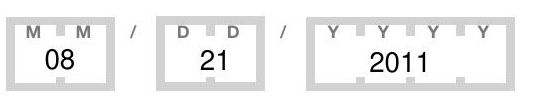

Transaction ID : A4B149A55922D4AD695E Date of Receipt

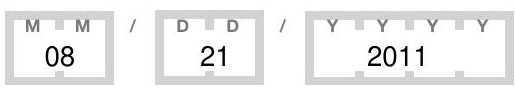

Amount of Each Receipt this Period

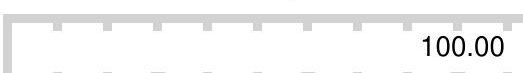

560.00

\section{Subtotal Of Receipts This Page (optional)}

Total This Period (last page this line number only) 


\section{SCHEDULE A-P} ITEMIZED RECEIPTS
Use separate schedule(s)

for each category of the

Detailed Summary Page
FOR LINE NUMBER: (check only one)

PAGE $350 / 1572$

\begin{tabular}{|c|c|c|c|c|c|}
\hline & & & & & \\
\hline 16 & X $17 a$ & $17 b$ & $17 c$ & $17 d$ & 18 \\
\hline $19 a$ & $19 b$ & $20 \mathrm{a}$ & $20 \mathrm{~b}$ & $20 \mathrm{c}$ & 21 \\
\hline
\end{tabular}

Any information copied from such Reports and Statements may not be sold or used by any person for the purpose of soliciting contributions or for commercial purposes, other than using the name and address of any political committee to solicit contributions from such committee.

NAME OF COMMITTEE (In Full)

Friends of Herman Cain

A. Full Name (Last, First, Middle Initial)

Richard Butler

Mailing Address 177 Blue Sky Dr

\begin{tabular}{lcc}
\hline City & State & Zip Code \\
Marietta & GA & $30068-3812$
\end{tabular}

FEC ID number of contributing

federal political committee.

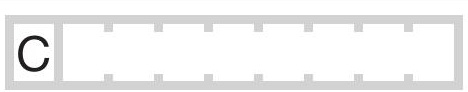

Name of Employer
Associates Express nlnc
Receipt For: 2012
X Primary $\quad \square$ General
Other (specify)

Occupation

truck driver

Election Cycle-to-Date

550.00

B. Full Name (Last, First, Middle Initial)

Jonathan Conwell

Mailing Address 104 Township Road 1343

\begin{tabular}{lcc}
\hline City & State & Zip Code \\
South Point & OH & $45680-7917$
\end{tabular}

FEC ID number of contributing

federal political committee.

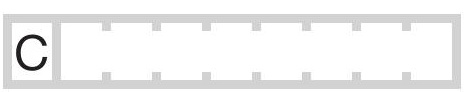

\begin{tabular}{l} 
Name of Employer \\
Federal Government \\
Receipt For: 2012 \\
X Primary \\
\hline Other (specify) General
\end{tabular}

Occupation

IT Specialist

Election Cycle-to-Date

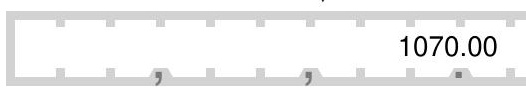

C. Full Name (Last, First, Middle Initial)

Steve Bridal

Mailing Address PO Box 1222

\begin{tabular}{lcc}
\hline City & State & Zip Code \\
Woodward & OK & $73802-1222$
\end{tabular}

FEC ID number of contributing federal political committee.

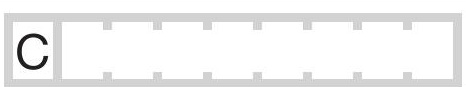

Name of Employer
Information Requested
Receipt For: 2012
X Primary
Other (specify) General

\section{Occupation}

Information Requested

Election Cycle-to-Date

Transaction ID : A81F72D9DCAC74A408BE Date of Receipt

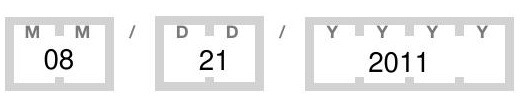

Amount of Each Receipt this Period

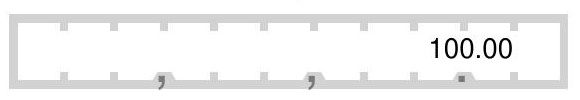

Amount of Each Receipt this Period

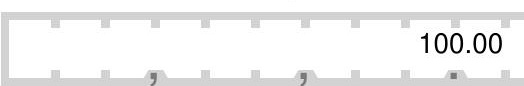

Date of Receipt

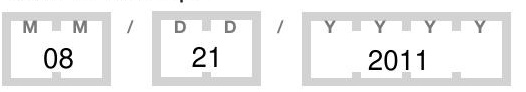

Amount of Each Receipt this Period

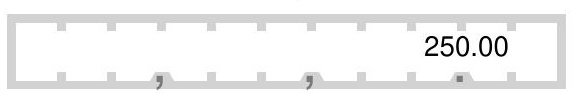

Transaction ID : A58EB6A8A6BC54373AC2 Date of Receipt

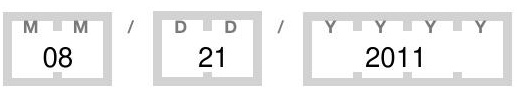

\section{Subtotal Of Receipts This Page (optional)}

Total This Period (last page this line number only) 
SCHEDULE A-P ITEMIZED RECEIPTS
Use separate schedule(s) for each category of the Detailed Summary Page
FOR LINE NUMBER: (check only one)

PAGE $351 / 1572$

\begin{tabular}{|c|c|c|c|c|c|}
\hline & & & & & \\
\hline 16 & $\begin{array}{l}\mathbf{X} \\
17 a\end{array}$ & $17 b$ & $17 c$ & $17 d$ & 18 \\
\hline $19 a$ & $19 \mathrm{~b}$ & $20 \mathrm{a}$ & $20 \mathrm{~b}$ & $20 \mathrm{c}$ & 21 \\
\hline
\end{tabular}

Any information copied from such Reports and Statements may not be sold or used by any person for the purpose of soliciting contributions or for commercial purposes, other than using the name and address of any political committee to solicit contributions from such committee.

NAME OF COMMITTEE (In Full)

\section{Friends of Herman Cain}

A. Full Name (Last, First, Middle Initial)

\section{Charlene Yde}

Mailing Address 1603 Pine Creek Way

\begin{tabular}{lcc}
\hline City & State & Zip Code \\
Woodstock & GA & $30188-4358$
\end{tabular}

FEC ID number of contributing federal political committee.

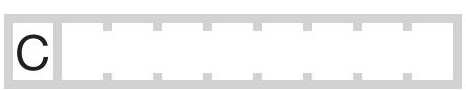

Name of Employer
The Paradies Shops
Receipt For: 2012
X Primary
Other (specify)

Occupation Manager

Election Cycle-to-Date

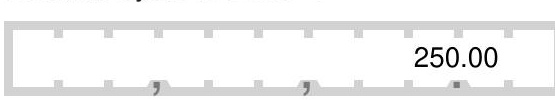

B. Full Name (Last, First, Middle Initial)

Walter Burton

Mailing Address P.O. Box 772

\begin{tabular}{lcc}
\hline City & State & Zip Code \\
Statesboro & GA & $30459-0772$ \\
\hline
\end{tabular}

FEC ID number of contributing

federal political committee.

C

Name of Employer

Retired

Occupation

Receipt For: 2012

$\chi \begin{aligned} & \text { Primary } \\ & \text { Other (specify) }\end{aligned}$

Information Requested

Election Cycle-to-Date

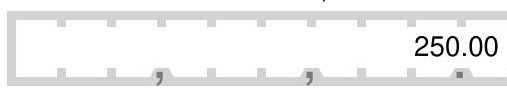

C. Full Name (Last, First, Middle Initial)

CHARLIE WARD

Mailing Address 12852 HEARN RD

\begin{tabular}{lcc}
\hline City & State & Zip Code \\
Corpus Christi & TX & $78410-4308$
\end{tabular}

FEC ID number of contributing

federal political committee.

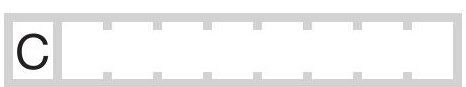

$\begin{aligned} & \text { Name of Employer } \\ & \text { self }\end{aligned}$
Receipt For: 2012
X Primary $\quad \square$ General
Other (specify)

Occupation

Realtor

Election Cycle-to-Date

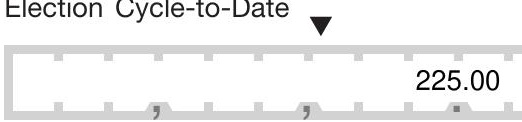

Transaction ID : AC98A6C2229854293BE4

Date of Receipt

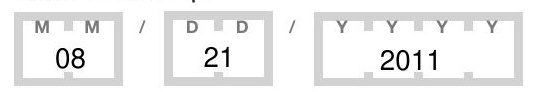

Amount of Each Receipt this Period

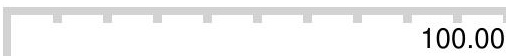

100.00

Transaction ID : A0B162A85E60046D296C

Date of Receipt

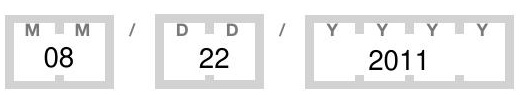

Amount of Each Receipt this Period

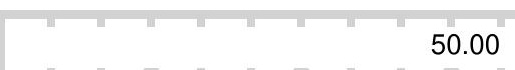

Transaction ID : A42AF625786D643AEBB9 Date of Receipt

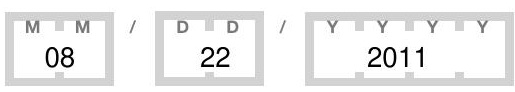

Amount of Each Receipt this Period

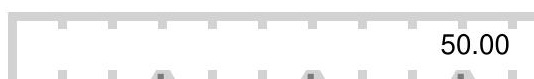

200.00

Subtotal Of Receipts This Page (optional)

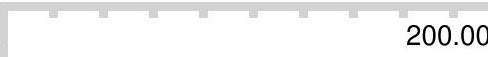

Total This Period (last page this line number only) 
SCHEDULE A-P ITEMIZED RECEIPTS
Use separate schedule(s) for each category of the Detailed Summary Page
FOR LINE NUMBER: (check only one)

PAGE 352 / 1572

\begin{tabular}{|c|c|c|c|c|c|}
\hline & & & & & \\
\hline 16 & $\begin{array}{l}\mathbf{X} \\
17 a\end{array}$ & $17 b$ & $17 c$ & $17 d$ & 18 \\
\hline $19 a$ & $19 \mathrm{~b}$ & $20 \mathrm{a}$ & $20 \mathrm{~b}$ & $20 \mathrm{c}$ & 21 \\
\hline
\end{tabular}

Any information copied from such Reports and Statements may not be sold or used by any person for the purpose of soliciting contributions or for commercial purposes, other than using the name and address of any political committee to solicit contributions from such committee.

NAME OF COMMITTEE (In Full)

\section{Friends of Herman Cain}

A. Full Name (Last, First, Middle Initial) James Stewart

Mailing Address 3560 E. Via Colonia del Sol

\begin{tabular}{lcc}
\hline City & State & Zip Code \\
Tucson & AZ & $85718-6065$
\end{tabular}

FEC ID number of contributing federal political committee.

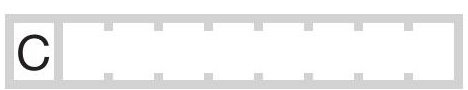

Name of Employer
Information Requested
Receipt For: 2012
X Primary
Other (specify) General

Occupation Information Requested

Election Cycle-to-Date

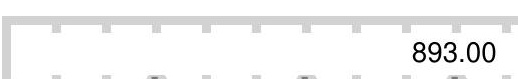

B. Full Name (Last, First, Middle Initial)

Rush Clark

Mailing Address 7725 Bamby Rd

\begin{tabular}{lcc}
\hline City & State & Zip Code \\
Cumming & GA & $30041-8101$
\end{tabular}

FEC ID number of contributing

federal political committee.

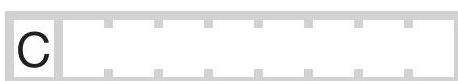

Name of Employer
None
Receipt For: 2012
X Primary
Other (specify)

\section{Occupation}

Retired

Election Cycle-to-Date

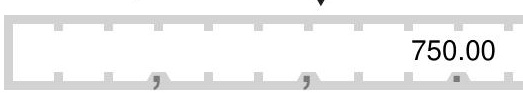

Transaction ID : A96333DDEB13A45D8933

Date of Receipt

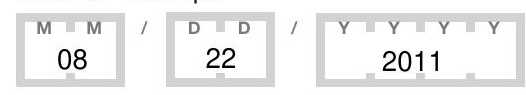

Amount of Each Receipt this Period

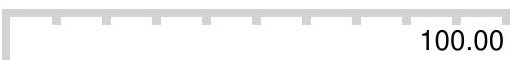

Amount of Each Receipt this Period

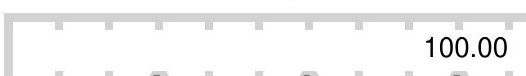

C. Full Name (Last, First, Middle Initial)

Michael Marchman

Mailing Address 1625 E 72nd St STE 700 PMB 224

\begin{tabular}{lcc}
\hline City & State & Zip Code \\
Tacoma & WA & $98404-5455$
\end{tabular}

FEC ID number of contributing federal political committee.

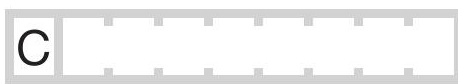

Name of Employer

U.S. Customs and Border Protection

\section{Occupation}

CBP Officer

Transaction ID : A1E788B51346245519A7

Date of Receipt

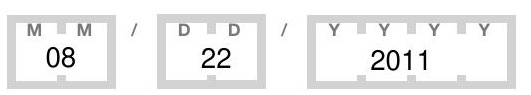

Receipt For: 2012

Х $\begin{aligned} & \text { Primary } \square \text { General } \\ & \text { Other (specify) }\end{aligned}$

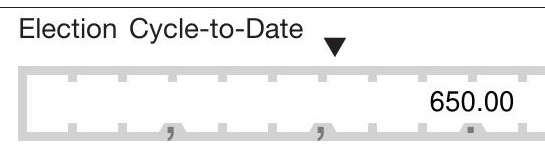

Subtotal Of Receipts This Page (optional)

250.00

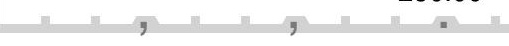

Total This Period (last page this line number only)
Amount of Each Receipt this Period

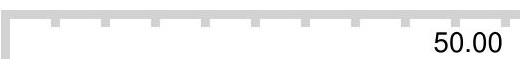

50.00

Transaction ID : AE74F295C25294B74AAC Date of Receipt
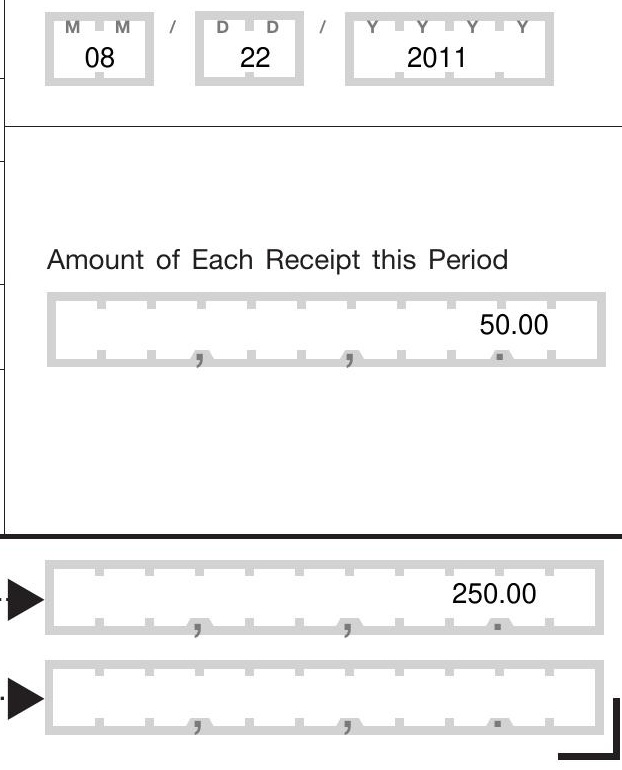

FEC Schedule A-P (Form 3P) (Rev. 03/2011) 
SCHEDULE A-P ITEMIZED RECEIPTS
Use separate schedule(s) for each category of the Detailed Summary Page
FOR LINE NUMBER: (check only one)

PAGE $353 / 1572$

\begin{tabular}{|c|c|c|c|c|c|}
\hline & & & & & \\
\hline 16 & $\mathbf{X} 17 a$ & $17 b$ & $17 c$ & $17 d$ & 18 \\
\hline $19 a$ & $19 b$ & $20 \mathrm{a}$ & $20 \mathrm{~b}$ & $20 \mathrm{c}$ & 21 \\
\hline
\end{tabular}

Any information copied from such Reports and Statements may not be sold or used by any person for the purpose of soliciting contributions or for commercial purposes, other than using the name and address of any political committee to solicit contributions from such committee.

NAME OF COMMITTEE (In Full)

\section{Friends of Herman Cain}

A. Full Name (Last, First, Middle Initial)

Rodney Bennett

Mailing Address 414 Morris Ln

\begin{tabular}{lcc}
\hline City & State & Zip Code \\
Greenville & TX & $75402-5454$ \\
\hline
\end{tabular}

FEC ID number of contributing federal political committee.

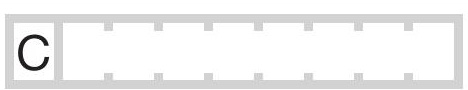

Name of Employer
TYBRIN
Receipt For: 2012
X Primary $\quad$ General
Other (specify)

Occupation

Systems Engineer

Election Cycle-to-Date

225.00

B. Full Name (Last, First, Middle Initial)

Gary Shawver

Mailing Address 551 Excelsior Lane

\begin{tabular}{lcc}
\hline City & State & Zip Code \\
Waterloo & IA & $50701-4967$ \\
\hline
\end{tabular}

FEC ID number of contributing

federal political committee.

C

Name of Employer

Shawver Well Co. Inc

Occupation

Receipt For: 2012

Х Primary $\square$ General

Water well contractor

Election Cycle-to-Date

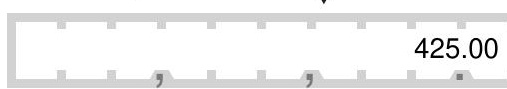

C. Full Name (Last, First, Middle Initial)

richard craig

Mailing Address p.o. box 899

\begin{tabular}{lcc}
\hline City & State & Zip Code \\
Edwards & CO & $81632-0899$
\end{tabular}

FEC ID number of contributing

federal political committee.

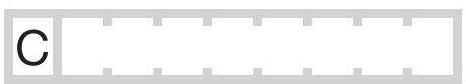

Name of Employer

Information Requested

Occupation

Information Requested

Receipt For: 2012

Х $\begin{aligned} & \text { Primary } \\ & \text { Other (specify) }\end{aligned}$

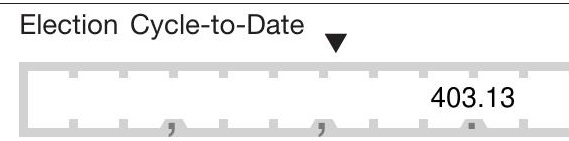

Amount of Each Receipt this Period

Transaction ID : AA22337E5A03B4AEA8E7 Date of Receipt
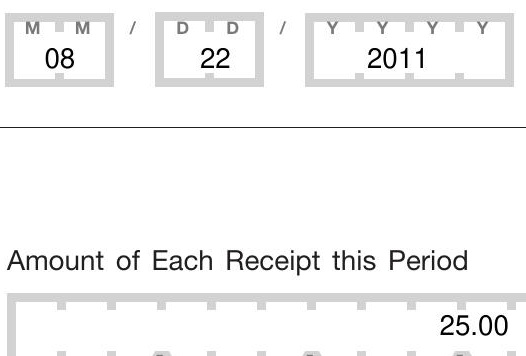

Transaction ID : AD6466553BF6242E0AE8

Date of Receipt

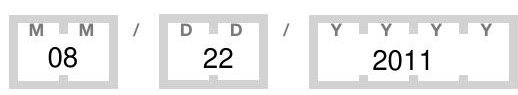

Amount of Each Receipt this Period

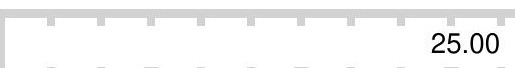

Subtotal Of Receipts This Page (optional)

100.00

Total This Period (last page this line number only) 
SCHEDULE A-P ITEMIZED RECEIPTS
Use separate schedule(s)

for each category of the

Detailed Summary Page
FOR LINE NUMBER: (check only one)

Any information or for commercial purposes, other than using the name and address of any political committee to solicit contributions from such committee.

NAME OF COMMITTEE (In Full)

\section{Friends of Herman Cain}

A. Full Name (Last, First, Middle Initial)

Mr. Paul R Messinger

Mailing Address 11060 N 94th St

\begin{tabular}{lcc}
\hline City & State & Zip Code \\
Scottsdale & AZ & $85260-6111$
\end{tabular}

FEC ID number of contributing federal political committee.

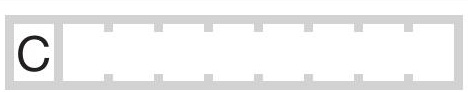

Name of Employer
Messinger Mortuary
Receipt For: 2012
X Primary
Other (specify) General

Occupation

Funeral Directo

Election Cycle-to-Date

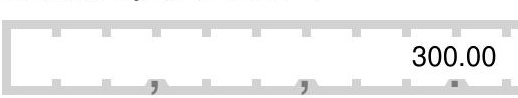

B. Full Name (Last, First, Middle Initial)

Louis Shirley III

Mailing Address 1359 Central Ave

\begin{tabular}{lcc}
\hline City & State & Zip Code \\
Atlanta & GA & $30344-4946$ \\
\hline
\end{tabular}

FEC ID number of contributing

federal political committee.

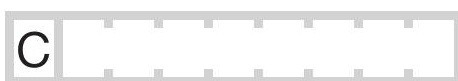

Name of Employer
Newell Recycling LLC
Receipt For: 2012
X Primary
Other (specify)

Occupation

Executive

Election Cycle-to-Date

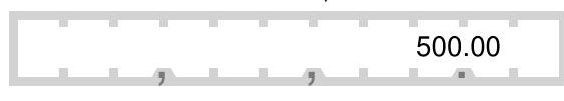

Transaction ID : A85FDA32BB7E84F5CB69

Date of Receipt

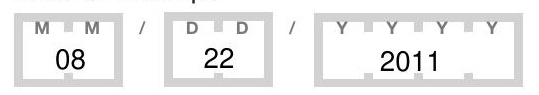

Amount of Each Receipt this Period

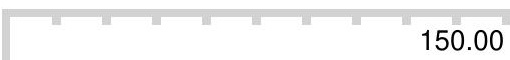

150.00

C. Full Name (Last, First, Middle Initial)

Phyllis Fine

Mailing Address 266 Trailwood Lane

\begin{tabular}{lcc}
\hline City & State & Zip Code \\
Northbrook & IL & $60062-1031$
\end{tabular}

FEC ID number of contributing federal political committee.

C

Name of Employer
homemaker
Receipt For: 2012
X Primary
Other (specify) General

Occupation

Homemaker

Election Cycle-to-Date

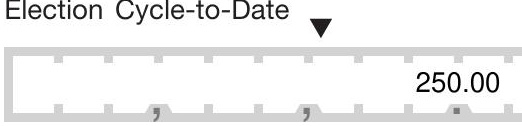

Transaction ID : A9E15267CAF28479F92A

Date of Receipt

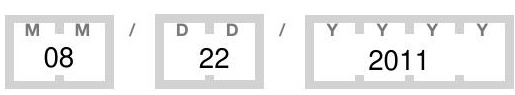

Amount of Each Receipt this Period

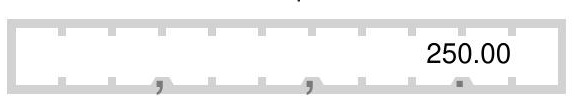

Transaction ID : A7C3DCD50A2A94FADB84 Date of Receipt

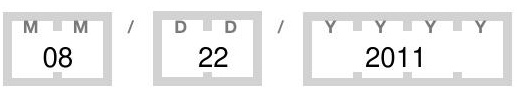

Amount of Each Receipt this Period

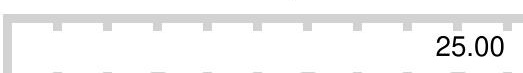

\section{Subtotal Of Receipts This Page (optional)}

Total This Period (last page this line number only) 
SCHEDULE A-P ITEMIZED RECEIPTS
Use separate schedule(s) for each category of the Detailed Summary Page
FOR LINE NUMBER: (check only one)

PAGE $355 / 1572$

\begin{tabular}{|c|c|c|c|c|c|}
\hline & & & & & \\
\hline 16 & $\begin{array}{l}\mathbf{X} \\
17 a\end{array}$ & $17 b$ & $17 c$ & $17 d$ & 18 \\
\hline $19 a$ & $19 \mathrm{~b}$ & $20 \mathrm{a}$ & $20 \mathrm{~b}$ & $20 \mathrm{c}$ & 21 \\
\hline
\end{tabular}

Any information copied from such Reports and Statements may not be sold or used by any person for the purpose of soliciting contributions or for commercial purposes, other than using the name and address of any political committee to solicit contributions from such committee.

NAME OF COMMITTEE (In Full)

\section{Friends of Herman Cain}

A. Full Name (Last, First, Middle Initial)

\section{J.B. McGuire}

Mailing Address PO Box 340

\begin{tabular}{lcc}
\hline City & State & Zip Code \\
Olga & WA & $98279-0340$ \\
\hline
\end{tabular}

FEC ID number of contributing federal political committee.

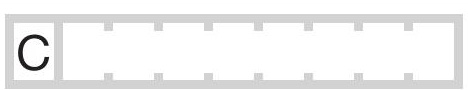

Name of Employer
Information Requested
Receipt For: 2012
X Primary
Other (specify) General

Occupation Information Requested

Election Cycle-to-Date

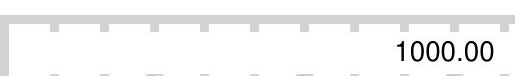

B. Full Name (Last, First, Middle Initial)

Stephen H Perry

Mailing Address 517 Carilion Ln

\begin{tabular}{lcc}
\hline City & State & Zip Code \\
Greenville & SC & $29617-7914$
\end{tabular}

FEC ID number of contributing

federal political committee.

C

Name of Employer
Information Requested
Receipt For: 2012
X Primary
Other (specify)

Occupation

Information Requested

Election Cycle-to-Date

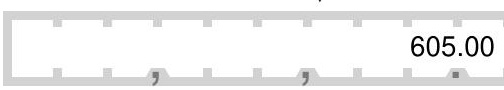

C. Full Name (Last, First, Middle Initial)

william snell

Mailing Address 1185 byrnwyck way

\begin{tabular}{lcc}
\hline City & State & Zip Code \\
Atlanta & GA & $30319-1650$
\end{tabular}

FEC ID number of contributing federal political committee.

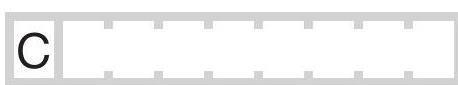

$\begin{aligned} & \text { Name of Employer } \\ & \text { self }\end{aligned}$
Receipt For: 2012
X Primary $\square$ General
Other (specify)

Occupation

Physician

Election Cycle-to-Date

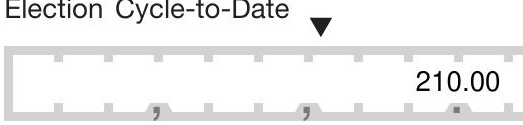

Transaction ID : AAE03F917B8BC4EC18ED

Date of Receipt

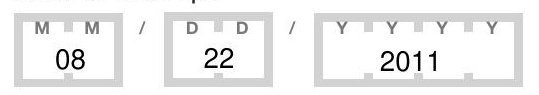

Amount of Each Receipt this Period

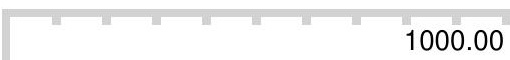

1000.00

Transaction ID : A42C85C69D5894908917

Date of Receipt

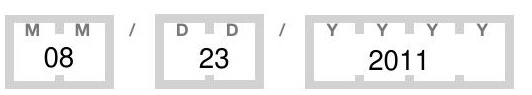

Amount of Each Receipt this Period

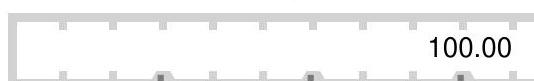

Transaction ID : A96957B4EF83248969E1

Date of Receipt

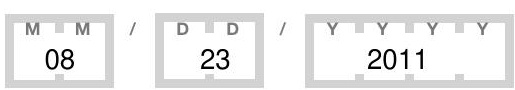

Amount of Each Receipt this Period

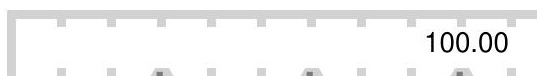

\section{Subtotal Of Receipts This Page (optional)}

Total This Period (last page this line number only) 
SCHEDULE A-P ITEMIZED RECEIPTS
Use separate schedule(s) for each category of the Detailed Summary Page
FOR LINE NUMBER: (check only one)

PAGE 356 / 1572

\begin{tabular}{|c|c|c|c|c|c|}
\hline & & & & & \\
\hline 16 & $\begin{array}{l}\mathbf{X} \\
17 a\end{array}$ & $17 b$ & $17 c$ & $17 d$ & 18 \\
\hline $19 a$ & $19 \mathrm{~b}$ & $20 \mathrm{a}$ & $20 \mathrm{~b}$ & $20 \mathrm{c}$ & 21 \\
\hline
\end{tabular}

Any information copied from such Reports and Statements may not be sold or used by any person for the purpose of soliciting contributions or for commercial purposes, other than using the name and address of any political committee to solicit contributions from such committee.

NAME OF COMMITTEE (In Full)

\section{Friends of Herman Cain}

A. Full Name (Last, First, Middle Initial)

ANDREW MELNICK

Mailing Address 901 NAVESINK RIVER ROAD

\begin{tabular}{lcc}
\hline City & State & Zip Code \\
Rumson & NJ & $07760-2329$
\end{tabular}

FEC ID number of contributing

federal political committee.

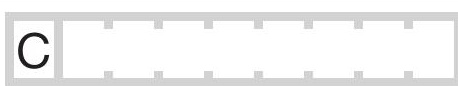

Name of Employer
Information Requested
Receipt For: 2012
X Primary
Other (specify) General

Occupation

Information Requested

Election Cycle-to-Date

250.00

B. Full Name (Last, First, Middle Initial)

Douglas Jones

Mailing Address 500 Falling Springs Rd

\begin{tabular}{lcc}
\hline City & State & Zip Code \\
Rydal & GA & $30171-1332$
\end{tabular}

FEC ID number of contributing

federal political committee.

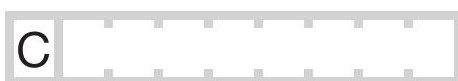

Name of Employer
n/a
Receipt For: 2012
X Primary
Other (specify)

Occupation

Retired

Election Cycle-to-Date

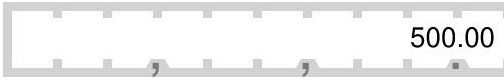

C. Full Name (Last, First, Middle Initial)

Connie Brownback

Mailing Address 11 Bastian Lane

\begin{tabular}{lcc}
\hline City & State & Zip Code \\
Allentown & PA & $18104-9558$
\end{tabular}

FEC ID number of contributing federal political committee.

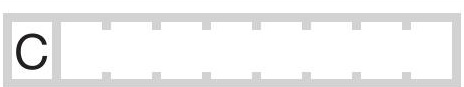

Name of Employer
NA
Receipt For: 2012
Х Primary $\quad \square$ General
Other (specify)

Occupation

Retired

Election Cycle-to-Date

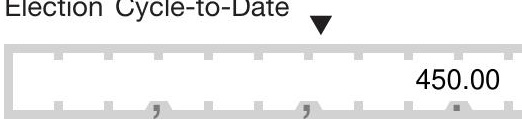

Transaction ID : A1AF56090E7344345969

Date of Receipt

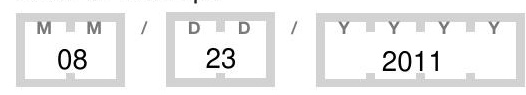

Amount of Each Receipt this Period

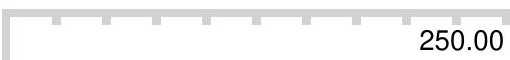

250.00
Amount of Each Receipt this Period

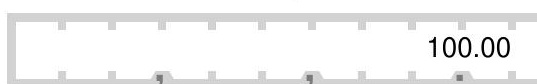

Transaction ID : A18902D9C9E5549D4819 Date of Receipt

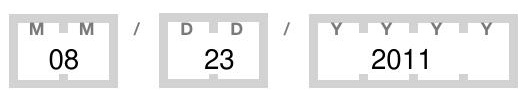

Amount of Each Receipt this Period

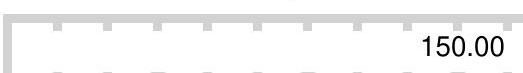

Transaction ID : AD5E82E7E17F44DC9BAF Date of Receipt
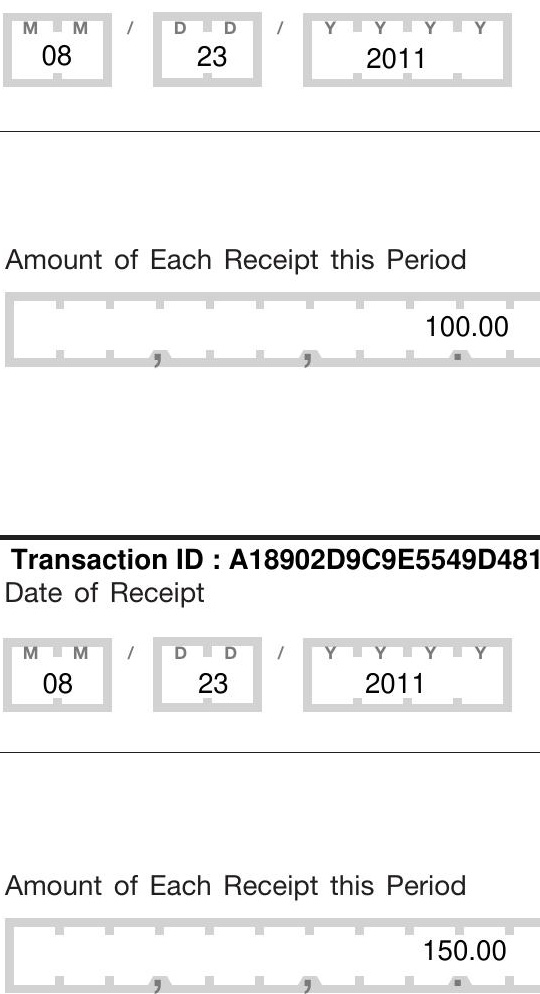

Subtotal Of Receipts This Page (optional).

500.00

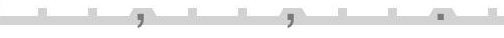

Total This Period (last page this line number only)

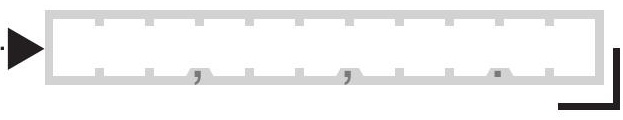


SCHEDULE A-P ITEMIZED RECEIPTS
Use separate schedule(s)

for each category of the

Detailed Summary Page
FOR LINE NUMBER: (check only one)

\begin{tabular}{|c|c|c|c|c|c|}
\hline & & & & & \\
\hline 16 & $\begin{array}{ll}X & 17 a \\
\end{array}$ & $17 \mathrm{~b}$ & $17 c$ & $17 d$ & 18 \\
\hline $19 a$ & $19 b$ & $20 \mathrm{a}$ & $20 \mathrm{~b}$ & $20 c$ & 21 \\
\hline
\end{tabular}

Any information copied from such Reports and Statements may not be sold or used by any person for the purpose of soliciting contributions or for commercial purposes, other than using the name and address of any political committee to solicit contributions from such committee.

NAME OF COMMITTEE (In Full)

Friends of Herman Cain

A. Full Name (Last, First, Middle Initial) richard clampitt

Mailing Address 7261 ashington dr

\begin{tabular}{lcc}
\hline City & State & Zip Code \\
Dallas & TX & $75225-1704$
\end{tabular}

FEC ID number of contributing federal political committee.

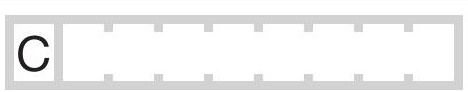

Name of Employer
red river paper
Receipt For: 2012
Primary
Other (specify) General

Occupation

Executive

Election Cycle-to-Date

1500.00
Transaction ID : A4EC855D0F8C04E8DBF7

Date of Receipt

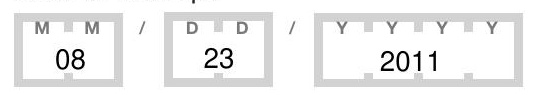

Amount of Each Receipt this Period

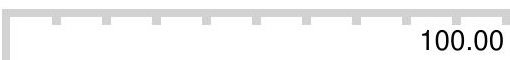

B. Full Name (Last, First, Middle Initial)

Michael Richardson

Mailing Address PO Box 12

\begin{tabular}{lcc}
\hline City & State & Zip Code \\
Ardmore & OK & $73402-0012$ \\
\hline
\end{tabular}

FEC ID number of contributing

federal political committee.

C

Name of Employer
Information Requested
Receipt For: 2012
X Primary
Other (specify)

Occupation

Information Requested

Election Cycle-to-Date

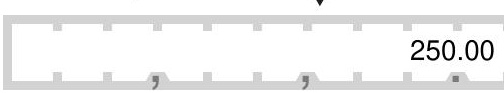

C. Full Name (Last, First, Middle Initial)

Glen Ebbing

Mailing Address 1400 Huntleigh Rd

\begin{tabular}{lcc}
\hline City & State & Zip Code \\
Quincy & IL & $62305-6017$
\end{tabular}

FEC ID number of contributing

federal political committee.

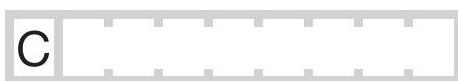

Name of Employer
ColorMaster Pain Inc
Receipt For: 2012
X Primary $\quad \square$ General
Other (specify)

\section{Occupation}

sales representative

Election Cycle-to-Date

Transaction ID : ACE8CA4BB33D2419A848 Date of Receipt

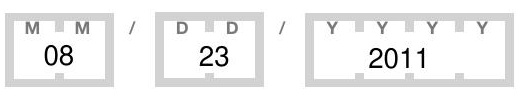

Amount of Each Receipt this Period

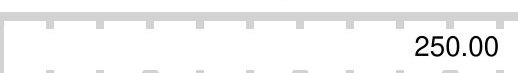

Transaction ID : A08F3C7CE786F46C49DB Date of Receipt

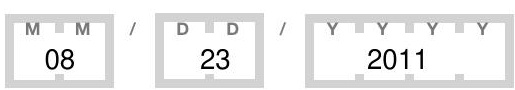

Amount of Each Receipt this Period

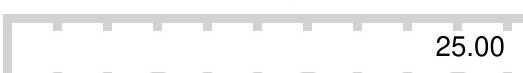

378.00

\section{Subtotal Of Receipts This Page (optional)}

Total This Period (last page this line number only)
375.00

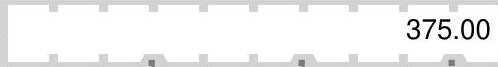

a

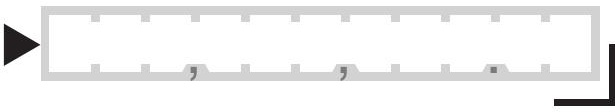

FEC Schedule A-P (Form 3P) (Rev. 03/2011) 
SCHEDULE A-P ITEMIZED RECEIPTS
Use separate schedule(s)

for each category of the

Detailed Summary Page
FOR LINE NUMBER: (check only one)

\begin{tabular}{|c|c|c|c|c|c|}
\hline & & & & & \\
\hline 16 & $\begin{array}{ll}X & 17 a \\
\end{array}$ & $17 \mathrm{~b}$ & $17 c$ & $17 d$ & 18 \\
\hline $19 a$ & $19 b$ & $20 \mathrm{a}$ & $20 \mathrm{~b}$ & $20 c$ & 21 \\
\hline
\end{tabular}

Any information copied from such Reports and Statements may not be sold or used by any person for the purpose of soliciting contributions or for commercial purposes, other than using the name and address of any political committee to solicit contributions from such committee.

NAME OF COMMITTEE (In Full)

Friends of Herman Cain

A. Full Name (Last, First, Middle Initial)

alice shapiro

Mailing Address 5845 ridgeview drive

\begin{tabular}{lcc}
\hline City & State & Zip Code \\
Doylestown & PA & $18902-1366$
\end{tabular}

FEC ID number of contributing

federal political committee.

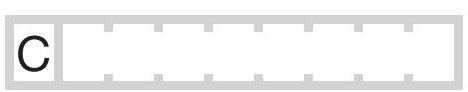

\begin{tabular}{l} 
Name of Employer \\
None \\
Receipt For: 2012 \\
X Primary $\quad$ General \\
\hline Other (specify)
\end{tabular}

Occupation

Retired

Election Cycle-to-Date

243.00

B. Full Name (Last, First, Middle Initial)

james tristani

Mailing Address 904 southern dr

\begin{tabular}{lcc}
\hline City & State & Zip Code \\
Bel Air & MD & $21014-2527$
\end{tabular}

FEC ID number of contributing

federal political committee.

C

Name of Employer
Information Requested
Receipt For: 2012
Primary
Other (specify)

Occupation

Information Requested

Election Cycle-to-Date

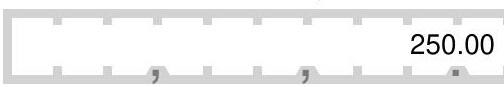

Transaction ID : A352BEA93CBF248C398F

Date of Receipt

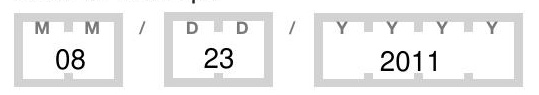

Amount of Each Receipt this Period

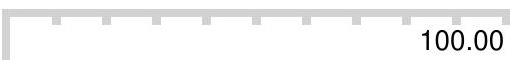

Transaction ID : AF2CCC89DA798407399E

Date of Receipt

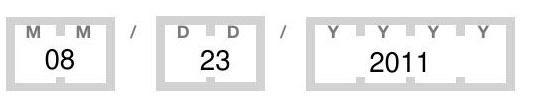

Amount of Each Receipt this Period

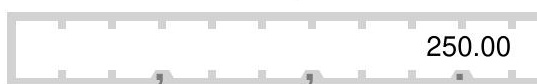

Transaction ID : A7452B0BE369B4AA2B41 Date of Receipt

\section{Susan Walter}

Mailing Address P.O. Box 690

\begin{tabular}{lcc}
\hline City & State & Zip Code \\
Sautee Nacoochee & GA & $30571-0690$
\end{tabular}

FEC ID number of contributing federal political committee.

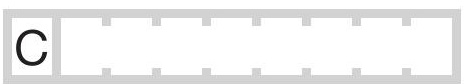

Name of Employer
None
Receipt For: 2012
X Primary
Other (specify) General

Occupation

Retired

Election Cycle-to-Date

\section{Subtotal Of Receipts This Page (optional)}

400.00

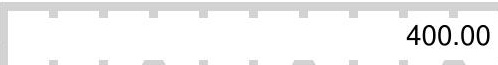

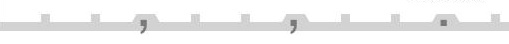

Total This Period (last page this line number only)
Amount of Each Receipt this Period

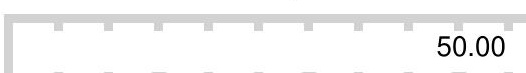

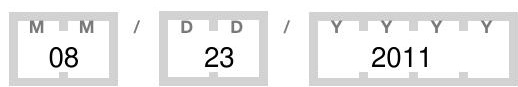

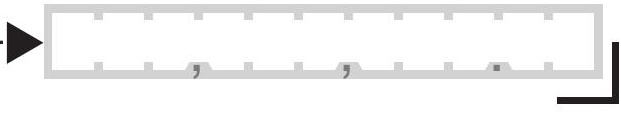

FEC Schedule A-P (Form 3P) (Rev. 03/2011) 
SCHEDULE A-P ITEMIZED RECEIPTS
Use separate schedule(s) for each category of the Detailed Summary Page
FOR LINE NUMBER: (check only one)

PAGE 359 / 1572

\begin{tabular}{|c|c|c|c|c|c|}
\hline & & & & & \\
\hline 16 & $\begin{array}{l}\mathbf{X} \\
17 a\end{array}$ & $17 b$ & $17 c$ & $17 d$ & 18 \\
\hline $19 a$ & $19 \mathrm{~b}$ & $20 \mathrm{a}$ & $20 \mathrm{~b}$ & $20 \mathrm{c}$ & 21 \\
\hline
\end{tabular}

Any information copied from such Reports and Statements may not be sold or used by any person for the purpose of soliciting contributions or for commercial purposes, other than using the name and address of any political committee to solicit contributions from such committee.

NAME OF COMMITTEE (In Full)

\section{Friends of Herman Cain}

A. Full Name (Last, First, Middle Initial)

Linda K Cummings

Mailing Address PO Box 2001

\begin{tabular}{lcc}
\hline City & State & Zip Code \\
Danville & KY & $40423-2001$
\end{tabular}

FEC ID number of contributing federal political committee.

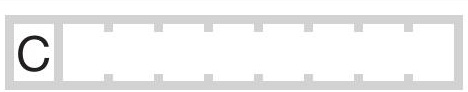

Name of Employer
Self Employed
Receipt For: 2012
X Primary $\quad$ General
Other (specify)

Occupation farmer

Election Cycle-to-Date

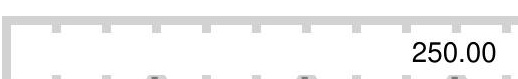

B. Full Name (Last, First, Middle Initial)

Gerri Crowell

Mailing Address 1346 Fort Jefferson Ave

\begin{tabular}{lcc}
\hline City & State & Zip Code \\
Greenville & OH & $45331-1048$
\end{tabular}

FEC ID number of contributing

federal political committee.

C

Name of Employer
Information Requested
Receipt For: 2012
X Primary
Other (specify)

Occupation

Information Requested

Election Cycle-to-Date

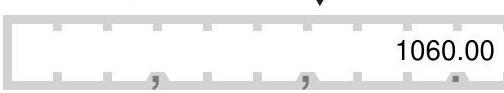

Transaction ID : A05051E66DFA246A6B58

Date of Receipt

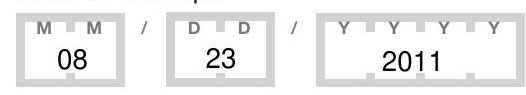

Amount of Each Receipt this Period

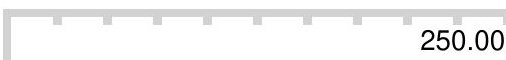

C. Full Name (Last, First, Middle Initial)

kenneth james

Mailing Address 12401 sw 7 th St

\begin{tabular}{lcc}
\hline City & State & Zip Code \\
Davie & FL & $33325-3427$
\end{tabular}

FEC ID number of contributing federal political committee.

C

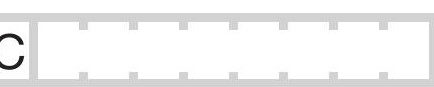

Name of Employer
Heartland Express
Receipt For: 2012
X Primary $\quad \square$ General
Other (specify)

\section{Occupation}

truck driver

Election Cycle-to-Date

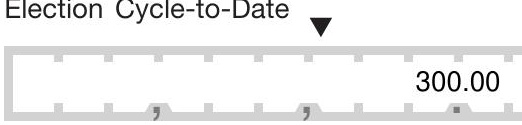

Amount of Each Receipt this Period

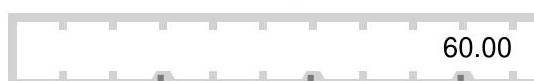

Transaction ID : AA4880ECB40DA4A30A63 Date of Receipt

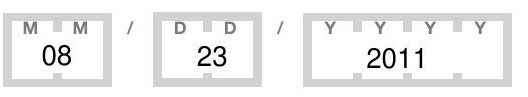

Transaction ID : AA314B0CD0FAF4AFEB16 Date of Receipt

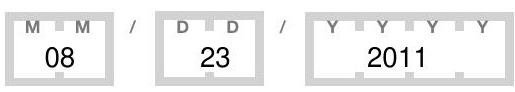

Amount of Each Receipt this Period

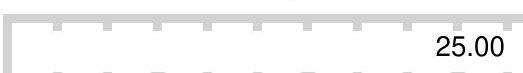

\section{Subtotal Of Receipts This Page (optional)}

Total This Period (last page this line number only) 
SCHEDULE A-P ITEMIZED RECEIPTS
Use separate schedule(s) for each category of the Detailed Summary Page
FOR LINE NUMBER: (check only one)

PAGE $360 / 1572$

\begin{tabular}{|c|c|c|c|c|c|}
\hline & & & & & \\
\hline 16 & $\begin{array}{l}\mathbf{X} \\
17 a\end{array}$ & $17 b$ & $17 c$ & $17 d$ & 18 \\
\hline $19 a$ & $19 \mathrm{~b}$ & $20 \mathrm{a}$ & $20 \mathrm{~b}$ & $20 \mathrm{c}$ & 21 \\
\hline
\end{tabular}

Any information copied from such Reports and Statements may not be sold or used by any person for the purpose of soliciting contributions or for commercial purposes, other than using the name and address of any political committee to solicit contributions from such committee.

NAME OF COMMITTEE (In Full)

\section{Friends of Herman Cain}

A. Full Name (Last, First, Middle Initial)

H. Legare Coleman

Mailing Address 683 Faulkner Dr.

\begin{tabular}{lcc}
\hline City & State & Zip Code \\
Mount Pleasant & SC & $29466-8347$
\end{tabular}

FEC ID number of contributing

federal political committee.

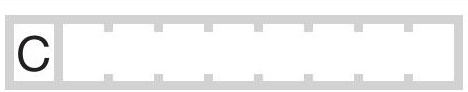

Name of Employer
Information Requested
Receipt For: 2012
X Primary $\quad \square$ General
Other (specify)

Occupation

Information Requested

Election Cycle-to-Date

400.00

B. Full Name (Last, First, Middle Initial)

Tom Young

Mailing Address 1241 Cantrell Mountain Rd.

\begin{tabular}{lcc}
\hline City & State & Zip Code \\
Brevard & NC & $28712-6525$ \\
\hline
\end{tabular}

FEC ID number of contributing

federal political committee.

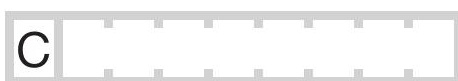

Name of Employer
None
Receipt For: 2012
X Primary
Other (specify)

\section{Occupation}

Retired

Election Cycle-to-Date

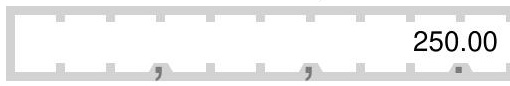

C. Full Name (Last, First, Middle Initial)

Mr Donald A Geiger

Mailing Address 7858 S County Road 9

\begin{tabular}{l|ll}
\hline $\begin{array}{l}\text { City } \\
\text { Hartford }\end{array}$ & $\begin{array}{c}\text { State } \\
\text { AL }\end{array}$ & $\begin{array}{c}\text { Zip Code } \\
36344-6652\end{array}$ \\
\hline $\begin{array}{l}\text { FEC ID number of contributing } \\
\text { federal political committee. }\end{array}$ & $\mathrm{C}$ & \\
\hline $\begin{array}{l}\text { Name of Employer } \\
\text { Space Science Services In }\end{array}$ & $\begin{array}{l}\text { Occupation } \\
\text { Engineer }\end{array}$ \\
\hline $\begin{array}{l}\text { Receipt For: } 2012 \\
\text { Primary } \\
\text { Other (specify) }\end{array}$ & Election Cycle-to-Date & \\
\hline
\end{tabular}

Transaction ID : A6E32B0AAD6F44C6786F

Date of Receipt

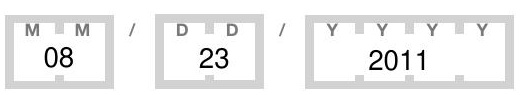

Amount of Each Receipt this Period

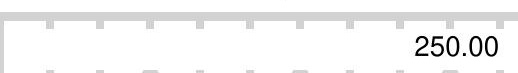

Amount of Each Receipt this Period

Transaction ID : A39A173C1C1864E99BB7 Date of Receipt
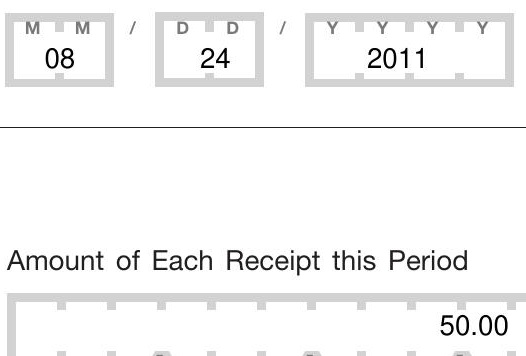

50.00

400.00

Subtotal Of Receipts This Page (optional)

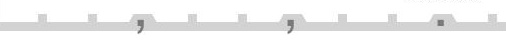

Total This Period (last page this line number only)

FEC Schedule A-P (Form 3P) (Rev. 03/2011) 
SCHEDULE A-P ITEMIZED RECEIPTS
Use separate schedule(s) for each category of the Detailed Summary Page
FOR LINE NUMBER: (check only one)

PAGE $361 / 1572$

\begin{tabular}{|c|c|c|c|c|c|}
\hline & & & & & \\
\hline 16 & $\begin{array}{l}\mathbf{X} \\
17 a\end{array}$ & $17 b$ & $17 c$ & $17 d$ & 18 \\
\hline $19 a$ & $19 \mathrm{~b}$ & $20 \mathrm{a}$ & $20 \mathrm{~b}$ & $20 \mathrm{c}$ & 21 \\
\hline
\end{tabular}

Any information copied from such Reports and Statements may not be sold or used by any person for the purpose of soliciting contributions or for commercial purposes, other than using the name and address of any political committee to solicit contributions from such committee.

NAME OF COMMITTEE (In Full)

\section{Friends of Herman Cain}

A. Full Name (Last, First, Middle Initial)

\section{Cecelia LeClair}

Mailing Address 175 2nd St S Ph 10

\begin{tabular}{lcc}
\hline City & State & Zip Code \\
Saint Petersburg & FL & $33701-4321$
\end{tabular}

FEC ID number of contributing federal political committee.

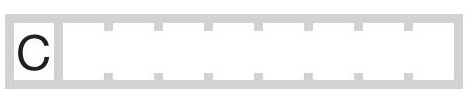

Name of Employer
None
Receipt For: 2012
X Primary $\quad$ General
Other (specify)

Occupation Retired

Election Cycle-to-Date

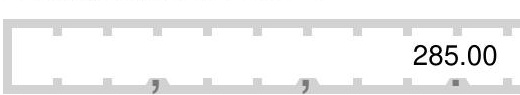

B. Full Name (Last, First, Middle Initial)

Arthur Robinson

Mailing Address 105 Bonaventure PI

\begin{tabular}{lcc}
\hline City & State & Zip Code \\
Locust Grove & GA & $30248-4552$ \\
\hline
\end{tabular}

FEC ID number of contributing

federal political committee.

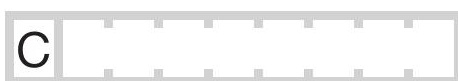

Name of Employer
DRC
Receipt For: 2012
X Primary
Other (specify)

\section{Occupation}

Contractor

Election Cycle-to-Date

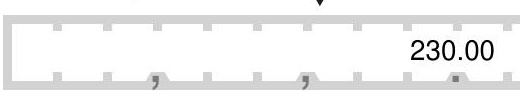

Transaction ID : ADB39656AEC0B497B82B

Date of Receipt

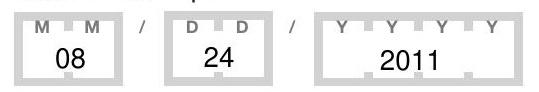

Amount of Each Receipt this Period

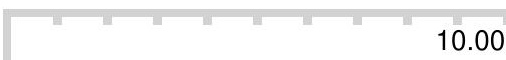

Transaction ID : AE0CDD5866AB643AFB0A Date of Receipt

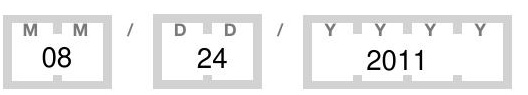

Amount of Each Receipt this Period

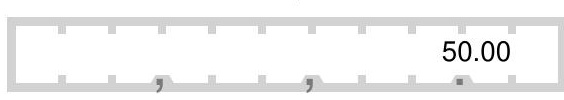

Transaction ID : A87FF553D318E4F678EC Date of Receipt

Mrs. Helen Armstrong

Mailing Address 753 Hillcrest St.

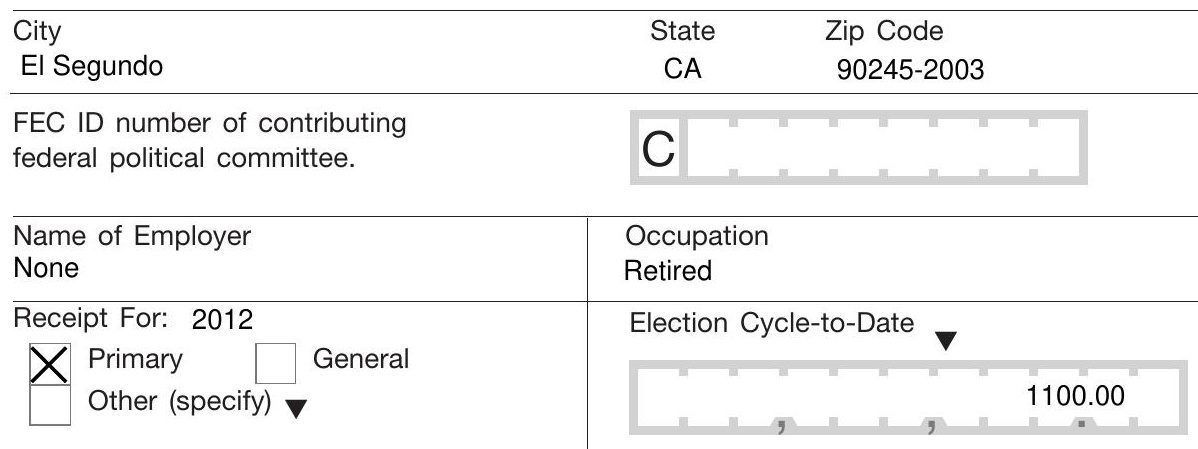

Amount of Each Receipt this Period

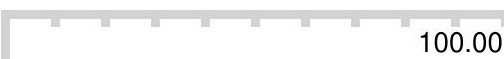

100.00

Subtotal Of Receipts This Page (optional)

160.00

Total This Period (last page this line number only) 
SCHEDULE A-P ITEMIZED RECEIPTS
Use separate schedule(s) for each category of the Detailed Summary Page
FOR LINE NUMBER: (check only one)

PAGE 362 / 1572

\begin{tabular}{|c|c|c|c|c|c|}
\hline & & & & & \\
\hline 16 & $\begin{array}{l}\mathbf{X} \\
17 a\end{array}$ & $17 b$ & $17 c$ & $17 d$ & 18 \\
\hline $19 a$ & $19 \mathrm{~b}$ & $20 \mathrm{a}$ & $20 \mathrm{~b}$ & $20 \mathrm{c}$ & 21 \\
\hline
\end{tabular}

Any information copied from such Reports and Statements may not be sold or used by any person for the purpose of soliciting contributions or for commercial purposes, other than using the name and address of any political committee to solicit contributions from such committee.

NAME OF COMMITTEE (In Full)

\section{Friends of Herman Cain}

A. Full Name (Last, First, Middle Initial)

\section{Lannie Keen}

Mailing Address 3673 Stolen Horse Trce

\begin{tabular}{lcc}
\hline City & State & Zip Code \\
Lexington & KY & $40509-2144$
\end{tabular}

FEC ID number of contributing federal political committee.

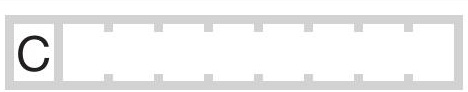

Name of Employer
ZeroChaos
Receipt For: 2012
X Primary $\quad$ General
Other (specify)

Occupation

Computer Support

Election Cycle-to-Date

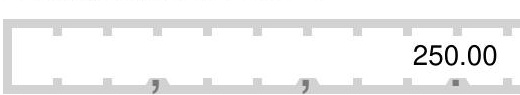

B. Full Name (Last, First, Middle Initial)

Jayne D Wayson

Mailing Address 400 E Colonial Dr Apt 402

\begin{tabular}{lcc}
\hline City & State & Zip Code \\
Orlando & FL & $32803-4530$
\end{tabular}

FEC ID number of contributing

federal political committee.

C

\begin{tabular}{l} 
Name of Employer \\
Information Requested \\
Receipt For: 2012 \\
X Primary \\
\hline Other (specify)
\end{tabular}

Occupation

Information Requested

Election Cycle-to-Date

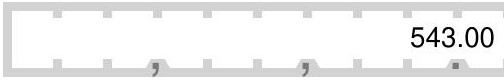

C. Full Name (Last, First, Middle Initial)

Arnold Barnett

Mailing Address PO Box 11322

\begin{tabular}{lcc}
\hline City & State & Zip Code \\
Cincinnati & OH & $45211-0322$ \\
\hline
\end{tabular}

FEC ID number of contributing federal political committee.

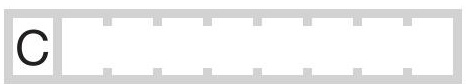

Name of Employer

Information Requested

\section{Occupation}

Information Requested

Receipt For: 2012

Х $\begin{aligned} & \text { Primary } \square \text { General } \\ & \text { Other (specify) }\end{aligned}$

Transaction ID : AF269E0934AAE432086A

Date of Receipt

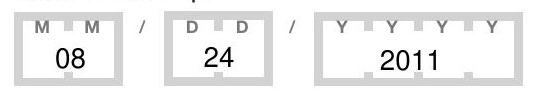

Amount of Each Receipt this Period

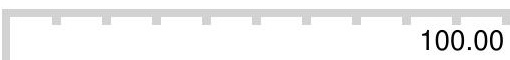

100.00

Amount of Each Receipt this Period

Transaction ID : AAED0F7ECBA56495F800 Date of Receipt
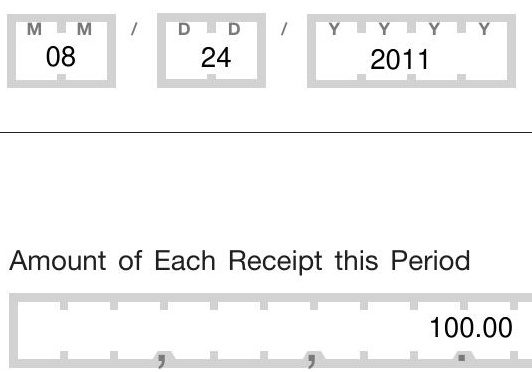

Transaction ID : A8EE2751835E44B67B48 Date of Receipt

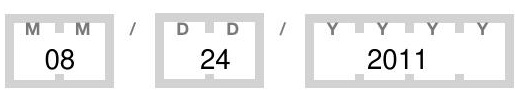

Amount of Each Receipt this Period

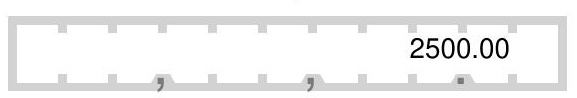

5000.00

\section{Subtotal Of Receipts This Page (optional)}

Total This Period (last page this line number only) 
SCHEDULE A-P ITEMIZED RECEIPTS
Use separate schedule(s) for each category of the Detailed Summary Page
FOR LINE NUMBER: (check only one)

PAGE $363 / 1572$

\begin{tabular}{|c|c|c|c|c|c|}
\hline & & & & & \\
\hline 16 & $\mathbf{X} 17 a$ & $17 b$ & $17 c$ & $17 d$ & 18 \\
\hline $19 a$ & $19 b$ & $20 \mathrm{a}$ & $20 \mathrm{~b}$ & $20 \mathrm{c}$ & 21 \\
\hline
\end{tabular}

Any information copied from such Reports and Statements may not be sold or used by any person for the purpose of soliciting contributions or for commercial purposes, other than using the name and address of any political committee to solicit contributions from such committee.

NAME OF COMMITTEE (In Full)

\section{Friends of Herman Cain}

A. Full Name (Last, First, Middle Initial)

Mr. Charles D Sears

Mailing Address 3609 Via La Selva

\begin{tabular}{lcc}
\hline City & State & Zip Code \\
Palos Verdes Estates & CA & $90274-1115$
\end{tabular}

FEC ID number of contributing

federal political committee.

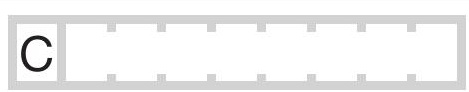

Name of Employer
Information Requested
Receipt For: 2012
X Primary $\quad \square$ General
Other (specify)

Occupation

Information Requested

Election Cycle-to-Date

300.00

B. Full Name (Last, First, Middle Initial)

Bruce Battle

Mailing Address 5917 Charleycote Drive

\begin{tabular}{lcc}
\hline City & State & Zip Code \\
Raleigh & NC & $27614-7253$ \\
\hline
\end{tabular}

FEC ID number of contributing

federal political committee.

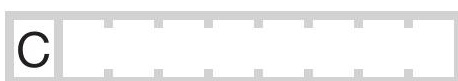

Name of Employer

Majestic Marble and Glass Company

Occupation

Receipt For: 2012

$\chi \begin{aligned} & \text { Primary } \\ & \text { Other (specify) } \boldsymbol{\nabla}\end{aligned}$ General

Business Owner

Election Cycle-to-Date

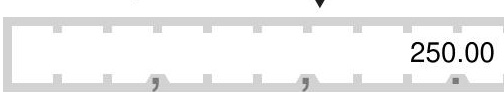

C. Full Name (Last, First, Middle Initial)

Mary Jo Barnett

Mailing Address PO Box 11322

\begin{tabular}{lcc}
\hline City & State & Zip Code \\
Cincinnati & OH & $45211-0322$
\end{tabular}

FEC ID number of contributing federal political committee.

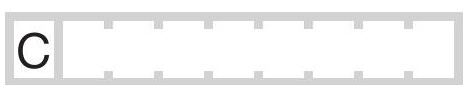

Name of Employer

Information Requested

Occupation

Information Requested

Receipt For: 2012

$\square$ Primary \ General

Other (specify)

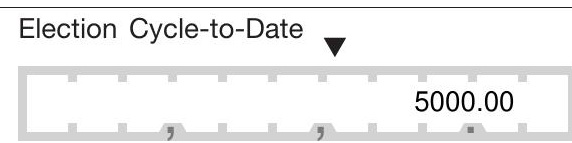

Amount of Each Receipt this Period

Transaction ID : A62DD05DD2EDC41909C3

Date of Receipt

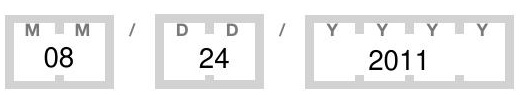

Amount of Each Receipt this Period

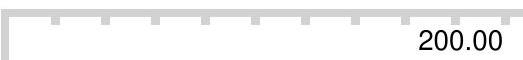

200.00

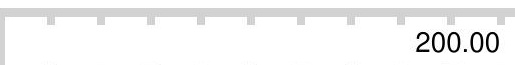

Transaction ID : AFC1BC98876704D4680D

Date of Receipt

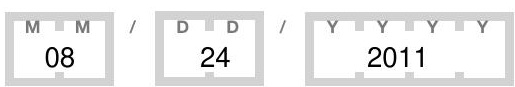

Amount of Each Receipt this Period

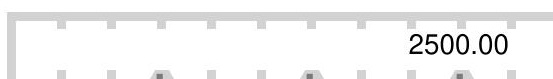

2900.00

Subtotal Of Receipts This Page (optional)

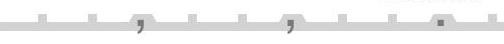

Total This Period (last page this line number only)

FEC Schedule A-P (Form 3P) (Rev. 03/2011) 
SCHEDULE A-P ITEMIZED RECEIPTS
Use separate schedule(s) for each category of the Detailed Summary Page
FOR LINE NUMBER: (check only one)

\begin{tabular}{|c|c|c|c|c|c|c|}
\hline & & & & & & \\
\hline 16 & $\times 1$ & $17 a$ & $17 b$ & $17 c$ & $17 d$ & 18 \\
\hline $19 a$ & & $19 b$ & $20 \mathrm{a}$ & $20 \mathrm{~b}$ & $20 \mathrm{c}$ & 21 \\
\hline
\end{tabular}

Any information copied from such Reports and Statements may not be sold or used by any person for the purpose of soliciting contributions or for commercial purposes, other than using the name and address of any political committee to solicit contributions from such committee.

NAME OF COMMITTEE (In Full)

\section{Friends of Herman Cain}

A. Full Name (Last, First, Middle Initial)

\section{Leann L Davis}

Mailing Address 602 W 4th St

\begin{tabular}{lcc}
\hline City & State & Zip Code \\
Delavan & IL & $61734-9689$ \\
\hline
\end{tabular}

FEC ID number of contributing federal political committee.

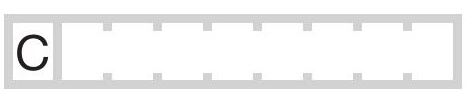

Name of Employer
self
Receipt For: 2012
X Primary $\quad$ General
Other (specify)

Occupation landscape designer

Election Cycle-to-Date

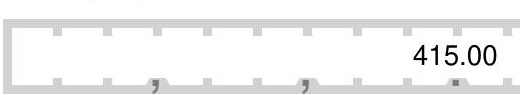

B. Full Name (Last, First, Middle Initial)

Arnold Barnett

Mailing Address PO Box 11322

\begin{tabular}{lcc}
\hline City & State & Zip Code \\
Cincinnati & OH & $45211-0322$ \\
\hline
\end{tabular}

FEC ID number of contributing

federal political committee.

C

\begin{tabular}{l} 
Name of Employer \\
Information Requested \\
\hline Receipt For: 2012 \\
$\square$ Primary $\quad$ Other (specify) $\mathbf{V}$
\end{tabular}

Occupation

Information Requested

Election Cycle-to-Date

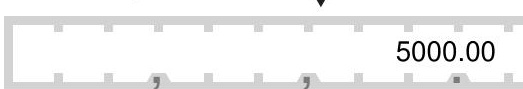

Transaction ID : A4DB448E3CABD4DD0A2D

Date of Receipt

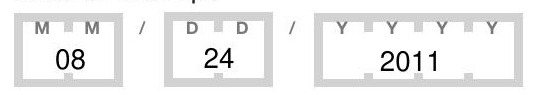

Amount of Each Receipt this Period

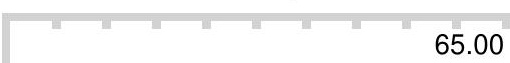

65.00

C. Full Name (Last, First, Middle Initial)

Roswell Jackson, Jr.

Mailing Address 892 Perry Lane

\begin{tabular}{lcc}
\hline City & State & Zip Code \\
Teaneck & NJ & $07666-6627$
\end{tabular}

FEC ID number of contributing federal political committee.

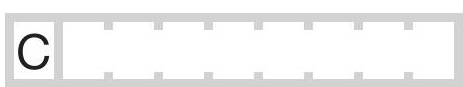

Name of Employer
None
Receipt For: 2012
Х Primary $\quad \square$ General
Other (specify)

Occupation

Retired

Election Cycle-to-Date

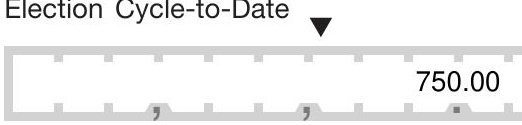

Transaction ID : A1CF9225EC0324C0F867

Date of Receipt

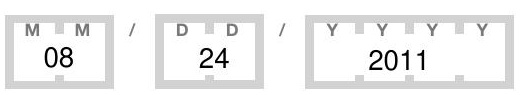

Amount of Each Receipt this Period

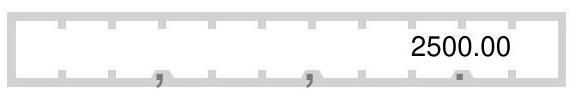

Transaction ID : A6CE4D6D41C4F4D76BF2 Date of Receipt

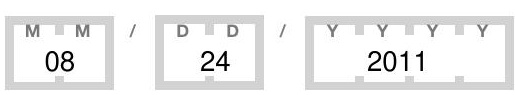

Amount of Each Receipt this Period

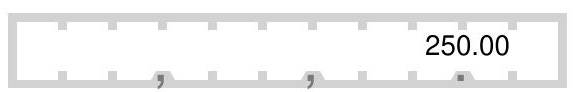

Subtotal Of Receipts This Page (optional)

2815.00

-

Total This Period (last page this line number only)

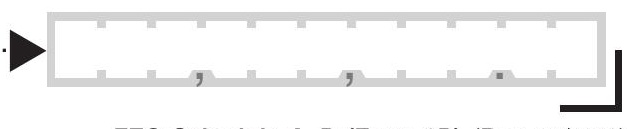

FEC Schedule A-P (Form 3P) (Rev. 03/2011) 
SCHEDULE A-P ITEMIZED RECEIPTS
Use separate schedule(s) for each category of the Detailed Summary Page
FOR LINE NUMBER: (check only one)

PAGE $365 / 1572$

\begin{tabular}{|c|c|c|c|c|c|}
\hline & & & & & \\
\hline 16 & $\begin{array}{l}\mathbf{X} \\
17 a\end{array}$ & $17 b$ & $17 c$ & $17 d$ & 18 \\
\hline $19 a$ & $19 \mathrm{~b}$ & $20 \mathrm{a}$ & $20 \mathrm{~b}$ & $20 \mathrm{c}$ & 21 \\
\hline
\end{tabular}

Any information copied from such Reports and Statements may not be sold or used by any person for the purpose of soliciting contributions or for commercial purposes, other than using the name and address of any political committee to solicit contributions from such committee.

NAME OF COMMITTEE (In Full)

\section{Friends of Herman Cain}

A. Full Name (Last, First, Middle Initial)

Mary Sugarman

Mailing Address 9440 Santa Monica Blvd. \#407

\begin{tabular}{lcc}
\hline City & State & Zip Code \\
Beverly Hills & CA & $90210-4607$ \\
\hline
\end{tabular}

FEC ID number of contributing

federal political committee.

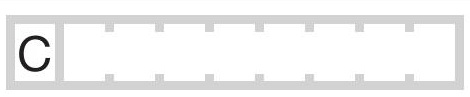

Name of Employer
CBS
Receipt For: 2012
X Primary $\quad$ General
Other (specify)

Occupation

TV Anchor

Transaction ID : A71376082DA164EBE9E7

Date of Receipt

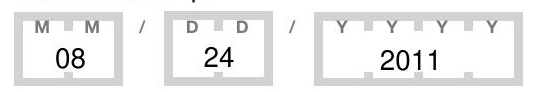

Election Cycle-to-Date

2500.00

B. Full Name (Last, First, Middle Initial)

Beverly Hill

Mailing Address 2750 Jean Lafitte Dr

\begin{tabular}{lcc}
\hline City & State & Zip Code \\
Fernandina Beach & FL & $32034-4836$
\end{tabular}

FEC ID number of contributing

federal political committee.

C

Name of Employer
Information Requested
Receipt For: 2012
X Primary
Other (specify)

Occupation

Information Requested

Election Cycle-to-Date

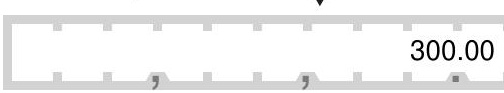

C. Full Name (Last, First, Middle Initial)

William Holloway

Mailing Address 10222 Old Stagecoach Rd

\begin{tabular}{lcc}
\hline City & State & Zip Code \\
Chappell Hill & TX & $77426-6032$
\end{tabular}

FEC ID number of contributing

federal political committee.

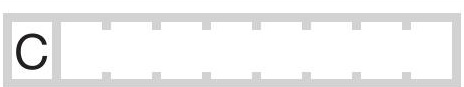

$\begin{aligned} & \text { Name of Employer } \\ & \text { self }\end{aligned}$
Receipt For: 2012
X Primary $\quad \square$ General
Other (specify)

\section{Occupation}

plumbing contractor

Election Cycle-to-Date

Transaction ID : A69734DFCD54D4EB3988

Date of Receipt

Amount of Each Receipt this Period

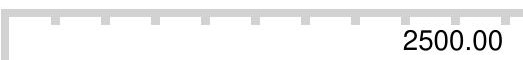

2500.00

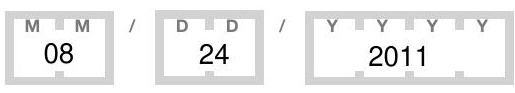

Amount of Each Receipt this Period

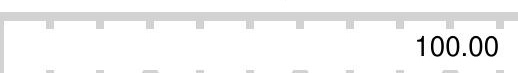

Transaction ID : A3A9AEED9FB94490682C Date of Receipt

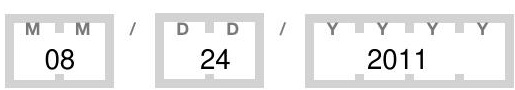

Amount of Each Receipt this Period

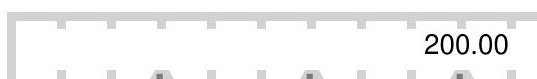

500.00

\section{Subtotal Of Receipts This Page (optional)}

Total This Period (last page this line number only) 
SCHEDULE A-P ITEMIZED RECEIPTS
Use separate schedule(s) for each category of the Detailed Summary Page
FOR LINE NUMBER: (check only one)

PAGE 366 / 1572

\begin{tabular}{|c|c|c|c|c|c|}
\hline & & & & & \\
\hline 16 & $\begin{array}{l}\mathbf{X} \\
17 a\end{array}$ & $17 b$ & $17 c$ & $17 d$ & 18 \\
\hline $19 a$ & $19 \mathrm{~b}$ & $20 \mathrm{a}$ & $20 \mathrm{~b}$ & $20 \mathrm{c}$ & 21 \\
\hline
\end{tabular}

Any information copied from such Reports and Statements may not be sold or used by any person for the purpose of soliciting contributions or for commercial purposes, other than using the name and address of any political committee to solicit contributions from such committee.

NAME OF COMMITTEE (In Full)

\section{Friends of Herman Cain}

A. Full Name (Last, First, Middle Initial)

Mrs. Dama L Curtright

Mailing Address P.O. Box 1350

\begin{tabular}{lcc}
\hline City & State & Zip Code \\
Jefferson & OR & $97352-1350$
\end{tabular}

FEC ID number of contributing federal political committee.

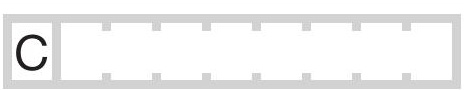

Name of Employer

Ames Research Laboratory, Inc.

Occupation

Co-Owner

Receipt For: 2012

$\square$ Primary Х General

Other (specify)

Election Cycle-to-Date

5020.00

B. Full Name (Last, First, Middle Initial)

Mary Jo Barnett

Mailing Address PO Box 11322

\begin{tabular}{lcc}
\hline City & State & Zip Code \\
Cincinnati & OH & $45211-0322$ \\
\hline
\end{tabular}

FEC ID number of contributing

federal political committee.

C

Name of Employer
Information Requested
Receipt For: 2012
X Primary
Other (specify)

Occupation

Information Requested

Election Cycle-to-Date

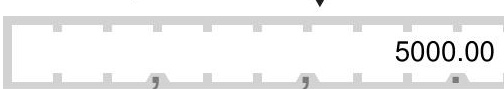

C. Full Name (Last, First, Middle Initial)

Tod Fredericks

Mailing Address 101 Virginia Terrace

\begin{tabular}{lcc}
\hline City & State & Zip Code \\
Madison & WI & $53726-5339$
\end{tabular}

FEC ID number of contributing

federal political committee.

C

Name of Employer

Information Requested

Occupation

Receipt For: 2012

Х $\begin{aligned} & \text { Primary } \square \text { General } \\ & \text { Other (specify) }\end{aligned}$

Information Requested

Election Cycle-to-Date

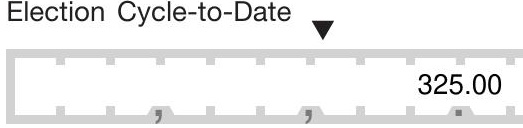

Transaction ID : A11319A5159EE43958E2

Date of Receipt

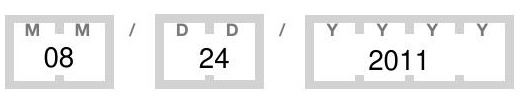

Amount of Each Receipt this Period

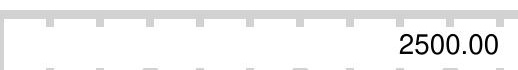

Transaction ID : AEC3BCE1CF250485D9EF Date of Receipt

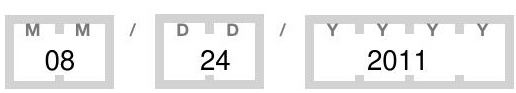

Amount of Each Receipt this Period

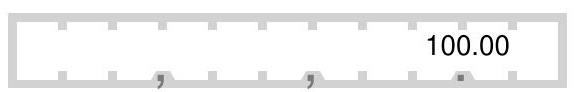

Subtotal Of Receipts This Page (optional)

2620.00

Total This Period (last page this line number only) 
SCHEDULE A-P ITEMIZED RECEIPTS
Use separate schedule(s) for each category of the Detailed Summary Page
FOR LINE NUMBER: (check only one)

PAGE 367 / 1572

\begin{tabular}{|c|c|c|c|c|c|}
\hline & & & & & \\
\hline 16 & $\begin{array}{l}\mathbf{X} \\
17 a\end{array}$ & $17 b$ & $17 c$ & $17 d$ & 18 \\
\hline $19 a$ & $19 \mathrm{~b}$ & $20 \mathrm{a}$ & $20 \mathrm{~b}$ & $20 \mathrm{c}$ & 21 \\
\hline
\end{tabular}

Any information copied from such Reports and Statements may not be sold or used by any person for the purpose of soliciting contributions or for commercial purposes, other than using the name and address of any political committee to solicit contributions from such committee.

NAME OF COMMITTEE (In Full)

\section{Friends of Herman Cain}

A. Full Name (Last, First, Middle Initial)

Barbara Hennigan

Mailing Address 5130 Anita Road

\begin{tabular}{lcc}
\hline City & State & Zip Code \\
Chico & CA & $95973-9759$ \\
\hline
\end{tabular}

FEC ID number of contributing federal political committee.

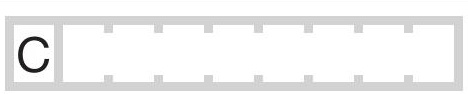

\begin{tabular}{l} 
Name of Employer \\
None \\
Receipt For: 2012 \\
X Primary $\quad$ General \\
\hline Other (specify)
\end{tabular}

Occupation

Retired

Election Cycle-to-Date

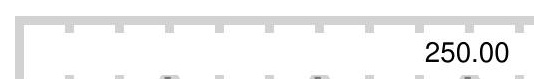

B. Full Name (Last, First, Middle Initial)

Burt Sugarman

Mailing Address 9440 Santa Monica Blvd. \#407

\begin{tabular}{lcc}
\hline City & State & Zip Code \\
Beverly Hills & CA & $90210-4607$
\end{tabular}

FEC ID number of contributing

federal political committee.

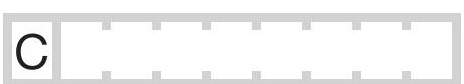

Name of Employer
Giant Group Limited
Receipt For: 2012
X Primary
Other (specify)

\section{Occupation} CEO

Election Cycle-to-Date

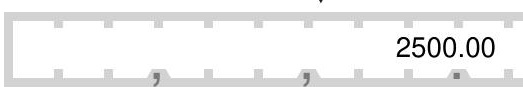

C. Full Name (Last, First, Middle Initial)

Greg Yacobian

Mailing Address 1916 Zenaida Ave

\begin{tabular}{lcc}
\hline City & State & Zip Code \\
McAllen & TX & $78504-5625$
\end{tabular}

FEC ID number of contributing federal political committee.

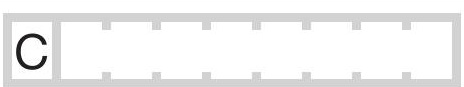

Name of Employer
Retired
Receipt For: 2012
Х Primary $\square$ General
Other (specify)

\section{Occupation}

Retired

Election Cycle-to-Date

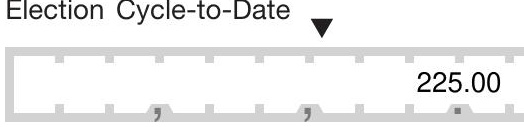

Transaction ID : A4A49A5D4BFCD44DB9DC

Date of Receipt

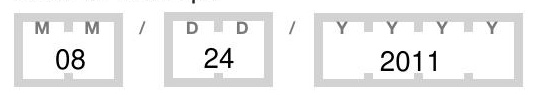

Amount of Each Receipt this Period

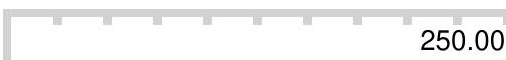

250.00

Transaction ID : A910C6DA16E0643829CB

Date of Receipt

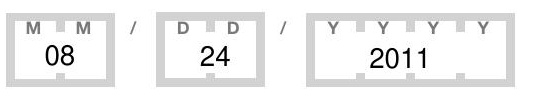

Amount of Each Receipt this Period

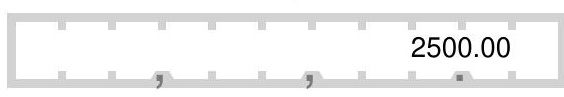

Transaction ID : AF043C4639FBE4C908A3 Date of Receipt

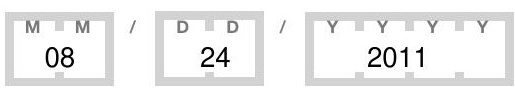

Amount of Each Receipt this Period

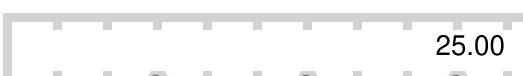

Subtotal Of Receipts This Page (optional)

Total This Period (last page this line number only) 
SCHEDULE A-P ITEMIZED RECEIPTS
Use separate schedule(s) for each category of the Detailed Summary Page
FOR LINE NUMBER: (check only one)

PAGE $368 / 1572$

\begin{tabular}{|c|c|c|c|c|c|}
\hline & & & & & \\
\hline 16 & $\begin{array}{l}\mathbf{X} \\
17 a\end{array}$ & $17 b$ & $17 c$ & $17 d$ & 18 \\
\hline $19 a$ & $19 \mathrm{~b}$ & $20 \mathrm{a}$ & $20 \mathrm{~b}$ & $20 \mathrm{c}$ & 21 \\
\hline
\end{tabular}

Any information copied from such Reports and Statements may not be sold or used by any person for the purpose of soliciting contributions or for commercial purposes, other than using the name and address of any political committee to solicit contributions from such committee.

NAME OF COMMITTEE (In Full)

\section{Friends of Herman Cain}

A. Full Name (Last, First, Middle Initial)

\section{Brian McGean}

Mailing Address 3027 General Lee Rd

\begin{tabular}{lcc}
\hline City & State & Zip Code \\
Macon & GA & $31204-1517$
\end{tabular}

FEC ID number of contributing federal political committee.

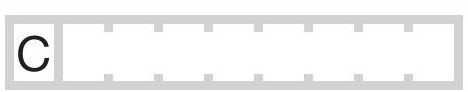

Name of Employer
self emplyed
Receipt For: 2012
X Primary
Other (specify) General

Occupation Psychology

Election Cycle-to-Date

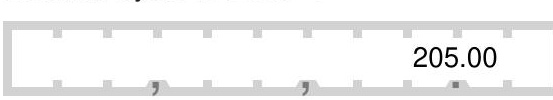

B. Full Name (Last, First, Middle Initial)

Laurie Miller

Mailing Address 1076 Northshire Ct., NE

\begin{tabular}{lcc}
\hline City & State & Zip Code \\
Keizer & OR & $97303-1838$
\end{tabular}

FEC ID number of contributing

federal political committee.

C

Name of Employer
Salem Hospital
Receipt For: 2012
X Primary
Other (specify)

Occupation NURSE

Election Cycle-to-Date

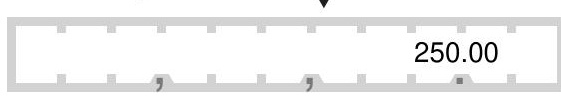

Transaction ID : A9CB626E754B94C768E6

Date of Receipt

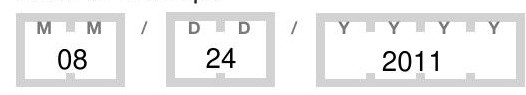

Amount of Each Receipt this Period

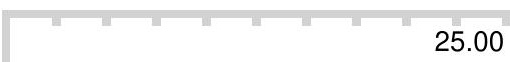

C. Full Name (Last, First, Middle Initial)

Mr Edward L Reed

Mailing Address 1337 Briarcliff Dr

\section{City}

Rantoul

FEC ID number of contributing federal political committee.

\section{Name of Employer}

Retired

Receipt For: 2012

Х $\begin{aligned} & \text { Primary } \square \text { General } \\ & \text { Other (specify) }\end{aligned}$

\section{State Zip Code \\ IL $\quad 61866-1701$}

C

\section{Occupation}

Retired

Election Cycle-to-Date

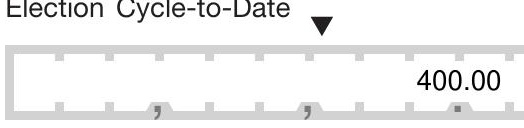

Transaction ID : A1D77C0D19AAA4122BCA Date of Receipt

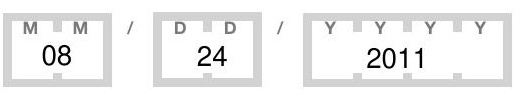

Amount of Each Receipt this Period

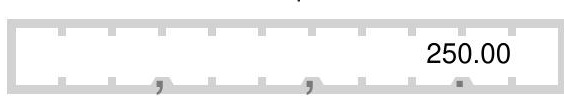

Transaction ID : A88A69FB779E844EEACD Date of Receipt

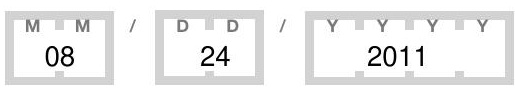

Amount of Each Receipt this Period

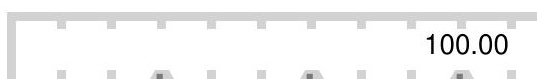

\section{Subtotal Of Receipts This Page (optional)}

375.00

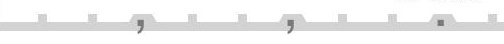

Total This Period (last page this line number only)

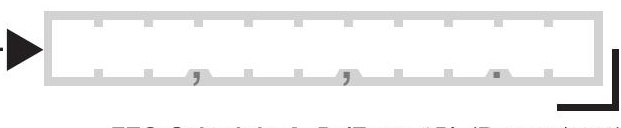

FEC Schedule A-P (Form 3P) (Rev. 03/2011) 
SCHEDULE A-P ITEMIZED RECEIPTS
Use separate schedule(s) for each category of the Detailed Summary Page
FOR LINE NUMBER: (check only one)

PAGE 369 / 1572

\begin{tabular}{|c|c|c|c|c|c|}
\hline & & & & & \\
\hline 16 & $\begin{array}{l}\mathbf{X} \\
17 a\end{array}$ & $17 b$ & $17 c$ & $17 d$ & 18 \\
\hline $19 a$ & $19 \mathrm{~b}$ & $20 \mathrm{a}$ & $20 \mathrm{~b}$ & $20 \mathrm{c}$ & 21 \\
\hline
\end{tabular}

Any information copied from such Reports and Statements may not be sold or used by any person for the purpose of soliciting contributions or for commercial purposes, other than using the name and address of any political committee to solicit contributions from such committee.

NAME OF COMMITTEE (In Full)

\section{Friends of Herman Cain}

A. Full Name (Last, First, Middle Initial) claire mencke

Mailing Address 5 tudor city place apt 305

\begin{tabular}{lcc}
\hline City & State & Zip Code \\
New York & NY & $10017-6858$
\end{tabular}

FEC ID number of contributing federal political committee.

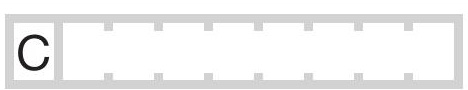

Name of Employer
buckingham research group
Receipt For: 2012
Primary
Other (specify) General

Occupation research assoc

Election Cycle-to-Date

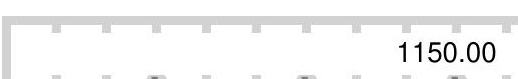

B. Full Name (Last, First, Middle Initial)

Doug Eames

Mailing Address 1385 West Coach Rd.
DO NOT MAIL

\begin{tabular}{lcc}
\hline City & State & Zip Code \\
Boulder & CO & $80302-9475$
\end{tabular}

FEC ID number of contributing

federal political committee.

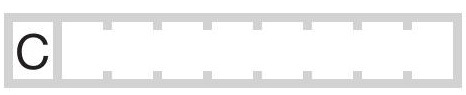

\begin{tabular}{l} 
Name of Employer \\
self \\
Receipt For: 2012 \\
X Primary $\square$ General \\
\hline Other (specify)
\end{tabular}

\section{Occupation \\ Announcer}

Election Cycle-to-Date

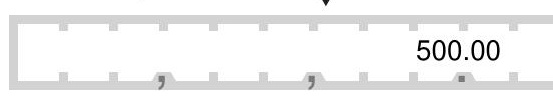

Transaction ID : AF30C2C08666644C7A87

Date of Receipt

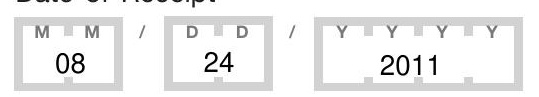

Amount of Each Receipt this Period

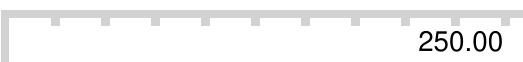

C. Full Name (Last, First, Middle Initial)

Janine Platt

Mailing Address 141 Wave Drive

\begin{tabular}{lcc}
\hline City & State & Zip Code \\
Whitethorn & CA & $95589-9158$
\end{tabular}

FEC ID number of contributing federal political committee.

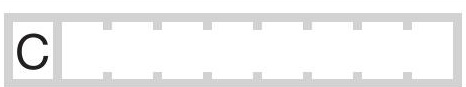

Name of Employer
NA
Receipt For: 2012
Х Primary $\quad \square$ General
Other (specify)

Occupation

Retired

Election Cycle-to-Date

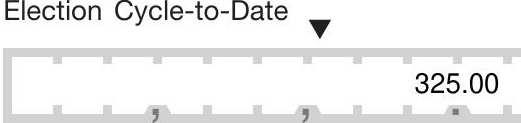

Amount of Each Receipt this Period

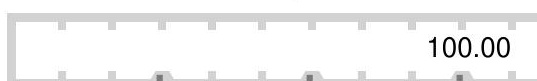

Transaction ID : AC485B251311B421AADC Date of Receipt

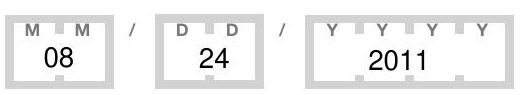

Transaction ID : ACA990D9C255342DABBA Date of Receipt

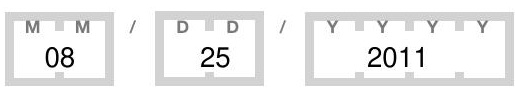

Amount of Each Receipt this Period

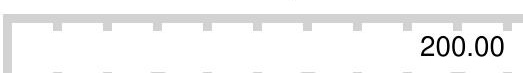

Subtotal Of Receipts This Page (optional).

Total This Period (last page this line number only) 
SCHEDULE A-P ITEMIZED RECEIPTS
Use separate schedule(s) for each category of the Detailed Summary Page
FOR LINE NUMBER: (check only one)

PAGE $370 / 1572$

\begin{tabular}{|c|c|c|c|c|c|}
\hline & & & & & \\
\hline 16 & $\begin{array}{l}\mathbf{X} \\
17 a\end{array}$ & $17 b$ & $17 c$ & $17 d$ & 18 \\
\hline $19 a$ & $19 \mathrm{~b}$ & $20 \mathrm{a}$ & $20 \mathrm{~b}$ & $20 \mathrm{c}$ & 21 \\
\hline
\end{tabular}

Any information copied from such Reports and Statements may not be sold or used by any person for the purpose of soliciting contributions or for commercial purposes, other than using the name and address of any political committee to solicit contributions from such committee.

NAME OF COMMITTEE (In Full)

\section{Friends of Herman Cain}

A. Full Name (Last, First, Middle Initial)

Cynthia Knudson

Mailing Address 5812 Colwell Rd

\begin{tabular}{lcc}
\hline City & State & Zip Code \\
Penryn & CA & $95663-9521$ \\
\hline
\end{tabular}

FEC ID number of contributing federal political committee.

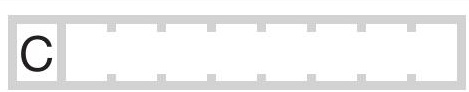

Name of Employer
Sacramento Coca-Cola Bottling
Receipt For: 2012
X Primary
Other (specify) General

Occupation

Director

Election Cycle-to-Date

300.00

B. Full Name (Last, First, Middle Initial)

KARL KORDECKI

Mailing Address 897 Miller Ave

\begin{tabular}{lcc}
\hline City & State & Zip Code \\
Dayton & OH & $45417-8331$ \\
\hline
\end{tabular}

FEC ID number of contributing

federal political committee.

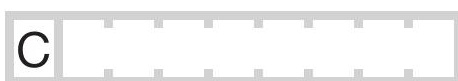

Name of Employer
ABF
Receipt For: 2012
X Primary
Other (specify)

Occupation

city driver/dock worker

Election Cycle-to-Date

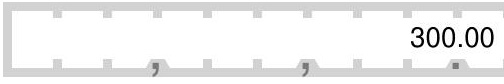

C. Full Name (Last, First, Middle Initial)

William White

Mailing Address 345 Willow Rd

\begin{tabular}{lcc}
\hline City & State & Zip Code \\
Winnetka & IL & $60093-4129$
\end{tabular}

FEC ID number of contributing federal political committee.

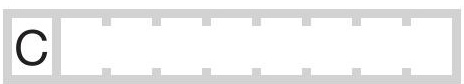

Name of Employer
None
Receipt For: 2012
Х Primary $\quad \square$ General
Other (specify)

Occupation

Retired

Election Cycle-to-Date

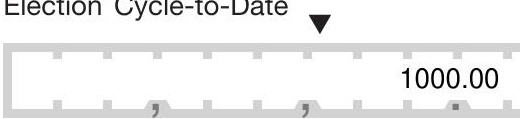

Transaction ID : A993382DFBB2A44E1A2B

Date of Receipt

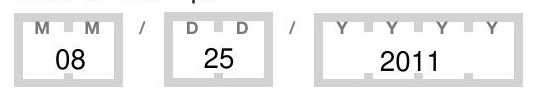

Amount of Each Receipt this Period

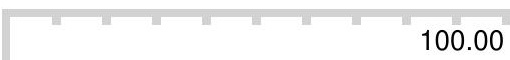

100.00

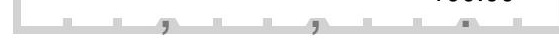

Transaction ID : AE51D365FF21B4341AC8

Date of Receipt

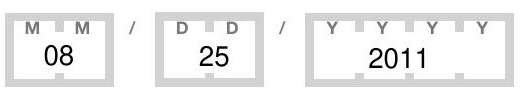

Amount of Each Receipt this Period

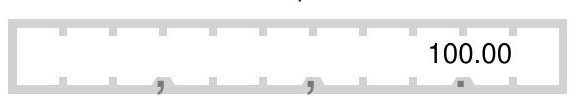

Transaction ID : A959ED17119C6412EB4F

Date of Receipt

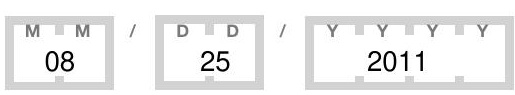

Amount of Each Receipt this Period

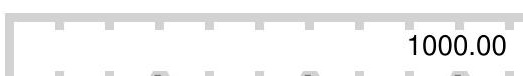

1000.00
Subtotal Of Receipts This Page (optional)

1200.00

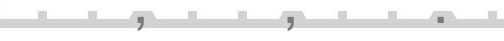

Total This Period (last page this line number only)

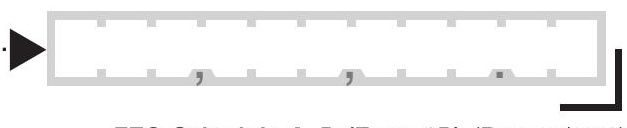

FEC Schedule A-P (Form 3P) (Rev. 03/2011) 
SCHEDULE A-P ITEMIZED RECEIPTS
Use separate schedule(s) for each category of the Detailed Summary Page
FOR LINE NUMBER: (check only one)

PAGE $371 / 1572$

\begin{tabular}{|c|c|c|c|c|c|c|}
\hline & & & & & & \\
\hline 16 & $\lambda$ & $17 \mathrm{a}$ & $17 \mathrm{~b}$ & $17 \mathrm{c}$ & $-17 d$ & -18 \\
\hline $19 a$ & & $19 b$ & $20 a$ & $20 \mathrm{~b}$ & $20 \mathrm{c}$ & 21 \\
\hline
\end{tabular}

Any information copied from such Reports and Statements may not be sold or used by any person for the purpose of soliciting contributions or for commercial purposes, other than using the name and address of any political committee to solicit contributions from such committee.

NAME OF COMMITTEE (In Full)

\section{Friends of Herman Cain}

A. Full Name (Last, First, Middle Initial) david brusso

Mailing Address 869 southwest drive

\begin{tabular}{lcc}
\hline City & State & Zip Code \\
Davidson & NC & $28036-7910$ \\
\hline
\end{tabular}

FEC ID number of contributing federal political committee.

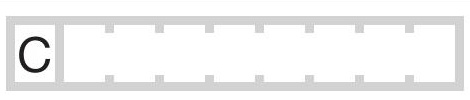

Name of Employer
self
Receipt For: 2012
X Primary $\quad$ General
Other (specify)

Occupation

Sales

Election Cycle-to-Date

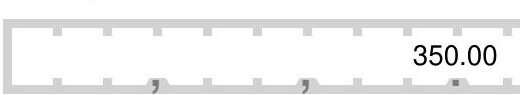

B. Full Name (Last, First, Middle Initial)

Reita King

Mailing Address 3870 Streamside Dr SE

\begin{tabular}{lcc}
\hline City & State & Zip Code \\
Marietta & GA & $30067-4700$ \\
\hline
\end{tabular}

FEC ID number of contributing

federal political committee.

C

Name of Employer
Information Requested
Receipt For: 2012
X Primary
Other (specify)

Occupation

Information Requested

Election Cycle-to-Date

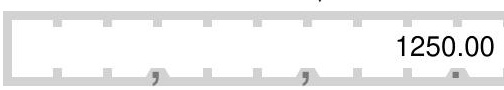

Transaction ID : A9D3B7D5490FF4C4E8FB

Date of Receipt

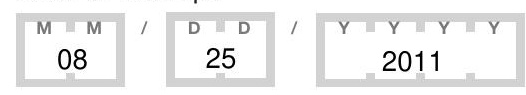

Amount of Each Receipt this Period

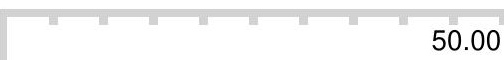

C. Full Name (Last, First, Middle Initial)

Lynn Zody

Mailing Address 708 Callaway $\mathrm{Dr}$

\begin{tabular}{lcc}
\hline City & State & Zip Code \\
Graniteville & SC & $29829-4054$
\end{tabular}

FEC ID number of contributing federal political committee.

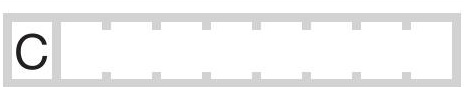

Name of Employer
Stix \& Co. Inc.
Receipt For: 2012
X Primary
Other (specify) General

Occupation FOOD SERVICE

Election Cycle-to-Date

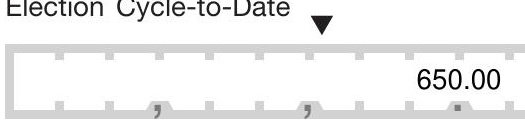

Transaction ID : A7CC18A97204C4E70B1A Date of Receipt

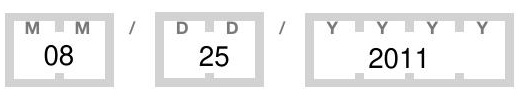

Amount of Each Receipt this Period

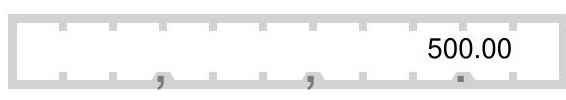

Transaction ID : AF7C7F7B74D8F4878881

Date of Receipt

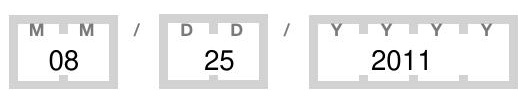

Amount of Each Receipt this Period

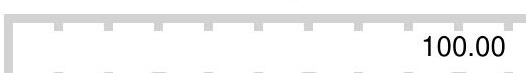

100.00

\section{Subtotal Of Receipts This Page (optional)}

Total This Period (last page this line number only) 
SCHEDULE A-P ITEMIZED RECEIPTS
Use separate schedule(s) for each category of the Detailed Summary Page
FOR LINE NUMBER: (check only one)

PAGE 372 / 1572

\begin{tabular}{|c|c|c|c|c|c|}
\hline & & & & & \\
\hline 16 & $\begin{array}{l}\mathbf{X} \\
17 a\end{array}$ & $17 b$ & $17 c$ & $17 d$ & 18 \\
\hline $19 a$ & $19 \mathrm{~b}$ & $20 \mathrm{a}$ & $20 \mathrm{~b}$ & $20 \mathrm{c}$ & 21 \\
\hline
\end{tabular}

Any information copied from such Reports and Statements may not be sold or used by any person for the purpose of soliciting contributions or for commercial purposes, other than using the name and address of any political committee to solicit contributions from such committee.

NAME OF COMMITTEE (In Full)

\section{Friends of Herman Cain}

A. Full Name (Last, First, Middle Initial)

Mary-Anne Mahaffy

Mailing Address 532 Lower Georges Valley Rd

\begin{tabular}{lcc}
\hline City & State & Zip Code \\
Spring Mills & PA & $16875-8200$
\end{tabular}

FEC ID number of contributing

federal political committee.

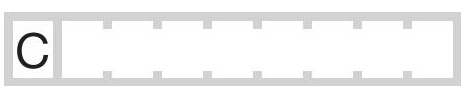

Name of Employer
Information Requested
Receipt For: 2012
X Primary
Other (specify) General

Occupation

Information Requested

Election Cycle-to-Date

400.00

B. Full Name (Last, First, Middle Initial)

John Scott

Mailing Address PO Box 66

\begin{tabular}{lcc}
\hline City & State & Zip Code \\
Lake Delton & WI & $53940-0066$
\end{tabular}

FEC ID number of contributing

federal political committee.

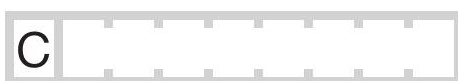

Name of Employer
Scott Construction
Receipt For: 2012
X Primary
Other (specify)

Occupation

Executive

Election Cycle-to-Date

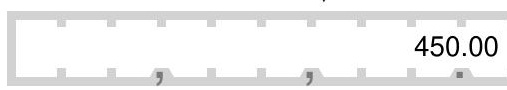

Transaction ID : A793A69315728432D8DC

Date of Receipt

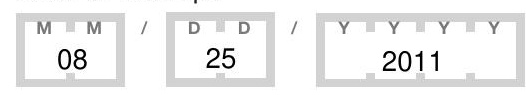

Amount of Each Receipt this Period

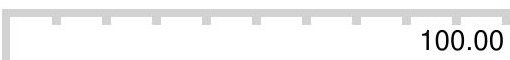

C. Full Name (Last, First, Middle Initial)

Beverly Kidder

Mailing Address 52 Railroad Place

\begin{tabular}{lcc}
\hline City & State & Zip Code \\
Hopewell & NJ & $08525-1818$
\end{tabular}

FEC ID number of contributing

federal political committee.

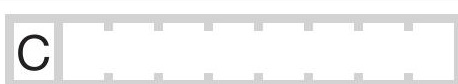

$\begin{aligned} & \text { Name of Employer } \\ & \text { self }\end{aligned}$
Receipt For: 2012
X Primary
Other (specify) General

Occupation

Sales

Election Cycle-to-Date

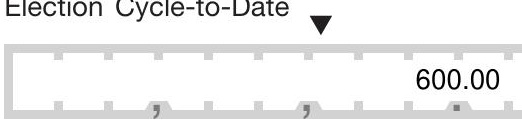

Amount of Each Receipt this Period

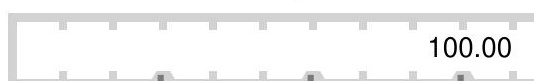

Transaction ID : AA1748D42758B48DC8FC

Date of Receipt

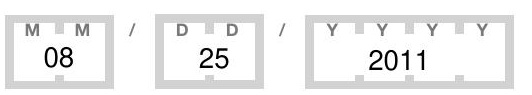

Transaction ID : A3028C32508FA4164AC2

Date of Receipt

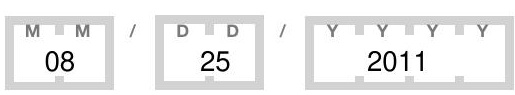

Amount of Each Receipt this Period

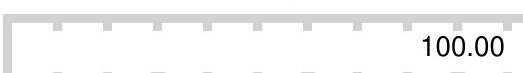

\section{Subtotal Of Receipts This Page (optional)}

300.00

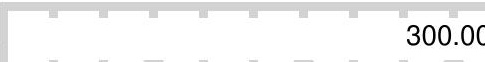

Total This Period (last page this line number only)

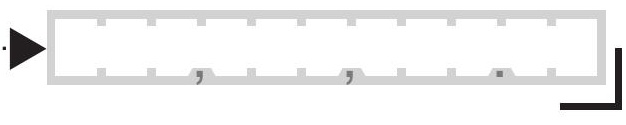

FEC Schedule A-P (Form 3P) (Rev. 03/2011) 
SCHEDULE A-P ITEMIZED RECEIPTS
Use separate schedule(s) for each category of the Detailed Summary Page
FOR LINE NUMBER: (check only one)

PAGE $373 / 1572$

\begin{tabular}{|c|c|c|c|c|c|}
\hline & & & & & \\
\hline 16 & $\mathbf{X} 17 a$ & $17 b$ & $17 c$ & $17 d$ & 18 \\
\hline $19 a$ & $19 b$ & $20 \mathrm{a}$ & $20 \mathrm{~b}$ & $20 \mathrm{c}$ & 21 \\
\hline
\end{tabular}

Any information copied from such Reports and Statements may not be sold or used by any person for the purpose of soliciting contributions or for commercial purposes, other than using the name and address of any political committee to solicit contributions from such committee.

NAME OF COMMITTEE (In Full)

\section{Friends of Herman Cain}

A. Full Name (Last, First, Middle Initial)

John Litland

Mailing Address 2958 Summitop Ct NE

\begin{tabular}{lcc}
\hline City & State & Zip Code \\
Marietta & GA & $30066-1632$
\end{tabular}

FEC ID number of contributing

federal political committee.

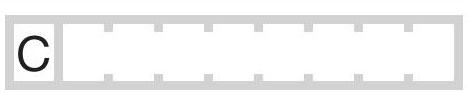

Name of Employer
Self Employed
Receipt For: 2012
X Primary $\quad$ General
Other (specify)

Occupation

Sales

Election Cycle-to-Date

400.00

B. Full Name (Last, First, Middle Initial)

Allen Simon

Mailing Address 1383 N Criss St

\begin{tabular}{lcc}
\hline City & State & Zip Code \\
Chandler & AZ & $85226-1307$ \\
\hline
\end{tabular}

FEC ID number of contributing

federal political committee.

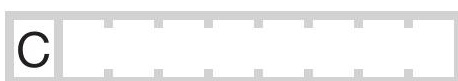

Name of Employer
Retired
Receipt For: 2012
X Primary
Other (specify)

\section{Occupation}

Retired

Election Cycle-to-Date

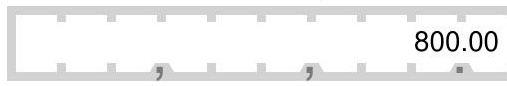

C. Full Name (Last, First, Middle Initial)

Alicia Wills

Mailing Address PO Box 67474

\begin{tabular}{lcc}
\hline City & State & Zip Code \\
Topeka & KS & $66667-0474$
\end{tabular}

FEC ID number of contributing federal political committee.

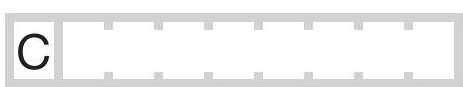

Name of Employer
Information Requested
Receipt For: 2012
X Primary
Other (specify) General

Occupation

Information Requested

Election Cycle-to-Date

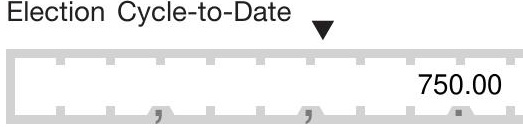

Transaction ID : AC8BB9DDFE5524257BED

Date of Receipt

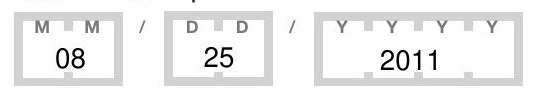

Amount of Each Receipt this Period

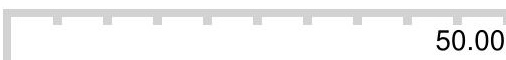

50.00

Transaction ID : AF24D331EF56E49C1852

Date of Receipt

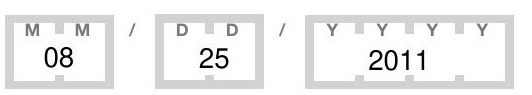

Amount of Each Receipt this Period

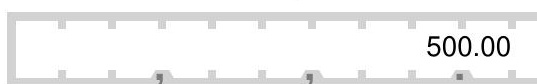

Transaction ID : A1965F289AEE74106B99

Date of Receipt

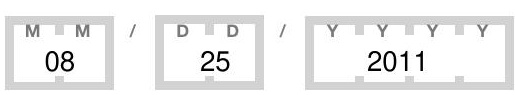

Amount of Each Receipt this Period

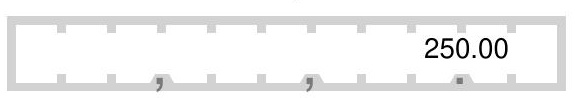

800.00

가.

Total This Period (last page this line number only)

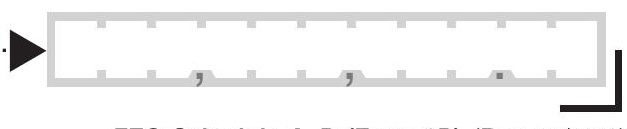

FEC Schedule A-P (Form 3P) (Rev. 03/2011) 
SCHEDULE A-P ITEMIZED RECEIPTS
Use separate schedule(s) for each category of the Detailed Summary Page
FOR LINE NUMBER: (check only one)

PAGE 374 / 1572

\begin{tabular}{|c|c|c|c|c|c|}
\hline & & & & & \\
\hline 16 & $\begin{array}{l}\mathbf{X} \\
17 a\end{array}$ & $17 b$ & $17 c$ & $17 d$ & 18 \\
\hline $19 a$ & $19 \mathrm{~b}$ & $20 \mathrm{a}$ & $20 \mathrm{~b}$ & $20 \mathrm{c}$ & 21 \\
\hline
\end{tabular}

Any information copied from such Reports and Statements may not be sold or used by any person for the purpose of soliciting contributions or for commercial purposes, other than using the name and address of any political committee to solicit contributions from such committee.

NAME OF COMMITTEE (In Full)

\section{Friends of Herman Cain}

A. Full Name (Last, First, Middle Initial)

Sylvia D Barnes

Mailing Address 75495 Road 436

\begin{tabular}{lcc}
\hline City & State & Zip Code \\
Lexington & NE & $68850-5638$ \\
\hline
\end{tabular}

FEC ID number of contributing federal political committee.

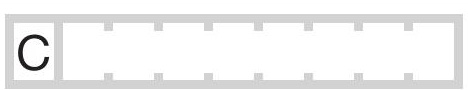

Name of Employer
None
Receipt For: 2012
X Primary $\quad$ General
Other (specify)

Occupation

Retired

Election Cycle-to-Date

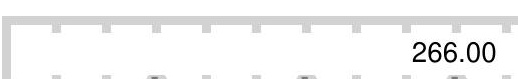

B. Full Name (Last, First, Middle Initial)

John Mansur

Mailing Address 4365 Hield Rd NW

\begin{tabular}{lcc}
\hline City & State & Zip Code \\
Palm Bay & FL & $32907-6312$ \\
\hline
\end{tabular}

FEC ID number of contributing

federal political committee.

C

Name of Employer
Information Requested
Receipt For: 2012
X Primary
Other (specify)

Occupation

Information Requested

Election Cycle-to-Date

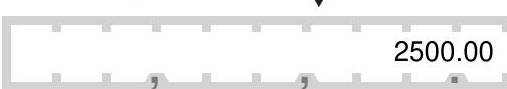

C. Full Name (Last, First, Middle Initial)

Jeanne Downer

Mailing Address $6007 \mathrm{~N}$ Kansas AVe

\begin{tabular}{lcc}
\hline City & State & Zip Code \\
Kansas City & MO & $64119-2115$
\end{tabular}

FEC ID number of contributing

federal political committee.

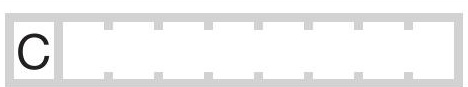

Name of Employer

WNB Architects

Occupation

Office Manager

Receipt For: 2012

Х $\begin{aligned} & \text { Primary } \square \text { General } \\ & \text { Other (specify) }\end{aligned}$

Election Cycle-to-Date

370.00

Transaction ID : AADC8B11F904E4717899

Date of Receipt

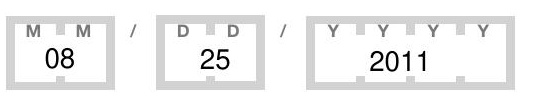

Amount of Each Receipt this Period

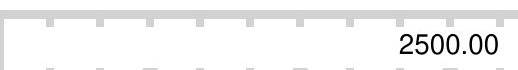

Transaction ID : AF3811AF235DF494DAD1

Date of Receipt

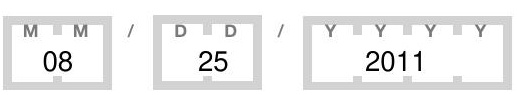

Amount of Each Receipt this Period

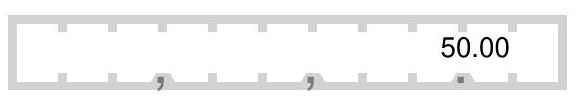

Subtotal Of Receipts This Page (optional).

2575.00

Total This Period (last page this line number only) 
SCHEDULE A-P ITEMIZED RECEIPTS
Use separate schedule(s) for each category of the Detailed Summary Page
FOR LINE NUMBER: (check only one)

PAGE $375 / 1572$

\begin{tabular}{|c|c|c|c|c|c|}
\hline & & & & & \\
\hline 16 & $\begin{array}{l}\mathbf{X} \\
17 a\end{array}$ & $17 b$ & $17 c$ & $17 d$ & 18 \\
\hline $19 a$ & $19 \mathrm{~b}$ & $20 \mathrm{a}$ & $20 \mathrm{~b}$ & $20 \mathrm{c}$ & 21 \\
\hline
\end{tabular}

Any information copied from such Reports and Statements may not be sold or used by any person for the purpose of soliciting contributions or for commercial purposes, other than using the name and address of any political committee to solicit contributions from such committee.

NAME OF COMMITTEE (In Full)

\section{Friends of Herman Cain}

A. Full Name (Last, First, Middle Initial)

Susan Geoffrion

Mailing Address 290 Seamarsh Ct NW

\begin{tabular}{lcc}
\hline City & State & Zip Code \\
Atlanta & GA & $30328-2741$
\end{tabular}

FEC ID number of contributing federal political committee.

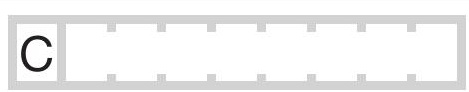

Name of Employer
Cobb county BOE Marietta Ga
Receipt For: 2012
X Primary
Other (specify) General

Occupation school psychologist

Election Cycle-to-Date 325.00

B. Full Name (Last, First, Middle Initial)

William Beal

Mailing Address 22474 470th Avenue

\begin{tabular}{lcc}
\hline City & State & Zip Code \\
Colman & SD & $57017-7127$
\end{tabular}

FEC ID number of contributing

federal political committee.

C

Name of Employer
Detp of Veterans Affairs
Receipt For: 2012
X Primary
Other (specify)

Occupation

IT Specialist

Election Cycle-to-Date

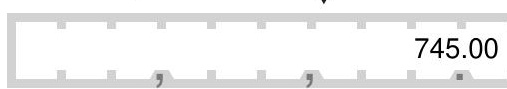

Transaction ID : A91C06AB21C434262B9A

Date of Receipt

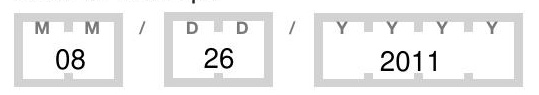

Amount of Each Receipt this Period

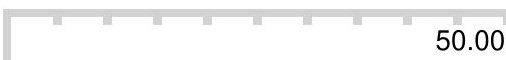

50.00

C. Full Name (Last, First, Middle Initial)

James Fincher

Mailing Address 1881 Calvin Drive

\begin{tabular}{lcc}
\hline City & State & Zip Code \\
Duluth & GA & $30097-5123$
\end{tabular}

FEC ID number of contributing

federal political committee.

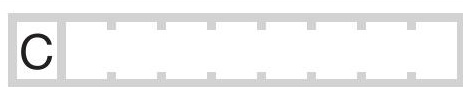

Name of Employer

Self Employed

Occupation

Receipt For: 2012

Х $\begin{aligned} & \text { Primary } \\ & \text { Other (specify) }\end{aligned}$

RE Developer

Transaction ID : A472A7F2ED86A41FC9F7

Date of Receipt

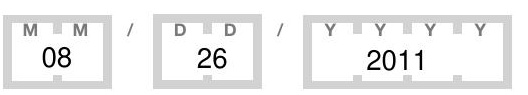

Amount of Each Receipt this Period

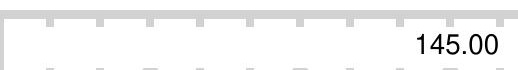

Transaction ID : A24FBDC2D80E74E57AB1 Date of Receipt

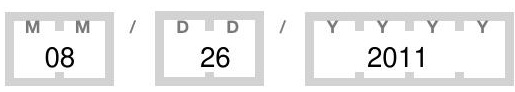

Amount of Each Receipt this Period

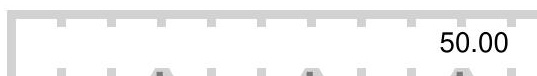

375.00

Subtotal Of Receipts This Page (optional)

245.00

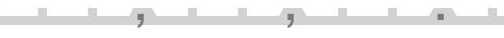

Total This Period (last page this line number only)

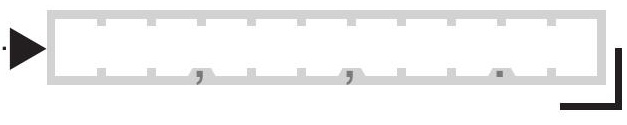

FEC Schedule A-P (Form 3P) (Rev. 03/2011) 
SCHEDULE A-P ITEMIZED RECEIPTS
Use separate schedule(s) for each category of the Detailed Summary Page
FOR LINE NUMBER: (check only one)

PAGE $376 / 1572$

\begin{tabular}{|c|c|c|c|c|c|}
\hline & & & & & \\
\hline 16 & $\begin{array}{l}\mathbf{X} \\
17 a\end{array}$ & $17 b$ & $17 c$ & $17 d$ & 18 \\
\hline $19 a$ & $19 \mathrm{~b}$ & $20 \mathrm{a}$ & $20 \mathrm{~b}$ & $20 \mathrm{c}$ & 21 \\
\hline
\end{tabular}

Any information copied from such Reports and Statements may not be sold or used by any person for the purpose of soliciting contributions or for commercial purposes, other than using the name and address of any political committee to solicit contributions from such committee.

NAME OF COMMITTEE (In Full)

\section{Friends of Herman Cain}

A. Full Name (Last, First, Middle Initial) Jack Dean

Mailing Address 4294 Highborne Dr

\begin{tabular}{lcc}
\hline City & State & Zip Code \\
Marietta & GA & $30066-2426$
\end{tabular}

FEC ID number of contributing federal political committee.

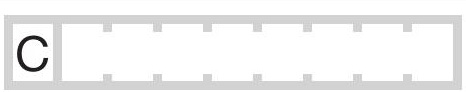

Name of Employer
Wells Fargo Bank NA
Receipt For: 2012
X Primary
Other (specify) General

Occupation

Systems Engineer

Election Cycle-to-Date

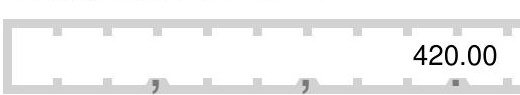

B. Full Name (Last, First, Middle Initial)

Gary Lindner

Mailing Address 5016 Prestwick Dr

\begin{tabular}{lcc}
\hline City & State & Zip Code \\
Fairfax & VA & $22030-4523$ \\
\hline
\end{tabular}

FEC ID number of contributing

federal political committee.

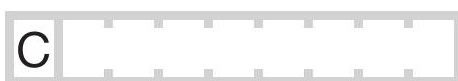

Name of Employer
GW Community School
Receipt For: 2012
X Primary
Other (specify)

\section{Occupation}

Teacher

Election Cycle-to-Date

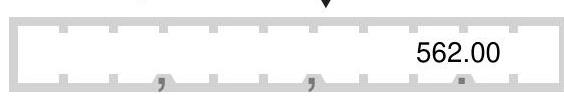

Transaction ID : A4546C871B7074DFA88E

Date of Receipt

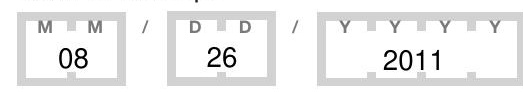

Amount of Each Receipt this Period

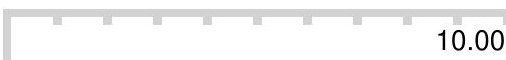

Transaction ID : A211B9B711DBF4A59AD5 Date of Receipt

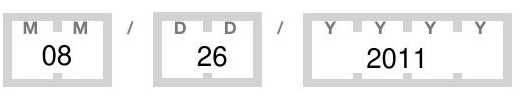

Amount of Each Receipt this Period

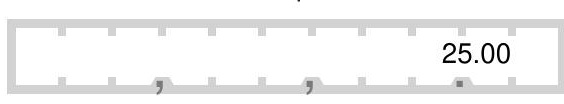

Transaction ID : A3A6BC830F02F41DB98A Date of Receipt

James Dowling

Mailing Address 2234 Meadowbrook Rd.

\begin{tabular}{lcc}
\hline City & State & Zip Code \\
Benton Harbor & MI & $49022-9605$
\end{tabular}

FEC ID number of contributing federal political committee.

C

Name of Employer

Not Employed

Occupation

Not Employed

Receipt For: 2012

Х $\begin{aligned} & \text { Primary } \square \text { General } \\ & \text { Other (specify) }\end{aligned}$

Subtotal Of Receipts This Page (optional).

Amount of Each Receipt this Period

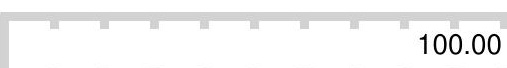

Total This Period (last page this line number only)

135.00

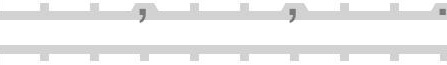

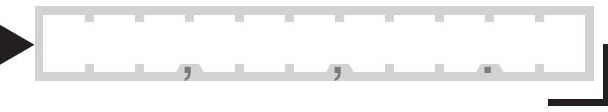

FEC Schedule A-P (Form 3P) (Rev. 03/2011) 
SCHEDULE A-P ITEMIZED RECEIPTS
Use separate schedule(s) for each category of the Detailed Summary Page
FOR LINE NUMBER: (check only one)

PAGE 377 / 1572

\begin{tabular}{|c|c|c|c|c|c|}
\hline & & & & & \\
\hline 16 & $\begin{array}{l}\mathbf{X} \\
17 a\end{array}$ & $17 b$ & $17 c$ & $17 d$ & 18 \\
\hline $19 a$ & $19 \mathrm{~b}$ & $20 \mathrm{a}$ & $20 \mathrm{~b}$ & $20 \mathrm{c}$ & 21 \\
\hline
\end{tabular}

Any information copied from such Reports and Statements may not be sold or used by any person for the purpose of soliciting contributions or for commercial purposes, other than using the name and address of any political committee to solicit contributions from such committee.

NAME OF COMMITTEE (In Full)

\section{Friends of Herman Cain}

A. Full Name (Last, First, Middle Initial)

\section{Carol Cook}

Mailing Address 43 Oak Alley

\section{City}

Kerrville

FEC ID number of contributing federal political committee.

Name of Employer
James Avery
Receipt For: 2012
X Primary $\quad \square$ General
Other (specify)

B. Full Name (Last, First, Middle Initial)

Mrs Margo C Cuthbert

Mailing Address 1684 Old Spring House Ln

\begin{tabular}{lcc}
\hline City & State & Zip Code \\
Atlanta & GA & $30338-6132$
\end{tabular}

FEC ID number of contributing

federal political committee.

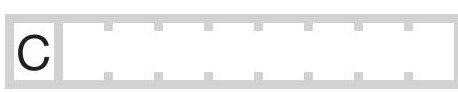

Name of Employer
None
Receipt For: 2012
X Primary
Other (specify)

C. Full Name (Last, First, Middle Initial) Joseph Daniell

Mailing Address 805 Streamside Dr.

\section{City}

McDonough

FEC ID number of contributing federal political committee.

Name of Employer
Dynamac Corp.
Receipt For: 2012
X Primary
Other (specify) General

\section{Occupation}

Sales Team Leader

Election Cycle-to-Date
Retired

Election Cycle-to-Date

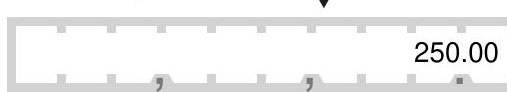

206.60
Transaction ID : AD5EB740602C74370926

Date of Receipt

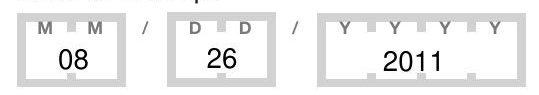

Amount of Each Receipt this Period

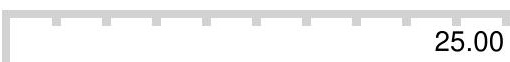

Transaction ID : AB8719AEDD2654D7B9E5 Date of Receipt

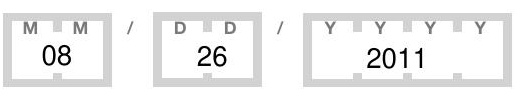

Amount of Each Receipt this Period

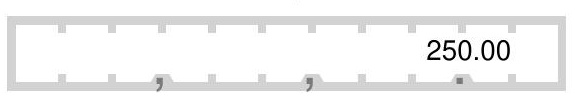

Transaction ID : ABC766CDB770F4A3CBBE Date of Receipt

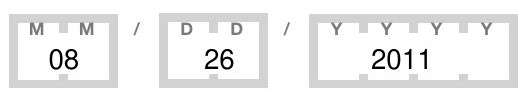

Amount of Each Receipt this Period

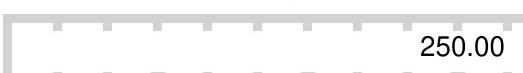

\section{Subtotal Of Receipts This Page (optional)}

Total This Period (last page this line number only) 
SCHEDULE A-P ITEMIZED RECEIPTS
Use separate schedule(s) for each category of the Detailed Summary Page
FOR LINE NUMBER: (check only one)

PAGE $378 / 1572$

\begin{tabular}{|c|c|c|c|c|c|}
\hline & & & & & \\
\hline 16 & $\begin{array}{l}\mathbf{X} \\
17 a\end{array}$ & $17 b$ & $17 c$ & $17 d$ & 18 \\
\hline $19 a$ & $19 \mathrm{~b}$ & $20 \mathrm{a}$ & $20 \mathrm{~b}$ & $20 \mathrm{c}$ & 21 \\
\hline
\end{tabular}

Any information copied from such Reports and Statements may not be sold or used by any person for the purpose of soliciting contributions or for commercial purposes, other than using the name and address of any political committee to solicit contributions from such committee.

NAME OF COMMITTEE (In Full)

\section{Friends of Herman Cain}

A. Full Name (Last, First, Middle Initial) John Leseth

Mailing Address 826 S Shore Dr

\begin{tabular}{lcc}
\hline City & State & Zip Code \\
Detroit Lakes & MN & $56501-4814$ \\
\hline
\end{tabular}

FEC ID number of contributing federal political committee.

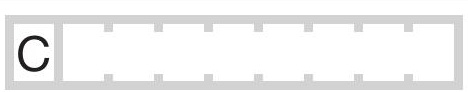

\begin{tabular}{l} 
Name of Employer \\
None \\
Receipt For: 2012 \\
X Primary $\quad$ General \\
\hline Other (specify)
\end{tabular}

Occupation Retired Election Cycle-to-Date

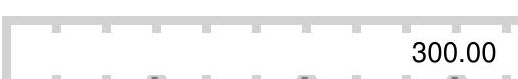

B. Full Name (Last, First, Middle Initial)

Mr D Stokes Sr

Mailing Address PO Box 47909

\begin{tabular}{lcc}
\hline City & State & Zip Code \\
Atlanta & GA & $30362-0909$ \\
\hline
\end{tabular}

FEC ID number of contributing

federal political committee.

C

Name of Employer
self
Receipt For: 2012
X Primary
Other (specify)

Occupation

Real Est Mgmnt

Election Cycle-to-Date

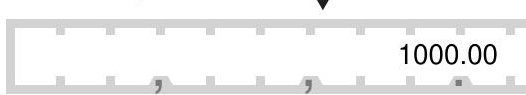

C. Full Name (Last, First, Middle Initial)

Ottis Cameron

Mailing Address 844 FM 473

\begin{tabular}{lcc}
\hline City & State & Zip Code \\
Comfort & TX & 78013-3607
\end{tabular}

FEC ID number of contributing federal political committee.

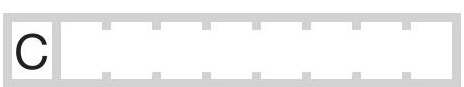

Name of Employer
self
Receipt For: 2012
X Primary $\quad \square$ General
Other (specify)

\section{Occupation}

aviation consultant

Election Cycle-to-Date
Transaction ID : AB908E0AF45B7480E89A

Date of Receipt

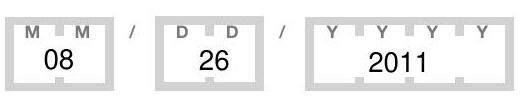

Amount of Each Receipt this Period

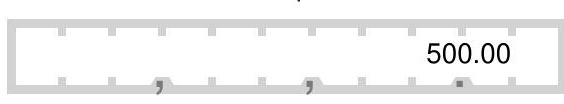

Transaction ID : A57CBD75DB3164D79B1A Date of Receipt

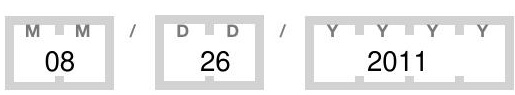

Amount of Each Receipt this Period

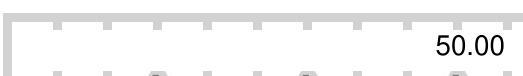

\section{Subtotal Of Receipts This Page (optional)}

Total This Period (last page this line number only) 
SCHEDULE A-P ITEMIZED RECEIPTS
Use separate schedule(s) for each category of the Detailed Summary Page
FOR LINE NUMBER: (check only one)

PAGE $379 / 1572$

\begin{tabular}{|c|c|c|c|c|c|}
\hline & & & & & \\
\hline 16 & $\begin{array}{l}\mathbf{X} \\
17 a\end{array}$ & $17 b$ & $17 c$ & $17 d$ & 18 \\
\hline $19 a$ & $19 \mathrm{~b}$ & $20 \mathrm{a}$ & $20 \mathrm{~b}$ & $20 \mathrm{c}$ & 21 \\
\hline
\end{tabular}

Any information copied from such Reports and Statements may not be sold or used by any person for the purpose of soliciting contributions or for commercial purposes, other than using the name and address of any political committee to solicit contributions from such committee.

NAME OF COMMITTEE (In Full)

\section{Friends of Herman Cain}

A. Full Name (Last, First, Middle Initial)

\section{Rex German}

Mailing Address P. O. Box 45

\section{City}

Cozad

State

NE

FEC ID number of contributing federal political committee.

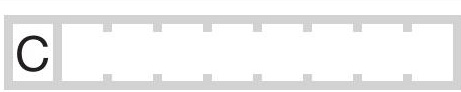

Name of Employer
Nebraska Plastics Inc.
Receipt For: 2012
X Primary
$\square$ Other (specify)

B. Full Name (Last, First, Middle Initial)

Michael Burgess

Mailing Address 22865 Redwood Dr

\begin{tabular}{lcc}
\hline City & State & Zip Code \\
Lawrenceburg & IN & $47025-7433$ \\
\hline
\end{tabular}

FEC ID number of contributing

federal political committee.

C

Name of Employer
Dearborn County Indiana
Receipt For: 2012
Primary
Other (specify)

C. Full Name (Last, First, Middle Initial)

Daniel Rucker

Mailing Address 1401 Timber Creek Dr

City

Friendswood

FEC ID number of contributing

federal political committee.

Name of Employer
Coastal Bend Property
Receipt For: 2012
X Primary
Other (specify) General

\section{Occupation}

CEO

Election Cycle-to-Date

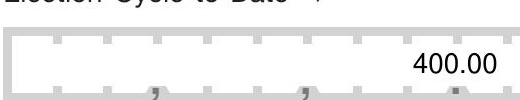

Occupation

Veterans Service Officer

Election Cycle-to-Date

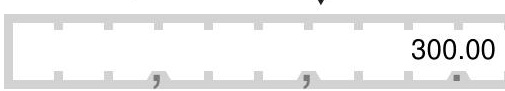

Transaction ID : AC7BD095D2D014B939A1

Date of Receipt

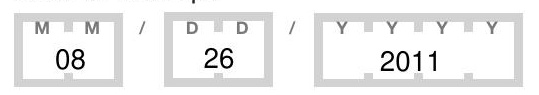

Amount of Each Receipt this Period

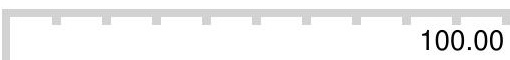

100.00

Transaction ID : A07FA4E6C144A4E93821

Date of Receipt

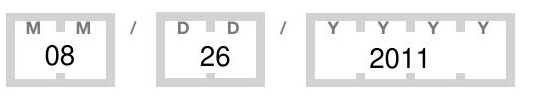

Amount of Each Receipt this Period

25.00

Transaction ID : A5E9DA6CE892447E988A Date of Receipt

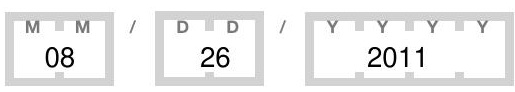

Amount of Each Receipt this Period

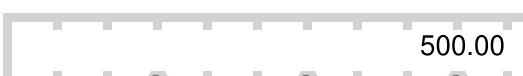

\section{Subtotal Of Receipts This Page (optional)}

625.00

Real Estate Developer

Election Cycle-to-Date

2500.00

Total This Period (last page this line number only) 
SCHEDULE A-P ITEMIZED RECEIPTS
Use separate schedule(s) for each category of the Detailed Summary Page
FOR LINE NUMBER: (check only one)

PAGE $380 / 1572$

\begin{tabular}{|c|c|c|c|c|c|}
\hline & & & & & \\
\hline 16 & $\begin{array}{l}\mathbf{X} \\
17 a\end{array}$ & $17 b$ & $17 c$ & $17 d$ & 18 \\
\hline $19 a$ & $19 \mathrm{~b}$ & $20 \mathrm{a}$ & $20 \mathrm{~b}$ & $20 \mathrm{c}$ & 21 \\
\hline
\end{tabular}

Any information copied from such Reports and Statements may not be sold or used by any person for the purpose of soliciting contributions or for commercial purposes, other than using the name and address of any political committee to solicit contributions from such committee.

NAME OF COMMITTEE (In Full)

\section{Friends of Herman Cain}

A. Full Name (Last, First, Middle Initial)

Mr. Larry Hochhalter

Mailing Address 24528 Madewood Ave

\begin{tabular}{lcc}
\hline City & State & Zip Code \\
Leesburg & FL & $34748-7879$ \\
\hline
\end{tabular}

FEC ID number of contributing federal political committee.

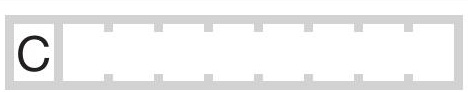

\begin{tabular}{l} 
Name of Employer \\
None \\
Receipt For: 2012 \\
X Primary $\quad$ General \\
\hline Other (specify)
\end{tabular}

Occupation

Retired

Election Cycle-to-Date

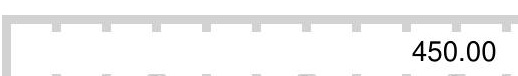

B. Full Name (Last, First, Middle Initial)

Haburn Arnold

Mailing Address 10510 Rivertown Rd

\begin{tabular}{lcc}
\hline City & State & Zip Code \\
Fairburn & GA & $30213-2169$ \\
\hline
\end{tabular}

FEC ID number of contributing

federal political committee.

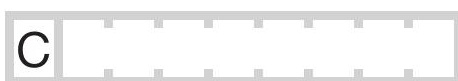

Name of Employer
Bruske Products Inc.
Receipt For: 2012
X Primary
Other (specify)

Occupation

Factory Rep.

Election Cycle-to-Date

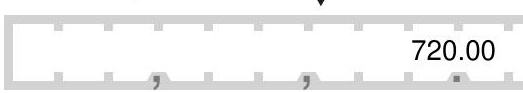

Transaction ID : A24E2D262E0A445B4B40

Date of Receipt

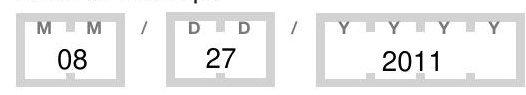

Amount of Each Receipt this Period

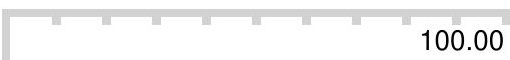

Transaction ID : A5DAF6E94538E4042BA8

Date of Receipt

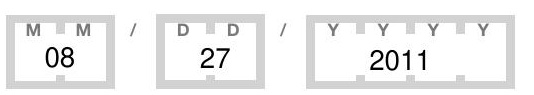

Amount of Each Receipt this Period

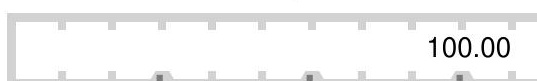

Transaction ID : AFE5D3DEEA0214AE182C Date of Receipt

lisa nichol

Mailing Address P.O.Box 2778

\begin{tabular}{lcc}
\hline City & State & Zip Code \\
Gainesville & GA & $30503-2778$
\end{tabular}

FEC ID number of contributing federal political committee.

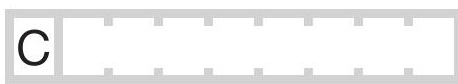

Name of Employer
comprehensive nursing care
Receipt For: 2012
X Primary
Other (specify) General

Occupation

President

Election Cycle-to-Date

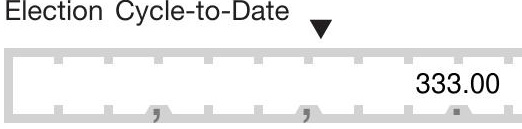

Subtotal Of Receipts This Page (optional)

Amount of Each Receipt this Period

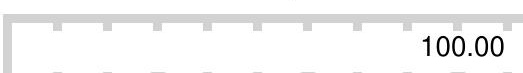

Total This Period (last page this line number only)

$\quad 300.00$

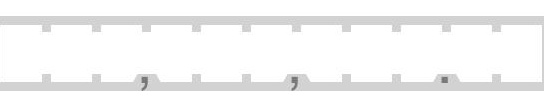

FEC Schedule A-P (Form 3P) (Rev. 03/2011) 
SCHEDULE A-P ITEMIZED RECEIPTS
Use separate schedule(s) for each category of the Detailed Summary Page

FOR LINE NUMBER:
(check only one)

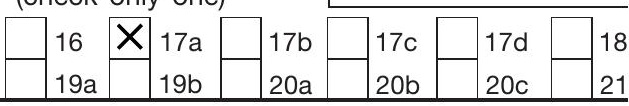

Any information copied from such Reports and Statements may not be sold or used by any person for the purpose of soliciting contributions or for commercial purposes, other than using the name and address of any political committee to solicit contributions from such committee.

NAME OF COMMITTEE (In Full)

\section{Friends of Herman Cain}

A. Full Name (Last, First, Middle Initial)

Rachel Little

Mailing Address 3945 Beaver Road

\begin{tabular}{lcc}
\hline City & State & Zip Code \\
Loganville & GA & $30052-7554$ \\
\hline
\end{tabular}

FEC ID number of contributing federal political committee.

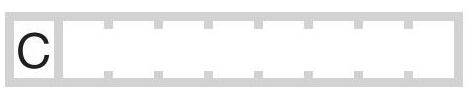

Name of Employer
Merial Limited
Receipt For: 2012
X Primary
Other (specify) General

Occupation Paralegal

Election Cycle-to-Date 2021.00

B. Full Name (Last, First, Middle Initial)

Wade Eppler

Mailing Address 1565 E 99th PI

\begin{tabular}{lcc}
\hline City & State & Zip Code \\
Thornton & CO & $80229-2220$
\end{tabular}

FEC ID number of contributing

federal political committee.

C

Name of Employer
G4S Security Solutions
Receipt For: 2012
$X$ Primary
Other (specify)

Occupation

Security Office

Election Cycle-to-Date

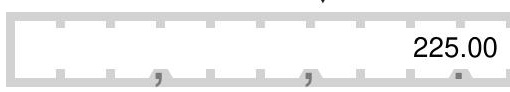

Transaction ID : A814D177BA1034E2DA62

Date of Receipt

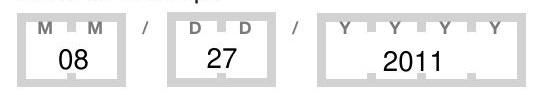

In-kind:Event Bus Rental

Amount of Each Receipt this Period

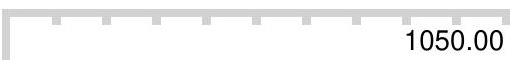

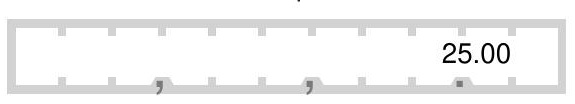

C. Full Name (Last, First, Middle Initial)

Leighton Wells

Mailing Address 717 Edgemont Way

\begin{tabular}{lcc}
\hline City & State & Zip Code \\
Springfield & OR & $97477-3607$
\end{tabular}

FEC ID number of contributing federal political committee.

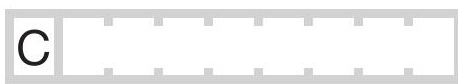

Name of Employer
$\mathrm{n} / \mathrm{a}$
Receipt For: 2012
X Primary

\section{Occupation}

Retired

Election Cycle-to-Date

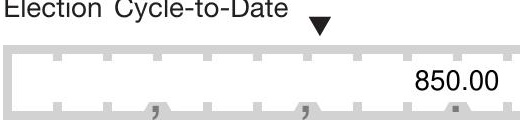

Transaction ID : AC76525BA2C2547FC839

Date of Receipt

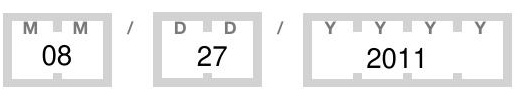

Amount of Each Receipt this Period

Transaction ID : A3EE8B57D0F2D4A63979 Date of Receipt

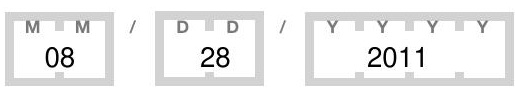

Amount of Each Receipt this Period

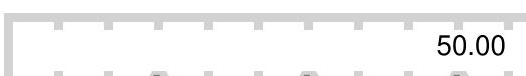

\section{Subtotal Of Receipts This Page (optional)}

Total This Period (last page this line number only) 


\section{SCHEDULE A-P} ITEMIZED RECEIPTS
Use separate schedule(s) for each category of the Detailed Summary Page

FOR LINE NUMBER:
(check only one)

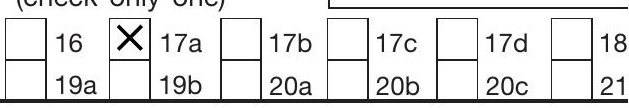

Any information copied from such Reports and Statements may not be sold or used by any person for the purpose of soliciting contributions or for commercial purposes, other than using the name and address of any political committee to solicit contributions from such committee.

NAME OF COMMITTEE (In Full)

\section{Friends of Herman Cain}

A. Full Name (Last, First, Middle Initial) James Stewart

Mailing Address 3560 E. Via Colonia del Sol

\begin{tabular}{lcc}
\hline City & State & Zip Code \\
Tucson & AZ & $85718-6065$
\end{tabular}

FEC ID number of contributing federal political committee.

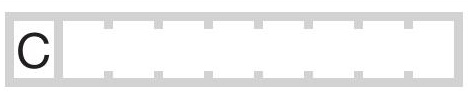

Name of Employer
Information Requested
Receipt For: 2012
X Primary
$\square$ Other (specify)

Occupation Information Requested

Election Cycle-to-Date

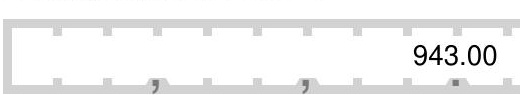

B. Full Name (Last, First, Middle Initial) Janelle Carter

Mailing Address 610 Elmwood Drive

\begin{tabular}{lcc}
\hline City & State & Zip Code \\
Marshalltown & IA & $50158-3886$ \\
\hline
\end{tabular}

FEC ID number of contributing

federal political committee.

C

Name of Employer
Information Requested
Receipt For: 2012
Primary
Other (specify)

Occupation

Information Requested

Election Cycle-to-Date

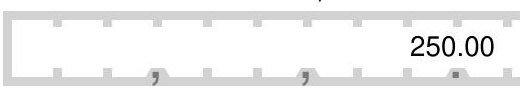

Transaction ID : A08EB91DC9FFB426687A

Date of Receipt

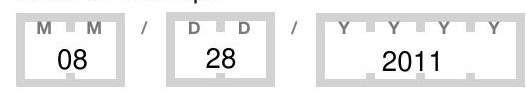

Amount of Each Receipt this Period

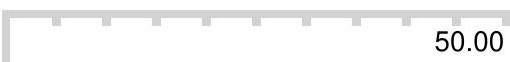

Transaction ID : A999256D3ECD44453A86

Date of Receipt

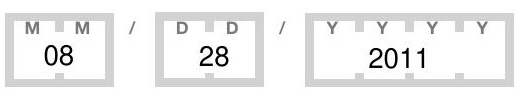

Amount of Each Receipt this Period

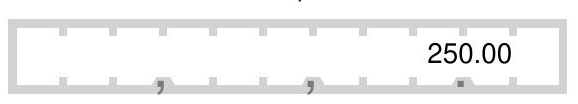

Transaction ID : AB388BCDA937541AD94B Date of Receipt

\section{Cliff Beveridge}

Mailing Address 1216 Gotier Trace Rd.

\begin{tabular}{lcc}
\hline City & State & Zip Code \\
Paige & TX & $78659-4400$ \\
\hline
\end{tabular}

FEC ID number of contributing federal political committee.

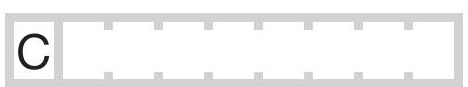

Name of Employer
Ultra Electronics-ATS
Receipt For: 2012
X Primary $\quad \square$ General
Other (specify)

Occupation

Senior Software Engineer

Election Cycle-to-Date

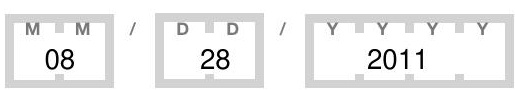

Amount of Each Receipt this Period

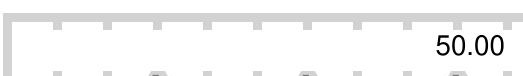

750.00
Subtotal Of Receipts This Page (optional).

350.00

a

Total This Period (last page this line number only)

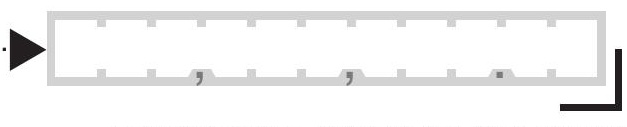

FEC Schedule A-P (Form 3P) (Rev. 03/2011) 
SCHEDULE A-P ITEMIZED RECEIPTS
Use separate schedule(s) for each category of the Detailed Summary Page
FOR LINE NUMBER: (check only one)

PAGE $383 / 1572$

\begin{tabular}{|c|c|c|c|c|c|}
\hline & & & & & \\
\hline 16 & $\begin{array}{lll}X & 17 a \\
\end{array}$ & $17 \mathrm{~b}$ & $17 c$ & $17 d$ & 18 \\
\hline $19 a$ & $19 b$ & $20 a$ & $20 \mathrm{~b}$ & $20 c$ & 21 \\
\hline
\end{tabular}

Any information copied from such Reports and Statements may not be sold or used by any person for the purpose of soliciting contributions or for commercial purposes, other than using the name and address of any political committee to solicit contributions from such committee.

NAME OF COMMITTEE (In Full)

\section{Friends of Herman Cain}

A. Full Name (Last, First, Middle Initial)

Sarajane Jablinske

Mailing Address 95 Cartis Parker Road

\begin{tabular}{lcc}
\hline City & State & Zip Code \\
Alexander & NC & 28701-9772
\end{tabular}

FEC ID number of contributing

federal political committee.

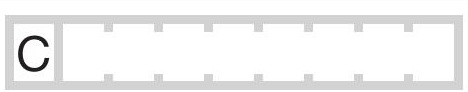

Name of Employer
Retired
Receipt For: 2012
X Primary $\quad$ General
Other (specify)

Occupation

Retired

Election Cycle-to-Date

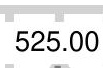

B. Full Name (Last, First, Middle Initial)

Carla Sanders

Mailing Address 342 Matson Rd

\begin{tabular}{llc}
\hline City & State & Zip Code \\
Kalama & WA & $98625-9719$ \\
\hline
\end{tabular}

FEC ID number of contributing

federal political committee.

C

Name of Employer
None
Receipt For: 2012
Primary
Other (specify)

\section{Occupation}

Homemaker

Election Cycle-to-Date

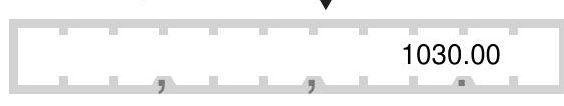

C. Full Name (Last, First, Middle Initial)

Carla Sanders

Mailing Address 342 Matson Rd

\begin{tabular}{lcc}
\hline City & State & Zip Code \\
Kalama & WA & $98625-9719$
\end{tabular}

FEC ID number of contributing federal political committee.

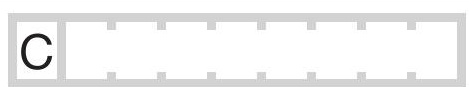

Name of Employer
None
Receipt For: 2012
Х Primary $\quad \square$ General
Other (specify)

Occupation

Homemaker

Election Cycle-to-Date

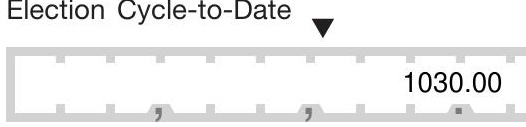

Transaction ID : A9B457393B14D4A8C9A4

Date of Receipt

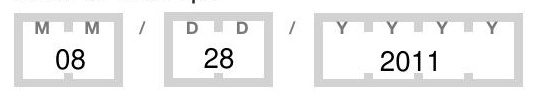

Amount of Each Receipt this Period

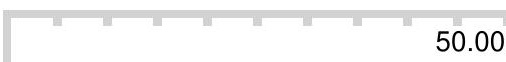

50.00
Amount of Each Receipt this Period

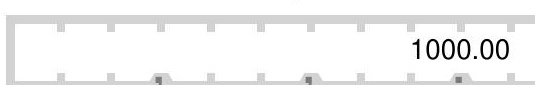

Transaction ID : AAD92D9A8D8D6473B872 Date of Receipt

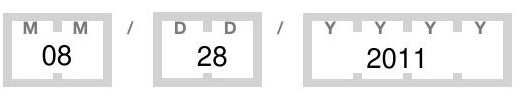

Transaction ID : ABADE2F2FBB5048C8B39 Date of Receipt

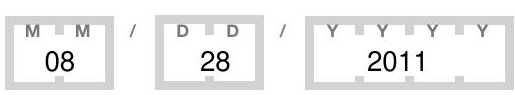

Amount of Each Receipt this Period

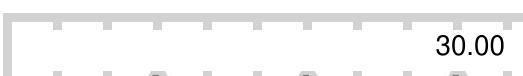

\section{Subtotal Of Receipts This Page (optional)}

Total This Period (last page this line number only) 
SCHEDULE A-P ITEMIZED RECEIPTS
Use separate schedule(s) for each category of the Detailed Summary Page
FOR LINE NUMBER: (check only one)

PAGE 384 / 1572

\begin{tabular}{|c|c|c|c|c|c|}
\hline & & & & & \\
\hline 16 & $\begin{array}{l}\mathbf{X} \\
17 a\end{array}$ & $17 b$ & $17 c$ & $17 d$ & 18 \\
\hline $19 a$ & $19 \mathrm{~b}$ & $20 \mathrm{a}$ & $20 \mathrm{~b}$ & $20 \mathrm{c}$ & 21 \\
\hline
\end{tabular}

Any information copied from such Reports and Statements may not be sold or used by any person for the purpose of soliciting contributions or for commercial purposes, other than using the name and address of any political committee to solicit contributions from such committee.

NAME OF COMMITTEE (In Full)

\section{Friends of Herman Cain}

A. Full Name (Last, First, Middle Initial)

EDWARD MURPHY

Mailing Address 214 CAMINO VISTA REAL

\begin{tabular}{lcc}
\hline City & State & Zip Code \\
Chula Vista & CA & $91910-6326$
\end{tabular}

FEC ID number of contributing federal political committee.

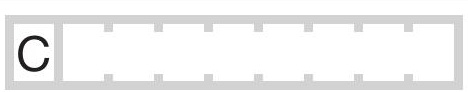

Name of Employer
navy exchange
Receipt For: 2012
X Primary
Other (specify) General

Occupation Retired

Election Cycle-to-Date

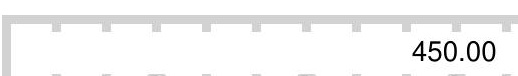

B. Full Name (Last, First, Middle Initial)

Miriam Burrows

Mailing Address 502 E 34th Street

\begin{tabular}{lcc}
\hline City & State & Zip Code \\
Silver City & NM & $\mathbf{8 8 0 6 1 - 5 9 1 4}$ \\
\hline
\end{tabular}

FEC ID number of contributing

federal political committee.

C

Name of Employer

Hallmark Cards

Occupation

Receipt For: 2012

Х $\begin{aligned} & \text { Primary } \\ & \text { Other (specify) }\end{aligned}$

part time merchandizer

Election Cycle-to-Date

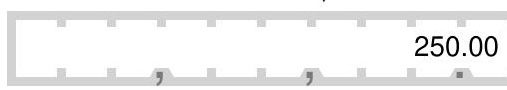

C. Full Name (Last, First, Middle Initial)

Mr Frederick Muzi

Mailing Address 10 Powisset St

\begin{tabular}{lcc}
\hline City & State & Zip Code \\
Dover & MA & $02030-1601$
\end{tabular}

FEC ID number of contributing federal political committee.

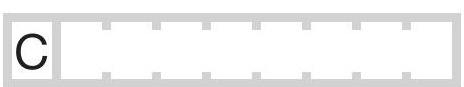

Name of Employer
None
Receipt For: 2012
Х Primary $\quad \square$ General
Other (specify)

Occupation

Retired

Election Cycle-to-Date

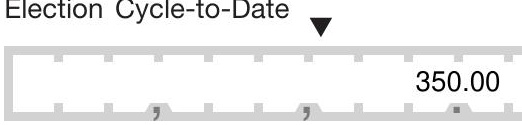

Transaction ID : AC75967964A8A4869938

Date of Receipt

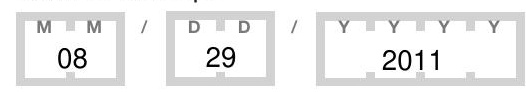

Amount of Each Receipt this Period

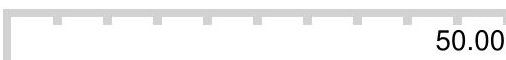

50.00

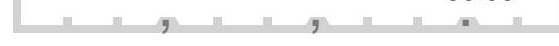

Transaction ID : A39D572B4E414462E863

Date of Receipt

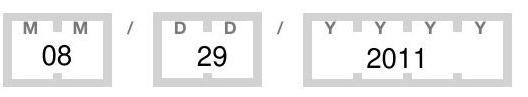

Amount of Each Receipt this Period

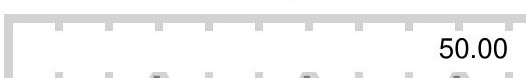

Transaction ID : A354FBF1DE0B94707A34 Date of Receipt

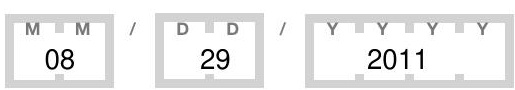

Amount of Each Receipt this Period

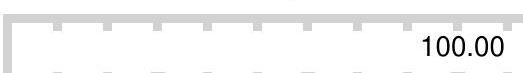

100.00

\section{Subtotal Of Receipts This Page (optional)}

Total This Period (last page this line number only) 
SCHEDULE A-P ITEMIZED RECEIPTS
Use separate schedule(s) for each category of the Detailed Summary Page
FOR LINE NUMBER: (check only one)

PAGE $385 / 1572$

\begin{tabular}{|c|c|c|c|c|c|}
\hline & & & & & \\
\hline 16 & $\begin{array}{l}\mathbf{X} \\
17 a\end{array}$ & $17 b$ & $17 c$ & $17 d$ & 18 \\
\hline $19 a$ & $19 \mathrm{~b}$ & $20 \mathrm{a}$ & $20 \mathrm{~b}$ & $20 \mathrm{c}$ & 21 \\
\hline
\end{tabular}

Any information copied from such Reports and Statements may not be sold or used by any person for the purpose of soliciting contributions or for commercial purposes, other than using the name and address of any political committee to solicit contributions from such committee.

NAME OF COMMITTEE (In Full)

\section{Friends of Herman Cain}

A. Full Name (Last, First, Middle Initial) James Montgomery

Mailing Address 2715 Lange Ct NE

\begin{tabular}{lcc}
\hline City & State & Zip Code \\
Marietta & GA & $30062-4427$
\end{tabular}

FEC ID number of contributing federal political committee.

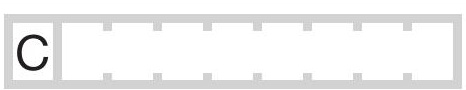

Name of Employer
Kennesaw State University
Receipt For: 2012
X Primary $\quad \square$ General
Other (specify)

Occupation

Teacher/Coach

Election Cycle-to-Date

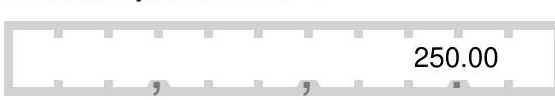

B. Full Name (Last, First, Middle Initial)

Susan Walter

Mailing Address P.O. Box 690

\begin{tabular}{lcc}
\hline City & State & Zip Code \\
Sautee Nacoochee & GA & $30571-0690$
\end{tabular}

FEC ID number of contributing

federal political committee.

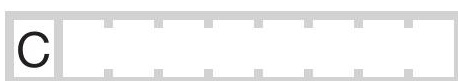

Name of Employer
None
Receipt For: 2012
X Primary
Other (specify)

\section{Occupation}

Retired

Election Cycle-to-Date

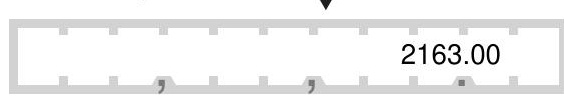

Transaction ID : A04D2AE8E51D14938B6E

Date of Receipt

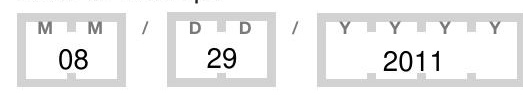

Amount of Each Receipt this Period

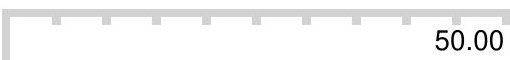

50.00

C. Full Name (Last, First, Middle Initial)

Bill Douglass

Mailing Address 2301 San Miguel

\begin{tabular}{lcc}
\hline City & State & Zip Code \\
Sherman & TX & $75092-2345$
\end{tabular}

FEC ID number of contributing federal political committee.

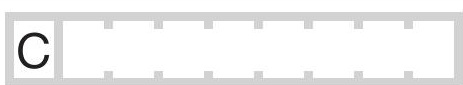

Name of Employer

Douglass Distributing Company

Receipt For: 2012

Х $\begin{aligned} & \text { Primary } \square \text { General } \\ & \text { Other (specify) }\end{aligned}$

\section{Occupation}

Owner

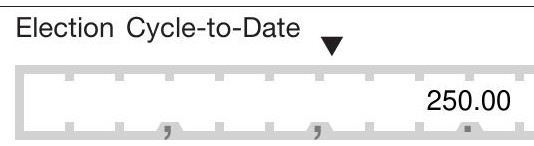

Transaction ID : A1413DDC0DEEA41F3A67 Date of Receipt

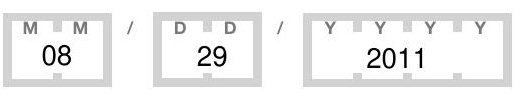

Amount of Each Receipt this Period

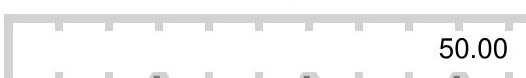

Transaction ID : A1863243F124444BFA70

Date of Receipt

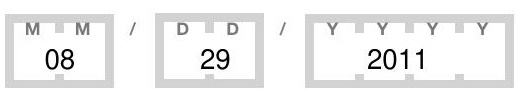

Amount of Each Receipt this Period

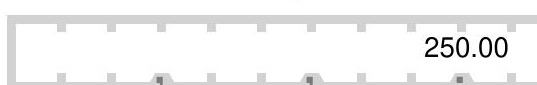

\section{Subtotal Of Receipts This Page (optional)}

Total This Period (last page this line number only) 
SCHEDULE A-P ITEMIZED RECEIPTS
Use separate schedule(s) for each category of the Detailed Summary Page
FOR LINE NUMBER: (check only one)

\begin{tabular}{|c|c|c|c|c|c|}
\hline & & & & & \\
\hline 16 & $\begin{array}{ll}X & 17 a \\
\end{array}$ & $17 \mathrm{~b}$ & $17 c$ & $17 d$ & 18 \\
\hline $19 a$ & $19 b$ & $20 \mathrm{a}$ & $20 \mathrm{~b}$ & $20 c$ & 21 \\
\hline
\end{tabular}

Any information copied from such Reports and Statements may not be sold or used by any person for the purpose of soliciting contributions or for commercial purposes, other than using the name and address of any political committee to solicit contributions from such committee.

NAME OF COMMITTEE (In Full)

\section{Friends of Herman Cain}

A. Full Name (Last, First, Middle Initial)

Phillip Matthews

Mailing Address 538 S Cavalier Ave.

\begin{tabular}{lcc}
\hline City & State & Zip Code \\
Springfield & MO & $65802-2620$
\end{tabular}

FEC ID number of contributing federal political committee.

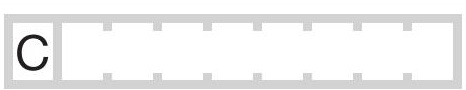

Name of Employer
Not Employed
Receipt For: 2012
X Primary $\quad$ General
Other (specify)

Occupation Not Employed

Election Cycle-to-Date

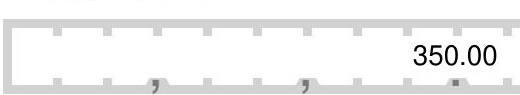

B. Full Name (Last, First, Middle Initial)

Jim Eure Jr.

Mailing Address PO Box 156

\begin{tabular}{lcc}
\hline City & State & Zip Code \\
Dahlonega & GA & $30533-0003$ \\
\hline
\end{tabular}

FEC ID number of contributing

federal political committee.

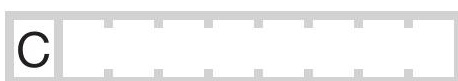

Name of Employer
Protex Security Systems
Receipt For: 2012
X Primary
Other (specify)

\section{Occupation}

Owner

Election Cycle-to-Date

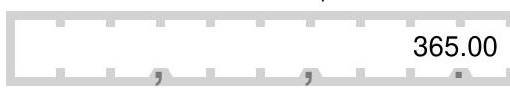

C. Full Name (Last, First, Middle Initial)

Walter Watkins

Mailing Address 1870 Bridle Ridge Trce

\begin{tabular}{lcc}
\hline City & State & Zip Code \\
Roswell & GA & $30075-2151$
\end{tabular}

FEC ID number of contributing federal political committee.

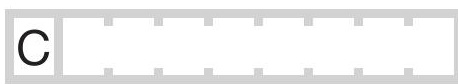

Name of Employer
ApolloMD
Receipt For: 2012
X Primary $\quad \square$ General
Other (specify)

Occupation

Physician

Election Cycle-to-Date

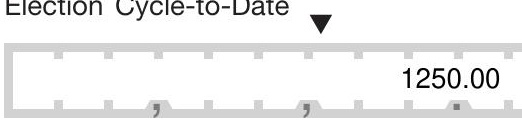

Transaction ID : A2A9F8074672A473083F

Date of Receipt

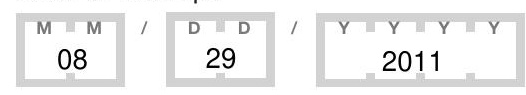

Amount of Each Receipt this Period

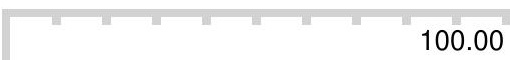

100.00

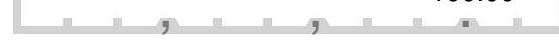

Transaction ID : A9AA38783825D4AB2B62

Date of Receipt

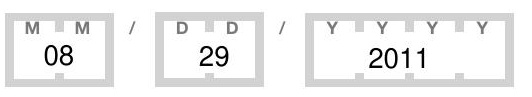

Amount of Each Receipt this Period

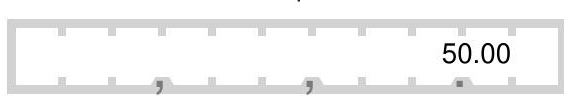

Transaction ID : AE6156BE35FC345F3949

Date of Receipt

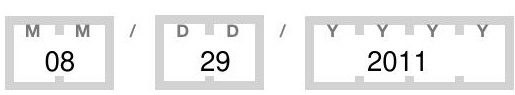

Amount of Each Receipt this Period

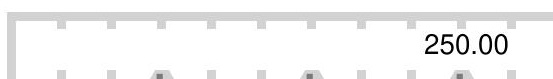

\section{Subtotal Of Receipts This Page (optional)}

400.00

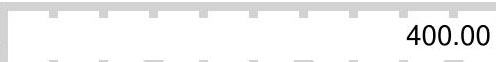

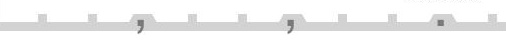

Total This Period (last page this line number only)

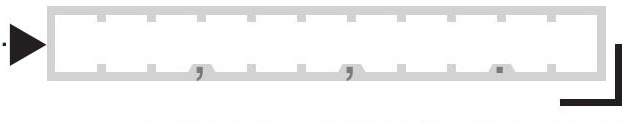

FEC Schedule A-P (Form 3P) (Rev. 03/2011) 
SCHEDULE A-P ITEMIZED RECEIPTS
Use separate schedule(s) for each category of the Detailed Summary Page
FOR LINE NUMBER: (check only one)

PAGE 387 / 1572

\begin{tabular}{|c|c|c|c|c|c|}
\hline & & & & & \\
\hline 16 & $\begin{array}{l}\mathbf{X} \\
17 a\end{array}$ & $17 b$ & $17 c$ & $17 d$ & 18 \\
\hline $19 a$ & $19 \mathrm{~b}$ & $20 \mathrm{a}$ & $20 \mathrm{~b}$ & $20 \mathrm{c}$ & 21 \\
\hline
\end{tabular}

Any information copied from such Reports and Statements may not be sold or used by any person for the purpose of soliciting contributions or for commercial purposes, other than using the name and address of any political committee to solicit contributions from such committee.

NAME OF COMMITTEE (In Full)

\section{Friends of Herman Cain}

A. Full Name (Last, First, Middle Initial) Jackie Jenkins

Mailing Address 4700 Balley Shannon Drive

\begin{tabular}{lcc}
\hline City & State & Zip Code \\
Mableton & GA & $30126-1752$
\end{tabular}

FEC ID number of contributing federal political committee.

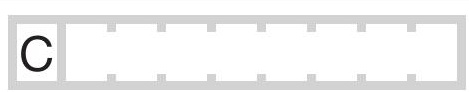

Name of Employer
MedSolutions
Receipt For: 2012
X Primary $\quad$ General
Other (specify)

Occupation medical management

Election Cycle-to-Date

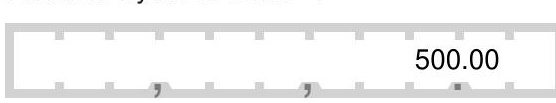

B. Full Name (Last, First, Middle Initial)

Carol Cook

\section{Mailing Address 43 Oak Alley}

\begin{tabular}{lcc}
\hline City & State & Zip Code \\
Kerrville & TX & $78028-1711$ \\
\hline
\end{tabular}

FEC ID number of contributing

federal political committee.

C

Name of Employer
James Avery
Receipt For: 2012
X Primary
Other (specify)

Occupation

Sales Team Leader

Election Cycle-to-Date

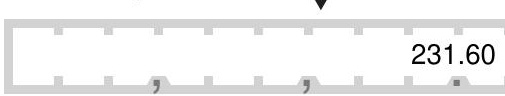

Transaction ID : AC17C37E94E214E539B6

Date of Receipt

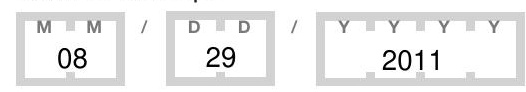

Amount of Each Receipt this Period

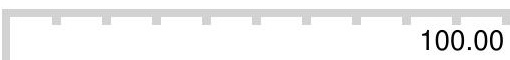

100.00

C. Full Name (Last, First, Middle Initial)

Susan Krechel

Mailing Address blackhorsefarm@myway.com

\begin{tabular}{lcc}
\hline City & State & Zip Code \\
Jonesburg & MO & 63351
\end{tabular}

FEC ID number of contributing federal political committee.

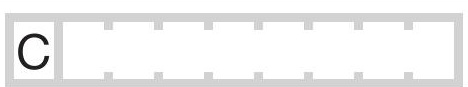

Name of Employer
None
Receipt For: 2012
Х Primary $\quad \square$ General
Other (specify)

Occupation

Retired

Election Cycle-to-Date

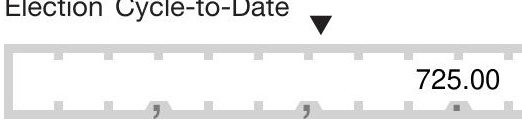

Transaction ID : AB6CEC71733214B00925

Date of Receipt

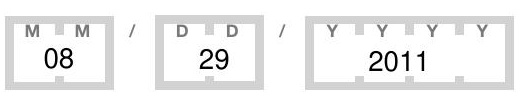

Amount of Each Receipt this Period

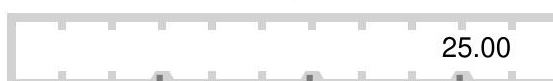

Transaction ID : A40A60323CCDD4E45A88 Date of Receipt

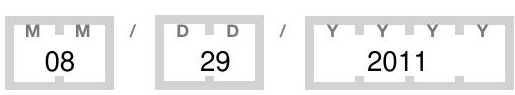

Amount of Each Receipt this Period

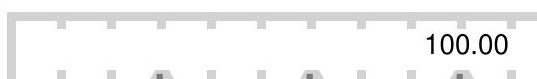

\section{Subtotal Of Receipts This Page (optional)}

Total This Period (last page this line number only) 
SCHEDULE A-P ITEMIZED RECEIPTS
Use separate schedule(s) for each category of the Detailed Summary Page
FOR LINE NUMBER: (check only one)

PAGE $388 / 1572$

\begin{tabular}{|c|c|c|c|c|c|}
\hline & & & & & \\
\hline 16 & $\begin{array}{l}\mathbf{X} \\
17 a\end{array}$ & $17 b$ & $17 c$ & $17 d$ & 18 \\
\hline $19 a$ & $19 \mathrm{~b}$ & $20 \mathrm{a}$ & $20 \mathrm{~b}$ & $20 \mathrm{c}$ & 21 \\
\hline
\end{tabular}

Any information copied from such Reports and Statements may not be sold or used by any person for the purpose of soliciting contributions or for commercial purposes, other than using the name and address of any political committee to solicit contributions from such committee.

NAME OF COMMITTEE (In Full)

\section{Friends of Herman Cain}

A. Full Name (Last, First, Middle Initial) Jack Mason

Mailing Address 762 Leonard Court

\begin{tabular}{lcc}
\hline City & State & Zip Code \\
Lawrenceville & GA & $30046-4789$ \\
\hline
\end{tabular}

FEC ID number of contributing federal political committee.

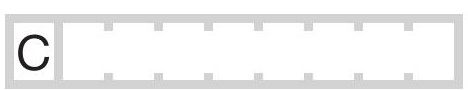

Name of Employer
Information Requested
Receipt For: 2012
X Primary
Other (specify) General

Occupation Information Requested

Election Cycle-to-Date

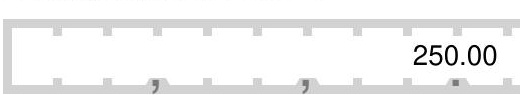

B. Full Name (Last, First, Middle Initial)

judy lund

Mailing Address 13903 110th Ave. Ct. E.

\begin{tabular}{llc}
\hline City & State & Zip Code \\
Puyallup & WA & $98374-3318$ \\
\hline
\end{tabular}

FEC ID number of contributing

federal political committee.

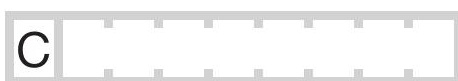

Name of Employer
None
Receipt For: 2012
X Primary
Other (specify)

\section{Occupation}

Retired

Election Cycle-to-Date

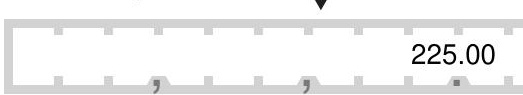

Transaction ID : ACD5DCA2882814968B12

Date of Receipt

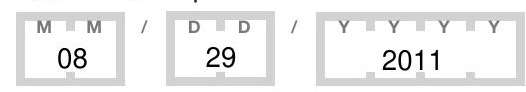

Amount of Each Receipt this Period

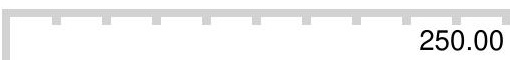

C. Full Name (Last, First, Middle Initial)

Jon Vincent

Mailing Address 1508 Miltary Cut-off road

\begin{tabular}{lcc}
\hline City & State & Zip Code \\
Wilmington & NC & $28403-5730$
\end{tabular}

FEC ID number of contributing federal political committee.

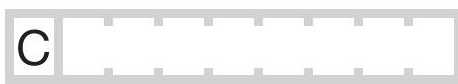

Name of Employer

Information Requested

\section{Occupation}

Information Requested

Receipt For: 2012

Х $\begin{aligned} & \text { Primary } \square \text { General } \\ & \text { Other (specify) }\end{aligned}$

Amount of Each Receipt this Period

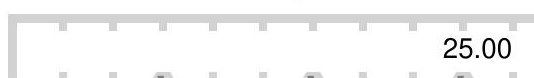

Transaction ID : AB5E96E2015AB4122AF2

Date of Receipt

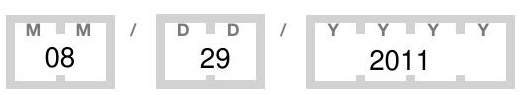

Transaction ID : ACB5823C9C3B5448DA22 Date of Receipt

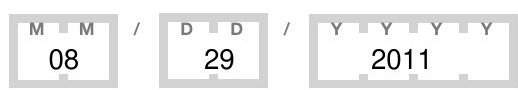

Amount of Each Receipt this Period

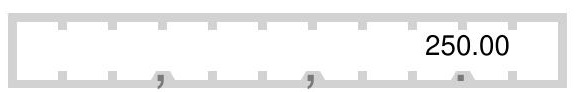

250.00

\section{Subtotal Of Receipts This Page (optional)}

Total This Period (last page this line number only) 
SCHEDULE A-P ITEMIZED RECEIPTS
Use separate schedule(s) for each category of the Detailed Summary Page
FOR LINE NUMBER: (check only one)

PAGE 389 / 1572

\begin{tabular}{|c|c|c|c|c|c|}
\hline & & & & & \\
\hline 16 & $\begin{array}{l}\mathbf{X} \\
17 a\end{array}$ & $17 b$ & $17 c$ & $17 d$ & 18 \\
\hline $19 a$ & $19 \mathrm{~b}$ & $20 \mathrm{a}$ & $20 \mathrm{~b}$ & $20 \mathrm{c}$ & 21 \\
\hline
\end{tabular}

Any information copied from such Reports and Statements may not be sold or used by any person for the purpose of soliciting contributions or for commercial purposes, other than using the name and address of any political committee to solicit contributions from such committee.

NAME OF COMMITTEE (In Full)

\section{Friends of Herman Cain}

A. Full Name (Last, First, Middle Initial)

Robby Lawson

Mailing Address 9622 Vermilion Dr

\begin{tabular}{lcc}
\hline City & State & Zip Code \\
Knoxville & TN & 37922-5821 \\
\hline
\end{tabular}

FEC ID number of contributing federal political committee.

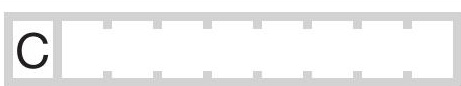

\section{Name of Employer}

ABF Freight System, Inc.

Occupation

Receipt For: 2012

Х Primary $\square$ General operations supervisor

Election Cycle-to-Date

275.00

B. Full Name (Last, First, Middle Initial)

Norman Boyd

Mailing Address 9145 Old Southwick Pass

\begin{tabular}{lcc}
\hline City & State & Zip Code \\
Alpharetta & GA & $30022-6253$
\end{tabular}

FEC ID number of contributing

federal political committee.

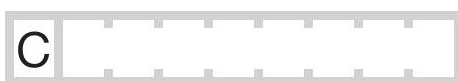

Name of Employer

International Business Divisions, LLC

Occupation

Receipt For: 2012

$\chi \begin{aligned} & \text { Primary } \\ & \text { Other (specify) }\end{aligned}$

Consultant

Transaction ID : A15C9FF7B21DD4A2AB44

Date of Receipt

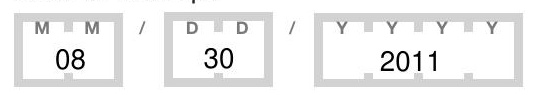

Amount of Each Receipt this Period

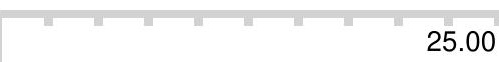

25.00

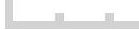

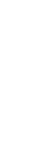

Transaction ID : A56192EA8F3D44923B60

Date of Receipt

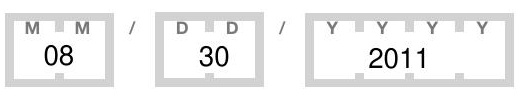

Amount of Each Receipt this Period

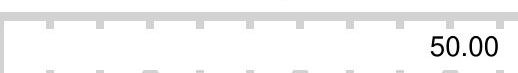

Election Cycle-to-Date

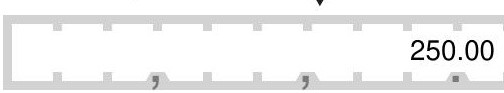

C. Full Name (Last, First, Middle Initial)

James Stewart

Mailing Address 3560 E. Via Colonia del Sol

\begin{tabular}{lcc}
\hline City & State & Zip Code \\
Tucson & AZ & $85718-6065$
\end{tabular}

FEC ID number of contributing

federal political committee.

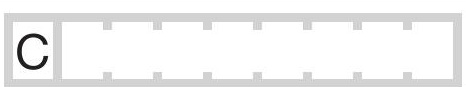

Name of Employer

Occupation

Information Requested

Information Requested

Receipt For: 2012

Х $\begin{aligned} & \text { Primary } \\ & \text { Other (specify) }\end{aligned}$

Transaction ID : A372B57995E3A4E6AA5C Date of Receipt

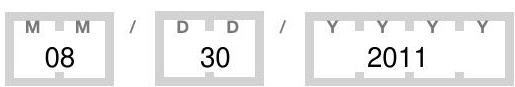

Amount of Each Receipt this Period

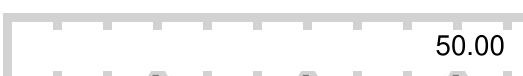

\section{Subtotal Of Receipts This Page (optional)}

Total This Period (last page this line number only) 
SCHEDULE A-P ITEMIZED RECEIPTS
Use separate schedule(s) for each category of the Detailed Summary Page
FOR LINE NUMBER: (check only one)

PAGE $390 / 1572$

\begin{tabular}{|c|c|c|c|c|c|}
\hline & & & & & \\
\hline 16 & $\begin{array}{l}\mathbf{X} \\
17 a\end{array}$ & $17 b$ & $17 c$ & $17 d$ & 18 \\
\hline $19 a$ & $19 \mathrm{~b}$ & $20 \mathrm{a}$ & $20 \mathrm{~b}$ & $20 \mathrm{c}$ & 21 \\
\hline
\end{tabular}

Any information copied from such Reports and Statements may not be sold or used by any person for the purpose of soliciting contributions or for commercial purposes, other than using the name and address of any political committee to solicit contributions from such committee.

NAME OF COMMITTEE (In Full)

\section{Friends of Herman Cain}

A. Full Name (Last, First, Middle Initial)

\section{Gerald Hudgins}

Mailing Address 125 Westridge Ind. Blvd.

Ste. 200

\begin{tabular}{lcc}
\hline City & State & Zip Code \\
McDonough & GA & $30253-9099$
\end{tabular}

FEC ID number of contributing

federal political committee.

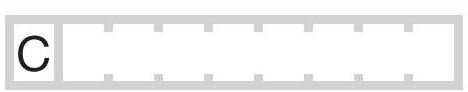

Name of Employer
Self Employed
Receipt For: 2012
X Primary $\quad$ General
Other (specify)

\section{Occupation}

Real Estate

Election Cycle-to-Date

1500.00

B. Full Name (Last, First, Middle Initial)

Donna Coghlan

Mailing Address 173 Massey Rd

\begin{tabular}{lcc}
\hline City & State & Zip Code \\
Homer & GA & $30547-1646$ \\
\hline
\end{tabular}

FEC ID number of contributing

federal political committee.

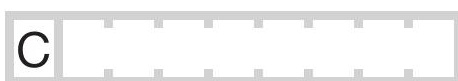

Name of Employer
n/a
Receipt For: 2012
X Primary
Other (specify)

\section{Occupation}

Retired

Election Cycle-to-Date

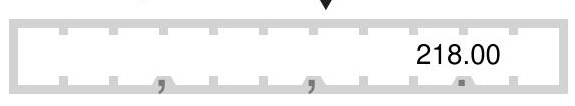

C. Full Name (Last, First, Middle Initial)

R.E. Goff

Mailing Address 2201 S. Brink Ave.

\begin{tabular}{lcc}
\hline City & State & Zip Code \\
Sarasota & FL & $34239-4206$
\end{tabular}

FEC ID number of contributing federal political committee.

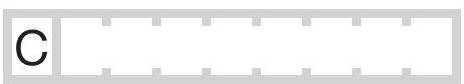

Name of Employer
Information Requested
Receipt For: 2012
X Primary $\quad \square$ General
Other (specify)

\section{Occupation}

Information Requested

Election Cycle-to-Date
Transaction ID : A90C8AAD0F6A045D986F

Date of Receipt

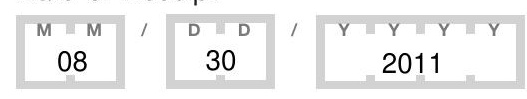

Amount of Each Receipt this Period

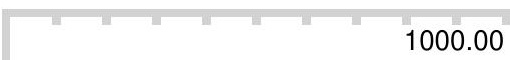

1000.00
Amount of Each Receipt this Period

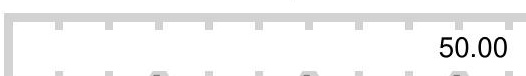

Transaction ID : A5CA5988837E8454497C

Date of Receipt

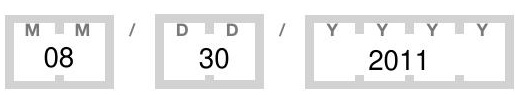

Transaction ID : A907BA04D92674E9999F Date of Receipt

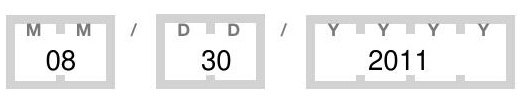

Amount of Each Receipt this Period

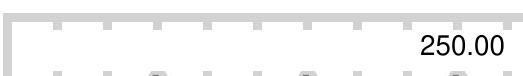

350.00

\section{Subtotal Of Receipts This Page (optional)}

Total This Period (last page this line number only) 


\section{SCHEDULE A-P} ITEMIZED RECEIPTS
Use separate schedule(s)

for each category of the

Detailed Summary Page
FOR LINE NUMBER: (check only one)

PAGE $391 / 1572$

\begin{tabular}{|c|c|c|c|c|c|}
\hline & & & & & \\
\hline 16 & $\mathbf{X} 17 \mathrm{a}$ & $17 \mathrm{~b}$ & $17 c$ & $17 d$ & 18 \\
\hline $19 a$ & $19 \mathrm{~b}$ & $20 a$ & $20 \mathrm{~b}$ & $20 c$ & 21 \\
\hline
\end{tabular}

Any information copied from such Reports and Statements may not be sold or used by any person for the purpose of soliciting contributions or for commercial purposes, other than using the name and address of any political committee to solicit contributions from such committee.

NAME OF COMMITTEE (In Full)

Friends of Herman Cain

A. Full Name (Last, First, Middle Initial)

James R Thompson

Mailing Address 4018 Keeneland Court

\begin{tabular}{lcc}
\hline City & State & Zip Code \\
Duluth & GA & $30096-5419$
\end{tabular}

FEC ID number of contributing

federal political committee.

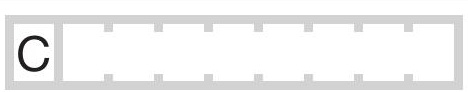

Name of Employer
Information Requested
Receipt For: 2012
X Primary $\quad \square$ General
Other (specify)

Occupation

Information Requested

Election Cycle-to-Date

1530.00

B. Full Name (Last, First, Middle Initial)

Thomas E Hennigan

Mailing Address 56 Lydia Dr

\begin{tabular}{lcc}
\hline City & State & Zip Code \\
West New York & NJ & $07093-8367$
\end{tabular}

FEC ID number of contributing

federal political committee.

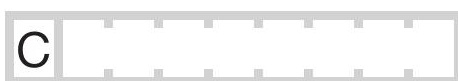

Name of Employer
Information Requested
Receipt For: 2012
X Primary
Other (specify)

Occupation

Information Requested

Election Cycle-to-Date

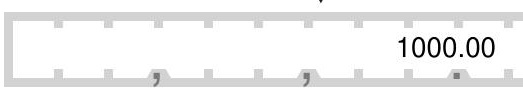

C. Full Name (Last, First, Middle Initial)

James Revennaugh

Mailing Address 1012 Token Way

\begin{tabular}{lcc}
\hline City & State & Zip Code \\
Kennesaw & GA & $30152-3981$ \\
\hline
\end{tabular}

FEC ID number of contributing

federal political committee.

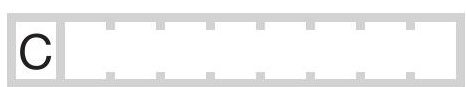

Name of Employer

\section{Occupation}

Emory University

Receipt For: 2012

Х $\begin{aligned} & \text { Primary } \\ & \text { Other (specify) }\end{aligned}$

IT

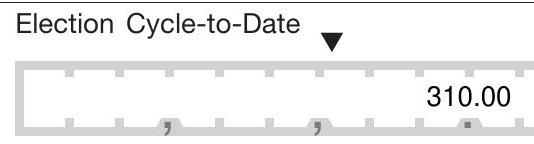

Amount of Each Receipt this Period

Transaction ID : A4A68622746C540CFB69

Date of Receipt

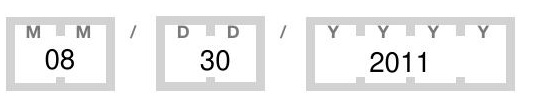

Amount of Each Receipt this Period
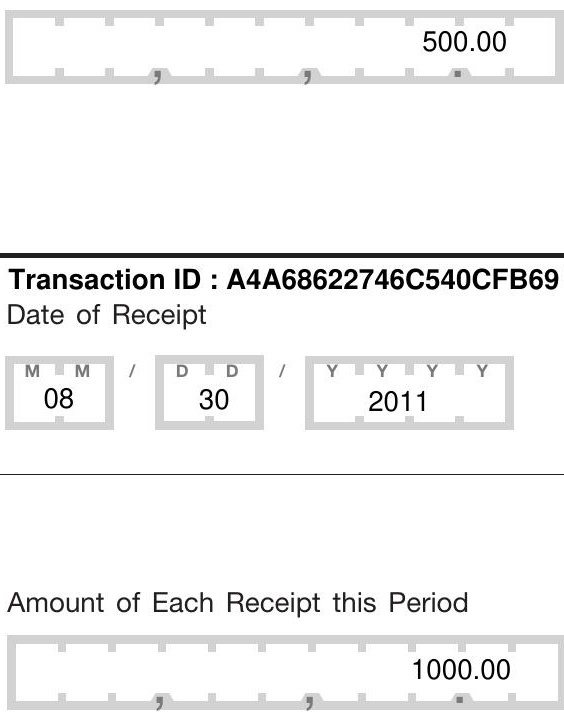

Transaction ID : AE0350364EDE946FDB83

Date of Receipt

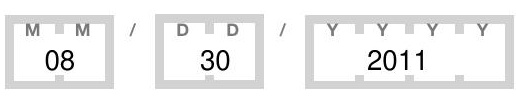

Amount of Each Receipt this Period

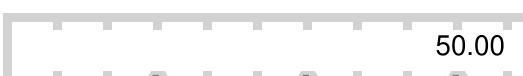

50.00

1550.00

Subtotal Of Receipts This Page (optional)

Total This Period (last page this line number only) 
SCHEDULE A-P ITEMIZED RECEIPTS
Use separate schedule(s) for each category of the Detailed Summary Page
FOR LINE NUMBER: (check only one)

PAGE 392 / 1572

\begin{tabular}{|c|c|c|c|c|c|c|}
\hline & & & & & & \\
\hline 16 & $\lambda$ & $17 \mathrm{a}$ & $17 \mathrm{~b}$ & $17 \mathrm{c}$ & $-17 d$ & -18 \\
\hline $19 a$ & & $19 b$ & $20 a$ & $20 \mathrm{~b}$ & $20 \mathrm{c}$ & 21 \\
\hline
\end{tabular}

Any information copied from such Reports and Statements may not be sold or used by any person for the purpose of soliciting contributions or for commercial purposes, other than using the name and address of any political committee to solicit contributions from such committee.

NAME OF COMMITTEE (In Full)

\section{Friends of Herman Cain}

A. Full Name (Last, First, Middle Initial)

\section{Edward J Phelan}

Mailing Address 1049 Pecan Grive Place

\begin{tabular}{lcc}
\hline City & State & Zip Code \\
Lawrenceville & GA & $30046-5517$
\end{tabular}

FEC ID number of contributing federal political committee.

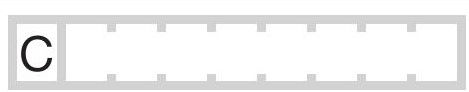

Name of Employer
None
Receipt For: 2012
X Primary $\quad$ General
Other (specify)

Occupation Retired

Election Cycle-to-Date

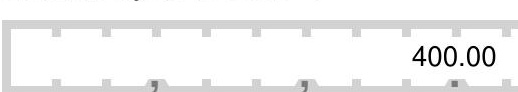

B. Full Name (Last, First, Middle Initial)

Mr. James S Parsons, Jr.

Mailing Address 2427 Fairway Drive

\begin{tabular}{lcc}
\hline City & State & Zip Code \\
Winston Salem & NC & $27103-3508$ \\
\hline
\end{tabular}

FEC ID number of contributing

federal political committee.

C

Name of Employer

Womble Carlyle Sandridge \& Rice

Occupation

Receipt For: 2012

$\chi \begin{aligned} & \text { Primary } \\ & \text { Other (specify) }\end{aligned}$

Attorney

Election Cycle-to-Date

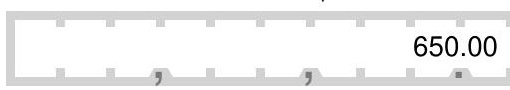

C. Full Name (Last, First, Middle Initial)

Rene Oberer

Mailing Address 2757 Evermur Dr.

\begin{tabular}{lcc}
\hline City & State & Zip Code \\
Dayton & $\mathrm{OH}$ & $45414-1405$
\end{tabular}

FEC ID number of contributing

federal political committee.

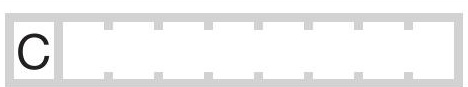

Name of Employer
None
Receipt For: 2012
Х Primary $\quad \square$ General
Other (specify)

Occupation

Retired

Election Cycle-to-Date

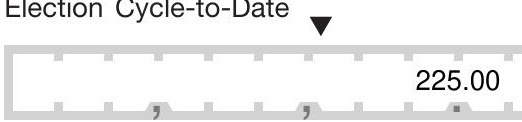

Transaction ID : A90341BC0D56F43508E8

Date of Receipt

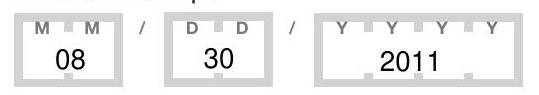

Amount of Each Receipt this Period

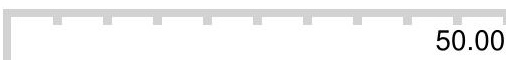

50.00

Transaction ID : AAB812FC064384F38AF0

Date of Receipt

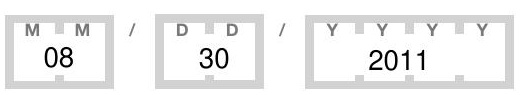

Amount of Each Receipt this Period

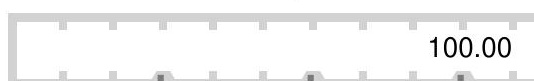

Transaction ID : A0EEE6A5D2B014E8DA85 Date of Receipt

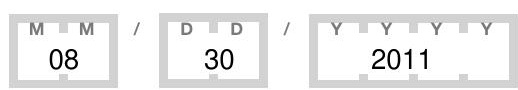

Amount of Each Receipt this Period

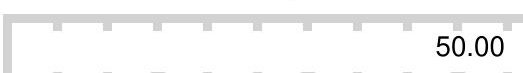

50.00

\section{Subtotal Of Receipts This Page (optional)}

200.00

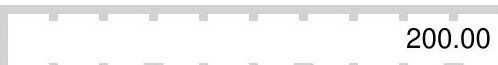

Total This Period (last page this line number only)

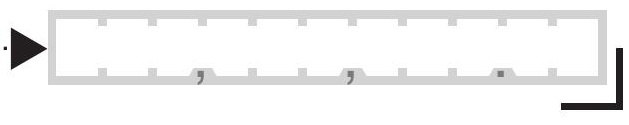

FEC Schedule A-P (Form 3P) (Rev. 03/2011) 
SCHEDULE A-P ITEMIZED RECEIPTS
Use separate schedule(s) for each category of the Detailed Summary Page
FOR LINE NUMBER: (check only one)

PAGE $393 / 1572$

\begin{tabular}{|c|c|c|c|c|c|}
\hline & & & & & \\
\hline 16 & $\begin{array}{lll}X & 17 a \\
\end{array}$ & $17 \mathrm{~b}$ & $17 c$ & $17 d$ & 18 \\
\hline $19 a$ & $19 b$ & $20 a$ & $20 \mathrm{~b}$ & $20 c$ & 21 \\
\hline
\end{tabular}

Any information copied from such Reports and Statements may not be sold or used by any person for the purpose of soliciting contributions or for commercial purposes, other than using the name and address of any political committee to solicit contributions from such committee.

NAME OF COMMITTEE (In Full)

\section{Friends of Herman Cain}

A. Full Name (Last, First, Middle Initial)

Richard B Brookfield

Mailing Address 1050 Riverside Dr

\begin{tabular}{lcc}
\hline City & State & Zip Code \\
Lagrange & GA & $30240-9154$ \\
\hline
\end{tabular}

FEC ID number of contributing federal political committee.

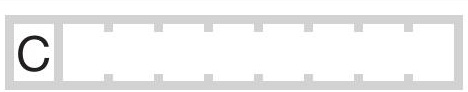

Name of Employer
VWC Construction Company
Receipt For: 2012
X Primary
Other (specify) General

Occupation

Construction

Election Cycle-to-Date

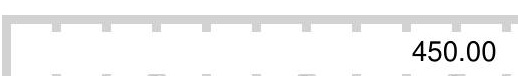

B. Full Name (Last, First, Middle Initial)

Sylvia D Barnes

Mailing Address 75495 Road 436

\begin{tabular}{lcc}
\hline City & State & Zip Code \\
Lexington & NE & $68850-5638$ \\
\hline
\end{tabular}

FEC ID number of contributing

federal political committee.

C

Name of Employer
None
Receipt For: 2012
X Primary
Other (specify)

Occupation

Retired

Election Cycle-to-Date

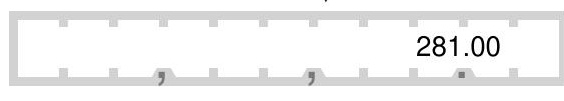

Transaction ID : A9A905AAA4A5F4D0A8C9

Date of Receipt

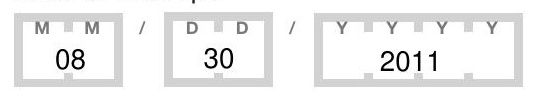

Amount of Each Receipt this Period
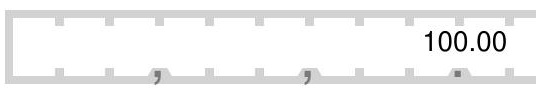

Transaction ID : AB83982C78C674F8FA25

Date of Receipt

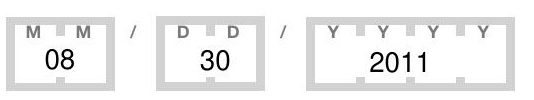

Amount of Each Receipt this Period

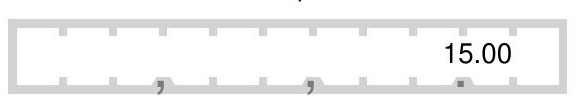

Transaction ID : A53BBEE4275E147C2B72 Date of Receipt

Mr Robert D Long

Mailing Address 47 Savannah Trl

\begin{tabular}{lcc}
\hline City & State & Zip Code \\
Hilton Head Island & SC & $29926-2693$
\end{tabular}

FEC ID number of contributing federal political committee.

C

Name of Employer
None
Receipt For: 2012
X Primary

Other (specify) General

Occupation

Retired

Election Cycle-to-Date

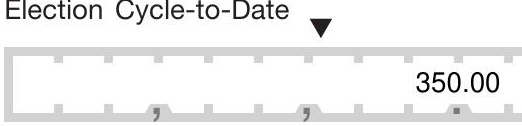

Subtotal Of Receipts This Page (optional)

Amount of Each Receipt this Period

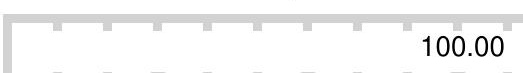

Total This Period (last page this line number only)

215.00

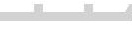

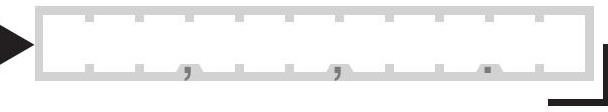

FEC Schedule A-P (Form 3P) (Rev. 03/2011) 
SCHEDULE A-P ITEMIZED RECEIPTS
Use separate schedule(s) for each category of the Detailed Summary Page
FOR LINE NUMBER: (check only one)

PAGE 394 / 1572

\begin{tabular}{|c|c|c|c|c|c|}
\hline & & & & & \\
\hline 16 & $\begin{array}{l}\mathbf{X} \\
17 a\end{array}$ & $17 b$ & $17 c$ & $17 d$ & 18 \\
\hline $19 a$ & $19 \mathrm{~b}$ & $20 \mathrm{a}$ & $20 \mathrm{~b}$ & $20 \mathrm{c}$ & 21 \\
\hline
\end{tabular}

Any information copied from such Reports and Statements may not be sold or used by any person for the purpose of soliciting contributions or for commercial purposes, other than using the name and address of any political committee to solicit contributions from such committee.

NAME OF COMMITTEE (In Full)

\section{Friends of Herman Cain}

A. Full Name (Last, First, Middle Initial)

David Werner

Mailing Address 2459 Due West Cir

\begin{tabular}{lcc}
\hline City & State & Zip Code \\
Kennesaw & GA & $30152-3303$
\end{tabular}

FEC ID number of contributing

federal political committee.

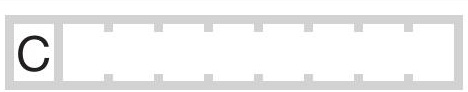

Name of Employer
Henry Schein Dental
Receipt For: 2012
X Primary
Other (specify) General

Occupation

Service Technician

Election Cycle-to-Date

800.00

B. Full Name (Last, First, Middle Initial)

Jim Rogers

Mailing Address 1416 Paseo La Cresta

\begin{tabular}{lcc}
\hline City & State & Zip Code \\
Palos Verdes Estates & CA & $90274-2073$ \\
\hline
\end{tabular}

FEC ID number of contributing

federal political committee.

C

Name of Employer
Information Requested
Receipt For: 2012
X Primary
Other (specify)

Occupation

Information Requested

Election Cycle-to-Date

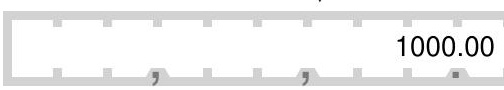

Transaction ID : AC488052D3DBE4893B92

Date of Receipt

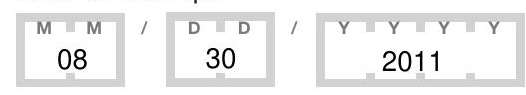

Amount of Each Receipt this Period

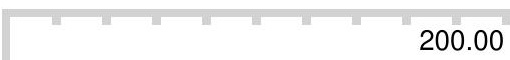

Amount of Each Receipt this Period

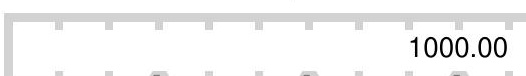

C. Full Name (Last, First, Middle Initial)

Jonathan Gold

Mailing Address 1033 Clifton Avenue

\begin{tabular}{lcc}
\hline City & State & Zip Code \\
Clifton & NJ & $07013-3517$
\end{tabular}

FEC ID number of contributing

federal political committee.

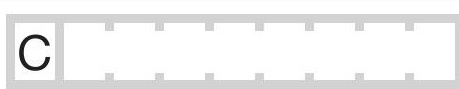

Name of Employer

Occupation

Dermatology Ctr

Doctor

Transaction ID : ACEB1BD2C155D41C3916

Date of Receipt

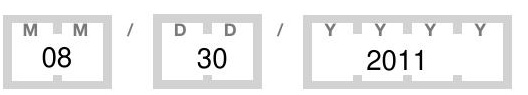

Receipt For: 2012

Х $\begin{aligned} & \text { Primary } \square \text { General } \\ & \text { Other (specify) }\end{aligned}$

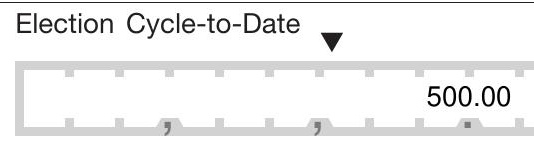

Amount of Each Receipt this Period

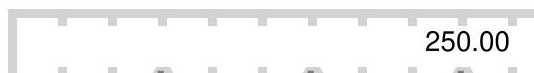

1450.00

Subtotal Of Receipts This Page (optional)

Transaction ID : AC5519439A2084F76A45

Date of Receipt

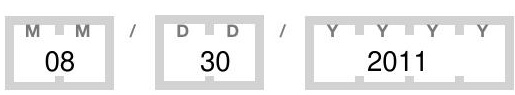

Total This Period (last page this line number only) 
SCHEDULE A-P ITEMIZED RECEIPTS
Use separate schedule(s)

for each category of the

Detailed Summary Page
FOR LINE NUMBER: (check only one)

\begin{tabular}{|c|c|c|c|c|c|}
\hline & & & & & \\
\hline 16 & $\begin{array}{ll}X & 17 a \\
\end{array}$ & $17 \mathrm{~b}$ & $17 c$ & $17 d$ & 18 \\
\hline $19 a$ & $19 b$ & $20 \mathrm{a}$ & $20 \mathrm{~b}$ & $20 c$ & 21 \\
\hline
\end{tabular}

Any information copied from such Reports and Statements may not be sold or used by any person for the purpose of soliciting contributions or for commercial purposes, other than using the name and address of any political committee to solicit contributions from such committee.

NAME OF COMMITTEE (In Full)

\section{Friends of Herman Cain}

A. Full Name (Last, First, Middle Initial)

Scott Lounsbury

Mailing Address 28218 SW Strawberry Hill Rd

\begin{tabular}{lcc}
\hline City & State & Zip Code \\
Hillsboro & OR & $97123-9442$
\end{tabular}

FEC ID number of contributing

federal political committee.

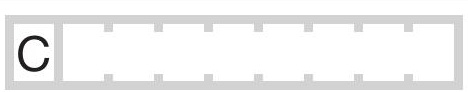

Name of Employer
Nike
Receipt For: 2012
X Primary $\quad$ General
Other (specify)

Occupation

Sales

Election Cycle-to-Date

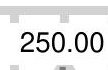

B. Full Name (Last, First, Middle Initial)

Fred D Backer Jr

Mailing Address 18 Narry Ln

\begin{tabular}{lcc}
\hline City & State & Zip Code \\
Mount Morris & NY & $14510-1519$
\end{tabular}

FEC ID number of contributing

federal political committee.

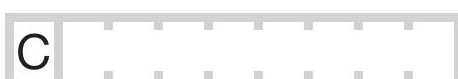

Name of Employer
None
Receipt For: 2012
X Primary
Other (specify)

\section{Occupation}

Retired

Election Cycle-to-Date

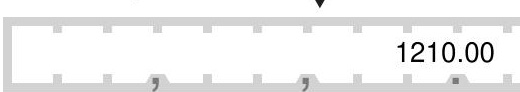

Transaction ID : A4A13773A99C548CEB22

Date of Receipt

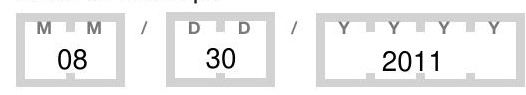

Amount of Each Receipt this Period

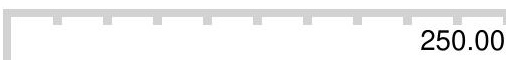

Amount of Each Receipt this Period

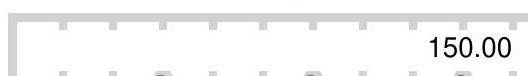

C. Full Name (Last, First, Middle Initial)

John Ellery

Mailing Address 2488 Old Fork Rd

\begin{tabular}{lcc}
\hline City & State & Zip Code \\
Gainesville & GA & $30506-1124$
\end{tabular}

FEC ID number of contributing

federal political committee.

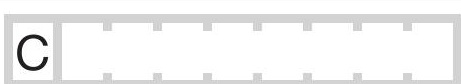

Name of Employer

Occupation

Automatic IT Corp

IT Consultant

Transaction ID : A2729FC2DDBBA4F4D9DC Date of Receipt

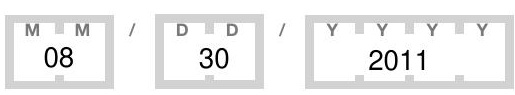

Receipt For: 2012

Х $\begin{aligned} & \text { Primary } \square \text { General } \\ & \text { Other (specify) }\end{aligned}$

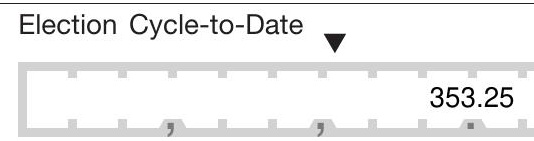

Amount of Each Receipt this Period

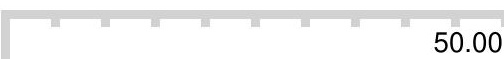

50.00

Subtotal Of Receipts This Page (optional)

450.00

Total This Period (last page this line number only) 
SCHEDULE A-P ITEMIZED RECEIPTS
Use separate schedule(s) for each category of the Detailed Summary Page
FOR LINE NUMBER: (check only one)

PAGE $396 / 1572$

\begin{tabular}{|c|c|c|c|c|c|c|}
\hline & & & & & & \\
\hline 16 & $\lambda$ & $17 \mathrm{a}$ & $17 \mathrm{~b}$ & $17 \mathrm{c}$ & $-17 d$ & -18 \\
\hline $19 a$ & & $19 b$ & $20 a$ & $20 \mathrm{~b}$ & $20 \mathrm{c}$ & 21 \\
\hline
\end{tabular}

Any information copied from such Reports and Statements may not be sold or used by any person for the purpose of soliciting contributions or for commercial purposes, other than using the name and address of any political committee to solicit contributions from such committee.

NAME OF COMMITTEE (In Full)

\section{Friends of Herman Cain}

A. Full Name (Last, First, Middle Initial)

\section{Fernande Silvers}

Mailing Address 5850 Birch Ridge Trl

\begin{tabular}{lcc}
\hline City & State & Zip Code \\
Cumming & GA & $30028-3410$ \\
\hline
\end{tabular}

FEC ID number of contributing federal political committee.

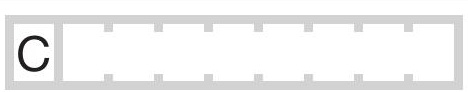

\begin{tabular}{l}
\hline Name of Employer \\
Spielman \& Hicks. LLC \\
Receipt For: 2012 \\
X Primary $\quad \square$ General \\
Other (specify)
\end{tabular}

Occupation

Paralegal

Election Cycle-to-Date

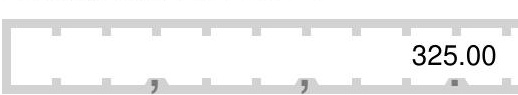

B. Full Name (Last, First, Middle Initial)

MARK LOPEZ

Mailing Address 1830 BREA BLVD \#3

\begin{tabular}{lcc}
\hline City & State & Zip Code \\
Fullerton & CA & $92835-3944$ \\
\hline
\end{tabular}

FEC ID number of contributing

federal political committee.

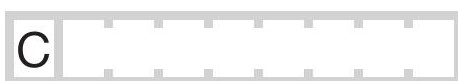

Name of Employer
BECKMAN COULTER INC
Receipt For: 2012
X Primary
Other (specify)

Occupation

SW Engineer

Election Cycle-to-Date

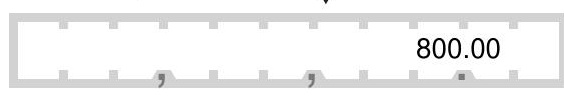

Transaction ID : A8A5CC860B3BA4B40811

Date of Receipt

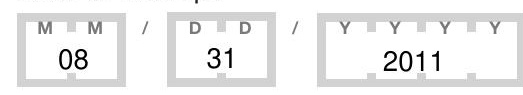

Amount of Each Receipt this Period

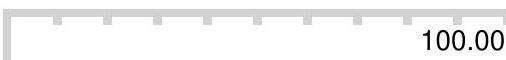

100.00

C. Full Name (Last, First, Middle Initial)

Josh McKoon

Mailing Address PO Box 2565

\begin{tabular}{lcc}
\hline City & State & Zip Code \\
Columbus & GA & $31902-2565$
\end{tabular}

FEC ID number of contributing federal political committee.

C

Name of Employer
Day | Crowley
Receipt For: 2012
X Primary $\quad \square$ General
Other (specify)

\section{Occupation}

Attorney

Election Cycle-to-Date

Transaction ID : AFB4411FDFC7C4C9ABB6 Date of Receipt

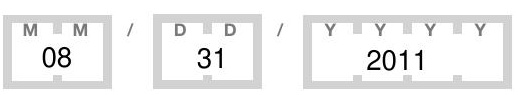

Amount of Each Receipt this Period

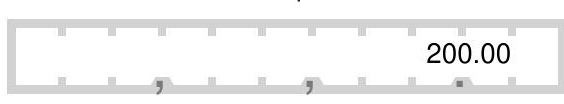

Transaction ID : A9FB2CFF21D494D6FA35 Date of Receipt

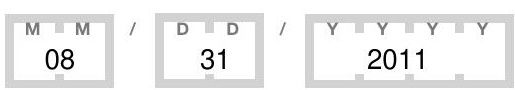

In-kind:Event Catering

Amount of Each Receipt this Period

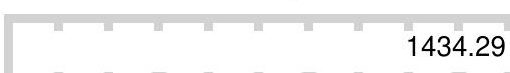

1434.29

Subtotal Of Receipts This Page (optional)

Total This Period (last page this line number only) 
SCHEDULE A-P ITEMIZED RECEIPTS
Use separate schedule(s) for each category of the Detailed Summary Page
FOR LINE NUMBER: (check only one)

PAGE 397 / 1572

\begin{tabular}{|c|c|c|c|c|c|}
\hline & & & & & \\
\hline 16 & $\begin{array}{l}\mathbf{X} \\
17 a\end{array}$ & $17 b$ & $17 c$ & $17 d$ & 18 \\
\hline $19 a$ & $19 \mathrm{~b}$ & $20 \mathrm{a}$ & $20 \mathrm{~b}$ & $20 \mathrm{c}$ & 21 \\
\hline
\end{tabular}

Any information copied from such Reports and Statements may not be sold or used by any person for the purpose of soliciting contributions or for commercial purposes, other than using the name and address of any political committee to solicit contributions from such committee.

NAME OF COMMITTEE (In Full)

\section{Friends of Herman Cain}

A. Full Name (Last, First, Middle Initial)

Gus Buder III

Mailing Address 560 Rayado Creek Rd

\begin{tabular}{lcc}
\hline City & State & Zip Code \\
Cimarron & NM & $87714-9684$
\end{tabular}

FEC ID number of contributing federal political committee.

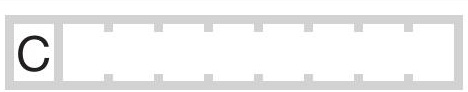

\begin{tabular}{l} 
Name of Employer \\
None \\
Receipt For: 2012 \\
X Primary $\quad$ General \\
\hline Other (specify)
\end{tabular}

Occupation Retired

Election Cycle-to-Date

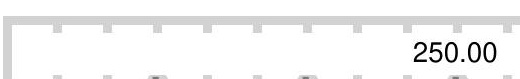

B. Full Name (Last, First, Middle Initial)

Patrick O Rayes

Mailing Address PO Box 7409

\begin{tabular}{lcc}
\hline City & State & Zip Code \\
Dallas & TX & $75209-0409$ \\
\hline
\end{tabular}

FEC ID number of contributing

federal political committee.

C

Name of Employer
Information Requested
Receipt For: 2012
X Primary
Other (specify)

Occupation

Information Requested

Election Cycle-to-Date

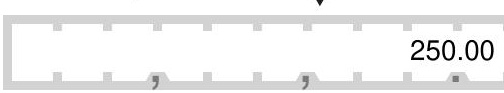

Transaction ID : AD5D8277CD47C4D628F4

Date of Receipt

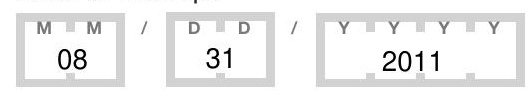

Amount of Each Receipt this Period

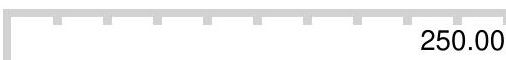

250.00

C. Full Name (Last, First, Middle Initial)

Susan Walter

Mailing Address P.O. Box 690

\begin{tabular}{lcc}
\hline City & State & Zip Code \\
Sautee Nacoochee & GA & $30571-0690$
\end{tabular}

FEC ID number of contributing

federal political committee.

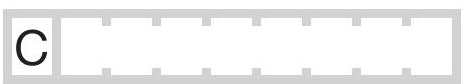

Name of Employer
None
Receipt For: 2012
X Primary $\quad \square$ General
Other (specify)

Occupation

Retired

Election Cycle-to-Date

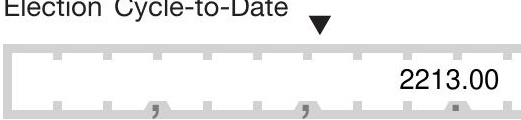

Transaction ID : A52D16A080C864E3E8E3

Date of Receipt

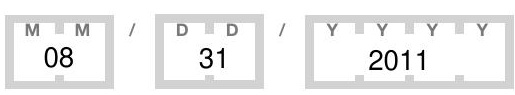

Amount of Each Receipt this Period

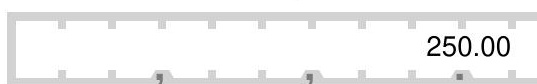

Transaction ID : AC4F49E7A679344B5ABF Date of Receipt

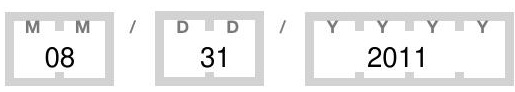

Amount of Each Receipt this Period

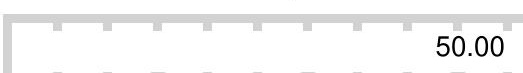

\section{Subtotal Of Receipts This Page (optional)}

Total This Period (last page this line number only) 
SCHEDULE A-P ITEMIZED RECEIPTS
Use separate schedule(s) for each category of the Detailed Summary Page
FOR LINE NUMBER: (check only one)

PAGE $398 / 1572$

\begin{tabular}{|c|c|c|c|c|c|}
\hline & & & & & \\
\hline 16 & $\begin{array}{l}\mathbf{X} \\
17 a\end{array}$ & $17 b$ & $17 c$ & $17 d$ & 18 \\
\hline $19 a$ & $19 \mathrm{~b}$ & $20 \mathrm{a}$ & $20 \mathrm{~b}$ & $20 \mathrm{c}$ & 21 \\
\hline
\end{tabular}

Any information copied from such Reports and Statements may not be sold or used by any person for the purpose of soliciting contributions or for commercial purposes, other than using the name and address of any political committee to solicit contributions from such committee.

NAME OF COMMITTEE (In Full)

\section{Friends of Herman Cain}

A. Full Name (Last, First, Middle Initial)

Arrie M Wiley

Mailing Address 3265 Chestatee Rd

\begin{tabular}{lcc}
\hline City & State & Zip Code \\
Gainesville & GA & $30506-3558$
\end{tabular}

FEC ID number of contributing federal political committee.

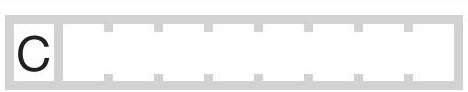

Name of Employer
$\mathrm{J} \& \mathrm{~J}$ Foods
Receipt For: 2012
X Primary $\quad$ General
Other (specify)

Occupation Grocery

Election Cycle-to-Date

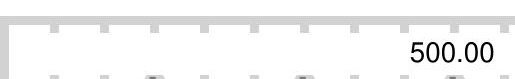

B. Full Name (Last, First, Middle Initial)

Mr. Vernon L. Hastings

Mailing Address 8500 E Southern Ave Lot 58

\begin{tabular}{lcc}
\hline City & State & Zip Code \\
Mesa & AZ & $85209-3623$
\end{tabular}

FEC ID number of contributing

federal political committee.

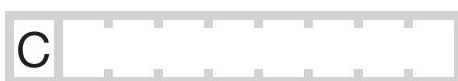

Name of Employer
None
Receipt For: 2012
X Primary
Other (specify)

\section{Occupation}

Retired

Election Cycle-to-Date

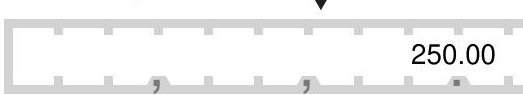

Transaction ID : AEE2CFC88BAB946FAA9A

Date of Receipt

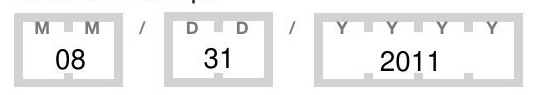

Amount of Each Receipt this Period

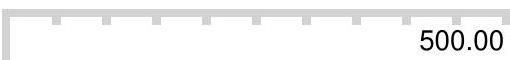

C. Full Name (Last, First, Middle Initial)

James Carpenter

Mailing Address 624 Sibley Ave

\begin{tabular}{lcc}
\hline City & State & Zip Code \\
Union Point & GA & $30669-1140$
\end{tabular}

FEC ID number of contributing federal political committee.

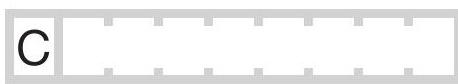

Name of Employer
Self-Employed
Receipt For: 2012
X Primary $\quad \square$ General
Other (specify)

\section{Occupation}

Pharmacist

\section{Election Cycle-to-Date}

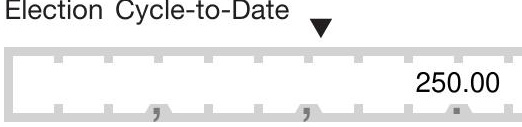

Amount of Each Receipt this Period

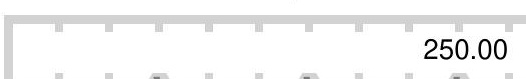

Transaction ID : A0053BE44291E4DF29BA

Date of Receipt

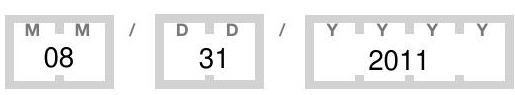

Transaction ID : A93652981108740C0A0F Date of Receipt

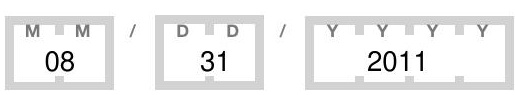

Amount of Each Receipt this Period

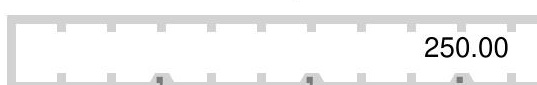

\section{Subtotal Of Receipts This Page (optional)}

Total This Period (last page this line number only) 
SCHEDULE A-P ITEMIZED RECEIPTS
Use separate schedule(s)

for each category of the

Detailed Summary Page
FOR LINE NUMBER: (check only one)

PAGE $399 / 1572$

\begin{tabular}{|c|c|c|c|c|c|}
\hline & & & & & \\
\hline 16 & $\begin{array}{l}\mathbf{X} \\
17 a\end{array}$ & $17 b$ & $17 c$ & $17 d$ & 18 \\
\hline $19 a$ & $19 \mathrm{~b}$ & $20 \mathrm{a}$ & $20 \mathrm{~b}$ & $20 \mathrm{c}$ & 21 \\
\hline
\end{tabular}

Any information copied from such Reports and Statements may not be sold or used by any person for the purpose of soliciting contributions or for commercial purposes, other than using the name and address of any political committee to solicit contributions from such committee.

NAME OF COMMITTEE (In Full)

\section{Friends of Herman Cain}

A. Full Name (Last, First, Middle Initial)

Gregory Capin

Mailing Address 1575 Mount McKinley Drive

\begin{tabular}{lcc}
\hline City & State & Zip Code \\
Grayson & GA & $30017-2981$ \\
\hline
\end{tabular}

FEC ID number of contributing federal political committee.

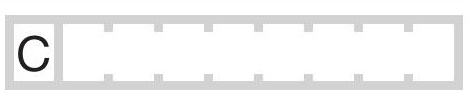

Name of Employer
Capin Crouse LLP
Receipt For: 2012
X Primary $\quad$ General
Other (specify)

Occupation

CPA

Election Cycle-to-Date

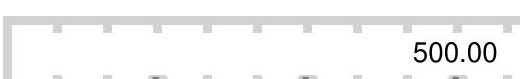

B. Full Name (Last, First, Middle Initial)

Alvin Jones

Mailing Address 3300 Pearl Street P.O. Box 28

\begin{tabular}{lcc}
\hline City & State & Zip Code \\
Shellman & GA & $39886-0028$
\end{tabular}

FEC ID number of contributing

federal political committee.

C

Name of Employer
Information Requested
Receipt For: 2012
X Primary
Other (specify)

Occupation

Information Requested

Election Cycle-to-Date

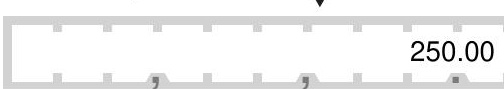

Transaction ID : A8A2457B80CE9463089B

Date of Receipt

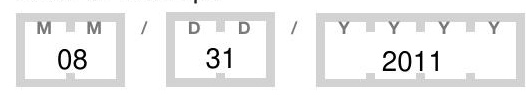

Amount of Each Receipt this Period

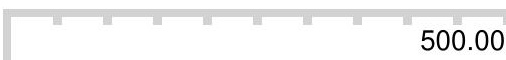

C. Full Name (Last, First, Middle Initial)

Carl Harbert

Mailing Address 405 Barrett Ln

\begin{tabular}{lcc}
\hline City & State & Zip Code \\
Cabot & AR & $72023-8779$
\end{tabular}

FEC ID number of contributing federal political committee.

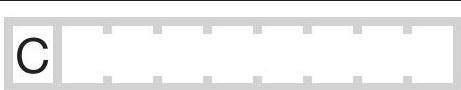

Name of Employer
US Postal Service
Receipt For: 2012
X Primary $\quad \square$ General
Other (specify)

\section{Occupation}

rural mail carrier

Election Cycle-to-Date
Transaction ID : AB30C75C6EC28442A810

Date of Receipt

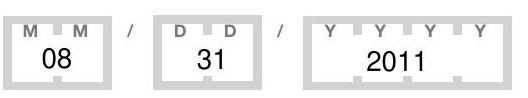

Amount of Each Receipt this Period

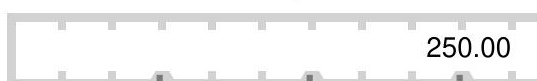

Transaction ID : A9B0A617CAE8244A1A89 Date of Receipt

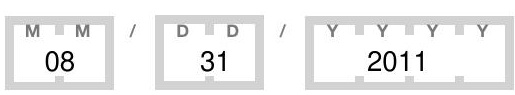

Amount of Each Receipt this Period

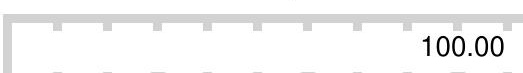

\section{Subtotal Of Receipts This Page (optional)}

Total This Period (last page this line number only) 


\section{SCHEDULE A-P} ITEMIZED RECEIPTS
Use separate schedule(s)

for each category of the

Detailed Summary Page
FOR LINE NUMBER: (check only one)

PAGE $400 / 1572$

\begin{tabular}{|c|c|c|c|c|c|}
\hline & & & & & \\
\hline 16 & $\begin{array}{l}\mathbf{X} \\
17 a\end{array}$ & $17 b$ & $17 c$ & $17 d$ & 18 \\
\hline $19 a$ & $19 \mathrm{~b}$ & $20 \mathrm{a}$ & $20 \mathrm{~b}$ & $20 \mathrm{c}$ & 21 \\
\hline
\end{tabular}

Any information copied from such Reports and Statements may not be sold or used by any person for the purpose of soliciting contributions or for commercial purposes, other than using the name and address of any political committee to solicit contributions from such committee.

NAME OF COMMITTEE (In Full)

Friends of Herman Cain

A. Full Name (Last, First, Middle Initial)

William Graham

Mailing Address 12450 SW Haverhill Rd

\begin{tabular}{lcc}
\hline City & State & Zip Code \\
Augusta & KS & $67010-8317$ \\
\hline
\end{tabular}

FEC ID number of contributing

federal political committee.

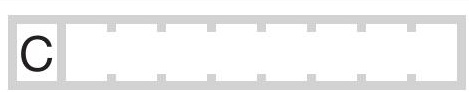

Name of Employer
Information Requested
Receipt For: 2012
X Primary $\quad \square$ General
Other (specify)

Occupation

Information Requested

Election Cycle-to-Date

500.00

B. Full Name (Last, First, Middle Initial)

Richard Butler

Mailing Address 177 Blue Sky Dr

\begin{tabular}{lcc}
\hline City & State & Zip Code \\
Marietta & GA & $30068-3812$ \\
\hline
\end{tabular}

FEC ID number of contributing

federal political committee.

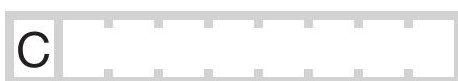

Name of Employer
Associates Express nlnc
Receipt For: 2012
X Primary
Other (specify)

\section{Occupation} truck driver

Election Cycle-to-Date

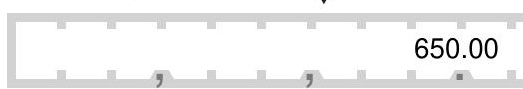

Transaction ID : AE37DCF63F09549D3BB5

Date of Receipt

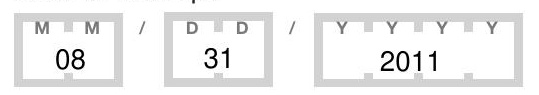

Amount of Each Receipt this Period

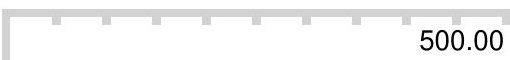

C. Full Name (Last, First, Middle Initial)

lois edgerly

Mailing Address 32 highland street

\begin{tabular}{lcc}
\hline City & State & Zip Code \\
Cambridge & MA & $02138-2210$
\end{tabular}

FEC ID number of contributing

federal political committee.

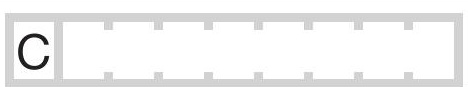

Name of Employer
Retired
Receipt For: 2012
X Primary $\quad \square$ General
Other (specify)

Occupation

Retired

Election Cycle-to-Date

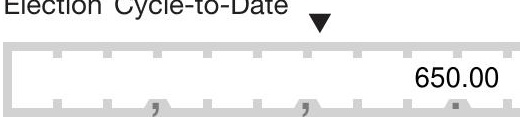

Amount of Each Receipt this Period

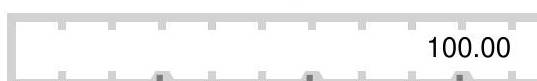

Transaction ID : AB01FEA4543E14BE387B

Date of Receipt

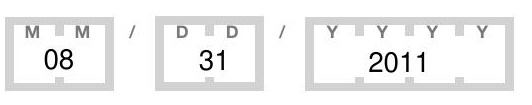

Transaction ID : A9C5D8542C8E34A08B02 Date of Receipt

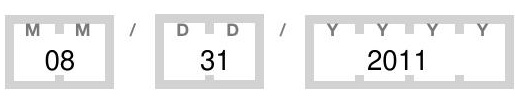

Amount of Each Receipt this Period

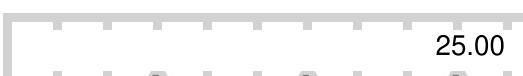

Subtotal Of Receipts This Page (optional).

625.00

a

Total This Period (last page this line number only)

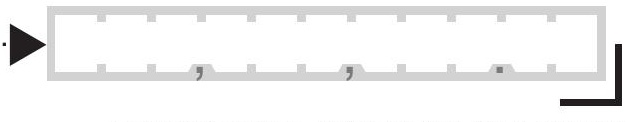

FEC Schedule A-P (Form 3P) (Rev. 03/2011) 
SCHEDULE A-P ITEMIZED RECEIPTS
Use separate schedule(s) for each category of the Detailed Summary Page
FOR LINE NUMBER: (check only one)
PAGE $401 / 1572$

\begin{tabular}{|c|c|c|c|c|c|}
\hline & & & & & \\
\hline 16 & $\begin{array}{lll}X & 17 a \\
\end{array}$ & $17 \mathrm{~b}$ & $17 c$ & $17 d$ & 18 \\
\hline $19 a$ & $19 b$ & $20 a$ & $20 \mathrm{~b}$ & $20 c$ & 21 \\
\hline
\end{tabular}

Any information copied from such Reports and Statements may not be sold or used by any person for the purpose of soliciting contributions or for commercial purposes, other than using the name and address of any political committee to solicit contributions from such committee.

NAME OF COMMITTEE (In Full)

\section{Friends of Herman Cain}

A. Full Name (Last, First, Middle Initial)

Mary Daniel

Transaction ID : A96F34CA6E9ED430F9D1

Mailing Address 131 South End Street

\begin{tabular}{lcc}
\hline City & State & Zip Code \\
Saint Augustine & FL & $32095-6821$
\end{tabular}

FEC ID number of contributing federal political committee.

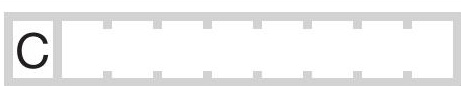

Name of Employer
The Shannon Group
Receipt For: 2012
X Primary
Other (specify)

Occupation medical management

Election Cycle-to-Date

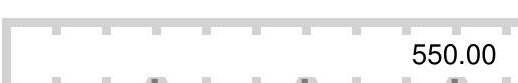

B. Full Name (Last, First, Middle Initial)

Marion Valerio

Mailing Address 3575 Heritage Rd

\begin{tabular}{lcc}
\hline City & State & Zip Code \\
Alum Bank & PA & 15521 \\
\hline
\end{tabular}

FEC ID number of contributing

federal political committee.

C

Name of Employer
Retired
Receipt For: 2012
X Primary
Other (specify)

Occupation

veterinary pathologist

Election Cycle-to-Date

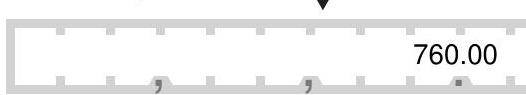

C. Full Name (Last, First, Middle Initial)

Mr Donald C Proctor

Mailing Address 218 Rudder Rd

\begin{tabular}{lcc}
\hline City & State & Zip Code \\
Vero Beach & FL & $32963-2934$
\end{tabular}

FEC ID number of contributing federal political committee.

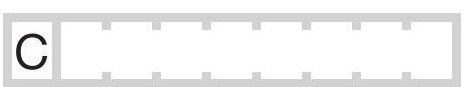

Name of Employer
Proctor Construction
Receipt For: 2012
X Primary
Other (specify) General

\section{Occupation}

$\mathrm{Gc}$

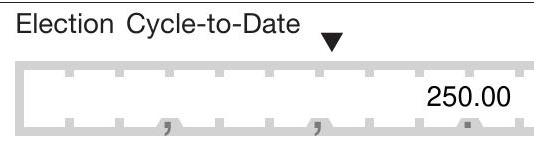

Date of Receipt

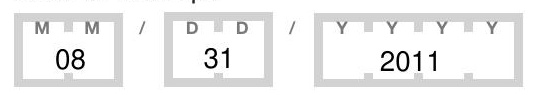

Amount of Each Receipt this Period

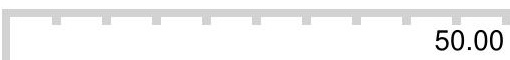

50.00

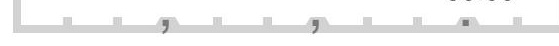

Transaction ID : ABF788F85FE654D37848

Date of Receipt

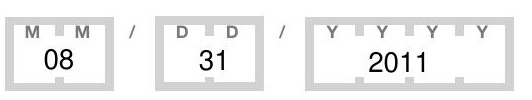

Amount of Each Receipt this Period

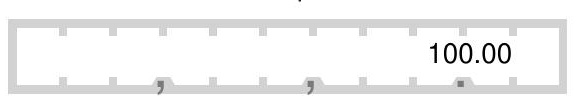

Transaction ID : A891DB734815C4A7B80C Date of Receipt

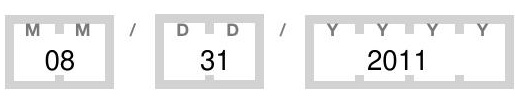

Amount of Each Receipt this Period

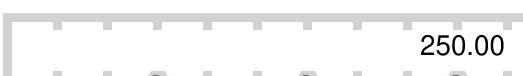

\section{Subtotal Of Receipts This Page (optional)}

Total This Period (last page this line number only) 
SCHEDULE A-P ITEMIZED RECEIPTS
Use separate schedule(s) for each category of the Detailed Summary Page
FOR LINE NUMBER: (check only one)

PAGE 402 / 1572

\begin{tabular}{|c|c|c|c|c|c|c|}
\hline & & & & & & \\
\hline 16 & $\lambda$ & $17 \mathrm{a}$ & $17 \mathrm{~b}$ & $17 \mathrm{c}$ & $-17 d$ & -18 \\
\hline $19 a$ & & $19 b$ & $20 a$ & $20 \mathrm{~b}$ & $20 \mathrm{c}$ & 21 \\
\hline
\end{tabular}

Any information copied from such Reports and Statements may not be sold or used by any person for the purpose of soliciting contributions or for commercial purposes, other than using the name and address of any political committee to solicit contributions from such committee.

NAME OF COMMITTEE (In Full)

\section{Friends of Herman Cain}

A. Full Name (Last, First, Middle Initial)

Mr. Dudney A Harris

Mailing Address 1801 Sugar Creek Trl

\begin{tabular}{lcc}
\hline City & State & Zip Code \\
Buckhead & GA & $30625-2517$
\end{tabular}

FEC ID number of contributing

federal political committee.

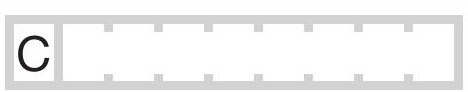

\begin{tabular}{l} 
Name of Employer \\
None \\
Receipt For: 2012 \\
X Primary $\quad$ General \\
\hline Other (specify)
\end{tabular}

Occupation

Retired

Election Cycle-to-Date

1800.00

B. Full Name (Last, First, Middle Initial)

Mr James McCown

Mailing Address PO Box 8872

\begin{tabular}{lcc}
\hline City & State & Zip Code \\
Amarillo & TX & $79114-8872$
\end{tabular}

FEC ID number of contributing

federal political committee.

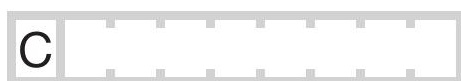

Name of Employer
Benson-McCown \& Co.
Receipt For: 2012
X Primary
Other (specify)

\section{Occupation}

Owner

Election Cycle-to-Date

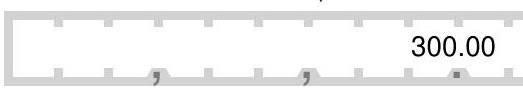

Transaction ID : A4359DC2709CE4B57BC0

Date of Receipt

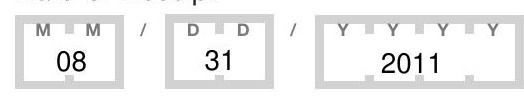

Amount of Each Receipt this Period

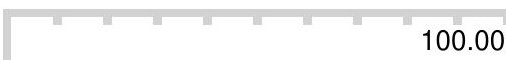

C. Full Name (Last, First, Middle Initial)

Ms Carol Nolan

Mailing Address 3336 W Congress St

\begin{tabular}{lcc}
\hline City & State & Zip Code \\
Allentown & PA & $18104-2666$
\end{tabular}

FEC ID number of contributing federal political committee.

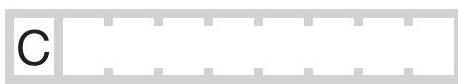

Name of Employer
techniceutica
Receipt For: 2012
X Primary $\quad \square$ General
Other (specify)

\section{Occupation}

Consultant

Election Cycle-to-Date

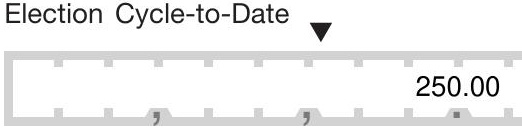

Amount of Each Receipt this Period

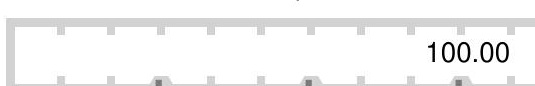

Transaction ID : A61B4F1D1C70D4AE3A2A Date of Receipt

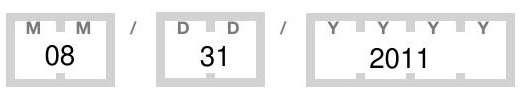

Transaction ID : A6FA98938CC1549BBBA1 Date of Receipt

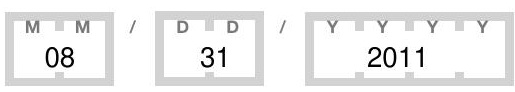

Amount of Each Receipt this Period

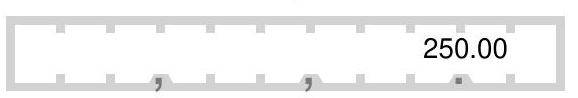

\section{Subtotal Of Receipts This Page (optional)}

Total This Period (last page this line number only) 
SCHEDULE A-P ITEMIZED RECEIPTS
Use separate schedule(s) for each category of the Detailed Summary Page
FOR LINE NUMBER: (check only one)

PAGE $403 / 1572$

\begin{tabular}{|c|c|c|c|c|c|c|}
\hline & & & & & & \\
\hline 16 & $\lambda$ & $17 \mathrm{a}$ & $17 \mathrm{~b}$ & $17 \mathrm{c}$ & $-17 d$ & -18 \\
\hline $19 a$ & & $19 b$ & $20 a$ & $20 \mathrm{~b}$ & $20 \mathrm{c}$ & 21 \\
\hline
\end{tabular}

Any information copied from such Reports and Statements may not be sold or used by any person for the purpose of soliciting contributions or for commercial purposes, other than using the name and address of any political committee to solicit contributions from such committee.

NAME OF COMMITTEE (In Full)

\section{Friends of Herman Cain}

A. Full Name (Last, First, Middle Initial)

Miss Karen Barbour

Mailing Address 3319 E Fairmont Ave

\begin{tabular}{lcc}
\hline City & State & Zip Code \\
Fresno & CA & $93726-0653$
\end{tabular}

FEC ID number of contributing federal political committee.

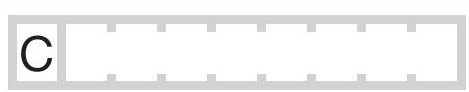

\begin{tabular}{l} 
Name of Employer \\
None \\
Receipt For: 2012 \\
X Primary $\quad$ General \\
\hline Other (specify)
\end{tabular}

Occupation Retired

Election Cycle-to-Date

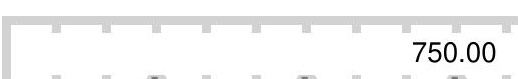

B. Full Name (Last, First, Middle Initial)

Ms Sarah Newland

Mailing Address PO Box 1162

\begin{tabular}{llc}
\hline City & State & Zip Code \\
Buckley & WA & $98321-1162$ \\
\hline
\end{tabular}

FEC ID number of contributing

federal political committee.

C

Name of Employer
n/a
Receipt For: 2012
X Primary
Other (specify)

\section{Occupation} Homemaker

Election Cycle-to-Date

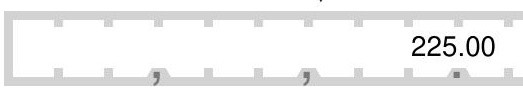

C. Full Name (Last, First, Middle Initial)

Mr Robert W Garthwait Sr

Mailing Address PO Box 1367

\begin{tabular}{lcc}
\hline City & State & Zip Code \\
Waterbury & CT & $06721-1367$
\end{tabular}

FEC ID number of contributing federal political committee.

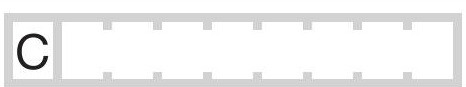

Name of Employer
cly-delmfg co
Receipt For: 2012
X Primary
Other (specify) General

\section{Occupation}

Chairmain

Election Cycle-to-Date

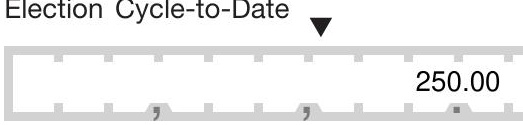

Transaction ID : A97045BF0B0F74CFD98A

Date of Receipt

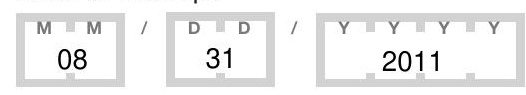

Amount of Each Receipt this Period

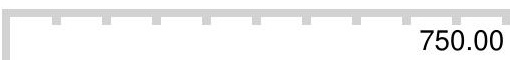

750.00

Transaction ID : ACD107E5CDB144E11840

Date of Receipt

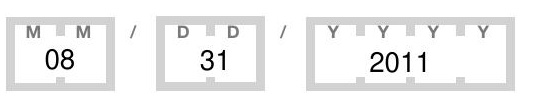

Amount of Each Receipt this Period

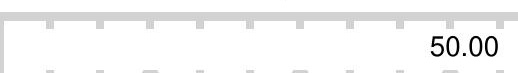

Transaction ID : AF1E6BAFD03024831920

Date of Receipt

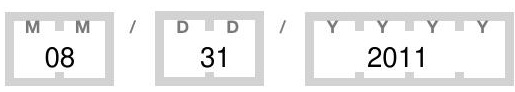

Amount of Each Receipt this Period

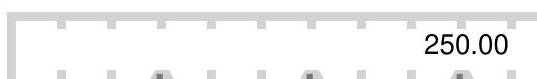

1050.00

Subtotal Of Receipts This Page (optional)

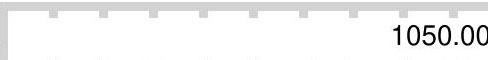

Total This Period (last page this line number only) 
SCHEDULE A-P ITEMIZED RECEIPTS
Use separate schedule(s) for each category of the Detailed Summary Page
FOR LINE NUMBER: (check only one)

PAGE 404 / 1572

\begin{tabular}{|c|c|c|c|c|c|}
\hline & & & & & \\
\hline 16 & $\begin{array}{l}\mathbf{X} \\
17 a\end{array}$ & $17 b$ & $17 c$ & $17 d$ & 18 \\
\hline $19 a$ & $19 \mathrm{~b}$ & $20 \mathrm{a}$ & $20 \mathrm{~b}$ & $20 \mathrm{c}$ & 21 \\
\hline
\end{tabular}

Any information copied from such Reports and Statements may not be sold or used by any person for the purpose of soliciting contributions or for commercial purposes, other than using the name and address of any political committee to solicit contributions from such committee.

NAME OF COMMITTEE (In Full)

\section{Friends of Herman Cain}

A. Full Name (Last, First, Middle Initial)

Susan Stahl

Transaction ID : A32F8E10A7FBB493C847

Mailing Address 12 Dewberry Court

\begin{tabular}{lcc}
\hline City & State & Zip Code \\
Fernandina Beach & FL & $32034-6578$
\end{tabular}

FEC ID number of contributing federal political committee.

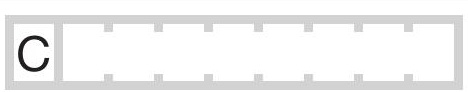

\begin{tabular}{l} 
Name of Employer \\
None \\
Receipt For: 2012 \\
X Primary $\quad$ General \\
\hline Other (specify)
\end{tabular}

Occupation

Retired

Election Cycle-to-Date

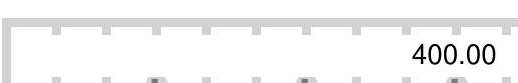

B. Full Name (Last, First, Middle Initial)

Ms Wilma Miller

Mailing Address P. O. Box 434

\begin{tabular}{lcc}
\hline City & State & Zip Code \\
Washington & OK & $73093-0434$ \\
\hline
\end{tabular}

FEC ID number of contributing

federal political committee.

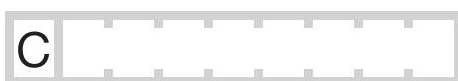

Name of Employer
Kenneth Sturgell
Receipt For: 2012
X Primary
Other (specify)

\section{Occupation}

File Clerk

Election Cycle-to-Date

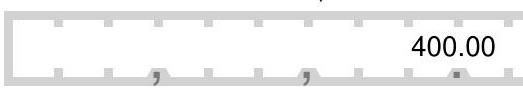

C. Full Name (Last, First, Middle Initial)

Charles Ernest Lance

Mailing Address 103 Cedar Branch Dr

\begin{tabular}{lcc}
\hline City & State & Zip Code \\
Georgetown & TX & $78628-7118$
\end{tabular}

FEC ID number of contributing

federal political committee.

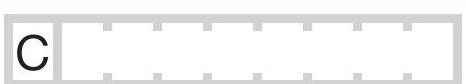

Name of Employer
lance law
Receipt For: 2012
X Primary $\quad \square$ General
Other (specify)

\section{Occupation}

Attorney

Election Cycle-to-Date

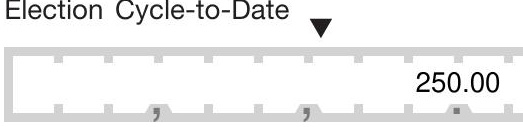

Date of Receipt

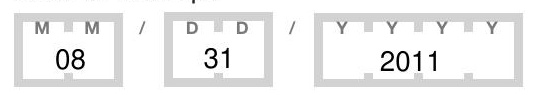

Amount of Each Receipt this Period

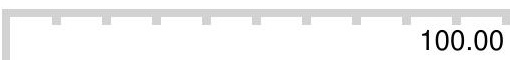

100.00

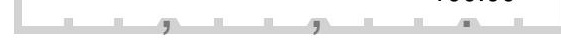

Transaction ID : A8D56155E0B094BD693D

Date of Receipt

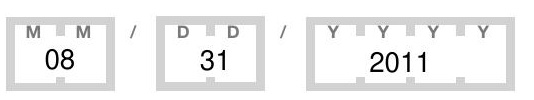

Amount of Each Receipt this Period

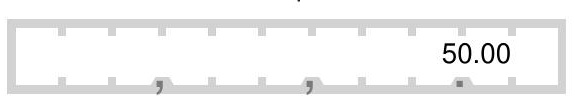

Transaction ID : AE46295D239334F09A1C

Date of Receipt

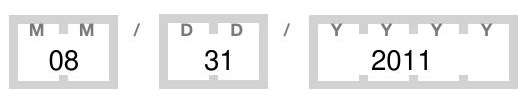

Amount of Each Receipt this Period

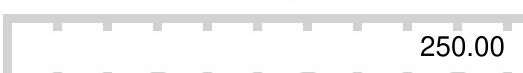

\section{Subtotal Of Receipts This Page (optional)}

400.00

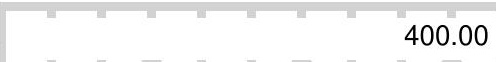

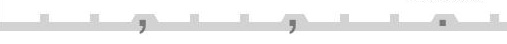

Total This Period (last page this line number only)

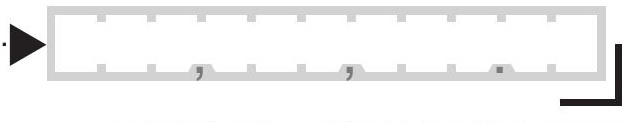

FEC Schedule A-P (Form 3P) (Rev. 03/2011) 


\section{SCHEDULE A-P} ITEMIZED RECEIPTS
Use separate schedule(s)

for each category of the

Detailed Summary Page
FOR LINE NUMBER: (check only one)

PAGE 405 / 1572

\begin{tabular}{|c|c|c|c|c|c|}
\hline & & & & & \\
\hline 16 & X $17 a$ & $17 b$ & $17 c$ & $17 d$ & 18 \\
\hline $19 a$ & $19 b$ & $20 \mathrm{a}$ & $20 \mathrm{~b}$ & $20 \mathrm{c}$ & 21 \\
\hline
\end{tabular}

Any information copied from such Reports and Statements may not be sold or used by any person for the purpose of soliciting contributions or for commercial purposes, other than using the name and address of any political committee to solicit contributions from such committee.

NAME OF COMMITTEE (In Full)

Friends of Herman Cain

A. Full Name (Last, First, Middle Initial)

Karen Narramore

Mailing Address 26437 N Lewisburg Rd

\begin{tabular}{lcc}
\hline City & State & Zip Code \\
North Lewisburg & OH & $43060-9608$
\end{tabular}

FEC ID number of contributing

federal political committee.

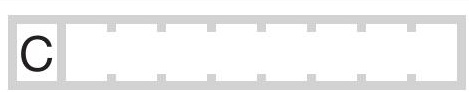

Name of Employer
Information Requested
Receipt For: 2012
X Primary $\quad \square$ General
Other (specify)

Occupation

Information Requested

Election Cycle-to-Date

390.00

B. Full Name (Last, First, Middle Initial)

Eugene Key

Mailing Address 115 Sycamore Bend

\begin{tabular}{lcc}
\hline City & State & Zip Code \\
Fayetteville & GA & $30214-1239$
\end{tabular}

FEC ID number of contributing

federal political committee.

C

\begin{tabular}{l} 
Name of Employer \\
Information Requested \\
Receipt For: 2012 \\
X Primary \\
\hline Other (specify)
\end{tabular}

Occupation

Information Requested

Election Cycle-to-Date

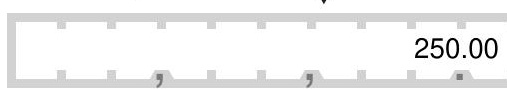

Transaction ID : A833F67FB85704BAE9AD

Date of Receipt

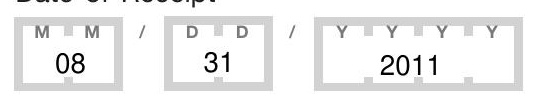

Amount of Each Receipt this Period

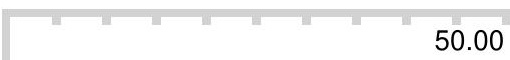

50.00

C. Full Name (Last, First, Middle Initial)

Robert Ryan

Mailing Address 95 Riimfire Circle

\begin{tabular}{lcc}
\hline City & State & Zip Code \\
Reno & NV & $89519-2989$
\end{tabular}

FEC ID number of contributing federal political committee.

C

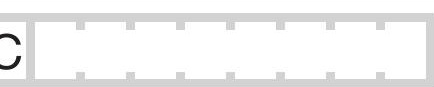

Name of Employer

Information Requested

Occupation

Information Requested

Receipt For: 2012

Х $\begin{aligned} & \text { Primary } \\ & \text { Other (specify) }\end{aligned}$

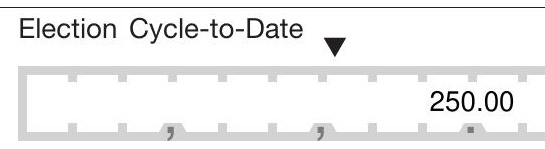

Amount of Each Receipt this Period

Transaction ID : AD3611F49936D4341941

Date of Receipt
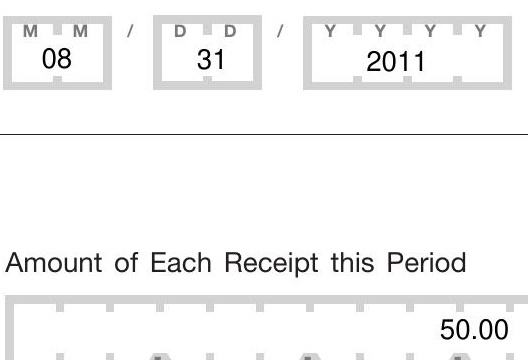

Transaction ID : A219D97DF9F974EC68AE Date of Receipt

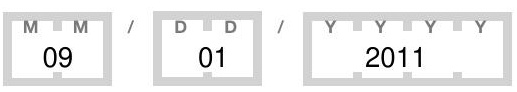

Amount of Each Receipt this Period

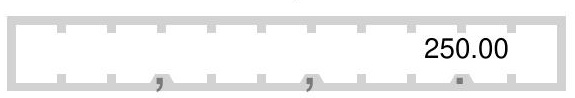

Subtotal Of Receipts This Page (optional)

350.00

Total This Period (last page this line number only) 
SCHEDULE A-P ITEMIZED RECEIPTS
Use separate schedule(s) for each category of the Detailed Summary Page
FOR LINE NUMBER: (check only one)

PAGE 406 / 1572

\begin{tabular}{|c|c|c|c|c|c|}
\hline & & & & & \\
\hline 16 & $\begin{array}{l}\mathbf{X} \\
17 a\end{array}$ & $17 b$ & $17 c$ & $17 d$ & 18 \\
\hline $19 a$ & $19 \mathrm{~b}$ & $20 \mathrm{a}$ & $20 \mathrm{~b}$ & $20 \mathrm{c}$ & 21 \\
\hline
\end{tabular}

Any information copied from such Reports and Statements may not be sold or used by any person for the purpose of soliciting contributions or for commercial purposes, other than using the name and address of any political committee to solicit contributions from such committee.

NAME OF COMMITTEE (In Full)

\section{Friends of Herman Cain}

A. Full Name (Last, First, Middle Initial)

JOhn Berggreen

Mailing Address 101 Timmons Ranch Rd.

\begin{tabular}{lcc}
\hline City & State & Zip Code \\
Etna & CA & $96027-9774$
\end{tabular}

FEC ID number of contributing federal political committee.

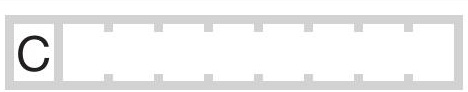

Name of Employer
PERS
Receipt For: 2012
X Primary $\quad$ General
Other (specify)

Occupation Retired

Election Cycle-to-Date

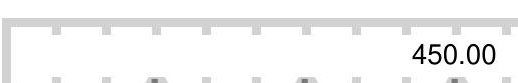

B. Full Name (Last, First, Middle Initial)

Ms. Susan Seadon

Mailing Address 1954 th Ct SE

\begin{tabular}{lcc}
\hline City & State & Zip Code \\
Vero Beach & FL & $32962-7307$
\end{tabular}

FEC ID number of contributing

federal political committee.

C

Name of Employer
Walgreens
Receipt For: 2012
X Primary
Other (specify)

Occupation

Pharmacist

Election Cycle-to-Date

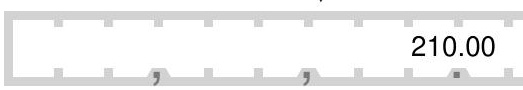

Transaction ID : AEFD10D9B6BBC4C6790E

Date of Receipt

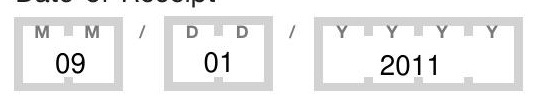

Amount of Each Receipt this Period

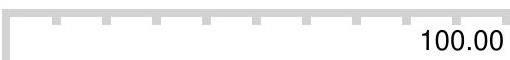

C. Full Name (Last, First, Middle Initial)

Doug Buchanan

Mailing Address 9811 ascot

\begin{tabular}{lcc}
\hline City & State & Zip Code \\
Omaha & NE & $68114-3847$
\end{tabular}

FEC ID number of contributing federal political committee.

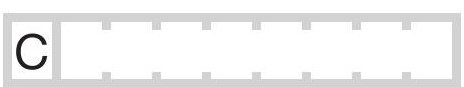

Name of Employer
renze display
Receipt For: 2012
X Primary $\square$ General
Other (specify)

Occupation

President

Election Cycle-to-Date
Transaction ID : ADF12EC5BC9EB4990AA1 Date of Receipt

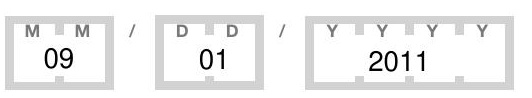

Amount of Each Receipt this Period

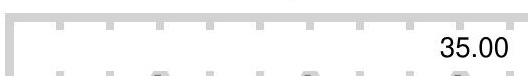

Transaction ID : A8229509E8D394B8BA18

Date of Receipt

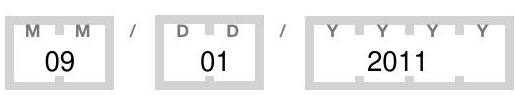

Amount of Each Receipt this Period

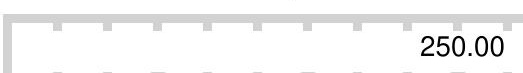

\section{Subtotal Of Receipts This Page (optional)}

Total This Period (last page this line number only) 
SCHEDULE A-P ITEMIZED RECEIPTS
Use separate schedule(s) for each category of the Detailed Summary Page
FOR LINE NUMBER: (check only one)

PAGE 407 / 1572

\begin{tabular}{|c|c|c|c|c|c|}
\hline & & & & & \\
\hline 16 & $\begin{array}{l}\mathbf{X} \\
17 a\end{array}$ & $17 b$ & $17 c$ & $17 d$ & 18 \\
\hline $19 a$ & $19 \mathrm{~b}$ & $20 \mathrm{a}$ & $20 \mathrm{~b}$ & $20 \mathrm{c}$ & 21 \\
\hline
\end{tabular}

Any information copied from such Reports and Statements may not be sold or used by any person for the purpose of soliciting contributions or for commercial purposes, other than using the name and address of any political committee to solicit contributions from such committee.

NAME OF COMMITTEE (In Full)

\section{Friends of Herman Cain}

A. Full Name (Last, First, Middle Initial)

Mr Harry L Wallace

Mailing Address 2204 W Charter Mall

\begin{tabular}{lcc}
\hline City & State & Zip Code \\
Mequon & WI & $53092-5451$
\end{tabular}

FEC ID number of contributing federal political committee.

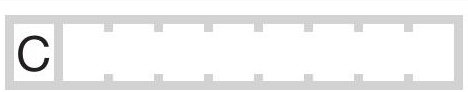

\begin{tabular}{l} 
Name of Employer \\
None \\
Receipt For: 2012 \\
X Primary $\quad$ General \\
\hline Other (specify)
\end{tabular}

Occupation

Retired

Election Cycle-to-Date

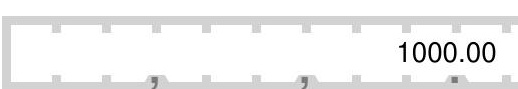

B. Full Name (Last, First, Middle Initial)

Mr Kade Matthews

Mailing Address PO Box 1170

\begin{tabular}{lcc}
\hline City & State & Zip Code \\
Clarendon & TX & $79226-1170$
\end{tabular}

FEC ID number of contributing

federal political committee.

C

Name of Employer
self
Receipt For: 2012
X Primary
Other (specify)

Occupation

rancher

Election Cycle-to-Date

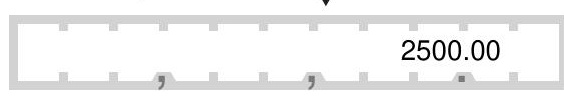

Transaction ID : A25558905BC8447659B1

Date of Receipt

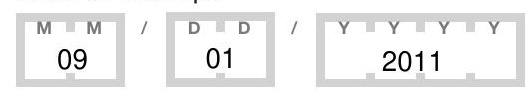

Amount of Each Receipt this Period

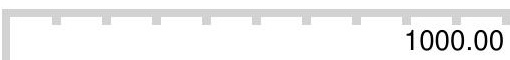

C. Full Name (Last, First, Middle Initial)

Beatrice Humphris

Mailing Address 14 Manassas $\mathrm{Dr}$

\begin{tabular}{lcc}
\hline City & State & Zip Code \\
Toms River & NJ & $08757-5807$
\end{tabular}

FEC ID number of contributing federal political committee.

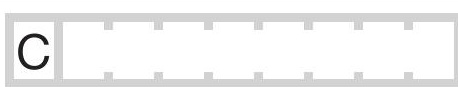

Name of Employer
None
Receipt For: 2012
Х Primary $\quad \square$ General
Other (specify)

Occupation

Retired

Election Cycle-to-Date
Amount of Each Receipt this Period

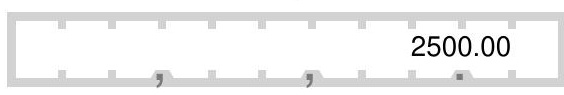

Transaction ID : A2E71FFE615F9487886C

Date of Receipt

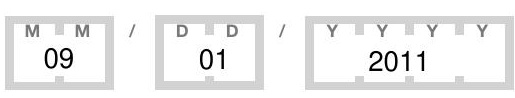

Transaction ID : AFDFAD2C9ED944DE49D5 Date of Receipt

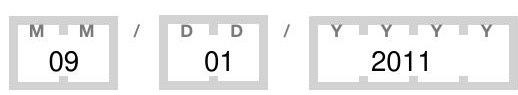

Amount of Each Receipt this Period

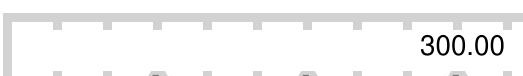

\section{Subtotal Of Receipts This Page (optional)}

Total This Period (last page this line number only) 
SCHEDULE A-P ITEMIZED RECEIPTS
Use separate schedule(s) for each category of the Detailed Summary Page
FOR LINE NUMBER: (check only one)

PAGE 408 / 1572

\begin{tabular}{|c|c|c|c|c|c|}
\hline & & & & & \\
\hline 16 & $\begin{array}{l}\mathbf{X} \\
17 a\end{array}$ & $17 b$ & $17 c$ & $17 d$ & 18 \\
\hline $19 a$ & $19 \mathrm{~b}$ & $20 \mathrm{a}$ & $20 \mathrm{~b}$ & $20 \mathrm{c}$ & 21 \\
\hline
\end{tabular}

Any information copied from such Reports and Statements may not be sold or used by any person for the purpose of soliciting contributions or for commercial purposes, other than using the name and address of any political committee to solicit contributions from such committee.

NAME OF COMMITTEE (In Full)

\section{Friends of Herman Cain}

A. Full Name (Last, First, Middle Initial)

Robert Shive

Mailing Address 1080 Cherry Tree Rd.

\begin{tabular}{lcc}
\hline City & State & Zip Code \\
Saint Augustine & FL & $32086-5028$
\end{tabular}

FEC ID number of contributing federal political committee.

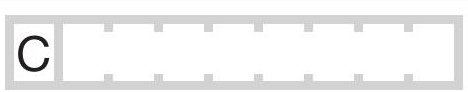

\begin{tabular}{l} 
Name of Employer \\
None \\
Receipt For: 2012 \\
X Primary $\quad$ General \\
\hline Other (specify)
\end{tabular}

Occupation

Retired

Election Cycle-to-Date

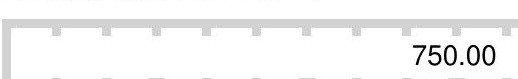

B. Full Name (Last, First, Middle Initial)

Les Love

Mailing Address 25 Scenic View Dr

\begin{tabular}{lcc}
\hline City & State & Zip Code \\
Weaverville & NC & $28787-9379$ \\
\hline
\end{tabular}

FEC ID number of contributing

federal political committee.

C

Name of Employer
Foliage Concepts
Receipt For: 2012
Primary
Other (specify) General

Occupation

President

Election Cycle-to-Date

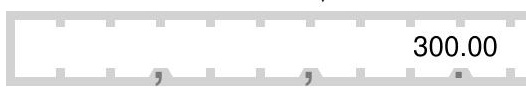

C. Full Name (Last, First, Middle Initial)

Mr Thomas E McNamara

Mailing Address PO Box 1827

\begin{tabular}{lcc}
\hline City & State & Zip Code \\
Atascadero & CA & $93423-1827$
\end{tabular}

FEC ID number of contributing federal political committee.

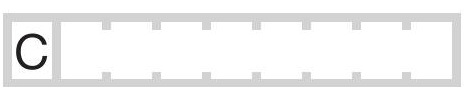

Name of Employer
Information Requested
Receipt For: 2012
X Primary
Other (specify) General

Occupation

Information Requested

Election Cycle-to-Date
Transaction ID : A7ED8171B996C479A982

Date of Receipt

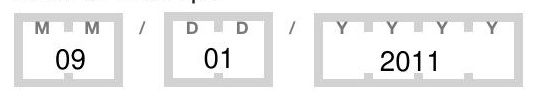

Amount of Each Receipt this Period

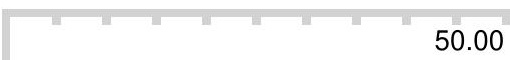

50.00

Amount of Each Receipt this Period

Transaction ID : A4C1941F71C4A4471A8A

Date of Receipt
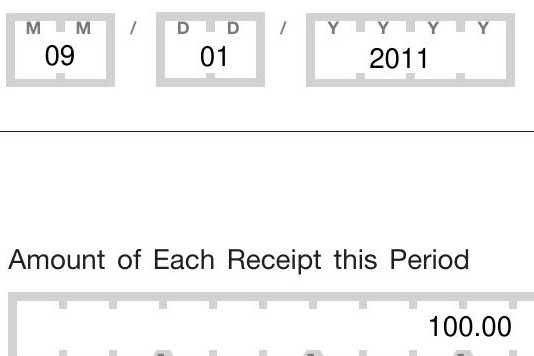

Transaction ID : A322364BC3A3E46B697E Date of Receipt

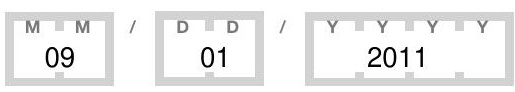

Amount of Each Receipt this Period

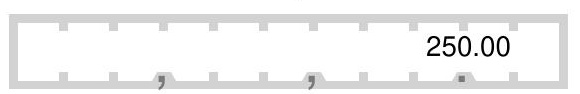

250.00

\section{Subtotal Of Receipts This Page (optional)}

Total This Period (last page this line number only) 
SCHEDULE A-P ITEMIZED RECEIPTS
Use separate schedule(s) for each category of the Detailed Summary Page
FOR LINE NUMBER: (check only one)

PAGE 409 / 1572

\begin{tabular}{|c|c|c|c|c|c|}
\hline & & & & & \\
\hline 16 & $\begin{array}{l}\mathbf{X} \\
17 a\end{array}$ & $17 b$ & $17 c$ & $17 d$ & 18 \\
\hline $19 a$ & $19 \mathrm{~b}$ & $20 \mathrm{a}$ & $20 \mathrm{~b}$ & $20 \mathrm{c}$ & 21 \\
\hline
\end{tabular}

Any information copied from such Reports and Statements may not be sold or used by any person for the purpose of soliciting contributions or for commercial purposes, other than using the name and address of any political committee to solicit contributions from such committee.

NAME OF COMMITTEE (In Full)

\section{Friends of Herman Cain}

A. Full Name (Last, First, Middle Initial)

Mr Anthony L Federico

Mailing Address 12306 Van Nuys Blvd

\begin{tabular}{lcc}
\hline City & State & Zip Code \\
Sylmar & CA & $91342-6049$
\end{tabular}

FEC ID number of contributing federal political committee.

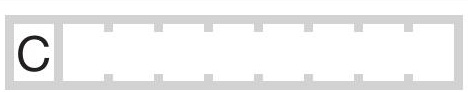

Name of Employer
superior gunite
Receipt For: 2012
X Primary
Other (specify) General

Occupation contractor

Election Cycle-to-Date

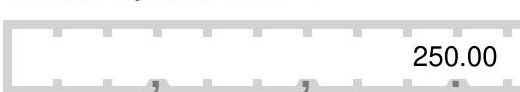

B. Full Name (Last, First, Middle Initial)

Mr. Vincent T McManus

Mailing Address 1 Blackberry Ln

\begin{tabular}{lcc}
\hline City & State & Zip Code \\
Wallingford & CT & $06492-2701$
\end{tabular}

FEC ID number of contributing

federal political committee.

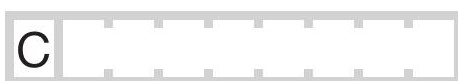

Name of Employer
Self Employed
Receipt For: 2012
X Primary
Other (specify)

Occupation

Attorney

Election Cycle-to-Date

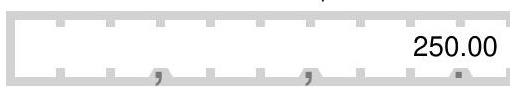

C. Full Name (Last, First, Middle Initial)

Mr Ken Wade

Mailing Address 1704 Hidden Hills Rd Suite 206

\begin{tabular}{lcc}
\hline City & State & Zip Code \\
Gatlinburg & TN & $37738-5827$
\end{tabular}

FEC ID number of contributing federal political committee.

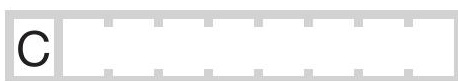

Name of Employer
Retired
Receipt For: 2012
X Primary $\quad \square$ General
Other (specify)

\section{Occupation}

Retired

Election Cycle-to-Date

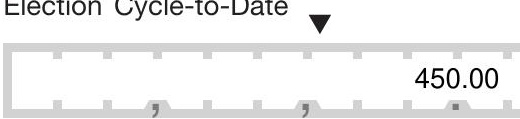

Transaction ID : A10225D244DF34B5BAB9

Date of Receipt

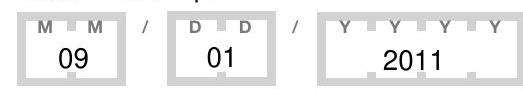

Amount of Each Receipt this Period

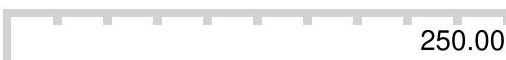

250.00

Transaction ID : A29C4CEF9B3E24C25A49

Date of Receipt

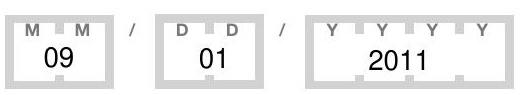

Amount of Each Receipt this Period

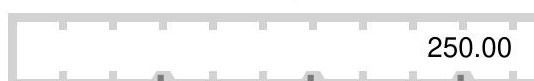

Transaction ID : A5C83F1113B7A47CDA43 Date of Receipt

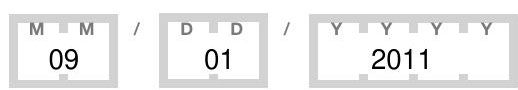

Amount of Each Receipt this Period

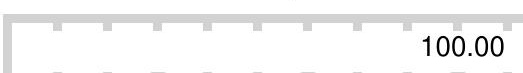

100.00

\section{Subtotal Of Receipts This Page (optional)}

600.00

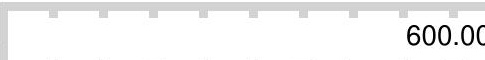

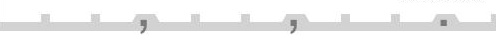

Total This Period (last page this line number only)

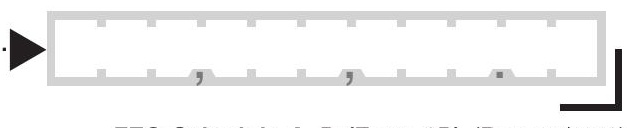

FEC Schedule A-P (Form 3P) (Rev. 03/2011) 
SCHEDULE A-P ITEMIZED RECEIPTS
Use separate schedule(s) for each category of the Detailed Summary Page
FOR LINE NUMBER: (check only one)

\begin{tabular}{|c|c|c|c|c|c|}
\hline & & & & & \\
\hline 16 & $\begin{array}{ll}X & 17 a \\
\end{array}$ & $17 \mathrm{~b}$ & $17 c$ & $17 d$ & 18 \\
\hline $19 a$ & $19 b$ & $20 \mathrm{a}$ & $20 \mathrm{~b}$ & $20 c$ & 21 \\
\hline
\end{tabular}

Any information copied from such Reports and Statements may not be sold or used by any person for the purpose of soliciting contributions or for commercial purposes, other than using the name and address of any political committee to solicit contributions from such committee.

NAME OF COMMITTEE (In Full)

\section{Friends of Herman Cain}

A. Full Name (Last, First, Middle Initial)

Nels Nelson

Mailing Address 302 Canton St. P.O.B. 123

\begin{tabular}{lcc}
\hline City & State & Zip Code \\
Woosung & IL & $61091-0123$
\end{tabular}

FEC ID number of contributing

federal political committee.

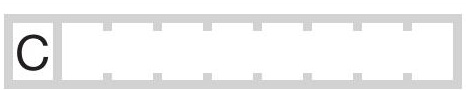

Name of Employer
self
Receipt For: 2012
X Primary $\quad$ General
Other (specify)

Occupation

Retired

Election Cycle-to-Date

221.00

B. Full Name (Last, First, Middle Initial)

James Dyer

Mailing Address 5435 Keats Ave N

\begin{tabular}{llc}
\hline City & State & Zip Code \\
Lake Elmo & MN & $55042-9557$
\end{tabular}

FEC ID number of contributing

federal political committee.

C

Name of Employer
Brocade Communications
Receipt For: 2012
X Primary
Other (specify)

Occupation

Sales Manager

Election Cycle-to-Date

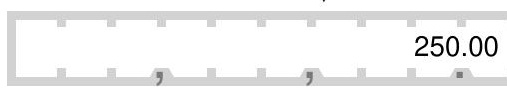

Transaction ID : A71CC1376BF144594A1E

Date of Receipt

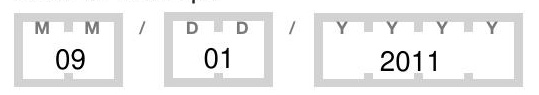

Amount of Each Receipt this Period

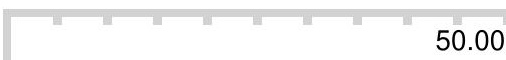

50.00

C. Full Name (Last, First, Middle Initial)

John Lehman

Mailing Address PMB 311 - 1133 Bal Harbor Blvd.

\begin{tabular}{lcc}
\hline City & State & Zip Code \\
Punta Gorda & FL & $33950-6577$
\end{tabular}

FEC ID number of contributing

federal political committee.

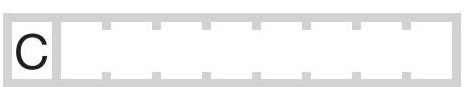

$\begin{aligned} & \text { Name of Employer } \\ & \text { self }\end{aligned}$
Receipt For: 2012
X Primary $\square$ General
Other (specify)

\section{Occupation}

Sales

Election Cycle-to-Date

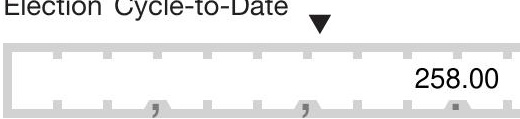

Transaction ID : AF3532C4F8ED74C25ACA Date of Receipt

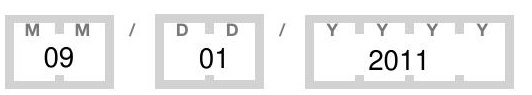

Amount of Each Receipt this Period

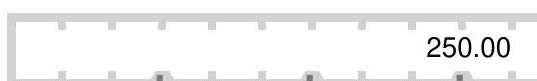

Transaction ID : AA241AABDE4C34974BA8 Date of Receipt

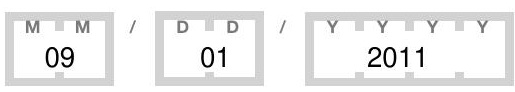

Amount of Each Receipt this Period

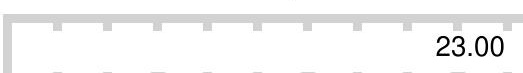

\section{Subtotal Of Receipts This Page (optional)}

Total This Period (last page this line number only) 
SCHEDULE A-P ITEMIZED RECEIPTS
Use separate schedule(s) for each category of the Detailed Summary Page
FOR LINE NUMBER: (check only one)

PAGE $411 / 1572$

\begin{tabular}{|c|c|c|c|c|c|}
\hline & & & & & \\
\hline 16 & $\begin{array}{l}\mathbf{X} \\
17 a\end{array}$ & $17 b$ & $17 c$ & $17 d$ & 18 \\
\hline $19 a$ & $19 \mathrm{~b}$ & $20 \mathrm{a}$ & $20 \mathrm{~b}$ & $20 \mathrm{c}$ & 21 \\
\hline
\end{tabular}

Any information copied from such Reports and Statements may not be sold or used by any person for the purpose of soliciting contributions or for commercial purposes, other than using the name and address of any political committee to solicit contributions from such committee.

NAME OF COMMITTEE (In Full)

\section{Friends of Herman Cain}

A. Full Name (Last, First, Middle Initial)

Mr Thomas L Mitchel

Mailing Address 611 W 146th St

\begin{tabular}{lcc}
\hline City & State & Zip Code \\
Carmel & IN & $46074-9609$
\end{tabular}

FEC ID number of contributing federal political committee.

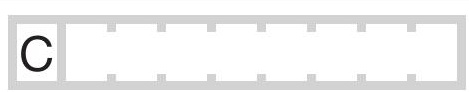

Name of Employer
MG Inc
Receipt For: 2012
X Primary
Other (specify) General

Occupation Engineer

Election Cycle-to-Date

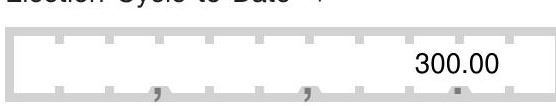

B. Full Name (Last, First, Middle Initial)

Mr Richard Cunniff Jr

Mailing Address 360 West 43rd Street

\begin{tabular}{lcc}
\hline City & State & Zip Code \\
New York & NY & $10036-6410$
\end{tabular}

FEC ID number of contributing

federal political committee.

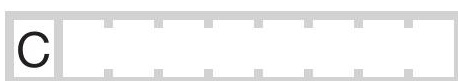

Name of Employer
morgan stanley
Receipt For: 2012
X Primary
Other (specify)

\section{Occupation}

Editor

Election Cycle-to-Date

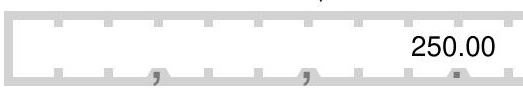

Transaction ID : A1F219C4B544D434FB57

Date of Receipt

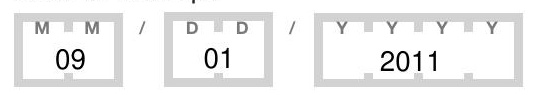

Amount of Each Receipt this Period

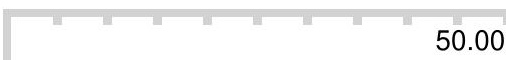

C. Full Name (Last, First, Middle Initial)

Carol Cook

Mailing Address 43 Oak Alley

\begin{tabular}{lcc}
\hline City & State & Zip Code \\
Kerrville & TX & 78028-1711
\end{tabular}

FEC ID number of contributing federal political committee.

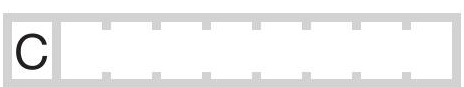

Name of Employer
James Avery
Receipt For: 2012
X Primary
Other (specify) General

\section{Occupation}

Sales Team Leader

Election Cycle-to-Date

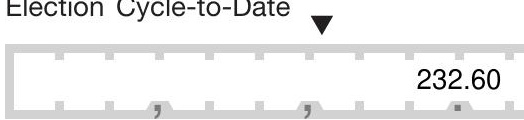

Transaction ID : AD0DD380984C54DFE84F Date of Receipt

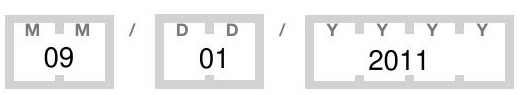

Amount of Each Receipt this Period

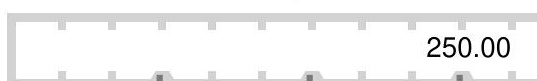

Transaction ID : A7E8B7F5DF44648EB9AC Date of Receipt

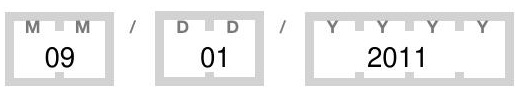

Amount of Each Receipt this Period

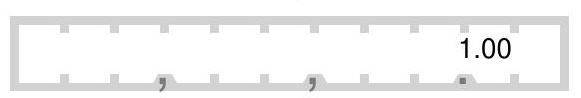

Subtotal Of Receipts This Page (optional)

$-301.00$

Total This Period (last page this line number only)

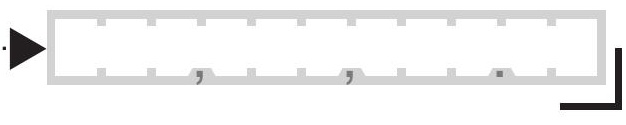

FEC Schedule A-P (Form 3P) (Rev. 03/2011) 


\section{SCHEDULE A-P} ITEMIZED RECEIPTS
Use separate schedule(s)

for each category of the

Detailed Summary Page
FOR LINE NUMBER: (check only one)

PAGE 412 / 1572

\begin{tabular}{|c|c|c|c|c|c|}
\hline & & & & & \\
\hline 16 & X $17 a$ & $17 b$ & $17 c$ & $17 d$ & 18 \\
\hline $19 a$ & $19 b$ & $20 \mathrm{a}$ & $20 \mathrm{~b}$ & $20 \mathrm{c}$ & 21 \\
\hline
\end{tabular}

Any information copied from such Reports and Statements may not be sold or used by any person for the purpose of soliciting contributions or for commercial purposes, other than using the name and address of any political committee to solicit contributions from such committee.

NAME OF COMMITTEE (In Full)

Friends of Herman Cain

A. Full Name (Last, First, Middle Initial)

barbara rembiesa

Mailing Address 1063 meandering creek

\begin{tabular}{lcc}
\hline City & State & Zip Code \\
Uniontown & OH & $44685-8280$
\end{tabular}

FEC ID number of contributing

federal political committee.

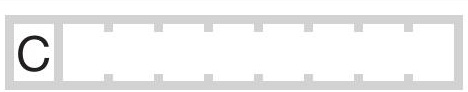

Name of Employer
Information Requested
Receipt For: 2012
X Primary $\quad \square$ General
Other (specify)

Occupation

Information Requested

Election Cycle-to-Date

465.00

B. Full Name (Last, First, Middle Initial)

Mr. Ben Cole Scott

Mailing Address 3201 Hobcaw Ln

\begin{tabular}{lcc}
\hline City & State & Zip Code \\
Lexington & KY & $40502-3523$ \\
\hline
\end{tabular}

FEC ID number of contributing

federal political committee.

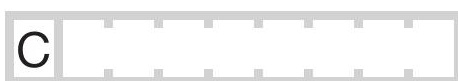

Name of Employer
home care medical
Receipt For: 2012
Primary
Other (specify) General

Occupation

Pharmacist

Election Cycle-to-Date

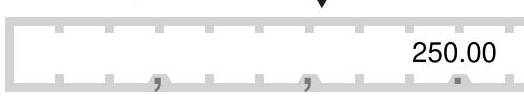

C. Full Name (Last, First, Middle Initial)

richard willman

Mailing Address 5501 NW 65th St

\begin{tabular}{lcc}
\hline City & State & Zip Code \\
Warr Acres & OK & $73132-7758$
\end{tabular}

FEC ID number of contributing

federal political committee.

C

Name of Employer

Raytheon Technical Services

Receipt For: 2012

Х $\begin{aligned} & \text { Primary } \square \text { General } \\ & \text { Other (specify) }\end{aligned}$

Occupation

Air Traffic Control Instructor

Election Cycle-to-Date

Transaction ID : A455934BABD3C4FE5848

Date of Receipt

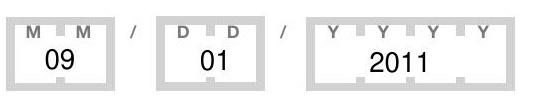

Amount of Each Receipt this Period

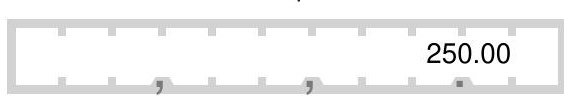

Amount of Each Receipt this Period

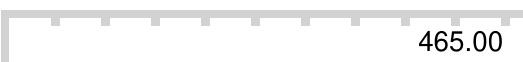

465.00

Date of Receipt

Date of Receipt

09

2011

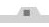


SCHEDULE A-P ITEMIZED RECEIPTS
Use separate schedule(s) for each category of the Detailed Summary Page
FOR LINE NUMBER: (check only one)

PAGE $413 / 1572$

\begin{tabular}{|c|c|c|c|c|c|c|}
\hline & & & & & & \\
\hline 16 & $\lambda$ & $17 \mathrm{a}$ & $17 \mathrm{~b}$ & $17 \mathrm{c}$ & $-17 d$ & -18 \\
\hline $19 a$ & & $19 b$ & $20 a$ & $20 \mathrm{~b}$ & $20 \mathrm{c}$ & 21 \\
\hline
\end{tabular}

Any information copied from such Reports and Statements may not be sold or used by any person for the purpose of soliciting contributions or for commercial purposes, other than using the name and address of any political committee to solicit contributions from such committee.

NAME OF COMMITTEE (In Full)

\section{Friends of Herman Cain}

A. Full Name (Last, First, Middle Initial)

Mr. Robert E Hawkins

Mailing Address 5005 Birch Rd

\begin{tabular}{lcc}
\hline City & State & Zip Code \\
Fayetteville & NC & 28304-1901
\end{tabular}

FEC ID number of contributing federal political committee.

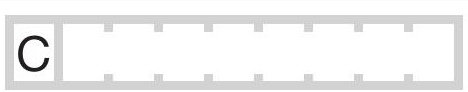

Name of Employer
Information Requested
Receipt For: 2012
X Primary
Other (specify) General

Occupation Information Requested

Election Cycle-to-Date

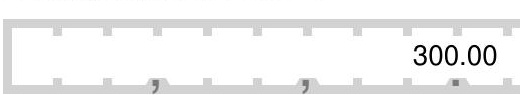

B. Full Name (Last, First, Middle Initial)

Donald Johnston

Mailing Address 6147 West 76th Street

\begin{tabular}{lcc}
\hline City & State & Zip Code \\
Los Angeles & CA & $90045-1637$
\end{tabular}

FEC ID number of contributing

federal political committee.

C

Name of Employer
Information Requested
Receipt For: 2012
X Primary
Other (specify)

Occupation

Information Requested

Election Cycle-to-Date

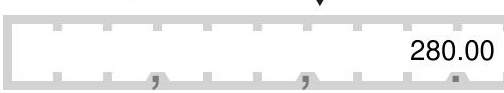

Transaction ID : AB117C5C24B6449EE989

Date of Receipt

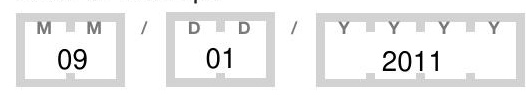

Amount of Each Receipt this Period

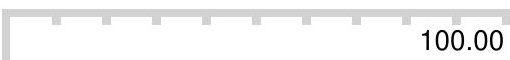

Transaction ID : A3C5BB17B6C884D88B50 Date of Receipt

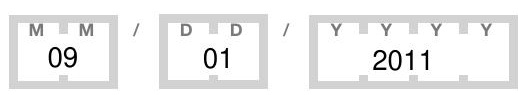

Amount of Each Receipt this Period

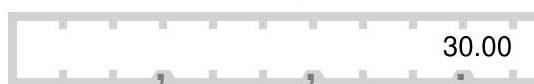

Transaction ID : A74D0C4D559AF4DC1801 Date of Receipt

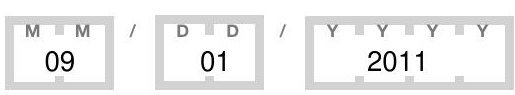

Amount of Each Receipt this Period

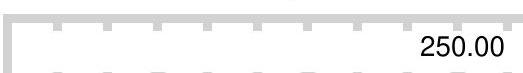

C. Full Name (Last, First, Middle Initial)

Ms Susan Mitchem

Mailing Address 4703 Shetland Ln

\begin{tabular}{lcc}
\hline City & State & Zip Code \\
Houston & TX & $77027-6209$
\end{tabular}

FEC ID number of contributing federal political committee.

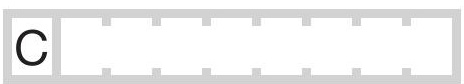

Name of Employer
Medicis
Receipt For: 2012
X Primary
Other (specify) General

\section{Occupation}

Sales Rep

Election Cycle-to-Date

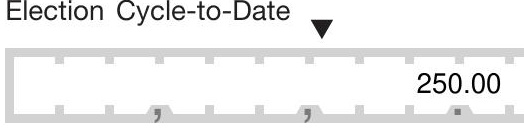

Subtotal Of Receipts This Page (optional)

380.00

a

Total This Period (last page this line number only)

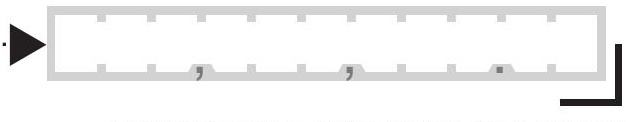

FEC Schedule A-P (Form 3P) (Rev. 03/2011) 
SCHEDULE A-P ITEMIZED RECEIPTS
Use separate schedule(s) for each category of the Detailed Summary Page
FOR LINE NUMBER: (check only one)

PAGE 414 / 1572

\begin{tabular}{|c|c|c|c|c|c|}
\hline & & & & & \\
\hline 16 & $\begin{array}{l}\mathbf{X} \\
17 a\end{array}$ & $17 b$ & $17 c$ & $17 d$ & 18 \\
\hline $19 a$ & $19 \mathrm{~b}$ & $20 \mathrm{a}$ & $20 \mathrm{~b}$ & $20 \mathrm{c}$ & 21 \\
\hline
\end{tabular}

Any information copied from such Reports and Statements may not be sold or used by any person for the purpose of soliciting contributions or for commercial purposes, other than using the name and address of any political committee to solicit contributions from such committee.

NAME OF COMMITTEE (In Full)

\section{Friends of Herman Cain}

A. Full Name (Last, First, Middle Initial) Jesus Rancano

Mailing Address 4419 Timber Ridge Drive

\begin{tabular}{lcc}
\hline City & State & Zip Code \\
Douglasville & GA & $30135-1218$ \\
\hline
\end{tabular}

FEC ID number of contributing federal political committee.

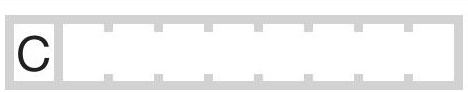

Name of Employer
Atlantic Southeast Airlines
Receipt For: 2012
X Primary
Other (specify) General

\section{Occupation}

Pilot

Election Cycle-to-Date

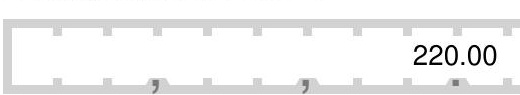

B. Full Name (Last, First, Middle Initial) James Fraser

Mailing Address 263 Barefoot Bch Blvd Apt 201

\begin{tabular}{lcc}
\hline City & State & Zip Code \\
Bonita Springs & FL & $34134-8580$
\end{tabular}

FEC ID number of contributing

federal political committee.

C

Name of Employer
None
Receipt For: 2012
X Primary
Other (specify)

Occupation

Retired

Election Cycle-to-Date

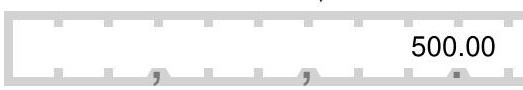

Transaction ID : A79D49CCB364A48349EA

Date of Receipt

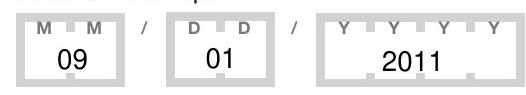

Amount of Each Receipt this Period

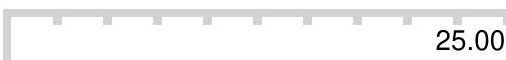

Transaction ID : A937E9F5C8586480486C

Date of Receipt

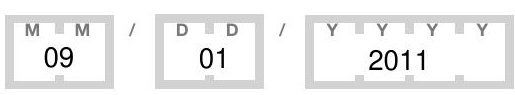

Amount of Each Receipt this Period

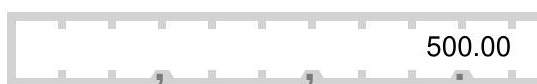

Transaction ID : A440C2A24407C4525A28

Date of Receipt

meaghan keeley

Mailing Address 7209 Governors Row

\begin{tabular}{lcc}
\hline City & State & Zip Code \\
Charlotte & NC & $28277-0377$
\end{tabular}

FEC ID number of contributing federal political committee.

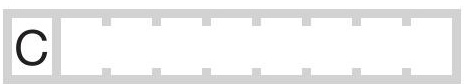

Name of Employer
None
Receipt For: 2012
Х Primary $\quad \square$ General
Other (specify)

Occupation

Homemaker

Election Cycle-to-Date

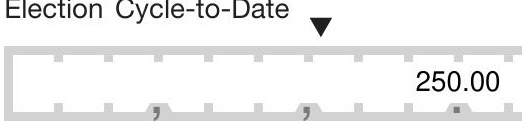

Subtotal Of Receipts This Page (optional).

775.00

Amount of Each Receipt this Period

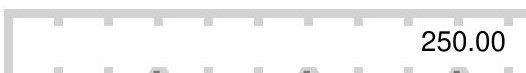

Total This Period (last page this line number only) 
SCHEDULE A-P ITEMIZED RECEIPTS
Use separate schedule(s) for each category of the Detailed Summary Page
FOR LINE NUMBER: (check only one)

PAGE 415 / 1572

\begin{tabular}{|c|c|c|c|c|c|}
\hline & & & & & \\
\hline 16 & $\begin{array}{l}\mathbf{X} \\
17 a\end{array}$ & $17 b$ & $17 c$ & $17 d$ & 18 \\
\hline $19 a$ & $19 \mathrm{~b}$ & $20 \mathrm{a}$ & $20 \mathrm{~b}$ & $20 \mathrm{c}$ & 21 \\
\hline
\end{tabular}

Any information copied from such Reports and Statements may not be sold or used by any person for the purpose of soliciting contributions or for commercial purposes, other than using the name and address of any political committee to solicit contributions from such committee.

NAME OF COMMITTEE (In Full)

\section{Friends of Herman Cain}

A. Full Name (Last, First, Middle Initial)

\section{Chi C Mao MD}

Mailing Address 427 W 20th St Ste 212

\begin{tabular}{lcc}
\hline City & State & Zip Code \\
Houston & TX & $77008-2400$
\end{tabular}

FEC ID number of contributing federal political committee.

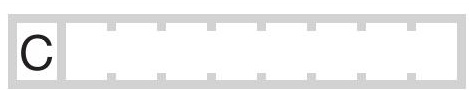

Name of Employer
self
Receipt For: 2012
X Primary $\quad$ General
Other (specify)

Occupation Physician

Election Cycle-to-Date

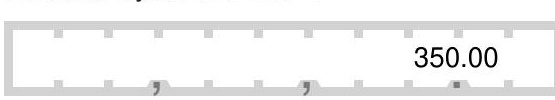

B. Full Name (Last, First, Middle Initial)

William R Dahlgren

Mailing Address 1345 Via Coronel

\begin{tabular}{lcc}
\hline City & State & Zip Code \\
Palos Verdes Estates & CA & $90274-1937$ \\
\hline
\end{tabular}

FEC ID number of contributing

federal political committee.

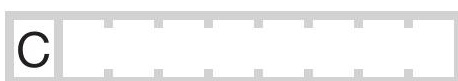

Name of Employer
airtech inc
Receipt For: 2012
X Primary
Other (specify)

\section{Occupation}

Owner

Election Cycle-to-Date

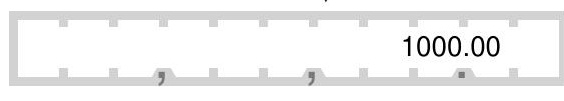

Transaction ID : A173CC4C6FEFB4C8A8D6

Date of Receipt

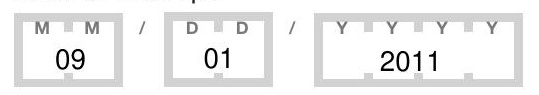

Amount of Each Receipt this Period

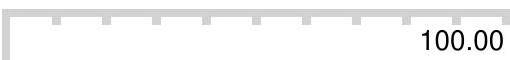

Amount of Each Receipt this Period

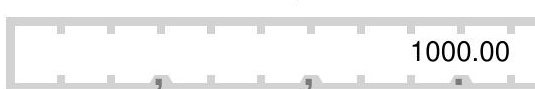

C. Full Name (Last, First, Middle Initial)

Dean McDonald

Mailing Address 155 Sims Drive

\begin{tabular}{lcc}
\hline City & State & Zip Code \\
Stockbridge & GA & $30281-2228$
\end{tabular}

FEC ID number of contributing federal political committee.

C

Name of Employer
Information Requested
Receipt For: 2012
X Primary
Other (specify) General

Occupation

Information Requested

Election Cycle-to-Date

Transaction ID : A69E4540C55EB4194906

Date of Receipt

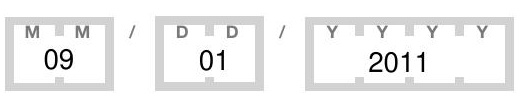

Transaction ID : A97E7F8E8C04047668A9 Date of Receipt

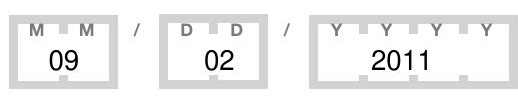

Amount of Each Receipt this Period

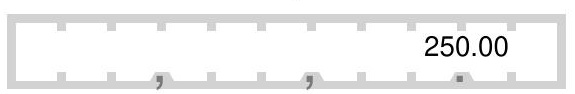

250.00

\section{Subtotal Of Receipts This Page (optional)}

Total This Period (last page this line number only) 
SCHEDULE A-P ITEMIZED RECEIPTS
Use separate schedule(s) for each category of the Detailed Summary Page
FOR LINE NUMBER: (check only one)

PAGE 416 / 1572

\begin{tabular}{|c|c|c|c|c|c|}
\hline & & & & & \\
\hline 16 & $\begin{array}{l}\mathbf{X} \\
17 a\end{array}$ & $17 b$ & $17 c$ & $17 d$ & 18 \\
\hline $19 a$ & $19 \mathrm{~b}$ & $20 \mathrm{a}$ & $20 \mathrm{~b}$ & $20 \mathrm{c}$ & 21 \\
\hline
\end{tabular}

Any information copied from such Reports and Statements may not be sold or used by any person for the purpose of soliciting contributions or for commercial purposes, other than using the name and address of any political committee to solicit contributions from such committee.

NAME OF COMMITTEE (In Full)

\section{Friends of Herman Cain}

A. Full Name (Last, First, Middle Initial)

\section{David DeRousse}

Mailing Address 241 Duncan Loop West Apt. 101

\begin{tabular}{lcc}
\hline City & State & Zip Code \\
Dunedin & FL & $34698-1324$
\end{tabular}

FEC ID number of contributing federal political committee.

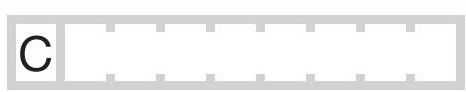

Name of Employer
Retired
Receipt For: 2012
X Primary $\quad$ General
Other (specify)

Occupation Retired

Election Cycle-to-Date

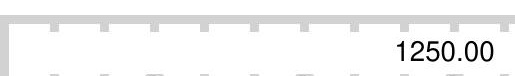

B. Full Name (Last, First, Middle Initial)

Ronald Coffey

Mailing Address 155 Millcreek Ln

\begin{tabular}{lcc}
\hline City & State & Zip Code \\
Chagrin Falls & OH & $44022-1266$
\end{tabular}

FEC ID number of contributing

federal political committee.

C

Name of Employer
Information Requested
Receipt For: 2012
X Primary
Other (specify)

Occupation

Information Requested

Election Cycle-to-Date

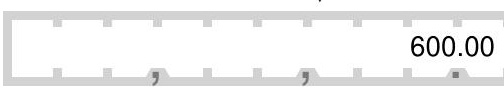

Transaction ID : A7CAC68DF70C54F3F963

Date of Receipt

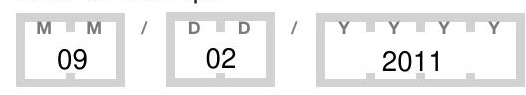

Amount of Each Receipt this Period

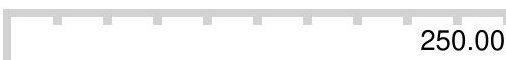

C. Full Name (Last, First, Middle Initial) richard clampitt

Mailing Address 7261 ashington dr

\begin{tabular}{lcc}
\hline City & State & Zip Code \\
Dallas & TX & $75225-1704$
\end{tabular}

FEC ID number of contributing federal political committee.

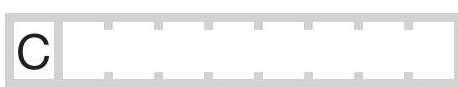

Name of Employer
red river paper
Receipt For: 2012
Xrimary $\quad \square$ General
Other (specify)

\section{Occupation}

Executive

\section{Election Cycle-to-Date}

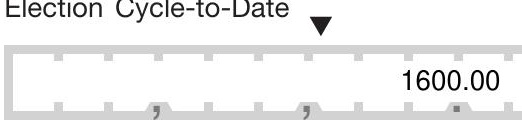

Amount of Each Receipt this Period

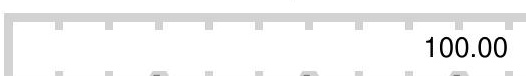

Transaction ID : AE48EE15569BC446BBE7 Date of Receipt

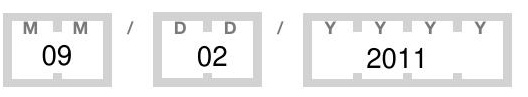

Transaction ID : A0ACA5906182F4D388AF Date of Receipt

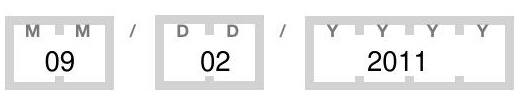

Amount of Each Receipt this Period

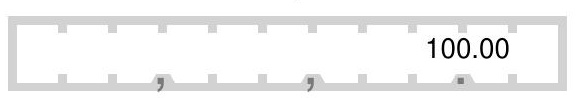

\section{Subtotal Of Receipts This Page (optional)}

Total This Period (last page this line number only) 
SCHEDULE A-P ITEMIZED RECEIPTS
Use separate schedule(s) for each category of the Detailed Summary Page
FOR LINE NUMBER: (check only one)

PAGE 417 / 1572

\begin{tabular}{|c|c|c|c|c|c|}
\hline & & & & & \\
\hline 16 & $\begin{array}{l}\mathbf{X} \\
17 a\end{array}$ & $17 b$ & $17 c$ & $17 d$ & 18 \\
\hline $19 a$ & $19 \mathrm{~b}$ & $20 \mathrm{a}$ & $20 \mathrm{~b}$ & $20 \mathrm{c}$ & 21 \\
\hline
\end{tabular}

Any information copied from such Reports and Statements may not be sold or used by any person for the purpose of soliciting contributions or for commercial purposes, other than using the name and address of any political committee to solicit contributions from such committee.

NAME OF COMMITTEE (In Full)

\section{Friends of Herman Cain}

A. Full Name (Last, First, Middle Initial) Jeanne Downer

Mailing Address $6007 \mathrm{~N}$ Kansas AVe

\begin{tabular}{lcc}
\hline City & State & Zip Code \\
Kansas City & MO & $64119-2115$ \\
\hline
\end{tabular}

FEC ID number of contributing federal political committee.

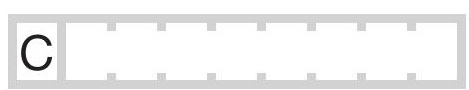

Name of Employer
WNB Architects
Receipt For: 2012
X Primary $\quad$ General
Other (specify)

Occupation Office Manager

Election Cycle-to-Date

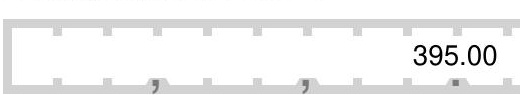

B. Full Name (Last, First, Middle Initial)

Carl A Voigtsberger

Mailing Address 7249 Manhattan Lane

\begin{tabular}{llc}
\hline City & State & Zip Code \\
Cheyenne & WY & $82009-2003$
\end{tabular}

FEC ID number of contributing

federal political committee.

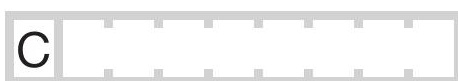

Name of Employer
None
Receipt For: 2012
X Primary
Other (specify)

Occupation

Retired

Election Cycle-to-Date

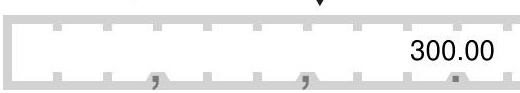

Transaction ID : A6DE40F2F617342349A3

Date of Receipt

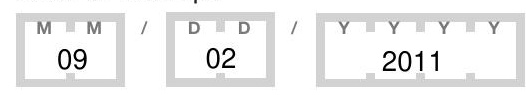

Amount of Each Receipt this Period

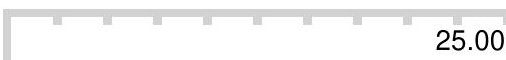

25.00

C. Full Name (Last, First, Middle Initial)

Mr. Richard M. Callahan

Mailing Address 4465 Buchanan Hwy

\begin{tabular}{lcc}
\hline City & State & Zip Code \\
Buchanan & GA & $30113-2123$
\end{tabular}

FEC ID number of contributing federal political committee.

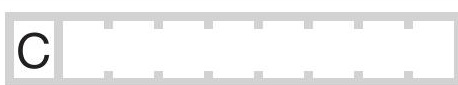

Name of Employer
None
Receipt For: 2012
Х Primary $\quad \square$ General
Other (specify)

Occupation

Retired

Election Cycle-to-Date

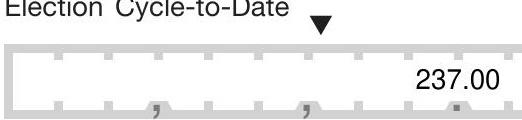

Transaction ID : A93BE88D3552F4462870

Date of Receipt

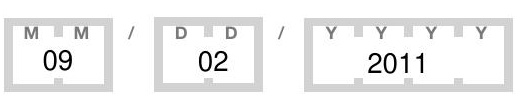

Amount of Each Receipt this Period

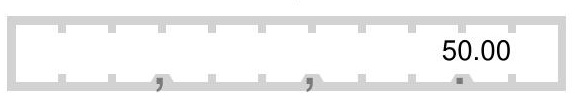

Transaction ID : A104871991A9C40BD92F

Date of Receipt

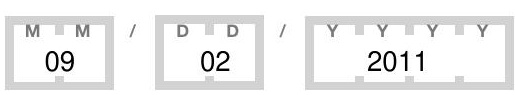

Amount of Each Receipt this Period

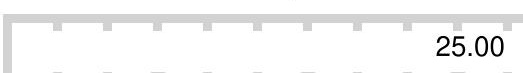

\section{Subtotal Of Receipts This Page (optional)}

100.00

(1)

Total This Period (last page this line number only)

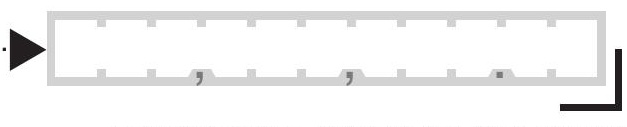

FEC Schedule A-P (Form 3P) (Rev. 03/2011) 
SCHEDULE A-P ITEMIZED RECEIPTS
Use separate schedule(s) for each category of the Detailed Summary Page
FOR LINE NUMBER: (check only one)

PAGE $418 / 1572$

\begin{tabular}{|c|c|c|c|c|c|}
\hline & & & & & \\
\hline 16 & $\begin{array}{l}\mathbf{X} \\
17 a\end{array}$ & $17 b$ & $17 c$ & $17 d$ & 18 \\
\hline $19 a$ & $19 \mathrm{~b}$ & $20 \mathrm{a}$ & $20 \mathrm{~b}$ & $20 \mathrm{c}$ & 21 \\
\hline
\end{tabular}

Any information copied from such Reports and Statements may not be sold or used by any person for the purpose of soliciting contributions or for commercial purposes, other than using the name and address of any political committee to solicit contributions from such committee.

NAME OF COMMITTEE (In Full)

\section{Friends of Herman Cain}

A. Full Name (Last, First, Middle Initial)

Michelle McDonald

Mailing Address 155 Sims Drive

\begin{tabular}{lcc}
\hline City & State & Zip Code \\
Stockbridge & GA & $30281-2228$ \\
\hline
\end{tabular}

FEC ID number of contributing

federal political committee.

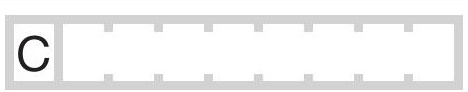

Name of Employer
Information Requested
Receipt For: 2012
X Primary
Other (specify) General

Occupation

Information Requested

Election Cycle-to-Date

250.00

B. Full Name (Last, First, Middle Initial)

Thomas Niehaus

Mailing Address 2490 Black Rock Turnpike \#450

\begin{tabular}{lcc}
\hline City & State & Zip Code \\
Fairfield & CT & $06825-2400$
\end{tabular}

FEC ID number of contributing

federal political committee.

C

Name of Employer
Information Requested
Receipt For: 2012
X Primary
Other (specify)

Occupation

Information Requested

Election Cycle-to-Date

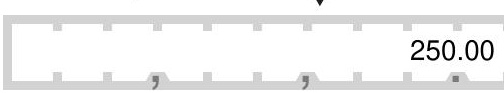

Transaction ID : A737BB71D56914C39B37

Date of Receipt

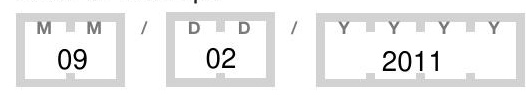

Amount of Each Receipt this Period

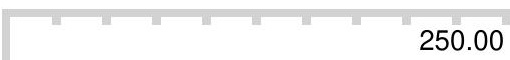

C. Full Name (Last, First, Middle Initial)

Craig Evans

Mailing Address 6275 Avalon Lane East DR

\begin{tabular}{lcc}
\hline City & State & Zip Code \\
Indianapolis & IN & $46220-5077$
\end{tabular}

FEC ID number of contributing

federal political committee.

$\mathrm{C}$

Name of Employer
AT\&T
Receipt For: 2012
X Primary

Other (specify) General

Occupation

Sales

Election Cycle-to-Date

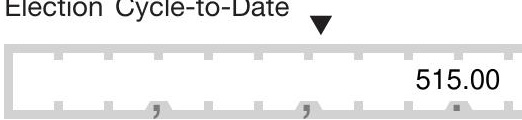

Amount of Each Receipt this Period

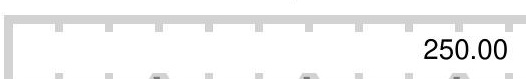

Transaction ID : A7D90FA2B6B104556AF4

Date of Receipt

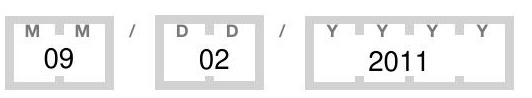

Transaction ID : A96BE670A36F641A390B Date of Receipt

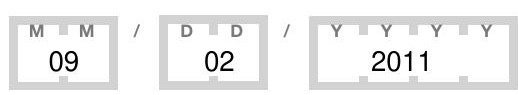

Amount of Each Receipt this Period

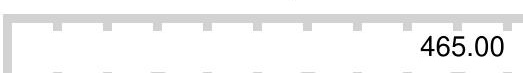

Subtotal Of Receipts This Page (optional).

965.00

a

Total This Period (last page this line number only)

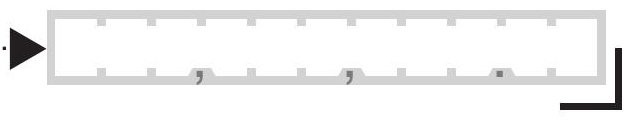

FEC Schedule A-P (Form 3P) (Rev. 03/2011) 
SCHEDULE A-P ITEMIZED RECEIPTS
Use separate schedule(s) for each category of the Detailed Summary Page
FOR LINE NUMBER: (check only one)

PAGE 419 / 1572

\begin{tabular}{|c|c|c|c|c|c|}
\hline & & & & & \\
\hline 16 & $\begin{array}{l}\mathbf{X} \\
17 a\end{array}$ & $17 b$ & $17 c$ & $17 d$ & 18 \\
\hline $19 a$ & $19 \mathrm{~b}$ & $20 \mathrm{a}$ & $20 \mathrm{~b}$ & $20 \mathrm{c}$ & 21 \\
\hline
\end{tabular}

Any information copied from such Reports and Statements may not be sold or used by any person for the purpose of soliciting contributions or for commercial purposes, other than using the name and address of any political committee to solicit contributions from such committee.

NAME OF COMMITTEE (In Full)

\section{Friends of Herman Cain}

A. Full Name (Last, First, Middle Initial) Jim Waddle

Mailing Address 711 Arnold Mill Road

\begin{tabular}{lcc}
\hline City & State & Zip Code \\
Woodstock & GA & $30188-3010$ \\
\hline
\end{tabular}

FEC ID number of contributing federal political committee.

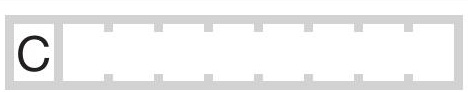

Name of Employer
Chick-Fil-A
Receipt For: 2012
X Primary $\quad$ General
Other (specify)

Occupation

Sales

Election Cycle-to-Date 350.00

B. Full Name (Last, First, Middle Initial)

Patricia Dabbs

Mailing Address 1406 Reidsboro Rd

\begin{tabular}{lcc}
\hline City & State & Zip Code \\
Williamson & GA & $30292-3463$ \\
\hline
\end{tabular}

FEC ID number of contributing

federal political committee.

C

Name of Employer
Information Requested
Receipt For: 2012
Primary
Other (specify)

Occupation

Information Requested

Election Cycle-to-Date

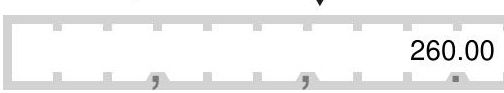

Transaction ID : A8740CB8C0FD7471DB41

Date of Receipt

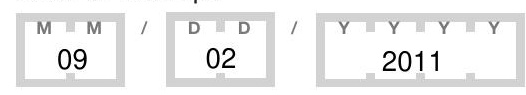

Amount of Each Receipt this Period

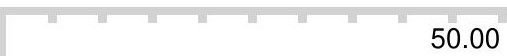

50.00

C. Full Name (Last, First, Middle Initial)

John Hooper

Mailing Address 40 Costleys Bridge $\mathrm{Dr}$

\begin{tabular}{lcc}
\hline City & State & Zip Code \\
Oxford & GA & $30054-2647$ \\
\hline
\end{tabular}

FEC ID number of contributing

federal political committee.

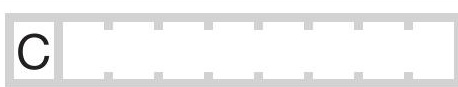

Name of Employer

Georgia School Superintendents Associa

\section{Occupation}

Educator

Transaction ID : A8D46A84BF6DF4615BED

Date of Receipt

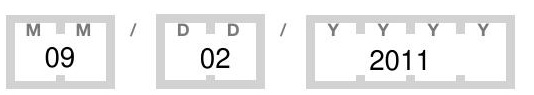

Amount of Each Receipt this Period

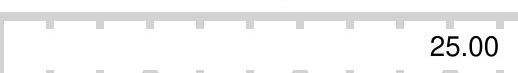

Transaction ID : ADCB2CF200109468C8CF Date of Receipt

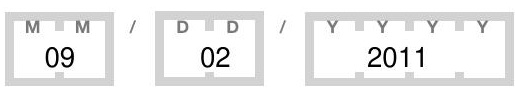

Receipt For: 2012
X Primary
Other (specify)

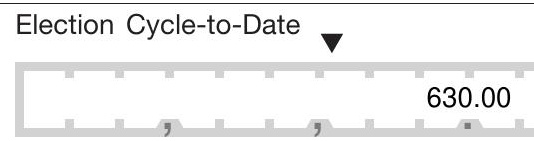

Amount of Each Receipt this Period

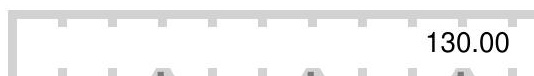

130.00

Subtotal Of Receipts This Page (optional)

205.00

Total This Period (last page this line number only) 
SCHEDULE A-P ITEMIZED RECEIPTS
Use separate schedule(s) for each category of the Detailed Summary Page
FOR LINE NUMBER: (check only one)

PAGE 420 / 1572

\begin{tabular}{|c|c|c|c|c|c|}
\hline & & & & & \\
\hline 16 & $\begin{array}{l}\mathbf{X} \\
17 a\end{array}$ & $17 b$ & $17 c$ & $17 d$ & 18 \\
\hline $19 a$ & $19 \mathrm{~b}$ & $20 \mathrm{a}$ & $20 \mathrm{~b}$ & $20 \mathrm{c}$ & 21 \\
\hline
\end{tabular}

Any information copied from such Reports and Statements may not be sold or used by any person for the purpose of soliciting contributions or for commercial purposes, other than using the name and address of any political committee to solicit contributions from such committee.

NAME OF COMMITTEE (In Full)

\section{Friends of Herman Cain}

A. Full Name (Last, First, Middle Initial) Jennifer Major

Mailing Address 4010 Jenkins Ct

\begin{tabular}{lcc}
\hline City & State & Zip Code \\
Alpharetta & GA & $30009-7115$ \\
\hline
\end{tabular}

FEC ID number of contributing federal political committee.

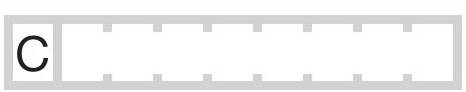

Name of Employer
CMR Residential Properties LLC
Receipt For: 2012
X Primary
Other (specify) General

Occupation

Real Estate Investor

Election Cycle-to-Date

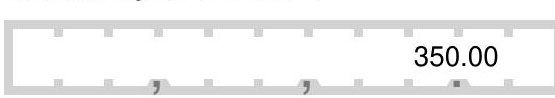

B. Full Name (Last, First, Middle Initial)

Greg Gordon

Mailing Address 2110 Norwood Ave

\begin{tabular}{lcc}
\hline City & State & Zip Code \\
Boulder & CO & $80304-1331$
\end{tabular}

FEC ID number of contributing

federal political committee.

C

Name of Employer
Information Requested
Receipt For: 2012
X Primary
Other (specify)

\section{Occupation}

Information Requested

Election Cycle-to-Date

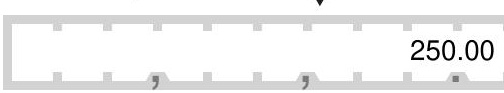

Transaction ID : A6E8CFB2530FE455C8FA

Date of Receipt

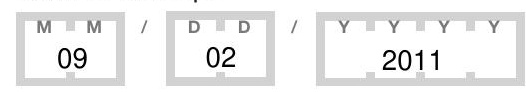

Amount of Each Receipt this Period

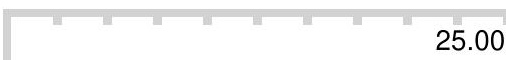

25.00

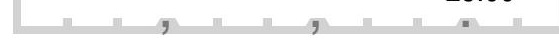

Transaction ID : A9F68C9D085354105AFB

Date of Receipt

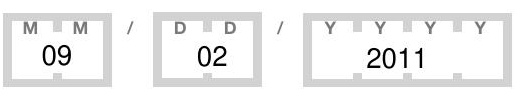

Amount of Each Receipt this Period

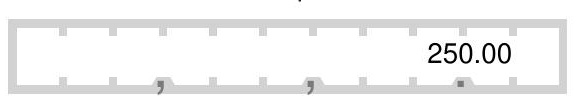

Transaction ID : A463FC54FE4CB471387F Date of Receipt

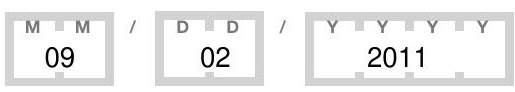

Amount of Each Receipt this Period

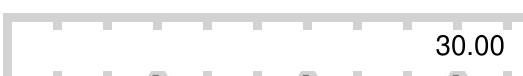

Name of Employer

Precision Dry Wall Inc.

Receipt For: 2012

Х $\begin{aligned} & \text { Primary } \\ & \text { Other (specify) }\end{aligned}$

$\begin{array}{cc}\text { State } & \text { Zip Code } \\ \text { IN } & 46226-3931\end{array}$

C

\section{Occupation}

Construction

Election Cycle-to-Date

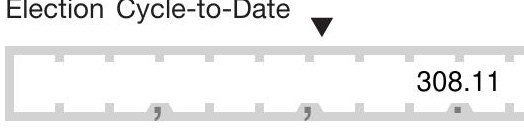

Subtotal Of Receipts This Page (optional)

305.00

.

Total This Period (last page this line number only) 
SCHEDULE A-P ITEMIZED RECEIPTS
Use separate schedule(s) for each category of the Detailed Summary Page
FOR LINE NUMBER: (check only one)

\begin{tabular}{|c|c|c|c|c|c|}
\hline & & & & & \\
\hline 16 & $\begin{array}{ll}X & 17 a \\
\end{array}$ & $17 \mathrm{~b}$ & $17 c$ & $17 d$ & 18 \\
\hline $19 a$ & $19 b$ & $20 \mathrm{a}$ & $20 \mathrm{~b}$ & $20 c$ & 21 \\
\hline
\end{tabular}

Any information copied from such Reports and Statements may not be sold or used by any person for the purpose of soliciting contributions or for commercial purposes, other than using the name and address of any political committee to solicit contributions from such committee.

NAME OF COMMITTEE (In Full)

\section{Friends of Herman Cain}

A. Full Name (Last, First, Middle Initial)

Keith Oulson

Mailing Address 5425 Ripple Creek Dr

\begin{tabular}{lcc}
\hline City & State & Zip Code \\
Tampa & FL & $33625-6416$
\end{tabular}

FEC ID number of contributing federal political committee.

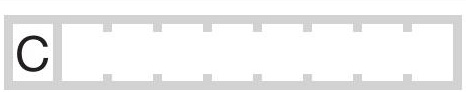

Name of Employer
Tampa General Hospital
Receipt For: 2012
X Primary $\quad \square$ General
Other (specify)

Occupation Interface Analyst

Election Cycle-to-Date

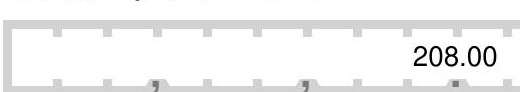

B. Full Name (Last, First, Middle Initial)

Marianne Mason

Mailing Address 30 Tall Oaks Trail

\begin{tabular}{lcc}
\hline City & State & Zip Code \\
Austin & TX & $78737-9306$ \\
\hline
\end{tabular}

FEC ID number of contributing

federal political committee.

C

Name of Employer
MMA Int. LLC
Receipt For: 2012
X Primary
Other (specify)

Occupation

Accountant

Election Cycle-to-Date

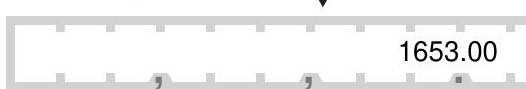

Transaction ID : AB4D0944562274C3E99D

Date of Receipt

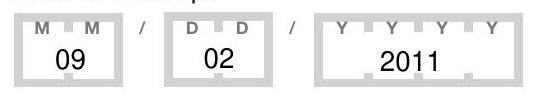

Amount of Each Receipt this Period

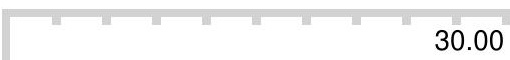

30.00

C. Full Name (Last, First, Middle Initial)

Susan Walter

Mailing Address P.O. Box 690

\begin{tabular}{lcc}
\hline City & State & Zip Code \\
Sautee Nacoochee & GA & $30571-0690$
\end{tabular}

FEC ID number of contributing

federal political committee.

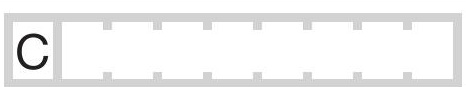

Name of Employer
None
Receipt For: 2012
Х Primary $\quad \square$ General
Other (specify)

Occupation

Retired

Election Cycle-to-Date

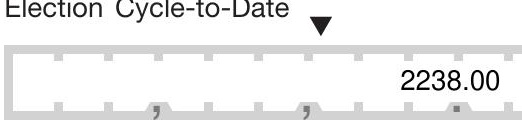

Transaction ID : AEBD9FCB2CD634DFE80B Date of Receipt

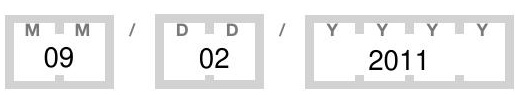

Amount of Each Receipt this Period

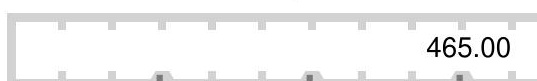

Transaction ID : A7465FE3FBB5A4882B5B Date of Receipt

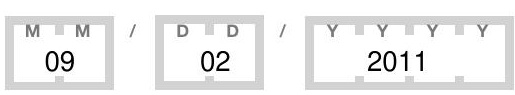

Amount of Each Receipt this Period

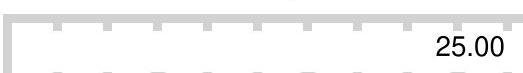

\section{Subtotal Of Receipts This Page (optional)}

Total This Period (last page this line number only) 
SCHEDULE A-P ITEMIZED RECEIPTS
Use separate schedule(s) for each category of the Detailed Summary Page
FOR LINE NUMBER: (check only one)

PAGE 422 / 1572

\begin{tabular}{|c|c|c|c|c|c|}
\hline & & & & & \\
\hline 16 & $\begin{array}{l}\mathbf{X} \\
17 a\end{array}$ & $17 b$ & $17 c$ & $17 d$ & 18 \\
\hline $19 a$ & $19 \mathrm{~b}$ & $20 \mathrm{a}$ & $20 \mathrm{~b}$ & $20 \mathrm{c}$ & 21 \\
\hline
\end{tabular}

Any information copied from such Reports and Statements may not be sold or used by any person for the purpose of soliciting contributions or for commercial purposes, other than using the name and address of any political committee to solicit contributions from such committee.

NAME OF COMMITTEE (In Full)

\section{Friends of Herman Cain}

A. Full Name (Last, First, Middle Initial)

Tamela McKemie

Mailing Address 596 Inglis Drive

\begin{tabular}{lcc}
\hline City & State & Zip Code \\
Marietta & GA & $30067-6710$
\end{tabular}

FEC ID number of contributing federal political committee.

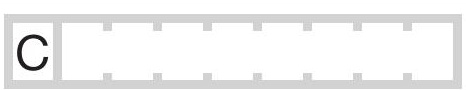

Name of Employer
Troutman Sanders
Receipt For: 2012
X Primary
Other (specify) General

Occupation

Secretary

Election Cycle-to-Date

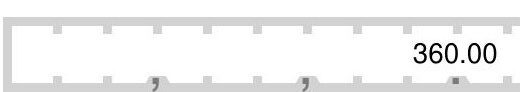

B. Full Name (Last, First, Middle Initial)

Susan McHugh

Mailing Address 114 Indian Pipe Ln

\begin{tabular}{lcc}
\hline City & State & Zip Code \\
Concord & MA & $01742-4766$ \\
\hline
\end{tabular}

FEC ID number of contributing

federal political committee.

C

Name of Employer
Not Employed
Receipt For: 2012
X Primary
Other (specify)

Occupation

Not Employed

Election Cycle-to-Date

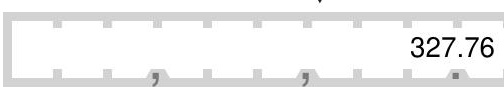

Transaction ID : A2FCD5CABB3DA431CB0D

Date of Receipt

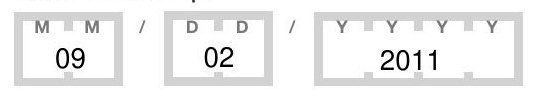

Amount of Each Receipt this Period

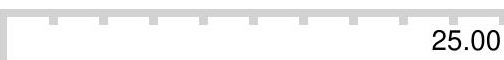

25.00

C. Full Name (Last, First, Middle Initial)

Gertrude Gatto

Mailing Address 222 Clark Drive

\begin{tabular}{lcc}
\hline City & State & Zip Code \\
Johnstown & OH & $43031-8902$
\end{tabular}

FEC ID number of contributing federal political committee.

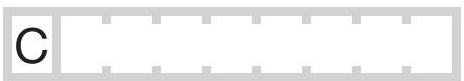

Name of Employer

Berkeley Park at New Albany LLC

Receipt For: 2012

Х $\begin{aligned} & \text { Primary } \\ & \text { Other (specify) }\end{aligned}$

\section{Occupation}

Office Assistant

Election Cycle-to-Date

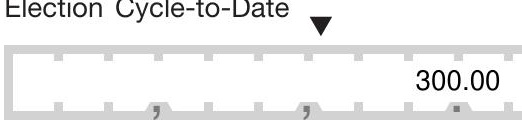

Transaction ID : A8765588E9A274FFC97B

Date of Receipt

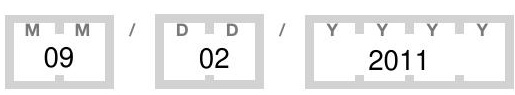

Amount of Each Receipt this Period

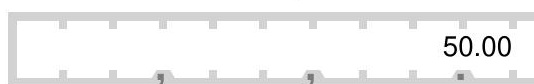

Transaction ID : AF2BE9AA5DF2F45729A4 Date of Receipt

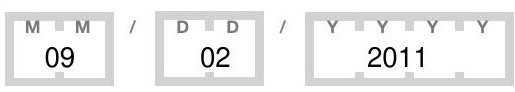

Amount of Each Receipt this Period

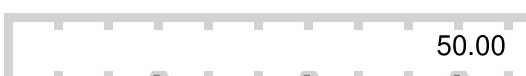

50.00

\section{Subtotal Of Receipts This Page (optional)}

Total This Period (last page this line number only) 
SCHEDULE A-P ITEMIZED RECEIPTS
Use separate schedule(s) for each category of the Detailed Summary Page
FOR LINE NUMBER: (check only one)

PAGE 423 / 1572

\begin{tabular}{|c|c|c|c|c|c|}
\hline & & & & & \\
\hline 16 & $\begin{array}{lll}X & 17 a \\
\end{array}$ & $17 \mathrm{~b}$ & $17 c$ & $17 d$ & 18 \\
\hline $19 a$ & $19 b$ & $20 a$ & $20 \mathrm{~b}$ & $20 c$ & 21 \\
\hline
\end{tabular}

Any information copied from such Reports and Statements may not be sold or used by any person for the purpose of soliciting contributions or for commercial purposes, other than using the name and address of any political committee to solicit contributions from such committee.

NAME OF COMMITTEE (In Full)

\section{Friends of Herman Cain}

A. Full Name (Last, First, Middle Initial)

\section{Carol Cook}

Mailing Address 43 Oak Alley

\begin{tabular}{lcc}
\hline City & State & Zip Code \\
Kerrville & TX & $78028-1711$
\end{tabular}

FEC ID number of contributing federal political committee.

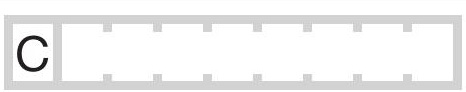

Name of Employer
James Avery
Receipt For: 2012
X Primary $\quad$ General
Other (specify)

\section{Occupation}

Sales Team Leader

Election Cycle-to-Date

234.60

B. Full Name (Last, First, Middle Initial)

James Waddle

\section{Mailing Address 711 Arnold Mill Road}

\begin{tabular}{lcc}
\hline City & State & Zip Code \\
Woodstock & GA & $30188-3010$
\end{tabular}

FEC ID number of contributing

federal political committee.

C

\begin{tabular}{l} 
Name of Employer \\
Chick-Fil-A \\
Receipt For: 2012 \\
X Primary \\
\hline Other (specify)
\end{tabular}

\section{Occupation}

Franchise Owner

Election Cycle-to-Date

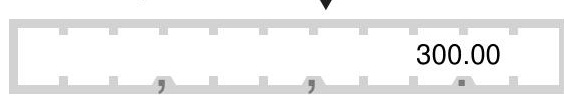

C. Full Name (Last, First, Middle Initial)

Peaches Kavanaugh

Mailing Address 216 Monty Manor

\begin{tabular}{l|ll}
\hline $\begin{array}{l}\text { City } \\
\text { Yorktown }\end{array}$ & $\begin{array}{c}\text { State } \\
\text { VA }\end{array}$ & $\begin{array}{c}\text { Zip Code } \\
\text { 23693-4414 }\end{array}$ \\
\hline $\begin{array}{l}\text { FEC ID number of contributing } \\
\text { federal political committee. }\end{array}$ & C \\
\hline $\begin{array}{l}\text { Name of Employer } \\
\text { Air Force }\end{array}$ & $\begin{array}{l}\text { Occupation } \\
\text { Retired }\end{array}$ \\
\hline $\begin{array}{l}\text { Receipt For: } 2012 \\
\text { X }\end{array}$ & Election Cycle-to-Date \\
Other (specify)
\end{tabular}

Transaction ID : A0673C095B4B94354B56

Date of Receipt

Amount of Each Receipt this Period

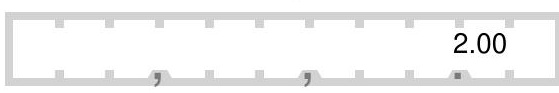

Date of Receipt
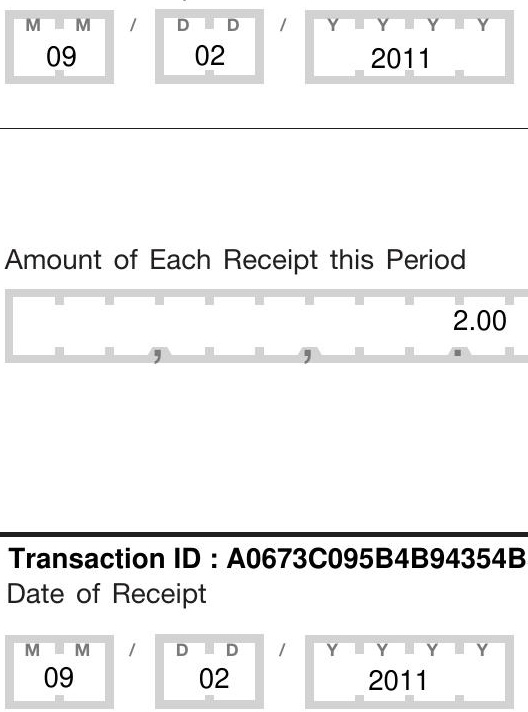

Amount of Each Receipt this Period

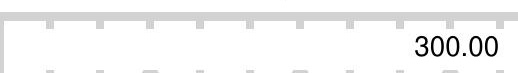

Amount of Each Receipt this Period

Transaction ID : A5DAACD7329C94AF18B1 Date of Receipt
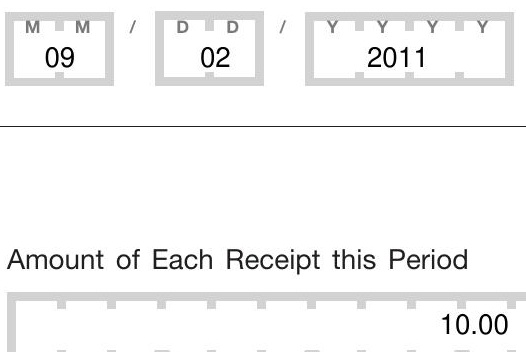

Subtotal Of Receipts This Page (optional).

Total This Period (last page this line number only) 
SCHEDULE A-P ITEMIZED RECEIPTS
Use separate schedule(s) for each category of the Detailed Summary Page
FOR LINE NUMBER: (check only one)

\begin{tabular}{|c|c|c|c|c|c|}
\hline & & & & & \\
\hline 16 & $\begin{array}{ll}X & 17 a \\
\end{array}$ & $17 \mathrm{~b}$ & $17 c$ & $17 d$ & 18 \\
\hline $19 a$ & $19 b$ & $20 \mathrm{a}$ & $20 \mathrm{~b}$ & $20 c$ & 21 \\
\hline
\end{tabular}

Any information copied from such Reports and Statements may not be sold or used by any person for the purpose of soliciting contributions or for commercial purposes, other than using the name and address of any political committee to solicit contributions from such committee.

NAME OF COMMITTEE (In Full)

\section{Friends of Herman Cain}

A. Full Name (Last, First, Middle Initial)

\section{Mark Clark}

Mailing Address 8806 Groveland Dr

\begin{tabular}{lcc}
\hline City & State & Zip Code \\
Dallas & TX & $75218-4214$
\end{tabular}

FEC ID number of contributing federal political committee.

C

Name of Employe

Dell

Receipt For: 2012

Х Primary $\square$ General Other (specify)
Occupation

Director of Sales Engineering

Election Cycle-to-Date

Transaction ID : AF09320E588884A3DA0A

Date of Receipt

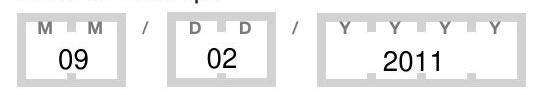

Amount of Each Receipt this Period

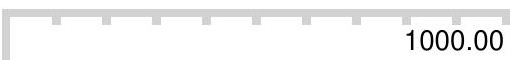

1000.00

B. Full Name (Last, First, Middle Initial)

William R Wiggins Jr

Mailing Address P.O. Box 1251

\begin{tabular}{lcc}
\hline City & State & Zip Code \\
Lindale & TX & $75771-1251$ \\
\hline
\end{tabular}

FEC ID number of contributing

federal political committee.

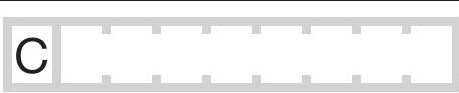

Name of Employer
Colonial Life
Receipt For: 2012
X Primary
Other (specify)

\section{Occupation}

Sales

Election Cycle-to-Date

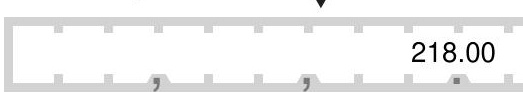

C. Full Name (Last, First, Middle Initial)

Gregory Christy

Mailing Address 6212 Parliament drive

\begin{tabular}{lcc}
\hline City & State & Zip Code \\
Indianapolis & IN & $46220-4740$
\end{tabular}

FEC ID number of contributing federal political committee.

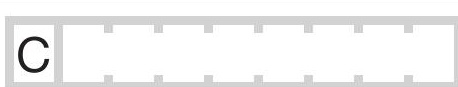

Name of Employer
Nova Hydraulics
Receipt For: 2012
X Primary $\quad \square$ General
Other (specify)

\section{Occupation}

Owner

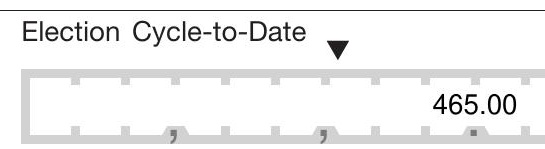

Transaction ID : A560754DCE2FD4A72A2B

Date of Receipt

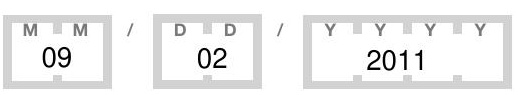

Amount of Each Receipt this Period

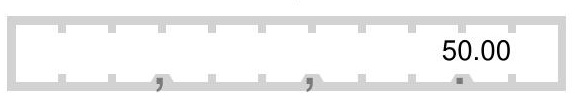

Transaction ID : A39F2FF39BDB6444FA85 Date of Receipt

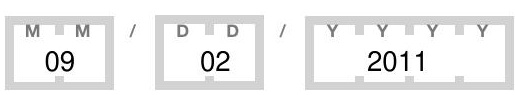

Amount of Each Receipt this Period

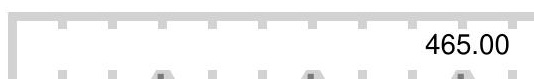

\section{Subtotal Of Receipts This Page (optional)}

Total This Period (last page this line number only) 
SCHEDULE A-P ITEMIZED RECEIPTS
Use separate schedule(s) for each category of the Detailed Summary Page
FOR LINE NUMBER: (check only one)

PAGE 425 / 1572

\begin{tabular}{|c|c|c|c|c|c|}
\hline & & & & & \\
\hline 16 & $\begin{array}{l}\mathbf{X} \\
17 a\end{array}$ & $17 b$ & $17 c$ & $17 d$ & 18 \\
\hline $19 a$ & $19 \mathrm{~b}$ & $20 \mathrm{a}$ & $20 \mathrm{~b}$ & $20 \mathrm{c}$ & 21 \\
\hline
\end{tabular}

Any information copied from such Reports and Statements may not be sold or used by any person for the purpose of soliciting contributions or for commercial purposes, other than using the name and address of any political committee to solicit contributions from such committee.

NAME OF COMMITTEE (In Full)

\section{Friends of Herman Cain}

A. Full Name (Last, First, Middle Initial) Jackie Stonecipher

Mailing Address 1060 Olde Towne Lane

\begin{tabular}{lcc}
\hline City & State & Zip Code \\
Woodstock & GA & $30189-8187$
\end{tabular}

FEC ID number of contributing federal political committee.

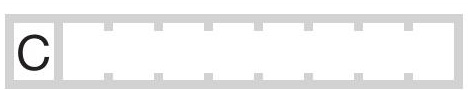

Name of Employer
Quick Weight Loss
Receipt For: 2012
X Primary
Other (specify) General

Occupation Management Election Cycle-to-Date

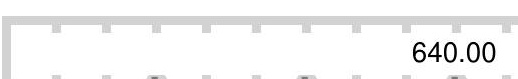

B. Full Name (Last, First, Middle Initial)

Sue Hull

Mailing Address PO Box 357

\begin{tabular}{lcc}
\hline City & State & Zip Code \\
Craig & AK & $99921-0357$
\end{tabular}

FEC ID number of contributing

federal political committee.

C

Name of Employer
Peace Health
Receipt For: 2012
X Primary
Other (specify)

Occupation

Registered Nurse

Election Cycle-to-Date

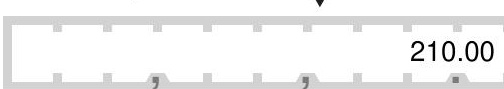

Transaction ID : A72A10F98C9BE42049B7

Date of Receipt

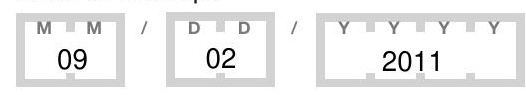

Amount of Each Receipt this Period

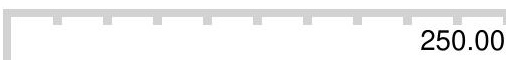

Amount of Each Receipt this Period

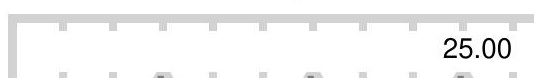

C. Full Name (Last, First, Middle Initial)

Leslie Jenkins

Mailing Address 233 Swanson Drive Suite A

\begin{tabular}{lcc}
\hline City & State & Zip Code \\
Lawrenceville & GA & $30043-8532$
\end{tabular}

FEC ID number of contributing federal political committee.

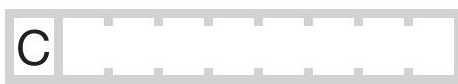

Name of Employer

Occupation

Reliance Mechanical Inc.

Management

Receipt For: 2012

Х $\begin{aligned} & \text { Primary } \\ & \text { Other (specify) }\end{aligned}$

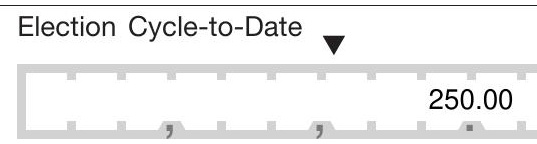

Transaction ID : A46750947F7E3434C92C

Date of Receipt

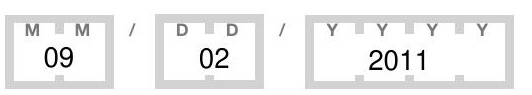

Transaction ID : AD076873DCE25483CB7C Date of Receipt

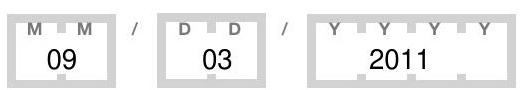

Amount of Each Receipt this Period

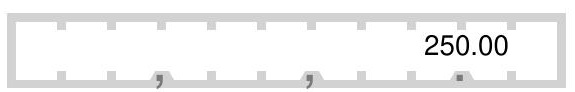

Subtotal Of Receipts This Page (optional)

Total This Period (last page this line number only) 
SCHEDULE A-P ITEMIZED RECEIPTS
Use separate schedule(s) for each category of the Detailed Summary Page
FOR LINE NUMBER: (check only one)

PAGE 426 / 1572

\begin{tabular}{|c|c|c|c|c|c|}
\hline & & & & & \\
\hline 16 & $\begin{array}{l}\mathbf{X} \\
17 a\end{array}$ & $17 b$ & $17 c$ & $17 d$ & 18 \\
\hline $19 a$ & $19 \mathrm{~b}$ & $20 \mathrm{a}$ & $20 \mathrm{~b}$ & $20 \mathrm{c}$ & 21 \\
\hline
\end{tabular}

Any information copied from such Reports and Statements may not be sold or used by any person for the purpose of soliciting contributions or for commercial purposes, other than using the name and address of any political committee to solicit contributions from such committee.

NAME OF COMMITTEE (In Full)

\section{Friends of Herman Cain}

A. Full Name (Last, First, Middle Initial)

\section{Dianne Sula}

Mailing Address 6 E. Walker Ave.

\begin{tabular}{lcc}
\hline City & State & Zip Code \\
Temple & TX & $76501-1724$
\end{tabular}

FEC ID number of contributing federal political committee.

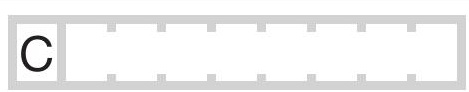

Name of Employer
US Postal Service
Receipt For: 2012
X Primary $\quad$ General
Other (specify)

\section{Occupation} mail processor

Election Cycle-to-Date 250.00

B. Full Name (Last, First, Middle Initial) Glen Ebbing

Mailing Address 1400 Huntleigh Rd

\begin{tabular}{lcc}
\hline City & State & Zip Code \\
Quincy & IL & $62305-6017$
\end{tabular}

FEC ID number of contributing

federal political committee.

C

Name of Employer
ColorMaster Pain Inc
Receipt For: 2012
Primary
Other (specify)

Occupation

sales representative

Election Cycle-to-Date

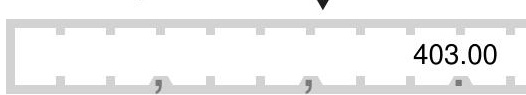

Transaction ID : AF2170F318339448EB5F

Date of Receipt

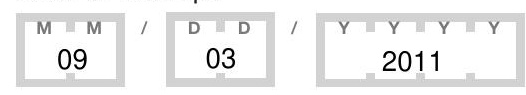

Amount of Each Receipt this Period

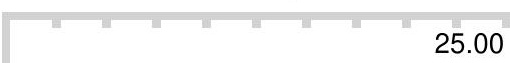

25.00

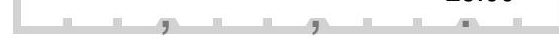

Transaction ID : A3A50E1E49E25461A839

Date of Receipt

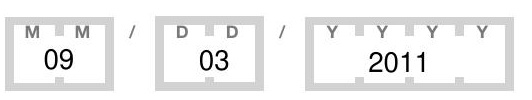

Amount of Each Receipt this Period

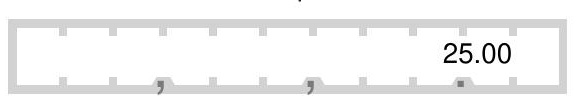

Transaction ID : AC972DC00B91E4BADBD4 Date of Receipt

Daniel Stone

Mailing Address 4417 Sterling Pointe $\mathrm{Dr}$

\begin{tabular}{lcc}
\hline City & State & Zip Code \\
Kennesaw & GA & $30152-7348$
\end{tabular}

FEC ID number of contributing federal political committee.

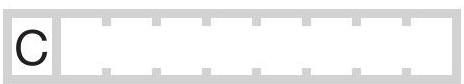

Name of Employer

INVISTA S.a.r.I.

\section{Occupation}

VP - Business Analysis

Receipt For: 2012

Х $\begin{aligned} & \text { Primary } \\ & \text { Other (specify) }\end{aligned}$

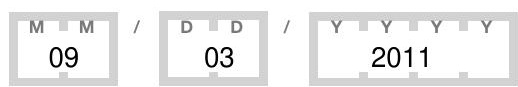

Amount of Each Receipt this Period

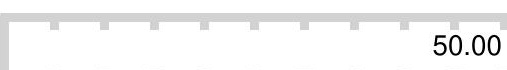

\section{Subtotal Of Receipts This Page (optional)}

Total This Period (last page this line number only) 
SCHEDULE A-P ITEMIZED RECEIPTS
Use separate schedule(s) for each category of the Detailed Summary Page
FOR LINE NUMBER: (check only one)

PAGE 427 / 1572

\begin{tabular}{|c|c|c|c|c|c|}
\hline & & & & & \\
\hline 16 & $\begin{array}{l}\mathbf{X} \\
17 a\end{array}$ & $17 b$ & $17 c$ & $17 d$ & 18 \\
\hline $19 a$ & $19 \mathrm{~b}$ & $20 \mathrm{a}$ & $20 \mathrm{~b}$ & $20 \mathrm{c}$ & 21 \\
\hline
\end{tabular}

Any information copied from such Reports and Statements may not be sold or used by any person for the purpose of soliciting contributions or for commercial purposes, other than using the name and address of any political committee to solicit contributions from such committee.

NAME OF COMMITTEE (In Full)

\section{Friends of Herman Cain}

A. Full Name (Last, First, Middle Initial)

Mr. John P Vanderpool

Mailing Address $7330 \mathrm{~N}$ Vandiver Rd

\begin{tabular}{lcc}
\hline City & State & Zip Code \\
San Antonio & TX & $78209-3040$
\end{tabular}

FEC ID number of contributing federal political committee.

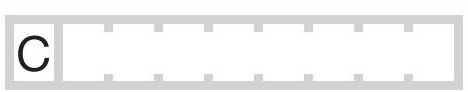

Name of Employer
self
Receipt For: 2012
X Primary $\quad$ General
Other (specify)

Occupation Physician

Election Cycle-to-Date

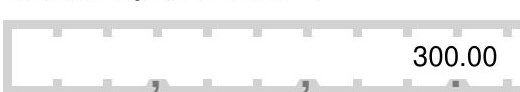

B. Full Name (Last, First, Middle Initial)

Stephen Ray

Mailing Address 1611 Cameron Landing Drive

\begin{tabular}{lcc}
\hline City & State & Zip Code \\
Stockbridge & GA & $30281-6863$
\end{tabular}

FEC ID number of contributing

federal political committee.

C

Name of Employer
Delat Air Lines
Receipt For: 2012
X Primary
Other (specify) General

Occupation

Maintenance Coodinator

Election Cycle-to-Date

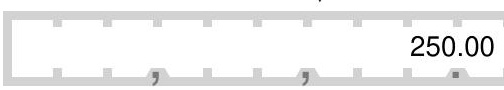

Transaction ID : A54796A09DD134CE6A1E

Date of Receipt

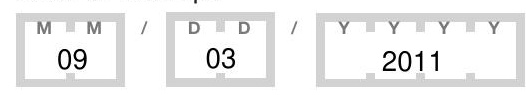

Amount of Each Receipt this Period

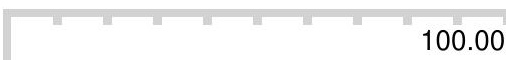

100.00

C. Full Name (Last, First, Middle Initial)

Eric Rhodus, Sr.

Mailing Address 25145 Merchant Rd.

\begin{tabular}{lcc}
\hline City & State & Zip Code \\
Denham Springs & LA & $70726-6833$
\end{tabular}

FEC ID number of contributing federal political committee.

C

70726-6833

Name of Employer

Information Requested

Occupation

Information Requested

Receipt For: 2012

Х $\begin{aligned} & \text { Primary } \\ & \text { Other (specify) }\end{aligned}$

Election Cycle-to-Date

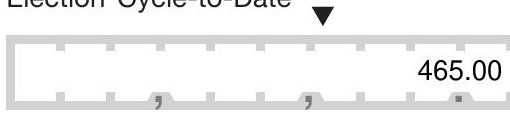

Amount of Each Receipt this Period

Transaction ID : A5B5B2098244E4922922

Date of Receipt
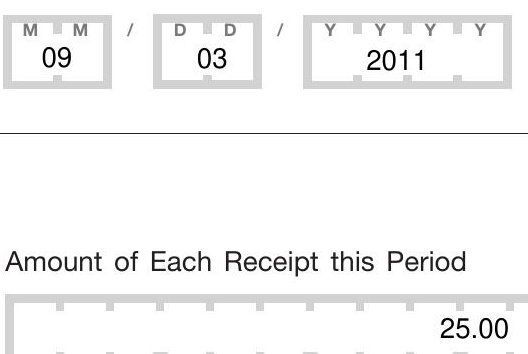

Transaction ID : AC1CF9C4234A641A78B6 Date of Receipt

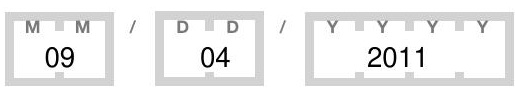

Amount of Each Receipt this Period

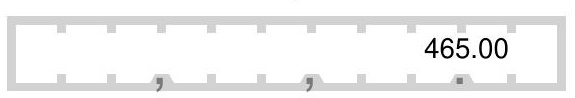

Subtotal Of Receipts This Page (optional)

590.00

Total This Period (last page this line number only) 
SCHEDULE A-P ITEMIZED RECEIPTS
Use separate schedule(s) for each category of the Detailed Summary Page
FOR LINE NUMBER: (check only one)

PAGE 428 / 1572

\begin{tabular}{|c|c|c|c|c|c|}
\hline & & & & & \\
\hline 16 & $\begin{array}{l}\mathbf{X} \\
17 a\end{array}$ & $17 b$ & $17 c$ & $17 d$ & 18 \\
\hline $19 a$ & $19 \mathrm{~b}$ & $20 \mathrm{a}$ & $20 \mathrm{~b}$ & $20 \mathrm{c}$ & 21 \\
\hline
\end{tabular}

Any information copied from such Reports and Statements may not be sold or used by any person for the purpose of soliciting contributions or for commercial purposes, other than using the name and address of any political committee to solicit contributions from such committee.

NAME OF COMMITTEE (In Full)

\section{Friends of Herman Cain}

A. Full Name (Last, First, Middle Initial)

\section{Christine Preble}

Mailing Address 3847 Monument Rd.

\begin{tabular}{lcc}
\hline City & State & Zip Code \\
Jasper & GA & $30143-2402$
\end{tabular}

FEC ID number of contributing federal political committee.

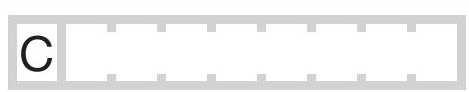

Name of Employer
Retired
Receipt For: 2012
X Primary $\quad$ General
Other (specify)

Occupation

RN Childbirth Educator

Election Cycle-to-Date

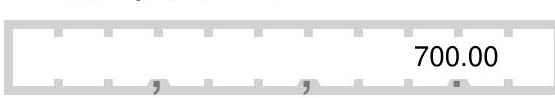

B. Full Name (Last, First, Middle Initial)

Carol Cook

Mailing Address 43 Oak Alley

\begin{tabular}{lcc}
\hline City & State & Zip Code \\
Kerrville & TX & $78028-1711$ \\
\hline
\end{tabular}

FEC ID number of contributing

federal political committee.

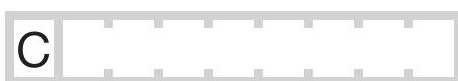

Name of Employer
James Avery
Receipt For: 2012
X Primary
Other (specify)

Occupation

Sales Team Leader

Election Cycle-to-Date

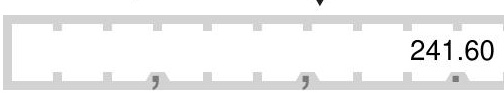

Transaction ID : A87ECC9105AAC4433B77

Date of Receipt

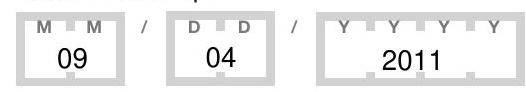

Amount of Each Receipt this Period

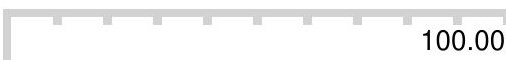

100.00

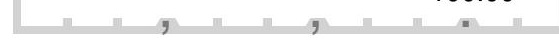

Transaction ID : A1E31C29F90444A4D9E1

Date of Receipt

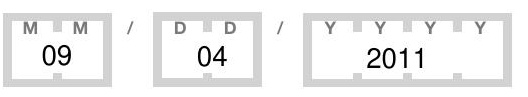

Amount of Each Receipt this Period

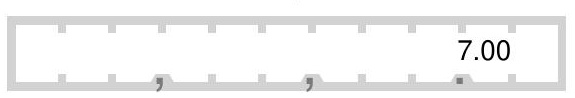

Transaction ID : A573F43564C1F4B6C811 Date of Receipt

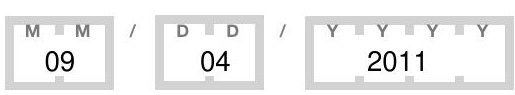

Amount of Each Receipt this Period

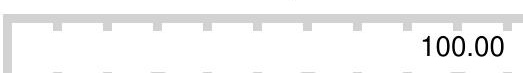

Occupation
Robert Osborn

Election Cycle-to-Date

Receipt For: 2012

Х $\begin{aligned} & \text { Primary } \square \text { General } \\ & \text { Other (specify) }\end{aligned}$

350.00

Subtotal Of Receipts This Page (optional)

Total This Period (last page this line number only)
207.00

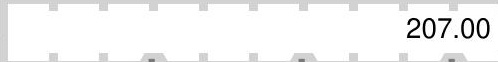

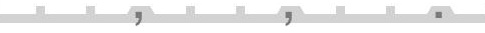

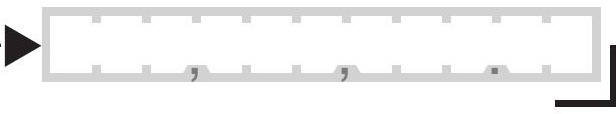

FEC Schedule A-P (Form 3P) (Rev. 03/2011) 
SCHEDULE A-P ITEMIZED RECEIPTS
Use separate schedule(s) for each category of the Detailed Summary Page
FOR LINE NUMBER: (check only one)

PAGE 429 / 1572

\begin{tabular}{|c|c|c|c|c|c|}
\hline & & & & & \\
\hline 16 & $\begin{array}{l}\mathbf{X} \\
17 a\end{array}$ & $17 b$ & $17 c$ & $17 d$ & 18 \\
\hline $19 a$ & $19 \mathrm{~b}$ & $20 \mathrm{a}$ & $20 \mathrm{~b}$ & $20 \mathrm{c}$ & 21 \\
\hline
\end{tabular}

Any information copied from such Reports and Statements may not be sold or used by any person for the purpose of soliciting contributions or for commercial purposes, other than using the name and address of any political committee to solicit contributions from such committee.

NAME OF COMMITTEE (In Full)

\section{Friends of Herman Cain}

A. Full Name (Last, First, Middle Initial)

Donald Dennis

Mailing Address 6104 Portrush Dr

\begin{tabular}{lcc}
\hline City & State & Zip Code \\
Fort Worth & TX & $76116-7418$
\end{tabular}

FEC ID number of contributing

federal political committee.

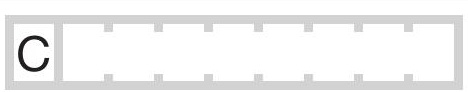

Name of Employer
Information Requested
Receipt For: 2012
X Primary $\quad \square$ General
Other (specify)

Occupation

Information Requested

Election Cycle-to-Date

500.00

B. Full Name (Last, First, Middle Initial)

Gary Branch

Mailing Address 5676 Long Island Drive

\begin{tabular}{lcc}
\hline City & State & Zip Code \\
Atlanta & GA & $30327-4842$ \\
\hline
\end{tabular}

FEC ID number of contributing

federal political committee.

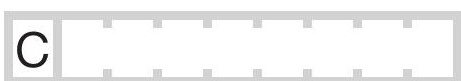

Name of Employer
Self Employed
Receipt For: 2012
X Primary
Other (specify)

\section{Occupation}

Chick-fil-A At Peachtree Center

Election Cycle-to-Date

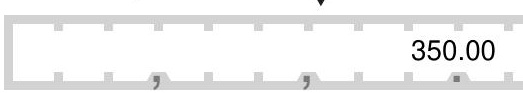

C. Full Name (Last, First, Middle Initial)

Michael Marchman

Mailing Address 1625 E 72nd St STE 700 PMB 224

\begin{tabular}{lcc}
\hline City & State & Zip Code \\
Tacoma & WA & $98404-5455$
\end{tabular}

FEC ID number of contributing

federal political committee.

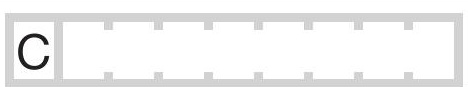

Name of Employer

U.S. Customs and Border Protection

\section{Occupation}

CBP Officer

\begin{tabular}{l|l}
\hline Receipt For: 2012 & Election Cycle-to-Date
\end{tabular}

Х $\begin{aligned} & \text { Primary } \\ & \text { Other (specify) }\end{aligned}$

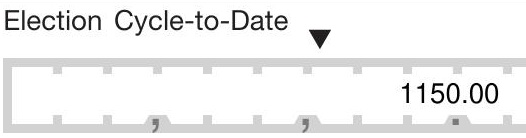

Transaction ID : A3EDD99D3BFB8420DAEA

Date of Receipt

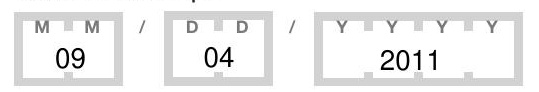

Amount of Each Receipt this Period

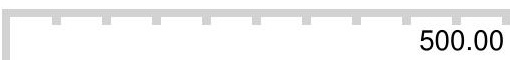

500.00

Transaction ID : A2E0E65653AFE44C1876

Date of Receipt

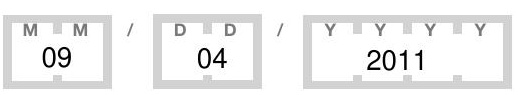

Amount of Each Receipt this Period

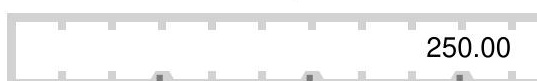

Transaction ID : AAF04483623FB4F08B61

Date of Receipt

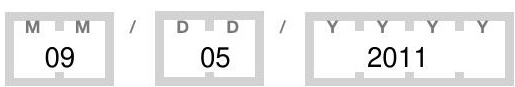

Amount of Each Receipt this Period

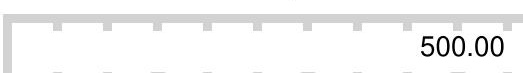

1250.00

Subtotal Of Receipts This Page (optional)

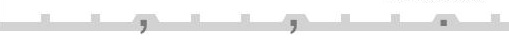

Total This Period (last page this line number only)

FEC Schedule A-P (Form 3P) (Rev. 03/2011) 
SCHEDULE A-P ITEMIZED RECEIPTS
Use separate schedule(s) for each category of the Detailed Summary Page
FOR LINE NUMBER: (check only one)

PAGE $430 / 1572$

\begin{tabular}{|c|c|c|c|c|c|}
\hline & & & & & \\
\hline 16 & $\begin{array}{l}\mathbf{X} \\
17 a\end{array}$ & $17 b$ & $17 c$ & $17 d$ & 18 \\
\hline $19 a$ & $19 \mathrm{~b}$ & $20 \mathrm{a}$ & $20 \mathrm{~b}$ & $20 \mathrm{c}$ & 21 \\
\hline
\end{tabular}

Any information copied from such Reports and Statements may not be sold or used by any person for the purpose of soliciting contributions or for commercial purposes, other than using the name and address of any political committee to solicit contributions from such committee.

NAME OF COMMITTEE (In Full)

\section{Friends of Herman Cain}

A. Full Name (Last, First, Middle Initial)

Mr. David M. Crenshaw

Mailing Address 216 Kings Hwy

\begin{tabular}{lcc}
\hline City & State & Zip Code \\
Decatur & GA & $30030-5226$
\end{tabular}

FEC ID number of contributing federal political committee.

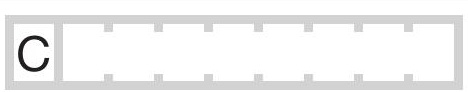

Name of Employer
None
Receipt For: 2012
X Primary $\quad$ General
Other (specify)

Occupation

Retired

Election Cycle-to-Date

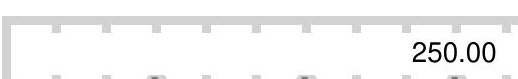

B. Full Name (Last, First, Middle Initial)

Cynthia Sisto

Mailing Address 1594 Kingswood Dr

\begin{tabular}{lcc}
\hline City & State & Zip Code \\
Neenah & WI & $54956-1698$ \\
\hline
\end{tabular}

FEC ID number of contributing

federal political committee.

C

Name of Employer
Information Requested
Receipt For: 2012
Xrimary
Other (specify)

Occupation

Information Requested

Election Cycle-to-Date

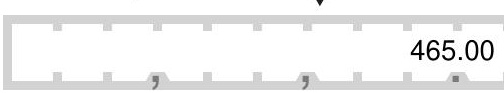

Transaction ID : A61205D5ABBDD43E2BA7

Date of Receipt

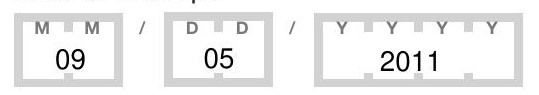

Amount of Each Receipt this Period

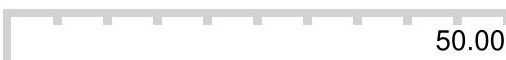

50.00

C. Full Name (Last, First, Middle Initial)

thomas mims

Mailing Address 1655 Banks St

\begin{tabular}{lcc}
\hline City & State & Zip Code \\
Houston & TX & $77006-6021$
\end{tabular}

FEC ID number of contributing

federal political committee.

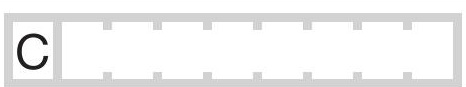

Name of Employer

Self Employed

Occupation

Receipt For: 2012

Х $\begin{aligned} & \text { Primary } \square \text { General } \\ & \text { Other (specify) }\end{aligned}$

Physician

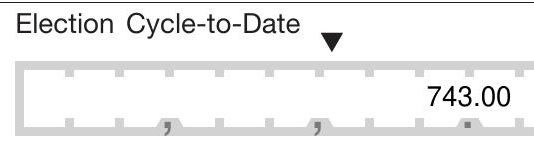

Amount of Each Receipt this Period

Transaction ID : A4D6519E7FBA448BEAB6

Date of Receipt
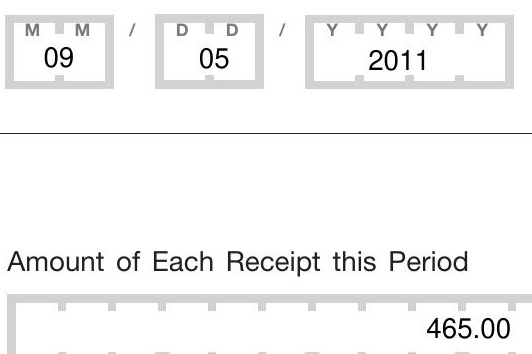

Transaction ID : AEFB6A204610F43D6862

Date of Receipt

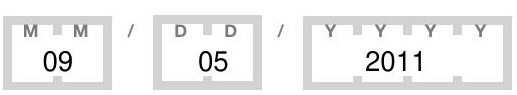

Amount of Each Receipt this Period

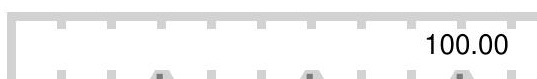

615.00

Subtotal Of Receipts This Page (optional)

Total This Period (last page this line number only) 
SCHEDULE A-P ITEMIZED RECEIPTS
Use separate schedule(s) for each category of the Detailed Summary Page
FOR LINE NUMBER: (check only one)

PAGE $431 / 1572$

\begin{tabular}{|c|c|c|c|c|c|c|}
\hline & & & & & & \\
\hline 16 & $\lambda$ & $17 \mathrm{a}$ & $17 \mathrm{~b}$ & $17 \mathrm{c}$ & $-17 d$ & -18 \\
\hline $19 a$ & & $19 b$ & $20 a$ & $20 \mathrm{~b}$ & $20 \mathrm{c}$ & 21 \\
\hline
\end{tabular}

Any information copied from such Reports and Statements may not be sold or used by any person for the purpose of soliciting contributions or for commercial purposes, other than using the name and address of any political committee to solicit contributions from such committee.

NAME OF COMMITTEE (In Full)

\section{Friends of Herman Cain}

A. Full Name (Last, First, Middle Initial)

\section{Susan Walter}

Mailing Address P.O. Box 690

\begin{tabular}{lcc}
\hline City & State & Zip Code \\
Sautee Nacoochee & GA & $30571-0690$ \\
\hline
\end{tabular}

FEC ID number of contributing federal political committee.

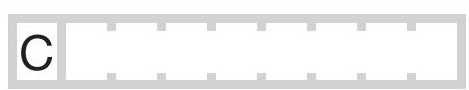

Name of Employer
None
Receipt For: 2012
X Primary $\quad$ General
Other (specify)

Occupation Retired

Election Cycle-to-Date

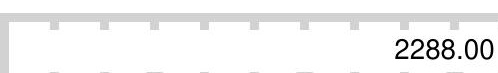

B. Full Name (Last, First, Middle Initial)

\section{Sharon Tidd}

Mailing Address 839 Sandra Way

\begin{tabular}{lcc}
\hline City & State & Zip Code \\
Kodak & TN & $37764-1749$ \\
\hline
\end{tabular}

FEC ID number of contributing

federal political committee.

C

Name of Employer
Dollywood
Receipt For: 2012
X Primary
Other (specify)

C. Full Name (Last, First, Middle Initial)

Carol Cook

Mailing Address 43 Oak Alley

\begin{tabular}{lll}
\hline $\begin{array}{l}\text { City } \\
\text { Kerrville }\end{array}$ & $\begin{array}{c}\text { State } \\
\text { TX }\end{array}$ & $\begin{array}{c}\text { Zip Code } \\
\text { 78028-1711 }\end{array}$ \\
\hline $\begin{array}{l}\text { FEC ID number of contributing } \\
\text { federal political committee. }\end{array}$ & C \\
\hline $\begin{array}{l}\text { Name of Employer } \\
\text { James Avery }\end{array}$ & $\begin{array}{l}\text { Occupation } \\
\text { Sales Team Leader }\end{array}$ \\
$\begin{array}{l}\text { Receipt For: } 2012 \\
\text { Primary } \\
\text { Other (specify) }\end{array}$ & Election Cycle-to-Date \\
\end{tabular}

Transaction ID : AFA3FE8E13C3441E78D8

Date of Receipt

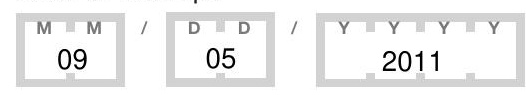

Amount of Each Receipt this Period

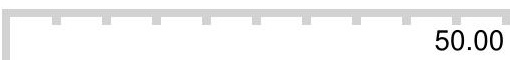

50.00
Amount of Each Receipt this Period

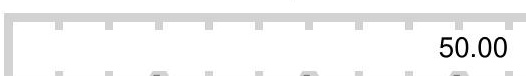

Amount of Each Receipt this Period

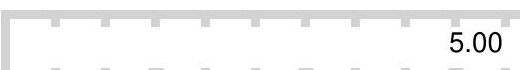

\section{Subtotal Of Receipts This Page (optional)}

Transaction ID : A1F5017774F854A1C95D Date of Receipt
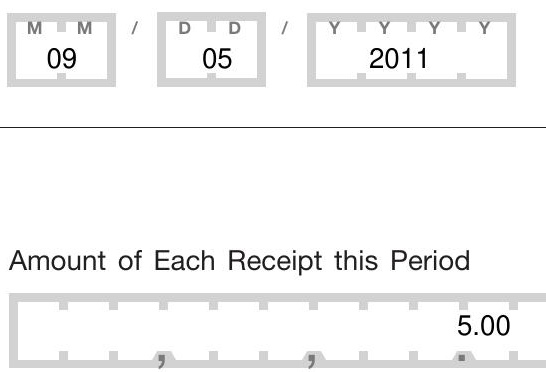

Total This Period (last page this line number only) 
SCHEDULE A-P ITEMIZED RECEIPTS
Use separate schedule(s) for each category of the Detailed Summary Page
FOR LINE NUMBER: (check only one)

PAGE 432 / 1572

\begin{tabular}{|c|c|c|c|c|c|c|}
\hline & & & & & & \\
\hline 16 & $\lambda$ & $17 \mathrm{a}$ & $17 \mathrm{~b}$ & $17 \mathrm{c}$ & $-17 d$ & -18 \\
\hline $19 a$ & & $19 b$ & $20 a$ & $20 \mathrm{~b}$ & $20 \mathrm{c}$ & 21 \\
\hline
\end{tabular}

Any information copied from such Reports and Statements may not be sold or used by any person for the purpose of soliciting contributions or for commercial purposes, other than using the name and address of any political committee to solicit contributions from such committee.

NAME OF COMMITTEE (In Full)

\section{Friends of Herman Cain}

A. Full Name (Last, First, Middle Initial)

hollis curtis

Mailing Address 6314 Carbonton Rd

\begin{tabular}{lcc}
\hline City & State & Zip Code \\
Sanford & NC & $27330-3027$
\end{tabular}

FEC ID number of contributing federal political committee.

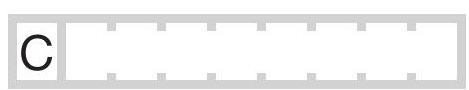

Name of Employer
$\mathrm{h} \mathrm{r}$ curtis plumbing contractor
Receipt For: 2012
X Primary
Other (specify) General

Occupation plumbing contractor

Election Cycle-to-Date 335.00

B. Full Name (Last, First, Middle Initial) Ruth Bavier

Mailing Address 489 Dennison Ridge

\begin{tabular}{lcc}
\hline City & State & Zip Code \\
Manchester & CT & $06040-6839$
\end{tabular}

FEC ID number of contributing

federal political committee.

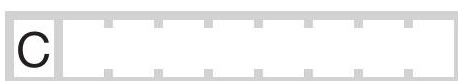

Name of Employer
Perricone MD
Receipt For: 2012
X Primary
Other (specify)

\section{Occupation}

Finance Assistant

Election Cycle-to-Date

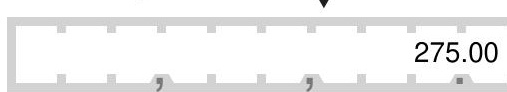

Transaction ID : A11D19ACA38FA41858F2

Date of Receipt

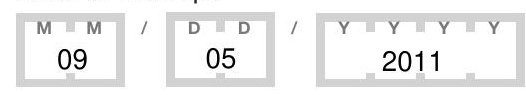

Amount of Each Receipt this Period

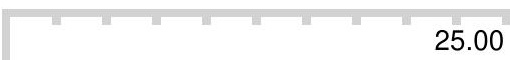

25.00

Transaction ID : A131932F5374D41E18EF

Date of Receipt

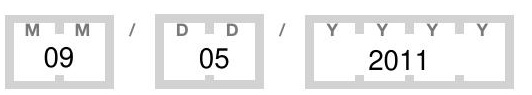

Amount of Each Receipt this Period

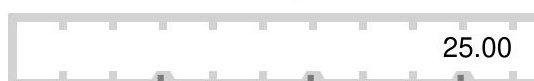

Transaction ID : AF3028B02FECB49FF83D Date of Receipt

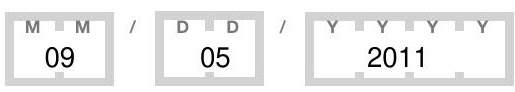

Amount of Each Receipt this Period

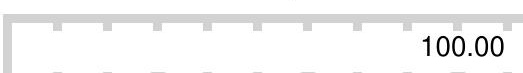

homemaker

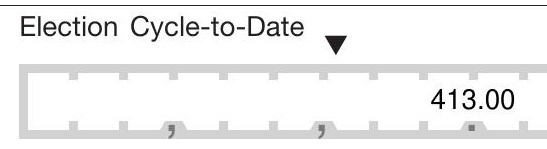

Subtotal Of Receipts This Page (optional)

150.00

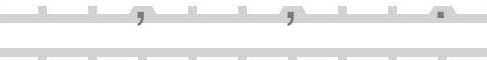

Total This Period (last page this line number only) 
SCHEDULE A-P ITEMIZED RECEIPTS
Use separate schedule(s) for each category of the Detailed Summary Page
FOR LINE NUMBER: (check only one)

PAGE $433 / 1572$

\begin{tabular}{|c|c|c|c|c|c|}
\hline & & & & & \\
\hline 16 & $\begin{array}{lll}X & 17 a \\
\end{array}$ & $17 \mathrm{~b}$ & $17 c$ & $17 d$ & 18 \\
\hline $19 a$ & $19 b$ & $20 a$ & $20 \mathrm{~b}$ & $20 c$ & 21 \\
\hline
\end{tabular}

Any information copied from such Reports and Statements may not be sold or used by any person for the purpose of soliciting contributions or for commercial purposes, other than using the name and address of any political committee to solicit contributions from such committee.

NAME OF COMMITTEE (In Full)

\section{Friends of Herman Cain}

A. Full Name (Last, First, Middle Initial)

Scott McEachin

Mailing Address 7032 East 100th Street

\begin{tabular}{lcc}
\hline City & State & Zip Code \\
Tulsa & OK & $74133-6235$
\end{tabular}

FEC ID number of contributing federal political committee.

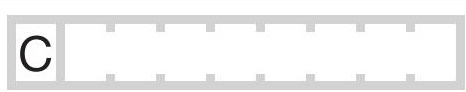

Name of Employer
Scott William McEachin PC
Receipt For: 2012
X Primary $\quad \square$ General
Other (specify)

Occupation Attorney

Election Cycle-to-Date

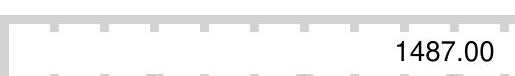

B. Full Name (Last, First, Middle Initial)

James Stewart

Mailing Address 3560 E. Via Colonia del Sol

\begin{tabular}{lcc}
\hline City & State & Zip Code \\
Tucson & AZ & $85718-6065$
\end{tabular}

FEC ID number of contributing

federal political committee.

C

Name of Employer
Information Requested
Receipt For: 2012
X Primary
Other (specify)

Occupation

Information Requested

Election Cycle-to-Date

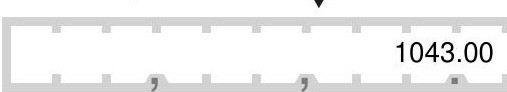

Transaction ID : A98693C6C65B7423390B

Date of Receipt

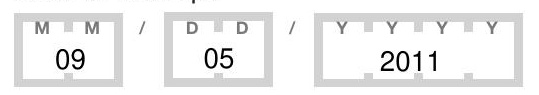

Amount of Each Receipt this Period

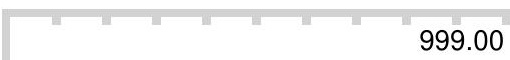

999.00

C. Full Name (Last, First, Middle Initial)

Vickie Mitchell

Mailing Address PO Box 795

\begin{tabular}{lcc}
\hline City & State & Zip Code \\
Douglasville & GA & $30133-0795$
\end{tabular}

FEC ID number of contributing federal political committee.

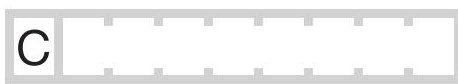

Name of Employer
Mitchell Appliance Co.
Receipt For: 2012
X Primary
Other (specify) General

Occupation

Retail Sales

Election Cycle-to-Date

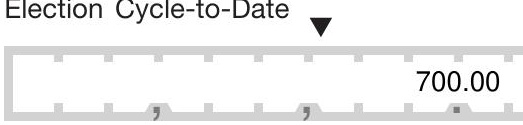

Transaction ID : A85556C72A27844A5887

Date of Receipt

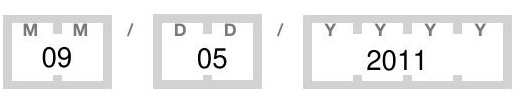

Amount of Each Receipt this Period

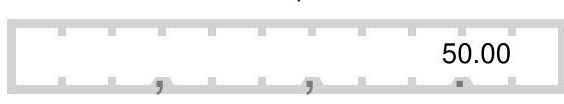

Transaction ID : A07B4E212B93F4893AE3

Date of Receipt

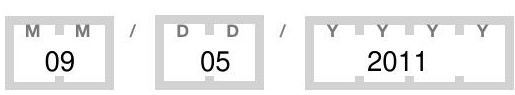

Amount of Each Receipt this Period

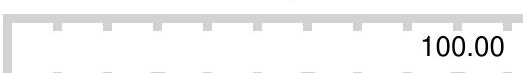

100.00

\section{Subtotal Of Receipts This Page (optional)}

Total This Period (last page this line number only) 
SCHEDULE A-P ITEMIZED RECEIPTS
Use separate schedule(s) for each category of the Detailed Summary Page
FOR LINE NUMBER: (check only one)

PAGE 434 / 1572

\begin{tabular}{|c|c|c|c|c|c|}
\hline & & & & & \\
\hline 16 & $\begin{array}{l}\mathbf{X} \\
17 a\end{array}$ & $17 b$ & $17 c$ & $17 d$ & 18 \\
\hline $19 a$ & $19 \mathrm{~b}$ & $20 \mathrm{a}$ & $20 \mathrm{~b}$ & $20 \mathrm{c}$ & 21 \\
\hline
\end{tabular}

Any information copied from such Reports and Statements may not be sold or used by any person for the purpose of soliciting contributions or for commercial purposes, other than using the name and address of any political committee to solicit contributions from such committee.

NAME OF COMMITTEE (In Full)

Friends of Herman Cain

A. Full Name (Last, First, Middle Initial)

Mr. Baron F. Newton

Mailing Address 3260 Sutcliffe Rdg NW

\begin{tabular}{lcc}
\hline City & State & Zip Code \\
Marietta & GA & $30064-1736$
\end{tabular}

FEC ID number of contributing federal political committee.

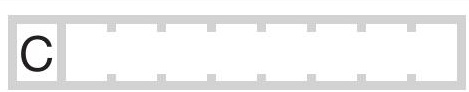

Name of Employer
Lockheed Marietta
Receipt For: 2012
X Primary
$\square$ Other (specify) General

Occupation CNC Machinist

Election Cycle-to-Date

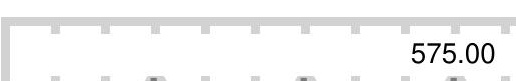

B. Full Name (Last, First, Middle Initial)

Mrs. Susan K. McLaurine

Mailing Address 114 La Encinal Court

\begin{tabular}{lcc}
\hline City & State & Zip Code \\
Clayton & CA & $94517-1750$
\end{tabular}

FEC ID number of contributing

federal political committee.

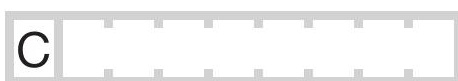

Name of Employer
Vantage Consulting LLC
Receipt For: 2012
X Primary
Other (specify)

Occupation

Business Consul

Election Cycle-to-Date

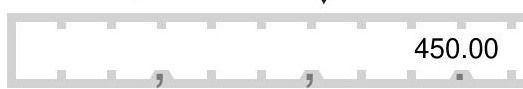

C. Full Name (Last, First, Middle Initial)

Linda Luce

Mailing Address 3604 Maple Forge Ln

\begin{tabular}{lcc}
\hline City & State & Zip Code \\
Gainesville & GA & $30504-5763$
\end{tabular}

FEC ID number of contributing

federal political committee.

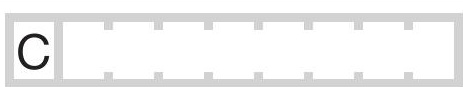

Name of Employer

Northeast Georgia Medical Center

Receipt For: 2012

Х $\begin{aligned} & \text { Primary } \square \text { General } \\ & \text { Other (specify) }\end{aligned}$

Occupation

Medical Technologist

Election Cycle-to-Date

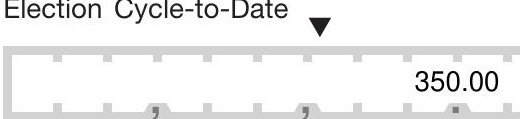

Transaction ID : A89397170201B40EF9EF

Date of Receipt

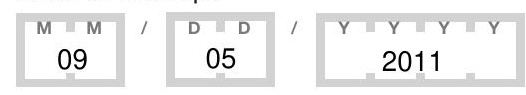

Amount of Each Receipt this Period

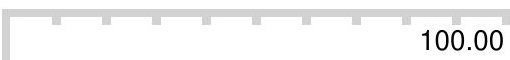

100.00

Transaction ID : AF28574F48A624D7D8EC

Date of Receipt

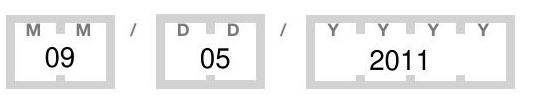

Amount of Each Receipt this Period

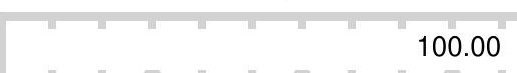

Transaction ID : AD5CE4B0529564FAAA4B Date of Receipt

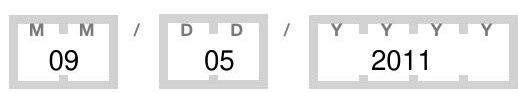

Amount of Each Receipt this Period

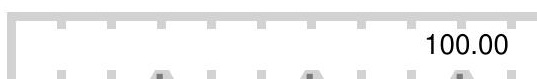

300.00

Subtotal Of Receipts This Page (optional)

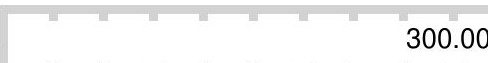

Total This Period (last page this line number only) 
SCHEDULE A-P ITEMIZED RECEIPTS
Use separate schedule(s) for each category of the Detailed Summary Page
FOR LINE NUMBER: (check only one)

\begin{tabular}{|c|c|c|c|c|c|}
\hline & & & & & \\
\hline 16 & $\begin{array}{ll}X & 17 a \\
\end{array}$ & $17 \mathrm{~b}$ & $17 c$ & $17 d$ & 18 \\
\hline $19 a$ & $19 b$ & $20 \mathrm{a}$ & $20 \mathrm{~b}$ & $20 c$ & 21 \\
\hline
\end{tabular}

Any information copied from such Reports and Statements may not be sold or used by any person for the purpose of soliciting contributions or for commercial purposes, other than using the name and address of any political committee to solicit contributions from such committee.

NAME OF COMMITTEE (In Full)

\section{Friends of Herman Cain}

A. Full Name (Last, First, Middle Initial)

kimberly nichols

Mailing Address 441 1st ave so

\begin{tabular}{lcc}
\hline City & State & Zip Code \\
Naples & FL & $34102-5963$
\end{tabular}

FEC ID number of contributing federal political committee.

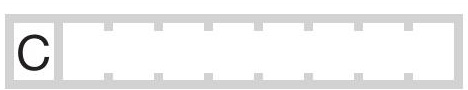

Name of Employer
Delta Airlines
Receipt For: 2012
X Primary
Other (specify) General

Occupation flight attendant

Election Cycle-to-Date

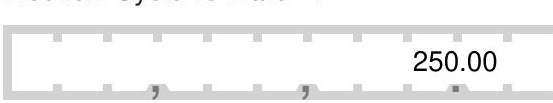

B. Full Name (Last, First, Middle Initial)

Carol Cook

\section{Mailing Address 43 Oak Alley}

\begin{tabular}{lcc}
\hline City & State & Zip Code \\
Kerrville & TX & $78028-1711$ \\
\hline
\end{tabular}

FEC ID number of contributing

federal political committee.

C

Name of Employer
James Avery
Receipt For: 2012
X Primary
Other (specify)

Occupation

Sales Team Leader

Election Cycle-to-Date

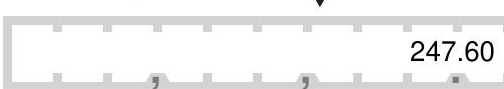

Transaction ID : AAFE580332D3948CBB6E

Date of Receipt

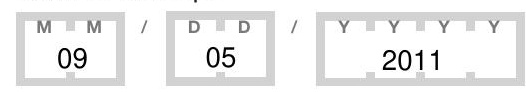

Amount of Each Receipt this Period

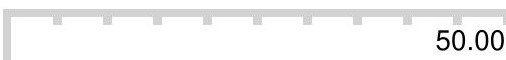

50.00

C. Full Name (Last, First, Middle Initial)

Sally Sidman

Mailing Address 21 Coachlight Drive

\begin{tabular}{lcc}
\hline City & State & Zip Code \\
Danville & IL & $61832-8240$
\end{tabular}

FEC ID number of contributing

federal political committee.

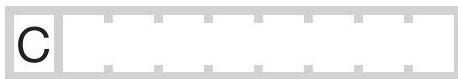

Name of Employer
Ascension Health
Receipt For: 2012
X Primary $\quad \square$ General
Other (specify)

\section{Occupation}

Health Care

Election Cycle-to-Date

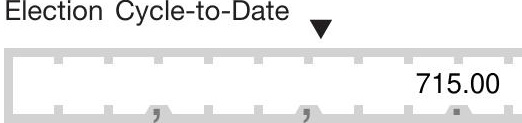

Transaction ID : ACA29B912C80640DEA9C Date of Receipt

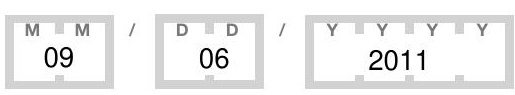

Amount of Each Receipt this Period

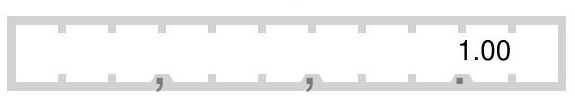

Transaction ID : AA59A9B0985BB42B798C Date of Receipt

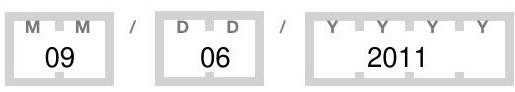

Amount of Each Receipt this Period

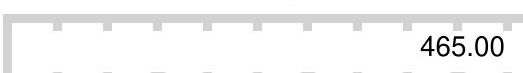

465.00

\section{Subtotal Of Receipts This Page (optional)}

Total This Period (last page this line number only) 
SCHEDULE A-P ITEMIZED RECEIPTS
Use separate schedule(s) for each category of the Detailed Summary Page
FOR LINE NUMBER: (check only one)

PAGE 436 / 1572

\begin{tabular}{|c|c|c|c|c|c|}
\hline & & & & & \\
\hline 16 & $\begin{array}{l}\mathbf{X} \\
17 a\end{array}$ & $17 b$ & $17 c$ & $17 d$ & 18 \\
\hline $19 a$ & $19 \mathrm{~b}$ & $20 \mathrm{a}$ & $20 \mathrm{~b}$ & $20 \mathrm{c}$ & 21 \\
\hline
\end{tabular}

Any information copied from such Reports and Statements may not be sold or used by any person for the purpose of soliciting contributions or for commercial purposes, other than using the name and address of any political committee to solicit contributions from such committee.

NAME OF COMMITTEE (In Full)

\section{Friends of Herman Cain}

A. Full Name (Last, First, Middle Initial)

\section{David Stewart}

Mailing Address 10740 Stargate Lane

\begin{tabular}{lcc}
\hline City & State & Zip Code \\
Cincinnati & $\mathrm{OH}$ & $45240-3532$
\end{tabular}

FEC ID number of contributing federal political committee.

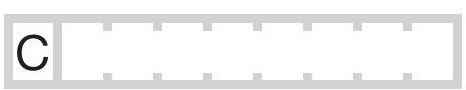

Name of Employer
Casco Manufacturing Solutions
Receipt For: 2012
X Primary
Other (specify) General

Occupation

Customer Service/Sales

Election Cycle-to-Date $\boldsymbol{\nabla}$

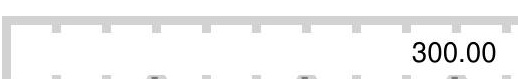

B. Full Name (Last, First, Middle Initial)

Jean Lucero

Mailing Address 205 Arrow Wood Dr

\begin{tabular}{lcc}
\hline City & State & Zip Code \\
Waleska & GA & $30183-2895$
\end{tabular}

FEC ID number of contributing

federal political committee.

C

Name of Employer
Information Requested
Receipt For: 2012
X Primary
Other (specify)

Occupation

Information Requested

Election Cycle-to-Date

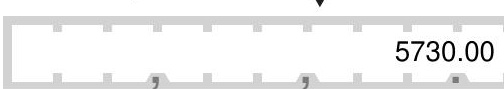

Transaction ID : A5CB72F35E8924B23B47

Date of Receipt

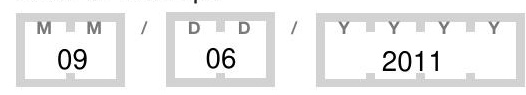

Amount of Each Receipt this Period

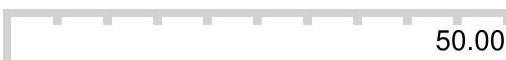

50.00

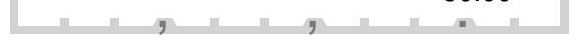

Transaction ID : AC313592C89614F069F1

Date of Receipt

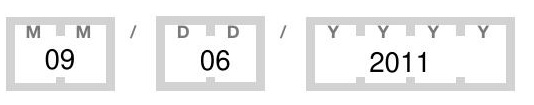

Amount of Each Receipt this Period

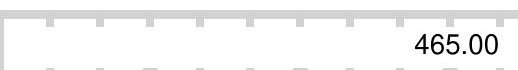

Transaction ID : AC8C62E75CA8A4F94997 Date of Receipt

Jean Lucero

Mailing Address 205 Arrow Wood Dr

\begin{tabular}{lcc}
\hline City & State & Zip Code \\
Waleska & GA & $30183-2895$
\end{tabular}

FEC ID number of contributing federal political committee.

C

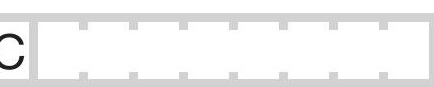

Name of Employer

Information Requested

Occupation

Information Requested

Receipt For: 2012

Х $\begin{aligned} & \text { Primary } \\ & \text { Other (specify) }\end{aligned}$

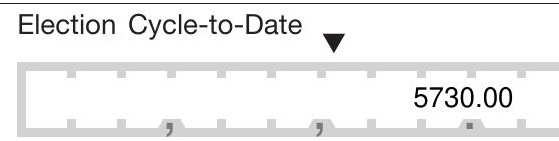

Amount of Each Receipt this Period

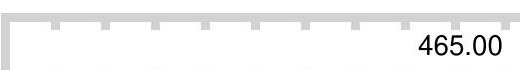

465.00

Subtotal Of Receipts This Page (optional)

980.00

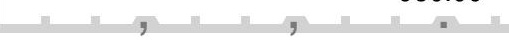

Total This Period (last page this line number only)

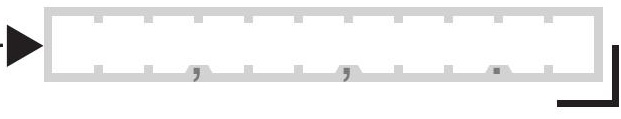

FEC Schedule A-P (Form 3P) (Rev. 03/2011) 
SCHEDULE A-P ITEMIZED RECEIPTS
Use separate schedule(s) for each category of the Detailed Summary Page
FOR LINE NUMBER: (check only one)

\begin{tabular}{|c|c|c|c|c|c|}
\hline & 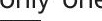 & & & & \\
\hline 16 & X $17 a$ & $17 \mathrm{~b}$ & $17 c$ & $17 d$ & 18 \\
\hline $19 a$ & $19 b$ & $20 \mathrm{a}$ & $20 \mathrm{~b}$ & $20 c$ & 21 \\
\hline
\end{tabular}

Any information copied from such Reports and Statements may not be sold or used by any person for the purpose of soliciting contributions or for commercial purposes, other than using the name and address of any political committee to solicit contributions from such committee.

NAME OF COMMITTEE (In Full)

\section{Friends of Herman Cain}

A. Full Name (Last, First, Middle Initial)

Georgine Demarino

Mailing Address 1320 Meridian Dr

\begin{tabular}{lcc}
\hline City & State & Zip Code \\
Presto & PA & $15142-1034$
\end{tabular}

FEC ID number of contributing federal political committee.

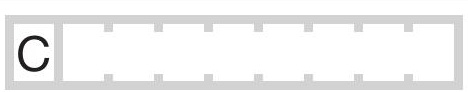

Name of Employer
Self Employed
Receipt For: 2012
X Primary $\quad$ General
Other (specify)

Occupation Physician Election Cycle-to-Date

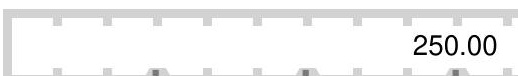

B. Full Name (Last, First, Middle Initial)

Susan Walter

Mailing Address P.O. Box 690

\begin{tabular}{lcc}
\hline City & State & Zip Code \\
Sautee Nacoochee & GA & $30571-0690$ \\
\hline
\end{tabular}

FEC ID number of contributing

federal political committee.

C

Name of Employer
None
Receipt For: 2012
X Primary
Other (specify)

C. Full Name (Last, First, Middle Initial)

Susan Walter

Mailing Address P.O. Box 690

\section{City}

Sautee Nacoochee

FEC ID number of contributing federal political committee.

Name of Employer
None
Receipt For: 2012
X Primary

Other (specify) General

\section{Occupation}

Retired

Election Cycle-to-Date

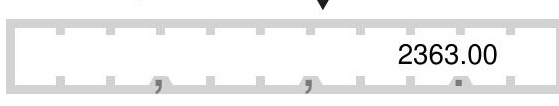

Transaction ID : A24B2DA5BE0014F4984F

Date of Receipt

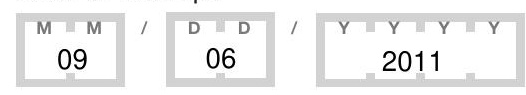

Amount of Each Receipt this Period

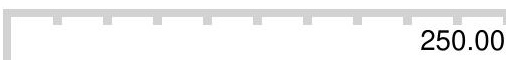

Amount of Each Receipt this Period

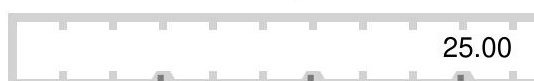

Transaction ID : A2A73E4E45C0144EF9F2 Date of Receipt

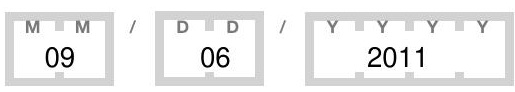

Amount of Each Receipt this Period

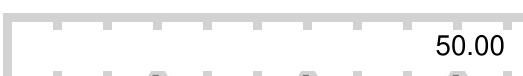

\section{Subtotal Of Receipts This Page (optional)}

Total This Period (last page this line number only) 
SCHEDULE A-P ITEMIZED RECEIPTS
Use separate schedule(s) for each category of the Detailed Summary Page
FOR LINE NUMBER: (check only one)
PAGE 438 / 1572

\begin{tabular}{|c|c|c|c|c|c|}
\hline & & & & & \\
\hline 16 & $\begin{array}{lll}X & 17 a \\
\end{array}$ & $17 \mathrm{~b}$ & $17 c$ & $17 d$ & 18 \\
\hline $19 a$ & $19 b$ & $20 a$ & $20 \mathrm{~b}$ & $20 c$ & 21 \\
\hline
\end{tabular}

Any information copied from such Reports and Statements may not be sold or used by any person for the purpose of soliciting contributions or for commercial purposes, other than using the name and address of any political committee to solicit contributions from such committee.

NAME OF COMMITTEE (In Full)

\section{Friends of Herman Cain}

A. Full Name (Last, First, Middle Initial) Jean Lucero

Mailing Address 205 Arrow Wood Dr

\begin{tabular}{lcc}
\hline City & State & Zip Code \\
Waleska & GA & $30183-2895$
\end{tabular}

FEC ID number of contributing federal political committee.

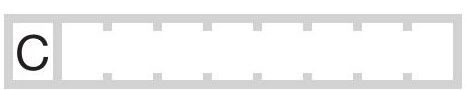

Name of Employer
Information Requested
Receipt For: 2012
X Primary $\quad \square$ General
Other (specify)

Occupation Information Requested

Election Cycle-to-Date

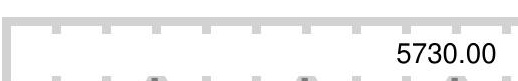

B. Full Name (Last, First, Middle Initial) Jean Lucero

Mailing Address 205 Arrow Wood Dr

\begin{tabular}{lcc}
\hline City & State & Zip Code \\
Waleska & GA & $30183-2895$
\end{tabular}

FEC ID number of contributing

federal political committee.

C

Name of Employer
Information Requested
Receipt For: 2012
X Primary
Other (specify)

Occupation

Information Requested

Election Cycle-to-Date

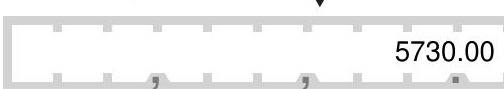

Transaction ID : ABED6C65A44874F78BC0

Date of Receipt

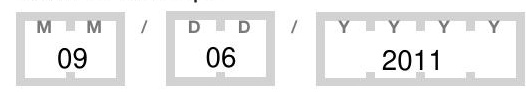

Amount of Each Receipt this Period

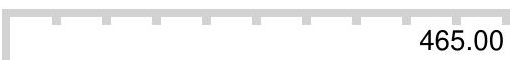

465.00

C. Full Name (Last, First, Middle Initial)

Jean Lucero

Mailing Address 205 Arrow Wood Dr

\begin{tabular}{lcc}
\hline City & State & Zip Code \\
Waleska & GA & $30183-2895$
\end{tabular}

FEC ID number of contributing federal political committee.

C

GA

Name of Employer
Information Requested
Receipt For: 2012
Primary
Other (specify) General

$\begin{aligned} & \text { Occupation } \\ & \text { Information Requested }\end{aligned}$
Election Cycle-to-Date

Amount of Each Receipt this Period

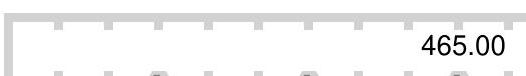

Transaction ID : AB8091F25F5494A098A7

Date of Receipt

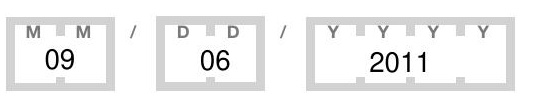

Amount of Each Receipt this Period

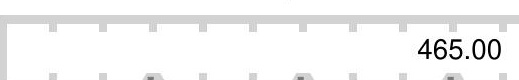

Transaction ID : A25EDAF9FE7F74D8493E Date of Receipt

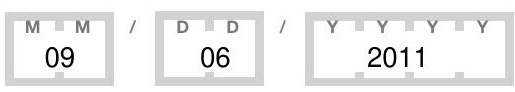

\section{Subtotal Of Receipts This Page (optional)}

Total This Period (last page this line number only) 
SCHEDULE A-P ITEMIZED RECEIPTS
Use separate schedule(s) for each category of the Detailed Summary Page
FOR LINE NUMBER: (check only one)

PAGE 439 / 1572

\begin{tabular}{|c|c|c|c|c|c|}
\hline & & & & & \\
\hline 16 & $\begin{array}{l}\mathbf{X} \\
17 a\end{array}$ & $17 b$ & $17 c$ & $17 d$ & 18 \\
\hline $19 a$ & $19 \mathrm{~b}$ & $20 \mathrm{a}$ & $20 \mathrm{~b}$ & $20 \mathrm{c}$ & 21 \\
\hline
\end{tabular}

Any information copied from such Reports and Statements may not be sold or used by any person for the purpose of soliciting contributions or for commercial purposes, other than using the name and address of any political committee to solicit contributions from such committee.

NAME OF COMMITTEE (In Full)

\section{Friends of Herman Cain}

A. Full Name (Last, First, Middle Initial) Jean Lucero

Mailing Address 205 Arrow Wood Dr

\begin{tabular}{lcc}
\hline City & State & Zip Code \\
Waleska & GA & $30183-2895$
\end{tabular}

FEC ID number of contributing federal political committee.

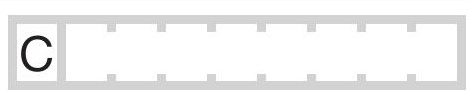

Name of Employer
Information Requested
Receipt For: 2012
X Primary
Other (specify) General

Occupation Information Requested

Election Cycle-to-Date

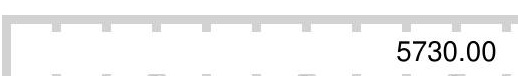

B. Full Name (Last, First, Middle Initial) Jean Lucero

Mailing Address 205 Arrow Wood Dr

\begin{tabular}{lcc}
\hline City & State & Zip Code \\
Waleska & GA & $30183-2895$ \\
\hline
\end{tabular}

FEC ID number of contributing

federal political committee.

C

Name of Employer
Information Requested
Receipt For: 2012
X Primary
Other (specify)

Occupation

Information Requested

Election Cycle-to-Date

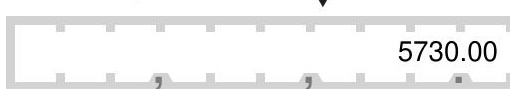

Transaction ID : A0A5FF3D6F34D45F09BE

Date of Receipt

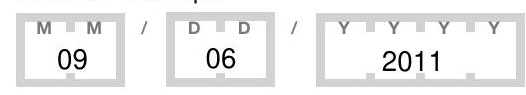

Amount of Each Receipt this Period

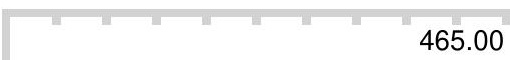

465.00

C. Full Name (Last, First, Middle Initial)

Dorothea Cist

Mailing Address 28 Monarch Bay Plaza Suite Q

\begin{tabular}{lcc}
\hline City & State & Zip Code \\
Dana Point & CA & $92629-3460$
\end{tabular}

FEC ID number of contributing

federal political committee.

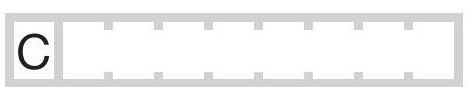

Name of Employer

Self Employed

Occupation

Receipt For: 2012

Х $\begin{aligned} & \text { Primary } \square \text { General } \\ & \text { Other (specify) }\end{aligned}$

Physician

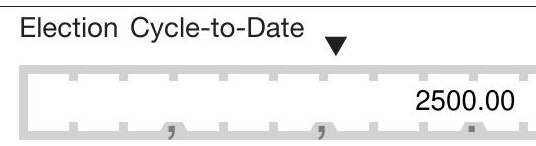

Amount of Each Receipt this Period

Transaction ID : ACA727146920F4320BBB

Date of Receipt
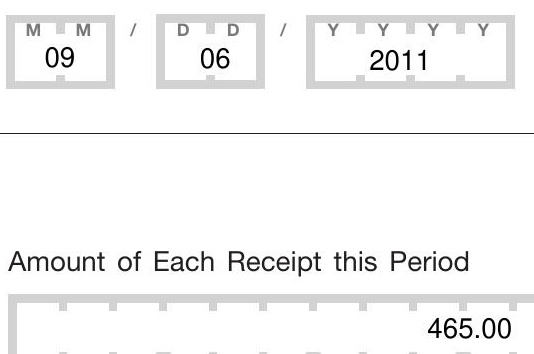

Transaction ID : A13A99B8C53864E9DB15 Date of Receipt

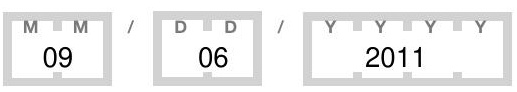

Amount of Each Receipt this Period

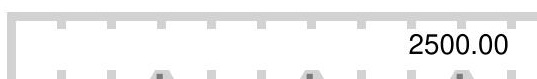

3430.00

Subtotal Of Receipts This Page (optional)

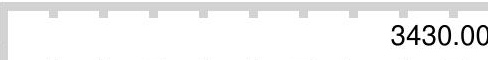

Total This Period (last page this line number only) 
SCHEDULE A-P ITEMIZED RECEIPTS
Use separate schedule(s) for each category of the Detailed Summary Page
FOR LINE NUMBER: (check only one)

PAGE 440 / 1572

\begin{tabular}{|c|c|c|c|c|c|}
\hline & & & & & \\
\hline 16 & $\begin{array}{l}\mathbf{X} \\
17 a\end{array}$ & $17 b$ & $17 c$ & $17 d$ & 18 \\
\hline $19 a$ & $19 \mathrm{~b}$ & $20 \mathrm{a}$ & $20 \mathrm{~b}$ & $20 \mathrm{c}$ & 21 \\
\hline
\end{tabular}

Any information copied from such Reports and Statements may not be sold or used by any person for the purpose of soliciting contributions or for commercial purposes, other than using the name and address of any political committee to solicit contributions from such committee.

NAME OF COMMITTEE (In Full)

\section{Friends of Herman Cain}

A. Full Name (Last, First, Middle Initial) Jean Lucero

Mailing Address 205 Arrow Wood Dr

\begin{tabular}{lcc}
\hline City & State & Zip Code \\
Waleska & GA & $30183-2895$
\end{tabular}

FEC ID number of contributing federal political committee.

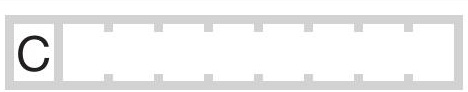

Name of Employer
Information Requested
Receipt For: 2012
X Primary
Other (specify) General

Occupation Information Requested

Election Cycle-to-Date

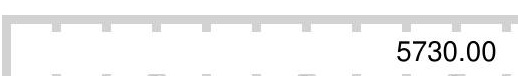

B. Full Name (Last, First, Middle Initial)

Don F Hatten MD

Mailing Address $300 \mathrm{~N}$ Indiana St

\begin{tabular}{lcc}
\hline City & State & Zip Code \\
Olney & IL & $62450-3108$
\end{tabular}

FEC ID number of contributing

federal political committee.

C

Name of Employer
Neber Medical Clinic
Receipt For: 2012
X Primary
Other (specify)

Occupation

Physician

Election Cycle-to-Date

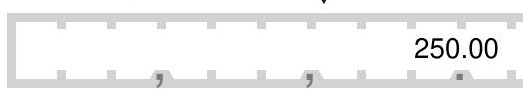

Transaction ID : A1F8D6CEFC5AA4EAE902

Date of Receipt

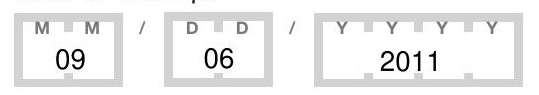

Amount of Each Receipt this Period

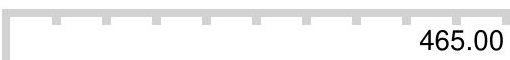

465.00

C. Full Name (Last, First, Middle Initial)

Charlotte Cable

Mailing Address $2111 \mathrm{E}$ 34th PI

\begin{tabular}{lcc}
\hline City & State & Zip Code \\
Joplin & MO & $64804-4214$
\end{tabular}

FEC ID number of contributing federal political committee.

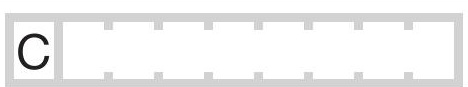

Name of Employer
None
Receipt For: 2012
Х Primary $\quad \square$ General
Other (specify)

Occupation

Retired

Election Cycle-to-Date

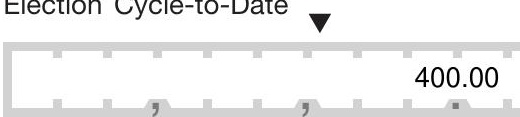

Transaction ID : A238BFCF4C6D44B129B3

Date of Receipt

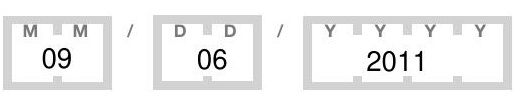

Amount of Each Receipt this Period

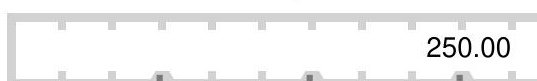

Transaction ID : A13E339A5A1BC48CC913 Date of Receipt

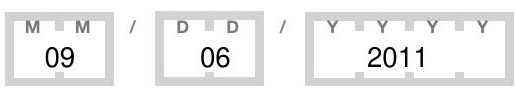

Amount of Each Receipt this Period

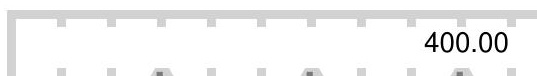

\section{Subtotal Of Receipts This Page (optional)}

Total This Period (last page this line number only) 


\section{SCHEDULE A-P} ITEMIZED RECEIPTS
Use separate schedule(s) for each category of the Detailed Summary Page

FOR LINE NUMBER:
(check only one)

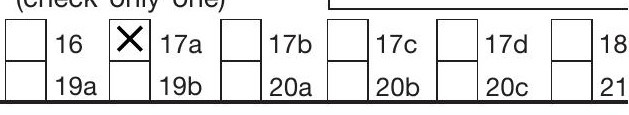

Any information copied from such Reports and Statements may not be sold or used by any person for the purpose of soliciting contributions or for commercial purposes, other than using the name and address of any political committee to solicit contributions from such committee.

NAME OF COMMITTEE (In Full)

\section{Friends of Herman Cain}

A. Full Name (Last, First, Middle Initial)

Alfred Persson

Mailing Address 35099 State Hwy 74 spc F3

\begin{tabular}{lcc}
\hline City & State & Zip Code \\
Hemet & CA & $92545-3461$
\end{tabular}

FEC ID number of contributing federal political committee.

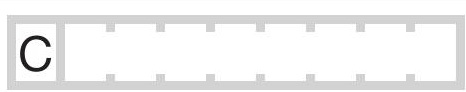

Name of Employer
Discount Answering Service
Receipt For: 2012
X Primary
$\square$ Other (specify)

Occupation CEO

Election Cycle-to-Date

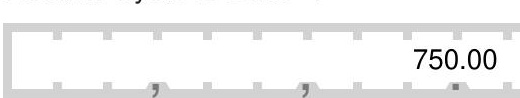

B. Full Name (Last, First, Middle Initial) Jean Lucero

Mailing Address 205 Arrow Wood Dr

\begin{tabular}{lcc}
\hline City & State & Zip Code \\
Waleska & GA & $30183-2895$ \\
\hline
\end{tabular}

FEC ID number of contributing

federal political committee.

C

Name of Employer
Information Requested
Receipt For: 2012
X Primary
Other (specify)

Occupation

Information Requested

Election Cycle-to-Date

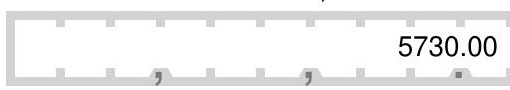

Transaction ID : A7C682B66C9D042A1BF5

Date of Receipt

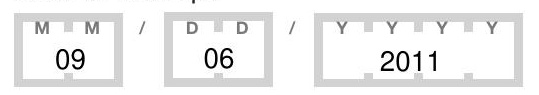

Amount of Each Receipt this Period

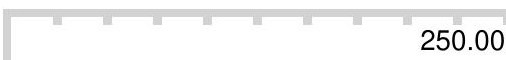

C. Full Name (Last, First, Middle Initial)

Nicholas Thompson

Mailing Address 1 Alexander Rd

\begin{tabular}{lcc}
\hline City & State & Zip Code \\
Kintnersville & PA & $18930-9800$
\end{tabular}

FEC ID number of contributing federal political committee.

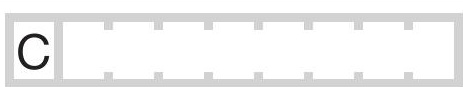

Name of Employer

Groupmark Financial Services Ltd

Occupation

Investment Banking

Receipt For: 2012

Х $\begin{aligned} & \text { Primary } \square \text { General } \\ & \text { Other (specify) }\end{aligned}$
Amount of Each Receipt this Period

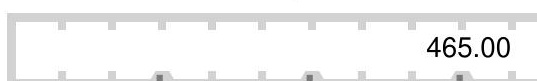

Transaction ID : A75CC17566A244A8D9B6 Date of Receipt

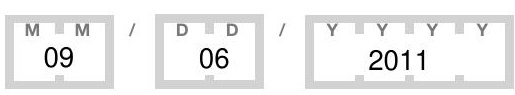

Transaction ID : A12B3B8DFDA644BA0952 Date of Receipt

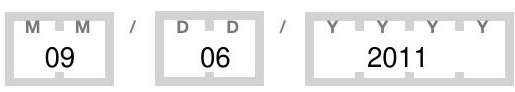

Amount of Each Receipt this Period

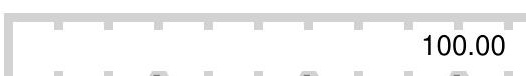

\section{Subtotal Of Receipts This Page (optional)}

Total This Period (last page this line number only) 
SCHEDULE A-P ITEMIZED RECEIPTS
Use separate schedule(s) for each category of the Detailed Summary Page
FOR LINE NUMBER: (check only one)

PAGE 442 / 1572

\begin{tabular}{|c|c|c|c|c|c|}
\hline & & & & & \\
\hline 16 & $\begin{array}{l}\mathbf{X} \\
17 a\end{array}$ & $17 b$ & $17 c$ & $17 d$ & 18 \\
\hline $19 a$ & $19 \mathrm{~b}$ & $20 \mathrm{a}$ & $20 \mathrm{~b}$ & $20 \mathrm{c}$ & 21 \\
\hline
\end{tabular}

Any information copied from such Reports and Statements may not be sold or used by any person for the purpose of soliciting contributions or for commercial purposes, other than using the name and address of any political committee to solicit contributions from such committee.

NAME OF COMMITTEE (In Full)

\section{Friends of Herman Cain}

A. Full Name (Last, First, Middle Initial)

Sylvia D Barnes

Mailing Address 75495 Road 436

\begin{tabular}{lcc}
\hline City & State & Zip Code \\
Lexington & NE & $68850-5638$ \\
\hline
\end{tabular}

FEC ID number of contributing federal political committee.

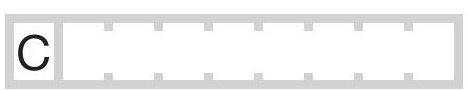

\begin{tabular}{l} 
Name of Employer \\
None \\
Receipt For: 2012 \\
X Primary $\quad$ General \\
\hline Other (specify)
\end{tabular}

Occupation

Retired

Election Cycle-to-Date

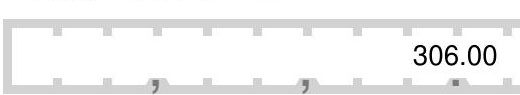

B. Full Name (Last, First, Middle Initial)

Gaetano Cicatiello

Mailing Address 2976 Mediterranean Loop

\begin{tabular}{lcc}
\hline City & State & Zip Code \\
Tavares & FL & $32778-9244$ \\
\hline
\end{tabular}

FEC ID number of contributing

federal political committee.

C

Name of Employer
None
Receipt For: 2012
X Primary
Other (specify)

C. Full Name (Last, First, Middle Initial)

Jean Lucero

Mailing Address 205 Arrow Wood Dr

\begin{tabular}{lcc}
\hline City & State & Zip Code \\
Waleska & GA & $30183-2895$
\end{tabular}

FEC ID number of contributing federal political committee.

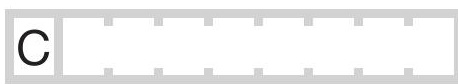

Name of Employer
Information Requested
Receipt For: 2012
X Primary $\quad \square$ General
Other (specify)

\section{Occupation}

Retired

Election Cycle-to-Date

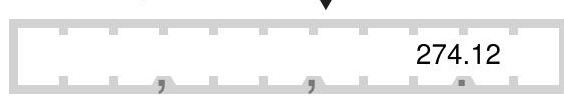

Transaction ID : ADC5856C45A7C46EFA17

Date of Receipt

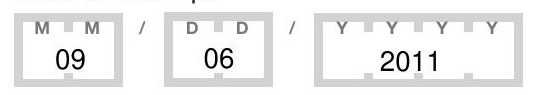

Amount of Each Receipt this Period

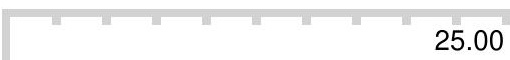

25.00
Amount of Each Receipt this Period

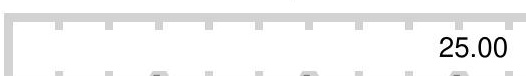

Transaction ID : A86B4E5CF6BA94295B1C Date of Receipt

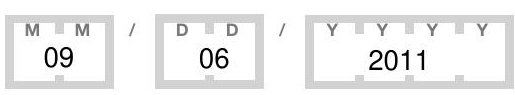

Transaction ID : A609FAD34834247DBA76 Date of Receipt

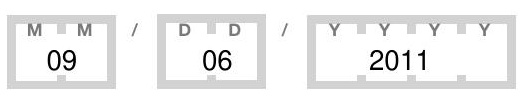

Amount of Each Receipt this Period

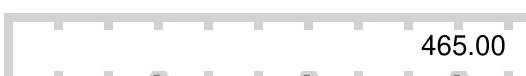

Subtotal Of Receipts This Page (optional)

Total This Period (last page this line number only) 
SCHEDULE A-P ITEMIZED RECEIPTS
Use separate schedule(s) for each category of the Detailed Summary Page
FOR LINE NUMBER: (check only one)

PAGE $443 / 1572$

\begin{tabular}{|c|c|c|c|c|c|c|}
\hline & & & & & & \\
\hline 16 & $\lambda$ & $17 \mathrm{a}$ & $17 \mathrm{~b}$ & $17 \mathrm{c}$ & $-17 d$ & -18 \\
\hline $19 a$ & & $19 b$ & $20 a$ & $20 \mathrm{~b}$ & $20 \mathrm{c}$ & 21 \\
\hline
\end{tabular}

Any information copied from such Reports and Statements may not be sold or used by any person for the purpose of soliciting contributions or for commercial purposes, other than using the name and address of any political committee to solicit contributions from such committee.

NAME OF COMMITTEE (In Full)

\section{Friends of Herman Cain}

A. Full Name (Last, First, Middle Initial) Jean Lucero

Mailing Address 205 Arrow Wood Dr

\begin{tabular}{lcc}
\hline City & State & Zip Code \\
Waleska & GA & $30183-2895$
\end{tabular}

FEC ID number of contributing federal political committee.

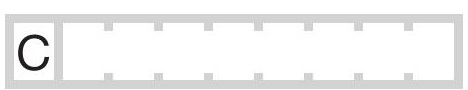

Name of Employer
Information Requested
Receipt For: 2012
X Primary
Other (specify) General

Occupation Information Requested

Election Cycle-to-Date

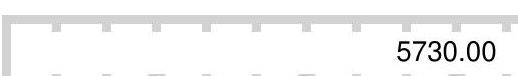

B. Full Name (Last, First, Middle Initial) STEVEN FIELDS

Mailing Address 139 April Point Dr N

\begin{tabular}{lcc}
\hline City & State & Zip Code \\
Montgomery & TX & $77356-5832$ \\
\hline
\end{tabular}

FEC ID number of contributing

federal political committee.

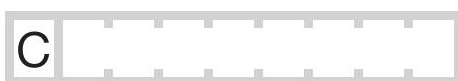

Name of Employer
n/a
Receipt For: 2012
X Primary
Other (specify)

Occupation

Retired

Election Cycle-to-Date

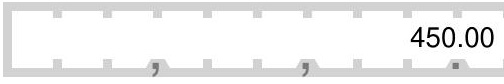

C. Full Name (Last, First, Middle Initial)

Mrs. Barbara C. Mathews

Mailing Address 2367 LAvista Road

\begin{tabular}{lcc}
\hline City & State & Zip Code \\
Atlanta & GA & $30329-3346$ \\
\hline
\end{tabular}

FEC ID number of contributing federal political committee.

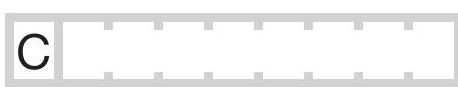

Name of Employer
None
Receipt For: 2012
Х Primary $\quad \square$ General
Other (specify)

Occupation

Retired

Election Cycle-to-Date

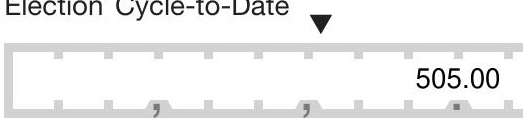

Transaction ID : A3B7028764B014F33A1F

Date of Receipt

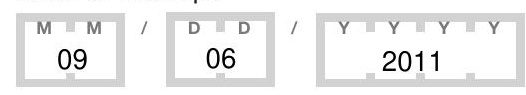

Amount of Each Receipt this Period

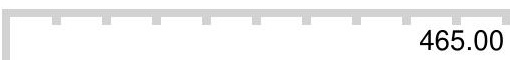

465.00

Transaction ID : A42BAE8CF2D764EB6884

Date of Receipt

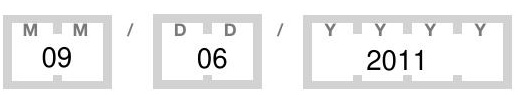

Amount of Each Receipt this Period

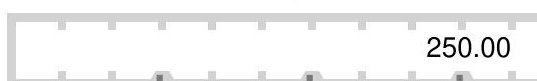

Transaction ID : AF832BCA624B94832A79

Date of Receipt

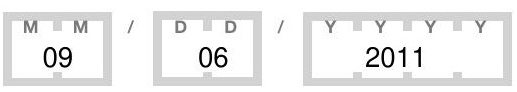

Amount of Each Receipt this Period

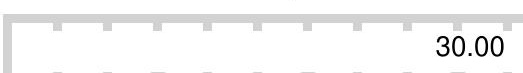

\section{Subtotal Of Receipts This Page (optional)}

Total This Period (last page this line number only) 
SCHEDULE A-P ITEMIZED RECEIPTS
Use separate schedule(s) for each category of the Detailed Summary Page

FOR LINE NUMBER:
(check only one)

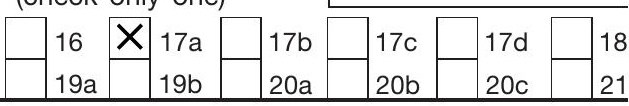

Any information copied from such Reports and Statements may not be sold or used by any person for the purpose of soliciting contributions or for commercial purposes, other than using the name and address of any political committee to solicit contributions from such committee.

NAME OF COMMITTEE (In Full)

\section{Friends of Herman Cain}

A. Full Name (Last, First, Middle Initial)

Rose Mare Distefano

Mailing Address 2881 Jonesboro Rd

\begin{tabular}{lcc}
\hline City & State & Zip Code \\
Hampton & GA & $30228-2730$ \\
\hline
\end{tabular}

FEC ID number of contributing federal political committee.

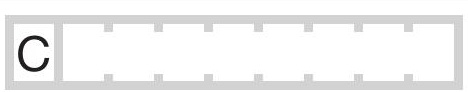

\begin{tabular}{l} 
Name of Employer \\
None \\
Receipt For: 2012 \\
X Primary $\quad$ General \\
\hline Other (specify)
\end{tabular}

Occupation

Retired

Election Cycle-to-Date

3100.00

B. Full Name (Last, First, Middle Initial)

EDWARD MURPHY

Mailing Address 214 CAMINO VISTA REAL

\begin{tabular}{lcc}
\hline City & State & Zip Code \\
Chula Vista & CA & $91910-6326$
\end{tabular}

FEC ID number of contributing

federal political committee.

C

Name of Employer
navy exchange
Receipt For: 2012
X Primary
Other (specify)

Occupation

Retired

Election Cycle-to-Date

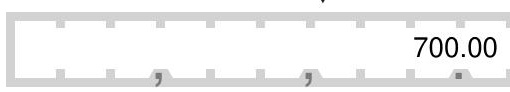

Transaction ID : A6E4ADEBAD56E4E218A7

Date of Receipt

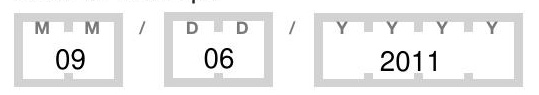

Amount of Each Receipt this Period

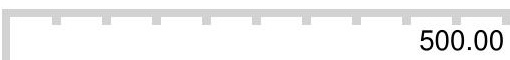

C. Full Name (Last, First, Middle Initial)

Beverly McVey

Mailing Address 11925 S. 49th W. Avenue

\begin{tabular}{lcc}
\hline City & State & Zip Code \\
Sapulpa & OK & $74066-7407$
\end{tabular}

FEC ID number of contributing

federal political committee.

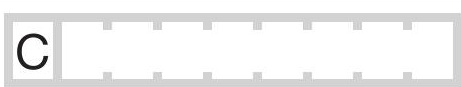

Name of Employer
NA
Receipt For: 2012
X Primary

Other (specify) General

Occupation

Homemaker

Election Cycle-to-Date

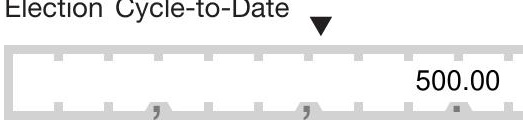

Transaction ID : AC1B4A7D8DD0F4D2CA3C Date of Receipt

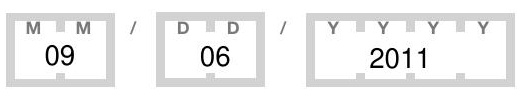

Amount of Each Receipt this Period

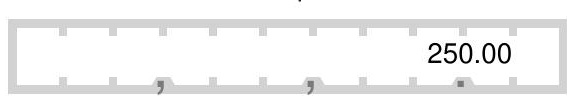

Transaction ID : AE3A8EAF0425F47378FE

Date of Receipt

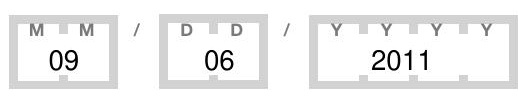

Amount of Each Receipt this Period

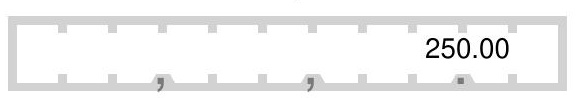

\section{Subtotal Of Receipts This Page (optional)}

1000.00

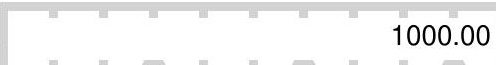

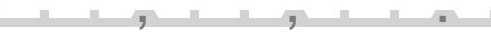

Total This Period (last page this line number only)

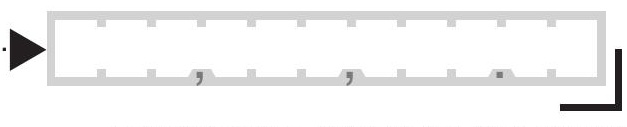

FEC Schedule A-P (Form 3P) (Rev. 03/2011) 
SCHEDULE A-P ITEMIZED RECEIPTS
Use separate schedule(s) for each category of the Detailed Summary Page
FOR LINE NUMBER: (check only one)

PAGE 445 / 1572

\begin{tabular}{|c|c|c|c|c|c|}
\hline & & & & & \\
\hline 16 & $\begin{array}{l}\mathbf{X} \\
17 a\end{array}$ & $17 b$ & $17 c$ & $17 d$ & 18 \\
\hline $19 a$ & $19 \mathrm{~b}$ & $20 \mathrm{a}$ & $20 \mathrm{~b}$ & $20 \mathrm{c}$ & 21 \\
\hline
\end{tabular}

Any information copied from such Reports and Statements may not be sold or used by any person for the purpose of soliciting contributions or for commercial purposes, other than using the name and address of any political committee to solicit contributions from such committee.

NAME OF COMMITTEE (In Full)

\section{Friends of Herman Cain}

A. Full Name (Last, First, Middle Initial)

Mr Michael Doyle

Mailing Address 12 Kinkora Ct E

\begin{tabular}{lcc}
\hline City & State & Zip Code \\
Toms River & NJ & $08757-6429$
\end{tabular}

FEC ID number of contributing federal political committee.

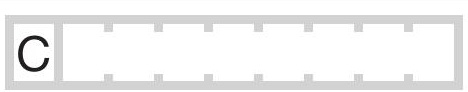

Name of Employer
Information Requested
Receipt For: 2012
X Primary
Other (specify) General

Occupation Information Requested

Election Cycle-to-Date

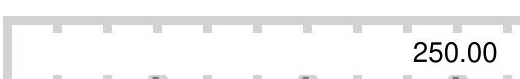

B. Full Name (Last, First, Middle Initial)

Mr. Dudney A Harris

Mailing Address 1801 Sugar Creek Trl

\begin{tabular}{lcc}
\hline City & State & Zip Code \\
Buckhead & GA & $30625-2517$
\end{tabular}

FEC ID number of contributing

federal political committee.

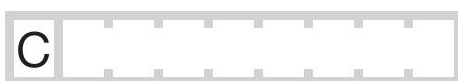

Name of Employer
None
Receipt For: 2012
X Primary
Other (specify)

\section{Occupation}

Retired

Election Cycle-to-Date

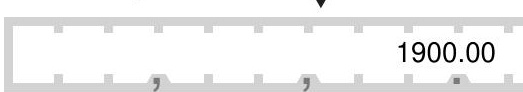

Transaction ID : AF9E6ABF94433457A9BC

Date of Receipt

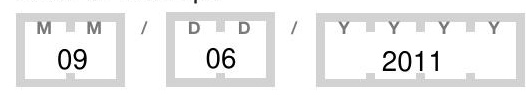

Amount of Each Receipt this Period

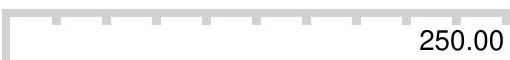

Amount of Each Receipt this Period

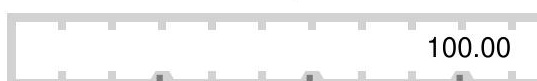

C. Full Name (Last, First, Middle Initial)

Jean Lucero

Mailing Address 205 Arrow Wood Dr

\begin{tabular}{lcc}
\hline City & State & Zip Code \\
Waleska & GA & $30183-2895$
\end{tabular}

FEC ID number of contributing federal political committee.

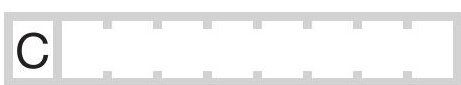

Name of Employer

Information Requested

\section{Occupation}

Information Requested

Receipt For: 2012

Х $\begin{aligned} & \text { Primary } \square \text { General } \\ & \text { Other (specify) }\end{aligned}$

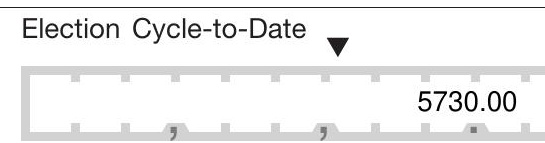

Amount of Each Receipt this Period

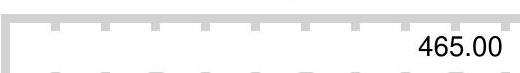

Transaction ID : A35046EE5885A4F09BFC

Date of Receipt

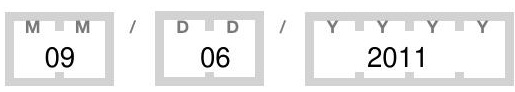

Subtotal Of Receipts This Page (optional)

815.00

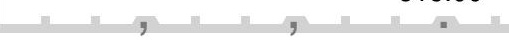

Total This Period (last page this line number only)
Transaction ID : AAFE3BD4EFA1843518EF Date of Receipt

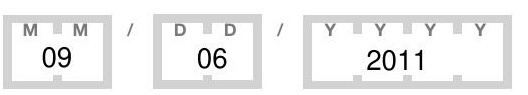

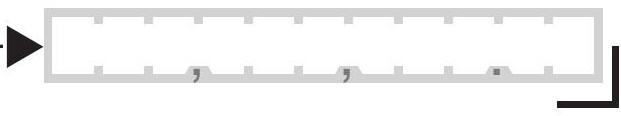


SCHEDULE A-P ITEMIZED RECEIPTS
Use separate schedule(s) for each category of the Detailed Summary Page
FOR LINE NUMBER: (check only one)

PAGE 446 / 1572

\begin{tabular}{|c|c|c|c|c|c|}
\hline & & & & & \\
\hline 16 & $\begin{array}{l}\mathbf{X} \\
17 a\end{array}$ & $17 b$ & $17 c$ & $17 d$ & 18 \\
\hline $19 a$ & $19 \mathrm{~b}$ & $20 \mathrm{a}$ & $20 \mathrm{~b}$ & $20 \mathrm{c}$ & 21 \\
\hline
\end{tabular}

Any information copied from such Reports and Statements may not be sold or used by any person for the purpose of soliciting contributions or for commercial purposes, other than using the name and address of any political committee to solicit contributions from such committee.

NAME OF COMMITTEE (In Full)

\section{Friends of Herman Cain}

A. Full Name (Last, First, Middle Initial) Linda Broyles

Mailing Address 6030 Sweet Creek Road

\begin{tabular}{lcc}
\hline City & State & Zip Code \\
Duluth & GA & $30097-7185$
\end{tabular}

FEC ID number of contributing federal political committee.

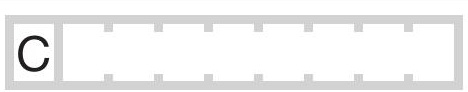

Name of Employer
self
Receipt For: 2012
X Primary $\quad$ General
Other (specify)

Occupation Homemaker

Election Cycle-to-Date

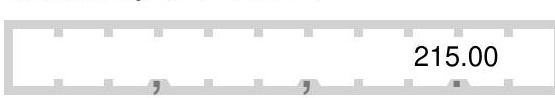

B. Full Name (Last, First, Middle Initial)

Keith Mann

Mailing Address 7239 MARLOW PL

\begin{tabular}{lcc}
\hline City & State & Zip Code \\
University Park & FL & $34201-2269$
\end{tabular}

FEC ID number of contributing

federal political committee.

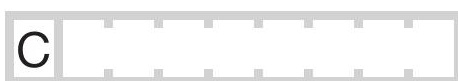

Name of Employer
US ARMY
Receipt For: 2012
X Primary
Other (specify)

\section{Occupation}

Soldier

Election Cycle-to-Date

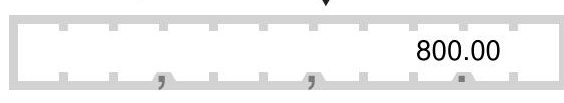

Transaction ID : ABA5E0B60C2484BFCBB2

Date of Receipt

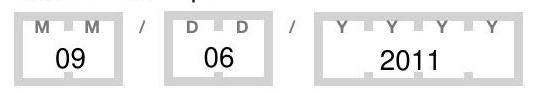

Amount of Each Receipt this Period

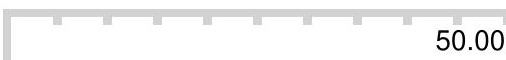

50.00

C. Full Name (Last, First, Middle Initial)

Jeanna Carley

Mailing Address 425 E Pennsylvania Ave

\begin{tabular}{lcc}
\hline City & State & Zip Code \\
Deland & FL & $32724-3573$
\end{tabular}

FEC ID number of contributing

federal political committee.

C

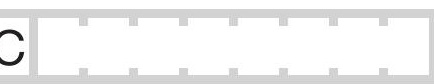

\section{Name of Employer}

Self Employed

Occupation

Receipt For: 2012

Х $\begin{aligned} & \text { Primary } \\ & \text { Other (specify) }\end{aligned}$

Aviation

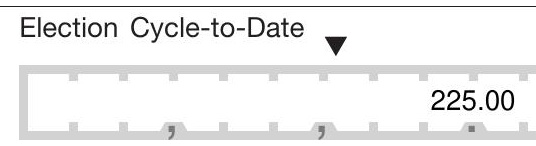

Amount of Each Receipt this Period

Transaction ID : A3941F82F87454CF4AD8

Date of Receipt
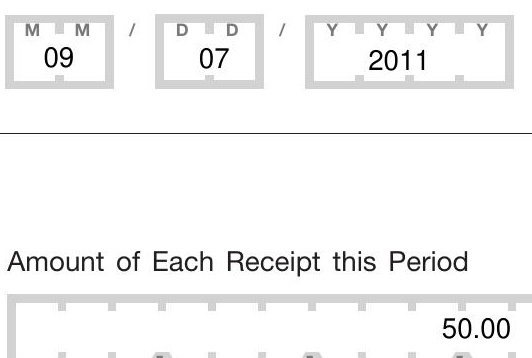

Transaction ID : AF5EBBB61A965416F938

Date of Receipt

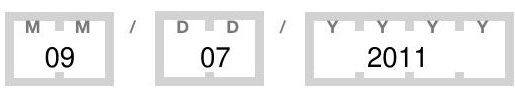

Amount of Each Receipt this Period

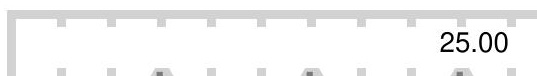

125.00

Subtotal Of Receipts This Page (optional)

Total This Period (last page this line number only) 
SCHEDULE A-P ITEMIZED RECEIPTS
Use separate schedule(s) for each category of the Detailed Summary Page
FOR LINE NUMBER: (check only one)

PAGE 447 / 1572

\begin{tabular}{|c|c|c|c|c|c|}
\hline & & & & & \\
\hline 16 & $\begin{array}{l}\mathbf{X} \\
17 a\end{array}$ & $17 b$ & $17 c$ & $17 d$ & 18 \\
\hline $19 a$ & $19 \mathrm{~b}$ & $20 \mathrm{a}$ & $20 \mathrm{~b}$ & $20 \mathrm{c}$ & 21 \\
\hline
\end{tabular}

Any information copied from such Reports and Statements may not be sold or used by any person for the purpose of soliciting contributions or for commercial purposes, other than using the name and address of any political committee to solicit contributions from such committee.

NAME OF COMMITTEE (In Full)

\section{Friends of Herman Cain}

A. Full Name (Last, First, Middle Initial)

kevin herbert

Mailing Address 7430 shadburn ferry rd

\begin{tabular}{lcc}
\hline City & State & Zip Code \\
Cumming & GA & $30041-8153$ \\
\hline
\end{tabular}

FEC ID number of contributing federal political committee.

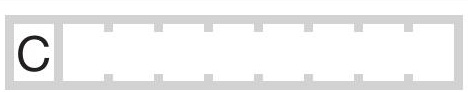

Name of Employer

Kevin Herbert Automotive, Inc.

Occupation

Owner

Receipt For: 2012

X Primary $\square$ General Other (specify)

Election Cycle-to-Date

250.00

B. Full Name (Last, First, Middle Initial)

Robert Porter

Mailing Address 5710 Grand Reunion Dr

\begin{tabular}{lcc}
\hline City & State & Zip Code \\
Hoschton & GA & $30548-4045$
\end{tabular}

FEC ID number of contributing

federal political committee.

C

Name of Employer
Information Requested
Receipt For: 2012
X Primary
Other (specify)

Occupation

Information Requested

Election Cycle-to-Date

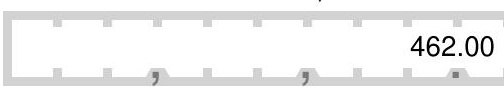

Transaction ID : AF424436FA5B74B61951

Date of Receipt

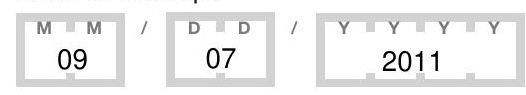

Amount of Each Receipt this Period

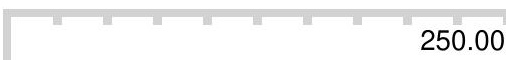

250.00

C. Full Name (Last, First, Middle Initial)

Judy Novak

Mailing Address 5995 Lac du Lune Road

\begin{tabular}{lcc}
\hline City & State & Zip Code \\
Land O Lakes & WI & $54540-9633$
\end{tabular}

FEC ID number of contributing

federal political committee.

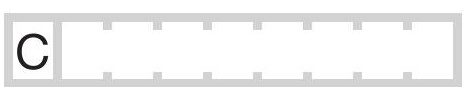

Name of Employer

Information Requested

Occupation

Information Requested

Receipt For: 2012

Х $\begin{aligned} & \text { Primary } \\ & \text { Other (specify) }\end{aligned}$

Election Cycle-to-Date

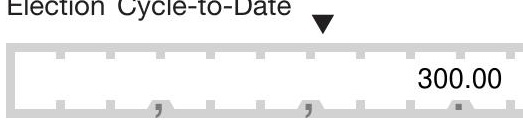

Amount of Each Receipt this Period

Transaction ID : A9C8B9E6F52F34497ABE

Date of Receipt
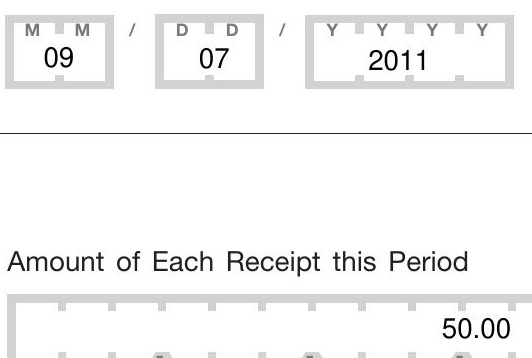

Transaction ID : A834C29EACBA54E47966 Date of Receipt

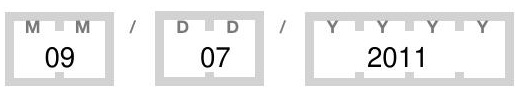

Amount of Each Receipt this Period

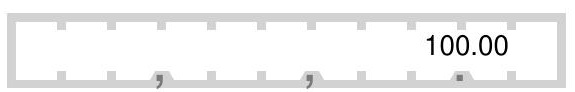

Subtotal Of Receipts This Page (optional).

400.00

Total This Period (last page this line number only) 
SCHEDULE A-P ITEMIZED RECEIPTS
Use separate schedule(s) for each category of the Detailed Summary Page
FOR LINE NUMBER: (check only one)

PAGE 448 / 1572

\begin{tabular}{|c|c|c|c|c|c|}
\hline & & & & & \\
\hline 16 & $\begin{array}{l}\mathbf{X} \\
17 a\end{array}$ & $17 b$ & $17 c$ & $17 d$ & 18 \\
\hline $19 a$ & $19 \mathrm{~b}$ & $20 \mathrm{a}$ & $20 \mathrm{~b}$ & $20 \mathrm{c}$ & 21 \\
\hline
\end{tabular}

Any information copied from such Reports and Statements may not be sold or used by any person for the purpose of soliciting contributions or for commercial purposes, other than using the name and address of any political committee to solicit contributions from such committee.

NAME OF COMMITTEE (In Full)

\section{Friends of Herman Cain}

A. Full Name (Last, First, Middle Initial)

Ross Delash

Mailing Address 515 Mask Rd

\begin{tabular}{lcc}
\hline City & State & Zip Code \\
Brooks & GA & $30205-2214$
\end{tabular}

FEC ID number of contributing federal political committee.

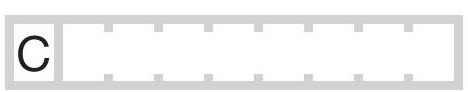

Name of Employer
Atlantic Southeast Airlines
Receipt For: 2012
X Primary
Other (specify) General

Occupation

Pilot

Election Cycle-to-Date

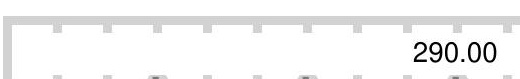

B. Full Name (Last, First, Middle Initial)

Mrs. Jane T Twilling

Mailing Address 420 Bates Rd SE

\begin{tabular}{lcc}
\hline City & State & Zip Code \\
Cartersville & GA & $30120-6981$ \\
\hline
\end{tabular}

FEC ID number of contributing

federal political committee.

C

Name of Employer
Information Requested
Receipt For: 2012
Primary
Other (specify)

Occupation

Information Requested

Election Cycle-to-Date

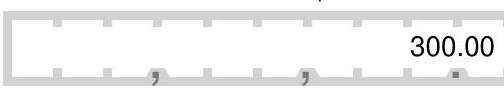

Transaction ID : A3FDBBCABD1594956AB3

Date of Receipt

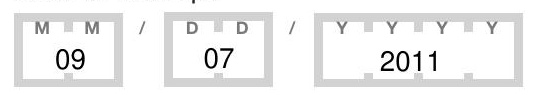

Amount of Each Receipt this Period

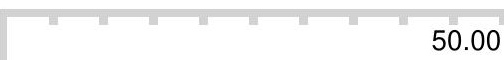

C. Full Name (Last, First, Middle Initial)

Neil Hobart

Mailing Address 219 N Barry Avenue

\begin{tabular}{lcc}
\hline City & State & Zip Code \\
Mamaroneck & NY & $10543-2827$
\end{tabular}

FEC ID number of contributing

federal political committee.

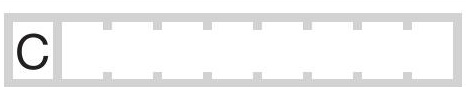

Name of Employer
None
Receipt For: 2012
Х Primary $\quad \square$ General
Other (specify)

Occupation

unemployed

Election Cycle-to-Date

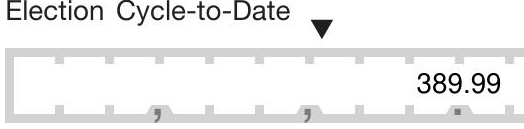

Transaction ID : A9B93BA876BC14E2CA05 Date of Receipt

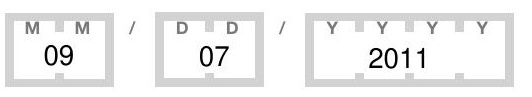

Amount of Each Receipt this Period

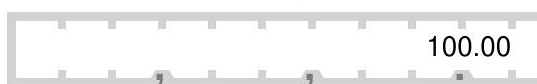

Transaction ID : AC7A55857997C4A4F840

Date of Receipt

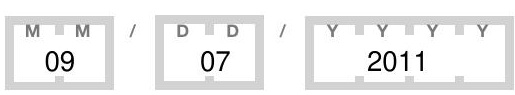

Amount of Each Receipt this Period

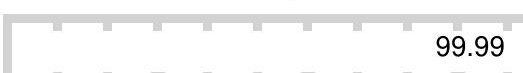

99.99

\section{Subtotal Of Receipts This Page (optional)}

Total This Period (last page this line number only) 
SCHEDULE A-P ITEMIZED RECEIPTS
Use separate schedule(s) for each category of the Detailed Summary Page
FOR LINE NUMBER: (check only one)

PAGE 449 / 1572

\begin{tabular}{|c|c|c|c|c|c|}
\hline & & & & & \\
\hline 16 & $\begin{array}{l}\mathbf{X} \\
17 a\end{array}$ & $17 b$ & $17 c$ & $17 d$ & 18 \\
\hline $19 a$ & $19 \mathrm{~b}$ & $20 \mathrm{a}$ & $20 \mathrm{~b}$ & $20 \mathrm{c}$ & 21 \\
\hline
\end{tabular}

Any information copied from such Reports and Statements may not be sold or used by any person for the purpose of soliciting contributions or for commercial purposes, other than using the name and address of any political committee to solicit contributions from such committee.

NAME OF COMMITTEE (In Full)

\section{Friends of Herman Cain}

A. Full Name (Last, First, Middle Initial)

Richard Gauthier

Mailing Address 14310 Clearview Lane

\begin{tabular}{lcc}
\hline City & State & Zip Code \\
Urbandale & IA & $50323-2083$
\end{tabular}

FEC ID number of contributing federal political committee.

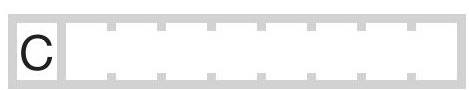

Name of Employer
The Cheesecake Factory
Receipt For: 2012
X Primary
Other (specify) General

Occupation General Manager

Election Cycle-to-Date

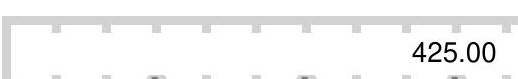

B. Full Name (Last, First, Middle Initial)

Peter Stent

Mailing Address 170 Josselyn Lane

\begin{tabular}{lcc}
\hline City & State & Zip Code \\
Woodside & CA & $94062-3610$
\end{tabular}

FEC ID number of contributing

federal political committee.

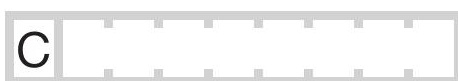

Name of Employer
self
Receipt For: 2012
Primary
Other (specify)

Occupation

Rancher/Farmer

Election Cycle-to-Date

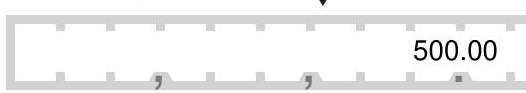

Transaction ID : A86A30025377A474788B

Date of Receipt

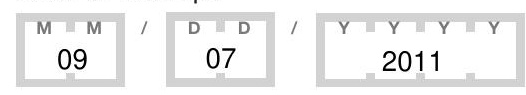

Amount of Each Receipt this Period

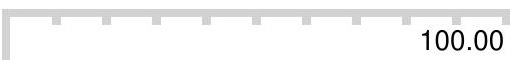

Transaction ID : AFC2CF1948DDF47E5BFA Date of Receipt

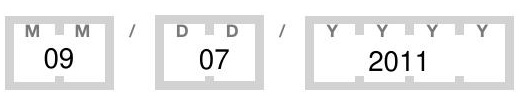

Amount of Each Receipt this Period

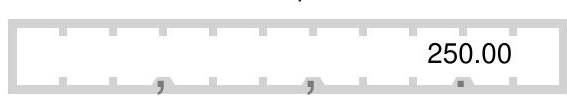

C. Full Name (Last, First, Middle Initial)

Jeanne Downer

Mailing Address $6007 \mathrm{~N}$ Kansas AVe

\begin{tabular}{lcc}
\hline City & State & Zip Code \\
Kansas City & MO & $64119-2115$
\end{tabular}

FEC ID number of contributing federal political committee.

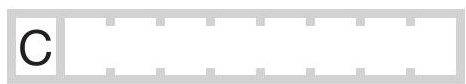

Name of Employer
WNB Architects
Receipt For: 2012
X Primary $\quad \square$ General
Other (specify)

\section{Occupation}

Office Manager

Election Cycle-to-Date

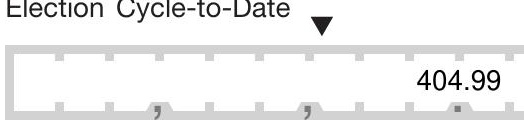

Subtotal Of Receipts This Page (optional).

359.99

Transaction ID : A7023526523524DDCB1D Date of Receipt

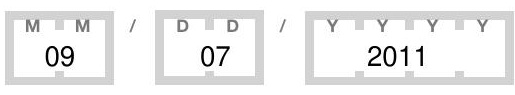

Amount of Each Receipt this Period

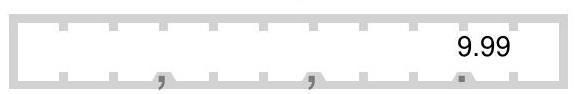

Total This Period (last page this line number only) 
SCHEDULE A-P ITEMIZED RECEIPTS
Use separate schedule(s) for each category of the Detailed Summary Page
FOR LINE NUMBER: (check only one)

PAGE 450 / 1572

\begin{tabular}{|c|c|c|c|c|c|}
\hline & & & & & \\
\hline 16 & $\begin{array}{l}\mathbf{X} \\
17 a\end{array}$ & $17 b$ & $17 c$ & $17 d$ & 18 \\
\hline $19 a$ & $19 \mathrm{~b}$ & $20 \mathrm{a}$ & $20 \mathrm{~b}$ & $20 \mathrm{c}$ & 21 \\
\hline
\end{tabular}

Any information copied from such Reports and Statements may not be sold or used by any person for the purpose of soliciting contributions or for commercial purposes, other than using the name and address of any political committee to solicit contributions from such committee.

NAME OF COMMITTEE (In Full)

\section{Friends of Herman Cain}

A. Full Name (Last, First, Middle Initial)

\section{Carol Cook}

Mailing Address 43 Oak Alley

\section{City}

Kerrville

FEC ID number of contributing federal political committee.

Name of Employer
James Avery
Receipt For: 2012
X Primary $\quad \square$ General
Other (specify)

B. Full Name (Last, First, Middle Initial) sabra ingeman

Mailing Address 8755 SE water oak place

\begin{tabular}{lcc}
\hline City & State & Zip Code \\
Jupiter & FL & $33469-1811$
\end{tabular}

FEC ID number of contributing

federal political committee.

Name of Employer
n/a
Receipt For: 2012
X Primary
Other (specify)

C. Full Name (Last, First, Middle Initial)

Christina Williams

Mailing Address 2430 Prince Howard Way

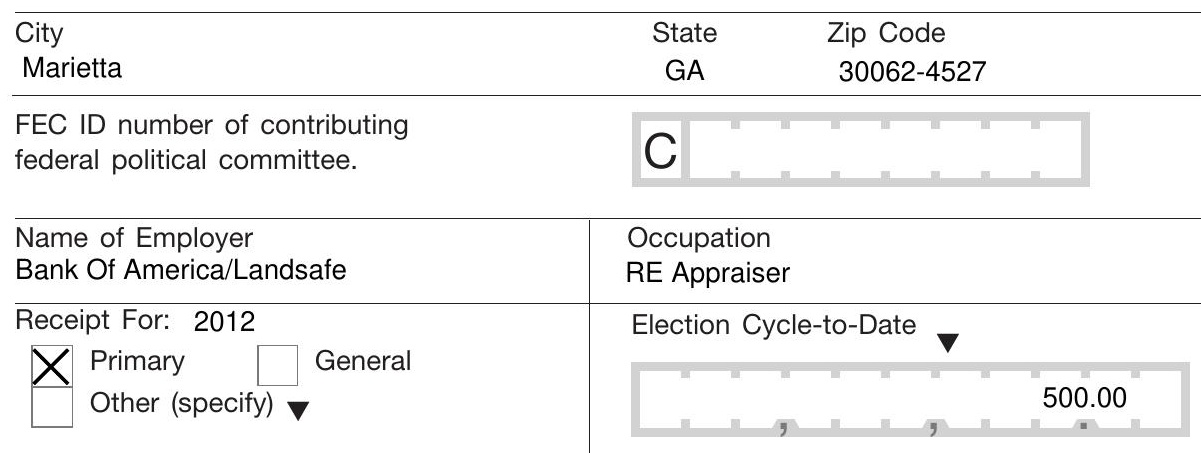

C

Transaction ID : AC61DD6E9532E4C1CA01

Date of Receipt

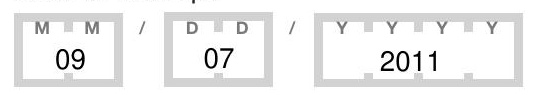

Amount of Each Receipt this Period

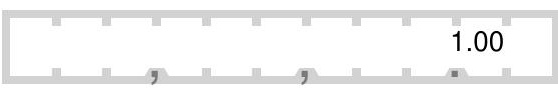

Sales Team Leader

Election Cycle-to-Date

248.60

Transaction ID : A643FC60B2C1F4535AB7

Date of Receipt

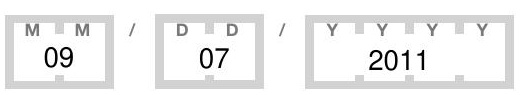

Amount of Each Receipt this Period

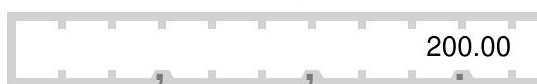

Election Cycle-to-Date

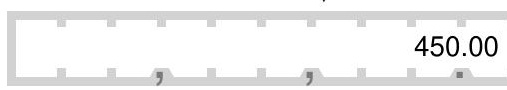

Amount of Each Receipt this Period

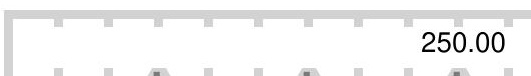

\section{Subtotal Of Receipts This Page (optional)}

Transaction ID : AF751951461E846549A3 Date of Receipt

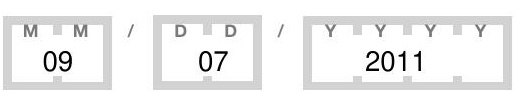

Am

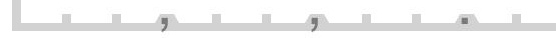

Total This Period (last page this line number only) 
SCHEDULE A-P ITEMIZED RECEIPTS
Use separate schedule(s) for each category of the Detailed Summary Page
FOR LINE NUMBER: (check only one)

PAGE $451 / 1572$

\begin{tabular}{|c|c|c|c|c|c|}
\hline & & & & & \\
\hline 16 & $\begin{array}{l}\mathbf{X} \\
17 a\end{array}$ & $17 b$ & $17 c$ & $17 d$ & 18 \\
\hline $19 a$ & $19 \mathrm{~b}$ & $20 \mathrm{a}$ & $20 \mathrm{~b}$ & $20 \mathrm{c}$ & 21 \\
\hline
\end{tabular}

Any information copied from such Reports and Statements may not be sold or used by any person for the purpose of soliciting contributions or for commercial purposes, other than using the name and address of any political committee to solicit contributions from such committee.

NAME OF COMMITTEE (In Full)

\section{Friends of Herman Cain}

A. Full Name (Last, First, Middle Initial) Lois Bowman

Mailing Address 2640 W Rd

\begin{tabular}{lcc}
\hline City & State & Zip Code \\
Natoma & KS & $67651-8816$
\end{tabular}

FEC ID number of contributing federal political committee.

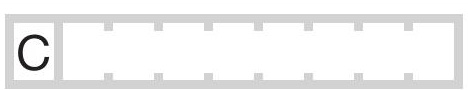

Name of Employer
None
Receipt For: 2012
X Primary $\quad$ General
Other (specify)

Occupation Retired Election Cycle-to-Date

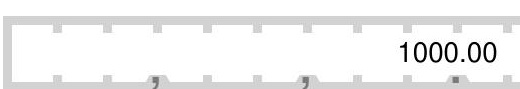

B. Full Name (Last, First, Middle Initial)

\section{Benny Moretz}

\section{Mailing Address PO Box 1389}

\begin{tabular}{lcc}
\hline City & State & Zip Code \\
Manvel & TX & $77578-1389$
\end{tabular}

FEC ID number of contributing

federal political committee.

\begin{tabular}{l} 
Name of Employer \\
Information Requested \\
Receipt For: 2012 \\
X Primary \\
\hline Other (specify)
\end{tabular}

C. Full Name (Last, First, Middle Initial)

Jim Eure Jr.

Mailing Address PO Box 156

\begin{tabular}{l|ll}
\hline $\begin{array}{l}\text { City } \\
\text { Dahlonega }\end{array}$ & $\begin{array}{c}\text { State } \\
\text { GA }\end{array}$ & $\begin{array}{c}\text { Zip Code } \\
30533-0003\end{array}$ \\
\hline $\begin{array}{l}\text { FEC ID number of contributing } \\
\text { federal political committee. }\end{array}$ & C & \\
\hline $\begin{array}{l}\text { Name of Employer } \\
\text { Protex Security Systems }\end{array}$ & $\begin{array}{l}\text { Occupation } \\
\text { Owner }\end{array}$ \\
\hline $\begin{array}{l}\text { Receipt For: } 2012 \\
\text { Xrimary } \\
\text { Other (specify) }\end{array}$ & Election Cycle-to-Date & \\
\hline
\end{tabular}

Subtotal Of Receipts This Page (optional).

Total This Period (last page this line number only)
Transaction ID : A1E54F10E9229474BABC

Date of Receipt

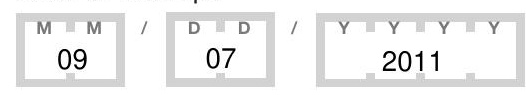

Amount of Each Receipt this Period

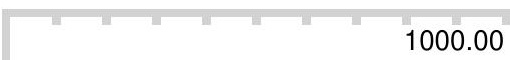

1000.00

Transaction ID : A7E7927ECCE6E4DA180C Date of Receipt

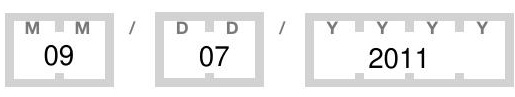

Amount of Each Receipt this Period

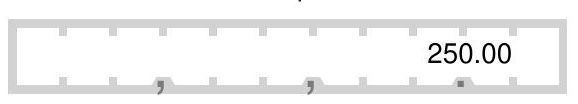

Amount of Each Receipt this Period

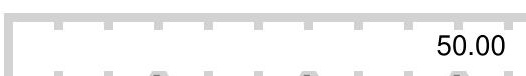

50.00

Transaction ID : ACEDF30D9A8C34AB2B2F Date of Receipt
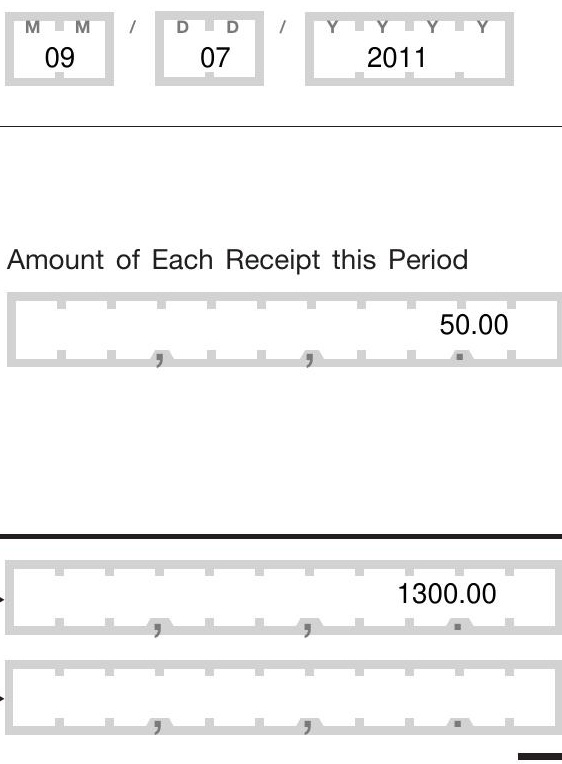

FEC Schedule A-P (Form 3P) (Rev. 03/2011) 
SCHEDULE A-P ITEMIZED RECEIPTS
Use separate schedule(s) for each category of the Detailed Summary Page
FOR LINE NUMBER: (check only one)

PAGE 452 / 1572

\begin{tabular}{|c|c|c|c|c|c|c|}
\hline & & & & & & \\
\hline 16 & $\lambda$ & $17 \mathrm{a}$ & $17 \mathrm{~b}$ & $17 \mathrm{c}$ & $-17 d$ & -18 \\
\hline $19 a$ & & $19 b$ & $20 a$ & $20 \mathrm{~b}$ & $20 \mathrm{c}$ & 21 \\
\hline
\end{tabular}

Any information copied from such Reports and Statements may not be sold or used by any person for the purpose of soliciting contributions or for commercial purposes, other than using the name and address of any political committee to solicit contributions from such committee.

NAME OF COMMITTEE (In Full)

\section{Friends of Herman Cain}

A. Full Name (Last, First, Middle Initial)

\section{Beatrice A Santelli}

Mailing Address 7342 Firefly Court

\begin{tabular}{lcc}
\hline City & State & Zip Code \\
Hoschton & GA & $30548-4078$ \\
\hline
\end{tabular}

FEC ID number of contributing federal political committee.

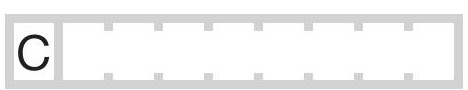

Name of Employer
self
Receipt For: 2012
X Primary $\quad$ General
Other (specify)

\section{Occupation}

Psychotherapist

Election Cycle-to-Date

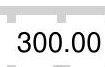

B. Full Name (Last, First, Middle Initial)

Thomas W Freeze

Mailing Address 16970 Woodshire Ct

\begin{tabular}{lcc}
\hline City & State & Zip Code \\
Granger & IN & $46530-9787$
\end{tabular}

FEC ID number of contributing

federal political committee.

C

Name of Employer
None
Receipt For: 2012
X Primary
Other (specify)

\section{Occupation}

Retired

$46530-9787$

(1)

Transaction ID : A0B5A280A17184E55B33

Date of Receipt

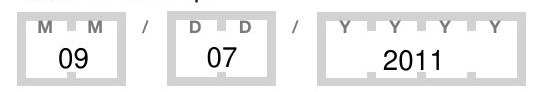

Amount of Each Receipt this Period

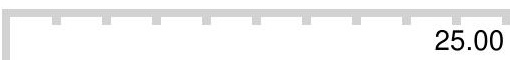

25.00

(1) (1)

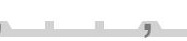

Transaction ID : A96E832A9C5F749E58BE

Date of Receipt

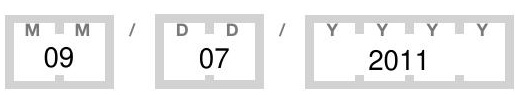

Amount of Each Receipt this Period

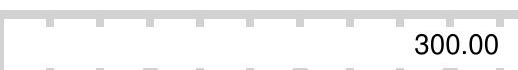

Election Cycle-to-Date

300.00

C. Full Name (Last, First, Middle Initial)

David Ford

Mailing Address 5162 Anton Dr Apt 308

\begin{tabular}{lcc}
\hline City & State & Zip Code \\
Fitchburg & WI & $53719-1717$
\end{tabular}

FEC ID number of contributing

federal political committee.

C

Name of Employer

University of Wisconsin Hospital

Receipt For: 2012

Х $\begin{aligned} & \text { Primary } \\ & \text { Other (specify) }\end{aligned}$

Occupation

Registered Nurse

Election Cycle-to-Date

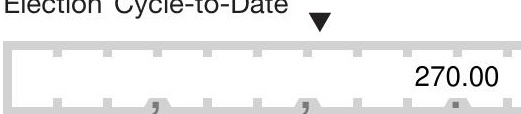

Transaction ID : A8AAB0394F4E14E17B0B Date of Receipt

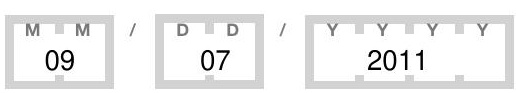

Amount of Each Receipt this Period

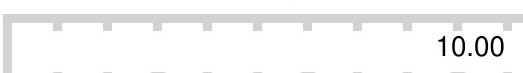

\section{Subtotal Of Receipts This Page (optional)}

Total This Period (last page this line number only) 
SCHEDULE A-P ITEMIZED RECEIPTS
Use separate schedule(s) for each category of the Detailed Summary Page
FOR LINE NUMBER: (check only one)

PAGE $453 / 1572$

\begin{tabular}{|c|c|c|c|c|c|}
\hline & & & & & \\
\hline 16 & $\begin{array}{l}\mathbf{X} \\
17 a\end{array}$ & $17 b$ & $17 c$ & $17 d$ & 18 \\
\hline $19 a$ & $19 \mathrm{~b}$ & $20 \mathrm{a}$ & $20 \mathrm{~b}$ & $20 \mathrm{c}$ & 21 \\
\hline
\end{tabular}

Any information copied from such Reports and Statements may not be sold or used by any person for the purpose of soliciting contributions or for commercial purposes, other than using the name and address of any political committee to solicit contributions from such committee.

NAME OF COMMITTEE (In Full)

\section{Friends of Herman Cain}

A. Full Name (Last, First, Middle Initial) James M McPeak

Mailing Address 1363 Calle Christopher

\begin{tabular}{lcc}
\hline City & State & Zip Code \\
Encinitas & CA & $92024-5511$
\end{tabular}

FEC ID number of contributing federal political committee.

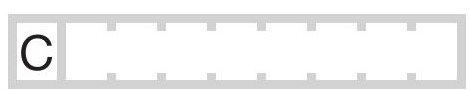

Name of Employer
McPeak Corporation
Receipt For: 2012
X Primary $\quad \square$ General
Other (specify)

Occupation Director

Election Cycle-to-Date

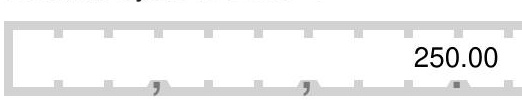

B. Full Name (Last, First, Middle Initial) Jerry Glenn

Mailing Address 54 Fairway Dr.

\begin{tabular}{lcc}
\hline City & State & Zip Code \\
Southgate & KY & $41071-3025$
\end{tabular}

FEC ID number of contributing

federal political committee.

C

Name of Employer
Retired
Receipt For: 2012
X Primary
Other (specify) General

Occupation

Retired

Election Cycle-to-Date

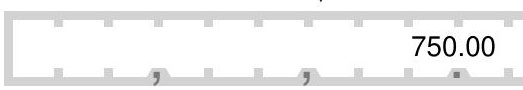

Transaction ID : A3F5A430B2BFC494889F

Date of Receipt

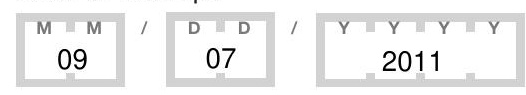

Amount of Each Receipt this Period

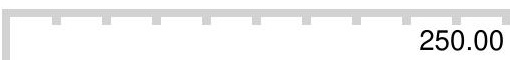

C. Full Name (Last, First, Middle Initial)

Heather Luther

Mailing Address 1000 Greystone Manor Pkwy

\begin{tabular}{lcc}
\hline City & State & Zip Code \\
Chesterfield & MO & $63005-4941$
\end{tabular}

FEC ID number of contributing federal political committee.

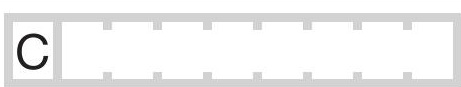

Name of Employer

ICL Performance Products LP

Receipt For: 2012

Х $\begin{aligned} & \text { Primary } \square \text { General } \\ & \text { Other (specify) }\end{aligned}$

Occupation

Lawyer

Election Cycle-to-Date

Transaction ID : A4BC39BB9D20C45CF922

Date of Receipt

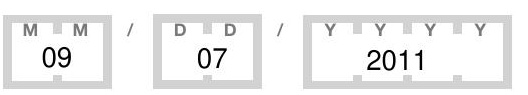

Amount of Each Receipt this Period

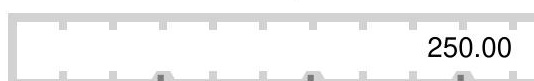

Transaction ID : AF654E391B67C4EDAA0F Date of Receipt

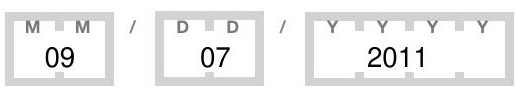

Amount of Each Receipt this Period

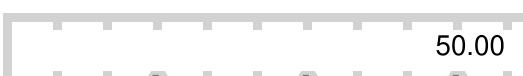

50.00

\section{Subtotal Of Receipts This Page (optional)}

Total This Period (last page this line number only) 
SCHEDULE A-P ITEMIZED RECEIPTS
Use separate schedule(s) for each category of the Detailed Summary Page
FOR LINE NUMBER: (check only one)
PAGE 454 / 1572

\begin{tabular}{|c|c|c|c|c|c|}
\hline & & & & & \\
\hline 16 & $\begin{array}{lll}X & 17 a \\
\end{array}$ & $17 \mathrm{~b}$ & $17 c$ & $17 d$ & 18 \\
\hline $19 a$ & $19 b$ & $20 a$ & $20 \mathrm{~b}$ & $20 c$ & 21 \\
\hline
\end{tabular}

Any information copied from such Reports and Statements may not be sold or used by any person for the purpose of soliciting contributions or for commercial purposes, other than using the name and address of any political committee to solicit contributions from such committee.

NAME OF COMMITTEE (In Full)

\section{Friends of Herman Cain}

A. Full Name (Last, First, Middle Initial) Joan Scott

Mailing Address 133 Nail Dr

\begin{tabular}{lcc}
\hline City & State & Zip Code \\
McDonough & GA & $30253-7344$ \\
\hline
\end{tabular}

FEC ID number of contributing federal political committee.

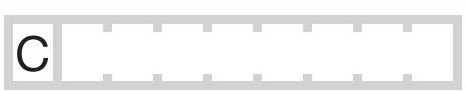

Name of Employer
DOT/FAA
Receipt For: 2012
X Primary $\quad$ General
Other (specify)

Occupation

Administrative Assistant

Election Cycle-to-Date

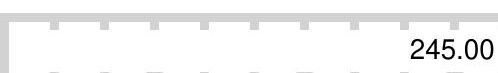

B. Full Name (Last, First, Middle Initial)

Ryan Colburn

Mailing Address 1410-A John B White Blvd

\begin{tabular}{lcc}
\hline City & State & Zip Code \\
Spartanburg & SC & 29306 \\
\hline
\end{tabular}

FEC ID number of contributing

federal political committee.

C

Name of Employer
Colburn and Colburn
Receipt For: 2012
X Primary
Other (specify)

Occupation

Dentist

Election Cycle-to-Date

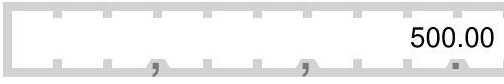

C. Full Name (Last, First, Middle Initial)

Dennis Callewaert

Mailing Address $301 \mathrm{~N}$ 5th Ave

\begin{tabular}{l|ll}
\hline $\begin{array}{l}\text { City } \\
\text { Redgranite }\end{array}$ & $\begin{array}{c}\text { State } \\
\text { WI }\end{array}$ & $\begin{array}{c}\text { Zip Code } \\
54970-9801\end{array}$ \\
\hline $\begin{array}{l}\text { FEC ID number of contributing } \\
\text { federal political committee. }\end{array}$ & C & \\
\hline $\begin{array}{l}\text { Name of Employer } \\
\text { Not Employed }\end{array}$ & $\begin{array}{l}\text { Occupation } \\
\text { Retired }\end{array}$ \\
\hline $\begin{array}{l}\text { Receipt For: } 2012 \\
\text { Xrimary } \\
\text { Other (specify) }\end{array}$ & Election Cycle-to-Date & \\
\hline
\end{tabular}

Transaction ID : ACD0360333ED9435A8EB

Date of Receipt

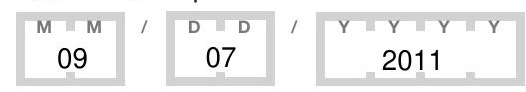

Amount of Each Receipt this Period

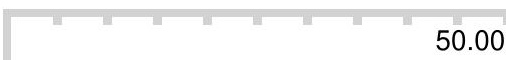

50.00

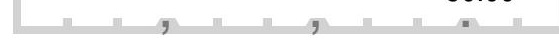

Transaction ID : A150344076216477988B

Date of Receipt

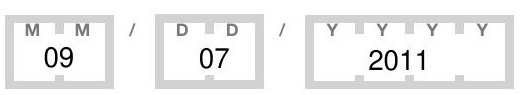

Amount of Each Receipt this Period

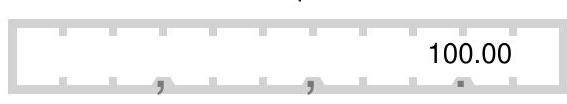

Amount of Each Receipt this Period

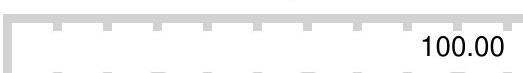

100.00

\section{Subtotal Of Receipts This Page (optional)}

Total This Period (last page this line number only) 
SCHEDULE A-P ITEMIZED RECEIPTS
Use separate schedule(s) for each category of the Detailed Summary Page
FOR LINE NUMBER: (check only one)

PAGE 455 / 1572

\begin{tabular}{|c|c|c|c|c|c|}
\hline & & & & & \\
\hline 16 & $\begin{array}{l}\mathbf{X} \\
17 a\end{array}$ & $17 b$ & $17 c$ & $17 d$ & 18 \\
\hline $19 a$ & $19 \mathrm{~b}$ & $20 \mathrm{a}$ & $20 \mathrm{~b}$ & $20 \mathrm{c}$ & 21 \\
\hline
\end{tabular}

Any information copied from such Reports and Statements may not be sold or used by any person for the purpose of soliciting contributions or for commercial purposes, other than using the name and address of any political committee to solicit contributions from such committee.

NAME OF COMMITTEE (In Full)

\section{Friends of Herman Cain}

A. Full Name (Last, First, Middle Initial) John M Corothers

Mailing Address 47617 181s Street

\begin{tabular}{lcc}
\hline City & State & Zip Code \\
Clear Lake & SD & 57226 \\
\hline
\end{tabular}

FEC ID number of contributing federal political committee.

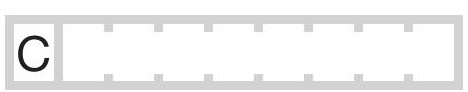

Name of Employer
None
Receipt For: 2012
X Primary $\quad$ General
Other (specify)

Occupation Retired

Election Cycle-to-Date

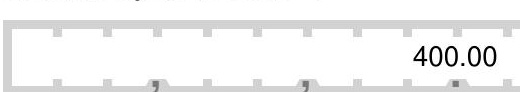

B. Full Name (Last, First, Middle Initial)

Deborah Baratka

Mailing Address 1228 Fairridge Cr SW

\begin{tabular}{lcc}
\hline City & State & Zip Code \\
Marietta & GA & $30008-6837$
\end{tabular}

FEC ID number of contributing

federal political committee.

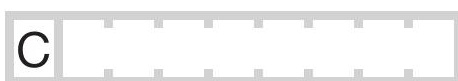

Name of Employer
Batson Cook Co
Receipt For: 2012
X Primary $\quad$ General
Other (specify)

\section{Occupation}

Construction

Election Cycle-to-Date

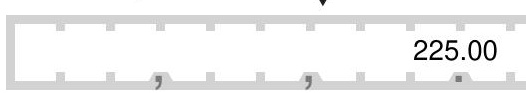

Transaction ID : A583C0A40EF3146CEA7F

Date of Receipt

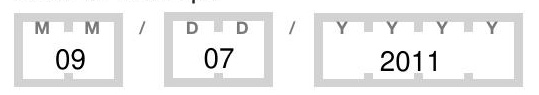

Amount of Each Receipt this Period

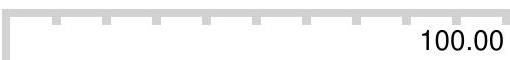

C. Full Name (Last, First, Middle Initial)

Kathy Siders

Mailing Address 6254 W 200 North

\begin{tabular}{l|ll}
\hline $\begin{array}{l}\text { City } \\
\text { Rochester }\end{array}$ & $\begin{array}{c}\text { State } \\
\text { IN }\end{array}$ & $\begin{array}{c}\text { Zip Code } \\
46975-8876\end{array}$ \\
\hline $\begin{array}{l}\text { FEC ID number of contributing } \\
\text { federal political committee. }\end{array}$ & C \\
$\begin{array}{l}\text { Name of Employer } \\
\text { self }\end{array}$ & $\begin{array}{l}\text { Occupation } \\
\text { farmer }\end{array}$ \\
$\begin{array}{l}\text { Receipt For: } 2012 \\
\text { Xrimary } \\
\text { Other (specify) }\end{array}$ & Election Cycle-to-Date & \\
\hline
\end{tabular}

Transaction ID : AD625CF21B0F84404BF4

Date of Receipt

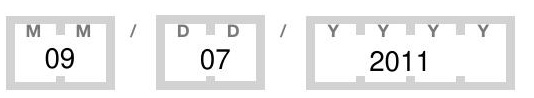

Amount of Each Receipt this Period

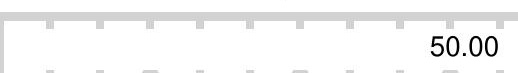

Amount of Each Receipt this Period

Transaction ID : A208CBC3481B44D8C8E1 Date of Receipt
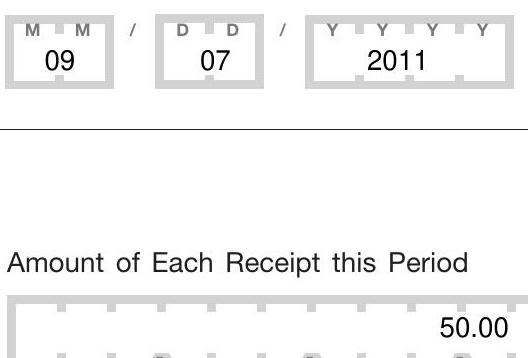

Subtotal Of Receipts This Page (optional)

Total This Period (last page this line number only) 
SCHEDULE A-P ITEMIZED RECEIPTS
Use separate schedule(s) for each category of the Detailed Summary Page
FOR LINE NUMBER: (check only one)
PAGE 456 / 1572

\begin{tabular}{|c|c|c|c|c|c|}
\hline & & & & & \\
\hline 16 & $\begin{array}{lll}X & 17 a \\
\end{array}$ & $17 \mathrm{~b}$ & $17 c$ & $17 d$ & 18 \\
\hline $19 a$ & $19 b$ & $20 a$ & $20 \mathrm{~b}$ & $20 c$ & 21 \\
\hline
\end{tabular}

Any information copied from such Reports and Statements may not be sold or used by any person for the purpose of soliciting contributions or for commercial purposes, other than using the name and address of any political committee to solicit contributions from such committee.

NAME OF COMMITTEE (In Full)

Friends of Herman Cain

A. Full Name (Last, First, Middle Initial)

steven kimball

Mailing Address 2224spininngwheel lane

\begin{tabular}{lcc}
\hline City & State & Zip Code \\
Cincinnati & OH & 45244
\end{tabular}

FEC ID number of contributing

federal political committee.

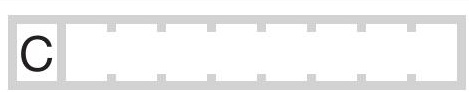

Name of Employer
Emersion Design
Receipt For: 2012
X Primary $\square$ General
$\square$ Other (specify)

Occupation CEO

Election Cycle-to-Date

\subsection{0}

B. Full Name (Last, First, Middle Initial)

Van P Cunningham

Mailing Address 111 Barkwood Dr

\begin{tabular}{lcc}
\hline City & State & Zip Code \\
Dahlonega & GA & $30533-4641$
\end{tabular}

FEC ID number of contributing

federal political committee.

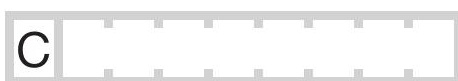

Name of Employer
None
Receipt For: 2012
X Primary
Other (specify)

Occupation

Retired

Election Cycle-to-Date

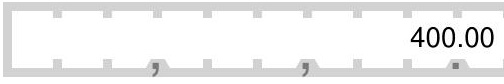

C. Full Name (Last, First, Middle Initial)

David Dunnavant Jr

Mailing Address 29415 Lakeview Dr

\begin{tabular}{lcc}
\hline City & State & Zip Code \\
Ardmore & AL & $35739-7747$
\end{tabular}

FEC ID number of contributing federal political committee.

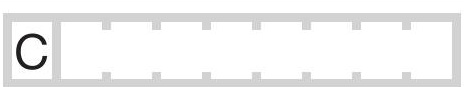

Name of Employer
Information Requested
Receipt For: 2012
X Primary $\quad \square$ General
Other (specify)

Occupation

Information Requested

Election Cycle-to-Date

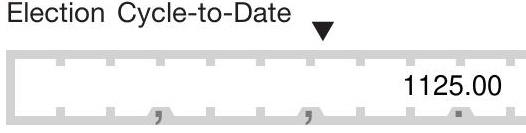

Transaction ID : A0CA1348CEA9241949B6

Date of Receipt

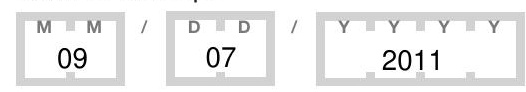

Amount of Each Receipt this Period

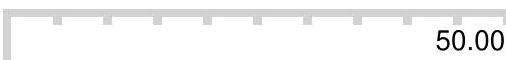

50.00
Amount of Each Receipt this Period

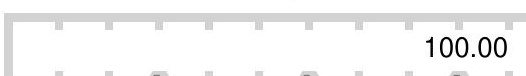

Transaction ID : A5D000FAB980E4E74942 Date of Receipt

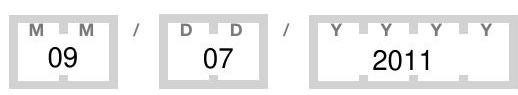

Transaction ID : AFBD7126DD8D14453810 Date of Receipt

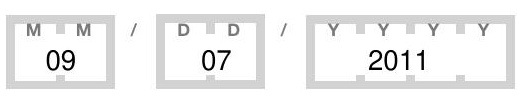

Amount of Each Receipt this Period

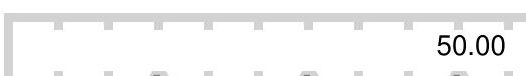

50.00

Subtotal Of Receipts This Page (optional)

200.00

Total This Period (last page this line number only) 
SCHEDULE A-P ITEMIZED RECEIPTS
Use separate schedule(s) for each category of the Detailed Summary Page
FOR LINE NUMBER: (check only one)
PAGE 457 / 1572

\begin{tabular}{|c|c|c|c|c|c|}
\hline & & & & & \\
\hline 16 & $\begin{array}{lll}X & 17 a \\
\end{array}$ & $17 \mathrm{~b}$ & $17 c$ & $17 d$ & 18 \\
\hline $19 a$ & $19 b$ & $20 a$ & $20 \mathrm{~b}$ & $20 c$ & 21 \\
\hline
\end{tabular}

Any information copied from such Reports and Statements may not be sold or used by any person for the purpose of soliciting contributions or for commercial purposes, other than using the name and address of any political committee to solicit contributions from such committee.

NAME OF COMMITTEE (In Full)

\section{Friends of Herman Cain}

A. Full Name (Last, First, Middle Initial)

Jessie Knight

Mailing Address 404 San Antonio Ave. Ste. F

\begin{tabular}{lcc}
\hline City & State & Zip Code \\
San Diego & CA & $92106-3534$
\end{tabular}

FEC ID number of contributing

federal political committee.

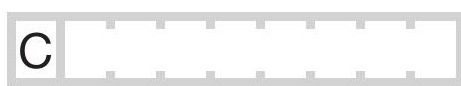

Name of Employer
San Diego Gas and Electric
Receipt For: 2012
X Primary
Other (specify) General

Occupation

CEO

Election Cycle-to-Date

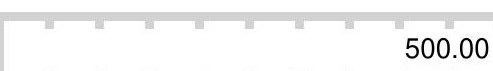

B. Full Name (Last, First, Middle Initial)

Adele Kirkpatrick

Mailing Address 2426 Medina Way

\begin{tabular}{lcc}
\hline City & State & Zip Code \\
West Palm Beach & FL & $33401-8020$
\end{tabular}

FEC ID number of contributing

federal political committee.

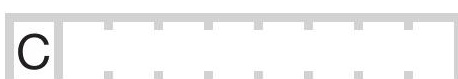

Name of Employer
None
Receipt For: 2012
X Primary
Other (specify)

\section{Occupation}

Retired

Election Cycle-to-Date

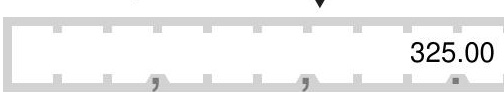

Transaction ID : A3EB55F7F714145079C1

Date of Receipt

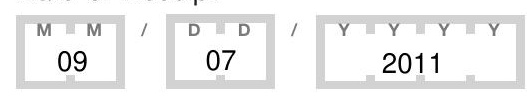

Amount of Each Receipt this Period

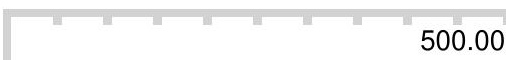

C. Full Name (Last, First, Middle Initial)

Carol Cook

Mailing Address 43 Oak Alley

\begin{tabular}{lcc}
\hline City & State & Zip Code \\
Kerrville & TX & $78028-1711$
\end{tabular}

FEC ID number of contributing federal political committee.

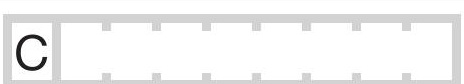

Name of Employer
James Avery
Receipt For: 2012
X Primary
Other (specify) General

\section{Occupation}

Sales Team Leader

Election Cycle-to-Date

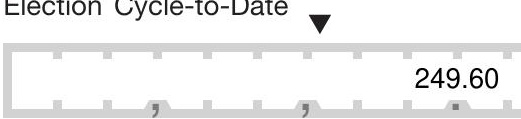

Transaction ID : A22E93223BE9F4C0EA87

Date of Receipt

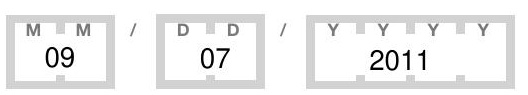

Amount of Each Receipt this Period

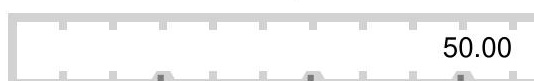

Transaction ID : A574ABC2BE60145139FA Date of Receipt

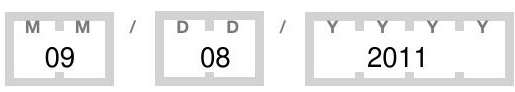

Amount of Each Receipt this Period

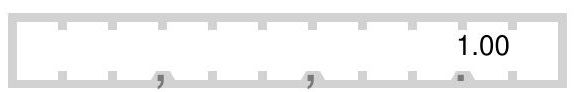

Subtotal Of Receipts This Page (optional)

551.00

Total This Period (last page this line number only)

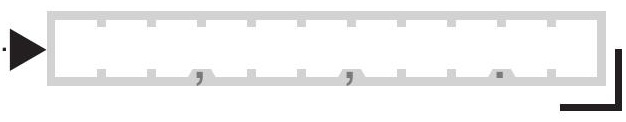

FEC Schedule A-P (Form 3P) (Rev. 03/2011) 
SCHEDULE A-P ITEMIZED RECEIPTS
Use separate schedule(s) for each category of the Detailed Summary Page
FOR LINE NUMBER: (check only one)
PAGE 458 / 1572

\begin{tabular}{|c|c|c|c|c|c|}
\hline & & & & & \\
\hline 16 & $\begin{array}{lll}X & 17 a \\
\end{array}$ & $17 \mathrm{~b}$ & $17 c$ & $17 d$ & 18 \\
\hline $19 a$ & $19 b$ & $20 a$ & $20 \mathrm{~b}$ & $20 c$ & 21 \\
\hline
\end{tabular}

Any information copied from such Reports and Statements may not be sold or used by any person for the purpose of soliciting contributions or for commercial purposes, other than using the name and address of any political committee to solicit contributions from such committee.

NAME OF COMMITTEE (In Full)

Friends of Herman Cain

A. Full Name (Last, First, Middle Initial)

Loren Lanter

Mailing Address 58 Zanmi Rd

\begin{tabular}{lcc}
\hline City & State & Zip Code \\
Swannanoa & NC & $28778-2263$
\end{tabular}

FEC ID number of contributing

federal political committee.

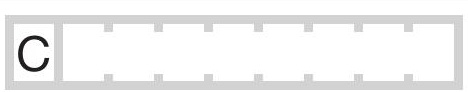

Name of Employer
Brisco Inc.
Receipt For: 2012
X Primary
Other (specify) General

Occupation

Engineer

Election Cycle-to-Date

400.00

B. Full Name (Last, First, Middle Initial)

Nancy McKee

Mailing Address 339 Springhill Road

\begin{tabular}{lcc}
\hline City & State & Zip Code \\
Huntsville & AL & $35806-1735$
\end{tabular}

FEC ID number of contributing

federal political committee.

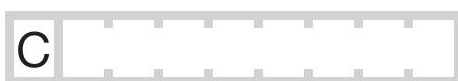

Name of Employer

The Aussie Pouch Company Inc.

Occupation

BUSINESS OWNER

Receipt For: 2012

Х $\begin{aligned} & \text { Primary } \\ & \text { Other (specify) }\end{aligned}$

Election Cycle-to-Date

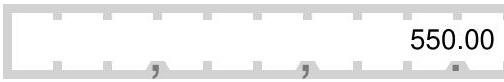

C. Full Name (Last, First, Middle Initial)

Shannon Jennings

Mailing Address 7845 Karnes Rd.

\begin{tabular}{lcc}
\hline City & State & Zip Code \\
Corryton & TN & $37721-2310$
\end{tabular}

FEC ID number of contributing

federal political committee.

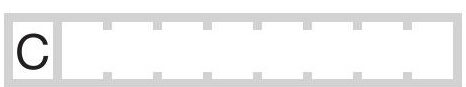

Name of Employer
Coal Creek Armory
Receipt For: 2012
X Primary $\quad \square$ General
Other (specify)

\section{Occupation}

Gunsmith

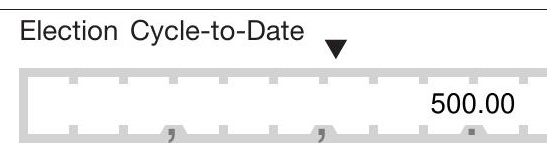

Amount of Each Receipt this Period

Amount of Each Receipt this Period

Transaction ID : A34DBAB4C0C064169AF0

Date of Receipt
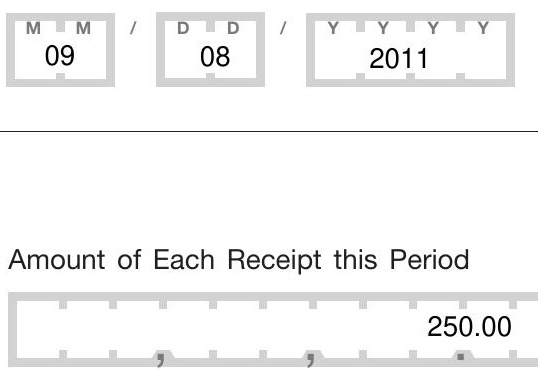

Transaction ID : A2C6DB1493A2B427C893

Date of Receipt
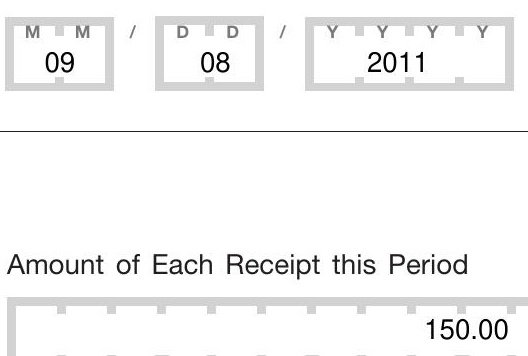

150.00

Subtotal Of Receipts This Page (optional).

450.00

Total This Period (last page this line number only) 
SCHEDULE A-P ITEMIZED RECEIPTS
Use separate schedule(s) for each category of the Detailed Summary Page
FOR LINE NUMBER: (check only one)

PAGE 459 / 1572

\begin{tabular}{|c|c|c|c|c|c|}
\hline & & & & & \\
\hline 16 & $\begin{array}{l}\mathbf{X} \\
17 a\end{array}$ & $17 b$ & $17 c$ & $17 d$ & 18 \\
\hline $19 a$ & $19 \mathrm{~b}$ & $20 \mathrm{a}$ & $20 \mathrm{~b}$ & $20 \mathrm{c}$ & 21 \\
\hline
\end{tabular}

Any information copied from such Reports and Statements may not be sold or used by any person for the purpose of soliciting contributions or for commercial purposes, other than using the name and address of any political committee to solicit contributions from such committee.

NAME OF COMMITTEE (In Full)

\section{Friends of Herman Cain}

A. Full Name (Last, First, Middle Initial)

\section{Susan Walter}

Mailing Address P.O. Box 690

\begin{tabular}{lcc}
\hline City & State & Zip Code \\
Sautee Nacoochee & GA & $30571-0690$ \\
\hline
\end{tabular}

FEC ID number of contributing federal political committee.

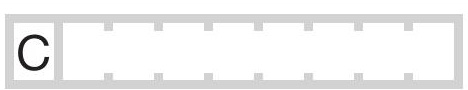

Name of Employer
None
Receipt For: 2012
X Primary $\quad$ General
Other (specify)

Occupation Retired

Election Cycle-to-Date

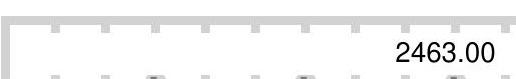

B. Full Name (Last, First, Middle Initial)

Marion Valerio

Mailing Address 3575 Heritage Rd

\begin{tabular}{lcc}
\hline City & State & Zip Code \\
Alum Bank & PA & 15521 \\
\hline
\end{tabular}

FEC ID number of contributing

federal political committee.

C

Name of Employer
Retired
Receipt For: 2012
X Primary
Other (specify)

Occupation

veterinary pathologist

Election Cycle-to-Date

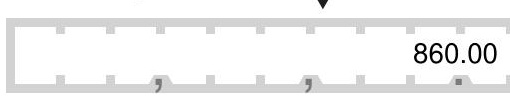

Transaction ID : AC89877AC60BF4DC6871

Date of Receipt

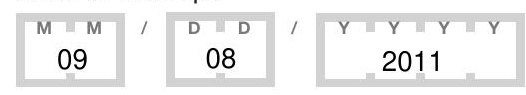

Amount of Each Receipt this Period

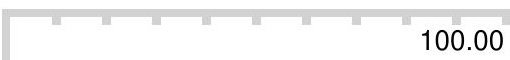

Transaction ID : A165F38FA05A342C9842

Date of Receipt

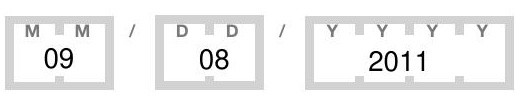

Amount of Each Receipt this Period

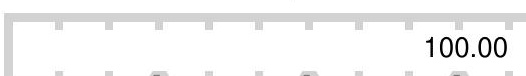

Transaction ID : AB90B4E915D124689B56

Date of Receipt

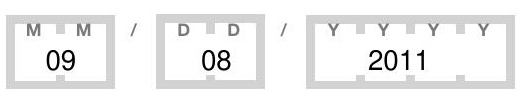

Amount of Each Receipt this Period

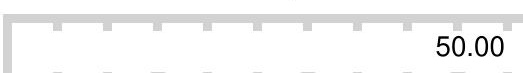

Director of IT

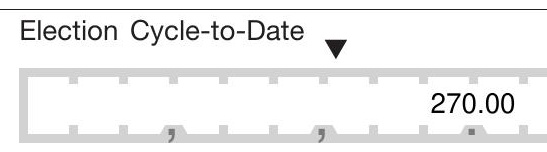

Subtotal Of Receipts This Page (optional)

250.00

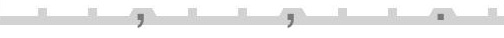

Total This Period (last page this line number only)

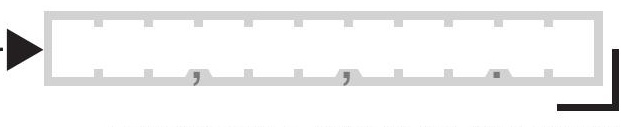

FEC Schedule A-P (Form 3P) (Rev. 03/2011) 
SCHEDULE A-P ITEMIZED RECEIPTS
Use separate schedule(s) for each category of the Detailed Summary Page
FOR LINE NUMBER: (check only one)

PAGE 460 / 1572

\begin{tabular}{|c|c|c|c|c|c|}
\hline & & & & & \\
\hline 16 & $\begin{array}{l}\mathbf{X} \\
17 a\end{array}$ & $17 b$ & $17 c$ & $17 d$ & 18 \\
\hline $19 a$ & $19 \mathrm{~b}$ & $20 \mathrm{a}$ & $20 \mathrm{~b}$ & $20 \mathrm{c}$ & 21 \\
\hline
\end{tabular}

Any information copied from such Reports and Statements may not be sold or used by any person for the purpose of soliciting contributions or for commercial purposes, other than using the name and address of any political committee to solicit contributions from such committee.

NAME OF COMMITTEE (In Full)

\section{Friends of Herman Cain}

A. Full Name (Last, First, Middle Initial)

Peaches Kavanaugh

Mailing Address 216 Monty Manor

\begin{tabular}{lcc}
\hline City & State & Zip Code \\
Yorktown & VA & $23693-4414$
\end{tabular}

FEC ID number of contributing federal political committee.

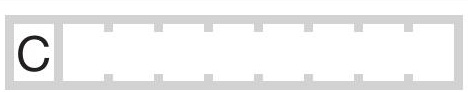

Name of Employer
Air Force
Receipt For: 2012
X Primary $\quad$ General
Other (specify)

Occupation Retired

Election Cycle-to-Date

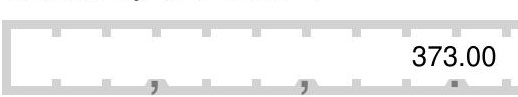

B. Full Name (Last, First, Middle Initial)

Randolph White

Mailing Address 3265 Hembree Court

\begin{tabular}{lcc}
\hline City & State & Zip Code \\
Marietta & GA & $30062-4219$
\end{tabular}

FEC ID number of contributing

federal political committee.

C

Name of Employer
Automationdirect.com
Receipt For: 2012
X Primary
Other (specify)

Occupation

technical writer

Election Cycle-to-Date

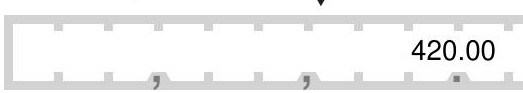

Transaction ID : A007FDE732F6D4548919

Date of Receipt

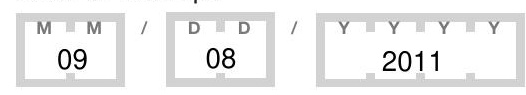

Amount of Each Receipt this Period

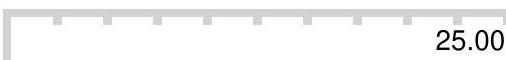

25.00

C. Full Name (Last, First, Middle Initial)

Mary Drennan

Mailing Address PO Box 2204

\begin{tabular}{lcc}
\hline City & State & Zip Code \\
Coeur D Alene & ID & $83816-2204$
\end{tabular}

FEC ID number of contributing

federal political committee.

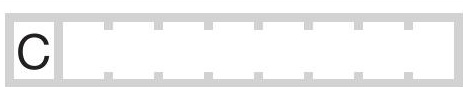

Name of Employer
None
Receipt For: 2012
X Primary $\quad \square$ General
Other (specify)

Occupation

Retired

Election Cycle-to-Date

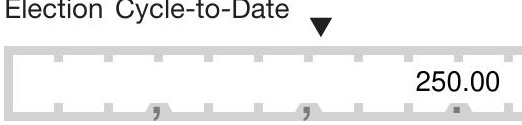

Transaction ID : AACCEAAA2F19F4DB489F Date of Receipt

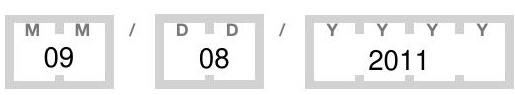

Amount of Each Receipt this Period

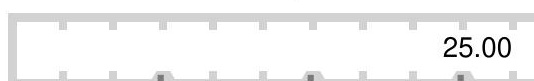

Transaction ID : AFDFD6D3B6EF34A00AF0 Date of Receipt

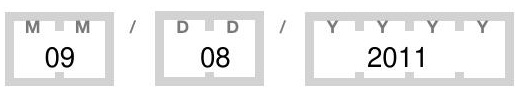

Amount of Each Receipt this Period

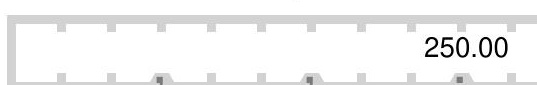

\section{Subtotal Of Receipts This Page (optional)}

300.00

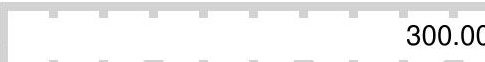

Total This Period (last page this line number only)

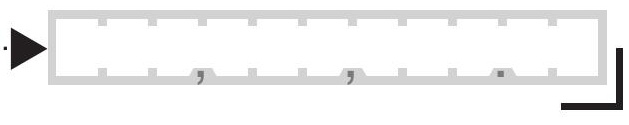

FEC Schedule A-P (Form 3P) (Rev. 03/2011) 
SCHEDULE A-P ITEMIZED RECEIPTS
Use separate schedule(s) for each category of the Detailed Summary Page
FOR LINE NUMBER: (check only one)
PAGE $461 / 1572$

\begin{tabular}{|c|c|c|c|c|c|}
\hline & & & & & \\
\hline 16 & $\begin{array}{lll}X & 17 a \\
\end{array}$ & $17 \mathrm{~b}$ & $17 c$ & $17 d$ & 18 \\
\hline $19 a$ & $19 b$ & $20 a$ & $20 \mathrm{~b}$ & $20 c$ & 21 \\
\hline
\end{tabular}

Any information copied from such Reports and Statements may not be sold or used by any person for the purpose of soliciting contributions or for commercial purposes, other than using the name and address of any political committee to solicit contributions from such committee.

NAME OF COMMITTEE (In Full)

\section{Friends of Herman Cain}

A. Full Name (Last, First, Middle Initial)

Ms. Susan Seadon

Mailing Address 1954 5th Ct SE

\begin{tabular}{lcc}
\hline City & State & Zip Code \\
Vero Beach & FL & $32962-7307$
\end{tabular}

FEC ID number of contributing federal political committee.

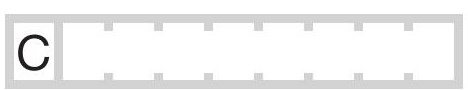

Name of Employer
Walgreens
Receipt For: 2012
X Primary $\quad$ General
Other (specify)

Occupation Pharmacist

Election Cycle-to-Date

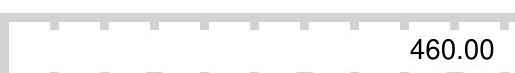

B. Full Name (Last, First, Middle Initial)

Lynn Zody

Mailing Address 708 Callaway $\mathrm{Dr}$

\begin{tabular}{lcc}
\hline City & State & Zip Code \\
Graniteville & SC & $29829-4054$
\end{tabular}

FEC ID number of contributing

federal political committee.

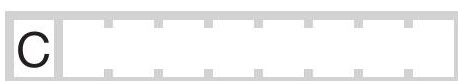

Name of Employer
Stix \& Co. Inc.
Receipt For: 2012
X Primary
Other (specify)

Occupation

FOOD SERVICE

Election Cycle-to-Date

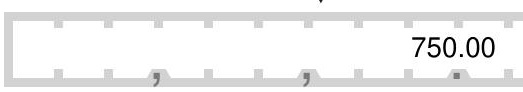

C. Full Name (Last, First, Middle Initial)

Clete Kelly

Mailing Address 5640 Manuel Place

\begin{tabular}{l|ll}
\hline $\begin{array}{l}\text { City } \\
\text { Buford }\end{array}$ & $\begin{array}{c}\text { State } \\
\text { GA }\end{array}$ & $\begin{array}{c}\text { Zip Code } \\
30518-5602\end{array}$ \\
\hline $\begin{array}{l}\text { FEC ID number of contributing } \\
\text { federal political committee. }\end{array}$ & C & \\
\hline $\begin{array}{l}\text { Name of Employer } \\
\text { Exhibits South Corp. }\end{array}$ & $\begin{array}{l}\text { Occupation } \\
\text { VP/Owner }\end{array}$ \\
\hline $\begin{array}{l}\text { Receipt For: } 2012 \\
\text { Primary } \\
\text { Other (specify) }\end{array}$ & Election Cycle-to-Date & \\
\hline
\end{tabular}

Transaction ID : AEF9B9D840803455BA75

Date of Receipt

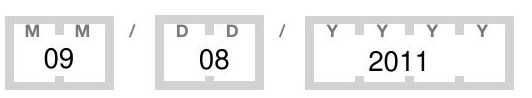

Amount of Each Receipt this Period

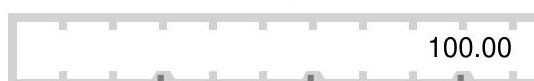

Amount of Each Receipt this Period

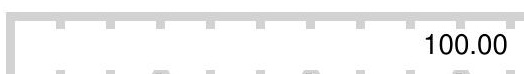

Transaction ID : A75F12958961F471BAC1

Date of Receipt

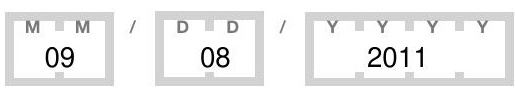

\section{Subtotal Of Receipts This Page (optional)}

Total This Period (last page this line number only)

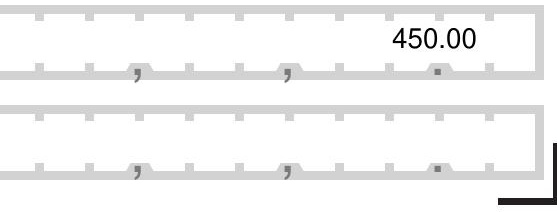

FEC Schedule A-P (Form 3P) (Rev. 03/2011) 
SCHEDULE A-P ITEMIZED RECEIPTS
Use separate schedule(s) for each category of the Detailed Summary Page
FOR LINE NUMBER: (check only one)

PAGE 462 / 1572

\begin{tabular}{|c|c|c|c|c|c|}
\hline & & & & & \\
\hline 16 & $\begin{array}{l}\mathbf{X} \\
17 a\end{array}$ & $17 b$ & $17 c$ & $17 d$ & 18 \\
\hline $19 a$ & $19 \mathrm{~b}$ & $20 \mathrm{a}$ & $20 \mathrm{~b}$ & $20 \mathrm{c}$ & 21 \\
\hline
\end{tabular}

Any information copied from such Reports and Statements may not be sold or used by any person for the purpose of soliciting contributions or for commercial purposes, other than using the name and address of any political committee to solicit contributions from such committee.

NAME OF COMMITTEE (In Full)

\section{Friends of Herman Cain}

A. Full Name (Last, First, Middle Initial)

\section{Catharine Nunn}

Mailing Address 2208 Forest Park Circle

\begin{tabular}{lcc}
\hline City & State & Zip Code \\
Mansfield & TX & $76063-7638$
\end{tabular}

FEC ID number of contributing

federal political committee.

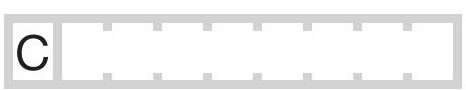

Name of Employer
Information Requested
Receipt For: 2012
X Primary
Other (specify) General

Occupation

Information Requested

Election Cycle-to-Date

250.00

B. Full Name (Last, First, Middle Initial)

alice shapiro

Mailing Address 5845 ridgeview drive

\begin{tabular}{lcc}
\hline City & State & Zip Code \\
Doylestown & PA & $18902-1366$
\end{tabular}

FEC ID number of contributing

federal political committee.

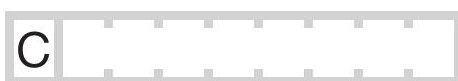

Name of Employer
None
Receipt For: 2012
X Primary
Other (specify)

\section{Occupation}

Retired

Election Cycle-to-Date

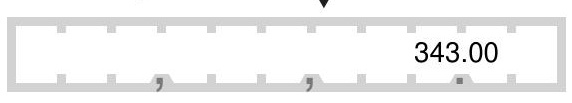

C. Full Name (Last, First, Middle Initial)

Jill Davis

Mailing Address 998 E Elizabeth St

\begin{tabular}{lcc}
\hline City & State & Zip Code \\
Pasadena & CA & $91104-2408$
\end{tabular}

FEC ID number of contributing

federal political committee.

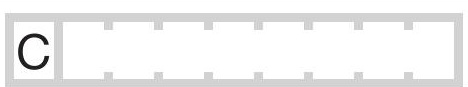

Name of Employer

Information Requested

Occupation

Information Requested

Receipt For: 2012

Х $\begin{aligned} & \text { Primary } \square \text { General } \\ & \text { Other (specify) }\end{aligned}$

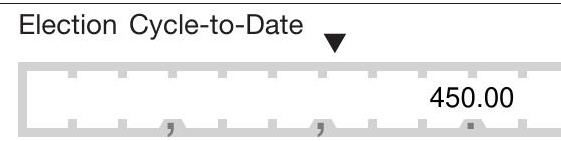

Transaction ID : AFC497E013258476291B

Date of Receipt

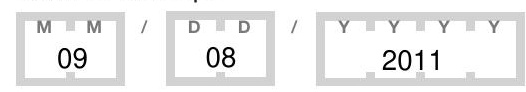

Amount of Each Receipt this Period

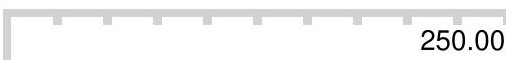

250.00

Transaction ID : A4A1CDACA89C64949A77

Date of Receipt

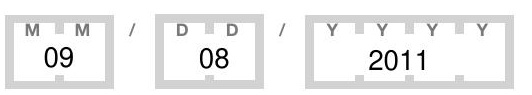

Amount of Each Receipt this Period

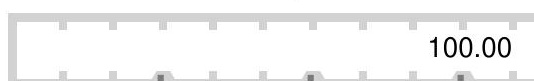

Transaction ID : A0AFFB2F86B884BD9921

Date of Receipt

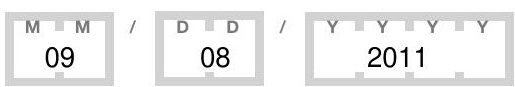

Amount of Each Receipt this Period

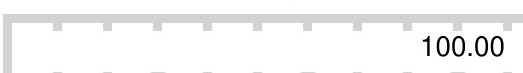

100.00
Subtotal Of Receipts This Page (optional)

450.00

(2)

Total This Period (last page this line number only)

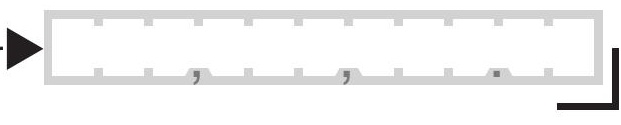

FEC Schedule A-P (Form 3P) (Rev. 03/2011) 
SCHEDULE A-P ITEMIZED RECEIPTS
Use separate schedule(s) for each category of the Detailed Summary Page
FOR LINE NUMBER: (check only one)

\begin{tabular}{|c|c|c|c|c|c|}
\hline & & & & & \\
\hline 16 & $\begin{array}{ll}X & 17 a \\
\end{array}$ & $17 \mathrm{~b}$ & $17 c$ & $17 d$ & 18 \\
\hline $19 a$ & $19 b$ & $20 \mathrm{a}$ & $20 \mathrm{~b}$ & $20 c$ & 21 \\
\hline
\end{tabular}

Any information copied from such Reports and Statements may not be sold or used by any person for the purpose of soliciting contributions or for commercial purposes, other than using the name and address of any political committee to solicit contributions from such committee.

NAME OF COMMITTEE (In Full)

\section{Friends of Herman Cain}

A. Full Name (Last, First, Middle Initial)

\section{Dr Roland R Tindle}

Mailing Address 4535 Orion Rd

\begin{tabular}{lcc}
\hline City & State & Zip Code \\
Rochester & MI & $48306-1710$
\end{tabular}

FEC ID number of contributing federal political committee.

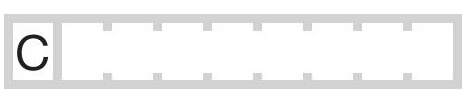

Name of Employer
self
Receipt For: 2012
X Primary $\quad$ General
Other (specify)

Occupation Physician

Election Cycle-to-Date

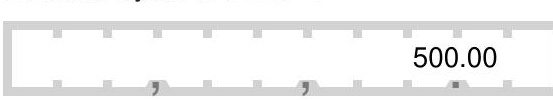

B. Full Name (Last, First, Middle Initial)

Lisa Fitzsimmons

Mailing Address po box540

\begin{tabular}{lcc}
\hline City & State & Zip Code \\
Chester & CT & $06412-0540$
\end{tabular}

FEC ID number of contributing

federal political committee.

C

Name of Employer
Ctd
Receipt For: 2012
X Primary
Other (specify)

C. Full Name (Last, First, Middle Initial)

Frank Moore

Mailing Address 1057 Hessen Dr.

\begin{tabular}{lcc}
\hline City & State & Zip Code \\
Fort Collins & CO & $80524-6079$
\end{tabular}

FEC ID number of contributing federal political committee.

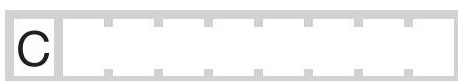

Name of Employer
Information Requested
Receipt For: 2012
X Primary $\quad \square$ General
Other (specify)

Information Requested

Election Cycle-to-Date
Transaction ID : A43A57790436840979F7

Date of Receipt

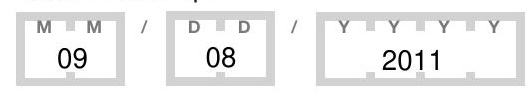

Amount of Each Receipt this Period

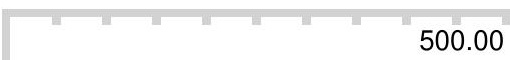

\section{Occupation}

Toolmaker

Election Cycle-to-Date

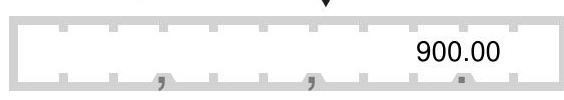

Transaction ID : AC633BD3A43294F0E908

Date of Receipt

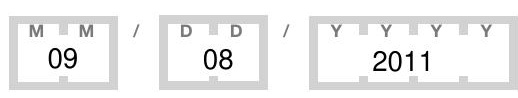

Amount of Each Receipt this Period

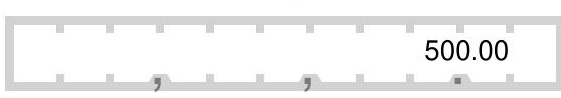

Transaction ID : A80D38E5D485E427DBC8 Date of Receipt

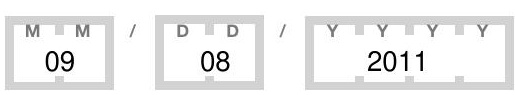

Amount of Each Receipt this Period

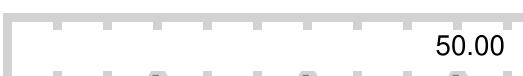

225.00
Subtotal Of Receipts This Page (optional)

1050.00

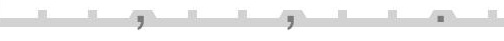

Total This Period (last page this line number only)

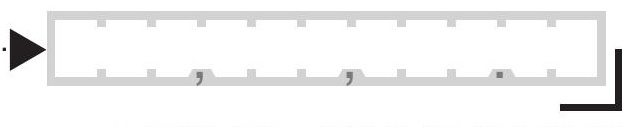

FEC Schedule A-P (Form 3P) (Rev. 03/2011) 
SCHEDULE A-P ITEMIZED RECEIPTS
Use separate schedule(s) for each category of the Detailed Summary Page
FOR LINE NUMBER: (check only one)
PAGE 464 / 1572

\begin{tabular}{|c|c|c|c|c|c|}
\hline & & & & & \\
\hline 16 & $\begin{array}{lll}X & 17 a \\
\end{array}$ & $17 \mathrm{~b}$ & $17 c$ & $17 d$ & 18 \\
\hline $19 a$ & $19 b$ & $20 a$ & $20 \mathrm{~b}$ & $20 c$ & 21 \\
\hline
\end{tabular}

Any information copied from such Reports and Statements may not be sold or used by any person for the purpose of soliciting contributions or for commercial purposes, other than using the name and address of any political committee to solicit contributions from such committee.

NAME OF COMMITTEE (In Full)

Friends of Herman Cain

A. Full Name (Last, First, Middle Initial) richard craig

Mailing Address p.o. box 899

\begin{tabular}{lcc}
\hline City & State & Zip Code \\
Edwards & CO & $81632-0899$
\end{tabular}

FEC ID number of contributing federal political committee.

Name of Employer
Information Requested
Receipt For: 2012
X Primary
Other (specify) General

B. Full Name (Last, First, Middle Initial)

Arthur Griffin

Mailing Address 2414 Cofer Cir

\begin{tabular}{lcc}
\hline City & State & Zip Code \\
Tucker & GA & $30084-3707$ \\
\hline
\end{tabular}

FEC ID number of contributing

federal political committee.

Name of Employer
None
Receipt For: 2012
X Primary $\quad$ General
Other (specify)

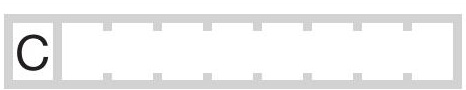

Occupation Information Requested

Election Cycle-to-Date

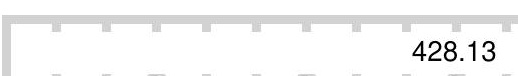

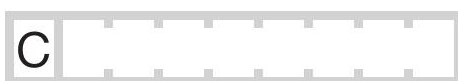

Occupation

Retired

Election Cycle-to-Date

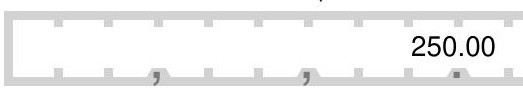

Transaction ID : AF51878F6CDB246BFB70

Date of Receipt

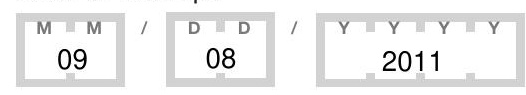

Amount of Each Receipt this Period

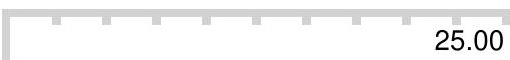

25.00

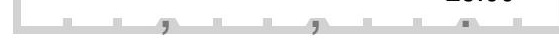

Transaction ID : A17E1E80DEAF3441C89B

Date of Receipt

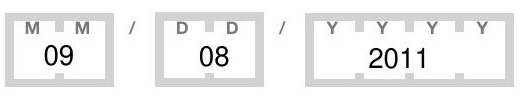

Amount of Each Receipt this Period

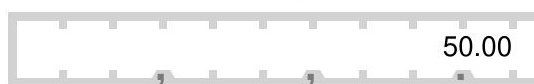

Transaction ID : A179AF02E16774951A3C

Date of Receipt

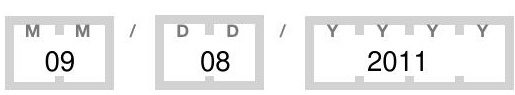

Amount of Each Receipt this Period

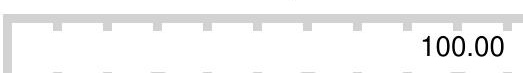

Physician

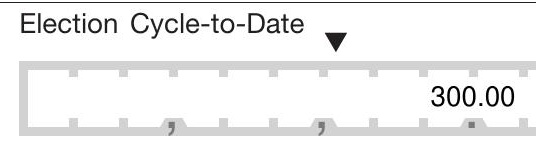

Subtotal Of Receipts This Page (optional)

175.00

‥

Total This Period (last page this line number only) 
SCHEDULE A-P ITEMIZED RECEIPTS
Use separate schedule(s)

for each category of the

Detailed Summary Page
FOR LINE NUMBER: (check only one)

\begin{tabular}{|c|c|c|c|c|c|}
\hline & & & & & \\
\hline 16 & $\begin{array}{ll}X & 17 a \\
\end{array}$ & $17 \mathrm{~b}$ & $17 c$ & $17 d$ & 18 \\
\hline $19 a$ & $19 b$ & $20 \mathrm{a}$ & $20 \mathrm{~b}$ & $20 c$ & 21 \\
\hline
\end{tabular}

Any information copied from such Reports and Statements may not be sold or used by any person for the purpose of soliciting contributions or for commercial purposes, other than using the name and address of any political committee to solicit contributions from such committee.

NAME OF COMMITTEE (In Full)

\section{Friends of Herman Cain}

A. Full Name (Last, First, Middle Initial)

Ms Patricia A Noland

Mailing Address 4161 Falcon Dr

\begin{tabular}{lcc}
\hline City & State & Zip Code \\
Austell & GA & $30106-3070$
\end{tabular}

FEC ID number of contributing federal political committee.

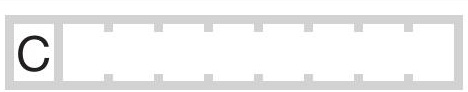

\begin{tabular}{l} 
Name of Employer \\
None \\
Receipt For: 2012 \\
X Primary $\quad$ General \\
\hline Other (specify)
\end{tabular}

Occupation

Retired

Election Cycle-to-Date

250.00

B. Full Name (Last, First, Middle Initial)

Eleanor Goodwin

Mailing Address 1759 Dunridge Court

\begin{tabular}{lcc}
\hline City & State & Zip Code \\
Atlanta & GA & $30338-3501$
\end{tabular}

FEC ID number of contributing

federal political committee.

C

Name of Employer
NA
Receipt For: 2012
X Primary
Other (specify)

\section{Occupation}

homemaker

Election Cycle-to-Date

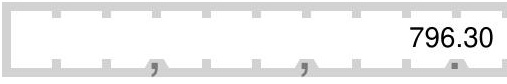

Transaction ID : A472575F663F94C4FABF

Date of Receipt

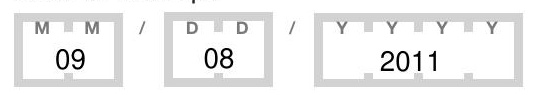

Amount of Each Receipt this Period

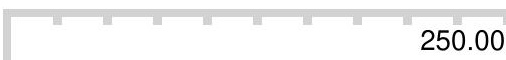

250.00

C. Full Name (Last, First, Middle Initial)

Leighton Wells

Mailing Address 717 Edgemont Way

\begin{tabular}{lcc}
\hline City & State & Zip Code \\
Springfield & OR & $97477-3607$
\end{tabular}

FEC ID number of contributing

federal political committee.

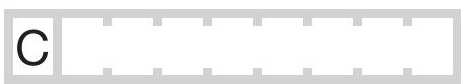

Name of Employer
n/a
Receipt For: 2012
X Primary $\square$ General
Other (specify)

Occupation

Retired

Election Cycle-to-Date

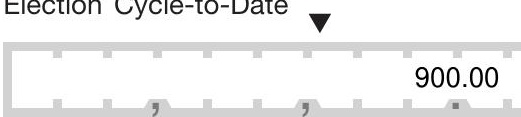

Transaction ID : A500F4D216FC145869B2

Date of Receipt

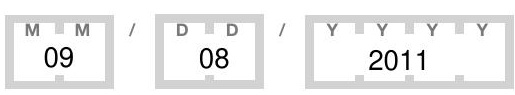

Amount of Each Receipt this Period

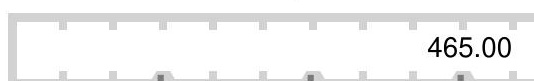

Transaction ID : A1B15E9661EEC49429FD Date of Receipt

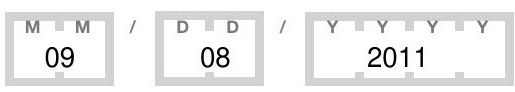

Amount of Each Receipt this Period

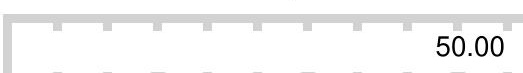

\section{Subtotal Of Receipts This Page (optional)}

Total This Period (last page this line number only) 
SCHEDULE A-P ITEMIZED RECEIPTS
Use separate schedule(s) for each category of the Detailed Summary Page
FOR LINE NUMBER: (check only one)

PAGE 466 / 1572

\begin{tabular}{|c|c|c|c|c|c|}
\hline & & & & & \\
\hline 16 & $\begin{array}{l}\mathbf{X} \\
17 a\end{array}$ & $17 b$ & $17 c$ & $17 d$ & 18 \\
\hline $19 a$ & $19 \mathrm{~b}$ & $20 \mathrm{a}$ & $20 \mathrm{~b}$ & $20 \mathrm{c}$ & 21 \\
\hline
\end{tabular}

Any information copied from such Reports and Statements may not be sold or used by any person for the purpose of soliciting contributions or for commercial purposes, other than using the name and address of any political committee to solicit contributions from such committee.

NAME OF COMMITTEE (In Full)

\section{Friends of Herman Cain}

A. Full Name (Last, First, Middle Initial) John Fulton

Mailing Address 5417 Cross Creek Rd

\begin{tabular}{lcc}
\hline City & State & Zip Code \\
Wilmington & NC & $28403-3456$ \\
\hline
\end{tabular}

FEC ID number of contributing federal political committee.

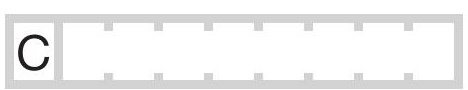

Name of Employer
Corbett Timber Co.
Receipt For: 2012
X Primary $\quad$ General
Other (specify)

Occupation Forester Election Cycle-to-Date

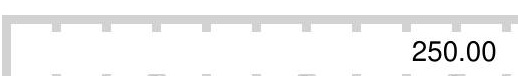

B. Full Name (Last, First, Middle Initial)

Ernest Swible Jr. Jr.

Mailing Address PO Box 561108

\begin{tabular}{lcc}
\hline City & State & Zip Code \\
Orlando & FL & $32856-1108$
\end{tabular}

FEC ID number of contributing

federal political committee.

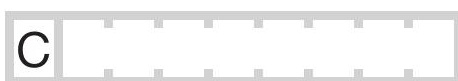

Name of Employer
Charles Rutenberg Realty
Receipt For: 2012
X Primary
Other (specify)

\section{Occupation}

Realtor

Election Cycle-to-Date

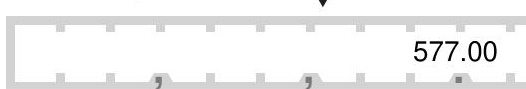

Transaction ID : AEB4AA9380DE04594936

Date of Receipt

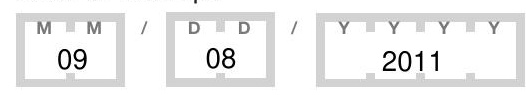

Amount of Each Receipt this Period

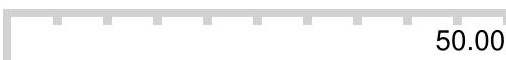

50.00

C. Full Name (Last, First, Middle Initial)

Donna Norris

Mailing Address 16327 Wytchwood Circle

\begin{tabular}{lcc}
\hline City & State & Zip Code \\
Cypress & TX & $77429-4859$ \\
\hline
\end{tabular}

FEC ID number of contributing federal political committee.

C

$77429-4859$

Name of Employer

Family

Receipt For: 2012

Х $\begin{aligned} & \text { Primary } \\ & \text { Other (specify) }\end{aligned}$

Occupation

Home Manager

Election Cycle-to-Date

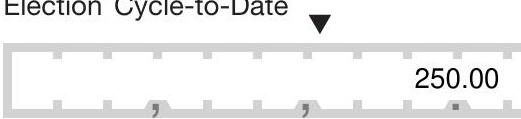

Transaction ID : A1F305A19C4784AC3963

Date of Receipt

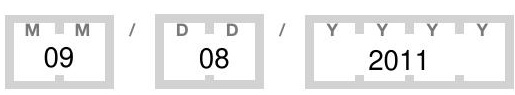

Amount of Each Receipt this Period

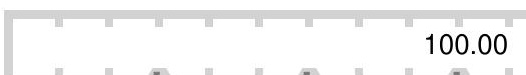

Transaction ID : A59DE8D9DB5294C64971 Date of Receipt

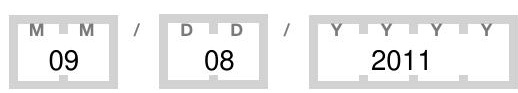

Amount of Each Receipt this Period

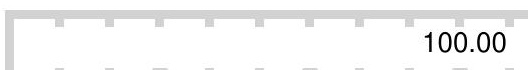

\section{Subtotal Of Receipts This Page (optional)}

Total This Period (last page this line number only) 
SCHEDULE A-P ITEMIZED RECEIPTS
Use separate schedule(s) for each category of the Detailed Summary Page
FOR LINE NUMBER: (check only one)
PAGE 467 / 1572

\begin{tabular}{|c|c|c|c|c|c|}
\hline & & & & & \\
\hline 16 & $\begin{array}{lll}X & 17 a \\
\end{array}$ & $17 \mathrm{~b}$ & $17 c$ & $17 d$ & 18 \\
\hline $19 a$ & $19 b$ & $20 a$ & $20 \mathrm{~b}$ & $20 c$ & 21 \\
\hline
\end{tabular}

Any information copied from such Reports and Statements may not be sold or used by any person for the purpose of soliciting contributions or for commercial purposes, other than using the name and address of any political committee to solicit contributions from such committee.

NAME OF COMMITTEE (In Full)

\section{Friends of Herman Cain}

A. Full Name (Last, First, Middle Initial)

Carol Baril

Mailing Address 1932 Hamby Place Dr.

\begin{tabular}{lcc}
\hline City & State & Zip Code \\
Acworth & GA & $30102-6435$
\end{tabular}

FEC ID number of contributing

federal political committee.

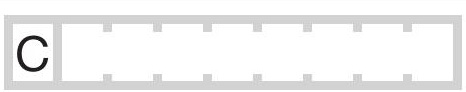

Name of Employer
phoenix systems inc.
Receipt For: 2012
X Primary
Other (specify) General

Occupation

Computer Programmer

Election Cycle-to-Date

212.00

B. Full Name (Last, First, Middle Initial)

Glen Ebbing

Mailing Address 1400 Huntleigh Rd

\begin{tabular}{lcc}
\hline City & State & Zip Code \\
Quincy & IL & $62305-6017$
\end{tabular}

FEC ID number of contributing

federal political committee.

C

Name of Employer
ColorMaster Pain Inc
Receipt For: 2012
X Primary
Other (specify)

Occupation

sales representative

Election Cycle-to-Date

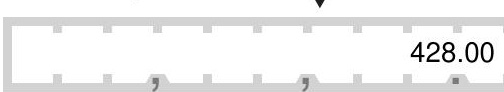

Transaction ID : AB72B1D5479EF404D88A

Date of Receipt

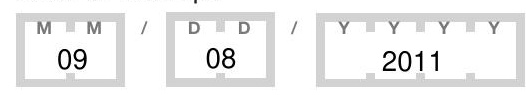

Amount of Each Receipt this Period

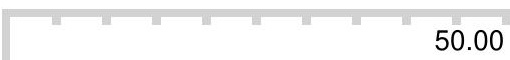

50.00

C. Full Name (Last, First, Middle Initial)

Florence Attridge

Mailing Address 2820 Habersham Rd

\begin{tabular}{lcc}
\hline City & State & Zip Code \\
Atlanta & GA & $30305-2959$ \\
\hline
\end{tabular}

FEC ID number of contributing federal political committee.

C

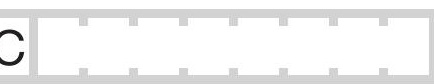

Transaction ID : A62A8C72D520F4E9A8A2

Date of Receipt

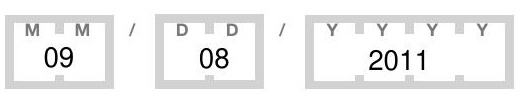

Amount of Each Receipt this Period

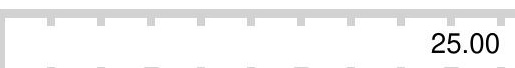

Transaction ID : AAE62F8E7E9C445658DA Date of Receipt

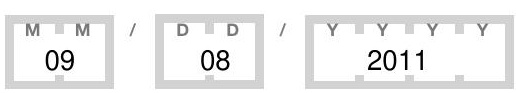

Amount of Each Receipt this Period

Name of Employer
Information Requested
Receipt For: 2012
X Primary
Other (specify) General

Occupation

Information Requested

Election Cycle-to-Date

400.00

Subtotal Of Receipts This Page (optional).

175.00

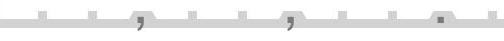

Total This Period (last page this line number only)

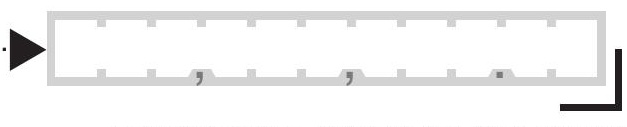

FEC Schedule A-P (Form 3P) (Rev. 03/2011) 
SCHEDULE A-P ITEMIZED RECEIPTS
Use separate schedule(s) for each category of the Detailed Summary Page
FOR LINE NUMBER: (check only one)
PAGE 468 / 1572

\begin{tabular}{|c|c|c|c|c|c|}
\hline & & & & & \\
\hline 16 & $\begin{array}{lll}X & 17 a \\
\end{array}$ & $17 \mathrm{~b}$ & $17 c$ & $17 d$ & 18 \\
\hline $19 a$ & $19 b$ & $20 a$ & $20 \mathrm{~b}$ & $20 c$ & 21 \\
\hline
\end{tabular}

Any information copied from such Reports and Statements may not be sold or used by any person for the purpose of soliciting contributions or for commercial purposes, other than using the name and address of any political committee to solicit contributions from such committee.

NAME OF COMMITTEE (In Full)

\section{Friends of Herman Cain}

A. Full Name (Last, First, Middle Initial) richard clampitt

Mailing Address 7261 ashington dr

\begin{tabular}{lcc}
\hline City & State & Zip Code \\
Dallas & TX & $75225-1704$
\end{tabular}

FEC ID number of contributing federal political committee.

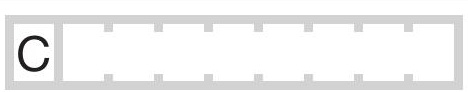

Name of Employer
red river paper
Receipt For: 2012
Primary
Other (specify) General

Occupation

Executive

Election Cycle-to-Date 1700.00

B. Full Name (Last, First, Middle Initial)

Nancy Pihera

Mailing Address 2452 Kings Ct

\begin{tabular}{lcc}
\hline City & State & Zip Code \\
Atlanta & GA & $30345-2120$ \\
\hline
\end{tabular}

FEC ID number of contributing

federal political committee.

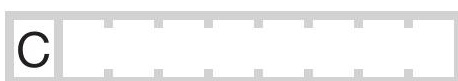

$\begin{aligned} & \text { Name of Employer } \\ & \text { self }\end{aligned}$
Receipt For: 2012
X Primary
Other (specify)

\section{Occupation}

Designer

Election Cycle-to-Date

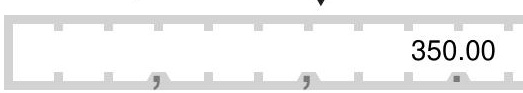

Transaction ID : A124E74A1DC13420DBD3

Date of Receipt

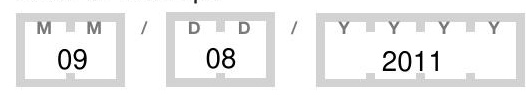

Amount of Each Receipt this Period

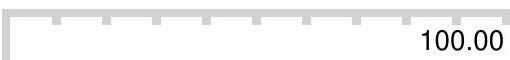

Transaction ID : ACC127F268A2B468CB5C Date of Receipt

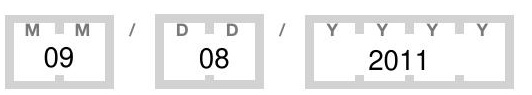

Amount of Each Receipt this Period

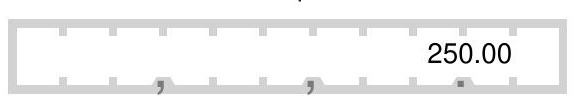

Transaction ID : ADF365AC4C5D541A0A2E Date of Receipt

\section{Peter Larson}

Mailing Address 1619 Beaver Creek Lane

\begin{tabular}{lcc}
\hline City & State & Zip Code \\
Snellville & GA & $30078-6679$
\end{tabular}

FEC ID number of contributing federal political committee.

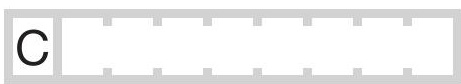

\section{Name of Employer}

FLOYD KINGSTON ASSOCIATES INC.

\section{Occupation}

President

Receipt For: 2012

Х $\begin{aligned} & \text { Primary } \square \text { General } \\ & \text { Other (specify) }\end{aligned}$

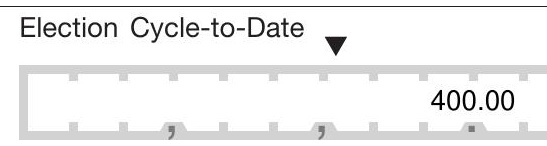

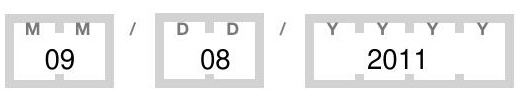

Amount of Each Receipt this Period

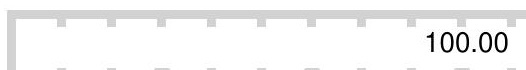

\section{Subtotal Of Receipts This Page (optional)}

Total This Period (last page this line number only) 
SCHEDULE A-P ITEMIZED RECEIPTS
Use separate schedule(s)

for each category of the

Detailed Summary Page
FOR LINE NUMBER: (check only one)

Any information copied from such Repor or for commercial purposes, other than using the name and address of any political committee to solicit contributions from such committee.

NAME OF COMMITTEE (In Full)

\section{Friends of Herman Cain}

A. Full Name (Last, First, Middle Initial)

Mr. Warren Y. Jobe

Mailing Address 4050 Club Dr NE

\begin{tabular}{lcc}
\hline City & State & Zip Code \\
Atlanta & GA & $30319-1161$
\end{tabular}

FEC ID number of contributing federal political committee.

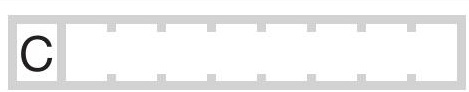

Name of Employer
None
Receipt For: 2012
X Primary $\quad$ General
Other (specify)

Occupation

Retired

Election Cycle-to-Date

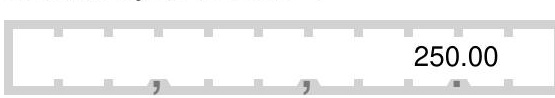

B. Full Name (Last, First, Middle Initial)

Roberto Eaton

Mailing Address 12640 W 66th Place

\begin{tabular}{lcc}
\hline City & State & Zip Code \\
Arvada & CO & $80004-2213$ \\
\hline
\end{tabular}

FEC ID number of contributing

federal political committee.

C

Name of Employer

Maintenance Manager

Occupation

Receipt For: 2012

X Primary $\square$ General Other (specify)

Transaction ID : A44D6B016BC7C41A9AAA

Date of Receipt

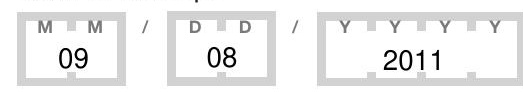

Amount of Each Receipt this Period

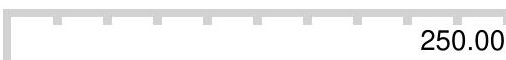

250.00

C. Full Name (Last, First, Middle Initial)

Donald A Bohlin

Mailing Address 32934 SE 20th St

\begin{tabular}{lcc}
\hline City & State & Zip Code \\
Washougal & WA & $98671-9708$
\end{tabular}

FEC ID number of contributing federal political committee.

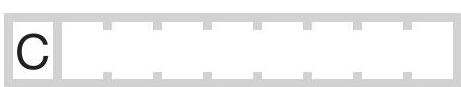

Name of Employer
Information Requested
Receipt For: 2012
X Primary $\quad \square$ General
Other (specify)

Occupation

Information Requested

Election Cycle-to-Date
250.00

Transaction ID : A25731E5E114347D8969

Date of Receipt

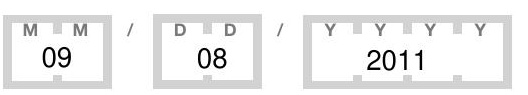

Amount of Each Receipt this Period

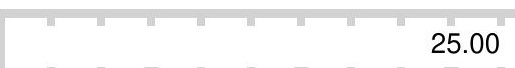

Transaction ID : A5AEB72F9C6344B82ADB Date of Receipt

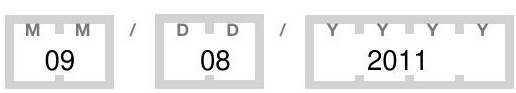

Amount of Each Receipt this Period

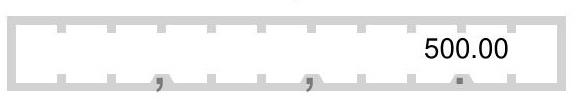

500.00

\section{Subtotal Of Receipts This Page (optional)}

Total This Period (last page this line number only) 
SCHEDULE A-P ITEMIZED RECEIPTS
Use separate schedule(s) for each category of the Detailed Summary Page
FOR LINE NUMBER: (check only one)

PAGE $470 / 1572$

\begin{tabular}{|c|c|c|c|c|c|}
\hline & & & & & \\
\hline 16 & $\begin{array}{l}\mathbf{X} \\
17 a\end{array}$ & $17 b$ & $17 c$ & $17 d$ & 18 \\
\hline $19 a$ & $19 \mathrm{~b}$ & $20 \mathrm{a}$ & $20 \mathrm{~b}$ & $20 \mathrm{c}$ & 21 \\
\hline
\end{tabular}

Any information copied from such Reports and Statements may not be sold or used by any person for the purpose of soliciting contributions or for commercial purposes, other than using the name and address of any political committee to solicit contributions from such committee.

NAME OF COMMITTEE (In Full)

\section{Friends of Herman Cain}

A. Full Name (Last, First, Middle Initial)

Mr. Thomas A Sweat II

Mailing Address 3080 Dowry Dr

\begin{tabular}{lcc}
\hline City & State & Zip Code \\
Lawrenceville & GA & $30044-2672$
\end{tabular}

FEC ID number of contributing federal political committee.

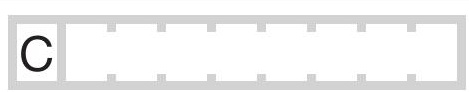

\begin{tabular}{l} 
Name of Employer \\
None \\
Receipt For: 2012 \\
X Primary $\quad$ General \\
\hline Other (specify)
\end{tabular}

Occupation

Retired

Election Cycle-to-Date

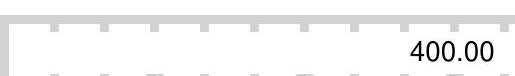

B. Full Name (Last, First, Middle Initial)

John Bearden

Mailing Address 1310 Winding River $\mathrm{Tr}$

\begin{tabular}{lcc}
\hline City & State & Zip Code \\
Woodstock & GA & $30188-5305$ \\
\hline
\end{tabular}

FEC ID number of contributing

federal political committee.

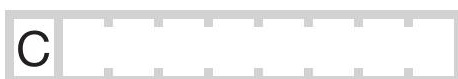

Name of Employer
PrecisionJet
Receipt For: 2012
X Primary
Other (specify)

Occupation

Engineer Manager

Election Cycle-to-Date

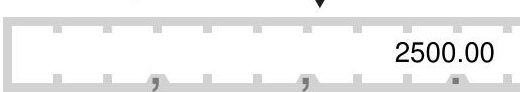

C. Full Name (Last, First, Middle Initial)

Judith A Dodson

Mailing Address 2100 Wyckham PI.

\begin{tabular}{lcc}
\hline City & State & Zip Code \\
Norman & OK & $73072-3042$
\end{tabular}

FEC ID number of contributing

federal political committee.

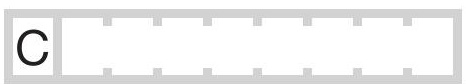

Name of Employer
None
Receipt For: 2012
Х Primary $\quad \square$ General
Other (specify)

Occupation

Retired

Election Cycle-to-Date

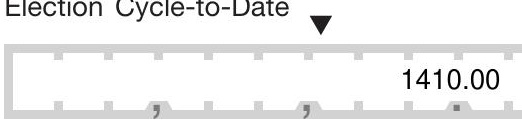

Transaction ID : AFD812FDE8A914EF0AF6

Date of Receipt

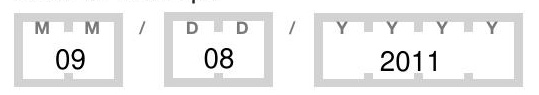

Amount of Each Receipt this Period

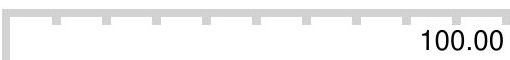

100.00

Transaction ID : A0500F8DCC9B84858BAF Date of Receipt

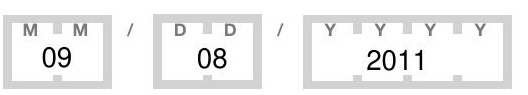

Amount of Each Receipt this Period

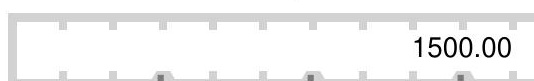

Transaction ID : A6C8122DFA357401A87D Date of Receipt

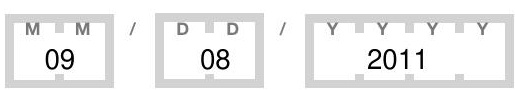

Amount of Each Receipt this Period

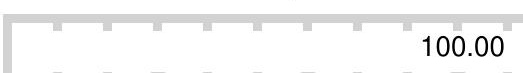

1700.00

Subtotal Of Receipts This Page (optional)

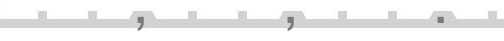

Total This Period (last page this line number only) 
SCHEDULE A-P ITEMIZED RECEIPTS
Use separate schedule(s) for each category of the Detailed Summary Page
FOR LINE NUMBER: (check only one)

\begin{tabular}{|c|c|c|c|c|c|}
\hline & & & & & \\
\hline 16 & $\begin{array}{ll}X & 17 a \\
\end{array}$ & $17 \mathrm{~b}$ & $17 c$ & $17 d$ & 18 \\
\hline $19 a$ & $19 b$ & $20 \mathrm{a}$ & $20 \mathrm{~b}$ & $20 c$ & 21 \\
\hline
\end{tabular}

Any information copied from such Reports and Statements may not be sold or used by any person for the purpose of soliciting contributions or for commercial purposes, other than using the name and address of any political committee to solicit contributions from such committee.

NAME OF COMMITTEE (In Full)

\section{Friends of Herman Cain}

A. Full Name (Last, First, Middle Initial) Joseph Prigge

Mailing Address 210 coventry court

\begin{tabular}{lcc}
\hline City & State & Zip Code \\
Elgin & IL & $60123-5081$ \\
\hline
\end{tabular}

FEC ID number of contributing federal political committee.

Name of Employer
William Prigge
Receipt For: 2012
X Primary
Other (specify) General

B. Full Name (Last, First, Middle Initial)

Doug Eames

Mailing Address 1385 West Coach Rd. DO NOT MAIL

\begin{tabular}{lcc}
\hline City & State & Zip Code \\
Boulder & CO & $80302-9475$
\end{tabular}

FEC ID number of contributing

federal political committee.

C

Name of Employer
self
Receipt For: 2012
X Primary
Other (specify)

C. Full Name (Last, First, Middle Initial)

Melinda Earley

Mailing Address 1109 Shannon Dr

\section{City}

Cleburne

FEC ID number of contributing federal political committee.

Name of Employer
None
Receipt For: 2012
X Primary

Other (specify) General

Occupation

Announcer

Election Cycle-to-Date

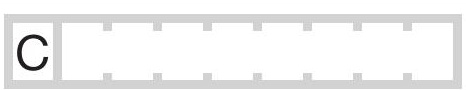

Occupation

Geotechnical Technician

Election Cycle-to-Date $\boldsymbol{\nabla}$

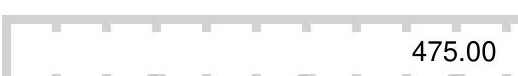

Transaction ID : A32A2B8D7F5804391906

Date of Receipt

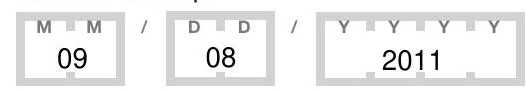

Amount of Each Receipt this Period

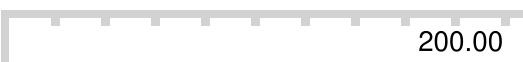

200.00

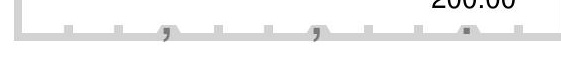

Transaction ID : AE7EC361C06BA4CC1928 Date of Receipt

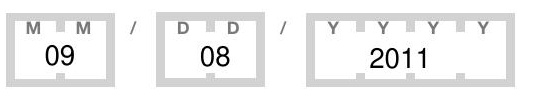

Amount of Each Receipt this Period
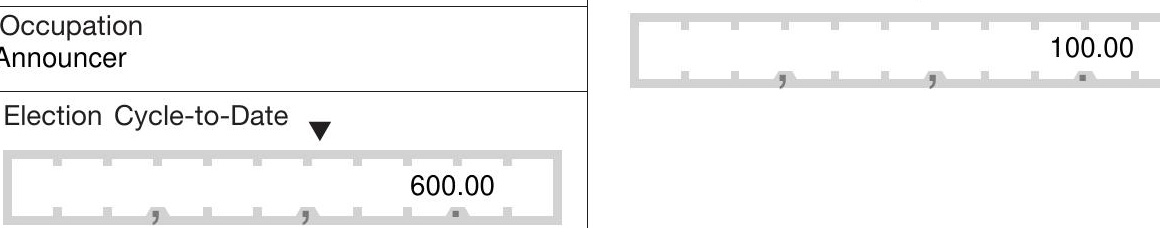

Transaction ID : AC72DE870AF8E429BBED Date of Receipt

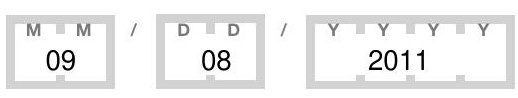

Amount of Each Receipt this Period

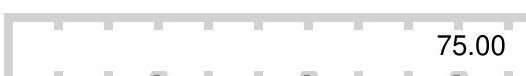

225.00

Subtotal Of Receipts This Page (optional)

375.00

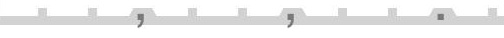

Total This Period (last page this line number only)

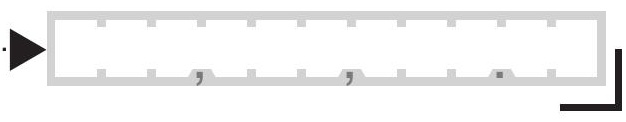

FEC Schedule A-P (Form 3P) (Rev. 03/2011) 
SCHEDULE A-P ITEMIZED RECEIPTS
Use separate schedule(s) for each category of the Detailed Summary Page
FOR LINE NUMBER: (check only one)

PAGE 472 / 1572

\begin{tabular}{|c|c|c|c|c|c|c|}
\hline & & & & & & \\
\hline 16 & $\lambda$ & $17 \mathrm{a}$ & $17 \mathrm{~b}$ & $17 \mathrm{c}$ & $-17 d$ & -18 \\
\hline $19 a$ & & $19 b$ & $20 a$ & $20 \mathrm{~b}$ & $20 \mathrm{c}$ & 21 \\
\hline
\end{tabular}

Any information copied from such Reports and Statements may not be sold or used by any person for the purpose of soliciting contributions or for commercial purposes, other than using the name and address of any political committee to solicit contributions from such committee.

NAME OF COMMITTEE (In Full)

\section{Friends of Herman Cain}

A. Full Name (Last, First, Middle Initial)

William Choisser

Mailing Address 1409 Kingsley Ave

\begin{tabular}{lcc}
\hline City & State & Zip Code \\
Orange Park & FL & $32073-4537$ \\
\hline
\end{tabular}

FEC ID number of contributing federal political committee.

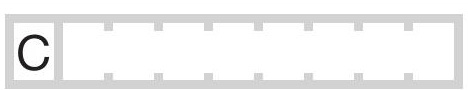

Name of Employer
self
Receipt For: 2012
X Primary $\quad$ General
Other (specify)

Occupation

Physician

Election Cycle-to-Date

215.00

B. Full Name (Last, First, Middle Initial)

Loretta Twiford

Mailing Address 215 MacGregor Drive

\begin{tabular}{lcc}
\hline City & State & Zip Code \\
Blue Ridge & VA & $24064-1566$
\end{tabular}

FEC ID number of contributing

federal political committee.

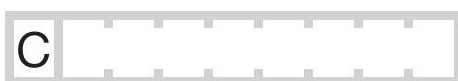

Name of Employer
n/a
Receipt For: 2012
X Primary
Other (specify)

Occupation

Retired

Election Cycle-to-Date

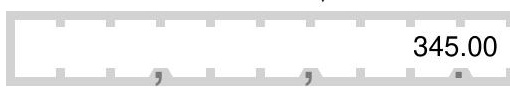

Transaction ID : A87205EE11E384028821

Date of Receipt

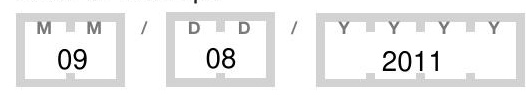

Amount of Each Receipt this Period

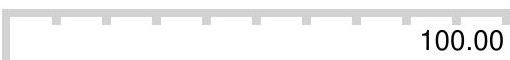

Transaction ID : A6AF453D168F047CC9C7

Date of Receipt

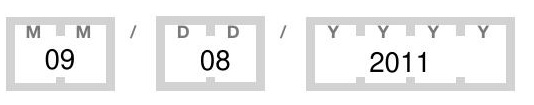

Amount of Each Receipt this Period

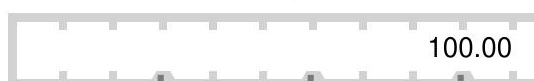

Transaction ID : ABB6FBAE4CBD24686970 Date of Receipt

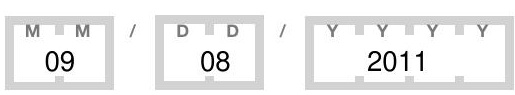

Amount of Each Receipt this Period

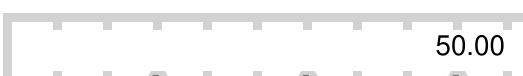

\section{Subtotal Of Receipts This Page (optional)}

Total This Period (last page this line number only) 
SCHEDULE A-P ITEMIZED RECEIPTS
Use separate schedule(s) for each category of the Detailed Summary Page
FOR LINE NUMBER: (check only one)

PAGE $473 / 1572$

\begin{tabular}{|c|c|c|c|c|c|}
\hline & & & & & \\
\hline 16 & $\begin{array}{lll}X & 17 a \\
\end{array}$ & $17 \mathrm{~b}$ & $17 c$ & $17 d$ & 18 \\
\hline $19 a$ & $19 b$ & $20 a$ & $20 \mathrm{~b}$ & $20 c$ & 21 \\
\hline
\end{tabular}

Any information copied from such Reports and Statements may not be sold or used by any person for the purpose of soliciting contributions or for commercial purposes, other than using the name and address of any political committee to solicit contributions from such committee.

NAME OF COMMITTEE (In Full)

\section{Friends of Herman Cain}

A. Full Name (Last, First, Middle Initial)

Charles Fay

Mailing Address 12120 Belle Meade Rd

\begin{tabular}{lcc}
\hline City & State & Zip Code \\
Saint Louis & MO & $63131-3801$
\end{tabular}

FEC ID number of contributing

federal political committee.

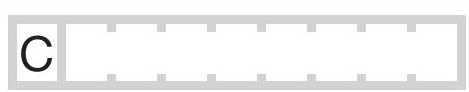

\begin{tabular}{l} 
Name of Employer \\
None \\
Receipt For: 2012 \\
X Primary $\quad$ General \\
\hline Other (specify)
\end{tabular}

Occupation

Retired

Election Cycle-to-Date

250.00

B. Full Name (Last, First, Middle Initial)

Mr. Stephen K. Boots

Mailing Address 564 Cesarea PI NW

\begin{tabular}{lcc}
\hline City & State & Zip Code \\
Lilburn & GA & $30047-6002$
\end{tabular}

FEC ID number of contributing

federal political committee.

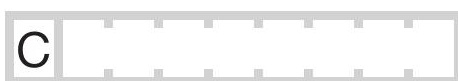

Name of Employer
self
Receipt For: 2012
Primary $\quad$ General
Other (specify)

\section{Occupation}

Tax Consultant

Election Cycle-to-Date

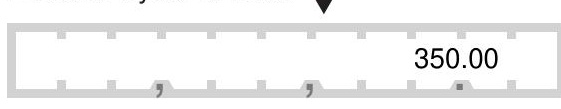

C. Full Name (Last, First, Middle Initial)

Darin Kohles

Mailing Address 21410 SE Hwy 224

\begin{tabular}{lcc}
\hline City & State & Zip Code \\
Damascus & OR & $97089-7825$
\end{tabular}

FEC ID number of contributing federal political committee.

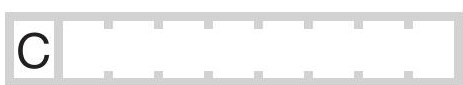

Name of Employer
Information Requested
Receipt For: 2012
X Primary $\quad \square$ General
Other (specify)

Occupation

Information Requested

Election Cycle-to-Date

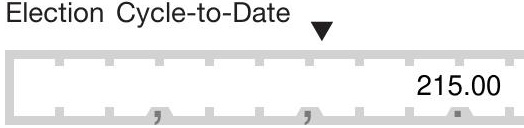

Transaction ID : A46E7439B1DEA43EFB72

Date of Receipt

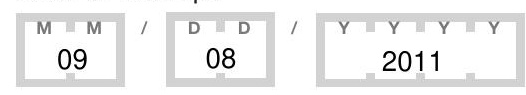

Amount of Each Receipt this Period

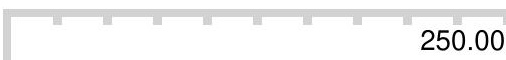

250.00
Transaction ID : A6559CB5443B64ED0BCC Date of Receipt

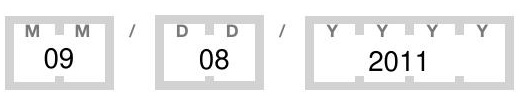

Amount of Each Receipt this Period

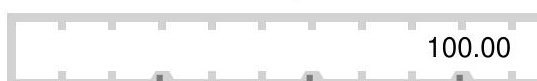

Transaction ID : AE645AC5BE3174EDE877 Date of Receipt

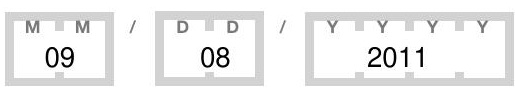

Amount of Each Receipt this Period

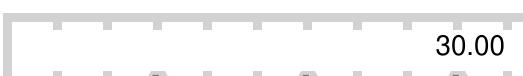

\section{Subtotal Of Receipts This Page (optional)}

Total This Period (last page this line number only) 
SCHEDULE A-P ITEMIZED RECEIPTS
Use separate schedule(s) for each category of the Detailed Summary Page
FOR LINE NUMBER: (check only one)

PAGE 474 / 1572

\begin{tabular}{|c|c|c|c|c|c|}
\hline & & & & & \\
\hline 16 & $\begin{array}{l}\mathbf{X} \\
17 a\end{array}$ & $17 b$ & $17 c$ & $17 d$ & 18 \\
\hline $19 a$ & $19 \mathrm{~b}$ & $20 \mathrm{a}$ & $20 \mathrm{~b}$ & $20 \mathrm{c}$ & 21 \\
\hline
\end{tabular}

Any information copied from such Reports and Statements may not be sold or used by any person for the purpose of soliciting contributions or for commercial purposes, other than using the name and address of any political committee to solicit contributions from such committee.

NAME OF COMMITTEE (In Full)

\section{Friends of Herman Cain}

A. Full Name (Last, First, Middle Initial) Jeanne Downer

Mailing Address $6007 \mathrm{~N}$ Kansas AVe

\begin{tabular}{lcc}
\hline City & State & Zip Code \\
Kansas City & MO & $64119-2115$ \\
\hline
\end{tabular}

FEC ID number of contributing federal political committee.

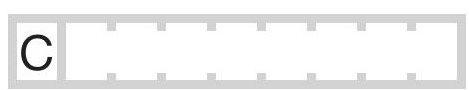

Name of Employer
WNB Architects
Receipt For: 2012
X Primary $\quad$ General
Other (specify)

Occupation Office Manager

Election Cycle-to-Date

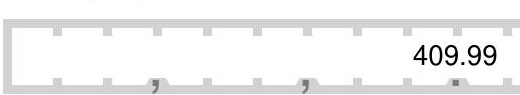

B. Full Name (Last, First, Middle Initial)

Carol Cook

Mailing Address 43 Oak Alley

\begin{tabular}{lcc}
\hline City & State & Zip Code \\
Kerrville & TX & $78028-1711$
\end{tabular}

FEC ID number of contributing

federal political committee.

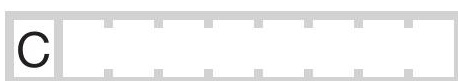

Name of Employer
James Avery
Receipt For: 2012
X Primary
Other (specify) General

Occupation

Sales Team Leader

Election Cycle-to-Date

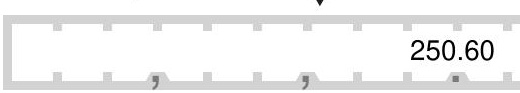

Transaction ID : A87F23F29423E469FB69

Date of Receipt

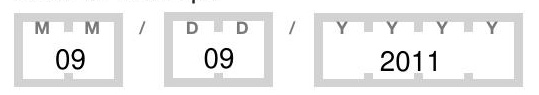

Amount of Each Receipt this Period

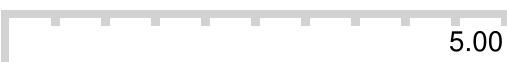

Amount of Each Receipt this Period

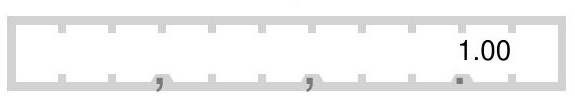

C. Full Name (Last, First, Middle Initial)

James Oneill

Mailing Address 2929 Floyd Ave Apt 325

\begin{tabular}{lcc}
\hline City & State & Zip Code \\
Modesto & CA & $95355-8756$
\end{tabular}

FEC ID number of contributing

federal political committee.

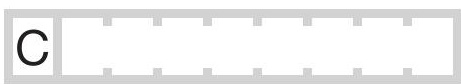

Name of Employer

Occupation

St Of Delaware

Retired

Receipt For: 2012

Х $\begin{aligned} & \text { Primary } \\ & \text { Other (specify) }\end{aligned}$

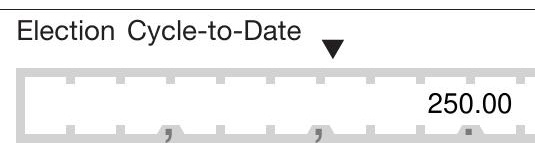

Amount of Each Receipt this Period

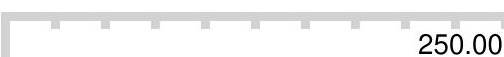

250.00

Subtotal Of Receipts This Page (optional)

256.00

Total This Period (last page this line number only) 
SCHEDULE A-P ITEMIZED RECEIPTS
Use separate schedule(s) for each category of the Detailed Summary Page
FOR LINE NUMBER: (check only one)

PAGE 475 / 1572

\begin{tabular}{|c|c|c|c|c|c|}
\hline & & & & & \\
\hline 16 & $\begin{array}{l}\mathbf{X} \\
17 a\end{array}$ & $17 b$ & $17 c$ & $17 d$ & 18 \\
\hline $19 a$ & $19 \mathrm{~b}$ & $20 \mathrm{a}$ & $20 \mathrm{~b}$ & $20 \mathrm{c}$ & 21 \\
\hline
\end{tabular}

Any information copied from such Reports and Statements may not be sold or used by any person for the purpose of soliciting contributions or for commercial purposes, other than using the name and address of any political committee to solicit contributions from such committee.

NAME OF COMMITTEE (In Full)

\section{Friends of Herman Cain}

A. Full Name (Last, First, Middle Initial)

Kate C Thompson

Mailing Address PO Box 221

\begin{tabular}{lcc}
\hline City & State & Zip Code \\
Port Washington & OH & $43837-0221$
\end{tabular}

FEC ID number of contributing

federal political committee.

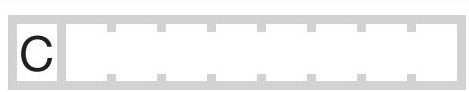

Name of Employer
Retired
Receipt For: 2012
X Primary $\quad$ General
Other (specify)

Occupation

Retired

Election Cycle-to-Date

450.00

B. Full Name (Last, First, Middle Initial)

Bruce R Clegg

Mailing Address 4401 Orwood Rd

\begin{tabular}{lcc}
\hline City & State & Zip Code \\
Brentwood & CA & $94513-5219$
\end{tabular}

FEC ID number of contributing

federal political committee.

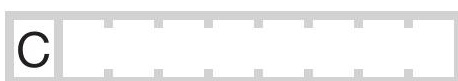

Name of Employer
None
Receipt For: 2012
X Primary
Other (specify)

\section{Occupation}

Retired

Election Cycle-to-Date

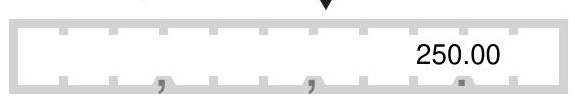

C. Full Name (Last, First, Middle Initial)

Mr Robert F Sprowls

Mailing Address 6929 Sandpiper PI

\begin{tabular}{lcc}
\hline City & State & Zip Code \\
Carlsbad & CA & $92009-4132$ \\
\hline
\end{tabular}

FEC ID number of contributing

federal political committee.

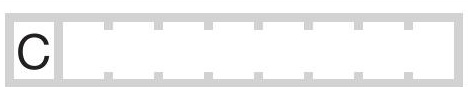

Name of Employer

Information Requested

Occupation

Information Requested

Receipt For: 2012

Х $\begin{aligned} & \text { Primary } \square \text { General } \\ & \text { Other (specify) }\end{aligned}$

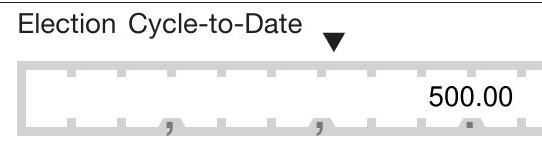

Transaction ID : A4228A132AF6C418389E

Date of Receipt

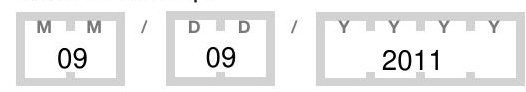

Amount of Each Receipt this Period

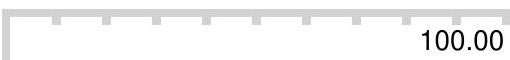

100.00

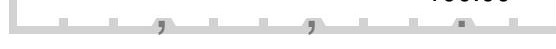

Transaction ID : A3B64B189D18B4150A14

Date of Receipt

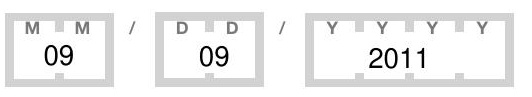

Amount of Each Receipt this Period

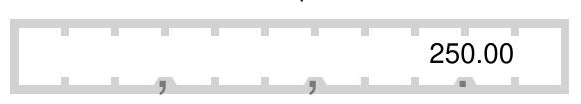

Transaction ID : ADDABC848A52E4CC9BD4 Date of Receipt

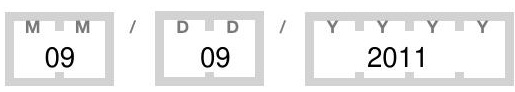

Amount of Each Receipt this Period

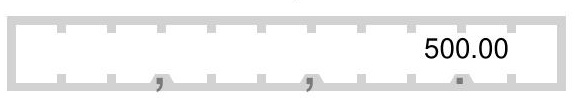

850.00

가.

Total This Period (last page this line number only) 


\section{SCHEDULE A-P} ITEMIZED RECEIPTS
Use separate schedule(s)

for each category of the

Detailed Summary Page
FOR LINE NUMBER: (check only one)

PAGE 476 / 1572

\begin{tabular}{|c|c|c|c|c|c|}
\hline & & & & & \\
\hline 16 & X $17 a$ & $17 b$ & $17 c$ & $17 d$ & 18 \\
\hline $19 a$ & $19 b$ & $20 \mathrm{a}$ & $20 \mathrm{~b}$ & $20 \mathrm{c}$ & 21 \\
\hline
\end{tabular}

Any information copied from such Reports and Statements may not be sold or used by any person for the purpose of soliciting contributions or for commercial purposes, other than using the name and address of any political committee to solicit contributions from such committee.

NAME OF COMMITTEE (In Full)

Friends of Herman Cain

A. Full Name (Last, First, Middle Initial)

Margaret Dudley

Mailing Address 102 Lacey Oak

\begin{tabular}{lcc}
\hline City & State & Zip Code \\
Shavano Park & TX & $78230-5611$
\end{tabular}

FEC ID number of contributing

federal political committee.

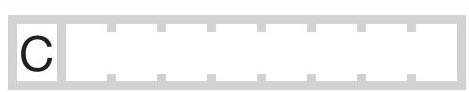

Name of Employer
Information Requested
Receipt For: 2012
X Primary $\quad \square$ General
Other (specify)

Occupation

Information Requested

Election Cycle-to-Date

2500.00

B. Full Name (Last, First, Middle Initial)

Gary Graham Bahre

Mailing Address PO Box 900

\begin{tabular}{lcc}
\hline City & State & Zip Code \\
Alton & $\mathrm{NH}$ & $03809-0900$ \\
\hline
\end{tabular}

FEC ID number of contributing

federal political committee.

C

Name of Employer
Information Requested
Receipt For: 2012
X Primary
Other (specify)

Occupation

Information Requested

Election Cycle-to-Date

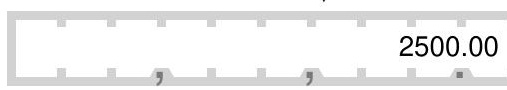

C. Full Name (Last, First, Middle Initial)

Mr. Phillip Mullinax

Mailing Address 965 Oak Grove Rd

\begin{tabular}{lcc}
\hline City & State & Zip Code \\
Dahlonega & GA & $30533-4840$
\end{tabular}

FEC ID number of contributing

federal political committee.

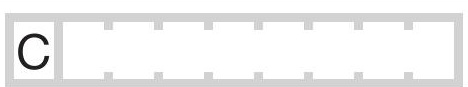

$\begin{aligned} & \text { Name of Employer } \\ & \text { self }\end{aligned}$
Receipt For: 2012
X Primary $\square$ General
Other (specify)

Occupation

entrepreneur

Election Cycle-to-Date

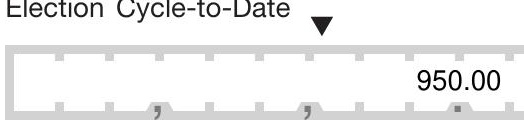

Transaction ID : A26FAB62294BD4BDA8A6

Date of Receipt

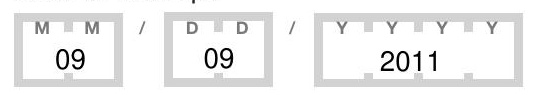

Amount of Each Receipt this Period

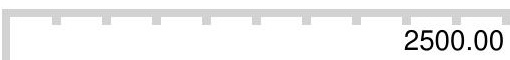

2500.00

Transaction ID : A13C58499736A4821B99

Date of Receipt

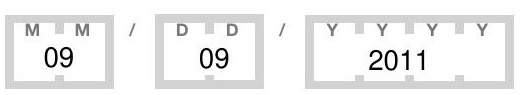

Amount of Each Receipt this Period

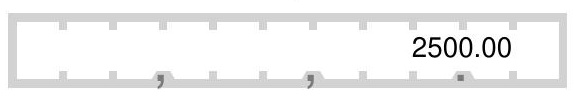

Transaction ID : AFCEF071F8E5242BE882

Date of Receipt

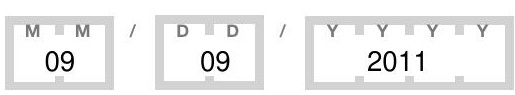

Amount of Each Receipt this Period

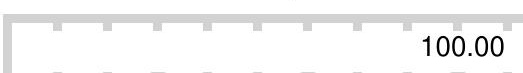

100.00

\section{Subtotal Of Receipts This Page (optional).}

Total This Period (last page this line number only) 
SCHEDULE A-P ITEMIZED RECEIPTS
Use separate schedule(s) for each category of the Detailed Summary Page
FOR LINE NUMBER: (check only one)
PAGE 477 / 1572

\begin{tabular}{|c|c|c|c|c|c|}
\hline & & & & & \\
\hline 16 & $\begin{array}{lll}X & 17 a \\
\end{array}$ & $17 \mathrm{~b}$ & $17 c$ & $17 d$ & 18 \\
\hline $19 a$ & $19 b$ & $20 a$ & $20 \mathrm{~b}$ & $20 c$ & 21 \\
\hline
\end{tabular}

Any information copied from such Reports and Statements may not be sold or used by any person for the purpose of soliciting contributions or for commercial purposes, other than using the name and address of any political committee to solicit contributions from such committee.

NAME OF COMMITTEE (In Full)

Friends of Herman Cain

A. Full Name (Last, First, Middle Initial)

Mr. William H Randolph IV

Mailing Address 1490 Sanden Ferry Dr

\begin{tabular}{lcc}
\hline City & State & Zip Code \\
Decatur & GA & $30033-3323$ \\
\hline
\end{tabular}

FEC ID number of contributing

federal political committee.

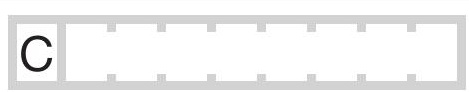

Name of Employer
King Industrial Realty
Receipt For: 2012
X Primary
Other (specify) General

Occupation

Real Estate Broker

Election Cycle-to-Date

300.00

B. Full Name (Last, First, Middle Initial)

Sharon Waite

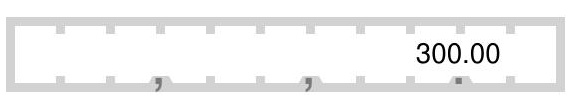

Mailing Address 8301 W Business Highway 83

\begin{tabular}{lcc}
\hline City & State & Zip Code \\
Mission & TX & $78572-9445$
\end{tabular}

FEC ID number of contributing

federal political committee.

C

Name of Employer
Self Employed
Receipt For: 2012
X Primary
Other (specify) General

Occupation

Agriculture

Election Cycle-to-Date

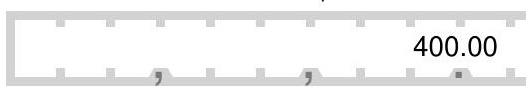

Transaction ID : A707B58EA13274D5BB15

Date of Receipt

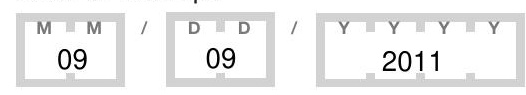

Amount of Each Receipt this Period

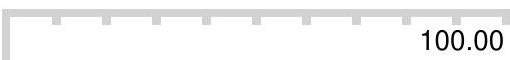

Transaction ID : AEF50DCF50F934119AD9

Date of Receipt

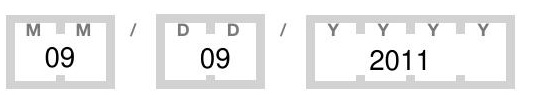

Amount of Each Receipt this Period

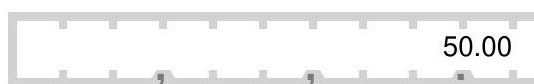

Transaction ID : A3DB0A083ADF248A6A67 Date of Receipt

Rodney Bennett

Mailing Address 414 Morris Ln

\begin{tabular}{lcc}
\hline City & State & Zip Code \\
Greenville & TX & $75402-5454$
\end{tabular}

FEC ID number of contributing federal political committee.

C

75402-5454

Name of Employer

TYBRIN

Occupation

Systems Engineer

Receipt For: 2012

Х $\begin{aligned} & \text { Primary } \\ & \text { Other (specify) }\end{aligned}$

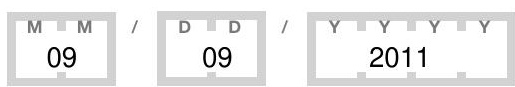

Amount of Each Receipt this Period

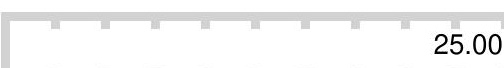

\section{Subtotal Of Receipts This Page (optional)}

Total This Period (last page this line number only) 
SCHEDULE A-P ITEMIZED RECEIPTS
Use separate schedule(s) for each category of the Detailed Summary Page
FOR LINE NUMBER: (check only one)

PAGE $478 / 1572$

\begin{tabular}{|c|c|c|c|c|c|}
\hline & & & & & \\
\hline 16 & $\begin{array}{l}\mathbf{X} \\
17 a\end{array}$ & $17 b$ & $17 c$ & $17 d$ & 18 \\
\hline $19 a$ & $19 \mathrm{~b}$ & $20 \mathrm{a}$ & $20 \mathrm{~b}$ & $20 \mathrm{c}$ & 21 \\
\hline
\end{tabular}

Any information copied from such Reports and Statements may not be sold or used by any person for the purpose of soliciting contributions or for commercial purposes, other than using the name and address of any political committee to solicit contributions from such committee.

NAME OF COMMITTEE (In Full)

\section{Friends of Herman Cain}

A. Full Name (Last, First, Middle Initial)

Mr Richard Cunniff

Mailing Address 14 E Gate Rd

\begin{tabular}{lcc}
\hline City & State & Zip Code \\
Huntington & NY & $11743-1606$
\end{tabular}

FEC ID number of contributing federal political committee.

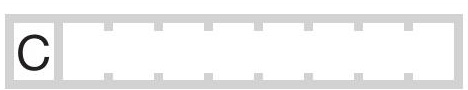

Name of Employer

Ruane, Cunniff \& Goldfarb

Occupation

Receipt For: 2012

X Primary $\square$ General Other (specify)

Invest Manager

Election Cycle-to-Date

500.00

B. Full Name (Last, First, Middle Initial)

Walter Janson

Mailing Address 4611 Trails Drive

\begin{tabular}{lcc}
\hline City & State & Zip Code \\
Sarasota & FL & $34232-3482$ \\
\hline
\end{tabular}

FEC ID number of contributing

federal political committee.

C

Name of Employer
Information Requested
Receipt For: 2012
Primary
Other (specify)

Occupation

Information Requested

Election Cycle-to-Date

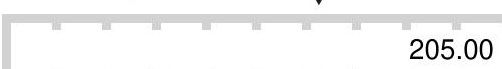

Transaction ID : A46EF348AC8FC448E842

Date of Receipt

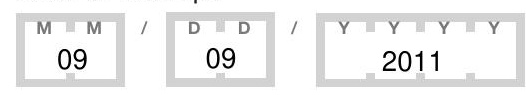

Amount of Each Receipt this Period

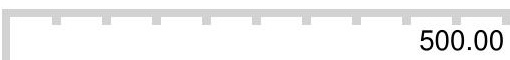

Transaction ID : A7D3BB344A0054768B5F

Date of Receipt

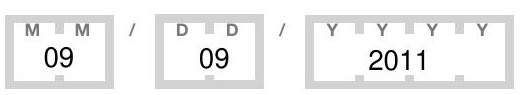

Amount of Each Receipt this Period

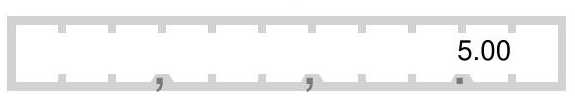

Transaction ID : A582E378768B24A649B5 Date of Receipt

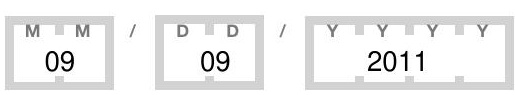

Amount of Each Receipt this Period

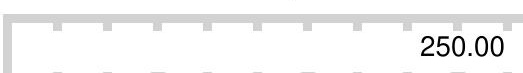

$\begin{array}{cc}\text { State } & \text { Zip Code } \\ \text { GA } & 30047-3955\end{array}$

C

\section{Occupation}

tutor

Election Cycle-to-Date

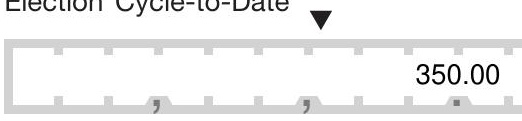

Subtotal Of Receipts This Page (optional).

755.00

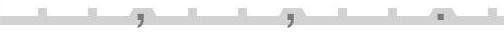

Total This Period (last page this line number only)

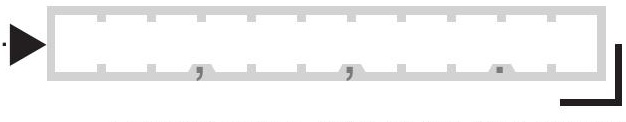

FEC Schedule A-P (Form 3P) (Rev. 03/2011) 
SCHEDULE A-P ITEMIZED RECEIPTS
Use separate schedule(s) for each category of the Detailed Summary Page
FOR LINE NUMBER: (check only one)

PAGE 479 / 1572

\begin{tabular}{|c|c|c|c|c|c|}
\hline & & & & & \\
\hline 16 & $\begin{array}{l}\mathbf{X} \\
17 a\end{array}$ & $17 b$ & $17 c$ & $17 d$ & 18 \\
\hline $19 a$ & $19 \mathrm{~b}$ & $20 \mathrm{a}$ & $20 \mathrm{~b}$ & $20 \mathrm{c}$ & 21 \\
\hline
\end{tabular}

Any information copied from such Reports and Statements may not be sold or used by any person for the purpose of soliciting contributions or for commercial purposes, other than using the name and address of any political committee to solicit contributions from such committee.

NAME OF COMMITTEE (In Full)

\section{Friends of Herman Cain}

A. Full Name (Last, First, Middle Initial)

Gary Dudley

Mailing Address 102 Lacey Oak

\begin{tabular}{lcc}
\hline City & State & Zip Code \\
Shavano Park & TX & $78230-5611$
\end{tabular}

FEC ID number of contributing federal political committee.

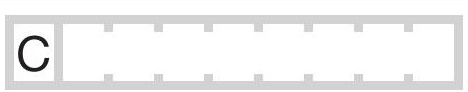

Name of Employer
Information Requested
Receipt For: 2012
X Primary
Other (specify) General

Occupation Information Requested

Election Cycle-to-Date

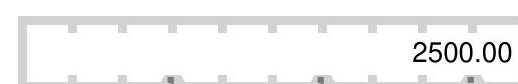

B. Full Name (Last, First, Middle Initial)

Bob Hill

Mailing Address 12147 Caminito Mira Del Mar

\begin{tabular}{lcc}
\hline City & State & Zip Code \\
San Diego & CA & $92130-2302$
\end{tabular}

FEC ID number of contributing

federal political committee.

C

Name of Employer

Occupation

Retired

the man in charge

Receipt For: 2012

Х $\begin{aligned} & \text { Primary } \square \text { General } \\ & \text { Other (specify) } \boldsymbol{\nabla}\end{aligned}$

Election Cycle-to-Date

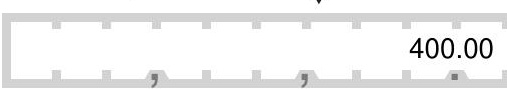

C. Full Name (Last, First, Middle Initial)

Stacie Curtis

Mailing Address 267 Stardust Cir

\begin{tabular}{lcc}
\hline City & State & Zip Code \\
Toney & AL & $35773-9396$
\end{tabular}

FEC ID number of contributing federal political committee.

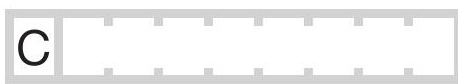

\section{Name of Employer}

The A/C Doctor

Receipt For: 2012

Х $\begin{aligned} & \text { Primary } \square \text { General } \\ & \text { Other (specify) }\end{aligned}$

\section{Occupation}

Office Manager

Election Cycle-to-Date

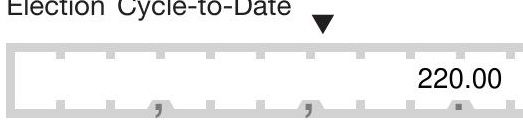

Transaction ID : AD80BD90093DB472B988

Date of Receipt

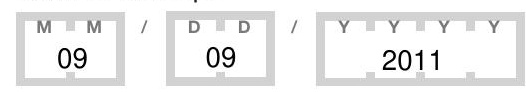

Amount of Each Receipt this Period

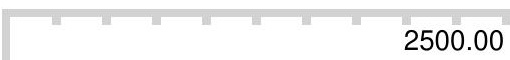

2500.00

Transaction ID : AFE707F23AF9540B79F8

Date of Receipt

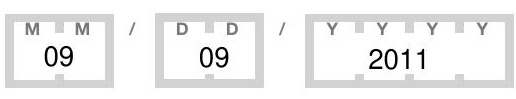

Amount of Each Receipt this Period

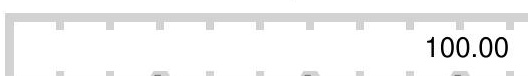

Transaction ID : AA812E84778C744659F0

Date of Receipt

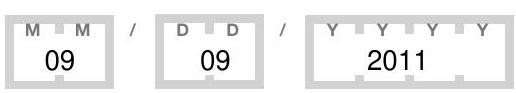

Amount of Each Receipt this Period

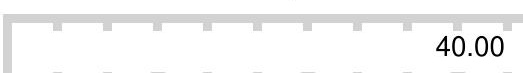

40.00

\section{Subtotal Of Receipts This Page (optional)}

Total This Period (last page this line number only) 
SCHEDULE A-P ITEMIZED RECEIPTS
Use separate schedule(s) for each category of the Detailed Summary Page
FOR LINE NUMBER: (check only one)

PAGE 480 / 1572

\begin{tabular}{|c|c|c|c|c|c|}
\hline & & & & & \\
\hline 16 & $\begin{array}{l}\mathbf{X} \\
17 a\end{array}$ & $17 b$ & $17 c$ & $17 d$ & 18 \\
\hline $19 a$ & $19 \mathrm{~b}$ & $20 \mathrm{a}$ & $20 \mathrm{~b}$ & $20 \mathrm{c}$ & 21 \\
\hline
\end{tabular}

Any information copied from such Reports and Statements may not be sold or used by any person for the purpose of soliciting contributions or for commercial purposes, other than using the name and address of any political committee to solicit contributions from such committee.

NAME OF COMMITTEE (In Full)

\section{Friends of Herman Cain}

A. Full Name (Last, First, Middle Initial)

\section{Dana Plttman}

Mailing Address 1726 Majestic Oak Dr.

\begin{tabular}{lcc}
\hline City & State & Zip Code \\
Apopka & FL & $32712-2528$ \\
\hline
\end{tabular}

FEC ID number of contributing federal political committee.

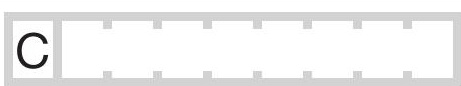

Name of Employer

Computer Solutions Engineering

Occupation

Receipt For: 2012

Х Primary $\square$ General

VP Sales \&amp; Service

Election Cycle-to-Date $\boldsymbol{\nabla}$

250.00

B. Full Name (Last, First, Middle Initial)

MARK LOPEZ

Mailing Address 1830 BREA BLVD \#3

\begin{tabular}{lcc}
\hline City & State & Zip Code \\
Fullerton & CA & $92835-3944$ \\
\hline
\end{tabular}

FEC ID number of contributing

federal political committee.

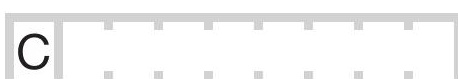

Name of Employer
BECKMAN COULTER INC
Receipt For: 2012
X Primary
Other (specify)

Occupation

SW Engineer

Election Cycle-to-Date

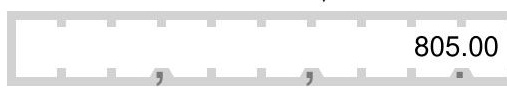

Transaction ID : AE8E0CDBE6C544EF59B3

Date of Receipt

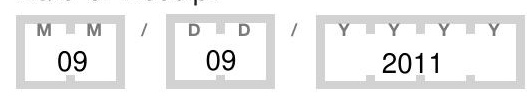

Amount of Each Receipt this Period

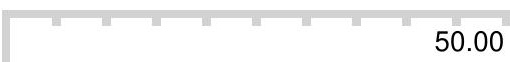

50.00

C. Full Name (Last, First, Middle Initial)

Mr. Nick Searcy

Mailing Address $813 \mathrm{n}$ pass ave

\begin{tabular}{lcc}
\hline City & State & Zip Code \\
Burbank & CA & $91505-2702$
\end{tabular}

FEC ID number of contributing federal political committee.

C

Name of Employer
Information Requested
Receipt For: 2012
X Primary $\quad \square$ General
Other (specify)

Occupation

Information Requested

Election Cycle-to-Date
Transaction ID : A7A485DEE75FB4CED976 Date of Receipt

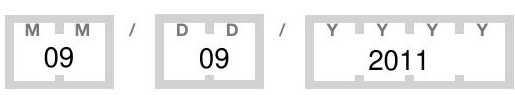

Amount of Each Receipt this Period

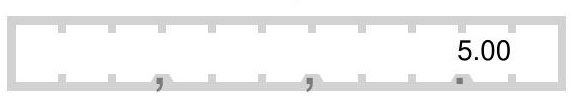

Transaction ID : A7A82F2D845444F369C9 Date of Receipt

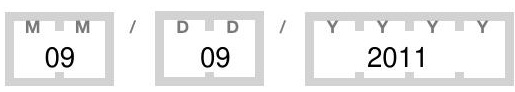

Amount of Each Receipt this Period

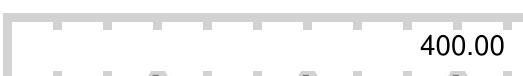

\section{Subtotal Of Receipts This Page (optional)}

Total This Period (last page this line number only) 
SCHEDULE A-P ITEMIZED RECEIPTS
Use separate schedule(s) for each category of the Detailed Summary Page
FOR LINE NUMBER: (check only one)
PAGE $481 / 1572$

\begin{tabular}{|c|c|c|c|c|c|}
\hline & & & & & \\
\hline 16 & $\begin{array}{lll}X & 17 a \\
\end{array}$ & $17 \mathrm{~b}$ & $17 c$ & $17 d$ & 18 \\
\hline $19 a$ & $19 b$ & $20 a$ & $20 \mathrm{~b}$ & $20 c$ & 21 \\
\hline
\end{tabular}

Any information copied from such Reports and Statements may not be sold or used by any person for the purpose of soliciting contributions or for commercial purposes, other than using the name and address of any political committee to solicit contributions from such committee.

NAME OF COMMITTEE (In Full)

\section{Friends of Herman Cain}

A. Full Name (Last, First, Middle Initial)

Kenneth A Ebi

Mailing Address 6822 Rock Crest Ln

\begin{tabular}{lcc}
\hline City & State & Zip Code \\
Citrus Heights & CA & $95621-8369$ \\
\hline
\end{tabular}

FEC ID number of contributing federal political committee.

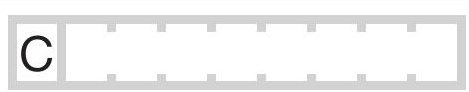

Name of Employer
None
Receipt For: 2012
X Primary $\quad$ General
$\quad$ Other (specify)

Occupation

Retired

Election Cycle-to-Date

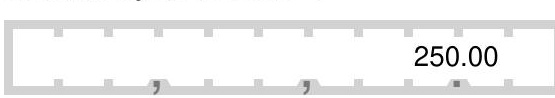

B. Full Name (Last, First, Middle Initial)

Jan Jinyoung Kim

Mailing Address 2636 Harman Park Ct

\begin{tabular}{lcc}
\hline City & State & Zip Code \\
Duluth & GA & $30097-4959$
\end{tabular}

FEC ID number of contributing

federal political committee.

C

Name of Employer
Prime Home Loans Inc
Receipt For: 2012
X Primary
Other (specify)

\section{Occupation}

Manager

Election Cycle-to-Date

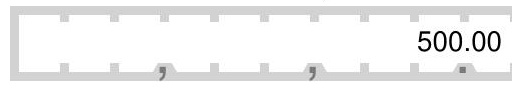

C. Full Name (Last, First, Middle Initial)

Drucilla Jacobs

Mailing Address 3075 Rice Mill Rd None

\begin{tabular}{lcc}
\hline City & State & Zip Code \\
Macon & GA & $31206-3301$ \\
\hline
\end{tabular}

FEC ID number of contributing federal political committee.

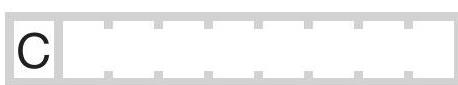

Name of Employer
n/a
Receipt For: 2012
X Primary $\quad \square$ General
Other (specify)

$\begin{aligned} & \text { Occupation } \\ & \text { Retired }\end{aligned}$
Election Cycle-to-Date

Transaction ID : A2077D827CD6B4B61A21

Date of Receipt

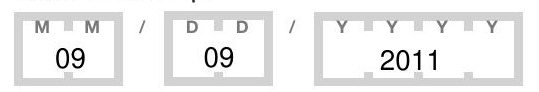

Amount of Each Receipt this Period

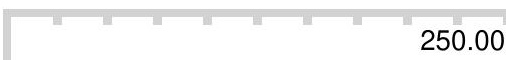

250.00
Amount of Each Receipt this Period

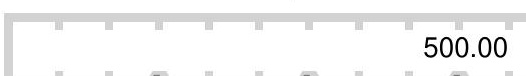

Transaction ID : A647260D74DAA42E3B4A Date of Receipt

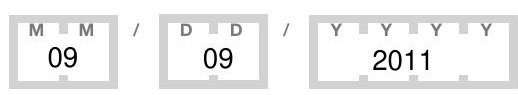

Transaction ID : A698751206C424DFA852 Date of Receipt

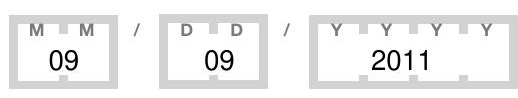

Amount of Each Receipt this Period

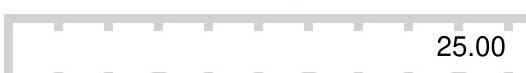

25.00

\section{Subtotal Of Receipts This Page (optional)}

Total This Period (last page this line number only) 
SCHEDULE A-P ITEMIZED RECEIPTS
Use separate schedule(s) for each category of the Detailed Summary Page
FOR LINE NUMBER: (check only one)

PAGE 482 / 1572

\begin{tabular}{|c|c|c|c|c|c|c|}
\hline & & & & & & \\
\hline 16 & $\lambda$ & $17 \mathrm{a}$ & $17 \mathrm{~b}$ & $17 \mathrm{c}$ & $-17 d$ & -18 \\
\hline $19 a$ & & $19 b$ & $20 a$ & $20 \mathrm{~b}$ & $20 \mathrm{c}$ & 21 \\
\hline
\end{tabular}

Any information copied from such Reports and Statements may not be sold or used by any person for the purpose of soliciting contributions or for commercial purposes, other than using the name and address of any political committee to solicit contributions from such committee.

NAME OF COMMITTEE (In Full)

\section{Friends of Herman Cain}

A. Full Name (Last, First, Middle Initial)

Mr Ronald G Larson

Mailing Address 2624 Pin Oak Dr

\begin{tabular}{lcc}
\hline City & State & Zip Code \\
Ann Arbor & MI & $48103-2369$
\end{tabular}

FEC ID number of contributing federal political committee.

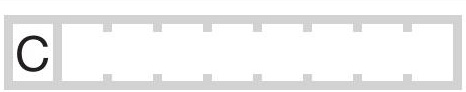

Name of Employer
Information Requested
Receipt For: 2012
X Primary
Other (specify) General

Occupation Information Requested

Election Cycle-to-Date

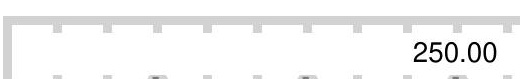

B. Full Name (Last, First, Middle Initial)

Sylvia D Barnes

Mailing Address 75495 Road 436

\begin{tabular}{lcc}
\hline City & State & Zip Code \\
Lexington & NE & $68850-5638$ \\
\hline
\end{tabular}

FEC ID number of contributing

federal political committee.

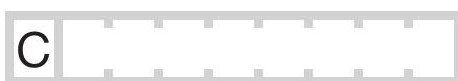

Name of Employer
None
Receipt For: 2012
X Primary
Other (specify)

Occupation

Retired

Election Cycle-to-Date

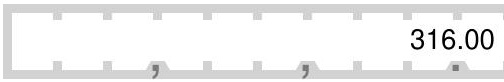

Transaction ID : A044C0C20AB144BD6965

Date of Receipt

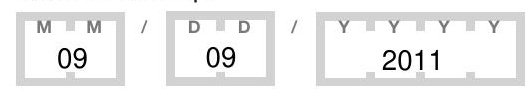

Amount of Each Receipt this Period

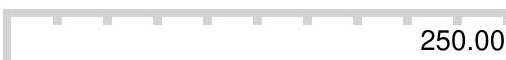

250.00

C. Full Name (Last, First, Middle Initial)

Brian Whitlow

Mailing Address 4310 Shillham Court

\begin{tabular}{lcc}
\hline City & State & Zip Code \\
Cumming & GA & $30040-1553$
\end{tabular}

FEC ID number of contributing federal political committee.

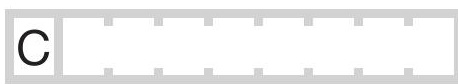

Name of Employer
FleetCor Technologies
Receipt For: 2012
X Primary $\quad \square$ General
Other (specify)

\section{Occupation}

IT Analyst

Election Cycle-to-Date

Transaction ID : A9EA971F37FC245C5865

Date of Receipt

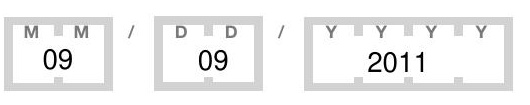

Amount of Each Receipt this Period

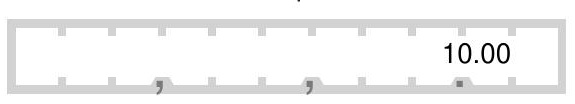

Transaction ID : A1E4113ED57B3422188F

Date of Receipt

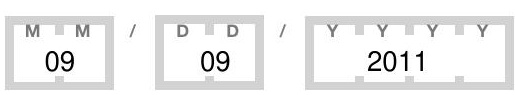

Amount of Each Receipt this Period

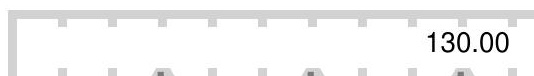

580.00

Subtotal Of Receipts This Page (optional).

390.00

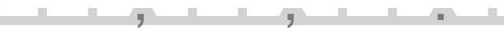

Total This Period (last page this line number only)

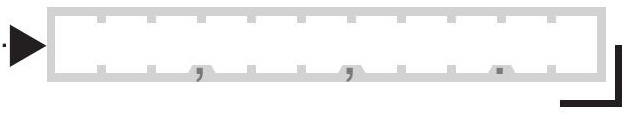

FEC Schedule A-P (Form 3P) (Rev. 03/2011) 
SCHEDULE A-P ITEMIZED RECEIPTS
Use separate schedule(s) for each category of the Detailed Summary Page
FOR LINE NUMBER: (check only one)

PAGE 483 / 1572

\begin{tabular}{|c|c|c|c|c|c|}
\hline & & & & & \\
\hline 16 & $\begin{array}{lll}X & 17 a \\
\end{array}$ & $17 \mathrm{~b}$ & $17 c$ & $17 d$ & 18 \\
\hline $19 a$ & $19 b$ & $20 a$ & $20 \mathrm{~b}$ & $20 c$ & 21 \\
\hline
\end{tabular}

Any information copied from such Reports and Statements may not be sold or used by any person for the purpose of soliciting contributions or for commercial purposes, other than using the name and address of any political committee to solicit contributions from such committee.

NAME OF COMMITTEE (In Full)

\section{Friends of Herman Cain}

A. Full Name (Last, First, Middle Initial) James O Barlow

Mailing Address 194 W 12650 S

\begin{tabular}{lcc}
\hline City & State & Zip Code \\
Draper & UT & $84020-8615$
\end{tabular}

FEC ID number of contributing federal political committee.

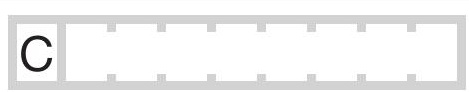

Name of Employer
J \& S Mech Contr
Receipt For: 2012
X Primary
Other (specify) General

Occupation

Executive

Election Cycle-to-Date 500.00

B. Full Name (Last, First, Middle Initial) Joan Scott

Mailing Address 133 Nail Dr

\begin{tabular}{lcc}
\hline City & State & Zip Code \\
McDonough & GA & $30253-7344$ \\
\hline
\end{tabular}

FEC ID number of contributing

federal political committee.

C

Name of Employer
DOT/FAA
Receipt For: 2012
X Primary
Other (specify)

\section{Occupation}

Administrative Assistant

Election Cycle-to-Date

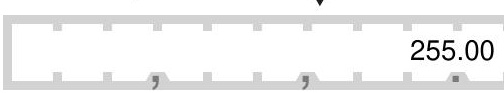

Transaction ID : A35F7AB361A8E434EBFE

Date of Receipt

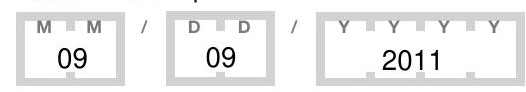

Amount of Each Receipt this Period

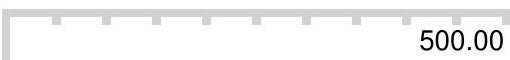

Amount of Each Receipt this Period

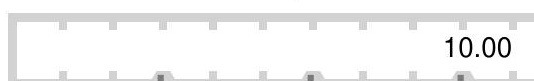

C. Full Name (Last, First, Middle Initial)

Andy Hill

Mailing Address 409 N. Roosevelt St.

\begin{tabular}{lcc}
\hline City & State & Zip Code \\
Bloomington & IN & $47408-4186$
\end{tabular}

FEC ID number of contributing federal political committee.

C

47408-4186

Name of Employer

Information Requested

Occupation

Receipt For: 2012

Х $\begin{aligned} & \text { Primary } \square \text { General } \\ & \text { Other (specify) }\end{aligned}$

Information Requested

Election Cycle-to-Date

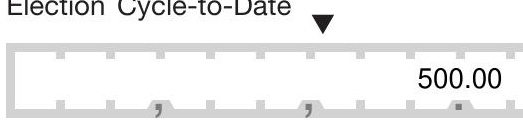

Transaction ID : A7EE8505B665C4B19A16

Date of Receipt

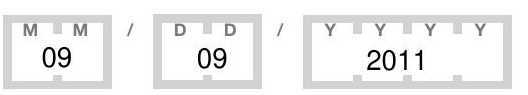

Transaction ID : A988CE73E64C24E28BD1 Date of Receipt

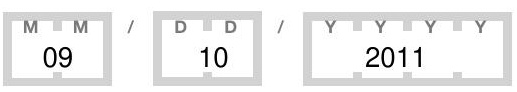

Amount of Each Receipt this Period

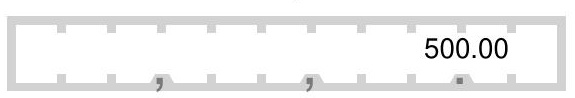

Subtotal Of Receipts This Page (optional).

1010.00

Total This Period (last page this line number only) 
SCHEDULE A-P ITEMIZED RECEIPTS
Use separate schedule(s) for each category of the Detailed Summary Page
FOR LINE NUMBER: (check only one)
PAGE 484 / 1572

\begin{tabular}{|c|c|c|c|c|c|}
\hline & & & & & \\
\hline 16 & $\begin{array}{lll}X & 17 a \\
\end{array}$ & $17 \mathrm{~b}$ & $17 c$ & $17 d$ & 18 \\
\hline $19 a$ & $19 b$ & $20 a$ & $20 \mathrm{~b}$ & $20 c$ & 21 \\
\hline
\end{tabular}

Any information copied from such Reports and Statements may not be sold or used by any person for the purpose of soliciting contributions or for commercial purposes, other than using the name and address of any political committee to solicit contributions from such committee.

NAME OF COMMITTEE (In Full)

\section{Friends of Herman Cain}

A. Full Name (Last, First, Middle Initial)

Stephen Prior

Mailing Address 9606 Atom Rd.

\begin{tabular}{lcc}
\hline City & State & Zip Code \\
Clinton & MD & $20735-2903$ \\
\hline
\end{tabular}

FEC ID number of contributing federal political committee.

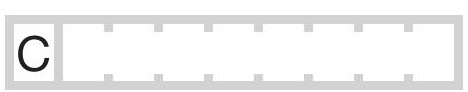

Name of Employer
US Navy
Receipt For: 2012
X Primary $\quad$ General
Other (specify)

Occupation

Management Analyst

Election Cycle-to-Date

700.00

B. Full Name (Last, First, Middle Initial)

Debra Gilliam

Mailing Address 1807 Rockybranch Pass

\begin{tabular}{lcc}
\hline City & State & Zip Code \\
Marietta & GA & $30066-8014$ \\
\hline
\end{tabular}

FEC ID number of contributing

federal political committee.

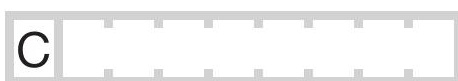

Name of Employer
Information Requested
Receipt For: 2012
X Primary
Other (specify)

\section{Occupation}

Information Requested

Election Cycle-to-Date

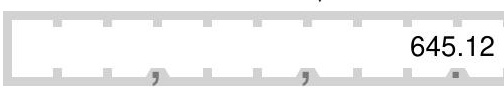

Transaction ID : A3AD2CDCC27E648E1B2B

Date of Receipt

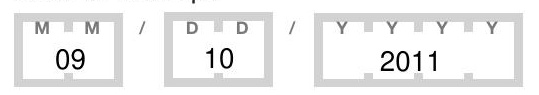

Amount of Each Receipt this Period

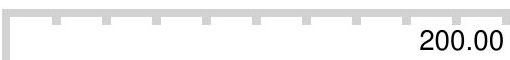

C. Full Name (Last, First, Middle Initial)

Paul Engleson

Mailing Address 5877 Pontiac Dr.

\begin{tabular}{lcc}
\hline City & State & Zip Code \\
Woodbridge & VA & $22193-3801$
\end{tabular}

FEC ID number of contributing federal political committee.

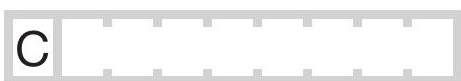

Name of Employer
GWS
Receipt For: 2012
X Primary
Other (specify) General

Occupation

bench marking

Election Cycle-to-Date

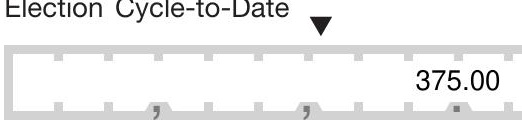

Amount of Each Receipt this Period

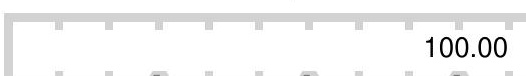

Transaction ID : AE35D5EA8AAC84404883

Date of Receipt

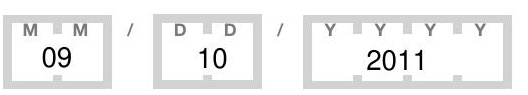

Transaction ID : AFE383796A7D24603B5F Date of Receipt

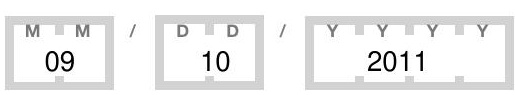

Amount of Each Receipt this Period

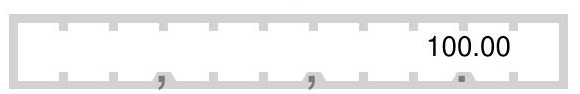

\section{Subtotal Of Receipts This Page (optional)}

400.00

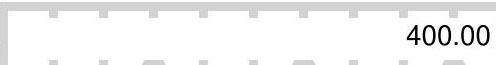

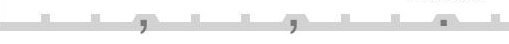

Total This Period (last page this line number only)

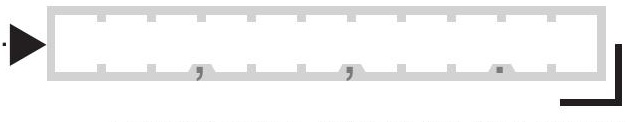

FEC Schedule A-P (Form 3P) (Rev. 03/2011) 
SCHEDULE A-P ITEMIZED RECEIPTS
Use separate schedule(s) for each category of the Detailed Summary Page
FOR LINE NUMBER: (check only one)
PAGE 485 / 1572

\begin{tabular}{|c|c|c|c|c|c|}
\hline & & & & & \\
\hline 16 & $\begin{array}{lll}X & 17 a \\
\end{array}$ & $17 \mathrm{~b}$ & $17 c$ & $17 d$ & 18 \\
\hline $19 a$ & $19 b$ & $20 a$ & $20 \mathrm{~b}$ & $20 c$ & 21 \\
\hline
\end{tabular}

Any information copied from such Reports and Statements may not be sold or used by any person for the purpose of soliciting contributions or for commercial purposes, other than using the name and address of any political committee to solicit contributions from such committee.

NAME OF COMMITTEE (In Full)

\section{Friends of Herman Cain}

A. Full Name (Last, First, Middle Initial) Janice Pinkston

Mailing Address 20 Tamalpais Avenue

\begin{tabular}{lcc}
\hline City & State & Zip Code \\
Belvedere Tiburon & CA & $94920-2468$
\end{tabular}

FEC ID number of contributing federal political committee.

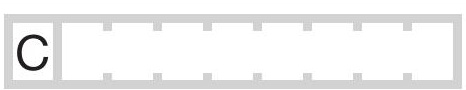

Name of Employer
None
Receipt For: 2012
X Primary $\quad$ General
Other (specify)

Occupation Homemaker

Election Cycle-to-Date

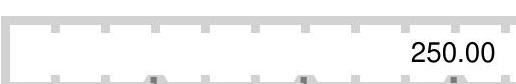

B. Full Name (Last, First, Middle Initial) Larry Williams

Mailing Address 5907 Wesleyan Dr N

\begin{tabular}{lcc}
\hline City & State & Zip Code \\
Macon & GA & $31210-6011$ \\
\hline
\end{tabular}

FEC ID number of contributing

federal political committee.

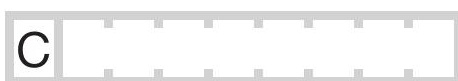

Name of Employer
U. S. Air Force
Receipt For: 2012
X Primary
Other (specify)

\section{Occupation}

Engineer

Election Cycle-to-Date

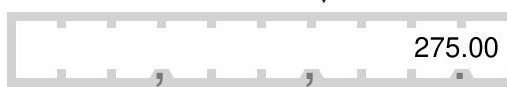

C. Full Name (Last, First, Middle Initial)

Angie Bettencourt

Mailing Address 5056 Academy St.

\begin{tabular}{lcc}
\hline City & State & Zip Code \\
Houston & TX & $77005-1083$
\end{tabular}

FEC ID number of contributing federal political committee.

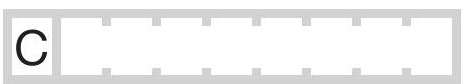

Name of Employer

Information Requested

Occupation

Information Requested

Receipt For: 2012

Х $\begin{aligned} & \text { Primary } \\ & \text { Other (specify) }\end{aligned}$

Election Cycle-to-Date

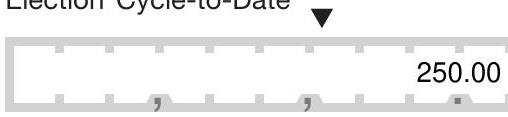

Transaction ID : A001B8FFB277340EFA7D

Date of Receipt

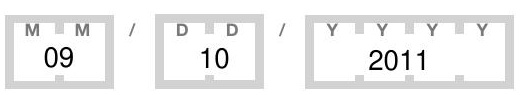

Amount of Each Receipt this Period

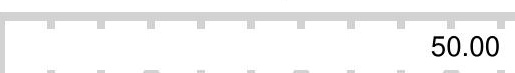

Transaction ID : AE264059F682C4597802

Date of Receipt

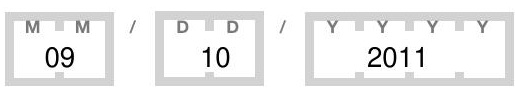

Amount of Each Receipt this Period

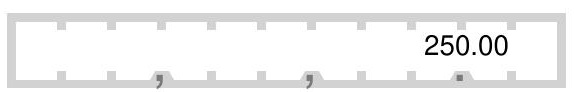

Subtotal Of Receipts This Page (optional)

550.00

Total This Period (last page this line number only) 
SCHEDULE A-P ITEMIZED RECEIPTS
Use separate schedule(s) for each category of the Detailed Summary Page
FOR LINE NUMBER: (check only one)
PAGE 486 / 1572

\begin{tabular}{|c|c|c|c|c|c|}
\hline & & & & & \\
\hline 16 & $\begin{array}{lll}X & 17 a \\
\end{array}$ & $17 \mathrm{~b}$ & $17 c$ & $17 d$ & 18 \\
\hline $19 a$ & $19 b$ & $20 a$ & $20 \mathrm{~b}$ & $20 c$ & 21 \\
\hline
\end{tabular}

Any information copied from such Reports and Statements may not be sold or used by any person for the purpose of soliciting contributions or for commercial purposes, other than using the name and address of any political committee to solicit contributions from such committee.

NAME OF COMMITTEE (In Full)

\section{Friends of Herman Cain}

A. Full Name (Last, First, Middle Initial)

\section{Daniel Stone}

Mailing Address 4417 Sterling Pointe Dr

\begin{tabular}{lcc}
\hline City & State & Zip Code \\
Kennesaw & GA & $30152-7348$ \\
\hline
\end{tabular}

FEC ID number of contributing

federal political committee.

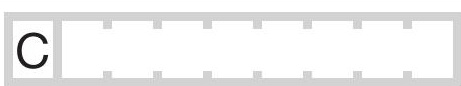

Name of Employer
INVISTA S.a.r.I.
Receipt For: 2012
X Primary
Other (specify)

Occupation

VP - Business Analysis

Election Cycle-to-Date

440.00

B. Full Name (Last, First, Middle Initial)

Michael Roth

Mailing Address 4393 Westminster Place

\begin{tabular}{lcc}
\hline City & State & Zip Code \\
Saint Louis & MO & $63108-2623$
\end{tabular}

FEC ID number of contributing

federal political committee.

C

Name of Employer
Information Requested
Receipt For: 2012
X Primary
Other (specify)

Occupation

Information Requested

Election Cycle-to-Date

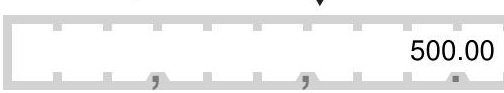

Transaction ID : AED45906293AB41A7B0A

Date of Receipt

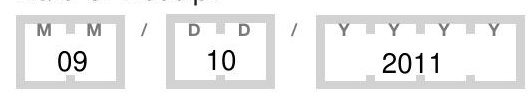

Amount of Each Receipt this Period

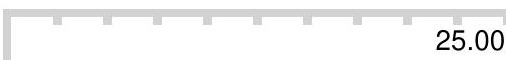

25.00

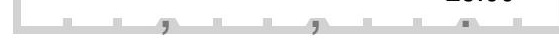

C. Full Name (Last, First, Middle Initial)

Jim Eure Jr.

Mailing Address PO Box 156

\begin{tabular}{lcc}
\hline City & State & Zip Code \\
Dahlonega & GA & $30533-0003$
\end{tabular}

FEC ID number of contributing federal political committee.

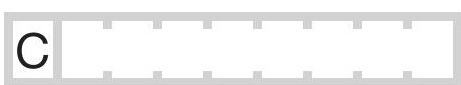

Name of Employer

Occupation

Protex Security Systems

Owner

Transaction ID : AE78BB1B6DEBA4185B58

Date of Receipt

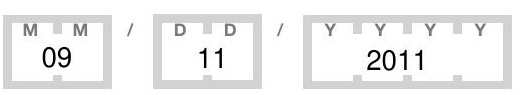

Amount of Each Receipt this Period

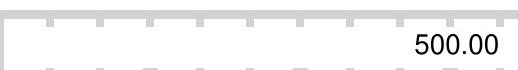

Transaction ID : A68D0BFD760E944E6866

Date of Receipt

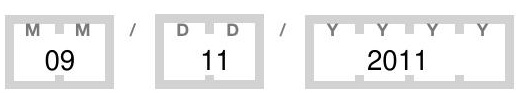

Amount of Each Receipt this Period

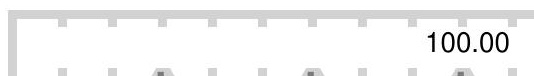

515.00

Subtotal Of Receipts This Page (optional)

625.00

(I)

Total This Period (last page this line number only)

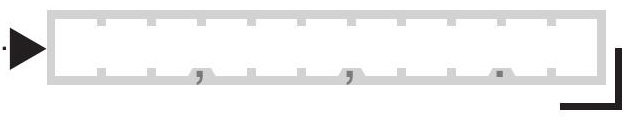

FEC Schedule A-P (Form 3P) (Rev. 03/2011) 
SCHEDULE A-P ITEMIZED RECEIPTS
Use separate schedule(s) for each category of the Detailed Summary Page
FOR LINE NUMBER: (check only one)
PAGE 487 / 1572

\begin{tabular}{|c|c|c|c|c|c|}
\hline & & & & & \\
\hline 16 & $\begin{array}{lll}X & 17 a \\
\end{array}$ & $17 \mathrm{~b}$ & $17 c$ & $17 d$ & 18 \\
\hline $19 a$ & $19 b$ & $20 a$ & $20 \mathrm{~b}$ & $20 c$ & 21 \\
\hline
\end{tabular}

Any information copied from such Reports and Statements may not be sold or used by any person for the purpose of soliciting contributions or for commercial purposes, other than using the name and address of any political committee to solicit contributions from such committee.

NAME OF COMMITTEE (In Full)

\section{Friends of Herman Cain}

A. Full Name (Last, First, Middle Initial)

\section{Carol Cook}

Mailing Address 43 Oak Alley

\begin{tabular}{lcc}
\hline City & State & Zip Code \\
Kerrville & TX & 78028-1711
\end{tabular}

FEC ID number of contributing federal political committee.

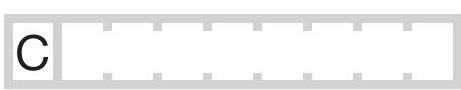

Name of Employer
James Avery
Receipt For: 2012
X Primary $\quad$ General
Other (specify)

B. Full Name (Last, First, Middle Initial)

Carol Cook

Mailing Address 43 Oak Alley

\begin{tabular}{lcc}
\hline City & State & Zip Code \\
Kerrville & TX & $78028-1711$
\end{tabular}

FEC ID number of contributing

federal political committee.

Name of Employer
James Avery
Receipt For: 2012
X Primary
Other (specify)

C. Full Name (Last, First, Middle Initial)

James Irwin

Mailing Address 4761 county road 5

\begin{tabular}{lcc}
\hline City & State & Zip Code \\
Delta & OH & $43515-9262$ \\
\hline
\end{tabular}

FEC ID number of contributing federal political committee.

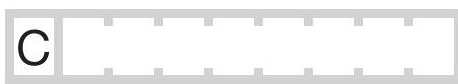

Name of Employer
regal cabinet
Receipt For: 2012
X Primary $\quad \square$ General
Other (specify)

C

Occupation Sales Team Leader Election Cycle-to-Date Occupation Sales Team Leader Election Cycle-to-Date 252.60

\begin{tabular}{l}
$\begin{array}{l}\text { Occupation } \\
\text { cabinet maker } \\
\text { Election Cycle-to-Date }\end{array}$ \\
\hline
\end{tabular}

Transaction ID : A2FBA2E2BEC764BBB957

Date of Receipt

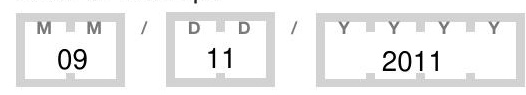

Amount of Each Receipt this Period

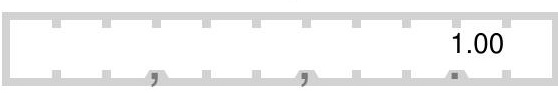

Transaction ID : A171B547F76824401A61

Date of Receipt

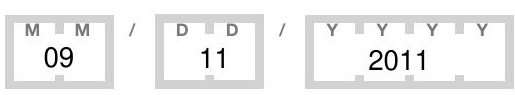

Amount of Each Receipt this Period

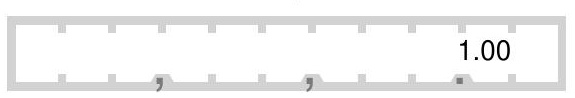

Transaction ID : A1C0A356B9478433A90F

Date of Receipt

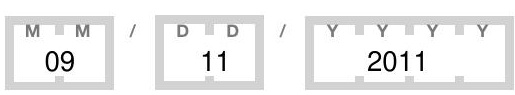

Amount of Each Receipt this Period

Subtotal Of Receipts This Page (optional)

102.00

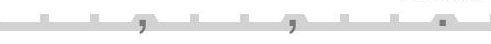

Total This Period (last page this line number only)

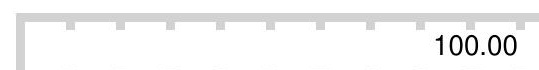

100.00

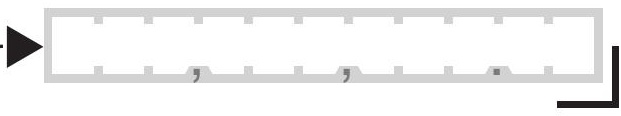


SCHEDULE A-P ITEMIZED RECEIPTS
Use separate schedule(s) for each category of the Detailed Summary Page
FOR LINE NUMBER: (check only one)
PAGE 488 / 1572

\begin{tabular}{|c|c|c|c|c|c|}
\hline & & & & & \\
\hline 16 & $\begin{array}{lll}X & 17 a \\
\end{array}$ & $17 \mathrm{~b}$ & $17 c$ & $17 d$ & 18 \\
\hline $19 a$ & $19 b$ & $20 a$ & $20 \mathrm{~b}$ & $20 c$ & 21 \\
\hline
\end{tabular}

Any information copied from such Reports and Statements may not be sold or used by any person for the purpose of soliciting contributions or for commercial purposes, other than using the name and address of any political committee to solicit contributions from such committee.

NAME OF COMMITTEE (In Full)

\section{Friends of Herman Cain}

A. Full Name (Last, First, Middle Initial)

Mr. Richard M. Campbell

Mailing Address 1535 Bamwick Dr.

\begin{tabular}{lcc}
\hline City & State & Zip Code \\
Houston & TX & $77090-1111$
\end{tabular}

FEC ID number of contributing federal political committee.

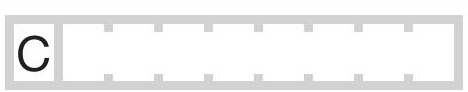

Name of Employer
None
Receipt For: 2012
X Primary $\quad$ General
Other (specify)

Occupation

Retired

Election Cycle-to-Date

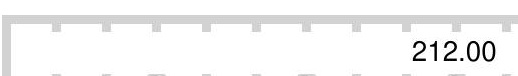

B. Full Name (Last, First, Middle Initial)

Paul Strunk

Mailing Address 802 N Carancahua St Ste 1250

\begin{tabular}{lcc}
\hline City & State & Zip Code \\
Corpus Christi & TX & $78401-0019$ \\
\hline
\end{tabular}

FEC ID number of contributing

federal political committee.

C

Name of Employer

American Shoreline, Inc.

Occupation

Receipt For: 2012

$\chi \begin{aligned} & \text { Primary } \\ & \text { Other (specify) }\end{aligned}$

Geologist

Transaction ID : A9F64A8582536446A8E0

Date of Receipt

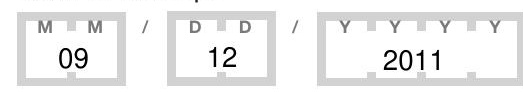

Amount of Each Receipt this Period

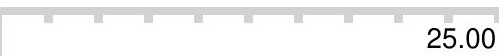

25.00

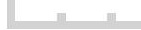

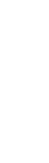

Transaction ID : A2425DA8C7F634A82AC1

Date of Receipt

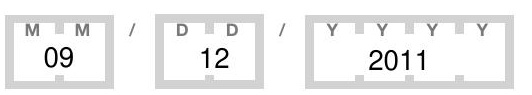

Amount of Each Receipt this Period

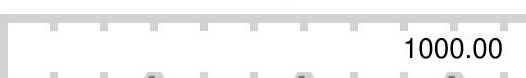

Election Cycle-to-Date

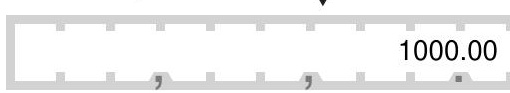

C. Full Name (Last, First, Middle Initial)

john deloreto

Mailing Address 1013 via regina

\begin{tabular}{lcc}
\hline City & State & Zip Code \\
Santa Barbara & CA & 93111-1339
\end{tabular}

FEC ID number of contributing

federal political committee.

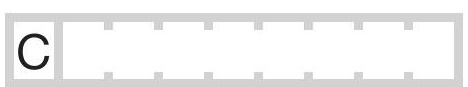

Name of Employer

Information Requested

Occupation

Information Requested

Receipt For: 2012

Х $\begin{aligned} & \text { Primary } \square \text { General } \\ & \text { Other (specify) }\end{aligned}$

Election Cycle-to-Date

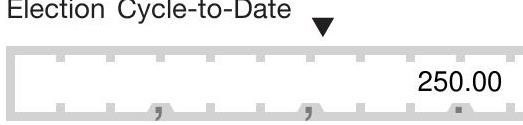

Amount of Each Receipt this Period

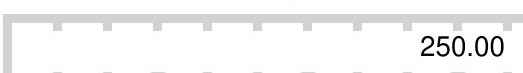

Transaction ID : ABACDC02439E042B78C3

Date of Receipt

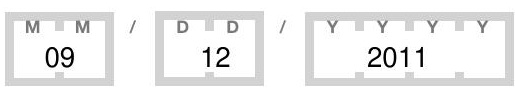

Subtotal Of Receipts This Page (optional)

1275.00

Total This Period (last page this line number only) 
SCHEDULE A-P ITEMIZED RECEIPTS
Use separate schedule(s)

for each category of the

Detailed Summary Page
FOR LINE NUMBER: (check only one)

Any information copied from such Repor or for commercial purposes, other than using the name and address of any political committee to solicit contributions from such committee.

NAME OF COMMITTEE (In Full)

\section{Friends of Herman Cain}

A. Full Name (Last, First, Middle Initial)

Jacqueline Castagno

Mailing Address 4906 NW 65th Way

\begin{tabular}{lcc}
\hline City & State & Zip Code \\
Gainesville & FL & $32653-3937$
\end{tabular}

FEC ID number of contributing

federal political committee.

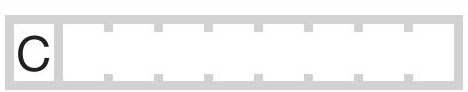

Name of Employer
Univ Florida
Receipt For: 2012
X Primary
Other (specify) General

Occupation

Physician

Election Cycle-to-Date

700.00

B. Full Name (Last, First, Middle Initial)

William R Wiggins Jr

Mailing Address P.O. Box 1251

\begin{tabular}{lcc}
\hline City & State & Zip Code \\
Lindale & TX & $75771-1251$ \\
\hline
\end{tabular}

FEC ID number of contributing

federal political committee.

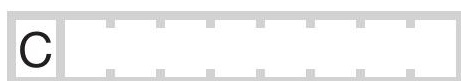

Name of Employer
Colonial Life
Receipt For: 2012
X Primary
Other (specify)

\section{Occupation}

Sales

Election Cycle-to-Date

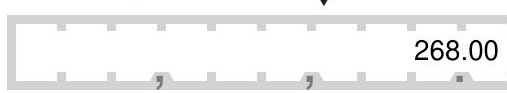

Transaction ID : A73D32E5853854604A32

Date of Receipt

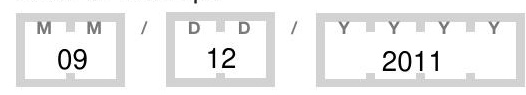

Amount of Each Receipt this Period

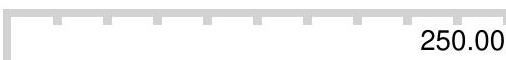

C. Full Name (Last, First, Middle Initial)

Robert Protzman

Mailing Address 230 ash park jefferson city mo 230

\begin{tabular}{lcc}
\hline City & State & Zip Code \\
Jefferson City & MO & 65109 \\
\hline
\end{tabular}

FEC ID number of contributing federal political committee.

C

Name of Employer
retired dentist
Receipt For: 2012
X Primary
Other (specify) General

\section{Occupation}

Retired

Election Cycle-to-Date

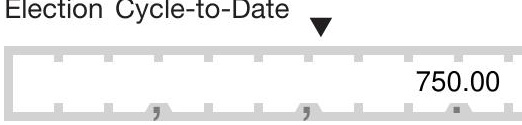

Amount of Each Receipt this Period

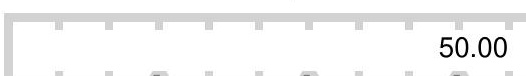

Transaction ID : A3CEB8745FCA24AFB8E4 Date of Receipt

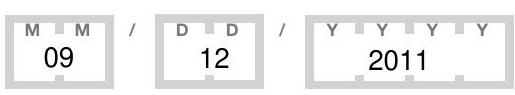

Transaction ID : A0CCE631B5177481A809 Date of Receipt

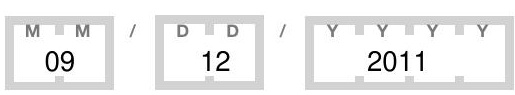

Amount of Each Receipt this Period

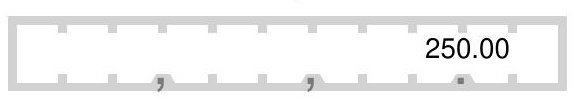

\section{Subtotal Of Receipts This Page (optional)}

Total This Period (last page this line number only) 
SCHEDULE A-P ITEMIZED RECEIPTS
Use separate schedule(s) for each category of the Detailed Summary Page
FOR LINE NUMBER: (check only one)

PAGE $490 / 1572$

\begin{tabular}{|c|c|c|c|c|c|c|}
\hline & & & & & & \\
\hline 16 & $\lambda$ & $17 \mathrm{a}$ & $17 \mathrm{~b}$ & $17 \mathrm{c}$ & $-17 d$ & -18 \\
\hline $19 a$ & & $19 b$ & $20 a$ & $20 \mathrm{~b}$ & $20 \mathrm{c}$ & 21 \\
\hline
\end{tabular}

Any information copied from such Reports and Statements may not be sold or used by any person for the purpose of soliciting contributions or for commercial purposes, other than using the name and address of any political committee to solicit contributions from such committee.

NAME OF COMMITTEE (In Full)

\section{Friends of Herman Cain}

A. Full Name (Last, First, Middle Initial)

Julia Jones Matthews

Mailing Address PO Box 176

\begin{tabular}{lcc}
\hline City & State & Zip Code \\
Abilene & TX & 79604-0176
\end{tabular}

FEC ID number of contributing

federal political committee.

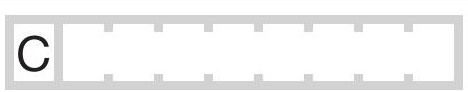

Name of Employer
self
Receipt For: 2012
X Primary $\quad$ General
Other (specify)

Occupation

Retired

Election Cycle-to-Date

1500.00

B. Full Name (Last, First, Middle Initial)

Kenneth Cook

Mailing Address 175 Wilder Drive

\begin{tabular}{lcc}
\hline City & State & Zip Code \\
Jackson & GA & $30233-4101$
\end{tabular}

FEC ID number of contributing

federal political committee.

C

Name of Employer
Information Requested
Receipt For: 2012
Primary
Other (specify)

Occupation

Information Requested

Election Cycle-to-Date

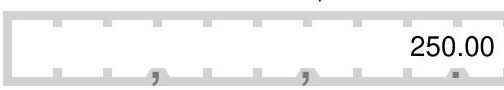

Transaction ID : A8E2E8532D98A477596D

Date of Receipt

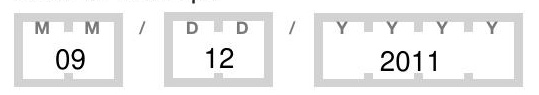

Amount of Each Receipt this Period

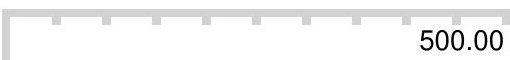

C. Full Name (Last, First, Middle Initial)

Joseph Moderow

Mailing Address 11292 Big Canoe

\begin{tabular}{lcc}
\hline City & State & Zip Code \\
Big Canoe & GA & $30143-5105$
\end{tabular}

FEC ID number of contributing

federal political committee.

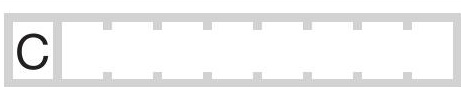

Name of Employer
self
Receipt For: 2012
X Primary
Other (specify) General

Occupation

Writer

Election Cycle-to-Date

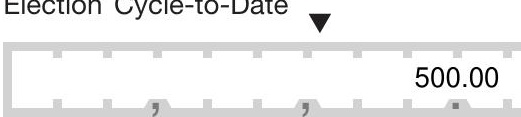

Amount of Each Receipt this Period

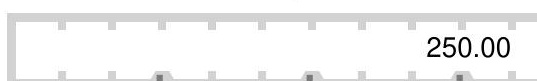

Transaction ID : A912395057B354591A87

Date of Receipt

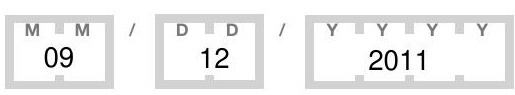

Transaction ID : AF6DC45675E274BD1B1A Date of Receipt

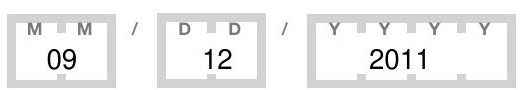

Amount of Each Receipt this Period

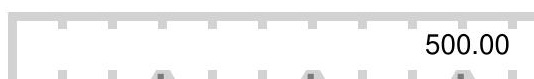

Subtotal Of Receipts This Page (optional).

Total This Period (last page this line number only) 
SCHEDULE A-P ITEMIZED RECEIPTS
Use separate schedule(s) for each category of the Detailed Summary Page
FOR LINE NUMBER: (check only one)
PAGE $491 / 1572$

\begin{tabular}{|c|c|c|c|c|c|}
\hline & & & & & \\
\hline 16 & $\begin{array}{lll}X & 17 a \\
\end{array}$ & $17 \mathrm{~b}$ & $17 c$ & $17 d$ & 18 \\
\hline $19 a$ & $19 b$ & $20 a$ & $20 \mathrm{~b}$ & $20 c$ & 21 \\
\hline
\end{tabular}

Any information copied from such Reports and Statements may not be sold or used by any person for the purpose of soliciting contributions or for commercial purposes, other than using the name and address of any political committee to solicit contributions from such committee.

NAME OF COMMITTEE (In Full)

\section{Friends of Herman Cain}

A. Full Name (Last, First, Middle Initial)

\section{Ms Patricia B Earnest}

Mailing Address 1307 Redwine Road

\begin{tabular}{lcc}
\hline City & State & Zip Code \\
Fayetteville & GA & $30215-2351$
\end{tabular}

FEC ID number of contributing federal political committee.

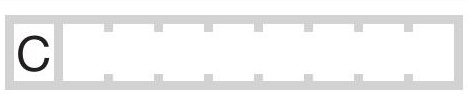

Name of Employer
None
Receipt For: 2012
X Primary $\quad$ General
Other (specify)

Occupation Retired

Election Cycle-to-Date

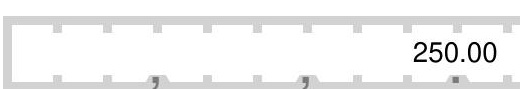

B. Full Name (Last, First, Middle Initial)

Mrs. Patricia B Thomas

Mailing Address 1400 N Harris Rdg NW

\begin{tabular}{lcc}
\hline City & State & Zip Code \\
Atlanta & GA & $30327-4423$ \\
\hline
\end{tabular}

FEC ID number of contributing

federal political committee.

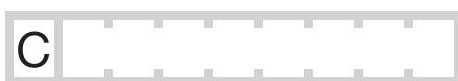

Name of Employer
None
Receipt For: 2012
X Primary
Other (specify)

\section{Occupation}

Retired

Election Cycle-to-Date

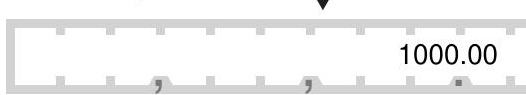

Transaction ID : AA494B57182194F4BA47

Date of Receipt

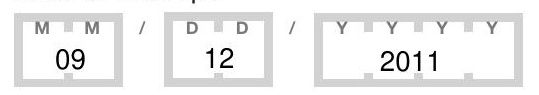

Amount of Each Receipt this Period

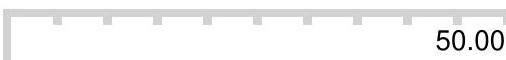

Transaction ID : AD2B6506D8DF74531B21

Date of Receipt

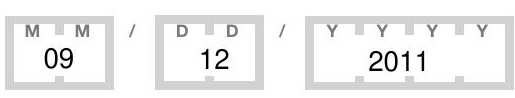

Amount of Each Receipt this Period

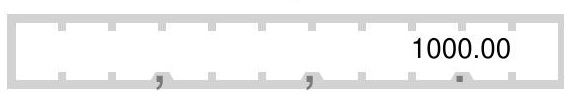

Transaction ID : ACB7E6EBC26594A63A24 Date of Receipt

\section{Mr James Owens}

Mailing Address 2701 NW 59th St

\begin{tabular}{lcc}
\hline City & State & Zip Code \\
Oklahoma City & OK & $73112-7025$ \\
\hline
\end{tabular}

FEC ID number of contributing federal political committee.

C

$\begin{aligned} & \text { Name of Employer } \\ & \text { self }\end{aligned}$
Receipt For: 2012
X Primary $\square$ General
Other (specify)

Occupation

Petroleum Engin

Election Cycle-to-Date

Subtotal Of Receipts This Page (optional)

Amount of Each Receipt this Period

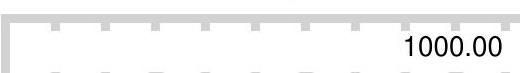

Total This Period (last page this line number only)

2050.00

‥

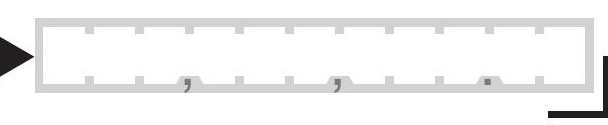

FEC Schedule A-P (Form 3P) (Rev. 03/2011) 
SCHEDULE A-P ITEMIZED RECEIPTS
Use separate schedule(s) for each category of the Detailed Summary Page
FOR LINE NUMBER: (check only one)

PAGE 492 / 1572

\begin{tabular}{|c|c|c|c|c|c|c|}
\hline & & & & & & \\
\hline 16 & $\lambda$ & $17 \mathrm{a}$ & $17 \mathrm{~b}$ & $17 \mathrm{c}$ & $-17 d$ & -18 \\
\hline $19 a$ & & $19 b$ & $20 a$ & $20 \mathrm{~b}$ & $20 \mathrm{c}$ & 21 \\
\hline
\end{tabular}

Any information copied from such Reports and Statements may not be sold or used by any person for the purpose of soliciting contributions or for commercial purposes, other than using the name and address of any political committee to solicit contributions from such committee.

NAME OF COMMITTEE (In Full)

\section{Friends of Herman Cain}

A. Full Name (Last, First, Middle Initial)

\section{Clifford Cash}

Mailing Address W172N7888 Shady Ln

\begin{tabular}{lcc}
\hline City & State & Zip Code \\
Menomonee Falls & WI & $53051-4172$
\end{tabular}

FEC ID number of contributing

federal political committee.

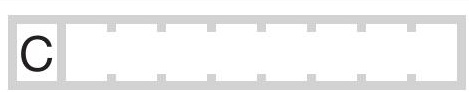

Name of Employer
Unemployed
Receipt For: 2012
X Primary $\quad$ General
Other (specify)

Occupation architect

Election Cycle-to-Date

\subsection{0}

B. Full Name (Last, First, Middle Initial)

Mr Tom Hill

Mailing Address 938 Evans Cook Road

\begin{tabular}{lcc}
\hline City & State & Zip Code \\
Canton & GA & $30115-5700$ \\
\hline
\end{tabular}

FEC ID number of contributing

federal political committee.

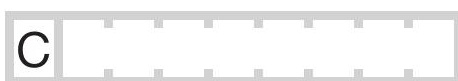

Name of Employer
Retired
Receipt For: 2012
X Primary
Other (specify)

\section{Occupation}

Retired

Election Cycle-to-Date

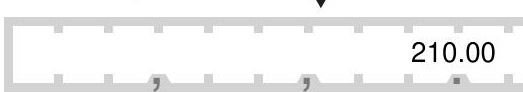

Transaction ID : A6296603A9EE1482E8C5

Date of Receipt

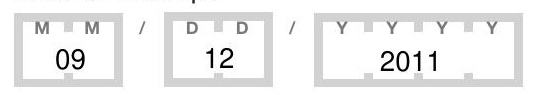

Amount of Each Receipt this Period

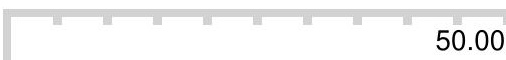

C. Full Name (Last, First, Middle Initial) richard craig

Mailing Address p.o. box 899

\begin{tabular}{lcc}
\hline City & State & Zip Code \\
Edwards & CO & $81632-0899$
\end{tabular}

FEC ID number of contributing federal political committee.

C

81632-0899

Name of Employer

Information Requested

Occupation

Information Requested

Receipt For: 2012

Х $\begin{aligned} & \text { Primary } \\ & \text { Other (specify) }\end{aligned}$

Transaction ID : AEBF938ACE47C4BCC931 Date of Receipt

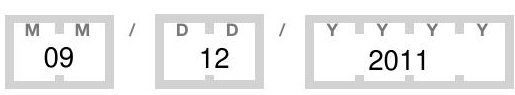

Amount of Each Receipt this Period

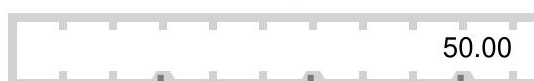

Transaction ID : A170A077E043340C6812

Date of Receipt

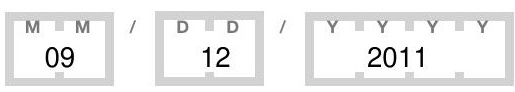

Amount of Each Receipt this Period

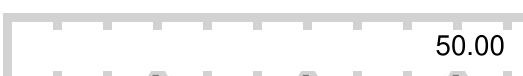

478.13
Subtotal Of Receipts This Page (optional)

150.00

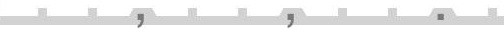

Total This Period (last page this line number only)

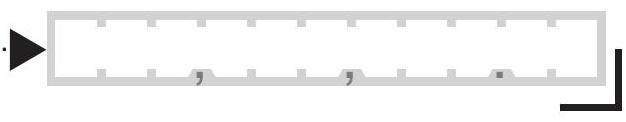

FEC Schedule A-P (Form 3P) (Rev. 03/2011) 
SCHEDULE A-P ITEMIZED RECEIPTS
Use separate schedule(s) for each category of the Detailed Summary Page
FOR LINE NUMBER: (check only one)

PAGE $493 / 1572$

\begin{tabular}{|c|c|c|c|c|c|}
\hline & & & & & \\
\hline 16 & $\begin{array}{lll}X & 17 a \\
\end{array}$ & $17 \mathrm{~b}$ & $17 c$ & $17 d$ & 18 \\
\hline $19 a$ & $19 b$ & $20 a$ & $20 \mathrm{~b}$ & $20 c$ & 21 \\
\hline
\end{tabular}

Any information copied from such Reports and Statements may not be sold or used by any person for the purpose of soliciting contributions or for commercial purposes, other than using the name and address of any political committee to solicit contributions from such committee.

NAME OF COMMITTEE (In Full)

\section{Friends of Herman Cain}

A. Full Name (Last, First, Middle Initial)

Laura A Hay

Mailing Address 231 Burke Circle

\begin{tabular}{lcc}
\hline City & State & Zip Code \\
McDonough & GA & $30253-2012$
\end{tabular}

FEC ID number of contributing federal political committee.

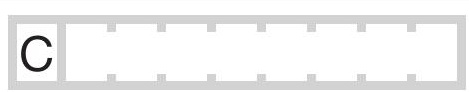

Name of Employer
Retired
Receipt For: 2012
X Primary $\quad$ General
Other (specify)

\section{Occupation} N/A

Election Cycle-to-Date

\subsection{0}

B. Full Name (Last, First, Middle Initial)

Marcia Hugghins

Mailing Address 479 Creighton $\mathrm{Rd}$

\begin{tabular}{lcc}
\hline City & State & Zip Code \\
Fleming Island & FL & $32003-7477$ \\
\hline
\end{tabular}

FEC ID number of contributing

federal political committee.

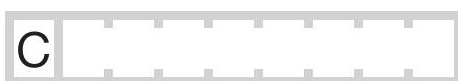

Name of Employer
Retired
Receipt For: 2012
X Primary
Other (specify)

\section{Occupation}

Retired

Election Cycle-to-Date

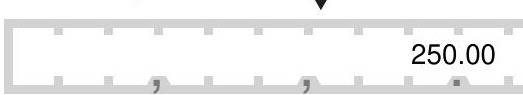

Transaction ID : AE36B7C67EA314BBE94C

Date of Receipt

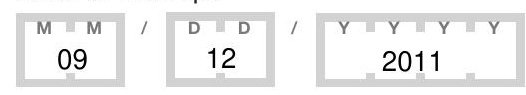

Amount of Each Receipt this Period

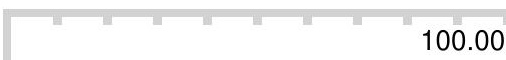

C. Full Name (Last, First, Middle Initial)

Brenda Friedman

Mailing Address 3274 Chipping Wood Ct

\begin{tabular}{lcc}
\hline City & State & Zip Code \\
Alpharetta & GA & $30004-4305$
\end{tabular}

FEC ID number of contributing federal political committee.

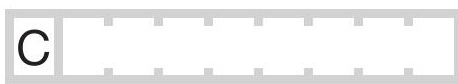

Name of Employer

Information Requested

Occupation

Information Requested

Receipt For: 2012

Х $\begin{aligned} & \text { Primary } \\ & \text { Other (specify) }\end{aligned}$

Amount of Each Receipt this Period

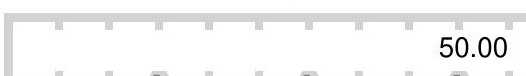

Transaction ID : A302506866C064138843

Date of Receipt

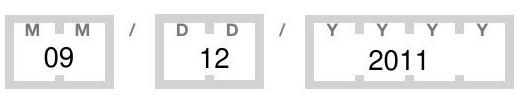

Transaction ID : AF9AF7AB2428F423FBA8 Date of Receipt

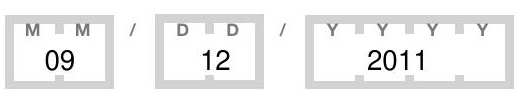

Amount of Each Receipt this Period

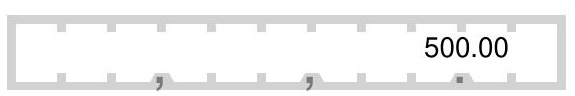

500.00
Subtotal Of Receipts This Page (optional)

650.00

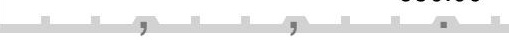

Total This Period (last page this line number only)

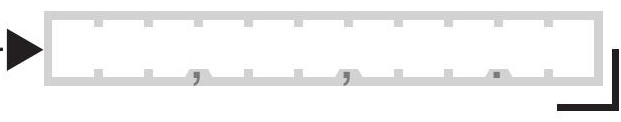

FEC Schedule A-P (Form 3P) (Rev. 03/2011) 
SCHEDULE A-P ITEMIZED RECEIPTS
Use separate schedule(s) for each category of the Detailed Summary Page
FOR LINE NUMBER: (check only one)
PAGE 494 / 1572

\begin{tabular}{|c|c|c|c|c|c|}
\hline & & & & & \\
\hline 16 & $\begin{array}{lll}X & 17 a \\
\end{array}$ & $17 \mathrm{~b}$ & $17 c$ & $17 d$ & 18 \\
\hline $19 a$ & $19 b$ & $20 a$ & $20 \mathrm{~b}$ & $20 c$ & 21 \\
\hline
\end{tabular}

Any information copied from such Reports and Statements may not be sold or used by any person for the purpose of soliciting contributions or for commercial purposes, other than using the name and address of any political committee to solicit contributions from such committee.

NAME OF COMMITTEE (In Full)

\section{Friends of Herman Cain}

A. Full Name (Last, First, Middle Initial)

\section{PHILLIP GRANQUIST}

Mailing Address 13105 W Berridge Ct

\begin{tabular}{lcc}
\hline City & State & Zip Code \\
Litchfield Park & AZ & $85340-7328$ \\
\hline
\end{tabular}

FEC ID number of contributing federal political committee.

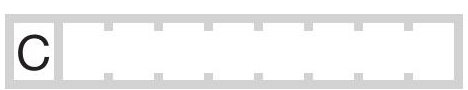

Name of Employer
Retired
Receipt For: 2012
X Primary $\quad$ General
Other (specify)

Occupation Retired

Election Cycle-to-Date

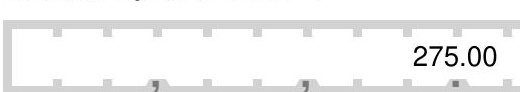

B. Full Name (Last, First, Middle Initial)

Terry Chick

Mailing Address 13650 N Heritage Canyon Dr

\begin{tabular}{lcc}
\hline City & State & Zip Code \\
Marana & AZ & $85658-4073$
\end{tabular}

FEC ID number of contributing

federal political committee.

C

Name of Employer
Retired
Receipt For: 2012
X Primary
Other (specify)

C. Full Name (Last, First, Middle Initial)

Patricia Durham

Mailing Address 205 Saint Elizabeth Ter

\begin{tabular}{lcc}
\hline City & State & Zip Code \\
Stockbridge & GA & $30281-9701$
\end{tabular}

FEC ID number of contributing federal political committee.

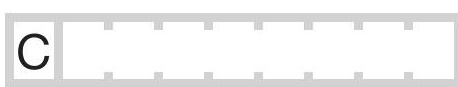

Name of Employer
Henry Medical Center
Receipt For: 2012
X Primary
Other (specify) General

\section{Occupation}

Retired

Election Cycle-to-Date

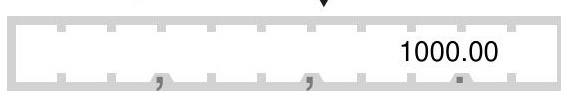

Transaction ID : A02DCF26B055843FC889

Date of Receipt

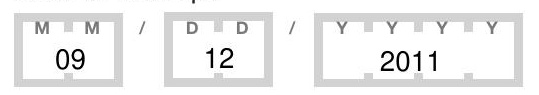

Amount of Each Receipt this Period

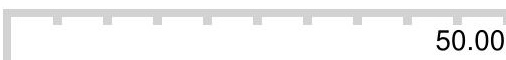

Amount of Each Receipt this Period

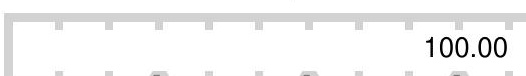

Transaction ID : A19ADCA38A8C5457584F Date of Receipt

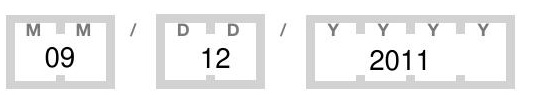

Transaction ID : A789D2852865D40E1AE3 Date of Receipt

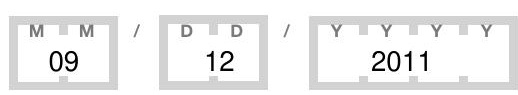

Amount of Each Receipt this Period

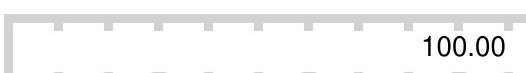

\section{Subtotal Of Receipts This Page (optional)}

Total This Period (last page this line number only) 
SCHEDULE A-P ITEMIZED RECEIPTS
Use separate schedule(s) for each category of the Detailed Summary Page
FOR LINE NUMBER: (check only one)

PAGE 495 / 1572

\begin{tabular}{|c|c|c|c|c|c|}
\hline & & & & & \\
\hline 16 & $\begin{array}{l}\mathbf{X} \\
17 a\end{array}$ & $17 b$ & $17 c$ & $17 d$ & 18 \\
\hline $19 a$ & $19 \mathrm{~b}$ & $20 \mathrm{a}$ & $20 \mathrm{~b}$ & $20 \mathrm{c}$ & 21 \\
\hline
\end{tabular}

Any information copied from such Reports and Statements may not be sold or used by any person for the purpose of soliciting contributions or for commercial purposes, other than using the name and address of any political committee to solicit contributions from such committee.

NAME OF COMMITTEE (In Full)

\section{Friends of Herman Cain}

A. Full Name (Last, First, Middle Initial)

Mr Louis C Dietz

Mailing Address 33126 Forest West St

\begin{tabular}{lcc}
\hline City & State & Zip Code \\
Magnolia & TX & $77354-6844$ \\
\hline
\end{tabular}

FEC ID number of contributing

federal political committee.

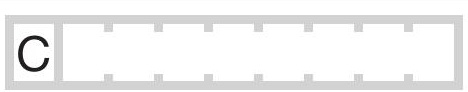

Name of Employer
CYFAIR HOSPITAL
Receipt For: 2012
X Primary $\quad \square$ General
Other (specify)

Occupation

$\mathrm{RN}$

Election Cycle-to-Date

434.00

B. Full Name (Last, First, Middle Initial)

Erik Anhaus

Mailing Address 6395 Queens Court Trce

\begin{tabular}{lcc}
\hline City & State & Zip Code \\
Mableton & GA & $30126-7242$ \\
\hline
\end{tabular}

FEC ID number of contributing

federal political committee.

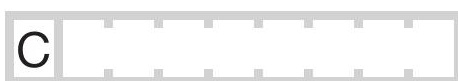

Name of Employer
Ameriprise Financial
Receipt For: 2012
X Primary
Other (specify)

Occupation

Financial Advisor

Election Cycle-to-Date

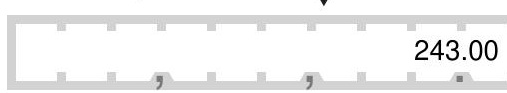

Transaction ID : AB981FE652EE64C2CBDD

Date of Receipt

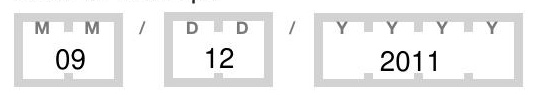

Amount of Each Receipt this Period

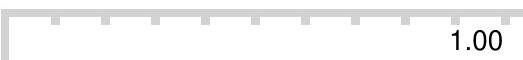

C. Full Name (Last, First, Middle Initial)

Carol Cook

Mailing Address 43 Oak Alley

\begin{tabular}{lcc}
\hline City & State & Zip Code \\
Kerrville & TX & $78028-1711$
\end{tabular}

FEC ID number of contributing federal political committee.

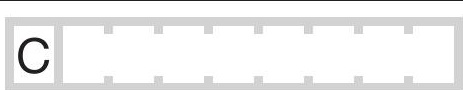

Name of Employer
James Avery
Receipt For: 2012
X Primary $\quad \square$ General
Other (specify)

\section{Occupation}

Sales Team Leader

Election Cycle-to-Date

Transaction ID : A2EF80E90E24D4F839A2

Date of Receipt

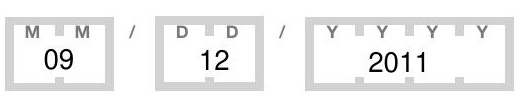

Amount of Each Receipt this Period

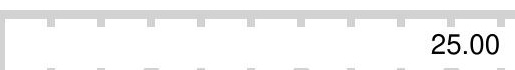

Transaction ID : A8F643E985C614C83B5B

Date of Receipt

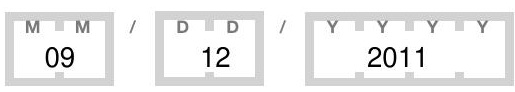

Amount of Each Receipt this Period

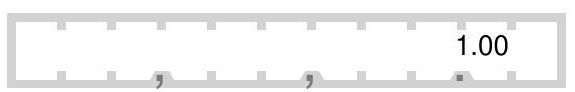

253.60

\section{Subtotal Of Receipts This Page (optional)}

27.00

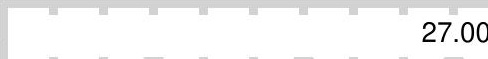

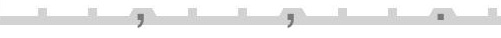

Total This Period (last page this line number only)

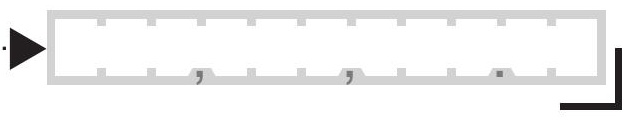

FEC Schedule A-P (Form 3P) (Rev. 03/2011) 
SCHEDULE A-P ITEMIZED RECEIPTS
Use separate schedule(s) for each category of the Detailed Summary Page
FOR LINE NUMBER: (check only one)

PAGE 496 / 1572

\begin{tabular}{|c|c|c|c|c|c|c|}
\hline & & & & & & \\
\hline 16 & $\lambda$ & $17 \mathrm{a}$ & $17 \mathrm{~b}$ & $17 \mathrm{c}$ & $-17 d$ & -18 \\
\hline $19 a$ & & $19 b$ & $20 a$ & $20 \mathrm{~b}$ & $20 \mathrm{c}$ & 21 \\
\hline
\end{tabular}

Any information copied from such Reports and Statements may not be sold or used by any person for the purpose of soliciting contributions or for commercial purposes, other than using the name and address of any political committee to solicit contributions from such committee.

NAME OF COMMITTEE (In Full)

\section{Friends of Herman Cain}

A. Full Name (Last, First, Middle Initial)

Mr Patrick Burns

Mailing Address 35 Parkview Ave

\begin{tabular}{lcc}
\hline City & State & Zip Code \\
Bronxville & NY & $10708-2953$
\end{tabular}

FEC ID number of contributing federal political committee.

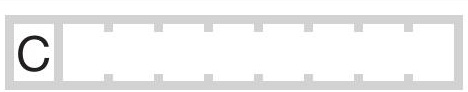

Name of Employer
Self Employed
Receipt For: 2012
X Primary $\quad$ General
Other (specify)

Occupation Attorney

Election Cycle-to-Date

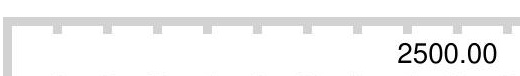

B. Full Name (Last, First, Middle Initial) Julia Jones Matthews

Mailing Address PO Box 176

\begin{tabular}{lcc}
\hline City & State & Zip Code \\
Abilene & TX & 79604-0176 \\
\hline
\end{tabular}

FEC ID number of contributing

federal political committee.

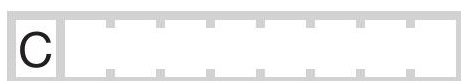

$\begin{aligned} & \text { Name of Employer } \\ & \text { self }\end{aligned}$
Receipt For: 2012
Primary $\quad$ General
Other (specify)

Occupation

Retired

Election Cycle-to-Date

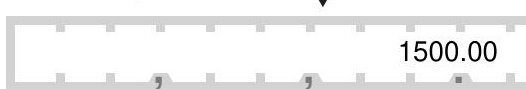

C. Full Name (Last, First, Middle Initial)

Nels Nelson

Mailing Address 302 Canton St. P.O.B. 123

\begin{tabular}{lcc}
\hline City & State & Zip Code \\
Woosung & IL & $61091-0123$
\end{tabular}

FEC ID number of contributing federal political committee.

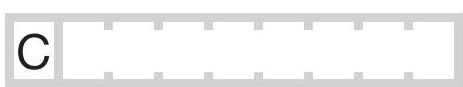

Name of Employer
self
Receipt For: 2012
X Primary
Other (specify) General

Occupation

Retired

Election Cycle-to-Date
Transaction ID : AC318F76221F14CDE934

Date of Receipt

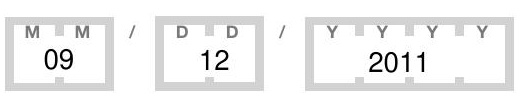

Amount of Each Receipt this Period

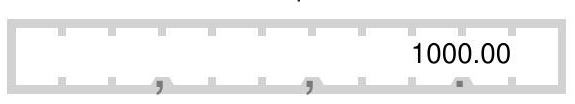

Transaction ID : A3414B2054DCD4133A85 Date of Receipt

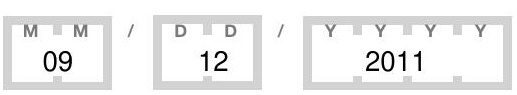

Amount of Each Receipt this Period

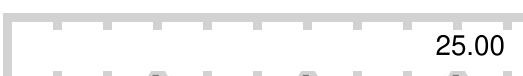

Subtotal Of Receipts This Page (optional).

Total This Period (last page this line number only) 
SCHEDULE A-P ITEMIZED RECEIPTS
Use separate schedule(s) for each category of the Detailed Summary Page
FOR LINE NUMBER: (check only one)
PAGE 497 / 1572

\begin{tabular}{|c|c|c|c|c|c|}
\hline & & & & & \\
\hline 16 & $\begin{array}{lll}X & 17 a \\
\end{array}$ & $17 \mathrm{~b}$ & $17 c$ & $17 d$ & 18 \\
\hline $19 a$ & $19 b$ & $20 a$ & $20 \mathrm{~b}$ & $20 c$ & 21 \\
\hline
\end{tabular}

Any information copied from such Reports and Statements may not be sold or used by any person for the purpose of soliciting contributions or for commercial purposes, other than using the name and address of any political committee to solicit contributions from such committee.

NAME OF COMMITTEE (In Full)

\section{Friends of Herman Cain}

A. Full Name (Last, First, Middle Initial)

Donald Taylor

Mailing Address 26476 North Street Box 448

\begin{tabular}{lcc}
\hline City & State & Zip Code \\
Coolville & $\mathrm{OH}$ & $45723-8143$
\end{tabular}

FEC ID number of contributing

federal political committee.

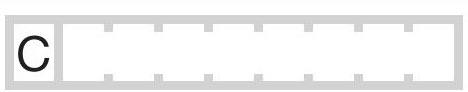

Name of Employer
Dupont
Receipt For: 2012
X Primary $\quad$ General
Other (specify)

Occupation

Retired

Election Cycle-to-Date

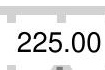

B. Full Name (Last, First, Middle Initial)

Mr Royce Flandro

Mailing Address 2949 Apache Way

\begin{tabular}{lcc}
\hline City & State & Zip Code \\
Provo & UT & $84604-4363$
\end{tabular}

FEC ID number of contributing

federal political committee.

C

Name of Employer
Brigham Young Univ
Receipt For: 2012
X Primary
Other (specify)

Occupation

Professor Ret

Election Cycle-to-Date

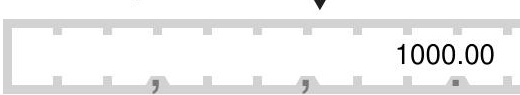

Transaction ID : AF73E4997768E44518B3

Date of Receipt

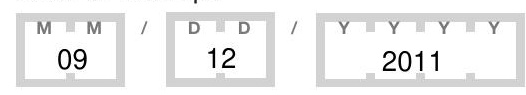

Amount of Each Receipt this Period

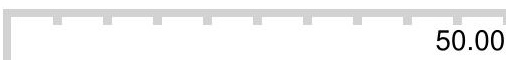

50.00

C. Full Name (Last, First, Middle Initial)

William Johnson

Mailing Address 948 Duchess $\mathrm{Dr}$

\begin{tabular}{lcc}
\hline City & State & Zip Code \\
Oconomowoc & WI & $53066-3468$
\end{tabular}

FEC ID number of contributing

federal political committee.

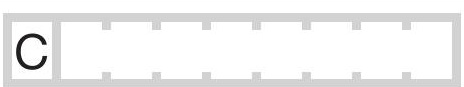

Name of Employer

Eagle Printing

Receipt For: 2012

Х $\begin{aligned} & \text { Primary } \square \text { General } \\ & \text { Other (specify) }\end{aligned}$

\section{Occupation}

Printer

Election Cycle-to-Date

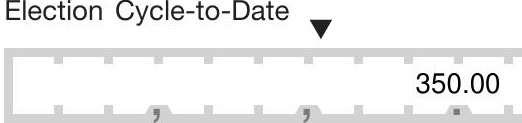

Transaction ID : AB8E13D8BF22F4A10B6C

Date of Receipt

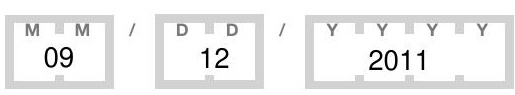

Amount of Each Receipt this Period

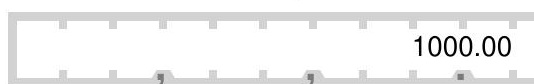

Transaction ID : A742F5DDBF7AF4EF3A84 Date of Receipt

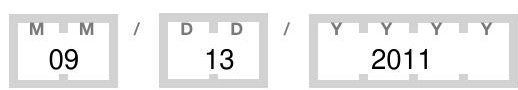

Amount of Each Receipt this Period

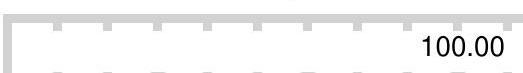

100.00

\section{Subtotal Of Receipts This Page (optional)}

Total This Period (last page this line number only) 
SCHEDULE A-P ITEMIZED RECEIPTS
Use separate schedule(s) for each category of the Detailed Summary Page
FOR LINE NUMBER: (check only one)

PAGE $498 / 1572$

\begin{tabular}{|c|c|c|c|c|c|}
\hline & & & & & \\
\hline 16 & $\begin{array}{l}\mathbf{X} \\
17 a\end{array}$ & $17 b$ & $17 c$ & $17 d$ & 18 \\
\hline $19 a$ & $19 \mathrm{~b}$ & $20 \mathrm{a}$ & $20 \mathrm{~b}$ & $20 \mathrm{c}$ & 21 \\
\hline
\end{tabular}

Any information copied from such Reports and Statements may not be sold or used by any person for the purpose of soliciting contributions or for commercial purposes, other than using the name and address of any political committee to solicit contributions from such committee.

NAME OF COMMITTEE (In Full)

\section{Friends of Herman Cain}

A. Full Name (Last, First, Middle Initial)

Bridget Breland

Mailing Address 2111 Pinnacle Cir N

\begin{tabular}{lcc}
\hline City & State & Zip Code \\
Palm Harbor & FL & $34684-1769$ \\
\hline
\end{tabular}

FEC ID number of contributing federal political committee.

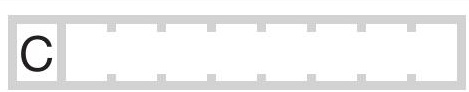

Name of Employer
self
Receipt For: 2012
X Primary $\quad$ General
Other (specify)

Occupation Realtor

Election Cycle-to-Date

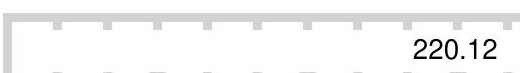

B. Full Name (Last, First, Middle Initial)

Frances little

Mailing Address 1700 White Oak Ln Unit 14

\begin{tabular}{lcc}
\hline City & State & Zip Code \\
Dalton & GA & $30721-2300$ \\
\hline
\end{tabular}

FEC ID number of contributing

federal political committee.

C

Name of Employer
Retired
Receipt For: 2012
X Primary $\quad$ General
Other (specify)

C. Full Name (Last, First, Middle Initial)

elka king

Mailing Address 1483 Rocky Ridge Rd

\begin{tabular}{lcc}
\hline $\begin{array}{l}\text { City } \\
\text { Mountain Home }\end{array}$ & $\begin{array}{c}\text { State } \\
\text { AR }\end{array}$ & $\begin{array}{c}\text { Zip Code } \\
72653-8445\end{array}$ \\
\hline $\begin{array}{l}\text { FEC ID number of contributing } \\
\text { federal political committee. }\end{array}$ & C & \\
\hline
\end{tabular}

Name of Employer
ponder health
Receipt For: 2012
X Primary
Other (specify) General

\section{Occupation}

Retired

Election Cycle-to-Date

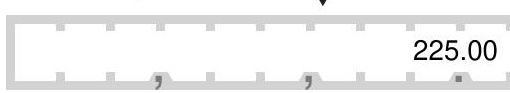

Pharmacist

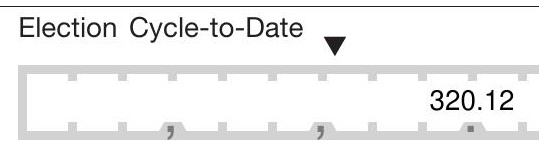

Transaction ID : AE2BFFC5AC6B74EA29D5

Date of Receipt

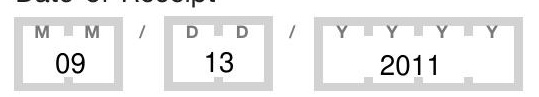

Amount of Each Receipt this Period

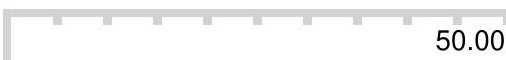

50.00
Amount of Each Receipt this Period

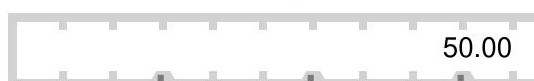

Transaction ID : ACF36000E11FF478D898 Date of Receipt

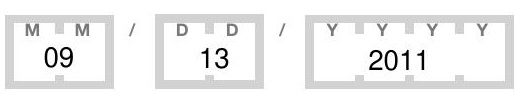

Transaction ID : A0438D10D31E146EFAF7 Date of Receipt

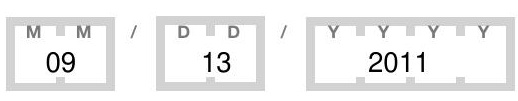

Amount of Each Receipt this Period

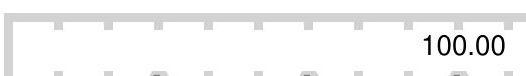

Subtotal Of Receipts This Page (optional).

200.00

‥

Total This Period (last page this line number only) 
SCHEDULE A-P ITEMIZED RECEIPTS
Use separate schedule(s) for each category of the Detailed Summary Page
FOR LINE NUMBER: (check only one)

PAGE 499 / 1572

\begin{tabular}{|c|c|c|c|c|c|}
\hline & & & & & \\
\hline 16 & $\begin{array}{l}\mathbf{X} \\
17 a\end{array}$ & $17 b$ & $17 c$ & $17 d$ & 18 \\
\hline $19 a$ & $19 \mathrm{~b}$ & $20 \mathrm{a}$ & $20 \mathrm{~b}$ & $20 \mathrm{c}$ & 21 \\
\hline
\end{tabular}

Any information copied from such Reports and Statements may not be sold or used by any person for the purpose of soliciting contributions or for commercial purposes, other than using the name and address of any political committee to solicit contributions from such committee.

NAME OF COMMITTEE (In Full)

\section{Friends of Herman Cain}

A. Full Name (Last, First, Middle Initial)

\section{Gerri Crowell}

Mailing Address 1346 Fort Jefferson Ave

\begin{tabular}{lcc}
\hline City & State & Zip Code \\
Greenville & $\mathrm{OH}$ & $45331-1048$ \\
\hline
\end{tabular}

FEC ID number of contributing federal political committee.

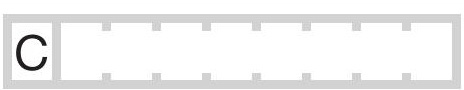

Name of Employer
Information Requested
Receipt For: 2012
X Primary
Other (specify) General

Occupation Information Requested

Election Cycle-to-Date

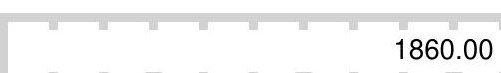

B. Full Name (Last, First, Middle Initial)

Shirley Hill

Mailing Address 202 W. Hill St Apt. 3400

\begin{tabular}{lcc}
\hline City & State & Zip Code \\
Champaign & IL & $61820-8652$
\end{tabular}

FEC ID number of contributing

federal political committee.

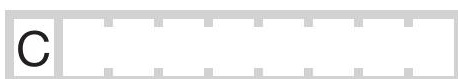

Name of Employer
Martin E. Hill DDS
Receipt For: 2012
X Primary
Other (specify)

\section{Occupation}

Office staff

Election Cycle-to-Date

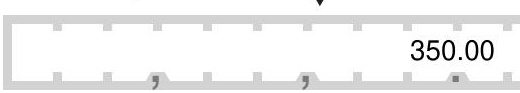

Transaction ID : A75C533FCD0AB42A08DF

Date of Receipt

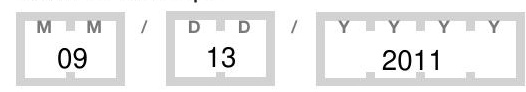

Amount of Each Receipt this Period

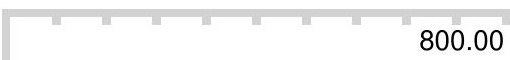

800.00

C. Full Name (Last, First, Middle Initial)

Darin Kohles

Mailing Address 21410 SE Hwy 224

\begin{tabular}{lcc}
\hline City & State & Zip Code \\
Damascus & OR & $97089-7825$
\end{tabular}

FEC ID number of contributing federal political committee.

C

97089-7825

Name of Employer

Information Requested

Occupation

Receipt For: 2012

Х $\begin{aligned} & \text { Primary } \square \text { General } \\ & \text { Other (specify) }\end{aligned}$

Information Requested

Election Cycle-to-Date

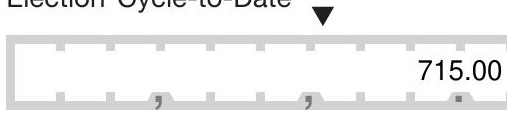

Transaction ID : A843684AFD8FF4D5484C

Date of Receipt

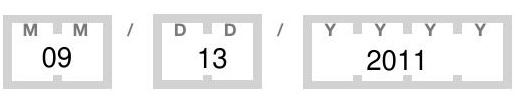

Amount of Each Receipt this Period

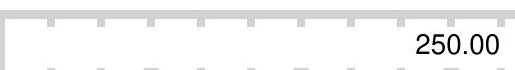

Transaction ID : A8F82135A43A8459D85C

Date of Receipt

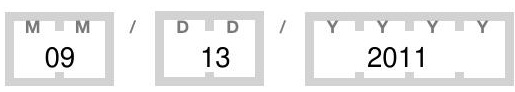

Amount of Each Receipt this Period

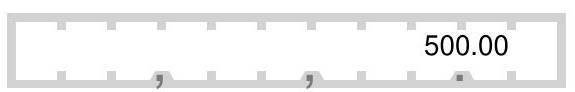

Subtotal Of Receipts This Page (optional)

1550.00

Total This Period (last page this line number only) 


\section{SCHEDULE A-P} ITEMIZED RECEIPTS
Use separate schedule(s)

for each category of the

Detailed Summary Page
FOR LINE NUMBER: (check only one)

PAGE $500 / 1572$

\begin{tabular}{|c|c|c|c|c|c|}
\hline & & & & & \\
\hline 16 & X $17 a$ & $17 b$ & $17 c$ & $17 d$ & 18 \\
\hline $19 a$ & $19 b$ & $20 \mathrm{a}$ & $20 \mathrm{~b}$ & $20 \mathrm{c}$ & 21 \\
\hline
\end{tabular}

Any information copied from such Reports and Statements may not be sold or used by any person for the purpose of soliciting contributions or for commercial purposes, other than using the name and address of any political committee to solicit contributions from such committee.

NAME OF COMMITTEE (In Full)

Friends of Herman Cain

A. Full Name (Last, First, Middle Initial)

Russell Staggs

Mailing Address 10906 E 74th St

\begin{tabular}{lcc}
\hline City & State & Zip Code \\
Tulsa & OK & $74133-2512$
\end{tabular}

FEC ID number of contributing federal political committee.

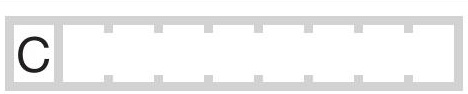

Name of Employer
Information Requested
Receipt For: 2012
X Primary
$\square$ Other (specify)

Occupation

Information Requested

Election Cycle-to-Date

465.00

B. Full Name (Last, First, Middle Initial)

Joseph T. Freitas III

Mailing Address PO Box 677

\begin{tabular}{lcc}
\hline City & State & Zip Code \\
La Pine & OR & $97739-0677$
\end{tabular}

FEC ID number of contributing

federal political committee.

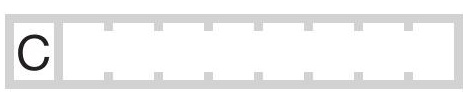

Name of Employer
None
Receipt For: 2012
X Primary
Other (specify)

Occupation

Retired

Election Cycle-to-Date

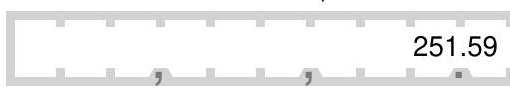

Transaction ID : A64464AF35A96452AB03

Date of Receipt

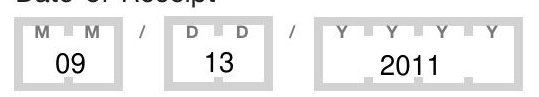

Amount of Each Receipt this Period

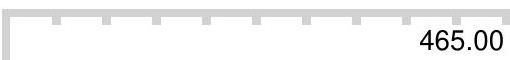

C. Full Name (Last, First, Middle Initial)

Mr Weldon Yarbro

Mailing Address 1103 W Avenue K

\begin{tabular}{lcc}
\hline City & State & Zip Code \\
Lovington & NM & $88260-5039$
\end{tabular}

FEC ID number of contributing federal political committee.

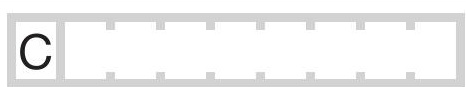

Name of Employer

Information Requested

Occupation

Information Requested

Receipt For: 2012

Х $\begin{aligned} & \text { Primary } \square \text { General } \\ & \text { Other (specify) }\end{aligned}$

Election Cycle-to-Date

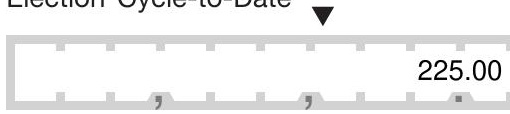

Transaction ID : ADF11DD1A2B76470EBCA Date of Receipt

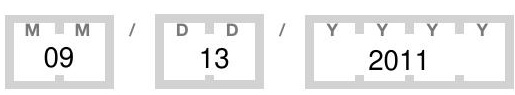

Amount of Each Receipt this Period

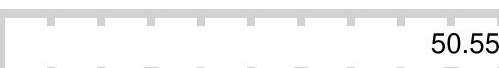

Transaction ID : A5AA3BC000C1641AEBE3 Date of Receipt

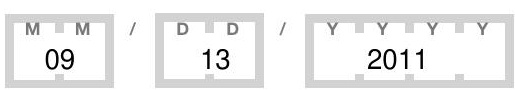

Amount of Each Receipt this Period

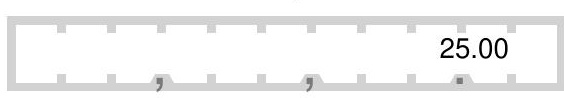

Subtotal Of Receipts This Page (optional)

540.55

Total This Period (last page this line number only) 
SCHEDULE A-P ITEMIZED RECEIPTS
Use separate schedule(s) for each category of the Detailed Summary Page
FOR LINE NUMBER: (check only one)

PAGE $501 / 1572$

\begin{tabular}{|c|c|c|c|c|c|}
\hline & & & & & \\
\hline 16 & $\begin{array}{l}\mathbf{X} \\
17 a\end{array}$ & $17 b$ & $17 c$ & $17 d$ & 18 \\
\hline $19 a$ & $19 \mathrm{~b}$ & $20 \mathrm{a}$ & $20 \mathrm{~b}$ & $20 \mathrm{c}$ & 21 \\
\hline
\end{tabular}

Any information copied from such Reports and Statements may not be sold or used by any person for the purpose of soliciting contributions or for commercial purposes, other than using the name and address of any political committee to solicit contributions from such committee.

NAME OF COMMITTEE (In Full)

\section{Friends of Herman Cain}

A. Full Name (Last, First, Middle Initial)

\section{Orville Loos}

Mailing Address 4915 Club Court

\begin{tabular}{lcc}
\hline City & State & Zip Code \\
Quincy & IL & $62305-1026$ \\
\hline
\end{tabular}

FEC ID number of contributing federal political committee.

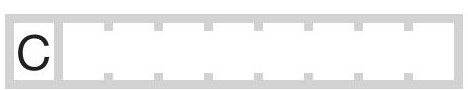

Name of Employer
Information Requested
Receipt For: 2012
X Primary
Other (specify) General

Occupation Information Requested

Election Cycle-to-Date

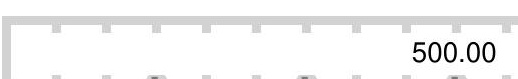

B. Full Name (Last, First, Middle Initial) charles murphy

Mailing Address 299 cherokee drive

\begin{tabular}{lcc}
\hline City & State & Zip Code \\
Harrisburg & IL & $62946-3798$ \\
\hline
\end{tabular}

FEC ID number of contributing

federal political committee.

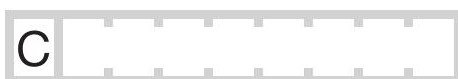

Name of Employer
murphy homes inc
Receipt For: 2012
Primary
Other (specify) General

\section{Occupation} homebuilder

Election Cycle-to-Date

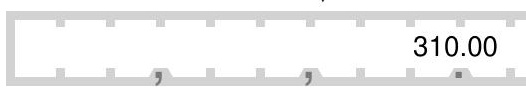

Transaction ID : A077D8C2BDB924ECF9EE

Date of Receipt

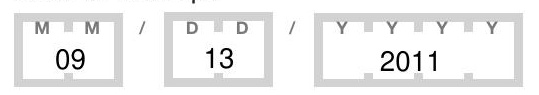

Amount of Each Receipt this Period

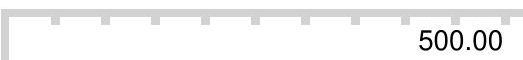

C. Full Name (Last, First, Middle Initial)

Martha Roberts

Mailing Address 6680 Lawson Circle

\begin{tabular}{lcc}
\hline City & State & Zip Code \\
Gainesville & GA & $30506-4716$
\end{tabular}

FEC ID number of contributing federal political committee.

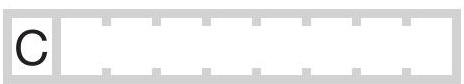

Name of Employer
n/a
Receipt For: 2012
X Primary $\square$ General
Other (specify)

Occupation

Retired

Election Cycle-to-Date

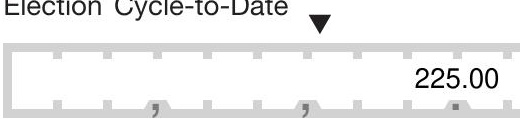

Transaction ID : ACF6DD93657804ADBAFB Date of Receipt

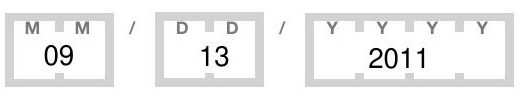

Amount of Each Receipt this Period

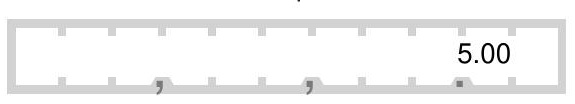

Transaction ID : AA31133E86BC74C6195D Date of Receipt

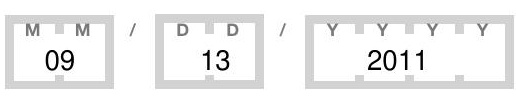

Amount of Each Receipt this Period

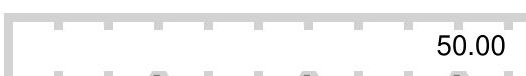

\section{Subtotal Of Receipts This Page (optional)}

Total This Period (last page this line number only) 
SCHEDULE A-P ITEMIZED RECEIPTS
Use separate schedule(s) for each category of the Detailed Summary Page
FOR LINE NUMBER: (check only one)

PAGE 502 / 1572

\begin{tabular}{|c|c|c|c|c|c|c|}
\hline & & & & & & \\
\hline 16 & $\lambda$ & $17 \mathrm{a}$ & $17 \mathrm{~b}$ & $17 \mathrm{c}$ & $-17 d$ & -18 \\
\hline $19 a$ & & $19 b$ & $20 a$ & $20 \mathrm{~b}$ & $20 \mathrm{c}$ & 21 \\
\hline
\end{tabular}

Any information copied from such Reports and Statements may not be sold or used by any person for the purpose of soliciting contributions or for commercial purposes, other than using the name and address of any political committee to solicit contributions from such committee.

NAME OF COMMITTEE (In Full)

\section{Friends of Herman Cain}

A. Full Name (Last, First, Middle Initial)

\section{Cathie Serrano}

Mailing Address 5641 Shadow View Dr

\begin{tabular}{lcc}
\hline City & State & Zip Code \\
Stone Mountain & GA & $30087-2953$
\end{tabular}

FEC ID number of contributing federal political committee.

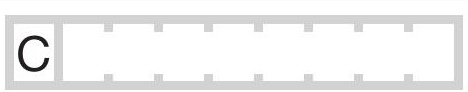

Name of Employer
n/a
Receipt For: 2012
X Primary $\quad$ General
Other (specify)

Occupation Retired

Election Cycle-to-Date

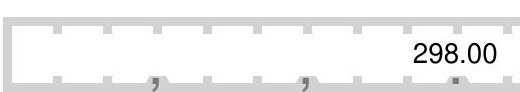

B. Full Name (Last, First, Middle Initial) Jerry Cook

Mailing Address 8308 Gaylord Rd

\begin{tabular}{lcc}
\hline City & State & Zip Code \\
Henrico & VA & $23229-4124$
\end{tabular}

FEC ID number of contributing

federal political committee.

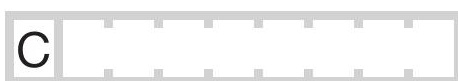

Name of Employer
JELD-WEN Windows \& Doors
Receipt For: 2012
X Primary
Other (specify)

\section{Occupation}

Sales

Election Cycle-to-Date

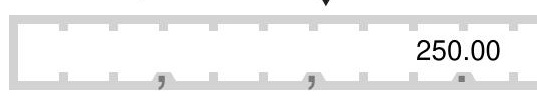

C. Full Name (Last, First, Middle Initial)

Charles Schoen

Mailing Address 6190 Mountain Brook Way NW

\begin{tabular}{lcc}
\hline City & State & Zip Code \\
Atlanta & GA & $30328-3608$ \\
\hline
\end{tabular}

FEC ID number of contributing federal political committee.

C

Name of Employer
Adaptive Learning Center
Receipt For: 2012
X Primary
Other (specify) General

Occupation

Executive Director

Election Cycle-to-Date
Transaction ID : AEC98D29FA24E4E11B21 Date of Receipt

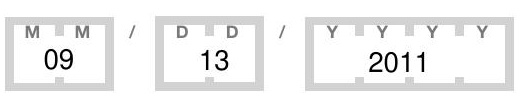

Amount of Each Receipt this Period

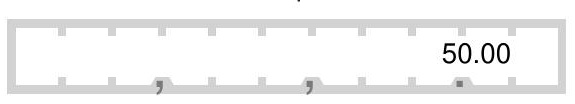

Transaction ID : A05577BFB57D2407FBB7 Date of Receipt

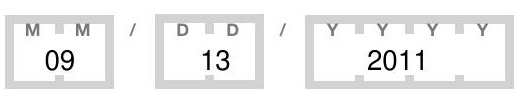

Amount of Each Receipt this Period

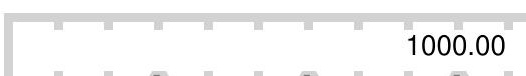

\section{Subtotal Of Receipts This Page (optional)}

1100.00

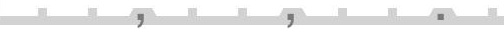

Total This Period (last page this line number only)
Transaction ID : A58805C3E5D604607A44

Date of Receipt

Amount of Each Receipt this Period 50.00

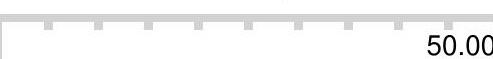


SCHEDULE A-P ITEMIZED RECEIPTS
Use separate schedule(s) for each category of the Detailed Summary Page
FOR LINE NUMBER: (check only one)

PAGE $503 / 1572$

\begin{tabular}{|c|c|c|c|c|c|c|}
\hline & & & & & & \\
\hline 16 & $\lambda$ & $17 \mathrm{a}$ & $17 \mathrm{~b}$ & $17 \mathrm{c}$ & $-17 d$ & -18 \\
\hline $19 a$ & & $19 b$ & $20 a$ & $20 \mathrm{~b}$ & $20 \mathrm{c}$ & 21 \\
\hline
\end{tabular}

Any information copied from such Reports and Statements may not be sold or used by any person for the purpose of soliciting contributions or for commercial purposes, other than using the name and address of any political committee to solicit contributions from such committee.

NAME OF COMMITTEE (In Full)

\section{Friends of Herman Cain}

A. Full Name (Last, First, Middle Initial)

Stephen Northington

Mailing Address 1915 Landfall Pass NW

\begin{tabular}{lcc}
\hline City & State & Zip Code \\
Kennesaw & GA & $30152-7736$
\end{tabular}

FEC ID number of contributing federal political committee.

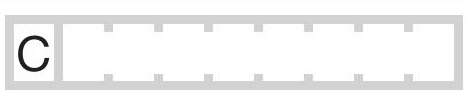

Name of Employer

Group Insurance Solutions LLC.

Receipt For: 2012

Х Primary $\square$ General

Occupation

Sales Director

Election Cycle-to-Date

470.00

B. Full Name (Last, First, Middle Initial)

charles murphy

Mailing Address 299 cherokee drive

\begin{tabular}{lcc}
\hline City & State & Zip Code \\
Harrisburg & IL & $62946-3798$ \\
\hline
\end{tabular}

FEC ID number of contributing

federal political committee.

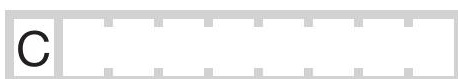

Name of Employer
murphy homes inc
Receipt For: 2012
Primary
Other (specify)

\section{Occupation}

homebuilder

Election Cycle-to-Date

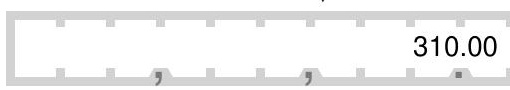

Transaction ID : A6707C96512184737999

Date of Receipt

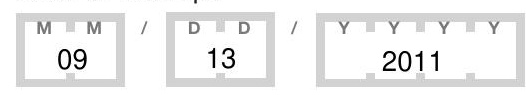

Amount of Each Receipt this Period

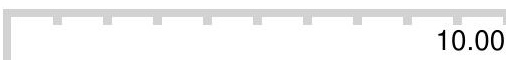

10.00

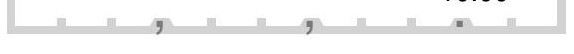

Transaction ID : AE9D174DE9D844A3E9A8

Date of Receipt

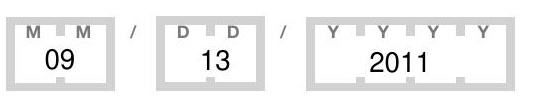

Amount of Each Receipt this Period

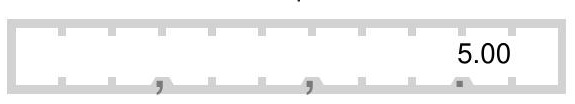

Transaction ID : A4FA8E506FD7E4C55A90 Date of Receipt

Keith Oulson

Mailing Address 5425 Ripple Creek Dr

\begin{tabular}{lcc}
\hline City & State & Zip Code \\
Tampa & FL & $33625-6416$
\end{tabular}

FEC ID number of contributing federal political committee.

C

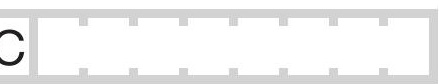

Name of Employer

Tampa General Hospital

Occupation

Receipt For: 2012

Х $\begin{aligned} & \text { Primary } \square \text { General } \\ & \text { Other (specify) }\end{aligned}$

Interface Analyst

Election Cycle-to-Date

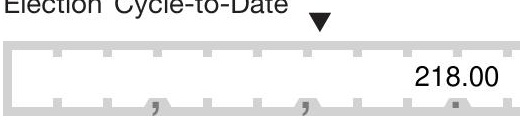

Subtotal Of Receipts This Page (optional)

Amount of Each Receipt this Period

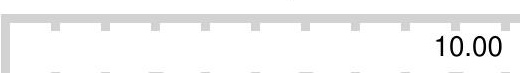

Total This Period (last page this line number only)

25.00

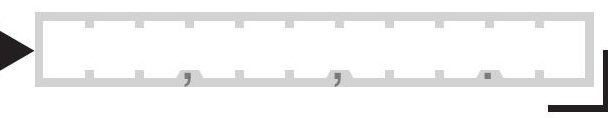

FEC Schedule A-P (Form 3P) (Rev. 03/2011) 
SCHEDULE A-P ITEMIZED RECEIPTS
Use separate schedule(s) for each category of the Detailed Summary Page
FOR LINE NUMBER: (check only one)

PAGE 504 / 1572

\begin{tabular}{|c|c|c|c|c|c|}
\hline & & & & & \\
\hline 16 & $\begin{array}{l}\mathbf{X} \\
17 a\end{array}$ & $17 b$ & $17 c$ & $17 d$ & 18 \\
\hline $19 a$ & $19 \mathrm{~b}$ & $20 \mathrm{a}$ & $20 \mathrm{~b}$ & $20 \mathrm{c}$ & 21 \\
\hline
\end{tabular}

Any information copied from such Reports and Statements may not be sold or used by any person for the purpose of soliciting contributions or for commercial purposes, other than using the name and address of any political committee to solicit contributions from such committee.

NAME OF COMMITTEE (In Full)

\section{Friends of Herman Cain}

A. Full Name (Last, First, Middle Initial)

Cynthia Carson

Mailing Address 68 Avenue Of Oaks

\begin{tabular}{lcc}
\hline City & State & Zip Code \\
Saint Helena Island & SC & $29920-3636$ \\
\hline
\end{tabular}

FEC ID number of contributing

federal political committee.

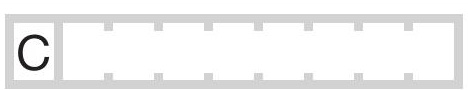

Name of Employer
Self Employed
Receipt For: 2012
X Primary $\quad$ General
Other (specify)

Occupation

Anesthestist (CRNA)

Election Cycle-to-Date

400.00

B. Full Name (Last, First, Middle Initial)

Kimberly Bucciero

Mailing Address 1085 Monroe Drive

\begin{tabular}{lcc}
\hline City & State & Zip Code \\
Atlanta & GA & $30306-3665$ \\
\hline
\end{tabular}

FEC ID number of contributing

federal political committee.

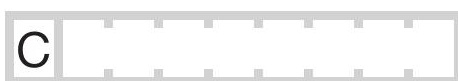

Name of Employer
Goodman Networks
Receipt For: 2012
X Primary
Other (specify)

Occupation

Project Manger

Election Cycle-to-Date

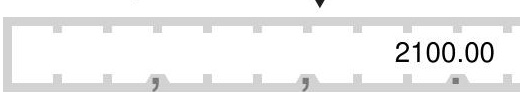

Transaction ID : A43DFDA8FAC2A4E9CA30

Date of Receipt

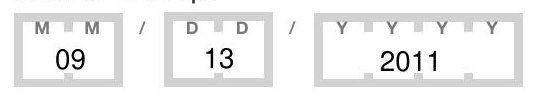

Amount of Each Receipt this Period

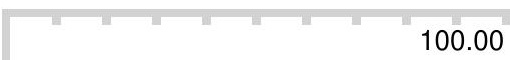

Transaction ID : AF3C03C55E73048699ED

Date of Receipt

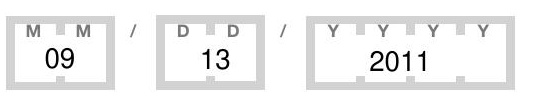

Amount of Each Receipt this Period

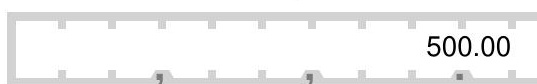

Transaction ID : A6667944C6FCC4E21A48

Date of Receipt

Christopher White

Mailing Address 14613 Pawnee St

\begin{tabular}{lcc}
\hline City & State & Zip Code \\
Overland Park & KS & $66224-3938$
\end{tabular}

FEC ID number of contributing

federal political committee.

C

66224-3938

Name of Employer
IHI Inc.
Receipt For: 2012
X Primary
Other (specify) General

Occupation

Project Manager

Election Cycle-to-Date

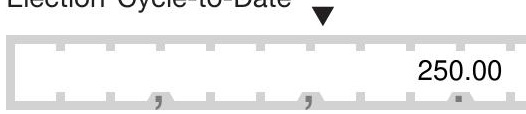

Amount of Each Receipt this Period

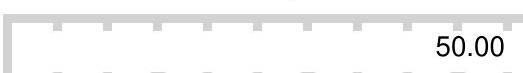

50.00

Subtotal Of Receipts This Page (optional)

650.00

Total This Period (last page this line number only) 
SCHEDULE A-P ITEMIZED RECEIPTS
Use separate schedule(s) for each category of the Detailed Summary Page
FOR LINE NUMBER: (check only one)

PAGE $505 / 1572$

\begin{tabular}{|c|c|c|c|c|c|c|}
\hline & & & & & & \\
\hline 16 & $\lambda$ & $17 \mathrm{a}$ & $17 \mathrm{~b}$ & $17 \mathrm{c}$ & $-17 d$ & -18 \\
\hline $19 a$ & & $19 b$ & $20 a$ & $20 \mathrm{~b}$ & $20 \mathrm{c}$ & 21 \\
\hline
\end{tabular}

Any information copied from such Reports and Statements may not be sold or used by any person for the purpose of soliciting contributions or for commercial purposes, other than using the name and address of any political committee to solicit contributions from such committee.

NAME OF COMMITTEE (In Full)

\section{Friends of Herman Cain}

A. Full Name (Last, First, Middle Initial)

Karen Beagle

Mailing Address 601 Revelstoke Ct

\begin{tabular}{lcc}
\hline City & State & Zip Code \\
Troy & OH & 45373 \\
\hline
\end{tabular}

FEC ID number of contributing federal political committee.

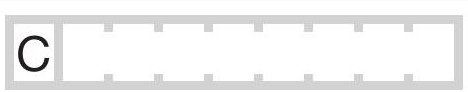

Name of Employer
MRL Services
Receipt For: 2012
X Primary $\quad$ General
Other (specify)

Occupation

Executive

Election Cycle-to-Date

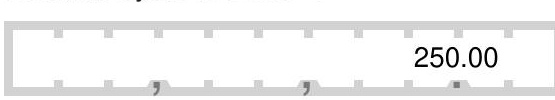

B. Full Name (Last, First, Middle Initial)

mary miller

Mailing Address 234 Hudson Cir

\begin{tabular}{lcc}
\hline City & State & Zip Code \\
Douglasville & GA & $30134-5850$
\end{tabular}

FEC ID number of contributing

federal political committee.

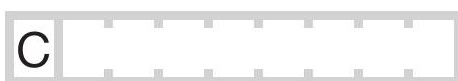

Name of Employer
City of Atlanta
Receipt For: 2012
X Primary
Other (specify)

Occupation

Project Manager

Election Cycle-to-Date

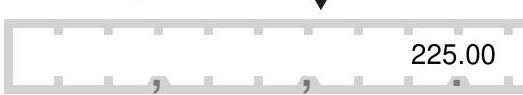

Transaction ID : A03072960C2E94FE2A13

Date of Receipt

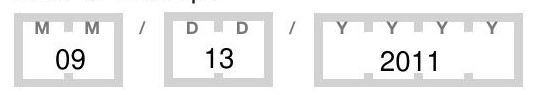

Amount of Each Receipt this Period

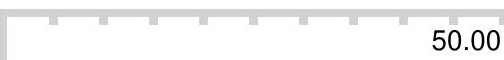

50.00

C. Full Name (Last, First, Middle Initial)

Paula Sandell

Mailing Address 16619 Sunlight Way

\begin{tabular}{lcc}
\hline City & State & Zip Code \\
Houston & TX & $77058-2243$
\end{tabular}

FEC ID number of contributing

federal political committee.

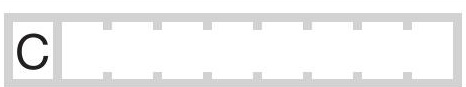

Name of Employer
None
Receipt For: 2012
Х Primary $\quad \square$ General
Other (specify)

Occupation

Retired

Election Cycle-to-Date

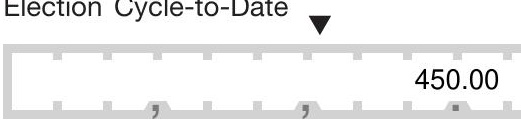

Transaction ID : A73891A954CA7473DA0B

Date of Receipt

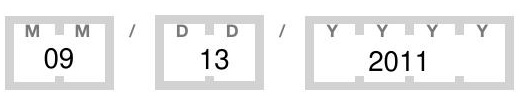

Amount of Each Receipt this Period

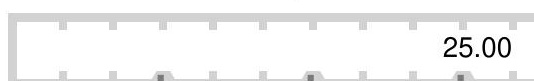

Transaction ID : A59746BFBE0D54A2082F

Date of Receipt

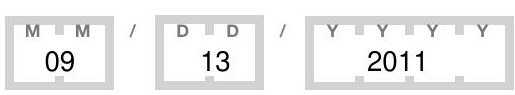

Amount of Each Receipt this Period

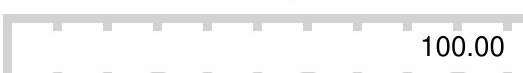

\section{Subtotal Of Receipts This Page (optional)}

175.00

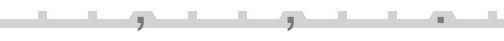

Total This Period (last page this line number only)

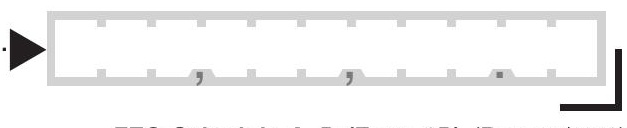

FEC Schedule A-P (Form 3P) (Rev. 03/2011) 
SCHEDULE A-P ITEMIZED RECEIPTS
Use separate schedule(s) for each category of the Detailed Summary Page
FOR LINE NUMBER: (check only one)

PAGE $506 / 1572$

\begin{tabular}{|c|c|c|c|c|c|}
\hline & & & & & \\
\hline 16 & $\begin{array}{l}\mathbf{X} \\
17 a\end{array}$ & $17 b$ & $17 c$ & $17 d$ & 18 \\
\hline $19 a$ & $19 \mathrm{~b}$ & $20 \mathrm{a}$ & $20 \mathrm{~b}$ & $20 \mathrm{c}$ & 21 \\
\hline
\end{tabular}

Any information copied from such Reports and Statements may not be sold or used by any person for the purpose of soliciting contributions or for commercial purposes, other than using the name and address of any political committee to solicit contributions from such committee.

NAME OF COMMITTEE (In Full)

\section{Friends of Herman Cain}

A. Full Name (Last, First, Middle Initial)

Helen Heinle

Mailing Address 9304 Kelly Bridge Rd

\begin{tabular}{lcc}
\hline City & State & Zip Code \\
Dawsonville & GA & $30534-4936$
\end{tabular}

FEC ID number of contributing

federal political committee.

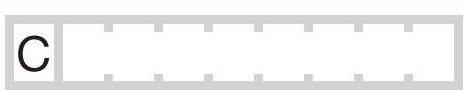

Name of Employer
Information Requested
Receipt For: 2012
X Primary $\quad \square$ General
Other (specify)

Occupation

Information Requested

Election Cycle-to-Date

490.00

B. Full Name (Last, First, Middle Initial)

Cantey Deeter

Mailing Address 3288 Ivanhoe Drive

\begin{tabular}{lcc}
\hline City & State & Zip Code \\
Atlanta & GA & $30327-1528$ \\
\hline
\end{tabular}

FEC ID number of contributing

federal political committee.

C

Name of Employer
Information Requested
Receipt For: 2012
X Primary
Other (specify)

Occupation

Information Requested

Election Cycle-to-Date

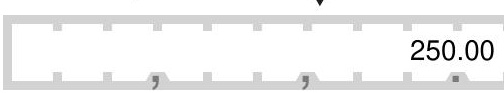

Transaction ID : A37DEA88C6EB84D709B8

Date of Receipt

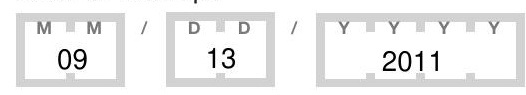

Amount of Each Receipt this Period

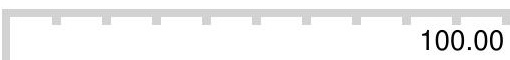

Transaction ID : A0BC543921CB741D09F4

Date of Receipt

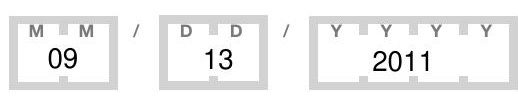

Amount of Each Receipt this Period

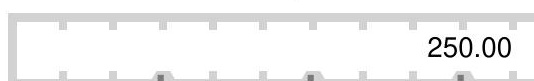

Transaction ID : A989FD35F0F1A4710A3C Date of Receipt

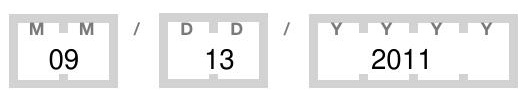

Amount of Each Receipt this Period

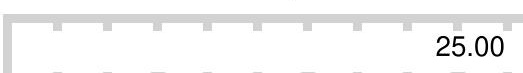

\section{Occupation}

Attorney

Election Cycle-to-Date

Receipt For: 2012

Х $\begin{aligned} & \text { Primary } \\ & \text { Other (specify) }\end{aligned}$

225.00

Subtotal Of Receipts This Page (optional)

375.00

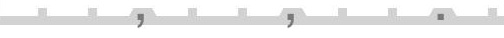

Total This Period (last page this line number only)

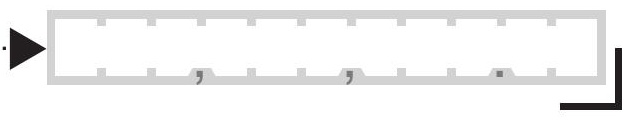

FEC Schedule A-P (Form 3P) (Rev. 03/2011) 
SCHEDULE A-P ITEMIZED RECEIPTS
Use separate schedule(s) for each category of the Detailed Summary Page
FOR LINE NUMBER: (check only one)

PAGE 507 / 1572

\begin{tabular}{|c|c|c|c|c|c|}
\hline & & & & & \\
\hline 16 & $\begin{array}{l}\mathbf{X} \\
17 a\end{array}$ & $17 b$ & $17 c$ & $17 d$ & 18 \\
\hline $19 a$ & $19 \mathrm{~b}$ & $20 \mathrm{a}$ & $20 \mathrm{~b}$ & $20 \mathrm{c}$ & 21 \\
\hline
\end{tabular}

Any information copied from such Reports and Statements may not be sold or used by any person for the purpose of soliciting contributions or for commercial purposes, other than using the name and address of any political committee to solicit contributions from such committee.

NAME OF COMMITTEE (In Full)

\section{Friends of Herman Cain}

A. Full Name (Last, First, Middle Initial)

Rex Holloway

Mailing Address 7119 Miltondale Rd

\begin{tabular}{lcc}
\hline City & State & Zip Code \\
Macclenny & FL & $32063-5538$ \\
\hline
\end{tabular}

FEC ID number of contributing

federal political committee.

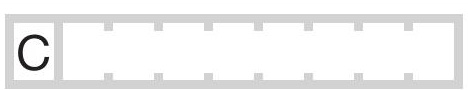

Name of Employer
Retired
Receipt For: 2012
X Primary $\quad$ General
Other (specify)

Occupation

Retired

Election Cycle-to-Date

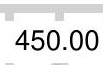

B. Full Name (Last, First, Middle Initial)

Sylvia Downey

Mailing Address 134 S Hawk Dr

\begin{tabular}{lcc}
\hline City & State & Zip Code \\
Rainbow City & AL & $35906-3608$
\end{tabular}

FEC ID number of contributing

federal political committee.

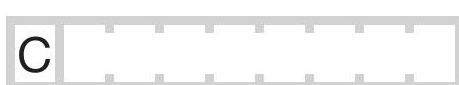

Name of Employer
None
Receipt For: 2012
X Primary
Other (specify)

\section{Occupation}

Retired

Election Cycle-to-Date

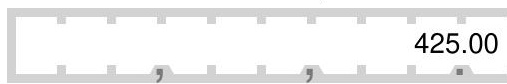

C. Full Name (Last, First, Middle Initial)

Phyllis Fine

Mailing Address 266 Trailwood Lane

\begin{tabular}{lcc}
\hline City & State & Zip Code \\
Northbrook & IL & $60062-103$
\end{tabular}

FEC ID number of contributing federal political committee.

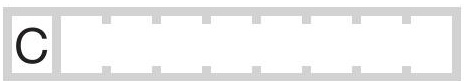

Name of Employer
homemaker
Receipt For: 2012
X Primary
Other (specify) General

\section{Occupation}

Homemaker

Election Cycle-to-Date

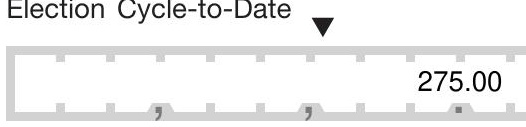

Transaction ID : A9AB806CBF0F7441FB0B

Date of Receipt

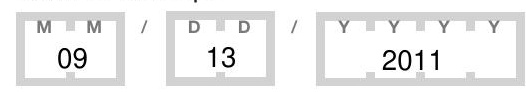

Amount of Each Receipt this Period

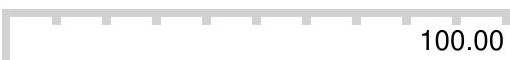

100.00

Transaction ID : ABA99F159D8154453B41

Date of Receipt

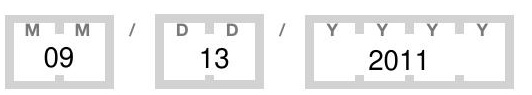

Amount of Each Receipt this Period

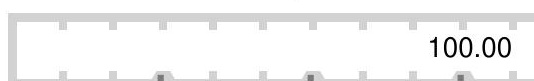

Transaction ID : A3BE5A5CE96B24587871

Date of Receipt

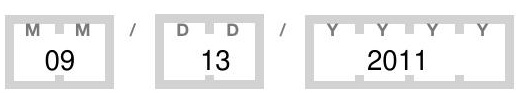

Amount of Each Receipt this Period

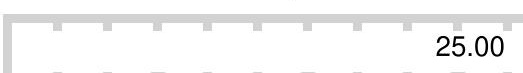

25.00

Subtotal Of Receipts This Page (optional)

Total This Period (last page this line number only) 
SCHEDULE A-P ITEMIZED RECEIPTS
Use separate schedule(s) for each category of the Detailed Summary Page
FOR LINE NUMBER: (check only one)

PAGE $508 / 1572$

\begin{tabular}{|c|c|c|c|c|c|}
\hline & & & & & \\
\hline 16 & $\begin{array}{l}\mathbf{X} \\
17 a\end{array}$ & $17 b$ & $17 c$ & $17 d$ & 18 \\
\hline $19 a$ & $19 \mathrm{~b}$ & $20 \mathrm{a}$ & $20 \mathrm{~b}$ & $20 \mathrm{c}$ & 21 \\
\hline
\end{tabular}

Any information copied from such Reports and Statements may not be sold or used by any person for the purpose of soliciting contributions or for commercial purposes, other than using the name and address of any political committee to solicit contributions from such committee.

NAME OF COMMITTEE (In Full)

\section{Friends of Herman Cain}

A. Full Name (Last, First, Middle Initial)

Lynn Wallis

Mailing Address 106 E. Washington St.

\begin{tabular}{lcc}
\hline City & State & Zip Code \\
Cuba & MO & $65453-1827$
\end{tabular}

FEC ID number of contributing federal political committee.

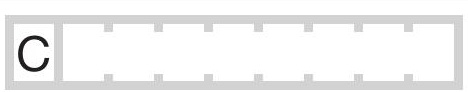

Name of Employer
Wallis Companies
Receipt For: 2012
X Primary $\quad$ General
Other (specify)

Occupation

Executive

Election Cycle-to-Date

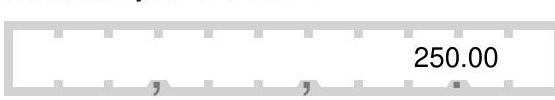

B. Full Name (Last, First, Middle Initial)

Maureen Krueger

Mailing Address 7802 E Lakeview Trail

\begin{tabular}{lcc}
\hline City & State & Zip Code \\
Orange & CA & $92869-2447$
\end{tabular}

FEC ID number of contributing

federal political committee.

C

Name of Employer
None
Receipt For: 2012
X Primary
Other (specify)

\section{Occupation}

Unemployed

Election Cycle-to-Date

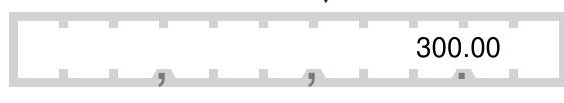

Transaction ID : A6E6AA3E0ECC643B7989

Date of Receipt

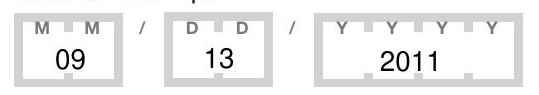

Amount of Each Receipt this Period

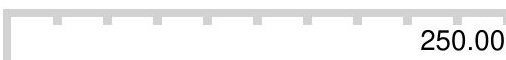

Transaction ID : A30504C316970487CA45

Date of Receipt

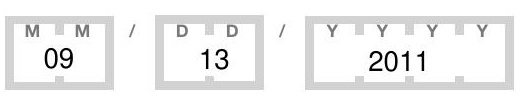

Amount of Each Receipt this Period

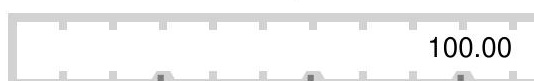

C. Full Name (Last, First, Middle Initial)

Glenwood Grunder

Mailing Address 4429 M-66 SE

\begin{tabular}{lcc}
\hline City & State & Zip Code \\
Kalkaska & MI & 49646 \\
\hline
\end{tabular}

FEC ID number of contributing federal political committee.

C

Name of Employer
None
Receipt For: 2012
Х Primary $\quad \square$ General
Other (specify)

Occupation

Retired

Election Cycle-to-Date

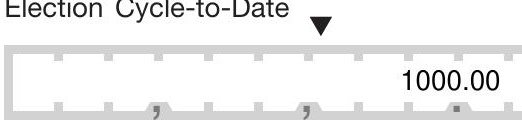

Transaction ID : A1CA0CA75B67649CDB67 Date of Receipt

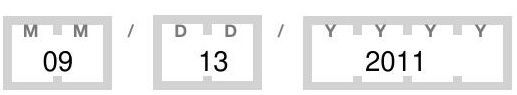

Amount of Each Receipt this Period

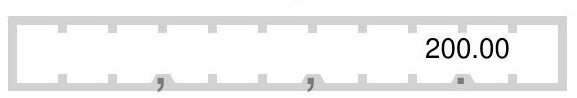

\section{Subtotal Of Receipts This Page (optional)}

Total This Period (last page this line number only) 
SCHEDULE A-P ITEMIZED RECEIPTS
Use separate schedule(s) for each category of the Detailed Summary Page
FOR LINE NUMBER: (check only one)

PAGE 509 / 1572

\begin{tabular}{|c|c|c|c|c|c|}
\hline & & & & & \\
\hline 16 & $\begin{array}{l}\mathbf{X} \\
17 a\end{array}$ & $17 b$ & $17 c$ & $17 d$ & 18 \\
\hline $19 a$ & $19 \mathrm{~b}$ & $20 \mathrm{a}$ & $20 \mathrm{~b}$ & $20 \mathrm{c}$ & 21 \\
\hline
\end{tabular}

Any information copied from such Reports and Statements may not be sold or used by any person for the purpose of soliciting contributions or for commercial purposes, other than using the name and address of any political committee to solicit contributions from such committee.

NAME OF COMMITTEE (In Full)

\section{Friends of Herman Cain}

A. Full Name (Last, First, Middle Initial)

Adrienne King

Mailing Address 1163 Kaeleku Street

\begin{tabular}{lcc}
\hline City & State & Zip Code \\
Honolulu & HI & $96825-3007$ \\
\hline
\end{tabular}

FEC ID number of contributing

federal political committee.

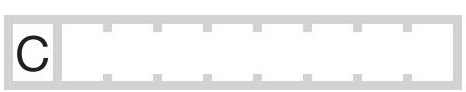

Name of Employer
Self Employed
Receipt For: 2012
X Primary $\quad$ General
Other (specify)

Occupation

Attorney

Election Cycle-to-Date

250.00

B. Full Name (Last, First, Middle Initial)

Glen Ebbing

Mailing Address 1400 Huntleigh Rd

\begin{tabular}{lcc}
\hline City & State & Zip Code \\
Quincy & IL & $62305-6017$
\end{tabular}

FEC ID number of contributing

federal political committee.

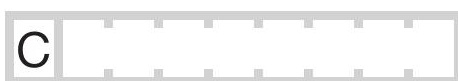

Name of Employer
ColorMaster Pain Inc
Receipt For: 2012
X Primary
Other (specify)

Occupation

sales representative

Election Cycle-to-Date

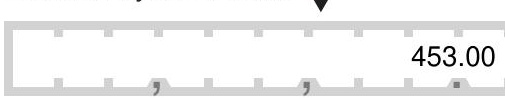

Transaction ID : A97036D6B24C74D98AE6

Date of Receipt

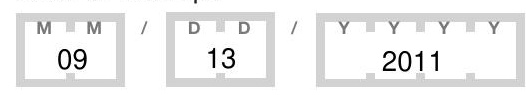

Amount of Each Receipt this Period

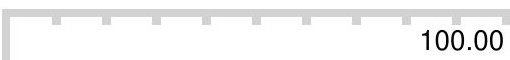

Transaction ID : A45B35904E74D4A1882F

Date of Receipt

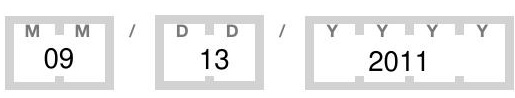

Amount of Each Receipt this Period

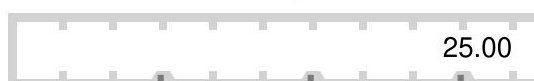

Transaction ID : A4A6971A6F7744EE9873

Date of Receipt

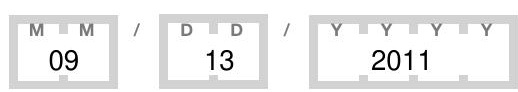

Amount of Each Receipt this Period

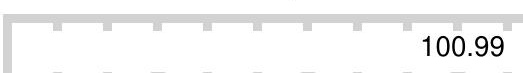

Name of Employer

Checker Cab of Bloomington Inc.

\section{Occupation}

Taxi Owner

Receipt For: 2012

Х $\begin{aligned} & \text { Primary } \square \text { General } \\ & \text { Other (specify) }\end{aligned}$

$\begin{array}{cc}\text { State } & \text { Zip Code } \\ \text { IL } & 61701-2623\end{array}$

C

Election Cycle-to-Date

350.99

Subtotal Of Receipts This Page (optional).

225.99

ㄱ․․

Total This Period (last page this line number only)

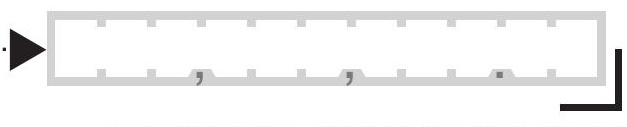

FEC Schedule A-P (Form 3P) (Rev. 03/2011) 
SCHEDULE A-P ITEMIZED RECEIPTS
Use separate schedule(s) for each category of the Detailed Summary Page
FOR LINE NUMBER: (check only one)

PAGE $510 / 1572$

\begin{tabular}{|c|c|c|c|c|c|c|}
\hline & & & & & & \\
\hline 16 & $\lambda$ & $17 \mathrm{a}$ & $17 \mathrm{~b}$ & $17 \mathrm{c}$ & $-17 d$ & -18 \\
\hline $19 a$ & & $19 b$ & $20 a$ & $20 \mathrm{~b}$ & $20 \mathrm{c}$ & 21 \\
\hline
\end{tabular}

Any information copied from such Reports and Statements may not be sold or used by any person for the purpose of soliciting contributions or for commercial purposes, other than using the name and address of any political committee to solicit contributions from such committee.

NAME OF COMMITTEE (In Full)

\section{Friends of Herman Cain}

A. Full Name (Last, First, Middle Initial)

Paul Chadek

Transaction ID : AD8C5DA97996B4420B4C

Mailing Address 1300 Cologna Road

\begin{tabular}{lcc}
\hline City & State & Zip Code \\
Marshfield & MO & $65706-9828$
\end{tabular}

FEC ID number of contributing federal political committee.

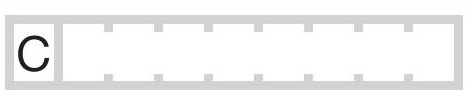

Name of Employer
CoxHealth
Receipt For: 2012
X Primary $\quad$ General
Other (specify)

Occupation Registered Nurse

Election Cycle-to-Date

Date of Receipt

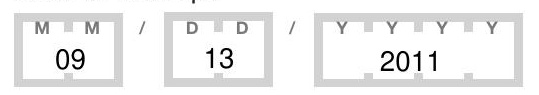

Amount of Each Receipt this Period

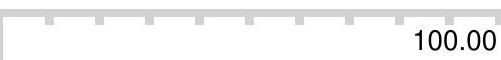

100.00

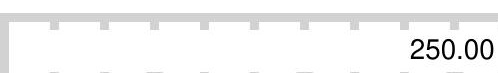

B. Full Name (Last, First, Middle Initial)

Carol Cook

Mailing Address 43 Oak Alley

\begin{tabular}{lcc}
\hline City & State & Zip Code \\
Kerrville & TX & $78028-1711$
\end{tabular}

FEC ID number of contributing

federal political committee.

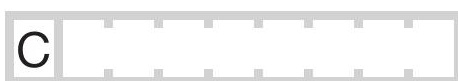

Name of Employer
James Avery
Receipt For: 2012
X Primary
Other (specify)

Occupation

Sales Team Leader

Election Cycle-to-Date

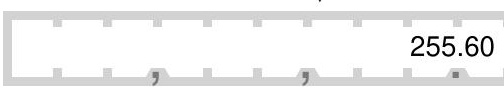

C. Full Name (Last, First, Middle Initial)

Judy Renault

Mailing Address 3420 Salem Trace

\begin{tabular}{lcc}
\hline City & State & Zip Code \\
Marietta & GA & $30062-4352$
\end{tabular}

FEC ID number of contributing

federal political committee.

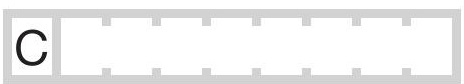

Name of Employer
Retired
Receipt For: 2012
X Primary $\quad \square$ General
Other (specify)

Occupation

Retired

Election Cycle-to-Date

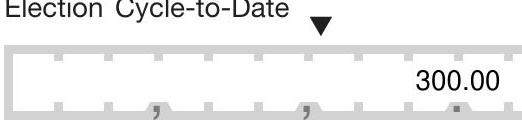

Transaction ID : A34843BF140CA40318C8

Date of Receipt

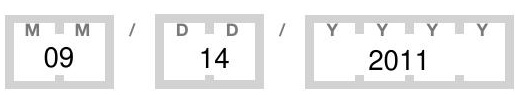

Amount of Each Receipt this Period

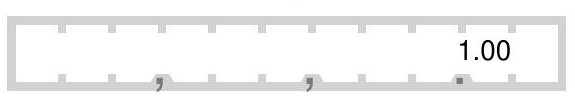

Transaction ID : A0184C9EEA392456BB9F Date of Receipt

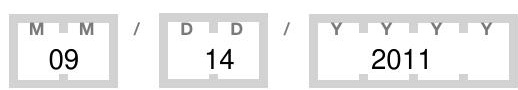

Amount of Each Receipt this Period

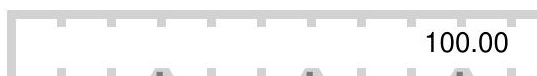

\section{Subtotal Of Receipts This Page (optional)}

201.00

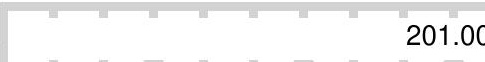

.

Total This Period (last page this line number only)

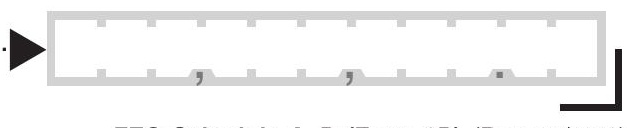

FEC Schedule A-P (Form 3P) (Rev. 03/2011) 
SCHEDULE A-P ITEMIZED RECEIPTS
Use separate schedule(s) for each category of the Detailed Summary Page
FOR LINE NUMBER: (check only one)

PAGE $511 / 1572$

\begin{tabular}{|c|c|c|c|c|c|c|}
\hline & & & & & & \\
\hline 16 & $\lambda$ & $17 \mathrm{a}$ & $17 \mathrm{~b}$ & $17 \mathrm{c}$ & $-17 d$ & -18 \\
\hline $19 a$ & & $19 b$ & $20 a$ & $20 \mathrm{~b}$ & $20 \mathrm{c}$ & 21 \\
\hline
\end{tabular}

Any information copied from such Reports and Statements may not be sold or used by any person for the purpose of soliciting contributions or for commercial purposes, other than using the name and address of any political committee to solicit contributions from such committee.

NAME OF COMMITTEE (In Full)

\section{Friends of Herman Cain}

A. Full Name (Last, First, Middle Initial)

Ms Wilma M Edwards

Mailing Address PO Box 471

\begin{tabular}{lcc}
\hline City & State & Zip Code \\
Del Mar & CA & $92014-0471$
\end{tabular}

FEC ID number of contributing federal political committee.

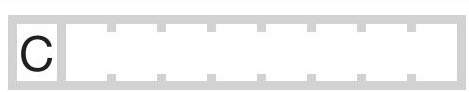

\begin{tabular}{l} 
Name of Employer \\
None \\
Receipt For: 2012 \\
X Primary $\quad$ General \\
\hline Other (specify)
\end{tabular}

Occupation Retired

Election Cycle-to-Date

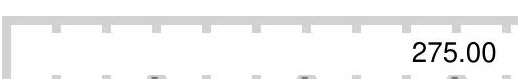

B. Full Name (Last, First, Middle Initial)

Mrs. Suzanne G Callihan

Mailing Address 442 Sooner Park Rd

\begin{tabular}{lcc}
\hline City & State & Zip Code \\
Bartlesville & OK & $74006-2915$
\end{tabular}

FEC ID number of contributing

federal political committee.

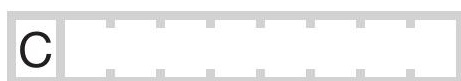

Name of Employer
Conoco Phillips
Receipt For: 2012
X Primary
Other (specify)

\section{Occupation}

CPA/Fin Sys Adv

Election Cycle-to-Date

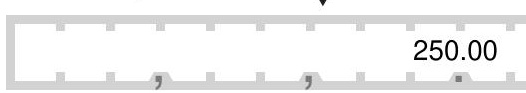

C. Full Name (Last, First, Middle Initial)

Robert Stewart-Lewis

Mailing Address 1900 Sipe Rd

\begin{tabular}{lcc}
\hline City & State & Zip Code \\
Conover & NC & 28613-8818
\end{tabular}

FEC ID number of contributing federal political committee.

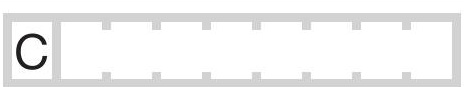

Name of Employer
Univ Of GA
Receipt For: 2012
X Primary
Other (specify) General

\section{Occupation}

vet

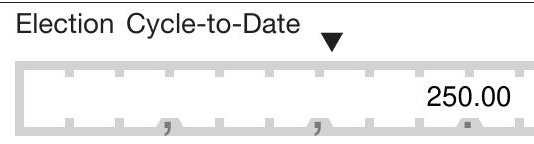

Transaction ID : A83F66D2D969246B984D

Date of Receipt

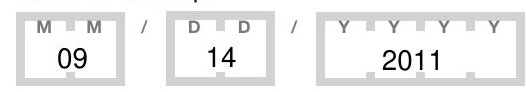

Amount of Each Receipt this Period

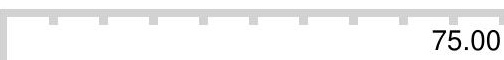

75.00
Amount of Each Receipt this Period

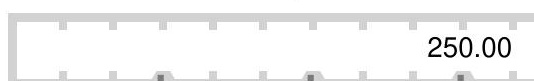

Transaction ID : AEC97CF3F17D04829906 Date of Receipt

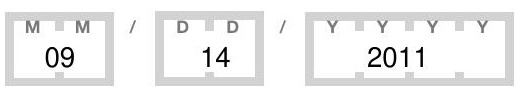

Amount of Each Receipt this Period

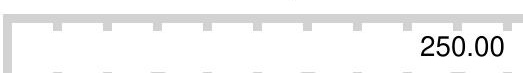

Transaction ID : A6AB789D7F5CB406DAEA Date of Receipt
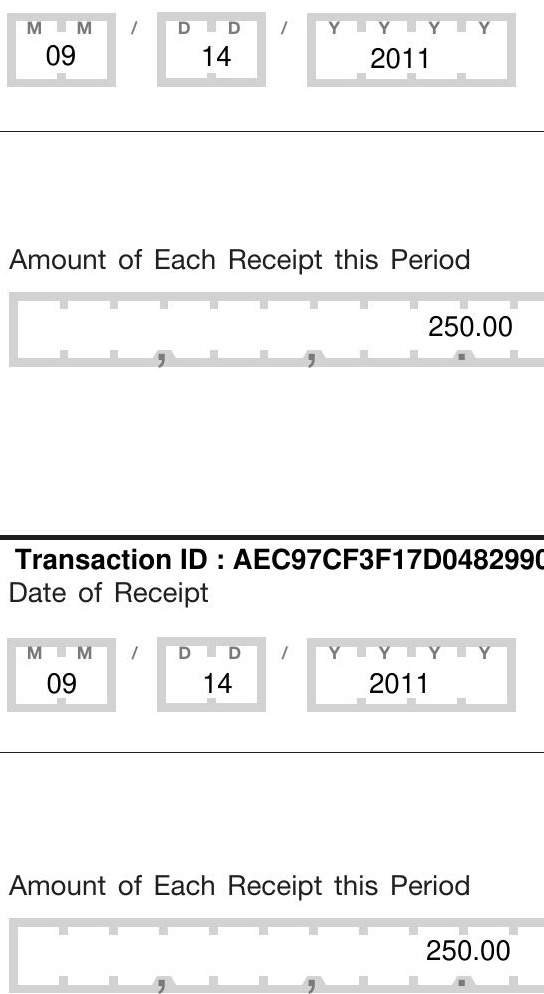

\section{Subtotal Of Receipts This Page (optional)}

575.00

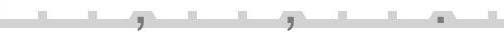

Total This Period (last page this line number only)

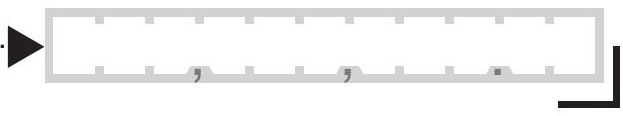




\section{SCHEDULE A-P} ITEMIZED RECEIPTS
Use separate schedule(s) for each category of the Detailed Summary Page

\begin{tabular}{|c|c|c|c|c|c|}
\hline \multicolumn{3}{|c|}{$\begin{array}{l}\text { FOR LINE NUMBER: } \\
\text { (check only one) }\end{array}$} & \multicolumn{3}{|c|}{ PAGE 512 / 1572} \\
\hline 16 & $X$ 17a & $17 b$ & $17 \mathrm{c}$ & $17 d$ & 18 \\
\hline $19 a$ & $19 \mathrm{~b}$ & $20 a$ & $20 \mathrm{~b}$ & $20 c$ & 21 \\
\hline
\end{tabular}

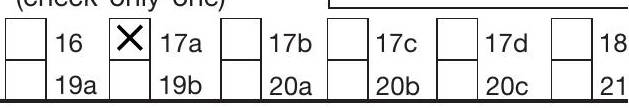

Any information copied from such Reports and Statements may not be sold or used by any person for the purpose of soliciting contributions or for commercial purposes, other than using the name and address of any political committee to solicit contributions from such committee.

NAME OF COMMITTEE (In Full)

\section{Friends of Herman Cain}

A. Full Name (Last, First, Middle Initial)

Mr David Cookson

Mailing Address 4910 Lake Mendota Dr

\begin{tabular}{lcc}
\hline City & State & Zip Code \\
Madison & WI & $53705-1376$
\end{tabular}

FEC ID number of contributing federal political committee.

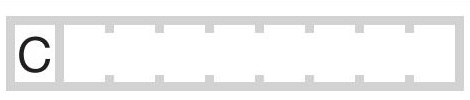

Name of Employer
Information Requested
Receipt For: 2012
X Primary
$\square$ Other (specify)

Occupation Information Requested

Election Cycle-to-Date

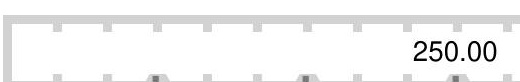

B. Full Name (Last, First, Middle Initial)

David Morris

\section{Mailing Address 7921 E 46th Street}

\begin{tabular}{lcc}
\hline City & State & Zip Code \\
Indianapolis & IN & $46226-3931$ \\
\hline
\end{tabular}

FEC ID number of contributing

federal political committee.

C

Name of Employer
Precision Dry Wall Inc.
Receipt For: 2012
$X$ Primary
Other (specify)

\section{Occupation}

Construction

Election Cycle-to-Date

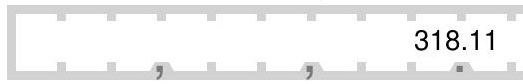

Transaction ID : ACBBF488533C847F49ED

Date of Receipt

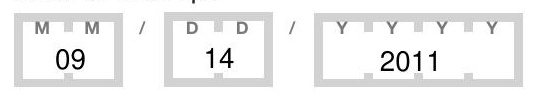

Amount of Each Receipt this Period

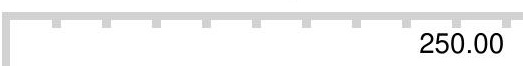

Amount of Each Receipt this Period

Transaction ID : A138AF80DA9694AF5978

Date of Receipt
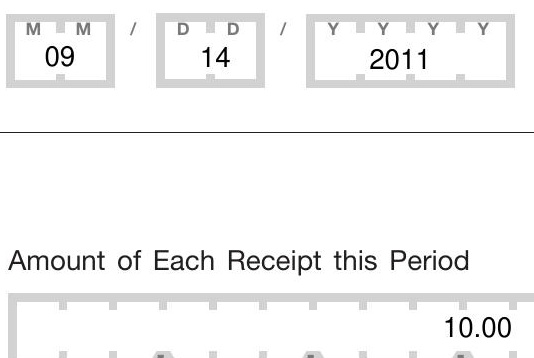

C. Full Name (Last, First, Middle Initial)

darral Simmons

Mailing Address 9315 Enclave Green Ln E

\begin{tabular}{lcc}
\hline City & State & Zip Code \\
Germantown & TN & $38139-5719$
\end{tabular}

FEC ID number of contributing federal political committee.

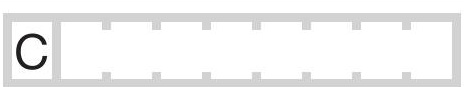

Name of Employer

Information Requested

\section{Occupation}

Information Requested

Receipt For: 2012

Х $\begin{aligned} & \text { Primary } \square \text { General } \\ & \text { Other (specify) }\end{aligned}$

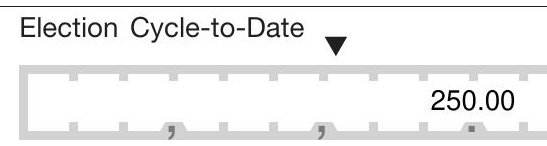

Transaction ID : AF7751E76383E4E0E86A

Date of Receipt

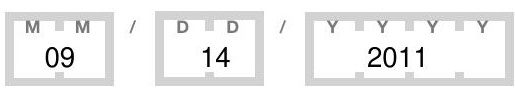

Amount of Each Receipt this Period

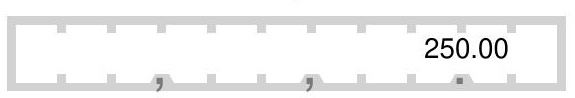

Subtotal Of Receipts This Page (optional).

510.00

Total This Period (last page this line number only) 
SCHEDULE A-P ITEMIZED RECEIPTS
Use separate schedule(s) for each category of the Detailed Summary Page
FOR LINE NUMBER: (check only one)

PAGE $513 / 1572$

\begin{tabular}{|c|c|c|c|c|c|c|}
\hline & & & & & & \\
\hline 16 & $\lambda$ & $17 \mathrm{a}$ & $17 \mathrm{~b}$ & $17 \mathrm{c}$ & $-17 d$ & -18 \\
\hline $19 a$ & & $19 b$ & $20 a$ & $20 \mathrm{~b}$ & $20 \mathrm{c}$ & 21 \\
\hline
\end{tabular}

Any information copied from such Reports and Statements may not be sold or used by any person for the purpose of soliciting contributions or for commercial purposes, other than using the name and address of any political committee to solicit contributions from such committee.

NAME OF COMMITTEE (In Full)

\section{Friends of Herman Cain}

A. Full Name (Last, First, Middle Initial)

Edward Logue

Mailing Address 5205 Saint Regis PI

\begin{tabular}{lcc}
\hline City & State & Zip Code \\
Belle Isle & FL & $32812-1033$
\end{tabular}

FEC ID number of contributing federal political committee.

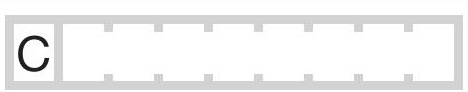

Name of Employer
Computer Sciences Corporation
Receipt For: 2012
X Primary
Other (specify) General

Occupation

Program Manager

Election Cycle-to-Date

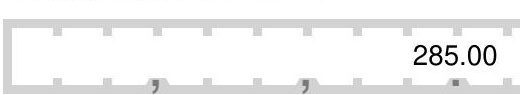

B. Full Name (Last, First, Middle Initial)

Patricia Montgomery

Mailing Address 4035 Dollar Circle

\begin{tabular}{lcc}
\hline City & State & Zip Code \\
Suwanee & GA & $30024-2360$ \\
\hline
\end{tabular}

FEC ID number of contributing

federal political committee.

C

Name of Employer
Information Requested
Receipt For: 2012
Primary
Other (specify)

Occupation

Information Requested

Election Cycle-to-Date

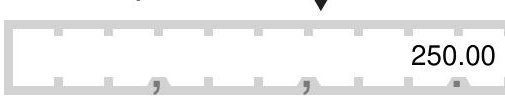

Transaction ID : A65E0B384E8D044869BB

Date of Receipt

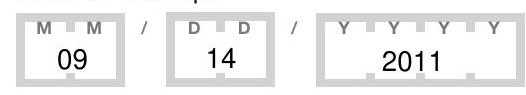

Amount of Each Receipt this Period

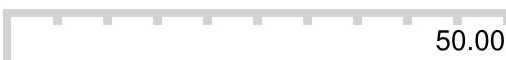

50.00

C. Full Name (Last, First, Middle Initial)

Gary Shawver

Mailing Address 551 Excelsior Lane

\begin{tabular}{lcc}
\hline City & State & Zip Code \\
Waterloo & IA & $50701-4967$
\end{tabular}

FEC ID number of contributing

federal political committee.

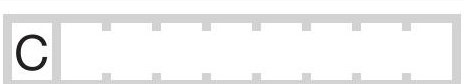

Name of Employer

Shawver Well Co. Inc

Occupation

Receipt For: 2012

Х $\begin{aligned} & \text { Primary } \square \text { General } \\ & \text { Other (specify) }\end{aligned}$

Water well contractor

Election Cycle-to-Date

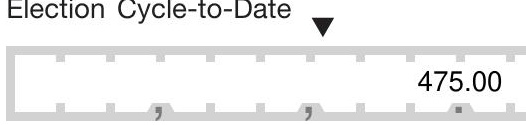

Transaction ID : A69B87951BEFE4D828C5

Date of Receipt

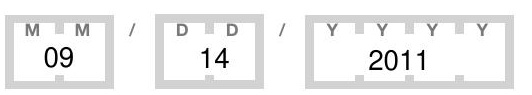

Amount of Each Receipt this Period

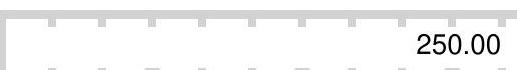

Transaction ID : AE21458326E604432B1E

Date of Receipt

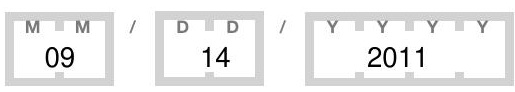

Amount of Each Receipt this Period

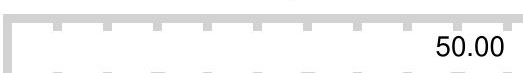

50.00

350.00

Subtotal Of Receipts This Page (optional)

Total This Period (last page this line number only) 
SCHEDULE A-P ITEMIZED RECEIPTS
Use separate schedule(s) for each category of the Detailed Summary Page
FOR LINE NUMBER: (check only one)

\begin{tabular}{|c|c|c|c|c|c|}
\hline & & & & & \\
\hline 16 & $\begin{array}{ll}X & 17 a \\
\end{array}$ & $17 \mathrm{~b}$ & $17 c$ & $17 d$ & 18 \\
\hline $19 a$ & $19 b$ & $20 \mathrm{a}$ & $20 \mathrm{~b}$ & $20 c$ & 21 \\
\hline
\end{tabular}

Any information copied from such Reports and Statements may not be sold or used by any person for the purpose of soliciting contributions or for commercial purposes, other than using the name and address of any political committee to solicit contributions from such committee.

NAME OF COMMITTEE (In Full)

\section{Friends of Herman Cain}

A. Full Name (Last, First, Middle Initial)

Marianne Mason

Mailing Address 30 Tall Oaks Trail

\begin{tabular}{lcc}
\hline City & State & Zip Code \\
Austin & TX & $78737-9306$
\end{tabular}

FEC ID number of contributing federal political committee.

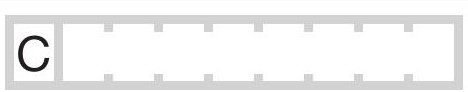

Name of Employer

MMA Int. LLC

Receipt For: 2012

Х Primary $\square$ General Other (specify)
Occupation

Accountant

Election Cycle-to-Date
1753.00

B. Full Name (Last, First, Middle Initial)

Ms. Maxine Terk

Mailing Address 1354 The By Way NE

\begin{tabular}{lcc}
\hline City & State & Zip Code \\
Atlanta & GA & $30306-2616$
\end{tabular}

FEC ID number of contributing

federal political committee.

C

Name of Employer
None
Receipt For: 2012
X Primary $\quad$ General
Other (specify)

\section{Occupation}

Retired

Election Cycle-to-Date

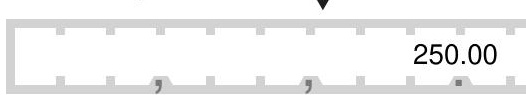

Transaction ID : A54548FB075B242DCB5D

Date of Receipt

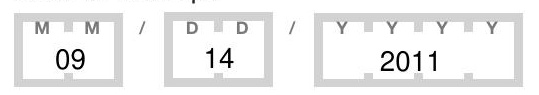

Amount of Each Receipt this Period

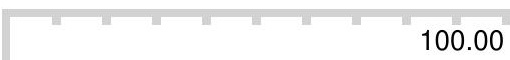

100.00

C. Full Name (Last, First, Middle Initial)

Carol Cook

Mailing Address 43 Oak Alley

\begin{tabular}{lcc}
\hline City & State & Zip Code \\
Kerrville & TX & $78028-1711$
\end{tabular}

FEC ID number of contributing federal political committee.

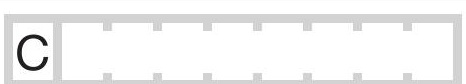

Name of Employer
James Avery
Receipt For: 2012
X Primary
Other (specify) General

\section{Occupation}

Sales Team Leader

Election Cycle-to-Date

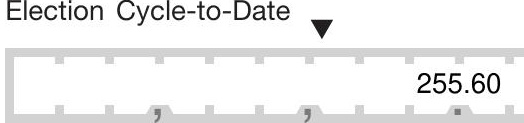

Transaction ID : AB3B8711B44F84107880

Date of Receipt

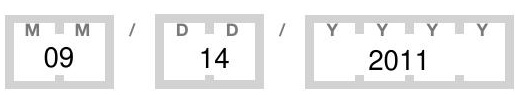

Amount of Each Receipt this Period

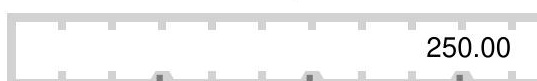

Transaction ID : A6D5E086A7FAE44C388F Date of Receipt

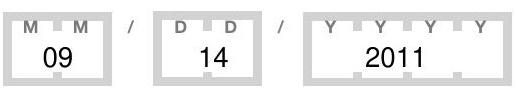

Amount of Each Receipt this Period

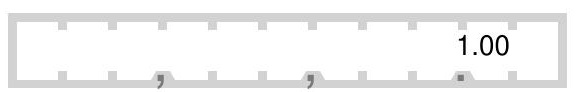

\section{Subtotal Of Receipts This Page (optional)}

Total This Period (last page this line number only) 
SCHEDULE A-P ITEMIZED RECEIPTS
Use separate schedule(s) for each category of the Detailed Summary Page
FOR LINE NUMBER: (check only one)

PAGE $515 / 1572$

\begin{tabular}{|c|c|c|c|c|c|}
\hline & & & & & \\
\hline 16 & $\begin{array}{l}\mathbf{X} \\
17 a\end{array}$ & $17 b$ & $17 c$ & $17 d$ & 18 \\
\hline $19 a$ & $19 \mathrm{~b}$ & $20 \mathrm{a}$ & $20 \mathrm{~b}$ & $20 \mathrm{c}$ & 21 \\
\hline
\end{tabular}

Any information copied from such Reports and Statements may not be sold or used by any person for the purpose of soliciting contributions or for commercial purposes, other than using the name and address of any political committee to solicit contributions from such committee.

NAME OF COMMITTEE (In Full)

\section{Friends of Herman Cain}

A. Full Name (Last, First, Middle Initial)

Douglas Johnson

Mailing Address 13 Clear Ridge

\begin{tabular}{lcc}
\hline City & State & Zip Code \\
Carriere & MS & $39426-8144$
\end{tabular}

FEC ID number of contributing federal political committee.

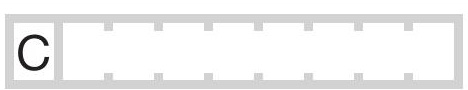

Name of Employer
Northshore Specialty Hospital
Receipt For: 2012
X Primary
Other (specify) General

Occupation

Hospital Administrator

Election Cycle-to-Date

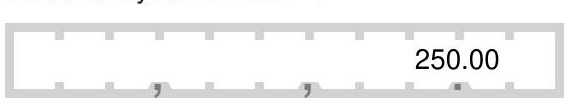

B. Full Name (Last, First, Middle Initial)

Ms Wilma M Edwards

Mailing Address PO Box 471

\begin{tabular}{lcc}
\hline City & State & Zip Code \\
Del Mar & CA & $92014-0471$
\end{tabular}

FEC ID number of contributing

federal political committee.

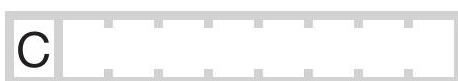

Name of Employer
None
Receipt For: 2012
X Primary
Other (specify)

Occupation

Retired

Election Cycle-to-Date

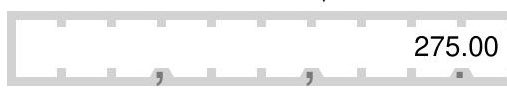

Transaction ID : A816EE68352244EEEB89

Date of Receipt

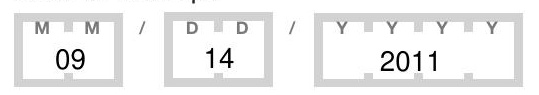

Amount of Each Receipt this Period

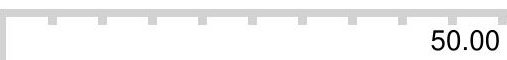

50.00

C. Full Name (Last, First, Middle Initial)

Lisa Philbrook

Mailing Address 807 Circle Dr

\begin{tabular}{lcc}
\hline City & State & Zip Code \\
Bellaire & TX & $77401-2808$
\end{tabular}

FEC ID number of contributing federal political committee.

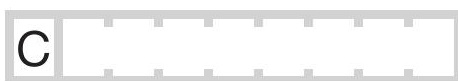

Name of Employer

Greater Houston Anesthesiology

Receipt For: 2012

Х $\begin{aligned} & \text { Primary } \\ & \text { Other (specify) }\end{aligned}$

Occupation

Physician

Election Cycle-to-Date

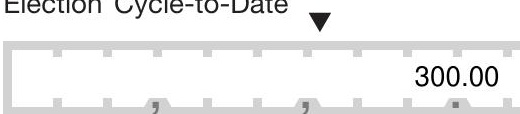

Transaction ID : AB52CE5C01A294614B27

Date of Receipt

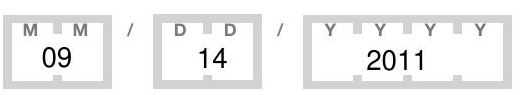

Amount of Each Receipt this Period

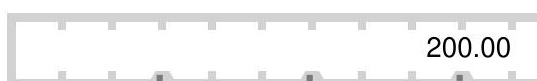

Transaction ID : A1E0D023BA4A84BEF933 Date of Receipt

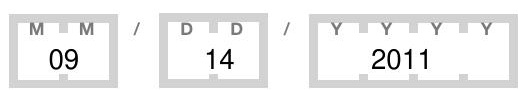

Amount of Each Receipt this Period

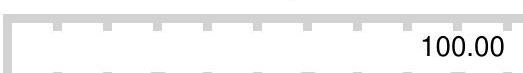

\section{Subtotal Of Receipts This Page (optional)}

Total This Period (last page this line number only) 
SCHEDULE A-P ITEMIZED RECEIPTS
Use separate schedule(s) for each category of the Detailed Summary Page
FOR LINE NUMBER: (check only one)

PAGE $516 / 1572$

\begin{tabular}{|c|c|c|c|c|c|}
\hline & & & & & \\
\hline 16 & $\begin{array}{l}\mathbf{X} \\
17 a\end{array}$ & $17 b$ & $17 c$ & $17 d$ & 18 \\
\hline $19 a$ & $19 \mathrm{~b}$ & $20 \mathrm{a}$ & $20 \mathrm{~b}$ & $20 \mathrm{c}$ & 21 \\
\hline
\end{tabular}

Any information copied from such Reports and Statements may not be sold or used by any person for the purpose of soliciting contributions or for commercial purposes, other than using the name and address of any political committee to solicit contributions from such committee.

NAME OF COMMITTEE (In Full)

\section{Friends of Herman Cain}

A. Full Name (Last, First, Middle Initial)

Anthony H Ryan

Mailing Address 393 Dorchester Rd

\begin{tabular}{lcc}
\hline City & State & Zip Code \\
Lyme & $\mathrm{NH}$ & $03768-3900$ \\
\hline
\end{tabular}

FEC ID number of contributing federal political committee.

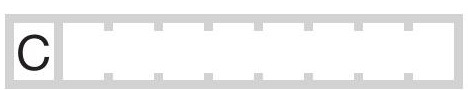

Name of Employer
None
Receipt For: 2012
X Primary $\quad$ General
Other (specify)

Occupation

Retired

Election Cycle-to-Date

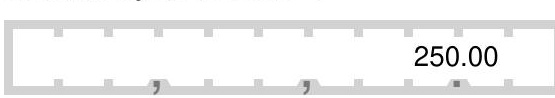

B. Full Name (Last, First, Middle Initial)

Daniel Stone

Mailing Address 4417 Sterling Pointe Dr

\begin{tabular}{lcc}
\hline City & State & Zip Code \\
Kennesaw & GA & $30152-7348$ \\
\hline
\end{tabular}

FEC ID number of contributing

federal political committee.

C

Name of Employer
INVISTA S.a.r.I.
Receipt For: 2012
X Primary
Other (specify)

\section{Occupation}

VP - Business Analysis

Election Cycle-to-Date

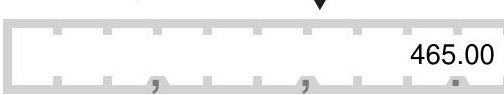

Transaction ID : AA64A31A6ED584E7083C

Date of Receipt

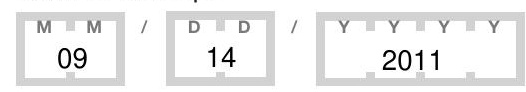

Amount of Each Receipt this Period

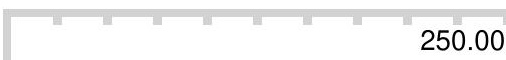

250.00

C. Full Name (Last, First, Middle Initial)

Mark Holmes

Mailing Address 8104 Mason Ridge Ln

\begin{tabular}{lcc}
\hline City & State & Zip Code \\
Wilmington & NC & $28409-3031$
\end{tabular}

FEC ID number of contributing federal political committee.

C

Name of Employer

Information Requested

Occupation

Information Requested

Receipt For: 2012

Х $\begin{aligned} & \text { Primary } \square \text { General } \\ & \text { Other (specify) }\end{aligned}$

Election Cycle-to-Date

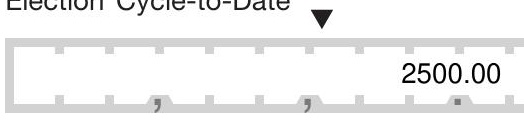

Transaction ID : AD838AB0F449A458DB89

Date of Receipt

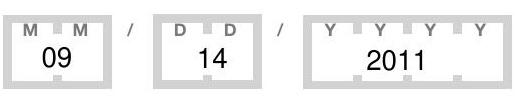

Amount of Each Receipt this Period

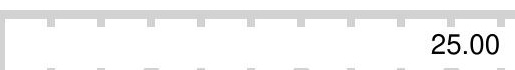

Transaction ID : A6F68083018374A65802

Date of Receipt

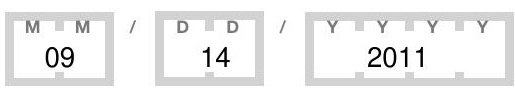

Amount of Each Receipt this Period

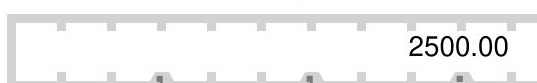

2775.00

Subtotal Of Receipts This Page (optional)

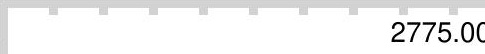

Total This Period (last page this line number only) 
SCHEDULE A-P ITEMIZED RECEIPTS
Use separate schedule(s) for each category of the Detailed Summary Page
FOR LINE NUMBER: (check only one)

PAGE $517 / 1572$

\begin{tabular}{|c|c|c|c|c|c|}
\hline & & & & & \\
\hline 16 & $\begin{array}{l}\mathbf{X} \\
17 a\end{array}$ & $17 b$ & $17 c$ & $17 d$ & 18 \\
\hline $19 a$ & $19 \mathrm{~b}$ & $20 \mathrm{a}$ & $20 \mathrm{~b}$ & $20 \mathrm{c}$ & 21 \\
\hline
\end{tabular}

Any information copied from such Reports and Statements may not be sold or used by any person for the purpose of soliciting contributions or for commercial purposes, other than using the name and address of any political committee to solicit contributions from such committee.

NAME OF COMMITTEE (In Full)

\section{Friends of Herman Cain}

A. Full Name (Last, First, Middle Initial)

Mr Kent Price

Mailing Address 101 Coventry Ct

\begin{tabular}{lcc}
\hline City & State & Zip Code \\
San Carlos & CA & $94070-1515$
\end{tabular}

FEC ID number of contributing federal political committee.

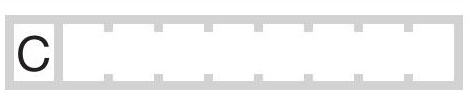

Name of Employer
Space Systems
Receipt For: 2012
X Primary
Other (specify) General

Occupation Engineer

Election Cycle-to-Date

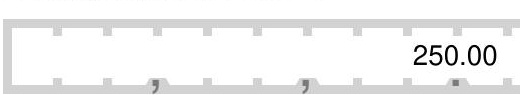

B. Full Name (Last, First, Middle Initial)

Mr Leon E Lombard

Mailing Address 20 Grove St

\begin{tabular}{lcc}
\hline City & State & Zip Code \\
Arlington & MA & $02476-4603$ \\
\hline
\end{tabular}

FEC ID number of contributing

federal political committee.

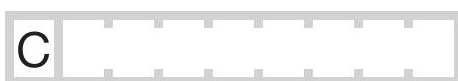

Name of Employer
None
Receipt For: 2012
X Primary
Other (specify)

\section{Occupation}

Retired

Election Cycle-to-Date

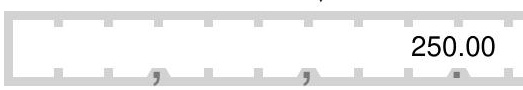

C. Full Name (Last, First, Middle Initial)

annette ryan

Mailing Address 155 johnson ferry rd

\begin{tabular}{l|ll}
\hline $\begin{array}{l}\text { City } \\
\text { Marietta }\end{array}$ & $\begin{array}{c}\text { State } \\
\text { GA }\end{array}$ & $\begin{array}{c}\text { Zip Code } \\
30068-4923\end{array}$ \\
\hline $\begin{array}{l}\text { FEC ID number of contributing } \\
\text { federal political committee. }\end{array}$ & C \\
\hline $\begin{array}{l}\text { Name of Employer } \\
\text { Retired }\end{array}$ & $\begin{array}{l}\text { Occupation } \\
\text { Retired }\end{array}$ \\
\hline $\begin{array}{l}\text { Receipt For: } 2012 \\
\text { X }\end{array}$ & Election Cycle-to-Date \\
Other (specify)
\end{tabular}

Transaction ID : AC2B3A4E0FDAC44BEB52 Date of Receipt

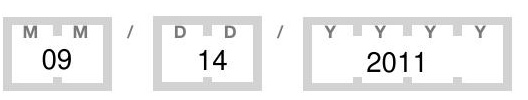

Amount of Each Receipt this Period

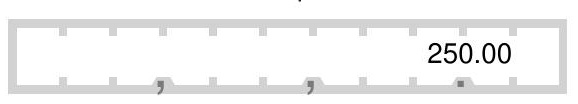

Amount of Each Receipt this Period

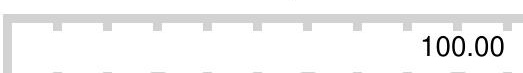

Transaction ID : AD61F3CF8A84F49528C5 Date of Receipt

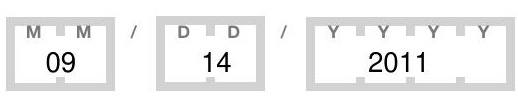

\section{Subtotal Of Receipts This Page (optional)}

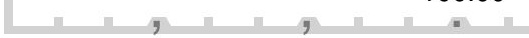

Total This Period (last page this line number only) 
SCHEDULE A-P ITEMIZED RECEIPTS
Use separate schedule(s) for each category of the Detailed Summary Page
FOR LINE NUMBER: (check only one)

PAGE $518 / 1572$

\begin{tabular}{|c|c|c|c|c|c|}
\hline & & & & & \\
\hline 16 & $\begin{array}{l}\mathbf{X} \\
17 a\end{array}$ & $17 b$ & $17 c$ & $17 d$ & 18 \\
\hline $19 a$ & $19 \mathrm{~b}$ & $20 \mathrm{a}$ & $20 \mathrm{~b}$ & $20 \mathrm{c}$ & 21 \\
\hline
\end{tabular}

Any information copied from such Reports and Statements may not be sold or used by any person for the purpose of soliciting contributions or for commercial purposes, other than using the name and address of any political committee to solicit contributions from such committee.

NAME OF COMMITTEE (In Full)

\section{Friends of Herman Cain}

A. Full Name (Last, First, Middle Initial)

Mr Edward L Reed

Mailing Address 1337 Briarcliff Dr

\begin{tabular}{lcc}
\hline City & State & Zip Code \\
Rantoul & IL & $61866-1701$
\end{tabular}

FEC ID number of contributing federal political committee.

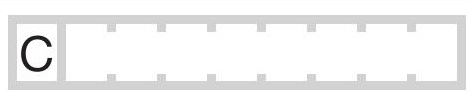

Name of Employer
Retired
Receipt For: 2012
X Primary $\quad$ General
Other (specify)

Occupation Retired

Election Cycle-to-Date

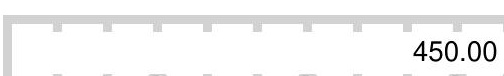

B. Full Name (Last, First, Middle Initial)

Miss Jacqueline Taylor

Mailing Address 2365 Peachwood Cir NE

\begin{tabular}{lcc}
\hline City & State & Zip Code \\
Atlanta & GA & $30345-1801$
\end{tabular}

FEC ID number of contributing

federal political committee.

C

Name of Employer
None
Receipt For: 2012
Primary
Other (specify)

Occupation

Retired (Military)

Election Cycle-to-Date

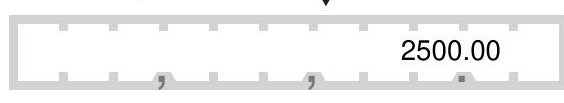

Transaction ID : AFD0D79D760C9456D8C3

Date of Receipt

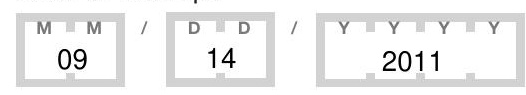

Amount of Each Receipt this Period

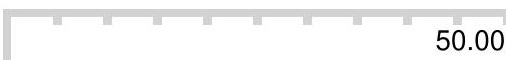

C. Full Name (Last, First, Middle Initial)

Mr Dwight Tyree

Mailing Address 2675 Spring Place Rd

\begin{tabular}{lcc}
\hline City & State & Zip Code \\
Belfast & TN & $37019-2041$
\end{tabular}

FEC ID number of contributing federal political committee.

C

Name of Employer
USPS
Receipt For: 2012
X Primary $\quad \square$ General
Other (specify)

\section{Occupation}

rural mail carrier

Election Cycle-to-Date
Transaction ID : AF72162645B7945BD818

Date of Receipt

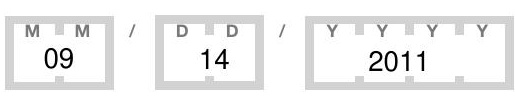

Amount of Each Receipt this Period

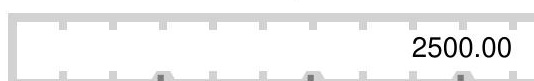

Transaction ID : A174EF9B6158142FD8D2

Date of Receipt

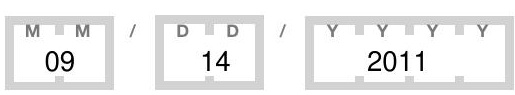

Amount of Each Receipt this Period

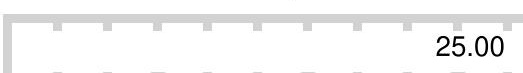

\section{Subtotal Of Receipts This Page (optional)}

Total This Period (last page this line number only) 
SCHEDULE A-P ITEMIZED RECEIPTS
Use separate schedule(s) for each category of the Detailed Summary Page
FOR LINE NUMBER: (check only one)

PAGE $519 / 1572$

\begin{tabular}{|c|c|c|c|c|c|}
\hline & & & & & \\
\hline 16 & $\begin{array}{l}\mathbf{X} \\
17 a\end{array}$ & $17 b$ & $17 c$ & $17 d$ & 18 \\
\hline $19 a$ & $19 \mathrm{~b}$ & $20 \mathrm{a}$ & $20 \mathrm{~b}$ & $20 \mathrm{c}$ & 21 \\
\hline
\end{tabular}

Any information copied from such Reports and Statements may not be sold or used by any person for the purpose of soliciting contributions or for commercial purposes, other than using the name and address of any political committee to solicit contributions from such committee.

NAME OF COMMITTEE (In Full)

\section{Friends of Herman Cain}

A. Full Name (Last, First, Middle Initial)

Mr Michael Muzyczyn

Mailing Address 5402 Wedgewood Ln

\begin{tabular}{lcc}
\hline City & State & Zip Code \\
Corpus Christi & TX & 78411-4833
\end{tabular}

FEC ID number of contributing federal political committee.

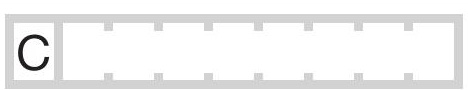

Name of Employer
Information Requested
Receipt For: 2012
X Primary
Other (specify) General

Occupation Information Requested

Election Cycle-to-Date

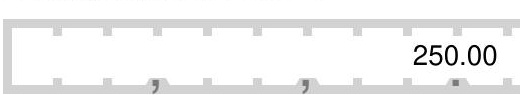

B. Full Name (Last, First, Middle Initial)

Mr David Mandalinich

Mailing Address 890 Wyburn Rd

\begin{tabular}{lcc}
\hline City & State & Zip Code \\
Mc Leansville & NC & $27301-9698$ \\
\hline
\end{tabular}

FEC ID number of contributing

federal political committee.

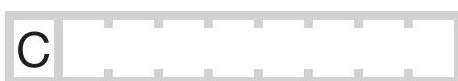

Name of Employer
self
Receipt For: 2012
Primary
Other (specify)

\section{Occupation}

Dentist

Election Cycle-to-Date

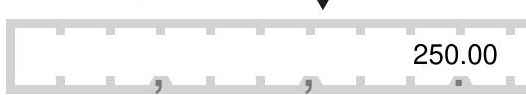

Transaction ID : AE55142D1C697414392F

Date of Receipt

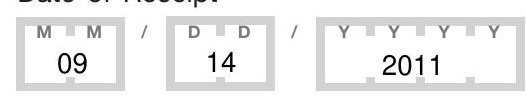

Amount of Each Receipt this Period

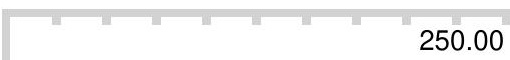

C. Full Name (Last, First, Middle Initial)

Aaron E Adair

Mailing Address 5073 Kapiolani Loop

\begin{tabular}{lcc}
\hline City & State & Zip Code \\
Princeville & HI & $96722-5224$
\end{tabular}

FEC ID number of contributing

federal political committee.

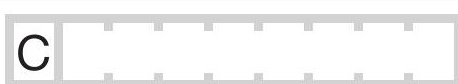

Name of Employer
self retired
Receipt For: 2012
X Primary
Other (specify) General

Occupation

chiropractor

Election Cycle-to-Date

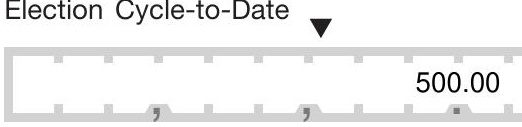

Amount of Each Receipt this Period

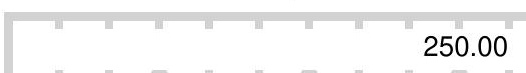

Transaction ID : A58185C608DF7430C8BD

Date of Receipt

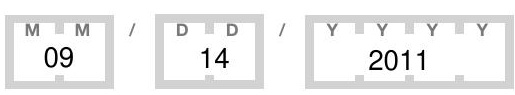

Transaction ID : AAAAA8AD0BCFA4E94873 Date of Receipt

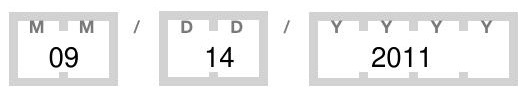

Amount of Each Receipt this Period

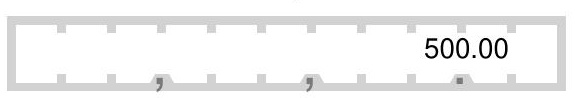

\section{Subtotal Of Receipts This Page (optional)}

Total This Period (last page this line number only) 
SCHEDULE A-P ITEMIZED RECEIPTS
Use separate schedule(s) for each category of the Detailed Summary Page
FOR LINE NUMBER: (check only one)

PAGE $520 / 1572$

\begin{tabular}{|c|c|c|c|c|c|}
\hline & & & & & \\
\hline 16 & $\begin{array}{l}\mathbf{X} \\
17 a\end{array}$ & $17 b$ & $17 c$ & $17 d$ & 18 \\
\hline $19 a$ & $19 \mathrm{~b}$ & $20 \mathrm{a}$ & $20 \mathrm{~b}$ & $20 \mathrm{c}$ & 21 \\
\hline
\end{tabular}

Any information copied from such Reports and Statements may not be sold or used by any person for the purpose of soliciting contributions or for commercial purposes, other than using the name and address of any political committee to solicit contributions from such committee.

NAME OF COMMITTEE (In Full)

\section{Friends of Herman Cain}

A. Full Name (Last, First, Middle Initial) bradley holder

Mailing Address 38 s. blue angel pwky PMB \# 108

\begin{tabular}{lcc}
\hline City & State & Zip Code \\
Pensacola & FL & $32506-6045$ \\
\hline
\end{tabular}

FEC ID number of contributing federal political committee.

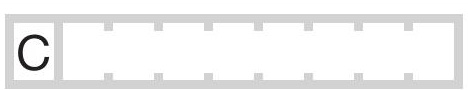

Name of Employer
Information Requested
Receipt For: 2012
X Primary
Other (specify) General

Occupation Information Requested

Election Cycle-to-Date

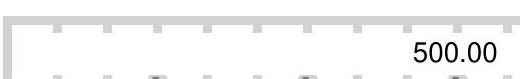

B. Full Name (Last, First, Middle Initial)

Mrs Carolyn Malion

Mailing Address 8264 Nc Highway 130 E

\begin{tabular}{lcc}
\hline City & State & Zip Code \\
Fairmont & NC & $28340-7812$ \\
\hline
\end{tabular}

FEC ID number of contributing

federal political committee.

C

Name of Employer
Information Requested
Receipt For: 2012
X Primary
Other (specify)

Occupation

Information Requested

Election Cycle-to-Date

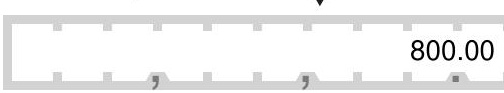

Transaction ID : AED4A0F7BFE424BFE9DA

Date of Receipt

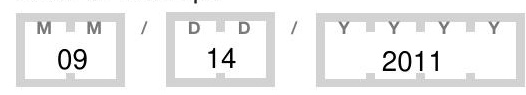

Amount of Each Receipt this Period

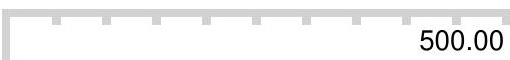

Amount of Each Receipt this Period

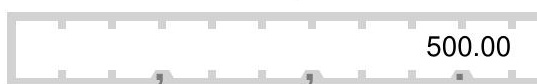

C. Full Name (Last, First, Middle Initial)

Mr Wayne B Bumgarner

Mailing Address $3751 \mathrm{~N}$ Sparklebrook Ln

\begin{tabular}{lcc}
\hline City & State & Zip Code \\
Strafford & MO & $65757-8872$
\end{tabular}

FEC ID number of contributing federal political committee.

C

$65757-8872$

Transaction ID : A0A00922C314141209C8

Date of Receipt

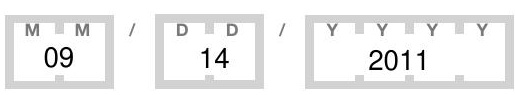

Name of Employer

Information Requested

Occupation
Information Requested

Receipt For: 2012

Х $\begin{aligned} & \text { Primary } \\ & \text { Other (specify) }\end{aligned}$

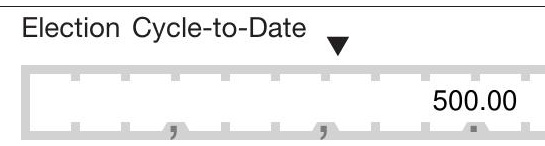

Amount of Each Receipt this Period

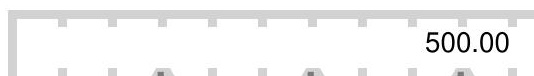

Transaction ID : A393FF410FB7F426CB07

Date of Receipt

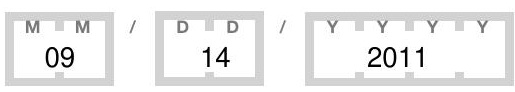

Subtotal Of Receipts This Page (optional)

1500.00

Total This Period (last page this line number only) 
SCHEDULE A-P ITEMIZED RECEIPTS
Use separate schedule(s) for each category of the Detailed Summary Page
FOR LINE NUMBER: (check only one)

PAGE $521 / 1572$

\begin{tabular}{|c|c|c|c|c|c|}
\hline & & & & & \\
\hline 16 & $\begin{array}{l}\mathbf{X} \\
17 a\end{array}$ & $17 b$ & $17 c$ & $17 d$ & 18 \\
\hline $19 a$ & $19 \mathrm{~b}$ & $20 \mathrm{a}$ & $20 \mathrm{~b}$ & $20 \mathrm{c}$ & 21 \\
\hline
\end{tabular}

Any information copied from such Reports and Statements may not be sold or used by any person for the purpose of soliciting contributions or for commercial purposes, other than using the name and address of any political committee to solicit contributions from such committee.

NAME OF COMMITTEE (In Full)

\section{Friends of Herman Cain}

A. Full Name (Last, First, Middle Initial)

Timothy Oneill

Mailing Address 4161 Thunderbird Dr SE

\begin{tabular}{lcc}
\hline City & State & Zip Code \\
Marietta & GA & $30067-4752$
\end{tabular}

FEC ID number of contributing

federal political committee.

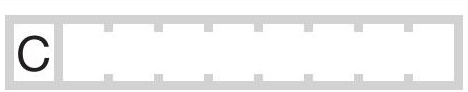

Name of Employer
None
Receipt For: 2012
X Primary $\quad$ General
Other (specify)

Occupation

Retired

Election Cycle-to-Date

500.00

B. Full Name (Last, First, Middle Initial)

STEVEN LAPP

Mailing Address 8796 SNELLGROVE AV N

\begin{tabular}{lcc}
\hline City & State & Zip Code \\
Jacksonville & FL & $32220-3206$
\end{tabular}

FEC ID number of contributing

federal political committee.

C

Name of Employer
CHAMPION TRTUCKING INC
Receipt For: 2012
Х Primary
Other (specify)

Occupation

trucker

Election Cycle-to-Date

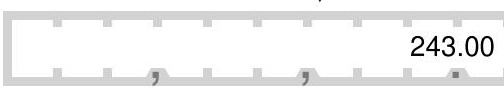

Transaction ID : A91FB62487AEB4EEBAA8

Date of Receipt

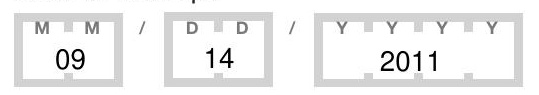

Amount of Each Receipt this Period

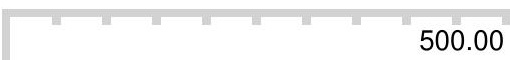

Amount of Each Receipt this Period

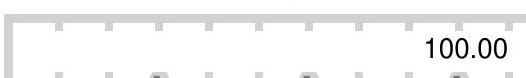

C. Full Name (Last, First, Middle Initial)

Michael F Smith

Mailing Address $1001 \mathrm{E} \mathrm{St}$

Apt 4

\begin{tabular}{lcc}
\hline City & State & Zip Code \\
Anchorage & AK & $99501-3584$
\end{tabular}

FEC ID number of contributing

federal political committee.

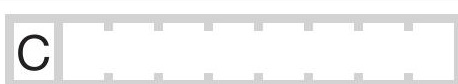

Name of Employer

Occupation

Exxon Mobil Corp

Attorney

Transaction ID : A222E42FF483041DD85D

Date of Receipt

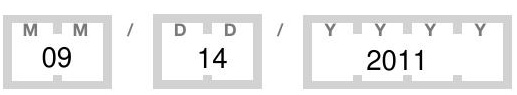

Receipt For: 2012

Х $\begin{aligned} & \text { Primary } \\ & \text { Other (specify) }\end{aligned}$

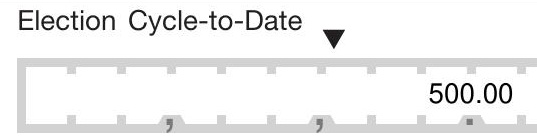

Amount of Each Receipt this Period

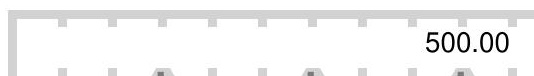

Transaction ID : A250620F588684B878E4

Date of Receipt

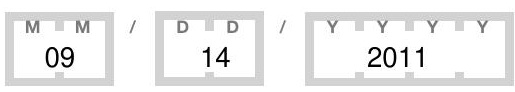

Subtotal Of Receipts This Page (optional)

1100.00

Total This Period (last page this line number only)

FEC Schedule A-P (Form 3P) (Rev. 03/2011) 
SCHEDULE A-P ITEMIZED RECEIPTS
Use separate schedule(s) for each category of the Detailed Summary Page
FOR LINE NUMBER: (check only one)

PAGE 522 / 1572

\begin{tabular}{|c|c|c|c|c|c|}
\hline & & & & & \\
\hline 16 & $\begin{array}{l}\mathbf{X} \\
17 a\end{array}$ & $17 b$ & $17 c$ & $17 d$ & 18 \\
\hline $19 a$ & $19 \mathrm{~b}$ & $20 \mathrm{a}$ & $20 \mathrm{~b}$ & $20 \mathrm{c}$ & 21 \\
\hline
\end{tabular}

Any information copied from such Reports and Statements may not be sold or used by any person for the purpose of soliciting contributions or for commercial purposes, other than using the name and address of any political committee to solicit contributions from such committee.

NAME OF COMMITTEE (In Full)

\section{Friends of Herman Cain}

A. Full Name (Last, First, Middle Initial) Joe Clevenger

Mailing Address 3467 Ivy Link

\begin{tabular}{lcc}
\hline City & State & Zip Code \\
Lynchburg & VA & $24503-3003$
\end{tabular}

FEC ID number of contributing federal political committee.

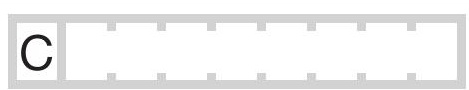

Name of Employer
Information Requested
Receipt For: 2012
X Primary
Other (specify) General

Occupation Information Requested

Election Cycle-to-Date

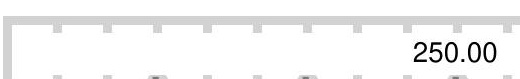

B. Full Name (Last, First, Middle Initial)

Kara McEowen

Mailing Address 209 Millstone Rd

\begin{tabular}{lcc}
\hline City & State & Zip Code \\
Aynor & SC & 29511 \\
\hline
\end{tabular}

FEC ID number of contributing

federal political committee.

C

Name of Employer
Grainger
Receipt For: 2012
Primary
Other (specify)

Occupation

Sales Rep

Election Cycle-to-Date

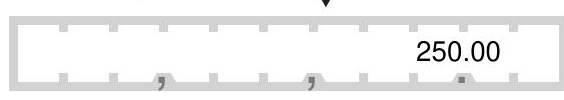

Transaction ID : AF2526DFD6A324E388C0

Date of Receipt

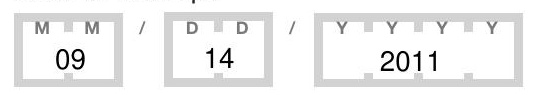

Amount of Each Receipt this Period

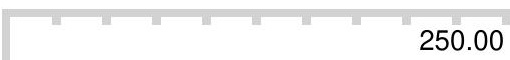

C. Full Name (Last, First, Middle Initial)

Travis Burgess

Mailing Address 905 North Elm

\begin{tabular}{lcc}
\hline City & State & Zip Code \\
Red Cloud & NE & $68970-2133$
\end{tabular}

FEC ID number of contributing federal political committee.

C

Name of Employer
US Postal Service
Receipt For: 2012
Х Primary $\quad \square$ General
Other (specify)

Occupation

Letter Carrier

Election Cycle-to-Date

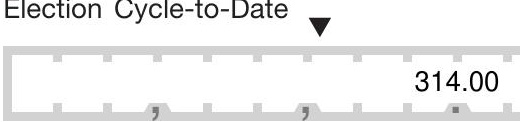

Amount of Each Receipt this Period

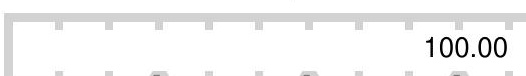

Transaction ID : ADC33A58E5FA94FEC8C6 Date of Receipt

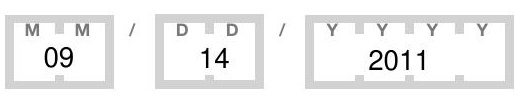

Transaction ID : A975D779E95944963ADF Date of Receipt

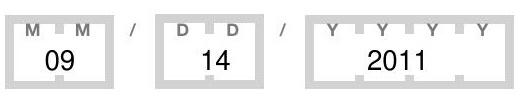

Amount of Each Receipt this Period

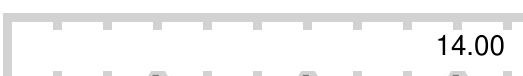

\section{Subtotal Of Receipts This Page (optional)}

Total This Period (last page this line number only) 
SCHEDULE A-P ITEMIZED RECEIPTS
Use separate schedule(s) for each category of the Detailed Summary Page
FOR LINE NUMBER: (check only one)

\begin{tabular}{|c|c|c|c|c|c|}
\hline & & & & & \\
\hline 16 & $\begin{array}{ll}X & 17 a \\
\end{array}$ & $17 \mathrm{~b}$ & $17 c$ & $17 d$ & 18 \\
\hline $19 a$ & $19 b$ & $20 \mathrm{a}$ & $20 \mathrm{~b}$ & $20 c$ & 21 \\
\hline
\end{tabular}

Any information copied from such Reports and Statements may not be sold or used by any person for the purpose of soliciting contributions or for commercial purposes, other than using the name and address of any political committee to solicit contributions from such committee.

NAME OF COMMITTEE (In Full)

\section{Friends of Herman Cain}

A. Full Name (Last, First, Middle Initial)

\section{Fred D Backer Jr}

Mailing Address 18 Narry Ln

City

Mount Morris

FEC ID number of contributing

federal political committee.

Name of Employer
None
Receipt For: 2012
X Primary $\quad \square$ General
$\square$ Other (specify)

B. Full Name (Last, First, Middle Initial)

R.C. Kim

Mailing Address 3692 Castlegate Dr. D118

\begin{tabular}{lcc}
\hline City & State & Zip Code \\
Atlanta & GA & $30327-2604$
\end{tabular}

FEC ID number of contributing

federal political committee.

C

Name of Employer
Speedy
Receipt For: 2012
X Primary
Other (specify)

C. Full Name (Last, First, Middle Initial)

Eleanor Curran

Mailing Address 4019 E. Ft. King Street

City

Ocala

FEC ID number of contributing

federal political committee.

\begin{tabular}{l} 
Name of Employer \\
Information Requested \\
\hline Receipt For: 2012 \\
X Primary \\
Other (specify) General
\end{tabular}

Occupation

Retired

Election Cycle-to-Date

Transaction ID : A9AB1392EA35E453D897

Date of Receipt

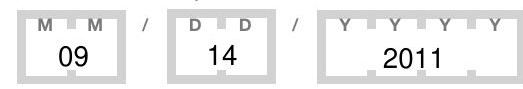

Amount of Each Receipt this Period

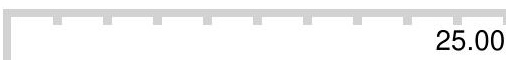

25.00

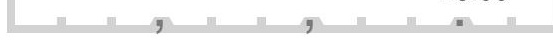

Transaction ID : AEF1224D2BD024CAD8A5 Date of Receipt

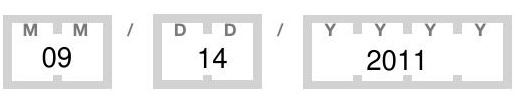

Amount of Each Receipt this Period

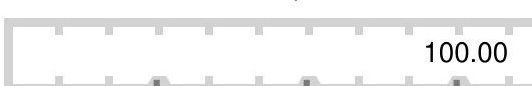

Transaction ID : ACC45BD51F746483AA36 Date of Receipt

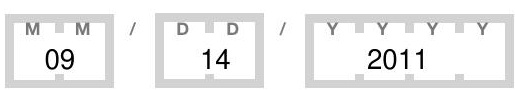

Amount of Each Receipt this Period

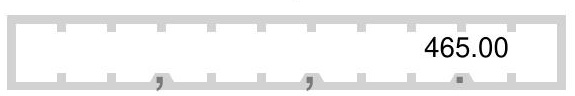

565.00
Subtotal Of Receipts This Page (optional)

590.00

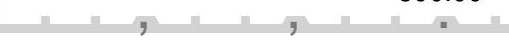

Total This Period (last page this line number only)

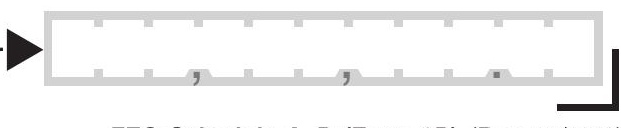

FEC Schedule A-P (Form 3P) (Rev. 03/2011) 
SCHEDULE A-P ITEMIZED RECEIPTS
Use separate schedule(s) for each category of the Detailed Summary Page
FOR LINE NUMBER: (check only one)

\begin{tabular}{|c|c|c|c|c|c|}
\hline & & & & & \\
\hline 16 & $\begin{array}{ll}X & 17 a \\
\end{array}$ & $17 \mathrm{~b}$ & $17 c$ & $17 d$ & 18 \\
\hline $19 a$ & $19 b$ & $20 \mathrm{a}$ & $20 \mathrm{~b}$ & $20 c$ & 21 \\
\hline
\end{tabular}

Any information copied from such Reports and Statements may not be sold or used by any person for the purpose of soliciting contributions or for commercial purposes, other than using the name and address of any political committee to solicit contributions from such committee.

NAME OF COMMITTEE (In Full)

\section{Friends of Herman Cain}

A. Full Name (Last, First, Middle Initial)

Vikki Brown

Mailing Address 391 Leeches Rd

\begin{tabular}{lcc}
\hline City & State & Zip Code \\
Ellijay & GA & $30540-7354$ \\
\hline
\end{tabular}

FEC ID number of contributing federal political committee.

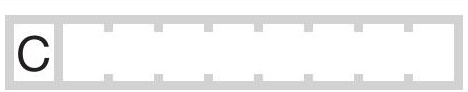

Name of Employer
AT\&T
Receipt For: 2012
X Primary $\quad$ General
Other (specify)

Occupation Intellectual Property Specialist

Election Cycle-to-Date

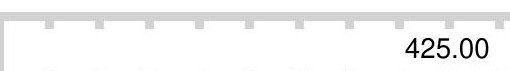

B. Full Name (Last, First, Middle Initial)

Mrs Cleta Renyer

Mailing Address 609 Castle St

\begin{tabular}{lcc}
\hline City & State & Zip Code \\
Seneca & KS & $66538-1830$
\end{tabular}

FEC ID number of contributing

federal political committee.

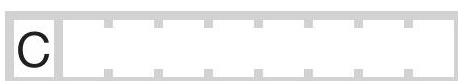

Name of Employer
None
Receipt For: 2012
X Primary
Other (specify)

\section{Occupation}

Retired

Election Cycle-to-Date

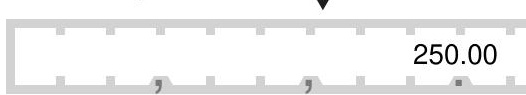

Transaction ID : A954F61DC29694C1691F

Date of Receipt

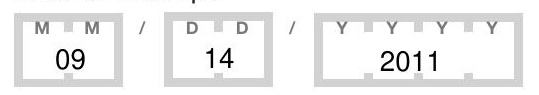

Amount of Each Receipt this Period

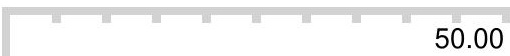

C. Full Name (Last, First, Middle Initial)

Frederick Mielke

Mailing Address 23300 Via Esplendor

Unit 57

\begin{tabular}{lcc}
\hline City & State & Zip Code \\
Cupertino & CA & $95014-6549$
\end{tabular}

FEC ID number of contributing

federal political committee.

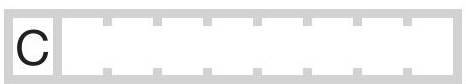

Name of Employer
None
Receipt For: 2012
X Primary $\quad$ General
Other (specify)

Occupation

Retired

Election Cycle-to-Date

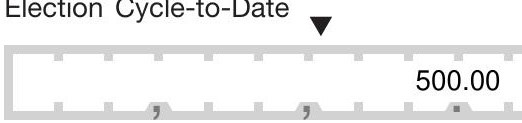

Amount of Each Receipt this Period

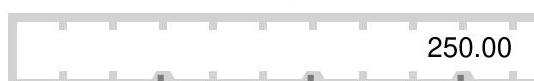

Transaction ID : ABC37A5CD3A714FFE82E Date of Receipt

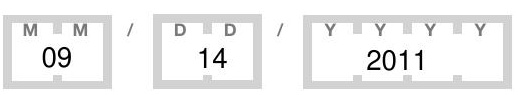

Transaction ID : A434B2D0112B248DAAAF Date of Receipt

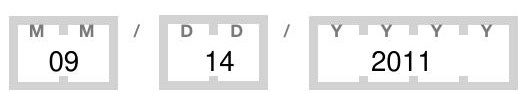

Amount of Each Receipt this Period

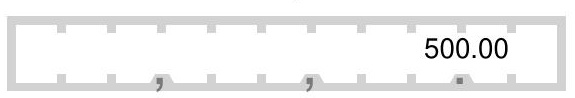

\section{Subtotal Of Receipts This Page (optional)}

800.00

a

Total This Period (last page this line number only)

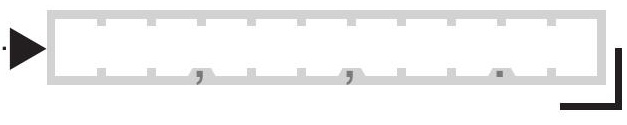

FEC Schedule A-P (Form 3P) (Rev. 03/2011) 
SCHEDULE A-P ITEMIZED RECEIPTS
Use separate schedule(s) for each category of the Detailed Summary Page
FOR LINE NUMBER: (check only one)

PAGE $525 / 1572$

\begin{tabular}{|c|c|c|c|c|c|}
\hline & & & & & \\
\hline 16 & $\begin{array}{l}\mathbf{X} \\
17 a\end{array}$ & $17 b$ & $17 c$ & $17 d$ & 18 \\
\hline $19 a$ & $19 \mathrm{~b}$ & $20 \mathrm{a}$ & $20 \mathrm{~b}$ & $20 \mathrm{c}$ & 21 \\
\hline
\end{tabular}

Any information copied from such Reports and Statements may not be sold or used by any person for the purpose of soliciting contributions or for commercial purposes, other than using the name and address of any political committee to solicit contributions from such committee.

NAME OF COMMITTEE (In Full)

\section{Friends of Herman Cain}

A. Full Name (Last, First, Middle Initial)

Walter Byers

Mailing Address 25707 Aiken Switch Rd

\begin{tabular}{lcc}
\hline City & State & Zip Code \\
Emmett & KS & $66422-9719$
\end{tabular}

FEC ID number of contributing federal political committee.

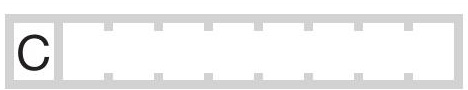

Name of Employer
None
Receipt For: 2012
X Primary $\quad$ General
Other (specify)

Occupation

Retired

Election Cycle-to-Date

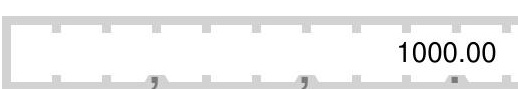

B. Full Name (Last, First, Middle Initial)

Mary Causey

Mailing Address 189 Lamplighter Lane

\begin{tabular}{lcc}
\hline City & State & Zip Code \\
Ponte Vedra Beach & FL & $32082-1951$ \\
\hline
\end{tabular}

FEC ID number of contributing

federal political committee.

C

\begin{tabular}{l} 
Name of Employer \\
Dat'l Do-It Inc. \\
Receipt For: 2012 \\
Primary \\
\hline Other (specify) General
\end{tabular}

Occupation

Small Business Owner

Election Cycle-to-Date

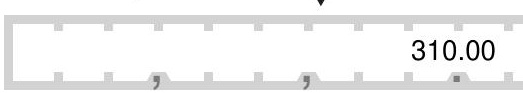

Transaction ID : A7340A43D6EE64223AB7

Date of Receipt

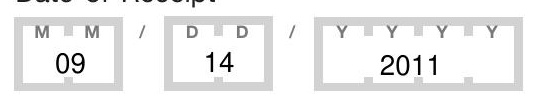

Amount of Each Receipt this Period

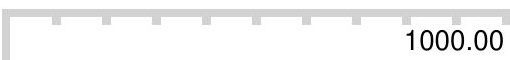

Amount of Each Receipt this Period

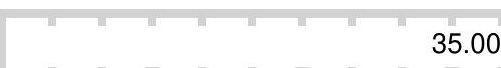

C. Full Name (Last, First, Middle Initial)

Dave Smith

Mailing Address 1707 Red Oak Rd SE

\begin{tabular}{lcc}
\hline City & State & Zip Code \\
Huntsville & AL & $35801-2145$
\end{tabular}

FEC ID number of contributing federal political committee.

C

Name of Employer
Kord Technologies
Receipt For: 2012
X Primary $\quad \square$ General
Other (specify)

Occupation

Software Engineer

Election Cycle-to-Date

Transaction ID : AD01C2F8F3209469797D

Date of Receipt

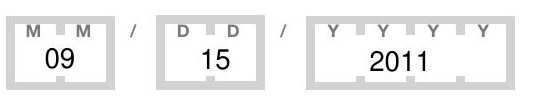

Transaction ID : A0E83F9542A4141FC8BE Date of Receipt

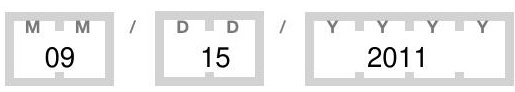

Amount of Each Receipt this Period

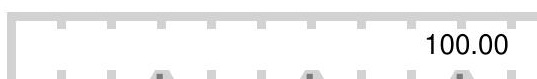

225.00

\section{Subtotal Of Receipts This Page (optional)}

Total This Period (last page this line number only) 
SCHEDULE A-P ITEMIZED RECEIPTS
Use separate schedule(s) for each category of the Detailed Summary Page
FOR LINE NUMBER: (check only one)

PAGE 526 / 1572

\begin{tabular}{|c|c|c|c|c|c|}
\hline & & & & & \\
\hline 16 & $\begin{array}{l}\mathbf{X} \\
17 a\end{array}$ & $17 b$ & $17 c$ & $17 d$ & 18 \\
\hline $19 a$ & $19 \mathrm{~b}$ & $20 \mathrm{a}$ & $20 \mathrm{~b}$ & $20 \mathrm{c}$ & 21 \\
\hline
\end{tabular}

Any information copied from such Reports and Statements may not be sold or used by any person for the purpose of soliciting contributions or for commercial purposes, other than using the name and address of any political committee to solicit contributions from such committee.

NAME OF COMMITTEE (In Full)

\section{Friends of Herman Cain}

A. Full Name (Last, First, Middle Initial)

Brian Harpster

Mailing Address 990 S. Fletcher Ave

\begin{tabular}{lcc}
\hline City & State & Zip Code \\
Fernandina Beach & FL & $32034-2234$
\end{tabular}

FEC ID number of contributing

federal political committee.

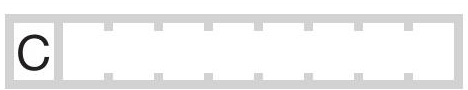

\begin{tabular}{l} 
Name of Employer \\
Self Employed \\
Receipt For: 2012 \\
$\square$ Primary \\
\hline Other (specify)
\end{tabular}

Occupation Investor

Election Cycle-to-Date 2584.99

B. Full Name (Last, First, Middle Initial) Reid Bowman

Mailing Address 164 Glen Eagle Way

\begin{tabular}{lcc}
\hline City & State & Zip Code \\
Stockbridge & GA & 30281 \\
\hline
\end{tabular}

FEC ID number of contributing

federal political committee.

C

\begin{tabular}{l} 
Name of Employer \\
Information Requested \\
Receipt For: 2012 \\
X Primary \\
\hline Other (specify)
\end{tabular}

Occupation

Information Requested

Election Cycle-to-Date

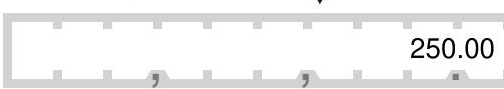

Transaction ID : A4C95C16F576E4B688C0

Date of Receipt

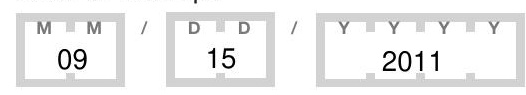

Amount of Each Receipt this Period

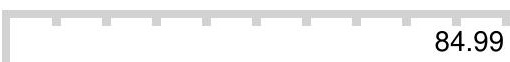

Transaction ID : AC20BFBD6AB6D4910ABF Date of Receipt

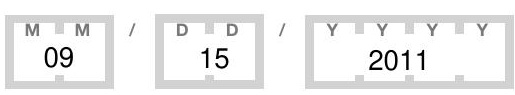

Amount of Each Receipt this Period

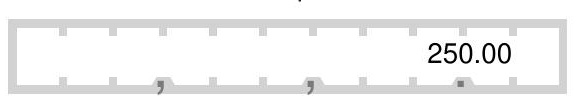

Transaction ID : AADEE6C7CF2394A6F86A Date of Receipt

Sandra McGarity

Mailing Address PO Box 2889

\begin{tabular}{lcc}
\hline City & State & Zip Code \\
McDonough & GA & $30253-1778$
\end{tabular}

FEC ID number of contributing federal political committee.

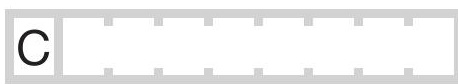

Name of Employer
None
Receipt For: 2012
X Primary
Other (specify) General

Occupation

Retired

Election Cycle-to-Date
Amount of Each Receipt this Period

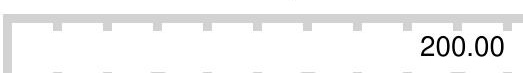

Subtotal Of Receipts This Page (optional).

Total This Period (last page this line number only) 
SCHEDULE A-P ITEMIZED RECEIPTS
Use separate schedule(s) for each category of the Detailed Summary Page
FOR LINE NUMBER: (check only one)

PAGE 527 / 1572

\begin{tabular}{|c|c|c|c|c|c|}
\hline & & & & & \\
\hline 16 & $\begin{array}{l}\mathbf{X} \\
17 a\end{array}$ & $17 b$ & $17 c$ & $17 d$ & 18 \\
\hline $19 a$ & $19 \mathrm{~b}$ & $20 \mathrm{a}$ & $20 \mathrm{~b}$ & $20 \mathrm{c}$ & 21 \\
\hline
\end{tabular}

Any information copied from such Reports and Statements may not be sold or used by any person for the purpose of soliciting contributions or for commercial purposes, other than using the name and address of any political committee to solicit contributions from such committee.

NAME OF COMMITTEE (In Full)

\section{Friends of Herman Cain}

A. Full Name (Last, First, Middle Initial)

Charles Irby

Mailing Address 1817 Tyne Blvd

\begin{tabular}{lcc}
\hline City & State & Zip Code \\
Nashville & TN & $37215-4701$
\end{tabular}

FEC ID number of contributing federal political committee.

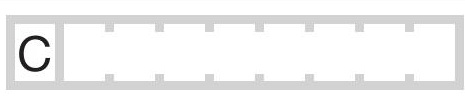

Name of Employer
Irby Investment, LLC
Receipt For: 2012
X Primary
Other (specify) General

Occupation Manager

Election Cycle-to-Date

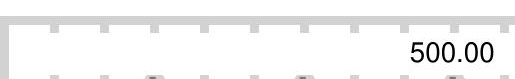

B. Full Name (Last, First, Middle Initial)

Mrs Marie J Lett

Mailing Address 3940 Lett Ln

\begin{tabular}{lcc}
\hline City & State & Zip Code \\
Burleson & TX & $76028-1742$ \\
\hline
\end{tabular}

FEC ID number of contributing

federal political committee.

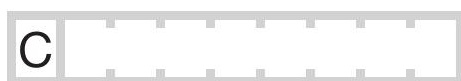

Name of Employer
Self Employed
Receipt For: 2012
X Primary
Other (specify)

\section{Occupation}

rancher

Election Cycle-to-Date

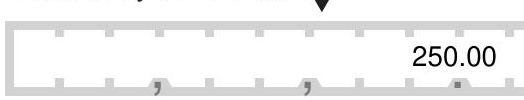

Transaction ID : AC76B9B2A64AA4B788C2

Date of Receipt

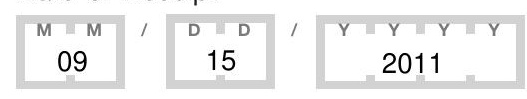

Amount of Each Receipt this Period

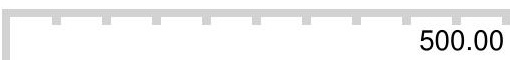

C. Full Name (Last, First, Middle Initial)

Greg Yacobian

Mailing Address 1916 Zenaida Ave

\begin{tabular}{lcc}
\hline City & State & Zip Code \\
McAllen & TX & $78504-5625$
\end{tabular}

FEC ID number of contributing federal political committee.

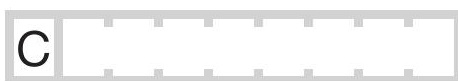

Name of Employer
Retired
Receipt For: 2012
X Primary $\quad \square$ General
Other (specify)

\section{Occupation}

Retired

Election Cycle-to-Date

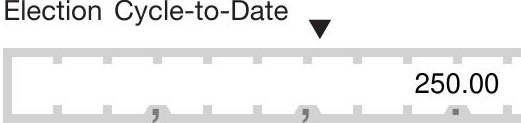

Amount of Each Receipt this Period

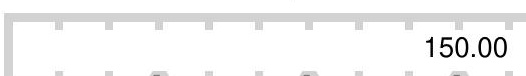

Transaction ID : AA7F0234C85314DE39D2

Date of Receipt

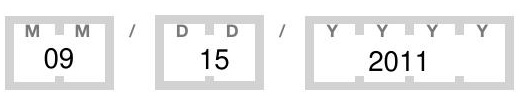

Transaction ID : A11DC8ED15BA6454CBA4 Date of Receipt

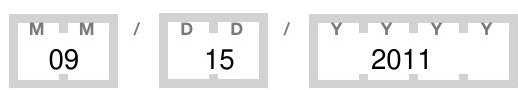

Amount of Each Receipt this Period

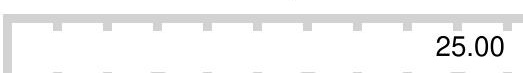

\section{Subtotal Of Receipts This Page (optional)}

675.00

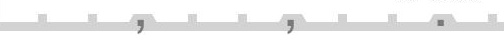

Total This Period (last page this line number only)

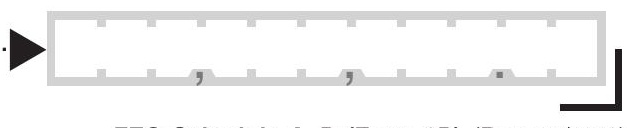

FEC Schedule A-P (Form 3P) (Rev. 03/2011) 
SCHEDULE A-P ITEMIZED RECEIPTS
Use separate schedule(s) for each category of the Detailed Summary Page
FOR LINE NUMBER: (check only one)

PAGE $528 / 1572$

\begin{tabular}{|c|c|c|c|c|c|}
\hline & & & & & \\
\hline 16 & $\begin{array}{l}\mathbf{X} \\
17 a\end{array}$ & $17 b$ & $17 c$ & $17 d$ & 18 \\
\hline $19 a$ & $19 \mathrm{~b}$ & $20 \mathrm{a}$ & $20 \mathrm{~b}$ & $20 \mathrm{c}$ & 21 \\
\hline
\end{tabular}

Any information copied from such Reports and Statements may not be sold or used by any person for the purpose of soliciting contributions or for commercial purposes, other than using the name and address of any political committee to solicit contributions from such committee.

NAME OF COMMITTEE (In Full)

\section{Friends of Herman Cain}

A. Full Name (Last, First, Middle Initial)

Michael Miller

Mailing Address 4402 Boxwood Rd

\begin{tabular}{lcc}
\hline City & State & Zip Code \\
Bethesda & MD & 20816-1818
\end{tabular}

FEC ID number of contributing federal political committee.

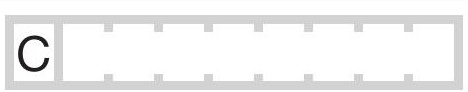

Name of Employer
Self-Employed
Receipt For: 2012
X Primary $\quad$ General
Other (specify)

Occupation Investments

Election Cycle-to-Date 600.00

B. Full Name (Last, First, Middle Initial) James Stewart

Mailing Address 3560 E. Via Colonia del Sol

\begin{tabular}{lcc}
\hline City & State & Zip Code \\
Tucson & AZ & $85718-6065$ \\
\hline
\end{tabular}

FEC ID number of contributing

federal political committee.

C

Name of Employer
Information Requested
Receipt For: 2012
X Primary
Other (specify)

Occupation

Information Requested

Election Cycle-to-Date

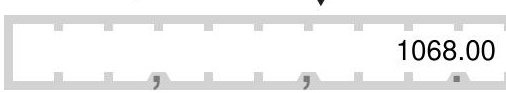

Transaction ID : A96F6FB39F49D409590E

Date of Receipt

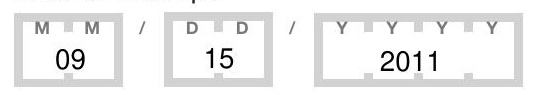

Amount of Each Receipt this Period

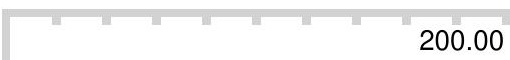

200.00

C. Full Name (Last, First, Middle Initial)

Mr. Redick Bryan III

Mailing Address 30100 Chualar Canyon Rd

\begin{tabular}{lcc}
\hline City & State & Zip Code \\
Chualar & CA & $93925-9500$
\end{tabular}

FEC ID number of contributing federal political committee.

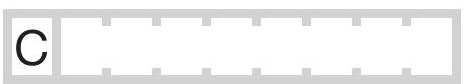

Name of Employer
California Grant, Inc.
Receipt For: 2012
X Primary $\quad \square$ General
Other (specify)

\section{Occupation}

Owner

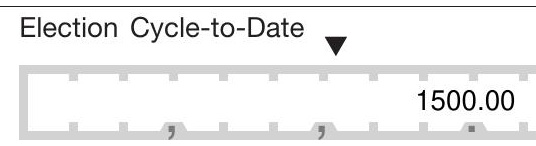

Transaction ID : AD44B2CDA492E42FFB42 Date of Receipt

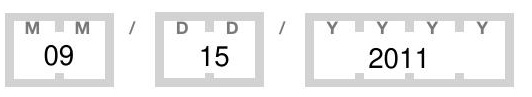

Amount of Each Receipt this Period

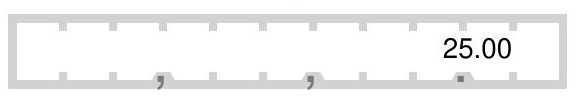

Transaction ID : A2AECBC7C447649898DC Date of Receipt

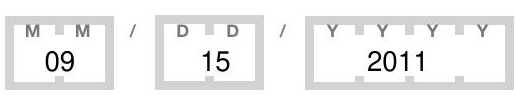

Amount of Each Receipt this Period

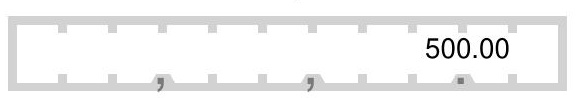

\section{Subtotal Of Receipts This Page (optional)}

Total This Period (last page this line number only) 
SCHEDULE A-P ITEMIZED RECEIPTS
Use separate schedule(s) for each category of the Detailed Summary Page
FOR LINE NUMBER: (check only one)

PAGE 529 / 1572

\begin{tabular}{|c|c|c|c|c|c|}
\hline & & & & & \\
\hline 16 & $\begin{array}{l}\mathbf{X} \\
17 a\end{array}$ & $17 b$ & $17 c$ & $17 d$ & 18 \\
\hline $19 a$ & $19 \mathrm{~b}$ & $20 \mathrm{a}$ & $20 \mathrm{~b}$ & $20 \mathrm{c}$ & 21 \\
\hline
\end{tabular}

Any information copied from such Reports and Statements may not be sold or used by any person for the purpose of soliciting contributions or for commercial purposes, other than using the name and address of any political committee to solicit contributions from such committee.

NAME OF COMMITTEE (In Full)

\section{Friends of Herman Cain}

A. Full Name (Last, First, Middle Initial)

\section{Brian Cox}

Mailing Address 4932 S Cherokee Ave

\begin{tabular}{lcc}
\hline City & State & Zip Code \\
Sierra Vista & AZ & $85650-8931$
\end{tabular}

FEC ID number of contributing federal political committee.

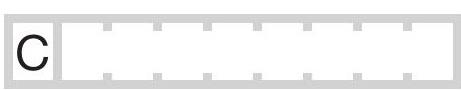

Name of Employer
Information Requested
Receipt For: 2012
X Primary
Other (specify) General

B. Full Name (Last, First, Middle Initial)

Frank Mahan

Mailing Address 6148 Madison

\begin{tabular}{lcc}
\hline City & State & Zip Code \\
Groves & TX & $77619-4706$ \\
\hline
\end{tabular}

FEC ID number of contributing

federal political committee.

C

Name of Employer
Motiva
Receipt For: 2012
X Primary
Other (specify)

C. Full Name (Last, First, Middle Initial)

Owen McNally

Mailing Address 20073 commission rd 80

\begin{tabular}{lcc}
\hline City & State & Zip Code \\
Oxford & MS & 38655
\end{tabular}

FEC ID number of contributing federal political committee.

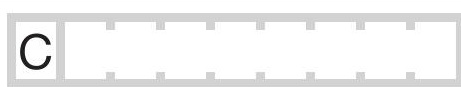

Name of Employer
Ole Miss
Receipt For: 2012
X Primary
Other (specify) General

\section{Occupation} Information Requested

Election Cycle-to-Date

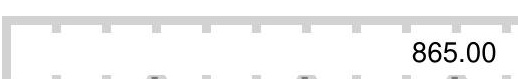

Productioin Foreman

Election Cycle-to-Date

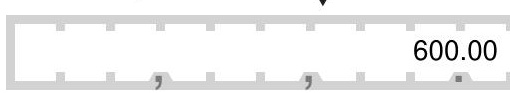

Occupation

Student

Election Cycle-to-Date
Transaction ID : A16273FF43951491EA6C

Date of Receipt

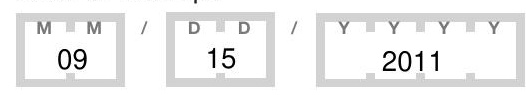

Amount of Each Receipt this Period

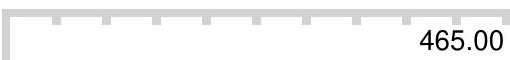

Transaction ID : A8BB17711A7AC4AADA96 Date of Receipt

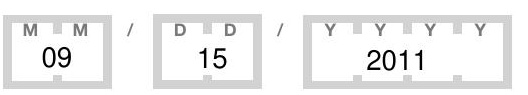

Amount of Each Receipt this Period

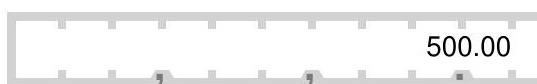

600.00

Transaction ID : A697415FA52294EA7A93

Date of Receipt

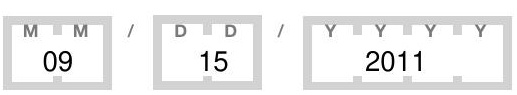

Amount of Each Receipt this Period

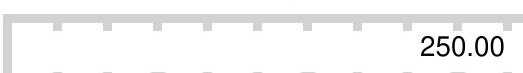

\section{Subtotal Of Receipts This Page (optional)}

Total This Period (last page this line number only) 
SCHEDULE A-P ITEMIZED RECEIPTS
Use separate schedule(s) for each category of the Detailed Summary Page
FOR LINE NUMBER: (check only one)

PAGE $530 / 1572$

\begin{tabular}{|c|c|c|c|c|c|}
\hline & & & & & \\
\hline 16 & $\mathbf{X} 17 a$ & $17 b$ & $17 c$ & $17 d$ & 18 \\
\hline $19 a$ & $19 b$ & $20 \mathrm{a}$ & $20 \mathrm{~b}$ & $20 \mathrm{c}$ & 21 \\
\hline
\end{tabular}

Any information copied from such Reports and Statements may not be sold or used by any person for the purpose of soliciting contributions or for commercial purposes, other than using the name and address of any political committee to solicit contributions from such committee.

NAME OF COMMITTEE (In Full)

\section{Friends of Herman Cain}

A. Full Name (Last, First, Middle Initial)

Mrs. Mary D. Hinton

Mailing Address 5207 Lakedale Dr

\begin{tabular}{lcc}
\hline City & State & Zip Code \\
Durham & NC & $27713-6088$
\end{tabular}

FEC ID number of contributing federal political committee.

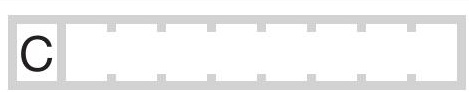

Name of Employer
Credit Sousse
Receipt For: 2012
X Primary $\quad$ General
Other (specify)

Occupation

Computer Programmer

Election Cycle-to-Date

700.00

B. Full Name (Last, First, Middle Initial)

Laurel Schaeffer

Mailing Address 5901 Gretna Ct

\begin{tabular}{lcc}
\hline City & State & Zip Code \\
Rex & GA & $30273-1559$ \\
\hline
\end{tabular}

FEC ID number of contributing

federal political committee.

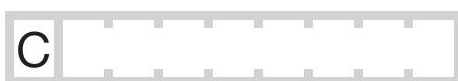

Name of Employer
Information Requested
Receipt For: 2012
X Primary
Other (specify)

\section{Occupation}

Information Requested

Election Cycle-to-Date

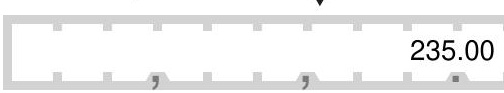

Transaction ID : A0EDDC7B2A3B34CDCA5C

Date of Receipt

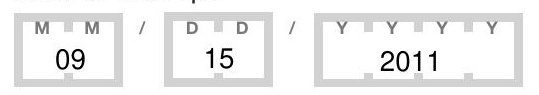

Amount of Each Receipt this Period

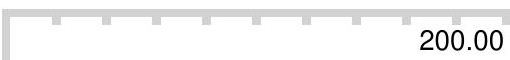

200.00

C. Full Name (Last, First, Middle Initial)

RANDY JOHNSON

Mailing Address 1915 W Macarthur Rd Lot 194

\begin{tabular}{lcc}
\hline City & State & Zip Code \\
Wichita & KS & $67217-6001$
\end{tabular}

FEC ID number of contributing federal political committee.

C

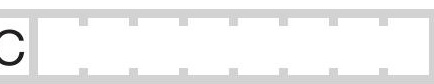

Transaction ID : A744245B2435E4E87B3C

Date of Receipt

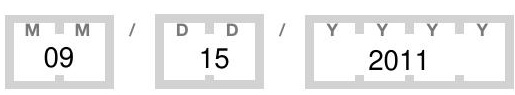

Amount of Each Receipt this Period

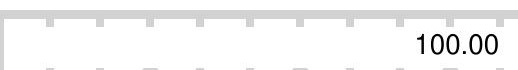

Transaction ID : A30557C671FDB436CBF0 Date of Receipt

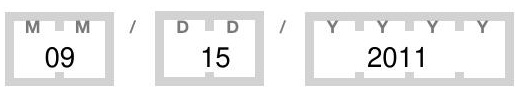

Amount of Each Receipt this Period

Name of Employer
Information Requested
Receipt For: 2012
X Primary
Other (specify) General

Occupation

Information Requested

Election Cycle-to-Date

\section{Subtotal Of Receipts This Page (optional)}

Total This Period (last page this line number only) 
SCHEDULE A-P ITEMIZED RECEIPTS
Use separate schedule(s) for each category of the Detailed Summary Page
FOR LINE NUMBER: (check only one)

PAGE $531 / 1572$

\begin{tabular}{|c|c|c|c|c|c|}
\hline & & & & & \\
\hline 16 & $\begin{array}{l}\mathbf{X} \\
17 a\end{array}$ & $17 b$ & $17 c$ & $17 d$ & 18 \\
\hline $19 a$ & $19 \mathrm{~b}$ & $20 \mathrm{a}$ & $20 \mathrm{~b}$ & $20 \mathrm{c}$ & 21 \\
\hline
\end{tabular}

Any information copied from such Reports and Statements may not be sold or used by any person for the purpose of soliciting contributions or for commercial purposes, other than using the name and address of any political committee to solicit contributions from such committee.

NAME OF COMMITTEE (In Full)

\section{Friends of Herman Cain}

A. Full Name (Last, First, Middle Initial)

Sandra McGarity

Mailing Address PO Box 2889

\begin{tabular}{lcc}
\hline City & State & Zip Code \\
McDonough & GA & $30253-1778$ \\
\hline
\end{tabular}

FEC ID number of contributing

federal political committee.

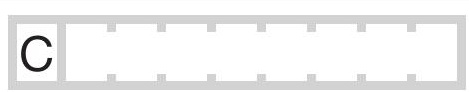

Name of Employer
None
Receipt For: 2012
X Primary $\quad$ General
Other (specify)

Occupation

Retired

Election Cycle-to-Date

250.00

B. Full Name (Last, First, Middle Initial)

William Strickland

Mailing Address PO Box 151

\begin{tabular}{lcc}
\hline City & State & Zip Code \\
McDonough & GA & $30253-0151$
\end{tabular}

FEC ID number of contributing

federal political committee.

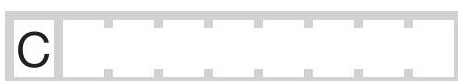

Name of Employer
Bellamy-Strickland
Receipt For: 2012
X Primary
Other (specify)

\section{Occupation}

Car dealer

Election Cycle-to-Date

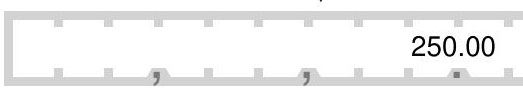

Transaction ID : A311959DAF04146C29D9

Date of Receipt

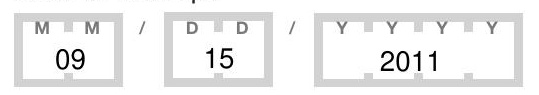

Amount of Each Receipt this Period

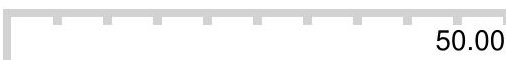

50.00

C. Full Name (Last, First, Middle Initial)

Richard Adelizzi

Mailing Address 291 Glendale Rd

\begin{tabular}{lcc}
\hline City & State & Zip Code \\
Upper Darby & PA & $19082-4017$
\end{tabular}

FEC ID number of contributing federal political committee.

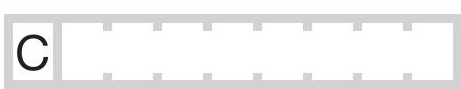

Name of Employer

Information Requested

Occupation

Information Requested

Receipt For: 2012

Х $\begin{aligned} & \text { Primary } \\ & \text { Other (specify) }\end{aligned}$

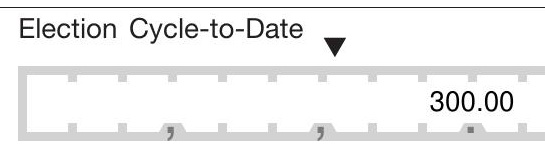

Amount of Each Receipt this Period

Transaction ID : AE233BB52FC1F4FD0A1D Date of Receipt
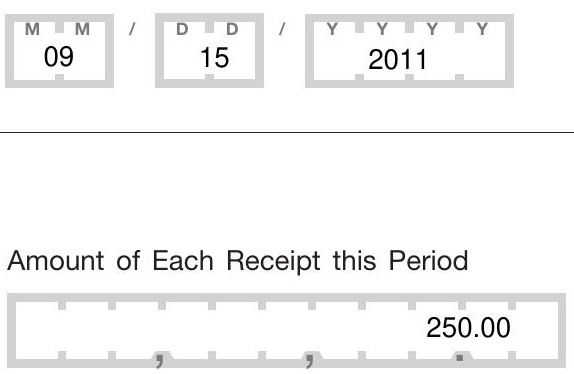

Transaction ID : ADBB119AC90A6426DA66 Date of Receipt

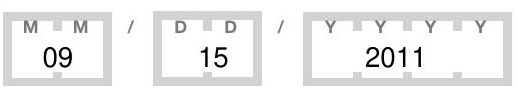

Amount of Each Receipt this Period

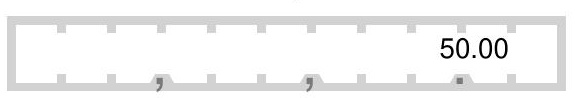

Subtotal Of Receipts This Page (optional).

350.00

Total This Period (last page this line number only) 
SCHEDULE A-P ITEMIZED RECEIPTS
Use separate schedule(s) for each category of the Detailed Summary Page
FOR LINE NUMBER: (check only one)

PAGE 532 / 1572

\begin{tabular}{|c|c|c|c|c|c|c|}
\hline & & & & & & \\
\hline 16 & $\lambda$ & $17 \mathrm{a}$ & $17 \mathrm{~b}$ & $17 \mathrm{c}$ & $-17 d$ & -18 \\
\hline $19 a$ & & $19 b$ & $20 a$ & $20 \mathrm{~b}$ & $20 \mathrm{c}$ & 21 \\
\hline
\end{tabular}

Any information copied from such Reports and Statements may not be sold or used by any person for the purpose of soliciting contributions or for commercial purposes, other than using the name and address of any political committee to solicit contributions from such committee.

NAME OF COMMITTEE (In Full)

\section{Friends of Herman Cain}

A. Full Name (Last, First, Middle Initial) Linda Joyce-Menk

Mailing Address 70 White Oak Drive

\begin{tabular}{lcc}
\hline City & State & Zip Code \\
Newnan & GA & $30265-1267$
\end{tabular}

FEC ID number of contributing federal political committee.

Name of Employer

Bellwether Real Estate Capital LLC

Receipt For: 2012

X Primary $\square$ General Other (specify)

B. Full Name (Last, First, Middle Initial)

Adam Osborn

Mailing Address 203 Blue Bell Rd

\begin{tabular}{lcc}
\hline City & State & Zip Code \\
Houston & TX & $77037-1307$ \\
\hline
\end{tabular}

FEC ID number of contributing

federal political committee.

Name of Employer
Information Requested
Receipt For: 2012
Primary
Other (specify)

C. Full Name (Last, First, Middle Initial)

Brian Harpster

Mailing Address 990 S. Fletcher Ave

\section{City}

Fernandina Beach

FEC ID number of contributing

federal political committee.

Name of Employer
Self Employed
Receipt For: 2012
X Primary
Other (specify) General

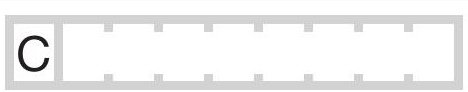

Occupation

Mortgage Banker

Election Cycle-to-Date 325.00

C
Occupation

Information Requested

Election Cycle-to-Date

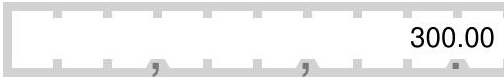

Transaction ID : A53096B0B405A4F11910

Date of Receipt

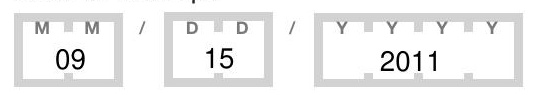

Amount of Each Receipt this Period

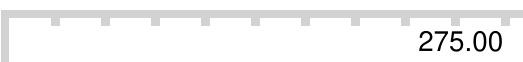

275.00

Transaction ID : A1F49BE63DB624ABD9FC

Date of Receipt

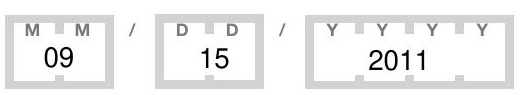

Amount of Each Receipt this Period

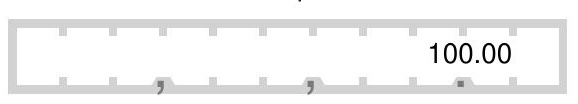

Transaction ID : AF83AAD1F5AAF430B9D3 Date of Receipt

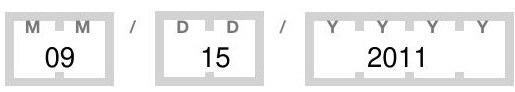

Amount of Each Receipt this Period

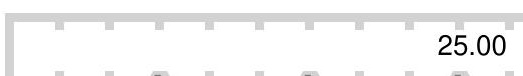

Occupation

Election Cycle-to-Date

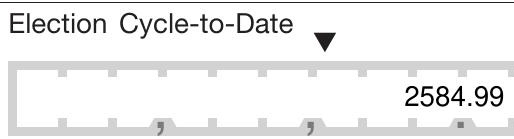

Subtotal Of Receipts This Page (optional).

400.00

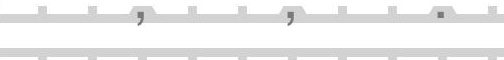

Total This Period (last page this line number only) 
SCHEDULE A-P ITEMIZED RECEIPTS
Use separate schedule(s) for each category of the Detailed Summary Page
FOR LINE NUMBER: (check only one)

PAGE $533 / 1572$

\begin{tabular}{|c|c|c|c|c|c|}
\hline & & & & & \\
\hline 16 & $\begin{array}{lll}X & 17 a \\
\end{array}$ & $17 \mathrm{~b}$ & $17 c$ & $17 d$ & 18 \\
\hline $19 a$ & $19 b$ & $20 a$ & $20 \mathrm{~b}$ & $20 c$ & 21 \\
\hline
\end{tabular}

Any information copied from such Reports and Statements may not be sold or used by any person for the purpose of soliciting contributions or for commercial purposes, other than using the name and address of any political committee to solicit contributions from such committee.

NAME OF COMMITTEE (In Full)

Friends of Herman Cain

A. Full Name (Last, First, Middle Initial)

Mr John G Penson

Mailing Address 1201 Elm St

City $\quad$ State $4240 \quad$ Zip Code

FEC ID number of contributing

federal political committee.

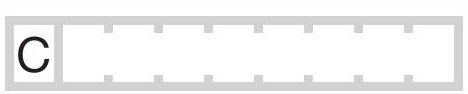

Name of Employer
Information Requested
Receipt For: 2012
X Primary $\quad \square$ General
Other (specify)

Occupation

Information Requested

Election Cycle-to-Date

250.00

B. Full Name (Last, First, Middle Initial)

Nancy Gunsallus

Mailing Address 3461 Donegal Way

\begin{tabular}{lcc}
\hline City & State & Zip Code \\
Snellville & GA & $30039-8635$ \\
\hline
\end{tabular}

FEC ID number of contributing

federal political committee.

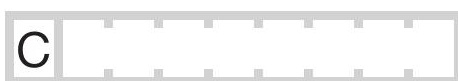

Name of Employer

American Shutter Components LLC

Occupation

co-owner

Receipt For: 2012

Х $\begin{aligned} & \text { Primary } \\ & \text { Other (specify) }\end{aligned}$

Election Cycle-to-Date

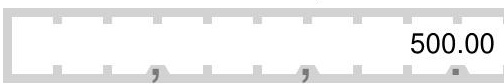

C. Full Name (Last, First, Middle Initial)

Suzanne Carter

Mailing Address 8012 Rose Terrace

\begin{tabular}{lcc}
\hline City & State & Zip Code \\
Seminole & FL & $33777-3020$
\end{tabular}

FEC ID number of contributing

federal political committee.

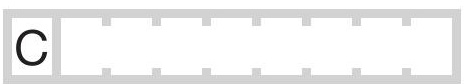

Name of Employer

Raymond James Financial

Receipt For: 2012

Х $\begin{aligned} & \text { Primary } \\ & \text { Other (specify) }\end{aligned}$

Occupation

Imaging Representive

Election Cycle-to-Date

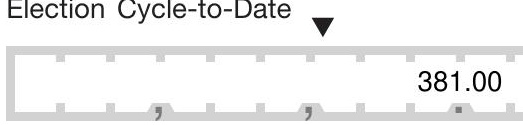

Transaction ID : A5C10CDC5EA7847E0B8A

Date of Receipt

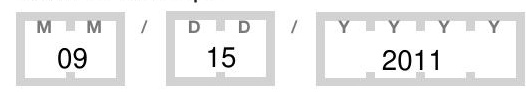

Amount of Each Receipt this Period

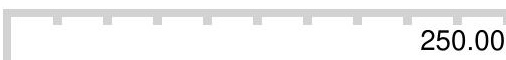

250.00

Transaction ID : AC2F12CE393B744D8B5F

Date of Receipt

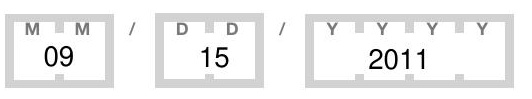

Amount of Each Receipt this Period

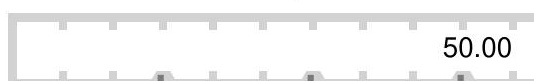

Transaction ID : A441AAC21F17346E884D Date of Receipt

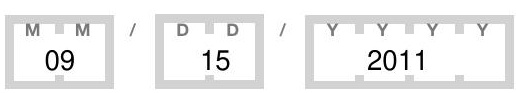

Amount of Each Receipt this Period

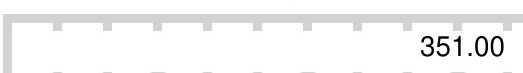

351.00
Subtotal Of Receipts This Page (optional)

651.00

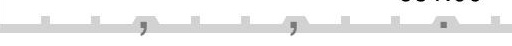

Total This Period (last page this line number only)

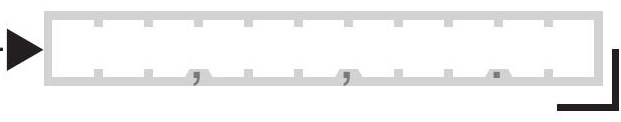

FEC Schedule A-P (Form 3P) (Rev. 03/2011) 
SCHEDULE A-P ITEMIZED RECEIPTS
Use separate schedule(s) for each category of the Detailed Summary Page

FOR LINE NUMBER:
(check only one)

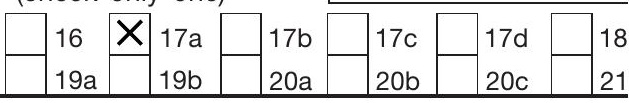

Any information copied from such Reports and Statements may not be sold or used by any person for the purpose of soliciting contributions or for commercial purposes, other than using the name and address of any political committee to solicit contributions from such committee.

NAME OF COMMITTEE (In Full)

\section{Friends of Herman Cain}

A. Full Name (Last, First, Middle Initial) John LaRosa

Mailing Address 273 Roslindale Ave.

\begin{tabular}{lcc}
\hline City & State & Zip Code \\
Roslindale & MA & $02131-3339$
\end{tabular}

FEC ID number of contributing federal political committee.

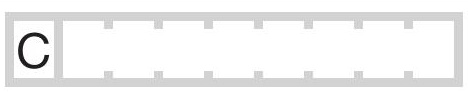

Name of Employer
self
Receipt For: 2012
X Primary $\quad$ General
Other (specify)

Occupation Consulting

Election Cycle-to-Date 387.76

B. Full Name (Last, First, Middle Initial) bob gershin

Mailing Address 6 Craig St

\begin{tabular}{lcc}
\hline City & State & Zip Code \\
Levittown & NY & $11756-4613$ \\
\hline
\end{tabular}

FEC ID number of contributing

federal political committee.

C

Name of Employer
Information Requested
Receipt For: 2012
Primary
Other (specify)

Occupation

Information Requested

Election Cycle-to-Date

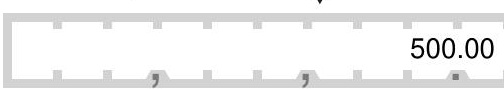

C. Full Name (Last, First, Middle Initial)

Lewis Halski

Mailing Address PO Box 908462

\begin{tabular}{lcc}
\hline City & State & Zip Code \\
Gainesville & GA & $30501-0923$
\end{tabular}

FEC ID number of contributing federal political committee.

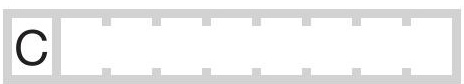

Name of Employer

Halski Systems LLC

Occupation

Receipt For: 2012

Х $\begin{aligned} & \text { Primary } \\ & \text { Other (specify) }\end{aligned}$

Small business owner Computer Technolo

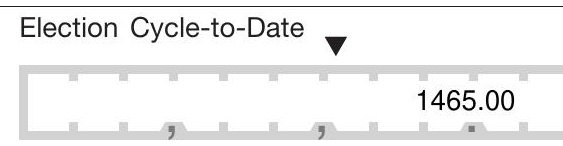

Amount of Each Receipt this Period

Transaction ID : AC3BB78F367954CEFA83

Date of Receipt

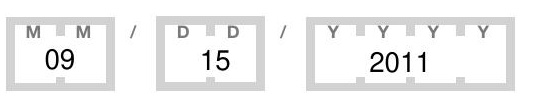

Amount of Each Receipt this Period
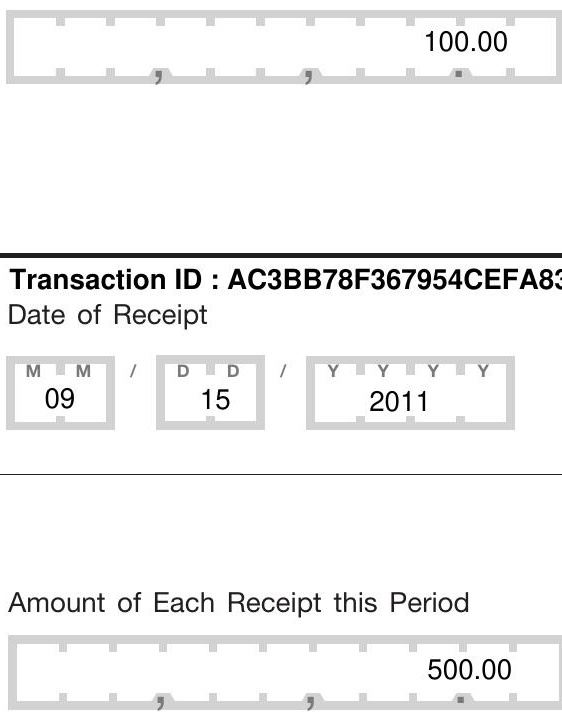

Amount of Each Receipt this Period

Transaction ID : A5835087B719B46A19FF

Date of Receipt
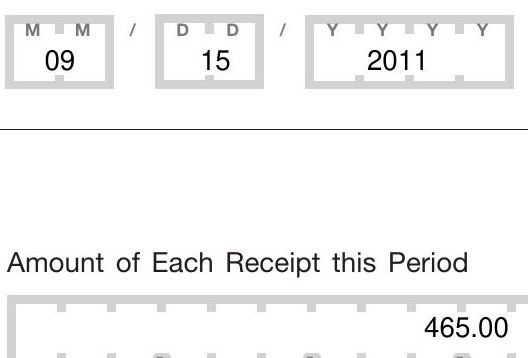

465.00

Subtotal Of Receipts This Page (optional)

1065.00

Total This Period (last page this line number only) 
SCHEDULE A-P ITEMIZED RECEIPTS
Use separate schedule(s) for each category of the Detailed Summary Page
FOR LINE NUMBER: (check only one)

PAGE $535 / 1572$

\begin{tabular}{|c|c|c|c|c|c|}
\hline & & & & & \\
\hline 16 & $\begin{array}{l}\mathbf{X} \\
17 a\end{array}$ & $17 b$ & $17 c$ & $17 d$ & 18 \\
\hline $19 a$ & $19 \mathrm{~b}$ & $20 \mathrm{a}$ & $20 \mathrm{~b}$ & $20 \mathrm{c}$ & 21 \\
\hline
\end{tabular}

Any information copied from such Reports and Statements may not be sold or used by any person for the purpose of soliciting contributions or for commercial purposes, other than using the name and address of any political committee to solicit contributions from such committee.

NAME OF COMMITTEE (In Full)

\section{Friends of Herman Cain}

A. Full Name (Last, First, Middle Initial) Joseph Edwards

Mailing Address 199 Hwy $341 \mathrm{~N}$

\begin{tabular}{lcc}
\hline City & State & Zip Code \\
Barnesville & GA & $30204-1931$
\end{tabular}

FEC ID number of contributing federal political committee.

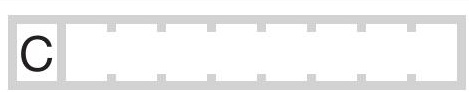

Name of Employer
United Bank Corporation
Receipt For: 2012
X Primary
Other (specify) General

Occupation Banker

Election Cycle-to-Date

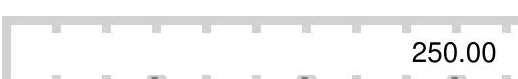

B. Full Name (Last, First, Middle Initial)

Carol Cook

Mailing Address 43 Oak Alley

\begin{tabular}{lcc}
\hline City & State & Zip Code \\
Kerrville & TX & $78028-1711$
\end{tabular}

FEC ID number of contributing

federal political committee.

C

Name of Employer
James Avery
Receipt For: 2012
X Primary
Other (specify)

C. Full Name (Last, First, Middle Initial)

Stacie Curtis

Mailing Address 267 Stardust Cir

\section{City}

Toney

FEC ID number of contributing federal political committee.

\section{Name of Employer}

The A/C Doctor

Receipt For: 2012

Х $\begin{aligned} & \text { Primary } \\ & \text { Other (specify) }\end{aligned}$

\section{Occupation \\ Office Manager}

Election Cycle-to-Date
Transaction ID : AC66E04755717472CB14

Date of Receipt

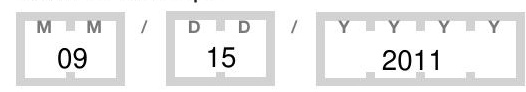

Amount of Each Receipt this Period

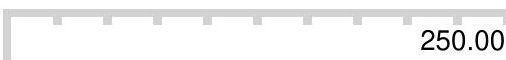

250.00
Amount of Each Receipt this Period

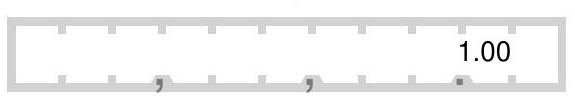

Transaction ID : AE790F95B210A4957B69

Date of Receipt

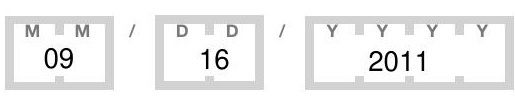

Occupation

Sales Team Leader

Election Cycle-to-Date

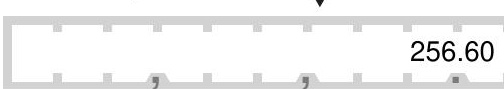

Transaction ID : A8BCD6AFDC38E4962879 Date of Receipt

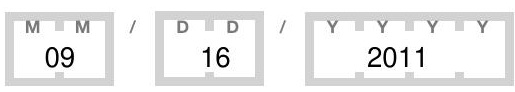

Amount of Each Receipt this Period
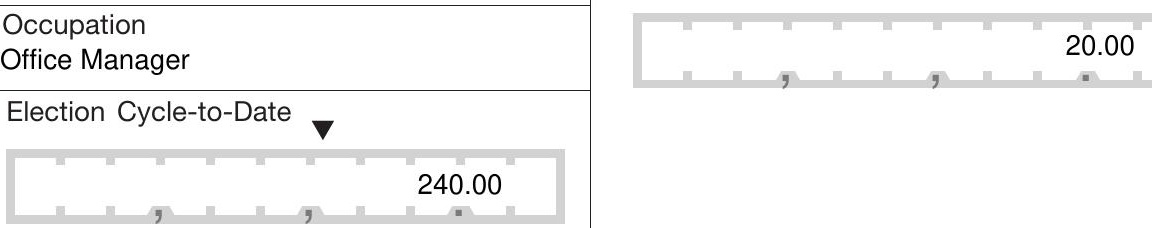

Subtotal Of Receipts This Page (optional)

271.00

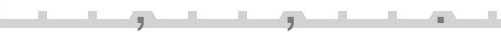

Total This Period (last page this line number only)

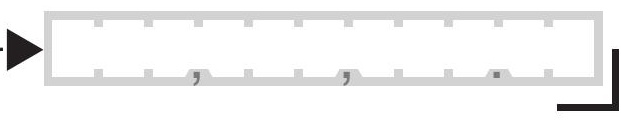

FEC Schedule A-P (Form 3P) (Rev. 03/2011) 
SCHEDULE A-P ITEMIZED RECEIPTS
Use separate schedule(s) for each category of the Detailed Summary Page
FOR LINE NUMBER: (check only one)

PAGE $536 / 1572$

\begin{tabular}{|c|c|c|c|c|c|}
\hline & & & & & \\
\hline 16 & $\begin{array}{l}\mathbf{X} \\
17 a\end{array}$ & $17 b$ & $17 c$ & $17 d$ & 18 \\
\hline $19 a$ & $19 \mathrm{~b}$ & $20 \mathrm{a}$ & $20 \mathrm{~b}$ & $20 \mathrm{c}$ & 21 \\
\hline
\end{tabular}

Any information copied from such Reports and Statements may not be sold or used by any person for the purpose of soliciting contributions or for commercial purposes, other than using the name and address of any political committee to solicit contributions from such committee.

NAME OF COMMITTEE (In Full)

\section{Friends of Herman Cain}

A. Full Name (Last, First, Middle Initial) Joseph Prigge

Mailing Address 210 coventry court

\begin{tabular}{lcc}
\hline City & State & Zip Code \\
Elgin & IL & $60123-5081$ \\
\hline
\end{tabular}

FEC ID number of contributing federal political committee.

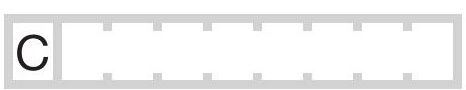

Name of Employer
William Prigge
Receipt For: 2012
X Primary
Other (specify) General

Occupation

Geotechnical Technician

Election Cycle-to-Date $\boldsymbol{\nabla}$

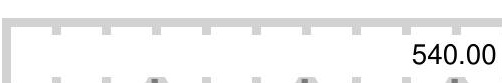

B. Full Name (Last, First, Middle Initial)

Christopher Blair

Mailing Address 21 8th Ave

\begin{tabular}{lcc}
\hline City & State & Zip Code \\
Milford & CT & $06460-5328$
\end{tabular}

FEC ID number of contributing

federal political committee.

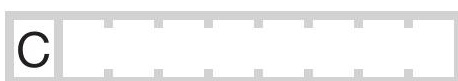

Name of Employer
AKUSTIKS
Receipt For: 2012
X Primary
Other (specify)

\section{Occupation}

consultant

Election Cycle-to-Date

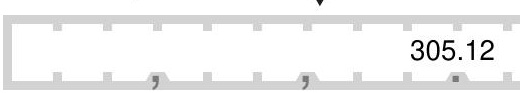

Transaction ID : A3BA80CB493F341D98A0

Date of Receipt

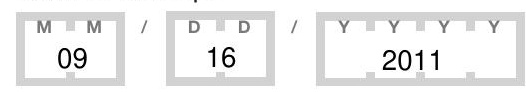

Amount of Each Receipt this Period

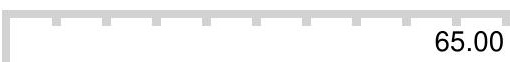

65.00

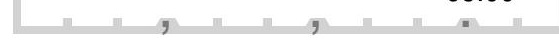

Transaction ID : A8AB171EF324A49A68CA

Date of Receipt

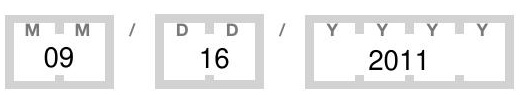

Amount of Each Receipt this Period

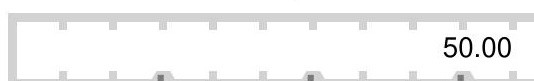

Transaction ID : A65C6049B00BF477BA57 Date of Receipt

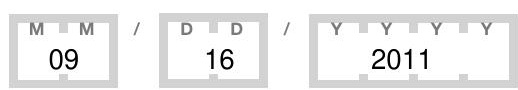

Amount of Each Receipt this Period

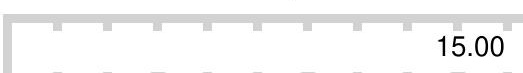

$\begin{array}{cc}\text { State } & \text { Zip Code } \\ \text { NE } & 68850-5638\end{array}$

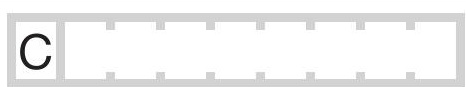

\section{Occupation}

Retired

Election Cycle-to-Date

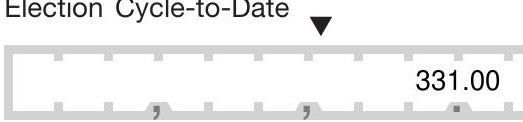

Subtotal Of Receipts This Page (optional)

130.00

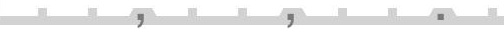

Total This Period (last page this line number only)

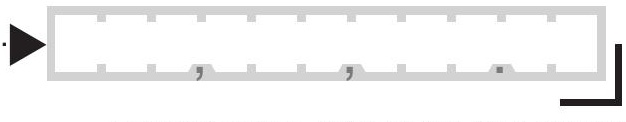

FEC Schedule A-P (Form 3P) (Rev. 03/2011) 
SCHEDULE A-P ITEMIZED RECEIPTS
Use separate schedule(s) for each category of the Detailed Summary Page
FOR LINE NUMBER: (check only one)

PAGE 537 / 1572

\begin{tabular}{|c|c|c|c|c|c|}
\hline & & & & & \\
\hline 16 & $\begin{array}{l}\mathbf{X} \\
17 a\end{array}$ & $17 b$ & $17 c$ & $17 d$ & 18 \\
\hline $19 a$ & $19 \mathrm{~b}$ & $20 \mathrm{a}$ & $20 \mathrm{~b}$ & $20 \mathrm{c}$ & 21 \\
\hline
\end{tabular}

Any information copied from such Reports and Statements may not be sold or used by any person for the purpose of soliciting contributions or for commercial purposes, other than using the name and address of any political committee to solicit contributions from such committee.

NAME OF COMMITTEE (In Full)

\section{Friends of Herman Cain}

A. Full Name (Last, First, Middle Initial)

Herrmann Glockler

Mailing Address 3265 Sierra Crest Way

\begin{tabular}{lcc}
\hline City & State & Zip Code \\
Reno & NV & $89519-8041$
\end{tabular}

FEC ID number of contributing

federal political committee.

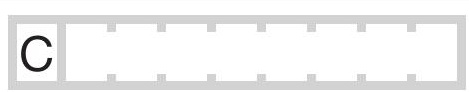

Name of Employer
Retired
Receipt For: 2012
X Primary $\quad$ General
Other (specify)

Occupation

Engineer

Election Cycle-to-Date

300.00

B. Full Name (Last, First, Middle Initial)

David Ford

Mailing Address 5162 Anton Dr Apt 308

\begin{tabular}{lcc}
\hline City & State & Zip Code \\
Fitchburg & WI & $53719-1717$
\end{tabular}

FEC ID number of contributing

federal political committee.

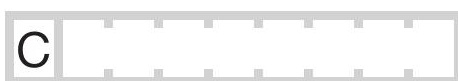

Name of Employer
University of Wisconsin Hospital
Receipt For: 2012
X Primary
Other (specify)

Occupation

Registered Nurse

Election Cycle-to-Date

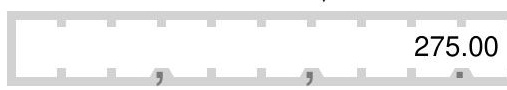

C. Full Name (Last, First, Middle Initial)

Neil Hobart

Mailing Address 219 N Barry Avenue

\begin{tabular}{lcc}
\hline City & State & Zip Code \\
Mamaroneck & NY & $10543-2827$
\end{tabular}

FEC ID number of contributing

federal political committee.

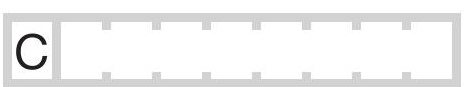

Name of Employer
None
Receipt For: 2012
X Primary $\quad \square$ General
Other (specify)

\section{Occupation}

unemployed

Election Cycle-to-Date

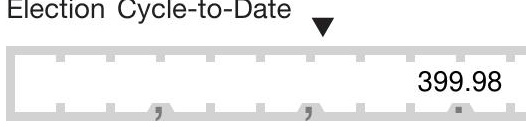

Transaction ID : A73A9802DC9564834A09

Date of Receipt

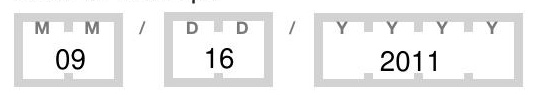

Amount of Each Receipt this Period

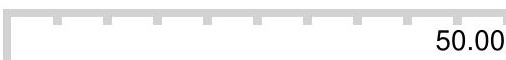

50.00

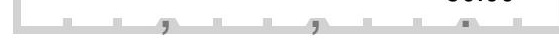

Transaction ID : A7B30D4CA78554C62A52

Date of Receipt

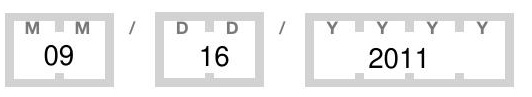

Amount of Each Receipt this Period

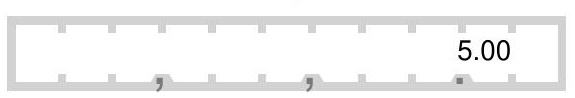

Transaction ID : A88B02F27E8444BC883D Date of Receipt

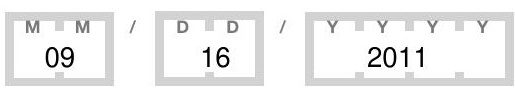

Amount of Each Receipt this Period

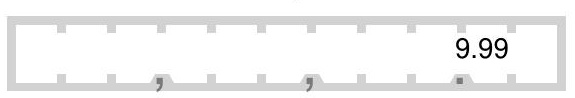

64.99

(1)

Total This Period (last page this line number only) 
SCHEDULE A-P ITEMIZED RECEIPTS
Use separate schedule(s) for each category of the Detailed Summary Page
FOR LINE NUMBER: (check only one)

\begin{tabular}{|c|c|c|c|c|c|}
\hline & & & & & \\
\hline 16 & $\begin{array}{ll}X & 17 a \\
\end{array}$ & $17 \mathrm{~b}$ & $17 c$ & $17 d$ & 18 \\
\hline $19 a$ & $19 b$ & $20 \mathrm{a}$ & $20 \mathrm{~b}$ & $20 c$ & 21 \\
\hline
\end{tabular}

Any information copied from such Reports and Statements may not be sold or used by any person for the purpose of soliciting contributions or for commercial purposes, other than using the name and address of any political committee to solicit contributions from such committee.

NAME OF COMMITTEE (In Full)

\section{Friends of Herman Cain}

A. Full Name (Last, First, Middle Initial)

\section{Susan Walter}

Mailing Address P.O. Box 690

\begin{tabular}{lcc}
\hline City & State & Zip Code \\
Sautee Nacoochee & GA & $30571-0690$ \\
\hline
\end{tabular}

FEC ID number of contributing federal political committee.

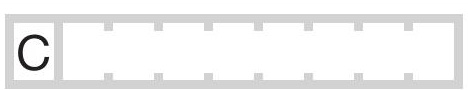

\begin{tabular}{l} 
Name of Employer \\
None \\
Receipt For: 2012 \\
X Primary $\quad$ General \\
\hline Other (specify)
\end{tabular}

Occupation Retired

Election Cycle-to-Date

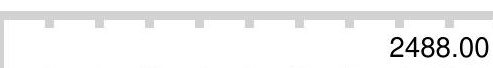

B. Full Name (Last, First, Middle Initial)

Travis Burgess

Mailing Address 905 North Elm

\begin{tabular}{lcc}
\hline City & State & Zip Code \\
Red Cloud & NE & $68970-2133$ \\
\hline
\end{tabular}

FEC ID number of contributing

federal political committee.

C

Name of Employer
US Postal Service
Receipt For: 2012
X Primary
Other (specify)

\section{Occupation}

Letter Carrier

Election Cycle-to-Date

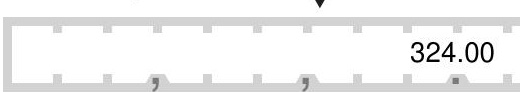

Transaction ID : AA26A66D74C0A46A8AFE

Date of Receipt

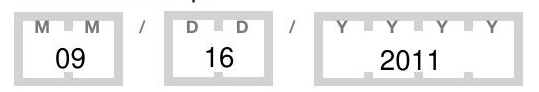

Amount of Each Receipt this Period

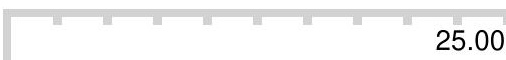

25.00

C. Full Name (Last, First, Middle Initial)

Steve Thomas

Mailing Address 6369 Pittman Cr.

\begin{tabular}{lcc}
\hline City & State & Zip Code \\
Casper & WY & $82604-3632$ \\
\hline
\end{tabular}

FEC ID number of contributing federal political committee.

C

WY

Name of Employer
john deere
Receipt For: 2012
X Primary $\quad$ General
Other (specify)

\section{Occupation}

Mechanic

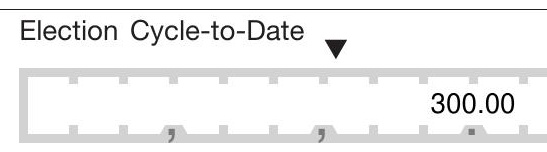

Transaction ID : AE74520A5A72B4F3ABDB Date of Receipt

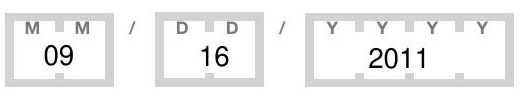

Amount of Each Receipt this Period

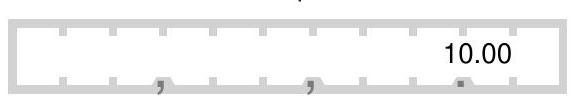

Transaction ID : AB957EF2B3A9149E9B78 Date of Receipt

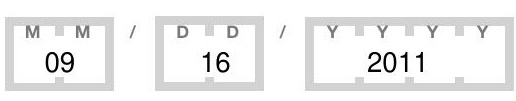

Amount of Each Receipt this Period

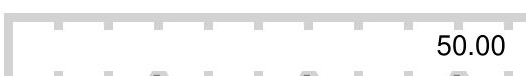

\section{Subtotal Of Receipts This Page (optional)}

Total This Period (last page this line number only) 
SCHEDULE A-P ITEMIZED RECEIPTS
Use separate schedule(s) for each category of the Detailed Summary Page
FOR LINE NUMBER: (check only one)

PAGE $539 / 1572$

\begin{tabular}{|c|c|c|c|c|c|}
\hline & & & & & \\
\hline 16 & $\begin{array}{l}\mathbf{X} \\
17 a\end{array}$ & $17 b$ & $17 c$ & $17 d$ & 18 \\
\hline $19 a$ & $19 \mathrm{~b}$ & $20 \mathrm{a}$ & $20 \mathrm{~b}$ & $20 \mathrm{c}$ & 21 \\
\hline
\end{tabular}

Any information copied from such Reports and Statements may not be sold or used by any person for the purpose of soliciting contributions or for commercial purposes, other than using the name and address of any political committee to solicit contributions from such committee.

NAME OF COMMITTEE (In Full)

\section{Friends of Herman Cain}

A. Full Name (Last, First, Middle Initial)

\section{Joe Mrazik}

Mailing Address 4843 E. Lee St.

\begin{tabular}{lcc}
\hline City & State & Zip Code \\
Tucson & AZ & $85712-4055$
\end{tabular}

FEC ID number of contributing federal political committee.

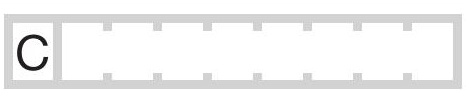

Name of Employer
Information Requested
Receipt For: 2012
X Primary
Other (specify) General

Occupation Information Requested

Election Cycle-to-Date

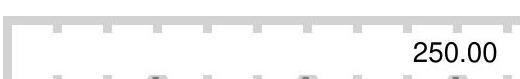

B. Full Name (Last, First, Middle Initial)

Ruth Bavier

Mailing Address 489 Dennison Ridge

\begin{tabular}{lcc}
\hline City & State & Zip Code \\
Manchester & CT & $06040-6839$
\end{tabular}

FEC ID number of contributing

federal political committee.

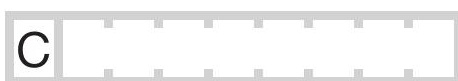

Name of Employer
Perricone MD
Receipt For: 2012
X Primary
Other (specify)

\section{Occupation}

Finance Assistant

Election Cycle-to-Date

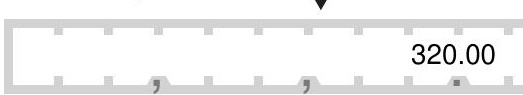

Transaction ID : AE39CDA65A3D74A1FB80

Date of Receipt

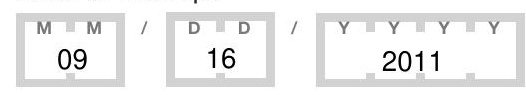

Amount of Each Receipt this Period

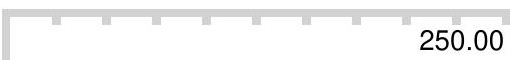

Amount of Each Receipt this Period

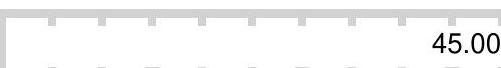

C. Full Name (Last, First, Middle Initial)

Robert Porter

Mailing Address 5710 Grand Reunion Dr

\begin{tabular}{lcc}
\hline City & State & Zip Code \\
Hoschton & GA & $30548-4045$
\end{tabular}

FEC ID number of contributing federal political committee.

C

Name of Employer
Information Requested
Receipt For: 2012
X Primary
Other (specify) General

Occupation

Information Requested

Election Cycle-to-Date
Transaction ID : A17B0533BA33C4FEFA90

Date of Receipt

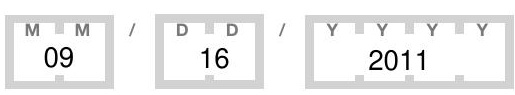

Transaction ID : AEAA28C9A7A674B02A64 Date of Receipt

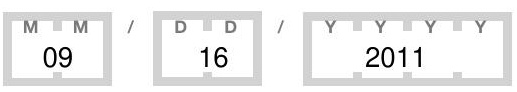

Amount of Each Receipt this Period

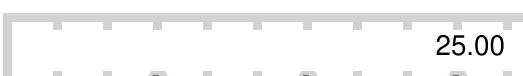

487.00

\section{Subtotal Of Receipts This Page (optional)}

Total This Period (last page this line number only) 
SCHEDULE A-P ITEMIZED RECEIPTS
Use separate schedule(s) for each category of the Detailed Summary Page

FOR LINE NUMBER:
(check only one)

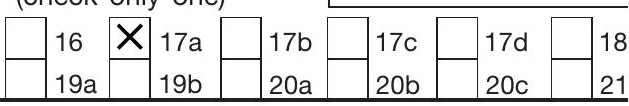

Any information copied from such Reports and Statements may not be sold or used by any person for the purpose of soliciting contributions or for commercial purposes, other than using the name and address of any political committee to solicit contributions from such committee.

NAME OF COMMITTEE (In Full)

\section{Friends of Herman Cain}

A. Full Name (Last, First, Middle Initial)

Wayne Thomas

Mailing Address 1533 Clark Avenue

\begin{tabular}{lcc}
\hline City & State & Zip Code \\
Cottage Grove & OR & $97424-1891$ \\
\hline
\end{tabular}

FEC ID number of contributing federal political committee.

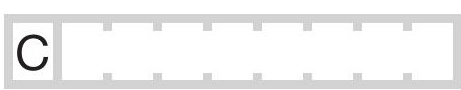

Name of Employer
PeaceHealth Laboratories
Receipt For: 2012
X Primary $\quad \square$ General
Other (specify)

Occupation courier

Election Cycle-to-Date

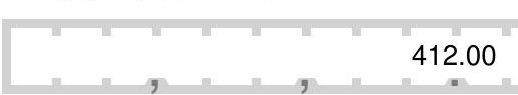

B. Full Name (Last, First, Middle Initial)

Vicki Taylor

Mailing Address 5457 Sparta Pike

\begin{tabular}{lcc}
\hline City & State & Zip Code \\
Watertown & TN & $37184-4319$ \\
\hline
\end{tabular}

FEC ID number of contributing

federal political committee.

C

Name of Employer
$\mathrm{n} / \mathrm{a}$

Occupation

Full-time Home-Maker

Election Cycle-to-Date

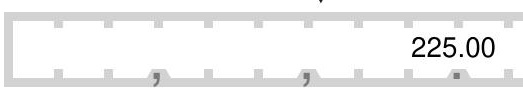

Transaction ID : AE75FB36594CA40ACB49

Date of Receipt

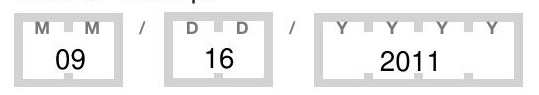

Amount of Each Receipt this Period

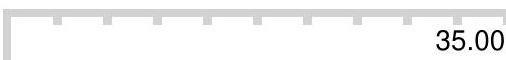

Transaction ID : A12FC083DB9FA4587B0F

Date of Receipt

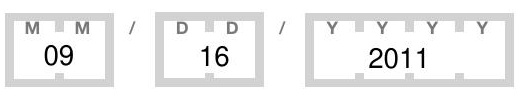

Amount of Each Receipt this Period

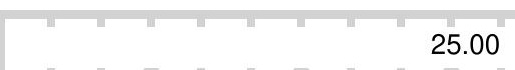

Transaction ID : A7841B825EE1C4AA4AA8 Date of Receipt

Rita Brown

Mailing Address 3804 Trinity Drive

\begin{tabular}{lcc}
\hline City & State & Zip Code \\
Midland & TX & $79707-4745$
\end{tabular}

FEC ID number of contributing federal political committee.

C

Name of Employer
None
Receipt For: 2012
X Primary $\quad \square$ General
Other (specify)

Occupation Homemaker Election Cycle-to-Date

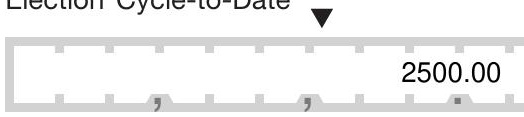

Subtotal Of Receipts This Page (optional)

2560.00

Amount of Each Receipt this Period

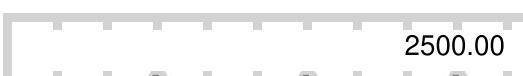

Total This Period (last page this line number only) 
SCHEDULE A-P ITEMIZED RECEIPTS
Use separate schedule(s) for each category of the Detailed Summary Page

FOR LINE NUMBER:
(check only one)

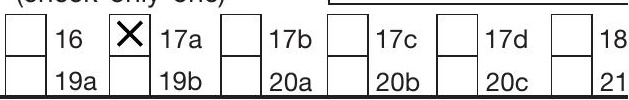

Any information copied from such Reports and Statements may not be sold or used by any person for the purpose of soliciting contributions or for commercial purposes, other than using the name and address of any political committee to solicit contributions from such committee.

NAME OF COMMITTEE (In Full)

\section{Friends of Herman Cain}

A. Full Name (Last, First, Middle Initial)

Carolyn Crilly

Mailing Address 65 Strathmore Rd \#46

\begin{tabular}{lcc}
\hline City & State & Zip Code \\
Brighton & MA & $02135-7743$ \\
\hline
\end{tabular}

FEC ID number of contributing federal political committee.

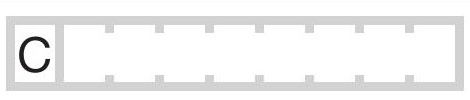

Name of Employer
St Elizabeth's Medical Center
Receipt For: 2012
X Primary
Other (specify)

Occupation

Registered Nurse

Election Cycle-to-Date

700.00

B. Full Name (Last, First, Middle Initial)

Thomas Walker

Mailing Address PO Box 482

\begin{tabular}{lcc}
\hline City & State & Zip Code \\
Brookline & $\mathrm{NH}$ & $03033-0482$ \\
\hline
\end{tabular}

FEC ID number of contributing

federal political committee.

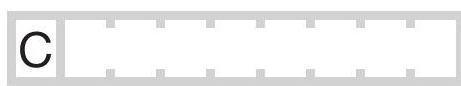

Name of Employer

Resource Environmental Group LLC

Occupation

Consultant

Receipt For: 2012

$\chi \begin{aligned} & \text { Primary } \\ & \text { Other (specify) }\end{aligned}$

Election Cycle-to-Date

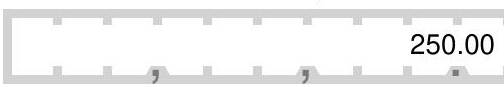

Transaction ID : A26919617C5A7434FBAB

Date of Receipt

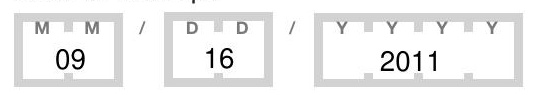

Amount of Each Receipt this Period

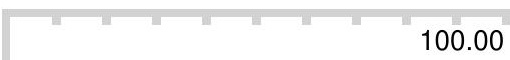

100.00
Amount of Each Receipt this Period

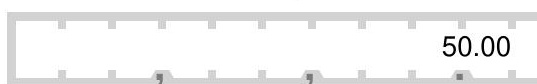

Transaction ID : ADB60625A0B874D0BA6D Date of Receipt

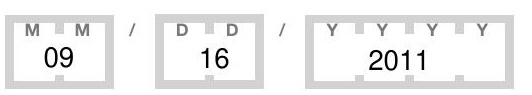

C. Full Name (Last, First, Middle Initial)

Brian Wall

Mailing Address $9281 \mathrm{~N}$ Fairmont Circle

\begin{tabular}{lcc}
\hline City & State & Zip Code \\
Collierville & TN & $38017-3588$
\end{tabular}

FEC ID number of contributing federal political committee.

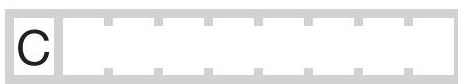

Name of Employer

Occupation

Baptist Hospital

Physician

Receipt For: 2012

Х $\begin{aligned} & \text { Primary } \square \text { General } \\ & \text { Other (specify) }\end{aligned}$

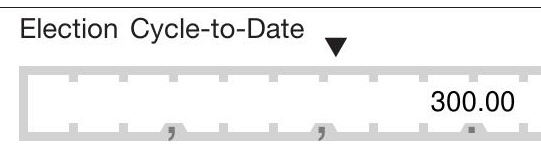

Transaction ID : A2DFD553CA9674B759E3 Date of Receipt

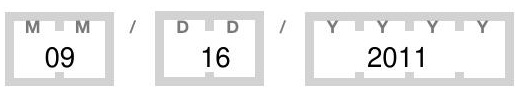

Amount of Each Receipt this Period

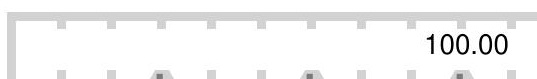

Subtotal Of Receipts This Page (optional)

Total This Period (last page this line number only) 
SCHEDULE A-P ITEMIZED RECEIPTS
Use separate schedule(s) for each category of the Detailed Summary Page
FOR LINE NUMBER: (check only one)

PAGE 542 / 1572

\begin{tabular}{|c|c|c|c|c|c|}
\hline & & & & & \\
\hline 16 & $\begin{array}{l}\mathbf{X} \\
17 a\end{array}$ & $17 b$ & $17 c$ & $17 d$ & 18 \\
\hline $19 a$ & $19 \mathrm{~b}$ & $20 \mathrm{a}$ & $20 \mathrm{~b}$ & $20 \mathrm{c}$ & 21 \\
\hline
\end{tabular}

Any information copied from such Reports and Statements may not be sold or used by any person for the purpose of soliciting contributions or for commercial purposes, other than using the name and address of any political committee to solicit contributions from such committee.

NAME OF COMMITTEE (In Full)

\section{Friends of Herman Cain}

A. Full Name (Last, First, Middle Initial) Jeanne Downer

Mailing Address $6007 \mathrm{~N}$ Kansas AVe

\begin{tabular}{lcc}
\hline City & State & Zip Code \\
Kansas City & MO & $64119-2115$ \\
\hline
\end{tabular}

FEC ID number of contributing federal political committee.

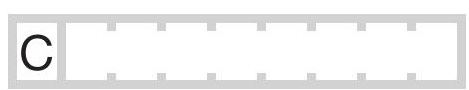

Name of Employer
WNB Architects
Receipt For: 2012
X Primary
$\square$ Other (specify) General

Occupation Office Manager

Election Cycle-to-Date

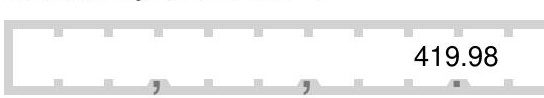

B. Full Name (Last, First, Middle Initial)

Brian Whitlow

Mailing Address 4310 Shillham Court

\begin{tabular}{lcc}
\hline City & State & Zip Code \\
Cumming & GA & $30040-1553$
\end{tabular}

FEC ID number of contributing

federal political committee.

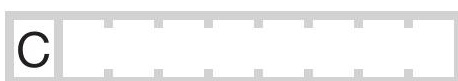

Name of Employer
FleetCor Technologies
Receipt For: 2012
X Primary
Other (specify)

Occupation

IT Analyst

Election Cycle-to-Date

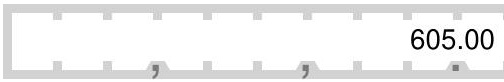

C. Full Name (Last, First, Middle Initial)

Cathy Spivey

Mailing Address 5041 Liberty Rd

\begin{tabular}{lcc}
\hline City & State & Zip Code \\
Villa Rica & GA & $30180-3187$
\end{tabular}

FEC ID number of contributing federal political committee.

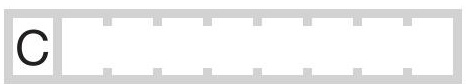

$\begin{aligned} & \text { Name of Employer } \\ & \text { self }\end{aligned}$
Receipt For: 2012
X Primary $\square$ General
Other (specify)

Occupation

Real Estate Appraiser

Election Cycle-to-Date
Transaction ID : A90AFEC2FFEE841A2B60

Date of Receipt

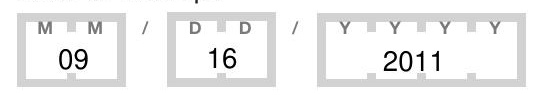

Amount of Each Receipt this Period

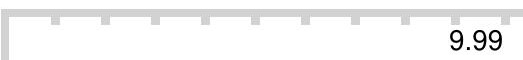

Amount of Each Receipt this Period

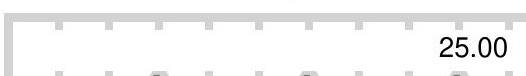

Transaction ID : AC87D50FA410541E291C Date of Receipt

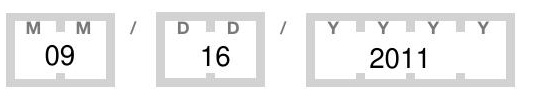

Transaction ID : A9DA51F85E5474A9FA93 Date of Receipt

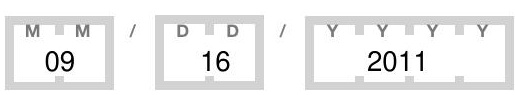

Amount of Each Receipt this Period

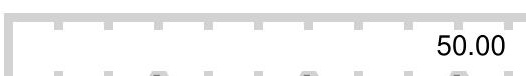

Subtotal Of Receipts This Page (optional).

Total This Period (last page this line number only) 
SCHEDULE A-P ITEMIZED RECEIPTS
Use separate schedule(s) for each category of the Detailed Summary Page
FOR LINE NUMBER: (check only one)

PAGE $543 / 1572$

\begin{tabular}{|c|c|c|c|c|c|}
\hline & & & & & \\
\hline 16 & $\begin{array}{l}\mathbf{X} \\
17 a\end{array}$ & $17 b$ & $17 c$ & $17 d$ & 18 \\
\hline $19 a$ & $19 \mathrm{~b}$ & $20 \mathrm{a}$ & $20 \mathrm{~b}$ & $20 \mathrm{c}$ & 21 \\
\hline
\end{tabular}

Any information copied from such Reports and Statements may not be sold or used by any person for the purpose of soliciting contributions or for commercial purposes, other than using the name and address of any political committee to solicit contributions from such committee.

NAME OF COMMITTEE (In Full)

\section{Friends of Herman Cain}

A. Full Name (Last, First, Middle Initial)

Romey Bensen

Mailing Address 127 President Madison 2C

\begin{tabular}{lcc}
\hline City & State & Zip Code \\
New Orleans & LA & 70115
\end{tabular}

FEC ID number of contributing federal political committee.

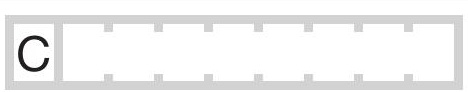

Name of Employer
Information Requested
Receipt For: 2012
X Primary
$\square$ Other (specify)

Occupation Information Requested

Election Cycle-to-Date

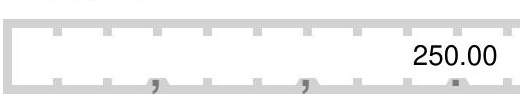

B. Full Name (Last, First, Middle Initial) John Bertel

\section{Mailing Address 343 Vincent Ave}

\begin{tabular}{lcc}
\hline City & State & Zip Code \\
Metairie & LA & $70005-4419$ \\
\hline
\end{tabular}

FEC ID number of contributing

federal political committee.

C

Name of Employer
Hayes Dockside Inc
Receipt For: 2012
X Primary
Other (specify)

Occupation

Business Executive

Election Cycle-to-Date

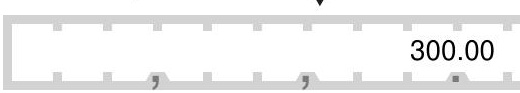

Transaction ID : A97476767D7774BF58A2

Date of Receipt

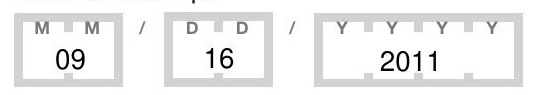

Amount of Each Receipt this Period

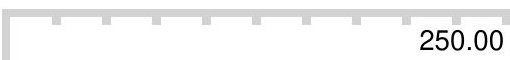

C. Full Name (Last, First, Middle Initial)

Raymond Manson

Mailing Address 1044 Foxshire Place

\begin{tabular}{lcc}
\hline City & State & Zip Code \\
Dayton & $\mathrm{OH}$ & $45458-1951$
\end{tabular}

FEC ID number of contributing federal political committee.

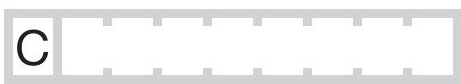

Name of Employer
DMAX-Ltd.
Receipt For: 2012
X Primary $\quad \square$ General
Other (specify)

Occupation

Information Requested

Election Cycle-to-Date
Amount of Each Receipt this Period

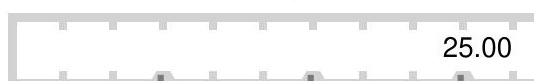

Transaction ID : A51A285899FC7453D87C Date of Receipt

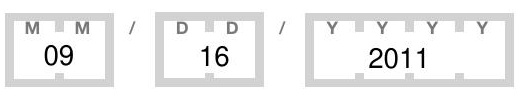

Transaction ID : A5E9C55C642184AE2BBC Date of Receipt

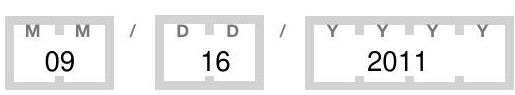

Amount of Each Receipt this Period

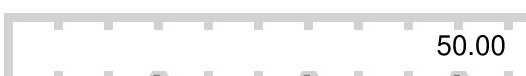

\section{Subtotal Of Receipts This Page (optional)}

Total This Period (last page this line number only) 
SCHEDULE A-P ITEMIZED RECEIPTS
Use separate schedule(s) for each category of the Detailed Summary Page

FOR LINE NUMBER:
(check only one)

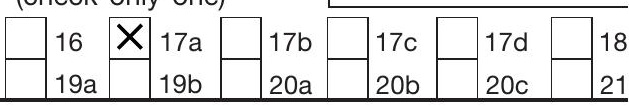

Any information copied from such Reports and Statements may not be sold or used by any person for the purpose of soliciting contributions or for commercial purposes, other than using the name and address of any political committee to solicit contributions from such committee.

NAME OF COMMITTEE (In Full)

\section{Friends of Herman Cain}

A. Full Name (Last, First, Middle Initial) Sandy Tilton

Mailing Address 1305 Waters Edge Trail

\begin{tabular}{lcc}
\hline City & State & Zip Code \\
Roswell & GA & $30075-8202$ \\
\hline
\end{tabular}

FEC ID number of contributing federal political committee.

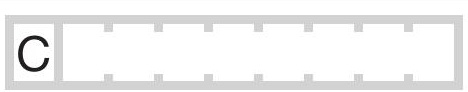

Name of Employer
IBM
Receipt For: 2012
X Primary $\quad$ General
Other (specify)

Occupation Retired

Election Cycle-to-Date

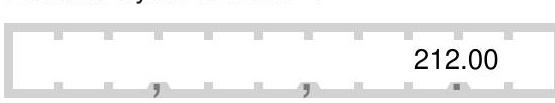

B. Full Name (Last, First, Middle Initial)

Gary Locke

Mailing Address 2602 Booger Hill Road

\begin{tabular}{lcc}
\hline City & State & Zip Code \\
Danielsville & GA & $30633-6102$
\end{tabular}

FEC ID number of contributing

federal political committee.

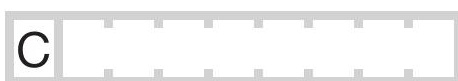

Name of Employer
None
Receipt For: 2012
X Primary
Other (specify)

\section{Occupation}

Retired

Election Cycle-to-Date

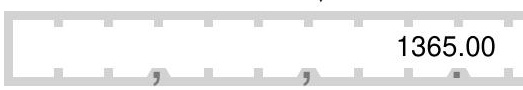

Transaction ID : A9E22E09FFF3842DDBB5

Date of Receipt

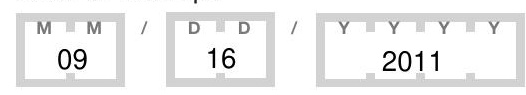

Amount of Each Receipt this Period

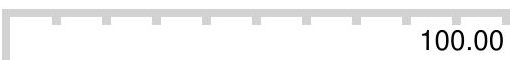

Transaction ID : ACAA1767398304BD9930

Date of Receipt

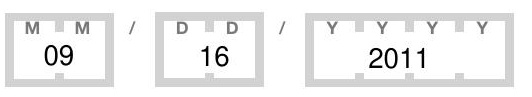

Amount of Each Receipt this Period

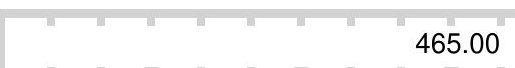

Transaction ID : A48D2E94F2BB94138B9F

Date of Receipt

Rochelle Starr

Mailing Address 12410 84th St. SE

\begin{tabular}{lcc}
\hline City & State & Zip Code \\
Snohomish & WA & $98290-6277$
\end{tabular}

FEC ID number of contributing federal political committee.

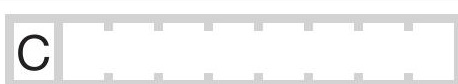

Name of Employer

Occupation

Information Requested

Information Requested

Receipt For: 2012

Х $\begin{aligned} & \text { Primary } \\ & \text { Other (specify) }\end{aligned}$

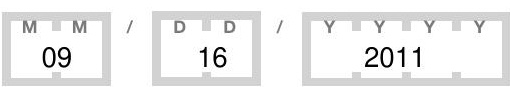

Amount of Each Receipt this Period

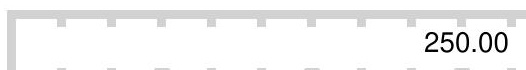

\section{Subtotal Of Receipts This Page (optional)}

Total This Period (last page this line number only) 
SCHEDULE A-P ITEMIZED RECEIPTS
Use separate schedule(s) for each category of the Detailed Summary Page
FOR LINE NUMBER: (check only one)
PAGE $545 / 1572$

\begin{tabular}{|c|c|c|c|c|c|}
\hline & & & & & \\
\hline 16 & $\begin{array}{lll}X & 17 a \\
\end{array}$ & $17 \mathrm{~b}$ & $17 c$ & $17 d$ & 18 \\
\hline $19 a$ & $19 b$ & $20 a$ & $20 \mathrm{~b}$ & $20 c$ & 21 \\
\hline
\end{tabular}

Any information copied from such Reports and Statements may not be sold or used by any person for the purpose of soliciting contributions or for commercial purposes, other than using the name and address of any political committee to solicit contributions from such committee.

NAME OF COMMITTEE (In Full)

\section{Friends of Herman Cain}

A. Full Name (Last, First, Middle Initial)

Cliff Beveridge

Mailing Address 1216 Gotier Trace Rd.

\begin{tabular}{lcc}
\hline City & State & Zip Code \\
Paige & TX & $78659-4400$ \\
\hline
\end{tabular}

FEC ID number of contributing

federal political committee.

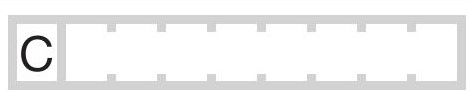

Name of Employer
Ultra Electronics-ATS
Receipt For: 2012
X Primary
Other (specify) General

Occupation

Senior Software Engineer

Election Cycle-to-Date $\boldsymbol{\nabla}$

800.00

B. Full Name (Last, First, Middle Initial)

Gary Lindner

Mailing Address 5016 Prestwick Dr

\begin{tabular}{lcc}
\hline City & State & Zip Code \\
Fairfax & VA & $22030-4523$ \\
\hline
\end{tabular}

FEC ID number of contributing

federal political committee.

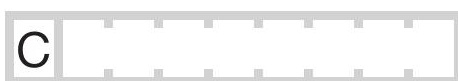

Name of Employer
GW Community School
Receipt For: 2012
X Primary
Other (specify)

Occupation

Teacher

Election Cycle-to-Date

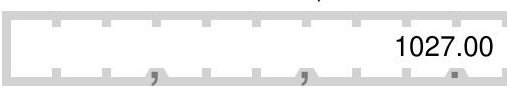

Transaction ID : A2E7BD2EA3E7A4DDAA02

Date of Receipt

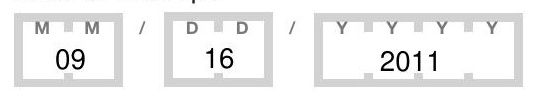

Amount of Each Receipt this Period

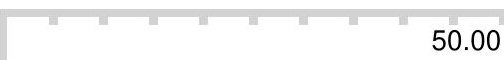

50.00

C. Full Name (Last, First, Middle Initial)

Rick Papandrea

Mailing Address N28W30628 Red Fox Court

\begin{tabular}{lcc}
\hline City & State & Zip Code \\
Pewaukee & WI & $53072-4292$
\end{tabular}

FEC ID number of contributing

federal political committee.

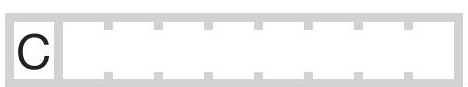

Name of Employer
self
Receipt For: 2012
X Primary $\quad \square$ General
Other (specify)

\section{Occupation}

Doctor

Election Cycle-to-Date

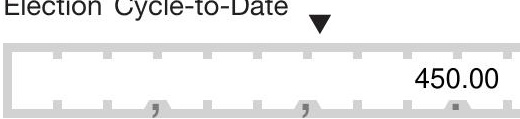

Transaction ID : A80F509E82E444782B00

Date of Receipt

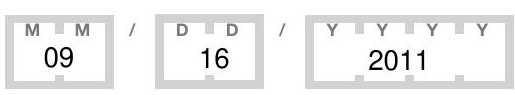

Amount of Each Receipt this Period

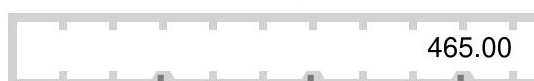

Transaction ID : A471A7A7193CF4511A9A Date of Receipt

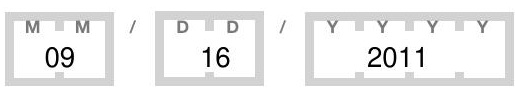

Amount of Each Receipt this Period

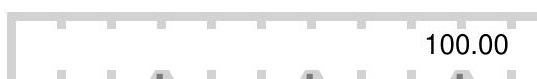

\section{Subtotal Of Receipts This Page (optional)}

615.00

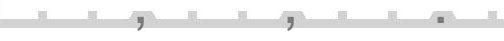

Total This Period (last page this line number only)

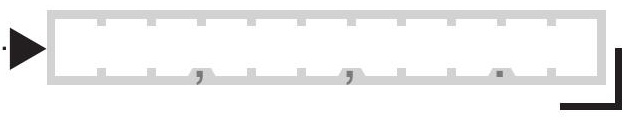

FEC Schedule A-P (Form 3P) (Rev. 03/2011) 
SCHEDULE A-P ITEMIZED RECEIPTS
Use separate schedule(s) for each category of the Detailed Summary Page
FOR LINE NUMBER: (check only one)

PAGE 546 / 1572

\begin{tabular}{|c|c|c|c|c|c|}
\hline & & & & & \\
\hline 16 & $\begin{array}{l}\mathbf{X} \\
17 a\end{array}$ & $17 b$ & $17 c$ & $17 d$ & 18 \\
\hline $19 a$ & $19 \mathrm{~b}$ & $20 \mathrm{a}$ & $20 \mathrm{~b}$ & $20 \mathrm{c}$ & 21 \\
\hline
\end{tabular}

Any information copied from such Reports and Statements may not be sold or used by any person for the purpose of soliciting contributions or for commercial purposes, other than using the name and address of any political committee to solicit contributions from such committee.

NAME OF COMMITTEE (In Full)

\section{Friends of Herman Cain}

A. Full Name (Last, First, Middle Initial)

\section{Sam Spadaro}

Mailing Address 6911 Tradewinds Drive

\begin{tabular}{lcc}
\hline City & State & Zip Code \\
Carlsbad & CA & $92011-3226$
\end{tabular}

FEC ID number of contributing federal political committee.

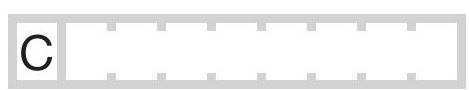

Name of Employer
Unemployed
Receipt For: 2012
X Primary $\quad$ General
Other (specify)

\section{Occupation} project mgr

Election Cycle-to-Date 300.00

B. Full Name (Last, First, Middle Initial) Suzanne Scanlan

Mailing Address 2966 Emory Rd SE

\begin{tabular}{lcc}
\hline City & State & Zip Code \\
Smyrna & GA & $30080-3716$ \\
\hline
\end{tabular}

FEC ID number of contributing

federal political committee.

C

Name of Employer
AP
Receipt For: 2012
Primary
Other (specify)

\section{Occupation} Marketing

Election Cycle-to-Date

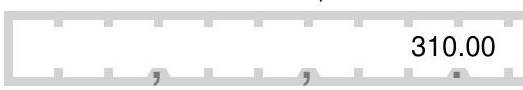

Transaction ID : AEE58498284544BD6ADF

Date of Receipt

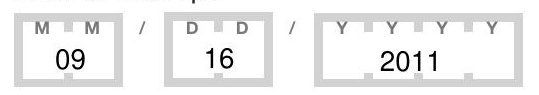

Amount of Each Receipt this Period

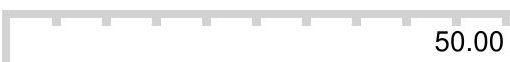

Amount of Each Receipt this Period

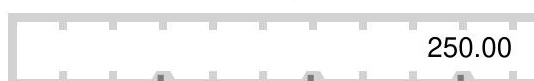

C. Full Name (Last, First, Middle Initial)

Andrew Ramsey

Mailing Address 740 West Main Street

\begin{tabular}{lcc}
\hline City & State & Zip Code \\
Bruceville & IN & $47516-6207$
\end{tabular}

FEC ID number of contributing federal political committee.

C

Name of Employer
Standard Labs
Receipt For: 2012
X Primary
Other (specify) General

\section{Occupation} coalsampler

Election Cycle-to-Date

Transaction ID : AAC515EF317AD446CA60 Date of Receipt

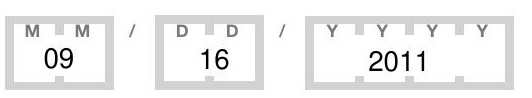

Transaction ID : AED2E62FEE38C44D28A4 Date of Receipt

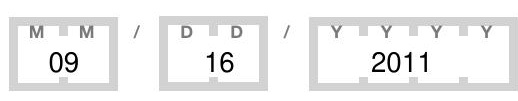

Amount of Each Receipt this Period

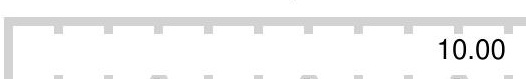

\section{Subtotal Of Receipts This Page (optional)}

Total This Period (last page this line number only) 
SCHEDULE A-P ITEMIZED RECEIPTS
Use separate schedule(s) for each category of the Detailed Summary Page
FOR LINE NUMBER: (check only one)
PAGE 547 / 1572

\begin{tabular}{|c|c|c|c|c|c|}
\hline & & & & & \\
\hline 16 & $\begin{array}{lll}X & 17 a \\
\end{array}$ & $17 \mathrm{~b}$ & $17 c$ & $17 d$ & 18 \\
\hline $19 a$ & $19 b$ & $20 a$ & $20 \mathrm{~b}$ & $20 c$ & 21 \\
\hline
\end{tabular}

Any information copied from such Reports and Statements may not be sold or used by any person for the purpose of soliciting contributions or for commercial purposes, other than using the name and address of any political committee to solicit contributions from such committee.

NAME OF COMMITTEE (In Full)

\section{Friends of Herman Cain}

A. Full Name (Last, First, Middle Initial)

Andrew Ramsey

Mailing Address 740 West Main Street

\begin{tabular}{lcc}
\hline City & State & Zip Code \\
Bruceville & IN & $47516-6207$ \\
\hline
\end{tabular}

FEC ID number of contributing

federal political committee.

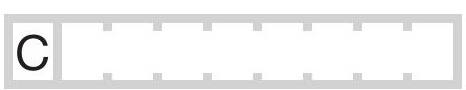

Name of Employer
Standard Labs
Receipt For: 2012
X Primary
Other (specify) General

Occupation coalsampler

Election Cycle-to-Date

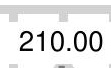

B. Full Name (Last, First, Middle Initial)

Joan Scott

Mailing Address 133 Nail Dr

\begin{tabular}{lcc}
\hline City & State & Zip Code \\
McDonough & GA & $30253-7344$
\end{tabular}

FEC ID number of contributing

federal political committee.

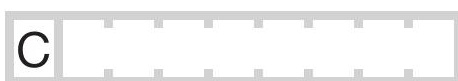

Name of Employer
DOT/FAA
Receipt For: 2012
X Primary
Other (specify)

Occupation

Administrative Assistant

Election Cycle-to-Date

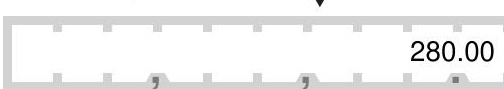

Transaction ID : A90C8E0D21 A204DEEB22

Date of Receipt

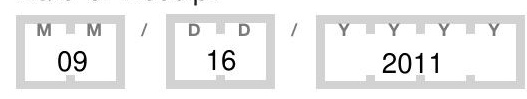

Amount of Each Receipt this Period

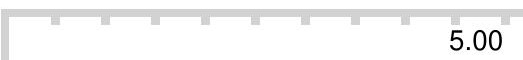

C. Full Name (Last, First, Middle Initial)

MARK LOPEZ

Mailing Address 1830 BREA BLVD \#3

\begin{tabular}{lcc}
\hline City & State & Zip Code \\
Fullerton & CA & $92835-3944$
\end{tabular}

FEC ID number of contributing

federal political committee.

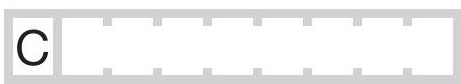

Name of Employer

BECKMAN COULTER INC

Receipt For: 2012

Х $\begin{aligned} & \text { Primary } \square \text { General } \\ & \text { Other (specify) }\end{aligned}$

Occupation

SW Engineer

Election Cycle-to-Date

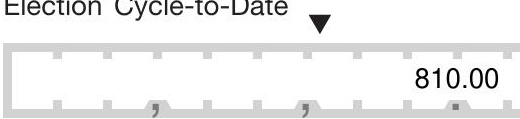

Transaction ID : AE736C7B1DA4B479FB93

Date of Receipt

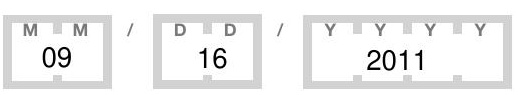

Amount of Each Receipt this Period

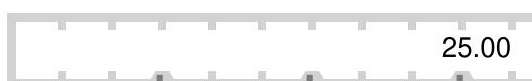

Transaction ID : A4E218E2A495041A0AC6 Date of Receipt

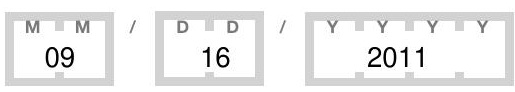

Amount of Each Receipt this Period

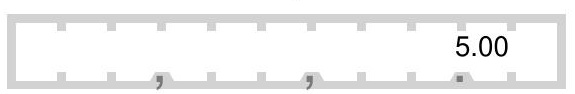

\section{Subtotal Of Receipts This Page (optional)}

35.00

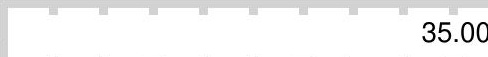

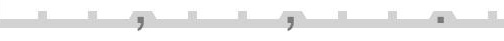

Total This Period (last page this line number only) 
SCHEDULE A-P ITEMIZED RECEIPTS
Use separate schedule(s) for each category of the Detailed Summary Page
FOR LINE NUMBER: (check only one)

PAGE $548 / 1572$

\begin{tabular}{|c|c|c|c|c|c|}
\hline & & & & & \\
\hline 16 & $\begin{array}{l}\mathbf{X} \\
17 a\end{array}$ & $17 b$ & $17 c$ & $17 d$ & 18 \\
\hline $19 a$ & $19 \mathrm{~b}$ & $20 \mathrm{a}$ & $20 \mathrm{~b}$ & $20 \mathrm{c}$ & 21 \\
\hline
\end{tabular}

Any information copied from such Reports and Statements may not be sold or used by any person for the purpose of soliciting contributions or for commercial purposes, other than using the name and address of any political committee to solicit contributions from such committee.

NAME OF COMMITTEE (In Full)

\section{Friends of Herman Cain}

A. Full Name (Last, First, Middle Initial)

Ron Kessner

Mailing Address 856 Mill Stream Road

\begin{tabular}{lcc}
\hline City & State & Zip Code \\
Ponte Vedra Beach & FL & $32082-4147$
\end{tabular}

FEC ID number of contributing

federal political committee.

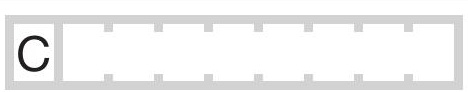

Name of Employer
Information Requested
Receipt For: 2012
X Primary $\quad \square$ General
Other (specify)

Occupation

Information Requested

Election Cycle-to-Date

500.00

B. Full Name (Last, First, Middle Initial)

James Waddle

Mailing Address 711 Arnold Mill Road

\begin{tabular}{lcc}
\hline City & State & Zip Code \\
Woodstock & GA & $30188-3010$ \\
\hline
\end{tabular}

FEC ID number of contributing

federal political committee.

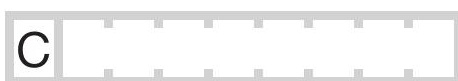

Name of Employer
Chick-Fil-A
Receipt For: 2012
X Primary
Other (specify)

\section{Occupation}

Franchise Owner

Election Cycle-to-Date

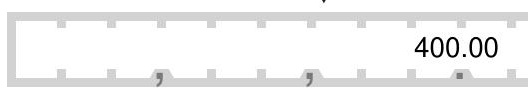

C. Full Name (Last, First, Middle Initial)

John Word

Mailing Address 12426 CR 216

\begin{tabular}{lcc}
\hline City & State & Zip Code \\
Findlay & OH & $45840-9719$
\end{tabular}

FEC ID number of contributing federal political committee.

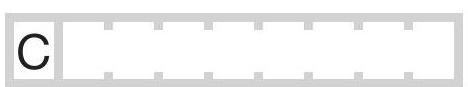

Name of Employer
Information Requested
Receipt For: 2012
X Primary
Other (specify) General

Occupation

Information Requested

Election Cycle-to-Date
Transaction ID : ACB760D5088754BD8842

Date of Receipt

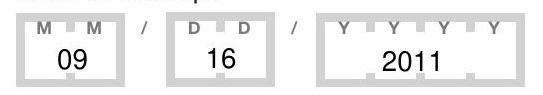

Amount of Each Receipt this Period

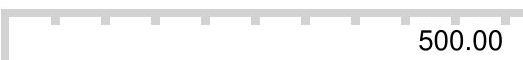

Amount of Each Receipt this Period

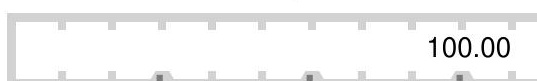

Transaction ID : AFFB2307632EA483FB31

Date of Receipt

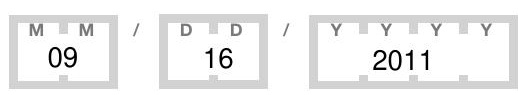

Transaction ID : ACC1248DDCF054B65AA4 Date of Receipt

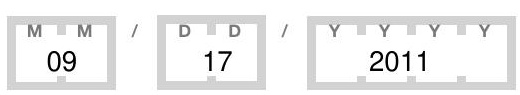

Amount of Each Receipt this Period

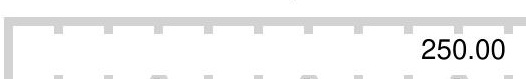

250.00

Subtotal Of Receipts This Page (optional).

850.00

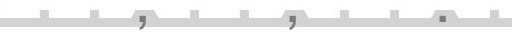

Total This Period (last page this line number only)

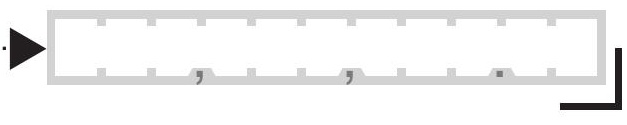

FEC Schedule A-P (Form 3P) (Rev. 03/2011) 
SCHEDULE A-P ITEMIZED RECEIPTS
Use separate schedule(s) for each category of the Detailed Summary Page
FOR LINE NUMBER: (check only one)

PAGE 549 / 1572

\begin{tabular}{|c|c|c|c|c|c|}
\hline & & & & & \\
\hline 16 & $\begin{array}{l}\mathbf{X} \\
17 a\end{array}$ & $17 b$ & $17 c$ & $17 d$ & 18 \\
\hline $19 a$ & $19 \mathrm{~b}$ & $20 \mathrm{a}$ & $20 \mathrm{~b}$ & $20 \mathrm{c}$ & 21 \\
\hline
\end{tabular}

Any information copied from such Reports and Statements may not be sold or used by any person for the purpose of soliciting contributions or for commercial purposes, other than using the name and address of any political committee to solicit contributions from such committee.

NAME OF COMMITTEE (In Full)

\section{Friends of Herman Cain}

A. Full Name (Last, First, Middle Initial)

\section{Carol Cook}

Mailing Address 43 Oak Alley

\begin{tabular}{lcc}
\hline City & State & Zip Code \\
Kerrville & TX & $78028-1711$ \\
\hline
\end{tabular}

FEC ID number of contributing federal political committee.

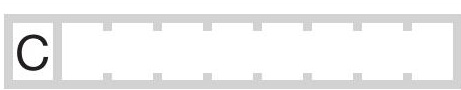

Name of Employer
James Avery
Receipt For: 2012
X Primary
$\square$ Other (specify) General

B. Full Name (Last, First, Middle Initial) Eric Omdahl

Mailing Address 10 Hunt Terrace

\begin{tabular}{lcc}
\hline City & State & Zip Code \\
Greenwich & CT & $06831-4147$
\end{tabular}

FEC ID number of contributing

federal political committee.

C

Name of Employer
Retired
Receipt For: 2012
Primary
Other (specify)

C. Full Name (Last, First, Middle Initial)

Spencer George

Mailing Address 671 Wagonwheel Dr

\begin{tabular}{lcc}
\hline City & State & Zip Code \\
Dayton & OH & $45431-2712$
\end{tabular}

FEC ID number of contributing federal political committee.

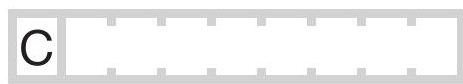

Name of Employer
QbaselT
Receipt For: 2012
X Primary
Other (specify) General

\section{Occupation} Sales Team Leader Election Cycle-to-Date

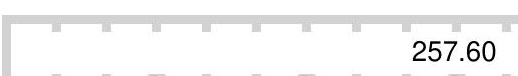

Transaction ID : A5012D7BA6F12467E9C2

Date of Receipt

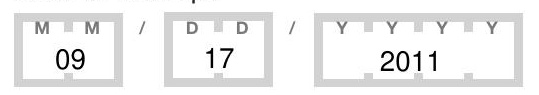

Amount of Each Receipt this Period

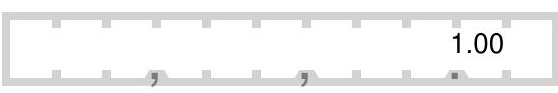

Transaction ID : A5DD6E6B2BFCA4A23A3A Date of Receipt

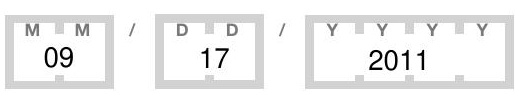

Amount of Each Receipt this Period

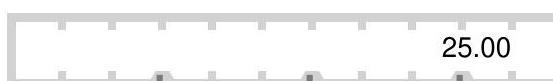

Amount of Each Receipt this Period

Transaction ID : A627AD5CCFB6B4658AB9 Date of Receipt
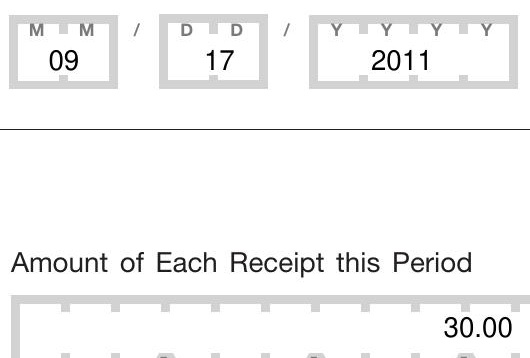

Subtotal Of Receipts This Page (optional).

Total This Period (last page this line number only) 
SCHEDULE A-P ITEMIZED RECEIPTS
Use separate schedule(s) for each category of the Detailed Summary Page
FOR LINE NUMBER: (check only one)

PAGE $550 / 1572$

\begin{tabular}{|c|c|c|c|c|c|}
\hline & & & & & \\
\hline 16 & $\begin{array}{l}\mathbf{X} \\
17 a\end{array}$ & $17 b$ & $17 c$ & $17 d$ & 18 \\
\hline $19 a$ & $19 \mathrm{~b}$ & $20 \mathrm{a}$ & $20 \mathrm{~b}$ & $20 \mathrm{c}$ & 21 \\
\hline
\end{tabular}

Any information copied from such Reports and Statements may not be sold or used by any person for the purpose of soliciting contributions or for commercial purposes, other than using the name and address of any political committee to solicit contributions from such committee.

NAME OF COMMITTEE (In Full)

\section{Friends of Herman Cain}

A. Full Name (Last, First, Middle Initial) Jonathan Joss

Mailing Address 5 Corte Sombrita

\begin{tabular}{lcc}
\hline City & State & Zip Code \\
Orinda & CA & $94563-4305$
\end{tabular}

FEC ID number of contributing federal political committee.

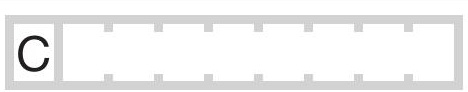

Name of Employer
Fidelity Investments
Receipt For: 2012
X Primary
Other (specify) General

Occupation

Senior Vice President

Election Cycle-to-Date

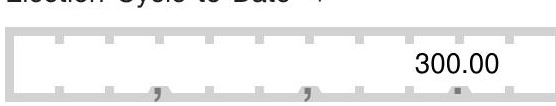

B. Full Name (Last, First, Middle Initial)

Loraine Whitehead

Mailing Address PO Box 218869

\begin{tabular}{lcc}
\hline City & State & Zip Code \\
Houston & TX & $77218-8869$ \\
\hline
\end{tabular}

FEC ID number of contributing

federal political committee.

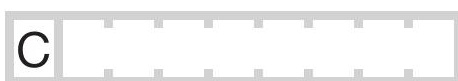

\begin{tabular}{l} 
Name of Employer \\
ConocoPhillips \\
Receipt For: 2012 \\
X Primary $\quad$ General \\
\hline Other (specify)
\end{tabular}

Occupation

Analyst

Election Cycle-to-Date

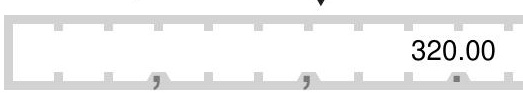

Transaction ID : AF33E187155464467AF1

Date of Receipt

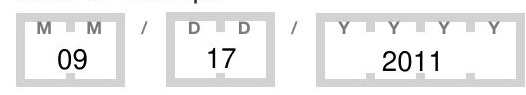

Amount of Each Receipt this Period

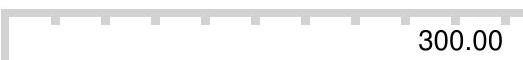

Transaction ID : AD62B3A7CDFE24F35930

Date of Receipt

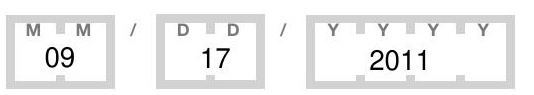

Amount of Each Receipt this Period

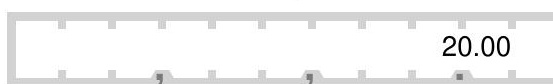

Transaction ID : A4D64153A719A415797E

Date of Receipt

Ted Kirkpatrick

Mailing Address 11434 Huntsman Dr

\begin{tabular}{lcc}
\hline City & State & Zip Code \\
Manassas & VA & $20112-2761$
\end{tabular}

FEC ID number of contributing federal political committee.

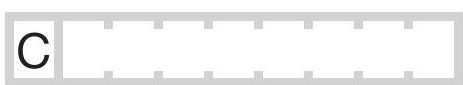

Name of Employer

Ardaiolo Bausman and Associates

Receipt For: 2012

Х $\begin{aligned} & \text { Primary } \\ & \text { Other (specify) }\end{aligned}$

Occupation

Financial Advisor

Election Cycle-to-Date

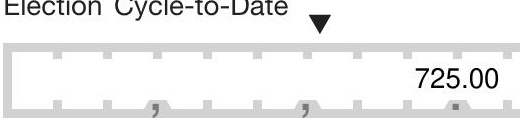

Subtotal Of Receipts This Page (optional)

Amount of Each Receipt this Period

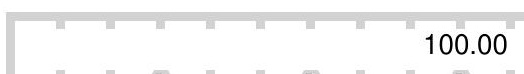

Total This Period (last page this line number only)

420.00

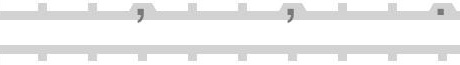

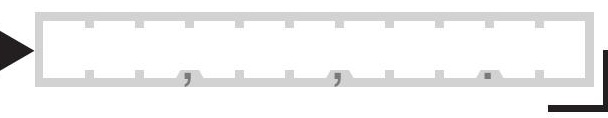

FEC Schedule A-P (Form 3P) (Rev. 03/2011) 
SCHEDULE A-P ITEMIZED RECEIPTS
Use separate schedule(s) for each category of the Detailed Summary Page
FOR LINE NUMBER: (check only one)

\begin{tabular}{|c|c|c|c|c|c|}
\hline & & & & & \\
\hline 16 & $\begin{array}{ll}X & 17 a \\
\end{array}$ & $17 \mathrm{~b}$ & $17 c$ & $17 d$ & 18 \\
\hline $19 a$ & $19 b$ & $20 \mathrm{a}$ & $20 \mathrm{~b}$ & $20 c$ & 21 \\
\hline
\end{tabular}

Any information copied from such Reports and Statements may not be sold or used by any person for the purpose of soliciting contributions or for commercial purposes, other than using the name and address of any political committee to solicit contributions from such committee.

NAME OF COMMITTEE (In Full)

\section{Friends of Herman Cain}

A. Full Name (Last, First, Middle Initial)

Dianne Sula

Mailing Address 6 E. Walker Ave.

\begin{tabular}{lcc}
\hline City & State & Zip Code \\
Temple & TX & $76501-1724$
\end{tabular}

FEC ID number of contributing federal political committee.

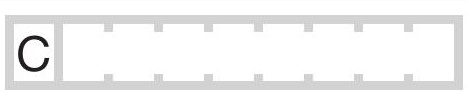

Name of Employer
US Postal Service
Receipt For: 2012
X Primary $\quad$ General
Other (specify)

Occupation mail processor

Election Cycle-to-Date

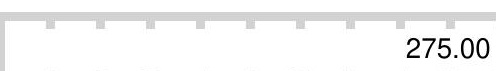

B. Full Name (Last, First, Middle Initial)

Bruce Bowen

Mailing Address 4406 Sarong Dr

\begin{tabular}{lcc}
\hline City & State & Zip Code \\
Houston & TX & $77096-4427$ \\
\hline
\end{tabular}

FEC ID number of contributing

federal political committee.

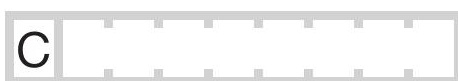

Name of Employer
self
Receipt For: 2012
Primary
Other (specify)

Occupation

Geologist

Election Cycle-to-Date

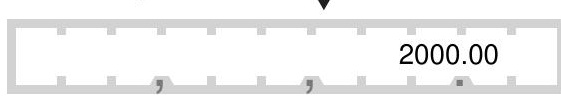

Transaction ID : ABD179BF72CCC4F37AF7

Date of Receipt

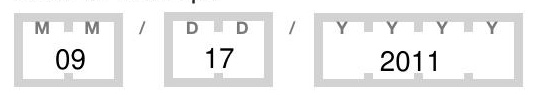

Amount of Each Receipt this Period

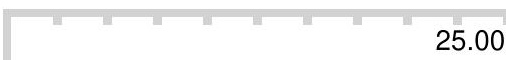

25.00

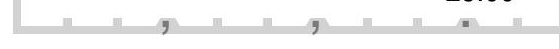

Transaction ID : AB95640E774A145FE9C6

Date of Receipt

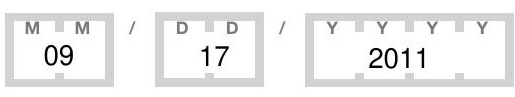

Amount of Each Receipt this Period

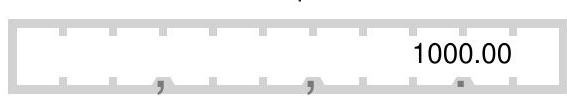

Transaction ID : A2A19B78F797345EB8DD Date of Receipt

Carol Cook

Mailing Address 43 Oak Alley

\begin{tabular}{lcc}
\hline City & State & Zip Code \\
Kerrville & TX & $78028-1711$
\end{tabular}

FEC ID number of contributing federal political committee.

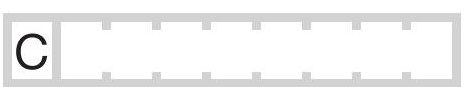

Name of Employer
James Avery
Receipt For: 2012
X Primary
Other (specify) General

\section{Occupation}

Sales Team Leader

Election Cycle-to-Date

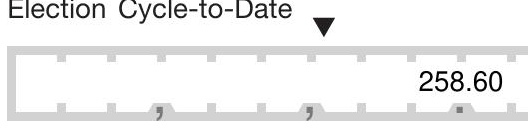

Subtotal Of Receipts This Page (optional)

1026.00

Amount of Each Receipt this Period

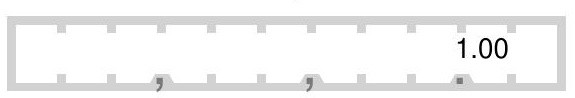

Total This Period (last page this line number only)

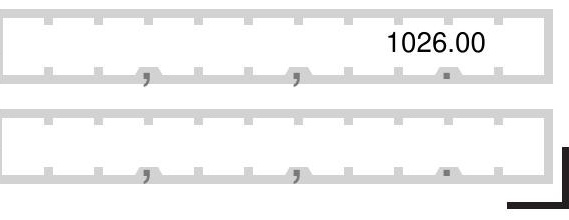


SCHEDULE A-P ITEMIZED RECEIPTS
Use separate schedule(s) for each category of the Detailed Summary Page
FOR LINE NUMBER: (check only one)

PAGE 552 / 1572

\begin{tabular}{|c|c|c|c|c|c|}
\hline & & & & & \\
\hline 16 & $\begin{array}{l}\mathbf{X} \\
17 a\end{array}$ & $17 b$ & $17 c$ & $17 d$ & 18 \\
\hline $19 a$ & $19 \mathrm{~b}$ & $20 \mathrm{a}$ & $20 \mathrm{~b}$ & $20 \mathrm{c}$ & 21 \\
\hline
\end{tabular}

Any information copied from such Reports and Statements may not be sold or used by any person for the purpose of soliciting contributions or for commercial purposes, other than using the name and address of any political committee to solicit contributions from such committee.

NAME OF COMMITTEE (In Full)

\section{Friends of Herman Cain}

A. Full Name (Last, First, Middle Initial)

Rob Buckman

Mailing Address 1961 Waterford Ridge Rd

\begin{tabular}{lcc}
\hline City & State & Zip Code \\
Fort Walton Beach & FL & $32547-7191$
\end{tabular}

FEC ID number of contributing

federal political committee.

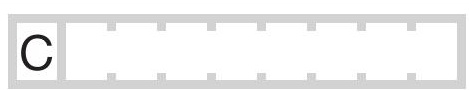

Name of Employer
US Air Force
Receipt For: 2012
X Primary
$\square$ Other (specify) General

Occupation

Information Technology Specialist

Election Cycle-to-Date $\boldsymbol{\nabla}$

250.00

B. Full Name (Last, First, Middle Initial)

Sarah Pellerito

Mailing Address 5555 Wg Robinson Rd.

\begin{tabular}{lcc}
\hline City & State & Zip Code \\
Gainesville & GA & $30506-5434$
\end{tabular}

FEC ID number of contributing

federal political committee.

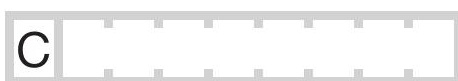

\begin{tabular}{l} 
Name of Employer \\
Information Requested \\
Receipt For: 2012 \\
X Primary \\
\hline Other (specify)
\end{tabular}

Occupation

Information Requested

Election Cycle-to-Date

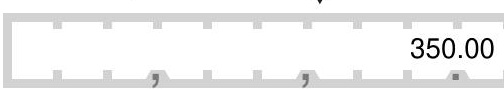

Transaction ID : AD121AC471FF44209987

Date of Receipt

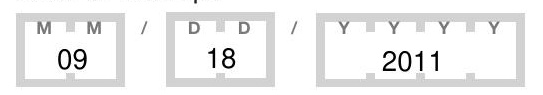

Amount of Each Receipt this Period

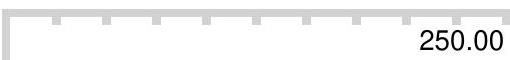

Amount of Each Receipt this Period

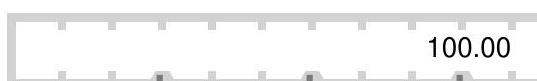

C. Full Name (Last, First, Middle Initial)

Diane Bowen

Mailing Address 732 Bacon St

\begin{tabular}{lcc}
\hline City & State & Zip Code \\
Madison & GA & $30650-1861$
\end{tabular}

FEC ID number of contributing

federal political committee.

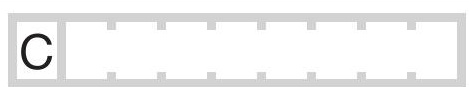

Name of Employer

Occupation

Stone Mtn. Heights

property manager

Receipt For: 2012

Х $\begin{aligned} & \text { Primary } \square \text { General } \\ & \text { Other (specify) }\end{aligned}$

Election Cycle-to-Date

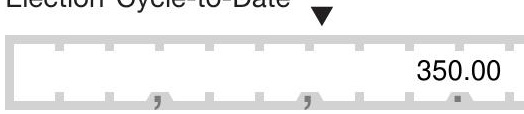

Transaction ID : A7BC0DD7F6AE8491590A

Date of Receipt

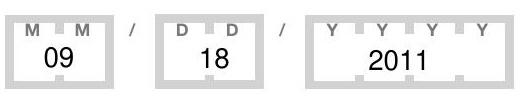

Transaction ID : AB31A81AC1E4846EFBB8 Date of Receipt

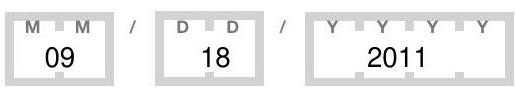

Amount of Each Receipt this Period

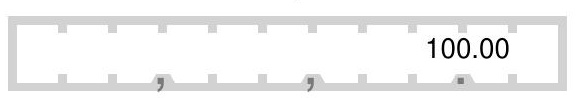

Subtotal Of Receipts This Page (optional).

450.00

Total This Period (last page this line number only) 
SCHEDULE A-P ITEMIZED RECEIPTS
Use separate schedule(s) for each category of the Detailed Summary Page
FOR LINE NUMBER: (check only one)

PAGE $553 / 1572$

\begin{tabular}{|c|c|c|c|c|c|}
\hline & & & & & \\
\hline 16 & $\begin{array}{lll}X & 17 a \\
\end{array}$ & $17 \mathrm{~b}$ & $17 c$ & $17 d$ & 18 \\
\hline $19 a$ & $19 b$ & $20 a$ & $20 \mathrm{~b}$ & $20 c$ & 21 \\
\hline
\end{tabular}

Any information copied from such Reports and Statements may not be sold or used by any person for the purpose of soliciting contributions or for commercial purposes, other than using the name and address of any political committee to solicit contributions from such committee.

NAME OF COMMITTEE (In Full)

\section{Friends of Herman Cain}

A. Full Name (Last, First, Middle Initial) frederick moser

Mailing Address 15421 Brodick Dr

\begin{tabular}{lcc}
\hline City & State & Zip Code \\
Austin & TX & $78717-3923$
\end{tabular}

FEC ID number of contributing federal political committee.

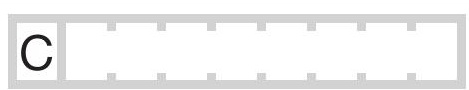

Name of Employer
True World Services
Receipt For: 2012
X Primary $\quad$ General
Other (specify)

Occupation Sales Rep Election Cycle-to-Date

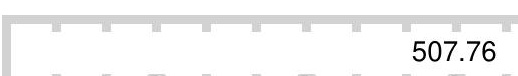

B. Full Name (Last, First, Middle Initial)

Susan Walter

Mailing Address P.O. Box 690

\begin{tabular}{lcc}
\hline City & State & Zip Code \\
Sautee Nacoochee & GA & $30571-0690$ \\
\hline
\end{tabular}

FEC ID number of contributing

federal political committee.

C

Name of Employer
None
Receipt For: 2012
X Primary
Other (specify)

C. Full Name (Last, First, Middle Initial)

Dale McClary

Mailing Address 849 Bypass 72 W

\begin{tabular}{lcc}
\hline City & State & Zip Code \\
Greenwood & SC & $29649-1203$
\end{tabular}

FEC ID number of contributing federal political committee.

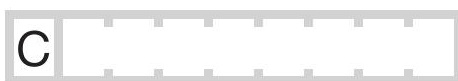

Name of Employer
Information Requested
Receipt For: 2012
X Primary $\quad \square$ General
Other (specify)

\section{Occupation}

Retired

Election Cycle-to-Date

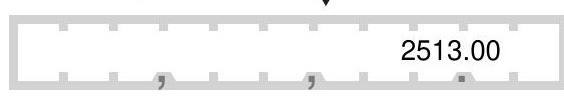

Transaction ID : AA357135E33D34F3FAAA

Date of Receipt

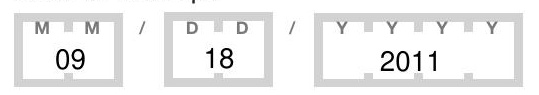

Amount of Each Receipt this Period

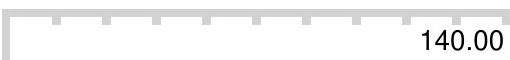

140.00
Transaction ID : AD609BC643EF84845B72

Date of Receipt

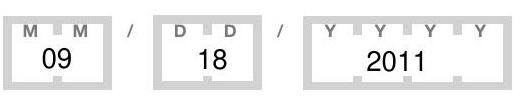

Amount of Each Receipt this Period

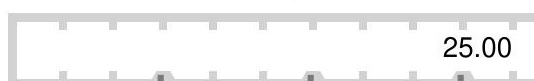

Transaction ID : A504C04FFBA0941F1AF7 Date of Receipt

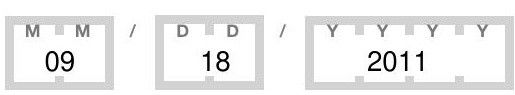

Amount of Each Receipt this Period

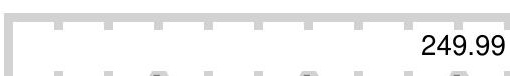

\section{Subtotal Of Receipts This Page (optional)}

Total This Period (last page this line number only) 
SCHEDULE A-P ITEMIZED RECEIPTS
Use separate schedule(s) for each category of the Detailed Summary Page
FOR LINE NUMBER: (check only one)

PAGE 554 / 1572

\begin{tabular}{|c|c|c|c|c|c|}
\hline & & & & & \\
\hline 16 & $\begin{array}{l}\mathbf{X} \\
17 a\end{array}$ & $17 b$ & $17 c$ & $17 d$ & 18 \\
\hline $19 a$ & $19 \mathrm{~b}$ & $20 \mathrm{a}$ & $20 \mathrm{~b}$ & $20 \mathrm{c}$ & 21 \\
\hline
\end{tabular}

Any information copied from such Reports and Statements may not be sold or used by any person for the purpose of soliciting contributions or for commercial purposes, other than using the name and address of any political committee to solicit contributions from such committee.

NAME OF COMMITTEE (In Full)

\section{Friends of Herman Cain}

A. Full Name (Last, First, Middle Initial) claire mencke

Mailing Address 5 tudor city place apt 305

\begin{tabular}{lcc}
\hline City & State & Zip Code \\
New York & NY & $10017-6858$
\end{tabular}

FEC ID number of contributing federal political committee.

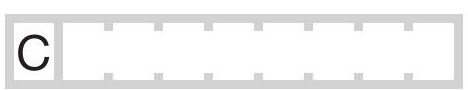

Name of Employer
buckingham research group
Receipt For: 2012
Primary
Other (specify) General

Occupation research assoc

Election Cycle-to-Date

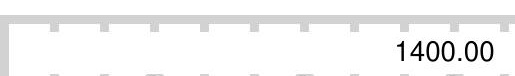

B. Full Name (Last, First, Middle Initial)

Denver Jones

Mailing Address 1271 Owego road

\begin{tabular}{lcc}
\hline City & State & Zip Code \\
Owego & NY & $13827-2532$ \\
\hline
\end{tabular}

FEC ID number of contributing

federal political committee.

C

\begin{tabular}{l} 
Name of Employer \\
Information Requested \\
Receipt For: 2012 \\
X Primary \\
\hline Other (specify)
\end{tabular}

Occupation

Information Requested

Election Cycle-to-Date

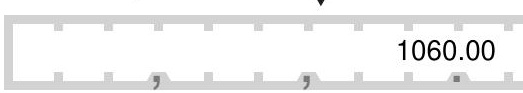

Transaction ID : A3422C6B53454425EBC3

Date of Receipt

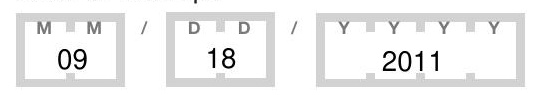

Amount of Each Receipt this Period

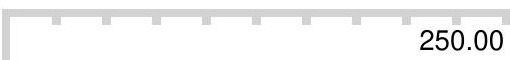

250.00

C. Full Name (Last, First, Middle Initial)

Tim Cunningham

Mailing Address 88 main St

\begin{tabular}{lcc}
\hline City & State & Zip Code \\
Southampton & NY & $11968-4834$
\end{tabular}

FEC ID number of contributing federal political committee.

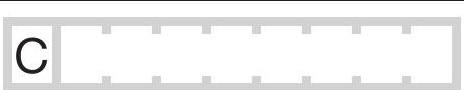

Name of Employer

\section{Occupation}

Cunningham Insurance

Pres.

Receipt For: 2012
Х
$\begin{aligned} & \text { Primary } \\ & \text { Other (specify) }\end{aligned}$

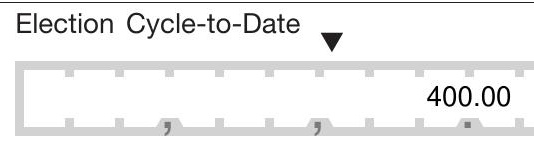

Amount of Each Receipt this Period

Transaction ID : AF014B40238E54FE9926

Date of Receipt
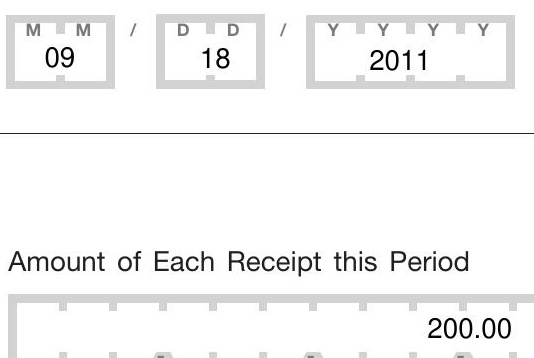

Amount of Each Receipt this Period

Transaction ID : AF019E55A22364D4C803

Date of Receipt
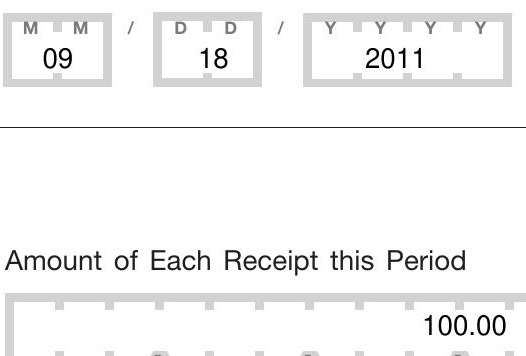

100.00

\section{Subtotal Of Receipts This Page (optional)}

Total This Period (last page this line number only) 
SCHEDULE A-P ITEMIZED RECEIPTS
Use separate schedule(s) for each category of the Detailed Summary Page
FOR LINE NUMBER: (check only one)

PAGE $555 / 1572$

\begin{tabular}{|c|c|c|c|c|c|}
\hline & & & & & \\
\hline 16 & $\begin{array}{l}\mathbf{X} \\
17 a\end{array}$ & $17 b$ & $17 c$ & $17 d$ & 18 \\
\hline $19 a$ & $19 \mathrm{~b}$ & $20 \mathrm{a}$ & $20 \mathrm{~b}$ & $20 \mathrm{c}$ & 21 \\
\hline
\end{tabular}

Any information copied from such Reports and Statements may not be sold or used by any person for the purpose of soliciting contributions or for commercial purposes, other than using the name and address of any political committee to solicit contributions from such committee.

NAME OF COMMITTEE (In Full)

\section{Friends of Herman Cain}

A. Full Name (Last, First, Middle Initial)

\section{Veronica McMahon}

Mailing Address 4 Diane Drive

\begin{tabular}{lcc}
\hline City & State & Zip Code \\
Manorville & NY & $11949-3033$
\end{tabular}

FEC ID number of contributing federal political committee.

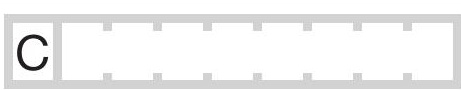

Name of Employer
Information Requested
Receipt For: 2012
X Primary
Other (specify) General

B. Full Name (Last, First, Middle Initial) Lannie Keen

Mailing Address 3673 Stolen Horse Trce

\begin{tabular}{lcc}
\hline City & State & Zip Code \\
Lexington & KY & $40509-2144$ \\
\hline
\end{tabular}

FEC ID number of contributing

federal political committee.

C

Name of Employer
ZeroChaos
Receipt For: 2012
X Primary
Other (specify)

Occupation Information Requested Election Cycle-to-Date 250.00
Transaction ID : AA94ACA7C233B4E7CA3A Date of Receipt

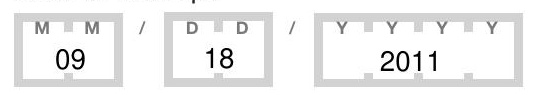

Amount of Each Receipt this Period

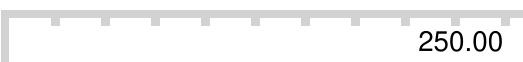

Amount of Each Receipt this Period

\section{Occupation \\ Computer Support}

Election Cycle-to-Date
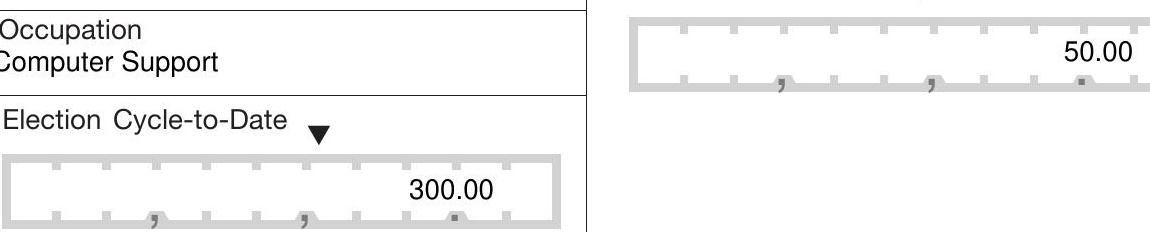

C. Full Name (Last, First, Middle Initial) Joseph Walker

Mailing Address 382 Saint Andrews Fairway

\begin{tabular}{lcc}
\hline City & State & Zip Code \\
Memphis & TN & 38111 \\
\hline
\end{tabular}

FEC ID number of contributing federal political committee.

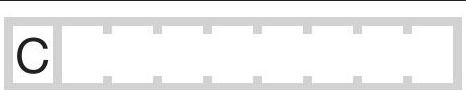

Name of Employer

Adams and Reese, LLC

Receipt For: 2012

Х $\begin{aligned} & \text { Primary } \square \text { General } \\ & \text { Other (specify) }\end{aligned}$

\section{Occupation}

Attorney

Election Cycle-to-Date

Transaction ID : A906DB33859FD4E96BDA Date of Receipt

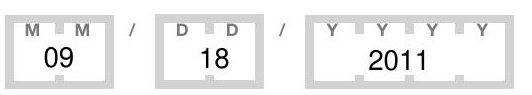

Transaction ID : A89D2B41179EA46BA997 Date of Receipt

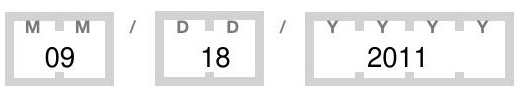

Amount of Each Receipt this Period

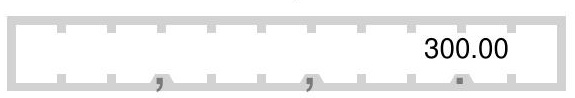

300.00

\section{Subtotal Of Receipts This Page (optional)}

600.00

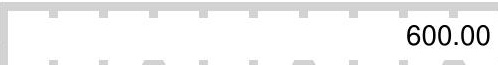

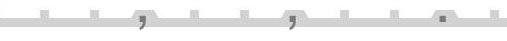

Total This Period (last page this line number only) 
SCHEDULE A-P ITEMIZED RECEIPTS
Use separate schedule(s) for each category of the Detailed Summary Page
FOR LINE NUMBER: (check only one)

PAGE 556 / 1572

\begin{tabular}{|c|c|c|c|c|c|}
\hline & & & & & \\
\hline 16 & $\begin{array}{l}\mathbf{X} \\
17 a\end{array}$ & $17 b$ & $17 c$ & $17 d$ & 18 \\
\hline $19 a$ & $19 \mathrm{~b}$ & $20 \mathrm{a}$ & $20 \mathrm{~b}$ & $20 \mathrm{c}$ & 21 \\
\hline
\end{tabular}

Any information copied from such Reports and Statements may not be sold or used by any person for the purpose of soliciting contributions or for commercial purposes, other than using the name and address of any political committee to solicit contributions from such committee.

NAME OF COMMITTEE (In Full)

\section{Friends of Herman Cain}

A. Full Name (Last, First, Middle Initial)

Mr. Charles Comeau

Mailing Address 220 Laurel Ave

\begin{tabular}{lcc}
\hline City & State & Zip Code \\
Comer & GA & $30629-3454$
\end{tabular}

FEC ID number of contributing federal political committee.

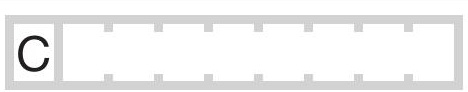

Name of Employer
None
Receipt For: 2012
X Primary $\quad$ General
Other (specify)

Occupation

Retired

Election Cycle-to-Date

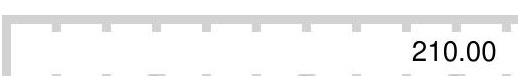

B. Full Name (Last, First, Middle Initial)

Keith Bernstein

Mailing Address 339 Barton Ct. \#4262

\begin{tabular}{lcc}
\hline City & State & Zip Code \\
Stateline & NV & 89449 \\
\hline
\end{tabular}

FEC ID number of contributing

federal political committee.

C

Name of Employer
Information Requested
Receipt For: 2012
X Primary
Other (specify)

Occupation

Information Requested

Election Cycle-to-Date

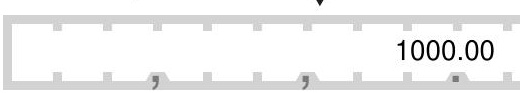

Transaction ID : A033F3329EFD04A5A92A

Date of Receipt

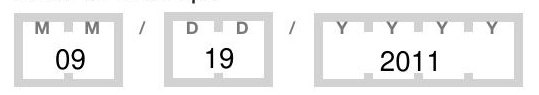

Amount of Each Receipt this Period

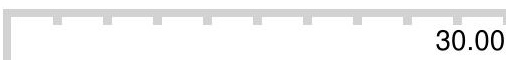

30.00

C. Full Name (Last, First, Middle Initial)

James Clowdus

Mailing Address 375 Country Club Drive

\begin{tabular}{lcc}
\hline City & State & Zip Code \\
Stockbridge & GA & $30281-7351$
\end{tabular}

FEC ID number of contributing

federal political committee.

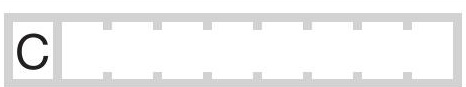

Name of Employer

Information Requested

Occupation

Information Requested

Receipt For: 2012

Х $\begin{aligned} & \text { Primary } \square \text { General } \\ & \text { Other (specify) }\end{aligned}$

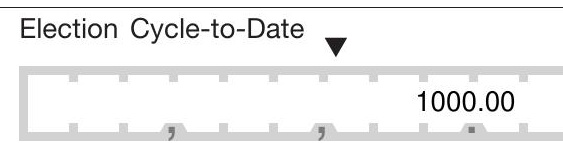

Amount of Each Receipt this Period

Transaction ID : A6808C53DCF8548D99FC

Date of Receipt
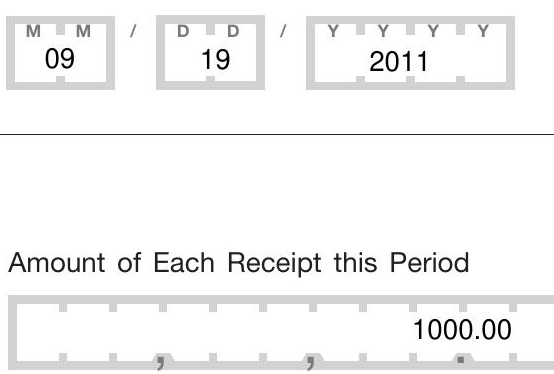

Transaction ID : AC1785A8CA3B24C1FBF7 Date of Receipt

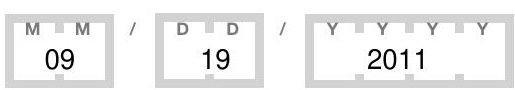

Amount of Each Receipt this Period

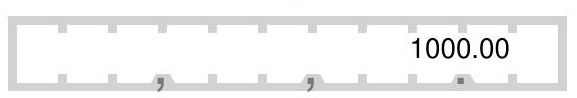

Subtotal Of Receipts This Page (optional)

2030.00

Total This Period (last page this line number only) 
SCHEDULE A-P ITEMIZED RECEIPTS
Use separate schedule(s) for each category of the Detailed Summary Page
FOR LINE NUMBER: (check only one)

PAGE $557 / 1572$

\begin{tabular}{|c|c|c|c|c|c|}
\hline & & & & & \\
\hline 16 & $\begin{array}{l}\mathbf{X} \\
17 a\end{array}$ & $17 b$ & $17 c$ & $17 d$ & 18 \\
\hline $19 a$ & $19 \mathrm{~b}$ & $20 \mathrm{a}$ & $20 \mathrm{~b}$ & $20 \mathrm{c}$ & 21 \\
\hline
\end{tabular}

Any information copied from such Reports and Statements may not be sold or used by any person for the purpose of soliciting contributions or for commercial purposes, other than using the name and address of any political committee to solicit contributions from such committee.

NAME OF COMMITTEE (In Full)

\section{Friends of Herman Cain}

A. Full Name (Last, First, Middle Initial)

hollis curtis

Mailing Address 6314 Carbonton Rd

\begin{tabular}{lcc}
\hline City & State & Zip Code \\
Sanford & NC & $27330-3027$
\end{tabular}

FEC ID number of contributing federal political committee.

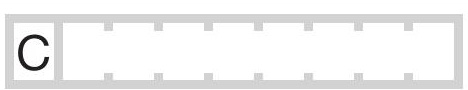

Name of Employer

$\mathrm{h} r$ curtis plumbing contractor

Occupation

plumbing contractor

Receipt For: 2012

X Primary $\square$ General Other (specify)

Election Cycle-to-Date

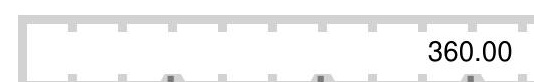

B. Full Name (Last, First, Middle Initial)

Douglas Gesso

Mailing Address 402 Blue Bird Dr

\begin{tabular}{lcc}
\hline City & State & Zip Code \\
Grayson & KY & $41143-8177$ \\
\hline
\end{tabular}

FEC ID number of contributing

federal political committee.

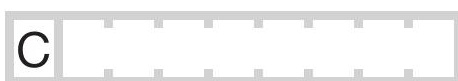

\begin{tabular}{l} 
Name of Employer \\
Unemployed \\
Receipt For: 2012 \\
X Primary \\
\hline Other (specify) General
\end{tabular}

Occupation

Civil Engineer

Election Cycle-to-Date

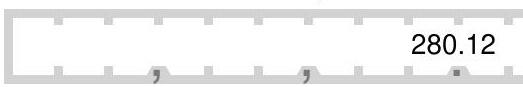

Transaction ID : AODF261C4129D4EAFBFE

Date of Receipt

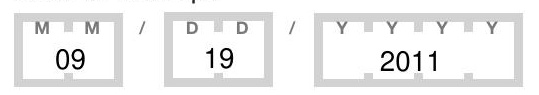

Amount of Each Receipt this Period

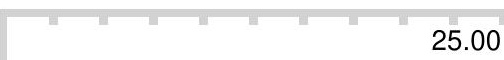

25.00

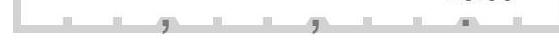

Transaction ID : A85EF5C44FA0540459C4

Date of Receipt

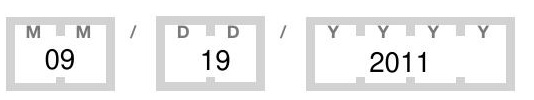

Amount of Each Receipt this Period

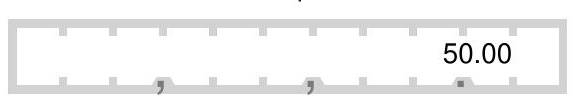

Transaction ID : AFFC69AEFB5C3475E826 Date of Receipt

Michael D White

Mailing Address 4 New Canaan Way

\begin{tabular}{lcc}
\hline City & State & Zip Code \\
Norwalk & CT & $06850-1443$
\end{tabular}

FEC ID number of contributing federal political committee.

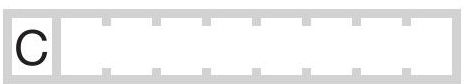

Name of Employer
DirecTv
Receipt For: 2012
Primary
Other (specify) General

Occupation

Businessperson

Election Cycle-to-Date

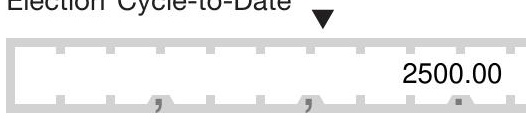

Subtotal Of Receipts This Page (optional).

Amount of Each Receipt this Period

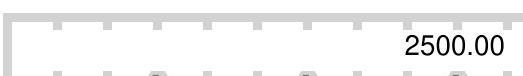

Total This Period (last page this line number only)

2575.00

a

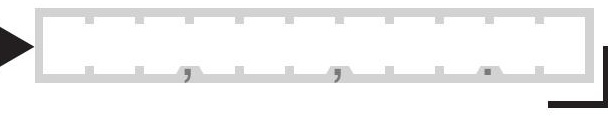

FEC Schedule A-P (Form 3P) (Rev. 03/2011) 
SCHEDULE A-P ITEMIZED RECEIPTS
Use separate schedule(s) for each category of the Detailed Summary Page
FOR LINE NUMBER: (check only one)

PAGE $558 / 1572$

\begin{tabular}{|c|c|c|c|c|c|}
\hline & & & & & \\
\hline 16 & $\begin{array}{l}\mathbf{X} \\
17 a\end{array}$ & $17 b$ & $17 c$ & $17 d$ & 18 \\
\hline $19 a$ & $19 \mathrm{~b}$ & $20 \mathrm{a}$ & $20 \mathrm{~b}$ & $20 \mathrm{c}$ & 21 \\
\hline
\end{tabular}

Any information copied from such Reports and Statements may not be sold or used by any person for the purpose of soliciting contributions or for commercial purposes, other than using the name and address of any political committee to solicit contributions from such committee.

NAME OF COMMITTEE (In Full)

\section{Friends of Herman Cain}

A. Full Name (Last, First, Middle Initial)

\section{Susan Walter}

Mailing Address P.O. Box 690

\begin{tabular}{lcc}
\hline City & State & Zip Code \\
Sautee Nacoochee & GA & $30571-0690$ \\
\hline
\end{tabular}

FEC ID number of contributing federal political committee.

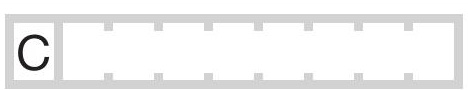

Name of Employer
None
Receipt For: 2012
X Primary $\quad$ General
Other (specify)

Occupation Retired

Election Cycle-to-Date

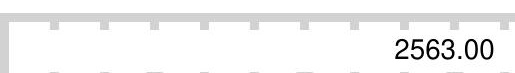

B. Full Name (Last, First, Middle Initial)

Robert Bahre

Mailing Address PO Box 900

\begin{tabular}{lcc}
\hline City & State & Zip Code \\
Alton & $\mathrm{NH}$ & $03809-0900$
\end{tabular}

FEC ID number of contributing

federal political committee.

C

Name of Employer
Speedway, Inc.
Receipt For: 2012
X Primary
Other (specify)

Name of Employer

Speedway, Inc.

$\searrow \begin{aligned} & \text { Primary } \square \text { General } \\ & \text { Other (specify) }\end{aligned}$

C. Full Name (Last, First, Middle Initial)

Mary McCane

Mailing Address 3389 East Fairview Rd.

\section{City}

Stockbridge

FEC ID number of contributing federal political committee.

Name of Employer

Contrary Mary's Greenhouse

Receipt For: 2012

Х $\begin{aligned} & \text { Primary } \square \text { General } \\ & \text { Other (specify) }\end{aligned}$

\section{Occupation}

Owner

\section{Occupation}

Real Estate Developer

Election Cycle-to-Date

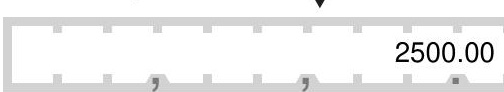

Transaction ID : A5CA8A02F997B4B14879

Date of Receipt

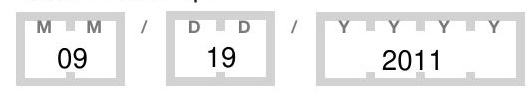

Amount of Each Receipt this Period

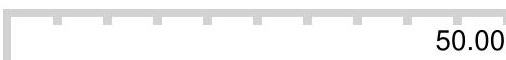

50.00

Transaction ID : AFD62DEA6929645428BC

Date of Receipt

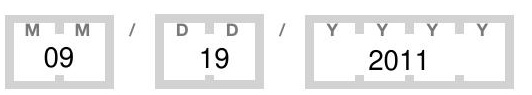

Amount of Each Receipt this Period

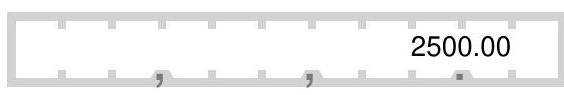

Transaction ID : A406223E612DA458D9E8

Date of Receipt

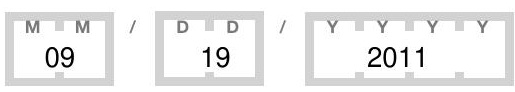

Amount of Each Receipt this Period

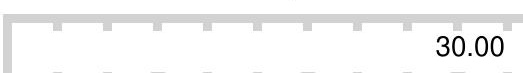

Subtotal Of Receipts This Page (optional)

2580.00

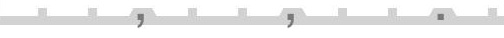

Total This Period (last page this line number only)

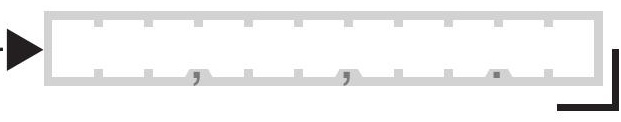

FEC Schedule A-P (Form 3P) (Rev. 03/2011) 
SCHEDULE A-P ITEMIZED RECEIPTS
Use separate schedule(s) for each category of the Detailed Summary Page
FOR LINE NUMBER: (check only one)

PAGE 559 / 1572

\begin{tabular}{|c|c|c|c|c|c|}
\hline & & & & & \\
\hline 16 & $\begin{array}{l}\mathbf{X} \\
17 a\end{array}$ & $17 b$ & $17 c$ & $17 d$ & 18 \\
\hline $19 a$ & $19 \mathrm{~b}$ & $20 \mathrm{a}$ & $20 \mathrm{~b}$ & $20 \mathrm{c}$ & 21 \\
\hline
\end{tabular}

Any information copied from such Reports and Statements may not be sold or used by any person for the purpose of soliciting contributions or for commercial purposes, other than using the name and address of any political committee to solicit contributions from such committee.

NAME OF COMMITTEE (In Full)

\section{Friends of Herman Cain}

A. Full Name (Last, First, Middle Initial)

Dennis Ragone

Mailing Address 374 Marsh Landing Way

\begin{tabular}{lcc}
\hline City & State & Zip Code \\
Venice & FL & $34292-5316$
\end{tabular}

FEC ID number of contributing federal political committee.

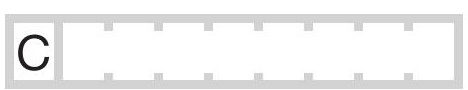

Name of Employer
Retired
Receipt For: 2012
X Primary $\quad$ General
Other (specify)

Occupation Information Requested

Election Cycle-to-Date

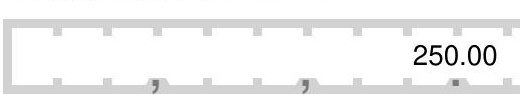

B. Full Name (Last, First, Middle Initial)

\section{Edward Clarke}

Mailing Address 50 Ledge Rd

Apt 127

\begin{tabular}{lcc}
\hline City & State & Zip Code \\
Darien & CT & $06820-4499$
\end{tabular}

FEC ID number of contributing

federal political committee.

C

Name of Employer
None
Receipt For: 2012
X Primary
Other (specify)

\section{Occupation}

Retired

Election Cycle-to-Date

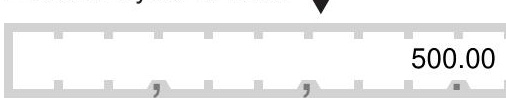

Transaction ID : A0E39DC8600CA4C72AE5

Date of Receipt

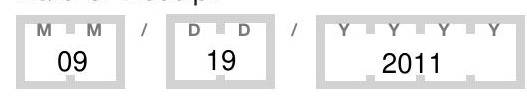

Amount of Each Receipt this Period

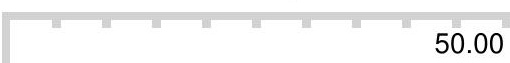

C. Full Name (Last, First, Middle Initial)

K. Scott Malone

Mailing Address 3051 Watson Blvd. Ste. 400

\begin{tabular}{lcc}
\hline City & State & Zip Code \\
Warner Robins & GA & $31093-8556$
\end{tabular}

FEC ID number of contributing federal political committee.

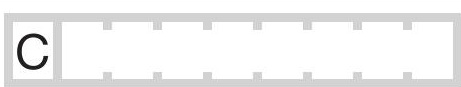

Name of Employer

Information Requested

\section{Occupation}

Information Requested

Receipt For: 2012

Х $\begin{aligned} & \text { Primary } \square \text { General } \\ & \text { Other (specify) }\end{aligned}$

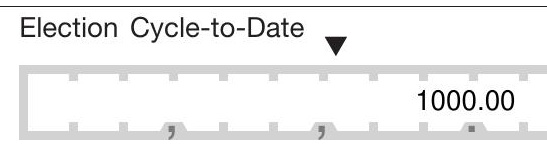

Amount of Each Receipt this Period

Transaction ID : AAA58BFE11B2D49A8A59 Date of Receipt
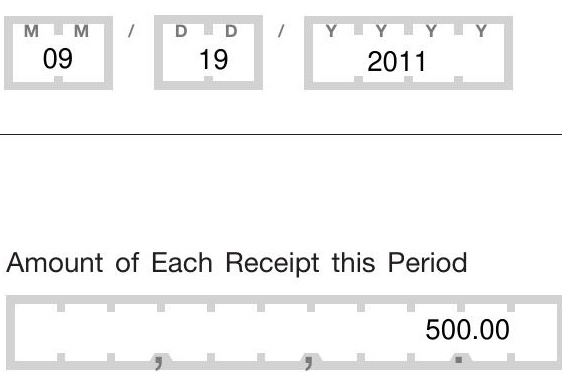

Transaction ID : A17C63167C987418494C Date of Receipt

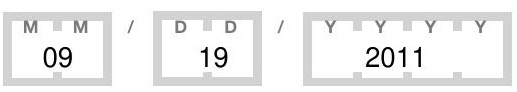

Amount of Each Receipt this Period

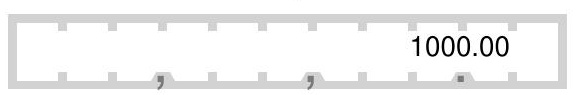

\section{Subtotal Of Receipts This Page (optional)}

Total This Period (last page this line number only) 
SCHEDULE A-P ITEMIZED RECEIPTS
Use separate schedule(s) for each category of the Detailed Summary Page

FOR LINE NUMBER:
(check only one)

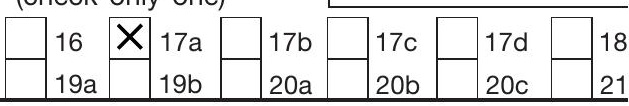

Any information copied from such Reports and Statements may not be sold or used by any person for the purpose of soliciting contributions or for commercial purposes, other than using the name and address of any political committee to solicit contributions from such committee.

NAME OF COMMITTEE (In Full)

\section{Friends of Herman Cain}

A. Full Name (Last, First, Middle Initial) Leigh Steele

Mailing Address 617 Magnolia Lane

\begin{tabular}{lcc}
\hline City & State & Zip Code \\
Peachtree City & GA & $30269-1151$ \\
\hline
\end{tabular}

FEC ID number of contributing federal political committee.

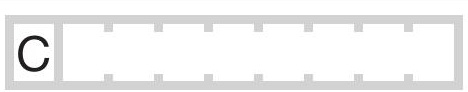

Name of Employer
Information Requested
Receipt For: 2012
X Primary
$\square$ Other (specify)

Occupation Information Requested Election Cycle-to-Date 500.00

B. Full Name (Last, First, Middle Initial) Robert Efferth

Mailing Address 355 Sable Court

\begin{tabular}{lcc}
\hline City & State & Zip Code \\
Alpharetta & GA & $30004-8011$
\end{tabular}

FEC ID number of contributing

federal political committee.

C

Name of Employer
Dell Inc.
Receipt For: 2012
X Primary
Other (specify)

Occupation

Sales Executive

Election Cycle-to-Date

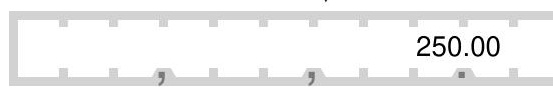

Transaction ID : A365ED2C7966C46E4BD3

Date of Receipt

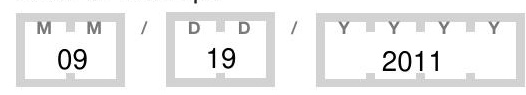

Amount of Each Receipt this Period

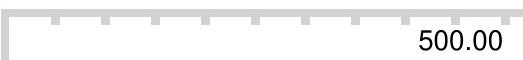

C. Full Name (Last, First, Middle Initial)

David Bryant

Mailing Address 2265 Sussex Court

\begin{tabular}{lcc}
\hline City & State & Zip Code \\
Snellville & GA & $30078-3120$
\end{tabular}

FEC ID number of contributing federal political committee.

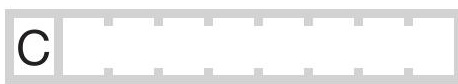

Name of Employer
Information Requested
Receipt For: 2012
X Primary $\quad \square$ General
Other (specify)

\section{Occupation}

Information Requested

Election Cycle-to-Date
Transaction ID : AFA17EA05CC1F4298987

Date of Receipt

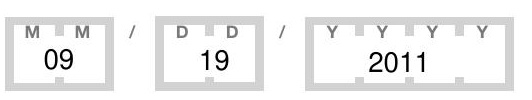

Amount of Each Receipt this Period

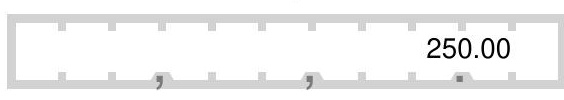

Transaction ID : A29B76911E89F499CB76 Date of Receipt

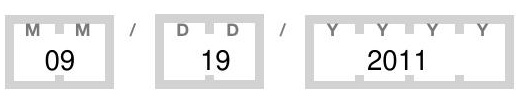

Amount of Each Receipt this Period

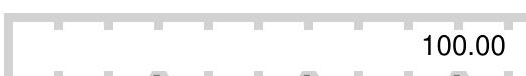

525.00

\section{Subtotal Of Receipts This Page (optional)}

Total This Period (last page this line number only) 
SCHEDULE A-P ITEMIZED RECEIPTS
Use separate schedule(s) for each category of the Detailed Summary Page
FOR LINE NUMBER: (check only one)

PAGE $561 / 1572$

\begin{tabular}{|c|c|c|c|c|c|c|}
\hline & & & & & & \\
\hline 16 & $\lambda$ & $17 \mathrm{a}$ & $17 \mathrm{~b}$ & $17 \mathrm{c}$ & $-17 d$ & -18 \\
\hline $19 a$ & & $19 b$ & $20 a$ & $20 \mathrm{~b}$ & $20 \mathrm{c}$ & 21 \\
\hline
\end{tabular}

Any information copied from such Reports and Statements may not be sold or used by any person for the purpose of soliciting contributions or for commercial purposes, other than using the name and address of any political committee to solicit contributions from such committee.

NAME OF COMMITTEE (In Full)

\section{Friends of Herman Cain}

A. Full Name (Last, First, Middle Initial) thomas mims

Mailing Address 1655 Banks St

\begin{tabular}{lcc}
\hline City & State & Zip Code \\
Houston & TX & $77006-6021$
\end{tabular}

FEC ID number of contributing federal political committee.

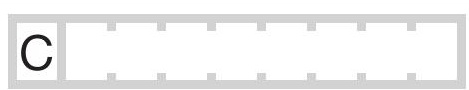

Name of Employer
Self Employed
Receipt For: 2012
X Primary $\quad$ General
Other (specify)

Occupation Physician Election Cycle-to-Date

B. Full Name (Last, First, Middle Initial)

Ms Gail M Gilliland

Mailing Address 132 Julia Chambers Dr

\begin{tabular}{lcc}
\hline City & State & Zip Code \\
Jacksonville & AR & $72076-8185$
\end{tabular}

FEC ID number of contributing

federal political committee.

C

Name of Employer
None
Receipt For: 2012
X Primary
Other (specify)

\section{Occupation}

Retired

Election Cycle-to-Date

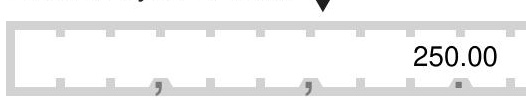

Transaction ID : AA82F6F19AF8144C4802

Date of Receipt

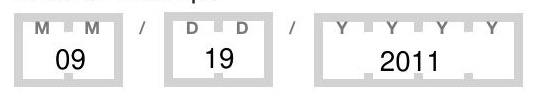

Amount of Each Receipt this Period

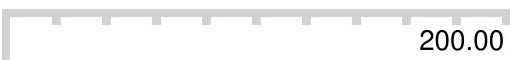

200.00

C. Full Name (Last, First, Middle Initial)

Jesus Rancano

Mailing Address 4419 Timber Ridge Drive

\begin{tabular}{lcc}
\hline City & State & Zip Code \\
Douglasville & GA & $30135-1218$
\end{tabular}

FEC ID number of contributing federal political committee.

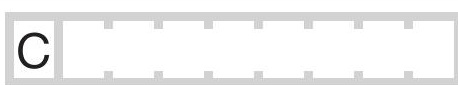

Name of Employer
Atlantic Southeast Airlines
Receipt For: 2012
X Primary
Other (specify) General

\section{Occupation}

Pilot

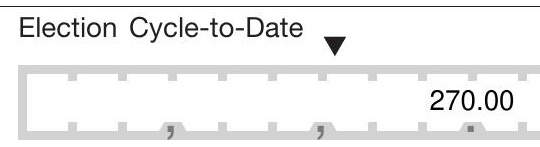

Transaction ID : ADF69BE48C8C844BBA81 Date of Receipt

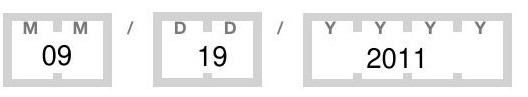

Amount of Each Receipt this Period

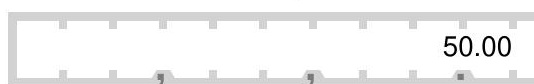

Transaction ID : A53269277A2FF421FA01

Date of Receipt

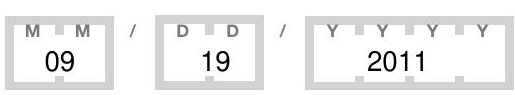

Amount of Each Receipt this Period

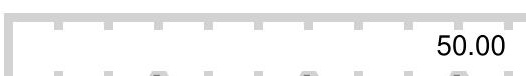

\section{Subtotal Of Receipts This Page (optional)}

Total This Period (last page this line number only) 
SCHEDULE A-P ITEMIZED RECEIPTS
Use separate schedule(s) for each category of the Detailed Summary Page
FOR LINE NUMBER: (check only one)

PAGE 562 / 1572

\begin{tabular}{|c|c|c|c|c|c|}
\hline & & & & & \\
\hline 16 & $\begin{array}{l}\mathbf{X} \\
17 a\end{array}$ & $17 b$ & $17 c$ & $17 d$ & 18 \\
\hline $19 a$ & $19 \mathrm{~b}$ & $20 \mathrm{a}$ & $20 \mathrm{~b}$ & $20 \mathrm{c}$ & 21 \\
\hline
\end{tabular}

Any information copied from such Reports and Statements may not be sold or used by any person for the purpose of soliciting contributions or for commercial purposes, other than using the name and address of any political committee to solicit contributions from such committee.

NAME OF COMMITTEE (In Full)

\section{Friends of Herman Cain}

A. Full Name (Last, First, Middle Initial)

\section{Walter Watkins}

Mailing Address 1870 Bridle Ridge Trce

\begin{tabular}{lcc}
\hline City & State & Zip Code \\
Roswell & GA & $30075-2151$
\end{tabular}

FEC ID number of contributing federal political committee.

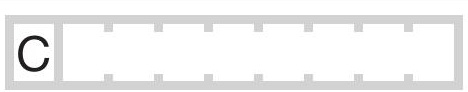

Name of Employer
ApolloMD
Receipt For: 2012
X Primary $\quad$ General
Other (specify)

Occupation Physician Election Cycle-to-Date

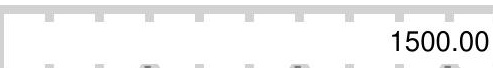

B. Full Name (Last, First, Middle Initial)

Allen Richardson

Mailing Address PO Box 609

\begin{tabular}{lcc}
\hline City & State & Zip Code \\
Warner Robins & GA & $31099-0609$ \\
\hline
\end{tabular}

FEC ID number of contributing

federal political committee.

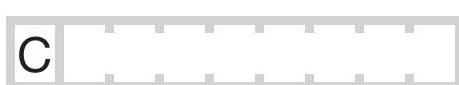

Name of Employer
None
Receipt For: 2012
X Primary
Other (specify)

\section{Occupation}

Retired

Election Cycle-to-Date

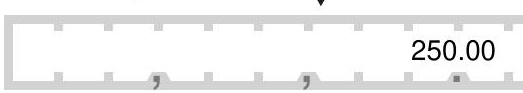

Transaction ID : A85CE169AB9374FE9807

Date of Receipt

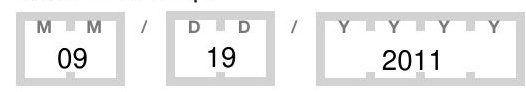

Amount of Each Receipt this Period

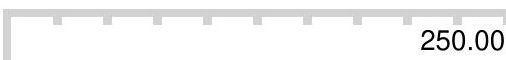

C. Full Name (Last, First, Middle Initial)

Carol Cook

Mailing Address 43 Oak Alley

\begin{tabular}{lcc}
\hline City & State & Zip Code \\
Kerrville & TX & 78028-1711
\end{tabular}

FEC ID number of contributing federal political committee.

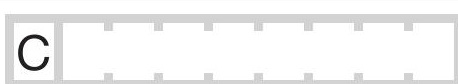

Name of Employer
James Avery
Receipt For: 2012
X Primary
Other (specify) General

\section{Occupation}

Sales Team Leader

Election Cycle-to-Date

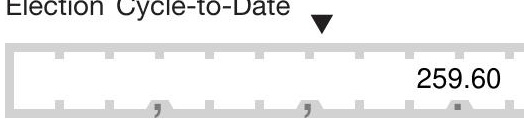

Amount of Each Receipt this Period

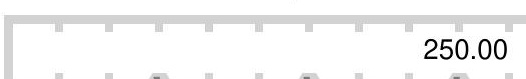

Transaction ID : AFBE2BE8A37EA42198E7

Date of Receipt

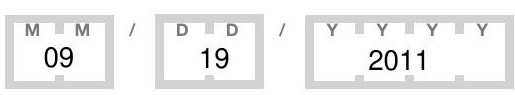

Transaction ID : A9DD92E376C00478A970 Date of Receipt

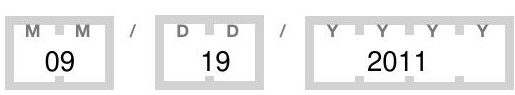

Amount of Each Receipt this Period

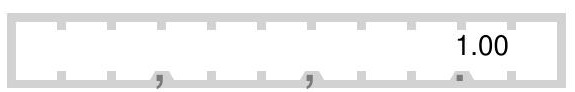

\section{Subtotal Of Receipts This Page (optional)}

501.00

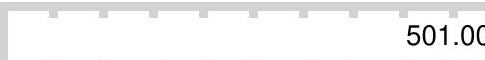

.

Total This Period (last page this line number only)

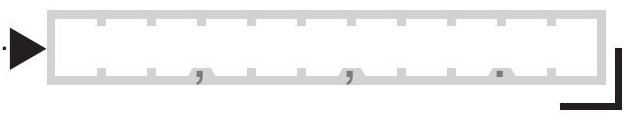

FEC Schedule A-P (Form 3P) (Rev. 03/2011) 
SCHEDULE A-P ITEMIZED RECEIPTS
Use separate schedule(s) for each category of the Detailed Summary Page
FOR LINE NUMBER: (check only one)

PAGE $563 / 1572$

\begin{tabular}{|c|c|c|c|c|c|c|}
\hline & & & & & & \\
\hline 16 & $\lambda$ & $17 \mathrm{a}$ & $17 \mathrm{~b}$ & $17 \mathrm{c}$ & $-17 d$ & -18 \\
\hline $19 a$ & & $19 b$ & $20 a$ & $20 \mathrm{~b}$ & $20 \mathrm{c}$ & 21 \\
\hline
\end{tabular}

Any information copied from such Reports and Statements may not be sold or used by any person for the purpose of soliciting contributions or for commercial purposes, other than using the name and address of any political committee to solicit contributions from such committee.

NAME OF COMMITTEE (In Full)

\section{Friends of Herman Cain}

A. Full Name (Last, First, Middle Initial)

\section{Edward J Phelan}

Mailing Address 1049 Pecan Grive Place

\begin{tabular}{lcc}
\hline City & State & Zip Code \\
Lawrenceville & GA & $30046-5517$
\end{tabular}

FEC ID number of contributing federal political committee.

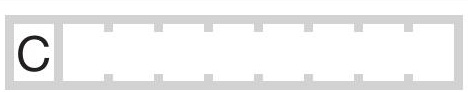

\begin{tabular}{l} 
Name of Employer \\
None \\
Receipt For: 2012 \\
X Primary $\quad$ General \\
\hline Other (specify)
\end{tabular}

Occupation Retired

Election Cycle-to-Date

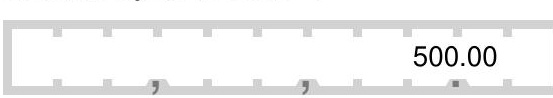

B. Full Name (Last, First, Middle Initial)

lisa nichol

Mailing Address P.O.Box 2778

\begin{tabular}{lcc}
\hline City & State & Zip Code \\
Gainesville & GA & $30503-2778$
\end{tabular}

FEC ID number of contributing

federal political committee.

C

Name of Employer
comprehensive nursing care
Receipt For: 2012
X Primary
Other (specify)

Occupation

President

Election Cycle-to-Date

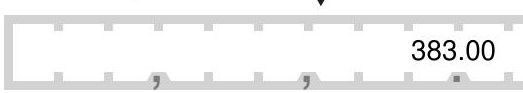

Transaction ID : A2179A0191C964306819

Date of Receipt

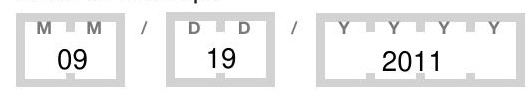

Amount of Each Receipt this Period

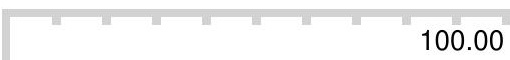

Amount of Each Receipt this Period

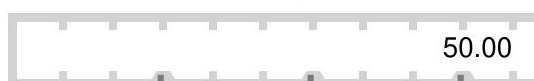

C. Full Name (Last, First, Middle Initial)

Connie Alyea

Mailing Address 2033 Winton Ave

\begin{tabular}{lcc}
\hline City & State & Zip Code \\
Indianapolis & IN & $46224-5627$
\end{tabular}

FEC ID number of contributing federal political committee.

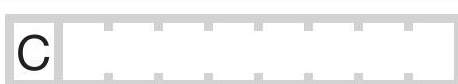

Name of Employer
None
Receipt For: 2012
Х Primary $\quad \square$ General
Other (specify)

\section{Occupation}

Retired

Election Cycle-to-Date

Transaction ID : A46EBC26786B14100ABE Date of Receipt

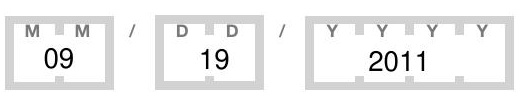

Transaction ID : AC9CF01D454994FCD80A Date of Receipt

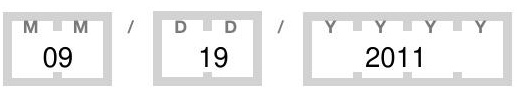

Amount of Each Receipt this Period

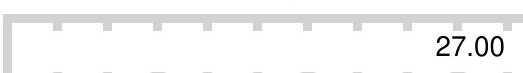

207.00

Subtotal Of Receipts This Page (optional)

177.00

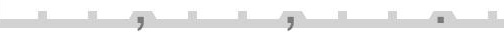

Total This Period (last page this line number only)

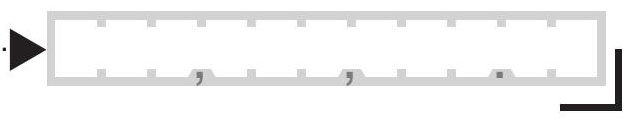

FEC Schedule A-P (Form 3P) (Rev. 03/2011) 
SCHEDULE A-P ITEMIZED RECEIPTS
Use separate schedule(s) for each category of the Detailed Summary Page
FOR LINE NUMBER: (check only one)

PAGE 564 / 1572

\begin{tabular}{|c|c|c|c|c|c|}
\hline & & & & & \\
\hline 16 & $\begin{array}{l}\mathbf{X} \\
17 a\end{array}$ & $17 b$ & $17 c$ & $17 d$ & 18 \\
\hline $19 a$ & $19 \mathrm{~b}$ & $20 \mathrm{a}$ & $20 \mathrm{~b}$ & $20 \mathrm{c}$ & 21 \\
\hline
\end{tabular}

Any information copied from such Reports and Statements may not be sold or used by any person for the purpose of soliciting contributions or for commercial purposes, other than using the name and address of any political committee to solicit contributions from such committee.

NAME OF COMMITTEE (In Full)

\section{Friends of Herman Cain}

A. Full Name (Last, First, Middle Initial)

Earl Bixby

Mailing Address 17335 SE 67th St.

FEC ID number of contributing

federal political committee.

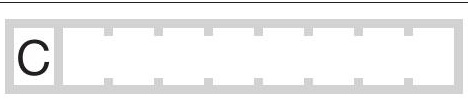

Name of Employer
Retired
Receipt For: 2012
X Primary $\quad$ General
Other (specify)

Occupation

Retired

Election Cycle-to-Date

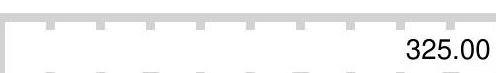

B. Full Name (Last, First, Middle Initial)

john lucas

Mailing Address 105 edgewater ct

\begin{tabular}{lcc}
\hline City & State & Zip Code \\
Warner Robins & GA & $31088-7544$ \\
\hline
\end{tabular}

FEC ID number of contributing

federal political committee.

C

Name of Employer
Information Requested
Receipt For: 2012
X Primary
Other (specify)

\section{Occupation}

Information Requested

Election Cycle-to-Date

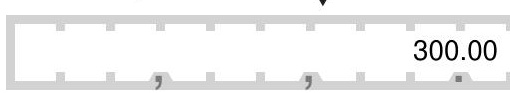

Transaction ID : AE76A6D5BA96046CD940

Date of Receipt

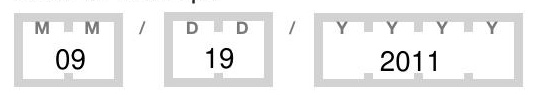

Amount of Each Receipt this Period

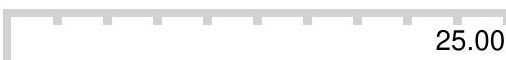

25.00

C. Full Name (Last, First, Middle Initial)

Stephen Ray

Mailing Address 1611 Cameron Landing Drive

\begin{tabular}{lcc}
\hline City & State & Zip Code \\
Stockbridge & GA & $30281-6863$
\end{tabular}

FEC ID number of contributing

federal political committee.

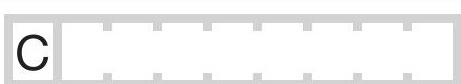

Name of Employer
Delat Air Lines
Receipt For: 2012
X Primary $\quad \square$ General
Other (specify)

Occupation

Maintenance Coodinator

Election Cycle-to-Date
Transaction ID : A94DE50E31F52433FB87

Date of Receipt

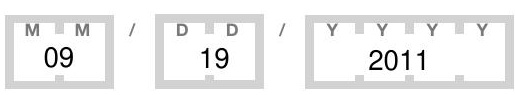

Amount of Each Receipt this Period

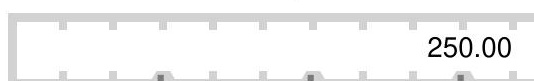

Transaction ID : AF7DCBDC7A0504C52848 Date of Receipt

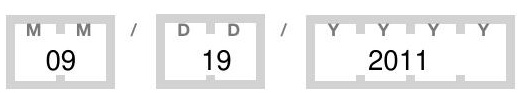

Amount of Each Receipt this Period

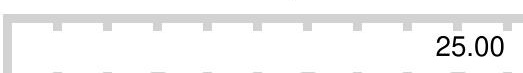

\section{Subtotal Of Receipts This Page (optional)}

Total This Period (last page this line number only) 
SCHEDULE A-P ITEMIZED RECEIPTS
Use separate schedule(s) for each category of the Detailed Summary Page
FOR LINE NUMBER: (check only one)

PAGE $565 / 1572$

\begin{tabular}{|c|c|c|c|c|c|}
\hline & & & & & \\
\hline 16 & $\begin{array}{l}\mathbf{X} \\
17 a\end{array}$ & $17 b$ & $17 c$ & $17 d$ & 18 \\
\hline $19 a$ & $19 \mathrm{~b}$ & $20 \mathrm{a}$ & $20 \mathrm{~b}$ & $20 \mathrm{c}$ & 21 \\
\hline
\end{tabular}

Any information copied from such Reports and Statements may not be sold or used by any person for the purpose of soliciting contributions or for commercial purposes, other than using the name and address of any political committee to solicit contributions from such committee.

NAME OF COMMITTEE (In Full)

\section{Friends of Herman Cain}

A. Full Name (Last, First, Middle Initial)

Paula Spagnuolo

Mailing Address 1909 Shippan Ave

\begin{tabular}{lcc}
\hline City & State & Zip Code \\
Stamford & CT & $06902-8103$
\end{tabular}

FEC ID number of contributing federal political committee.

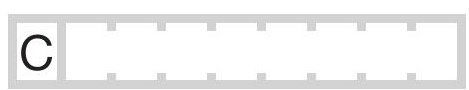

Name of Employer
SP\&G Inc
Receipt For: 2012
X Primary
Other (specify) General

Occupation Graphic Designer

Election Cycle-to-Date

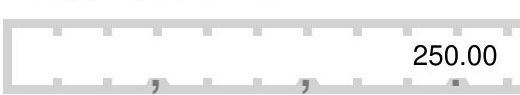

B. Full Name (Last, First, Middle Initial)

Mr Alfred L McCarthy

Mailing Address 9504 Puffin Cir

\begin{tabular}{lcc}
\hline City & State & Zip Code \\
Eagle River & AK & $99577-8636$
\end{tabular}

FEC ID number of contributing

federal political committee.

C

Name of Employer
L\&M Inc.
Receipt For: 2012
Primary
Other (specify)

Occupation

Inspector

Election Cycle-to-Date

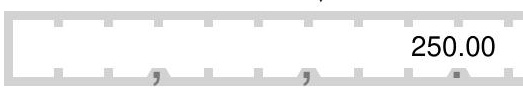

Transaction ID : A8D378D4A6CF04FE5B85

Date of Receipt

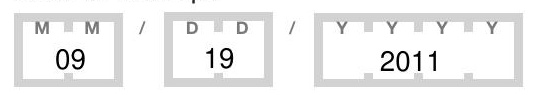

Amount of Each Receipt this Period

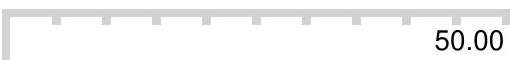

50.00

C. Full Name (Last, First, Middle Initial)

Brian McGean

Mailing Address 3027 General Lee Rd

\begin{tabular}{lcc}
\hline City & State & Zip Code \\
Macon & GA & $31204-1517$
\end{tabular}

FEC ID number of contributing

federal political committee.

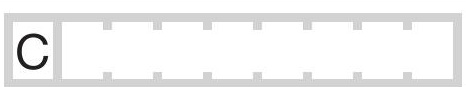

Name of Employer
self emplyed
Receipt For: 2012
X Primary $\square$ General
Other (specify)

Occupation

Psychology

Election Cycle-to-Date

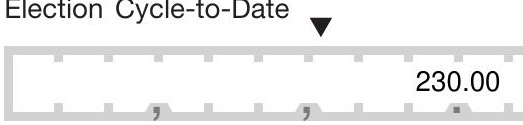

Transaction ID : AD0AB6B747D8E4733AE1

Date of Receipt

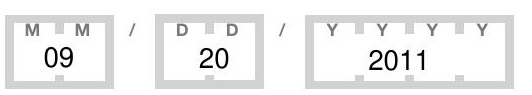

Amount of Each Receipt this Period

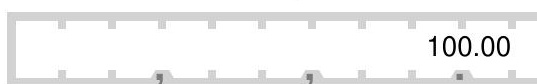

Transaction ID : A53014854BD33422EAD5

Date of Receipt

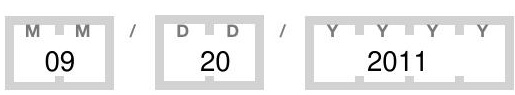

Amount of Each Receipt this Period

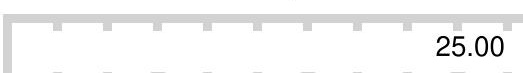

\section{Subtotal Of Receipts This Page (optional)}

175.00

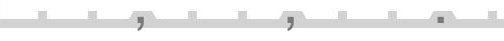

Total This Period (last page this line number only)

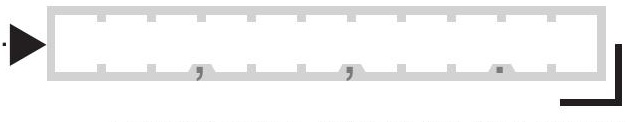

FEC Schedule A-P (Form 3P) (Rev. 03/2011) 
SCHEDULE A-P ITEMIZED RECEIPTS
Use separate schedule(s) for each category of the Detailed Summary Page
FOR LINE NUMBER: (check only one)

PAGE 566 / 1572

\begin{tabular}{|c|c|c|c|c|c|}
\hline & & & & & \\
\hline 16 & $\begin{array}{l}\mathbf{X} \\
17 a\end{array}$ & $17 b$ & $17 c$ & $17 d$ & 18 \\
\hline $19 a$ & $19 \mathrm{~b}$ & $20 \mathrm{a}$ & $20 \mathrm{~b}$ & $20 \mathrm{c}$ & 21 \\
\hline
\end{tabular}

Any information copied from such Reports and Statements may not be sold or used by any person for the purpose of soliciting contributions or for commercial purposes, other than using the name and address of any political committee to solicit contributions from such committee.

NAME OF COMMITTEE (In Full)

\section{Friends of Herman Cain}

A. Full Name (Last, First, Middle Initial)

Kathleen Vadakin

Mailing Address 120 Echo Lane

\begin{tabular}{lcc}
\hline City & State & Zip Code \\
Fairhope & AL & $36532-1432$
\end{tabular}

FEC ID number of contributing federal political committee.

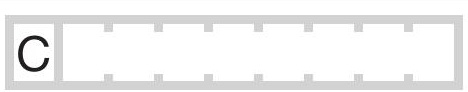

Name of Employer
ReMax/Advantage
Receipt For: 2012
X Primary $\quad$ General
Other (specify)

Occupation Realtor

Election Cycle-to-Date

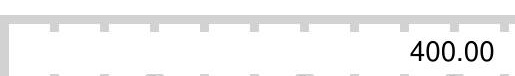

B. Full Name (Last, First, Middle Initial)

Ms Wilma Miller

Mailing Address P. O. Box 434

\begin{tabular}{lcc}
\hline City & State & Zip Code \\
Washington & OK & $73093-0434$ \\
\hline
\end{tabular}

FEC ID number of contributing

federal political committee.

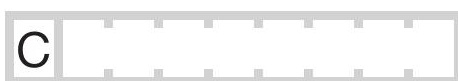

Name of Employer
Kenneth Sturgell
Receipt For: 2012
X Primary
Other (specify)

\section{Occupation}

File Clerk

Election Cycle-to-Date

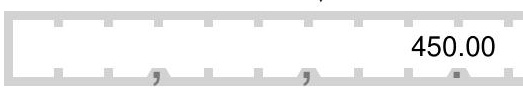

Transaction ID : A957FD9EC74B04EA3B84

Date of Receipt

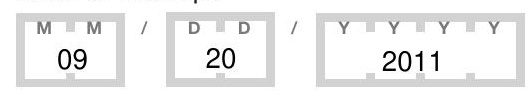

Amount of Each Receipt this Period

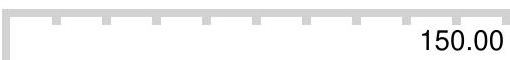

150.00

C. Full Name (Last, First, Middle Initial)

Eric Renz

Mailing Address 514 Huffer Rd.

\begin{tabular}{lcc}
\hline City & State & Zip Code \\
Hilton & NY & $14468-9575$
\end{tabular}

FEC ID number of contributing federal political committee.

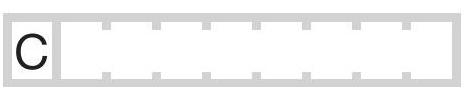

Name of Employer
Retired
Receipt For: 2012
Х Primary $\square$ General
Other (specify)

Occupation

Retired

Election Cycle-to-Date

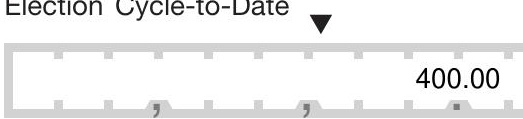

Transaction ID : A831CA8A514114F41BAE Date of Receipt

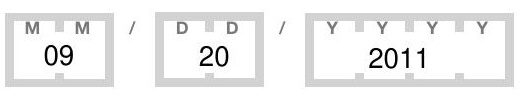

Amount of Each Receipt this Period

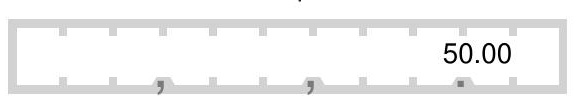

Transaction ID : A999FADBD36D5463086D Date of Receipt

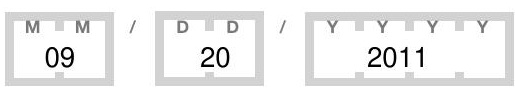

Amount of Each Receipt this Period

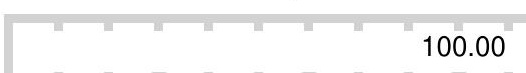

\section{Subtotal Of Receipts This Page (optional)}

Total This Period (last page this line number only) 
SCHEDULE A-P ITEMIZED RECEIPTS
Use separate schedule(s) for each category of the Detailed Summary Page
FOR LINE NUMBER: (check only one)
PAGE 567 / 1572

\begin{tabular}{|c|c|c|c|c|c|}
\hline & & & & & \\
\hline 16 & $\begin{array}{lll}X & 17 a \\
\end{array}$ & $17 \mathrm{~b}$ & $17 c$ & $17 d$ & 18 \\
\hline $19 a$ & $19 b$ & $20 a$ & $20 \mathrm{~b}$ & $20 c$ & 21 \\
\hline
\end{tabular}

Any information copied from such Reports and Statements may not be sold or used by any person for the purpose of soliciting contributions or for commercial purposes, other than using the name and address of any political committee to solicit contributions from such committee.

NAME OF COMMITTEE (In Full)

Friends of Herman Cain

A. Full Name (Last, First, Middle Initial) Linda Carroll

Mailing Address 191 North Bayshore Drive

\begin{tabular}{lcc}
\hline City & State & Zip Code \\
Eastpoint & FL & $32328-3363$ \\
\hline
\end{tabular}

FEC ID number of contributing federal political committee.

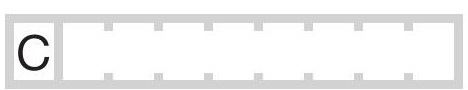

Name of Employer
elf-employed
Receipt For: 2012
X Primary $\quad$ General
Other (specify)

Occupation musician

Election Cycle-to-Date

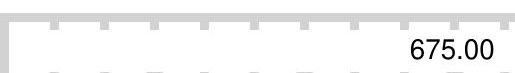

B. Full Name (Last, First, Middle Initial)

Mr James C White

Mailing Address 6223 Costa Lake Pt

\begin{tabular}{lcc}
\hline City & State & Zip Code \\
Flowery Branch & GA & $30542-2588$ \\
\hline
\end{tabular}

FEC ID number of contributing

federal political committee.

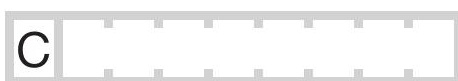

Name of Employer
None
Receipt For: 2012
X Primary $\quad$ General
Other (specify)

Occupation

Retired

Election Cycle-to-Date

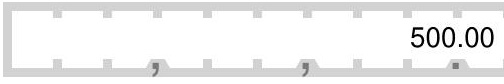

C. Full Name (Last, First, Middle Initial)

Donald Johnston

Mailing Address 6147 West 76th Street

\begin{tabular}{lcc}
\hline City & State & Zip Code \\
Los Angeles & CA & $90045-1637$
\end{tabular}

FEC ID number of contributing federal political committee.

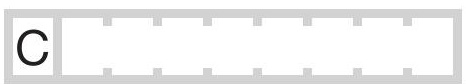

Name of Employer

Information Requested

\section{Occupation}

Information Requested

Receipt For: 2012

Х $\begin{aligned} & \text { Primary } \square \text { General } \\ & \text { Other (specify) }\end{aligned}$

Transaction ID : AD328705BA40B40FC9A0

Date of Receipt

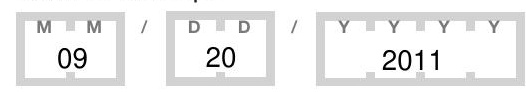

Amount of Each Receipt this Period

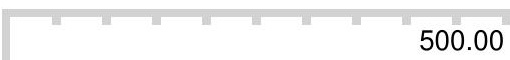

500.00

Transaction ID : A1325B04F520647E5864

Date of Receipt

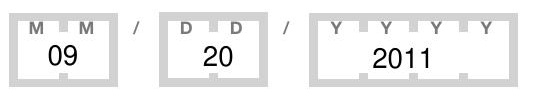

Amount of Each Receipt this Period

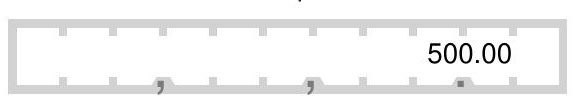

Transaction ID : AC81A592DB5EE4A1E887 Date of Receipt

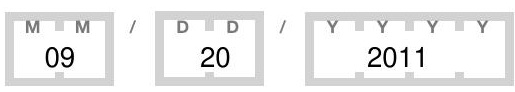

Amount of Each Receipt this Period

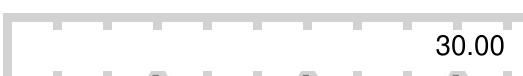

310.00

\section{Subtotal Of Receipts This Page (optional)}

Total This Period (last page this line number only) 
SCHEDULE A-P ITEMIZED RECEIPTS
Use separate schedule(s) for each category of the Detailed Summary Page
FOR LINE NUMBER: (check only one)

PAGE $568 / 1572$

\begin{tabular}{|c|c|c|c|c|c|}
\hline & & & & & \\
\hline 16 & $\begin{array}{l}\mathbf{X} \\
17 a\end{array}$ & $17 b$ & $17 c$ & $17 d$ & 18 \\
\hline $19 a$ & $19 \mathrm{~b}$ & $20 \mathrm{a}$ & $20 \mathrm{~b}$ & $20 \mathrm{c}$ & 21 \\
\hline
\end{tabular}

Any information copied from such Reports and Statements may not be sold or used by any person for the purpose of soliciting contributions or for commercial purposes, other than using the name and address of any political committee to solicit contributions from such committee.

NAME OF COMMITTEE (In Full)

\section{Friends of Herman Cain}

A. Full Name (Last, First, Middle Initial)

Amy E Tjoa

Mailing Address 392 Independence Dr

\begin{tabular}{lcc}
\hline City & State & Zip Code \\
Jefferson City & TN & $37760-3844$ \\
\hline
\end{tabular}

FEC ID number of contributing federal political committee.

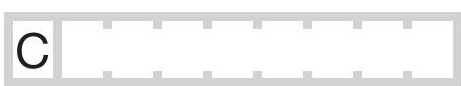

Name of Employer
Not Employed
Receipt For: 2012
X Primary $\quad \square$ General
Other (specify)

\section{Occupation} Not Employed

Election Cycle-to-Date 500.00

B. Full Name (Last, First, Middle Initial)

Debra Gunnoe

\section{Mailing Address PO Box 5057}

\begin{tabular}{lcc}
\hline City & State & Zip Code \\
Navarre & FL & $32566-0057$
\end{tabular}

FEC ID number of contributing

federal political committee.

C

Name of Employer
Information Requested
Receipt For: 2012
X Primary
Other (specify)

\section{Occupation}

Information Requested

Election Cycle-to-Date

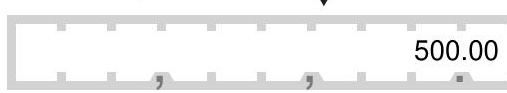

Transaction ID : AC246AA043283448EA72

Date of Receipt

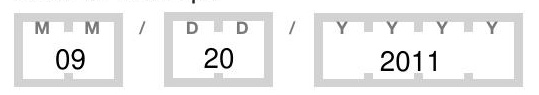

Amount of Each Receipt this Period

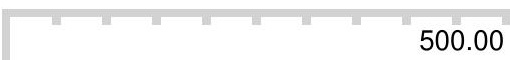

Amount of Each Receipt this Period

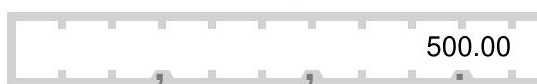

C. Full Name (Last, First, Middle Initial)

Mr Gordon S Hassing

Mailing Address 1 Killdeer Ln

\begin{tabular}{lcc}
\hline City & State & Zip Code \\
Hilton Head Island & SC & $29928-5621$
\end{tabular}

FEC ID number of contributing federal political committee.

C

Name of Employer
Information Requested
Receipt For: 2012
X Primary $\quad \square$ General
Other (specify)

Occupation

Information Requested

Election Cycle-to-Date
Transaction ID : AA030732698C144838A4

Date of Receipt

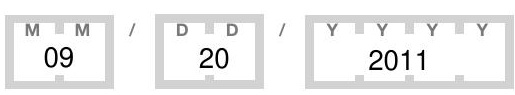

Transaction ID : A1D87AF2D0249401793A Date of Receipt

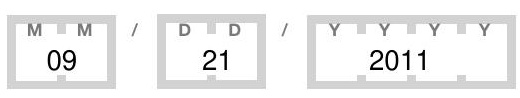

Amount of Each Receipt this Period

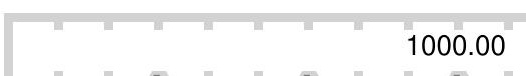

1000.00

\section{Subtotal Of Receipts This Page (optional)}

Total This Period (last page this line number only) 
SCHEDULE A-P ITEMIZED RECEIPTS
Use separate schedule(s) for each category of the Detailed Summary Page
FOR LINE NUMBER: (check only one)

PAGE 569 / 1572

\begin{tabular}{|c|c|c|c|c|c|}
\hline & & & & & \\
\hline 16 & $\begin{array}{l}\mathbf{X} \\
17 a\end{array}$ & $17 b$ & $17 c$ & $17 d$ & 18 \\
\hline $19 a$ & $19 \mathrm{~b}$ & $20 \mathrm{a}$ & $20 \mathrm{~b}$ & $20 \mathrm{c}$ & 21 \\
\hline
\end{tabular}

Any information copied from such Reports and Statements may not be sold or used by any person for the purpose of soliciting contributions or for commercial purposes, other than using the name and address of any political committee to solicit contributions from such committee.

NAME OF COMMITTEE (In Full)

\section{Friends of Herman Cain}

A. Full Name (Last, First, Middle Initial)

\section{Peter Stent}

Mailing Address 170 Josselyn Lane

\begin{tabular}{lcc}
\hline City & State & Zip Code \\
Woodside & CA & $94062-3610$
\end{tabular}

FEC ID number of contributing federal political committee.

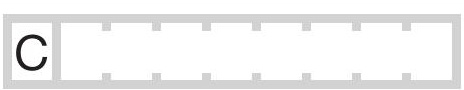

Name of Employer
self
Receipt For: 2012
X Primary $\quad$ General
Other (specify)

B. Full Name (Last, First, Middle Initial)

Deborah Robinson

Mailing Address 1807 Cool Springs Drive

\begin{tabular}{lcc}
\hline City & State & Zip Code \\
Alexandria & VA & $22308-1631$ \\
\hline
\end{tabular}

FEC ID number of contributing

federal political committee.

Name of Employer
None
Receipt For: 2012
X Primary
Other (specify)

C. Full Name (Last, First, Middle Initial)

Philip Stagg

Mailing Address 60017 Longleaf Point

\section{City}

Bogalusa

FEC ID number of contributing

federal political committee.

Name of Employer
First Presbyterian Church
Receipt For: 2012
X Primary
Other (specify) General

Occupation Rancher/Farmer

Election Cycle-to-Date

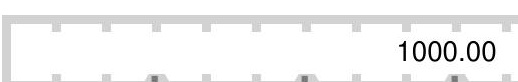

\section{Occupation}

Pastor

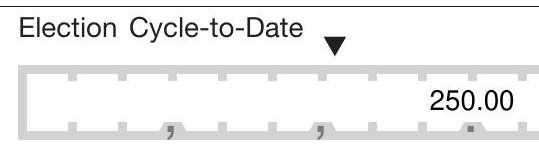

Transaction ID : AB15238D355704885B5B

Date of Receipt

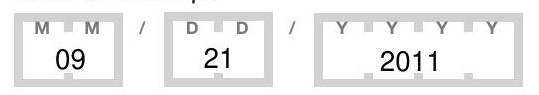

Amount of Each Receipt this Period

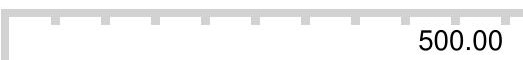

C
Amount of Each Receipt this Period

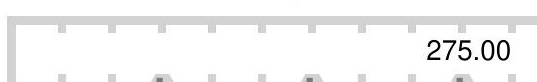

Transaction ID : A4CDB546B6DCA46C4840 Date of Receipt

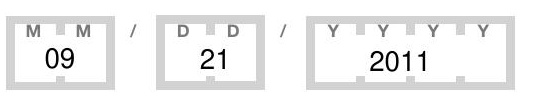

\section{Occupation}

Homemaker

Election Cycle-to-Date

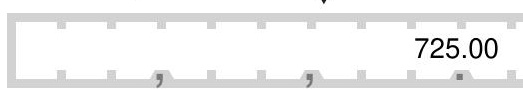

Transaction ID : A26457D3CEBB541B197F Date of Receipt

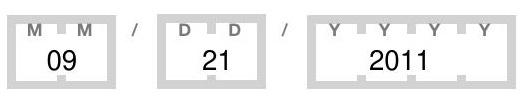

Amount of Each Receipt this Period

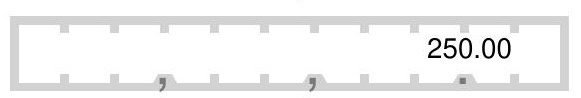

Subtotal Of Receipts This Page (optional).

1025.00

a 1 ,

Total This Period (last page this line number only)

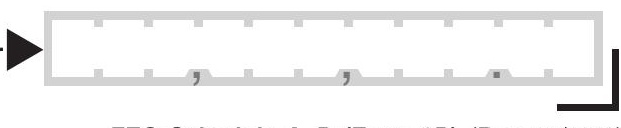

FEC Schedule A-P (Form 3P) (Rev. 03/2011) 
SCHEDULE A-P ITEMIZED RECEIPTS
Use separate schedule(s) for each category of the Detailed Summary Page
FOR LINE NUMBER: (check only one)

PAGE $570 / 1572$

\begin{tabular}{|c|c|c|c|c|c|}
\hline & & & & & \\
\hline 16 & $\begin{array}{l}\mathbf{X} \\
17 a\end{array}$ & $17 b$ & $17 c$ & $17 d$ & 18 \\
\hline $19 a$ & $19 \mathrm{~b}$ & $20 \mathrm{a}$ & $20 \mathrm{~b}$ & $20 \mathrm{c}$ & 21 \\
\hline
\end{tabular}

Any information copied from such Reports and Statements may not be sold or used by any person for the purpose of soliciting contributions or for commercial purposes, other than using the name and address of any political committee to solicit contributions from such committee.

NAME OF COMMITTEE (In Full)

\section{Friends of Herman Cain}

A. Full Name (Last, First, Middle Initial)

Mary Daniel

Mailing Address 131 South End Street

\begin{tabular}{lcc}
\hline City & State & Zip Code \\
Saint Augustine & FL & $32095-6821$
\end{tabular}

FEC ID number of contributing federal political committee.

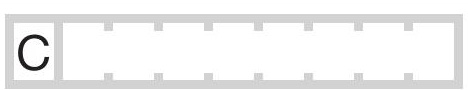

Name of Employer
The Shannon Group
Receipt For: 2012
X Primary
Other (specify) General

Occupation medical management

Election Cycle-to-Date

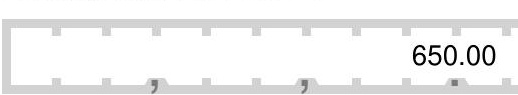

B. Full Name (Last, First, Middle Initial)

Kelly Holloway

Mailing Address 3610 31st Street

\begin{tabular}{lcc}
\hline City & State & Zip Code \\
Lubbock & TX & $79410-2735$ \\
\hline
\end{tabular}

FEC ID number of contributing

federal political committee.

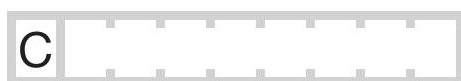

Name of Employer
Hawkeye Road Boring
Receipt For: 2012
X Primary
Other (specify)

\section{Occupation}

Construction

Election Cycle-to-Date

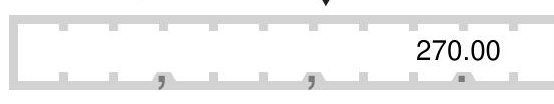

Transaction ID : AE325A3CD6D0F4E6D82C

Date of Receipt

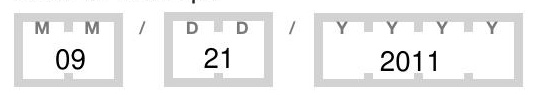

Amount of Each Receipt this Period

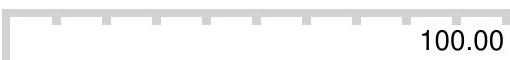

100.00

C. Full Name (Last, First, Middle Initial)

Ms. Deborah Schmalshof

Mailing Address 519 Bill Anderson Rd.

\begin{tabular}{lcc}
\hline City & State & Zip Code \\
Dahlonega & GA & $30533-4045$
\end{tabular}

FEC ID number of contributing federal political committee.

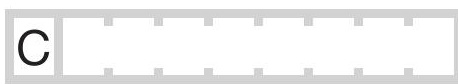

Name of Employer
Information Requested
Receipt For: 2012
X Primary $\quad \square$ General
Other (specify)

\section{Occupation}

Information Requested

Election Cycle-to-Date
Transaction ID : A2E32890C8FD543208B7

Date of Receipt

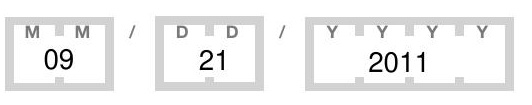

Amount of Each Receipt this Period

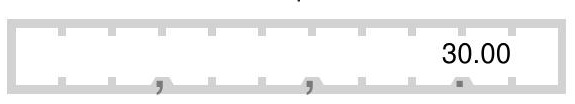

Transaction ID : AAA9860E45AD3477689C Date of Receipt

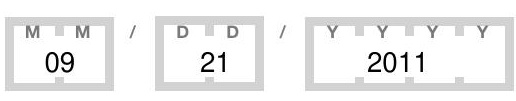

Amount of Each Receipt this Period

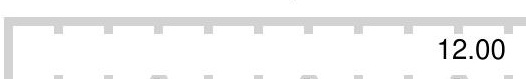

\section{Subtotal Of Receipts This Page (optional)}

Total This Period (last page this line number only) 
SCHEDULE A-P ITEMIZED RECEIPTS
Use separate schedule(s) for each category of the Detailed Summary Page
FOR LINE NUMBER: (check only one)

PAGE $571 / 1572$

\begin{tabular}{|c|c|c|c|c|c|}
\hline & & & & & \\
\hline 16 & $\begin{array}{l}\mathbf{X} \\
17 a\end{array}$ & $17 b$ & $17 c$ & $17 d$ & 18 \\
\hline $19 a$ & $19 \mathrm{~b}$ & $20 \mathrm{a}$ & $20 \mathrm{~b}$ & $20 \mathrm{c}$ & 21 \\
\hline
\end{tabular}

Any information copied from such Reports and Statements may not be sold or used by any person for the purpose of soliciting contributions or for commercial purposes, other than using the name and address of any political committee to solicit contributions from such committee.

NAME OF COMMITTEE (In Full)

\section{Friends of Herman Cain}

A. Full Name (Last, First, Middle Initial)

Daniel Callisto

Mailing Address 152 BROOKFIELD ST

\begin{tabular}{lcc}
\hline City & State & Zip Code \\
Louisville & $\mathrm{OH}$ & $44641-2510$ \\
\hline
\end{tabular}

FEC ID number of contributing federal political committee.

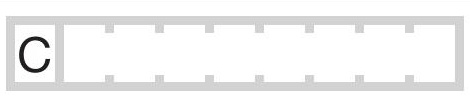

Name of Employer
Self Employed
Receipt For: 2012
X Primary
$\square$ Other (specify) General

Occupation

Physician

Election Cycle-to-Date

715.00

B. Full Name (Last, First, Middle Initial)

Darryl Wright

Mailing Address 18415 N CR 3010

\begin{tabular}{lcc}
\hline City & State & Zip Code \\
Lindsay & OK & $73052-9682$ \\
\hline
\end{tabular}

FEC ID number of contributing

federal political committee.

C

Name of Employer
Newfield Exploration
Receipt For: 2012
Primary
Other (specify)

Occupation

Petroleum Engineer

Election Cycle-to-Date

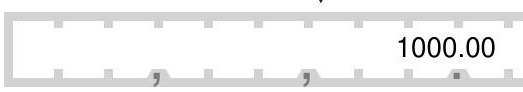

C. Full Name (Last, First, Middle Initial)

Michael Stahl

Mailing Address 443 Verdos $\mathrm{Dr}$

\begin{tabular}{lcc}
\hline City & State & Zip Code \\
Elizabeth & CO & $80107-8544$
\end{tabular}

FEC ID number of contributing federal political committee.

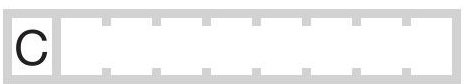

Name of Employer
Whiting Petroleum
Receipt For: 2012
X Primary
Other (specify) General

\section{Occupation}

Engineer

Election Cycle-to-Date

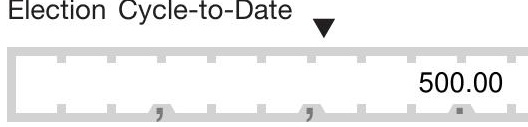

Transaction ID : A73813D2BB9BC4D6AA14

Date of Receipt

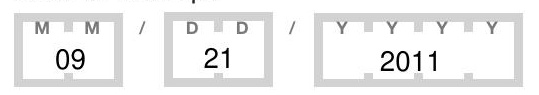

Amount of Each Receipt this Period

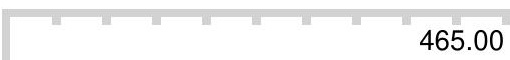

465.00

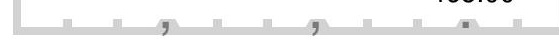

Transaction ID : AA8B102C300D54E46925

Date of Receipt

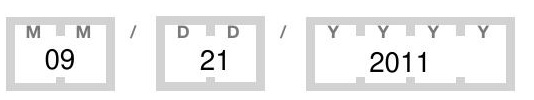

Amount of Each Receipt this Period

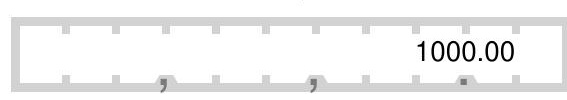

Transaction ID : A5BBA5D456249493B97C Date of Receipt

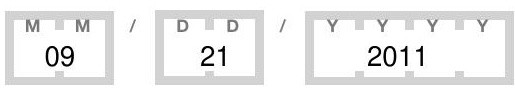

Amount of Each Receipt this Period

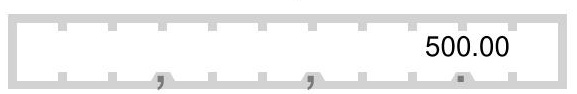

1965.00

가.

Total This Period (last page this line number only) 
SCHEDULE A-P ITEMIZED RECEIPTS
Use separate schedule(s) for each category of the Detailed Summary Page
FOR LINE NUMBER: (check only one)

PAGE 572 / 1572

\begin{tabular}{|c|c|c|c|c|c|}
\hline & & & & & \\
\hline 16 & $\begin{array}{l}\mathbf{X} \\
17 a\end{array}$ & $17 b$ & $17 c$ & $17 d$ & 18 \\
\hline $19 a$ & $19 \mathrm{~b}$ & $20 \mathrm{a}$ & $20 \mathrm{~b}$ & $20 \mathrm{c}$ & 21 \\
\hline
\end{tabular}

Any information copied from such Reports and Statements may not be sold or used by any person for the purpose of soliciting contributions or for commercial purposes, other than using the name and address of any political committee to solicit contributions from such committee.

NAME OF COMMITTEE (In Full)

\section{Friends of Herman Cain}

A. Full Name (Last, First, Middle Initial)

David Kilcy

Mailing Address 119 Maximillian Ct SW

\begin{tabular}{lcc}
\hline City & State & Zip Code \\
Leesburg & VA & $20175-2711$ \\
\hline
\end{tabular}

FEC ID number of contributing federal political committee.

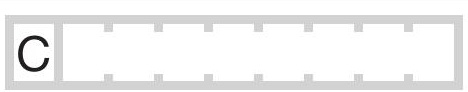

Name of Employer

Transaction Network Services Inc

Occupation

Receipt For: 2012

X Primary $\square$ General Other (specify)

Senior Systems Developer

Election Cycle-to-Date

320.00

B. Full Name (Last, First, Middle Initial)

Basil Kelley

Mailing Address 22025 Airport Rd. NE

\begin{tabular}{lcc}
\hline City & State & Zip Code \\
Tualatin & OR & 97062 \\
\hline
\end{tabular}

FEC ID number of contributing

federal political committee.

C

Name of Employer
Loti Corporation
Receipt For: 2012
X Primary $\quad$ General
Other (specify)

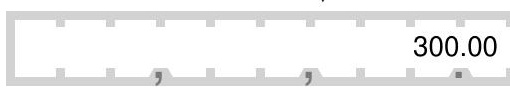

C. Full Name (Last, First, Middle Initial)

Carol Montgomery

Mailing Address 1177 Westmoreland Rd.

\begin{tabular}{lcc}
\hline City & State & Zip Code \\
Cleveland & GA & $30528-5947$
\end{tabular}

FEC ID number of contributing

federal political committee.

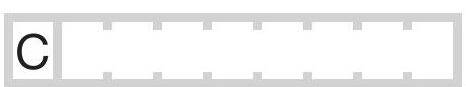

Name of Employer

Yonah Mountain Treasures

Receipt For: 2012

Х $\begin{aligned} & \text { Primary } \square \text { General } \\ & \text { Other (specify) }\end{aligned}$

Occupation

Store Manager

Election Cycle-to-Date

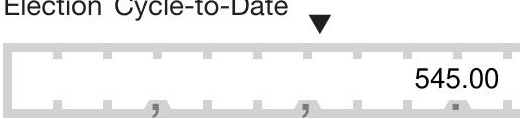

Transaction ID : AA3F4C6EDAE7E4478BE4

Date of Receipt

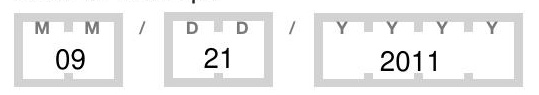

Amount of Each Receipt this Period

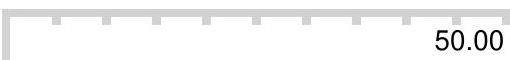

50.00

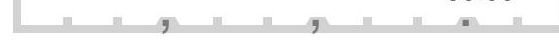

Transaction ID : AF6C5E0E8137A43928A3

Date of Receipt

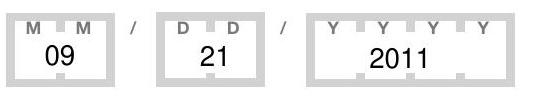

Amount of Each Receipt this Period

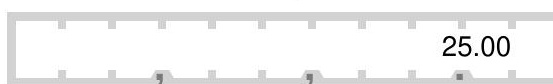

Transaction ID : AC61CBDD478D94835B28 Date of Receipt

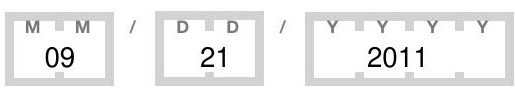

Amount of Each Receipt this Period

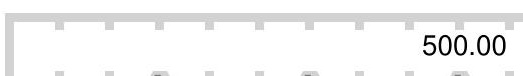

500.00

\section{Subtotal Of Receipts This Page (optional)}

575.00

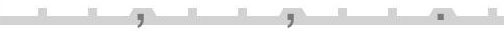

Total This Period (last page this line number only)

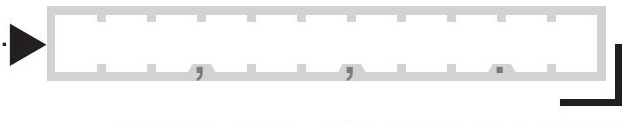

FEC Schedule A-P (Form 3P) (Rev. 03/2011) 
SCHEDULE A-P ITEMIZED RECEIPTS
Use separate schedule(s) for each category of the Detailed Summary Page
FOR LINE NUMBER: (check only one)

PAGE $573 / 1572$

\begin{tabular}{|c|c|c|c|c|c|}
\hline & & & & & \\
\hline 16 & $\begin{array}{l}\mathbf{X} \\
17 a\end{array}$ & $17 b$ & $17 c$ & $17 d$ & 18 \\
\hline $19 a$ & $19 \mathrm{~b}$ & $20 \mathrm{a}$ & $20 \mathrm{~b}$ & $20 \mathrm{c}$ & 21 \\
\hline
\end{tabular}

Any information copied from such Reports and Statements may not be sold or used by any person for the purpose of soliciting contributions or for commercial purposes, other than using the name and address of any political committee to solicit contributions from such committee.

NAME OF COMMITTEE (In Full)

\section{Friends of Herman Cain}

A. Full Name (Last, First, Middle Initial)

Mrs. Jane P Bath

Mailing Address 2430 Snows Mill Rd

\begin{tabular}{lcc}
\hline City & State & Zip Code \\
Bogart & GA & 30622-2713 \\
\hline
\end{tabular}

FEC ID number of contributing federal political committee.

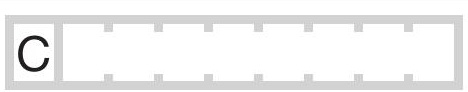

Name of Employer
None
Receipt For: 2012
X Primary $\quad$ General
Other (specify)

Occupation

Retired

Election Cycle-to-Date

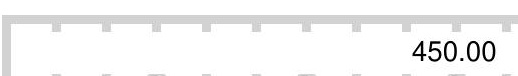

B. Full Name (Last, First, Middle Initial)

Kenneth J. Mosteller

Mailing Address 14900 Black Oak Dr.

\begin{tabular}{lcc}
\hline City & State & Zip Code \\
Wichita & KS & $67230-7602$ \\
\hline
\end{tabular}

FEC ID number of contributing

federal political committee.

C

Name of Employer
Information Requested
Receipt For: 2012
X Primary
Other (specify)

Occupation

Information Requested

Election Cycle-to-Date

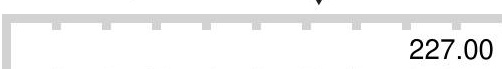

Transaction ID : AC121DA79550B49A38F0

Date of Receipt

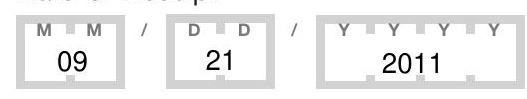

Amount of Each Receipt this Period

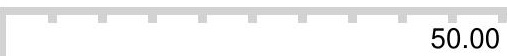

50.00

C. Full Name (Last, First, Middle Initial)

Jeffery Stidham

Mailing Address 121 Winnebago Street

\begin{tabular}{lcc}
\hline City & State & Zip Code \\
Walla Walla & WA & $99362-4451$
\end{tabular}

FEC ID number of contributing federal political committee.

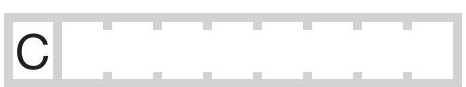

Name of Employer

Information Requested

Occupation

Information Requested

Receipt For: 2012

Х $\begin{aligned} & \text { Primary } \\ & \text { Other (specify) }\end{aligned}$

Election Cycle-to-Date

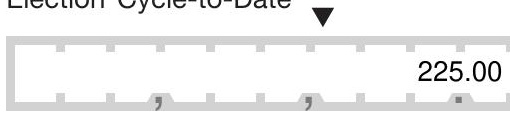

Amount of Each Receipt this Period

Transaction ID : A5FDCA9CAD9DE49BB825 Date of Receipt
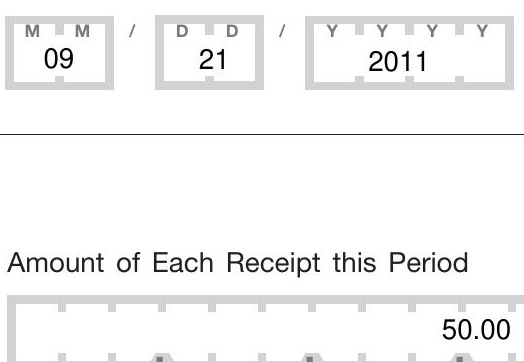

Transaction ID : A3A4900CC197E47C0AA7 Date of Receipt

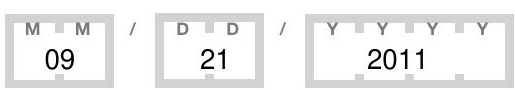

Amount of Each Receipt this Period

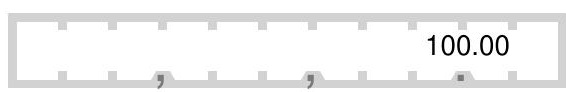

Subtotal Of Receipts This Page (optional)

200.00

Total This Period (last page this line number only) 
SCHEDULE A-P ITEMIZED RECEIPTS
Use separate schedule(s) for each category of the Detailed Summary Page
FOR LINE NUMBER: (check only one)

PAGE 574 / 1572

\begin{tabular}{|c|c|c|c|c|c|}
\hline & & & & & \\
\hline 16 & $\begin{array}{l}\mathbf{X} \\
17 a\end{array}$ & $17 b$ & $17 c$ & $17 d$ & 18 \\
\hline $19 a$ & $19 \mathrm{~b}$ & $20 \mathrm{a}$ & $20 \mathrm{~b}$ & $20 \mathrm{c}$ & 21 \\
\hline
\end{tabular}

Any information copied from such Reports and Statements may not be sold or used by any person for the purpose of soliciting contributions or for commercial purposes, other than using the name and address of any political committee to solicit contributions from such committee.

NAME OF COMMITTEE (In Full)

\section{Friends of Herman Cain}

A. Full Name (Last, First, Middle Initial)

\section{Carol Cook}

Mailing Address 43 Oak Alley

\section{City}

Kerrville

FEC ID number of contributing federal political committee.

Name of Employer
James Avery
Receipt For: 2012
X Primary $\quad \square$ General
Other (specify)

B. Full Name (Last, First, Middle Initial)

Steven Nicoletos

\section{Mailing Address 80 Buckingham Road}

\begin{tabular}{lcc}
\hline City & State & Zip Code \\
Montclair & NJ & $07043-2502$ \\
\hline
\end{tabular}

FEC ID number of contributing

federal political committee.

C

Name of Employer
Information Requested
Receipt For: 2012
X Primary
Other (specify)

\section{Occupation}

Sales Team Leader

Election Cycle-to-Date

Transaction ID : AB9E81FADC3A74BF79FB

Date of Receipt

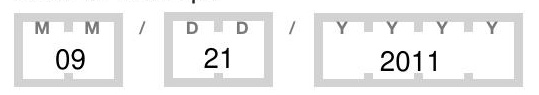

Amount of Each Receipt this Period

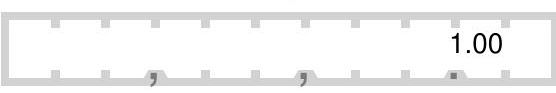

Transaction ID : AD0EF07F3CB6B46FA812 Date of Receipt

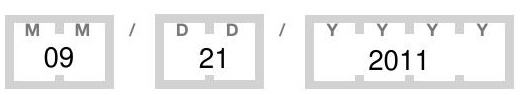

Amount of Each Receipt this Period

Occupation

Information Requested

Election Cycle-to-Date

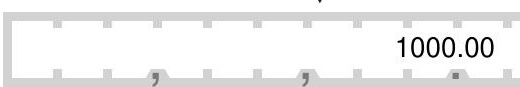

C. Full Name (Last, First, Middle Initial)

Fred D Backer Jr

Mailing Address 18 Narry Ln

\begin{tabular}{lcc}
\hline City & State & Zip Code \\
Mount Morris & NY & $14510-1519$
\end{tabular}

FEC ID number of contributing federal political committee.

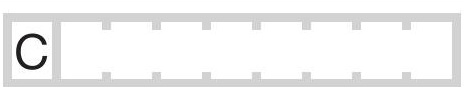

Name of Employer
None
Receipt For: 2012
X Primary $\quad \square$ General
Other (specify)

Occupation

Retired

Election Cycle-to-Date

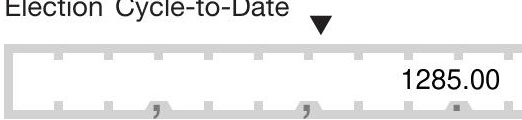

Subtotal Of Receipts This Page (optional)

1051.00

Amount of Each Receipt this Period

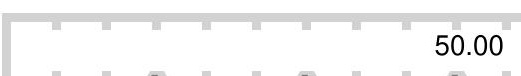

Total This Period (last page this line number only)

Transaction ID : AB98F41077D354045909

Date of Receipt

\begin{tabular}{|c|c|c|c|c|}
\hline 09 & 1 & 21 & & $\begin{array}{ccc}Y & Y & Y \\
2011 & Y\end{array}$ \\
\hline
\end{tabular}


SCHEDULE A-P ITEMIZED RECEIPTS
Use separate schedule(s) for each category of the Detailed Summary Page
FOR LINE NUMBER: (check only one)

PAGE $575 / 1572$

\begin{tabular}{|c|c|c|c|c|c|}
\hline & & & & & \\
\hline 16 & $\begin{array}{l}\mathbf{X} \\
17 a\end{array}$ & $17 b$ & $17 c$ & $17 d$ & 18 \\
\hline $19 a$ & $19 \mathrm{~b}$ & $20 \mathrm{a}$ & $20 \mathrm{~b}$ & $20 \mathrm{c}$ & 21 \\
\hline
\end{tabular}

Any information copied from such Reports and Statements may not be sold or used by any person for the purpose of soliciting contributions or for commercial purposes, other than using the name and address of any political committee to solicit contributions from such committee.

NAME OF COMMITTEE (In Full)

\section{Friends of Herman Cain}

A. Full Name (Last, First, Middle Initial)

April Ziegenfelder

Mailing Address 10199 Waterford Ave.

\begin{tabular}{lcc}
\hline City & State & Zip Code \\
Englewood & FL & $34224-7966$
\end{tabular}

FEC ID number of contributing

federal political committee.

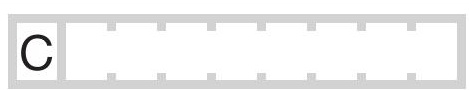

Name of Employer
Information Requested
Receipt For: 2012
X Primary $\quad \square$ General
Other (specify)

Occupation

Information Requested

Election Cycle-to-Date

500.00

B. Full Name (Last, First, Middle Initial)

April Ziegenfelder

Mailing Address 10199 Waterford Ave.

\begin{tabular}{lcc}
\hline City & State & Zip Code \\
Englewood & FL & $34224-7966$ \\
\hline
\end{tabular}

FEC ID number of contributing

federal political committee.

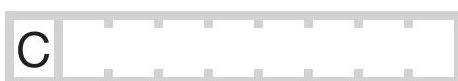

Name of Employer
Information Requested
Receipt For: 2012
X Primary
Other (specify)

Occupation

Information Requested

Election Cycle-to-Date

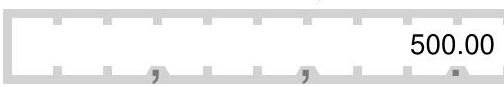

Transaction ID : ADD6845E4E9B641E7AA2

Date of Receipt

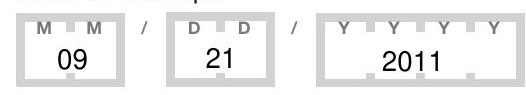

Amount of Each Receipt this Period

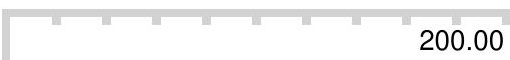

C. Full Name (Last, First, Middle Initial)

Kelly Holloway

Mailing Address 3610 31st Street

\begin{tabular}{lcc}
\hline City & State & Zip Code \\
Lubbock & TX & $79410-2735$
\end{tabular}

FEC ID number of contributing federal political committee.

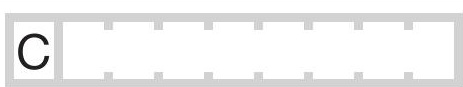

Name of Employer
Hawkeye Road Boring
Receipt For: 2012
Х Primary $\quad \square$ General
Other (specify)

\section{Occupation}

Construction

Election Cycle-to-Date
Amount of Each Receipt this Period

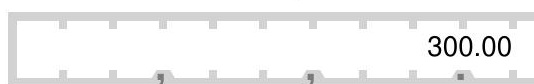

Date of Receipt

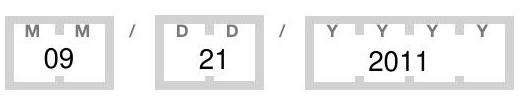

Transaction ID : A6FDC6FD2193D4F2EA18 Date of Receipt

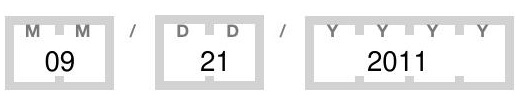

Amount of Each Receipt this Period

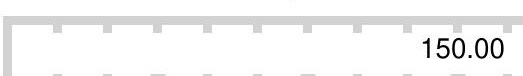

150.00

\section{Subtotal Of Receipts This Page (optional)}

650.00

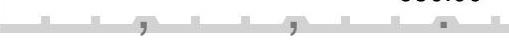

Total This Period (last page this line number only)

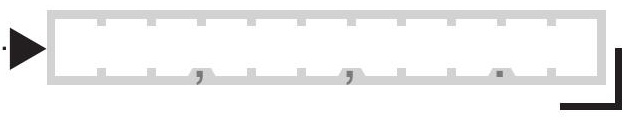

FEC Schedule A-P (Form 3P) (Rev. 03/2011) 
SCHEDULE A-P ITEMIZED RECEIPTS
Use separate schedule(s) for each category of the Detailed Summary Page
FOR LINE NUMBER: (check only one)

PAGE $576 / 1572$

\begin{tabular}{|c|c|c|c|c|c|}
\hline & & & & & \\
\hline 16 & $\begin{array}{l}\mathbf{X} \\
17 a\end{array}$ & $17 b$ & $17 c$ & $17 d$ & 18 \\
\hline $19 a$ & $19 \mathrm{~b}$ & $20 \mathrm{a}$ & $20 \mathrm{~b}$ & $20 \mathrm{c}$ & 21 \\
\hline
\end{tabular}

Any information copied from such Reports and Statements may not be sold or used by any person for the purpose of soliciting contributions or for commercial purposes, other than using the name and address of any political committee to solicit contributions from such committee.

NAME OF COMMITTEE (In Full)

\section{Friends of Herman Cain}

A. Full Name (Last, First, Middle Initial)

klaus schoening Sr.

Mailing Address 205 Waverly Hall Ln

\begin{tabular}{lcc}
\hline City & State & Zip Code \\
Simpsonville & SC & $29681-5287$
\end{tabular}

FEC ID number of contributing federal political committee.

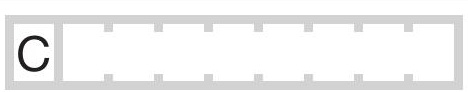

Name of Employer
self
Receipt For: 2012
X Primary $\quad$ General
Other (specify)

Occupation

Financial Advisor

Election Cycle-to-Date

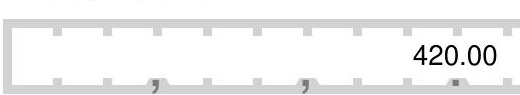

B. Full Name (Last, First, Middle Initial)

Peaches Kavanaugh

Mailing Address 216 Monty Manor

\begin{tabular}{lcc}
\hline City & State & Zip Code \\
Yorktown & VA & $23693-4414$ \\
\hline
\end{tabular}

FEC ID number of contributing

federal political committee.

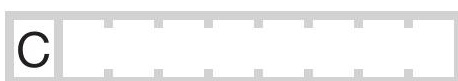

Name of Employer
Air Force
Receipt For: 2012
X Primary
$\square$ Other (specify) General

Occupation

Retired

Election Cycle-to-Date

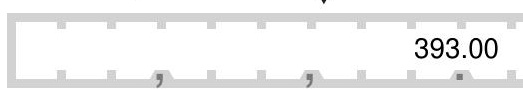

Transaction ID : AC152549C9C054BD0924

Date of Receipt

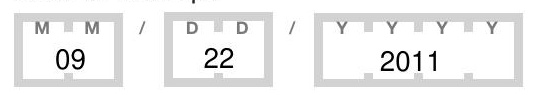

Amount of Each Receipt this Period

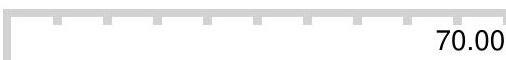

70.00

C. Full Name (Last, First, Middle Initial)

Elizabeth Fleming

Mailing Address 11025 NE 17th Street

\begin{tabular}{lcc}
\hline City & State & Zip Code \\
Bellevue & WA & $98004-3703$
\end{tabular}

FEC ID number of contributing federal political committee.

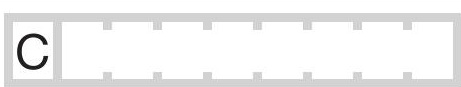

Name of Employer

Information Requested

\section{Occupation}

Information Requested

Receipt For: 2012

Х $\begin{aligned} & \text { Primary } \square \text { General } \\ & \text { Other (specify) }\end{aligned}$

Transaction ID : A5E33FE015A2B4668BA0

Date of Receipt

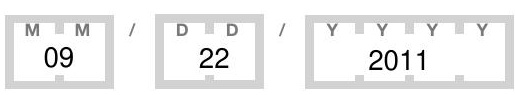

Amount of Each Receipt this Period

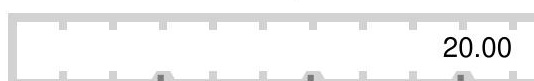

Transaction ID : AE636DEB40B8246FAACF Date of Receipt

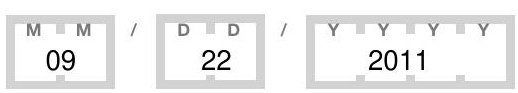

Amount of Each Receipt this Period

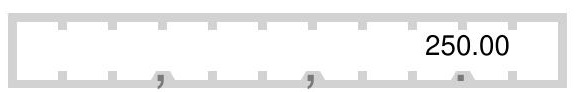

350.00

\section{Subtotal Of Receipts This Page (optional)}

Total This Period (last page this line number only) 
SCHEDULE A-P ITEMIZED RECEIPTS
Use separate schedule(s) for each category of the Detailed Summary Page
FOR LINE NUMBER: (check only one)

PAGE 577 / 1572

\begin{tabular}{|c|c|c|c|c|c|}
\hline & & & & & \\
\hline 16 & $\begin{array}{l}\mathbf{X} \\
17 a\end{array}$ & $17 b$ & $17 c$ & $17 d$ & 18 \\
\hline $19 a$ & $19 \mathrm{~b}$ & $20 \mathrm{a}$ & $20 \mathrm{~b}$ & $20 \mathrm{c}$ & 21 \\
\hline
\end{tabular}

Any information copied from such Reports and Statements may not be sold or used by any person for the purpose of soliciting contributions or for commercial purposes, other than using the name and address of any political committee to solicit contributions from such committee.

NAME OF COMMITTEE (In Full)

\section{Friends of Herman Cain}

A. Full Name (Last, First, Middle Initial)

\section{Carol McGahee}

Mailing Address 606 Pebble Beach Ct.

\begin{tabular}{lcc}
\hline City & State & Zip Code \\
Augusta & GA & $30907-9536$ \\
\hline
\end{tabular}

FEC ID number of contributing federal political committee.

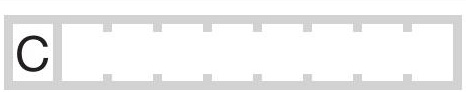

\section{Name of Employer}

Amelia Investment Properties

Receipt For: 2012

X Primary $\square$ General Other (specify)

\section{Occupation}

Office Manager

Election Cycle-to-Date

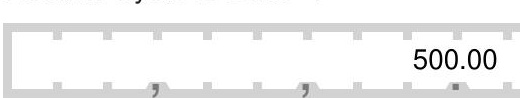

B. Full Name (Last, First, Middle Initial)

Robert Berning

Mailing Address 120 Pine Needle Rd.

\begin{tabular}{lcc}
\hline City & State & Zip Code \\
Aiken & SC & $29803-2630$
\end{tabular}

FEC ID number of contributing

federal political committee.

C

Name of Employer
Information Requested
Receipt For: 2012
X Primary
Other (specify)

\section{Occupation}

Information Requested

Election Cycle-to-Date

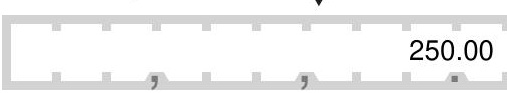

Transaction ID : AF434B8A7A61B47218B5

Date of Receipt

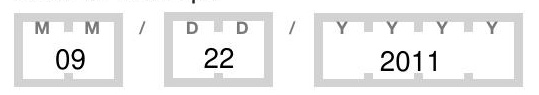

Amount of Each Receipt this Period

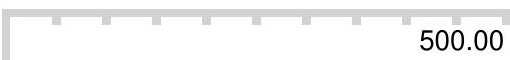

500.00

C. Full Name (Last, First, Middle Initial)

Sharon Waite

Mailing Address 8301 W Business Highway 83

\begin{tabular}{lcc}
\hline City & State & Zip Code \\
Mission & TX & $78572-9445$
\end{tabular}

FEC ID number of contributing

federal political committee.

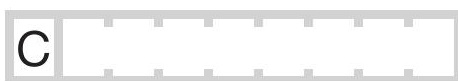

Name of Employer

Occupation

Self Employed

Agriculture

Receipt For: 2012

Х $\begin{aligned} & \text { Primary } \square \text { General } \\ & \text { Other (specify) }\end{aligned}$

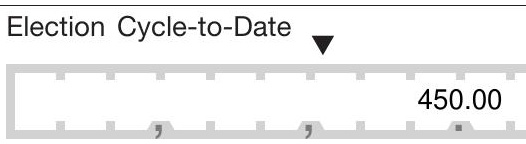

Amount of Each Receipt this Period

Transaction ID : A3D34998ED0A64F4295B

Date of Receipt
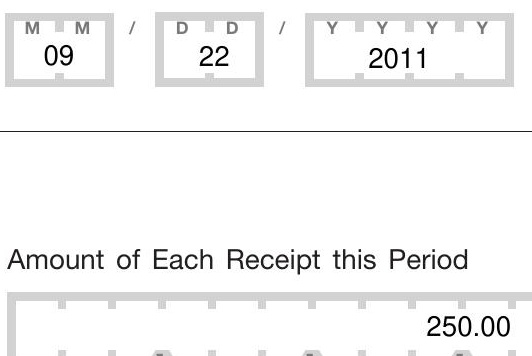

Transaction ID : A4368C11DACD14C539D8 Date of Receipt

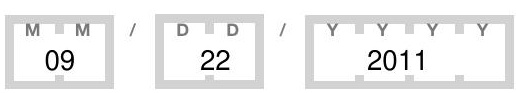

Amount of Each Receipt this Period

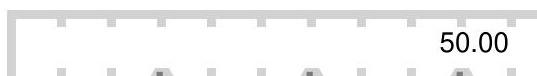

Subtotal Of Receipts This Page (optional)

800.00

Total This Period (last page this line number only) 
SCHEDULE A-P ITEMIZED RECEIPTS
Use separate schedule(s) for each category of the Detailed Summary Page
FOR LINE NUMBER: (check only one)

PAGE $578 / 1572$

\begin{tabular}{|c|c|c|c|c|c|}
\hline & & & & & \\
\hline 16 & $\begin{array}{l}\mathbf{X} \\
17 a\end{array}$ & $17 b$ & $17 c$ & $17 d$ & 18 \\
\hline $19 a$ & $19 \mathrm{~b}$ & $20 \mathrm{a}$ & $20 \mathrm{~b}$ & $20 \mathrm{c}$ & 21 \\
\hline
\end{tabular}

Any information copied from such Reports and Statements may not be sold or used by any person for the purpose of soliciting contributions or for commercial purposes, other than using the name and address of any political committee to solicit contributions from such committee.

NAME OF COMMITTEE (In Full)

\section{Friends of Herman Cain}

A. Full Name (Last, First, Middle Initial)

Judy Novak

Mailing Address 5995 Lac du Lune Road

\begin{tabular}{lcc}
\hline City & State & Zip Code \\
Land O Lakes & WI & $54540-9633$
\end{tabular}

FEC ID number of contributing federal political committee.

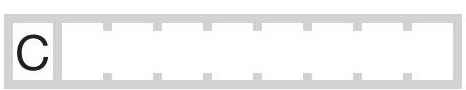

Name of Employer
Information Requested
Receipt For: 2012
X Primary
Other (specify) General

Occupation Information Requested

Election Cycle-to-Date

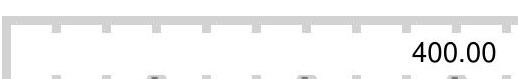

B. Full Name (Last, First, Middle Initial)

Ruth E Meyer

Mailing Address 4294 South Germantown Rd

\begin{tabular}{lcc}
\hline City & State & Zip Code \\
Memphis & TN & $38125-2908$
\end{tabular}

FEC ID number of contributing

federal political committee.

C

Name of Employer
None
Receipt For: 2012
X Primary
Other (specify)

Occupation

Retired

Election Cycle-to-Date

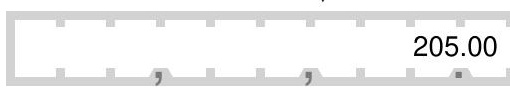

Transaction ID : A06ABA9A6B2C34791A4C

Date of Receipt

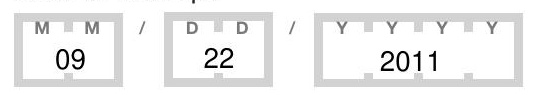

Amount of Each Receipt this Period

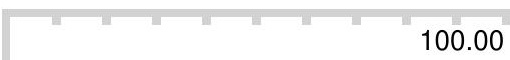

Transaction ID : AA5F416EC794C48918EA

Date of Receipt

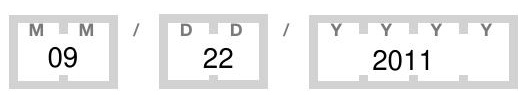

Amount of Each Receipt this Period

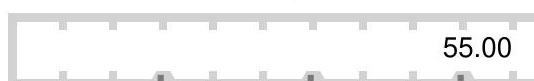

Amount of Each Receipt this Period

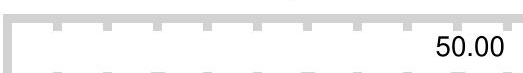

Transaction ID : AFA2B2BF49C8F455DA48 Date of Receipt
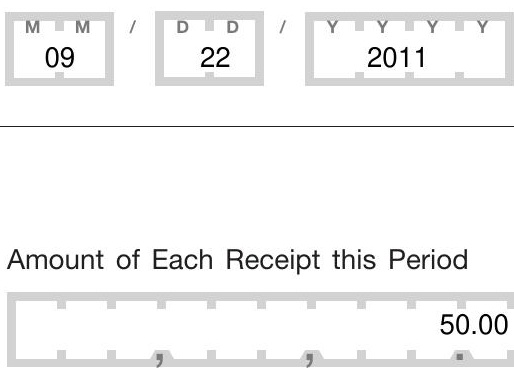

C. Full Name (Last, First, Middle Initial)

robert daidone

Mailing Address 490 baldwin \#11

\begin{tabular}{lcc}
\hline City & State & Zip Code \\
Rochester & MI & $48307-2144$
\end{tabular}

FEC ID number of contributing

federal political committee.

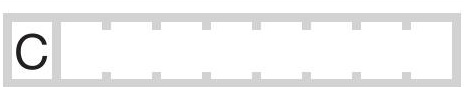

Name of Employer
IBM
Receipt For: 2012
X Primary $\quad \square$ General
Other (specify)

\section{Occupation}

Recruiter

Election Cycle-to-Date

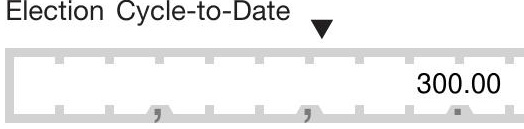

\section{Subtotal Of Receipts This Page (optional)}

205.00

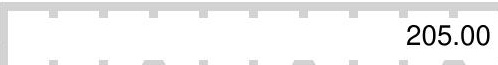

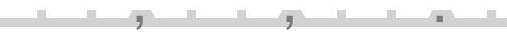

Total This Period (last page this line number only) 
SCHEDULE A-P ITEMIZED RECEIPTS
Use separate schedule(s)

for each category of the

Detailed Summary Page
FOR LINE NUMBER: (check only one)

PAGE $579 / 1572$

\begin{tabular}{|c|c|c|c|c|c|}
\hline & & & & & \\
\hline 16 & $\begin{array}{l}\mathbf{X} \\
17 a\end{array}$ & $17 b$ & $17 c$ & $17 d$ & 18 \\
\hline $19 a$ & $19 \mathrm{~b}$ & $20 \mathrm{a}$ & $20 \mathrm{~b}$ & $20 \mathrm{c}$ & 21 \\
\hline
\end{tabular}

Any information copied from such Reports and Statements may not be sold or used by any person for the purpose of soliciting contributions or for commercial purposes, other than using the name and address of any political committee to solicit contributions from such committee.

NAME OF COMMITTEE (In Full)

\section{Friends of Herman Cain}

A. Full Name (Last, First, Middle Initial) Joanna Dickens

Mailing Address 3321 Missouri Ave

\begin{tabular}{lcc}
\hline City & State & Zip Code \\
Bryan & TX & $77803-0712$ \\
\hline
\end{tabular}

FEC ID number of contributing federal political committee.

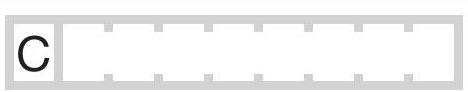

Name of Employer
Texas Transportation Institute
Receipt For: 2012
X Primary
Other (specify) General

Occupation

editor

Election Cycle-to-Date

\subsection{0}

B. Full Name (Last, First, Middle Initial)

Deborah Baratka

Mailing Address 1228 Fairridge Cr SW

\begin{tabular}{lcc}
\hline City & State & Zip Code \\
Marietta & GA & $30008-6837$
\end{tabular}

FEC ID number of contributing

federal political committee.

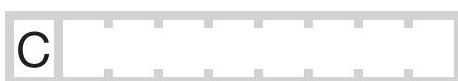

Name of Employer
Batson Cook Co
Receipt For: 2012
X Primary
Other (specify)

\section{Occupation}

Construction

Election Cycle-to-Date

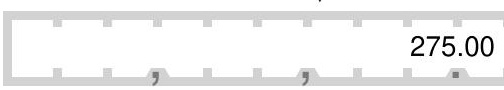

Transaction ID : A911D2C68C4FB45FAB0A

Date of Receipt

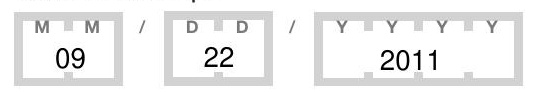

Amount of Each Receipt this Period

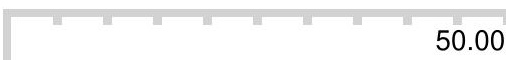

50.00

C. Full Name (Last, First, Middle Initial)

David Fox

Mailing Address 12108 Deer Trail

\begin{tabular}{lcc}
\hline City & State & Zip Code \\
Alpharetta & GA & $30004-8589$
\end{tabular}

FEC ID number of contributing federal political committee.

C

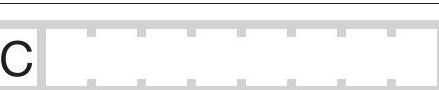

Name of Employer

Occupation

Information Requested

Information Requested

Receipt For: 2012

Х $\begin{aligned} & \text { Primary } \\ & \text { Other (specify) }\end{aligned}$

Election Cycle-to-Date

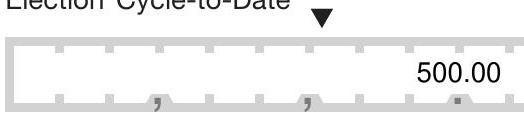

Amount of Each Receipt this Period

Transaction ID : AC31850F3B08B46EFA4E

Date of Receipt
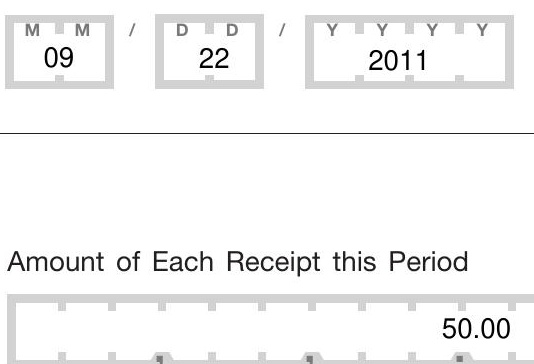

Transaction ID : A47489865D4054CC2BB1

Date of Receipt

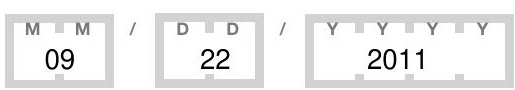

Amount of Each Receipt this Period

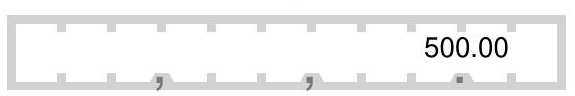

Subtotal Of Receipts This Page (optional)

600.00

Total This Period (last page this line number only) 
SCHEDULE A-P ITEMIZED RECEIPTS
Use separate schedule(s) for each category of the Detailed Summary Page
FOR LINE NUMBER: (check only one)

PAGE $580 / 1572$

\begin{tabular}{|c|c|c|c|c|c|}
\hline & & & & & \\
\hline 16 & $\begin{array}{l}\mathbf{X} \\
17 a\end{array}$ & $17 b$ & $17 c$ & $17 d$ & 18 \\
\hline $19 a$ & $19 \mathrm{~b}$ & $20 \mathrm{a}$ & $20 \mathrm{~b}$ & $20 \mathrm{c}$ & 21 \\
\hline
\end{tabular}

Any information copied from such Reports and Statements may not be sold or used by any person for the purpose of soliciting contributions or for commercial purposes, other than using the name and address of any political committee to solicit contributions from such committee.

NAME OF COMMITTEE (In Full)

\section{Friends of Herman Cain}

A. Full Name (Last, First, Middle Initial) Jeanne Downer

Mailing Address $6007 \mathrm{~N}$ Kansas AVe

\begin{tabular}{lcc}
\hline City & State & Zip Code \\
Kansas City & MO & $64119-2115$ \\
\hline
\end{tabular}

FEC ID number of contributing federal political committee.

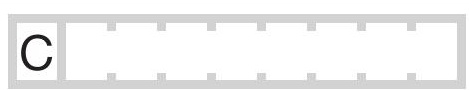

Name of Employer
WNB Architects
Receipt For: 2012
X Primary $\quad$ General
Other (specify)

Occupation Office Manager

Election Cycle-to-Date

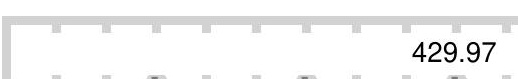

B. Full Name (Last, First, Middle Initial)

Gilbert Digiannantonio

Mailing Address 107 Hampton Rd., Ste. 200

\begin{tabular}{lcc}
\hline City & State & Zip Code \\
Clearwater & FL & $33759-4960$
\end{tabular}

FEC ID number of contributing

federal political committee.

C

\begin{tabular}{l} 
Name of Employer \\
Information Requested \\
Receipt For: 2012 \\
X Primary \\
\hline Other (specify)
\end{tabular}

Occupation

Information Requested

Election Cycle-to-Date

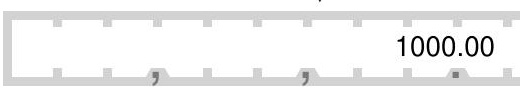

C. Full Name (Last, First, Middle Initial)

John Allen

Mailing Address 16 Park Forest Curve

\begin{tabular}{lcc}
\hline City & State & Zip Code \\
Newnan & GA & $30265-5519$
\end{tabular}

FEC ID number of contributing

federal political committee.

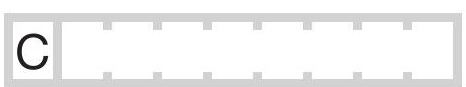

Name of Employer

Macy's

Receipt For: 2012

Х $\begin{aligned} & \text { Primary } \\ & \text { Other (specify) }\end{aligned}$

Occupation

Systems Engineer

Election Cycle-to-Date
Transaction ID : A1D5358760BBB44C7A51

Date of Receipt

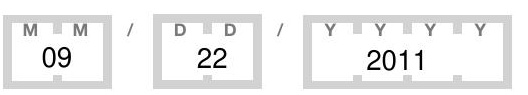

Amount of Each Receipt this Period

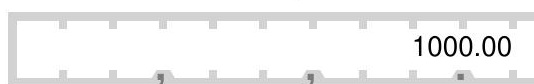

Transaction ID : AFD53CE48505F426B973

Date of Receipt

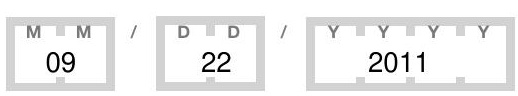

Amount of Each Receipt this Period

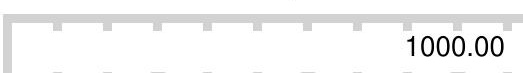

Subtotal Of Receipts This Page (optional).

Total This Period (last page this line number only)

2009.99

a
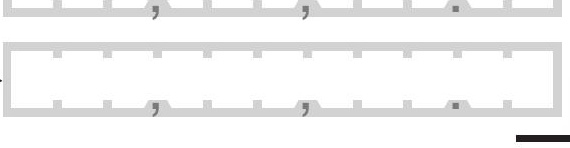

FEC Schedule A-P (Form 3P) (Rev. 03/2011) 
SCHEDULE A-P ITEMIZED RECEIPTS
Use separate schedule(s) for each category of the Detailed Summary Page
FOR LINE NUMBER: (check only one)

PAGE $581 / 1572$

\begin{tabular}{|c|c|c|c|c|c|c|}
\hline & & & & & & \\
\hline 16 & $\lambda$ & $17 \mathrm{a}$ & $17 \mathrm{~b}$ & $17 \mathrm{c}$ & $-17 d$ & -18 \\
\hline $19 a$ & & $19 b$ & $20 a$ & $20 \mathrm{~b}$ & $20 \mathrm{c}$ & 21 \\
\hline
\end{tabular}

Any information copied from such Reports and Statements may not be sold or used by any person for the purpose of soliciting contributions or for commercial purposes, other than using the name and address of any political committee to solicit contributions from such committee.

NAME OF COMMITTEE (In Full)

\section{Friends of Herman Cain}

A. Full Name (Last, First, Middle Initial) Lindley Winslow

Mailing Address 30033 Sunset Pointe

\begin{tabular}{lcc}
\hline City & State & Zip Code \\
Deer Island & FL & $32778-9017$
\end{tabular}

FEC ID number of contributing federal political committee.

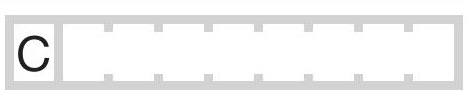

\begin{tabular}{l} 
Name of Employer \\
None \\
Receipt For: 2012 \\
X Primary $\quad$ General \\
\hline Other (specify)
\end{tabular}

Occupation Retired Election Cycle-to-Date

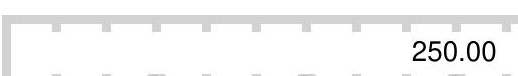

B. Full Name (Last, First, Middle Initial)

KARL KORDECKI

Mailing Address 897 Miller Ave

\begin{tabular}{lcc}
\hline City & State & Zip Code \\
Dayton & OH & $45417-8331$ \\
\hline
\end{tabular}

FEC ID number of contributing

federal political committee.

C

\begin{tabular}{l} 
Name of Employer \\
ABF \\
Receipt For: 2012 \\
X Primary \\
\hline Other (specify)
\end{tabular}

Occupation

city driver/dock worker

Election Cycle-to-Date

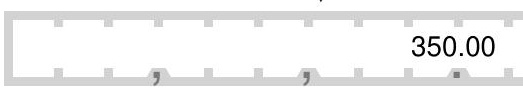

Transaction ID : AF971BF19053D444B9A5

Date of Receipt

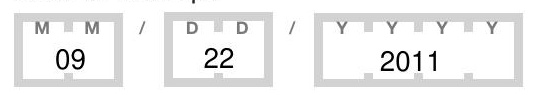

Amount of Each Receipt this Period

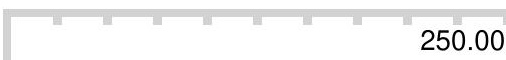

C. Full Name (Last, First, Middle Initial)

Steve Lyle

Mailing Address 320 WCR 3460

\begin{tabular}{lcc}
\hline City & State & Zip Code \\
Hawkins & TX & 75765 \\
\hline
\end{tabular}

FEC ID number of contributing federal political committee.

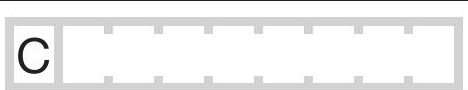

Name of Employer
CCH of Tyler
Receipt For: 2012
X Primary
Other (specify) General

\section{Occupation}

$\mathrm{RN}$

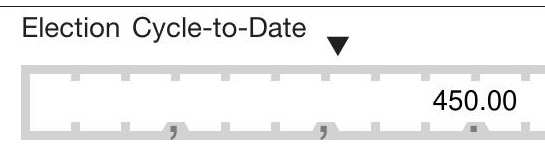

Amount of Each Receipt this Period

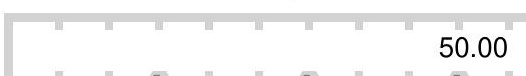

Transaction ID : A1A10A888823C4E3DBE1 Date of Receipt

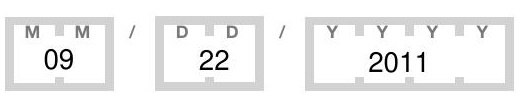

Transaction ID : A4F04264CCFA34FBAA64 Date of Receipt

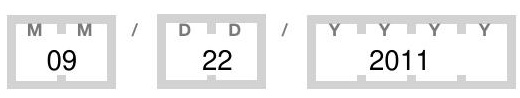

Amount of Each Receipt this Period

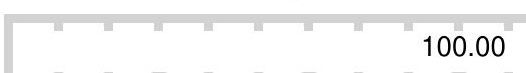

\section{Subtotal Of Receipts This Page (optional)}

400.00

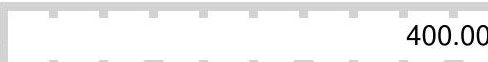

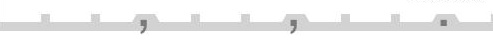

Total This Period (last page this line number only)

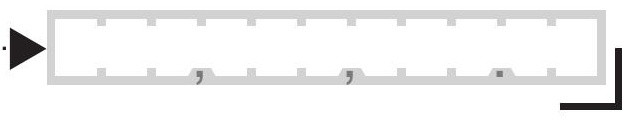

FEC Schedule A-P (Form 3P) (Rev. 03/2011) 
SCHEDULE A-P ITEMIZED RECEIPTS
Use separate schedule(s) for each category of the Detailed Summary Page
FOR LINE NUMBER: (check only one)

PAGE 582 / 1572

\begin{tabular}{|c|c|c|c|c|c|}
\hline & & & & & \\
\hline 16 & $\begin{array}{l}\mathbf{X} \\
17 a\end{array}$ & $17 b$ & $17 c$ & $17 d$ & 18 \\
\hline $19 a$ & $19 \mathrm{~b}$ & $20 \mathrm{a}$ & $20 \mathrm{~b}$ & $20 \mathrm{c}$ & 21 \\
\hline
\end{tabular}

Any information copied from such Reports and Statements may not be sold or used by any person for the purpose of soliciting contributions or for commercial purposes, other than using the name and address of any political committee to solicit contributions from such committee.

NAME OF COMMITTEE (In Full)

\section{Friends of Herman Cain}

A. Full Name (Last, First, Middle Initial)

Nicholas Cambas

Mailing Address 2939 Elysium Way

\begin{tabular}{lcc}
\hline City & State & Zip Code \\
Clearwater & FL & $33759-1414$ \\
\hline
\end{tabular}

FEC ID number of contributing federal political committee.

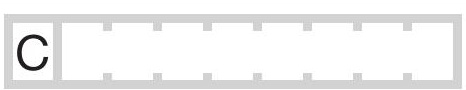

Name of Employer
Information Requested
Receipt For: 2012
X Primary
Other (specify) General

Occupation Information Requested

Election Cycle-to-Date

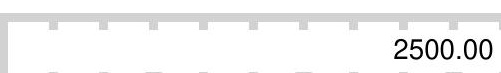

B. Full Name (Last, First, Middle Initial)

William Long Jr.

Mailing Address 3106 W. Agawan

\begin{tabular}{lcc}
\hline City & State & Zip Code \\
Tampa & FL & $33629-5202$
\end{tabular}

FEC ID number of contributing

federal political committee.

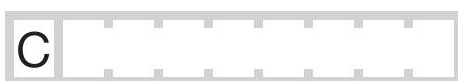

Name of Employer
Self Employed
Receipt For: 2012
X Primary
Other (specify)

\section{Occupation}

CPA

Election Cycle-to-Date

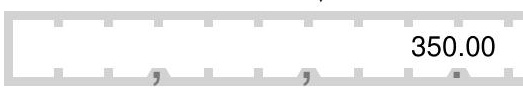

Transaction ID : A793F4D30D44449B6AED

Date of Receipt

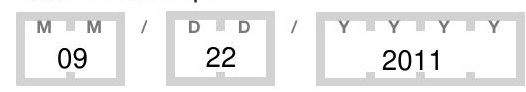

Amount of Each Receipt this Period

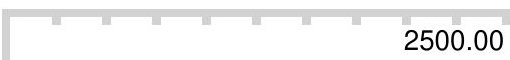

C. Full Name (Last, First, Middle Initial)

Carol Cook

Mailing Address 43 Oak Alley

\begin{tabular}{lcc}
\hline City & State & Zip Code \\
Kerrville & TX & $78028-1711$
\end{tabular}

FEC ID number of contributing federal political committee.

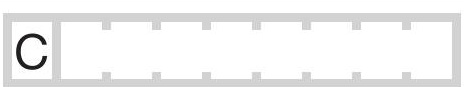

Name of Employer
James Avery
Receipt For: 2012
X Primary
Other (specify) General

\section{Occupation}

Sales Team Leader

Election Cycle-to-Date

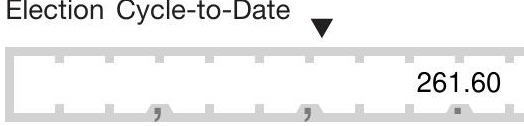

Transaction ID : ABC3DA1C1EB8B4190BF1 Date of Receipt

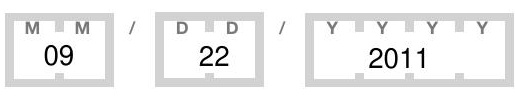

Amount of Each Receipt this Period

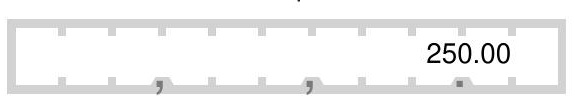

Transaction ID : A7F03EFEBCAB24E388CA Date of Receipt

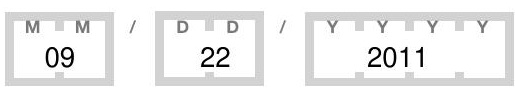

Amount of Each Receipt this Period

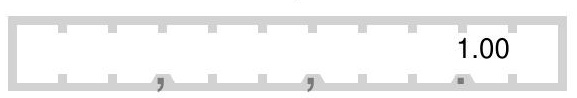

Subtotal Of Receipts This Page (optional)

2751.00

$+, \quad, \quad, \quad, \quad 2751.00$

Total This Period (last page this line number only)

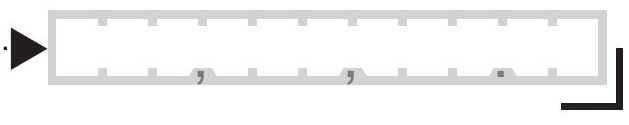

FEC Schedule A-P (Form 3P) (Rev. 03/2011) 
SCHEDULE A-P ITEMIZED RECEIPTS
Use separate schedule(s) for each category of the Detailed Summary Page
FOR LINE NUMBER: (check only one)

PAGE $583 / 1572$

\begin{tabular}{|c|c|c|c|c|c|c|}
\hline & & & & & & \\
\hline 16 & $\lambda$ & $17 \mathrm{a}$ & $17 \mathrm{~b}$ & $17 \mathrm{c}$ & $-17 d$ & -18 \\
\hline $19 a$ & & $19 b$ & $20 a$ & $20 \mathrm{~b}$ & $20 \mathrm{c}$ & 21 \\
\hline
\end{tabular}

Any information copied from such Reports and Statements may not be sold or used by any person for the purpose of soliciting contributions or for commercial purposes, other than using the name and address of any political committee to solicit contributions from such committee.

NAME OF COMMITTEE (In Full)

\section{Friends of Herman Cain}

A. Full Name (Last, First, Middle Initial)

\section{Patricia A Eddins}

Mailing Address 336 8th ST NE

\begin{tabular}{lcc}
\hline City & State & Zip Code \\
Winter Haven & FL & $33881-4716$
\end{tabular}

FEC ID number of contributing federal political committee.

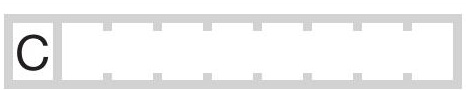

\begin{tabular}{l} 
Name of Employer \\
None \\
Receipt For: 2012 \\
X Primary $\quad$ General \\
\hline Other (specify)
\end{tabular}

Occupation Retired

Election Cycle-to-Date

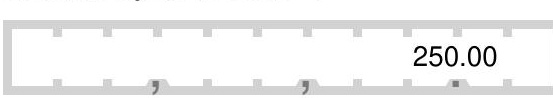

B. Full Name (Last, First, Middle Initial)

John Ellery

Mailing Address 2488 Old Fork Rd

\begin{tabular}{lcc}
\hline City & State & Zip Code \\
Gainesville & GA & $30506-1124$
\end{tabular}

FEC ID number of contributing

federal political committee.

Name of Employer
Automatic IT Corp
Receipt For: 2012
Primary
Other (specify)

C. Full Name (Last, First, Middle Initial)

RICHARD BAILEY

Mailing Address 6803 TRANQUIL LN

\begin{tabular}{lcc}
\hline City & State & Zip Code \\
Lynden & WA & $98264-9659$
\end{tabular}

FEC ID number of contributing federal political committee.

Name of Employer
None
Receipt For: 2012
X Primary $\quad \square$ General
Other (specify)

\section{Occupation}

IT Consultant

Election Cycle-to-Date

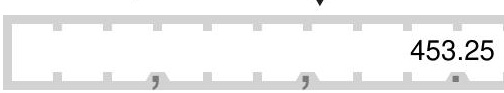

Transaction ID : AEC5222145B504D368BB

Date of Receipt

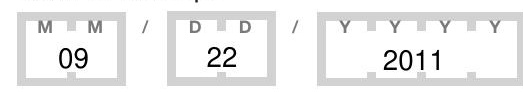

Amount of Each Receipt this Period

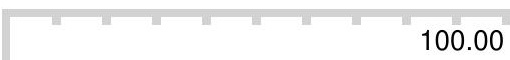

C

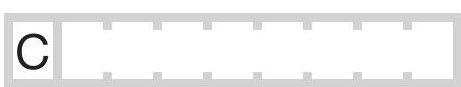

Transaction ID : A66B5B6E976D1494C8D3 Date of Receipt

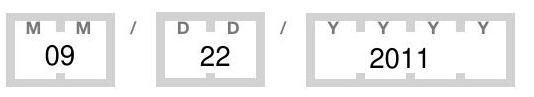

Amount of Each Receipt this Period

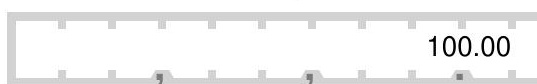

Transaction ID : A31A96E52D1144E999B7 Date of Receipt

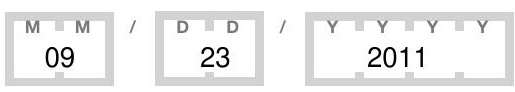

Amount of Each Receipt this Period

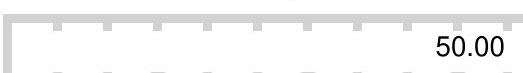

Retired

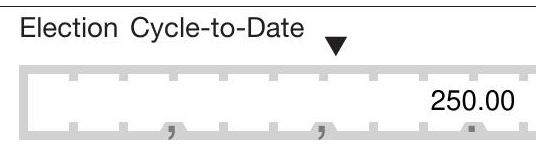

Subtotal Of Receipts This Page (optional)

250.00

(1)

Total This Period (last page this line number only) 
SCHEDULE A-P ITEMIZED RECEIPTS
Use separate schedule(s) for each category of the Detailed Summary Page
FOR LINE NUMBER: (check only one)

\begin{tabular}{|c|c|c|c|c|c|}
\hline & & & & & \\
\hline 16 & $\begin{array}{ll}X & 17 a \\
\end{array}$ & $17 \mathrm{~b}$ & $17 c$ & $17 d$ & 18 \\
\hline $19 a$ & $19 b$ & $20 \mathrm{a}$ & $20 \mathrm{~b}$ & $20 c$ & 21 \\
\hline
\end{tabular}

Any information copied from such Reports and Statements may not be sold or used by any person for the purpose of soliciting contributions or for commercial purposes, other than using the name and address of any political committee to solicit contributions from such committee.

NAME OF COMMITTEE (In Full)

\section{Friends of Herman Cain}

A. Full Name (Last, First, Middle Initial)

\section{Glenn Pauls}

Mailing Address 7676 Hwy 145

\begin{tabular}{lcc}
\hline City & State & Zip Code \\
Telluride & CO & $81435-4100$
\end{tabular}

FEC ID number of contributing federal political committee.

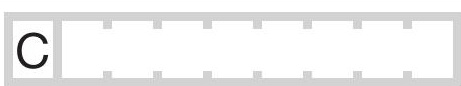

Name of Employer
self
Receipt For: 2012
X Primary $\quad$ General
Other (specify)

Occupation Rancher

Election Cycle-to-Date

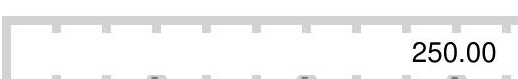

B. Full Name (Last, First, Middle Initial)

Paul Lawrenz

Mailing Address 2632 Thorngrove Ct

\begin{tabular}{lcc}
\hline City & State & Zip Code \\
Fayetteville & NC & 28303-2883
\end{tabular}

FEC ID number of contributing

federal political committee.

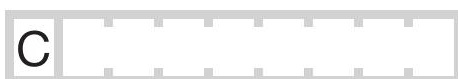

Name of Employer
US Air Force
Receipt For: 2012
X Primary
Other (specify)

\section{Occupation} Officer

Election Cycle-to-Date

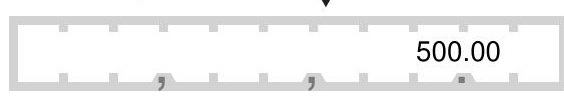

Transaction ID : AC1536C7F72E74E09B59

Date of Receipt

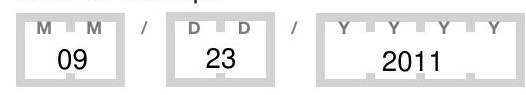

Amount of Each Receipt this Period

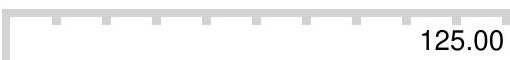

125.00

C. Full Name (Last, First, Middle Initial)

Mr. Lee Kearney

Mailing Address 7611 SE Evergreen Hwy

\begin{tabular}{lcc}
\hline City & State & Zip Code \\
Vancouver & WA & $98664-1721$
\end{tabular}

FEC ID number of contributing federal political committee.

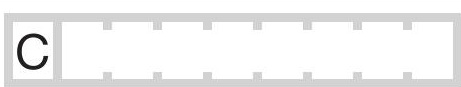

Name of Employer
None
Receipt For: 2012
Х Primary $\quad \square$ General
Other (specify)

Occupation

Retired

Election Cycle-to-Date

Transaction ID : A6AA5191D37AB488082B Date of Receipt

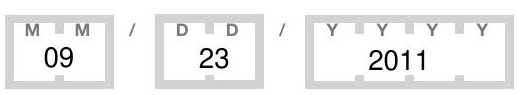

Amount of Each Receipt this Period

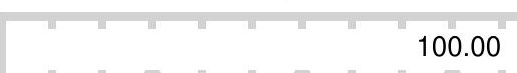

Transaction ID : AADC061CF8E2E4240838 Date of Receipt

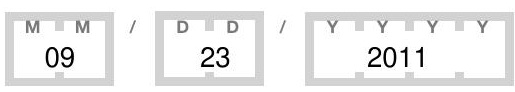

Amount of Each Receipt this Period

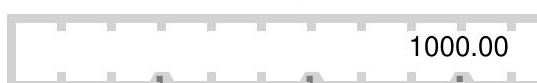

1000.00

\section{Subtotal Of Receipts This Page (optional)}

Total This Period (last page this line number only) 
SCHEDULE A-P ITEMIZED RECEIPTS
Use separate schedule(s)

for each category of the

Detailed Summary Page
FOR LINE NUMBER: (check only one)

PAGE $585 / 1572$

\begin{tabular}{|c|c|c|c|c|c|}
\hline & & & & & \\
\hline 16 & $\begin{array}{l}\mathbf{X} \\
17 a\end{array}$ & $17 b$ & $17 c$ & $17 d$ & 18 \\
\hline $19 a$ & $19 \mathrm{~b}$ & $20 \mathrm{a}$ & $20 \mathrm{~b}$ & $20 \mathrm{c}$ & 21 \\
\hline
\end{tabular}

Any information copied from such Reports and Statements may not be sold or used by any person for the purpose of soliciting contributions or for commercial purposes, other than using the name and address of any political committee to solicit contributions from such committee.

NAME OF COMMITTEE (In Full)

\section{Friends of Herman Cain}

A. Full Name (Last, First, Middle Initial) robert swartz

Mailing Address 4001 n. new braunfels ave

\begin{tabular}{lcc}
\hline City & State & Zip Code \\
San Antonio & TX & $78209-6349$
\end{tabular}

FEC ID number of contributing federal political committee.

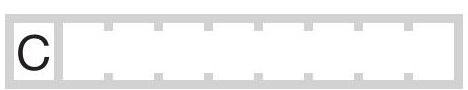

\begin{tabular}{l} 
Name of Employer \\
None \\
Receipt For: 2012 \\
X Primary $\quad$ General \\
\hline Other (specify)
\end{tabular}

Occupation Retired Election Cycle-to-Date

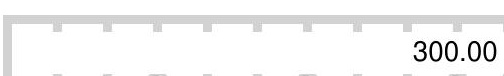

B. Full Name (Last, First, Middle Initial)

KIM SCHMIDT

Mailing Address 5118 POMMEROY DRIVE

\begin{tabular}{lcc}
\hline City & State & Zip Code \\
Fairfax & VA & $22032-2806$ \\
\hline
\end{tabular}

FEC ID number of contributing

federal political committee.

C

Name of Employer
Not Employed
Receipt For: 2012
X Primary
Other (specify)

\section{Occupation} Not Employed

Election Cycle-to-Date

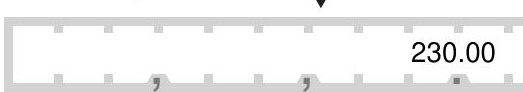

Transaction ID : AB3D4C80BF7274ED19CA

Date of Receipt

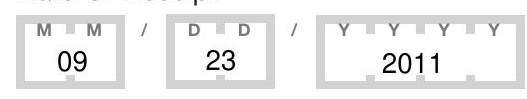

Amount of Each Receipt this Period

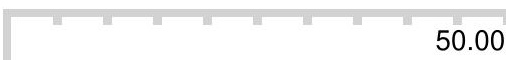

50.00

C. Full Name (Last, First, Middle Initial)

Andre Therrien

Mailing Address PO BOX 2456

\begin{tabular}{lcc}
\hline City & State & Zip Code \\
Ogunquit & ME & $03907-2456$
\end{tabular}

FEC ID number of contributing federal political committee.

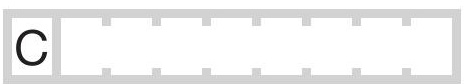

Name of Employer
Retired
Receipt For: 2012
Х Primary $\square$ General
Other (specify)

\section{Occupation}

Retired

Election Cycle-to-Date

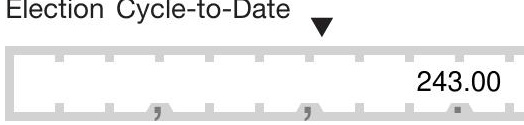

Transaction ID : AF9250A7BB78A47D083B Date of Receipt

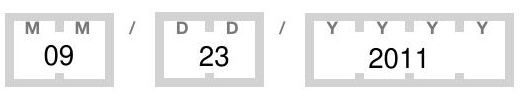

Amount of Each Receipt this Period

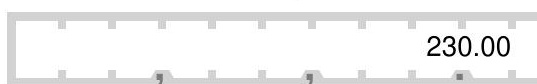

Transaction ID : AF478EF24B41E4D73993 Date of Receipt

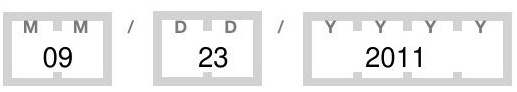

Amount of Each Receipt this Period

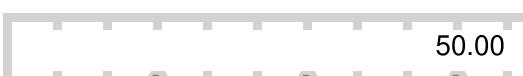

\section{Subtotal Of Receipts This Page (optional)}

Total This Period (last page this line number only) 
SCHEDULE A-P ITEMIZED RECEIPTS
Use separate schedule(s) for each category of the Detailed Summary Page
FOR LINE NUMBER: (check only one)

PAGE $586 / 1572$

\begin{tabular}{|c|c|c|c|c|c|}
\hline & & & & & \\
\hline 16 & $\begin{array}{l}\mathbf{X} \\
17 a\end{array}$ & $17 b$ & $17 c$ & $17 d$ & 18 \\
\hline $19 a$ & $19 \mathrm{~b}$ & $20 \mathrm{a}$ & $20 \mathrm{~b}$ & $20 \mathrm{c}$ & 21 \\
\hline
\end{tabular}

Any information copied from such Reports and Statements may not be sold or used by any person for the purpose of soliciting contributions or for commercial purposes, other than using the name and address of any political committee to solicit contributions from such committee.

NAME OF COMMITTEE (In Full)

\section{Friends of Herman Cain}

A. Full Name (Last, First, Middle Initial) Judy Barker

Mailing Address 2783 Jodeco Drive

\begin{tabular}{lcc}
\hline City & State & Zip Code \\
Jonesboro & GA & $30236-5313$
\end{tabular}

FEC ID number of contributing federal political committee.

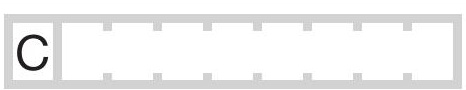

Name of Employer
Georgia Fleet Service Inc
Receipt For: 2012
X Primary $\quad \square$ General
Other (specify)

Occupation OWNER

Election Cycle-to-Date

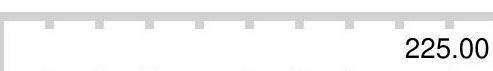

B. Full Name (Last, First, Middle Initial) eugene wordehoff

Mailing Address 692 Solano Ct

\begin{tabular}{lcc}
\hline City & State & Zip Code \\
Marco Island & FL & $34145-1928$
\end{tabular}

FEC ID number of contributing

federal political committee.

C

Name of Employer
Self Employed
Receipt For: 2012
X Primary $\quad$ General
Other (specify)

\section{Occupation}

Consultant

Election Cycle-to-Date

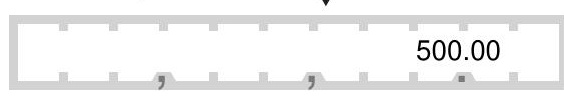

Transaction ID : A0C57070EE32848378A6

Date of Receipt

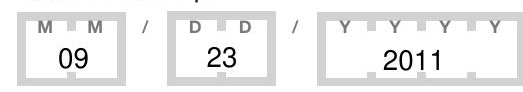

Amount of Each Receipt this Period

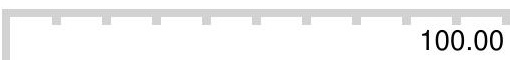

C. Full Name (Last, First, Middle Initial)

Elisabeth Orvosh

Mailing Address 917 Chipaway Dr

City

Apollo Beach

FEC ID number of contributing federal political committee.

Name of Employer
n/a
Receipt For: 2012
X Primary
Other (specify) General

Transaction ID : A9D14035EA9DA4645945 Date of Receipt

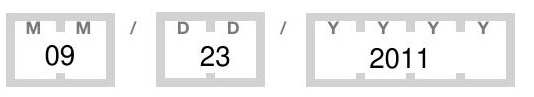

Amount of Each Receipt this Period

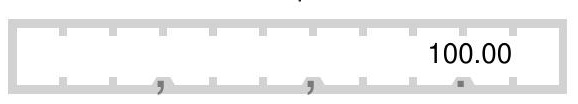

Transaction ID : AAEBBE579CFD04D51B3C Date of Receipt

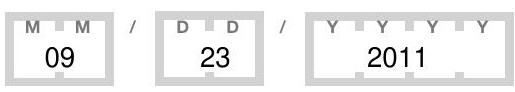

Amount of Each Receipt this Period

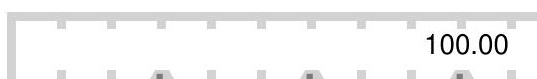

\section{Subtotal Of Receipts This Page (optional)}

300.00

Total This Period (last page this line number only) 
SCHEDULE A-P ITEMIZED RECEIPTS
Use separate schedule(s) for each category of the Detailed Summary Page
FOR LINE NUMBER: (check only one)

PAGE 587 / 1572

\begin{tabular}{|c|c|c|c|c|c|}
\hline & & & & & \\
\hline 16 & $\begin{array}{l}\mathbf{X} \\
17 a\end{array}$ & $17 b$ & $17 c$ & $17 d$ & 18 \\
\hline $19 a$ & $19 \mathrm{~b}$ & $20 \mathrm{a}$ & $20 \mathrm{~b}$ & $20 \mathrm{c}$ & 21 \\
\hline
\end{tabular}

Any information copied from such Reports and Statements may not be sold or used by any person for the purpose of soliciting contributions or for commercial purposes, other than using the name and address of any political committee to solicit contributions from such committee.

NAME OF COMMITTEE (In Full)

\section{Friends of Herman Cain}

A. Full Name (Last, First, Middle Initial)

Gwen Archer

Mailing Address 324 C C Chandler Road

\begin{tabular}{lcc}
\hline City & State & Zip Code \\
Burleson & TX & $76028-3046$
\end{tabular}

FEC ID number of contributing federal political committee.

Name of Employer

Biggs \& Mathews Environmental

Receipt For: 2012

Х Primary $\square$ General

B. Full Name (Last, First, Middle Initial)

Joseph Niswonger

Mailing Address 6088 Windchase Drive

\begin{tabular}{lcc}
\hline City & State & Zip Code \\
Rocky Mount & NC & $27803-8774$ \\
\hline
\end{tabular}

FEC ID number of contributing

federal political committee.

Name of Employer

First Carolina Management

Receipt For: 2012

Х $\begin{aligned} & \text { Primary } \square \text { General } \\ & \text { Other (specify) }\end{aligned}$

C. Full Name (Last, First, Middle Initial)

Diane Speedling

Mailing Address 2927 Sand Pine Rd

City

Miramar Beach

FEC ID number of contributing

federal political committee.

Name of Employer

Self Employed

Receipt For: 2012

Х $\begin{aligned} & \text { Primary } \square \text { General } \\ & \text { Other (specify) }\end{aligned}$

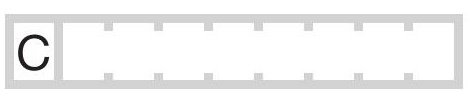

Occupation

Office Manager

Election Cycle-to-Date

260.00

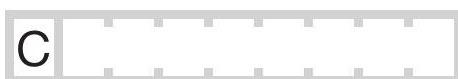

Occupation

VP Sales \& Marketing

Election Cycle-to-Date

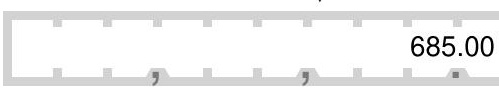

Transaction ID : ABD3335F1C71E462E9C7

Date of Receipt

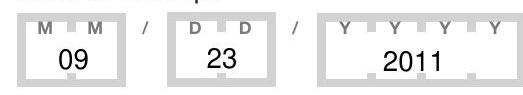

Amount of Each Receipt this Period

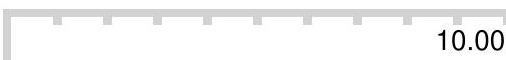

10.00

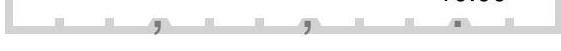

Transaction ID : A02E563F2185B41E3A82

Date of Receipt

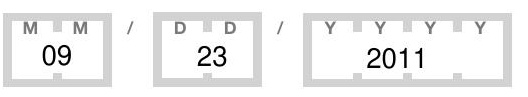

Amount of Each Receipt this Period

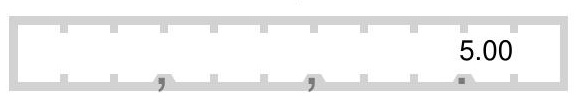

Transaction ID : A28ABC7A1EF9D4077AEC Date of Receipt

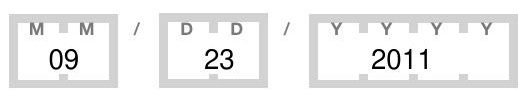

Amount of Each Receipt this Period

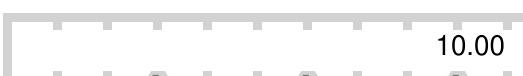

Anesthesiologist

Election Cycle-to-Date

240.00
Subtotal Of Receipts This Page (optional)

25.00

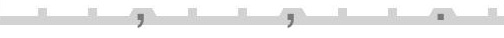

Total This Period (last page this line number only)

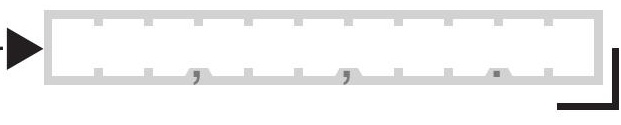

FEC Schedule A-P (Form 3P) (Rev. 03/2011) 
SCHEDULE A-P ITEMIZED RECEIPTS
Use separate schedule(s) for each category of the Detailed Summary Page
FOR LINE NUMBER: (check only one)

PAGE $588 / 1572$

\begin{tabular}{|c|c|c|c|c|c|}
\hline & & & & & \\
\hline 16 & $\begin{array}{l}\mathbf{X} \\
17 a\end{array}$ & $17 b$ & $17 c$ & $17 d$ & 18 \\
\hline $19 a$ & $19 \mathrm{~b}$ & $20 \mathrm{a}$ & $20 \mathrm{~b}$ & $20 \mathrm{c}$ & 21 \\
\hline
\end{tabular}

Any information copied from such Reports and Statements may not be sold or used by any person for the purpose of soliciting contributions or for commercial purposes, other than using the name and address of any political committee to solicit contributions from such committee.

NAME OF COMMITTEE (In Full)

\section{Friends of Herman Cain}

A. Full Name (Last, First, Middle Initial) Glen Ebbing

Mailing Address 1400 Huntleigh Rd

\begin{tabular}{lcc}
\hline City & State & Zip Code \\
Quincy & IL & $62305-6017$ \\
\hline
\end{tabular}

FEC ID number of contributing federal political committee.

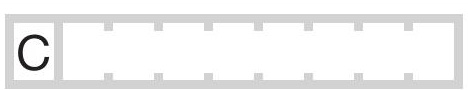

Name of Employer
ColorMaster Pain Inc
Receipt For: 2012
X Primary
Other (specify) General

Occupation sales representative

Election Cycle-to-Date

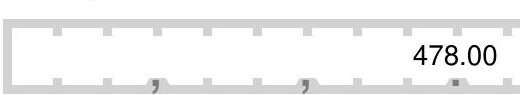

B. Full Name (Last, First, Middle Initial)

Kendall Collier

Mailing Address 500 Rock Springs Road

\begin{tabular}{lcc}
\hline City & State & Zip Code \\
Atlanta & GA & $30324-5104$ \\
\hline
\end{tabular}

FEC ID number of contributing

federal political committee.

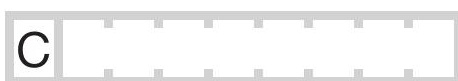

Name of Employer
A Divine Event
Receipt For: 2012
Primary
Other (specify) General

Occupation

Special Event Producer

Election Cycle-to-Date

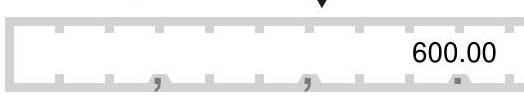

C. Full Name (Last, First, Middle Initial)

Carlotta Monningh

Mailing Address 70 Seabolt Dr

\begin{tabular}{lcc}
\hline City & State & Zip Code \\
Locust Grove & GA & $30248-2143$
\end{tabular}

FEC ID number of contributing federal political committee.

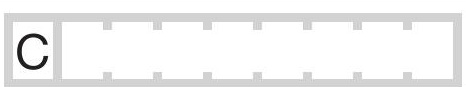

Name of Employer

Coldwell Banker Bullard Rlty

Receipt For: 2012

Х $\begin{aligned} & \text { Primary } \square \text { General } \\ & \text { Other (specify) }\end{aligned}$

\section{Occupation}

Realtor

Election Cycle-to-Date

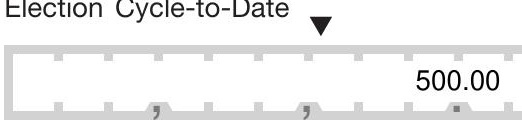

Transaction ID : A9C03B0F9718F461AAE7

Date of Receipt

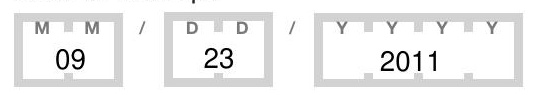

Amount of Each Receipt this Period

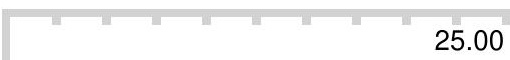

25.00

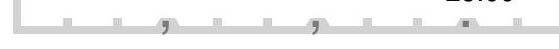

Transaction ID : AB13B3E50F6B14DDC851

Date of Receipt

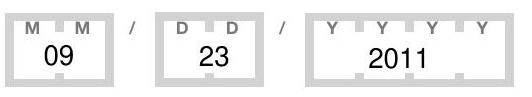

Amount of Each Receipt this Period

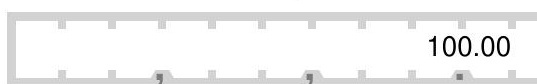

Transaction ID : A4B73C58159714878896

Date of Receipt

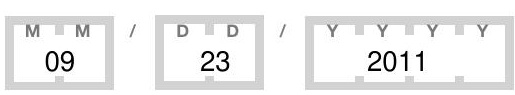

Amount of Each Receipt this Period

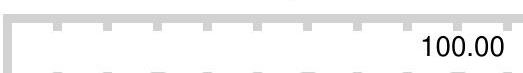

100.00

\section{Subtotal Of Receipts This Page (optional)}

Total This Period (last page this line number only) 
SCHEDULE A-P ITEMIZED RECEIPTS
Use separate schedule(s) for each category of the Detailed Summary Page
FOR LINE NUMBER: (check only one)

PAGE 589 / 1572

\begin{tabular}{|c|c|c|c|c|c|}
\hline & & & & & \\
\hline 16 & $\begin{array}{l}\mathbf{X} \\
17 a\end{array}$ & $17 b$ & $17 c$ & $17 d$ & 18 \\
\hline $19 a$ & $19 \mathrm{~b}$ & $20 \mathrm{a}$ & $20 \mathrm{~b}$ & $20 \mathrm{c}$ & 21 \\
\hline
\end{tabular}

Any information copied from such Reports and Statements may not be sold or used by any person for the purpose of soliciting contributions or for commercial purposes, other than using the name and address of any political committee to solicit contributions from such committee.

NAME OF COMMITTEE (In Full)

\section{Friends of Herman Cain}

A. Full Name (Last, First, Middle Initial)

Wayne Fogel

Mailing Address 7140 SE 172nd Hazelwood Loop

\begin{tabular}{lcc}
\hline City & State & Zip Code \\
The Villages & FL & $32162-5359$
\end{tabular}

FEC ID number of contributing

federal political committee.

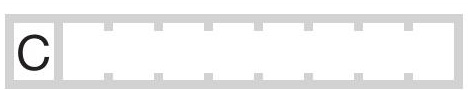

Name of Employer
None
Receipt For: 2012
X Primary $\quad$ General
Other (specify)

Occupation

Retired

Election Cycle-to-Date

450.00

B. Full Name (Last, First, Middle Initial)

Nancy McKee

Mailing Address 339 Springhill Road

\begin{tabular}{lcc}
\hline City & State & Zip Code \\
Huntsville & AL & $35806-1735$
\end{tabular}

FEC ID number of contributing

federal political committee.

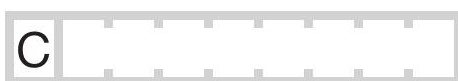

Name of Employer

The Aussie Pouch Company Inc.

Occupation

BUSINESS OWNER

Receipt For: 2012

Х $\begin{aligned} & \text { Primary } \\ & \text { Other (specify) }\end{aligned}$

Election Cycle-to-Date

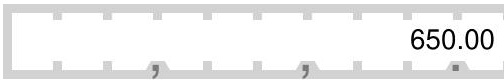

C. Full Name (Last, First, Middle Initial)

Heidi Hernandez

Mailing Address 113 Dominica Court

\begin{tabular}{lcc}
\hline City & State & Zip Code \\
Slidell & LA & $70458-5797$
\end{tabular}

FEC ID number of contributing

federal political committee.

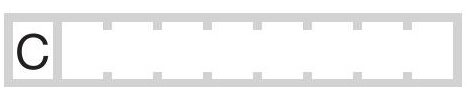

Name of Employer

Information Requested

Occupation

Information Requested

Receipt For: 2012

Х $\begin{aligned} & \text { Primary } \\ & \text { Other (specify) }\end{aligned}$

Transaction ID : AF6772468FBD943D3BE9

Date of Receipt

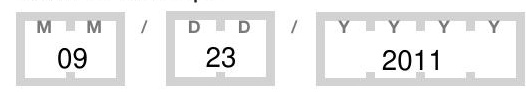

Amount of Each Receipt this Period

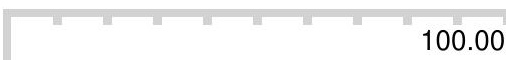

100.00

Transaction ID : AC5062F1F2B5144938AD

Date of Receipt

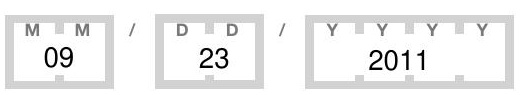

Amount of Each Receipt this Period

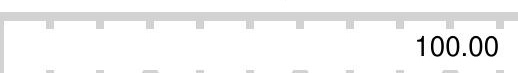

Transaction ID : ADC03109C23014A7A8E9

Date of Receipt

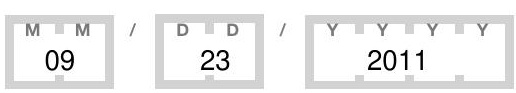

Amount of Each Receipt this Period

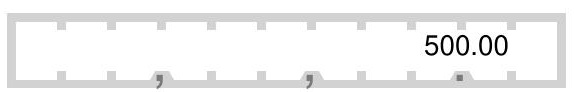

650.00

\section{Subtotal Of Receipts This Page (optional)}

Total This Period (last page this line number only) 
SCHEDULE A-P ITEMIZED RECEIPTS
Use separate schedule(s) for each category of the Detailed Summary Page
FOR LINE NUMBER: (check only one)

PAGE $590 / 1572$

\begin{tabular}{|c|c|c|c|c|c|}
\hline & & & & & \\
\hline 16 & $\begin{array}{l}\mathbf{X} \\
17 a\end{array}$ & $17 b$ & $17 c$ & $17 d$ & 18 \\
\hline $19 a$ & $19 \mathrm{~b}$ & $20 \mathrm{a}$ & $20 \mathrm{~b}$ & $20 \mathrm{c}$ & 21 \\
\hline
\end{tabular}

Any information copied from such Reports and Statements may not be sold or used by any person for the purpose of soliciting contributions or for commercial purposes, other than using the name and address of any political committee to solicit contributions from such committee.

NAME OF COMMITTEE (In Full)

\section{Friends of Herman Cain}

A. Full Name (Last, First, Middle Initial)

Ben Krohmer

Mailing Address 816 W 4th Ave

\begin{tabular}{lcc}
\hline City & State & Zip Code \\
Mitchell & SD & $57301-2407$
\end{tabular}

FEC ID number of contributing federal political committee.

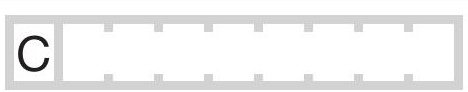

Name of Employer
Frank
Receipt For: 2012
X Primary $\quad$ Other (specify) General

\section{Occupation}

Construction

Election Cycle-to-Date

\subsection{0}

B. Full Name (Last, First, Middle Initial)

Scott L Page

Mailing Address 4578 Treeside Ct NE

\begin{tabular}{lcc}
\hline City & State & Zip Code \\
Salem & OR & $97305-2257$
\end{tabular}

FEC ID number of contributing

federal political committee.

C

Name of Employer
Information Requested
Receipt For: 2012
X Primary
Other (specify)

\section{Occupation}

Information Requested

Election Cycle-to-Date

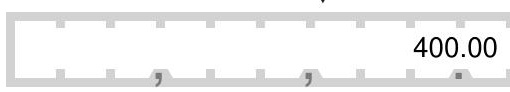

Transaction ID : A0D831F7683FE44878BD

Date of Receipt

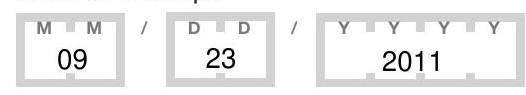

Amount of Each Receipt this Period

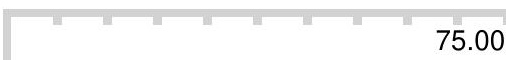

75.00

C. Full Name (Last, First, Middle Initial)

Samuel Sylvester

Mailing Address 701 S. University Blvd. Apt. 312

\begin{tabular}{lcc}
\hline City & State & Zip Code \\
Mobile & AL & $36609-7801$
\end{tabular}

FEC ID number of contributing federal political committee.

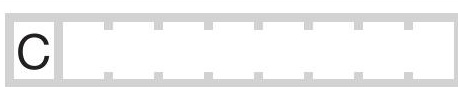

\section{Name of Employer}

The SSI Group

\section{Occupation}

R\&D Programmer

Receipt For: 2012

Х $\begin{aligned} & \text { Primary } \square \text { General } \\ & \text { Other (specify) }\end{aligned}$

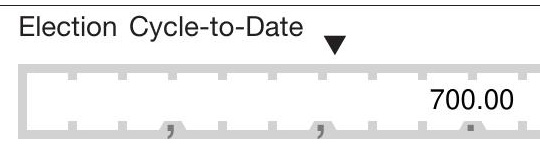

Amount of Each Receipt this Period

Transaction ID : A8A206A6408B548FB927

Date of Receipt
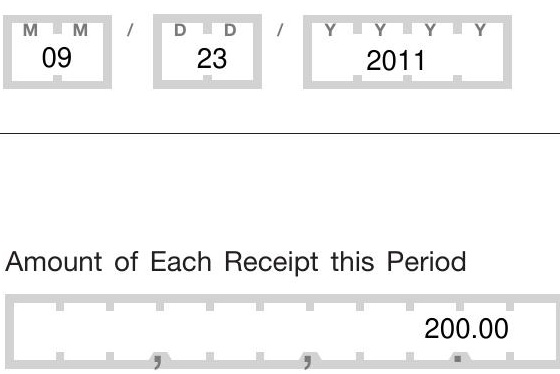

Transaction ID : AB8815209BAC94A4C877 Date of Receipt

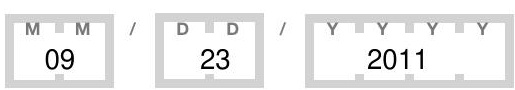

Amount of Each Receipt this Period

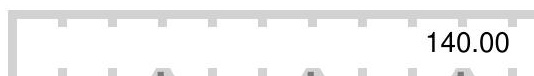

415.00

Subtotal Of Receipts This Page (optional)

Total This Period (last page this line number only) 
SCHEDULE A-P ITEMIZED RECEIPTS
Use separate schedule(s) for each category of the Detailed Summary Page
FOR LINE NUMBER: (check only one)
PAGE $591 / 1572$

\begin{tabular}{|c|c|c|c|c|c|}
\hline & & & & & \\
\hline 16 & $\begin{array}{lll}X & 17 a \\
\end{array}$ & $17 \mathrm{~b}$ & $17 c$ & $17 d$ & 18 \\
\hline $19 a$ & $19 b$ & $20 a$ & $20 \mathrm{~b}$ & $20 c$ & 21 \\
\hline
\end{tabular}

Any information copied from such Reports and Statements may not be sold or used by any person for the purpose of soliciting contributions or for commercial purposes, other than using the name and address of any political committee to solicit contributions from such committee.

NAME OF COMMITTEE (In Full)

\section{Friends of Herman Cain}

A. Full Name (Last, First, Middle Initial)

\section{Steve fish}

Mailing Address 15975 manor club dr

\begin{tabular}{lcc}
\hline City & State & Zip Code \\
Alpharetta & GA & $30004-8849$
\end{tabular}

FEC ID number of contributing federal political committee.

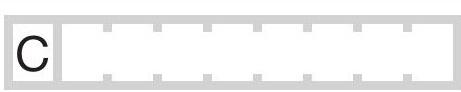

Name of Employer
dewolff boberg \& associates
Receipt For: 2012
X Primary
Other (specify) General

B. Full Name (Last, First, Middle Initial)

Nathan Moore

Mailing Address 1513 ocean breeze Ln

\begin{tabular}{lcc}
\hline City & State & Zip Code \\
Gulf Breeze & FL & $32563-9222$
\end{tabular}

FEC ID number of contributing

federal political committee.

C

Name of Employer
self
Receipt For: 2012
X Primary
Other (specify)

Occupation Consultant Election Cycle-to-Date

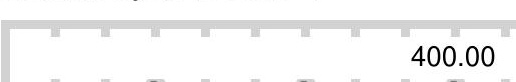

Transaction ID : A63D6744EC6314C90A3E

Date of Receipt

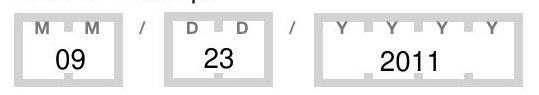

Amount of Each Receipt this Period

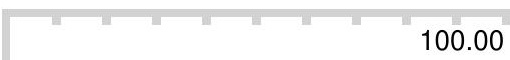

Amount of Each Receipt this Period

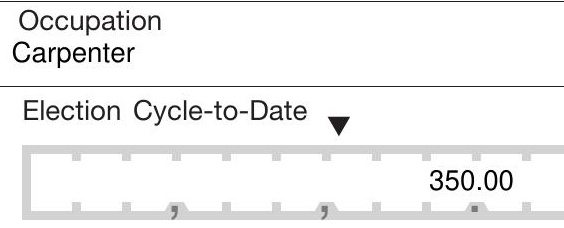

C. Full Name (Last, First, Middle Initial)

judy kapke

Mailing Address 1819 rolling river dr.

\begin{tabular}{lcc}
\hline City & State & Zip Code \\
Lilburn & GA & $30047-4520$
\end{tabular}

FEC ID number of contributing federal political committee.

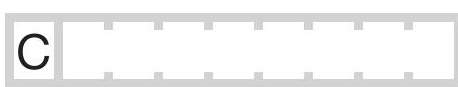

Name of Employer
Emory Healthcare
Receipt For: 2012
X Primary $\quad \square$ General
Other (specify)

\section{Occupation}

$\mathrm{RN}$

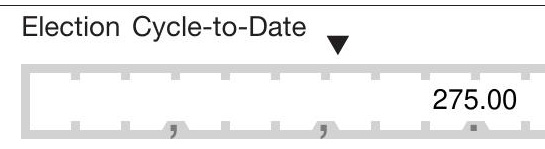

Transaction ID : AC641893AA70B47BDA7E Date of Receipt
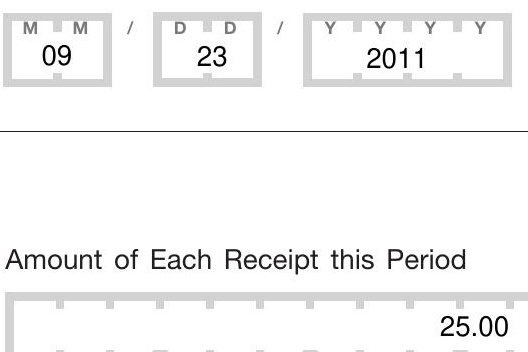

Transaction ID : A7E45C8E6E9F14514BB3 Date of Receipt

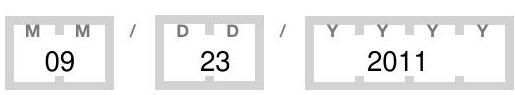

Amount of Each Receipt this Period

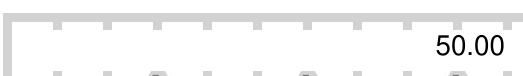

\section{Subtotal Of Receipts This Page (optional)}

Total This Period (last page this line number only) 
SCHEDULE A-P ITEMIZED RECEIPTS
Use separate schedule(s) for each category of the Detailed Summary Page
FOR LINE NUMBER: (check only one)

PAGE 592 / 1572

\begin{tabular}{|c|c|c|c|c|c|}
\hline & & & & & \\
\hline 16 & $\begin{array}{l}\mathbf{X} \\
17 a\end{array}$ & $17 b$ & $17 c$ & $17 d$ & 18 \\
\hline $19 a$ & $19 \mathrm{~b}$ & $20 \mathrm{a}$ & $20 \mathrm{~b}$ & $20 \mathrm{c}$ & 21 \\
\hline
\end{tabular}

Any information copied from such Reports and Statements may not be sold or used by any person for the purpose of soliciting contributions or for commercial purposes, other than using the name and address of any political committee to solicit contributions from such committee.

NAME OF COMMITTEE (In Full)

\section{Friends of Herman Cain}

A. Full Name (Last, First, Middle Initial)

Sharon Rodgers

Mailing Address 1447 Glenover Circle

\begin{tabular}{lcc}
\hline City & State & Zip Code \\
Marietta & GA & $30062-2151$
\end{tabular}

FEC ID number of contributing

federal political committee.

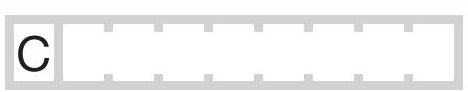

Name of Employer
Rutherfoord
Receipt For: 2012
X Primary $\quad$ General
Other (specify)

Occupation

sales/service

Election Cycle-to-Date

B. Full Name (Last, First, Middle Initial)

Robert Gruninger

Mailing Address 32 Sedgewood Rd

\begin{tabular}{lcc}
\hline City & State & Zip Code \\
Chapel Hill & NC & $27514-9235$ \\
\hline
\end{tabular}

FEC ID number of contributing

federal political committee.

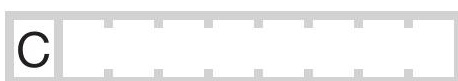

Name of Employer
Home
Receipt For: 2012
X Primary $\quad$ General
Other (specify) $\nabla$

\section{Occupation}

Retired

Election Cycle-to-Date

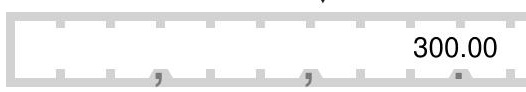

C. Full Name (Last, First, Middle Initial)

Tommy Morgan

Mailing Address 1811 McDaniel Mill Road, SW

\begin{tabular}{lcc}
\hline City & State & Zip Code \\
Conyers & GA & $30094-6023$
\end{tabular}

FEC ID number of contributing

federal political committee.

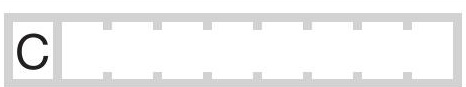

Name of Employer

Information Requested

Occupation

Information Requested

Receipt For: 2012

Х $\begin{aligned} & \text { Primary } \square \text { General } \\ & \text { Other (specify) }\end{aligned}$

450.00

Transaction ID : A8FB7CC646DAB4DF8BB4

Date of Receipt

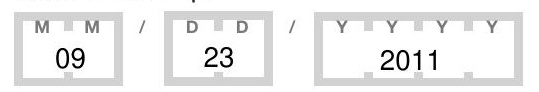

Amount of Each Receipt this Period

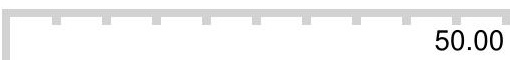

50.00

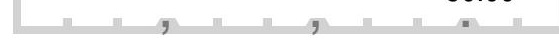

Transaction ID : ADB1BE5CBCA1F4F759BA Date of Receipt

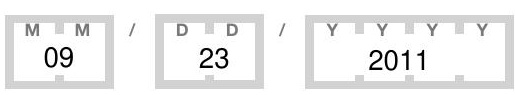

Amount of Each Receipt this Period

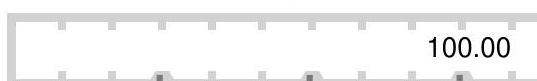

Amount of Each Receipt this Period

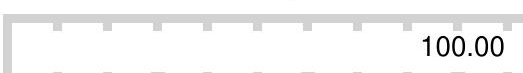

600.00

Transaction ID : ACBC75B0B0FF24DABA13 Date of Receipt

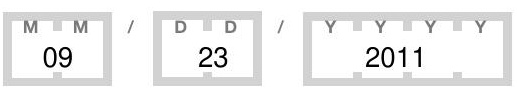

\section{Subtotal Of Receipts This Page (optional)}

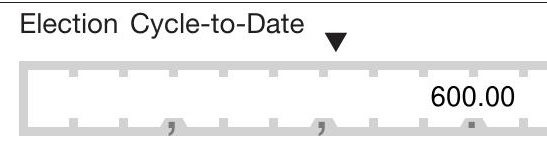

Total This Period (last page this line number only) 
SCHEDULE A-P ITEMIZED RECEIPTS
Use separate schedule(s) for each category of the Detailed Summary Page
FOR LINE NUMBER: (check only one)

PAGE $593 / 1572$

\begin{tabular}{|c|c|c|c|c|c|c|}
\hline & & & & & & \\
\hline 16 & $\lambda$ & $17 \mathrm{a}$ & $17 \mathrm{~b}$ & $17 \mathrm{c}$ & $-17 d$ & -18 \\
\hline $19 a$ & & $19 b$ & $20 a$ & $20 \mathrm{~b}$ & $20 \mathrm{c}$ & 21 \\
\hline
\end{tabular}

Any information copied from such Reports and Statements may not be sold or used by any person for the purpose of soliciting contributions or for commercial purposes, other than using the name and address of any political committee to solicit contributions from such committee.

NAME OF COMMITTEE (In Full)

\section{Friends of Herman Cain}

A. Full Name (Last, First, Middle Initial)

Connie Alyea

Mailing Address 2033 Winton Ave

\begin{tabular}{lcc}
\hline City & State & Zip Code \\
Indianapolis & IN & $46224-5627$
\end{tabular}

FEC ID number of contributing federal political committee.

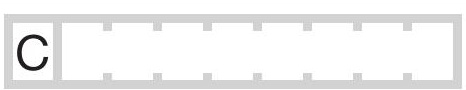

\begin{tabular}{l} 
Name of Employer \\
None \\
Receipt For: 2012 \\
X Primary $\quad$ General \\
\hline Other (specify)
\end{tabular}

Occupation

Retired

Election Cycle-to-Date

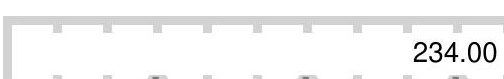

B. Full Name (Last, First, Middle Initial)

Stephen Northington

Mailing Address 1915 Landfall Pass NW

\begin{tabular}{lcc}
\hline City & State & Zip Code \\
Kennesaw & GA & $30152-7736$
\end{tabular}

FEC ID number of contributing

federal political committee.

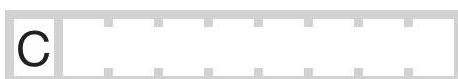

Name of Employer
Group Insurance Solutions LLC.
Receipt For: 2012
X Primary
Other (specify)

Occupation

Sales Director

Election Cycle-to-Date

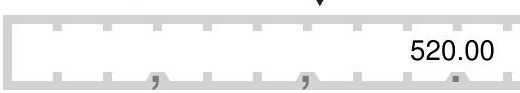

Transaction ID : A6A0887867018457CBE5

Date of Receipt

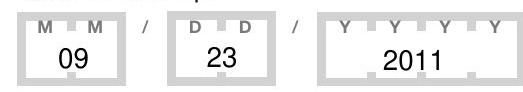

Amount of Each Receipt this Period

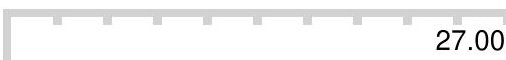

27.00

C. Full Name (Last, First, Middle Initial)

Walter Elsmore

Mailing Address 2017 Pintoresco Ct

\begin{tabular}{lcc}
\hline City & State & Zip Code \\
Carlsbad & CA & $92009-7915$
\end{tabular}

FEC ID number of contributing federal political committee.

C

Name of Employer
Picture Pocket Corporation
Receipt For: 2012
X Primary $\quad \square$ General
Other (specify)

Occupation

Manager

Election Cycle-to-Date

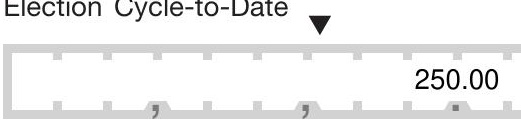

Transaction ID : AFE11902E436245B58B5

Date of Receipt

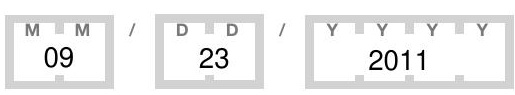

Amount of Each Receipt this Period

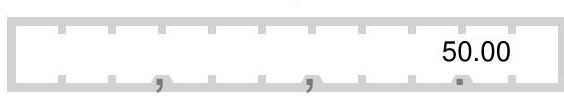

Transaction ID : AAD8A5D12645C4A078C8 Date of Receipt

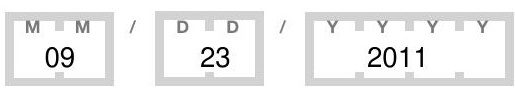

Amount of Each Receipt this Period

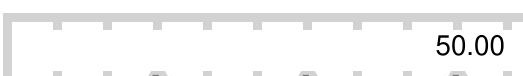

\section{Subtotal Of Receipts This Page (optional)}

Total This Period (last page this line number only) 
SCHEDULE A-P ITEMIZED RECEIPTS
Use separate schedule(s) for each category of the Detailed Summary Page
FOR LINE NUMBER: (check only one)

PAGE 594 / 1572

\begin{tabular}{|c|c|c|c|c|c|}
\hline & & & & & \\
\hline 16 & $\begin{array}{l}\mathbf{X} \\
17 a\end{array}$ & $17 b$ & $17 c$ & $17 d$ & 18 \\
\hline $19 a$ & $19 \mathrm{~b}$ & $20 \mathrm{a}$ & $20 \mathrm{~b}$ & $20 \mathrm{c}$ & 21 \\
\hline
\end{tabular}

Any information copied from such Reports and Statements may not be sold or used by any person for the purpose of soliciting contributions or for commercial purposes, other than using the name and address of any political committee to solicit contributions from such committee.

NAME OF COMMITTEE (In Full)

\section{Friends of Herman Cain}

A. Full Name (Last, First, Middle Initial)

Sarah Young

Mailing Address 204 E. Oak Cliff Ct.-Apt. 7

\begin{tabular}{lcc}
\hline City & State & Zip Code \\
Peoria & IL & $61614-6152$
\end{tabular}

FEC ID number of contributing

federal political committee.

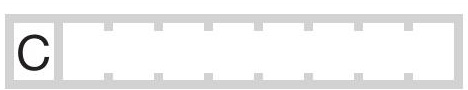

Name of Employer
Proctor Home Care
Receipt For: 2012
X Primary
$\square$ Other (specify) General

Occupation

Registered Nurse

Election Cycle-to-Date

250.00

B. Full Name (Last, First, Middle Initial)

Wayne Thomas

Mailing Address 1533 Clark Avenue

\begin{tabular}{lcc}
\hline City & State & Zip Code \\
Cottage Grove & OR & $97424-1891$
\end{tabular}

FEC ID number of contributing

federal political committee.

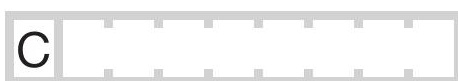

Name of Employer
PeaceHealth Laboratories
Receipt For: 2012
X Primary
Other (specify)

\section{Occupation}

courier

Election Cycle-to-Date

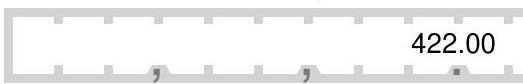

C. Full Name (Last, First, Middle Initial)

David G Stilley

Mailing Address 2 Sugar Creek Lane

\begin{tabular}{lcc}
\hline City & State & Zip Code \\
Waukee & IA & $50263-8144$
\end{tabular}

FEC ID number of contributing

federal political committee.

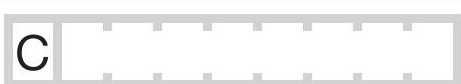

Name of Employer

Occupation

Self Employed

Physician

Receipt For: 2012

Х $\begin{aligned} & \text { Primary } \square \text { General } \\ & \text { Other (specify) }\end{aligned}$

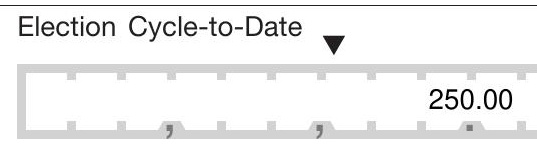

Amount of Each Receipt this Period

Transaction ID : A8BCA717066BD477A8C4

Date of Receipt

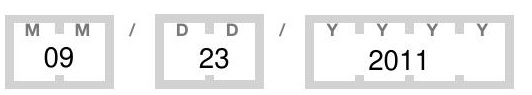

Amount of Each Receipt this Period

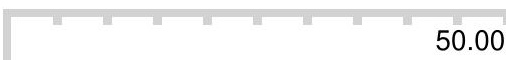

50.00

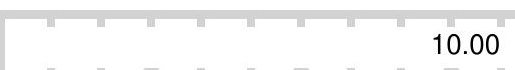

Transaction ID : A447D655AEB184BA68E2 Date of Receipt

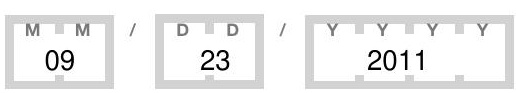

Amount of Each Receipt this Period

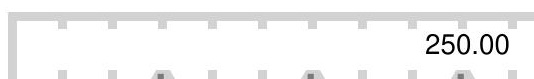

310.00

Subtotal Of Receipts This Page (optional)

Total This Period (last page this line number only) 
SCHEDULE A-P ITEMIZED RECEIPTS
Use separate schedule(s) for each category of the Detailed Summary Page
FOR LINE NUMBER: (check only one)

PAGE $595 / 1572$

\begin{tabular}{|c|c|c|c|c|c|}
\hline & & & & & \\
\hline 16 & $\begin{array}{l}\mathbf{X} \\
17 a\end{array}$ & $17 b$ & $17 c$ & $17 d$ & 18 \\
\hline $19 a$ & $19 \mathrm{~b}$ & $20 \mathrm{a}$ & $20 \mathrm{~b}$ & $20 \mathrm{c}$ & 21 \\
\hline
\end{tabular}

Any information copied from such Reports and Statements may not be sold or used by any person for the purpose of soliciting contributions or for commercial purposes, other than using the name and address of any political committee to solicit contributions from such committee.

NAME OF COMMITTEE (In Full)

\section{Friends of Herman Cain}

A. Full Name (Last, First, Middle Initial)

\section{Donald Gallo}

Mailing Address 6342 Puma Point Way

\begin{tabular}{lcc}
\hline City & State & Zip Code \\
Golden & CO & $80403-8005$
\end{tabular}

FEC ID number of contributing federal political committee.

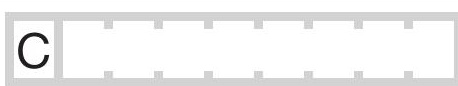

Name of Employer
Towers Watson
Receipt For: 2012
X Primary $\quad$ General
Other (specify)

Occupation

Management Consultant

Election Cycle-to-Date $\boldsymbol{\nabla}$

275.00

B. Full Name (Last, First, Middle Initial)

John Taylor

Mailing Address 92 Jackson Meadows Dr.

\begin{tabular}{lcc}
\hline City & State & Zip Code \\
Hoschton & GA & $30548-6345$
\end{tabular}

FEC ID number of contributing

federal political committee.

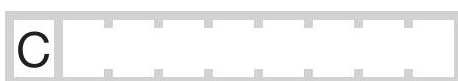

Name of Employer
Self Employed
Receipt For: 2012
X Primary
Other (specify)

\section{Occupation}

Musician

Transaction ID : AC0D325BE99CC4948AB1

Date of Receipt

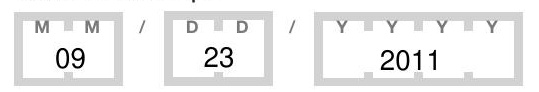

Amount of Each Receipt this Period

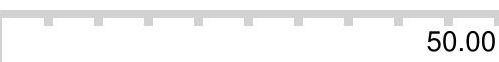

50.00
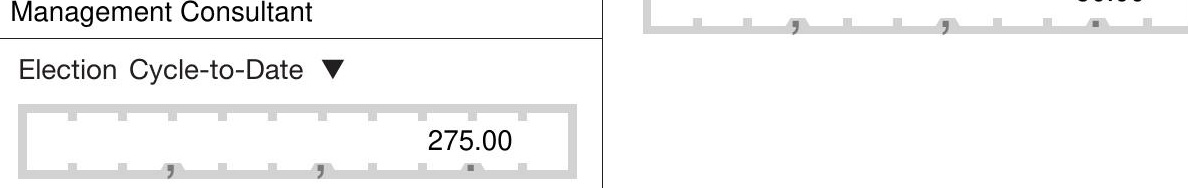

Transaction ID : A63B87C10FEE8482AB24

Date of Receipt

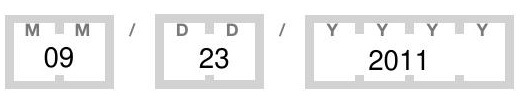

Amount of Each Receipt this Period

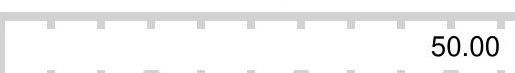

Election Cycle-to-Date

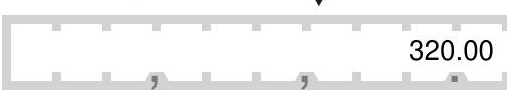

C. Full Name (Last, First, Middle Initial)

Mr Paul A Brock

Mailing Address 11 Juliana Ct

\begin{tabular}{lcc}
\hline City & State & Zip Code \\
Ellenwood & GA & $30294-2835$
\end{tabular}

FEC ID number of contributing

federal political committee.

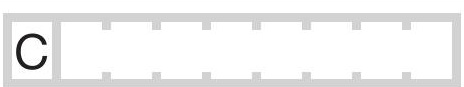

Name of Employer
None
Receipt For: 2012
X Primary $\quad$ General
Other (specify)

Occupation

Retired

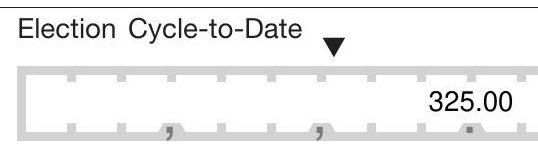

Subtotal Of Receipts This Page (optional)

125.00

Amount of Each Receipt this Period
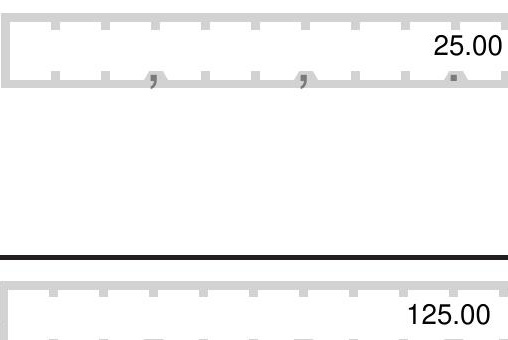

Total This Period (last page this line number only)

Transaction ID : A327262A4ECF44B3AB3F Date of Receipt

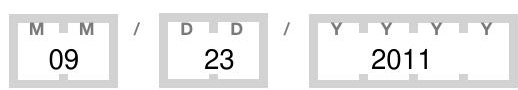

I L

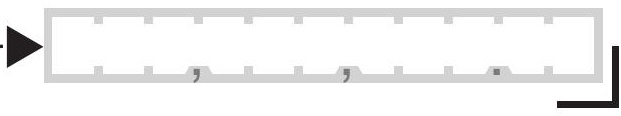


SCHEDULE A-P ITEMIZED RECEIPTS
Use separate schedule(s) for each category of the Detailed Summary Page
FOR LINE NUMBER: (check only one)

PAGE $596 / 1572$

\begin{tabular}{|c|c|c|c|c|c|}
\hline & & & & & \\
\hline 16 & $\begin{array}{l}\mathbf{X} \\
17 a\end{array}$ & $17 b$ & $17 c$ & $17 d$ & 18 \\
\hline $19 a$ & $19 \mathrm{~b}$ & $20 \mathrm{a}$ & $20 \mathrm{~b}$ & $20 \mathrm{c}$ & 21 \\
\hline
\end{tabular}

Any information copied from such Reports and Statements may not be sold or used by any person for the purpose of soliciting contributions or for commercial purposes, other than using the name and address of any political committee to solicit contributions from such committee.

NAME OF COMMITTEE (In Full)

\section{Friends of Herman Cain}

A. Full Name (Last, First, Middle Initial)

Kimberly Nelson

Mailing Address 5017 Granite Shoals Ave.

\begin{tabular}{lcc}
\hline City & State & Zip Code \\
Fort Worth & TX & $76103-1213$
\end{tabular}

FEC ID number of contributing federal political committee.

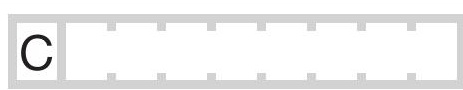

Name of Employer
Information Requested
Receipt For: 2012
X Primary
Other (specify) General

Occupation Information Requested

Election Cycle-to-Date

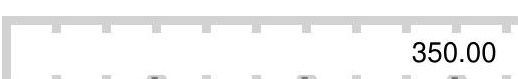

B. Full Name (Last, First, Middle Initial) charles murphy

Mailing Address 299 cherokee drive

\begin{tabular}{lcc}
\hline City & State & Zip Code \\
Harrisburg & IL & $62946-3798$ \\
\hline
\end{tabular}

FEC ID number of contributing

federal political committee.

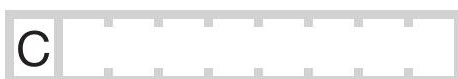

Name of Employer
murphy homes inc
Receipt For: 2012
Primary
Other (specify) General

\section{Occupation} homebuilder

Election Cycle-to-Date

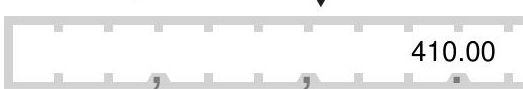

Transaction ID : A7D942B8301A94A66B45

Date of Receipt

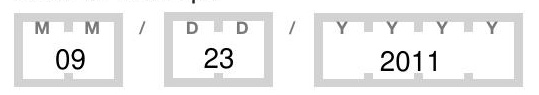

Amount of Each Receipt this Period

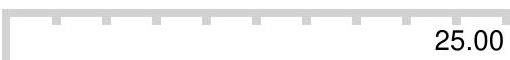

25.00

C. Full Name (Last, First, Middle Initial)

Mrs. Barbara C. Mathews

Mailing Address 2367 LAvista Road

\begin{tabular}{lcc}
\hline City & State & Zip Code \\
Atlanta & GA & $30329-3346$
\end{tabular}

FEC ID number of contributing federal political committee.

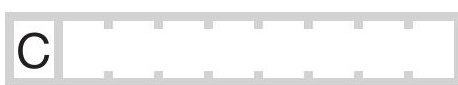

Name of Employer
None
Receipt For: 2012
Х Primary $\quad \square$ General
Other (specify)

Occupation

Retired

Election Cycle-to-Date

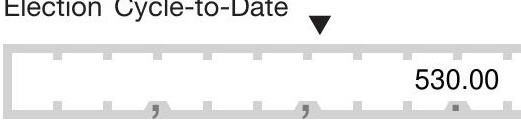

Transaction ID : A81B3BDF9C31140C6B60

Date of Receipt

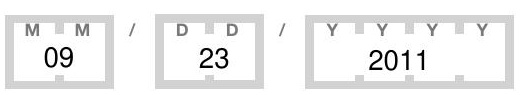

Amount of Each Receipt this Period

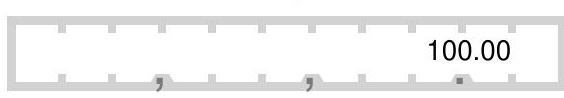

Transaction ID : ACC61FAFE6D554022933 Date of Receipt

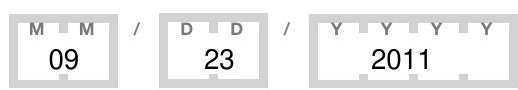

Amount of Each Receipt this Period

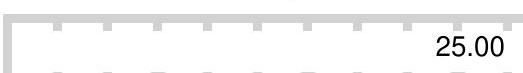

\section{Subtotal Of Receipts This Page (optional)}

Total This Period (last page this line number only) 
SCHEDULE A-P ITEMIZED RECEIPTS
Use separate schedule(s) for each category of the Detailed Summary Page
FOR LINE NUMBER: (check only one)

PAGE $597 / 1572$

\begin{tabular}{|c|c|c|c|c|c|}
\hline & & & & & \\
\hline 16 & $\begin{array}{l}\mathbf{X} \\
17 a\end{array}$ & $17 b$ & $17 c$ & $17 d$ & 18 \\
\hline $19 a$ & $19 \mathrm{~b}$ & $20 \mathrm{a}$ & $20 \mathrm{~b}$ & $20 \mathrm{c}$ & 21 \\
\hline
\end{tabular}

Any information copied from such Reports and Statements may not be sold or used by any person for the purpose of soliciting contributions or for commercial purposes, other than using the name and address of any political committee to solicit contributions from such committee.

NAME OF COMMITTEE (In Full)

\section{Friends of Herman Cain}

A. Full Name (Last, First, Middle Initial)

\section{Don Deal}

Mailing Address 238 Midvale Drive NE

\begin{tabular}{lcc}
\hline City & State & Zip Code \\
Atlanta & GA & $30342-3327$
\end{tabular}

FEC ID number of contributing federal political committee.

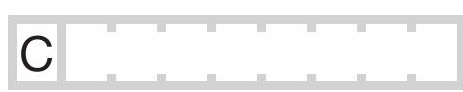

Name of Employer
Delphix
Receipt For: 2012
X Primary $\quad$ General
Other (specify)

B. Full Name (Last, First, Middle Initial)

Charles Rinek

Mailing Address 50 Cypress point Parkway Suite A-1

\begin{tabular}{lcc}
\hline City & State & Zip Code \\
Palm Coast & FL & $32164-2501$
\end{tabular}

FEC ID number of contributing

federal political committee.

C

Name of Employer

Charles Rinek Construction Inc.

Receipt For: 2012

X Primary $\square$ General Other (specify)
Occupation

Software Engineer

Election Cycle-to-Date
Occupation

General Contractor

Election Cycle-to-Date

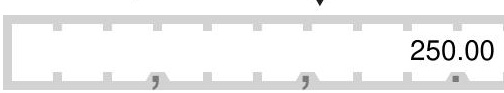

Transaction ID : A24190C67506F49F08CF

Date of Receipt

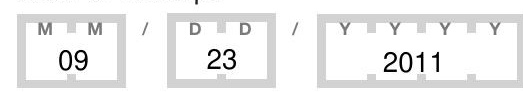

Amount of Each Receipt this Period

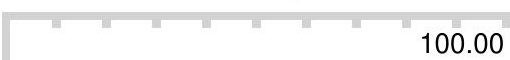

\subsection{0}

C. Full Name (Last, First, Middle Initial)

Darin Kohles

Mailing Address 21410 SE Hwy 224

\begin{tabular}{lcc}
\hline City & State & Zip Code \\
Damascus & OR & $97089-7825$
\end{tabular}

FEC ID number of contributing federal political committee.

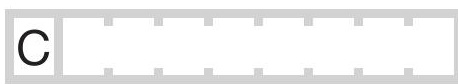

Name of Employer

Information Requested

250.00

Receipt For: 2012

Х $\begin{aligned} & \text { Primary } \square \text { General } \\ & \text { Other (specify) }\end{aligned}$

Occupation

Information Requested

Election Cycle-to-Date

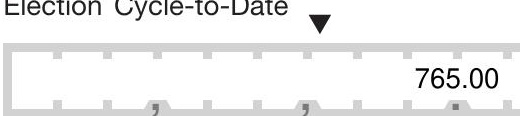

Transaction ID : A7CBA8EA4D531436F92A

Date of Receipt

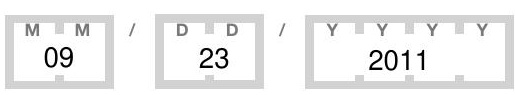

Amount of Each Receipt this Period

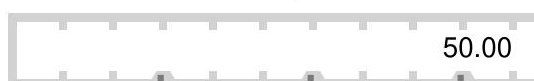

Transaction ID : AED5628632CA749FD867 Date of Receipt

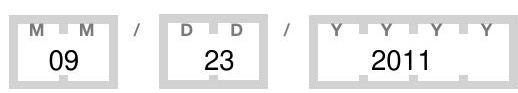

Amount of Each Receipt this Period

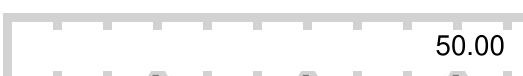

50.00

\section{Subtotal Of Receipts This Page (optional)}

200.00

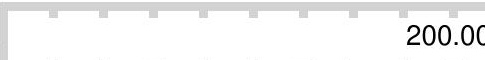

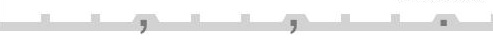

Total This Period (last page this line number only)

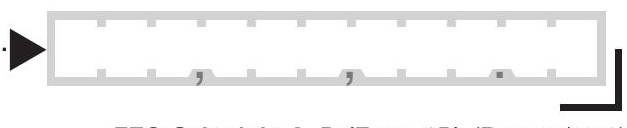

FEC Schedule A-P (Form 3P) (Rev. 03/2011) 
SCHEDULE A-P ITEMIZED RECEIPTS
Use separate schedule(s) for each category of the Detailed Summary Page
FOR LINE NUMBER: (check only one)

PAGE $598 / 1572$

\begin{tabular}{|c|c|c|c|c|c|}
\hline & & & & & \\
\hline 16 & $\begin{array}{l}\mathbf{X} \\
17 a\end{array}$ & $17 b$ & $17 c$ & $17 d$ & 18 \\
\hline $19 a$ & $19 \mathrm{~b}$ & $20 \mathrm{a}$ & $20 \mathrm{~b}$ & $20 \mathrm{c}$ & 21 \\
\hline
\end{tabular}

Any information copied from such Reports and Statements may not be sold or used by any person for the purpose of soliciting contributions or for commercial purposes, other than using the name and address of any political committee to solicit contributions from such committee.

NAME OF COMMITTEE (In Full)

\section{Friends of Herman Cain}

A. Full Name (Last, First, Middle Initial) Joseph Kassler

Mailing Address 4810 Smokey Rd

\begin{tabular}{lcc}
\hline City & State & Zip Code \\
Newnan & GA & $30263-4941$
\end{tabular}

FEC ID number of contributing federal political committee.

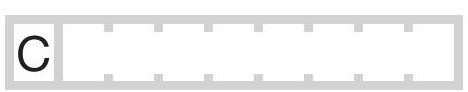

Name of Employer
Level 5
Receipt For: 2012
X Primary $\quad$ General
Other (specify)

Occupation

Own a Business

Election Cycle-to-Date

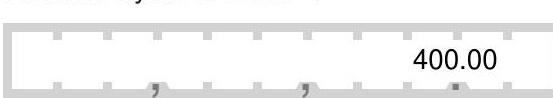

B. Full Name (Last, First, Middle Initial)

Patricia Dabbs

Mailing Address 1406 Reidsboro Rd

\begin{tabular}{lcc}
\hline City & State & Zip Code \\
Williamson & GA & $30292-3463$ \\
\hline
\end{tabular}

FEC ID number of contributing

federal political committee.

C

Name of Employer
Information Requested
Receipt For: 2012
Xrimary
Other (specify)

Occupation

Information Requested

Election Cycle-to-Date

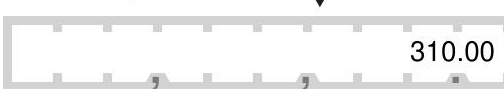

Transaction ID : A3C09F5DF2C794AA98DB

Date of Receipt

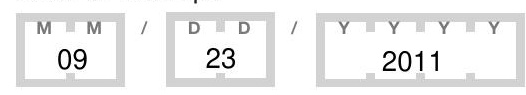

Amount of Each Receipt this Period

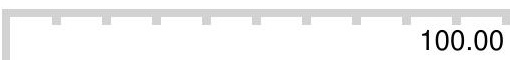

Transaction ID : AAF8BAB1A414C403EA9F Date of Receipt

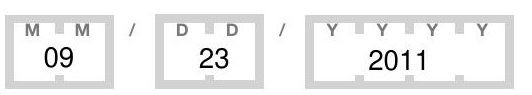

Amount of Each Receipt this Period

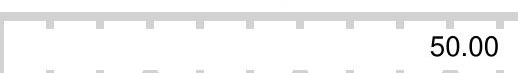

Transaction ID : A828EFF786E63447EB84 Date of Receipt

Andrea Infinger

Mailing Address 2442 Josh Court

\begin{tabular}{lcc}
\hline City & State & Zip Code \\
Marietta & GA & $30064-4531$
\end{tabular}

FEC ID number of contributing federal political committee.

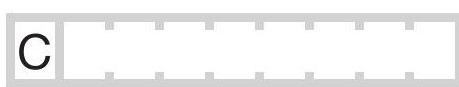

Name of Employer

Software Paradigms International

\section{Occupation}

Accountant

Receipt For: 2012

Х $\begin{aligned} & \text { Primary } \square \text { General } \\ & \text { Other (specify) }\end{aligned}$

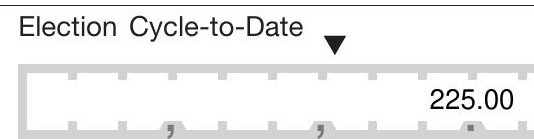

Amount of Each Receipt this Period

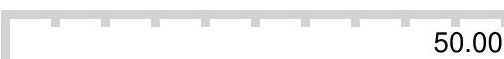

Subtotal Of Receipts This Page (optional)

200.00

(I)

Total This Period (last page this line number only)

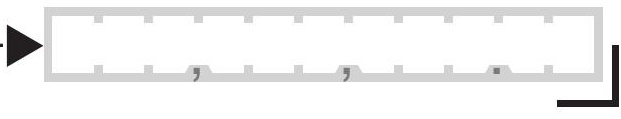

FEC Schedule A-P (Form 3P) (Rev. 03/2011) 
SCHEDULE A-P ITEMIZED RECEIPTS
Use separate schedule(s) for each category of the Detailed Summary Page
FOR LINE NUMBER: (check only one)

PAGE 599 / 1572

\begin{tabular}{|c|c|c|c|c|c|}
\hline & & & & & \\
\hline 16 & $\begin{array}{l}\mathbf{X} \\
17 a\end{array}$ & $17 b$ & $17 c$ & $17 d$ & 18 \\
\hline $19 a$ & $19 \mathrm{~b}$ & $20 \mathrm{a}$ & $20 \mathrm{~b}$ & $20 \mathrm{c}$ & 21 \\
\hline
\end{tabular}

Any information copied from such Reports and Statements may not be sold or used by any person for the purpose of soliciting contributions or for commercial purposes, other than using the name and address of any political committee to solicit contributions from such committee.

NAME OF COMMITTEE (In Full)

\section{Friends of Herman Cain}

A. Full Name (Last, First, Middle Initial) James Reardon

Mailing Address 414 Country Village Dr.

\begin{tabular}{lcc}
\hline City & State & Zip Code \\
Smyrna & TN & $37167-5571$
\end{tabular}

FEC ID number of contributing federal political committee.

C

Name of Employer

Occupation

Alive Hospice Inc

Registered Nurse

Receipt For: 2012

Х $\begin{aligned} & \text { Primary } \\ & \text { Other (specify) }\end{aligned}$

Election Cycle-to-Date

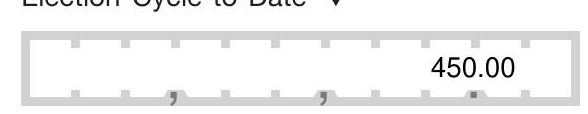

B. Full Name (Last, First, Middle Initial)

Toby Nelson

Mailing Address 811 2nd Street

\begin{tabular}{lcc}
\hline City & State & Zip Code \\
Milford & NE & $68405-9609$
\end{tabular}

FEC ID number of contributing

federal political committee.

C

Name of Employer
Nelson Contracting LLC
Receipt For: 2012
X Primary
Other (specify)

Occupation

contractor

Election Cycle-to-Date

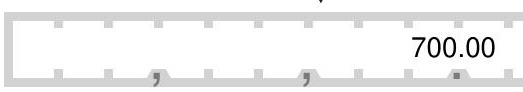

Transaction ID : AC89A3C67E95F439DA61

Date of Receipt

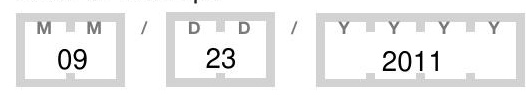

Amount of Each Receipt this Period

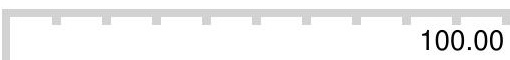

Transaction ID : A3F77561007734EFAA4E

Date of Receipt

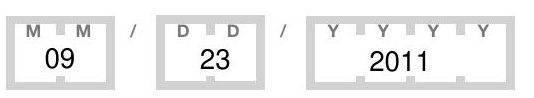

Amount of Each Receipt this Period

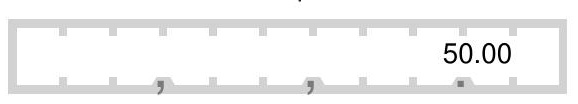

Transaction ID : ACCFF4FD1CB634989BB3 Date of Receipt

Mike Judge

Mailing Address po box 87

\begin{tabular}{lcc}
\hline City & State & Zip Code \\
Marshalltown & IA & $50158-0087$
\end{tabular}

FEC ID number of contributing federal political committee.

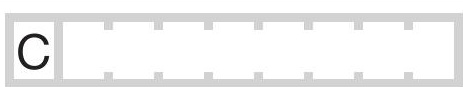

Name of Employer
klootwyk ph
Receipt For: 2012
X Primary
Other (specify) General

\section{Occupation}

plumber

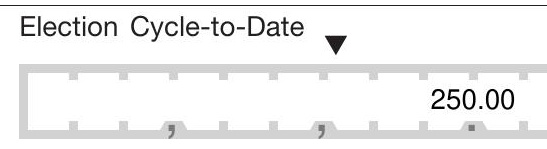

Subtotal Of Receipts This Page (optional).

$-200.00$

Total This Period (last page this line number only)
Amount of Each Receipt this Period

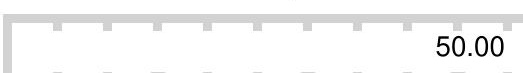

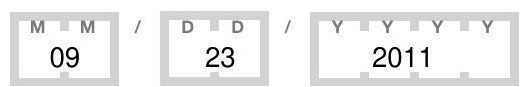

, 
SCHEDULE A-P ITEMIZED RECEIPTS
Use separate schedule(s) for each category of the Detailed Summary Page
FOR LINE NUMBER: (check only one)

PAGE $600 / 1572$

\begin{tabular}{|c|c|c|c|c|c|}
\hline & & & & & \\
\hline 16 & $\begin{array}{l}\mathbf{X} \\
17 a\end{array}$ & $17 b$ & $17 c$ & $17 d$ & 18 \\
\hline $19 a$ & $19 \mathrm{~b}$ & $20 \mathrm{a}$ & $20 \mathrm{~b}$ & $20 \mathrm{c}$ & 21 \\
\hline
\end{tabular}

Any information copied from such Reports and Statements may not be sold or used by any person for the purpose of soliciting contributions or for commercial purposes, other than using the name and address of any political committee to solicit contributions from such committee.

NAME OF COMMITTEE (In Full)

\section{Friends of Herman Cain}

A. Full Name (Last, First, Middle Initial)

\section{Leann L Davis}

Mailing Address 602 W 4th St

\begin{tabular}{lcc}
\hline City & State & Zip Code \\
Delavan & IL & $61734-9689$ \\
\hline
\end{tabular}

FEC ID number of contributing federal political committee.

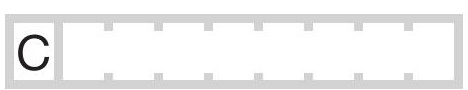

Name of Employer
self
Receipt For: 2012
X Primary $\quad$ General
Other (specify)

\section{Occupation} landscape designer

Election Cycle-to-Date 465.00

B. Full Name (Last, First, Middle Initial)

Mr. Thomas $\mathrm{H}$. Jones

Mailing Address 2301 Knollwood Dr.

\begin{tabular}{lcc}
\hline City & State & Zip Code \\
Leesburg & FL & $34748-9561$ \\
\hline
\end{tabular}

FEC ID number of contributing

federal political committee.

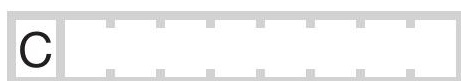

Name of Employer
Leesburg-Ocala Heart
Receipt For: 2012
X Primary
Other (specify)

Occupation

Physician Assistant

Election Cycle-to-Date

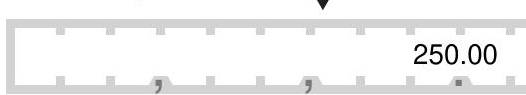

Transaction ID : A47B504B68F1240E38AB

Date of Receipt

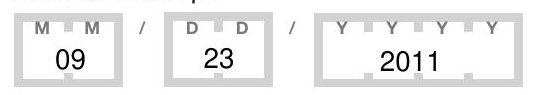

Amount of Each Receipt this Period

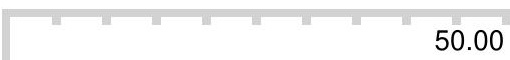

50.00

C. Full Name (Last, First, Middle Initial)

Patrick Berry

Mailing Address 7632 N La Cholla Blvd

\begin{tabular}{lcc}
\hline City & State & Zip Code \\
Tucson & AZ & $85741-4201$
\end{tabular}

FEC ID number of contributing federal political committee.

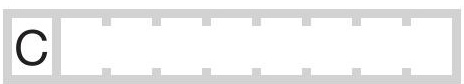

Name of Employer
Information Requested
Receipt For: 2012
X Primary $\quad \square$ General
Other (specify)

\section{Occupation}

Information Requested

Election Cycle-to-Date

Transaction ID : A99776CF350CC4069B80

Date of Receipt

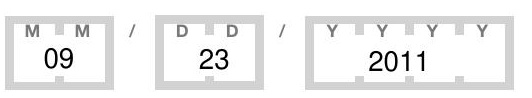

Amount of Each Receipt this Period

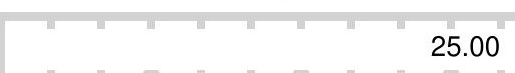

Transaction ID : AD8743717A8C647E3898

Date of Receipt

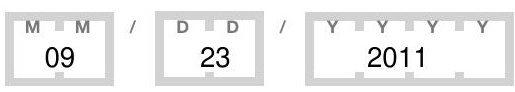

Amount of Each Receipt this Period

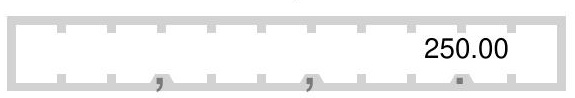

250.00

\section{Subtotal Of Receipts This Page (optional)}

Total This Period (last page this line number only) 


\section{SCHEDULE A-P} ITEMIZED RECEIPTS
Use separate schedule(s) for each category of the Detailed Summary Page

\begin{tabular}{|c|c|c|c|c|c|}
\hline \multicolumn{3}{|c|}{$\begin{array}{l}\text { FOR LINE NUMBER: } \\
\text { (check only one) }\end{array}$} & \multicolumn{3}{|c|}{ PAGE $601 / 1572$} \\
\hline 16 & $X$ 17a & $17 b$ & $17 c$ & $17 d$ & 18 \\
\hline $19 a$ & $19 \mathrm{~b}$ & $20 a$ & $20 \mathrm{~b}$ & $20 c$ & 21 \\
\hline
\end{tabular}

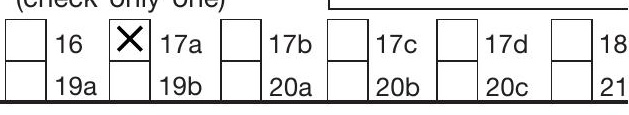

Any information copied from such Reports and Statements may not be sold or used by any person for the purpose of soliciting contributions or for commercial purposes, other than using the name and address of any political committee to solicit contributions from such committee.

NAME OF COMMITTEE (In Full)

\section{Friends of Herman Cain}

A. Full Name (Last, First, Middle Initial)

Kelly Holloway

Mailing Address 3610 31st Street

\begin{tabular}{lcc}
\hline City & State & Zip Code \\
Lubbock & TX & $79410-2735$ \\
\hline
\end{tabular}

FEC ID number of contributing federal political committee.

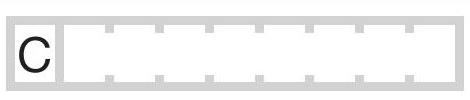

Name of Employer
Hawkeye Road Boring
Receipt For: 2012
X Primary
$\square$ Other (specify)

Occupation Construction

Election Cycle-to-Date 290.00

B. Full Name (Last, First, Middle Initial) Roger Givens

Mailing Address 3814 Crescent Ridge Ct

\begin{tabular}{lcc}
\hline City & State & Zip Code \\
Maryville & TN & $37804-3802$
\end{tabular}

FEC ID number of contributing

federal political committee.

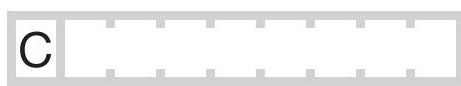

Name of Employer
Retired
Receipt For: 2012
X Primary
Other (specify)

\section{Occupation} reired

Election Cycle-to-Date

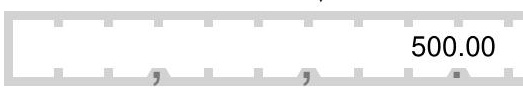

C. Full Name (Last, First, Middle Initial)

Anthony Babiak

Mailing Address 3415 E Barrington Dr

\begin{tabular}{lcc}
\hline City & State & Zip Code \\
Orange & CA & $92869-2579$
\end{tabular}

FEC ID number of contributing federal political committee.

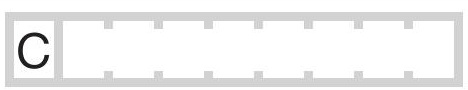

Name of Employer
V \& M Plating Co
Receipt For: 2012
X Primary
Other (specify) General

Occupation

Corp. Executive

Election Cycle-to-Date

Transaction ID : A5214A1FB48B24385AF2

Date of Receipt

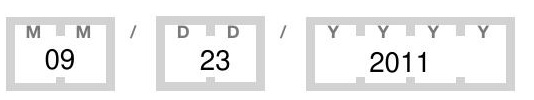

Amount of Each Receipt this Period

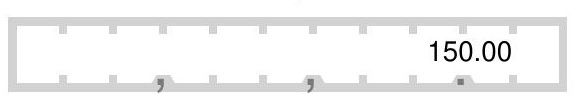

Amount of Each Receipt this Period

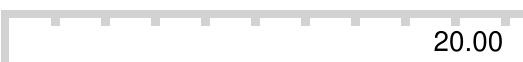

0.00

Date of Receipt

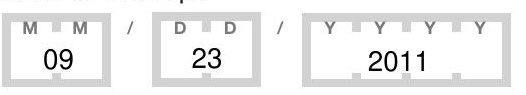

809 
SCHEDULE A-P ITEMIZED RECEIPTS
Use separate schedule(s) for each category of the Detailed Summary Page
FOR LINE NUMBER: (check only one)

PAGE 602 / 1572

\begin{tabular}{|c|c|c|c|c|c|}
\hline & & & & & \\
\hline 16 & $\begin{array}{l}\mathbf{X} \\
17 a\end{array}$ & $17 b$ & $17 c$ & $17 d$ & 18 \\
\hline $19 a$ & $19 \mathrm{~b}$ & $20 \mathrm{a}$ & $20 \mathrm{~b}$ & $20 \mathrm{c}$ & 21 \\
\hline
\end{tabular}

Any information copied from such Reports and Statements may not be sold or used by any person for the purpose of soliciting contributions or for commercial purposes, other than using the name and address of any political committee to solicit contributions from such committee.

NAME OF COMMITTEE (In Full)

\section{Friends of Herman Cain}

A. Full Name (Last, First, Middle Initial)

\section{Eric Rhodus}

Mailing Address 25145 Merchant Road

\begin{tabular}{lcc}
\hline City & State & Zip Code \\
Denham Springs & LA & $70726-6833$ \\
\hline
\end{tabular}

FEC ID number of contributing federal political committee.

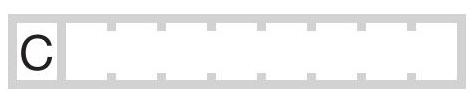

Name of Employer
Information Requested
Receipt For: 2012
X Primary
Other (specify) General

Occupation Information Requested

Election Cycle-to-Date

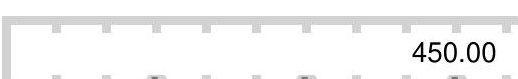

B. Full Name (Last, First, Middle Initial) steven miller

Mailing Address 6200 bradford hills dr

\begin{tabular}{lcc}
\hline City & State & Zip Code \\
Nashville & TN & $37211-7921$
\end{tabular}

FEC ID number of contributing

federal political committee.

C

Name of Employer
pharmmd
Receipt For: 2012
X Primary
Other (specify) General

Occupation

Pharmacist

Election Cycle-to-Date

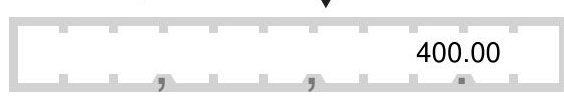

Transaction ID : AB5B67EBB8BA8471A9B2

Date of Receipt

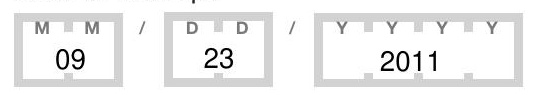

Amount of Each Receipt this Period

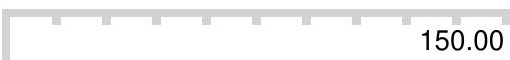

150.00

C. Full Name (Last, First, Middle Initial)

Tom Brown

Mailing Address 1566 Ridley Road

\begin{tabular}{lcc}
\hline City & State & Zip Code \\
Dahlonega & GA & $30533-1972$
\end{tabular}

FEC ID number of contributing federal political committee.

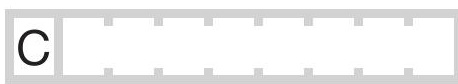

Name of Employer
None
Receipt For: 2012
Х Primary $\quad \square$ General
Other (specify)

Occupation

Retired

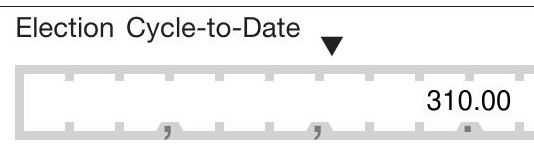

Transaction ID : A86AE48037EB24B0F9E2

Date of Receipt

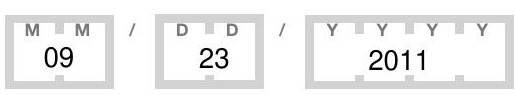

Amount of Each Receipt this Period

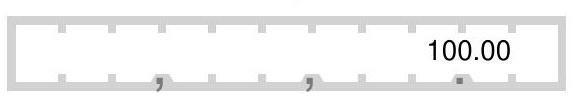

Transaction ID : A950D05CF43BE4BEE82A Date of Receipt

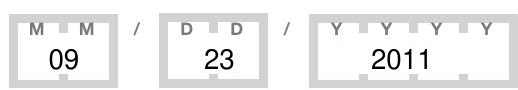

Amount of Each Receipt this Period

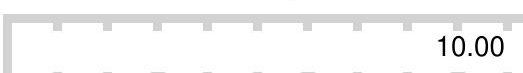

\section{Subtotal Of Receipts This Page (optional)}

Total This Period (last page this line number only) 
SCHEDULE A-P ITEMIZED RECEIPTS
Use separate schedule(s) for each category of the Detailed Summary Page
FOR LINE NUMBER: (check only one)

PAGE $603 / 1572$

\begin{tabular}{|c|c|c|c|c|c|c|}
\hline & & & & & & \\
\hline 16 & $\lambda$ & $17 \mathrm{a}$ & $17 \mathrm{~b}$ & $17 \mathrm{c}$ & $-17 d$ & -18 \\
\hline $19 a$ & & $19 b$ & $20 a$ & $20 \mathrm{~b}$ & $20 \mathrm{c}$ & 21 \\
\hline
\end{tabular}

Any information copied from such Reports and Statements may not be sold or used by any person for the purpose of soliciting contributions or for commercial purposes, other than using the name and address of any political committee to solicit contributions from such committee.

NAME OF COMMITTEE (In Full)

\section{Friends of Herman Cain}

A. Full Name (Last, First, Middle Initial)

\section{David Morris}

Mailing Address 7921 E 46th Street

\begin{tabular}{lcc}
\hline City & State & Zip Code \\
Indianapolis & IN & $46226-3931$
\end{tabular}

FEC ID number of contributing federal political committee.

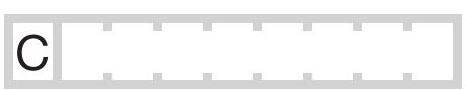

Name of Employer
Precision Dry Wall Inc.
Receipt For: 2012
X Primary $\quad \square$ General
Other (specify)

Occupation Construction

Election Cycle-to-Date

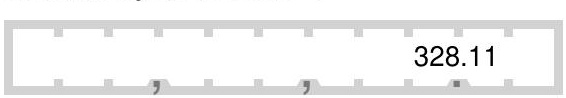

B. Full Name (Last, First, Middle Initial)

Col Jack Carmichael

Mailing Address 8101 Quebec Dr

\begin{tabular}{lcc}
\hline City & State & Zip Code \\
San Antonio & TX & $78239-3010$
\end{tabular}

FEC ID number of contributing

federal political committee.

C

Name of Employer
Information Requested
Receipt For: 2012
Primary
Other (specify)

C. Full Name (Last, First, Middle Initial)

Susan Sewald

Mailing Address 25025 E 4th PI

\begin{tabular}{lcc}
\hline City & State & Zip Code \\
Aurora & CO & $80018-1687$
\end{tabular}

FEC ID number of contributing federal political committee.

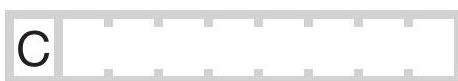

Name of Employer
Information Requested
Receipt For: 2012
X Primary $\quad \square$ General
Other (specify)

\section{Occupation}

Information Requested

Election Cycle-to-Date

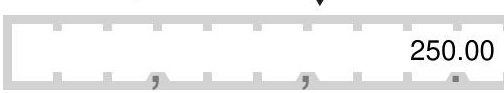

Transaction ID : A06766130F8184D17AA6

Date of Receipt

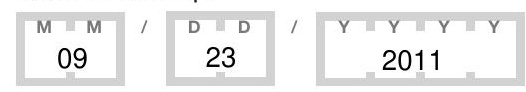

Amount of Each Receipt this Period

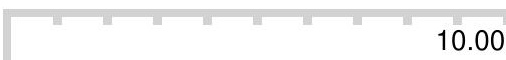

10.00

Transaction ID : A2A99D4731D254DB4BDB

Date of Receipt

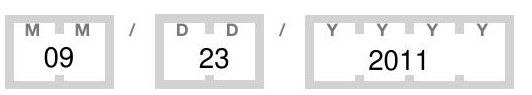

Amount of Each Receipt this Period

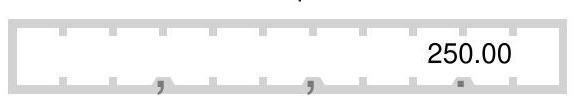

Transaction ID : AEAE96B8618F140CCBFB Date of Receipt

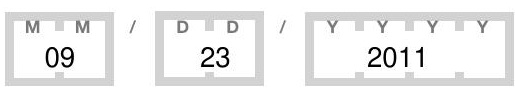

Amount of Each Receipt this Period

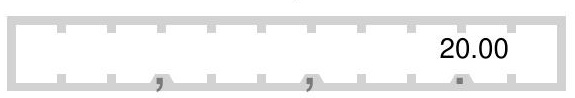

Subtotal Of Receipts This Page (optional)

$-\quad 280.00$

Total This Period (last page this line number only)

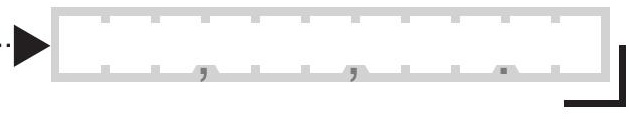

FEC Schedule A-P (Form 3P) (Rev. 03/2011) 
SCHEDULE A-P ITEMIZED RECEIPTS
Use separate schedule(s) for each category of the Detailed Summary Page
FOR LINE NUMBER: (check only one)

PAGE 604 / 1572

\begin{tabular}{|c|c|c|c|c|c|}
\hline & & & & & \\
\hline 16 & $\begin{array}{l}\mathbf{X} \\
17 a\end{array}$ & $17 b$ & $17 c$ & $17 d$ & 18 \\
\hline $19 a$ & $19 \mathrm{~b}$ & $20 \mathrm{a}$ & $20 \mathrm{~b}$ & $20 \mathrm{c}$ & 21 \\
\hline
\end{tabular}

Any information copied from such Reports and Statements may not be sold or used by any person for the purpose of soliciting contributions or for commercial purposes, other than using the name and address of any political committee to solicit contributions from such committee.

NAME OF COMMITTEE (In Full)

\section{Friends of Herman Cain}

A. Full Name (Last, First, Middle Initial) Janet Campfield

Mailing Address 8652 Enramada Ave

\begin{tabular}{lcc}
\hline City & State & Zip Code \\
Whittier & CA & $90605-1144$
\end{tabular}

FEC ID number of contributing federal political committee.

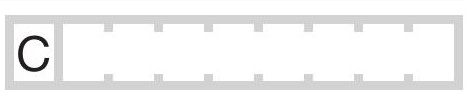

Name of Employer
None
Receipt For: 2012
X Primary $\quad$ General
$\quad$ Other (specify)

Occupation Retired

Election Cycle-to-Date

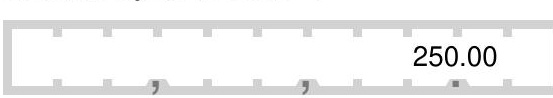

B. Full Name (Last, First, Middle Initial)

Thomas Sawyer

Mailing Address 100 Brassy Ct

\begin{tabular}{lcc}
\hline City & State & Zip Code \\
Cumming & GA & 30041 \\
\hline
\end{tabular}

FEC ID number of contributing

federal political committee.

C

Name of Employer
Information Requested
Receipt For: 2012
X Primary
Other (specify)

\begin{tabular}{l}
$\begin{array}{c}\text { Occupation } \\
\text { Information Requested } \\
\text { Election Cycle-to-Date }\end{array}$ \\
\hline
\end{tabular}

C. Full Name (Last, First, Middle Initial)

Mary Cook

Mailing Address 3235 Willow Branch Circle

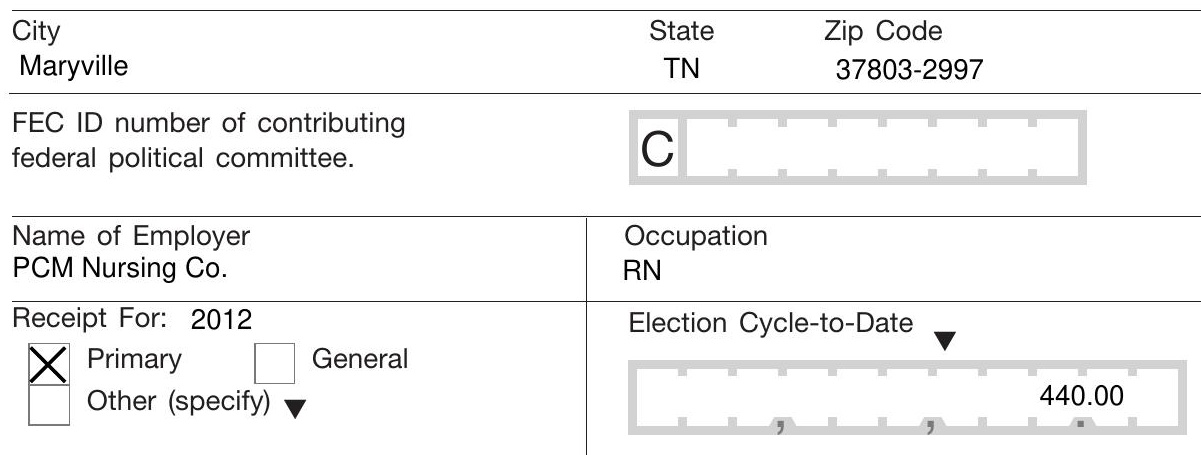

Subtotal Of Receipts This Page (optional)

Amount of Each Receipt this Period

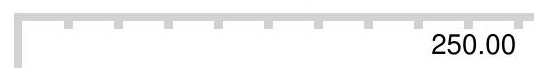

Amount of Each Receipt this Period

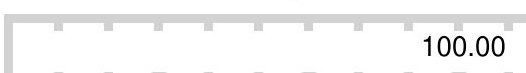

Amount of Each Receipt this Period

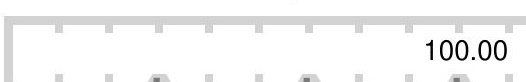

Transaction ID : ADD6523482CB24A6A851 Date of Receipt
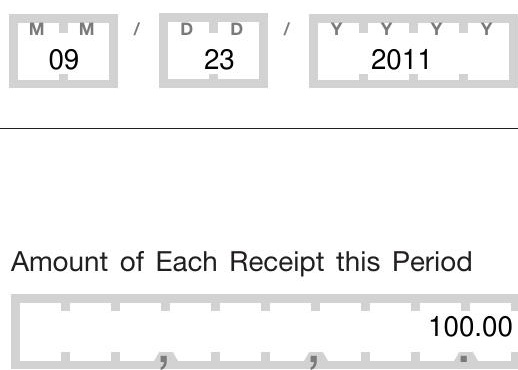

Total This Period (last page this line number only)

450.00

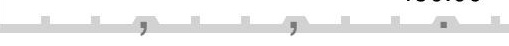

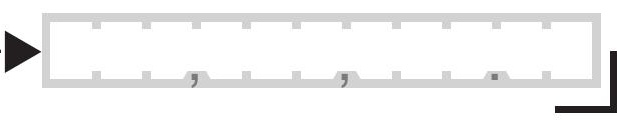

FEC Schedule A-P (Form 3P) (Rev. 03/2011) 
SCHEDULE A-P ITEMIZED RECEIPTS
Use separate schedule(s) for each category of the Detailed Summary Page
FOR LINE NUMBER: (check only one)

PAGE $605 / 1572$

\begin{tabular}{|c|c|c|c|c|c|}
\hline & & & & & \\
\hline 16 & $\begin{array}{l}\mathbf{X} \\
17 a\end{array}$ & $17 b$ & $17 c$ & $17 d$ & 18 \\
\hline $19 a$ & $19 \mathrm{~b}$ & $20 \mathrm{a}$ & $20 \mathrm{~b}$ & $20 \mathrm{c}$ & 21 \\
\hline
\end{tabular}

Any information copied from such Reports and Statements may not be sold or used by any person for the purpose of soliciting contributions or for commercial purposes, other than using the name and address of any political committee to solicit contributions from such committee.

NAME OF COMMITTEE (In Full)

\section{Friends of Herman Cain}

A. Full Name (Last, First, Middle Initial)

Robert Jones

Mailing Address 5600 Trail Blvd Ste 5

\begin{tabular}{lcc}
\hline City & State & Zip Code \\
Naples & FL & $34108-2860$ \\
\hline
\end{tabular}

FEC ID number of contributing

federal political committee.

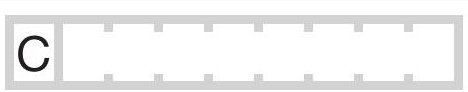

Name of Employer
Information Requested
Receipt For: 2012
X Primary $\quad \square$ General
Other (specify)

Occupation

Information Requested

Election Cycle-to-Date

1500.00

B. Full Name (Last, First, Middle Initial)

Stanley Weiner

Mailing Address 3028 Big Green Ln

\begin{tabular}{lcc}
\hline City & State & Zip Code \\
Las Vegas & NV & 89134-7454 \\
\hline
\end{tabular}

FEC ID number of contributing

federal political committee.

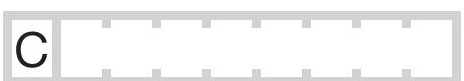

Name of Employer
Weiner Duranso \& Co LTD
Receipt For: 2012
X Primary
Other (specify)

\section{Occupation}

CPA

Election Cycle-to-Date

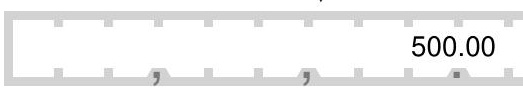

Transaction ID : A34EA56B5407C4A52AAE

Date of Receipt

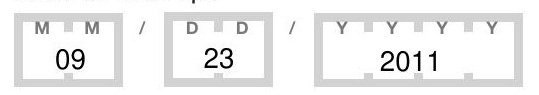

Amount of Each Receipt this Period

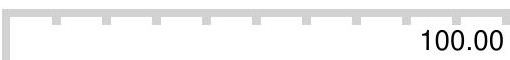

Amount of Each Receipt this Period

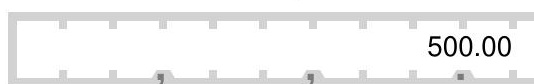

C. Full Name (Last, First, Middle Initial)

William Shanley

Mailing Address 140 Ashenfelter Rd.

\begin{tabular}{lcc}
\hline City & State & Zip Code \\
Malvern & PA & $19355-9681$
\end{tabular}

FEC ID number of contributing

federal political committee.

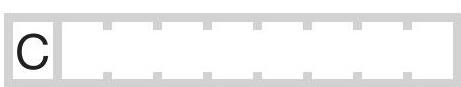

Name of Employer

Information Requested

Occupation

Information Requested

Receipt For: 2012

Х $\begin{aligned} & \text { Primary } \\ & \text { Other (specify) }\end{aligned}$

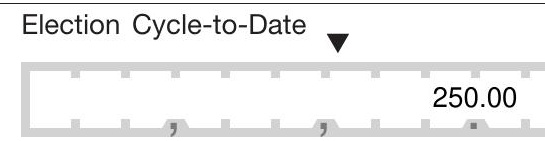

Amount of Each Receipt this Period

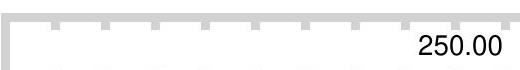

Transaction ID : A92EC30299B4F4BF2A7F

Date of Receipt

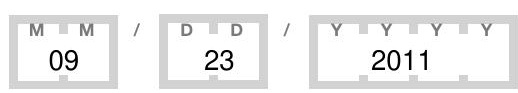

Subtotal Of Receipts This Page (optional)

850.00

Total This Period (last page this line number only) 
SCHEDULE A-P ITEMIZED RECEIPTS
Use separate schedule(s) for each category of the Detailed Summary Page
FOR LINE NUMBER: (check only one)

PAGE $606 / 1572$

\begin{tabular}{|c|c|c|c|c|c|c|}
\hline & & & & & & \\
\hline 16 & $\lambda$ & $17 \mathrm{a}$ & $17 \mathrm{~b}$ & $17 \mathrm{c}$ & $-17 d$ & -18 \\
\hline $19 a$ & & $19 b$ & $20 a$ & $20 \mathrm{~b}$ & $20 \mathrm{c}$ & 21 \\
\hline
\end{tabular}

Any information copied from such Reports and Statements may not be sold or used by any person for the purpose of soliciting contributions or for commercial purposes, other than using the name and address of any political committee to solicit contributions from such committee.

NAME OF COMMITTEE (In Full)

\section{Friends of Herman Cain}

A. Full Name (Last, First, Middle Initial) James Holten

Mailing Address 4003 CHESTNUT OAK DR

\begin{tabular}{lcc}
\hline City & State & Zip Code \\
Smithton & IL & $62285-3741$
\end{tabular}

FEC ID number of contributing federal political committee.

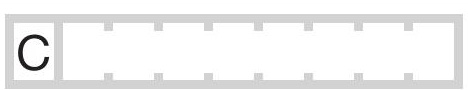

Name of Employer
Holten Meat Inc
Receipt For: 2012
X Primary
Other (specify) General

Occupation CEO

Election Cycle-to-Date

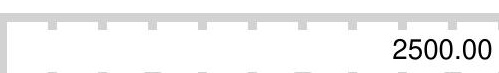

B. Full Name (Last, First, Middle Initial)

Diana Faulkner

Mailing Address 7823 Haverton Crossing

\begin{tabular}{lcc}
\hline City & State & Zip Code \\
Hixson & TN & $37343-2268$
\end{tabular}

FEC ID number of contributing

federal political committee.

C

Name of Employer

Children's Hospital of Chattanooga

Receipt For: 2012

$\chi \begin{aligned} & \text { Primary } \square \text { General } \\ & \text { Other (specify) } \nabla\end{aligned}$

C. Full Name (Last, First, Middle Initial)

Arnold Ferolito

Mailing Address 101 Waters Edge Dr

\section{City}

Jupiter

FEC ID number of contributing

federal political committee.

Name of Employer
None
Receipt For: 2012
X Primary
Other (specify) General

Retired

\section{Occupation}

Registered Nurse

Election Cycle-to-Date

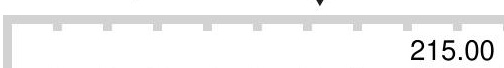

Transaction ID : A575EAF159C7E492E924

Date of Receipt

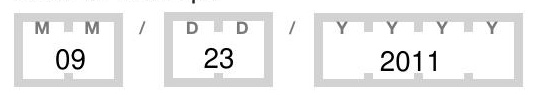

Amount of Each Receipt this Period

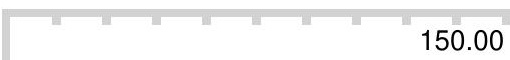

Amount of Each Receipt this Period

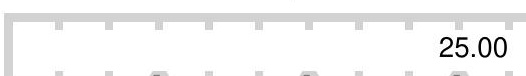

Transaction ID : A19122A82A3FF47D69F6

Date of Receipt

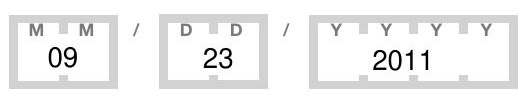

Transaction ID : A9F4219F8830444E6895

Date of Receipt

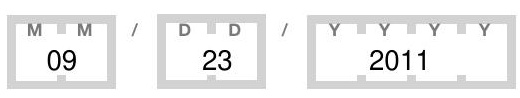

Amount of Each Receipt this Period
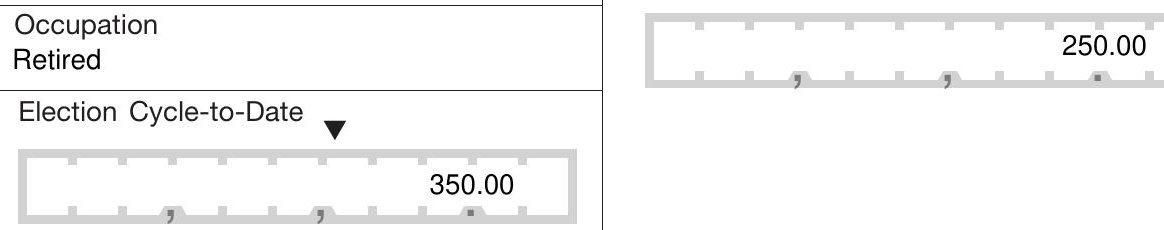

Subtotal Of Receipts This Page (optional)

425.00

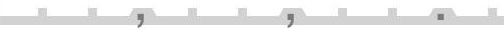

Total This Period (last page this line number only)

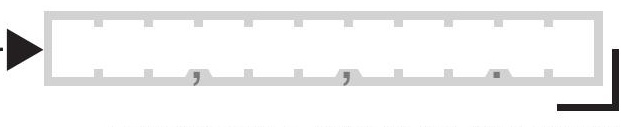

FEC Schedule A-P (Form 3P) (Rev. 03/2011) 
SCHEDULE A-P ITEMIZED RECEIPTS
Use separate schedule(s) for each category of the Detailed Summary Page
FOR LINE NUMBER: (check only one)

PAGE 607 / 1572

\begin{tabular}{|c|c|c|c|c|c|}
\hline & & & & & \\
\hline 16 & $\begin{array}{l}\mathbf{X} \\
17 a\end{array}$ & $17 b$ & $17 c$ & $17 d$ & 18 \\
\hline $19 a$ & $19 \mathrm{~b}$ & $20 \mathrm{a}$ & $20 \mathrm{~b}$ & $20 \mathrm{c}$ & 21 \\
\hline
\end{tabular}

Any information copied from such Reports and Statements may not be sold or used by any person for the purpose of soliciting contributions or for commercial purposes, other than using the name and address of any political committee to solicit contributions from such committee.

NAME OF COMMITTEE (In Full)

\section{Friends of Herman Cain}

A. Full Name (Last, First, Middle Initial)

\section{Donna Van Dries}

Mailing Address 11515 Autumn Chase

\begin{tabular}{lcc}
\hline City & State & Zip Code \\
Houston & TX & $77065-4927$
\end{tabular}

FEC ID number of contributing federal political committee.

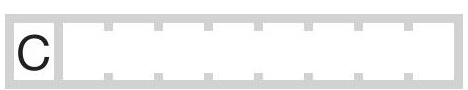

Name of Employer
State of Texas
Receipt For: 2012
X Primary
Other (specify) General

Occupation Retired

Election Cycle-to-Date

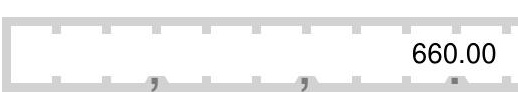

B. Full Name (Last, First, Middle Initial)

Allen Simon

Mailing Address 1383 N Criss St

\begin{tabular}{lcc}
\hline City & State & Zip Code \\
Chandler & AZ & $85226-1307$ \\
\hline
\end{tabular}

FEC ID number of contributing

federal political committee.

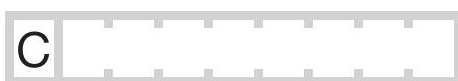

Name of Employer
Retired
Receipt For: 2012
X Primary
Other (specify)

Occupation

Retired

Election Cycle-to-Date

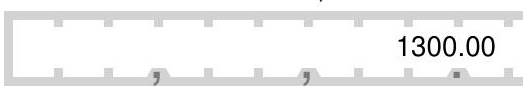

Transaction ID : AFF962C19793D4EA9A1F

Date of Receipt

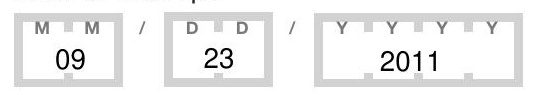

Amount of Each Receipt this Period

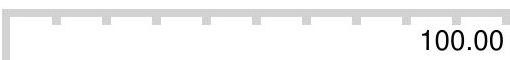

Transaction ID : AC14FA70AE7684254A59

Date of Receipt

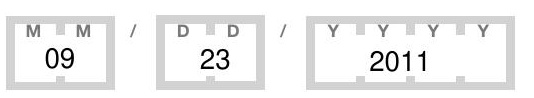

Amount of Each Receipt this Period

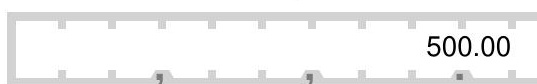

Transaction ID : A9C3838AFB0244B8BB55 Date of Receipt

Brent Barby

Mailing Address Rt. 2 Box 94

\begin{tabular}{lcc}
\hline City & State & Zip Code \\
Beaver & OK & $73932-9662$
\end{tabular}

FEC ID number of contributing federal political committee.

C

$\begin{aligned} & \text { Name of Employer } \\ & \text { self }\end{aligned}$
Receipt For: 2012
X Primary $\quad \square$ General
Other (specify)

Occupation

Rancher

Election Cycle-to-Date

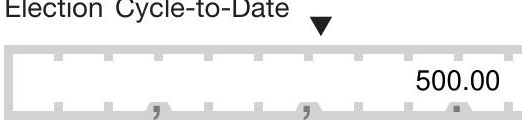

Subtotal Of Receipts This Page (optional)

700.00

Amount of Each Receipt this Period

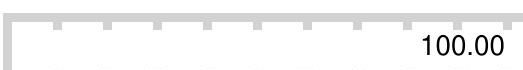

Total This Period (last page this line number only) 
SCHEDULE A-P ITEMIZED RECEIPTS
Use separate schedule(s) for each category of the Detailed Summary Page
FOR LINE NUMBER: (check only one)

PAGE $608 / 1572$

\begin{tabular}{|c|c|c|c|c|c|}
\hline & & & & & \\
\hline 16 & $\begin{array}{l}\mathbf{X} \\
17 a\end{array}$ & $17 b$ & $17 c$ & $17 d$ & 18 \\
\hline $19 a$ & $19 \mathrm{~b}$ & $20 \mathrm{a}$ & $20 \mathrm{~b}$ & $20 \mathrm{c}$ & 21 \\
\hline
\end{tabular}

Any information copied from such Reports and Statements may not be sold or used by any person for the purpose of soliciting contributions or for commercial purposes, other than using the name and address of any political committee to solicit contributions from such committee.

NAME OF COMMITTEE (In Full)

\section{Friends of Herman Cain}

A. Full Name (Last, First, Middle Initial) Jason Walker

Mailing Address 684 Queen Street SW

\begin{tabular}{lcc}
\hline City & State & Zip Code \\
Atlanta & GA & $30310-2612$
\end{tabular}

FEC ID number of contributing federal political committee.

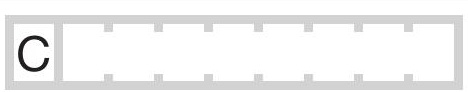

Name of Employer
TechSafari
Receipt For: 2012
X Primary $\quad$ General
Other (specify)

Occupation IT Election Cycle-to-Date

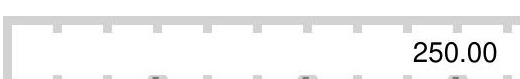

B. Full Name (Last, First, Middle Initial) Richard Adelizzi

Mailing Address 291 Glendale Rd

\begin{tabular}{lcc}
\hline City & State & Zip Code \\
Upper Darby & PA & $19082-4017$ \\
\hline
\end{tabular}

FEC ID number of contributing

federal political committee.

C

Name of Employer
Information Requested
Receipt For: 2012
Primary
Other (specify)

Occupation

Information Requested

Election Cycle-to-Date

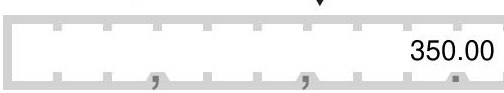

Transaction ID : AC12EC355315A4A63A5F

Date of Receipt

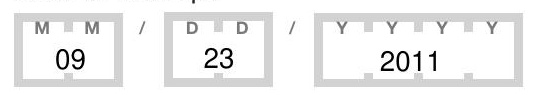

Amount of Each Receipt this Period

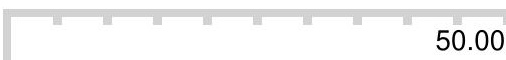

C. Full Name (Last, First, Middle Initial)

Dorothy Durrance

Mailing Address 409 Melody Ln

\begin{tabular}{lcc}
\hline City & State & Zip Code \\
Gainesville & TX & $76240-5137$
\end{tabular}

FEC ID number of contributing federal political committee.

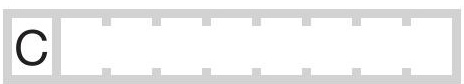

Name of Employer
Not Employed
Receipt For: 2012
X Primary $\quad \square$ General
Other (specify)

Occupation

Not Employed

Election Cycle-to-Date

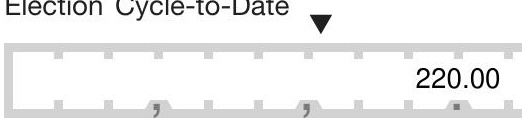

Transaction ID : A471F5D2AF8CA47BA97E Date of Receipt

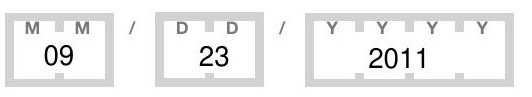

Amount of Each Receipt this Period

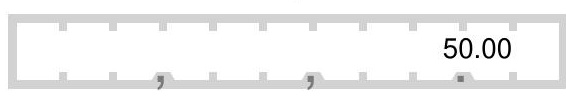

Transaction ID : A2A5959ED9BF34751B6A Date of Receipt

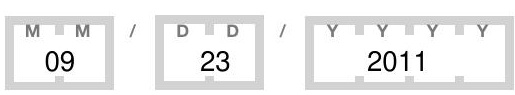

Amount of Each Receipt this Period

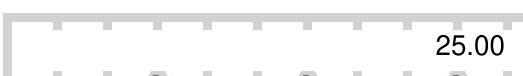

\section{Subtotal Of Receipts This Page (optional)}

Total This Period (last page this line number only) 
SCHEDULE A-P ITEMIZED RECEIPTS
Use separate schedule(s) for each category of the Detailed Summary Page
FOR LINE NUMBER: (check only one)

PAGE $609 / 1572$

\begin{tabular}{|c|c|c|c|c|c|}
\hline & & & & & \\
\hline 16 & $\begin{array}{l}\mathbf{X} \\
17 a\end{array}$ & $17 b$ & $17 c$ & $17 d$ & 18 \\
\hline $19 a$ & $19 \mathrm{~b}$ & $20 \mathrm{a}$ & $20 \mathrm{~b}$ & $20 \mathrm{c}$ & 21 \\
\hline
\end{tabular}

Any information copied from such Reports and Statements may not be sold or used by any person for the purpose of soliciting contributions or for commercial purposes, other than using the name and address of any political committee to solicit contributions from such committee.

NAME OF COMMITTEE (In Full)

\section{Friends of Herman Cain}

A. Full Name (Last, First, Middle Initial)

\section{Erica Daniell}

Mailing Address 805 Streamside Dr

\begin{tabular}{lcc}
\hline City & State & Zip Code \\
McDonough & GA & $30252-9035$ \\
\hline
\end{tabular}

FEC ID number of contributing federal political committee.

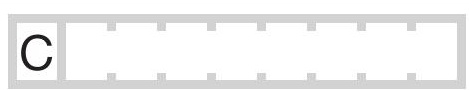

Name of Employer
Chevy's Diner
Receipt For: 2012
X Primary
Other (specify) General

Occupation OWNER

Election Cycle-to-Date

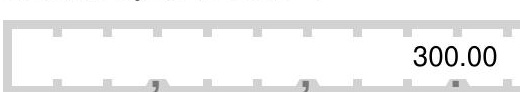

B. Full Name (Last, First, Middle Initial)

Donald Henager

Mailing Address 9222 E. Chirco PI.

\begin{tabular}{lcc}
\hline City & State & Zip Code \\
Tucson & AZ & 85710-3131 \\
\hline
\end{tabular}

FEC ID number of contributing

federal political committee.

C

\begin{tabular}{l} 
Name of Employer \\
SAIC \\
Receipt For: 2012 \\
X Primary \\
\hline Other (specify)
\end{tabular}

Occupation

Training Specialist

Election Cycle-to-Date

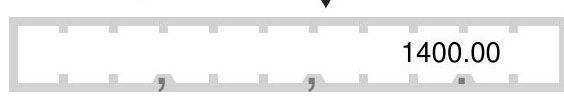

Transaction ID : A0716465C1DB146DC982

Date of Receipt

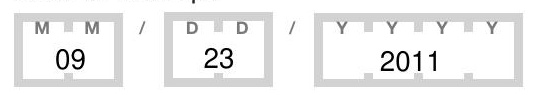

Amount of Each Receipt this Period

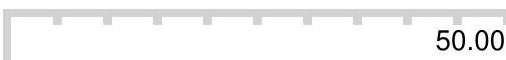

50.00

C. Full Name (Last, First, Middle Initial)

Cathy Brunicardi

Mailing Address PO Box 300

\begin{tabular}{lcc}
\hline City & State & Zip Code \\
Weesatche & TX & $77993-0300$
\end{tabular}

FEC ID number of contributing federal political committee.

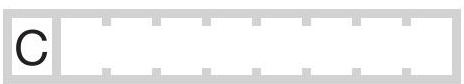

Name of Employer
None
Receipt For: 2012
X Primary $\quad \square$ General
Other (specify)

\section{Occupation}

Retired

Election Cycle-to-Date

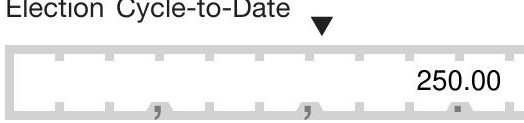

Transaction ID : A2012B1943B4046D5AC1

Date of Receipt

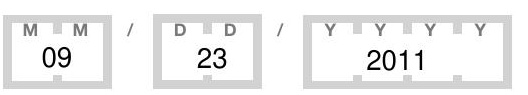

Amount of Each Receipt this Period

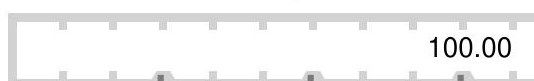

Transaction ID : A4B336DF5BB7145798DE Date of Receipt

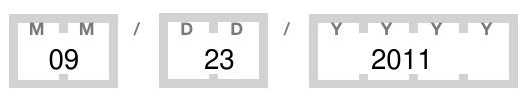

Amount of Each Receipt this Period

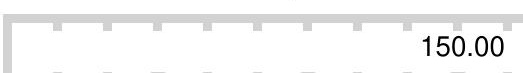

150.00

\section{Subtotal Of Receipts This Page (optional)}

300.00

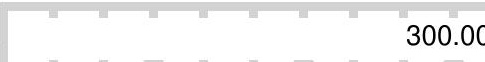

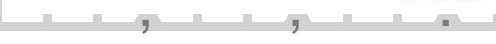

Total This Period (last page this line number only)

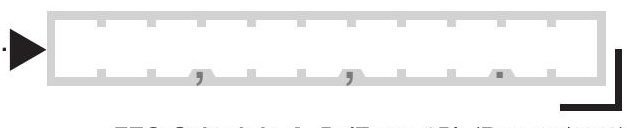

FEC Schedule A-P (Form 3P) (Rev. 03/2011) 


\section{SCHEDULE A-P} ITEMIZED RECEIPTS
Use separate schedule(s)

for each category of the

Detailed Summary Page
FOR LINE NUMBER: (check only one)

PAGE $610 / 1572$

\begin{tabular}{|c|c|c|c|c|c|}
\hline & & & & & \\
\hline 16 & X $17 a$ & $17 b$ & $17 c$ & $17 d$ & 18 \\
\hline $19 a$ & $19 b$ & $20 \mathrm{a}$ & $20 \mathrm{~b}$ & $20 \mathrm{c}$ & 21 \\
\hline
\end{tabular}

Any information copied from such Reports and Statements may not be sold or used by any person for the purpose of soliciting contributions or for commercial purposes, other than using the name and address of any political committee to solicit contributions from such committee.

NAME OF COMMITTEE (In Full)

Friends of Herman Cain

A. Full Name (Last, First, Middle Initial)

Thomas Park

Mailing Address 26614 Country Crk Ln

\begin{tabular}{lcc}
\hline City & State & Zip Code \\
Calabasas & CA & $91302-3587$
\end{tabular}

FEC ID number of contributing

federal political committee.

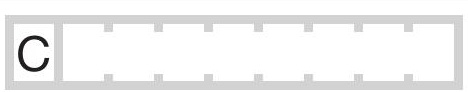

Name of Employer
Information Requested
Receipt For: 2012
X Primary $\quad \square$ General
Other (specify)

Occupation

Information Requested

Election Cycle-to-Date

450.00

B. Full Name (Last, First, Middle Initial)

Alison Clements

Mailing Address 365 S. Liberty St.

\begin{tabular}{lcc}
\hline City & State & Zip Code \\
Rushville & IL & $62681-1327$
\end{tabular}

FEC ID number of contributing

federal political committee.

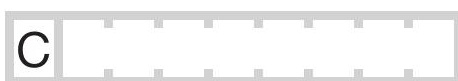

Name of Employer
Beardstown School District
Receipt For: 2012
X Primary
Other (specify)

Occupation

Teacher

Election Cycle-to-Date

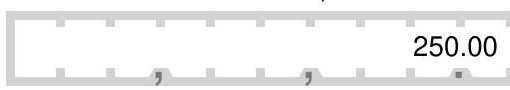

C. Full Name (Last, First, Middle Initial)

ernest blevins

Mailing Address 1472 Mathis Rd. True

\begin{tabular}{lcc}
\hline City & State & Zip Code \\
Danielsville & GA & 30633-3672
\end{tabular}

FEC ID number of contributing

federal political committee.

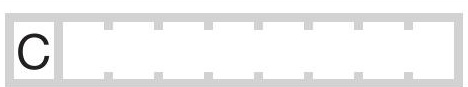

Name of Employer

Information Requested

Occupation

Information Requested

Receipt For: 2012

Х $\begin{aligned} & \text { Primary } \square \text { General } \\ & \text { Other (specify) }\end{aligned}$

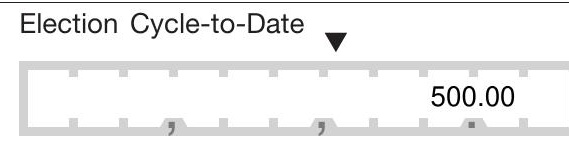

Amount of Each Receipt this Period

Transaction ID : A1608B438D1724452BBB

Date of Receipt

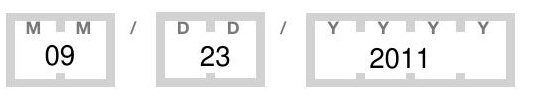

Amount of Each Receipt this Period
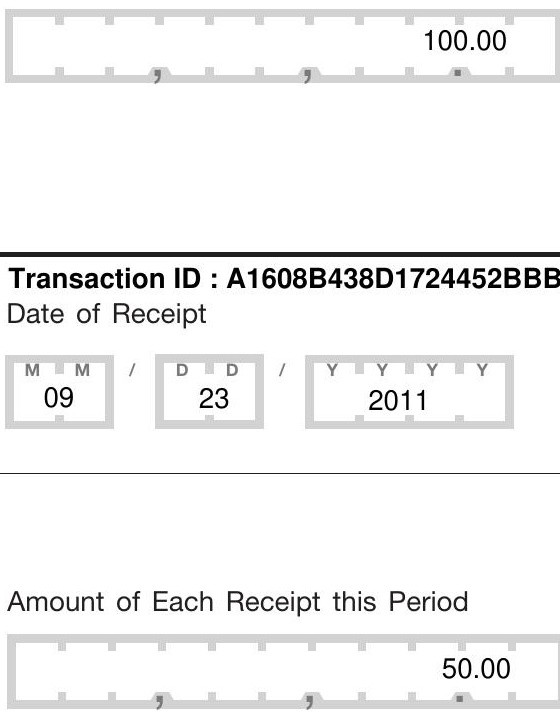

Transaction ID : A9CA1D0140D364959B5A Date of Receipt

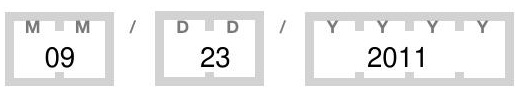

Amount of Each Receipt this Period

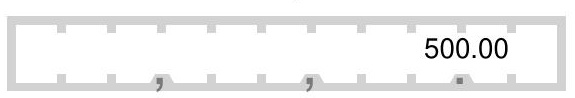

Subtotal Of Receipts This Page (optional).

650.00

Total This Period (last page this line number only) 
SCHEDULE A-P ITEMIZED RECEIPTS
Use separate schedule(s) for each category of the Detailed Summary Page

FOR LINE NUMBER:
(check only one)

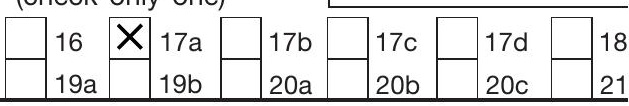

Any information copied from such Reports and Statements may not be sold or used by any person for the purpose of soliciting contributions or for commercial purposes, other than using the name and address of any political committee to solicit contributions from such committee.

NAME OF COMMITTEE (In Full)

\section{Friends of Herman Cain}

A. Full Name (Last, First, Middle Initial) Gary Stubblefield

Mailing Address 2001 Raymond Ave

\begin{tabular}{lcc}
\hline City & State & Zip Code \\
Signal Hill & CA & $90755-5930$ \\
\hline
\end{tabular}

FEC ID number of contributing federal political committee.

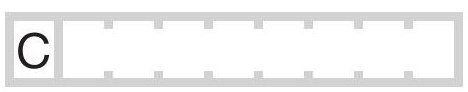

Name of Employer
Retired
Receipt For: 2012
X Primary $\quad \square$ General
$\square$ Other (specify)

Occupation Retired

Election Cycle-to-Date

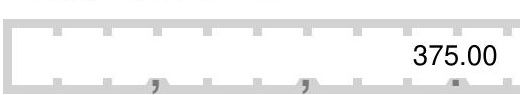

B. Full Name (Last, First, Middle Initial) Judy Williams

Mailing Address 12679 Biscayne Ct

\begin{tabular}{lcc}
\hline City & State & Zip Code \\
Naples & FL & $34105-4935$ \\
\hline
\end{tabular}

FEC ID number of contributing

federal political committee.

C

Name of Employer
Eli Lilly \& Company
Receipt For: 2012
Primary
Other (specify)

Occupation

Assoc Consultant - Clinical Trial Mana

Election Cycle-to-Date

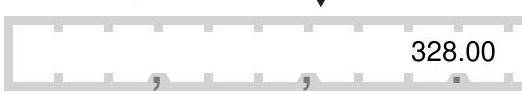

Transaction ID : AD9E8FC0ED55843A284A

Date of Receipt

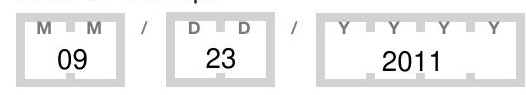

Amount of Each Receipt this Period

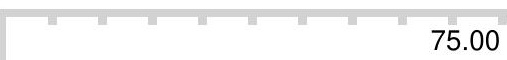

75.00

C. Full Name (Last, First, Middle Initial)

William Wortman

Mailing Address 1612 E 6th St

\begin{tabular}{lcc}
\hline City & State & Zip Code \\
Tulsa & OK & $74120-4028$
\end{tabular}

FEC ID number of contributing federal political committee.

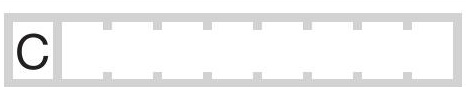

Name of Employer
$\mathrm{n} / \mathrm{a}$
Receipt For: 2012
X Primary

\section{Occupation}

Retired

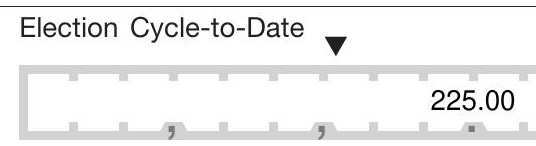

Transaction ID : A21660F6121E54DF9971

Date of Receipt

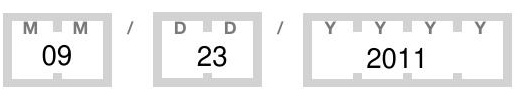

Amount of Each Receipt this Period

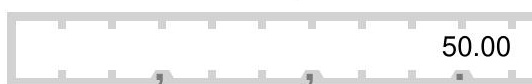

Transaction ID : A5F94BB3A84694BE69A9 Date of Receipt

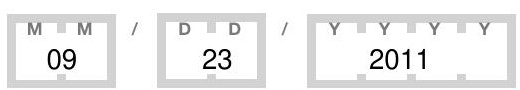

Amount of Each Receipt this Period

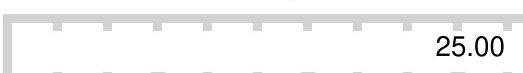

\section{Subtotal Of Receipts This Page (optional)}

Total This Period (last page this line number only) 


\section{SCHEDULE A-P} ITEMIZED RECEIPTS
Use separate schedule(s) for each category of the Detailed Summary Page

FOR LINE NUMBER:
(check only one)

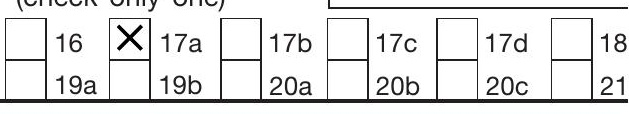

Any information copied from such Reports and Statements may not be sold or used by any person for the purpose of soliciting contributions or for commercial purposes, other than using the name and address of any political committee to solicit contributions from such committee.

NAME OF COMMITTEE (In Full)

\section{Friends of Herman Cain}

A. Full Name (Last, First, Middle Initial)

Eugene Adamson

Mailing Address 412 The Falls of Cherokee Dr

\begin{tabular}{lcc}
\hline City & State & Zip Code \\
Canton & GA & $30114-8142$
\end{tabular}

FEC ID number of contributing federal political committee.

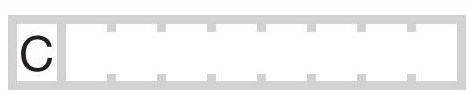

Name of Employer
CKI Service
Receipt For: 2012
X Primary
$\square$ Other (specify) General

Occupation OWNER

Election Cycle-to-Date 1000.00

B. Full Name (Last, First, Middle Initial) Evelina F Krout

Mailing Address 2124 Hakanu St

\begin{tabular}{lcc}
\hline City & State & Zip Code \\
Honolulu & HI & $96821-2602$ \\
\hline
\end{tabular}

FEC ID number of contributing

federal political committee.

C

Name of Employer
None
Receipt For: 2012
Primary
Other (specify)

Occupation

Retired

Election Cycle-to-Date

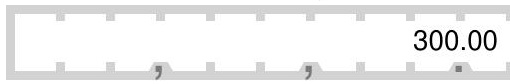

Transaction ID : AFAB1FD337CDF4B6FA0C

Date of Receipt

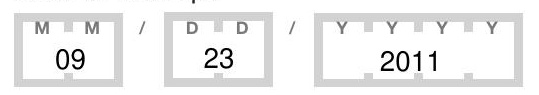

Amount of Each Receipt this Period

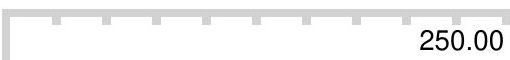

C. Full Name (Last, First, Middle Initial)

Joseph Niswonger

Mailing Address 6088 Windchase Drive

\begin{tabular}{lcc}
\hline City & State & Zip Code \\
Rocky Mount & NC & $27803-8774$
\end{tabular}

FEC ID number of contributing

federal political committee.

C

Name of Employer

First Carolina Management

Receipt For: 2012

Х $\begin{aligned} & \text { Primary } \square \text { General } \\ & \text { Other (specify) }\end{aligned}$

Occupation

VP Sales \& Marketing

Election Cycle-to-Date

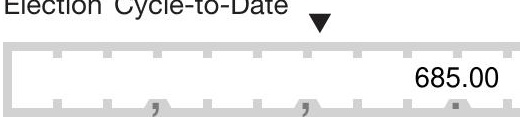

Transaction ID : A1E5CB4FF199344F1AA3

Date of Receipt

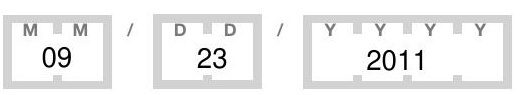

Amount of Each Receipt this Period

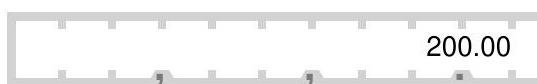

Transaction ID : A98309D2CC542419DA47 Date of Receipt

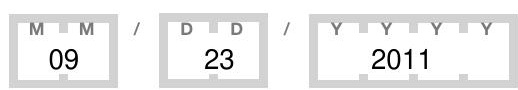

Amount of Each Receipt this Period

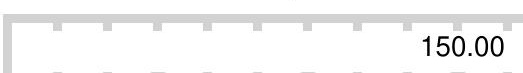

150.00

\section{Subtotal Of Receipts This Page (optional)}

600.00

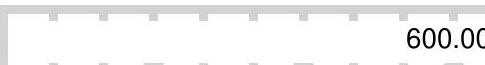

(1)

Total This Period (last page this line number only)

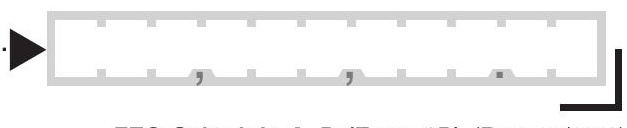

FEC Schedule A-P (Form 3P) (Rev. 03/2011) 
SCHEDULE A-P ITEMIZED RECEIPTS
Use separate schedule(s) for each category of the Detailed Summary Page
FOR LINE NUMBER: (check only one)

\begin{tabular}{|c|c|c|c|c|c|}
\hline & & & & & \\
\hline 16 & $\begin{array}{ll}X & 17 a \\
\end{array}$ & $17 \mathrm{~b}$ & $17 c$ & $17 d$ & 18 \\
\hline $19 a$ & $19 b$ & $20 \mathrm{a}$ & $20 \mathrm{~b}$ & $20 c$ & 21 \\
\hline
\end{tabular}

Any information copied from such Reports and Statements may not be sold or used by any person for the purpose of soliciting contributions or for commercial purposes, other than using the name and address of any political committee to solicit contributions from such committee.

NAME OF COMMITTEE (In Full)

\section{Friends of Herman Cain}

A. Full Name (Last, First, Middle Initial)

Mary Howlett

Mailing Address 1933 Swarthout Road

\begin{tabular}{lcc}
\hline City & State & Zip Code \\
Pinckney & Ml & $48169-9210$
\end{tabular}

FEC ID number of contributing federal political committee.

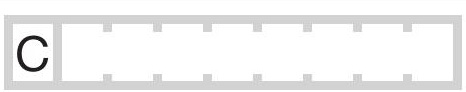

Name of Employer
Howlett Lock \& Door, Inc.
Receipt For: 2012
X Primary
Other (specify) General

Occupation

Secretary

Election Cycle-to-Date

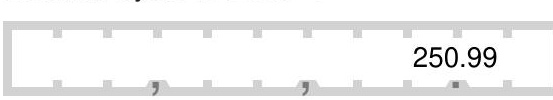

B. Full Name (Last, First, Middle Initial)

William Dixon

Mailing Address 2225 Ocotillo St

\begin{tabular}{lcc}
\hline City & State & Zip Code \\
League City & TX & $77573-2269$ \\
\hline
\end{tabular}

FEC ID number of contributing

federal political committee.

C

Name of Employer
Yu Dixon Enterprises
Receipt For: 2012
Primary
Other (specify)

Occupation

Project Manager

Election Cycle-to-Date

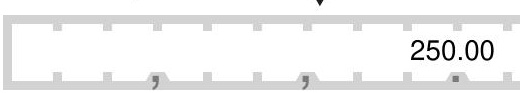

Transaction ID : A13C64F16132A4ECC801

Date of Receipt

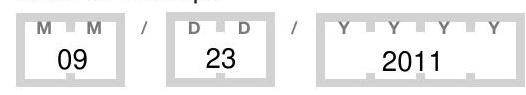

Amount of Each Receipt this Period

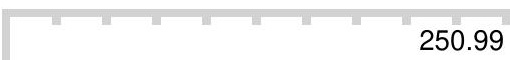

250.99

C. Full Name (Last, First, Middle Initial)

Ms. Susan Seadon

Mailing Address 1954 5th Ct SE

\begin{tabular}{lcc}
\hline City & State & Zip Code \\
Vero Beach & FL & $32962-7307$
\end{tabular}

FEC ID number of contributing federal political committee.

C

32962-7307

Name of Employer

Walgreens

Receipt For: 2012

Х $\begin{aligned} & \text { Primary } \\ & \text { Other (specify) }\end{aligned}$

Election Cycle-to-Date

\section{Occupation}

Pharmacist

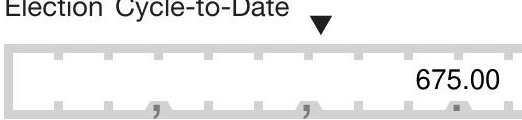

Transaction ID : A3D3D552E01864831BF1

Date of Receipt

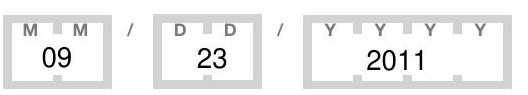

Amount of Each Receipt this Period

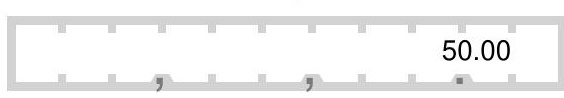

Transaction ID : AB67CC478A2FA43D4800 Date of Receipt

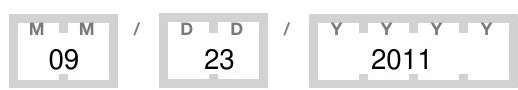

Amount of Each Receipt this Period

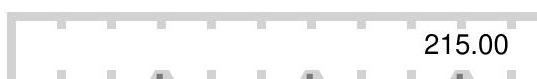

\section{Subtotal Of Receipts This Page (optional)}

Total This Period (last page this line number only) 
SCHEDULE A-P ITEMIZED RECEIPTS
Use separate schedule(s) for each category of the Detailed Summary Page
FOR LINE NUMBER: (check only one)

PAGE 614 / 1572

\begin{tabular}{|c|c|c|c|c|c|}
\hline & & & & & \\
\hline 16 & $\begin{array}{l}\mathbf{X} \\
17 a\end{array}$ & $17 b$ & $17 c$ & $17 d$ & 18 \\
\hline $19 a$ & $19 \mathrm{~b}$ & $20 \mathrm{a}$ & $20 \mathrm{~b}$ & $20 \mathrm{c}$ & 21 \\
\hline
\end{tabular}

Any information copied from such Reports and Statements may not be sold or used by any person for the purpose of soliciting contributions or for commercial purposes, other than using the name and address of any political committee to solicit contributions from such committee.

NAME OF COMMITTEE (In Full)

\section{Friends of Herman Cain}

A. Full Name (Last, First, Middle Initial)

\section{Gus Roux}

Mailing Address 14918 Hillcrest

\begin{tabular}{lcc}
\hline City & State & Zip Code \\
Dallas & TX & $75248-5536$
\end{tabular}

FEC ID number of contributing federal political committee.

C

Name of Employer

Hillcrest Brokerage

Receipt For: 2012 Х Primary $\square$ General
Occupation

Real Estate Investments

Election Cycle-to-Date $\boldsymbol{\nabla}$

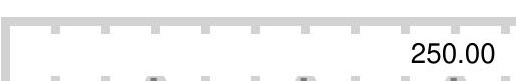

B. Full Name (Last, First, Middle Initial)

MARK LOPEZ

Mailing Address 1830 BREA BLVD \#3

\begin{tabular}{lcc}
\hline City & State & Zip Code \\
Fullerton & CA & $92835-3944$ \\
\hline
\end{tabular}

FEC ID number of contributing

federal political committee.

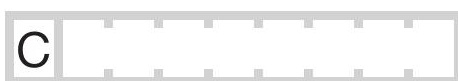

Name of Employer
BECKMAN COULTER INC
Receipt For: 2012
X Primary
Other (specify)

Occupation

SW Engineer

Election Cycle-to-Date

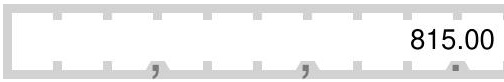

C. Full Name (Last, First, Middle Initial)

Matthew Phillips

Mailing Address 776 Streamview Lane

\begin{tabular}{lcc}
\hline City & State & Zip Code \\
Vineland & NJ & $08360-2479$
\end{tabular}

FEC ID number of contributing federal political committee.

C

Name of Employer
Public Service Enterpise Group
Receipt For: 2012
X Primary
Other (specify)

Occupation

Engineer

Election Cycle-to-Date
Transaction ID : AEE1F0E0957204801994

Date of Receipt

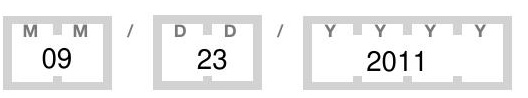

Amount of Each Receipt this Period

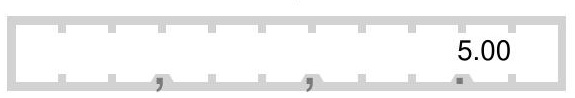

Transaction ID : AC5EF446C6D10475EAE9 Date of Receipt

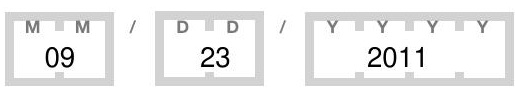

Amount of Each Receipt this Period

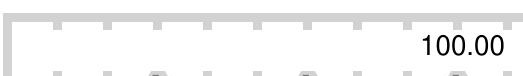

\section{Subtotal Of Receipts This Page (optional)}

205.00

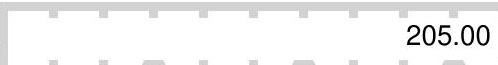

ㄱ․․

Total This Period (last page this line number only)

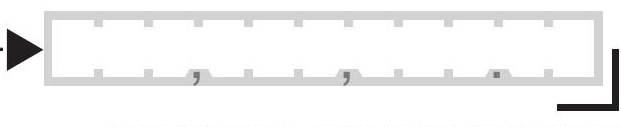

FEC Schedule A-P (Form 3P) (Rev. 03/2011) 
SCHEDULE A-P ITEMIZED RECEIPTS
Use separate schedule(s) for each category of the Detailed Summary Page
FOR LINE NUMBER: (check only one)

PAGE $615 / 1572$

\begin{tabular}{|c|c|c|c|c|c|}
\hline & & & & & \\
\hline 16 & $\begin{array}{l}\mathbf{X} \\
17 a\end{array}$ & $17 b$ & $17 c$ & $17 d$ & 18 \\
\hline $19 a$ & $19 \mathrm{~b}$ & $20 \mathrm{a}$ & $20 \mathrm{~b}$ & $20 \mathrm{c}$ & 21 \\
\hline
\end{tabular}

Any information copied from such Reports and Statements may not be sold or used by any person for the purpose of soliciting contributions or for commercial purposes, other than using the name and address of any political committee to solicit contributions from such committee.

NAME OF COMMITTEE (In Full)

\section{Friends of Herman Cain}

A. Full Name (Last, First, Middle Initial)

Amy E Schwartz

Mailing Address 120 Monticello Sq

\begin{tabular}{lcc}
\hline City & State & Zip Code \\
Winchester & VA & $22602-6293$ \\
\hline
\end{tabular}

FEC ID number of contributing federal political committee.

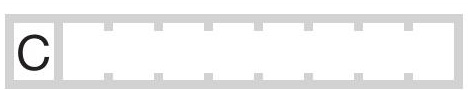

Name of Employer

Federal Bureau of Investigation

Occupation

Receipt For: 2012

X Primary $\square$ General Other (specify)

Program Analyst

Election Cycle-to-Date

250.00

B. Full Name (Last, First, Middle Initial)

CARLOS URUCHURTU SR Sr.

Mailing Address 33150 PAUBA RD

\begin{tabular}{lcc}
\hline City & State & Zip Code \\
Temecula & CA & $92592-9264$
\end{tabular}

FEC ID number of contributing

federal political committee.

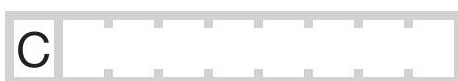

Name of Employer
GEORGE CHEVROLET
Receipt For: 2012
X Primary
Other (specify)

Occupation

VP/GM

Election Cycle-to-Date

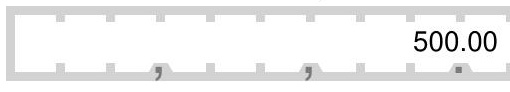

C. Full Name (Last, First, Middle Initial)

Marie Ring

Mailing Address 311 Birch Field

\begin{tabular}{lcc}
\hline City & State & Zip Code \\
Jefferson & GA & $30549-8310$
\end{tabular}

FEC ID number of contributing federal political committee.

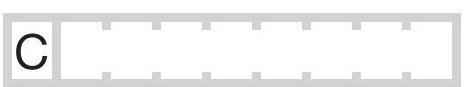

Name of Employer
Rescare Homecare
Receipt For: 2012
X Primary $\quad \square$ General
Other (specify)

\section{Occupation}

$\mathrm{RN}$

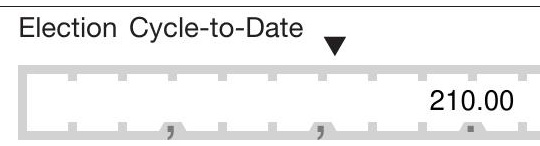

Transaction ID : AF3E03F942AEC4700948

Date of Receipt

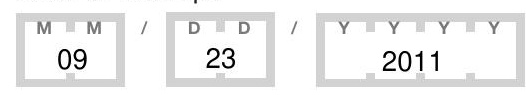

Amount of Each Receipt this Period

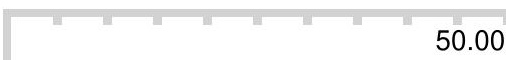

50.00

Transaction ID : A0AE61C8E7CC846A7860

Date of Receipt

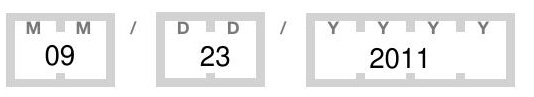

Amount of Each Receipt this Period

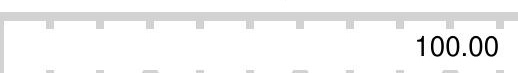

Transaction ID : A9BCD23A185874C8D950 Date of Receipt

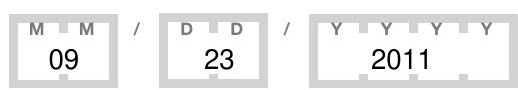

Amount of Each Receipt this Period

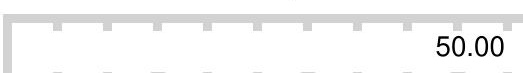

50.00

200.00

Subtotal Of Receipts This Page (optional)

Total This Period (last page this line number only) 
SCHEDULE A-P ITEMIZED RECEIPTS
Use separate schedule(s) for each category of the Detailed Summary Page
FOR LINE NUMBER: (check only one)

PAGE $616 / 1572$

\begin{tabular}{|c|c|c|c|c|c|}
\hline & & & & & \\
\hline 16 & $\begin{array}{l}\mathbf{X} \\
17 a\end{array}$ & $17 b$ & $17 c$ & $17 d$ & 18 \\
\hline $19 a$ & $19 \mathrm{~b}$ & $20 \mathrm{a}$ & $20 \mathrm{~b}$ & $20 \mathrm{c}$ & 21 \\
\hline
\end{tabular}

Any information copied from such Reports and Statements may not be sold or used by any person for the purpose of soliciting contributions or for commercial purposes, other than using the name and address of any political committee to solicit contributions from such committee.

NAME OF COMMITTEE (In Full)

\section{Friends of Herman Cain}

A. Full Name (Last, First, Middle Initial)

\section{Donna Van Dries}

Mailing Address 11515 Autumn Chase

\begin{tabular}{lcc}
\hline City & State & Zip Code \\
Houston & TX & $77065-4927$ \\
\hline
\end{tabular}

FEC ID number of contributing federal political committee.

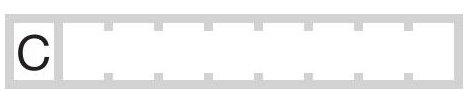

Name of Employer
State of Texas
Receipt For: 2012
X Primary
Other (specify) General

Occupation Retired

Election Cycle-to-Date

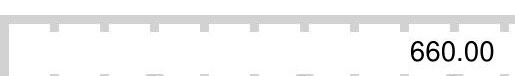

B. Full Name (Last, First, Middle Initial)

Kay Trettin-Benson

Mailing Address 11 Meadow Cove Drive

\begin{tabular}{lcc}
\hline City & State & Zip Code \\
Spring & TX & $77381-3323$
\end{tabular}

FEC ID number of contributing

federal political committee.

C

Name of Employer
Not Employed
Receipt For: 2012
X Primary
Other (specify)

\section{Occupation}

Not Employed

Election Cycle-to-Date

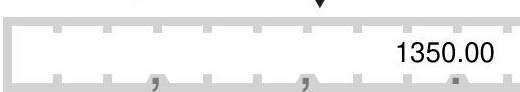

Transaction ID : A4B0BF1BDD7684D249E8

Date of Receipt

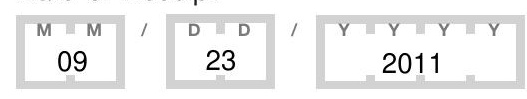

Amount of Each Receipt this Period

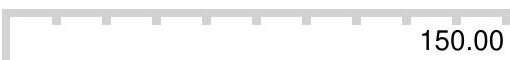

C. Full Name (Last, First, Middle Initial)

Peace Foxx

Mailing Address 120 Grandville Arch

\begin{tabular}{lcc}
\hline City & State & Zip Code \\
Smithfield & VA & $23430-6149$
\end{tabular}

FEC ID number of contributing federal political committee.

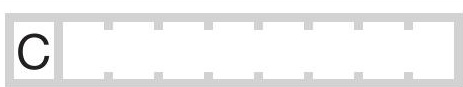

Name of Employer
None
Receipt For: 2012
X Primary $\quad \square$ General
Other (specify)

\section{Occupation}

Retired

Election Cycle-to-Date

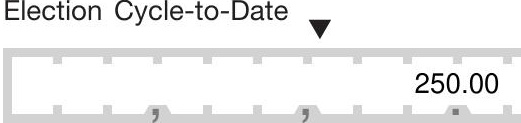

Amount of Each Receipt this Period

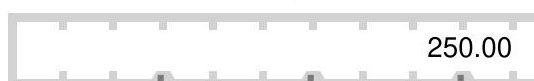

Transaction ID : A9096B7351B0042CEBDF Date of Receipt

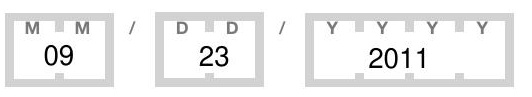

Transaction ID : A3079021BF3DA4B4C8D0 Date of Receipt

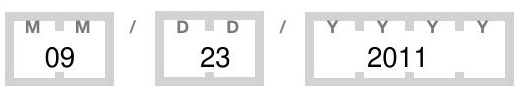

Amount of Each Receipt this Period

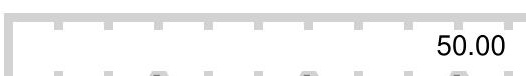

\section{Subtotal Of Receipts This Page (optional)}

Total This Period (last page this line number only) 
SCHEDULE A-P ITEMIZED RECEIPTS
Use separate schedule(s) for each category of the Detailed Summary Page
FOR LINE NUMBER: (check only one)

PAGE 617 / 1572

\begin{tabular}{|c|c|c|c|c|c|}
\hline & & & & & \\
\hline 16 & $\begin{array}{l}\mathbf{X} \\
17 a\end{array}$ & $17 b$ & $17 c$ & $17 d$ & 18 \\
\hline $19 a$ & $19 \mathrm{~b}$ & $20 \mathrm{a}$ & $20 \mathrm{~b}$ & $20 \mathrm{c}$ & 21 \\
\hline
\end{tabular}

Any information copied from such Reports and Statements may not be sold or used by any person for the purpose of soliciting contributions or for commercial purposes, other than using the name and address of any political committee to solicit contributions from such committee.

NAME OF COMMITTEE (In Full)

\section{Friends of Herman Cain}

A. Full Name (Last, First, Middle Initial)

William Rogers

Mailing Address 3010 Promenade PL

\begin{tabular}{lcc}
\hline City & State & Zip Code \\
Buford & GA & $30519-8912$
\end{tabular}

FEC ID number of contributing

federal political committee.

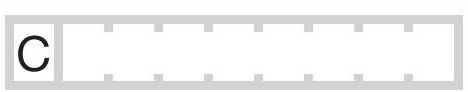

Name of Employer
Information Requested
Receipt For: 2012
X Primary $\quad \square$ General
Other (specify)

Occupation

Information Requested

Election Cycle-to-Date

250.00

B. Full Name (Last, First, Middle Initial)

Sally Sidman

Mailing Address 560 East C.R. 600 North

\begin{tabular}{lcc}
\hline City & State & Zip Code \\
Muncie & IN & 47303 \\
\hline
\end{tabular}

FEC ID number of contributing

federal political committee.

C

Name of Employer
Information Requested
Receipt For: 2012
Primary
Other (specify)

Occupation

Information Requested

Election Cycle-to-Date

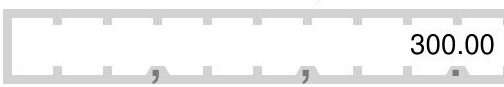

Transaction ID : AA0ED8861DEF74D32BA1

Date of Receipt

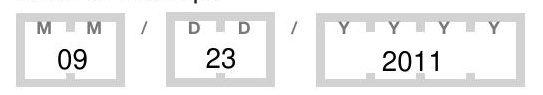

Amount of Each Receipt this Period

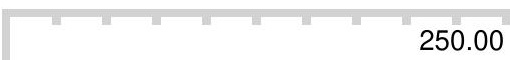

Amount of Each Receipt this Period

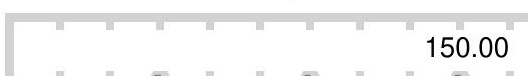

C. Full Name (Last, First, Middle Initial)

George Dennis

Mailing Address 135 E Harmon Ave Unit 50

\begin{tabular}{lcc}
\hline City & State & Zip Code \\
Las Vegas & NV & $89109-4610$
\end{tabular}

FEC ID number of contributing

federal political committee.

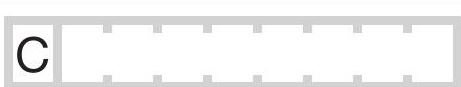

Name of Employer

TV Ears Inc.

Occupation

BUSINESS OWNER

Receipt For: 2012

Х $\begin{aligned} & \text { Primary } \\ & \text { Other (specify) }\end{aligned}$

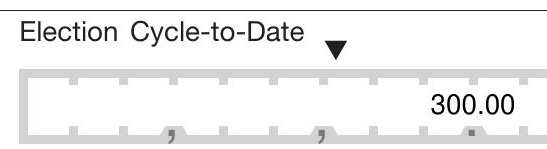

Amount of Each Receipt this Period

Transaction ID : A85273EB7C7314483B73

Date of Receipt
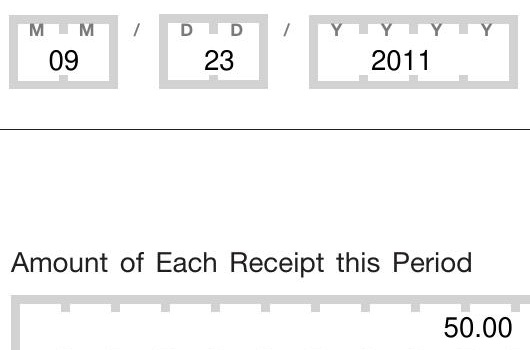

50.00

Subtotal Of Receipts This Page (optional)

450.00

Total This Period (last page this line number only) 
SCHEDULE A-P ITEMIZED RECEIPTS
Use separate schedule(s) for each category of the Detailed Summary Page
FOR LINE NUMBER: (check only one)

PAGE $618 / 1572$

\begin{tabular}{|c|c|c|c|c|c|c|}
\hline & & & & & & \\
\hline 16 & $\lambda$ & $17 \mathrm{a}$ & $17 \mathrm{~b}$ & $17 \mathrm{c}$ & $-17 d$ & -18 \\
\hline $19 a$ & & $19 b$ & $20 a$ & $20 \mathrm{~b}$ & $20 \mathrm{c}$ & 21 \\
\hline
\end{tabular}

Any information copied from such Reports and Statements may not be sold or used by any person for the purpose of soliciting contributions or for commercial purposes, other than using the name and address of any political committee to solicit contributions from such committee.

NAME OF COMMITTEE (In Full)

\section{Friends of Herman Cain}

A. Full Name (Last, First, Middle Initial)

Margaret Sorrells

Mailing Address 2394 Bold Springs Road

\begin{tabular}{lcc}
\hline City & State & Zip Code \\
Monroe & GA & $30656-4000$
\end{tabular}

FEC ID number of contributing

federal political committee.

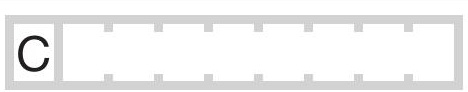

Name of Employer
Walton County Schools
Receipt For: 2012
X Primary $\quad \square$ General
Other (specify)

Occupation

Educator

Election Cycle-to-Date

300.00

B. Full Name (Last, First, Middle Initial)

Theodore Jenczewski

Mailing Address 2500 Chimney House Ct

\begin{tabular}{lcc}
\hline City & State & Zip Code \\
Midlothian & VA & $23112-4306$ \\
\hline
\end{tabular}

FEC ID number of contributing

federal political committee.

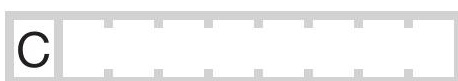

Name of Employer
NA
Receipt For: 2012
X Primary $\quad$ General
Other (specify) $\nabla$

Occupation

Retired

Election Cycle-to-Date

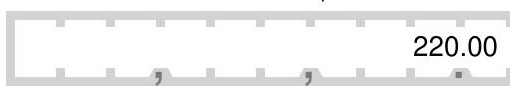

Transaction ID : A1039FD2683044EF6B26

Date of Receipt

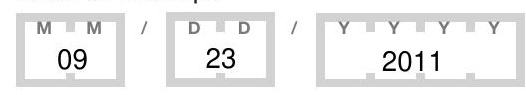

Amount of Each Receipt this Period

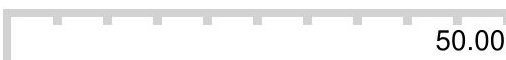

50.00

C. Full Name (Last, First, Middle Initial)

Robert McAdam

Mailing Address 341 Harbour Dr

\begin{tabular}{lcc}
\hline City & State & Zip Code \\
Dawsonville & GA & $30534-7084$
\end{tabular}

FEC ID number of contributing federal political committee.

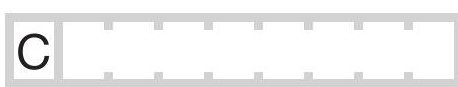

Name of Employer

Information Requested

Occupation

Information Requested

Receipt For: 2012

Х $\begin{aligned} & \text { Primary } \square \text { General } \\ & \text { Other (specify) }\end{aligned}$

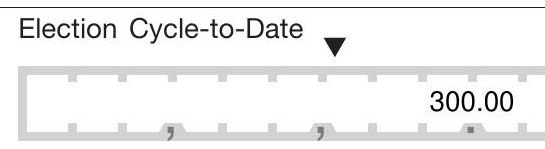

Amount of Each Receipt this Period

Transaction ID : A5F0322337B0E42F9B80

Date of Receipt
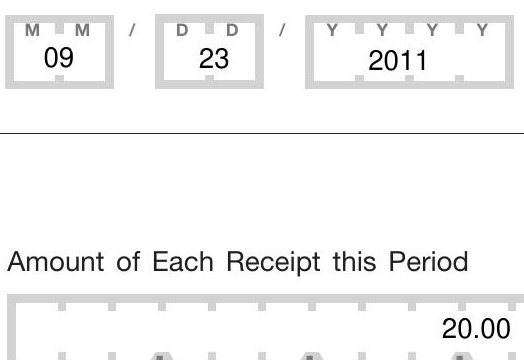

Transaction ID : A3714641F46EB48EB9F8

Date of Receipt

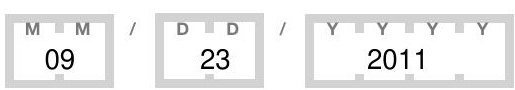

Amount of Each Receipt this Period

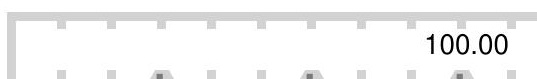

170.00

Subtotal Of Receipts This Page (optional)

Total This Period (last page this line number only) 
SCHEDULE A-P ITEMIZED RECEIPTS
Use separate schedule(s) for each category of the Detailed Summary Page
FOR LINE NUMBER: (check only one)

PAGE $619 / 1572$

\begin{tabular}{|c|c|c|c|c|c|}
\hline & & & & & \\
\hline 16 & $\begin{array}{l}\mathbf{X} \\
17 a\end{array}$ & $17 b$ & $17 c$ & $17 d$ & 18 \\
\hline $19 a$ & $19 \mathrm{~b}$ & $20 \mathrm{a}$ & $20 \mathrm{~b}$ & $20 \mathrm{c}$ & 21 \\
\hline
\end{tabular}

Any information copied from such Reports and Statements may not be sold or used by any person for the purpose of soliciting contributions or for commercial purposes, other than using the name and address of any political committee to solicit contributions from such committee.

NAME OF COMMITTEE (In Full)

\section{Friends of Herman Cain}

A. Full Name (Last, First, Middle Initial)

Bonnie Jones

Mailing Address 15373 Mansfield Way

\begin{tabular}{lcc}
\hline City & State & Zip Code \\
Warsaw & MO & $65355-5908$
\end{tabular}

FEC ID number of contributing federal political committee.

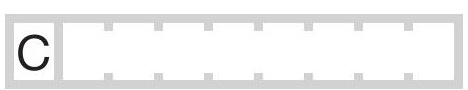

Name of Employer
Warsaw Health and Rehab
Receipt For: 2012
X Primary
Other (specify) General

Occupation $\mathrm{RN}$

Election Cycle-to-Date

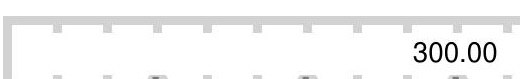

B. Full Name (Last, First, Middle Initial)

Andrew Ramsey

Mailing Address 740 West Main Street

\begin{tabular}{lcc}
\hline City & State & Zip Code \\
Bruceville & IN & $47516-6207$
\end{tabular}

FEC ID number of contributing

federal political committee.

C

Name of Employer
Standard Labs
Receipt For: 2012
X Primary
Other (specify)

\section{Occupation} coalsampler

Election Cycle-to-Date

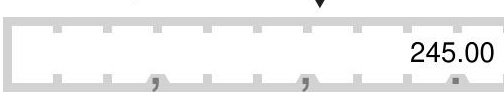

Transaction ID : AE49CB6831AEC4B59B98

Date of Receipt

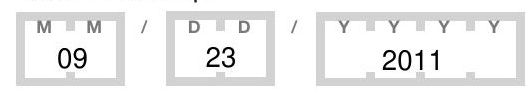

Amount of Each Receipt this Period

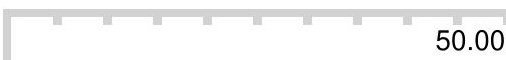

C. Full Name (Last, First, Middle Initial)

Sue Hull

Mailing Address PO Box 357

\begin{tabular}{lcc}
\hline City & State & Zip Code \\
Craig & AK & $99921-0357$
\end{tabular}

FEC ID number of contributing federal political committee.

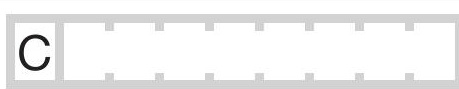

Name of Employer
Peace Health
Receipt For: 2012
X Primary $\quad \square$ General
Other (specify)

\section{Occupation}

Registered Nurse

Election Cycle-to-Date

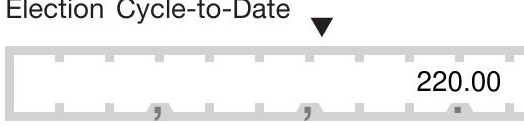

Transaction ID : A1151CDCC41E847B1B60 Date of Receipt

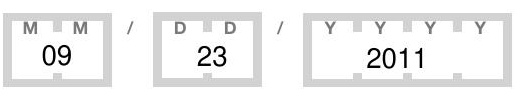

Amount of Each Receipt this Period

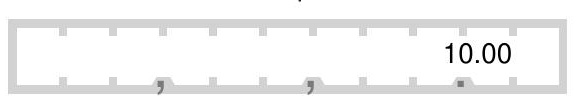

Transaction ID : A91699FE3BA5B4E618C6 Date of Receipt

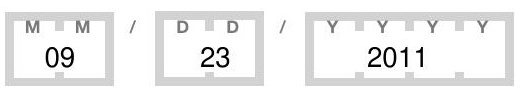

Amount of Each Receipt this Period

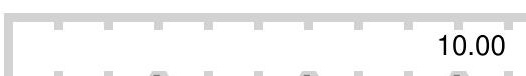

\section{Subtotal Of Receipts This Page (optional)}

Total This Period (last page this line number only) 
SCHEDULE A-P ITEMIZED RECEIPTS
Use separate schedule(s) for each category of the Detailed Summary Page
FOR LINE NUMBER: (check only one)

PAGE $620 / 1572$

\begin{tabular}{|c|c|c|c|c|c|}
\hline & & & & & \\
\hline 16 & $\begin{array}{l}\mathbf{X} \\
17 a\end{array}$ & $17 b$ & $17 c$ & $17 d$ & 18 \\
\hline $19 a$ & $19 \mathrm{~b}$ & $20 \mathrm{a}$ & $20 \mathrm{~b}$ & $20 \mathrm{c}$ & 21 \\
\hline
\end{tabular}

Any information copied from such Reports and Statements may not be sold or used by any person for the purpose of soliciting contributions or for commercial purposes, other than using the name and address of any political committee to solicit contributions from such committee.

NAME OF COMMITTEE (In Full)

\section{Friends of Herman Cain}

A. Full Name (Last, First, Middle Initial)

Dorothy Durrance

Mailing Address 409 Melody Ln

\begin{tabular}{lcc}
\hline City & State & Zip Code \\
Gainesville & TX & $76240-5137$
\end{tabular}

FEC ID number of contributing federal political committee.

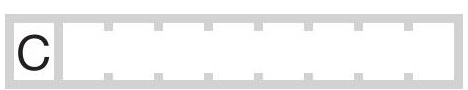

Name of Employer
Not Employed
Receipt For: 2012
X Primary
$\square$ Other (specify) General

Occupation Not Employed

Election Cycle-to-Date

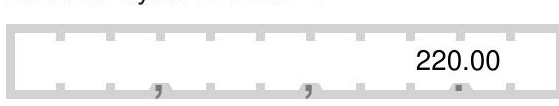

B. Full Name (Last, First, Middle Initial) Eric Rhodus

Mailing Address 25145 Merchant Road

\begin{tabular}{lcc}
\hline City & State & Zip Code \\
Denham Springs & LA & $70726-6833$ \\
\hline
\end{tabular}

FEC ID number of contributing

federal political committee.

C

Name of Employer
Information Requested
Receipt For: 2012
Primary
Other (specify)

Occupation

Information Requested

Election Cycle-to-Date

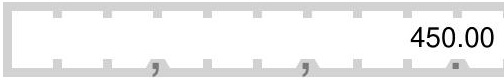

C. Full Name (Last, First, Middle Initial)

Matthew Marston

Mailing Address 90 Beacon St

\begin{tabular}{lcc}
\hline City & State & Zip Code \\
Boston & MA & $02108-3324$
\end{tabular}

FEC ID number of contributing federal political committee.

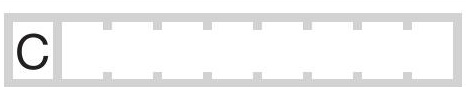

Name of Employer
FourTier Strategies
Receipt For: 2012
X Primary $\quad \square$ General
Other (specify)

\section{Occupation}

Partner

Election Cycle-to-Date
Transaction ID : A1555314400214901B9C

Date of Receipt

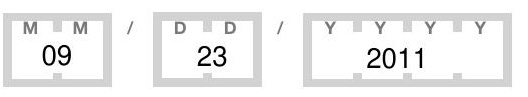

Amount of Each Receipt this Period

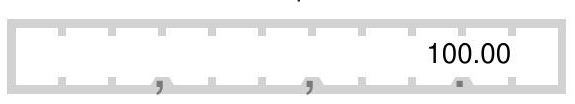

Transaction ID : A7B21BDAFBB564823A84 Date of Receipt

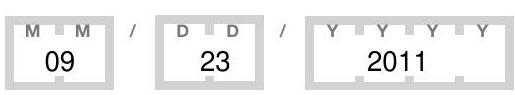

Amount of Each Receipt this Period

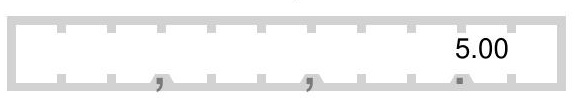

\section{Subtotal Of Receipts This Page (optional).}

Total This Period (last page this line number only) 
SCHEDULE A-P ITEMIZED RECEIPTS
Use separate schedule(s) for each category of the Detailed Summary Page
FOR LINE NUMBER: (check only one)

PAGE $621 / 1572$

\begin{tabular}{|c|c|c|c|c|c|}
\hline & & & & & \\
\hline 16 & $\begin{array}{l}\mathbf{X} \\
17 a\end{array}$ & $17 b$ & $17 c$ & $17 d$ & 18 \\
\hline $19 a$ & $19 \mathrm{~b}$ & $20 \mathrm{a}$ & $20 \mathrm{~b}$ & $20 \mathrm{c}$ & 21 \\
\hline
\end{tabular}

Any information copied from such Reports and Statements may not be sold or used by any person for the purpose of soliciting contributions or for commercial purposes, other than using the name and address of any political committee to solicit contributions from such committee.

NAME OF COMMITTEE (In Full)

\section{Friends of Herman Cain}

A. Full Name (Last, First, Middle Initial)

Heather Boyle

Mailing Address 94-025 Farrington Hwy

\begin{tabular}{lcc}
\hline City & State & Zip Code \\
Waipahu & HI & $96797-2201$
\end{tabular}

FEC ID number of contributing federal political committee.

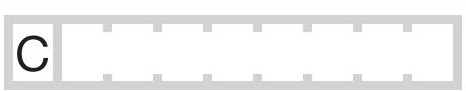

Name of Employer
Information Requested
Receipt For: 2012
X Primary
Other (specify) General

Occupation Information Requested

Election Cycle-to-Date

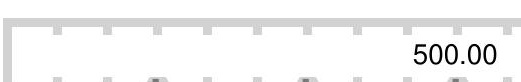

B. Full Name (Last, First, Middle Initial) richard hughes

Mailing Address 808 bayshore dr.

\begin{tabular}{lcc}
\hline City & State & Zip Code \\
Miramar Beach & FL & $32550-3927$
\end{tabular}

FEC ID number of contributing

federal political committee.

C

Name of Employer

Richard J. Hughes MD PA

Occupation

Receipt For: 2012

Х Primary $\square$ General

Physician

Transaction ID : A0EFF9B034CA34D13AEC

Date of Receipt

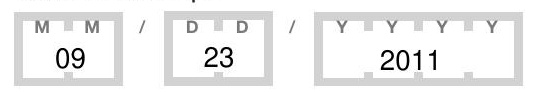

Amount of Each Receipt this Period
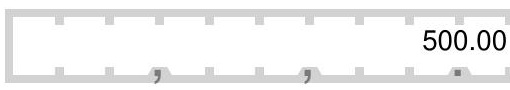

Transaction ID : A873B1FB8AE1F4CE3A7A Date of Receipt

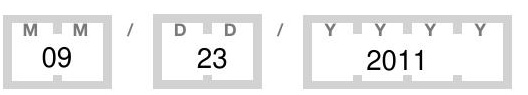

Amount of Each Receipt this Period

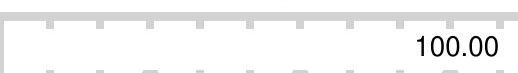

Election Cycle-to-Date

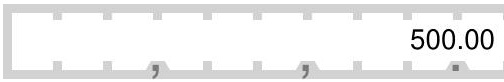

C. Full Name (Last, First, Middle Initial)

Roger Case

Mailing Address 1621 NE 6th Ave

\begin{tabular}{lcc}
\hline City & State & Zip Code \\
Oak Harbor & WA & $98277-4326$
\end{tabular}

FEC ID number of contributing federal political committee.

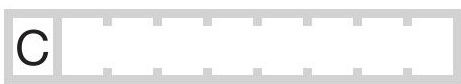

Name of Employer
Retired
Receipt For: 2012
Х Primary $\square$ General
Other (specify)

Occupation

Physician

Election Cycle-to-Date

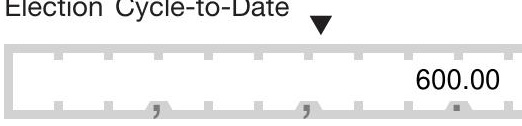

Subtotal Of Receipts This Page (optional)

700.00

Amount of Each Receipt this Period
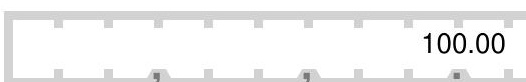

Total This Period (last page this line number only)

Transaction ID : A18747685B2DF4DB3A73

Date of Receipt
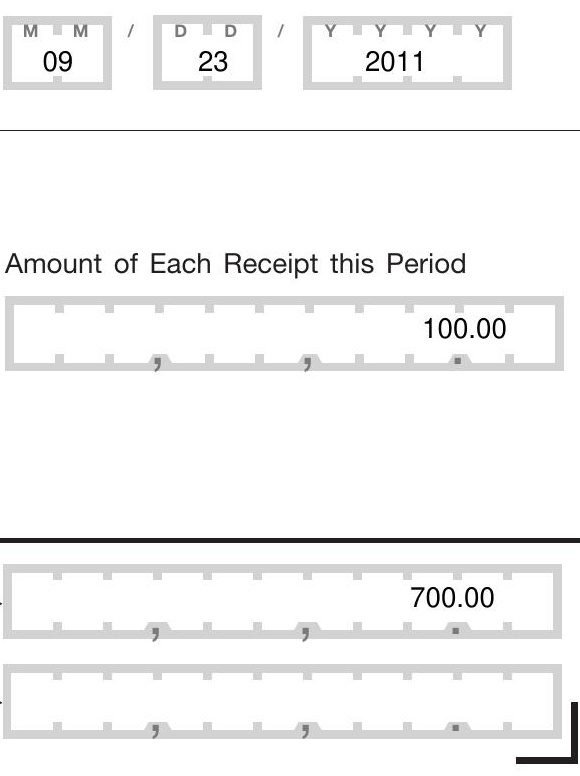
SCHEDULE A-P ITEMIZED RECEIPTS
Use separate schedule(s) for each category of the Detailed Summary Page
FOR LINE NUMBER: (check only one)

PAGE 622 / 1572

\begin{tabular}{|c|c|c|c|c|c|c|}
\hline & & & & & & \\
\hline 16 & $\lambda$ & $17 \mathrm{a}$ & $17 \mathrm{~b}$ & $17 \mathrm{c}$ & $-17 d$ & -18 \\
\hline $19 a$ & & $19 b$ & $20 a$ & $20 \mathrm{~b}$ & $20 \mathrm{c}$ & 21 \\
\hline
\end{tabular}

Any information copied from such Reports and Statements may not be sold or used by any person for the purpose of soliciting contributions or for commercial purposes, other than using the name and address of any political committee to solicit contributions from such committee.

NAME OF COMMITTEE (In Full)

\section{Friends of Herman Cain}

A. Full Name (Last, First, Middle Initial)

Mr Roland Ilsen

Mailing Address 6847 Abbottswood Dr

\begin{tabular}{lcc}
\hline City & State & Zip Code \\
Rancho Palos Verdes & CA & $90275-3058$
\end{tabular}

FEC ID number of contributing

federal political committee.

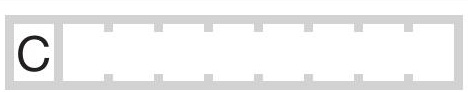

Name of Employer
None
Receipt For: 2012
X Primary $\quad \square$ General
Other (specify)

Occupation

Retired

Election Cycle-to-Date

250.00

B. Full Name (Last, First, Middle Initial)

Peyton Cook

Mailing Address 1475 Midland Road Unit 14

\begin{tabular}{lcc}
\hline City & State & Zip Code \\
Southern Pines & NC & $28387-2100$
\end{tabular}

FEC ID number of contributing

federal political committee.

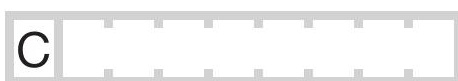

Name of Employer
None
Receipt For: 2012
X Primary
Other (specify)

\section{Occupation}

Retired

Election Cycle-to-Date

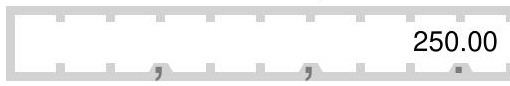

C. Full Name (Last, First, Middle Initial)

Annie Fields

Mailing Address 72 Cornwell $\mathrm{HI}$

\begin{tabular}{lcc}
\hline City & State & Zip Code \\
Marshfield & MA & $02050-6006$
\end{tabular}

FEC ID number of contributing federal political committee.

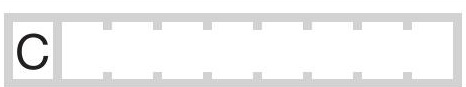

Name of Employer

Information Requested

Occupation

Information Requested

Receipt For: 2012

Х $\begin{aligned} & \text { Primary } \\ & \text { Other (specify) }\end{aligned}$

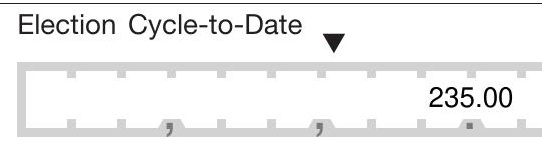

Transaction ID : A3129A37386FB49A0BE6

Date of Receipt

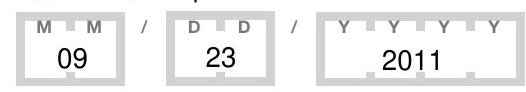

Amount of Each Receipt this Period

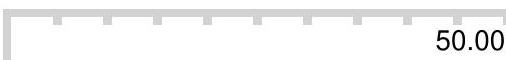

50.00

Transaction ID : A27A4487D003449758CD

Date of Receipt

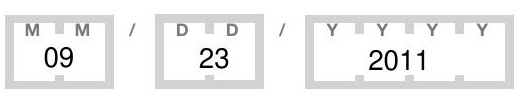

Amount of Each Receipt this Period

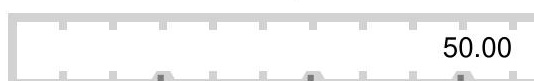

Transaction ID : A22F7820428D04AD59E8

Date of Receipt

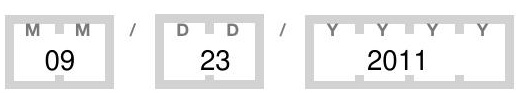

Amount of Each Receipt this Period

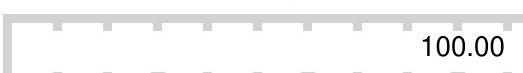

100.00

Subtotal Of Receipts This Page (optional)

200.00

Total This Period (last page this line number only) 
SCHEDULE A-P ITEMIZED RECEIPTS
Use separate schedule(s) for each category of the Detailed Summary Page
FOR LINE NUMBER: (check only one)

PAGE $623 / 1572$

\begin{tabular}{|c|c|c|c|c|c|c|}
\hline & & & & & & \\
\hline 16 & $\lambda$ & $17 \mathrm{a}$ & $17 \mathrm{~b}$ & $17 \mathrm{c}$ & $-17 d$ & -18 \\
\hline $19 a$ & & $19 b$ & $20 a$ & $20 \mathrm{~b}$ & $20 \mathrm{c}$ & 21 \\
\hline
\end{tabular}

Any information copied from such Reports and Statements may not be sold or used by any person for the purpose of soliciting contributions or for commercial purposes, other than using the name and address of any political committee to solicit contributions from such committee.

NAME OF COMMITTEE (In Full)

\section{Friends of Herman Cain}

A. Full Name (Last, First, Middle Initial)

Carl Berry

Mailing Address 4668 Pinecrest Dr.

\begin{tabular}{lcc}
\hline City & State & Zip Code \\
Sugar Hill & GA & $30518-4712$
\end{tabular}

FEC ID number of contributing

federal political committee.

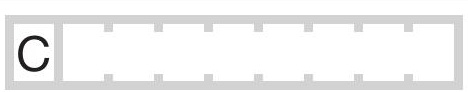

Name of Employer
Information Requested
Receipt For: 2012
X Primary
Other (specify) General

Occupation

Information Requested

Election Cycle-to-Date

1000.00

B. Full Name (Last, First, Middle Initial)

Cynthia Porter

Mailing Address 45 Militia Hill Road

\begin{tabular}{lcc}
\hline City & State & Zip Code \\
Warrington & PA & $18976-1120$
\end{tabular}

FEC ID number of contributing

federal political committee.

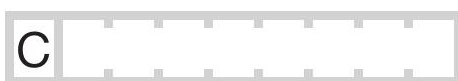

Name of Employer
None
Receipt For: 2012
X Primary
Other (specify)

\section{Occupation}

Homemaker

Election Cycle-to-Date

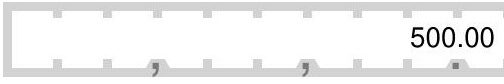

C. Full Name (Last, First, Middle Initial)

David Ford

Mailing Address 5162 Anton Dr Apt 308

\begin{tabular}{lcc}
\hline City & State & Zip Code \\
Fitchburg & WI & $53719-1717$
\end{tabular}

FEC ID number of contributing

federal political committee.

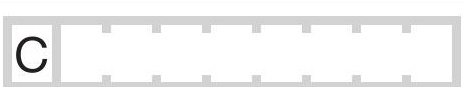

Name of Employer

University of Wisconsin Hospital

Receipt For: 2012

Х $\begin{aligned} & \text { Primary } \\ & \text { Other (specify) }\end{aligned}$

Occupation

Registered Nurse

Election Cycle-to-Date

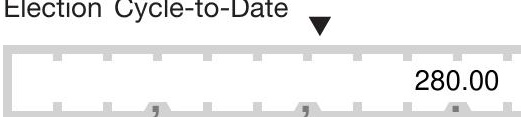

Transaction ID : A69F12A2C06BF4172AE1

Date of Receipt

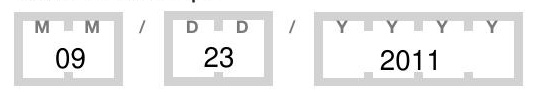

Amount of Each Receipt this Period

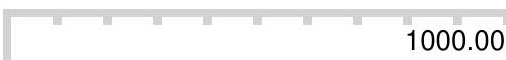

1000.00

Transaction ID : A673DB3DA3B934C2196D

Date of Receipt

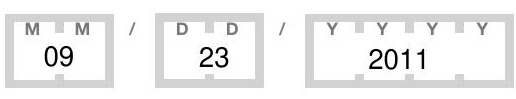

Amount of Each Receipt this Period

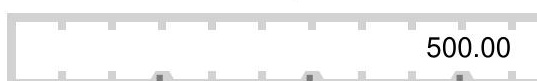

Transaction ID : AB046483559C44D168D2

Date of Receipt

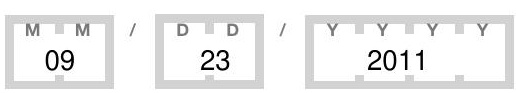

Amount of Each Receipt this Period

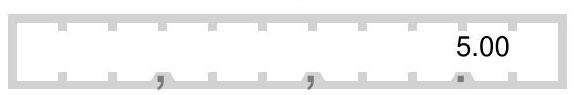

\section{Subtotal Of Receipts This Page (optional)}

Total This Period (last page this line number only) 
SCHEDULE A-P ITEMIZED RECEIPTS
Use separate schedule(s) for each category of the Detailed Summary Page
FOR LINE NUMBER: (check only one)

PAGE 624 / 1572

\begin{tabular}{|c|c|c|c|c|c|}
\hline & & & & & \\
\hline 16 & $\begin{array}{l}\mathbf{X} \\
17 a\end{array}$ & $17 b$ & $17 c$ & $17 d$ & 18 \\
\hline $19 a$ & $19 \mathrm{~b}$ & $20 \mathrm{a}$ & $20 \mathrm{~b}$ & $20 \mathrm{c}$ & 21 \\
\hline
\end{tabular}

Any information copied from such Reports and Statements may not be sold or used by any person for the purpose of soliciting contributions or for commercial purposes, other than using the name and address of any political committee to solicit contributions from such committee.

NAME OF COMMITTEE (In Full)

\section{Friends of Herman Cain}

A. Full Name (Last, First, Middle Initial)

Karen Huff

Mailing Address 302 Old Ivy Road NE

\begin{tabular}{lcc}
\hline City & State & Zip Code \\
Atlanta & GA & $30342-4524$ \\
\hline
\end{tabular}

FEC ID number of contributing federal political committee.

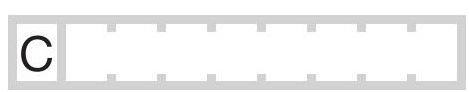

Name of Employer
Delta Airlines
Receipt For: 2012
X Primary
Other (specify) General

Occupation flight attendant

Election Cycle-to-Date

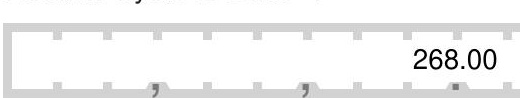

B. Full Name (Last, First, Middle Initial)

Anna Nataros

Mailing Address 1600 E Hanley Blvd. Suite 128

\begin{tabular}{lcc}
\hline City & State & Zip Code \\
Tucson & AZ & $85737-9180$ \\
\hline
\end{tabular}

FEC ID number of contributing

federal political committee.

C

Name of Employer
Information Requested
Receipt For: 2012
X Primary
Other (specify)

Occupation

Information Requested

Election Cycle-to-Date

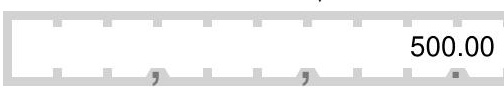

Transaction ID : AB644EAC1ADA84CF6827

Date of Receipt

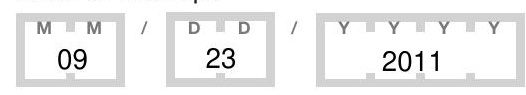

Amount of Each Receipt this Period

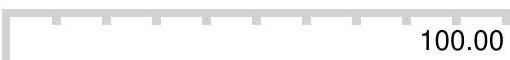

Transaction ID : A9A23572438BC45C3B30

Date of Receipt

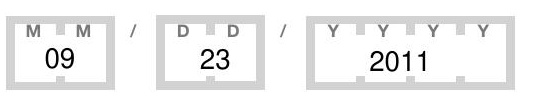

Amount of Each Receipt this Period

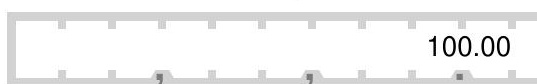

Transaction ID : A1E1911D1967C4CAB9C6 Date of Receipt

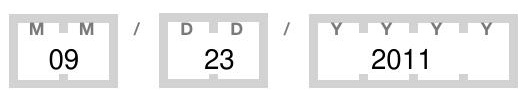

Amount of Each Receipt this Period

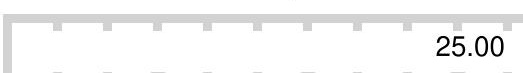

Construction

Election Cycle-to-Date

Receipt For: 2012

Х $\begin{aligned} & \text { Primary } \square \text { General } \\ & \text { Other (specify) }\end{aligned}$

State $\quad$ Zip Code

C

FEC ID number of contributing

federal political committee.

Occupation

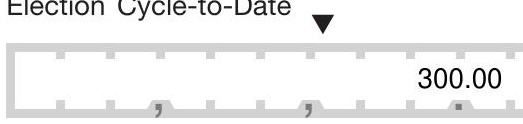

Subtotal Of Receipts This Page (optional)

225.00

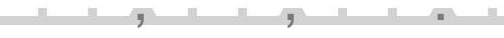

Total This Period (last page this line number only)

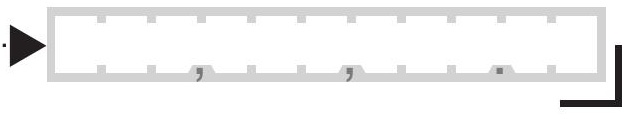

FEC Schedule A-P (Form 3P) (Rev. 03/2011) 
SCHEDULE A-P ITEMIZED RECEIPTS
Use separate schedule(s) for each category of the Detailed Summary Page
FOR LINE NUMBER: (check only one)

PAGE $625 / 1572$

\begin{tabular}{|c|c|c|c|c|c|}
\hline & & & & & \\
\hline 16 & $\begin{array}{l}\mathbf{X} \\
17 a\end{array}$ & $17 b$ & $17 c$ & $17 d$ & 18 \\
\hline $19 a$ & $19 \mathrm{~b}$ & $20 \mathrm{a}$ & $20 \mathrm{~b}$ & $20 \mathrm{c}$ & 21 \\
\hline
\end{tabular}

Any information copied from such Reports and Statements may not be sold or used by any person for the purpose of soliciting contributions or for commercial purposes, other than using the name and address of any political committee to solicit contributions from such committee.

NAME OF COMMITTEE (In Full)

\section{Friends of Herman Cain}

A. Full Name (Last, First, Middle Initial)

Florence Attridge

Mailing Address 2820 Habersham Rd

\begin{tabular}{lcc}
\hline City & State & Zip Code \\
Atlanta & GA & $30305-2959$ \\
\hline
\end{tabular}

FEC ID number of contributing

federal political committee.

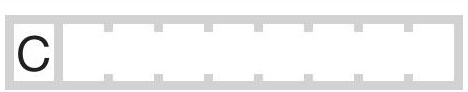

Name of Employer
Information Requested
Receipt For: 2012
X Primary $\quad \square$ General
Other (specify)

Occupation

Information Requested

Election Cycle-to-Date

500.00

B. Full Name (Last, First, Middle Initial)

Leslie Olson

Mailing Address 24218 SE $42 \mathrm{PI}$

\begin{tabular}{llc}
\hline City & State & Zip Code \\
Issaquah & WA & $98029-7516$
\end{tabular}

FEC ID number of contributing

federal political committee.

C

Name of Employer
LifeCenter NW
Receipt For: 2012
X Primary
Other (specify)

Occupation

Surgical Organ Recovery Specialist

Election Cycle-to-Date

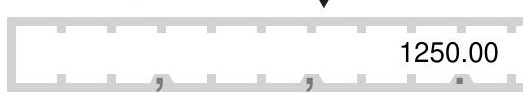

Transaction ID : AD1A36C0C5D304826960

Date of Receipt

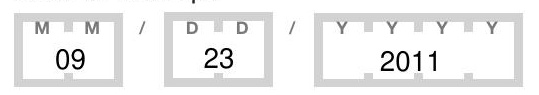

Amount of Each Receipt this Period

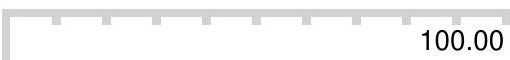

Transaction ID : A83713761E5BD47CE8A0

Date of Receipt

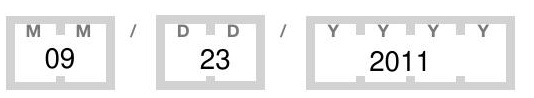

Amount of Each Receipt this Period

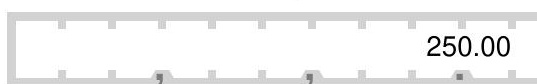

Transaction ID : AD92EE85BAAEB42CBA72

Date of Receipt

Tom Brown

Mailing Address 1566 Ridley Road

\begin{tabular}{lcc}
\hline City & State & Zip Code \\
Dahlonega & GA & $30533-1972$
\end{tabular}

FEC ID number of contributing

federal political committee.

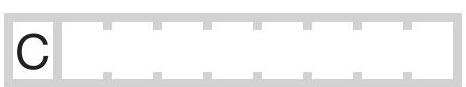

Name of Employer
None
Receipt For: 2012
X Primary $\quad \square$ General
Other (specify)

Occupation

Retired

Election Cycle-to-Date

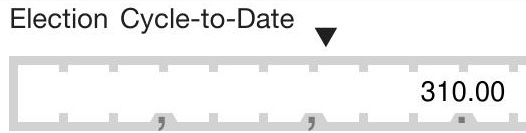

Subtotal Of Receipts This Page (optional).

Amount of Each Receipt this Period

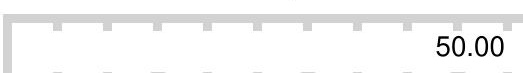

Total This Period (last page this line number only)

400.00

a

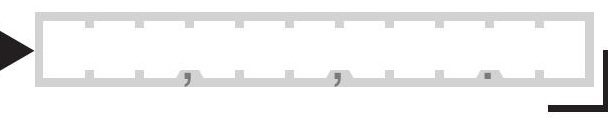

FEC Schedule A-P (Form 3P) (Rev. 03/2011) 
SCHEDULE A-P ITEMIZED RECEIPTS
Use separate schedule(s) for each category of the Detailed Summary Page
FOR LINE NUMBER: (check only one)

PAGE $626 / 1572$

\begin{tabular}{|c|c|c|c|c|c|}
\hline & & & & & \\
\hline 16 & $\begin{array}{l}\mathbf{X} \\
17 a\end{array}$ & $17 b$ & $17 c$ & $17 d$ & 18 \\
\hline $19 a$ & $19 \mathrm{~b}$ & $20 \mathrm{a}$ & $20 \mathrm{~b}$ & $20 \mathrm{c}$ & 21 \\
\hline
\end{tabular}

Any information copied from such Reports and Statements may not be sold or used by any person for the purpose of soliciting contributions or for commercial purposes, other than using the name and address of any political committee to solicit contributions from such committee.

NAME OF COMMITTEE (In Full)

\section{Friends of Herman Cain}

A. Full Name (Last, First, Middle Initial)

Richard Chen

Mailing Address 3377C Peachtree Corners Cir

\begin{tabular}{lcc}
\hline City & State & Zip Code \\
Norcross & GA & $30092-4338$
\end{tabular}

FEC ID number of contributing federal political committee.

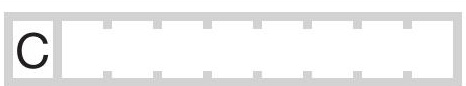

Name of Employer

Gwinnett County Public Schools

Receipt For: 2012

Х Primary $\square$ General

Occupation

SPED Bus Driver

Election Cycle-to-Date

250.00

B. Full Name (Last, First, Middle Initial)

Joseph Anderson

Mailing Address 376 Louisville Rd

\begin{tabular}{lcc}
\hline City & State & Zip Code \\
Grovetown & GA & $30813-4105$ \\
\hline
\end{tabular}

FEC ID number of contributing

federal political committee.

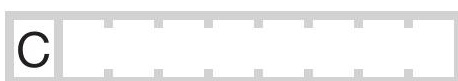

Name of Employer
Not Employed
Receipt For: 2012
X Primary
Other (specify)

Occupation

Not Employed

Election Cycle-to-Date

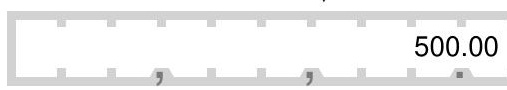

Transaction ID : ACC5AED1C3CB14FF1A2B

Date of Receipt

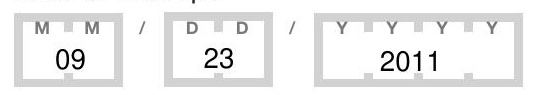

Amount of Each Receipt this Period

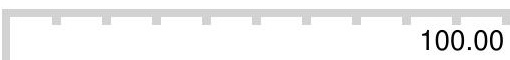

100.00

C. Full Name (Last, First, Middle Initial)

Marion Valerio

Mailing Address 3575 Heritage Rd

\begin{tabular}{lcc}
\hline City & State & Zip Code \\
Alum Bank & PA & 15521 \\
\hline
\end{tabular}

FEC ID number of contributing

federal political committee.

C

Name of Employer
Retired
Receipt For: 2012
Х Primary $\square$ General
Other (specify)

Occupation

veterinary pathologist

Election Cycle-to-Date

Transaction ID : A6E6E85CEE8014C09B56

Date of Receipt

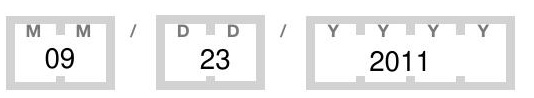

Amount of Each Receipt this Period

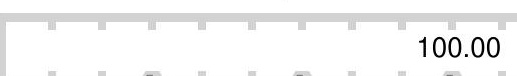

Transaction ID : A5ECC3BE074F64E0BB8D Date of Receipt

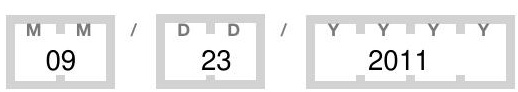

Amount of Each Receipt this Period

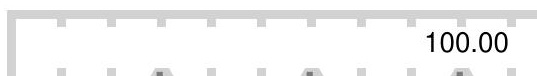

960.00

\section{Subtotal Of Receipts This Page (optional)}

Total This Period (last page this line number only) 
SCHEDULE A-P ITEMIZED RECEIPTS
Use separate schedule(s) for each category of the Detailed Summary Page
FOR LINE NUMBER: (check only one)

PAGE 627 / 1572

\begin{tabular}{|c|c|c|c|c|c|}
\hline & & & & & \\
\hline 16 & $\begin{array}{l}\mathbf{X} \\
17 a\end{array}$ & $17 b$ & $17 c$ & $17 d$ & 18 \\
\hline $19 a$ & $19 \mathrm{~b}$ & $20 \mathrm{a}$ & $20 \mathrm{~b}$ & $20 \mathrm{c}$ & 21 \\
\hline
\end{tabular}

Any information copied from such Reports and Statements may not be sold or used by any person for the purpose of soliciting contributions or for commercial purposes, other than using the name and address of any political committee to solicit contributions from such committee.

NAME OF COMMITTEE (In Full)

\section{Friends of Herman Cain}

A. Full Name (Last, First, Middle Initial)

Karen Herard

Mailing Address 507 S. City View Rd.

\begin{tabular}{lcc}
\hline City & State & Zip Code \\
Ponca City & OK & $74604-5844$
\end{tabular}

FEC ID number of contributing

federal political committee.

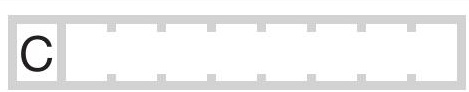

Name of Employer
n/a
Receipt For: 2012
X Primary $\quad$ General
Other (specify)

Occupation

Homemaker

Election Cycle-to-Date

250.00

B. Full Name (Last, First, Middle Initial)

David Girault

Mailing Address 512 S. Casa Linda St.

\begin{tabular}{lcc}
\hline City & State & Zip Code \\
McAllen & TX & $78501-9003$
\end{tabular}

FEC ID number of contributing

federal political committee.

C

Name of Employer
Royal Freight LP
Receipt For: 2012
X Primary
Other (specify) General

Occupation

Legal \& Finance

Election Cycle-to-Date

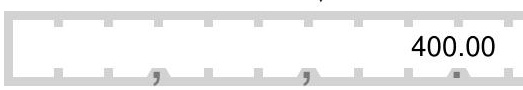

Transaction ID : AE2EBE746F5A54C04BBA

Date of Receipt

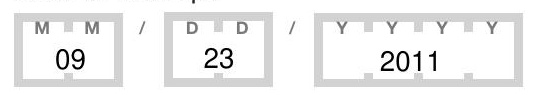

Amount of Each Receipt this Period

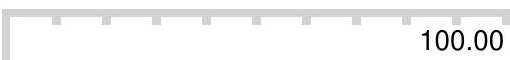

Amount of Each Receipt this Period

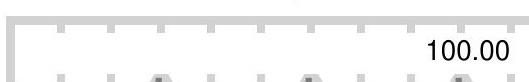

C. Full Name (Last, First, Middle Initial)

Andrew Ramsey

Mailing Address 740 West Main Street

\begin{tabular}{lcc}
\hline City & State & Zip Code \\
Bruceville & IN & $47516-6207$
\end{tabular}

FEC ID number of contributing

federal political committee.

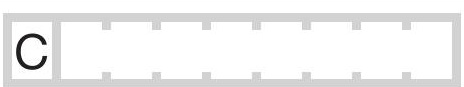

Name of Employer

Occupation

Standard Labs

coalsampler

Receipt For: 2012

Х $\begin{aligned} & \text { Primary } \square \text { General } \\ & \text { Other (specify) }\end{aligned}$

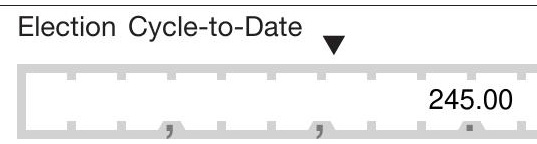

Amount of Each Receipt this Period

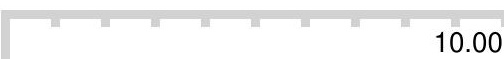

Subtotal Of Receipts This Page (optional)

Total This Period (last page this line number only) 
SCHEDULE A-P ITEMIZED RECEIPTS
Use separate schedule(s) for each category of the Detailed Summary Page
FOR LINE NUMBER: (check only one)

PAGE $628 / 1572$

\begin{tabular}{|c|c|c|c|c|c|}
\hline & & & & & \\
\hline 16 & $\begin{array}{l}\mathbf{X} \\
17 a\end{array}$ & $17 b$ & $17 c$ & $17 d$ & 18 \\
\hline $19 a$ & $19 \mathrm{~b}$ & $20 \mathrm{a}$ & $20 \mathrm{~b}$ & $20 \mathrm{c}$ & 21 \\
\hline
\end{tabular}

Any information copied from such Reports and Statements may not be sold or used by any person for the purpose of soliciting contributions or for commercial purposes, other than using the name and address of any political committee to solicit contributions from such committee.

NAME OF COMMITTEE (In Full)

\section{Friends of Herman Cain}

A. Full Name (Last, First, Middle Initial)

Andrew Ramsey

Mailing Address 740 West Main Street

\begin{tabular}{lcc}
\hline City & State & Zip Code \\
Bruceville & IN & $47516-6207$
\end{tabular}

FEC ID number of contributing

federal political committee.

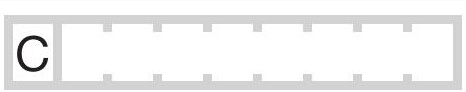

Name of Employer
Standard Labs
Receipt For: 2012
X Primary
Other (specify) General

Occupation coalsampler

Election Cycle-to-Date

\subsection{0}

B. Full Name (Last, First, Middle Initial)

Andrew Ramsey

Mailing Address 740 West Main Street

\begin{tabular}{lcc}
\hline City & State & Zip Code \\
Bruceville & IN & $47516-6207$ \\
\hline
\end{tabular}

FEC ID number of contributing

federal political committee.

C

\begin{tabular}{l} 
Name of Employer \\
Standard Labs \\
Receipt For: 2012 \\
Primary \\
\hline Other (specify) General
\end{tabular}

Occupation coalsampler

Election Cycle-to-Date

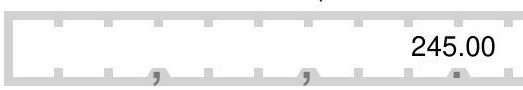

Transaction ID : ACD94DB9BFE4F4F39B22

Date of Receipt

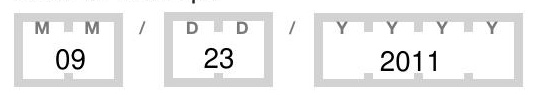

Amount of Each Receipt this Period

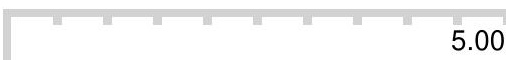

Transaction ID : A99150F214F7448FA881

Date of Receipt

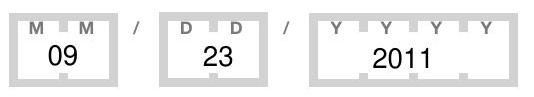

Amount of Each Receipt this Period

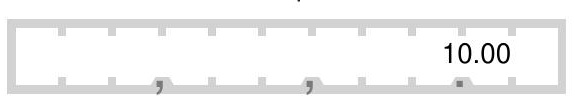

Transaction ID : A69A6B393BB4D41BB911 Date of Receipt

\section{Tyler Russell}

Mailing Address PO BOX 130474

\begin{tabular}{lcc}
\hline City & State & Zip Code \\
Spring & TX & $77393-0474$
\end{tabular}

FEC ID number of contributing federal political committee.

C

Name of Employer
Information Requested
Receipt For: 2012
X Primary
Other (specify) General

Occupation

Information Requested

Election Cycle-to-Date
Amount of Each Receipt this Period

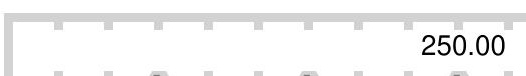

\section{Subtotal Of Receipts This Page (optional)}

Total This Period (last page this line number only) 
SCHEDULE A-P ITEMIZED RECEIPTS
Use separate schedule(s) for each category of the Detailed Summary Page
FOR LINE NUMBER: (check only one)

PAGE 629 / 1572

\begin{tabular}{|c|c|c|c|c|c|}
\hline & & & & & \\
\hline 16 & $\begin{array}{l}\mathbf{X} \\
17 a\end{array}$ & $17 b$ & $17 c$ & $17 d$ & 18 \\
\hline $19 a$ & $19 \mathrm{~b}$ & $20 \mathrm{a}$ & $20 \mathrm{~b}$ & $20 \mathrm{c}$ & 21 \\
\hline
\end{tabular}

Any information copied from such Reports and Statements may not be sold or used by any person for the purpose of soliciting contributions or for commercial purposes, other than using the name and address of any political committee to solicit contributions from such committee.

NAME OF COMMITTEE (In Full)

\section{Friends of Herman Cain}

A. Full Name (Last, First, Middle Initial)

Doreyne Douglas

Mailing Address 5848 Chabot Rd

\begin{tabular}{lcc}
\hline City & State & Zip Code \\
Oakland & CA & $94618-1251$ \\
\hline
\end{tabular}

FEC ID number of contributing federal political committee.

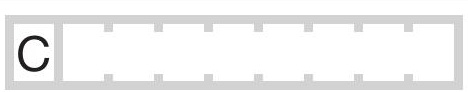

Name of Employer
Planetmagpie
Receipt For: 2012
X Primary $\quad \square$ General
$\square$ Other (specify)

Occupation

IT Consultant

Election Cycle-to-Date

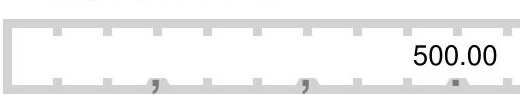

B. Full Name (Last, First, Middle Initial)

Kimberly Nelson

Mailing Address 5017 Granite Shoals Ave.

\begin{tabular}{lcc}
\hline City & State & Zip Code \\
Fort Worth & TX & $76103-1213$ \\
\hline
\end{tabular}

FEC ID number of contributing

federal political committee.

C

Name of Employer
Information Requested
Receipt For: 2012
Primary
Other (specify)

Occupation

Information Requested

Election Cycle-to-Date

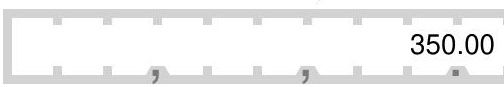

Transaction ID : A567AAFA0E03B46F3A43

Date of Receipt

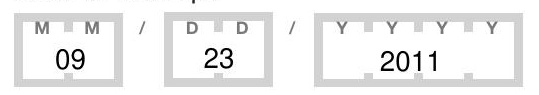

Amount of Each Receipt this Period

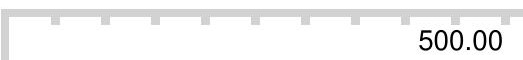

Amount of Each Receipt this Period

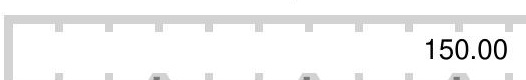

C. Full Name (Last, First, Middle Initial)

William Varney

Mailing Address 714 Church Road

\begin{tabular}{lcc}
\hline City & State & Zip Code \\
Bangor & ME & $04401-2142$
\end{tabular}

FEC ID number of contributing federal political committee.

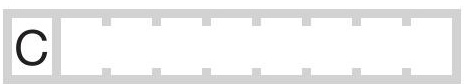

\section{Name of Employer}

VARNEY INC

Receipt For: 2012

Х $\begin{aligned} & \text { Primary } \\ & \text { Other (specify) }\end{aligned}$

\section{Occupation}

EXEC

Election Cycle-to-Date
Transaction ID : AB7E6A25E0F884DD4BBC Date of Receipt

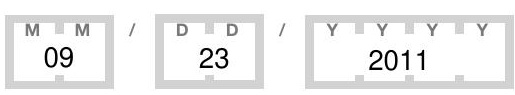

Transaction ID : AC43DB7259E1A446ABB0 Date of Receipt

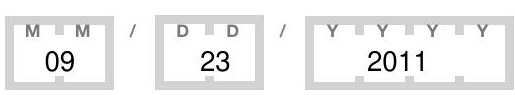

Amount of Each Receipt this Period

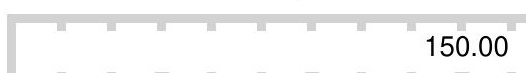

150.00

\section{Subtotal Of Receipts This Page (optional)}

800.00

a

Total This Period (last page this line number only)

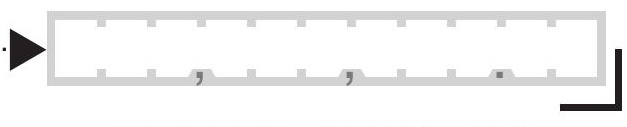

FEC Schedule A-P (Form 3P) (Rev. 03/2011) 
SCHEDULE A-P ITEMIZED RECEIPTS
Use separate schedule(s) for each category of the Detailed Summary Page
FOR LINE NUMBER: (check only one)

PAGE $630 / 1572$

\begin{tabular}{|c|c|c|c|c|c|}
\hline & & & & & \\
\hline 16 & $\begin{array}{l}\mathbf{X} \\
17 a\end{array}$ & $17 b$ & $17 c$ & $17 d$ & 18 \\
\hline $19 a$ & $19 \mathrm{~b}$ & $20 \mathrm{a}$ & $20 \mathrm{~b}$ & $20 \mathrm{c}$ & 21 \\
\hline
\end{tabular}

Any information copied from such Reports and Statements may not be sold or used by any person for the purpose of soliciting contributions or for commercial purposes, other than using the name and address of any political committee to solicit contributions from such committee.

NAME OF COMMITTEE (In Full)

\section{Friends of Herman Cain}

A. Full Name (Last, First, Middle Initial)

William Varney

Mailing Address 714 Church Road

\begin{tabular}{lcc}
\hline City & State & Zip Code \\
Bangor & ME & $04401-2142$ \\
\hline
\end{tabular}

FEC ID number of contributing federal political committee.

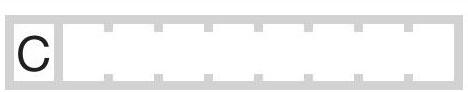

Name of Employer
VARNEY INC
Receipt For: 2012
X Primary $\quad$ General
Other (specify)

Occupation

EXEC

Election Cycle-to-Date 400.00

B. Full Name (Last, First, Middle Initial)

Molly Smithfield

Mailing Address 1844 W San Angelo St

\begin{tabular}{lcc}
\hline City & State & Zip Code \\
Gilbert & AZ & 85233-2925 \\
\hline
\end{tabular}

FEC ID number of contributing

federal political committee.

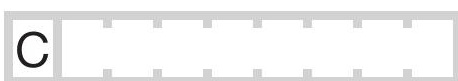

Name of Employer
None
Receipt For: 2012
X Primary
Other (specify)

\section{Occupation}

Homemaker

Election Cycle-to-Date

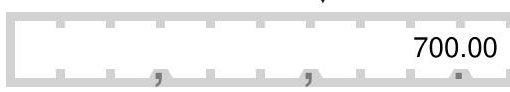

C. Full Name (Last, First, Middle Initial)

Maryanne Metcalfe

Mailing Address 1610 Wood Pointe Ln Apt 1

\begin{tabular}{lcc}
\hline City & State & Zip Code \\
Midland & MI & $48642-3380$
\end{tabular}

FEC ID number of contributing

federal political committee.

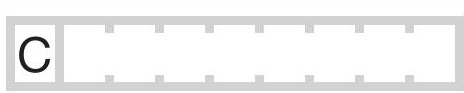

Name of Employer
None
Receipt For: 2012
Х Primary $\quad \square$ General
Other (specify)

\section{Occupation}

Retired

Election Cycle-to-Date

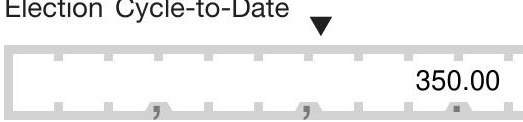

Transaction ID : ADE128EA4BDC94AD1AB0

Date of Receipt

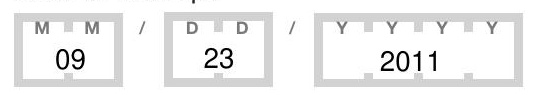

Amount of Each Receipt this Period

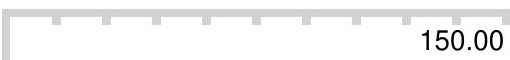

150.00
Amount of Each Receipt this Period

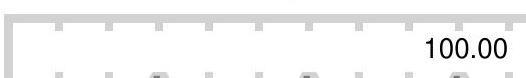

Transaction ID : A1D265C06790D41E686C

Date of Receipt

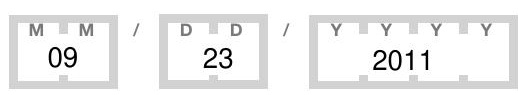

Transaction ID : A4EB59D663C704958971 Date of Receipt

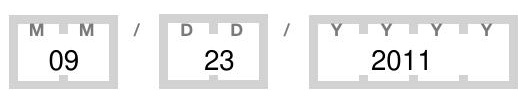

Amount of Each Receipt this Period

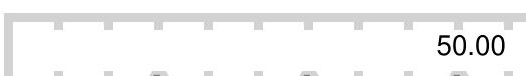

50.00

\section{Subtotal Of Receipts This Page (optional)}

300.00

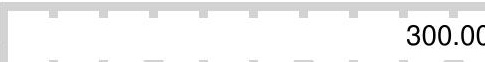

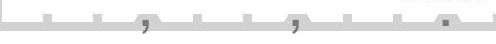

Total This Period (last page this line number only)

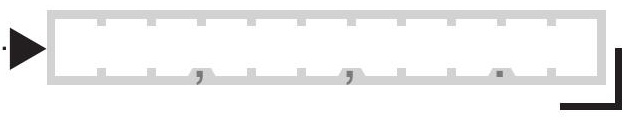

FEC Schedule A-P (Form 3P) (Rev. 03/2011) 
SCHEDULE A-P ITEMIZED RECEIPTS
Use separate schedule(s) for each category of the Detailed Summary Page
FOR LINE NUMBER: (check only one)

PAGE $631 / 1572$

\begin{tabular}{|c|c|c|c|c|c|c|}
\hline & & & & & & \\
\hline 16 & $\lambda$ & $17 \mathrm{a}$ & $17 \mathrm{~b}$ & $17 \mathrm{c}$ & $-17 d$ & -18 \\
\hline $19 a$ & & $19 b$ & $20 a$ & $20 \mathrm{~b}$ & $20 \mathrm{c}$ & 21 \\
\hline
\end{tabular}

Any information copied from such Reports and Statements may not be sold or used by any person for the purpose of soliciting contributions or for commercial purposes, other than using the name and address of any political committee to solicit contributions from such committee.

NAME OF COMMITTEE (In Full)

\section{Friends of Herman Cain}

A. Full Name (Last, First, Middle Initial) Joseph Prigge

Mailing Address 210 coventry court

\begin{tabular}{lcc}
\hline City & State & Zip Code \\
Elgin & IL & $60123-5081$ \\
\hline
\end{tabular}

FEC ID number of contributing federal political committee.

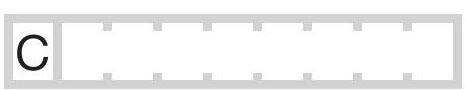

Name of Employer
William Prigge
Receipt For: 2012
X Primary
Other (specify) General

Occupation

Geotechnical Technician

Election Cycle-to-Date $\boldsymbol{\nabla}$

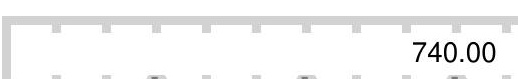

B. Full Name (Last, First, Middle Initial)

David Herman

Mailing Address 118 Greer Lane

\begin{tabular}{lcc}
\hline City & State & Zip Code \\
Toccoa & GA & $30577-3096$ \\
\hline
\end{tabular}

FEC ID number of contributing

federal political committee.

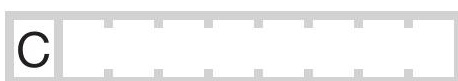

Name of Employer
Air Tran
Receipt For: 2012
X Primary
Other (specify)

\section{Occupation}

Pilot

Election Cycle-to-Date

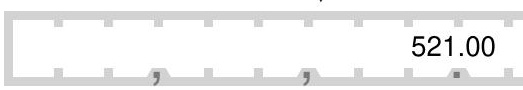

Transaction ID : A097CA7531EA84D44998

Date of Receipt

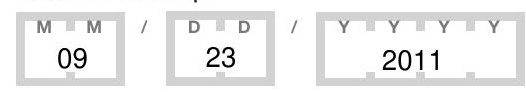

Amount of Each Receipt this Period

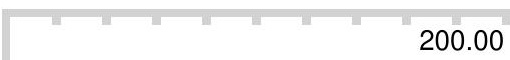

200.00

C. Full Name (Last, First, Middle Initial)

James F Robison

Mailing Address 3635 E Chukkar PI

City

Tucson

FEC ID number of contributing

federal political committee.

Name of Employer
None
Receipt For: 2012
X Primary
Other (specify) General

$\begin{array}{cc}\text { State } & \text { Zip Code } \\ \text { AZ } & 85739-9771\end{array}$

C

\section{Occupation}

Retired

Election Cycle-to-Date

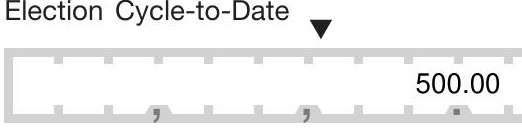

Transaction ID : A3A7F155C47AB43C1B58

Date of Receipt

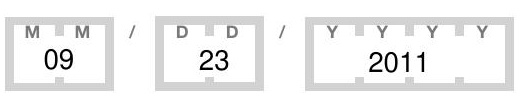

Amount of Each Receipt this Period

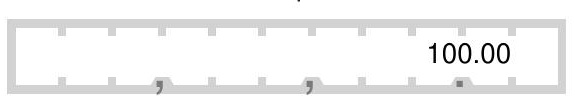

Transaction ID : AC86592CD15CE40CB917 Date of Receipt

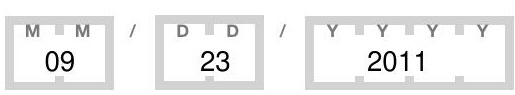

Amount of Each Receipt this Period

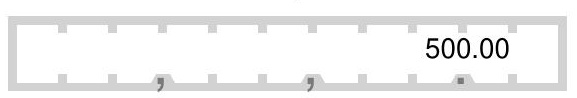

\section{Subtotal Of Receipts This Page (optional)}

800.00

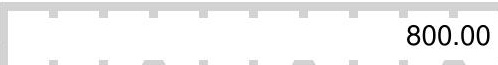

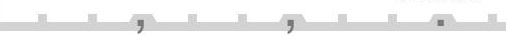

Total This Period (last page this line number only)

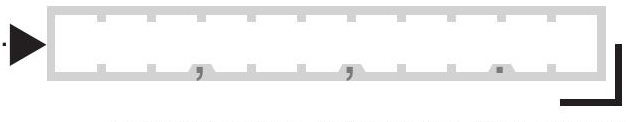

FEC Schedule A-P (Form 3P) (Rev. 03/2011) 
SCHEDULE A-P ITEMIZED RECEIPTS
Use separate schedule(s) for each category of the Detailed Summary Page
FOR LINE NUMBER: (check only one)

PAGE 632 / 1572

\begin{tabular}{|c|c|c|c|c|c|c|}
\hline & & & & & & \\
\hline 16 & $\lambda$ & $17 \mathrm{a}$ & $17 \mathrm{~b}$ & $17 \mathrm{c}$ & $-17 d$ & -18 \\
\hline $19 a$ & & $19 b$ & $20 a$ & $20 \mathrm{~b}$ & $20 \mathrm{c}$ & 21 \\
\hline
\end{tabular}

Any information copied from such Reports and Statements may not be sold or used by any person for the purpose of soliciting contributions or for commercial purposes, other than using the name and address of any political committee to solicit contributions from such committee.

NAME OF COMMITTEE (In Full)

Friends of Herman Cain

A. Full Name (Last, First, Middle Initial)

Stephen H Perry

Mailing Address 517 Carilion Ln

\begin{tabular}{lcc}
\hline City & State & Zip Code \\
Greenville & SC & $29617-7914$
\end{tabular}

FEC ID number of contributing

federal political committee.

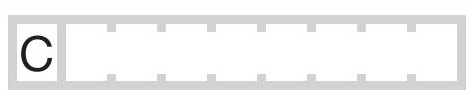

Name of Employer
Information Requested
Receipt For: 2012
X Primary $\quad \square$ General
Other (specify)

Occupation

Information Requested

Election Cycle-to-Date

\subsection{0}

B. Full Name (Last, First, Middle Initial)

William R Wiggins Jr

Mailing Address P.O. Box 1251

\begin{tabular}{lcc}
\hline City & State & Zip Code \\
Lindale & TX & $75771-1251$ \\
\hline
\end{tabular}

FEC ID number of contributing

federal political committee.

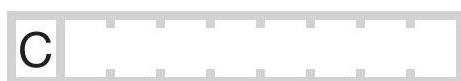

Name of Employer
Colonial Life
Receipt For: 2012
X Primary $\quad$ General
Other (specify)

\section{Occupation}

Sales

Election Cycle-to-Date

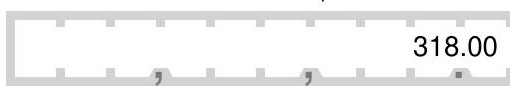

Transaction ID : ADFEAE6B979D8403897E

Date of Receipt

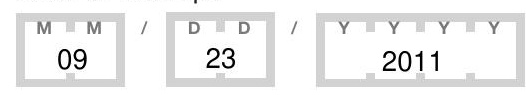

Amount of Each Receipt this Period

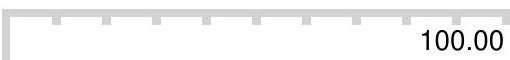

Amount of Each Receipt this Period

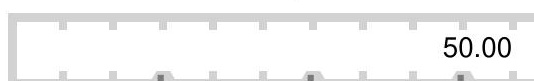

C. Full Name (Last, First, Middle Initial)

Sally Sidman

Mailing Address 560 East C.R. 600 North

\begin{tabular}{lcc}
\hline City & State & Zip Code \\
Muncie & IN & 47303 \\
\hline
\end{tabular}

FEC ID number of contributing federal political committee.

C

Name of Employer
Information Requested
Receipt For: 2012
X Primary
Other (specify) General

\section{Occupation}

Information Requested

Election Cycle-to-Date
Transaction ID : A97F80E0A185B432CAEA

Date of Receipt

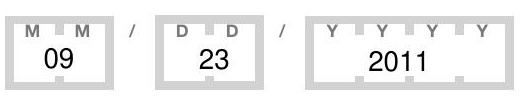

Transaction ID : ACB4F0E1001AF4D7EB5A Date of Receipt

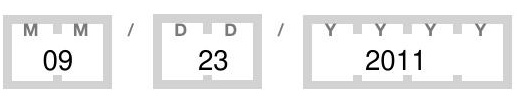

Amount of Each Receipt this Period

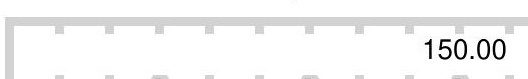

300.00

Subtotal Of Receipts This Page (optional).

300.00

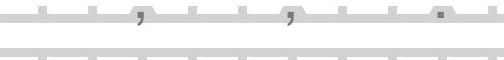

Total This Period (last page this line number only) 
SCHEDULE A-P ITEMIZED RECEIPTS
Use separate schedule(s) for each category of the Detailed Summary Page
FOR LINE NUMBER: (check only one)

PAGE $633 / 1572$

\begin{tabular}{|c|c|c|c|c|c|c|}
\hline & & & & & & \\
\hline 16 & $\lambda$ & $17 \mathrm{a}$ & $17 \mathrm{~b}$ & $17 \mathrm{c}$ & $-17 d$ & -18 \\
\hline $19 a$ & & $19 b$ & $20 a$ & $20 \mathrm{~b}$ & $20 \mathrm{c}$ & 21 \\
\hline
\end{tabular}

Any information copied from such Reports and Statements may not be sold or used by any person for the purpose of soliciting contributions or for commercial purposes, other than using the name and address of any political committee to solicit contributions from such committee.

NAME OF COMMITTEE (In Full)

\section{Friends of Herman Cain}

A. Full Name (Last, First, Middle Initial)

Allison Ficken

Mailing Address 5601 Queensborough Drive

\begin{tabular}{lcc}
\hline City & State & Zip Code \\
Atlanta & GA & $30338-2619$ \\
\hline
\end{tabular}

FEC ID number of contributing

federal political committee.

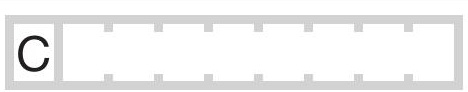

Name of Employer
Dovin Malkin \& Ficken
Receipt For: 2012
X Primary $\quad \square$ General
Other (specify)

Occupation

Attorney

Election Cycle-to-Date

400.00

B. Full Name (Last, First, Middle Initial)

Wendell Parkey

Mailing Address 2404 S.W. Ave. E

\begin{tabular}{lcc}
\hline City & State & Zip Code \\
Seminole & TX & 79360 \\
\hline
\end{tabular}

FEC ID number of contributing

federal political committee.

C

Name of Employer
Self Employed
Receipt For: 2012
Primary
Other (specify)

Occupation

Physician

Transaction ID : ADF310D10F0C74379A83

Date of Receipt

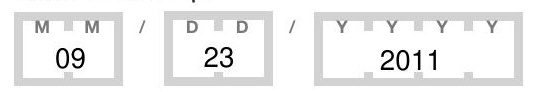

Amount of Each Receipt this Period

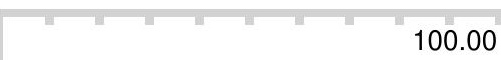

100.00

Transaction ID : A8B59405BC6D54518A5B

Date of Receipt

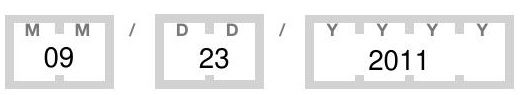

Amount of Each Receipt this Period

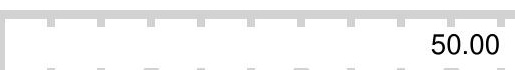

Election Cycle-to-Date

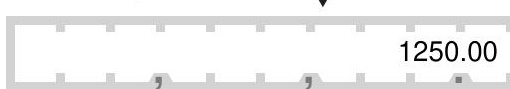

C. Full Name (Last, First, Middle Initial)

CHris Guarino

Mailing Address 2665 Ball Ground Hwy

\begin{tabular}{lcc}
\hline City & State & Zip Code \\
Canton & GA & $30114-7439$
\end{tabular}

FEC ID number of contributing

federal political committee.

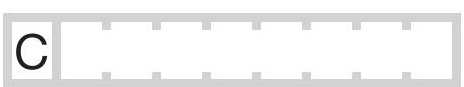

Name of Employer

Asset Technology Group

Receipt For: 2012

Х $\begin{aligned} & \text { Primary } \\ & \text { Other (specify) }\end{aligned}$

\section{Occupation}

BUSINESS OWNER

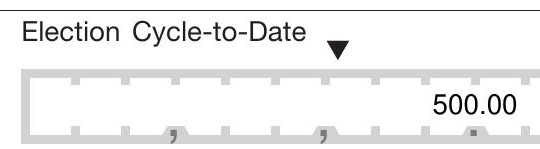

Transaction ID : A2612987782C74B57896

Date of Receipt

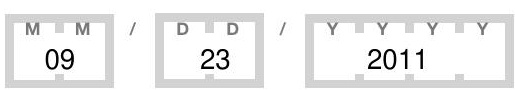

Amount of Each Receipt this Period

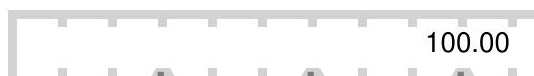

\section{Subtotal Of Receipts This Page (optional)}

Total This Period (last page this line number only) 
SCHEDULE A-P ITEMIZED RECEIPTS
Use separate schedule(s) for each category of the Detailed Summary Page

FOR LINE NUMBER:
(check only one)

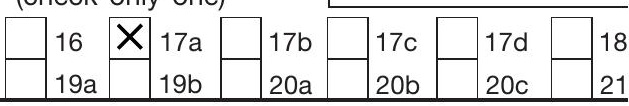

Any information copied from such Reports and Statements may not be sold or used by any person for the purpose of soliciting contributions or for commercial purposes, other than using the name and address of any political committee to solicit contributions from such committee.

NAME OF COMMITTEE (In Full)

\section{Friends of Herman Cain}

A. Full Name (Last, First, Middle Initial)

William Kubicz

Mailing Address CMR 411 Box 373

\begin{tabular}{lcc}
\hline City & State & Zip Code \\
Apo & AE & $09112-0004$ \\
\hline
\end{tabular}

FEC ID number of contributing federal political committee.

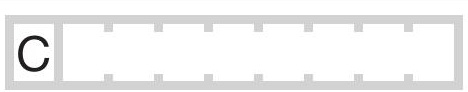

Name of Employer
Army
Receipt For: 2012
X Primary $\quad$ General
Other (specify)

\section{Occupation} Military

Election Cycle-to-Date

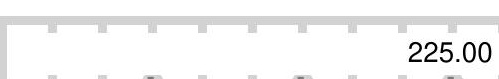

B. Full Name (Last, First, Middle Initial)

Steven Wisniewski

Mailing Address 647 Pecan Knoll Dr

\begin{tabular}{lcc}
\hline City & State & Zip Code \\
Marietta & GA & $30008-3100$ \\
\hline
\end{tabular}

FEC ID number of contributing

federal political committee.

C

Name of Employer
Information Requested
Receipt For: 2012
X Primary
Other (specify)

Occupation

Information Requested

Election Cycle-to-Date

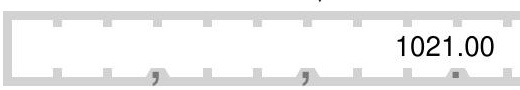

C. Full Name (Last, First, Middle Initial)

Mr Charles E Weaver

Mailing Address 6315 Holland $\mathrm{Dr}$

\begin{tabular}{lcc}
\hline City & State & Zip Code \\
Cumming & GA & $30041-4639$ \\
\hline
\end{tabular}

FEC ID number of contributing federal political committee.

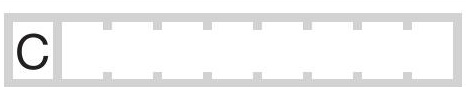

Name of Employer
retired UPS
Receipt For: 2012
X Primary $\square$ General
Other (specify)

\section{Occupation}

Executive

Election Cycle-to-Date
Transaction ID : AEFF72167FF334A7B80A

Date of Receipt

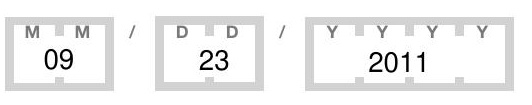

Amount of Each Receipt this Period

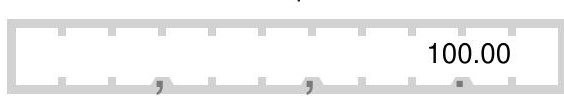

Transaction ID : A4E74F5017058400F9EF

Date of Receipt

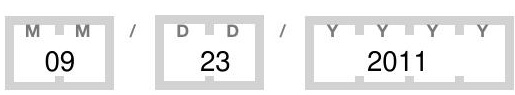

Amount of Each Receipt this Period

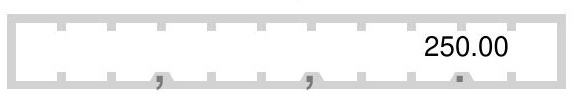

\section{Subtotal Of Receipts This Page (optional).}

375.00

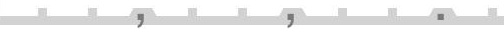

Total This Period (last page this line number only)

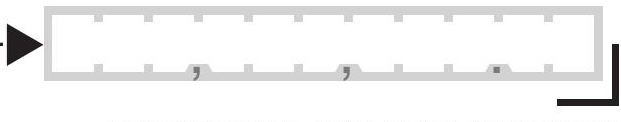

FEC Schedule A-P (Form 3P) (Rev. 03/2011) 
SCHEDULE A-P ITEMIZED RECEIPTS
Use separate schedule(s) for each category of the Detailed Summary Page

FOR LINE NUMBER:
(check only one)

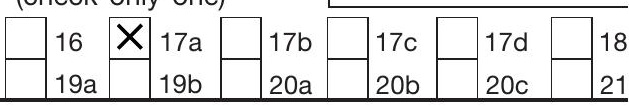

Any information copied from such Reports and Statements may not be sold or used by any person for the purpose of soliciting contributions or for commercial purposes, other than using the name and address of any political committee to solicit contributions from such committee.

NAME OF COMMITTEE (In Full)

\section{Friends of Herman Cain}

A. Full Name (Last, First, Middle Initial)

William Lowther

Mailing Address PO Box 806

\begin{tabular}{lcc}
\hline City & State & Zip Code \\
Macclenny & FL & $32063-0806$
\end{tabular}

FEC ID number of contributing federal political committee.

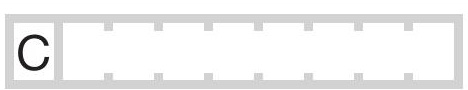

Name of Employer
Metal Container Corp
Receipt For: 2012
X Primary $\quad \square$ General
Other (specify)

Occupation maintanier

Election Cycle-to-Date 250.00

B. Full Name (Last, First, Middle Initial) Thomas E Weinshenker

Mailing Address 13513 Haines Ave NE

\begin{tabular}{lcc}
\hline City & State & Zip Code \\
Albuquerque & NM & $87112-4933$ \\
\hline
\end{tabular}

FEC ID number of contributing

federal political committee.

C

Name of Employer
Information Requested
Receipt For: 2012
X Primary
Other (specify)

Occupation

Information Requested

Election Cycle-to-Date

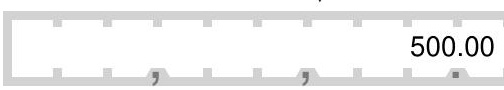

C. Full Name (Last, First, Middle Initial)

vittorio brod

Mailing Address 1895 Crystal Dr \# 213

\section{City}

Arlington

FEC ID number of contributing federal political committee.

Name of Employer
Retired
Receipt For: 2012
X Primary $\square$ General
Other (specify)

Transaction ID : A26C53A13BA9147509B8

Date of Receipt

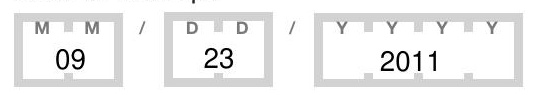

Amount of Each Receipt this Period

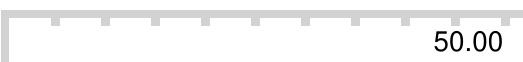

50.00
Amount of Each Receipt this Period

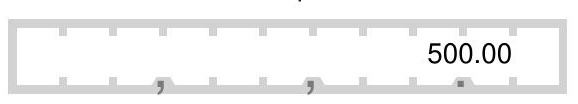

Transaction ID : ACBCF07EA7B0149859BF Date of Receipt

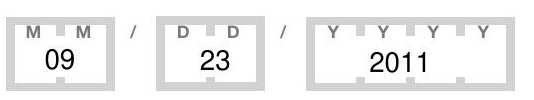

Transaction ID : ABBBB3914FD3D4AC18F3 Date of Receipt

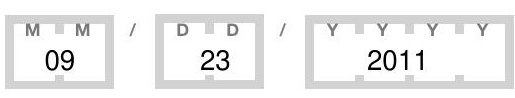

Amount of Each Receipt this Period

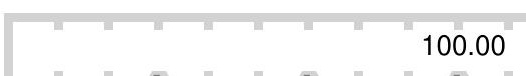

\section{Occupation}

Retired

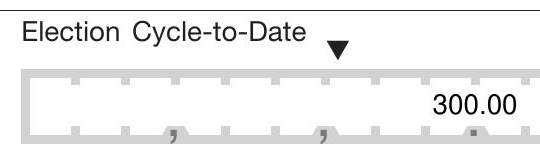

Subtotal Of Receipts This Page (optional).

650.00

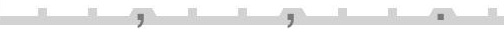

Total This Period (last page this line number only)

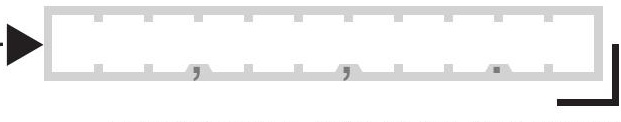

FEC Schedule A-P (Form 3P) (Rev. 03/2011) 
SCHEDULE A-P ITEMIZED RECEIPTS
Use separate schedule(s) for each category of the Detailed Summary Page
FOR LINE NUMBER: (check only one)

PAGE $636 / 1572$

\begin{tabular}{|c|c|c|c|c|c|}
\hline & & & & & \\
\hline 16 & $\begin{array}{l}\mathbf{X} \\
17 a\end{array}$ & $17 b$ & $17 c$ & $17 d$ & 18 \\
\hline $19 a$ & $19 \mathrm{~b}$ & $20 \mathrm{a}$ & $20 \mathrm{~b}$ & $20 \mathrm{c}$ & 21 \\
\hline
\end{tabular}

Any information copied from such Reports and Statements may not be sold or used by any person for the purpose of soliciting contributions or for commercial purposes, other than using the name and address of any political committee to solicit contributions from such committee.

NAME OF COMMITTEE (In Full)

\section{Friends of Herman Cain}

A. Full Name (Last, First, Middle Initial)

Robert Casper

Mailing Address 1720 Live Oak Trail

\begin{tabular}{lcc}
\hline City & State & Zip Code \\
Virginia Beach & VA & $23456-4081$
\end{tabular}

FEC ID number of contributing

federal political committee.

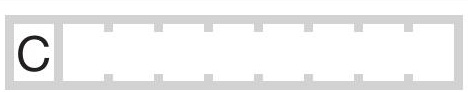

Name of Employer
U.S. Navy
Receipt For: 2012
X Primary $\quad$ General
Other (specify)

Occupation

Commander

Election Cycle-to-Date

250.00

B. Full Name (Last, First, Middle Initial)

Drucilla Jacobs

Mailing Address 3075 Rice Mill Rd None

\begin{tabular}{lcc}
\hline City & State & Zip Code \\
Macon & GA & $31206-3301$ \\
\hline
\end{tabular}

FEC ID number of contributing

federal political committee.

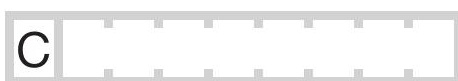

Name of Employer
n/a
Receipt For: 2012
X Primary
Other (specify)

\section{Occupation}

Retired

Election Cycle-to-Date

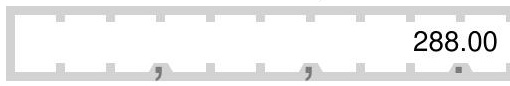

C. Full Name (Last, First, Middle Initial)

Ashley Turek

Mailing Address 959 Jackling Drive

\begin{tabular}{lcc}
\hline City & State & Zip Code \\
Hillsborough & CA & $94010-6127$
\end{tabular}

FEC ID number of contributing federal political committee.

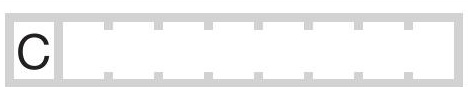

Name of Employer
Information Requested
Receipt For: 2012
X Primary $\quad \square$ General
Other (specify)

\section{Occupation}

Information Requested

Election Cycle-to-Date
Transaction ID : A8848A11BBBAE469DBDD

Date of Receipt

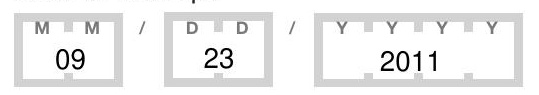

Amount of Each Receipt this Period

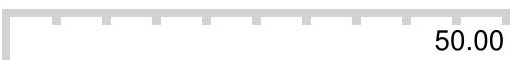

50.00

Amount of Each Receipt this Period

Transaction ID : A8790B147DB9549C588E

Date of Receipt
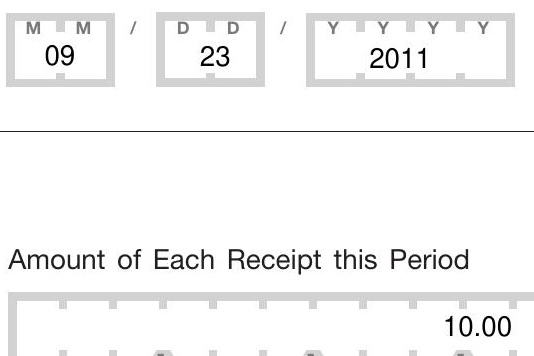

Transaction ID : AB2724989E5624BF48BA Date of Receipt

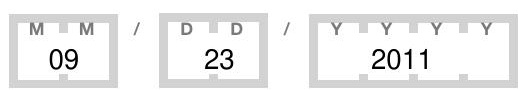

Amount of Each Receipt this Period

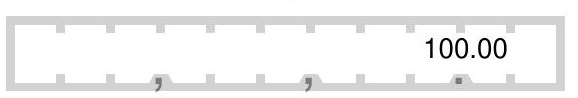

250.00

\section{Subtotal Of Receipts This Page (optional)}

Total This Period (last page this line number only) 
SCHEDULE A-P ITEMIZED RECEIPTS
Use separate schedule(s) for each category of the Detailed Summary Page
FOR LINE NUMBER: (check only one)

PAGE $637 / 1572$

\begin{tabular}{|c|c|c|c|c|c|}
\hline & & & & & \\
\hline 16 & $\begin{array}{l}\mathbf{X} \\
17 a\end{array}$ & $17 b$ & $17 c$ & $17 d$ & 18 \\
\hline $19 a$ & $19 \mathrm{~b}$ & $20 \mathrm{a}$ & $20 \mathrm{~b}$ & $20 \mathrm{c}$ & 21 \\
\hline
\end{tabular}

Any information copied from such Reports and Statements may not be sold or used by any person for the purpose of soliciting contributions or for commercial purposes, other than using the name and address of any political committee to solicit contributions from such committee.

NAME OF COMMITTEE (In Full)

\section{Friends of Herman Cain}

A. Full Name (Last, First, Middle Initial)

Christopher Gregerson

Mailing Address 1116 S. Esplanade

\begin{tabular}{lcc}
\hline City & State & Zip Code \\
Leavenworth & KS & $66048-3522$
\end{tabular}

FEC ID number of contributing

federal political committee.

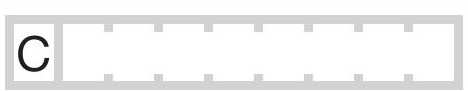

Name of Employer
Booz Allen Hamilton Inc
Receipt For: 2012
X Primary $\quad \square$ General
Other (specify)

Occupation

Consultant

Election Cycle-to-Date

500.00

B. Full Name (Last, First, Middle Initial)

christina lipsey

Mailing Address 1219 libby rd

\begin{tabular}{lcc}
\hline City & State & Zip Code \\
Heber Springs & AR & $72543-8985$ \\
\hline
\end{tabular}

FEC ID number of contributing

federal political committee.

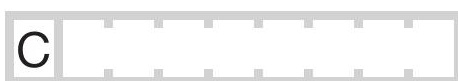

Name of Employer
little rock scool distrct
Receipt For: 2012
X Primary
Other (specify)

Occupation

Teacher

Election Cycle-to-Date

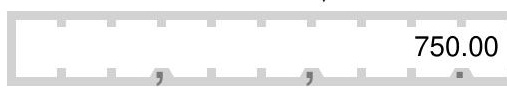

Transaction ID : A48E020D4D8B24D198A3

Date of Receipt

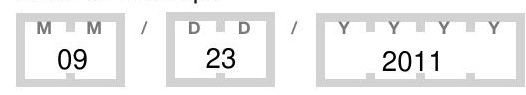

Amount of Each Receipt this Period

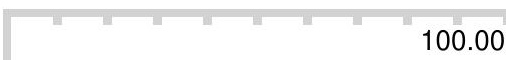

100.00

C. Full Name (Last, First, Middle Initial)

Norman Johnson

Mailing Address 2404 Stoney Point Road

\begin{tabular}{lcc}
\hline City & State & Zip Code \\
Cumming & GA & $30041-6753$
\end{tabular}

FEC ID number of contributing

federal political committee.

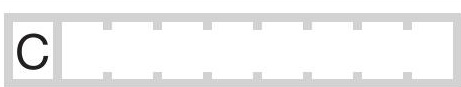

Name of Employer

EMS Technologies Inc.

Occupation

Receipt For: 2012

Х $\begin{aligned} & \text { Primary } \square \text { General } \\ & \text { Other (specify) }\end{aligned}$

Business Development/Engineering

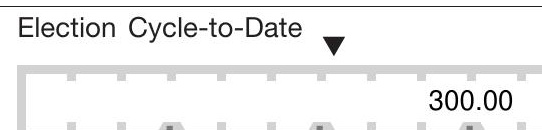

Amount of Each Receipt this Period

Transaction ID : A1EF7996422D440CF965

Date of Receipt
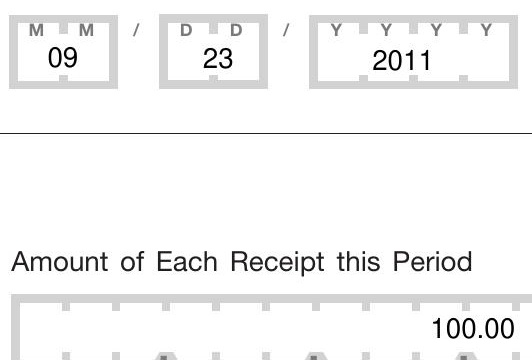

Transaction ID : A3A23B786723D43D5AEA Date of Receipt

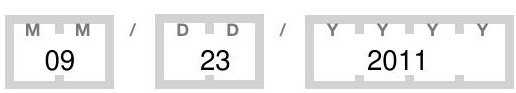

Amount of Each Receipt this Period

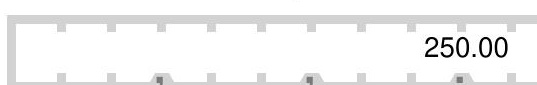

450.00

Subtotal Of Receipts This Page (optional)

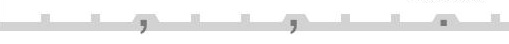

Total This Period (last page this line number only) 
SCHEDULE A-P ITEMIZED RECEIPTS
Use separate schedule(s) for each category of the Detailed Summary Page
FOR LINE NUMBER: (check only one)

PAGE $638 / 1572$

\begin{tabular}{|c|c|c|c|c|c|}
\hline & & & & & \\
\hline 16 & $\begin{array}{l}\mathbf{X} \\
17 a\end{array}$ & $17 b$ & $17 c$ & $17 d$ & 18 \\
\hline $19 a$ & $19 \mathrm{~b}$ & $20 \mathrm{a}$ & $20 \mathrm{~b}$ & $20 \mathrm{c}$ & 21 \\
\hline
\end{tabular}

Any information copied from such Reports and Statements may not be sold or used by any person for the purpose of soliciting contributions or for commercial purposes, other than using the name and address of any political committee to solicit contributions from such committee.

NAME OF COMMITTEE (In Full)

Friends of Herman Cain

A. Full Name (Last, First, Middle Initial)

Stephen Cavanna

Mailing Address 2 Christopher Road

\begin{tabular}{lcc}
\hline City & State & Zip Code \\
Branford & CT & $06405-3962$
\end{tabular}

FEC ID number of contributing federal political committee.

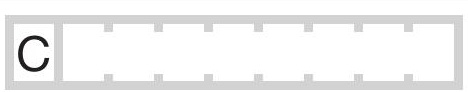

Name of Employer
Sargent Mfg Co
Receipt For: 2012
X Primary
$\square$ Other (specify) General

Occupation

Accountant

Election Cycle-to-Date

225.00

B. Full Name (Last, First, Middle Initial)

Charles White

Mailing Address 7001 Cole Ct

\begin{tabular}{lcc}
\hline City & State & Zip Code \\
Colleyville & TX & $76034-6421$
\end{tabular}

FEC ID number of contributing

federal political committee.

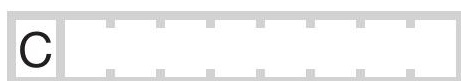

Name of Employer
Magic Touch
Receipt For: 2012
X Primary
Other (specify)

Occupation

Manager

Election Cycle-to-Date

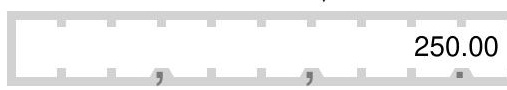

C. Full Name (Last, First, Middle Initial)

Mr. Richard M. Campbell

Mailing Address 1535 Bamwick Dr.

\begin{tabular}{lcc}
\hline City & State & Zip Code \\
Houston & TX & $77090-1111$
\end{tabular}

FEC ID number of contributing

federal political committee.

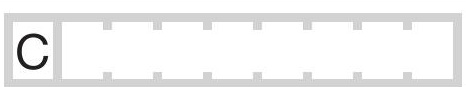

Name of Employer
None
Receipt For: 2012
Х Primary $\quad \square$ General
Other (specify)

Occupation

Retired

Election Cycle-to-Date

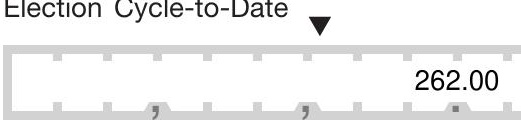

Transaction ID : AF7C3963BC20C4459A23

Date of Receipt

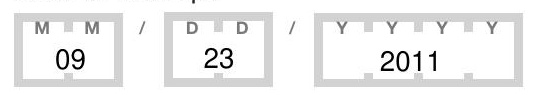

Amount of Each Receipt this Period

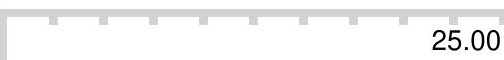

25.00

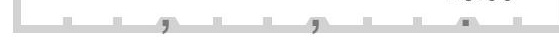

Transaction ID : A3B609A05803840198AD

Date of Receipt

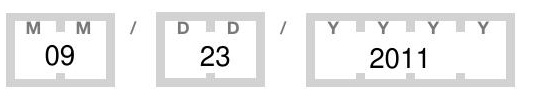

Amount of Each Receipt this Period

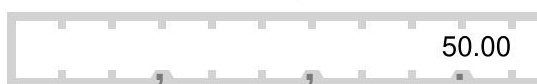

Transaction ID : AF353D1786A824474952

Date of Receipt

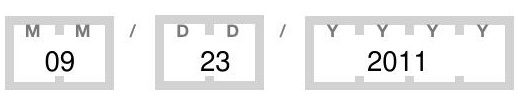

Amount of Each Receipt this Period

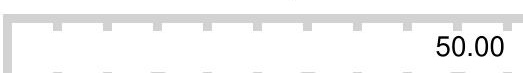

50.00

\section{Subtotal Of Receipts This Page (optional)}

125.00

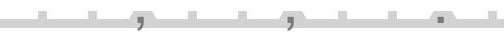

Total This Period (last page this line number only)

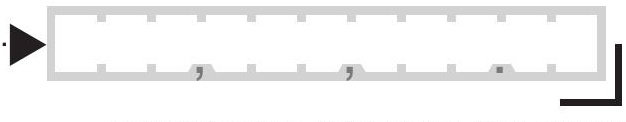

FEC Schedule A-P (Form 3P) (Rev. 03/2011) 
SCHEDULE A-P ITEMIZED RECEIPTS
Use separate schedule(s) for each category of the Detailed Summary Page
FOR LINE NUMBER: (check only one)

PAGE 639 / 1572

\begin{tabular}{|c|c|c|c|c|c|}
\hline & & & & & \\
\hline 16 & $\begin{array}{l}\mathbf{X} \\
17 a\end{array}$ & $17 b$ & $17 c$ & $17 d$ & 18 \\
\hline $19 a$ & $19 \mathrm{~b}$ & $20 \mathrm{a}$ & $20 \mathrm{~b}$ & $20 \mathrm{c}$ & 21 \\
\hline
\end{tabular}

Any information copied from such Reports and Statements may not be sold or used by any person for the purpose of soliciting contributions or for commercial purposes, other than using the name and address of any political committee to solicit contributions from such committee.

NAME OF COMMITTEE (In Full)

\section{Friends of Herman Cain}

A. Full Name (Last, First, Middle Initial)

Durward Pridgen

Mailing Address 1806 Silver Maple Drive

\begin{tabular}{lcc}
\hline City & State & Zip Code \\
North Augusta & SC & $29860-8440$ \\
\hline
\end{tabular}

FEC ID number of contributing

federal political committee.

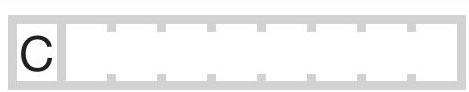

Name of Employer
Veterans Administration
Receipt For: 2012
X Primary $\quad \square$ General
Other (specify)

Occupation

Physician

Election Cycle-to-Date

500.00

B. Full Name (Last, First, Middle Initial)

Mr Louis C Dietz

Mailing Address 33126 Forest West St

\begin{tabular}{lcc}
\hline City & State & Zip Code \\
Magnolia & TX & $77354-6844$ \\
\hline
\end{tabular}

FEC ID number of contributing

federal political committee.

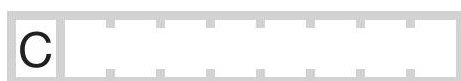

Name of Employer
CYFAIR HOSPITAL
Receipt For: 2012
X Primary
Other (specify)

\section{Occupation}

$\mathrm{RN}$

Election Cycle-to-Date

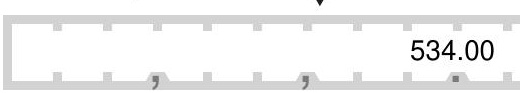

Transaction ID : A15A1482C6FDC49D5852

Date of Receipt

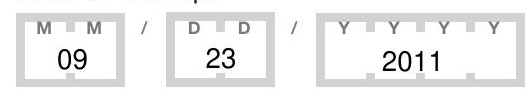

Amount of Each Receipt this Period

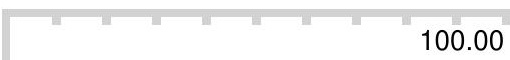

C. Full Name (Last, First, Middle Initial)

JoAnna Chun

Mailing Address 5244 E. Hamlin PI

\begin{tabular}{lcc}
\hline City & State & Zip Code \\
Yuma & AZ & $85365-5680$
\end{tabular}

FEC ID number of contributing federal political committee.

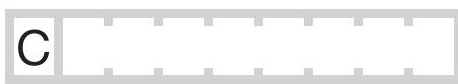

Name of Employer
None
Receipt For: 2012
Х Primary $\quad \square$ General
Other (specify)

Occupation

Homemaker

Election Cycle-to-Date

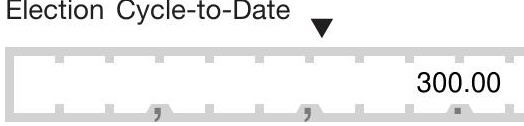

Amount of Each Receipt this Period

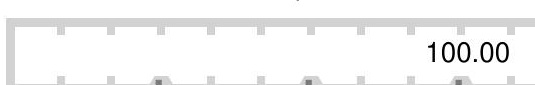

Transaction ID : ADE7C018C61BB48748CA Date of Receipt

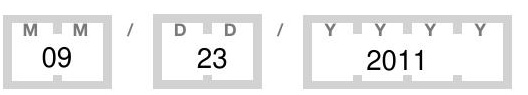

Transaction ID : A699D018BEAF144DCAA4 Date of Receipt

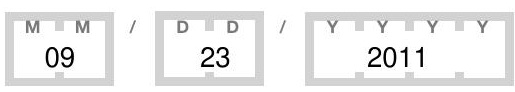

Amount of Each Receipt this Period

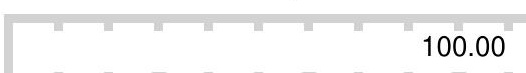

100.00

\section{Subtotal Of Receipts This Page (optional)}

Total This Period (last page this line number only) 
SCHEDULE A-P ITEMIZED RECEIPTS
Use separate schedule(s) for each category of the Detailed Summary Page
FOR LINE NUMBER: (check only one)

PAGE $640 / 1572$

\begin{tabular}{|c|c|c|c|c|c|c|}
\hline & & & & & & \\
\hline 16 & $\lambda$ & $17 \mathrm{a}$ & $17 \mathrm{~b}$ & $17 \mathrm{c}$ & $-17 d$ & -18 \\
\hline $19 a$ & & $19 b$ & $20 a$ & $20 \mathrm{~b}$ & $20 \mathrm{c}$ & 21 \\
\hline
\end{tabular}

Any information copied from such Reports and Statements may not be sold or used by any person for the purpose of soliciting contributions or for commercial purposes, other than using the name and address of any political committee to solicit contributions from such committee.

NAME OF COMMITTEE (In Full)

\section{Friends of Herman Cain}

A. Full Name (Last, First, Middle Initial)

KENNETH BROLIN

Mailing Address 6019 rose arbor court

\begin{tabular}{lcc}
\hline City & State & Zip Code \\
Chester & VA & $23831-8704$
\end{tabular}

FEC ID number of contributing federal political committee.

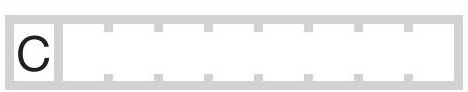

Name of Employer

TSS Photography in Central Virginia

Occupation

Executive

Receipt For: 2012

X Primary $\square$ General Other (specify)

Election Cycle-to-Date

587.76

B. Full Name (Last, First, Middle Initial)

Roger Givens

Mailing Address 3814 Crescent Ridge Ct

\begin{tabular}{lcc}
\hline City & State & Zip Code \\
Maryville & TN & $37804-3802$
\end{tabular}

FEC ID number of contributing

federal political committee.

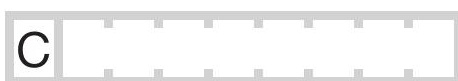

Name of Employer
Retired
Receipt For: 2012
X Primary $\quad$ General
Other (specify)

\section{Occupation}

reired

Election Cycle-to-Date

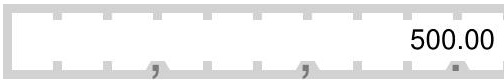

Transaction ID : A27E3EA1169EF456A95B

Date of Receipt

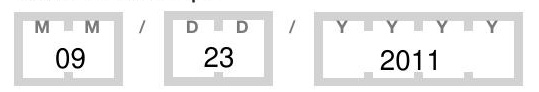

Amount of Each Receipt this Period

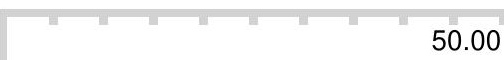

50.00

C. Full Name (Last, First, Middle Initial)

Frank Smith

Mailing Address Po box 70971

\begin{tabular}{lcc}
\hline City & State & Zip Code \\
Salt Lake City & UT & $84170-0971$
\end{tabular}

FEC ID number of contributing federal political committee.

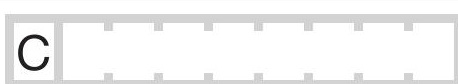

Name of Employer

Occupation

Pride Transport

truck driver

Transaction ID : AD0835437762F4E2295C

Date of Receipt

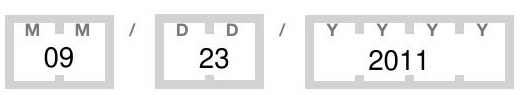

Amount of Each Receipt this Period

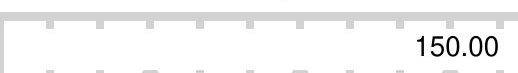

Transaction ID : A947D9E37C26F43E18C8

Date of Receipt

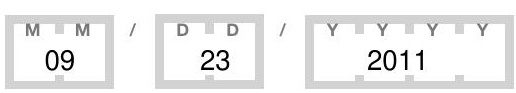

Amount of Each Receipt this Period

Receipt For: 2012

Х $\begin{aligned} & \text { Primary } \\ & \text { Other (specify) }\end{aligned}$

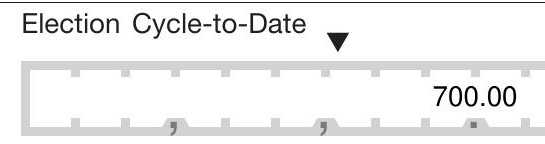

Subtotal Of Receipts This Page (optional)

300.00

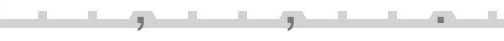

Total This Period (last page this line number only)

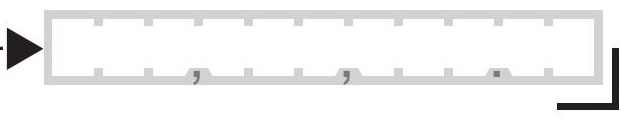

FEC Schedule A-P (Form 3P) (Rev. 03/2011) 
SCHEDULE A-P ITEMIZED RECEIPTS
Use separate schedule(s) for each category of the Detailed Summary Page

FOR LINE NUMBER:
(check only one)

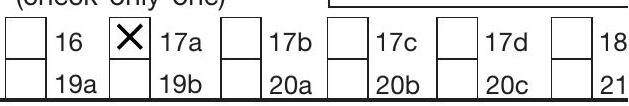

Any information copied from such Reports and Statements may not be sold or used by any person for the purpose of soliciting contributions or for commercial purposes, other than using the name and address of any political committee to solicit contributions from such committee.

NAME OF COMMITTEE (In Full)

\section{Friends of Herman Cain}

A. Full Name (Last, First, Middle Initial)

Allen Johnson

Mailing Address 4242 85th Ave. SE

\begin{tabular}{lcc}
\hline City & State & Zip Code \\
Mercer Island & WA & $98040-4022$
\end{tabular}

FEC ID number of contributing federal political committee.

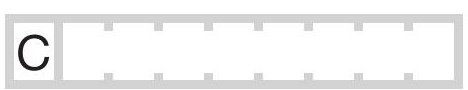

Name of Employer
Information Requested
Receipt For: 2012
X Primary
Other (specify) General

Occupation Information Requested

Election Cycle-to-Date 1000.00

B. Full Name (Last, First, Middle Initial)
Transaction ID : A097CAA3BE7CC47A8A02

Date of Receipt

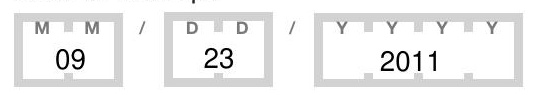

Amount of Each Receipt this Period

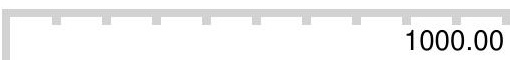

1000.00
Sandra Shackelford

Mailing Address 130 Middling Lane

\begin{tabular}{lcc}
\hline City & State & Zip Code \\
Fayetteville & GA & $30214-3767$ \\
\hline
\end{tabular}

FEC ID number of contributing

federal political committee.

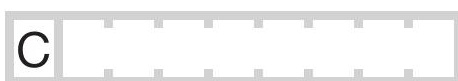

Name of Employer
Delta Airlines
Receipt For: 2012
Primary
Other (specify)

Occupation

Enterprise Document Mgmt

Election Cycle-to-Date

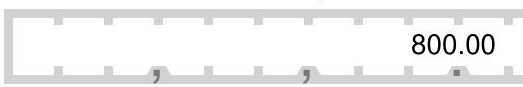

C. Full Name (Last, First, Middle Initial)

Ms Lori Civello

Mailing Address 919 Ridge $\mathrm{Tr}$

\begin{tabular}{lcc}
\hline City & State & Zip Code \\
Carol Stream & IL & $60188-9036$
\end{tabular}

FEC ID number of contributing federal political committee.

C

Name of Employer
Glendale Animal Hosp
Receipt For: 2012
X Primary $\quad \square$ General
Other (specify)

Occupation

Veterinarian

Election Cycle-to-Date

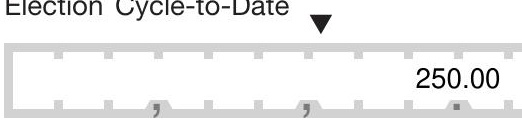

Transaction ID : AFCD7BD06E34B4CDDB2D Date of Receipt

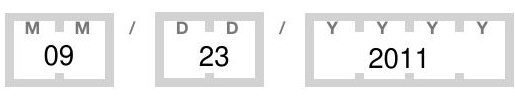

Amount of Each Receipt this Period

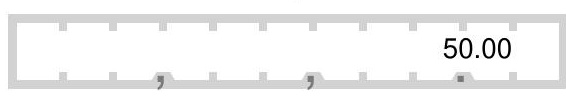

Transaction ID : A747CF81BA61A4492837

Date of Receipt

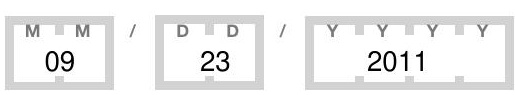

Amount of Each Receipt this Period

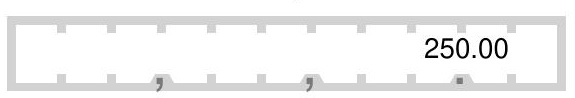

1300.00

Subtotal Of Receipts This Page (optional)

a

Total This Period (last page this line number only) 
SCHEDULE A-P ITEMIZED RECEIPTS
Use separate schedule(s) for each category of the Detailed Summary Page
FOR LINE NUMBER: (check only one)

PAGE 642 / 1572

\begin{tabular}{|c|c|c|c|c|c|}
\hline & & & & & \\
\hline 16 & $\begin{array}{l}\mathbf{X} \\
17 a\end{array}$ & $17 b$ & $17 c$ & $17 d$ & 18 \\
\hline $19 a$ & $19 \mathrm{~b}$ & $20 \mathrm{a}$ & $20 \mathrm{~b}$ & $20 \mathrm{c}$ & 21 \\
\hline
\end{tabular}

Any information copied from such Reports and Statements may not be sold or used by any person for the purpose of soliciting contributions or for commercial purposes, other than using the name and address of any political committee to solicit contributions from such committee.

NAME OF COMMITTEE (In Full)

\section{Friends of Herman Cain}

A. Full Name (Last, First, Middle Initial)

Eileen Million

Mailing Address 252 Vine Cliff Drive

\begin{tabular}{lcc}
\hline City & State & Zip Code \\
Harvest & AL & $35749-5816$
\end{tabular}

FEC ID number of contributing federal political committee.

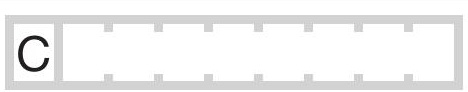

Name of Employer
None
Receipt For: 2012
X Primary $\quad$ General
Other (specify)

Occupation Homemaker

Election Cycle-to-Date 536.00

B. Full Name (Last, First, Middle Initial) Karon Baumann

Mailing Address 3333 SE 38th ST

\begin{tabular}{lcc}
\hline City & State & Zip Code \\
Ocala & FL & $34480-8454$ \\
\hline
\end{tabular}

FEC ID number of contributing

federal political committee.

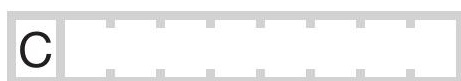

Name of Employer
Marion County School Board
Receipt For: 2012
Xrimary
Other (specify)

\section{Occupation}

Teacher

Election Cycle-to-Date

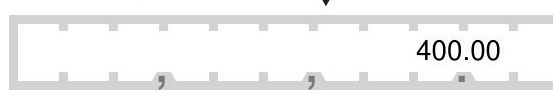

Transaction ID : A1AC84222F65641BBA45

Date of Receipt

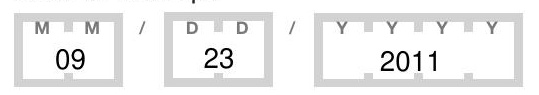

Amount of Each Receipt this Period

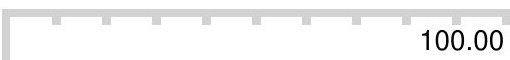

Transaction ID : A3DCF1976828D4787BD4 Date of Receipt

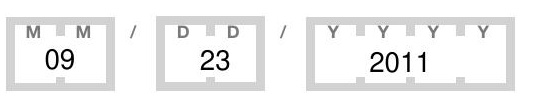

Amount of Each Receipt this Period

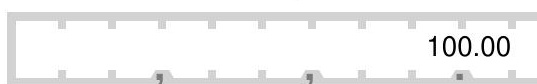

Transaction ID : A7280A27A002D429C994 Date of Receipt

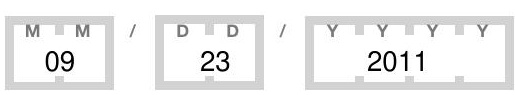

Amount of Each Receipt this Period

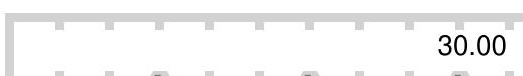

Name of Employer

First Carolina Management

Receipt For: 2012

Х $\begin{aligned} & \text { Primary } \\ & \text { Other (specify) }\end{aligned}$

$\begin{array}{cc}\text { State } & \text { Zip Code } \\ \text { NC } & 27803-8774\end{array}$

C

Occupation

VP Sales \& Marketing

Election Cycle-to-Date

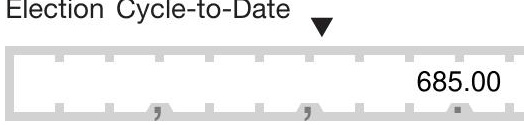

Subtotal Of Receipts This Page (optional)

230.00

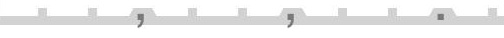

Total This Period (last page this line number only)

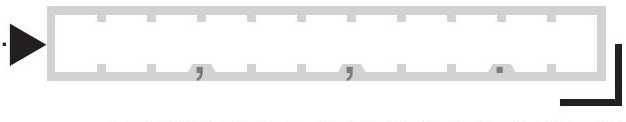

FEC Schedule A-P (Form 3P) (Rev. 03/2011) 
SCHEDULE A-P ITEMIZED RECEIPTS
Use separate schedule(s) for each category of the Detailed Summary Page
FOR LINE NUMBER: (check only one)

PAGE $643 / 1572$

\begin{tabular}{|c|c|c|c|c|c|c|}
\hline & & & & & & \\
\hline 16 & $\lambda$ & $17 \mathrm{a}$ & $17 \mathrm{~b}$ & $17 \mathrm{c}$ & $-17 d$ & -18 \\
\hline $19 a$ & & $19 b$ & $20 a$ & $20 \mathrm{~b}$ & $20 \mathrm{c}$ & 21 \\
\hline
\end{tabular}

Any information copied from such Reports and Statements may not be sold or used by any person for the purpose of soliciting contributions or for commercial purposes, other than using the name and address of any political committee to solicit contributions from such committee.

NAME OF COMMITTEE (In Full)

\section{Friends of Herman Cain}

A. Full Name (Last, First, Middle Initial)

\section{Vickie Boesdorfer}

Mailing Address 14005 Spanish Marsh Trl

\begin{tabular}{lcc}
\hline City & State & Zip Code \\
Jacksonville & FL & $32225-1920$
\end{tabular}

FEC ID number of contributing federal political committee.

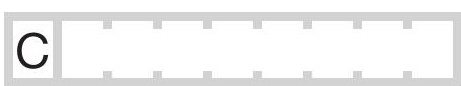

Name of Employer
United Distributors Inc
Receipt For: 2012
X Primary
Other (specify) General

Occupation Human Resources

Election Cycle-to-Date

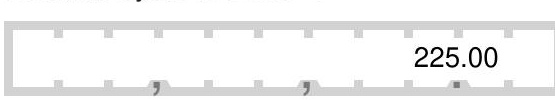

B. Full Name (Last, First, Middle Initial)

Linda Ray

Mailing Address 5912 Wandering Run Ct

\begin{tabular}{lcc}
\hline City & State & Zip Code \\
Haymarket & VA & $20169-3301$
\end{tabular}

FEC ID number of contributing

federal political committee.

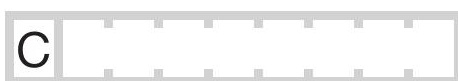

Name of Employer
Home
Receipt For: 2012
X Primary
Other (specify)

\section{Occupation}

Housewife

Election Cycle-to-Date

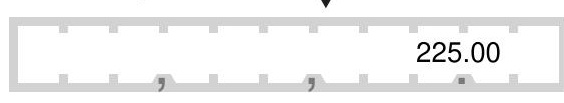

Transaction ID : A249273953A894447A92

Date of Receipt

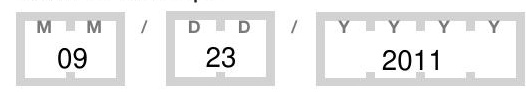

Amount of Each Receipt this Period

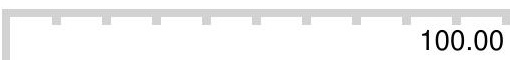

100.00

C. Full Name (Last, First, Middle Initial)

Mr Jack Ham

Mailing Address 333 State Highway 207

\begin{tabular}{lll}
\hline $\begin{array}{l}\text { City } \\
\text { Post }\end{array}$ & $\begin{array}{c}\text { State } \\
\text { TX }\end{array}$ & $\begin{array}{c}\text { Zip Code } \\
79356-5138\end{array}$ \\
\hline $\begin{array}{l}\text { FEC ID number of contributing } \\
\text { federal political committee. }\end{array}$ & C & \\
\hline $\begin{array}{l}\text { Name of Employer } \\
\text { None }\end{array}$ & $\begin{array}{l}\text { Occupation } \\
\text { Retired }\end{array}$ \\
\hline $\begin{array}{l}\text { Receipt For: } 2012 \\
\text { Primary } \\
\text { Other (specify) }\end{array}$ & Election Cycle-to-Date & \\
\end{tabular}

Amount of Each Receipt this Period

Transaction ID : A52789410AEC5478CADB Date of Receipt
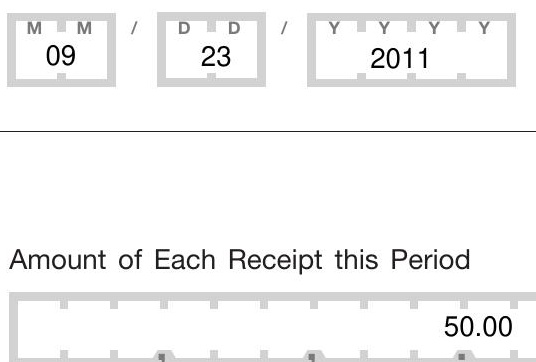

Amount of Each Receipt this Period

Transaction ID : A880884A536404503A3F

Date of Receipt
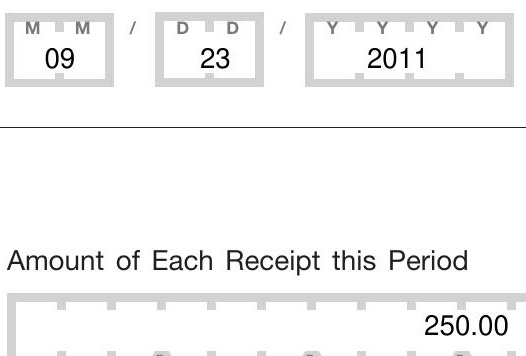

Subtotal Of Receipts This Page (optional)

400.00

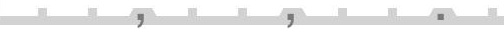

Total This Period (last page this line number only)

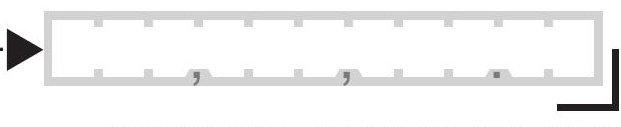

FEC Schedule A-P (Form 3P) (Rev. 03/2011) 
SCHEDULE A-P ITEMIZED RECEIPTS
Use separate schedule(s) for each category of the Detailed Summary Page
FOR LINE NUMBER: (check only one)

PAGE 644 / 1572

\begin{tabular}{|c|c|c|c|c|c|}
\hline & & & & & \\
\hline 16 & $\begin{array}{l}\mathbf{X} \\
17 a\end{array}$ & $17 b$ & $17 c$ & $17 d$ & 18 \\
\hline $19 a$ & $19 \mathrm{~b}$ & $20 \mathrm{a}$ & $20 \mathrm{~b}$ & $20 \mathrm{c}$ & 21 \\
\hline
\end{tabular}

Any information copied from such Reports and Statements may not be sold or used by any person for the purpose of soliciting contributions or for commercial purposes, other than using the name and address of any political committee to solicit contributions from such committee.

NAME OF COMMITTEE (In Full)

\section{Friends of Herman Cain}

A. Full Name (Last, First, Middle Initial)

MaryAnn Nystrom

Mailing Address 4075 - 149th Avenue NW

\begin{tabular}{lcc}
\hline City & State & Zip Code \\
Andover & MN & $55304-3132$
\end{tabular}

FEC ID number of contributing

federal political committee.

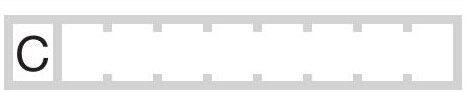

Name of Employer

Nystrom \& Associates Ltd.

Occupation

co-owner/social worker

Receipt For: 2012

X Primary $\square$ General Other (specify)

Election Cycle-to-Date

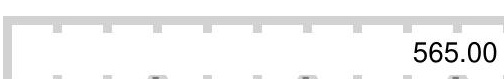

B. Full Name (Last, First, Middle Initial)

George Pownall

Mailing Address 2091 MASSACHUSETTS AVE NE

\begin{tabular}{lcc}
\hline City & State & Zip Code \\
Saint Petersburg & FL & $33703-3403$
\end{tabular}

FEC ID number of contributing

federal political committee.

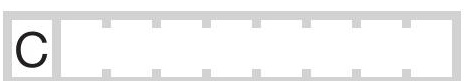

Name of Employer
Paymentech
Receipt For: 2012
X Primary
Other (specify)

Occupation

Analyst

Election Cycle-to-Date

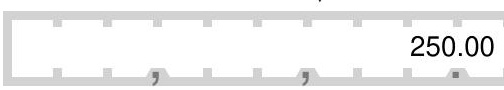

Transaction ID : A1B1F21741C4F4546B60

Date of Receipt

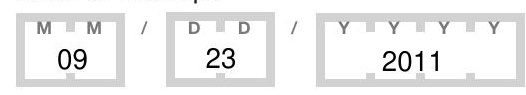

Amount of Each Receipt this Period

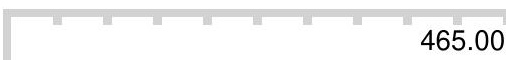

465.00

C. Full Name (Last, First, Middle Initial)

Craig Werner

Mailing Address 13110 Birch Dr Ste 148 Box 145

\begin{tabular}{lcc}
\hline City & State & Zip Code \\
Omaha & NE & $68164-4160$
\end{tabular}

FEC ID number of contributing

federal political committee.

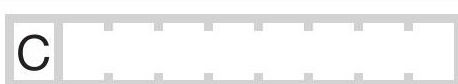

Name of Employer

Metl-Fab Inc.

Occupation

construction superintendent

Transaction ID : A9883F1A5592D438DB01

Date of Receipt

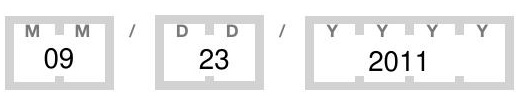

Amount of Each Receipt this Period

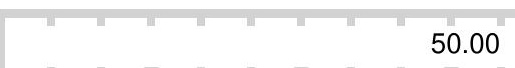

Transaction ID : A5A249A9A66B34076B16

Date of Receipt

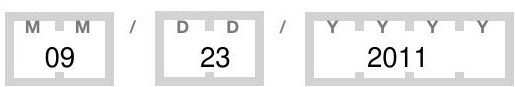

Amount of Each Receipt this Period

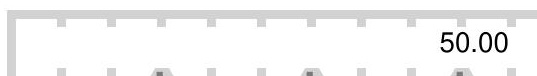

Election Cycle-to-Date

Х Primary $\quad \square$ General

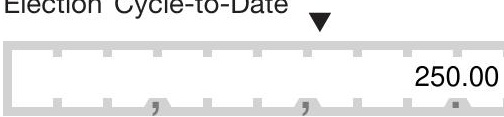

Subtotal Of Receipts This Page (optional)

565.00

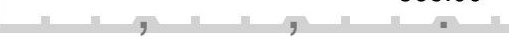

Total This Period (last page this line number only)

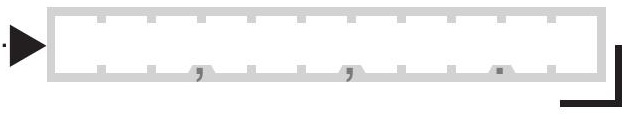

FEC Schedule A-P (Form 3P) (Rev. 03/2011) 
SCHEDULE A-P ITEMIZED RECEIPTS
Use separate schedule(s) for each category of the Detailed Summary Page
FOR LINE NUMBER: (check only one)
PAGE $645 / 1572$

\begin{tabular}{|c|c|c|c|c|c|}
\hline & & & & & \\
\hline 16 & $\begin{array}{lll}X & 17 a \\
\end{array}$ & $17 \mathrm{~b}$ & $17 c$ & $17 d$ & 18 \\
\hline $19 a$ & $19 b$ & $20 a$ & $20 \mathrm{~b}$ & $20 c$ & 21 \\
\hline
\end{tabular}

Any information copied from such Reports and Statements may not be sold or used by any person for the purpose of soliciting contributions or for commercial purposes, other than using the name and address of any political committee to solicit contributions from such committee.

NAME OF COMMITTEE (In Full)

Friends of Herman Cain

A. Full Name (Last, First, Middle Initial)

Scott Taranovich

Mailing Address 2913 Kimbrough LN

\begin{tabular}{lcc}
\hline City & State & Zip Code \\
McKinney & TX & $75071-2755$ \\
\hline
\end{tabular}

FEC ID number of contributing

federal political committee.

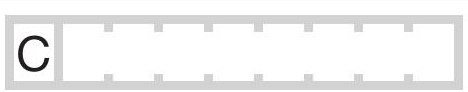

Name of Employer
Ericsson Inc
Receipt For: 2012
X Primary
$\square$ Other (specify) General

Occupation

Sr. Engineer

Election Cycle-to-Date

225.00

B. Full Name (Last, First, Middle Initial)

Carolyn Mason

Mailing Address 1529 Providence Rd.

\begin{tabular}{lcc}
\hline City & State & Zip Code \\
Whigham & GA & $39897-4168$ \\
\hline
\end{tabular}

FEC ID number of contributing

federal political committee.

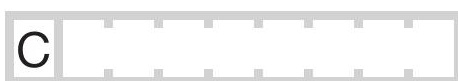

Name of Employer
Hunter Arms LLC
Receipt For: 2012
X Primary
Other (specify)

Occupation

Assistant to spouse

Election Cycle-to-Date

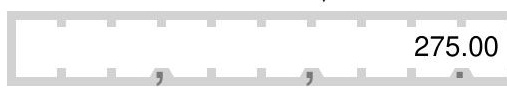

Transaction ID : A73A0A3D4FDE8464FB49

Date of Receipt

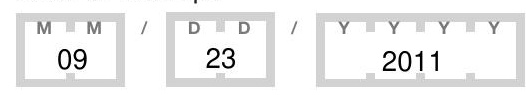

Amount of Each Receipt this Period

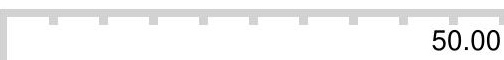

50.00

C. Full Name (Last, First, Middle Initial)

John Davis

Mailing Address 218 Gerard Cir

\begin{tabular}{lcc}
\hline City & State & Zip Code \\
Mc Cormick & SC & $29835-2425$
\end{tabular}

FEC ID number of contributing

federal political committee.

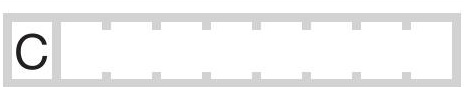

Name of Employer

Information Requested

Occupation

Information Requested

Receipt For: 2012

Х $\begin{aligned} & \text { Primary } \\ & \text { Other (specify) }\end{aligned}$

Election Cycle-to-Date

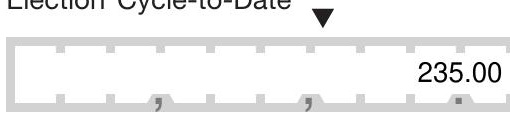

Amount of Each Receipt this Period

Transaction ID : A2DDF41DDE5E7459EBD9

Date of Receipt
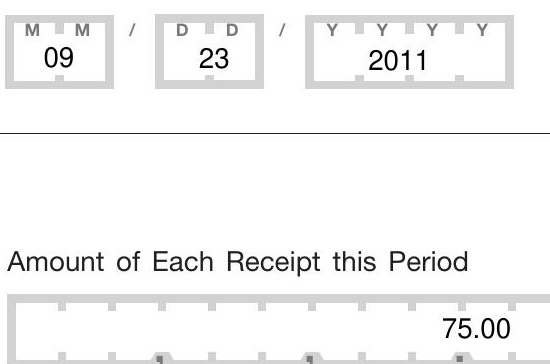

Transaction ID : A530D721854614B00BA1

Date of Receipt

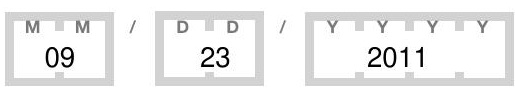

Amount of Each Receipt this Period

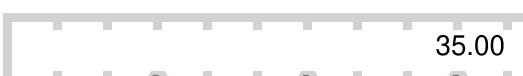

Subtotal Of Receipts This Page (optional)

Total This Period (last page this line number only) 
SCHEDULE A-P ITEMIZED RECEIPTS
Use separate schedule(s) for each category of the Detailed Summary Page
FOR LINE NUMBER: (check only one)

PAGE 646 / 1572

\begin{tabular}{|c|c|c|c|c|c|c|}
\hline & & & & & & \\
\hline 16 & $\lambda$ & $17 \mathrm{a}$ & $17 \mathrm{~b}$ & $17 \mathrm{c}$ & $-17 d$ & -18 \\
\hline $19 a$ & & $19 b$ & $20 a$ & $20 \mathrm{~b}$ & $20 \mathrm{c}$ & 21 \\
\hline
\end{tabular}

Any information copied from such Reports and Statements may not be sold or used by any person for the purpose of soliciting contributions or for commercial purposes, other than using the name and address of any political committee to solicit contributions from such committee.

NAME OF COMMITTEE (In Full)

\section{Friends of Herman Cain}

A. Full Name (Last, First, Middle Initial)

Douglas Buchanan

Mailing Address 9811 Ascot

\begin{tabular}{lcc}
\hline City & State & Zip Code \\
Omaha & NE & $68114-3847$
\end{tabular}

FEC ID number of contributing federal political committee.

Name of Employer
renze display
Receipt For: 2012
X Primary
Other (specify) General

B. Full Name (Last, First, Middle Initial)

\section{Todd Keefer}

Mailing Address 1020 Stevens Rd

\begin{tabular}{lcc}
\hline City & State & Zip Code \\
York Haven & PA & $17370-9238$ \\
\hline
\end{tabular}

FEC ID number of contributing

federal political committee.

Name of Employer
Not Employed
Receipt For: 2012
Primary
Other (specify)

C. Full Name (Last, First, Middle Initial)

$\mathrm{H}$ Harris

Mailing Address 2551 Crestview $\mathrm{Dr}$

\begin{tabular}{l|ll}
\hline $\begin{array}{l}\text { City } \\
\text { Newport Beach }\end{array}$ & $\begin{array}{c}\text { State } \\
\text { CA }\end{array}$ & $\begin{array}{c}\text { Zip Code } \\
92663-5624\end{array}$ \\
\hline $\begin{array}{l}\text { FEC ID number of contributing } \\
\text { federal political committee. }\end{array}$ & C \\
\hline $\begin{array}{l}\text { Name of Employer } \\
\text { Better Beverages }\end{array}$ & $\begin{array}{l}\text { Occupation } \\
\text { Sales }\end{array}$ \\
$\begin{array}{l}\text { Receipt For: } 2012 \\
\text { Primary } \\
\text { Other (specify) }\end{array}$ & Election Cycle-to-Date & \\
\hline
\end{tabular}

Subtotal Of Receipts This Page (optional).

Total This Period (last page this line number only)

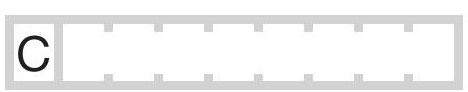

Occupation President

Election Cycle-to-Date

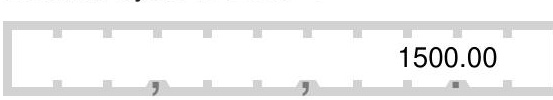

C

Transaction ID : AD6AD1102164142058B6

Date of Receipt

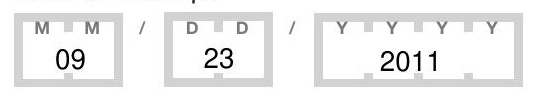

Amount of Each Receipt this Period

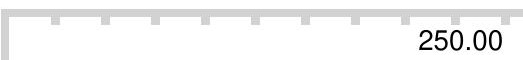

250.00

Transaction ID : A6911CE2FC6614C7F804

Date of Receipt

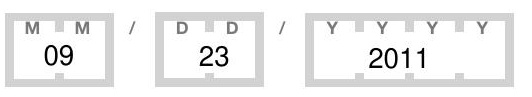

Amount of Each Receipt this Period
Occupation

Not Employed

Election Cycle-to-Date

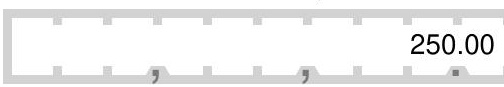

Amount of Each Receipt this Period

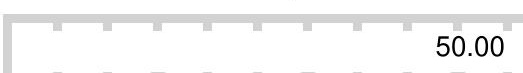

Transaction ID : AAD8221A56D024C5FA81 Date of Receipt
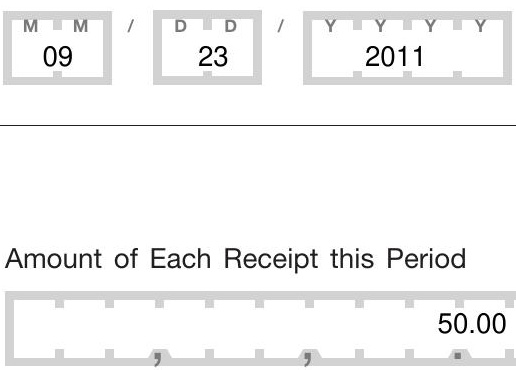

350.00

a 1 , L

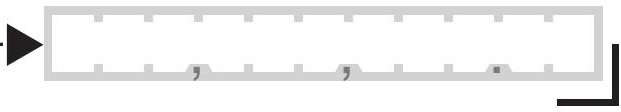

FEC Schedule A-P (Form 3P) (Rev. 03/2011) 
SCHEDULE A-P ITEMIZED RECEIPTS
Use separate schedule(s) for each category of the Detailed Summary Page
FOR LINE NUMBER: (check only one)

PAGE $647 / 1572$

\begin{tabular}{|c|c|c|c|c|c|}
\hline & & & & & \\
\hline 16 & $\begin{array}{l}\mathbf{X} \\
17 a\end{array}$ & $17 b$ & $17 c$ & $17 d$ & 18 \\
\hline $19 a$ & $19 \mathrm{~b}$ & $20 \mathrm{a}$ & $20 \mathrm{~b}$ & $20 \mathrm{c}$ & 21 \\
\hline
\end{tabular}

Any information copied from such Reports and Statements may not be sold or used by any person for the purpose of soliciting contributions or for commercial purposes, other than using the name and address of any political committee to solicit contributions from such committee.

NAME OF COMMITTEE (In Full)

\section{Friends of Herman Cain}

A. Full Name (Last, First, Middle Initial)

Mary-Anne Mahaffy

Mailing Address 532 Lower Georges Valley Rd

\begin{tabular}{lcc}
\hline City & State & Zip Code \\
Spring Mills & PA & $16875-8200$
\end{tabular}

FEC ID number of contributing

federal political committee.

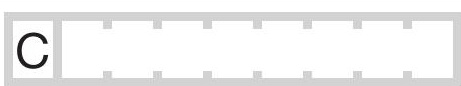

Name of Employer
Information Requested
Receipt For: 2012
X Primary
Other (specify) General

Occupation

Information Requested

Election Cycle-to-Date

500.00

B. Full Name (Last, First, Middle Initial)

Dwight Watson

Mailing Address 502 Maple St Ste C

\begin{tabular}{lcc}
\hline City & State & Zip Code \\
Murray & KY & $42071-2586$ \\
\hline
\end{tabular}

FEC ID number of contributing

federal political committee.

C

Name of Employer
Information Requested
Receipt For: 2012
X Primary
Other (specify)

Occupation

Information Requested

Election Cycle-to-Date

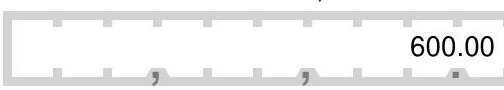

Transaction ID : AEC97C16E4D42475DA4B

Date of Receipt

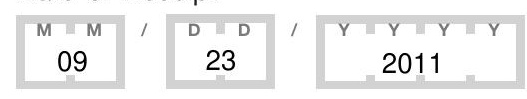

Amount of Each Receipt this Period

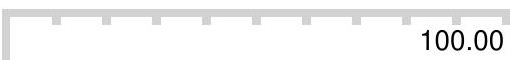

Amount of Each Receipt this Period

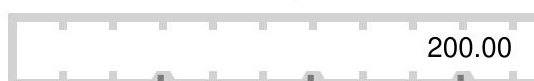

C. Full Name (Last, First, Middle Initial)

Barbara Baldwin

Mailing Address 6388 Silver Star Road Suite 2B

\begin{tabular}{lcc}
\hline City & State & Zip Code \\
Orlando & FL & $32818-3235$
\end{tabular}

FEC ID number of contributing

federal political committee.

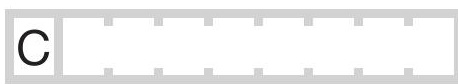

Name of Employer

Princeton Pediatrics

\section{Occupation}

pediatrician

Receipt For: 2012

Х $\begin{aligned} & \text { Primary } \square \text { General } \\ & \text { Other (specify) }\end{aligned}$

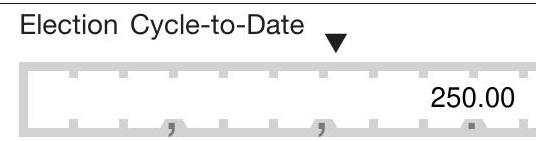

Amount of Each Receipt this Period

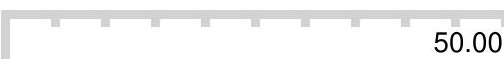

50.00

350.00

Subtotal Of Receipts This Page (optional)

Transaction ID : A6F1B8E066EDD4B31A5B Date of Receipt
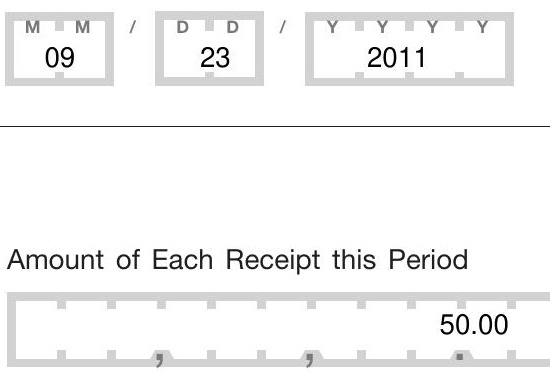

Total This Period (last page this line number only) 
SCHEDULE A-P ITEMIZED RECEIPTS
Use separate schedule(s) for each category of the Detailed Summary Page

FOR LINE NUMBER:
(check only one)

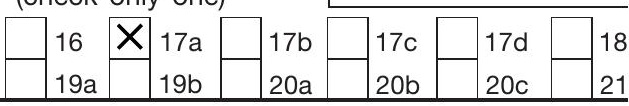

Any information copied from such Reports and Statements may not be sold or used by any person for the purpose of soliciting contributions or for commercial purposes, other than using the name and address of any political committee to solicit contributions from such committee.

NAME OF COMMITTEE (In Full)

\section{Friends of Herman Cain}

A. Full Name (Last, First, Middle Initial)

Larry Klipp

Mailing Address PO Box 279

\begin{tabular}{lcc}
\hline City & State & Zip Code \\
Belle Fourche & SD & $57717-0279$
\end{tabular}

FEC ID number of contributing federal political committee.

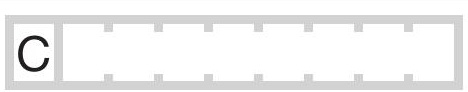

\begin{tabular}{l} 
Name of Employer \\
None \\
Receipt For: 2012 \\
X Primary $\quad \square$ General \\
\hline Other (specify)
\end{tabular}

Occupation Retired (Military)

Election Cycle-to-Date

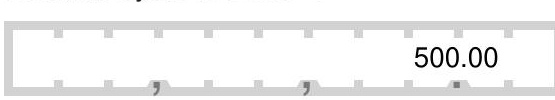

B. Full Name (Last, First, Middle Initial)

William Wortman

Mailing Address $2618 \mathrm{nw}$ 8th st

\begin{tabular}{lcc}
\hline City & State & Zip Code \\
Gainesville & FL & $32609-2936$
\end{tabular}

FEC ID number of contributing

federal political committee.

C

Name of Employer
self
Receipt For: 2012
Primary
Other (specify)

Occupation

contractor

Election Cycle-to-Date

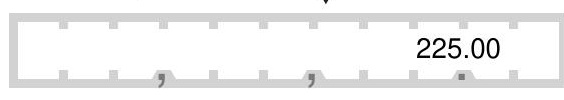

Transaction ID : AC0376BD7577A455D8C7

Date of Receipt

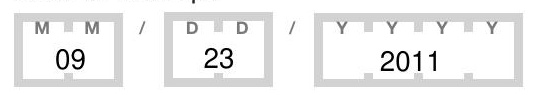

Amount of Each Receipt this Period

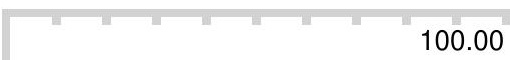

Amount of Each Receipt this Period

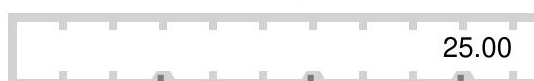

C. Full Name (Last, First, Middle Initial)

Nathan Moore

Mailing Address 1513 ocean breeze Ln

\begin{tabular}{lcc}
\hline City & State & Zip Code \\
Gulf Breeze & FL & $32563-9222$
\end{tabular}

FEC ID number of contributing federal political committee.

C

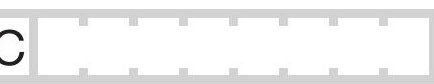

$\begin{aligned} & \text { Name of Employer } \\ & \text { self }\end{aligned}$
Receipt For: 2012
X Primary $\square$ General
Other (specify)

\section{Occupation}

Carpenter

Election Cycle-to-Date
Transaction ID : A71492F9CBC754D9FA78 Date of Receipt

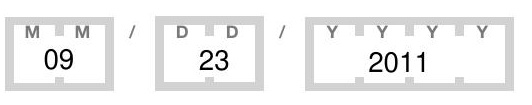

Transaction ID : A06579F9A4BBE484185C Date of Receipt

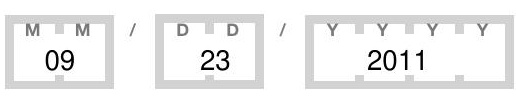

Amount of Each Receipt this Period

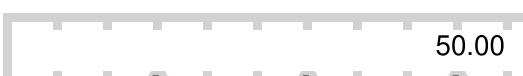

350.00

\section{Subtotal Of Receipts This Page (optional)}

175.00

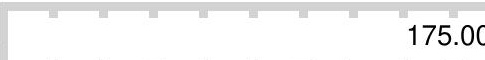

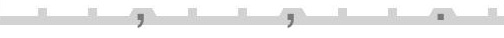

Total This Period (last page this line number only)

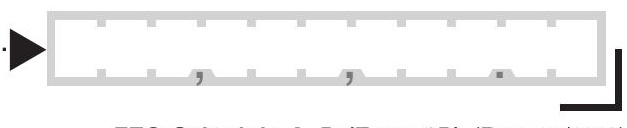

FEC Schedule A-P (Form 3P) (Rev. 03/2011) 
SCHEDULE A-P ITEMIZED RECEIPTS
Use separate schedule(s) for each category of the Detailed Summary Page
FOR LINE NUMBER: (check only one)

PAGE 649 / 1572

\begin{tabular}{|c|c|c|c|c|c|}
\hline & & & & & \\
\hline 16 & $\begin{array}{l}\mathbf{X} \\
17 a\end{array}$ & $17 b$ & $17 c$ & $17 d$ & 18 \\
\hline $19 a$ & $19 \mathrm{~b}$ & $20 \mathrm{a}$ & $20 \mathrm{~b}$ & $20 \mathrm{c}$ & 21 \\
\hline
\end{tabular}

Any information copied from such Reports and Statements may not be sold or used by any person for the purpose of soliciting contributions or for commercial purposes, other than using the name and address of any political committee to solicit contributions from such committee.

NAME OF COMMITTEE (In Full)

\section{Friends of Herman Cain}

A. Full Name (Last, First, Middle Initial)

Paul Combs

Mailing Address 490 Petross Rd

\begin{tabular}{lcc}
\hline City & State & Zip Code \\
Vidalia & GA & $30474-8016$
\end{tabular}

FEC ID number of contributing federal political committee.

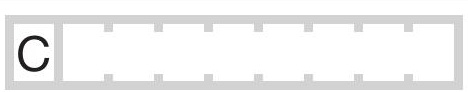

Name of Employer
Information Requested
Receipt For: 2012
X Primary
Other (specify) General

Occupation Information Requested

Election Cycle-to-Date

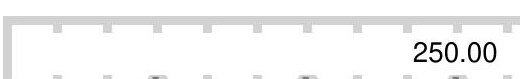

B. Full Name (Last, First, Middle Initial)

Vicki Taylor

Mailing Address 5457 Sparta Pike

\begin{tabular}{lcc}
\hline City & State & Zip Code \\
Watertown & TN & $37184-4319$ \\
\hline
\end{tabular}

FEC ID number of contributing

federal political committee.

C

Name of Employer
$\mathrm{n} / \mathrm{a}$

Occupation

Full-time Home-Maker

Election Cycle-to-Date

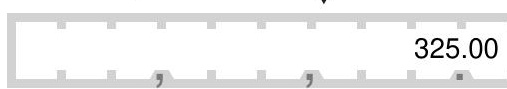

Transaction ID : ABFC657AB19F54BAFBF9

Date of Receipt

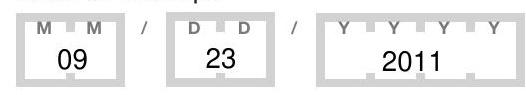

Amount of Each Receipt this Period

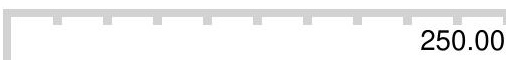

C. Full Name (Last, First, Middle Initial)

Rachel Peterson

Mailing Address 4676 Sullivan Rd

\begin{tabular}{lcc}
\hline City & State & Zip Code \\
Springfield & $\mathrm{OH}$ & $45502-8183$
\end{tabular}

FEC ID number of contributing federal political committee.

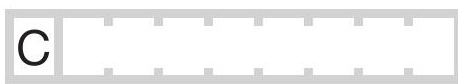

Name of Employer
Information Requested
Receipt For: 2012
X Primary $\quad \square$ General
Other (specify)

\section{Occupation}

Information Requested

Election Cycle-to-Date

Transaction ID : ADEA5F671D12C4D12872

Date of Receipt

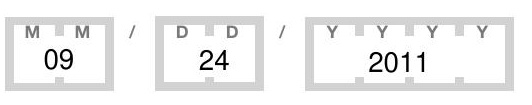

Amount of Each Receipt this Period

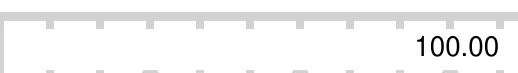

Transaction ID : A7797630B6DBF4754B62

Date of Receipt

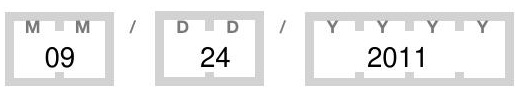

Amount of Each Receipt this Period

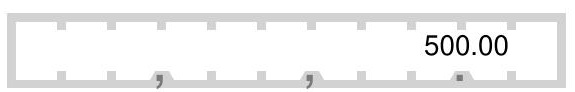

500.00

\section{Subtotal Of Receipts This Page (optional)}

Total This Period (last page this line number only) 
SCHEDULE A-P ITEMIZED RECEIPTS
Use separate schedule(s) for each category of the Detailed Summary Page
FOR LINE NUMBER: (check only one)

PAGE $650 / 1572$

\begin{tabular}{|c|c|c|c|c|c|}
\hline & & & & & \\
\hline 16 & $\begin{array}{l}\mathbf{X} \\
17 a\end{array}$ & $17 b$ & $17 c$ & $17 d$ & 18 \\
\hline $19 a$ & $19 \mathrm{~b}$ & $20 \mathrm{a}$ & $20 \mathrm{~b}$ & $20 \mathrm{c}$ & 21 \\
\hline
\end{tabular}

Any information copied from such Reports and Statements may not be sold or used by any person for the purpose of soliciting contributions or for commercial purposes, other than using the name and address of any political committee to solicit contributions from such committee.

NAME OF COMMITTEE (In Full)

\section{Friends of Herman Cain}

A. Full Name (Last, First, Middle Initial)

Michael Katin

Mailing Address 9150 Penzance Boulevard

\begin{tabular}{lcc}
\hline City & State & Zip Code \\
Fort Myers & FL & $33912-1402$ \\
\hline
\end{tabular}

FEC ID number of contributing

federal political committee.

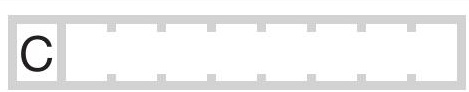

Name of Employer
21st Century Oncology
Receipt For: 2012
X Primary $\quad \square$ General
Other (specify)

Occupation

Physician

Election Cycle-to-Date

845.00

B. Full Name (Last, First, Middle Initial)

Janet West

Mailing Address $8320 \mathrm{McFall} \mathrm{Dr}$

\begin{tabular}{lcc}
\hline City & State & Zip Code \\
El Paso & TX & $79925-5002$
\end{tabular}

FEC ID number of contributing

federal political committee.

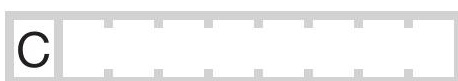

Name of Employer
Sterling Medical
Receipt For: 2012
X Primary
Other (specify)

\section{Occupation}

Physician Assistant

Election Cycle-to-Date

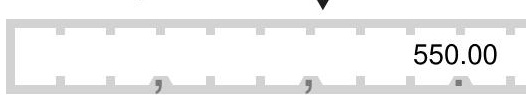

C. Full Name (Last, First, Middle Initial)

erik norrgard

Mailing Address 2 midbrook lane

\begin{tabular}{lcc}
\hline City & State & Zip Code \\
Old Greenwich & CT & $06870-1428$
\end{tabular}

FEC ID number of contributing federal political committee.

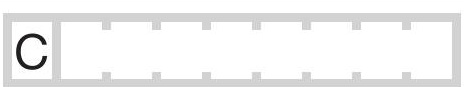

$$
\begin{aligned}
& \text { Name of Employer } \\
& \text { iron peak capital management } \\
& \text { Receipt For: } 2012 \\
& \text { X Primary } \\
& \text { Other (specify) General }
\end{aligned}
$$

\section{Occupation}

Finance

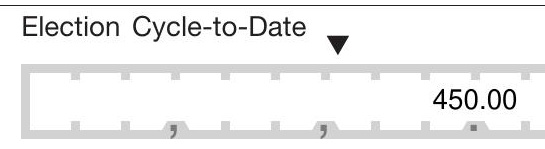

Transaction ID : A01830886153C4B779EE

Date of Receipt

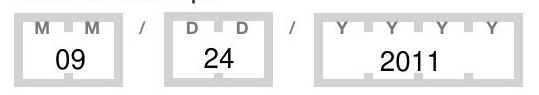

Amount of Each Receipt this Period

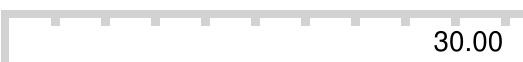

30.00

Transaction ID : A420E45560552417BB5F

Date of Receipt

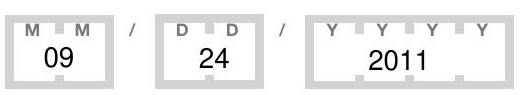

Amount of Each Receipt this Period

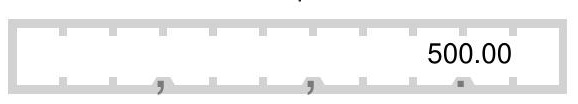

Transaction ID : A804ECCF881C34B799B3 Date of Receipt

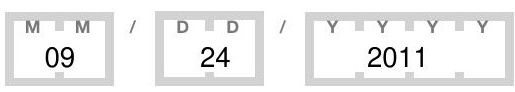

Amount of Each Receipt this Period

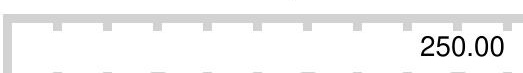

\section{Subtotal Of Receipts This Page (optional)}

Total This Period (last page this line number only) 
SCHEDULE A-P ITEMIZED RECEIPTS
Use separate schedule(s) for each category of the Detailed Summary Page
FOR LINE NUMBER: (check only one)

PAGE $651 / 1572$

\begin{tabular}{|c|c|c|c|c|c|c|}
\hline & & & & & & \\
\hline 16 & $\lambda$ & $17 \mathrm{a}$ & $17 \mathrm{~b}$ & $17 \mathrm{c}$ & $-17 d$ & -18 \\
\hline $19 a$ & & $19 b$ & $20 a$ & $20 \mathrm{~b}$ & $20 \mathrm{c}$ & 21 \\
\hline
\end{tabular}

Any information copied from such Reports and Statements may not be sold or used by any person for the purpose of soliciting contributions or for commercial purposes, other than using the name and address of any political committee to solicit contributions from such committee.

NAME OF COMMITTEE (In Full)

\section{Friends of Herman Cain}

A. Full Name (Last, First, Middle Initial)

Marcia Hugghins

Mailing Address 479 Creighton Rd

\begin{tabular}{lcc}
\hline City & State & Zip Code \\
Fleming Island & FL & $32003-7477$ \\
\hline
\end{tabular}

FEC ID number of contributing federal political committee.

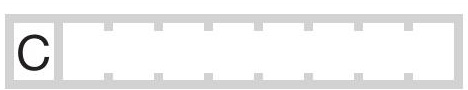

Name of Employer
Retired
Receipt For: 2012
X Primary $\quad$ General
Other (specify)

Occupation Retired

Election Cycle-to-Date

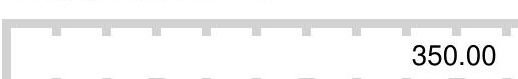

B. Full Name (Last, First, Middle Initial)

Richard Brakefield

Mailing Address 655 S. Vista Oro

\begin{tabular}{lcc}
\hline City & State & Zip Code \\
Palm Springs & CA & $92264-7669$ \\
\hline
\end{tabular}

FEC ID number of contributing

federal political committee.

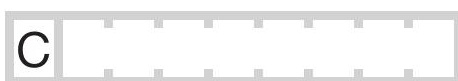

Name of Employer
None
Receipt For: 2012
X Primary
Other (specify)

\section{Occupation}

Retired

Election Cycle-to-Date

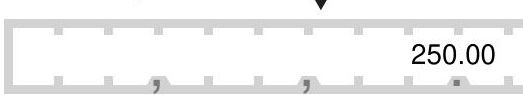

Transaction ID : AA5B275AFCA01478FA8F

Date of Receipt

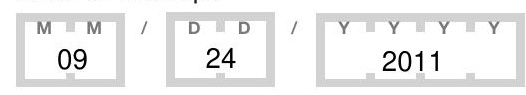

Amount of Each Receipt this Period

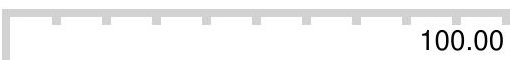

Amount of Each Receipt this Period

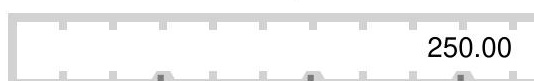

C. Full Name (Last, First, Middle Initial)

Mr. Alan Silverberg

Mailing Address 12323 Saint Simon Dr

\begin{tabular}{lcc}
\hline City & State & Zip Code \\
Boca Raton & FL & $33428-4648$
\end{tabular}

FEC ID number of contributing federal political committee.

C

Name of Employer
Information Requested
Receipt For: 2012
X Primary
Other (specify) General

Occupation

Information Requested

Election Cycle-to-Date

Transaction ID : A6CE38DECB58943FE9B0

Date of Receipt

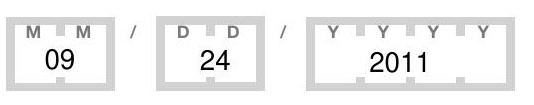

Transaction ID : A8B16008AAB614EF7AE2 Date of Receipt

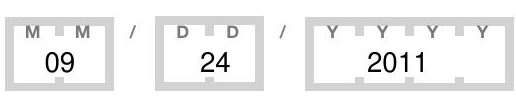

Amount of Each Receipt this Period

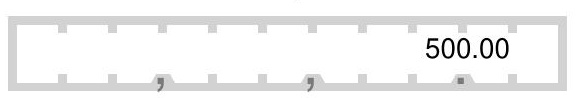

600.00

\section{Subtotal Of Receipts This Page (optional)}

Total This Period (last page this line number only) 


\section{SCHEDULE A-P} ITEMIZED RECEIPTS
Use separate schedule(s)

for each category of the

Detailed Summary Page
FOR LINE NUMBER: (check only one)

PAGE 652 / 1572

\begin{tabular}{|c|c|c|c|c|c|}
\hline & & & & & \\
\hline 16 & X $17 a$ & $17 b$ & $17 c$ & $17 d$ & 18 \\
\hline $19 a$ & $19 b$ & $20 \mathrm{a}$ & $20 \mathrm{~b}$ & $20 \mathrm{c}$ & 21 \\
\hline
\end{tabular}

Any information copied from such Reports and Statements may not be sold or used by any person for the purpose of soliciting contributions or for commercial purposes, other than using the name and address of any political committee to solicit contributions from such committee.

NAME OF COMMITTEE (In Full)

Friends of Herman Cain

A. Full Name (Last, First, Middle Initial)

Richard Scruggs

Mailing Address 2595 Ho Hum Hollow Road

\begin{tabular}{lcc}
\hline City & State & Zip Code \\
Monroe & GA & $30655-5533$
\end{tabular}

FEC ID number of contributing

federal political committee.

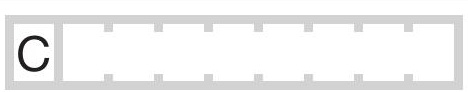

Name of Employer
Information Requested
Receipt For: 2012
X Primary $\quad \square$ General
Other (specify)

Occupation

Information Requested

Election Cycle-to-Date

380.00

B. Full Name (Last, First, Middle Initial)

Richard Scruggs

Mailing Address 2595 Ho Hum Hollow Road

\begin{tabular}{lcc}
\hline City & State & Zip Code \\
Monroe & GA & $30655-5533$ \\
\hline
\end{tabular}

FEC ID number of contributing

federal political committee.

C

\begin{tabular}{l} 
Name of Employer \\
Information Requested \\
Receipt For: 2012 \\
X Primary \\
\hline Other (specify)
\end{tabular}

Occupation

Information Requested

Election Cycle-to-Date

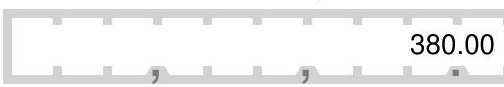

Transaction ID : A939DD6BE268943D7A25

Date of Receipt

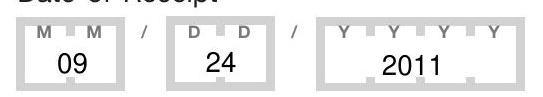

Amount of Each Receipt this Period

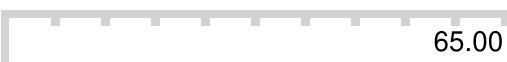

65.00

C. Full Name (Last, First, Middle Initial)

Kamie Fender

Mailing Address 2247 N Farm Road 71

\begin{tabular}{lcc}
\hline City & State & Zip Code \\
Bois D Arc & MO & $65612-2309$
\end{tabular}

FEC ID number of contributing

federal political committee.

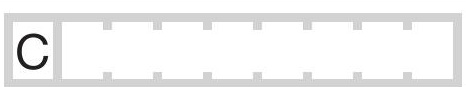

Name of Employer

Information Requested

Occupation

Information Requested

Receipt For: 2012

Х $\begin{aligned} & \text { Primary } \square \text { General } \\ & \text { Other (specify) }\end{aligned}$

Election Cycle-to-Date

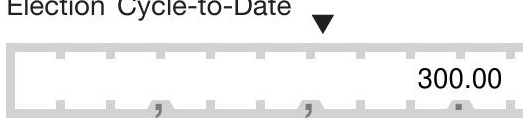

Amount of Each Receipt this Period

Transaction ID : AB8E36883D9714093A95

Date of Receipt
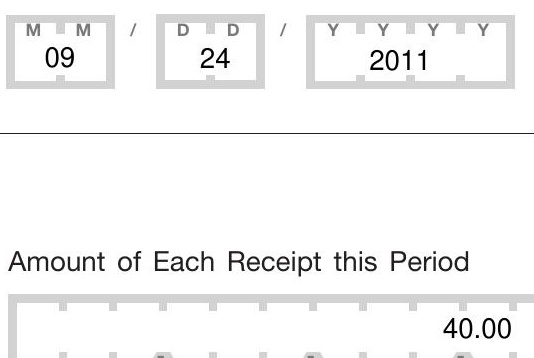

Transaction ID : A909522D2259F49F7B1C

Date of Receipt

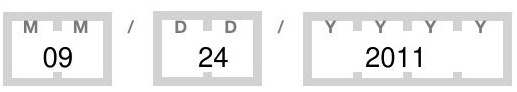

Amount of Each Receipt this Period

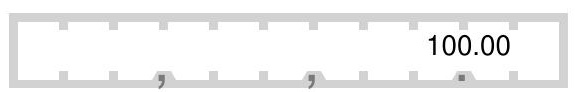

Subtotal Of Receipts This Page (optional).

205.00

Total This Period (last page this line number only) 
SCHEDULE A-P ITEMIZED RECEIPTS
Use separate schedule(s) for each category of the Detailed Summary Page
FOR LINE NUMBER: (check only one)

PAGE $653 / 1572$

\begin{tabular}{|c|c|c|c|c|c|}
\hline & & & & & \\
\hline 16 & $\begin{array}{lll}X & 17 a \\
\end{array}$ & $17 \mathrm{~b}$ & $17 c$ & $17 d$ & 18 \\
\hline $19 a$ & $19 b$ & $20 a$ & $20 \mathrm{~b}$ & $20 c$ & 21 \\
\hline
\end{tabular}

Any information copied from such Reports and Statements may not be sold or used by any person for the purpose of soliciting contributions or for commercial purposes, other than using the name and address of any political committee to solicit contributions from such committee.

NAME OF COMMITTEE (In Full)

\section{Friends of Herman Cain}

A. Full Name (Last, First, Middle Initial)

\section{Robert Allen}

Mailing Address 122 Young Dr

\begin{tabular}{lcc}
\hline City & State & Zip Code \\
Inglis & FL & $34449-9404$
\end{tabular}

FEC ID number of contributing federal political committee.

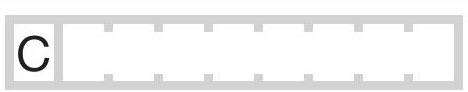

Name of Employer
self
Receipt For: 2012
X Primary $\quad$ General
Other (specify)

Occupation Retired

Election Cycle-to-Date

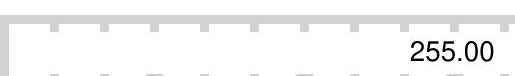

B. Full Name (Last, First, Middle Initial)

Leo Johns

Mailing Address 620 Hatchwood Dr

\begin{tabular}{lcc}
\hline City & State & Zip Code \\
Haines City & FL & $33844-8208$ \\
\hline
\end{tabular}

FEC ID number of contributing

federal political committee.

C

Name of Employer
Information Requested
Receipt For: 2012
Xrimary
Other (specify)

C. Full Name (Last, First, Middle Initial)

Michael Katin

Mailing Address 9150 Penzance Boulevard

\section{City}

Fort Myers

FEC ID number of contributing federal political committee.

Name of Employer
21 st Century Oncology
Receipt For: 2012
Primary
Other (specify) General

Physician

\section{Occupation}

Information Requested

Election Cycle-to-Date

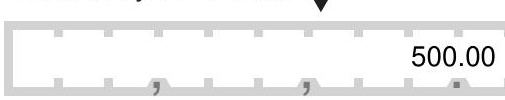

Transaction ID : A6D40D6699BC346EDA30

Date of Receipt

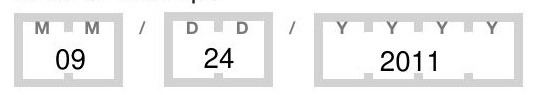

Amount of Each Receipt this Period

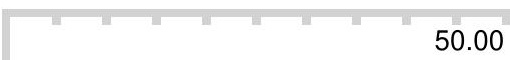

Transaction ID : AA408CB7DE3124E2A8BB Date of Receipt

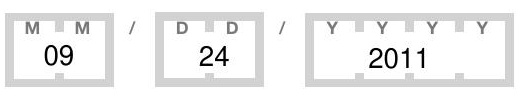

Amount of Each Receipt this Period

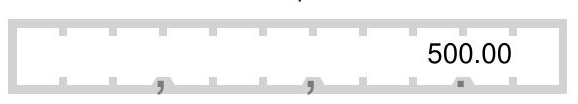

Transaction ID : A0F8BA9DC3651424B898 Date of Receipt

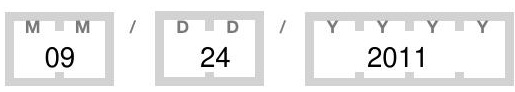

Amount of Each Receipt this Period
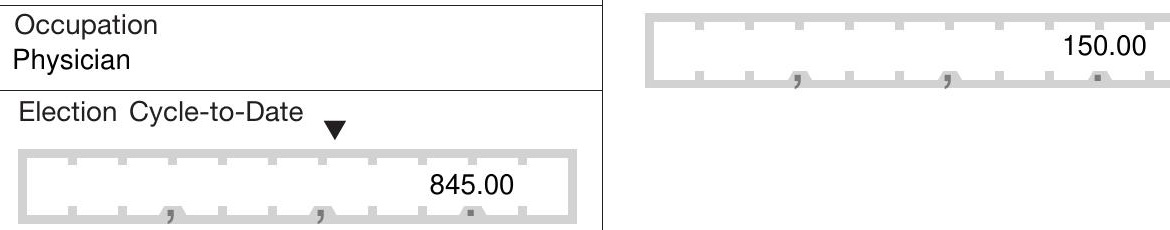

Subtotal Of Receipts This Page (optional)

700.00

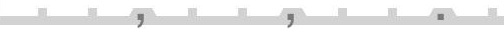

Total This Period (last page this line number only)

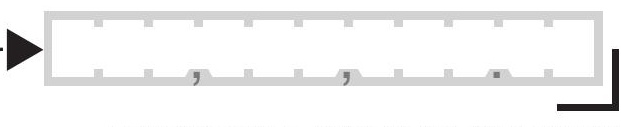

FEC Schedule A-P (Form 3P) (Rev. 03/2011) 
SCHEDULE A-P ITEMIZED RECEIPTS
Use separate schedule(s) for each category of the Detailed Summary Page
FOR LINE NUMBER: (check only one)
PAGE 654 / 1572

\begin{tabular}{|c|c|c|c|c|c|}
\hline & & & & & \\
\hline 16 & $\begin{array}{lll}X & 17 a \\
\end{array}$ & $17 \mathrm{~b}$ & $17 c$ & $17 d$ & 18 \\
\hline $19 a$ & $19 b$ & $20 a$ & $20 \mathrm{~b}$ & $20 c$ & 21 \\
\hline
\end{tabular}

Any information copied from such Reports and Statements may not be sold or used by any person for the purpose of soliciting contributions or for commercial purposes, other than using the name and address of any political committee to solicit contributions from such committee.

NAME OF COMMITTEE (In Full)

\section{Friends of Herman Cain}

A. Full Name (Last, First, Middle Initial)

Michael Katin

Mailing Address 9150 Penzance Boulevard

\begin{tabular}{lcc}
\hline City & State & Zip Code \\
Fort Myers & FL & $33912-1402$ \\
\hline
\end{tabular}

FEC ID number of contributing

federal political committee.

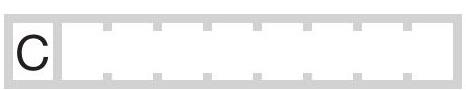

Name of Employer
21st Century Oncology
Receipt For: 2012
X Primary $\quad \square$ General
Other (specify)

Occupation

Physician

Election Cycle-to-Date

845.00

B. Full Name (Last, First, Middle Initial)

Melody Furr

Mailing Address 2725 Astoria Ave

\begin{tabular}{lcc}
\hline City & State & Zip Code \\
Cumming & GA & $30040-5373$
\end{tabular}

FEC ID number of contributing

federal political committee.

C

Name of Employer
Information Requested
Receipt For: 2012
X Primary
Other (specify)

Occupation

Information Requested

Election Cycle-to-Date

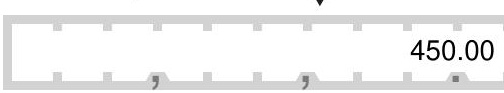

Transaction ID : A3350861F2CFD488DBD9

Date of Receipt

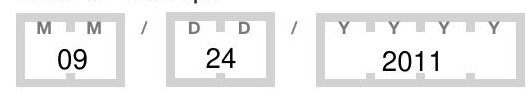

Amount of Each Receipt this Period

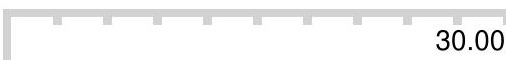

30.00

C. Full Name (Last, First, Middle Initial)

Jeff Beyers

Mailing Address 601 madison st. apt. b-5

\begin{tabular}{lcc}
\hline City & State & Zip Code \\
Fortville & IN & $46040-1151$
\end{tabular}

FEC ID number of contributing

federal political committee.

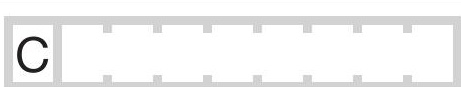

Name of Employer

Information Requested

Occupation

Information Requested

Receipt For: 2012

Х $\begin{aligned} & \text { Primary } \\ & \text { Other (specify) }\end{aligned}$

Transaction ID : AB5175C2C308546A6A3B

Date of Receipt

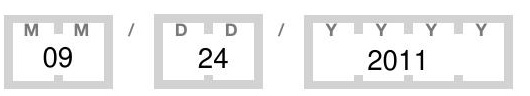

Amount of Each Receipt this Period

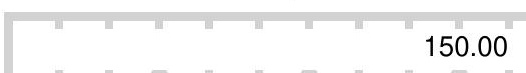

Transaction ID : A4A96DF818AB74729BB7 Date of Receipt

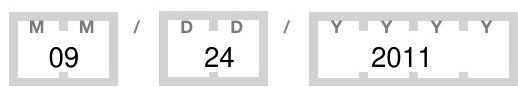

Amount of Each Receipt this Period

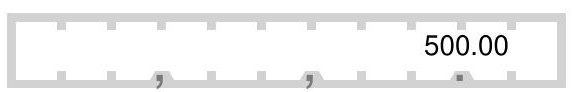

500.00
Subtotal Of Receipts This Page (optional)

680.00

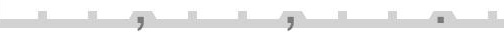

Total This Period (last page this line number only)

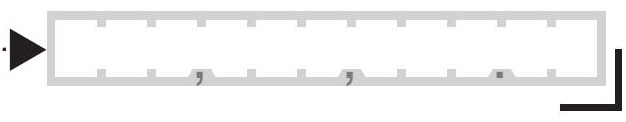

FEC Schedule A-P (Form 3P) (Rev. 03/2011) 
SCHEDULE A-P ITEMIZED RECEIPTS
Use separate schedule(s) for each category of the Detailed Summary Page
FOR LINE NUMBER: (check only one)

PAGE $655 / 1572$

\begin{tabular}{|c|c|c|c|c|c|}
\hline & & & & & \\
\hline 16 & $\begin{array}{l}\mathbf{X} \\
17 a\end{array}$ & $17 b$ & $17 c$ & $17 d$ & 18 \\
\hline $19 a$ & $19 \mathrm{~b}$ & $20 \mathrm{a}$ & $20 \mathrm{~b}$ & $20 \mathrm{c}$ & 21 \\
\hline
\end{tabular}

Any information copied from such Reports and Statements may not be sold or used by any person for the purpose of soliciting contributions or for commercial purposes, other than using the name and address of any political committee to solicit contributions from such committee.

NAME OF COMMITTEE (In Full)

\section{Friends of Herman Cain}

A. Full Name (Last, First, Middle Initial)

Karen Narramore

Mailing Address 26437 N Lewisburg Rd

\begin{tabular}{lcc}
\hline City & State & Zip Code \\
North Lewisburg & OH & $43060-9608$
\end{tabular}

FEC ID number of contributing

federal political committee.

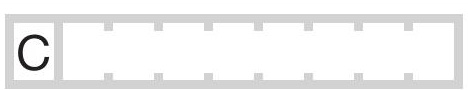

Name of Employer
Information Requested
Receipt For: 2012
X Primary $\quad \square$ General
Other (specify)

Occupation

Information Requested

Election Cycle-to-Date

440.00

B. Full Name (Last, First, Middle Initial)

Greg Yacobian

Mailing Address 1916 Zenaida Ave

\begin{tabular}{lcc}
\hline City & State & Zip Code \\
McAllen & TX & $78504-5625$ \\
\hline
\end{tabular}

FEC ID number of contributing

federal political committee.

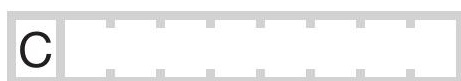

Name of Employer
Retired
Receipt For: 2012
X Primary
Other (specify)

\section{Occupation}

Retired

Election Cycle-to-Date

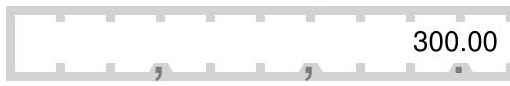

C. Full Name (Last, First, Middle Initial)

Ruth Stephenson

Mailing Address 13 Black Banks Drive

\begin{tabular}{lcc}
\hline City & State & Zip Code \\
Saint Simons Island & GA & $31522-1408$
\end{tabular}

FEC ID number of contributing

federal political committee.

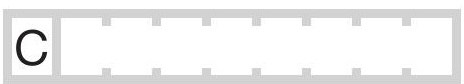

Name of Employer
None
Receipt For: 2012
X Primary $\quad \square$ General
Other (specify)

\section{Occupation}

Homemaker

Election Cycle-to-Date

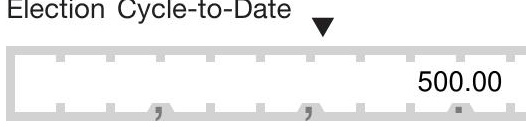

Transaction ID : AAF82EF68F7A14DD398C

Date of Receipt

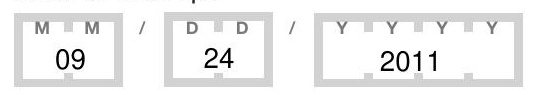

Amount of Each Receipt this Period

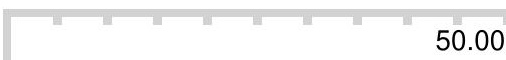

50.00

Transaction ID : A289ABC91AEE94876A47

Date of Receipt

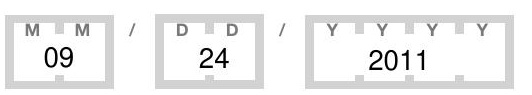

Amount of Each Receipt this Period

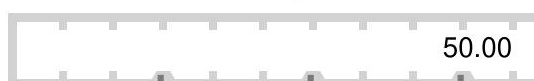

Transaction ID : A6EF14332592D40088C4

Date of Receipt

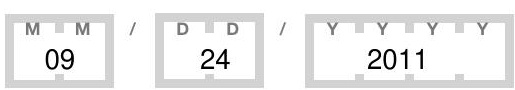

Amount of Each Receipt this Period

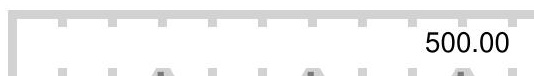

600.00

Subtotal Of Receipts This Page (optional)

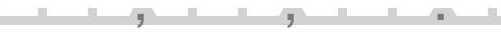

Total This Period (last page this line number only) 
SCHEDULE A-P ITEMIZED RECEIPTS
Use separate schedule(s) for each category of the Detailed Summary Page
FOR LINE NUMBER: (check only one)

PAGE $656 / 1572$

\begin{tabular}{|c|c|c|c|c|c|}
\hline & & & & & \\
\hline 16 & $\begin{array}{l}\mathbf{X} \\
17 a\end{array}$ & $17 b$ & $17 c$ & $17 d$ & 18 \\
\hline $19 a$ & $19 \mathrm{~b}$ & $20 \mathrm{a}$ & $20 \mathrm{~b}$ & $20 \mathrm{c}$ & 21 \\
\hline
\end{tabular}

Any information copied from such Reports and Statements may not be sold or used by any person for the purpose of soliciting contributions or for commercial purposes, other than using the name and address of any political committee to solicit contributions from such committee.

NAME OF COMMITTEE (In Full)

\section{Friends of Herman Cain}

A. Full Name (Last, First, Middle Initial)

William Buffington

Mailing Address 1175 Vintage Way

\begin{tabular}{lcc}
\hline City & State & Zip Code \\
Hoschton & GA & $30548-3453$
\end{tabular}

FEC ID number of contributing federal political committee.

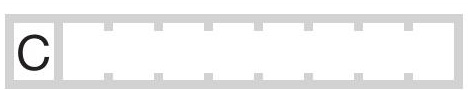

Name of Employer
Information Requested
Receipt For: 2012
X Primary
Other (specify) General

Occupation Information Requested

Election Cycle-to-Date 300.00

B. Full Name (Last, First, Middle Initial)

David Zeitz

Mailing Address 5109 Willow Oak Dr

\begin{tabular}{lcc}
\hline City & State & Zip Code \\
Lumberton & NC & $28358-1114$
\end{tabular}

FEC ID number of contributing

federal political committee.

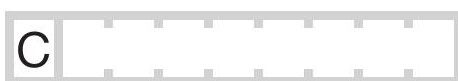

Name of Employer
Self Employed
Receipt For: 2012
X Primary
Other (specify)

\section{Occupation}

Realtor

Election Cycle-to-Date

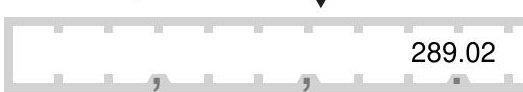

Transaction ID : AA5751BDA9F9846F581F

Date of Receipt

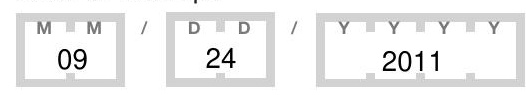

Amount of Each Receipt this Period

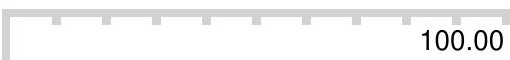

Amount of Each Receipt this Period

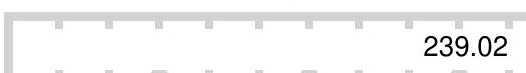

C. Full Name (Last, First, Middle Initial)

Maurice Heller

Mailing Address 4 Ministerial Circle

\begin{tabular}{lcc}
\hline City & State & Zip Code \\
Bedford & NH & $03110-5729$
\end{tabular}

FEC ID number of contributing federal political committee.

C

03110-5729

Name of Employer

Occupation

self

Arbitrator

Transaction ID : A9FB73F91DB464279803

Date of Receipt

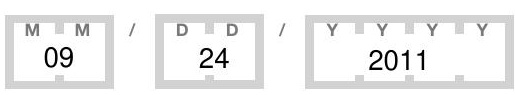

Receipt For: 2012

Х $\begin{aligned} & \text { Primary } \\ & \text { Other (specify) }\end{aligned}$

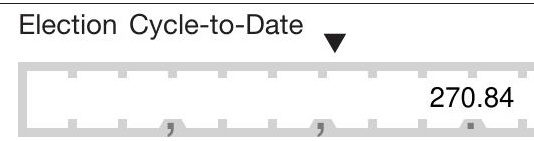

Amount of Each Receipt this Period

Transaction ID : A2B911E16BF7147BDBD4 Date of Receipt
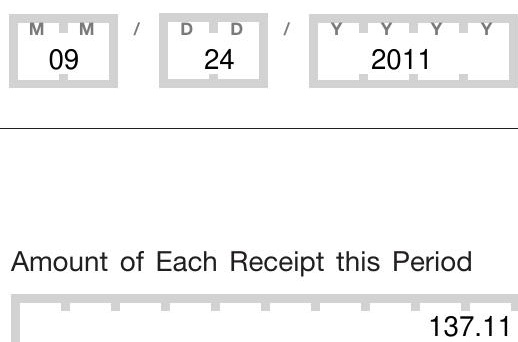

137.11

Subtotal Of Receipts This Page (optional)

476.13

Total This Period (last page this line number only) 


\section{SCHEDULE A-P} ITEMIZED RECEIPTS
Use separate schedule(s) for each category of the Detailed Summary Page

FOR LINE NUMBER:
(check only one)

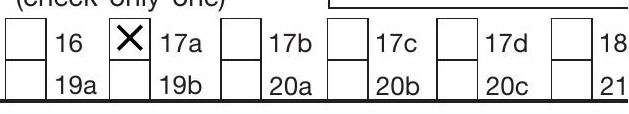

Any information copied from such Reports and Statements may not be sold or used by any person for the purpose of soliciting contributions or for commercial purposes, other than using the name and address of any political committee to solicit contributions from such committee.

NAME OF COMMITTEE (In Full)

\section{Friends of Herman Cain}

A. Full Name (Last, First, Middle Initial)

\section{Dillard Griffith}

Mailing Address 20207 COUNTY ROAD 13

\begin{tabular}{lcc}
\hline City & State & Zip Code \\
Mitchell & NE & $69357-2527$
\end{tabular}

FEC ID number of contributing federal political committee.

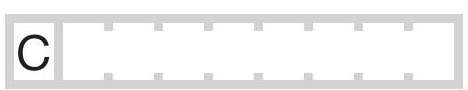

Name of Employer
Information Requested
Receipt For: 2012
X Primary
Other (specify) General

Occupation Information Requested

Election Cycle-to-Date

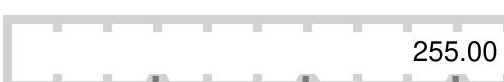

B. Full Name (Last, First, Middle Initial)

Armand Fonseca

Mailing Address P.O. Box 1151

\begin{tabular}{lcc}
\hline City & State & Zip Code \\
Walnut Grove & CA & $95690-1151$
\end{tabular}

FEC ID number of contributing

federal political committee.

C

Name of Employer
Information Requested
Receipt For: 2012
Primary
Other (specify)

Occupation

Information Requested

Election Cycle-to-Date

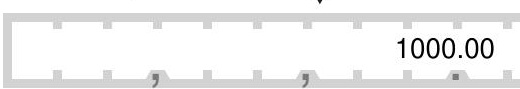

C. Full Name (Last, First, Middle Initial)

James Moates

Mailing Address 1410 Old Bethany Rd

\begin{tabular}{lcc}
\hline City & State & Zip Code \\
Greensboro & GA & $30642-4212$
\end{tabular}

FEC ID number of contributing

federal political committee.

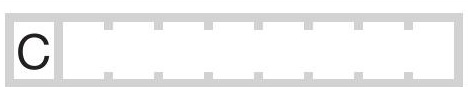

Name of Employer

Parsons-Brinckerhoff

\section{Occupation}

Engineering Consultant

Receipt For: 2012

Х $\begin{aligned} & \text { Primary } \\ & \text { Other (specify) }\end{aligned}$

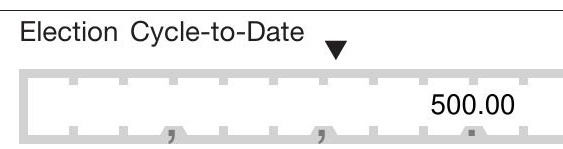

Transaction ID : A9813D8BE59044B6AAA4

Date of Receipt

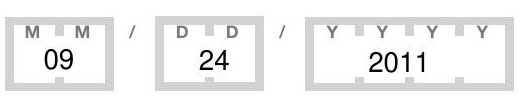

Amount of Each Receipt this Period

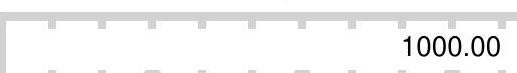

Transaction ID : A90AA80D2BBCF4768A3C Date of Receipt

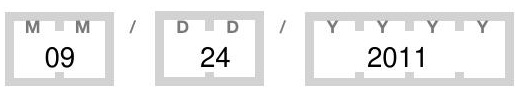

Amount of Each Receipt this Period

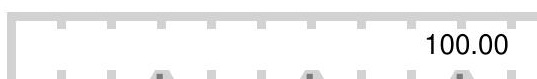

1355.00

Subtotal Of Receipts This Page (optional)

Total This Period (last page this line number only) 


\section{SCHEDULE A-P} ITEMIZED RECEIPTS
Use separate schedule(s) for each category of the Detailed Summary Page

FOR LINE NUMBER:
(check only one)

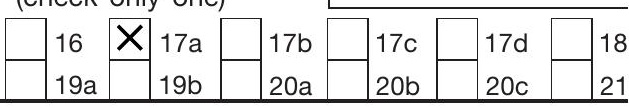

Any information copied from such Reports and Statements may not be sold or used by any person for the purpose of soliciting contributions or for commercial purposes, other than using the name and address of any political committee to solicit contributions from such committee.

NAME OF COMMITTEE (In Full)

\section{Friends of Herman Cain}

A. Full Name (Last, First, Middle Initial) RICHARD WOLF

Mailing Address 1324 NORTHRIDGE TERRACE

\begin{tabular}{lcc}
\hline City & State & Zip Code \\
Joplin & MO & $64801-9547$ \\
\hline
\end{tabular}

FEC ID number of contributing federal political committee.

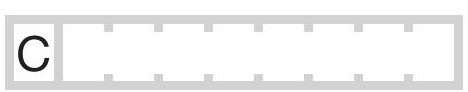

Name of Employer
Information Requested
Receipt For: 2012
X Primary
$\square$ Other (specify)

Occupation Information Requested Election Cycle-to-Date 1000.00

B. Full Name (Last, First, Middle Initial) Kenneth Smith

Mailing Address PO Box 38

\begin{tabular}{lcc}
\hline City & State & Zip Code \\
Rolla & KS & $67954-0038$ \\
\hline
\end{tabular}

FEC ID number of contributing

federal political committee.

C

Name of Employer
Information Requested
Receipt For: 2012
X Primary
Other (specify)

Occupation

Information Requested

Election Cycle-to-Date

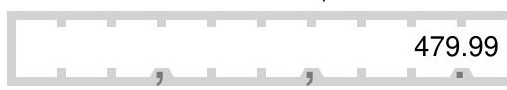

Transaction ID : AE3BB34DB02AA408380E

Date of Receipt

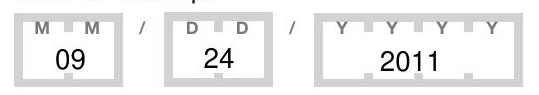

Amount of Each Receipt this Period

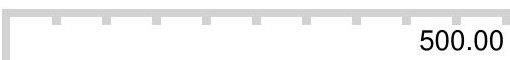

Amount of Each Receipt this Period

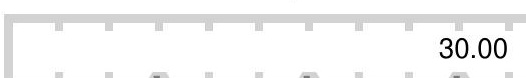

C. Full Name (Last, First, Middle Initial)

Rita Warren

Mailing Address 4225 Bayard St

\begin{tabular}{lcc}
\hline City & State & Zip Code \\
San Diego & CA & $92109-4002$
\end{tabular}

FEC ID number of contributing federal political committee.

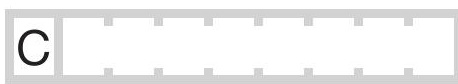

Name of Employer

Information Requested

\section{Occupation}

Information Requested

Receipt For: 2012

Х $\begin{aligned} & \text { Primary } \square \text { General } \\ & \text { Other (specify) }\end{aligned}$

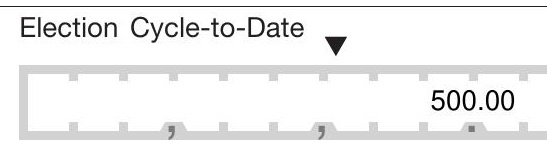

Amount of Each Receipt this Period

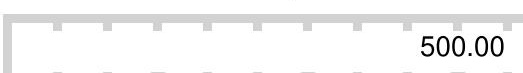

Transaction ID : AA83471761D134FB9ACE Date of Receipt

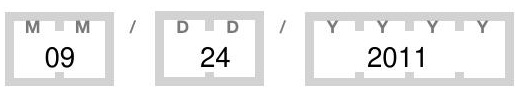

Subtotal Of Receipts This Page (optional)

Total This Period (last page this line number only) 
SCHEDULE A-P ITEMIZED RECEIPTS
Use separate schedule(s) for each category of the Detailed Summary Page
FOR LINE NUMBER: (check only one)

PAGE 659 / 1572

\begin{tabular}{|c|c|c|c|c|c|}
\hline & & & & & \\
\hline 16 & $\begin{array}{l}\mathbf{X} \\
17 a\end{array}$ & $17 b$ & $17 c$ & $17 d$ & 18 \\
\hline $19 a$ & $19 \mathrm{~b}$ & $20 \mathrm{a}$ & $20 \mathrm{~b}$ & $20 \mathrm{c}$ & 21 \\
\hline
\end{tabular}

Any information copied from such Reports and Statements may not be sold or used by any person for the purpose of soliciting contributions or for commercial purposes, other than using the name and address of any political committee to solicit contributions from such committee.

NAME OF COMMITTEE (In Full)

\section{Friends of Herman Cain}

A. Full Name (Last, First, Middle Initial)

Richard Scruggs

Mailing Address 2595 Ho Hum Hollow Road

\begin{tabular}{lcc}
\hline City & State & Zip Code \\
Monroe & GA & $30655-5533$
\end{tabular}

FEC ID number of contributing federal political committee.

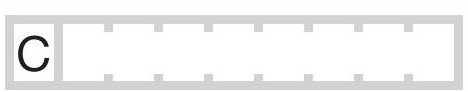

Name of Employer
Information Requested
Receipt For: 2012
X Primary
Other (specify) General

Occupation Information Requested

Election Cycle-to-Date

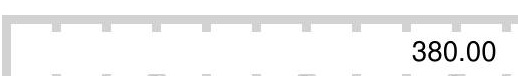

B. Full Name (Last, First, Middle Initial)

Jan Francis

Mailing Address PO Box 2186

\begin{tabular}{llc}
\hline City & State & Zip Code \\
Pasco & WA & $99302-2186$ \\
\hline
\end{tabular}

FEC ID number of contributing

federal political committee.

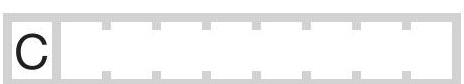

Name of Employer
Safeguard Business systems
Receipt For: 2012
X Primary
Other (specify)

\section{Occupation}

Print

Election Cycle-to-Date

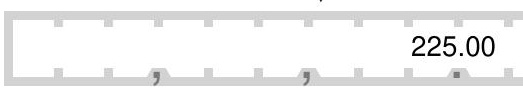

Transaction ID : A1D6FC561FDC74D16921

Date of Receipt

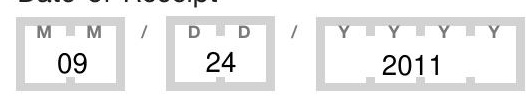

Amount of Each Receipt this Period

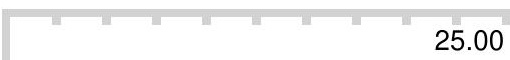

25.00

C. Full Name (Last, First, Middle Initial)

Scott Richardson

Mailing Address 20384 Pickford Way

\begin{tabular}{lcc}
\hline City & State & Zip Code \\
Redding & CA & $96002-9231$
\end{tabular}

FEC ID number of contributing federal political committee.

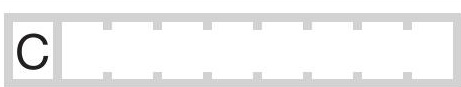

\section{Name of Employer}

RMC Refrigeration

\section{Occupation}

Information Requested

Receipt For: 2012

Х $\begin{aligned} & \text { Primary } \\ & \text { Other (specify) }\end{aligned}$

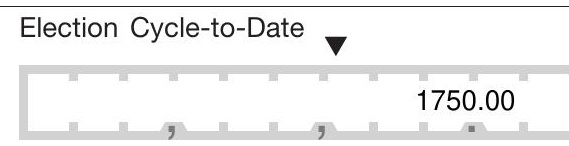

Amount of Each Receipt this Period

Transaction ID : AE1CC67A1D8F0490EB59

Date of Receipt
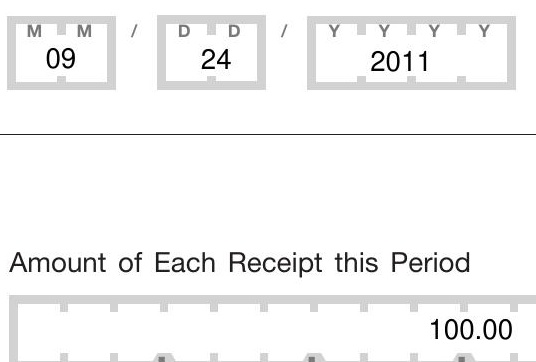

Transaction ID : A53D7EC6E20B34A05B32 Date of Receipt

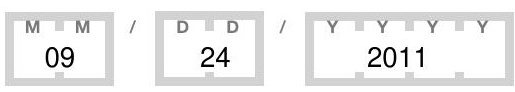

Amount of Each Receipt this Period

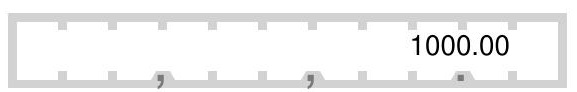

\section{Subtotal Of Receipts This Page (optional)}

Total This Period (last page this line number only) 
SCHEDULE A-P ITEMIZED RECEIPTS
Use separate schedule(s) for each category of the Detailed Summary Page
FOR LINE NUMBER: (check only one)

PAGE $660 / 1572$

\begin{tabular}{|c|c|c|c|c|c|}
\hline & & & & & \\
\hline 16 & $\begin{array}{l}\mathbf{X} \\
17 a\end{array}$ & $17 b$ & $17 c$ & $17 d$ & 18 \\
\hline $19 a$ & $19 \mathrm{~b}$ & $20 \mathrm{a}$ & $20 \mathrm{~b}$ & $20 \mathrm{c}$ & 21 \\
\hline
\end{tabular}

Any information copied from such Reports and Statements may not be sold or used by any person for the purpose of soliciting contributions or for commercial purposes, other than using the name and address of any political committee to solicit contributions from such committee.

NAME OF COMMITTEE (In Full)

\section{Friends of Herman Cain}

A. Full Name (Last, First, Middle Initial) barbara shaw

Mailing Address 630 fulton ave

\begin{tabular}{lcc}
\hline City & State & Zip Code \\
Rochester & IN & $46975-1335$
\end{tabular}

FEC ID number of contributing federal political committee.

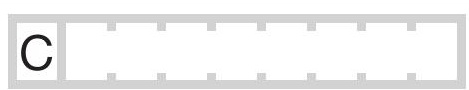

Name of Employer
CVS/Pharmacy
Receipt For: 2012
X Primary $\quad$ General
Other (specify)

Occupation Pharmacist

Election Cycle-to-Date

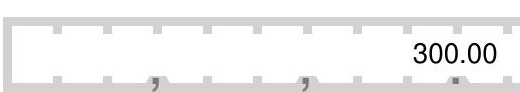

B. Full Name (Last, First, Middle Initial)

Susan Brown

Mailing Address 127 Verdant

\begin{tabular}{lcc}
\hline City & State & Zip Code \\
San Antonio & TX & $78209-2050$ \\
\hline
\end{tabular}

FEC ID number of contributing

federal political committee.

C

Name of Employer
Information Requested
Receipt For: 2012
X Primary
Other (specify)

Occupation

Information Requested

Election Cycle-to-Date

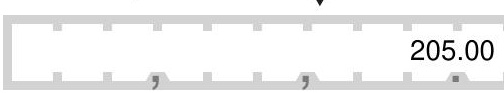

Transaction ID : AE2E5BD59E09647E8A78

Date of Receipt

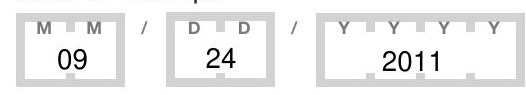

Amount of Each Receipt this Period

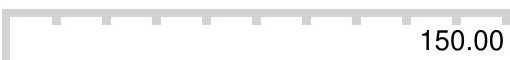

150.00

C. Full Name (Last, First, Middle Initial)

Ann Blakely

Mailing Address 6189 River Ridge RD SE

\begin{tabular}{lcc}
\hline City & State & Zip Code \\
Fife Lake & MI & $49633-8244$
\end{tabular}

FEC ID number of contributing federal political committee.

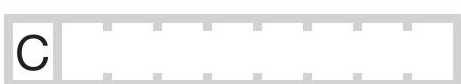

Name of Employer
Information Requested
Receipt For: 2012
X Primary $\quad \square$ General
Other (specify)

\section{Occupation}

Information Requested

Election Cycle-to-Date

Transaction ID : A73D3AEBEE7574B94ABD Date of Receipt

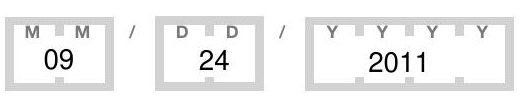

Amount of Each Receipt this Period

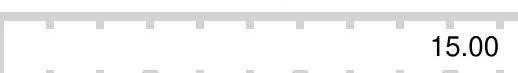

Transaction ID : A6EF1E042B2104318BA9

Date of Receipt

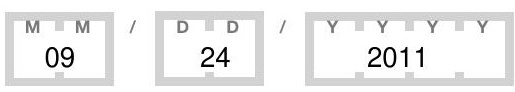

Amount of Each Receipt this Period

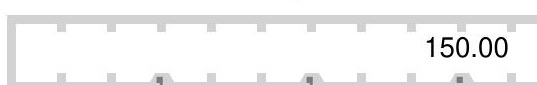

500.00

\section{Subtotal Of Receipts This Page (optional)}

Total This Period (last page this line number only) 


\section{SCHEDULE A-P} ITEMIZED RECEIPTS
Use separate schedule(s)

for each category of the

Detailed Summary Page
FOR LINE NUMBER: (check only one)

PAGE $661 / 1572$

\begin{tabular}{|c|c|c|c|c|c|}
\hline & & & & & \\
\hline 16 & X $17 a$ & $17 b$ & $17 c$ & $17 d$ & 18 \\
\hline $19 a$ & $19 b$ & $20 \mathrm{a}$ & $20 \mathrm{~b}$ & $20 \mathrm{c}$ & 21 \\
\hline
\end{tabular}

Any information copied from such Reports and Statements may not be sold or used by any person for the purpose of soliciting contributions or for commercial purposes, other than using the name and address of any political committee to solicit contributions from such committee.

NAME OF COMMITTEE (In Full)

\section{Friends of Herman Cain}

A. Full Name (Last, First, Middle Initial)

Harvey Bunyard

Mailing Address 13711 E. 125th St. N.

\begin{tabular}{lcc}
\hline City & State & Zip Code \\
Valley Center & KS & $67147-9270$ \\
\hline
\end{tabular}

FEC ID number of contributing

federal political committee.

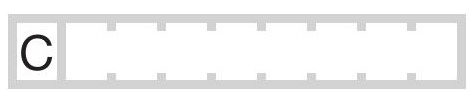

Name of Employer
Retired
Receipt For: 2012
X Primary $\quad$ General
Other (specify)

Occupation

Retired

Election Cycle-to-Date

225.00

B. Full Name (Last, First, Middle Initial)

Karen S Black

Mailing Address 1250 Celebration Avenue

\begin{tabular}{lcc}
\hline City & State & Zip Code \\
Kissimmee & FL & $34747-4866$
\end{tabular}

FEC ID number of contributing

federal political committee.

C

Name of Employer
Information Requested
Receipt For: 2012
X Primary
Other (specify)

Occupation

Information Requested

Election Cycle-to-Date

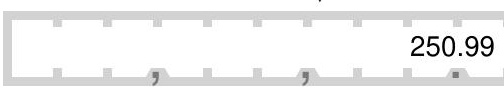

Transaction ID : A03BD689424E54801BE3

Date of Receipt

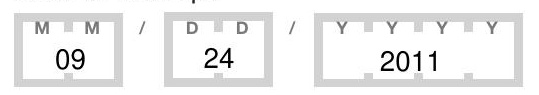

Amount of Each Receipt this Period

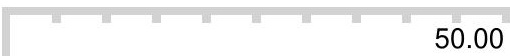

50.00

C. Full Name (Last, First, Middle Initial)

Hans Schmidt

Mailing Address POB 327

\begin{tabular}{lcc}
\hline City & State & Zip Code \\
Mc Lean & VA & $22101-0327$
\end{tabular}

FEC ID number of contributing federal political committee.

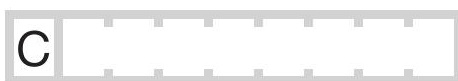

Name of Employer

Information Requested

Occupation

Information Requested

Receipt For: 2012

Х $\begin{aligned} & \text { Primary } \\ & \text { Other (specify) }\end{aligned}$

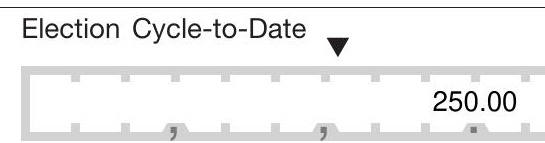

Amount of Each Receipt this Period

Transaction ID : AB1200DA8A49A42209AB

Date of Receipt
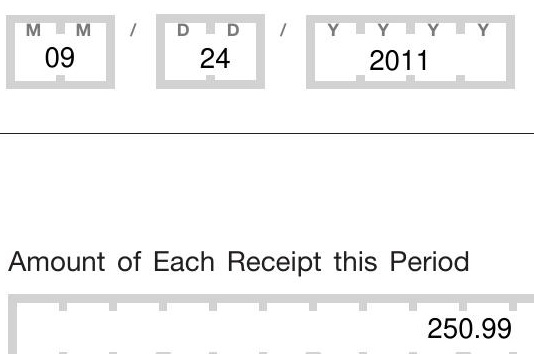

Transaction ID : A1A03D2BBDA9E47778B4 Date of Receipt

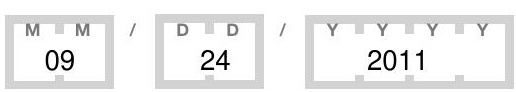

Amount of Each Receipt this Period

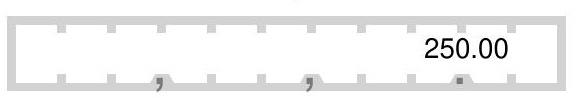

Subtotal Of Receipts This Page (optional)

550.99

Total This Period (last page this line number only) 
SCHEDULE A-P ITEMIZED RECEIPTS
Use separate schedule(s) for each category of the Detailed Summary Page
FOR LINE NUMBER: (check only one)

PAGE 662 / 1572

\begin{tabular}{|c|c|c|c|c|c|}
\hline & & & & & \\
\hline 16 & $\begin{array}{l}\mathbf{X} \\
17 a\end{array}$ & $17 b$ & $17 c$ & $17 d$ & 18 \\
\hline $19 a$ & $19 \mathrm{~b}$ & $20 \mathrm{a}$ & $20 \mathrm{~b}$ & $20 \mathrm{c}$ & 21 \\
\hline
\end{tabular}

Any information copied from such Reports and Statements may not be sold or used by any person for the purpose of soliciting contributions or for commercial purposes, other than using the name and address of any political committee to solicit contributions from such committee.

NAME OF COMMITTEE (In Full)

\section{Friends of Herman Cain}

A. Full Name (Last, First, Middle Initial)

Susan Brown

Mailing Address 127 Verdant

\begin{tabular}{lcc}
\hline City & State & Zip Code \\
San Antonio & TX & $78209-2050$
\end{tabular}

FEC ID number of contributing federal political committee.

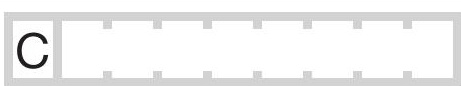

Name of Employer
Information Requested
Receipt For: 2012
X Primary $\quad \square$ General
Other (specify)

Occupation Information Requested

Election Cycle-to-Date

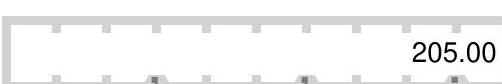

B. Full Name (Last, First, Middle Initial)

Ann Blakely

Mailing Address 6189 River Ridge RD SE

\begin{tabular}{lcc}
\hline City & State & Zip Code \\
Fife Lake & MI & $49633-8244$
\end{tabular}

FEC ID number of contributing

federal political committee.

C

Name of Employer
Information Requested
Receipt For: 2012
X Primary
Other (specify)

Occupation

Information Requested

Election Cycle-to-Date

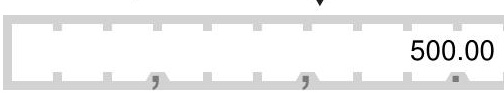

Transaction ID : AD5F48E32DC1C40B2A87

Date of Receipt

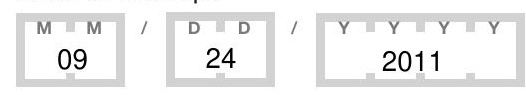

Amount of Each Receipt this Period

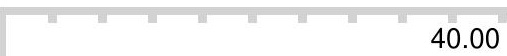

40.00

C. Full Name (Last, First, Middle Initial)

Michael Katin

Mailing Address 9150 Penzance Boulevard

\begin{tabular}{lcc}
\hline City & State & Zip Code \\
Fort Myers & FL & $33912-1402$
\end{tabular}

FEC ID number of contributing

federal political committee.

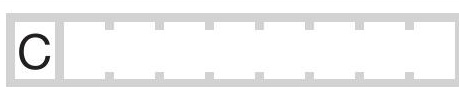

Name of Employer
21 st Century Oncology
Receipt For: 2012
X Primary $\quad \square$ General
Other (specify)

Occupation

Physician

Election Cycle-to-Date

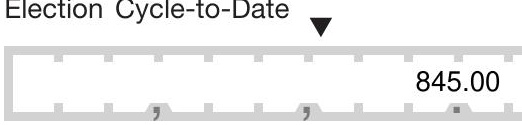

Transaction ID : A2C51535CC23D468F83B

Date of Receipt

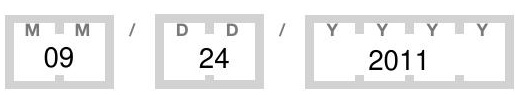

Amount of Each Receipt this Period

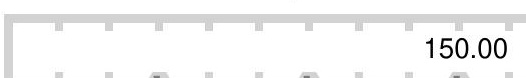

Transaction ID : ABE22FD827F4549B7BFF Date of Receipt

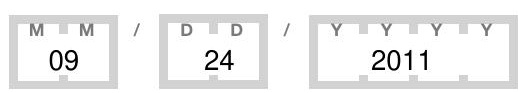

Amount of Each Receipt this Period

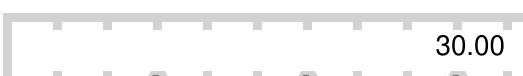

\section{Subtotal Of Receipts This Page (optional)}

Total This Period (last page this line number only) 
SCHEDULE A-P ITEMIZED RECEIPTS
Use separate schedule(s) for each category of the Detailed Summary Page
FOR LINE NUMBER: (check only one)

PAGE $663 / 1572$

\begin{tabular}{|c|c|c|c|c|c|}
\hline & & & & & \\
\hline 16 & $\begin{array}{lll}X & 17 a \\
\end{array}$ & $17 \mathrm{~b}$ & $17 c$ & $17 d$ & 18 \\
\hline $19 a$ & $19 b$ & $20 a$ & $20 \mathrm{~b}$ & $20 c$ & 21 \\
\hline
\end{tabular}

Any information copied from such Reports and Statements may not be sold or used by any person for the purpose of soliciting contributions or for commercial purposes, other than using the name and address of any political committee to solicit contributions from such committee.

NAME OF COMMITTEE (In Full)

\section{Friends of Herman Cain}

A. Full Name (Last, First, Middle Initial)

Robert Cardinal

Mailing Address 2999 N. Lake Shore Drive

\begin{tabular}{lcc}
\hline City & State & Zip Code \\
Harbor Springs & MI & $49740-9121$
\end{tabular}

FEC ID number of contributing federal political committee.

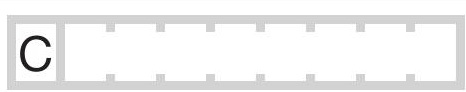

Name of Employer
Retired
Receipt For: 2012
X Primary $\quad$ General
Other (specify)

Occupation Retired

Election Cycle-to-Date

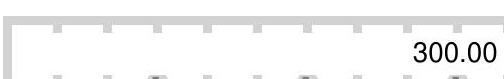

B. Full Name (Last, First, Middle Initial)

Eric Vigen

Mailing Address 23642 Clover Trl

\begin{tabular}{lcc}
\hline City & State & Zip Code \\
Calabasas & CA & $91302-2007$
\end{tabular}

FEC ID number of contributing

federal political committee.

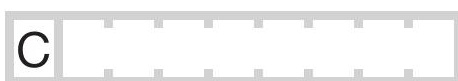

Name of Employer
Airespring Telecom
Receipt For: 2012
X Primary
Other (specify)

\section{Occupation}

CFO

Election Cycle-to-Date

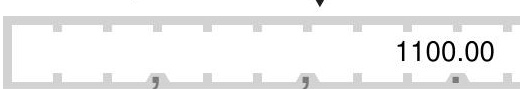

Transaction ID : AD4CC71CED8894AEFAD6

Date of Receipt

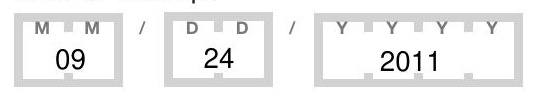

Amount of Each Receipt this Period

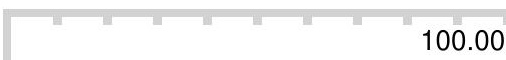

C. Full Name (Last, First, Middle Initial)

Trish Bruce

Mailing Address 1 Cross Creek Lane

\begin{tabular}{lcc}
\hline City & State & Zip Code \\
O Fallon & MO & $63366-4736$
\end{tabular}

FEC ID number of contributing federal political committee.

C

Name of Employer
Self Employed
Receipt For: 2012
Х Primary $\quad \square$ General
Other (specify)

Occupation

Massage Therapist

Election Cycle-to-Date
Amount of Each Receipt this Period

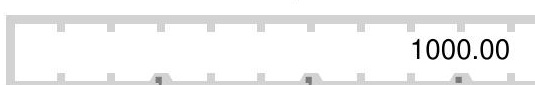

Transaction ID : A335CCB1D03C4484D9D9 Date of Receipt

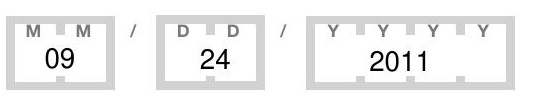

Transaction ID : A773D6C6F9C3E47C5B55 Date of Receipt

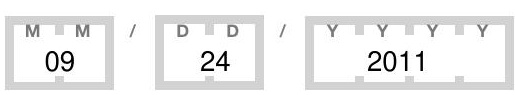

Amount of Each Receipt this Period

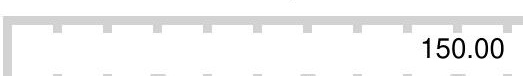

\section{Subtotal Of Receipts This Page (optional)}

Total This Period (last page this line number only) 
SCHEDULE A-P ITEMIZED RECEIPTS
Use separate schedule(s)

for each category of the

Detailed Summary Page
FOR LINE NUMBER: (check only one)

\begin{tabular}{|c|c|c|c|c|c|}
\hline & & & & & \\
\hline 16 & $\begin{array}{ll}X & 17 a \\
\end{array}$ & $17 \mathrm{~b}$ & $17 c$ & $17 d$ & 18 \\
\hline $19 a$ & $19 b$ & $20 \mathrm{a}$ & $20 \mathrm{~b}$ & $20 c$ & 21 \\
\hline
\end{tabular}

Any information copied from such Reports and Statements may not be sold or used by any person for the purpose of soliciting contributions or for commercial purposes, other than using the name and address of any political committee to solicit contributions from such committee.

NAME OF COMMITTEE (In Full)

Friends of Herman Cain

A. Full Name (Last, First, Middle Initial)

Gerald Steverson

Mailing Address 2331 Fairfield Ct

City State Zip Code

Fleming Island

FL 32003-7760

FEC ID number of contributing

federal political committee.

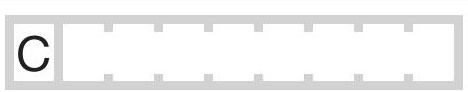

Name of Employer
DoD
Receipt For: 2012
X Primary $\quad \square$ General
$\square$ Other (specify)

Occupation

Aerospace engineer

Election Cycle-to-Date

350.00

B. Full Name (Last, First, Middle Initial)

Eric Omdahl

Mailing Address 10 Hunt Terrace

\begin{tabular}{lcc}
\hline City & State & Zip Code \\
Greenwich & CT & $06831-4147$
\end{tabular}

FEC ID number of contributing

federal political committee.

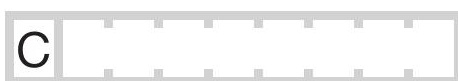

Name of Employer
Retired
Receipt For: 2012
Primary
Other (specify)

Occupation

Retired

Election Cycle-to-Date

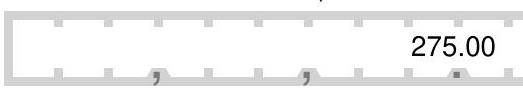

Transaction ID : AAFFB7F90121348A7A1F

Date of Receipt

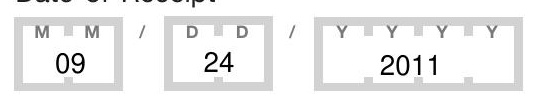

Amount of Each Receipt this Period

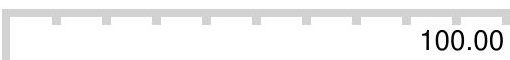

Transaction ID : A0D54E1E58C494D06BC5

Date of Receipt

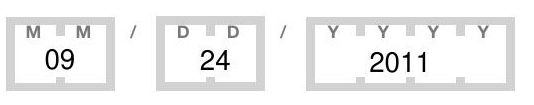

Amount of Each Receipt this Period

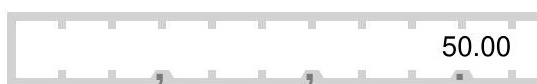

Transaction ID : A0D93FF10CEEA46F79E0 Date of Receipt

Alyn Holt

Mailing Address 10 Hessian Way

\begin{tabular}{lcc}
\hline City & State & Zip Code \\
Cherry Hill & NJ & $08003-2615$
\end{tabular}

FEC ID number of contributing federal political committee.

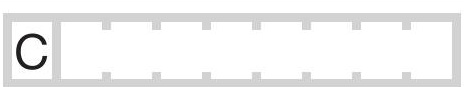

Name of Employer
inTEST Corp
Receipt For: 2012
X Primary $\quad \square$ General
Other (specify)

\section{Occupation}

Executive

Election Cycle-to-Date

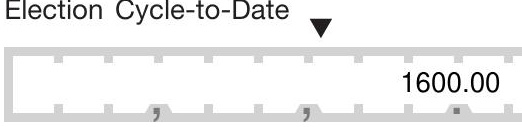

Subtotal Of Receipts This Page (optional)

650.00

Amount of Each Receipt this Period

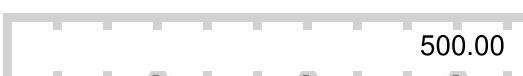

Total This Period (last page this line number only)

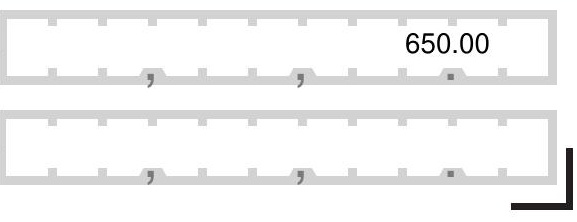


SCHEDULE A-P ITEMIZED RECEIPTS
Use separate schedule(s) for each category of the Detailed Summary Page
FOR LINE NUMBER: (check only one)

PAGE $665 / 1572$

\begin{tabular}{|c|c|c|c|c|c|}
\hline & & & & & \\
\hline 16 & $\begin{array}{l}\mathbf{X} \\
17 a\end{array}$ & $17 b$ & $17 c$ & $17 d$ & 18 \\
\hline $19 a$ & $19 \mathrm{~b}$ & $20 \mathrm{a}$ & $20 \mathrm{~b}$ & $20 \mathrm{c}$ & 21 \\
\hline
\end{tabular}

Any information copied from such Reports and Statements may not be sold or used by any person for the purpose of soliciting contributions or for commercial purposes, other than using the name and address of any political committee to solicit contributions from such committee.

NAME OF COMMITTEE (In Full)

\section{Friends of Herman Cain}

A. Full Name (Last, First, Middle Initial)

\section{Tom Crook}

Mailing Address 180 Freedom Ave

\begin{tabular}{lcc}
\hline City & State & Zip Code \\
Murfreesboro & TN & $37129-6926$
\end{tabular}

FEC ID number of contributing federal political committee.

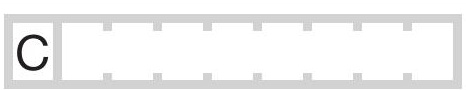

Name of Employer
RFE
Receipt For: 2012
X Primary $\quad$ General
$\quad$ Other (specify)

B. Full Name (Last, First, Middle Initial) Jane Miller

Mailing Address 321 Pleasant PI

\begin{tabular}{lcc}
\hline City & State & Zip Code \\
Charlottesville & VA & $22911-2212$ \\
\hline
\end{tabular}

FEC ID number of contributing

federal political committee.

Name of Employer
Charlottesville Family Medicine
Receipt For: 2012
X Primary
Other (specify)

C. Full Name (Last, First, Middle Initial)

Jane Miller

Mailing Address 321 Pleasant PI

\begin{tabular}{lcc}
\hline City & State & Zip Code \\
Charlottesville & VA & $22911-2212$ \\
\hline
\end{tabular}

FEC ID number of contributing federal political committee.

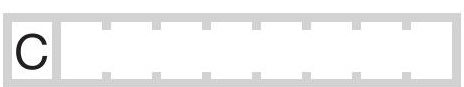

Name of Employer

Charlottesville Family Medicine

Receipt For: 2012

Х $\begin{aligned} & \text { Primary } \square \text { General } \\ & \text { Other (specify) }\end{aligned}$
C

\section{Occupation}

Chair

Election Cycle-to-Date

Occupation

Nurse Practitiner

Election Cycle-to-Date

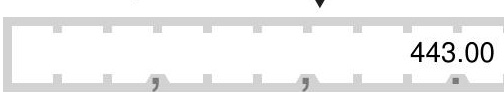

\subsection{0}

\section{Occupation}

Nurse Practitiner

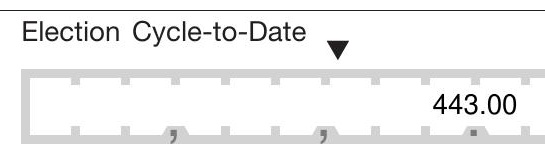

Transaction ID : A99D6E5CDC0E74E0BAD7

Date of Receipt

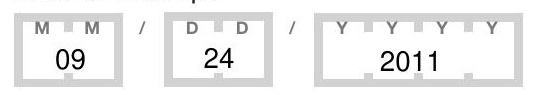

Amount of Each Receipt this Period

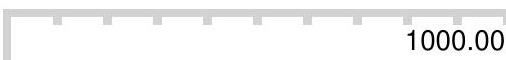

Transaction ID : ABD4DD45DF6074E13964

Date of Receipt

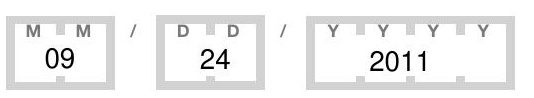

Amount of Each Receipt this Period

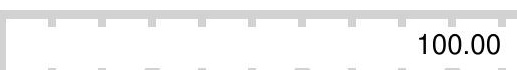

Transaction ID : A80AC404494A04D8592F Date of Receipt

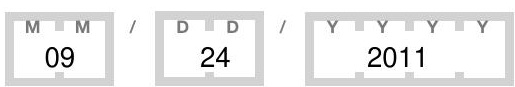

Amount of Each Receipt this Period

Subtotal Of Receipts This Page (optional)

1200.00

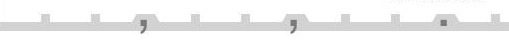

Total This Period (last page this line number only)

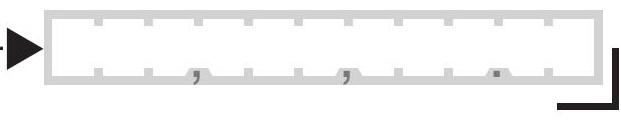

FEC Schedule A-P (Form 3P) (Rev. 03/2011) 
SCHEDULE A-P ITEMIZED RECEIPTS
Use separate schedule(s) for each category of the Detailed Summary Page
FOR LINE NUMBER: (check only one)
PAGE 666 / 1572

\begin{tabular}{|c|c|c|c|c|c|}
\hline & & & & & \\
\hline 16 & $\begin{array}{l}\mathbf{x} 17 a \\
\end{array}$ & $17 b$ & $17 c$ & $17 d$ & 18 \\
\hline $19 a$ & $19 b$ & $20 a$ & $20 b$ & $20 c$ & 21 \\
\hline
\end{tabular}

Any information copied from such Reports and Statements may not be sold or used by any person for the purpose of soliciting contributions or for commercial purposes, other than using the name and address of any political committee to solicit contributions from such committee.

NAME OF COMMITTEE (In Full)

Friends of Herman Cain

A. Full Name (Last, First, Middle Initial)

Marcia Lindquist

Mailing Address 10 9th Avenue Apt. \#105

\begin{tabular}{lcc}
\hline City & State & Zip Code \\
San Mateo & CA & $94401-4346$
\end{tabular}

FEC ID number of contributing

federal political committee.

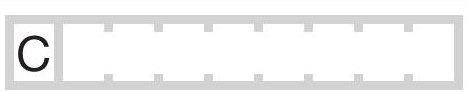

Name of Employer
United Airlines
Receipt For: 2012
X Primary $\quad \square$ General
Other (specify)

Occupation

flight attendant

Election Cycle-to-Date

600.00

B. Full Name (Last, First, Middle Initial)

Nathan Cushman

Mailing Address 369 Macewen Dr

\begin{tabular}{lcc}
\hline City & State & Zip Code \\
Osprey & FL & $34229-9281$
\end{tabular}

FEC ID number of contributing

federal political committee.

C

Name of Employer
Information Requested
Receipt For: 2012
Primary
Other (specify)

Occupation

Information Requested

Election Cycle-to-Date

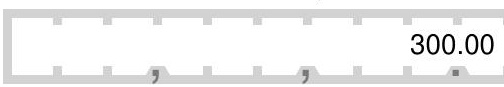

Transaction ID : A3458F9CD717D4B55A11

Date of Receipt

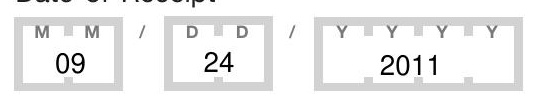

Amount of Each Receipt this Period

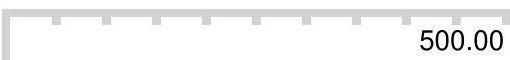

500.00

C. Full Name (Last, First, Middle Initial)

Kenneth Smith

Mailing Address PO Box 38

\begin{tabular}{lcc}
\hline City & State & Zip Code \\
Rolla & KS & $67954-0038$
\end{tabular}

FEC ID number of contributing federal political committee.

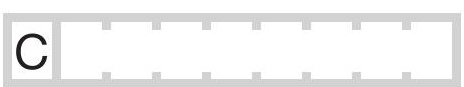

Name of Employer

Information Requested

\section{Occupation}

Information Requested

Receipt For: 2012

Х $\begin{aligned} & \text { Primary } \square \text { General } \\ & \text { Other (specify) }\end{aligned}$

Transaction ID : A65EE3C75D4E34BF19B0

Date of Receipt

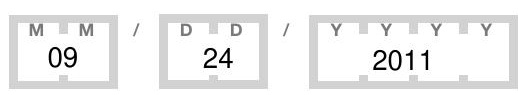

Amount of Each Receipt this Period

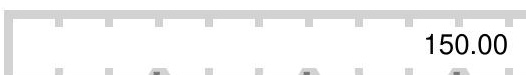

Transaction ID : A25B3F6B56EC44F47BAD Date of Receipt

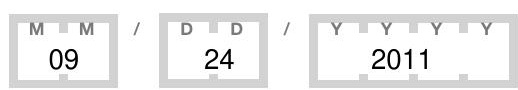

Amount of Each Receipt this Period

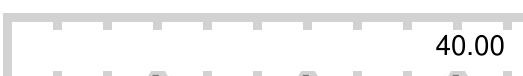

\section{Subtotal Of Receipts This Page (optional)}

Total This Period (last page this line number only) 
SCHEDULE A-P ITEMIZED RECEIPTS
Use separate schedule(s) for each category of the Detailed Summary Page
FOR LINE NUMBER: (check only one)

PAGE $667 / 1572$

\begin{tabular}{|c|c|c|c|c|c|}
\hline & & & & & \\
\hline 16 & $\begin{array}{l}\mathbf{X} \\
17 a\end{array}$ & $17 b$ & $17 c$ & $17 d$ & 18 \\
\hline $19 a$ & $19 \mathrm{~b}$ & $20 \mathrm{a}$ & $20 \mathrm{~b}$ & $20 \mathrm{c}$ & 21 \\
\hline
\end{tabular}

Any information copied from such Reports and Statements may not be sold or used by any person for the purpose of soliciting contributions or for commercial purposes, other than using the name and address of any political committee to solicit contributions from such committee.

NAME OF COMMITTEE (In Full)

\section{Friends of Herman Cain}

A. Full Name (Last, First, Middle Initial)

Kenneth Smith

Mailing Address PO Box 38

\begin{tabular}{lcc}
\hline City & State & Zip Code \\
Rolla & KS & $67954-0038$
\end{tabular}

FEC ID number of contributing federal political committee.

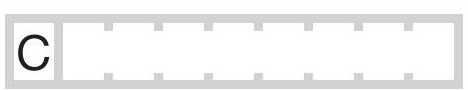

Name of Employer
Information Requested
Receipt For: 2012
X Primary
Other (specify) General

Occupation Information Requested

Election Cycle-to-Date

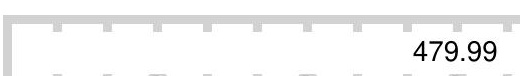

B. Full Name (Last, First, Middle Initial)

Richard Lindenauer

Mailing Address PO Box 520

\begin{tabular}{lcc}
\hline City & State & Zip Code \\
Locust Grove & VA & $22508-0520$
\end{tabular}

FEC ID number of contributing

federal political committee.

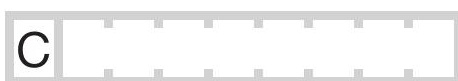

Name of Employer
Retired
Receipt For: 2012
X Primary
Other (specify)

Occupation

Retired

Election Cycle-to-Date

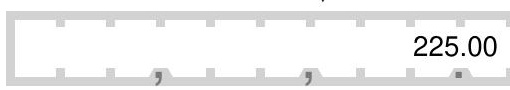

Transaction ID : ACB7936672692415B9E6

Date of Receipt

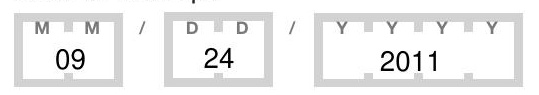

Amount of Each Receipt this Period

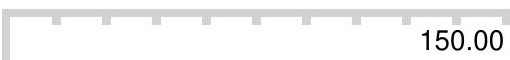

150.00

C. Full Name (Last, First, Middle Initial)

stephen byelick

Mailing Address 864 basswood lane

\begin{tabular}{lcc}
\hline City & State & Zip Code \\
Saint Paul & MN & $55123-2292$
\end{tabular}

FEC ID number of contributing federal political committee.

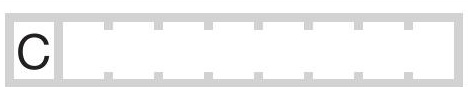

Name of Employer
Alliance Bank
Receipt For: 2012
X Primary $\quad \square$ General
Other (specify)

\section{Occupation}

CFO

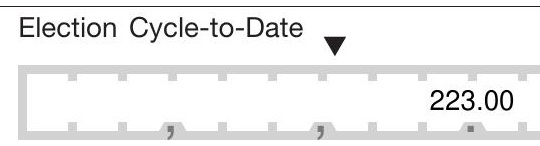

Transaction ID : A33CF6382F8F8473180A

Date of Receipt

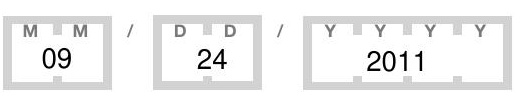

Amount of Each Receipt this Period

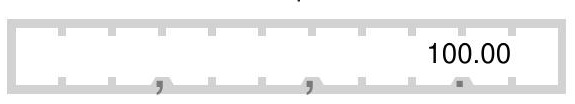

Transaction ID : AF3CA43CC71E143CB864 Date of Receipt

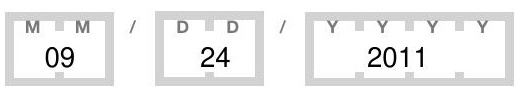

Amount of Each Receipt this Period

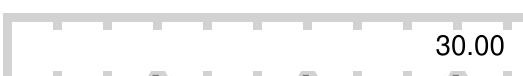

\section{Subtotal Of Receipts This Page (optional)}

Total This Period (last page this line number only) 


\section{SCHEDULE A-P} ITEMIZED RECEIPTS
Use separate schedule(s)

for each category of the

Detailed Summary Page
FOR LINE NUMBER: (check only one)

PAGE $668 / 1572$

\begin{tabular}{|c|c|c|c|c|c|}
\hline & & & & & \\
\hline 16 & X $17 a$ & $17 b$ & $17 c$ & $17 d$ & 18 \\
\hline $19 a$ & $19 b$ & $20 \mathrm{a}$ & $20 \mathrm{~b}$ & $20 \mathrm{c}$ & 21 \\
\hline
\end{tabular}

Any information copied from such Reports and Statements may not be sold or used by any person for the purpose of soliciting contributions or for commercial purposes, other than using the name and address of any political committee to solicit contributions from such committee.

NAME OF COMMITTEE (In Full)

Friends of Herman Cain

A. Full Name (Last, First, Middle Initial)

John Goldman

Mailing Address 5800 Timberlane Terrace

\begin{tabular}{lcc}
\hline City & State & Zip Code \\
Atlanta & GA & $30328-5230$
\end{tabular}

FEC ID number of contributing

federal political committee.

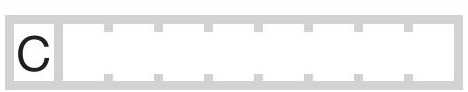

Name of Employer
John A. goldman MD PC
Receipt For: 2012
X Primary $\quad \square$ General
Other (specify)

Occupation

Rheumatologist

Election Cycle-to-Date

300.00

B. Full Name (Last, First, Middle Initial)

PENNY SCIRE

Mailing Address 52 Overlook Dr

\begin{tabular}{lcc}
\hline City & State & Zip Code \\
Dover & $\mathrm{NH}$ & $03820-4958$
\end{tabular}

FEC ID number of contributing

federal political committee.

C

Name of Employer
Information Requested
Receipt For: 2012
Primary
Other (specify)

Occupation

Information Requested

Election Cycle-to-Date

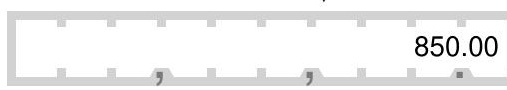

Transaction ID : AC922D6F14B5149D4B33

Date of Receipt

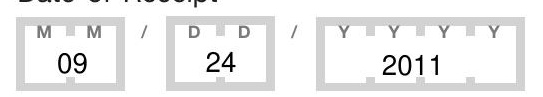

Amount of Each Receipt this Period

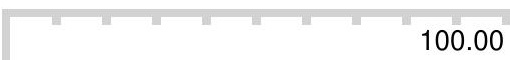

Transaction ID : A43552CAEA1944FD8A55

Date of Receipt

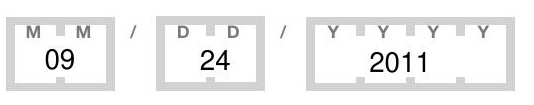

Amount of Each Receipt this Period

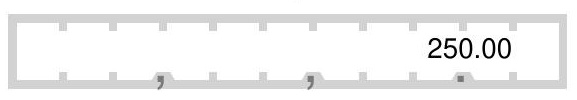

Transaction ID : AF55BA9DAF6CF49D8917 Date of Receipt

Bryan Eglet

Mailing Address 250 Corey Lane

\begin{tabular}{lcc}
\hline City & State & Zip Code \\
Yakima & WA & $98901-7986$
\end{tabular}

FEC ID number of contributing federal political committee.

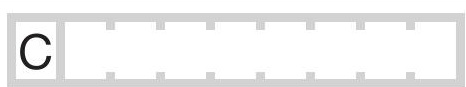

Name of Employer

Information Requested

\section{Occupation}

Information Requested

Receipt For: 2012

Х $\begin{aligned} & \text { Primary } \square \text { General } \\ & \text { Other (specify) }\end{aligned}$

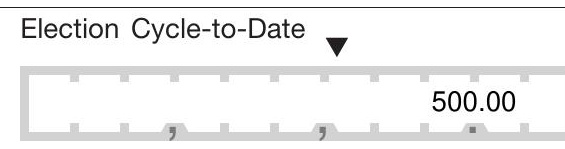

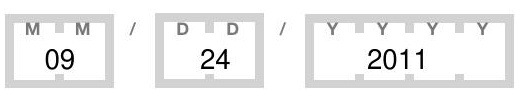

Amount of Each Receipt this Period

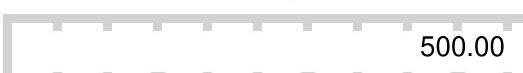

500.00

\section{Subtotal Of Receipts This Page (optional)}

850.00

a

Total This Period (last page this line number only)

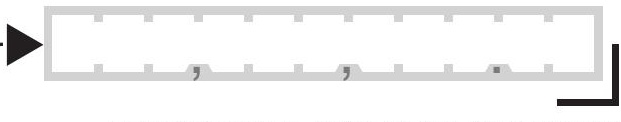

FEC Schedule A-P (Form 3P) (Rev. 03/2011) 
SCHEDULE A-P ITEMIZED RECEIPTS
Use separate schedule(s) for each category of the Detailed Summary Page
FOR LINE NUMBER: (check only one)

PAGE 669 / 1572

\begin{tabular}{|c|c|c|c|c|c|}
\hline & & & & & \\
\hline 16 & $\begin{array}{l}\mathbf{X} \\
17 a\end{array}$ & $17 b$ & $17 c$ & $17 d$ & 18 \\
\hline $19 a$ & $19 \mathrm{~b}$ & $20 \mathrm{a}$ & $20 \mathrm{~b}$ & $20 \mathrm{c}$ & 21 \\
\hline
\end{tabular}

Any information copied from such Reports and Statements may not be sold or used by any person for the purpose of soliciting contributions or for commercial purposes, other than using the name and address of any political committee to solicit contributions from such committee.

NAME OF COMMITTEE (In Full)

\section{Friends of Herman Cain}

A. Full Name (Last, First, Middle Initial) Jason Deitering

Mailing Address 1262 West Ocean View Ave \#5

\begin{tabular}{lcc}
\hline City & State & Zip Code \\
Norfolk & VA & $23503-1145$
\end{tabular}

FEC ID number of contributing federal political committee.

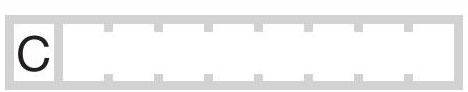

Name of Employer
US Navy
Receipt For: 2012
X Primary $\quad$ General
Other (specify)

Occupation Military

Election Cycle-to-Date

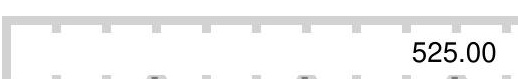

B. Full Name (Last, First, Middle Initial)

Mary Williamson

Mailing Address 4545 W Carr Hill Rd

\begin{tabular}{lcc}
\hline City & State & Zip Code \\
Columbus & IN & $47201-9182$ \\
\hline
\end{tabular}

FEC ID number of contributing

federal political committee.

C

Name of Employer
None
Receipt For: 2012
X Primary
Other (specify)

Occupation

Retired

Election Cycle-to-Date

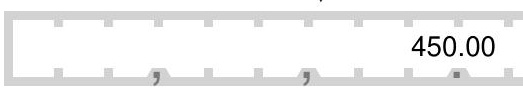

Transaction ID : A539E7D64AD4A41A581E

Date of Receipt

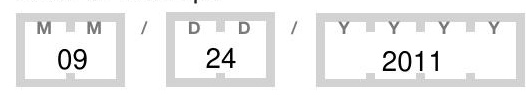

Amount of Each Receipt this Period

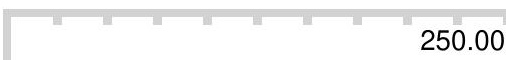

C. Full Name (Last, First, Middle Initial)

Donald Janacek

Mailing Address 2825 Gareths Sword Dr

\begin{tabular}{lcc}
\hline City & State & Zip Code \\
Lewisville & TX & $75056-5667$
\end{tabular}

FEC ID number of contributing federal political committee.

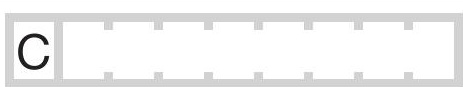

Name of Employer

Information Requested

\section{Occupation}

Information Requested

Receipt For: 2012

Х $\begin{aligned} & \text { Primary } \square \text { General } \\ & \text { Other (specify) }\end{aligned}$

Amount of Each Receipt this Period

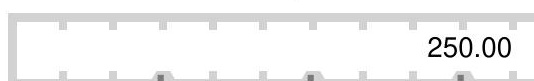

Transaction ID : A796A68EFEA674958874

Date of Receipt

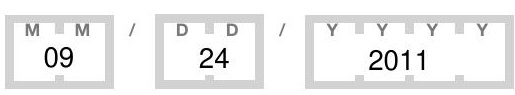

Transaction ID : AF01BDD8D2D8D42D6B93 Date of Receipt

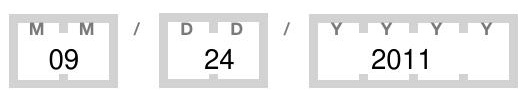

Amount of Each Receipt this Period

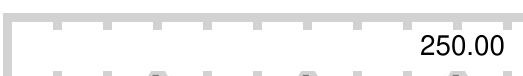

\section{Subtotal Of Receipts This Page (optional)}

Total This Period (last page this line number only) 
SCHEDULE A-P ITEMIZED RECEIPTS
Use separate schedule(s) for each category of the Detailed Summary Page
FOR LINE NUMBER: (check only one)

PAGE $670 / 1572$

\begin{tabular}{|c|c|c|c|c|c|}
\hline & & & & & \\
\hline 16 & $\begin{array}{l}\mathbf{X} \\
17 a\end{array}$ & $17 b$ & $17 c$ & $17 d$ & 18 \\
\hline $19 a$ & $19 \mathrm{~b}$ & $20 \mathrm{a}$ & $20 \mathrm{~b}$ & $20 \mathrm{c}$ & 21 \\
\hline
\end{tabular}

Any information copied from such Reports and Statements may not be sold or used by any person for the purpose of soliciting contributions or for commercial purposes, other than using the name and address of any political committee to solicit contributions from such committee.

NAME OF COMMITTEE (In Full)

\section{Friends of Herman Cain}

A. Full Name (Last, First, Middle Initial)

\section{Carol Lewis}

Mailing Address 1850 Tee Drive

\begin{tabular}{lcc}
\hline City & State & Zip Code \\
Braselton & GA & $30517-4080$
\end{tabular}

FEC ID number of contributing federal political committee.

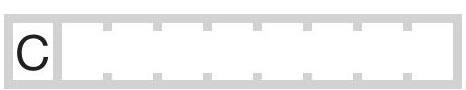

Name of Employer
Information Requested
Receipt For: 2012
X Primary
Other (specify) General

Occupation Information Requested

Election Cycle-to-Date

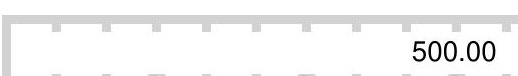

B. Full Name (Last, First, Middle Initial)

Michael Katin

Mailing Address 9150 Penzance Boulevard

\begin{tabular}{lcc}
\hline City & State & Zip Code \\
Fort Myers & FL & $33912-1402$ \\
\hline
\end{tabular}

FEC ID number of contributing

federal political committee.

C

Name of Employer
21st Century Oncology
Receipt For: 2012
X Primary
Other (specify)

Occupation

Physician

Election Cycle-to-Date

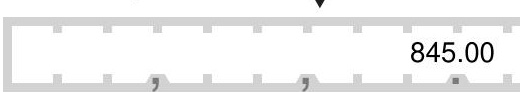

Transaction ID : A5B94EA728828463A90D

Date of Receipt

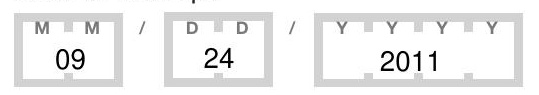

Amount of Each Receipt this Period

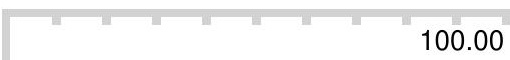

Transaction ID : A6B7D22F4748A4B1984D

Date of Receipt

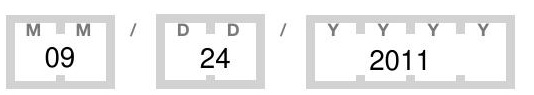

Amount of Each Receipt this Period

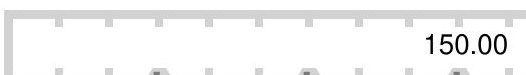

Transaction ID : A8B3E24A2034548AFAAE Date of Receipt

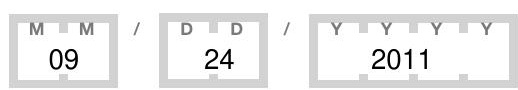

Amount of Each Receipt this Period

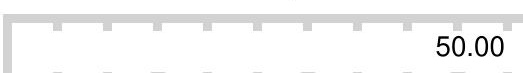

$\begin{array}{cc}\text { State } & \text { Zip Code } \\ \text { GA } & 30571-0690\end{array}$

C

\section{Occupation}

Retired

Election Cycle-to-Date

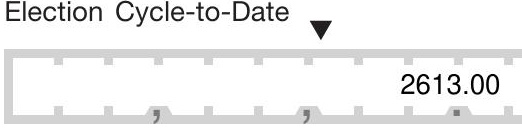

Subtotal Of Receipts This Page (optional)

300.00

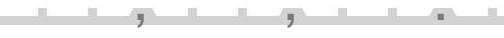

Total This Period (last page this line number only) 


\section{SCHEDULE A-P} ITEMIZED RECEIPTS
Use separate schedule(s)

for each category of the

Detailed Summary Page
FOR LINE NUMBER: (check only one)

PAGE $671 / 1572$

\begin{tabular}{|c|c|c|c|c|c|}
\hline & & & & & \\
\hline 16 & X $17 a$ & $17 b$ & $17 c$ & $17 d$ & 18 \\
\hline $19 a$ & $19 b$ & $20 \mathrm{a}$ & $20 \mathrm{~b}$ & $20 \mathrm{c}$ & 21 \\
\hline
\end{tabular}

Any information copied from such Reports and Statements may not be sold or used by any person for the purpose of soliciting contributions or for commercial purposes, other than using the name and address of any political committee to solicit contributions from such committee.

NAME OF COMMITTEE (In Full)

Friends of Herman Cain

A. Full Name (Last, First, Middle Initial)

Robert Williamson

Mailing Address 4545 W Carr Hill Rd

\begin{tabular}{lcc}
\hline City & State & Zip Code \\
Columbus & IN & $47201-9182$
\end{tabular}

FEC ID number of contributing

federal political committee.

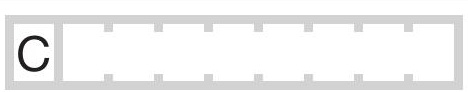

Name of Employer
Self Employed
Receipt For: 2012
X Primary
$\square$ Other (specify) General

Occupation

Accountant

Election Cycle-to-Date

450.00

B. Full Name (Last, First, Middle Initial)

Ronald Coffey

Mailing Address 155 Millcreek Ln

\begin{tabular}{lcc}
\hline City & State & Zip Code \\
Chagrin Falls & OH & $44022-1266$
\end{tabular}

FEC ID number of contributing

federal political committee.

C

\begin{tabular}{l} 
Name of Employer \\
Information Requested \\
\hline Receipt For: 2012 \\
$X$ Primary \\
Other (specify)
\end{tabular}

Occupation

Information Requested

Election Cycle-to-Date

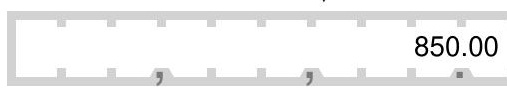

Transaction ID : A4D3121095B5549D8A74

Date of Receipt

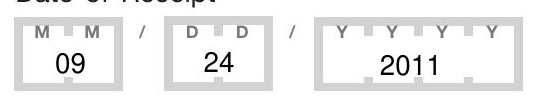

Amount of Each Receipt this Period

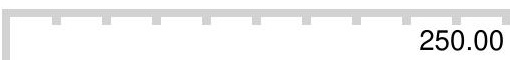

C. Full Name (Last, First, Middle Initial)

Kelly Holloway

Mailing Address 3610 31st Street

\begin{tabular}{lcc}
\hline City & State & Zip Code \\
Lubbock & TX & $79410-2735$
\end{tabular}

FEC ID number of contributing federal political committee.

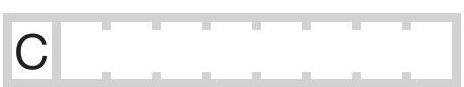

Name of Employer
Hawkeye Road Boring
Receipt For: 2012
Х Primary $\quad \square$ General
Other (specify)

\section{Occupation}

Construction

Election Cycle-to-Date

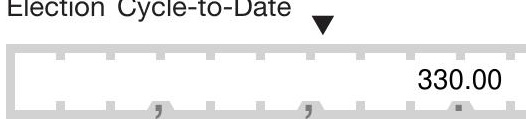

Amount of Each Receipt this Period

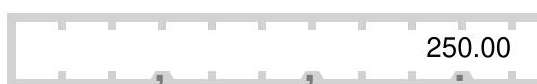

Transaction ID : AC6DCC7928A77456C843 Date of Receipt

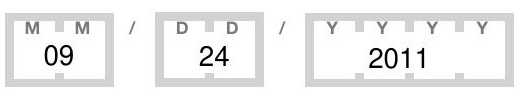

Transaction ID : A71DB72F125B44943B2A Date of Receipt

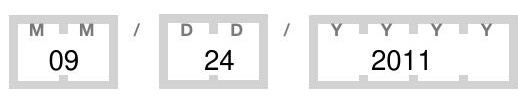

Amount of Each Receipt this Period

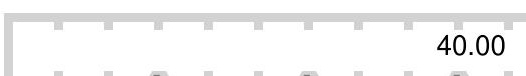

\section{Subtotal Of Receipts This Page (optional)}

Total This Period (last page this line number only) 
SCHEDULE A-P ITEMIZED RECEIPTS
Use separate schedule(s) for each category of the Detailed Summary Page
FOR LINE NUMBER: (check only one)

PAGE 672 / 1572

\begin{tabular}{|c|c|c|c|c|c|}
\hline & & & & & \\
\hline 16 & $\begin{array}{l}\mathbf{X} \\
17 a\end{array}$ & $17 b$ & $17 c$ & $17 d$ & 18 \\
\hline $19 a$ & $19 \mathrm{~b}$ & $20 \mathrm{a}$ & $20 \mathrm{~b}$ & $20 \mathrm{c}$ & 21 \\
\hline
\end{tabular}

Any information copied from such Reports and Statements may not be sold or used by any person for the purpose of soliciting contributions or for commercial purposes, other than using the name and address of any political committee to solicit contributions from such committee.

NAME OF COMMITTEE (In Full)

\section{Friends of Herman Cain}

A. Full Name (Last, First, Middle Initial)

Ann Blakely

Mailing Address 6189 River Ridge RD SE

\begin{tabular}{lcc}
\hline City & State & Zip Code \\
Fife Lake & MI & $49633-8244$ \\
\hline
\end{tabular}

FEC ID number of contributing

federal political committee.

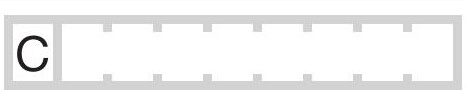

Name of Employer
Information Requested
Receipt For: 2012
X Primary $\quad \square$ General
Other (specify)

Occupation

Information Requested

Election Cycle-to-Date

500.00

B. Full Name (Last, First, Middle Initial)

Rachel Chiles

Mailing Address PO Box 294

\begin{tabular}{lcc}
\hline City & State & Zip Code \\
Oakland & FL & $34760-0294$ \\
\hline
\end{tabular}

FEC ID number of contributing

federal political committee.

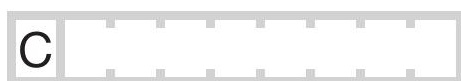

Name of Employer
Information Requested
Receipt For: 2012
X Primary
Other (specify)

Occupation

Information Requested

Election Cycle-to-Date

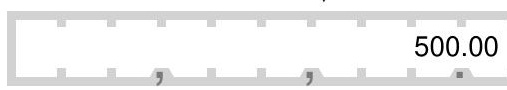

Transaction ID : AC82920C2F23942A79E2

Date of Receipt

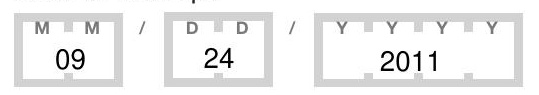

Amount of Each Receipt this Period

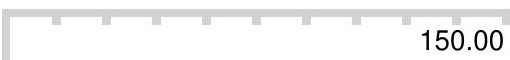

Transaction ID : A491EF2F55227474FB73

Date of Receipt

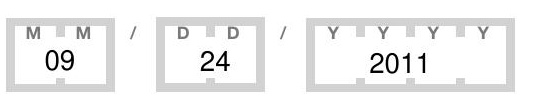

Amount of Each Receipt this Period

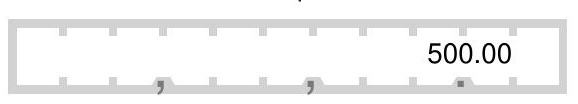

Transaction ID : A1ABC057671B549288CA Date of Receipt

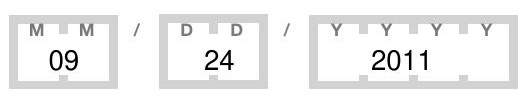

Amount of Each Receipt this Period

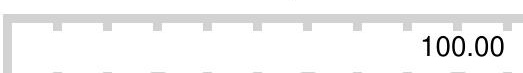

Name of Employer

Charlottesville Family Medicine

Receipt For: 2012

Х $\begin{aligned} & \text { Primary } \square \text { General } \\ & \text { Other (specify) }\end{aligned}$

$\begin{array}{cc}\text { State } & \text { Zip Code } \\ \text { VA } & 22911-2212\end{array}$

C

Occupation

Nurse Practitiner

Election Cycle-to-Date

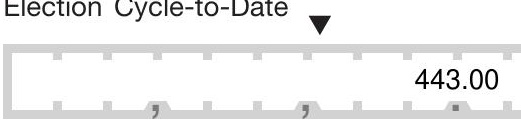

Subtotal Of Receipts This Page (optional).

750.00

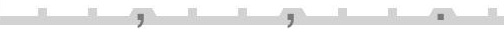

Total This Period (last page this line number only)

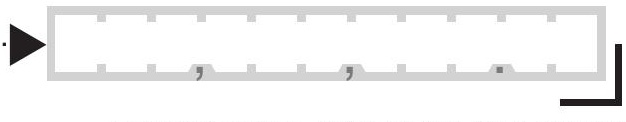

FEC Schedule A-P (Form 3P) (Rev. 03/2011) 
SCHEDULE A-P ITEMIZED RECEIPTS
Use separate schedule(s) for each category of the Detailed Summary Page
FOR LINE NUMBER: (check only one)

\begin{tabular}{|c|c|c|c|c|c|}
\hline & & & & & \\
\hline 16 & $\begin{array}{ll}X & 17 a \\
\end{array}$ & $17 \mathrm{~b}$ & $17 c$ & $17 d$ & 18 \\
\hline $19 a$ & $19 b$ & $20 \mathrm{a}$ & $20 \mathrm{~b}$ & $20 c$ & 21 \\
\hline
\end{tabular}

Any information copied from such Reports and Statements may not be sold or used by any person for the purpose of soliciting contributions or for commercial purposes, other than using the name and address of any political committee to solicit contributions from such committee.

NAME OF COMMITTEE (In Full)

\section{Friends of Herman Cain}

A. Full Name (Last, First, Middle Initial) gretchen waltz

Mailing Address 7467 makaa st.

\begin{tabular}{lcc}
\hline City & State & Zip Code \\
Honolulu & HI & $96825-3125$
\end{tabular}

FEC ID number of contributing federal political committee.

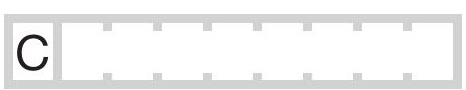

Name of Employer
Information Requested
Receipt For: 2012
X Primary
Other (specify) General

Occupation Information Requested

Election Cycle-to-Date

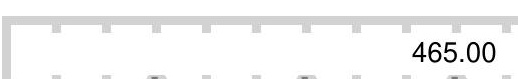

B. Full Name (Last, First, Middle Initial)

margy barr

Mailing Address PO Box 269

\begin{tabular}{llc}
\hline City & State & Zip Code \\
Bondurant & WY & 82922-0269 \\
\hline
\end{tabular}

FEC ID number of contributing

federal political committee.

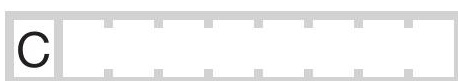

Name of Employer
Barr Inc
Receipt For: 2012
X Primary
Other (specify)

\section{Occupation}

Consultant

Election Cycle-to-Date

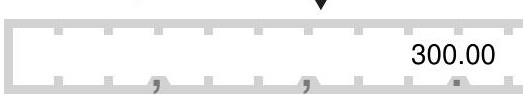

Transaction ID : A7B42FC35A6B14130A9E

Date of Receipt

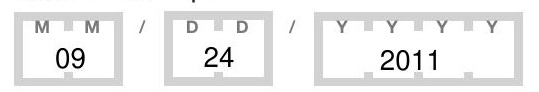

Amount of Each Receipt this Period

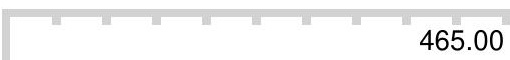

Amount of Each Receipt this Period

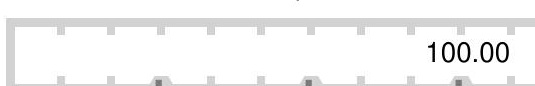

C. Full Name (Last, First, Middle Initial)

Steven Rigdon

Mailing Address 114 Lynbrook Blvd

\begin{tabular}{lcc}
\hline City & State & Zip Code \\
Madison & AL & $35758-8759$
\end{tabular}

FEC ID number of contributing

federal political committee.

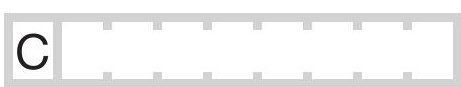

Name of Employer

The Housekeepers Inc

\section{Occupation}

Receipt For: 2012

Х $\begin{aligned} & \text { Primary } \square \text { General } \\ & \text { Other (specify) }\end{aligned}$

self

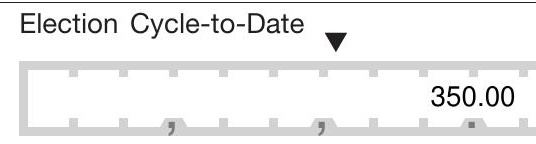

Transaction ID : ACBBE9E9675BE4FDDBE8 Date of Receipt

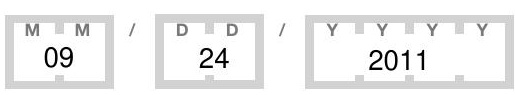

Transaction ID : A62A8260DDB574C4F9C1 Date of Receipt

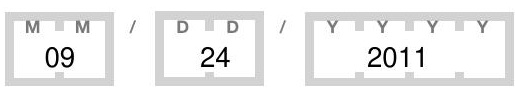

Amount of Each Receipt this Period

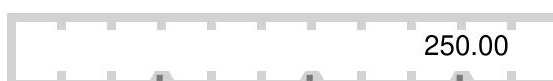

Subtotal Of Receipts This Page (optional)

815.00

Total This Period (last page this line number only) 
SCHEDULE A-P ITEMIZED RECEIPTS
Use separate schedule(s) for each category of the Detailed Summary Page
FOR LINE NUMBER: (check only one)

\begin{tabular}{|c|c|c|c|c|c|}
\hline & & & & & \\
\hline 16 & $\begin{array}{ll}X & 17 a \\
\end{array}$ & $17 \mathrm{~b}$ & $17 c$ & $17 d$ & 18 \\
\hline $19 a$ & $19 b$ & $20 \mathrm{a}$ & $20 \mathrm{~b}$ & $20 c$ & 21 \\
\hline
\end{tabular}

Any information copied from such Reports and Statements may not be sold or used by any person for the purpose of soliciting contributions or for commercial purposes, other than using the name and address of any political committee to solicit contributions from such committee.

NAME OF COMMITTEE (In Full)

\section{Friends of Herman Cain}

A. Full Name (Last, First, Middle Initial)

Edward Douglas

Mailing Address 1804 Eagle Dr

\begin{tabular}{lcc}
\hline City & State & Zip Code \\
League City & TX & $77573-5129$ \\
\hline
\end{tabular}

FEC ID number of contributing federal political committee.

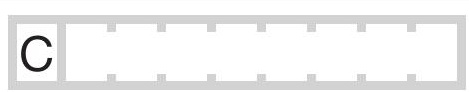

Name of Employer
City of Pasadena Texas
Receipt For: 2012
X Primary
Other (specify) General

Occupation

Police Officer

Election Cycle-to-Date

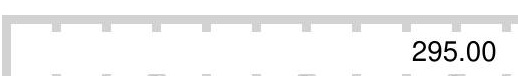

B. Full Name (Last, First, Middle Initial)

Thalia G Stoddard

Mailing Address 220 Red Shadow Road

\begin{tabular}{lcc}
\hline City & State & Zip Code \\
Wagener & SC & $29164-8853$
\end{tabular}

FEC ID number of contributing

federal political committee.

C

Name of Employer
Aiken Saddlery \& Supply
Receipt For: 2012
Primary
Other (specify)

C. Full Name (Last, First, Middle Initial)

Paul Kelly

Mailing Address 10104 Westland Dr

\begin{tabular}{lcc}
\hline $\begin{array}{l}\text { City } \\
\text { Knoxville }\end{array}$ & $\begin{array}{c}\text { State } \\
\text { TN }\end{array}$ & $\begin{array}{c}\text { Zip Code } \\
37922-5122\end{array}$ \\
\hline $\begin{array}{l}\text { FEC ID number of contributing } \\
\text { federal political committee. }\end{array}$ & C & \\
\hline
\end{tabular}

Name of Employer
$\mathrm{n} / \mathrm{a}$
Receipt For: 2012
X Primary
Other (specify) General

\section{Occupation}

sales clerk

Election Cycle-to-Date

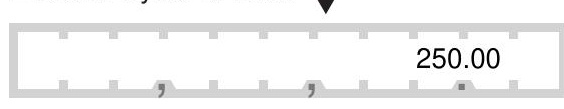

Retired

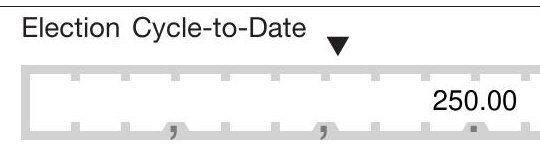

Transaction ID : AEC1876598F504A249BB

Date of Receipt

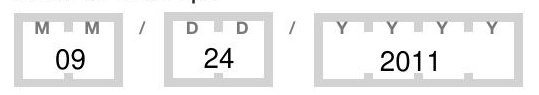

Amount of Each Receipt this Period

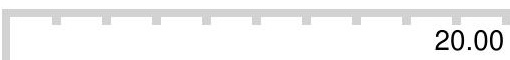

20.00
Amount of Each Receipt this Period

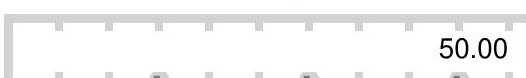

Transaction ID : A250040A0502449918FC Date of Receipt

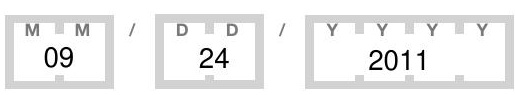

Transaction ID : AE5848172BEF2424A927 Date of Receipt

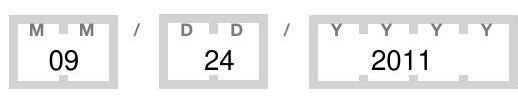

Amount of Each Receipt this Period

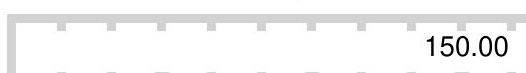

Subtotal Of Receipts This Page (optional)

220.00

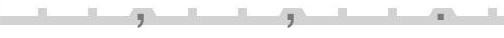

Total This Period (last page this line number only)

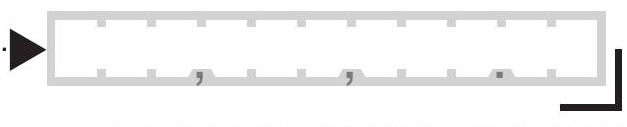

FEC Schedule A-P (Form 3P) (Rev. 03/2011) 
SCHEDULE A-P ITEMIZED RECEIPTS
Use separate schedule(s) for each category of the Detailed Summary Page
FOR LINE NUMBER: (check only one)

PAGE $675 / 1572$

\begin{tabular}{|c|c|c|c|c|c|}
\hline & & & & & \\
\hline 16 & $\begin{array}{l}\mathbf{X} \\
17 a\end{array}$ & $17 b$ & $17 c$ & $17 d$ & 18 \\
\hline $19 a$ & $19 \mathrm{~b}$ & $20 \mathrm{a}$ & $20 \mathrm{~b}$ & $20 \mathrm{c}$ & 21 \\
\hline
\end{tabular}

Any information copied from such Reports and Statements may not be sold or used by any person for the purpose of soliciting contributions or for commercial purposes, other than using the name and address of any political committee to solicit contributions from such committee.

NAME OF COMMITTEE (In Full)

\section{Friends of Herman Cain}

A. Full Name (Last, First, Middle Initial)

Richard Scruggs

Mailing Address 2595 Ho Hum Hollow Road

\begin{tabular}{lcc}
\hline City & State & Zip Code \\
Monroe & GA & $30655-5533$
\end{tabular}

FEC ID number of contributing

federal political committee.

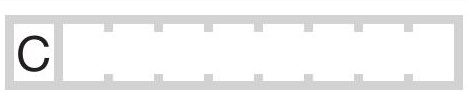

Name of Employer
Information Requested
Receipt For: 2012
X Primary $\quad \square$ General
Other (specify)

Occupation

Information Requested

Election Cycle-to-Date

380.00

B. Full Name (Last, First, Middle Initial)

Joan Scott

Mailing Address 133 Nail Dr

\begin{tabular}{lcc}
\hline City & State & Zip Code \\
McDonough & GA & $30253-7344$
\end{tabular}

FEC ID number of contributing

federal political committee.

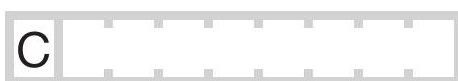

Name of Employer
DOT/FAA
Receipt For: 2012
X Primary
Other (specify)

\section{Occupation}

Administrative Assistant

Election Cycle-to-Date

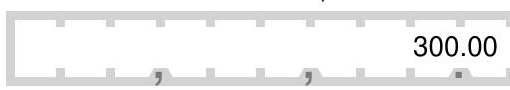

C. Full Name (Last, First, Middle Initial)

Joseph Daniell

Mailing Address 805 Streamside Dr.

\begin{tabular}{lcc}
\hline City & State & Zip Code \\
McDonough & GA & $30252-9035$
\end{tabular}

FEC ID number of contributing

federal political committee.

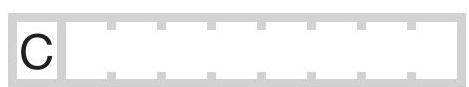

Name of Employer

Dynamac Corp.

Occupation

Sr. Project Mgr

Receipt For: 2012

Х $\begin{aligned} & \text { Primary } \square \text { General } \\ & \text { Other (specify) }\end{aligned}$

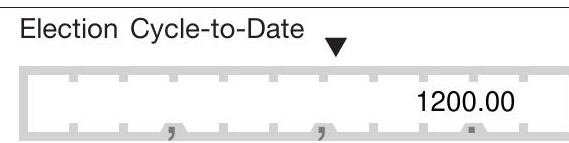

Transaction ID : AC8909E9DED9A4F47952

Date of Receipt

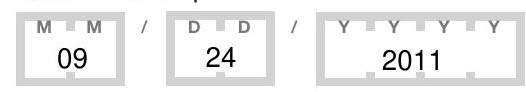

Amount of Each Receipt this Period

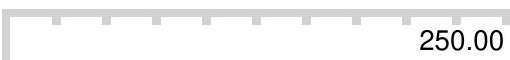

250.00

Transaction ID : AB24A9D75D8D241CFB84

Date of Receipt

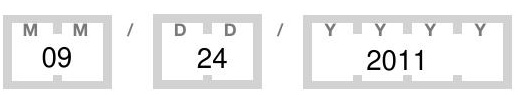

Amount of Each Receipt this Period

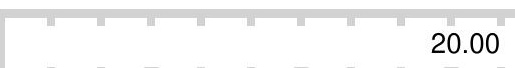

Transaction ID : A3AAE47F3C0334A50A46 Date of Receipt

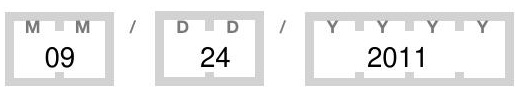

Amount of Each Receipt this Period

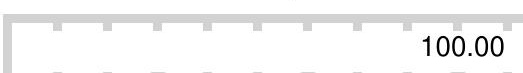

370.00

Subtotal Of Receipts This Page (optional)

a.

Total This Period (last page this line number only) 
SCHEDULE A-P ITEMIZED RECEIPTS
Use separate schedule(s) for each category of the Detailed Summary Page
FOR LINE NUMBER: (check only one)

PAGE $676 / 1572$

\begin{tabular}{|c|c|c|c|c|c|}
\hline & & & & & \\
\hline 16 & $\begin{array}{l}\mathbf{X} \\
17 a\end{array}$ & $17 b$ & $17 c$ & $17 d$ & 18 \\
\hline $19 a$ & $19 \mathrm{~b}$ & $20 \mathrm{a}$ & $20 \mathrm{~b}$ & $20 \mathrm{c}$ & 21 \\
\hline
\end{tabular}

Any information copied from such Reports and Statements may not be sold or used by any person for the purpose of soliciting contributions or for commercial purposes, other than using the name and address of any political committee to solicit contributions from such committee.

NAME OF COMMITTEE (In Full)

\section{Friends of Herman Cain}

A. Full Name (Last, First, Middle Initial) Janice Archie

Mailing Address 15 Covington Terr

\begin{tabular}{lcc}
\hline City & State & Zip Code \\
Newnan & GA & $30263-5771$
\end{tabular}

FEC ID number of contributing federal political committee.

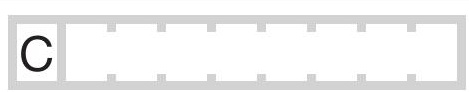

Name of Employer
Farnsworth Logistics
Receipt For: 2012
X Primary
Other (specify) General

Occupation

Sales

Election Cycle-to-Date

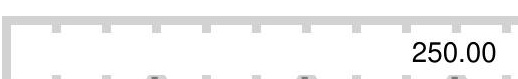

B. Full Name (Last, First, Middle Initial)

Howard Clark

Mailing Address 4227 S Meridian Ste C152

\begin{tabular}{llc}
\hline City & State & Zip Code \\
Puyallup & WA & $98373-3603$ \\
\hline
\end{tabular}

FEC ID number of contributing

federal political committee.

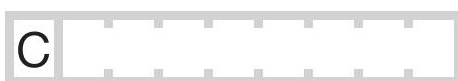

Name of Employer
RAA
Receipt For: 2012
X Primary $\quad$ General
Other (specify) $\nabla$

\section{Occupation}

md

Election Cycle-to-Date

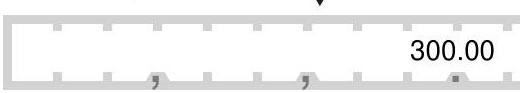

Transaction ID : A71841B4956384EDEB18

Date of Receipt

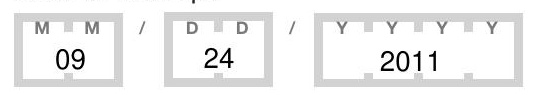

Amount of Each Receipt this Period

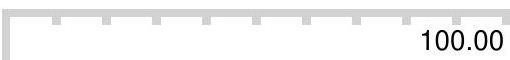

C. Full Name (Last, First, Middle Initial)

Mr. Phillip Mullinax

Mailing Address 965 Oak Grove Rd

\begin{tabular}{lcc}
\hline City & State & Zip Code \\
Dahlonega & GA & $30533-4840$
\end{tabular}

FEC ID number of contributing federal political committee.

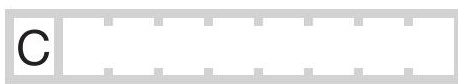

$\begin{aligned} & \text { Name of Employer } \\ & \text { self }\end{aligned}$
Receipt For: 2012
X Primary $\quad \square$ General
Other (specify)

Occupation

entrepreneur

Election Cycle-to-Date

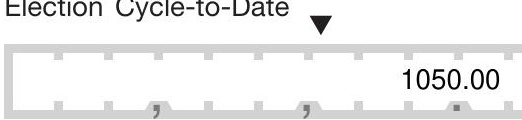

Amount of Each Receipt this Period

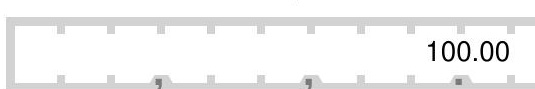

Transaction ID : AADB5E12A2ECB4DB9A44 Date of Receipt

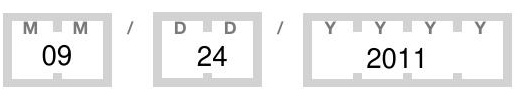

Transaction ID : A32334F76899840D483E Date of Receipt

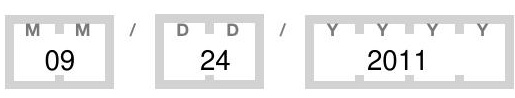

Amount of Each Receipt this Period

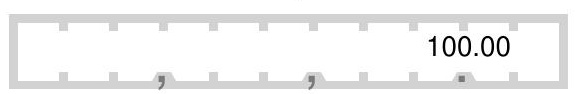

\section{Subtotal Of Receipts This Page (optional)}

300.00

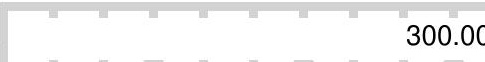

Total This Period (last page this line number only)

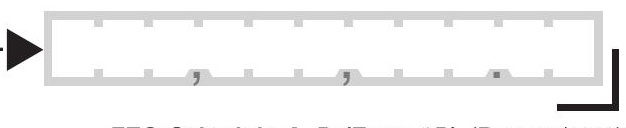

FEC Schedule A-P (Form 3P) (Rev. 03/2011) 
SCHEDULE A-P ITEMIZED RECEIPTS
Use separate schedule(s) for each category of the Detailed Summary Page
FOR LINE NUMBER: (check only one)

PAGE 677 / 1572

\begin{tabular}{|c|c|c|c|c|c|}
\hline & & & & & \\
\hline 16 & $\begin{array}{l}\mathbf{X} \\
17 a\end{array}$ & $17 b$ & $17 c$ & $17 d$ & 18 \\
\hline $19 a$ & $19 \mathrm{~b}$ & $20 \mathrm{a}$ & $20 \mathrm{~b}$ & $20 \mathrm{c}$ & 21 \\
\hline
\end{tabular}

Any information copied from such Reports and Statements may not be sold or used by any person for the purpose of soliciting contributions or for commercial purposes, other than using the name and address of any political committee to solicit contributions from such committee.

NAME OF COMMITTEE (In Full)

Friends of Herman Cain

A. Full Name (Last, First, Middle Initial)

barbara shaw

Mailing Address 630 fulton ave

\begin{tabular}{lcc}
\hline City & State & Zip Code \\
Rochester & IN & $46975-1335$
\end{tabular}

FEC ID number of contributing federal political committee.

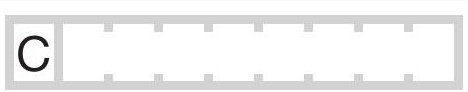

Name of Employer
cVS/Pharmacy
Receipt For: 2012
X Primary
$\square$ Other (specify) General

Occupation

Pharmacist

Election Cycle-to-Date

300.00

B. Full Name (Last, First, Middle Initial)

Michael Katin

Mailing Address 9150 Penzance Boulevard

\begin{tabular}{lcc}
\hline City & State & Zip Code \\
Fort Myers & FL & $33912-1402$ \\
\hline
\end{tabular}

FEC ID number of contributing

federal political committee.

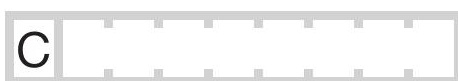

Name of Employer
21st Century Oncology
Receipt For: 2012
X Primary
Other (specify)

Occupation

Physician

Election Cycle-to-Date

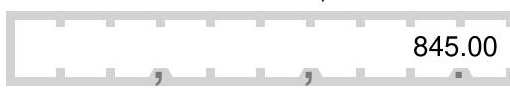

C. Full Name (Last, First, Middle Initial)

Michael Katin

Mailing Address 9150 Penzance Boulevard

\begin{tabular}{lcc}
\hline City & State & Zip Code \\
Fort Myers & FL & $33912-1402$
\end{tabular}

FEC ID number of contributing

federal political committee.

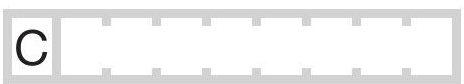

Name of Employer

21st Century Oncology

Occupation

Receipt For: 2012

Х $\begin{aligned} & \text { Primary } \square \text { General } \\ & \text { Other (specify) }\end{aligned}$

Physician

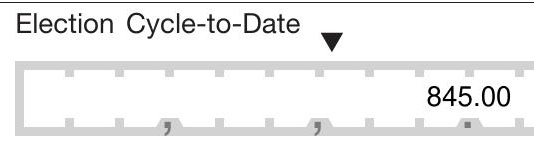

Transaction ID : AA0DBED444E2B4BECB87 Date of Receipt

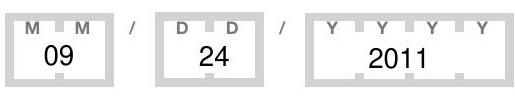

Amount of Each Receipt this Period

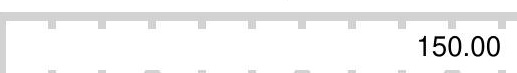

Transaction ID : AF321985AD640488AB18

Date of Receipt

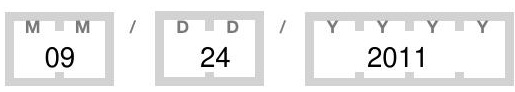

Amount of Each Receipt this Period

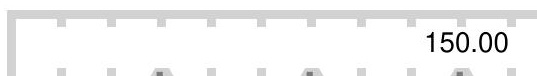

450.00

Subtotal Of Receipts This Page (optional)

Total This Period (last page this line number only) 
SCHEDULE A-P ITEMIZED RECEIPTS
Use separate schedule(s) for each category of the Detailed Summary Page
FOR LINE NUMBER: (check only one)

PAGE $678 / 1572$

\begin{tabular}{|c|c|c|c|c|c|}
\hline & & & & & \\
\hline 16 & $\begin{array}{l}\mathbf{X} \\
17 a\end{array}$ & $17 b$ & $17 c$ & $17 d$ & 18 \\
\hline $19 a$ & $19 \mathrm{~b}$ & $20 \mathrm{a}$ & $20 \mathrm{~b}$ & $20 \mathrm{c}$ & 21 \\
\hline
\end{tabular}

Any information copied from such Reports and Statements may not be sold or used by any person for the purpose of soliciting contributions or for commercial purposes, other than using the name and address of any political committee to solicit contributions from such committee.

NAME OF COMMITTEE (In Full)

\section{Friends of Herman Cain}

A. Full Name (Last, First, Middle Initial)

Trish Bruce

Transaction ID : AAA32DCEB432B450FAA6

Mailing Address 1 Cross Creek Lane

\begin{tabular}{lcc}
\hline City & State & Zip Code \\
O Fallon & MO & $63366-4736$
\end{tabular}

FEC ID number of contributing federal political committee.

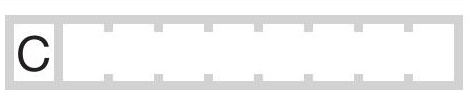

Name of Employer
Self Employed
Receipt For: 2012
X Primary $\quad$ General
Other (specify)

Occupation

Massage Therapist

Election Cycle-to-Date

Date of Receipt

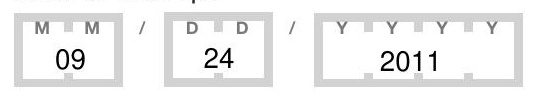

Amount of Each Receipt this Period

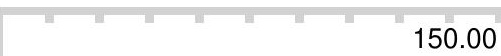

150.00

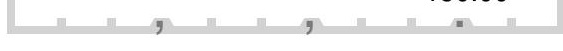

\subsection{0}

B. Full Name (Last, First, Middle Initial)

Linda Barron

Mailing Address P O Box 2719

\begin{tabular}{lcc}
\hline City & State & Zip Code \\
Cleveland & GA & $30528-0048$ \\
\hline
\end{tabular}

FEC ID number of contributing

federal political committee.

C

Name of Employer
Information Requested
Receipt For: 2012
X Primary
Other (specify)

Occupation

Information Requested

Election Cycle-to-Date

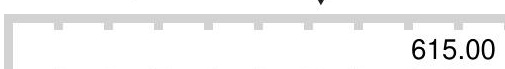

C. Full Name (Last, First, Middle Initial)

Michael Katin

Mailing Address 9150 Penzance Boulevard

\begin{tabular}{lcc}
\hline City & State & Zip Code \\
Fort Myers & FL & $33912-1402$
\end{tabular}

FEC ID number of contributing

federal political committee.

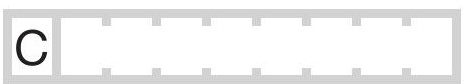

Name of Employer

21st Century Oncology

Occupation

Receipt For: 2012

Х $\begin{aligned} & \text { Primary } \square \text { General } \\ & \text { Other (specify) }\end{aligned}$

Physician

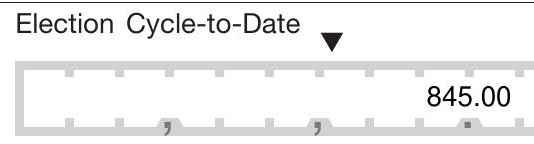

Amount of Each Receipt this Period

Transaction ID : A46942D74B84F4B429CA

Date of Receipt
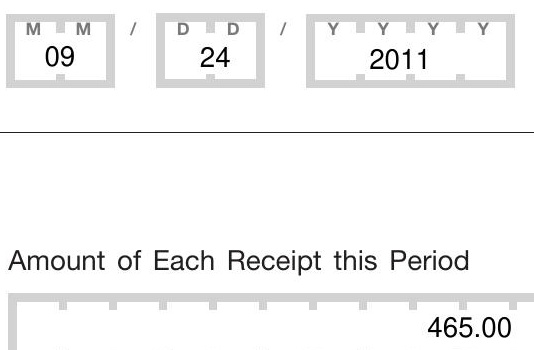

Transaction ID : A448DFA4914114954966

Date of Receipt

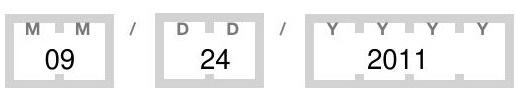

Amount of Each Receipt this Period

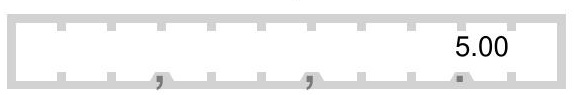

Subtotal Of Receipts This Page (optional)

620.00

Total This Period (last page this line number only) 
SCHEDULE A-P ITEMIZED RECEIPTS
Use separate schedule(s) for each category of the Detailed Summary Page
FOR LINE NUMBER: (check only one)

PAGE 679 / 1572

\begin{tabular}{|c|c|c|c|c|c|}
\hline & & & & & \\
\hline 16 & $\begin{array}{l}\mathbf{X} \\
17 a\end{array}$ & $17 b$ & $17 c$ & $17 d$ & 18 \\
\hline $19 a$ & $19 \mathrm{~b}$ & $20 \mathrm{a}$ & $20 \mathrm{~b}$ & $20 \mathrm{c}$ & 21 \\
\hline
\end{tabular}

Any information copied from such Reports and Statements may not be sold or used by any person for the purpose of soliciting contributions or for commercial purposes, other than using the name and address of any political committee to solicit contributions from such committee.

NAME OF COMMITTEE (In Full)

\section{Friends of Herman Cain}

A. Full Name (Last, First, Middle Initial)

\section{Patricia Witten}

Mailing Address 3802 Bosworth Dr

\begin{tabular}{lcc}
\hline City & State & Zip Code \\
Roanoke & VA & $24014-3008$ \\
\hline
\end{tabular}

FEC ID number of contributing federal political committee.

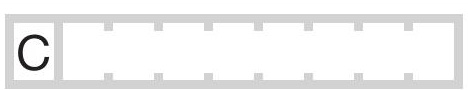

Name of Employer
None
Receipt For: 2012
X Primary $\quad$ General
Other (specify)

Occupation Retired

Election Cycle-to-Date

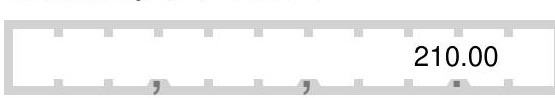

B. Full Name (Last, First, Middle Initial)

Melody Furr

Mailing Address 2725 Astoria Ave

\begin{tabular}{lcc}
\hline City & State & Zip Code \\
Cumming & GA & $30040-5373$ \\
\hline
\end{tabular}

FEC ID number of contributing

federal political committee.

C

Name of Employer
Information Requested
Receipt For: 2012
X Primary
Other (specify)

\section{Occupation}

Information Requested

Election Cycle-to-Date

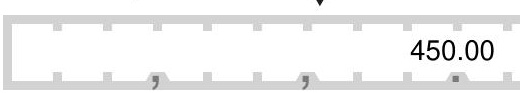

Transaction ID : A6A36E2975094430AB9A

Date of Receipt

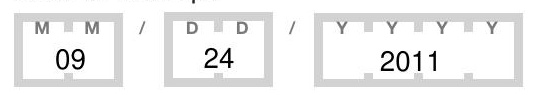

Amount of Each Receipt this Period

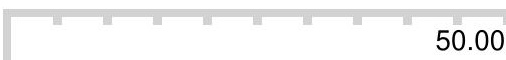

50.00

C. Full Name (Last, First, Middle Initial)

Terry Chick

Mailing Address $13650 \mathrm{~N}$ Heritage Canyon Dr

\begin{tabular}{lcc}
\hline City & State & Zip Code \\
Marana & AZ & $85658-4073$
\end{tabular}

FEC ID number of contributing

federal political committee.

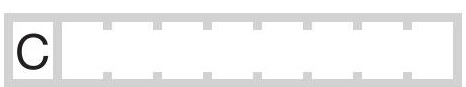

Name of Employer
Retired
Receipt For: 2012
X Primary $\quad \square$ General
Other (specify)

Occupation

Retired

Election Cycle-to-Date

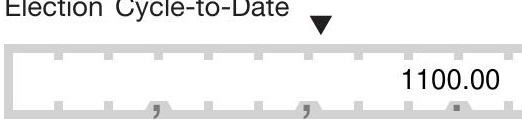

Transaction ID : A0971C61AD27246C281A

Date of Receipt

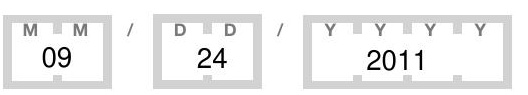

Amount of Each Receipt this Period

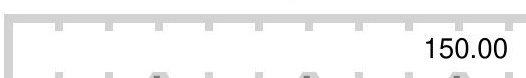

Transaction ID : ACFAE4D1A42D74C5594F Date of Receipt

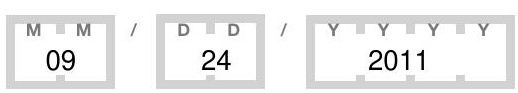

Amount of Each Receipt this Period

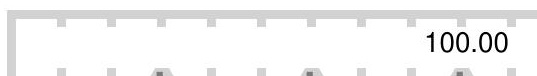

\section{Subtotal Of Receipts This Page (optional)}

300.00

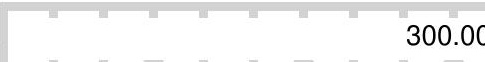

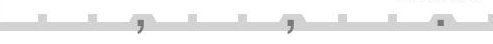

Total This Period (last page this line number only)

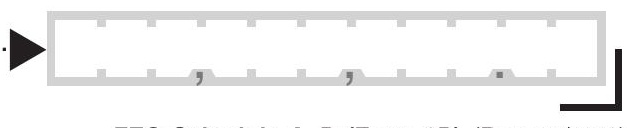

FEC Schedule A-P (Form 3P) (Rev. 03/2011) 
SCHEDULE A-P ITEMIZED RECEIPTS
Use separate schedule(s) for each category of the Detailed Summary Page
FOR LINE NUMBER: (check only one)

PAGE $680 / 1572$

\begin{tabular}{|c|c|c|c|c|c|}
\hline & & & & & \\
\hline 16 & $\begin{array}{l}\mathbf{X} \\
17 a\end{array}$ & $17 b$ & $17 c$ & $17 d$ & 18 \\
\hline $19 a$ & $19 \mathrm{~b}$ & $20 \mathrm{a}$ & $20 \mathrm{~b}$ & $20 \mathrm{c}$ & 21 \\
\hline
\end{tabular}

Any information copied from such Reports and Statements may not be sold or used by any person for the purpose of soliciting contributions or for commercial purposes, other than using the name and address of any political committee to solicit contributions from such committee.

NAME OF COMMITTEE (In Full)

\section{Friends of Herman Cain}

A. Full Name (Last, First, Middle Initial)

Faith Martin

Mailing Address 32 Northgate Drive

\begin{tabular}{lcc}
\hline City & State & Zip Code \\
Ponte Vedra Beach & FL & $32082-3305$
\end{tabular}

FEC ID number of contributing

federal political committee.

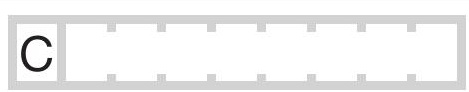

Name of Employer
n/a
Receipt For: 2012
X Primary $\quad$ General
Other (specify)

Occupation

Retired

Election Cycle-to-Date

225.00

B. Full Name (Last, First, Middle Initial)

Moseley Collins

Mailing Address 1700 Carnegie Way

\begin{tabular}{lcc}
\hline City & State & Zip Code \\
El Dorado Hills & CA & $95762-5811$ \\
\hline
\end{tabular}

FEC ID number of contributing

federal political committee.

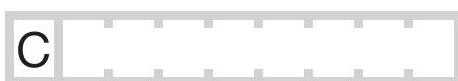

Name of Employer
Self Employed
Receipt For: 2012
X Primary
Other (specify)

Occupation

Attorney

Election Cycle-to-Date

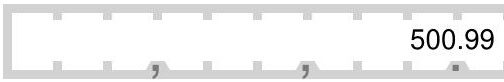

C. Full Name (Last, First, Middle Initial)

James Stehr

Mailing Address 1752 Sea Oats Drive

City

Atlantic Beach

FEC ID number of contributing

federal political committee.

Name of Employer

Duval County Public Schools

Receipt For: 2012

Х $\begin{aligned} & \text { Primary } \square \text { General } \\ & \text { Other (specify) }\end{aligned}$
Transaction ID : A918BC2584B664D20BCD

Date of Receipt

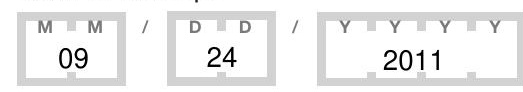

Amount of Each Receipt this Period

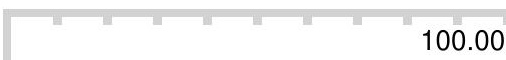

100.00

Transaction ID : A3B3C6A95C8D0433285B

Date of Receipt

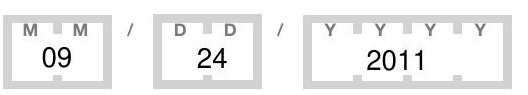

Amount of Each Receipt this Period

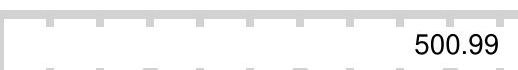

Transaction ID : A6A55161B1D2A477CA2D Date of Receipt

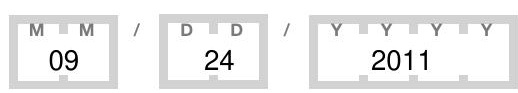

Amount of Each Receipt this Period

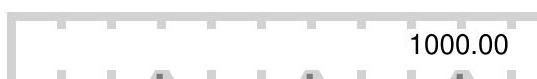

1200.00

\section{Subtotal Of Receipts This Page (optional)}

Total This Period (last page this line number only) 
SCHEDULE A-P ITEMIZED RECEIPTS
Use separate schedule(s) for each category of the Detailed Summary Page
FOR LINE NUMBER: (check only one)

PAGE $681 / 1572$

\begin{tabular}{|c|c|c|c|c|c|c|}
\hline & & & & & & \\
\hline 16 & $\lambda$ & $17 \mathrm{a}$ & $17 \mathrm{~b}$ & $17 \mathrm{c}$ & $-17 d$ & -18 \\
\hline $19 a$ & & $19 b$ & $20 a$ & $20 \mathrm{~b}$ & $20 \mathrm{c}$ & 21 \\
\hline
\end{tabular}

Any information copied from such Reports and Statements may not be sold or used by any person for the purpose of soliciting contributions or for commercial purposes, other than using the name and address of any political committee to solicit contributions from such committee.

NAME OF COMMITTEE (In Full)

\section{Friends of Herman Cain}

A. Full Name (Last, First, Middle Initial)

\section{Lisa Mazoch}

Mailing Address PO Box 459

\begin{tabular}{lcc}
\hline City & State & Zip Code \\
Slaughter & LA & $70777-0459$ \\
\hline
\end{tabular}

FEC ID number of contributing federal political committee.

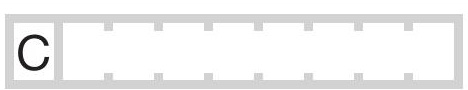

Name of Employer
Self Employed
Receipt For: 2012
X Primary $\quad$ General
Other (specify)

Occupation Retired Election Cycle-to-Date

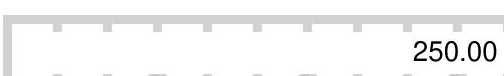

B. Full Name (Last, First, Middle Initial)

Thomas McArdle

Mailing Address 4104 Couts St

\begin{tabular}{lcc}
\hline City & State & Zip Code \\
San Diego & CA & $92103-1550$
\end{tabular}

FEC ID number of contributing

federal political committee.

C

Name of Employer
Information Requested
Receipt For: 2012
X Primary
Other (specify)

C. Full Name (Last, First, Middle Initial) James Irwin

Mailing Address 4761 county road 5

\begin{tabular}{lcc}
\hline City & State & Zip Code \\
Delta & OH & $43515-9262$ \\
\hline
\end{tabular}

FEC ID number of contributing federal political committee.

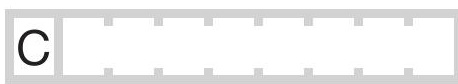

Name of Employer
regal cabinet
Receipt For: 2012
X Primary $\quad \square$ General
Other (specify)

\section{Occupation}

Information Requested

Election Cycle-to-Date

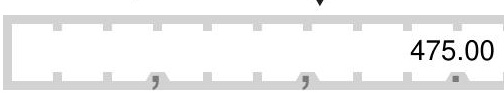

$\begin{aligned} & \text { Occupation } \\ & \text { cabinet maker }\end{aligned}$
Election Cycle-to-Date

Transaction ID : AD17DAE4977B347E9A58

Date of Receipt

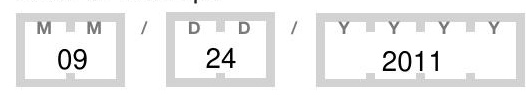

Amount of Each Receipt this Period

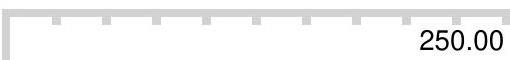

Amount of Each Receipt this Period

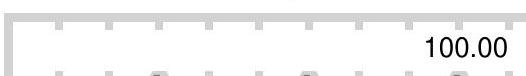

Transaction ID : AC7284FB12D154D97B0E Date of Receipt

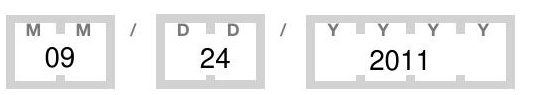

Transaction ID : A1F6A3E01292C4FA8886 Date of Receipt

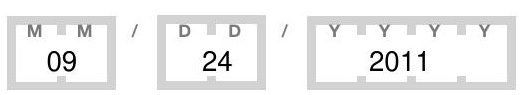

Amount of Each Receipt this Period

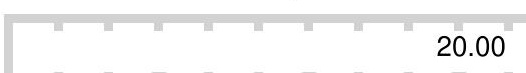

20.00

\section{Subtotal Of Receipts This Page (optional)}

Total This Period (last page this line number only) 


\section{SCHEDULE A-P} ITEMIZED RECEIPTS
Use separate schedule(s)

for each category of the

Detailed Summary Page
FOR LINE NUMBER: (check only one)

PAGE 682 / 1572

\begin{tabular}{|c|c|c|c|c|c|}
\hline & & & & & \\
\hline 16 & X $17 a$ & $17 b$ & $17 c$ & $17 d$ & 18 \\
\hline $19 a$ & $19 b$ & $20 \mathrm{a}$ & $20 \mathrm{~b}$ & $20 \mathrm{c}$ & 21 \\
\hline
\end{tabular}

Any information copied from such Reports and Statements may not be sold or used by any person for the purpose of soliciting contributions or for commercial purposes, other than using the name and address of any political committee to solicit contributions from such committee.

NAME OF COMMITTEE (In Full)

\section{Friends of Herman Cain}

A. Full Name (Last, First, Middle Initial) Jacob Osborn

Mailing Address 450 Massachusetts Ave. NW \#1310

\begin{tabular}{lcc}
\hline City & State & Zip Code \\
Washington & DC & 20001-6228 \\
\hline
\end{tabular}

FEC ID number of contributing federal political committee.

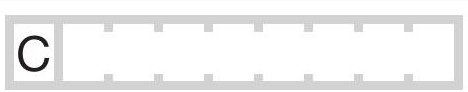

Name of Employer
Information Requested
Receipt For: 2012
X Primary
Other (specify) General

Occupation Information Requested

Election Cycle-to-Date

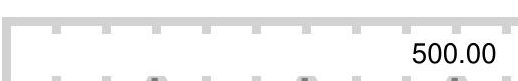

B. Full Name (Last, First, Middle Initial)

Al Seidel

Mailing Address 503 Whitehall Rd

\begin{tabular}{lcc}
\hline City & State & Zip Code \\
Camden & NC & $27921-6975$ \\
\hline
\end{tabular}

FEC ID number of contributing

federal political committee.

C

Name of Employer
Information Requested
Receipt For: 2012
Primary
Other (specify)

Occupation

Information Requested

Election Cycle-to-Date

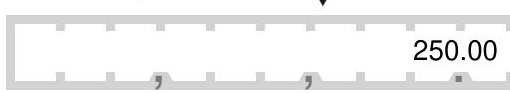

Transaction ID : A80DDBD8E40614338BD2

Date of Receipt

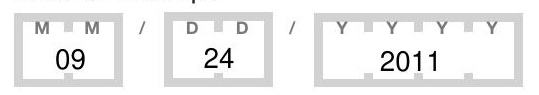

Amount of Each Receipt this Period

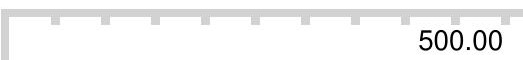

Amount of Each Receipt this Period

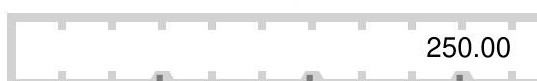

Transaction ID : A69A32C0987A24962B73 Date of Receipt

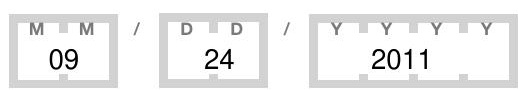

Amount of Each Receipt this Period

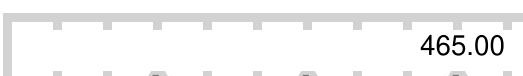

$\begin{array}{cc}\text { State } & \text { Zip Code } \\ \text { MI } & 48169-8239\end{array}$

C

\section{Occupation}

Information Requested

Election Cycle-to-Date

Receipt For: 2012

Х $\begin{aligned} & \text { Primary } \square \text { General } \\ & \text { Other (specify) }\end{aligned}$

465.00

\section{Subtotal Of Receipts This Page (optional)}

1215.00

Total This Period (last page this line number only)
Transaction ID : AFCC1DF50BB154CAB9F2 Date of Receipt

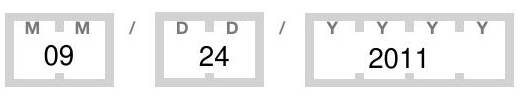


SCHEDULE A-P ITEMIZED RECEIPTS
Use separate schedule(s) for each category of the Detailed Summary Page
FOR LINE NUMBER: (check only one)

PAGE $683 / 1572$

\begin{tabular}{|c|c|c|c|c|c|c|}
\hline & & & & & & \\
\hline 16 & $\lambda$ & $17 \mathrm{a}$ & $17 \mathrm{~b}$ & $17 \mathrm{c}$ & $-17 d$ & -18 \\
\hline $19 a$ & & $19 b$ & $20 a$ & $20 \mathrm{~b}$ & $20 \mathrm{c}$ & 21 \\
\hline
\end{tabular}

Any information copied from such Reports and Statements may not be sold or used by any person for the purpose of soliciting contributions or for commercial purposes, other than using the name and address of any political committee to solicit contributions from such committee.

NAME OF COMMITTEE (In Full)

\section{Friends of Herman Cain}

A. Full Name (Last, First, Middle Initial)

Maria Honaski

Mailing Address 15414 Escapade St

\begin{tabular}{lcc}
\hline City & State & Zip Code \\
Corpus Christi & TX & $78418-6433$ \\
\hline
\end{tabular}

FEC ID number of contributing

federal political committee.

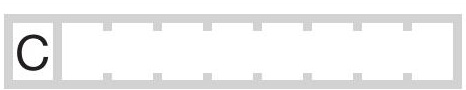

Name of Employer
Spohn
Receipt For: 2012
X Primary $\quad$ General
Other (specify)

Occupation healthcare

Election Cycle-to-Date 900.00

B. Full Name (Last, First, Middle Initial)

Kenneth Smith

Mailing Address PO Box 38

\begin{tabular}{lcc}
\hline City & State & Zip Code \\
Rolla & KS & $67954-0038$ \\
\hline
\end{tabular}

FEC ID number of contributing

federal political committee.

C

Name of Employer
Information Requested
Receipt For: 2012
X Primary
Other (specify)

Occupation

Information Requested

Election Cycle-to-Date

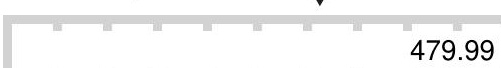

Transaction ID : AE4C189864841431F92D

Date of Receipt

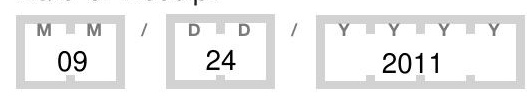

Amount of Each Receipt this Period

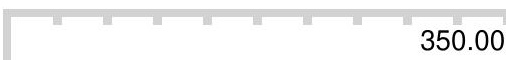

C. Full Name (Last, First, Middle Initial)

Kenneth Smith

Mailing Address PO Box 38

\begin{tabular}{lcc}
\hline City & State & Zip Code \\
Rolla & KS & $67954-0038$
\end{tabular}

FEC ID number of contributing federal political committee.

C

67954-0038

Name of Employer

Information Requested

Occupation

Information Requested

Receipt For: 2012

Х $\begin{aligned} & \text { Primary } \\ & \text { Other (specify) }\end{aligned}$

Amount of Each Receipt this Period

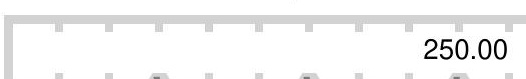

Transaction ID : AE385F3C342754392AE0

Date of Receipt

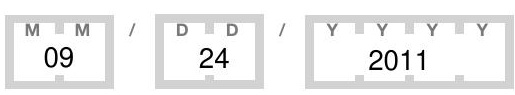

Transaction ID : AC3C740C156AE4A55A4F Date of Receipt

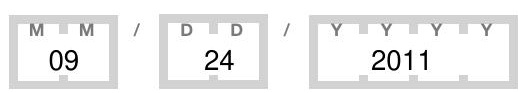

Amount of Each Receipt this Period

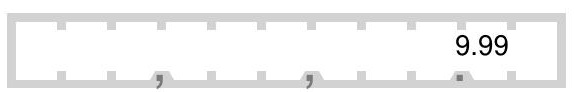

479.99
Subtotal Of Receipts This Page (optional)

609.99

(1)

Total This Period (last page this line number only)

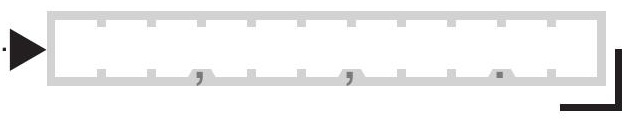

FEC Schedule A-P (Form 3P) (Rev. 03/2011) 
SCHEDULE A-P ITEMIZED RECEIPTS
Use separate schedule(s) for each category of the Detailed Summary Page
FOR LINE NUMBER: (check only one)
PAGE 684 / 1572

\begin{tabular}{|c|c|c|c|c|c|}
\hline & & & & & \\
\hline 16 & $\begin{array}{lll}X & 17 a \\
\end{array}$ & $17 \mathrm{~b}$ & $17 c$ & $17 d$ & 18 \\
\hline $19 a$ & $19 b$ & $20 a$ & $20 \mathrm{~b}$ & $20 c$ & 21 \\
\hline
\end{tabular}

Any information copied from such Reports and Statements may not be sold or used by any person for the purpose of soliciting contributions or for commercial purposes, other than using the name and address of any political committee to solicit contributions from such committee.

NAME OF COMMITTEE (In Full)

\section{Friends of Herman Cain}

A. Full Name (Last, First, Middle Initial)

Nathan Cushman

Mailing Address 369 Macewen Dr

\begin{tabular}{lcc}
\hline City & State & Zip Code \\
Osprey & FL & $34229-9281$ \\
\hline
\end{tabular}

FEC ID number of contributing federal political committee.

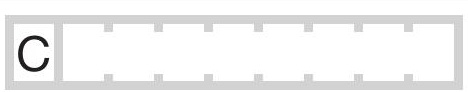

Name of Employer
Information Requested
Receipt For: 2012
X Primary
$\square$ Other (specify)

Occupation Information Requested

Election Cycle-to-Date

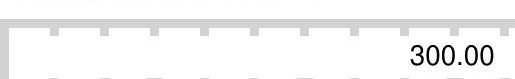

B. Full Name (Last, First, Middle Initial)

RICHARD WOLF

Mailing Address 1324 NORTHRIDGE TERRACE

\begin{tabular}{llc}
\hline City & State & Zip Code \\
Joplin & MO & $64801-9547$
\end{tabular}

FEC ID number of contributing

federal political committee.

C

Name of Employer
Information Requested
Receipt For: 2012
X Primary
Other (specify)

Occupation

Information Requested

Election Cycle-to-Date

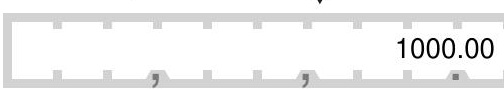

Transaction ID : AEFFE39D41C364CC5BB3

Date of Receipt

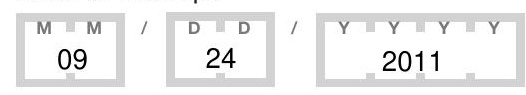

Amount of Each Receipt this Period

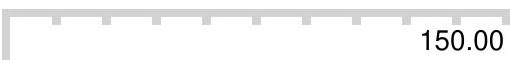

Transaction ID : ADABBE3871E60476BB83 Date of Receipt

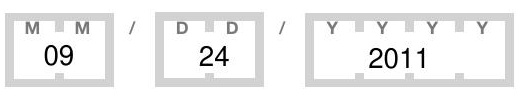

Amount of Each Receipt this Period

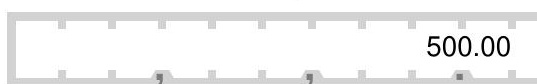

Transaction ID : A64492B71FEAE49F4B01 Date of Receipt

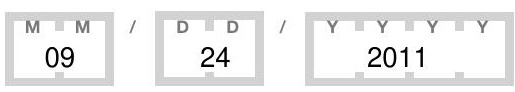

Amount of Each Receipt this Period

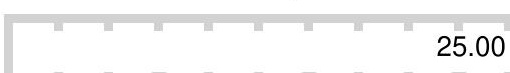

$\begin{array}{cc}\text { State } & \text { Zip Code } \\ \text { IN } & 47516-6207\end{array}$

C

\section{Occupation} coalsampler

Election Cycle-to-Date

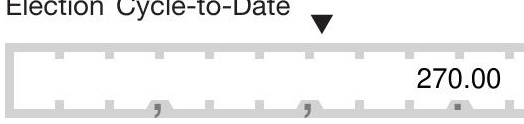

Subtotal Of Receipts This Page (optional)

675.00

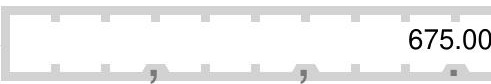

Total This Period (last page this line number only)

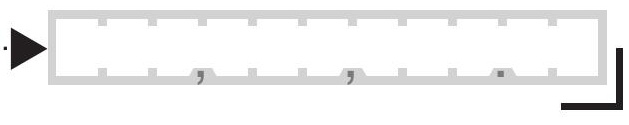

FEC Schedule A-P (Form 3P) (Rev. 03/2011) 
SCHEDULE A-P ITEMIZED RECEIPTS
Use separate schedule(s) for each category of the Detailed Summary Page
FOR LINE NUMBER: (check only one)

PAGE $685 / 1572$

\begin{tabular}{|c|c|c|c|c|c|c|}
\hline & & & & & & \\
\hline 16 & $\lambda$ & $17 \mathrm{a}$ & $17 \mathrm{~b}$ & $17 \mathrm{c}$ & $-17 d$ & -18 \\
\hline $19 a$ & & $19 b$ & $20 a$ & $20 \mathrm{~b}$ & $20 \mathrm{c}$ & 21 \\
\hline
\end{tabular}

Any information copied from such Reports and Statements may not be sold or used by any person for the purpose of soliciting contributions or for commercial purposes, other than using the name and address of any political committee to solicit contributions from such committee.

NAME OF COMMITTEE (In Full)

\section{Friends of Herman Cain}

A. Full Name (Last, First, Middle Initial) Jane Miller

Mailing Address 321 Pleasant PI

\begin{tabular}{lcc}
\hline City & State & Zip Code \\
Charlottesville & VA & $22911-2212$
\end{tabular}

FEC ID number of contributing federal political committee.

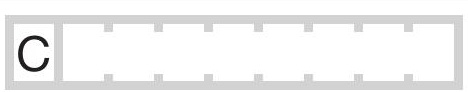

Name of Employer
Charlottesville Family Medicine
Receipt For: 2012
X Primary
Other (specify) General

Occupation Nurse Practitiner Election Cycle-to-Date

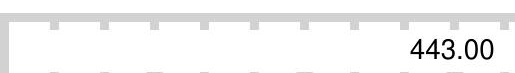

B. Full Name (Last, First, Middle Initial) Robert Lynch

Mailing Address 107 Brentwood Dr.

\begin{tabular}{lcc}
\hline City & State & Zip Code \\
Athens & TX & $75751-9077$
\end{tabular}

FEC ID number of contributing

federal political committee.

C

Name of Employer
Retired
Receipt For: 2012
Primary
Other (specify)

Occupation

Retired

Election Cycle-to-Date

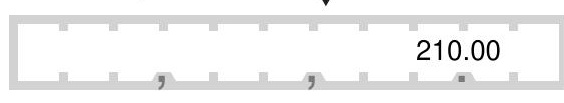

Transaction ID : A9FE50E45DBB64398BD3

Date of Receipt

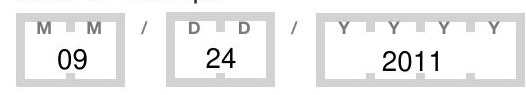

Amount of Each Receipt this Period

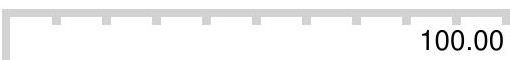

100.00

C. Full Name (Last, First, Middle Initial)

Michael Katin

Mailing Address 9150 Penzance Boulevard

\begin{tabular}{lcc}
\hline City & State & Zip Code \\
Fort Myers & FL & $33912-1402$
\end{tabular}

FEC ID number of contributing federal political committee.

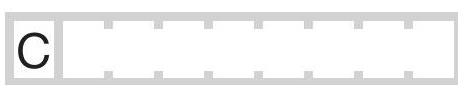

Name of Employer
21 st Century Oncology
Receipt For: 2012
X Primary $\quad \square$ General
Other (specify)

Occupation

Physician

Election Cycle-to-Date

Transaction ID : A6603A1D568684F62989

Date of Receipt

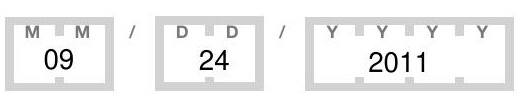

Amount of Each Receipt this Period

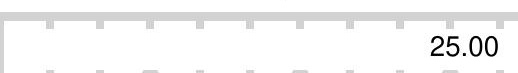

Transaction ID : A5B0F60F4D2C54B87927

Date of Receipt

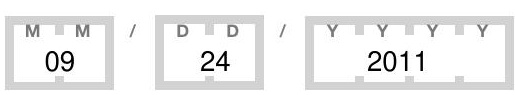

Amount of Each Receipt this Period

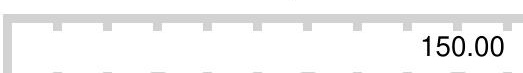

845.00

\section{Subtotal Of Receipts This Page (optional)}

Total This Period (last page this line number only) 
SCHEDULE A-P ITEMIZED RECEIPTS
Use separate schedule(s) for each category of the Detailed Summary Page
FOR LINE NUMBER: (check only one)

PAGE $686 / 1572$

\begin{tabular}{|c|c|c|c|c|c|c|}
\hline & & & & & & \\
\hline 16 & $\lambda$ & $17 \mathrm{a}$ & $17 \mathrm{~b}$ & $17 \mathrm{c}$ & $-17 d$ & -18 \\
\hline $19 a$ & & $19 b$ & $20 a$ & $20 \mathrm{~b}$ & $20 \mathrm{c}$ & 21 \\
\hline
\end{tabular}

Any information copied from such Reports and Statements may not be sold or used by any person for the purpose of soliciting contributions or for commercial purposes, other than using the name and address of any political committee to solicit contributions from such committee.

NAME OF COMMITTEE (In Full)

\section{Friends of Herman Cain}

A. Full Name (Last, First, Middle Initial)

Walter Apt Jr.

Mailing Address 369 Leisure Ct., SW

\begin{tabular}{lcc}
\hline City & State & Zip Code \\
Marietta & GA & $30064-3627$
\end{tabular}

FEC ID number of contributing federal political committee.

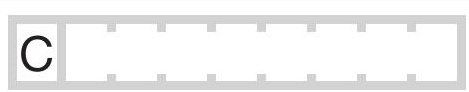

Name of Employer
State of Georgia
Receipt For: 2012
X Primary
Other (specify) General

Occupation Retired

Election Cycle-to-Date

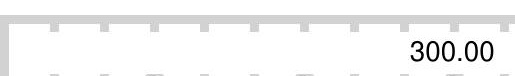

B. Full Name (Last, First, Middle Initial)

John Lehman

Mailing Address PMB 311 - 1133 Bal Harbor Blvd.

\begin{tabular}{lcc}
\hline City & State & Zip Code \\
Punta Gorda & FL & $33950-6577$ \\
\hline
\end{tabular}

FEC ID number of contributing

federal political committee.

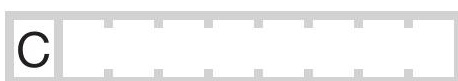

Name of Employer
self
Receipt For: 2012
X Primary
Other (specify)

\section{Occupation}

Sales

Election Cycle-to-Date

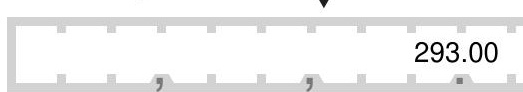

Transaction ID : A1AB4CE2CFC8D4897926

Date of Receipt

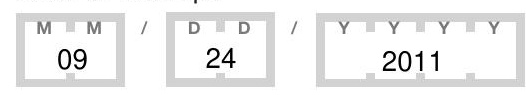

Amount of Each Receipt this Period

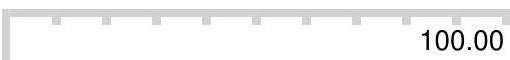

Transaction ID : A70F49E8EEB234118829

Date of Receipt

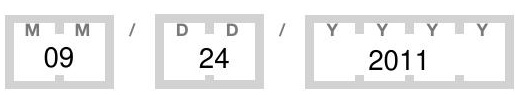

Amount of Each Receipt this Period

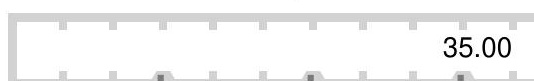

Transaction ID : ACF16DDFBE5174908AA5 Date of Receipt

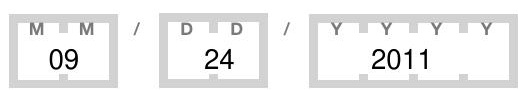

Amount of Each Receipt this Period

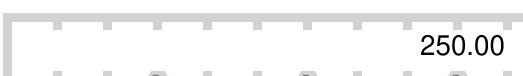

C. Full Name (Last, First, Middle Initial)

Mrs. Brenda C. Jinkins

Mailing Address 7550 Kelly Cove

\begin{tabular}{lcc}
\hline City & State & Zip Code \\
Olive Branch & MS & $38654-8250$
\end{tabular}

FEC ID number of contributing federal political committee.

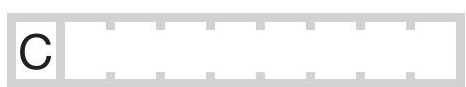

Name of Employer
Information Requested
Receipt For: 2012
X Primary $\quad \square$ General
Other (specify)

\section{Occupation}

Information Requested

Election Cycle-to-Date

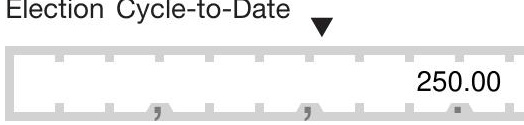

Subtotal Of Receipts This Page (optional)

385.00

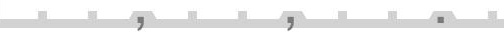

Total This Period (last page this line number only)

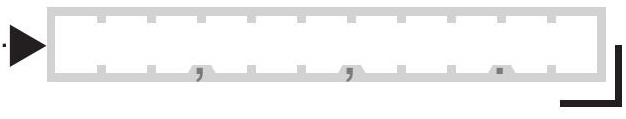

FEC Schedule A-P (Form 3P) (Rev. 03/2011) 
SCHEDULE A-P ITEMIZED RECEIPTS
Use separate schedule(s) for each category of the Detailed Summary Page
FOR LINE NUMBER: (check only one)
PAGE 687 / 1572

\begin{tabular}{|c|c|c|c|c|c|}
\hline & & & & & \\
\hline 16 & $\begin{array}{lll}X & 17 a \\
\end{array}$ & $17 \mathrm{~b}$ & $17 c$ & $17 d$ & 18 \\
\hline $19 a$ & $19 b$ & $20 a$ & $20 \mathrm{~b}$ & $20 c$ & 21 \\
\hline
\end{tabular}

Any information copied from such Reports and Statements may not be sold or used by any person for the purpose of soliciting contributions or for commercial purposes, other than using the name and address of any political committee to solicit contributions from such committee.

NAME OF COMMITTEE (In Full)

Friends of Herman Cain

A. Full Name (Last, First, Middle Initial) richard craig

Mailing Address p.o. box 899

\begin{tabular}{lcc}
\hline City & State & Zip Code \\
Edwards & CO & $81632-0899$ \\
\hline
\end{tabular}

FEC ID number of contributing federal political committee.

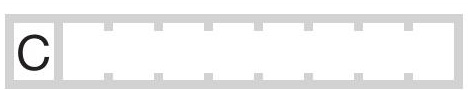

Name of Employer
Information Requested
Receipt For: 2012
X Primary
Other (specify) General

Occupation Information Requested

Election Cycle-to-Date

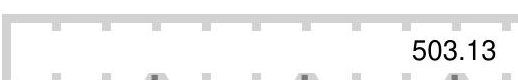

B. Full Name (Last, First, Middle Initial)

Millicent Holmes

\section{Mailing Address 5 Oakwood Rd}

\begin{tabular}{lcc}
\hline City & State & Zip Code \\
Indian Creek & IL & $60061-2202$ \\
\hline
\end{tabular}

FEC ID number of contributing

federal political committee.

C

Name of Employer
Information Requested
Receipt For: 2012
X Primary
Other (specify)

Occupation

Information Requested

Election Cycle-to-Date

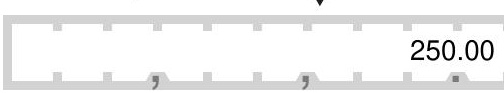

C. Full Name (Last, First, Middle Initial)

Melody Furr

Mailing Address 2725 Astoria Ave

\begin{tabular}{lcc}
\hline City & State & Zip Code \\
Cumming & GA & $30040-5373$
\end{tabular}

FEC ID number of contributing federal political committee.

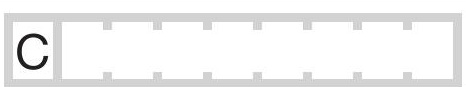

Name of Employer

Information Requested

\section{Occupation}

Information Requested

Receipt For: 2012

Х $\begin{aligned} & \text { Primary } \square \text { General } \\ & \text { Other (specify) }\end{aligned}$

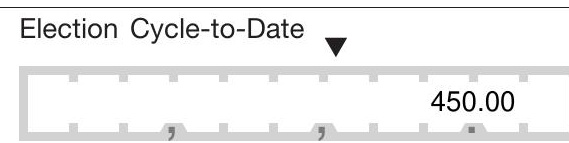

Amount of Each Receipt this Period

Transaction ID : AF823DE9395A847A0A23

Date of Receipt

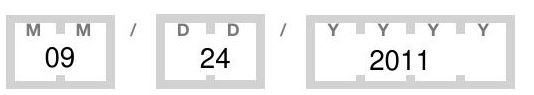

Amount of Each Receipt this Period
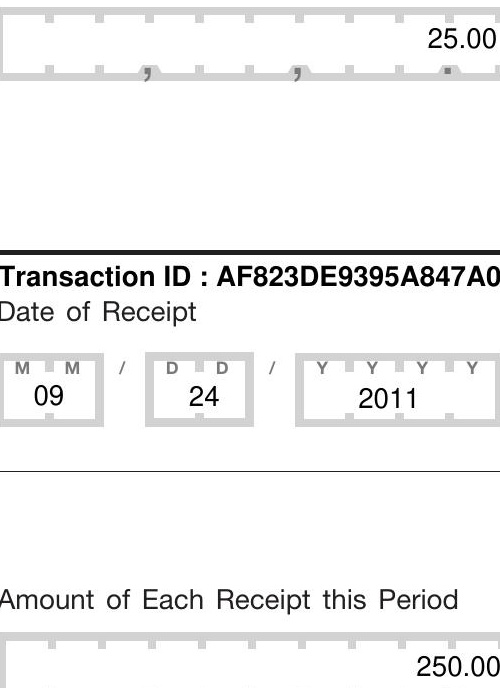

Transaction ID : A1B2E9F376B0645579A9

Date of Receipt

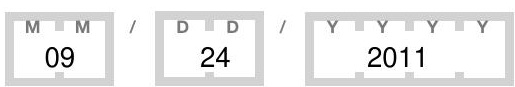

Amount of Each Receipt this Period

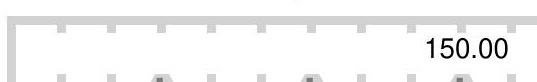

150.00

Subtotal Of Receipts This Page (optional)

425.00

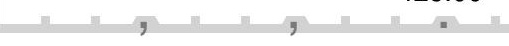

Total This Period (last page this line number only)

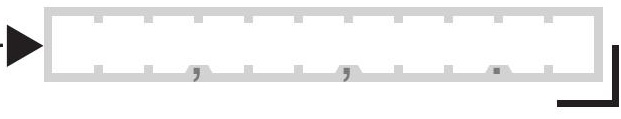

FEC Schedule A-P (Form 3P) (Rev. 03/2011) 
SCHEDULE A-P ITEMIZED RECEIPTS
Use separate schedule(s) for each category of the Detailed Summary Page

FOR LINE NUMBER:
(check only one)

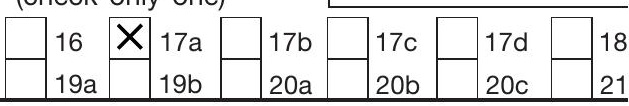

Any information copied from such Reports and Statements may not be sold or used by any person for the purpose of soliciting contributions or for commercial purposes, other than using the name and address of any political committee to solicit contributions from such committee.

NAME OF COMMITTEE (In Full)

\section{Friends of Herman Cain}

A. Full Name (Last, First, Middle Initial)

Bryan Kreger

Mailing Address 2931 chestnut hill rd

\begin{tabular}{lcc}
\hline City & State & Zip Code \\
Pottstown & PA & $19465-8558$ \\
\hline
\end{tabular}

FEC ID number of contributing federal political committee.

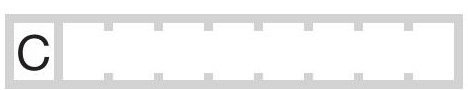

Name of Employer
Tri County Toyota
Receipt For: 2012
X Primary
Other (specify) General

\section{Occupation}

Auto Dealer

Election Cycle-to-Date

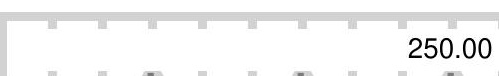

Transaction ID : A5B2DA291E06E4BB39B4

Date of Receipt

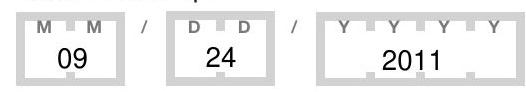

Amount of Each Receipt this Period

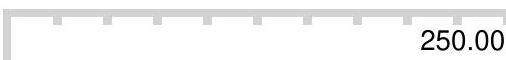

250.00

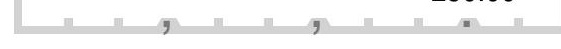

B. Full Name (Last, First, Middle Initial)

MaryJane Casablanca

Mailing Address 1701 Williams Court \#1105

\begin{tabular}{lcc}
\hline City & State & Zip Code \\
Columbus & GA & $31904-3916$ \\
\hline
\end{tabular}

FEC ID number of contributing

federal political committee.

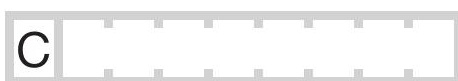

Name of Employer
None
Receipt For: 2012
X Primary
Other (specify)

\section{Occupation}

Retired

Election Cycle-to-Date

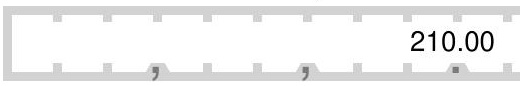

C. Full Name (Last, First, Middle Initial)

David Scott

Mailing Address 14583 Bridgepoint Court

\begin{tabular}{lcc}
\hline City & State & Zip Code \\
Willis & TX & $77318-4490$
\end{tabular}

FEC ID number of contributing federal political committee.

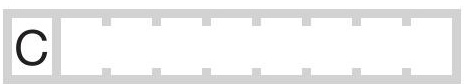

Name of Employer

Cornerstone Integrity Assurance

Receipt For: 2012

Х $\begin{aligned} & \text { Primary } \square \text { General } \\ & \text { Other (specify) }\end{aligned}$

\section{Occupation}

Pipeline Construction Manager

Election Cycle-to-Date

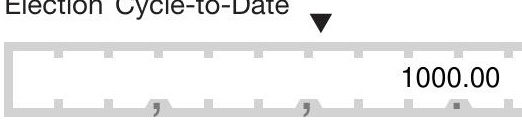

Transaction ID : A66754A1054644F5AB7D

Date of Receipt

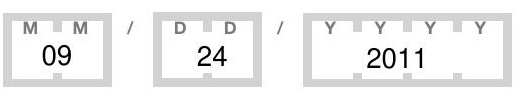

Amount of Each Receipt this Period

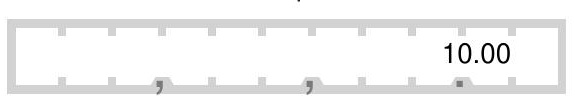

Transaction ID : A2BBD46C148584F79AA2 Date of Receipt

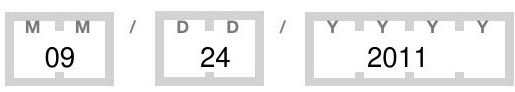

Amount of Each Receipt this Period

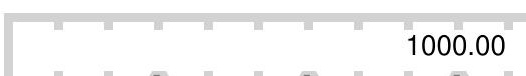

1260.00

Subtotal Of Receipts This Page (optional)

a

Total This Period (last page this line number only) 
SCHEDULE A-P ITEMIZED RECEIPTS
Use separate schedule(s)

for each category of the

Detailed Summary Page
FOR LINE NUMBER: (check only one)

Any information copied from such Repor or for commercial purposes, other than using the name and address of any political committee to solicit contributions from such committee.

NAME OF COMMITTEE (In Full)

\section{Friends of Herman Cain}

A. Full Name (Last, First, Middle Initial) Jo Canon

Mailing Address 102 Tiquewood Circle

\begin{tabular}{lcc}
\hline City & State & Zip Code \\
Abilene & TX & $79605-4937$
\end{tabular}

FEC ID number of contributing federal political committee.

C

Name of Employer

Information Requested

Occupation

Receipt For: 2012

X Primary $\square$ General Other (specify) Information Requested Election Cycle-to-Date 250.00

B. Full Name (Last, First, Middle Initial) Richard Warner

Mailing Address 131 Micah's Trail Drive

\begin{tabular}{lcc}
\hline City & State & Zip Code \\
Portsmouth & OH & $45662-8973$ \\
\hline
\end{tabular}

FEC ID number of contributing

federal political committee.

C

Name of Employer
Information Requested
Receipt For: 2012
X Primary
Other (specify)

Occupation

Information Requested

Election Cycle-to-Date

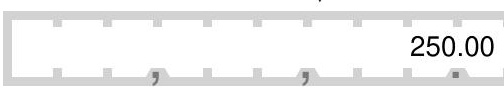

Transaction ID : AC5F94606C408487EB9F

Date of Receipt

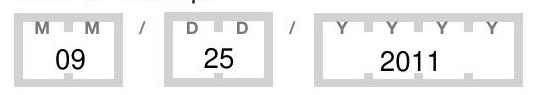

Amount of Each Receipt this Period

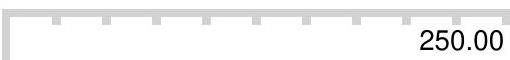

C. Full Name (Last, First, Middle Initial)

Robert Snyders

Mailing Address 3914 East Eden Roc Circle

\begin{tabular}{lcc}
\hline City & State & Zip Code \\
Tampa & FL & $33634-7418$
\end{tabular}

FEC ID number of contributing federal political committee.

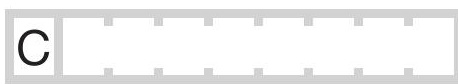

Name of Employer

Information Requested

\section{Occupation}

Information Requested

Receipt For: 2012

Х $\begin{aligned} & \text { Primary } \square \text { General } \\ & \text { Other (specify) }\end{aligned}$

Amount of Each Receipt this Period

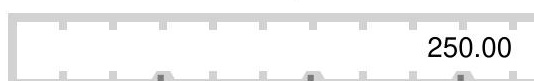

Transaction ID : A2D193A5B008D4300AEE Date of Receipt

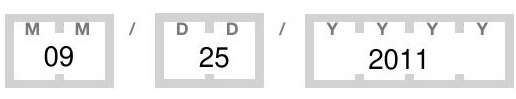

Transaction ID : A5C43D9A6675A4AC7981 Date of Receipt

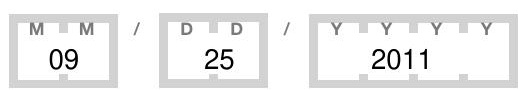

Amount of Each Receipt this Period

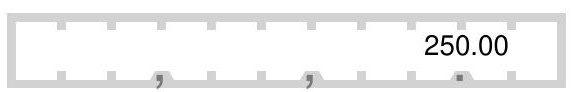

250.00
Subtotal Of Receipts This Page (optional)

$+\quad 750.00$

Total This Period (last page this line number only)

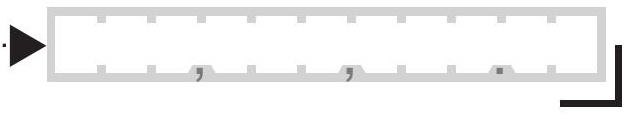

FEC Schedule A-P (Form 3P) (Rev. 03/2011) 
SCHEDULE A-P ITEMIZED RECEIPTS
Use separate schedule(s) for each category of the Detailed Summary Page

FOR LINE NUMBER:
(check only one)

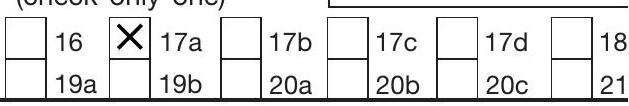

Any information copied from such Reports and Statements may not be sold or used by any person for the purpose of soliciting contributions or for commercial purposes, other than using the name and address of any political committee to solicit contributions from such committee.

NAME OF COMMITTEE (In Full)

\section{Friends of Herman Cain}

A. Full Name (Last, First, Middle Initial)

Henry Elizar

Mailing Address $5200 \mathrm{~N}$ Otto Ave.

\begin{tabular}{lcc}
\hline City & State & Zip Code \\
Chicago & IL & $60656-1011$ \\
\hline
\end{tabular}

FEC ID number of contributing federal political committee.

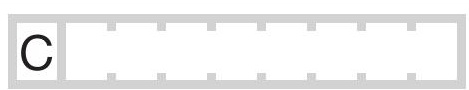

Name of Employer
Information Requested
Receipt For: 2012
X Primary
Other (specify) General

Occupation Information Requested

Election Cycle-to-Date 1000.00

B. Full Name (Last, First, Middle Initial) mary laseau

Mailing Address 121 pinnacle court

\begin{tabular}{lcc}
\hline City & State & Zip Code \\
Fairhope & AL & $36532-6380$
\end{tabular}

FEC ID number of contributing

federal political committee.

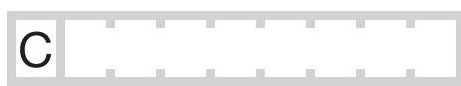

Name of Employer
self
Receipt For: 2012
X Primary
$\square$ Other (specify) General

\section{Occupation}

Human Resources

Election Cycle-to-Date

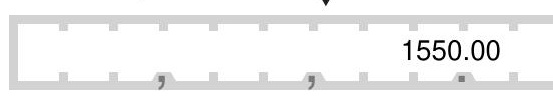

Transaction ID : AC1E02453999E42098E7

Date of Receipt

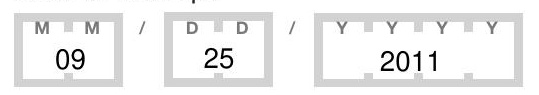

Amount of Each Receipt this Period

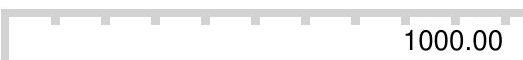

C. Full Name (Last, First, Middle Initial)

Cecelia LeClair

Mailing Address 175 2nd St S Ph 10

\begin{tabular}{lcc}
\hline City & State & Zip Code \\
Saint Petersburg & FL & $33701-4321$
\end{tabular}

FEC ID number of contributing federal political committee.

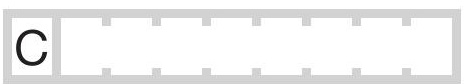

Name of Employer
None
Receipt For: 2012
Х Primary $\quad \square$ General
Other (specify)

\section{Occupation}

Retired

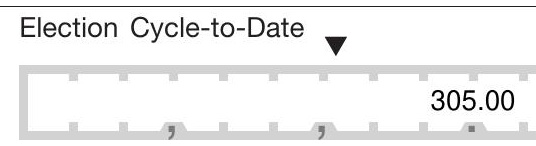

Amount of Each Receipt this Period

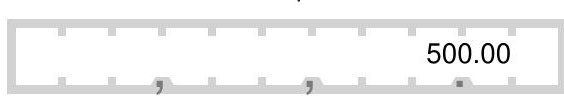

Transaction ID : AE1058B431D6643B6823

Date of Receipt

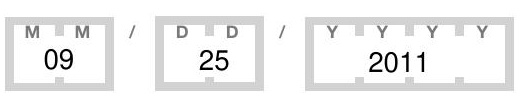

Transaction ID : A07E1F2B9AAF64CD5838 Date of Receipt

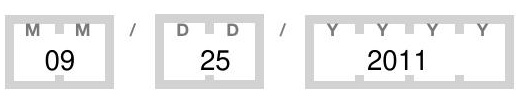

Amount of Each Receipt this Period

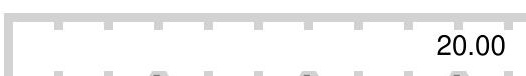

Subtotal Of Receipts This Page (optional).

Total This Period (last page this line number only) 
SCHEDULE A-P ITEMIZED RECEIPTS
Use separate schedule(s) for each category of the Detailed Summary Page
FOR LINE NUMBER: (check only one)
PAGE $691 / 1572$

\begin{tabular}{|c|c|c|c|c|c|}
\hline & & & & & \\
\hline 16 & $\begin{array}{lll}X & 17 a \\
\end{array}$ & $17 \mathrm{~b}$ & $17 c$ & $17 d$ & 18 \\
\hline $19 a$ & $19 b$ & $20 a$ & $20 \mathrm{~b}$ & $20 c$ & 21 \\
\hline
\end{tabular}

Any information copied from such Reports and Statements may not be sold or used by any person for the purpose of soliciting contributions or for commercial purposes, other than using the name and address of any political committee to solicit contributions from such committee.

NAME OF COMMITTEE (In Full)

\section{Friends of Herman Cain}

A. Full Name (Last, First, Middle Initial)

\section{Samuel Brian Goodrich}

Mailing Address 9620 Callaway Ct

\begin{tabular}{lcc}
\hline City & State & Zip Code \\
Denton & TX & 76207-5602
\end{tabular}

FEC ID number of contributing federal political committee.

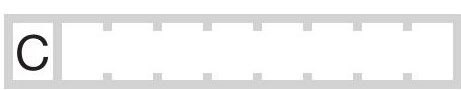

\begin{tabular}{l} 
Name of Employer \\
None \\
Receipt For: 2012 \\
X Primary $\quad$ General \\
\hline Other (specify)
\end{tabular}

B. Full Name (Last, First, Middle Initial) Jason Liu

Mailing Address 31945 Coast Hwy

\begin{tabular}{lcc}
\hline City & State & Zip Code \\
Laguna Beach & CA & $92651-6867$
\end{tabular}

FEC ID number of contributing

federal political committee.

C

Name of Employer
Jason Liu MD Inc.
Receipt For: 2012
Primary
Other (specify)

C. Full Name (Last, First, Middle Initial)

Mary Pilkington

Mailing Address 1281 sunset cliffs blvd

\begin{tabular}{lcc}
\hline City & State & Zip Code \\
San Diego & CA & $92107-4015$
\end{tabular}

FEC ID number of contributing federal political committee.

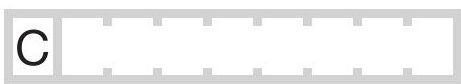

Name of Employer
Self Employed
Receipt For: 2012
X Primary $\quad \square$ General
Other (specify)

Occupation Retired Election Cycle-to-Date
Transaction ID : AC182BE228CAD4DE0966

Date of Receipt

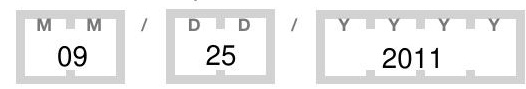

Amount of Each Receipt this Period

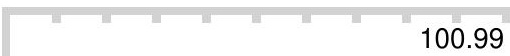

100.99
Transaction ID : A99D9398A76434A9DA09

Date of Receipt

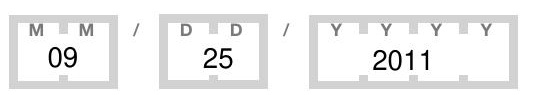

Amount of Each Receipt this Period

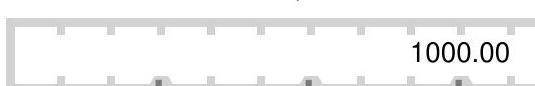

Transaction ID : A50A32DFBD0214E5A825 Date of Receipt

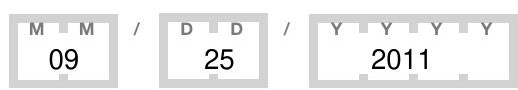

Amount of Each Receipt this Period

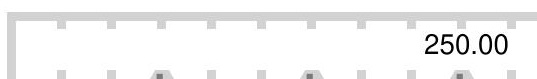

\section{Subtotal Of Receipts This Page (optional)}

Total This Period (last page this line number only) 
SCHEDULE A-P ITEMIZED RECEIPTS
Use separate schedule(s) for each category of the Detailed Summary Page
FOR LINE NUMBER: (check only one)

PAGE 692 / 1572

\begin{tabular}{|c|c|c|c|c|c|c|}
\hline & & & & & & \\
\hline 16 & $\lambda$ & $17 \mathrm{a}$ & $17 \mathrm{~b}$ & $17 \mathrm{c}$ & $-17 d$ & -18 \\
\hline $19 a$ & & $19 b$ & $20 a$ & $20 \mathrm{~b}$ & $20 \mathrm{c}$ & 21 \\
\hline
\end{tabular}

Any information copied from such Reports and Statements may not be sold or used by any person for the purpose of soliciting contributions or for commercial purposes, other than using the name and address of any political committee to solicit contributions from such committee.

NAME OF COMMITTEE (In Full)

\section{Friends of Herman Cain}

A. Full Name (Last, First, Middle Initial)

Daniel Button

Mailing Address 12934 Timber Ridge Drive

\begin{tabular}{lcc}
\hline City & State & Zip Code \\
Fort Myers & FL & $33913-8617$
\end{tabular}

FEC ID number of contributing

federal political committee.

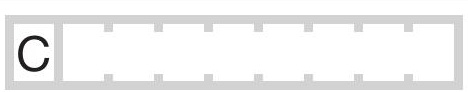

Name of Employer
Information Requested
Receipt For: 2012
X Primary $\quad \square$ General
Other (specify)

Occupation

Information Requested

Election Cycle-to-Date

250.00

B. Full Name (Last, First, Middle Initial)

Susan Vedros

Mailing Address 12628 NW Dosewallips Way

\begin{tabular}{llc}
\hline City & State & Zip Code \\
Seabeck & WA & $98380-8814$
\end{tabular}

FEC ID number of contributing

federal political committee.

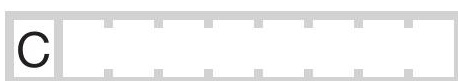

Name of Employer
None
Receipt For: 2012
X Primary $\quad$ General
Other (specify)

\section{Occupation}

Retired

Election Cycle-to-Date

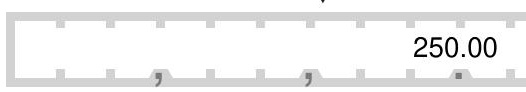

C. Full Name (Last, First, Middle Initial)

Dorothy Thomas

Mailing Address 1311 Northgate Drive

\begin{tabular}{lcc}
\hline City & State & Zip Code \\
Opelika & AL & $36801-2055$
\end{tabular}

FEC ID number of contributing

federal political committee.

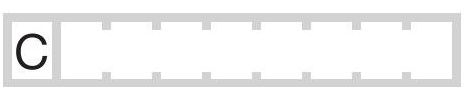

Name of Employer
Self Employed
Receipt For: 2012
X Primary $\quad \square$ General
Other (specify)

\section{Occupation}

Teacher

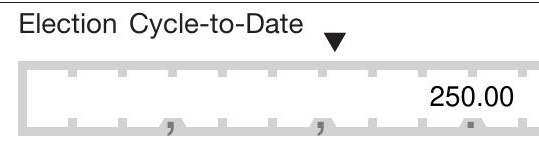

Transaction ID : A780D298934AC4DC2B0F

Date of Receipt

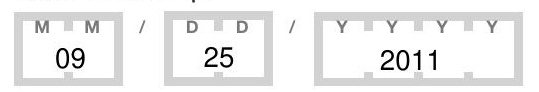

Amount of Each Receipt this Period

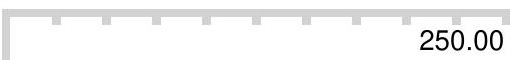

250.00

Transaction ID : AB9E72DAAAFC94EE2911

Date of Receipt

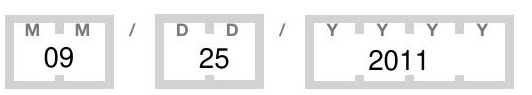

Amount of Each Receipt this Period

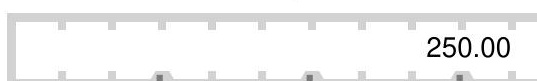

Transaction ID : A2B3A589169524DBF9EC Date of Receipt

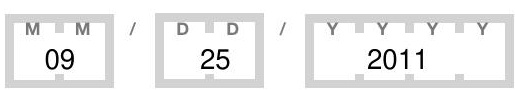

Amount of Each Receipt this Period

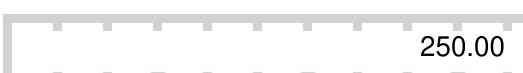

250.00

Subtotal Of Receipts This Page (optional)

Total This Period (last page this line number only) 
SCHEDULE A-P ITEMIZED RECEIPTS
Use separate schedule(s) for each category of the Detailed Summary Page
FOR LINE NUMBER: (check only one)

PAGE $693 / 1572$

\begin{tabular}{|c|c|c|c|c|c|}
\hline & & & & & \\
\hline 16 & $\begin{array}{lll}X & 17 a \\
\end{array}$ & $17 \mathrm{~b}$ & $17 c$ & $17 d$ & 18 \\
\hline $19 a$ & $19 b$ & $20 a$ & $20 \mathrm{~b}$ & $20 c$ & 21 \\
\hline
\end{tabular}

Any information copied from such Reports and Statements may not be sold or used by any person for the purpose of soliciting contributions or for commercial purposes, other than using the name and address of any political committee to solicit contributions from such committee.

NAME OF COMMITTEE (In Full)

\section{Friends of Herman Cain}

A. Full Name (Last, First, Middle Initial)

Robert Younger

Mailing Address 9595 Wilshire Blvd. Suite 1020

\begin{tabular}{lcc}
\hline City & State & Zip Code \\
Beverly Hills & CA & $90212-2510$ \\
\hline
\end{tabular}

FEC ID number of contributing

federal political committee.

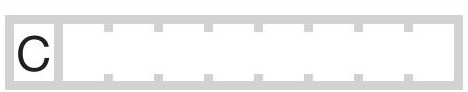

Name of Employer
Information Requested
Receipt For: 2012
X Primary $\quad \square$ General
Other (specify)

Occupation

Information Requested

Election Cycle-to-Date

250.00

B. Full Name (Last, First, Middle Initial)

donald ramsey

Mailing Address 3574 cold spring In.

\begin{tabular}{lcc}
\hline City & State & Zip Code \\
Atlanta & GA & $30341-2054$ \\
\hline
\end{tabular}

FEC ID number of contributing

federal political committee.

C

Name of Employer
Information Requested
Receipt For: 2012
X Primary
Other (specify)

Occupation

Information Requested

Election Cycle-to-Date

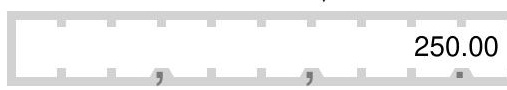

Transaction ID : AEA72624D08924DE288C

Date of Receipt

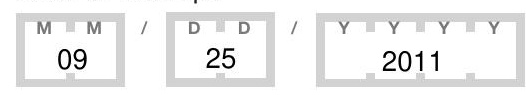

Amount of Each Receipt this Period

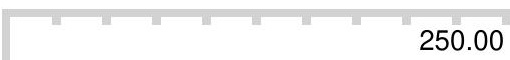

Amount of Each Receipt this Period

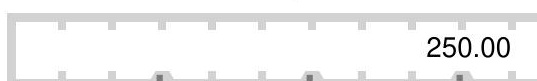

C. Full Name (Last, First, Middle Initial)

Timothy Sexton

Mailing Address 359 Centennial Dr.

\begin{tabular}{lcc}
\hline City & State & Zip Code \\
Bethlehem & GA & $30620-3337$
\end{tabular}

FEC ID number of contributing federal political committee.

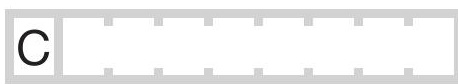

Name of Employer

Information Requested

Occupation

Information Requested

Receipt For: 2012

Х $\begin{aligned} & \text { Primary } \square \text { General } \\ & \text { Other (specify) }\end{aligned}$

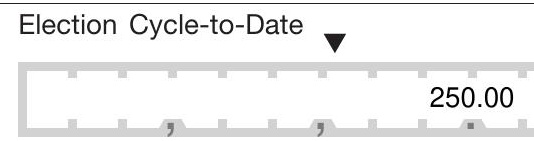

Amount of Each Receipt this Period

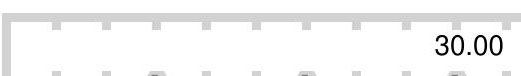

Transaction ID : AA5200E619C9D483CB1C Date of Receipt

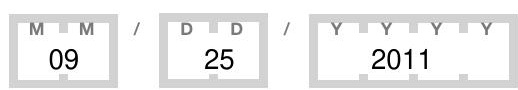

Subtotal Of Receipts This Page (optional)

530.00

Total This Period (last page this line number only) 
SCHEDULE A-P ITEMIZED RECEIPTS
Use separate schedule(s) for each category of the Detailed Summary Page
FOR LINE NUMBER: (check only one)
PAGE 694 / 1572

\begin{tabular}{|c|c|c|c|c|c|}
\hline & & & & & \\
\hline 16 & $\begin{array}{lll}X & 17 a \\
\end{array}$ & $17 \mathrm{~b}$ & $17 c$ & $17 d$ & 18 \\
\hline $19 a$ & $19 b$ & $20 a$ & $20 \mathrm{~b}$ & $20 c$ & 21 \\
\hline
\end{tabular}

Any information copied from such Reports and Statements may not be sold or used by any person for the purpose of soliciting contributions or for commercial purposes, other than using the name and address of any political committee to solicit contributions from such committee.

NAME OF COMMITTEE (In Full)

\section{Friends of Herman Cain}

A. Full Name (Last, First, Middle Initial)

Timothy Sexton

Mailing Address 359 Centennial Dr.

\begin{tabular}{lcc}
\hline City & State & Zip Code \\
Bethlehem & GA & $30620-3337$
\end{tabular}

FEC ID number of contributing

federal political committee.

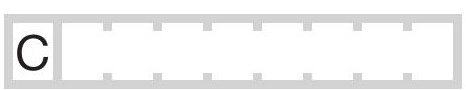

Name of Employer
Information Requested
Receipt For: 2012
X Primary
Other (specify) General

Occupation

Information Requested

Election Cycle-to-Date

250.00

B. Full Name (Last, First, Middle Initial)

Cory Zornizer

Mailing Address 331 Meadowtree Ct

\begin{tabular}{llc}
\hline City & State & Zip Code \\
Foley & MO & $63347-2867$
\end{tabular}

FEC ID number of contributing

federal political committee.

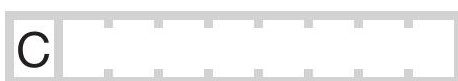

Name of Employer
Express-Scripts
Receipt For: 2012
X Primary
Other (specify)

Occupation

Operations Director

Election Cycle-to-Date

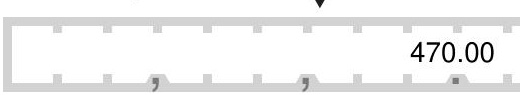

Transaction ID : A65CC9E4132E841FEBE0

Date of Receipt

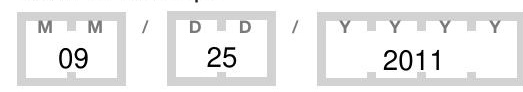

Amount of Each Receipt this Period

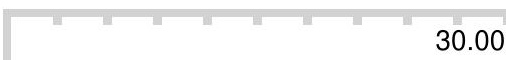

30.00

C. Full Name (Last, First, Middle Initial)

Frank Christensen

Mailing Address 447 Crosby Rd.

\begin{tabular}{lcc}
\hline City & State & Zip Code \\
Ferndale & CA & $95536-9514$
\end{tabular}

FEC ID number of contributing

federal political committee.

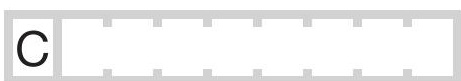

Name of Employer
Erma Darling
Receipt For: 2012
X Primary
Other (specify) General

Occupation

Apartment Manager

Election Cycle-to-Date

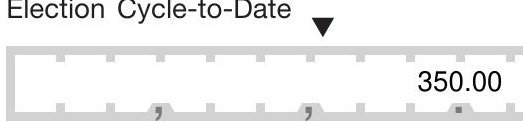

Transaction ID : A295685A6FCF049C0933

Date of Receipt

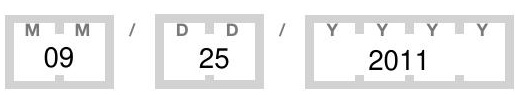

Amount of Each Receipt this Period

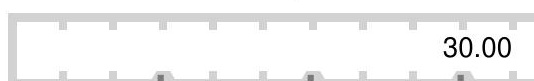

Transaction ID : A58F916BCD30C48BC8AA Date of Receipt

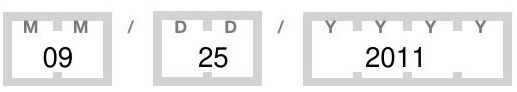

Amount of Each Receipt this Period

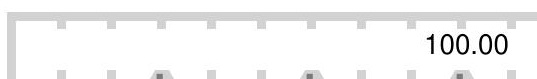

\section{Subtotal Of Receipts This Page (optional)}

160.00

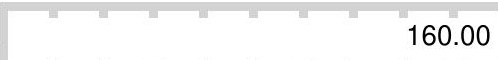

(2)

Total This Period (last page this line number only)

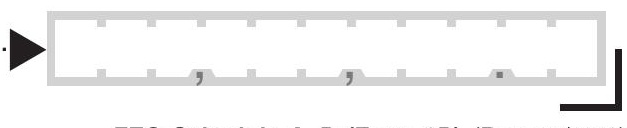

FEC Schedule A-P (Form 3P) (Rev. 03/2011) 


\section{SCHEDULE A-P} ITEMIZED RECEIPTS
Use separate schedule(s) for each category of the Detailed Summary Page

FOR LINE NUMBER:
(check only one)

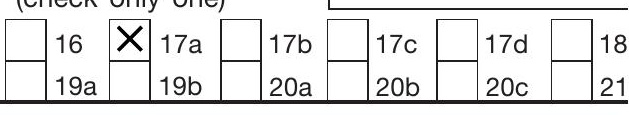

Any information copied from such Reports and Statements may not be sold or used by any person for the purpose of soliciting contributions or for commercial purposes, other than using the name and address of any political committee to solicit contributions from such committee.

NAME OF COMMITTEE (In Full)

\section{Friends of Herman Cain}

A. Full Name (Last, First, Middle Initial)

Mrs. Susan K. McLaurine

Mailing Address 114 La Encinal Court

\begin{tabular}{lcc}
\hline City & State & Zip Code \\
Clayton & CA & $94517-1750$ \\
\hline
\end{tabular}

FEC ID number of contributing federal political committee.

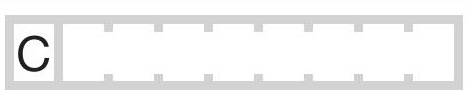

Name of Employer
Vantage Consulting LLC
Receipt For: 2012
X Primary $\quad \square$ General
Other (specify)

Occupation Business Consul

Election Cycle-to-Date

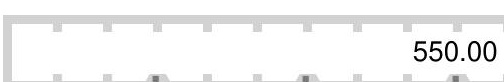

B. Full Name (Last, First, Middle Initial)

Paula Miller

Mailing Address 60 Schley Avenue

\begin{tabular}{lcc}
\hline City & State & Zip Code \\
Staten Island & NY & $10308-2065$ \\
\hline
\end{tabular}

FEC ID number of contributing

federal political committee.

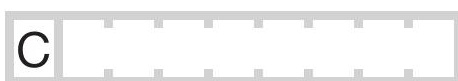

Name of Employer
Chartis Claims Inc.
Receipt For: 2012
Primary
Other (specify)

Occupation

Claim Analyst

Election Cycle-to-Date

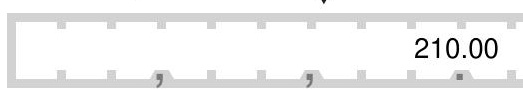

Transaction ID : A1C35F40170624FDA9AC

Date of Receipt

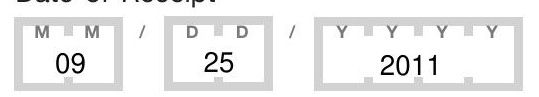

Amount of Each Receipt this Period

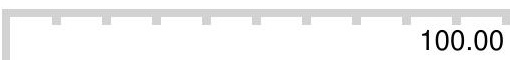

Amount of Each Receipt this Period

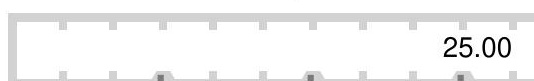

C. Full Name (Last, First, Middle Initial)

Dennis Michaud

Mailing Address 1107 Wilhelm Road

\begin{tabular}{lcc}
\hline City & State & Zip Code \\
Pine Bluffs & WY & $82082-9418$
\end{tabular}

FEC ID number of contributing federal political committee.

C $82082-9418$

Name of Employer
Information Requested
Receipt For: 2012
Primary
Other (specify) General

Occupation

Information Requested

Election Cycle-to-Date
Transaction ID : A3BA7D4AF93DD496DBC3 Date of Receipt

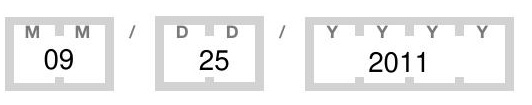

Transaction ID : AC62D6AB0D9AA40F0A1B Date of Receipt

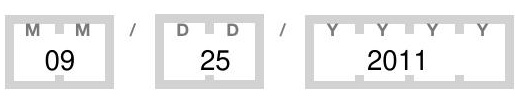

Amount of Each Receipt this Period

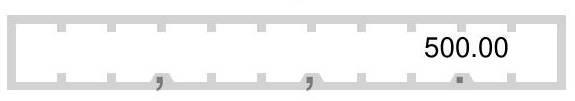

500.00

\section{Subtotal Of Receipts This Page (optional)}

625.00

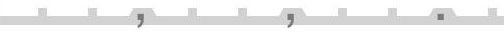

Total This Period (last page this line number only)

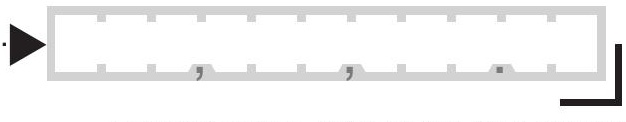

FEC Schedule A-P (Form 3P) (Rev. 03/2011) 
SCHEDULE A-P ITEMIZED RECEIPTS
Use separate schedule(s) for each category of the Detailed Summary Page
FOR LINE NUMBER: (check only one)

PAGE $696 / 1572$

\begin{tabular}{|c|c|c|c|c|c|c|}
\hline & & & & & & \\
\hline 16 & $\lambda$ & $17 \mathrm{a}$ & $17 \mathrm{~b}$ & $17 \mathrm{c}$ & $-17 d$ & -18 \\
\hline $19 a$ & & $19 b$ & $20 a$ & $20 \mathrm{~b}$ & $20 \mathrm{c}$ & 21 \\
\hline
\end{tabular}

Any information copied from such Reports and Statements may not be sold or used by any person for the purpose of soliciting contributions or for commercial purposes, other than using the name and address of any political committee to solicit contributions from such committee.

NAME OF COMMITTEE (In Full)

\section{Friends of Herman Cain}

A. Full Name (Last, First, Middle Initial)

\section{PHILLIP GRANQUIST}

Mailing Address 13105 W Berridge Ct

\begin{tabular}{lcc}
\hline City & State & Zip Code \\
Litchfield Park & AZ & $85340-7328$
\end{tabular}

FEC ID number of contributing federal political committee.

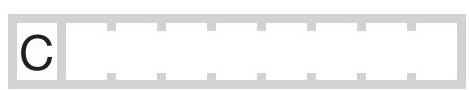

Name of Employer
Retired
Receipt For: 2012
X Primary $\quad$ General
Other (specify)

Occupation Retired

Election Cycle-to-Date

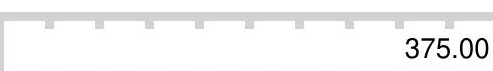

B. Full Name (Last, First, Middle Initial)

Keith Mann

Mailing Address 7239 MARLOW PL

\begin{tabular}{lcc}
\hline City & State & Zip Code \\
University Park & FL & $34201-2269$
\end{tabular}

FEC ID number of contributing

federal political committee.

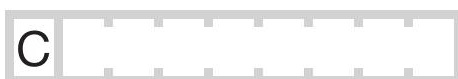

Name of Employer
US ARMY
Receipt For: 2012
X Primary
Other (specify)

\section{Occupation}

Soldier

Election Cycle-to-Date

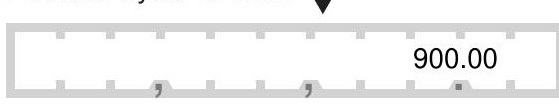

Transaction ID : A495AE3C5DB0542B9A6F

Date of Receipt

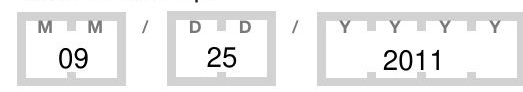

Amount of Each Receipt this Period

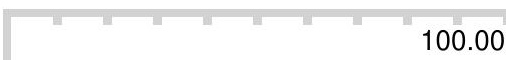

Amount of Each Receipt this Period

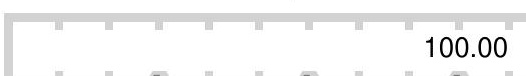

C. Full Name (Last, First, Middle Initial)

Lynne Vettel

Mailing Address 1500 Commons Drive

\begin{tabular}{lcc}
\hline City & State & Zip Code \\
Miamisburg & OH & $45342-7805$
\end{tabular}

FEC ID number of contributing federal political committee.

C

OH

Name of Employer
Information Requested
Receipt For: 2012
X Primary
$\square$ Other (specify) General

\section{Occupation}

Information Requested

Election Cycle-to-Date

Transaction ID : AD8FB0D96CE7F45779EF

Date of Receipt

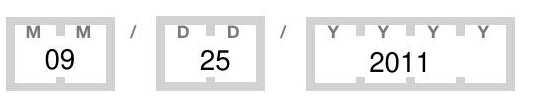

Transaction ID : A315AC53AA23B4576A73 Date of Receipt

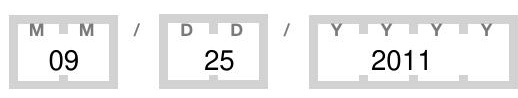

Amount of Each Receipt this Period

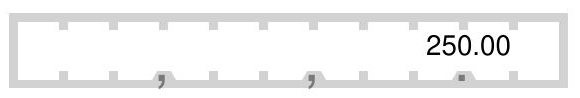

250.00

\section{Subtotal Of Receipts This Page (optional)}

Total This Period (last page this line number only) 
SCHEDULE A-P ITEMIZED RECEIPTS
Use separate schedule(s) for each category of the Detailed Summary Page
FOR LINE NUMBER: (check only one)
PAGE 697 / 1572

\begin{tabular}{|c|c|c|c|c|c|}
\hline & & & & & \\
\hline 16 & $\begin{array}{lll}X & 17 a \\
\end{array}$ & $17 \mathrm{~b}$ & $17 c$ & $17 d$ & 18 \\
\hline $19 a$ & $19 b$ & $20 a$ & $20 \mathrm{~b}$ & $20 c$ & 21 \\
\hline
\end{tabular}

Any information copied from such Reports and Statements may not be sold or used by any person for the purpose of soliciting contributions or for commercial purposes, other than using the name and address of any political committee to solicit contributions from such committee.

NAME OF COMMITTEE (In Full)

Friends of Herman Cain

A. Full Name (Last, First, Middle Initial)

John Carter

Mailing Address 7303 Merriam Road

\begin{tabular}{lcc}
\hline City & State & Zip Code \\
Indianapolis & IN & $46240-3524$
\end{tabular}

FEC ID number of contributing

federal political committee.

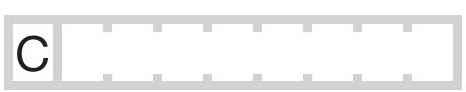

Name of Employer
Information Requested
Receipt For: 2012
X Primary $\quad \square$ General
$\square$ Other (specify)

Occupation

Information Requested

Election Cycle-to-Date

1000.00

B. Full Name (Last, First, Middle Initial)

Valerie Ramey

Mailing Address P. O. Box 1793

\begin{tabular}{lcc}
\hline City & State & Zip Code \\
Rancho Santa Fe & CA & $92067-1793$
\end{tabular}

FEC ID number of contributing

federal political committee.

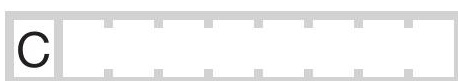

Name of Employer
None
Receipt For: 2012
X Primary
Other (specify)

\section{Occupation}

homemaker

Election Cycle-to-Date

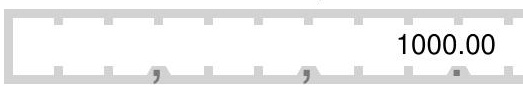

C. Full Name (Last, First, Middle Initial)

William Wardley

Mailing Address 243 W Main St

\begin{tabular}{lcc}
\hline City & State & Zip Code \\
Saint Paris & OH & $43072-9515$
\end{tabular}

FEC ID number of contributing federal political committee.

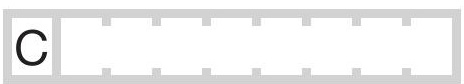

Name of Employer
Retired
Receipt For: 2012
X Primary $\quad \square$ General
Other (specify)

Occupation

Retired

Election Cycle-to-Date

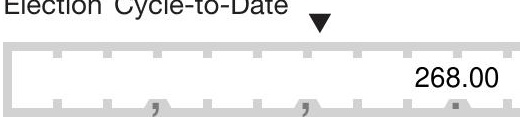

Transaction ID : A313FE586E0D941DB96A

Date of Receipt

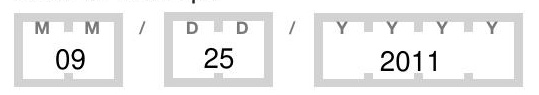

Amount of Each Receipt this Period

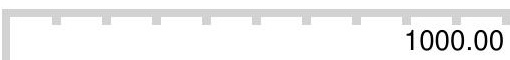

1000.00

Transaction ID : A1D6755003A5F48B6813

Date of Receipt

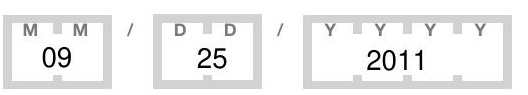

Amount of Each Receipt this Period

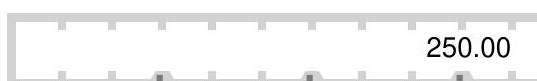

Transaction ID : AFB88F5924153457A94F

Date of Receipt

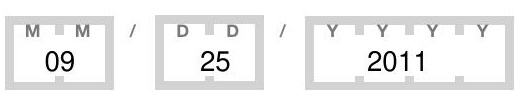

Amount of Each Receipt this Period

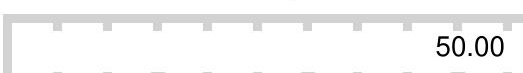

50.00

\section{Subtotal Of Receipts This Page (optional)}

1300.00

a

Total This Period (last page this line number only)

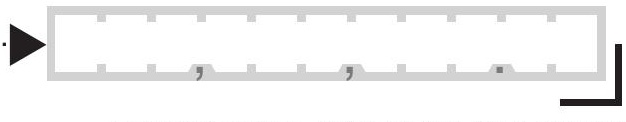

FEC Schedule A-P (Form 3P) (Rev. 03/2011) 


\section{SCHEDULE A-P} ITEMIZED RECEIPTS
Use separate schedule(s) for each category of the Detailed Summary Page

FOR LINE NUMBER:
(check only one)

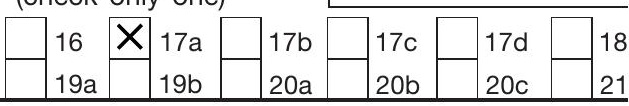

Any information copied from such Reports and Statements may not be sold or used by any person for the purpose of soliciting contributions or for commercial purposes, other than using the name and address of any political committee to solicit contributions from such committee.

NAME OF COMMITTEE (In Full)

\section{Friends of Herman Cain}

A. Full Name (Last, First, Middle Initial) Linda Swartz

Mailing Address 1602 W. Prince Rd.

\begin{tabular}{lcc}
\hline City & State & Zip Code \\
Tucson & AZ & $85705-3026$
\end{tabular}

FEC ID number of contributing federal political committee.

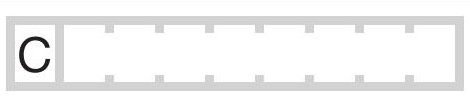

Name of Employer
Information Requested
Receipt For: 2012
X Primary $\square$ General
$\square$ Other (specify)

Occupation Information Requested Election Cycle-to-Date 250.00

B. Full Name (Last, First, Middle Initial) George H Wrape Jr Mailing Address 2320 Perryville Rd

\begin{tabular}{llc}
\hline City & State & Zip Code \\
Cape Girardeau & MO & $63701-1822$ \\
\hline
\end{tabular}

FEC ID number of contributing federal political committee.

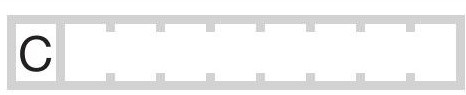

Name of Employer
Animal Technologies Inc.
Receipt For: 2012
X Primary
Other (specify)

\section{Occupation} CEO

Election Cycle-to-Date

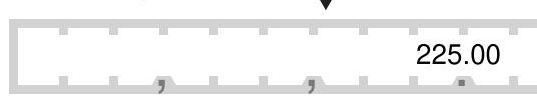

C. Full Name (Last, First, Middle Initial)

RICHARD WOLF

Mailing Address 1324 NORTHRIDGE TERRACE

\begin{tabular}{lcc}
\hline City & State & Zip Code \\
Joplin & MO & $64801-9547$
\end{tabular}

FEC ID number of contributing federal political committee.

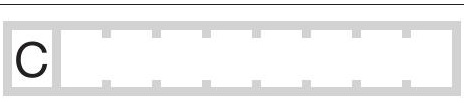

Name of Employer
Information Requested
Receipt For: 2012
X Primary
Other (specify)

$\begin{aligned} & \text { Occupation } \\ & \text { Information Requested }\end{aligned}$
Election Cycle-to-Date

Transaction ID : AE362BE742EF044EEA54

Date of Receipt

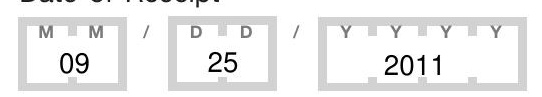

Amount of Each Receipt this Period

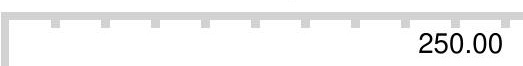

Amount of Each Receipt this Period

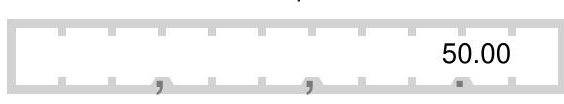

Transaction ID : A5462106A14B04ACD9BD Date of Receipt

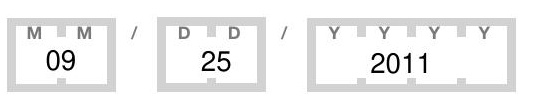

Transaction ID : AC787E582B63E4EB8B53 Date of Receipt

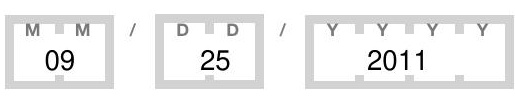

Amount of Each Receipt this Period

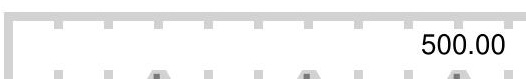

500.00

\section{Subtotal Of Receipts This Page (optional).}

800.00

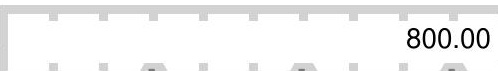

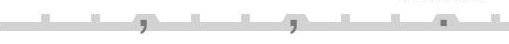

Total This Period (last page this line number only)

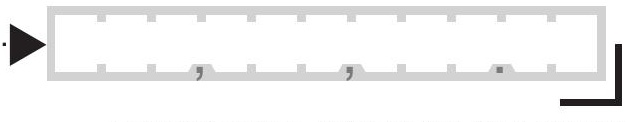

FEC Schedule A-P (Form 3P) (Rev. 03/2011) 
SCHEDULE A-P ITEMIZED RECEIPTS
Use separate schedule(s) for each category of the Detailed Summary Page
FOR LINE NUMBER: (check only one)

PAGE $699 / 1572$

\begin{tabular}{|c|c|c|c|c|c|c|}
\hline & & & & & & \\
\hline 16 & $\lambda$ & $17 \mathrm{a}$ & $17 \mathrm{~b}$ & $17 \mathrm{c}$ & $-17 d$ & -18 \\
\hline $19 a$ & & $19 b$ & $20 a$ & $20 \mathrm{~b}$ & $20 \mathrm{c}$ & 21 \\
\hline
\end{tabular}

Any information copied from such Reports and Statements may not be sold or used by any person for the purpose of soliciting contributions or for commercial purposes, other than using the name and address of any political committee to solicit contributions from such committee.

NAME OF COMMITTEE (In Full)

\section{Friends of Herman Cain}

A. Full Name (Last, First, Middle Initial)

\section{David Nichols}

Mailing Address 5500 Columbia Pike 927

\begin{tabular}{lcc}
\hline City & State & Zip Code \\
Arlington & VA & $22204-5865$
\end{tabular}

FEC ID number of contributing federal political committee.

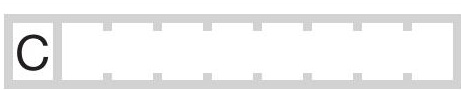

Name of Employer
Information Requested
Receipt For: 2012
X Primary $\quad \square$ General
Other (specify)

Occupation Information Requested

Election Cycle-to-Date

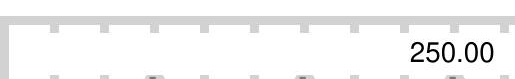

B. Full Name (Last, First, Middle Initial)

Daniel Thibault

Mailing Address 5392 LEXINGTON AVE N

\begin{tabular}{lcc}
\hline City & State & Zip Code \\
Saint Paul & MN & $55126-1356$
\end{tabular}

FEC ID number of contributing

federal political committee.

C

Name of Employer
Information Requested
Receipt For: 2012
X Primary
Other (specify)

\section{Occupation}

Information Requested

Election Cycle-to-Date

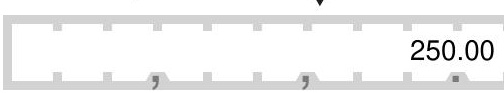

Transaction ID : AD1D3FF5964434619900

Date of Receipt

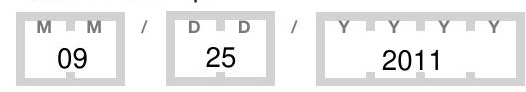

Amount of Each Receipt this Period

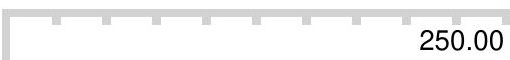

Amount of Each Receipt this Period

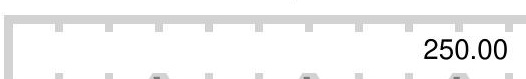

C. Full Name (Last, First, Middle Initial)

Lawrence Bolanowski

Mailing Address 96 Dickman Drive

\begin{tabular}{lcc}
\hline City & State & Zip Code \\
Lavallette & NJ & $08735-2805$
\end{tabular}

FEC ID number of contributing federal political committee.

C

Name of Employer
Retired
Receipt For: 2012
X Primary $\quad \square$ General
Other (specify)

Occupation

Retired

Election Cycle-to-Date

Transaction ID : A84A4492DBFDC4172A8A Date of Receipt

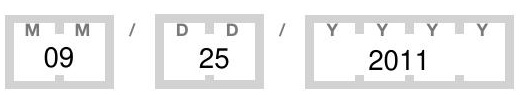

Transaction ID : A09A8535A7E174288886

Date of Receipt

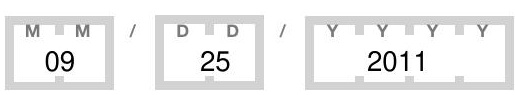

Amount of Each Receipt this Period

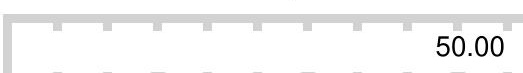

50.00

\section{Subtotal Of Receipts This Page (optional)}

Total This Period (last page this line number only) 


\section{SCHEDULE A-P} ITEMIZED RECEIPTS
Use separate schedule(s) for each category of the Detailed Summary Page

FOR LINE NUMBER:
(check only one)

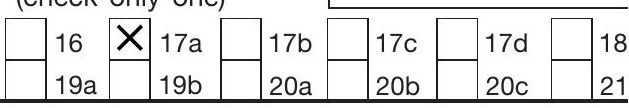

Any information copied from such Reports and Statements may not be sold or used by any person for the purpose of soliciting contributions or for commercial purposes, other than using the name and address of any political committee to solicit contributions from such committee.

NAME OF COMMITTEE (In Full)

\section{Friends of Herman Cain}

A. Full Name (Last, First, Middle Initial)

Tuckerman Babcock

Mailing Address PO Box 910

\begin{tabular}{lcc}
\hline City & State & Zip Code \\
Kenai & AK & $99611-0910$ \\
\hline
\end{tabular}

FEC ID number of contributing federal political committee.

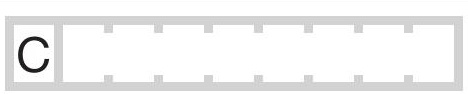

Name of Employer
self
Receipt For: 2012
X Primary
$\square$ Other (specify)

Occupation

Consultant

Election Cycle-to-Date

400.00

B. Full Name (Last, First, Middle Initial)

Mr. Michael E Brady

Mailing Address 399 Argonne Rd

\begin{tabular}{lcc}
\hline City & State & Zip Code \\
Southport & NC & $28461-7828$
\end{tabular}

FEC ID number of contributing

federal political committee.

C

Name of Employer
Progress Energy Carolinas
Receipt For: 2012
$X$ Primary
Other (specify)

Occupation

Licensed Reactor Operator

Election Cycle-to-Date

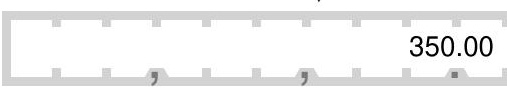

C. Full Name (Last, First, Middle Initial)

Julian Mann

Mailing Address 1621 North Crescent Heights BI

\begin{tabular}{lcc}
\hline City & State & Zip Code \\
Los Angeles & CA & $90069-1602$
\end{tabular}

FEC ID number of contributing federal political committee.

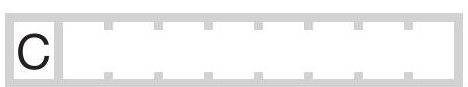

Name of Employer
Information Requested
Receipt For: 2012
X Primary
Other (specify) General

\section{Occupation}

Information Requested

Election Cycle-to-Date
Transaction ID : AED5E07AC3363407A832

Date of Receipt

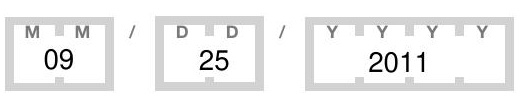

Amount of Each Receipt this Period

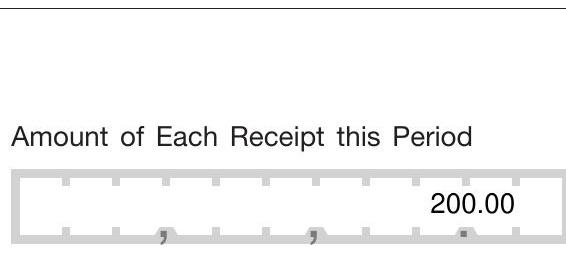

Amount of Each Receipt this Period

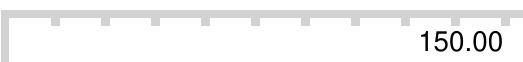

Date of Receipt
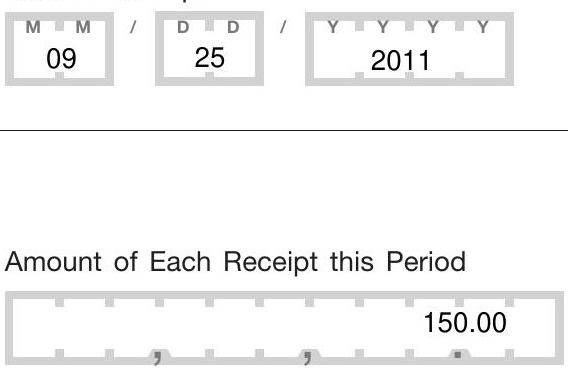

Transaction ID : A6DDFB2D4E461487D908 Date of Receipt

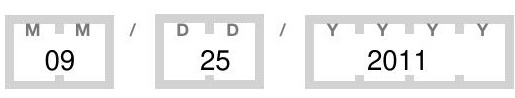

Amount of Each Receipt this Period

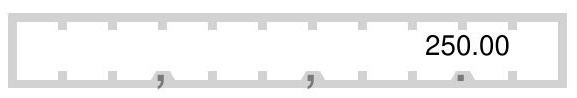

250.00

\section{Subtotal Of Receipts This Page (optional)}

600.00

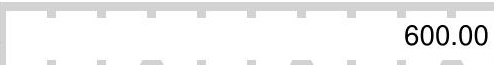

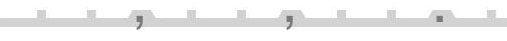

Total This Period (last page this line number only) 


\section{SCHEDULE A-P} ITEMIZED RECEIPTS
Use separate schedule(s)

for each category of the

Detailed Summary Page
FOR LINE NUMBER: (check only one)

PAGE $701 / 1572$

\begin{tabular}{|c|c|c|c|c|c|}
\hline & & & & & \\
\hline 16 & X $17 a$ & $17 b$ & $17 c$ & $17 d$ & 18 \\
\hline $19 a$ & $19 b$ & $20 \mathrm{a}$ & $20 \mathrm{~b}$ & $20 \mathrm{c}$ & 21 \\
\hline
\end{tabular}

Any information copied from such Reports and Statements may not be sold or used by any person for the purpose of soliciting contributions or for commercial purposes, other than using the name and address of any political committee to solicit contributions from such committee.

NAME OF COMMITTEE (In Full)

Friends of Herman Cain

A. Full Name (Last, First, Middle Initial)

Scarlett McLaughlin

Mailing Address 257 Shellhorse road

\begin{tabular}{lcc}
\hline City & State & Zip Code \\
Ranger & GA & $30734-9743$ \\
\hline
\end{tabular}

FEC ID number of contributing

federal political committee.

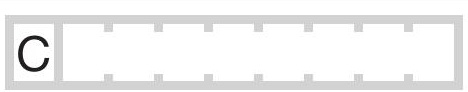

Name of Employer
Macy's
Receipt For: 2012
X Primary
$\square$ Other (specify) General

Occupation

Data Analyst

Election Cycle-to-Date

300.00

B. Full Name (Last, First, Middle Initial)

samuel borofsky

Mailing Address 435 Bryant Ave

\begin{tabular}{lcc}
\hline City & State & Zip Code \\
Roslyn & NY & $11576-1115$ \\
\hline
\end{tabular}

FEC ID number of contributing

federal political committee.

C

Name of Employer
Information Requested
Receipt For: 2012
Primary
Other (specify)

Occupation

Information Requested

Election Cycle-to-Date

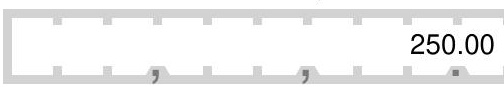

Transaction ID : A93DC98F242CC47ADBD9

Date of Receipt

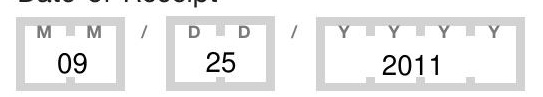

Amount of Each Receipt this Period

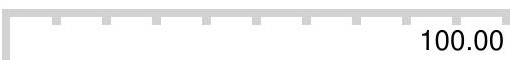

Transaction ID : A8E831BA811764759B9C

Date of Receipt

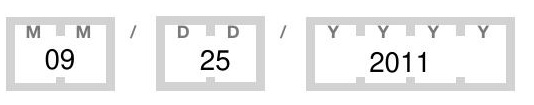

Amount of Each Receipt this Period

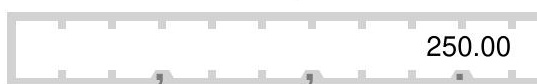

Transaction ID : A1D52EDFE352245868B4

Date of Receipt

Keith Brodie

Mailing Address 119 Oxford

\begin{tabular}{lcc}
\hline City & State & Zip Code \\
Irvine & CA & $92612-2666$
\end{tabular}

FEC ID number of contributing federal political committee.

C

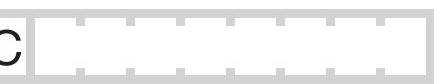

Name of Employer
Self Employed
Receipt For: 2012
Х Primary $\quad \square$ General
Other (specify)

Occupation

Engineer

Election Cycle-to-Date

500.00

Subtotal Of Receipts This Page (optional).

Amount of Each Receipt this Period

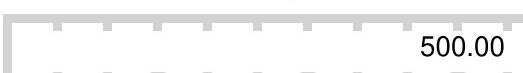

Total This Period (last page this line number only)

$\quad 850.00$

,

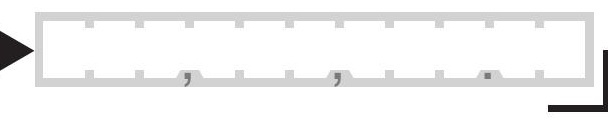

FEC Schedule A-P (Form 3P) (Rev. 03/2011) 


\section{SCHEDULE A-P} ITEMIZED RECEIPTS
Use separate schedule(s)

for each category of the

Detailed Summary Page
FOR LINE NUMBER: (check only one)

PAGE 702 / 1572

\begin{tabular}{|c|c|c|c|c|c|}
\hline & & & & & \\
\hline 16 & X $17 a$ & $17 b$ & $17 c$ & $17 d$ & 18 \\
\hline $19 a$ & $19 b$ & $20 \mathrm{a}$ & $20 \mathrm{~b}$ & $20 \mathrm{c}$ & 21 \\
\hline
\end{tabular}

Any information copied from such Reports and Statements may not be sold or used by any person for the purpose of soliciting contributions or for commercial purposes, other than using the name and address of any political committee to solicit contributions from such committee.

NAME OF COMMITTEE (In Full)

Friends of Herman Cain

A. Full Name (Last, First, Middle Initial)

James Lynch

Mailing Address 2983 Butterwood Drive

\begin{tabular}{lcc}
\hline City & State & Zip Code \\
Jamestown & NC & $27282-7753$
\end{tabular}

FEC ID number of contributing

federal political committee.

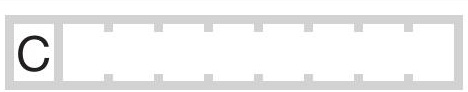

Name of Employer
Information Requested
Receipt For: 2012
X Primary $\quad \square$ General
Other (specify)

Occupation

Information Requested

Election Cycle-to-Date

250.00

B. Full Name (Last, First, Middle Initial)

shirley brend

Mailing Address 1906 south grandview In

\begin{tabular}{lcc}
\hline City & State & Zip Code \\
Bismarck & ND & $58503-0849$
\end{tabular}

FEC ID number of contributing

federal political committee.

C

Name of Employer
Information Requested
Receipt For: 2012
X Primary
Other (specify)

Occupation

Information Requested

Election Cycle-to-Date

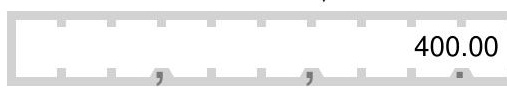

Transaction ID : A745F74BB6B8E45AEBD0

Date of Receipt

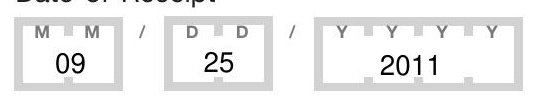

Amount of Each Receipt this Period

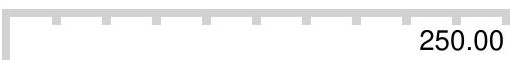

Amount of Each Receipt this Period

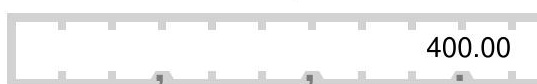

C. Full Name (Last, First, Middle Initial)

E Blake

Mailing Address 1632 Wisteria Way

\begin{tabular}{lcc}
\hline City & State & Zip Code \\
Richardson & TX & $75080-3132$
\end{tabular}

FEC ID number of contributing

federal political committee.

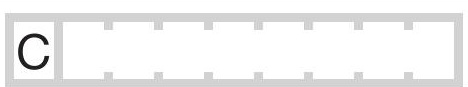

Name of Employer

Information Requested

Occupation

Information Requested

Receipt For: 2012

Х $\begin{aligned} & \text { Primary } \square \text { General } \\ & \text { Other (specify) }\end{aligned}$

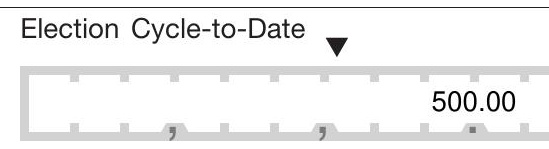

Amount of Each Receipt this Period

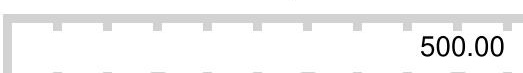

Transaction ID : ACE9D2EF2B1A84B5C8D9 Date of Receipt

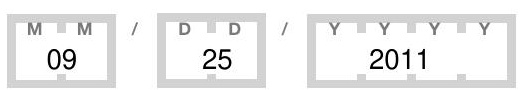

Subtotal Of Receipts This Page (optional)

1150.00

Total This Period (last page this line number only) 
SCHEDULE A-P ITEMIZED RECEIPTS
Use separate schedule(s) for each category of the Detailed Summary Page
FOR LINE NUMBER: (check only one)

PAGE $703 / 1572$

\begin{tabular}{|c|c|c|c|c|c|}
\hline & & & & & \\
\hline 16 & $\begin{array}{l}\mathbf{X} \\
17 a\end{array}$ & $17 b$ & $17 c$ & $17 d$ & 18 \\
\hline $19 a$ & $19 \mathrm{~b}$ & $20 \mathrm{a}$ & $20 \mathrm{~b}$ & $20 \mathrm{c}$ & 21 \\
\hline
\end{tabular}

Any information copied from such Reports and Statements may not be sold or used by any person for the purpose of soliciting contributions or for commercial purposes, other than using the name and address of any political committee to solicit contributions from such committee.

NAME OF COMMITTEE (In Full)

\section{Friends of Herman Cain}

A. Full Name (Last, First, Middle Initial)

Pierrette Goordon

Mailing Address 200 Lilac Drive \#201

\begin{tabular}{lcc}
\hline City & State & Zip Code \\
Marco Island & FL & 34145
\end{tabular}

FEC ID number of contributing

federal political committee.

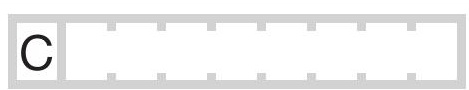

Name of Employer
Information Requested
Receipt For: 2012
X Primary $\quad \square$ General
$\square$ Other (specify)

Occupation

Information Requested

Election Cycle-to-Date

250.00

B. Full Name (Last, First, Middle Initial)

David Matthews

Mailing Address 6623 Heritage Ln

\begin{tabular}{lcc}
\hline City & State & Zip Code \\
Bradenton & FL & $34209-7447$
\end{tabular}

FEC ID number of contributing

federal political committee.

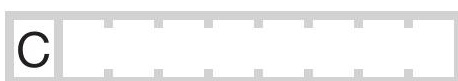

Name of Employer
Information Requested
Receipt For: 2012
X Primary
Other (specify)

Occupation

Information Requested

Election Cycle-to-Date

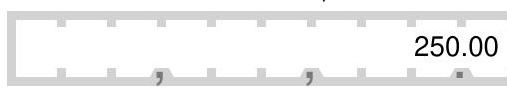

Transaction ID : A2516483193754BD5B1F

Date of Receipt

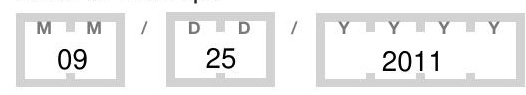

Amount of Each Receipt this Period

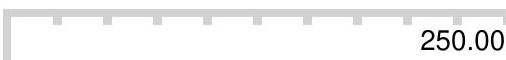

C. Full Name (Last, First, Middle Initial)

Colleen V Wynne

Mailing Address 221 Woodland Rd

\begin{tabular}{lcc}
\hline City & State & Zip Code \\
Gatlinburg & TN & $37738-5886$
\end{tabular}

FEC ID number of contributing

federal political committee.

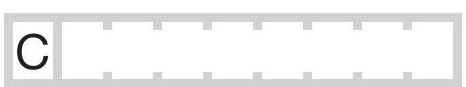

Name of Employer

Park Liquor

\section{Occupation}

clerk

Receipt For: 2012

Х $\begin{aligned} & \text { Primary } \square \text { General } \\ & \text { Other (specify) }\end{aligned}$

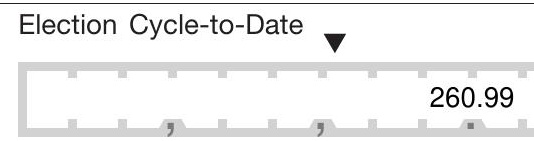

Amount of Each Receipt this Period

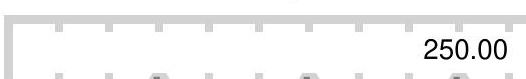

Transaction ID : A35EF032D974D47A6B81

Date of Receipt

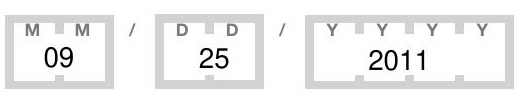

Transaction ID : A9A6A2769421F4B62800

Date of Receipt

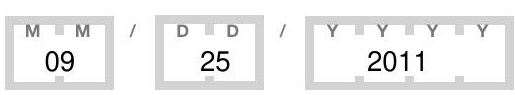

Amount of Each Receipt this Period

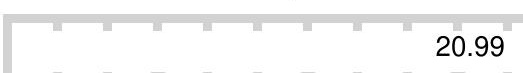

\section{Subtotal Of Receipts This Page (optional)}

Total This Period (last page this line number only) 
SCHEDULE A-P ITEMIZED RECEIPTS
Use separate schedule(s) for each category of the Detailed Summary Page
FOR LINE NUMBER: (check only one)
PAGE 704 / 1572

\begin{tabular}{|c|c|c|c|c|c|}
\hline & & & & & \\
\hline 16 & $\begin{array}{lll}X & 17 a \\
\end{array}$ & $17 \mathrm{~b}$ & $17 c$ & $17 d$ & 18 \\
\hline $19 a$ & $19 b$ & $20 a$ & $20 \mathrm{~b}$ & $20 c$ & 21 \\
\hline
\end{tabular}

Any information copied from such Reports and Statements may not be sold or used by any person for the purpose of soliciting contributions or for commercial purposes, other than using the name and address of any political committee to solicit contributions from such committee.

NAME OF COMMITTEE (In Full)

\section{Friends of Herman Cain}

A. Full Name (Last, First, Middle Initial)

Judy Phillips

Mailing Address PO Box 872

\begin{tabular}{lcc}
\hline City & State & Zip Code \\
Norwich & VT & $05055-0872$
\end{tabular}

FEC ID number of contributing

federal political committee.

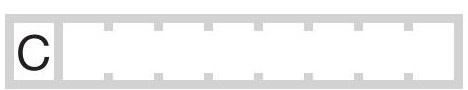

Name of Employer
Fmr. Self (currently NA)
Receipt For: 2012
X Primary
Other (specify) General

Occupation

Public Finance - Analyst

Election Cycle-to-Date $\boldsymbol{\nabla}$

1500.00

B. Full Name (Last, First, Middle Initial)

Bill Mann

Mailing Address PO Box 236

\begin{tabular}{lcc}
\hline City & State & Zip Code \\
Pauls Valley & OK & $73075-0236$ \\
\hline
\end{tabular}

FEC ID number of contributing

federal political committee.

C

Name of Employer
Information Requested
Receipt For: 2012
X Primary
Other (specify)

Occupation

Information Requested

Election Cycle-to-Date

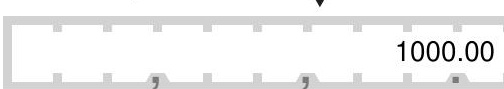

Transaction ID : A9165043482C34F2C848

Date of Receipt

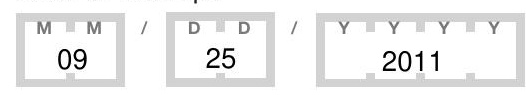

Amount of Each Receipt this Period

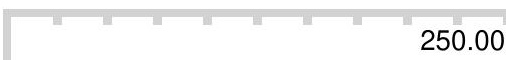

250.00

C. Full Name (Last, First, Middle Initial)

Barbara Powell

Mailing Address 604 Green St NE Ste 3

\begin{tabular}{lcc}
\hline City & State & Zip Code \\
Gainesville & GA & $30501-3354$
\end{tabular}

FEC ID number of contributing federal political committee.

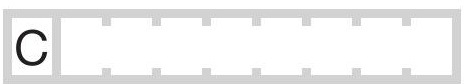

Name of Employer

Information Requested

\section{Occupation}

Information Requested

Receipt For: 2012

Х $\begin{aligned} & \text { Primary } \square \text { General } \\ & \text { Other (specify) }\end{aligned}$

Transaction ID : A025DE3706AEB43C49C3

Date of Receipt

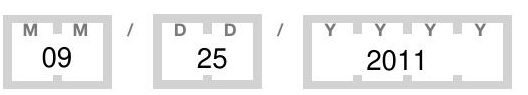

Amount of Each Receipt this Period

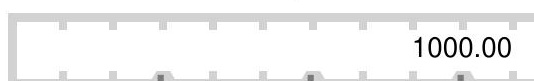

Transaction ID : A52DA3DDD0FA849259F1 Date of Receipt

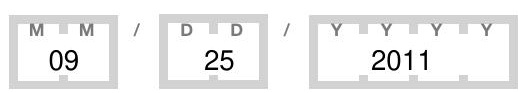

Amount of Each Receipt this Period

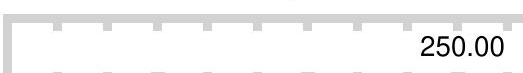

\section{Subtotal Of Receipts This Page (optional)}

Total This Period (last page this line number only) 
SCHEDULE A-P ITEMIZED RECEIPTS
Use separate schedule(s) for each category of the Detailed Summary Page
FOR LINE NUMBER: (check only one)

PAGE $705 / 1572$

\begin{tabular}{|c|c|c|c|c|c|}
\hline & & & & & \\
\hline 16 & $\begin{array}{l}\mathbf{X} \\
17 a\end{array}$ & $17 b$ & $17 c$ & $17 d$ & 18 \\
\hline $19 a$ & $19 \mathrm{~b}$ & $20 \mathrm{a}$ & $20 \mathrm{~b}$ & $20 \mathrm{c}$ & 21 \\
\hline
\end{tabular}

Any information copied from such Reports and Statements may not be sold or used by any person for the purpose of soliciting contributions or for commercial purposes, other than using the name and address of any political committee to solicit contributions from such committee.

NAME OF COMMITTEE (In Full)

\section{Friends of Herman Cain}

A. Full Name (Last, First, Middle Initial)

Gertrude Gatto

Mailing Address 222 Clark Drive

\begin{tabular}{lcc}
\hline City & State & Zip Code \\
Johnstown & OH & $43031-8902$
\end{tabular}

FEC ID number of contributing federal political committee.

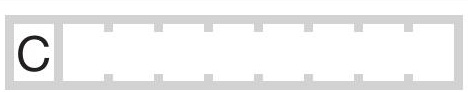

Name of Employer
Berkeley Park at New Albany LLC
Receipt For: 2012
X Primary $\quad \square$ General
Other (specify)

Occupation

Office Assistant

Election Cycle-to-Date

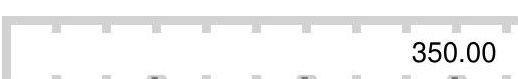

B. Full Name (Last, First, Middle Initial)

Ron Ayres

Mailing Address 2808 Princeton Place

\begin{tabular}{lcc}
\hline City & State & Zip Code \\
Plano & TX & $75075-8116$ \\
\hline
\end{tabular}

FEC ID number of contributing

federal political committee.

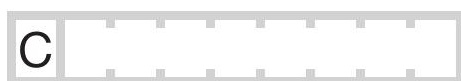

Name of Employer
Ayres Adventures
Receipt For: 2012
X Primary
Other (specify)

\section{Occupation} OWNER

Election Cycle-to-Date

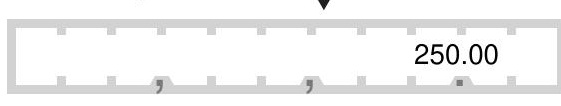

Transaction ID : A46D58EB8E7E54459B62

Date of Receipt

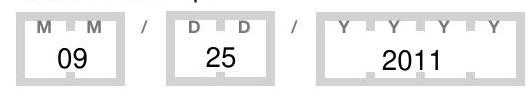

Amount of Each Receipt this Period

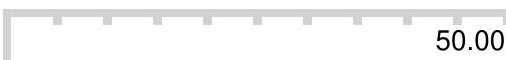

50.00

C. Full Name (Last, First, Middle Initial)

david brusso

Mailing Address 869 southwest drive

\begin{tabular}{lcc}
\hline City & State & Zip Code \\
Davidson & NC & $28036-7910$
\end{tabular}

FEC ID number of contributing federal political committee.

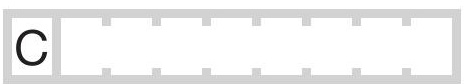

$\begin{aligned} & \text { Name of Employer } \\ & \text { self }\end{aligned}$
Receipt For: 2012
X Primary $\square$ General
Other (specify)

\section{Occupation}

Sales

Election Cycle-to-Date

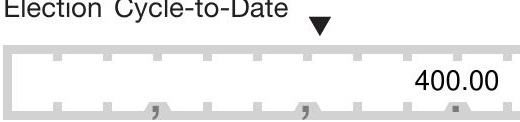

Transaction ID : ADBD5CE8251744AD88E8 Date of Receipt

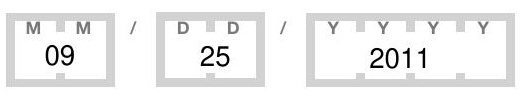

Amount of Each Receipt this Period

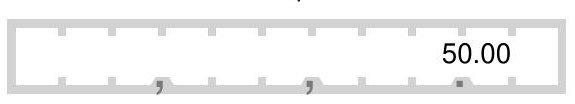

Transaction ID : AC9F88FB6D7CB4F07BD5 Date of Receipt

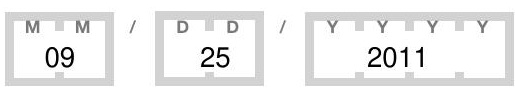

Amount of Each Receipt this Period

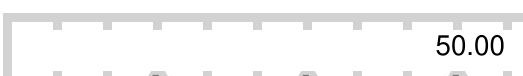

\section{Subtotal Of Receipts This Page (optional)}

Total This Period (last page this line number only) 
SCHEDULE A-P ITEMIZED RECEIPTS
Use separate schedule(s) for each category of the Detailed Summary Page
FOR LINE NUMBER: (check only one)

PAGE $706 / 1572$

\begin{tabular}{|c|c|c|c|c|c|}
\hline & & & & & \\
\hline 16 & $\begin{array}{l}\mathbf{X} \\
17 a\end{array}$ & $17 b$ & $17 c$ & $17 d$ & 18 \\
\hline $19 a$ & $19 \mathrm{~b}$ & $20 \mathrm{a}$ & $20 \mathrm{~b}$ & $20 \mathrm{c}$ & 21 \\
\hline
\end{tabular}

Any information copied from such Reports and Statements may not be sold or used by any person for the purpose of soliciting contributions or for commercial purposes, other than using the name and address of any political committee to solicit contributions from such committee.

NAME OF COMMITTEE (In Full)

\section{Friends of Herman Cain}

A. Full Name (Last, First, Middle Initial)

\section{Charles Lutz}

Mailing Address 6833 Holliston Circle

\begin{tabular}{lcc}
\hline City & State & Zip Code \\
Fayetteville & NY & $13066-1708$ \\
\hline
\end{tabular}

FEC ID number of contributing federal political committee.

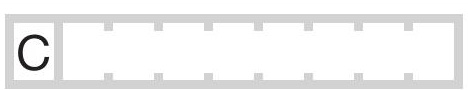

Name of Employer
Upstate Medical University
Receipt For: 2012
X Primary
Other (specify) General

Occupation

Physician

Election Cycle-to-Date

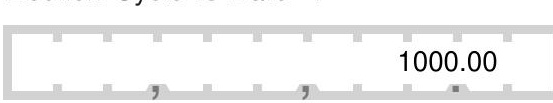

B. Full Name (Last, First, Middle Initial)

Cory Zornizer

Mailing Address 331 Meadowtree Ct

\begin{tabular}{lcc}
\hline City & State & Zip Code \\
Foley & MO & $63347-2867$ \\
\hline
\end{tabular}

FEC ID number of contributing

federal political committee.

C

Name of Employer

Occupation

Express-Scripts

Operations Director

Receipt For: 2012

Х $\begin{aligned} & \text { Primary } \square \text { General } \\ & \text { Other (specify) } \boldsymbol{\nabla}\end{aligned}$

Election Cycle-to-Date

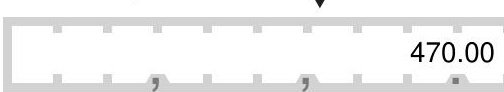

C. Full Name (Last, First, Middle Initial)

Stephan Demirjian

Mailing Address 5175 Alamosa Park Dr.

\begin{tabular}{lcc}
\hline City & State & Zip Code \\
Oceanside & CA & $92057-6303$
\end{tabular}

FEC ID number of contributing

federal political committee.

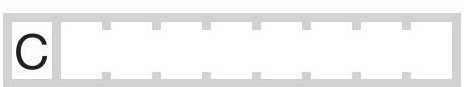

Name of Employer

Demirjian Auto Ent. Inc.

Occupation

Information Requested

Receipt For: 2012

Х $\begin{aligned} & \text { Primary } \square \text { General } \\ & \text { Other (specify) }\end{aligned}$

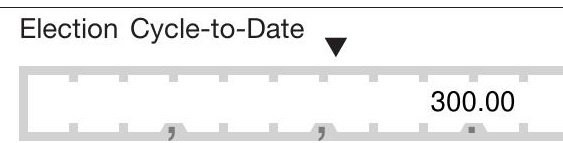

Transaction ID : A6308F8B57BF14F1F90E

Date of Receipt

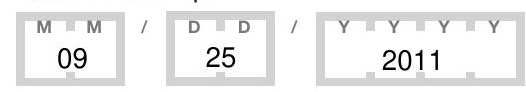

Amount of Each Receipt this Period

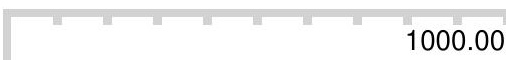

1000.00

Transaction ID : A89DCFE53A8554F389E6

Date of Receipt

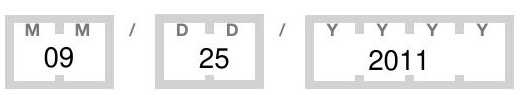

Amount of Each Receipt this Period

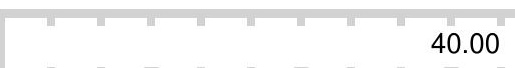

Transaction ID : A1863BAC98B2B4C9186F Date of Receipt

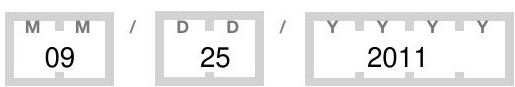

Amount of Each Receipt this Period

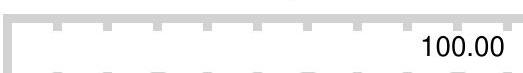

1140.00

Subtotal Of Receipts This Page (optional)

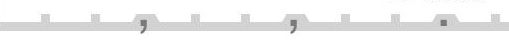

Total This Period (last page this line number only) 
SCHEDULE A-P ITEMIZED RECEIPTS
Use separate schedule(s) for each category of the Detailed Summary Page
FOR LINE NUMBER: (check only one)

PAGE $707 / 1572$

\begin{tabular}{|c|c|c|c|c|c|}
\hline & & & & & \\
\hline 16 & $\begin{array}{l}\mathbf{X} \\
17 a\end{array}$ & $17 b$ & $17 c$ & $17 d$ & 18 \\
\hline $19 a$ & $19 \mathrm{~b}$ & $20 \mathrm{a}$ & $20 \mathrm{~b}$ & $20 \mathrm{c}$ & 21 \\
\hline
\end{tabular}

Any information copied from such Reports and Statements may not be sold or used by any person for the purpose of soliciting contributions or for commercial purposes, other than using the name and address of any political committee to solicit contributions from such committee.

NAME OF COMMITTEE (In Full)

\section{Friends of Herman Cain}

A. Full Name (Last, First, Middle Initial)

Michael Vickers

Mailing Address 16618 Park Green Way

\begin{tabular}{lcc}
\hline City & State & Zip Code \\
Houston & TX & $77058-2244$ \\
\hline
\end{tabular}

FEC ID number of contributing federal political committee.

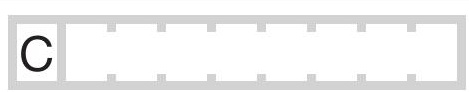

Name of Employer
Marathon Petroleum
Receipt For: 2012
X Primary $\quad$ General
Other (specify)

\section{Occupation}

Distribution Specialist

Election Cycle-to-Date

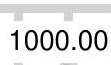

B. Full Name (Last, First, Middle Initial)

\section{Phillip Hinton}

Mailing Address 5207 Lakedale Dr

\begin{tabular}{lcc}
\hline City & State & Zip Code \\
Durham & NC & $27713-6088$ \\
\hline
\end{tabular}

FEC ID number of contributing

federal political committee.

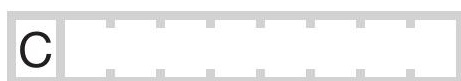

Name of Employer
EMC Corp.
Receipt For: 2012
X Primary
Other (specify)

Occupation

Software Engineer

Election Cycle-to-Date

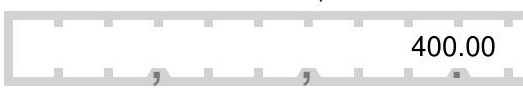

Transaction ID : AED2F6A5E312E40A49AE

Date of Receipt

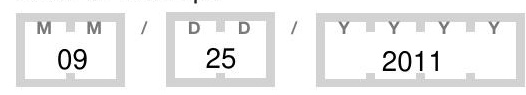

Amount of Each Receipt this Period

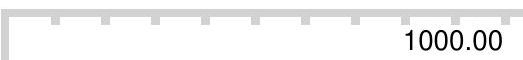

1000.00

C. Full Name (Last, First, Middle Initial)

Frederick Boelter

Mailing Address 31094 W Thompson Ln

\begin{tabular}{lcc}
\hline City & State & Zip Code \\
Hartland & WI & $53029-9705$
\end{tabular}

FEC ID number of contributing federal political committee.

C

53029-9705

Name of Employer

Information Requested

Occupation

Information Requested

Receipt For: 2012

Х $\begin{aligned} & \text { Primary } \\ & \text { Other (specify) }\end{aligned}$

Election Cycle-to-Date

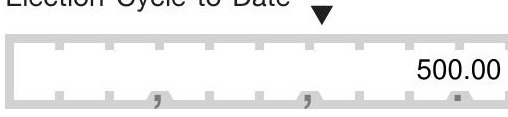

Transaction ID : A85DE9ECD09604051B12

Date of Receipt

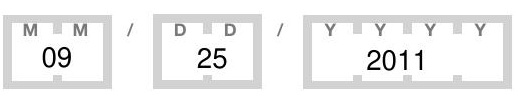

Amount of Each Receipt this Period

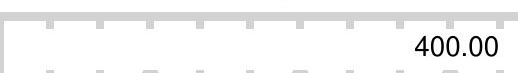

Transaction ID : AD5D2FF28DFC14482BDF Date of Receipt

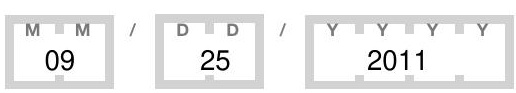

Amount of Each Receipt this Period

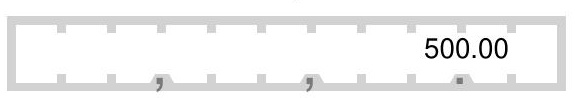

Subtotal Of Receipts This Page (optional)

1900.00

Total This Period (last page this line number only) 
SCHEDULE A-P ITEMIZED RECEIPTS
Use separate schedule(s) for each category of the Detailed Summary Page
FOR LINE NUMBER: (check only one)

PAGE $708 / 1572$

\begin{tabular}{|c|c|c|c|c|c|}
\hline & & & & & \\
\hline 16 & $\begin{array}{l}\mathbf{X} \\
17 a\end{array}$ & $17 b$ & $17 c$ & $17 d$ & 18 \\
\hline $19 a$ & $19 \mathrm{~b}$ & $20 \mathrm{a}$ & $20 \mathrm{~b}$ & $20 \mathrm{c}$ & 21 \\
\hline
\end{tabular}

Any information copied from such Reports and Statements may not be sold or used by any person for the purpose of soliciting contributions or for commercial purposes, other than using the name and address of any political committee to solicit contributions from such committee.

NAME OF COMMITTEE (In Full)

\section{Friends of Herman Cain}

A. Full Name (Last, First, Middle Initial)

\section{David DeRousse}

Mailing Address 241 Duncan Loop West Apt. 101

\begin{tabular}{lcc}
\hline City & State & Zip Code \\
Dunedin & FL & $34698-1324$
\end{tabular}

FEC ID number of contributing

federal political committee.

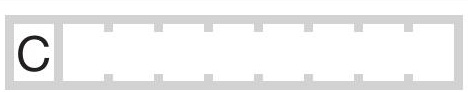

Name of Employer
Retired
Receipt For: 2012
X Primary $\quad$ General
Other (specify)

Occupation

Retired

Election Cycle-to-Date

1750.00

B. Full Name (Last, First, Middle Initial)

bradley holder

Mailing Address 38 s. blue angel pwky PMB \# 108

\begin{tabular}{lcc}
\hline City & State & Zip Code \\
Pensacola & FL & $32506-6045$ \\
\hline
\end{tabular}

FEC ID number of contributing

federal political committee.

C

Name of Employer
Information Requested
Receipt For: 2012
X Primary
Other (specify)

Occupation

Information Requested

Election Cycle-to-Date

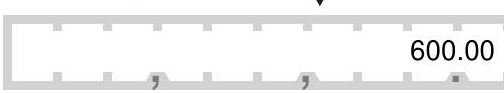

Transaction ID : ACE2449E856EC42CB94A

Date of Receipt

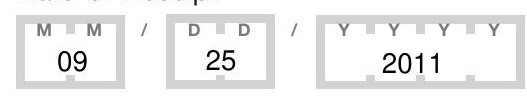

Amount of Each Receipt this Period

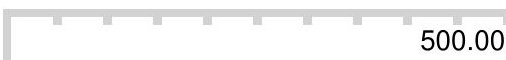

Amount of Each Receipt this Period

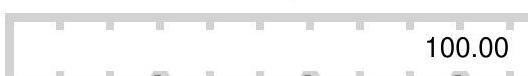

C. Full Name (Last, First, Middle Initial)

DAVID WILLIAMS

Mailing Address 2001 HALLUM

\begin{tabular}{lcc}
\hline City & State & Zip Code \\
Clovis & NM & $88101-8685$
\end{tabular}

FEC ID number of contributing federal political committee.

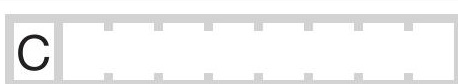

Name of Employer

Information Requested

Occupation

Receipt For: 2012

Х $\begin{aligned} & \text { Primary } \square \text { General } \\ & \text { Other (specify) }\end{aligned}$

Information Requested

Election Cycle-to-Date

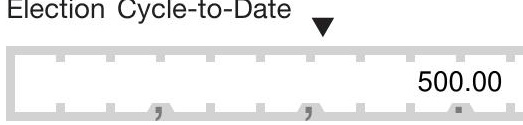

Transaction ID : A28F1419E0F8D496B8F7

Date of Receipt

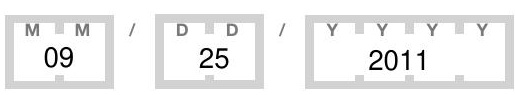

Transaction ID : AD81867C441344E20933

Date of Receipt

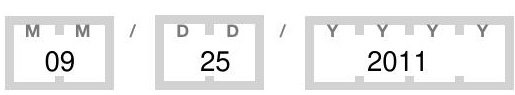

Amount of Each Receipt this Period

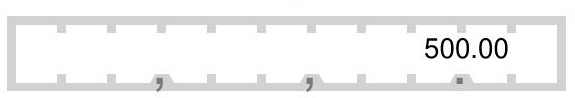

Subtotal Of Receipts This Page (optional)

1100.00

Total This Period (last page this line number only) 
SCHEDULE A-P ITEMIZED RECEIPTS
Use separate schedule(s) for each category of the Detailed Summary Page
FOR LINE NUMBER: (check only one)

PAGE $709 / 1572$

\begin{tabular}{|c|c|c|c|c|c|}
\hline & & & & & \\
\hline 16 & $\begin{array}{l}\mathbf{X} \\
17 a\end{array}$ & $17 b$ & $17 c$ & $17 d$ & 18 \\
\hline $19 a$ & $19 \mathrm{~b}$ & $20 \mathrm{a}$ & $20 \mathrm{~b}$ & $20 \mathrm{c}$ & 21 \\
\hline
\end{tabular}

Any information copied from such Reports and Statements may not be sold or used by any person for the purpose of soliciting contributions or for commercial purposes, other than using the name and address of any political committee to solicit contributions from such committee.

NAME OF COMMITTEE (In Full)

\section{Friends of Herman Cain}

A. Full Name (Last, First, Middle Initial)

William Paynter

Mailing Address PO Box 651

\begin{tabular}{lcc}
\hline City & State & Zip Code \\
Wilton & CA & $95693-0651$
\end{tabular}

FEC ID number of contributing federal political committee.

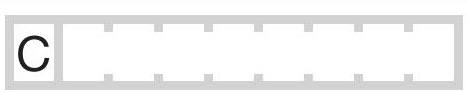

Name of Employer
None
Receipt For: 2012
X Primary $\quad \square$ General
Other (specify)

Occupation Retired

Election Cycle-to-Date

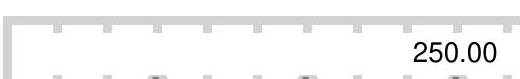

B. Full Name (Last, First, Middle Initial)

Robert Osborn

Mailing Address 255 Lakemont Dr

\begin{tabular}{lcc}
\hline City & State & Zip Code \\
Fayetteville & GA & $30215-8137$
\end{tabular}

FEC ID number of contributing

federal political committee.

C

Name of Employer
HR Select Consultants
Receipt For: 2012
X Primary
Other (specify)

C. Full Name (Last, First, Middle Initial)

Robert Decker

Mailing Address 10892 W 100 S

\section{City}

Russiaville

FEC ID number of contributing federal political committee.

Name of Employer
Information Requested
Receipt For: 2012
X Primary
Other (specify) General

\section{Occupation}

Robert Osborn

Election Cycle-to-Date

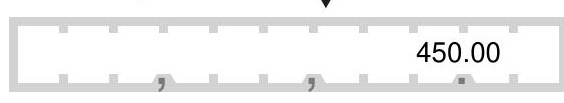

Transaction ID : A04BB5896320B47ACA9A

Date of Receipt

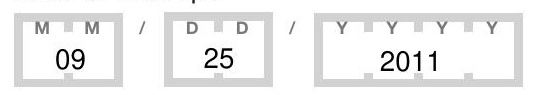

Amount of Each Receipt this Period

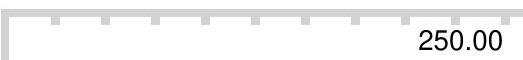

Amount of Each Receipt this Period

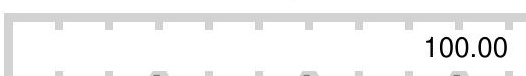

Transaction ID : A4B96D6B9019F4B71975 Date of Receipt

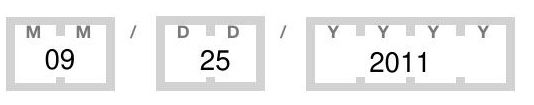

Transaction ID : A6CB4AC817E3B4BCABB7 Date of Receipt

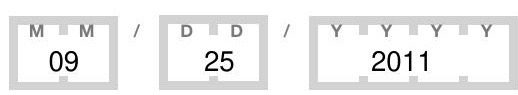

Amount of Each Receipt this Period

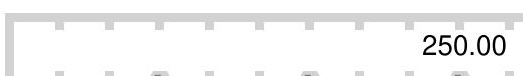

\section{Subtotal Of Receipts This Page (optional)}

600.00

Information Requested

Election Cycle-to-Date

250.00

Total This Period (last page this line number only) 


\section{SCHEDULE A-P} ITEMIZED RECEIPTS
Use separate schedule(s) for each category of the Detailed Summary Page

FOR LINE NUMBER:
(check only one)

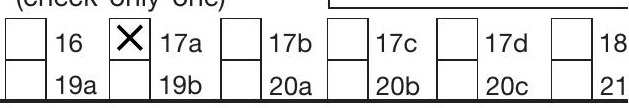

Any information copied from such Reports and Statements may not be sold or used by any person for the purpose of soliciting contributions or for commercial purposes, other than using the name and address of any political committee to solicit contributions from such committee.

NAME OF COMMITTEE (In Full)

\section{Friends of Herman Cain}

A. Full Name (Last, First, Middle Initial)

Pamela Cornutt

Mailing Address 1072 Woodruff Plantation CT

\begin{tabular}{lcc}
\hline City & State & Zip Code \\
Marietta & GA & $30067-9100$
\end{tabular}

FEC ID number of contributing federal political committee.

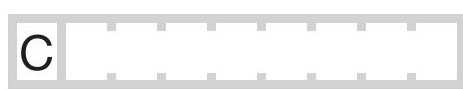

Name of Employer
Information Requested
Receipt For: 2012
X Primary
$\square$ Other (specify)

Occupation Information Requested

Election Cycle-to-Date 450.00

B. Full Name (Last, First, Middle Initial)

Christopher Bray

Mailing Address 12840 Brynwood Way

\begin{tabular}{lcc}
\hline City & State & Zip Code \\
Naples & FL & $34105-4807$
\end{tabular}

FEC ID number of contributing

federal political committee.

C

Name of Employer
Information Requested
Receipt For: 2012
Primary
Other (specify)

Occupation

Information Requested

Election Cycle-to-Date

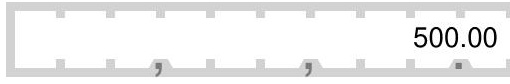

Transaction ID : A08A3BF55CD7B4BD1BB6

Date of Receipt

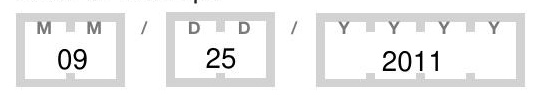

Amount of Each Receipt this Period

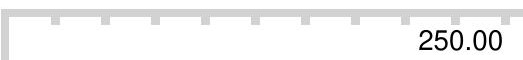

Amount of Each Receipt this Period

Transaction ID : AD2BA6320BEF64EC6813

Date of Receipt
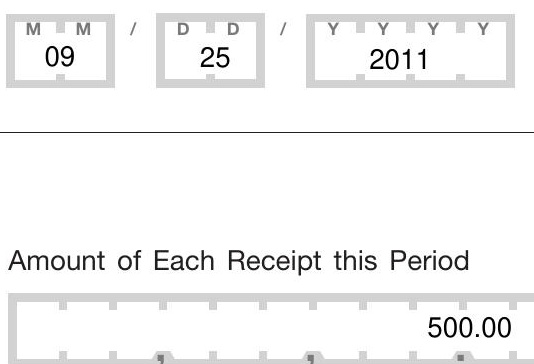

C. Full Name (Last, First, Middle Initial)

ROGER LOEB

Mailing Address 210 VIDAULAN CT

\begin{tabular}{lcc}
\hline City & State & Zip Code \\
Alpharetta & GA & $30022-1650$
\end{tabular}

FEC ID number of contributing federal political committee.

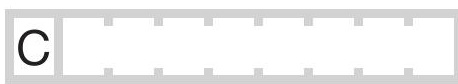

Name of Employer

TechSafari LLC

Occupation

Receipt For: 2012

Х $\begin{aligned} & \text { Primary } \square \text { General } \\ & \text { Other (specify) }\end{aligned}$

Project Manager

Election Cycle-to-Date

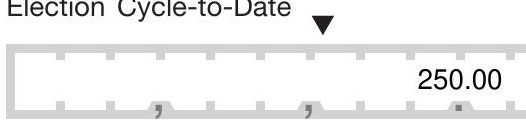

Transaction ID : AC93EE8BE2D584A1B930 Date of Receipt

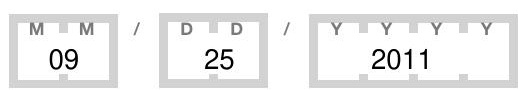

Amount of Each Receipt this Period

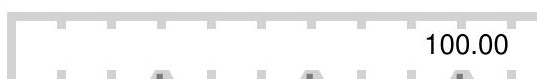

850.00

Subtotal Of Receipts This Page (optional)

Total This Period (last page this line number only) 
SCHEDULE A-P ITEMIZED RECEIPTS
Use separate schedule(s) for each category of the Detailed Summary Page
FOR LINE NUMBER: (check only one)

PAGE $711 / 1572$

\begin{tabular}{|c|c|c|c|c|c|c|}
\hline & & & & & & \\
\hline 16 & $\lambda$ & $17 \mathrm{a}$ & $17 \mathrm{~b}$ & $17 \mathrm{c}$ & $-17 d$ & -18 \\
\hline $19 a$ & & $19 b$ & $20 a$ & $20 \mathrm{~b}$ & $20 \mathrm{c}$ & 21 \\
\hline
\end{tabular}

Any information copied from such Reports and Statements may not be sold or used by any person for the purpose of soliciting contributions or for commercial purposes, other than using the name and address of any political committee to solicit contributions from such committee.

NAME OF COMMITTEE (In Full)

\section{Friends of Herman Cain}

A. Full Name (Last, First, Middle Initial)

Cherry Dyer

Mailing Address 2222 Westerland Dr Apt 207

\begin{tabular}{lcc}
\hline City & State & Zip Code \\
Houston & TX & $77063-2215$
\end{tabular}

FEC ID number of contributing

federal political committee.

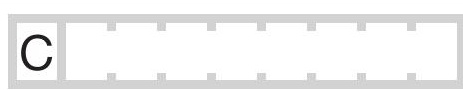

Name of Employer
Information Requested
Receipt For: 2012
X Primary $\quad \square$ General
Other (specify)

Occupation

Information Requested

Election Cycle-to-Date

250.99

B. Full Name (Last, First, Middle Initial)

marjorie Zimmerman

Mailing Address 6350 Pelican Bay Blvd

\begin{tabular}{lcc}
\hline City & State & Zip Code \\
Naples & FL & $34108-7132$ \\
\hline
\end{tabular}

FEC ID number of contributing

federal political committee.

C

Name of Employer
Information Requested
Receipt For: 2012
X Primary
Other (specify)

Occupation

Information Requested

Election Cycle-to-Date

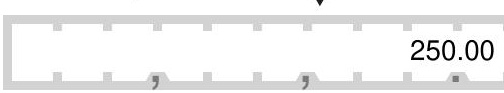

Transaction ID : AB35E2A685C154886BF7

Date of Receipt

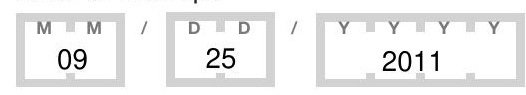

Amount of Each Receipt this Period

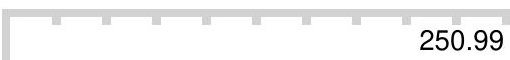

Transaction ID : A045EE4B5F510409EA8E

Date of Receipt

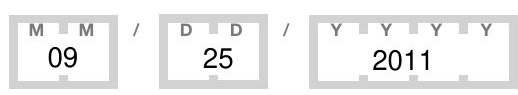

Amount of Each Receipt this Period

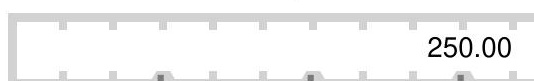

Transaction ID : A1D5BF9354A094330B1B Date of Receipt

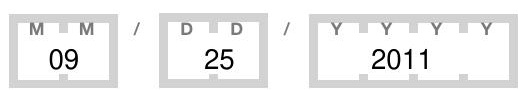

Amount of Each Receipt this Period

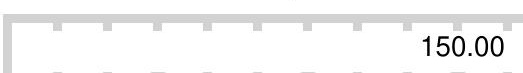

$\begin{array}{cc}\text { State } & \text { Zip Code } \\ \text { NJ } & 07410-4401\end{array}$

C

\section{Occupation}

Retired

Election Cycle-to-Date

Receipt For: 2012

Х $\begin{aligned} & \text { Primary } \square \text { General } \\ & \text { Other (specify) }\end{aligned}$

450.00

Subtotal Of Receipts This Page (optional).

650.99

a

Total This Period (last page this line number only)

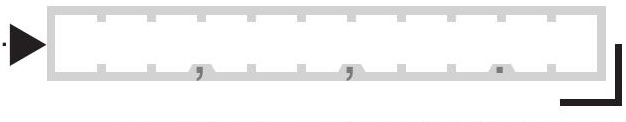

FEC Schedule A-P (Form 3P) (Rev. 03/2011) 


\section{SCHEDULE A-P} ITEMIZED RECEIPTS
Use separate schedule(s) for each category of the Detailed Summary Page

FOR LINE NUMBER:
(check only one)

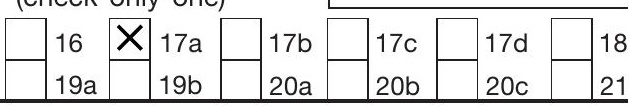

Any information copied from such Reports and Statements may not be sold or used by any person for the purpose of soliciting contributions or for commercial purposes, other than using the name and address of any political committee to solicit contributions from such committee.

NAME OF COMMITTEE (In Full)

\section{Friends of Herman Cain}

A. Full Name (Last, First, Middle Initial)

Kelly Hayes

Mailing Address PO Box 1253

\begin{tabular}{lcc}
\hline City & State & Zip Code \\
Anderson & MO & $64831-1253$ \\
\hline
\end{tabular}

FEC ID number of contributing federal political committee.

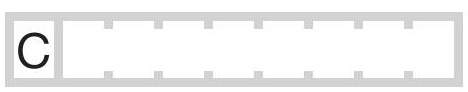

Name of Employer
Walmart
Receipt For: 2012
X Primary
Other (specify) General

Occupation Manager

Election Cycle-to-Date 300.00

B. Full Name (Last, First, Middle Initial) Richard Larrey

Mailing Address 2801 Jarrard St

\begin{tabular}{lcc}
\hline City & State & Zip Code \\
Houston & TX & $77005-3033$
\end{tabular}

FEC ID number of contributing

federal political committee.

C

Name of Employer
Information Requested
Receipt For: 2012
Primary
Other (specify)

Occupation

Information Requested

Election Cycle-to-Date

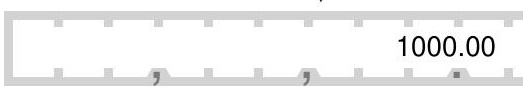

C. Full Name (Last, First, Middle Initial)

Ms Barbara Harrell

Mailing Address 2183 Kinridge Rd

\begin{tabular}{lcc}
\hline City & State & Zip Code \\
Marietta & GA & $30062-1819$
\end{tabular}

FEC ID number of contributing federal political committee.

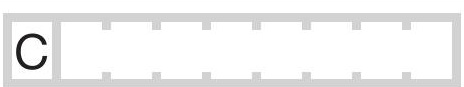

Name of Employer
Information Requested
Receipt For: 2012
X Primary
Other (specify) General

\section{Occupation}

Information Requested

Election Cycle-to-Date

Transaction ID : A223ADC6B94B54041817

Date of Receipt

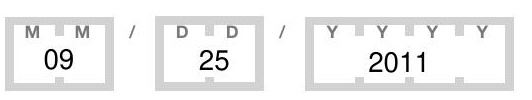

Amount of Each Receipt this Period

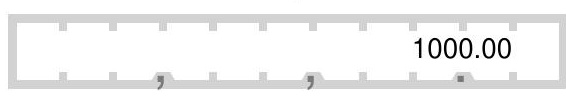

Amount of Each Receipt this Period

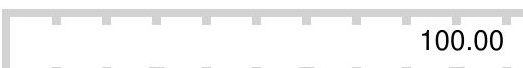

Date of Receipt

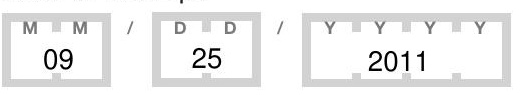

995 
SCHEDULE A-P ITEMIZED RECEIPTS
Use separate schedule(s) for each category of the Detailed Summary Page
FOR LINE NUMBER: (check only one)

PAGE $713 / 1572$

\begin{tabular}{|c|c|c|c|c|c|}
\hline & & & & & \\
\hline 16 & $\begin{array}{l}\mathbf{X} \\
17 a\end{array}$ & $17 b$ & $17 c$ & $17 d$ & 18 \\
\hline $19 a$ & $19 \mathrm{~b}$ & $20 \mathrm{a}$ & $20 \mathrm{~b}$ & $20 \mathrm{c}$ & 21 \\
\hline
\end{tabular}

Any information copied from such Reports and Statements may not be sold or used by any person for the purpose of soliciting contributions or for commercial purposes, other than using the name and address of any political committee to solicit contributions from such committee.

NAME OF COMMITTEE (In Full)

\section{Friends of Herman Cain}

A. Full Name (Last, First, Middle Initial)

Kristie Hillhouse

Mailing Address 257 Fisk Road

\begin{tabular}{lcc}
\hline City & State & Zip Code \\
Benton Harbor & MI & $49022-6718$
\end{tabular}

FEC ID number of contributing federal political committee.

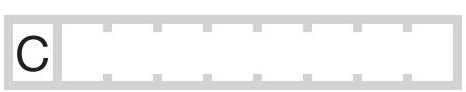

Name of Employer
Bob Evans Farms
Receipt For: 2012
X Primary
Other (specify) General

Occupation

Server

Election Cycle-to-Date

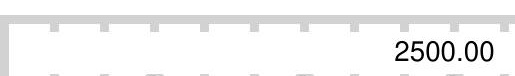

B. Full Name (Last, First, Middle Initial)

Buster Fontenot

Mailing Address PO Box 513

\begin{tabular}{lcc}
\hline City & State & Zip Code \\
Ville Platte & LA & $70586-0513$ \\
\hline
\end{tabular}

FEC ID number of contributing

federal political committee.

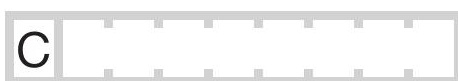

Name of Employer
Self Employed
Receipt For: 2012
X Primary
Other (specify)

\section{Occupation}

Consultant

Election Cycle-to-Date

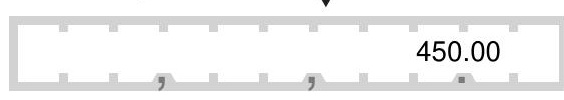

Transaction ID : AF01CF05E170C4D079D7

Date of Receipt

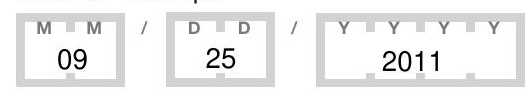

Amount of Each Receipt this Period

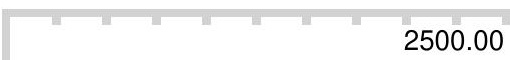

C. Full Name (Last, First, Middle Initial)

Scott Taranovich

Mailing Address 2913 Kimbrough LN

\begin{tabular}{lcc}
\hline City & State & Zip Code \\
McKinney & TX & $75071-2755$
\end{tabular}

FEC ID number of contributing

federal political committee.

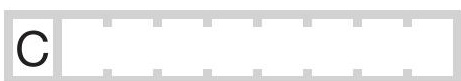

Name of Employer
Ericsson Inc
Receipt For: 2012
X Primary
Other (specify) General

Occupation

Sr. Engineer

Election Cycle-to-Date

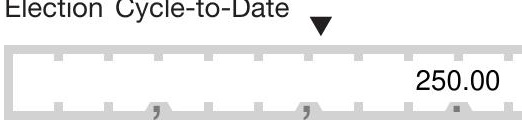

Amount of Each Receipt this Period

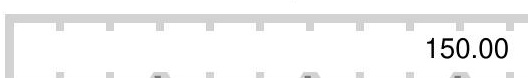

Transaction ID : A29A10A7FAFF94E158AF

Date of Receipt

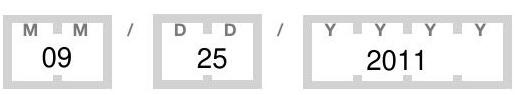

Transaction ID : A57C88567716045CAA7C Date of Receipt

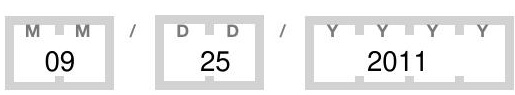

Amount of Each Receipt this Period

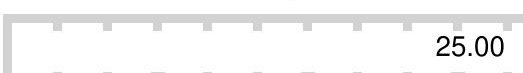

\section{Subtotal Of Receipts This Page (optional)}

2675.00

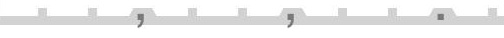

Total This Period (last page this line number only)

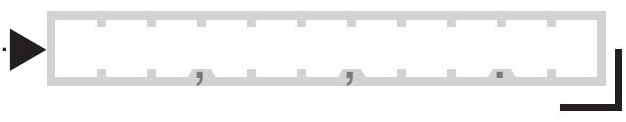

FEC Schedule A-P (Form 3P) (Rev. 03/2011) 
SCHEDULE A-P ITEMIZED RECEIPTS
Use separate schedule(s) for each category of the Detailed Summary Page
FOR LINE NUMBER: (check only one)

PAGE $714 / 1572$

\begin{tabular}{|c|c|c|c|c|c|}
\hline & & & & & \\
\hline 16 & $\begin{array}{l}\mathbf{X} \\
17 a\end{array}$ & $17 b$ & $17 c$ & $17 d$ & 18 \\
\hline $19 a$ & $19 \mathrm{~b}$ & $20 \mathrm{a}$ & $20 \mathrm{~b}$ & $20 \mathrm{c}$ & 21 \\
\hline
\end{tabular}

Any information copied from such Reports and Statements may not be sold or used by any person for the purpose of soliciting contributions or for commercial purposes, other than using the name and address of any political committee to solicit contributions from such committee.

NAME OF COMMITTEE (In Full)

\section{Friends of Herman Cain}

A. Full Name (Last, First, Middle Initial)

William Gingrich

Mailing Address 8 Live Oak

\begin{tabular}{lcc}
\hline City & State & Zip Code \\
Fernandina Beach & FL & $32034-5025$
\end{tabular}

FEC ID number of contributing

federal political committee.

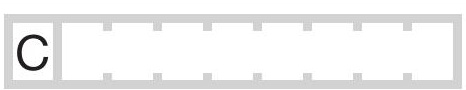

\begin{tabular}{l} 
Name of Employer \\
GE \\
Receipt For: 2012 \\
X Primary $\quad$ General \\
\hline Other (specify)
\end{tabular}

Occupation

Retired

Election Cycle-to-Date

2000.00

B. Full Name (Last, First, Middle Initial)

Richard Butler

Mailing Address 177 Blue Sky Dr

\begin{tabular}{lcc}
\hline City & State & Zip Code \\
Marietta & GA & $30068-3812$ \\
\hline
\end{tabular}

FEC ID number of contributing

federal political committee.

C

Name of Employer
Associates Express nlnc
Receipt For: 2012
X Primary
Other (specify)

\section{Occupation}

truck driver

Transaction ID : A91F7A00D08534470AFD

Date of Receipt

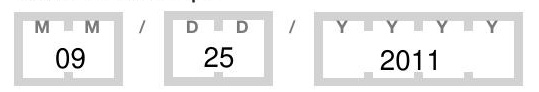

Amount of Each Receipt this Period

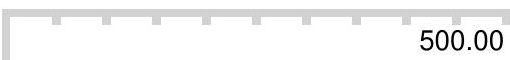

500.00

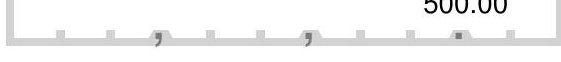

Transaction ID : A7E8539B5F88E409D93A

Date of Receipt

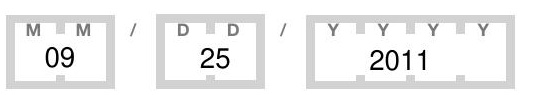

Amount of Each Receipt this Period

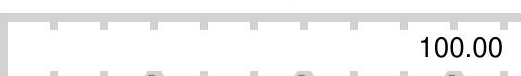

Election Cycle-to-Date

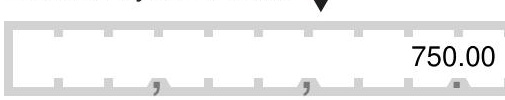

C. Full Name (Last, First, Middle Initial)

james Fletter

Mailing Address 4209 Los Coches Way

\begin{tabular}{lcc}
\hline City & State & Zip Code \\
Sacramento & CA & $95864-5241$
\end{tabular}

FEC ID number of contributing

federal political committee.

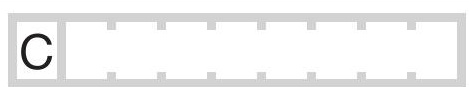

Name of Employer

Information Requested

Occupation

Information Requested

Receipt For: 2012

Х $\begin{aligned} & \text { Primary } \\ & \text { Other (specify) }\end{aligned}$

Transaction ID : AD17E7909983F43D1AFF

Date of Receipt

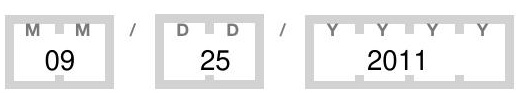

Amount of Each Receipt this Period

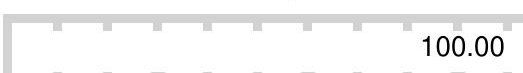

\section{Subtotal Of Receipts This Page (optional)}

Total This Period (last page this line number only) 
SCHEDULE A-P ITEMIZED RECEIPTS
Use separate schedule(s) for each category of the Detailed Summary Page
FOR LINE NUMBER: (check only one)
PAGE $715 / 1572$

\begin{tabular}{|c|c|c|c|c|c|}
\hline & & & & & \\
\hline 16 & $\begin{array}{lll}X & 17 a \\
\end{array}$ & $17 \mathrm{~b}$ & $17 c$ & $17 d$ & 18 \\
\hline $19 a$ & $19 b$ & $20 a$ & $20 \mathrm{~b}$ & $20 c$ & 21 \\
\hline
\end{tabular}

Any information copied from such Reports and Statements may not be sold or used by any person for the purpose of soliciting contributions or for commercial purposes, other than using the name and address of any political committee to solicit contributions from such committee.

NAME OF COMMITTEE (In Full)

\section{Friends of Herman Cain}

A. Full Name (Last, First, Middle Initial) Joe turosky

Mailing Address 527 Long Mountain Rd

\begin{tabular}{lcc}
\hline City & State & Zip Code \\
New Milford & CT & $06776-4803$
\end{tabular}

FEC ID number of contributing federal political committee.

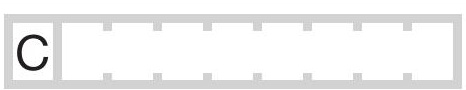

Name of Employer
Information Requested
Receipt For: 2012
X Primary
Other (specify) General

Occupation Information Requested

Election Cycle-to-Date

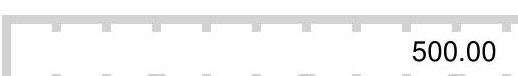

B. Full Name (Last, First, Middle Initial) Larry Rosner

Mailing Address 143 Park Ave Apt D

\begin{tabular}{lcc}
\hline City & State & Zip Code \\
Park Ridge & NJ & $07656-1356$
\end{tabular}

FEC ID number of contributing

federal political committee.

C

Name of Employer
Information Requested
Receipt For: 2012
Xrimary
Other (specify)

Occupation

Information Requested

Election Cycle-to-Date

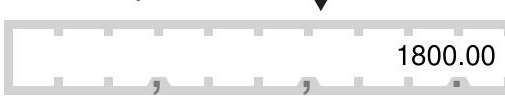

Transaction ID : ABD6B2900D17A493EBB1

Date of Receipt

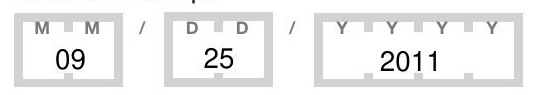

Amount of Each Receipt this Period

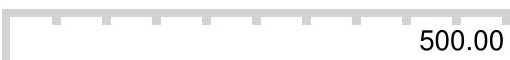

C. Full Name (Last, First, Middle Initial)

Michael Olcott

Mailing Address PO Box 330427

\begin{tabular}{lcc}
\hline City & State & Zip Code \\
Fort Worth & TX & $76163-0427$
\end{tabular}

FEC ID number of contributing federal political committee.

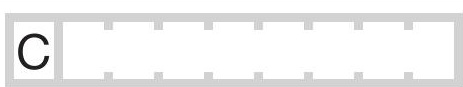

Name of Employer
Information Requested
Receipt For: 2012
X Primary $\quad \square$ General
Other (specify)

\section{Occupation}

Information Requested

Election Cycle-to-Date

Transaction ID : AD3DFD218D02F4A4CBF9 Date of Receipt

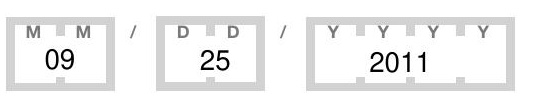

Amount of Each Receipt this Period

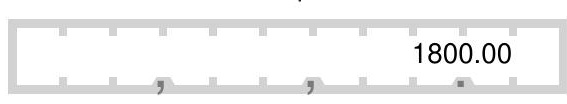

Transaction ID : A4AED9C4F67AA490C8F0 Date of Receipt

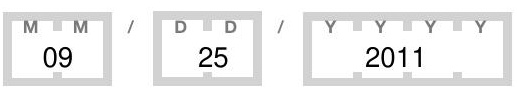

Amount of Each Receipt this Period

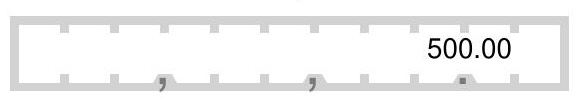

500.00

\section{Subtotal Of Receipts This Page (optional)}

Total This Period (last page this line number only) 
SCHEDULE A-P ITEMIZED RECEIPTS
Use separate schedule(s) for each category of the Detailed Summary Page
FOR LINE NUMBER: (check only one)

PAGE $716 / 1572$

\begin{tabular}{|c|c|c|c|c|c|}
\hline & & & & & \\
\hline 16 & $\begin{array}{l}\mathbf{X} \\
17 a\end{array}$ & $17 b$ & $17 c$ & $17 d$ & 18 \\
\hline $19 a$ & $19 \mathrm{~b}$ & $20 \mathrm{a}$ & $20 \mathrm{~b}$ & $20 \mathrm{c}$ & 21 \\
\hline
\end{tabular}

Any information copied from such Reports and Statements may not be sold or used by any person for the purpose of soliciting contributions or for commercial purposes, other than using the name and address of any political committee to solicit contributions from such committee.

NAME OF COMMITTEE (In Full)

\section{Friends of Herman Cain}

A. Full Name (Last, First, Middle Initial)

Terrence Leveck

Mailing Address 454 Plantation Blvd

\begin{tabular}{lcc}
\hline City & State & Zip Code \\
Lebanon & TN & $37087-3260$
\end{tabular}

FEC ID number of contributing federal political committee.

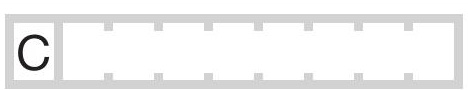

Name of Employer
Self Employed
Receipt For: 2012
X Primary $\quad \square$ General
Other (specify)

Occupation

Physician

Election Cycle-to-Date

1000.00

B. Full Name (Last, First, Middle Initial)

David Morgan

Mailing Address 18922 76th Ave SE

\begin{tabular}{llc}
\hline City & State & Zip Code \\
Snohomish & WA & $98296-7921$
\end{tabular}

FEC ID number of contributing

federal political committee.

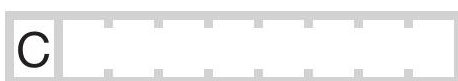

\begin{tabular}{l} 
Name of Employer \\
Information Requested \\
Receipt For: 2012 \\
X Primary \\
\hline Other (specify)
\end{tabular}

Occupation

Information Requested

Election Cycle-to-Date

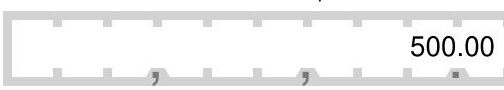

Transaction ID : A10F74255A5AB4C2E8B0

Date of Receipt

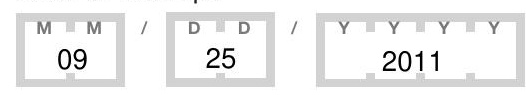

Amount of Each Receipt this Period

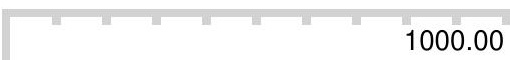

1000.00

C. Full Name (Last, First, Middle Initial)

John Lemire

Mailing Address 58 Lake Latimer Drive

\begin{tabular}{lcc}
\hline City & State & Zip Code \\
Kennesaw & GA & $30144-1597$
\end{tabular}

FEC ID number of contributing

federal political committee.

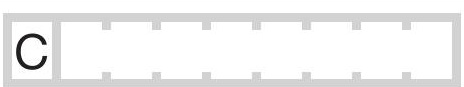

Name of Employer
n/a
Receipt For: 2012
X Primary $\square$ General
Other (specify)

Occupation

Retired

Election Cycle-to-Date

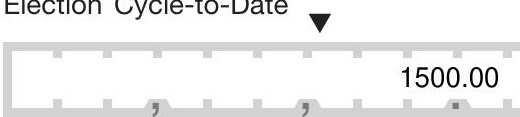

Transaction ID : A958A54F3B82341269D7

Date of Receipt

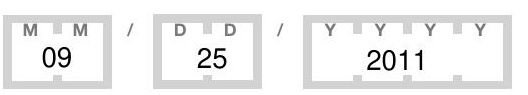

Amount of Each Receipt this Period

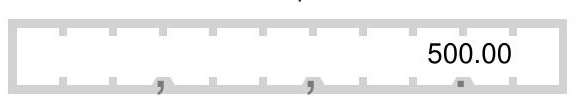

Transaction ID : AC017AECD48404D89B53 Date of Receipt

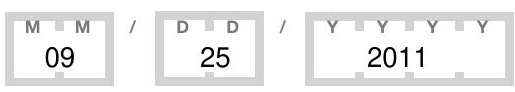

Amount of Each Receipt this Period

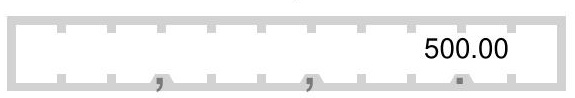

\section{Subtotal Of Receipts This Page (optional)}

Total This Period (last page this line number only) 
SCHEDULE A-P ITEMIZED RECEIPTS
Use separate schedule(s) for each category of the Detailed Summary Page
FOR LINE NUMBER: (check only one)

PAGE $717 / 1572$

\begin{tabular}{|c|c|c|c|c|c|}
\hline & & & & & \\
\hline 16 & $\begin{array}{l}\mathbf{X} \\
17 a\end{array}$ & $17 b$ & $17 c$ & $17 d$ & 18 \\
\hline $19 a$ & $19 \mathrm{~b}$ & $20 \mathrm{a}$ & $20 \mathrm{~b}$ & $20 \mathrm{c}$ & 21 \\
\hline
\end{tabular}

Any information copied from such Reports and Statements may not be sold or used by any person for the purpose of soliciting contributions or for commercial purposes, other than using the name and address of any political committee to solicit contributions from such committee.

NAME OF COMMITTEE (In Full)

\section{Friends of Herman Cain}

A. Full Name (Last, First, Middle Initial)

Gary Nie

Mailing Address 1325 W. Sunshine \#526

\begin{tabular}{lcc}
\hline City & State & Zip Code \\
Springfield & MO & $65807-2344$ \\
\hline
\end{tabular}

FEC ID number of contributing federal political committee.

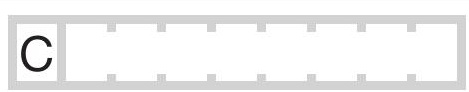

Name of Employer
Angel Animal Hospital
Receipt For: 2012
X Primary
Other (specify) General

Occupation Veterinarian

Election Cycle-to-Date

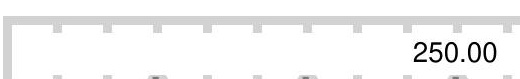

B. Full Name (Last, First, Middle Initial)

Mr. john B. davidson Jr.

Mailing Address 158 mill point drive

\begin{tabular}{lcc}
\hline City & State & Zip Code \\
Hampton & VA & $23669-3535$ \\
\hline
\end{tabular}

FEC ID number of contributing

federal political committee.

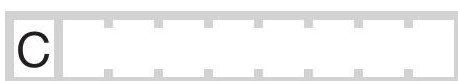

Name of Employer
Self Employed
Receipt For: 2012
X Primary
Other (specify)

Occupation

Physician

Election Cycle-to-Date

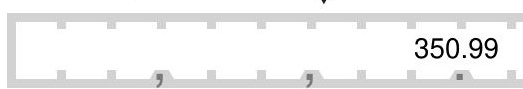

Transaction ID : A652C3AFE05894B25B37

Date of Receipt

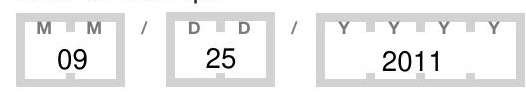

Amount of Each Receipt this Period

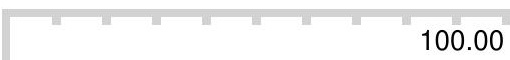

Transaction ID : A7422DC00A7124E11BA1

Date of Receipt

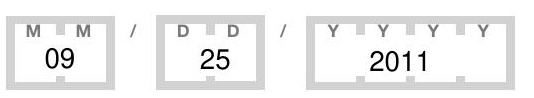

Amount of Each Receipt this Period

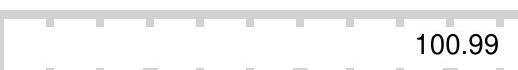

Transaction ID : A53C03E844E964C209A7

Date of Receipt

Brian Oneill

Mailing Address 8814 Orchard Lake

\begin{tabular}{lcc}
\hline City & State & Zip Code \\
Holland & OH & $43528-9200$
\end{tabular}

FEC ID number of contributing federal political committee.

C $43528-9200$

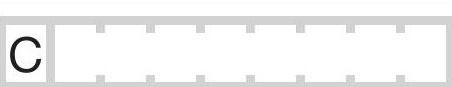

Name of Employer

Occupation

Information Requested

Information Requested

Receipt For: 2012

Х $\begin{aligned} & \text { Primary } \\ & \text { Other (specify) }\end{aligned}$

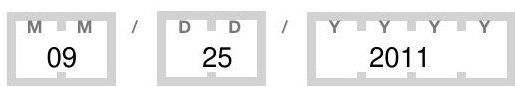

Amount of Each Receipt this Period

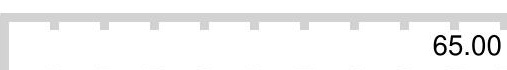

\section{Subtotal Of Receipts This Page (optional)}

Total This Period (last page this line number only) 


\section{SCHEDULE A-P} ITEMIZED RECEIPTS
Use separate schedule(s) for each category of the Detailed Summary Page

FOR LINE NUMBER:
(check only one)

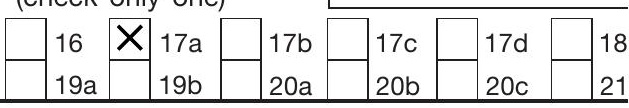

Any information copied from such Reports and Statements may not be sold or used by any person for the purpose of soliciting contributions or for commercial purposes, other than using the name and address of any political committee to solicit contributions from such committee.

NAME OF COMMITTEE (In Full)

\section{Friends of Herman Cain}

A. Full Name (Last, First, Middle Initial)

Blane Crandall

Mailing Address 777 Wedge Dr

\begin{tabular}{lcc}
\hline City & State & Zip Code \\
Naples & FL & $34103-4447$ \\
\hline
\end{tabular}

FEC ID number of contributing federal political committee.

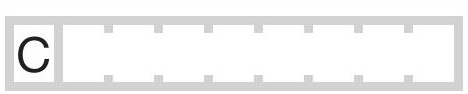

Name of Employer
Self Employed
Receipt For: 2012
X Primary
$\square$ Other (specify) General

Occupation

Physician

Election Cycle-to-Date

630.00

B. Full Name (Last, First, Middle Initial)

Karen Wade

Mailing Address 412 Copperhead Lane

\begin{tabular}{lcc}
\hline City & State & Zip Code \\
Winchester & VA & $22602-3448$ \\
\hline
\end{tabular}

FEC ID number of contributing

federal political committee.

C

Name of Employer
Blue Ridge Gyn/Ob
Receipt For: 2012
Primary
Other (specify) General

Occupation

Physician

Election Cycle-to-Date

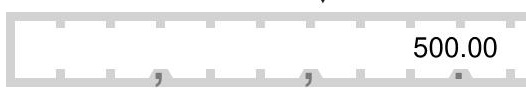

Transaction ID : AEE01DAE010434504944

Date of Receipt

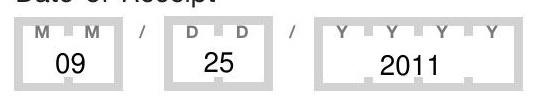

Amount of Each Receipt this Period

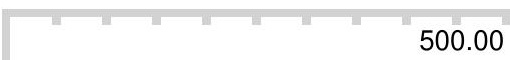

500.00

C. Full Name (Last, First, Middle Initial)

Mrs. Barbara C. Mathews

Mailing Address 2367 LAvista Road

\begin{tabular}{lcc}
\hline City & State & Zip Code \\
Atlanta & GA & $30329-3346$ \\
\hline
\end{tabular}

FEC ID number of contributing federal political committee.

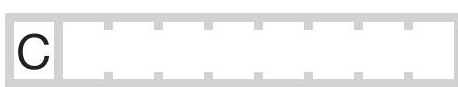

Name of Employer
None
Receipt For: 2012
X Primary $\quad \square$ General
Other (specify)

Occupation

Retired

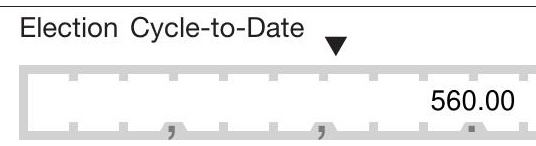

Transaction ID : AFE89078044EE4574839

Date of Receipt

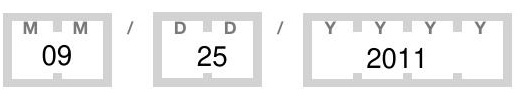

Amount of Each Receipt this Period

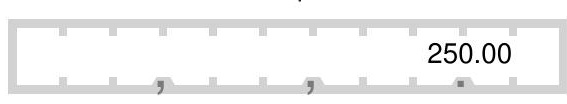

Transaction ID : A6D6C2555DC864859AFC Date of Receipt

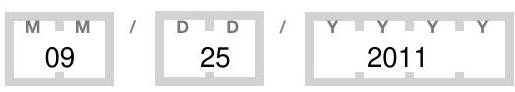

Amount of Each Receipt this Period

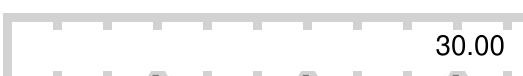

\section{Subtotal Of Receipts This Page (optional)}

Total This Period (last page this line number only) 
SCHEDULE A-P ITEMIZED RECEIPTS
Use separate schedule(s) for each category of the Detailed Summary Page
FOR LINE NUMBER: (check only one)

PAGE $719 / 1572$

\begin{tabular}{|c|c|c|c|c|c|}
\hline & & & & & \\
\hline 16 & $\begin{array}{l}\mathbf{X} \\
17 a\end{array}$ & $17 b$ & $17 c$ & $17 d$ & 18 \\
\hline $19 a$ & $19 \mathrm{~b}$ & $20 \mathrm{a}$ & $20 \mathrm{~b}$ & $20 \mathrm{c}$ & 21 \\
\hline
\end{tabular}

Any information copied from such Reports and Statements may not be sold or used by any person for the purpose of soliciting contributions or for commercial purposes, other than using the name and address of any political committee to solicit contributions from such committee.

NAME OF COMMITTEE (In Full)

\section{Friends of Herman Cain}

A. Full Name (Last, First, Middle Initial) John McCarstle

Mailing Address PO Box 926

\begin{tabular}{lcc}
\hline City & State & Zip Code \\
Baton Rouge & LA & $70821-0926$
\end{tabular}

FEC ID number of contributing federal political committee.

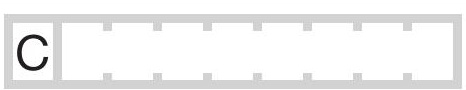

Name of Employer
Ace Armature Works, Inc.
Receipt For: 2012
X Primary $\quad \square$ General
Other (specify)

Occupation

Sales

Election Cycle-to-Date

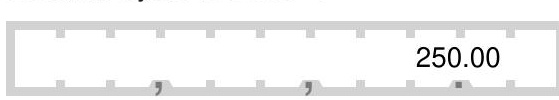

B. Full Name (Last, First, Middle Initial)

Roger Griggs

Mailing Address 10650 Big Bone Church

\begin{tabular}{lcc}
\hline City & State & Zip Code \\
Union & KY & $41091-9432$
\end{tabular}

FEC ID number of contributing

federal political committee.

C

Name of Employer
Union Springs Wellness
Receipt For: 2012
X Primary
Other (specify)

\section{Occupation}

Chairman Of The Board

Election Cycle-to-Date

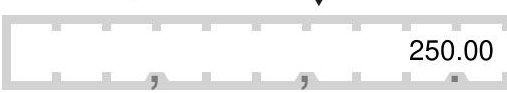

Transaction ID : ACDC653EBBCB1495CA42

Date of Receipt

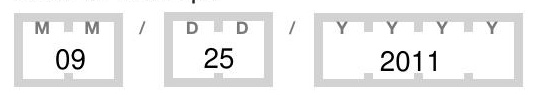

Amount of Each Receipt this Period

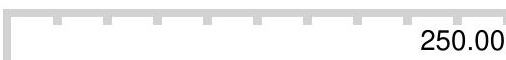

C. Full Name (Last, First, Middle Initial)

lynda felts

Mailing Address $3200 \mathrm{w}$ rollins $3200 \mathrm{w}$ rollins

\begin{tabular}{lcc}
\hline City & State & Zip Code \\
Moss Point & MS & 39563 \\
\hline
\end{tabular}

FEC ID number of contributing

federal political committee.

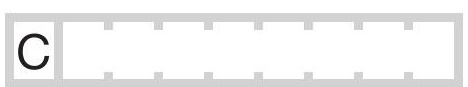

Name of Employer

Information Requested

\section{Occupation}

Information Requested

Receipt For: 2012

Х $\begin{aligned} & \text { Primary } \square \text { General } \\ & \text { Other (specify) }\end{aligned}$

Transaction ID : A03716CD9BEE44107840

Date of Receipt

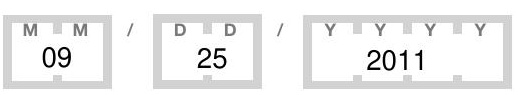

Amount of Each Receipt this Period

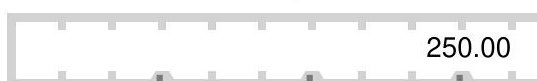

Transaction ID : A3F2DC2A2937544AEA6E Date of Receipt

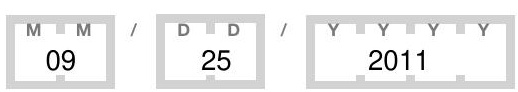

Amount of Each Receipt this Period

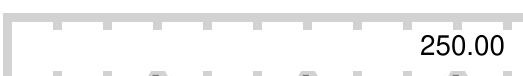

\section{Subtotal Of Receipts This Page (optional)}

Total This Period (last page this line number only) 
SCHEDULE A-P ITEMIZED RECEIPTS
Use separate schedule(s) for each category of the Detailed Summary Page
FOR LINE NUMBER: (check only one)

PAGE $720 / 1572$

\begin{tabular}{|c|c|c|c|c|c|}
\hline & & & & & \\
\hline 16 & $\begin{array}{l}\mathbf{X} \\
17 a\end{array}$ & $17 b$ & $17 c$ & $17 d$ & 18 \\
\hline $19 a$ & $19 \mathrm{~b}$ & $20 \mathrm{a}$ & $20 \mathrm{~b}$ & $20 \mathrm{c}$ & 21 \\
\hline
\end{tabular}

Any information copied from such Reports and Statements may not be sold or used by any person for the purpose of soliciting contributions or for commercial purposes, other than using the name and address of any political committee to solicit contributions from such committee.

NAME OF COMMITTEE (In Full)

\section{Friends of Herman Cain}

A. Full Name (Last, First, Middle Initial)

Virginia Reed

Mailing Address 4355 J Cobb Parkway, Suite 282

\begin{tabular}{lcc}
\hline City & State & Zip Code \\
Atlanta & GA & $30339-3811$ \\
\hline
\end{tabular}

FEC ID number of contributing federal political committee.

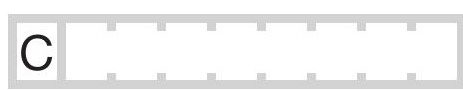

Name of Employer
Information Requested
Receipt For: 2012
X Primary
Other (specify) General

Occupation Information Requested

Election Cycle-to-Date

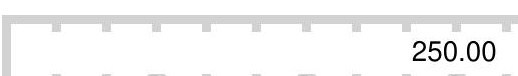

B. Full Name (Last, First, Middle Initial)

Vikki Brown

Mailing Address 391 Leeches Rd

\begin{tabular}{lcc}
\hline City & State & Zip Code \\
Ellijay & GA & $30540-7354$ \\
\hline
\end{tabular}

FEC ID number of contributing

federal political committee.

C

Name of Employer
AT\&T
Receipt For: 2012
X Primary
Other (specify)

Occupation

Intellectual Property Specialist

Election Cycle-to-Date

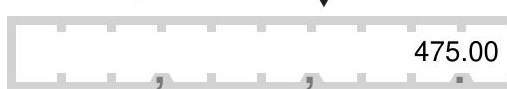

Transaction ID : A944EC32022494145A3F

Date of Receipt

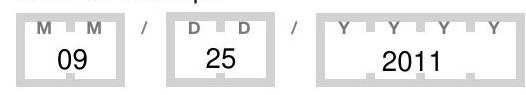

Amount of Each Receipt this Period

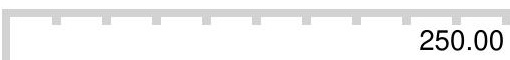

Transaction ID : AC16F62C9FA744B68B27 Date of Receipt

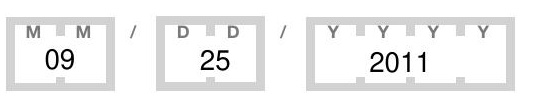

Amount of Each Receipt this Period

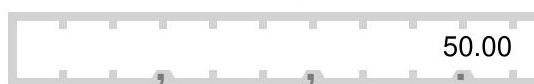

Transaction ID : AFE331EB8CD9A462A8D9 Date of Receipt

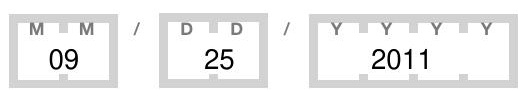

Amount of Each Receipt this Period

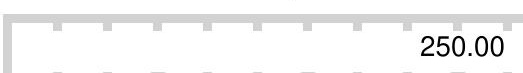

$\begin{array}{cc}\text { State } & \text { Zip Code } \\ \text { CA } & 92064-5846\end{array}$

C

\section{Occupation}

Founder

Election Cycle-to-Date

Receipt For: 2012

Х $\begin{aligned} & \text { Primary } \square \text { General } \\ & \text { Other (specify) }\end{aligned}$

250.00

Subtotal Of Receipts This Page (optional).

550.00

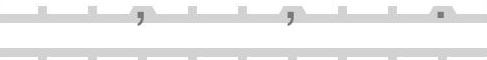

Total This Period (last page this line number only) 


\section{SCHEDULE A-P} ITEMIZED RECEIPTS
Use separate schedule(s)

for each category of the

Detailed Summary Page
FOR LINE NUMBER: (check only one)

PAGE $721 / 1572$

\begin{tabular}{|c|c|c|c|c|c|}
\hline & & & & & \\
\hline 16 & $\mathbf{X} 17 \mathrm{a}$ & $17 \mathrm{~b}$ & $17 c$ & $17 d$ & 18 \\
\hline $19 a$ & $19 \mathrm{~b}$ & $20 a$ & $20 \mathrm{~b}$ & $20 c$ & 21 \\
\hline
\end{tabular}

Any information copied from such Reports and Statements may not be sold or used by any person for the purpose of soliciting contributions or for commercial purposes, other than using the name and address of any political committee to solicit contributions from such committee.

NAME OF COMMITTEE (In Full)

\section{Friends of Herman Cain}

A. Full Name (Last, First, Middle Initial)

Timothy Sexton

Mailing Address 359 Centennial Dr.

\begin{tabular}{lcc}
\hline City & State & Zip Code \\
Bethlehem & GA & $30620-3337$
\end{tabular}

FEC ID number of contributing

federal political committee.

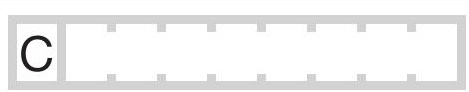

Name of Employer
Information Requested
Receipt For: 2012
X Primary $\quad \square$ General
Other (specify)

Occupation

Information Requested

Election Cycle-to-Date

250.00

B. Full Name (Last, First, Middle Initial)

Cory Zornizer

Mailing Address 331 Meadowtree Ct

\begin{tabular}{lcc}
\hline City & State & Zip Code \\
Foley & MO & $63347-2867$ \\
\hline
\end{tabular}

FEC ID number of contributing

federal political committee.

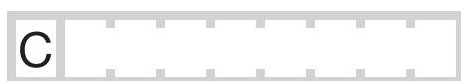

Name of Employer
Express-Scripts
Receipt For: 2012
X Primary
Other (specify)

Occupation

Operations Director

Election Cycle-to-Date

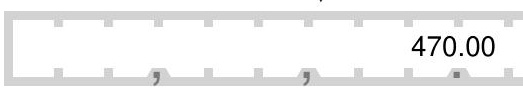

Transaction ID : A3DF4BBC839CD4B5FBF0

Date of Receipt

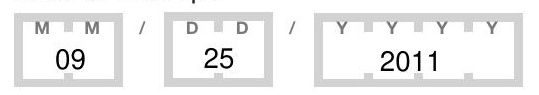

Amount of Each Receipt this Period

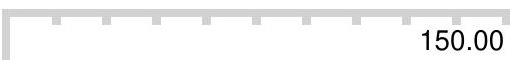

150.00

C. Full Name (Last, First, Middle Initial)

Anthony Acosta

Mailing Address 663 Avenue C

\begin{tabular}{lcc}
\hline City & State & Zip Code \\
Redondo Beach & CA & $90277-4840$
\end{tabular}

FEC ID number of contributing federal political committee.

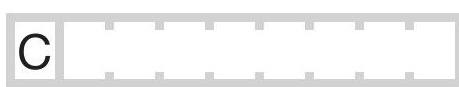

Name of Employer
northrop grumman
Receipt For: 2012
X Primary
Other (specify) General

\section{Occupation}

MATHEMATICIAN

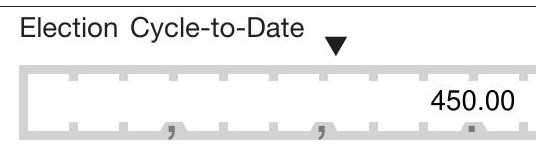

Transaction ID : AF0EDE9C4E5FF409793F

Date of Receipt

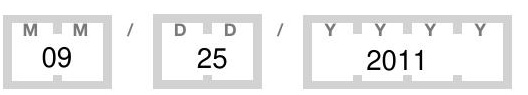

Amount of Each Receipt this Period

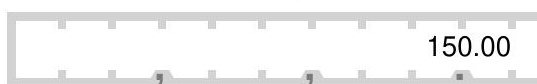

Transaction ID : AB183B254CD344F0D9C6 Date of Receipt

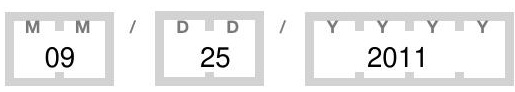

Amount of Each Receipt this Period

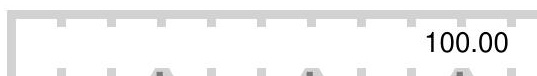

\section{Subtotal Of Receipts This Page (optional)}

400.00

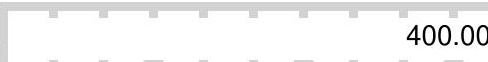

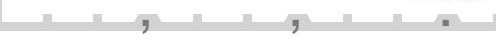

Total This Period (last page this line number only)

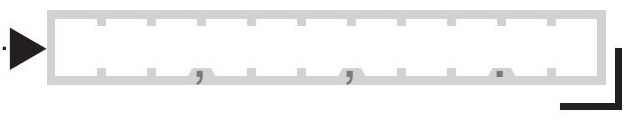

FEC Schedule A-P (Form 3P) (Rev. 03/2011) 
SCHEDULE A-P ITEMIZED RECEIPTS
Use separate schedule(s) for each category of the Detailed Summary Page
FOR LINE NUMBER: (check only one)

PAGE 722 / 1572

\begin{tabular}{|c|c|c|c|c|c|}
\hline & & & & & \\
\hline 16 & $\begin{array}{l}\mathbf{X} \\
17 a\end{array}$ & $17 b$ & $17 c$ & $17 d$ & 18 \\
\hline $19 a$ & $19 \mathrm{~b}$ & $20 \mathrm{a}$ & $20 \mathrm{~b}$ & $20 \mathrm{c}$ & 21 \\
\hline
\end{tabular}

Any information copied from such Reports and Statements may not be sold or used by any person for the purpose of soliciting contributions or for commercial purposes, other than using the name and address of any political committee to solicit contributions from such committee.

NAME OF COMMITTEE (In Full)

\section{Friends of Herman Cain}

A. Full Name (Last, First, Middle Initial)

Mrs. Sandy Heckart

Mailing Address 4754 Lakewood Dr

\begin{tabular}{lcc}
\hline City & State & Zip Code \\
Norwalk & IA & $50211-1818$
\end{tabular}

FEC ID number of contributing federal political committee.

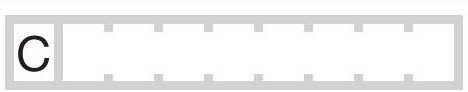

Name of Employer
None
Receipt For: 2012
X Primary $\quad$ General
Other (specify)

Occupation

Retired

Election Cycle-to-Date

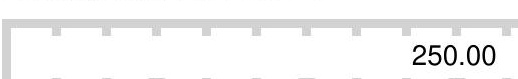

B. Full Name (Last, First, Middle Initial)

Roy Gay

Mailing Address 600 Beech Creek Road, South

\begin{tabular}{lcc}
\hline City & State & Zip Code \\
Brentwood & TN & $37027-3426$ \\
\hline
\end{tabular}

FEC ID number of contributing

federal political committee.

C

Name of Employer
Information Requested
Receipt For: 2012
Xrimary
Other (specify)

Occupation

Information Requested

Election Cycle-to-Date

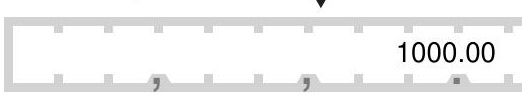

Transaction ID : AB4D3DD422C954E548AB

Date of Receipt

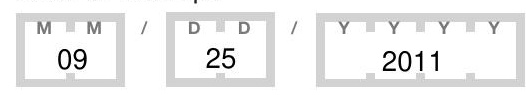

Amount of Each Receipt this Period

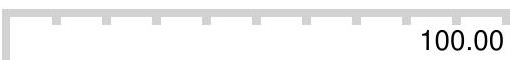

C. Full Name (Last, First, Middle Initial)

Linda Luce

Mailing Address 3604 Maple Forge Ln

\begin{tabular}{lcc}
\hline City & State & Zip Code \\
Gainesville & GA & $30504-5763$
\end{tabular}

FEC ID number of contributing

federal political committee.

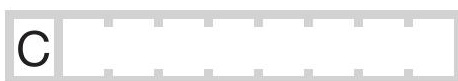

Name of Employer

Northeast Georgia Medical Center

Occupation

Receipt For: 2012

Х $\begin{aligned} & \text { Primary } \square \text { General } \\ & \text { Other (specify) }\end{aligned}$

Medical Technologist

Election Cycle-to-Date

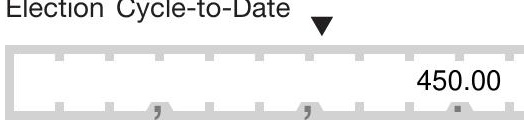

Amount of Each Receipt this Period

Transaction ID : A89FB3E1D71EE4E0799E Date of Receipt

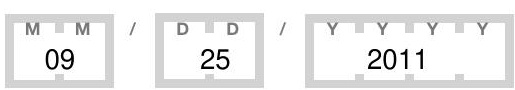

Subtotal Of Receipts This Page (optional)

Total This Period (last page this line number only) 
SCHEDULE A-P ITEMIZED RECEIPTS
Use separate schedule(s) for each category of the Detailed Summary Page
FOR LINE NUMBER: (check only one)

PAGE $723 / 1572$

\begin{tabular}{|c|c|c|c|c|c|}
\hline & & & & & \\
\hline 16 & $\begin{array}{lll}X & 17 a \\
\end{array}$ & $17 \mathrm{~b}$ & $17 c$ & $17 d$ & 18 \\
\hline $19 a$ & $19 b$ & $20 a$ & $20 \mathrm{~b}$ & $20 c$ & 21 \\
\hline
\end{tabular}

Any information copied from such Reports and Statements may not be sold or used by any person for the purpose of soliciting contributions or for commercial purposes, other than using the name and address of any political committee to solicit contributions from such committee.

NAME OF COMMITTEE (In Full)

\section{Friends of Herman Cain}

A. Full Name (Last, First, Middle Initial)

Eugene Rapoport

Mailing Address 15333 East Verbina Dr.

\begin{tabular}{lcc}
\hline City & State & Zip Code \\
Fountain Hills & AZ & 85268-3502 \\
\hline
\end{tabular}

FEC ID number of contributing

federal political committee.

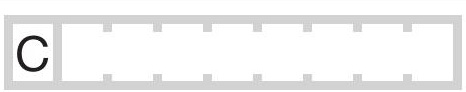

Name of Employer
Information Requested
Receipt For: 2012
X Primary
Other (specify) General

Occupation

Information Requested

Election Cycle-to-Date

1000.00

B. Full Name (Last, First, Middle Initial)

Stephanie Graham

Mailing Address 1311 48th Avenue NE

\begin{tabular}{lcc}
\hline City & State & Zip Code \\
Saint Petersburg & FL & $33703-4115$
\end{tabular}

FEC ID number of contributing

federal political committee.

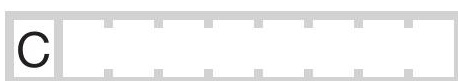

Name of Employer
n/a
Receipt For: 2012
X Primary
Other (specify)

\section{Occupation}

Retired

Election Cycle-to-Date

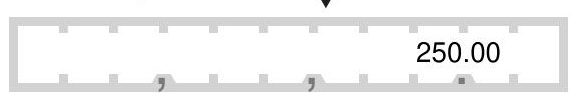

C. Full Name (Last, First, Middle Initial)

Frank Gafford, IV

Mailing Address 137 Bellington Ln

\begin{tabular}{lcc}
\hline City & State & Zip Code \\
Saint Louis & MO & $63141-8116$
\end{tabular}

FEC ID number of contributing

federal political committee.

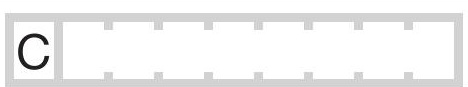

Name of Employer

Information Requested

Occupation

Information Requested

Receipt For: 2012

Х $\begin{aligned} & \text { Primary } \\ & \text { Other (specify) }\end{aligned}$

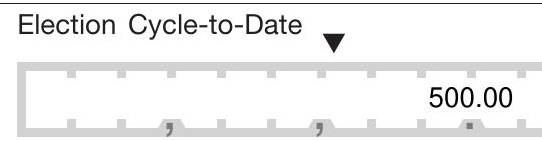

Transaction ID : A3813F619A0FC45E6BA3

Date of Receipt

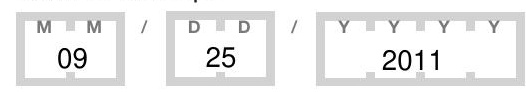

Amount of Each Receipt this Period

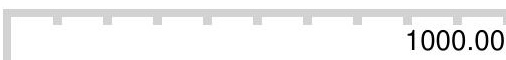

1000.00

Transaction ID : AE0A692DAA2614509801

Date of Receipt

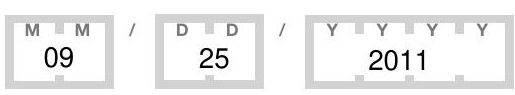

Amount of Each Receipt this Period

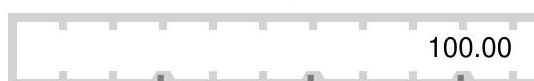

Transaction ID : A09F3834940ED480E87A

Date of Receipt

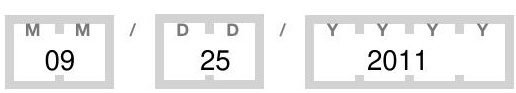

Amount of Each Receipt this Period

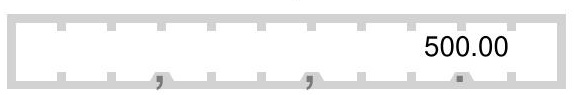

1600.00

Subtotal Of Receipts This Page (optional)

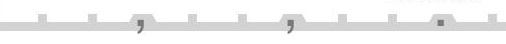

Total This Period (last page this line number only) 
SCHEDULE A-P ITEMIZED RECEIPTS
Use separate schedule(s) for each category of the Detailed Summary Page
FOR LINE NUMBER: (check only one)

PAGE 724 / 1572

\begin{tabular}{|c|c|c|c|c|c|}
\hline & & & & & \\
\hline 16 & $\begin{array}{l}\mathbf{X} \\
17 a\end{array}$ & $17 b$ & $17 c$ & $17 d$ & 18 \\
\hline $19 a$ & $19 \mathrm{~b}$ & $20 \mathrm{a}$ & $20 \mathrm{~b}$ & $20 \mathrm{c}$ & 21 \\
\hline
\end{tabular}

Any information copied from such Reports and Statements may not be sold or used by any person for the purpose of soliciting contributions or for commercial purposes, other than using the name and address of any political committee to solicit contributions from such committee.

NAME OF COMMITTEE (In Full)

\section{Friends of Herman Cain}

A. Full Name (Last, First, Middle Initial)

H Williams

Mailing Address 111 Lauderdale Rd

\begin{tabular}{lcc}
\hline City & State & Zip Code \\
Nashville & TN & $37205-1819$ \\
\hline
\end{tabular}

FEC ID number of contributing

federal political committee.

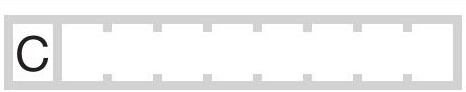

Name of Employer
Information Requested
Receipt For: 2012
X Primary
Other (specify) General

Occupation

Information Requested

Election Cycle-to-Date

250.00

B. Full Name (Last, First, Middle Initial)

Paul MacGregor

Mailing Address 3000 Old Alabama Road Suite 119-15

\begin{tabular}{lcc}
\hline City & State & Zip Code \\
Alpharetta & GA & $30022-5860$ \\
\hline
\end{tabular}

FEC ID number of contributing

federal political committee.

C

Name of Employer
Information Requested
Receipt For: 2012
X Primary
Other (specify)

Occupation

Information Requested

Election Cycle-to-Date

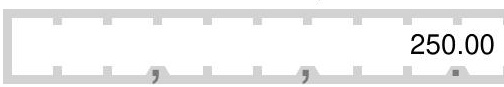

Transaction ID : A373A1B375C9441BCB07

Date of Receipt

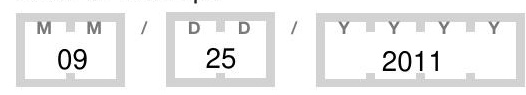

Amount of Each Receipt this Period

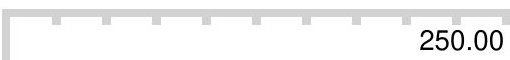

Transaction ID : ACEEB46E0657B44609C2

Date of Receipt

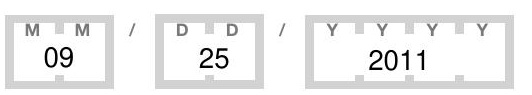

Amount of Each Receipt this Period

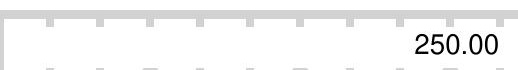

Transaction ID : A072B62C1B70641A5B4F

Date of Receipt

Gabrielle Manigault

Mailing Address 832 Greenough Rd.

\begin{tabular}{lcc}
\hline City & State & Zip Code \\
Recluse & WY & 82725 \\
\hline
\end{tabular}

FEC ID number of contributing

federal political committee.

C

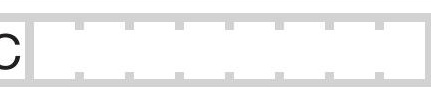

Name of Employer

Information Requested

Occupation

Information Requested

Receipt For: 2012

Х $\begin{aligned} & \text { Primary } \\ & \text { Other (specify) }\end{aligned}$

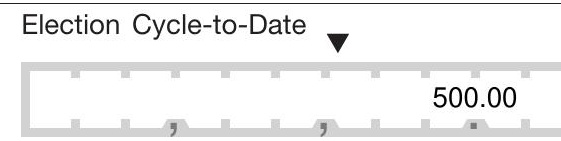

Amount of Each Receipt this Period

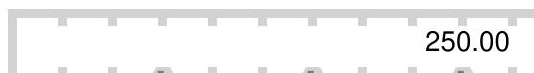

750.00

Subtotal Of Receipts This Page (optional)

Total This Period (last page this line number only) 
SCHEDULE A-P ITEMIZED RECEIPTS
Use separate schedule(s) for each category of the Detailed Summary Page
FOR LINE NUMBER: (check only one)

PAGE $725 / 1572$

\begin{tabular}{|c|c|c|c|c|c|}
\hline & & & & & \\
\hline 16 & $\mathbf{X} 17 a$ & $17 b$ & $17 c$ & $17 d$ & 18 \\
\hline $19 a$ & $19 b$ & $20 \mathrm{a}$ & $20 \mathrm{~b}$ & $20 \mathrm{c}$ & 21 \\
\hline
\end{tabular}

Any information copied from such Reports and Statements may not be sold or used by any person for the purpose of soliciting contributions or for commercial purposes, other than using the name and address of any political committee to solicit contributions from such committee.

NAME OF COMMITTEE (In Full)

\section{Friends of Herman Cain}

A. Full Name (Last, First, Middle Initial)

florence barnett

Mailing Address 760OLD Rucker Rd

\begin{tabular}{lcc}
\hline City & State & Zip Code \\
Alpharetta & GA & $30004-4041$
\end{tabular}

FEC ID number of contributing

federal political committee.

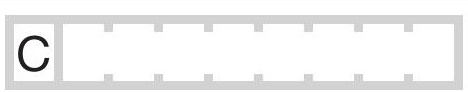

Name of Employer
Self Employed
Receipt For: 2012
X Primary $\quad$ General
Other (specify)

Occupation

Physician

Election Cycle-to-Date

1000.00

B. Full Name (Last, First, Middle Initial)

Janine Platt

Mailing Address 141 Wave Drive

\begin{tabular}{lcc}
\hline City & State & Zip Code \\
Whitethorn & CA & $95589-9158$ \\
\hline
\end{tabular}

FEC ID number of contributing

federal political committee.

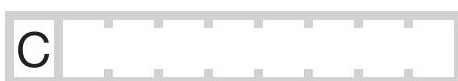

Name of Employer
NA
Receipt For: 2012
Primary
Other (specify)

Occupation

Retired

Election Cycle-to-Date

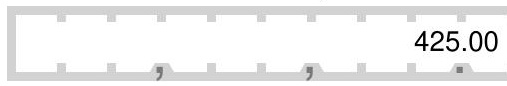

Transaction ID : A5CC6A36CA99C4D1B963

Date of Receipt

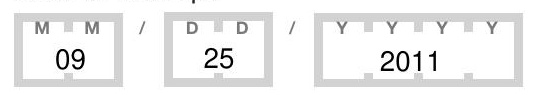

Amount of Each Receipt this Period

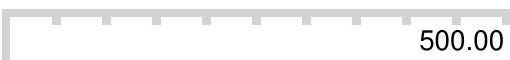

Amount of Each Receipt this Period

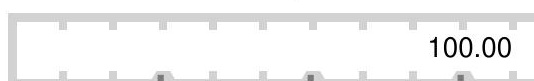

C. Full Name (Last, First, Middle Initial)

John Taulbee

Mailing Address 2434 Mount Vernon Dr

\begin{tabular}{lcc}
\hline City & State & Zip Code \\
Fairfield & $\mathrm{OH}$ & $45014-3906$
\end{tabular}

FEC ID number of contributing

federal political committee.

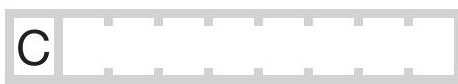

Name of Employer

Information Requested

Occupation

Information Requested

Receipt For: 2012

Х $\begin{aligned} & \text { Primary } \\ & \text { Other (specify) }\end{aligned}$

Election Cycle-to-Date

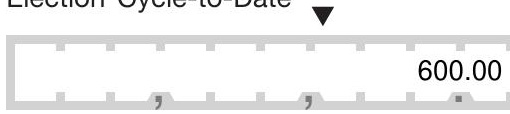

Transaction ID : A4B3446D6C6AD470AAA4

Date of Receipt

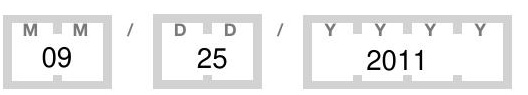

Transaction ID : ACFAFFBE9DEE94B6899A Date of Receipt

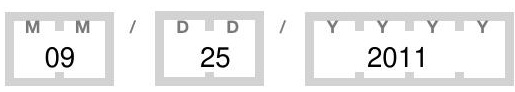

Amount of Each Receipt this Period

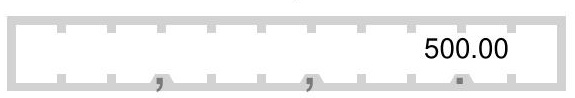

Subtotal Of Receipts This Page (optional).

1100.00

Total This Period (last page this line number only) 
SCHEDULE A-P ITEMIZED RECEIPTS
Use separate schedule(s) for each category of the Detailed Summary Page
FOR LINE NUMBER: (check only one)

PAGE $726 / 1572$

\begin{tabular}{|c|c|c|c|c|c|}
\hline & & & & & \\
\hline 16 & $\begin{array}{l}\mathbf{X} \\
17 a\end{array}$ & $17 b$ & $17 c$ & $17 d$ & 18 \\
\hline $19 a$ & $19 \mathrm{~b}$ & $20 \mathrm{a}$ & $20 \mathrm{~b}$ & $20 \mathrm{c}$ & 21 \\
\hline
\end{tabular}

Any information copied from such Reports and Statements may not be sold or used by any person for the purpose of soliciting contributions or for commercial purposes, other than using the name and address of any political committee to solicit contributions from such committee.

NAME OF COMMITTEE (In Full)

\section{Friends of Herman Cain}

A. Full Name (Last, First, Middle Initial)

RICHARD PERCOCO

Mailing Address 1 PINE BLUFF

\begin{tabular}{lcc}
\hline City & State & Zip Code \\
La Porte & TX & $77571-6677$
\end{tabular}

FEC ID number of contributing federal political committee.

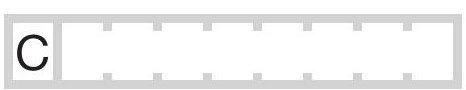

Name of Employer
Information Requested
Receipt For: 2012
X Primary
Other (specify) General

Occupation Information Requested

Election Cycle-to-Date

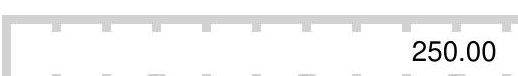

B. Full Name (Last, First, Middle Initial)

Keith Nalley

Mailing Address 17337 Mountain Plat Dr

\begin{tabular}{lcc}
\hline City & State & Zip Code \\
Grand Haven & MI & 49417-9385
\end{tabular}

FEC ID number of contributing

federal political committee.

C

Name of Employer
West Michigan Oral Surgery
Receipt For: 2012
X Primary
Other (specify)

Occupation

Oral Surgeon

Election Cycle-to-Date

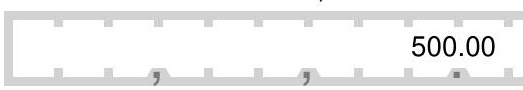

C. Full Name (Last, First, Middle Initial)

Buster Fontenot

Mailing Address PO Box 513

\begin{tabular}{lcc}
\hline City & State & Zip Code \\
Ville Platte & LA & $70586-0513$
\end{tabular}

FEC ID number of contributing federal political committee.

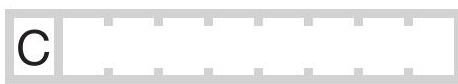

Name of Employer
Self Employed
Receipt For: 2012
X Primary $\quad \square$ General
Other (specify)

\section{Occupation}

Consultant

Election Cycle-to-Date

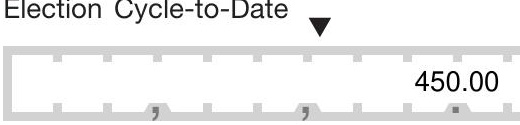

Transaction ID : AD5AB451B0794455AA68

Date of Receipt

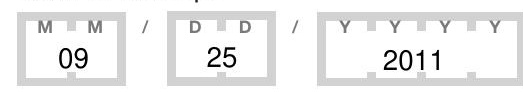

Amount of Each Receipt this Period

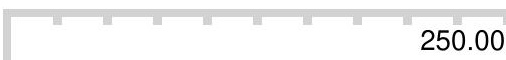

250.00

Transaction ID : A1DF61D5ABE734E7DBA2 Date of Receipt

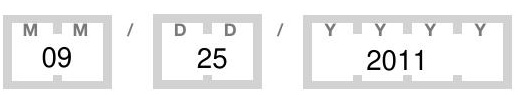

Amount of Each Receipt this Period

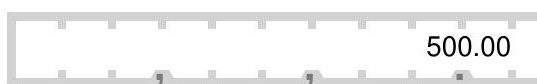

Transaction ID : A8E1D6160B65140F897A

Date of Receipt

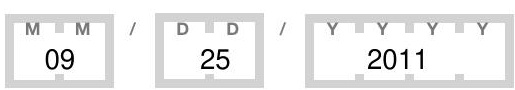

Amount of Each Receipt this Period

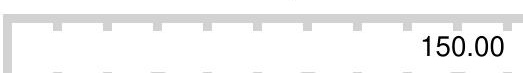

150.00

Subtotal Of Receipts This Page (optional).

900.00

Total This Period (last page this line number only) 
SCHEDULE A-P ITEMIZED RECEIPTS
Use separate schedule(s) for each category of the Detailed Summary Page
FOR LINE NUMBER: (check only one)

PAGE $727 / 1572$

\begin{tabular}{|c|c|c|c|c|c|}
\hline & & & & & \\
\hline 16 & $\begin{array}{l}\mathbf{X} \\
17 a\end{array}$ & $17 b$ & $17 c$ & $17 d$ & 18 \\
\hline $19 a$ & $19 \mathrm{~b}$ & $20 \mathrm{a}$ & $20 \mathrm{~b}$ & $20 \mathrm{c}$ & 21 \\
\hline
\end{tabular}

Any information copied from such Reports and Statements may not be sold or used by any person for the purpose of soliciting contributions or for commercial purposes, other than using the name and address of any political committee to solicit contributions from such committee.

NAME OF COMMITTEE (In Full)

Friends of Herman Cain

A. Full Name (Last, First, Middle Initial)

Buster Fontenot

Mailing Address PO Box 513

\begin{tabular}{lcc}
\hline City & State & Zip Code \\
Ville Platte & LA & $70586-0513$
\end{tabular}

FEC ID number of contributing federal political committee.

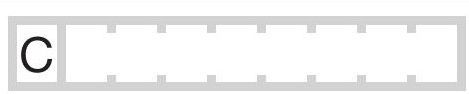

Name of Employer
Self Employed
Receipt For: 2012
X Primary
$\square$ Other (specify) General

Occupation

Consultant

Election Cycle-to-Date

450.00

B. Full Name (Last, First, Middle Initial) marilyn Sensney

Mailing Address 19528 Creekside Ct

\begin{tabular}{lcc}
\hline City & State & Zip Code \\
Salinas & CA & $93908-1245$
\end{tabular}

FEC ID number of contributing

federal political committee.

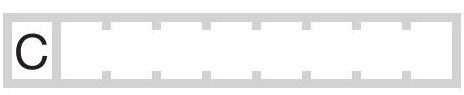

Name of Employer
Monerey School District
Receipt For: 2012
Xrimary
Other (specify)

Occupation

Teacher

Election Cycle-to-Date

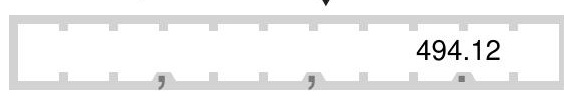

Transaction ID : A2180259433B74C09889

Date of Receipt

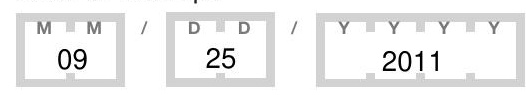

Amount of Each Receipt this Period

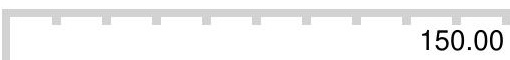

Transaction ID : A0EDCD90BEFF240E79D4 Date of Receipt

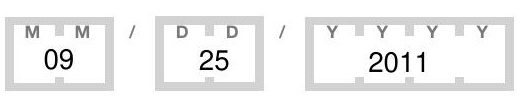

Amount of Each Receipt this Period

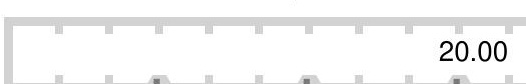

Transaction ID : AEBE31C0910C44AD9B08 Date of Receipt

Cynthia Witte

Mailing Address 1535 N. St. Paul

\begin{tabular}{lcc}
\hline City & State & Zip Code \\
Wichita & KS & $67203-1732$
\end{tabular}

FEC ID number of contributing federal political committee.

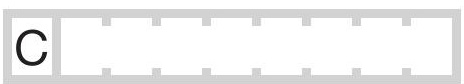

Name of Employer
None
Receipt For: 2012
X Primary
Other (specify) General

Occupation

Homemaker

Election Cycle-to-Date
Amount of Each Receipt this Period

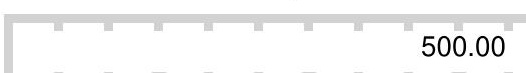

Subtotal Of Receipts This Page (optional).

670.00

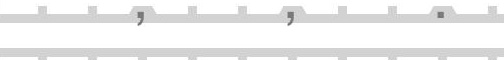

Total This Period (last page this line number only)

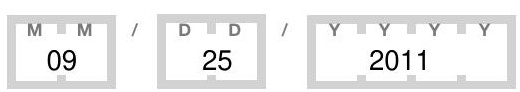


SCHEDULE A-P ITEMIZED RECEIPTS
Use separate schedule(s) for each category of the Detailed Summary Page
FOR LINE NUMBER: (check only one)
PAGE $728 / 1572$

\begin{tabular}{|c|c|c|c|c|c|}
\hline & & & & & \\
\hline 16 & $\begin{array}{lll}X & 17 a \\
\end{array}$ & $17 \mathrm{~b}$ & $17 c$ & $17 d$ & 18 \\
\hline $19 a$ & $19 b$ & $20 a$ & $20 \mathrm{~b}$ & $20 c$ & 21 \\
\hline
\end{tabular}

Any information copied from such Reports and Statements may not be sold or used by any person for the purpose of soliciting contributions or for commercial purposes, other than using the name and address of any political committee to solicit contributions from such committee.

NAME OF COMMITTEE (In Full)

\section{Friends of Herman Cain}

A. Full Name (Last, First, Middle Initial)

Douglas Watters

Mailing Address 5498 Saddle Ridge Ct

\begin{tabular}{lcc}
\hline City & State & Zip Code \\
Las Cruces & NM & $88011-2566$
\end{tabular}

FEC ID number of contributing federal political committee.

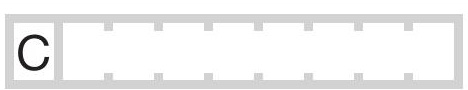

Name of Employer
Double D Enterprises Chula Vista
Receipt For: 2012
X Primary $\quad \square$ General
Other (specify)

Occupation Manager

Election Cycle-to-Date

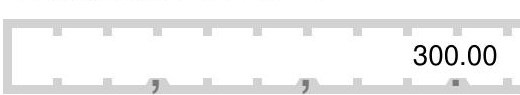

B. Full Name (Last, First, Middle Initial) Joe Alderman

Mailing Address 3214 Bay Hill Lane

\begin{tabular}{lcc}
\hline City & State & Zip Code \\
Round Rock & TX & $78664-6135$ \\
\hline
\end{tabular}

FEC ID number of contributing

federal political committee.

C

Name of Employer
Information Requested
Receipt For: 2012
X Primary
Other (specify)

Occupation

Information Requested

Election Cycle-to-Date

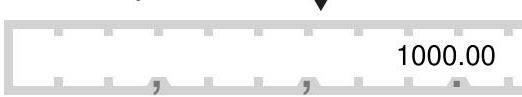

Transaction ID : A3C7CDD331EA14E1E9A4

Date of Receipt

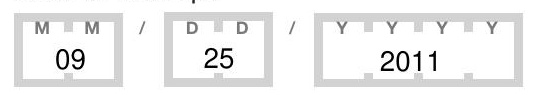

Amount of Each Receipt this Period

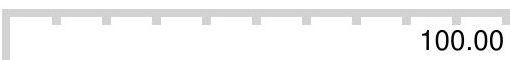

Transaction ID : A34797BBBB395441DA08 Date of Receipt

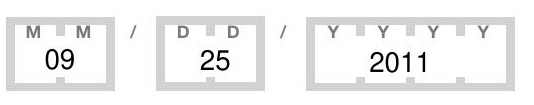

Amount of Each Receipt this Period

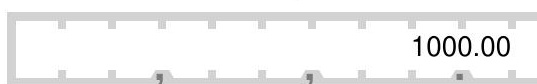

Transaction ID : A39B6386494014F5FA84 Date of Receipt

Jay Strittholt

Mailing Address 1520 Central Ave SE

\begin{tabular}{lcc}
\hline City & State & Zip Code \\
Le Mars & IA & $51031-2724$
\end{tabular}

FEC ID number of contributing federal political committee.

C

Name of Employer
Information Requested
Receipt For: 2012
X Primary
Other (specify) General

\section{Occupation}

Information Requested

Election Cycle-to-Date

Subtotal Of Receipts This Page (optional).

Amount of Each Receipt this Period

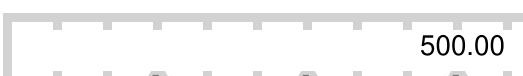

Total This Period (last page this line number only)

1600.00

․․․․

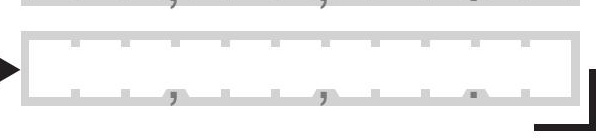

FEC Schedule A-P (Form 3P) (Rev. 03/2011) 
SCHEDULE A-P ITEMIZED RECEIPTS
Use separate schedule(s) for each category of the Detailed Summary Page
FOR LINE NUMBER: (check only one)

PAGE $729 / 1572$

\begin{tabular}{|c|c|c|c|c|c|}
\hline & & & & & \\
\hline 16 & $\begin{array}{l}\mathbf{X} \\
17 a\end{array}$ & $17 b$ & $17 c$ & $17 d$ & 18 \\
\hline $19 a$ & $19 \mathrm{~b}$ & $20 \mathrm{a}$ & $20 \mathrm{~b}$ & $20 \mathrm{c}$ & 21 \\
\hline
\end{tabular}

Any information copied from such Reports and Statements may not be sold or used by any person for the purpose of soliciting contributions or for commercial purposes, other than using the name and address of any political committee to solicit contributions from such committee.

NAME OF COMMITTEE (In Full)

Friends of Herman Cain

A. Full Name (Last, First, Middle Initial)

Michael Kim

Mailing Address 28715 Crestridge Rd

\begin{tabular}{lcc}
\hline City & State & Zip Code \\
Rancho Palos Verdes & CA & $90275-5066$
\end{tabular}

FEC ID number of contributing

federal political committee.

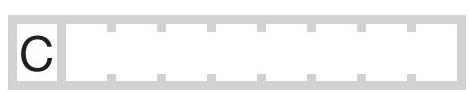

Name of Employer
Information Requested
Receipt For: 2012
X Primary
$\square$ Other (specify)

Occupation

Information Requested

Election Cycle-to-Date

250.00

B. Full Name (Last, First, Middle Initial)

Linda Archer

Mailing Address 16969 Timbers Edge Dr

\begin{tabular}{lcc}
\hline City & State & Zip Code \\
Noblesville & IN & $46062-7171$
\end{tabular}

FEC ID number of contributing

federal political committee.

C

Name of Employer
Not Employed
Receipt For: 2012
X Primary
Other (specify)

Occupation

Not Employed

Election Cycle-to-Date

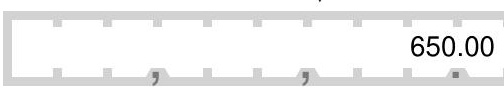

Transaction ID : A8B84B02AC0F448018B6

Date of Receipt

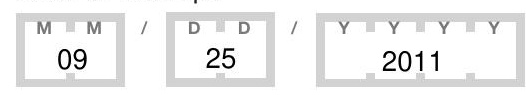

Amount of Each Receipt this Period

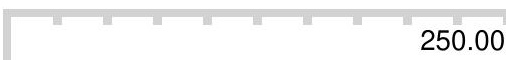

C. Full Name (Last, First, Middle Initial)

guy gamble

Mailing Address $7737 \mathrm{n}$ calle caballeros

\begin{tabular}{lcc}
\hline City & State & Zip Code \\
Paradise Valley & AZ & 85253-3116
\end{tabular}

FEC ID number of contributing

federal political committee.

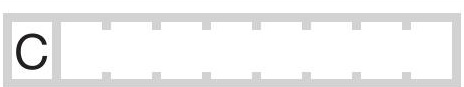

Name of Employer

Information Requested

Occupation

Information Requested

Receipt For: 2012

Х $\begin{aligned} & \text { Primary } \square \text { General } \\ & \text { Other (specify) }\end{aligned}$

Amount of Each Receipt this Period

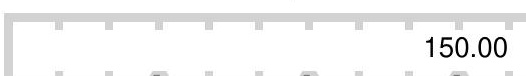

Transaction ID : A76ADBD7804B74BBDB7A Date of Receipt

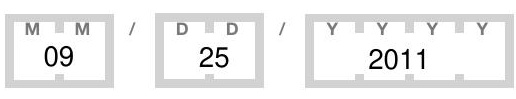

Transaction ID : A84D576F13ABA4FDE817 Date of Receipt

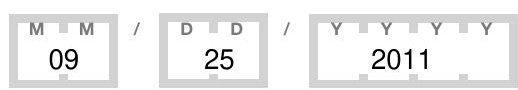

Amount of Each Receipt this Period

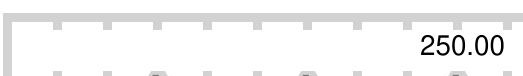

\section{Subtotal Of Receipts This Page (optional)}

Total This Period (last page this line number only) 
SCHEDULE A-P ITEMIZED RECEIPTS
Use separate schedule(s) for each category of the Detailed Summary Page
FOR LINE NUMBER: (check only one)

PAGE $730 / 1572$

\begin{tabular}{|c|c|c|c|c|c|}
\hline & & & & & \\
\hline 16 & $\begin{array}{l}\mathbf{X} \\
17 a\end{array}$ & $17 b$ & $17 c$ & $17 d$ & 18 \\
\hline $19 a$ & $19 \mathrm{~b}$ & $20 \mathrm{a}$ & $20 \mathrm{~b}$ & $20 \mathrm{c}$ & 21 \\
\hline
\end{tabular}

Any information copied from such Reports and Statements may not be sold or used by any person for the purpose of soliciting contributions or for commercial purposes, other than using the name and address of any political committee to solicit contributions from such committee.

NAME OF COMMITTEE (In Full)

\section{Friends of Herman Cain}

A. Full Name (Last, First, Middle Initial) Jerry Hood

Mailing Address 303 Swanson Drive

\begin{tabular}{lcc}
\hline City & State & Zip Code \\
Lawrenceville & GA & $30043-8533$
\end{tabular}

FEC ID number of contributing federal political committee.

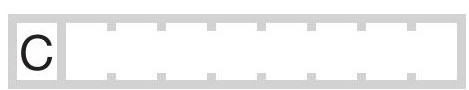

Name of Employer
EMI
Receipt For: 2012
X Primary $\quad$ General
Other (specify)

Occupation Engineer

Election Cycle-to-Date

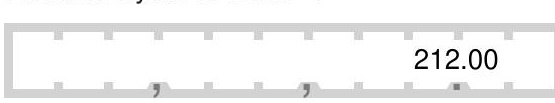

B. Full Name (Last, First, Middle Initial)

Thomas Cunningham

\section{Mailing Address 5148 Taylor Drive}

\begin{tabular}{lcc}
\hline City & State & Zip Code \\
Ave Maria & FL & $34142-9555$ \\
\hline
\end{tabular}

FEC ID number of contributing

federal political committee.

C

Name of Employer
Information Requested
Receipt For: 2012
Xrimary
Other (specify)

\section{Occupation}

Information Requested

Election Cycle-to-Date

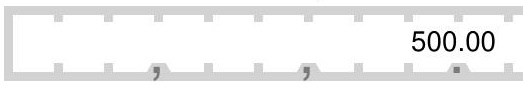

C. Full Name (Last, First, Middle Initial)

Mark Mauldin

Mailing Address 2374 S. Lakeview Dr.

\begin{tabular}{l|ll}
\hline $\begin{array}{l}\text { City } \\
\text { Gordon }\end{array}$ & $\begin{array}{c}\text { State } \\
\text { TX }\end{array}$ & $\begin{array}{c}\text { Zip Code } \\
76453-4811\end{array}$ \\
\hline $\begin{array}{l}\text { FEC ID number of contributing } \\
\text { federal political committee. }\end{array}$ & C \\
$\begin{array}{l}\text { Name of Employer } \\
\text { Information Requested }\end{array}$ & $\begin{array}{l}\text { Occupation } \\
\text { Information Requested }\end{array}$ \\
$\begin{array}{l}\text { Receipt For: } 2012 \\
\text { Xrimary } \\
\text { Other (specify) }\end{array}$ & Election Cycle-to-Date & \\
\hline
\end{tabular}

Transaction ID : A67BF7B1F254C4A22A0C Date of Receipt

Amount of Each Receipt this Period

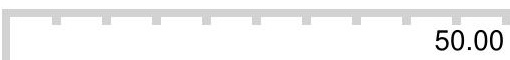

Date of Receipt

\begin{tabular}{|c|c|c|c|c|}
\hline M M / & D D / & $Y$ Y Y Y \\
09 & 25 & 2011 \\
\hline
\end{tabular}
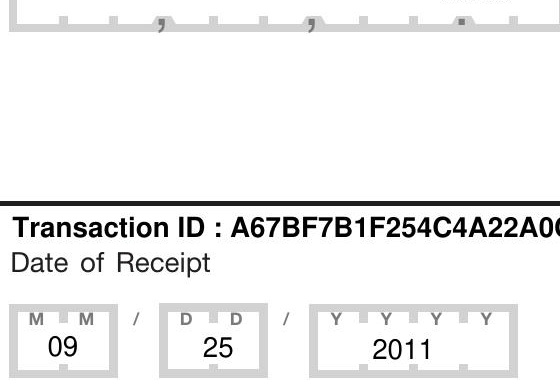

Amount of Each Receipt this Period

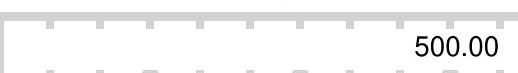

Amount of Each Receipt this Period

Transaction ID : AB3AA237751A24D58AAF Date of Receipt
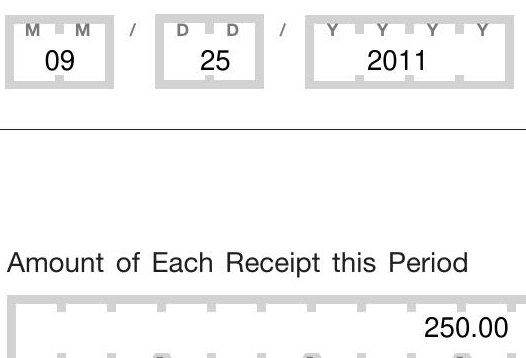

Subtotal Of Receipts This Page (optional)

800.00

Total This Period (last page this line number only) 
SCHEDULE A-P ITEMIZED RECEIPTS
Use separate schedule(s) for each category of the Detailed Summary Page
FOR LINE NUMBER: (check only one)

PAGE $731 / 1572$

\begin{tabular}{|c|c|c|c|c|c|}
\hline & & & & & \\
\hline 16 & $\begin{array}{l}\mathbf{X} \\
17 a\end{array}$ & $17 b$ & $17 c$ & $17 d$ & 18 \\
\hline $19 a$ & $19 \mathrm{~b}$ & $20 \mathrm{a}$ & $20 \mathrm{~b}$ & $20 \mathrm{c}$ & 21 \\
\hline
\end{tabular}

Any information copied from such Reports and Statements may not be sold or used by any person for the purpose of soliciting contributions or for commercial purposes, other than using the name and address of any political committee to solicit contributions from such committee.

NAME OF COMMITTEE (In Full)

\section{Friends of Herman Cain}

A. Full Name (Last, First, Middle Initial)

\section{Dana Lamb}

Mailing Address 244 N 4395

\begin{tabular}{lcc}
\hline City & State & Zip Code \\
Pryor & OK & $74361-9144$ \\
\hline
\end{tabular}

FEC ID number of contributing federal political committee.

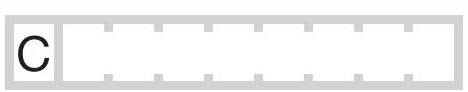

Name of Employer
Retired
Receipt For: 2012
X Primary $\quad$ General
Other (specify)

Occupation Attorney

Election Cycle-to-Date

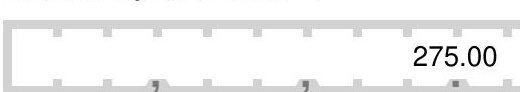

B. Full Name (Last, First, Middle Initial)

Val Kienast

Mailing Address 624 E Center St

\begin{tabular}{lcc}
\hline City & State & Zip Code \\
Providence & UT & $84332-9664$
\end{tabular}

FEC ID number of contributing

federal political committee.

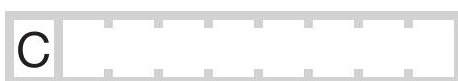

Name of Employer
Pearl Oil Thailand Ltd
Receipt For: 2012
X Primary
Other (specify)

Occupation

Geologist

Election Cycle-to-Date

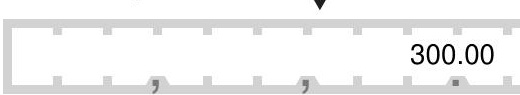

Transaction ID : A171A4B30B4EA40ADADC

Date of Receipt

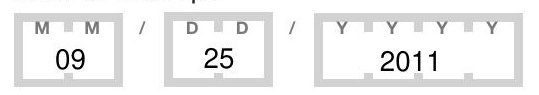

Amount of Each Receipt this Period

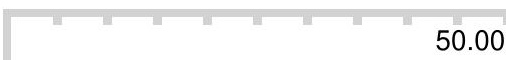

50.00

C. Full Name (Last, First, Middle Initial)

Paul J Decker

Mailing Address 3012 Thorndale Rd

\begin{tabular}{lcc}
\hline City & State & Zip Code \\
Indian Trail & NC & $28079-5393$
\end{tabular}

FEC ID number of contributing federal political committee.

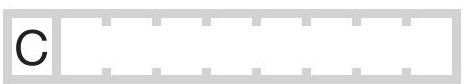

Name of Employer
Self Employed
Receipt For: 2012
X Primary $\quad \square$ General
Other (specify)

\section{Occupation}

Sales

Election Cycle-to-Date

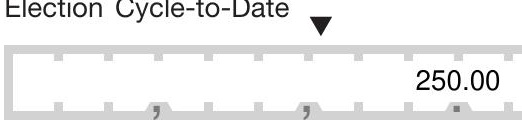

Transaction ID : AF8C5800748764D39858

Date of Receipt

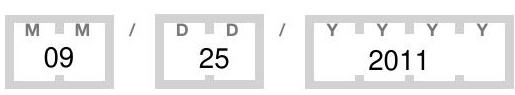

Amount of Each Receipt this Period

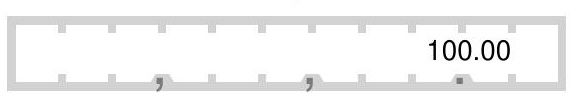

Transaction ID : A9296C249D4CC44DD8FF Date of Receipt

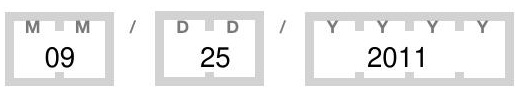

Amount of Each Receipt this Period

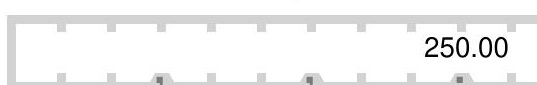

\section{Subtotal Of Receipts This Page (optional)}

400.00

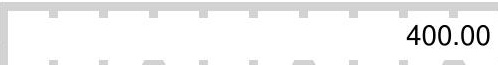

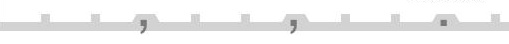

Total This Period (last page this line number only)

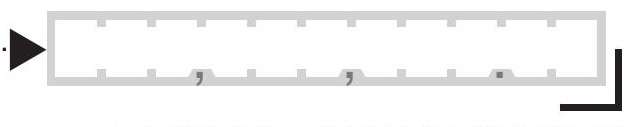

FEC Schedule A-P (Form 3P) (Rev. 03/2011) 
SCHEDULE A-P ITEMIZED RECEIPTS
Use separate schedule(s) for each category of the Detailed Summary Page
FOR LINE NUMBER: (check only one)

PAGE 732 / 1572

\begin{tabular}{|c|c|c|c|c|c|}
\hline & & & & & \\
\hline 16 & $\begin{array}{l}\mathbf{X} \\
17 a\end{array}$ & $17 b$ & $17 c$ & $17 d$ & 18 \\
\hline $19 a$ & $19 \mathrm{~b}$ & $20 \mathrm{a}$ & $20 \mathrm{~b}$ & $20 \mathrm{c}$ & 21 \\
\hline
\end{tabular}

Any information copied from such Reports and Statements may not be sold or used by any person for the purpose of soliciting contributions or for commercial purposes, other than using the name and address of any political committee to solicit contributions from such committee.

NAME OF COMMITTEE (In Full)

\section{Friends of Herman Cain}

A. Full Name (Last, First, Middle Initial) Leonard Carlson

Mailing Address 20 Mill Lane

\begin{tabular}{lcc}
\hline City & State & Zip Code \\
West Barnstable & MA & $02668-1362$
\end{tabular}

FEC ID number of contributing federal political committee.

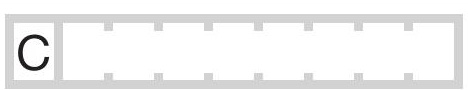

Name of Employer
self
Receipt For: 2012
X Primary $\quad$ General
Other (specify)

Occupation Dentist

Election Cycle-to-Date

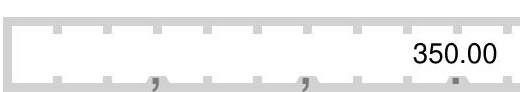

B. Full Name (Last, First, Middle Initial)

David Conatser

Mailing Address 212 Tammie Ln

\begin{tabular}{lcc}
\hline City & State & Zip Code \\
Greenville & KY & $42345-1822$
\end{tabular}

FEC ID number of contributing

federal political committee.

C

Name of Employer

Community Health Centers of Western Ke

Occupation

Receipt For: 2012

X Primary $\square$ General Other (specify) $\nabla$

Physician

Election Cycle-to-Date

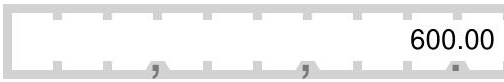

C. Full Name (Last, First, Middle Initial)

Cory Zornizer

Mailing Address 331 Meadowtree Ct

\begin{tabular}{lcc}
\hline City & State & Zip Code \\
Foley & MO & $63347-2867$
\end{tabular}

FEC ID number of contributing federal political committee.

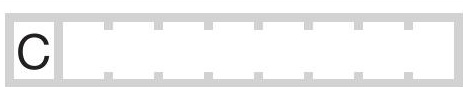

Name of Employer

Occupation

Express-Scripts

Operations Director

Receipt For: 2012

Х $\begin{aligned} & \text { Primary } \\ & \text { Other (specify) }\end{aligned}$

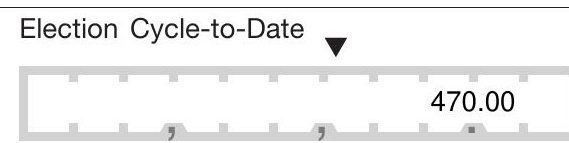

Amount of Each Receipt this Period

Transaction ID : A230AC4C51A59493E899

Date of Receipt
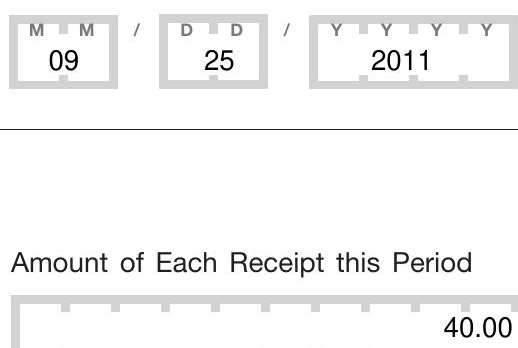

40.00

Subtotal Of Receipts This Page (optional)

390.00

Total This Period (last page this line number only) 
SCHEDULE A-P ITEMIZED RECEIPTS
Use separate schedule(s) for each category of the Detailed Summary Page
FOR LINE NUMBER: (check only one)

PAGE $733 / 1572$

\begin{tabular}{|c|c|c|c|c|c|}
\hline & & & & & \\
\hline 16 & $\mathbf{X} 17 a$ & $17 b$ & $17 c$ & $17 d$ & 18 \\
\hline $19 a$ & $19 b$ & $20 \mathrm{a}$ & $20 \mathrm{~b}$ & $20 \mathrm{c}$ & 21 \\
\hline
\end{tabular}

Any information copied from such Reports and Statements may not be sold or used by any person for the purpose of soliciting contributions or for commercial purposes, other than using the name and address of any political committee to solicit contributions from such committee.

NAME OF COMMITTEE (In Full)

\section{Friends of Herman Cain}

A. Full Name (Last, First, Middle Initial)

Mr. William Chernish

Mailing Address 620 Shaffer Rd

\begin{tabular}{lcc}
\hline City & State & Zip Code \\
Newfield & NY & $14867-9743$
\end{tabular}

FEC ID number of contributing federal political committee.

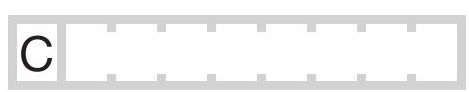

Name of Employer
SUNY Delhi
Receipt For: 2012
X Primary $\quad$ General
Other (specify)

Occupation

Professor

Election Cycle-to-Date

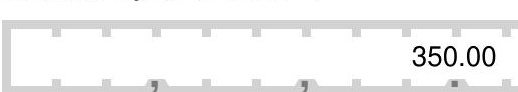

B. Full Name (Last, First, Middle Initial)

barbara heine

Mailing Address 9250 Corkscrew Rd Suite 1

\begin{tabular}{lcc}
\hline City & State & Zip Code \\
Estero & FL & $33928-3216$
\end{tabular}

FEC ID number of contributing

federal political committee.

C

Name of Employer
Information Requested
Receipt For: 2012
X Primary
Other (specify)

Occupation

Information Requested

Election Cycle-to-Date

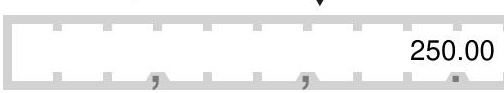

Transaction ID : AB22D43BFAC764A53A4A

Date of Receipt

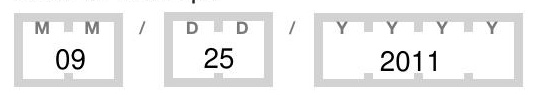

Amount of Each Receipt this Period

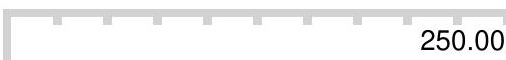

Transaction ID : A5B34CBBC570F4C3F801

Date of Receipt

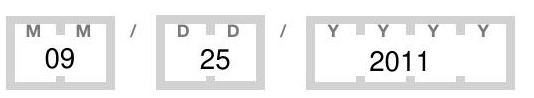

Amount of Each Receipt this Period

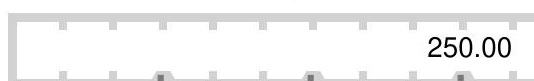

Transaction ID : AF4ECA3DFF67942049FF Date of Receipt

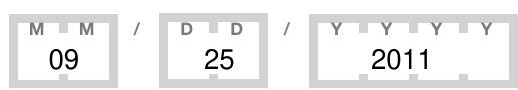

Amount of Each Receipt this Period

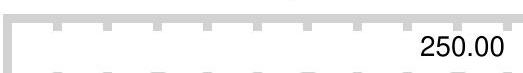

$\begin{array}{cc}\text { State } & \text { Zip Code } \\ \text { MS } & 38632-6759\end{array}$

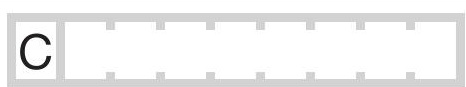

\section{Occupation}

Engineer

Election Cycle-to-Date

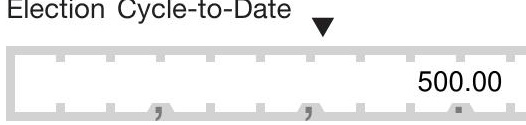

Subtotal Of Receipts This Page (optional)

750.00

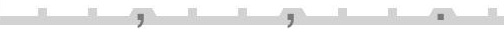

Total This Period (last page this line number only)

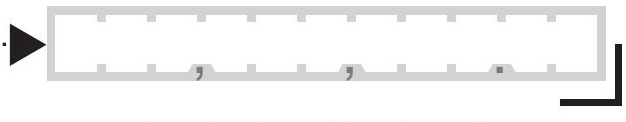

FEC Schedule A-P (Form 3P) (Rev. 03/2011) 
SCHEDULE A-P ITEMIZED RECEIPTS
Use separate schedule(s) for each category of the Detailed Summary Page
FOR LINE NUMBER: (check only one)

PAGE 734 / 1572

\begin{tabular}{|c|c|c|c|c|c|}
\hline & & & & & \\
\hline 16 & $\begin{array}{l}\mathbf{X} \\
17 a\end{array}$ & $17 b$ & $17 c$ & $17 d$ & 18 \\
\hline $19 a$ & $19 \mathrm{~b}$ & $20 \mathrm{a}$ & $20 \mathrm{~b}$ & $20 \mathrm{c}$ & 21 \\
\hline
\end{tabular}

Any information copied from such Reports and Statements may not be sold or used by any person for the purpose of soliciting contributions or for commercial purposes, other than using the name and address of any political committee to solicit contributions from such committee.

NAME OF COMMITTEE (In Full)

\section{Friends of Herman Cain}

A. Full Name (Last, First, Middle Initial)

Diane E Becker

Mailing Address 2010 Gallagher Ave

\begin{tabular}{lcc}
\hline City & State & Zip Code \\
Deltona & FL & $32725-3278$
\end{tabular}

FEC ID number of contributing federal political committee.

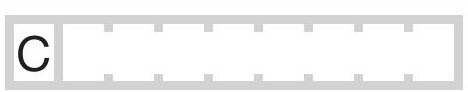

Name of Employer
None
Receipt For: 2012
X Primary $\quad$ General
Other (specify)

Occupation

Retired

Election Cycle-to-Date

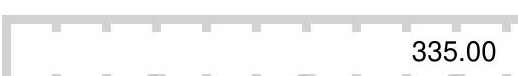

B. Full Name (Last, First, Middle Initial)

R Purdy

Mailing Address 5900 West 70th Street

\begin{tabular}{lcc}
\hline City & State & Zip Code \\
Minneapolis & MN & $55439-1700$ \\
\hline
\end{tabular}

FEC ID number of contributing

federal political committee.

C

Name of Employer
Information Requested
Receipt For: 2012
X Primary
Other (specify)

Occupation

Information Requested

Election Cycle-to-Date

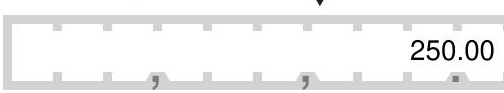

Transaction ID : A451B19E777DC49EC875

Date of Receipt

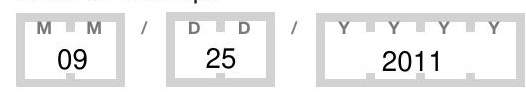

Amount of Each Receipt this Period

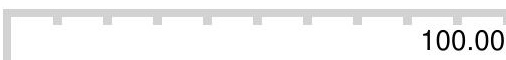

Transaction ID : AF172FB7A50984A85AE0

Date of Receipt

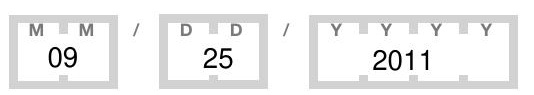

Amount of Each Receipt this Period

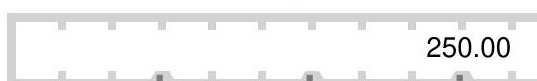

Transaction ID : A89DCB148A1854AFCBF3 Date of Receipt

Derwood Anderson

Mailing Address PO Box 2682

\begin{tabular}{lcc}
\hline City & State & Zip Code \\
Corpus Christi & TX & $78403-2682$ \\
\hline
\end{tabular}

FEC ID number of contributing federal political committee.

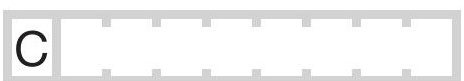

Name of Employer

Occupation

Information Requested

Information Requested

Receipt For: 2012

Х $\begin{aligned} & \text { Primary } \\ & \text { Other (specify) }\end{aligned}$

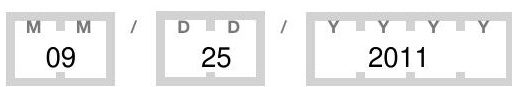

Amount of Each Receipt this Period

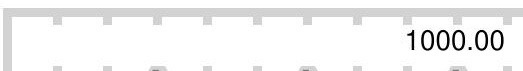

Subtotal Of Receipts This Page (optional)

Total This Period (last page this line number only) 
SCHEDULE A-P ITEMIZED RECEIPTS
Use separate schedule(s) for each category of the Detailed Summary Page
FOR LINE NUMBER: (check only one)

PAGE $735 / 1572$

\begin{tabular}{|c|c|c|c|c|c|}
\hline & & & & & \\
\hline 16 & $\begin{array}{l}\mathbf{X} \\
17 a\end{array}$ & $17 b$ & $17 c$ & $17 d$ & 18 \\
\hline $19 a$ & $19 \mathrm{~b}$ & $20 \mathrm{a}$ & $20 \mathrm{~b}$ & $20 \mathrm{c}$ & 21 \\
\hline
\end{tabular}

Any information copied from such Reports and Statements may not be sold or used by any person for the purpose of soliciting contributions or for commercial purposes, other than using the name and address of any political committee to solicit contributions from such committee.

NAME OF COMMITTEE (In Full)

\section{Friends of Herman Cain}

A. Full Name (Last, First, Middle Initial)

Phyllis Fine

Mailing Address 266 Trailwood Lane

\begin{tabular}{lcc}
\hline City & State & Zip Code \\
Northbrook & IL & $60062-1031$
\end{tabular}

FEC ID number of contributing federal political committee.

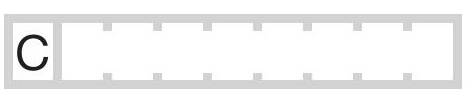

Name of Employer
homemaker
Receipt For: 2012
X Primary $\quad$ General
Other (specify)

Occupation Homemaker

Election Cycle-to-Date 300.00

B. Full Name (Last, First, Middle Initial) JERRY BOWMAN

Mailing Address 20959 STATE HWY 6

\begin{tabular}{lcc}
\hline City & State & Zip Code \\
Deerwood & MN & $56444-8550$ \\
\hline
\end{tabular}

FEC ID number of contributing

federal political committee.

C

Name of Employer
Information Requested
Receipt For: 2012
X Primary
Other (specify)

Occupation

Information Requested

Election Cycle-to-Date

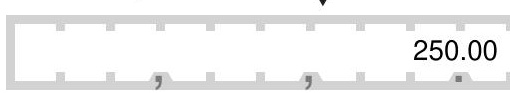

Transaction ID : A134F864E63BD43E4A7A

Date of Receipt

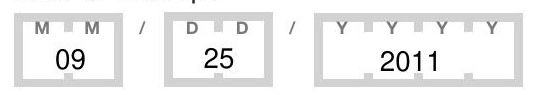

Amount of Each Receipt this Period

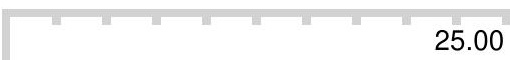

25.00

C. Full Name (Last, First, Middle Initial)

John Johnson

Mailing Address PO Box 3905

\section{City}

Saint Augustine

FEC ID number of contributing federal political committee.

Name of Employer

Saint Vincent Medical Center

Receipt For: 2012

Х $\begin{aligned} & \text { Primary } \square \text { General } \\ & \text { Other (specify) }\end{aligned}$

$\begin{array}{cc}\text { State } & \text { Zip Code } \\ \text { FL } & 32085-3905\end{array}$

C

\section{Occupation}

Pharmacist

Election Cycle-to-Date

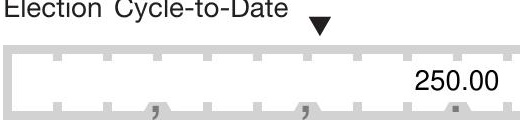

Transaction ID : AA8EE2E37EB6A441AB2B Date of Receipt

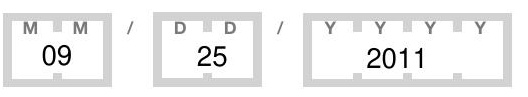

Amount of Each Receipt this Period

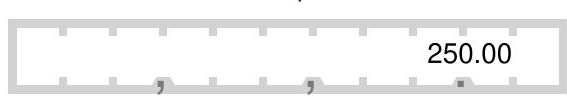

Transaction ID : A07421654470447B79D1

Date of Receipt

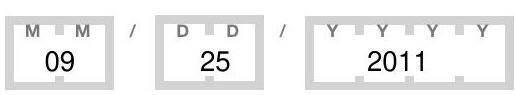

Amount of Each Receipt this Period

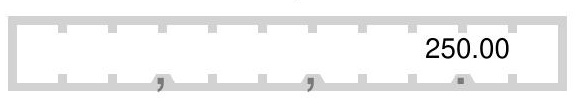

\section{Subtotal Of Receipts This Page (optional)}

Total This Period (last page this line number only) 
SCHEDULE A-P ITEMIZED RECEIPTS
Use separate schedule(s) for each category of the Detailed Summary Page
FOR LINE NUMBER: (check only one)

PAGE $736 / 1572$

\begin{tabular}{|c|c|c|c|c|c|}
\hline & & & & & \\
\hline 16 & $\begin{array}{l}\mathbf{X} \\
17 a\end{array}$ & $17 b$ & $17 c$ & $17 d$ & 18 \\
\hline $19 a$ & $19 \mathrm{~b}$ & $20 \mathrm{a}$ & $20 \mathrm{~b}$ & $20 \mathrm{c}$ & 21 \\
\hline
\end{tabular}

Any information copied from such Reports and Statements may not be sold or used by any person for the purpose of soliciting contributions or for commercial purposes, other than using the name and address of any political committee to solicit contributions from such committee.

NAME OF COMMITTEE (In Full)

\section{Friends of Herman Cain}

A. Full Name (Last, First, Middle Initial)

Ronald Bagwell

Mailing Address 750 Aronson Lake Court

\begin{tabular}{lcc}
\hline City & State & Zip Code \\
Roswell & GA & $30075-7171$
\end{tabular}

FEC ID number of contributing federal political committee.

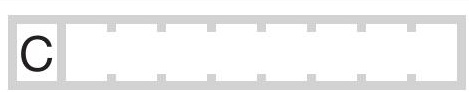

Name of Employer
Information Requested
Receipt For: 2012
X Primary
Other (specify) General

Occupation Information Requested

Election Cycle-to-Date 250.00

B. Full Name (Last, First, Middle Initial) CARTER KIRK

Mailing Address 5603 W 16th Ave

\begin{tabular}{lcc}
\hline City & State & Zip Code \\
Kennewick & WA & $99338-5004$
\end{tabular}

FEC ID number of contributing

federal political committee.

C

Name of Employer

Mission Support Alliance LLC

Occupation

Receipt For: 2012

Х ${ }_{\text {Other (specify) }}^{\square}$ General

Industrial Hygienist

Election Cycle-to-Date

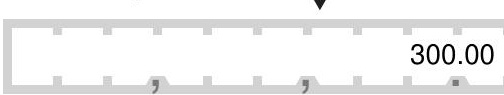

C. Full Name (Last, First, Middle Initial)

Grant Ward

Mailing Address 6299 Shelburne Park Lane

\begin{tabular}{lcc}
\hline City & State & Zip Code \\
Mableton & GA & $30126-7244$
\end{tabular}

FEC ID number of contributing

federal political committee.

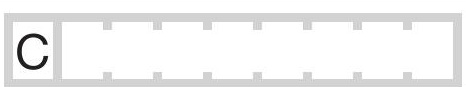

Name of Employer
P\&L
Receipt For: 2012
X Primary $\quad \square$ General
Other (specify)

\section{Occupation}

Project Manager

Election Cycle-to-Date

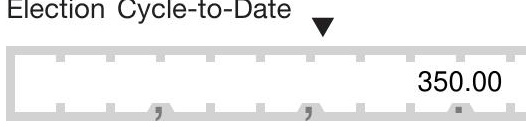

Transaction ID : A3FF07FBE5B74471C9D1

Date of Receipt

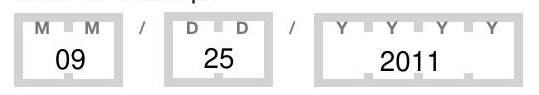

Amount of Each Receipt this Period

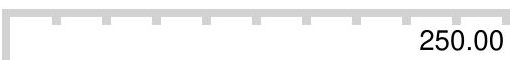

250.00

Transaction ID : AE812937C59BB44299E3

Date of Receipt

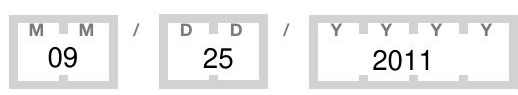

Amount of Each Receipt this Period

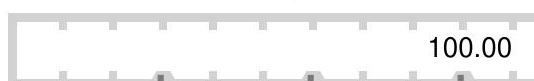

Transaction ID : A807D8CC6CC1A46CFAAE Date of Receipt

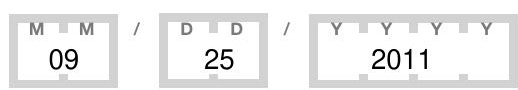

Amount of Each Receipt this Period

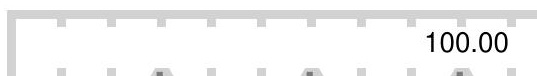

\section{Subtotal Of Receipts This Page (optional)}

Total This Period (last page this line number only) 
SCHEDULE A-P ITEMIZED RECEIPTS
Use separate schedule(s) for each category of the Detailed Summary Page
FOR LINE NUMBER: (check only one)

PAGE $737 / 1572$

\begin{tabular}{|c|c|c|c|c|c|}
\hline & & & & & \\
\hline 16 & $\begin{array}{l}\mathbf{X} \\
17 a\end{array}$ & $17 b$ & $17 c$ & $17 d$ & 18 \\
\hline $19 a$ & $19 \mathrm{~b}$ & $20 \mathrm{a}$ & $20 \mathrm{~b}$ & $20 \mathrm{c}$ & 21 \\
\hline
\end{tabular}

Any information copied from such Reports and Statements may not be sold or used by any person for the purpose of soliciting contributions or for commercial purposes, other than using the name and address of any political committee to solicit contributions from such committee.

NAME OF COMMITTEE (In Full)

Friends of Herman Cain

A. Full Name (Last, First, Middle Initial)

Jennifer Major

Mailing Address 4010 Jenkins Ct

\begin{tabular}{lcc}
\hline City & State & Zip Code \\
Alpharetta & GA & $30009-7115$
\end{tabular}

FEC ID number of contributing federal political committee.

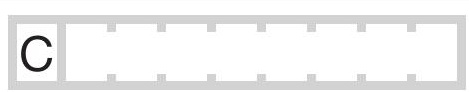

Name of Employer
CMR Residential Properties LLC
Receipt For: 2012
X Primary
$\square$ Other (specify)

Occupation

Real Estate Investor

Election Cycle-to-Date

400.00

B. Full Name (Last, First, Middle Initial)

Robert Sullentrup

Mailing Address 140 Hunters Ridge

\begin{tabular}{lcc}
\hline City & State & Zip Code \\
Saint Charles & MO & $63301-0427$
\end{tabular}

FEC ID number of contributing

federal political committee.

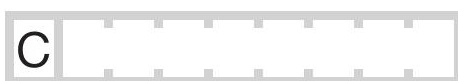

Name of Employer
Fiserv
Receipt For: 2012
X Primary
Other (specify)

Occupation

Computer Specialist

Election Cycle-to-Date

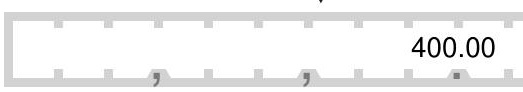

Transaction ID : AAD14E719CA7342DABD6

Date of Receipt

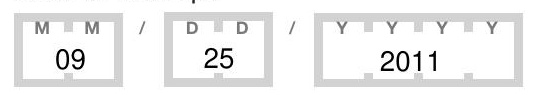

Amount of Each Receipt this Period

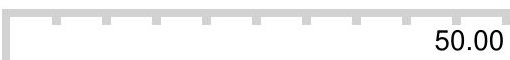

50.00

C. Full Name (Last, First, Middle Initial)

Arthur Ferguson

Mailing Address 3900 Wedgewood Ct.

\section{City}

Arlington

FEC ID number of contributing

federal political committee.

Name of Employer

American Airlines

Receipt For: 2012

Х $\begin{aligned} & \text { Primary } \\ & \text { Other (specify) }\end{aligned}$

$\begin{array}{cc}\text { State } & \text { Zip Code } \\ \text { TX } & 76013-1065\end{array}$

C

\section{Occupation}

Retired

Election Cycle-to-Date

Transaction ID : A45A1B1D8ADFC423EAA9 Date of Receipt

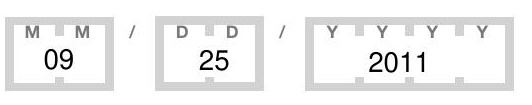

Amount of Each Receipt this Period

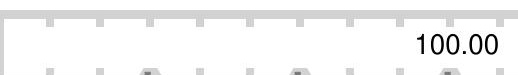

Transaction ID : A9E5D96D4748347529CF

Date of Receipt

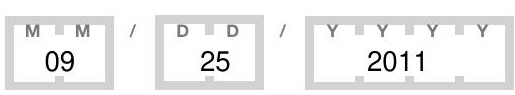

Amount of Each Receipt this Period

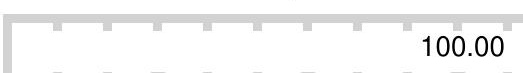

400.00

Subtotal Of Receipts This Page (optional).

Total This Period (last page this line number only) 
SCHEDULE A-P ITEMIZED RECEIPTS
Use separate schedule(s) for each category of the Detailed Summary Page
FOR LINE NUMBER: (check only one)

PAGE $738 / 1572$

\begin{tabular}{|c|c|c|c|c|c|}
\hline & & & & & \\
\hline 16 & $\begin{array}{l}\mathbf{X} \\
17 a\end{array}$ & $17 b$ & $17 c$ & $17 d$ & 18 \\
\hline $19 a$ & $19 \mathrm{~b}$ & $20 \mathrm{a}$ & $20 \mathrm{~b}$ & $20 \mathrm{c}$ & 21 \\
\hline
\end{tabular}

Any information copied from such Reports and Statements may not be sold or used by any person for the purpose of soliciting contributions or for commercial purposes, other than using the name and address of any political committee to solicit contributions from such committee.

NAME OF COMMITTEE (In Full)

\section{Friends of Herman Cain}

A. Full Name (Last, First, Middle Initial)

lisa jones

Mailing Address 13071 old dayton road

\begin{tabular}{lcc}
\hline City & State & Zip Code \\
New Lebanon & OH & $45345-9710$
\end{tabular}

FEC ID number of contributing

federal political committee.

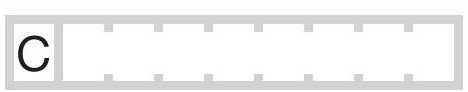

Name of Employer
Self Employed
Receipt For: 2012
X Primary $\quad$ General
Other (specify)

Occupation

Property Manager

Election Cycle-to-Date

250.00

B. Full Name (Last, First, Middle Initial)

Thomas Bowers

Mailing Address 648 Strawberry Hill Ct

\begin{tabular}{lcc}
\hline City & State & Zip Code \\
Covington & KY & $41017-9647$
\end{tabular}

FEC ID number of contributing

federal political committee.

C

Name of Employer
Information Requested
Receipt For: 2012
X Primary
Other (specify)

Occupation

Information Requested

Election Cycle-to-Date

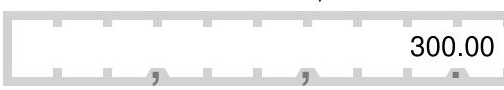

Transaction ID : A19AE108D2EA14410BD6

Date of Receipt

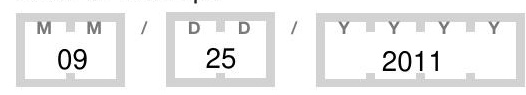

Amount of Each Receipt this Period

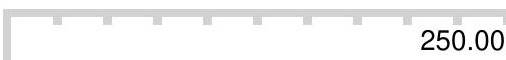

250.00

C. Full Name (Last, First, Middle Initial)

Michael Gregory

Mailing Address 912 West Kings Dr.

\begin{tabular}{lcc}
\hline City & State & Zip Code \\
Kingfisher & OK & $73750-4914$
\end{tabular}

FEC ID number of contributing

federal political committee.

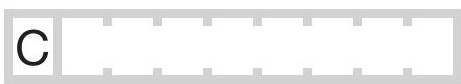

Name of Employer

Occupation

Tyson Fresh Meats

Cattlebuyer

Receipt For: 2012

Х $\begin{aligned} & \text { Primary } \\ & \text { Other (specify) }\end{aligned}$

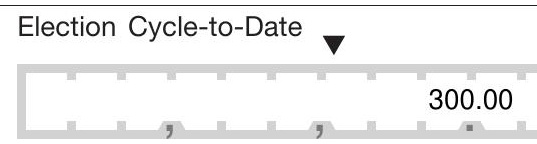

Amount of Each Receipt this Period

Transaction ID : A36C2D3C2824C46589A5

Date of Receipt
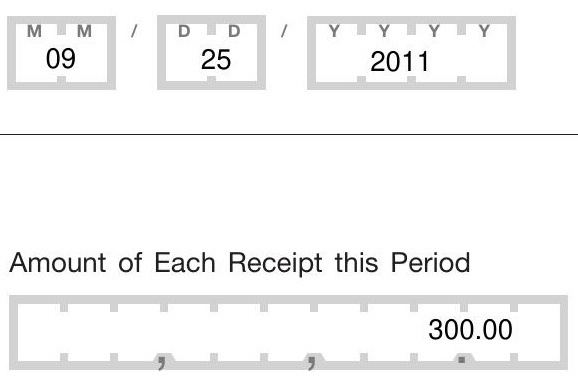

Transaction ID : A9D1CB312F88C4971A87

Date of Receipt

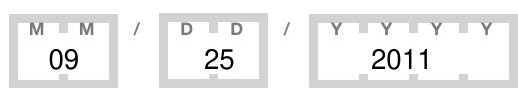

Amount of Each Receipt this Period

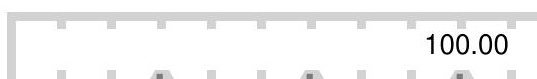

650.00

Subtotal Of Receipts This Page (optional)

Total This Period (last page this line number only) 
SCHEDULE A-P ITEMIZED RECEIPTS
Use separate schedule(s) for each category of the Detailed Summary Page
FOR LINE NUMBER: (check only one)

PAGE $739 / 1572$

\begin{tabular}{|c|c|c|c|c|c|}
\hline & & & & & \\
\hline 16 & $\begin{array}{l}\mathbf{X} \\
17 a\end{array}$ & $17 b$ & $17 c$ & $17 d$ & 18 \\
\hline $19 a$ & $19 \mathrm{~b}$ & $20 \mathrm{a}$ & $20 \mathrm{~b}$ & $20 \mathrm{c}$ & 21 \\
\hline
\end{tabular}

Any information copied from such Reports and Statements may not be sold or used by any person for the purpose of soliciting contributions or for commercial purposes, other than using the name and address of any political committee to solicit contributions from such committee.

NAME OF COMMITTEE (In Full)

\section{Friends of Herman Cain}

A. Full Name (Last, First, Middle Initial) John Scala

Mailing Address PO Box 630290 \#21

\begin{tabular}{lcc}
\hline City & State & Zip Code \\
Littleton & CO & $80163-0290$ \\
\hline
\end{tabular}

FEC ID number of contributing federal political committee.

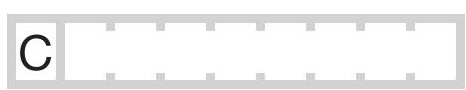

Name of Employer
Information Requested
Receipt For: 2012
X Primary
Other (specify) General

Occupation Information Requested

Election Cycle-to-Date

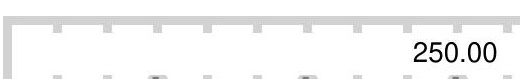

B. Full Name (Last, First, Middle Initial)

Frank Bergren

Mailing Address PO Box 4704

\begin{tabular}{lcc}
\hline City & State & Zip Code \\
Houston & TX & $77210-4704$ \\
\hline
\end{tabular}

FEC ID number of contributing

federal political committee.

C

\begin{tabular}{l} 
Name of Employer \\
Information Requested \\
\hline Receipt For: 2012 \\
$\square$ Primary $\quad$ Other (specify)
\end{tabular}

Occupation

Information Requested

Election Cycle-to-Date

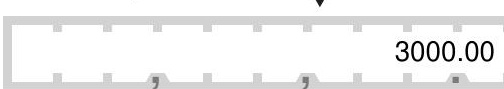

C. Full Name (Last, First, Middle Initial)

Thomas Schrade

Mailing Address 17 Via Visione \# 101

\begin{tabular}{lcc}
\hline City & State & Zip Code \\
Henderson & NV & $89011-3752$
\end{tabular}

FEC ID number of contributing federal political committee.

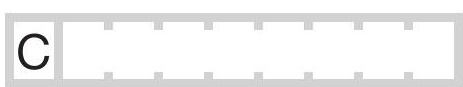

Name of Employer

Information Requested

\section{Occupation}

Information Requested

Receipt For: 2012

Х $\begin{aligned} & \text { Primary } \square \text { General } \\ & \text { Other (specify) }\end{aligned}$

Transaction ID : AE8647BD998B54AEEB6D

Date of Receipt

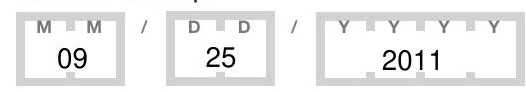

Amount of Each Receipt this Period

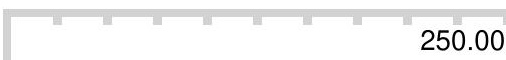

250.00
Amount of Each Receipt this Period

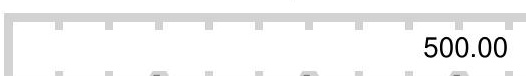

Transaction ID : A3C8DA386E4A34DF2AB6 Date of Receipt

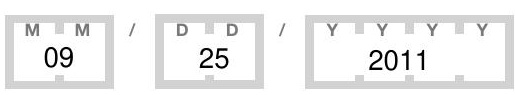

Transaction ID : A75EC5003B7FE4FB993D Date of Receipt

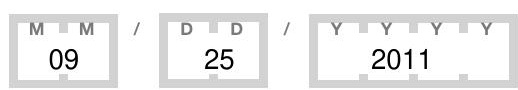

Amount of Each Receipt this Period

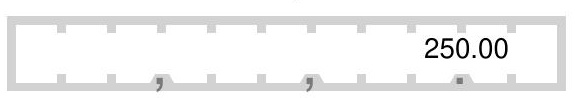

\section{Subtotal Of Receipts This Page (optional)}

Total This Period (last page this line number only) 


\section{SCHEDULE A-P} ITEMIZED RECEIPTS
Use separate schedule(s)

for each category of the

Detailed Summary Page
FOR LINE NUMBER: (check only one)

PAGE $740 / 1572$

\begin{tabular}{|c|c|c|c|c|c|}
\hline & & & & & \\
\hline 16 & X $17 a$ & $17 b$ & $17 c$ & $17 d$ & 18 \\
\hline $19 a$ & $19 b$ & $20 \mathrm{a}$ & $20 \mathrm{~b}$ & $20 \mathrm{c}$ & 21 \\
\hline
\end{tabular}

Any information copied from such Reports and Statements may not be sold or used by any person for the purpose of soliciting contributions or for commercial purposes, other than using the name and address of any political committee to solicit contributions from such committee.

NAME OF COMMITTEE (In Full)

Friends of Herman Cain

A. Full Name (Last, First, Middle Initial)

teresa bohlmeyer

Mailing Address 156 Vilulah Church Rd

\begin{tabular}{lcc}
\hline City & State & Zip Code \\
Coleman & GA & $39836-4412$ \\
\hline
\end{tabular}

FEC ID number of contributing

federal political committee.

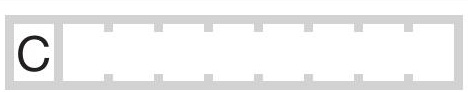

Name of Employer
Information Requested
Receipt For: 2012
X Primary $\quad \square$ General
Other (specify)

Occupation

Information Requested

Election Cycle-to-Date

250.00

B. Full Name (Last, First, Middle Initial)

Conrad Bessemer

Mailing Address 113 Solomons Ridge Ct

\begin{tabular}{lcc}
\hline City & State & Zip Code \\
Millersville & MD & $21108-1268$
\end{tabular}

FEC ID number of contributing

federal political committee.

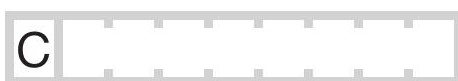

Name of Employer
Novatec Inc.
Receipt For: 2012
X Primary
Other (specify)

Occupation

President

Election Cycle-to-Date

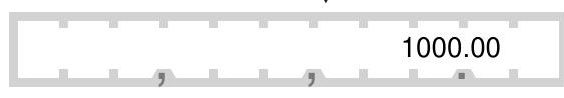

Transaction ID : A8AEEB3AD66204BD3A10

Date of Receipt

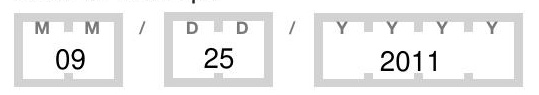

Amount of Each Receipt this Period

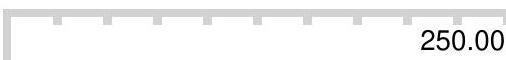

Amount of Each Receipt this Period

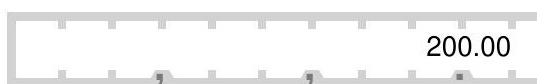

C. Full Name (Last, First, Middle Initial)

james clark

Mailing Address 479 harrison road

\begin{tabular}{lcc}
\hline City & State & Zip Code \\
Roebuck & SC & $29376-3615$
\end{tabular}

FEC ID number of contributing

federal political committee.

C

Name of Employer
Information Requested
Receipt For: 2012
X Primary
Other (specify) General

Occupation

Information Requested

Election Cycle-to-Date

Transaction ID : ADE56938706B14A5288A

Date of Receipt

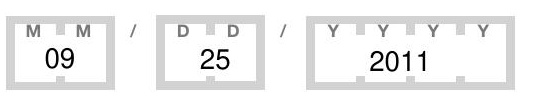

Transaction ID : A2C086F91EF904ECDAC8 Date of Receipt

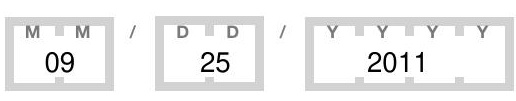

Amount of Each Receipt this Period

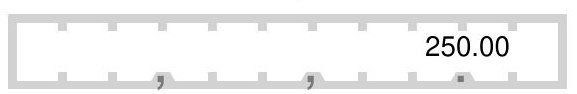

350.00

\section{Subtotal Of Receipts This Page (optional)}

700.00

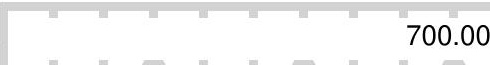

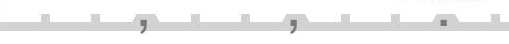

Total This Period (last page this line number only)

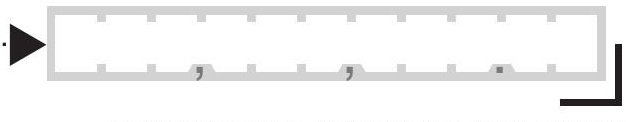

FEC Schedule A-P (Form 3P) (Rev. 03/2011) 
SCHEDULE A-P ITEMIZED RECEIPTS
Use separate schedule(s) for each category of the Detailed Summary Page
FOR LINE NUMBER: (check only one)

PAGE $741 / 1572$

\begin{tabular}{|c|c|c|c|c|c|c|}
\hline & & & & & & \\
\hline 16 & $\lambda$ & $17 \mathrm{a}$ & $17 \mathrm{~b}$ & $17 \mathrm{c}$ & $-17 d$ & -18 \\
\hline $19 a$ & & $19 b$ & $20 a$ & $20 \mathrm{~b}$ & $20 \mathrm{c}$ & 21 \\
\hline
\end{tabular}

Any information copied from such Reports and Statements may not be sold or used by any person for the purpose of soliciting contributions or for commercial purposes, other than using the name and address of any political committee to solicit contributions from such committee.

NAME OF COMMITTEE (In Full)

\section{Friends of Herman Cain}

A. Full Name (Last, First, Middle Initial) Judith Walker

Mailing Address 3079 Spring Hill Dr

\begin{tabular}{lcc}
\hline City & State & Zip Code \\
Monroe & GA & $30656-4093$
\end{tabular}

FEC ID number of contributing federal political committee.

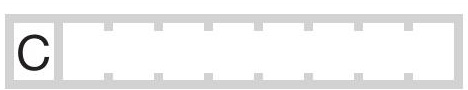

Name of Employer
FOOD LION
Receipt For: 2012
X Primary $\quad$ General
Other (specify)

Occupation Pharmacist

Election Cycle-to-Date

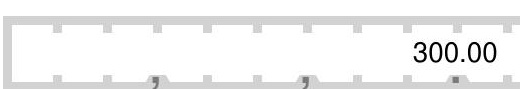

B. Full Name (Last, First, Middle Initial)

ron hewitt

Mailing Address 1191 turnbull bay road

\begin{tabular}{lcc}
\hline City & State & Zip Code \\
New Smyrna Beach & FL & $32168-6001$
\end{tabular}

FEC ID number of contributing

federal political committee.

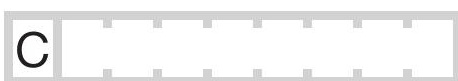

Name of Employer
daytona parts company
Receipt For: 2012
Primary
Other (specify)

\section{Occupation} OWNER

Election Cycle-to-Date

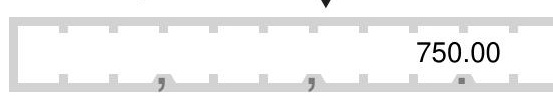

Transaction ID : A489C1EDFB92A4835B05

Date of Receipt

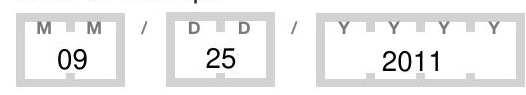

Amount of Each Receipt this Period

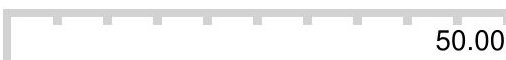

50.00

C. Full Name (Last, First, Middle Initial)

NICK BAKKER

Mailing Address 1394 PURDYTOWN TURNPIKE

\begin{tabular}{lcc}
\hline City & State & Zip Code \\
Hawley & PA & $18428-8264$
\end{tabular}

FEC ID number of contributing federal political committee.

C

Name of Employer

Information Requested

Occupation

Information Requested

Receipt For: 2012

Х $\begin{aligned} & \text { Primary } \\ & \text { Other (specify) }\end{aligned}$

Election Cycle-to-Date

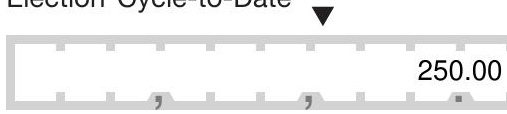

Transaction ID : AD740F3160A664A30890

Date of Receipt

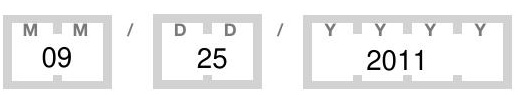

Amount of Each Receipt this Period

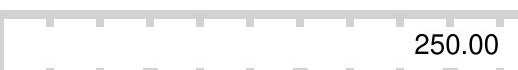

Transaction ID : AE1412A2140AE46D8838

Date of Receipt

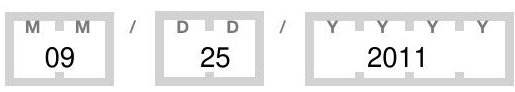

Amount of Each Receipt this Period

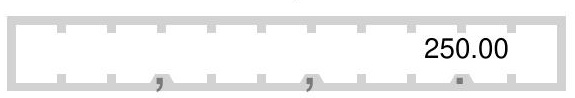

Subtotal Of Receipts This Page (optional).

550.00

Total This Period (last page this line number only) 


\section{SCHEDULE A-P} ITEMIZED RECEIPTS
Use separate schedule(s) for each category of the Detailed Summary Page

\begin{tabular}{|c|c|c|c|c|c|}
\hline \multicolumn{3}{|c|}{$\begin{array}{l}\text { FOR LINE NUMBER: } \\
\text { (check only one) }\end{array}$} & \multicolumn{3}{|c|}{ PAGE 742 / 1572} \\
\hline 16 & $X$ 17a & $17 b$ & $17 \mathrm{c}$ & $17 d$ & 18 \\
\hline $19 a$ & $19 \mathrm{~b}$ & $20 a$ & $20 \mathrm{~b}$ & $20 c$ & 21 \\
\hline
\end{tabular}

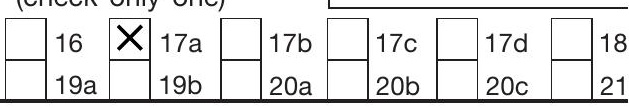

Any information copied from such Reports and Statements may not be sold or used by any person for the purpose of soliciting contributions or for commercial purposes, other than using the name and address of any political committee to solicit contributions from such committee.

NAME OF COMMITTEE (In Full)

\section{Friends of Herman Cain}

A. Full Name (Last, First, Middle Initial)

Dennis Danzik

Mailing Address 15111 N Hayden Rd Ste 160-3

\begin{tabular}{lcc}
\hline City & State & Zip Code \\
Scottsdale & AZ & $85260-2581$
\end{tabular}

FEC ID number of contributing federal political committee.

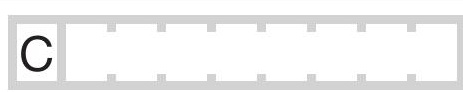

Name of Employer
Information Requested
Receipt For: 2012
X Primary
$\square$ Other (specify)

Occupation Information Requested

Election Cycle-to-Date 250.00

B. Full Name (Last, First, Middle Initial)

George Baccash

Mailing Address 10641 Blue Palm Street

\begin{tabular}{lcc}
\hline City & State & Zip Code \\
Plantation & FL & $33324-8231$ \\
\hline
\end{tabular}

FEC ID number of contributing

federal political committee.

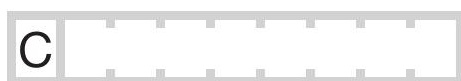

Name of Employer
PricewaterhouseCoopers LLP
Receipt For: 2012
X Primary
$\square$ Other (specify)

Occupation

Partner

Election Cycle-to-Date

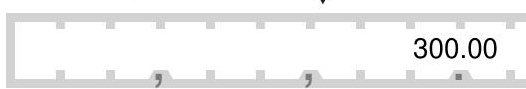

C. Full Name (Last, First, Middle Initial)

Dennis Callewaert

Mailing Address $301 \mathrm{~N}$ 5th Ave

\section{City}

Redgranite

FEC ID number of contributing federal political committee.

\begin{tabular}{l} 
Name of Employer \\
Not Employed \\
Receipt For: 2012 \\
X Primary \\
\hline Other (specify) General
\end{tabular}

Transaction ID : A71E1AFCBCB984DAEA38

Date of Receipt

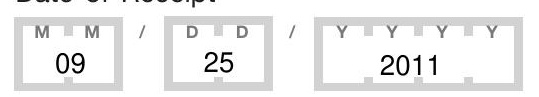

Amount of Each Receipt this Period

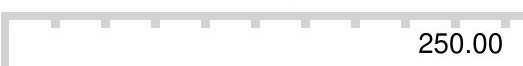

250.00
Amount of Each Receipt this Period

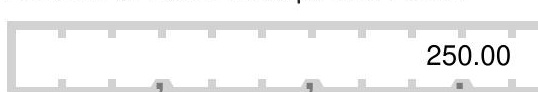

Transaction ID : AE712E54CFEC74425B4B Date of Receipt

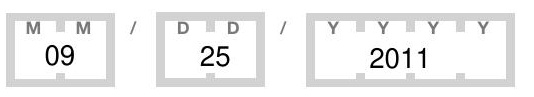

Transaction ID : AFAB8AB3A6FFF4A9A859 Date of Receipt

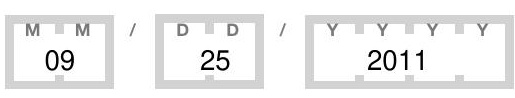

Amount of Each Receipt this Period

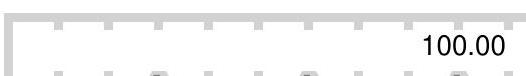

\section{Occupation}

Retired

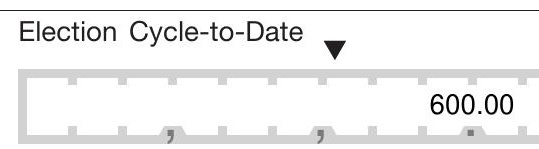

Subtotal Of Receipts This Page (optional).

600.00

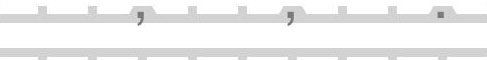

Total This Period (last page this line number only) 
SCHEDULE A-P ITEMIZED RECEIPTS
Use separate schedule(s) for each category of the Detailed Summary Page
FOR LINE NUMBER: (check only one)

PAGE $743 / 1572$

\begin{tabular}{|c|c|c|c|c|c|}
\hline & & & & & \\
\hline 16 & $\begin{array}{lll}X & 17 a \\
\end{array}$ & $17 \mathrm{~b}$ & $17 c$ & $17 d$ & 18 \\
\hline $19 a$ & $19 b$ & $20 a$ & $20 \mathrm{~b}$ & $20 c$ & 21 \\
\hline
\end{tabular}

Any information copied from such Reports and Statements may not be sold or used by any person for the purpose of soliciting contributions or for commercial purposes, other than using the name and address of any political committee to solicit contributions from such committee.

NAME OF COMMITTEE (In Full)

Friends of Herman Cain

A. Full Name (Last, First, Middle Initial)

John Greene

Mailing Address 682 Centerwood Dr

\begin{tabular}{lcc}
\hline City & State & Zip Code \\
Springfield & IL & $62711-6119$
\end{tabular}

FEC ID number of contributing

federal political committee.

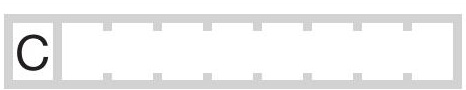

Name of Employer
Information Requested
Receipt For: 2012
X Primary
Other (specify) General

Occupation

Information Requested

Election Cycle-to-Date

250.00

B. Full Name (Last, First, Middle Initial)

Rodney Bennett

Mailing Address 414 Morris Ln

\begin{tabular}{lcc}
\hline City & State & Zip Code \\
Greenville & TX & $75402-5454$ \\
\hline
\end{tabular}

FEC ID number of contributing

federal political committee.

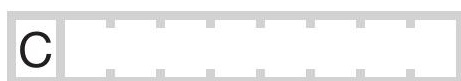

Name of Employer

Occupation

TYBRIN

Systems Engineer

Receipt For: 2012

Х $\begin{aligned} & \text { Primary } \square \text { General } \\ & \text { Other (specify) } \boldsymbol{\nabla}\end{aligned}$

Election Cycle-to-Date

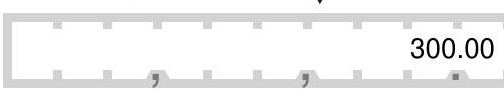

C. Full Name (Last, First, Middle Initial)

Frank Bergren

Mailing Address PO Box 4704

\begin{tabular}{lcc}
\hline City & State & Zip Code \\
Houston & TX & $77210-4704$
\end{tabular}

FEC ID number of contributing

federal political committee.

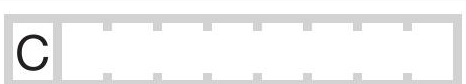

Name of Employer

Information Requested

Occupation

Information Requested

Receipt For: 2012

Х $\begin{aligned} & \text { Primary } \\ & \text { Other (specify) }\end{aligned}$

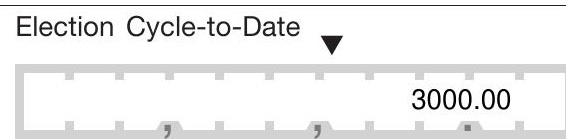

Transaction ID : A8A39CFF1DAE8498A96F

Date of Receipt

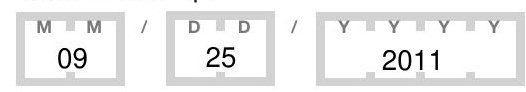

Amount of Each Receipt this Period

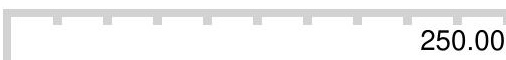

250.00

Transaction ID : A8AE8CCE610B3405C91B

Date of Receipt

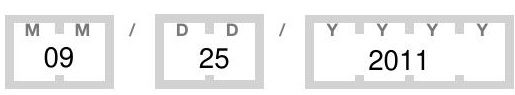

Amount of Each Receipt this Period

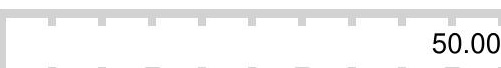

Transaction ID : ADEEC10B0CB754CC4AE4 Date of Receipt

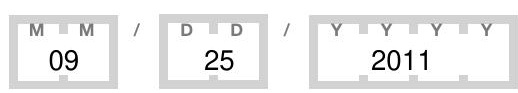

Amount of Each Receipt this Period

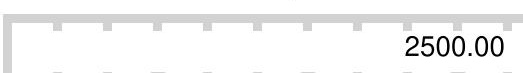

2800.00

Subtotal Of Receipts This Page (optional)

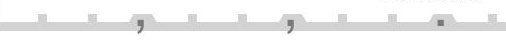

Total This Period (last page this line number only)

FEC Schedule A-P (Form 3P) (Rev. 03/2011) 
SCHEDULE A-P ITEMIZED RECEIPTS
Use separate schedule(s) for each category of the Detailed Summary Page
FOR LINE NUMBER: (check only one)

\begin{tabular}{|c|c|c|c|c|c|c|}
\hline & & & & & & \\
\hline 16 & $\times 1$ & $17 a$ & $17 b$ & $17 c$ & $17 d$ & 18 \\
\hline $19 a$ & & $19 b$ & $20 \mathrm{a}$ & $20 \mathrm{~b}$ & $20 \mathrm{c}$ & 21 \\
\hline
\end{tabular}

Any information copied from such Reports and Statements may not be sold or used by any person for the purpose of soliciting contributions or for commercial purposes, other than using the name and address of any political committee to solicit contributions from such committee.

NAME OF COMMITTEE (In Full)

\section{Friends of Herman Cain}

A. Full Name (Last, First, Middle Initial) Jon Bentz

Mailing Address 5108 W131st ST

\begin{tabular}{lcc}
\hline City & State & Zip Code \\
Leawood & KS & 66209
\end{tabular}

FEC ID number of contributing federal political committee.

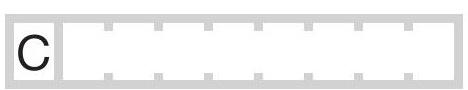

Name of Employer
The Mutual Fund Store
Receipt For: 2012
X Primary
Other (specify) General

Occupation VP

Election Cycle-to-Date

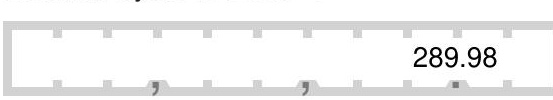

B. Full Name (Last, First, Middle Initial)

James Stewart

Mailing Address 3560 E. Via Colonia del Sol

\begin{tabular}{lcc}
\hline City & State & Zip Code \\
Tucson & AZ & $85718-6065$
\end{tabular}

FEC ID number of contributing

federal political committee.

C

Name of Employer
Information Requested
Receipt For: 2012
X Primary
Other (specify)

\section{Occupation}

Information Requested

Election Cycle-to-Date

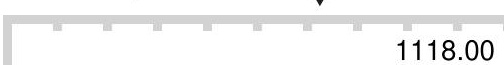

Transaction ID : AA6A753486BD94181A97

Date of Receipt

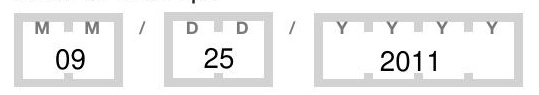

Amount of Each Receipt this Period

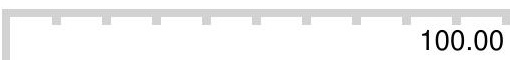

C. Full Name (Last, First, Middle Initial)

Cheryl Fineman

Mailing Address $706 \mathrm{~N}$ Beckley Station Rd

\begin{tabular}{lcc}
\hline City & State & Zip Code \\
Louisville & KY & $40245-4544$
\end{tabular}

FEC ID number of contributing

federal political committee.

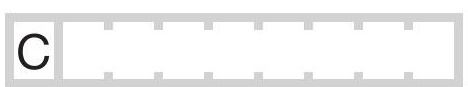

Name of Employer
None
Receipt For: 2012
X Primary
Other (specify) General

Occupation

Retired

Election Cycle-to-Date
Transaction ID : A616011FB6A844FA3B13

Date of Receipt

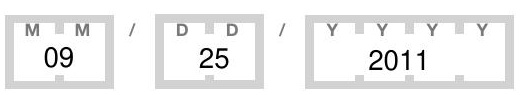

Amount of Each Receipt this Period

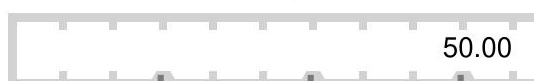

Transaction ID : A69E6B69694BA44438CA Date of Receipt

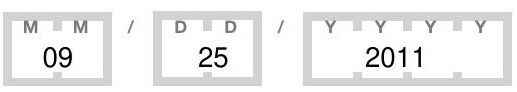

Amount of Each Receipt this Period

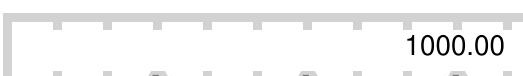

\section{Subtotal Of Receipts This Page (optional)}

Total This Period (last page this line number only) 
SCHEDULE A-P ITEMIZED RECEIPTS
Use separate schedule(s) for each category of the Detailed Summary Page
FOR LINE NUMBER: (check only one)

\begin{tabular}{|c|c|c|c|c|c|}
\hline & & & & & \\
\hline 16 & $\begin{array}{ll}X & 17 a \\
\end{array}$ & $17 \mathrm{~b}$ & $17 c$ & $17 d$ & 18 \\
\hline $19 a$ & $19 b$ & $20 \mathrm{a}$ & $20 \mathrm{~b}$ & $20 c$ & 21 \\
\hline
\end{tabular}

Any information copied from such Reports and Statements may not be sold or used by any person for the purpose of soliciting contributions or for commercial purposes, other than using the name and address of any political committee to solicit contributions from such committee.

NAME OF COMMITTEE (In Full)

\section{Friends of Herman Cain}

A. Full Name (Last, First, Middle Initial)

\section{Eric Forcade}

Mailing Address $2403 \mathrm{~N}$ Citrus Way

\begin{tabular}{lcc}
\hline City & State & Zip Code \\
Palm Harbor & FL & $34683-3318$
\end{tabular}

FEC ID number of contributing federal political committee.

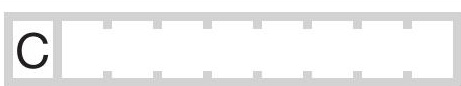

Name of Employer
Information Requested
Receipt For: 2012
X Primary
Other (specify) General

Occupation Information Requested

Election Cycle-to-Date

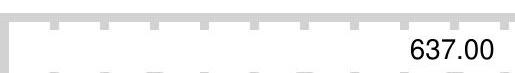

B. Full Name (Last, First, Middle Initial)

Jane Hyman

Mailing Address 17460 lh 35 N Ste 160-107

\begin{tabular}{lcc}
\hline City & State & Zip Code \\
Schertz & TX & $78154-1243$ \\
\hline
\end{tabular}

FEC ID number of contributing

federal political committee.

C

Name of Employer
None
Receipt For: 2012
X Primary
Other (specify)

Occupation

Retired

Election Cycle-to-Date

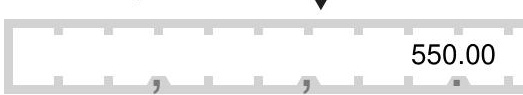

Transaction ID : AEFECCF55745347A484F

Date of Receipt

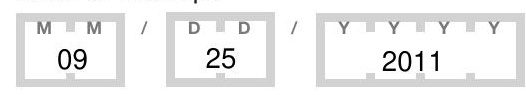

Amount of Each Receipt this Period

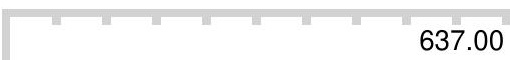

C. Full Name (Last, First, Middle Initial)

skip binkley

Mailing Address 1975 discovery dr

\begin{tabular}{lcc}
\hline City & State & Zip Code \\
Fairbanks & AK & $99709-4577$
\end{tabular}

FEC ID number of contributing federal political committee.

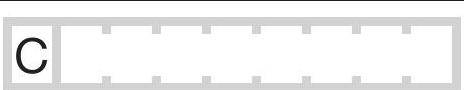

Name of Employer
alaska riverways
Receipt For: 2012
X Primary
Other (specify) General

\section{Occupation}

captain

Election Cycle-to-Date
Transaction ID : A9C09035E8A1641519F6

Date of Receipt

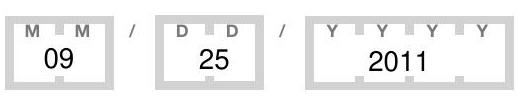

Amount of Each Receipt this Period

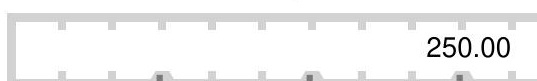

Transaction ID : AAE6C0C8827F940E7B88 Date of Receipt

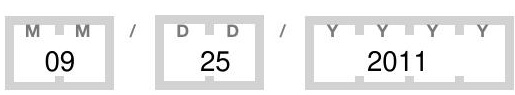

Amount of Each Receipt this Period

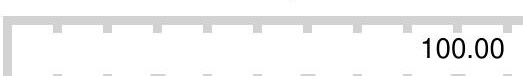

\section{Subtotal Of Receipts This Page (optional)}

987.00

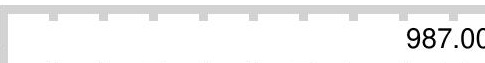

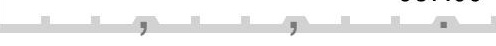

Total This Period (last page this line number only)

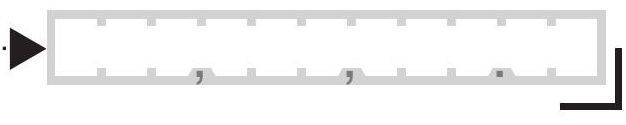

FEC Schedule A-P (Form 3P) (Rev. 03/2011) 
SCHEDULE A-P ITEMIZED RECEIPTS
Use separate schedule(s) for each category of the Detailed Summary Page
FOR LINE NUMBER: (check only one)

PAGE $746 / 1572$

\begin{tabular}{|c|c|c|c|c|c|}
\hline & & & & & \\
\hline 16 & $\begin{array}{l}\mathbf{X} \\
17 a\end{array}$ & $17 b$ & $17 c$ & $17 d$ & 18 \\
\hline $19 a$ & $19 \mathrm{~b}$ & $20 \mathrm{a}$ & $20 \mathrm{~b}$ & $20 \mathrm{c}$ & 21 \\
\hline
\end{tabular}

Any information copied from such Reports and Statements may not be sold or used by any person for the purpose of soliciting contributions or for commercial purposes, other than using the name and address of any political committee to solicit contributions from such committee.

NAME OF COMMITTEE (In Full)

\section{Friends of Herman Cain}

A. Full Name (Last, First, Middle Initial) Joseph Phillips

Mailing Address PO Box 872

\begin{tabular}{lcc}
\hline City & State & Zip Code \\
Norwich & VT & 05055-0872
\end{tabular}

FEC ID number of contributing federal political committee.

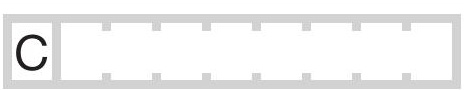

Name of Employer
Information Requested
Receipt For: 2012
X Primary
Other (specify) General

Occupation Information Requested

Election Cycle-to-Date

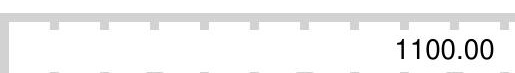

B. Full Name (Last, First, Middle Initial)

\section{Blane Crandall}

Mailing Address 777 Wedge Dr

\begin{tabular}{lcc}
\hline City & State & Zip Code \\
Naples & FL & $34103-4447$
\end{tabular}

FEC ID number of contributing

federal political committee.

C

Name of Employer
Self Employed
Receipt For: 2012
X Primary
Other (specify)

\section{Occupation}

Physician

Election Cycle-to-Date

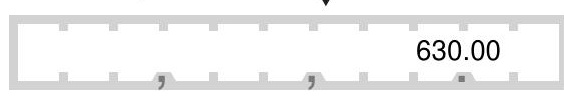

Transaction ID : A06FE803CB40B40F1802

Date of Receipt

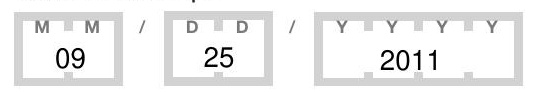

Amount of Each Receipt this Period

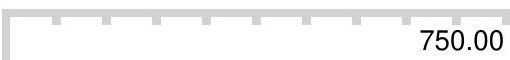

C. Full Name (Last, First, Middle Initial)

Stephen Losee

Mailing Address 17778 HWY 416E

\begin{tabular}{lcc}
\hline City & State & Zip Code \\
Henderson & KY & $42420-9495$
\end{tabular}

FEC ID number of contributing federal political committee.

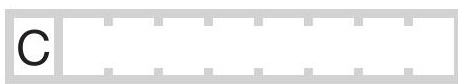

Name of Employer
Sysco
Receipt For: 2012
X Primary $\quad \square$ General
Other (specify)

\section{Occupation}

driver

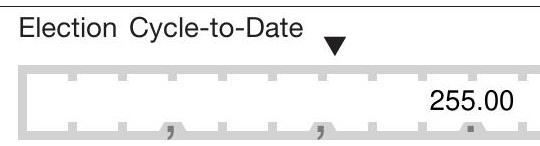

Amount of Each Receipt this Period

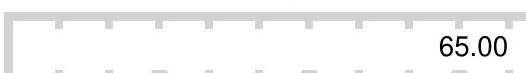

Transaction ID : A3F2FCE0D0D484C7C895 Date of Receipt

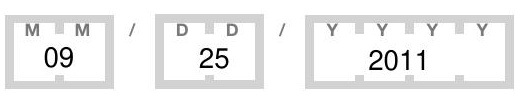

Transaction ID : A3B23B4D232B64BABA5A Date of Receipt

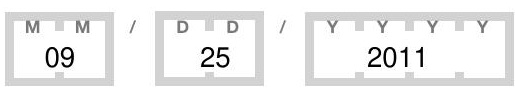

Amount of Each Receipt this Period

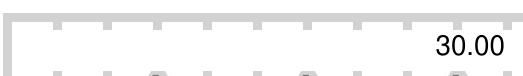

\section{Subtotal Of Receipts This Page (optional)}


SCHEDULE A-P ITEMIZED RECEIPTS
Use separate schedule(s) for each category of the Detailed Summary Page
FOR LINE NUMBER: (check only one)

PAGE $747 / 1572$

\begin{tabular}{|c|c|c|c|c|c|}
\hline & & & & & \\
\hline 16 & $\begin{array}{l}\mathbf{X} \\
17 a\end{array}$ & $17 b$ & $17 c$ & $17 d$ & 18 \\
\hline $19 a$ & $19 \mathrm{~b}$ & $20 \mathrm{a}$ & $20 \mathrm{~b}$ & $20 \mathrm{c}$ & 21 \\
\hline
\end{tabular}

Any information copied from such Reports and Statements may not be sold or used by any person for the purpose of soliciting contributions or for commercial purposes, other than using the name and address of any political committee to solicit contributions from such committee.

NAME OF COMMITTEE (In Full)

\section{Friends of Herman Cain}

A. Full Name (Last, First, Middle Initial)

\section{Gerald Camiener}

Mailing Address 7022 Green Tree Drive

\begin{tabular}{lcc}
\hline City & State & Zip Code \\
Naples & FL & $34108-7525$
\end{tabular}

FEC ID number of contributing federal political committee.

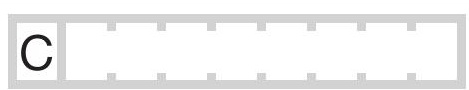

Name of Employer
n/a
Receipt For: 2012
X Primary $\quad$ General
Other (specify)

Occupation Retired

Election Cycle-to-Date

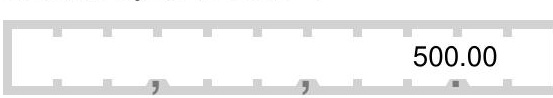

B. Full Name (Last, First, Middle Initial)

Paula Miller

Mailing Address 60 Schley Avenue

\begin{tabular}{lcc}
\hline City & State & Zip Code \\
Staten Island & NY & $10308-2065$ \\
\hline
\end{tabular}

FEC ID number of contributing

federal political committee.

C

Name of Employer
Chartis Claims Inc.
Receipt For: 2012
Primary
Other (specify)

Occupation

Claim Analyst

Election Cycle-to-Date

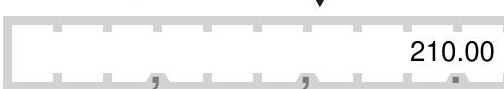

Transaction ID : A94F345D920AB4026800

Date of Receipt

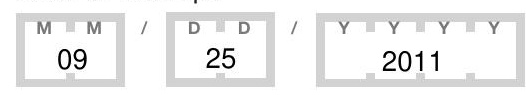

Amount of Each Receipt this Period

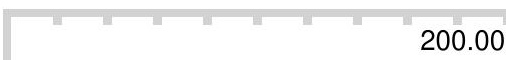

Amount of Each Receipt this Period

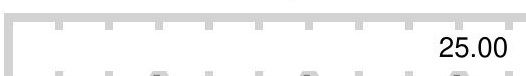

C. Full Name (Last, First, Middle Initial)

Betty Neisler

Transaction ID : AB7918E983B2A46B68C2

Date of Receipt

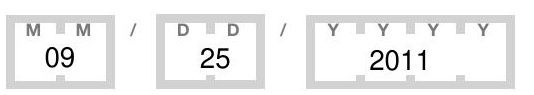

Mailing Address 1090 Riverbend Club Dr SE

\begin{tabular}{lcc}
\hline City & State & Zip Code \\
Atlanta & GA & $30339-2810$
\end{tabular}

FEC ID number of contributing federal political committee.

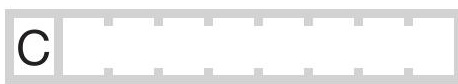

Name of Employer
Information Requested
Receipt For: 2012
X Primary $\quad \square$ General
Other (specify)

\section{Occupation}

Information Requested

Election Cycle-to-Date

Transaction ID : A2C8D3EE1022F42208C2

Date of Receipt

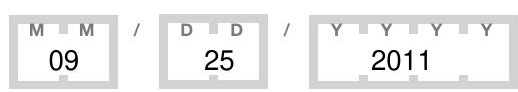

Amount of Each Receipt this Period

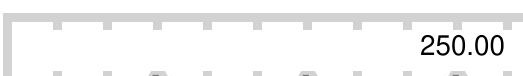

250.00

\section{Subtotal Of Receipts This Page (optional)}

Total This Period (last page this line number only) 
SCHEDULE A-P ITEMIZED RECEIPTS
Use separate schedule(s) for each category of the Detailed Summary Page
FOR LINE NUMBER: (check only one)

PAGE $748 / 1572$

\begin{tabular}{|c|c|c|c|c|c|}
\hline & & & & & \\
\hline 16 & $\begin{array}{l}\mathbf{X} \\
17 a\end{array}$ & $17 b$ & $17 c$ & $17 d$ & 18 \\
\hline $19 a$ & $19 \mathrm{~b}$ & $20 \mathrm{a}$ & $20 \mathrm{~b}$ & $20 \mathrm{c}$ & 21 \\
\hline
\end{tabular}

Any information copied from such Reports and Statements may not be sold or used by any person for the purpose of soliciting contributions or for commercial purposes, other than using the name and address of any political committee to solicit contributions from such committee.

NAME OF COMMITTEE (In Full)

\section{Friends of Herman Cain}

A. Full Name (Last, First, Middle Initial)

Vladimir Jaffe

Mailing Address 1735 E13th St Apt 6N

\begin{tabular}{lcc}
\hline City & State & Zip Code \\
Brooklyn & NY & 11229 \\
\hline
\end{tabular}

FEC ID number of contributing

federal political committee.

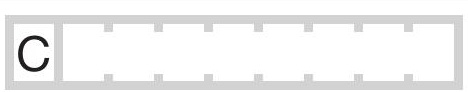

Name of Employer

Palace Imports Inc.

Receipt For: 2012

X Primary $\square$ General Other (specify)

Occupation BUSINESS OWNER

Election Cycle-to-Date

B. Full Name (Last, First, Middle Initial)

Mr Tom Hill

Mailing Address 938 Evans Cook Road

\begin{tabular}{lcc}
\hline City & State & Zip Code \\
Canton & GA & $30115-5700$ \\
\hline
\end{tabular}

FEC ID number of contributing

federal political committee.

C

Name of Employer

Retired

Occupation

Receipt For: 2012

Х $\begin{aligned} & \text { Primary } \square \text { General } \\ & \text { Other (specify) } \boldsymbol{\nabla}\end{aligned}$ Retired

Election Cycle-to-Date

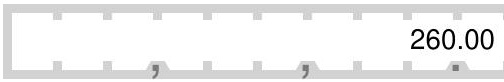

Transaction ID : AEE69EC0A86CA473E912

Date of Receipt

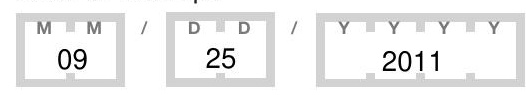

Amount of Each Receipt this Period

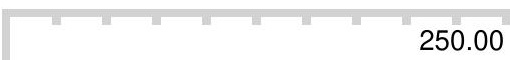

250.00

C. Full Name (Last, First, Middle Initial)

Donnie Fain

Mailing Address 3101 New haven Av

\begin{tabular}{lcc}
\hline City & State & Zip Code \\
Jacksonville & FL & 32225
\end{tabular}

FEC ID number of contributing federal political committee.

C 450.00

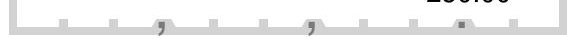

Transaction ID : AE28F3EB8B91741C9B54

Date of Receipt

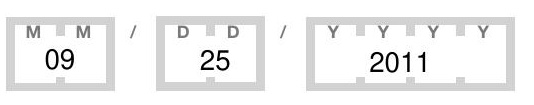

Amount of Each Receipt this Period

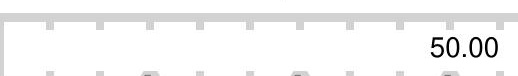

Transaction ID : A5093F1BA067741D4B29

Date of Receipt

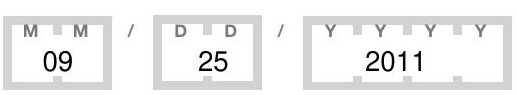

Amount of Each Receipt this Period

Name of Employer
Information Requested
Receipt For: 2012
X Primary
Other (specify) General

Occupation

Information Requested

Election Cycle-to-Date

Subtotal Of Receipts This Page (optional).

Total This Period (last page this line number only)

2800.00

ㄴ.

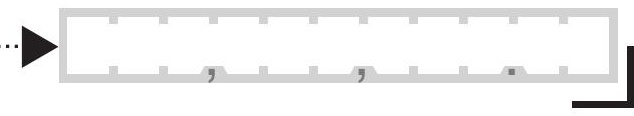


SCHEDULE A-P ITEMIZED RECEIPTS
Use separate schedule(s) for each category of the Detailed Summary Page
FOR LINE NUMBER: (check only one)

PAGE $749 / 1572$

\begin{tabular}{|c|c|c|c|c|c|}
\hline & & & & & \\
\hline 16 & $\begin{array}{l}\mathbf{X} \\
17 a\end{array}$ & $17 b$ & $17 c$ & $17 d$ & 18 \\
\hline $19 a$ & $19 \mathrm{~b}$ & $20 \mathrm{a}$ & $20 \mathrm{~b}$ & $20 \mathrm{c}$ & 21 \\
\hline
\end{tabular}

Any information copied from such Reports and Statements may not be sold or used by any person for the purpose of soliciting contributions or for commercial purposes, other than using the name and address of any political committee to solicit contributions from such committee.

NAME OF COMMITTEE (In Full)

\section{Friends of Herman Cain}

A. Full Name (Last, First, Middle Initial)

\section{Don Lewis}

Mailing Address 166 Merion

City

Saint Simons Island

FEC ID number of contributing

federal political committee.

Name of Employer
Sea Island Company
Receipt For: 2012
X Primary
Other (specify)

B. Full Name (Last, First, Middle Initial)

Robert Davenport

Mailing Address 23003 Willowcreek Stables

\begin{tabular}{lcc}
\hline City & State & Zip Code \\
Spring & TX & $77389-3530$
\end{tabular}

FEC ID number of contributing

federal political committee.

Name of Employer
RG Davenport P.E. (self)
Receipt For: 2012
X Primary
Other (specify)

Name of Employer

RG Davenport P.E. (self)

Receipt For: 2012

Х $\begin{aligned} & \text { Primary } \square \text { General } \\ & \text { Other (specify) } \boldsymbol{\nabla}\end{aligned}$

C. Full Name (Last, First, Middle Initial)

Scott Royster

Mailing Address 1425 Rhode Island Ave NW Penthouse

\begin{tabular}{lcc}
\hline City & State & Zip Code \\
Washington & DC & $20005-5453$
\end{tabular}

FEC ID number of contributing federal political committee.

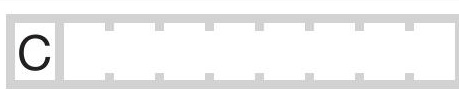

Name of Employer
Information Requested
Receipt For: 2012
X Primary $\quad \square$ General
Other (specify)

C

\section{Occupation}

Realtor

Election Cycle-to-Date

\section{Occupation}

Engineer

Election Cycle-to-Date

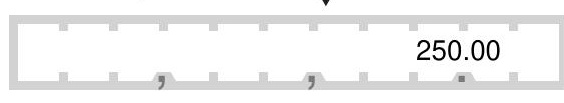

650.00
Information Requested

Election Cycle-to-Date
Transaction ID : A56D49B7B637B4747BFF

Date of Receipt

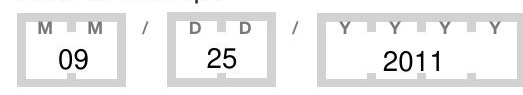

Amount of Each Receipt this Period

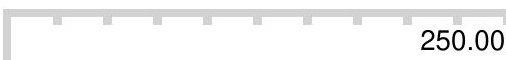

Transaction ID : A2E03A68061844FA7B8F

Date of Receipt

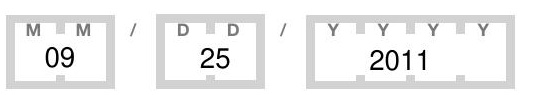

Amount of Each Receipt this Period

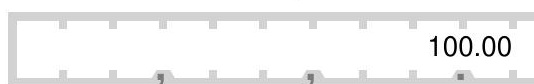

Transaction ID : AD4C753307644401FB5A Date of Receipt

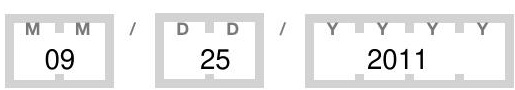

Amount of Each Receipt this Period

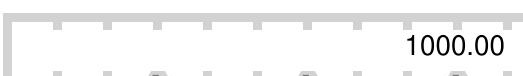

1000.00

Subtotal Of Receipts This Page (optional)

Total This Period (last page this line number only) 
SCHEDULE A-P ITEMIZED RECEIPTS
Use separate schedule(s) for each category of the Detailed Summary Page
FOR LINE NUMBER: (check only one)

PAGE $750 / 1572$

\begin{tabular}{|c|c|c|c|c|c|}
\hline & & & & & \\
\hline 16 & $\begin{array}{l}\mathbf{X} \\
17 a\end{array}$ & $17 b$ & $17 c$ & $17 d$ & 18 \\
\hline $19 a$ & $19 \mathrm{~b}$ & $20 \mathrm{a}$ & $20 \mathrm{~b}$ & $20 \mathrm{c}$ & 21 \\
\hline
\end{tabular}

Any information copied from such Reports and Statements may not be sold or used by any person for the purpose of soliciting contributions or for commercial purposes, other than using the name and address of any political committee to solicit contributions from such committee.

NAME OF COMMITTEE (In Full)

\section{Friends of Herman Cain}

A. Full Name (Last, First, Middle Initial)

Susan Geoffrion

Mailing Address 290 Seamarsh Ct NW

\begin{tabular}{lcc}
\hline City & State & Zip Code \\
Atlanta & GA & $30328-2741$
\end{tabular}

FEC ID number of contributing federal political committee.

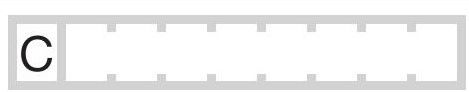

Name of Employer
Cobb county BOE Marietta Ga
Receipt For: 2012
X Primary
Other (specify) General

Occupation school psychologist

Election Cycle-to-Date 355.00

B. Full Name (Last, First, Middle Initial) theodore shepard

Mailing Address 1419 Northwoods Cove

\begin{tabular}{lcc}
\hline City & State & Zip Code \\
Murfreesboro & TN & $37130-1129$
\end{tabular}

FEC ID number of contributing

federal political committee.

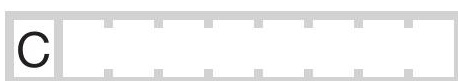

Name of Employer
self
Receipt For: 2012
X Primary
Other (specify)

Occupation

Physician

Election Cycle-to-Date

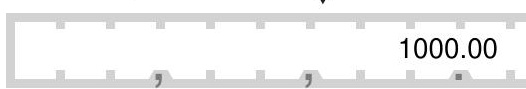

Transaction ID : AD8641524CFC44C3DA85

Date of Receipt

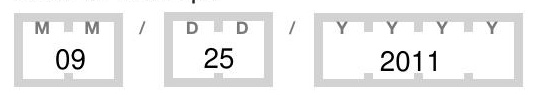

Amount of Each Receipt this Period

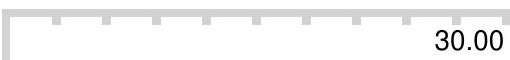

30.00

C. Full Name (Last, First, Middle Initial)

Edward Lewis

Mailing Address 3 Legend Park Drive

\begin{tabular}{lcc}
\hline City & State & Zip Code \\
Sugar Land & TX & $77479-2862$
\end{tabular}

FEC ID number of contributing federal political committee.

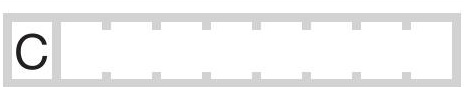

\section{Name of Employer}

Industrial Info Resources

Receipt For: 2012

Х $\begin{aligned} & \text { Primary } \\ & \text { Other (specify) }\end{aligned}$

\section{Occupation}

Owner/CEO

\section{Election Cycle-to-Date}

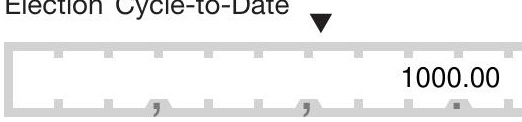

Transaction ID : AB101DBA706A645ECACB Date of Receipt

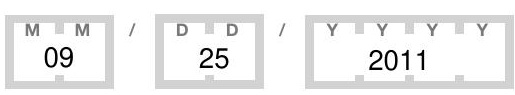

Amount of Each Receipt this Period

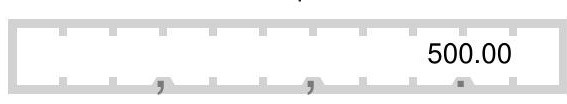

Transaction ID : ABD21426F01154CC1BAA Date of Receipt

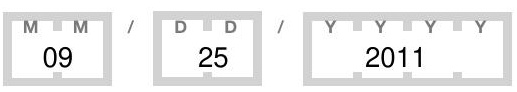

Amount of Each Receipt this Period

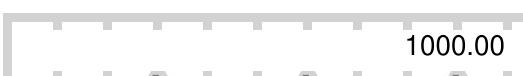

1000.00

Subtotal Of Receipts This Page (optional).

Total This Period (last page this line number only) 
SCHEDULE A-P ITEMIZED RECEIPTS
Use separate schedule(s) for each category of the Detailed Summary Page
FOR LINE NUMBER: (check only one)

PAGE $751 / 1572$

\begin{tabular}{|c|c|c|c|c|c|}
\hline & & & & & \\
\hline 16 & $\begin{array}{l}\mathbf{X} \\
17 a\end{array}$ & $17 b$ & $17 c$ & $17 d$ & 18 \\
\hline $19 a$ & $19 \mathrm{~b}$ & $20 \mathrm{a}$ & $20 \mathrm{~b}$ & $20 \mathrm{c}$ & 21 \\
\hline
\end{tabular}

Any information copied from such Reports and Statements may not be sold or used by any person for the purpose of soliciting contributions or for commercial purposes, other than using the name and address of any political committee to solicit contributions from such committee.

NAME OF COMMITTEE (In Full)

\section{Friends of Herman Cain}

A. Full Name (Last, First, Middle Initial)

Caryn Huizen

Mailing Address 15327 Lost Channel

\begin{tabular}{lcc}
\hline City & State & Zip Code \\
Grand Haven & MI & $49417-9516$
\end{tabular}

FEC ID number of contributing federal political committee.

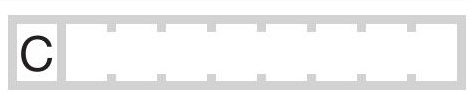

Name of Employer
Self Employed
Receipt For: 2012
X Primary $\quad$ General
Other (specify)

Occupation

Property Development

Election Cycle-to-Date

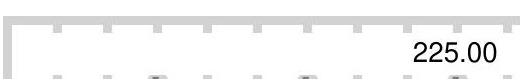

B. Full Name (Last, First, Middle Initial)

Susan Glascom

Mailing Address 28994 Shadow Creek Lane

\begin{tabular}{lcc}
\hline City & State & Zip Code \\
Highland & CA & $92346-3938$ \\
\hline
\end{tabular}

FEC ID number of contributing

federal political committee.

C

Name of Employer
Information Requested
Receipt For: 2012
Xrimary
Other (specify)

Occupation

Information Requested

Election Cycle-to-Date

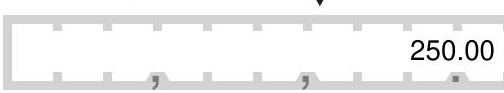

Transaction ID : A7320B495C31D4361BD0

Date of Receipt

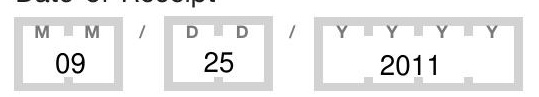

Amount of Each Receipt this Period

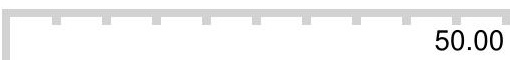

50.00

C. Full Name (Last, First, Middle Initial)

Jerry Klinger

Mailing Address 16405 Equestrian lane

\begin{tabular}{lcc}
\hline City & State & Zip Code \\
Derwood & MD & $20855-1658$
\end{tabular}

FEC ID number of contributing

federal political committee.

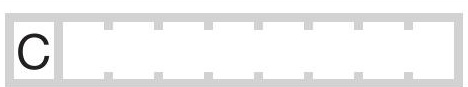

Name of Employer
Merrill Lynch
Receipt For: 2012
X Primary
Other (specify) General

\section{Occupation}

Sales

Election Cycle-to-Date

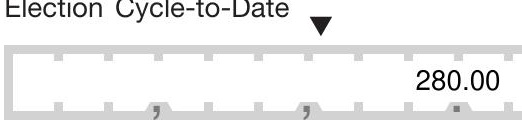

Transaction ID : A115886529BCE4F06B8D

Date of Receipt

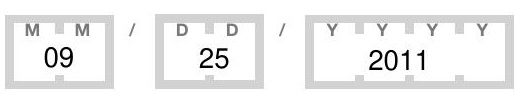

Amount of Each Receipt this Period

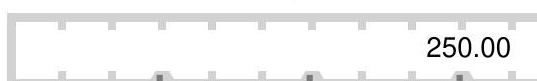

Transaction ID : A25DA339D66CB470DB74 Date of Receipt

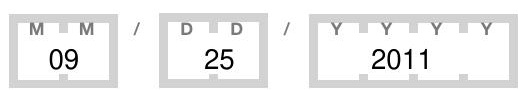

Amount of Each Receipt this Period

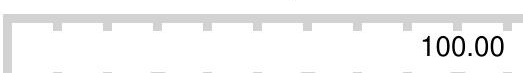

100.00

\section{Subtotal Of Receipts This Page (optional)}

400.00

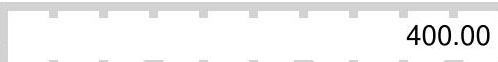

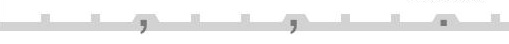

Total This Period (last page this line number only)

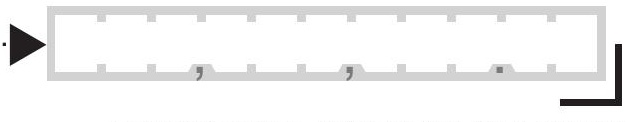

FEC Schedule A-P (Form 3P) (Rev. 03/2011) 


\section{SCHEDULE A-P} ITEMIZED RECEIPTS
Use separate schedule(s)

for each category of the

Detailed Summary Page
FOR LINE NUMBER: (check only one)

PAGE 752 / 1572

\begin{tabular}{|c|c|c|c|c|c|}
\hline & 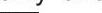 & & & & \\
\hline 16 & $\begin{array}{l}\times 17 a \\
\end{array}$ & $17 b$ & $17 c$ & $17 d$ & 18 \\
\hline $19 a$ & $19 b$ & $20 a$ & $20 \mathrm{~b}$ & $20 c$ & 21 \\
\hline
\end{tabular}

Any information copied from such Reports and Statements may not be sold or used by any person for the purpose of soliciting contributions or for commercial purposes, other than using the name and address of any political committee to solicit contributions from such committee.

NAME OF COMMITTEE (In Full)

Friends of Herman Cain

A. Full Name (Last, First, Middle Initial)

William Veronelli

Mailing Address 34 Parkview Road

\begin{tabular}{lcc}
\hline City & State & Zip Code \\
Reading & MA & $01867-2124$ \\
\hline
\end{tabular}

FEC ID number of contributing

federal political committee.

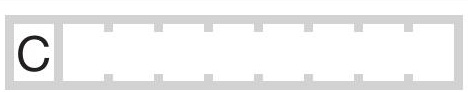

Name of Employer
Information Requested
Receipt For: 2012
X Primary $\quad \square$ General
Other (specify)

Occupation

Information Requested

Election Cycle-to-Date

500.00

B. Full Name (Last, First, Middle Initial)

Michael Freeman

Mailing Address 2116 N McComas St

\begin{tabular}{lcc}
\hline City & State & Zip Code \\
Wichita & KS & $67203-1046$ \\
\hline
\end{tabular}

FEC ID number of contributing

federal political committee.

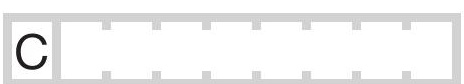

Name of Employer
SendThisFile Inc
Receipt For: 2012
X Primary
Other (specify) General

Occupation

CFO

Election Cycle-to-Date

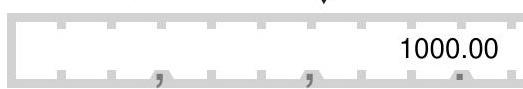

C. Full Name (Last, First, Middle Initial)

$\mathrm{mb}$ weiss

Mailing Address 1304 hawthorne lane

\begin{tabular}{lcc}
\hline City & State & Zip Code \\
Hinsdale & IL & $60521-2956$
\end{tabular}

FEC ID number of contributing federal political committee.

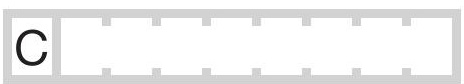

Name of Employer
Information Requested
Receipt For: 2012
X Primary
Other (specify) General

\section{Occupation}

Information Requested

Election Cycle-to-Date
Transaction ID : A2EFF1D872F4B490388D

Date of Receipt

Amount of Each Receipt this Period

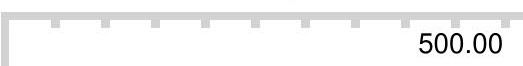

Transaction ID : A2F67AE92DE494A4BADA

Date of Receipt
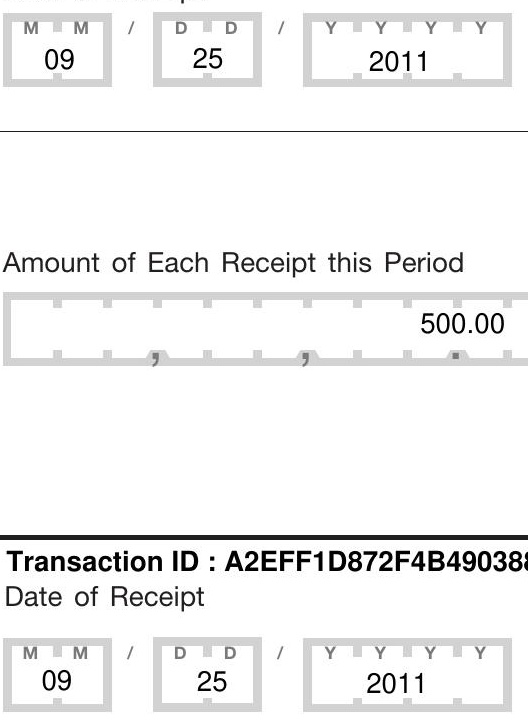

Amount of Each Receipt this Period

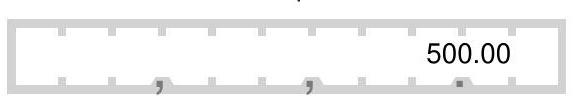

Transaction ID : ADB3C17F6DA0D49C8907 Date of Receipt

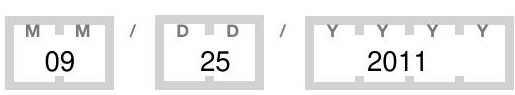

Amount of Each Receipt this Period

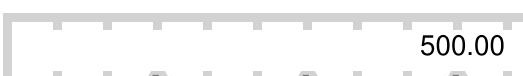

Subtotal Of Receipts This Page (optional).

Total This Period (last page this line number only) 
SCHEDULE A-P ITEMIZED RECEIPTS
Use separate schedule(s) for each category of the Detailed Summary Page
FOR LINE NUMBER: (check only one)
PAGE $753 / 1572$

\begin{tabular}{|c|c|c|c|c|c|}
\hline & & & & & \\
\hline 16 & $\begin{array}{lll}X & 17 a \\
\end{array}$ & $17 \mathrm{~b}$ & $17 c$ & $17 d$ & 18 \\
\hline $19 a$ & $19 b$ & $20 a$ & $20 \mathrm{~b}$ & $20 c$ & 21 \\
\hline
\end{tabular}

Any information copied from such Reports and Statements may not be sold or used by any person for the purpose of soliciting contributions or for commercial purposes, other than using the name and address of any political committee to solicit contributions from such committee.

NAME OF COMMITTEE (In Full)

Friends of Herman Cain

A. Full Name (Last, First, Middle Initial)

Howard Gillis

Mailing Address 791 Blvd of the Champions

\begin{tabular}{lcc}
\hline City & State & Zip Code \\
Shalimar & FL & $32579-2241$
\end{tabular}

FEC ID number of contributing

federal political committee.

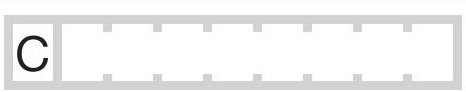

Name of Employer
Information Requested
Receipt For: 2012
X Primary $\quad \square$ General
Other (specify)

Occupation

Information Requested

Election Cycle-to-Date

250.00

B. Full Name (Last, First, Middle Initial)

Nancy Tschetter

Mailing Address 22907 Flume Lane

\begin{tabular}{lcc}
\hline City & State & Zip Code \\
Rapid City & SD & $57702-8509$ \\
\hline
\end{tabular}

FEC ID number of contributing

federal political committee.

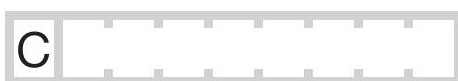

Name of Employer
None
Receipt For: 2012
X Primary
Other (specify)

\section{Occupation}

Homemaker

Election Cycle-to-Date

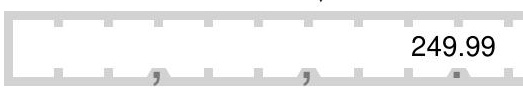

Transaction ID : A8FDA6263F2354DFC89D

Date of Receipt

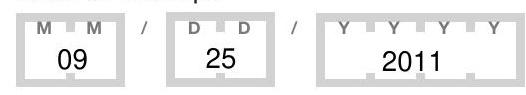

Amount of Each Receipt this Period

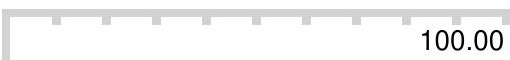

Transaction ID : A5A662D94B2054E24967

Date of Receipt

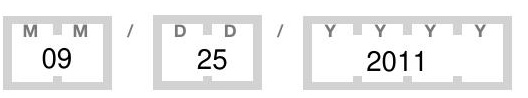

Amount of Each Receipt this Period

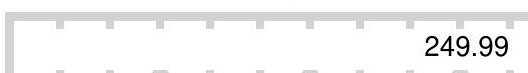

Transaction ID : A9EBAA2B8CF234476877 Date of Receipt

\section{JARROD FRIEDMAN}

C. Full Name (Last, First, Middle Initial)

Mailing Address 2519 north ocean blvd apt. 401

\begin{tabular}{lcc}
\hline City & State & Zip Code \\
Boca Raton & FL & $33431-7823$
\end{tabular}

FEC ID number of contributing federal political committee.

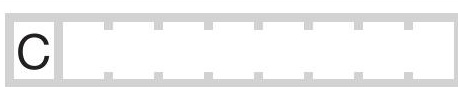

$$
\begin{aligned}
& \text { Name of Employer } \\
& \text { friedman spine and pain clinic } \\
& \text { Receipt For: } 2012 \\
& \text { X Primary } \\
& \text { Other (specify) }
\end{aligned}
$$

\section{Occupation}

Doctor

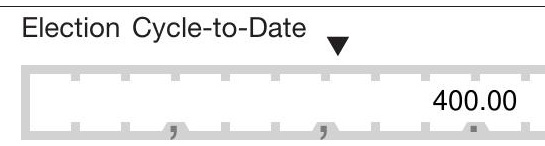

Amount of Each Receipt this Period

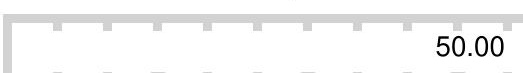

\section{Subtotal Of Receipts This Page (optional)}

399.99

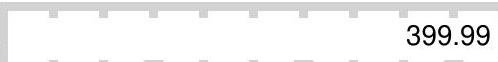

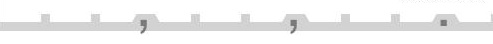

Total This Period (last page this line number only)

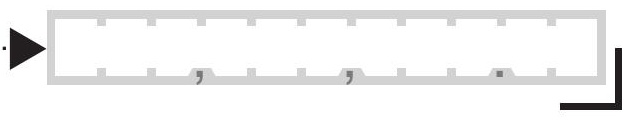

FEC Schedule A-P (Form 3P) (Rev. 03/2011) 
SCHEDULE A-P ITEMIZED RECEIPTS
Use separate schedule(s) for each category of the Detailed Summary Page
FOR LINE NUMBER: (check only one)
PAGE 754 / 1572

\begin{tabular}{|c|c|c|c|c|c|}
\hline & & & & & \\
\hline 16 & $\begin{array}{lll}X & 17 a \\
\end{array}$ & $17 \mathrm{~b}$ & $17 c$ & $17 d$ & 18 \\
\hline $19 a$ & $19 b$ & $20 a$ & $20 \mathrm{~b}$ & $20 c$ & 21 \\
\hline
\end{tabular}

Any information copied from such Reports and Statements may not be sold or used by any person for the purpose of soliciting contributions or for commercial purposes, other than using the name and address of any political committee to solicit contributions from such committee.

NAME OF COMMITTEE (In Full)

\section{Friends of Herman Cain}

A. Full Name (Last, First, Middle Initial)

william snell

Mailing Address 1185 byrnwyck way

\begin{tabular}{lcc}
\hline City & State & Zip Code \\
Atlanta & GA & $30319-1650$ \\
\hline
\end{tabular}

FEC ID number of contributing federal political committee.

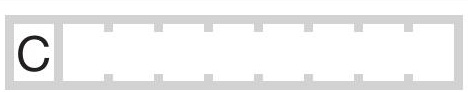

Name of Employer
self
Receipt For: 2012
X Primary $\quad$ General
Other (specify)

Occupation

Physician

Election Cycle-to-Date

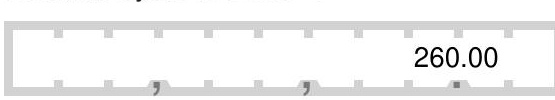

B. Full Name (Last, First, Middle Initial)

david phillips

Mailing Address 6457 memphis

\begin{tabular}{lcc}
\hline City & State & Zip Code \\
New Orleans & LA & $70124-3150$
\end{tabular}

FEC ID number of contributing

federal political committee.

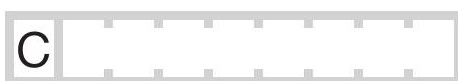

Name of Employer
Unemployed
Receipt For: 2012
X Primary
Other (specify)

\section{Occupation}

maintenance

Election Cycle-to-Date

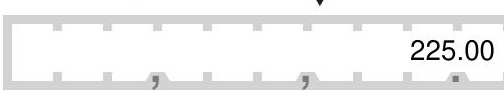

Transaction ID : A5C1DEE2CBA6047419C8

Date of Receipt

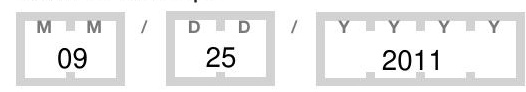

Amount of Each Receipt this Period

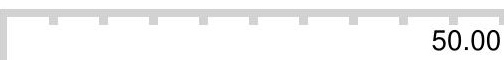

50.00

C. Full Name (Last, First, Middle Initial)

Darcie Smith

Mailing Address 5247 Vernon Springs Trl NW

\begin{tabular}{lcc}
\hline City & State & Zip Code \\
Atlanta & GA & $30327-4511$
\end{tabular}

FEC ID number of contributing

federal political committee.

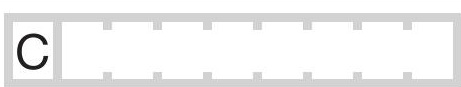

Name of Employer

Information Requested

Occupation

Information Requested

Receipt For: 2012

Х $\begin{aligned} & \text { Primary } \\ & \text { Other (specify) }\end{aligned}$

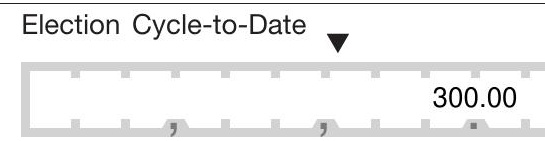

Amount of Each Receipt this Period

Transaction ID : A72524909B22946E4B65

Date of Receipt
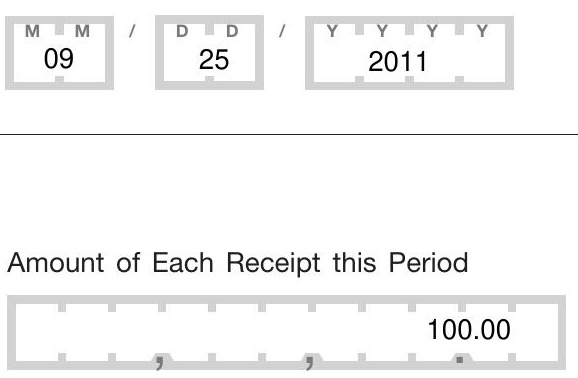

Transaction ID : A57C12908CBAB4B2E9D9

Date of Receipt

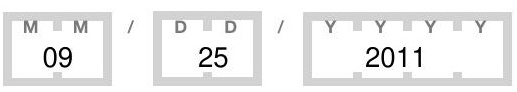

Amount of Each Receipt this Period

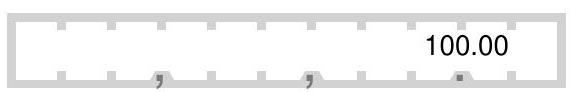

Subtotal Of Receipts This Page (optional).

250.00

Total This Period (last page this line number only) 
SCHEDULE A-P ITEMIZED RECEIPTS
Use separate schedule(s) for each category of the Detailed Summary Page
FOR LINE NUMBER: (check only one)

PAGE $755 / 1572$

\begin{tabular}{|c|c|c|c|c|c|}
\hline & & & & & \\
\hline 16 & $\begin{array}{l}\mathbf{X} \\
17 a\end{array}$ & $17 b$ & $17 c$ & $17 d$ & 18 \\
\hline $19 a$ & $19 \mathrm{~b}$ & $20 \mathrm{a}$ & $20 \mathrm{~b}$ & $20 \mathrm{c}$ & 21 \\
\hline
\end{tabular}

Any information copied from such Reports and Statements may not be sold or used by any person for the purpose of soliciting contributions or for commercial purposes, other than using the name and address of any political committee to solicit contributions from such committee.

NAME OF COMMITTEE (In Full)

\section{Friends of Herman Cain}

A. Full Name (Last, First, Middle Initial) Janis Talbot

Mailing Address 720 Montague Ave

\begin{tabular}{lcc}
\hline City & State & Zip Code \\
Greenwood & SC & $29649-1439$
\end{tabular}

FEC ID number of contributing federal political committee.

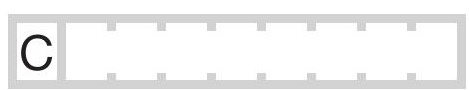

Name of Employer
self
Receipt For: 2012
X Primary $\quad$ General
Other (specify)

Occupation

Real Estate Abstractor

Election Cycle-to-Date

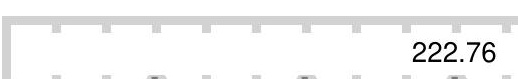

B. Full Name (Last, First, Middle Initial)

Edward Metzger

Mailing Address 820 Vista Bluff Drive

\begin{tabular}{lcc}
\hline City & State & Zip Code \\
Duluth & GA & $30097-6462$ \\
\hline
\end{tabular}

FEC ID number of contributing

federal political committee.

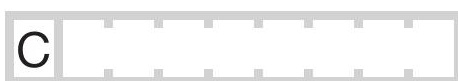

Name of Employer
Trane
Receipt For: 2012
X Primary
Other (specify)

\section{Occupation}

Engineer

Election Cycle-to-Date

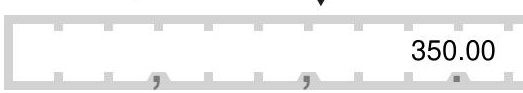

C. Full Name (Last, First, Middle Initial)

Glen Dasher

Mailing Address 613 Perkins Mill Road

\begin{tabular}{lcc}
\hline City & State & Zip Code \\
Claxton & GA & $30417-6453$
\end{tabular}

FEC ID number of contributing

federal political committee.

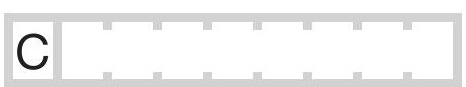

Name of Employer

Tri-Care Family Medicine

Receipt For: 2012

Х $\begin{aligned} & \text { Primary } \square \text { General } \\ & \text { Other (specify) }\end{aligned}$

Occupation

Physician

Election Cycle-to-Date

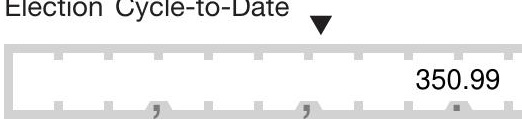

Transaction ID : A09BD87CCC1F745308EA

Date of Receipt

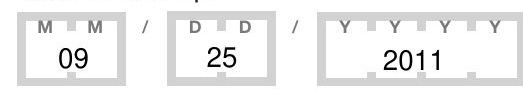

Amount of Each Receipt this Period

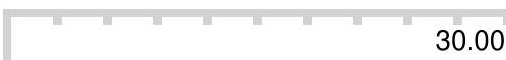

30.00
Transaction ID : A11324342234F4194871

Date of Receipt

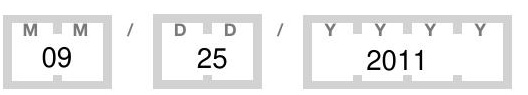

Amount of Each Receipt this Period

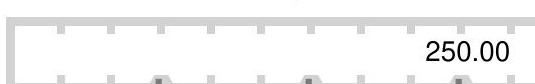

Transaction ID : A4E40B3BFB69548B390C Date of Receipt

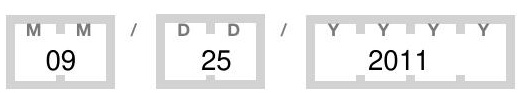

Amount of Each Receipt this Period

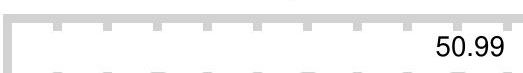

\section{Subtotal Of Receipts This Page (optional)}

Total This Period (last page this line number only) 


\section{SCHEDULE A-P} ITEMIZED RECEIPTS
Use separate schedule(s)

for each category of the

Detailed Summary Page
FOR LINE NUMBER: (check only one)

PAGE $756 / 1572$

\begin{tabular}{|c|c|c|c|c|c|}
\hline & & & & & \\
\hline 16 & X $17 a$ & $17 b$ & $17 c$ & $17 d$ & 18 \\
\hline $19 a$ & $19 b$ & $20 \mathrm{a}$ & $20 \mathrm{~b}$ & $20 \mathrm{c}$ & 21 \\
\hline
\end{tabular}

Any information copied from such Reports and Statements may not be sold or used by any person for the purpose of soliciting contributions or for commercial purposes, other than using the name and address of any political committee to solicit contributions from such committee.

NAME OF COMMITTEE (In Full)

\section{Friends of Herman Cain}

A. Full Name (Last, First, Middle Initial)

\section{Dorothea Cist}

Mailing Address 28 Monarch Bay Plaza Suite Q

\begin{tabular}{lcc}
\hline City & State & Zip Code \\
Dana Point & CA & $92629-3460$
\end{tabular}

FEC ID number of contributing

federal political committee.

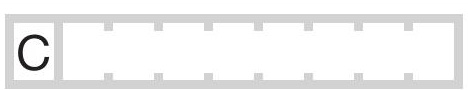

Name of Employer
Self Employed
Receipt For: 2012
\begin{tabular}{l}
$\square$ Primary General \\
\hline Other (specify)
\end{tabular}

Occupation

Physician

Election Cycle-to-Date

2600.00

B. Full Name (Last, First, Middle Initial)

Debbie Price

Mailing Address 4126 Shawnee Lane NE

\begin{tabular}{lcc}
\hline City & State & Zip Code \\
Atlanta & GA & $30319-1541$ \\
\hline
\end{tabular}

FEC ID number of contributing

federal political committee.

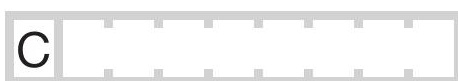

Name of Employer
None
Receipt For: 2012
X Primary
Other (specify)

\section{Occupation}

Homemaker

Election Cycle-to-Date

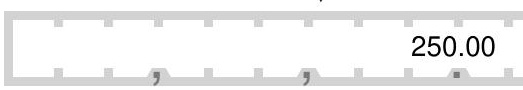

Transaction ID : A417E951A3F2C47759CC

Date of Receipt

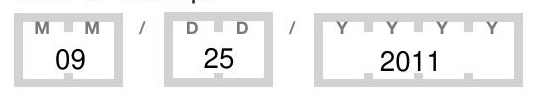

Amount of Each Receipt this Period

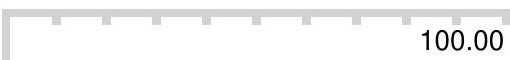

Transaction ID : A97244C210B33489B90D

Date of Receipt

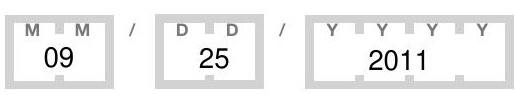

Amount of Each Receipt this Period

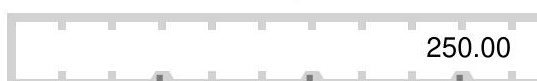

Transaction ID : A02A189D5C3E94D148D3

Date of Receipt

Philip Dobbs

Mailing Address 216 Pine Branch Drive

\begin{tabular}{lcc}
\hline City & State & Zip Code \\
Stockbridge & GA & $30281-6023$
\end{tabular}

FEC ID number of contributing

federal political committee.

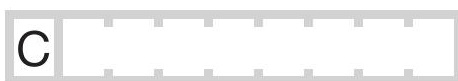

Name of Employer

Occupation

Ga Municipal Assoc

Graphics Manager

Receipt For: 2012

Х $\begin{aligned} & \text { Primary } \square \text { General } \\ & \text { Other (specify) }\end{aligned}$

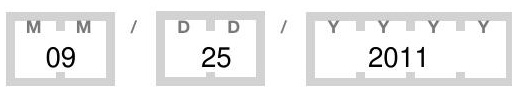

Amount of Each Receipt this Period

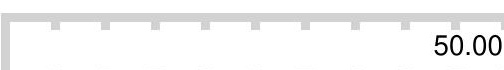

\section{Subtotal Of Receipts This Page (optional)}

400.00

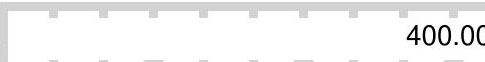

(1)

Total This Period (last page this line number only)

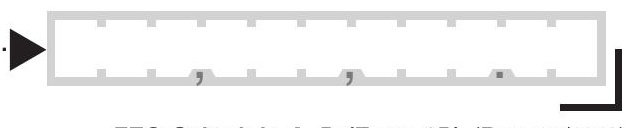

FEC Schedule A-P (Form 3P) (Rev. 03/2011) 


\section{SCHEDULE A-P} ITEMIZED RECEIPTS
Use separate schedule(s) for each category of the Detailed Summary Page
FOR LINE NUMBER: (check only one)

PAGE 757 / 1572

\begin{tabular}{|c|c|c|c|c|c|}
\hline & & & & & \\
\hline 16 & $\mathbf{X} 17 \mathrm{a}$ & $17 \mathrm{~b}$ & $17 c$ & $17 d$ & 18 \\
\hline $19 a$ & $19 \mathrm{~b}$ & $20 a$ & $20 \mathrm{~b}$ & $20 c$ & 21 \\
\hline
\end{tabular}

Any information copied from such Reports and Statements may not be sold or used by any person for the purpose of soliciting contributions or for commercial purposes, other than using the name and address of any political committee to solicit contributions from such committee.

NAME OF COMMITTEE (In Full)

Friends of Herman Cain

A. Full Name (Last, First, Middle Initial)

Blane Crandall

Mailing Address 777 Wedge Dr

\begin{tabular}{lcc}
\hline City & State & Zip Code \\
Naples & FL & $34103-4447$
\end{tabular}

FEC ID number of contributing federal political committee.

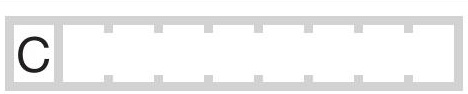

Name of Employer
Self Employed
Receipt For: 2012
X Primary
$\square$ Other (specify) General

Occupation

Physician

Election Cycle-to-Date

630.00

B. Full Name (Last, First, Middle Initial)

David Gray

Mailing Address 4216 Hilty

\begin{tabular}{lcc}
\hline City & State & Zip Code \\
Export & PA & $15632-1608$ \\
\hline
\end{tabular}

FEC ID number of contributing

federal political committee.

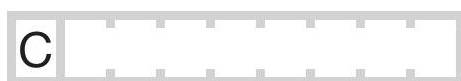

Name of Employer
RCL Itd
Receipt For: 2012
X Primary
Other (specify)

Occupation

Physician

Election Cycle-to-Date

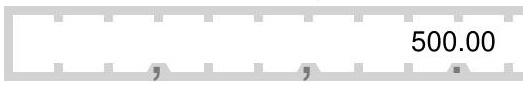

C. Full Name (Last, First, Middle Initial)

Russell Di Giallorenzo

Mailing Address 2000 S. A1A \#508

\begin{tabular}{lcc}
\hline City & State & Zip Code \\
Jupiter & FL & $33477-1448$
\end{tabular}

FEC ID number of contributing federal political committee.

C

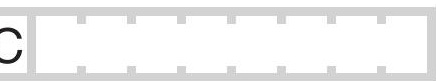

Name of Employer

Occupation

Information Requested

Information Requested

Receipt For: 2012

Х $\begin{aligned} & \text { Primary } \\ & \text { Other (specify) }\end{aligned}$

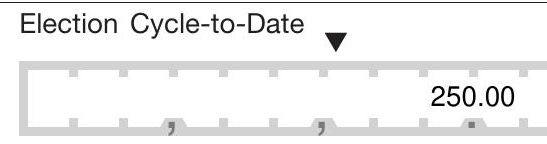

Transaction ID : ABB5FC42DD8FA410F986

Date of Receipt

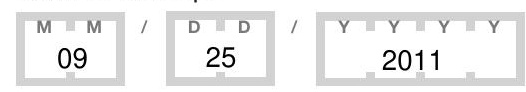

Amount of Each Receipt this Period

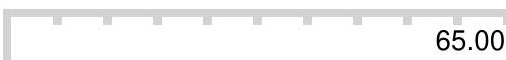

65.00

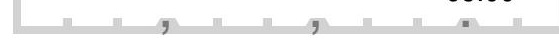

Transaction ID : AD18BC83BF6F046DF92B

Date of Receipt

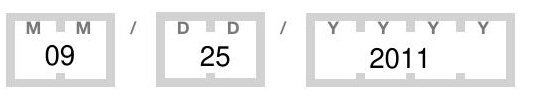

Amount of Each Receipt this Period

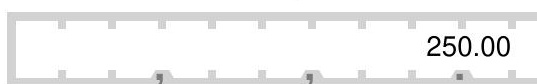

Transaction ID : A90BE526D14F940D9BA8 Date of Receipt

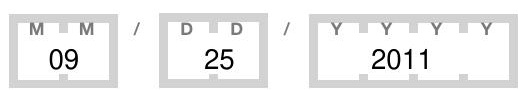

Amount of Each Receipt this Period

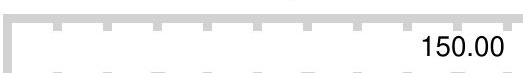

150.00

Subtotal Of Receipts This Page (optional)

465.00

Total This Period (last page this line number only) 


\section{SCHEDULE A-P} ITEMIZED RECEIPTS
Use separate schedule(s)

for each category of the

Detailed Summary Page
FOR LINE NUMBER: (check only one)

PAGE $758 / 1572$

\begin{tabular}{|c|c|c|c|c|c|}
\hline & & & & & \\
\hline 16 & X $17 a$ & $17 b$ & $17 c$ & $17 d$ & 18 \\
\hline $19 a$ & $19 b$ & $20 \mathrm{a}$ & $20 \mathrm{~b}$ & $20 \mathrm{c}$ & 21 \\
\hline
\end{tabular}

Any information copied from such Reports and Statements may not be sold or used by any person for the purpose of soliciting contributions or for commercial purposes, other than using the name and address of any political committee to solicit contributions from such committee.

NAME OF COMMITTEE (In Full)

\section{Friends of Herman Cain}

A. Full Name (Last, First, Middle Initial)

Nicholas Thompson

Mailing Address 1 Alexander Rd

\begin{tabular}{lcc}
\hline City & State & Zip Code \\
Kintnersville & PA & $18930-9800$
\end{tabular}

FEC ID number of contributing federal political committee.

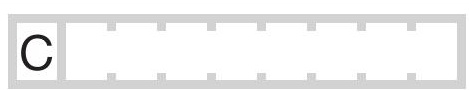

Name of Employer
Groupmark Financial Services Ltd
Receipt For: 2012
X Primary $\quad \square$ General
Other (specify)

Occupation Investment Banking

Election Cycle-to-Date

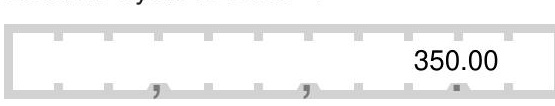

B. Full Name (Last, First, Middle Initial)

Joseph Jackson III

Mailing Address 2701 Meredyth Drive

\begin{tabular}{lcc}
\hline City & State & Zip Code \\
Albany & GA & $31707-2267$ \\
\hline
\end{tabular}

FEC ID number of contributing

federal political committee.

C

Name of Employer
Information Requested
Receipt For: 2012
X Primary
Other (specify)

Occupation

Information Requested

Election Cycle-to-Date

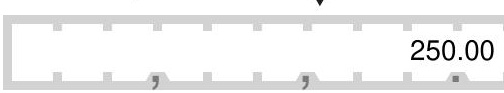

Transaction ID : A7FD73048E50244A3B5C

Date of Receipt

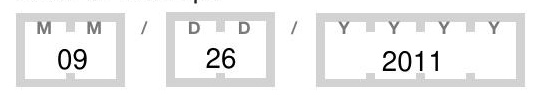

Amount of Each Receipt this Period

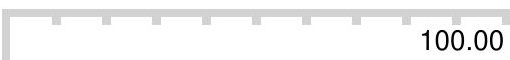

100.00

C. Full Name (Last, First, Middle Initial)

james kargman

Mailing Address $2223 \mathrm{~N}$ Burling St

\begin{tabular}{lcc}
\hline City & State & Zip Code \\
Chicago & IL & $60614-3711$
\end{tabular}

FEC ID number of contributing

federal political committee.

C

Name of Employer

National Systems Corp.

Occupation

Receipt For: 2012

Х $\begin{aligned} & \text { Primary } \square \text { General } \\ & \text { Other (specify) }\end{aligned}$

President

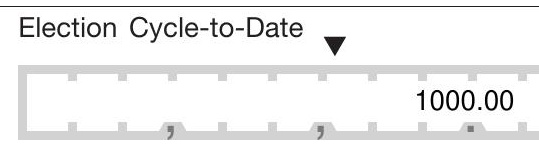

Amount of Each Receipt this Period

Transaction ID : AC7BF7184C4CF4410B25

Date of Receipt
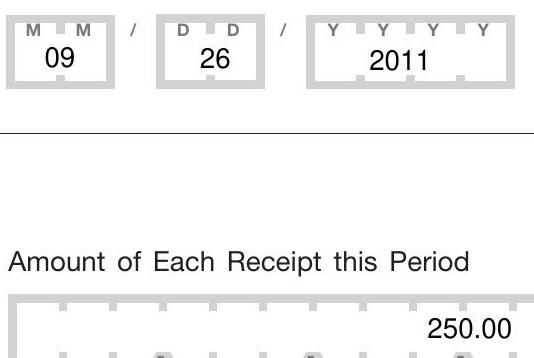

Transaction ID : A8F0B204627074542A1F

Date of Receipt

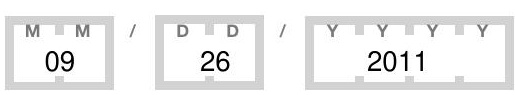

Amount of Each Receipt this Period

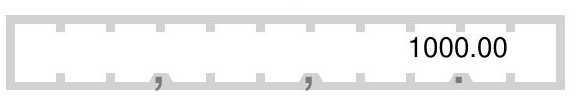

Subtotal Of Receipts This Page (optional).

1350.00

Total This Period (last page this line number only) 


\section{SCHEDULE A-P} ITEMIZED RECEIPTS
Use separate schedule(s) for each category of the Detailed Summary Page

\begin{tabular}{|c|c|c|c|c|c|}
\hline \multicolumn{3}{|c|}{$\begin{array}{l}\text { FOR LINE NUMBER: } \\
\text { (check only one) }\end{array}$} & \multicolumn{3}{|c|}{ PAGE 759 / 1572} \\
\hline 16 & $X$ 17a & $17 b$ & 17c & $17 d$ & 18 \\
\hline $19 a$ & $19 \mathrm{~b}$ & $20 a$ & $20 \mathrm{~b}$ & $20 c$ & 21 \\
\hline
\end{tabular}

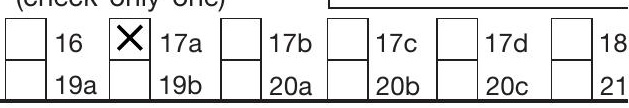

Any information copied from such Reports and Statements may not be sold or used by any person for the purpose of soliciting contributions or for commercial purposes, other than using the name and address of any political committee to solicit contributions from such committee.

NAME OF COMMITTEE (In Full)

\section{Friends of Herman Cain}

A. Full Name (Last, First, Middle Initial)

David Reynolds

Mailing Address 5460 Char Dr

\begin{tabular}{lcc}
\hline City & State & Zip Code \\
Indianapolis & IN & $46221-3706$
\end{tabular}

FEC ID number of contributing federal political committee.

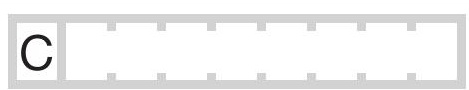

Name of Employer
Information Requested
Receipt For: 2012
X Primary
$\square$ Other (specify)

Occupation Information Requested

Election Cycle-to-Date 250.00

B. Full Name (Last, First, Middle Initial)

Terry Francescon

Mailing Address 1011 25th Ave Ct

\begin{tabular}{lcc}
\hline City & State & Zip Code \\
Moline & IL & $61265-4729$
\end{tabular}

FEC ID number of contributing

federal political committee.

C

Name of Employer
Information Requested
Receipt For: 2012
Primary
Other (specify)

Occupation

Information Requested

Election Cycle-to-Date

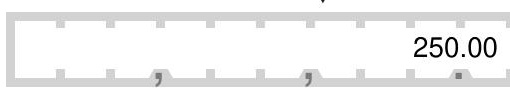

Transaction ID : A43D21449EE5E4F758DA

Date of Receipt

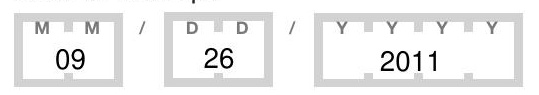

Amount of Each Receipt this Period

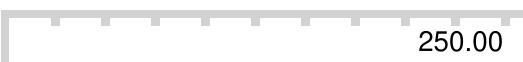

Transaction ID : AF52D3F19B9494763829

Date of Receipt

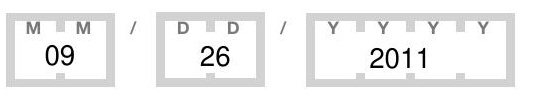

Amount of Each Receipt this Period

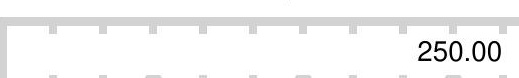

C. Full Name (Last, First, Middle Initial)

Kathy Phillips

Mailing Address 4094 Spy Glass Lane

\begin{tabular}{lcc}
\hline City & State & Zip Code \\
Longmont & CO & $80503-8355$
\end{tabular}

FEC ID number of contributing federal political committee.

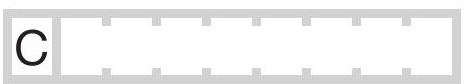

Name of Employer

Occupation

Infolink Consulting

IT Consultant

Transaction ID : A49ECF6D051134755AD9

Date of Receipt

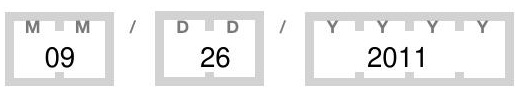

Amount of Each Receipt this Period

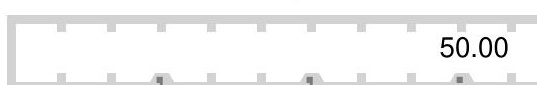

Subtotal Of Receipts This Page (optional)

225.00

550.00

Election Cycle-to-Date

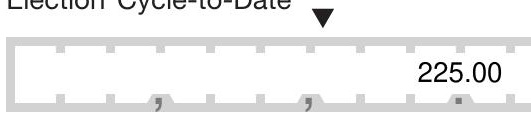

Total This Period (last page this line number only) 
SCHEDULE A-P ITEMIZED RECEIPTS
Use separate schedule(s) for each category of the Detailed Summary Page
FOR LINE NUMBER: (check only one)

PAGE $760 / 1572$

\begin{tabular}{|c|c|c|c|c|c|}
\hline & & & & & \\
\hline 16 & $\begin{array}{l}\mathbf{X} \\
17 a\end{array}$ & $17 b$ & $17 c$ & $17 d$ & 18 \\
\hline $19 a$ & $19 \mathrm{~b}$ & $20 \mathrm{a}$ & $20 \mathrm{~b}$ & $20 \mathrm{c}$ & 21 \\
\hline
\end{tabular}

Any information copied from such Reports and Statements may not be sold or used by any person for the purpose of soliciting contributions or for commercial purposes, other than using the name and address of any political committee to solicit contributions from such committee.

NAME OF COMMITTEE (In Full)

\section{Friends of Herman Cain}

A. Full Name (Last, First, Middle Initial)

hollis curtis

Mailing Address 6314 Carbonton Rd

\begin{tabular}{lcc}
\hline City & State & Zip Code \\
Sanford & NC & $27330-3027$
\end{tabular}

FEC ID number of contributing federal political committee.

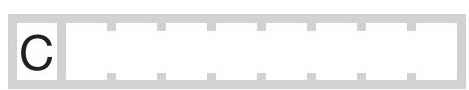

Name of Employer
$\mathrm{h} \mathrm{r}$ curtis plumbing contractor
Receipt For: 2012
X Primary
Other (specify) General

Occupation plumbing contractor

Election Cycle-to-Date 385.00

B. Full Name (Last, First, Middle Initial)

Ed Brown

Mailing Address 835 E. Lamar Blvd \#363

\begin{tabular}{lcc}
\hline City & State & Zip Code \\
Arlington & TX & $76011-3504$ \\
\hline
\end{tabular}

FEC ID number of contributing

federal political committee.

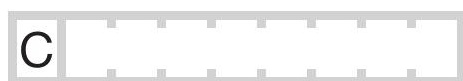

Name of Employer
Flexjet
Receipt For: 2012
X Primary $\quad$ General
Other (specify)

\section{Occupation}

Pilot

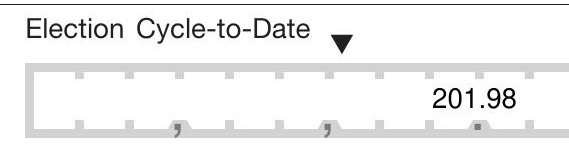

C. Full Name (Last, First, Middle Initial)

Denise Angrisani

Mailing Address 750 Maggie Court

\begin{tabular}{lcc}
\hline City & State & Zip Code \\
Kennesaw & GA & $30144-1392$
\end{tabular}

FEC ID number of contributing federal political committee.

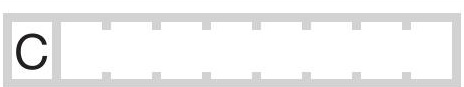

Name of Employer
None
Receipt For: 2012
Х Primary $\quad \square$ General
Other (specify)

Occupation

Retired

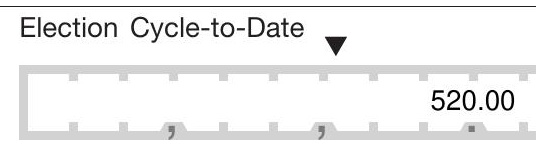

Transaction ID : A759296BA69544570BC3

Date of Receipt

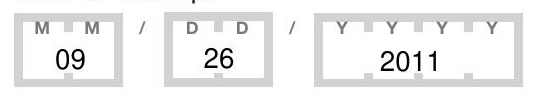

Amount of Each Receipt this Period

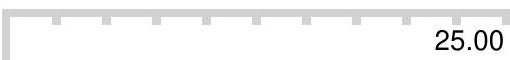

25.00

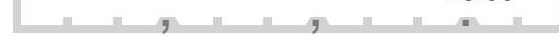

Transaction ID : A429A684DD6BB45BEB0C Date of Receipt

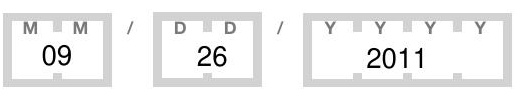

Amount of Each Receipt this Period

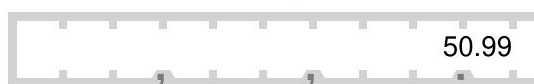

Transaction ID : A0BAAE67529C04AB688D Date of Receipt

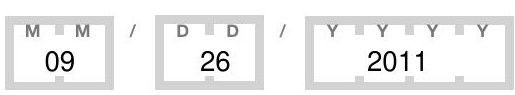

Amount of Each Receipt this Period

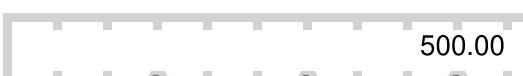

\section{Subtotal Of Receipts This Page (optional)}

Total This Period (last page this line number only) 


\section{SCHEDULE A-P} ITEMIZED RECEIPTS
Use separate schedule(s) for each category of the Detailed Summary Page

FOR LINE NUMBER:
(check only one)

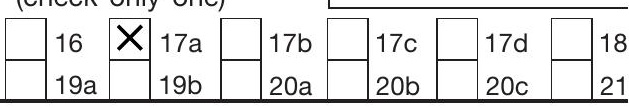

Any information copied from such Reports and Statements may not be sold or used by any person for the purpose of soliciting contributions or for commercial purposes, other than using the name and address of any political committee to solicit contributions from such committee.

NAME OF COMMITTEE (In Full)

\section{Friends of Herman Cain}

A. Full Name (Last, First, Middle Initial) Jim Evans

Mailing Address PO Box 27409

\begin{tabular}{lcc}
\hline City & State & Zip Code \\
Omaha & NE & $68127-0409$
\end{tabular}

FEC ID number of contributing federal political committee.

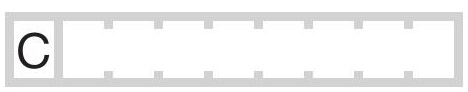

Name of Employer
Clean Country
Receipt For: 2012
X Primary
$\square$ Other (specify) General

Occupation President Election Cycle-to-Date 1000.00

B. Full Name (Last, First, Middle Initial) Richard Bammesberger

Mailing Address 1832 Ruby View Dr.

\begin{tabular}{lcc}
\hline City & State & Zip Code \\
Elko & NV & $89801-2631$
\end{tabular}

FEC ID number of contributing

federal political committee.

C

Name of Employer
Information Requested
Receipt For: 2012
X Primary
Other (specify)

Occupation

Information Requested

Election Cycle-to-Date

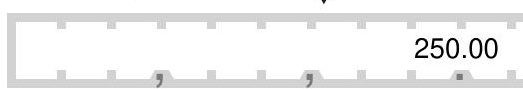

C. Full Name (Last, First, Middle Initial)

ZuAnn Hogan-Tuell

Mailing Address 31596 County Road 37

\begin{tabular}{lcc}
\hline City & State & Zip Code \\
Greeley & CO & 80631 \\
\hline
\end{tabular}

FEC ID number of contributing federal political committee.

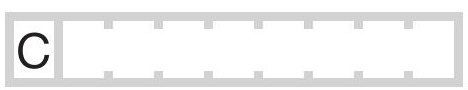

Name of Employer
Information Requested
Receipt For: 2012
Primary
Other (specify) General

\section{Occupation}

Information Requested

Election Cycle-to-Date
Transaction ID : A1207A0056790402B8C7

Date of Receipt

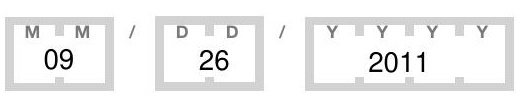

Amount of Each Receipt this Period

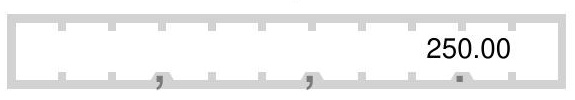

Transaction ID : A939B4C10A66E4BE5885 Date of Receipt

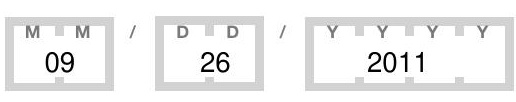

Amount of Each Receipt this Period

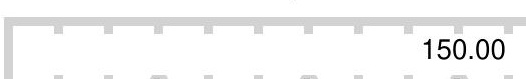

\section{Subtotal Of Receipts This Page (optional).}

900.00

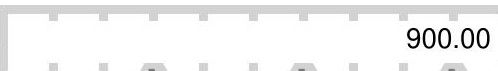

ㄱ․․

Total This Period (last page this line number only)
Transaction ID : ABE2C26E8FBFF47B384B

Date of Receipt

Amount of Each Receipt this Period

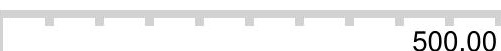




\section{SCHEDULE A-P} ITEMIZED RECEIPTS
Use separate schedule(s)

for each category of the

Detailed Summary Page
FOR LINE NUMBER: (check only one)

PAGE 762 / 1572

\begin{tabular}{|c|c|c|c|c|c|}
\hline & & & & & \\
\hline 16 & X $17 a$ & $17 b$ & $17 c$ & $17 d$ & 18 \\
\hline $19 a$ & $19 b$ & $20 \mathrm{a}$ & $20 \mathrm{~b}$ & $20 \mathrm{c}$ & 21 \\
\hline
\end{tabular}

Any information copied from such Reports and Statements may not be sold or used by any person for the purpose of soliciting contributions or for commercial purposes, other than using the name and address of any political committee to solicit contributions from such committee.

NAME OF COMMITTEE (In Full)

\section{Friends of Herman Cain}

A. Full Name (Last, First, Middle Initial)

\section{Donna Collins}

Mailing Address P. O. Box 1331

\begin{tabular}{lcc}
\hline City & State & Zip Code \\
Gainesville & GA & 30503-1331 \\
\hline
\end{tabular}

FEC ID number of contributing federal political committee.

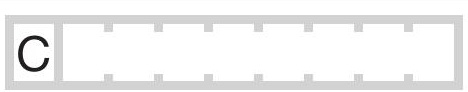

Name of Employer
Mincey Marble
Receipt For: 2012
X Primary
Other (specify) General

\section{Occupation} General Manager

Election Cycle-to-Date 600.00

B. Full Name (Last, First, Middle Initial) Colin Hanna

Mailing Address 603 Fairway $\mathrm{Dr}$

\begin{tabular}{lcc}
\hline City & State & Zip Code \\
West Chester & PA & $19382-2013$ \\
\hline
\end{tabular}

FEC ID number of contributing

federal political committee.

C

Name of Employer
Let Freedom Ring
Receipt For: 2012
Primary
Other (specify)

\section{Occupation}

Consultant

Election Cycle-to-Date

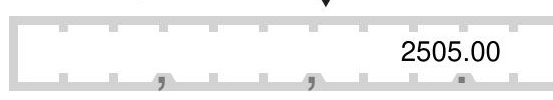

Transaction ID : AB6D73C7C91E64BC6A4C

Date of Receipt

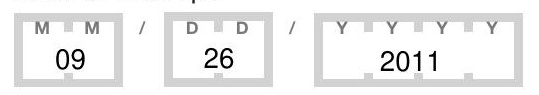

Amount of Each Receipt this Period

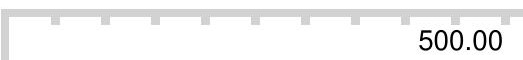

Amount of Each Receipt this Period

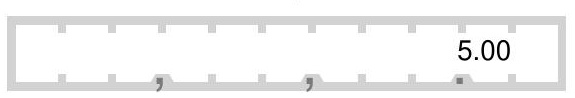

C. Full Name (Last, First, Middle Initial)

Linda Finkel

Mailing Address 21125 River Bluff Dr.

\begin{tabular}{lcc}
\hline City & State & Zip Code \\
Anderson & CA & $96007-9795$ \\
\hline
\end{tabular}

FEC ID number of contributing federal political committee.

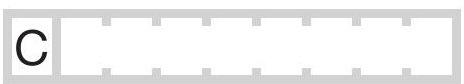

Name of Employer
None
Receipt For: 2012
Х Primary $\quad \square$ General
Other (specify)

\section{Occupation}

Retired

Election Cycle-to-Date

Transaction ID : A5670FF4DC4024B94BD6 Date of Receipt

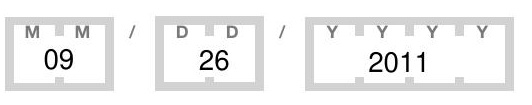

Transaction ID : AC44A6845CED1487BB39 Date of Receipt

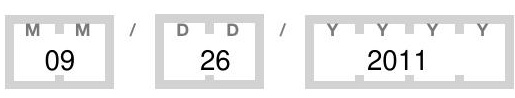

Amount of Each Receipt this Period

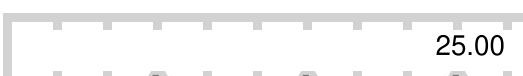

225.00

Subtotal Of Receipts This Page (optional).

Total This Period (last page this line number only) 
SCHEDULE A-P ITEMIZED RECEIPTS
Use separate schedule(s) for each category of the Detailed Summary Page
FOR LINE NUMBER: (check only one)

PAGE $763 / 1572$

\begin{tabular}{|c|c|c|c|c|c|}
\hline & & & & & \\
\hline 16 & $\mathbf{X} 17 a$ & $17 b$ & $17 c$ & $17 d$ & 18 \\
\hline $19 a$ & $19 b$ & $20 \mathrm{a}$ & $20 \mathrm{~b}$ & $20 \mathrm{c}$ & 21 \\
\hline
\end{tabular}

Any information copied from such Reports and Statements may not be sold or used by any person for the purpose of soliciting contributions or for commercial purposes, other than using the name and address of any political committee to solicit contributions from such committee.

NAME OF COMMITTEE (In Full)

\section{Friends of Herman Cain}

A. Full Name (Last, First, Middle Initial) william gibson

Mailing Address 340 lucian bland road

\begin{tabular}{lcc}
\hline City & State & Zip Code \\
Pittsboro & NC & $27312-8598$ \\
\hline
\end{tabular}

FEC ID number of contributing federal political committee.

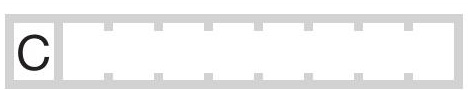

Name of Employer
Information Requested
Receipt For: 2012
X Primary
Other (specify) General

Occupation Information Requested

Election Cycle-to-Date

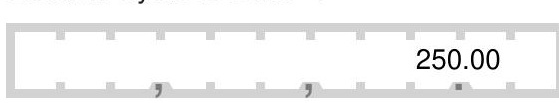

B. Full Name (Last, First, Middle Initial)

David Krueger

Mailing Address 3917 NW Sterling St

\begin{tabular}{lcc}
\hline City & State & Zip Code \\
Norman & OK & $73072-1241$ \\
\hline
\end{tabular}

FEC ID number of contributing

federal political committee.

C

Name of Employer
Information Requested
Receipt For: 2012
X Primary
Other (specify)

\section{Occupation}

Information Requested

Election Cycle-to-Date

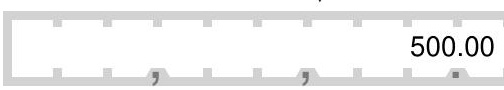

Transaction ID : A183A6EC808F049589B6

Date of Receipt

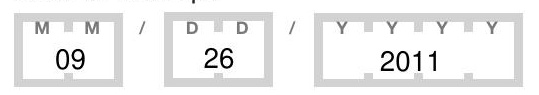

Amount of Each Receipt this Period

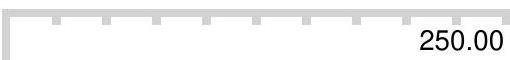

C. Full Name (Last, First, Middle Initial)

Daniel Bradley

Mailing Address 7300 Maple Street

\begin{tabular}{lcc}
\hline City & State & Zip Code \\
Overland Park & KS & $66204-2151$
\end{tabular}

FEC ID number of contributing federal political committee.

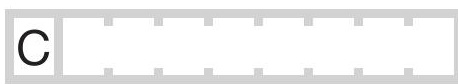

Name of Employer
Oldcastle Materials
Receipt For: 2012
X Primary
Other (specify) General

\section{Occupation}

Accountant

Election Cycle-to-Date

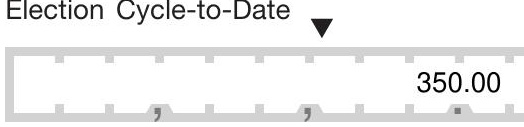

Transaction ID : AB96AEABDEAD64C17B21 Date of Receipt

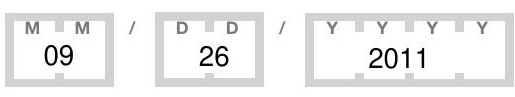

Amount of Each Receipt this Period

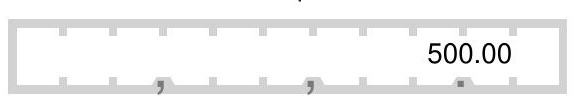

Transaction ID : AE96229FCA3BC46DABC1 Date of Receipt

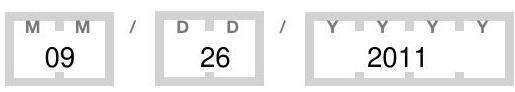

Amount of Each Receipt this Period

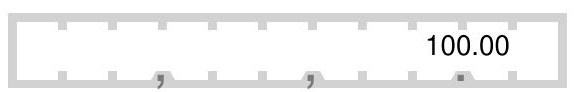

\section{Subtotal Of Receipts This Page (optional)}

Total This Period (last page this line number only) 
SCHEDULE A-P ITEMIZED RECEIPTS
Use separate schedule(s) for each category of the Detailed Summary Page
FOR LINE NUMBER: (check only one)

PAGE 764 / 1572

\begin{tabular}{|c|c|c|c|c|c|}
\hline & & & & & \\
\hline 16 & $\begin{array}{l}\mathbf{X} \\
17 a\end{array}$ & $17 b$ & $17 c$ & $17 d$ & 18 \\
\hline $19 a$ & $19 \mathrm{~b}$ & $20 \mathrm{a}$ & $20 \mathrm{~b}$ & $20 \mathrm{c}$ & 21 \\
\hline
\end{tabular}

Any information copied from such Reports and Statements may not be sold or used by any person for the purpose of soliciting contributions or for commercial purposes, other than using the name and address of any political committee to solicit contributions from such committee.

NAME OF COMMITTEE (In Full)

\section{Friends of Herman Cain}

A. Full Name (Last, First, Middle Initial)

\section{Dee Martin}

Mailing Address 2135 Northfield Ct

\section{City}

Marietta

FEC ID number of contributing federal political committee.

Name of Employer
One Hour Signs
Receipt For: 2012
X Primary
$\square$ Other (specify) General

B. Full Name (Last, First, Middle Initial)

Tim Blevins

\section{Mailing Address 3432 Conley Downs Drive}

\begin{tabular}{lcc}
\hline City & State & Zip Code \\
Powder Springs & GA & $30127-1199$ \\
\hline
\end{tabular}

FEC ID number of contributing

federal political committee.

Name of Employer
The Coca-Cola Company
Receipt For: 2012
Primary
Other (specify)

C. Full Name (Last, First, Middle Initial)

Alicia Wills

Mailing Address PO Box 67474

\section{City}

Topeka

FEC ID number of contributing federal political committee.

Name of Employer

Information Requested

Receipt For: 2012

Х $\begin{aligned} & \text { Primary } \square \text { General } \\ & \text { Other (specify) }\end{aligned}$

\section{Occupation} Manager

Election Cycle-to-Date

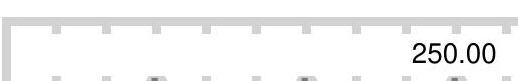

Transaction ID : AA999F0F9948645EA8B8

Date of Receipt

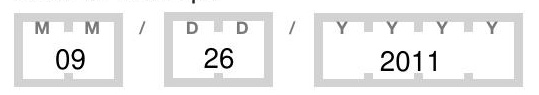

Amount of Each Receipt this Period

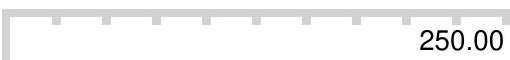

250.00
C

Transaction ID : AEC5BE1CBADB84FFB9FB Date of Receipt

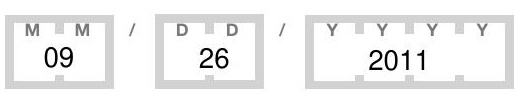

Amount of Each Receipt this Period

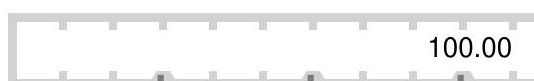

Learning \& Development

Election Cycle-to-Date

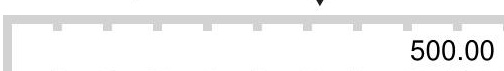

Transaction ID : A48699A519FBD4DFA814 Date of Receipt

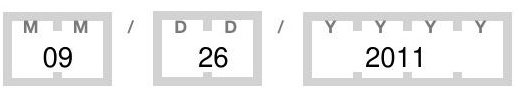

Amount of Each Receipt this Period

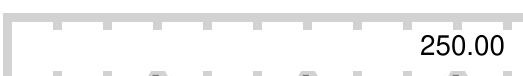

1000.00

\section{Subtotal Of Receipts This Page (optional)}

600.00

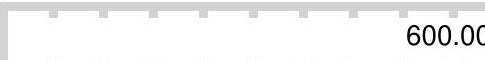

(1)

Total This Period (last page this line number only)

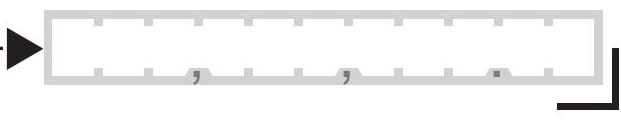

FEC Schedule A-P (Form 3P) (Rev. 03/2011) 
SCHEDULE A-P ITEMIZED RECEIPTS
Use separate schedule(s) for each category of the Detailed Summary Page
FOR LINE NUMBER: (check only one)

PAGE $765 / 1572$

\begin{tabular}{|c|c|c|c|c|c|}
\hline & & & & & \\
\hline 16 & $\begin{array}{l}\mathbf{X} \\
17 a\end{array}$ & $17 b$ & $17 c$ & $17 d$ & 18 \\
\hline $19 a$ & $19 \mathrm{~b}$ & $20 \mathrm{a}$ & $20 \mathrm{~b}$ & $20 \mathrm{c}$ & 21 \\
\hline
\end{tabular}

Any information copied from such Reports and Statements may not be sold or used by any person for the purpose of soliciting contributions or for commercial purposes, other than using the name and address of any political committee to solicit contributions from such committee.

NAME OF COMMITTEE (In Full)

\section{Friends of Herman Cain}

A. Full Name (Last, First, Middle Initial)

Martin Hartog

Mailing Address 5909 Blondo

\begin{tabular}{lcc}
\hline City & State & Zip Code \\
Omaha & NE & $68104-4849$
\end{tabular}

FEC ID number of contributing federal political committee.

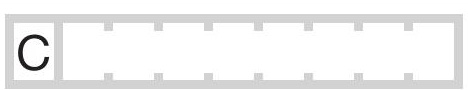

Name of Employer
International Gamco
Receipt For: 2012
X Primary
Other (specify) General

\section{Occupation}

Prepress Mgr

Election Cycle-to-Date

400.00

B. Full Name (Last, First, Middle Initial)

Thomas Bairnson

Mailing Address 6725 Virginia Crossing

\begin{tabular}{lcc}
\hline City & State & Zip Code \\
University Park & FL & $34201-2321$
\end{tabular}

FEC ID number of contributing

federal political committee.

C

Name of Employer
Information Requested
Receipt For: 2012
X Primary
Other (specify)

Occupation

Information Requested

Election Cycle-to-Date

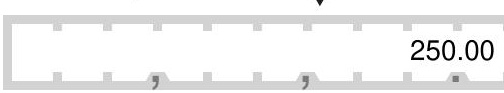

Transaction ID : A541D46DD550A4F04880

Date of Receipt

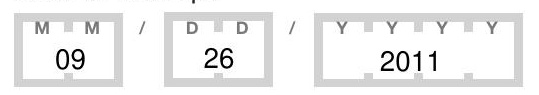

Amount of Each Receipt this Period

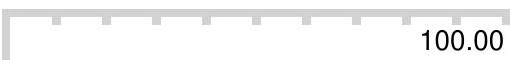

Transaction ID : ADE7349F7CF5D4AC9B92

Date of Receipt

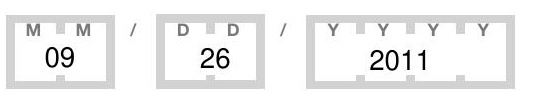

Amount of Each Receipt this Period

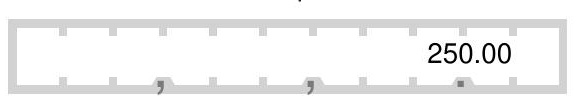

Transaction ID : A9CCFC2E03D2547CCB87 Date of Receipt

don weidler

Mailing Address 912 Woodland TrI SE

\begin{tabular}{lcc}
\hline City & State & Zip Code \\
Smyrna & GA & $30080-1536$
\end{tabular}

FEC ID number of contributing federal political committee.

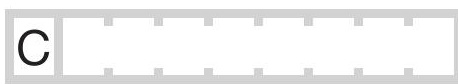

Name of Employer
Self Employed
Receipt For: 2012
X Primary $\quad \square$ General
Other (specify)

\section{Occupation}

courier

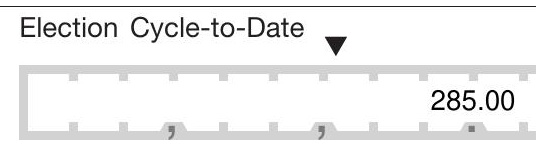

Subtotal Of Receipts This Page (optional)

Amount of Each Receipt this Period

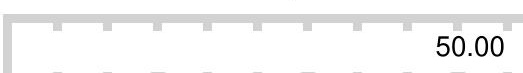

Total This Period (last page this line number only)

400.00

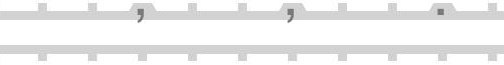

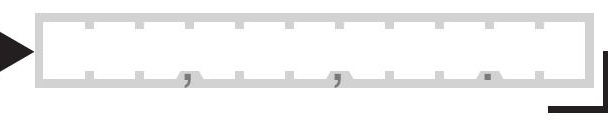

FEC Schedule A-P (Form 3P) (Rev. 03/2011) 


\section{SCHEDULE A-P} ITEMIZED RECEIPTS
Use separate schedule(s)

for each category of the

Detailed Summary Page
FOR LINE NUMBER: (check only one)

PAGE $766 / 1572$

\begin{tabular}{|c|c|c|c|c|c|}
\hline & & & & & \\
\hline 16 & X $17 a$ & $17 b$ & $17 c$ & $17 d$ & 18 \\
\hline $19 a$ & $19 b$ & $20 \mathrm{a}$ & $20 \mathrm{~b}$ & $20 \mathrm{c}$ & 21 \\
\hline
\end{tabular}

Any information copied from such Reports and Statements may not be sold or used by any person for the purpose of soliciting contributions or for commercial purposes, other than using the name and address of any political committee to solicit contributions from such committee.

NAME OF COMMITTEE (In Full)

\section{Friends of Herman Cain}

A. Full Name (Last, First, Middle Initial)

Richard Hazel Jr

Mailing Address 4200 Mebane Oaks Rd

\begin{tabular}{lcc}
\hline City & State & Zip Code \\
Mebane & NC & $27302-9288$
\end{tabular}

FEC ID number of contributing

federal political committee.

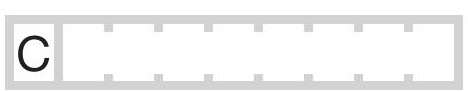

Name of Employer
Information Requested
Receipt For: 2012
X Primary $\quad \square$ General
Other (specify)

Occupation

Information Requested

Election Cycle-to-Date

250.00

B. Full Name (Last, First, Middle Initial)

Kathy Hoellen

Mailing Address 471 Swift Creek Cv

\begin{tabular}{lcc}
\hline City & State & Zip Code \\
Clover & SC & $29710-5500$ \\
\hline
\end{tabular}

FEC ID number of contributing

federal political committee.

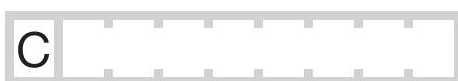

Name of Employer
York Technical College
Receipt For: 2012
X Primary
Other (specify)

Occupation

education

Election Cycle-to-Date

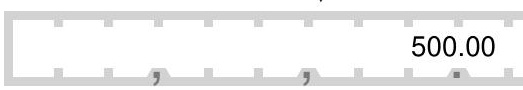

C. Full Name (Last, First, Middle Initial)

Eunice Bates

Mailing Address 16715 Shadow Wood Crt.

\begin{tabular}{lcc}
\hline City & State & Zip Code \\
Hudson & CO & $80642-7955$
\end{tabular}

FEC ID number of contributing

federal political committee.

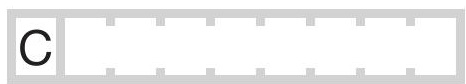

Name of Employer
None
Receipt For: 2012
Х Primary $\quad \square$ General
Other (specify)

\section{Occupation}

Homemaker

Election Cycle-to-Date

Transaction ID : AF2211A1A19FF44778F9

Date of Receipt

Amount of Each Receipt this Period

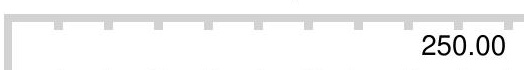

250.00

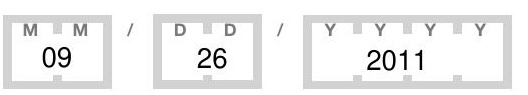

Amount of Each Receipt this Period

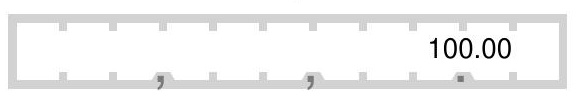

Transaction ID : A7D38AEEC1CCB4F1D857 Date of Receipt

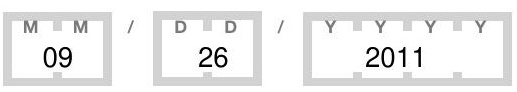

Amount of Each Receipt this Period

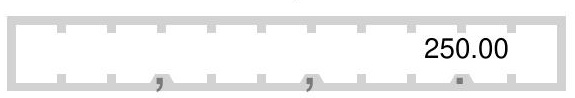

250.00

\section{Subtotal Of Receipts This Page (optional)}

600.00

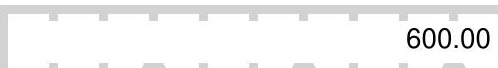

ㄱ․․

Total This Period (last page this line number only)

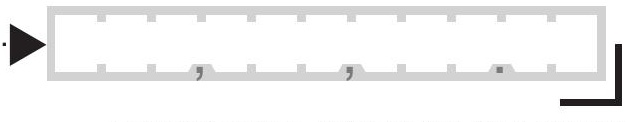

FEC Schedule A-P (Form 3P) (Rev. 03/2011) 


\section{SCHEDULE A-P} ITEMIZED RECEIPTS
Use separate schedule(s)

for each category of the

Detailed Summary Page
FOR LINE NUMBER: (check only one)

PAGE 767 / 1572

\begin{tabular}{|c|c|c|c|c|c|}
\hline & & & & & \\
\hline 16 & X $17 a$ & $17 b$ & $17 c$ & $17 d$ & 18 \\
\hline $19 a$ & $19 b$ & $20 \mathrm{a}$ & $20 \mathrm{~b}$ & $20 \mathrm{c}$ & 21 \\
\hline
\end{tabular}

Any information copied from such Reports and Statements may not be sold or used by any person for the purpose of soliciting contributions or for commercial purposes, other than using the name and address of any political committee to solicit contributions from such committee.

NAME OF COMMITTEE (In Full)

Friends of Herman Cain

A. Full Name (Last, First, Middle Initial)

Don Cole

Mailing Address 3575 Fannie Thompson Rd

\begin{tabular}{lcc}
\hline City & State & Zip Code \\
Monroe & GA & $30656-3454$
\end{tabular}

FEC ID number of contributing

federal political committee.

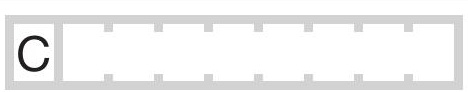

Name of Employer
winterville animal clinic
Receipt For: 2012
X Primary
$\square$ Other (specify)

Occupation

Veterinarian

Election Cycle-to-Date

600.00

B. Full Name (Last, First, Middle Initial)

Walter Nagle

Mailing Address 4720 Oakleaf Drive

\begin{tabular}{lcc}
\hline City & State & Zip Code \\
Tulsa & OK & $74132-2132$ \\
\hline
\end{tabular}

FEC ID number of contributing

federal political committee.

C

\begin{tabular}{l} 
Name of Employer \\
Tulstar Products, Inc. \\
Receipt For: 2012 \\
Xrimary \\
\hline Other (specify)
\end{tabular}

Occupation

President

Election Cycle-to-Date

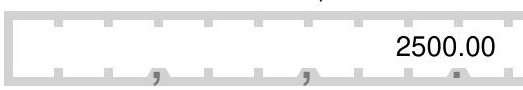

C. Full Name (Last, First, Middle Initial)

Alexander Lloyd

Mailing Address 300 Beale St.

\begin{tabular}{lcc}
\hline City & State & Zip Code \\
San Francisco & CA & $94105-2090$
\end{tabular}

FEC ID number of contributing federal political committee.

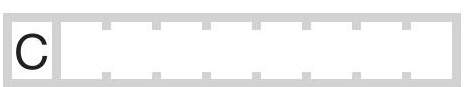

Name of Employer
Information Requested
Receipt For: 2012
X Primary
Other (specify) General

Occupation

Information Requested

Election Cycle-to-Date
Transaction ID : A36516EFF3BAC4F2EB11

Date of Receipt

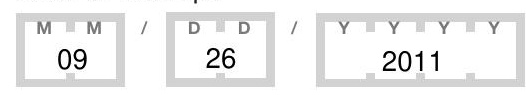

Amount of Each Receipt this Period

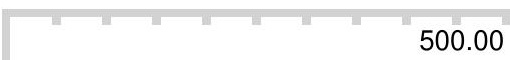

Amount of Each Receipt this Period

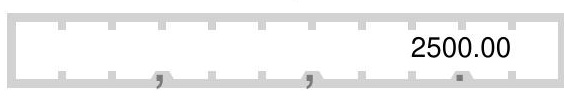

Transaction ID : A5F551A6E8226418586B

Date of Receipt

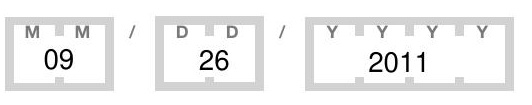

Transaction ID : A6E8339C630DD499DBCF Date of Receipt

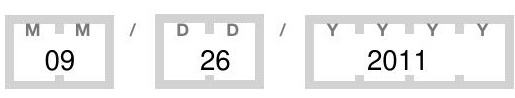

Amount of Each Receipt this Period

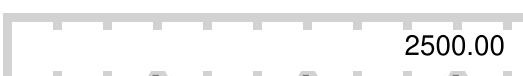

2500.00

Subtotal Of Receipts This Page (optional).

5500.00

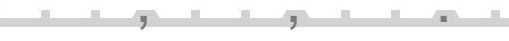

Total This Period (last page this line number only)

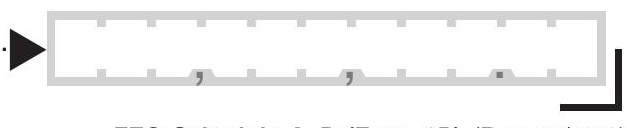

FEC Schedule A-P (Form 3P) (Rev. 03/2011) 


\section{SCHEDULE A-P} ITEMIZED RECEIPTS
Use separate schedule(s)

for each category of the

Detailed Summary Page
FOR LINE NUMBER: (check only one)

PAGE $768 / 1572$

\begin{tabular}{|c|c|c|c|c|c|}
\hline & & & & & \\
\hline 16 & X $17 a$ & $17 b$ & $17 c$ & $17 d$ & 18 \\
\hline $19 a$ & $19 b$ & $20 \mathrm{a}$ & $20 \mathrm{~b}$ & $20 \mathrm{c}$ & 21 \\
\hline
\end{tabular}

Any information copied from such Reports and Statements may not be sold or used by any person for the purpose of soliciting contributions or for commercial purposes, other than using the name and address of any political committee to solicit contributions from such committee.

NAME OF COMMITTEE (In Full)

Friends of Herman Cain

A. Full Name (Last, First, Middle Initial)

michael tipton

Mailing Address 19215 Sterling Hwy

\begin{tabular}{lcc}
\hline City & State & Zip Code \\
Ninilchik & AK & $99639-9676$
\end{tabular}

FEC ID number of contributing

federal political committee.

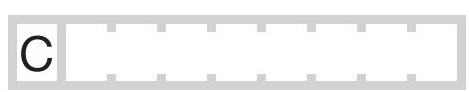

Name of Employer
Information Requested
Receipt For: 2012
X Primary $\quad \square$ General
Other (specify)

Occupation

Information Requested

Election Cycle-to-Date

\subsection{0}

B. Full Name (Last, First, Middle Initial)

Lester Bulla

Mailing Address 70 Northcrest Way

\begin{tabular}{lcc}
\hline City & State & Zip Code \\
Powder Springs & GA & $30127-5106$ \\
\hline
\end{tabular}

FEC ID number of contributing

federal political committee.

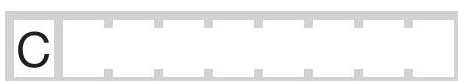

Name of Employer
Allied American Products Inc
Receipt For: 2012
X Primary
Other (specify)

Occupation

President

Election Cycle-to-Date

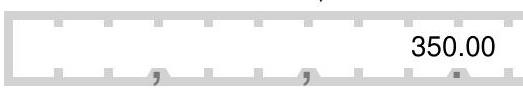

C. Full Name (Last, First, Middle Initial)

Roland May

Mailing Address 217 County Road 1941

\begin{tabular}{lcc}
\hline City & State & Zip Code \\
Yantis & TX & $75497-3910$
\end{tabular}

FEC ID number of contributing

federal political committee.

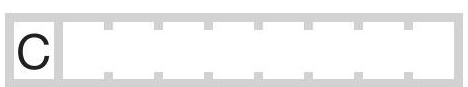

Name of Employer

Information Requested

Occupation

Information Requested

Receipt For: 2012

Х $\begin{aligned} & \text { Primary } \square \text { General } \\ & \text { Other (specify) }\end{aligned}$

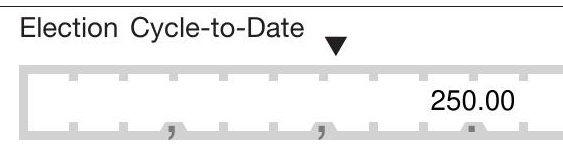

Amount of Each Receipt this Period

Transaction ID : A2F4241EC5CB14C6D9DD Date of Receipt

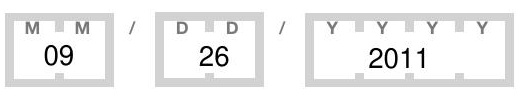

Amount of Each Receipt this Period
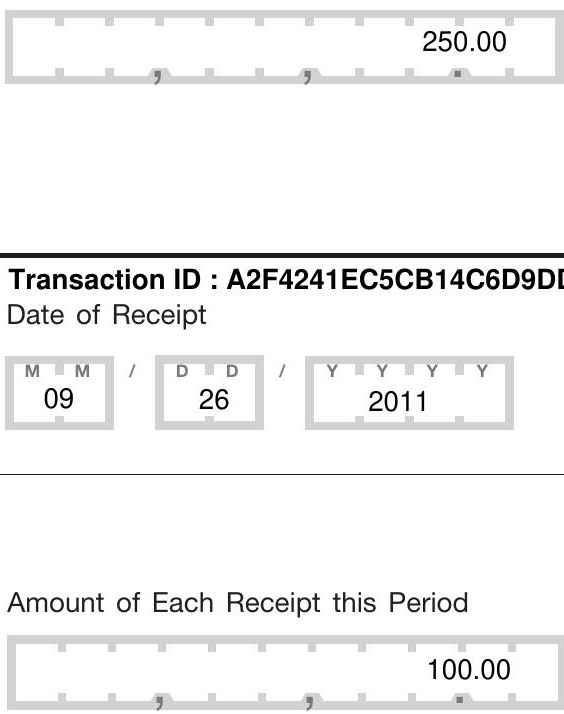

Transaction ID : A1E8E2266F8E44C85A33

Date of Receipt

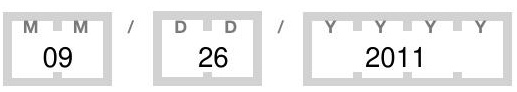

Amount of Each Receipt this Period

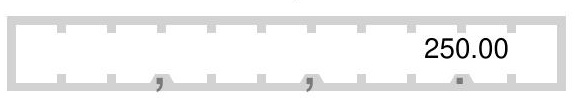

Subtotal Of Receipts This Page (optional).

600.00

Total This Period (last page this line number only) 
SCHEDULE A-P ITEMIZED RECEIPTS
Use separate schedule(s)

for each category of the

Detailed Summary Page
FOR LINE NUMBER: (check only one)

Any information or for commercial purposes, other than using the name and address of any political committee to solicit contributions from such committee.

NAME OF COMMITTEE (In Full)

\section{Friends of Herman Cain}

A. Full Name (Last, First, Middle Initial)

Ricki Ingalls

Mailing Address 2716 W 80th St

\begin{tabular}{lcc}
\hline City & State & Zip Code \\
Stillwater & OK & $74074-8192$ \\
\hline
\end{tabular}

FEC ID number of contributing federal political committee.

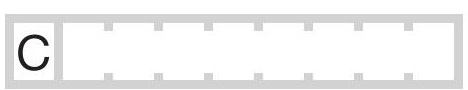

Name of Employer
Oklahoma State University
Receipt For: 2012
X Primary
Other (specify) General

Occupation

Professor

Election Cycle-to-Date

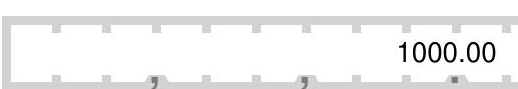

B. Full Name (Last, First, Middle Initial)

Louise McAlpin

Mailing Address 275 Catob Rd

\begin{tabular}{lcc}
\hline City & State & Zip Code \\
Harbor Springs & MI & $49740-9335$ \\
\hline
\end{tabular}

FEC ID number of contributing

federal political committee.

C

Name of Employer
Information Requested
Receipt For: 2012
Primary
Other (specify)

Occupation

Information Requested

Election Cycle-to-Date

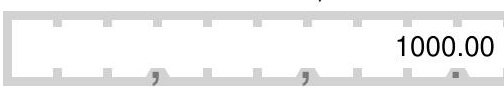

Transaction ID : A2913F1D2934F496D925

Date of Receipt

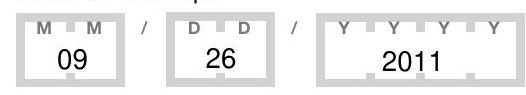

Amount of Each Receipt this Period

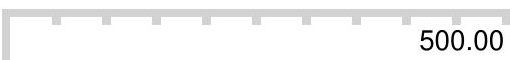

Transaction ID : AF81DA3433EDD4069BA5

Date of Receipt

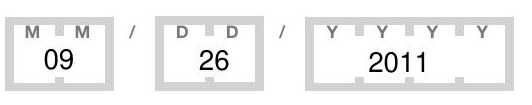

Amount of Each Receipt this Period

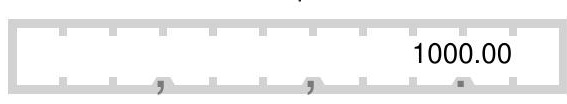

Transaction ID : AFD6B9399BDCA42938B5 Date of Receipt

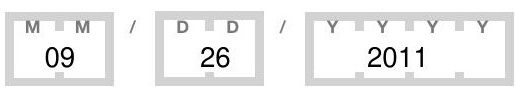

Amount of Each Receipt this Period

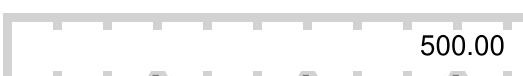

$\begin{array}{cc}\text { State } & \text { Zip Code } \\ \text { CA } & 93657-9006\end{array}$

C

\section{Occupation}

OWNER

Election Cycle-to-Date

Receipt For: 2012

Х $\begin{aligned} & \text { Primary } \\ & \text { Other (specify) }\end{aligned}$

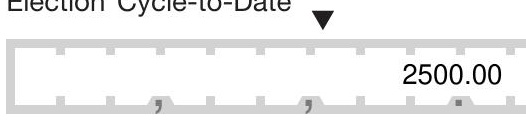

Subtotal Of Receipts This Page (optional)

2000.00

,

Total This Period (last page this line number only) 


\section{SCHEDULE A-P} ITEMIZED RECEIPTS
Use separate schedule(s)

for each category of the

Detailed Summary Page
FOR LINE NUMBER: (check only one)

PAGE $770 / 1572$

\begin{tabular}{|c|c|c|c|c|c|}
\hline & & & & & \\
\hline 16 & $\mathbf{X} 17 \mathrm{a}$ & $17 \mathrm{~b}$ & $17 c$ & $17 d$ & 18 \\
\hline $19 a$ & $19 \mathrm{~b}$ & $20 a$ & $20 \mathrm{~b}$ & $20 c$ & 21 \\
\hline
\end{tabular}

Any information copied from such Reports and Statements may not be sold or used by any person for the purpose of soliciting contributions or for commercial purposes, other than using the name and address of any political committee to solicit contributions from such committee.

NAME OF COMMITTEE (In Full)

Friends of Herman Cain

A. Full Name (Last, First, Middle Initial)

WILLIAM RUTHERFORD

Mailing Address PO BOX 42

\begin{tabular}{lcc}
\hline City & State & Zip Code \\
Geneseo & IL & $61254-0042$
\end{tabular}

FEC ID number of contributing

federal political committee.

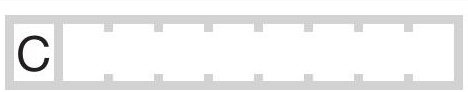

Name of Employer
Information Requested
Receipt For: 2012
X Primary
$\square$ Other (specify)

Occupation

Information Requested

Election Cycle-to-Date

1000.00

B. Full Name (Last, First, Middle Initial)

Jeffrey Kowitz

Mailing Address 11342 Valleydale Dr

\begin{tabular}{lcc}
\hline City & State & Zip Code \\
Dallas & TX & $75230-3228$
\end{tabular}

FEC ID number of contributing

federal political committee.

C

Name of Employer
Information Requested
Receipt For: 2012
Primary
Other (specify)

Occupation

Information Requested

Election Cycle-to-Date

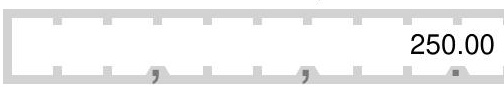

Transaction ID : AODF23D425E0F40A4AC6

Date of Receipt

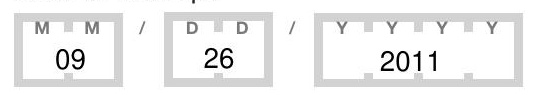

Amount of Each Receipt this Period

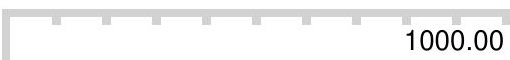

1000.00

C. Full Name (Last, First, Middle Initial)

Terry Sullivan

Mailing Address PO Box 5517

\begin{tabular}{lcc}
\hline City & State & Zip Code \\
Keystone & CO & $80435-5517$
\end{tabular}

FEC ID number of contributing federal political committee.

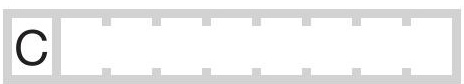

Name of Employer
Information Requested
Receipt For: 2012
X Primary $\quad \square$ General
Other (specify)

\section{Occupation}

Information Requested

Election Cycle-to-Date

Transaction ID : A2B0F3953CF4F4DF4A9B

Date of Receipt

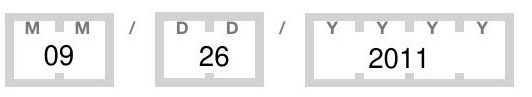

Amount of Each Receipt this Period

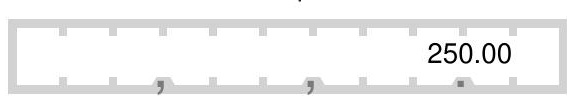

Transaction ID : A470A37B34BFD4789B53 Date of Receipt

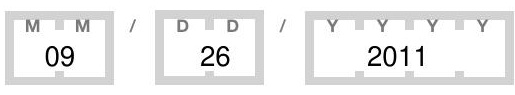

Amount of Each Receipt this Period

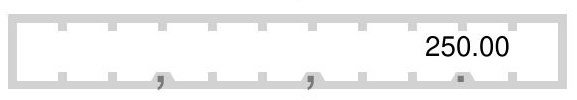

250.00

\section{Subtotal Of Receipts This Page (optional)}

Total This Period (last page this line number only) 


\section{SCHEDULE A-P} ITEMIZED RECEIPTS
Use separate schedule(s) for each category of the Detailed Summary Page

\begin{tabular}{|c|c|c|c|c|c|}
\hline \multicolumn{3}{|c|}{$\begin{array}{l}\text { FOR LINE NUMBER: } \\
\text { (check only one) }\end{array}$} & \multicolumn{3}{|c|}{ PAGE $771 / 1572$} \\
\hline 16 & $X$ 17a & $17 b$ & $17 \mathrm{c}$ & $17 d$ & 18 \\
\hline $19 a$ & $19 \mathrm{~b}$ & $20 a$ & $20 \mathrm{~b}$ & $20 c$ & 21 \\
\hline
\end{tabular}

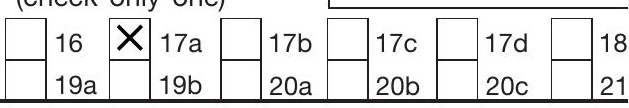

Any information copied from such Reports and Statements may not be sold or used by any person for the purpose of soliciting contributions or for commercial purposes, other than using the name and address of any political committee to solicit contributions from such committee.

NAME OF COMMITTEE (In Full)

\section{Friends of Herman Cain}

A. Full Name (Last, First, Middle Initial)

\section{Frank Lowe}

Mailing Address P.O. Box 127

\begin{tabular}{lcc}
\hline City & State & Zip Code \\
Amsterdam & NY & $12010-0127$
\end{tabular}

FEC ID number of contributing federal political committee.

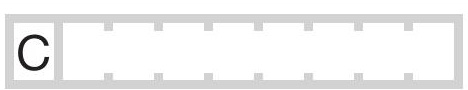

Name of Employer
Information Requested
Receipt For: 2012
X Primary
$\square$ Other (specify)

Occupation Information Requested

Election Cycle-to-Date

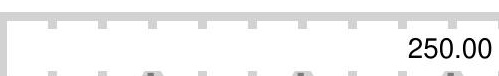

B. Full Name (Last, First, Middle Initial)

Charles Marino

Mailing Address $40 \mathrm{~N}$ Tower

\begin{tabular}{lcc}
\hline City & State & Zip Code \\
Oak Brook & IL & $60523-1155$
\end{tabular}

FEC ID number of contributing

federal political committee.

C

\begin{tabular}{l} 
Name of Employer \\
Information Requested \\
\hline Receipt For: 2012 \\
$X$ Primary \\
Other (specify)
\end{tabular}

Occupation

Information Requested

Election Cycle-to-Date

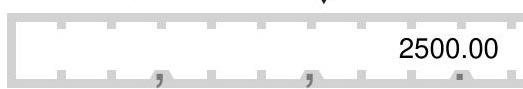

C. Full Name (Last, First, Middle Initial)

mary nestlerode

Mailing Address 26191 roymor dr

\begin{tabular}{lcc}
\hline City & State & Zip Code \\
Calabasas & CA & $91302-1045$
\end{tabular}

FEC ID number of contributing federal political committee.

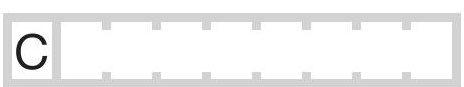

Name of Employer
Retired
Receipt For: 2012
Х Primary $\square$ General
Other (specify)

\section{Occupation}

Retired

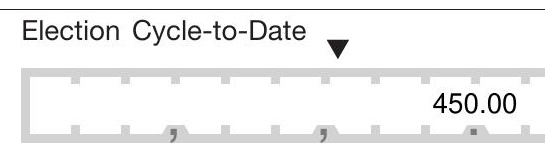

Transaction ID : AC5F30255C4D24CODABC

Date of Receipt

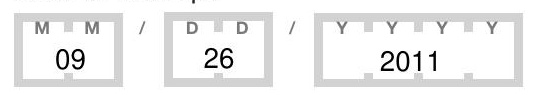

Amount of Each Receipt this Period

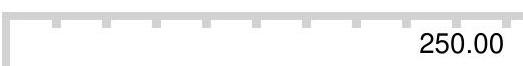

250.00

Transaction ID : AA18FF2A24F2C4626AA9

Date of Receipt

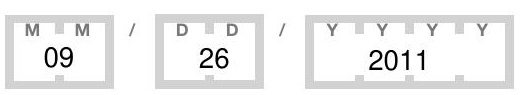

Amount of Each Receipt this Period

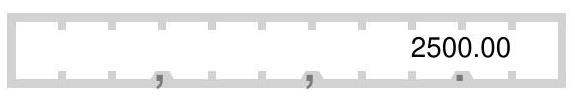

Transaction ID : A4CBAD9579CBB49E58C8 Date of Receipt

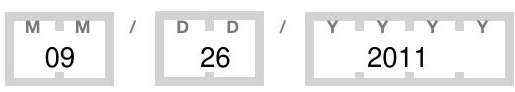

Amount of Each Receipt this Period

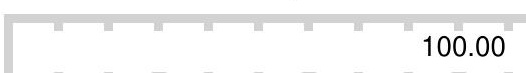

100.00

\section{Subtotal Of Receipts This Page (optional)}

Total This Period (last page this line number only) 


\section{SCHEDULE A-P} ITEMIZED RECEIPTS
Use separate schedule(s) for each category of the Detailed Summary Page

FOR LINE NUMBER:
(check only one)

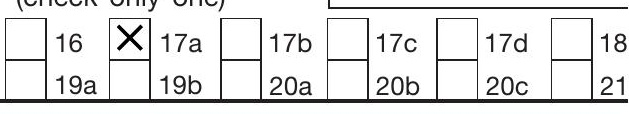

Any information copied from such Reports and Statements may not be sold or used by any person for the purpose of soliciting contributions or for commercial purposes, other than using the name and address of any political committee to solicit contributions from such committee.

NAME OF COMMITTEE (In Full)

\section{Friends of Herman Cain}

A. Full Name (Last, First, Middle Initial) phillip hampton

Mailing Address 365 Woodland Way

\begin{tabular}{lcc}
\hline City & State & Zip Code \\
Dublin & GA & $31021-0365$ \\
\hline
\end{tabular}

FEC ID number of contributing federal political committee.

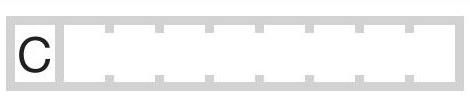

Name of Employer
Self Employed
Receipt For: 2012
X Primary
$\square$ Other (specify) General

Occupation Dentist Election Cycle-to-Date

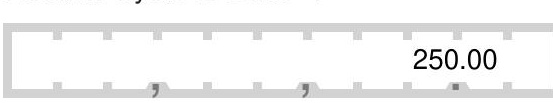

B. Full Name (Last, First, Middle Initial)

ZuAnn Hogan-Tuell

Mailing Address 31596 County Road 37

\begin{tabular}{lcc}
\hline City & State & Zip Code \\
Greeley & CO & 80631 \\
\hline
\end{tabular}

FEC ID number of contributing

federal political committee.

C

Name of Employer
Information Requested
Receipt For: 2012
X Primary
Other (specify)

Occupation

Information Requested

Election Cycle-to-Date

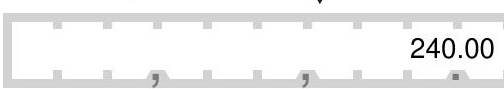

Transaction ID : A1DD1B9CA82114263841

Date of Receipt

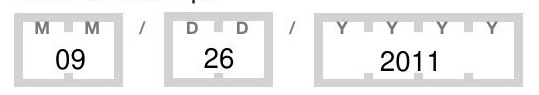

Amount of Each Receipt this Period

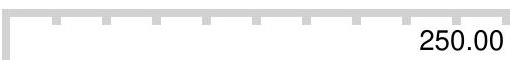

Amount of Each Receipt this Period

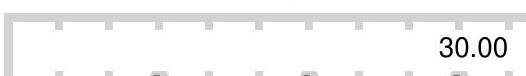

C. Full Name (Last, First, Middle Initial)

ZuAnn Hogan-Tuell

Mailing Address 31596 County Road 37

\begin{tabular}{lcc}
\hline City & State & Zip Code \\
Greeley & CO & 80631 \\
\hline
\end{tabular}

FEC ID number of contributing

federal political committee.

C

Name of Employer
Information Requested
Receipt For: 2012
X Primary
Other (specify) General

Occupation

Information Requested

Election Cycle-to-Date
Transaction ID : AF4A015A6872F49E19CB

Date of Receipt

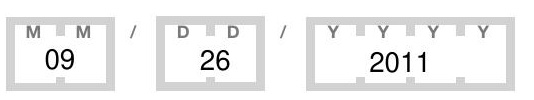

Transaction ID : A01D845BECEBC4D3FA02 Date of Receipt

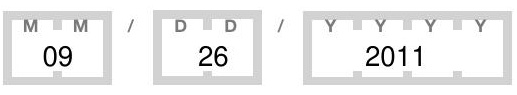

Amount of Each Receipt this Period

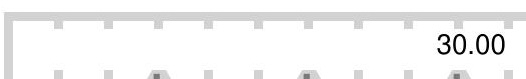

240.00
Subtotal Of Receipts This Page (optional).

$-\quad 310.00$

Total This Period (last page this line number only)

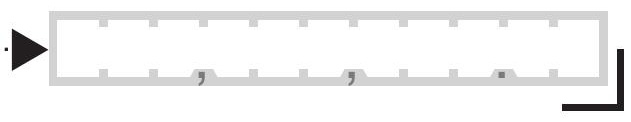

FEC Schedule A-P (Form 3P) (Rev. 03/2011) 
SCHEDULE A-P ITEMIZED RECEIPTS
Use separate schedule(s) for each category of the Detailed Summary Page
FOR LINE NUMBER: (check only one)

PAGE $773 / 1572$

\begin{tabular}{|c|c|c|c|c|c|}
\hline & & & & & \\
\hline 16 & $\begin{array}{lll}X & 17 a \\
\end{array}$ & $17 \mathrm{~b}$ & $17 c$ & $17 d$ & 18 \\
\hline $19 a$ & $19 b$ & $20 a$ & $20 \mathrm{~b}$ & $20 c$ & 21 \\
\hline
\end{tabular}

Any information copied from such Reports and Statements may not be sold or used by any person for the purpose of soliciting contributions or for commercial purposes, other than using the name and address of any political committee to solicit contributions from such committee.

NAME OF COMMITTEE (In Full)

\section{Friends of Herman Cain}

A. Full Name (Last, First, Middle Initial)

Russell Frank

Mailing Address PO Box 6920

\begin{tabular}{lcc}
\hline City & State & Zip Code \\
Ketchum & ID & $83340-6920$
\end{tabular}

FEC ID number of contributing federal political committee.

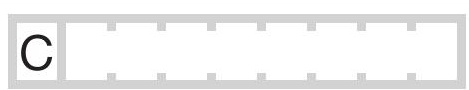

Name of Employer
self
Receipt For: 2012
X Primary $\quad$ General
Other (specify)

Occupation

Sporting Goods/Importing

Election Cycle-to-Date $\boldsymbol{\nabla}$

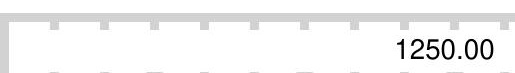

B. Full Name (Last, First, Middle Initial)

Luis Jordan

Mailing Address 170 Shady Oak Ln. SW

\begin{tabular}{lcc}
\hline City & State & Zip Code \\
Cartersville & GA & $30120-7465$ \\
\hline
\end{tabular}

FEC ID number of contributing

federal political committee.

C

Name of Employer
Information Requested
Receipt For: 2012
X Primary
Other (specify)

Occupation

Information Requested

Election Cycle-to-Date

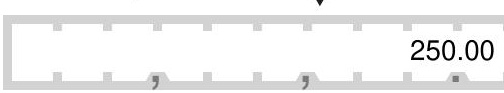

Transaction ID : A53776E72661B4E75ACB

Date of Receipt

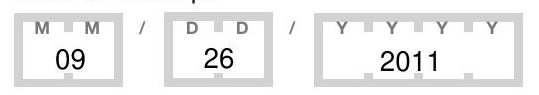

Amount of Each Receipt this Period

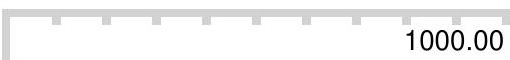

Amount of Each Receipt this Period

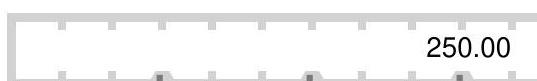

C. Full Name (Last, First, Middle Initial)

Dee Voelkel

Mailing Address 151 Manningham Drive

\begin{tabular}{lcc}
\hline City & State & Zip Code \\
Madison & AL & $35758-7439$
\end{tabular}

FEC ID number of contributing federal political committee.

C

Name of Employer
Information Requested
Receipt For: 2012
X Primary
Other (specify) General

Occupation

Information Requested

Election Cycle-to-Date
Transaction ID : AF7703D83C7204977A0E

Date of Receipt

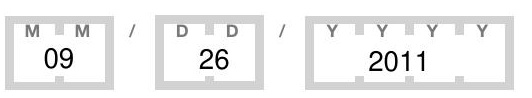

Transaction ID : AAAB0CEB0E3C541C0883 Date of Receipt

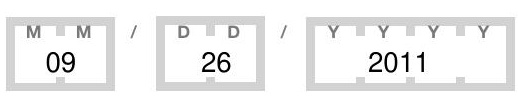

Amount of Each Receipt this Period

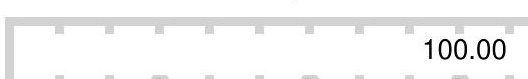

300.00

Subtotal Of Receipts This Page (optional).

Total This Period (last page this line number only) 


\section{SCHEDULE A-P} ITEMIZED RECEIPTS
Use separate schedule(s) for each category of the Detailed Summary Page

FOR LINE NUMBER:
(check only one)

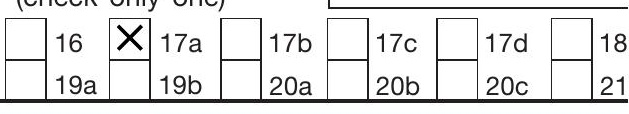

Any information copied from such Reports and Statements may not be sold or used by any person for the purpose of soliciting contributions or for commercial purposes, other than using the name and address of any political committee to solicit contributions from such committee.

NAME OF COMMITTEE (In Full)

\section{Friends of Herman Cain}

A. Full Name (Last, First, Middle Initial)

Arlene Eisenberg

Mailing Address 1074 So. La Luna Ave.

\begin{tabular}{lcc}
\hline City & State & Zip Code \\
Ojai & CA & $93023-3516$ \\
\hline
\end{tabular}

FEC ID number of contributing federal political committee.

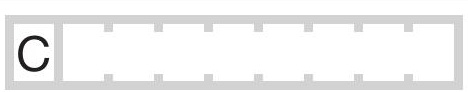

Name of Employer
Information Requested
Receipt For: 2012
X Primary
Other (specify) General

Occupation Information Requested

Election Cycle-to-Date

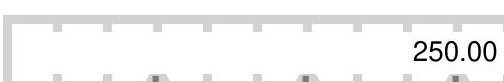

B. Full Name (Last, First, Middle Initial)

Mary Jansma

Mailing Address W260 Pete Reak Rd

\begin{tabular}{lcc}
\hline City & State & Zip Code \\
Randolph & WI & 53956-9735 \\
\hline
\end{tabular}

FEC ID number of contributing

federal political committee.

C

Name of Employer
Information Requested
Receipt For: 2012
X Primary
Other (specify)

Occupation

Information Requested

Election Cycle-to-Date

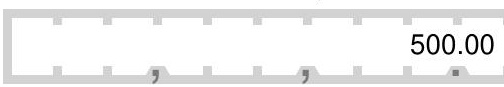

Transaction ID : A3928DCA7A5AC44C7B73

Date of Receipt

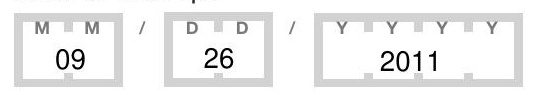

Amount of Each Receipt this Period

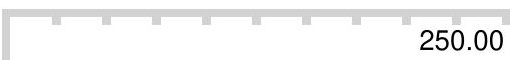

C. Full Name (Last, First, Middle Initial)

CHANNING FREDERICK

Mailing Address 2485 HIGHWAY $460 \mathrm{E}$

\begin{tabular}{lcc}
\hline City & State & Zip Code \\
West Liberty & KY & $41472-8248$
\end{tabular}

FEC ID number of contributing federal political committee.

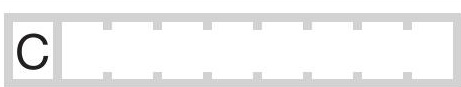

Name of Employer

FOOTHILLS CONTRACTING LLC

Receipt For: 2012

Х $\begin{aligned} & \text { Primary } \square \text { General } \\ & \text { Other (specify) }\end{aligned}$

\section{Occupation \\ FOOTHILLS CONTRACTING LLC}

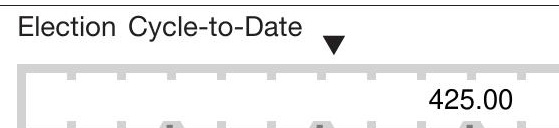

Amount of Each Receipt this Period

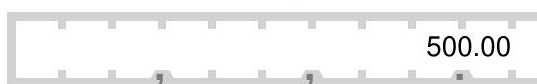

Transaction ID : A96D5D290C1A6468BABB Date of Receipt

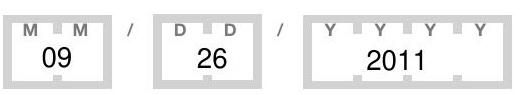

Transaction ID : A155BF737014144E99D4 Date of Receipt

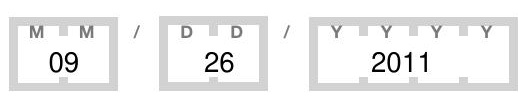

Amount of Each Receipt this Period

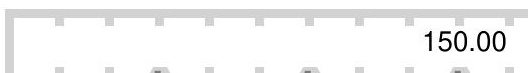

\section{Subtotal Of Receipts This Page (optional)}

900.00

a

Total This Period (last page this line number only)

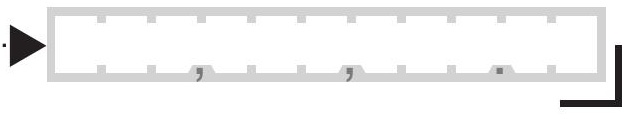

FEC Schedule A-P (Form 3P) (Rev. 03/2011) 
SCHEDULE A-P ITEMIZED RECEIPTS
Use separate schedule(s) for each category of the Detailed Summary Page
FOR LINE NUMBER: (check only one)

PAGE $775 / 1572$

\begin{tabular}{|c|c|c|c|c|c|}
\hline & & & & & \\
\hline 16 & $\begin{array}{l}\mathbf{X} \\
17 a\end{array}$ & $17 b$ & $17 c$ & $17 d$ & 18 \\
\hline $19 a$ & $19 \mathrm{~b}$ & $20 \mathrm{a}$ & $20 \mathrm{~b}$ & $20 \mathrm{c}$ & 21 \\
\hline
\end{tabular}

Any information copied from such Reports and Statements may not be sold or used by any person for the purpose of soliciting contributions or for commercial purposes, other than using the name and address of any political committee to solicit contributions from such committee.

NAME OF COMMITTEE (In Full)

\section{Friends of Herman Cain}

A. Full Name (Last, First, Middle Initial)

lois edgerly

Mailing Address 32 highland street

\begin{tabular}{lcc}
\hline City & State & Zip Code \\
Cambridge & MA & $02138-2210$ \\
\hline
\end{tabular}

FEC ID number of contributing federal political committee.

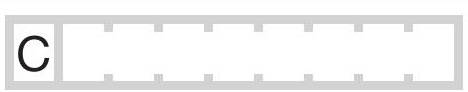

Name of Employer
Retired
Receipt For: 2012
X Primary $\quad$ General
Other (specify)

Occupation Retired

Election Cycle-to-Date

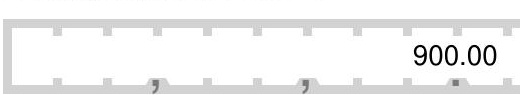

B. Full Name (Last, First, Middle Initial)

Douglas Hamilton

Mailing Address 170 Aqueduct Road

\begin{tabular}{lcc}
\hline City & State & Zip Code \\
Washington Crossing & PA & $18977-1326$ \\
\hline
\end{tabular}

FEC ID number of contributing

federal political committee.

C

Name of Employer
Information Requested
Receipt For: 2012
Primary
Other (specify)

Occupation

Information Requested

Election Cycle-to-Date

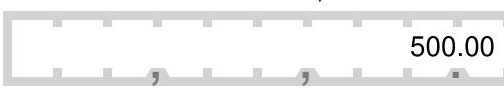

Transaction ID : AFA821E277E9A4931982

Date of Receipt

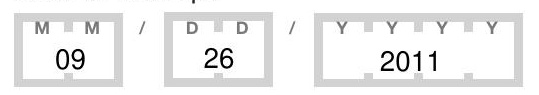

Amount of Each Receipt this Period

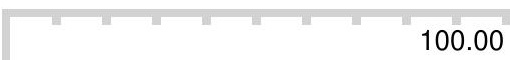

C. Full Name (Last, First, Middle Initial)

Michael Fagan

Mailing Address 2665 NW Cornell Rd

\begin{tabular}{lcc}
\hline City & State & Zip Code \\
Portland & OR & $97210-2801$
\end{tabular}

FEC ID number of contributing

federal political committee.

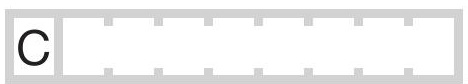

$\begin{aligned} & \text { Name of Employer } \\ & \text { self }\end{aligned}$
Receipt For: 2012
X Primary $\quad \square$ General
Other (specify)

Occupation

property manager

Election Cycle-to-Date

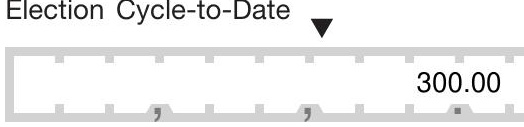

Transaction ID : AB5080377254F4355BE8

Date of Receipt

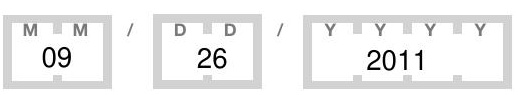

Amount of Each Receipt this Period

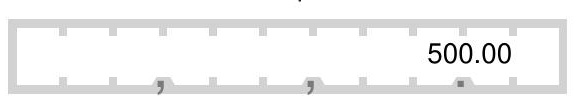

Transaction ID : AFB6BD14D0B714681AE9 Date of Receipt

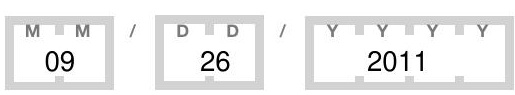

Amount of Each Receipt this Period

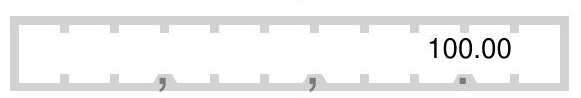

\section{Subtotal Of Receipts This Page (optional)}

Total This Period (last page this line number only) 


\section{SCHEDULE A-P} ITEMIZED RECEIPTS
Use separate schedule(s)

for each category of the

Detailed Summary Page
FOR LINE NUMBER: (check only one)

PAGE $776 / 1572$

\begin{tabular}{|c|c|c|c|c|c|}
\hline & & & & & \\
\hline 16 & X $17 a$ & $17 b$ & $17 c$ & $17 d$ & 18 \\
\hline $19 a$ & $19 b$ & $20 \mathrm{a}$ & $20 \mathrm{~b}$ & $20 \mathrm{c}$ & 21 \\
\hline
\end{tabular}

Any information copied from such Reports and Statements may not be sold or used by any person for the purpose of soliciting contributions or for commercial purposes, other than using the name and address of any political committee to solicit contributions from such committee.

NAME OF COMMITTEE (In Full)

Friends of Herman Cain

A. Full Name (Last, First, Middle Initial)

clifford clark

Mailing Address 240 E Berg Rd

\begin{tabular}{lcc}
\hline City & State & Zip Code \\
Salina & KS & $67401-8907$
\end{tabular}

FEC ID number of contributing federal political committee.

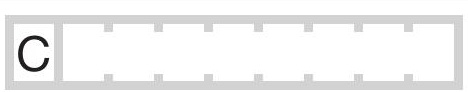

Name of Employer
Clark Enterprises 2000, Inc.
Receipt For: 2012
X Primary
$\square$ Other (specify)

Occupation

President

Election Cycle-to-Date

250.00

B. Full Name (Last, First, Middle Initial)

Jon Gober

Mailing Address 2638 Country Club rd

\begin{tabular}{lcc}
\hline City & State & Zip Code \\
San Angelo & TX & $76904-7992$ \\
\hline
\end{tabular}

FEC ID number of contributing

federal political committee.

C

Name of Employer
Information Requested
Receipt For: 2012
X Primary
Other (specify)

Occupation

Information Requested

Election Cycle-to-Date

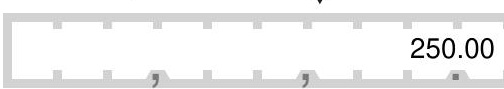

Transaction ID : AODB806E269874E99978

Date of Receipt

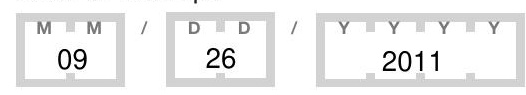

Amount of Each Receipt this Period

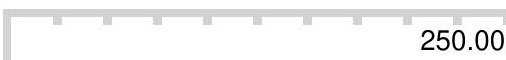

250.00

C. Full Name (Last, First, Middle Initial)

Ty Rulli

Mailing Address 6251 Cartwright Ave

\begin{tabular}{lcc}
\hline City & State & Zip Code \\
North Hollywood & CA & $91606-3801$
\end{tabular}

FEC ID number of contributing

federal political committee.

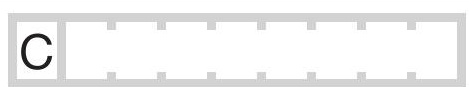

Name of Employer

Information Requested

Occupation

Information Requested

Receipt For: 2012

Х $\begin{aligned} & \text { Primary } \square \text { General } \\ & \text { Other (specify) }\end{aligned}$

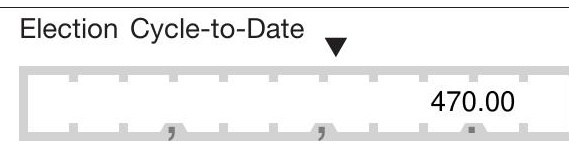

Amount of Each Receipt this Period

Transaction ID : A43E95E28F95C49FCBE4

Date of Receipt
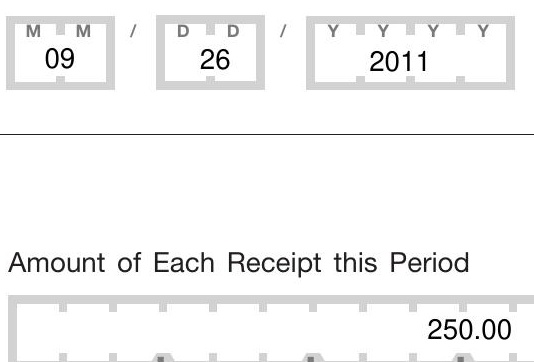

Transaction ID : AA02A090E175C43A5A7A Date of Receipt

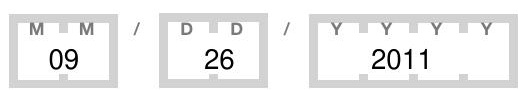

Amount of Each Receipt this Period

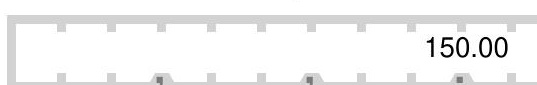

650.00

Subtotal Of Receipts This Page (optional)

Total This Period (last page this line number only) 


\section{SCHEDULE A-P} ITEMIZED RECEIPTS
Use separate schedule(s)

for each category of the

Detailed Summary Page
FOR LINE NUMBER: (check only one)

PAGE 777 / 1572

\begin{tabular}{|c|c|c|c|c|c|}
\hline & & & & & \\
\hline 16 & X $17 a$ & $17 b$ & $17 c$ & $17 d$ & 18 \\
\hline $19 a$ & $19 b$ & $20 \mathrm{a}$ & $20 \mathrm{~b}$ & $20 \mathrm{c}$ & 21 \\
\hline
\end{tabular}

Any information copied from such Reports and Statements may not be sold or used by any person for the purpose of soliciting contributions or for commercial purposes, other than using the name and address of any political committee to solicit contributions from such committee.

NAME OF COMMITTEE (In Full)

Friends of Herman Cain

A. Full Name (Last, First, Middle Initial)

\section{Carol Cook}

Mailing Address 43 Oak Alley

\section{City}

Kerrville

FEC ID number of contributing federal political committee.

Name of Employer
James Avery
Receipt For: 2012
X Primary
Other (specify)

B. Full Name (Last, First, Middle Initial)

Zachary Martinez

\section{Mailing Address 231 Weaver Street Apt 16E}

\begin{tabular}{lcc}
\hline City & State & Zip Code \\
Greenwich & CT & $06831-4251$
\end{tabular}

FEC ID number of contributing

federal political committee.

Name of Employer
Information Requested
Receipt For: 2012
$\searrow$ Primary
Other (specify)

Occupation

Sales Team Leader

Election Cycle-to-Date

Transaction ID : AD210205CC67749D6856

Date of Receipt

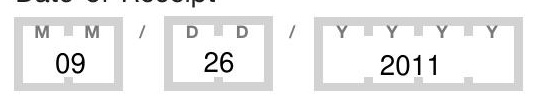

Amount of Each Receipt this Period

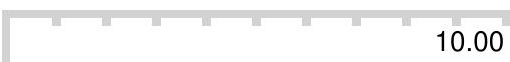

10.00

C

Transaction ID : A15A8988FA2FB4B7E9CF Date of Receipt

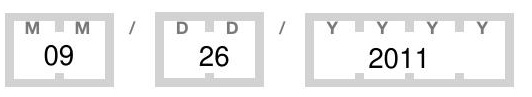

Amount of Each Receipt this Period

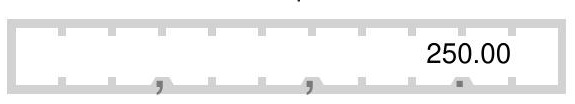

Information Requested

Election Cycle-to-Date

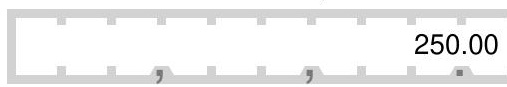

C. Full Name (Last, First, Middle Initial)

Andrew Martin

Mailing Address P.O. Box 586

\begin{tabular}{lcc}
\hline City & State & Zip Code \\
Elkton & MD & $21922-0586$
\end{tabular}

FEC ID number of contributing federal political committee.

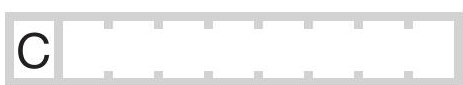

Name of Employer

Information Requested

\section{Occupation}

Information Requested

Receipt For: 2012

Х $\begin{aligned} & \text { Primary } \square \text { General } \\ & \text { Other (specify) }\end{aligned}$

Transaction ID : AD4A55B27790146FFAA4 Date of Receipt

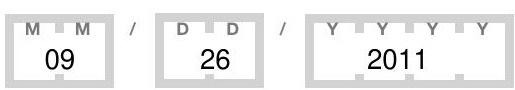

Amount of Each Receipt this Period

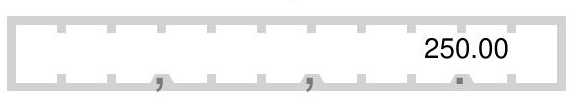

\section{Subtotal Of Receipts This Page (optional)}

Total This Period (last page this line number only) 


\section{SCHEDULE A-P} ITEMIZED RECEIPTS
Use separate schedule(s) for each category of the Detailed Summary Page

FOR LINE NUMBER:
(check only one)

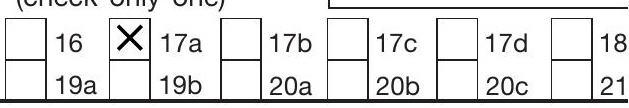

Any information copied from such Reports and Statements may not be sold or used by any person for the purpose of soliciting contributions or for commercial purposes, other than using the name and address of any political committee to solicit contributions from such committee.

NAME OF COMMITTEE (In Full)

\section{Friends of Herman Cain}

A. Full Name (Last, First, Middle Initial)

William Partee Jr

Mailing Address PO BOX 667

\begin{tabular}{lcc}
\hline City & State & Zip Code \\
Little Rock & AR & $72203-0667$
\end{tabular}

FEC ID number of contributing federal political committee.

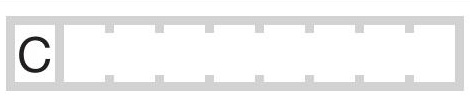

Name of Employer
Information Requested
Receipt For: 2012
X Primary
Other (specify) General

Occupation Information Requested

Election Cycle-to-Date 250.00

B. Full Name (Last, First, Middle Initial)

Thomas J Humphrey

Mailing Address 12902 W Mesa Verde Dr

\begin{tabular}{lcc}
\hline City & State & Zip Code \\
Sun City West & AZ & $85375-3226$ \\
\hline
\end{tabular}

FEC ID number of contributing

federal political committee.

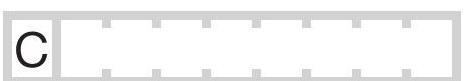

\begin{tabular}{l} 
Name of Employer \\
None \\
Receipt For: 2012 \\
X Primary $\quad$ General \\
\hline Other (specify)
\end{tabular}

\section{Occupation}

Retired

Election Cycle-to-Date

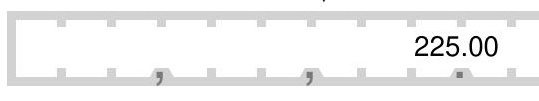

C. Full Name (Last, First, Middle Initial)

Charles Schoen

Mailing Address 6190 Mountain Brook Way NW

\begin{tabular}{lcc}
\hline City & State & Zip Code \\
Atlanta & GA & $30328-3608$ \\
\hline
\end{tabular}

FEC ID number of contributing federal political committee.

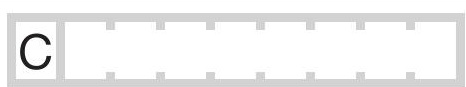

Name of Employer

Adaptive Learning Center

Receipt For: 2012

Х $\begin{aligned} & \text { Primary } \\ & \text { Other (specify) }\end{aligned}$
Transaction ID : A1DB06ADC01A04C4C8A2

Date of Receipt

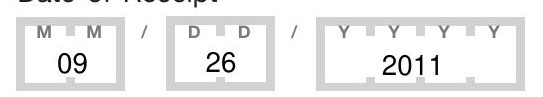

Amount of Each Receipt this Period

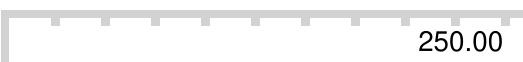

Transaction ID : AC235BDFA6F01495FBD5 Date of Receipt

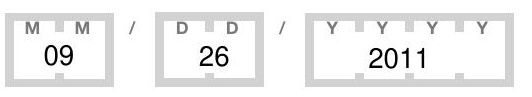

Amount of Each Receipt this Period

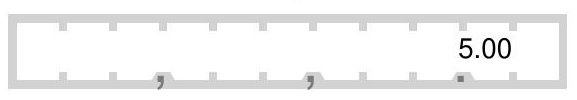

Transaction ID : ABEA355B857D1454683D Date of Receipt

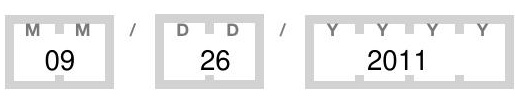

Amount of Each Receipt this Period
Occupation

Executive Director

Election Cycle-to-Date

\section{Subtotal Of Receipts This Page (optional).}

Total This Period (last page this line number only)

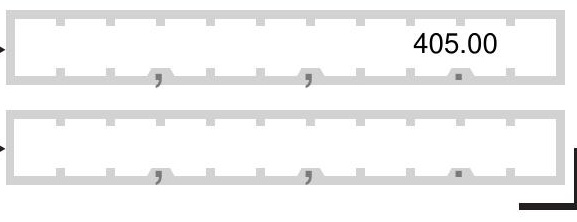




\section{SCHEDULE A-P} ITEMIZED RECEIPTS
Use separate schedule(s)

for each category of the

Detailed Summary Page
FOR LINE NUMBER: (check only one)

PAGE $779 / 1572$

\begin{tabular}{|c|c|c|c|c|c|}
\hline & & & & & \\
\hline 16 & $\mathbf{X} 17 \mathrm{a}$ & $17 \mathrm{~b}$ & $17 c$ & $17 d$ & 18 \\
\hline $19 a$ & $19 \mathrm{~b}$ & $20 a$ & $20 \mathrm{~b}$ & $20 c$ & 21 \\
\hline
\end{tabular}

Any information copied from such Reports and Statements may not be sold or used by any person for the purpose of soliciting contributions or for commercial purposes, other than using the name and address of any political committee to solicit contributions from such committee.

NAME OF COMMITTEE (In Full)

\section{Friends of Herman Cain}

A. Full Name (Last, First, Middle Initial)

Helmut Zimmerman

Mailing Address 1808 Hether Glen Cir.

\begin{tabular}{lcc}
\hline City & State & Zip Code \\
Allen & TX & $75002-8614$
\end{tabular}

FEC ID number of contributing federal political committee.

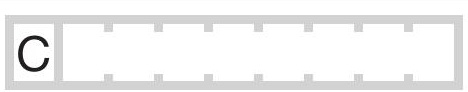

Name of Employer

Sanden International (U.S.A.) Inc.

Receipt For: 2012

Х Primary $\square$ General

Occupation

assembly worker

Election Cycle-to-Date

1250.00

B. Full Name (Last, First, Middle Initial)

Jakob Ernst

Mailing Address 27243M Seward Hwy.

\begin{tabular}{lcc}
\hline City & State & Zip Code \\
Seward & AK & $99664-9503$
\end{tabular}

FEC ID number of contributing

federal political committee.

C

\begin{tabular}{l} 
Name of Employer \\
Information Design Inc. \\
Receipt For: 2012 \\
Primary \\
\hline Other (specify)
\end{tabular}

Occupation

Internship

Election Cycle-to-Date

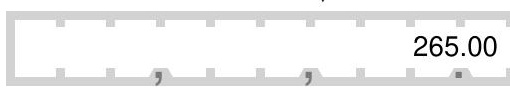

Transaction ID : A4766DBD053454DC3A7E

Date of Receipt

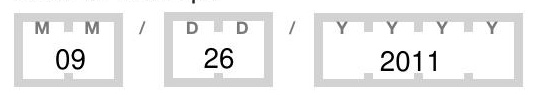

Amount of Each Receipt this Period

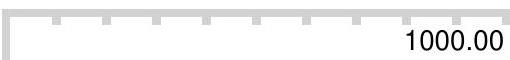

1000.00

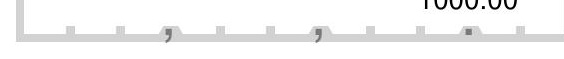

Transaction ID : A0D6056E7629B4C4E877

Date of Receipt

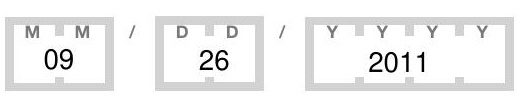

Amount of Each Receipt this Period

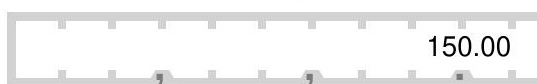

Transaction ID : AA5A7B66110D74F528B1

Date of Receipt

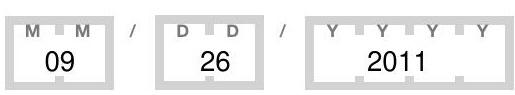

Amount of Each Receipt this Period

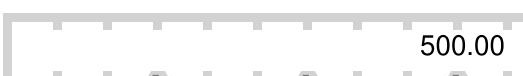

C. Full Name (Last, First, Middle Initial)

William Schwartz

Mailing Address 162 Machado Ct.

\begin{tabular}{lcc}
\hline City & State & Zip Code \\
Tracy & CA & $95376-1327$
\end{tabular}

FEC ID number of contributing federal political committee.

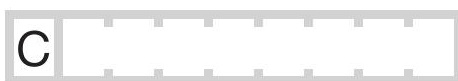

Name of Employer

Information Requested

Information Requested

Receipt For: 2012

Х $\begin{aligned} & \text { Primary } \\ & \text { Other (specify) }\end{aligned}$

Election Cycle-to-Date

500.00

Subtotal Of Receipts This Page (optional)

1650.00

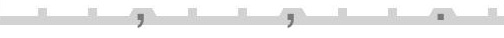

Total This Period (last page this line number only)

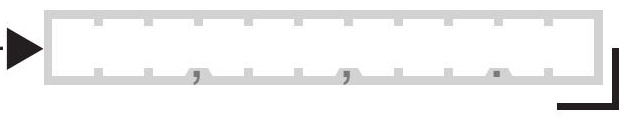

FEC Schedule A-P (Form 3P) (Rev. 03/2011) 


\section{SCHEDULE A-P} ITEMIZED RECEIPTS
Use separate schedule(s)

for each category of the

Detailed Summary Page
FOR LINE NUMBER: (check only one)

PAGE $780 / 1572$

\begin{tabular}{|c|c|c|c|c|c|}
\hline & & & & & \\
\hline 16 & X $17 a$ & $17 b$ & $17 c$ & $17 d$ & 18 \\
\hline $19 a$ & $19 b$ & $20 \mathrm{a}$ & $20 \mathrm{~b}$ & $20 \mathrm{c}$ & 21 \\
\hline
\end{tabular}

Any information copied from such Reports and Statements may not be sold or used by any person for the purpose of soliciting contributions or for commercial purposes, other than using the name and address of any political committee to solicit contributions from such committee.

NAME OF COMMITTEE (In Full)

Friends of Herman Cain

A. Full Name (Last, First, Middle Initial)

Stacey Utley

Mailing Address 130 Lakeland Drive

\begin{tabular}{lcc}
\hline City & State & Zip Code \\
Cabot & AR & $72023-9418$
\end{tabular}

FEC ID number of contributing

federal political committee.

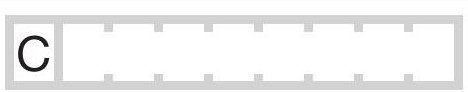

Name of Employer
Information Requested
Receipt For: 2012
X Primary $\quad \square$ General
Other (specify)

Occupation

Information Requested

Election Cycle-to-Date

500.00

B. Full Name (Last, First, Middle Initial)

Scott Darling

Mailing Address 3697 Arlington Ave

\begin{tabular}{lcc}
\hline City & State & Zip Code \\
Riverside & CA & $92506-3938$
\end{tabular}

FEC ID number of contributing

federal political committee.

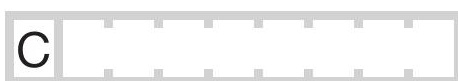

Name of Employer
Darling Law Office
Receipt For: 2012
X Primary
Other (specify) General

Occupation

Attorney

Election Cycle-to-Date

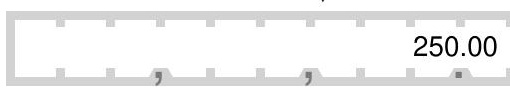

C. Full Name (Last, First, Middle Initial)

Joanne Zervos

Mailing Address 144 East 84th Street Apt 11F

\begin{tabular}{lcc}
\hline City & State & Zip Code \\
New York & NY & $10028-2038$
\end{tabular}

FEC ID number of contributing

federal political committee.

$\mathrm{C}$

Name of Employer

Information Requested

Occupation

Information Requested

Receipt For: 2012

Х $\begin{aligned} & \text { Primary } \square \text { General } \\ & \text { Other (specify) }\end{aligned}$

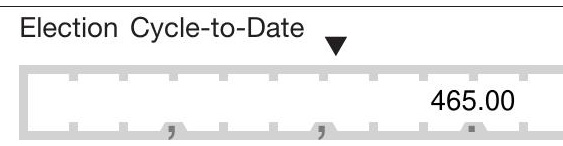

Amount of Each Receipt this Period

Transaction ID : ABA7486DBCE9747BD962

Date of Receipt

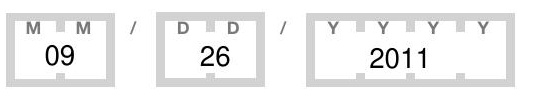

Amount of Each Receipt this Period
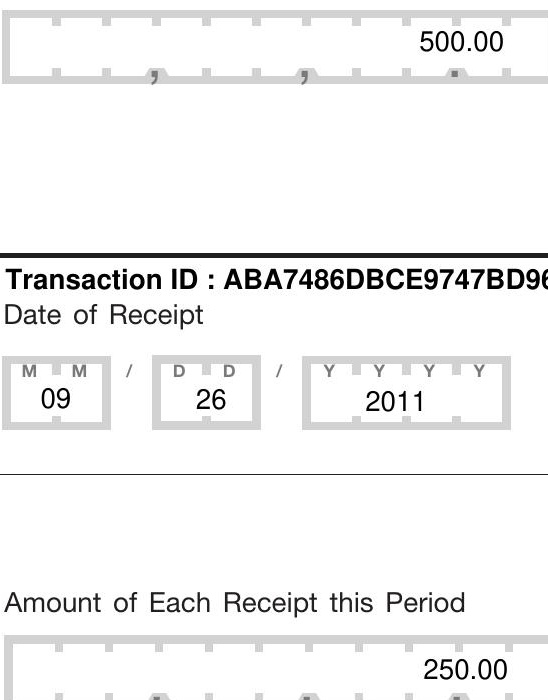

Transaction ID : AAA34B576B5174F07A8B

Date of Receipt

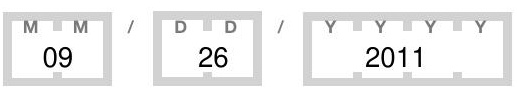

Amount of Each Receipt this Period

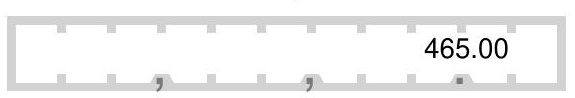

Subtotal Of Receipts This Page (optional).

1215.00

Total This Period (last page this line number only) 


\section{SCHEDULE A-P} ITEMIZED RECEIPTS
Use separate schedule(s)

for each category of the

Detailed Summary Page
FOR LINE NUMBER: (check only one)

PAGE $781 / 1572$

\begin{tabular}{|c|c|c|c|c|c|}
\hline & & & & & \\
\hline 16 & X $17 a$ & $17 b$ & $17 c$ & $17 d$ & 18 \\
\hline $19 a$ & $19 b$ & $20 \mathrm{a}$ & $20 \mathrm{~b}$ & $20 \mathrm{c}$ & 21 \\
\hline
\end{tabular}

Any information copied from such Reports and Statements may not be sold or used by any person for the purpose of soliciting contributions or for commercial purposes, other than using the name and address of any political committee to solicit contributions from such committee.

NAME OF COMMITTEE (In Full)

Friends of Herman Cain

A. Full Name (Last, First, Middle Initial)

Barry Rich

Mailing Address 1611 Greenview CT

\begin{tabular}{lcc}
\hline City & State & Zip Code \\
Woodstock & GA & $30189-1538$
\end{tabular}

FEC ID number of contributing

federal political committee.

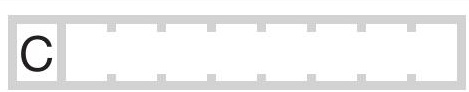

Name of Employer
Information Requested
Receipt For: 2012
X Primary $\quad \square$ General
Other (specify)

Occupation

Information Requested

Election Cycle-to-Date

500.00

B. Full Name (Last, First, Middle Initial)

David Fakier

Mailing Address 300 Ardoyne Drive

\begin{tabular}{lcc}
\hline City & State & Zip Code \\
Houma & LA & $70360-7924$
\end{tabular}

FEC ID number of contributing

federal political committee.

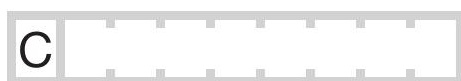

Name of Employer
Self Employed
Receipt For: 2012
X Primary
Other (specify)

Occupation

Physician

Election Cycle-to-Date

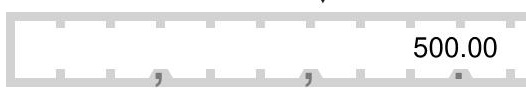

C. Full Name (Last, First, Middle Initial)

John Williams

Mailing Address 2 Coniston Dr

\begin{tabular}{lcc}
\hline City & State & Zip Code \\
West Chester & PA & $19382-6937$
\end{tabular}

FEC ID number of contributing

federal political committee.

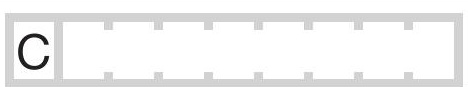

Name of Employer

Information Requested

Occupation

Information Requested

Receipt For: 2012

Х $\begin{aligned} & \text { Primary } \square \text { General } \\ & \text { Other (specify) }\end{aligned}$

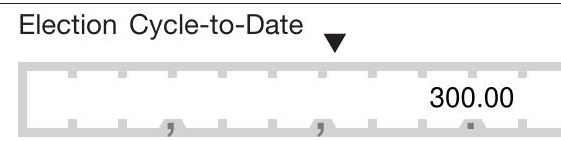

Transaction ID : A55BCD595CBCD4D02A2C

Date of Receipt

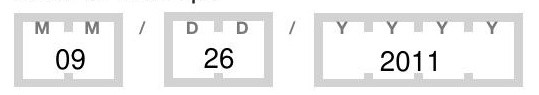

Amount of Each Receipt this Period

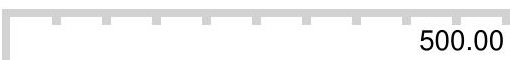

500.00

Transaction ID : A2EE5E5666C2242129FD

Date of Receipt

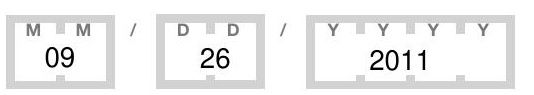

Amount of Each Receipt this Period

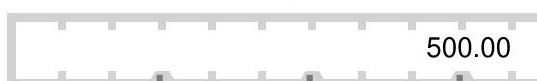

Transaction ID : A1A8469B0CA6D4FF9AEB Date of Receipt

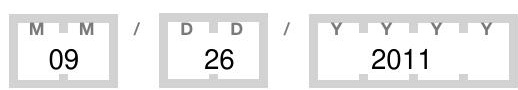

Amount of Each Receipt this Period

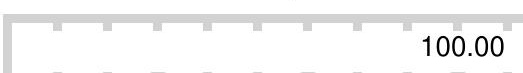

1100.00

Subtotal Of Receipts This Page (optional)

,

Total This Period (last page this line number only) 


\section{SCHEDULE A-P} ITEMIZED RECEIPTS
Use separate schedule(s) for each category of the Detailed Summary Page

FOR LINE NUMBER:
(check only one)

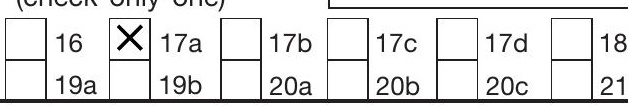

Any information copied from such Reports and Statements may not be sold or used by any person for the purpose of soliciting contributions or for commercial purposes, other than using the name and address of any political committee to solicit contributions from such committee.

NAME OF COMMITTEE (In Full)

\section{Friends of Herman Cain}

A. Full Name (Last, First, Middle Initial)

\section{Brian Harrison}

Mailing Address 4754 Luxley Drive

\begin{tabular}{lcc}
\hline City & State & Zip Code \\
Waterloo & IA & $50701-4305$
\end{tabular}

FEC ID number of contributing federal political committee.

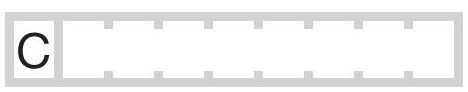

Name of Employer
Harrison Truck Centers
Receipt For: 2012
X Primary
Other (specify)

\section{Occupation}

President

Election Cycle-to-Date

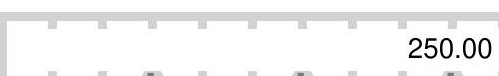

B. Full Name (Last, First, Middle Initial)

Peter Colwell

Mailing Address PO Box 281

\begin{tabular}{lcc}
\hline City & State & Zip Code \\
Manistique & MI & $49854-0281$
\end{tabular}

FEC ID number of contributing

federal political committee.

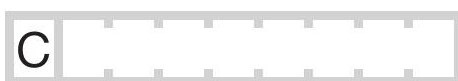

Name of Employer
n/a
Receipt For: 2012
X Primary
Other (specify)

\section{Occupation}

Retired

Election Cycle-to-Date

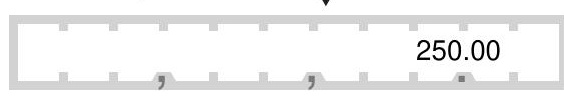

C. Full Name (Last, First, Middle Initial)

Joseph Spiegla

Mailing Address 12293 Beadle Lake Road

\begin{tabular}{l|ll}
\hline $\begin{array}{l}\text { City } \\
\text { Battle Creek }\end{array}$ & $\begin{array}{c}\text { State } \\
\text { MI }\end{array}$ & $\begin{array}{c}\text { Zip Code } \\
49014-8599\end{array}$ \\
\hline $\begin{array}{l}\text { FEC ID number of contributing } \\
\text { federal political committee. }\end{array}$ & C \\
\hline $\begin{array}{l}\text { Name of Employer } \\
\text { IAC Mendon LLC }\end{array}$ & $\begin{array}{l}\text { Occupation } \\
\text { Automotive Engineer }\end{array}$ \\
\hline $\begin{array}{l}\text { Receipt For: 2012 } \\
\text { Primary } \\
\text { Other (specify) }\end{array}$ & Election Cycle-to-Date & \\
\hline
\end{tabular}

Transaction ID : A90B25DD456AA4A27A1F

Date of Receipt

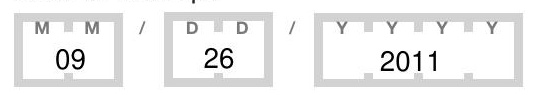

Amount of Each Receipt this Period

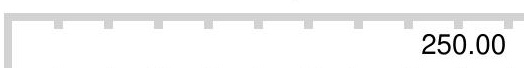

250.00

Transaction ID : ACC612DD21A01472EA6A

Date of Receipt

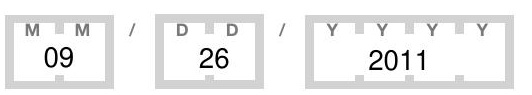

Amount of Each Receipt this Period

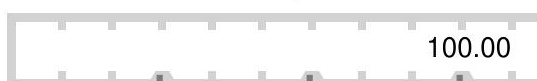

Amount of Each Receipt this Period

Transaction ID : AD413E77C45A54545A7A Date of Receipt
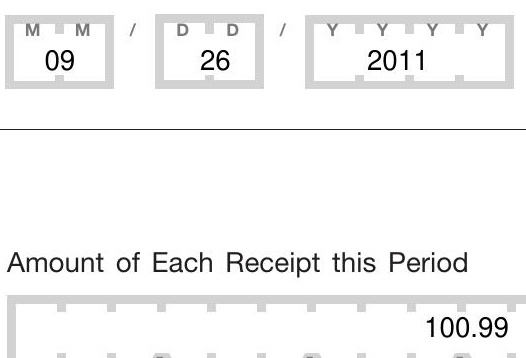

100.99

\section{Subtotal Of Receipts This Page (optional)}

Total This Period (last page this line number only) 
SCHEDULE A-P ITEMIZED RECEIPTS
Use separate schedule(s) for each category of the Detailed Summary Page
FOR LINE NUMBER: (check only one)

PAGE $783 / 1572$

\begin{tabular}{|c|c|c|c|c|c|}
\hline & & & & & \\
\hline 16 & $\begin{array}{l}\mathbf{X} \\
17 a\end{array}$ & $17 b$ & $17 c$ & $17 d$ & 18 \\
\hline $19 a$ & $19 \mathrm{~b}$ & $20 \mathrm{a}$ & $20 \mathrm{~b}$ & $20 \mathrm{c}$ & 21 \\
\hline
\end{tabular}

Any information copied from such Reports and Statements may not be sold or used by any person for the purpose of soliciting contributions or for commercial purposes, other than using the name and address of any political committee to solicit contributions from such committee.

NAME OF COMMITTEE (In Full)

\section{Friends of Herman Cain}

A. Full Name (Last, First, Middle Initial) susan boren

Mailing Address 8441 E. Bogota Place

\begin{tabular}{lcc}
\hline City & State & Zip Code \\
Tucson & AZ & $85715-5205$
\end{tabular}

FEC ID number of contributing federal political committee.

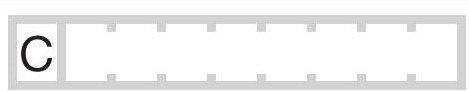

Name of Employer
Information Requested
Receipt For: 2012
X Primary
Other (specify) General

Occupation Information Requested

Election Cycle-to-Date

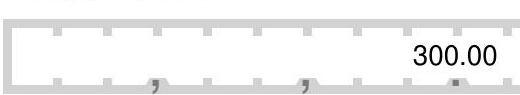

B. Full Name (Last, First, Middle Initial) John Zimmer

Mailing Address 1014 River Ct

\begin{tabular}{lcc}
\hline City & State & Zip Code \\
Manitowoc & WI & $54220-2948$
\end{tabular}

FEC ID number of contributing

federal political committee.

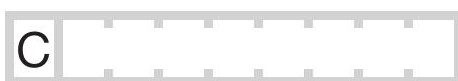

Name of Employer
None
Receipt For: 2012
X Primary
Other (specify)

\section{Occupation}

Retired

Election Cycle-to-Date

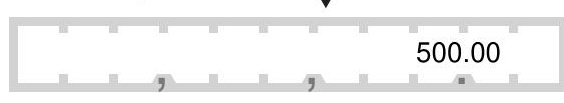

Transaction ID : AFA21628775D14E1D90C

Date of Receipt

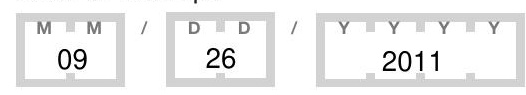

Amount of Each Receipt this Period

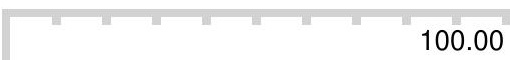

C. Full Name (Last, First, Middle Initial)

Judy Goldberg

Mailing Address 10 Bannockburn Court

\begin{tabular}{lcc}
\hline City & State & Zip Code \\
Bannockburn & IL & $60015-1818$
\end{tabular}

FEC ID number of contributing

federal political committee.

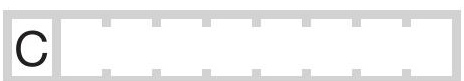

Name of Employer

Information Requested

Occupation

Information Requested

Receipt For: 2012

Х $\begin{aligned} & \text { Primary } \\ & \text { Other (specify) }\end{aligned}$

Amount of Each Receipt this Period

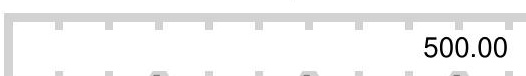

Transaction ID : A9642573B5CDE4AD4AE6 Date of Receipt

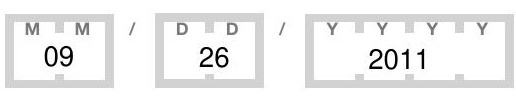

Transaction ID : A526010162AFD46AFA0F Date of Receipt

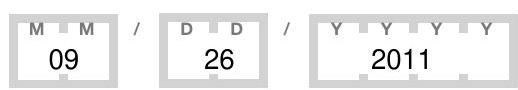

Amount of Each Receipt this Period

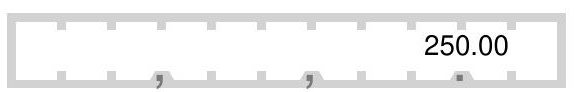

250.00
Subtotal Of Receipts This Page (optional)

850.00

a 1 .

Total This Period (last page this line number only)

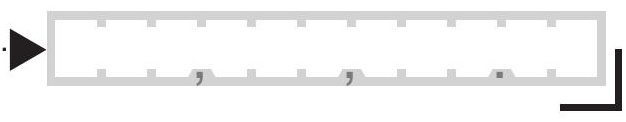

FEC Schedule A-P (Form 3P) (Rev. 03/2011) 
SCHEDULE A-P ITEMIZED RECEIPTS
Use separate schedule(s) for each category of the Detailed Summary Page
FOR LINE NUMBER: (check only one)
PAGE 784 / 1572

\begin{tabular}{|c|c|c|c|c|c|}
\hline & & & & & \\
\hline 16 & $\begin{array}{lll}X & 17 a \\
\end{array}$ & $17 \mathrm{~b}$ & $17 c$ & $17 d$ & 18 \\
\hline $19 a$ & $19 b$ & $20 a$ & $20 \mathrm{~b}$ & $20 c$ & 21 \\
\hline
\end{tabular}

Any information copied from such Reports and Statements may not be sold or used by any person for the purpose of soliciting contributions or for commercial purposes, other than using the name and address of any political committee to solicit contributions from such committee.

NAME OF COMMITTEE (In Full)

\section{Friends of Herman Cain}

A. Full Name (Last, First, Middle Initial)

\section{Charles Schoen}

Mailing Address 6190 Mountain Brook Way NW

\begin{tabular}{lcc}
\hline City & State & Zip Code \\
Atlanta & GA & $30328-3608$ \\
\hline
\end{tabular}

FEC ID number of contributing federal political committee.

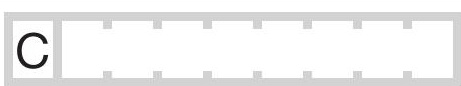

Name of Employer
Adaptive Learning Center
Receipt For: 2012
X Primary $\quad \square$ General
Other (specify)

Occupation

Executive Director

Election Cycle-to-Date

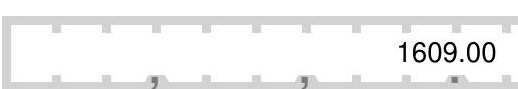

B. Full Name (Last, First, Middle Initial)

Ty Rulli

Mailing Address 6251 Cartwright Ave

\begin{tabular}{lcc}
\hline City & State & Zip Code \\
North Hollywood & CA & $91606-3801$
\end{tabular}

FEC ID number of contributing

federal political committee.

C

Name of Employer
Information Requested
Receipt For: 2012
X Primary
Other (specify)

Occupation

Information Requested

Election Cycle-to-Date

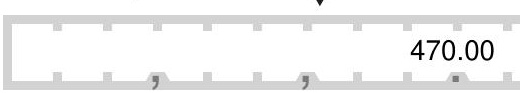

Transaction ID : AFCC7B7B57E2E41F4AA4

Date of Receipt

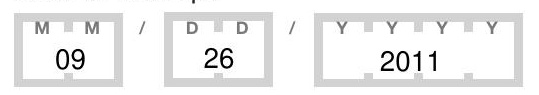

Amount of Each Receipt this Period

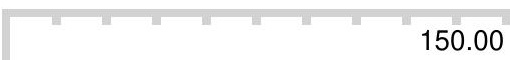

150.00

C. Full Name (Last, First, Middle Initial)

George Mills

Mailing Address 331 Milam Suite 300

\begin{tabular}{lcc}
\hline City & State & Zip Code \\
Shreveport & LA & $71101-5353$
\end{tabular}

FEC ID number of contributing

federal political committee.

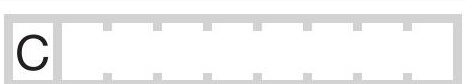

Name of Employer

Mills Turansky \& Griffith

Receipt For: 2012

Х $\begin{aligned} & \text { Primary } \\ & \text { Other (specify) }\end{aligned}$

\section{Occupation}

Attorney

Election Cycle-to-Date

Transaction ID : AD371AC18F6C944E0A76

Date of Receipt

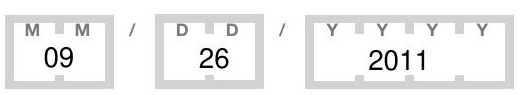

Amount of Each Receipt this Period

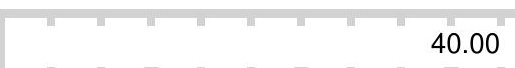

Transaction ID : AF9F297D834564DCD9D7 Date of Receipt

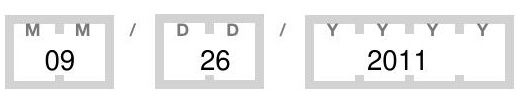

Amount of Each Receipt this Period

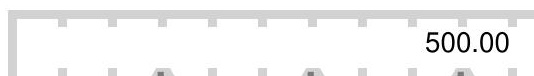

1100.00

\section{Subtotal Of Receipts This Page (optional)}

690.00

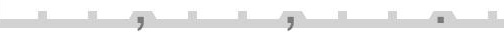

Total This Period (last page this line number only)

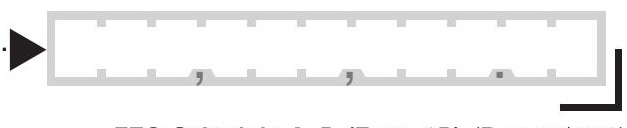

FEC Schedule A-P (Form 3P) (Rev. 03/2011) 


\section{SCHEDULE A-P} ITEMIZED RECEIPTS
Use separate schedule(s)

for each category of the

Detailed Summary Page
FOR LINE NUMBER: (check only one)

PAGE $785 / 1572$

\begin{tabular}{|c|c|c|c|c|c|}
\hline & & & & & \\
\hline 16 & X $17 a$ & $17 b$ & $17 c$ & $17 d$ & 18 \\
\hline $19 a$ & $19 b$ & $20 \mathrm{a}$ & $20 \mathrm{~b}$ & $20 \mathrm{c}$ & 21 \\
\hline
\end{tabular}

Any information copied from such Reports and Statements may not be sold or used by any person for the purpose of soliciting contributions or for commercial purposes, other than using the name and address of any political committee to solicit contributions from such committee.

NAME OF COMMITTEE (In Full)

Friends of Herman Cain

A. Full Name (Last, First, Middle Initial)

Scott Newton

Mailing Address 4739 Azucena Rd

City $\quad$ State $\quad$ Zip Code

Woodland Hills

CA $\quad 91364-4038$

FEC ID number of contributing

federal political committee.

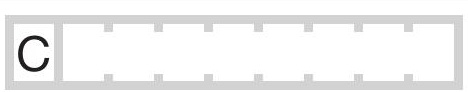

Name of Employer
Information Requested
Receipt For: 2012
X Primary $\quad \square$ General
Other (specify)

Occupation

Information Requested

Election Cycle-to-Date

500.00

B. Full Name (Last, First, Middle Initial)

David Brand

Mailing Address 2367 N Woodlawn Dr

\begin{tabular}{lcc}
\hline City & State & Zip Code \\
Blakely & GA & $39823-1638$ \\
\hline
\end{tabular}

FEC ID number of contributing

federal political committee.

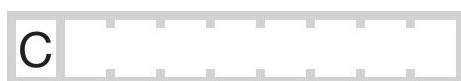

Name of Employer
Health Authority Calhoun County
Receipt For: 2012
X Primary
Other (specify)

Occupation

Physician

Election Cycle-to-Date

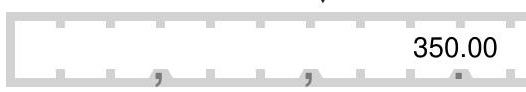

C. Full Name (Last, First, Middle Initial)

Kathi-Ann Rivard

Mailing Address 206 E. Seventh St.

\begin{tabular}{lcc}
\hline City & State & Zip Code \\
Prosper & TX & $75078-2536$
\end{tabular}

FEC ID number of contributing

federal political committee.

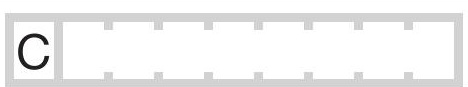

Name of Employer

Information Requested

Occupation

Information Requested

Receipt For: 2012

Х $\begin{aligned} & \text { Primary } \\ & \text { Other (specify) }\end{aligned}$

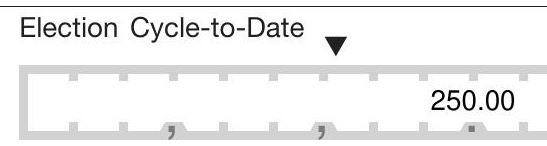

Transaction ID : A5C44AC8E72224B988AB

Date of Receipt

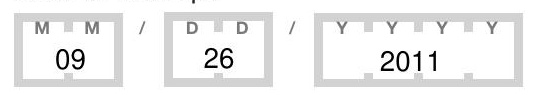

Amount of Each Receipt this Period

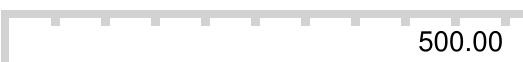

Amount of Each Receipt this Period

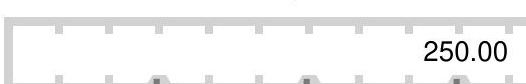

Transaction ID : A114E4043834A47ECAA8 Date of Receipt

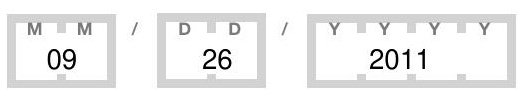

Amount of Each Receipt this Period

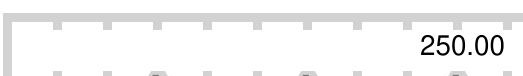

Transaction ID : A48DC822EF59148078F5

Date of Receipt
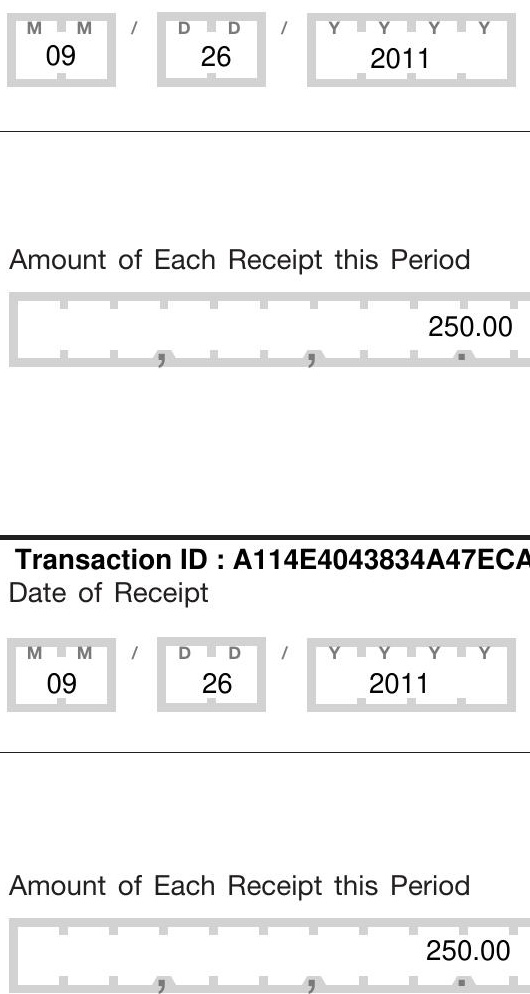

Subtotal Of Receipts This Page (optional).

1000.00

ㄱ․․

Total This Period (last page this line number only)

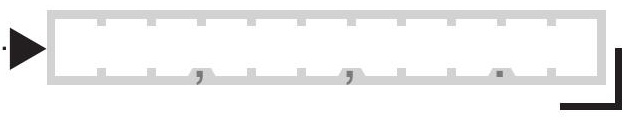




\section{SCHEDULE A-P} ITEMIZED RECEIPTS
Use separate schedule(s)

for each category of the

Detailed Summary Page
FOR LINE NUMBER: (check only one)

PAGE $786 / 1572$

\begin{tabular}{|c|c|c|c|c|c|}
\hline & & & & & \\
\hline 16 & $\begin{array}{l}\mathbf{X} \\
17 a\end{array}$ & $17 b$ & $17 c$ & $17 d$ & 18 \\
\hline $19 a$ & $19 \mathrm{~b}$ & $20 \mathrm{a}$ & $20 \mathrm{~b}$ & $20 \mathrm{c}$ & 21 \\
\hline
\end{tabular}

Any information copied from such Reports and Statements may not be sold or used by any person for the purpose of soliciting contributions or for commercial purposes, other than using the name and address of any political committee to solicit contributions from such committee.

NAME OF COMMITTEE (In Full)

Friends of Herman Cain

A. Full Name (Last, First, Middle Initial)

christina lipsey

Mailing Address 1219 libby rd

\begin{tabular}{lcc}
\hline City & State & Zip Code \\
Heber Springs & AR & $72543-8985$
\end{tabular}

FEC ID number of contributing

federal political committee.

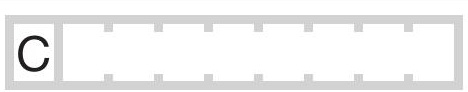

Name of Employer
little rock scool distrct
Receipt For: 2012
Х Primary $\square$ General
Other (specify)

Occupation

Teacher

Election Cycle-to-Date

900.00

B. Full Name (Last, First, Middle Initial)

MICHAEL MOORE

Mailing Address 66 WEST WILSHIRE DRIVE

\begin{tabular}{lcc}
\hline City & State & Zip Code \\
Phoenix & AZ & 85003-1025 \\
\hline
\end{tabular}

FEC ID number of contributing

federal political committee.

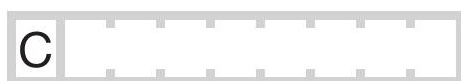

Name of Employer
Self Employed
Receipt For: 2012
X Primary
Other (specify)

Occupation

Farmer

Election Cycle-to-Date

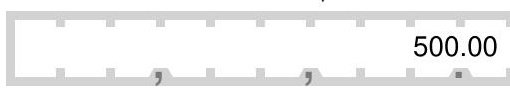

C. Full Name (Last, First, Middle Initial)

Vicky Scott

Mailing Address 555 Ben Franklin Drive

\begin{tabular}{l|ll}
\hline $\begin{array}{l}\text { City } \\
\text { Sarasota }\end{array}$ & $\begin{array}{c}\text { State } \\
\text { FL }\end{array}$ & $\begin{array}{c}\text { Zip Code } \\
34236-2050\end{array}$ \\
\hline $\begin{array}{l}\text { FEC ID number of contributing } \\
\text { federal political committee. }\end{array}$ & C & \\
\hline $\begin{array}{l}\text { Name of Employer } \\
\text { None }\end{array}$ & $\begin{array}{l}\text { Occupation } \\
\text { Retired }\end{array}$ \\
\hline $\begin{array}{l}\text { Receipt For: } 2012 \\
\text { Primary } \\
\text { Other (specify) }\end{array}$ & Election Cycle-to-Date & \\
\hline
\end{tabular}

Transaction ID : A4F20E37393254C688E9

Date of Receipt

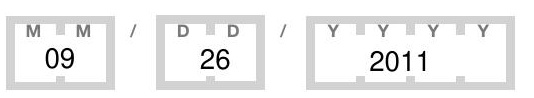

Amount of Each Receipt this Period

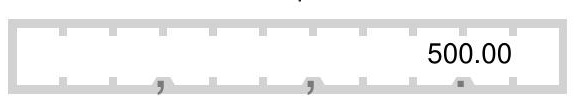

Amount of Each Receipt this Period

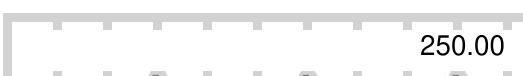

Transaction ID : A3DEEA2FD46EA492F9E9 Date of Receipt

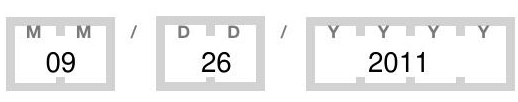

Subtotal Of Receipts This Page (optional).

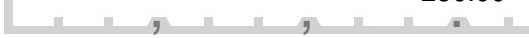

Total This Period (last page this line number only) 


\section{SCHEDULE A-P} ITEMIZED RECEIPTS
Use separate schedule(s)

for each category of the

Detailed Summary Page
FOR LINE NUMBER: (check only one)

PAGE 787 / 1572

\begin{tabular}{|c|c|c|c|c|c|}
\hline & & & & & \\
\hline 16 & X $17 a$ & $17 b$ & $17 c$ & $17 d$ & 18 \\
\hline $19 a$ & $19 b$ & $20 \mathrm{a}$ & $20 \mathrm{~b}$ & $20 \mathrm{c}$ & 21 \\
\hline
\end{tabular}

Any information copied from such Reports and Statements may not be sold or used by any person for the purpose of soliciting contributions or for commercial purposes, other than using the name and address of any political committee to solicit contributions from such committee.

NAME OF COMMITTEE (In Full)

Friends of Herman Cain

A. Full Name (Last, First, Middle Initial)

Sean Servey

Mailing Address 30073 Saint Andrews Road

\begin{tabular}{lcc}
\hline City & State & Zip Code \\
Perrysburg & OH & $43551-3527$ \\
\hline
\end{tabular}

FEC ID number of contributing

federal political committee.

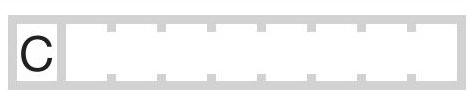

Name of Employer
Information Requested
Receipt For: 2012
X Primary $\quad \square$ General
Other (specify)

Occupation

Information Requested

Election Cycle-to-Date

250.00

B. Full Name (Last, First, Middle Initial)

lois edgerly

Mailing Address 32 highland street

\begin{tabular}{lcc}
\hline City & State & Zip Code \\
Cambridge & MA & $02138-2210$
\end{tabular}

FEC ID number of contributing

federal political committee.

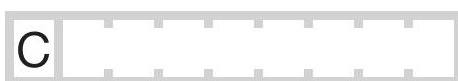

Name of Employer
Retired
Receipt For: 2012
X Primary
Other (specify)

\section{Occupation}

Retired

Election Cycle-to-Date

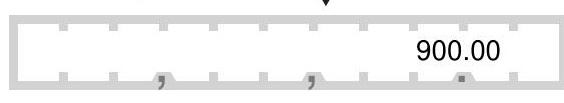

C. Full Name (Last, First, Middle Initial)

David Porter

Mailing Address 11231 US Highway 1 Suite 317

\begin{tabular}{lcc}
\hline City & State & Zip Code \\
North Palm Beach & FL & $33408-3216$
\end{tabular}

FEC ID number of contributing

federal political committee.

C

Name of Employer
E Minus LLC
Receipt For: 2012
X Primary

Other (specify) General

\section{Occupation}

Economist/Energy Trader

Election Cycle-to-Date

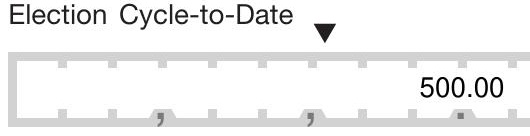

Transaction ID : A6A312BEB6EC3482691C

Date of Receipt

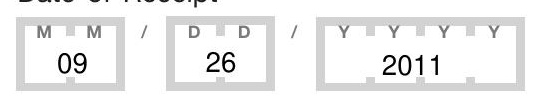

Amount of Each Receipt this Period

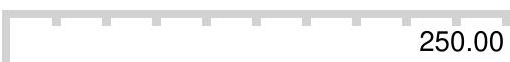

250.00

Transaction ID : A8323240FC1F2468E9F5

Date of Receipt

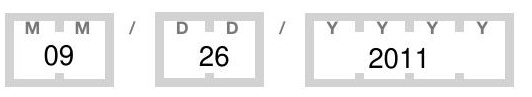

Amount of Each Receipt this Period

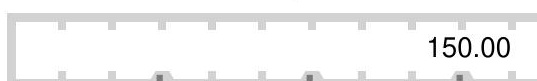

Transaction ID : ACBAF94CAF6DD40A2B7C Date of Receipt

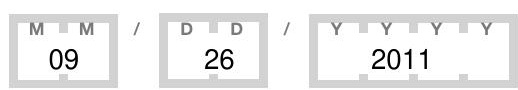

Amount of Each Receipt this Period

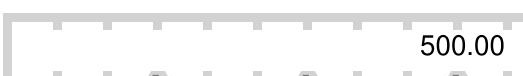

500.00

Subtotal Of Receipts This Page (optional).

900.00

Total This Period (last page this line number only) 


\section{SCHEDULE A-P} ITEMIZED RECEIPTS
Use separate schedule(s) for each category of the Detailed Summary Page

FOR LINE NUMBER:
(check only one)

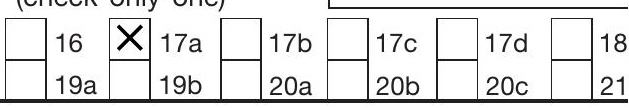

Any information copied from such Reports and Statements may not be sold or used by any person for the purpose of soliciting contributions or for commercial purposes, other than using the name and address of any political committee to solicit contributions from such committee.

NAME OF COMMITTEE (In Full)

\section{Friends of Herman Cain}

A. Full Name (Last, First, Middle Initial) james lorence

Mailing Address 6424 Hidden Holw

\begin{tabular}{lcc}
\hline City & State & Zip Code \\
Holland & MI & $49423-7901$
\end{tabular}

FEC ID number of contributing federal political committee.

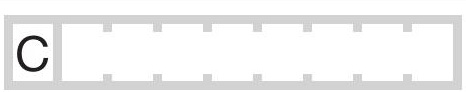

Name of Employer
J. lorence \& assoc.
Receipt For: 2012
X Primary
Other (specify) General

Occupation investment advisor Election Cycle-to-Date

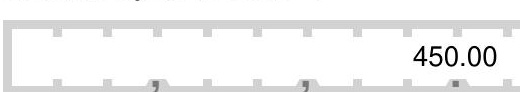

B. Full Name (Last, First, Middle Initial)

Michael Ryan

Mailing Address 112 E. First Street

\begin{tabular}{lcc}
\hline City & State & Zip Code \\
Kankakee & IL & 60901 \\
\hline
\end{tabular}

FEC ID number of contributing

federal political committee.

C

Name of Employer
Information Requested
Receipt For: 2012
Primary
Other (specify)

Occupation

Information Requested

Election Cycle-to-Date

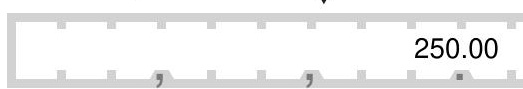

Transaction ID : A8702661DDC8F4431B86

Date of Receipt

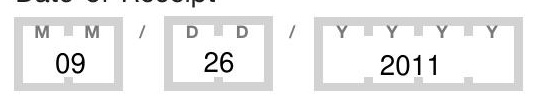

Amount of Each Receipt this Period

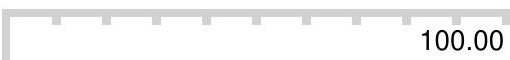

Transaction ID : A14D32000DB024DDEA6B Date of Receipt

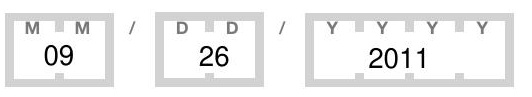

Amount of Each Receipt this Period

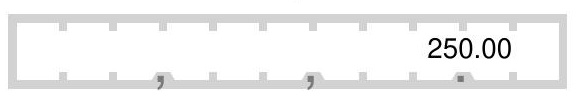

C. Full Name (Last, First, Middle Initial)

Dr Thomas E Hanes

Mailing Address 5223 Heathrow Hills Dr

\begin{tabular}{lcc}
\hline City & State & Zip Code \\
Brentwood & TN & $37027-6548$
\end{tabular}

FEC ID number of contributing federal political committee.

C

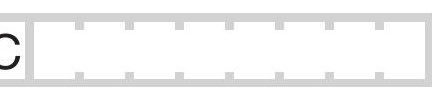

Name of Employer
Path Group
Receipt For: 2012
X Primary $\quad \square$ General
Other (specify)

Occupation Pathologist

Election Cycle-to-Date
Amount of Each Receipt this Period

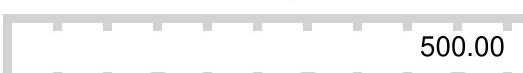

Subtotal Of Receipts This Page (optional).

Total This Period (last page this line number only)

Transaction ID : AA1898638B639488CBD7 Date of Receipt

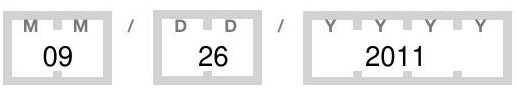




\section{SCHEDULE A-P} ITEMIZED RECEIPTS
Use separate schedule(s)

for each category of the

Detailed Summary Page
FOR LINE NUMBER: (check only one)

PAGE $789 / 1572$

\begin{tabular}{|c|c|c|c|c|c|}
\hline & & & & & \\
\hline 16 & X $17 a$ & $17 b$ & $17 c$ & $17 d$ & 18 \\
\hline $19 a$ & $19 b$ & $20 \mathrm{a}$ & $20 \mathrm{~b}$ & $20 \mathrm{c}$ & 21 \\
\hline
\end{tabular}

Any information copied from such Reports and Statements may not be sold or used by any person for the purpose of soliciting contributions or for commercial purposes, other than using the name and address of any political committee to solicit contributions from such committee.

NAME OF COMMITTEE (In Full)

Friends of Herman Cain

A. Full Name (Last, First, Middle Initial)

Robert Dodd

Mailing Address 120 Siege LANE

\begin{tabular}{lcc}
\hline City & State & Zip Code \\
Yorktown & VA & $23692-4055$
\end{tabular}

FEC ID number of contributing

federal political committee.

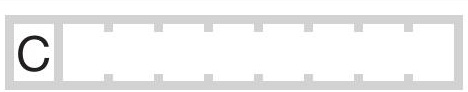

Name of Employer
Information Requested
Receipt For: 2012
X Primary $\quad \square$ General
Other (specify)

Occupation

Information Requested

Election Cycle-to-Date

250.00

B. Full Name (Last, First, Middle Initial)

Tim geiken

Mailing Address 9315 nesbit lakes dr

\begin{tabular}{lcc}
\hline City & State & Zip Code \\
Alpharetta & GA & $30022-4022$ \\
\hline
\end{tabular}

FEC ID number of contributing

federal political committee.

C

\begin{tabular}{l} 
Name of Employer \\
Information Requested \\
Receipt For: 2012 \\
X Primary \\
\hline Other (specify)
\end{tabular}

Occupation

Information Requested

Election Cycle-to-Date

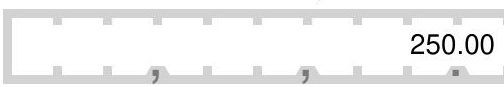

Transaction ID : A24A7C854E0C84B2193E

Date of Receipt

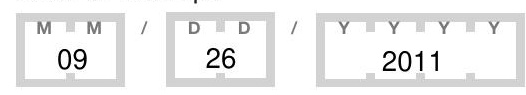

Amount of Each Receipt this Period

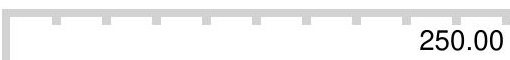

Amount of Each Receipt this Period

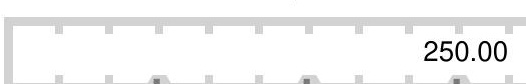

C. Full Name (Last, First, Middle Initial)

MaryAnne Sakson

Mailing Address 9330 Triana Ter Apt 4

\begin{tabular}{lcc}
\hline City & State & Zip Code \\
Fort Myers & FL & $33912-0929$
\end{tabular}

FEC ID number of contributing

federal political committee.

C

33912-0929

Name of Employer
Information Requested
Receipt For: 2012
Primary
Other (specify) General

Occupation

Information Requested

Election Cycle-to-Date

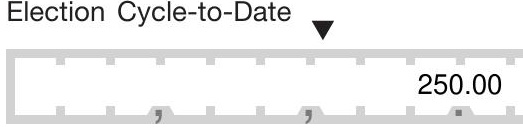

Transaction ID : A746FF5929B8E4DD98C9

Date of Receipt

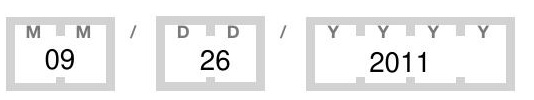

Transaction ID : A24C9C195A25049EEA5E Date of Receipt

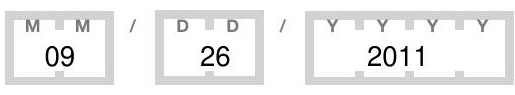

Amount of Each Receipt this Period

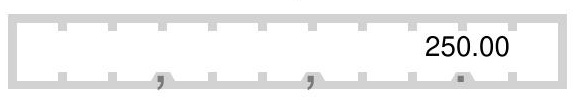

Subtotal Of Receipts This Page (optional).

750.00

Total This Period (last page this line number only) 


\section{SCHEDULE A-P} ITEMIZED RECEIPTS
Use separate schedule(s) for each category of the Detailed Summary Page

\begin{tabular}{|c|c|c|c|c|c|}
\hline \multicolumn{3}{|c|}{$\begin{array}{l}\text { FOR LINE NUMBER: } \\
\text { (check only one) }\end{array}$} & \multicolumn{3}{|c|}{ PAGE 790 / 1572} \\
\hline 16 & $X$ 17a & $17 b$ & 17c & $17 d$ & 18 \\
\hline $19 a$ & $19 \mathrm{~b}$ & $20 a$ & $20 \mathrm{~b}$ & $20 c$ & 21 \\
\hline
\end{tabular}

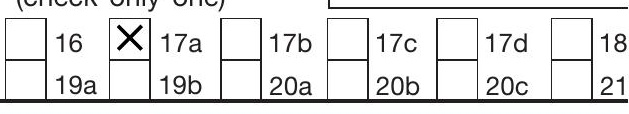

Any information copied from such Reports and Statements may not be sold or used by any person for the purpose of soliciting contributions or for commercial purposes, other than using the name and address of any political committee to solicit contributions from such committee.

NAME OF COMMITTEE (In Full)

\section{Friends of Herman Cain}

A. Full Name (Last, First, Middle Initial) James McClure

Mailing Address 2100 W Petty Rd

\begin{tabular}{lcc}
\hline City & State & Zip Code \\
Muncie & IN & $47304-3034$
\end{tabular}

FEC ID number of contributing federal political committee.

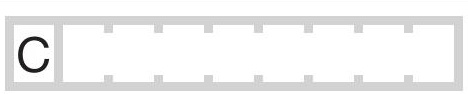

Name of Employer
Ball State University
Receipt For: 2012
X Primary $\quad \square$ General
Other (specify)

Occupation Economist Election Cycle-to-Date

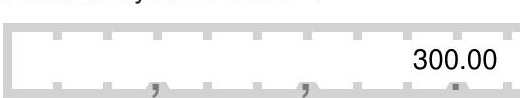

B. Full Name (Last, First, Middle Initial) Lowell Atchley

Mailing Address 20439 Sugarloaf Mountain Rd.

\begin{tabular}{lcc}
\hline City & State & Zip Code \\
Clermont & FL & $34715-9013$
\end{tabular}

FEC ID number of contributing

federal political committee.

C

Name of Employer
Lockheed Martin
Receipt For: 2012
Primary
Other (specify)

Occupation

Retired

Election Cycle-to-Date

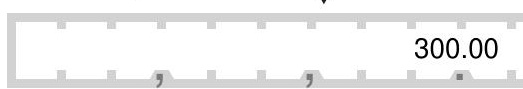

Transaction ID : A3813C3950D7D4D75AF9

Date of Receipt

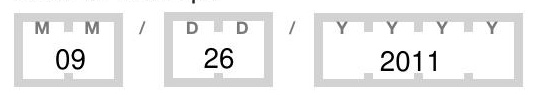

Amount of Each Receipt this Period

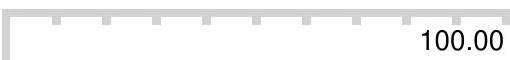

Amount of Each Receipt this Period

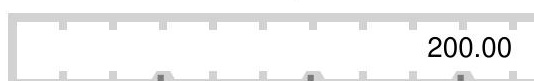

C. Full Name (Last, First, Middle Initial)

Sharon Brandt

Mailing Address PO Box 548

\begin{tabular}{lcc}
\hline City & State & Zip Code \\
Alva & OK & $73717-0548$
\end{tabular}

FEC ID number of contributing federal political committee.

C

Name of Employer
Information Requested
Receipt For: 2012
X Primary $\quad \square$ General
Other (specify)

Occupation

Information Requested

Election Cycle-to-Date
Transaction ID : A18CF8D8223F44C1AA80

Date of Receipt

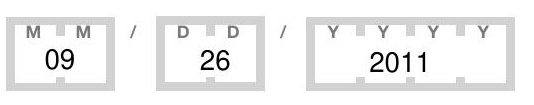

Transaction ID : A33DCB3A419EE4AE1877 Date of Receipt

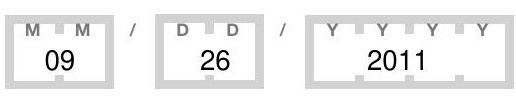

Amount of Each Receipt this Period

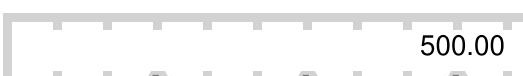

500.00
Subtotal Of Receipts This Page (optional).

800.00

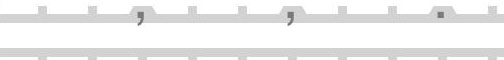

Total This Period (last page this line number only) 


\section{SCHEDULE A-P} ITEMIZED RECEIPTS
Use separate schedule(s)

for each category of the

Detailed Summary Page
FOR LINE NUMBER: (check only one)

PAGE $791 / 1572$

\begin{tabular}{|c|c|c|c|c|c|}
\hline & & & & & \\
\hline 16 & X $17 a$ & $17 b$ & $17 c$ & $17 d$ & 18 \\
\hline $19 a$ & $19 b$ & $20 \mathrm{a}$ & $20 \mathrm{~b}$ & $20 \mathrm{c}$ & 21 \\
\hline
\end{tabular}

Any information copied from such Reports and Statements may not be sold or used by any person for the purpose of soliciting contributions or for commercial purposes, other than using the name and address of any political committee to solicit contributions from such committee.

NAME OF COMMITTEE (In Full)

\section{Friends of Herman Cain}

A. Full Name (Last, First, Middle Initial)

Rich Welsh

Mailing Address 23206 Sandsage Lane

\begin{tabular}{lcc}
\hline City & State & Zip Code \\
Katy & TX & $77494-4207$ \\
\hline
\end{tabular}

FEC ID number of contributing

federal political committee.

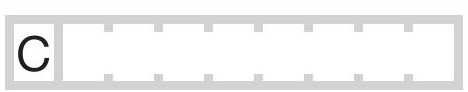

Name of Employer
Information Requested
Receipt For: 2012
X Primary $\quad \square$ General
Other (specify)

Occupation

Information Requested

Election Cycle-to-Date

250.00

B. Full Name (Last, First, Middle Initial)

Michael Neill

Mailing Address 1511 Campbell Road

\begin{tabular}{lcc}
\hline City & State & Zip Code \\
Waxahachie & TX & $75167-8032$ \\
\hline
\end{tabular}

FEC ID number of contributing

federal political committee.

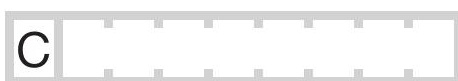

Name of Employer
Neill Enterprises, Inc.
Receipt For: 2012
X Primary
Other (specify)

Occupation

President \& CEO

Election Cycle-to-Date

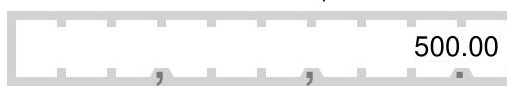

C. Full Name (Last, First, Middle Initial)

Kay Connelly

Mailing Address 10 Dartmouth Avenue

\begin{tabular}{lcc}
\hline City & State & Zip Code \\
Avondale Estates & GA & $30002-1410$
\end{tabular}

FEC ID number of contributing

federal political committee.

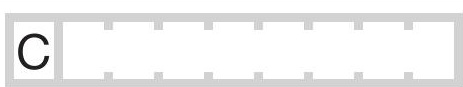

Name of Employer

Information Requested

Occupation

Information Requested

Receipt For: 2012

Х $\begin{aligned} & \text { Primary } \square \text { General } \\ & \text { Other (specify) }\end{aligned}$

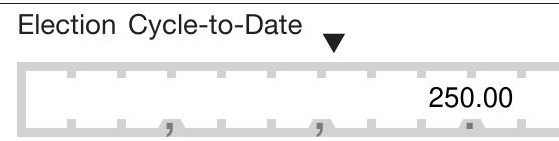

Transaction ID : ADEC9B7B252E94F71896

Date of Receipt

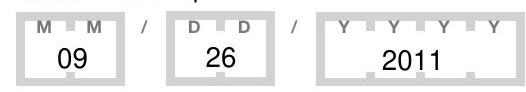

Amount of Each Receipt this Period

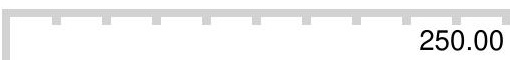

250.00

Transaction ID : A8D56478922E2485B8F1

Date of Receipt

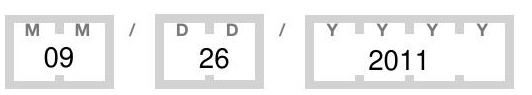

Amount of Each Receipt this Period

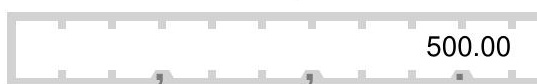

Transaction ID : AB237093C93544BA289A

Date of Receipt

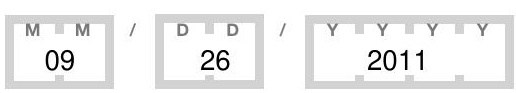

Amount of Each Receipt this Period

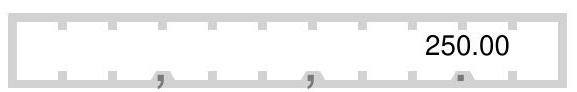

1000.00

Subtotal Of Receipts This Page (optional)

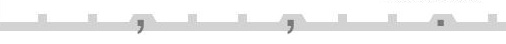

Total This Period (last page this line number only) 


\section{SCHEDULE A-P} ITEMIZED RECEIPTS
Use separate schedule(s)

for each category of the

Detailed Summary Page
FOR LINE NUMBER: (check only one)

PAGE 792 / 1572

\begin{tabular}{|c|c|c|c|c|c|}
\hline & & & & & \\
\hline 16 & X $17 a$ & $17 b$ & $17 c$ & $17 d$ & 18 \\
\hline $19 a$ & $19 b$ & $20 \mathrm{a}$ & $20 \mathrm{~b}$ & $20 \mathrm{c}$ & 21 \\
\hline
\end{tabular}

Any information copied from such Reports and Statements may not be sold or used by any person for the purpose of soliciting contributions or for commercial purposes, other than using the name and address of any political committee to solicit contributions from such committee.

NAME OF COMMITTEE (In Full)

Friends of Herman Cain

A. Full Name (Last, First, Middle Initial)

LISA GALLAGHER

Mailing Address 4 PERKINS WAY

\begin{tabular}{lcc}
\hline City & State & Zip Code \\
Newburyport & MA & $01950-4016$ \\
\hline
\end{tabular}

FEC ID number of contributing

federal political committee.

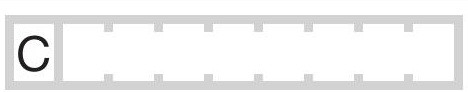

Name of Employer
Hawtan Leathers, LLC
Receipt For: 2012
X Primary $\quad \square$ General
Other (specify)

Occupation

Leather Sales

Election Cycle-to-Date

250.00

B. Full Name (Last, First, Middle Initial)

Jason Capozzoli

Mailing Address 638 East College Avenue

\begin{tabular}{lcc}
\hline City & State & Zip Code \\
Tallahassee & FL & $32301-2511$
\end{tabular}

FEC ID number of contributing

federal political committee.

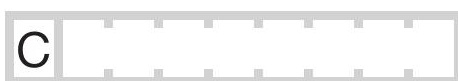

Name of Employer
Information Requested
Receipt For: 2012
X Primary
Other (specify)

Occupation

Information Requested

Election Cycle-to-Date

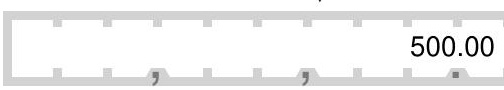

Transaction ID : ADD81F4F5A56942EE96E

Date of Receipt

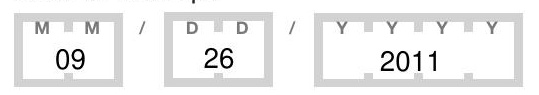

Amount of Each Receipt this Period

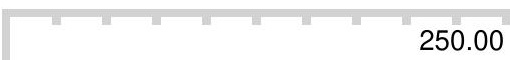

Transaction ID : A51F75AF6CC8540B9AC8

Date of Receipt

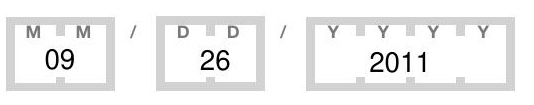

Amount of Each Receipt this Period

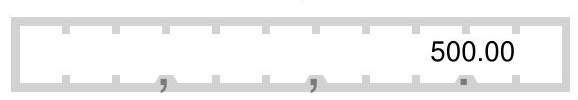

Transaction ID : AC763D80519A44F2BABC Date of Receipt

\section{DH Johnston}

Mailing Address 1803 Brookhaven Drive

\begin{tabular}{lcc}
\hline City & State & Zip Code \\
Austin & TX & $78704-2748$
\end{tabular}

FEC ID number of contributing federal political committee.

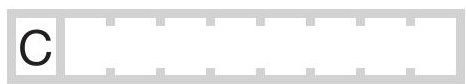

$\begin{aligned} & \text { Name of Employer } \\ & \text { self }\end{aligned}$
Receipt For: 2012
X Primary $\square$ General
Other (specify)

\section{Occupation}

Attorney

Election Cycle-to-Date

1200.00

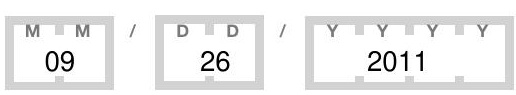

Amount of Each Receipt this Period

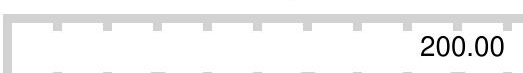

Subtotal Of Receipts This Page (optional).

950.00

a

Total This Period (last page this line number only)

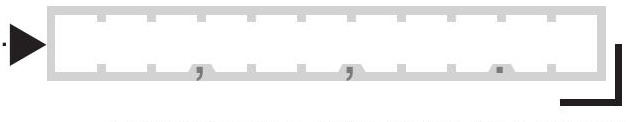

FEC Schedule A-P (Form 3P) (Rev. 03/2011) 
SCHEDULE A-P ITEMIZED RECEIPTS
Use separate schedule(s) for each category of the Detailed Summary Page
FOR LINE NUMBER: (check only one)
PAGE $793 / 1572$

\begin{tabular}{|c|c|c|c|c|c|}
\hline & & & & & \\
\hline 16 & $\begin{array}{lll}X & 17 a \\
\end{array}$ & $17 \mathrm{~b}$ & $17 c$ & $17 d$ & 18 \\
\hline $19 a$ & $19 b$ & $20 a$ & $20 \mathrm{~b}$ & $20 c$ & 21 \\
\hline
\end{tabular}

Any information copied from such Reports and Statements may not be sold or used by any person for the purpose of soliciting contributions or for commercial purposes, other than using the name and address of any political committee to solicit contributions from such committee.

NAME OF COMMITTEE (In Full)

\section{Friends of Herman Cain}

A. Full Name (Last, First, Middle Initial)

Sara Winter

Mailing Address 30931 N. 152nd Street

\begin{tabular}{lcc}
\hline City & State & Zip Code \\
Scottsdale & AZ & $85262-7911$
\end{tabular}

FEC ID number of contributing

federal political committee.

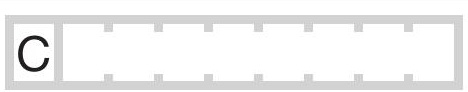

Name of Employer
Information Requested
Receipt For: 2012
X Primary
Other (specify) General

Occupation

Information Requested

Election Cycle-to-Date

250.00

B. Full Name (Last, First, Middle Initial)

Paul Henninger

Mailing Address 85 Harvest Dr

\begin{tabular}{lcc}
\hline City & State & Zip Code \\
Gettysburg & PA & $17325-7761$ \\
\hline
\end{tabular}

FEC ID number of contributing

federal political committee.

C

Name of Employer
Information Requested
Receipt For: 2012
X Primary
Other (specify)

Occupation

Information Requested

Election Cycle-to-Date

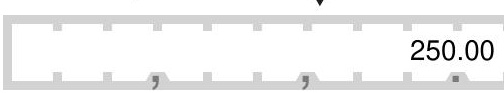

Transaction ID : A5590EB26A0FD4C15A38

Date of Receipt

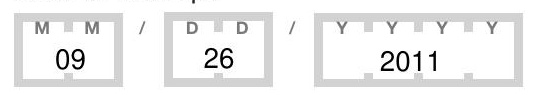

Amount of Each Receipt this Period

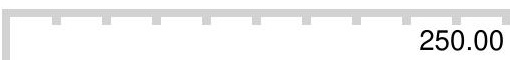

C. Full Name (Last, First, Middle Initial)

Arlo DeKraai

Mailing Address 6224 S. Oswego Ave

\begin{tabular}{lcc}
\hline City & State & Zip Code \\
Tulsa & OK & $74136-1531$
\end{tabular}

FEC ID number of contributing federal political committee.

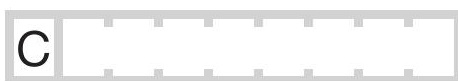

Name of Employer

Information Requested

Occupation

Information Requested

Receipt For: 2012

Х $\begin{aligned} & \text { Primary } \\ & \text { Other (specify) }\end{aligned}$

Amount of Each Receipt this Period

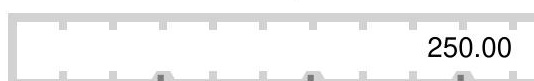

Transaction ID : A29EAB66F9ACF4AFBB78 Date of Receipt

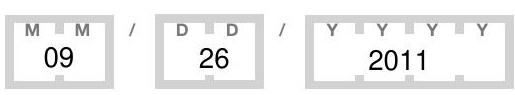

Transaction ID : A4F97F1969EF44A84ABC Date of Receipt

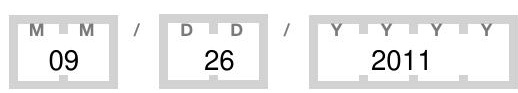

Amount of Each Receipt this Period

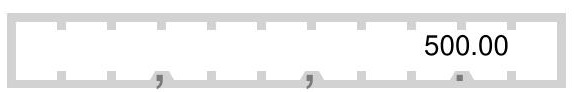

500.00

\section{Subtotal Of Receipts This Page (optional)}

Total This Period (last page this line number only) 


\section{SCHEDULE A-P} ITEMIZED RECEIPTS
Use separate schedule(s)

for each category of the

Detailed Summary Page
FOR LINE NUMBER: (check only one)

PAGE 794 / 1572

\begin{tabular}{|c|c|c|c|c|c|}
\hline & & & & & \\
\hline 16 & X $17 a$ & $17 b$ & $17 c$ & $17 d$ & 18 \\
\hline $19 a$ & $19 b$ & $20 \mathrm{a}$ & $20 \mathrm{~b}$ & $20 \mathrm{c}$ & 21 \\
\hline
\end{tabular}

Any information copied from such Reports and Statements may not be sold or used by any person for the purpose of soliciting contributions or for commercial purposes, other than using the name and address of any political committee to solicit contributions from such committee.

NAME OF COMMITTEE (In Full)

Friends of Herman Cain

A. Full Name (Last, First, Middle Initial)

Randy Lamartiniere

Mailing Address 723 Place Saint Etienne

\begin{tabular}{lcc}
\hline City & State & Zip Code \\
Covington & LA & $70433-8141$ \\
\hline
\end{tabular}

FEC ID number of contributing federal political committee.

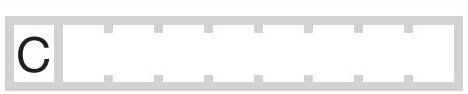

Name of Employer
Ochsner Clinic
Receipt For: 2012
X Primary
$\square$ Other (specify) General

Occupation

Physician

Election Cycle-to-Date

400.00

B. Full Name (Last, First, Middle Initial)

John Picone

Mailing Address 14550 Meravi Drive

\begin{tabular}{lcc}
\hline City & State & Zip Code \\
Bonita Springs & FL & $34135-8375$
\end{tabular}

FEC ID number of contributing

federal political committee.

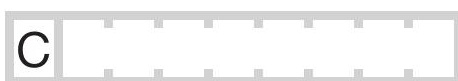

Name of Employer
self
Receipt For: 2012
X Primary
Other (specify)

\section{Occupation}

Financial Advisor

Election Cycle-to-Date

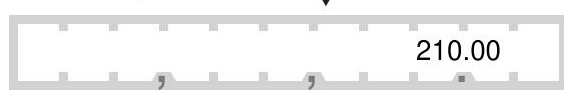

C. Full Name (Last, First, Middle Initial)

william price

Mailing Address $901 \mathrm{~s}$. bond st.

\begin{tabular}{lcc}
\hline City & State & Zip Code \\
Bonita Springs & FL & 34134 \\
\hline
\end{tabular}

FEC ID number of contributing

federal political committee.

C

Name of Employer
Information Requested
Receipt For: 2012
Primary
Other (specify) General

Transaction ID : AAA2B53BE5CA342049C7

Date of Receipt

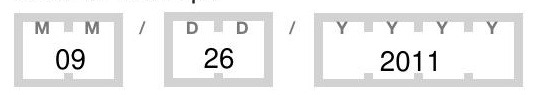

Amount of Each Receipt this Period

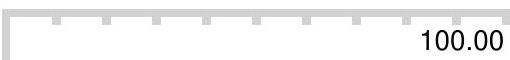

100.00

Transaction ID : AFA73CC54949F40B2A06

Date of Receipt

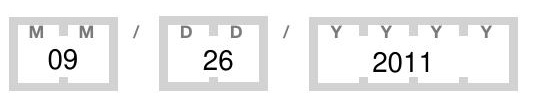

Amount of Each Receipt this Period

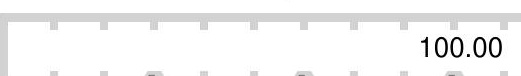

Transaction ID : A3314EA6F54B540A1A12 Date of Receipt

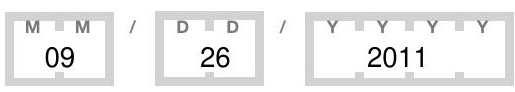

Amount of Each Receipt this Period

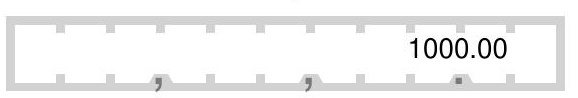
Occupation
Information Requested
Election Cycle-to-Date
1000.00

Subtotal Of Receipts This Page (optional)

1200.00

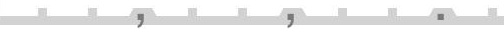

Total This Period (last page this line number only)

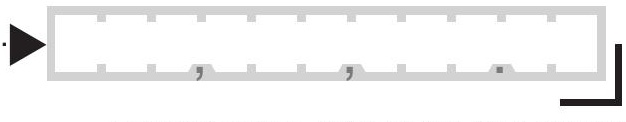

FEC Schedule A-P (Form 3P) (Rev. 03/2011) 


\section{SCHEDULE A-P} ITEMIZED RECEIPTS
Use separate schedule(s)

for each category of the

Detailed Summary Page
FOR LINE NUMBER: (check only one)

PAGE $795 / 1572$

\begin{tabular}{|c|c|c|c|c|c|}
\hline & & & & & \\
\hline 16 & X $17 a$ & $17 b$ & $17 c$ & $17 d$ & 18 \\
\hline $19 a$ & $19 b$ & $20 \mathrm{a}$ & $20 \mathrm{~b}$ & $20 \mathrm{c}$ & 21 \\
\hline
\end{tabular}

Any information copied from such Reports and Statements may not be sold or used by any person for the purpose of soliciting contributions or for commercial purposes, other than using the name and address of any political committee to solicit contributions from such committee.

NAME OF COMMITTEE (In Full)

Friends of Herman Cain

A. Full Name (Last, First, Middle Initial)

James Vincent

Mailing Address 670 N. 57th Ave

\begin{tabular}{lcc}
\hline City & State & Zip Code \\
Omaha & NE & $68132-2038$
\end{tabular}

FEC ID number of contributing federal political committee.

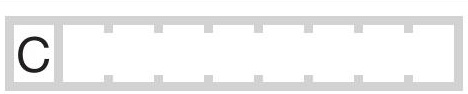

Name of Employer
Information Requested
Receipt For: 2012
X Primary
$\square$ Other (specify)

Occupation

Information Requested

Election Cycle-to-Date

500.00

B. Full Name (Last, First, Middle Initial)

James Dooley

Mailing Address 17 Redfern Ct

\begin{tabular}{lcc}
\hline City & State & Zip Code \\
Lincroft & NJ & $07738-1830$
\end{tabular}

FEC ID number of contributing

federal political committee.

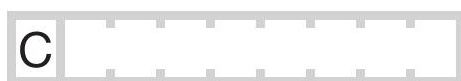

Name of Employer

Stone Harbor Investment Partners

Occupation

Receipt For: 2012

Х Primary $\square$ General

Manager

Election Cycle-to-Date

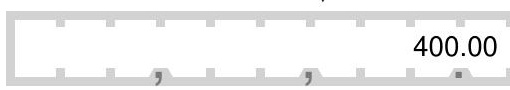

C. Full Name (Last, First, Middle Initial)

Walter Scott

Mailing Address 741 Wilderness Way

\begin{tabular}{lcc}
\hline City & State & Zip Code \\
Ellijay & GA & $30536-7403$
\end{tabular}

FEC ID number of contributing

federal political committee.

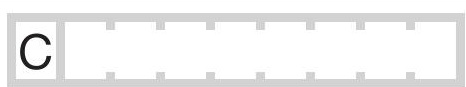

Name of Employer

Information Requested

Occupation

Information Requested

Receipt For: 2012

Х $\begin{aligned} & \text { Primary } \\ & \text { Other (specify) }\end{aligned}$

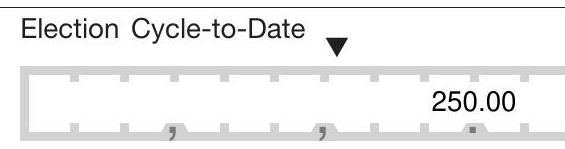

Transaction ID : A1B4CAF3C0EAC44B69D6

Date of Receipt

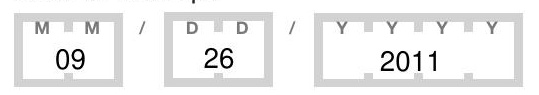

Amount of Each Receipt this Period

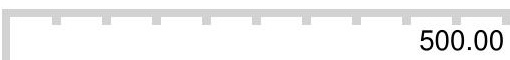

500.00

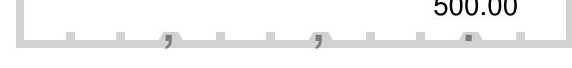

Transaction ID : A0DF013A9239C415EB67

Date of Receipt

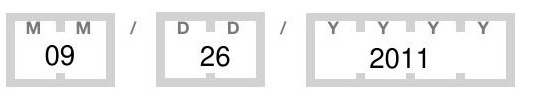

Amount of Each Receipt this Period

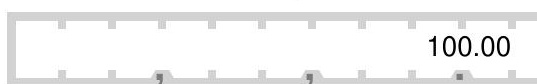

Transaction ID : A63A5FA6774684167B45

Date of Receipt

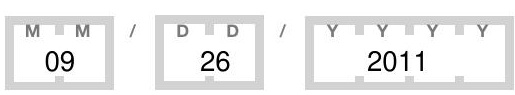

Amount of Each Receipt this Period

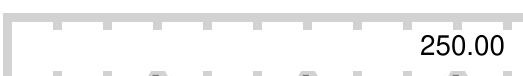

250.00

Subtotal Of Receipts This Page (optional)

850.00

Total This Period (last page this line number only) 


\section{SCHEDULE A-P} ITEMIZED RECEIPTS
Use separate schedule(s) for each category of the Detailed Summary Page

FOR LINE NUMBER:
(check only one)

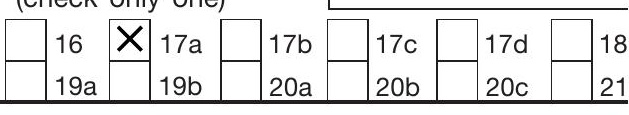

Any information copied from such Reports and Statements may not be sold or used by any person for the purpose of soliciting contributions or for commercial purposes, other than using the name and address of any political committee to solicit contributions from such committee.

NAME OF COMMITTEE (In Full)

\section{Friends of Herman Cain}

A. Full Name (Last, First, Middle Initial) Thomas Tracy

Mailing Address 1347 Caroline Circle

\begin{tabular}{lcc}
\hline City & State & Zip Code \\
Franklin & TN & $37064-6740$
\end{tabular}

FEC ID number of contributing federal political committee.

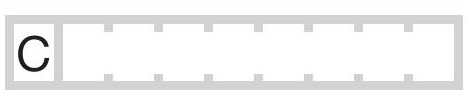

Name of Employer
Information Requested
Receipt For: 2012
X Primary
$\square$ Other (specify)

Occupation Information Requested Election Cycle-to-Date

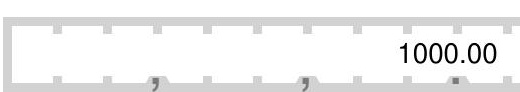

B. Full Name (Last, First, Middle Initial) John Rivard

Mailing Address 14910 Flowerwood Dr

\begin{tabular}{lcc}
\hline City & State & Zip Code \\
Houston & TX & $77062-2816$ \\
\hline
\end{tabular}

FEC ID number of contributing

federal political committee.

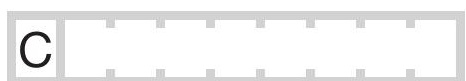

\begin{tabular}{l} 
Name of Employer \\
$\mathrm{n} / \mathrm{a}$ \\
\hline Receipt For: 2012 \\
X Primary \\
Other (specify)
\end{tabular}

\section{Occupation}

$\mathrm{N} / \mathrm{A}$

Election Cycle-to-Date

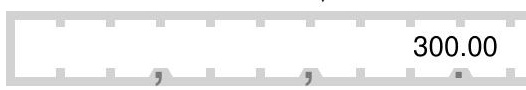

C. Full Name (Last, First, Middle Initial)

Linda Reutzel

Mailing Address 3011 Minutemen Way

\begin{tabular}{lcc}
\hline City & State & Zip Code \\
Cape Girardeau & MO & $63701-2685$
\end{tabular}

FEC ID number of contributing federal political committee.

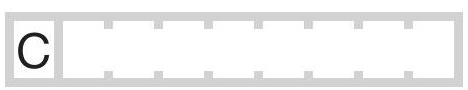

Name of Employer

FGR Mechanical Inc.

Receipt For: 2012

Х $\begin{aligned} & \text { Primary } \square \text { General } \\ & \text { Other (specify) }\end{aligned}$
Occupation

Accountant

Election Cycle-to-Date
Transaction ID : A28415AFF4E2742AD9C3

Date of Receipt

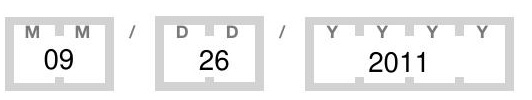

Amount of Each Receipt this Period

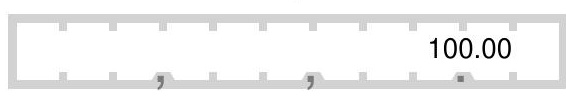

Transaction ID : A528ED73873814B5C934

Date of Receipt

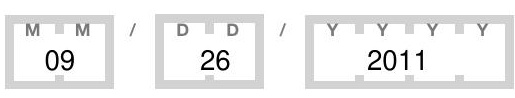

Amount of Each Receipt this Period

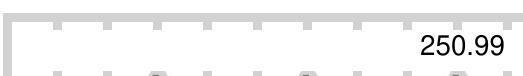

250.99
Date of Receipt

Amount of Each Receipt this Period

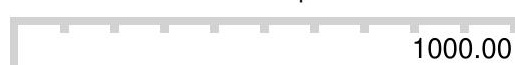

Subtotal Of Receipts This Page (optional).

Total This Period (last page this line number only) 


\section{SCHEDULE A-P} ITEMIZED RECEIPTS
Use separate schedule(s) for each category of the Detailed Summary Page

FOR LINE NUMBER:
(check only one)

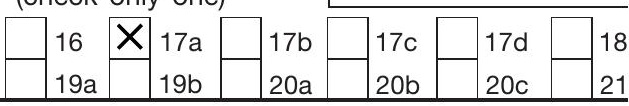

Any information copied from such Reports and Statements may not be sold or used by any person for the purpose of soliciting contributions or for commercial purposes, other than using the name and address of any political committee to solicit contributions from such committee.

NAME OF COMMITTEE (In Full)

\section{Friends of Herman Cain}

A. Full Name (Last, First, Middle Initial) James Spradlin

Mailing Address 2180 Lower Kemp Dr

\begin{tabular}{lcc}
\hline City & State & Zip Code \\
Cumming & GA & $30041-5392$
\end{tabular}

FEC ID number of contributing federal political committee.

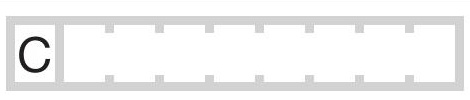

Name of Employer
Northside Hospital
Receipt For: 2012
X Primary
$\square$ Other (specify) General

Occupation Physician

Election Cycle-to-Date 300.00

B. Full Name (Last, First, Middle Initial) Ms Wanda Gragg

Mailing Address 13651 High Chapel

\begin{tabular}{lcc}
\hline City & State & Zip Code \\
San Antonio & TX & $78231-1960$ \\
\hline
\end{tabular}

FEC ID number of contributing

federal political committee.

C

\begin{tabular}{l} 
Name of Employer \\
Gragg \& Associates \\
Receipt For: 2012 \\
X Primary \\
\hline Other (specify) General
\end{tabular}

Occupation

Real Estate

Election Cycle-to-Date

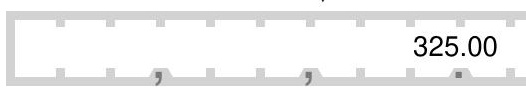

Transaction ID : A04D37295D52944D88A1

Date of Receipt

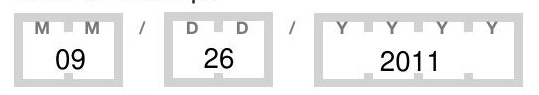

Amount of Each Receipt this Period

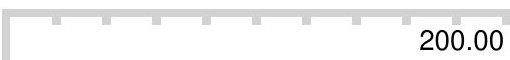

Amount of Each Receipt this Period

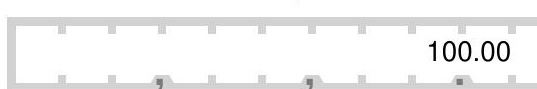

C. Full Name (Last, First, Middle Initial)

Paola Dell'Osso

Transaction ID : A66D4F64A4BBF4F57AC5 Date of Receipt

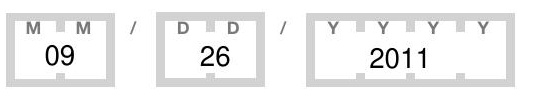

Mailing Address 29 South State Street \#412

\begin{tabular}{lcc}
\hline City & State & Zip Code \\
Salt Lake City & UT & $84111-1512$ \\
\hline
\end{tabular}

FEC ID number of contributing federal political committee.

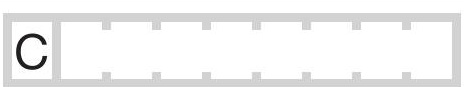

Name of Employer

Information Requested

\section{Occupation}

Information Requested

Receipt For: 2012

Х $\begin{aligned} & \text { Primary } \\ & \text { Other (specify) }\end{aligned}$
Transaction ID : A5C0F1CF7857F494FAE4 Date of Receipt

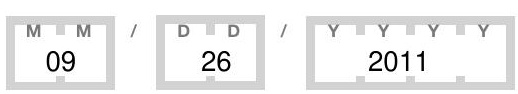

Amount of Each Receipt this Period

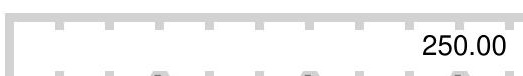

\section{Subtotal Of Receipts This Page (optional)}

Total This Period (last page this line number only) 


\section{SCHEDULE A-P} ITEMIZED RECEIPTS
Use separate schedule(s) for each category of the Detailed Summary Page

FOR LINE NUMBER:
(check only one)

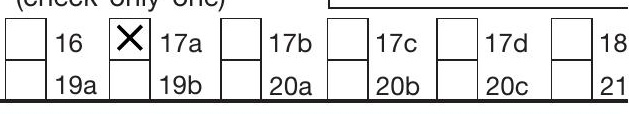

Any information copied from such Reports and Statements may not be sold or used by any person for the purpose of soliciting contributions or for commercial purposes, other than using the name and address of any political committee to solicit contributions from such committee.

NAME OF COMMITTEE (In Full)

\section{Friends of Herman Cain}

A. Full Name (Last, First, Middle Initial) kelye stites

Mailing Address 4501 bowman dr

\begin{tabular}{lcc}
\hline City & State & Zip Code \\
Colleyville & TX & $76034-4326$ \\
\hline
\end{tabular}

FEC ID number of contributing federal political committee.

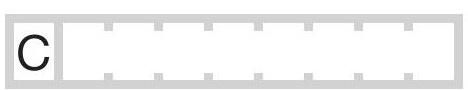

Name of Employer
Information Requested
Receipt For: 2012
X Primary
$\square$ Other (specify)

Occupation Information Requested

Election Cycle-to-Date

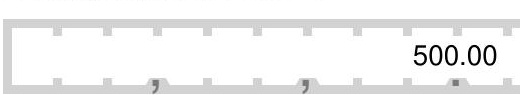

B. Full Name (Last, First, Middle Initial)

Thomas Scrutchin

Mailing Address 30805 Man O War

\begin{tabular}{lcc}
\hline City & State & Zip Code \\
Boerne & TX & $78015-4293$
\end{tabular}

FEC ID number of contributing

federal political committee.

C

Name of Employer
Information Requested
Receipt For: 2012
Primary
Other (specify)

\section{Occupation}

Information Requested

Election Cycle-to-Date

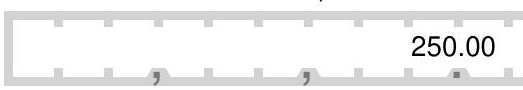

Transaction ID : A836E0C1C49C44A97A1C

Date of Receipt

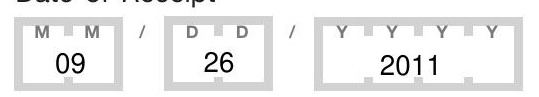

Amount of Each Receipt this Period

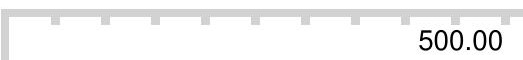

Amount of Each Receipt this Period

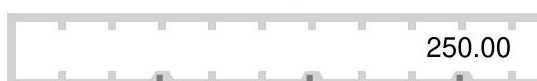

C. Full Name (Last, First, Middle Initial)

Lynn Zody

Mailing Address 708 Callaway $\mathrm{Dr}$

\begin{tabular}{lcc}
\hline City & State & Zip Code \\
Graniteville & SC & $29829-4054$
\end{tabular}

FEC ID number of contributing federal political committee.

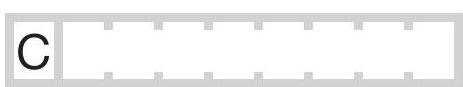

Name of Employer

Stix \& Co. Inc.

Occupation

FOOD SERVICE

Receipt For: 2012

Х $\begin{aligned} & \text { Primary } \square \text { General } \\ & \text { Other (specify) }\end{aligned}$

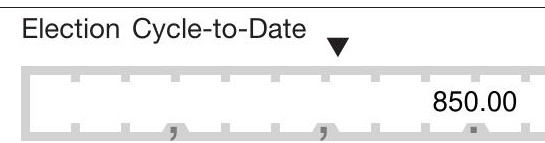

Amount of Each Receipt this Period

Transaction ID : A1BEFA88ABFC3451380B Date of Receipt
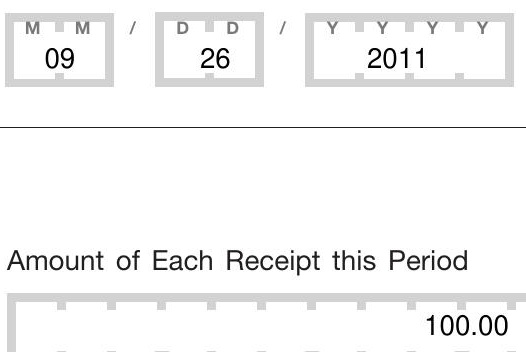

850.00

Subtotal Of Receipts This Page (optional)

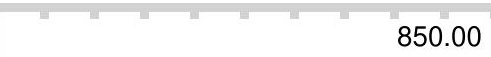

Total This Period (last page this line number only) 


\section{SCHEDULE A-P} ITEMIZED RECEIPTS
Use separate schedule(s)

for each category of the

Detailed Summary Page
FOR LINE NUMBER: (check only one)

PAGE $799 / 1572$

\begin{tabular}{|c|c|c|c|c|c|}
\hline & & & & & \\
\hline 16 & X $17 a$ & $17 b$ & $17 c$ & $17 d$ & 18 \\
\hline $19 a$ & $19 b$ & $20 \mathrm{a}$ & $20 \mathrm{~b}$ & $20 \mathrm{c}$ & 21 \\
\hline
\end{tabular}

Any information copied from such Reports and Statements may not be sold or used by any person for the purpose of soliciting contributions or for commercial purposes, other than using the name and address of any political committee to solicit contributions from such committee.

NAME OF COMMITTEE (In Full)

Friends of Herman Cain

A. Full Name (Last, First, Middle Initial)

Diane Speedling

Mailing Address 2927 Sand Pine Rd

\begin{tabular}{lcc}
\hline City & State & Zip Code \\
Miramar Beach & FL & $32550-7835$
\end{tabular}

FEC ID number of contributing

federal political committee.

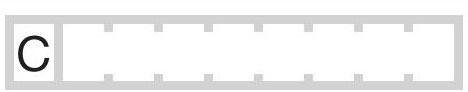

Name of Employer
Self Employed
Receipt For: 2012
X Primary
$\square$ Other (specify) General

Occupation

Anesthesiologist

Election Cycle-to-Date

290.00

B. Full Name (Last, First, Middle Initial)

CAROLYN BRAUN

Mailing Address 46 W 14 RD

\begin{tabular}{lcc}
\hline City & State & Zip Code \\
Broad Channel & NY & $11693-1139$
\end{tabular}

FEC ID number of contributing

federal political committee.

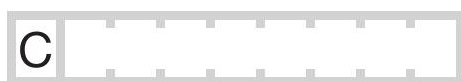

Name of Employer
self
Receipt For: 2012
X Primary
Other (specify)

\section{Occupation}

COPYWRITER

Election Cycle-to-Date

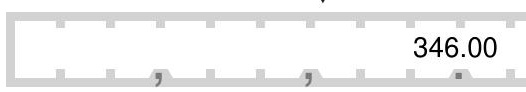

C. Full Name (Last, First, Middle Initial)

Michael Lewis

Mailing Address 4905 Simon Dr. NW

\begin{tabular}{lcc}
\hline City & State & Zip Code \\
Albuquerque & NM & $87114-4328$
\end{tabular}

FEC ID number of contributing federal political committee.

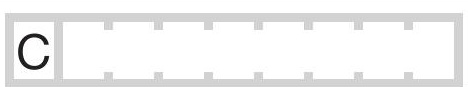

Name of Employer
Information Requested
Receipt For: 2012
X Primary
Other (specify) General

\section{Occupation}

Information Requested

Election Cycle-to-Date

Transaction ID : A406AB738DDFC46E3AFA Date of Receipt

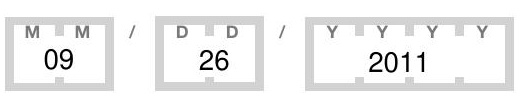

Amount of Each Receipt this Period

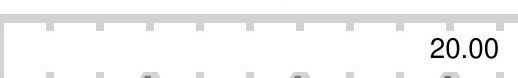

Transaction ID : A8575F4B1E4E7457D9AE Date of Receipt

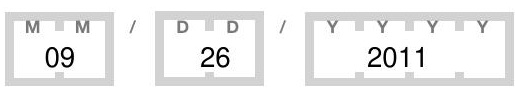

Amount of Each Receipt this Period

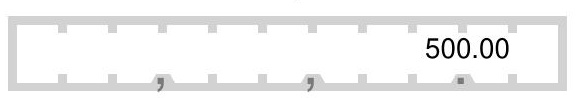

500.00

\section{Subtotal Of Receipts This Page (optional)}

570.00

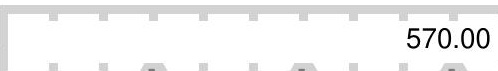

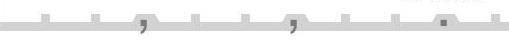

Total This Period (last page this line number only)
Transaction ID : AF25B6075A24C4F838F0

Date of Receipt

Amount of Each Receipt this Period

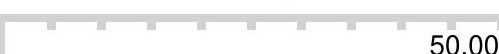

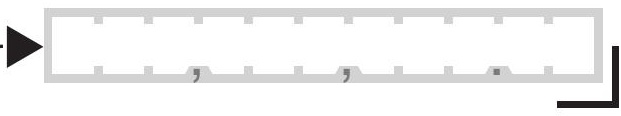




\section{SCHEDULE A-P} ITEMIZED RECEIPTS
Use separate schedule(s)

for each category of the

Detailed Summary Page
FOR LINE NUMBER: (check only one)

Any information or for commercial purposes, other than using the name and address of any political committee to solicit contributions from such committee.

NAME OF COMMITTEE (In Full)

Friends of Herman Cain

A. Full Name (Last, First, Middle Initial)

Roberto Eaton

Mailing Address 12640 W 66th Place

\begin{tabular}{lcc}
\hline City & State & Zip Code \\
Arvada & CO & $80004-2213$ \\
\hline
\end{tabular}

FEC ID number of contributing

federal political committee.

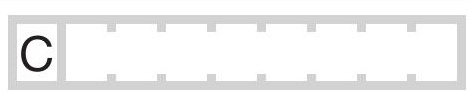

Name of Employer
Maintenance Manager
Receipt For: 2012
X Primary $\square$ General
$\square$ Other (specify)

Occupation

Manager

Election Cycle-to-Date

275.00

B. Full Name (Last, First, Middle Initial)

Richard Powers

Mailing Address 2261 Selwyn Ave.

\begin{tabular}{lcc}
\hline City & State & Zip Code \\
Charlotte & NC & $28207-2797$
\end{tabular}

FEC ID number of contributing

federal political committee.

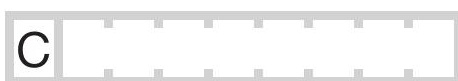

Name of Employer
Filtration Group
Receipt For: 2012
X Primary
Other (specify)

Occupation

Supersivor

Election Cycle-to-Date

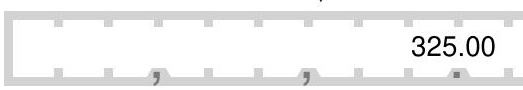

C. Full Name (Last, First, Middle Initial)

Charles Schoen

Mailing Address 6190 Mountain Brook Way NW

\begin{tabular}{lcc}
\hline City & State & Zip Code \\
Atlanta & GA & $30328-3608$ \\
\hline
\end{tabular}

FEC ID number of contributing

federal political committee.

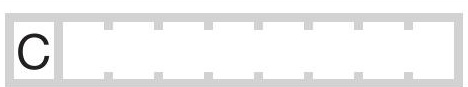

Name of Employer

Adaptive Learning Center

Receipt For: 2012

Х $\begin{aligned} & \text { Primary } \\ & \text { Other (specify) }\end{aligned}$

Occupation

Executive Director

Election Cycle-to-Date
Transaction ID : A79045B685A104EAF828

Date of Receipt

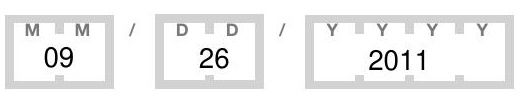

Amount of Each Receipt this Period

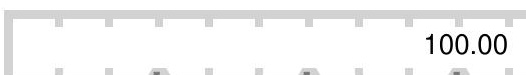

Transaction ID : A4924606814494883983

Date of Receipt

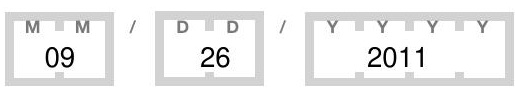

Amount of Each Receipt this Period

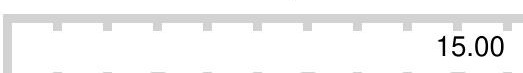

\section{Subtotal Of Receipts This Page (optional)}

Total This Period (last page this line number only) 


\section{SCHEDULE A-P} ITEMIZED RECEIPTS
Use separate schedule(s)

for each category of the

Detailed Summary Page
FOR LINE NUMBER: (check only one)

PAGE $801 / 1572$

\begin{tabular}{|c|c|c|c|c|c|}
\hline & & & & & \\
\hline 16 & $\begin{array}{l}\mathbf{X} \\
17 a\end{array}$ & $17 b$ & $17 c$ & $17 d$ & 18 \\
\hline $19 a$ & $19 \mathrm{~b}$ & $20 \mathrm{a}$ & $20 \mathrm{~b}$ & $20 \mathrm{c}$ & 21 \\
\hline
\end{tabular}

Any information copied from such Reports and Statements may not be sold or used by any person for the purpose of soliciting contributions or for commercial purposes, other than using the name and address of any political committee to solicit contributions from such committee.

NAME OF COMMITTEE (In Full)

Friends of Herman Cain

A. Full Name (Last, First, Middle Initial)

Charles Schoen

Mailing Address 6190 Mountain Brook Way NW

\begin{tabular}{lcc}
\hline City & State & Zip Code \\
Atlanta & GA & $30328-3608$ \\
\hline
\end{tabular}

FEC ID number of contributing

federal political committee.

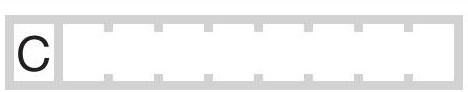

\section{Name of Employer}

Adaptive Learning Center

Receipt For: 2012

X Primary $\square$ General Other (specify)

Occupation

Executive Director

Election Cycle-to-Date

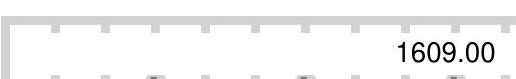

B. Full Name (Last, First, Middle Initial)

William Lytkowski

Mailing Address PO box 715

\begin{tabular}{lcc}
\hline City & State & Zip Code \\
Ardmore & OK & $73402-0715$ \\
\hline
\end{tabular}

FEC ID number of contributing

federal political committee.

C

Name of Employer
Information Requested
Receipt For: 2012
Primary
Other (specify)

Occupation

Information Requested

Election Cycle-to-Date

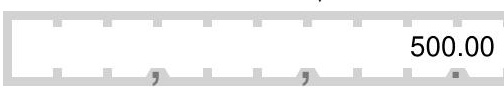

Transaction ID : A82A81E19F4374714AB8

Date of Receipt

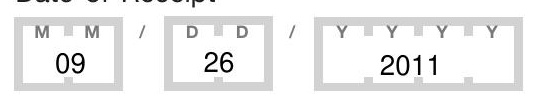

Amount of Each Receipt this Period

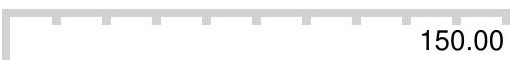

150.00

C. Full Name (Last, First, Middle Initial)

Edna Klein

Mailing Address 10 Tree Top Dr

\begin{tabular}{lcc}
\hline City & State & Zip Code \\
Springfield & NJ & $07081-3729$
\end{tabular}

FEC ID number of contributing

federal political committee.

$\mathrm{C}$

Name of Employer
None
Receipt For: 2012
X Primary $\quad \square$ General
Other (specify)

Occupation

Retired

Election Cycle-to-Date

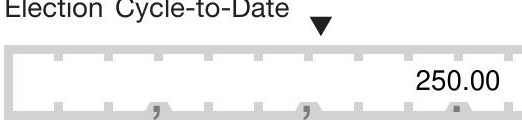

Transaction ID : AD054355FA263424FB6A

Date of Receipt

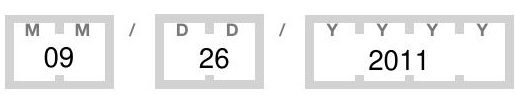

Amount of Each Receipt this Period

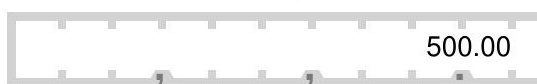

Transaction ID : AD23ABB91D498451BB54 Date of Receipt

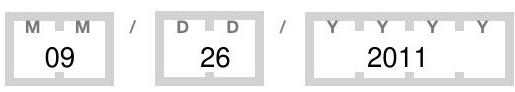

Amount of Each Receipt this Period

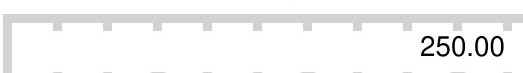

\section{Subtotal Of Receipts This Page (optional)}

900.00

a

Total This Period (last page this line number only)

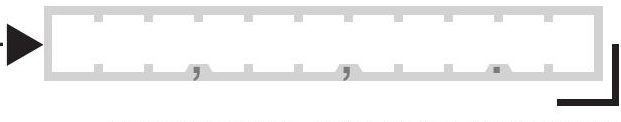

FEC Schedule A-P (Form 3P) (Rev. 03/2011) 


\section{SCHEDULE A-P} ITEMIZED RECEIPTS
Use separate schedule(s) for each category of the Detailed Summary Page

FOR LINE NUMBER:
(check only one)

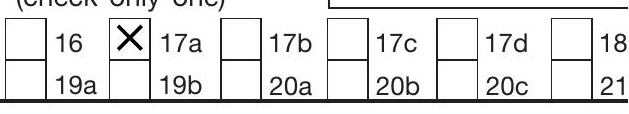

Any information copied from such Reports and Statements may not be sold or used by any person for the purpose of soliciting contributions or for commercial purposes, other than using the name and address of any political committee to solicit contributions from such committee.

NAME OF COMMITTEE (In Full)

\section{Friends of Herman Cain}

A. Full Name (Last, First, Middle Initial) Joe Benites

Mailing Address 9667 Minter Ct

\begin{tabular}{lcc}
\hline City & State & Zip Code \\
Rancho Cucamonga & CA & $91737-2218$
\end{tabular}

FEC ID number of contributing federal political committee.

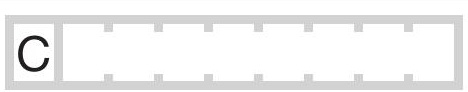

Name of Employer
Clearwater Graphics, Inc.
Receipt For: 2012
X Primary
$\square$ Other (specify)

Occupation President Election Cycle-to-Date

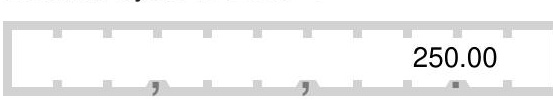

B. Full Name (Last, First, Middle Initial) Sandra Montgomery

Mailing Address 14409 Wilden Dr

\begin{tabular}{lcc}
\hline City & State & Zip Code \\
Urbandale & IA & $50323-2056$
\end{tabular}

FEC ID number of contributing

federal political committee.

C

Name of Employer
Information Requested
Receipt For: 2012
Primary
Other (specify)

Occupation

Information Requested

Election Cycle-to-Date

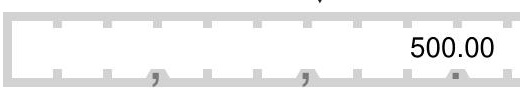

Transaction ID : A5BE77775B98B42B0A56

Date of Receipt

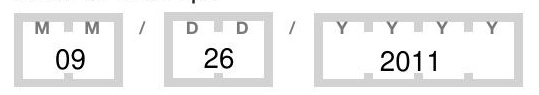

Amount of Each Receipt this Period

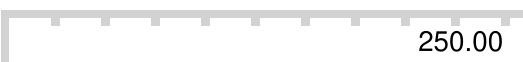

Amount of Each Receipt this Period

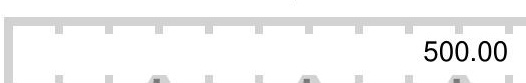

C. Full Name (Last, First, Middle Initial)

George Fitzgerald

Mailing Address Unit 5770 Box 129

\begin{tabular}{lcc}
\hline City & State & Zip Code \\
Dpo & AE & $09715-0129$
\end{tabular}

FEC ID number of contributing federal political committee.

C

Name of Employer
Information Requested
Receipt For: 2012
X Primary
Other (specify) General

Occupation

Information Requested

Election Cycle-to-Date
Transaction ID : AD45A414B8AD241C4AA6 Date of Receipt

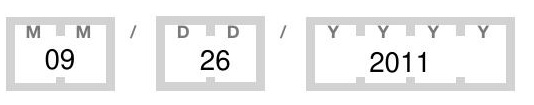

Transaction ID : AA1686CADECB64C8CACF Date of Receipt

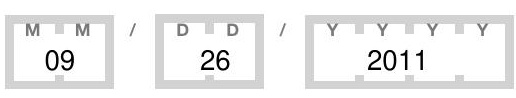

Amount of Each Receipt this Period

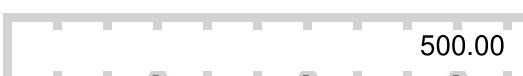

500.00

\section{Subtotal Of Receipts This Page (optional)}

Total This Period (last page this line number only) 
SCHEDULE A-P ITEMIZED RECEIPTS
Use separate schedule(s) for each category of the Detailed Summary Page
FOR LINE NUMBER: (check only one)

PAGE $803 / 1572$

\begin{tabular}{|c|c|c|c|c|c|c|}
\hline & & & & & & \\
\hline 16 & $\lambda$ & $17 \mathrm{a}$ & $17 \mathrm{~b}$ & $17 \mathrm{c}$ & $-17 d$ & -18 \\
\hline $19 a$ & & $19 b$ & $20 a$ & $20 \mathrm{~b}$ & $20 \mathrm{c}$ & 21 \\
\hline
\end{tabular}

Any information copied from such Reports and Statements may not be sold or used by any person for the purpose of soliciting contributions or for commercial purposes, other than using the name and address of any political committee to solicit contributions from such committee.

NAME OF COMMITTEE (In Full)

\section{Friends of Herman Cain}

A. Full Name (Last, First, Middle Initial)

Mary Scott

Mailing Address 372 Hartert Dr.

\begin{tabular}{lcc}
\hline City & State & Zip Code \\
Idaho Falls & ID & $83404-7152$ \\
\hline
\end{tabular}

FEC ID number of contributing federal political committee.

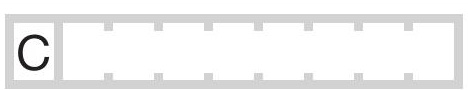

Name of Employer
None
Receipt For: 2012
X Primary $\quad$ General
Other (specify)

Occupation

Retired

Election Cycle-to-Date

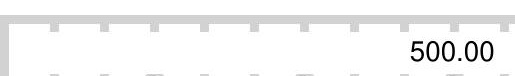

B. Full Name (Last, First, Middle Initial)

Jennifer Holland

Mailing Address 412 Bowdoin Circle

\begin{tabular}{lcc}
\hline City & State & Zip Code \\
Sarasota & FL & $34236-1102$ \\
\hline
\end{tabular}

FEC ID number of contributing

federal political committee.

C

Name of Employer
Information Requested
Receipt For: 2012
X Primary
Other (specify)

Occupation

Information Requested

Election Cycle-to-Date

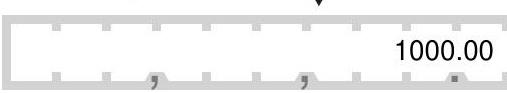

Transaction ID : A43BF43441F0A45F79EA

Date of Receipt

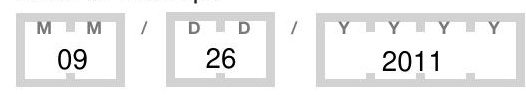

Amount of Each Receipt this Period

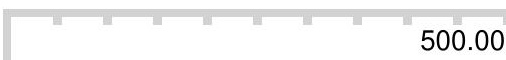

Amount of Each Receipt this Period

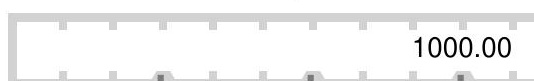

C. Full Name (Last, First, Middle Initial)

RICHARD GREEN

Mailing Address 1215 West 57th Street

\begin{tabular}{lcc}
\hline City & State & Zip Code \\
Kansas City & MO & $64113-1144$
\end{tabular}

FEC ID number of contributing

federal political committee.

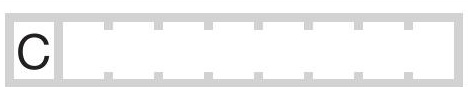

Name of Employer

Corridor Energy, LLC

Occupation

Receipt For: 2012

Х $\begin{aligned} & \text { Primary } \\ & \text { Other (specify) }\end{aligned}$

Managing Director

Election Cycle-to-Date

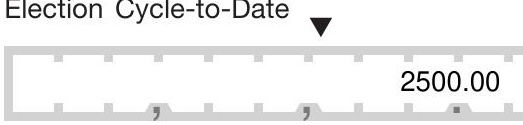

Amount of Each Receipt this Period

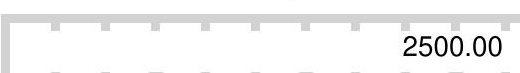

Transaction ID : A9DA49B8DDD08409EB01 Date of Receipt

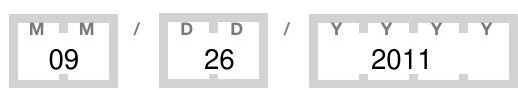

Subtotal Of Receipts This Page (optional)

4000.00

Total This Period (last page this line number only) 
SCHEDULE A-P ITEMIZED RECEIPTS
Use separate schedule(s) for each category of the Detailed Summary Page
FOR LINE NUMBER: (check only one)

PAGE 804 / 1572

\begin{tabular}{|c|c|c|c|c|c|}
\hline & & & & & \\
\hline 16 & $\begin{array}{l}\mathbf{X} \\
17 a\end{array}$ & $17 b$ & $17 c$ & $17 d$ & 18 \\
\hline $19 a$ & $19 \mathrm{~b}$ & $20 \mathrm{a}$ & $20 \mathrm{~b}$ & $20 \mathrm{c}$ & 21 \\
\hline
\end{tabular}

Any information copied from such Reports and Statements may not be sold or used by any person for the purpose of soliciting contributions or for commercial purposes, other than using the name and address of any political committee to solicit contributions from such committee.

NAME OF COMMITTEE (In Full)

\section{Friends of Herman Cain}

A. Full Name (Last, First, Middle Initial)

\section{Ms Patricia B Earnest}

Mailing Address 1307 Redwine Road

\begin{tabular}{lcc}
\hline City & State & Zip Code \\
Fayetteville & GA & $30215-2351$ \\
\hline
\end{tabular}

FEC ID number of contributing federal political committee.

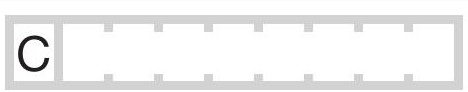

\begin{tabular}{l} 
Name of Employer \\
None \\
Receipt For: 2012 \\
X Primary $\quad$ General \\
\hline Other (specify)
\end{tabular}

Occupation Retired

Election Cycle-to-Date

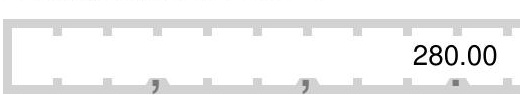

B. Full Name (Last, First, Middle Initial)

\section{Chad Simmons}

Mailing Address 10101 Wenonga Ln

\begin{tabular}{lcc}
\hline City & State & Zip Code \\
Leawood & KS & $66206-2444$
\end{tabular}

FEC ID number of contributing

federal political committee.

C

Name of Employer
Information Requested
Receipt For: 2012
X Primary
Other (specify)

\section{Occupation}

Information Requested

Election Cycle-to-Date

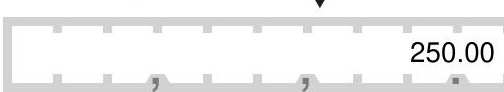

Transaction ID : A62AADF2D3FA742B8B7E

Date of Receipt

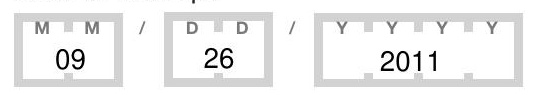

Amount of Each Receipt this Period

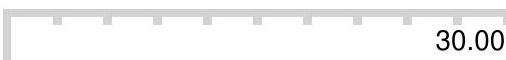

C. Full Name (Last, First, Middle Initial)

Delia M Rose

Mailing Address 3405 Via Cabo Verde

\begin{tabular}{lcc}
\hline City & State & Zip Code \\
Escondido & CA & $92029-7457$
\end{tabular}

FEC ID number of contributing federal political committee.

C

Name of Employer
None
Receipt For: 2012
Х Primary $\quad \square$ General
Other (specify)

Occupation

Retired

Election Cycle-to-Date
Transaction ID : A35E6544D128B49BB84D

Date of Receipt

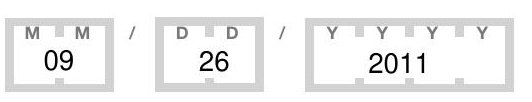

Amount of Each Receipt this Period

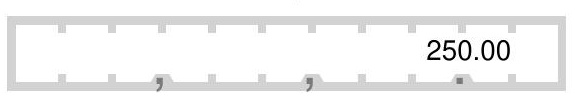

Transaction ID : A32AC6D06CCE149B385F Date of Receipt

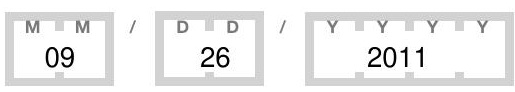

Amount of Each Receipt this Period

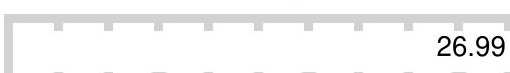

\section{Subtotal Of Receipts This Page (optional)}

Total This Period (last page this line number only) 


\section{SCHEDULE A-P} ITEMIZED RECEIPTS
Use separate schedule(s)

for each category of the

Detailed Summary Page

FOR LINE NUMBER:
(check only one)

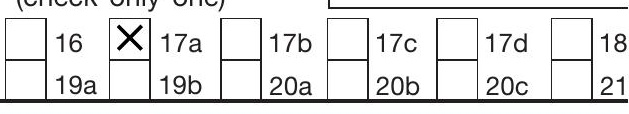

Any information copied from such Reports and Statements may not be sold or used by any person for the purpose of soliciting contributions or for commercial purposes, other than using the name and address of any political committee to solicit contributions from such committee.

NAME OF COMMITTEE (In Full)

\section{Friends of Herman Cain}

A. Full Name (Last, First, Middle Initial)

\section{Lewis Halski}

Mailing Address PO Box 908462

\begin{tabular}{lcc}
\hline City & State & Zip Code \\
Gainesville & GA & $30501-0923$
\end{tabular}

FEC ID number of contributing federal political committee.

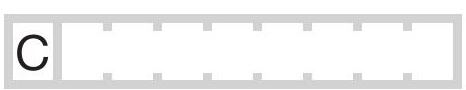

Name of Employer
Halski Systems LLC
Receipt For: 2012
X Primary $\quad$ General
Other (specify)

Occupation

Small business owner Computer Technolo

Election Cycle-to-Date

1965.00

B. Full Name (Last, First, Middle Initial)

Ed Stiften

Mailing Address 2223 Oberhelman Rd.

\begin{tabular}{lcc}
\hline City & State & Zip Code \\
Foristell & MO & $63348-2008$ \\
\hline
\end{tabular}

FEC ID number of contributing

federal political committee.

C

Name of Employer
Information Requested
Receipt For: 2012
X Primary
Other (specify)

\section{Occupation}

Information Requested

Election Cycle-to-Date

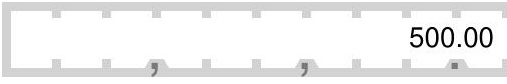

Transaction ID : A911CABD3D4D140BA9D1

Date of Receipt

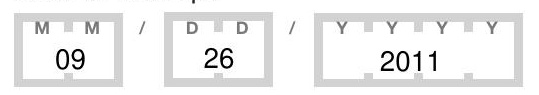

Amount of Each Receipt this Period

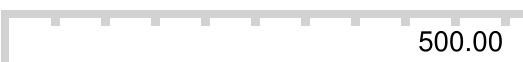

Transaction ID : ACDB2C5F0BCE140C495E Date of Receipt

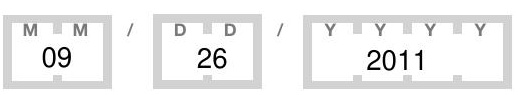

Amount of Each Receipt this Period

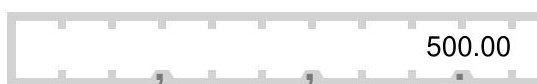

Transaction ID : A79B592CFF5C44A39853

Date of Receipt

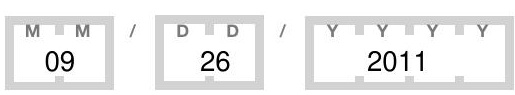

Amount of Each Receipt this Period

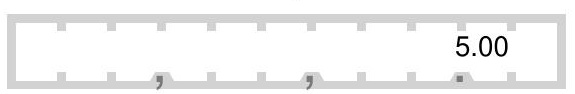

C. Full Name (Last, First, Middle Initial)

Thomas J Humphrey

Mailing Address 12902 W Mesa Verde Dr

\begin{tabular}{lcc}
\hline City & State & Zip Code \\
Sun City West & AZ & $85375-3226$
\end{tabular}

FEC ID number of contributing

federal political committee.

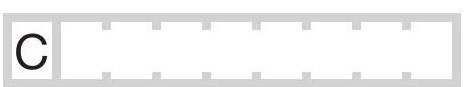

Name of Employer
None
Receipt For: 2012
Х Primary $\quad \square$ General
Other (specify)

Occupation

Retired

Election Cycle-to-Date

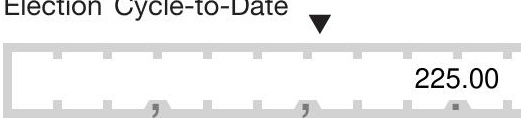

Subtotal Of Receipts This Page (optional)

1005.00

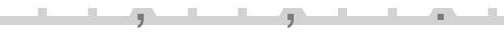

Total This Period (last page this line number only)

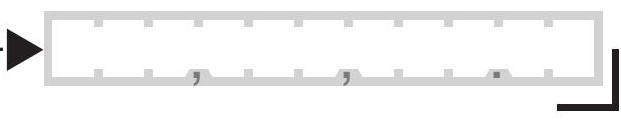

FEC Schedule A-P (Form 3P) (Rev. 03/2011) 


\section{SCHEDULE A-P} ITEMIZED RECEIPTS
Use separate schedule(s)

for each category of the

Detailed Summary Page
FOR LINE NUMBER: (check only one)

PAGE $806 / 1572$

\begin{tabular}{|c|c|c|c|c|c|}
\hline & & & & & \\
\hline 16 & $\begin{array}{l}\mathbf{X} \\
17 a\end{array}$ & $17 b$ & $17 c$ & $17 d$ & 18 \\
\hline $19 a$ & $19 \mathrm{~b}$ & $20 \mathrm{a}$ & $20 \mathrm{~b}$ & $20 \mathrm{c}$ & 21 \\
\hline
\end{tabular}

Any information copied from such Reports and Statements may not be sold or used by any person for the purpose of soliciting contributions or for commercial purposes, other than using the name and address of any political committee to solicit contributions from such committee.

NAME OF COMMITTEE (In Full)

Friends of Herman Cain

A. Full Name (Last, First, Middle Initial)

Robert Klopp

Mailing Address 1251 Colebrook Road

\begin{tabular}{lcc}
\hline City & State & Zip Code \\
Lebanon & PA & $17042-6912$ \\
\hline
\end{tabular}

FEC ID number of contributing

federal political committee.

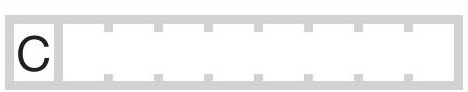

Name of Employer
New holland Auto Parts
Receipt For: 2012
X Primary
Other (specify) General

Occupation

Manager

Election Cycle-to-Date

212.00

B. Full Name (Last, First, Middle Initial)

Richard Van Dresser

Mailing Address 602 Maple Ave

\begin{tabular}{lcc}
\hline City & State & Zip Code \\
Pueblo & CO & $81005-1716$ \\
\hline
\end{tabular}

FEC ID number of contributing

federal political committee.

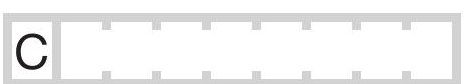

Name of Employer
ABC Rail Corp.
Receipt For: 2012
X Primary
Other (specify)

Occupation

Retired

Election Cycle-to-Date

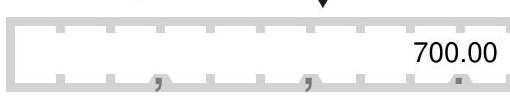

C. Full Name (Last, First, Middle Initial)

James Montgomery

Mailing Address 2715 Lange Ct NE

\begin{tabular}{lcc}
\hline City & State & Zip Code \\
Marietta & GA & $30062-4427$
\end{tabular}

FEC ID number of contributing

federal political committee.

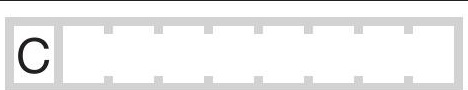

Name of Employer

Kennesaw State University

Receipt For: 2012

Х $\begin{aligned} & \text { Primary } \square \text { General } \\ & \text { Other (specify) }\end{aligned}$

\section{Occupation}

Teacher/Coach

Election Cycle-to-Date
Transaction ID : A1A372D1CA396427488E

Date of Receipt

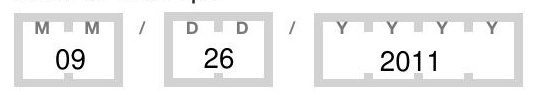

Amount of Each Receipt this Period

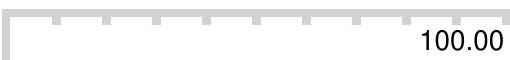

Amount of Each Receipt this Period

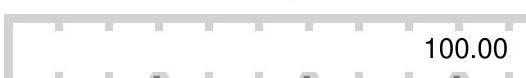

Transaction ID : A771D87322C9247229F1

Date of Receipt

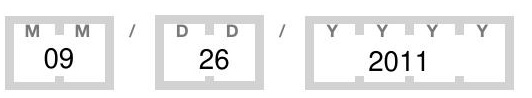

Transaction ID : AE848003655A24F65994 Date of Receipt

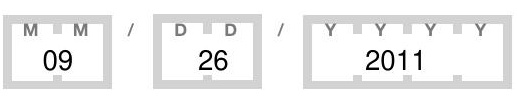

Amount of Each Receipt this Period

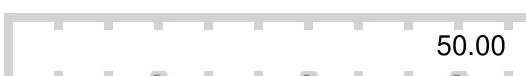

300.00

Subtotal Of Receipts This Page (optional).

Total This Period (last page this line number only) 


\section{SCHEDULE A-P} ITEMIZED RECEIPTS
Use separate schedule(s)

for each category of the

Detailed Summary Page
FOR LINE NUMBER: (check only one)

PAGE 807 / 1572

\begin{tabular}{|c|c|c|c|c|c|}
\hline & & & & & \\
\hline 16 & $\begin{array}{l}\mathbf{X} \\
17 a\end{array}$ & $17 b$ & $17 c$ & $17 d$ & 18 \\
\hline $19 a$ & $19 \mathrm{~b}$ & $20 \mathrm{a}$ & $20 \mathrm{~b}$ & $20 \mathrm{c}$ & 21 \\
\hline
\end{tabular}

Any information copied from such Reports and Statements may not be sold or used by any person for the purpose of soliciting contributions or for commercial purposes, other than using the name and address of any political committee to solicit contributions from such committee.

NAME OF COMMITTEE (In Full)

Friends of Herman Cain

A. Full Name (Last, First, Middle Initial)

Brian Brookheart

Mailing Address $3723 \mathrm{~N}$ Van Rd

\begin{tabular}{lcc}
\hline City & State & Zip Code \\
Olney & IL & $62450-4733$ \\
\hline
\end{tabular}

FEC ID number of contributing federal political committee.

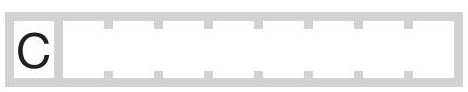

Name of Employer
Self Employed
Receipt For: 2012
X Primary
$\square$ Other (specify) General

Occupation

Contractor

Election Cycle-to-Date

250.00

B. Full Name (Last, First, Middle Initial)

Evelyn Whalen

Mailing Address 3131 Moss Oak Drive

\begin{tabular}{lcc}
\hline City & State & Zip Code \\
Atlanta & GA & $30340-1320$ \\
\hline
\end{tabular}

FEC ID number of contributing

federal political committee.

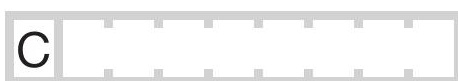

Name of Employer
husband
Receipt For: 2012
Primary
Other (specify)

\section{Occupation}

Housewife

Election Cycle-to-Date

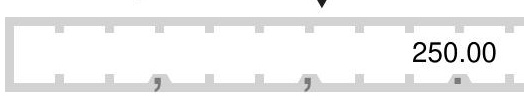

Transaction ID : AD48FC2779A304DE18D7

Date of Receipt

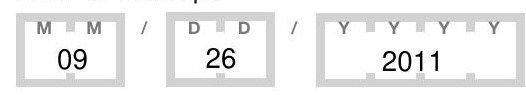

Amount of Each Receipt this Period

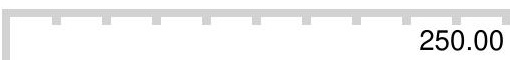

250.00

C. Full Name (Last, First, Middle Initial)

Robert Roach

Mailing Address 13950 W. 72nd St

\begin{tabular}{lcc}
\hline City & State & Zip Code \\
Shawnee & KS & $66216-3752$
\end{tabular}

FEC ID number of contributing

federal political committee.

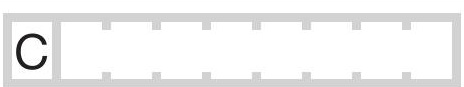

Name of Employer
Cubic
Receipt For: 2012
X Primary $\quad \square$ General
Other (specify)

\section{Occupation}

Analyst

Election Cycle-to-Date

Transaction ID : A87A6F8F140F24097871

Date of Receipt

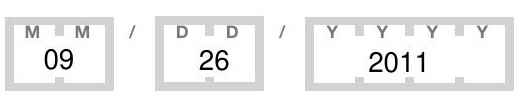

Amount of Each Receipt this Period

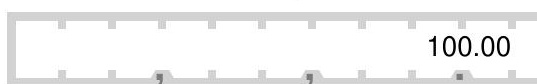

Transaction ID : A514A2146F9EB4E97AF1

Date of Receipt

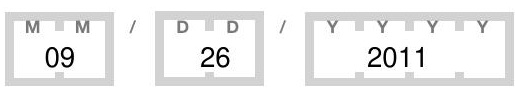

Amount of Each Receipt this Period

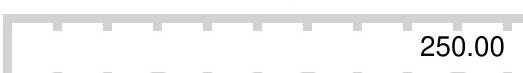

750.00

Subtotal Of Receipts This Page (optional)

600.00

,

Total This Period (last page this line number only) 


\section{SCHEDULE A-P} ITEMIZED RECEIPTS
Use separate schedule(s)

for each category of the

Detailed Summary Page
FOR LINE NUMBER: (check only one)

PAGE $808 / 1572$

\begin{tabular}{|c|c|c|c|c|c|}
\hline & & & & & \\
\hline 16 & X $17 a$ & $17 b$ & $17 c$ & $17 d$ & 18 \\
\hline $19 a$ & $19 b$ & $20 \mathrm{a}$ & $20 \mathrm{~b}$ & $20 \mathrm{c}$ & 21 \\
\hline
\end{tabular}

Any information copied from such Reports and Statements may not be sold or used by any person for the purpose of soliciting contributions or for commercial purposes, other than using the name and address of any political committee to solicit contributions from such committee.

NAME OF COMMITTEE (In Full)

Friends of Herman Cain

A. Full Name (Last, First, Middle Initial)

Ty Rulli

Mailing Address 6251 Cartwright Ave

\begin{tabular}{lcc}
\hline City & State & Zip Code \\
North Hollywood & CA & $91606-3801$
\end{tabular}

FEC ID number of contributing

federal political committee.

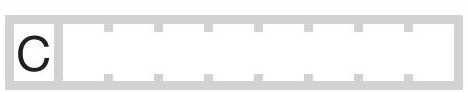

Name of Employer
Information Requested
Receipt For: 2012
X Primary $\quad \square$ General
Other (specify)

Occupation

Information Requested

Election Cycle-to-Date

470.00

B. Full Name (Last, First, Middle Initial)

George Lyons

Mailing Address 2732 Highway 9 S

\begin{tabular}{lcc}
\hline City & State & Zip Code \\
Dawsonville & GA & $30534-5242$ \\
\hline
\end{tabular}

FEC ID number of contributing

federal political committee.

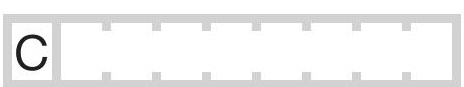

Name of Employer
Lyons Farm Inc.
Receipt For: 2012
X Primary
Other (specify) General

\section{Occupation}

self

Election Cycle-to-Date

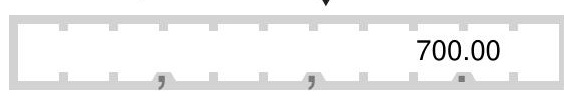

Transaction ID : AB7BB897ACB24460D99C

Date of Receipt

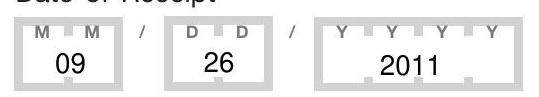

Amount of Each Receipt this Period

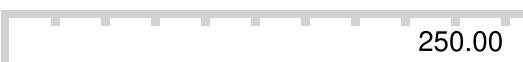

C. Full Name (Last, First, Middle Initial)

sabra ingeman

Mailing Address 8755 SE water oak place

\begin{tabular}{lcc}
\hline City & State & Zip Code \\
Jupiter & FL & $33469-1811$
\end{tabular}

FEC ID number of contributing

federal political committee.

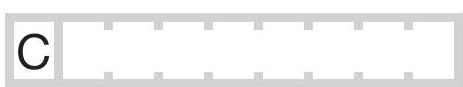

Name of Employer
n/a
Receipt For: 2012
X Primary $\square$ General
Other (specify)

Occupation

Homemaker

Election Cycle-to-Date

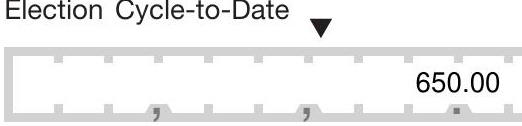

Transaction ID : A9A5A30FA668B452ABD7 Date of Receipt

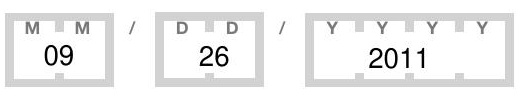

Amount of Each Receipt this Period

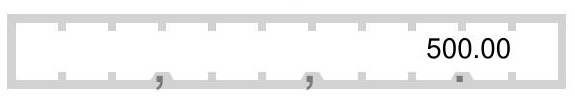

Transaction ID : A80897CB52B894496BF2

Date of Receipt

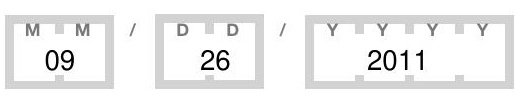

Amount of Each Receipt this Period

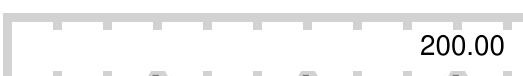

\section{Subtotal Of Receipts This Page (optional)}

Total This Period (last page this line number only) 
SCHEDULE A-P ITEMIZED RECEIPTS
Use separate schedule(s) for each category of the Detailed Summary Page
FOR LINE NUMBER: (check only one)

PAGE 809 / 1572

\begin{tabular}{|c|c|c|c|c|c|}
\hline & & & & & \\
\hline 16 & $\begin{array}{l}\mathbf{X} \\
17 a\end{array}$ & $17 b$ & $17 c$ & $17 d$ & 18 \\
\hline $19 a$ & $19 \mathrm{~b}$ & $20 \mathrm{a}$ & $20 \mathrm{~b}$ & $20 \mathrm{c}$ & 21 \\
\hline
\end{tabular}

Any information copied from such Reports and Statements may not be sold or used by any person for the purpose of soliciting contributions or for commercial purposes, other than using the name and address of any political committee to solicit contributions from such committee.

NAME OF COMMITTEE (In Full)

\section{Friends of Herman Cain}

A. Full Name (Last, First, Middle Initial)

Michelle Dorman

Mailing Address 1345 Chandler Rd.

\begin{tabular}{lcc}
\hline City & State & Zip Code \\
Lake Oswego & OR & $97034-2807$
\end{tabular}

FEC ID number of contributing federal political committee.

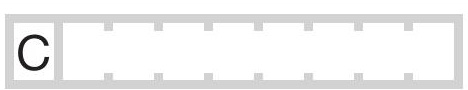

Name of Employer
Life 101
Receipt For: 2012
X Primary $\quad$ General
Other (specify)

Occupation

Full time mother and wife

Election Cycle-to-Date $\boldsymbol{\nabla}$

715.00

B. Full Name (Last, First, Middle Initial)

Eugene Smith

Mailing Address PO BOX 888166

\begin{tabular}{lcc}
\hline City & State & Zip Code \\
Atlanta & GA & $30356-0166$ \\
\hline
\end{tabular}

FEC ID number of contributing

federal political committee.

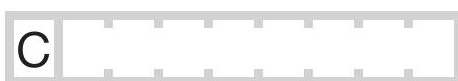

Name of Employer
self
Receipt For: 2012
X Primary
Other (specify)

Occupation

Physician

Election Cycle-to-Date

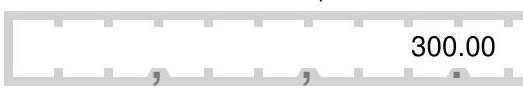

Transaction ID : AB5672140D23C479DA29

Date of Receipt

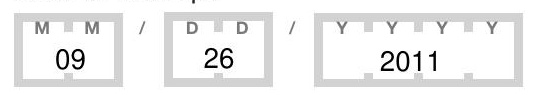

Amount of Each Receipt this Period

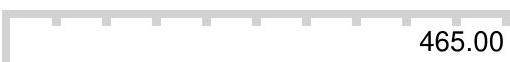

Transaction ID : AB43FF54EACCD47D780E Date of Receipt

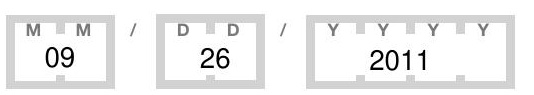

Amount of Each Receipt this Period

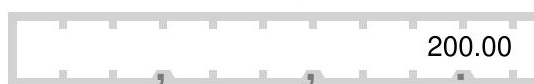

Transaction ID : A768B5CEC264E47D8A4A Date of Receipt

\section{$\mathrm{R}$ Wells}

Mailing Address 2288 Gunbarrel Road

\begin{tabular}{lcc}
\hline City & State & Zip Code \\
Chattanooga & TN & $37421-2685$
\end{tabular}

FEC ID number of contributing federal political committee.

C

Name of Employer
Information Requested
Receipt For: 2012
X Primary
Other (specify) General

Occupation

Information Requested

Election Cycle-to-Date

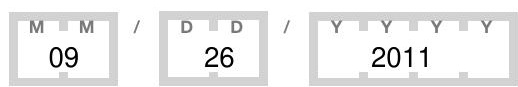

Amount of Each Receipt this Period

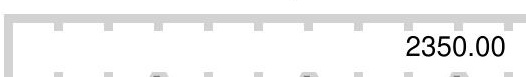

\section{Subtotal Of Receipts This Page (optional)}

3015.00

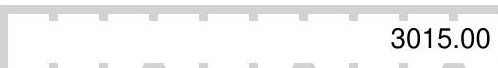

(1)

Total This Period (last page this line number only)
2350.00

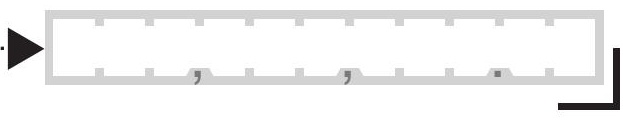




\section{SCHEDULE A-P} ITEMIZED RECEIPTS
Use separate schedule(s) for each category of the Detailed Summary Page

\begin{tabular}{|c|c|c|c|c|c|}
\hline \multicolumn{3}{|c|}{$\begin{array}{l}\text { FOR LINE NUMBER: } \\
\text { (check only one) }\end{array}$} & \multicolumn{3}{|c|}{ PAGE 810 / 1572} \\
\hline 16 & $X$ 17a & $17 b$ & 17c & $17 d$ & 18 \\
\hline $19 a$ & $19 \mathrm{~b}$ & $20 a$ & $20 \mathrm{~b}$ & $20 c$ & 21 \\
\hline
\end{tabular}

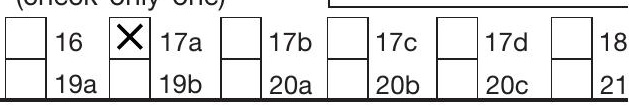

Any information copied from such Reports and Statements may not be sold or used by any person for the purpose of soliciting contributions or for commercial purposes, other than using the name and address of any political committee to solicit contributions from such committee.

NAME OF COMMITTEE (In Full)

\section{Friends of Herman Cain}

A. Full Name (Last, First, Middle Initial)

Dorothy Taylor

Mailing Address 805 Rivershore Rd.

\begin{tabular}{lcc}
\hline City & State & Zip Code \\
Elizabeth City & NC & $27909-5451$ \\
\hline
\end{tabular}

FEC ID number of contributing federal political committee.

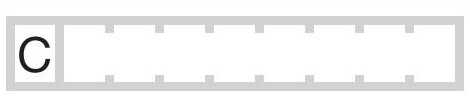

Name of Employer
Information Requested
Receipt For: 2012
X Primary
$\square$ Other (specify)

Occupation Information Requested

Election Cycle-to-Date 250.00

B. Full Name (Last, First, Middle Initial)

Margaret Silaghi

Mailing Address 10909 Scott Dr

\begin{tabular}{lcc}
\hline City & State & Zip Code \\
Fairfax & VA & $22030-3025$ \\
\hline
\end{tabular}

FEC ID number of contributing

federal political committee.

C

Name of Employer
Information Requested
Receipt For: 2012
X Primary
Other (specify)

Occupation

Information Requested

Election Cycle-to-Date

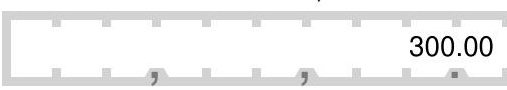

Transaction ID : A2ADE1F96DB824248820

Date of Receipt

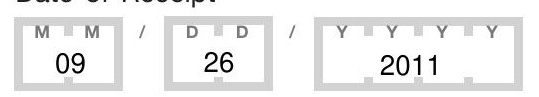

Amount of Each Receipt this Period

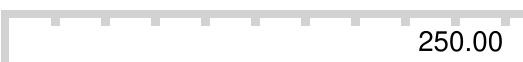

Amount of Each Receipt this Period

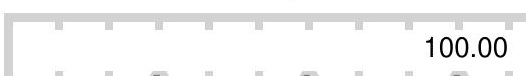

C. Full Name (Last, First, Middle Initial) edward blick

Mailing Address 1909 crestmont st

\begin{tabular}{lcc}
\hline City & State & Zip Code \\
Norman & OK & $73069-6411$
\end{tabular}

FEC ID number of contributing federal political committee.

C

Name of Employer
Information Requested
Receipt For: 2012
X Primary
Other (specify) General

\section{Occupation}

Information Requested

Election Cycle-to-Date
Transaction ID : AF01F6FC60A4A4F38B89

Date of Receipt
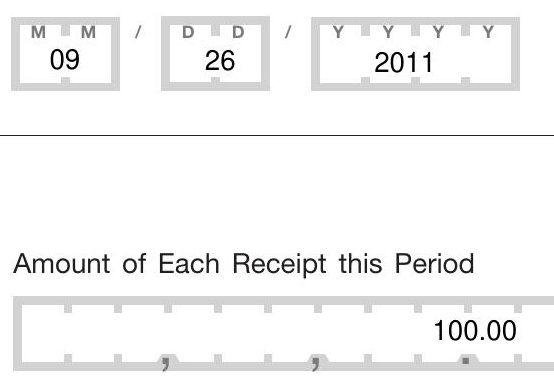

Transaction ID : ACD36758867F74F1499A Date of Receipt

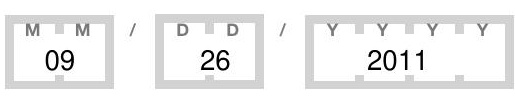

Amount of Each Receipt this Period

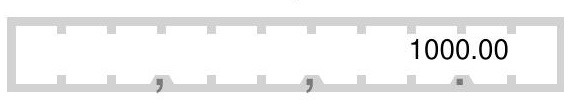

1000.00

\section{Subtotal Of Receipts This Page (optional)}

Total This Period (last page this line number only) 


\section{SCHEDULE A-P} ITEMIZED RECEIPTS
Use separate schedule(s)

for each category of the

Detailed Summary Page
FOR LINE NUMBER: (check only one)

PAGE $811 / 1572$

\begin{tabular}{|c|c|c|c|c|c|}
\hline & & & & & \\
\hline 16 & X $17 a$ & $17 b$ & $17 c$ & $17 d$ & 18 \\
\hline $19 a$ & $19 b$ & $20 \mathrm{a}$ & $20 \mathrm{~b}$ & $20 \mathrm{c}$ & 21 \\
\hline
\end{tabular}

Any information copied from such Reports and Statements may not be sold or used by any person for the purpose of soliciting contributions or for commercial purposes, other than using the name and address of any political committee to solicit contributions from such committee.

NAME OF COMMITTEE (In Full)

Friends of Herman Cain

A. Full Name (Last, First, Middle Initial)

John Abney

Mailing Address 522 Briar Path

\begin{tabular}{lcc}
\hline City & State & Zip Code \\
Houston & TX & $77079-6529$ \\
\hline
\end{tabular}

FEC ID number of contributing

federal political committee.

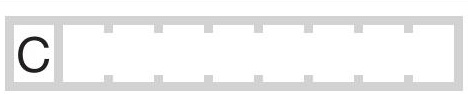

Name of Employer
NES Global
Receipt For: 2012
X Primary
$\square$ Other (specify)

Occupation

Consultant

Election Cycle-to-Date

350.00

B. Full Name (Last, First, Middle Initial)

Suzanne Leupold

Mailing Address 8815 W. Hallett Rd.

\begin{tabular}{llc}
\hline City & State & Zip Code \\
Cheney & WA & $99004-9050$
\end{tabular}

FEC ID number of contributing

federal political committee.

C

Name of Employer
Information Requested
Receipt For: 2012
X Primary
Other (specify)

Occupation

Information Requested

Election Cycle-to-Date

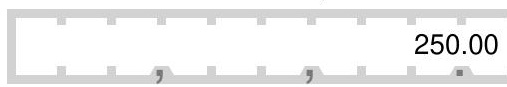

Transaction ID : A18F4CB21A8FD4DD7BCC

Date of Receipt

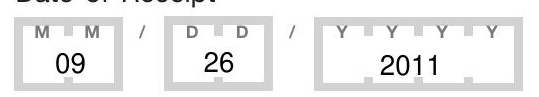

Amount of Each Receipt this Period

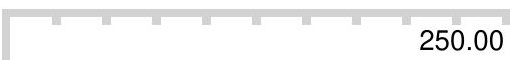

C. Full Name (Last, First, Middle Initial)

Rebecca Maxwell

Mailing Address 3007 Lockheed Dr

\begin{tabular}{lcc}
\hline City & State & Zip Code \\
Midland & TX & $79701-3866$
\end{tabular}

FEC ID number of contributing

federal political committee.

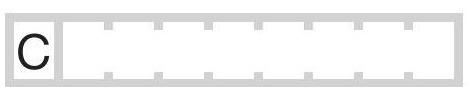

Name of Employer

Information Requested

Occupation

Information Requested

Receipt For: 2012

Х $\begin{aligned} & \text { Primary } \square \text { General } \\ & \text { Other (specify) }\end{aligned}$

Amount of Each Receipt this Period

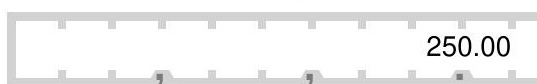

Transaction ID : A8C87233BE52C4DBCB19 Date of Receipt

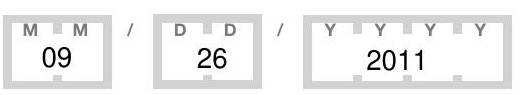

Transaction ID : A1E7DDD8AE2D44607923 Date of Receipt

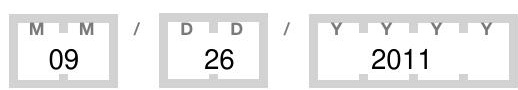

Amount of Each Receipt this Period

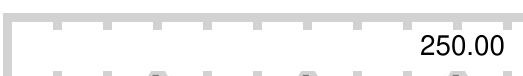

\section{Subtotal Of Receipts This Page (optional)}

Total This Period (last page this line number only) 


\section{SCHEDULE A-P} ITEMIZED RECEIPTS
Use separate schedule(s) for each category of the Detailed Summary Page

\begin{tabular}{|c|c|c|c|c|c|}
\hline \multicolumn{3}{|c|}{$\begin{array}{l}\text { FOR LINE NUMBER: } \\
\text { (check only one) }\end{array}$} & \multicolumn{3}{|c|}{ PAGE 812 / 1572} \\
\hline 16 & $X$ 17a & $17 b$ & $17 c$ & $17 d$ & 18 \\
\hline $19 a$ & $19 \mathrm{~b}$ & $20 a$ & $20 \mathrm{~b}$ & $20 c$ & 21 \\
\hline
\end{tabular}

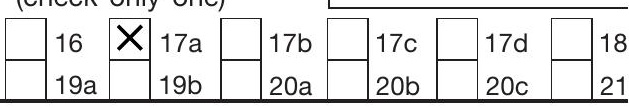

Any information copied from such Reports and Statements may not be sold or used by any person for the purpose of soliciting contributions or for commercial purposes, other than using the name and address of any political committee to solicit contributions from such committee.

NAME OF COMMITTEE (In Full)

\section{Friends of Herman Cain}

A. Full Name (Last, First, Middle Initial) Jim McGuinness

Mailing Address 1010 Briardale Court

\begin{tabular}{lcc}
\hline City & State & Zip Code \\
McKinney & TX & $75069-1592$
\end{tabular}

FEC ID number of contributing federal political committee.

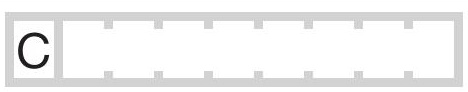

Name of Employer
Self-Employed
Receipt For: 2012
X Primary
$\square$ Other (specify) General

Occupation Consultant Election Cycle-to-Date

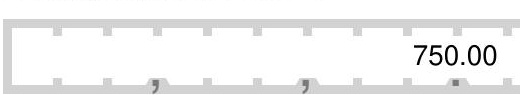

B. Full Name (Last, First, Middle Initial) Richard Copple

Mailing Address 3111 Parker Drive

\begin{tabular}{lcc}
\hline City & State & Zip Code \\
Georgetown & TX & $78628-2763$
\end{tabular}

FEC ID number of contributing

federal political committee.

C

Name of Employer
Information Requested
Receipt For: 2012
Primary
Other (specify)

Occupation Information Requested Election Cycle-to-Date 250.00
Transaction ID : A9D2F2168B7DE4A0E999

Date of Receipt

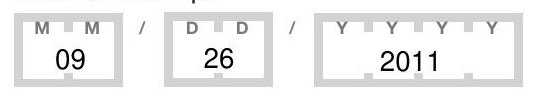

Amount of Each Receipt this Period

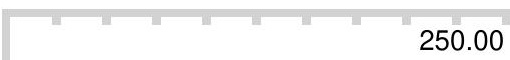

Amount of Each Receipt this Period

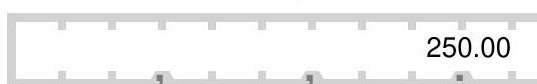

C. Full Name (Last, First, Middle Initial)

James RS Manion

Mailing Address 7030 Burro Ave

\begin{tabular}{lcc}
\hline City & State & Zip Code \\
Inyokern & CA & $93527-2519$
\end{tabular}

FEC ID number of contributing federal political committee.

C

Name of Employer
Survice Engineering
Receipt For: 2012
X Primary
Other (specify) General

Occupation

MATHEMATICIAN

Election Cycle-to-Date
Transaction ID : ACA40F4169DC94B7090E Date of Receipt

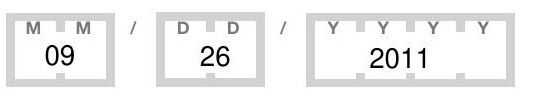

Transaction ID : A58E55E1FD160413C89D Date of Receipt

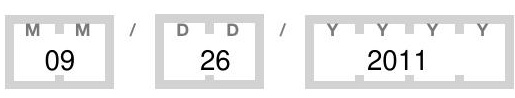

Amount of Each Receipt this Period

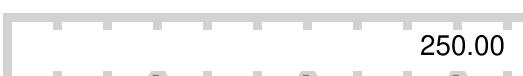

350.00

Subtotal Of Receipts This Page (optional).

Total This Period (last page this line number only) 
SCHEDULE A-P ITEMIZED RECEIPTS
Use separate schedule(s) for each category of the Detailed Summary Page
FOR LINE NUMBER: (check only one)

PAGE $813 / 1572$

\begin{tabular}{|c|c|c|c|c|c|c|}
\hline & & & & & & \\
\hline 16 & $\lambda$ & $17 \mathrm{a}$ & $17 \mathrm{~b}$ & $17 \mathrm{c}$ & $-17 d$ & -18 \\
\hline $19 a$ & & $19 b$ & $20 a$ & $20 \mathrm{~b}$ & $20 \mathrm{c}$ & 21 \\
\hline
\end{tabular}

Any information copied from such Reports and Statements may not be sold or used by any person for the purpose of soliciting contributions or for commercial purposes, other than using the name and address of any political committee to solicit contributions from such committee.

NAME OF COMMITTEE (In Full)

\section{Friends of Herman Cain}

A. Full Name (Last, First, Middle Initial) Judith McDonald

Mailing Address 130 Heritage Ct

\begin{tabular}{lcc}
\hline City & State & Zip Code \\
Macon & GA & $31210-1201$
\end{tabular}

FEC ID number of contributing federal political committee.

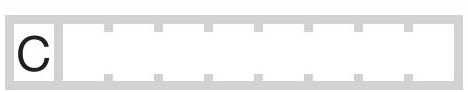

Name of Employer
Information Requested
Receipt For: 2012
X Primary
Other (specify) General

Occupation Information Requested

Election Cycle-to-Date

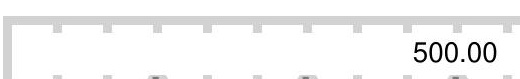

B. Full Name (Last, First, Middle Initial)

Glen Doll

Mailing Address 7 Taylor Street

\begin{tabular}{lcc}
\hline City & State & Zip Code \\
Roseville & CA & $95678-2643$ \\
\hline
\end{tabular}

FEC ID number of contributing

federal political committee.

C

Name of Employer
Information Requested
Receipt For: 2012
Primary
Other (specify)

Occupation

Information Requested

Election Cycle-to-Date

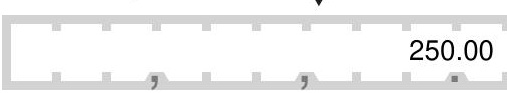

Transaction ID : AC5B3930BB16C4244AC3

Date of Receipt

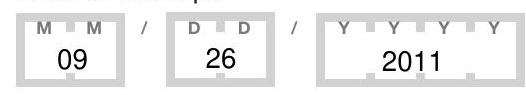

Amount of Each Receipt this Period

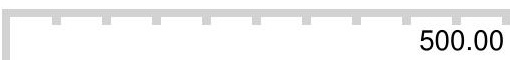

Amount of Each Receipt this Period

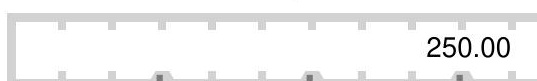

C. Full Name (Last, First, Middle Initial)

Terry Goodkind

Mailing Address 1505 San Felipe Dr

\begin{tabular}{lcc}
\hline City & State & Zip Code \\
Boulder City & NV & $89005-3451$
\end{tabular}

FEC ID number of contributing federal political committee.

C

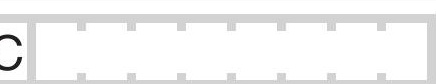

Name of Employer

Information Requested

Occupation

Receipt For: 2012

Х $\begin{aligned} & \text { Primary } \square \text { General } \\ & \text { Other (specify) }\end{aligned}$

Information Requested

Election Cycle-to-Date

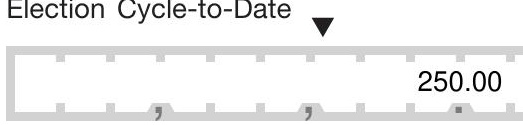

Transaction ID : A40C3BEAE087E4848A8B

Date of Receipt

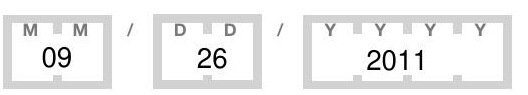

Transaction ID : A70A41AB842E54B6BBFA Date of Receipt

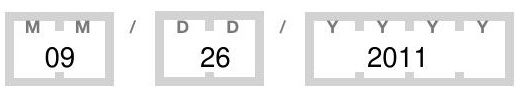

Amount of Each Receipt this Period

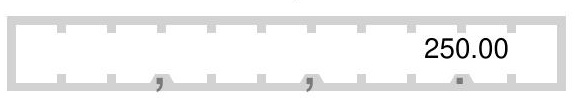

Subtotal Of Receipts This Page (optional).

1000.00

Total This Period (last page this line number only) 


\section{SCHEDULE A-P} ITEMIZED RECEIPTS
Use separate schedule(s) for each category of the Detailed Summary Page

FOR LINE NUMBER:
(check only one)

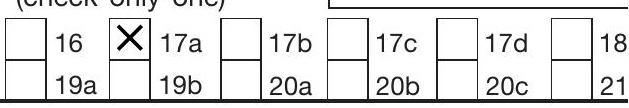

Any information copied from such Reports and Statements may not be sold or used by any person for the purpose of soliciting contributions or for commercial purposes, other than using the name and address of any political committee to solicit contributions from such committee.

NAME OF COMMITTEE (In Full)

\section{Friends of Herman Cain}

A. Full Name (Last, First, Middle Initial)

Richard E Hull

Mailing Address 1634 N.W. 10TH ST.

\begin{tabular}{lcc}
\hline City & State & Zip Code \\
Oklahoma City & OK & $73106-4824$
\end{tabular}

FEC ID number of contributing federal political committee.

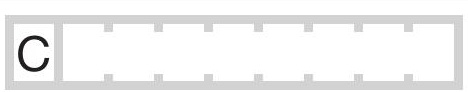

Name of Employer
Nabholz Corp
Receipt For: 2012
X Primary
$\square$ Other (specify) General

Occupation Construction

Election Cycle-to-Date 400.00

B. Full Name (Last, First, Middle Initial) laura paxton

Mailing Address 2728 fox creek drive

\begin{tabular}{lcc}
\hline City & State & Zip Code \\
Germantown & TN & $38138-6249$
\end{tabular}

FEC ID number of contributing

federal political committee.

C

Name of Employer
Information Requested
Receipt For: 2012
X Primary
$\square$ Other (specify) General

Occupation

Information Requested

Election Cycle-to-Date

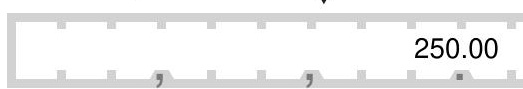

C. Full Name (Last, First, Middle Initial) anthony elias

Mailing Address 1884 fox hill ct

\begin{tabular}{lcc}
\hline City & State & Zip Code \\
Hartsville & SC & $29550-9319$
\end{tabular}

FEC ID number of contributing federal political committee.

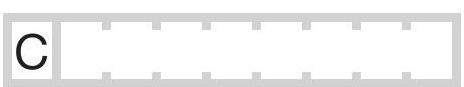

Name of Employer
Information Requested
Receipt For: 2012
X Primary
Other (specify) General

\section{Occupation}

Information Requested

Election Cycle-to-Date
Transaction ID : ABF01006D57AA4759BE6 Date of Receipt

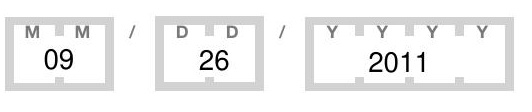

Amount of Each Receipt this Period

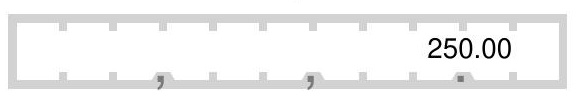

Amount of Each Receipt this Period
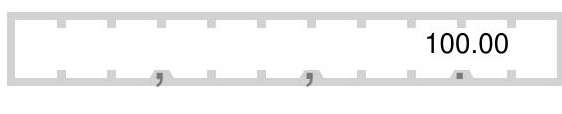

Date of Receipt

$M-M, / D$

09

2011

BA3

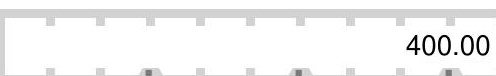

Transaction ID : A0F4A7798A4914D4A9E5

Date of Receipt

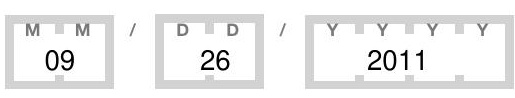

Amount of Each Receipt this Period

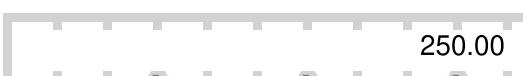

250.00

Subtotal Of Receipts This Page (optional).

600.00

Total This Period (last page this line number only) 


\section{SCHEDULE A-P} ITEMIZED RECEIPTS
Use separate schedule(s)

for each category of the

Detailed Summary Page
FOR LINE NUMBER: (check only one)

PAGE $815 / 1572$

\begin{tabular}{|c|c|c|c|c|c|}
\hline & & & & & \\
\hline 16 & X $17 a$ & $17 b$ & $17 c$ & $17 d$ & 18 \\
\hline $19 a$ & $19 b$ & $20 \mathrm{a}$ & $20 \mathrm{~b}$ & $20 \mathrm{c}$ & 21 \\
\hline
\end{tabular}

Any information copied from such Reports and Statements may not be sold or used by any person for the purpose of soliciting contributions or for commercial purposes, other than using the name and address of any political committee to solicit contributions from such committee.

NAME OF COMMITTEE (In Full)

Friends of Herman Cain

A. Full Name (Last, First, Middle Initial)

Randi Helgeson

Mailing Address 16485 Ellerdale Lane

\begin{tabular}{lcc}
\hline City & State & Zip Code \\
Eden Prairie & MN & $55346-1431$
\end{tabular}

FEC ID number of contributing

federal political committee.

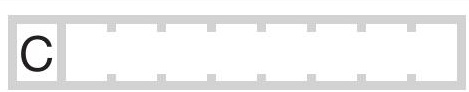

Name of Employer
Retired
Receipt For: 2012
X Primary $\square$ General
$\square$ Other (specify)

Occupation

CPA

Election Cycle-to-Date

850.00

B. Full Name (Last, First, Middle Initial)

Gail Cardon

Mailing Address 7060 Wills Road

\begin{tabular}{lcc}
\hline City & State & Zip Code \\
Cumming & GA & $30040-6250$
\end{tabular}

FEC ID number of contributing

federal political committee.

C

Name of Employer
Information Requested
Receipt For: 2012
Primary
Other (specify)

Occupation

Information Requested

Election Cycle-to-Date

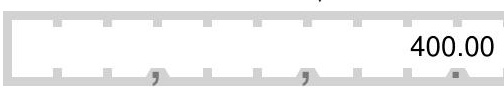

Transaction ID : ACCCCB9F470E2478BAC5

Date of Receipt

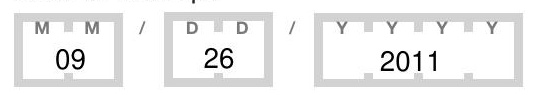

Amount of Each Receipt this Period

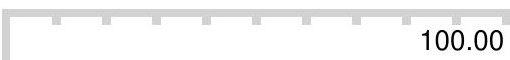

C. Full Name (Last, First, Middle Initial)

Sean Smith

Mailing Address 7768 S Pheasant Wood Dr

\begin{tabular}{lcc}
\hline City & State & Zip Code \\
Sandy & UT & $84093-6291$
\end{tabular}

FEC ID number of contributing

federal political committee.

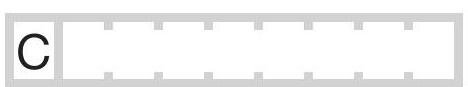

Name of Employer

Information Requested

Occupation

Information Requested

Receipt For: 2012

Х $\begin{aligned} & \text { Primary } \square \text { General } \\ & \text { Other (specify) }\end{aligned}$

Election Cycle-to-Date

250.00

Transaction ID : AC951C0A3A8C541FFA9F Date of Receipt

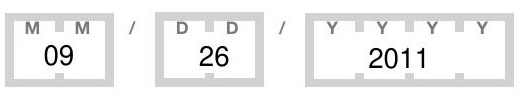

Amount of Each Receipt this Period

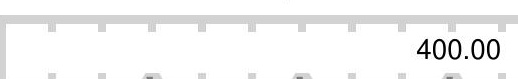

Transaction ID : ADC94766E40A04AB5AB2 Date of Receipt

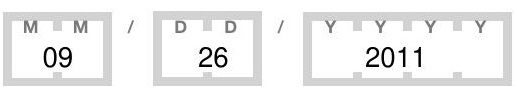

Amount of Each Receipt this Period

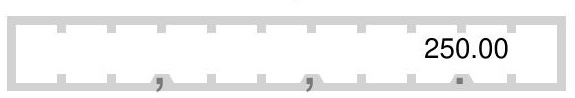

Subtotal Of Receipts This Page (optional).

750.00

Total This Period (last page this line number only) 


\section{SCHEDULE A-P} ITEMIZED RECEIPTS
Use separate schedule(s)

for each category of the

Detailed Summary Page
FOR LINE NUMBER: (check only one)

PAGE $816 / 1572$

\begin{tabular}{|c|c|c|c|c|c|}
\hline & & & & & \\
\hline 16 & X $17 a$ & $17 b$ & $17 c$ & $17 d$ & 18 \\
\hline $19 a$ & $19 b$ & $20 \mathrm{a}$ & $20 \mathrm{~b}$ & $20 \mathrm{c}$ & 21 \\
\hline
\end{tabular}

Any information copied from such Reports and Statements may not be sold or used by any person for the purpose of soliciting contributions or for commercial purposes, other than using the name and address of any political committee to solicit contributions from such committee.

NAME OF COMMITTEE (In Full)

Friends of Herman Cain

A. Full Name (Last, First, Middle Initial)

\section{David West}

Mailing Address 2328 Simsbury Ct

\begin{tabular}{lcc}
\hline City & State & Zip Code \\
Naperville & IL & $60564-9559$
\end{tabular}

FEC ID number of contributing federal political committee.

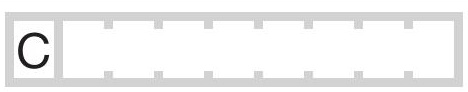

Name of Employer
Essential Products
Receipt For: 2012
X Primary
$\square$ Other (specify) General

Occupation

Sales

Election Cycle-to-Date

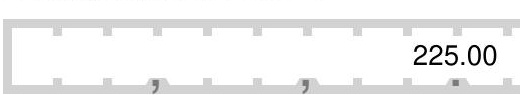

B. Full Name (Last, First, Middle Initial)

Max Arnold

Mailing Address 10510 Rivertown Road

\begin{tabular}{lcc}
\hline City & State & Zip Code \\
Fairburn & GA & $30213-2169$ \\
\hline
\end{tabular}

FEC ID number of contributing

federal political committee.

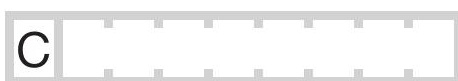

Name of Employer
Bruske Products Inc.
Receipt For: 2012
X Primary
Other (specify)

Occupation

Factory Rep.

Election Cycle-to-Date

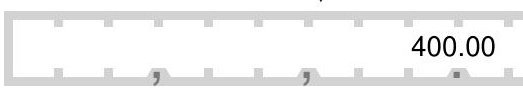

C. Full Name (Last, First, Middle Initial)

Diane Warpinski

Mailing Address 3252 Bitters Court

\begin{tabular}{lcc}
\hline City & State & Zip Code \\
Green Bay & WI & $54301-1545$
\end{tabular}

FEC ID number of contributing federal political committee.

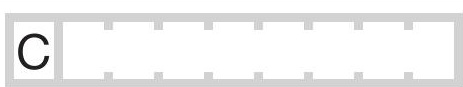

Name of Employer

Information Requested

\section{Occupation}

Information Requested

Receipt For: 2012

Х $\begin{aligned} & \text { Primary } \square \text { General } \\ & \text { Other (specify) }\end{aligned}$

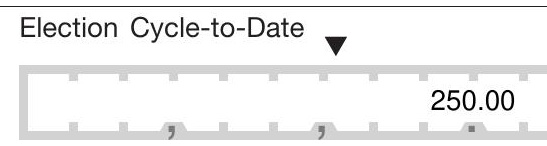

Amount of Each Receipt this Period

Transaction ID : AD560CA52097747C9828

Date of Receipt

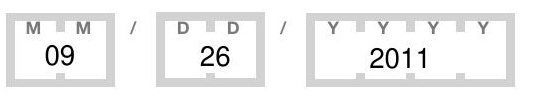

Amount of Each Receipt this Period
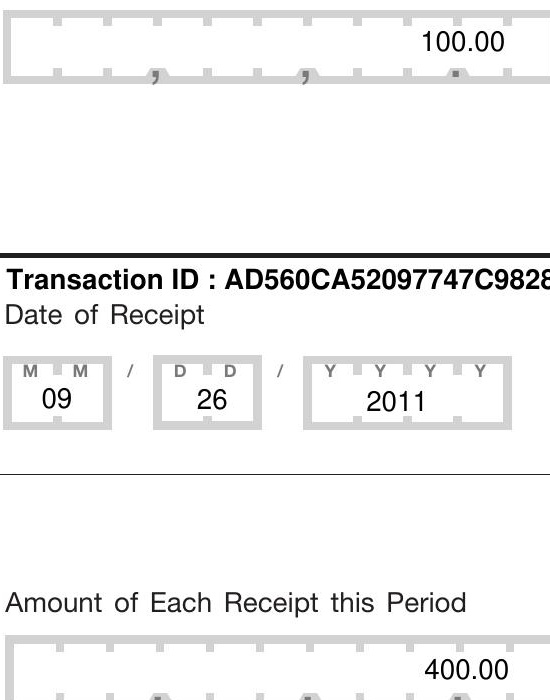

Transaction ID : AFC7339B049364B7CBDD Date of Receipt

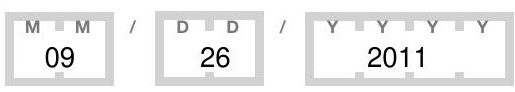

Amount of Each Receipt this Period

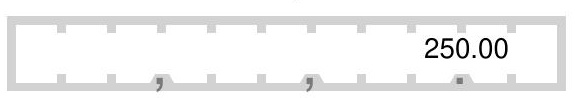

\section{Subtotal Of Receipts This Page (optional)}

Total This Period (last page this line number only) 


\section{SCHEDULE A-P} ITEMIZED RECEIPTS
Use separate schedule(s) for each category of the Detailed Summary Page

\begin{tabular}{|c|c|c|c|c|c|}
\hline \multicolumn{3}{|c|}{$\begin{array}{l}\text { FOR LINE NUMBER: } \\
\text { (check only one) }\end{array}$} & \multicolumn{3}{|c|}{ PAGE 817 / 1572} \\
\hline 16 & $X$ 17a & $17 b$ & $17 c$ & $17 d$ & 18 \\
\hline $19 a$ & $19 \mathrm{~b}$ & $20 a$ & $20 \mathrm{~b}$ & $20 c$ & 21 \\
\hline
\end{tabular}

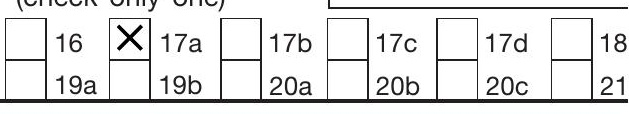

Any information copied from such Reports and Statements may not be sold or used by any person for the purpose of soliciting contributions or for commercial purposes, other than using the name and address of any political committee to solicit contributions from such committee.

NAME OF COMMITTEE (In Full)

\section{Friends of Herman Cain}

A. Full Name (Last, First, Middle Initial)

Mrs. Shelia B. Ponder

Mailing Address 120 Siege Ln

\begin{tabular}{lcc}
\hline City & State & Zip Code \\
Yorktown & VA & $23692-4055$
\end{tabular}

FEC ID number of contributing federal political committee.

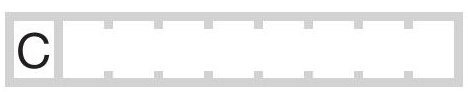

Name of Employer
None
Receipt For: 2012
X Primary $\quad \square$ General
$\square$ Other (specify)

Occupation

Retired

Election Cycle-to-Date

\subsection{0}

B. Full Name (Last, First, Middle Initial)

Marsha Krohn

Mailing Address 10 Cornelius Road

\begin{tabular}{lcc}
\hline City & State & Zip Code \\
Los Lunas & NM & $87031-9549$ \\
\hline
\end{tabular}

FEC ID number of contributing

federal political committee.

C

Name of Employer
Wausau Financial Systems
Receipt For: 2012
X Primary
Other (specify)

Occupation

Computer Programmer

Election Cycle-to-Date

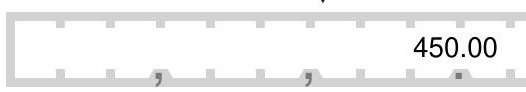

Transaction ID : A194FB8BAE43D4580A28

Date of Receipt

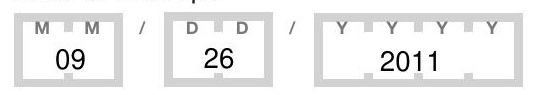

Amount of Each Receipt this Period

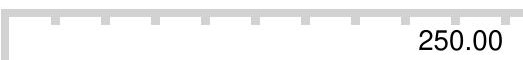

C. Full Name (Last, First, Middle Initial)

Caroline Ferguson

Mailing Address 189 Baldwin Ct.

\begin{tabular}{lcc}
\hline City & State & Zip Code \\
Newnan & GA & $30263-6951$ \\
\hline
\end{tabular}

FEC ID number of contributing federal political committee.

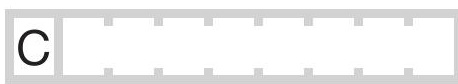

Name of Employer
Generis
Receipt For: 2012
Х Primary $\quad \square$ General
Other (specify)

\section{Occupation}

Office Assistant

Election Cycle-to-Date

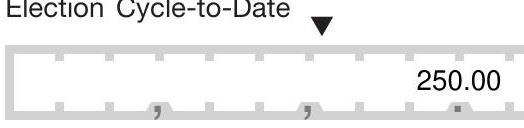

Transaction ID : A7621CD9AA51B4FB0805 Date of Receipt

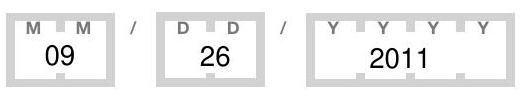

Amount of Each Receipt this Period

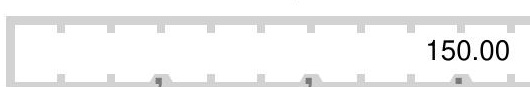

Transaction ID : A0F473FA4073549249B8

Date of Receipt

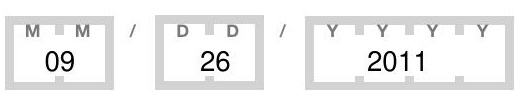

Amount of Each Receipt this Period

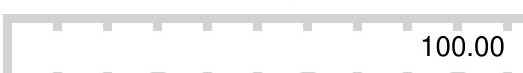

100.00

\section{Subtotal Of Receipts This Page (optional)}

Total This Period (last page this line number only) 


\section{SCHEDULE A-P} ITEMIZED RECEIPTS
Use separate schedule(s)

for each category of the

Detailed Summary Page

\begin{tabular}{|c|c|c|c|c|c|}
\hline \multicolumn{3}{|c|}{$\begin{array}{l}\text { FOR LINE NUMBER: } \\
\text { (check only one) }\end{array}$} & \multicolumn{3}{|c|}{ PAGE 818 / 1572} \\
\hline 16 & $X$ 17a & $17 b$ & $17 c$ & $17 d$ & 18 \\
\hline $19 a$ & $19 \mathrm{~b}$ & $20 a$ & $20 \mathrm{~b}$ & $20 c$ & 21 \\
\hline
\end{tabular}

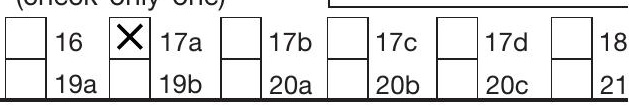

Any information copied from such Reports and Statements may not be sold or used by any person for the purpose of soliciting contributions or for commercial purposes, other than using the name and address of any political committee to solicit contributions from such committee.

NAME OF COMMITTEE (In Full)

\section{Friends of Herman Cain}

A. Full Name (Last, First, Middle Initial) HORACE MEDAY

Mailing Address 15300 PALM DRIVE SPC73

\begin{tabular}{lcc}
\hline City & State & Zip Code \\
Desert Hot Springs & CA & $92240-6939$ \\
\hline
\end{tabular}

FEC ID number of contributing federal political committee.

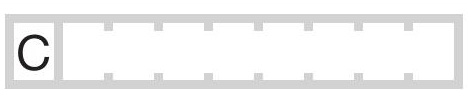

Name of Employer
Information Requested
Receipt For: 2012
X Primary
$\square$ Other (specify)

Occupation Information Requested Election Cycle-to-Date 250.00

B. Full Name (Last, First, Middle Initial) Judy Caines

Mailing Address 383 Jack Creek Rd

\begin{tabular}{lcc}
\hline City & State & Zip Code \\
Hiawassee & GA & $30546-2769$
\end{tabular}

FEC ID number of contributing

federal political committee.

C

Name of Employer
None
Receipt For: 2012
X Primary
Other (specify)

Occupation

Retired

Election Cycle-to-Date

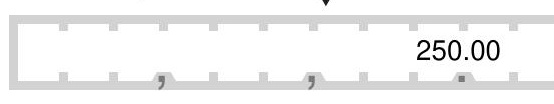

Transaction ID : A30B022116C864137B00

Date of Receipt

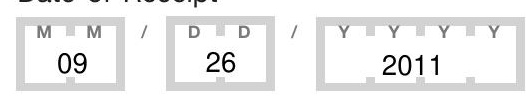

Amount of Each Receipt this Period

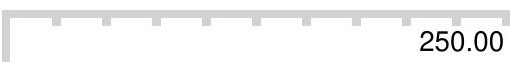

C. Full Name (Last, First, Middle Initial)

Genevieve DuBois

Mailing Address 265 Summer Walk Dr.

\begin{tabular}{lcc}
\hline City & State & Zip Code \\
Covington & GA & $30016-8805$
\end{tabular}

FEC ID number of contributing federal political committee.

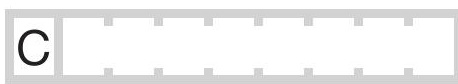

Name of Employer
None
Receipt For: 2012
Х Primary $\quad \square$ General
Other (specify)

Occupation

Homemaker

Election Cycle-to-Date

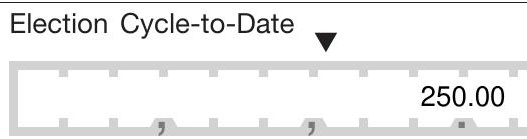

Transaction ID : A6A2F68272AC140C0A0B Date of Receipt

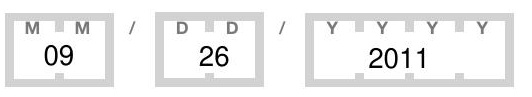

Amount of Each Receipt this Period

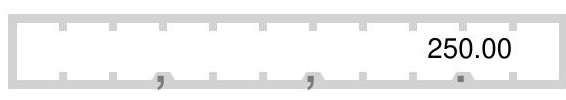

Transaction ID : ADD10E304793340DFB8A Date of Receipt

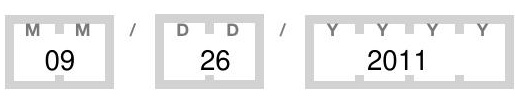

Amount of Each Receipt this Period

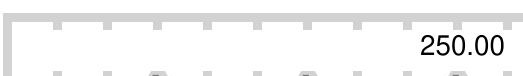

\section{Subtotal Of Receipts This Page (optional)}

Total This Period (last page this line number only) 


\section{SCHEDULE A-P} ITEMIZED RECEIPTS
Use separate schedule(s)

for each category of the

Detailed Summary Page
FOR LINE NUMBER: (check only one)

PAGE $819 / 1572$

\begin{tabular}{|c|c|c|c|c|c|}
\hline & & & & & \\
\hline 16 & X $17 a$ & $17 b$ & $17 c$ & $17 d$ & 18 \\
\hline $19 a$ & $19 b$ & $20 \mathrm{a}$ & $20 \mathrm{~b}$ & $20 \mathrm{c}$ & 21 \\
\hline
\end{tabular}

Any information copied from such Reports and Statements may not be sold or used by any person for the purpose of soliciting contributions or for commercial purposes, other than using the name and address of any political committee to solicit contributions from such committee.

NAME OF COMMITTEE (In Full)

Friends of Herman Cain

A. Full Name (Last, First, Middle Initial)

Lelia Farr

Mailing Address 1 Fair Oaks Dr

\begin{tabular}{lcc}
\hline City & State & Zip Code \\
Saint Louis & MO & $63124-1514$
\end{tabular}

FEC ID number of contributing federal political committee.

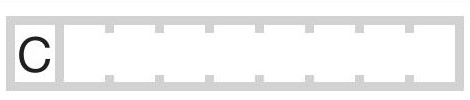

Name of Employer
None
Receipt For: 2012
X Primary $\quad \square$ General
$\square$ Other (specify)

Occupation

Retired

Election Cycle-to-Date

1000.00

B. Full Name (Last, First, Middle Initial)

Richard Bearss

Mailing Address 1602 River Rd

\begin{tabular}{lcc}
\hline City & State & Zip Code \\
Maumee & OH & $43537-3508$ \\
\hline
\end{tabular}

FEC ID number of contributing

federal political committee.

C

Name of Employer
Information Requested
Receipt For: 2012
X Primary
Other (specify)

Occupation

Information Requested

Election Cycle-to-Date

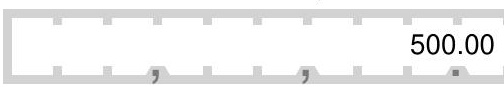

Transaction ID : A729E6287FE464380BF7

Date of Receipt

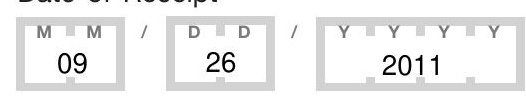

Amount of Each Receipt this Period

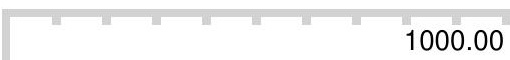

1000.00

C. Full Name (Last, First, Middle Initial)

ARTHUR DEBOLT

Mailing Address 3862 DENWOOD AVE.

\begin{tabular}{lcc}
\hline City & State & Zip Code \\
Los Alamitos & CA & $90720-3935$ \\
\hline
\end{tabular}

FEC ID number of contributing federal political committee.

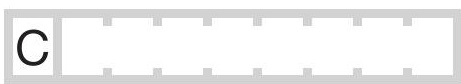

Name of Employer

Information Requested

\section{Occupation}

Information Requested

Receipt For: 2012

Х $\begin{aligned} & \text { Primary } \square \text { General } \\ & \text { Other (specify) }\end{aligned}$

Transaction ID : A402C79BB14944C6D962

Date of Receipt

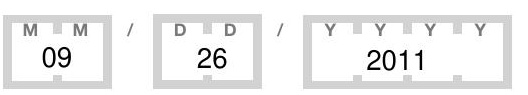

Amount of Each Receipt this Period

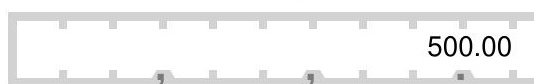

Transaction ID : AF637D64B50F84EFA97D Date of Receipt

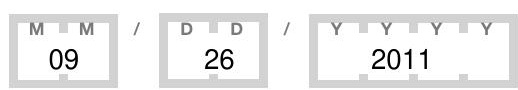

Amount of Each Receipt this Period

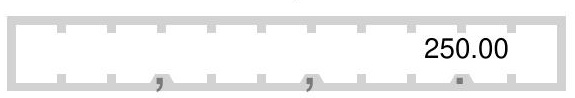

250.00

Subtotal Of Receipts This Page (optional).

Total This Period (last page this line number only) 


\section{SCHEDULE A-P} ITEMIZED RECEIPTS
Use separate schedule(s)

for each category of the

Detailed Summary Page
FOR LINE NUMBER: (check only one)

PAGE $820 / 1572$

\begin{tabular}{|c|c|c|c|c|c|}
\hline & & & & & \\
\hline 16 & X $17 a$ & $17 b$ & $17 c$ & $17 d$ & 18 \\
\hline $19 a$ & $19 b$ & $20 \mathrm{a}$ & $20 \mathrm{~b}$ & $20 \mathrm{c}$ & 21 \\
\hline
\end{tabular}

Any information copied from such Reports and Statements may not be sold or used by any person for the purpose of soliciting contributions or for commercial purposes, other than using the name and address of any political committee to solicit contributions from such committee.

NAME OF COMMITTEE (In Full)

\section{Friends of Herman Cain}

A. Full Name (Last, First, Middle Initial)

\section{Thomas McGovern}

Mailing Address 2435Tanglewood Dr.

\begin{tabular}{lcc}
\hline City & State & Zip Code \\
Lisle & IL & $60532-3447$
\end{tabular}

FEC ID number of contributing federal political committee.

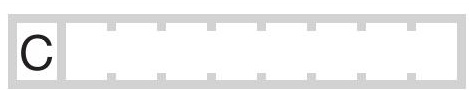

Name of Employer
Information Requested
Receipt For: 2012
X Primary
Other (specify) General

Occupation Information Requested

Election Cycle-to-Date

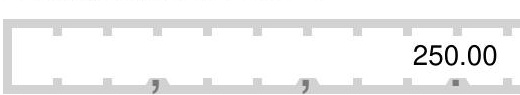

B. Full Name (Last, First, Middle Initial)

Charles Davis

Mailing Address 181 LAKESHORE DRIVE

\begin{tabular}{lcc}
\hline City & State & Zip Code \\
Americus & GA & $31719-8236$ \\
\hline
\end{tabular}

FEC ID number of contributing

federal political committee.

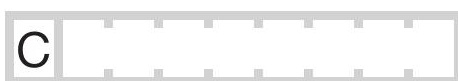

Name of Employer
Phoebe Physician Group
Receipt For: 2012
X Primary
Other (specify)

Occupation

Physician

Election Cycle-to-Date

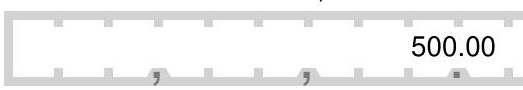

C. Full Name (Last, First, Middle Initial)

Ken Tankersley

Mailing Address 109 Thorpes Parish

\begin{tabular}{lcc}
\hline City & State & Zip Code \\
Williamsburg & VA & $23185-5119$
\end{tabular}

FEC ID number of contributing federal political committee.

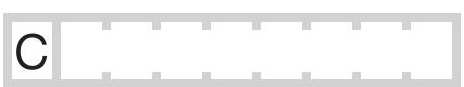

Name of Employer

Information Requested

\section{Occupation}

Information Requested

Receipt For: 2012

Х $\begin{aligned} & \text { Primary } \square \text { General } \\ & \text { Other (specify) }\end{aligned}$

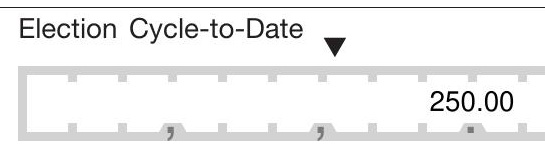

Amount of Each Receipt this Period

Transaction ID : A77FD92E079534C82B5A

Date of Receipt

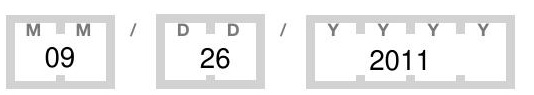

Amount of Each Receipt this Period
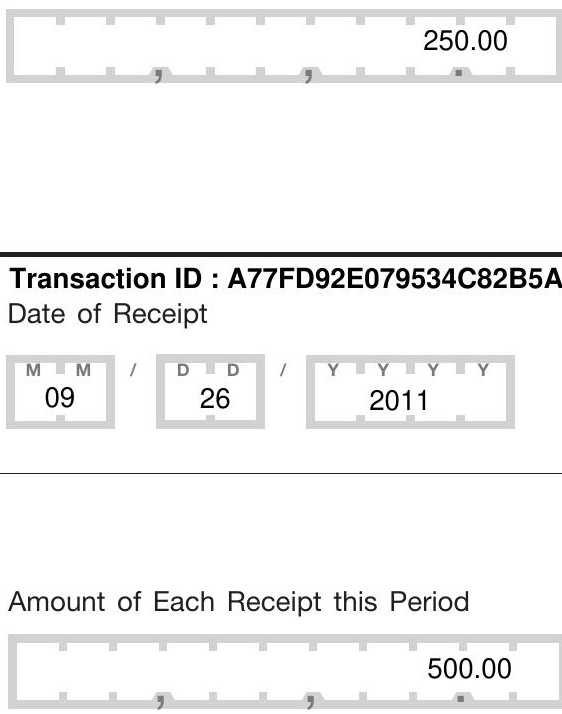

Transaction ID : A1B3D9D29D5084CE3BE7 Date of Receipt

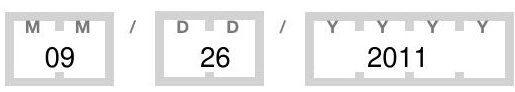

Amount of Each Receipt this Period

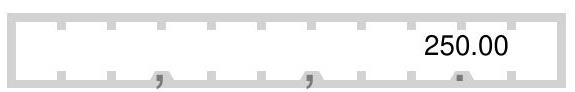

\section{Subtotal Of Receipts This Page (optional)}

Total This Period (last page this line number only) 


\section{SCHEDULE A-P} ITEMIZED RECEIPTS
Use separate schedule(s) for each category of the Detailed Summary Page

FOR LINE NUMBER:
(check only one)

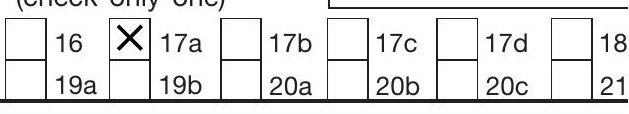

Any information copied from such Reports and Statements may not be sold or used by any person for the purpose of soliciting contributions or for commercial purposes, other than using the name and address of any political committee to solicit contributions from such committee.

NAME OF COMMITTEE (In Full)

\section{Friends of Herman Cain}

A. Full Name (Last, First, Middle Initial) Scott Buck

Mailing Address 4725 Belladonna Dr

\begin{tabular}{lcc}
\hline City & State & Zip Code \\
Fort Worth & TX & 76123-1844 \\
\hline
\end{tabular}

FEC ID number of contributing federal political committee.

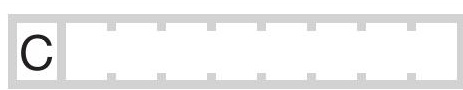

Name of Employer
Information Requested
Receipt For: 2012
X Primary
$\square$ Other (specify)

Occupation Information Requested

Election Cycle-to-Date 250.00

B. Full Name (Last, First, Middle Initial) Michael Burgess

Mailing Address 22865 Redwood Dr

\begin{tabular}{lcc}
\hline City & State & Zip Code \\
Lawrenceburg & IN & $47025-7433$
\end{tabular}

FEC ID number of contributing

federal political committee.

C

Name of Employer
Dearborn County Indiana
Receipt For: 2012
Primary
Other (specify)

Occupation

Veterans Service Officer

Election Cycle-to-Date

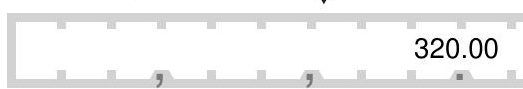

Transaction ID : A018D371BDC104E159D0

Date of Receipt

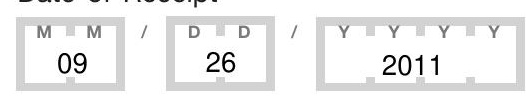

Amount of Each Receipt this Period

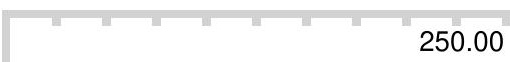

250.00

C. Full Name (Last, First, Middle Initial)

Marianne Mason

Mailing Address 30 Tall Oaks Trail

\begin{tabular}{lcc}
\hline City & State & Zip Code \\
Austin & TX & $78737-9306$
\end{tabular}

FEC ID number of contributing federal political committee.

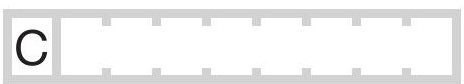

Name of Employer
MMA Int. LLC
Receipt For: 2012
Х Primary $\quad \square$ General
Other (specify)

Occupation

Accountant

Election Cycle-to-Date
Transaction ID : A71F0602208DE4A60883

Date of Receipt

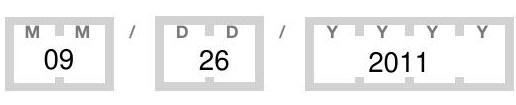

Amount of Each Receipt this Period

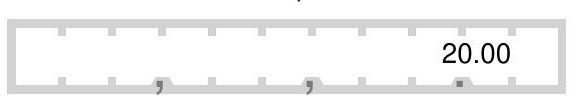

Transaction ID : AFCDFA118F64E43FB8CC Date of Receipt

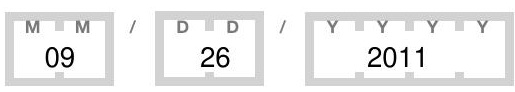

Amount of Each Receipt this Period

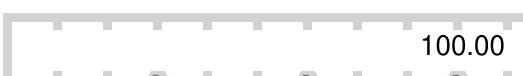

\section{Subtotal Of Receipts This Page (optional)}

Total This Period (last page this line number only) 
SCHEDULE A-P ITEMIZED RECEIPTS
Use separate schedule(s) for each category of the Detailed Summary Page
FOR LINE NUMBER: (check only one)

PAGE 822 / 1572

\begin{tabular}{|c|c|c|c|c|c|c|}
\hline & & & & & & \\
\hline 16 & $\lambda$ & $17 \mathrm{a}$ & $17 \mathrm{~b}$ & $17 \mathrm{c}$ & $-17 d$ & -18 \\
\hline $19 a$ & & $19 b$ & $20 a$ & $20 \mathrm{~b}$ & $20 \mathrm{c}$ & 21 \\
\hline
\end{tabular}

Any information copied from such Reports and Statements may not be sold or used by any person for the purpose of soliciting contributions or for commercial purposes, other than using the name and address of any political committee to solicit contributions from such committee.

NAME OF COMMITTEE (In Full)

\section{Friends of Herman Cain}

A. Full Name (Last, First, Middle Initial) James Bowers

Mailing Address 4301 Vine Avenue

\begin{tabular}{lcc}
\hline City & State & Zip Code \\
Sioux City & IA & $51106-1958$
\end{tabular}

FEC ID number of contributing federal political committee.

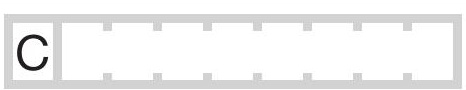

Name of Employer
Bowers Art
Receipt For: 2012
X Primary $\quad$ General
Other (specify)

Occupation Artist

Election Cycle-to-Date

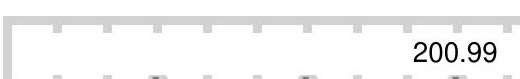

B. Full Name (Last, First, Middle Initial)

Marc Shapiro

Mailing Address 609 Atlantic St

\begin{tabular}{lcc}
\hline City & State & Zip Code \\
Melbourne Beach & FL & $32951-2013$
\end{tabular}

FEC ID number of contributing

federal political committee.

C

Name of Employer
Information Requested
Receipt For: 2012
X Primary
Other (specify)

Occupation

Information Requested

Election Cycle-to-Date

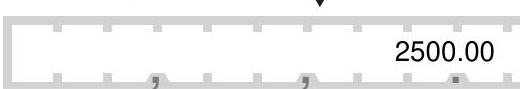

Transaction ID : ACFE66796A2C948E9B29

Date of Receipt

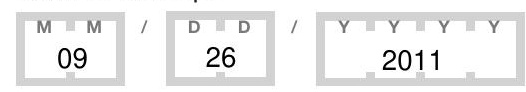

Amount of Each Receipt this Period

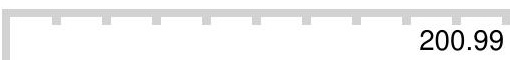

C. Full Name (Last, First, Middle Initial)

Carl Ploeger

Mailing Address 404 CR 2255

\begin{tabular}{lcc}
\hline City & State & Zip Code \\
Valley View & TX & $76272-7689$
\end{tabular}

FEC ID number of contributing federal political committee.

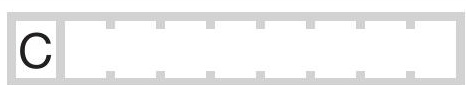

Name of Employer
Retired
Receipt For: 2012
Х Primary $\square$ General
Other (specify)

Occupation

Retired

Election Cycle-to-Date

Transaction ID : A1EA343320C0C4AC18B0

Date of Receipt

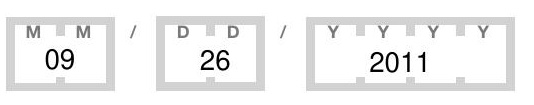

Amount of Each Receipt this Period

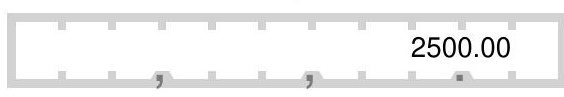

Transaction ID : AA784F823F62D4FEFBAA Date of Receipt

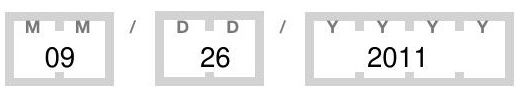

Amount of Each Receipt this Period

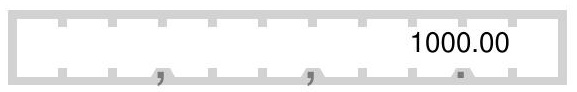

1500.00

\section{Subtotal Of Receipts This Page (optional)}

Total This Period (last page this line number only) 
SCHEDULE A-P ITEMIZED RECEIPTS
Use separate schedule(s) for each category of the Detailed Summary Page
FOR LINE NUMBER: (check only one)

PAGE $823 / 1572$

\begin{tabular}{|c|c|c|c|c|c|c|}
\hline & & & & & & \\
\hline 16 & $\lambda$ & $17 \mathrm{a}$ & $17 \mathrm{~b}$ & $17 \mathrm{c}$ & $-17 d$ & -18 \\
\hline $19 a$ & & $19 b$ & $20 a$ & $20 \mathrm{~b}$ & $20 \mathrm{c}$ & 21 \\
\hline
\end{tabular}

Any information copied from such Reports and Statements may not be sold or used by any person for the purpose of soliciting contributions or for commercial purposes, other than using the name and address of any political committee to solicit contributions from such committee.

NAME OF COMMITTEE (In Full)

\section{Friends of Herman Cain}

A. Full Name (Last, First, Middle Initial) andrews oakey

Mailing Address 4560 se 5th place \#208

\begin{tabular}{lcc}
\hline City & State & Zip Code \\
Cape Coral & FL & $33904-2516$ \\
\hline
\end{tabular}

FEC ID number of contributing federal political committee.

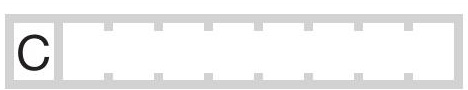

Name of Employer
Information Requested
Receipt For: 2012
X Primary
Other (specify) General

Occupation Information Requested

Election Cycle-to-Date

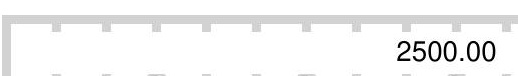

B. Full Name (Last, First, Middle Initial)

\section{Elizabeth Cole}

Mailing Address 852 N FM 1194

\begin{tabular}{lcc}
\hline City & State & Zip Code \\
Lufkin & TX & $75904-0505$ \\
\hline
\end{tabular}

FEC ID number of contributing

federal political committee.

C

Name of Employer
Information Requested
Receipt For: 2012
Primary
Other (specify)

Name of Employer

Information Requested

Receipt For: 2012

Other (specify)

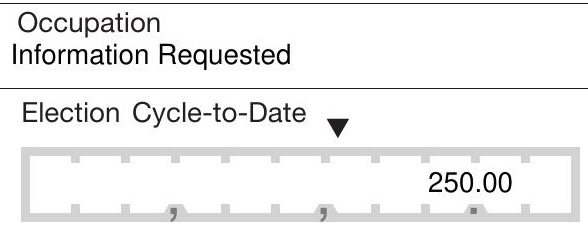

Transaction ID : A585F2CF70795492687B

Date of Receipt

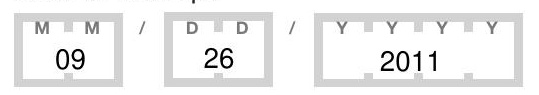

Amount of Each Receipt this Period

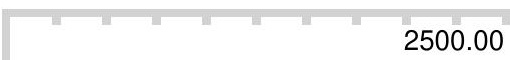

2500.00

Amount of Each Receipt this Period

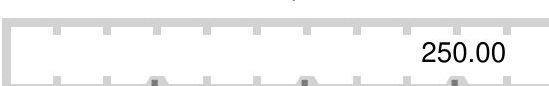

Transaction ID : A0A1F46C062074DCDB11 Date of Receipt

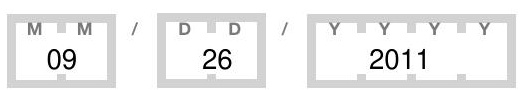

Amount of Each Receipt this Period

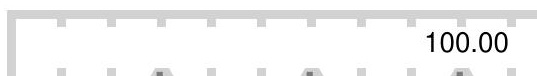

Transaction ID : A93339E9852024B20939

Date of Receipt

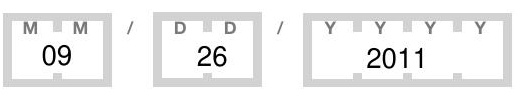

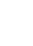

Name of Employer
CoNetrix
Receipt For: 2012
X Primary $\quad \square$ General
Other (specify)

$\begin{array}{cc}\text { State } & \text { Zip Code } \\ \text { TX } & 79424-6791\end{array}$

C

Occupation

Network Engineer

Election Cycle-to-Date

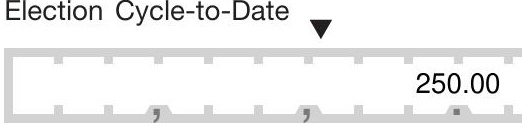

Subtotal Of Receipts This Page (optional)

2850.00

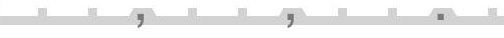

Total This Period (last page this line number only) 
SCHEDULE A-P ITEMIZED RECEIPTS
Use separate schedule(s) for each category of the Detailed Summary Page
FOR LINE NUMBER: (check only one)

PAGE 824 / 1572

\begin{tabular}{|c|c|c|c|c|c|}
\hline & & & & & \\
\hline 16 & $\begin{array}{l}\mathbf{X} \\
17 a\end{array}$ & $17 b$ & $17 c$ & $17 d$ & 18 \\
\hline $19 a$ & $19 \mathrm{~b}$ & $20 \mathrm{a}$ & $20 \mathrm{~b}$ & $20 \mathrm{c}$ & 21 \\
\hline
\end{tabular}

Any information copied from such Reports and Statements may not be sold or used by any person for the purpose of soliciting contributions or for commercial purposes, other than using the name and address of any political committee to solicit contributions from such committee.

NAME OF COMMITTEE (In Full)

\section{Friends of Herman Cain}

A. Full Name (Last, First, Middle Initial)

ZuAnn Hogan-Tuell

Mailing Address 31596 County Road 37

\begin{tabular}{lcc}
\hline City & State & Zip Code \\
Greeley & CO & 80631 \\
\hline
\end{tabular}

FEC ID number of contributing

federal political committee.

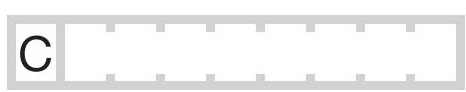

Name of Employer
Information Requested
Receipt For: 2012
X Primary
Other (specify) General

Occupation

Information Requested

Election Cycle-to-Date

240.00

B. Full Name (Last, First, Middle Initial)

Diane Nuno

Mailing Address 1535 Morningside Dr

\begin{tabular}{lcc}
\hline City & State & Zip Code \\
Laguna Beach & CA & $92651-2849$
\end{tabular}

FEC ID number of contributing

federal political committee.

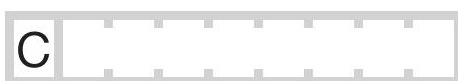

Name of Employer
n/a
Receipt For: 2012
X Primary
Other (specify)

Occupation

Retired

Election Cycle-to-Date

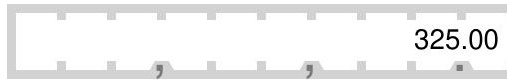

C. Full Name (Last, First, Middle Initial)

Miichael Heslin

Mailing Address 311 park central east

\begin{tabular}{lcc}
\hline City & State & Zip Code \\
Springfield & MO & $65806-2206$
\end{tabular}

FEC ID number of contributing

federal political committee.

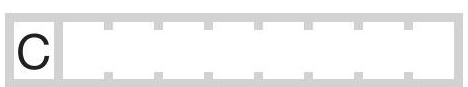

Name of Employer

Self Employed

Occupation

Receipt For: 2012

Х $\begin{aligned} & \text { Primary } \square \text { General } \\ & \text { Other (specify) }\end{aligned}$

Small Business Owner

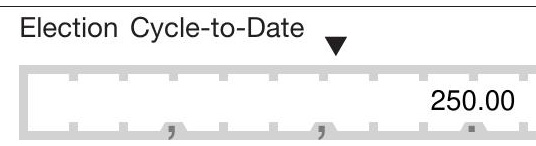

Amount of Each Receipt this Period

Transaction ID : AE47411282D26467F82E

Date of Receipt

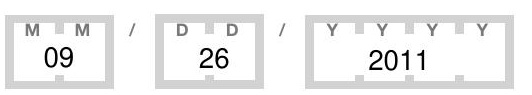

Amount of Each Receipt this Period

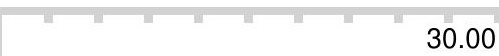

30.00

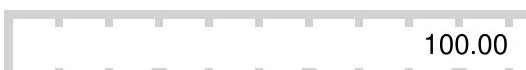

Transaction ID : AC2E52DB686214B62B38

Date of Receipt

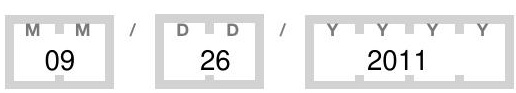

Amount of Each Receipt this Period

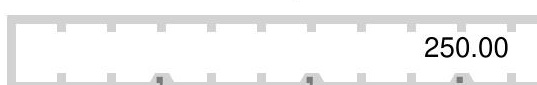

380.00

Subtotal Of Receipts This Page (optional)

Total This Period (last page this line number only) 
SCHEDULE A-P ITEMIZED RECEIPTS
Use separate schedule(s) for each category of the Detailed Summary Page
FOR LINE NUMBER: (check only one)

PAGE $825 / 1572$

\begin{tabular}{|c|c|c|c|c|c|}
\hline & & & & & \\
\hline 16 & $\begin{array}{l}\mathbf{X} \\
17 a\end{array}$ & $17 b$ & $17 c$ & $17 d$ & 18 \\
\hline $19 a$ & $19 \mathrm{~b}$ & $20 \mathrm{a}$ & $20 \mathrm{~b}$ & $20 \mathrm{c}$ & 21 \\
\hline
\end{tabular}

Any information copied from such Reports and Statements may not be sold or used by any person for the purpose of soliciting contributions or for commercial purposes, other than using the name and address of any political committee to solicit contributions from such committee.

NAME OF COMMITTEE (In Full)

\section{Friends of Herman Cain}

A. Full Name (Last, First, Middle Initial) James Reed

Mailing Address 614 98th Avenue SE

\begin{tabular}{lcc}
\hline City & State & Zip Code \\
Bellevue & WA & $98004-6567$
\end{tabular}

FEC ID number of contributing federal political committee.

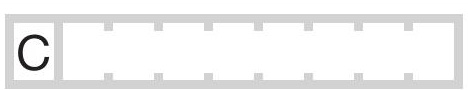

\begin{tabular}{l} 
Name of Employer \\
None \\
Receipt For: 2012 \\
X Primary $\quad$ General \\
\hline Other (specify)
\end{tabular}

Occupation Retired Election Cycle-to-Date

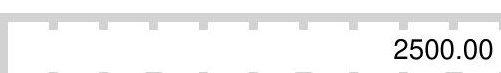

B. Full Name (Last, First, Middle Initial)

Dorothy Rowley

Mailing Address HC 65 Box 6335

\begin{tabular}{lcc}
\hline City & State & Zip Code \\
Amado & AZ & 85645-9614 \\
\hline
\end{tabular}

FEC ID number of contributing

federal political committee.

C

Name of Employer
Information Requested
Receipt For: 2012
Primary
Other (specify)

\section{Occupation}

Information Requested

Election Cycle-to-Date

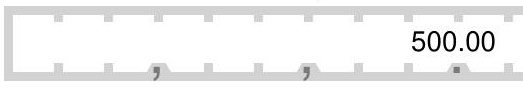

C. Full Name (Last, First, Middle Initial)

Dennis Miller

Mailing Address 1735 Glen Oaks Dr.

\begin{tabular}{lcc}
\hline City & State & Zip Code \\
Santa Barbara & CA & $93108-2111$
\end{tabular}

FEC ID number of contributing federal political committee.

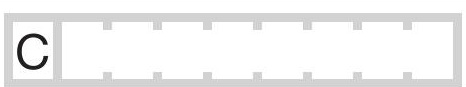

Name of Employer
Information Requested
Receipt For: 2012
X Primary $\quad \square$ General
Other (specify)

\section{Occupation}

Information Requested

Election Cycle-to-Date

Transaction ID : A35B35E578CC24E9D90C

Date of Receipt

Amount of Each Receipt this Period

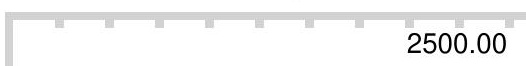

2500.00

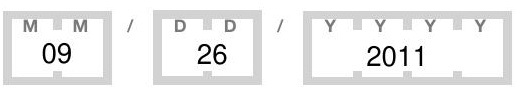

Amount of Each Receipt this Period

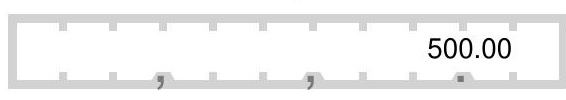

Transaction ID : A46C9BB14587F4803821

Date of Receipt

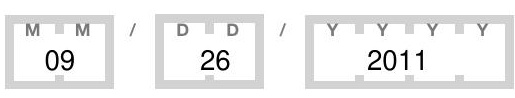

Amount of Each Receipt this Period

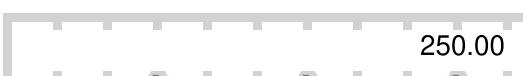

250.00

\section{Subtotal Of Receipts This Page (optional)}

Total This Period (last page this line number only) 


\section{SCHEDULE A-P} ITEMIZED RECEIPTS
Use separate schedule(s)

for each category of the

Detailed Summary Page
FOR LINE NUMBER: (check only one)

Any information or for commercial purposes, other than using the name and address of any political committee to solicit contributions from such committee.

NAME OF COMMITTEE (In Full)

Friends of Herman Cain

A. Full Name (Last, First, Middle Initial)

Evelyn Twigg-Smith

Mailing Address P.O. Box 437356

\begin{tabular}{lcc}
\hline City & State & Zip Code \\
Kamuela & HI & $96743-3056$
\end{tabular}

FEC ID number of contributing federal political committee.

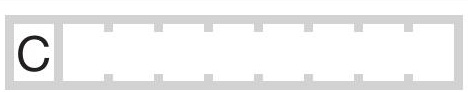

Name of Employer
Self-Employed
Receipt For: 2012
X Primary
$\square$ Other (specify) General

Occupation investor

Election Cycle-to-Date

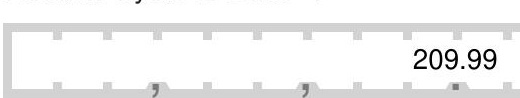

B. Full Name (Last, First, Middle Initial)

Roz McCoy

Mailing Address 12825 220th Road

\begin{tabular}{lcc}
\hline City & State & Zip Code \\
Chanute & KS & $66720-6448$ \\
\hline
\end{tabular}

FEC ID number of contributing

federal political committee.

C

Name of Employer
Information Requested
Receipt For: 2012
Primary
Other (specify)

Occupation

Information Requested

Election Cycle-to-Date

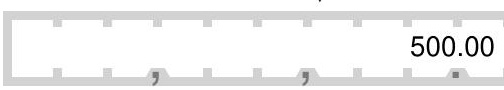

Transaction ID : AA33E0491DBFE46DC8D1

Date of Receipt

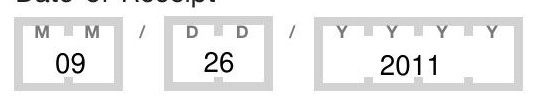

Amount of Each Receipt this Period

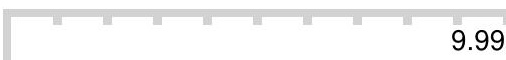

C. Full Name (Last, First, Middle Initial)

Thomas Cutcher

Mailing Address $75 \mathrm{~N}$ Wexford Dr E

\begin{tabular}{lcc}
\hline City & State & Zip Code \\
Oak Harbor & OH & $43449-9386$
\end{tabular}

FEC ID number of contributing federal political committee.

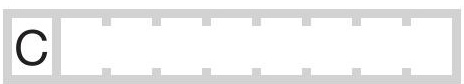

Name of Employer

Information Requested

\section{Occupation}

Information Requested

Receipt For: 2012

Х $\begin{aligned} & \text { Primary } \\ & \text { Other (specify) }\end{aligned}$

Transaction ID : A30AD9789625547D185D

Date of Receipt

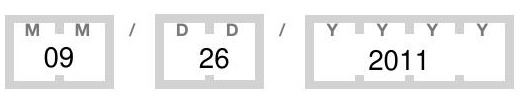

Amount of Each Receipt this Period

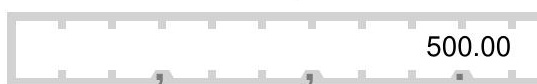

Transaction ID : AEE16DEC434484F18B14 Date of Receipt

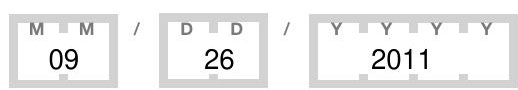

Amount of Each Receipt this Period

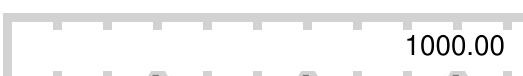

1000.00

\section{Subtotal Of Receipts This Page (optional)}

Total This Period (last page this line number only) 
SCHEDULE A-P ITEMIZED RECEIPTS
Use separate schedule(s) for each category of the Detailed Summary Page
FOR LINE NUMBER: (check only one)

PAGE 827 / 1572

\begin{tabular}{|c|c|c|c|c|c|}
\hline & & & & & \\
\hline 16 & $\begin{array}{l}\mathbf{X} \\
17 a\end{array}$ & $17 b$ & $17 c$ & $17 d$ & 18 \\
\hline $19 a$ & $19 \mathrm{~b}$ & $20 \mathrm{a}$ & $20 \mathrm{~b}$ & $20 \mathrm{c}$ & 21 \\
\hline
\end{tabular}

Any information copied from such Reports and Statements may not be sold or used by any person for the purpose of soliciting contributions or for commercial purposes, other than using the name and address of any political committee to solicit contributions from such committee.

NAME OF COMMITTEE (In Full)

\section{Friends of Herman Cain}

A. Full Name (Last, First, Middle Initial)

Ms. Brenda Smith

Mailing Address 4271 Garmon Rd

\begin{tabular}{lcc}
\hline City & State & Zip Code \\
Atlanta & GA & $30327-3833$
\end{tabular}

FEC ID number of contributing federal political committee.

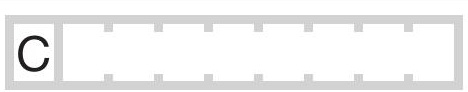

Name of Employer
Ga. State Un
Receipt For: 2012
X Primary $\quad$ General
Other (specify)

Occupation Retired

Election Cycle-to-Date

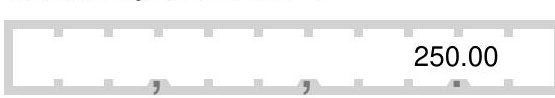

B. Full Name (Last, First, Middle Initial)

Christopher Blair

Mailing Address 21 8th Ave

\begin{tabular}{lcc}
\hline City & State & Zip Code \\
Milford & CT & $06460-5328$
\end{tabular}

FEC ID number of contributing

federal political committee.

C

Name of Employer
AKUSTIKS
Receipt For: 2012
X Primary
Other (specify) General

Occupation

consultant

Election Cycle-to-Date

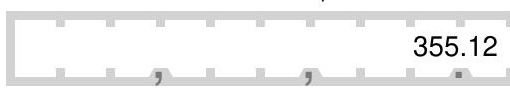

Transaction ID : A85EC0BF7BB2241C3A7A

Date of Receipt

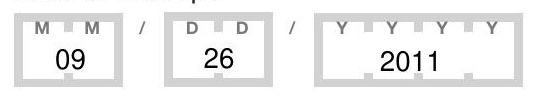

Amount of Each Receipt this Period

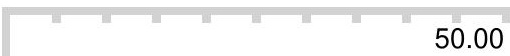

50.00

C. Full Name (Last, First, Middle Initial)

Eugene Goldsmith

Mailing Address 5840 Church Road

\begin{tabular}{lcc}
\hline City & State & Zip Code \\
Ferndale & WA & $98248-9678$
\end{tabular}

FEC ID number of contributing federal political committee.

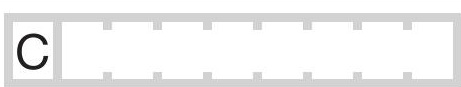

Name of Employer

Information Requested

Occupation

Information Requested

Receipt For: 2012

Х $\begin{aligned} & \text { Primary } \\ & \text { Other (specify) }\end{aligned}$

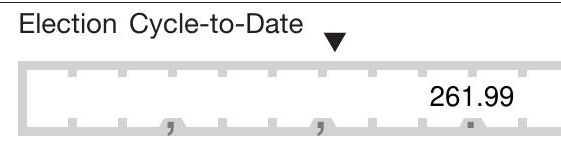

Amount of Each Receipt this Period

Transaction ID : A20AB3491CD3746348F5

Date of Receipt
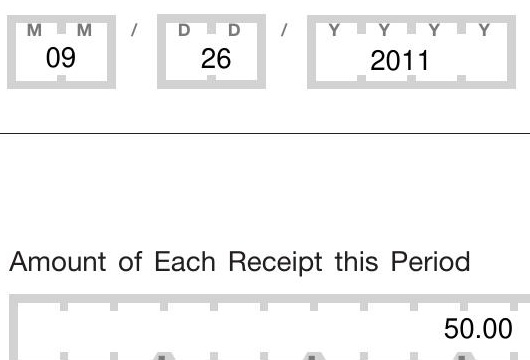

Transaction ID : A265D6509FC8E411DB08

Date of Receipt

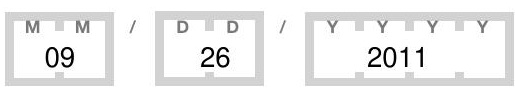

Amount of Each Receipt this Period

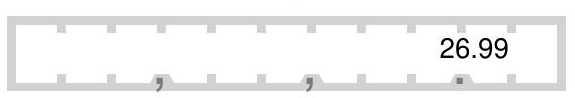

Subtotal Of Receipts This Page (optional)

126.99

Total This Period (last page this line number only) 
SCHEDULE A-P ITEMIZED RECEIPTS
Use separate schedule(s) for each category of the Detailed Summary Page
FOR LINE NUMBER: (check only one)

PAGE $828 / 1572$

\begin{tabular}{|c|c|c|c|c|c|}
\hline & & & & & \\
\hline 16 & $\begin{array}{l}\mathbf{X} \\
17 a\end{array}$ & $17 b$ & $17 c$ & $17 d$ & 18 \\
\hline $19 a$ & $19 \mathrm{~b}$ & $20 \mathrm{a}$ & $20 \mathrm{~b}$ & $20 \mathrm{c}$ & 21 \\
\hline
\end{tabular}

Any information copied from such Reports and Statements may not be sold or used by any person for the purpose of soliciting contributions or for commercial purposes, other than using the name and address of any political committee to solicit contributions from such committee.

NAME OF COMMITTEE (In Full)

\section{Friends of Herman Cain}

A. Full Name (Last, First, Middle Initial)

\section{Tim Blevins}

Mailing Address 3432 Conley Downs Drive

\begin{tabular}{lcc}
\hline City & State & Zip Code \\
Powder Springs & GA & $30127-1199$ \\
\hline
\end{tabular}

FEC ID number of contributing

federal political committee.

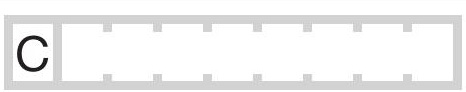

Name of Employer
The Coca-Cola Company
Receipt For: 2012
X Primary
Other (specify) General

Occupation

Learning \& Development

Election Cycle-to-Date $\boldsymbol{\nabla}$

500.00

B. Full Name (Last, First, Middle Initial)

Alec Jason

Mailing Address PO Box 375

\begin{tabular}{lcc}
\hline City & State & Zip Code \\
Pinole & CA & $94564-0375$ \\
\hline
\end{tabular}

FEC ID number of contributing

federal political committee.

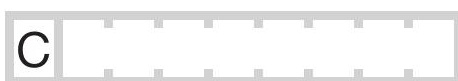

Name of Employer
Information Requested
Receipt For: 2012
X Primary
Other (specify)

\section{Occupation}

Information Requested

Election Cycle-to-Date

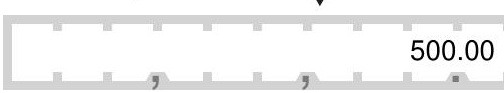

Transaction ID : AABEF47C4E2C54173AE3

Date of Receipt

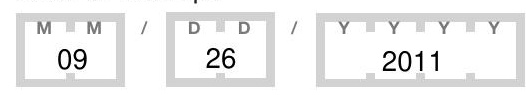

Amount of Each Receipt this Period

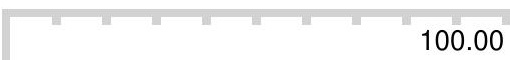

Amount of Each Receipt this Period

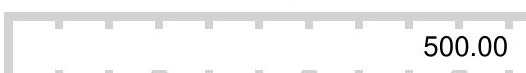

C. Full Name (Last, First, Middle Initial)

Barbara Haley

Mailing Address 1717 Old Shell Road

\begin{tabular}{lcc}
\hline City & State & Zip Code \\
Mobile & AL & $36604-1323$
\end{tabular}

FEC ID number of contributing

federal political committee.

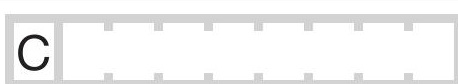

Name of Employer

Occupation

Alabama Administrators

CPA

Receipt For: 2012

Х $\begin{aligned} & \text { Primary } \\ & \text { Other (specify) }\end{aligned}$

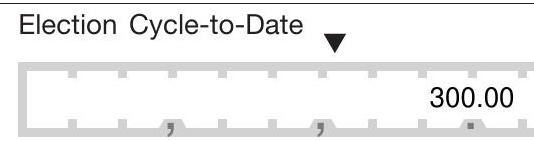

Amount of Each Receipt this Period

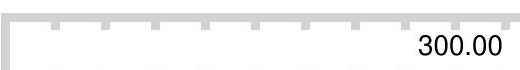

Transaction ID : A0D4C33C9F55544A9865

Date of Receipt

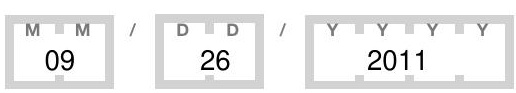

Subtotal Of Receipts This Page (optional)

900.00

Total This Period (last page this line number only) 


\section{SCHEDULE A-P} ITEMIZED RECEIPTS
Use separate schedule(s) for each category of the Detailed Summary Page

FOR LINE NUMBER:
(check only one)

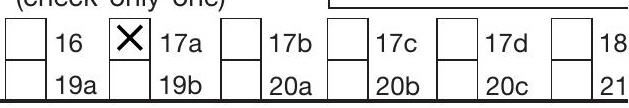

Any information copied from such Reports and Statements may not be sold or used by any person for the purpose of soliciting contributions or for commercial purposes, other than using the name and address of any political committee to solicit contributions from such committee.

NAME OF COMMITTEE (In Full)

\section{Friends of Herman Cain}

A. Full Name (Last, First, Middle Initial)

Ty Rulli

Mailing Address 6251 Cartwright Ave

\begin{tabular}{lcc}
\hline City & State & Zip Code \\
North Hollywood & CA & $91606-3801$
\end{tabular}

FEC ID number of contributing federal political committee.

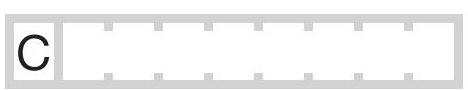

Name of Employer
Information Requested
Receipt For: 2012
X Primary
Other (specify) General

Occupation Information Requested

Election Cycle-to-Date 470.00

B. Full Name (Last, First, Middle Initial)

Amy E Schwartz

Mailing Address 120 Monticello Sq

\begin{tabular}{lcc}
\hline City & State & Zip Code \\
Winchester & VA & $22602-6293$
\end{tabular}

FEC ID number of contributing

federal political committee.

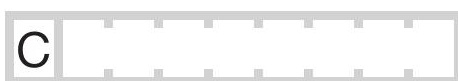

Name of Employer
Federal Bureau of Investigation
Receipt For: 2012
X Primary
Other (specify)

Occupation

Program Analyst

Election Cycle-to-Date

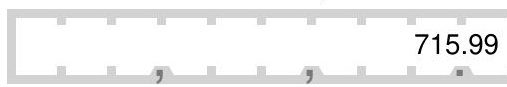

Transaction ID : ABBAB213991D148FE8F4

Date of Receipt

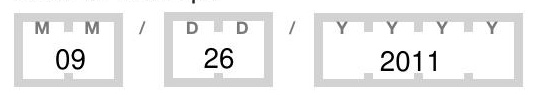

Amount of Each Receipt this Period

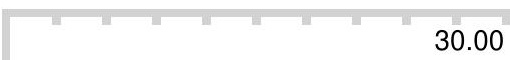

30.00
Amount of Each Receipt this Period

Transaction ID : AF14567FE162A4E00917

Date of Receipt
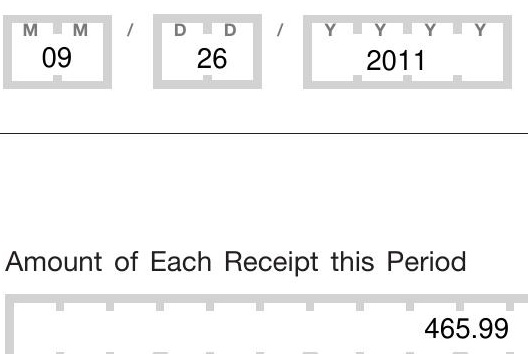

C. Full Name (Last, First, Middle Initial)

Ilona English

Mailing Address 9 Runyon Mill Rd

\begin{tabular}{lcc}
\hline City & State & Zip Code \\
Ringoes & NJ & $08551-1514$
\end{tabular}

FEC ID number of contributing federal political committee.

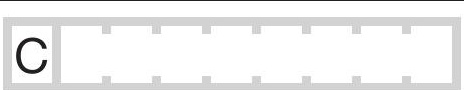

Name of Employer

Information Requested

\section{Occupation}

Information Requested

Receipt For: 2012

Х $\begin{aligned} & \text { Primary } \square \text { General } \\ & \text { Other (specify) }\end{aligned}$

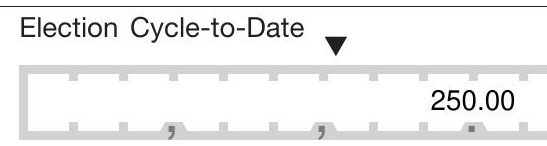

Transaction ID : A34B4F2C49660409996B

Date of Receipt

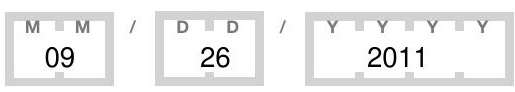

Amount of Each Receipt this Period

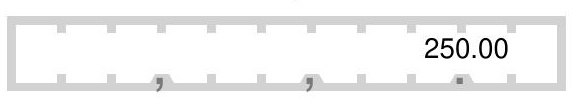

Subtotal Of Receipts This Page (optional).

745.99

Total This Period (last page this line number only) 


\section{SCHEDULE A-P} ITEMIZED RECEIPTS
Use separate schedule(s) for each category of the Detailed Summary Page

FOR LINE NUMBER:
(check only one)

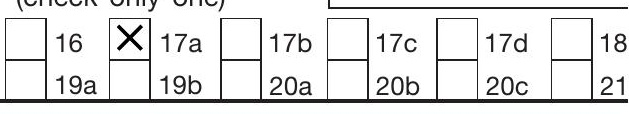

Any information copied from such Reports and Statements may not be sold or used by any person for the purpose of soliciting contributions or for commercial purposes, other than using the name and address of any political committee to solicit contributions from such committee.

NAME OF COMMITTEE (In Full)

\section{Friends of Herman Cain}

A. Full Name (Last, First, Middle Initial)

Carl Longley

Mailing Address 302 W. 2nd St.

\begin{tabular}{lcc}
\hline City & State & Zip Code \\
Cassville & MO & $65625-1636$
\end{tabular}

FEC ID number of contributing federal political committee.

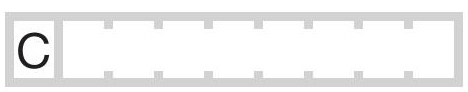

Name of Employer
Information Requested
Receipt For: 2012
X Primary
Other (specify) General

Occupation Information Requested

Election Cycle-to-Date 1000.00

B. Full Name (Last, First, Middle Initial) Thomas Moran

Mailing Address 340 West Street

\begin{tabular}{lcc}
\hline City & State & Zip Code \\
Naples & FL & $34108-2912$ \\
\hline
\end{tabular}

FEC ID number of contributing

federal political committee.

C

Name of Employer
Wells Fargo Advisors
Receipt For: 2012
Primary
Other (specify)

Occupation

Director-Investments

Election Cycle-to-Date

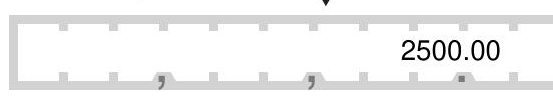

C. Full Name (Last, First, Middle Initial)

Brian Collins

Mailing Address 2405 Hunter Hills Ln

\begin{tabular}{lcc}
\hline City & State & Zip Code \\
Cookeville & TN & $38506-3428$ \\
\hline
\end{tabular}

FEC ID number of contributing federal political committee.

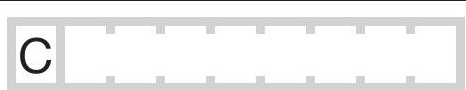

Name of Employer
Self Employed
Receipt For: 2012
X Primary
Other (specify) General

Transaction ID : AF671D304FB624CD8AD3

Date of Receipt

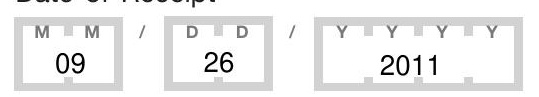

Amount of Each Receipt this Period

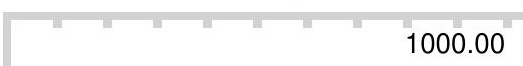

Amount of Each Receipt this Period

Transaction ID : A6975D3796E3848AE8F3

Date of Receipt
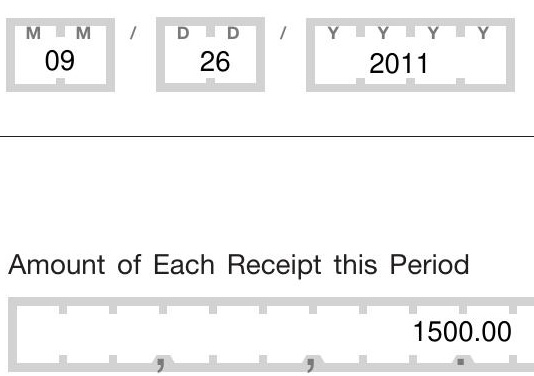

Transaction ID : AE649FC6307154685BF2 Date of Receipt

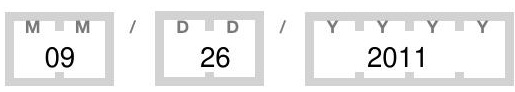

Amount of Each Receipt this Period

$\begin{aligned} & \text { Occupation } \\ & \text { courier }\end{aligned}$
Election Cycle-to-Date

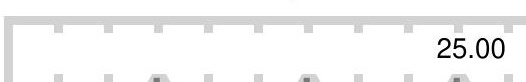

25.00

\section{Subtotal Of Receipts This Page (optional)}

Total This Period (last page this line number only) 


\section{SCHEDULE A-P} ITEMIZED RECEIPTS
Use separate schedule(s)

for each category of the

Detailed Summary Page
FOR LINE NUMBER: (check only one)

PAGE $831 / 1572$

\begin{tabular}{|c|c|c|c|c|c|}
\hline & & & & & \\
\hline 16 & X $17 a$ & $17 b$ & $17 c$ & $17 d$ & 18 \\
\hline $19 a$ & $19 b$ & $20 \mathrm{a}$ & $20 \mathrm{~b}$ & $20 \mathrm{c}$ & 21 \\
\hline
\end{tabular}

Any information copied from such Reports and Statements may not be sold or used by any person for the purpose of soliciting contributions or for commercial purposes, other than using the name and address of any political committee to solicit contributions from such committee.

NAME OF COMMITTEE (In Full)

Friends of Herman Cain

A. Full Name (Last, First, Middle Initial)

KEN THOMPSON

Mailing Address P.O. OX 1017

\begin{tabular}{lcc}
\hline City & State & Zip Code \\
Zolfo Springs & FL & 33890
\end{tabular}

FEC ID number of contributing

federal political committee.

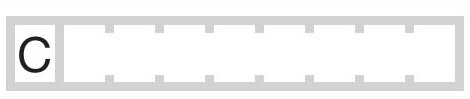

Name of Employer
self
Receipt For: 2012
X Primary $\quad \square$ General
Other (specify)

Occupation

self

Election Cycle-to-Date

299.90

B. Full Name (Last, First, Middle Initial)

clint langley

Mailing Address 602 ebissell

\begin{tabular}{lcc}
\hline City & State & Zip Code \\
Hugo & OK & $74743-7046$
\end{tabular}

FEC ID number of contributing

federal political committee.

C

Name of Employer
Information Requested
Receipt For: 2012
X Primary
Other (specify)

Occupation

Information Requested

Election Cycle-to-Date

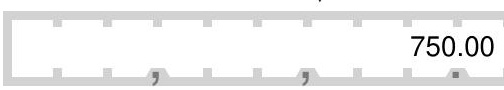

Transaction ID : A174124B0598F4578B6A

Date of Receipt

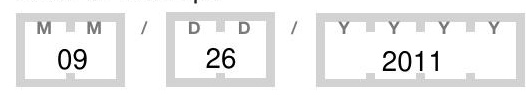

Amount of Each Receipt this Period

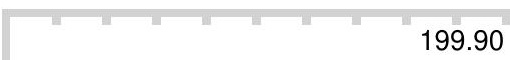

C. Full Name (Last, First, Middle Initial)

Ann Schmucker

Mailing Address 169 Sunset Lane

\begin{tabular}{lcc}
\hline City & State & Zip Code \\
Stahlstown & PA & $15687-1117$
\end{tabular}

FEC ID number of contributing

federal political committee.

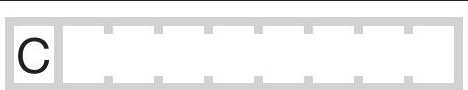

Name of Employer

Carboline Company

Occupation

Receipt For: 2012

Х $\begin{aligned} & \text { Primary } \square \text { General } \\ & \text { Other (specify) }\end{aligned}$

Industrial Sales

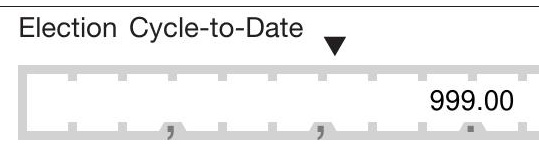

Amount of Each Receipt this Period

Transaction ID : AE4EE36160B484257ACB

Date of Receipt
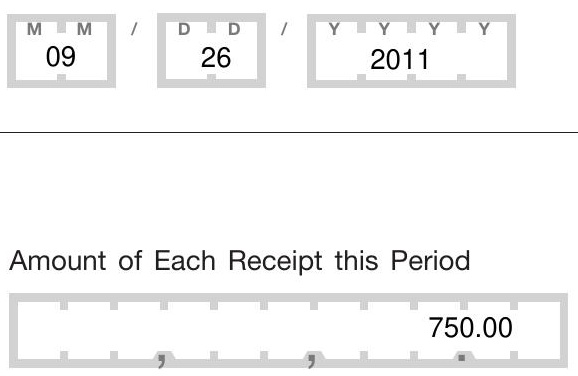

Transaction ID : AEA8FFD7534934FACAC2 Date of Receipt

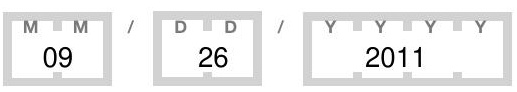

Amount of Each Receipt this Period

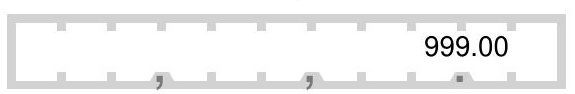

Subtotal Of Receipts This Page (optional).

1948.90

Total This Period (last page this line number only) 


\section{SCHEDULE A-P} ITEMIZED RECEIPTS
Use separate schedule(s)

for each category of the

Detailed Summary Page
FOR LINE NUMBER: (check only one)

PAGE 832 / 1572

\begin{tabular}{|c|c|c|c|c|c|}
\hline & & & & & \\
\hline 16 & X $17 a$ & $17 b$ & $17 c$ & $17 d$ & 18 \\
\hline $19 a$ & $19 b$ & $20 \mathrm{a}$ & $20 \mathrm{~b}$ & $20 \mathrm{c}$ & 21 \\
\hline
\end{tabular}

Any information copied from such Reports and Statements may not be sold or used by any person for the purpose of soliciting contributions or for commercial purposes, other than using the name and address of any political committee to solicit contributions from such committee.

NAME OF COMMITTEE (In Full)

Friends of Herman Cain

A. Full Name (Last, First, Middle Initial)

Craig Hendrix

Mailing Address 523 Missouri Avenue

\begin{tabular}{lcc}
\hline City & State & Zip Code \\
Saint Cloud & FL & $34769-2750$
\end{tabular}

FEC ID number of contributing

federal political committee.

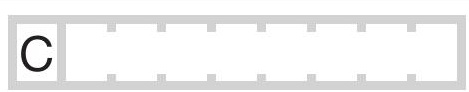

Name of Employer
Information Requested
Receipt For: 2012
X Primary $\quad \square$ General
Other (specify)

Occupation

Information Requested

Election Cycle-to-Date

500.00

B. Full Name (Last, First, Middle Initial)

JACK MOORE

Mailing Address 8414 FORESTSIDE LN

\begin{tabular}{lcc}
\hline City & State & Zip Code \\
Houston & TX & $77095-1915$ \\
\hline
\end{tabular}

FEC ID number of contributing

federal political committee.

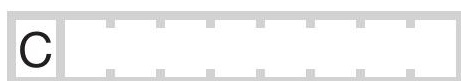

Name of Employer
self
Receipt For: 2012
X Primary
Other (specify)

Occupation

car repair

Election Cycle-to-Date

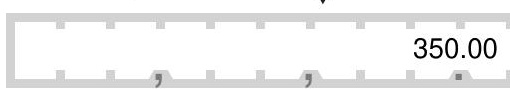

Transaction ID : A037585ED043B4F0292D

Date of Receipt

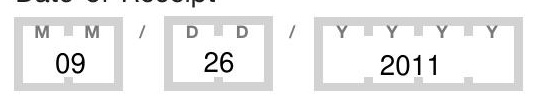

Amount of Each Receipt this Period

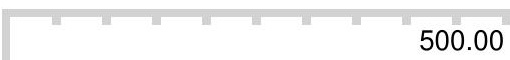

Amount of Each Receipt this Period

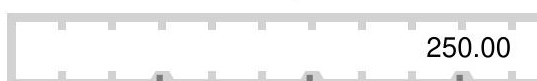

C. Full Name (Last, First, Middle Initial)

Richard Christiansen II

Mailing Address 1301 N. Courthouse Rd Ste. 1802

\begin{tabular}{lcc}
\hline City & State & Zip Code \\
Arlington & VA & $22201-2520$
\end{tabular}

FEC ID number of contributing

federal political committee.

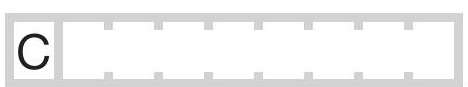

Name of Employer

Information Requested

Occupation

Information Requested

Receipt For: 2012

Х $\begin{aligned} & \text { Primary } \square \text { General } \\ & \text { Other (specify) }\end{aligned}$

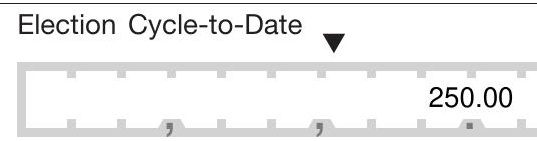

Transaction ID : AAF554A7CCA354B8693E

Date of Receipt

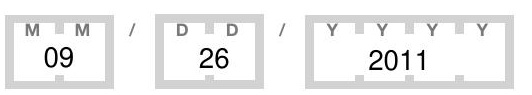

Transaction ID : A327AC26B125C4862936

Date of Receipt

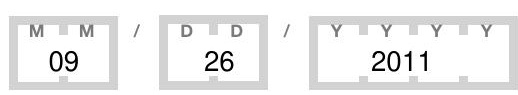

Amount of Each Receipt this Period

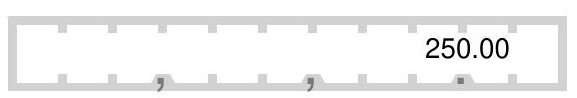

Subtotal Of Receipts This Page (optional).

1000.00

Total This Period (last page this line number only) 
SCHEDULE A-P ITEMIZED RECEIPTS
Use separate schedule(s) for each category of the Detailed Summary Page
FOR LINE NUMBER: (check only one)

PAGE $833 / 1572$

\begin{tabular}{|c|c|c|c|c|c|c|}
\hline & & & & & & \\
\hline 16 & $\lambda$ & $17 \mathrm{a}$ & $17 \mathrm{~b}$ & $17 \mathrm{c}$ & $-17 d$ & -18 \\
\hline $19 a$ & & $19 b$ & $20 a$ & $20 \mathrm{~b}$ & $20 \mathrm{c}$ & 21 \\
\hline
\end{tabular}

Any information copied from such Reports and Statements may not be sold or used by any person for the purpose of soliciting contributions or for commercial purposes, other than using the name and address of any political committee to solicit contributions from such committee.

NAME OF COMMITTEE (In Full)

\section{Friends of Herman Cain}

A. Full Name (Last, First, Middle Initial)

Mark Hoffman

Mailing Address 995 North Avenue

\begin{tabular}{lcc}
\hline City & State & Zip Code \\
Deerfield & IL & $60015-2203$
\end{tabular}

FEC ID number of contributing federal political committee.

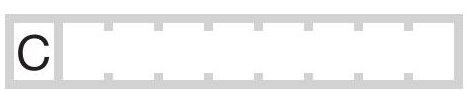

Name of Employer
Information Requested
Receipt For: 2012
X Primary
Other (specify) General

Occupation Information Requested

Election Cycle-to-Date

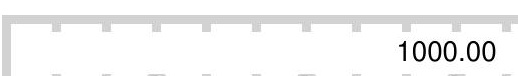

B. Full Name (Last, First, Middle Initial) James Revennaugh

Mailing Address 1012 Token Way

\begin{tabular}{lcc}
\hline City & State & Zip Code \\
Kennesaw & GA & $30152-3981$
\end{tabular}

FEC ID number of contributing

federal political committee.

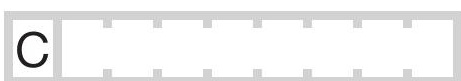

Name of Employer
Emory University
Receipt For: 2012
X Primary
$\square$ Other (specify) General

\section{Occupation}

IT

Election Cycle-to-Date

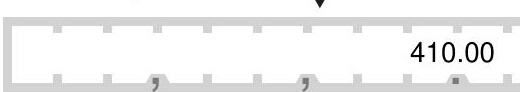

Transaction ID : A53FADB1711314E3187D

Date of Receipt

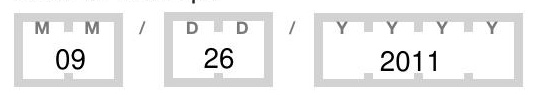

Amount of Each Receipt this Period

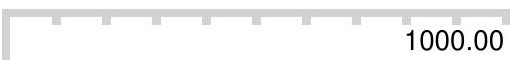

1000.00

C. Full Name (Last, First, Middle Initial)

Linda Finkel

Mailing Address 21125 River Bluff Dr.

\begin{tabular}{lcc}
\hline City & State & Zip Code \\
Anderson & CA & $96007-9795$
\end{tabular}

FEC ID number of contributing federal political committee.

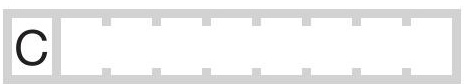

Name of Employer
None
Receipt For: 2012
Х Primary $\quad \square$ General
Other (specify)

Occupation

Retired

Election Cycle-to-Date

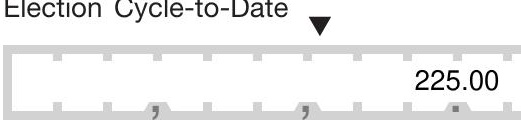

Transaction ID : A8DC0A0793DF94D61832

Date of Receipt

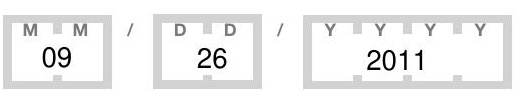

Amount of Each Receipt this Period

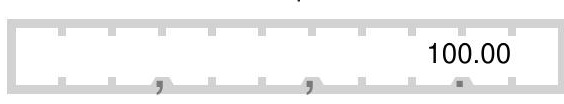

Transaction ID : A6FA41A60398641AFA39

Date of Receipt

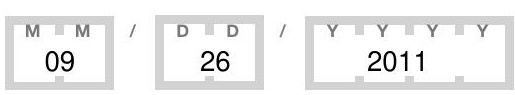

Amount of Each Receipt this Period

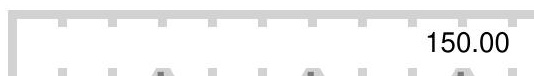

\section{Subtotal Of Receipts This Page (optional)}

Total This Period (last page this line number only) 
SCHEDULE A-P ITEMIZED RECEIPTS
Use separate schedule(s) for each category of the Detailed Summary Page
FOR LINE NUMBER: (check only one)

PAGE 834 / 1572

\begin{tabular}{|c|c|c|c|c|c|}
\hline & & & & & \\
\hline 16 & $\begin{array}{l}\mathbf{X} \\
17 a\end{array}$ & $17 b$ & $17 c$ & $17 d$ & 18 \\
\hline $19 a$ & $19 \mathrm{~b}$ & $20 \mathrm{a}$ & $20 \mathrm{~b}$ & $20 \mathrm{c}$ & 21 \\
\hline
\end{tabular}

Any information copied from such Reports and Statements may not be sold or used by any person for the purpose of soliciting contributions or for commercial purposes, other than using the name and address of any political committee to solicit contributions from such committee.

NAME OF COMMITTEE (In Full)

\section{Friends of Herman Cain}

A. Full Name (Last, First, Middle Initial)

Preston Calvert

Mailing Address 10112 New London Dr

\begin{tabular}{lcc}
\hline City & State & Zip Code \\
Potomac & MD & 20854-4849 \\
\hline
\end{tabular}

FEC ID number of contributing federal political committee.

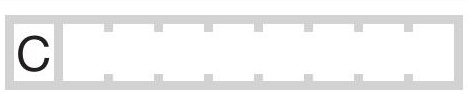

Name of Employer
self
Receipt For: 2012
X Primary $\quad$ General
Other (specify)

Occupation Physician

Election Cycle-to-Date

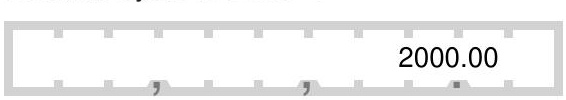

B. Full Name (Last, First, Middle Initial)

Mrs. Mathilda A. Oostveen

Mailing Address 39 Crowel Rd

\begin{tabular}{lcc}
\hline City & State & Zip Code \\
Hillsborough & NJ & $08844-5248$
\end{tabular}

FEC ID number of contributing

federal political committee.

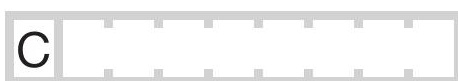

Name of Employer
Arch Reinsurance Company
Receipt For: 2012
X Primary
Other (specify)

\section{Occupation}

Director

Election Cycle-to-Date

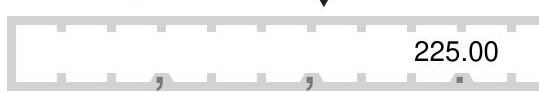

C. Full Name (Last, First, Middle Initial)

Alan Friedman

Mailing Address One Gracie Terrace Apt 6D

\begin{tabular}{l|ll}
\hline $\begin{array}{l}\text { City } \\
\text { New York }\end{array}$ & $\begin{array}{c}\text { State } \\
\text { NY }\end{array}$ & $\begin{array}{c}\text { Zip Code } \\
10028-7965\end{array}$ \\
\hline $\begin{array}{l}\text { FEC ID number of contributing } \\
\text { federal political committee. }\end{array}$ & C \\
\hline $\begin{array}{l}\text { Name of Employer } \\
\text { Information Requested }\end{array}$ & $\begin{array}{l}\text { Occupation } \\
\text { Information Requested }\end{array}$ \\
\hline $\begin{array}{l}\text { Receipt For: } 2012 \\
\text { Xrimary } \\
\text { Other (specify) }\end{array}$ & Election Cycle-to-Date \\
\hline
\end{tabular}

Transaction ID : A70E71E615D0D40ACA64 Date of Receipt

Amount of Each Receipt this Period

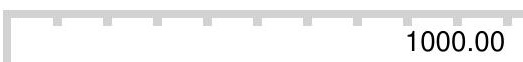

Date of Receipt
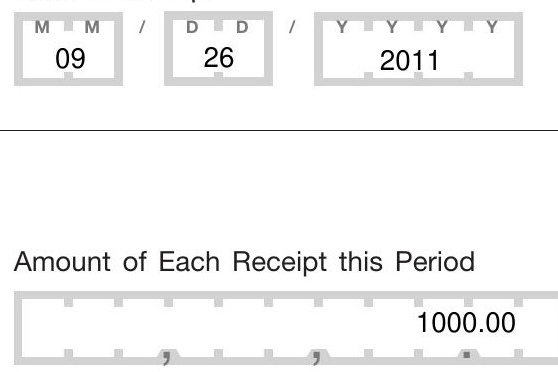

Amount of Each Receipt this Period
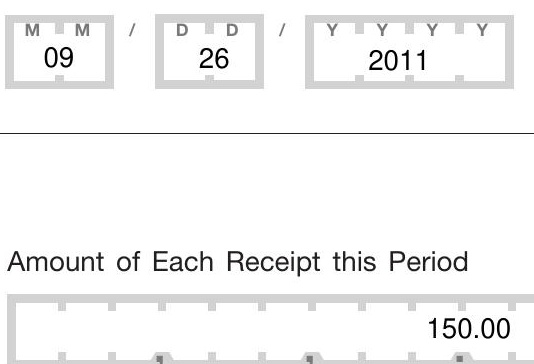

Amount of Each Receipt this Period

Transaction ID : AADD739A016C043678BF Date of Receipt
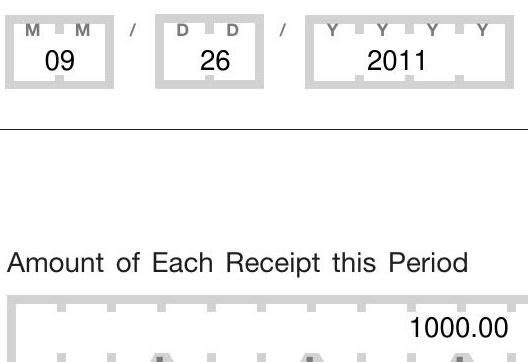

Subtotal Of Receipts This Page (optional).

Total This Period (last page this line number only) 


\section{SCHEDULE A-P} ITEMIZED RECEIPTS
Use separate schedule(s) for each category of the Detailed Summary Page

FOR LINE NUMBER:
(check only one)

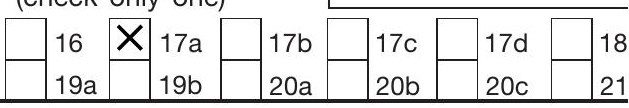

Any information copied from such Reports and Statements may not be sold or used by any person for the purpose of soliciting contributions or for commercial purposes, other than using the name and address of any political committee to solicit contributions from such committee.

NAME OF COMMITTEE (In Full)

\section{Friends of Herman Cain}

A. Full Name (Last, First, Middle Initial) Richard Harman

Mailing Address $635 \mathrm{~N}$ Sunset Dr

\begin{tabular}{lcc}
\hline City & State & Zip Code \\
Camano Island & WA & $98282-7322$
\end{tabular}

FEC ID number of contributing federal political committee.

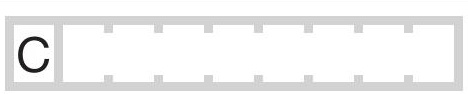

Name of Employer
The Harman Eye Clinic
Receipt For: 2012
X Primary
$\square$ Other (specify)

Occupation Opthamologist Election Cycle-to-Date

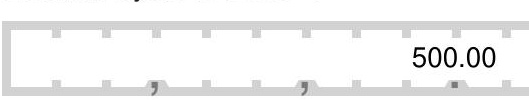

B. Full Name (Last, First, Middle Initial) Rick Jennings

Mailing Address 2021 Edgewood Ct

\begin{tabular}{llc}
\hline City & State & Zip Code \\
Chanhassen & MN & $55317-4577$ \\
\hline
\end{tabular}

FEC ID number of contributing

federal political committee.

C

Name of Employer
Information Requested
Receipt For: 2012
Primary
Other (specify)

Occupation

Information Requested

Election Cycle-to-Date

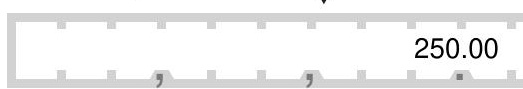

Transaction ID : AC75CC49AEE5945099C8

Date of Receipt

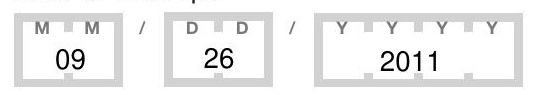

Amount of Each Receipt this Period

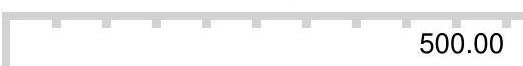

C. Full Name (Last, First, Middle Initial)

james bradburn

Mailing Address $42121 \mathrm{~N}$ Anthem Creek Dr

\begin{tabular}{lcc}
\hline City & State & Zip Code \\
Anthem & AZ & $85086-3018$
\end{tabular}

FEC ID number of contributing federal political committee.

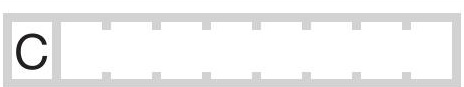

Name of Employer

Information Requested

\section{Occupation}

Information Requested

Receipt For: 2012

Х $\begin{aligned} & \text { Primary } \\ & \text { Other (specify) }\end{aligned}$

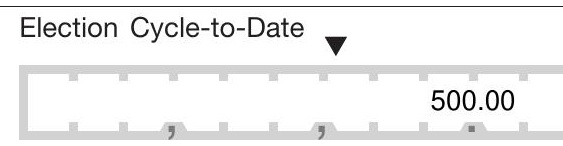

Amount of Each Receipt this Period

Transaction ID : AB9B0EDF585764F2B874

Date of Receipt
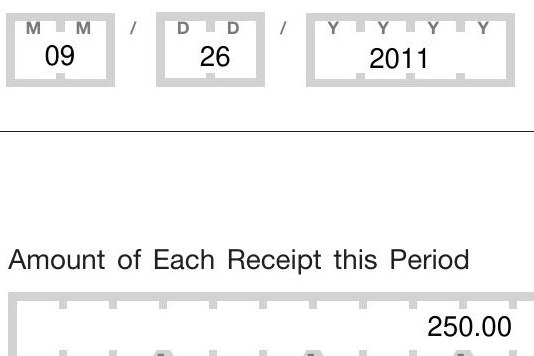

Transaction ID : AEAF0F2BDC52E44A8A63 Date of Receipt

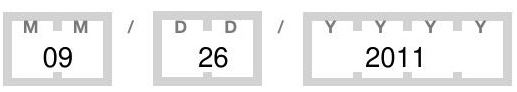

Amount of Each Receipt this Period

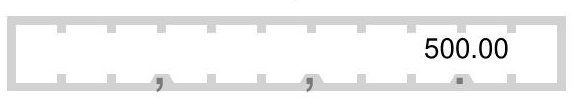

Subtotal Of Receipts This Page (optional).

1250.00

Total This Period (last page this line number only) 


\section{SCHEDULE A-P} ITEMIZED RECEIPTS
Use separate schedule(s)

for each category of the

Detailed Summary Page
FOR LINE NUMBER: (check only one)

PAGE $836 / 1572$

\begin{tabular}{|c|c|c|c|c|c|}
\hline & & & & & \\
\hline 16 & X $17 a$ & $17 b$ & $17 c$ & $17 d$ & 18 \\
\hline $19 a$ & $19 b$ & $20 \mathrm{a}$ & $20 \mathrm{~b}$ & $20 \mathrm{c}$ & 21 \\
\hline
\end{tabular}

Any information copied from such Reports and Statements may not be sold or used by any person for the purpose of soliciting contributions or for commercial purposes, other than using the name and address of any political committee to solicit contributions from such committee.

NAME OF COMMITTEE (In Full)

Friends of Herman Cain

A. Full Name (Last, First, Middle Initial)

Thomas Phillips

Mailing Address 1111 N 10th Street Ste. E

\begin{tabular}{lcc}
\hline City & State & Zip Code \\
McAllen & TX & $78501-4307$
\end{tabular}

FEC ID number of contributing

federal political committee.

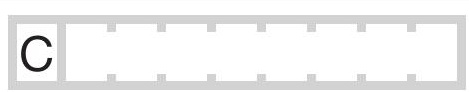

Name of Employer
None
Receipt For: 2012
X Primary $\square$ General
$\square$ Other (specify)

Occupation

Information Requested

Election Cycle-to-Date

850.00

B. Full Name (Last, First, Middle Initial)

Zachary Comeaux

Mailing Address P.O. Box 1026

\begin{tabular}{lcc}
\hline City & State & Zip Code \\
Scott & LA & $70583-1026$
\end{tabular}

FEC ID number of contributing

federal political committee.

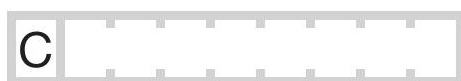

Name of Employer
Information Requested
Receipt For: 2012
X Primary
Other (specify)

Occupation

Information Requested

Election Cycle-to-Date

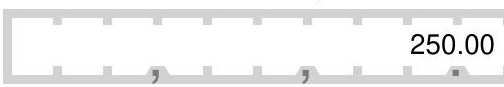

Transaction ID : AF15C57885BC849EB9D6

Date of Receipt

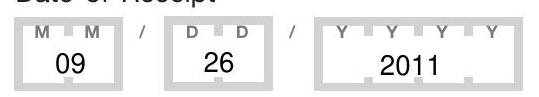

Amount of Each Receipt this Period

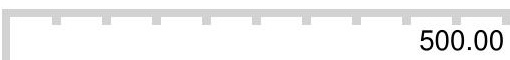

Amount of Each Receipt this Period

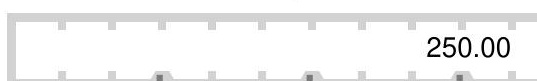

C. Full Name (Last, First, Middle Initial)

Gayle Herrington

Mailing Address PO Box 10507

\begin{tabular}{lcc}
\hline City & State & Zip Code \\
Brooksville & FL & $34603-0507$
\end{tabular}

FEC ID number of contributing federal political committee.

C

34603-0507

Name of Employer
Information Requested
Receipt For: 2012
Primary
Other (specify) General

Occupation

Information Requested

Election Cycle-to-Date

Transaction ID : AD58419062A8B43CB9DF

Date of Receipt
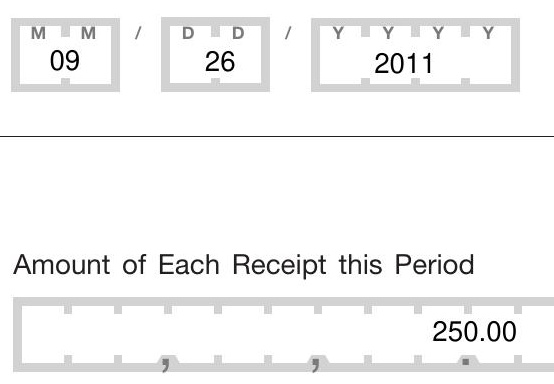

Transaction ID : A3C904ADB407746ADA9E Date of Receipt

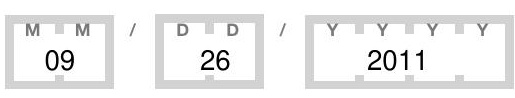

Amount of Each Receipt this Period

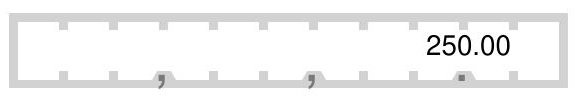

250.00

\section{Subtotal Of Receipts This Page (optional)}

Total This Period (last page this line number only) 


\section{SCHEDULE A-P} ITEMIZED RECEIPTS
Use separate schedule(s)

for each category of the

Detailed Summary Page
FOR LINE NUMBER: (check only one)

PAGE 837 / 1572

\begin{tabular}{|c|c|c|c|c|c|}
\hline & & & & & \\
\hline 16 & X $17 a$ & $17 b$ & $17 c$ & $17 d$ & 18 \\
\hline $19 a$ & $19 b$ & $20 \mathrm{a}$ & $20 \mathrm{~b}$ & $20 \mathrm{c}$ & 21 \\
\hline
\end{tabular}

Any information copied from such Reports and Statements may not be sold or used by any person for the purpose of soliciting contributions or for commercial purposes, other than using the name and address of any political committee to solicit contributions from such committee.

NAME OF COMMITTEE (In Full)

\section{Friends of Herman Cain}

A. Full Name (Last, First, Middle Initial)

\section{Frank Steed}

Mailing Address 3514 Francisco Bay Drive

\begin{tabular}{lcc}
\hline City & State & Zip Code \\
Kerens & TX & $75144-6197$
\end{tabular}

FEC ID number of contributing federal political committee.

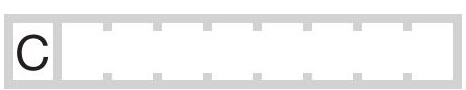

Name of Employer
The Steed Consultancy
Receipt For: 2012
X Primary
Other (specify) General

Occupation Consultant

Election Cycle-to-Date

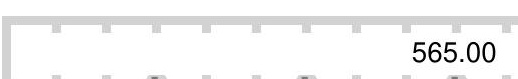

B. Full Name (Last, First, Middle Initial)

Norman Woodworth

Mailing Address 5063 Watson Rd.

\begin{tabular}{lcc}
\hline City & State & Zip Code \\
Elba & NY & $14058-9796$ \\
\hline
\end{tabular}

FEC ID number of contributing

federal political committee.

C

Name of Employer
Information Requested
Receipt For: 2012
X Primary
Other (specify)

Occupation

Information Requested

Election Cycle-to-Date

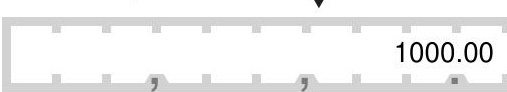

C. Full Name (Last, First, Middle Initial)

Grant LeRoux

Mailing Address PO Box 408

\begin{tabular}{lcc}
\hline City & State & Zip Code \\
Atlanta & GA & $30301-0408$ \\
\hline
\end{tabular}

FEC ID number of contributing federal political committee.

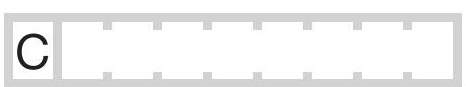

Name of Employer

Information Requested

\section{Occupation}

Information Requested

Receipt For: 2012

Х $\begin{aligned} & \text { Primary } \square \text { General } \\ & \text { Other (specify) }\end{aligned}$

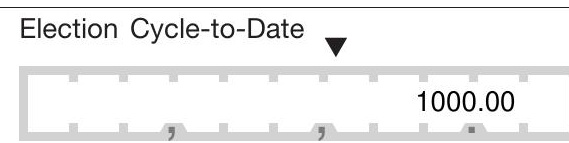

Amount of Each Receipt this Period

Transaction ID : A680EAFC1A99F40EF9E2

Date of Receipt

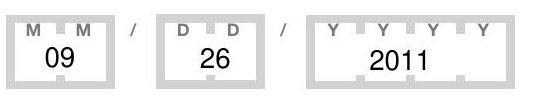

Amount of Each Receipt this Period
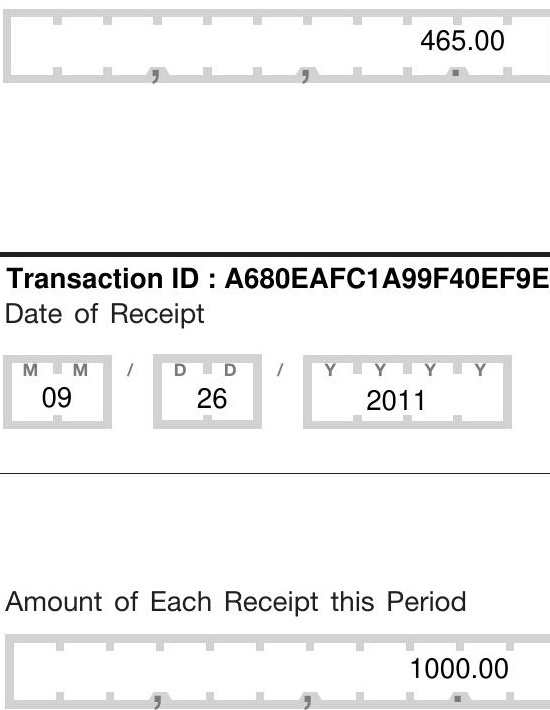

Transaction ID : A79292575386D421287F

Date of Receipt

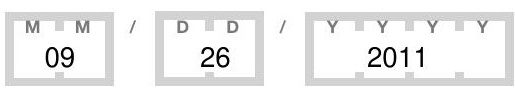

Amount of Each Receipt this Period

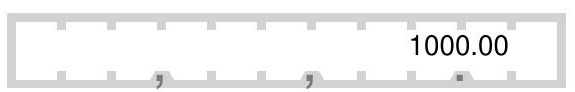

Subtotal Of Receipts This Page (optional)

2465.00

Total This Period (last page this line number only) 


\section{SCHEDULE A-P} ITEMIZED RECEIPTS
Use separate schedule(s)

for each category of the

Detailed Summary Page
FOR LINE NUMBER: (check only one)

PAGE $838 / 1572$

\begin{tabular}{|c|c|c|c|c|c|}
\hline & & & & & \\
\hline 16 & X $17 a$ & $17 b$ & $17 c$ & $17 d$ & 18 \\
\hline $19 a$ & $19 b$ & $20 \mathrm{a}$ & $20 \mathrm{~b}$ & $20 \mathrm{c}$ & 21 \\
\hline
\end{tabular}

Any information copied from such Reports and Statements may not be sold or used by any person for the purpose of soliciting contributions or for commercial purposes, other than using the name and address of any political committee to solicit contributions from such committee.

NAME OF COMMITTEE (In Full)

Friends of Herman Cain

A. Full Name (Last, First, Middle Initial)

Herman smith

Mailing Address 4971 East Lafayette Blvd

\begin{tabular}{lcc}
\hline City & State & Zip Code \\
Phoenix & AZ & $85018-4429$ \\
\hline
\end{tabular}

FEC ID number of contributing

federal political committee.

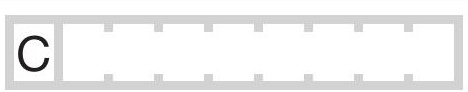

Name of Employer
Information Requested
Receipt For: 2012
X Primary $\quad \square$ General
Other (specify)

Occupation

Information Requested

Election Cycle-to-Date

250.00

B. Full Name (Last, First, Middle Initial)

Scott Vaughn

Mailing Address 1107 61st Ct

\begin{tabular}{lcc}
\hline City & State & Zip Code \\
Meridian & MS & $39305-1230$
\end{tabular}

FEC ID number of contributing

federal political committee.

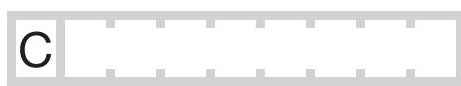

Name of Employer
Self Employed
Receipt For: 2012
X Primary
Other (specify) General

Occupation

Restaurant Owner

Election Cycle-to-Date

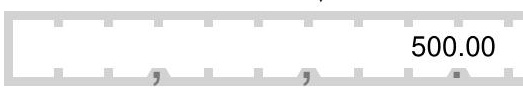

Transaction ID : A17BC9F452CAD42469CB

Date of Receipt

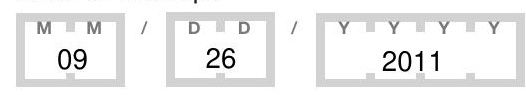

Amount of Each Receipt this Period

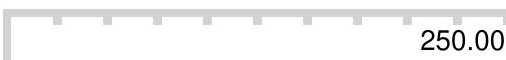

250.00

C. Full Name (Last, First, Middle Initial)

Eric Wood

Mailing Address 8231 Sutter-lone Rd.

\begin{tabular}{lcc}
\hline City & State & Zip Code \\
lone & CA & $95640-9547$
\end{tabular}

FEC ID number of contributing federal political committee.

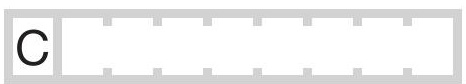

Name of Employer
Information Requested
Receipt For: 2012
X Primary $\quad \square$ General
Other (specify)

\section{Occupation}

Information Requested

Election Cycle-to-Date

Transaction ID : A98C1F72938FA4883A28

Date of Receipt

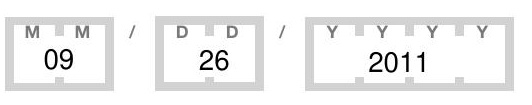

Amount of Each Receipt this Period

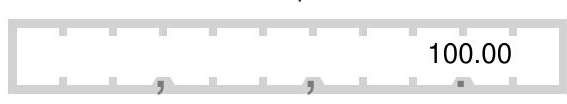

Transaction ID : A273DAD3911DD4738B54 Date of Receipt

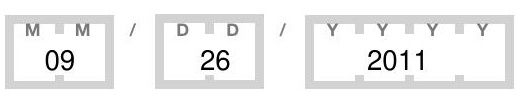

Amount of Each Receipt this Period

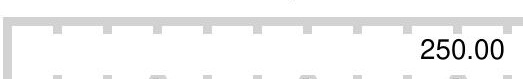

250.00

\section{Subtotal Of Receipts This Page (optional)}

600.00

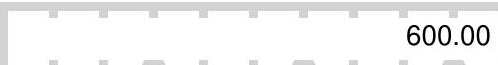

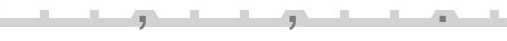

Total This Period (last page this line number only)

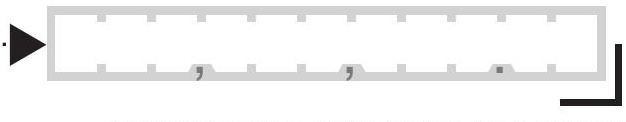

FEC Schedule A-P (Form 3P) (Rev. 03/2011) 


\section{SCHEDULE A-P} ITEMIZED RECEIPTS
Use separate schedule(s)

for each category of the

Detailed Summary Page
FOR LINE NUMBER: (check only one)

PAGE $839 / 1572$

\begin{tabular}{|c|c|c|c|c|c|}
\hline & & & & & \\
\hline 16 & X $17 a$ & $17 b$ & $17 c$ & $17 d$ & 18 \\
\hline $19 a$ & $19 b$ & $20 \mathrm{a}$ & $20 \mathrm{~b}$ & $20 \mathrm{c}$ & 21 \\
\hline
\end{tabular}

Any information copied from such Reports and Statements may not be sold or used by any person for the purpose of soliciting contributions or for commercial purposes, other than using the name and address of any political committee to solicit contributions from such committee.

NAME OF COMMITTEE (In Full)

Friends of Herman Cain

A. Full Name (Last, First, Middle Initial)

Thomas Parrott

Mailing Address 6153 Stadium Ct

\begin{tabular}{lcc}
\hline City & State & Zip Code \\
Norcross & GA & $30092-2340$
\end{tabular}

FEC ID number of contributing federal political committee.

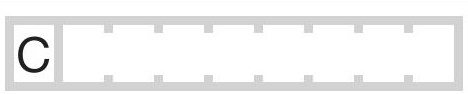

Name of Employer
IBM
Receipt For: 2012
X Primary $\quad$ General
Other (specify)

Occupation

Sales

Election Cycle-to-Date

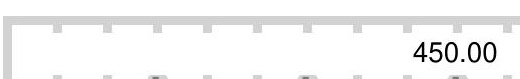

B. Full Name (Last, First, Middle Initial)

Patricia Brown

Mailing Address 3270 Rustic Oak

\begin{tabular}{lcc}
\hline City & State & Zip Code \\
San Antonio & TX & $78261-2202$ \\
\hline
\end{tabular}

FEC ID number of contributing

federal political committee.

C

Name of Employer
Supreme Lending
Receipt For: 2012
Primary
Other (specify) General

Occupation

Branch Manager

Election Cycle-to-Date

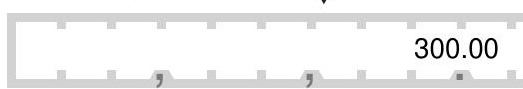

Transaction ID : AA99087ABD93E433BBBA

Date of Receipt

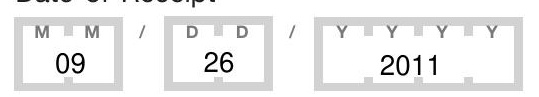

Amount of Each Receipt this Period

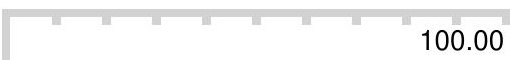

C. Full Name (Last, First, Middle Initial)

sang suh

Mailing Address 1415 2nd ave \#1210

\begin{tabular}{lcc}
\hline City & State & Zip Code \\
Seattle & WA & $98101-2033$
\end{tabular}

FEC ID number of contributing

federal political committee.

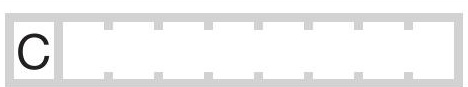

Name of Employer

Information Requested

Occupation

Information Requested

Receipt For: 2012

Х $\begin{aligned} & \text { Primary } \square \text { General } \\ & \text { Other (specify) }\end{aligned}$

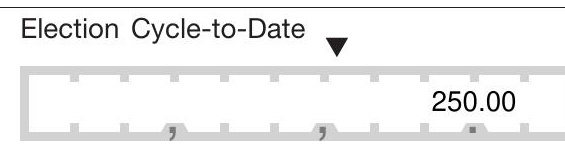

Amount of Each Receipt this Period

Transaction ID : AC207C87889794C87B89

Date of Receipt
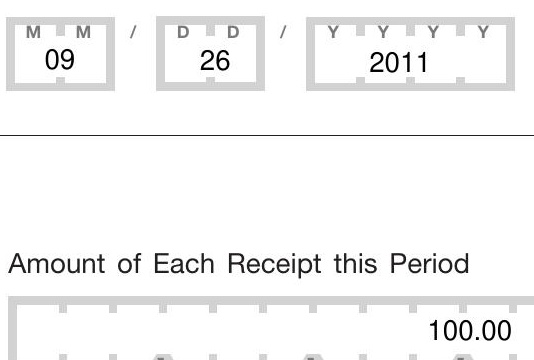

Transaction ID : AEE32EF5252744ECAA43

Date of Receipt

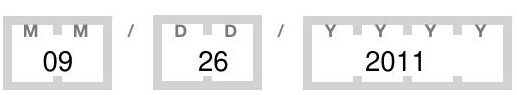

Amount of Each Receipt this Period

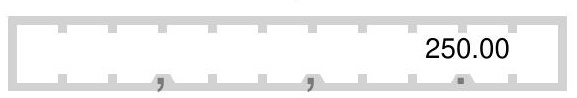

Subtotal Of Receipts This Page (optional).

450.00

Total This Period (last page this line number only) 


\section{SCHEDULE A-P} ITEMIZED RECEIPTS
Use separate schedule(s)

for each category of the

Detailed Summary Page
FOR LINE NUMBER: (check only one)

Any information or for commercial purposes, other than using the name and address of any political committee to solicit contributions from such committee.

NAME OF COMMITTEE (In Full)

Friends of Herman Cain

A. Full Name (Last, First, Middle Initial)

Roddis Stewart Jones

Mailing Address 353 NE 24th Court

\begin{tabular}{lcc}
\hline City & State & Zip Code \\
Renton & WA & 98056 \\
\hline
\end{tabular}

FEC ID number of contributing

federal political committee.

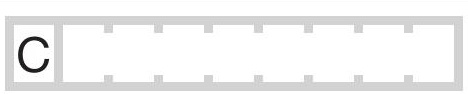

Name of Employer
None
Receipt For: 2012
X Primary $\square$ General
$\square$ Other (specify)

Occupation

Retired

Election Cycle-to-Date

B. Full Name (Last, First, Middle Initial)

DOUGLAS ALLEN

Mailing Address P.O. BOX 985

\begin{tabular}{lcc}
\hline City & State & Zip Code \\
Wrightsville Beach & NC & $28480-0985$ \\
\hline
\end{tabular}

FEC ID number of contributing

federal political committee.

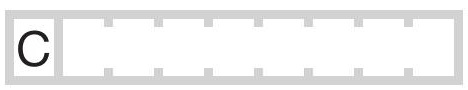

\section{Name of Employer}

ALLEN INSURANCE\& RETIREMENT

$\triangle A I \Delta !$ VCIC-F

Receipt For: 2012

X Primary $\square$ General

Other (specify)

Occupation

self

Election Cycle-to-Date

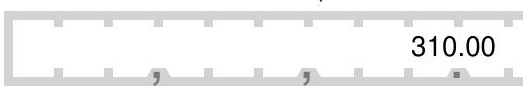

C. Full Name (Last, First, Middle Initial)

John C Houghton

Mailing Address 7145 Potomac Place

\begin{tabular}{lcc}
\hline City & State & Zip Code \\
Gilroy & CA & $95020-6326$
\end{tabular}

FEC ID number of contributing

federal political committee.

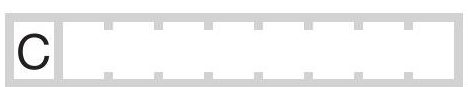

Name of Employer

Occupation

The Energy House

Sales

Receipt For: 2012

Х $\begin{aligned} & \text { Primary } \\ & \text { Other (specify) }\end{aligned}$

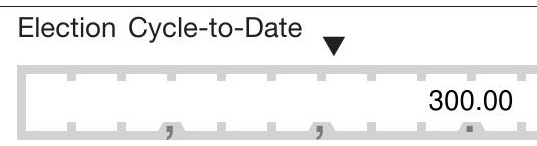

Amount of Each Receipt this Period

Transaction ID : A3BEC9396EDF046EBAEF Date of Receipt

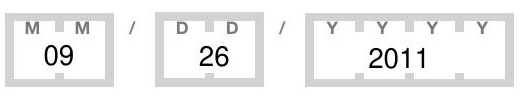

Amount of Each Receipt this Period
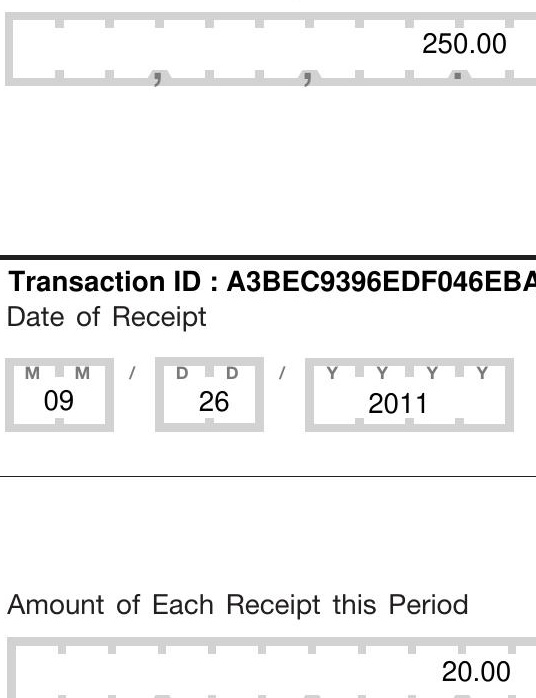

Transaction ID : AFC62E785024843C09FB

Date of Receipt

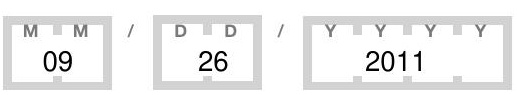

Amount of Each Receipt this Period

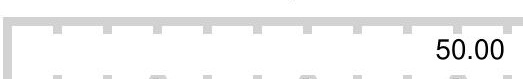

50.00

320.00

Subtotal Of Receipts This Page (optional)....

Total This Period (last page this line number only) 


\section{SCHEDULE A-P} ITEMIZED RECEIPTS
Use separate schedule(s)

for each category of the

Detailed Summary Page
FOR LINE NUMBER: (check only one)

PAGE $841 / 1572$

\begin{tabular}{|c|c|c|c|c|c|}
\hline & & & & & \\
\hline 16 & X $17 a$ & $17 b$ & $17 c$ & $17 d$ & 18 \\
\hline $19 a$ & $19 b$ & $20 \mathrm{a}$ & $20 \mathrm{~b}$ & $20 \mathrm{c}$ & 21 \\
\hline
\end{tabular}

Any information copied from such Reports and Statements may not be sold or used by any person for the purpose of soliciting contributions or for commercial purposes, other than using the name and address of any political committee to solicit contributions from such committee.

NAME OF COMMITTEE (In Full)

\section{Friends of Herman Cain}

A. Full Name (Last, First, Middle Initial)

Harry Craycroft

Mailing Address 1284 Pinecrest Drive

\begin{tabular}{lcc}
\hline City & State & Zip Code \\
Concord & CA & $94521-3521$
\end{tabular}

FEC ID number of contributing federal political committee.

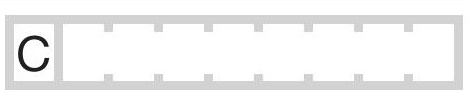

Name of Employer
Information Requested
Receipt For: 2012
X Primary
Other (specify) General

Occupation Information Requested

Election Cycle-to-Date

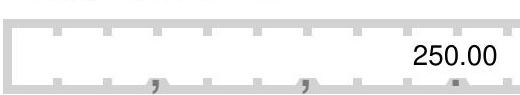

B. Full Name (Last, First, Middle Initial)

Ellis Coleman

Mailing Address 1145 Eaglewood Trail

\begin{tabular}{lcc}
\hline City & State & Zip Code \\
Charleston & SC & $29412-9453$ \\
\hline
\end{tabular}

FEC ID number of contributing

federal political committee.

C

Name of Employer
Information Requested
Receipt For: 2012
X Primary
Other (specify)

Occupation

Information Requested

Election Cycle-to-Date

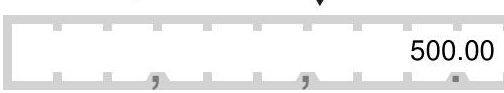

Transaction ID : AF60E1EC57B0B4F07A31

Date of Receipt

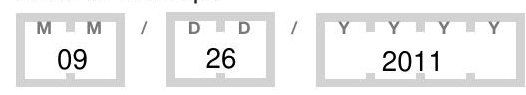

Amount of Each Receipt this Period

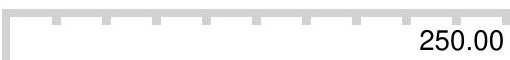

Amount of Each Receipt this Period

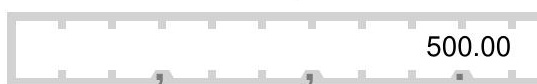

C. Full Name (Last, First, Middle Initial)

Thomas Webber

Mailing Address 1 Saint Helaine PI

\begin{tabular}{lcc}
\hline City & State & Zip Code \\
Greer & SC & $29650-3657$
\end{tabular}

FEC ID number of contributing federal political committee.

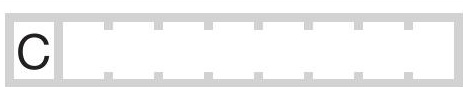

Name of Employer

Occupation

Supo Dupo Inc.

Education

Receipt For: 2012

Х $\begin{aligned} & \text { Primary } \square \text { General } \\ & \text { Other (specify) }\end{aligned}$

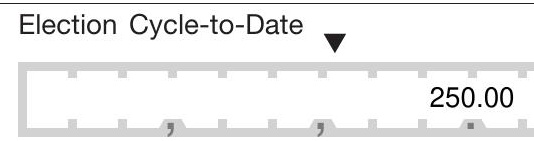

Transaction ID : A2CFAFD0237E340DD83F

Date of Receipt

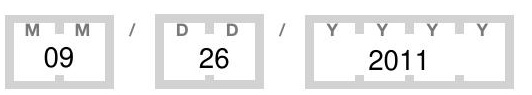

Transaction ID : AE13073DD1E2848E8918

Date of Receipt

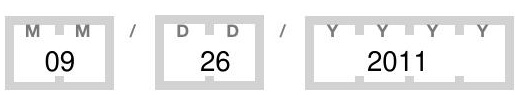

Amount of Each Receipt this Period

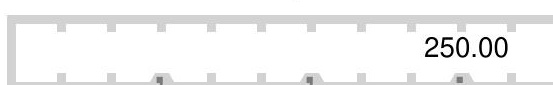

1000.00

Subtotal Of Receipts This Page (optional)

Total This Period (last page this line number only) 
SCHEDULE A-P ITEMIZED RECEIPTS
Use separate schedule(s) for each category of the Detailed Summary Page
FOR LINE NUMBER: (check only one)

PAGE 842 / 1572

\begin{tabular}{|c|c|c|c|c|c|}
\hline & & & & & \\
\hline 16 & $\begin{array}{lll}X & 17 a \\
\end{array}$ & $17 \mathrm{~b}$ & $17 c$ & $17 d$ & 18 \\
\hline $19 a$ & $19 b$ & $20 a$ & $20 \mathrm{~b}$ & $20 c$ & 21 \\
\hline
\end{tabular}

Any information copied from such Reports and Statements may not be sold or used by any person for the purpose of soliciting contributions or for commercial purposes, other than using the name and address of any political committee to solicit contributions from such committee.

NAME OF COMMITTEE (In Full)

\section{Friends of Herman Cain}

A. Full Name (Last, First, Middle Initial)

\section{Eric Hankins}

Mailing Address PO Box 412

\begin{tabular}{lcc}
\hline City & State & Zip Code \\
Clinton & MO & $64735-0412$ \\
\hline
\end{tabular}

FEC ID number of contributing federal political committee.

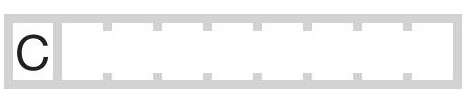

Name of Employer
Hankins Grain Co
Receipt For: 2012
X Primary
Other (specify) General

Occupation Manager

Election Cycle-to-Date

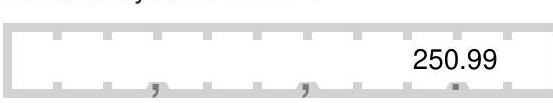

B. Full Name (Last, First, Middle Initial)

William Wagener

Mailing Address PO Box 621348

\begin{tabular}{lcc}
\hline City & State & Zip Code \\
Littleton & CO & $80162-1348$
\end{tabular}

FEC ID number of contributing

federal political committee.

C

Name of Employer
Minergy Group LLC
Receipt For: 2012
X Primary
Other (specify)

\section{Occupation}

Mining Engineer

Election Cycle-to-Date

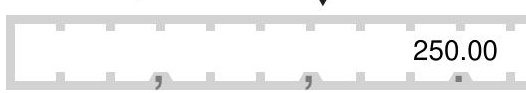

Transaction ID : A83EF15D49BE24D8DB61

Date of Receipt

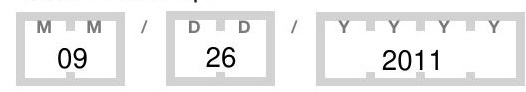

Amount of Each Receipt this Period

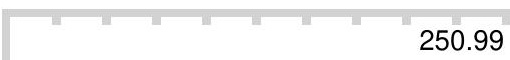

C. Full Name (Last, First, Middle Initial)

Zane Hagy

Mailing Address PO Box 4824

\begin{tabular}{lcc}
\hline City & State & Zip Code \\
Oak Ridge & TN & $37831-4824$ \\
\hline
\end{tabular}

FEC ID number of contributing federal political committee.

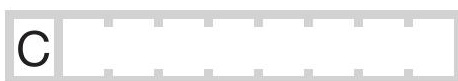

Name of Employer

Information Requested

Occupation

Information Requested

Receipt For: 2012

Х $\begin{aligned} & \text { Primary } \\ & \text { Other (specify) }\end{aligned}$

Amount of Each Receipt this Period

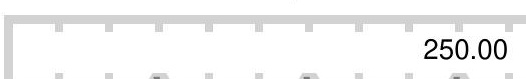

Transaction ID : A1383FDE844084E4C8F6

Date of Receipt

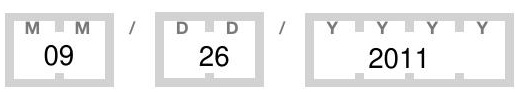

Transaction ID : A8262C5460C3A492CA39 Date of Receipt

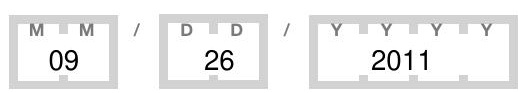

Amount of Each Receipt this Period

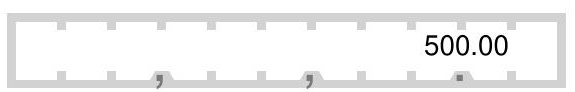

500.00
Subtotal Of Receipts This Page (optional)

1000.99

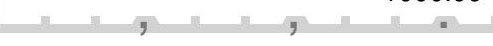

Total This Period (last page this line number only)

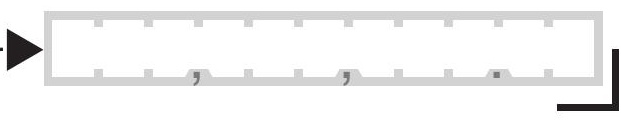

FEC Schedule A-P (Form 3P) (Rev. 03/2011) 
SCHEDULE A-P ITEMIZED RECEIPTS
Use separate schedule(s) for each category of the Detailed Summary Page
FOR LINE NUMBER: (check only one)

PAGE $843 / 1572$

\begin{tabular}{|c|c|c|c|c|c|}
\hline & & & & & \\
\hline 16 & $\mathbf{X} 17 a$ & $17 b$ & $17 c$ & $17 d$ & 18 \\
\hline $19 a$ & $19 b$ & $20 \mathrm{a}$ & $20 \mathrm{~b}$ & $20 \mathrm{c}$ & 21 \\
\hline
\end{tabular}

Any information copied from such Reports and Statements may not be sold or used by any person for the purpose of soliciting contributions or for commercial purposes, other than using the name and address of any political committee to solicit contributions from such committee.

NAME OF COMMITTEE (In Full)

\section{Friends of Herman Cain}

A. Full Name (Last, First, Middle Initial)

Stefanie Brotheridge

Mailing Address 110 Ridge View Drive

\begin{tabular}{lcc}
\hline City & State & Zip Code \\
Ball Ground & GA & $30107-5178$
\end{tabular}

FEC ID number of contributing

federal political committee.

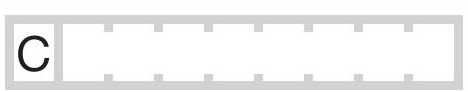

Name of Employer
Information Requested
Receipt For: 2012
X Primary $\quad \square$ General
Other (specify)

Occupation

Information Requested

Election Cycle-to-Date

250.00

B. Full Name (Last, First, Middle Initial)

Robert Jones

Mailing Address 511 E 114th ST

\begin{tabular}{lcc}
\hline City & State & Zip Code \\
Carmel & IN & $46032-4503$ \\
\hline
\end{tabular}

FEC ID number of contributing

federal political committee.

C

Name of Employer
Information Requested
Receipt For: 2012
X Primary
Other (specify)

Occupation

Information Requested

Election Cycle-to-Date

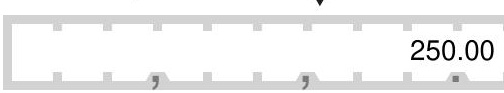

Transaction ID : AA5CEF349AF6A46BE84D

Date of Receipt

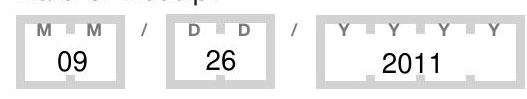

Amount of Each Receipt this Period

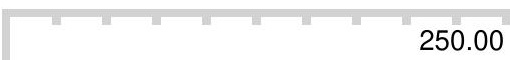

C. Full Name (Last, First, Middle Initial)

Mary Causey

Mailing Address 189 Lamplighter Lane

\section{City}

Ponte Vedra Beach

FEC ID number of contributing

federal political committee.

Name of Employer

Dat'l Do-It Inc.

Receipt For: 2012

Х $\begin{aligned} & \text { Primary } \square \text { General } \\ & \text { Other (specify) }\end{aligned}$

\section{State Zip Code \\ FL 32082-1951}

C

\section{Occupation}

Small Business Owner

Election Cycle-to-Date

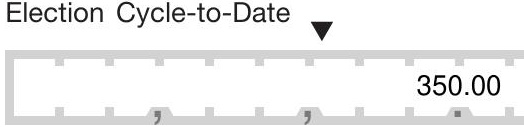

Amount of Each Receipt this Period

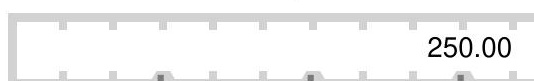

Transaction ID : ABA7A1A2FDB6D4D94A36 Date of Receipt

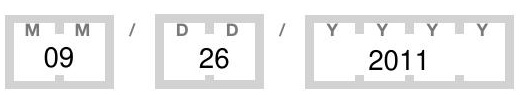

Transaction ID : A6EFC78EEDC2C41D680B Date of Receipt

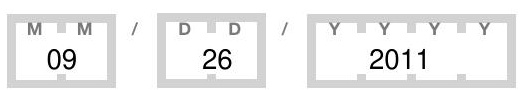

Amount of Each Receipt this Period

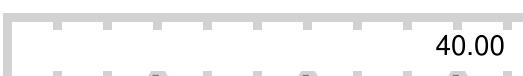

\section{Subtotal Of Receipts This Page (optional)}

Total This Period (last page this line number only) 
SCHEDULE A-P ITEMIZED RECEIPTS
Use separate schedule(s) for each category of the Detailed Summary Page

FOR LINE NUMBER:
(check only one)

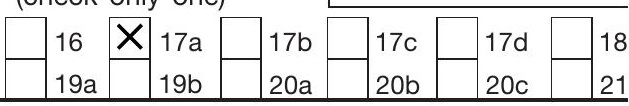

Any information copied from such Reports and Statements may not be sold or used by any person for the purpose of soliciting contributions or for commercial purposes, other than using the name and address of any political committee to solicit contributions from such committee.

NAME OF COMMITTEE (In Full)

\section{Friends of Herman Cain}

A. Full Name (Last, First, Middle Initial) john H zengilowski

Mailing Address 2312 Beech St

\begin{tabular}{lcc}
\hline City & State & Zip Code \\
Virginia Beach & VA & $23451-1304$
\end{tabular}

FEC ID number of contributing federal political committee.

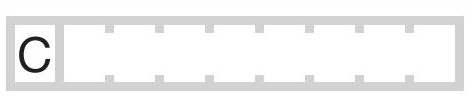

Name of Employer
Re/Max
Receipt For: 2012
X Primary $\quad \square$ General
$\square$ Other (specify)

\section{Occupation} Real Estate

Election Cycle-to-Date

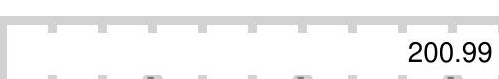

Transaction ID : A5F5A8C8F6034435AA62

Date of Receipt

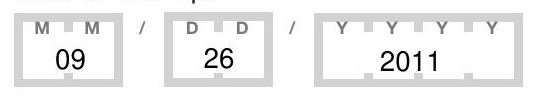

Amount of Each Receipt this Period

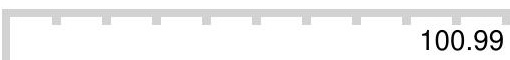

100.99
B. Full Name (Last, First, Middle Initial)

Mark Roque

Mailing Address 705 Ashgrove Ter

\begin{tabular}{lcc}
\hline City & State & Zip Code \\
Sanford & FL & $32771-7149$
\end{tabular}

FEC ID number of contributing

federal political committee.

C

Name of Employer
Information Requested
Receipt For: 2012
Primary
Other (specify)

Occupation

Information Requested

Election Cycle-to-Date

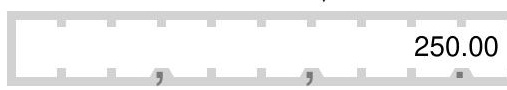

C. Full Name (Last, First, Middle Initial)

Andrea Lee

Mailing Address p.o. box 231081

\begin{tabular}{lcc}
\hline City & State & Zip Code \\
Encinitas & CA & $92023-1081$
\end{tabular}

FEC ID number of contributing federal political committee.

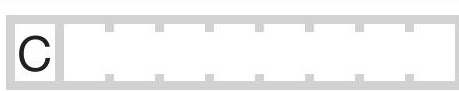

Name of Employer
None
Receipt For: 2012
Х Primary $\quad \square$ General
Other (specify)

Occupation

Homemaker

Election Cycle-to-Date

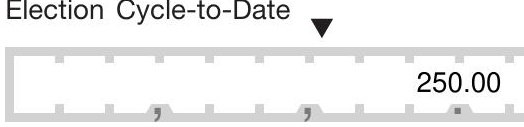

Transaction ID : A542E78BFA8C041248DA

Date of Receipt

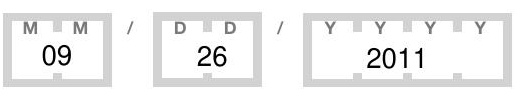

Amount of Each Receipt this Period

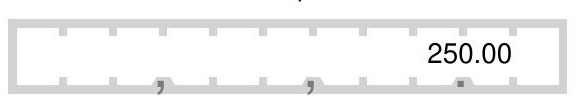

Transaction ID : A0D72642C5EFC4302BDC Date of Receipt

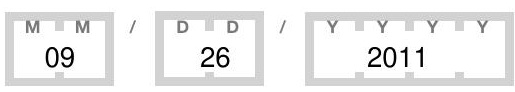

Amount of Each Receipt this Period

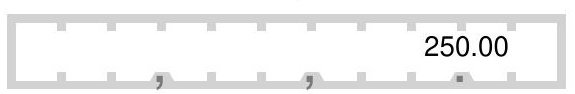

600.99

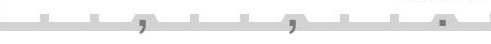

Total This Period (last page this line number only)

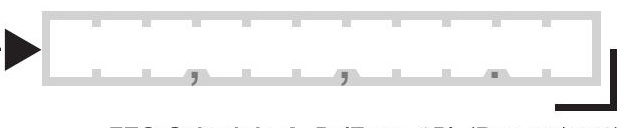

FEC Schedule A-P (Form 3P) (Rev. 03/2011) 


\section{SCHEDULE A-P} ITEMIZED RECEIPTS
Use separate schedule(s)

for each category of the

Detailed Summary Page
FOR LINE NUMBER: (check only one)

PAGE $845 / 1572$

\begin{tabular}{|c|c|c|c|c|c|}
\hline & & & & & \\
\hline 16 & X $17 a$ & $17 b$ & $17 c$ & $17 d$ & 18 \\
\hline $19 a$ & $19 b$ & $20 \mathrm{a}$ & $20 \mathrm{~b}$ & $20 \mathrm{c}$ & 21 \\
\hline
\end{tabular}

Any information copied from such Reports and Statements may not be sold or used by any person for the purpose of soliciting contributions or for commercial purposes, other than using the name and address of any political committee to solicit contributions from such committee.

NAME OF COMMITTEE (In Full)

Friends of Herman Cain

A. Full Name (Last, First, Middle Initial)

claire mencke

Mailing Address 5 tudor city place apt 305

\begin{tabular}{lcc}
\hline City & State & Zip Code \\
New York & NY & $10017-6858$
\end{tabular}

FEC ID number of contributing

federal political committee.

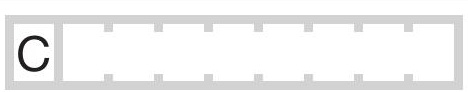

Name of Employer

buckingham research group

Receipt For: 2012

X Primary $\square$ General

Other (specify)

Occupation

research assoc

Election Cycle-to-Date

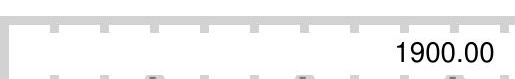

B. Full Name (Last, First, Middle Initial)

John Walter Degner

Mailing Address 3752 Lake St

\begin{tabular}{lcc}
\hline City & State & Zip Code \\
Houston & TX & $77098-5522$ \\
\hline
\end{tabular}

FEC ID number of contributing

federal political committee.

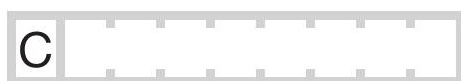

Name of Employer
Global Geophysical Servic
Receipt For: 2012
Primary
Other (specify)

Occupation

Equip Superviso

Election Cycle-to-Date

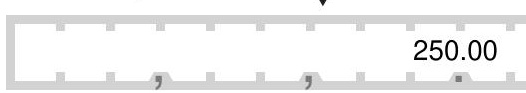

C. Full Name (Last, First, Middle Initial)

Shelley Gates

Mailing Address 734 Sunset PI

\begin{tabular}{lcc}
\hline City & State & Zip Code \\
Hendricks & MN & $56136-1241$
\end{tabular}

FEC ID number of contributing federal political committee.

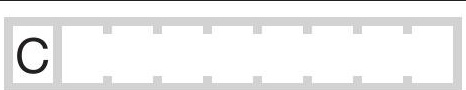

Name of Employer

Information Requested

Occupation

Information Requested

Receipt For: 2012

Х $\begin{aligned} & \text { Primary } \square \text { General } \\ & \text { Other (specify) }\end{aligned}$

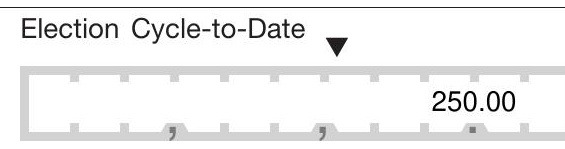

Amount of Each Receipt this Period

Transaction ID : A3D8F4FD0396E4E92BB9

Date of Receipt

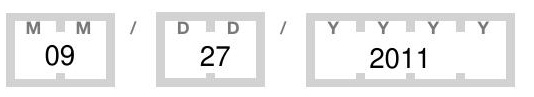

Amount of Each Receipt this Period
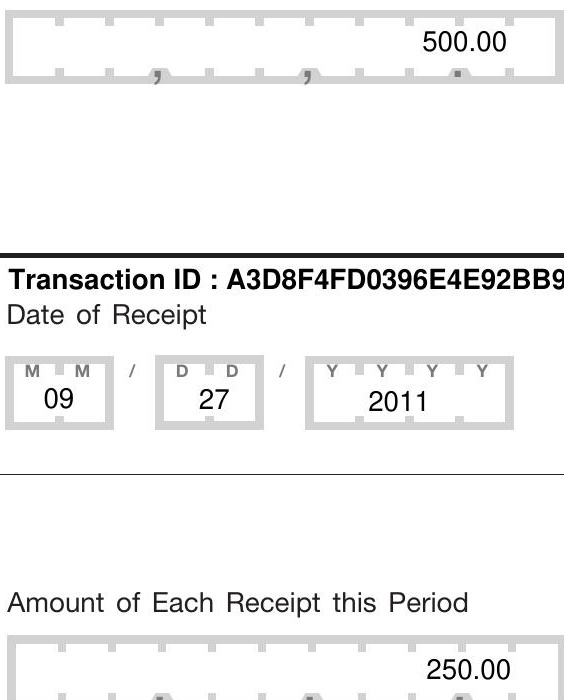

Transaction ID : A8AF4BD8A475C45FE850 Date of Receipt

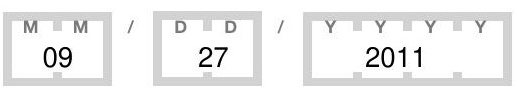

Amount of Each Receipt this Period

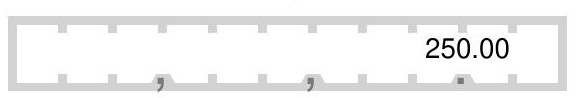

Subtotal Of Receipts This Page (optional).

1000.00

Total This Period (last page this line number only) 


\section{SCHEDULE A-P} ITEMIZED RECEIPTS
Use separate schedule(s)

for each category of the

Detailed Summary Page
FOR LINE NUMBER: (check only one)

PAGE 846 / 1572

\begin{tabular}{|c|c|c|c|c|c|}
\hline & & & & & \\
\hline 16 & X $17 a$ & $17 b$ & $17 c$ & $17 d$ & 18 \\
\hline $19 a$ & $19 b$ & $20 \mathrm{a}$ & $20 \mathrm{~b}$ & $20 \mathrm{c}$ & 21 \\
\hline
\end{tabular}

Any information copied from such Reports and Statements may not be sold or used by any person for the purpose of soliciting contributions or for commercial purposes, other than using the name and address of any political committee to solicit contributions from such committee.

NAME OF COMMITTEE (In Full)

\section{Friends of Herman Cain}

A. Full Name (Last, First, Middle Initial) John Francis

Mailing Address 2413 Dove Terrace

\begin{tabular}{lcc}
\hline City & State & Zip Code \\
Great Bend & KS & $67530-6812$
\end{tabular}

FEC ID number of contributing federal political committee.

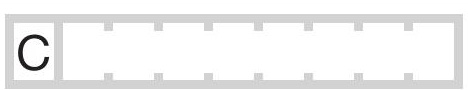

Name of Employer
Information Requested
Receipt For: 2012
X Primary
Other (specify) General

Occupation Information Requested

Election Cycle-to-Date

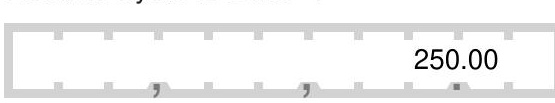

B. Full Name (Last, First, Middle Initial)

Dan Black

Mailing Address 2300 Crows Nest Pkwy

\begin{tabular}{lcc}
\hline City & State & Zip Code \\
Reno & NV & $89519-5726$ \\
\hline
\end{tabular}

FEC ID number of contributing

federal political committee.

C

Name of Employer
Information Requested
Receipt For: 2012
X Primary
Other (specify)

Occupation

Information Requested

Election Cycle-to-Date

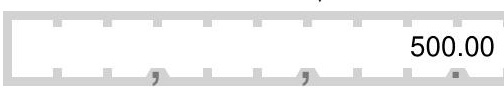

Transaction ID : AFB5735585C6A4FE380F

Date of Receipt

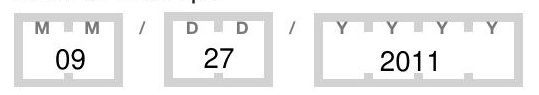

Amount of Each Receipt this Period

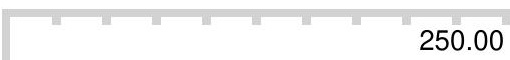

Transaction ID : A7F4E60C5BABB4E389A5 Date of Receipt

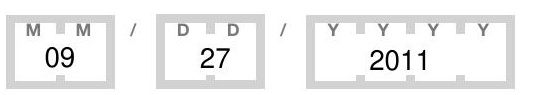

Amount of Each Receipt this Period

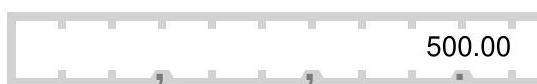

C. Full Name (Last, First, Middle Initial)

Robert Linz

Mailing Address 9570 Monteverdi Way

\begin{tabular}{lcc}
\hline City & State & Zip Code \\
Fort Myers & FL & $33912-0903$
\end{tabular}

FEC ID number of contributing federal political committee.

C

Name of Employer
Information Requested
Receipt For: 2012
X Primary
Other (specify) General

Occupation

Information Requested

Election Cycle-to-Date

Transaction ID : A287B88C3E1D644FCA2D Date of Receipt

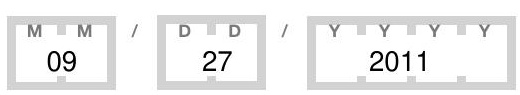

Amount of Each Receipt this Period

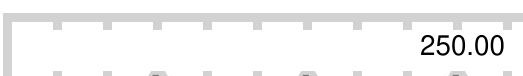

250.00

\section{Subtotal Of Receipts This Page (optional)}

Total This Period (last page this line number only) 


\section{SCHEDULE A-P} ITEMIZED RECEIPTS
Use separate schedule(s)

for each category of the

Detailed Summary Page
FOR LINE NUMBER: (check only one)

PAGE 847 / 1572

\begin{tabular}{|c|c|c|c|c|c|}
\hline & & & & & \\
\hline 16 & $\mathbf{X} 17 \mathrm{a}$ & $17 \mathrm{~b}$ & $17 c$ & $17 d$ & 18 \\
\hline $19 a$ & $19 \mathrm{~b}$ & $20 a$ & $20 \mathrm{~b}$ & $20 c$ & 21 \\
\hline
\end{tabular}

Any information copied from such Reports and Statements may not be sold or used by any person for the purpose of soliciting contributions or for commercial purposes, other than using the name and address of any political committee to solicit contributions from such committee.

NAME OF COMMITTEE (In Full)

Friends of Herman Cain

A. Full Name (Last, First, Middle Initial) Linda Thompson

Mailing Address 3171 Hickory St

\begin{tabular}{lcc}
\hline City & State & Zip Code \\
Navarre & FL & $32566-9712$
\end{tabular}

FEC ID number of contributing federal political committee.

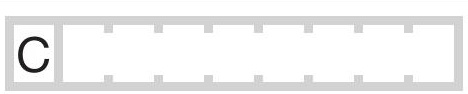

Name of Employer
n/a
Receipt For: 2012
X Primary $\quad \square$ General
$\square$ Other (specify)

Occupation Retired

Election Cycle-to-Date

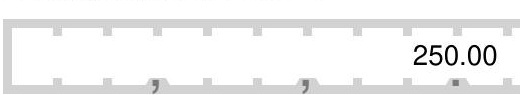

B. Full Name (Last, First, Middle Initial)

William Donohue

\section{Mailing Address 7 Vicksburg Ct.}

\begin{tabular}{lcc}
\hline City & State & Zip Code \\
Madison & WI & $53718-3154$ \\
\hline
\end{tabular}

FEC ID number of contributing

federal political committee.

C

Name of Employer
State Farm Insurance Co.
Receipt For: 2012
X Primary
Other (specify)

Occupation

Retired

Election Cycle-to-Date

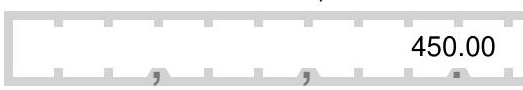

Transaction ID : A6DAD9E42C9344A67834

Date of Receipt

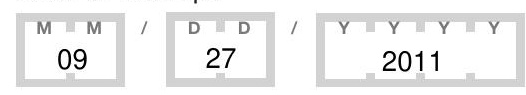

Amount of Each Receipt this Period

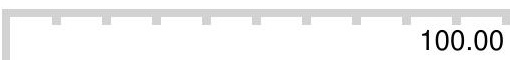

Transaction ID : A575412BCC57A45F4923

Date of Receipt

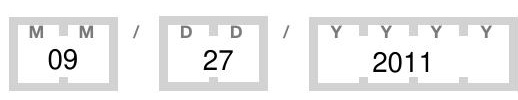

Amount of Each Receipt this Period

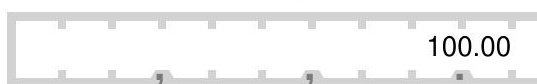

Transaction ID : AFCB4626F547E465798D

Date of Receipt

William Hall

Mailing Address 1018 Dornoch RD

\begin{tabular}{lcc}
\hline City & State & Zip Code \\
Gastonia & NC & 28054-6435
\end{tabular}

FEC ID number of contributing federal political committee.

C

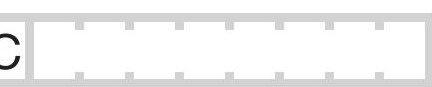

Name of Employer

Information Requested

Occupation

Information Requested

Receipt For: 2012

Х $\begin{aligned} & \text { Primary } \square \text { General } \\ & \text { Other (specify) }\end{aligned}$

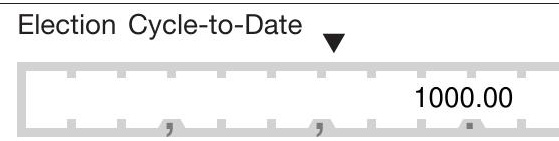

Amount of Each Receipt this Period

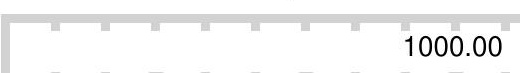

1200.00

Subtotal Of Receipts This Page (optional)

Total This Period (last page this line number only) 


\section{SCHEDULE A-P} ITEMIZED RECEIPTS
Use separate schedule(s)

for each category of the

Detailed Summary Page
FOR LINE NUMBER: (check only one)

Any information or for commercial purposes, other than using the name and address of any political committee to solicit contributions from such committee.

NAME OF COMMITTEE (In Full)

Friends of Herman Cain

A. Full Name (Last, First, Middle Initial)

Michael Lyons

Mailing Address 3617 W. Lincoln Ave

\begin{tabular}{lcc}
\hline City & State & Zip Code \\
Sacramento & CA & $95818-4162$
\end{tabular}

FEC ID number of contributing

federal political committee.

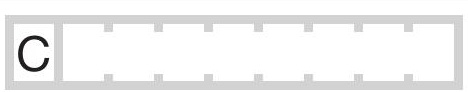

Name of Employer
Information Requested
Receipt For: 2012
X Primary $\quad \square$ General
Other (specify)

Occupation

Information Requested

Election Cycle-to-Date

250.00

B. Full Name (Last, First, Middle Initial)

Alexander Croke

Mailing Address 705 N MITCHELL AVE

\begin{tabular}{lcc}
\hline City & State & Zip Code \\
Arlington Heights & IL & $60004-5428$ \\
\hline
\end{tabular}

FEC ID number of contributing

federal political committee.

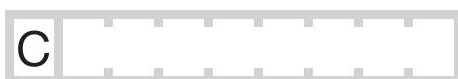

Name of Employer
Information Requested
Receipt For: 2012
X Primary
Other (specify)

Occupation

Information Requested

Election Cycle-to-Date

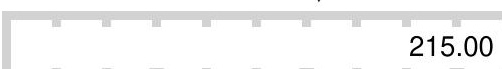

Transaction ID : A9D18337B191844FEBA0

Date of Receipt

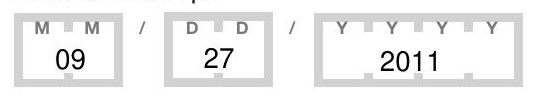

Amount of Each Receipt this Period

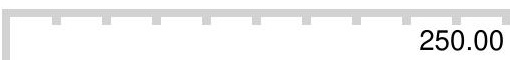

250.00

C. Full Name (Last, First, Middle Initial)

ted king

Mailing Address 113 timberidge court

\begin{tabular}{lcc}
\hline City & State & Zip Code \\
Woodstock & GA & $30188-2262$
\end{tabular}

FEC ID number of contributing

federal political committee.

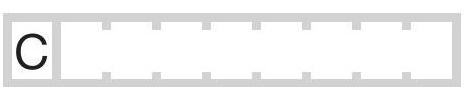

Name of Employer
self
Receipt For: 2012
X Primary
Other (specify) General

Occupation

Retired

Election Cycle-to-Date

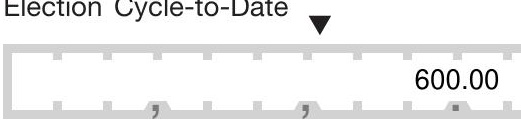

Transaction ID : A1D513E4F0E8643F5A90

Date of Receipt

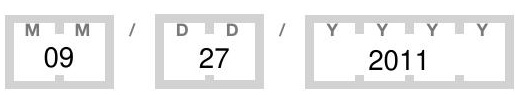

Amount of Each Receipt this Period

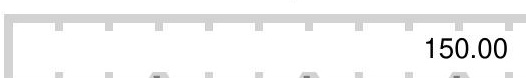

Transaction ID : AF6F7799B25CB4A21A87 Date of Receipt

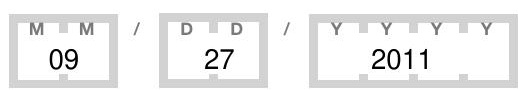

Amount of Each Receipt this Period

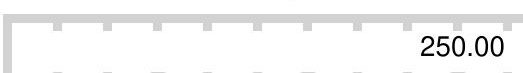

\section{Subtotal Of Receipts This Page (optional)}

650.00

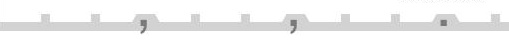

Total This Period (last page this line number only)

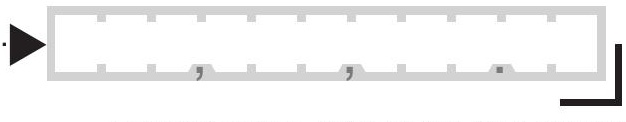

FEC Schedule A-P (Form 3P) (Rev. 03/2011) 
SCHEDULE A-P ITEMIZED RECEIPTS
Use separate schedule(s)

for each category of the

Detailed Summary Page
FOR LINE NUMBER: (check only one)

PAGE 849 / 1572

\begin{tabular}{|c|c|c|c|c|c|}
\hline & & & & & \\
\hline 16 & $\begin{array}{l}\mathbf{X} \\
17 a\end{array}$ & $17 b$ & $17 c$ & $17 d$ & 18 \\
\hline $19 a$ & $19 \mathrm{~b}$ & $20 \mathrm{a}$ & $20 \mathrm{~b}$ & $20 \mathrm{c}$ & 21 \\
\hline
\end{tabular}

Any information copied from such Reports and Statements may not be sold or used by any person for the purpose of soliciting contributions or for commercial purposes, other than using the name and address of any political committee to solicit contributions from such committee.

NAME OF COMMITTEE (In Full)

\section{Friends of Herman Cain}

A. Full Name (Last, First, Middle Initial)

Robert Bolling

Mailing Address 2109 Freeman Rd

\begin{tabular}{lcc}
\hline City & State & Zip Code \\
Jonesboro & GA & $30236-6711$
\end{tabular}

FEC ID number of contributing

federal political committee.

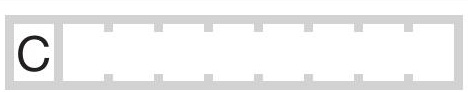

Name of Employer
self
Receipt For: 2012
X Primary $\quad$ General
Other (specify)

Occupation contractor

Election Cycle-to-Date 330.00

B. Full Name (Last, First, Middle Initial) Shellyn McCaffrey

Mailing Address 814 Green Street

\begin{tabular}{lcc}
\hline City & State & Zip Code \\
Alexandria & VA & $22314-4213$
\end{tabular}

FEC ID number of contributing

federal political committee.

C

Name of Employer
Information Requested
Receipt For: 2012
Primary
Other (specify)

Occupation

Information Requested

Election Cycle-to-Date

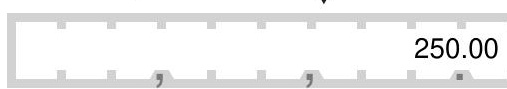

Transaction ID : AC5F276A7F0974DA9AAE

Date of Receipt

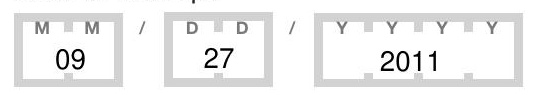

Amount of Each Receipt this Period

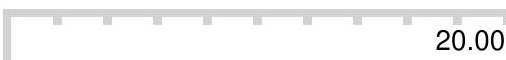

20.00

C. Full Name (Last, First, Middle Initial)

Richard Morrison

Mailing Address 411 Gentlemen's Ridge

\begin{tabular}{lcc}
\hline City & State & Zip Code \\
Signal Mountain & TN & $37377-3250$
\end{tabular}

FEC ID number of contributing

federal political committee.

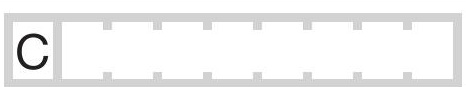

Name of Employer

MSA, Inc.

Occupation

Receipt For: 2012

Х $\begin{aligned} & \text { Primary } \square \text { General } \\ & \text { Other (specify) }\end{aligned}$

President

Transaction ID : A26DC7A05B9A54302B7A

Date of Receipt

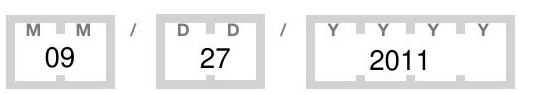

Amount of Each Receipt this Period

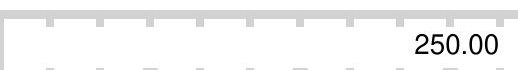

Transaction ID : A888BDAF934814607945

Date of Receipt

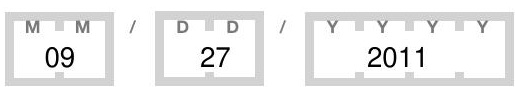

Amount of Each Receipt this Period

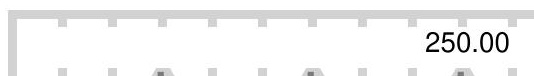

250.00

\section{Subtotal Of Receipts This Page (optional)}

Total This Period (last page this line number only) 
SCHEDULE A-P ITEMIZED RECEIPTS
Use separate schedule(s) for each category of the Detailed Summary Page
FOR LINE NUMBER: (check only one)

PAGE $850 / 1572$

\begin{tabular}{|c|c|c|c|c|c|c|}
\hline & & & & & & \\
\hline 16 & $\lambda$ & $17 \mathrm{a}$ & $17 \mathrm{~b}$ & $17 \mathrm{c}$ & $-17 d$ & -18 \\
\hline $19 a$ & & $19 b$ & $20 a$ & $20 \mathrm{~b}$ & $20 \mathrm{c}$ & 21 \\
\hline
\end{tabular}

Any information copied from such Reports and Statements may not be sold or used by any person for the purpose of soliciting contributions or for commercial purposes, other than using the name and address of any political committee to solicit contributions from such committee.

NAME OF COMMITTEE (In Full)

\section{Friends of Herman Cain}

A. Full Name (Last, First, Middle Initial)

George Davis Jr

Mailing Address P. O. Box 277

\begin{tabular}{lcc}
\hline City & State & Zip Code \\
Swanquarter & NC & $27885-0277$
\end{tabular}

FEC ID number of contributing federal political committee.

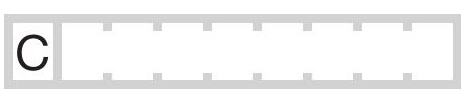

Name of Employer
Information Requested
Receipt For: 2012
X Primary
Other (specify) General

B. Full Name (Last, First, Middle Initial)

Mr Ray Miller

Mailing Address 10933 SE 219th PI

\begin{tabular}{llc}
\hline City & State & Zip Code \\
Kent & WA & $98031-1313$
\end{tabular}

FEC ID number of contributing

federal political committee.

C

Name of Employer
None
Receipt For: 2012
X Primary
Other (specify)

C. Full Name (Last, First, Middle Initial)

NELSON TOMPKINS

Mailing Address 1041 S EDINBURGH DRIVE

\begin{tabular}{lcc}
\hline City & State & Zip Code \\
Loveland & CO & $80537-6686$
\end{tabular}

FEC ID number of contributing federal political committee.

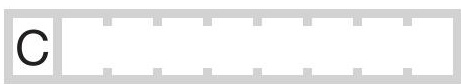

Name of Employer
SPITZER
Receipt For: 2012
X Primary $\square$ General
Other (specify)

\section{Occupation} Information Requested

Election Cycle-to-Date

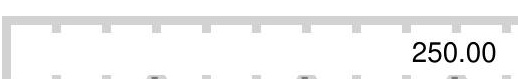

Transaction ID : AACB3440417ED4202B47

Date of Receipt

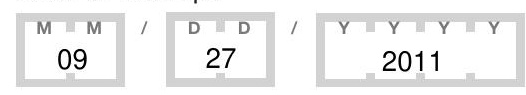

Amount of Each Receipt this Period

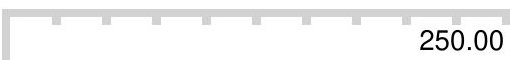

Amount of Each Receipt this Period

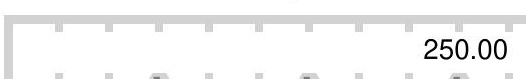

Amount of Each Receipt this Period

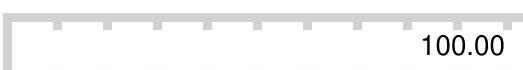

Subtotal Of Receipts This Page (optional)

600.00 CONTROLER

Election Cycle-to-Date 300.00

Total This Period (last page this line number only) 


\section{SCHEDULE A-P} ITEMIZED RECEIPTS
Use separate schedule(s) for each category of the Detailed Summary Page

FOR LINE NUMBER:
(check only one)

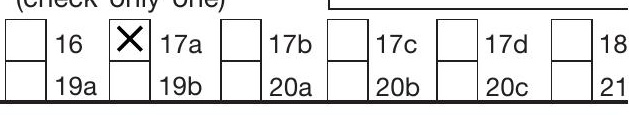

Any information copied from such Reports and Statements may not be sold or used by any person for the purpose of soliciting contributions or for commercial purposes, other than using the name and address of any political committee to solicit contributions from such committee.

NAME OF COMMITTEE (In Full)

\section{Friends of Herman Cain}

A. Full Name (Last, First, Middle Initial)

Daniel A Coleman

Mailing Address 8735 Jenkins Rd

\begin{tabular}{lcc}
\hline City & State & Zip Code \\
Winston & GA & $30187-1910$
\end{tabular}

FEC ID number of contributing federal political committee.

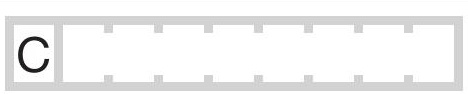

Name of Employer
Danco Financial
Receipt For: 2012
X Primary
$\square$ Other (specify) General

Occupation Finance

Election Cycle-to-Date

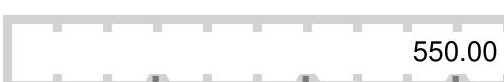

B. Full Name (Last, First, Middle Initial)

David Callard

Mailing Address 3160 Louis Road Unit B

\begin{tabular}{lcc}
\hline City & State & Zip Code \\
Palo Alto & CA & $94303-3954$
\end{tabular}

FEC ID number of contributing

federal political committee.

C

Name of Employer
Information Requested
Receipt For: 2012
X Primary
Other (specify)

Occupation

Information Requested

Election Cycle-to-Date

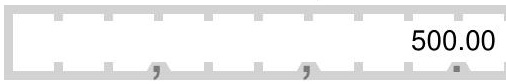

Transaction ID : AC83C115B961A4156B1B

Date of Receipt

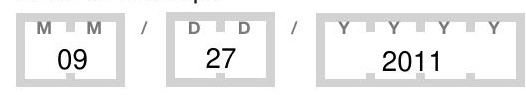

Amount of Each Receipt this Period

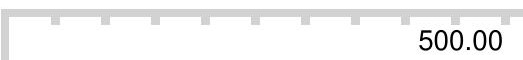

Amount of Each Receipt this Period

Transaction ID : AFD422228B55043F29F3

Date of Receipt
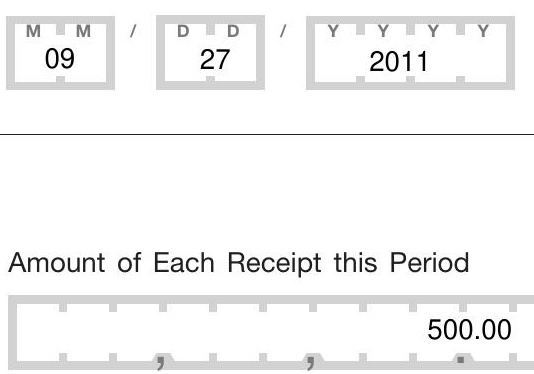

C. Full Name (Last, First, Middle Initial)

Mary Lowery

Mailing Address 425 Via Las Aguilas

\begin{tabular}{l|ll}
\hline $\begin{array}{l}\text { City } \\
\text { Arroyo Grande }\end{array}$ & $\begin{array}{c}\text { State } \\
\text { CA }\end{array}$ & $\begin{array}{c}\text { Zip Code } \\
93420-1946\end{array}$ \\
\hline $\begin{array}{l}\text { FEC ID number of contributing } \\
\text { federal political committee. }\end{array}$ & C & \\
\hline $\begin{array}{l}\text { Name of Employer } \\
\text { Self-Employed }\end{array}$ & $\begin{array}{l}\text { Occupation } \\
\text { Physician }\end{array}$ \\
\hline $\begin{array}{l}\text { Receipt For: } 2012 \\
\text { Primary } \\
\text { Other (specify) }\end{array}$ & Election Cycle-to-Date & \\
\end{tabular}

Amount of Each Receipt this Period

Transaction ID : A13351FC6D129404F99B

Date of Receipt
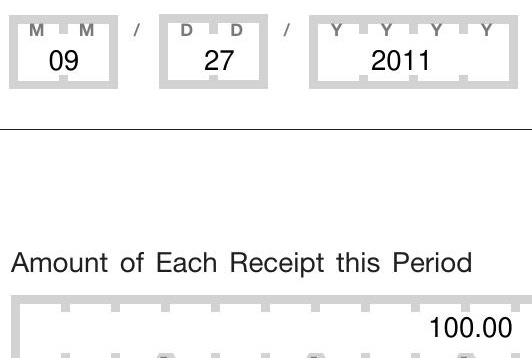

1100.00

Subtotal Of Receipts This Page (optional)

Total This Period (last page this line number only) 
SCHEDULE A-P ITEMIZED RECEIPTS
Use separate schedule(s) for each category of the Detailed Summary Page
FOR LINE NUMBER: (check only one)

PAGE 852 / 1572

\begin{tabular}{|c|c|c|c|c|c|c|}
\hline & & & & & & \\
\hline 16 & $\lambda$ & $17 \mathrm{a}$ & $17 \mathrm{~b}$ & $17 \mathrm{c}$ & $-17 d$ & -18 \\
\hline $19 a$ & & $19 b$ & $20 a$ & $20 \mathrm{~b}$ & $20 \mathrm{c}$ & 21 \\
\hline
\end{tabular}

Any information copied from such Reports and Statements may not be sold or used by any person for the purpose of soliciting contributions or for commercial purposes, other than using the name and address of any political committee to solicit contributions from such committee.

NAME OF COMMITTEE (In Full)

\section{Friends of Herman Cain}

A. Full Name (Last, First, Middle Initial)

\section{Patti Green}

Mailing Address 350 Woldunn Circle

\begin{tabular}{lcc}
\hline City & State & Zip Code \\
Lake Mary & FL & $32746-3941$ \\
\hline
\end{tabular}

FEC ID number of contributing federal political committee.

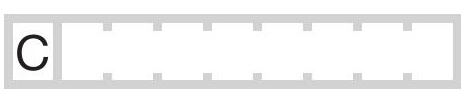

Name of Employer
n/a
Receipt For: 2012
X Primary $\quad$ General
Other (specify)

B. Full Name (Last, First, Middle Initial)

Mike Parton

Mailing Address 251 Painters Gap Rd.

\begin{tabular}{lcc}
\hline City & State & Zip Code \\
Rutherfordton & NC & $28139-9512$ \\
\hline
\end{tabular}

FEC ID number of contributing

federal political committee.

C

Name of Employer
Silkey Lumber Co.
Receipt For: 2012
X Primary
Other (specify)

\section{Occupation}

Manager

Election Cycle-to-Date

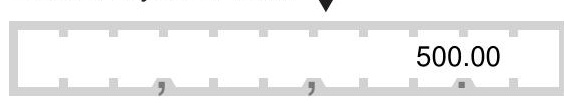

\subsection{0}

Transaction ID : A432E57F63B7B4536B73

Date of Receipt

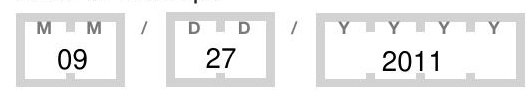

Amount of Each Receipt this Period

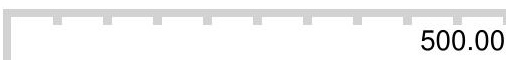

C. Full Name (Last, First, Middle Initial)

ronald loiselle

Mailing Address 503 ann street

\begin{tabular}{lcc}
\hline City & State & Zip Code \\
Plymouth & MI & $48170-1219$
\end{tabular}

FEC ID number of contributing federal political committee.

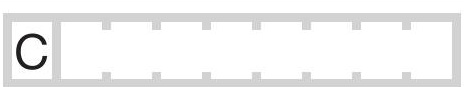

\section{Name of Employer}

Self Employed

Receipt For: 2012

Х $\begin{aligned} & \text { Primary } \square \text { General } \\ & \text { Other (specify) }\end{aligned}$

\section{Occupation}

Retired

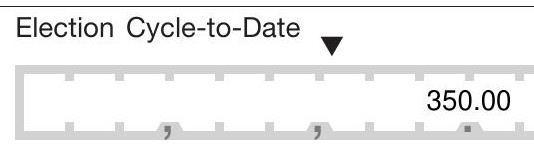

Transaction ID : A82264044E00F4160839

Date of Receipt

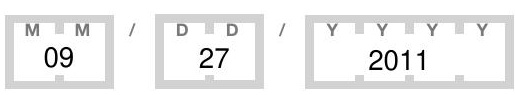

Amount of Each Receipt this Period

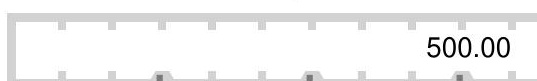

Transaction ID : A165FF5AC6F554D3EB48 Date of Receipt

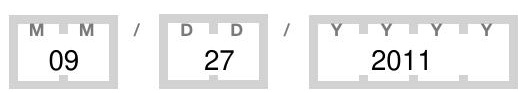

Amount of Each Receipt this Period

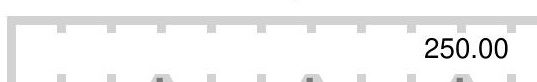

\section{Subtotal Of Receipts This Page (optional)}

Total This Period (last page this line number only) 
SCHEDULE A-P ITEMIZED RECEIPTS
Use separate schedule(s) for each category of the Detailed Summary Page
FOR LINE NUMBER: (check only one)

PAGE $853 / 1572$

\begin{tabular}{|c|c|c|c|c|c|c|}
\hline & & & & & & \\
\hline 16 & $\lambda$ & $17 \mathrm{a}$ & $17 \mathrm{~b}$ & $17 \mathrm{c}$ & $-17 d$ & -18 \\
\hline $19 a$ & & $19 b$ & $20 a$ & $20 \mathrm{~b}$ & $20 \mathrm{c}$ & 21 \\
\hline
\end{tabular}

Any information copied from such Reports and Statements may not be sold or used by any person for the purpose of soliciting contributions or for commercial purposes, other than using the name and address of any political committee to solicit contributions from such committee.

NAME OF COMMITTEE (In Full)

\section{Friends of Herman Cain}

A. Full Name (Last, First, Middle Initial) Julie Durrett

Mailing Address 3319 Jack Burke Ln

\begin{tabular}{lcc}
\hline City & State & Zip Code \\
Billings & MT & $59106-1111$
\end{tabular}

FEC ID number of contributing federal political committee.

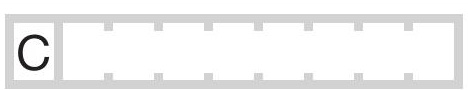

Name of Employer
Information Requested
Receipt For: 2012
X Primary
Other (specify) General

Occupation Information Requested

Election Cycle-to-Date

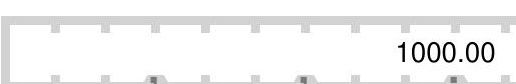

B. Full Name (Last, First, Middle Initial)

Eva Zukotynski

Mailing Address 1905 E University Dr \#253

\begin{tabular}{lcc}
\hline City & State & Zip Code \\
Tempe & AZ & $85281-8711$ \\
\hline
\end{tabular}

FEC ID number of contributing

federal political committee.

C

Name of Employer
Information Requested
Receipt For: 2012
X Primary
Other (specify)

\section{Occupation}

Information Requested

Election Cycle-to-Date

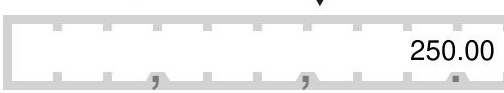

Transaction ID : AB8464D80D5F3429E8A9

Date of Receipt

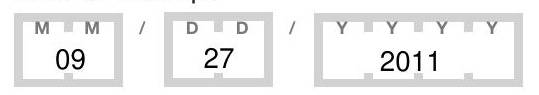

Amount of Each Receipt this Period

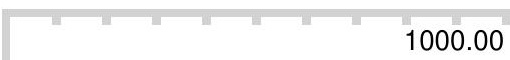

1000.00

C. Full Name (Last, First, Middle Initial)

Marty Ellis

Mailing Address 7976 Saddle Ridge Trce

\begin{tabular}{lcc}
\hline City & State & Zip Code \\
Nashville & TN & $37221-1023$
\end{tabular}

FEC ID number of contributing federal political committee.

C

Name of Employer
Self/Owner
Receipt For: 2012
Х Primary $\quad \square$ General
Other (specify)

Occupation

Concert Merchandise Company

Election Cycle-to-Date

Transaction ID : A203E8681454D40C9B98

Date of Receipt

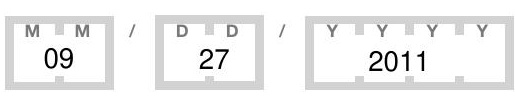

Amount of Each Receipt this Period

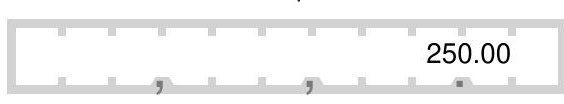

Transaction ID : A24C7743BBC424D68997 Date of Receipt

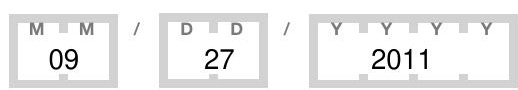

Amount of Each Receipt this Period

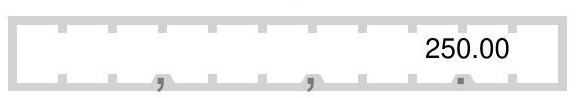

1250.00

\section{Subtotal Of Receipts This Page (optional)}

Total This Period (last page this line number only) 
SCHEDULE A-P ITEMIZED RECEIPTS
Use separate schedule(s) for each category of the Detailed Summary Page
FOR LINE NUMBER: (check only one)
PAGE 854 / 1572

\begin{tabular}{|c|c|c|c|c|c|}
\hline & & & & & \\
\hline 16 & $\begin{array}{lll}X & 17 a \\
\end{array}$ & $17 \mathrm{~b}$ & $17 c$ & $17 d$ & 18 \\
\hline $19 a$ & $19 b$ & $20 a$ & $20 \mathrm{~b}$ & $20 c$ & 21 \\
\hline
\end{tabular}

Any information copied from such Reports and Statements may not be sold or used by any person for the purpose of soliciting contributions or for commercial purposes, other than using the name and address of any political committee to solicit contributions from such committee.

NAME OF COMMITTEE (In Full)

\section{Friends of Herman Cain}

A. Full Name (Last, First, Middle Initial)

Michael Leonard

Mailing Address 147 Hubbard Rd

\begin{tabular}{lcc}
\hline City & State & Zip Code \\
Woodstock & GA & $30188-5036$ \\
\hline
\end{tabular}

FEC ID number of contributing

federal political committee.

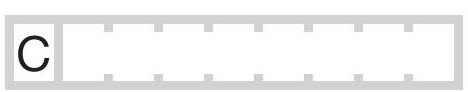

Name of Employer
Information Requested
Receipt For: 2012
X Primary $\quad \square$ General
Other (specify)

Occupation

Information Requested

Election Cycle-to-Date

1000.00

B. Full Name (Last, First, Middle Initial)

John Halston

Mailing Address 141 W. Jackson Blvd Suite 2020A

\begin{tabular}{lcc}
\hline City & State & Zip Code \\
Chicago & IL & $60604-3156$ \\
\hline
\end{tabular}

FEC ID number of contributing

federal political committee.

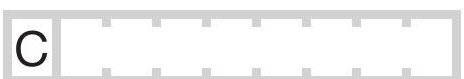

Name of Employer
Quiet Light Securities, LLC
Receipt For: 2012
X Primary
Other (specify)

\section{Occupation}

CEO

Election Cycle-to-Date

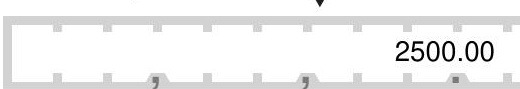

C. Full Name (Last, First, Middle Initial)

Frank Levy

Mailing Address 1615 Poydras St. Suite 1280

\begin{tabular}{lcc}
\hline City & State & Zip Code \\
New Orleans & LA & $70112-1284$
\end{tabular}

FEC ID number of contributing

federal political committee.

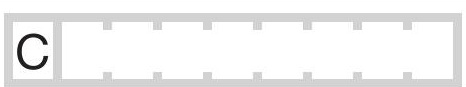

Name of Employer

Information Requested

Occupation

Information Requested

Receipt For: 2012

Х $\begin{aligned} & \text { Primary } \square \text { General } \\ & \text { Other (specify) }\end{aligned}$

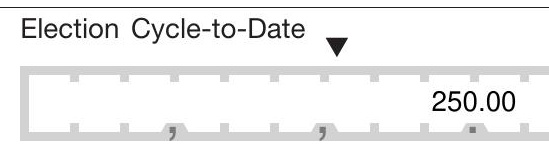

Amount of Each Receipt this Period

Transaction ID : AF1B3F30320824A059F0

Date of Receipt

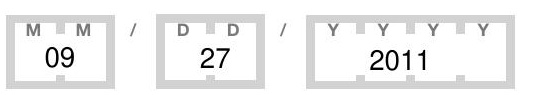

Amount of Each Receipt this Period
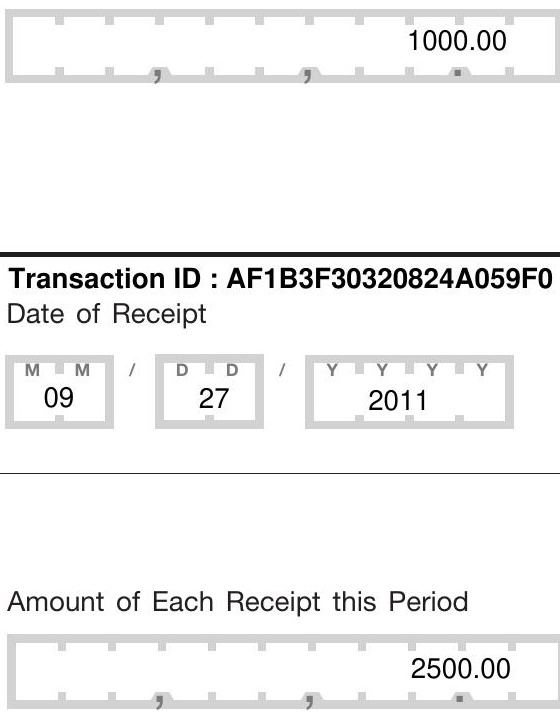

Transaction ID : ABFA7C82831F044B88DF Date of Receipt

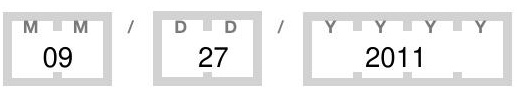

Amount of Each Receipt this Period

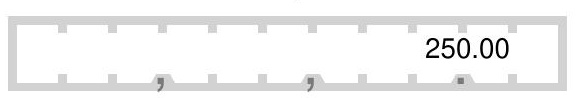

Subtotal Of Receipts This Page (optional).

3750.00

Total This Period (last page this line number only) 
SCHEDULE A-P ITEMIZED RECEIPTS
Use separate schedule(s) for each category of the Detailed Summary Page
FOR LINE NUMBER: (check only one)

PAGE $855 / 1572$

\begin{tabular}{|c|c|c|c|c|c|}
\hline & & & & & \\
\hline 16 & $\begin{array}{l}\mathbf{X} \\
17 a\end{array}$ & $17 b$ & $17 c$ & $17 d$ & 18 \\
\hline $19 a$ & $19 \mathrm{~b}$ & $20 \mathrm{a}$ & $20 \mathrm{~b}$ & $20 \mathrm{c}$ & 21 \\
\hline
\end{tabular}

Any information copied from such Reports and Statements may not be sold or used by any person for the purpose of soliciting contributions or for commercial purposes, other than using the name and address of any political committee to solicit contributions from such committee.

NAME OF COMMITTEE (In Full)

\section{Friends of Herman Cain}

A. Full Name (Last, First, Middle Initial) john lee

Mailing Address 3240 Granite Creek PI

\begin{tabular}{lcc}
\hline City & State & Zip Code \\
Newcastle & CA & $95658-9307$
\end{tabular}

FEC ID number of contributing federal political committee.

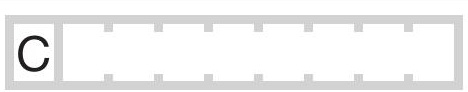

Name of Employer
stifel nicolaus
Receipt For: 2012
X Primary
Other (specify) General

Occupation

Executive

Election Cycle-to-Date

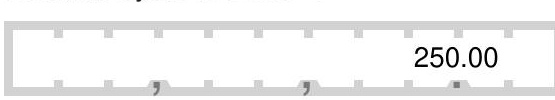

B. Full Name (Last, First, Middle Initial) eric buterbaugh

Mailing Address 109 apache drive

\begin{tabular}{lcc}
\hline City & State & Zip Code \\
Indiana & PA & $15701-8959$ \\
\hline
\end{tabular}

FEC ID number of contributing

federal political committee.

C

Name of Employer
Self Employed
Receipt For: 2012
X Primary
Other (specify)

Occupation

Petroleum Landman

Election Cycle-to-Date

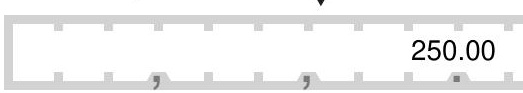

Transaction ID : AEEA733E3F3084638B22

Date of Receipt

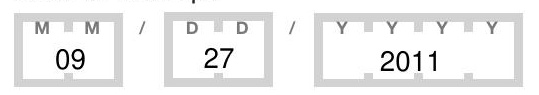

Amount of Each Receipt this Period

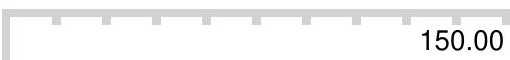

150.00

C. Full Name (Last, First, Middle Initial)

carl zies

Mailing Address 29 oyster landing

\begin{tabular}{lcc}
\hline City & State & Zip Code \\
Hilton Head Island & SC & 29928 \\
\hline
\end{tabular}

FEC ID number of contributing federal political committee.

C

Name of Employer
Information Requested
Receipt For: 2012
X Primary
Other (specify) General

\section{Occupation}

Information Requested

Election Cycle-to-Date
Transaction ID : A25F02B93F4A84AFBA68

Date of Receipt

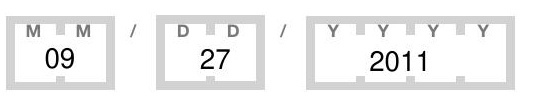

Amount of Each Receipt this Period

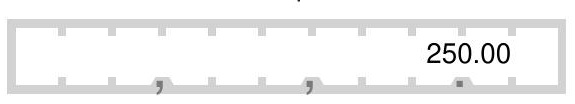

Transaction ID : A0CF785B46D804914B3E Date of Receipt

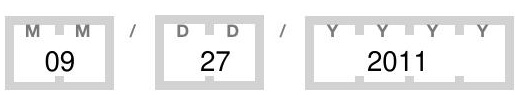

Amount of Each Receipt this Period

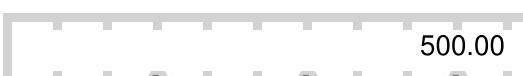

\section{Subtotal Of Receipts This Page (optional)}

900.00

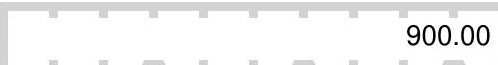

ㄱ․․

Total This Period (last page this line number only)

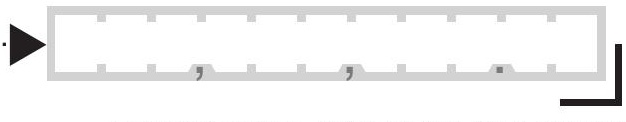

FEC Schedule A-P (Form 3P) (Rev. 03/2011) 


\section{SCHEDULE A-P} ITEMIZED RECEIPTS
Use separate schedule(s)

for each category of the

Detailed Summary Page
FOR LINE NUMBER: (check only one)

PAGE $856 / 1572$

\begin{tabular}{|c|c|c|c|c|c|}
\hline & & & & & \\
\hline 16 & X $17 a$ & $17 b$ & $17 c$ & $17 d$ & 18 \\
\hline $19 a$ & $19 b$ & $20 \mathrm{a}$ & $20 \mathrm{~b}$ & $20 \mathrm{c}$ & 21 \\
\hline
\end{tabular}

Any information copied from such Reports and Statements may not be sold or used by any person for the purpose of soliciting contributions or for commercial purposes, other than using the name and address of any political committee to solicit contributions from such committee.

NAME OF COMMITTEE (In Full)

Friends of Herman Cain

A. Full Name (Last, First, Middle Initial)

Timothy Graney

Mailing Address 26223 Rustic Ranch Ln

\begin{tabular}{lcc}
\hline City & State & Zip Code \\
Katy & TX & $77494-5360$ \\
\hline
\end{tabular}

FEC ID number of contributing federal political committee.

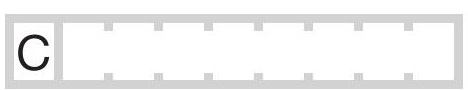

Name of Employer
self
Receipt For: 2012
X Primary
$\square$ Other (specify)

Occupation

Consultant

Election Cycle-to-Date

250.00

B. Full Name (Last, First, Middle Initial)

caron trese

Mailing Address 3675 Franklin rd

\begin{tabular}{lcc}
\hline City & State & Zip Code \\
Bloomfield Hills & MI & $48302-0962$
\end{tabular}

FEC ID number of contributing

federal political committee.

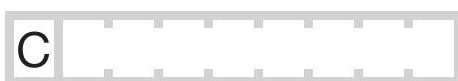

Name of Employer
Beaumont Hosp
Receipt For: 2012
X Primary
Other (specify)

Occupation

nurse anesthetist(ret)

Election Cycle-to-Date

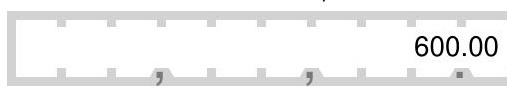

C. Full Name (Last, First, Middle Initial)

Phyllis Fine

Mailing Address 266 Trailwood Lane

\begin{tabular}{lcc}
\hline City & State & Zip Code \\
Northbrook & IL & $60062-1031$
\end{tabular}

FEC ID number of contributing federal political committee.

C

Name of Employer
homemaker
Receipt For: 2012
X Primary
Other (specify) General

Occupation

Homemaker

Election Cycle-to-Date
Transaction ID : A269D520384E044C7AB6

Date of Receipt

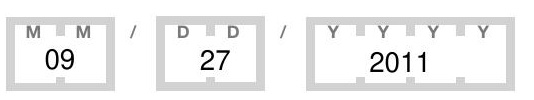

Amount of Each Receipt this Period

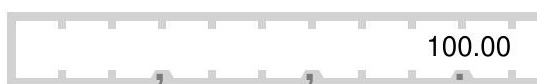

Transaction ID : A7C5001BB444D4EEAB44 Date of Receipt

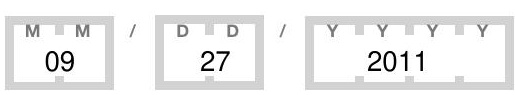

Amount of Each Receipt this Period

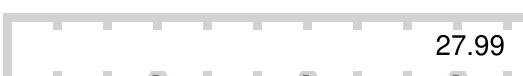

\section{Subtotal Of Receipts This Page (optional).}

277.99

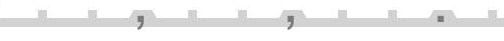

Total This Period (last page this line number only)
Transaction ID : AEA14C99EAB2E42EDA3F

Date of Receipt

Amount of Each Receipt this Period

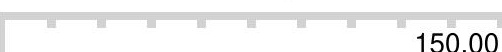

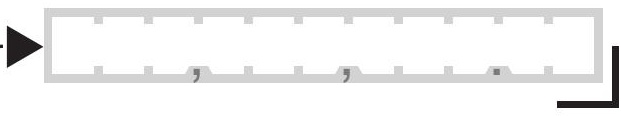




\section{SCHEDULE A-P} ITEMIZED RECEIPTS
Use separate schedule(s)

for each category of the

Detailed Summary Page
FOR LINE NUMBER: (check only one)
PAGE 857 / 1572

\begin{tabular}{|c|c|c|c|c|c|}
\hline & & & & & \\
\hline 16 & $\begin{array}{l}\mathbf{X} \\
17 a\end{array}$ & $17 b$ & $17 c$ & $17 d$ & 18 \\
\hline $19 a$ & $19 \mathrm{~b}$ & $20 \mathrm{a}$ & $20 \mathrm{~b}$ & $20 \mathrm{c}$ & 21 \\
\hline
\end{tabular}

Any information copied from such Reports and Statements may not be sold or used by any person for the purpose of soliciting contributions or for commercial purposes, other than using the name and address of any political committee to solicit contributions from such committee.

NAME OF COMMITTEE (In Full)

Friends of Herman Cain

A. Full Name (Last, First, Middle Initial)

Donald Dudlley

Mailing Address 2134 Branard St

\begin{tabular}{lcc}
\hline City & State & Zip Code \\
Houston & TX & $77098-2406$
\end{tabular}

FEC ID number of contributing

federal political committee.

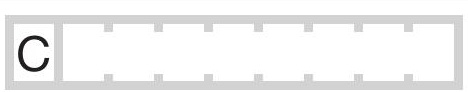

Name of Employer
Information Requested
Receipt For: 2012
X Primary $\quad \square$ General
$\square$ Other (specify)

Occupation

Information Requested

Election Cycle-to-Date

250.00

B. Full Name (Last, First, Middle Initial)

Mr Thomas McGuire

Mailing Address PO Box 328

\begin{tabular}{lcc}
\hline City & State & Zip Code \\
Bonners Ferry & ID & $83805-0328$ \\
\hline
\end{tabular}

FEC ID number of contributing

federal political committee.

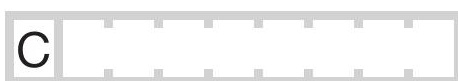

Name of Employer
None
Receipt For: 2012
X Primary
Other (specify)

Occupation

Retired

Election Cycle-to-Date

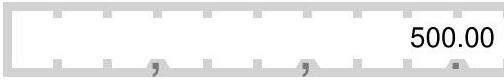

C. Full Name (Last, First, Middle Initial)

Joseph Niswonger

Mailing Address 6088 Windchase Drive

\begin{tabular}{lcc}
\hline City & State & Zip Code \\
Rocky Mount & NC & $27803-8774$
\end{tabular}

FEC ID number of contributing

federal political committee.

C

Name of Employer

First Carolina Management

Receipt For: 2012

Х $\begin{aligned} & \text { Primary } \square \text { General } \\ & \text { Other (specify) }\end{aligned}$

Occupation

VP Sales \& Marketing

Election Cycle-to-Date
Transaction ID : AD004EBE5E5A54E198D6

Date of Receipt

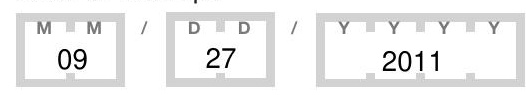

Amount of Each Receipt this Period

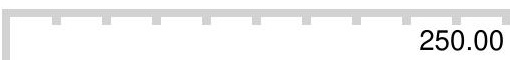

Amount of Each Receipt this Period

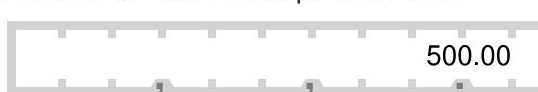

Transaction ID : A9E6A37D56CC448AA8C7 Date of Receipt

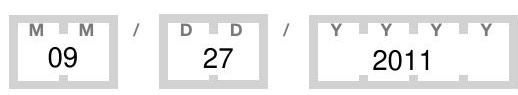

Transaction ID : A943AC36FB78748C4B55 Date of Receipt

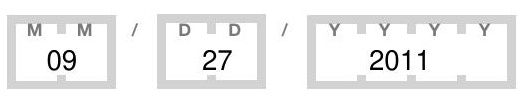

Amount of Each Receipt this Period

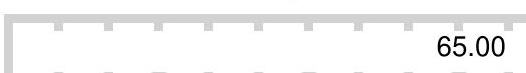

900.00

Subtotal Of Receipts This Page (optional).

815.00

a

Total This Period (last page this line number only)

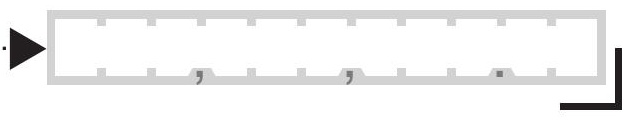

FEC Schedule A-P (Form 3P) (Rev. 03/2011) 


\section{SCHEDULE A-P} ITEMIZED RECEIPTS
Use separate schedule(s)

for each category of the

Detailed Summary Page
FOR LINE NUMBER: (check only one)

PAGE $858 / 1572$

\begin{tabular}{|c|c|c|c|c|c|}
\hline & & & & & \\
\hline 16 & X $17 a$ & $17 b$ & $17 c$ & $17 d$ & 18 \\
\hline $19 a$ & $19 b$ & $20 \mathrm{a}$ & $20 \mathrm{~b}$ & $20 \mathrm{c}$ & 21 \\
\hline
\end{tabular}

Any information copied from such Reports and Statements may not be sold or used by any person for the purpose of soliciting contributions or for commercial purposes, other than using the name and address of any political committee to solicit contributions from such committee.

NAME OF COMMITTEE (In Full)

Friends of Herman Cain

A. Full Name (Last, First, Middle Initial)

steven pittendrigh

Mailing Address 7272 E Gainey Ranch Rd unit 29

\begin{tabular}{lcc}
\hline City & State & Zip Code \\
Scottsdale & AZ & $85258-1505$
\end{tabular}

FEC ID number of contributing

federal political committee.

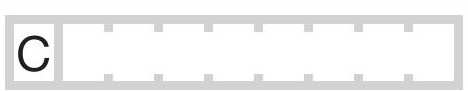

Name of Employer
Information Requested
Receipt For: 2012
X Primary $\quad \square$ General
Other (specify)

Occupation

Information Requested

Election Cycle-to-Date

1000.00

B. Full Name (Last, First, Middle Initial)

Mark Yunque

Mailing Address 401 Franklin Ave

\begin{tabular}{lcc}
\hline City & State & Zip Code \\
Princeton & NJ & $08540-3949$ \\
\hline
\end{tabular}

FEC ID number of contributing

federal political committee.

C

Name of Employer
Information Requested
Receipt For: 2012
Primary
Other (specify)

Occupation

Information Requested

Election Cycle-to-Date

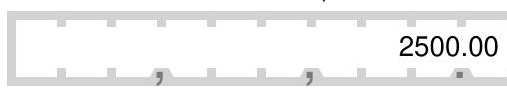

Transaction ID : AFEBAC1B12B414E72AC2

Date of Receipt

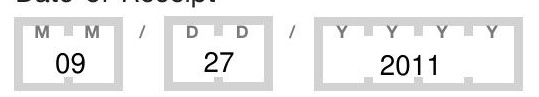

Amount of Each Receipt this Period

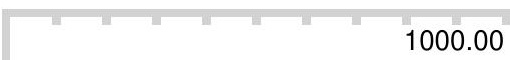

1000.00

C. Full Name (Last, First, Middle Initial)

Drucilla Jacobs

Mailing Address 3075 Rice Mill Rd None

\begin{tabular}{lcc}
\hline City & State & Zip Code \\
Macon & GA & $31206-3301$
\end{tabular}

FEC ID number of contributing

federal political committee.

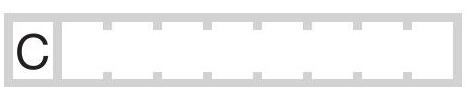

Name of Employer
$\mathrm{n} / \mathrm{a}$
Receipt For: 2012
X Primary
Other (specify) General

Occupation

Retired

Election Cycle-to-Date

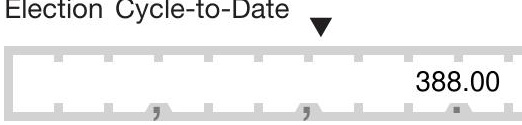

Transaction ID : A934F5D4861CA4C81812

Date of Receipt

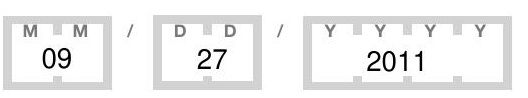

Amount of Each Receipt this Period

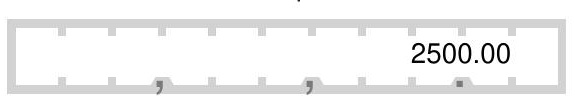

Transaction ID : A1F87EC1AD17D4168BB9 Date of Receipt

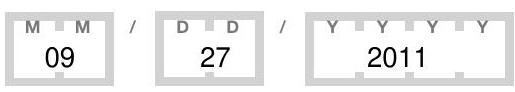

Amount of Each Receipt this Period

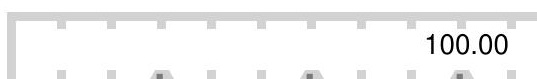

Subtotal Of Receipts This Page (optional).

3600.00

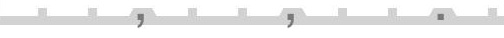

Total This Period (last page this line number only)

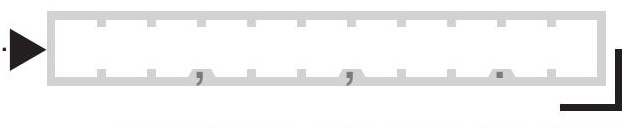

FEC Schedule A-P (Form 3P) (Rev. 03/2011) 
SCHEDULE A-P ITEMIZED RECEIPTS
Use separate schedule(s) for each category of the Detailed Summary Page
FOR LINE NUMBER: (check only one)

PAGE 859 / 1572

\begin{tabular}{|c|c|c|c|c|c|c|}
\hline & & & & & & \\
\hline 16 & $\lambda$ & $17 \mathrm{a}$ & $17 \mathrm{~b}$ & $17 \mathrm{c}$ & $-17 d$ & -18 \\
\hline $19 a$ & & $19 b$ & $20 a$ & $20 \mathrm{~b}$ & $20 \mathrm{c}$ & 21 \\
\hline
\end{tabular}

Any information copied from such Reports and Statements may not be sold or used by any person for the purpose of soliciting contributions or for commercial purposes, other than using the name and address of any political committee to solicit contributions from such committee.

NAME OF COMMITTEE (In Full)

\section{Friends of Herman Cain}

A. Full Name (Last, First, Middle Initial)

Robert Taylor IV

Mailing Address 9925 Huntcliff Trace

\begin{tabular}{lcc}
\hline City & State & Zip Code \\
Atlanta & GA & $30350-2717$
\end{tabular}

FEC ID number of contributing federal political committee.

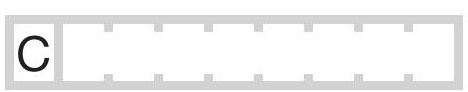

Name of Employer

Taylor Consulting Group, Inc.

Occupation

CPA

Receipt For: 2012

X Primary $\square$ General Other (specify)

Election Cycle-to-Date

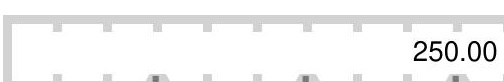

B. Full Name (Last, First, Middle Initial)

Robert Bridge

Mailing Address 10085 Dougherty Avenue

\begin{tabular}{lcc}
\hline City & State & Zip Code \\
Morgan Hill & CA & $95037-9390$
\end{tabular}

FEC ID number of contributing

federal political committee.

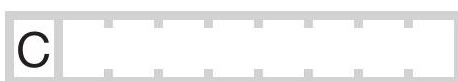

Name of Employer
Not Applicable
Receipt For: 2012
X Primary
Other (specify)

Occupation

Retired

Election Cycle-to-Date

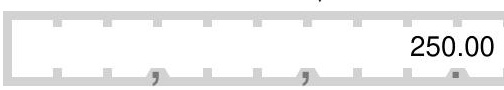

Transaction ID : AE465A312C14C440383D

Date of Receipt

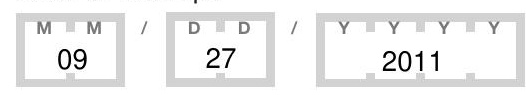

Amount of Each Receipt this Period

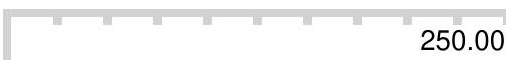

Amount of Each Receipt this Period

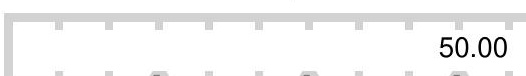

C. Full Name (Last, First, Middle Initial)

Lee Wallace

Mailing Address 1442 CR 313E

\begin{tabular}{lcc}
\hline City & State & Zip Code \\
Tyler & TX & $75706-3610$
\end{tabular}

FEC ID number of contributing

federal political committee.

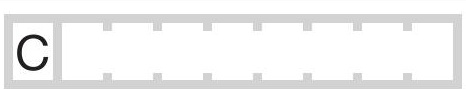

Name of Employer

Self Employed

Occupation

Receipt For: 2012

Х $\begin{aligned} & \text { Primary } \square \text { General } \\ & \text { Other (specify) }\end{aligned}$

Rancher

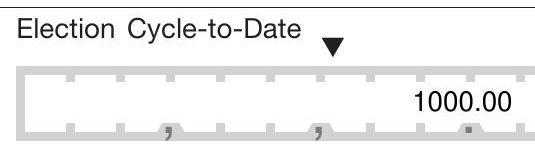

Amount of Each Receipt this Period

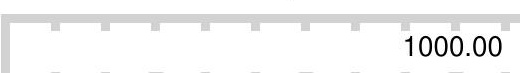

Transaction ID : A61018683BA50402FB24

Date of Receipt

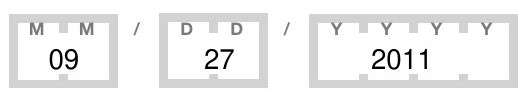

Subtotal Of Receipts This Page (optional)

1300.00

Total This Period (last page this line number only) 


\section{SCHEDULE A-P} ITEMIZED RECEIPTS
Use separate schedule(s)

for each category of the

Detailed Summary Page
FOR LINE NUMBER: (check only one)

PAGE $860 / 1572$

\begin{tabular}{|c|c|c|c|c|c|}
\hline & & & & & \\
\hline 16 & X $17 a$ & $17 b$ & $17 c$ & $17 d$ & 18 \\
\hline $19 a$ & $19 b$ & $20 \mathrm{a}$ & $20 \mathrm{~b}$ & $20 \mathrm{c}$ & 21 \\
\hline
\end{tabular}

Any information copied from such Reports and Statements may not be sold or used by any person for the purpose of soliciting contributions or for commercial purposes, other than using the name and address of any political committee to solicit contributions from such committee.

NAME OF COMMITTEE (In Full)

Friends of Herman Cain

A. Full Name (Last, First, Middle Initial)

Mason Mayhew

Mailing Address 1808 Westdale Way NW

\begin{tabular}{lcc}
\hline City & State & Zip Code \\
Albuquerque & NM & $87114-5969$ \\
\hline
\end{tabular}

FEC ID number of contributing

federal political committee.

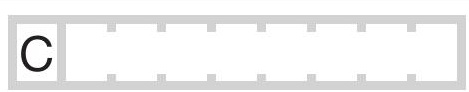

Name of Employer
El Pamco, Inc.
Receipt For: 2012
X Primary
$\square$ Other (specify) General

Occupation

Executive

Election Cycle-to-Date

250.00

B. Full Name (Last, First, Middle Initial)

Andrew Richardson

Mailing Address 2525 N. Pearl Street \#1402

\begin{tabular}{lcc}
\hline City & State & Zip Code \\
Dallas & TX & $75201-2231$ \\
\hline
\end{tabular}

FEC ID number of contributing

federal political committee.

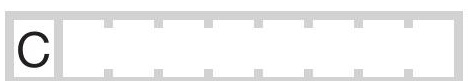

Name of Employer

The Howard Hughes Corporation

Occupation

Receipt For: 2012

$\chi \begin{aligned} & \text { Primary } \\ & \text { Other (specify) }\end{aligned}$

CFO

Election Cycle-to-Date

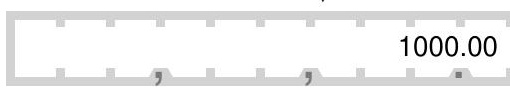

C. Full Name (Last, First, Middle Initial)

Curt Balchunas

Mailing Address 1740 sunset dr

\begin{tabular}{lcc}
\hline City & State & Zip Code \\
Clearwater & FL & $33755-1759$
\end{tabular}

FEC ID number of contributing

federal political committee.

C

Name of Employer

Information Requested

Occupation

Information Requested

Receipt For: 2012

Х $\begin{aligned} & \text { Primary } \square \text { General } \\ & \text { Other (specify) }\end{aligned}$

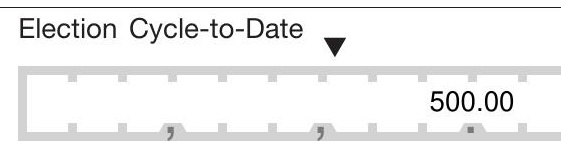

Transaction ID : AE2029E6EE9334BBB89C

Date of Receipt

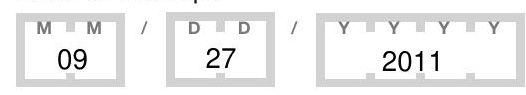

Amount of Each Receipt this Period

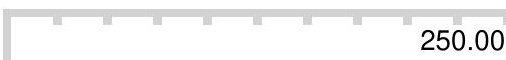

250.00

Transaction ID : A894FB2ECBFED4601845

Date of Receipt

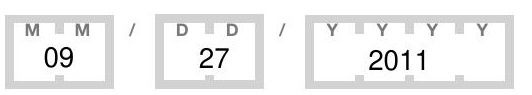

Amount of Each Receipt this Period

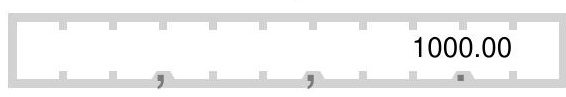

Transaction ID : A68778537ECB4458A880

Date of Receipt

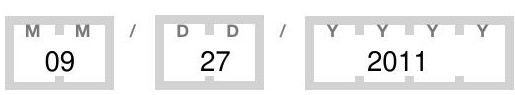

Amount of Each Receipt this Period

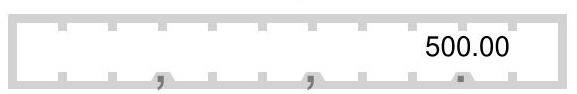

1750.00

Subtotal Of Receipts This Page (optional)

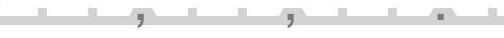

Total This Period (last page this line number only) 


\section{SCHEDULE A-P} ITEMIZED RECEIPTS
Use separate schedule(s)

for each category of the

Detailed Summary Page
FOR LINE NUMBER: (check only one)

PAGE $861 / 1572$

\begin{tabular}{|c|c|c|c|c|c|}
\hline & & & & & \\
\hline 16 & X $17 a$ & $17 b$ & $17 c$ & $17 d$ & 18 \\
\hline $19 a$ & $19 b$ & $20 \mathrm{a}$ & $20 \mathrm{~b}$ & $20 \mathrm{c}$ & 21 \\
\hline
\end{tabular}

Any information copied from such Reports and Statements may not be sold or used by any person for the purpose of soliciting contributions or for commercial purposes, other than using the name and address of any political committee to solicit contributions from such committee.

NAME OF COMMITTEE (In Full)

Friends of Herman Cain

A. Full Name (Last, First, Middle Initial)

Michael Evans

Mailing Address 6169 Cyril Ave.

\begin{tabular}{lcc}
\hline City & State & Zip Code \\
Orlando & FL & $32809-5045$
\end{tabular}

FEC ID number of contributing federal political committee.

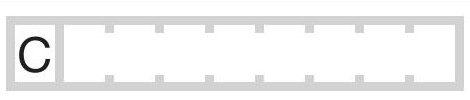

Name of Employer
Information Requested
Receipt For: 2012
X Primary
$\square$ Other (specify)

Occupation

Information Requested

Election Cycle-to-Date

500.00

B. Full Name (Last, First, Middle Initial)

Brian Poe

Mailing Address 4121 Bridgemont Lane

\begin{tabular}{lcc}
\hline City & State & Zip Code \\
Lexington & KY & $40515-6006$ \\
\hline
\end{tabular}

FEC ID number of contributing

federal political committee.

C

Name of Employer
Information Requested
Receipt For: 2012
X Primary
Other (specify)

Occupation

Information Requested

Election Cycle-to-Date

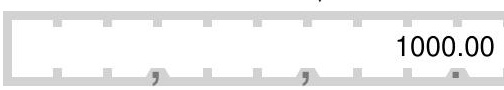

Transaction ID : A4A0E6EA11381497F8B3

Date of Receipt

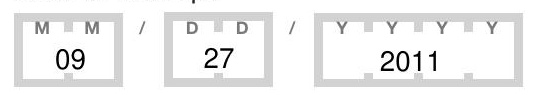

Amount of Each Receipt this Period

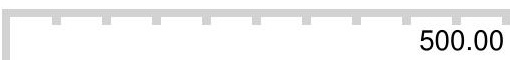

C. Full Name (Last, First, Middle Initial)

Norman Walen

Mailing Address 2100 NE 60th Avenue

\begin{tabular}{lcc}
\hline City & State & Zip Code \\
Des Moines & IA & $50313-1648$
\end{tabular}

FEC ID number of contributing

federal political committee.

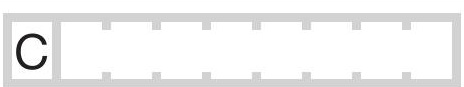

Name of Employer

Self-Barrett Plating Inc.

Receipt For: 2012

Х $\begin{aligned} & \text { Primary } \\ & \text { Other (specify) }\end{aligned}$

\section{Occupation}

Owner

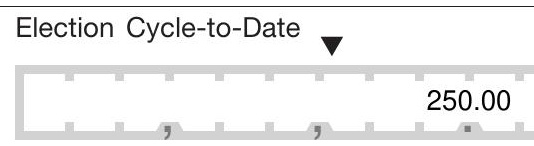

Amount of Each Receipt this Period

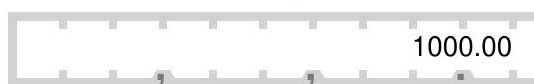

Transaction ID : A1C0D40C1FD344266ABD Date of Receipt

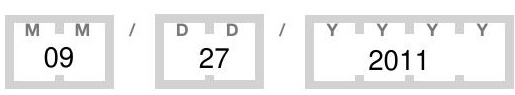

Transaction ID : A008B4AAC4C7442FA86C Date of Receipt

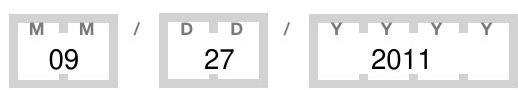

Amount of Each Receipt this Period

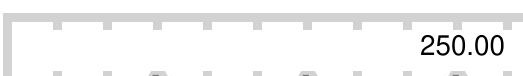

\section{Subtotal Of Receipts This Page (optional)}

Total This Period (last page this line number only) 
SCHEDULE A-P ITEMIZED RECEIPTS
Use separate schedule(s) for each category of the Detailed Summary Page
FOR LINE NUMBER: (check only one)
PAGE 862 / 1572

\begin{tabular}{|c|c|c|c|c|c|}
\hline & & & & & \\
\hline 16 & $\begin{array}{lll}X & 17 a \\
\end{array}$ & $17 \mathrm{~b}$ & $17 c$ & $17 d$ & 18 \\
\hline $19 a$ & $19 b$ & $20 a$ & $20 \mathrm{~b}$ & $20 c$ & 21 \\
\hline
\end{tabular}

Any information copied from such Reports and Statements may not be sold or used by any person for the purpose of soliciting contributions or for commercial purposes, other than using the name and address of any political committee to solicit contributions from such committee.

NAME OF COMMITTEE (In Full)

Friends of Herman Cain

A. Full Name (Last, First, Middle Initial) Janet Weidman

Mailing Address 222 Oak Ln

\begin{tabular}{lcc}
\hline City & State & Zip Code \\
Lewisburg & PA & $17837-9351$
\end{tabular}

FEC ID number of contributing federal political committee.

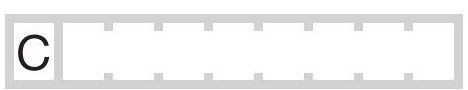

Name of Employer

Evangelical Community Hospital

Occupation

Receipt For: 2012

Х $\begin{aligned} & \text { Primary } \square \text { General } \\ & \text { Other (specify) } \boldsymbol{\nabla}\end{aligned}$

Registered Nurse

Election Cycle-to-Date

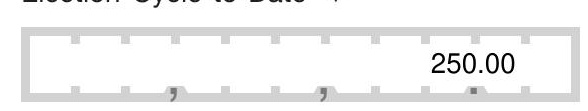

B. Full Name (Last, First, Middle Initial)

Janice Smith

Mailing Address 1983 Linda Flora Drive

\begin{tabular}{lcc}
\hline City & State & Zip Code \\
Los Angeles & CA & $90077-1404$ \\
\hline
\end{tabular}

FEC ID number of contributing

federal political committee.

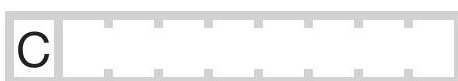

Name of Employer

Connect Management Partners

Occupation

Receipt For: 2012

Х $\begin{aligned} & \text { Primary } \square \text { General } \\ & \text { Other (specify) }\end{aligned}$

Executive

Transaction ID : A93909A4B930A4D8C920

Date of Receipt

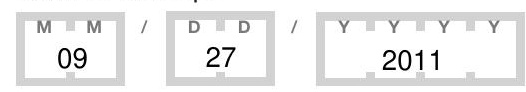

Amount of Each Receipt this Period
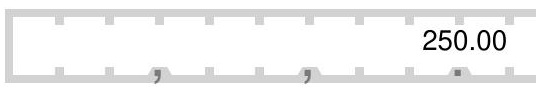

Transaction ID : A65B7846F689145C6B70

Date of Receipt

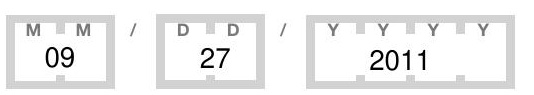

Amount of Each Receipt this Period

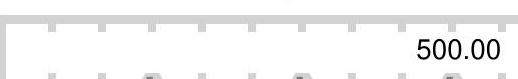

Election Cycle-to-Date

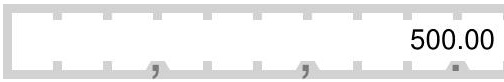

C. Full Name (Last, First, Middle Initial)

Stephen Palmer

Mailing Address 265 Westbrook St.

\begin{tabular}{lcc}
\hline City & State & Zip Code \\
South Portland & ME & $04106-3327$
\end{tabular}

FEC ID number of contributing

federal political committee.

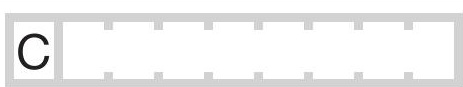

Name of Employer

Self Employed

Occupation

Health Care Provider

Receipt For: 2012

Х $\begin{aligned} & \text { Primary } \square \text { General } \\ & \text { Other (specify) }\end{aligned}$

Election Cycle-to-Date

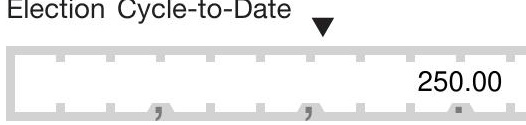

Amount of Each Receipt this Period

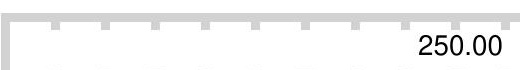

Transaction ID : A1F63C641E3394A8DA70

Date of Receipt

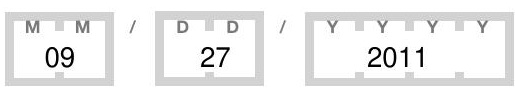

Subtotal Of Receipts This Page (optional)

1000.00

Total This Period (last page this line number only)

FEC Schedule A-P (Form 3P) (Rev. 03/2011) 
SCHEDULE A-P ITEMIZED RECEIPTS
Use separate schedule(s) for each category of the Detailed Summary Page
FOR LINE NUMBER: (check only one)

\begin{tabular}{|c|c|c|c|c|c|}
\hline & & & & & \\
\hline 16 & $\begin{array}{ll}X & 17 a \\
\end{array}$ & $17 \mathrm{~b}$ & $17 c$ & $17 d$ & 18 \\
\hline $19 a$ & $19 b$ & $20 \mathrm{a}$ & $20 \mathrm{~b}$ & $20 c$ & 21 \\
\hline
\end{tabular}

Any information copied from such Reports and Statements may not be sold or used by any person for the purpose of soliciting contributions or for commercial purposes, other than using the name and address of any political committee to solicit contributions from such committee.

NAME OF COMMITTEE (In Full)

\section{Friends of Herman Cain}

A. Full Name (Last, First, Middle Initial)

Ronald Hovis

Mailing Address 2518 Monarch Terrace Dr.

\begin{tabular}{lcc}
\hline City & State & Zip Code \\
Katy & TX & $77494-0669$ \\
\hline
\end{tabular}

FEC ID number of contributing federal political committee.

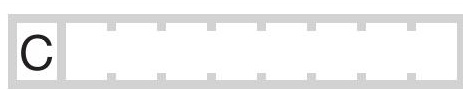

Name of Employer
None
Receipt For: 2012
X Primary $\quad$ General
$\quad$ Other (specify)

Occupation Retired

Election Cycle-to-Date

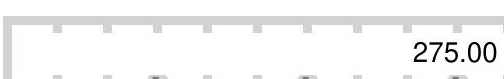

B. Full Name (Last, First, Middle Initial)

\section{Ronald Hovis}

Mailing Address 2518 Monarch Terrace Dr.

\begin{tabular}{lcc}
\hline City & State & Zip Code \\
Katy & TX & $77494-0669$ \\
\hline
\end{tabular}

FEC ID number of contributing

federal political committee.

C

Name of Employer
None
Receipt For: 2012
X Primary
Other (specify)

C. Full Name (Last, First, Middle Initial)

Ronald Hovis

Mailing Address 2518 Monarch Terrace Dr.

\begin{tabular}{lcc}
\hline City & State & Zip Code \\
Katy & TX & $77494-0669$
\end{tabular}

FEC ID number of contributing federal political committee.

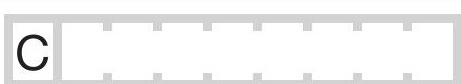

Name of Employer
None
Receipt For: 2012
X Primary $\quad \square$ General
Other (specify)

\section{Occupation}

Retired

Election Cycle-to-Date

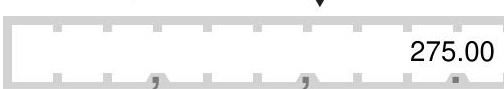

$\begin{aligned} & \text { Occupation } \\ & \text { Retired }\end{aligned}$
Election Cycle-to-Date

Transaction ID : AEB6BEDB568624E9283E

Date of Receipt

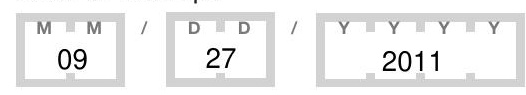

Amount of Each Receipt this Period

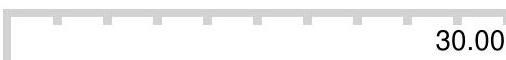

30.00
Amount of Each Receipt this Period

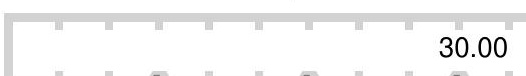

Transaction ID : A4FA78FE966174A629FB

Date of Receipt

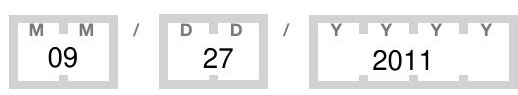

Transaction ID : A0FD40CF7B70A4C26892 Date of Receipt

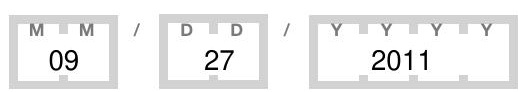

Amount of Each Receipt this Period

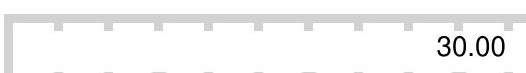

30.00

\section{Subtotal Of Receipts This Page (optional)}

Total This Period (last page this line number only) 
SCHEDULE A-P ITEMIZED RECEIPTS
Use separate schedule(s) for each category of the Detailed Summary Page
FOR LINE NUMBER: (check only one)
PAGE 864 / 1572

\begin{tabular}{|c|c|c|c|c|c|}
\hline & & & & & \\
\hline 16 & $\begin{array}{l}\mathbf{x} 17 a \\
\end{array}$ & $17 b$ & $17 c$ & $17 d$ & 18 \\
\hline $19 a$ & $19 b$ & $20 a$ & $20 b$ & $20 c$ & 21 \\
\hline
\end{tabular}

Any information copied from such Reports and Statements may not be sold or used by any person for the purpose of soliciting contributions or for commercial purposes, other than using the name and address of any political committee to solicit contributions from such committee.

NAME OF COMMITTEE (In Full)

\section{Friends of Herman Cain}

A. Full Name (Last, First, Middle Initial)

\section{Edward Hatfield}

Mailing Address 49805 Burley Hills Drive

\begin{tabular}{lcc}
\hline City & State & Zip Code \\
Cincinnati & OH & 45243
\end{tabular}

FEC ID number of contributing federal political committee.

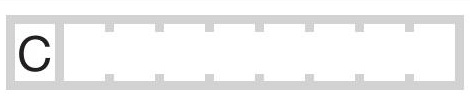

Name of Employer
River Trading Company
Receipt For: 2012
X Primary
Other (specify) General

Occupation President Election Cycle-to-Date

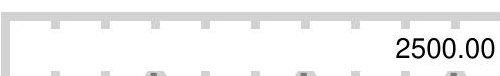

B. Full Name (Last, First, Middle Initial) John Mckenzie

Mailing Address 2100 Valley View Parkway \#2218

\begin{tabular}{lcc}
\hline City & State & Zip Code \\
El Dorado Hills & CA & $95762-5544$
\end{tabular}

FEC ID number of contributing

federal political committee.

C

Name of Employer
Information Requested
Receipt For: 2012
X Primary
Other (specify)

\section{Occupation}

Information Requested

Election Cycle-to-Date

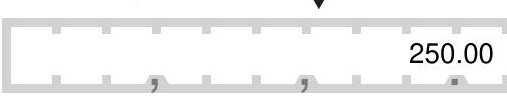

Transaction ID : A049E0A457AB94A91ADC

Date of Receipt

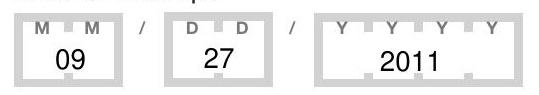

Amount of Each Receipt this Period

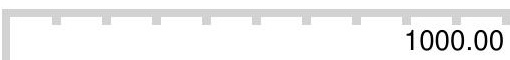

1000.00

C. Full Name (Last, First, Middle Initial)

Thomas Knox

Mailing Address 28437 Bridle Path

\begin{tabular}{lcc}
\hline City & State & Zip Code \\
Boerne & TX & $78006-5153$
\end{tabular}

FEC ID number of contributing federal political committee.

C

78006-5153

Name of Employer

Information Requested

Occupation

Information Requested

Receipt For: 2012

Х $\begin{aligned} & \text { Primary } \\ & \text { Other (specify) }\end{aligned}$

Election Cycle-to-Date

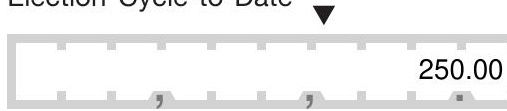

Amount of Each Receipt this Period

Transaction ID : A01BF19F834404CD0A16

Date of Receipt
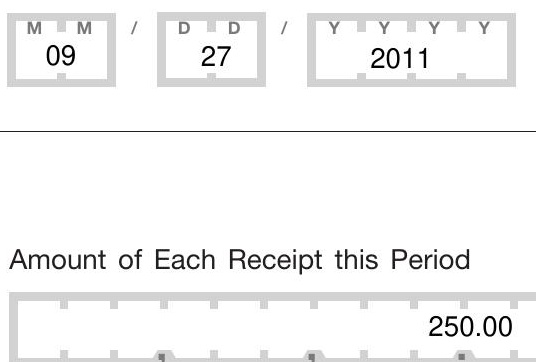

Transaction ID : A0695B612548F417588B

Date of Receipt

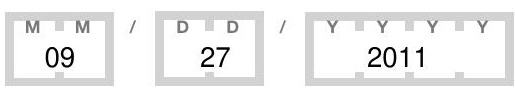

Amount of Each Receipt this Period

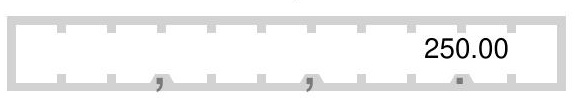

Subtotal Of Receipts This Page (optional).

1500.00

Total This Period (last page this line number only) 
SCHEDULE A-P ITEMIZED RECEIPTS
Use separate schedule(s) for each category of the Detailed Summary Page
FOR LINE NUMBER: (check only one)
PAGE $865 / 1572$

\begin{tabular}{|c|c|c|c|c|c|}
\hline & & & & & \\
\hline 16 & $\begin{array}{lll}X & 17 a \\
\end{array}$ & $17 \mathrm{~b}$ & $17 c$ & $17 d$ & 18 \\
\hline $19 a$ & $19 b$ & $20 a$ & $20 \mathrm{~b}$ & $20 c$ & 21 \\
\hline
\end{tabular}

Any information copied from such Reports and Statements may not be sold or used by any person for the purpose of soliciting contributions or for commercial purposes, other than using the name and address of any political committee to solicit contributions from such committee.

NAME OF COMMITTEE (In Full)

\section{Friends of Herman Cain}

A. Full Name (Last, First, Middle Initial)

\section{Susan Walter}

Mailing Address P.O. Box 690

\begin{tabular}{lcc}
\hline City & State & Zip Code \\
Sautee Nacoochee & GA & $30571-0690$
\end{tabular}

FEC ID number of contributing federal political committee.

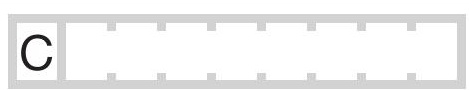

Name of Employer
None
Receipt For: 2012
X Primary $\quad$ General
Other (specify)

Occupation Retired

Election Cycle-to-Date

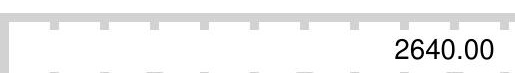

B. Full Name (Last, First, Middle Initial) James Sammons

Mailing Address 1000 River Ranch Rd

\begin{tabular}{lcc}
\hline City & State & Zip Code \\
Aledo & TX & $76008-4841$
\end{tabular}

FEC ID number of contributing

federal political committee.

C

Name of Employer
Information Requested
Receipt For: 2012
X Primary
Other (specify)

Occupation

Information Requested

Election Cycle-to-Date

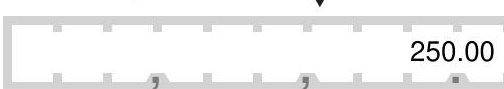

Transaction ID : A917CDCB347BD4E35B34

Date of Receipt

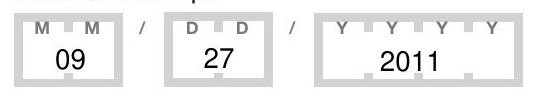

Amount of Each Receipt this Period

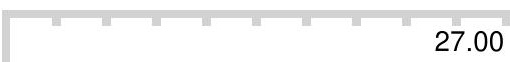

27.00

C. Full Name (Last, First, Middle Initial)

Corbin Moore

Mailing Address 5547 East Pitt Ave.

\begin{tabular}{lcc}
\hline City & State & Zip Code \\
Fresno & CA & $93727-6334$
\end{tabular}

FEC ID number of contributing federal political committee.

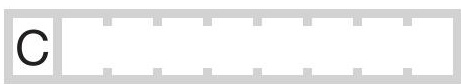

Name of Employer

Information Requested

\section{Occupation}

Information Requested

Receipt For: 2012

Х $\begin{aligned} & \text { Primary } \square \text { General } \\ & \text { Other (specify) }\end{aligned}$

Transaction ID : A6AC86839E26C4C3BA96

Date of Receipt

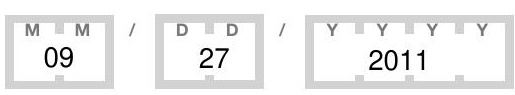

Amount of Each Receipt this Period

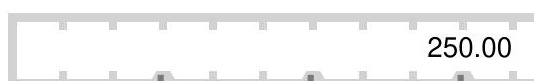

Transaction ID : A6728BC903498413E8EC Date of Receipt

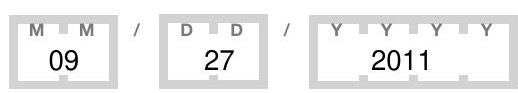

Amount of Each Receipt this Period

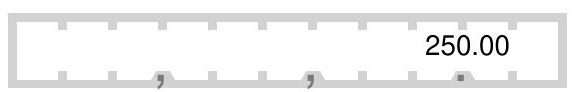

250.00
Subtotal Of Receipts This Page (optional)

527.00

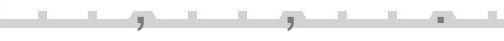

Total This Period (last page this line number only)

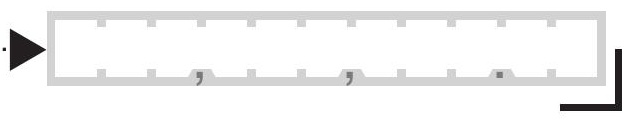

FEC Schedule A-P (Form 3P) (Rev. 03/2011) 


\section{SCHEDULE A-P} ITEMIZED RECEIPTS
Use separate schedule(s)

for each category of the

Detailed Summary Page
FOR LINE NUMBER: (check only one)
PAGE 866 / 1572

\begin{tabular}{|c|c|c|c|c|c|}
\hline & & & & & \\
\hline 16 & $\mathbf{X} 17 \mathrm{a}$ & $17 \mathrm{~b}$ & $17 c$ & $17 d$ & 18 \\
\hline $19 a$ & $19 b$ & $20 a$ & $20 \mathrm{~b}$ & $20 c$ & 21 \\
\hline
\end{tabular}

Any information copied from such Reports and Statements may not be sold or used by any person for the purpose of soliciting contributions or for commercial purposes, other than using the name and address of any political committee to solicit contributions from such committee.

NAME OF COMMITTEE (In Full)

\section{Friends of Herman Cain}

A. Full Name (Last, First, Middle Initial)

Gary Manning

Mailing Address 4106 Oberlin St

\begin{tabular}{lcc}
\hline City & State & Zip Code \\
Houston & TX & $77005-3523$ \\
\hline
\end{tabular}

FEC ID number of contributing federal political committee.

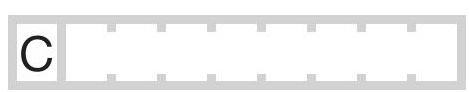

Name of Employer
Greater Houston Anesthesiology
Receipt For: 2012
X Primary
Other (specify) General

Occupation

Anesthesiologist

Election Cycle-to-Date

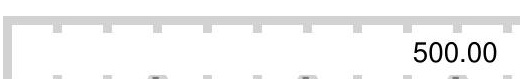

B. Full Name (Last, First, Middle Initial)

Charlene Yde

Mailing Address 1603 Pine Creek Way

\begin{tabular}{lcc}
\hline City & State & Zip Code \\
Woodstock & GA & $30188-4358$ \\
\hline
\end{tabular}

FEC ID number of contributing

federal political committee.

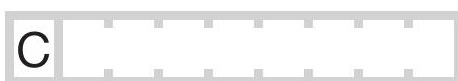

Name of Employer
The Paradies Shops
Receipt For: 2012
X Primary
Other (specify)

\section{Occupation} Manager

Election Cycle-to-Date

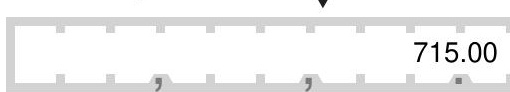

Transaction ID : ACD72DE2F42824539BE2

Date of Receipt

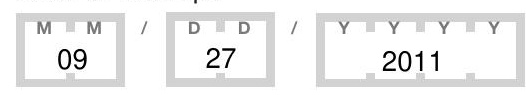

Amount of Each Receipt this Period

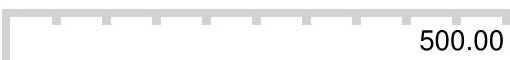

500.00

C. Full Name (Last, First, Middle Initial)

Christopher Taylor

Mailing Address 313 Saddle Ridge Dr

\begin{tabular}{lcc}
\hline City & State & Zip Code \\
Knoxville & TN & $37934-7405$
\end{tabular}

FEC ID number of contributing federal political committee.

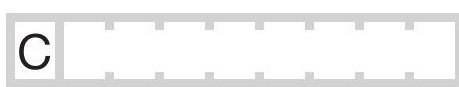

Name of Employer

Information Requested

Occupation

Information Requested

Receipt For: 2012

Х $\begin{aligned} & \text { Primary } \square \text { General } \\ & \text { Other (specify) }\end{aligned}$

Transaction ID : A051812E01FE745C8A3F

Date of Receipt

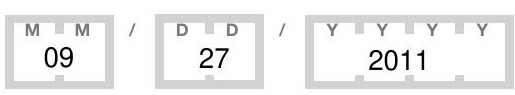

Amount of Each Receipt this Period

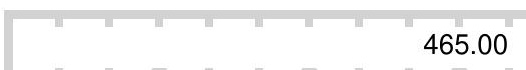

Transaction ID : A6BA41D938C3B43098A8 Date of Receipt

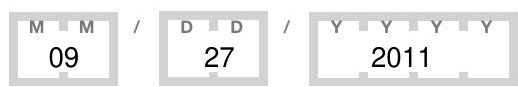

Amount of Each Receipt this Period

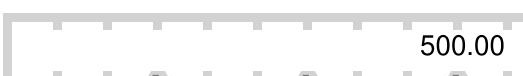

500.00

\section{Subtotal Of Receipts This Page (optional)}

Total This Period (last page this line number only) 
SCHEDULE A-P ITEMIZED RECEIPTS
Use separate schedule(s)

for each category of the

Detailed Summary Page
FOR LINE NUMBER: (check only one)

\begin{tabular}{|c|c|c|c|c|c|}
\hline & & & & & \\
\hline 16 & $\begin{array}{ll}X & 17 a \\
\end{array}$ & $17 \mathrm{~b}$ & $17 c$ & $17 d$ & 18 \\
\hline $19 a$ & $19 b$ & $20 \mathrm{a}$ & $20 \mathrm{~b}$ & $20 c$ & 21 \\
\hline
\end{tabular}

Any information copied from such Reports and Statements may not be sold or used by any person for the purpose of soliciting contributions or for commercial purposes, other than using the name and address of any political committee to solicit contributions from such committee.

NAME OF COMMITTEE (In Full)

\section{Friends of Herman Cain}

A. Full Name (Last, First, Middle Initial)

Joe Glenn

Mailing Address 932 Henley PI

\begin{tabular}{lcc}
\hline City & State & Zip Code \\
Charlotte & NC & 28207-1618
\end{tabular}

FEC ID number of contributing federal political committee.

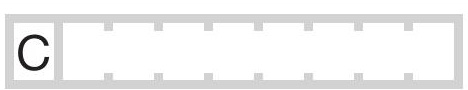

Name of Employer
Self-Employed
Receipt For: 2012
X Primary $\quad \square$ General
Other (specify)

Occupation Finance

Election Cycle-to-Date

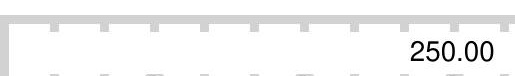

B. Full Name (Last, First, Middle Initial)

Sharon Daily

Mailing Address 18 Overbrook Drive

\begin{tabular}{lcc}
\hline City & State & Zip Code \\
Saint Louis & MO & $63124-1482$
\end{tabular}

FEC ID number of contributing

federal political committee.

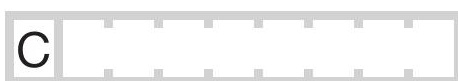

Name of Employer
Self Employed
Receipt For: 2012
X Primary
Other (specify)

Occupation

Attorney

Election Cycle-to-Date

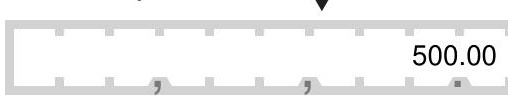

C. Full Name (Last, First, Middle Initial)

joseph FULLER

Mailing Address 11935 FOREST DR.

\begin{tabular}{lcc}
\hline City & State & Zip Code \\
Carmel & IN & $46033-4347$
\end{tabular}

FEC ID number of contributing

federal political committee.

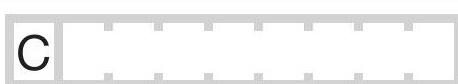

Name of Employer

Information Requested

Occupation

Information Requested

Receipt For: 2012

Х $\begin{aligned} & \text { Primary } \\ & \text { Other (specify) }\end{aligned}$

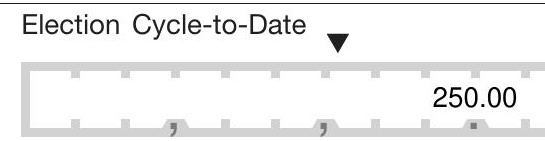

Amount of Each Receipt this Period

Transaction ID : A2B74F8B2E2184C1C9AC Date of Receipt

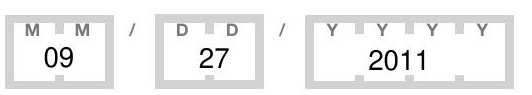

Amount of Each Receipt this Period

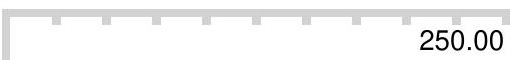

250.00

Date of Receipt
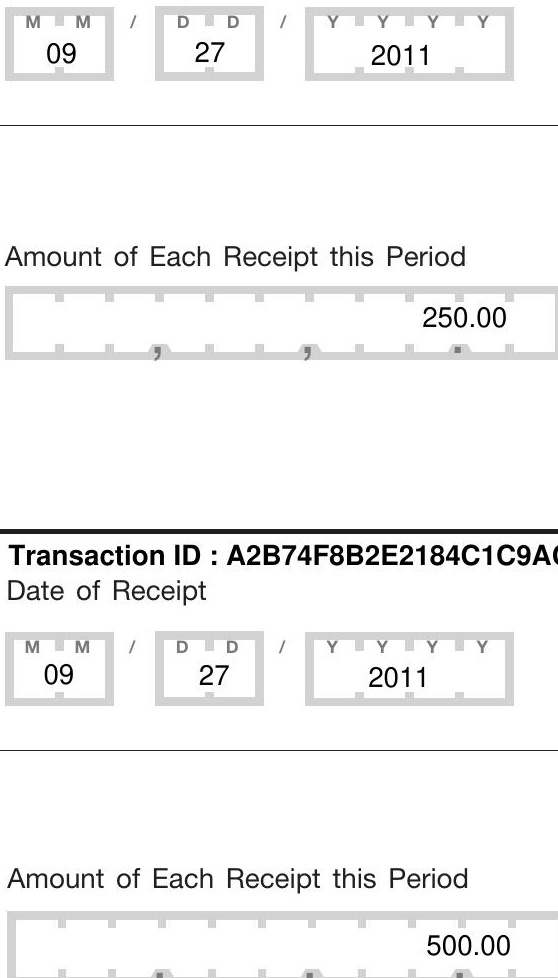

Transaction ID : AA49E629C57444921848

Date of Receipt

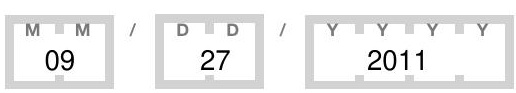

Amount of Each Receipt this Period

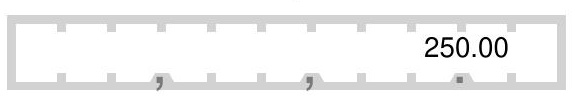

Subtotal Of Receipts This Page (optional)

1000.00

Total This Period (last page this line number only) 
SCHEDULE A-P ITEMIZED RECEIPTS
Use separate schedule(s) for each category of the Detailed Summary Page
FOR LINE NUMBER: (check only one)

PAGE $868 / 1572$

\begin{tabular}{|c|c|c|c|c|c|}
\hline & & & & & \\
\hline 16 & $\begin{array}{l}\mathbf{X} \\
17 a\end{array}$ & $17 b$ & $17 c$ & $17 d$ & 18 \\
\hline $19 a$ & $19 \mathrm{~b}$ & $20 \mathrm{a}$ & $20 \mathrm{~b}$ & $20 \mathrm{c}$ & 21 \\
\hline
\end{tabular}

Any information copied from such Reports and Statements may not be sold or used by any person for the purpose of soliciting contributions or for commercial purposes, other than using the name and address of any political committee to solicit contributions from such committee.

NAME OF COMMITTEE (In Full)

\section{Friends of Herman Cain}

A. Full Name (Last, First, Middle Initial)

Vernon Keyser

Mailing Address 5951 Mill Branch Rd

\begin{tabular}{lcc}
\hline City & State & Zip Code \\
Huntingtown & MD & $20639-9729$
\end{tabular}

FEC ID number of contributing federal political committee.

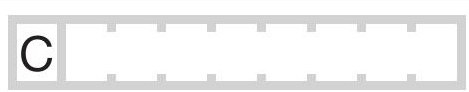

\begin{tabular}{l} 
Name of Employer \\
None \\
Receipt For: 2012 \\
X Primary $\quad$ General \\
\hline Other (specify)
\end{tabular}

Occupation

Retired

Election Cycle-to-Date

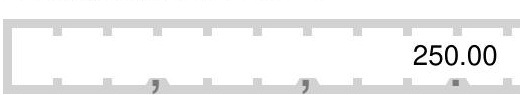

B. Full Name (Last, First, Middle Initial)

Winnie Guerdon

Mailing Address 5169 SW 27th Dr

\begin{tabular}{lcc}
\hline City & State & Zip Code \\
Gainesville & FL & $32608-3980$
\end{tabular}

FEC ID number of contributing

federal political committee.

C

Name of Employer
None
Receipt For: 2012
X Primary
Other (specify)

\section{Occupation} Homemaker

Election Cycle-to-Date

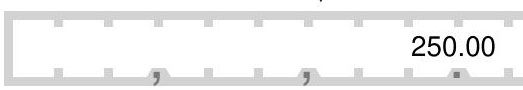

Transaction ID : AA7D1D037832F476D83E

Date of Receipt

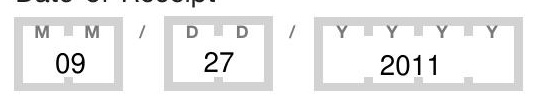

Amount of Each Receipt this Period

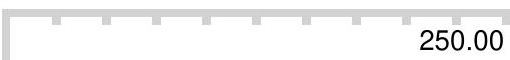

Amount of Each Receipt this Period

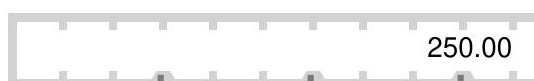

C. Full Name (Last, First, Middle Initial)

Scott Whittier

Mailing Address 22020 Moore Rd

\begin{tabular}{lcc}
\hline City & State & Zip Code \\
Brooksville & FL & $34604-6720$
\end{tabular}

FEC ID number of contributing federal political committee.

C

34604-6720

Name of Employer
Suncoast Urgent Care
Receipt For: 2012
X Primary
Other (specify) General

Occupation

Physician

Election Cycle-to-Date

Transaction ID : AF7624FE851AA4B78855

Date of Receipt

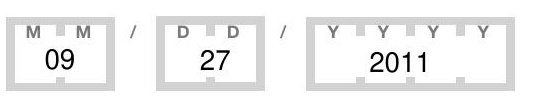

Transaction ID : A7AF9447ABDE24CCF9EA Date of Receipt

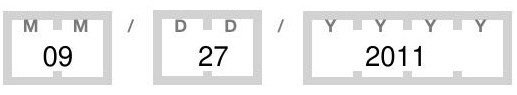

Amount of Each Receipt this Period

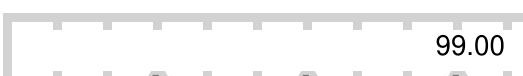

399.00

\section{Subtotal Of Receipts This Page (optional)}

Total This Period (last page this line number only) 
SCHEDULE A-P ITEMIZED RECEIPTS
Use separate schedule(s) for each category of the Detailed Summary Page
FOR LINE NUMBER: (check only one)

PAGE 869 / 1572

\begin{tabular}{|c|c|c|c|c|c|}
\hline & & & & & \\
\hline 16 & $\begin{array}{l}\mathbf{X} \\
17 a\end{array}$ & $17 b$ & $17 c$ & $17 d$ & 18 \\
\hline $19 a$ & $19 \mathrm{~b}$ & $20 \mathrm{a}$ & $20 \mathrm{~b}$ & $20 \mathrm{c}$ & 21 \\
\hline
\end{tabular}

Any information copied from such Reports and Statements may not be sold or used by any person for the purpose of soliciting contributions or for commercial purposes, other than using the name and address of any political committee to solicit contributions from such committee.

NAME OF COMMITTEE (In Full)

\section{Friends of Herman Cain}

A. Full Name (Last, First, Middle Initial)

Virgil R Williams

Mailing Address PO Box 2589

\begin{tabular}{lcc}
\hline City & State & Zip Code \\
Suwanee & GA & $30024-0982$
\end{tabular}

FEC ID number of contributing federal political committee.

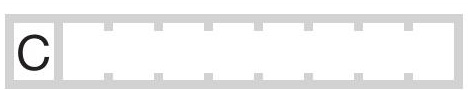

Name of Employer
Information Requested
Receipt For: 2012
X Primary $\quad \square$ General
Other (specify)

Occupation Information Requested

Election Cycle-to-Date

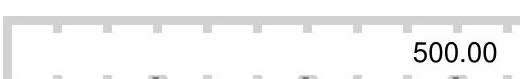

B. Full Name (Last, First, Middle Initial)

Peter Bancroft

Mailing Address 276 Cheshire Tpke

\begin{tabular}{lcc}
\hline City & State & Zip Code \\
Langdon & $\mathrm{NH}$ & $03602-8608$ \\
\hline
\end{tabular}

FEC ID number of contributing

federal political committee.

C

Name of Employer
Information Requested
Receipt For: 2012
X Primary
Other (specify)

Occupation

Information Requested

Election Cycle-to-Date

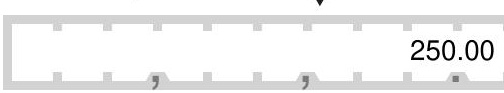

Transaction ID : A4671523643D846409CC

Date of Receipt

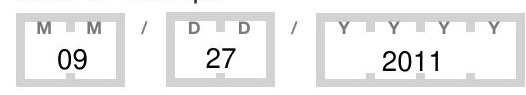

Amount of Each Receipt this Period

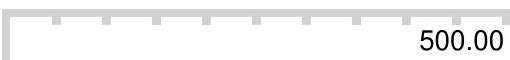

Transaction ID : A3C9F0EDA4A6A4658BEA Date of Receipt

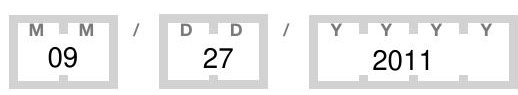

Amount of Each Receipt this Period

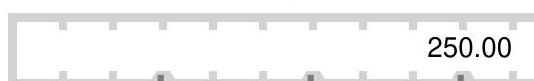

Transaction ID : AE442EC8043BE4AD2AA4 Date of Receipt

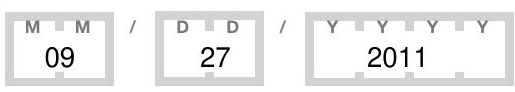

Amount of Each Receipt this Period

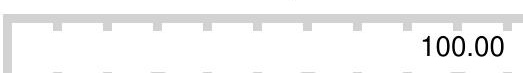

Occupation
N/A
Election Cycle-to-Date

Subtotal Of Receipts This Page (optional)

850.00

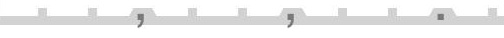

Total This Period (last page this line number only)

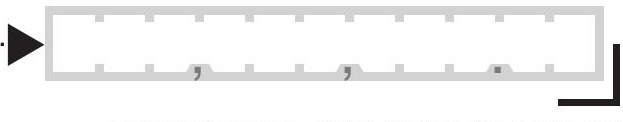

FEC Schedule A-P (Form 3P) (Rev. 03/2011) 
SCHEDULE A-P ITEMIZED RECEIPTS
Use separate schedule(s) for each category of the Detailed Summary Page
FOR LINE NUMBER: (check only one)

PAGE $870 / 1572$

\begin{tabular}{|c|c|c|c|c|c|}
\hline & & & & & \\
\hline 16 & $\begin{array}{l}\mathbf{X} \\
17 a\end{array}$ & $17 b$ & $17 c$ & $17 d$ & 18 \\
\hline $19 a$ & $19 \mathrm{~b}$ & $20 \mathrm{a}$ & $20 \mathrm{~b}$ & $20 \mathrm{c}$ & 21 \\
\hline
\end{tabular}

Any information copied from such Reports and Statements may not be sold or used by any person for the purpose of soliciting contributions or for commercial purposes, other than using the name and address of any political committee to solicit contributions from such committee.

NAME OF COMMITTEE (In Full)

\section{Friends of Herman Cain}

A. Full Name (Last, First, Middle Initial) brian maes

Mailing Address 15 lyndhurst way

\begin{tabular}{lcc}
\hline City & State & Zip Code \\
Sharpsburg & GA & $30277-3466$
\end{tabular}

FEC ID number of contributing federal political committee.

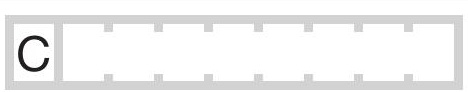

Name of Employer
SunTrust Bank
Receipt For: 2012
X Primary
Other (specify) General

Occupation Accountant Election Cycle-to-Date

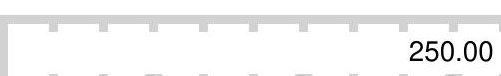

B. Full Name (Last, First, Middle Initial) John Russell

Mailing Address 48 Lake Bluff

\begin{tabular}{lcc}
\hline City & State & Zip Code \\
Montgomery & TX & $77356-8610$
\end{tabular}

FEC ID number of contributing

federal political committee.

C

Name of Employer
Information Requested
Receipt For: 2012
X Primary
Other (specify)

Occupation

Information Requested

Election Cycle-to-Date

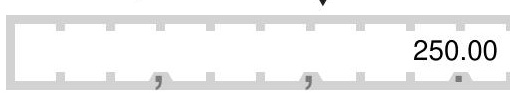

Transaction ID : AA41B43282D0442C084A

Date of Receipt

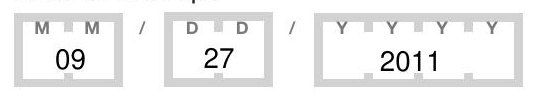

Amount of Each Receipt this Period

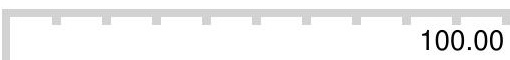

100.00

C. Full Name (Last, First, Middle Initial)

bruce rathkamp

Mailing Address po box 718

\begin{tabular}{lcc}
\hline City & State & Zip Code \\
Chillicothe & OH & $45601-0718$
\end{tabular}

FEC ID number of contributing federal political committee.

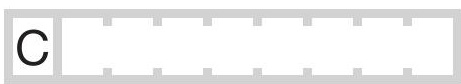

Name of Employer
Information Requested
Receipt For: 2012
X Primary $\quad \square$ General
Other (specify)

\section{Occupation}

Information Requested

Election Cycle-to-Date

Transaction ID : A44291035E11F4AFF8AA

Date of Receipt

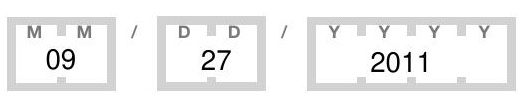

Amount of Each Receipt this Period

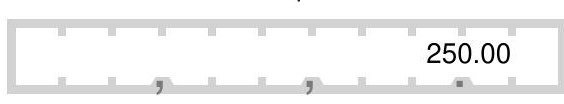

Transaction ID : ADD4126DC47464ACF894 Date of Receipt

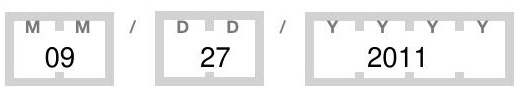

Amount of Each Receipt this Period

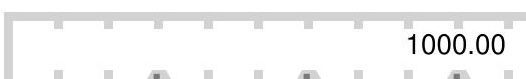

1000.00

\section{Subtotal Of Receipts This Page (optional)}

Total This Period (last page this line number only) 


\section{SCHEDULE A-P} ITEMIZED RECEIPTS
Use separate schedule(s) for each category of the Detailed Summary Page

\begin{tabular}{|c|c|c|c|c|c|}
\hline \multicolumn{3}{|c|}{$\begin{array}{l}\text { FOR LINE NUMBER: } \\
\text { (check only one) }\end{array}$} & \multicolumn{3}{|c|}{ PAGE $871 / 1572$} \\
\hline 16 & $X$ 17a & $17 b$ & 17c & $17 d$ & 18 \\
\hline $19 a$ & $19 \mathrm{~b}$ & $20 a$ & $20 \mathrm{~b}$ & $20 c$ & 21 \\
\hline
\end{tabular}

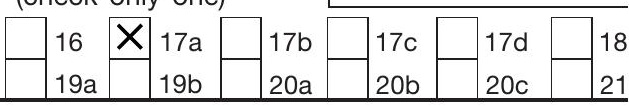

Any information copied from such Reports and Statements may not be sold or used by any person for the purpose of soliciting contributions or for commercial purposes, other than using the name and address of any political committee to solicit contributions from such committee.

NAME OF COMMITTEE (In Full)

\section{Friends of Herman Cain}

A. Full Name (Last, First, Middle Initial)

Kelly Cortez

Mailing Address 760 Lakeshore Drive

\begin{tabular}{lcc}
\hline City & State & Zip Code \\
Berkeley Lake & GA & $30096-3040$ \\
\hline
\end{tabular}

FEC ID number of contributing federal political committee.

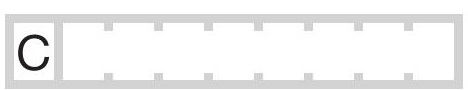

Name of Employer
self
Receipt For: 2012
X Primary $\quad$ General
Other (specify)

Occupation

RN/Licensed Prof. Counselor

Election Cycle-to-Date

650.00

B. Full Name (Last, First, Middle Initial)

laurie newsom

Mailing Address 2521 nw 41 street

\begin{tabular}{lcc}
\hline City & State & Zip Code \\
Gainesville & FL & $32606-6630$
\end{tabular}

FEC ID number of contributing

federal political committee.

C

Name of Employer
self
Receipt For: 2012
Primary
Other (specify)

Occupation

ambulatory surgical center administrat

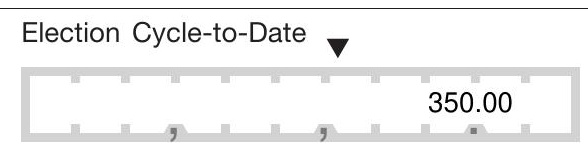

C. Full Name (Last, First, Middle Initial)

Damian Kondrotas

Mailing Address 340 1st Street N Apt H

\begin{tabular}{|c|c|c|}
\hline $\begin{array}{l}\text { City } \\
\text { Saint Petersburg }\end{array}$ & $\begin{array}{l}\text { State } \\
\text { FL }\end{array}$ & $\begin{array}{l}\text { Zip Code } \\
33701-2929\end{array}$ \\
\hline $\begin{array}{l}\text { FEC ID number of contributing } \\
\text { federal political committee. }\end{array}$ & C & \\
\hline $\begin{array}{l}\text { Name of Employer } \\
\text { Information Requested }\end{array}$ & $\begin{array}{l}\text { Occupa } \\
\text { Informa }\end{array}$ & uested \\
\hline \multirow{2}{*}{$\begin{array}{l}\text { Receipt For: } 2012 \\
\text { Х } \begin{array}{l}\text { Primary } \\
\text { Other (specify) }\end{array}\end{array}$} & Electior & to-Date $\nabla$ \\
\hline & 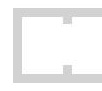 & 1000.00 \\
\hline
\end{tabular}

Subtotal Of Receipts This Page (optional).

1750.00

Total This Period (last page this line number only)

Amount of Each Receipt this Period

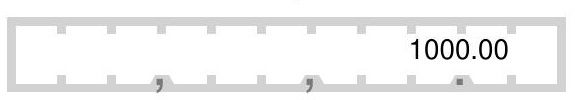

Amount of Each Receipt this Period

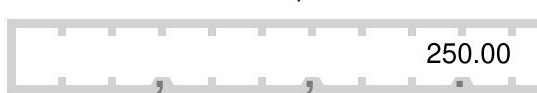

Transaction ID : A2170F911DA564244B61

Date of Receipt

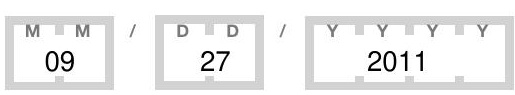

Date of Receip

$09 \quad 27$

A 


\section{SCHEDULE A-P} ITEMIZED RECEIPTS
Use separate schedule(s)

for each category of the

Detailed Summary Page
FOR LINE NUMBER: (check only one)

PAGE 872 / 1572

\begin{tabular}{|c|c|c|c|c|c|}
\hline & & & & & \\
\hline 16 & X $17 a$ & $17 b$ & $17 c$ & $17 d$ & 18 \\
\hline $19 a$ & $19 b$ & $20 \mathrm{a}$ & $20 \mathrm{~b}$ & $20 \mathrm{c}$ & 21 \\
\hline
\end{tabular}

Any information copied from such Reports and Statements may not be sold or used by any person for the purpose of soliciting contributions or for commercial purposes, other than using the name and address of any political committee to solicit contributions from such committee.

NAME OF COMMITTEE (In Full)

Friends of Herman Cain

A. Full Name (Last, First, Middle Initial)

Bruce Donaldson

Mailing Address 511 Park St SE

\begin{tabular}{lcc}
\hline City & State & Zip Code \\
Vienna & VA & $22180-5808$ \\
\hline
\end{tabular}

FEC ID number of contributing federal political committee.

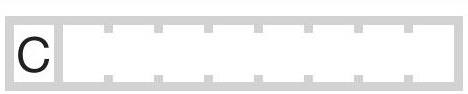

Name of Employer
Information Requested
Receipt For: 2012
X Primary
$\square$ Other (specify)

Occupation

Information Requested

Election Cycle-to-Date

500.00

B. Full Name (Last, First, Middle Initial)

Cyril Boys

Mailing Address 2001 Flightway Drive

\begin{tabular}{lcc}
\hline City & State & Zip Code \\
Atlanta & GA & $30341-3320$ \\
\hline
\end{tabular}

FEC ID number of contributing

federal political committee.

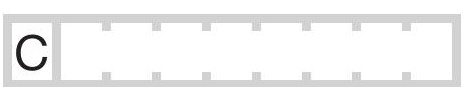

Name of Employer
Field Support Services
Receipt For: 2012
X Primary
Other (specify)

Occupation

Owner

Election Cycle-to-Date

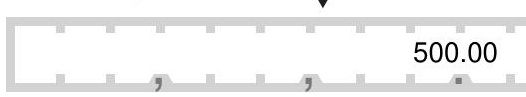

C. Full Name (Last, First, Middle Initial)

Celeste Bennett

Mailing Address PO Box 10162

\begin{tabular}{lcc}
\hline City & State & Zip Code \\
Fleming Island & FL & $32006-0041$
\end{tabular}

FEC ID number of contributing

federal political committee.

C

Name of Employer

Information Requested

Occupation

Information Requested

Receipt For: 2012

Х $\begin{aligned} & \text { Primary } \\ & \text { Other (specify) }\end{aligned}$

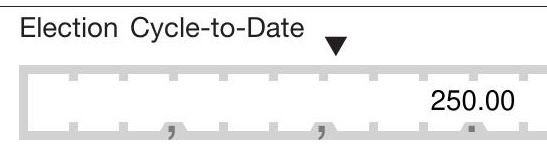

Amount of Each Receipt this Period

Transaction ID : A905EBE9FB3464CD9B93

Date of Receipt

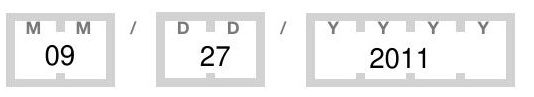

Amount of Each Receipt this Period
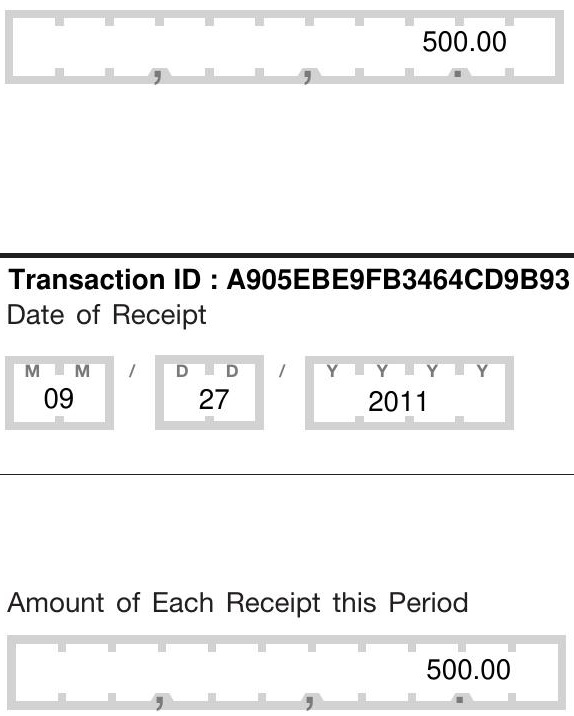

Transaction ID : A7D40C3FCFAA94AF180C Date of Receipt

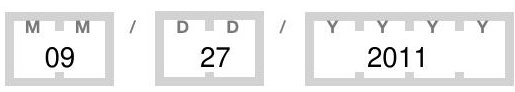

Amount of Each Receipt this Period

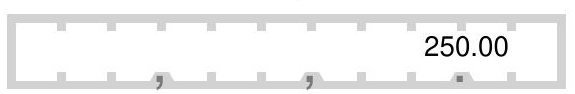

Subtotal Of Receipts This Page (optional).

1250.00

Total This Period (last page this line number only) 
SCHEDULE A-P ITEMIZED RECEIPTS
Use separate schedule(s) for each category of the Detailed Summary Page
FOR LINE NUMBER: (check only one)

PAGE $873 / 1572$

\begin{tabular}{|c|c|c|c|c|c|}
\hline & & & & & \\
\hline 16 & $\begin{array}{lll}X & 17 a \\
\end{array}$ & $17 \mathrm{~b}$ & $17 c$ & $17 d$ & 18 \\
\hline $19 a$ & $19 b$ & $20 a$ & $20 \mathrm{~b}$ & $20 c$ & 21 \\
\hline
\end{tabular}

Any information copied from such Reports and Statements may not be sold or used by any person for the purpose of soliciting contributions or for commercial purposes, other than using the name and address of any political committee to solicit contributions from such committee.

NAME OF COMMITTEE (In Full)

Friends of Herman Cain

A. Full Name (Last, First, Middle Initial)

LARRY ROBERTS

Mailing Address 1022 MASTERS DRIVE

\begin{tabular}{lcc}
\hline City & State & Zip Code \\
Mansfield & TX & 76063-2699
\end{tabular}

FEC ID number of contributing

federal political committee.

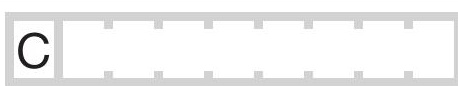

Name of Employer
Information Requested
Receipt For: 2012
X Primary
Other (specify) General

Occupation

Information Requested

Election Cycle-to-Date

250.00

B. Full Name (Last, First, Middle Initial)

Chris Siedentop

Mailing Address 6504 E. Nisbet Road

\begin{tabular}{lcc}
\hline City & State & Zip Code \\
Scottsdale & AZ & $85254-2612$ \\
\hline
\end{tabular}

FEC ID number of contributing

federal political committee.

C

Name of Employer
Information Requested
Receipt For: 2012
X Primary
Other (specify)

Occupation

Information Requested

Election Cycle-to-Date

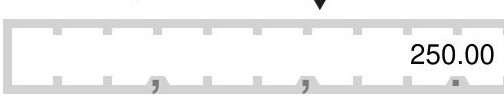

Transaction ID : A3DC5A80488BA41A7837

Date of Receipt

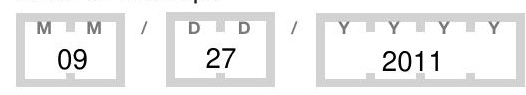

Amount of Each Receipt this Period

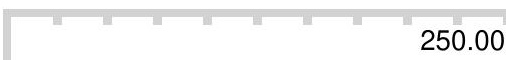

Amount of Each Receipt this Period

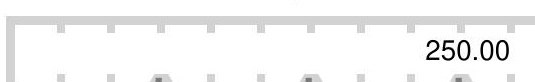

C. Full Name (Last, First, Middle Initial)

David Colehour

Mailing Address 18524 Creeks Bend Drive

\begin{tabular}{lcc}
\hline City & State & Zip Code \\
Minnetonka & MN & $55345-6142$
\end{tabular}

FEC ID number of contributing federal political committee.

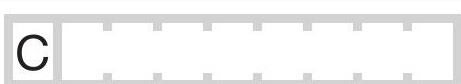

Name of Employer

Occupation

Best Cleaners Inc.

Delivery Manager

Receipt For: 2012

Х $\begin{aligned} & \text { Primary } \\ & \text { Other (specify) }\end{aligned}$

Election Cycle-to-Date

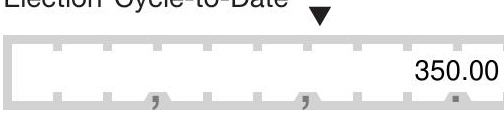

Transaction ID : A078ADEB429A44445A6E

Date of Receipt

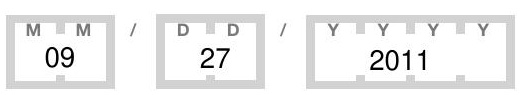

Transaction ID : A7208D8BC16664AB49EC Date of Receipt

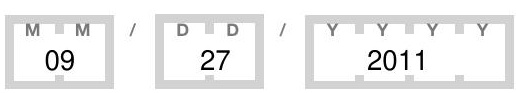

Amount of Each Receipt this Period

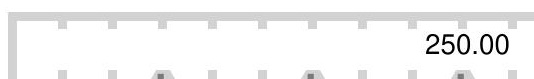

750.00

Subtotal Of Receipts This Page (optional)

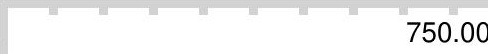

Total This Period (last page this line number only) 
SCHEDULE A-P ITEMIZED RECEIPTS
Use separate schedule(s) for each category of the Detailed Summary Page
FOR LINE NUMBER: (check only one)

\begin{tabular}{|c|c|c|c|c|c|}
\hline & & & & & \\
\hline 16 & $\begin{array}{ll}X & 17 a \\
\end{array}$ & $17 \mathrm{~b}$ & $17 c$ & $17 d$ & 18 \\
\hline $19 a$ & $19 b$ & $20 \mathrm{a}$ & $20 \mathrm{~b}$ & $20 c$ & 21 \\
\hline
\end{tabular}

Any information copied from such Reports and Statements may not be sold or used by any person for the purpose of soliciting contributions or for commercial purposes, other than using the name and address of any political committee to solicit contributions from such committee.

NAME OF COMMITTEE (In Full)

\section{Friends of Herman Cain}

A. Full Name (Last, First, Middle Initial)

John Hunter

Mailing Address 5326 Retreat Way

\begin{tabular}{lcc}
\hline City & State & Zip Code \\
Carmichael & CA & $95608-5768$ \\
\hline
\end{tabular}

FEC ID number of contributing federal political committee.

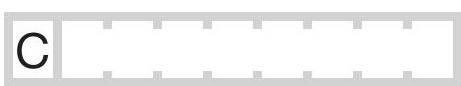

Name of Employer
Information Requested
Receipt For: 2012
X Primary
Other (specify) General

Occupation Information Requested

Election Cycle-to-Date

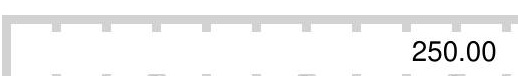

B. Full Name (Last, First, Middle Initial)

John Lier

Mailing Address 6565 Caicos Ct.

\begin{tabular}{lcc}
\hline City & State & Zip Code \\
Vero Beach & FL & $32967-7586$
\end{tabular}

FEC ID number of contributing

federal political committee.

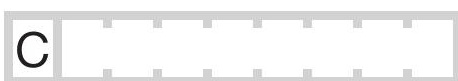

Name of Employer
self
Receipt For: 2012
X Primary
Other (specify)

\section{Occupation}

self

Election Cycle-to-Date

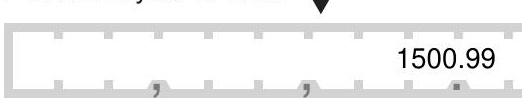

Transaction ID : AOBOBBB6700414711931

Date of Receipt

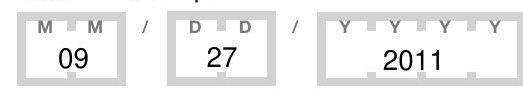

Amount of Each Receipt this Period

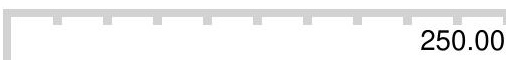

C. Full Name (Last, First, Middle Initial)

Cynthia Hughes

Mailing Address 128 Victoria Drive

\begin{tabular}{lcc}
\hline City & State & Zip Code \\
Telluride & CO & $81435-9430$
\end{tabular}

FEC ID number of contributing federal political committee.

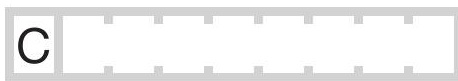

Name of Employer
None
Receipt For: 2012
X Primary $\quad \square$ General
Other (specify)

Occupation

Homemaker

Election Cycle-to-Date

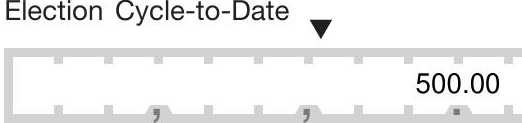

Amount of Each Receipt this Period

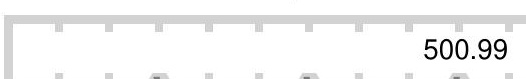

Transaction ID : A066EAFF410894FDCB25

Date of Receipt

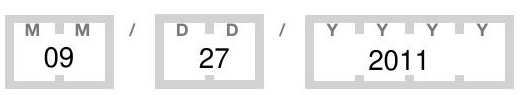

Transaction ID : A7E519A52EEBB4A0C824 Date of Receipt

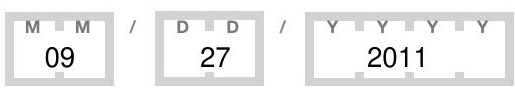

Amount of Each Receipt this Period

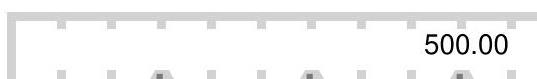

\section{Subtotal Of Receipts This Page (optional)}

Total This Period (last page this line number only) 


\section{SCHEDULE A-P} ITEMIZED RECEIPTS
Use separate schedule(s)

for each category of the

Detailed Summary Page
FOR LINE NUMBER: (check only one)

PAGE $875 / 1572$

\begin{tabular}{|c|c|c|c|c|c|}
\hline & & & & & \\
\hline 16 & X $17 a$ & $17 b$ & $17 c$ & $17 d$ & 18 \\
\hline $19 a$ & $19 b$ & $20 \mathrm{a}$ & $20 \mathrm{~b}$ & $20 \mathrm{c}$ & 21 \\
\hline
\end{tabular}

Any information copied from such Reports and Statements may not be sold or used by any person for the purpose of soliciting contributions or for commercial purposes, other than using the name and address of any political committee to solicit contributions from such committee.

NAME OF COMMITTEE (In Full)

\section{Friends of Herman Cain}

A. Full Name (Last, First, Middle Initial)

Arthur Robinson

Mailing Address 105 Bonaventure PI

\begin{tabular}{lcc}
\hline City & State & Zip Code \\
Locust Grove & GA & $30248-4552$ \\
\hline
\end{tabular}

FEC ID number of contributing

federal political committee.

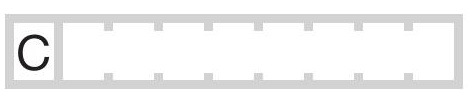

Name of Employer
DRC
Receipt For: 2012
X Primary $\quad$ General
Other (specify)

Occupation

Contractor

Election Cycle-to-Date

330.00

B. Full Name (Last, First, Middle Initial)

Donald Lamberti

Mailing Address 3602 SW Golfview Circle

\begin{tabular}{lcc}
\hline City & State & Zip Code \\
Ankeny & IA & $50023-9676$
\end{tabular}

FEC ID number of contributing

federal political committee.

C

Name of Employer
Information Requested
Receipt For: 2012
X Primary
Other (specify)

Occupation

Information Requested

Election Cycle-to-Date

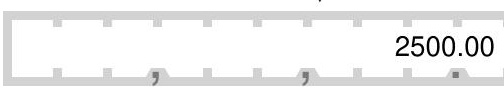

C. Full Name (Last, First, Middle Initial)

Philip Miller

Mailing Address 938 Wedgewood Drive

\begin{tabular}{lcc}
\hline City & State & Zip Code \\
Glenview & IL & $60025-4100$
\end{tabular}

FEC ID number of contributing

federal political committee.

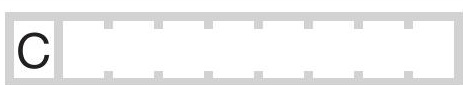

$\begin{aligned} & \text { Name of Employer } \\ & \text { me }\end{aligned}$
Receipt For: 2012
X Primary $\square$ General
Other (specify)

Occupation

Retired

Election Cycle-to-Date

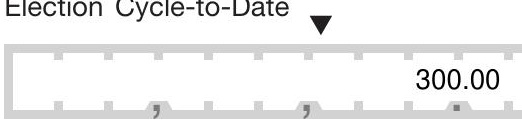

Transaction ID : A73BDD928EED5492ABB8

Date of Receipt

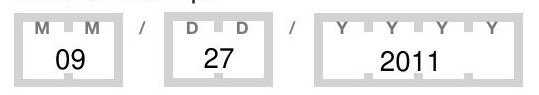

Amount of Each Receipt this Period

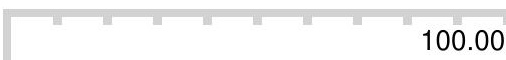

100.00

Transaction ID : A7BF8F454453C48B2942

Date of Receipt

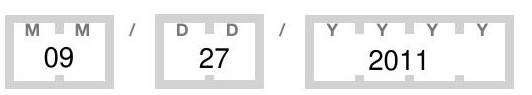

Amount of Each Receipt this Period

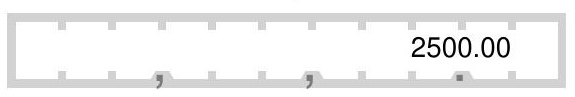

Transaction ID : AF5EB23D8C6C34BC484C Date of Receipt

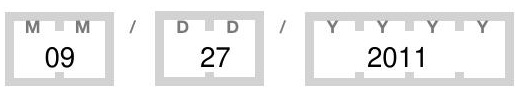

Amount of Each Receipt this Period

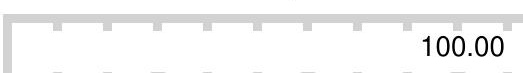

100.00

\section{Subtotal Of Receipts This Page (optional)}

Total This Period (last page this line number only) 


\section{SCHEDULE A-P} ITEMIZED RECEIPTS
Use separate schedule(s)

for each category of the

Detailed Summary Page
FOR LINE NUMBER: (check only one)

PAGE $876 / 1572$

\begin{tabular}{|c|c|c|c|c|c|}
\hline & & & & & \\
\hline 16 & X $17 a$ & $17 b$ & $17 c$ & $17 d$ & 18 \\
\hline $19 a$ & $19 b$ & $20 \mathrm{a}$ & $20 \mathrm{~b}$ & $20 \mathrm{c}$ & 21 \\
\hline
\end{tabular}

Any information copied from such Reports and Statements may not be sold or used by any person for the purpose of soliciting contributions or for commercial purposes, other than using the name and address of any political committee to solicit contributions from such committee.

NAME OF COMMITTEE (In Full)

Friends of Herman Cain

A. Full Name (Last, First, Middle Initial)

\section{Robert Heiks}

Mailing Address 178 Snow Rd.

\begin{tabular}{lcc}
\hline City & State & Zip Code \\
Pelzer & SC & $29669-9320$
\end{tabular}

FEC ID number of contributing federal political committee.

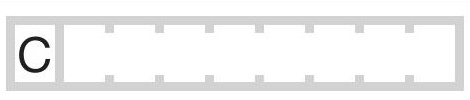

Name of Employer
Information Requested
Receipt For: 2012
X Primary
$\square$ Other (specify)

Occupation

Information Requested

Election Cycle-to-Date

250.00

B. Full Name (Last, First, Middle Initial)

Ricardo Pocurull

Mailing Address 4904 whistling straits loop

\begin{tabular}{lcc}
\hline City & State & Zip Code \\
College Station & TX & $77845-3865$ \\
\hline
\end{tabular}

FEC ID number of contributing

federal political committee.

C

Name of Employer
Information Requested
Receipt For: 2012
X Primary
Other (specify)

Occupation

Information Requested

Election Cycle-to-Date

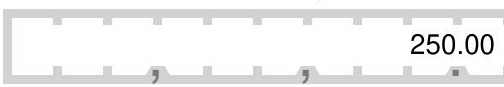

Transaction ID : A6025E1E473A84B95AF1

Date of Receipt

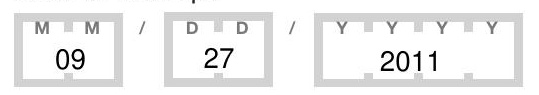

Amount of Each Receipt this Period

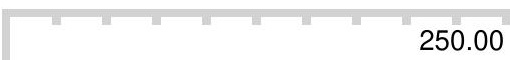

C. Full Name (Last, First, Middle Initial)

Ronald Hovis

Mailing Address 2518 Monarch Terrace Dr.

\begin{tabular}{lcc}
\hline City & State & Zip Code \\
Katy & TX & $77494-0669$
\end{tabular}

FEC ID number of contributing federal political committee.

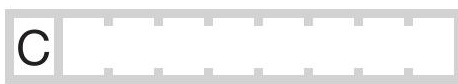

Name of Employer
None
Receipt For: 2012
Х Primary $\quad \square$ General
Other (specify)

Occupation

Retired

Election Cycle-to-Date

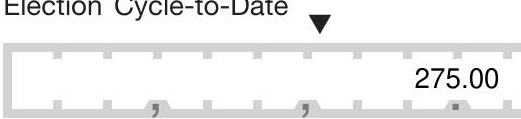

Amount of Each Receipt this Period

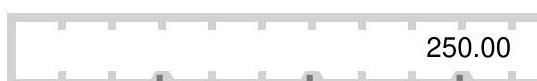

Transaction ID : A624021E8E6F24B4D80E

Date of Receipt

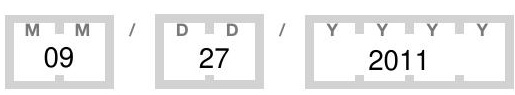

Transaction ID : A85CBCB10EF0D43B78E2 Date of Receipt

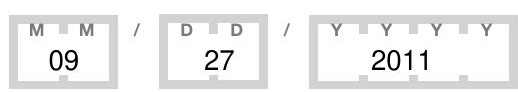

Amount of Each Receipt this Period

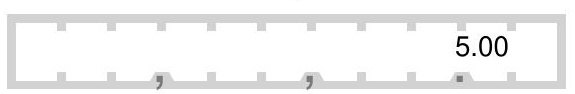

\section{Subtotal Of Receipts This Page (optional)}

505.00

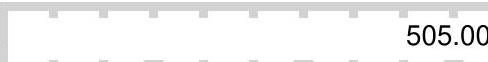

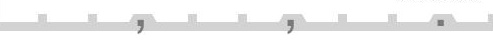

Total This Period (last page this line number only)

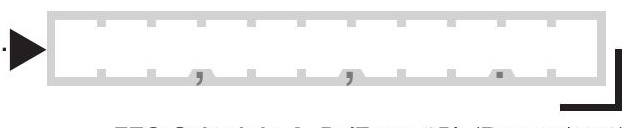

FEC Schedule A-P (Form 3P) (Rev. 03/2011) 


\section{SCHEDULE A-P} ITEMIZED RECEIPTS
Use separate schedule(s)

for each category of the

Detailed Summary Page
FOR LINE NUMBER: (check only one)

PAGE 877 / 1572

\begin{tabular}{|c|c|c|c|c|c|}
\hline & & & & & \\
\hline 16 & X $17 a$ & $17 b$ & $17 c$ & $17 d$ & 18 \\
\hline $19 a$ & $19 b$ & $20 \mathrm{a}$ & $20 \mathrm{~b}$ & $20 \mathrm{c}$ & 21 \\
\hline
\end{tabular}

Any information copied from such Reports and Statements may not be sold or used by any person for the purpose of soliciting contributions or for commercial purposes, other than using the name and address of any political committee to solicit contributions from such committee.

NAME OF COMMITTEE (In Full)

Friends of Herman Cain

A. Full Name (Last, First, Middle Initial)

Ronald Hovis

Mailing Address 2518 Monarch Terrace Dr.

\begin{tabular}{lcc}
\hline City & State & Zip Code \\
Katy & TX & $77494-0669$ \\
\hline
\end{tabular}

FEC ID number of contributing federal political committee.

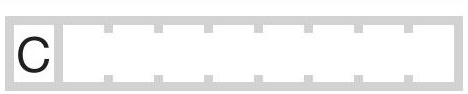

Name of Employer
None
Receipt For: 2012
X Primary $\quad \square$ General
Other (specify)

Occupation

Retired

Election Cycle-to-Date

\subsection{0}

B. Full Name (Last, First, Middle Initial)

Chris Petrin

Mailing Address 448 Greenwood Beach Road

\begin{tabular}{lcc}
\hline City & State & Zip Code \\
Belvedere Tiburon & CA & $94920-2215$
\end{tabular}

FEC ID number of contributing

federal political committee.

C

Name of Employer
Information Requested
Receipt For: 2012
X Primary
Other (specify)

Occupation

Information Requested

Election Cycle-to-Date

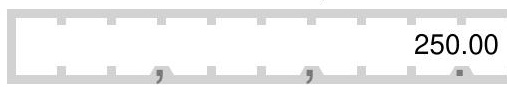

Transaction ID : ACBE02D44CACD4804A99

Date of Receipt

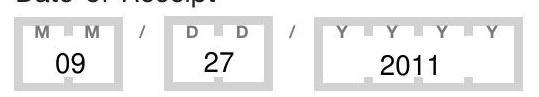

Amount of Each Receipt this Period

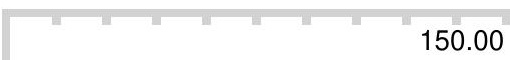

Amount of Each Receipt this Period

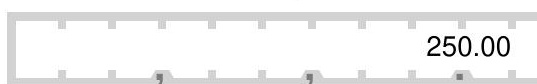

C. Full Name (Last, First, Middle Initial)

Andrew SanClemente

Mailing Address 17 Settlers Rd

\begin{tabular}{lcc}
\hline City & State & Zip Code \\
Shrewsbury & MA & $01545-7720$
\end{tabular}

FEC ID number of contributing federal political committee.

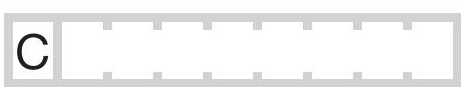

Name of Employer

\section{Occupation}

Digital Health Systems

programmer

Receipt For: 2012

Х $\begin{aligned} & \text { Primary } \\ & \text { Other (specify) }\end{aligned}$

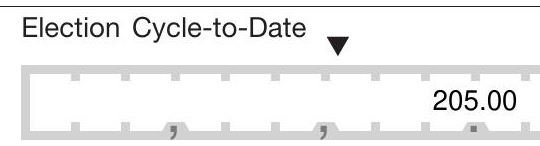

Amount of Each Receipt this Period

Transaction ID : A646A0B0C0043435B8B6

Date of Receipt
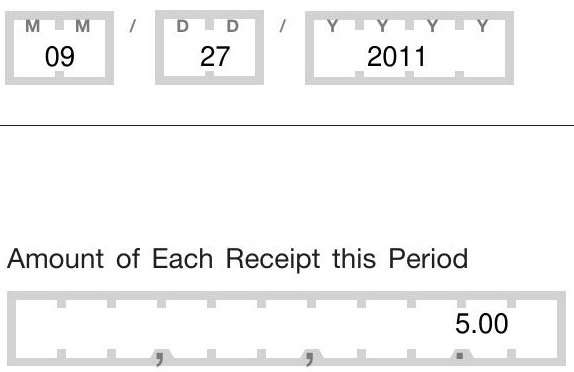

Subtotal Of Receipts This Page (optional)

405.00

Total This Period (last page this line number only) 


\section{SCHEDULE A-P} ITEMIZED RECEIPTS
Use separate schedule(s)

for each category of the

Detailed Summary Page
FOR LINE NUMBER: (check only one)

PAGE $878 / 1572$

\begin{tabular}{|c|c|c|c|c|c|}
\hline & & & & & \\
\hline 16 & X $17 a$ & $17 b$ & $17 c$ & $17 d$ & 18 \\
\hline $19 a$ & $19 b$ & $20 \mathrm{a}$ & $20 \mathrm{~b}$ & $20 \mathrm{c}$ & 21 \\
\hline
\end{tabular}

Any information copied from such Reports and Statements may not be sold or used by any person for the purpose of soliciting contributions or for commercial purposes, other than using the name and address of any political committee to solicit contributions from such committee.

NAME OF COMMITTEE (In Full)

Friends of Herman Cain

A. Full Name (Last, First, Middle Initial)

Michael Ransdell

Mailing Address 1009 Doric Circle

\begin{tabular}{lcc}
\hline City & State & Zip Code \\
Louisville & KY & $40205-1734$ \\
\hline
\end{tabular}

FEC ID number of contributing federal political committee.

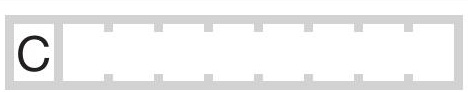

Name of Employer
Information Requested
Receipt For: 2012
X Primary
$\square$ Other (specify)

Occupation

Information Requested

Election Cycle-to-Date

250.00

B. Full Name (Last, First, Middle Initial)

John Blomquist

Mailing Address 1218 spring cress

\begin{tabular}{lcc}
\hline City & State & Zip Code \\
Seabrook & TX & $77586-4720$
\end{tabular}

FEC ID number of contributing

federal political committee.

C

Name of Employer
Information Requested
Receipt For: 2012
Primary
Other (specify)

Occupation

Information Requested

Election Cycle-to-Date

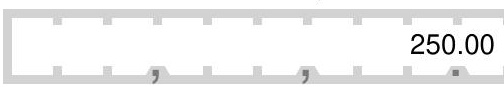

Transaction ID : A3E2F01D8D1A14A3EB48

Date of Receipt

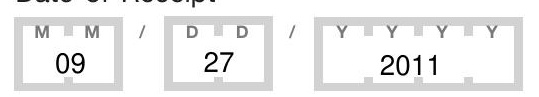

Amount of Each Receipt this Period

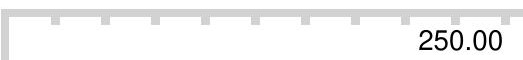

C. Full Name (Last, First, Middle Initial)

William Varney

Mailing Address 714 Church Road

\begin{tabular}{lcc}
\hline City & State & Zip Code \\
Bangor & ME & $04401-2142$
\end{tabular}

FEC ID number of contributing

federal political committee.

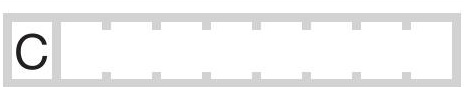

Name of Employer

VARNEY INC

Occupation

EXEC

Transaction ID : A19DAF8035C2043E3B33

Date of Receipt

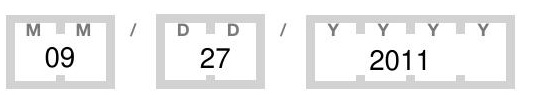

Amount of Each Receipt this Period

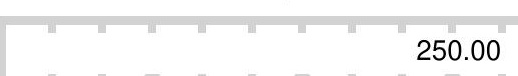

Transaction ID : A32C58FCC79304EFDB7E Date of Receipt

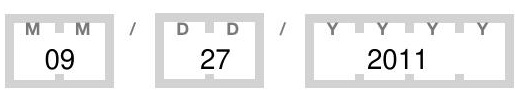

Amount of Each Receipt this Period

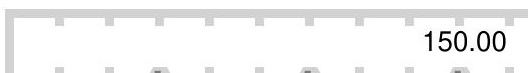

550.00

Subtotal Of Receipts This Page (optional).

650.00

Total This Period (last page this line number only) 
SCHEDULE A-P ITEMIZED RECEIPTS
Use separate schedule(s) for each category of the Detailed Summary Page
FOR LINE NUMBER: (check only one)

PAGE 879 / 1572

\begin{tabular}{|c|c|c|c|c|c|}
\hline & & & & & \\
\hline 16 & $\begin{array}{l}\mathbf{X} \\
17 a\end{array}$ & $17 b$ & $17 c$ & $17 d$ & 18 \\
\hline $19 a$ & $19 \mathrm{~b}$ & $20 \mathrm{a}$ & $20 \mathrm{~b}$ & $20 \mathrm{c}$ & 21 \\
\hline
\end{tabular}

Any information copied from such Reports and Statements may not be sold or used by any person for the purpose of soliciting contributions or for commercial purposes, other than using the name and address of any political committee to solicit contributions from such committee.

NAME OF COMMITTEE (In Full)

\section{Friends of Herman Cain}

A. Full Name (Last, First, Middle Initial) carl waterman

Mailing Address 333 north pennington drive unit 58

\begin{tabular}{lcc}
\hline City & State & Zip Code \\
Chandler & AZ & $85224-8269$
\end{tabular}

FEC ID number of contributing federal political committee.

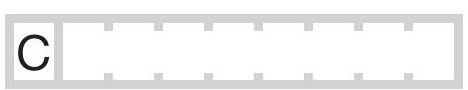

Name of Employer
Information Requested
Receipt For: 2012
X Primary
Other (specify) General

Occupation Information Requested

Election Cycle-to-Date

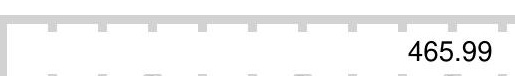

B. Full Name (Last, First, Middle Initial)

Michael McDermott

Mailing Address 4007 Killion Drive

\begin{tabular}{lcc}
\hline City & State & Zip Code \\
Dallas & TX & $75229-6226$ \\
\hline
\end{tabular}

FEC ID number of contributing

federal political committee.

C

\begin{tabular}{l} 
Name of Employer \\
Information Requested \\
Receipt For: 2012 \\
X Primary \\
\hline Other (specify)
\end{tabular}

Occupation

Information Requested

Election Cycle-to-Date

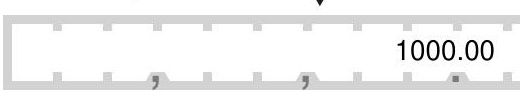

Transaction ID : AD00888748E27420EA23

Date of Receipt

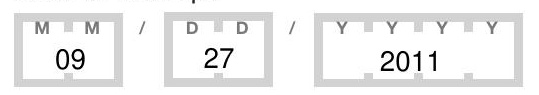

Amount of Each Receipt this Period

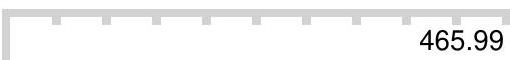

465.99

C. Full Name (Last, First, Middle Initial)

Erik Anhaus

Mailing Address 6395 Queens Court Trce

\begin{tabular}{lcc}
\hline City & State & Zip Code \\
Mableton & GA & $30126-7242$
\end{tabular}

FEC ID number of contributing federal political committee.

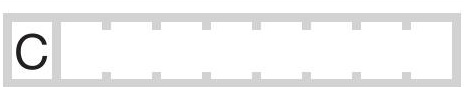

Name of Employer
Ameriprise Financial
Receipt For: 2012
X Primary
Other (specify) General

\section{Occupation}

Financial Advisor

Election Cycle-to-Date

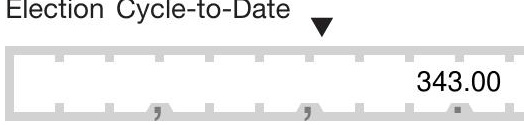

Transaction ID : AAODAE590990244189FB

Date of Receipt

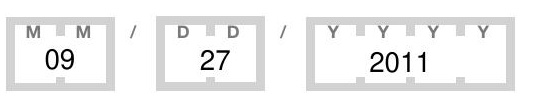

Amount of Each Receipt this Period

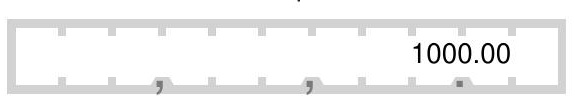

Transaction ID : A58718B23CCFC4888B9F Date of Receipt

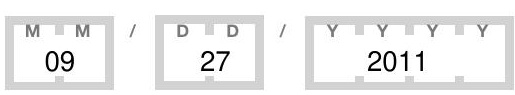

Amount of Each Receipt this Period

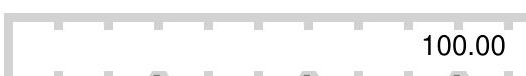

\section{Subtotal Of Receipts This Page (optional)}

Total This Period (last page this line number only) 


\section{SCHEDULE A-P} ITEMIZED RECEIPTS
Use separate schedule(s)

for each category of the

Detailed Summary Page
FOR LINE NUMBER: (check only one)

PAGE $880 / 1572$

\begin{tabular}{|c|c|c|c|c|c|}
\hline & & & & & \\
\hline 16 & X $17 a$ & $17 b$ & $17 c$ & $17 d$ & 18 \\
\hline $19 a$ & $19 b$ & $20 \mathrm{a}$ & $20 \mathrm{~b}$ & $20 \mathrm{c}$ & 21 \\
\hline
\end{tabular}

Any information copied from such Reports and Statements may not be sold or used by any person for the purpose of soliciting contributions or for commercial purposes, other than using the name and address of any political committee to solicit contributions from such committee.

NAME OF COMMITTEE (In Full)

Friends of Herman Cain

A. Full Name (Last, First, Middle Initial)

Stephen Grande

Mailing Address 781 S Stillwater Ln

\begin{tabular}{lcc}
\hline City & State & Zip Code \\
Anaheim & CA & $92807-4820$
\end{tabular}

FEC ID number of contributing

federal political committee.

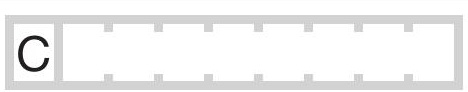

Name of Employer
MIDCOM Corporation
Receipt For: 2012
X Primary
$\square$ Other (specify)

Occupation

Executive

Election Cycle-to-Date

300.00

B. Full Name (Last, First, Middle Initial)

Harold Lukas

Mailing Address 7541 W 119th

\begin{tabular}{lcc}
\hline City & State & Zip Code \\
Overland Park & KS & $66213-1107$
\end{tabular}

FEC ID number of contributing

federal political committee.

C

\begin{tabular}{l} 
Name of Employer \\
Information Requested \\
Receipt For: 2012 \\
X Primary \\
\hline Other (specify)
\end{tabular}

Occupation

Information Requested

Election Cycle-to-Date

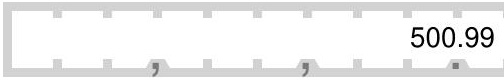

C. Full Name (Last, First, Middle Initial)

Susan Euart

Mailing Address 2612 Parkside Dr.

\begin{tabular}{lcc}
\hline City & State & Zip Code \\
Atlanta & GA & $30305-3734$ \\
\hline
\end{tabular}

FEC ID number of contributing

federal political committee.

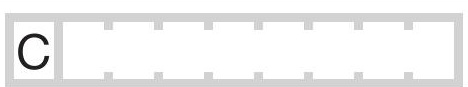

Name of Employer
self
Receipt For: 2012
X Primary
Other (specify) General

Occupation

Photographer

Election Cycle-to-Date

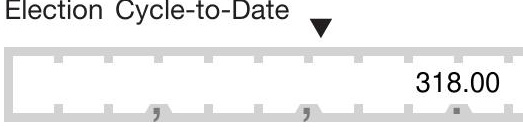

Transaction ID : A3DD9FFA4AFA0415D856

Date of Receipt

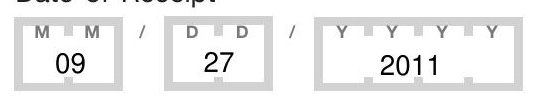

Amount of Each Receipt this Period

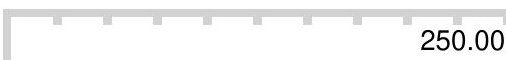

250.00

Transaction ID : A89919F8080594467B94

Date of Receipt

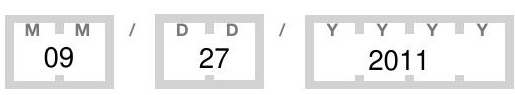

Amount of Each Receipt this Period

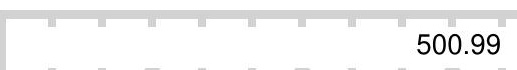

Transaction ID : AF610044C494448C29DB

Date of Receipt

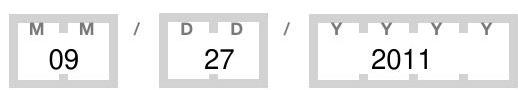

Amount of Each Receipt this Period

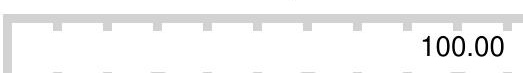

100.00

Subtotal Of Receipts This Page (optional)

850.99

Total This Period (last page this line number only) 


\section{SCHEDULE A-P} ITEMIZED RECEIPTS
Use separate schedule(s) for each category of the Detailed Summary Page

FOR LINE NUMBER:
(check only one)

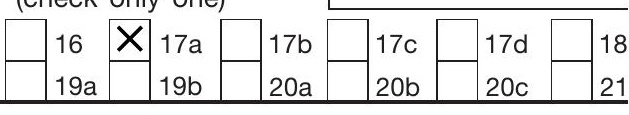

Any information copied from such Reports and Statements may not be sold or used by any person for the purpose of soliciting contributions or for commercial purposes, other than using the name and address of any political committee to solicit contributions from such committee.

NAME OF COMMITTEE (In Full)

\section{Friends of Herman Cain}

A. Full Name (Last, First, Middle Initial)

Aaron Bliss

Mailing Address 2719 Rivendell Road

\begin{tabular}{lcc}
\hline City & State & Zip Code \\
Lake Oswego & OR & $97034-7391$
\end{tabular}

FEC ID number of contributing federal political committee.

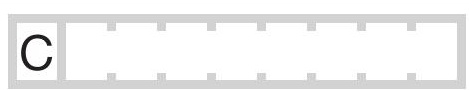

Name of Employer
Information Requested
Receipt For: 2012
X Primary
$\square$ Other (specify)

Occupation Information Requested

Election Cycle-to-Date 500.00

B. Full Name (Last, First, Middle Initial)

Walter Whetstine

Mailing Address 6960 E. Balancing Rock Rd.

\begin{tabular}{lcc}
\hline City & State & Zip Code \\
Scottsdale & AZ & $85266-8541$ \\
\hline
\end{tabular}

FEC ID number of contributing

federal political committee.

C

Name of Employer
Information Requested
Receipt For: 2012
X Primary
Other (specify)

Occupation

Information Requested

Election Cycle-to-Date

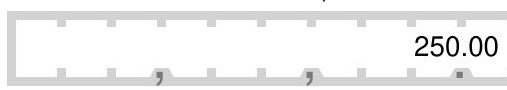

Transaction ID : A28ED03CE3FF645A7914

Date of Receipt

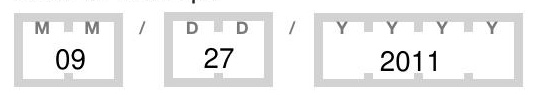

Amount of Each Receipt this Period

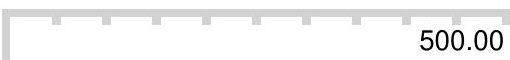

C. Full Name (Last, First, Middle Initial)

David Dunnavant Jr

Mailing Address 29415 Lakeview $\mathrm{Dr}$

\begin{tabular}{lcc}
\hline City & State & Zip Code \\
Ardmore & AL & $35739-7747$
\end{tabular}

FEC ID number of contributing federal political committee.

C

(35739-7747

C

Occupation

Information Requested

Election Cycle-to-Date

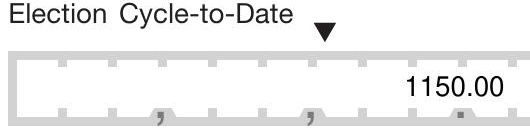

Amount of Each Receipt this Period

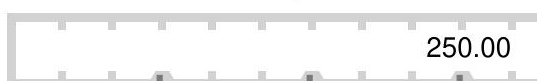

Transaction ID : A240CB67D5E664363AB8 Date of Receipt

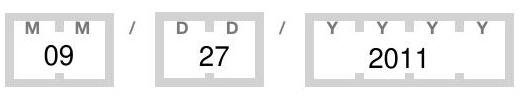

Transaction ID : A29C4153C70E6434FBB2 Date of Receipt

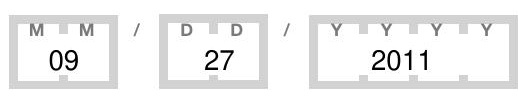

Amount of Each Receipt this Period

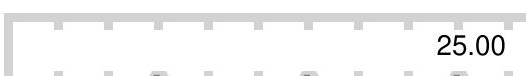

\section{Subtotal Of Receipts This Page (optional)}

775.00

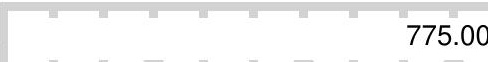

(1)

Total This Period (last page this line number only)

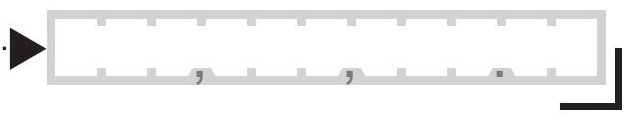

FEC Schedule A-P (Form 3P) (Rev. 03/2011) 


\section{SCHEDULE A-P} ITEMIZED RECEIPTS
Use separate schedule(s)

for each category of the

Detailed Summary Page
FOR LINE NUMBER: (check only one)

PAGE 882 / 1572

\begin{tabular}{|c|c|c|c|c|c|}
\hline & & & & & \\
\hline 16 & X $17 a$ & $17 b$ & $17 c$ & $17 d$ & 18 \\
\hline $19 a$ & $19 b$ & $20 \mathrm{a}$ & $20 \mathrm{~b}$ & $20 \mathrm{c}$ & 21 \\
\hline
\end{tabular}

Any information copied from such Reports and Statements may not be sold or used by any person for the purpose of soliciting contributions or for commercial purposes, other than using the name and address of any political committee to solicit contributions from such committee.

NAME OF COMMITTEE (In Full)

Friends of Herman Cain

A. Full Name (Last, First, Middle Initial)

Clifford Wagner

Mailing Address 103 Mishoe Rd

\begin{tabular}{lcc}
\hline City & State & Zip Code \\
Castle Hayne & NC & $28429-5565$
\end{tabular}

FEC ID number of contributing federal political committee.

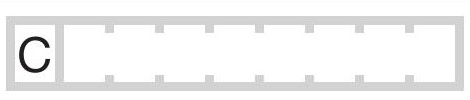

Name of Employer
Information Requested
Receipt For: 2012
X Primary
Other (specify) General

Occupation

Information Requested

Election Cycle-to-Date

250.00

B. Full Name (Last, First, Middle Initial)

Alfred Persson

Mailing Address 35099 State Hwy 74 spc F3

\begin{tabular}{lcc}
\hline City & State & Zip Code \\
Hemet & CA & $92545-3461$
\end{tabular}

FEC ID number of contributing

federal political committee.

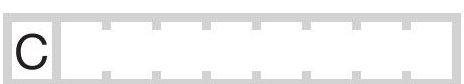

Name of Employer
Discount Answering Service
Receipt For: 2012
X Primary
Other (specify)

\section{Occupation}

CEO

Election Cycle-to-Date

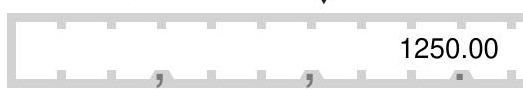

C. Full Name (Last, First, Middle Initial)

Scott Henderson

Mailing Address 894 Saddlebrook Dri

\begin{tabular}{lcc}
\hline City & State & Zip Code \\
Frisco & TX & $75034-8874$ \\
\hline
\end{tabular}

FEC ID number of contributing

federal political committee.

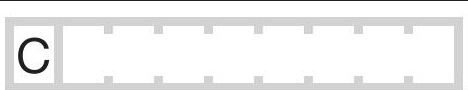

Name of Employer

Information Requested

Occupation

Information Requested

Receipt For: 2012

Х $\begin{aligned} & \text { Primary } \square \text { General } \\ & \text { Other (specify) }\end{aligned}$

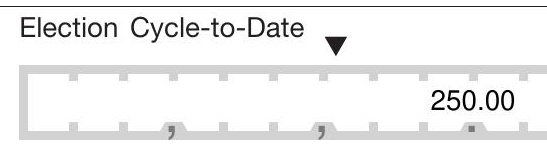

Amount of Each Receipt this Period

Transaction ID : A3795F0505D9B46A68EF

Date of Receipt

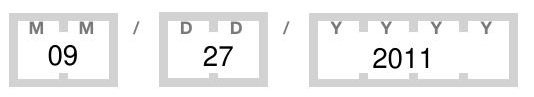

Amount of Each Receipt this Period

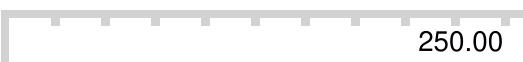

250.00

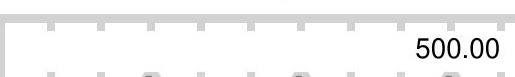

Transaction ID : AE8EB5ABAF01D43CA844 Date of Receipt

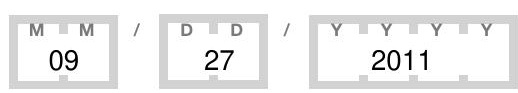

Amount of Each Receipt this Period

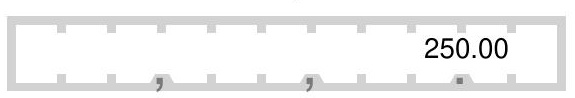

Subtotal Of Receipts This Page (optional)

1000.00

Total This Period (last page this line number only) 
SCHEDULE A-P ITEMIZED RECEIPTS
Use separate schedule(s) for each category of the Detailed Summary Page
FOR LINE NUMBER: (check only one)

PAGE $883 / 1572$

\begin{tabular}{|c|c|c|c|c|c|}
\hline & & & & & \\
\hline 16 & $\begin{array}{lll}X & 17 a \\
\end{array}$ & $17 \mathrm{~b}$ & $17 c$ & $17 d$ & 18 \\
\hline $19 a$ & $19 b$ & $20 a$ & $20 \mathrm{~b}$ & $20 c$ & 21 \\
\hline
\end{tabular}

Any information copied from such Reports and Statements may not be sold or used by any person for the purpose of soliciting contributions or for commercial purposes, other than using the name and address of any political committee to solicit contributions from such committee.

NAME OF COMMITTEE (In Full)

\section{Friends of Herman Cain}

A. Full Name (Last, First, Middle Initial) pattie frierson

Mailing Address 551 pine valley rd

\begin{tabular}{lcc}
\hline City & State & Zip Code \\
Marietta & GA & $30067-4827$ \\
\hline
\end{tabular}

FEC ID number of contributing federal political committee.

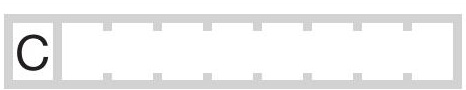

Name of Employer
Retired
Receipt For: 2012
X Primary $\quad$ General
Other (specify)

Occupation Registered Nurse Election Cycle-to-Date

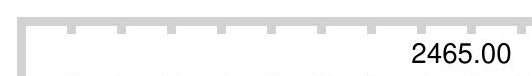

B. Full Name (Last, First, Middle Initial)

Bob Hill

Mailing Address 12147 Caminito Mira Del Mar

\begin{tabular}{lcc}
\hline City & State & Zip Code \\
San Diego & CA & $92130-2302$
\end{tabular}

FEC ID number of contributing

federal political committee.

C

Name of Employer

Occupation

Retired

the man in charge

Receipt For: 2012

Х $\begin{aligned} & \text { Primary } \square \text { General } \\ & \text { Other (specify) } \boldsymbol{\nabla}\end{aligned}$

Election Cycle-to-Date

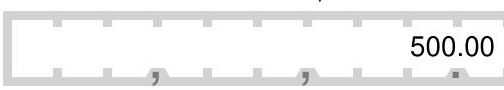

C. Full Name (Last, First, Middle Initial)

Pravin Mundkur

Mailing Address 9 Belfry Terrace

\begin{tabular}{lcc}
\hline City & State & Zip Code \\
Lexington & MA & $02421-4909$ \\
\hline
\end{tabular}

FEC ID number of contributing federal political committee.

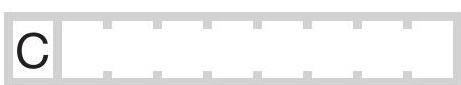

$\begin{aligned} & \text { Name of Employer } \\ & \text { self }\end{aligned}$
Receipt For: 2012
X Primary $\quad \square$ General
Other (specify)

Occupation

Internet Technologies

Election Cycle-to-Date
Transaction ID : AEB8A9769D0794A67B99

Date of Receipt

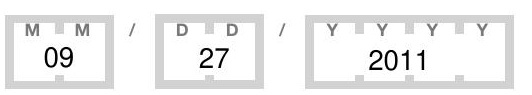

Amount of Each Receipt this Period

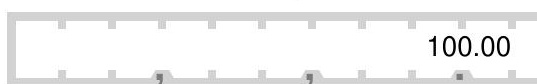

Transaction ID : AD43584FB26194CE88D2 Date of Receipt

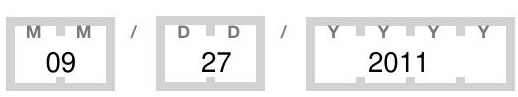

Amount of Each Receipt this Period

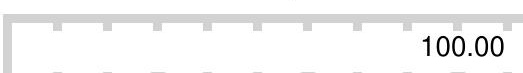

\section{Subtotal Of Receipts This Page (optional)}

665.00

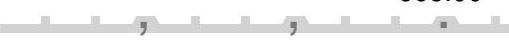

Total This Period (last page this line number only)
Transaction ID : A1D3903D89010443EACD

Date of Receipt

Amount of Each Receipt this Period

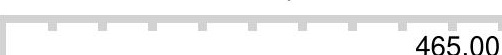

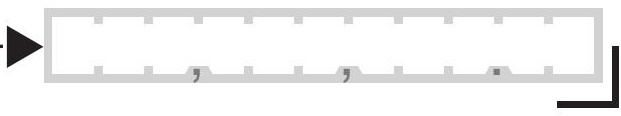


SCHEDULE A-P ITEMIZED RECEIPTS
Use separate schedule(s) for each category of the Detailed Summary Page
FOR LINE NUMBER: (check only one)
PAGE 884 / 1572

\begin{tabular}{|c|c|c|c|c|c|}
\hline & & & & & \\
\hline 16 & $\begin{array}{lll}X & 17 a \\
\end{array}$ & $17 \mathrm{~b}$ & $17 c$ & $17 d$ & 18 \\
\hline $19 a$ & $19 b$ & $20 a$ & $20 \mathrm{~b}$ & $20 c$ & 21 \\
\hline
\end{tabular}

Any information copied from such Reports and Statements may not be sold or used by any person for the purpose of soliciting contributions or for commercial purposes, other than using the name and address of any political committee to solicit contributions from such committee.

NAME OF COMMITTEE (In Full)

\section{Friends of Herman Cain}

A. Full Name (Last, First, Middle Initial)

Kevin Gustainis

Mailing Address P.O. Box 491

\begin{tabular}{lcc}
\hline City & State & Zip Code \\
Billings & MT & $59103-0491$
\end{tabular}

FEC ID number of contributing federal political committee.

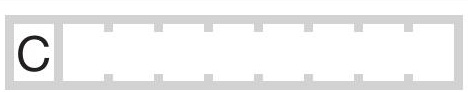

Name of Employer
Information Requested
Receipt For: 2012
X Primary
Other (specify) General

Occupation Information Requested

Election Cycle-to-Date

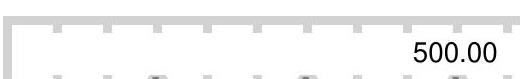

B. Full Name (Last, First, Middle Initial)

Lynn Pfost

Mailing Address 11601 Carrollwood Drive

\begin{tabular}{lcc}
\hline City & State & Zip Code \\
Tampa & FL & $33618-3713$
\end{tabular}

FEC ID number of contributing

federal political committee.

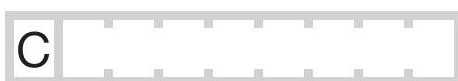

Name of Employer
None
Receipt For: 2012
X Primary
Other (specify)

\section{Occupation}

Mom

Election Cycle-to-Date

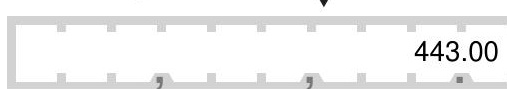

Transaction ID : AC895098BE1F64AD28B9

Date of Receipt

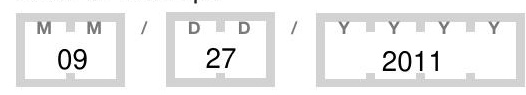

Amount of Each Receipt this Period

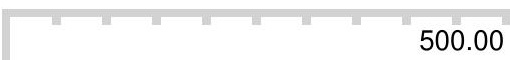

Amount of Each Receipt this Period

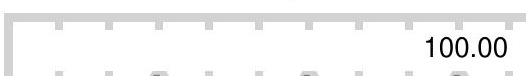

C. Full Name (Last, First, Middle Initial)

MARK Feighner

Mailing Address 460 east jeter rd 460 EAST JETER $R$

\begin{tabular}{lcc}
\hline City & State & Zip Code \\
Argyle & TX & 76226 \\
\hline
\end{tabular}

FEC ID number of contributing

federal political committee.

C

Name of Employer
Information Requested
Receipt For: 2012
X Primary
Other (specify) General

Occupation

Information Requested

Election Cycle-to-Date

Transaction ID : A04FEC72A8F0E49258D6

Date of Receipt

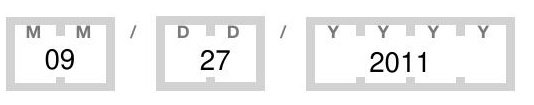

Amount of Each Receipt this Period

Transaction ID : AB483335BB6994891955

Date of Receipt
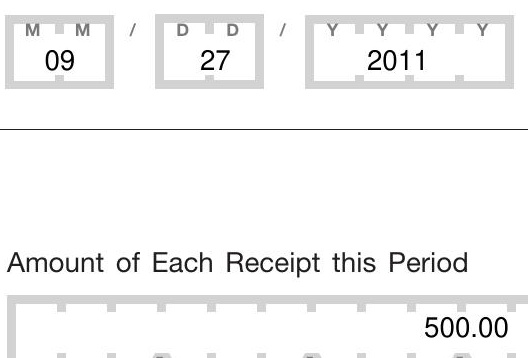

500.00

\section{Subtotal Of Receipts This Page (optional)}

Total This Period (last page this line number only) 


\section{SCHEDULE A-P} ITEMIZED RECEIPTS
Use separate schedule(s)

for each category of the

Detailed Summary Page
FOR LINE NUMBER: (check only one)

PAGE $885 / 1572$

\begin{tabular}{|c|c|c|c|c|c|}
\hline & & & & & \\
\hline 16 & X $17 a$ & $17 b$ & $17 c$ & $17 d$ & 18 \\
\hline $19 a$ & $19 b$ & $20 \mathrm{a}$ & $20 \mathrm{~b}$ & $20 \mathrm{c}$ & 21 \\
\hline
\end{tabular}

Any information copied from such Reports and Statements may not be sold or used by any person for the purpose of soliciting contributions or for commercial purposes, other than using the name and address of any political committee to solicit contributions from such committee.

NAME OF COMMITTEE (In Full)

Friends of Herman Cain

A. Full Name (Last, First, Middle Initial)

Bjorn Lindgren

Mailing Address 4318 E Fm 1462 Rd

\begin{tabular}{lcc}
\hline City & State & Zip Code \\
Rosharon & TX & $77583-7838$
\end{tabular}

FEC ID number of contributing

federal political committee.

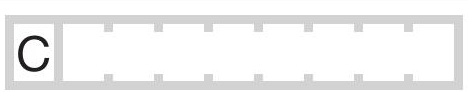

Name of Employer
Information Requested
Receipt For: 2012
X Primary $\quad \square$ General
$\square$ Other (specify)

Occupation

Information Requested

Election Cycle-to-Date

250.00

B. Full Name (Last, First, Middle Initial)

James Atkiins Jr

Mailing Address 221 South Plant Ave

\begin{tabular}{lcc}
\hline City & State & Zip Code \\
Boerne & TX & $78006-2141$
\end{tabular}

FEC ID number of contributing

federal political committee.

C

\begin{tabular}{l} 
Name of Employer \\
Information Requested \\
Receipt For: 2012 \\
X Primary \\
\hline Other (specify)
\end{tabular}

Occupation

Information Requested

Election Cycle-to-Date

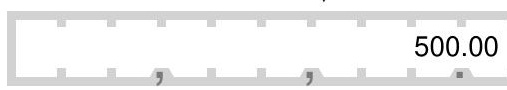

Transaction ID : A66BEB7A710414C23927

Date of Receipt

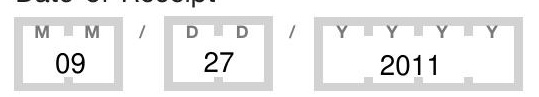

Amount of Each Receipt this Period

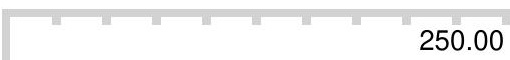

C. Full Name (Last, First, Middle Initial)

Stephen Shiver

Mailing Address 410 E. McPherson Avenue

\begin{tabular}{lcc}
\hline City & State & Zip Code \\
Nashville & GA & $31639-2266$
\end{tabular}

FEC ID number of contributing

federal political committee.

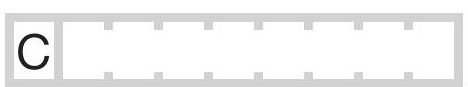

Name of Employer

Self Employed

Receipt For: 2012

Х $\begin{aligned} & \text { Primary } \square \text { General } \\ & \text { Other (specify) }\end{aligned}$

\section{Occupation}

Dentist

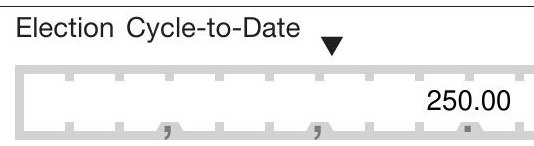

Amount of Each Receipt this Period

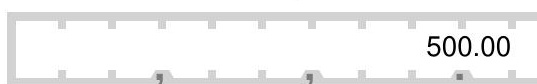

Transaction ID : A84314B81CF7745EB9F1

Date of Receipt

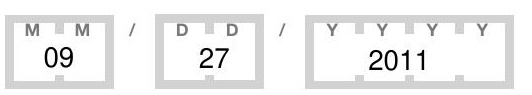

Transaction ID : AD85F9144035A41D3B71

Date of Receipt

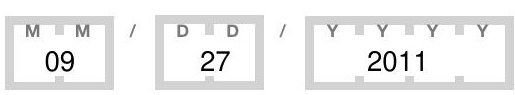

Amount of Each Receipt this Period

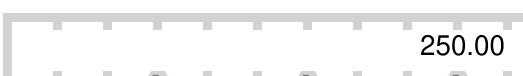

Subtotal Of Receipts This Page (optional).

1000.00

ㄱ․․

Total This Period (last page this line number only)

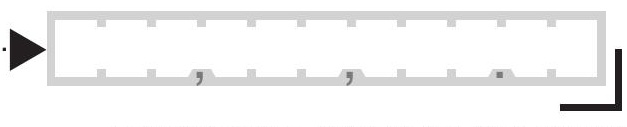

FEC Schedule A-P (Form 3P) (Rev. 03/2011) 


\section{SCHEDULE A-P} ITEMIZED RECEIPTS
Use separate schedule(s)

for each category of the

Detailed Summary Page
FOR LINE NUMBER: (check only one)

PAGE $886 / 1572$

\begin{tabular}{|c|c|c|c|c|c|}
\hline & & & & & \\
\hline 16 & $\begin{array}{l}\mathbf{X} \\
17 a\end{array}$ & $17 b$ & $17 c$ & $17 d$ & 18 \\
\hline $19 a$ & $19 \mathrm{~b}$ & $20 \mathrm{a}$ & $20 \mathrm{~b}$ & $20 \mathrm{c}$ & 21 \\
\hline
\end{tabular}

Any information copied from such Reports and Statements may not be sold or used by any person for the purpose of soliciting contributions or for commercial purposes, other than using the name and address of any political committee to solicit contributions from such committee.

NAME OF COMMITTEE (In Full)

Friends of Herman Cain

A. Full Name (Last, First, Middle Initial)

Robert McTamaney

Mailing Address 908 West Francis

\begin{tabular}{lcc}
\hline City & State & Zip Code \\
Belvedere Tiburon & CA & 94920
\end{tabular}

FEC ID number of contributing

federal political committee.

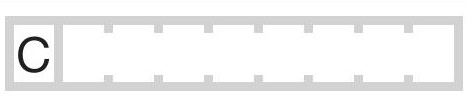

Name of Employer
Information Requested
Receipt For: 2012
X Primary $\quad \square$ General
Other (specify)

Occupation

Information Requested

Election Cycle-to-Date

2500.00

B. Full Name (Last, First, Middle Initial)

Gaetano Cicatiello

Mailing Address 2976 Mediterranean Loop

\begin{tabular}{lcc}
\hline City & State & Zip Code \\
Tavares & FL & $32778-9244$
\end{tabular}

FEC ID number of contributing

federal political committee.

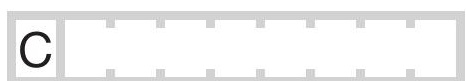

Name of Employer
None
Receipt For: 2012
X Primary
Other (specify)

Occupation

Retired

Election Cycle-to-Date

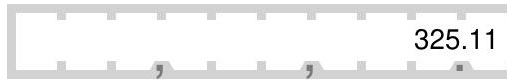

Transaction ID : A4419BF16FCA149EC866

Date of Receipt

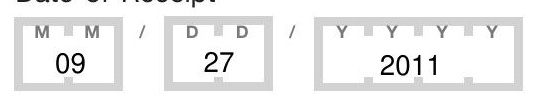

Amount of Each Receipt this Period

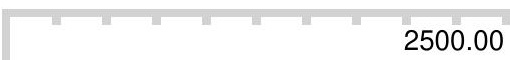

C. Full Name (Last, First, Middle Initial)

DAVID bowser

Mailing Address 4699 LAWRENCE 1205

\begin{tabular}{lcc}
\hline City & State & Zip Code \\
Everton & MO & $65646-8240$
\end{tabular}

FEC ID number of contributing

federal political committee.

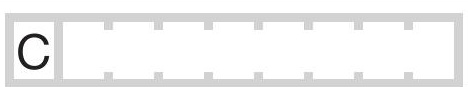

Name of Employer

Occupation

Double S transport

O.T.R. truck driver

Receipt For: 2012

Х $\begin{aligned} & \text { Primary } \square \text { General } \\ & \text { Other (specify) }\end{aligned}$

Transaction ID : AC66A725C03BC4D569C2

Date of Receipt

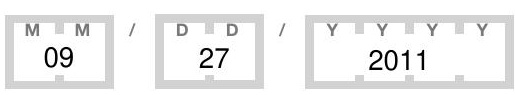

Amount of Each Receipt this Period

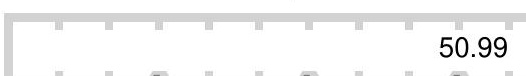

Transaction ID : A965C0937814B437EBC9

Date of Receipt

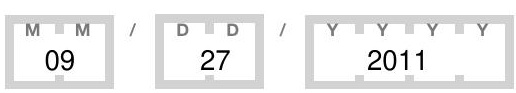

Amount of Each Receipt this Period

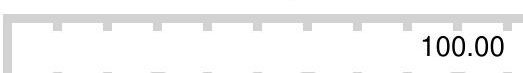

Subtotal Of Receipts This Page (optional).

Total This Period (last page this line number only) 
SCHEDULE A-P ITEMIZED RECEIPTS
Use separate schedule(s) for each category of the Detailed Summary Page
FOR LINE NUMBER: (check only one)
PAGE 887 / 1572

\begin{tabular}{|c|c|c|c|c|c|}
\hline & & & & & \\
\hline 16 & $\begin{array}{lll}X & 17 a \\
\end{array}$ & $17 \mathrm{~b}$ & $17 c$ & $17 d$ & 18 \\
\hline $19 a$ & $19 b$ & $20 a$ & $20 \mathrm{~b}$ & $20 c$ & 21 \\
\hline
\end{tabular}

Any information copied from such Reports and Statements may not be sold or used by any person for the purpose of soliciting contributions or for commercial purposes, other than using the name and address of any political committee to solicit contributions from such committee.

NAME OF COMMITTEE (In Full)

\section{Friends of Herman Cain}

A. Full Name (Last, First, Middle Initial)

Kimberly Jackson

Mailing Address 375 Mistwater Trace

\begin{tabular}{lcc}
\hline City & State & Zip Code \\
Alpharetta & GA & $30022-4027$
\end{tabular}

FEC ID number of contributing

federal political committee.

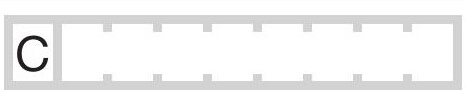

Name of Employer
Information Requested
Receipt For: 2012
X Primary
Other (specify) General

Occupation

Information Requested

Election Cycle-to-Date

500.00

B. Full Name (Last, First, Middle Initial)

John Prizer

Mailing Address 2360 Hametown Rd

\begin{tabular}{lcc}
\hline City & State & Zip Code \\
Glen Rock & PA & $17327-9157$
\end{tabular}

FEC ID number of contributing

federal political committee.

C

Name of Employer
Information Requested
Receipt For: 2012
X Primary
Other (specify)

Occupation

Information Requested

Election Cycle-to-Date

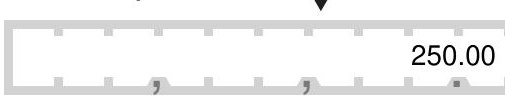

Transaction ID : A9526972D12974C1BB79

Date of Receipt

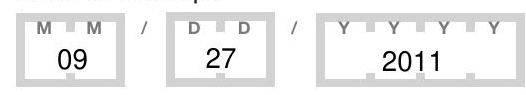

Amount of Each Receipt this Period

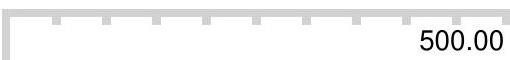

Amount of Each Receipt this Period

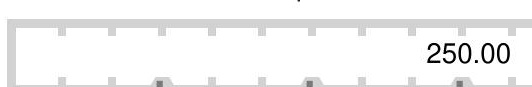

C. Full Name (Last, First, Middle Initial)

Randy Holt

Mailing Address 867 Arnold Mill Rd

\begin{tabular}{lcc}
\hline City & State & Zip Code \\
Woodstock & GA & $30188-3006$
\end{tabular}

FEC ID number of contributing federal political committee.

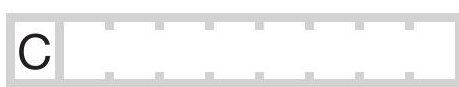

Name of Employer

Information Requested

Occupation

Information Requested

Receipt For: 2012

Х $\begin{aligned} & \text { Primary } \\ & \text { Other (specify) }\end{aligned}$

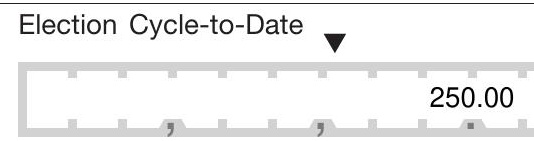

Amount of Each Receipt this Period

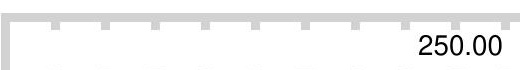

Transaction ID : ADDE5B049100143E1B04

Date of Receipt

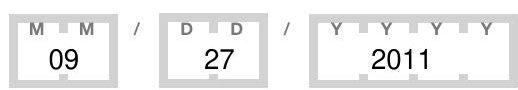

Subtotal Of Receipts This Page (optional)

1000.00

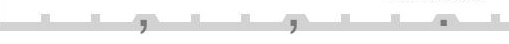

Total This Period (last page this line number only) 


\section{SCHEDULE A-P} ITEMIZED RECEIPTS
Use separate schedule(s)

for each category of the

Detailed Summary Page
FOR LINE NUMBER: (check only one)

PAGE $888 / 1572$

\begin{tabular}{|c|c|c|c|c|c|}
\hline & & & & & \\
\hline 16 & X $17 a$ & $17 b$ & $17 c$ & $17 d$ & 18 \\
\hline $19 a$ & $19 b$ & $20 \mathrm{a}$ & $20 \mathrm{~b}$ & $20 \mathrm{c}$ & 21 \\
\hline
\end{tabular}

Any information copied from such Reports and Statements may not be sold or used by any person for the purpose of soliciting contributions or for commercial purposes, other than using the name and address of any political committee to solicit contributions from such committee.

NAME OF COMMITTEE (In Full)

Friends of Herman Cain

A. Full Name (Last, First, Middle Initial)

Mr John Mumford

Mailing Address 2925 Woodside Rd

\begin{tabular}{lcc}
\hline City & State & Zip Code \\
Woodside & CA & $94062-2443$
\end{tabular}

FEC ID number of contributing

federal political committee.

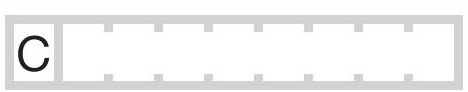

Name of Employer
crosspoint venture capita
Receipt For: 2012
X Primary
$\square$ Other (specify)

Occupation

Venture Capital

Election Cycle-to-Date

2500.00

B. Full Name (Last, First, Middle Initial)

Scott Frandsen

Mailing Address 510 Oglethorpe Dr., NE

\begin{tabular}{lcc}
\hline City & State & Zip Code \\
Atlanta & GA & $30319-2774$ \\
\hline
\end{tabular}

FEC ID number of contributing

federal political committee.

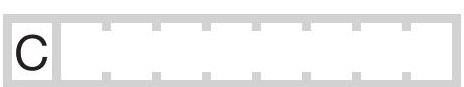

Name of Employer
Information Requested
Receipt For: 2012
X Primary
Other (specify)

Occupation

Information Requested

Election Cycle-to-Date

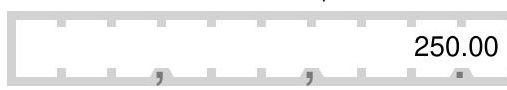

Transaction ID : A0C2586B24C5345ABA61

Date of Receipt

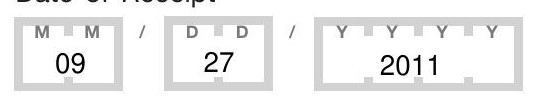

Amount of Each Receipt this Period

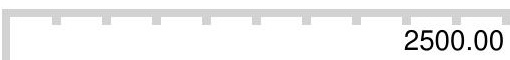

2500.00

C. Full Name (Last, First, Middle Initial)

Timothy Holmes

Mailing Address 2530 S Wallis Smith Blvd

\begin{tabular}{lcc}
\hline City & State & Zip Code \\
Springfield & MO & $65804-3253$
\end{tabular}

FEC ID number of contributing

federal political committee.

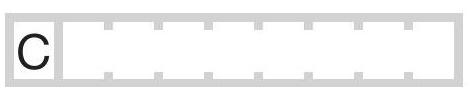

Name of Employer

The Shutter Shop, Inc.

Receipt For: 2012

Х $\begin{aligned} & \text { Primary } \\ & \text { Other (specify) }\end{aligned}$

Occupation

Owner/ Operator

Election Cycle-to-Date

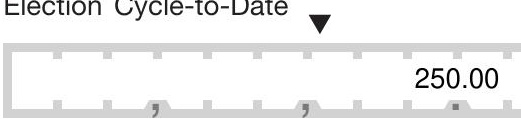

Transaction ID : A807544D8A4264BA5A4E

Date of Receipt

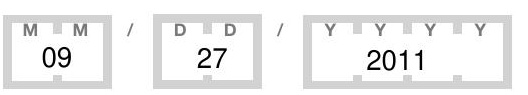

Amount of Each Receipt this Period

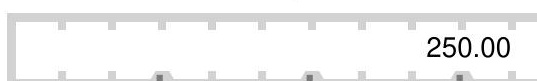

Transaction ID : A2B86E560ABF3443C868

Date of Receipt

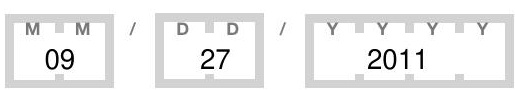

Amount of Each Receipt this Period

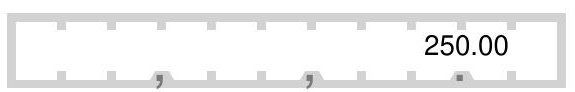

\section{Subtotal Of Receipts This Page (optional)}

Total This Period (last page this line number only) 
SCHEDULE A-P ITEMIZED RECEIPTS
Use separate schedule(s)

for each category of the

Detailed Summary Page
FOR LINE NUMBER: (check only one)

Any information copied from such Repor or for commercial purposes, other than using the name and address of any political committee to solicit contributions from such committee.

NAME OF COMMITTEE (In Full)

\section{Friends of Herman Cain}

A. Full Name (Last, First, Middle Initial)

Ronald Hovis

Mailing Address 2518 Monarch Terrace Dr.

\begin{tabular}{lcc}
\hline City & State & Zip Code \\
Katy & TX & $77494-0669$ \\
\hline
\end{tabular}

FEC ID number of contributing federal political committee.

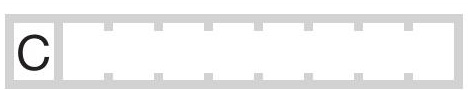

Name of Employer
None
Receipt For: 2012
X Primary $\quad$ General
Other (specify)

Occupation

Retired

Election Cycle-to-Date

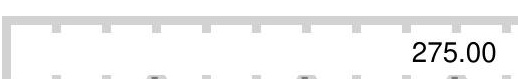

B. Full Name (Last, First, Middle Initial)

\section{Todd Ziems}

Mailing Address 4213 Mockingbird Lane

\begin{tabular}{lcc}
\hline City & State & Zip Code \\
Toledo & OH & $43623-3216$ \\
\hline
\end{tabular}

FEC ID number of contributing

federal political committee.

C

Name of Employer
Information Requested
Receipt For: 2012
X Primary
Other (specify)

\section{Occupation}

Information Requested

Election Cycle-to-Date

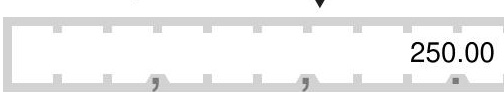

Transaction ID : AB3629F91BFA2411AAA1

Date of Receipt

Amount of Each Receipt this Period
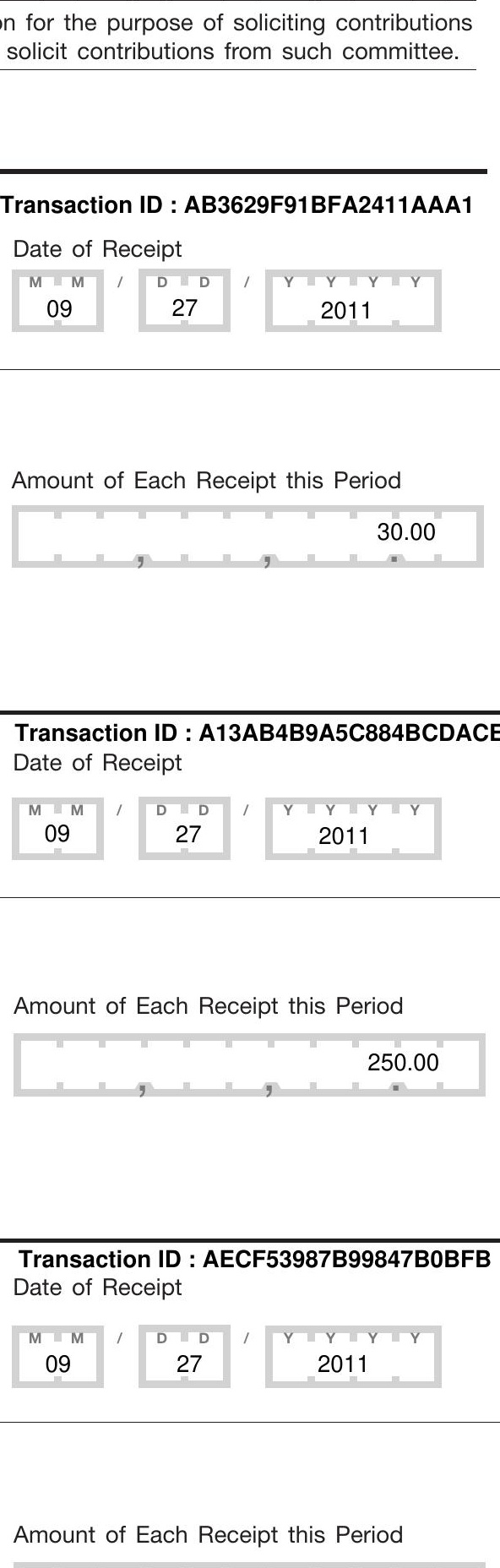

Amount of Each Receipt this Period

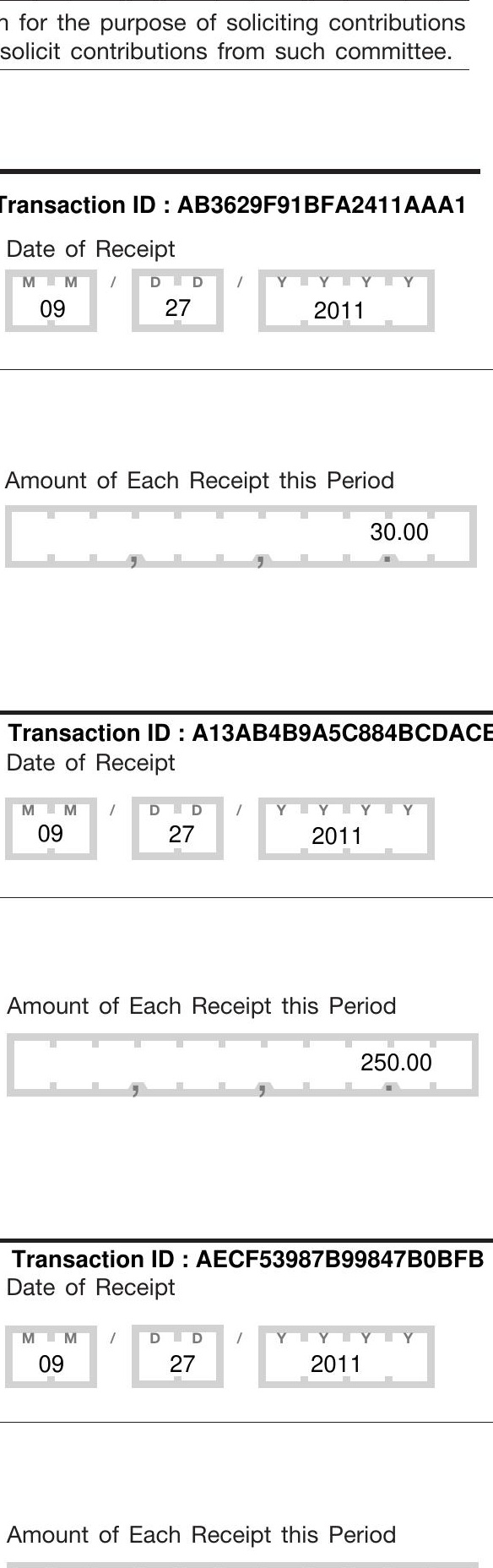

C. Full Name (Last, First, Middle Initial)

john fountain

Mailing Address 142 mountain springs circle

\begin{tabular}{lcc}
\hline City & State & Zip Code \\
Ellijay & GA & $30536-3892$ \\
\hline
\end{tabular}

FEC ID number of contributing federal political committee.

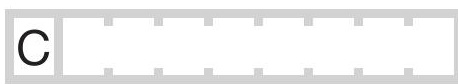

Name of Employer

Information Requested

Occupation

Information Requested

Receipt For: 2012

Х $\begin{aligned} & \text { Primary } \square \text { General } \\ & \text { Other (specify) }\end{aligned}$

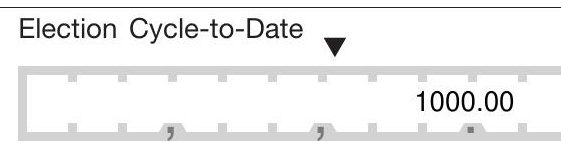

Amount of Each Receipt this Period

Transaction ID : A13AB4B9A5C884BCDACE Date of Receip

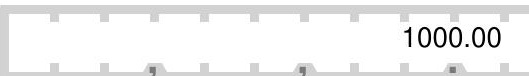

Subtotal Of Receipts This Page (optional).

1280.00

Total This Period (last page this line number only) 
SCHEDULE A-P ITEMIZED RECEIPTS
Use separate schedule(s) for each category of the Detailed Summary Page
FOR LINE NUMBER: (check only one)

PAGE $890 / 1572$

\begin{tabular}{|c|c|c|c|c|c|}
\hline & & & & & \\
\hline 16 & $\begin{array}{l}\mathbf{X} \\
17 a\end{array}$ & $17 b$ & $17 c$ & $17 d$ & 18 \\
\hline $19 a$ & $19 \mathrm{~b}$ & $20 \mathrm{a}$ & $20 \mathrm{~b}$ & $20 \mathrm{c}$ & 21 \\
\hline
\end{tabular}

Any information copied from such Reports and Statements may not be sold or used by any person for the purpose of soliciting contributions or for commercial purposes, other than using the name and address of any political committee to solicit contributions from such committee.

NAME OF COMMITTEE (In Full)

\section{Friends of Herman Cain}

A. Full Name (Last, First, Middle Initial)

Wayne Fogel

Mailing Address 7140 SE 172nd Hazelwood Loop

\begin{tabular}{lcc}
\hline City & State & Zip Code \\
The Villages & FL & $32162-5359$
\end{tabular}

FEC ID number of contributing

federal political committee.

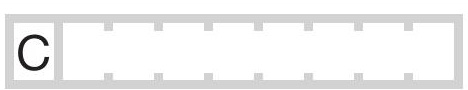

Name of Employer
None
Receipt For: 2012
X Primary $\quad$ General
Other (specify)

Occupation

Retired

Election Cycle-to-Date

550.00

B. Full Name (Last, First, Middle Initial)

Richard Roesch

Mailing Address 2537 Old San Pasqual Rd.

\begin{tabular}{lcc}
\hline City & State & Zip Code \\
Escondido & CA & $92027-4753$
\end{tabular}

FEC ID number of contributing

federal political committee.

C

Name of Employer
Information Requested
Receipt For: 2012
X Primary
Other (specify)

Occupation

Information Requested

Election Cycle-to-Date

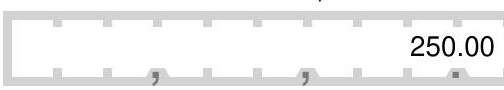

Transaction ID : AB99458D6AC8F4233903

Date of Receipt

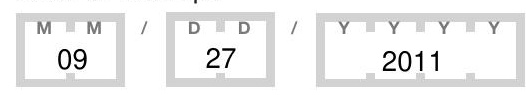

Amount of Each Receipt this Period

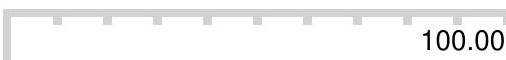

Transaction ID : A413FC2E96F024E868D5

Date of Receipt

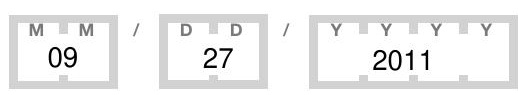

Amount of Each Receipt this Period

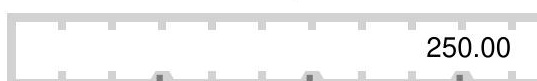

Transaction ID : A4FF8B62322A244A1977

Date of Receipt

\section{Steven Lehar}

Mailing Address 14 Crooked Lane

\begin{tabular}{lcc}
\hline City & State & Zip Code \\
Manchester & MA & $01944-1004$
\end{tabular}

FEC ID number of contributing federal political committee.

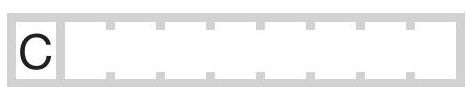

\section{Name of Employer}

Boston University

Receipt For: 2012

Х $\begin{aligned} & \text { Primary } \square \text { General } \\ & \text { Other (specify) }\end{aligned}$

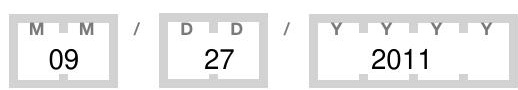

Amount of Each Receipt this Period

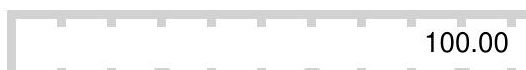

Subtotal Of Receipts This Page (optional)

450.00

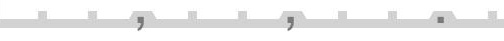

Total This Period (last page this line number only)

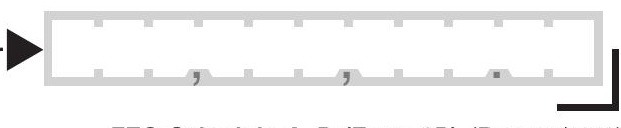

FEC Schedule A-P (Form 3P) (Rev. 03/2011) 
SCHEDULE A-P ITEMIZED RECEIPTS
Use separate schedule(s) for each category of the Detailed Summary Page
FOR LINE NUMBER: (check only one)
PAGE $891 / 1572$

\begin{tabular}{|c|c|c|c|c|c|}
\hline & & & & & \\
\hline 16 & $\begin{array}{lll}X & 17 a \\
\end{array}$ & $17 \mathrm{~b}$ & $17 c$ & $17 d$ & 18 \\
\hline $19 a$ & $19 b$ & $20 a$ & $20 \mathrm{~b}$ & $20 c$ & 21 \\
\hline
\end{tabular}

Any information copied from such Reports and Statements may not be sold or used by any person for the purpose of soliciting contributions or for commercial purposes, other than using the name and address of any political committee to solicit contributions from such committee.

NAME OF COMMITTEE (In Full)

\section{Friends of Herman Cain}

A. Full Name (Last, First, Middle Initial)

Alfonso Migliara Jr

Mailing Address 820 Montego Bay Drive S

\begin{tabular}{lcc}
\hline City & State & Zip Code \\
Merritt Island & FL & $32953-3261$
\end{tabular}

FEC ID number of contributing

federal political committee.

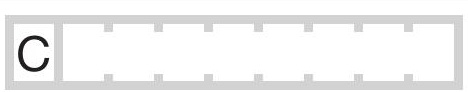

Name of Employer
n/a
Receipt For: 2012
X Primary $\quad$ General
Other (specify)

\section{Occupation}

$\mathrm{N} / \mathrm{A}$

Election Cycle-to-Date

\subsection{0}

B. Full Name (Last, First, Middle Initial)

Jeremy Rouse

Mailing Address 28876 King Arthur Court

\begin{tabular}{lcc}
\hline City & State & Zip Code \\
Rancho Palos Verdes & CA & $90275-7209$
\end{tabular}

FEC ID number of contributing

federal political committee.

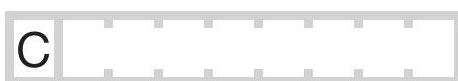

Name of Employer
Information Requested
Receipt For: 2012
X Primary
Other (specify)

\section{Occupation}

Information Requested

Election Cycle-to-Date

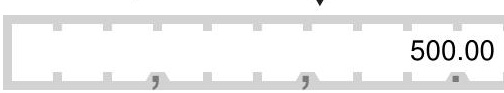

Transaction ID : A835F623987AA420F8B0

Date of Receipt

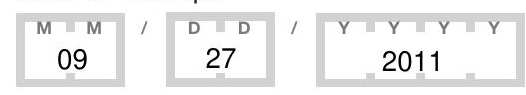

Amount of Each Receipt this Period

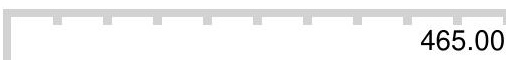

C. Full Name (Last, First, Middle Initial)

Craig Priebe

Mailing Address 214 Horseshoe Bnd N

\begin{tabular}{lcc}
\hline City & State & Zip Code \\
Madison & AL & $35758-7456$
\end{tabular}

FEC ID number of contributing

federal political committee.

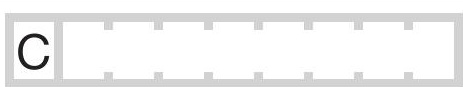

Name of Employer

Computer Sciences Corp.

Receipt For: 2012

Х $\begin{aligned} & \text { Primary } \square \text { General } \\ & \text { Other (specify) }\end{aligned}$

\section{Occupation}

Senior Analyst

Election Cycle-to-Date

Transaction ID : AB24FA3DC65E74C1EB1B Date of Receipt

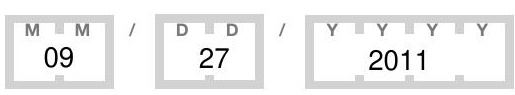

Amount of Each Receipt this Period

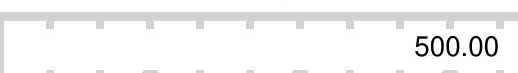

Transaction ID : A5010A811B8CA4D9FA2C Date of Receipt

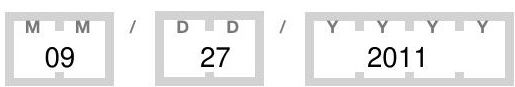

Amount of Each Receipt this Period

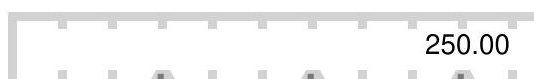

250.00

\section{Subtotal Of Receipts This Page (optional)}

Total This Period (last page this line number only) 


\section{SCHEDULE A-P} ITEMIZED RECEIPTS
Use separate schedule(s)

for each category of the

Detailed Summary Page
FOR LINE NUMBER: (check only one)

PAGE 892 / 1572

\begin{tabular}{|c|c|c|c|c|c|}
\hline & & & & & \\
\hline 16 & X $17 a$ & $17 b$ & $17 c$ & $17 d$ & 18 \\
\hline $19 a$ & $19 b$ & $20 \mathrm{a}$ & $20 \mathrm{~b}$ & $20 \mathrm{c}$ & 21 \\
\hline
\end{tabular}

Any information copied from such Reports and Statements may not be sold or used by any person for the purpose of soliciting contributions or for commercial purposes, other than using the name and address of any political committee to solicit contributions from such committee.

NAME OF COMMITTEE (In Full)

Friends of Herman Cain

A. Full Name (Last, First, Middle Initial)

Noble Wise Jr.

Mailing Address 2777 Century Court

\begin{tabular}{lcc}
\hline City & State & Zip Code \\
Atlanta & GA & $30340-3222$ \\
\hline
\end{tabular}

FEC ID number of contributing

federal political committee.

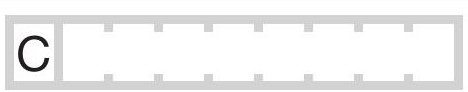

Name of Employer
Doorsetters, Inc.
Receipt For: 2012
X Primary
$\square$ Other (specify) General

Occupation

Owner

Election Cycle-to-Date

500.00

B. Full Name (Last, First, Middle Initial)

peter zombori

Mailing Address 47898 janet In

\begin{tabular}{lcc}
\hline City & State & Zip Code \\
Media & PA & 19063 \\
\hline
\end{tabular}

FEC ID number of contributing

federal political committee.

C

\begin{tabular}{l} 
Name of Employer \\
Information Requested \\
Receipt For: 2012 \\
X Primary \\
\hline Other (specify)
\end{tabular}

Occupation

Information Requested

Election Cycle-to-Date

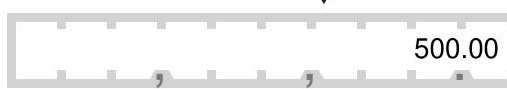

Transaction ID : A75AA481DF2EE4BD1B43

Date of Receipt

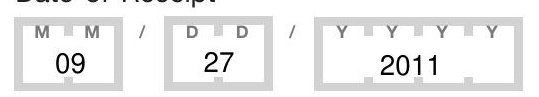

Amount of Each Receipt this Period

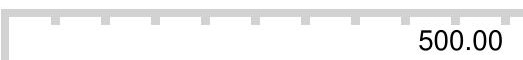

Amount of Each Receipt this Period

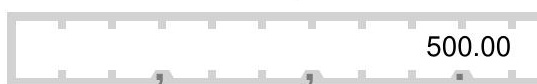

C. Full Name (Last, First, Middle Initial)

Doug Kathol

Mailing Address 11145 Boulder Ridge $\mathrm{Dr}$

\begin{tabular}{lcc}
\hline City & State & Zip Code \\
Fort Worth & TX & $76140-6531$
\end{tabular}

FEC ID number of contributing

federal political committee.

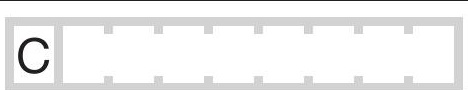

Name of Employer

Information Requested

Occupation

Information Requested

Receipt For: 2012

Х $\begin{aligned} & \text { Primary } \square \text { General } \\ & \text { Other (specify) }\end{aligned}$

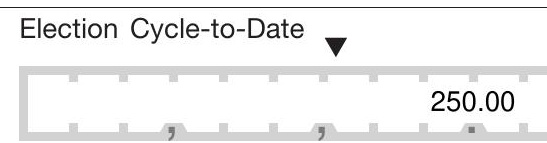

Amount of Each Receipt this Period

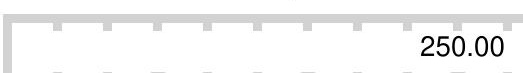

Transaction ID : A76F7E94491CD4341915

Date of Receipt

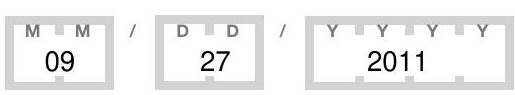

Subtotal Of Receipts This Page (optional)

1250.00

Total This Period (last page this line number only) 
SCHEDULE A-P ITEMIZED RECEIPTS
Use separate schedule(s) for each category of the Detailed Summary Page
FOR LINE NUMBER: (check only one)

PAGE $893 / 1572$

\begin{tabular}{|c|c|c|c|c|c|c|}
\hline & & & & & & \\
\hline 16 & $\lambda$ & $17 \mathrm{a}$ & $17 \mathrm{~b}$ & $17 \mathrm{c}$ & $-17 d$ & -18 \\
\hline $19 a$ & & $19 b$ & $20 a$ & $20 \mathrm{~b}$ & $20 \mathrm{c}$ & 21 \\
\hline
\end{tabular}

Any information copied from such Reports and Statements may not be sold or used by any person for the purpose of soliciting contributions or for commercial purposes, other than using the name and address of any political committee to solicit contributions from such committee.

NAME OF COMMITTEE (In Full)

\section{Friends of Herman Cain}

A. Full Name (Last, First, Middle Initial)

Jay Stump

Mailing Address 4 Cliffholme Road

\begin{tabular}{lcc}
\hline City & State & Zip Code \\
Owings Mills & MD & $21117-4321$ \\
\hline
\end{tabular}

FEC ID number of contributing federal political committee.

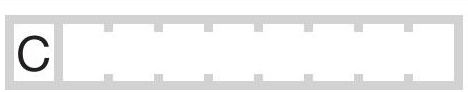

Name of Employer
Spring Valley
Receipt For: 2012
X Primary
Other (specify) General

Occupation landscape

Election Cycle-to-Date

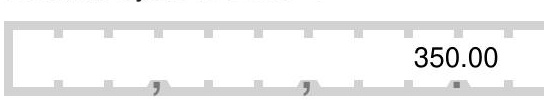

B. Full Name (Last, First, Middle Initial)

Robert Visger

Mailing Address 34 Timberlake Pointe

\begin{tabular}{lcc}
\hline City & State & Zip Code \\
Cartersville & GA & $30121-5290$ \\
\hline
\end{tabular}

FEC ID number of contributing

federal political committee.

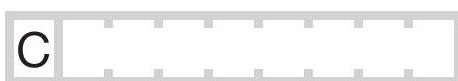

Name of Employer
n/a
Receipt For: 2012
X Primary
Other (specify)

Occupation

Retired

Election Cycle-to-Date

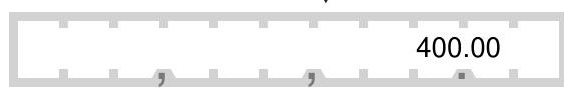

Transaction ID : AD6E3E895BF41484D96C

Date of Receipt

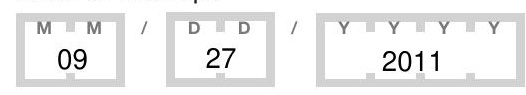

Amount of Each Receipt this Period

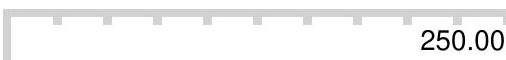

C. Full Name (Last, First, Middle Initial)

Daniel Grieb

Mailing Address 2205 S 183 Circle

\begin{tabular}{lcc}
\hline City & State & Zip Code \\
Omaha & NE & $68130-2783$
\end{tabular}

FEC ID number of contributing

federal political committee.

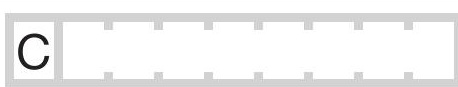

Name of Employer

Occupation

Self Employed

Accountant

Receipt For: 2012

Х $\begin{aligned} & \text { Primary } \\ & \text { Other (specify) }\end{aligned}$

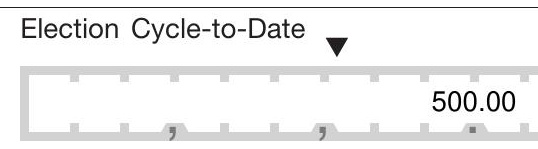

Amount of Each Receipt this Period

Transaction ID : AC4021B8B0FBB4A83BF4 Date of Receipt
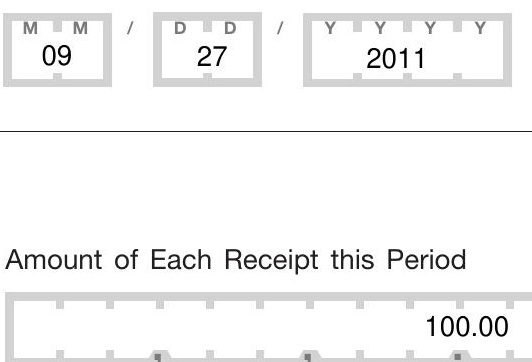

Transaction ID : A71F6989D34604D53A8B Date of Receipt

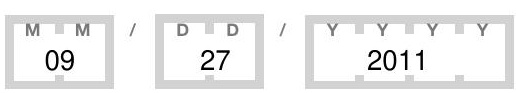

Amount of Each Receipt this Period

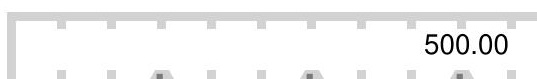

850.00

Subtotal Of Receipts This Page (optional)

Total This Period (last page this line number only) 
SCHEDULE A-P ITEMIZED RECEIPTS
Use separate schedule(s) for each category of the Detailed Summary Page
FOR LINE NUMBER: (check only one)
PAGE 894 / 1572

\begin{tabular}{|c|c|c|c|c|c|}
\hline & & & & & \\
\hline 16 & $\begin{array}{lll}X & 17 a \\
\end{array}$ & $17 \mathrm{~b}$ & $17 c$ & $17 d$ & 18 \\
\hline $19 a$ & $19 b$ & $20 a$ & $20 \mathrm{~b}$ & $20 c$ & 21 \\
\hline
\end{tabular}

Any information copied from such Reports and Statements may not be sold or used by any person for the purpose of soliciting contributions or for commercial purposes, other than using the name and address of any political committee to solicit contributions from such committee.

NAME OF COMMITTEE (In Full)

\section{Friends of Herman Cain}

A. Full Name (Last, First, Middle Initial)

Harold Deas

Mailing Address 2225 Dinsmore Road

\begin{tabular}{lcc}
\hline City & State & Zip Code \\
Alpharetta & GA & $30004-2730$
\end{tabular}

FEC ID number of contributing

federal political committee.

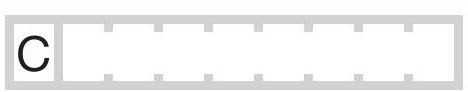

Name of Employer
Information Requested
Receipt For: 2012
X Primary $\quad \square$ General
Other (specify)

Occupation

Information Requested

Election Cycle-to-Date

749.99

B. Full Name (Last, First, Middle Initial)

Robert Sikes

Mailing Address 1050 Obarr Dr

\begin{tabular}{lcc}
\hline City & State & Zip Code \\
Gastonia & NC & $28054-6470$
\end{tabular}

FEC ID number of contributing

federal political committee.

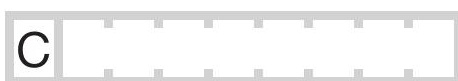

Name of Employer

Occupation

Premier, Inc.

Computer System Admin

Receipt For: 2012

$凶 \begin{aligned} & \text { Primary } \square \text { General } \\ & \text { Other (specify) } \boldsymbol{\nabla}\end{aligned}$

Election Cycle-to-Date

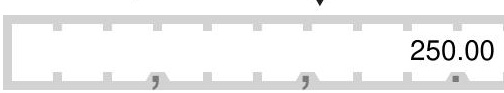

C. Full Name (Last, First, Middle Initial)

Andrew SanClemente

Mailing Address 17 Settlers Rd

\begin{tabular}{lcc}
\hline City & State & Zip Code \\
Shrewsbury & MA & $01545-7720$
\end{tabular}

FEC ID number of contributing

federal political committee.

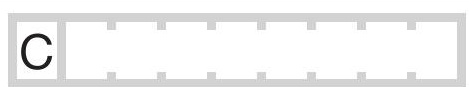

Name of Employer

Digital Health Systems

\section{Occupation}

programmer

Receipt For: 2012

Х $\begin{aligned} & \text { Primary } \\ & \text { Other (specify) }\end{aligned}$

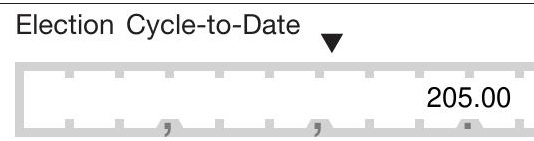

Amount of Each Receipt this Period

Transaction ID : A4CE6241C9C3A4A3698E

Date of Receipt

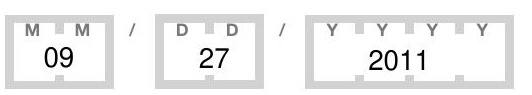

Amount of Each Receipt this Period

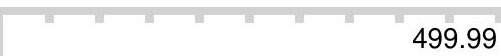

499.99

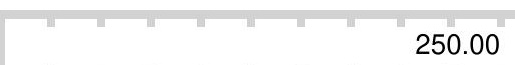

Transaction ID : AF26EC318C4B94EDF8C6

Date of Receipt

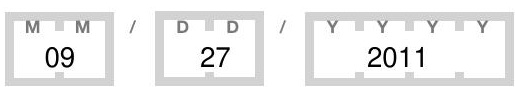

Amount of Each Receipt this Period

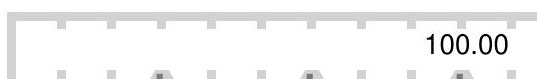

849.99

Subtotal Of Receipts This Page (optional)

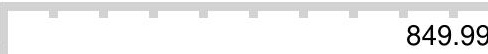

Total This Period (last page this line number only) 


\section{SCHEDULE A-P} ITEMIZED RECEIPTS
Use separate schedule(s)

for each category of the

Detailed Summary Page
FOR LINE NUMBER: (check only one)

PAGE $895 / 1572$

\begin{tabular}{|c|c|c|c|c|c|}
\hline & & & & & \\
\hline 16 & $\begin{array}{l}\mathbf{X} \\
17 a\end{array}$ & $17 b$ & $17 c$ & $17 d$ & 18 \\
\hline $19 a$ & $19 \mathrm{~b}$ & $20 \mathrm{a}$ & $20 \mathrm{~b}$ & $20 \mathrm{c}$ & 21 \\
\hline
\end{tabular}

Any information copied from such Reports and Statements may not be sold or used by any person for the purpose of soliciting contributions or for commercial purposes, other than using the name and address of any political committee to solicit contributions from such committee.

NAME OF COMMITTEE (In Full)

Friends of Herman Cain

A. Full Name (Last, First, Middle Initial)

Sharon Waite

Mailing Address 8301 W Business Highway 83

\begin{tabular}{lcc}
\hline City & State & Zip Code \\
Mission & TX & $78572-9445$
\end{tabular}

FEC ID number of contributing

federal political committee.

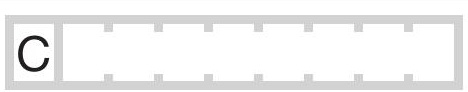

Name of Employer
Self Employed
Receipt For: 2012
X Primary $\quad \square$ General
Other (specify)

Occupation

Agriculture

Election Cycle-to-Date

480.00

B. Full Name (Last, First, Middle Initial)

Sandy Tilton

Mailing Address 1305 Waters Edge Trail

\begin{tabular}{lcc}
\hline City & State & Zip Code \\
Roswell & GA & $30075-8202$ \\
\hline
\end{tabular}

FEC ID number of contributing

federal political committee.

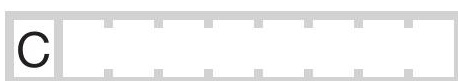

Name of Employer
IBM
Receipt For: 2012
Xrimary $\quad$ General
Other (specify) $\nabla$

\section{Occupation}

Retired

Election Cycle-to-Date

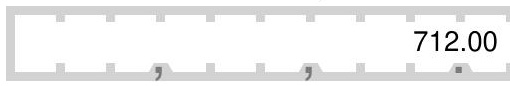

C. Full Name (Last, First, Middle Initial)

Greg fuhr

Mailing Address 102 Wells Point Dr.

\begin{tabular}{lcc}
\hline $\begin{array}{l}\text { City } \\
\text { Irmo }\end{array}$ & $\begin{array}{c}\text { State } \\
\text { SC }\end{array}$ & $\begin{array}{c}\text { Zip Code } \\
29063-9265\end{array}$ \\
\hline $\begin{array}{l}\text { FEC ID number of contributing } \\
\text { federal political committee. }\end{array}$ & C & \\
\hline
\end{tabular}

\begin{tabular}{l|l}
\hline $\begin{array}{l}\text { Name of Employer } \\
\text { Information Requested }\end{array}$ & $\begin{array}{l}\text { Occupation } \\
\text { Information Requested }\end{array}$ \\
\hline Receipt For: 2012 & Election Cycle-to-Date \\
X Primary \\
$\begin{array}{l}\text { Other (specify) General } \\
\square\end{array}$
\end{tabular}

Subtotal Of Receipts This Page (optional).

780.00

Total This Period (last page this line number only)

Amount of Each Receipt this Period

Amount of Each Receipt this Period

Transaction ID : AE593B0C591854F6589D

Date of Receipt
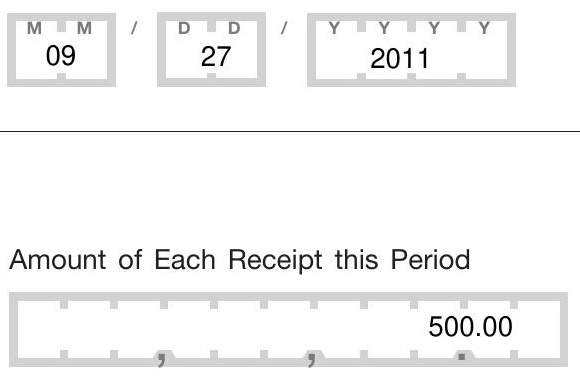

Transaction ID : A8ACE0CE2BAB04A28A49 Date of Receipt
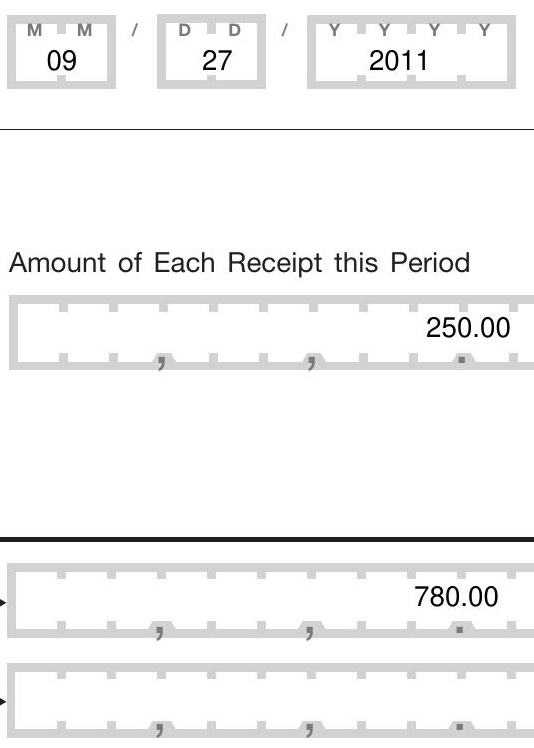

FEC Schedule A-P (Form 3P) (Rev. 03/2011) 


\section{SCHEDULE A-P} ITEMIZED RECEIPTS
Use separate schedule(s)

for each category of the

Detailed Summary Page
FOR LINE NUMBER: (check only one)

PAGE $896 / 1572$

\begin{tabular}{|c|c|c|c|c|c|}
\hline & & & & & \\
\hline 16 & X $17 a$ & $17 b$ & $17 c$ & $17 d$ & 18 \\
\hline $19 a$ & $19 b$ & $20 \mathrm{a}$ & $20 \mathrm{~b}$ & $20 \mathrm{c}$ & 21 \\
\hline
\end{tabular}

Any information copied from such Reports and Statements may not be sold or used by any person for the purpose of soliciting contributions or for commercial purposes, other than using the name and address of any political committee to solicit contributions from such committee.

NAME OF COMMITTEE (In Full)

Friends of Herman Cain

A. Full Name (Last, First, Middle Initial)

John Crosland III

Mailing Address 7439 Morrocroft Farm Ln

\begin{tabular}{lcc}
\hline City & State & Zip Code \\
Charlotte & NC & $28211-5012$ \\
\hline
\end{tabular}

FEC ID number of contributing

federal political committee.

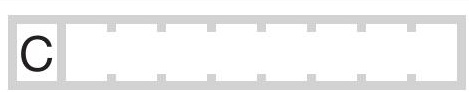

\begin{tabular}{l} 
Name of Employer \\
Crosland, LLC \\
Receipt For: 2012 \\
X Primary \\
\hline Other (specify) General
\end{tabular}

Occupation

Real Estate

Election Cycle-to-Date

250.00

B. Full Name (Last, First, Middle Initial)

Sharon Garner

Mailing Address PO Box 220

\begin{tabular}{lcc}
\hline City & State & Zip Code \\
Ranger & TX & $76470-0220$ \\
\hline
\end{tabular}

FEC ID number of contributing

federal political committee.

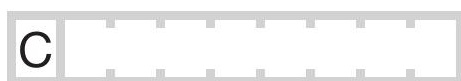

Name of Employer
Information Requested
Receipt For: 2012
X Primary
Other (specify)

Occupation

Information Requested

Election Cycle-to-Date

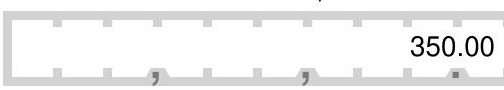

Transaction ID : A75F17B668B7A40068A6

Date of Receipt

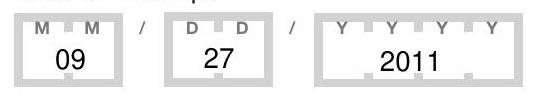

Amount of Each Receipt this Period

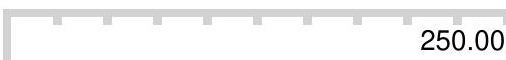

250.00

C. Full Name (Last, First, Middle Initial)

Joseph Niswonger

Mailing Address 6088 Windchase Drive

\begin{tabular}{lcc}
\hline City & State & Zip Code \\
Rocky Mount & NC & $27803-8774$
\end{tabular}

FEC ID number of contributing

federal political committee.

C

Name of Employer

First Carolina Management

Receipt For: 2012

Х $\begin{aligned} & \text { Primary } \square \text { General } \\ & \text { Other (specify) }\end{aligned}$

Occupation

VP Sales \& Marketing

Election Cycle-to-Date
Transaction ID : ADC4E308D58574E3782F

Date of Receipt

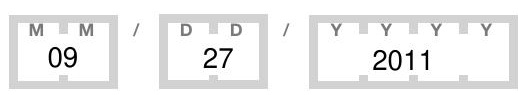

Amount of Each Receipt this Period

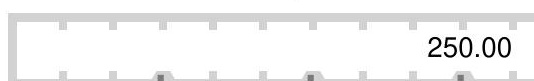

Transaction ID : A3312E1905F464C3DBCE Date of Receipt

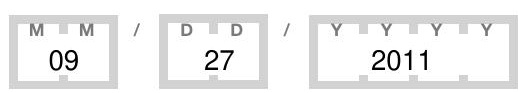

Amount of Each Receipt this Period

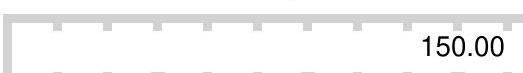

\section{Subtotal Of Receipts This Page (optional)}

Total This Period (last page this line number only) 


\section{SCHEDULE A-P} ITEMIZED RECEIPTS
Use separate schedule(s)

for each category of the

Detailed Summary Page
FOR LINE NUMBER: (check only one)

PAGE 897 / 1572

\begin{tabular}{|c|c|c|c|c|c|}
\hline & & & & & \\
\hline 16 & X $17 a$ & $17 b$ & $17 c$ & $17 d$ & 18 \\
\hline $19 a$ & $19 b$ & $20 \mathrm{a}$ & $20 \mathrm{~b}$ & $20 \mathrm{c}$ & 21 \\
\hline
\end{tabular}

Any information copied from such Reports and Statements may not be sold or used by any person for the purpose of soliciting contributions or for commercial purposes, other than using the name and address of any political committee to solicit contributions from such committee.

NAME OF COMMITTEE (In Full)

Friends of Herman Cain

A. Full Name (Last, First, Middle Initial)

Mr Robert J Hajek

Mailing Address PO Box 50787

\begin{tabular}{lcc}
\hline City & State & Zip Code \\
Albuquerque & NM & $87181-0787$
\end{tabular}

FEC ID number of contributing federal political committee.

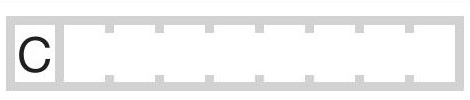

Name of Employer
PNM Resources
Receipt For: 2012
X Primary
$\square$ Other (specify) General

Occupation

Engineer

Election Cycle-to-Date

250.00

B. Full Name (Last, First, Middle Initial)

Douglas Madden

Mailing Address 370 Hillview Ave

\begin{tabular}{lcc}
\hline City & State & Zip Code \\
Redwood City & CA & $94062-2124$
\end{tabular}

FEC ID number of contributing

federal political committee.

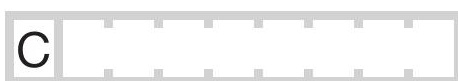

Name of Employer
Information Requested
Receipt For: 2012
X Primary
Other (specify)

Occupation

Information Requested

Election Cycle-to-Date

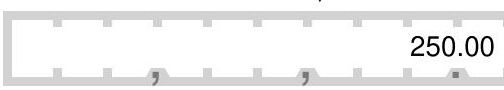

Transaction ID : A7AF399F14D9C421A801

Date of Receipt

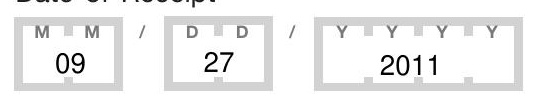

Amount of Each Receipt this Period

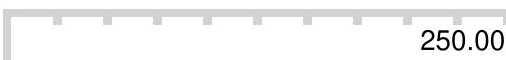

C. Full Name (Last, First, Middle Initial)

Adele Kirkpatrick

Mailing Address 2426 Medina Way

\begin{tabular}{lcc}
\hline City & State & Zip Code \\
West Palm Beach & FL & $33401-8020$
\end{tabular}

FEC ID number of contributing

federal political committee.

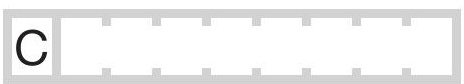

Name of Employer
None
Receipt For: 2012
X Primary $\quad$ General
Other (specify)

Occupation

Retired

Election Cycle-to-Date

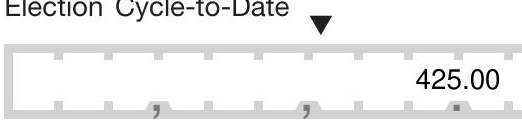

Amount of Each Receipt this Period

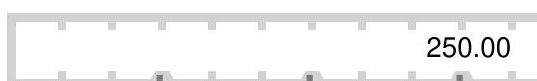

Transaction ID : AEE8053921CC5411B846

Date of Receipt

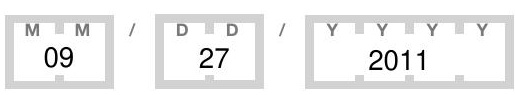

Transaction ID : A98FDD6DC705A42DFB46 Date of Receipt

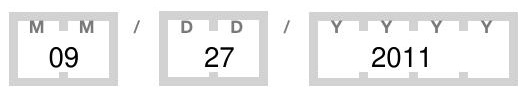

Amount of Each Receipt this Period

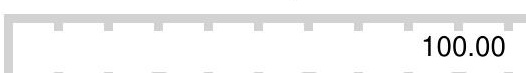

Subtotal Of Receipts This Page (optional).

600.00

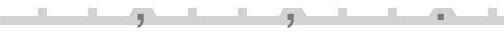

Total This Period (last page this line number only)

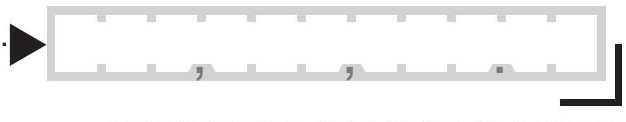

FEC Schedule A-P (Form 3P) (Rev. 03/2011) 


\section{SCHEDULE A-P} ITEMIZED RECEIPTS
Use separate schedule(s)

for each category of the

Detailed Summary Page
FOR LINE NUMBER: (check only one)

PAGE $898 / 1572$

\begin{tabular}{|c|c|c|c|c|c|}
\hline & & & & & \\
\hline 16 & X $17 a$ & $17 b$ & $17 c$ & $17 d$ & 18 \\
\hline $19 a$ & $19 b$ & $20 \mathrm{a}$ & $20 \mathrm{~b}$ & $20 \mathrm{c}$ & 21 \\
\hline
\end{tabular}

Any information copied from such Reports and Statements may not be sold or used by any person for the purpose of soliciting contributions or for commercial purposes, other than using the name and address of any political committee to solicit contributions from such committee.

NAME OF COMMITTEE (In Full)

\section{Friends of Herman Cain}

A. Full Name (Last, First, Middle Initial) Jualene Lewis

Mailing Address 2802 NW 4th Ln

\begin{tabular}{lcc}
\hline City & State & Zip Code \\
Gainesville & FL & $32607-2508$
\end{tabular}

FEC ID number of contributing federal political committee.

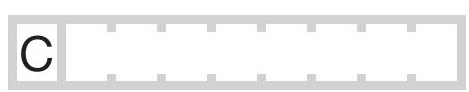

Name of Employer
Information Requested
Receipt For: 2012
X Primary
Other (specify) General

Occupation Information Requested

Election Cycle-to-Date

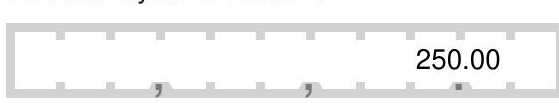

B. Full Name (Last, First, Middle Initial)

George Phelps

Mailing Address 3083 Milledge Gate Court

\begin{tabular}{lcc}
\hline City & State & Zip Code \\
Marietta & GA & $30067-5098$ \\
\hline
\end{tabular}

FEC ID number of contributing

federal political committee.

C

Name of Employer
Primary Capital
Receipt For: 2012
X Primary
Other (specify)

Occupation

Executive

Election Cycle-to-Date

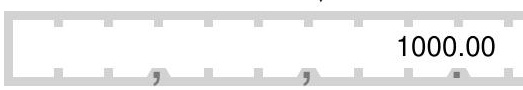

Transaction ID : A92F754C980C44924A4A

Date of Receipt

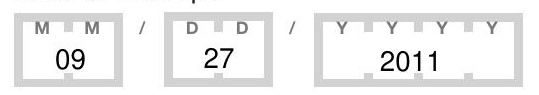

Amount of Each Receipt this Period

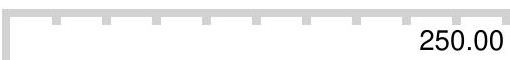

C. Full Name (Last, First, Middle Initial)

Charles Plunkett

Mailing Address 255 Hunters GIn

\begin{tabular}{lcc}
\hline City & State & Zip Code \\
Fayetteville & GA & $30215-1944$
\end{tabular}

FEC ID number of contributing federal political committee.

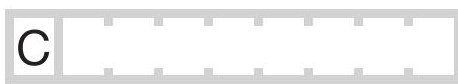

Name of Employer
Delta Airlines
Receipt For: 2012
X Primary $\quad \square$ General
Other (specify)

\section{Occupation}

Retired

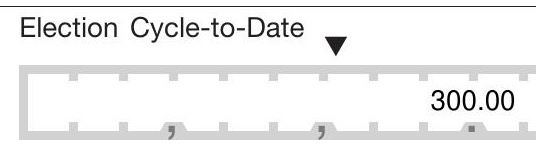

Amount of Each Receipt this Period

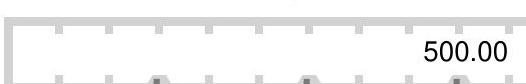

Transaction ID : A2CEE7E3DAB0A4147AD7 Date of Receipt

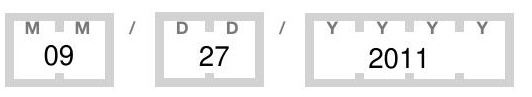

Transaction ID : ABF7405E890FD4808A6B Date of Receipt

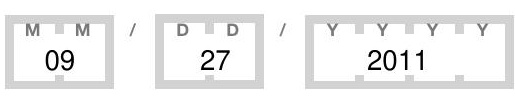

Amount of Each Receipt this Period

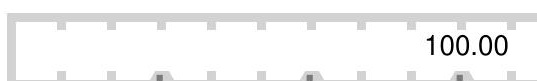

\section{Subtotal Of Receipts This Page (optional)}


SCHEDULE A-P ITEMIZED RECEIPTS
Use separate schedule(s) for each category of the Detailed Summary Page
FOR LINE NUMBER: (check only one)

PAGE $899 / 1572$

\begin{tabular}{|c|c|c|c|c|c|c|}
\hline & & & & & & \\
\hline 16 & $\lambda$ & $17 \mathrm{a}$ & $17 \mathrm{~b}$ & $17 \mathrm{c}$ & $-17 d$ & -18 \\
\hline $19 a$ & & $19 b$ & $20 a$ & $20 \mathrm{~b}$ & $20 \mathrm{c}$ & 21 \\
\hline
\end{tabular}

Any information copied from such Reports and Statements may not be sold or used by any person for the purpose of soliciting contributions or for commercial purposes, other than using the name and address of any political committee to solicit contributions from such committee.

NAME OF COMMITTEE (In Full)

\section{Friends of Herman Cain}

A. Full Name (Last, First, Middle Initial)

Renay E Bryant

Mailing Address 1917 Hurstgreen Dr

\begin{tabular}{lcc}
\hline City & State & Zip Code \\
Saint Louis & MO & $63114-5735$
\end{tabular}

FEC ID number of contributing federal political committee.

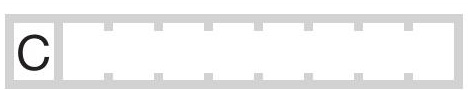

Name of Employer
Soliant Health
Receipt For: 2012
X Primary
Other (specify) General

Occupation

Pharmacist

Election Cycle-to-Date

225.00

B. Full Name (Last, First, Middle Initial)

Kathy Carruth

Mailing Address 3200 NW 40th

\begin{tabular}{lcc}
\hline City & State & Zip Code \\
Oklahoma City & OK & $73112-6212$ \\
\hline
\end{tabular}

FEC ID number of contributing

federal political committee.

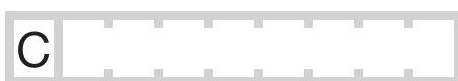

Name of Employer
None
Receipt For: 2012
X Primary
Other (specify)

Occupation

Retired

Election Cycle-to-Date

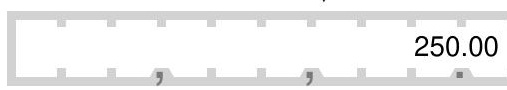

Transaction ID : AC621F986E80A4BDF82A

Date of Receipt

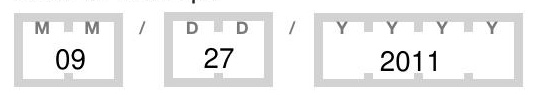

Amount of Each Receipt this Period

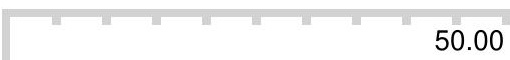

50.00

C. Full Name (Last, First, Middle Initial)

diana curren

Mailing Address 7703 ne 203 rd street

\begin{tabular}{lcc}
\hline City & State & Zip Code \\
Kenmore & WA & $98028-2032$
\end{tabular}

FEC ID number of contributing federal political committee.

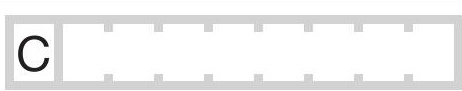

Name of Employer

Information Requested

Occupation

Information Requested

Receipt For: 2012

Х $\begin{aligned} & \text { Primary } \\ & \text { Other (specify) }\end{aligned}$

Election Cycle-to-Date

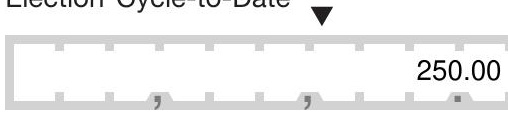

Transaction ID : ADE467AFFB82D4F0CACB Date of Receipt

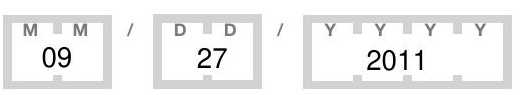

Amount of Each Receipt this Period

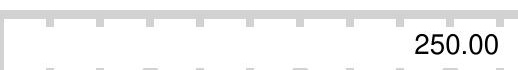

Transaction ID : A85212EA218514869BD1

Date of Receipt

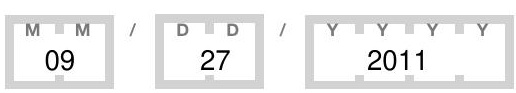

Amount of Each Receipt this Period

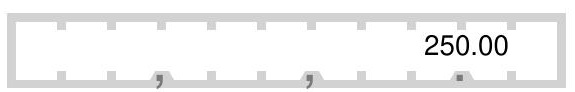

Subtotal Of Receipts This Page (optional)

550.00

Total This Period (last page this line number only) 


\section{SCHEDULE A-P} ITEMIZED RECEIPTS
Use separate schedule(s)

for each category of the

Detailed Summary Page
FOR LINE NUMBER: (check only one)

PAGE $900 / 1572$

\begin{tabular}{|c|c|c|c|c|c|}
\hline & & & & & \\
\hline 16 & X $17 a$ & $17 b$ & $17 c$ & $17 d$ & 18 \\
\hline $19 a$ & $19 b$ & $20 \mathrm{a}$ & $20 \mathrm{~b}$ & $20 \mathrm{c}$ & 21 \\
\hline
\end{tabular}

Any information copied from such Reports and Statements may not be sold or used by any person for the purpose of soliciting contributions or for commercial purposes, other than using the name and address of any political committee to solicit contributions from such committee.

NAME OF COMMITTEE (In Full)

Friends of Herman Cain

A. Full Name (Last, First, Middle Initial)

Letty Goodman Lutzker MD

Mailing Address 408 S 2nd St

\begin{tabular}{lcc}
\hline City & State & Zip Code \\
Bangor & PA & $18013-2514$ \\
\hline
\end{tabular}

FEC ID number of contributing

federal political committee.

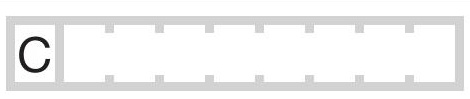

Name of Employer
Self Employed
Receipt For: 2012
X Primary $\quad \square$ General
Other (specify)

Occupation

Physician

Election Cycle-to-Date

1000.00

B. Full Name (Last, First, Middle Initial)

William O'Neal

Mailing Address 1617 North Altman Road

\begin{tabular}{lll}
\hline City & State & Zip Code \\
Beals & ME & 04611 \\
\hline
\end{tabular}

FEC ID number of contributing

federal political committee.

C

Name of Employer
Information Requested
Receipt For: 2012
X Primary
Other (specify)

Occupation

Information Requested

Election Cycle-to-Date

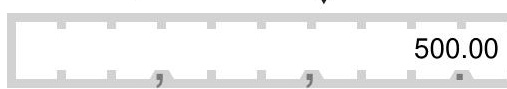

Transaction ID : AA485A8BAAE2F4A25918

Date of Receipt

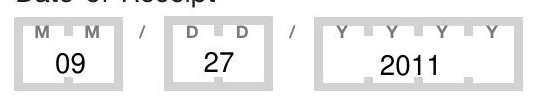

Amount of Each Receipt this Period

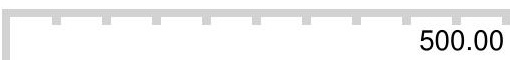

Amount of Each Receipt this Period

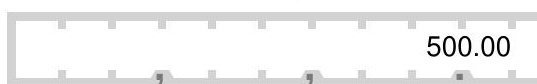

C. Full Name (Last, First, Middle Initial)

Clover Shearey

Mailing Address 261 Rue des Chateaux

\begin{tabular}{lcc}
\hline City & State & Zip Code \\
Tarpon Springs & FL & $34688-8606$
\end{tabular}

FEC ID number of contributing

federal political committee.

C

Name of Employer

Information Requested

Occupation

Information Requested

Receipt For: 2012

Х $\begin{aligned} & \text { Primary } \\ & \text { Other (specify) }\end{aligned}$

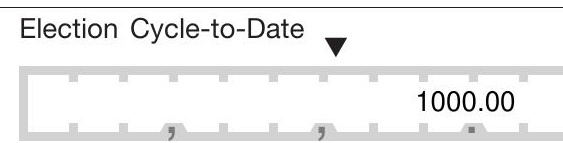

Amount of Each Receipt this Period

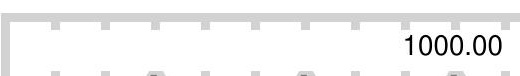

Transaction ID : AD0A313F1362141148A9

Date of Receipt

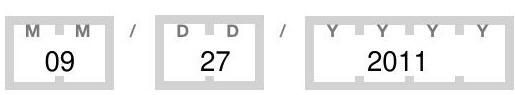

Subtotal Of Receipts This Page (optional)

2000.00

Total This Period (last page this line number only)

FEC Schedule A-P (Form 3P) (Rev. 03/2011) 


\section{SCHEDULE A-P} ITEMIZED RECEIPTS
Use separate schedule(s)

for each category of the

Detailed Summary Page

FOR LINE NUMBER:
(check only one)

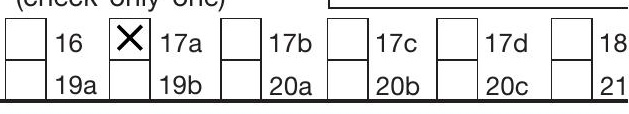

Any information copied from such Reports and Statements may not be sold or used by any person for the purpose of soliciting contributions or for commercial purposes, other than using the name and address of any political committee to solicit contributions from such committee.

NAME OF COMMITTEE (In Full)

\section{Friends of Herman Cain}

A. Full Name (Last, First, Middle Initial)

Michelle Dickman

Mailing Address 1324 N. Liberty Lake Road Suite 27

\begin{tabular}{lcc}
\hline City & State & Zip Code \\
Liberty Lake & WA & $99019-8523$ \\
\hline
\end{tabular}

FEC ID number of contributing federal political committee.

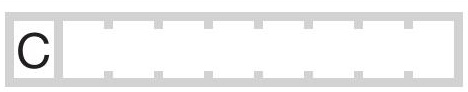

Name of Employer
Information Requested
Receipt For: 2012
X Primary
Other (specify) General

Occupation Information Requested

Election Cycle-to-Date

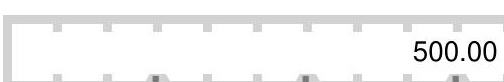

B. Full Name (Last, First, Middle Initial) Jonathan Conwell

\section{Mailing Address 104 Township Road 1343}

\begin{tabular}{lcc}
\hline City & State & Zip Code \\
South Point & OH & $45680-7917$
\end{tabular}

FEC ID number of contributing

federal political committee.

C

Name of Employer
Federal Government
Receipt For: 2012
X Primary
Other (specify)

\section{Occupation}

IT Specialist

Election Cycle-to-Date

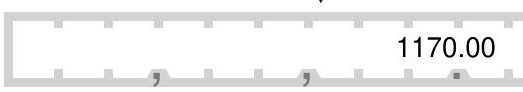

Transaction ID : A6A525E8C7575464B832

Date of Receipt

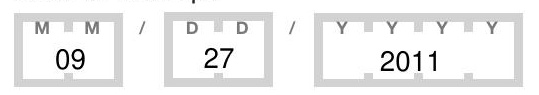

Amount of Each Receipt this Period

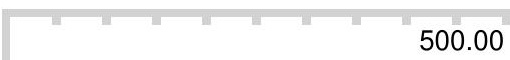

C. Full Name (Last, First, Middle Initial)

June Koth

Mailing Address 3011 Sandpiper Bay Cir \# 203

\begin{tabular}{lcc}
\hline City & State & Zip Code \\
Naples & FL & $34112-5603$
\end{tabular}

FEC ID number of contributing

federal political committee.

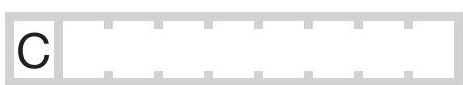

Name of Employer
n/a
Receipt For: 2012
X Primary $\square$ General
Other (specify)

Occupation

Retired

Election Cycle-to-Date

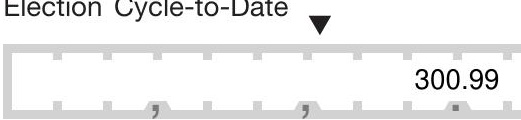

Amount of Each Receipt this Period

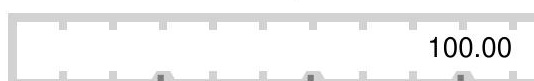

Transaction ID : A29FADB3D26234E04BEC Date of Receipt

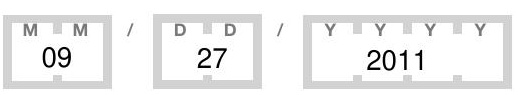

Transaction ID : AF87C096B9CED41DF947 Date of Receipt

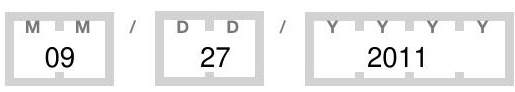

Amount of Each Receipt this Period

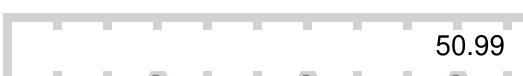

\section{Subtotal Of Receipts This Page (optional)}

Total This Period (last page this line number only) 


\section{SCHEDULE A-P} ITEMIZED RECEIPTS
Use separate schedule(s) for each category of the Detailed Summary Page

\begin{tabular}{|c|c|c|c|c|c|}
\hline \multicolumn{3}{|c|}{$\begin{array}{l}\text { FOR LINE NUMBER: } \\
\text { (check only one) }\end{array}$} & \multicolumn{3}{|c|}{ PAGE 902 / 1572} \\
\hline 16 & $X$ 17a & $17 b$ & $17 c$ & $17 d$ & 18 \\
\hline $19 a$ & $19 \mathrm{~b}$ & $20 a$ & $20 \mathrm{~b}$ & $20 c$ & 21 \\
\hline
\end{tabular}

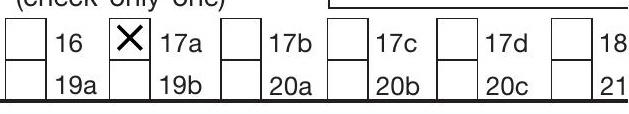

Any information copied from such Reports and Statements may not be sold or used by any person for the purpose of soliciting contributions or for commercial purposes, other than using the name and address of any political committee to solicit contributions from such committee.

NAME OF COMMITTEE (In Full)

\section{Friends of Herman Cain}

A. Full Name (Last, First, Middle Initial)

Thomas Krieser

Mailing Address 4032 Trinidad Way

\begin{tabular}{lcc}
\hline City & State & Zip Code \\
Naples & FL & $34119-7507$ \\
\hline
\end{tabular}

FEC ID number of contributing federal political committee.

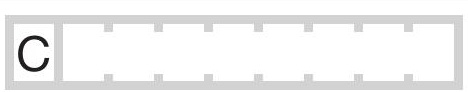

Name of Employer
Ability Management, Inc.
Receipt For: 2012
X Primary
Other (specify)

Occupation property manager

Election Cycle-to-Date 220.00

B. Full Name (Last, First, Middle Initial)

Carl A Voigtsberger

Mailing Address 7249 Manhattan Lane

\begin{tabular}{llc}
\hline City & State & Zip Code \\
Cheyenne & WY & 82009-2003
\end{tabular}

FEC ID number of contributing

federal political committee.

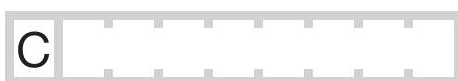

Name of Employer
None
Receipt For: 2012
X Primary
Other (specify)

\section{Occupation}

Retired

Election Cycle-to-Date

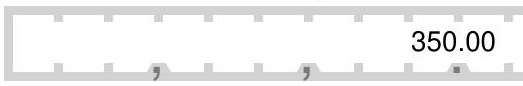

Transaction ID : AF134C1F426154E909E7

Date of Receipt

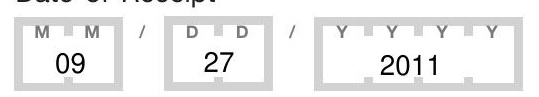

Amount of Each Receipt this Period

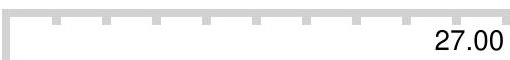

27.00

C. Full Name (Last, First, Middle Initial)

Robert Bodoin

Mailing Address 1999 Lebanon Church Rd.

\begin{tabular}{lcc}
\hline City & State & Zip Code \\
Jefferson & GA & $30549-5946$
\end{tabular}

FEC ID number of contributing federal political committee.

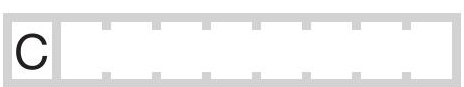

Name of Employer
Retired
Receipt For: 2012
Х Primary $\square$ General
Other (specify)

\section{Occupation}

Retired

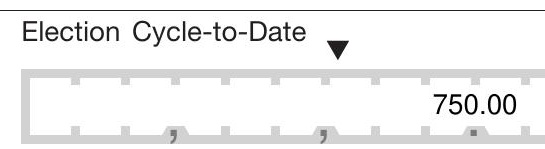

Transaction ID : AC171C482DC664B5C8F3 Date of Receipt

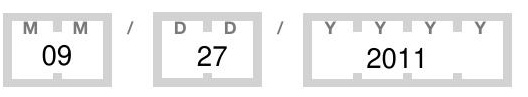

Amount of Each Receipt this Period

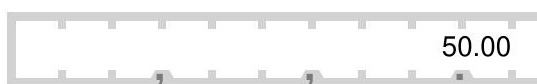

Transaction ID : A7EF05B94EF894692B34

Date of Receipt

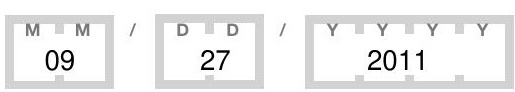

Amount of Each Receipt this Period

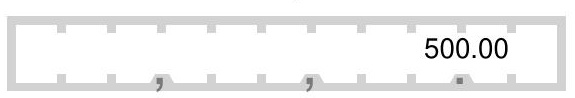

\section{Subtotal Of Receipts This Page (optional)}

577.00

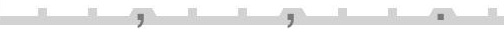

Total This Period (last page this line number only)

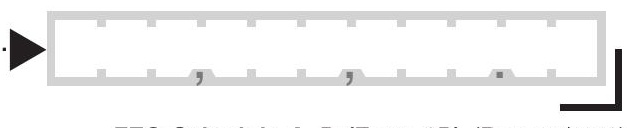

FEC Schedule A-P (Form 3P) (Rev. 03/2011) 
SCHEDULE A-P ITEMIZED RECEIPTS
Use separate schedule(s) for each category of the Detailed Summary Page
FOR LINE NUMBER: (check only one)

PAGE $903 / 1572$

\begin{tabular}{|c|c|c|c|c|c|}
\hline & & & & & \\
\hline 16 & $\begin{array}{l}\mathbf{X} \\
17 a\end{array}$ & $17 b$ & $17 c$ & $17 d$ & 18 \\
\hline $19 a$ & $19 \mathrm{~b}$ & $20 \mathrm{a}$ & $20 \mathrm{~b}$ & $20 \mathrm{c}$ & 21 \\
\hline
\end{tabular}

Any information copied from such Reports and Statements may not be sold or used by any person for the purpose of soliciting contributions or for commercial purposes, other than using the name and address of any political committee to solicit contributions from such committee.

NAME OF COMMITTEE (In Full)

\section{Friends of Herman Cain}

A. Full Name (Last, First, Middle Initial) Jennifer Sacksen

Mailing Address 274 Saddle Rd

\begin{tabular}{lcc}
\hline City & State & Zip Code \\
Somerset & PA & $15501-5447$
\end{tabular}

FEC ID number of contributing federal political committee.

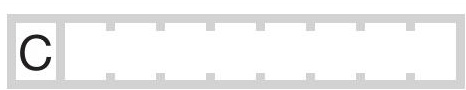

Name of Employer
Spruce Run Equine Veterinary
Receipt For: 2012
X Primary
Other (specify) General

Occupation Information Requested

Election Cycle-to-Date

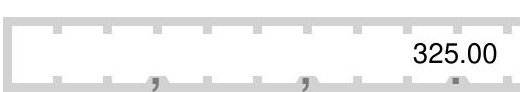

B. Full Name (Last, First, Middle Initial)

Scott Ladner

Mailing Address 4498 Paradise Cove

\begin{tabular}{lcc}
\hline City & State & Zip Code \\
Sherrills Ford & NC & $28673-8301$
\end{tabular}

FEC ID number of contributing

federal political committee.

C

Name of Employer
Information Requested
Receipt For: 2012
X Primary
Other (specify)

Occupation

Information Requested

Election Cycle-to-Date

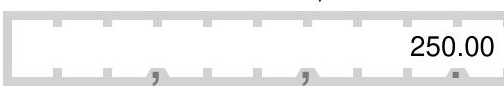

Transaction ID : A16682E8EE31C493987E

Date of Receipt

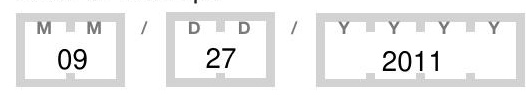

Amount of Each Receipt this Period

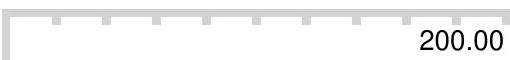

200.00

C. Full Name (Last, First, Middle Initial)

Todd Powers

Mailing Address 6609 S US Hwy 25E

\begin{tabular}{lcc}
\hline City & State & Zip Code \\
Flat Lick & KY & $40935-6313$
\end{tabular}

FEC ID number of contributing federal political committee.

C

40935-6313

Name of Employer

Information Requested

Occupation

Receipt For: 2012

Х $\begin{aligned} & \text { Primary } \square \text { General } \\ & \text { Other (specify) }\end{aligned}$

Information Requested

Election Cycle-to-Date

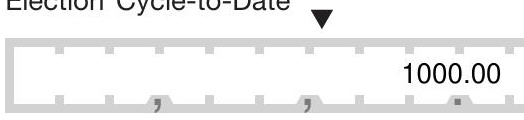

Amount of Each Receipt this Period

Transaction ID : A390B5B26FAFB40EBBD8

Date of Receipt
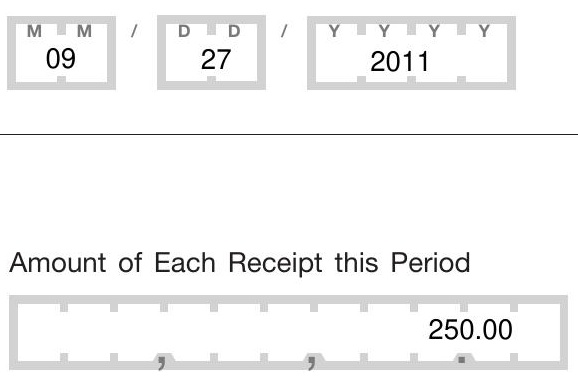

Transaction ID : A1FC547258C8D4E74AAD Date of Receipt

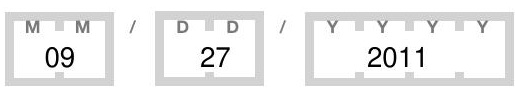

Amount of Each Receipt this Period

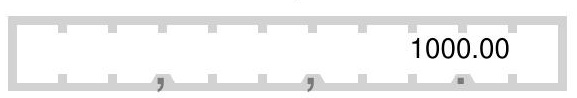

Subtotal Of Receipts This Page (optional).

1450.00

Total This Period (last page this line number only) 
SCHEDULE A-P ITEMIZED RECEIPTS
Use separate schedule(s) for each category of the Detailed Summary Page
FOR LINE NUMBER: (check only one)
PAGE 904 / 1572

\begin{tabular}{|c|c|c|c|c|c|}
\hline & & & & & \\
\hline 16 & $\begin{array}{lll}X & 17 a \\
\end{array}$ & $17 \mathrm{~b}$ & $17 c$ & $17 d$ & 18 \\
\hline $19 a$ & $19 b$ & $20 a$ & $20 \mathrm{~b}$ & $20 c$ & 21 \\
\hline
\end{tabular}

Any information copied from such Reports and Statements may not be sold or used by any person for the purpose of soliciting contributions or for commercial purposes, other than using the name and address of any political committee to solicit contributions from such committee.

NAME OF COMMITTEE (In Full)

\section{Friends of Herman Cain}

A. Full Name (Last, First, Middle Initial)

\section{Jeff MacPherson}

Mailing Address 129 Palette Ct.

\begin{tabular}{lcc}
\hline City & State & Zip Code \\
Bozeman & MT & $59715-8093$ \\
\hline
\end{tabular}

FEC ID number of contributing federal political committee.

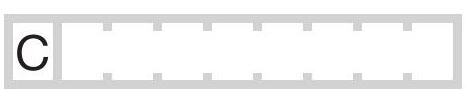

Name of Employer
self
Receipt For: 2012
X Primary $\quad$ General
Other (specify)

Occupation fabricator

Election Cycle-to-Date

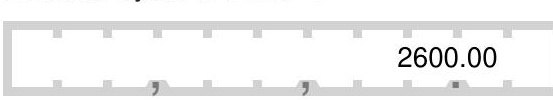

B. Full Name (Last, First, Middle Initial) mark perdue

Mailing Address 3641 cascade road

\begin{tabular}{lcc}
\hline City & State & Zip Code \\
Jacksonville & FL & $32207-5708$
\end{tabular}

FEC ID number of contributing

federal political committee.

C

\begin{tabular}{l} 
Name of Employer \\
Information Requested \\
Receipt For: 2012 \\
X Primary \\
\hline Other (specify)
\end{tabular}

Occupation

Information Requested

Election Cycle-to-Date

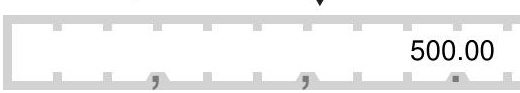

Transaction ID : AEE2D2E16AD2E4733BFC

Date of Receipt

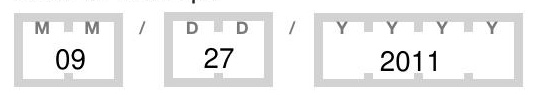

Amount of Each Receipt this Period

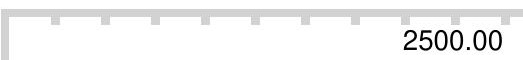

C. Full Name (Last, First, Middle Initial)

Anthony Ziehler

Mailing Address 3883 Golden Wood Way

\begin{tabular}{lcc}
\hline City & State & Zip Code \\
Uniontown & OH & $44685-7727$
\end{tabular}

FEC ID number of contributing federal political committee.

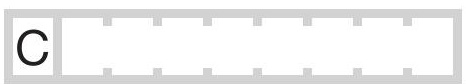

Name of Employer
Information Requested
Receipt For: 2012
X Primary
Other (specify) General

\section{Occupation}

Information Requested

Election Cycle-to-Date

Transaction ID : A9C12009F9C1B41A7B8D

Date of Receipt

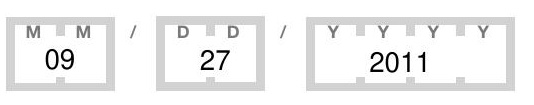

Amount of Each Receipt this Period

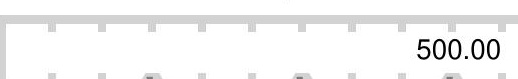

Transaction ID : A3BE6C66045C843C8985

Date of Receipt

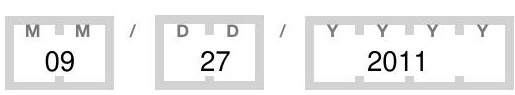

Amount of Each Receipt this Period

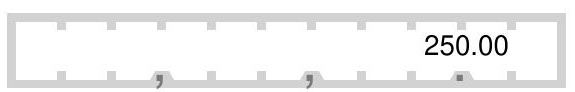

350.00

\section{Subtotal Of Receipts This Page (optional)}

Total This Period (last page this line number only) 


\section{SCHEDULE A-P} ITEMIZED RECEIPTS
Use separate schedule(s)

for each category of the

Detailed Summary Page
FOR LINE NUMBER: (check only one)

PAGE $905 / 1572$

\begin{tabular}{|c|c|c|c|c|c|}
\hline & & & & & \\
\hline 16 & X $17 a$ & $17 b$ & $17 c$ & $17 d$ & 18 \\
\hline $19 a$ & $19 b$ & $20 \mathrm{a}$ & $20 \mathrm{~b}$ & $20 \mathrm{c}$ & 21 \\
\hline
\end{tabular}

Any information copied from such Reports and Statements may not be sold or used by any person for the purpose of soliciting contributions or for commercial purposes, other than using the name and address of any political committee to solicit contributions from such committee.

NAME OF COMMITTEE (In Full)

Friends of Herman Cain

A. Full Name (Last, First, Middle Initial) cooledge butler

Mailing Address 517 derrydown rd

\begin{tabular}{lcc}
\hline City & State & Zip Code \\
Orlando & FL & $32806-7005$
\end{tabular}

FEC ID number of contributing federal political committee.

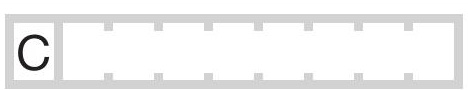

Name of Employer
Information Requested
Receipt For: 2012
X Primary
Other (specify) General

Occupation Information Requested

Election Cycle-to-Date 500.00

B. Full Name (Last, First, Middle Initial) Mark Robertson

Mailing Address 4731 CR 172

\begin{tabular}{lcc}
\hline City & State & Zip Code \\
Alvin & TX & $77511-0325$
\end{tabular}

FEC ID number of contributing

federal political committee.

C

Name of Employer
Information Requested
Receipt For: 2012
X Primary
Other (specify)

Occupation

Information Requested

Election Cycle-to-Date

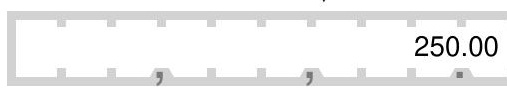

Transaction ID : A889F6C61D3B742FAA6B

Date of Receipt

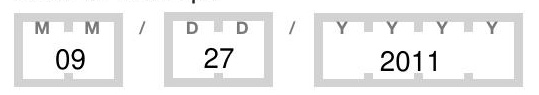

Amount of Each Receipt this Period

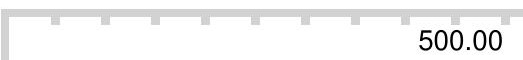

C. Full Name (Last, First, Middle Initial)

Paul Seminara

Mailing Address 14006 278th PI NE

\begin{tabular}{lcc}
\hline City & State & Zip Code \\
Duvall & WA & $98019-8100$
\end{tabular}

FEC ID number of contributing federal political committee.

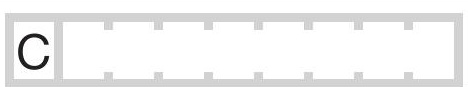

Name of Employer

Occupation

Aerojet - GenCorp

Sr. Quality Engineer

Receipt For: 2012

Х $\begin{aligned} & \text { Primary } \square \text { General } \\ & \text { Other (specify) }\end{aligned}$

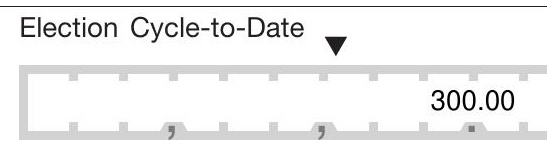

Amount of Each Receipt this Period

Transaction ID : AF826324E9F734B91B2E

Date of Receipt
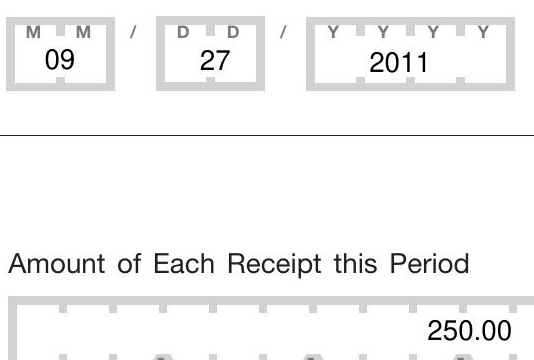

Transaction ID : AD48A3FAB7D904E9A8B0 Date of Receipt

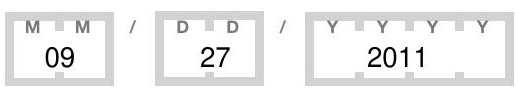

Amount of Each Receipt this Period

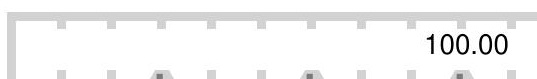

850.00

Subtotal Of Receipts This Page (optional)

Total This Period (last page this line number only) 


\section{SCHEDULE A-P} ITEMIZED RECEIPTS
Use separate schedule(s) for each category of the Detailed Summary Page

FOR LINE NUMBER:
(check only one)

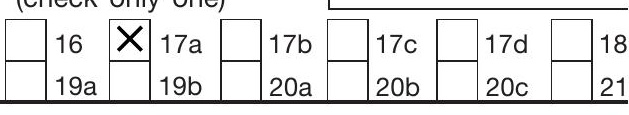

Any information copied from such Reports and Statements may not be sold or used by any person for the purpose of soliciting contributions or for commercial purposes, other than using the name and address of any political committee to solicit contributions from such committee.

NAME OF COMMITTEE (In Full)

\section{Friends of Herman Cain}

A. Full Name (Last, First, Middle Initial)

Martin Shapiro

Mailing Address 140 Ox Hill Road

\begin{tabular}{lcc}
\hline City & State & Zip Code \\
Norwich & CT & $06360-2034$
\end{tabular}

FEC ID number of contributing federal political committee.

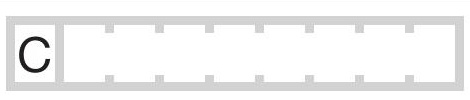

Name of Employer
self
Receipt For: 2012
X Primary $\quad \square$ General
$\square$ Other (specify)

\section{Occupation} author, novelist

Election Cycle-to-Date 350.00

B. Full Name (Last, First, Middle Initial) David Greth

\section{Mailing Address 2314 Herb Rd}

\begin{tabular}{lcc}
\hline City & State & Zip Code \\
Temple & PA & $19560-9618$ \\
\hline
\end{tabular}

FEC ID number of contributing

federal political committee.

C

Name of Employer
Information Requested
Receipt For: 2012
X Primary
Other (specify)

Occupation
Information Requested
Election Cycle-to-Date

C. Full Name (Last, First, Middle Initial)

Meredith Wiles

Mailing Address 2320 Dairyland Drive

\begin{tabular}{lll}
\hline $\begin{array}{l}\text { City } \\
\text { Westminster }\end{array}$ & $\begin{array}{c}\text { State } \\
\text { MD }\end{array}$ & $\begin{array}{c}\text { Zip Code } \\
21158-2837\end{array}$ \\
\hline $\begin{array}{l}\text { FEC ID number of contributing } \\
\text { federal political committee. }\end{array}$ & C & \\
\hline $\begin{array}{l}\text { Name of Employer } \\
\text { Jacobs }\end{array}$ & $\begin{array}{l}\text { Occupation } \\
\text { Engineer }\end{array}$ \\
$\begin{array}{l}\text { Receipt For: } 2012 \\
\text { X } \begin{array}{l}\text { Primary } \\
\text { Other (specify) }\end{array}\end{array}$ & Election Cycle-to-Date & \\
\hline
\end{tabular}

Transaction ID : AAE15CD1BD53442369E6

Date of Receipt

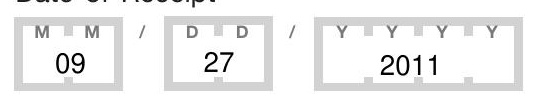

Amount of Each Receipt this Period

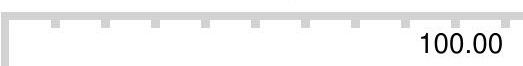

Amount of Each Receipt this Period

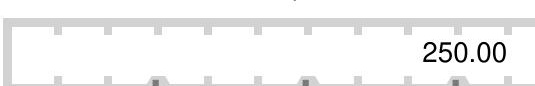

Amount of Each Receipt this Period

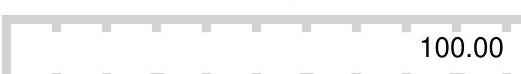
Date of Receipt

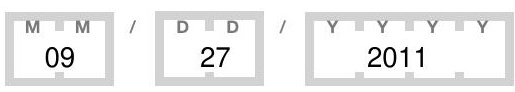

Subtotal Of Receipts This Page (optional).

450.00

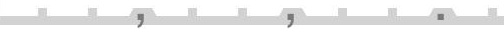

Total This Period (last page this line number only)
Transaction ID : ACDDB99C6A0E546B4B9D

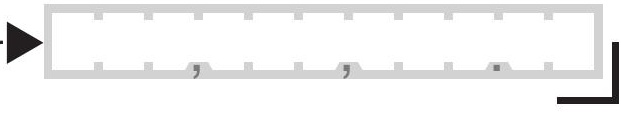

FEC Schedule A-P (Form 3P) (Rev. 03/2011) 


\section{SCHEDULE A-P} ITEMIZED RECEIPTS
Use separate schedule(s) for each category of the Detailed Summary Page

\begin{tabular}{|c|c|c|c|c|c|}
\hline \multicolumn{3}{|c|}{$\begin{array}{l}\text { FOR LINE NUMBER: } \\
\text { (check only one) }\end{array}$} & \multicolumn{3}{|c|}{ PAGE 907 / 1572} \\
\hline 16 & $X$ 17a & $17 b$ & $17 \mathrm{c}$ & $17 d$ & 18 \\
\hline $19 a$ & $19 \mathrm{~b}$ & $20 a$ & $20 \mathrm{~b}$ & $20 c$ & 21 \\
\hline
\end{tabular}

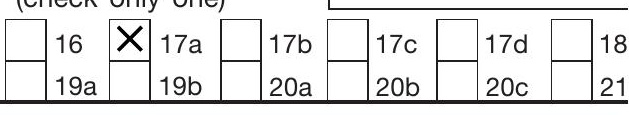

Any information copied from such Reports and Statements may not be sold or used by any person for the purpose of soliciting contributions or for commercial purposes, other than using the name and address of any political committee to solicit contributions from such committee.

NAME OF COMMITTEE (In Full)

\section{Friends of Herman Cain}

A. Full Name (Last, First, Middle Initial)

Anthony Rue

Mailing Address 12 Whitecliff

\begin{tabular}{lcc}
\hline City & State & Zip Code \\
Laguna Niguel & CA & $92677-9237$
\end{tabular}

FEC ID number of contributing federal political committee.

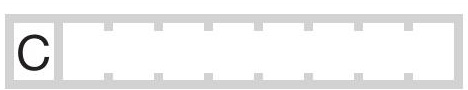

Name of Employer
Information Requested
Receipt For: 2012
X Primary
Other (specify) General

Occupation Information Requested

Election Cycle-to-Date

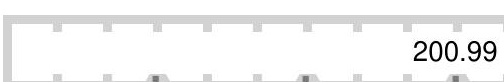

B. Full Name (Last, First, Middle Initial) martin mccaffrey

Mailing Address 1008 ADAMS MOUNTAIN RD

\begin{tabular}{lcc}
\hline City & State & Zip Code \\
Raleigh & NC & $27614-8185$ \\
\hline
\end{tabular}

FEC ID number of contributing

federal political committee.

C

Name of Employer
Information Requested
Receipt For: 2012
X Primary
Other (specify)

Occupation

Information Requested

Election Cycle-to-Date

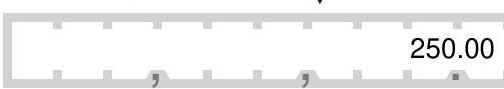

C. Full Name (Last, First, Middle Initial)

sam gregg

Mailing Address 1128 state rd

\begin{tabular}{lcc}
\hline City & State & Zip Code \\
Eliot & ME & 03903-1870
\end{tabular}

FEC ID number of contributing federal political committee.

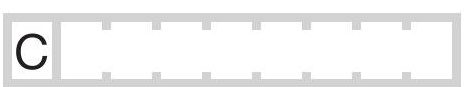

Name of Employer
Information Requested
Receipt For: 2012
X Primary
Other (specify) General

Occupation

Information Requested

Election Cycle-to-Date
Transaction ID : A0E46CD41F1374C979BA

Date of Receipt

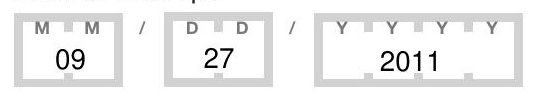

Amount of Each Receipt this Period

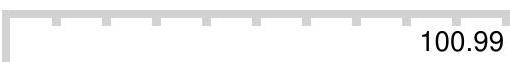

Transaction ID : A88F039FB77644FFBB7B

Date of Receipt

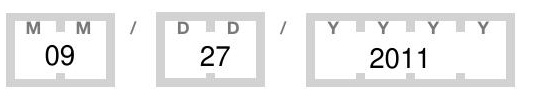

Amount of Each Receipt this Period

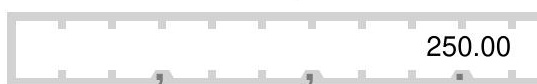

Transaction ID : A1610086490F740E09E6

Date of Receipt

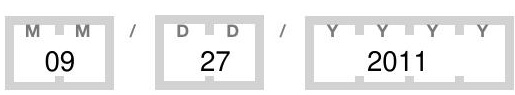

Amount of Each Receipt this Period

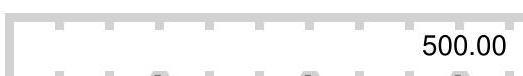

500.00

Subtotal Of Receipts This Page (optional).

Total This Period (last page this line number only) 


\section{SCHEDULE A-P} ITEMIZED RECEIPTS
Use separate schedule(s)

for each category of the

Detailed Summary Page
FOR LINE NUMBER: (check only one)

PAGE $908 / 1572$

\begin{tabular}{|c|c|c|c|c|c|}
\hline & & & & & \\
\hline 16 & X $17 a$ & $17 b$ & $17 c$ & $17 d$ & 18 \\
\hline $19 a$ & $19 b$ & $20 \mathrm{a}$ & $20 \mathrm{~b}$ & $20 \mathrm{c}$ & 21 \\
\hline
\end{tabular}

Any information copied from such Reports and Statements may not be sold or used by any person for the purpose of soliciting contributions or for commercial purposes, other than using the name and address of any political committee to solicit contributions from such committee.

NAME OF COMMITTEE (In Full)

Friends of Herman Cain

A. Full Name (Last, First, Middle Initial)

Alexander Croke

Mailing Address 705 N MITCHELL AVE

\begin{tabular}{lcc}
\hline City & State & Zip Code \\
Arlington Heights & IL & $60004-5428$
\end{tabular}

FEC ID number of contributing

federal political committee.

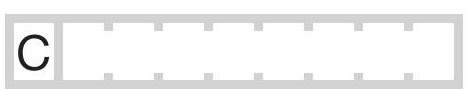

Name of Employer
Information Requested
Receipt For: 2012
X Primary $\quad \square$ General
Other (specify)

Occupation

Information Requested

Election Cycle-to-Date

215.00

B. Full Name (Last, First, Middle Initial)

Mrs Carlene D Robinson

Mailing Address 6337 Morris Rd.

\begin{tabular}{lcc}
\hline City & State & Zip Code \\
Hamilton & OH & $45011-5123$
\end{tabular}

FEC ID number of contributing

federal political committee.

C

Name of Employer
Kai Vac Inc
Receipt For: 2012
Primary
Other (specify)

Occupation

self employed

Election Cycle-to-Date

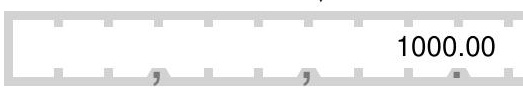

Transaction ID : AE8CBC1CD5B164A06AE1

Date of Receipt

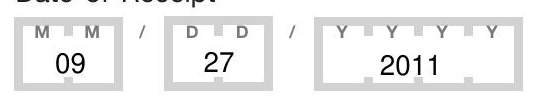

Amount of Each Receipt this Period

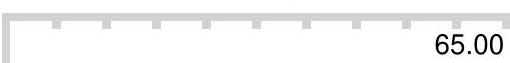

65.00

C. Full Name (Last, First, Middle Initial)

Roger Burdi

Mailing Address 5635 Ada Drive SE

\begin{tabular}{lcc}
\hline City & State & Zip Code \\
Ada & MI & $49301-7819$
\end{tabular}

FEC ID number of contributing federal political committee.

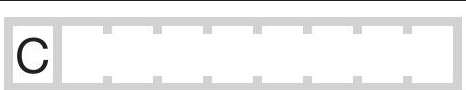

Name of Employer

Information Requested

\section{Occupation}

Information Requested

Receipt For: 2012

Х $\begin{aligned} & \text { Primary } \square \text { General } \\ & \text { Other (specify) }\end{aligned}$

Transaction ID : A1CEC55E9178A4F51936

Date of Receipt

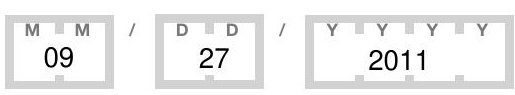

Amount of Each Receipt this Period

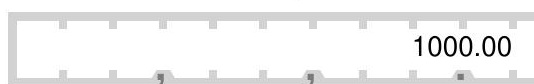

Transaction ID : A48BE2E01A656420FA10 Date of Receipt

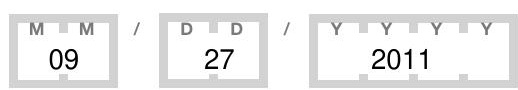

Amount of Each Receipt this Period

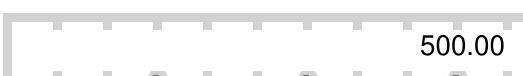

\section{Subtotal Of Receipts This Page (optional)}

Total This Period (last page this line number only) 
SCHEDULE A-P ITEMIZED RECEIPTS
Use separate schedule(s) for each category of the Detailed Summary Page
FOR LINE NUMBER: (check only one)

PAGE $909 / 1572$

\begin{tabular}{|c|c|c|c|c|c|c|}
\hline & & & & & & \\
\hline 16 & $\lambda$ & $17 \mathrm{a}$ & $17 \mathrm{~b}$ & $17 \mathrm{c}$ & $-17 d$ & -18 \\
\hline $19 a$ & & $19 b$ & $20 a$ & $20 \mathrm{~b}$ & $20 \mathrm{c}$ & 21 \\
\hline
\end{tabular}

Any information copied from such Reports and Statements may not be sold or used by any person for the purpose of soliciting contributions or for commercial purposes, other than using the name and address of any political committee to solicit contributions from such committee.

NAME OF COMMITTEE (In Full)

\section{Friends of Herman Cain}

A. Full Name (Last, First, Middle Initial)

Scott Holmes

Mailing Address 10444 E Vashon St

\begin{tabular}{lcc}
\hline City & State & Zip Code \\
Tucson & AZ & $85747-5737$
\end{tabular}

FEC ID number of contributing federal political committee.

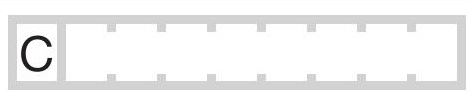

Name of Employer
Information Requested
Receipt For: 2012
X Primary
Other (specify) General

Occupation Information Requested

Election Cycle-to-Date

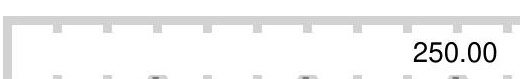

B. Full Name (Last, First, Middle Initial)

Alex Bell

Mailing Address 328 Margie Dr

\begin{tabular}{lcc}
\hline City & State & Zip Code \\
Warner Robins & GA & $31088-8933$ \\
\hline
\end{tabular}

FEC ID number of contributing

federal political committee.

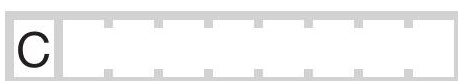

Name of Employer
Family Dental ASssociates
Receipt For: 2012
X Primary
Other (specify)

\section{Occupation}

Dentist

Election Cycle-to-Date

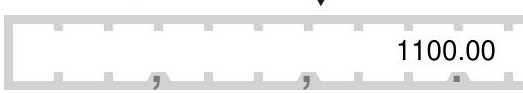

Transaction ID : A8864FE0215E34E65B83

Date of Receipt

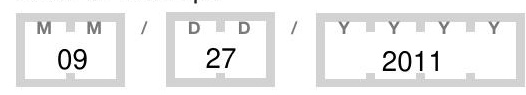

Amount of Each Receipt this Period

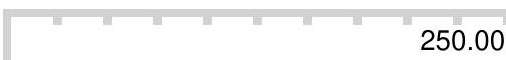

C. Full Name (Last, First, Middle Initial)

James Waddle

Mailing Address 711 Arnold Mill Road

\begin{tabular}{lcc}
\hline City & State & Zip Code \\
Woodstock & GA & $30188-3010$
\end{tabular}

FEC ID number of contributing

federal political committee.

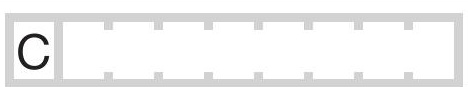

Name of Employer
Chick-Fil-A
Receipt For: 2012
X Primary $\quad \square$ General
Other (specify)

Occupation

Franchise Owner

Election Cycle-to-Date

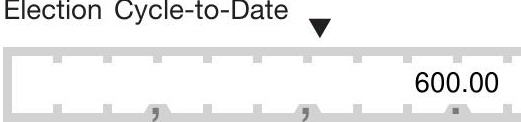

Amount of Each Receipt this Period

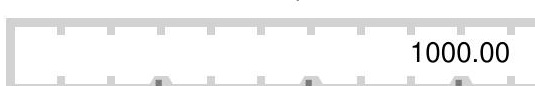

Transaction ID : AA368AEB351ED4294B3B Date of Receipt

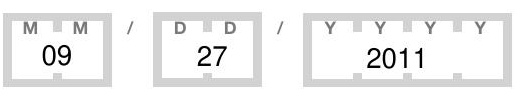

Transaction ID : A281D85E8D2AB4FC697C Date of Receipt

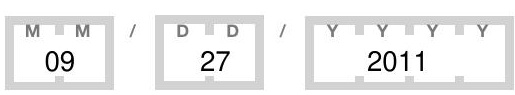

Amount of Each Receipt this Period

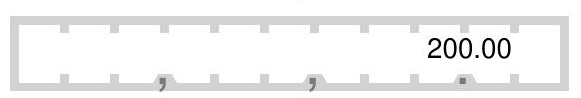

\section{Subtotal Of Receipts This Page (optional)}

Total This Period (last page this line number only) 


\section{SCHEDULE A-P} ITEMIZED RECEIPTS
Use separate schedule(s)

for each category of the

Detailed Summary Page
FOR LINE NUMBER: (check only one)

PAGE $910 / 1572$

\begin{tabular}{|c|c|c|c|c|c|}
\hline & & & & & \\
\hline 16 & X $17 a$ & $17 b$ & $17 c$ & $17 d$ & 18 \\
\hline $19 a$ & $19 b$ & $20 \mathrm{a}$ & $20 \mathrm{~b}$ & $20 \mathrm{c}$ & 21 \\
\hline
\end{tabular}

Any information copied from such Reports and Statements may not be sold or used by any person for the purpose of soliciting contributions or for commercial purposes, other than using the name and address of any political committee to solicit contributions from such committee.

NAME OF COMMITTEE (In Full)

Friends of Herman Cain

A. Full Name (Last, First, Middle Initial)

Enrique Ospina

Mailing Address 6007 Memorial Dr \#305

\begin{tabular}{lcc}
\hline City & State & Zip Code \\
Houston & TX & $77007-7065$
\end{tabular}

FEC ID number of contributing

federal political committee.

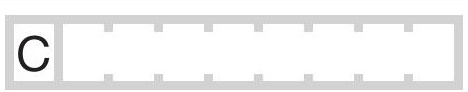

Name of Employer
Self Employed
Receipt For: 2012
X Primary
$\square$ Other (specify) General

Occupation Investor

Election Cycle-to-Date

\subsection{0}

B. Full Name (Last, First, Middle Initial)

Rustin Kretz

Mailing Address 25101 Smokewood Way

\begin{tabular}{lcc}
\hline City & State & Zip Code \\
Stevenson Ranch & CA & $91381-2269$
\end{tabular}

FEC ID number of contributing

federal political committee.

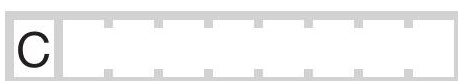

Name of Employer
Information Requested
Receipt For: 2012
X Primary
Other (specify)

Occupation

Information Requested

Election Cycle-to-Date

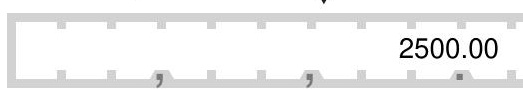

C. Full Name (Last, First, Middle Initial)

Malcolm Kirkbride

Mailing Address 12851

\begin{tabular}{lcc}
\hline City & State & Zip Code \\
Cedar Key & FL & 32625 \\
\hline
\end{tabular}

FEC ID number of contributing

federal political committee.

C

Name of Employer
Information Requested
Receipt For: 2012
Primary
Other (specify) General

Occupation

Information Requested

Election Cycle-to-Date
Transaction ID : A899082B35282401D805

Date of Receipt

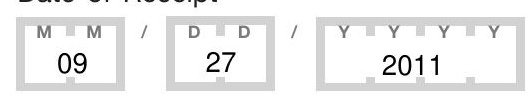

Amount of Each Receipt this Period

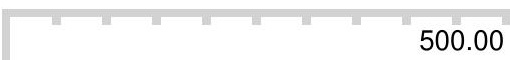

Amount of Each Receipt this Period

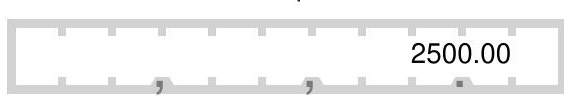

Transaction ID : A9B895B76A2904246876

Date of Receipt

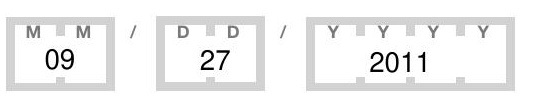

Transaction ID : ABE0C20A311414AAB96C Date of Receipt

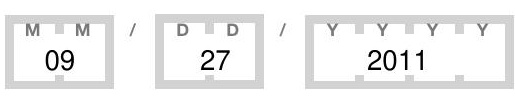

Amount of Each Receipt this Period

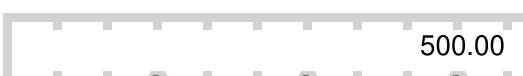

500.00

Subtotal Of Receipts This Page (optional).

Total This Period (last page this line number only) 


\section{SCHEDULE A-P} ITEMIZED RECEIPTS
Use separate schedule(s)

for each category of the

Detailed Summary Page

FOR LINE NUMBER:
(check only one)

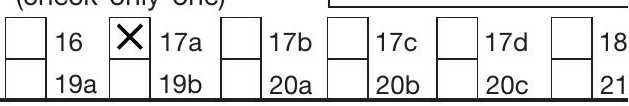

Any information copied from such Reports and Statements may not be sold or used by any person for the purpose of soliciting contributions or for commercial purposes, other than using the name and address of any political committee to solicit contributions from such committee.

NAME OF COMMITTEE (In Full)

\section{Friends of Herman Cain}

A. Full Name (Last, First, Middle Initial) Robert Vettorel

Mailing Address 3047 Bedillion Road

\begin{tabular}{lcc}
\hline City & State & Zip Code \\
Washington & PA & $15301-8122$ \\
\hline
\end{tabular}

FEC ID number of contributing federal political committee.

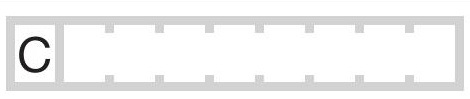

Name of Employer
Information Requested
Receipt For: 2012
X Primary
$\square$ Other (specify)

Occupation Information Requested Election Cycle-to-Date 500.00

B. Full Name (Last, First, Middle Initial) calvin STEWART

\section{Mailing Address 340 W32ND}

\begin{tabular}{lcc}
\hline City & State & Zip Code \\
Yuma & AZ & 85364
\end{tabular}

FEC ID number of contributing

federal political committee.

C

Name of Employer
ups manager
Receipt For: 2012
X Primary
Other (specify)

\section{Occupation} Retired

Election Cycle-to-Date

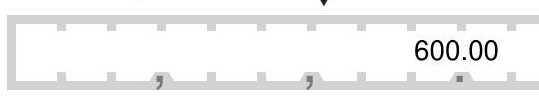

C. Full Name (Last, First, Middle Initial)

Anna Nataros

Mailing Address 1600 E Hanley Blvd. Suite 128

\begin{tabular}{lcc}
\hline City & State & Zip Code \\
Tucson & AZ & $85737-9180$
\end{tabular}

FEC ID number of contributing federal political committee.

C

Name of Employer
Information Requested
Receipt For: 2012
X Primary
Other (specify) General

Transaction ID : A5A62234F02154F86955

Date of Receipt

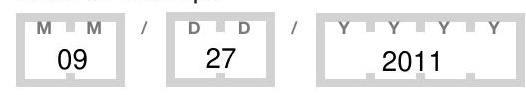

Amount of Each Receipt this Period

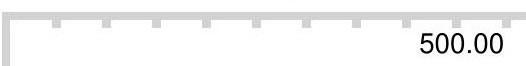

Amount of Each Receipt this Period

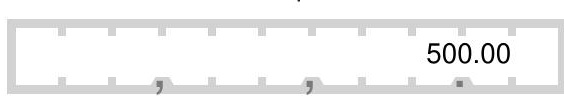

Transaction ID : AAD8B8AC0430048EDB4A Date of Receipt

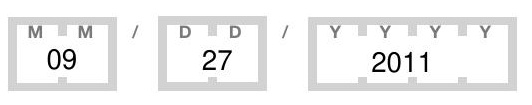

Transaction ID : A700902CB8DE7492B93D Date of Receipt

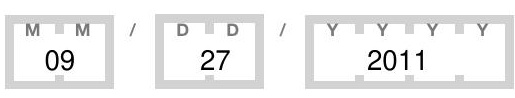

Amount of Each Receipt this Period

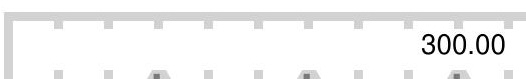

Subtotal Of Receipts This Page (optional).

Total This Period (last page this line number only) 


\section{SCHEDULE A-P} ITEMIZED RECEIPTS
Use separate schedule(s) for each category of the Detailed Summary Page

FOR LINE NUMBER:
(check only one)

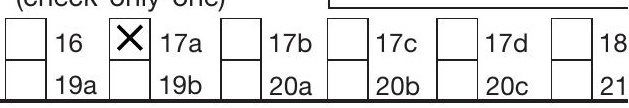

Any information copied from such Reports and Statements may not be sold or used by any person for the purpose of soliciting contributions or for commercial purposes, other than using the name and address of any political committee to solicit contributions from such committee.

NAME OF COMMITTEE (In Full)

\section{Friends of Herman Cain}

A. Full Name (Last, First, Middle Initial)

ANDREW CHAMPION

Mailing Address 3832 SOUTHWESTERN ST

\begin{tabular}{lcc}
\hline City & State & Zip Code \\
Houston & TX & $77005-4337$ \\
\hline
\end{tabular}

FEC ID number of contributing federal political committee.

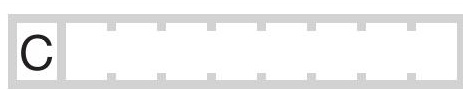

Name of Employer
Scotia Capital
Receipt For: 2012
X Primary
$\square$ Other (specify) General

Occupation Programmer

Election Cycle-to-Date 500.00

B. Full Name (Last, First, Middle Initial) danny bowlin

Mailing Address 4226 Rolling Oaks Dr

\begin{tabular}{lcc}
\hline City & State & Zip Code \\
Carrollton & TX & $75010-1310$
\end{tabular}

FEC ID number of contributing

federal political committee.

C

Name of Employer
Bowlin Transportation LLC
Receipt For: 2012
X Primary
$\square$ Other (specify)

Occupation Truck Driver

Election Cycle-to-Date

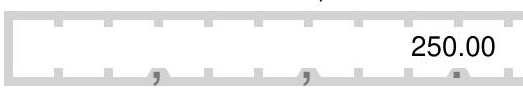

C. Full Name (Last, First, Middle Initial)

Thomas Cauchois

Mailing Address 1 Dock St Ste 101

\begin{tabular}{lcc}
\hline City & State & Zip Code \\
Stamford & CT & $06902-5872$
\end{tabular}

FEC ID number of contributing federal political committee.

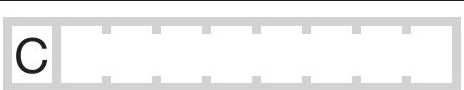

Name of Employer
Information Requested
Receipt For: 2012
X Primary
Other (specify) General

\section{Occupation}

Information Requested

Election Cycle-to-Date

Transaction ID : A932F0D64E8B54ED8B1D Date of Receipt

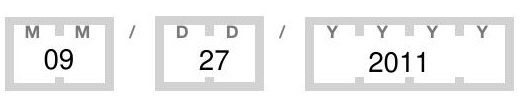

Amount of Each Receipt this Period

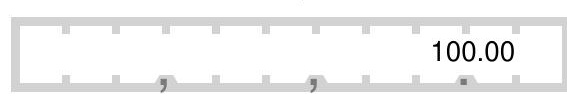

Amount of Each Receipt this Period

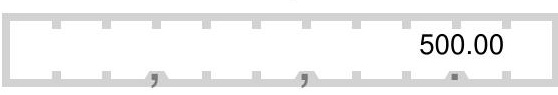

Date of Receipt

M M / D

09

2011

\section{(1)}


SCHEDULE A-P ITEMIZED RECEIPTS
Use separate schedule(s) for each category of the Detailed Summary Page
FOR LINE NUMBER: (check only one)

PAGE $913 / 1572$

\begin{tabular}{|c|c|c|c|c|c|c|}
\hline & & & & & & \\
\hline 16 & $\lambda$ & $17 \mathrm{a}$ & $17 \mathrm{~b}$ & $17 \mathrm{c}$ & $-17 d$ & -18 \\
\hline $19 a$ & & $19 b$ & $20 a$ & $20 \mathrm{~b}$ & $20 \mathrm{c}$ & 21 \\
\hline
\end{tabular}

Any information copied from such Reports and Statements may not be sold or used by any person for the purpose of soliciting contributions or for commercial purposes, other than using the name and address of any political committee to solicit contributions from such committee.

NAME OF COMMITTEE (In Full)

\section{Friends of Herman Cain}

A. Full Name (Last, First, Middle Initial)

Mary Cruz

Mailing Address 3459 Sagecrest Terrace

\begin{tabular}{lcc}
\hline City & State & Zip Code \\
Fort Worth & TX & $76109-2556$
\end{tabular}

FEC ID number of contributing federal political committee.

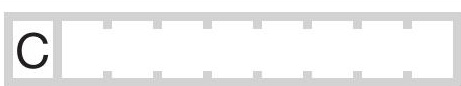

Name of Employer
Information Requested
Receipt For: 2012
X Primary
Other (specify) General

Occupation Information Requested

Election Cycle-to-Date

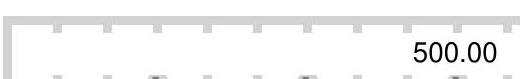

B. Full Name (Last, First, Middle Initial)

Mr. Thomas G. Walker

Mailing Address PO Box 724472

\begin{tabular}{lcc}
\hline City & State & Zip Code \\
Atlanta & GA & $31139-1472$
\end{tabular}

FEC ID number of contributing

federal political committee.

C

Name of Employer
Information Requested
Receipt For: 2012
X Primary
Other (specify)

\section{Occupation}

Information Requested

Election Cycle-to-Date

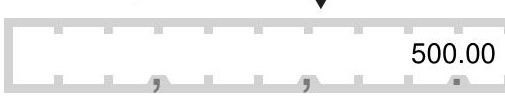

Transaction ID : A42FA031E04CE445FB22

Date of Receipt

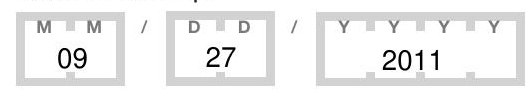

Amount of Each Receipt this Period

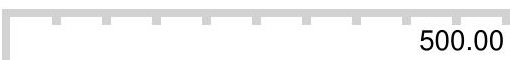

Amount of Each Receipt this Period

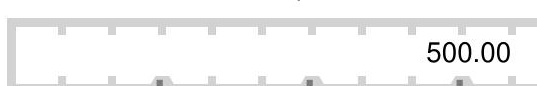

C. Full Name (Last, First, Middle Initial)

Scott Barthel

Mailing Address 347 Skyland

\begin{tabular}{lcc}
\hline City & State & Zip Code \\
Boerne & TX & $78006-5957$
\end{tabular}

FEC ID number of contributing federal political committee.

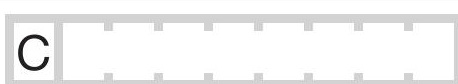

Name of Employer

Information Requested

Occupation

Receipt For: 2012

Х $\begin{aligned} & \text { Primary } \\ & \text { Other (specify) }\end{aligned}$

Information Requested

Election Cycle-to-Date

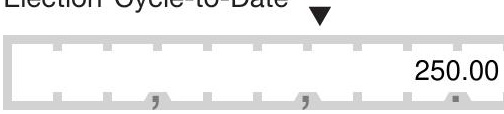

Transaction ID : AD806912D6F3A4C6CA99

Date of Receipt

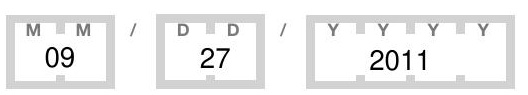

Transaction ID : A2AA6851F0EF64AD18ED Date of Receipt

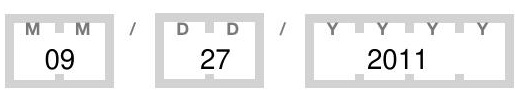

Amount of Each Receipt this Period

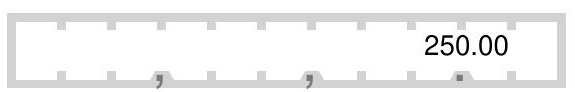

Subtotal Of Receipts This Page (optional)

Total This Period (last page this line number only) 
SCHEDULE A-P ITEMIZED RECEIPTS
Use separate schedule(s) for each category of the Detailed Summary Page

FOR LINE NUMBER:
(check only one)

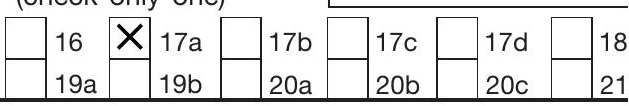

Any information copied from such Reports and Statements may not be sold or used by any person for the purpose of soliciting contributions or for commercial purposes, other than using the name and address of any political committee to solicit contributions from such committee.

NAME OF COMMITTEE (In Full)

\section{Friends of Herman Cain}

A. Full Name (Last, First, Middle Initial)

\section{Al Ritchie}

Mailing Address PO Box 3009

\begin{tabular}{lcc}
\hline City & State & Zip Code \\
Eustis & FL & $32727-3009$
\end{tabular}

FEC ID number of contributing federal political committee.

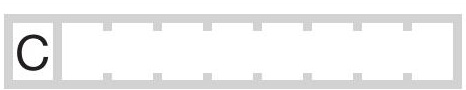

Name of Employer
Information Requested
Receipt For: 2012
X Primary
$\square$ Other (specify)

\section{Occupation} Information Requested

Election Cycle-to-Date

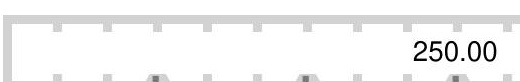

B. Full Name (Last, First, Middle Initial)

Bruce Shelby

Mailing Address 3098 Dillon Lane

\begin{tabular}{lcc}
\hline City & State & Zip Code \\
West Linn & OR & $97068-9230$
\end{tabular}

FEC ID number of contributing

federal political committee.

C

Name of Employer
Information Requested
Receipt For: 2012
Primary
Other (specify)

Occupation

Information Requested

Election Cycle-to-Date

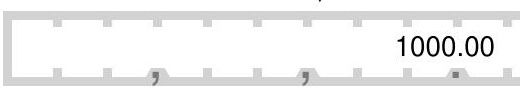

C. Full Name (Last, First, Middle Initial)

Matthew Bures

Mailing Address 2611 Dove Creek Lane Unit A

\begin{tabular}{lcc}
\hline City & State & Zip Code \\
Pasadena & CA & $91107-1455$
\end{tabular}

FEC ID number of contributing federal political committee.

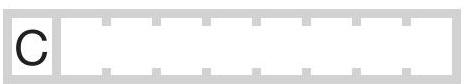

Name of Employer

Matthew Clark Bures, P.C.

Receipt For: 2012

Х $\begin{aligned} & \text { Primary } \square \text { General } \\ & \text { Other (specify) }\end{aligned}$

\section{Occupation}

Attorney

Election Cycle-to-Date
Transaction ID : A87356AA213C44C5A963

Date of Receipt

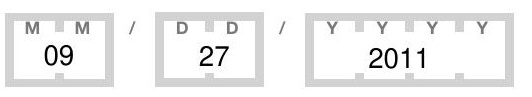

Amount of Each Receipt this Period

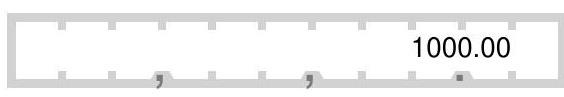

Transaction ID : ACD517A530B2E4176914 Date of Receipt

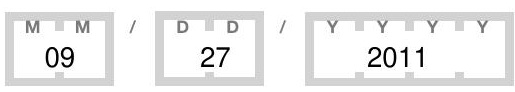

Amount of Each Receipt this Period

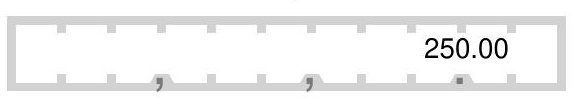

250.00

\section{Subtotal Of Receipts This Page (optional)}

Total This Period (last page this line number only) 


\section{SCHEDULE A-P} ITEMIZED RECEIPTS
Use separate schedule(s)

for each category of the

Detailed Summary Page
FOR LINE NUMBER: (check only one)

PAGE $915 / 1572$

\begin{tabular}{|c|c|c|c|c|c|}
\hline & & & & & \\
\hline 16 & X $17 a$ & $17 b$ & $17 c$ & $17 d$ & 18 \\
\hline $19 a$ & $19 b$ & $20 \mathrm{a}$ & $20 \mathrm{~b}$ & $20 \mathrm{c}$ & 21 \\
\hline
\end{tabular}

Any information copied from such Reports and Statements may not be sold or used by any person for the purpose of soliciting contributions or for commercial purposes, other than using the name and address of any political committee to solicit contributions from such committee.

NAME OF COMMITTEE (In Full)

Friends of Herman Cain

A. Full Name (Last, First, Middle Initial)

Craig Lake

Mailing Address 4545 W. Reno Ave B2

\begin{tabular}{lcc}
\hline City & State & Zip Code \\
Las Vegas & NV & 89118-4902 \\
\hline
\end{tabular}

FEC ID number of contributing federal political committee.

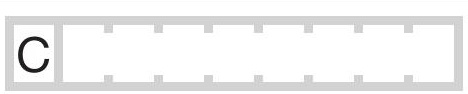

Name of Employer
Rise \& Shine Lighting
Receipt For: 2012
X Primary
$\square$ Other (specify)

Occupation

Sales

Election Cycle-to-Date

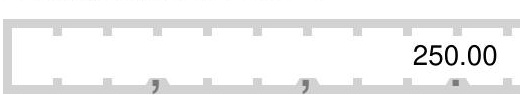

B. Full Name (Last, First, Middle Initial)

Scott Moss

Mailing Address 2230 Oakland Road

\begin{tabular}{llc}
\hline City & State & Zip Code \\
Hopkins & MN & $55305-2203$
\end{tabular}

FEC ID number of contributing

federal political committee.

C

Name of Employer
Mill Creek Entertainment
Receipt For: 2012
X Primary
Other (specify)

Occupation

management

Election Cycle-to-Date

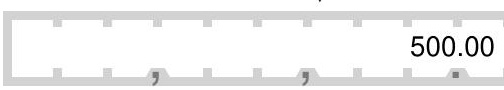

Transaction ID : A2BA45192577942088E3

Date of Receipt

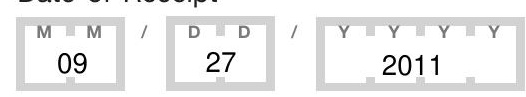

Amount of Each Receipt this Period

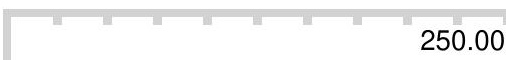

Transaction ID : A39F871D7154540A5989

Date of Receipt

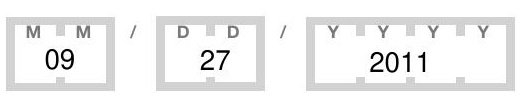

Amount of Each Receipt this Period

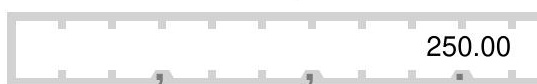

Transaction ID : A104AC7EC94274A6194B Date of Receipt

\section{LUCINDA NACHMAN}

Mailing Address 2566 WILLIAMSBURG ST

\begin{tabular}{lcc}
\hline City & State & Zip Code \\
Henderson & NV & $89052-4933$
\end{tabular}

FEC ID number of contributing federal political committee.

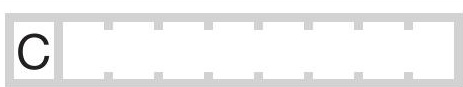

Name of Employer

Information Requested

Occupation

Information Requested

Receipt For: 2012

Х $\begin{aligned} & \text { Primary } \square \text { General } \\ & \text { Other (specify) }\end{aligned}$

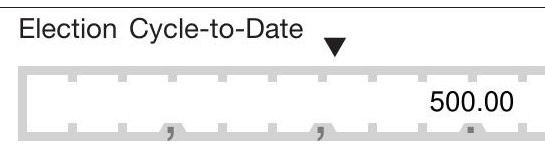

Amount of Each Receipt this Period

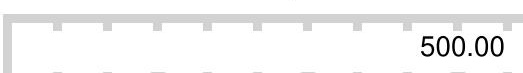

1000.00

Subtotal Of Receipts This Page (optional)

Total This Period (last page this line number only) 


\section{SCHEDULE A-P} ITEMIZED RECEIPTS
Use separate schedule(s) for each category of the Detailed Summary Page

FOR LINE NUMBER:
(check only one)

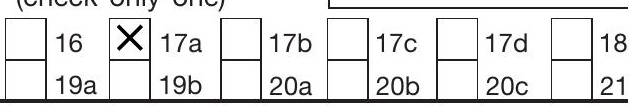

Any information copied from such Reports and Statements may not be sold or used by any person for the purpose of soliciting contributions or for commercial purposes, other than using the name and address of any political committee to solicit contributions from such committee.

NAME OF COMMITTEE (In Full)

\section{Friends of Herman Cain}

A. Full Name (Last, First, Middle Initial) HAROLD AYERS

Mailing Address PO BOX 589

\begin{tabular}{lcc}
\hline City & State & Zip Code \\
Tonasket & WA & $98855-0589$
\end{tabular}

FEC ID number of contributing federal political committee.

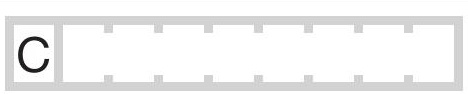

Name of Employer
None
Receipt For: 2012
X Primary $\quad \square$ General
$\square$ Other (specify)

Occupation Retired Election Cycle-to-Date

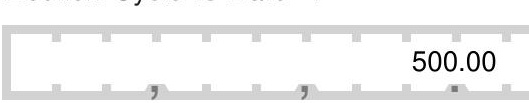

B. Full Name (Last, First, Middle Initial) John D Lilly

Mailing Address 7388 W Farm Road 88

\begin{tabular}{lll}
\hline City & State & Zip Code \\
Willard & MO & $65781-8310$ \\
\hline
\end{tabular}

FEC ID number of contributing

federal political committee.

C

Name of Employer
St. Johns Clinic
Receipt For: 2012
X Primary
Other (specify)

Occupation

Physician

Election Cycle-to-Date

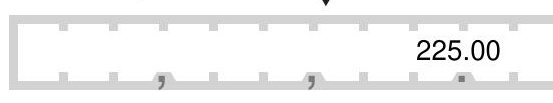

C. Full Name (Last, First, Middle Initial)

Frank Mazur

Mailing Address 627 Morgan St

\begin{tabular}{lcc}
\hline City & State & Zip Code \\
Scranton & PA & $18519-1507$
\end{tabular}

FEC ID number of contributing federal political committee.

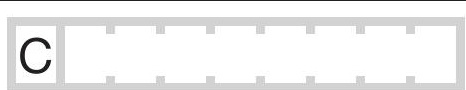

Name of Employer
Information Requested
Receipt For: 2012
Primary
Other (specify) General

Occupation

Information Requested

Election Cycle-to-Date
Transaction ID : A5E5ECBA7307C454EAD8 Date of Receipt

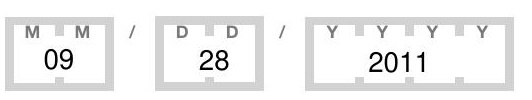

Amount of Each Receipt this Period

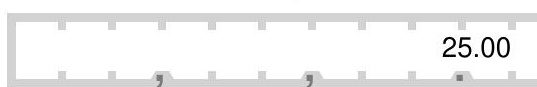

Transaction ID : A1C71BC9478854213A36

Date of Receipt

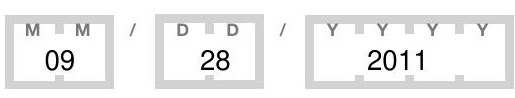

Amount of Each Receipt this Period

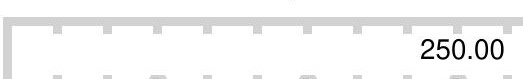

250.00
Transaction ID : A06D658B0830C464AACA

Date of Receipt

Amount of Each Receipt this Period

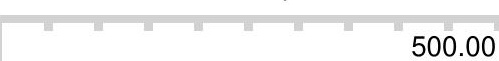

\section{Subtotal Of Receipts This Page (optional)}

775.00

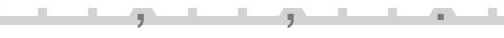

Total This Period (last page this line number only)

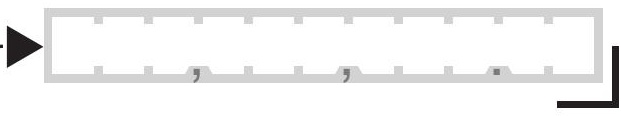




\section{SCHEDULE A-P} ITEMIZED RECEIPTS
Use separate schedule(s)

for each category of the

Detailed Summary Page
FOR LINE NUMBER: (check only one)

PAGE 917 / 1572

\begin{tabular}{|c|c|c|c|c|c|}
\hline & & & & & \\
\hline 16 & $\mathbf{X} 17 \mathrm{a}$ & $17 \mathrm{~b}$ & $17 c$ & $17 d$ & 18 \\
\hline $19 a$ & $19 \mathrm{~b}$ & $20 a$ & $20 \mathrm{~b}$ & $20 c$ & 21 \\
\hline
\end{tabular}

Any information copied from such Reports and Statements may not be sold or used by any person for the purpose of soliciting contributions or for commercial purposes, other than using the name and address of any political committee to solicit contributions from such committee.

NAME OF COMMITTEE (In Full)

Friends of Herman Cain

A. Full Name (Last, First, Middle Initial)

Judy Siebert

Mailing Address P.O. Box 65 P.O. Box 65

\begin{tabular}{lcc}
\hline City & State & Zip Code \\
Oran & MO & $63771-0065$
\end{tabular}

FEC ID number of contributing federal political committee.

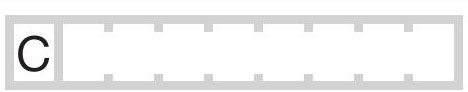

Name of Employer
Information Requested
Receipt For: 2012
X Primary
$\square$ Other (specify)

Occupation

Information Requested

Election Cycle-to-Date

500.00

B. Full Name (Last, First, Middle Initial)

Jason Christiano

Mailing Address 8433 Dunham Station Drive

\begin{tabular}{lcc}
\hline City & State & Zip Code \\
Tampa & FL & $33647-3339$ \\
\hline
\end{tabular}

FEC ID number of contributing

federal political committee.

C

Name of Employer
Information Requested
Receipt For: 2012
X Primary
Other (specify)

Occupation

Information Requested

Election Cycle-to-Date

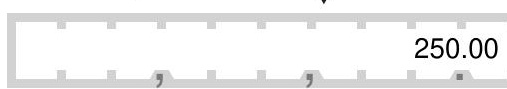

Transaction ID : A057082903DD1423F8E6

Date of Receipt

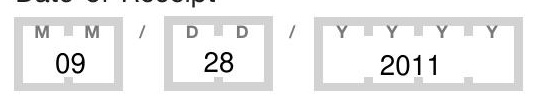

Amount of Each Receipt this Period

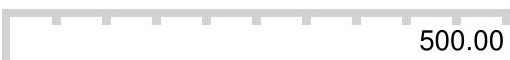

Amount of Each Receipt this Period

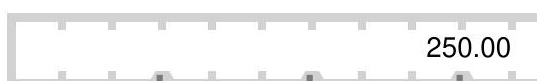

C. Full Name (Last, First, Middle Initial)

Steve Loghry

Mailing Address 775 Cove View Circle

\begin{tabular}{lcc}
\hline City & State & Zip Code \\
Galveston & TX & 77554 \\
\hline
\end{tabular}

FEC ID number of contributing

federal political committee.

C

Name of Employer
Information Requested
Receipt For: 2012
X Primary
Other (specify) General

Occupation

Information Requested

Election Cycle-to-Date

Transaction ID : ABDE83CB616CC45E6A70 Date of Receipt
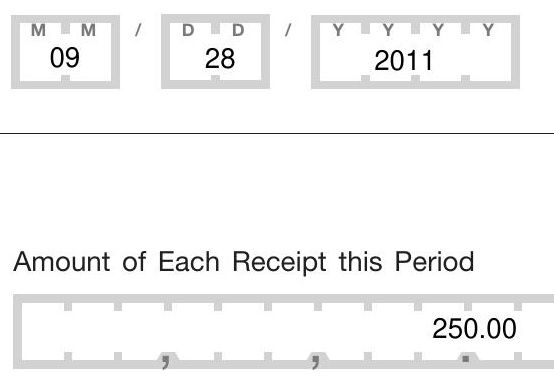

Transaction ID : A09CFA07AA0C0479DB7C Date of Receipt

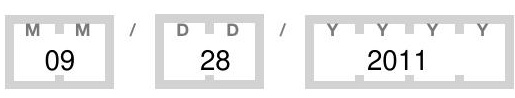

Amount of Each Receipt this Period

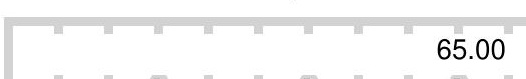

240.00

Subtotal Of Receipts This Page (optional).

815.00

ㄱ․․

Total This Period (last page this line number only)

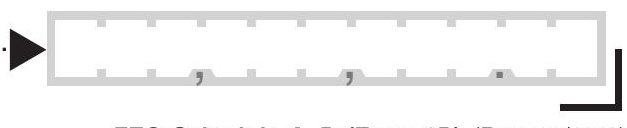

FEC Schedule A-P (Form 3P) (Rev. 03/2011) 


\section{SCHEDULE A-P} ITEMIZED RECEIPTS
Use separate schedule(s)

for each category of the

Detailed Summary Page
FOR LINE NUMBER: (check only one)

PAGE $918 / 1572$

\begin{tabular}{|c|c|c|c|c|c|}
\hline & & & & & \\
\hline 16 & X $17 a$ & $17 b$ & $17 c$ & $17 d$ & 18 \\
\hline $19 a$ & $19 b$ & $20 \mathrm{a}$ & $20 \mathrm{~b}$ & $20 \mathrm{c}$ & 21 \\
\hline
\end{tabular}

Any information copied from such Reports and Statements may not be sold or used by any person for the purpose of soliciting contributions or for commercial purposes, other than using the name and address of any political committee to solicit contributions from such committee.

NAME OF COMMITTEE (In Full)

Friends of Herman Cain

A. Full Name (Last, First, Middle Initial)

Tad Vollmar

Mailing Address 6821 Platteview Rd

\begin{tabular}{lcc}
\hline City & State & Zip Code \\
Papillion & NE & $68133-2620$ \\
\hline
\end{tabular}

FEC ID number of contributing

federal political committee.

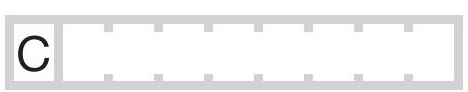

Name of Employer
Regent Financial Group
Receipt For: 2012
X Primary $\quad \square$ General
Other (specify)

Occupation

Mortgage Banker

Election Cycle-to-Date

350.00

B. Full Name (Last, First, Middle Initial)

Pete Martinelli

Mailing Address 2781 Harbins Rd SE

\begin{tabular}{lcc}
\hline City & State & Zip Code \\
Bethlehem & GA & $30620-4519$
\end{tabular}

FEC ID number of contributing

federal political committee.

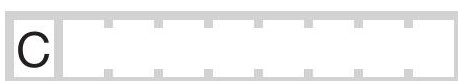

Name of Employer
Information Requested
Receipt For: 2012
X Primary
Other (specify)

Occupation

Information Requested

Election Cycle-to-Date

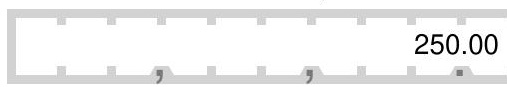

Transaction ID : A637059424DAD44EFBC2

Date of Receipt

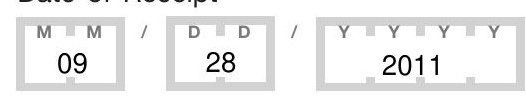

Amount of Each Receipt this Period

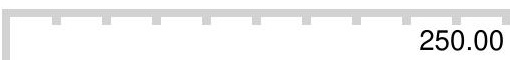

C. Full Name (Last, First, Middle Initial)

Janet Tague

Mailing Address 250 Elk Circle

\begin{tabular}{lcc}
\hline City & State & Zip Code \\
Dillon & CO & $80435-7816$
\end{tabular}

FEC ID number of contributing federal political committee.

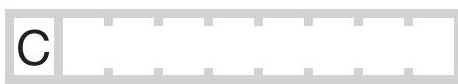

Name of Employer

Information Requested

\section{Occupation}

Information Requested

Receipt For: 2012

Х $\begin{aligned} & \text { Primary } \square \text { General } \\ & \text { Other (specify) }\end{aligned}$

Amount of Each Receipt this Period

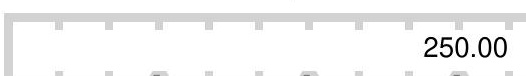

Transaction ID : A164C8D3C81244414B05

Date of Receipt

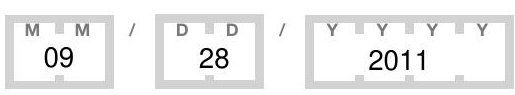

Transaction ID : AB8AA3FEBAED64D88ADA Date of Receipt

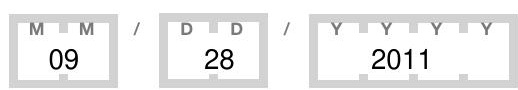

Amount of Each Receipt this Period

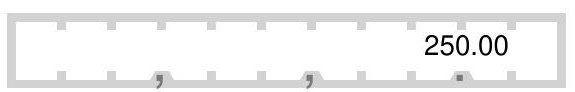

250.00
Subtotal Of Receipts This Page (optional).

750.00

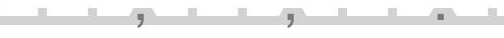

Total This Period (last page this line number only)

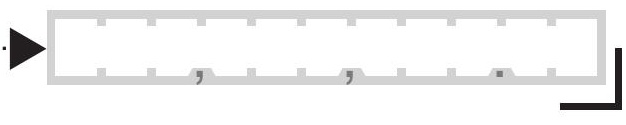

FEC Schedule A-P (Form 3P) (Rev. 03/2011) 
SCHEDULE A-P ITEMIZED RECEIPTS
Use separate schedule(s) for each category of the Detailed Summary Page
FOR LINE NUMBER: (check only one)

PAGE $919 / 1572$

\begin{tabular}{|c|c|c|c|c|c|}
\hline & & & & & \\
\hline 16 & $\begin{array}{l}\mathbf{X} \\
17 a\end{array}$ & $17 b$ & $17 c$ & $17 d$ & 18 \\
\hline $19 a$ & $19 \mathrm{~b}$ & $20 \mathrm{a}$ & $20 \mathrm{~b}$ & $20 \mathrm{c}$ & 21 \\
\hline
\end{tabular}

Any information copied from such Reports and Statements may not be sold or used by any person for the purpose of soliciting contributions or for commercial purposes, other than using the name and address of any political committee to solicit contributions from such committee.

NAME OF COMMITTEE (In Full)

\section{Friends of Herman Cain}

A. Full Name (Last, First, Middle Initial) Joshua Morris

Mailing Address 830 Revere Way East

\begin{tabular}{lcc}
\hline City & State & Zip Code \\
Bartlesville & OK & $74006-8870$
\end{tabular}

FEC ID number of contributing federal political committee.

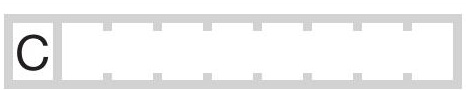

Name of Employer
Information Requested
Receipt For: 2012
X Primary
Other (specify) General

Occupation Information Requested

Election Cycle-to-Date

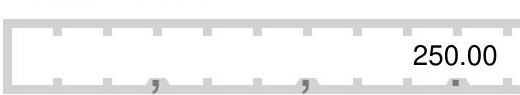

B. Full Name (Last, First, Middle Initial)

Mr Thomas Berryman

Mailing Address PO Box 787

\begin{tabular}{lcc}
\hline City & State & Zip Code \\
Ashland & KS & $67831-0787$
\end{tabular}

FEC ID number of contributing

federal political committee.

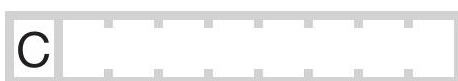

Name of Employer
self
Receipt For: 2012
X Primary
Other (specify)

Occupation

Carpenter

Election Cycle-to-Date

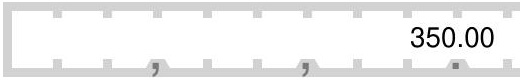

C. Full Name (Last, First, Middle Initial) clayton scott

Mailing Address 4809 normandy lane

\begin{tabular}{lcc}
\hline City & State & Zip Code \\
Memphis & TN & $38117-2603$
\end{tabular}

FEC ID number of contributing federal political committee.

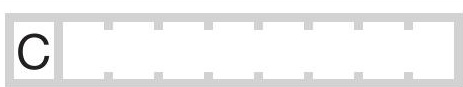

Name of Employer
Information Requested
Receipt For: 2012
X Primary
Other (specify) General

\section{Occupation}

Information Requested

Election Cycle-to-Date

Transaction ID : A9C2A1A959E704E5083C

Date of Receipt

Amount of Each Receipt this Period
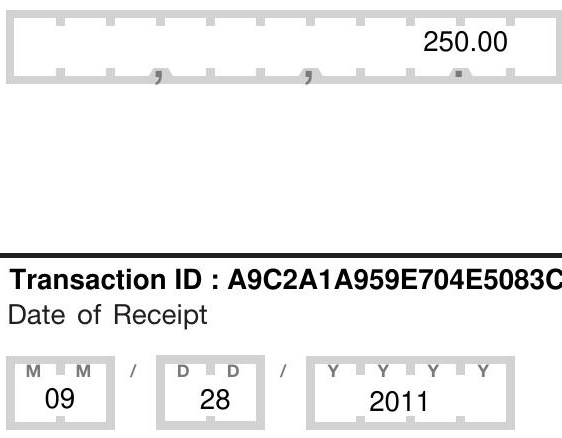

Amount of Each Receipt this Period

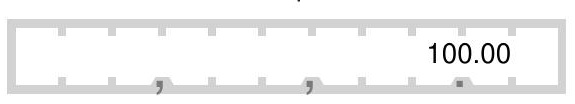

Transaction ID : A238EAA2D0B804126B6E Date of Receipt

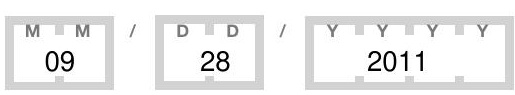

Amount of Each Receipt this Period

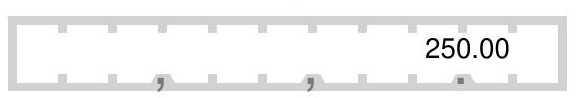

250.00

\section{Subtotal Of Receipts This Page (optional)}

600.00

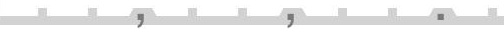

Total This Period (last page this line number only)

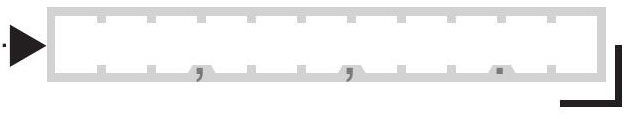

FEC Schedule A-P (Form 3P) (Rev. 03/2011) 


\section{SCHEDULE A-P} ITEMIZED RECEIPTS
Use separate schedule(s)

for each category of the

Detailed Summary Page
FOR LINE NUMBER: (check only one)

PAGE $920 / 1572$

\begin{tabular}{|c|c|c|c|c|c|}
\hline & & & & & \\
\hline 16 & $\mathbf{X} 17 \mathrm{a}$ & $17 \mathrm{~b}$ & $17 c$ & $17 d$ & 18 \\
\hline $19 a$ & $19 \mathrm{~b}$ & $20 a$ & $20 \mathrm{~b}$ & $20 c$ & 21 \\
\hline
\end{tabular}

Any information copied from such Reports and Statements may not be sold or used by any person for the purpose of soliciting contributions or for commercial purposes, other than using the name and address of any political committee to solicit contributions from such committee.

NAME OF COMMITTEE (In Full)

Friends of Herman Cain

A. Full Name (Last, First, Middle Initial)

Brian Bidne

Mailing Address 17075 Weir Street

\begin{tabular}{lcc}
\hline City & State & Zip Code \\
Omaha & NE & $68135-1431$
\end{tabular}

FEC ID number of contributing

federal political committee.

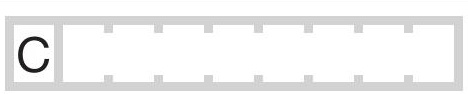

Name of Employer
Information Requested
Receipt For: 2012
X Primary $\quad \square$ General
Other (specify)

Occupation

Information Requested

Election Cycle-to-Date

250.00

B. Full Name (Last, First, Middle Initial)

Larry Rigdon

Mailing Address 914 Main Street Suite 1805

\begin{tabular}{lcc}
\hline City & State & Zip Code \\
Houston & TX & $77002-6222$ \\
\hline
\end{tabular}

FEC ID number of contributing

federal political committee.

C

\begin{tabular}{l} 
Name of Employer \\
Information Requested \\
\hline Receipt For: 2012 \\
$X$ Primary \\
Other (specify)
\end{tabular}

Occupation

Information Requested

Election Cycle-to-Date

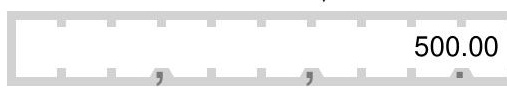

Transaction ID : A76EEFC12C2EE4B29B47

Date of Receipt

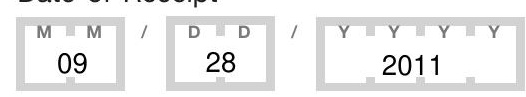

Amount of Each Receipt this Period

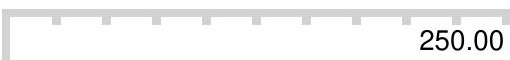

Transaction ID : A1601473565534062B61

Date of Receipt

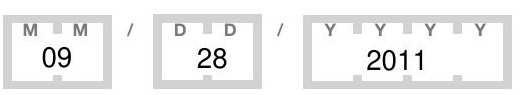

Amount of Each Receipt this Period

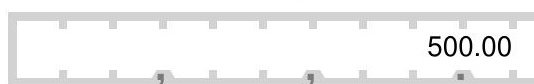

Transaction ID : AF3B648F7A88045539D8

Date of Receipt

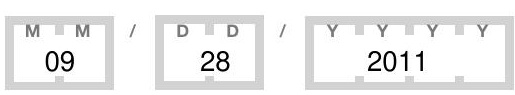

Amount of Each Receipt this Period

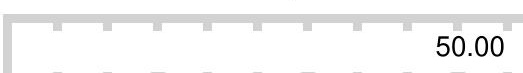

$\begin{array}{cc}\text { State } & \text { Zip Code } \\ \text { GA } & 30097-5123\end{array}$

C

\section{Occupation}

RE Developer

Election Cycle-to-Date

Receipt For: 2012

Х $\begin{aligned} & \text { Primary } \square \text { General } \\ & \text { Other (specify) }\end{aligned}$

425.00

Subtotal Of Receipts This Page (optional).

800.00

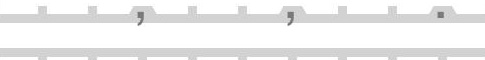

Total This Period (last page this line number only) 


\section{SCHEDULE A-P} ITEMIZED RECEIPTS
Use separate schedule(s)

for each category of the

Detailed Summary Page
FOR LINE NUMBER: (check only one)

PAGE $921 / 1572$

\begin{tabular}{|c|c|c|c|c|c|}
\hline & & & & & \\
\hline 16 & $\mathbf{X} 17 \mathrm{a}$ & $17 \mathrm{~b}$ & $17 c$ & $17 d$ & 18 \\
\hline $19 a$ & $19 \mathrm{~b}$ & $20 a$ & $20 \mathrm{~b}$ & $20 c$ & 21 \\
\hline
\end{tabular}

Any information copied from such Reports and Statements may not be sold or used by any person for the purpose of soliciting contributions or for commercial purposes, other than using the name and address of any political committee to solicit contributions from such committee.

NAME OF COMMITTEE (In Full)

Friends of Herman Cain

A. Full Name (Last, First, Middle Initial)

ARTHUR WISSEL

Mailing Address 412 BUTLER ROAD PO BOX 3611

\begin{tabular}{lcc}
\hline City & State & Zip Code \\
Glyndon & MD & $21071-3611$ \\
\hline
\end{tabular}

FEC ID number of contributing

federal political committee.

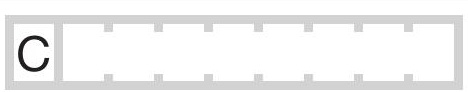

Name of Employer
Not Employed
Receipt For: 2012
X Primary
$\square$ Other (specify) General

Occupation

Not Employed

Election Cycle-to-Date

250.00

B. Full Name (Last, First, Middle Initial)

Darrel Wilkerson Jr.

Mailing Address 19100 Highway 152

\begin{tabular}{lcc}
\hline City & State & Zip Code \\
Union City & OK & $73090-6104$
\end{tabular}

FEC ID number of contributing

federal political committee.

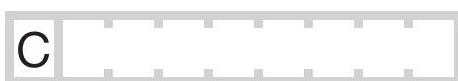

Name of Employer
DRW LLC
Receipt For: 2012
X Primary $\quad$ General
Other (specify)

Occupation

Manager

Election Cycle-to-Date

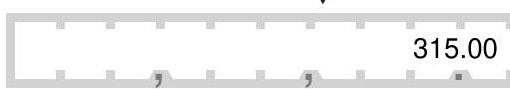

Transaction ID : A4EFE963EC1534F85BFA

Date of Receipt

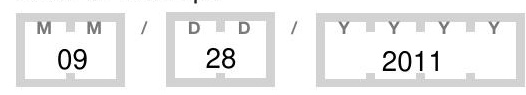

Amount of Each Receipt this Period

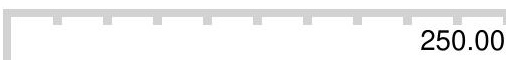

Amount of Each Receipt this Period

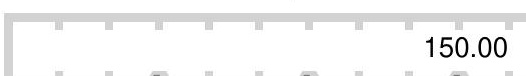

C. Full Name (Last, First, Middle Initial)

John Young

Mailing Address 2929 Ground Robin Drive

\begin{tabular}{lcc}
\hline City & State & Zip Code \\
North Las Vegas & NV & 89084-3708
\end{tabular}

FEC ID number of contributing

federal political committee.

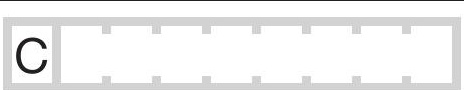

Name of Employer

Information Requested

Occupation

Information Requested

Receipt For: 2012

Х $\begin{aligned} & \text { Primary } \square \text { General } \\ & \text { Other (specify) }\end{aligned}$

Election Cycle-to-Date

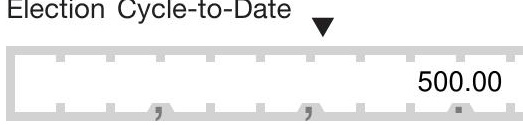

Amount of Each Receipt this Period

Transaction ID : A6A6C41DDC2064D2F861 Date of Receipt
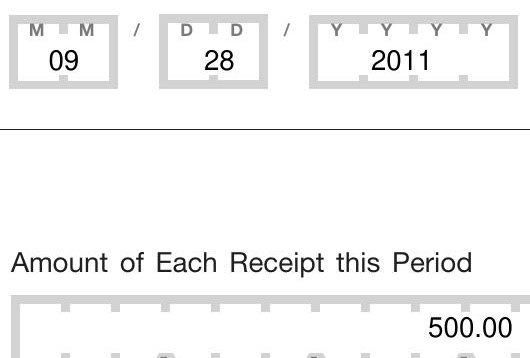

Subtotal Of Receipts This Page (optional)

900.00

Total This Period (last page this line number only) 


\section{SCHEDULE A-P} ITEMIZED RECEIPTS
Use separate schedule(s)

for each category of the

Detailed Summary Page
FOR LINE NUMBER: (check only one)

PAGE 922 / 1572

\begin{tabular}{|c|c|c|c|c|c|}
\hline & & & & & \\
\hline 16 & X $17 a$ & $17 b$ & $17 c$ & $17 d$ & 18 \\
\hline $19 a$ & $19 b$ & $20 \mathrm{a}$ & $20 \mathrm{~b}$ & $20 \mathrm{c}$ & 21 \\
\hline
\end{tabular}

Any information copied from such Reports and Statements may not be sold or used by any person for the purpose of soliciting contributions or for commercial purposes, other than using the name and address of any political committee to solicit contributions from such committee.

NAME OF COMMITTEE (In Full)

Friends of Herman Cain

A. Full Name (Last, First, Middle Initial)

JAMES BRANDEL

Mailing Address 5713 JACK ROAD

\begin{tabular}{lcc}
\hline City & State & Zip Code \\
Jacksonville & FL & $32277-2429$
\end{tabular}

FEC ID number of contributing

federal political committee.

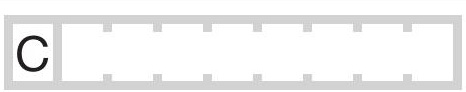

Name of Employer
Information Requested
Receipt For: 2012
X Primary $\quad \square$ General
Other (specify)

Occupation

Information Requested

Election Cycle-to-Date

390.00

B. Full Name (Last, First, Middle Initial)

Robert Cox

Mailing Address 4663 Township Walk

\begin{tabular}{lcc}
\hline City & State & Zip Code \\
Marietta & GA & $30066-1717$ \\
\hline
\end{tabular}

FEC ID number of contributing

federal political committee.

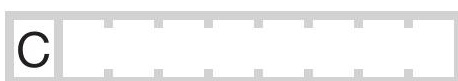

Name of Employer
Information Requested
Receipt For: 2012
X Primary
Other (specify)

Occupation

Information Requested

Election Cycle-to-Date

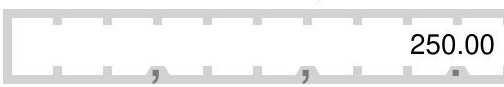

Transaction ID : AFAA2A19081934F44943

Date of Receipt

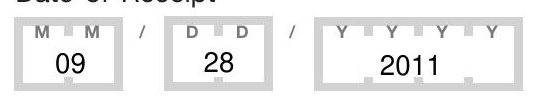

Amount of Each Receipt this Period

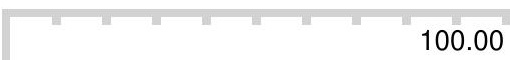

C. Full Name (Last, First, Middle Initial)

Carole Crocker

Mailing Address 1348 SW Bedenbaugh Lane

\begin{tabular}{lcc}
\hline City & State & Zip Code \\
Lake City & FL & $32025-2444$ \\
\hline
\end{tabular}

FEC ID number of contributing

federal political committee.

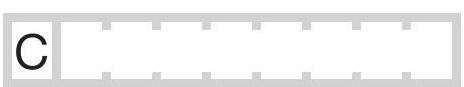

Name of Employer
None
Receipt For: 2012
X Primary $\quad \square$ General
Other (specify)

Occupation

Retired

Election Cycle-to-Date

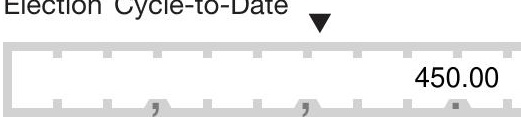

Amount of Each Receipt this Period

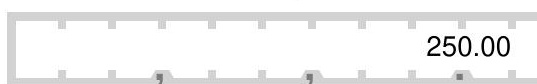

Transaction ID : A58021AFD4D6C43E19BE

Date of Receipt

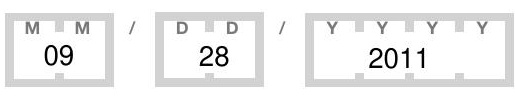

Transaction ID : AE6028F3E1500408E8AD Date of Receipt

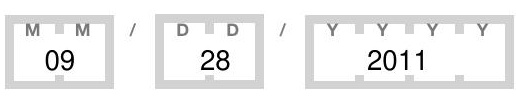

Amount of Each Receipt this Period

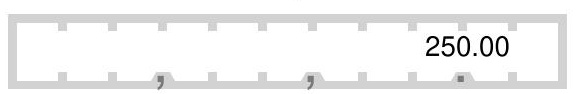

\section{Subtotal Of Receipts This Page (optional)}

600.00

a

Total This Period (last page this line number only)

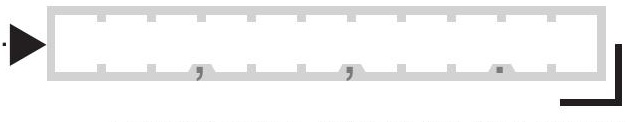

FEC Schedule A-P (Form 3P) (Rev. 03/2011) 
SCHEDULE A-P ITEMIZED RECEIPTS
Use separate schedule(s) for each category of the Detailed Summary Page
FOR LINE NUMBER: (check only one)

PAGE $923 / 1572$

\begin{tabular}{|c|c|c|c|c|c|}
\hline & & & & & \\
\hline 16 & $\begin{array}{lll}X & 17 a \\
\end{array}$ & $17 \mathrm{~b}$ & $17 c$ & $17 d$ & 18 \\
\hline $19 a$ & $19 b$ & $20 a$ & $20 \mathrm{~b}$ & $20 c$ & 21 \\
\hline
\end{tabular}

Any information copied from such Reports and Statements may not be sold or used by any person for the purpose of soliciting contributions or for commercial purposes, other than using the name and address of any political committee to solicit contributions from such committee.

NAME OF COMMITTEE (In Full)

\section{Friends of Herman Cain}

A. Full Name (Last, First, Middle Initial)

Michael McClure

Mailing Address 55 Tristram Way

\begin{tabular}{lcc}
\hline City & State & Zip Code \\
Miramar Beach & FL & $32550-3843$
\end{tabular}

FEC ID number of contributing

federal political committee.

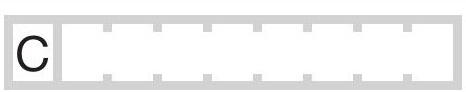

Name of Employer
Information Requested
Receipt For: 2012
X Primary $\quad \square$ General
Other (specify)

Occupation

Information Requested

Election Cycle-to-Date

750.00

B. Full Name (Last, First, Middle Initial)

Jan Petersen

Mailing Address 8951 Lake Dr Apt 503

\begin{tabular}{lcc}
\hline City & State & Zip Code \\
Cape Canaveral & FL & $32920-5504$ \\
\hline
\end{tabular}

FEC ID number of contributing

federal political committee.

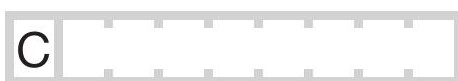

Name of Employer
Information Requested
Receipt For: 2012
X Primary
Other (specify)

Occupation

Information Requested

Election Cycle-to-Date

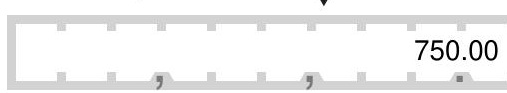

Transaction ID : AC0A78C2FDA724DC384E

Date of Receipt

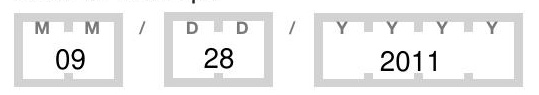

Amount of Each Receipt this Period

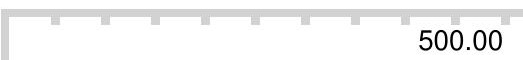

Amount of Each Receipt this Period

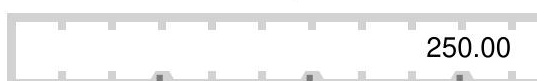

C. Full Name (Last, First, Middle Initial)

Katherine Weiss

Mailing Address 4676 Skyview Drive

\begin{tabular}{lcc}
\hline City & State & Zip Code \\
Glenville & PA & $17329-9275$
\end{tabular}

FEC ID number of contributing federal political committee.

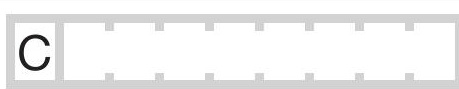

Name of Employer

Information Requested

Occupation

Receipt For: 2012

Х $\begin{aligned} & \text { Primary } \\ & \text { Other (specify) }\end{aligned}$

Information Requested

Election Cycle-to-Date

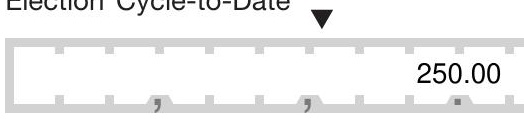

Transaction ID : ABF2F3E9B0A8546B496F

Date of Receipt

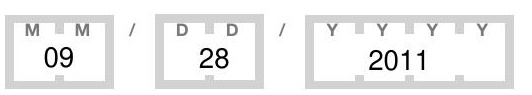

Transaction ID : A87C8F0B37044482D8FC

Date of Receipt

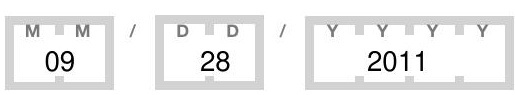

Amount of Each Receipt this Period

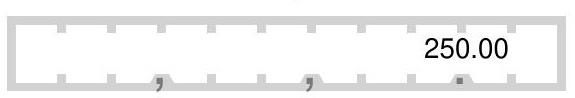

Subtotal Of Receipts This Page (optional).

1000.00

Total This Period (last page this line number only) 
SCHEDULE A-P ITEMIZED RECEIPTS
Use separate schedule(s)

for each category of the

Detailed Summary Page
FOR LINE NUMBER: (check only one)

Any information copied from such Repor or for commercial purposes, other than using the name and address of any political committee to solicit contributions from such committee.

NAME OF COMMITTEE (In Full)

\section{Friends of Herman Cain}

A. Full Name (Last, First, Middle Initial)

Susan Krechel

Mailing Address blackhorsefarm@myway.com

\begin{tabular}{lcc}
\hline City & State & Zip Code \\
Jonesburg & MO & 63351 \\
\hline
\end{tabular}

FEC ID number of contributing

federal political committee.

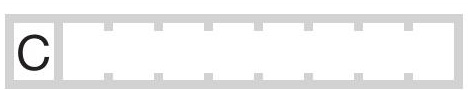

Name of Employer
None
Receipt For: 2012
X Primary $\square$ General
$\square$ Other (specify)

Occupation

Retired

Election Cycle-to-Date

\subsection{0}

B. Full Name (Last, First, Middle Initial)

William Scheifley

Mailing Address 714 Winston Lane

\begin{tabular}{lcc}
\hline City & State & Zip Code \\
Sugar Land & TX & $77479-5835$
\end{tabular}

FEC ID number of contributing

federal political committee.

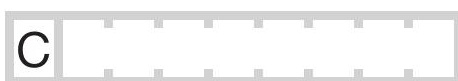

Name of Employer
None
Receipt For: 2012
X Primary
Other (specify)

Occupation

Retired

Election Cycle-to-Date

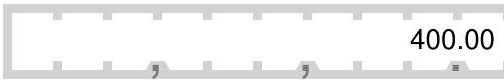

C. Full Name (Last, First, Middle Initial) scott mushkin

Mailing Address 1313 smith ridge rd

\begin{tabular}{l|ll}
\hline $\begin{array}{l}\text { City } \\
\text { New Canaan }\end{array}$ & $\begin{array}{c}\text { State } \\
\text { CT }\end{array}$ & $\begin{array}{c}\text { Zip Code } \\
\text { 06840-2337 }\end{array}$ \\
\hline $\begin{array}{l}\text { FEC ID number of contributing } \\
\text { federal political committee. }\end{array}$ & C & \\
\hline $\begin{array}{l}\text { Name of Employer } \\
\text { Information Requested }\end{array}$ & $\begin{array}{l}\text { Occupation } \\
\text { Information Requested }\end{array}$ \\
$\begin{array}{l}\text { Receipt For: } 2012 \\
\text { Xrimary } \\
\text { Other (specify) }\end{array}$ & Election Cycle-to-Date & \\
\hline
\end{tabular}

Transaction ID : A6FD1F6AD91E74E7CAA4 Date of Receipt

Amount of Each Receipt this Period

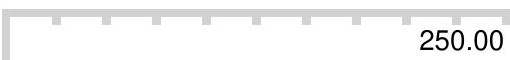

Date of Receipt

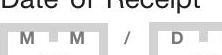

09

28

2011

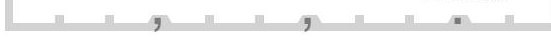

Amount of Each Receipt this Period

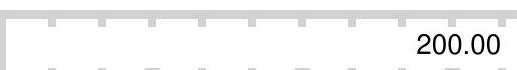

Amount of Each Receipt this Period

Transaction ID : AF6BDBD8CC4A441FB8B8 Date of Receipt
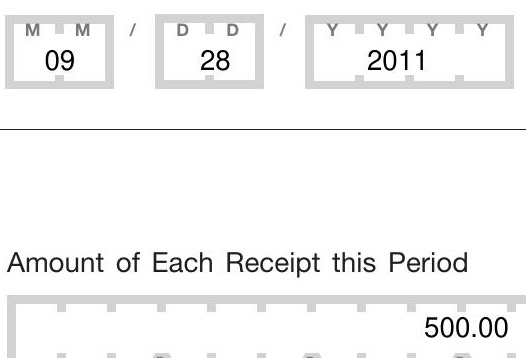

Subtotal Of Receipts This Page (optional)

950.00

Total This Period (last page this line number only) 
SCHEDULE A-P ITEMIZED RECEIPTS
Use separate schedule(s)

for each category of the

Detailed Summary Page
FOR LINE NUMBER: (check only one)

Any information copied from such Repor or for commercial purposes, other than using the name and address of any political committee to solicit contributions from such committee.

NAME OF COMMITTEE (In Full)

\section{Friends of Herman Cain}

A. Full Name (Last, First, Middle Initial) JoAnna Chun

Mailing Address 5244 E. Hamlin PI.

\begin{tabular}{lcc}
\hline City & State & Zip Code \\
Yuma & AZ & $85365-5680$ \\
\hline
\end{tabular}

FEC ID number of contributing federal political committee.

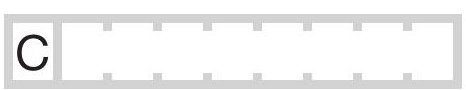

Name of Employer
Aaron Chun MDPC
Receipt For: 2012
X Primary
Other (specify) General

Occupation Bookkeeper Election Cycle-to-Date

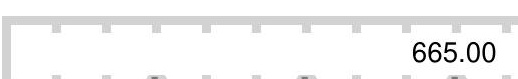

B. Full Name (Last, First, Middle Initial) Joseph Wootten

Mailing Address 159 Weybridge Drive

\begin{tabular}{lcc}
\hline City & State & Zip Code \\
Malvern & PA & $19355-2168$ \\
\hline
\end{tabular}

FEC ID number of contributing

federal political committee.

C

Name of Employer
Unemployed
Receipt For: 2012
X Primary
Other (specify)

\section{Occupation}

Consultant

Election Cycle-to-Date

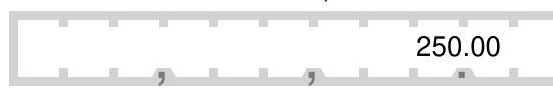

Transaction ID : A78432E6A996F4F7CABB

Date of Receipt

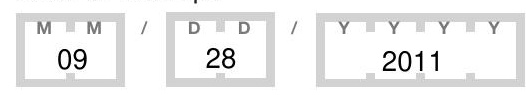

Amount of Each Receipt this Period

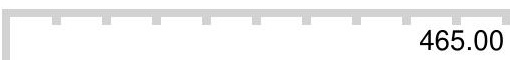

Transaction ID : A202EDEE73B344959B07 Date of Receipt

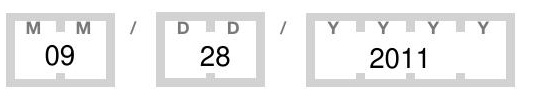

Amount of Each Receipt this Period

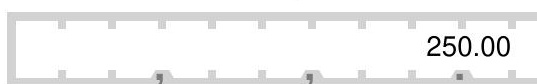

Transaction ID : A07D73F69660C4FEDB4A Date of Receipt

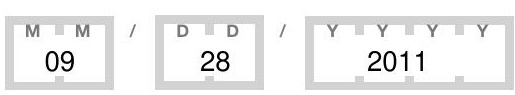

Amount of Each Receipt this Period

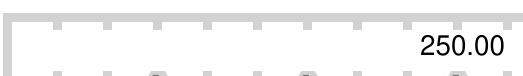

$\begin{array}{cc}\text { State } & \text { Zip Code } \\ \text { GA } & 31502-2008\end{array}$

C

Occupation

Financial Advisor

Election Cycle-to-Date
Subtotal Of Receipts This Page (optional).

965.00

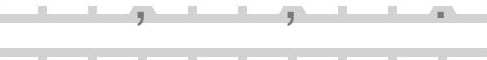

Total This Period (last page this line number only) 
SCHEDULE A-P ITEMIZED RECEIPTS
Use separate schedule(s) for each category of the Detailed Summary Page
FOR LINE NUMBER: (check only one)

PAGE 926 / 1572

\begin{tabular}{|c|c|c|c|c|c|}
\hline & & & & & \\
\hline 16 & $\begin{array}{l}\mathbf{X} \\
17 a\end{array}$ & $17 b$ & $17 c$ & $17 d$ & 18 \\
\hline $19 a$ & $19 \mathrm{~b}$ & $20 \mathrm{a}$ & $20 \mathrm{~b}$ & $20 \mathrm{c}$ & 21 \\
\hline
\end{tabular}

Any information copied from such Reports and Statements may not be sold or used by any person for the purpose of soliciting contributions or for commercial purposes, other than using the name and address of any political committee to solicit contributions from such committee.

NAME OF COMMITTEE (In Full)

\section{Friends of Herman Cain}

A. Full Name (Last, First, Middle Initial)

Mr David A Doyle

Mailing Address 1243 Eagles Flight Way

\begin{tabular}{lcc}
\hline City & State & Zip Code \\
North Port & FL & $34287-4407$
\end{tabular}

FEC ID number of contributing

federal political committee.

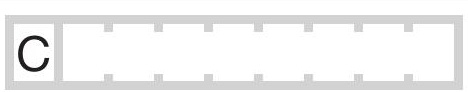

Name of Employer
None
Receipt For: 2012
X Primary $\quad$ General
Other (specify)

Occupation

Retired

Election Cycle-to-Date

250.00

B. Full Name (Last, First, Middle Initial)

ronald westby

Mailing Address 21 west lane ct

\begin{tabular}{lcc}
\hline City & State & Zip Code \\
Dearborn & MI & $48124-1131$
\end{tabular}

FEC ID number of contributing

federal political committee.

C

Name of Employer
Information Requested
Receipt For: 2012
X Primary
Other (specify)

Occupation

Information Requested

Election Cycle-to-Date

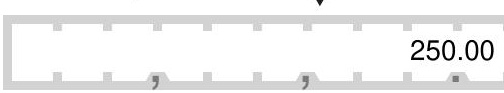

Transaction ID : A6F8C21150DD74855808

Date of Receipt

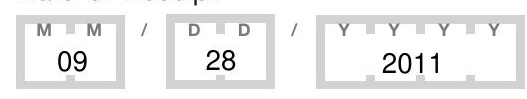

Amount of Each Receipt this Period

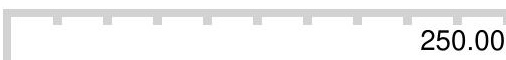

C. Full Name (Last, First, Middle Initial)

Cortland Brown

Mailing Address 1133 Bal Habor Blvd., \#1139

\begin{tabular}{lcc}
\hline City & State & Zip Code \\
Punta Gorda & FL & $33950-6574$
\end{tabular}

FEC ID number of contributing

federal political committee.

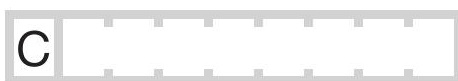

Name of Employer

Remax Harbor Realty

Occupation

Receipt For: 2012

Х $\begin{aligned} & \text { Primary } \\ & \text { Other (specify) }\end{aligned}$

Real Estate

Election Cycle-to-Date

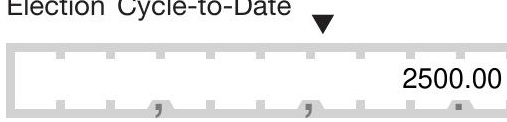

Amount of Each Receipt this Period

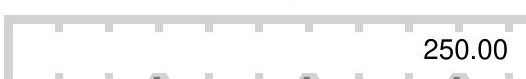

Transaction ID : AD045F3784239418091F

Date of Receipt

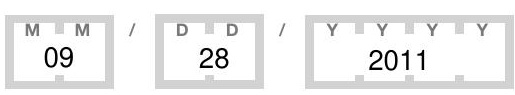

Transaction ID : A41946CAF3FB54372BA7 Date of Receipt

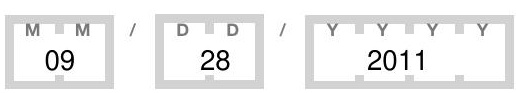

Amount of Each Receipt this Period

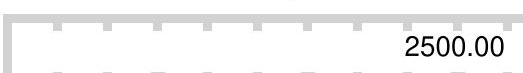

2500.00

\section{Subtotal Of Receipts This Page (optional)}

Total This Period (last page this line number only) 
SCHEDULE A-P ITEMIZED RECEIPTS
Use separate schedule(s) for each category of the Detailed Summary Page
FOR LINE NUMBER: (check only one)

PAGE 927 / 1572

\begin{tabular}{|c|c|c|c|c|c|}
\hline & & & & & \\
\hline 16 & $\begin{array}{l}\mathbf{X} \\
17 a\end{array}$ & $17 b$ & $17 c$ & $17 d$ & 18 \\
\hline $19 a$ & $19 \mathrm{~b}$ & $20 \mathrm{a}$ & $20 \mathrm{~b}$ & $20 \mathrm{c}$ & 21 \\
\hline
\end{tabular}

Any information copied from such Reports and Statements may not be sold or used by any person for the purpose of soliciting contributions or for commercial purposes, other than using the name and address of any political committee to solicit contributions from such committee.

NAME OF COMMITTEE (In Full)

Friends of Herman Cain

A. Full Name (Last, First, Middle Initial)

Steven McClellan

Mailing Address 3890 Sundowner Court

\begin{tabular}{lcc}
\hline City & State & Zip Code \\
Conyers & GA & $30094-3870$ \\
\hline
\end{tabular}

FEC ID number of contributing

federal political committee.

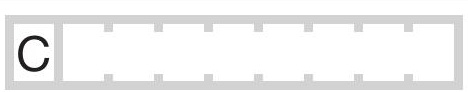

Name of Employer
Information Requested
Receipt For: 2012
X Primary $\quad \square$ General
Other (specify)

Occupation

Information Requested

Election Cycle-to-Date

250.00

B. Full Name (Last, First, Middle Initial)

Lloyd Snively

Mailing Address 2580 Roxburgh Dr

\begin{tabular}{lcc}
\hline City & State & Zip Code \\
Roswell & GA & $30076-2455$ \\
\hline
\end{tabular}

FEC ID number of contributing

federal political committee.

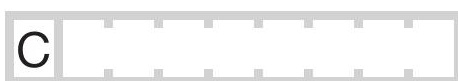

Name of Employer
Coca-Cola Refreshments
Receipt For: 2012
X Primary
Other (specify)

Occupation

Technical Manager

Election Cycle-to-Date

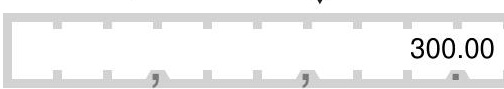

C. Full Name (Last, First, Middle Initial)

Diane Biegel

Mailing Address 2927 Ella Lee Lane

\begin{tabular}{lcc}
\hline City & State & Zip Code \\
Houston & TX & $77019-5907$
\end{tabular}

FEC ID number of contributing

federal political committee.

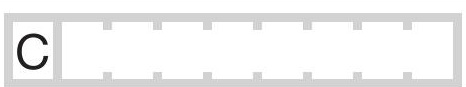

Name of Employer

Information Requested

Occupation

Information Requested

Receipt For: 2012

Х $\begin{aligned} & \text { Primary } \square \text { General } \\ & \text { Other (specify) }\end{aligned}$

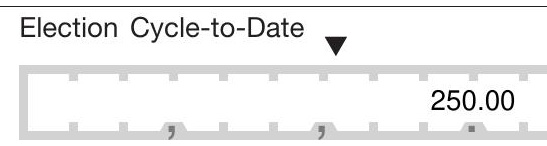

Amount of Each Receipt this Period

Transaction ID : AAB839FD7500F49E1BAB Date of Receipt

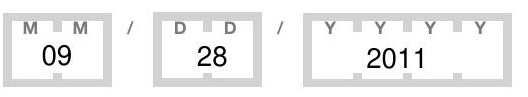

Amount of Each Receipt this Period
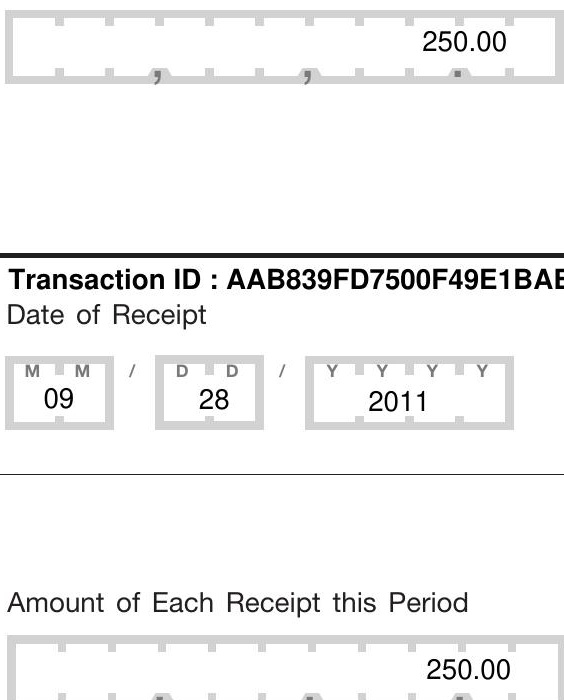

Transaction ID : A93CDA479F410491F940

Date of Receipt

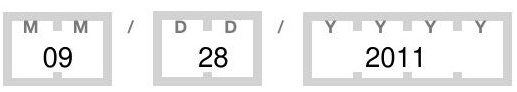

Amount of Each Receipt this Period

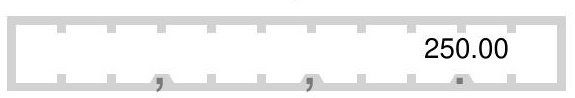

Subtotal Of Receipts This Page (optional).

750.00

Total This Period (last page this line number only) 
SCHEDULE A-P ITEMIZED RECEIPTS
Use separate schedule(s) for each category of the Detailed Summary Page
FOR LINE NUMBER: (check only one)
PAGE 928 / 1572

\begin{tabular}{|c|c|c|c|c|c|}
\hline & & & & & \\
\hline 16 & $\begin{array}{lll}X & 17 a \\
\end{array}$ & $17 \mathrm{~b}$ & $17 c$ & $17 d$ & 18 \\
\hline $19 a$ & $19 b$ & $20 a$ & $20 \mathrm{~b}$ & $20 c$ & 21 \\
\hline
\end{tabular}

Any information copied from such Reports and Statements may not be sold or used by any person for the purpose of soliciting contributions or for commercial purposes, other than using the name and address of any political committee to solicit contributions from such committee.

NAME OF COMMITTEE (In Full)

\section{Friends of Herman Cain}

A. Full Name (Last, First, Middle Initial) Joseph Russell

Mailing Address 3100 Saddleback Mtn. Rd.

\begin{tabular}{lcc}
\hline City & State & Zip Code \\
Marietta & GA & $30062-1342$
\end{tabular}

FEC ID number of contributing federal political committee.

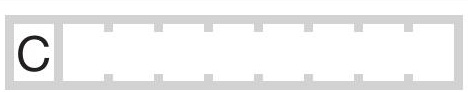

Name of Employer
Retired
Receipt For: 2012
X Primary $\quad$ General
Other (specify)

Occupation Information Requested

Election Cycle-to-Date

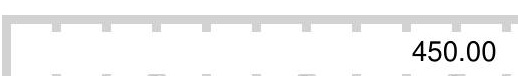

B. Full Name (Last, First, Middle Initial) michael eberly

Mailing Address 9912 frost creek dr

\begin{tabular}{lcc}
\hline City & State & Zip Code \\
Ooltewah & TN & $37363-9314$
\end{tabular}

FEC ID number of contributing

federal political committee.

C

Name of Employer
Information Requested
Receipt For: 2012
X Primary
Other (specify)

\section{Occupation}

Information Requested

Election Cycle-to-Date

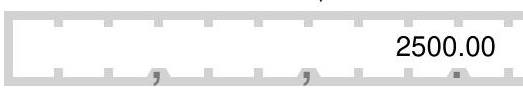

C. Full Name (Last, First, Middle Initial)

Cathy Coggin

Mailing Address 7956 Vaughn Road 363

\begin{tabular}{lcc}
\hline City & State & Zip Code \\
Pike Road & AL & 36064 \\
\hline
\end{tabular}

FEC ID number of contributing federal political committee.

C

Name of Employer
Information Requested
Receipt For: 2012
X Primary
Other (specify) General

\section{Occupation}

Information Requested

Election Cycle-to-Date

Transaction ID : AED505313644A4A1E9F6

Date of Receipt

Amount of Each Receipt this Period

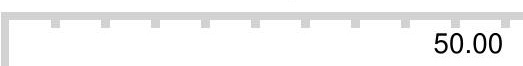

50.00

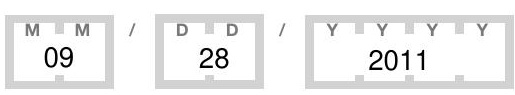

Amount of Each Receipt this Period

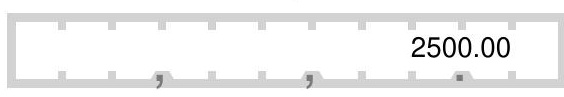

Transaction ID : A62A0A20F93ED4C7CA71 Date of Receipt

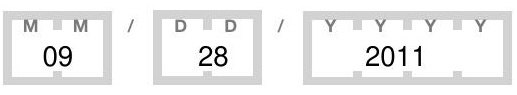

Amount of Each Receipt this Period

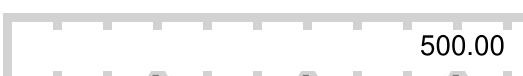

500.00

\section{Subtotal Of Receipts This Page (optional)}

3050.00

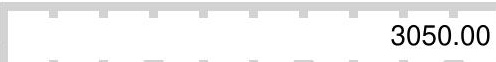

․․․․

Total This Period (last page this line number only) 
SCHEDULE A-P ITEMIZED RECEIPTS
Use separate schedule(s)

for each category of the

Detailed Summary Page
FOR LINE NUMBER: (check only one)

Any information copied from such Repor or for commercial purposes, other than using the name and address of any political committee to solicit contributions from such committee.

NAME OF COMMITTEE (In Full)

\section{Friends of Herman Cain}

A. Full Name (Last, First, Middle Initial)

Thomas Wilkinson

Mailing Address 2026 Sumter St. Nw

\begin{tabular}{lcc}
\hline City & State & Zip Code \\
Atlanta & GA & $30318-2036$ \\
\hline
\end{tabular}

FEC ID number of contributing

federal political committee.

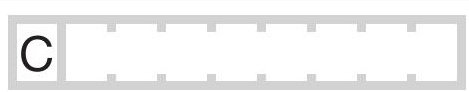

Name of Employer
self
Receipt For: 2012
X Primary $\quad$ General
Other (specify)

Occupation

Retired

Election Cycle-to-Date

\subsection{0}

B. Full Name (Last, First, Middle Initial)

D. Russell Vaughn

Mailing Address P.O. Box 568

\begin{tabular}{lcc}
\hline City & State & Zip Code \\
Bolingbroke & GA & $31004-0568$ \\
\hline
\end{tabular}

FEC ID number of contributing

federal political committee.

C

Name of Employer
Information Requested
Receipt For: 2012
X Primary
Other (specify)

Occupation

Information Requested

Election Cycle-to-Date

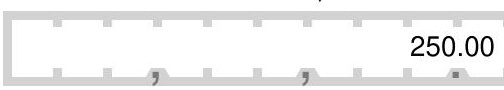

Transaction ID : A66CAF669887A4C84B5D

Date of Receipt

Amount of Each Receipt this Period
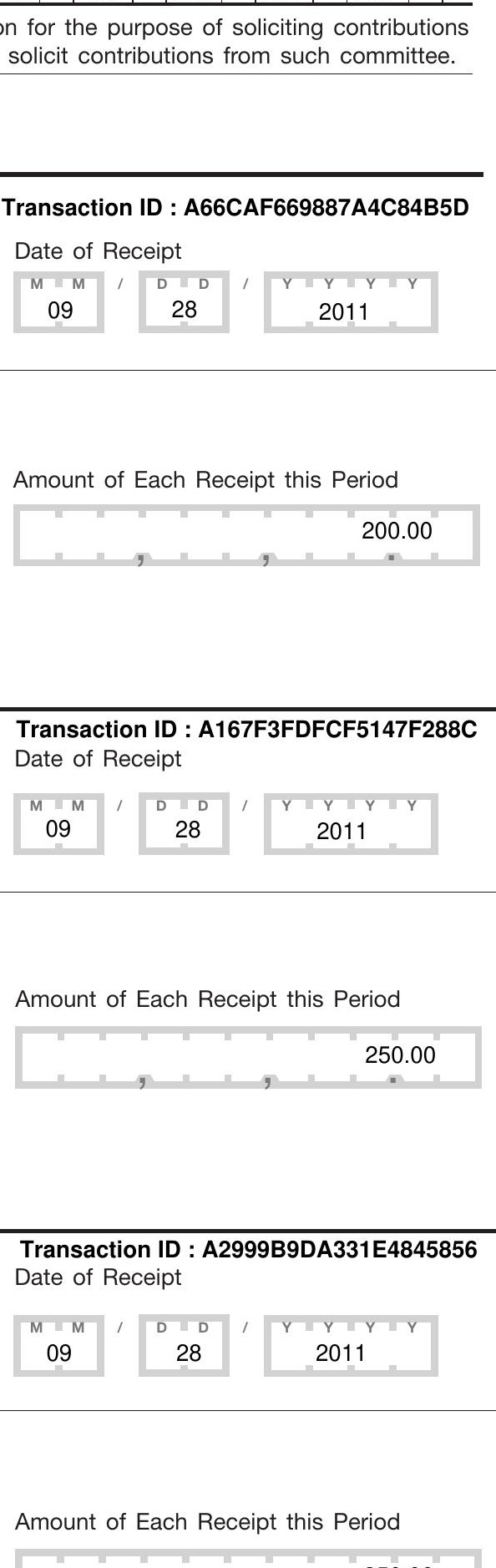

C. Full Name (Last, First, Middle Initial)

steven hoke

Mailing Address 11909 73rd Place NE

\begin{tabular}{lcc}
\hline City & State & Zip Code \\
Kirkland & WA & $98034-2429$
\end{tabular}

FEC ID number of contributing

federal political committee.

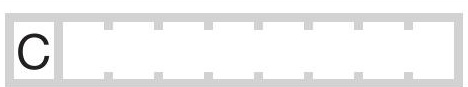

Name of Employer

Information Requested

Occupation

Information Requested

Receipt For: 2012

Х $\begin{aligned} & \text { Primary } \\ & \text { Other (specify) }\end{aligned}$

Election Cycle-to-Date

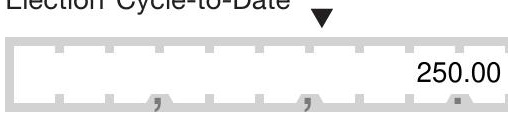

Amount of Each Receipt this Period

Transaction ID : A167F3FDFCF5147F288C

Date of Receipt
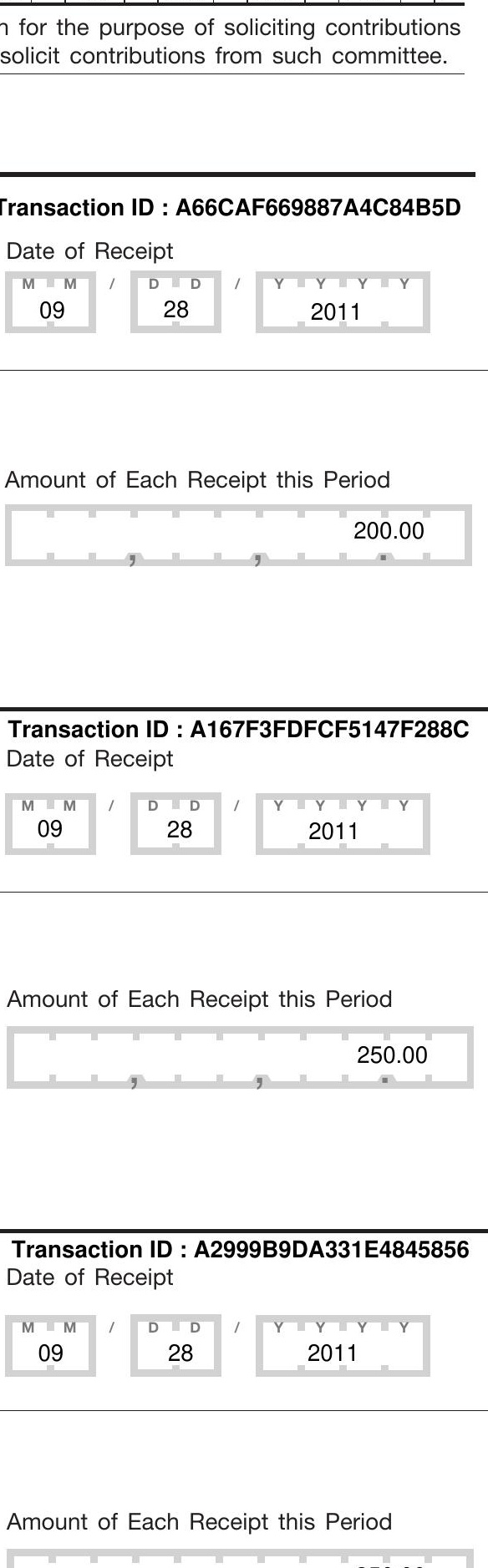

Transaction ID : A2999B9DA331E4845856

Date of Receipt

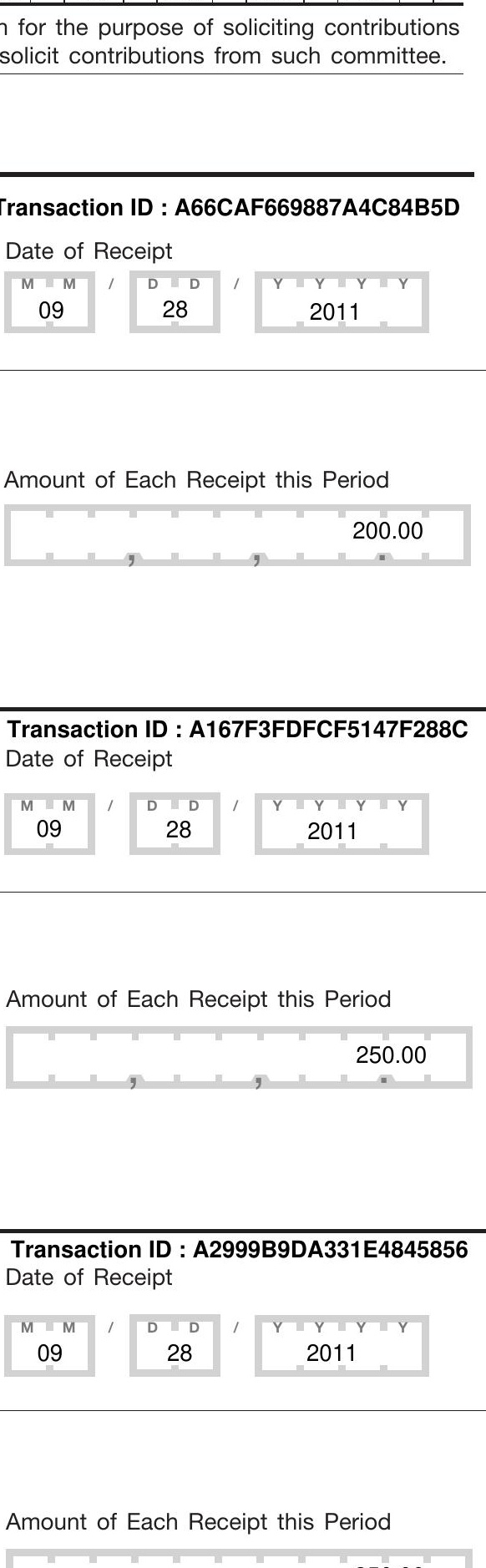

Amount of Each Receipt this Period

Subtotal Of Receipts This Page (optional)

Total This Period (last page this line number only) 
SCHEDULE A-P ITEMIZED RECEIPTS
Use separate schedule(s) for each category of the Detailed Summary Page
FOR LINE NUMBER: (check only one)

PAGE $930 / 1572$

\begin{tabular}{|c|c|c|c|c|c|}
\hline & & & & & \\
\hline 16 & $\begin{array}{l}\mathbf{X} \\
17 a\end{array}$ & $17 b$ & $17 c$ & $17 d$ & 18 \\
\hline $19 a$ & $19 \mathrm{~b}$ & $20 \mathrm{a}$ & $20 \mathrm{~b}$ & $20 \mathrm{c}$ & 21 \\
\hline
\end{tabular}

Any information copied from such Reports and Statements may not be sold or used by any person for the purpose of soliciting contributions or for commercial purposes, other than using the name and address of any political committee to solicit contributions from such committee.

NAME OF COMMITTEE (In Full)

\section{Friends of Herman Cain}

A. Full Name (Last, First, Middle Initial)

\section{Gary Levinson}

Mailing Address 610 Singing Hills Rd

\begin{tabular}{lcc}
\hline City & State & Zip Code \\
Parker & CO & $80138-4650$
\end{tabular}

FEC ID number of contributing federal political committee.

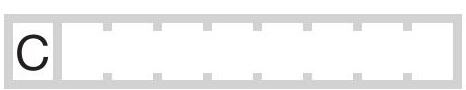

Name of Employer
Information Requested
Receipt For: 2012
X Primary
Other (specify) General

Occupation Information Requested

Election Cycle-to-Date

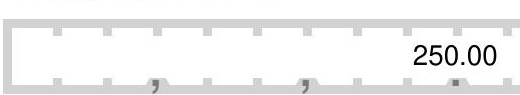

Transaction ID : ABA63AD83DC784471A7D

Date of Receipt

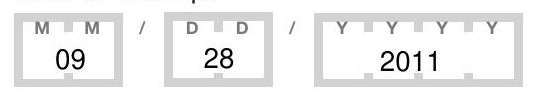

Amount of Each Receipt this Period

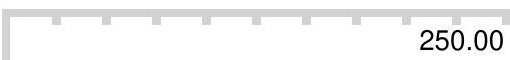

250.00
B. Full Name (Last, First, Middle Initial)

Griffith Harlow

Mailing Address 142 Orchard Park Dr

\begin{tabular}{lcc}
\hline City & State & Zip Code \\
Advance & NC & $27006-7474$
\end{tabular}

FEC ID number of contributing

federal political committee.

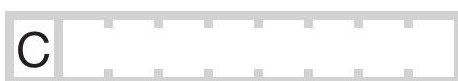

Name of Employer
None
Receipt For: 2012
X Primary
Other (specify)

\section{Occupation}

Retired

Election Cycle-to-Date

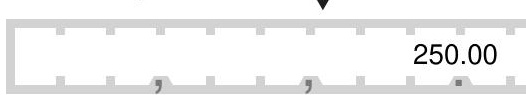

C. Full Name (Last, First, Middle Initial)

quentin ryan

Mailing Address 57 Osborn Rd

\begin{tabular}{lcc}
\hline City & State & Zip Code \\
Litchfield & CT & $06759-2319$
\end{tabular}

FEC ID number of contributing federal political committee.

C

06759-2319

Name of Employer
Self Employed
Receipt For: 2012
X Primary
Other (specify) General

Occupation

Private Investor

Election Cycle-to-Date

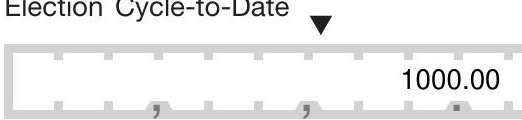

Transaction ID : AC9832E867F2C40439DB

Date of Receipt

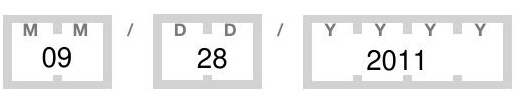

Amount of Each Receipt this Period

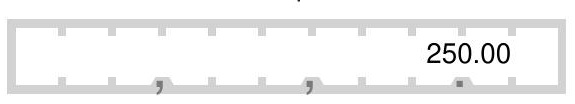

Transaction ID : AA4E9B48C2C6D41DD9DE Date of Receipt

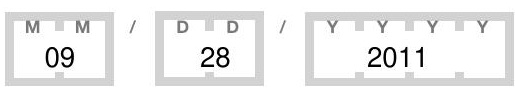

Amount of Each Receipt this Period

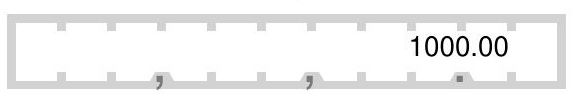

1500.00

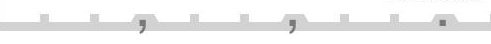

Total This Period (last page this line number only)

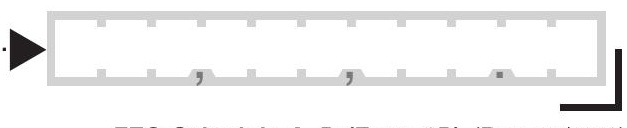

FEC Schedule A-P (Form 3P) (Rev. 03/2011) 
SCHEDULE A-P ITEMIZED RECEIPTS
Use separate schedule(s) for each category of the Detailed Summary Page
FOR LINE NUMBER: (check only one)

PAGE $931 / 1572$

\begin{tabular}{|c|c|c|c|c|c|}
\hline & & & & & \\
\hline 16 & $\begin{array}{l}\mathbf{X} \\
17 a\end{array}$ & $17 b$ & $17 c$ & $17 d$ & 18 \\
\hline $19 a$ & $19 \mathrm{~b}$ & $20 \mathrm{a}$ & $20 \mathrm{~b}$ & $20 \mathrm{c}$ & 21 \\
\hline
\end{tabular}

Any information copied from such Reports and Statements may not be sold or used by any person for the purpose of soliciting contributions or for commercial purposes, other than using the name and address of any political committee to solicit contributions from such committee.

NAME OF COMMITTEE (In Full)

\section{Friends of Herman Cain}

A. Full Name (Last, First, Middle Initial)

\section{David Wills}

Mailing Address 6308 Pratt Dr

\begin{tabular}{lcc}
\hline City & State & Zip Code \\
New Orleans & LA & $70122-2823$
\end{tabular}

FEC ID number of contributing federal political committee.

Name of Employer
United Medical Providers
Receipt For: 2012
X Primary
$\square$ Other (specify)

B. Full Name (Last, First, Middle Initial) john sturm

Mailing Address 179 euclid ave.

\begin{tabular}{lcc}
\hline City & State & Zip Code \\
Ponte Vedra Beach & FL & 32082 \\
\hline
\end{tabular}

FEC ID number of contributing

federal political committee.

\begin{tabular}{l} 
Name of Employer \\
Information Requested \\
Receipt For: 2012 \\
X Primary \\
\hline Other (specify)
\end{tabular}

C. Full Name (Last, First, Middle Initial)

Lance Richmond

Mailing Address 215 S Juanita Ave \# A

\begin{tabular}{l|ll}
\hline $\begin{array}{l}\text { City } \\
\text { Redondo Beach }\end{array}$ & $\begin{array}{c}\text { State } \\
\text { CA }\end{array}$ & $\begin{array}{c}\text { Zip Code } \\
90277-3439\end{array}$ \\
\hline $\begin{array}{l}\text { FEC ID number of contributing } \\
\text { federal political committee. }\end{array}$ & C \\
\hline $\begin{array}{l}\text { Name of Employer } \\
\text { self }\end{array}$ & $\begin{array}{l}\text { Occupation } \\
\text { Consultant }\end{array}$ \\
\hline $\begin{array}{l}\text { Receipt For: } 2012 \\
\text { Primary } \\
\text { Other (specify) }\end{array}$ & Election Cycle-to-Date & \\
\hline
\end{tabular}

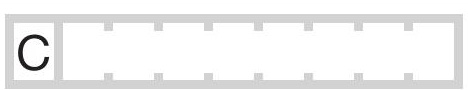

C

Transaction ID : A1E740B9824AA4D56AFF

Date of Receipt

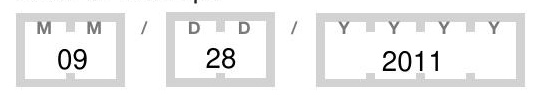

Amount of Each Receipt this Period

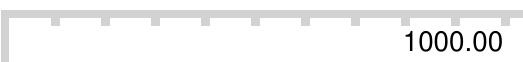

President

Election Cycle-to-Date

1000.00

Occupation

Information Requested

Election Cycle-to-Date

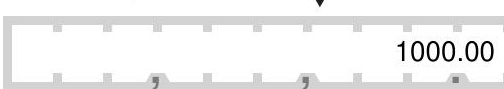

Transaction ID : A0A20898EA4D54D409D2

Date of Receipt

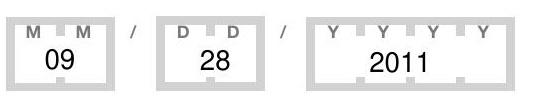

Amount of Each Receipt this Period

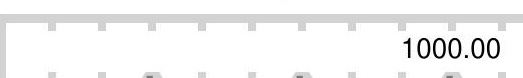

Amount of Each Receipt this Period

Transaction ID : AB6ACF18BF89A4CC5AFE Date of Receipt
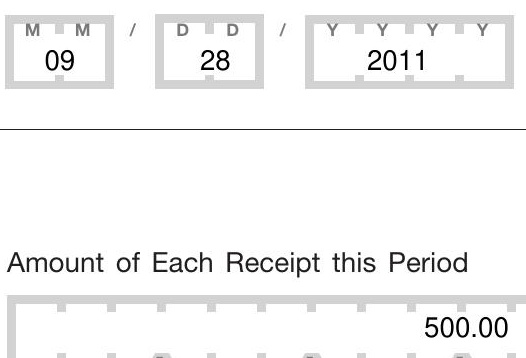

2500.00

Subtotal Of Receipts This Page (optional)

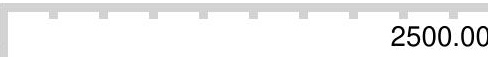

Total This Period (last page this line number only) 


\section{SCHEDULE A-P} ITEMIZED RECEIPTS
Use separate schedule(s) for each category of the Detailed Summary Page

FOR LINE NUMBER:
(check only one)

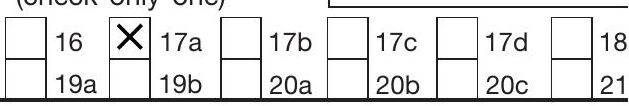

Any information copied from such Reports and Statements may not be sold or used by any person for the purpose of soliciting contributions or for commercial purposes, other than using the name and address of any political committee to solicit contributions from such committee.

NAME OF COMMITTEE (In Full)

\section{Friends of Herman Cain}

A. Full Name (Last, First, Middle Initial)

Alan Sommer

Mailing Address 16009 Deepwood Place

\begin{tabular}{lcc}
\hline City & State & Zip Code \\
Indian Trail & NC & $28079-4110$
\end{tabular}

FEC ID number of contributing federal political committee.

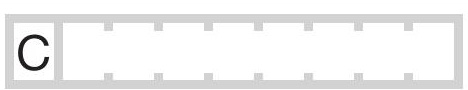

Name of Employer
Invensys Systems Inc.
Receipt For: 2012
X Primary
Other (specify)

\section{Occupation}

Technical Sales

Election Cycle-to-Date

\subsection{0}

B. Full Name (Last, First, Middle Initial)

Patricia Thoman

Mailing Address 2012 Armstrong Mill Rd

\begin{tabular}{lcc}
\hline City & State & Zip Code \\
Franklin & GA & $30217-3751$ \\
\hline
\end{tabular}

FEC ID number of contributing

federal political committee.

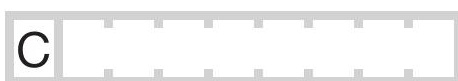

Name of Employer
None
Receipt For: 2012
X Primary $\quad$ General
Other (specify)

\section{Occupation}

Retired

Election Cycle-to-Date

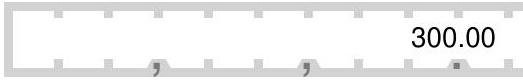

Transaction ID : A2EFD4CB2F51F4BCE951

Date of Receipt

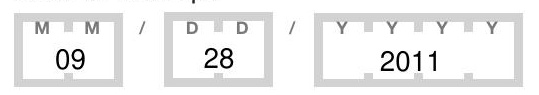

Amount of Each Receipt this Period

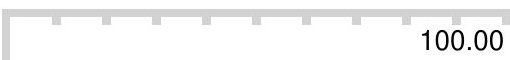

100.00
Amount of Each Receipt this Period

Transaction ID : ADAE44D2F23B94B45AD4 Date of Receipt
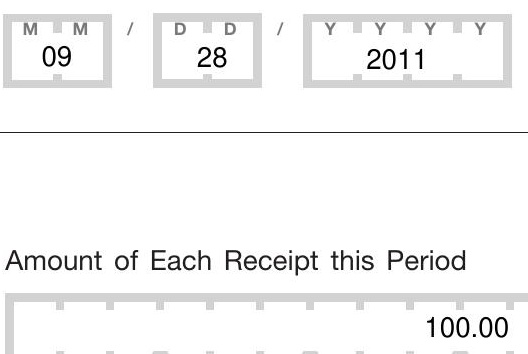

C. Full Name (Last, First, Middle Initial)

Jeffrey Winslow

Mailing Address PO Box 130504

\begin{tabular}{lcc}
\hline City & State & Zip Code \\
Carlsbad & CA & $92013-0504$ \\
\hline
\end{tabular}

FEC ID number of contributing federal political committee.

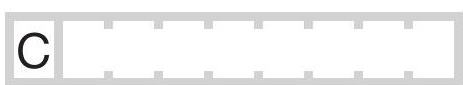

Name of Employer

Information Requested

Occupation

Information Requested

Receipt For: 2012

Х $\begin{aligned} & \text { Primary } \square \text { General } \\ & \text { Other (specify) }\end{aligned}$

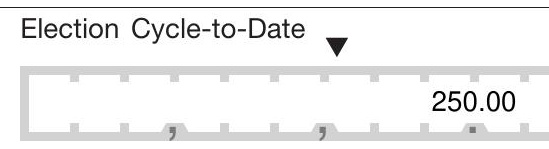

Transaction ID : A6D7E97F4EE834DD59CB Date of Receipt

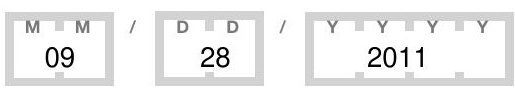

Amount of Each Receipt this Period

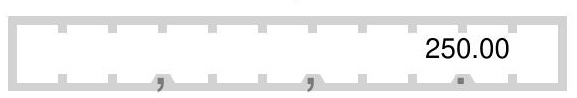

Subtotal Of Receipts This Page (optional)

Total This Period (last page this line number only) 
SCHEDULE A-P ITEMIZED RECEIPTS
Use separate schedule(s) for each category of the Detailed Summary Page
FOR LINE NUMBER: (check only one)

PAGE $933 / 1572$

\begin{tabular}{|c|c|c|c|c|c|}
\hline & & & & & \\
\hline 16 & $\begin{array}{l}\mathbf{X} \\
17 a\end{array}$ & $17 b$ & $17 c$ & $17 d$ & 18 \\
\hline $19 a$ & $19 \mathrm{~b}$ & $20 \mathrm{a}$ & $20 \mathrm{~b}$ & $20 \mathrm{c}$ & 21 \\
\hline
\end{tabular}

Any information copied from such Reports and Statements may not be sold or used by any person for the purpose of soliciting contributions or for commercial purposes, other than using the name and address of any political committee to solicit contributions from such committee.

NAME OF COMMITTEE (In Full)

\section{Friends of Herman Cain}

A. Full Name (Last, First, Middle Initial)

kirk Lincoln

Mailing Address 891 los molinos

\begin{tabular}{lcc}
\hline City & State & Zip Code \\
Sacramento & CA & $95864-5251$
\end{tabular}

FEC ID number of contributing federal political committee.

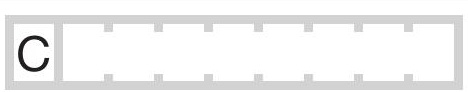

Name of Employer
Information Requested
Receipt For: 2012
X Primary
Other (specify) General

Occupation Information Requested

Election Cycle-to-Date

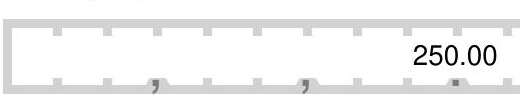

B. Full Name (Last, First, Middle Initial) John Hoerner

Mailing Address 8225 E 550 S

\begin{tabular}{lcc}
\hline City & State & Zip Code \\
Zionsville & IN & $46077-8609$
\end{tabular}

FEC ID number of contributing

federal political committee.

C

Name of Employer
Information Requested
Receipt For: 2012
Xrimary
Other (specify)

Occupation

Information Requested

Election Cycle-to-Date

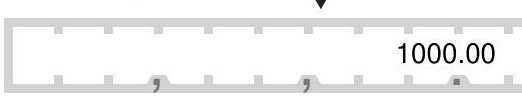

Transaction ID : A82B433C670994FF0BA2

Date of Receipt

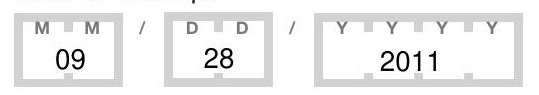

Amount of Each Receipt this Period

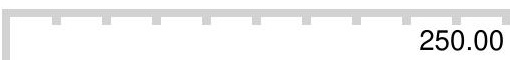

Amount of Each Receipt this Period

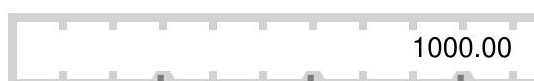

C. Full Name (Last, First, Middle Initial)

Mr Don Adams

Mailing Address 818 Jeff Davis $\mathrm{Dr}$

\begin{tabular}{lcc}
\hline City & State & Zip Code \\
Tyler & TX & $75703-5510$
\end{tabular}

FEC ID number of contributing federal political committee.

C

Name of Employer
Kouse Energy \& Equipment
Receipt For: 2012
X Primary
Other (specify) General

Occupation

Sales Rep

Election Cycle-to-Date

Transaction ID : A3FD4BCB15C6349B6A1C Date of Receipt

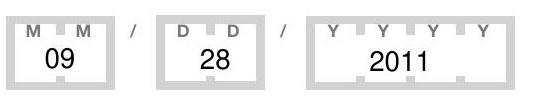

Transaction ID : A94DB46A3BEAA46F8927 Date of Receipt

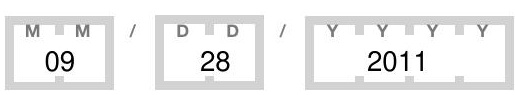

Amount of Each Receipt this Period

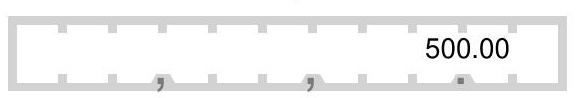

500.00

\section{Subtotal Of Receipts This Page (optional)}

Total This Period (last page this line number only) 
SCHEDULE A-P ITEMIZED RECEIPTS
Use separate schedule(s) for each category of the Detailed Summary Page
FOR LINE NUMBER: (check only one)

PAGE 934 / 1572

\begin{tabular}{|c|c|c|c|c|c|}
\hline & & & & & \\
\hline 16 & $\begin{array}{l}\mathbf{X} \\
17 a\end{array}$ & $17 b$ & $17 c$ & $17 d$ & 18 \\
\hline $19 a$ & $19 \mathrm{~b}$ & $20 \mathrm{a}$ & $20 \mathrm{~b}$ & $20 \mathrm{c}$ & 21 \\
\hline
\end{tabular}

Any information copied from such Reports and Statements may not be sold or used by any person for the purpose of soliciting contributions or for commercial purposes, other than using the name and address of any political committee to solicit contributions from such committee.

NAME OF COMMITTEE (In Full)

\section{Friends of Herman Cain}

A. Full Name (Last, First, Middle Initial) coy wehunt

Mailing Address 183 crystal springs rd

\begin{tabular}{lcc}
\hline City & State & Zip Code \\
Homer & GA & $30547-1673$
\end{tabular}

FEC ID number of contributing federal political committee.

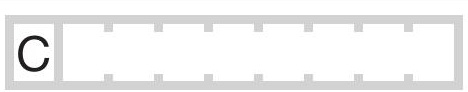

Name of Employer
Self Employed
Receipt For: 2012
X Primary $\quad$ General
Other (specify)

Occupation

Exterminator

Election Cycle-to-Date

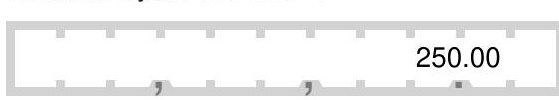

B. Full Name (Last, First, Middle Initial)

Steve Umansky

\section{Mailing Address 113 Stirling Lane}

\begin{tabular}{lcc}
\hline City & State & Zip Code \\
Versailles & KY & $40383-9270$ \\
\hline
\end{tabular}

FEC ID number of contributing

federal political committee.

C

Name of Employer
Information Requested
Receipt For: 2012
Primary
Other (specify)

\section{Occupation}

Information Requested

Election Cycle-to-Date

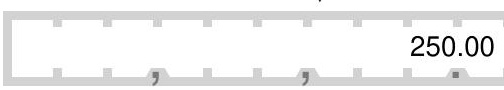

Transaction ID : A1CE7C52FD836447DA27

Date of Receipt

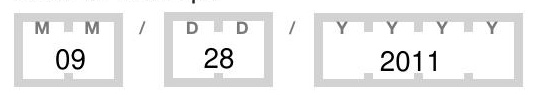

Amount of Each Receipt this Period

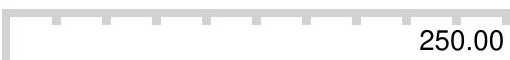

250.00

C. Full Name (Last, First, Middle Initial)

Brock Oliverio

Mailing Address RR 3 Box 224-2

\begin{tabular}{lcc}
\hline City & State & Zip Code \\
Bridgeport & WV & $26330-9430$
\end{tabular}

FEC ID number of contributing federal political committee.

C

Name of Employer

United Hospital Center

Occupation

Receipt For: 2012

Х $\begin{aligned} & \text { Primary } \square \text { General } \\ & \text { Other (specify) }\end{aligned}$

Physician

Election Cycle-to-Date

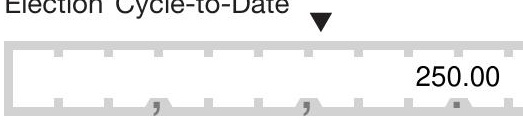

Amount of Each Receipt this Period

Amount of Each Receipt this Period

Transaction ID : A480BFB186ADE47A4A16

Date of Receipt
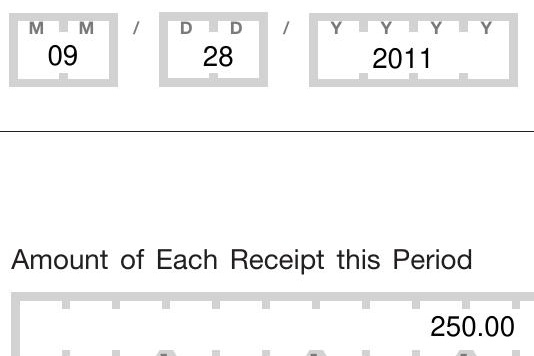

Transaction ID : A22ED7862CB2E44949AC Date of Receipt
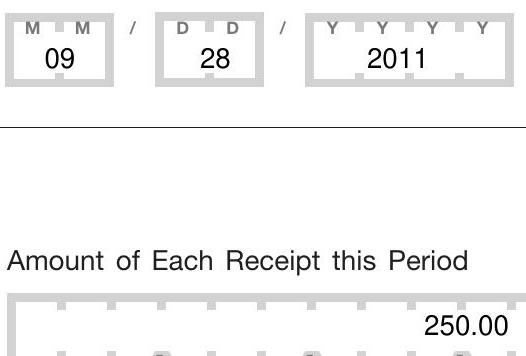

Subtotal Of Receipts This Page (optional).

Total This Period (last page this line number only) 
SCHEDULE A-P ITEMIZED RECEIPTS
Use separate schedule(s) for each category of the Detailed Summary Page
FOR LINE NUMBER: (check only one)
PAGE 935 / 1572

\begin{tabular}{|c|c|c|c|c|c|}
\hline & & & & & \\
\hline 16 & $\begin{array}{lll}X & 17 a \\
\end{array}$ & $17 \mathrm{~b}$ & $17 c$ & $17 d$ & 18 \\
\hline $19 a$ & $19 b$ & $20 a$ & $20 \mathrm{~b}$ & $20 c$ & 21 \\
\hline
\end{tabular}

Any information copied from such Reports and Statements may not be sold or used by any person for the purpose of soliciting contributions or for commercial purposes, other than using the name and address of any political committee to solicit contributions from such committee.

NAME OF COMMITTEE (In Full)

\section{Friends of Herman Cain}

A. Full Name (Last, First, Middle Initial)

Philip Porter

Mailing Address 6255 Courtside Drive

\begin{tabular}{lcc}
\hline City & State & Zip Code \\
Norcross & GA & $30092-4524$ \\
\hline
\end{tabular}

FEC ID number of contributing

federal political committee.

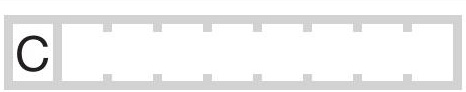

Name of Employer
BellSouth
Receipt For: 2012
X Primary $\quad$ General
Other (specify)

Occupation

Retired

Election Cycle-to-Date

500.00

B. Full Name (Last, First, Middle Initial)

David Zehrer

Mailing Address 715 University $\mathrm{Dr}$

\begin{tabular}{lcc}
\hline City & State & Zip Code \\
Woodland Park & CO & $80863-8826$ \\
\hline
\end{tabular}

FEC ID number of contributing

federal political committee.

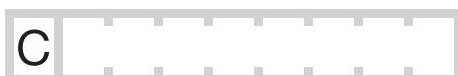

Name of Employer
None
Receipt For: 2012
X Primary
Other (specify)

\section{Occupation}

Retired (Military)

Election Cycle-to-Date

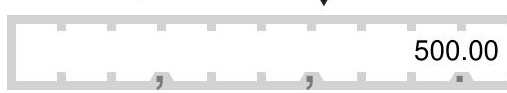

Transaction ID : AA30F24582BFA4F8EAD6

Date of Receipt

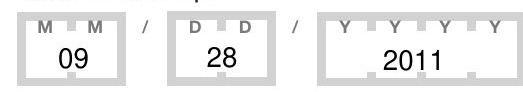

Amount of Each Receipt this Period

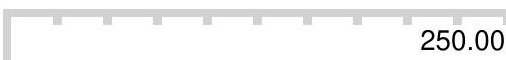

Amount of Each Receipt this Period

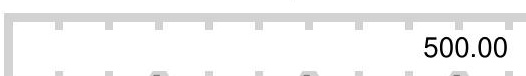

C. Full Name (Last, First, Middle Initial)

Stuckey Mclntosh

Mailing Address One Baltimore Place NW Suite 140

\begin{tabular}{lcc}
\hline City & State & Zip Code \\
Atlanta & GA & $30308-2118$
\end{tabular}

FEC ID number of contributing

federal political committee.

C

30308-2118

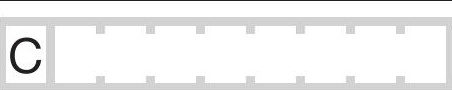

Name of Employer

Occupation

Recon Aeronautics, LLC

Engineer

Receipt For: 2012

Х $\begin{aligned} & \text { Primary } \square \text { General } \\ & \text { Other (specify) }\end{aligned}$

Election Cycle-to-Date

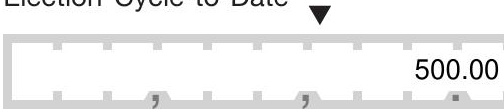

Transaction ID : AD40E9A3E544B444BBA4

Date of Receipt

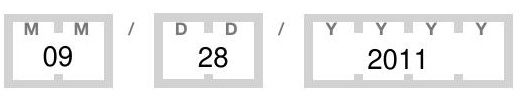

Transaction ID : A1541B11077F545BA84D

Date of Receipt

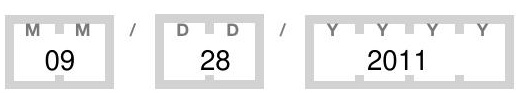

Amount of Each Receipt this Period

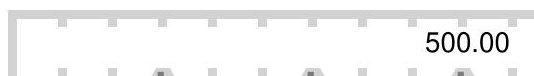

1250.00

Subtotal Of Receipts This Page (optional)

(1)

Total This Period (last page this line number only) 


\section{SCHEDULE A-P} ITEMIZED RECEIPTS
Use separate schedule(s)

for each category of the

Detailed Summary Page
FOR LINE NUMBER: (check only one)

PAGE 936 / 1572

\begin{tabular}{|c|c|c|c|c|c|}
\hline & & & & & \\
\hline 16 & X $17 a$ & $17 b$ & $17 c$ & $17 d$ & 18 \\
\hline $19 a$ & $19 b$ & $20 \mathrm{a}$ & $20 \mathrm{~b}$ & $20 \mathrm{c}$ & 21 \\
\hline
\end{tabular}

Any information copied from such Reports and Statements may not be sold or used by any person for the purpose of soliciting contributions or for commercial purposes, other than using the name and address of any political committee to solicit contributions from such committee.

NAME OF COMMITTEE (In Full)

Friends of Herman Cain

A. Full Name (Last, First, Middle Initial)

Tamie Peters

Mailing Address 23 Seawatch Dr

\begin{tabular}{lcc}
\hline City & State & Zip Code \\
Savannah & GA & $31411-2600$
\end{tabular}

FEC ID number of contributing federal political committee.

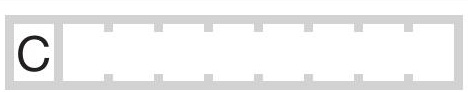

Name of Employer
Information Requested
Receipt For: 2012
X Primary
Other (specify) General

Occupation

Information Requested

Election Cycle-to-Date

250.00

B. Full Name (Last, First, Middle Initial)

Bruce Calhoun

Mailing Address 306 Cedar Ridge Way

\begin{tabular}{lcc}
\hline City & State & Zip Code \\
Durham & NC & $27705-1983$ \\
\hline
\end{tabular}

FEC ID number of contributing

federal political committee.

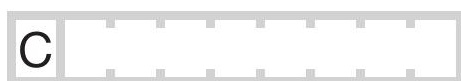

Name of Employer
None
Receipt For: 2012
X Primary
Other (specify)

Occupation

Retired

Election Cycle-to-Date

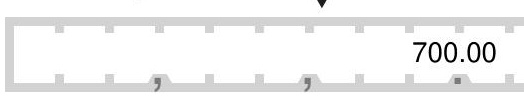

Transaction ID : A08293C05566946DAB42

Date of Receipt

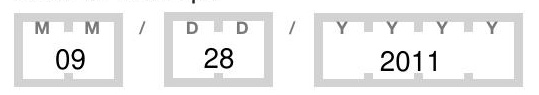

Amount of Each Receipt this Period

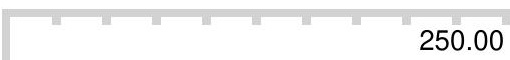

Transaction ID : A3BFA479223464AFF9FD

Date of Receipt

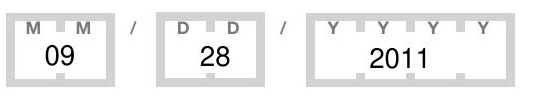

Amount of Each Receipt this Period

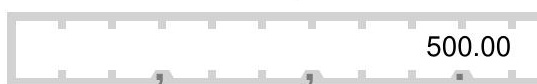

Transaction ID : A98990253C3614B2880A

Date of Receipt

Pat Montgomery

Mailing Address 4035 Dollar Circle

\begin{tabular}{lcc}
\hline City & State & Zip Code \\
Suwanee & GA & $30024-2360$
\end{tabular}

FEC ID number of contributing

federal political committee.

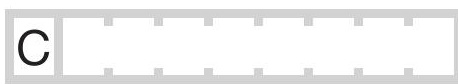

Name of Employer

MQEI Inc.

Occupation

Consultant

Receipt For: 2012

X $\underset{\text { Other (specify) }}{\square}$ General
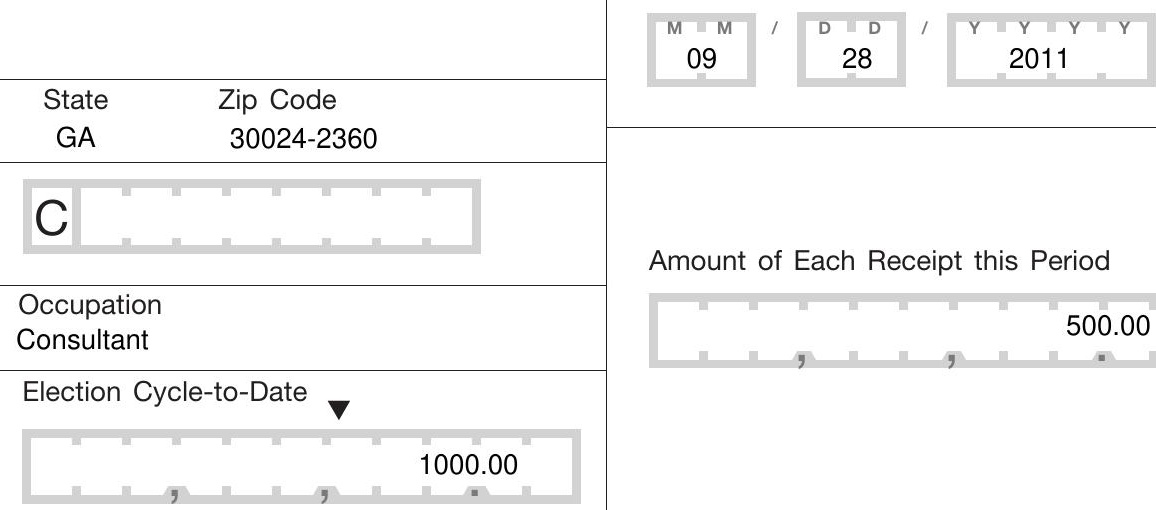

Amount of Each Receipt this Period

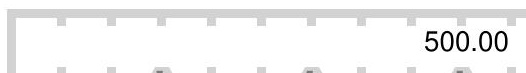

1250.00

Subtotal Of Receipts This Page (optional)

(1)

Total This Period (last page this line number only) 
SCHEDULE A-P ITEMIZED RECEIPTS
Use separate schedule(s) for each category of the Detailed Summary Page
FOR LINE NUMBER: (check only one)

PAGE 937 / 1572

\begin{tabular}{|c|c|c|c|c|c|}
\hline & & & & & \\
\hline 16 & $\begin{array}{l}\mathbf{X} \\
17 a\end{array}$ & $17 b$ & $17 c$ & $17 d$ & 18 \\
\hline $19 a$ & $19 \mathrm{~b}$ & $20 \mathrm{a}$ & $20 \mathrm{~b}$ & $20 \mathrm{c}$ & 21 \\
\hline
\end{tabular}

Any information copied from such Reports and Statements may not be sold or used by any person for the purpose of soliciting contributions or for commercial purposes, other than using the name and address of any political committee to solicit contributions from such committee.

NAME OF COMMITTEE (In Full)

\section{Friends of Herman Cain}

A. Full Name (Last, First, Middle Initial)

\section{Carla Lewis}

Mailing Address 3433 12th Ave S

\begin{tabular}{lcc}
\hline City & State & Zip Code \\
Great Falls & MT & $59405-5556$
\end{tabular}

FEC ID number of contributing federal political committee.

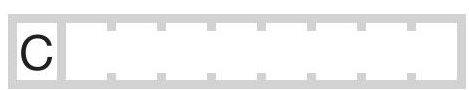

Name of Employer
Information Requested
Receipt For: 2012
X Primary $\quad \square$ General
Other (specify)

Occupation Information Requested

Election Cycle-to-Date

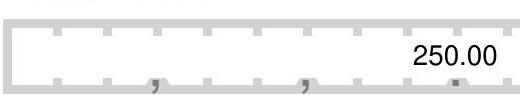

B. Full Name (Last, First, Middle Initial)

\section{Brian Rafalski}

Mailing Address 4709 Rue Belle Mer

\begin{tabular}{lcc}
\hline City & State & Zip Code \\
Sanibel & FL & $33957-2709$
\end{tabular}

FEC ID number of contributing

federal political committee.

C

Name of Employer
Information Requested
Receipt For: 2012
Primary
Other (specify)

C. Full Name (Last, First, Middle Initial)

Linda Evans

Mailing Address 1694 W Hibiscus Blvd

\begin{tabular}{lcc}
\hline City & State & Zip Code \\
Melbourne & FL & $32901-2636$
\end{tabular}

FEC ID number of contributing federal political committee.

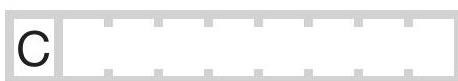

Name of Employer
None
Receipt For: 2012
X Primary $\quad \square$ General
Other (specify)

\section{Occupation}

Information Requested

Election Cycle-to-Date

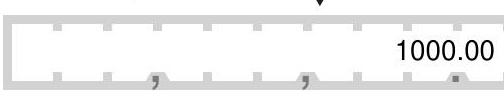

Transaction ID : A35E16792E7874565AB8

Date of Receipt

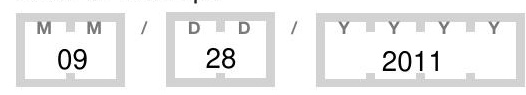

Amount of Each Receipt this Period

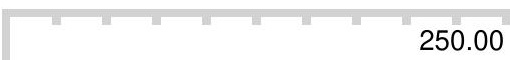

Amount of Each Receipt this Period

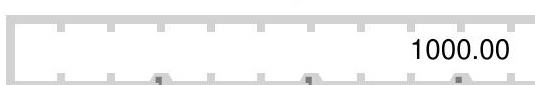

Transaction ID : A7BC2200B8D874EC3B87 Date of Receipt

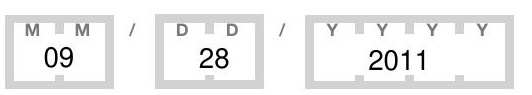

Transaction ID : AFA198DCB3E23434B82F Date of Receipt

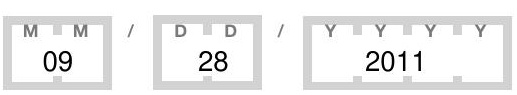

Amount of Each Receipt this Period

$\begin{aligned} & \text { Occupation } \\ & \text { Homemaker }\end{aligned}$
Election Cycle-to-Date

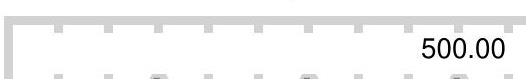

500.00

\section{Subtotal Of Receipts This Page (optional)}

Total This Period (last page this line number only) 


\section{SCHEDULE A-P} ITEMIZED RECEIPTS
Use separate schedule(s)

for each category of the

Detailed Summary Page
FOR LINE NUMBER: (check only one)

PAGE $938 / 1572$

\begin{tabular}{|c|c|c|c|c|c|}
\hline & & & & & \\
\hline 16 & X $17 a$ & $17 b$ & $17 c$ & $17 d$ & 18 \\
\hline $19 a$ & $19 b$ & $20 \mathrm{a}$ & $20 \mathrm{~b}$ & $20 \mathrm{c}$ & 21 \\
\hline
\end{tabular}

Any information copied from such Reports and Statements may not be sold or used by any person for the purpose of soliciting contributions or for commercial purposes, other than using the name and address of any political committee to solicit contributions from such committee.

NAME OF COMMITTEE (In Full)

Friends of Herman Cain

A. Full Name (Last, First, Middle Initial)

Carolyn Gerwin

Mailing Address 705 S Locust St

\begin{tabular}{lcc}
\hline City & State & Zip Code \\
Pontiac & IL & $61764-2632$ \\
\hline
\end{tabular}

FEC ID number of contributing federal political committee.

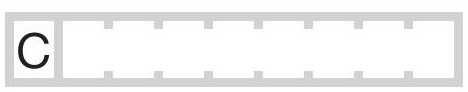

Name of Employer
Self-Employed
Receipt For: 2012
X Primary
$\square$ Other (specify) General

Occupation Attorney

Election Cycle-to-Date 500.00

B. Full Name (Last, First, Middle Initial)

Randall Meinen

Mailing Address 2501 Parkview Dr. Suite 210

\begin{tabular}{lcc}
\hline City & State & Zip Code \\
Fort Worth & TX & $76102-5814$ \\
\hline
\end{tabular}

FEC ID number of contributing

federal political committee.

C

Name of Employer
Information Requested
Receipt For: 2012
Primary
Other (specify)

Occupation

Information Requested

Election Cycle-to-Date

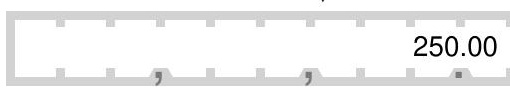

Transaction ID : AEA9FA97A8F82403BBA9

Date of Receipt

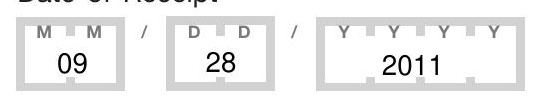

Amount of Each Receipt this Period

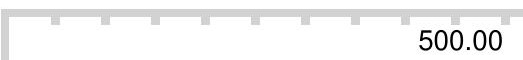

C. Full Name (Last, First, Middle Initial)

Timothy Clinkscales

Mailing Address 3922 Edgewood Road

\begin{tabular}{lcc}
\hline City & State & Zip Code \\
Wilmington & NC & $28403-5409$
\end{tabular}

FEC ID number of contributing federal political committee.

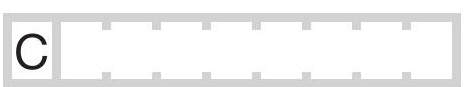

Name of Employer

Information Requested

\section{Occupation}

Information Requested

Receipt For: 2012

Х $\begin{aligned} & \text { Primary } \square \text { General } \\ & \text { Other (specify) }\end{aligned}$

Amount of Each Receipt this Period

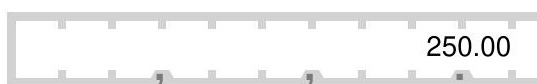

Transaction ID : AB2FAC7CA933E44F29C6

Date of Receipt

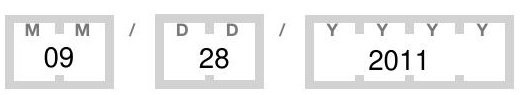

Transaction ID : A4F8EFE6D32AA4F66A42 Date of Receipt

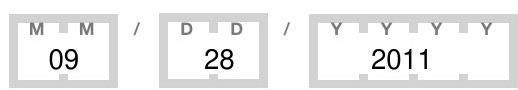

Amount of Each Receipt this Period

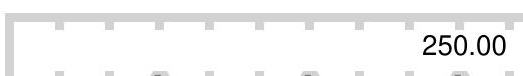

\section{Subtotal Of Receipts This Page (optional)}

1000.00

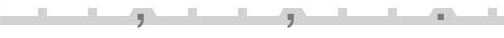

Total This Period (last page this line number only)

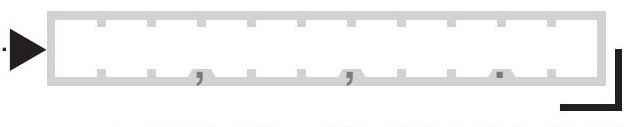

FEC Schedule A-P (Form 3P) (Rev. 03/2011) 
SCHEDULE A-P ITEMIZED RECEIPTS
Use separate schedule(s) for each category of the Detailed Summary Page
FOR LINE NUMBER: (check only one)

PAGE $939 / 1572$

\begin{tabular}{|c|c|c|c|c|c|}
\hline & & & & & \\
\hline 16 & $\begin{array}{l}\mathbf{X} \\
17 a\end{array}$ & $17 b$ & $17 c$ & $17 d$ & 18 \\
\hline $19 a$ & $19 \mathrm{~b}$ & $20 \mathrm{a}$ & $20 \mathrm{~b}$ & $20 \mathrm{c}$ & 21 \\
\hline
\end{tabular}

Any information copied from such Reports and Statements may not be sold or used by any person for the purpose of soliciting contributions or for commercial purposes, other than using the name and address of any political committee to solicit contributions from such committee.

NAME OF COMMITTEE (In Full)

\section{Friends of Herman Cain}

A. Full Name (Last, First, Middle Initial)

\section{Mona Peake}

Mailing Address 1909 Monument Rd.

\begin{tabular}{lcc}
\hline City & State & Zip Code \\
Rio Dell & CA & $95562-1812$
\end{tabular}

FEC ID number of contributing federal political committee.

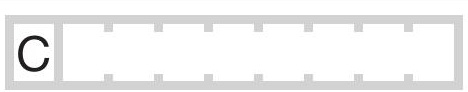

Name of Employer
Information Requested
Receipt For: 2012
Primary
Other (specify) General

Occupation Information Requested

Election Cycle-to-Date

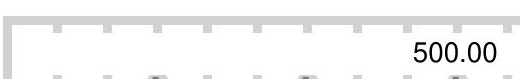

B. Full Name (Last, First, Middle Initial)

Cary FitzHugh

Mailing Address 6921 Glen Ellyn Drive

\begin{tabular}{lcc}
\hline City & State & Zip Code \\
Loveland & OH & $45140-9496$ \\
\hline
\end{tabular}

FEC ID number of contributing

federal political committee.

C

Name of Employer
Information Requested
Receipt For: 2012
Primary
Other (specify)

\section{Occupation}

Information Requested

Election Cycle-to-Date

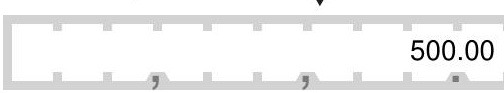

Transaction ID : A66D7B655485A4F62AB1

Date of Receipt

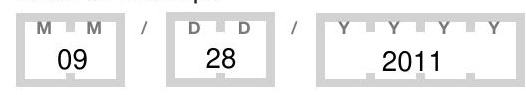

Amount of Each Receipt this Period

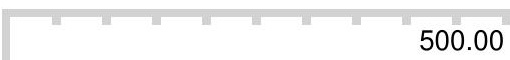

Amount of Each Receipt this Period

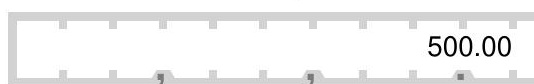

C. Full Name (Last, First, Middle Initial)

Alison Belknap

Mailing Address 149 Meeting House Rd.

\begin{tabular}{lcc}
\hline City & State & Zip Code \\
Mount Kisco & NY & $10549-4240$
\end{tabular}

FEC ID number of contributing federal political committee.

C

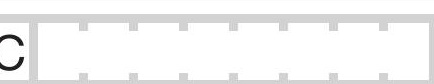

Transaction ID : A8111A55B2F4E489684E Date of Receipt

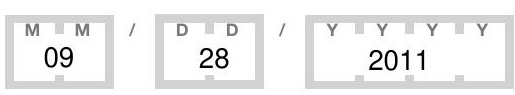

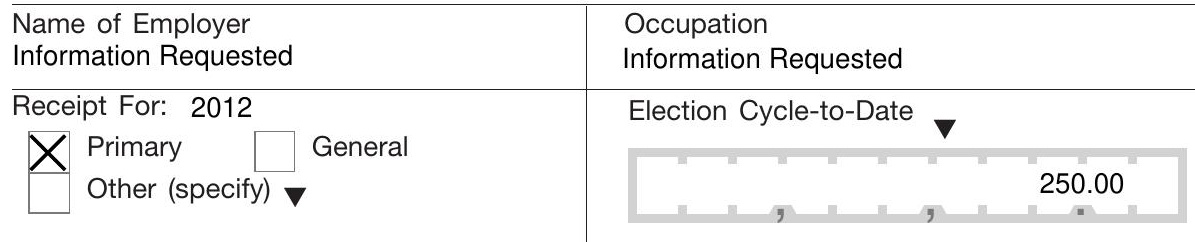

Amount of Each Receipt this Period

Transaction ID : AB896D647CF1F41F196D Date of Receipt
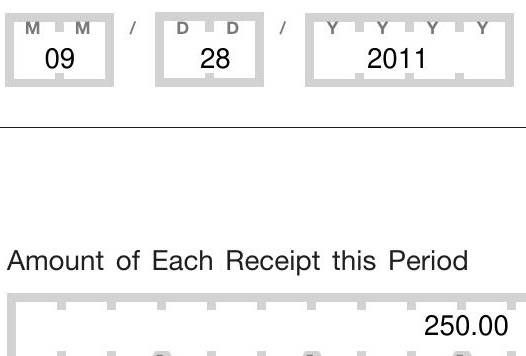

Subtotal Of Receipts This Page (optional).

Total This Period (last page this line number only) 


\section{SCHEDULE A-P} ITEMIZED RECEIPTS
Use separate schedule(s)

for each category of the

Detailed Summary Page
FOR LINE NUMBER: (check only one)

PAGE $940 / 1572$

\begin{tabular}{|c|c|c|c|c|c|}
\hline & & & & & \\
\hline 16 & X $17 a$ & $17 b$ & $17 c$ & $17 d$ & 18 \\
\hline $19 a$ & $19 b$ & $20 \mathrm{a}$ & $20 \mathrm{~b}$ & $20 \mathrm{c}$ & 21 \\
\hline
\end{tabular}

Any information copied from such Reports and Statements may not be sold or used by any person for the purpose of soliciting contributions or for commercial purposes, other than using the name and address of any political committee to solicit contributions from such committee.

NAME OF COMMITTEE (In Full)

Friends of Herman Cain

A. Full Name (Last, First, Middle Initial)

Gordon Bruner

Mailing Address 3119 NW Park Drive

\begin{tabular}{lcc}
\hline City & State & Zip Code \\
Knoxville & TN & $37921-1033$ \\
\hline
\end{tabular}

FEC ID number of contributing

federal political committee.

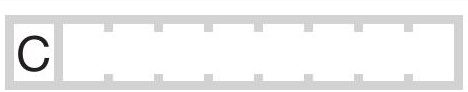

Name of Employer
Information Requested
Receipt For: 2012
X Primary $\quad \square$ General
Other (specify)

Occupation

Information Requested

Election Cycle-to-Date

500.00

B. Full Name (Last, First, Middle Initial)

Steve Loghry

Mailing Address 775 Cove View Circle

\begin{tabular}{lcc}
\hline City & State & Zip Code \\
Galveston & TX & 77554 \\
\hline
\end{tabular}

FEC ID number of contributing

federal political committee.

C

Name of Employer
Information Requested
Receipt For: 2012
X Primary
Other (specify)

Occupation

Information Requested

Election Cycle-to-Date

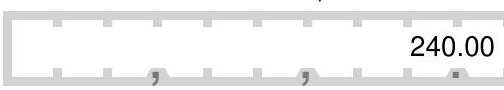

Transaction ID : AACCAFCFC108D47848D3

Date of Receipt

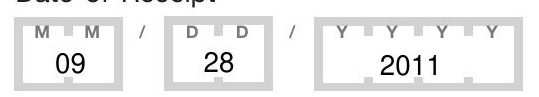

Amount of Each Receipt this Period

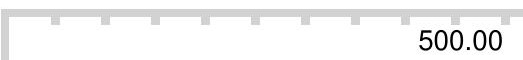

C. Full Name (Last, First, Middle Initial)

Jim Evans

Mailing Address PO Box 27409

\begin{tabular}{lcc}
\hline City & State & Zip Code \\
Omaha & NE & $68127-0409$
\end{tabular}

FEC ID number of contributing federal political committee.

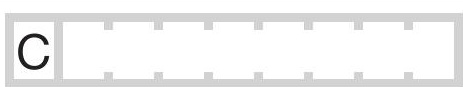

Name of Employer
Clean Country
Receipt For: 2012
X Primary
Other (specify) General

\section{Occupation}

President

\section{Election Cycle-to-Date}

Amount of Each Receipt this Period

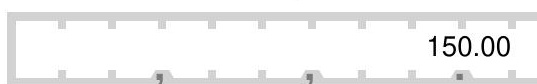

Transaction ID : AF8F6264C3B9D404FB2E Date of Receipt

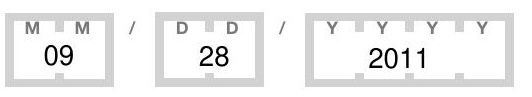

Transaction ID : A1E4B3A2B66F24618BEE Date of Receipt

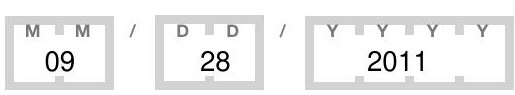

Amount of Each Receipt this Period

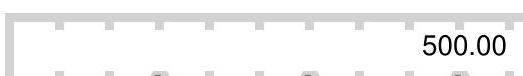

Subtotal Of Receipts This Page (optional).

Total This Period (last page this line number only) 


\section{SCHEDULE A-P} ITEMIZED RECEIPTS
Use separate schedule(s) for each category of the Detailed Summary Page

\begin{tabular}{|c|c|c|c|c|c|}
\hline \multicolumn{3}{|c|}{$\begin{array}{l}\text { FOR LINE NUMBER: } \\
\text { (check only one) }\end{array}$} & \multicolumn{3}{|c|}{ PAGE $941 / 1572$} \\
\hline 16 & $X$ 17a & $17 b$ & $17 c$ & $17 d$ & 18 \\
\hline $19 a$ & $19 \mathrm{~b}$ & $20 a$ & $20 \mathrm{~b}$ & $20 c$ & 21 \\
\hline
\end{tabular}

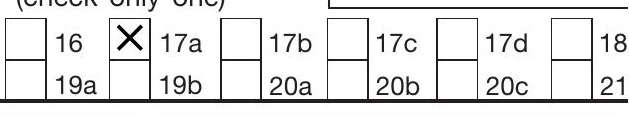

Any information copied from such Reports and Statements may not be sold or used by any person for the purpose of soliciting contributions or for commercial purposes, other than using the name and address of any political committee to solicit contributions from such committee.

NAME OF COMMITTEE (In Full)

\section{Friends of Herman Cain}

A. Full Name (Last, First, Middle Initial) James McGrane

Mailing Address 33 Lindy Dr

\begin{tabular}{lcc}
\hline City & State & Zip Code \\
Carmel & NY & $10512-1917$
\end{tabular}

FEC ID number of contributing federal political committee.

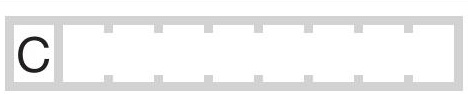

Name of Employer
Information Requested
Receipt For: 2012
X Primary
$\square$ Other (specify)

Occupation Information Requested Election Cycle-to-Date 250.00

B. Full Name (Last, First, Middle Initial) Bianca Beary

Mailing Address 10451 Grandoaks Ln

\begin{tabular}{lcc}
\hline City & State & Zip Code \\
Montgomery & OH & $45242-5033$
\end{tabular}

FEC ID number of contributing

federal political committee.

C

Name of Employer
Information Requested
Receipt For: 2012
X Primary
Other (specify)

Occupation

Information Requested

Election Cycle-to-Date

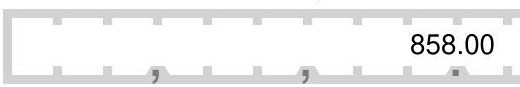

C. Full Name (Last, First, Middle Initial)

Carla Brady

Mailing Address 847 Southern Shore Dr.

\begin{tabular}{|c|c|}
\hline $\begin{array}{l}\text { City } \\
\text { Peachtree City }\end{array}$ & $\begin{array}{l}\text { Zip Code } \\
\text { 30269-3229 }\end{array}$ \\
\hline $\begin{array}{l}\text { FEC ID number of contributing } \\
\text { federal political committee. }\end{array}$ & C \\
\hline $\begin{array}{l}\text { Name of Employer } \\
\text { Information Requested }\end{array}$ & $\begin{array}{l}\text { Occupation } \\
\text { Information Requested }\end{array}$ \\
\hline Receipt For: 2012 & Election Cycle-to-Date $\boldsymbol{\nabla}$ \\
\hline $\begin{array}{l}\text { X } \\
\\
\text { Other (specify) }\end{array}$ & 250.00 \\
\hline
\end{tabular}

Transaction ID : AC634948011C8462598E Date of Receipt

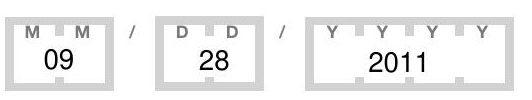

Amount of Each Receipt this Period

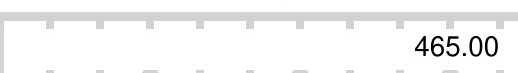

Amount of Each Receipt this Period

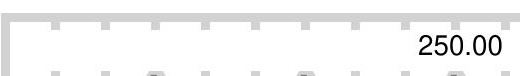

Transaction ID : AB3AAD2B090C54C83874 Date of Receipt

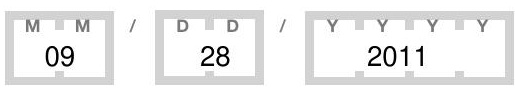

Subtotal Of Receipts This Page (optional).

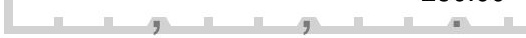

Total This Period (last page this line number only)

$+\quad 965.00$

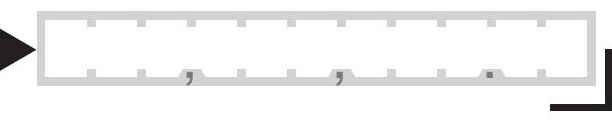

FEC Schedule A-P (Form 3P) (Rev. 03/2011) 


\section{SCHEDULE A-P} ITEMIZED RECEIPTS
Use separate schedule(s)

for each category of the

Detailed Summary Page
FOR LINE NUMBER: (check only one)

PAGE 942 / 1572

\begin{tabular}{|c|c|c|c|c|c|}
\hline & & & & & \\
\hline 16 & $\mathbf{X} 17 \mathrm{a}$ & $17 \mathrm{~b}$ & $17 c$ & $17 d$ & 18 \\
\hline $19 a$ & $19 \mathrm{~b}$ & $20 a$ & $20 \mathrm{~b}$ & $20 c$ & 21 \\
\hline
\end{tabular}

Any information copied from such Reports and Statements may not be sold or used by any person for the purpose of soliciting contributions or for commercial purposes, other than using the name and address of any political committee to solicit contributions from such committee.

NAME OF COMMITTEE (In Full)

\section{Friends of Herman Cain}

A. Full Name (Last, First, Middle Initial)

\section{Evander Chambers}

Mailing Address 1601 W. Rupe Ave.

\begin{tabular}{lcc}
\hline City & State & Zip Code \\
Enid & OK & $73703-8033$ \\
\hline
\end{tabular}

FEC ID number of contributing federal political committee.

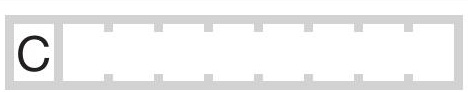

Name of Employer
Information Requested
Receipt For: 2012
X Primary
Other (specify) General

Occupation Information Requested

Election Cycle-to-Date

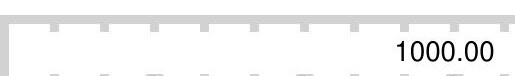

B. Full Name (Last, First, Middle Initial)

\section{Warren Weeks}

Mailing Address Box 379

\begin{tabular}{lcc}
\hline City & State & Zip Code \\
Lyme & $\mathrm{NH}$ & $03768-0379$ \\
\hline
\end{tabular}

FEC ID number of contributing

federal political committee.

C

Name of Employer
Information Requested
Receipt For: 2012
X Primary
Other (specify)

\section{Occupation}

Information Requested

Election Cycle-to-Date

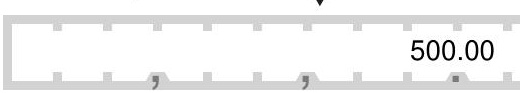

Transaction ID : A749CDE459A3443B19D1

Date of Receipt

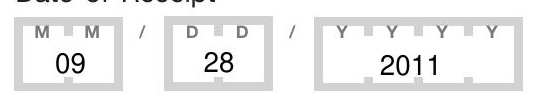

Amount of Each Receipt this Period

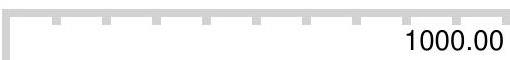

Transaction ID : AC7388171E2DE4E4CB95

Date of Receipt

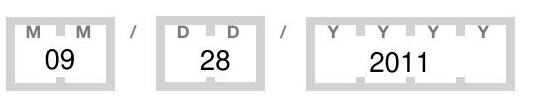

Amount of Each Receipt this Period

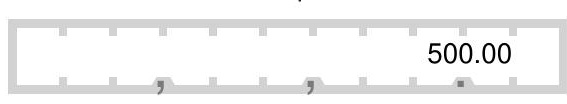

Transaction ID : A909F139FBC364A4FA13 Date of Receipt

\section{James L Mammoser}

Mailing Address 2613 Riverglenn Cir

\begin{tabular}{lcc}
\hline City & State & Zip Code \\
Atlanta & GA & $30338-5946$ \\
\hline
\end{tabular}

FEC ID number of contributing federal political committee.

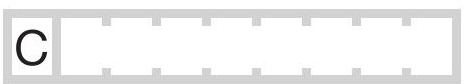

Name of Employer
None
Receipt For: 2012
Х Primary $\quad \square$ General
Other (specify)

Occupation

Retired

Election Cycle-to-Date
Amount of Each Receipt this Period

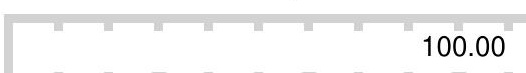

Subtotal Of Receipts This Page (optional).

1600.00

a

Total This Period (last page this line number only)

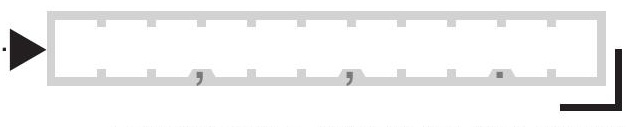

FEC Schedule A-P (Form 3P) (Rev. 03/2011) 
SCHEDULE A-P ITEMIZED RECEIPTS
Use separate schedule(s) for each category of the Detailed Summary Page
FOR LINE NUMBER: (check only one)

PAGE $943 / 1572$

\begin{tabular}{|c|c|c|c|c|c|}
\hline & & & & & \\
\hline 16 & $\begin{array}{lll}X & 17 a \\
\end{array}$ & $17 \mathrm{~b}$ & $17 c$ & $17 d$ & 18 \\
\hline $19 a$ & $19 b$ & $20 a$ & $20 \mathrm{~b}$ & $20 c$ & 21 \\
\hline
\end{tabular}

Any information copied from such Reports and Statements may not be sold or used by any person for the purpose of soliciting contributions or for commercial purposes, other than using the name and address of any political committee to solicit contributions from such committee.

NAME OF COMMITTEE (In Full)

\section{Friends of Herman Cain}

A. Full Name (Last, First, Middle Initial)

Miriam Fisher

Mailing Address 1007 Panorama Court

\begin{tabular}{lcc}
\hline City & State & Zip Code \\
Fircrest & WA & $98466-6527$
\end{tabular}

FEC ID number of contributing federal political committee.

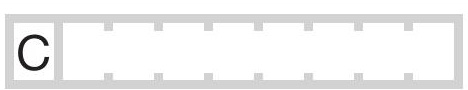

Name of Employer
Information Requested
Receipt For: 2012
X Primary
Other (specify) General

Occupation Information Requested

Election Cycle-to-Date

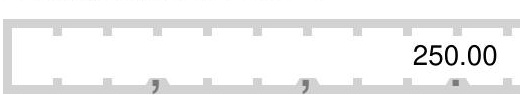

B. Full Name (Last, First, Middle Initial)

MARK SHOOK

Mailing Address 7956 AEROSTAR

\begin{tabular}{lcc}
\hline City & State & Zip Code \\
Peyton & CO & $80831-8000$ \\
\hline
\end{tabular}

FEC ID number of contributing

federal political committee.

C

Name of Employer
Information Requested
Receipt For: 2012
Primary
Other (specify)

Occupation

Information Requested

Election Cycle-to-Date

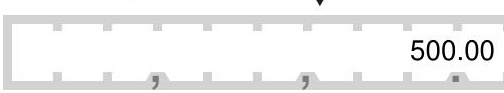

Transaction ID : A6212E570AD4C48BE9C0

Date of Receipt

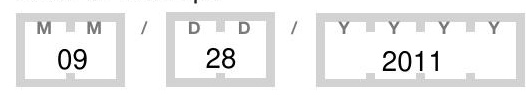

Amount of Each Receipt this Period

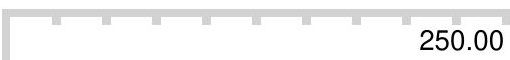

C. Full Name (Last, First, Middle Initial)

William Hustwit

Mailing Address 7231 So Eastern Ave B181

\begin{tabular}{lcc}
\hline City & State & Zip Code \\
Las Vegas & NV & $89119-0451$
\end{tabular}

FEC ID number of contributing federal political committee.

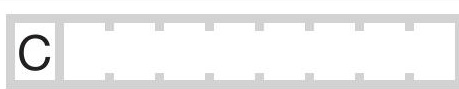

Name of Employer

Information Requested

\section{Occupation}

Information Requested

Receipt For: 2012

Х $\begin{aligned} & \text { Primary } \square \text { General } \\ & \text { Other (specify) }\end{aligned}$

Amount of Each Receipt this Period

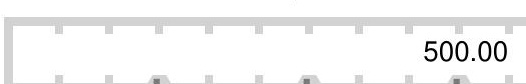

Transaction ID : A37FD734734D4456E923

Date of Receipt

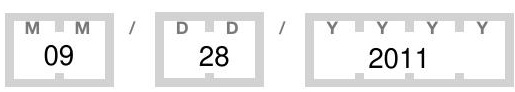

Transaction ID : A43FF86802C714805958

Date of Receipt

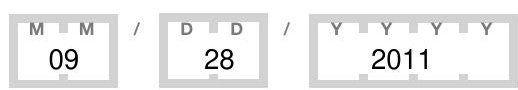

Amount of Each Receipt this Period

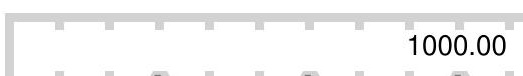

\section{Subtotal Of Receipts This Page (optional)}

Total This Period (last page this line number only) 
SCHEDULE A-P ITEMIZED RECEIPTS
Use separate schedule(s) for each category of the Detailed Summary Page

FOR LINE NUMBER:
(check only one)

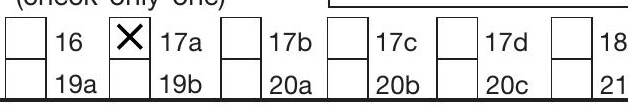

Any information copied from such Reports and Statements may not be sold or used by any person for the purpose of soliciting contributions or for commercial purposes, other than using the name and address of any political committee to solicit contributions from such committee.

NAME OF COMMITTEE (In Full)

\section{Friends of Herman Cain}

A. Full Name (Last, First, Middle Initial)

Sandra Kriha

Mailing Address 21803 Van Dorn St

\begin{tabular}{lcc}
\hline City & State & Zip Code \\
Eagle & NE & $68347-1977$ \\
\hline
\end{tabular}

FEC ID number of contributing federal political committee.

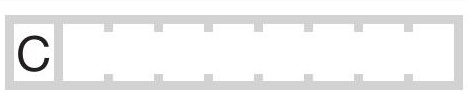

Name of Employer
Kriha Fluid Power
Receipt For: 2012
X Primary
Other (specify) General

Occupation Business Owner

Election Cycle-to-Date 250.00

B. Full Name (Last, First, Middle Initial) Stanley Tong

Mailing Address 635 Kite Hollow Road

\begin{tabular}{lcc}
\hline City & State & Zip Code \\
Stanley & VA & $22851-4711$
\end{tabular}

FEC ID number of contributing

federal political committee.

C

Name of Employer
Information Requested
Receipt For: 2012
X Primary
Other (specify)

Occupation

Information Requested

Election Cycle-to-Date

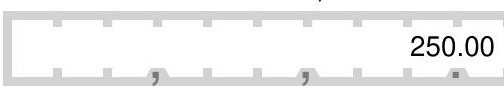

C. Full Name (Last, First, Middle Initial)

Lynne Galton

Mailing Address 845 Lookingglass Lane NW

\begin{tabular}{l|ll}
\hline $\begin{array}{l}\text { City } \\
\text { Marietta }\end{array}$ & $\begin{array}{c}\text { State } \\
\text { GA }\end{array}$ & $\begin{array}{c}\text { Zip Code } \\
30064-1464\end{array}$ \\
\hline $\begin{array}{l}\text { FEC ID number of contributing } \\
\text { federal political committee. }\end{array}$ & C & \\
\hline $\begin{array}{l}\text { Name of Employer } \\
\text { Retired }\end{array}$ & $\begin{array}{l}\text { Occupation } \\
\text { Retired }\end{array}$ \\
\hline $\begin{array}{l}\text { Receipt For: } 2012 \\
\text { X }\end{array}$ & Election Cycle-to-Date \\
Other (specify)
\end{tabular}

Transaction ID : A66F29E633E2F4D0CB03

Date of Receipt

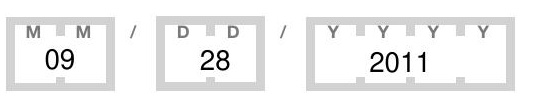

Amount of Each Receipt this Period

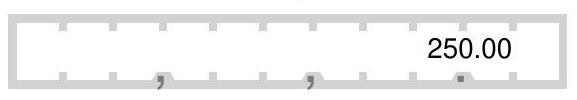

Amount of Each Receipt this Period

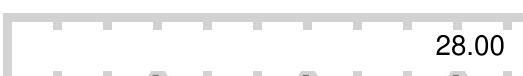

Transaction ID : AF649843985454A5AA88 Date of Receipt

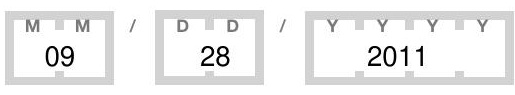

Subtotal Of Receipts This Page (optional).

Total This Period (last page this line number only) 
SCHEDULE A-P ITEMIZED RECEIPTS
Use separate schedule(s) for each category of the Detailed Summary Page
FOR LINE NUMBER: (check only one)

PAGE $945 / 1572$

\begin{tabular}{|c|c|c|c|c|c|}
\hline & & & & & \\
\hline 16 & $\begin{array}{l}\mathbf{X} \\
17 a\end{array}$ & $17 b$ & $17 c$ & $17 d$ & 18 \\
\hline $19 a$ & $19 \mathrm{~b}$ & $20 \mathrm{a}$ & $20 \mathrm{~b}$ & $20 \mathrm{c}$ & 21 \\
\hline
\end{tabular}

Any information copied from such Reports and Statements may not be sold or used by any person for the purpose of soliciting contributions or for commercial purposes, other than using the name and address of any political committee to solicit contributions from such committee.

NAME OF COMMITTEE (In Full)

\section{Friends of Herman Cain}

A. Full Name (Last, First, Middle Initial)

Carolyn Crilly

Mailing Address 65 Strathmore Rd \#46

\begin{tabular}{lcc}
\hline City & State & Zip Code \\
Brighton & MA & $02135-7743$ \\
\hline
\end{tabular}

FEC ID number of contributing federal political committee.

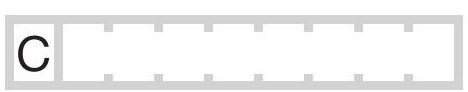

Name of Employer
St Elizabeth's Medical Center
Receipt For: 2012
X Primary
Other (specify) General

Occupation

Registered Nurse

Election Cycle-to-Date

750.00

B. Full Name (Last, First, Middle Initial)

Harold Bone

Mailing Address 324 Clearlake Drive West

\begin{tabular}{lcc}
\hline City & State & Zip Code \\
Nashville & TN & $37217-4521$ \\
\hline
\end{tabular}

FEC ID number of contributing

federal political committee.

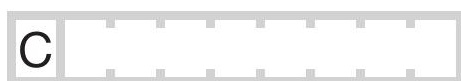

Name of Employer
None
Receipt For: 2012
X Primary
Other (specify)

Occupation

Retired

Election Cycle-to-Date

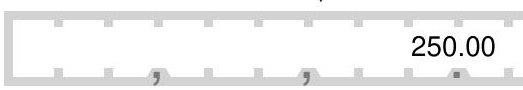

Transaction ID : A4423E5B335564F2FA53

Date of Receipt

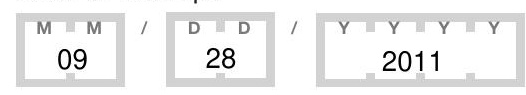

Amount of Each Receipt this Period

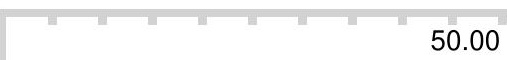

50.00

C. Full Name (Last, First, Middle Initial)

Theodora Berg

Mailing Address 301 Michigan Rd.

\begin{tabular}{lcc}
\hline City & State & Zip Code \\
New Canaan & CT & $06840-2230$
\end{tabular}

FEC ID number of contributing federal political committee.

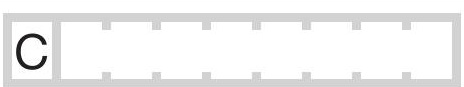

Name of Employer

Information Requested

Occupation

Information Requested

Receipt For: 2012

Х $\begin{aligned} & \text { Primary } \square \text { General } \\ & \text { Other (specify) }\end{aligned}$

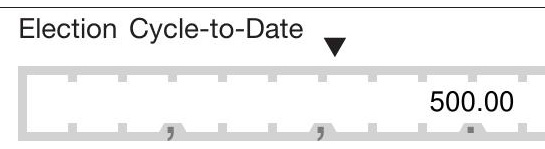

Amount of Each Receipt this Period

Transaction ID : A75FFE8CA18064518B3F

Date of Receipt
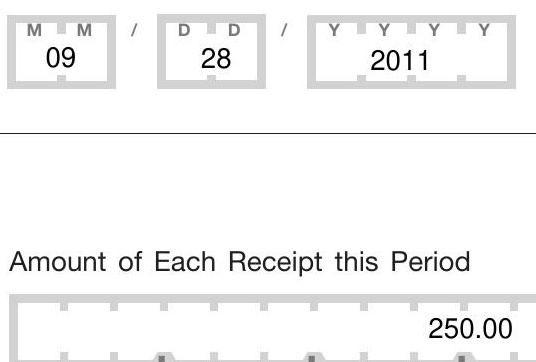

Transaction ID : AE0CFC500B0F341BDBA9 Date of Receipt

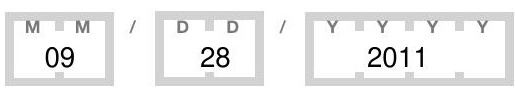

Amount of Each Receipt this Period

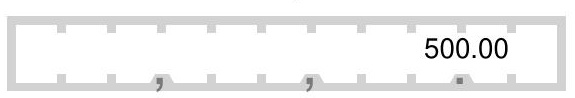

Subtotal Of Receipts This Page (optional)

800.00

Total This Period (last page this line number only) 
SCHEDULE A-P ITEMIZED RECEIPTS
Use separate schedule(s) for each category of the Detailed Summary Page
FOR LINE NUMBER: (check only one)
PAGE 946 / 1572

\begin{tabular}{|c|c|c|c|c|c|}
\hline & & & & & \\
\hline 16 & $\begin{array}{lll}X & 17 a \\
\end{array}$ & $17 \mathrm{~b}$ & $17 c$ & $17 d$ & 18 \\
\hline $19 a$ & $19 b$ & $20 a$ & $20 \mathrm{~b}$ & $20 c$ & 21 \\
\hline
\end{tabular}

Any information copied from such Reports and Statements may not be sold or used by any person for the purpose of soliciting contributions or for commercial purposes, other than using the name and address of any political committee to solicit contributions from such committee.

NAME OF COMMITTEE (In Full)

\section{Friends of Herman Cain}

A. Full Name (Last, First, Middle Initial)

Don Grove

Mailing Address 32449 Barclay Loop

\begin{tabular}{lcc}
\hline City & State & Zip Code \\
Warsaw & MO & $65355-4814$
\end{tabular}

FEC ID number of contributing

federal political committee.

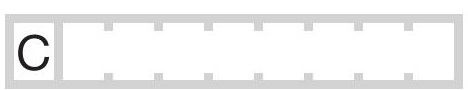

Name of Employer
TED Pharmacy
Receipt For: 2012
X Primary $\quad$ General
Other (specify)

Occupation

Pharmacist

Election Cycle-to-Date

250.00

B. Full Name (Last, First, Middle Initial)

Blake Molter

Mailing Address 5818 Glenn Dale Rd

\begin{tabular}{lcc}
\hline City & State & Zip Code \\
Glenn Dale & MD & $20769-9106$
\end{tabular}

FEC ID number of contributing

federal political committee.

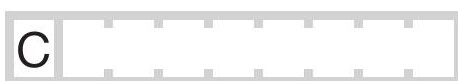

Name of Employer
Omnitec Solutions Inc.
Receipt For: 2012
X Primary
Other (specify)

Occupation

DoD Contractor

Election Cycle-to-Date

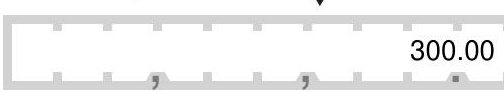

C. Full Name (Last, First, Middle Initial)

William Mills

Mailing Address 802 Sunrise Blvd

\begin{tabular}{lcc}
\hline City & State & Zip Code \\
Prescott & AZ & $86301-5890$
\end{tabular}

FEC ID number of contributing

federal political committee.

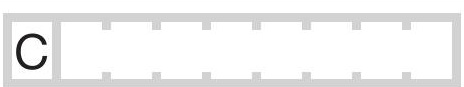

Name of Employer

The Coca-Cola Company

Receipt For: 2012

Х $\begin{aligned} & \text { Primary } \square \text { General } \\ & \text { Other (specify) }\end{aligned}$

\section{Occupation}

Retired

Election Cycle-to-Date

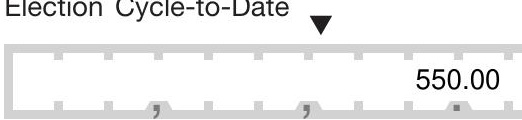

Transaction ID : AA5B4FFBB122F42F980D

Date of Receipt

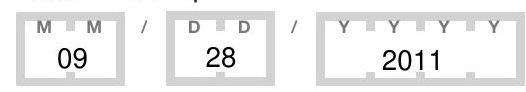

Amount of Each Receipt this Period

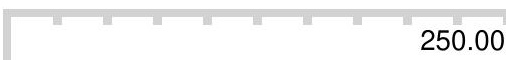

250.00

Transaction ID : A037F43D7B6974A3885A

Date of Receipt

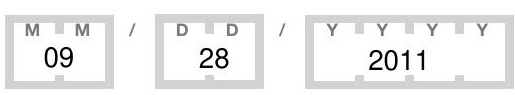

Amount of Each Receipt this Period

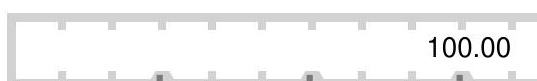

Transaction ID : AC628A6CC04A3469EAF4 Date of Receipt

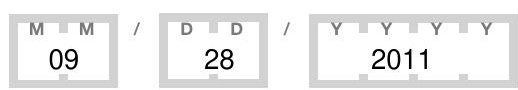

Amount of Each Receipt this Period

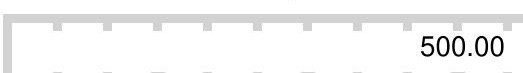

500.00

\section{Subtotal Of Receipts This Page (optional)}

Total This Period (last page this line number only) 


\section{SCHEDULE A-P} ITEMIZED RECEIPTS
Use separate schedule(s)

for each category of the

Detailed Summary Page
FOR LINE NUMBER: (check only one)

PAGE 947 / 1572

\begin{tabular}{|c|c|c|c|c|c|}
\hline & & & & & \\
\hline 16 & $\mathbf{X} 17 \mathrm{a}$ & $17 \mathrm{~b}$ & $17 c$ & $17 d$ & 18 \\
\hline $19 a$ & $19 \mathrm{~b}$ & $20 a$ & $20 \mathrm{~b}$ & $20 c$ & 21 \\
\hline
\end{tabular}

Any information copied from such Reports and Statements may not be sold or used by any person for the purpose of soliciting contributions or for commercial purposes, other than using the name and address of any political committee to solicit contributions from such committee.

NAME OF COMMITTEE (In Full)

Friends of Herman Cain

A. Full Name (Last, First, Middle Initial)

Richard Nord

Mailing Address 6256 Shadyside Drive

\begin{tabular}{lcc}
\hline City & State & Zip Code \\
Vermilion & OH & $44089-1052$
\end{tabular}

FEC ID number of contributing

federal political committee.

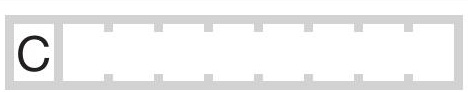

Name of Employer
Information Requested
Receipt For: 2012
X Primary $\quad \square$ General
Other (specify)

Occupation

Information Requested

Election Cycle-to-Date

1000.00

B. Full Name (Last, First, Middle Initial)

John Bertel

Mailing Address 343 Vincent Ave

\begin{tabular}{lcc}
\hline City & State & Zip Code \\
Metairie & LA & $70005-4419$
\end{tabular}

FEC ID number of contributing

federal political committee.

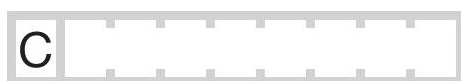

Name of Employer
Hayes Dockside Inc
Receipt For: 2012
X Primary
Other (specify)

Occupation

Business Executive

Election Cycle-to-Date

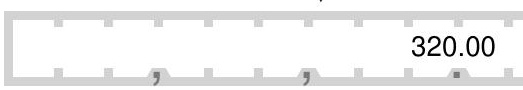

Transaction ID : AB113ADA500904F2383C

Date of Receipt

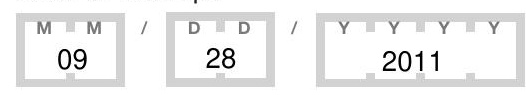

Amount of Each Receipt this Period

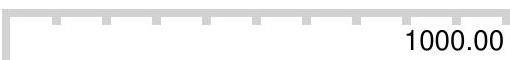

Amount of Each Receipt this Period

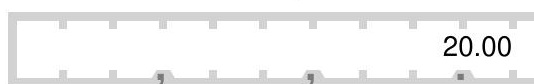

C. Full Name (Last, First, Middle Initial)

Gabrielle Manigault

Mailing Address 832 Greenough Rd.

\begin{tabular}{lcc}
\hline City & State & Zip Code \\
Recluse & WY & 82725 \\
\hline
\end{tabular}

FEC ID number of contributing

federal political committee.

C

Name of Employer
Information Requested
Receipt For: 2012
X Primary
Other (specify) General

Occupation

Information Requested

Election Cycle-to-Date

Transaction ID : AB66ED139F1674A208CF

Date of Receipt

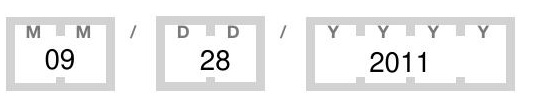

Transaction ID : A01713C8125BB45B0A33

Date of Receipt

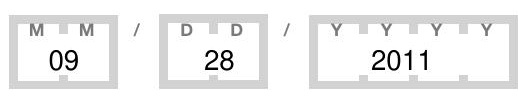

Amount of Each Receipt this Period

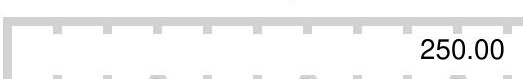

750.00

Subtotal Of Receipts This Page (optional).

Total This Period (last page this line number only) 


\section{SCHEDULE A-P} ITEMIZED RECEIPTS
Use separate schedule(s)

for each category of the

Detailed Summary Page
FOR LINE NUMBER: (check only one)

PAGE $948 / 1572$

\begin{tabular}{|c|c|c|c|c|c|}
\hline & & & & & \\
\hline 16 & X $17 a$ & $17 b$ & $17 c$ & $17 d$ & 18 \\
\hline $19 a$ & $19 b$ & $20 \mathrm{a}$ & $20 \mathrm{~b}$ & $20 \mathrm{c}$ & 21 \\
\hline
\end{tabular}

Any information copied from such Reports and Statements may not be sold or used by any person for the purpose of soliciting contributions or for commercial purposes, other than using the name and address of any political committee to solicit contributions from such committee.

NAME OF COMMITTEE (In Full)

Friends of Herman Cain

A. Full Name (Last, First, Middle Initial)

PAUL DESROSIERS

Mailing Address 7002 WARWICK RD

\begin{tabular}{lcc}
\hline City & State & Zip Code \\
Indianapolis & IN & $46220-1051$ \\
\hline
\end{tabular}

FEC ID number of contributing

federal political committee.

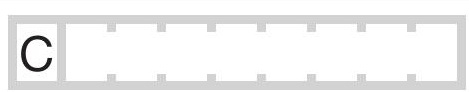

Name of Employer
Information Requested
Receipt For: 2012
X Primary $\quad \square$ General
Other (specify)

Occupation

Information Requested

Election Cycle-to-Date

250.00

B. Full Name (Last, First, Middle Initial)

Judith Pittman

Mailing Address 9 Todd Terrace

\begin{tabular}{lcc}
\hline City & State & Zip Code \\
Danville & IN & $46122-1043$ \\
\hline
\end{tabular}

FEC ID number of contributing

federal political committee.

C

Name of Employer
None
Receipt For: 2012
Primary
Other (specify)

Occupation

Retired

Election Cycle-to-Date

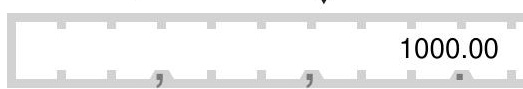

Transaction ID : A8E985A672E954994926

Date of Receipt

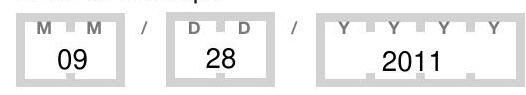

Amount of Each Receipt this Period

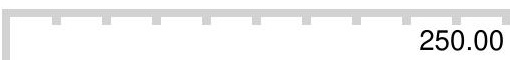

C. Full Name (Last, First, Middle Initial)

Natalie Campbell

Mailing Address 1420 E 240 N

\begin{tabular}{lcc}
\hline City & State & Zip Code \\
Anderson & IN & $46012-9582$ \\
\hline
\end{tabular}

FEC ID number of contributing federal political committee.

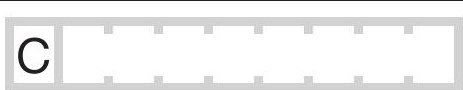

Name of Employer

Information Requested

\section{Occupation}

Information Requested

Receipt For: 2012

Х $\begin{aligned} & \text { Primary } \square \text { General } \\ & \text { Other (specify) }\end{aligned}$

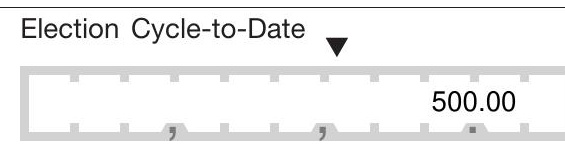

Amount of Each Receipt this Period

Transaction ID : A1C395EE814224876B92

Date of Receipt
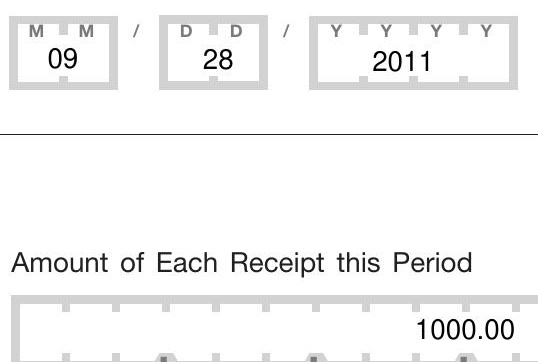

Transaction ID : A3F8D4F5093F14FE5BF1

Date of Receipt

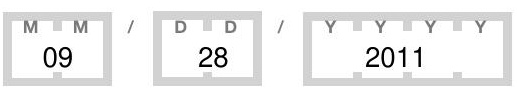

Amount of Each Receipt this Period

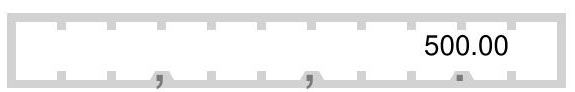

Subtotal Of Receipts This Page (optional).

1750.00

Total This Period (last page this line number only) 
SCHEDULE A-P ITEMIZED RECEIPTS
Use separate schedule(s) for each category of the Detailed Summary Page
FOR LINE NUMBER: (check only one)

PAGE 949 / 1572

\begin{tabular}{|c|c|c|c|c|c|}
\hline & & & & & \\
\hline 16 & $\begin{array}{l}\mathbf{X} \\
17 a\end{array}$ & $17 b$ & $17 c$ & $17 d$ & 18 \\
\hline $19 a$ & $19 \mathrm{~b}$ & $20 \mathrm{a}$ & $20 \mathrm{~b}$ & $20 \mathrm{c}$ & 21 \\
\hline
\end{tabular}

Any information copied from such Reports and Statements may not be sold or used by any person for the purpose of soliciting contributions or for commercial purposes, other than using the name and address of any political committee to solicit contributions from such committee.

NAME OF COMMITTEE (In Full)

\section{Friends of Herman Cain}

A. Full Name (Last, First, Middle Initial)

Ronald Cantrrell

Mailing Address P O Box 864

\begin{tabular}{lcc}
\hline City & State & Zip Code \\
Cleveland & GA & $30528-0016$
\end{tabular}

FEC ID number of contributing federal political committee.

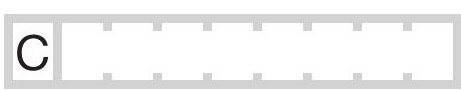

Name of Employer
Information Requested
Receipt For: 2012
X Primary
Other (specify) General

B. Full Name (Last, First, Middle Initial) George Villa

Mailing Address PO Box 534

\begin{tabular}{lcc}
\hline City & State & Zip Code \\
Oldwick & NJ & $08858-0534$
\end{tabular}

FEC ID number of contributing

federal political committee.

C

Name of Employer
Information Requested
Receipt For: 2012
X Primary
Other (specify)

\section{Occupation}

Information Requested

Election Cycle-to-Date

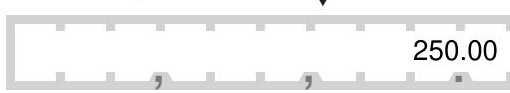

\subsection{0}

Transaction ID : AA1085163AD974F948F0

Date of Receipt

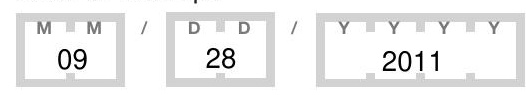

Amount of Each Receipt this Period

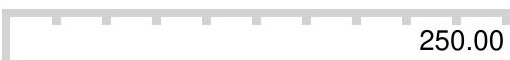

C. Full Name (Last, First, Middle Initial)

Joe Plunkett Jr

Mailing Address 3814 Cloudland $\mathrm{Dr}$

\begin{tabular}{lcc}
\hline City & State & Zip Code \\
Smyrna & GA & $30082-3211$
\end{tabular}

FEC ID number of contributing federal political committee.

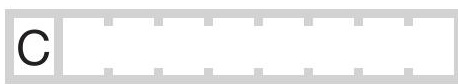

Name of Employer
JSP Consulting LLC
Receipt For: 2012
X Primary
Other (specify) General

\section{Occupation}

Consultant

\section{Election Cycle-to-Date}

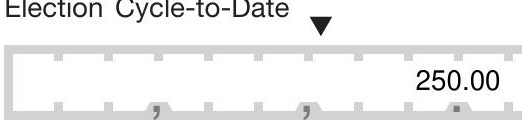

Transaction ID : A228BFC83B8E24AC98F7 Date of Receipt

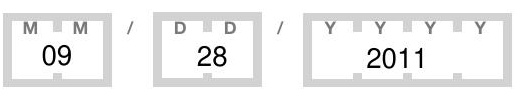

Amount of Each Receipt this Period

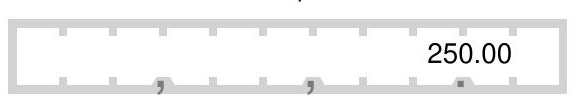

Transaction ID : ABA5717702D2A490CAB8 Date of Receipt

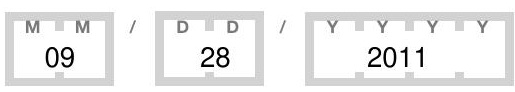

Amount of Each Receipt this Period

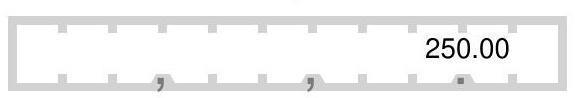

\section{Subtotal Of Receipts This Page (optional)}

Total This Period (last page this line number only) 


\section{SCHEDULE A-P} ITEMIZED RECEIPTS
Use separate schedule(s)

for each category of the

Detailed Summary Page
FOR LINE NUMBER: (check only one)

PAGE $950 / 1572$

\begin{tabular}{|c|c|c|c|c|c|}
\hline & & & & & \\
\hline 16 & X $17 a$ & $17 b$ & $17 c$ & $17 d$ & 18 \\
\hline $19 a$ & $19 b$ & $20 \mathrm{a}$ & $20 \mathrm{~b}$ & $20 \mathrm{c}$ & 21 \\
\hline
\end{tabular}

Any information copied from such Reports and Statements may not be sold or used by any person for the purpose of soliciting contributions or for commercial purposes, other than using the name and address of any political committee to solicit contributions from such committee.

NAME OF COMMITTEE (In Full)

\section{Friends of Herman Cain}

A. Full Name (Last, First, Middle Initial)

Kelvin Jasper

Mailing Address 6555 Sunset Drive

\begin{tabular}{lcc}
\hline City & State & Zip Code \\
Jacksonville & FL & $32208-4637$
\end{tabular}

FEC ID number of contributing federal political committee.

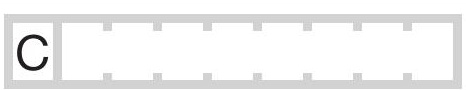

Name of Employer
AllcomGS
Receipt For: 2012
X Primary $\quad$ General
Other (specify)

Occupation technician

Election Cycle-to-Date 225.00

B. Full Name (Last, First, Middle Initial)

Mr Don Shipe

Mailing Address 3 Lombardy Ter

\begin{tabular}{lcc}
\hline City & State & Zip Code \\
Benbrook & TX & $76132-1011$
\end{tabular}

FEC ID number of contributing

federal political committee.

C

Name of Employer
Information Requested
Receipt For: 2012
X Primary
Other (specify)

Occupation

Information Requested

Election Cycle-to-Date

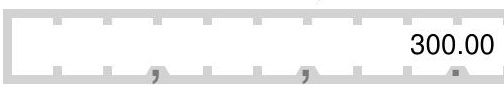

Transaction ID : AF64281AF25E849929C7

Date of Receipt

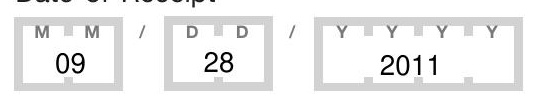

Amount of Each Receipt this Period

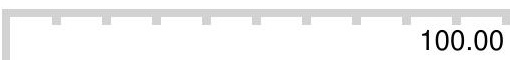

Amount of Each Receipt this Period

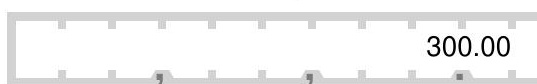

C. Full Name (Last, First, Middle Initial)

Ronnie DaY

Mailing Address 11934 Lake Elly Rd.

\begin{tabular}{lcc}
\hline City & State & Zip Code \\
Oakwood & IL & $61858-9597$
\end{tabular}

FEC ID number of contributing federal political committee.

C

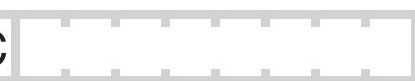

Name of Employer

Professional Physical Therapy

Receipt For: 2012

Х $\begin{aligned} & \text { Primary } \square \text { General } \\ & \text { Other (specify) }\end{aligned}$

\section{Occupation}

physical therapist

Election Cycle-to-Date

Transaction ID : A1FFBF3C65E6145C6B0D

Date of Receipt

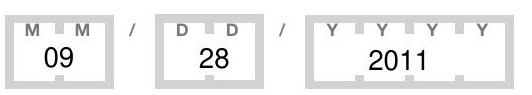

Transaction ID : AC25A0B7B53B34619A59

Date of Receipt

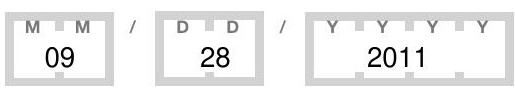

Amount of Each Receipt this Period

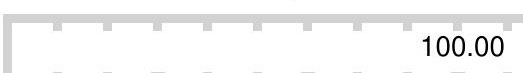

300.00

Subtotal Of Receipts This Page (optional).

500.00

a

Total This Period (last page this line number only) 
SCHEDULE A-P ITEMIZED RECEIPTS
Use separate schedule(s) for each category of the Detailed Summary Page
FOR LINE NUMBER: (check only one)

PAGE $951 / 1572$

\begin{tabular}{|c|c|c|c|c|c|c|}
\hline & & & & & & \\
\hline 16 & $\lambda$ & $17 \mathrm{a}$ & $17 \mathrm{~b}$ & $17 \mathrm{c}$ & $-17 d$ & -18 \\
\hline $19 a$ & & $19 b$ & $20 a$ & $20 \mathrm{~b}$ & $20 \mathrm{c}$ & 21 \\
\hline
\end{tabular}

Any information copied from such Reports and Statements may not be sold or used by any person for the purpose of soliciting contributions or for commercial purposes, other than using the name and address of any political committee to solicit contributions from such committee.

NAME OF COMMITTEE (In Full)

\section{Friends of Herman Cain}

A. Full Name (Last, First, Middle Initial) randy rogers

Mailing Address 3334 peachtree rd 1414

\begin{tabular}{lcc}
\hline City & State & Zip Code \\
Atlanta & GA & $30326-6817$
\end{tabular}

FEC ID number of contributing federal political committee.

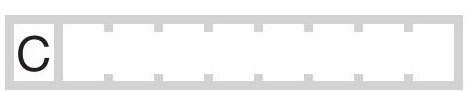

Name of Employer
Information Requested
Receipt For: 2012
X Primary
Other (specify) General

Occupation Information Requested

Election Cycle-to-Date

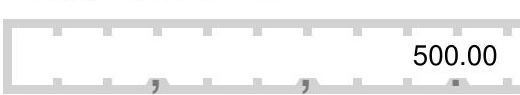

B. Full Name (Last, First, Middle Initial) mark tracy

Mailing Address 3028 caring way \#9

\begin{tabular}{lcc}
\hline City & State & Zip Code \\
Port Charlotte & FL & $33952-5300$
\end{tabular}

FEC ID number of contributing

federal political committee.

C

Name of Employer
Information Requested
Receipt For: 2012
Xrimary
Other (specify)

Occupation

Information Requested

Election Cycle-to-Date

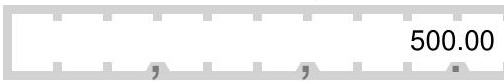

C. Full Name (Last, First, Middle Initial)

Michael Handa

Mailing Address 377 Salem Street

\begin{tabular}{lcc}
\hline City & State & Zip Code \\
Andover & MA & $01810-2314$
\end{tabular}

FEC ID number of contributing federal political committee.

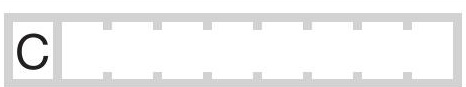

Name of Employer

Information Requested

\section{Occupation}

Information Requested

Receipt For: 2012

Х $\begin{aligned} & \text { Primary } \square \text { General } \\ & \text { Other (specify) }\end{aligned}$

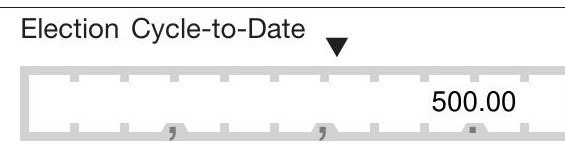

Amount of Each Receipt this Period

Transaction ID : A5291774467874BE1933

Date of Receipt

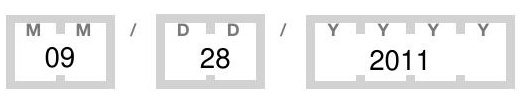

Amount of Each Receipt this Period
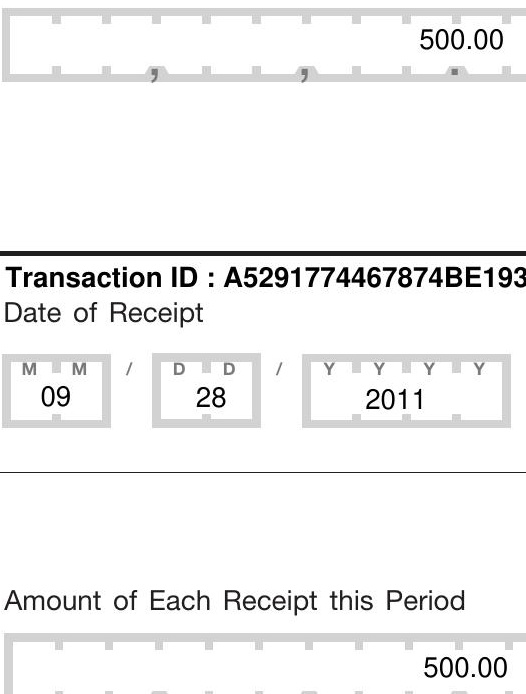

Transaction ID : A6FEB663E0A204469801

Date of Receipt

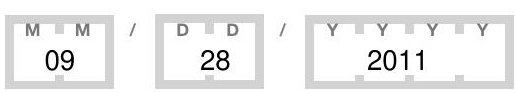

Amount of Each Receipt this Period

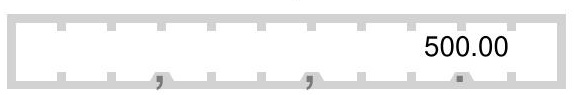

\section{Subtotal Of Receipts This Page (optional)}

Total This Period (last page this line number only) 


\section{SCHEDULE A-P} ITEMIZED RECEIPTS
Use separate schedule(s)

for each category of the

Detailed Summary Page
FOR LINE NUMBER: (check only one)

PAGE 952 / 1572

\begin{tabular}{|c|c|c|c|c|c|}
\hline & & & & & \\
\hline 16 & X $17 a$ & $17 b$ & $17 c$ & $17 d$ & 18 \\
\hline $19 a$ & $19 b$ & $20 \mathrm{a}$ & $20 \mathrm{~b}$ & $20 \mathrm{c}$ & 21 \\
\hline
\end{tabular}

Any information copied from such Reports and Statements may not be sold or used by any person for the purpose of soliciting contributions or for commercial purposes, other than using the name and address of any political committee to solicit contributions from such committee.

NAME OF COMMITTEE (In Full)

Friends of Herman Cain

A. Full Name (Last, First, Middle Initial)

Laura A Hay

Mailing Address 231 Burke Circle

\begin{tabular}{lcc}
\hline City & State & Zip Code \\
McDonough & GA & $30253-2012$
\end{tabular}

FEC ID number of contributing

federal political committee.

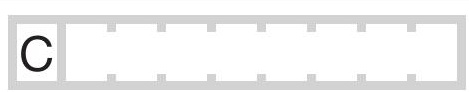

Name of Employer
Retired
Receipt For: 2012
X Primary $\quad \square$ General
Other (specify)

Occupation

$\mathrm{N} / \mathrm{A}$

Election Cycle-to-Date

615.00

B. Full Name (Last, First, Middle Initial)

Arlene C Dewitt

Mailing Address 401 Poplar Ln

\begin{tabular}{lcc}
\hline City & State & Zip Code \\
Stockbridge & GA & $30281-1612$
\end{tabular}

FEC ID number of contributing

federal political committee.

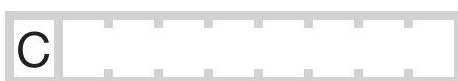

Name of Employer
Information Requested
Receipt For: 2012
X Primary
Other (specify)

Occupation

Information Requested

Election Cycle-to-Date

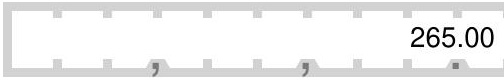

C. Full Name (Last, First, Middle Initial)

Arlene C Dewitt

Mailing Address 401 Poplar Ln

\begin{tabular}{lcc}
\hline City & State & Zip Code \\
Stockbridge & GA & $30281-1612$
\end{tabular}

FEC ID number of contributing federal political committee.

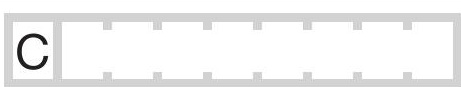

Name of Employer

Information Requested

\section{Occupation}

Information Requested

Receipt For: 2012

Х $\begin{aligned} & \text { Primary } \square \text { General } \\ & \text { Other (specify) }\end{aligned}$

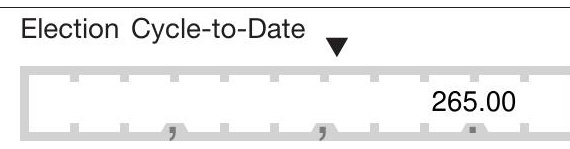

Amount of Each Receipt this Period

Transaction ID : AC4F92737D3BB40EBA54 Date of Receipt

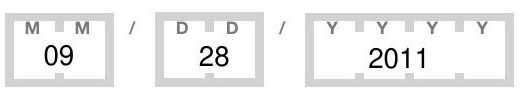

Amount of Each Receipt this Period
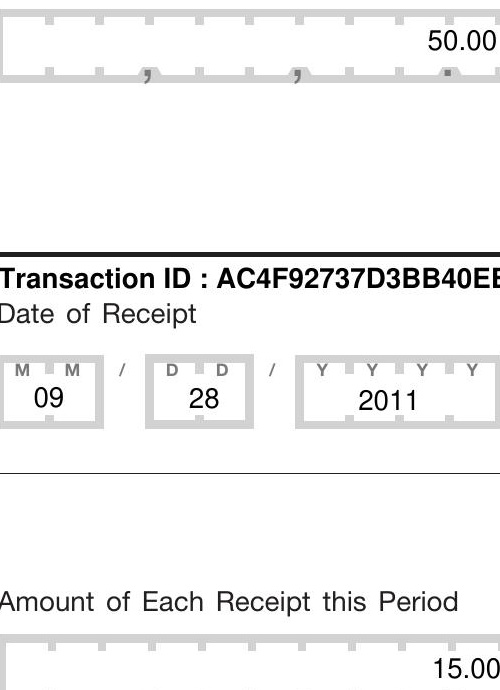

Transaction ID : A3D8D3A54778A4683BAB Date of Receipt

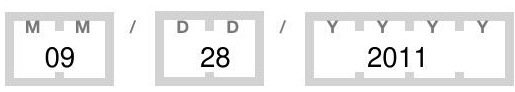

Amount of Each Receipt this Period

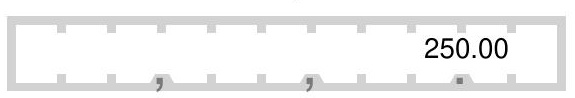

Subtotal Of Receipts This Page (optional)

Total This Period (last page this line number only) 
SCHEDULE A-P ITEMIZED RECEIPTS
Use separate schedule(s) for each category of the Detailed Summary Page
FOR LINE NUMBER: (check only one)

PAGE $953 / 1572$

\begin{tabular}{|c|c|c|c|c|c|}
\hline & & & & & \\
\hline 16 & $\begin{array}{l}\mathbf{X} \\
17 a\end{array}$ & $17 b$ & $17 c$ & $17 d$ & 18 \\
\hline $19 a$ & $19 \mathrm{~b}$ & $20 \mathrm{a}$ & $20 \mathrm{~b}$ & $20 \mathrm{c}$ & 21 \\
\hline
\end{tabular}

Any information copied from such Reports and Statements may not be sold or used by any person for the purpose of soliciting contributions or for commercial purposes, other than using the name and address of any political committee to solicit contributions from such committee.

NAME OF COMMITTEE (In Full)

\section{Friends of Herman Cain}

A. Full Name (Last, First, Middle Initial)

Jimmy Sapp

Mailing Address 1061 crenshaw rd.

\begin{tabular}{lcc}
\hline City & State & Zip Code \\
Pitts & GA & $31072-4909$
\end{tabular}

FEC ID number of contributing federal political committee.

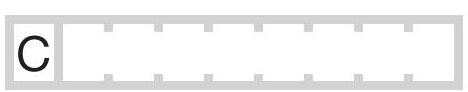

Name of Employer
DR Pallets LLC
Receipt For: 2012
X Primary
Other (specify) General

Occupation small business owner

Election Cycle-to-Date 1000.00

B. Full Name (Last, First, Middle Initial) Lonnie Jarrell

Mailing Address 925 South Main St Apt. 3241

\begin{tabular}{lcc}
\hline City & State & Zip Code \\
Grapevine & TX & $76051-7562$ \\
\hline
\end{tabular}

FEC ID number of contributing

federal political committee.

C

Name of Employer
None
Receipt For: 2012
X Primary
Other (specify)

\section{Occupation}

Retired

Election Cycle-to-Date

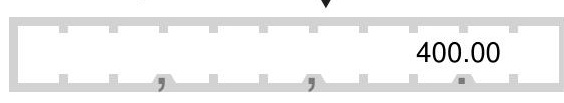

Transaction ID : AD18C193C4FD2436E8F5

Date of Receipt

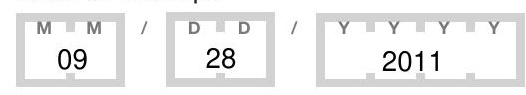

Amount of Each Receipt this Period

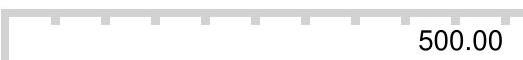

C. Full Name (Last, First, Middle Initial)

Debi Coffey

Mailing Address 100 Pickett Court

\begin{tabular}{lcc}
\hline City & State & Zip Code \\
Warner Robins & GA & $31093-6644$
\end{tabular}

FEC ID number of contributing federal political committee.

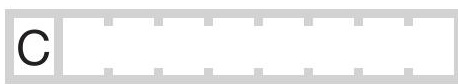

Name of Employer
Comair Airlines
Receipt For: 2012
X Primary $\quad \square$ General
Other (specify)

Occupation

flight attendant

Election Cycle-to-Date

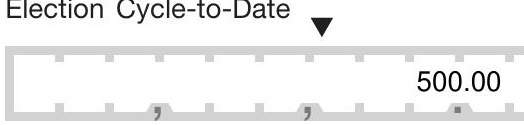

Transaction ID : AF2F336F62C6B4BCEB2A Date of Receipt

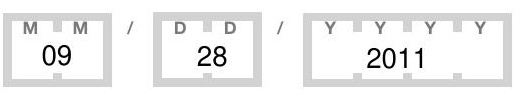

Amount of Each Receipt this Period

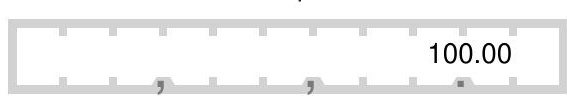

Transaction ID : A271697A3BE444841BB6 Date of Receipt

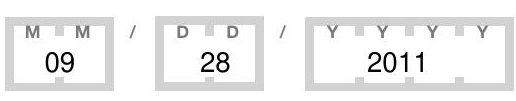

Amount of Each Receipt this Period

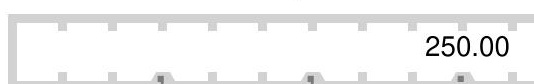

\section{Subtotal Of Receipts This Page (optional)}

Total This Period (last page this line number only) 
SCHEDULE A-P ITEMIZED RECEIPTS
Use separate schedule(s) for each category of the Detailed Summary Page
FOR LINE NUMBER: (check only one)
PAGE 954 / 1572

\begin{tabular}{|c|c|c|c|c|c|}
\hline & & & & & \\
\hline 16 & $\begin{array}{lll}X & 17 a \\
\end{array}$ & $17 \mathrm{~b}$ & $17 c$ & $17 d$ & 18 \\
\hline $19 a$ & $19 b$ & $20 a$ & $20 \mathrm{~b}$ & $20 c$ & 21 \\
\hline
\end{tabular}

Any information copied from such Reports and Statements may not be sold or used by any person for the purpose of soliciting contributions or for commercial purposes, other than using the name and address of any political committee to solicit contributions from such committee.

NAME OF COMMITTEE (In Full)

\section{Friends of Herman Cain}

A. Full Name (Last, First, Middle Initial)

\section{David Baker}

Mailing Address PO Box F

\begin{tabular}{lcc}
\hline City & State & Zip Code \\
Lakeside & OR & $97449-0805$
\end{tabular}

FEC ID number of contributing federal political committee.

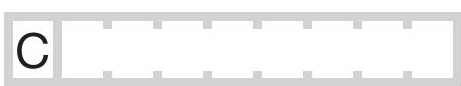

Name of Employer
Information Requested
Receipt For: 2012
X Primary
Other (specify) General

B. Full Name (Last, First, Middle Initial)

Kelly D Long

Mailing Address 346 Shaw Rd

\begin{tabular}{lcc}
\hline City & State & Zip Code \\
Sharpsburg & GA & $30277-1601$
\end{tabular}

FEC ID number of contributing

federal political committee.

C

Name of Employer
11 F Data Soultion Inc.
Receipt For: 2012
X Primary
Other (specify)

Name of Employer

11F Data Soultion Inc

Receipt For: 2012

Х Primary $\square$ General

C. Full Name (Last, First, Middle Initial)

Gregory Travis

Mailing Address 11418 Riverview Drive

\begin{tabular}{lcc}
\hline City & State & Zip Code \\
Houston & TX & $77077-3223$
\end{tabular}

FEC ID number of contributing federal political committee.

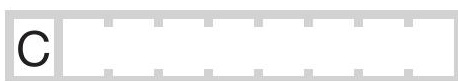

Name of Employer

The Trans Law Firm, P.C.

Receipt For: 2012

Х $\begin{aligned} & \text { Primary } \\ & \text { Other (specify) }\end{aligned}$
Occupation

Information Requested

Election Cycle-to-Date

500.00
Transaction ID : AD148B31FD7854258857

Date of Receipt

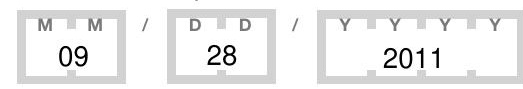

Amount of Each Receipt this Period

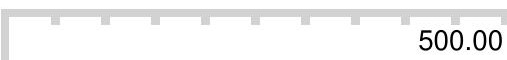

Amount of Each Receipt this Period

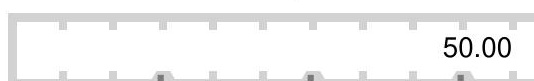

Amount of Each Receipt this Period

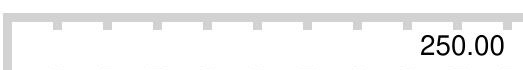

\section{Subtotal Of Receipts This Page (optional)}

800.00 Attorney

Election Cycle-to-Date

250.00

Transaction ID : A817B383B9FF04BC1A1B Date of Receipt

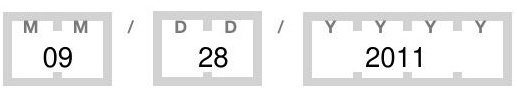

Total This Period (last page this line number only) 


\section{SCHEDULE A-P} ITEMIZED RECEIPTS
Use separate schedule(s) for each category of the Detailed Summary Page

FOR LINE NUMBER:
(check only one)

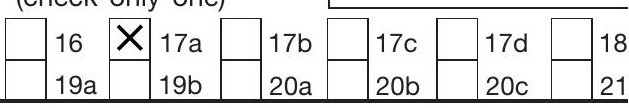

Any information copied from such Reports and Statements may not be sold or used by any person for the purpose of soliciting contributions or for commercial purposes, other than using the name and address of any political committee to solicit contributions from such committee.

NAME OF COMMITTEE (In Full)

\section{Friends of Herman Cain}

A. Full Name (Last, First, Middle Initial)

Karen Zeliff

Mailing Address 118 Chapel Road

\begin{tabular}{lcc}
\hline City & State & Zip Code \\
Easton & MD & $21601-3973$ \\
\hline
\end{tabular}

FEC ID number of contributing federal political committee.

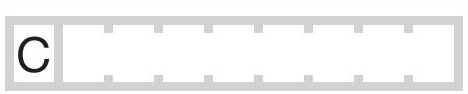

Name of Employer
Self Employed
Receipt For: 2012
X Primary
$\square$ Other (specify) General

Occupation Consultant

Election Cycle-to-Date 1000.00

B. Full Name (Last, First, Middle Initial) Nancy Besly

Mailing Address 3210 Wildlife Cir

\begin{tabular}{lcc}
\hline City & State & Zip Code \\
Bryan & TX & $77802-3035$
\end{tabular}

FEC ID number of contributing

federal political committee.

C

Name of Employer
Early Childhood Intervent
Receipt For: 2012
Xrimary
Other (specify)

Occupation

Speech Pathologist

Election Cycle-to-Date

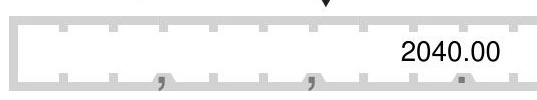

C. Full Name (Last, First, Middle Initial)

Kathy Hoskins

Mailing Address 16896 NW 180th St

\begin{tabular}{lcc}
\hline City & State & Zip Code \\
Williston & FL & $32696-4377$
\end{tabular}

FEC ID number of contributing federal political committee.

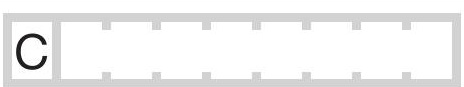

Name of Employer

Taylor, Cotton \& Ridley Inc.

Receipt For: 2012

Х $\begin{aligned} & \text { Primary } \\ & \text { Other (specify) }\end{aligned}$

\section{Occupation}

Administrative Assistant

Election Cycle-to-Date
Transaction ID : A7BCADC6F7E6247FF853

Date of Receipt

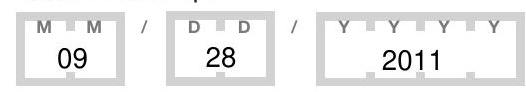

Amount of Each Receipt this Period

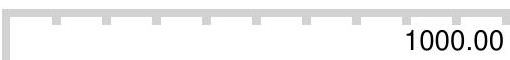

1000.00
Amount of Each Receipt this Period

Transaction ID : A4FC78BFF6E034BD49A8

Date of Receipt
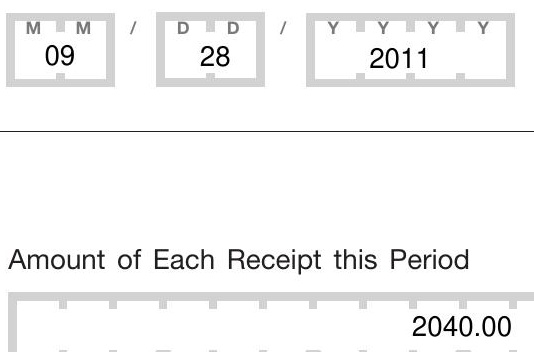

Transaction ID : ABAFB7BFFDA494DD4BBB Date of Receipt

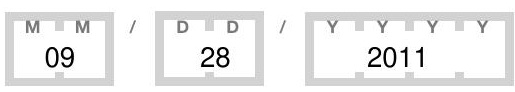

Amount of Each Receipt this Period

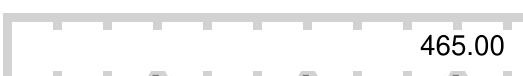

465.00
Subtotal Of Receipts This Page (optional)

3505.00

a 1 ,

Total This Period (last page this line number only)

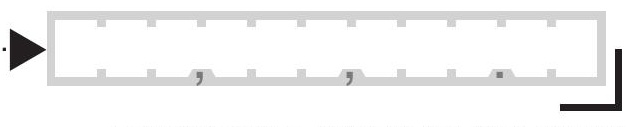

FEC Schedule A-P (Form 3P) (Rev. 03/2011) 


\section{SCHEDULE A-P} ITEMIZED RECEIPTS
Use separate schedule(s) for each category of the Detailed Summary Page

FOR LINE NUMBER:
(check only one)

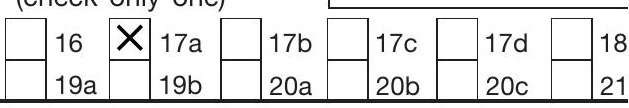

Any information copied from such Reports and Statements may not be sold or used by any person for the purpose of soliciting contributions or for commercial purposes, other than using the name and address of any political committee to solicit contributions from such committee.

NAME OF COMMITTEE (In Full)

\section{Friends of Herman Cain}

A. Full Name (Last, First, Middle Initial)

\section{Walter Watkins}

Mailing Address 1870 Bridle Ridge Trce

\begin{tabular}{lcc}
\hline City & State & Zip Code \\
Roswell & GA & $30075-2151$
\end{tabular}

FEC ID number of contributing federal political committee.

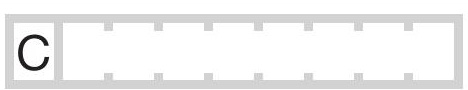

Name of Employer
ApolloMD
Receipt For: 2012
X Primary $\quad$ General
Other (specify)

Occupation Physician

Election Cycle-to-Date 2000.00

B. Full Name (Last, First, Middle Initial) Harold Workman

Mailing Address 212 W Tedrow Dr

\begin{tabular}{lcc}
\hline City & State & Zip Code \\
Glendora & CA & $91740-4851$
\end{tabular}

FEC ID number of contributing

federal political committee.

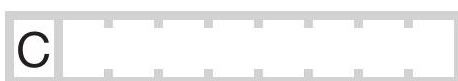

Name of Employer
Workman Construction Inc.
Receipt For: 2012
X Primary
Other (specify)

\section{Occupation}

Owner

Election Cycle-to-Date

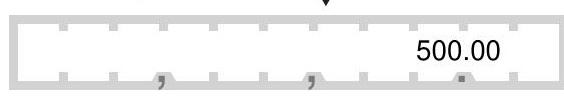

C. Full Name (Last, First, Middle Initial)

Dan Prevo

Mailing Address 3767 W. Gulf Dr

\section{City}

Sanibel

FEC ID number of contributing federal political committee.

Name of Employer

DP Properties LLC

Receipt For: 2012

Х $\begin{aligned} & \text { Primary } \\ & \text { Other (specify) }\end{aligned}$
Transaction ID : A4ACC09B636FF4DCF8BE

Date of Receipt

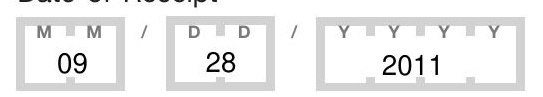

Amount of Each Receipt this Period

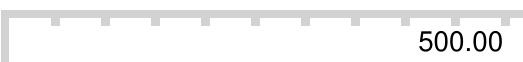

Amount of Each Receipt this Period

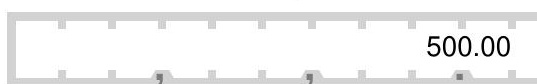

Transaction ID : A93161E509E9542B5A3A Date of Receipt

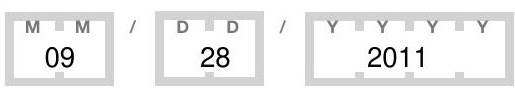

Amount of Each Receipt this Period

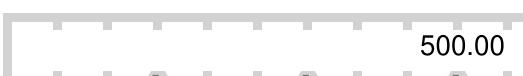

\section{Subtotal Of Receipts This Page (optional)}

Total This Period (last page this line number only) 


\section{SCHEDULE A-P} ITEMIZED RECEIPTS
Use separate schedule(s) for each category of the Detailed Summary Page

FOR LINE NUMBER:
(check only one)

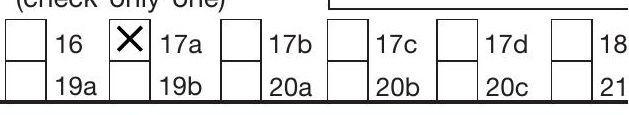

Any information copied from such Reports and Statements may not be sold or used by any person for the purpose of soliciting contributions or for commercial purposes, other than using the name and address of any political committee to solicit contributions from such committee.

NAME OF COMMITTEE (In Full)

\section{Friends of Herman Cain}

A. Full Name (Last, First, Middle Initial) Gerald Schmidt

Mailing Address 884 Herr Rd

\begin{tabular}{lcc}
\hline City & State & Zip Code \\
Fairborn & OH & $45324-9490$
\end{tabular}

FEC ID number of contributing federal political committee.

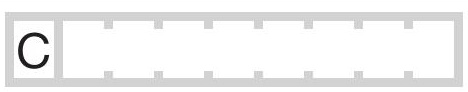

Name of Employer
None
Receipt For: 2012
X Primary $\quad \square$ General
$\square$ Other (specify)

Occupation Retired Election Cycle-to-Date

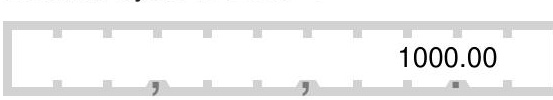

B. Full Name (Last, First, Middle Initial) Robert Kobles

Mailing Address 47 Spencer Brook Road

\begin{tabular}{lcc}
\hline City & State & Zip Code \\
New Hartford & CT & $06057-3634$
\end{tabular}

FEC ID number of contributing

federal political committee.

C

Name of Employer
Information Requested
Receipt For: 2012
X Primary
Other (specify)

Occupation

Information Requested

Election Cycle-to-Date

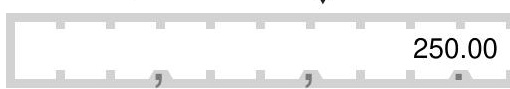

C. Full Name (Last, First, Middle Initial)

william brannan

Mailing Address 9703 eagle rising cove

\begin{tabular}{l|ll}
\hline $\begin{array}{l}\text { City } \\
\text { Austin }\end{array}$ & $\begin{array}{c}\text { State } \\
\text { TX }\end{array}$ & $\begin{array}{c}\text { Zip Code } \\
78730-3362\end{array}$ \\
\hline $\begin{array}{l}\text { FEC ID number of contributing } \\
\text { federal political committee. }\end{array}$ & C \\
\hline $\begin{array}{l}\text { Name of Employer } \\
\text { Information Requested }\end{array}$ & $\begin{array}{l}\text { Occupation } \\
\text { Information Requested }\end{array}$ \\
\hline $\begin{array}{l}\text { Receipt For: } 2012 \\
\text { X } \begin{array}{l}\text { Primary } \\
\text { Other (specify) }\end{array}\end{array}$ & Election Cycle-to-Date & \\
\hline
\end{tabular}

Transaction ID : A7CE988C253024210A94

Date of Receipt

Amount of Each Receipt this Period
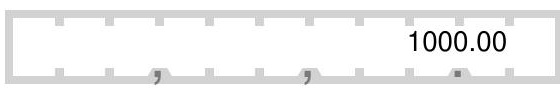

Date of Receipt

M M / D

09

2011

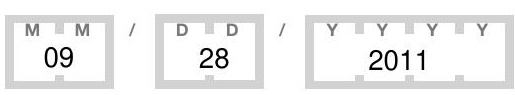

Amount of Each Receipt this Period

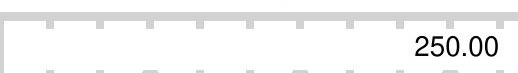

Amount of Each Receipt this Period

Transaction ID : AAB0928FC320D4866A86

Date of Receipt
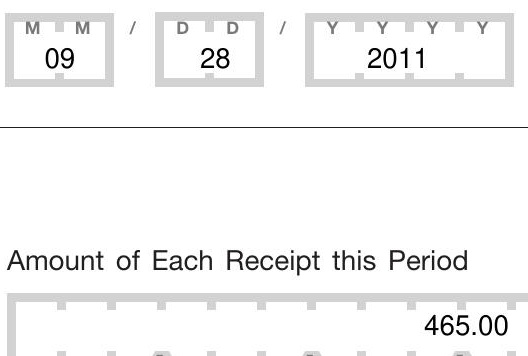

465.00

Subtotal Of Receipts This Page (optional).

1715.00

Total This Period (last page this line number only) 


\section{SCHEDULE A-P} ITEMIZED RECEIPTS
Use separate schedule(s)

for each category of the

Detailed Summary Page
FOR LINE NUMBER: (check only one)

Any information or for commercial purposes, other than using the name and address of any political committee to solicit contributions from such committee.

NAME OF COMMITTEE (In Full)

\section{Friends of Herman Cain}

A. Full Name (Last, First, Middle Initial)

Roger Spring

Mailing Address 118 Lake Aluma Dr

\begin{tabular}{lcc}
\hline City & State & Zip Code \\
Oklahoma City & OK & $73121-3402$
\end{tabular}

FEC ID number of contributing federal political committee.

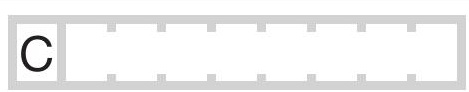

Name of Employer
Information Requested
Receipt For: 2012
X Primary
Other (specify) General

Occupation Information Requested

Election Cycle-to-Date

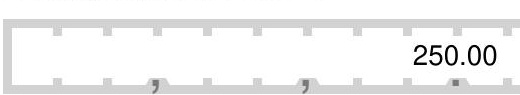

B. Full Name (Last, First, Middle Initial) John Eck Sr

Mailing Address 1058 Rocky Springs Rd

\begin{tabular}{lcc}
\hline City & State & Zip Code \\
Madisonville & TN & $37354-6686$
\end{tabular}

FEC ID number of contributing

federal political committee.

C

Name of Employer
Covanta Energy Corp
Receipt For: 2012
X Primary
Other (specify)

Occupation

Field Technician

Election Cycle-to-Date

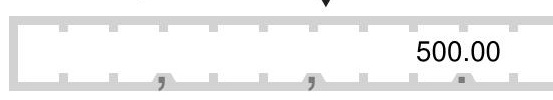

Transaction ID : AD2D8C16A16214363B7A

Date of Receipt

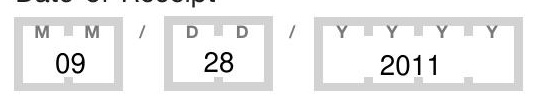

Amount of Each Receipt this Period

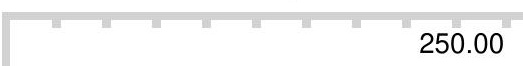

C. Full Name (Last, First, Middle Initial)

James Cloutier

Mailing Address PO Box 179

\begin{tabular}{lcc}
\hline City & State & Zip Code \\
Marion & KS & $66861-0179$
\end{tabular}

FEC ID number of contributing federal political committee.

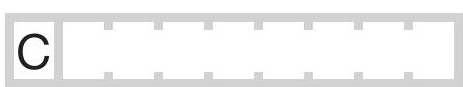

Name of Employer

Information Requested

\section{Occupation}

Information Requested

Receipt For: 2012

Х $\begin{aligned} & \text { Primary } \square \text { General } \\ & \text { Other (specify) }\end{aligned}$

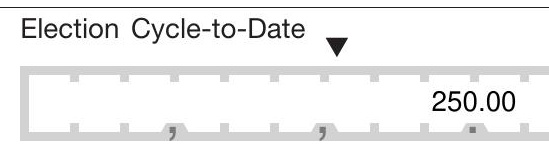

Amount of Each Receipt this Period

Transaction ID : AA9E65433873F4FE7AA7

Date of Receipt
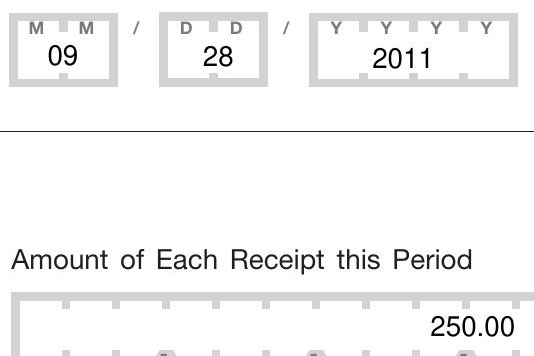

Transaction ID : AF261D245A7604AE8942

Date of Receipt

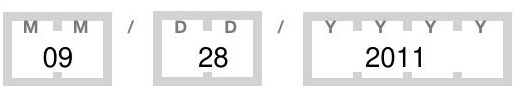

Amount of Each Receipt this Period

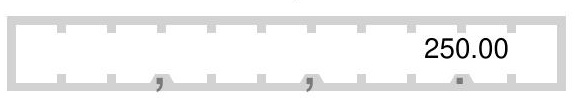

Subtotal Of Receipts This Page (optional).

750.00

Total This Period (last page this line number only) 
SCHEDULE A-P ITEMIZED RECEIPTS
Use separate schedule(s) for each category of the Detailed Summary Page
FOR LINE NUMBER: (check only one)

PAGE 959 / 1572

\begin{tabular}{|c|c|c|c|c|c|}
\hline & & & & & \\
\hline 16 & $\begin{array}{l}\mathbf{X} \\
17 a\end{array}$ & $17 b$ & $17 c$ & $17 d$ & 18 \\
\hline $19 a$ & $19 \mathrm{~b}$ & $20 \mathrm{a}$ & $20 \mathrm{~b}$ & $20 \mathrm{c}$ & 21 \\
\hline
\end{tabular}

Any information copied from such Reports and Statements may not be sold or used by any person for the purpose of soliciting contributions or for commercial purposes, other than using the name and address of any political committee to solicit contributions from such committee.

NAME OF COMMITTEE (In Full)

\section{Friends of Herman Cain}

A. Full Name (Last, First, Middle Initial)

MaryJane Casablanca

Mailing Address 1701 Williams Court \#1105

\begin{tabular}{lcc}
\hline City & State & Zip Code \\
Columbus & GA & $31904-3916$
\end{tabular}

FEC ID number of contributing federal political committee.

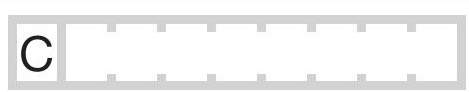

Name of Employer
None
Receipt For: 2012
X Primary $\quad$ General
Other (specify)

Occupation Retired

Election Cycle-to-Date

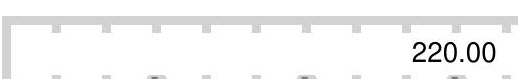

B. Full Name (Last, First, Middle Initial)

barry killman

Mailing Address p.o. box 66

\begin{tabular}{lcc}
\hline City & State & Zip Code \\
Paw Creek & NC & $28130-0066$ \\
\hline
\end{tabular}

FEC ID number of contributing

federal political committee.

C

Name of Employer
Information Requested
Receipt For: 2012
X Primary
Other (specify)

Occupation

Information Requested

Election Cycle-to-Date

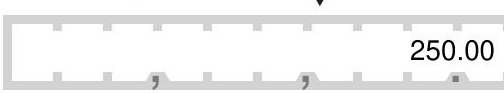

Transaction ID : A75BC17036793445497E

Date of Receipt

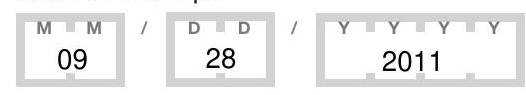

Amount of Each Receipt this Period

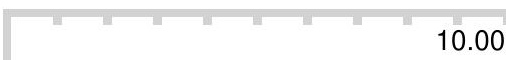

Transaction ID : A2D2E4E12A1614CB9BED Date of Receipt

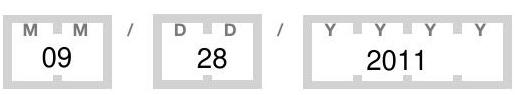

Amount of Each Receipt this Period

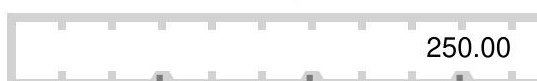

Transaction ID : AC89A12A3EC1C4FC586D Date of Receipt

Thomas Caldwell

Mailing Address P. O. Box 280

\section{City}

Franklin

FEC ID number of contributing federal political committee.

Name of Employer

State of Illinois

Receipt For: 2012

Х $\begin{aligned} & \text { Primary } \square \text { General } \\ & \text { Other (specify) }\end{aligned}$

\section{State Zip Code \\ IL $\quad 62638$}

C

\section{Occupation}

Manager

Election Cycle-to-Date

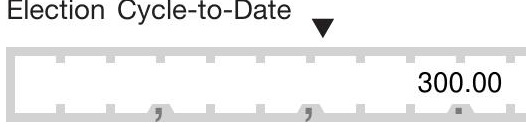

Subtotal Of Receipts This Page (optional)

Amount of Each Receipt this Period

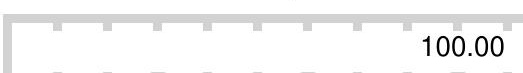

Total This Period (last page this line number only)

360.00

a

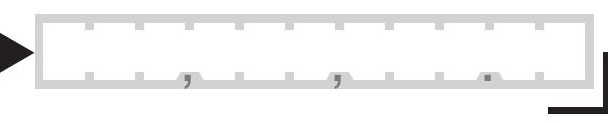

FEC Schedule A-P (Form 3P) (Rev. 03/2011) 


\section{SCHEDULE A-P} ITEMIZED RECEIPTS
Use separate schedule(s)

for each category of the

Detailed Summary Page
FOR LINE NUMBER: (check only one)

PAGE $960 / 1572$

\begin{tabular}{|c|c|c|c|c|c|}
\hline & & & & & \\
\hline 16 & X $17 a$ & $17 b$ & $17 c$ & $17 d$ & 18 \\
\hline $19 a$ & $19 b$ & $20 \mathrm{a}$ & $20 \mathrm{~b}$ & $20 \mathrm{c}$ & 21 \\
\hline
\end{tabular}

Any information copied from such Reports and Statements may not be sold or used by any person for the purpose of soliciting contributions or for commercial purposes, other than using the name and address of any political committee to solicit contributions from such committee.

NAME OF COMMITTEE (In Full)

Friends of Herman Cain

A. Full Name (Last, First, Middle Initial)

Ted Dickie

Mailing Address 7930 FM 1783

\begin{tabular}{lcc}
\hline City & State & Zip Code \\
Gatesville & TX & $76528-4706$
\end{tabular}

FEC ID number of contributing federal political committee.

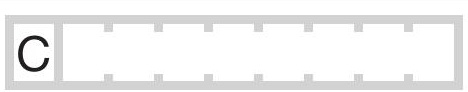

Name of Employer
Information Requested
Receipt For: 2012
X Primary
$\square$ Other (specify)

Occupation

Information Requested

Election Cycle-to-Date

250.00

B. Full Name (Last, First, Middle Initial)

Tim Cunningham

Mailing Address 88 main St

\begin{tabular}{lcc}
\hline City & State & Zip Code \\
Southampton & NY & $11968-4834$
\end{tabular}

FEC ID number of contributing

federal political committee.

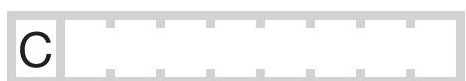

Name of Employer
Cunningham Insurance
Receipt For: 2012
X Primary
Other (specify)

\section{Occupation}

Pres.

Election Cycle-to-Date

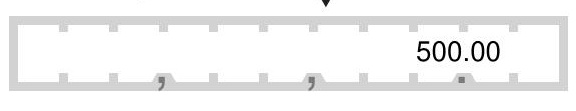

C. Full Name (Last, First, Middle Initial)

Laura Flynt

Mailing Address 109 Danbury Ln \# R

\begin{tabular}{lcc}
\hline City & State & Zip Code \\
Hattiesburg & MS & $39402-3011$
\end{tabular}

FEC ID number of contributing

federal political committee.

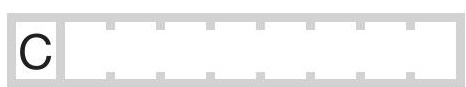

Name of Employer

Northpark Town Homes, LLC

Receipt For: 2012

Х $\begin{aligned} & \text { Primary } \square \text { General } \\ & \text { Other (specify) }\end{aligned}$

\section{Occupation}

Owner

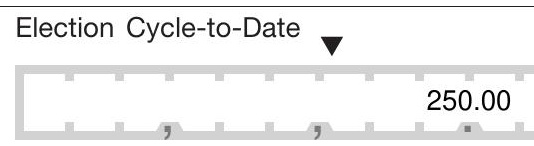

Transaction ID : A942DBF0E233443108EB

Date of Receipt

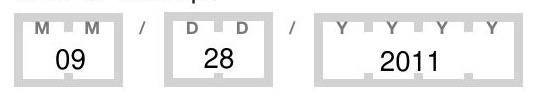

Amount of Each Receipt this Period

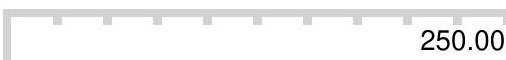

250.00

Amount of Each Receipt this Period

Transaction ID : AE8FDBEFC32094634982

Date of Receipt
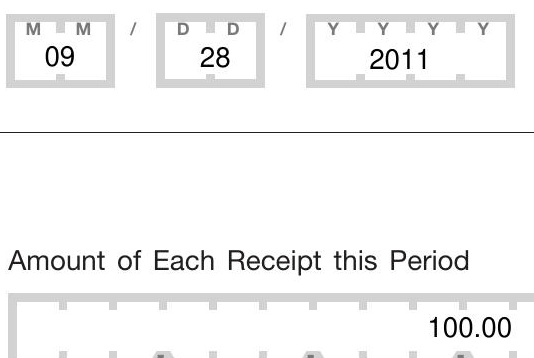

Transaction ID : A65B4D0530E264719B27

Date of Receipt

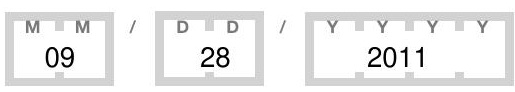

Amount of Each Receipt this Period

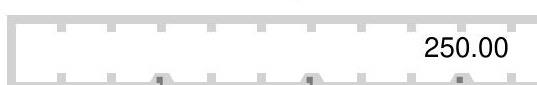

600.00

Subtotal Of Receipts This Page (optional)

,

Total This Period (last page this line number only)

FEC Schedule A-P (Form 3P) (Rev. 03/2011) 


\section{SCHEDULE A-P} ITEMIZED RECEIPTS
Use separate schedule(s) for each category of the Detailed Summary Page

FOR LINE NUMBER:
(check only one)

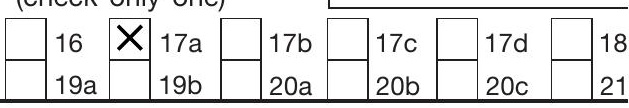

Any information copied from such Reports and Statements may not be sold or used by any person for the purpose of soliciting contributions or for commercial purposes, other than using the name and address of any political committee to solicit contributions from such committee.

NAME OF COMMITTEE (In Full)

\section{Friends of Herman Cain}

A. Full Name (Last, First, Middle Initial)

\section{Davis Brasfield}

Mailing Address 5161 Silver Acres Ct

\begin{tabular}{lcc}
\hline City & State & Zip Code \\
San Jose & CA & $95138-2103$ \\
\hline
\end{tabular}

FEC ID number of contributing federal political committee.

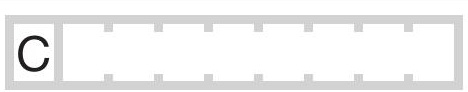

Name of Employer
Information Requested
Receipt For: 2012
X Primary
$\square$ Other (specify)

\section{Occupation} Information Requested

Election Cycle-to-Date

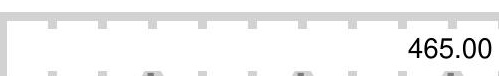

B. Full Name (Last, First, Middle Initial)

Katherine Johnson

Mailing Address 4231 Turtle Mound Road

\begin{tabular}{lcc}
\hline City & State & Zip Code \\
Melbourne & FL & $32934-8506$
\end{tabular}

FEC ID number of contributing

federal political committee.

C

Name of Employer
Intercoastal Accounting, Inc.
Receipt For: 2012
Х Primary
Other (specify)

\section{Occupation}

Accountant

Election Cycle-to-Date

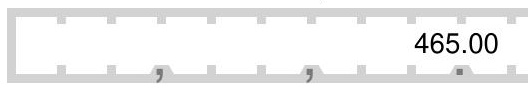

C. Full Name (Last, First, Middle Initial)

Michael Barron

Mailing Address 6650 Via austi pky

\begin{tabular}{lcc}
\hline City & State & Zip Code \\
Las Vegas & NV & $89119-3550$
\end{tabular}

FEC ID number of contributing federal political committee.

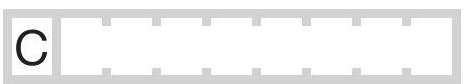

Name of Employer
Information Requested
Receipt For: 2012
Primary
Other (specify) General

Name of Employer

Information Requested

Occupation

Information Requested

Election Cycle-to-Date

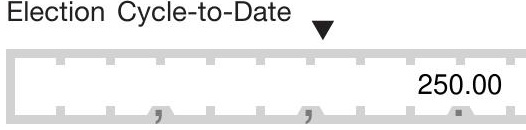

Transaction ID : AB96E5B9D87814601840

Date of Receipt

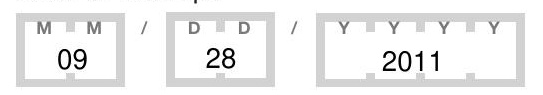

Amount of Each Receipt this Period

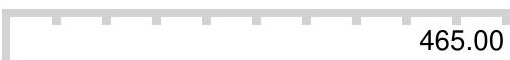

465.00

Transaction ID : A5A768F021F8946B1868

Date of Receipt

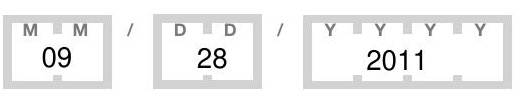

Amount of Each Receipt this Period

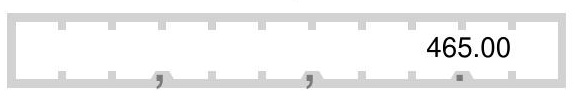

Transaction ID : A4723DCCBA1234990BEE Date of Receipt

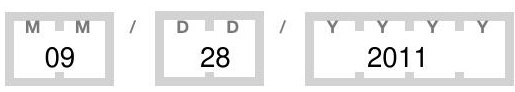

Amount of Each Receipt this Period

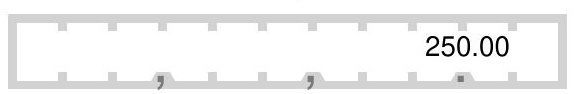

1180.00

Subtotal Of Receipts This Page (optional)

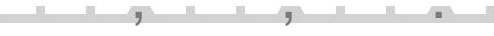

Total This Period (last page this line number only) 


\section{SCHEDULE A-P} ITEMIZED RECEIPTS
Use separate schedule(s) for each category of the Detailed Summary Page

\begin{tabular}{|c|c|c|c|c|c|}
\hline \multicolumn{3}{|c|}{$\begin{array}{l}\text { FOR LINE NUMBER: } \\
\text { (check only one) }\end{array}$} & \multicolumn{3}{|c|}{ PAGE 962 / 1572} \\
\hline 16 & $X$ 17a & $17 b$ & $17 \mathrm{c}$ & $17 d$ & 18 \\
\hline $19 a$ & $19 \mathrm{~b}$ & $20 a$ & $20 \mathrm{~b}$ & $20 c$ & 21 \\
\hline
\end{tabular}

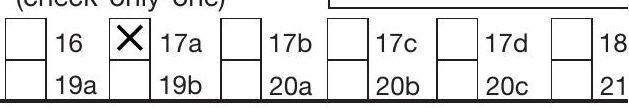

Any information copied from such Reports and Statements may not be sold or used by any person for the purpose of soliciting contributions or for commercial purposes, other than using the name and address of any political committee to solicit contributions from such committee.

NAME OF COMMITTEE (In Full)

\section{Friends of Herman Cain}

A. Full Name (Last, First, Middle Initial)

Rachel Arredondo

Mailing Address PO Box 16788

\begin{tabular}{lcc}
\hline City & State & Zip Code \\
Lubbock & TX & $79490-6788$ \\
\hline
\end{tabular}

FEC ID number of contributing federal political committee.

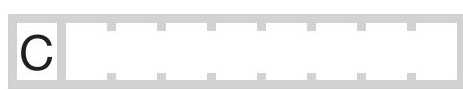

Name of Employer
Information Requested
Receipt For: 2012
X Primary
$\square$ Other (specify)

Occupation Information Requested

Election Cycle-to-Date 250.00

B. Full Name (Last, First, Middle Initial) sue campbell

Mailing Address 26 turtleback rd

\begin{tabular}{lcc}
\hline City & State & Zip Code \\
Sunapee & $\mathrm{NH}$ & $03782-2324$ \\
\hline
\end{tabular}

FEC ID number of contributing

federal political committee.

C

Name of Employer
Information Requested
Receipt For: 2012
Primary
Other (specify)

Occupation

Information Requested

Election Cycle-to-Date

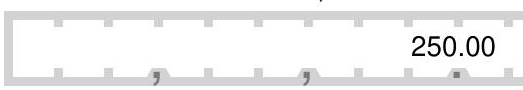

C. Full Name (Last, First, Middle Initial)

Nanci Rotello

Mailing Address 3133 Elk Clover

\begin{tabular}{lcc}
\hline City & State & Zip Code \\
Las Vegas & NV & $89135-1819$ \\
\hline
\end{tabular}

FEC ID number of contributing federal political committee.

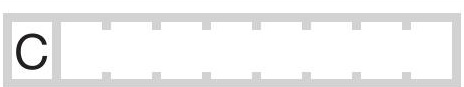

Name of Employer
None
Receipt For: 2012
Х Primary $\quad \square$ General
Other (specify)

\section{Occupation}

Homemaker
Election Cycle-to-Date
Transaction ID : A838BCD56CB474A1DBA7 Date of Receipt

Amount of Each Receipt this Period

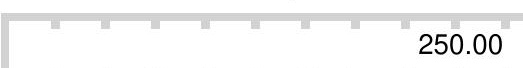

Transaction ID : ACDFF761A562543159B5

Date of Receipt
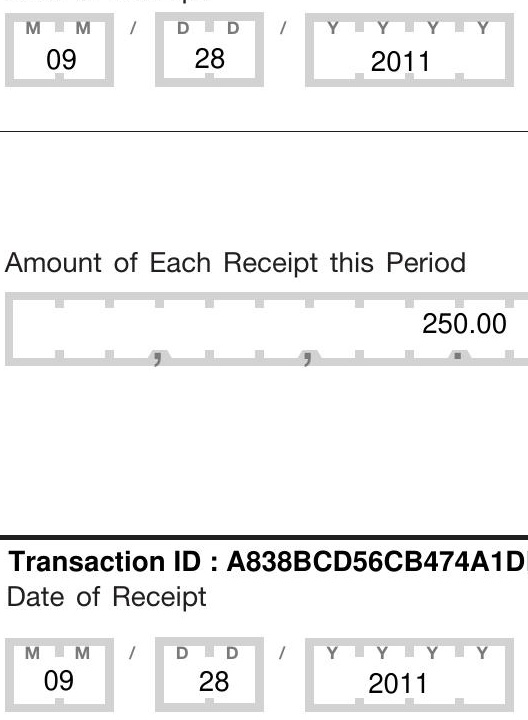

Amount of Each Receipt this Period

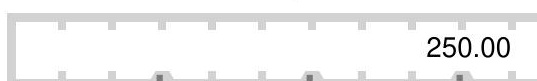

Transaction ID : AADD6F7B86BDD4BA5884 Date of Receipt

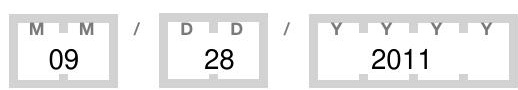

Amount of Each Receipt this Period

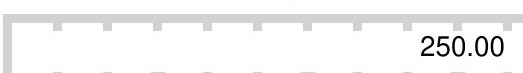

\section{Subtotal Of Receipts This Page (optional).}

Total This Period (last page this line number only) 
SCHEDULE A-P ITEMIZED RECEIPTS
Use separate schedule(s) for each category of the Detailed Summary Page
FOR LINE NUMBER: (check only one)

PAGE $963 / 1572$

\begin{tabular}{|c|c|c|c|c|c|}
\hline & & & & & \\
\hline 16 & $\mathbf{X} 17 a$ & $17 b$ & $17 c$ & $17 d$ & 18 \\
\hline $19 a$ & $19 b$ & $20 \mathrm{a}$ & $20 \mathrm{~b}$ & $20 \mathrm{c}$ & 21 \\
\hline
\end{tabular}

Any information copied from such Reports and Statements may not be sold or used by any person for the purpose of soliciting contributions or for commercial purposes, other than using the name and address of any political committee to solicit contributions from such committee.

NAME OF COMMITTEE (In Full)

\section{Friends of Herman Cain}

A. Full Name (Last, First, Middle Initial) Jason Highley

Mailing Address 185 Providence St. Unit A414

\begin{tabular}{lcc}
\hline City & State & Zip Code \\
West Warwick & RI & $02893-2580$
\end{tabular}

FEC ID number of contributing federal political committee.

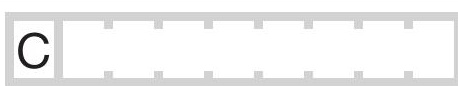

Name of Employer
Information Requested
Receipt For: 2012
X Primary
Other (specify) General

Occupation Information Requested

Election Cycle-to-Date

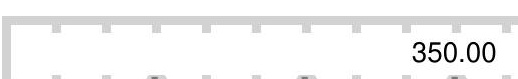

B. Full Name (Last, First, Middle Initial)

Susan Walter

Mailing Address P.O. Box 690

\begin{tabular}{lcc}
\hline City & State & Zip Code \\
Sautee Nacoochee & GA & $30571-0690$ \\
\hline
\end{tabular}

FEC ID number of contributing

federal political committee.

C

Name of Employer
None
Receipt For: 2012
X Primary
Other (specify)

C. Full Name (Last, First, Middle Initial) anne Kornak

Mailing Address p.o. box 909

\begin{tabular}{lcc}
\hline City & State & Zip Code \\
Opelousas & LA & $70571-0909$
\end{tabular}

FEC ID number of contributing federal political committee.

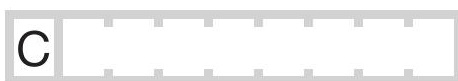

Name of Employer
Information Requested
Receipt For: 2012
X Primary $\quad \square$ General
Other (specify)

\section{Occupation}

Retired

Election Cycle-to-Date

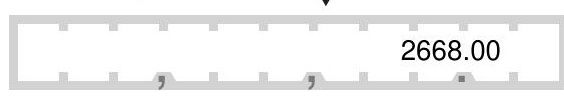

Transaction ID : AABBBB7FDBD054EC4929

Date of Receipt

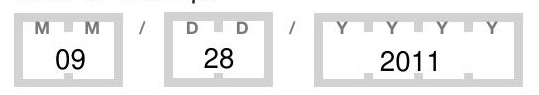

Amount of Each Receipt this Period

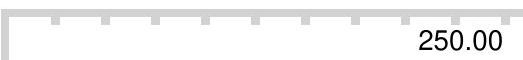

Amount of Each Receipt this Period

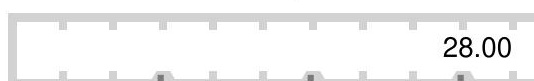

Transaction ID : A98DF8BD566FA42A9A4A Date of Receipt

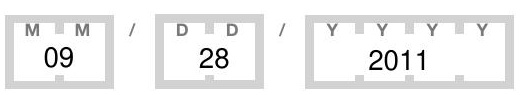

Transaction ID : AFDA139E2F66F4E62AAB Date of Receipt

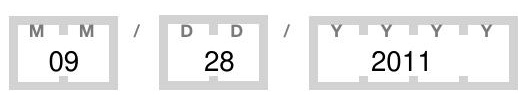

Amount of Each Receipt this Period

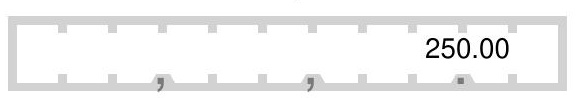

\section{Subtotal Of Receipts This Page (optional)}

Total This Period (last page this line number only) 
SCHEDULE A-P ITEMIZED RECEIPTS
Use separate schedule(s) for each category of the Detailed Summary Page
FOR LINE NUMBER: (check only one)
PAGE 964 / 1572

\begin{tabular}{|c|c|c|c|c|c|}
\hline & & & & & \\
\hline 16 & $\begin{array}{lll}X & 17 a \\
\end{array}$ & $17 \mathrm{~b}$ & $17 c$ & $17 d$ & 18 \\
\hline $19 a$ & $19 b$ & $20 a$ & $20 \mathrm{~b}$ & $20 c$ & 21 \\
\hline
\end{tabular}

Any information copied from such Reports and Statements may not be sold or used by any person for the purpose of soliciting contributions or for commercial purposes, other than using the name and address of any political committee to solicit contributions from such committee.

NAME OF COMMITTEE (In Full)

Friends of Herman Cain

A. Full Name (Last, First, Middle Initial)

Wendell Faile

Mailing Address 28-190 Avenida Primavera

\begin{tabular}{lcc}
\hline City & State & Zip Code \\
Cathedral City & CA & $92234-3781$ \\
\hline
\end{tabular}

FEC ID number of contributing

federal political committee.

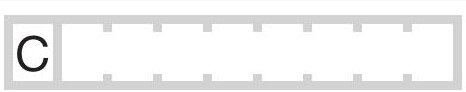

Name of Employer
Information Requested
Receipt For: 2012
X Primary $\quad \square$ General
Other (specify)

Occupation

Information Requested

Election Cycle-to-Date

250.00

B. Full Name (Last, First, Middle Initial)

Rene Oberer

Mailing Address 2757 Evermur Dr.

\begin{tabular}{lcc}
\hline City & State & Zip Code \\
Dayton & OH & $45414-1405$ \\
\hline
\end{tabular}

FEC ID number of contributing

federal political committee.

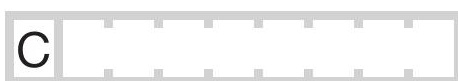

Name of Employer
None
Receipt For: 2012
X Primary
Other (specify)

Occupation

Retired

Election Cycle-to-Date

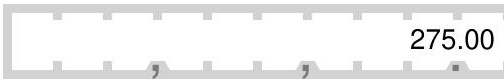

C. Full Name (Last, First, Middle Initial)

Alan Roell

Mailing Address 1308 Stymie Court

\begin{tabular}{lcc}
\hline City & State & Zip Code \\
Indianapolis & IN & $46217-4319$
\end{tabular}

FEC ID number of contributing federal political committee.

C

Name of Employer
self-employed Gill Carbide \& Saw
Receipt For: 2012
X Primary
Other (specify)

Occupation

Saw and Tool Smith

Election Cycle-to-Date

Transaction ID : A52317CD55C07422CB07

Date of Receipt

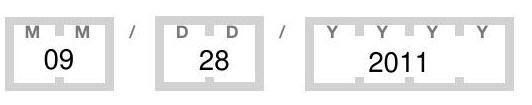

Amount of Each Receipt this Period

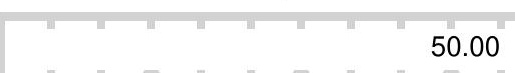

Transaction ID : A448491314EF8415A880

Date of Receipt

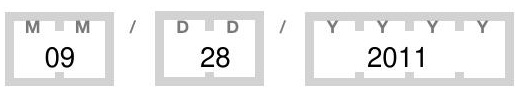

Amount of Each Receipt this Period

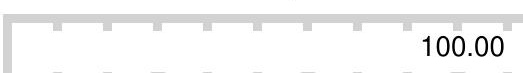

300.00

Subtotal Of Receipts This Page (optional).

400.00

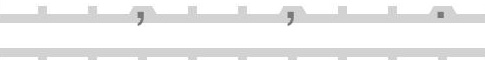

Total This Period (last page this line number only) 


\section{SCHEDULE A-P} ITEMIZED RECEIPTS
Use separate schedule(s)

for each category of the

Detailed Summary Page
FOR LINE NUMBER: (check only one)

PAGE $965 / 1572$

\begin{tabular}{|c|c|c|c|c|c|}
\hline & & & & & \\
\hline 16 & X $17 a$ & $17 b$ & $17 c$ & $17 d$ & 18 \\
\hline $19 a$ & $19 b$ & $20 \mathrm{a}$ & $20 \mathrm{~b}$ & $20 \mathrm{c}$ & 21 \\
\hline
\end{tabular}

Any information copied from such Reports and Statements may not be sold or used by any person for the purpose of soliciting contributions or for commercial purposes, other than using the name and address of any political committee to solicit contributions from such committee.

NAME OF COMMITTEE (In Full)

\section{Friends of Herman Cain}

A. Full Name (Last, First, Middle Initial)

\section{Paul Martin}

Mailing Address PO Box 31963

\begin{tabular}{lcc}
\hline City & State & Zip Code \\
Knoxville & TN & $37930-1963$
\end{tabular}

FEC ID number of contributing federal political committee.

C

Name of Employer

Information Requested

Receipt For: 2012

X Primary $\square$ General Other (specify)
Occupation

Information Requested

Election Cycle-to-Date

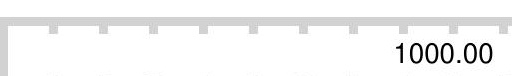

B. Full Name (Last, First, Middle Initial)

Bruce Batewell

Mailing Address 787 Route 434

\begin{tabular}{lcc}
\hline City & State & Zip Code \\
Shohola & PA & $18458-3711$ \\
\hline
\end{tabular}

FEC ID number of contributing

federal political committee.

C

Name of Employer
Information Requested
Receipt For: 2012
Primary
Other (specify)

Occupation

Information Requested

Election Cycle-to-Date

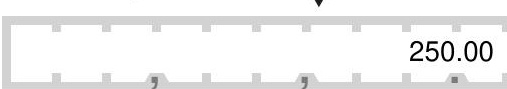

Transaction ID : A930962AA89D940489C4

Date of Receipt

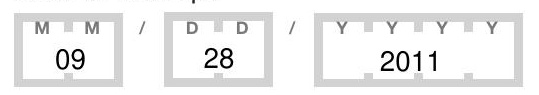

Amount of Each Receipt this Period

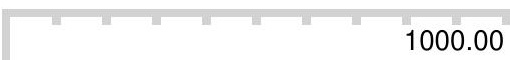

Transaction ID : AD260A20EB72D4EB98D9 Date of Receipt

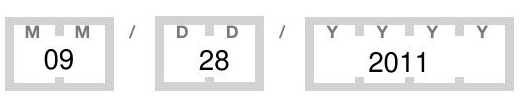

Amount of Each Receipt this Period

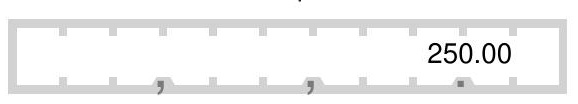

Transaction ID : AD16A95B7A5524D74BD3 Date of Receipt

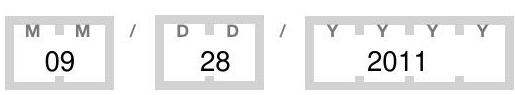

Amount of Each Receipt this Period

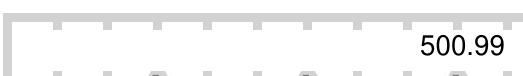

$\begin{array}{cc}\text { State } & \text { Zip Code } \\ \text { FL } & 33579-2396\end{array}$

C

Occupation

Information Requested

Election Cycle-to-Date

500.99

Subtotal Of Receipts This Page (optional).

1750.99

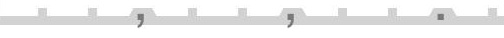

Total This Period (last page this line number only)

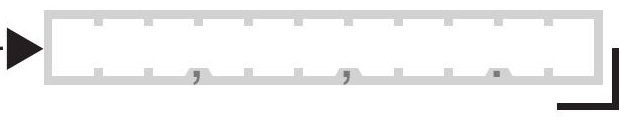

FEC Schedule A-P (Form 3P) (Rev. 03/2011) 


\section{SCHEDULE A-P} ITEMIZED RECEIPTS
Use separate schedule(s) for each category of the Detailed Summary Page

FOR LINE NUMBER:
(check only one)

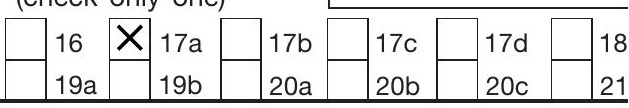

Any information copied from such Reports and Statements may not be sold or used by any person for the purpose of soliciting contributions or for commercial purposes, other than using the name and address of any political committee to solicit contributions from such committee.

NAME OF COMMITTEE (In Full)

\section{Friends of Herman Cain}

A. Full Name (Last, First, Middle Initial)

Marsha Brown

Mailing Address 388 Pencarrow Circle

\begin{tabular}{lcc}
\hline City & State & Zip Code \\
Madisonville & LA & $70447-3424$
\end{tabular}

FEC ID number of contributing federal political committee.

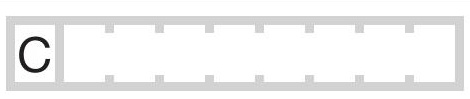

Name of Employer
Remax Real Estate Partners
Receipt For: 2012
X Primary
Other (specify)

Occupation

Realtor

Election Cycle-to-Date

B. Full Name (Last, First, Middle Initial)

Brian Alwan

Mailing Address 5724 W. Rachael Ct.

\begin{tabular}{lcc}
\hline City & State & Zip Code \\
Peoria & IL & $61615-3062$ \\
\hline
\end{tabular}

FEC ID number of contributing

federal political committee.

C

\begin{tabular}{l} 
Name of Employer \\
Information Requested \\
\hline Receipt For: 2012 \\
$X$ Primary \\
Other (specify)
\end{tabular}

Occupation

Information Requested

Election Cycle-to-Date

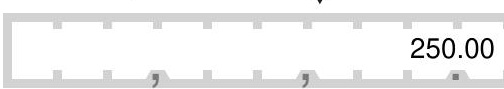

Transaction ID : A7BDCAB9D6AF04BA6A84

Date of Receipt

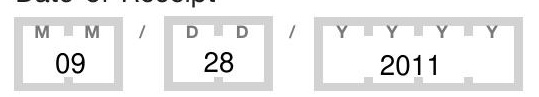

Amount of Each Receipt this Period

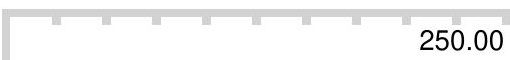

250.00

C. Full Name (Last, First, Middle Initial)

Cynthia Mitchell

Mailing Address 110 Caverns Way

\begin{tabular}{lcc}
\hline City & State & Zip Code \\
Calhoun & GA & $30701-4738$
\end{tabular}

FEC ID number of contributing federal political committee.

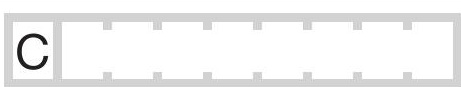

Name of Employer

Information Requested

\section{Occupation}

Information Requested

Receipt For: 2012

Х $\begin{aligned} & \text { Primary } \\ & \text { Other (specify) }\end{aligned}$

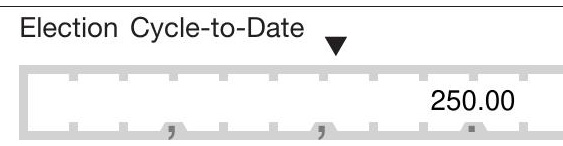

Amount of Each Receipt this Period

Transaction ID : AB485D979433A4FD8A74

Date of Receipt
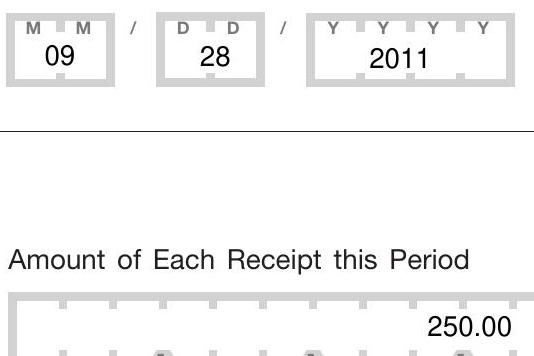

Transaction ID : AEB4982381E17489FBB0

Date of Receipt

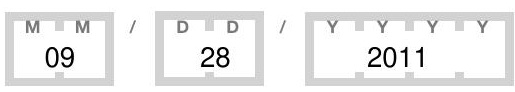

Amount of Each Receipt this Period

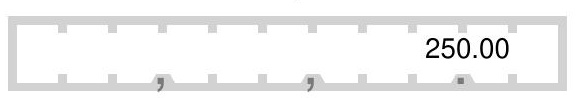

Subtotal Of Receipts This Page (optional).

750.00

Total This Period (last page this line number only) 


\section{SCHEDULE A-P} ITEMIZED RECEIPTS
Use separate schedule(s)

for each category of the

Detailed Summary Page
FOR LINE NUMBER: (check only one)

PAGE 967 / 1572

\begin{tabular}{|c|c|c|c|c|c|}
\hline & & & & & \\
\hline 16 & X $17 a$ & $17 b$ & $17 c$ & $17 d$ & 18 \\
\hline $19 a$ & $19 b$ & $20 \mathrm{a}$ & $20 \mathrm{~b}$ & $20 \mathrm{c}$ & 21 \\
\hline
\end{tabular}

Any information copied from such Reports and Statements may not be sold or used by any person for the purpose of soliciting contributions or for commercial purposes, other than using the name and address of any political committee to solicit contributions from such committee.

NAME OF COMMITTEE (In Full)

Friends of Herman Cain

A. Full Name (Last, First, Middle Initial)

David White

Mailing Address 3689 Wentworth Lane

\begin{tabular}{lcc}
\hline City & State & Zip Code \\
Lilburn & GA & $30047-2256$ \\
\hline
\end{tabular}

FEC ID number of contributing federal political committee.

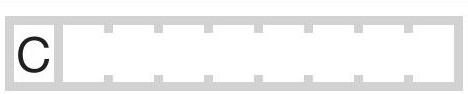

Name of Employer
Delta Airlines
Receipt For: 2012
X Primary
$\square$ Other (specify) General

Occupation

Aviation Maintenance

Election Cycle-to-Date

585.00

B. Full Name (Last, First, Middle Initial)

Robert Gribble

Mailing Address 1166 West Main

\begin{tabular}{lcc}
\hline City & State & Zip Code \\
Hallsville & TX & $75650-5023$
\end{tabular}

FEC ID number of contributing

federal political committee.

C

Name of Employer
Information Requested
Receipt For: 2012
Primary
Other (specify)

Occupation

Information Requested

Election Cycle-to-Date

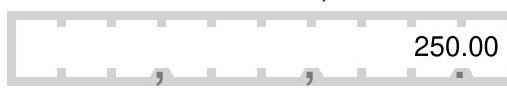

Transaction ID : AE1590886BB64479DA96

Date of Receipt

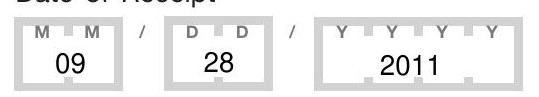

Amount of Each Receipt this Period

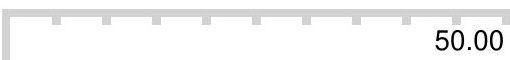

50.00

C. Full Name (Last, First, Middle Initial)

Gary Lyon

Mailing Address P.O. Box 19428

\begin{tabular}{lcc}
\hline City & State & Zip Code \\
Cool & CA & 95614 \\
\hline
\end{tabular}

FEC ID number of contributing

federal political committee.

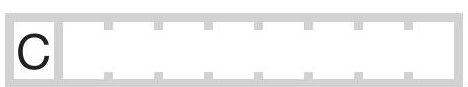

Name of Employer

Information Requested

Occupation

Information Requested

Receipt For: 2012

Х $\begin{aligned} & \text { Primary } \\ & \text { Other (specify) }\end{aligned}$

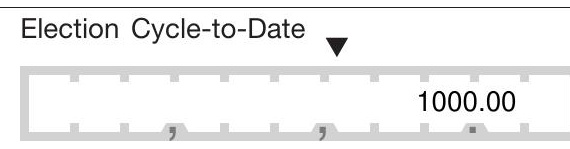

Amount of Each Receipt this Period

Transaction ID : AF19D164A37754E049A7

Date of Receipt
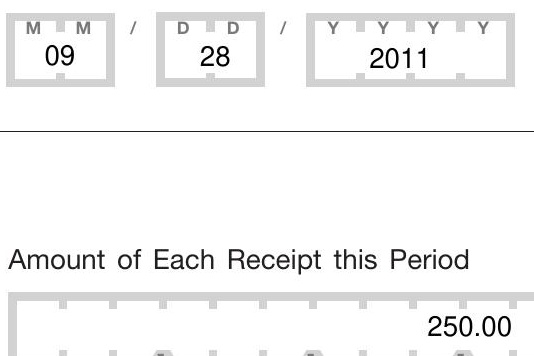

Transaction ID : A888C64B70A6047A3B1F Date of Receipt

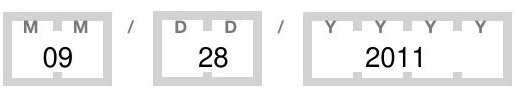

Amount of Each Receipt this Period

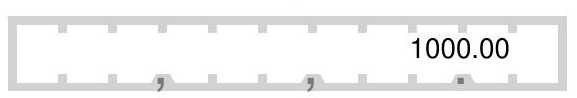

Subtotal Of Receipts This Page (optional).

1300.00

Total This Period (last page this line number only) 


\section{SCHEDULE A-P} ITEMIZED RECEIPTS
Use separate schedule(s)

for each category of the

Detailed Summary Page
FOR LINE NUMBER: (check only one)

PAGE $968 / 1572$

\begin{tabular}{|c|c|c|c|c|c|}
\hline & & & & & \\
\hline 16 & X $17 a$ & $17 b$ & $17 c$ & $17 d$ & 18 \\
\hline $19 a$ & $19 b$ & $20 \mathrm{a}$ & $20 \mathrm{~b}$ & $20 \mathrm{c}$ & 21 \\
\hline
\end{tabular}

Any information copied from such Reports and Statements may not be sold or used by any person for the purpose of soliciting contributions or for commercial purposes, other than using the name and address of any political committee to solicit contributions from such committee.

NAME OF COMMITTEE (In Full)

\section{Friends of Herman Cain}

A. Full Name (Last, First, Middle Initial)

\section{Andria Louis}

Mailing Address 10051 Quail Ridge Dr.

\begin{tabular}{lcc}
\hline City & State & Zip Code \\
La Vista & NE & $68128-3196$ \\
\hline
\end{tabular}

FEC ID number of contributing federal political committee.

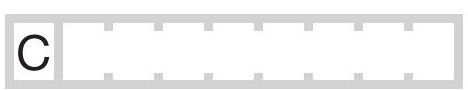

Name of Employer
Information Requested
Receipt For: 2012
X Primary
Other (specify) General

Occupation Information Requested

Election Cycle-to-Date

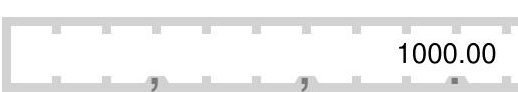

B. Full Name (Last, First, Middle Initial) joseph mcdonough

Mailing Address 5212 village creek dr

\begin{tabular}{lcc}
\hline City & State & Zip Code \\
Plano & TX & $75093-5066$ \\
\hline
\end{tabular}

FEC ID number of contributing

federal political committee.

C

Name of Employer
Information Requested
Receipt For: 2012
X Primary
Other (specify)

Occupation

Information Requested

Election Cycle-to-Date

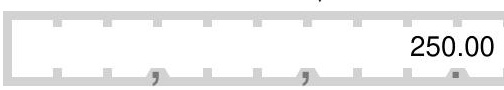

Transaction ID : AC1367B85E6A44C43A9F

Date of Receipt

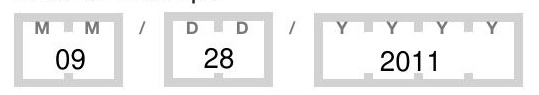

Amount of Each Receipt this Period

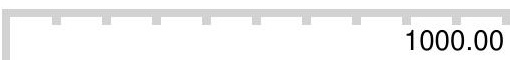

C. Full Name (Last, First, Middle Initial)

Baylor Walker

Mailing Address 817 Overton Rd.

\begin{tabular}{lcc}
\hline City & State & Zip Code \\
Big Spring & TX & $79720-7933$
\end{tabular}

FEC ID number of contributing federal political committee.

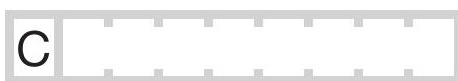

Name of Employer

Information Requested

Occupation

Information Requested

Receipt For: 2012

Х $\begin{aligned} & \text { Primary } \square \text { General } \\ & \text { Other (specify) }\end{aligned}$

Amount of Each Receipt this Period

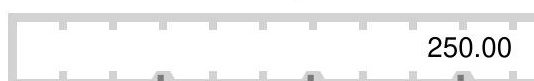

Transaction ID : AD3CAA0C8E24746C7B7F Date of Receipt

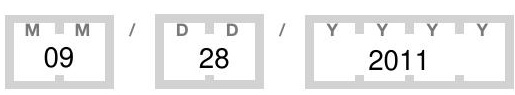

Transaction ID : A5AEF602B29BC4BA09DE Date of Receipt

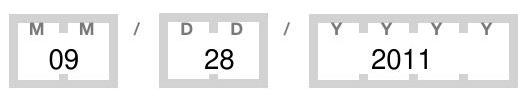

Amount of Each Receipt this Period

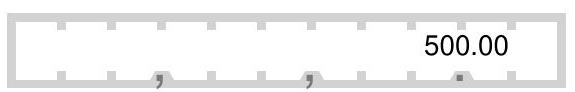

500.00

\section{Subtotal Of Receipts This Page (optional)}

Total This Period (last page this line number only) 


\section{SCHEDULE A-P} ITEMIZED RECEIPTS
Use separate schedule(s)

for each category of the

Detailed Summary Page
FOR LINE NUMBER: (check only one)

PAGE 969 / 1572

\begin{tabular}{|c|c|c|c|c|c|}
\hline & & & & & \\
\hline 16 & X $17 a$ & $17 b$ & $17 c$ & $17 d$ & 18 \\
\hline $19 a$ & $19 b$ & $20 \mathrm{a}$ & $20 \mathrm{~b}$ & $20 \mathrm{c}$ & 21 \\
\hline
\end{tabular}

Any information copied from such Reports and Statements may not be sold or used by any person for the purpose of soliciting contributions or for commercial purposes, other than using the name and address of any political committee to solicit contributions from such committee.

NAME OF COMMITTEE (In Full)

Friends of Herman Cain

A. Full Name (Last, First, Middle Initial)

Patricia Pinholster

Mailing Address PO Box 2038

\begin{tabular}{lcc}
\hline City & State & Zip Code \\
McDonough & GA & $30253-1720$ \\
\hline
\end{tabular}

FEC ID number of contributing federal political committee.

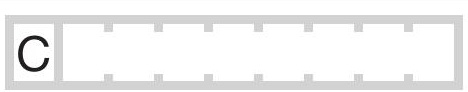

Name of Employer
Dr. Jerry Coleman
Receipt For: 2012
X Primary
$\square$ Other (specify) General

Occupation dental assistant

Election Cycle-to-Date 300.00

B. Full Name (Last, First, Middle Initial)

Robert Beauchamp

Mailing Address 2454 alton parkway

\begin{tabular}{lcc}
\hline City & State & Zip Code \\
Dana Point & CA & 92629
\end{tabular}

FEC ID number of contributing

federal political committee.

C

Name of Employer
Information Requested
Receipt For: 2012
Primary
Other (specify)

Occupation

Information Requested

Election Cycle-to-Date

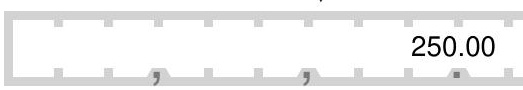

Transaction ID : AA4764F832727495F9BA

Date of Receipt

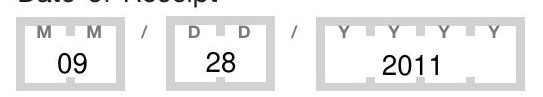

Amount of Each Receipt this Period

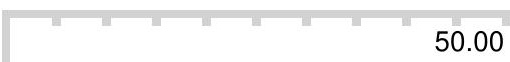

50.00

C. Full Name (Last, First, Middle Initial)

Mr. Robert E Hawkins

Mailing Address 5005 Birch Rd

\begin{tabular}{lcc}
\hline City & State & Zip Code \\
Fayetteville & NC & $28304-1901$
\end{tabular}

FEC ID number of contributing federal political committee.

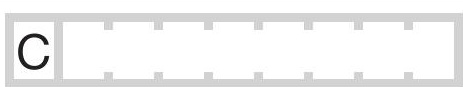

Name of Employer

Information Requested

\section{Occupation}

Information Requested

Receipt For: 2012

Х $\begin{aligned} & \text { Primary } \\ & \text { Other (specify) }\end{aligned}$

Transaction ID : A0DFC069D50D24849B9D

Date of Receipt

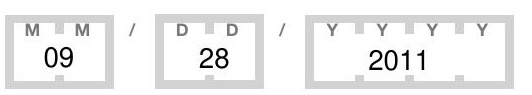

Amount of Each Receipt this Period

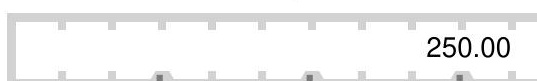

Transaction ID : A41570B62B73247C2AA4 Date of Receipt

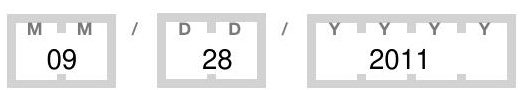

Amount of Each Receipt this Period

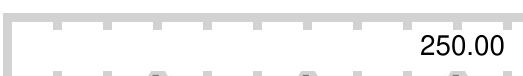

\section{Subtotal Of Receipts This Page (optional)}

Total This Period (last page this line number only) 


\section{SCHEDULE A-P} ITEMIZED RECEIPTS
Use separate schedule(s)

for each category of the

Detailed Summary Page
FOR LINE NUMBER: (check only one)

PAGE $970 / 1572$

\begin{tabular}{|c|c|c|c|c|c|}
\hline & & & & & \\
\hline 16 & $\begin{array}{l}\mathbf{X} \\
17 a\end{array}$ & $17 b$ & $17 c$ & $17 d$ & 18 \\
\hline $19 a$ & $19 \mathrm{~b}$ & $20 \mathrm{a}$ & $20 \mathrm{~b}$ & $20 \mathrm{c}$ & 21 \\
\hline
\end{tabular}

Any information copied from such Reports and Statements may not be sold or used by any person for the purpose of soliciting contributions or for commercial purposes, other than using the name and address of any political committee to solicit contributions from such committee.

NAME OF COMMITTEE (In Full)

Friends of Herman Cain

A. Full Name (Last, First, Middle Initial)

Scott Smith

Mailing Address 19680 Sunshine Way

\begin{tabular}{lcc}
\hline City & State & Zip Code \\
Bend & OR & $97702-1983$ \\
\hline
\end{tabular}

FEC ID number of contributing federal political committee.

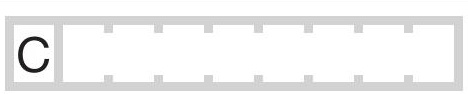

Name of Employer
None
Receipt For: 2012
X Primary $\quad \square$ General
$\square$ Other (specify)

Occupation

Retired

Election Cycle-to-Date

\subsection{0}

B. Full Name (Last, First, Middle Initial)

roy schmidt

Mailing Address 1844 highpoint rd

\begin{tabular}{lcc}
\hline City & State & Zip Code \\
Snellville & GA & $30078-2802$ \\
\hline
\end{tabular}

FEC ID number of contributing

federal political committee.

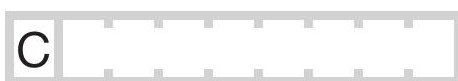

Name of Employer
None
Receipt For: 2012
X Primary
Other (specify)

Occupation

Retired

Election Cycle-to-Date

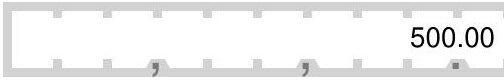

C. Full Name (Last, First, Middle Initial)

Patricia garrison

Mailing Address 6 hiibury

\begin{tabular}{lcc}
\hline City & State & Zip Code \\
Houston & TX & $77024-7113$ \\
\hline
\end{tabular}

FEC ID number of contributing

federal political committee.

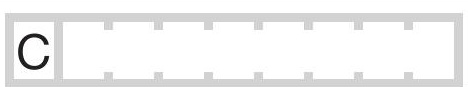

Name of Employer

Information Requested

Occupation

Information Requested

Receipt For: 2012

Х $\begin{aligned} & \text { Primary } \square \text { General } \\ & \text { Other (specify) }\end{aligned}$

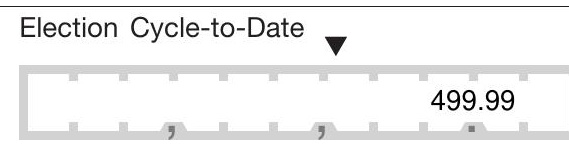

Amount of Each Receipt this Period

Transaction ID : ABD11E5CA571A4520841

Date of Receipt

Amount of Each Receipt this Period
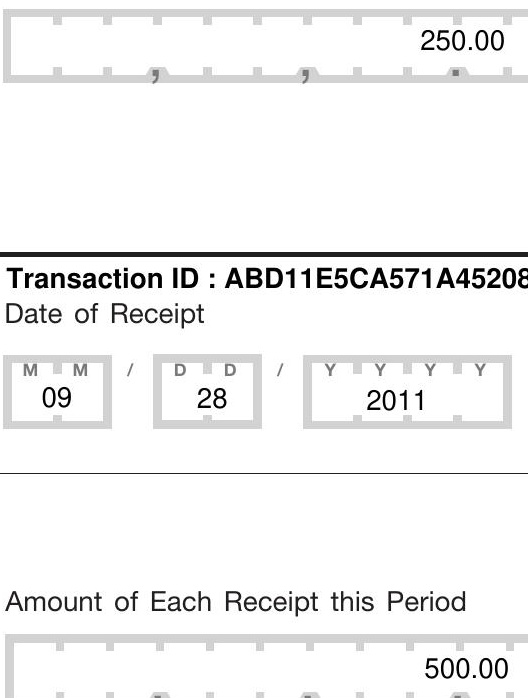

Transaction ID : A176605B346554099A3F

Date of Receipt

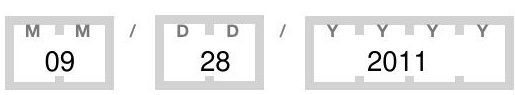

Amount of Each Receipt this Period

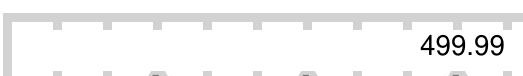

499.99

1249.99

Subtotal Of Receipts This Page (optional)...

․․․․

Total This Period (last page this line number only) 


\section{SCHEDULE A-P} ITEMIZED RECEIPTS
Use separate schedule(s) for each category of the Detailed Summary Page

FOR LINE NUMBER:
(check only one)

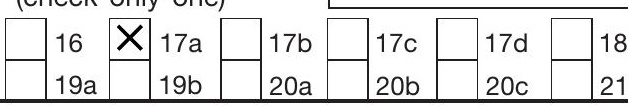

Any information copied from such Reports and Statements may not be sold or used by any person for the purpose of soliciting contributions or for commercial purposes, other than using the name and address of any political committee to solicit contributions from such committee.

NAME OF COMMITTEE (In Full)

\section{Friends of Herman Cain}

A. Full Name (Last, First, Middle Initial) Joni Martin

Mailing Address 4347 Westside Dr.

\begin{tabular}{lcc}
\hline City & State & Zip Code \\
Dallas & TX & $75209-6515$
\end{tabular}

FEC ID number of contributing federal political committee.

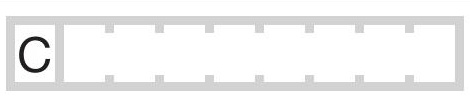

Name of Employer
N A
Receipt For: 2012
X Primary $\square$ General
$\square$ Other (specify)

Occupation Retired Election Cycle-to-Date

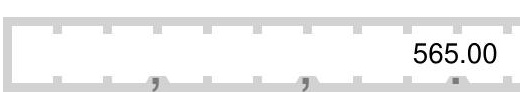

B. Full Name (Last, First, Middle Initial)

Barbara Barrett

Mailing Address 4617 E. Ocotillo Road

\begin{tabular}{lcc}
\hline City & State & Zip Code \\
Paradise Valley & AZ & $85253-4032$ \\
\hline
\end{tabular}

FEC ID number of contributing

federal political committee.

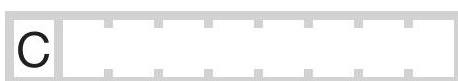

Name of Employer
Triple Creek Ranch
Receipt For: 2012
X Primary
Other (specify)

Occupation

President

Election Cycle-to-Date

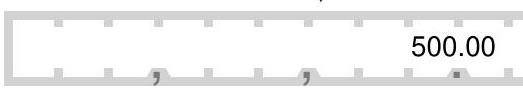

C. Full Name (Last, First, Middle Initial)

Steven Tunney, Sr

Mailing Address 20743 Steamside Place

\begin{tabular}{lcc}
\hline City & State & Zip Code \\
Ashburn & VA & $20147-4455$
\end{tabular}

FEC ID number of contributing federal political committee.

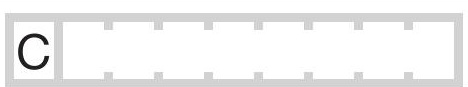

Name of Employer

Information Requested

\section{Occupation}

Information Requested

Receipt For: 2012

Х $\begin{aligned} & \text { Primary } \\ & \text { Other (specify) }\end{aligned}$

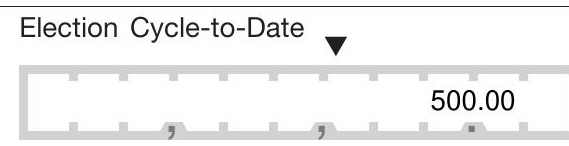

Amount of Each Receipt this Period

Transaction ID : A642F03BADE894A50BA1

Date of Receipt

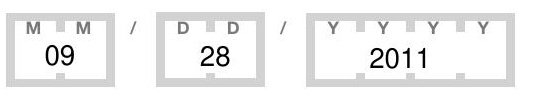

Amount of Each Receipt this Period

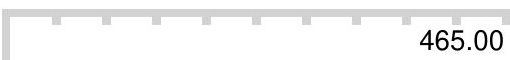

465.00

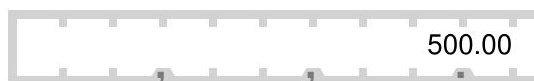

Transaction ID : AA028B169A15940C4A7D Date of Receipt

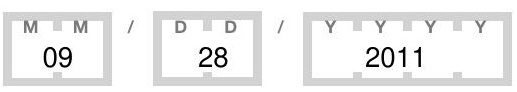

Amount of Each Receipt this Period

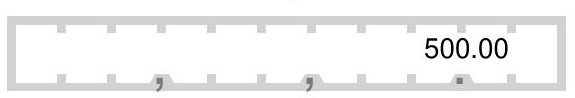

Subtotal Of Receipts This Page (optional).

1465.00

Total This Period (last page this line number only) 


\section{SCHEDULE A-P} ITEMIZED RECEIPTS
Use separate schedule(s)

for each category of the

Detailed Summary Page
FOR LINE NUMBER: (check only one)

PAGE 972 / 1572

\begin{tabular}{|c|c|c|c|c|c|}
\hline & & & & & \\
\hline 16 & $\mathbf{X} 17 \mathrm{a}$ & $17 \mathrm{~b}$ & $17 c$ & $17 d$ & 18 \\
\hline $19 a$ & $19 \mathrm{~b}$ & $20 a$ & $20 \mathrm{~b}$ & $20 c$ & 21 \\
\hline
\end{tabular}

Any information copied from such Reports and Statements may not be sold or used by any person for the purpose of soliciting contributions or for commercial purposes, other than using the name and address of any political committee to solicit contributions from such committee.

NAME OF COMMITTEE (In Full)

\section{Friends of Herman Cain}

A. Full Name (Last, First, Middle Initial)

Valerie Baldwin

Mailing Address 112 Windsong Island Lane

\begin{tabular}{lcc}
\hline City & State & Zip Code \\
Chapin & SC & 29036 \\
\hline
\end{tabular}

FEC ID number of contributing federal political committee.

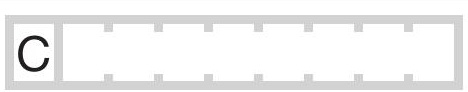

Name of Employer
Information Requested
Receipt For: 2012
X Primary
$\square$ Other (specify)

Occupation Information Requested

Election Cycle-to-Date 1000.00

B. Full Name (Last, First, Middle Initial) thomas vardell

Mailing Address po box 1261

\begin{tabular}{lcc}
\hline City & State & Zip Code \\
Pleasanton & CA & $94566-0126$
\end{tabular}

FEC ID number of contributing

federal political committee.

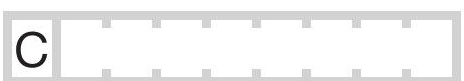

\begin{tabular}{l} 
Name of Employer \\
Information Requested \\
Receipt For: 2012 \\
X Primary \\
\hline Other (specify)
\end{tabular}

Occupation

Information Requested

Election Cycle-to-Date

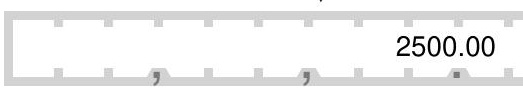

C. Full Name (Last, First, Middle Initial) martin lemoine

Mailing Address 207 north carolina ave

\begin{tabular}{l|ll}
\hline $\begin{array}{l}\text { City } \\
\text { New Roads }\end{array}$ & $\begin{array}{c}\text { State } \\
\text { LA }\end{array}$ & $\begin{array}{c}\text { Zip Code } \\
70760-3605\end{array}$ \\
\hline $\begin{array}{l}\text { FEC ID number of contributing } \\
\text { federal political committee. }\end{array}$ & C \\
$\begin{array}{l}\text { Name of Employer } \\
\text { Information Requested }\end{array}$ & $\begin{array}{l}\text { Occupation } \\
\text { Information Requested }\end{array}$ \\
$\begin{array}{l}\text { Receipt For: } 2012 \\
\text { Xrimary } \\
\text { Other (specify) }\end{array}$ & Election Cycle-to-Date & \\
\hline
\end{tabular}

Transaction ID : AD4374AD1AE7F4A0BA37 Date of Receipt

Amount of Each Receipt this Period

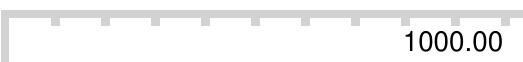

Date of Receipt

M M / D

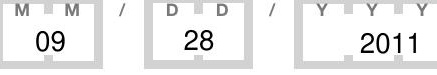

1000.00

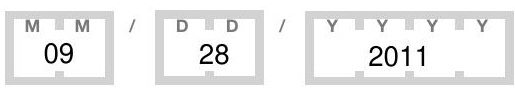

Amount of Each Receipt this Period

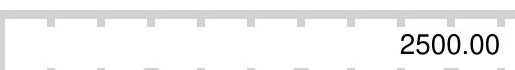

Amount of Each Receipt this Period

Transaction ID : A72A25FD94A744861A4E

Date of Receipt
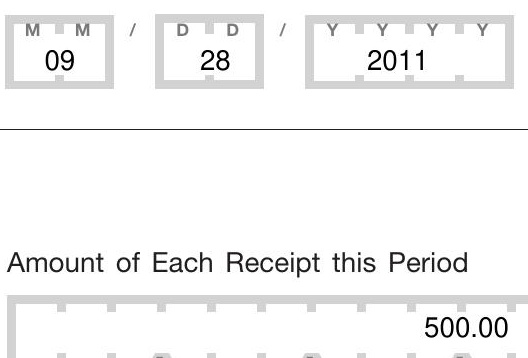

4000.00

Subtotal Of Receipts This Page (optional).

Total This Period (last page this line number only) 
SCHEDULE A-P ITEMIZED RECEIPTS
Use separate schedule(s) for each category of the Detailed Summary Page
FOR LINE NUMBER: (check only one)

PAGE $973 / 1572$

\begin{tabular}{|c|c|c|c|c|c|}
\hline & & & & & \\
\hline 16 & $\begin{array}{l}\mathbf{X} \\
17 a\end{array}$ & $17 b$ & $17 c$ & $17 d$ & 18 \\
\hline $19 a$ & $19 \mathrm{~b}$ & $20 \mathrm{a}$ & $20 \mathrm{~b}$ & $20 \mathrm{c}$ & 21 \\
\hline
\end{tabular}

Any information copied from such Reports and Statements may not be sold or used by any person for the purpose of soliciting contributions or for commercial purposes, other than using the name and address of any political committee to solicit contributions from such committee.

NAME OF COMMITTEE (In Full)

\section{Friends of Herman Cain}

A. Full Name (Last, First, Middle Initial)

Mrs. Dama L Curtright

Mailing Address P.O. Box 1350

\begin{tabular}{lcc}
\hline City & State & Zip Code \\
Jefferson & OR & $97352-1350$
\end{tabular}

FEC ID number of contributing federal political committee.

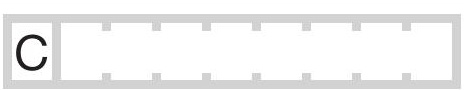

Name of Employer

Ames Research Laboratory, Inc.

Occupation

Co-Owner

Receipt For: 2012

X Primary $\square$ General Other (specify)

Election Cycle-to-Date

5170.00

B. Full Name (Last, First, Middle Initial)

Michael Fogarty

Mailing Address POBox 300

\begin{tabular}{lcc}
\hline City & State & Zip Code \\
Canaan & $\mathrm{NH}$ & $03741-0300$ \\
\hline
\end{tabular}

FEC ID number of contributing

federal political committee.

C

Name of Employer
Information Requested
Receipt For: 2012
X Primary
Other (specify)

Occupation

Information Requested

Election Cycle-to-Date

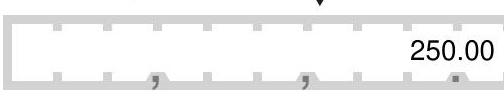

Transaction ID : A3005168BA2BA42B6B6F

Date of Receipt

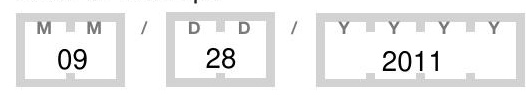

Amount of Each Receipt this Period

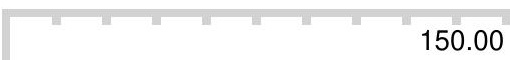

150.00

C. Full Name (Last, First, Middle Initial)

Charles Cook

Mailing Address 25 Brookhouse Drive

\begin{tabular}{lcc}
\hline City & State & Zip Code \\
Marblehead & MA & $01945-1638$
\end{tabular}

FEC ID number of contributing federal political committee.

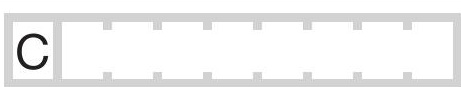

Name of Employer

Information Requested

Occupation

Information Requested

Receipt For: 2012

Х $\begin{aligned} & \text { Primary } \square \text { General } \\ & \text { Other (specify) }\end{aligned}$

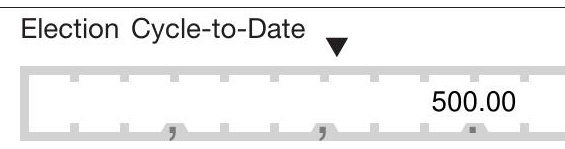

Amount of Each Receipt this Period

Transaction ID : AD31FA6329C9E435884B

Date of Receipt
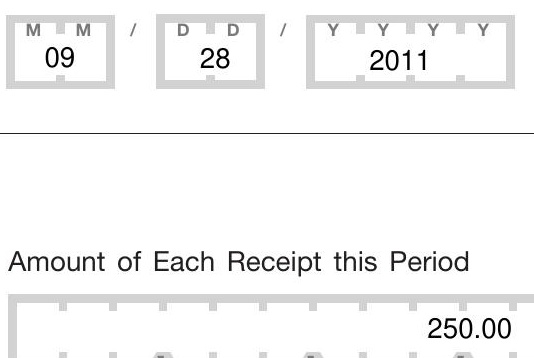

Transaction ID : AC9D1724069D042B6861

Date of Receipt

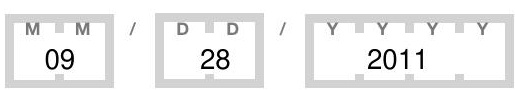

Amount of Each Receipt this Period

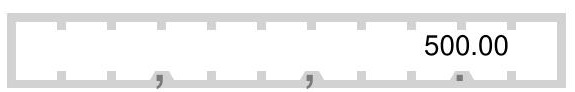

Subtotal Of Receipts This Page (optional)

900.00

Total This Period (last page this line number only) 


\section{SCHEDULE A-P} ITEMIZED RECEIPTS
Use separate schedule(s) for each category of the Detailed Summary Page

FOR LINE NUMBER:
(check only one)

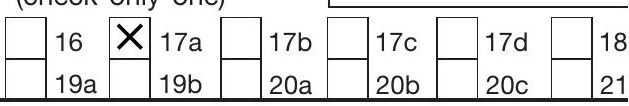

Any information copied from such Reports and Statements may not be sold or used by any person for the purpose of soliciting contributions or for commercial purposes, other than using the name and address of any political committee to solicit contributions from such committee.

NAME OF COMMITTEE (In Full)

\section{Friends of Herman Cain}

A. Full Name (Last, First, Middle Initial)

Georg Maharg II

Mailing Address 13201 NW Gainesville Rd

\begin{tabular}{lcc}
\hline City & State & Zip Code \\
Reddick & FL & $32686-3950$ \\
\hline
\end{tabular}

FEC ID number of contributing federal political committee.

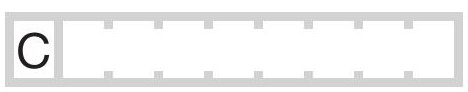

Name of Employer
Information Requested
Receipt For: 2012
X Primary
Other (specify) General

Occupation Information Requested

Election Cycle-to-Date

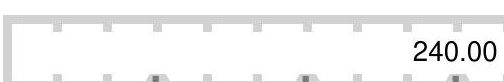

B. Full Name (Last, First, Middle Initial)

Steven Evans

Mailing Address 6303 Central Park Ln NW

\begin{tabular}{lcc}
\hline City & State & Zip Code \\
Huntsville & AL & $35806-5003$ \\
\hline
\end{tabular}

FEC ID number of contributing

federal political committee.

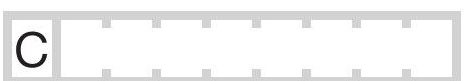

Name of Employer
Self Employed
Receipt For: 2012
X Primary $\quad$ General
Other (specify)

\section{Occupation}

Engineer

Election Cycle-to-Date

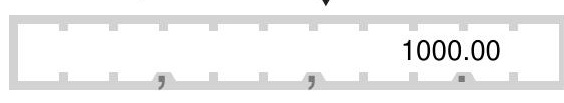

C. Full Name (Last, First, Middle Initial)

Ryan Posner

Mailing Address PO Box 725286

\begin{tabular}{lcc}
\hline City & State & Zip Code \\
Atlanta & GA & $31139-2286$
\end{tabular}

FEC ID number of contributing federal political committee.

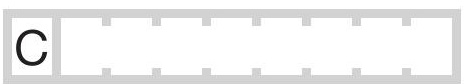

Name of Employer
Oldcastle
Receipt For: 2012
X Primary
Other (specify) General

Transaction ID : A4F64F980B6DE4190A9A

Date of Receipt

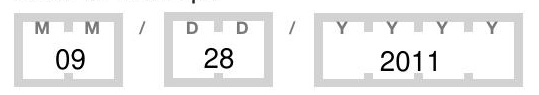

Amount of Each Receipt this Period

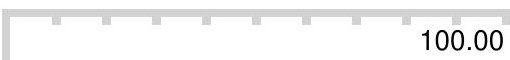

100.00

Transaction ID : A6704BCEE338642F5868

Date of Receipt

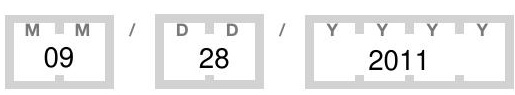

Amount of Each Receipt this Period

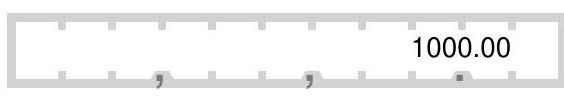

Transaction ID : A9017D9539A824D89A6F

Date of Receipt

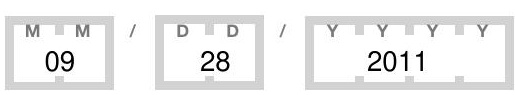

Amount of Each Receipt this Period

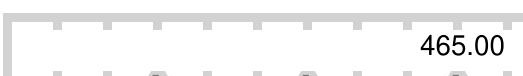

Subtotal Of Receipts This Page (optional).

1565.00

ㄱ․․

Total This Period (last page this line number only)

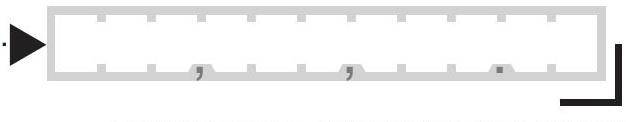

FEC Schedule A-P (Form 3P) (Rev. 03/2011) 


\section{SCHEDULE A-P} ITEMIZED RECEIPTS
Use separate schedule(s) for each category of the Detailed Summary Page

FOR LINE NUMBER:
(check only one)

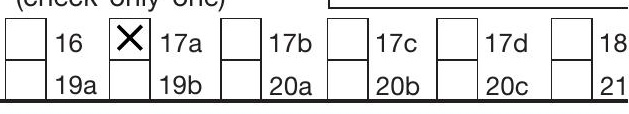

Any information copied from such Reports and Statements may not be sold or used by any person for the purpose of soliciting contributions or for commercial purposes, other than using the name and address of any political committee to solicit contributions from such committee.

NAME OF COMMITTEE (In Full)

\section{Friends of Herman Cain}

A. Full Name (Last, First, Middle Initial)

benjamin hulburt

Mailing Address 134 roundhill road

\begin{tabular}{lcc}
\hline City & State & Zip Code \\
Boalsburg & PA & $16827-1814$ \\
\hline
\end{tabular}

FEC ID number of contributing federal political committee.

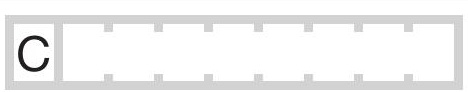

Name of Employer
Information Requested
Receipt For: 2012
X Primary
$\square$ Other (specify)

Occupation Information Requested

Election Cycle-to-Date 2500.00

B. Full Name (Last, First, Middle Initial) kathie stansell

Mailing Address 3111 Buckingham Rd.

\begin{tabular}{lcc}
\hline City & State & Zip Code \\
Durham & NC & $27707-4505$ \\
\hline
\end{tabular}

FEC ID number of contributing

federal political committee.

C

Name of Employer
Grimball Jewelers
Receipt For: 2012
X Primary
Other (specify)

Occupation

Sales Manager

Election Cycle-to-Date

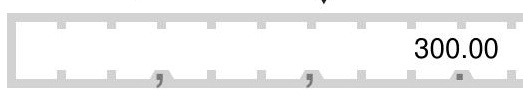

C. Full Name (Last, First, Middle Initial)

Sheila Goetz

Mailing Address 9399 Rivercourt Way

\begin{tabular}{lcc}
\hline City & State & Zip Code \\
Juneau & AK & $99801-9630$
\end{tabular}

FEC ID number of contributing federal political committee.

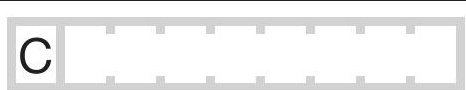

Name of Employer
Information Requested
Receipt For: 2012
X Primary
Other (specify) General

\section{Occupation}

Information Requested

Election Cycle-to-Date

Transaction ID : A0DBDA70367424A9F859

Date of Receipt

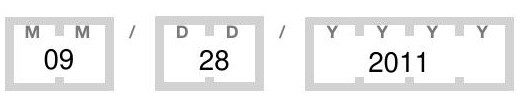

Amount of Each Receipt this Period

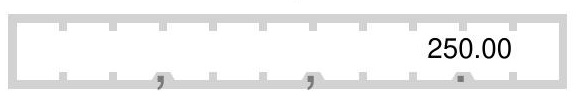

Amount of Each Receipt this Period

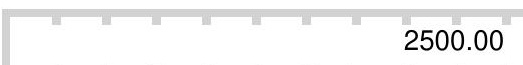

2500.00

Date of Receipt
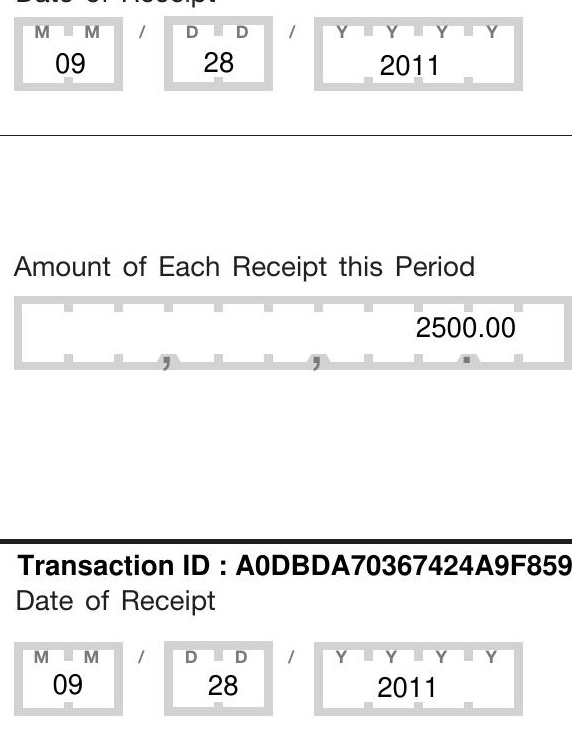

(1)

Transaction ID : A4720CA6C0FC44A14858

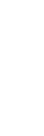




\section{SCHEDULE A-P} ITEMIZED RECEIPTS
Use separate schedule(s)

for each category of the

Detailed Summary Page
FOR LINE NUMBER: (check only one)

PAGE 976 / 1572

\begin{tabular}{|c|c|c|c|c|c|}
\hline & & & & & \\
\hline 16 & X $17 a$ & $17 b$ & $17 c$ & $17 d$ & 18 \\
\hline $19 a$ & $19 b$ & $20 \mathrm{a}$ & $20 \mathrm{~b}$ & $20 \mathrm{c}$ & 21 \\
\hline
\end{tabular}

Any information copied from such Reports and Statements may not be sold or used by any person for the purpose of soliciting contributions or for commercial purposes, other than using the name and address of any political committee to solicit contributions from such committee.

NAME OF COMMITTEE (In Full)

Friends of Herman Cain

A. Full Name (Last, First, Middle Initial)

James Farmer

Mailing Address 108 North Cay Drive

\begin{tabular}{lcc}
\hline City & State & Zip Code \\
Milledgeville & GA & $31061-8829$
\end{tabular}

FEC ID number of contributing

federal political committee.

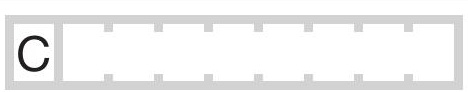

Name of Employer
Dekalb Medical Hillandale
Receipt For: 2012
X Primary $\quad \square$ General
Other (specify)

Occupation

Engineering Supervisor

Election Cycle-to-Date

\subsection{0}

B. Full Name (Last, First, Middle Initial)

Robert Goetz

Mailing Address 9399 Rivercourt Way

\begin{tabular}{lcc}
\hline City & State & Zip Code \\
Juneau & AK & $99801-9630$
\end{tabular}

FEC ID number of contributing

federal political committee.

C

Name of Employer
Information Requested
Receipt For: 2012
Primary
Other (specify)

Occupation

Information Requested

Election Cycle-to-Date

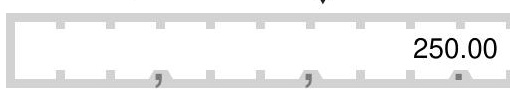

Transaction ID : A405EDE4C61FE49CE9FC

Date of Receipt

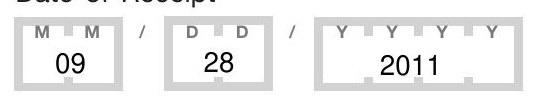

Amount of Each Receipt this Period

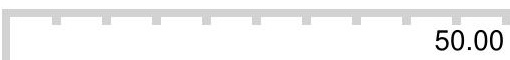

50.00

C. Full Name (Last, First, Middle Initial)

Carla Fitch

Mailing Address 29234 55th Ave S

\begin{tabular}{lcc}
\hline City & State & Zip Code \\
Auburn & WA & $98001-2154$
\end{tabular}

FEC ID number of contributing

federal political committee.

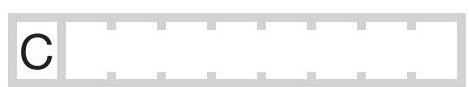

Name of Employer

Information Requested

Occupation

Information Requested

Receipt For: 2012

Х $\begin{aligned} & \text { Primary } \square \text { General } \\ & \text { Other (specify) }\end{aligned}$

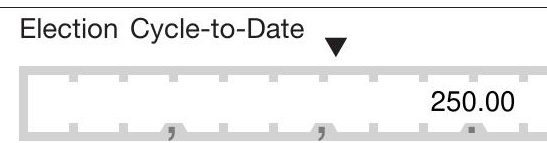

Amount of Each Receipt this Period

Transaction ID : ACFD12B7A1DAB4C458A8 Date of Receipt
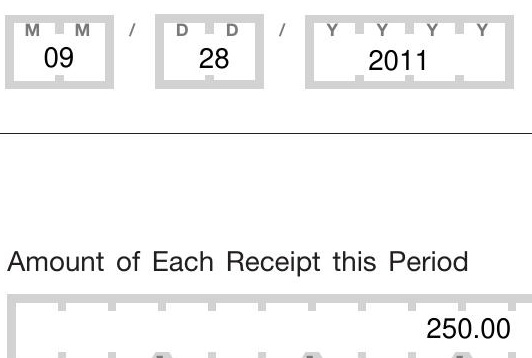

Transaction ID : A68EC966E649A4721B19

Date of Receipt

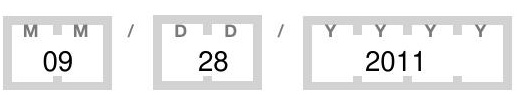

Amount of Each Receipt this Period

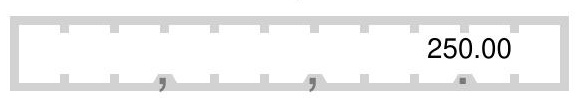

Subtotal Of Receipts This Page (optional).

550.00

Total This Period (last page this line number only) 


\section{SCHEDULE A-P} ITEMIZED RECEIPTS
Use separate schedule(s) for each category of the Detailed Summary Page

\begin{tabular}{|c|c|c|c|c|c|}
\hline \multicolumn{3}{|c|}{$\begin{array}{l}\text { FOR LINE NUMBER: } \\
\text { (check only one) }\end{array}$} & \multicolumn{3}{|c|}{ PAGE 977 / 1572} \\
\hline 16 & $X$ 17a & $17 b$ & $17 \mathrm{c}$ & $17 d$ & 18 \\
\hline $19 a$ & $19 \mathrm{~b}$ & $20 a$ & $20 \mathrm{~b}$ & $20 c$ & 21 \\
\hline
\end{tabular}

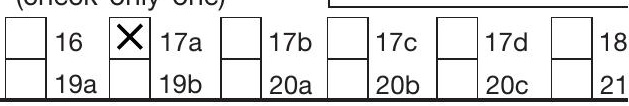

Any information copied from such Reports and Statements may not be sold or used by any person for the purpose of soliciting contributions or for commercial purposes, other than using the name and address of any political committee to solicit contributions from such committee.

NAME OF COMMITTEE (In Full)

\section{Friends of Herman Cain}

A. Full Name (Last, First, Middle Initial)

\section{Gary Shawver}

Mailing Address 551 Excelsior Lane

\begin{tabular}{lcc}
\hline City & State & Zip Code \\
Waterloo & IA & $50701-4967$ \\
\hline
\end{tabular}

FEC ID number of contributing federal political committee.

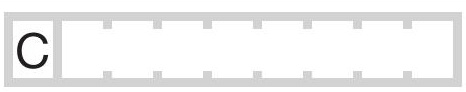

Name of Employer
Shawver Well Co. Inc
Receipt For: 2012
X Primary
$\square$ Other (specify)

\section{Occupation}

Water well contractor

Election Cycle-to-Date

B. Full Name (Last, First, Middle Initial)

William Ellison

Mailing Address 55 Cushing Dr

\begin{tabular}{lcc}
\hline City & State & Zip Code \\
Duxbury & MA & $02332-4854$
\end{tabular}

FEC ID number of contributing

federal political committee.

C

Name of Employer
Information Requested
Receipt For: 2012
X Primary
Other (specify)

\section{Occupation}

Information Requested

Election Cycle-to-Date

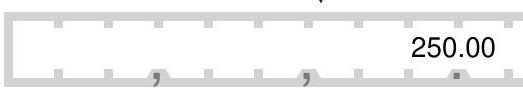

Transaction ID : A8532E45B9B8A4E38B64

Date of Receipt

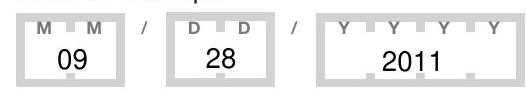

Amount of Each Receipt this Period

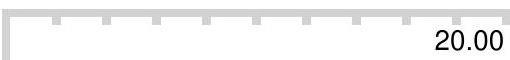

20.00
Amount of Each Receipt this Period

Transaction ID : A9B6C6A1164014404A0C

Date of Receipt
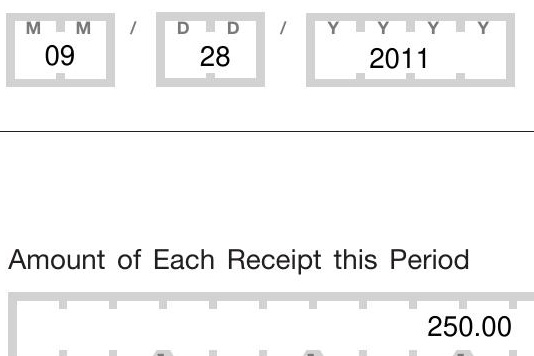

C. Full Name (Last, First, Middle Initial)

Leo Kingston

Mailing Address PO Box 12920 Oklahoma City

\begin{tabular}{lcc}
\hline City & State & Zip Code \\
Oklahoma City & OK & $73157-2920$
\end{tabular}

FEC ID number of contributing federal political committee.

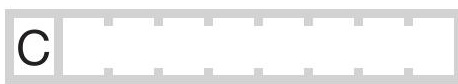

Name of Employer

Information Requested

Occupation

Information Requested

Receipt For: 2012

Х $\begin{aligned} & \text { Primary } \square \text { General } \\ & \text { Other (specify) }\end{aligned}$

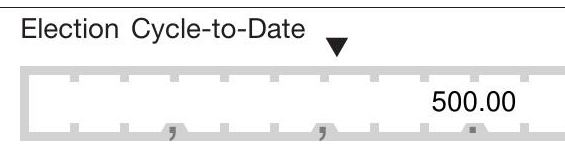

Transaction ID : A04F904246FB5451EB17

Date of Receipt

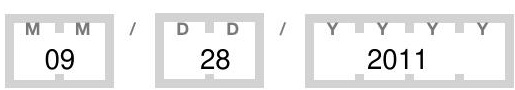

Amount of Each Receipt this Period

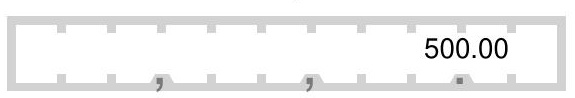

Subtotal Of Receipts This Page (optional).

770.00

Total This Period (last page this line number only) 


\section{SCHEDULE A-P} ITEMIZED RECEIPTS
Use separate schedule(s) for each category of the Detailed Summary Page

\begin{tabular}{|c|c|c|c|c|c|}
\hline \multicolumn{3}{|c|}{$\begin{array}{l}\text { FOR LINE NUMBER: } \\
\text { (check only one) }\end{array}$} & \multicolumn{3}{|c|}{ PAGE 978 / 1572} \\
\hline 16 & $X$ 17a & $17 b$ & 17c & $17 d$ & 18 \\
\hline $19 a$ & $19 \mathrm{~b}$ & $20 a$ & $20 \mathrm{~b}$ & $20 c$ & 21 \\
\hline
\end{tabular}

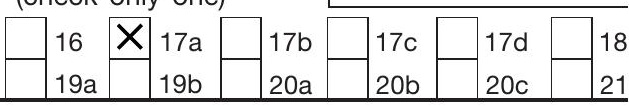

Any information copied from such Reports and Statements may not be sold or used by any person for the purpose of soliciting contributions or for commercial purposes, other than using the name and address of any political committee to solicit contributions from such committee.

NAME OF COMMITTEE (In Full)

\section{Friends of Herman Cain}

A. Full Name (Last, First, Middle Initial) David Manly

Mailing Address 39 Arrowhead Road

\begin{tabular}{lcc}
\hline City & State & Zip Code \\
Duxbury & MA & $02332-5035$ \\
\hline
\end{tabular}

FEC ID number of contributing federal political committee.

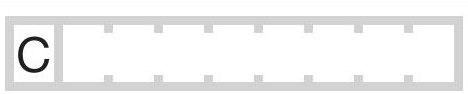

Name of Employer
Information Requested
Receipt For: 2012
X Primary $\quad \square$ General
Other (specify)

Occupation Information Requested Election Cycle-to-Date 250.00

B. Full Name (Last, First, Middle Initial) Gary Garrett

Mailing Address 737 Yellow Creek Rd.

\begin{tabular}{lcc}
\hline City & State & Zip Code \\
Ball Ground & GA & $30107-3146$
\end{tabular}

FEC ID number of contributing

federal political committee.

C

\begin{tabular}{l} 
Name of Employer \\
Information Requested \\
Receipt For: 2012 \\
X Primary \\
\hline Other (specify)
\end{tabular}

Occupation

Information Requested

Election Cycle-to-Date

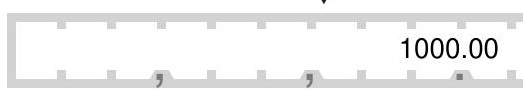

C. Full Name (Last, First, Middle Initial)

Robert Shive

Mailing Address 1080 Cherry Tree Rd.

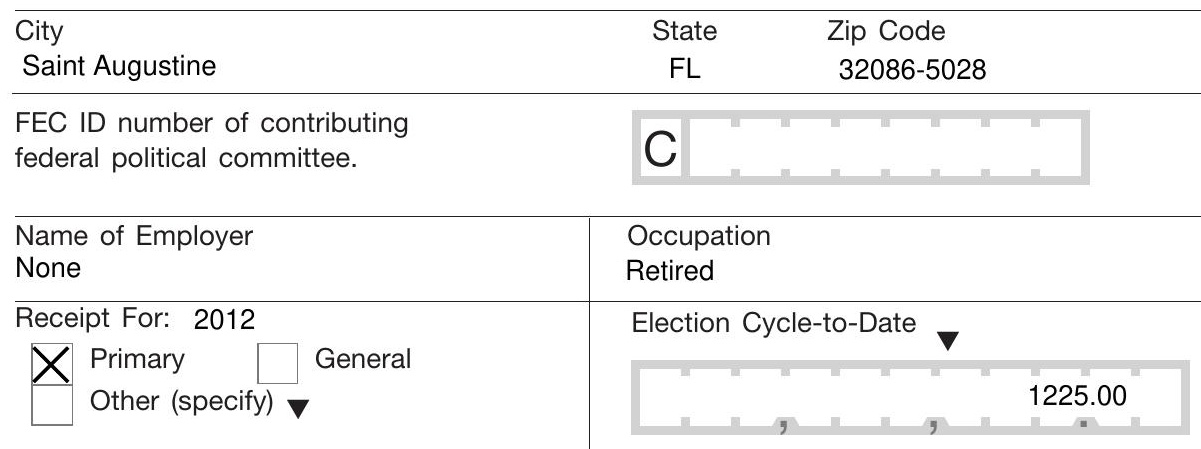

Transaction ID : A3FC19A96F3284D9E89C

Date of Receipt

Amount of Each Receipt this Period

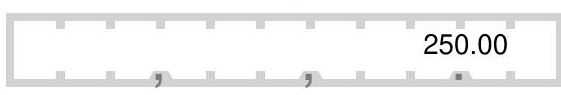

Date of Receipt
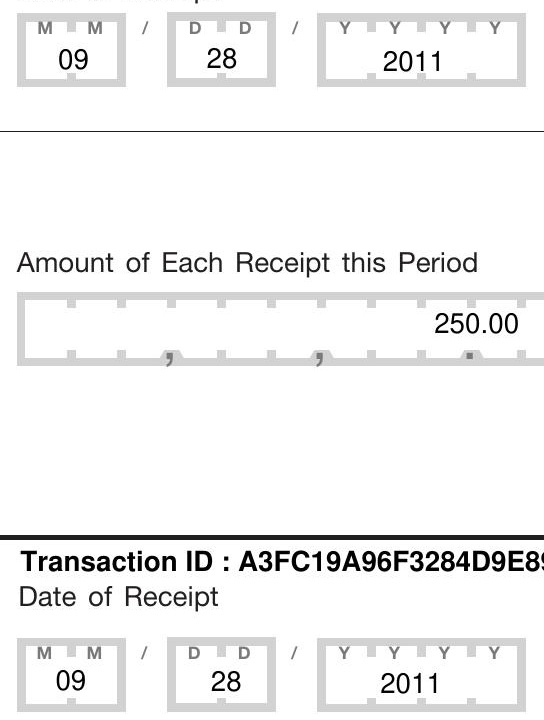

Amount of Each Receipt this Period

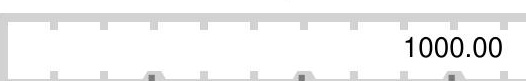

Amount of Each Receipt this Period

Transaction ID : A2E071FEA5BED405B9E6 Date of Receipt
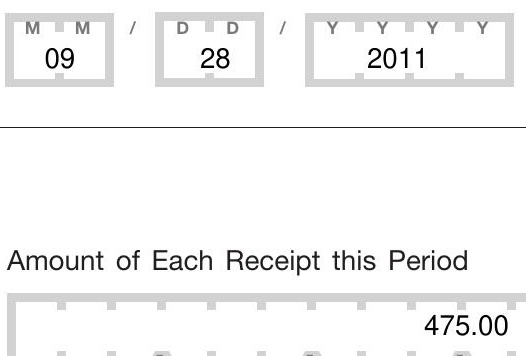

Subtotal Of Receipts This Page (optional)

Total This Period (last page this line number only) 


\section{SCHEDULE A-P} ITEMIZED RECEIPTS
Use separate schedule(s)

for each category of the

Detailed Summary Page
FOR LINE NUMBER: (check only one)

PAGE 979 / 1572

\begin{tabular}{|c|c|c|c|c|c|}
\hline & & & & & \\
\hline 16 & X $17 a$ & $17 b$ & $17 c$ & $17 d$ & 18 \\
\hline $19 a$ & $19 b$ & $20 \mathrm{a}$ & $20 \mathrm{~b}$ & $20 \mathrm{c}$ & 21 \\
\hline
\end{tabular}

Any information copied from such Reports and Statements may not be sold or used by any person for the purpose of soliciting contributions or for commercial purposes, other than using the name and address of any political committee to solicit contributions from such committee.

NAME OF COMMITTEE (In Full)

Friends of Herman Cain

A. Full Name (Last, First, Middle Initial)

William Brabec

Mailing Address 2151 Sheffield Dr.

\begin{tabular}{lcc}
\hline City & State & Zip Code \\
Jackson & MS & $39211-5851$
\end{tabular}

FEC ID number of contributing federal political committee.

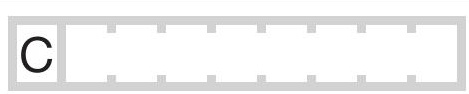

Name of Employer
Adams and Reese Law Firm
Receipt For: 2012
X Primary
$\square$ Other (specify)

Occupation Attorney

Election Cycle-to-Date

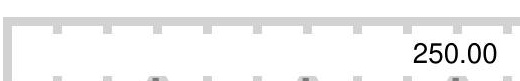

B. Full Name (Last, First, Middle Initial)

Ron Allen

Mailing Address 3605 Taurus Drive

\begin{tabular}{lcc}
\hline City & State & Zip Code \\
Racine & WI & $53406-1333$
\end{tabular}

FEC ID number of contributing

federal political committee.

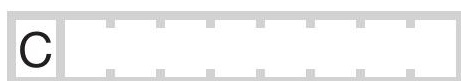

Name of Employer
Self Employed
Receipt For: 2012
X Primary
Other (specify)

Occupation

Surgeon

Election Cycle-to-Date

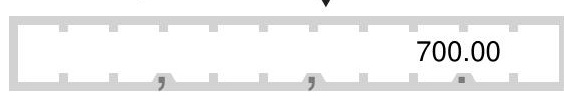

Transaction ID : A074D50D1D2064050843

Date of Receipt

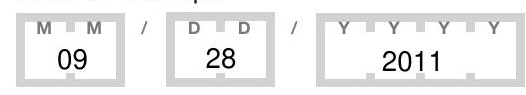

Amount of Each Receipt this Period

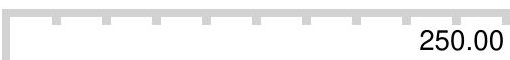

C. Full Name (Last, First, Middle Initial)

Martha Lang

Mailing Address 2374 Tabbystone Lane NW

\begin{tabular}{lcc}
\hline City & State & Zip Code \\
Marietta & GA & $30064-4756$
\end{tabular}

FEC ID number of contributing

federal political committee.

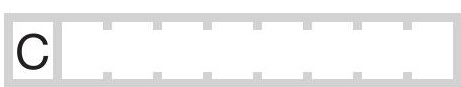

Name of Employer
n/a
Receipt For: 2012
X Primary $\quad \square$ General
Other (specify)

\section{Occupation}

$\mathrm{N} / \mathrm{A}$

Election Cycle-to-Date

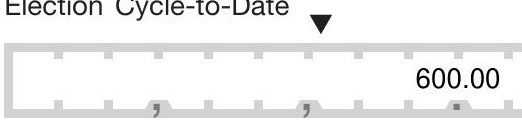

Transaction ID : A1AB7A77F258E4BAEAE1 Date of Receipt

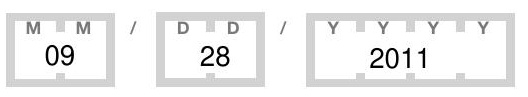

Amount of Each Receipt this Period

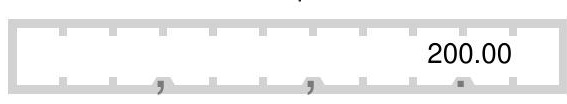

Transaction ID : AC45E5B5E9A28403F9BE Date of Receipt

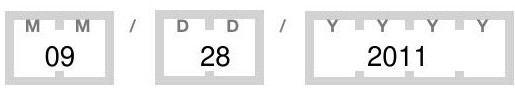

Amount of Each Receipt this Period

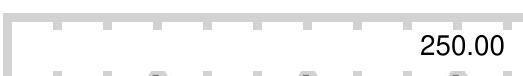

\section{Subtotal Of Receipts This Page (optional)}

Total This Period (last page this line number only) 


\section{SCHEDULE A-P} ITEMIZED RECEIPTS
Use separate schedule(s) for each category of the Detailed Summary Page

FOR LINE NUMBER:
(check only one)

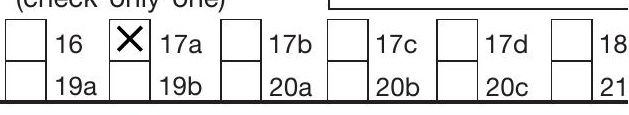

Any information copied from such Reports and Statements may not be sold or used by any person for the purpose of soliciting contributions or for commercial purposes, other than using the name and address of any political committee to solicit contributions from such committee.

NAME OF COMMITTEE (In Full)

\section{Friends of Herman Cain}

A. Full Name (Last, First, Middle Initial)

Steve Loghry

Mailing Address 775 Cove View Circle

\begin{tabular}{lcc}
\hline City & State & Zip Code \\
Galveston & TX & 77554 \\
\hline
\end{tabular}

FEC ID number of contributing federal political committee.

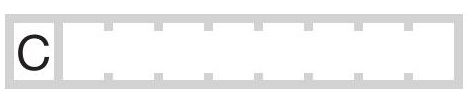

Name of Employer
Information Requested
Receipt For: 2012
X Primary $\quad \square$ General
Other (specify)

Occupation Information Requested

Election Cycle-to-Date

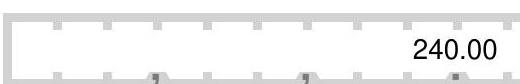

B. Full Name (Last, First, Middle Initial)

David Kilcy

Mailing Address 119 Maximillian Ct SW

\begin{tabular}{lcc}
\hline City & State & Zip Code \\
Leesburg & VA & $20175-2711$
\end{tabular}

FEC ID number of contributing

federal political committee.

C

Name of Employer

Transaction Network Services Inc

Receipt For: 2012

Х $\begin{aligned} & \text { Primary } \\ & \text { Other (specify) } \nabla\end{aligned}$

Occupation

Senior Systems Developer

Election Cycle-to-Date

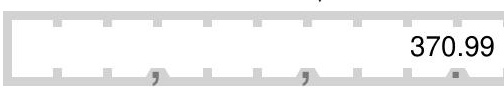

Transaction ID : AB9AA5DB0D2B04E30B3A

Date of Receipt

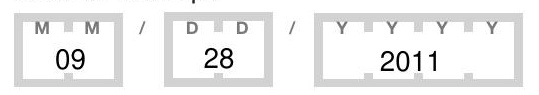

Amount of Each Receipt this Period

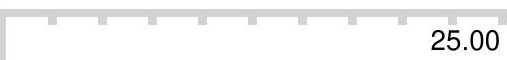

25.00

C. Full Name (Last, First, Middle Initial)

Herbert C Jardine

Mailing Address 1451 Summer Oaks Ct

\begin{tabular}{lcc}
\hline City & State & Zip Code \\
Marietta & GA & $30062-6155$
\end{tabular}

FEC ID number of contributing

federal political committee.

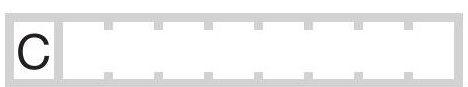

Name of Employer
None
Receipt For: 2012
Х Primary $\quad \square$ General
Other (specify)

Occupation

Retired

Election Cycle-to-Date

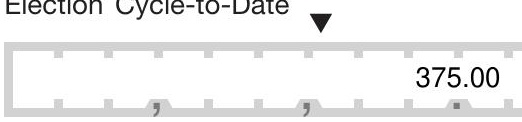

Transaction ID : A175DE593DCBC4788BEC Date of Receipt

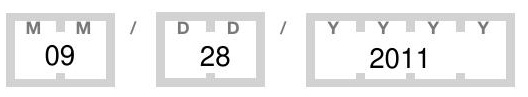

Amount of Each Receipt this Period

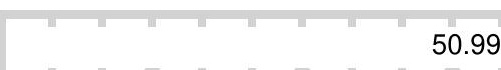

Transaction ID : AEABFB39674E6402E93B Date of Receipt

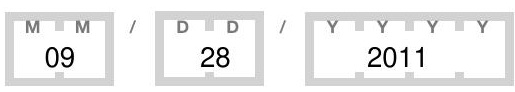

Amount of Each Receipt this Period

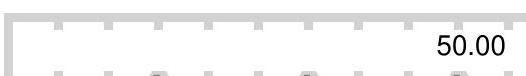

\section{Subtotal Of Receipts This Page (optional)}

Total This Period (last page this line number only) 


\section{SCHEDULE A-P} ITEMIZED RECEIPTS
Use separate schedule(s)

for each category of the

Detailed Summary Page
FOR LINE NUMBER: (check only one)

PAGE $981 / 1572$

\begin{tabular}{|c|c|c|c|c|c|}
\hline & & & & & \\
\hline 16 & X $17 a$ & $17 b$ & $17 c$ & $17 d$ & 18 \\
\hline $19 a$ & $19 b$ & $20 \mathrm{a}$ & $20 \mathrm{~b}$ & $20 \mathrm{c}$ & 21 \\
\hline
\end{tabular}

Any information copied from such Reports and Statements may not be sold or used by any person for the purpose of soliciting contributions or for commercial purposes, other than using the name and address of any political committee to solicit contributions from such committee.

NAME OF COMMITTEE (In Full)

\section{Friends of Herman Cain}

A. Full Name (Last, First, Middle Initial)

Allan Moynihan

Mailing Address 1221 NW 35 Ave

\begin{tabular}{lcc}
\hline City & State & Zip Code \\
Gainesville & FL & $32609-2112$
\end{tabular}

FEC ID number of contributing

federal political committee.

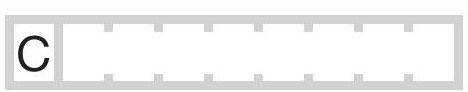

Name of Employer
Information Requested
Receipt For: 2012
X Primary $\quad \square$ General
Other (specify)

Occupation

Information Requested

Election Cycle-to-Date

400.00

B. Full Name (Last, First, Middle Initial)

Nancy Fountain

Mailing Address 142 Mountain Springs Cir

\begin{tabular}{lcc}
\hline City & State & Zip Code \\
Ellijay & GA & $30536-3892$ \\
\hline
\end{tabular}

FEC ID number of contributing

federal political committee.

C

Name of Employer
Information Requested
Receipt For: 2012
X Primary
Other (specify)

Occupation

Information Requested

Election Cycle-to-Date

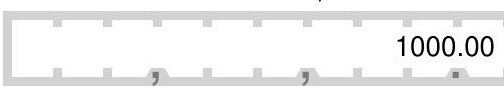

Transaction ID : A5FFE9EBD30CF40DEA4E

Date of Receipt

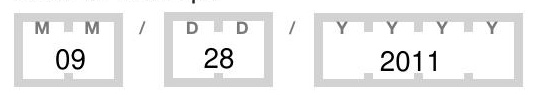

Amount of Each Receipt this Period

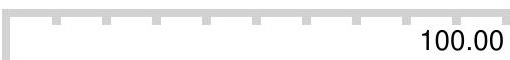

Transaction ID : A75671EAB3CFC43D5A11

Date of Receipt

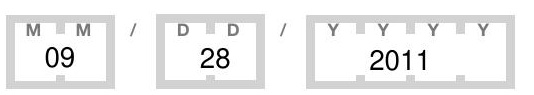

Amount of Each Receipt this Period

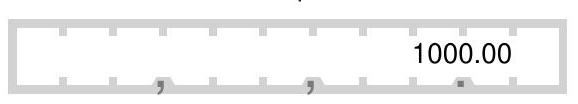

Transaction ID : AF4787DA01DA34E98BBB Date of Receipt

james morrell

Mailing Address po box 633

\begin{tabular}{lcc}
\hline City & State & Zip Code \\
Brunswick & ME & 04011-0633
\end{tabular}

FEC ID number of contributing federal political committee.

C

Name of Employer

Information Requested

Occupation

Information Requested

Receipt For: 2012

Х $\begin{aligned} & \text { Primary } \square \text { General } \\ & \text { Other (specify) }\end{aligned}$

Election Cycle-to-Date

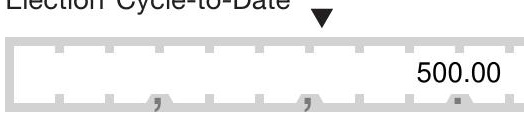

Subtotal Of Receipts This Page (optional)

Amount of Each Receipt this Period

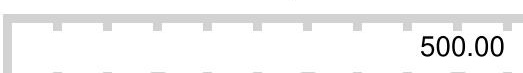

Total This Period (last page this line number only)

1600.00

,

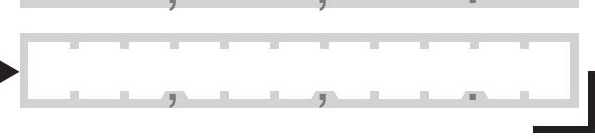

FEC Schedule A-P (Form 3P) (Rev. 03/2011) 


\section{SCHEDULE A-P} ITEMIZED RECEIPTS
Use separate schedule(s) for each category of the Detailed Summary Page

\begin{tabular}{|c|c|c|c|c|c|}
\hline \multicolumn{3}{|c|}{$\begin{array}{l}\text { FOR LINE NUMBER: } \\
\text { (check only one) }\end{array}$} & \multicolumn{3}{|c|}{ PAGE 982 / 1572} \\
\hline 16 & $X$ 17a & $17 b$ & $17 \mathrm{c}$ & $17 d$ & 18 \\
\hline $19 a$ & $19 \mathrm{~b}$ & $20 a$ & $20 \mathrm{~b}$ & $20 c$ & 21 \\
\hline
\end{tabular}

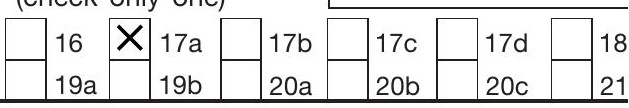

Any information copied from such Reports and Statements may not be sold or used by any person for the purpose of soliciting contributions or for commercial purposes, other than using the name and address of any political committee to solicit contributions from such committee.

NAME OF COMMITTEE (In Full)

\section{Friends of Herman Cain}

A. Full Name (Last, First, Middle Initial)

Sharon Lofton

Mailing Address PO Box 3010

\begin{tabular}{lcc}
\hline City & State & Zip Code \\
Roxboro & NC & $27573-3010$ \\
\hline
\end{tabular}

FEC ID number of contributing federal political committee.

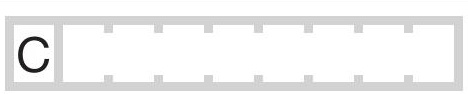

Name of Employer
Information Requested
Receipt For: 2012
X Primary
$\square$ Other (specify)

Occupation Information Requested

Election Cycle-to-Date 500.00

B. Full Name (Last, First, Middle Initial) Jean Morris

Mailing Address 876 Pinellas Pt. Dr. S.

\begin{tabular}{lcc}
\hline City & State & Zip Code \\
Saint Petersburg & FL & $33705-6257$
\end{tabular}

FEC ID number of contributing

federal political committee.

C

\begin{tabular}{l} 
Name of Employer \\
Information Requested \\
Receipt For: 2012 \\
X Primary \\
\hline Other (specify)
\end{tabular}

Occupation

Information Requested

Election Cycle-to-Date

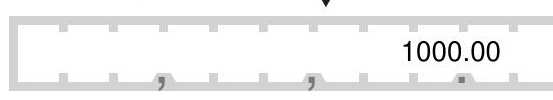

Transaction ID : A1417EEC615FA494783F

Date of Receipt

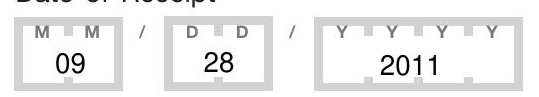

Amount of Each Receipt this Period

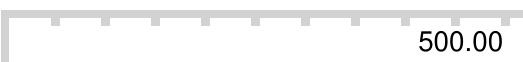

Amount of Each Receipt this Period

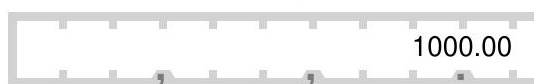

C. Full Name (Last, First, Middle Initial)

Bruce Donnelly

Mailing Address $23790 \mathrm{~N}$ Hillfarm Rd

\begin{tabular}{lcc}
\hline City & State & Zip Code \\
Lake Barrington & IL & $60010-1085$
\end{tabular}

FEC ID number of contributing federal political committee.

C

Name of Employer
Information Requested
Receipt For: 2012
X Primary
Other (specify) General

\section{Occupation}

Information Requested

Election Cycle-to-Date
Transaction ID : ABD1E7FC2116444C49EA

Date of Receipt

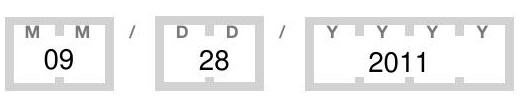

Transaction ID : A66E71F2255B74671A22 Date of Receipt

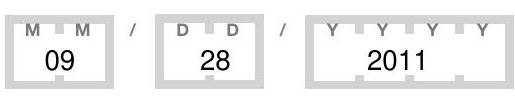

Amount of Each Receipt this Period

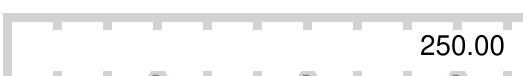

250.00

Subtotal Of Receipts This Page (optional).

Total This Period (last page this line number only) 
SCHEDULE A-P ITEMIZED RECEIPTS
Use separate schedule(s) for each category of the Detailed Summary Page
FOR LINE NUMBER: (check only one)

PAGE $983 / 1572$

\begin{tabular}{|c|c|c|c|c|c|}
\hline & & & & & \\
\hline 16 & $\begin{array}{l}\mathbf{X} \\
17 a\end{array}$ & $17 b$ & $17 c$ & $17 d$ & 18 \\
\hline $19 a$ & $19 \mathrm{~b}$ & $20 \mathrm{a}$ & $20 \mathrm{~b}$ & $20 \mathrm{c}$ & 21 \\
\hline
\end{tabular}

Any information copied from such Reports and Statements may not be sold or used by any person for the purpose of soliciting contributions or for commercial purposes, other than using the name and address of any political committee to solicit contributions from such committee.

NAME OF COMMITTEE (In Full)

\section{Friends of Herman Cain}

A. Full Name (Last, First, Middle Initial)

Billy Callicoatt

Mailing Address 2530 Dowell Rd

\begin{tabular}{lcc}
\hline City & State & Zip Code \\
Grants Pass & OR & $97527-9170$
\end{tabular}

FEC ID number of contributing federal political committee.

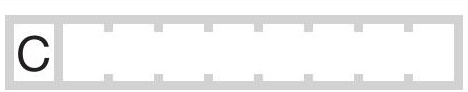

Name of Employer
Information Requested
Receipt For: 2012
X Primary
Other (specify) General

Occupation Information Requested

Election Cycle-to-Date

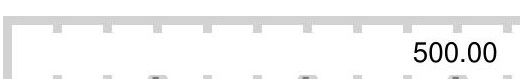

B. Full Name (Last, First, Middle Initial)

Thomas Fonseca

Mailing Address 23 N Fenwick St

\begin{tabular}{lcc}
\hline City & State & Zip Code \\
Arlington & VA & $22201-1015$ \\
\hline
\end{tabular}

FEC ID number of contributing

federal political committee.

C

Name of Employer
Information Requested
Receipt For: 2012
Primary
Other (specify)

Occupation

Information Requested

Election Cycle-to-Date

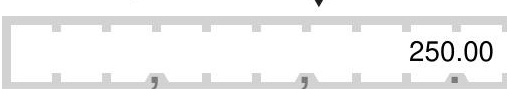

Transaction ID : A621AC2AB39E94867869

Date of Receipt

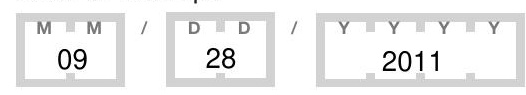

Amount of Each Receipt this Period

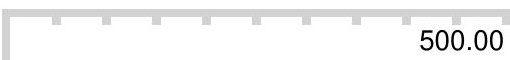

Amount of Each Receipt this Period

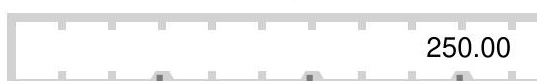

C. Full Name (Last, First, Middle Initial)

Ms. Deborah Schmalshof

Mailing Address 519 Bill Anderson Rd.

\begin{tabular}{lcc}
\hline City & State & Zip Code \\
Dahlonega & GA & $30533-4045$
\end{tabular}

FEC ID number of contributing federal political committee.

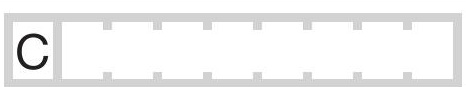

Name of Employer Information Requested

\section{Occupation}

Information Requested

Receipt For: 2012

Х $\begin{aligned} & \text { Primary } \square \text { General } \\ & \text { Other (specify) }\end{aligned}$

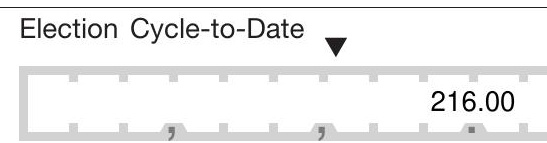

Amount of Each Receipt this Period

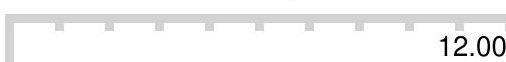

Subtotal Of Receipts This Page (optional)

Total This Period (last page this line number only) 
SCHEDULE A-P ITEMIZED RECEIPTS
Use separate schedule(s) for each category of the Detailed Summary Page
FOR LINE NUMBER: (check only one)
PAGE 984 / 1572

\begin{tabular}{|c|c|c|c|c|c|}
\hline & & & & & \\
\hline 16 & $\begin{array}{lll}X & 17 a \\
\end{array}$ & $17 \mathrm{~b}$ & $17 c$ & $17 d$ & 18 \\
\hline $19 a$ & $19 b$ & $20 a$ & $20 \mathrm{~b}$ & $20 c$ & 21 \\
\hline
\end{tabular}

Any information copied from such Reports and Statements may not be sold or used by any person for the purpose of soliciting contributions or for commercial purposes, other than using the name and address of any political committee to solicit contributions from such committee.

NAME OF COMMITTEE (In Full)

\section{Friends of Herman Cain}

A. Full Name (Last, First, Middle Initial)

\section{Cary Katz}

Mailing Address 9021 Grove Crest Ln

\begin{tabular}{lcc}
\hline City & State & Zip Code \\
Las Vegas & NV & $89134-0522$
\end{tabular}

FEC ID number of contributing federal political committee.

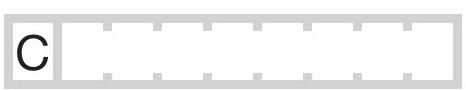

Name of Employer
College Loan Corporation
Receipt For: 2012
X Primary $\quad \square$ General
Other (specify)

Occupation CEO

Election Cycle-to-Date

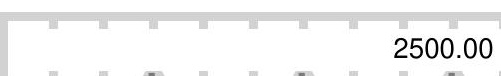

B. Full Name (Last, First, Middle Initial)

Wade Eppler

Mailing Address 1565 E 99th PI

\begin{tabular}{lcc}
\hline City & State & Zip Code \\
Thornton & CO & $80229-2220$
\end{tabular}

FEC ID number of contributing

federal political committee.

C

Name of Employer
G4S Security Solutions
Receipt For: 2012
X Primary
Other (specify)

Occupation

Security Office

Election Cycle-to-Date

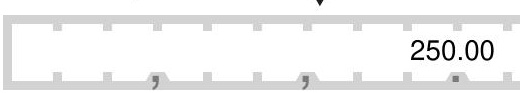

Transaction ID : ABC210699BA114831A60

Date of Receipt

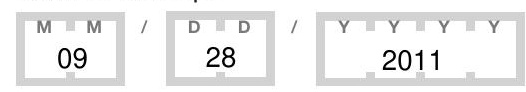

Amount of Each Receipt this Period

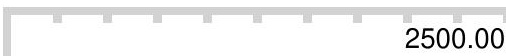

C. Full Name (Last, First, Middle Initial)

kathleen edwards

Mailing Address 307 east convent st

\begin{tabular}{lcc}
\hline City & State & Zip Code \\
Victoria & TX & $77901-8109$ \\
\hline
\end{tabular}

FEC ID number of contributing federal political committee.

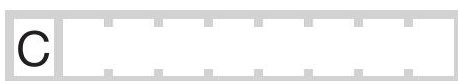

Name of Employer
Self Employed
Receipt For: 2012
X Primary $\quad \square$ General
Other (specify)

\section{Occupation}

Artist

Election Cycle-to-Date

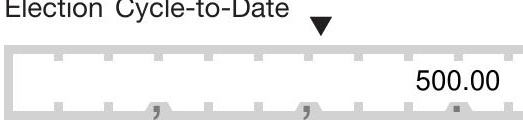

Transaction ID : A460D15C8B9C64C2096A

Date of Receipt

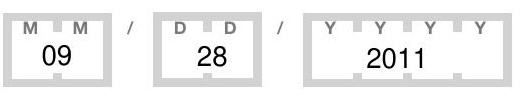

Amount of Each Receipt this Period

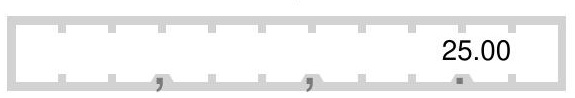

Transaction ID : A9C17EEC673E74BC6894 Date of Receipt

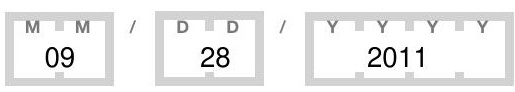

Amount of Each Receipt this Period

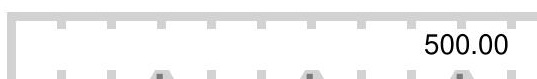

\section{Subtotal Of Receipts This Page (optional)}

Total This Period (last page this line number only) 


\section{SCHEDULE A-P} ITEMIZED RECEIPTS
Use separate schedule(s)

for each category of the

Detailed Summary Page
FOR LINE NUMBER: (check only one)
PAGE 985 / 1572

\begin{tabular}{|c|c|c|c|c|c|}
\hline & & & & & \\
\hline 16 & $\begin{array}{l}\mathbf{X} \\
17 a\end{array}$ & $17 b$ & $17 c$ & $17 d$ & 18 \\
\hline $19 a$ & $19 \mathrm{~b}$ & $20 \mathrm{a}$ & $20 \mathrm{~b}$ & $20 \mathrm{c}$ & 21 \\
\hline
\end{tabular}

Any information copied from such Reports and Statements may not be sold or used by any person for the purpose of soliciting contributions or for commercial purposes, other than using the name and address of any political committee to solicit contributions from such committee.

NAME OF COMMITTEE (In Full)

Friends of Herman Cain

A. Full Name (Last, First, Middle Initial)

Gina Skinner

Mailing Address 110 W Greenbriar Lane

\begin{tabular}{lcc}
\hline City & State & Zip Code \\
Colleyville & TX & $76034-8619$ \\
\hline
\end{tabular}

FEC ID number of contributing

federal political committee.

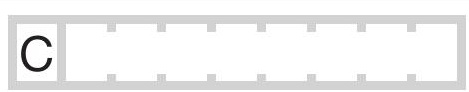

Name of Employer
None
Receipt For: 2012
X Primary $\square$ General
$\square$ Other (specify)

Occupation

Retired

Election Cycle-to-Date

1000.00

B. Full Name (Last, First, Middle Initial)

Robert Wyrick

Mailing Address 341 S Timberline Drive

\begin{tabular}{lcc}
\hline City & State & Zip Code \\
Atoka & OK & $74525-4003$ \\
\hline
\end{tabular}

FEC ID number of contributing

federal political committee.

C

Name of Employer
Information Requested
Receipt For: 2012
X Primary
Other (specify)

Occupation

Information Requested

Election Cycle-to-Date

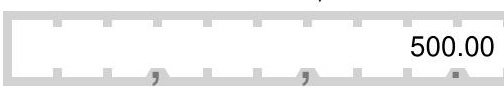

Transaction ID : A57C4FFE505594CACB81

Date of Receipt

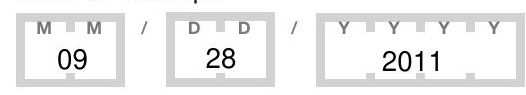

Amount of Each Receipt this Period

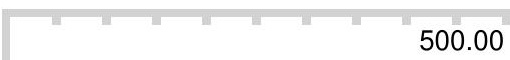

Amount of Each Receipt this Period

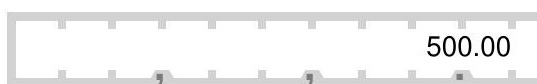

C. Full Name (Last, First, Middle Initial)

Robyn Edgerton

Mailing Address 5207 Court of York

\begin{tabular}{lcc}
\hline City & State & Zip Code \\
Houston & TX & $77069-1937$
\end{tabular}

FEC ID number of contributing

federal political committee.

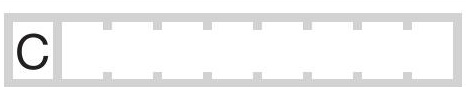

Name of Employer

Information Requested

Occupation

Information Requested

Receipt For: 2012

X Primary $\square$ General

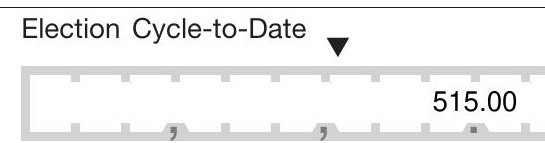

Amount of Each Receipt this Period

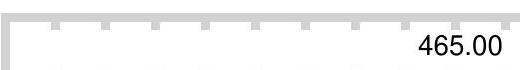

Transaction ID : A9EE949669E594F2FAF1

Date of Receipt

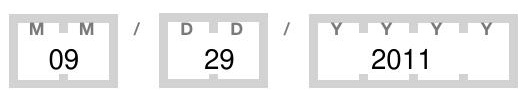

Subtotal Of Receipts This Page (optional)

1465.00

Total This Period (last page this line number only) 


\section{SCHEDULE A-P} ITEMIZED RECEIPTS
Use separate schedule(s)

for each category of the

Detailed Summary Page
FOR LINE NUMBER: (check only one)

PAGE 986 / 1572

\begin{tabular}{|c|c|c|c|c|c|}
\hline & & & & & \\
\hline 16 & $\begin{array}{l}\mathbf{X} \\
17 a\end{array}$ & $17 b$ & $17 c$ & $17 d$ & 18 \\
\hline $19 a$ & $19 \mathrm{~b}$ & $20 \mathrm{a}$ & $20 \mathrm{~b}$ & $20 \mathrm{c}$ & 21 \\
\hline
\end{tabular}

Any information copied from such Reports and Statements may not be sold or used by any person for the purpose of soliciting contributions or for commercial purposes, other than using the name and address of any political committee to solicit contributions from such committee.

NAME OF COMMITTEE (In Full)

Friends of Herman Cain

A. Full Name (Last, First, Middle Initial)

\section{Ernest Goff}

Mailing Address PO Box 2746

\begin{tabular}{lcc}
\hline City & State & Zip Code \\
Sarasota & FL & $34230-2746$
\end{tabular}

FEC ID number of contributing federal political committee.

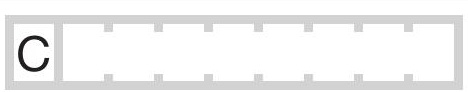

Name of Employer
BB\&T
Receipt For: 2012
X Primary $\quad$ General
Other (specify)

Occupation

Commercial Banking

Election Cycle-to-Date

650.00

B. Full Name (Last, First, Middle Initial)

Beverly Green

Mailing Address 3990 Paces Ferry Rd NW

\begin{tabular}{lcc}
\hline City & State & Zip Code \\
Atlanta & GA & $30327-3008$ \\
\hline
\end{tabular}

FEC ID number of contributing

federal political committee.

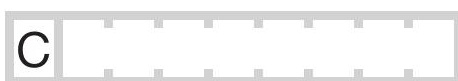

Name of Employer
None
Receipt For: 2012
X Primary $\quad$ General
Other (specify)

Occupation

Retired

Election Cycle-to-Date

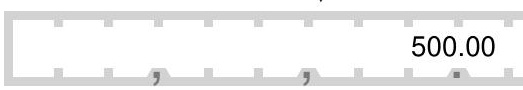

Transaction ID : A8F53BD4AF19946D08C3

Date of Receipt

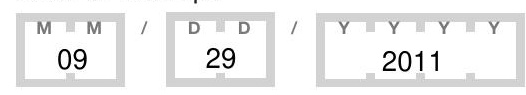

Amount of Each Receipt this Period

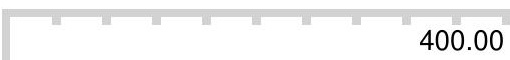

400.00

C. Full Name (Last, First, Middle Initial)

bob davis

Mailing Address 1812 middle rd

\begin{tabular}{lcc}
\hline City & State & Zip Code \\
Calverton & NY & $11933-1420$
\end{tabular}

FEC ID number of contributing federal political committee.

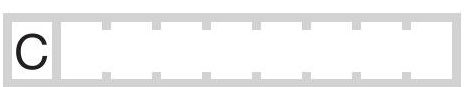

Name of Employer

Information Requested

Occupation

Information Requested

Receipt For: 2012

Х $\begin{aligned} & \text { Primary } \square \text { General } \\ & \text { Other (specify) }\end{aligned}$

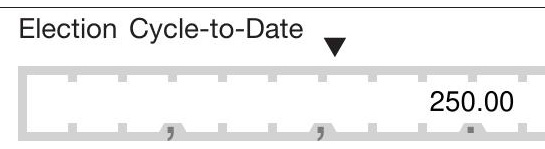

Amount of Each Receipt this Period

Transaction ID : AC989F872476C4C29883

Date of Receipt
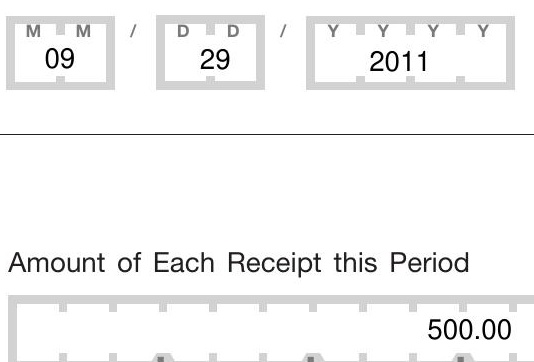

Transaction ID : A6B696B8FD0D0497C9BD Date of Receipt

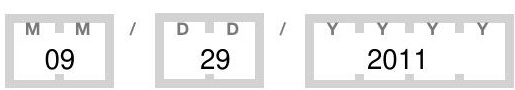

Amount of Each Receipt this Period

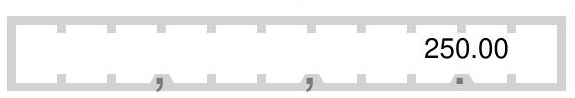

Subtotal Of Receipts This Page (optional).

1150.00

Total This Period (last page this line number only) 


\section{SCHEDULE A-P} ITEMIZED RECEIPTS
Use separate schedule(s) for each category of the Detailed Summary Page

FOR LINE NUMBER:
(check only one)

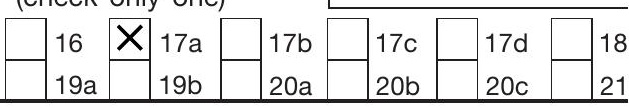

Any information copied from such Reports and Statements may not be sold or used by any person for the purpose of soliciting contributions or for commercial purposes, other than using the name and address of any political committee to solicit contributions from such committee.

NAME OF COMMITTEE (In Full)

\section{Friends of Herman Cain}

A. Full Name (Last, First, Middle Initial)

\section{Daniel Grennan}

Mailing Address 12764 Burning Tree Ln E

\begin{tabular}{lcc}
\hline City & State & Zip Code \\
Jacksonville & FL & $32223-2004$
\end{tabular}

FEC ID number of contributing federal political committee.

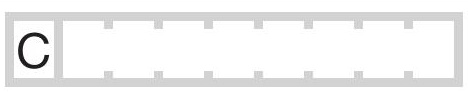

Name of Employer
Information Requested
Receipt For: 2012
X Primary
$\square$ Other (specify)

Occupation Information Requested

Election Cycle-to-Date

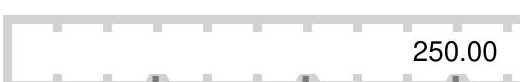

B. Full Name (Last, First, Middle Initial)

Andrew Wallace

Mailing Address 505 Westwood Circle

\begin{tabular}{lcc}
\hline City & State & Zip Code \\
Waynesville & NC & $28786-1991$ \\
\hline
\end{tabular}

FEC ID number of contributing

federal political committee.

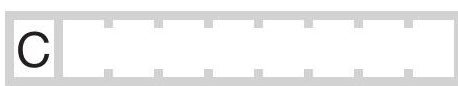

\begin{tabular}{l} 
Name of Employer \\
Information Requested \\
Receipt For: 2012 \\
X Primary \\
\hline Other (specify)
\end{tabular}

Occupation

Information Requested

Election Cycle-to-Date

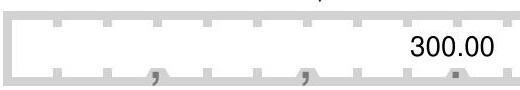

Transaction ID : A6C61EAB036D94C33BD4

Date of Receipt

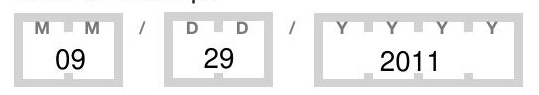

Amount of Each Receipt this Period

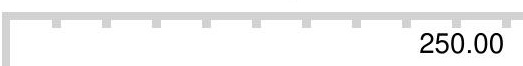

Amount of Each Receipt this Period

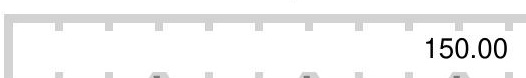

C. Full Name (Last, First, Middle Initial)

Al Harrell

Mailing Address 230 E Ponce de Leon Av Unit 426

\begin{tabular}{lcc}
\hline City & State & Zip Code \\
Decatur & GA & $30030-3462$ \\
\hline
\end{tabular}

FEC ID number of contributing federal political committee.

C

Name of Employer
Information Requested
Receipt For: 2012
X Primary
Other (specify) General

Occupation

Information Requested

Election Cycle-to-Date
Transaction ID : ABEBBEDA231514AA3A4B Date of Receipt

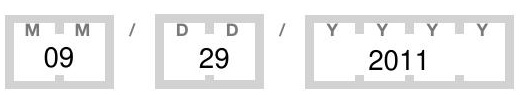

Transaction ID : AC90A52C2488543B69B9 Date of Receipt

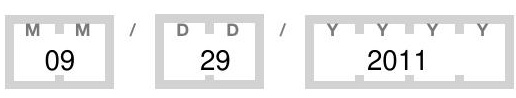

Amount of Each Receipt this Period

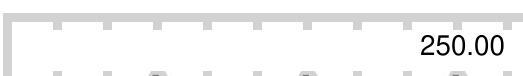

250.00
Subtotal Of Receipts This Page (optional).

650.00

a

Total This Period (last page this line number only)

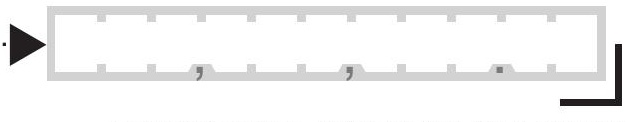

FEC Schedule A-P (Form 3P) (Rev. 03/2011) 


\section{SCHEDULE A-P} ITEMIZED RECEIPTS
Use separate schedule(s)

for each category of the

Detailed Summary Page
FOR LINE NUMBER: (check only one)

PAGE $988 / 1572$

\begin{tabular}{|c|c|c|c|c|c|}
\hline & & & & & \\
\hline 16 & X $17 a$ & $17 b$ & $17 c$ & $17 d$ & 18 \\
\hline $19 a$ & $19 b$ & $20 \mathrm{a}$ & $20 \mathrm{~b}$ & $20 \mathrm{c}$ & 21 \\
\hline
\end{tabular}

Any information copied from such Reports and Statements may not be sold or used by any person for the purpose of soliciting contributions or for commercial purposes, other than using the name and address of any political committee to solicit contributions from such committee.

NAME OF COMMITTEE (In Full)

\section{Friends of Herman Cain}

A. Full Name (Last, First, Middle Initial)

Nels Hansen

Mailing Address 3310 Thicket Run Dr.

\begin{tabular}{lcc}
\hline City & State & Zip Code \\
Spring & TX & $77388-4181$ \\
\hline
\end{tabular}

FEC ID number of contributing federal political committee.

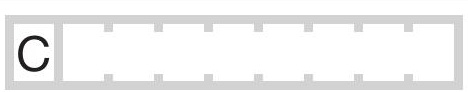

Name of Employer
Information Requested
Receipt For: 2012
X Primary
Other (specify) General

Occupation

Information Requested

Election Cycle-to-Date

250.00

B. Full Name (Last, First, Middle Initial)

Joe Billion

Mailing Address 32 Kean Drive

\begin{tabular}{lcc}
\hline City & State & Zip Code \\
Bozeman & MT & $59718-8706$ \\
\hline
\end{tabular}

FEC ID number of contributing

federal political committee.

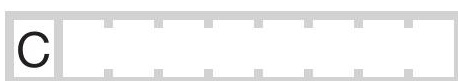

Name of Employer
J C Billion Inc
Receipt For: 2012
X Primary
Other (specify)

\section{Occupation}

Auto Sales

Transaction ID : ACC30FE99381C460D95D

Date of Receipt

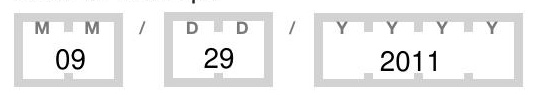

Amount of Each Receipt this Period

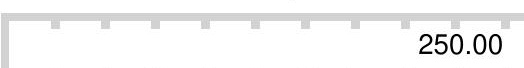

C. Full Name (Last, First, Middle Initial)

Richard Jahnel

Mailing Address 6601 w. plano parkway apt. 2014

\begin{tabular}{lcc}
\hline City & State & Zip Code \\
Plano & TX & $75093-8875$
\end{tabular}

FEC ID number of contributing federal political committee.

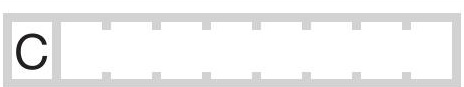

Name of Employer

Election Cycle-to-Date

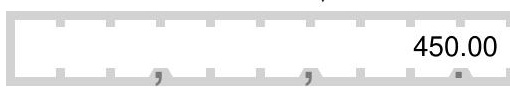

Transaction ID : A268256D64B5B4D7DBCA Date of Receipt

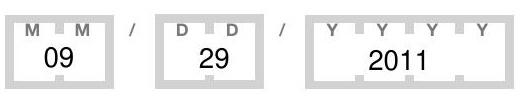

Amount of Each Receipt this Period

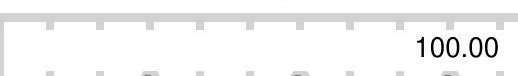

Transaction ID : AB4754F295C094614A68

Date of Receipt

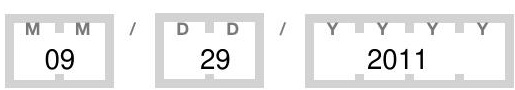

Information Requested

Occupation
Information Requested

Amount of Each Receipt this Period

Receipt For: 2012

Х $\begin{aligned} & \text { Primary } \square \text { General } \\ & \text { Other (specify) }\end{aligned}$

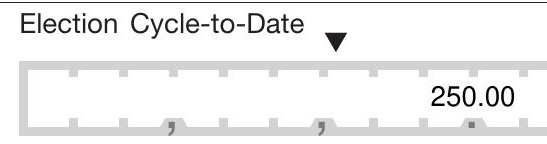

250.00

Subtotal Of Receipts This Page (optional)

600.00

ㄱ․․

Total This Period (last page this line number only)

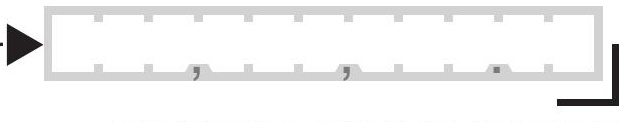

FEC Schedule A-P (Form 3P) (Rev. 03/2011) 


\section{SCHEDULE A-P} ITEMIZED RECEIPTS
Use separate schedule(s)

for each category of the

Detailed Summary Page
FOR LINE NUMBER: (check only one)

PAGE 989 / 1572

\begin{tabular}{|c|c|c|c|c|c|}
\hline & & & & & \\
\hline 16 & X $17 a$ & $17 b$ & $17 c$ & $17 d$ & 18 \\
\hline $19 a$ & $19 b$ & $20 \mathrm{a}$ & $20 \mathrm{~b}$ & $20 \mathrm{c}$ & 21 \\
\hline
\end{tabular}

Any information copied from such Reports and Statements may not be sold or used by any person for the purpose of soliciting contributions or for commercial purposes, other than using the name and address of any political committee to solicit contributions from such committee.

NAME OF COMMITTEE (In Full)

Friends of Herman Cain

A. Full Name (Last, First, Middle Initial)

Eric Peterson

Mailing Address Box 388

\begin{tabular}{lcc}
\hline City & State & Zip Code \\
Strasburg & VA & $22657-0388$ \\
\hline
\end{tabular}

FEC ID number of contributing federal political committee.

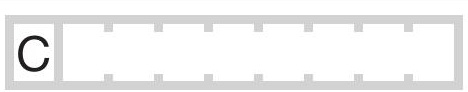

Name of Employer
Information Requested
Receipt For: 2012
X Primary
$\square$ Other (specify)

Occupation

Information Requested

Election Cycle-to-Date

500.00

B. Full Name (Last, First, Middle Initial)

Steve Nolan

Mailing Address 3420 So. 79th Street

\begin{tabular}{lcc}
\hline City & State & Zip Code \\
Lincoln & NE & $68506-7322$ \\
\hline
\end{tabular}

FEC ID number of contributing

federal political committee.

C

Name of Employer
Information Requested
Receipt For: 2012
X Primary
Other (specify)

Occupation

Information Requested

Election Cycle-to-Date

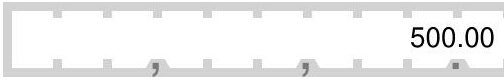

C. Full Name (Last, First, Middle Initial)

Jeffrey VanDyke

Mailing Address 5008 Watkings Ct

\begin{tabular}{lcc}
\hline City & State & Zip Code \\
Winston & GA & $30187-1159$
\end{tabular}

FEC ID number of contributing

federal political committee.

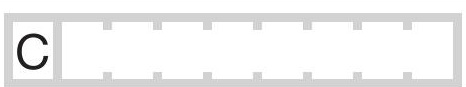

Name of Employer
RS\&H
Receipt For: 2012
Х Primary $\quad \square$ General
Other (specify)

\section{Occupation}

Engineer

Election Cycle-to-Date

Transaction ID : A3654CC00DDFE413BB0E Date of Receipt

Amount of Each Receipt this Period
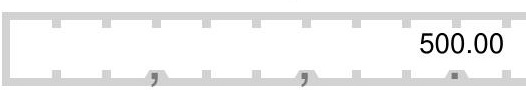

Amount of Each Receipt this Period

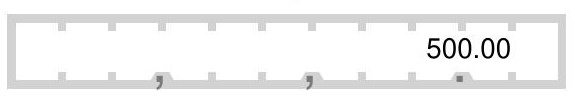

Transaction ID : A811DA8D0C5DA49C1B16 Date of Receipt

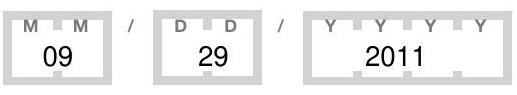

Amount of Each Receipt this Period

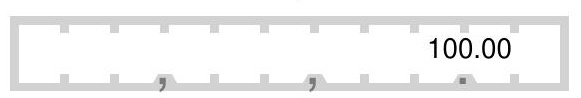

300.00

\section{Subtotal Of Receipts This Page (optional)}

1100.00

a 1 ,

Total This Period (last page this line number only)

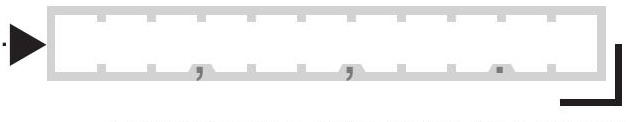

FEC Schedule A-P (Form 3P) (Rev. 03/2011) 


\section{SCHEDULE A-P} ITEMIZED RECEIPTS
Use separate schedule(s)

for each category of the

Detailed Summary Page
FOR LINE NUMBER: (check only one)

PAGE $990 / 1572$

\begin{tabular}{|c|c|c|c|c|c|}
\hline & & & & & \\
\hline 16 & X $17 a$ & $17 b$ & $17 c$ & $17 d$ & 18 \\
\hline $19 a$ & $19 b$ & $20 \mathrm{a}$ & $20 \mathrm{~b}$ & $20 \mathrm{c}$ & 21 \\
\hline
\end{tabular}

Any information copied from such Reports and Statements may not be sold or used by any person for the purpose of soliciting contributions or for commercial purposes, other than using the name and address of any political committee to solicit contributions from such committee.

NAME OF COMMITTEE (In Full)

Friends of Herman Cain

A. Full Name (Last, First, Middle Initial)

mp kehoe

Mailing Address 519 sleepy hollow rd

\begin{tabular}{lcc}
\hline City & State & Zip Code \\
Henrico & VA & $23229-7131$ \\
\hline
\end{tabular}

FEC ID number of contributing

federal political committee.

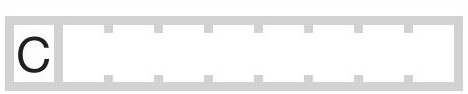

Name of Employer
Information Requested
Receipt For: 2012
X Primary $\quad \square$ General
Other (specify)

Occupation

Information Requested

Election Cycle-to-Date

1000.00

B. Full Name (Last, First, Middle Initial)

Scott Dodd

Mailing Address 701 Divide Pass

\begin{tabular}{lcc}
\hline City & State & Zip Code \\
Blanco & TX & $78606-5518$ \\
\hline
\end{tabular}

FEC ID number of contributing

federal political committee.

C

Name of Employer
Information Requested
Receipt For: 2012
Primary
Other (specify)

Occupation

Information Requested

Election Cycle-to-Date

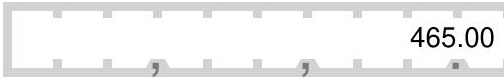

C. Full Name (Last, First, Middle Initial)

Damon Templeton

Mailing Address 3507 Lakestone Ct

\begin{tabular}{lcc}
\hline City & State & Zip Code \\
Augusta & GA & $30907-8979$ \\
\hline
\end{tabular}

FEC ID number of contributing

federal political committee.

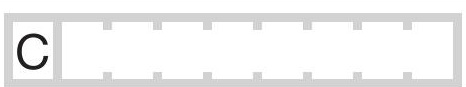

Name of Employer

Anesthesia Consultants of Augusta, LLC

Occupation

Receipt For: 2012

Х $\begin{aligned} & \text { Primary } \square \text { General } \\ & \text { Other (specify) }\end{aligned}$

Physician

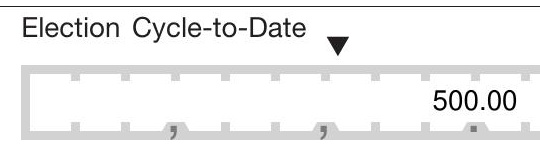

Transaction ID : A33F1A858EAAC4CCB93B Date of Receipt

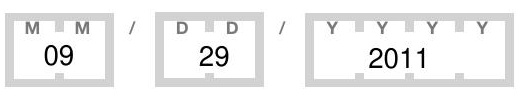

Amount of Each Receipt this Period

Amount of Each Receipt this Period
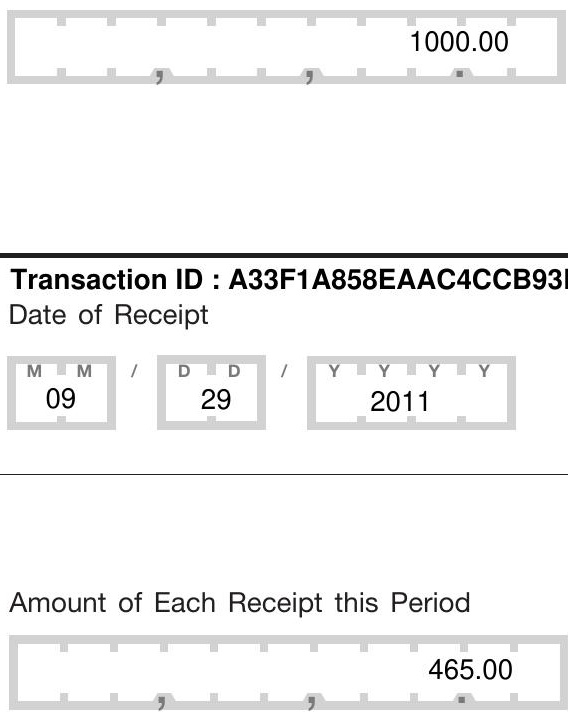

Transaction ID : A7E5C13F1F13D407FAB7 Date of Receipt

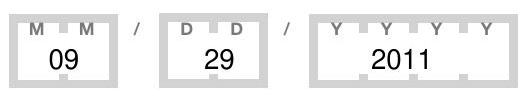

Amount of Each Receipt this Period

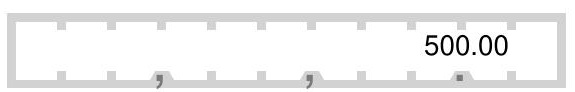

Subtotal Of Receipts This Page (optional).

1965.00

Total This Period (last page this line number only) 


\section{SCHEDULE A-P} ITEMIZED RECEIPTS
Use separate schedule(s)

for each category of the

Detailed Summary Page
FOR LINE NUMBER: (check only one)

PAGE $991 / 1572$

\begin{tabular}{|c|c|c|c|c|c|}
\hline & & & & & \\
\hline 16 & X $17 a$ & $17 b$ & $17 c$ & $17 d$ & 18 \\
\hline $19 a$ & $19 b$ & $20 \mathrm{a}$ & $20 \mathrm{~b}$ & $20 \mathrm{c}$ & 21 \\
\hline
\end{tabular}

Any information copied from such Reports and Statements may not be sold or used by any person for the purpose of soliciting contributions or for commercial purposes, other than using the name and address of any political committee to solicit contributions from such committee.

NAME OF COMMITTEE (In Full)

Friends of Herman Cain

A. Full Name (Last, First, Middle Initial)

Laura Hirschmann

Mailing Address 5 Bush St

\begin{tabular}{lcc}
\hline City & State & Zip Code \\
South Dartmouth & MA & $02748-3101$
\end{tabular}

FEC ID number of contributing

federal political committee.

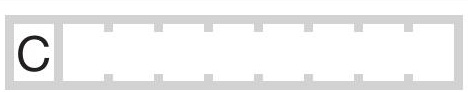

Name of Employer
Information Requested
Receipt For: 2012
X Primary $\quad \square$ General
Other (specify)

Occupation

Information Requested

Election Cycle-to-Date

\subsection{0}

B. Full Name (Last, First, Middle Initial)

Chad Neely

Mailing Address 300 LeGrande Ave \#5

\begin{tabular}{lcc}
\hline City & State & Zip Code \\
Austin & TX & $78704-1860$
\end{tabular}

FEC ID number of contributing

federal political committee.

C

\begin{tabular}{l} 
Name of Employer \\
Information Requested \\
Receipt For: 2012 \\
X Primary \\
\hline Other (specify)
\end{tabular}

Occupation

Information Requested

Election Cycle-to-Date

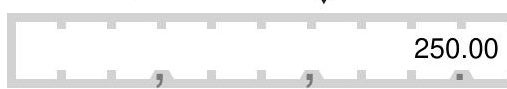

Transaction ID : A2FC17A3BF43C4310ABE

Date of Receipt

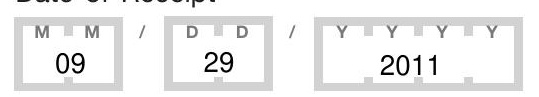

Amount of Each Receipt this Period

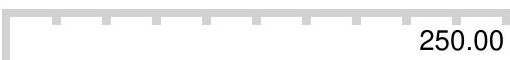

C. Full Name (Last, First, Middle Initial)

Mr. Stephen K. Boots

Mailing Address 564 Cesarea PI NW

\begin{tabular}{lcc}
\hline City & State & Zip Code \\
Lilburn & GA & $30047-6002$
\end{tabular}

FEC ID number of contributing federal political committee.

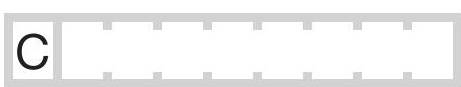

Name of Employer
self
Receipt For: 2012
X Primary $\quad \square$ General
Other (specify)

Occupation

Tax Consultant

Election Cycle-to-Date

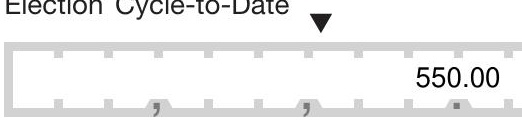

Amount of Each Receipt this Period

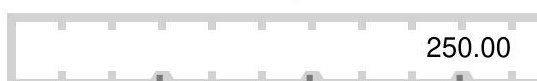

Transaction ID : AEE168EDF444A40B2BA2 Date of Receipt

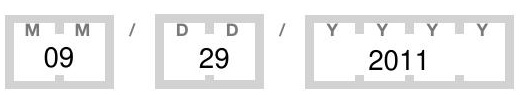

Transaction ID : A5372F899AEC74115BB1 Date of Receipt

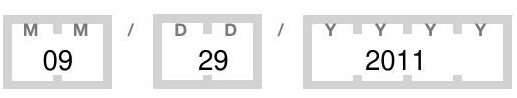

Amount of Each Receipt this Period

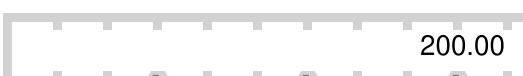

\section{Subtotal Of Receipts This Page (optional)}

Total This Period (last page this line number only) 


\section{SCHEDULE A-P} ITEMIZED RECEIPTS
Use separate schedule(s) for each category of the Detailed Summary Page

FOR LINE NUMBER:
(check only one)

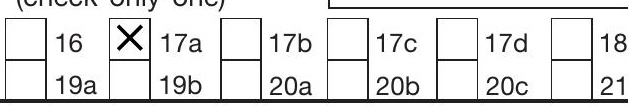

Any information copied from such Reports and Statements may not be sold or used by any person for the purpose of soliciting contributions or for commercial purposes, other than using the name and address of any political committee to solicit contributions from such committee.

NAME OF COMMITTEE (In Full)

\section{Friends of Herman Cain}

A. Full Name (Last, First, Middle Initial) jerrod griffith

Mailing Address 1010 harlan rd

\begin{tabular}{lcc}
\hline City & State & Zip Code \\
Seagoville & TX & $75159-5835$
\end{tabular}

FEC ID number of contributing federal political committee.

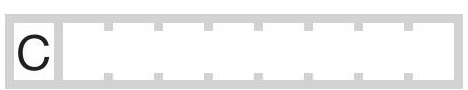

Name of Employer
Information Requested
Receipt For: 2012
X Primary
$\square$ Other (specify)

Occupation Information Requested

Election Cycle-to-Date

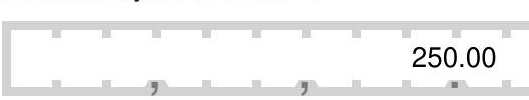

B. Full Name (Last, First, Middle Initial)

Jim Eure Jr.

Mailing Address PO Box 156

\begin{tabular}{lcc}
\hline City & State & Zip Code \\
Dahlonega & GA & $30533-0003$
\end{tabular}

FEC ID number of contributing

federal political committee.

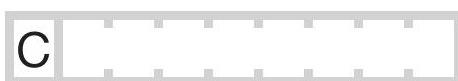

Name of Employer
Protex Security Systems
Receipt For: 2012
X Primary
Other (specify)

\section{Occupation}

Owner

Election Cycle-to-Date

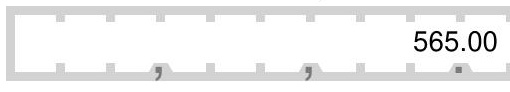

C. Full Name (Last, First, Middle Initial)

Charles Henderson

Mailing Address 9 Sleepy Hollow Ln

\begin{tabular}{lcc}
\hline City & State & Zip Code \\
Newtown Square & PA & $19073-3914$ \\
\hline
\end{tabular}

FEC ID number of contributing federal political committee.

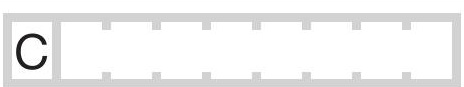

Name of Employer

Information Requested

\section{Occupation}

Information Requested

Receipt For: 2012

Х $\begin{aligned} & \text { Primary } \square \text { General } \\ & \text { Other (specify) }\end{aligned}$

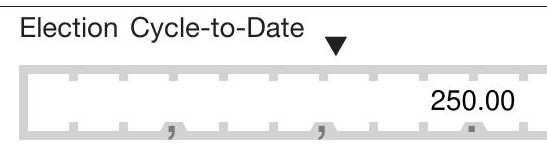

Transaction ID : ABB1AB6A430EE4D3681A

Date of Receipt

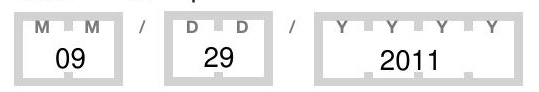

Amount of Each Receipt this Period

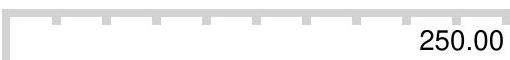

250.00

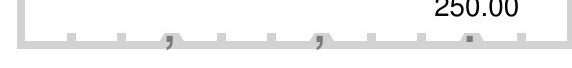

Transaction ID : A480A9091D8D240AA9B0

Date of Receipt

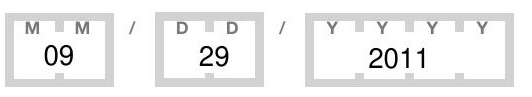

Amount of Each Receipt this Period

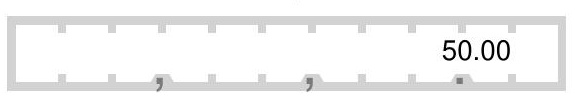

Transaction ID : AC5E2F00E762445BB9C5 Date of Receipt

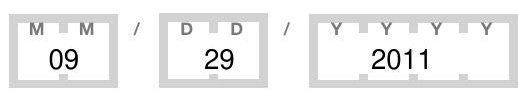

Amount of Each Receipt this Period

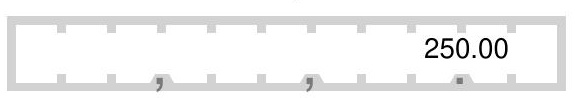

550.00

Subtotal Of Receipts This Page (optional)

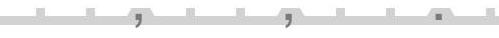

Total This Period (last page this line number only) 
SCHEDULE A-P ITEMIZED RECEIPTS
Use separate schedule(s) for each category of the Detailed Summary Page
FOR LINE NUMBER: (check only one)

PAGE $993 / 1572$

\begin{tabular}{|c|c|c|c|c|c|}
\hline & & & & & \\
\hline 16 & $\begin{array}{lll}X & 17 a \\
\end{array}$ & $17 \mathrm{~b}$ & $17 c$ & $17 d$ & 18 \\
\hline $19 a$ & $19 b$ & $20 a$ & $20 \mathrm{~b}$ & $20 c$ & 21 \\
\hline
\end{tabular}

Any information copied from such Reports and Statements may not be sold or used by any person for the purpose of soliciting contributions or for commercial purposes, other than using the name and address of any political committee to solicit contributions from such committee.

NAME OF COMMITTEE (In Full)

\section{Friends of Herman Cain}

A. Full Name (Last, First, Middle Initial)

Robert Rueter

Mailing Address 4319 S National Ave \# 110

\begin{tabular}{lcc}
\hline City & State & Zip Code \\
Springfield & MO & $65810-2607$
\end{tabular}

FEC ID number of contributing

federal political committee.

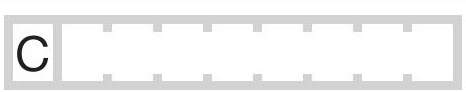

Name of Employer
Dameron Color Labs
Receipt For: 2012
X Primary
$\square$ Other (specify)

Occupation

Vice President

Election Cycle-to-Date

300.00

B. Full Name (Last, First, Middle Initial)

Russell Smith

Mailing Address 3759 McCart Av

\begin{tabular}{lcc}
\hline City & State & Zip Code \\
Fort Worth & TX & $76110-4618$ \\
\hline
\end{tabular}

FEC ID number of contributing

federal political committee.

C

Name of Employer
Information Requested
Receipt For: 2012
X Primary
Other (specify)

Occupation

Information Requested

Election Cycle-to-Date

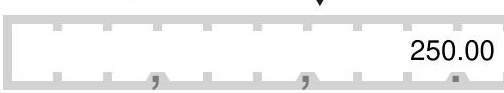

Transaction ID : ACOF47215C03D45189BD

Date of Receipt

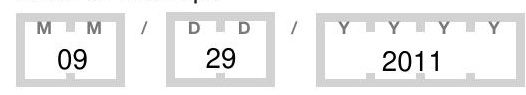

Amount of Each Receipt this Period

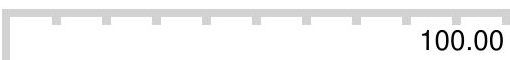

Transaction ID : A6187BE1E340B4C99B91

Date of Receipt

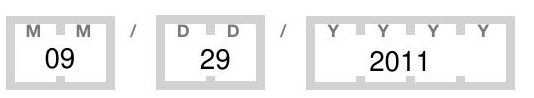

Amount of Each Receipt this Period

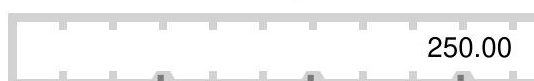

Transaction ID : AB3BE09C9D8894F008AA Date of Receipt

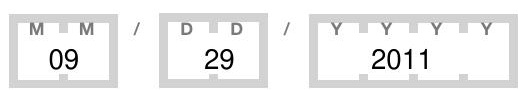

Amount of Each Receipt this Period

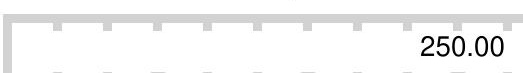

$\begin{array}{cc}\text { State } & \text { Zip Code } \\ \mathrm{OH} & 43044-9521\end{array}$

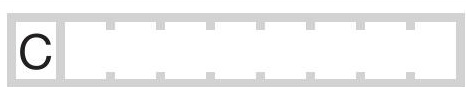

\section{Occupation}

Insurance Agent

Election Cycle-to-Date

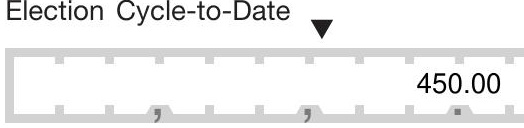

Subtotal Of Receipts This Page (optional).

600.00

a 1 ,

Total This Period (last page this line number only)

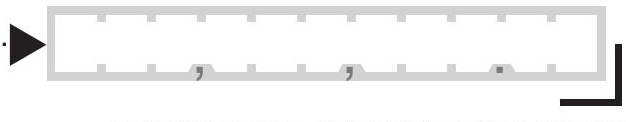

FEC Schedule A-P (Form 3P) (Rev. 03/2011) 
SCHEDULE A-P ITEMIZED RECEIPTS
Use separate schedule(s) for each category of the Detailed Summary Page
FOR LINE NUMBER: (check only one)

PAGE 994 / 1572

\begin{tabular}{|c|c|c|c|c|c|}
\hline & & & & & \\
\hline 16 & $\begin{array}{l}\mathbf{X} \\
17 a\end{array}$ & $17 b$ & $17 c$ & $17 d$ & 18 \\
\hline $19 a$ & $19 \mathrm{~b}$ & $20 \mathrm{a}$ & $20 \mathrm{~b}$ & $20 \mathrm{c}$ & 21 \\
\hline
\end{tabular}

Any information copied from such Reports and Statements may not be sold or used by any person for the purpose of soliciting contributions or for commercial purposes, other than using the name and address of any political committee to solicit contributions from such committee.

NAME OF COMMITTEE (In Full)

\section{Friends of Herman Cain}

A. Full Name (Last, First, Middle Initial) John Motta

Mailing Address 32 Preserve Drive

\begin{tabular}{lcc}
\hline City & State & Zip Code \\
Nashua & NH & $03064-8107$
\end{tabular}

FEC ID number of contributing federal political committee.

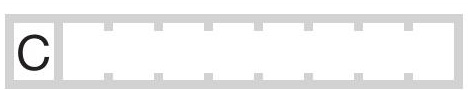

Name of Employer
Information Requested
Receipt For: 2012
X Primary
Other (specify) General

Occupation Information Requested

Election Cycle-to-Date

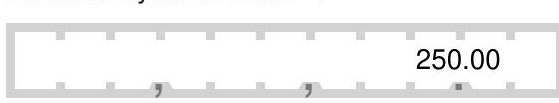

B. Full Name (Last, First, Middle Initial)

David Unger

Mailing Address 5415 Reynolds St

\begin{tabular}{lcc}
\hline City & State & Zip Code \\
Savannah & GA & $31405-5430$
\end{tabular}

FEC ID number of contributing

federal political committee.

C

Name of Employer
Information Requested
Receipt For: 2012
Primary
Other (specify)

Occupation

Information Requested

Election Cycle-to-Date

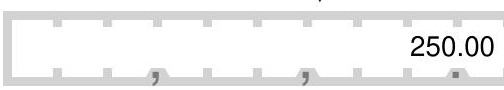

Transaction ID : A7C6728C7FEBF4677BA5

Date of Receipt

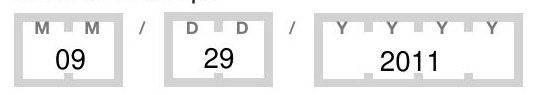

Amount of Each Receipt this Period

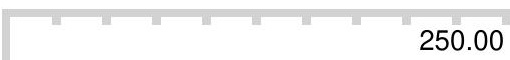

Transaction ID : A89177D53E3224614A08

Date of Receipt

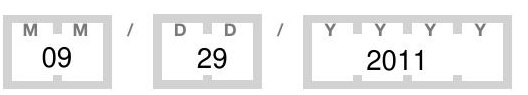

Amount of Each Receipt this Period

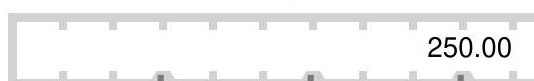

Transaction ID : A3FEDB227A01345B2813 Date of Receipt

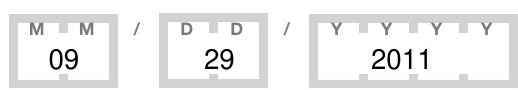

Amount of Each Receipt this Period

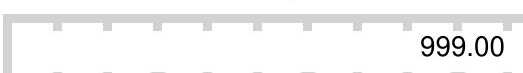

$\begin{array}{cc}\text { State } & \text { Zip Code } \\ \text { GA } & \text { 30024-7096 }\end{array}$

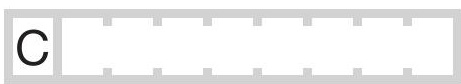

\section{Occupation}

CEO

Election Cycle-to-Date

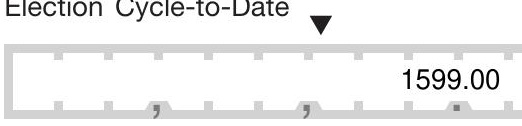

Subtotal Of Receipts This Page (optional).

1499.00

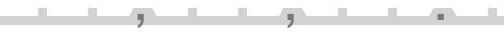

Total This Period (last page this line number only)

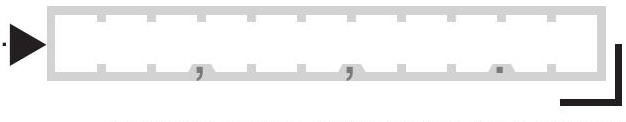

FEC Schedule A-P (Form 3P) (Rev. 03/2011) 


\section{SCHEDULE A-P} ITEMIZED RECEIPTS
Use separate schedule(s) for each category of the Detailed Summary Page

FOR LINE NUMBER:
(check only one)

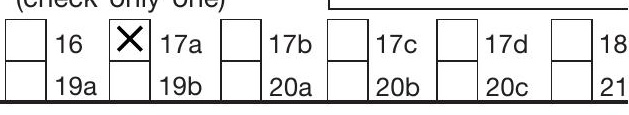

Any information copied from such Reports and Statements may not be sold or used by any person for the purpose of soliciting contributions or for commercial purposes, other than using the name and address of any political committee to solicit contributions from such committee.

NAME OF COMMITTEE (In Full)

\section{Friends of Herman Cain}

A. Full Name (Last, First, Middle Initial)

Mrs. Audrey P. Chambers

Mailing Address 121 Robson Trl

\begin{tabular}{lcc}
\hline City & State & Zip Code \\
McDonough & GA & $30252-4208$ \\
\hline
\end{tabular}

FEC ID number of contributing federal political committee.

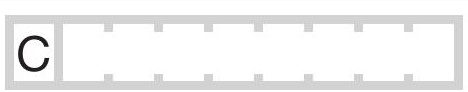

Name of Employer
None
Receipt For: 2012
X Primary $\quad \square$ General
$\square$ Other (specify)

Occupation

Retired

Election Cycle-to-Date 400.00

B. Full Name (Last, First, Middle Initial) Richard Allen

Mailing Address 718 Patrick Rd

\begin{tabular}{lcc}
\hline City & State & Zip Code \\
Auburn & AL & $36830-7572$ \\
\hline
\end{tabular}

FEC ID number of contributing

federal political committee.

C

Name of Employer
Information Requested
Receipt For: 2012
X Primary
Other (specify)

Occupation

Information Requested

Election Cycle-to-Date

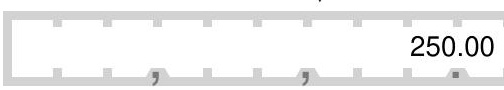

C. Full Name (Last, First, Middle Initial)

Mary Watkins

Mailing Address 1870 Bridle Ridge Trce

\begin{tabular}{l|ll}
\hline $\begin{array}{l}\text { City } \\
\text { Roswell }\end{array}$ & $\begin{array}{c}\text { State } \\
\text { GA }\end{array}$ & $\begin{array}{c}\text { Zip Code } \\
\text { 30075-2151 }\end{array}$ \\
\hline $\begin{array}{l}\text { FEC ID number of contributing } \\
\text { federal political committee. }\end{array}$ & C \\
\hline $\begin{array}{l}\text { Name of Employer } \\
\mathrm{n} / \mathrm{a}\end{array}$ & $\begin{array}{l}\text { Occupation } \\
\text { Homemaker }\end{array}$ \\
\hline $\begin{array}{l}\text { Receipt For: } 2012 \\
\text { X } \begin{array}{l}\text { Primary } \\
\text { Other (specify) }\end{array}\end{array}$ & Election Cycle-to-Date \\
\hline
\end{tabular}

Transaction ID : A3228AB4684B84F0FA59

Date of Receipt

Amount of Each Receipt this Period

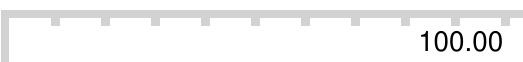

Date of Receipt
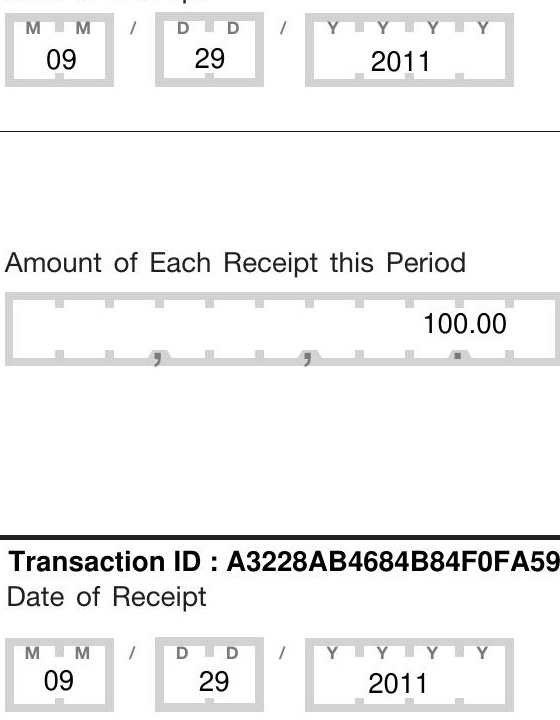

Amount of Each Receipt this Period

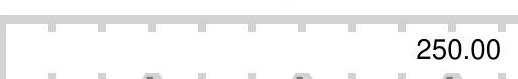

Amount of Each Receipt this Period

Transaction ID : A36BCF4B2522B4FE8B9A Date of Receipt
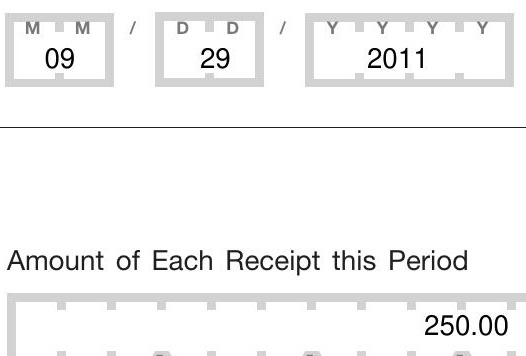

Subtotal Of Receipts This Page (optional)

600.00

Total This Period (last page this line number only) 


\section{SCHEDULE A-P} ITEMIZED RECEIPTS
Use separate schedule(s)

for each category of the

Detailed Summary Page
FOR LINE NUMBER: (check only one)

PAGE 996 / 1572

\begin{tabular}{|c|c|c|c|c|c|}
\hline & & & & & \\
\hline 16 & $\begin{array}{l}\mathbf{X} \\
17 a\end{array}$ & $17 b$ & $17 c$ & $17 d$ & 18 \\
\hline $19 a$ & $19 \mathrm{~b}$ & $20 \mathrm{a}$ & $20 \mathrm{~b}$ & $20 \mathrm{c}$ & 21 \\
\hline
\end{tabular}

Any information copied from such Reports and Statements may not be sold or used by any person for the purpose of soliciting contributions or for commercial purposes, other than using the name and address of any political committee to solicit contributions from such committee.

NAME OF COMMITTEE (In Full)

Friends of Herman Cain

A. Full Name (Last, First, Middle Initial)

Ruth Lemler

Mailing Address PO Box 1837

\begin{tabular}{lcc}
\hline City & State & Zip Code \\
Blooming Grove & TX & 76626 \\
\hline
\end{tabular}

FEC ID number of contributing federal political committee.

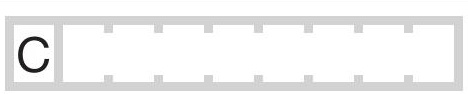

Name of Employer
Self Main St. Motors
Receipt For: 2012
X Primary
$\square$ Other (specify) General

Occupation

Car dealer

Election Cycle-to-Date

500.00

B. Full Name (Last, First, Middle Initial)

Mark Coleman

Mailing Address 3983 Earney Rd

\begin{tabular}{lcc}
\hline City & State & Zip Code \\
Woodstock & GA & $30188-2223$ \\
\hline
\end{tabular}

FEC ID number of contributing

federal political committee.

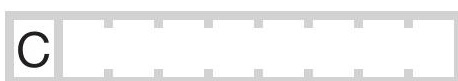

Name of Employer
TLM Automotive
Receipt For: 2012
X Primary
$\square$ Other (specify) General

Occupation

Manager

Election Cycle-to-Date

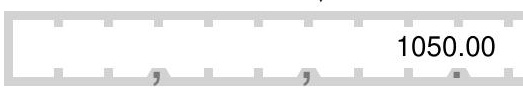

C. Full Name (Last, First, Middle Initial)

Stephen Northington

Mailing Address 1915 Landfall Pass NW

\begin{tabular}{lcc}
\hline City & State & Zip Code \\
Kennesaw & GA & $30152-7736$
\end{tabular}

FEC ID number of contributing

federal political committee.

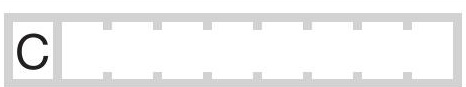

Name of Employer

Group Insurance Solutions LLC.

Receipt For: 2012

Х $\begin{aligned} & \text { Primary } \\ & \text { Other (specify) }\end{aligned}$

Occupation

Sales Director

Election Cycle-to-Date

Transaction ID : A5A3450E4CEEF4D16AE3

Date of Receipt

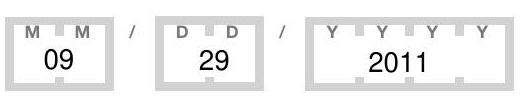

Amount of Each Receipt this Period

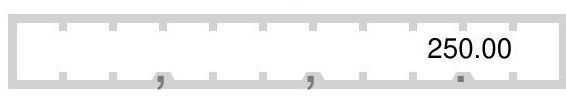

Amount of Each Receipt this Period

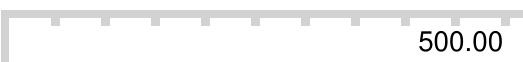

500.00

Date of Receipt
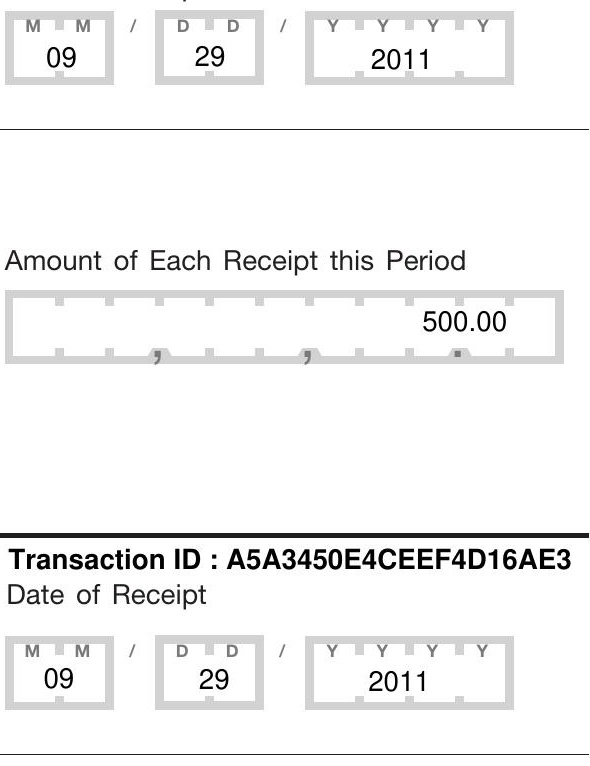
3 


\section{SCHEDULE A-P} ITEMIZED RECEIPTS
Use separate schedule(s) for each category of the Detailed Summary Page

FOR LINE NUMBER:
(check only one)

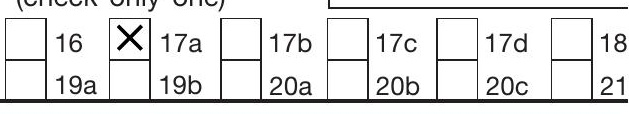

Any information copied from such Reports and Statements may not be sold or used by any person for the purpose of soliciting contributions or for commercial purposes, other than using the name and address of any political committee to solicit contributions from such committee.

NAME OF COMMITTEE (In Full)

\section{Friends of Herman Cain}

A. Full Name (Last, First, Middle Initial)

Mark Lampton

Mailing Address 423 Saint Andrews Drive

\begin{tabular}{lcc}
\hline City & State & Zip Code \\
Augusta & GA & $30909-7805$ \\
\hline
\end{tabular}

FEC ID number of contributing federal political committee.

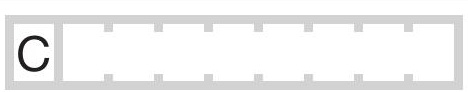

Name of Employer
Information Requested
Receipt For: 2012
X Primary
Other (specify) General

Occupation Information Requested

Election Cycle-to-Date 500.00

B. Full Name (Last, First, Middle Initial)

David Torrence

Mailing Address 928 Blackburn Road

\begin{tabular}{lcc}
\hline City & State & Zip Code \\
Sewickley & PA & $15143-1491$
\end{tabular}

FEC ID number of contributing

federal political committee.

C

Name of Employer
Information Requested
Receipt For: 2012
Primary
Other (specify)

Occupation

Information Requested

Election Cycle-to-Date

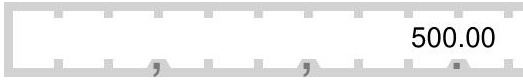

Transaction ID : A135557C29D8A46A983D

Date of Receipt

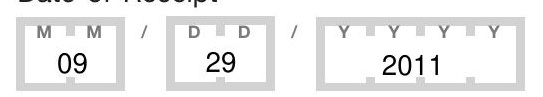

Amount of Each Receipt this Period

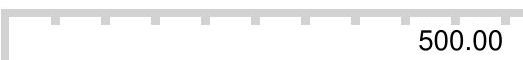

C. Full Name (Last, First, Middle Initial)

Paul Niesen

Mailing Address 15220 Buckeye Court

\begin{tabular}{lcc}
\hline City & State & Zip Code \\
Gaithersburg & MD & $20878-3522$
\end{tabular}

FEC ID number of contributing federal political committee.

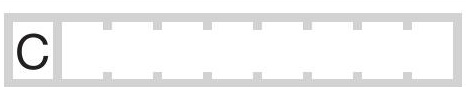

Name of Employer

Information Requested

\section{Occupation}

Information Requested

Receipt For: 2012

Х $\begin{aligned} & \text { Primary } \\ & \text { Other (specify) }\end{aligned}$

Transaction ID : A36BB4A2912C54873B72

Date of Receipt

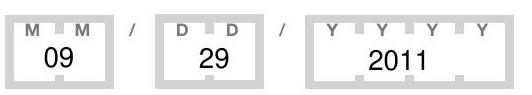

Amount of Each Receipt this Period

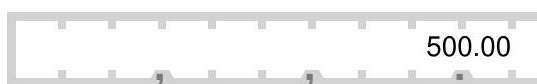

Transaction ID : A17BF533350F24C548C1

Date of Receipt

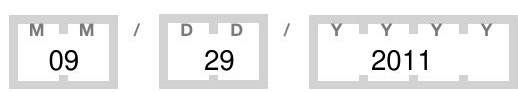

Amount of Each Receipt this Period

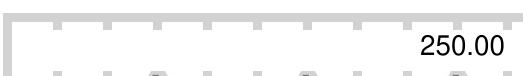

\section{Subtotal Of Receipts This Page (optional)}

Total This Period (last page this line number only) 


\section{SCHEDULE A-P} ITEMIZED RECEIPTS
Use separate schedule(s)

for each category of the

Detailed Summary Page
FOR LINE NUMBER: (check only one)

PAGE $998 / 1572$

\begin{tabular}{|c|c|c|c|c|c|}
\hline & & & & & \\
\hline 16 & X $17 a$ & $17 b$ & $17 c$ & $17 d$ & 18 \\
\hline $19 a$ & $19 b$ & $20 \mathrm{a}$ & $20 \mathrm{~b}$ & $20 \mathrm{c}$ & 21 \\
\hline
\end{tabular}

Any information copied from such Reports and Statements may not be sold or used by any person for the purpose of soliciting contributions or for commercial purposes, other than using the name and address of any political committee to solicit contributions from such committee.

NAME OF COMMITTEE (In Full)

Friends of Herman Cain

A. Full Name (Last, First, Middle Initial)

Carey W Robinson

Mailing Address 5825 Winnbrook Ct

\begin{tabular}{lcc}
\hline City & State & Zip Code \\
Roanoke & VA & $24018-7900$ \\
\hline
\end{tabular}

FEC ID number of contributing federal political committee.

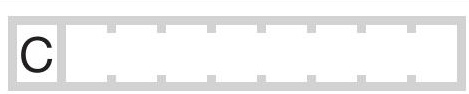

Name of Employer
Self Employed
Receipt For: 2012
X Primary $\quad$ General
Other (specify)

Occupation

Physician

Election Cycle-to-Date

500.00

B. Full Name (Last, First, Middle Initial)

sheldon severinghaus

Mailing Address 66 cleary ct--\#609

\begin{tabular}{lcc}
\hline City & State & Zip Code \\
San Francisco & CA & 94109 \\
\hline
\end{tabular}

FEC ID number of contributing

federal political committee.

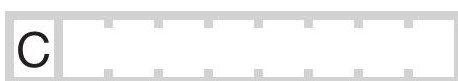

\begin{tabular}{l} 
Name of Employer \\
Information Requested \\
Receipt For: 2012 \\
X Primary \\
\hline Other (specify)
\end{tabular}

Occupation

Information Requested

Election Cycle-to-Date

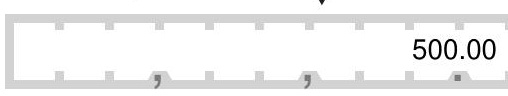

Transaction ID : A88E1D7FC97D84A1CA1C

Date of Receipt

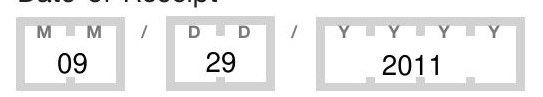

Amount of Each Receipt this Period

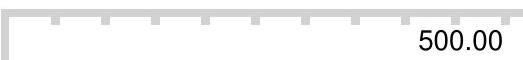

Amount of Each Receipt this Period

Transaction ID : A56439780316F4DABA68

Date of Receipt
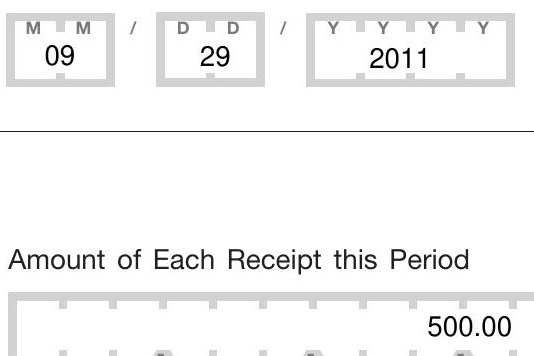

Transaction ID : ACC47C375B93E42F1972

Date of Receipt

John Huffman

Mailing Address 215 Tanglewood Way

\begin{tabular}{lcc}
\hline City & State & Zip Code \\
Collierville & TN & $38017-5791$
\end{tabular}

FEC ID number of contributing

federal political committee.

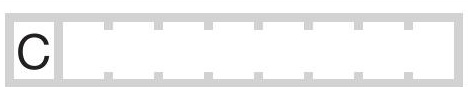

Name of Employer

Occupation

Information Requested

Information Requested

Receipt For: 2012

Х $\begin{aligned} & \text { Primary } \\ & \text { Other (specify) }\end{aligned}$

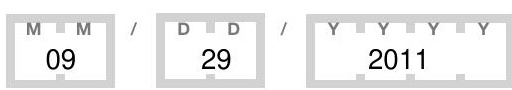

Amount of Each Receipt this Period

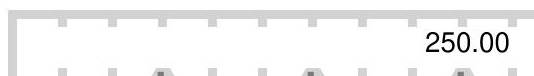

Subtotal Of Receipts This Page (optional).

Total This Period (last page this line number only) 


\section{SCHEDULE A-P} ITEMIZED RECEIPTS
Use separate schedule(s)

for each category of the

Detailed Summary Page
FOR LINE NUMBER: (check only one)

PAGE 999 / 1572

\begin{tabular}{|c|c|c|c|c|c|}
\hline & & & & & \\
\hline 16 & X $17 a$ & $17 b$ & $17 c$ & $17 d$ & 18 \\
\hline $19 a$ & $19 b$ & $20 \mathrm{a}$ & $20 \mathrm{~b}$ & $20 \mathrm{c}$ & 21 \\
\hline
\end{tabular}

Any information copied from such Reports and Statements may not be sold or used by any person for the purpose of soliciting contributions or for commercial purposes, other than using the name and address of any political committee to solicit contributions from such committee.

NAME OF COMMITTEE (In Full)

Friends of Herman Cain

A. Full Name (Last, First, Middle Initial)

David Vaughn

Mailing Address 1002 Hayshed Road

\begin{tabular}{lcc}
\hline City & State & Zip Code \\
Dickson & TN & $37055-5746$
\end{tabular}

FEC ID number of contributing

federal political committee.

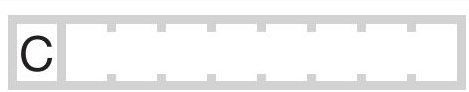

Name of Employer
Information Requested
Receipt For: 2012
X Primary $\quad \square$ General
Other (specify)

Occupation

Information Requested

Election Cycle-to-Date

250.00

B. Full Name (Last, First, Middle Initial)

James McKinney

Mailing Address 3046 Woodveil Lane

\begin{tabular}{lcc}
\hline City & State & Zip Code \\
Orange Park & FL & $32073-6941$
\end{tabular}

FEC ID number of contributing

federal political committee.

C

Name of Employer
Information Requested
Receipt For: 2012
Primary
Other (specify)

Occupation

Information Requested

Election Cycle-to-Date

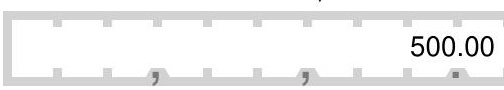

Transaction ID : A75DE54EFE48D4B41939

Date of Receipt

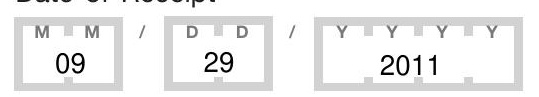

Amount of Each Receipt this Period

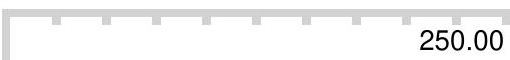

C. Full Name (Last, First, Middle Initial)

Kevin North

Mailing Address 15 Pennington $\mathrm{Dr}$

\begin{tabular}{lcc}
\hline City & State & Zip Code \\
Simsbury & CT & $06070-2648$
\end{tabular}

FEC ID number of contributing federal political committee.

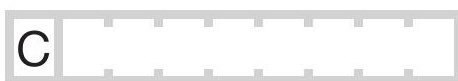

Name of Employer

Information Requested

\section{Occupation}

Information Requested

Receipt For: 2012

Х $\begin{aligned} & \text { Primary } \square \text { General } \\ & \text { Other (specify) }\end{aligned}$

Amount of Each Receipt this Period

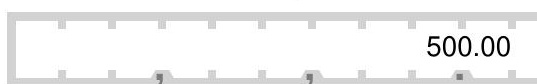

Transaction ID : ADB69CA3981AC40DE878 Date of Receipt

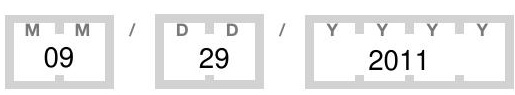

Transaction ID : A4C77B046CC334966BC9 Date of Receipt

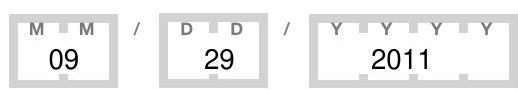

Amount of Each Receipt this Period

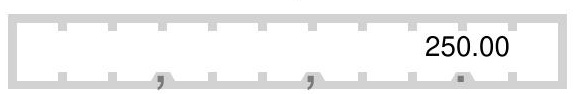

250.00
Subtotal Of Receipts This Page (optional).

1000.00

,

Total This Period (last page this line number only) 


\section{SCHEDULE A-P} ITEMIZED RECEIPTS
Use separate schedule(s)

for each category of the

Detailed Summary Page
FOR LINE NUMBER: (check only one)

Any information copion the purpose of soliciting contributions or for commercial purposes, other than using the name and address of any political committee to solicit contributions from such committee.

NAME OF COMMITTEE (In Full)

Friends of Herman Cain

A. Full Name (Last, First, Middle Initial)

Gregory Sampognaro

Mailing Address 2503 Broadmoor Blvd

\begin{tabular}{lcc}
\hline City & State & Zip Code \\
Monroe & LA & $71201-2987$
\end{tabular}

FEC ID number of contributing

federal political committee.

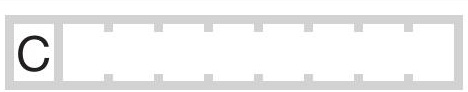

Name of Employer
Information Requested
Receipt For: 2012
X Primary $\quad \square$ General
Other (specify)

Occupation

Information Requested

Election Cycle-to-Date

250.00

B. Full Name (Last, First, Middle Initial)

Kerry Williams

Mailing Address 10 Great Laurel Court

\begin{tabular}{lcc}
\hline City & State & Zip Code \\
Spring & TX & $77381-4833$
\end{tabular}

FEC ID number of contributing

federal political committee.

C

Name of Employer
Information Requested
Receipt For: 2012
X Primary
Other (specify)

Occupation

Information Requested

Election Cycle-to-Date

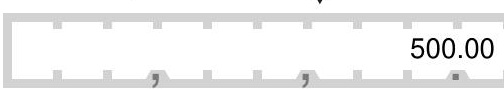

Transaction ID : A0854B46D4D7940C08FE

Date of Receipt

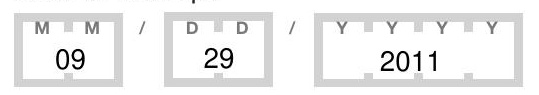

Amount of Each Receipt this Period

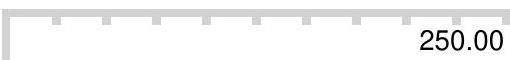

Transaction ID : A017E7ACA80534A0096E

Date of Receipt

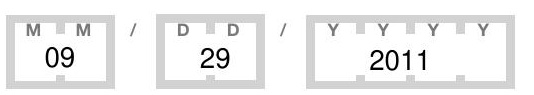

Amount of Each Receipt this Period

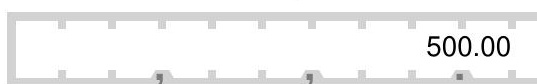

Transaction ID : A0E8A4851F63D44E68A6

Date of Receipt

Sharon Tidd

Mailing Address 839 Sandra Way

\begin{tabular}{lcc}
\hline City & State & Zip Code \\
Kodak & TN & $37764-1749$
\end{tabular}

FEC ID number of contributing

federal political committee.

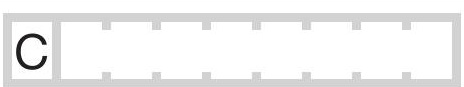

Name of Employer

Dollywood

Receipt For: 2012

Х $\begin{aligned} & \text { Primary } \\ & \text { Other (specify) }\end{aligned}$

Occupation

park associate

Election Cycle-to-Date

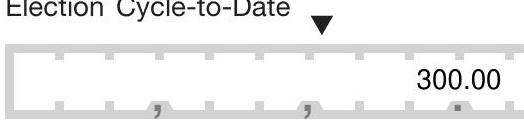

Subtotal Of Receipts This Page (optional)

Amount of Each Receipt this Period

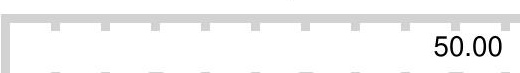

Total This Period (last page this line number only)

$\quad 800.00$

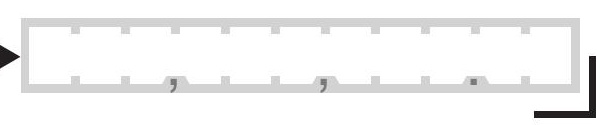

FEC Schedule A-P (Form 3P) (Rev. 03/2011) 


\section{SCHEDULE A-P} ITEMIZED RECEIPTS
Use separate schedule(s) for each category of the Detailed Summary Page

\begin{tabular}{|c|c|c|c|c|c|}
\hline \multicolumn{3}{|c|}{$\begin{array}{l}\text { FOR LINE NUMBER: } \\
\text { (check only one) }\end{array}$} & \multicolumn{3}{|c|}{ PAGE 1001 / 1572} \\
\hline 16 & $X$ 17a & $17 b$ & $17 c$ & $17 d$ & 18 \\
\hline $19 a$ & $19 \mathrm{~b}$ & $20 a$ & $20 \mathrm{~b}$ & $20 c$ & 21 \\
\hline
\end{tabular}

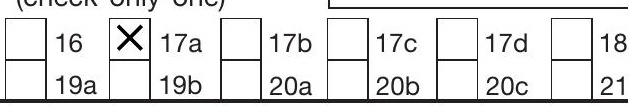

Any information copied from such Reports and Statements may not be sold or used by any person for the purpose of soliciting contributions or for commercial purposes, other than using the name and address of any political committee to solicit contributions from such committee.

NAME OF COMMITTEE (In Full)

\section{Friends of Herman Cain}

A. Full Name (Last, First, Middle Initial)

Brian Machtley

Mailing Address $121 \mathrm{~W}$ 48th Street \#703

\begin{tabular}{lcc}
\hline City & State & Zip Code \\
Kansas City & MO & $64112-3833$ \\
\hline
\end{tabular}

FEC ID number of contributing federal political committee.

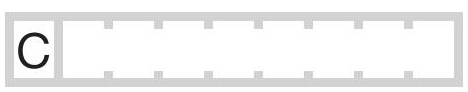

Name of Employer
Information Requested
Receipt For: 2012
X Primary
Other (specify) General

Occupation Information Requested

Election Cycle-to-Date 250.00

B. Full Name (Last, First, Middle Initial)

Martin Hogan

Mailing Address 2409 Hickory Dr NW

\begin{tabular}{lcc}
\hline City & State & Zip Code \\
Cleveland & TN & $37311-3624$ \\
\hline
\end{tabular}

FEC ID number of contributing

federal political committee.

C

Name of Employer
Information Requested
Receipt For: 2012
Primary
Other (specify)

Occupation

Information Requested

Election Cycle-to-Date

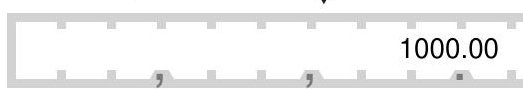

C. Full Name (Last, First, Middle Initial)

James Burford

Mailing Address P.O. Box 5379

\begin{tabular}{lcc}
\hline City & State & Zip Code \\
Mohave Valley & AZ & $86446-5379$
\end{tabular}

FEC ID number of contributing federal political committee.

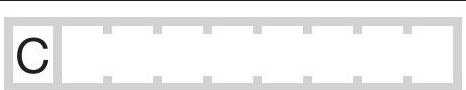

Name of Employer
Information Requested
Receipt For: 2012
X Primary
Other (specify) General

\section{Occupation}

Information Requested

Election Cycle-to-Date
Transaction ID : AAB29C10BFF3446E3931

Date of Receipt

Amount of Each Receipt this Period

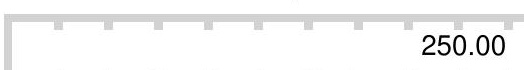

Transaction ID : A585CCCE9EA0F42A4A36

Date of Receipt
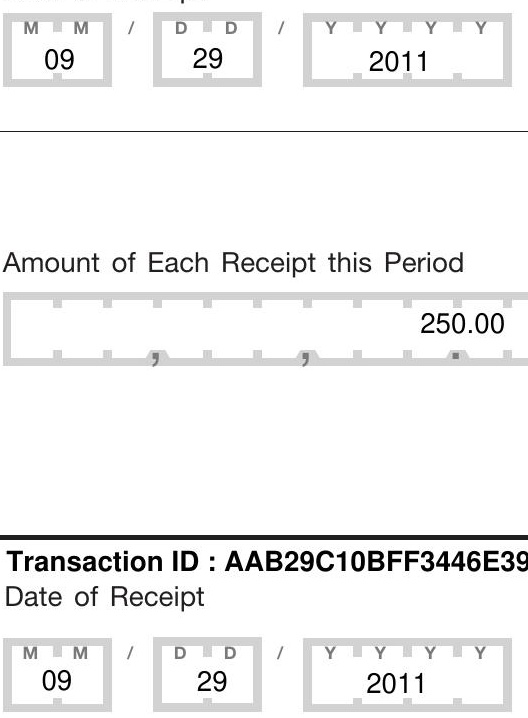

Amount of Each Receipt this Period

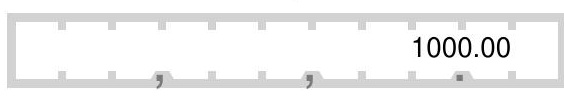

Transaction ID : A227381ED4DEB4B77B47 Date of Receipt

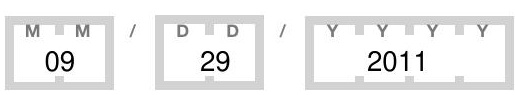

Amount of Each Receipt this Period

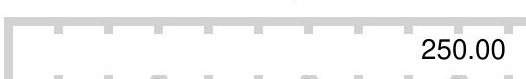

\section{Subtotal Of Receipts This Page (optional).}

Total This Period (last page this line number only) 


\section{SCHEDULE A-P} ITEMIZED RECEIPTS
Use separate schedule(s)

for each category of the

Detailed Summary Page
FOR LINE NUMBER: (check only one)

Any information or for commercial purposes, other than using the name and address of any political committee to solicit contributions from such committee.

NAME OF COMMITTEE (In Full)

Friends of Herman Cain

A. Full Name (Last, First, Middle Initial)

Mike Jones

Mailing Address 10302 S 86 E Ave

\begin{tabular}{lcc}
\hline City & State & Zip Code \\
Tulsa & OK & $74133-6976$
\end{tabular}

FEC ID number of contributing

federal political committee.

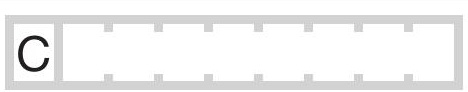

Name of Employer
Independent Tubulan Corp.
Receipt For: 2012
X Primary $\quad \square$ General
Other (specify)

Occupation

CPA

Election Cycle-to-Date

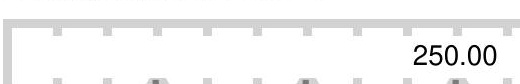

B. Full Name (Last, First, Middle Initial)

Ryan Novaczyk

Mailing Address 100 3rd Ave S \#1805

\begin{tabular}{llc}
\hline City & State & Zip Code \\
Minneapolis & MN & $55401-2714$
\end{tabular}

FEC ID number of contributing

federal political committee.

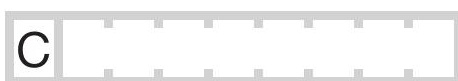

Name of Employer

New Perspective Senior Living

Occupation

Receipt For: 2012

$\searrow \begin{aligned} & \text { Primary } \\ & \text { Other (specify) }\end{aligned}$

Finance

Election Cycle-to-Date

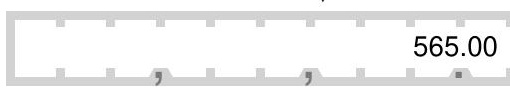

C. Full Name (Last, First, Middle Initial)

Charles Adams

Mailing Address 5230 ACR 2202

\begin{tabular}{lcc}
\hline City & State & Zip Code \\
Palestine & TX & 75803 \\
\hline
\end{tabular}

FEC ID number of contributing

federal political committee.

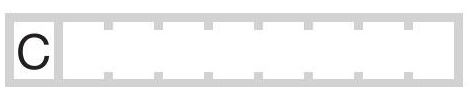

Name of Employer

Univ. of Texas Medical Branch

Receipt For: 2012

Х $\begin{aligned} & \text { Primary } \\ & \text { Other (specify) }\end{aligned}$

Occupation

Physician

Election Cycle-to-Date

Transaction ID : A0A3FABB754534FE19F1

Date of Receipt

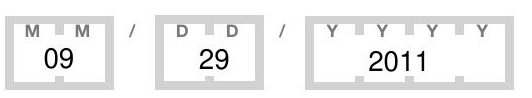

Amount of Each Receipt this Period

Amount of Each Receipt this Period

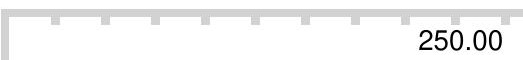

$+250.00$

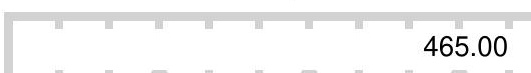

Transaction ID : A35C3336B51174FC29CE

Date of Receipt

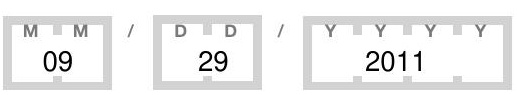

Amount of Each Receipt this Period

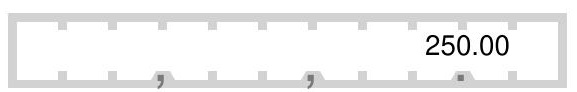

850.00

\section{Subtotal Of Receipts This Page (optional)}

965.00

a

Total This Period (last page this line number only)

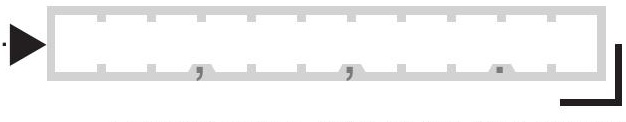

FEC Schedule A-P (Form 3P) (Rev. 03/2011) 
SCHEDULE A-P ITEMIZED RECEIPTS
Use separate schedule(s) for each category of the Detailed Summary Page
FOR LINE NUMBER: (check only one)

PAGE $1003 / 1572$

\begin{tabular}{|c|c|c|c|c|c|}
\hline & & & & & \\
\hline 16 & $\begin{array}{lll}X & 17 a \\
\end{array}$ & $17 \mathrm{~b}$ & $17 c$ & $17 d$ & 18 \\
\hline $19 a$ & $19 b$ & $20 a$ & $20 \mathrm{~b}$ & $20 c$ & 21 \\
\hline
\end{tabular}

Any information copied from such Reports and Statements may not be sold or used by any person for the purpose of soliciting contributions or for commercial purposes, other than using the name and address of any political committee to solicit contributions from such committee.

NAME OF COMMITTEE (In Full)

\section{Friends of Herman Cain}

A. Full Name (Last, First, Middle Initial)

Amy OConnor

Mailing Address PO Box 429

\begin{tabular}{lcc}
\hline City & State & Zip Code \\
Evergreen & AL & $36401-0429$ \\
\hline
\end{tabular}

FEC ID number of contributing federal political committee.

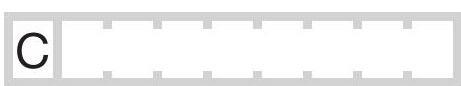

\begin{tabular}{l} 
Name of Employer \\
None \\
Receipt For: 2012 \\
X Primary $\quad$ General \\
\hline Other (specify)
\end{tabular}

\section{Occupation} Homemaker

Election Cycle-to-Date 250.00

B. Full Name (Last, First, Middle Initial)

Krisopher Kuehn

Mailing Address 26 Turtle Creek Lane

\begin{tabular}{lcc}
\hline City & State & Zip Code \\
Roxboro & NC & $27574-9482$
\end{tabular}

FEC ID number of contributing

federal political committee.

C

Name of Employer
Information Requested
Receipt For: 2012
X Primary
Other (specify)

\section{Occupation}

Information Requested

Election Cycle-to-Date

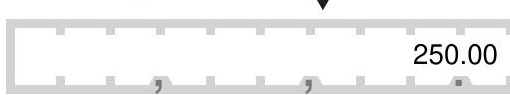

Transaction ID : A66EED6F6A7084F51858

Date of Receipt

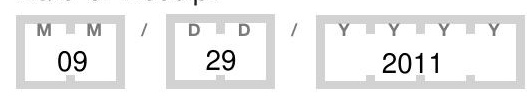

Amount of Each Receipt this Period

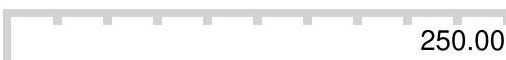

C. Full Name (Last, First, Middle Initial)

Cherin Perham

Mailing Address PO Box 6994

\begin{tabular}{lcc}
\hline City & State & Zip Code \\
Folsom & CA & $95763-6994$ \\
\hline
\end{tabular}

FEC ID number of contributing federal political committee.

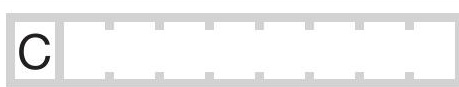

Name of Employer
Information Requested
Receipt For: 2012
X Primary $\quad \square$ General
Other (specify)

\section{Occupation}

Information Requested

Election Cycle-to-Date

Transaction ID : AEAD3BFFD7BE84433AA6 Date of Receipt

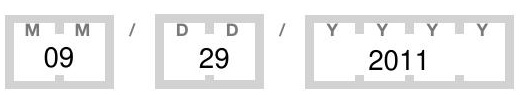

Amount of Each Receipt this Period

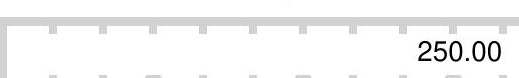

Transaction ID : ADFE0894AE0714D86958

Date of Receipt

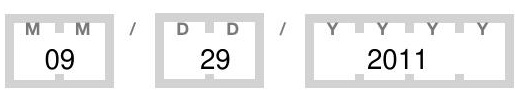

Amount of Each Receipt this Period

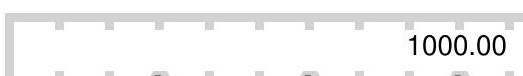

1000.00

\section{Subtotal Of Receipts This Page (optional)}

Total This Period (last page this line number only) 


\section{SCHEDULE A-P} ITEMIZED RECEIPTS
Use separate schedule(s) for each category of the Detailed Summary Page

\begin{tabular}{|c|c|c|c|c|c|}
\hline \multicolumn{3}{|c|}{$\begin{array}{l}\text { FOR LINE NUMBER: } \\
\text { (check only one) }\end{array}$} & \multicolumn{3}{|c|}{ PAGE 1004 / 1572} \\
\hline 16 & $X$ 17a & $17 b$ & $17 \mathrm{c}$ & $17 d$ & 18 \\
\hline $19 a$ & $19 \mathrm{~b}$ & $20 a$ & $20 \mathrm{~b}$ & $20 c$ & 21 \\
\hline
\end{tabular}

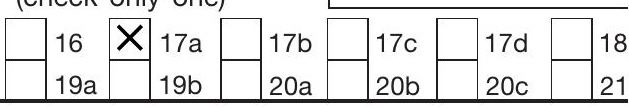

Any information copied from such Reports and Statements may not be sold or used by any person for the purpose of soliciting contributions or for commercial purposes, other than using the name and address of any political committee to solicit contributions from such committee.

NAME OF COMMITTEE (In Full)

\section{Friends of Herman Cain}

A. Full Name (Last, First, Middle Initial)

\section{Carlos Assid}

Mailing Address 14 E 2ND ST PMB 30294

\begin{tabular}{lcc}
\hline City & State & Zip Code \\
Calexico & CA & $92231-2618$
\end{tabular}

FEC ID number of contributing federal political committee.

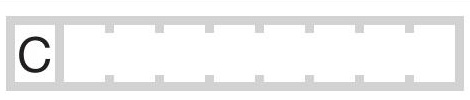

Name of Employer
Information Requested
Receipt For: 2012
X Primary
$\square$ Other (specify)

Occupation Information Requested

Election Cycle-to-Date

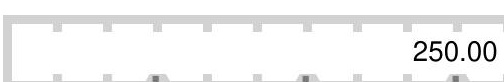

B. Full Name (Last, First, Middle Initial)

Tyler Keeley

Mailing Address 7209 Governors Row

\begin{tabular}{lcc}
\hline City & State & Zip Code \\
Charlotte & NC & $28277-0377$
\end{tabular}

FEC ID number of contributing

federal political committee.

C

Name of Employer
Information Requested
Receipt For: 2012
Primary
Other (specify)

Occupation

Information Requested

Election Cycle-to-Date

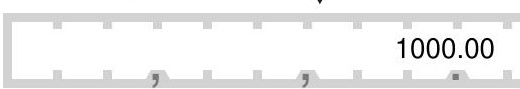

Transaction ID : AE797B571DFF54F8CB73

Date of Receipt

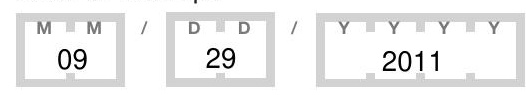

Amount of Each Receipt this Period

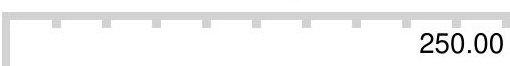

Amount of Each Receipt this Period

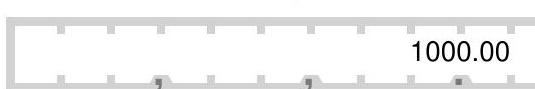

C. Full Name (Last, First, Middle Initial)

Keith Jordan

Mailing Address 7259 Brookwood Dr

\begin{tabular}{lcc}
\hline City & State & Zip Code \\
Mandeville & LA & $70471-7443$
\end{tabular}

FEC ID number of contributing federal political committee.

C

Name of Employer
Information Requested
Receipt For: 2012
Primary
Other (specify) General

Occupation

Information Requested

Election Cycle-to-Date
Transaction ID : ADE5A3F7A1C2A4C1281D Date of Receipt

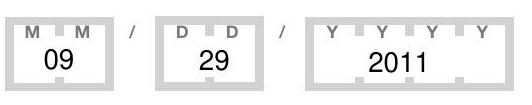

Transaction ID : A725068FDA06D49A5AB9 Date of Receipt

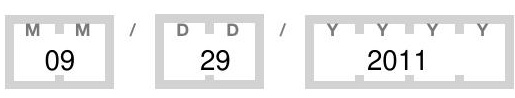

Amount of Each Receipt this Period

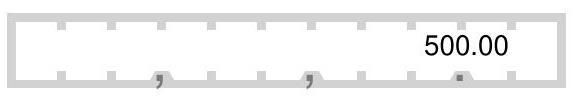

500.00

\section{Subtotal Of Receipts This Page (optional)}

Total This Period (last page this line number only) 


\section{SCHEDULE A-P} ITEMIZED RECEIPTS
Use separate schedule(s) for each category of the Detailed Summary Page
FOR LINE NUMBER: (check only one)

Any information or for commercial purposes, other than using the name and address of any political committee to solicit contributions from such committee.

NAME OF COMMITTEE (In Full)

Friends of Herman Cain

A. Full Name (Last, First, Middle Initial)

David Dunnavant

Mailing Address 21125 dunnavant Rd

\begin{tabular}{lcc}
\hline City & State & Zip Code \\
Elkmont & AL & $35620-5925$
\end{tabular}

FEC ID number of contributing

federal political committee.

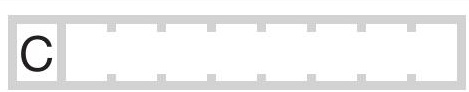

Name of Employer
Information Requested
Receipt For: 2012
X Primary $\quad \square$ General
Other (specify)

Occupation

Information Requested

Election Cycle-to-Date

300.00

B. Full Name (Last, First, Middle Initial)

Constance Pritchett

Mailing Address 6001 Bollinger Canyon Rd

\begin{tabular}{lcc}
\hline City & State & Zip Code \\
San Ramon & CA & $94583-2324$
\end{tabular}

FEC ID number of contributing

federal political committee.

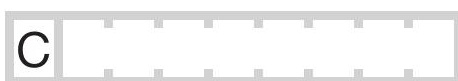

Name of Employer
Information Requested
Receipt For: 2012
X Primary
Other (specify)

Occupation

Information Requested

Election Cycle-to-Date

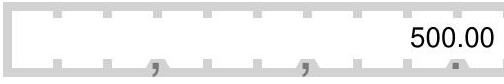

C. Full Name (Last, First, Middle Initial)

Wayne Gray

Mailing Address 3816 Appomattox Circle

\begin{tabular}{lcc}
\hline City & State & Zip Code \\
Plano & TX & $75023-6021$
\end{tabular}

FEC ID number of contributing

federal political committee.

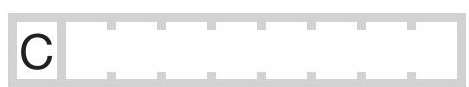

Name of Employer

Information Requested

Occupation

Information Requested

Receipt For: 2012

Х $\begin{aligned} & \text { Primary } \square \text { General } \\ & \text { Other (specify) }\end{aligned}$

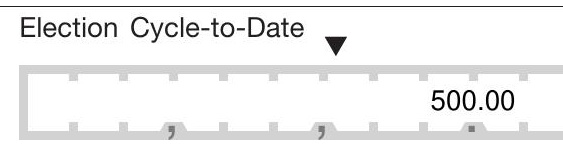

Amount of Each Receipt this Period

Transaction ID : A321FEEB06FC641A683A

Date of Receipt

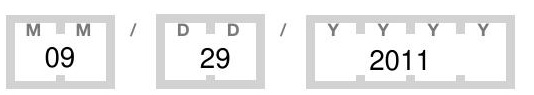

Amount of Each Receipt this Period
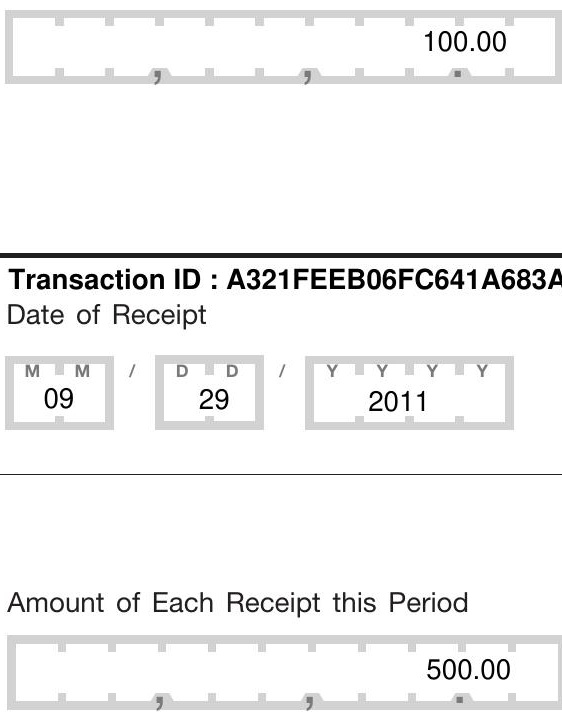

Transaction ID : ACF09D078BD70411DADE Date of Receipt

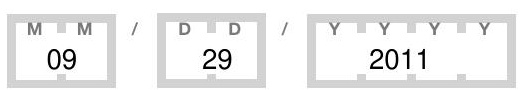

Amount of Each Receipt this Period

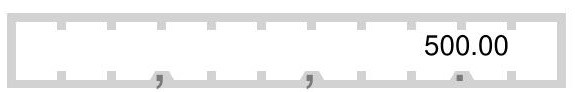

Subtotal Of Receipts This Page (optional).

1100.00

Total This Period (last page this line number only) 


\section{SCHEDULE A-P} ITEMIZED RECEIPTS
Use separate schedule(s) for each category of the Detailed Summary Page

\begin{tabular}{|c|c|c|c|c|c|}
\hline \multicolumn{3}{|c|}{$\begin{array}{l}\text { FOR LINE NUMBER: } \\
\text { (check only one) }\end{array}$} & \multicolumn{3}{|c|}{ PAGE 1006 / 1572} \\
\hline 16 & $X$ 17a & $17 b$ & $17 c$ & $17 d$ & 18 \\
\hline $19 a$ & $19 \mathrm{~b}$ & $20 a$ & $20 \mathrm{~b}$ & $20 c$ & 21 \\
\hline
\end{tabular}

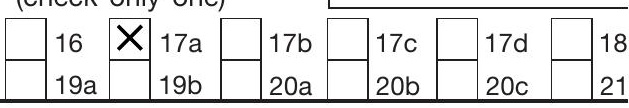

Any information copied from such Reports and Statements may not be sold or used by any person for the purpose of soliciting contributions or for commercial purposes, other than using the name and address of any political committee to solicit contributions from such committee.

NAME OF COMMITTEE (In Full)

\section{Friends of Herman Cain}

A. Full Name (Last, First, Middle Initial)

David Bennett

Mailing Address 6717 Beatrix Drive

\begin{tabular}{lcc}
\hline City & State & Zip Code \\
Jacksonville & FL & $32226-3343$
\end{tabular}

FEC ID number of contributing federal political committee.

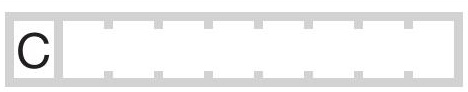

Name of Employer
Information Requested
Receipt For: 2012
X Primary
$\square$ Other (specify)

Occupation Information Requested

Election Cycle-to-Date 250.00

B. Full Name (Last, First, Middle Initial) Robert Sparks

Mailing Address 2814 Sapphire Court

\begin{tabular}{lcc}
\hline City & State & Zip Code \\
Tallahassee & FL & $32309-7282$ \\
\hline
\end{tabular}

FEC ID number of contributing

federal political committee.

C

Name of Employer
Information Requested
Receipt For: 2012
X Primary
Other (specify)

Occupation

Information Requested

Election Cycle-to-Date

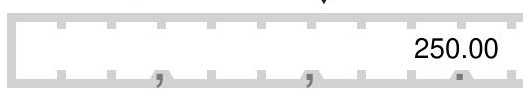

Transaction ID : AE0DBE57A6D984082AC5

Date of Receipt

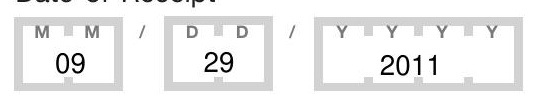

Amount of Each Receipt this Period

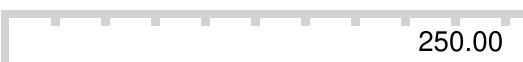

C. Full Name (Last, First, Middle Initial)

Carmine Pescatore

Mailing Address PO Box 1254

\begin{tabular}{lcc}
\hline City & State & Zip Code \\
Jackson & NJ & $08527-0261$
\end{tabular}

FEC ID number of contributing federal political committee.

C

Name of Employer
Information Requested
Receipt For: 2012
X Primary $\quad \square$ General
Other (specify)

Occupation

Information Requested

Election Cycle-to-Date
Transaction ID : AAAC0200573914041A00

Date of Receipt

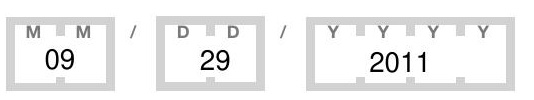

Amount of Each Receipt this Period

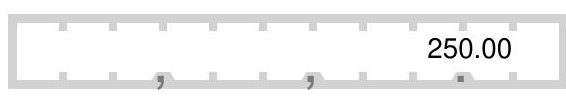

Transaction ID : A75FA5E4025D047F09C1 Date of Receipt

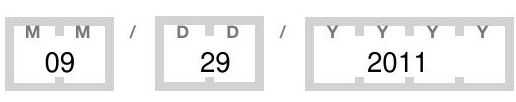

Amount of Each Receipt this Period

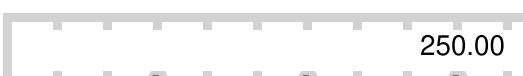

300.00

Subtotal Of Receipts This Page (optional).

Total This Period (last page this line number only) 


\section{SCHEDULE A-P} ITEMIZED RECEIPTS
Use separate schedule(s) for each category of the Detailed Summary Page
FOR LINE NUMBER: (check only one)
PAGE 1007 / 1572

\begin{tabular}{|c|c|c|c|c|c|}
\hline & & & & & \\
\hline 16 & $\begin{array}{l}X 17 a \\
\end{array}$ & $17 \mathrm{~b}$ & $17 c$ & $17 d$ & 18 \\
\hline $19 a$ & $19 b$ & $20 a$ & $20 \mathrm{~b}$ & $20 c$ & 21 \\
\hline
\end{tabular}

Any information copied from such Reports and Statements may not be sold or used by any person for the purpose of soliciting contributions or for commercial purposes, other than using the name and address of any political committee to solicit contributions from such committee.

NAME OF COMMITTEE (In Full)

\section{Friends of Herman Cain}

A. Full Name (Last, First, Middle Initial)

Kathleen Commins

Mailing Address 91 Douglas Road

\begin{tabular}{lcc}
\hline City & State & Zip Code \\
Friday Harbor & WA & $98250-8263$ \\
\hline
\end{tabular}

FEC ID number of contributing

federal political committee.

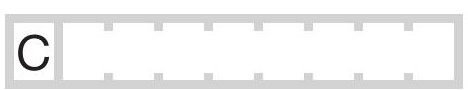

Name of Employer
Self Employed
Receipt For: 2012
X Primary
$\square$ Other (specify) General

Occupation

Commins Manufacturing, Inc.

Election Cycle-to-Date

\subsection{0}

B. Full Name (Last, First, Middle Initial)

Ron Pomeroy

Mailing Address PO Box 703

\begin{tabular}{lcc}
\hline City & State & Zip Code \\
Belle Plaine & KS & $67013-0703$
\end{tabular}

FEC ID number of contributing

federal political committee.

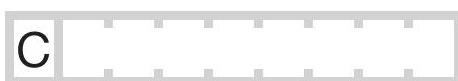

Name of Employer
Kansas Castings Inc
Receipt For: 2012
X Primary
Other (specify)

\section{Occupation}

Metalcasting

Election Cycle-to-Date

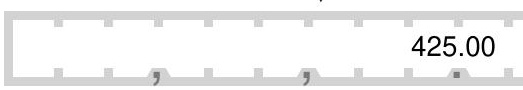

Transaction ID : AAD21F880A8814A89880

Date of Receipt

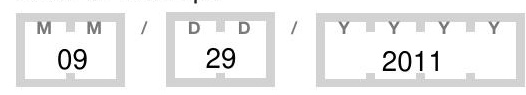

Amount of Each Receipt this Period

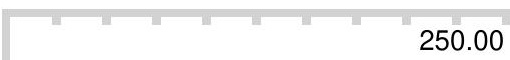

250.00

C. Full Name (Last, First, Middle Initial)

Dan Shore

Mailing Address 541 Lake Road

\section{City}

Ponte Vedra Beach

FEC ID number of contributing federal political committee.

Name of Employer

Information Requested

Receipt For: 2012

Х $\begin{aligned} & \text { Primary } \square \text { General } \\ & \text { Other (specify) }\end{aligned}$

$\begin{array}{cc}\text { State } & \text { Zip Code } \\ \text { FL } & 32082-2307\end{array}$

C

Occupation

Information Requested

Election Cycle-to-Date

Transaction ID : A30367317702947829EB

Date of Receipt

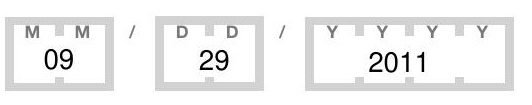

Amount of Each Receipt this Period

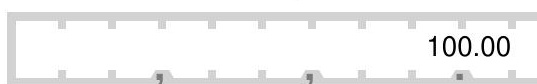

Transaction ID : A352B4977422C4C3B900

Date of Receipt

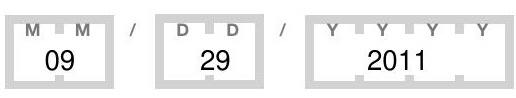

Amount of Each Receipt this Period

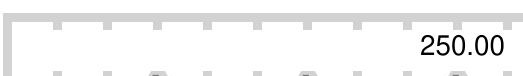

250.00

Subtotal Of Receipts This Page (optional).

600.00

.

Total This Period (last page this line number only)

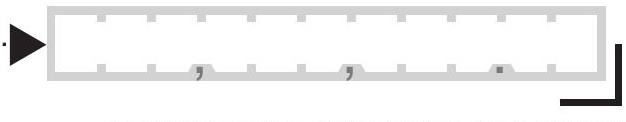

FEC Schedule A-P (Form 3P) (Rev. 03/2011) 


\section{SCHEDULE A-P} ITEMIZED RECEIPTS
Use separate schedule(s)

for each category of the

Detailed Summary Page
FOR LINE NUMBER: (check only one)

Any information or for commercial purposes, other than using the name and address of any political committee to solicit contributions from such committee.

NAME OF COMMITTEE (In Full)

Friends of Herman Cain

A. Full Name (Last, First, Middle Initial)

Kevin Hill

Mailing Address 4015 millstone mtn rd

\begin{tabular}{lcc}
\hline City & State & Zip Code \\
Rockwood & TN & $37854-7245$
\end{tabular}

FEC ID number of contributing

federal political committee.

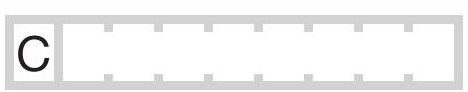

Name of Employer
Information Requested
Receipt For: 2012
X Primary $\quad \square$ General
Other (specify)

Occupation

Information Requested

Election Cycle-to-Date

465.00

B. Full Name (Last, First, Middle Initial)

Karen Caruso

Mailing Address 2913 Northlake Dr

\begin{tabular}{lcc}
\hline City & State & Zip Code \\
Henrico & VA & $23233-6637$
\end{tabular}

FEC ID number of contributing

federal political committee.

C

Name of Employer
Information Requested
Receipt For: 2012
Primary
Other (specify)

Occupation

Information Requested

Election Cycle-to-Date

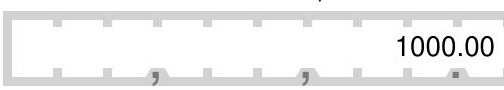

C. Full Name (Last, First, Middle Initial)

Matthew Rycyk

Mailing Address 223 Osmanthus Way

\begin{tabular}{lcc}
\hline City & State & Zip Code \\
Canton & GA & $30114-7198$ \\
\hline
\end{tabular}

FEC ID number of contributing

federal political committee.

C

Name of Employer

Dendreon

Occupation

Receipt For: 2012

Х $\begin{aligned} & \text { Primary } \square \text { General } \\ & \text { Other (specify) }\end{aligned}$

Regulatory Affairs

Election Cycle-to-Date

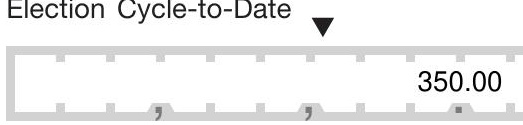

Transaction ID : ACB9245118E384B1598E

Date of Receipt

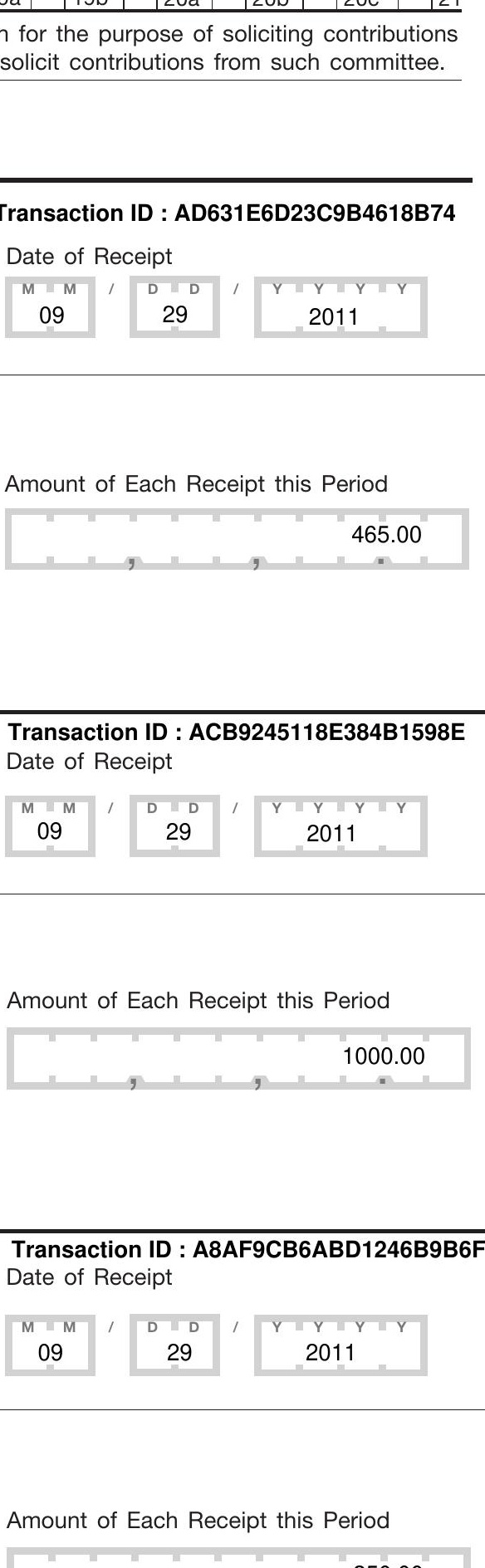

Amount of Each Receipt this Period

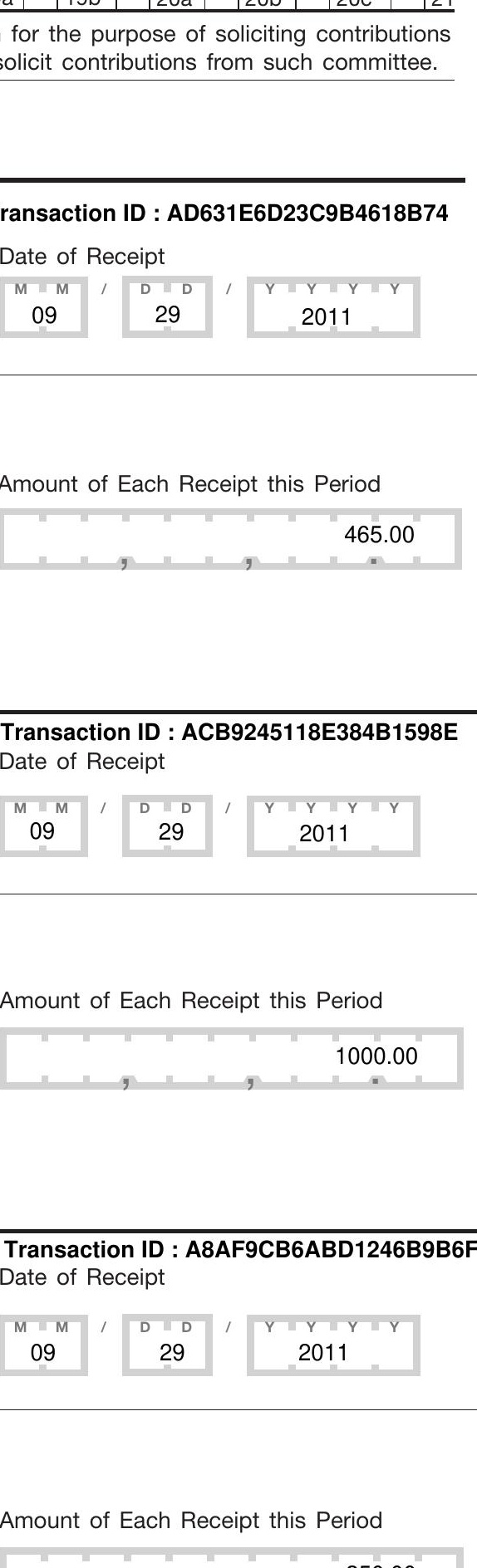

Transaction ID : A8AF9CB6ABD1246B9B6F Date of Receipt

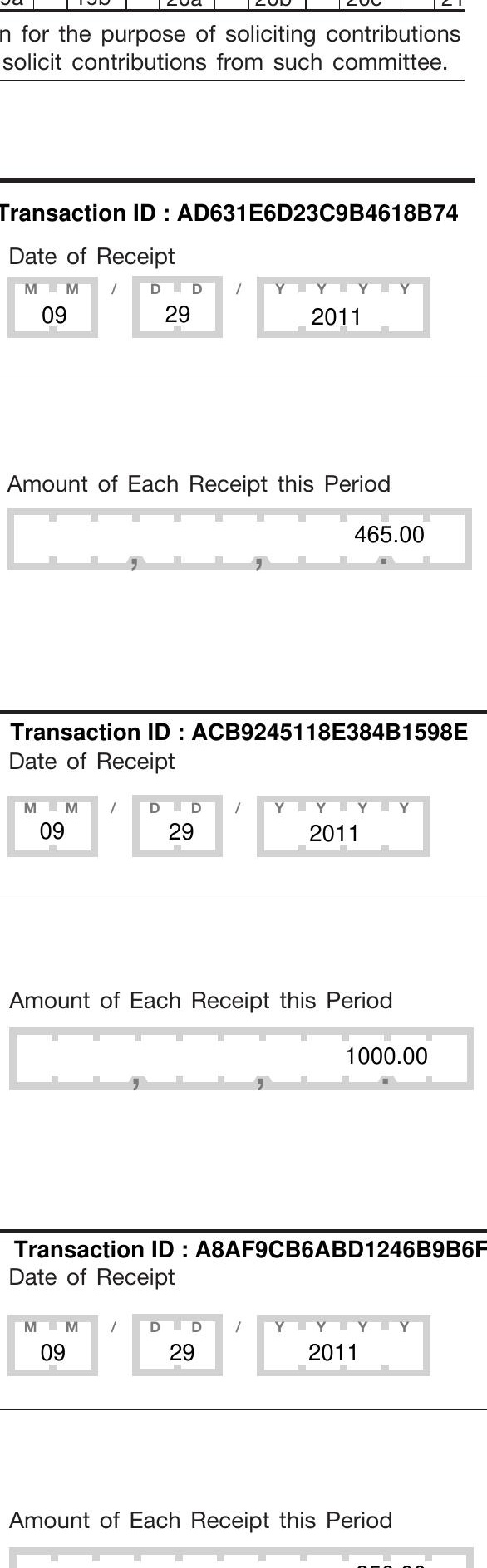

Amount of Each Receipt this Period

Subtotal Of Receipts This Page (optional)

1715.00

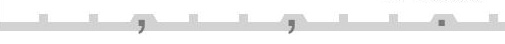

Total This Period (last page this line number only)

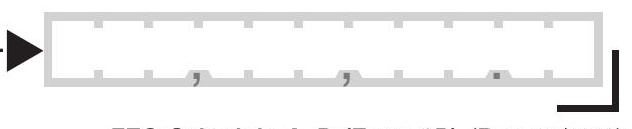

FEC Schedule A-P (Form 3P) (Rev. 03/2011) 


\section{SCHEDULE A-P} ITEMIZED RECEIPTS
Use separate schedule(s)

for each category of the

Detailed Summary Page
FOR LINE NUMBER: (check only one)

Any information or for commercial purposes, other than using the name and address of any political committee to solicit contributions from such committee.

NAME OF COMMITTEE (In Full)

\section{Friends of Herman Cain}

A. Full Name (Last, First, Middle Initial)

Bryan Bauer

Mailing Address 911 Genesee Dr.

City $\quad$ State $\quad$ Zip Code

Naperville

IL $\quad 60563-4114$

FEC ID number of contributing federal political committee.

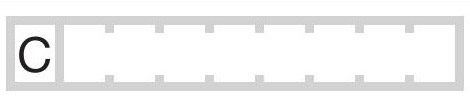

Name of Employer
Information Requested
Receipt For: 2012
X Primary
$\square$ Other (specify)

Occupation Information Requested

Election Cycle-to-Date

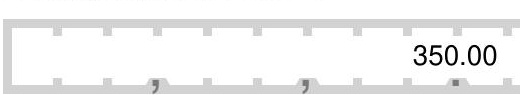

B. Full Name (Last, First, Middle Initial)

Laurel Goeckeritz

Mailing Address 240 Full Circle Dr

\begin{tabular}{lcc}
\hline City & State & Zip Code \\
Evans & GA & $30809-8041$
\end{tabular}

FEC ID number of contributing

federal political committee.

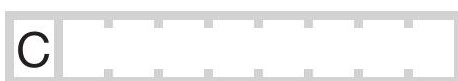

Name of Employer
University Hospital Augusta GA
Receipt For: 2012
Primary
Other (specify)

Occupation

Registered Nurse

Election Cycle-to-Date

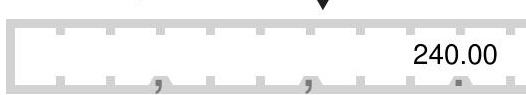

C. Full Name (Last, First, Middle Initial)

Eugene Cross

Mailing Address 473 School

\begin{tabular}{lcc}
\hline City & State & Zip Code \\
Fremont & CA & $94536-2829$
\end{tabular}

FEC ID number of contributing federal political committee.

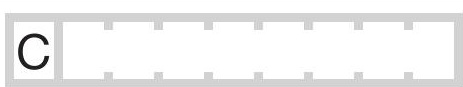

Name of Employer
Information Requested
Receipt For: 2012
X Primary
Other (specify) General

Occupation

Information Requested

Election Cycle-to-Date
Transaction ID : A70E1A4B39B97427B819

Date of Receipt

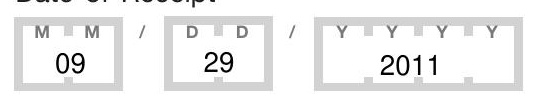

Amount of Each Receipt this Period

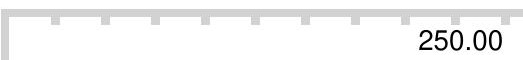

Amount of Each Receipt this Period

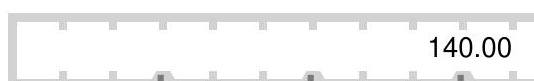

Transaction ID : A8EC38CD3C2D74C54A6B Date of Receipt

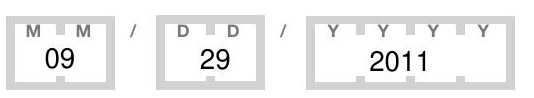

Transaction ID : A5832C236E81640BD859 Date of Receipt

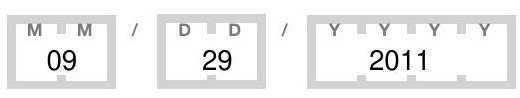

Amount of Each Receipt this Period

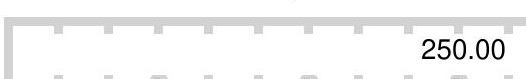

\section{Subtotal Of Receipts This Page (optional)}

640.00

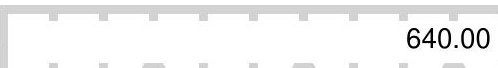

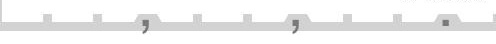

Total This Period (last page this line number only) 


\section{SCHEDULE A-P} ITEMIZED RECEIPTS
Use separate schedule(s) for each category of the Detailed Summary Page
FOR LINE NUMBER: (check only one)

Any information or for commercial purposes, other than using the name and address of any political committee to solicit contributions from such committee.

NAME OF COMMITTEE (In Full)

\section{Friends of Herman Cain}

A. Full Name (Last, First, Middle Initial)

Mr. John P. Cole

Mailing Address 1070 Powers PI

\begin{tabular}{lcc}
\hline City & State & Zip Code \\
Alpharetta & GA & $30009-8396$
\end{tabular}

FEC ID number of contributing federal political committee.

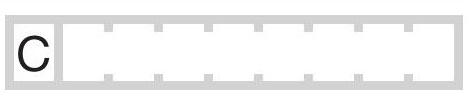

Name of Employer
Self Employed
Receipt For: 2012
X Primary
$\square$ Other (specify) General

Occupation Physician Election Cycle-to-Date

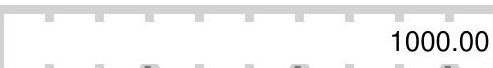

B. Full Name (Last, First, Middle Initial) Jo Canon

Mailing Address 102 Tiquewood Circle

\begin{tabular}{lcc}
\hline City & State & Zip Code \\
Abilene & TX & $79605-4937$
\end{tabular}

FEC ID number of contributing

federal political committee.

C

\begin{tabular}{l} 
Name of Employer \\
Information Requested \\
Receipt For: 2012 \\
X Primary \\
\hline Other (specify)
\end{tabular}

Occupation

Information Requested

Election Cycle-to-Date

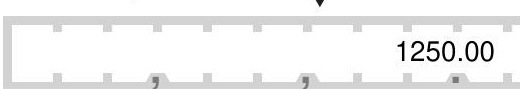

Transaction ID : A2A9B882582E242F58FB

Date of Receipt

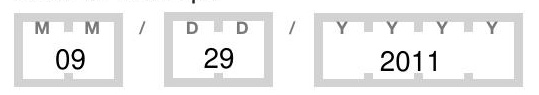

Amount of Each Receipt this Period

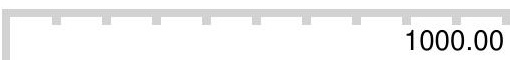

1000.00

C. Full Name (Last, First, Middle Initial)

James herren

Mailing Address 13710 West 78th Ave.

\begin{tabular}{lcc}
\hline City & State & Zip Code \\
Arvada & CO & $80005-2713$
\end{tabular}

FEC ID number of contributing federal political committee.

C

Name of Employer
Information Requested
Receipt For: 2012
X Primary
Other (specify) General

\section{Occupation}

Information Requested

Election Cycle-to-Date

Transaction ID : AF255AD8D155E40F9B98

Date of Receipt

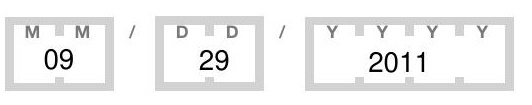

Amount of Each Receipt this Period

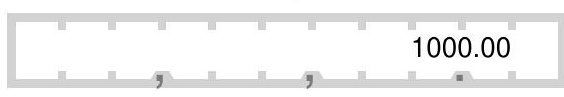

Transaction ID : A5807EFF2A62645BCA91 Date of Receipt

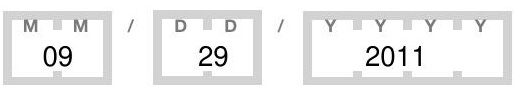

Amount of Each Receipt this Period

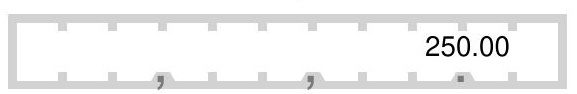

250.00

\section{Subtotal Of Receipts This Page (optional)}

Total This Period (last page this line number only) 


\section{SCHEDULE A-P} ITEMIZED RECEIPTS
Use separate schedule(s) for each category of the Detailed Summary Page

FOR LINE NUMBER:
(check only one)

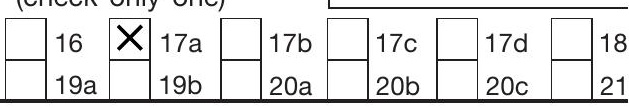

Any information copied from such Reports and Statements may not be sold or used by any person for the purpose of soliciting contributions or for commercial purposes, other than using the name and address of any political committee to solicit contributions from such committee.

NAME OF COMMITTEE (In Full)

\section{Friends of Herman Cain}

A. Full Name (Last, First, Middle Initial)

William R Wiggins Jr

Mailing Address P.O. Box 1251

\begin{tabular}{lcc}
\hline City & State & Zip Code \\
Lindale & TX & $75771-1251$ \\
\hline
\end{tabular}

FEC ID number of contributing federal political committee.

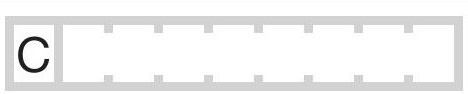

Name of Employer
Colonial Life
Receipt For: 2012
X Primary
$\square$ Other (specify) General

Occupation

Sales

Election Cycle-to-Date

\subsection{0}

B. Full Name (Last, First, Middle Initial)

Mike Harrison

Mailing Address 235 Hatteras Lane

\begin{tabular}{lcc}
\hline City & State & Zip Code \\
Simpsonville & SC & $29680-2840$
\end{tabular}

FEC ID number of contributing

federal political committee.

C

Name of Employer
Lockheed Martin
Receipt For: 2012
Xrimary
Other (specify)

Occupation

Aircraft Mechanic

Election Cycle-to-Date

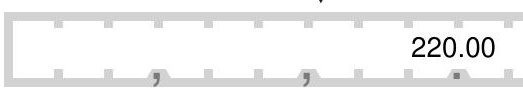

Transaction ID : AFEC405CBA07346F7A12

Date of Receipt

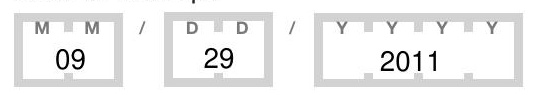

Amount of Each Receipt this Period

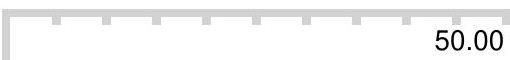

50.00

C. Full Name (Last, First, Middle Initial)

Theron Peterson

Mailing Address 4809 Wild Horse Cove

\begin{tabular}{lcc}
\hline City & State & Zip Code \\
Spicewood & TX & $78669-6141$
\end{tabular}

FEC ID number of contributing federal political committee.

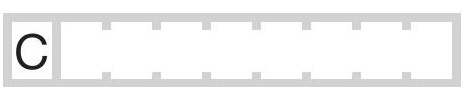

Name of Employer
None
Receipt For: 2012
Х Primary $\quad \square$ General
Other (specify)

\section{Occupation}

Retired

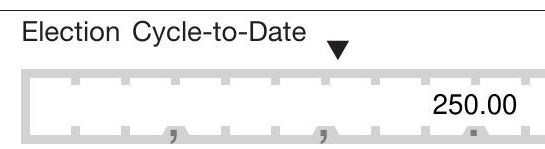

Transaction ID : AECF74406CD864DC8A7A Date of Receipt

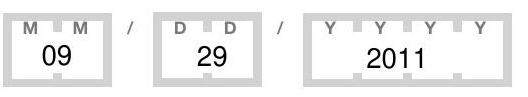

Amount of Each Receipt this Period

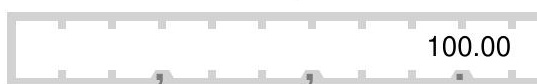

Transaction ID : A842F272FCD8A42DAA12 Date of Receipt

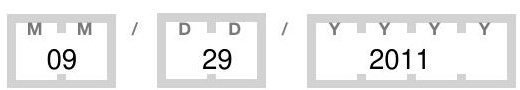

Amount of Each Receipt this Period

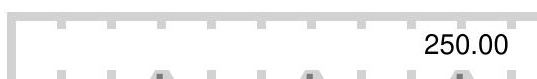

\section{Subtotal Of Receipts This Page (optional)}

400.00

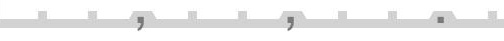

Total This Period (last page this line number only)

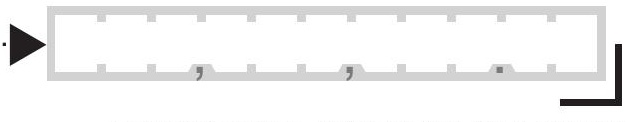

FEC Schedule A-P (Form 3P) (Rev. 03/2011) 


\section{SCHEDULE A-P} ITEMIZED RECEIPTS
Use separate schedule(s) for each category of the Detailed Summary Page
FOR LINE NUMBER: (check only one)
PAGE 1012 / 1572

\begin{tabular}{|c|c|c|c|c|c|}
\hline & & & & & \\
\hline 16 & $\begin{array}{ll}\mathbf{X} & 17 a \\
\end{array}$ & $17 \mathrm{~b}$ & $17 c$ & $17 d$ & 18 \\
\hline $19 a$ & $19 b$ & $20 \mathrm{a}$ & $20 \mathrm{~b}$ & $20 c$ & 21 \\
\hline
\end{tabular}

Any information copied from such Reports and Statements may not be sold or used by any person for the purpose of soliciting contributions or for commercial purposes, other than using the name and address of any political committee to solicit contributions from such committee.

NAME OF COMMITTEE (In Full)

Friends of Herman Cain

A. Full Name (Last, First, Middle Initial)

Mark Henry

Mailing Address P.O. Box 2864

\begin{tabular}{lcc}
\hline City & State & Zip Code \\
Carefree & AZ & $85377-2864$
\end{tabular}

FEC ID number of contributing federal political committee.

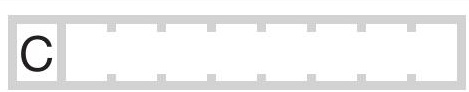

Name of Employer
Information Requested
Receipt For: 2012
X Primary
$\square$ Other (specify)

Occupation

Information Requested

Election Cycle-to-Date

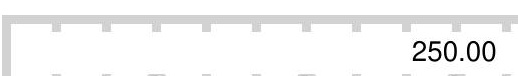

B. Full Name (Last, First, Middle Initial)

James Rogers

Mailing Address 2100 Rolling Rock Place

\begin{tabular}{lcc}
\hline City & State & Zip Code \\
College Station & TX & $77845-4165$
\end{tabular}

FEC ID number of contributing

federal political committee.

C

Name of Employer
Information Requested
Receipt For: 2012
X Primary
Other (specify)

Occupation

Information Requested

Election Cycle-to-Date

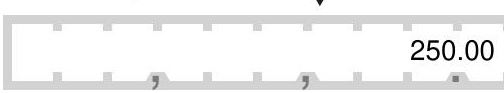

Transaction ID : A0C573EADD91B4D44BA8

Date of Receipt

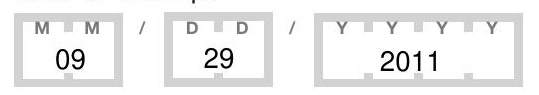

Amount of Each Receipt this Period

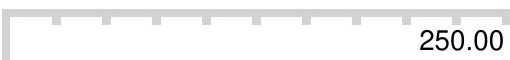

Transaction ID : A97ECE64E478049C090F

Date of Receipt

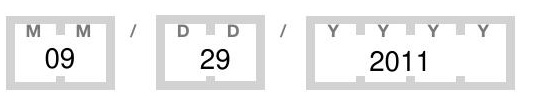

Amount of Each Receipt this Period

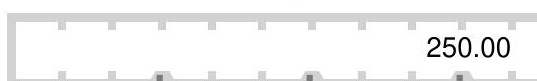

Transaction ID : A8031D9DD169A47B2980

Date of Receipt

Benjamin Fritz

Mailing Address 26434 Lares Lane

\begin{tabular}{lcc}
\hline City & State & Zip Code \\
Murrieta & CA & $92563-4347$
\end{tabular}

FEC ID number of contributing federal political committee.

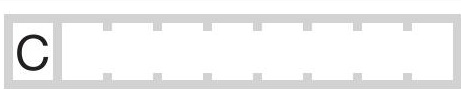

Name of Employer

Information Requested

Occupation

Information Requested

Receipt For: 2012

X Primary $\square$ General

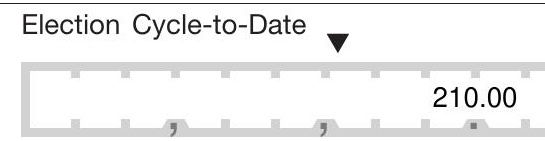

Amount of Each Receipt this Period

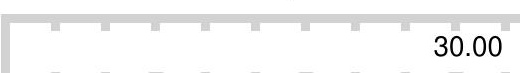

Subtotal Of Receipts This Page (optional)

530.00

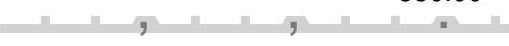

Total This Period (last page this line number only)

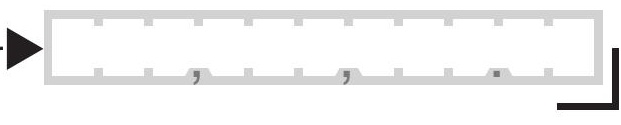

FEC Schedule A-P (Form 3P) (Rev. 03/2011) 


\section{SCHEDULE A-P} ITEMIZED RECEIPTS
Use separate schedule(s) for each category of the Detailed Summary Page
FOR LINE NUMBER: (check only one)
PAGE 1013 / 1572

\begin{tabular}{|c|c|c|c|c|c|}
\hline & & & & & \\
\hline 16 & $\begin{array}{ll}\mathbf{X} & 17 a \\
\end{array}$ & $17 \mathrm{~b}$ & $17 c$ & $17 d$ & 18 \\
\hline $19 a$ & $19 b$ & $20 \mathrm{a}$ & $20 \mathrm{~b}$ & $20 c$ & 21 \\
\hline
\end{tabular}

Any information copied from such Reports and Statements may not be sold or used by any person for the purpose of soliciting contributions or for commercial purposes, other than using the name and address of any political committee to solicit contributions from such committee.

NAME OF COMMITTEE (In Full)

Friends of Herman Cain

A. Full Name (Last, First, Middle Initial)

Mr. William H Randolph IV

Mailing Address 1490 Sanden Ferry Dr

\begin{tabular}{lcc}
\hline City & State & Zip Code \\
Decatur & GA & $30033-3323$ \\
\hline
\end{tabular}

FEC ID number of contributing federal political committee.

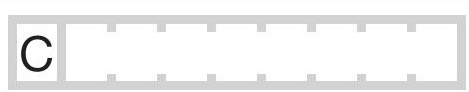

Name of Employer
King Industrial Realty
Receipt For: 2012
X Primary
Other (specify) General

Occupation

Real Estate Broker

Election Cycle-to-Date
Transaction ID : A327008E43EB54EA097F

Date of Receipt

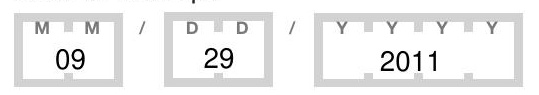

Amount of Each Receipt this Period

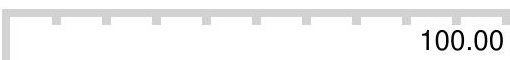

B. Full Name (Last, First, Middle Initial)

Mr Paul Hoffmann

Mailing Address 69 Carleon Ave

\begin{tabular}{lcc}
\hline City & State & Zip Code \\
Larchmont & NY & $10538-3221$
\end{tabular}

FEC ID number of contributing

federal political committee.

C

Name of Employer
self
Receipt For: 2012
X Primary
Other (specify)

\section{Occupation}

Real Estate

Election Cycle-to-Date

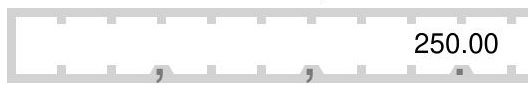

C. Full Name (Last, First, Middle Initial)

lisa nichol

Mailing Address P.O.Box 2778

\begin{tabular}{lcc}
\hline City & State & Zip Code \\
Gainesville & GA & $30503-2778$
\end{tabular}

FEC ID number of contributing federal political committee.

C

Name of Employer
comprehensive nursing care
Receipt For: 2012
X Primary
Other (specify) General

Occupation

President

Election Cycle-to-Date

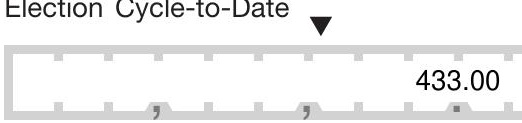

Transaction ID : A8ADCAAC84ADE44F2A44 Date of Receipt

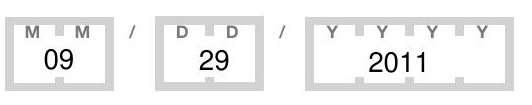

Amount of Each Receipt this Period

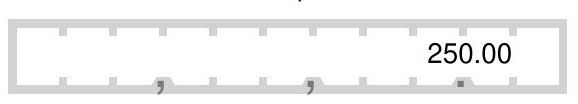

Transaction ID : A5CEC7E9D6913462F887 Date of Receipt

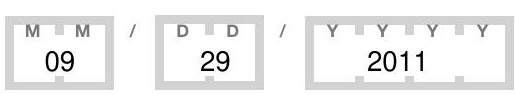

Amount of Each Receipt this Period

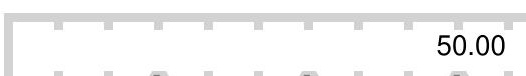

50.00

\section{Subtotal Of Receipts This Page (optional)}

400.00

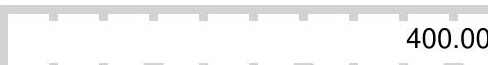

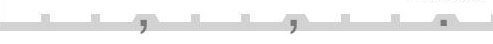

Total This Period (last page this line number only)

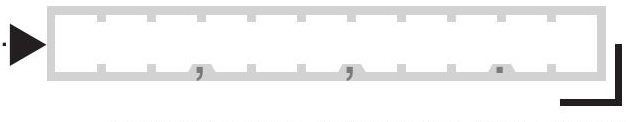

FEC Schedule A-P (Form 3P) (Rev. 03/2011) 


\section{SCHEDULE A-P} ITEMIZED RECEIPTS
Use separate schedule(s)

for each category of the

Detailed Summary Page
FOR LINE NUMBER: (check only one)

Any information or for commercial purposes, other than using the name and address of any political committee to solicit contributions from such committee.

NAME OF COMMITTEE (In Full)

Friends of Herman Cain

A. Full Name (Last, First, Middle Initial)

George Walker

Mailing Address 15417 Lake Magdalene Blvd.

\begin{tabular}{lcc}
\hline City & State & Zip Code \\
Tampa & FL & $33613-1005$
\end{tabular}

FEC ID number of contributing

federal political committee.

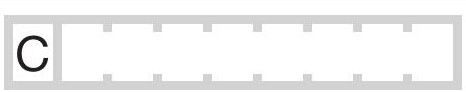

Name of Employer
Information Requested
Receipt For: 2012
X Primary $\quad \square$ General
Other (specify)

Occupation

Information Requested

Election Cycle-to-Date

250.00

B. Full Name (Last, First, Middle Initial)

Lisa Dolan

Mailing Address 202-12 38 ave

\begin{tabular}{lcc}
\hline City & State & Zip Code \\
Bayside & NY & 11361 \\
\hline
\end{tabular}

FEC ID number of contributing

federal political committee.

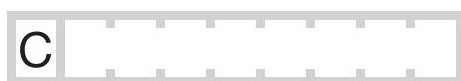

Name of Employer
Information Requested
Receipt For: 2012
X Primary
Other (specify)

Occupation

Information Requested

Election Cycle-to-Date

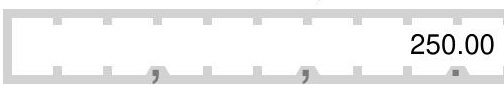

Transaction ID : A771B604E777147FC9E9

Date of Receipt

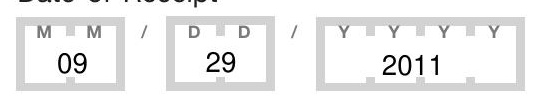

Amount of Each Receipt this Period

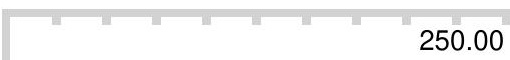

Amount of Each Receipt this Period

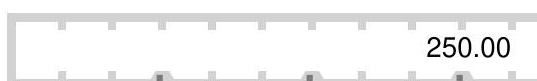

C. Full Name (Last, First, Middle Initial)

Robert Hahn

Mailing Address 2811 Grants River Cir

\begin{tabular}{lcc}
\hline City & State & Zip Code \\
Sugar Land & TX & $77479-1366$
\end{tabular}

FEC ID number of contributing

federal political committee.

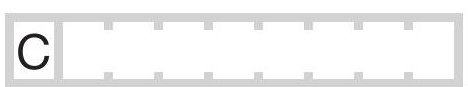

Name of Employer

Occupation

7DS Associates

Consultant

Transaction ID : AFD158AB29D8C412AB35

Date of Receipt

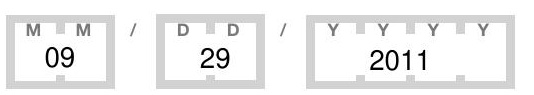

Receipt For: 2012

Х $\begin{aligned} & \text { Primary } \\ & \text { Other (specify) }\end{aligned}$

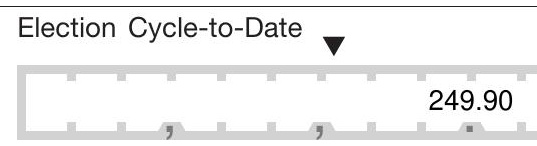

Amount of Each Receipt this Period

Transaction ID : AC32F9C871DF540BD92C Date of Receipt
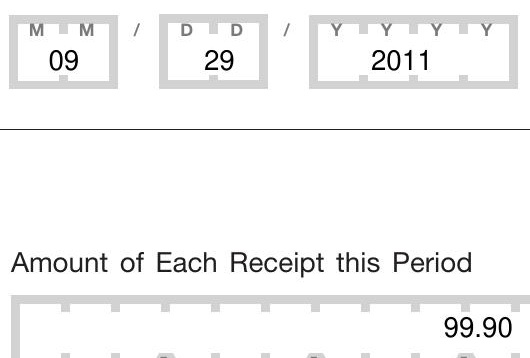

Subtotal Of Receipts This Page (optional)....

599.90

Total This Period (last page this line number only) 


\section{SCHEDULE A-P} ITEMIZED RECEIPTS
Use separate schedule(s) for each category of the Detailed Summary Page

FOR LINE NUMBER:
(check only one)

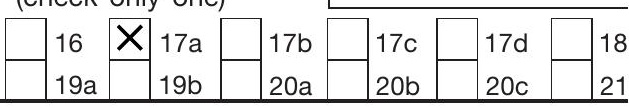

Any information copied from such Reports and Statements may not be sold or used by any person for the purpose of soliciting contributions or for commercial purposes, other than using the name and address of any political committee to solicit contributions from such committee.

NAME OF COMMITTEE (In Full)

\section{Friends of Herman Cain}

A. Full Name (Last, First, Middle Initial)

Cynthia Carson

Mailing Address 68 Avenue Of Oaks

\begin{tabular}{lcc}
\hline City & State & Zip Code \\
Saint Helena Island & SC & $29920-3636$
\end{tabular}

FEC ID number of contributing federal political committee.

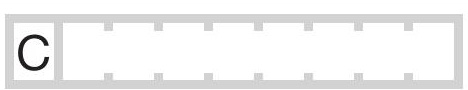

Name of Employer
Self Employed
Receipt For: 2012
X Primary
$\square$ Other (specify)

Occupation

Anesthestist (CRNA)

Election Cycle-to-Date

500.00

B. Full Name (Last, First, Middle Initial)

Richard E Hull

Mailing Address 1634 N.W. 10TH ST.

\begin{tabular}{lcc}
\hline City & State & Zip Code \\
Oklahoma City & OK & $73106-4824$
\end{tabular}

FEC ID number of contributing

federal political committee.

C

\begin{tabular}{l} 
Name of Employer \\
Nabholz Corp \\
Receipt For: 2012 \\
X Primary \\
\hline Other (specify) General
\end{tabular}

\section{Occupation}

Construction

Election Cycle-to-Date

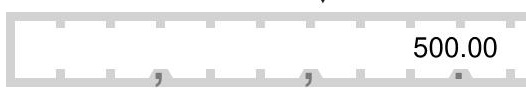

Transaction ID : A34865989035B43A29DB

Date of Receipt

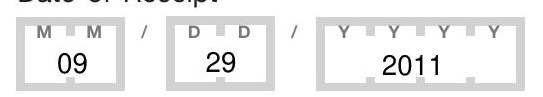

Amount of Each Receipt this Period

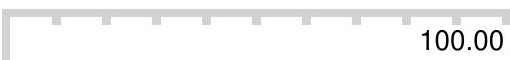

Transaction ID : AAE8F3015FCC84CF28B2

Date of Receipt

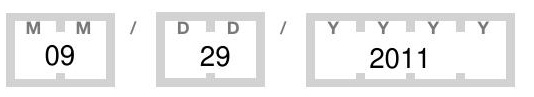

Amount of Each Receipt this Period

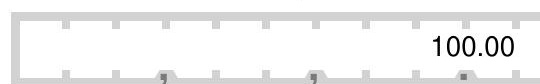

Transaction ID : AD6B83215AC5B42C591F Date of Receipt

Larry Seaman

Mailing Address 215 E. 41st PI.

\begin{tabular}{lcc}
\hline City & State & Zip Code \\
Kennewick & WA & $99337-5813$
\end{tabular}

FEC ID number of contributing federal political committee.

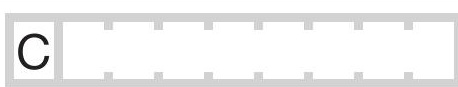

Name of Employer

Information Requested

Occupation

Information Requested

Receipt For: 2012

Х $\begin{aligned} & \text { Primary } \square \text { General } \\ & \text { Other (specify) }\end{aligned}$

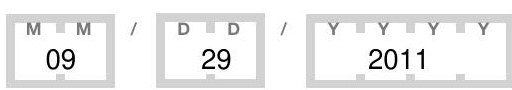

Amount of Each Receipt this Period

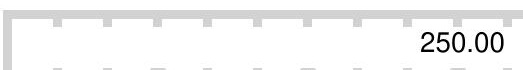

Subtotal Of Receipts This Page (optional)

Total This Period (last page this line number only) 


\section{SCHEDULE A-P} ITEMIZED RECEIPTS
Use separate schedule(s)

for each category of the

Detailed Summary Page
FOR LINE NUMBER: (check only one)

Any information or for commercial purposes, other than using the name and address of any political committee to solicit contributions from such committee.

NAME OF COMMITTEE (In Full)

Friends of Herman Cain

A. Full Name (Last, First, Middle Initial)

patrick klodt

Mailing Address 13664 reeder ave ne

\begin{tabular}{lcc}
\hline City & State & Zip Code \\
Alliance & $\mathrm{OH}$ & $44601-8857$
\end{tabular}

FEC ID number of contributing

federal political committee.

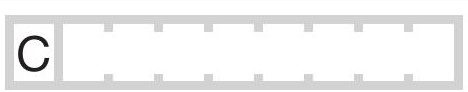

Name of Employer
None
Receipt For: 2012
X Primary $\quad \square$ General
$\square$ Other (specify)

Occupation

Retired

Election Cycle-to-Date

500.00

B. Full Name (Last, First, Middle Initial)

Marlene Wise

Mailing Address 1002 Woodland Way

\begin{tabular}{lcc}
\hline City & State & Zip Code \\
Richardson & TX & $75080-4030$
\end{tabular}

FEC ID number of contributing

federal political committee.

C

\begin{tabular}{l} 
Name of Employer \\
Information Requested \\
Receipt For: 2012 \\
X Primary \\
\hline Other (specify)
\end{tabular}

Occupation

Information Requested

Election Cycle-to-Date

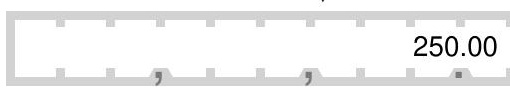

Transaction ID : AA605675B313B4CD386B

Date of Receipt

Amount of Each Receipt this Period
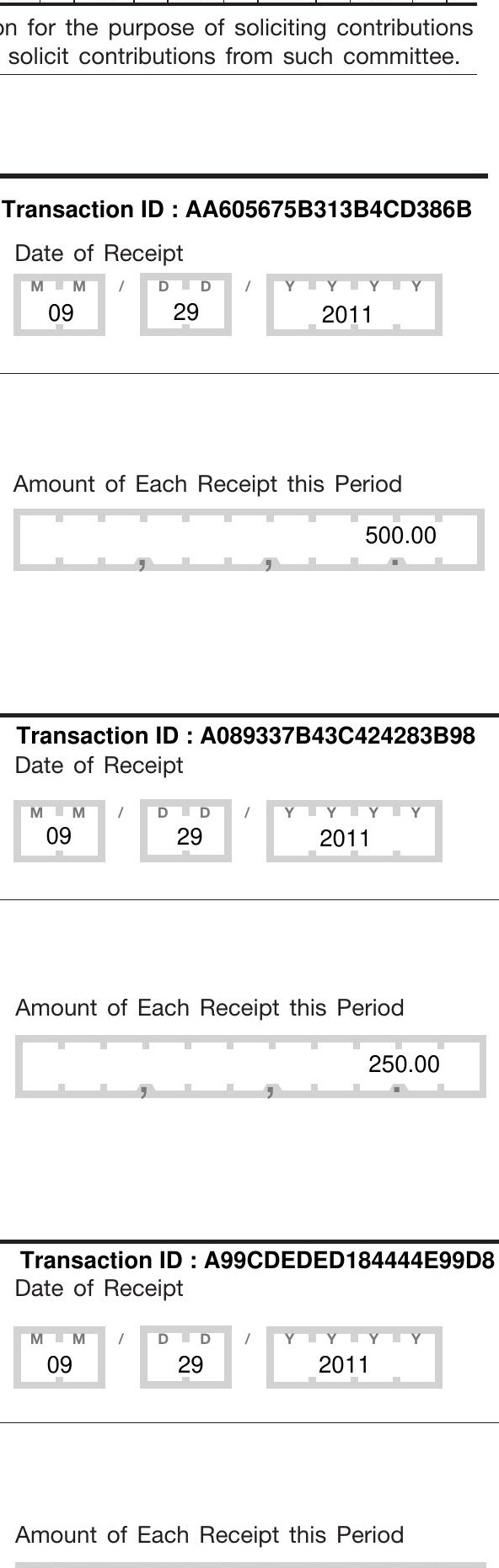

Amount of Each Receipt this Period

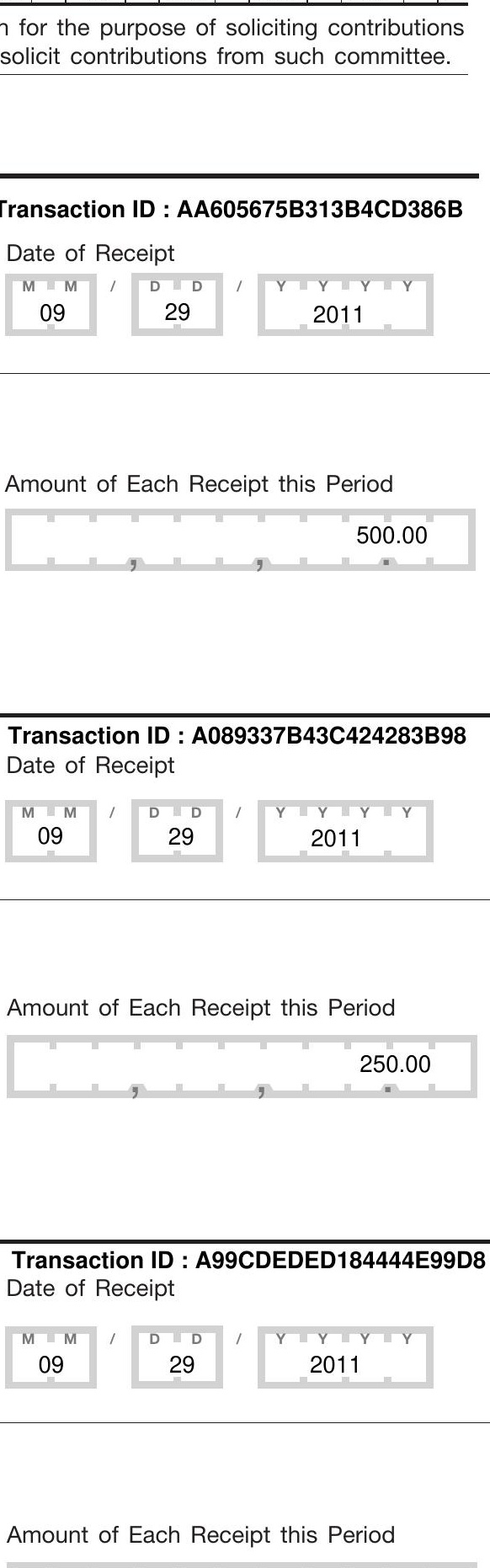

C. Full Name (Last, First, Middle Initial)

Jeffrey Braaten

Mailing Address 1314 Elmwood Dr.

\begin{tabular}{lcc}
\hline City & State & Zip Code \\
Abilene & TX & $79605-4906$
\end{tabular}

FEC ID number of contributing

federal political committee.

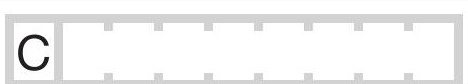

Name of Employer

Information Requested

Occupation

Information Requested

Receipt For: 2012

Х $\begin{aligned} & \text { Primary } \square \text { General } \\ & \text { Other (specify) }\end{aligned}$

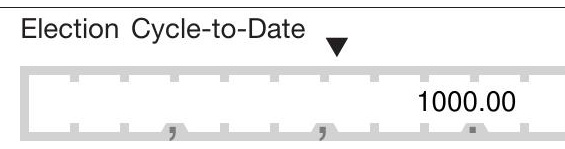

Amount of Each Receipt this Period

Transaction ID : A089337B43C424283B98

Date of Receip

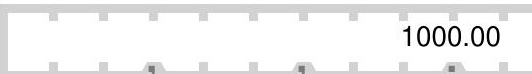

Subtotal Of Receipts This Page (optional).

1750.00

Total This Period (last page this line number only) 


\section{SCHEDULE A-P} ITEMIZED RECEIPTS
Use separate schedule(s) for each category of the Detailed Summary Page
FOR LINE NUMBER: (check only one)
PAGE 1017 / 1572

\begin{tabular}{|c|c|c|c|c|c|}
\hline & & & & & \\
\hline 16 & $\begin{array}{ll}\mathbf{X} & 17 a \\
\end{array}$ & $17 \mathrm{~b}$ & $17 c$ & $17 d$ & 18 \\
\hline $19 a$ & $19 b$ & $20 \mathrm{a}$ & $20 \mathrm{~b}$ & $20 c$ & 21 \\
\hline
\end{tabular}

Any information copied from such Reports and Statements may not be sold or used by any person for the purpose of soliciting contributions or for commercial purposes, other than using the name and address of any political committee to solicit contributions from such committee.

NAME OF COMMITTEE (In Full)

Friends of Herman Cain

A. Full Name (Last, First, Middle Initial)

Richard Douglas

Mailing Address PO Box 2368

\begin{tabular}{lcc}
\hline City & State & Zip Code \\
Clarksburg & WV & 26302-2368 \\
\hline
\end{tabular}

FEC ID number of contributing federal political committee.

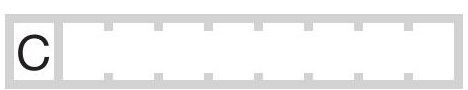

Name of Employer
Information Requested
Receipt For: 2012
X Primary
$\square$ Other (specify)

Occupation Information Requested

Election Cycle-to-Date 250.00

B. Full Name (Last, First, Middle Initial)

William Kimmins

Mailing Address 16 Country Club Woods Dr

\begin{tabular}{lll}
\hline City & State & Zip Code \\
Saint Charles & MO & $63303-3300$
\end{tabular}

FEC ID number of contributing

federal political committee.

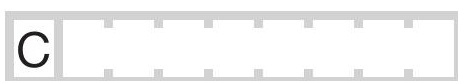

Name of Employer
None
Receipt For: 2012
X Primary
Other (specify)

Occupation

Retired

Election Cycle-to-Date

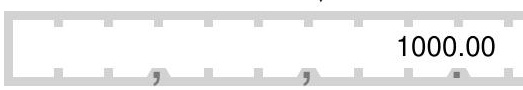

C. Full Name (Last, First, Middle Initial)

Erle Bridgewater

Mailing Address 140 Industrial Loop W

\begin{tabular}{lcc}
\hline City & State & Zip Code \\
Orange Park & FL & $32073-6221$
\end{tabular}

FEC ID number of contributing federal political committee.

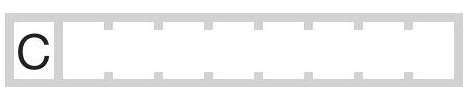

Name of Employer

Occupation

GEM Products, Inc.

Executive

Receipt For: 2012

Х $\begin{aligned} & \text { Primary } \square \text { General } \\ & \text { Other (specify) }\end{aligned}$

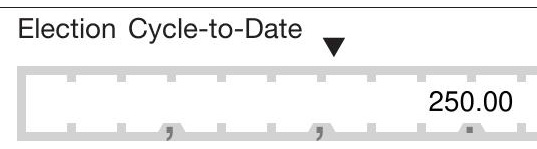

Amount of Each Receipt this Period

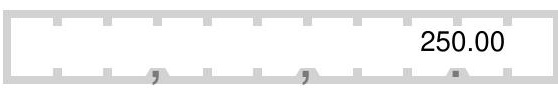

Date of Receipt

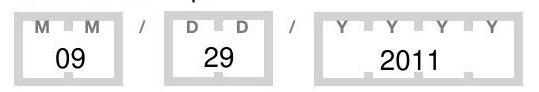

Transaction ID : AED4B151F1A484898A46

Date of Receipt

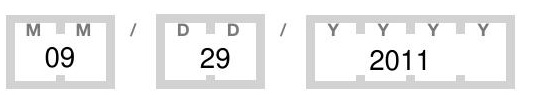

Amount of Each Receipt this Period

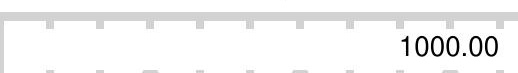

Transaction ID : A445A225FB6724A9DB37 Date of Receipt

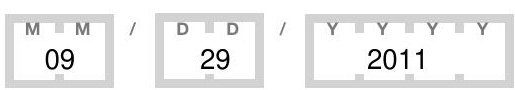

Amount of Each Receipt this Period

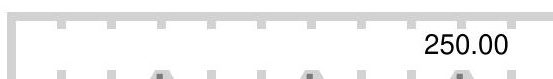

Subtotal Of Receipts This Page (optional)

1500.00

Total This Period (last page this line number only) 


\section{SCHEDULE A-P} ITEMIZED RECEIPTS
Use separate schedule(s)

for each category of the

Detailed Summary Page
FOR LINE NUMBER: (check only one)

Any information or for commercial purposes, other than using the name and address of any political committee to solicit contributions from such committee.

NAME OF COMMITTEE (In Full)

Friends of Herman Cain

A. Full Name (Last, First, Middle Initial)

John Grimstad

Mailing Address 6616 Iroquois Trl

\begin{tabular}{lcc}
\hline City & State & Zip Code \\
Minneapolis & MN & $55439-1016$
\end{tabular}

FEC ID number of contributing

federal political committee.

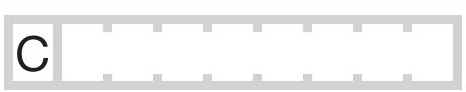

Name of Employer
Information Requested
Receipt For: 2012
X Primary $\quad \square$ General
$\square$ Other (specify)

Occupation

Information Requested

Election Cycle-to-Date

500.00

B. Full Name (Last, First, Middle Initial)

gerry jeffries

Mailing Address 230 wildflower path

\begin{tabular}{lcc}
\hline City & State & Zip Code \\
Dallas & GA & $30157-6304$ \\
\hline
\end{tabular}

FEC ID number of contributing

federal political committee.

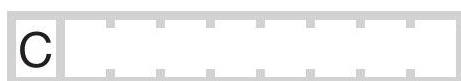

Name of Employer
self
Receipt For: 2012
X Primary
$\square$ Other (specify) General

Occupation

MACHINE SHOP OWNER

Election Cycle-to-Date

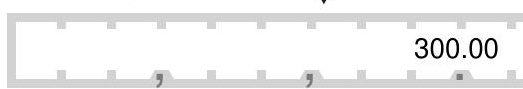

Transaction ID : A6C92A8233B104461B1B

Date of Receipt

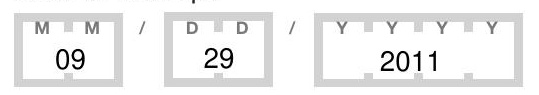

Amount of Each Receipt this Period

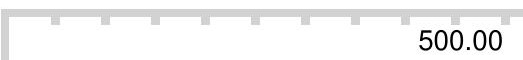

C. Full Name (Last, First, Middle Initial)

Burke McKinney

Mailing Address POB 3088

\begin{tabular}{lcc}
\hline City & State & Zip Code \\
Cashiers & NC & $28717-3088$
\end{tabular}

FEC ID number of contributing federal political committee.

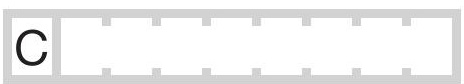

Name of Employer

Information Requested

\section{Occupation}

Information Requested

Receipt For: 2012

Х $\begin{aligned} & \text { Primary } \square \text { General } \\ & \text { Other (specify) }\end{aligned}$

Election Cycle-to-Date

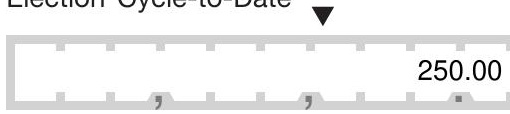

Transaction ID : ABEA2183A3D8C4A819DE

Date of Receipt

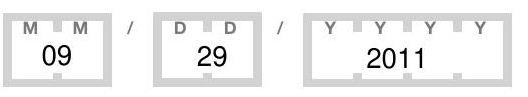

Amount of Each Receipt this Period

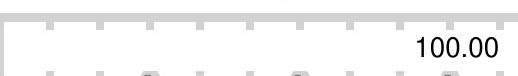

Transaction ID : A2AD7CC0BF1F84D22AAD Date of Receipt

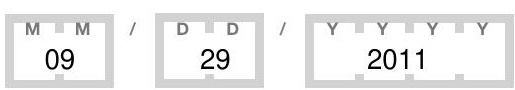

Amount of Each Receipt this Period

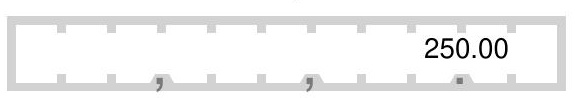

Subtotal Of Receipts This Page (optional)

850.00

Total This Period (last page this line number only) 


\section{SCHEDULE A-P} ITEMIZED RECEIPTS
Use separate schedule(s)

for each category of the

Detailed Summary Page
FOR LINE NUMBER: (check only one)

Any information or for commercial purposes, other than using the name and address of any political committee to solicit contributions from such committee.

NAME OF COMMITTEE (In Full)

Friends of Herman Cain

A. Full Name (Last, First, Middle Initial)

Joy Ammerman

Mailing Address 3721 Red Bud Lane

\begin{tabular}{lcc}
\hline City & State & Zip Code \\
Kokomo & IN & $46902-4353$
\end{tabular}

FEC ID number of contributing

federal political committee.

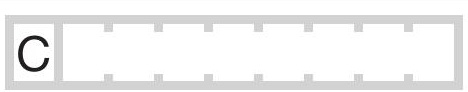

Name of Employer
None
Receipt For: 2012
X Primary $\square$ General
$\square$ Other (specify)

Occupation

Retired

Election Cycle-to-Date

500.00

B. Full Name (Last, First, Middle Initial)

jules knoulton

Mailing Address 818 piedmont

\begin{tabular}{lcc}
\hline City & State & Zip Code \\
Sugar Land & TX & $77478-3322$
\end{tabular}

FEC ID number of contributing

federal political committee.

C

\begin{tabular}{l} 
Name of Employer \\
Information Requested \\
Receipt For: 2012 \\
X Primary \\
\hline Other (specify)
\end{tabular}

Occupation

Information Requested

Election Cycle-to-Date

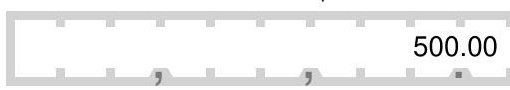

Transaction ID : ABB6023F4576B4A079E9

Date of Receipt

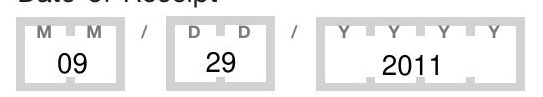

Amount of Each Receipt this Period

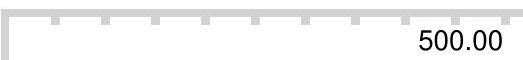

C. Full Name (Last, First, Middle Initial)

John Dowd

Mailing Address 1529 Crowell Road

\begin{tabular}{lcc}
\hline City & State & Zip Code \\
Vienna & VA & $22182-1514$
\end{tabular}

FEC ID number of contributing federal political committee.

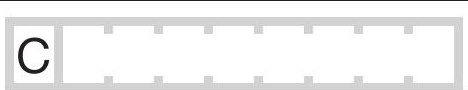

Name of Employer

Information Requested

\section{Occupation}

Information Requested

Receipt For: 2012

Х $\begin{aligned} & \text { Primary } \square \text { General } \\ & \text { Other (specify) }\end{aligned}$

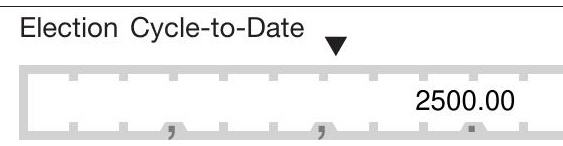

Amount of Each Receipt this Period

Transaction ID : A3FE677861BD944BFBF4

Date of Receipt
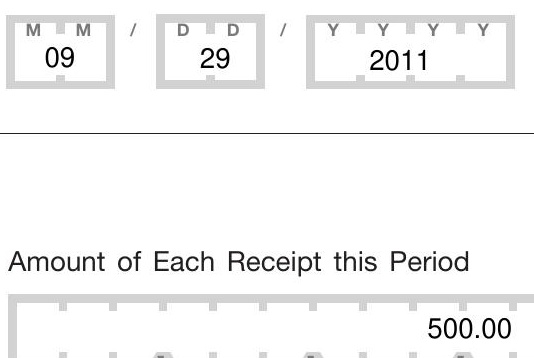

Transaction ID : AB1B5BF9FDF324C90836

Date of Receipt

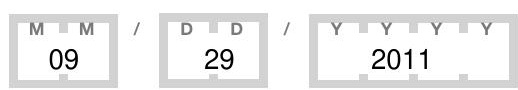

Amount of Each Receipt this Period

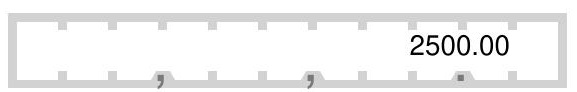

Subtotal Of Receipts This Page (optional).

3500.00

Total This Period (last page this line number only) 


\section{SCHEDULE A-P} ITEMIZED RECEIPTS
Use separate schedule(s) for each category of the Detailed Summary Page

\begin{tabular}{|c|c|c|c|c|c|}
\hline \multicolumn{3}{|c|}{$\begin{array}{l}\text { FOR LINE NUMBER: } \\
\text { (check only one) }\end{array}$} & \multicolumn{3}{|c|}{ PAGE 1020 / 1572} \\
\hline 16 & $X$ 17a & $17 b$ & $17 c$ & $17 d$ & 18 \\
\hline $19 a$ & $19 \mathrm{~b}$ & $20 a$ & $20 \mathrm{~b}$ & $20 c$ & 21 \\
\hline
\end{tabular}

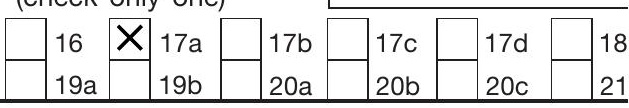

Any information copied from such Reports and Statements may not be sold or used by any person for the purpose of soliciting contributions or for commercial purposes, other than using the name and address of any political committee to solicit contributions from such committee.

NAME OF COMMITTEE (In Full)

\section{Friends of Herman Cain}

A. Full Name (Last, First, Middle Initial) Jeff Muir

Mailing Address 4660 Brook Hollow Rd

\begin{tabular}{lcc}
\hline City & State & Zip Code \\
Atlanta & GA & $30327-3513$ \\
\hline
\end{tabular}

FEC ID number of contributing federal political committee.

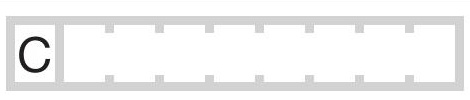

Name of Employer
Information Requested
Receipt For: 2012
X Primary
$\square$ Other (specify)

Occupation Information Requested Election Cycle-to-Date

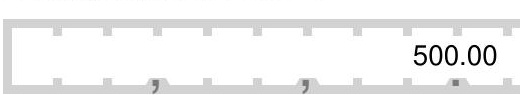

B. Full Name (Last, First, Middle Initial) alexis lodde

Mailing Address 520 West Ave Apt 2103

\begin{tabular}{lcc}
\hline City & State & Zip Code \\
Miami Beach & FL & $33139-6796$ \\
\hline
\end{tabular}

FEC ID number of contributing

federal political committee.

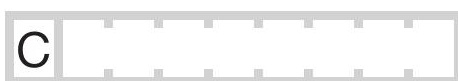

Name of Employer
None
Receipt For: 2012
X Primary
Other (specify)

\section{Occupation}

Retired

Election Cycle-to-Date

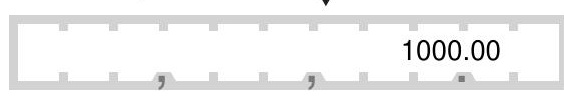

Transaction ID : A8C1B84D2F5884A2CB12

Date of Receipt

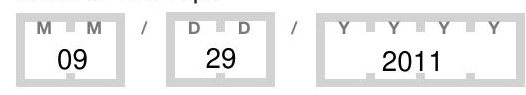

Amount of Each Receipt this Period

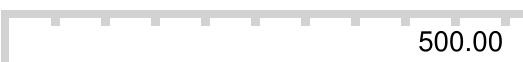

C. Full Name (Last, First, Middle Initial)

Mitchel Opremcak

Mailing Address 2391 Klondike Rd

\begin{tabular}{lcc}
\hline City & State & Zip Code \\
Delaware & OH & $43015-8859$
\end{tabular}

FEC ID number of contributing federal political committee.

C

Name of Employer
Information Requested
Receipt For: 2012
X Primary
Other (specify) General

Occupation

Information Requested

Election Cycle-to-Date
Transaction ID : AF8D54D2E2A104515BC5

Date of Receipt

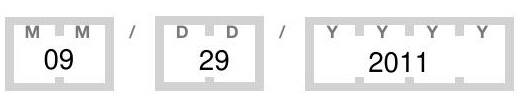

Amount of Each Receipt this Period

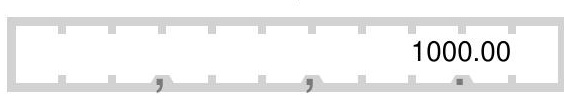

Transaction ID : A332B91554D0C4394930

Date of Receipt

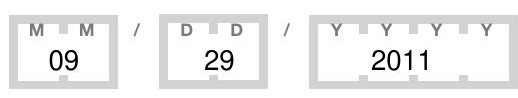

Amount of Each Receipt this Period

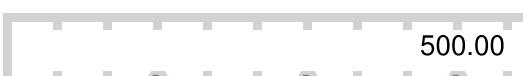

500.00

Subtotal Of Receipts This Page (optional).

Total This Period (last page this line number only) 


\section{SCHEDULE A-P} ITEMIZED RECEIPTS
Use separate schedule(s) for each category of the Detailed Summary Page

FOR LINE NUMBER:
(check only one)

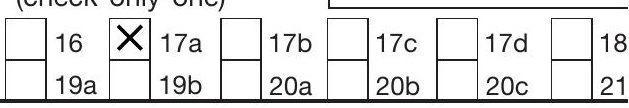

Any information copied from such Reports and Statements may not be sold or used by any person for the purpose of soliciting contributions or for commercial purposes, other than using the name and address of any political committee to solicit contributions from such committee.

NAME OF COMMITTEE (In Full)

\section{Friends of Herman Cain}

A. Full Name (Last, First, Middle Initial) Joe Daly

Mailing Address 6820 Farmbrook Dr

\begin{tabular}{lcc}
\hline City & State & Zip Code \\
Cincinnati & OH & $45230-3834$
\end{tabular}

FEC ID number of contributing federal political committee.

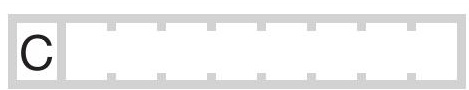

\begin{tabular}{l|l|}
\hline $\begin{array}{l}\text { Name of Employer } \\
\text { Information Requested }\end{array}$ & $\begin{array}{l}\text { Occupation } \\
\text { Information Requested }\end{array}$ \\
\hline $\begin{array}{l}\text { Receipt For: } 2012 \\
\text { X Primary } \square \text { General } \\
\text { Other (specify) }\end{array}$ & Election Cycle-to-Date $\boldsymbol{\nabla}$ \\
\end{tabular}

Occupation Information Requested Election Cycle-to-Date 500.00

B. Full Name (Last, First, Middle Initial) Thomas Roberts

Mailing Address 12500 W. 148th St.

\begin{tabular}{lcc}
\hline City & State & Zip Code \\
Olathe & KS & $66062-9454$ \\
\hline
\end{tabular}

FEC ID number of contributing

federal political committee.

C

Name of Employer
Information Requested
Receipt For: 2012
Primary
Other (specify)

Occupation

Information Requested

Election Cycle-to-Date

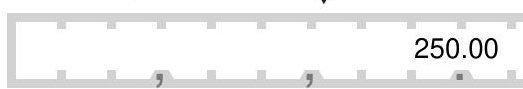

C. Full Name (Last, First, Middle Initial)

Daniel Bell

Mailing Address 2565 Bethany Creek Rd

\begin{tabular}{lcc}
\hline City & State & Zip Code \\
Alpharetta & GA & $30004-4343$ \\
\hline
\end{tabular}

FEC ID number of contributing federal political committee.

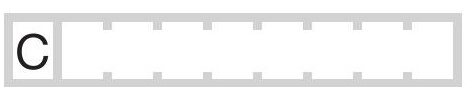

Name of Employer
Information Requested
Receipt For: 2012
X Primary
Other (specify) General

\section{Occupation}

Information Requested

Election Cycle-to-Date

Transaction ID : A08EA70D5A0114AB1BA5 Date of Receipt

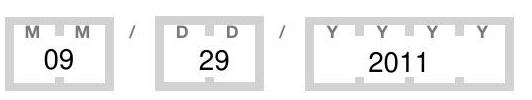

Amount of Each Receipt this Period

Amount of Each Receipt this Period

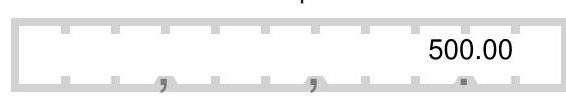

Date of Receipt

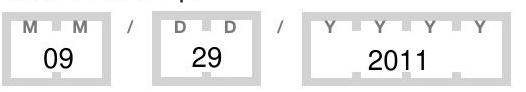

\section{9}

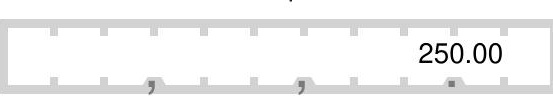

Amount of Each Receipt this Period

Transaction ID : A49BFF914FF2D4258A8C Date of Receipt
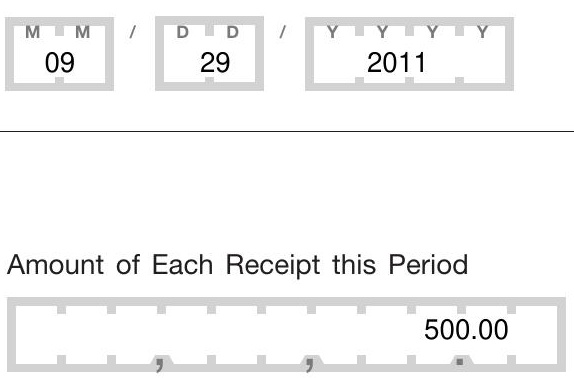

Subtotal Of Receipts This Page (optional).

1250.00

Total This Period (last page this line number only) 


\section{SCHEDULE A-P} ITEMIZED RECEIPTS
Use separate schedule(s) for each category of the Detailed Summary Page
FOR LINE NUMBER: (check only one)
PAGE 1022 / 1572

\begin{tabular}{|c|c|c|c|c|c|}
\hline & & & & & \\
\hline 16 & $\begin{array}{ll}\mathbf{X} & 17 a \\
\end{array}$ & $17 \mathrm{~b}$ & $17 c$ & $17 d$ & 18 \\
\hline $19 a$ & $19 b$ & $20 \mathrm{a}$ & $20 \mathrm{~b}$ & $20 c$ & 21 \\
\hline
\end{tabular}

Any information copied from such Reports and Statements may not be sold or used by any person for the purpose of soliciting contributions or for commercial purposes, other than using the name and address of any political committee to solicit contributions from such committee.

NAME OF COMMITTEE (In Full)

Friends of Herman Cain

A. Full Name (Last, First, Middle Initial)

Andrew Brunsink

Mailing Address 16565 Rougeway

\begin{tabular}{lcc}
\hline City & State & Zip Code \\
Livonia & MI & $48154-3445$
\end{tabular}

FEC ID number of contributing federal political committee.

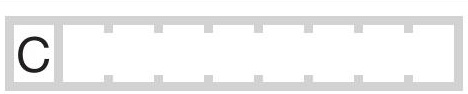

Name of Employer
Information Requested
Receipt For: 2012
X Primary
$\square$ Other (specify)

Occupation

Information Requested

Election Cycle-to-Date

400.00

B. Full Name (Last, First, Middle Initial)

Colleen A Fillian

Mailing Address 4840 Ansley Lane

\begin{tabular}{lcc}
\hline City & State & Zip Code \\
Cumming & GA & $30040-6020$ \\
\hline
\end{tabular}

FEC ID number of contributing

federal political committee.

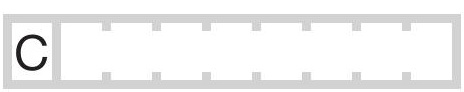

Name of Employer
self
Receipt For: 2012
X Primary
$\square$ Other (specify) General

Occupation

Realtor

Election Cycle-to-Date

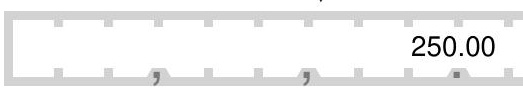

C. Full Name (Last, First, Middle Initial)

Matthew Larkin

Mailing Address 12641 Atherton Rd

\begin{tabular}{lcc}
\hline City & State & Zip Code \\
Anchorage & AK & $99516-2914$
\end{tabular}

FEC ID number of contributing

federal political committee.

C

Name of Employer

Dittman Research \& Communications

\section{Occupation}

Pollster

Receipt For: 2012
$\times \begin{aligned} & \text { Primary } \\ & \text { Other (specify) }\end{aligned}$

Pollster

Transaction ID : A2B09CC7B92C049E59E9

Date of Receipt

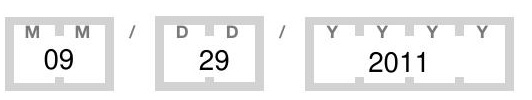

Amount of Each Receipt this Period

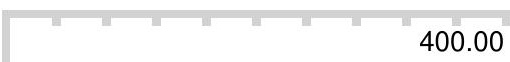

Date of Receipt

M M / D

09

2011

400.00

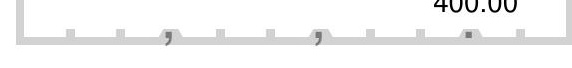

Amount of Each Receipt this Period

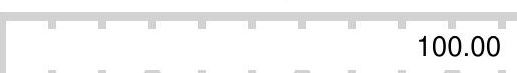

Transaction ID : A0EB2E77C61614667B7B Date of Receipt

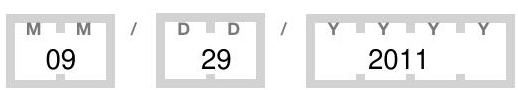

Amount of Each Receipt this Period

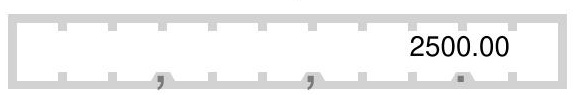

2500.00

\section{Subtotal Of Receipts This Page (optional)}

3000.00

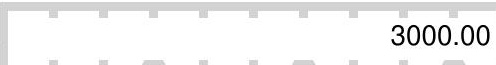

․․․․

Total This Period (last page this line number only) 
SCHEDULE A-P ITEMIZED RECEIPTS
Use separate schedule(s) for each category of the Detailed Summary Page
FOR LINE NUMBER: (check only one)
PAGE 1023 / 1572

\begin{tabular}{|c|c|c|c|c|c|}
\hline & & & & & \\
\hline 16 & $\begin{array}{lll}X & 17 a \\
\end{array}$ & $17 \mathrm{~b}$ & $17 c$ & $17 d$ & 18 \\
\hline $19 a$ & $19 b$ & $20 a$ & $20 \mathrm{~b}$ & $20 c$ & 21 \\
\hline
\end{tabular}

Any information copied from such Reports and Statements may not be sold or used by any person for the purpose of soliciting contributions or for commercial purposes, other than using the name and address of any political committee to solicit contributions from such committee.

NAME OF COMMITTEE (In Full)

\section{Friends of Herman Cain}

A. Full Name (Last, First, Middle Initial)

Robert McEntyre

Mailing Address 4800 Summitop Lane

\begin{tabular}{lcc}
\hline City & State & Zip Code \\
Marietta & GA & $30066-1633$
\end{tabular}

FEC ID number of contributing

federal political committee.

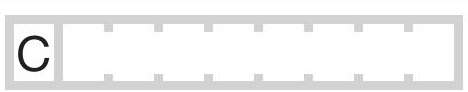

\begin{tabular}{l} 
Name of Employer \\
None \\
Receipt For: 2012 \\
X Primary $\quad$ General \\
\hline Other (specify)
\end{tabular}

Occupation

Retired

Election Cycle-to-Date

250.00

B. Full Name (Last, First, Middle Initial)

Jim Kincaid

Mailing Address 245 Cameron Ridge Dr., NW

\begin{tabular}{lcc}
\hline City & State & Zip Code \\
Atlanta & GA & $30328-4708$ \\
\hline
\end{tabular}

FEC ID number of contributing

federal political committee.

C

Name of Employer
Self Employed
Receipt For: 2012
X Primary
Other (specify)

Occupation

Dentist

Election Cycle-to-Date

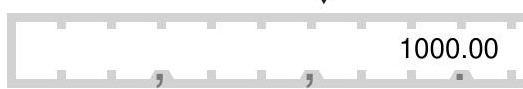

Transaction ID : AFA35C74105C24829A78

Date of Receipt

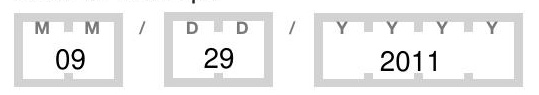

Amount of Each Receipt this Period

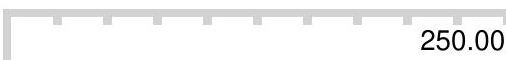

C. Full Name (Last, First, Middle Initial)

Robert Towner

Mailing Address P.O. Box 1574

\begin{tabular}{lcc}
\hline City & State & Zip Code \\
Litchfield Park & AZ & $85340-1574$
\end{tabular}

FEC ID number of contributing federal political committee.

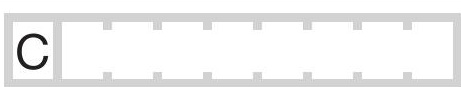

Name of Employer
NA
Receipt For: 2012
Х Primary $\quad \square$ General
Other (specify)

Occupation

Retired

Election Cycle-to-Date

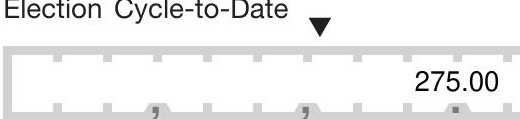

Amount of Each Receipt this Period

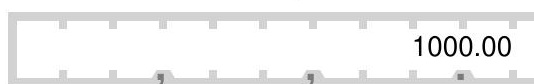

Transaction ID : AE9C59EB56F444F8DB4D Date of Receipt

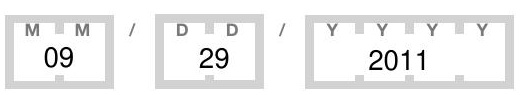

Transaction ID : AAC75FCF699D24166810 Date of Receipt

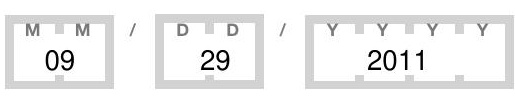

Amount of Each Receipt this Period

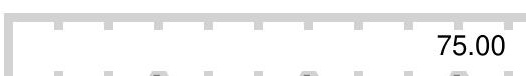

\section{Subtotal Of Receipts This Page (optional)}

Total This Period (last page this line number only) 
SCHEDULE A-P ITEMIZED RECEIPTS
Use separate schedule(s) for each category of the Detailed Summary Page
FOR LINE NUMBER: (check only one)

PAGE 1024 / 1572

\begin{tabular}{|c|c|c|c|c|c|}
\hline & & & & & \\
\hline 16 & $\begin{array}{lll}X & 17 a \\
\end{array}$ & $17 \mathrm{~b}$ & $17 c$ & $17 d$ & 18 \\
\hline $19 a$ & $19 b$ & $20 a$ & $20 \mathrm{~b}$ & $20 c$ & 21 \\
\hline
\end{tabular}

Any information copied from such Reports and Statements may not be sold or used by any person for the purpose of soliciting contributions or for commercial purposes, other than using the name and address of any political committee to solicit contributions from such committee.

NAME OF COMMITTEE (In Full)

\section{Friends of Herman Cain}

A. Full Name (Last, First, Middle Initial)

\section{Stacie Curtis}

Mailing Address 267 Stardust Cir

\begin{tabular}{lcc}
\hline City & State & Zip Code \\
Toney & AL & $35773-9396$ \\
\hline
\end{tabular}

FEC ID number of contributing federal political committee.

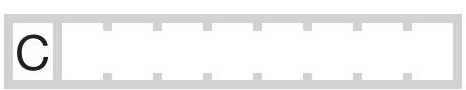

Name of Employer
The A/C Doctor
Receipt For: 2012
X Primary
Other (specify) General

\section{Occupation} Office Manager

Election Cycle-to-Date 260.00

B. Full Name (Last, First, Middle Initial) LARRY VAUGHN

\section{Mailing Address 320 STONEHAVEN DR}

\begin{tabular}{lcc}
\hline City & State & Zip Code \\
Fayetteville & GA & $30215-2979$ \\
\hline
\end{tabular}

FEC ID number of contributing

federal political committee.

C

Name of Employer
Team Health
Receipt For: 2012
X Primary
Other (specify)

Occupation

Physician

Election Cycle-to-Date

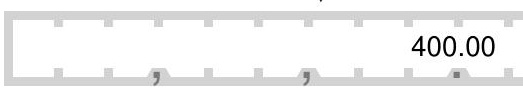

Transaction ID : A4551EFA643724A87992

Date of Receipt

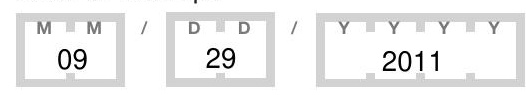

Amount of Each Receipt this Period

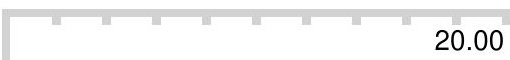

20.00

Transaction ID : A7DCFEB3FC3C441AD86B Date of Receipt

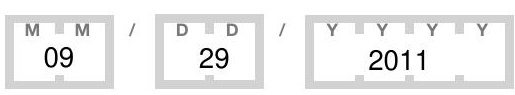

Amount of Each Receipt this Period

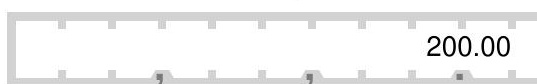

Transaction ID : A70D17B7824FB4091AA4 Date of Receipt

Michael Collins

Mailing Address 3975 N. Cliff Rd

\begin{tabular}{lcc}
\hline City & State & Zip Code \\
Port Clinton & OH & $43452-9139$
\end{tabular}

FEC ID number of contributing federal political committee.

C $43452-9139$

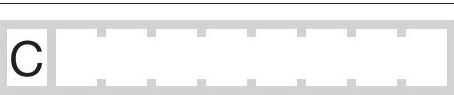

Name of Employer

Occupation

Information Requested

Information Requested

Receipt For: 2012

Х $\begin{aligned} & \text { Primary } \\ & \text { Other (specify) }\end{aligned}$

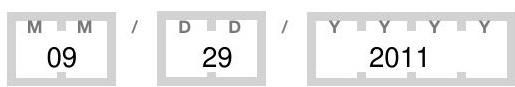

Amount of Each Receipt this Period

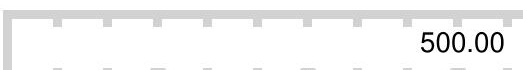

\section{Subtotal Of Receipts This Page (optional)}

Total This Period (last page this line number only) 
SCHEDULE A-P ITEMIZED RECEIPTS
Use separate schedule(s) for each category of the Detailed Summary Page
FOR LINE NUMBER: (check only one)
PAGE $1025 / 1572$

\begin{tabular}{|c|c|c|c|c|c|}
\hline & & & & & \\
\hline 16 & $\begin{array}{l}\mathbf{x} 17 a \\
\end{array}$ & $17 b$ & $17 c$ & $17 d$ & 18 \\
\hline $19 a$ & $19 b$ & $20 a$ & $20 b$ & $20 c$ & 21 \\
\hline
\end{tabular}

Any information copied from such Reports and Statements may not be sold or used by any person for the purpose of soliciting contributions or for commercial purposes, other than using the name and address of any political committee to solicit contributions from such committee.

NAME OF COMMITTEE (In Full)

\section{Friends of Herman Cain}

A. Full Name (Last, First, Middle Initial)

\section{Laura Neubert}

Mailing Address 7597 Dixie Blanchard Rd

\begin{tabular}{lcc}
\hline City & State & Zip Code \\
Shreveport & LA & $71107-8809$
\end{tabular}

FEC ID number of contributing federal political committee.

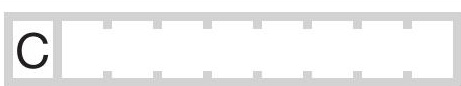

Name of Employer
Information Requested
Receipt For: 2012
X Primary
Other (specify) General

Occupation Information Requested

Election Cycle-to-Date

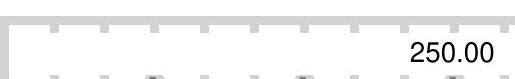

B. Full Name (Last, First, Middle Initial)

Dottie Williams

Mailing Address 7760 Paces Lane

\begin{tabular}{lcc}
\hline City & State & Zip Code \\
Gainesville & GA & $30506-7923$
\end{tabular}

FEC ID number of contributing

federal political committee.

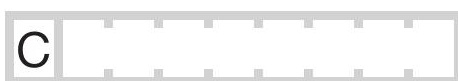

Name of Employer
Fidelity
Receipt For: 2012
X Primary $\quad$ General
Other (specify)

\section{Occupation} banker

Election Cycle-to-Date

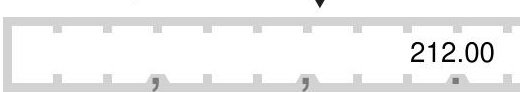

Transaction ID : AF5ACFE6A27AB416C920

Date of Receipt

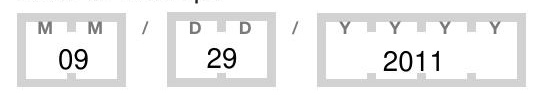

Amount of Each Receipt this Period

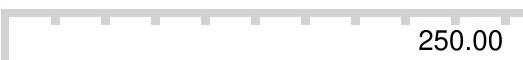

C. Full Name (Last, First, Middle Initial)

Michael Cohen

Mailing Address 28 Shepard Ct

\begin{tabular}{lcc}
\hline City & State & Zip Code \\
Winchester & MA & $01890-1626$
\end{tabular}

FEC ID number of contributing federal political committee.

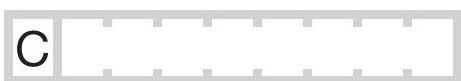

Name of Employer

Information Requested

Occupation

Information Requested

Receipt For: 2012

Х $\begin{aligned} & \text { Primary } \\ & \text { Other (specify) }\end{aligned}$

Amount of Each Receipt this Period

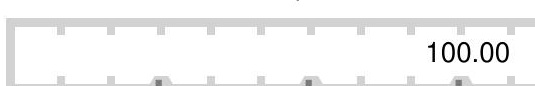

Transaction ID : AD34B77DA273240EA98B Date of Receipt

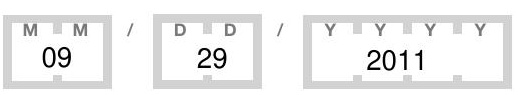

Transaction ID : AD5B6CE286E6D4376B74 Date of Receipt

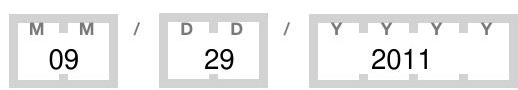

Amount of Each Receipt this Period

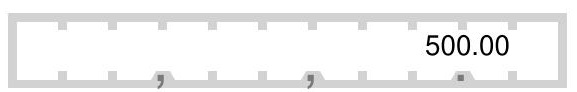

500.00

\section{Subtotal Of Receipts This Page (optional)}

Total This Period (last page this line number only) 


\section{SCHEDULE A-P} ITEMIZED RECEIPTS
Use separate schedule(s) for each category of the Detailed Summary Page
FOR LINE NUMBER: (check only one)
PAGE 1026 / 1572

\begin{tabular}{|c|c|c|c|c|c|}
\hline & & & & & \\
\hline 16 & $\begin{array}{ll}\mathbf{X} & 17 a \\
\end{array}$ & $17 \mathrm{~b}$ & $17 c$ & $17 d$ & 18 \\
\hline $19 a$ & $19 b$ & $20 \mathrm{a}$ & $20 \mathrm{~b}$ & $20 c$ & 21 \\
\hline
\end{tabular}

Any information copied from such Reports and Statements may not be sold or used by any person for the purpose of soliciting contributions or for commercial purposes, other than using the name and address of any political committee to solicit contributions from such committee.

NAME OF COMMITTEE (In Full)

Friends of Herman Cain

A. Full Name (Last, First, Middle Initial)

Jake Anderson

Mailing Address 9041 East Karen Drive

\begin{tabular}{lcc}
\hline City & State & Zip Code \\
Scottsdale & AZ & $85260-2752$
\end{tabular}

FEC ID number of contributing federal political committee.

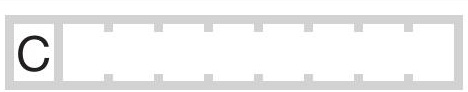

Name of Employer

Anderson Information Systems

Occupation

Receipt For: 2012

Х $\begin{aligned} & \text { Primary } \\ & \text { Other (specify) } \nabla\end{aligned}$

IT Consultant

Election Cycle-to-Date

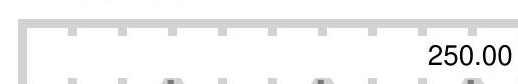

B. Full Name (Last, First, Middle Initial)

Melissa Dickens

Mailing Address 1070 Cambridge Square Suite B

\begin{tabular}{lcc}
\hline City & State & Zip Code \\
Alpharetta & GA & $30009-1877$
\end{tabular}

FEC ID number of contributing

federal political committee.

C

Name of Employer
Information Requested
Receipt For: 2012
X Primary
Other (specify)

Occupation

Information Requested

Election Cycle-to-Date

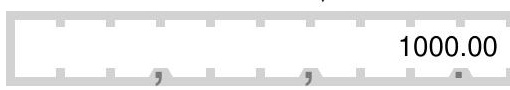

Transaction ID : A76BC3422C40D46D1A03

Date of Receipt

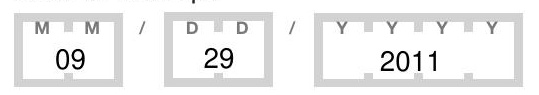

Amount of Each Receipt this Period

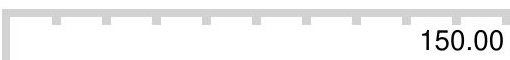

150.00

C. Full Name (Last, First, Middle Initial)

Benjamin Fritz

Mailing Address 26434 Lares Lane

\begin{tabular}{lcc}
\hline City & State & Zip Code \\
Murrieta & CA & $92563-4347$
\end{tabular}

FEC ID number of contributing federal political committee.

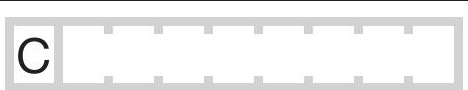

Name of Employer

Information Requested

\section{Occupation}

Information Requested

Receipt For: 2012

Х $\begin{aligned} & \text { Primary } \square \text { General } \\ & \text { Other (specify) }\end{aligned}$

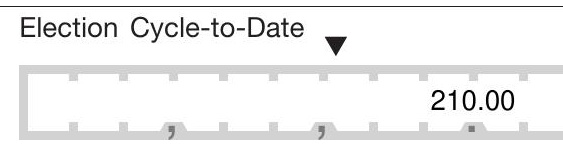

Amount of Each Receipt this Period

Transaction ID : A857CE19D4631475D827

Date of Receipt
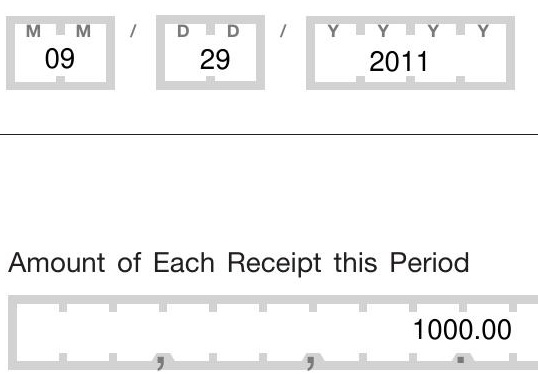

Amount of Each Receipt this Period

Transaction ID : ACB6685019BC3497BB99 Date of Receipt
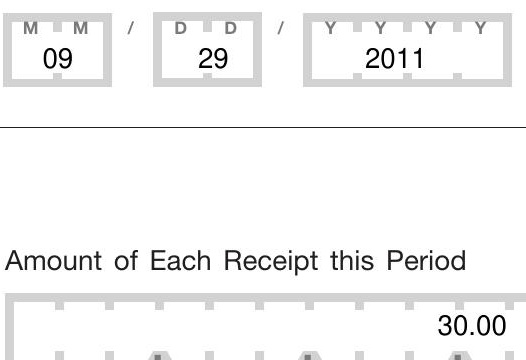

Subtotal Of Receipts This Page (optional).

1180.00

Total This Period (last page this line number only) 


\section{SCHEDULE A-P} ITEMIZED RECEIPTS
Use separate schedule(s) for each category of the Detailed Summary Page
FOR LINE NUMBER: (check only one)
PAGE 1027 / 1572

\begin{tabular}{|c|c|c|c|c|c|}
\hline & & & & & \\
\hline 16 & $\mathbf{X} 17 a$ & $17 b$ & $17 c$ & $17 d$ & 18 \\
\hline $19 a$ & $19 b$ & $20 \mathrm{a}$ & $20 \mathrm{~b}$ & $20 \mathrm{c}$ & 21 \\
\hline
\end{tabular}

Any information copied from such Reports and Statements may not be sold or used by any person for the purpose of soliciting contributions or for commercial purposes, other than using the name and address of any political committee to solicit contributions from such committee.

NAME OF COMMITTEE (In Full)

Friends of Herman Cain

A. Full Name (Last, First, Middle Initial)

Benjamin Fritz

Mailing Address 26434 Lares Lane

\begin{tabular}{lcc}
\hline City & State & Zip Code \\
Murrieta & CA & $92563-4347$
\end{tabular}

FEC ID number of contributing

federal political committee.

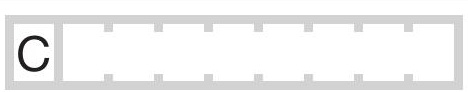

Name of Employer
Information Requested
Receipt For: 2012
X Primary $\quad \square$ General
Other (specify)

Occupation

Information Requested

Election Cycle-to-Date

210.00

B. Full Name (Last, First, Middle Initial)

David Oatway

Mailing Address 623 Simonton St

\begin{tabular}{lcc}
\hline City & State & Zip Code \\
Key West & FL & $33040-6896$ \\
\hline
\end{tabular}

FEC ID number of contributing

federal political committee.

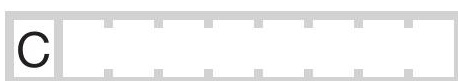

Name of Employer
chesapeake applied technology
Receipt For: 2012
Xrimary
Other (specify)

Occupation

Registered Nurse

Election Cycle-to-Date

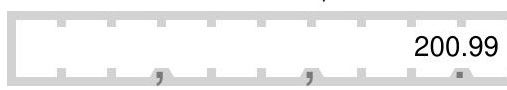

C. Full Name (Last, First, Middle Initial)

Kelley Howard

Mailing Address 400 S Prescott St

\begin{tabular}{lcc}
\hline City & State & Zip Code \\
Eustis & FL & $32726-4653$
\end{tabular}

FEC ID number of contributing

federal political committee.

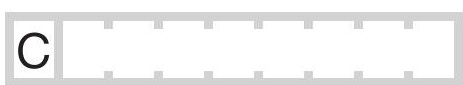

Name of Employer

Information Requested

Occupation

Information Requested

Receipt For: 2012

Х $\begin{aligned} & \text { Primary } \square \text { General } \\ & \text { Other (specify) }\end{aligned}$

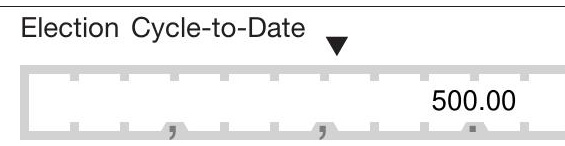

Amount of Each Receipt this Period

Transaction ID : A6A77FEB8149A49C1AB1

Date of Receipt

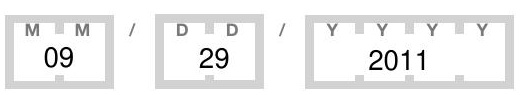

Amount of Each Receipt this Period
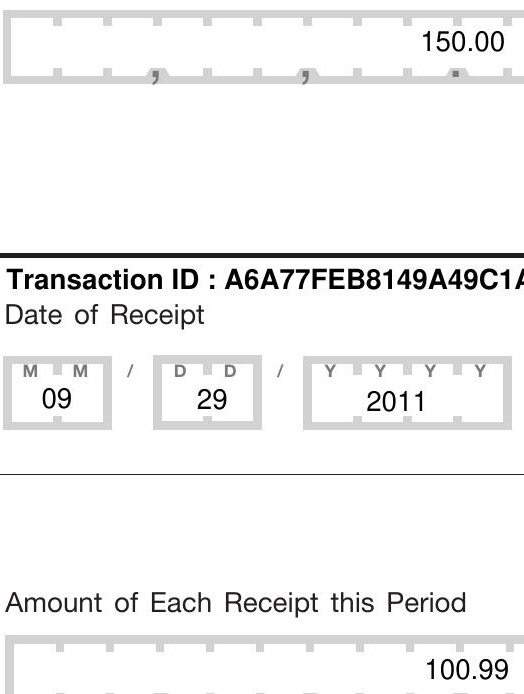

Transaction ID : A7A2B387D6F8F4DB2A9E Date of Receipt

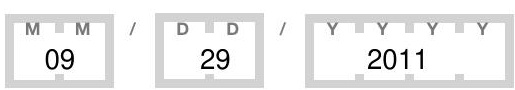

Amount of Each Receipt this Period

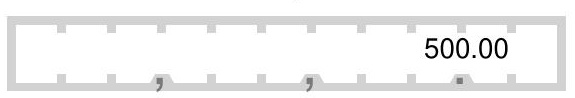

Subtotal Of Receipts This Page (optional).

750.99

Total This Period (last page this line number only) 


\section{SCHEDULE A-P} ITEMIZED RECEIPTS
Use separate schedule(s)

for each category of the

Detailed Summary Page
FOR LINE NUMBER: (check only one)

Any information or for commercial purposes, other than using the name and address of any political committee to solicit contributions from such committee.

NAME OF COMMITTEE (In Full)

Friends of Herman Cain

A. Full Name (Last, First, Middle Initial)

Matthew Miller

Mailing Address 3763 7th Road

\begin{tabular}{lcc}
\hline City & State & Zip Code \\
Bremen & IN & $46506-9115$
\end{tabular}

FEC ID number of contributing federal political committee.

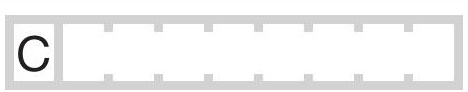

Name of Employer
Newman Corp
Receipt For: 2012
X Primary $\quad \square$ General
$\square$ Other (specify)

Occupation manufacturer

Election Cycle-to-Date 2500.00

B. Full Name (Last, First, Middle Initial) Larry Butler

Mailing Address 801 N. Post Oak Rd. \#801

\begin{tabular}{lcc}
\hline City & State & Zip Code \\
Houston & TX & $77024-3879$ \\
\hline
\end{tabular}

FEC ID number of contributing

federal political committee.

C

\begin{tabular}{l} 
Name of Employer \\
Information Requested \\
Receipt For: 2012 \\
X Primary \\
\hline Other (specify)
\end{tabular}

Occupation

Information Requested

Election Cycle-to-Date

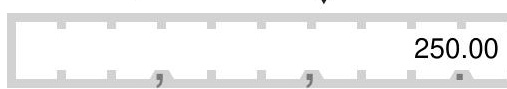

Transaction ID : A3524F16D81EB4677897

Date of Receipt

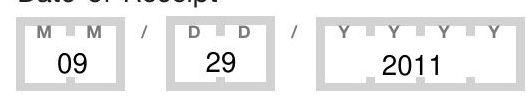

Amount of Each Receipt this Period

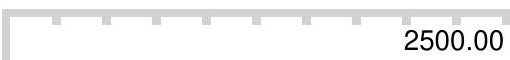

2500.00

Transaction ID : A968145AD89F84354B39

Date of Receipt

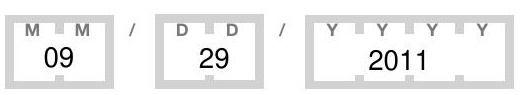

Amount of Each Receipt this Period

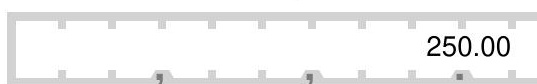

Transaction ID : A1158740658AB49D0A24

Date of Receipt

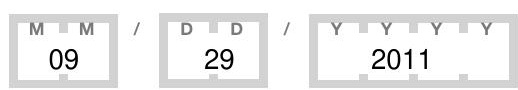

Amount of Each Receipt this Period

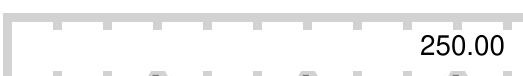

C. Full Name (Last, First, Middle Initial)

Jim Wordsworth

Mailing Address 2900 Brians Hill Lane

\begin{tabular}{lcc}
\hline City & State & Zip Code \\
Oakton & VA & $22124-1228$
\end{tabular}

FEC ID number of contributing federal political committee.

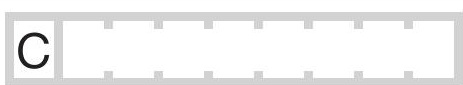

Name of Employer
Information Requested
Receipt For: 2012
X Primary
Other (specify) General

\section{Occupation}

Information Requested

Election Cycle-to-Date

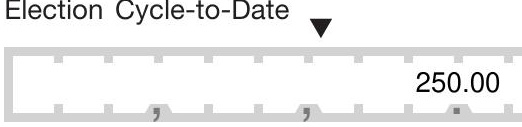

Subtotal Of Receipts This Page (optional).

$+\quad 3000.00$

Total This Period (last page this line number only)

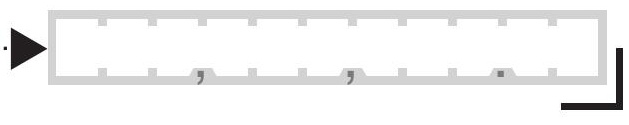

FEC Schedule A-P (Form 3P) (Rev. 03/2011) 
SCHEDULE A-P ITEMIZED RECEIPTS
Use separate schedule(s) for each category of the Detailed Summary Page
FOR LINE NUMBER: (check only one)

Any information copied from or for commercial purposes, other than using the name and address of any political committee to solicit contributions from such committee.

NAME OF COMMITTEE (In Full)

\section{Friends of Herman Cain}

A. Full Name (Last, First, Middle Initial)

\section{Carol Godsave}

Mailing Address 2131 Ardis Dr

\begin{tabular}{lcc}
\hline City & State & Zip Code \\
San Jose & CA & $95125-2604$
\end{tabular}

FEC ID number of contributing federal political committee.

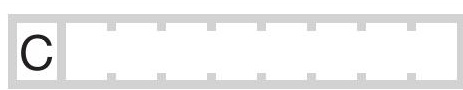

Name of Employer
Self Employed
Receipt For: 2012
X Primary $\quad$ General
Other (specify)

B. Full Name (Last, First, Middle Initial)

Matthew Camp

Mailing Address 4065 Hickory Fairway Dr.

\begin{tabular}{lcc}
\hline City & State & Zip Code \\
Woodstock & GA & $30188-2343$
\end{tabular}

FEC ID number of contributing

federal political committee.

C

\begin{tabular}{l} 
Name of Employer \\
Georgia Mountain Optholmology \\
Receipt For: 2012 \\
X Primary \\
\hline Other (specify)
\end{tabular}

Name of Employer

Georgia Mountain Optholmology

Receipt For: 2012

Other (specify)
Occupation

Financial Planner

Election Cycle-to-Date
Occupation

Physician

Election Cycle-to-Date

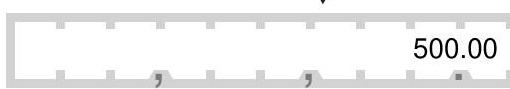

Transaction ID : A76330B2279034221BF8

Date of Receipt

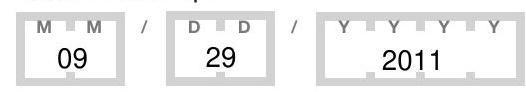

Amount of Each Receipt this Period

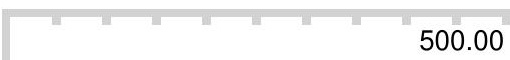

500.00

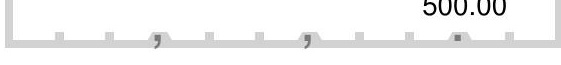

Transaction ID : A7CAE6497BDC54EB7A40

Date of Receipt

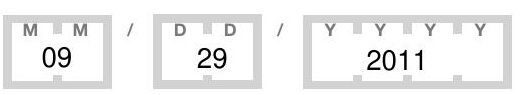

Amount of Each Receipt this Period

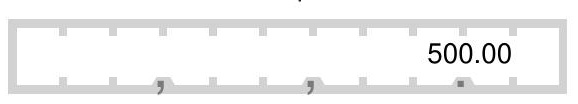

500.00

C. Full Name (Last, First, Middle Initial)

Bill Burke

Mailing Address 225 Old Farm Rd

\begin{tabular}{lcc}
\hline City & State & Zip Code \\
Fayetteville & GA & $30215-5816$
\end{tabular}

FEC ID number of contributing

federal political committee.

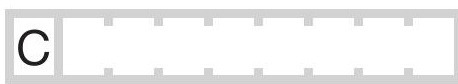

Name of Employer

Information Requested

Occupation

Information Requested

Receipt For: 2012

Х $\begin{aligned} & \text { Primary } \square \text { General } \\ & \text { Other (specify) }\end{aligned}$

Transaction ID : AF44AD6402A6443CD821

Date of Receipt

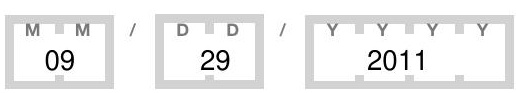

Amount of Each Receipt this Period

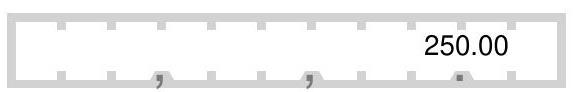

250.00

Subtotal Of Receipts This Page (optional)

Total This Period (last page this line number only) 


\section{SCHEDULE A-P} ITEMIZED RECEIPTS
Use separate schedule(s)

for each category of the

Detailed Summary Page
FOR LINE NUMBER: (check only one)

Any information or for commercial purposes, other than using the name and address of any political committee to solicit contributions from such committee.

NAME OF COMMITTEE (In Full)

Friends of Herman Cain

A. Full Name (Last, First, Middle Initial) david delaware

Mailing Address 42725 center street

\begin{tabular}{lcc}
\hline City & State & Zip Code \\
Chantilly & VA & $20152-3954$
\end{tabular}

FEC ID number of contributing federal political committee.

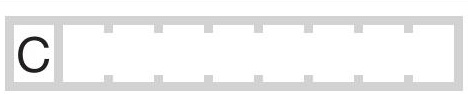

Name of Employer
Information Requested
Receipt For: 2012
X Primary
$\square$ Other (specify)

Occupation Information Requested

Election Cycle-to-Date

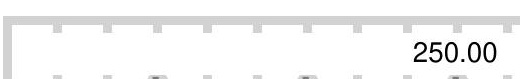

B. Full Name (Last, First, Middle Initial)

Thomas Sloan

Mailing Address 171 Southmoreland PI

\begin{tabular}{lcc}
\hline City & State & Zip Code \\
Decatur & IL & $62521-3738$
\end{tabular}

FEC ID number of contributing

federal political committee.

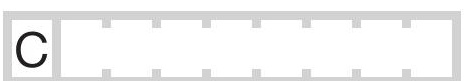

Name of Employer

Sloan Supplement Co. Inc.

Occupation

Receipt For: 2012

Х ${ }_{\text {Other (specify) }}^{\square}$ General

Sales

Election Cycle-to-Date

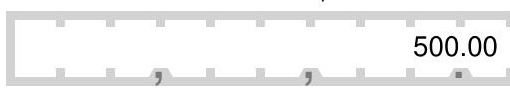

C. Full Name (Last, First, Middle Initial)

Paul Jensen

Mailing Address 17 Fairways Ln

\begin{tabular}{lcc}
\hline City & State & Zip Code \\
Methuen & MA & $01844-2125$
\end{tabular}

FEC ID number of contributing federal political committee.

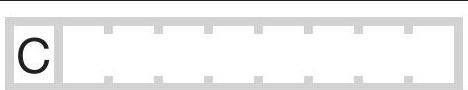

Name of Employer
Halo Defense
Receipt For: 2012
Х Primary $\square$ General
Other (specify)

\section{Occupation}

CEO

Election Cycle-to-Date

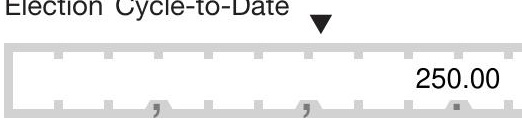

Transaction ID : A91E605A367354710B24

Date of Receipt

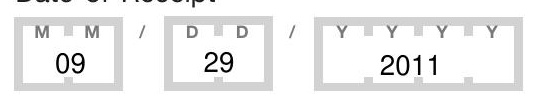

Amount of Each Receipt this Period

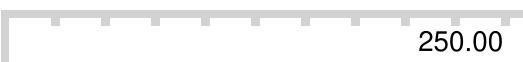

250.00

Transaction ID : AC118048BCB344E11920

Date of Receipt

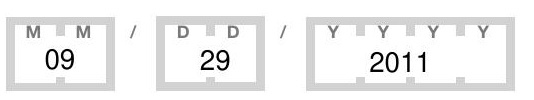

Amount of Each Receipt this Period

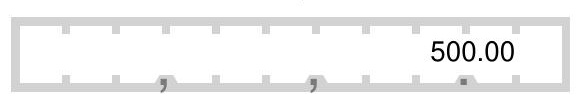

Transaction ID : A253AEB8C91D842FF8E5 Date of Receipt

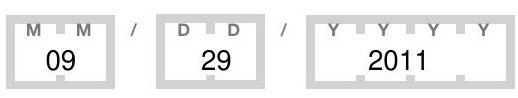

Amount of Each Receipt this Period

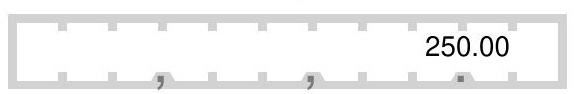

Subtotal Of Receipts This Page (optional).

1000.00

Total This Period (last page this line number only) 


\section{SCHEDULE A-P} ITEMIZED RECEIPTS
Use separate schedule(s)

for each category of the

Detailed Summary Page
FOR LINE NUMBER: (check only one)

Any information or for commercial purposes, other than using the name and address of any political committee to solicit contributions from such committee.

NAME OF COMMITTEE (In Full)

Friends of Herman Cain

A. Full Name (Last, First, Middle Initial)

Benjamin Agee

Mailing Address 11901 Heritage Ln

\begin{tabular}{lcc}
\hline City & State & Zip Code \\
Houston & TX & $77024-5021$
\end{tabular}

FEC ID number of contributing

federal political committee.

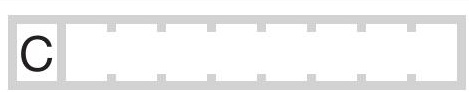

Name of Employer
Information Requested
Receipt For: 2012
X Primary $\quad \square$ General
Other (specify)

Occupation

Information Requested

Election Cycle-to-Date

1000.00

B. Full Name (Last, First, Middle Initial)

Craig Ruhe

Mailing Address 921 Eden Plains Road

\begin{tabular}{lcc}
\hline City & State & Zip Code \\
Brentwood & CA & $94513-2806$
\end{tabular}

FEC ID number of contributing

federal political committee.

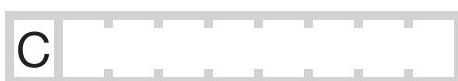

Name of Employer
Information Requested
Receipt For: 2012
X Primary
Other (specify)

Occupation

Information Requested

Election Cycle-to-Date

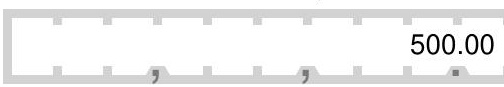

Transaction ID : AD62E2AE690934A399DD

Date of Receipt

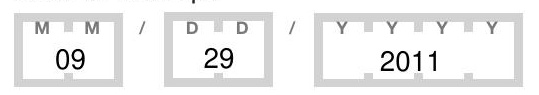

Amount of Each Receipt this Period

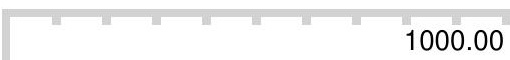

1000.00

C. Full Name (Last, First, Middle Initial)

Phyllis Landzert

Mailing Address 6302 Springhouse Circle

\begin{tabular}{lcc}
\hline City & State & Zip Code \\
Stone Mountain & GA & $30087-6740$
\end{tabular}

FEC ID number of contributing

federal political committee.

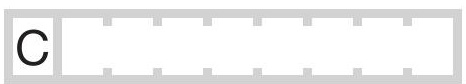

Name of Employer

Information Requested

Occupation

Information Requested

Receipt For: 2012

Х $\begin{aligned} & \text { Primary } \\ & \text { Other (specify) }\end{aligned}$

Election Cycle-to-Date

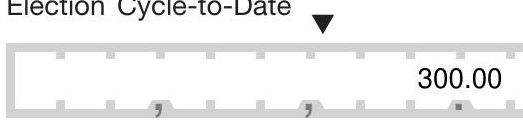

Amount of Each Receipt this Period

Amount of Each Receipt this Period

Transaction ID : A6732495F6B404C3384E

Date of Receipt
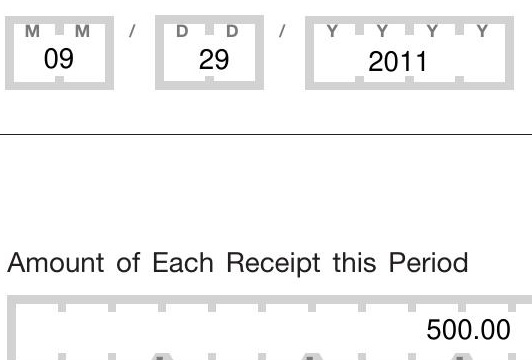

Transaction ID : ABDD6DF82497D4D23ADD Date of Receipt
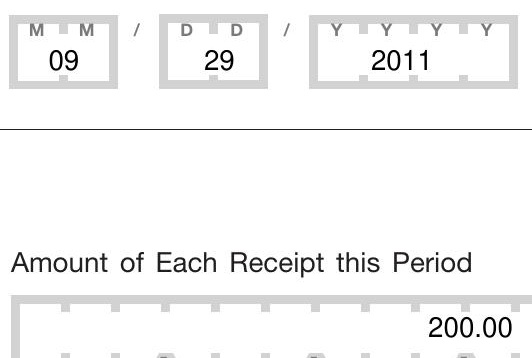

1700.00

Subtotal Of Receipts This Page (optional)

Total This Period (last page this line number only) 


\section{SCHEDULE A-P} ITEMIZED RECEIPTS
Use separate schedule(s) for each category of the Detailed Summary Page

\begin{tabular}{|c|c|c|c|c|c|}
\hline \multicolumn{3}{|c|}{$\begin{array}{l}\text { FOR LINE NUMBER: } \\
\text { (check only one) }\end{array}$} & \multicolumn{3}{|c|}{ PAGE 1032 / 1572} \\
\hline 16 & $X$ 17a & $17 b$ & $17 c$ & $17 d$ & 18 \\
\hline $19 a$ & $19 \mathrm{~b}$ & $20 a$ & $20 \mathrm{~b}$ & $20 c$ & 21 \\
\hline
\end{tabular}

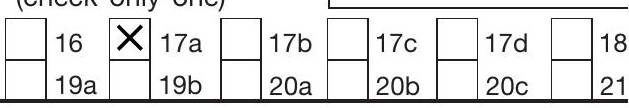

Any information copied from such Reports and Statements may not be sold or used by any person for the purpose of soliciting contributions or for commercial purposes, other than using the name and address of any political committee to solicit contributions from such committee.

NAME OF COMMITTEE (In Full)

\section{Friends of Herman Cain}

A. Full Name (Last, First, Middle Initial)

Steve Krulin

Mailing Address 14 Lemp Road

\begin{tabular}{lcc}
\hline City & State & Zip Code \\
Saint Louis & MO & $63122-6900$
\end{tabular}

FEC ID number of contributing federal political committee.

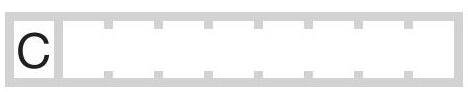

Name of Employer
Information Requested
Receipt For: 2012
X Primary
Other (specify) General

Occupation Information Requested

Election Cycle-to-Date 250.00

B. Full Name (Last, First, Middle Initial)

Stephen VanderBloemen

Mailing Address 3455 Pilgrim Road

\begin{tabular}{lcc}
\hline City & State & Zip Code \\
Brookfield & WI & $53005-2831$
\end{tabular}

FEC ID number of contributing

federal political committee.

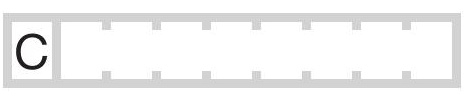

Name of Employer
The VanderBloemen Group
Receipt For: 2012
X Primary
Other (specify)

\section{Occupation}

CPA

Election Cycle-to-Date

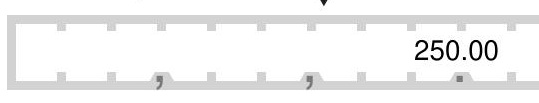

C. Full Name (Last, First, Middle Initial)

Betty Stedman

Mailing Address 3744 Willowick Rd

\begin{tabular}{lcc}
\hline City & State & Zip Code \\
Houston & TX & $77019-1116$
\end{tabular}

FEC ID number of contributing federal political committee.

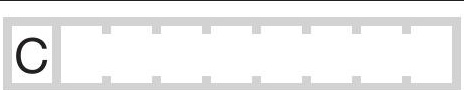

Name of Employer

Stedman West Interests

Receipt For: 2012

Х $\begin{aligned} & \text { Primary } \square \text { General } \\ & \text { Other (specify) }\end{aligned}$

\section{Occupation}

Investor

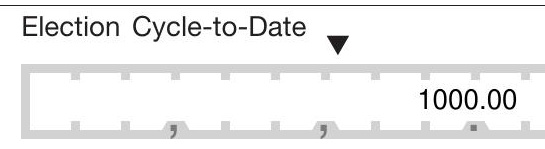

Transaction ID : A5473EDBDCA4F4BC5AC6

Date of Receipt

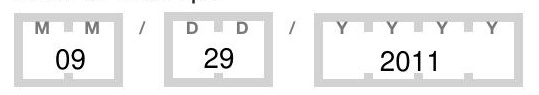

Amount of Each Receipt this Period

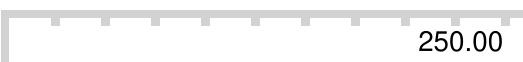

250.00
Amount of Each Receipt this Period

Transaction ID : AB6F591B9FC104D3C921

Date of Receipt
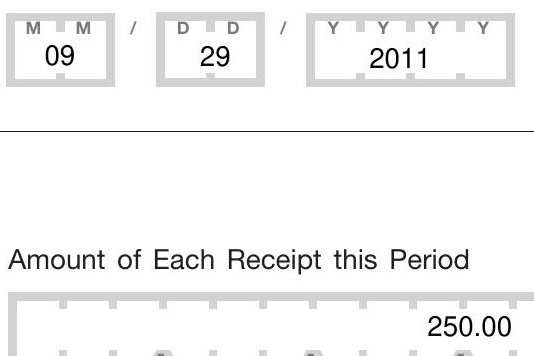

Transaction ID : A7222DF20366745A7947

Date of Receipt

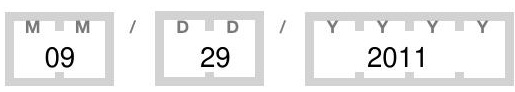

Amount of Each Receipt this Period

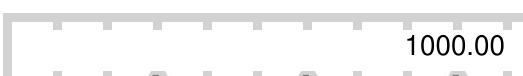

1000.00

Subtotal Of Receipts This Page (optional)

1500.00

Total This Period (last page this line number only) 


\section{SCHEDULE A-P} ITEMIZED RECEIPTS
Use separate schedule(s) for each category of the Detailed Summary Page
FOR LINE NUMBER: (check only one)
PAGE $1033 / 1572$

\begin{tabular}{|c|c|c|c|c|c|}
\hline & & & & & \\
\hline 16 & $\begin{array}{ll}\mathbf{X} & 17 a \\
\end{array}$ & $17 \mathrm{~b}$ & $17 c$ & $17 d$ & 18 \\
\hline $19 a$ & $19 b$ & $20 \mathrm{a}$ & $20 \mathrm{~b}$ & $20 c$ & 21 \\
\hline
\end{tabular}

Any information copied from such Reports and Statements may not be sold or used by any person for the purpose of soliciting contributions or for commercial purposes, other than using the name and address of any political committee to solicit contributions from such committee.

NAME OF COMMITTEE (In Full)

Friends of Herman Cain

A. Full Name (Last, First, Middle Initial)

Keith Becker

Mailing Address 2573 Oak Bluff Dr

\begin{tabular}{lcc}
\hline City & State & Zip Code \\
Dacula & GA & $30019-6664$
\end{tabular}

FEC ID number of contributing federal political committee.

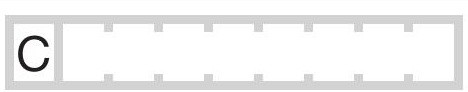

Name of Employer
Information Requested
Receipt For: 2012
X Primary
Other (specify) General

Occupation

Information Requested

Election Cycle-to-Date

250.00

B. Full Name (Last, First, Middle Initial)

Edward Hogan

Mailing Address 900 W. Stafford Road

\begin{tabular}{lcc}
\hline City & State & Zip Code \\
Thousand Oaks & CA & $91361-5333$
\end{tabular}

FEC ID number of contributing

federal political committee.

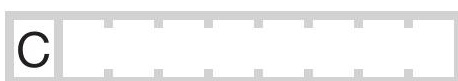

Name of Employer

Pleasant Travel Service, Inc.

Occupation

Receipt For: 2012

Х Primary $\square$ General

Chairman

Transaction ID : AFAE63EBE9E704DF3860

Date of Receipt

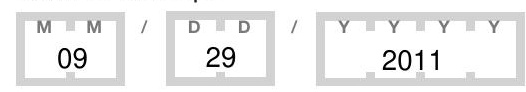

Amount of Each Receipt this Period

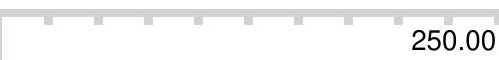

250.00

Transaction ID : A3C30514F164A493CAF5

Date of Receipt

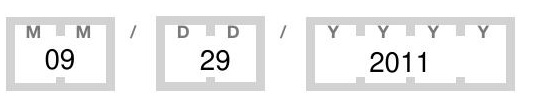

Amount of Each Receipt this Period

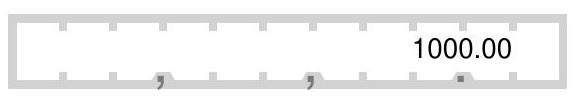

Election Cycle-to-Date

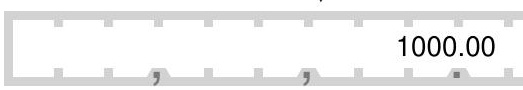

C. Full Name (Last, First, Middle Initial)

Christie DaVanzo

Mailing Address 708 James Doak Pkwy

\begin{tabular}{lcc}
\hline City & State & Zip Code \\
Greensboro & NC & $27455-8304$ \\
\hline
\end{tabular}

FEC ID number of contributing

federal political committee.

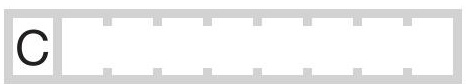

Name of Employer

Piedmont Neonatology, PC

Receipt For: 2012

Х $\begin{aligned} & \text { Primary } \\ & \text { Other (specify) }\end{aligned}$

Occupation

Physician

Election Cycle-to-Date

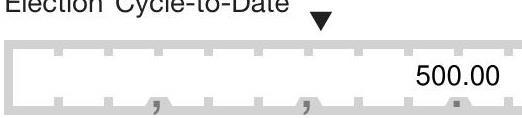

Transaction ID : A592B6C5BF7684F8CB19 Date of Receipt

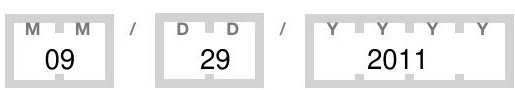

Amount of Each Receipt this Period

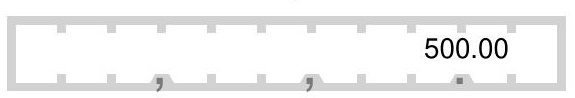

\section{Subtotal Of Receipts This Page (optional)}

Total This Period (last page this line number only) 
SCHEDULE A-P ITEMIZED RECEIPTS
Use separate schedule(s) for each category of the Detailed Summary Page
FOR LINE NUMBER: (check only one)

PAGE 1034 / 1572

\begin{tabular}{|c|c|c|c|c|c|}
\hline & & & & & \\
\hline 16 & $\begin{array}{lll}X & 17 a \\
\end{array}$ & $17 \mathrm{~b}$ & $17 c$ & $17 d$ & 18 \\
\hline $19 a$ & $19 b$ & $20 a$ & $20 \mathrm{~b}$ & $20 c$ & 21 \\
\hline
\end{tabular}

Any information copied from such Reports and Statements may not be sold or used by any person for the purpose of soliciting contributions or for commercial purposes, other than using the name and address of any political committee to solicit contributions from such committee.

NAME OF COMMITTEE (In Full)

\section{Friends of Herman Cain}

A. Full Name (Last, First, Middle Initial)

Sally Brodie

Mailing Address 6721 SE Harbor Cir

\begin{tabular}{lcc}
\hline City & State & Zip Code \\
Stuart & FL & $34996-1964$
\end{tabular}

FEC ID number of contributing federal political committee.

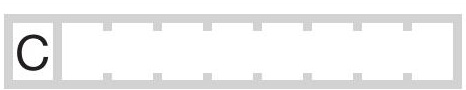

Name of Employer
Self-Employed
Receipt For: 2012
X Primary $\quad$ General
Other (specify)

\section{Occupation}

Real Estate

Election Cycle-to-Date

250.00

B. Full Name (Last, First, Middle Initial)

Peter Grant

Mailing Address 1595 SW Orchard Ave

\begin{tabular}{lcc}
\hline City & State & Zip Code \\
Gresham & OR & $97080-9644$
\end{tabular}

FEC ID number of contributing

federal political committee.

C

Name of Employer
None
Receipt For: 2012
X Primary
Other (specify)

\section{Occupation}

Retired

Election Cycle-to-Date

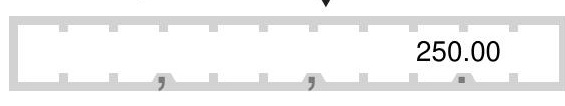

C. Full Name (Last, First, Middle Initial)

Gerrit Boyle

Mailing Address $430 \mathrm{H}$ Street Road

\begin{tabular}{lcc}
\hline City & State & Zip Code \\
Lynden & WA & $98264-8405$
\end{tabular}

FEC ID number of contributing federal political committee.

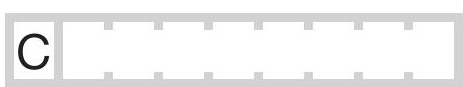

Name of Employer
Information Requested
Receipt For: 2012
X Primary $\quad \square$ General
Other (specify)

Occupation

Information Requested

Election Cycle-to-Date
Transaction ID : A22B681D3E103401DA40

Date of Receipt

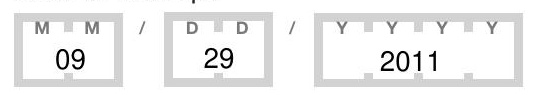

Amount of Each Receipt this Period

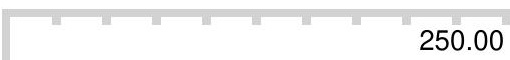

250.00
Amount of Each Receipt this Period

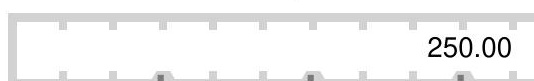

Transaction ID : A48DBB849D2F245699B6 Date of Receipt

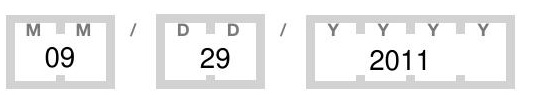

Transaction ID : AB225A42815F241FD83D Date of Receipt

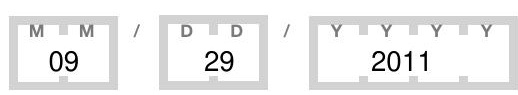

Amount of Each Receipt this Period

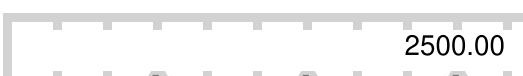

\section{Subtotal Of Receipts This Page (optional)}

3000.00

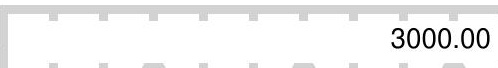

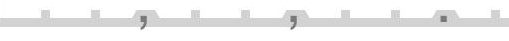

Total This Period (last page this line number only)

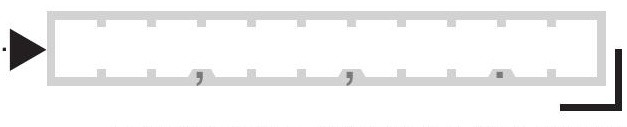

FEC Schedule A-P (Form 3P) (Rev. 03/2011) 


\section{SCHEDULE A-P} ITEMIZED RECEIPTS
Use separate schedule(s)

for each category of the

Detailed Summary Page
FOR LINE NUMBER: (check only one)

Any information or for commercial purposes, other than using the name and address of any political committee to solicit contributions from such committee.

NAME OF COMMITTEE (In Full)

Friends of Herman Cain

A. Full Name (Last, First, Middle Initial)

Michael Valletutti

Mailing Address PO Box 1138

\begin{tabular}{lcc}
\hline City & State & Zip Code \\
Merritt Island & FL & 32952 \\
\hline
\end{tabular}

FEC ID number of contributing

federal political committee.

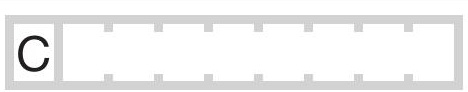

Name of Employer
Information Requested
Receipt For: 2012
X Primary $\quad \square$ General
Other (specify)

Occupation

Information Requested

Election Cycle-to-Date

1000.00

B. Full Name (Last, First, Middle Initial)

Kenneth Geyer

Mailing Address 10557 Tiger Point

\begin{tabular}{lcc}
\hline City & State & Zip Code \\
Lone Tree & CO & $80124-9583$
\end{tabular}

FEC ID number of contributing

federal political committee.

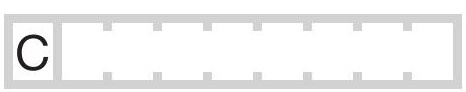

\begin{tabular}{l} 
Name of Employer \\
Liteye Systems \\
Receipt For: 2012 \\
X Primary \\
\hline Other (specify) General
\end{tabular}

Occupation

VP

Election Cycle-to-Date

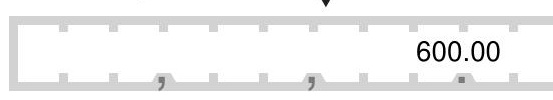

Transaction ID : A8689C81FF6B54344B77

Date of Receipt

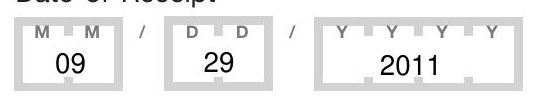

Amount of Each Receipt this Period

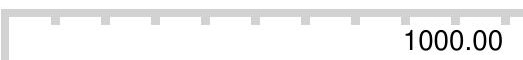

C. Full Name (Last, First, Middle Initial)

Larry Guinn

Mailing Address 1375 Frontier

\begin{tabular}{lcc}
\hline City & State & Zip Code \\
Spring Branch & TX & $78070-5948$
\end{tabular}

FEC ID number of contributing

federal political committee.

C

Name of Employer

Information Requested

Occupation

Information Requested

Receipt For: 2012

Х $\begin{aligned} & \text { Primary } \square \text { General } \\ & \text { Other (specify) }\end{aligned}$

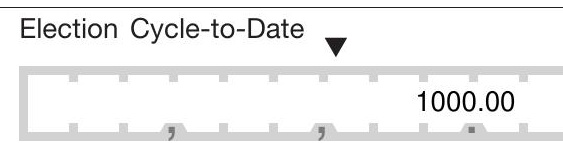

Amount of Each Receipt this Period

Transaction ID : AD69F5DF657784D718CF

Date of Receipt
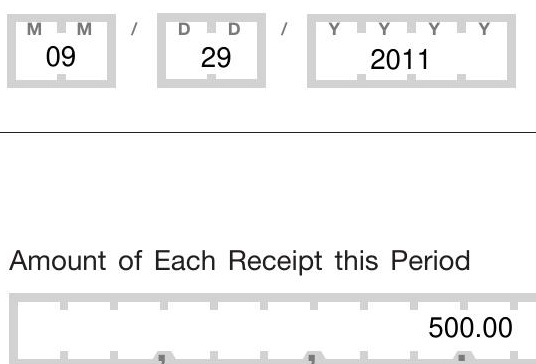

Transaction ID : AB7F607D617804ADA814

Date of Receipt

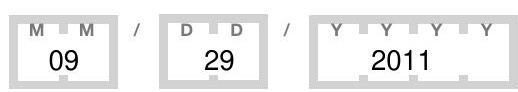

Amount of Each Receipt this Period

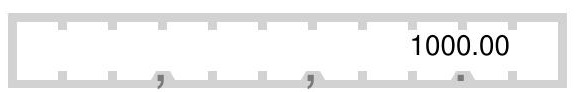

Subtotal Of Receipts This Page (optional).

2500.00

Total This Period (last page this line number only) 


\section{SCHEDULE A-P} ITEMIZED RECEIPTS
Use separate schedule(s)

for each category of the

Detailed Summary Page
FOR LINE NUMBER: (check only one)

Any information or for commercial purposes, other than using the name and address of any political committee to solicit contributions from such committee.

NAME OF COMMITTEE (In Full)

Friends of Herman Cain

A. Full Name (Last, First, Middle Initial)

ALAN Carmichael

Mailing Address 18583 Spring Creek Oaks Cir

\begin{tabular}{lcc}
\hline City & State & Zip Code \\
Spring & TX & $77379-8867$ \\
\hline
\end{tabular}

FEC ID number of contributing federal political committee.

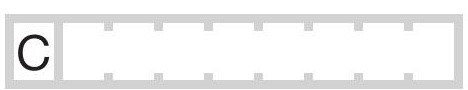

Name of Employer
Information Requested
Receipt For: 2012
X Primary
$\square$ Other (specify)

Occupation

Information Requested

Election Cycle-to-Date

2500.00

B. Full Name (Last, First, Middle Initial)

Michael Mullins

Mailing Address 310 Megan Ct

\begin{tabular}{lcc}
\hline City & State & Zip Code \\
Savannah & GA & $31405-5956$ \\
\hline
\end{tabular}

FEC ID number of contributing

federal political committee.

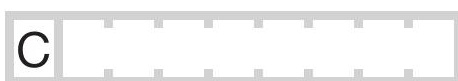

Name of Employer

Southeast Lung \& Critical Care

Occupation

Receipt For: 2012

$\chi \begin{aligned} & \text { Primary } \\ & \text { Other (specify) }\end{aligned}$

Pulmonologist

Election Cycle-to-Date

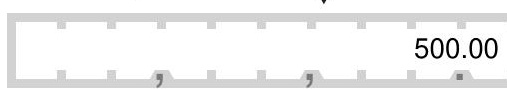

C. Full Name (Last, First, Middle Initial)

Robert Coughlin

Mailing Address 17985 Brownsferry Road

\begin{tabular}{lcc}
\hline City & State & Zip Code \\
Athens & AL & $35611-5604$
\end{tabular}

FEC ID number of contributing

federal political committee.

C

Name of Employer

Information Requested

Occupation

Information Requested

Receipt For: 2012

Х $\begin{aligned} & \text { Primary } \square \text { General } \\ & \text { Other (specify) }\end{aligned}$

Transaction ID : AEE297ED428FC47CD817

Date of Receipt

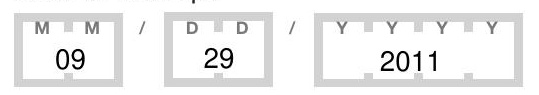

Amount of Each Receipt this Period

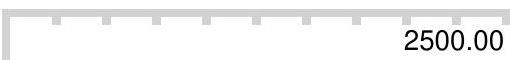

2500.00
Amount of Each Receipt this Period

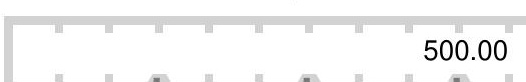

Transaction ID : A518B0DDC53CF4E319F9 Date of Receipt

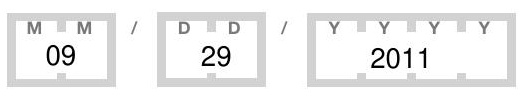

Transaction ID : AF33E3969E5D64668857 Date of Receipt

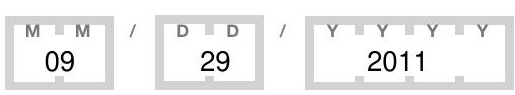

Amount of Each Receipt this Period

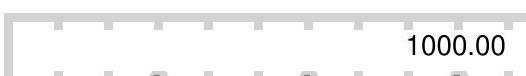

\section{Subtotal Of Receipts This Page (optional)}

4000.00

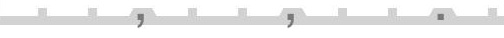

Total This Period (last page this line number only) 


\section{SCHEDULE A-P} ITEMIZED RECEIPTS
Use separate schedule(s)

for each category of the

Detailed Summary Page
FOR LINE NUMBER: (check only one)

Any information or for commercial purposes, other than using the name and address of any political committee to solicit contributions from such committee.

NAME OF COMMITTEE (In Full)

\section{Friends of Herman Cain}

A. Full Name (Last, First, Middle Initial)

Robert Schurr

Mailing Address 5014 Limerick Lane

\begin{tabular}{lcc}
\hline City & State & Zip Code \\
Flowery Branch & GA & $30542-6435$
\end{tabular}

FEC ID number of contributing

federal political committee.

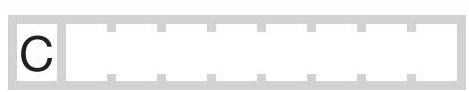

Name of Employer
Sound Image Media
Receipt For: 2012
X Primary
Other (specify) General

Occupation

Owner

Election Cycle-to-Date

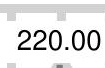

B. Full Name (Last, First, Middle Initial)

Richard Wise

Mailing Address 3615 Senna Way

\begin{tabular}{lcc}
\hline City & State & Zip Code \\
Grand Junction & CO & $81506-8496$
\end{tabular}

FEC ID number of contributing

federal political committee.

C

Name of Employer
Information Requested
Receipt For: 2012
Primary
Other (specify)

Occupation

Information Requested

Election Cycle-to-Date

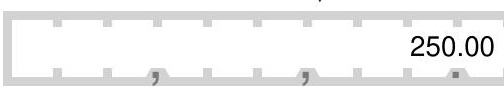

Transaction ID : A4E89081777C54149BF5

Date of Receipt

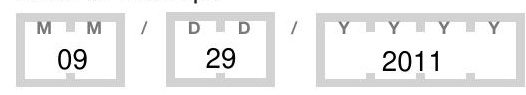

Amount of Each Receipt this Period

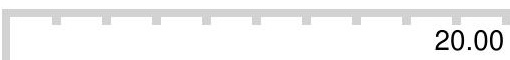

20.00

C. Full Name (Last, First, Middle Initial)

Deborah Zimmermann

Mailing Address 8884 Nichols Ave. Ext.

\begin{tabular}{lcc}
\hline City & State & Zip Code \\
Fairhope & AL & $36532-3602$
\end{tabular}

FEC ID number of contributing federal political committee.

C

36532-3602

Name of Employer
Information Requested
Receipt For: 2012
X Primary
Other (specify) General

Occupation

Information Requested

Election Cycle-to-Date
Transaction ID : A288BDB4C45F54091BC1

Date of Receipt

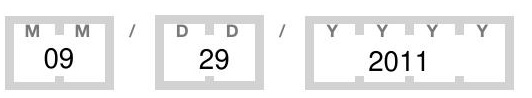

Amount of Each Receipt this Period

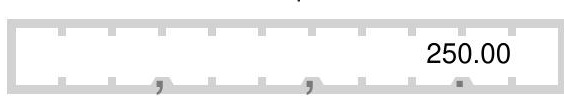

Transaction ID : A3382704208184A68B02

Date of Receipt

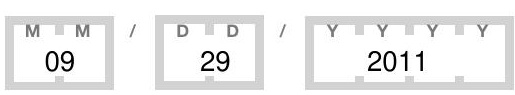

Amount of Each Receipt this Period

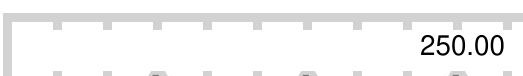

\section{Subtotal Of Receipts This Page (optional)}

Total This Period (last page this line number only) 


\section{SCHEDULE A-P} ITEMIZED RECEIPTS
Use separate schedule(s)

for each category of the

Detailed Summary Page
FOR LINE NUMBER: (check only one)

Any information or for commercial purposes, other than using the name and address of any political committee to solicit contributions from such committee.

NAME OF COMMITTEE (In Full)

Friends of Herman Cain

A. Full Name (Last, First, Middle Initial)

Michael Farrow

Mailing Address 3310 Dry Creek Road

\begin{tabular}{lcc}
\hline City & State & Zip Code \\
Healdsburg & CA & $95448-9187$ \\
\hline
\end{tabular}

FEC ID number of contributing

federal political committee.

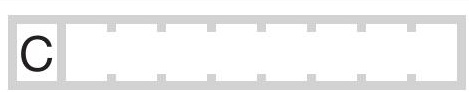

Name of Employer
Information Requested
Receipt For: 2012
X Primary $\quad \square$ General
Other (specify)

Occupation

Information Requested

Election Cycle-to-Date

500.00

B. Full Name (Last, First, Middle Initial)

Charles Neal

Mailing Address 24825 Eilat St.

\begin{tabular}{lcc}
\hline City & State & Zip Code \\
Woodland Hills & CA & $91367-1036$
\end{tabular}

FEC ID number of contributing

federal political committee.

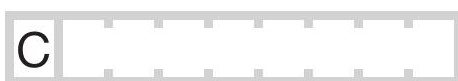

Name of Employer
Information Requested
Receipt For: 2012
X Primary
Other (specify)

Occupation

Information Requested

Election Cycle-to-Date

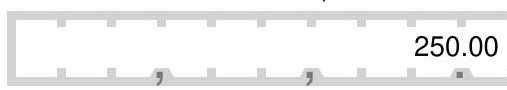

Transaction ID : A8954D1106BAE499C8CB

Date of Receipt

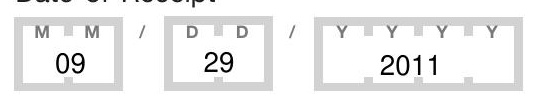

Amount of Each Receipt this Period

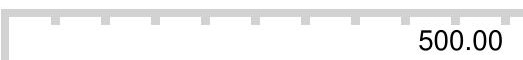

C. Full Name (Last, First, Middle Initial)

Nancy Snow

Mailing Address 1021 Main Street, \#2310

\begin{tabular}{lcc}
\hline City & State & Zip Code \\
Houston & TX & $77002-6506$
\end{tabular}

FEC ID number of contributing

federal political committee.

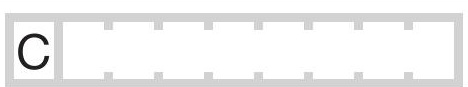

Name of Employer

Information Requested

Occupation

Information Requested

Receipt For: 2012

Х $\begin{aligned} & \text { Primary } \square \text { General } \\ & \text { Other (specify) }\end{aligned}$

Election Cycle-to-Date

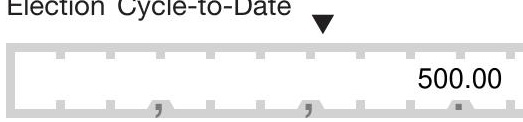

Amount of Each Receipt this Period

Transaction ID : A487B5261045247DB98E

Date of Receipt
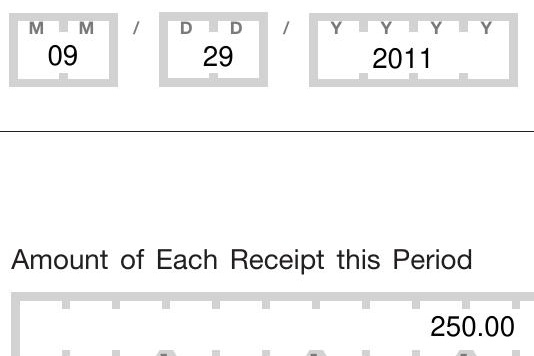

Transaction ID : A4E88B24C5D62457483A

Date of Receipt

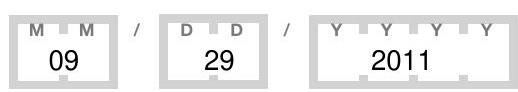

Amount of Each Receipt this Period

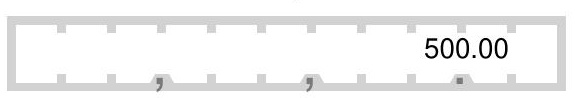

Subtotal Of Receipts This Page (optional).

1250.00

Total This Period (last page this line number only) 


\section{SCHEDULE A-P} ITEMIZED RECEIPTS
Use separate schedule(s) for each category of the Detailed Summary Page

FOR LINE NUMBER:
(check only one)

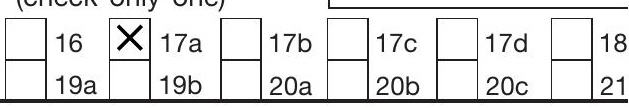

Any information copied from such Reports and Statements may not be sold or used by any person for the purpose of soliciting contributions or for commercial purposes, other than using the name and address of any political committee to solicit contributions from such committee.

NAME OF COMMITTEE (In Full)

\section{Friends of Herman Cain}

A. Full Name (Last, First, Middle Initial)

Dirk Leverant

Mailing Address 11435 N 73rd Way

\begin{tabular}{lcc}
\hline City & State & Zip Code \\
Scottsdale & AZ & $85260-5451$
\end{tabular}

FEC ID number of contributing federal political committee.

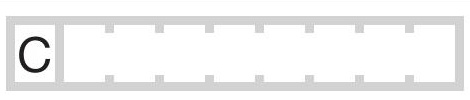

Name of Employer
Retired
Receipt For: 2012
X Primary
Other (specify) General

Occupation

Retired

Election Cycle-to-Date

350.00

B. Full Name (Last, First, Middle Initial)

Edmund Aleks

Mailing Address 9551 NE Southbeach Dr. \#2A

\begin{tabular}{llc}
\hline City & State & Zip Code \\
Bainbridge Island & WA & $98110-4822$
\end{tabular}

FEC ID number of contributing

federal political committee.

C

Name of Employer
Information Requested
Receipt For: 2012
X Primary
Other (specify)

Occupation

Information Requested

Election Cycle-to-Date

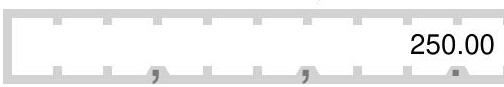

Transaction ID : A7BB98B13B50145EAA98

Date of Receipt

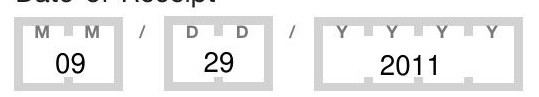

Amount of Each Receipt this Period

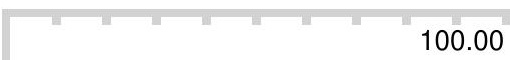

C. Full Name (Last, First, Middle Initial)

Henry Rakov

Mailing Address 2 Tavish Way

\begin{tabular}{lcc}
\hline City & State & Zip Code \\
Sandwich & MA & 02563-1888
\end{tabular}

FEC ID number of contributing federal political committee.

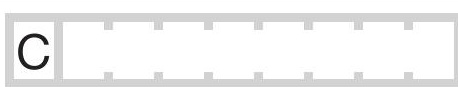

Name of Employer

Information Requested

Occupation

Information Requested

Receipt For: 2012

Х $\begin{aligned} & \text { Primary } \square \text { General } \\ & \text { Other (specify) }\end{aligned}$

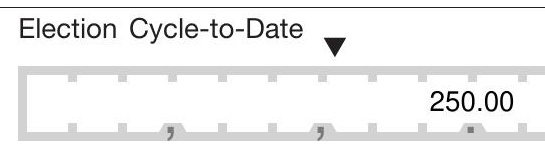

Amount of Each Receipt this Period

Transaction ID : AF0848DBF1A4D432BBD3 Date of Receipt
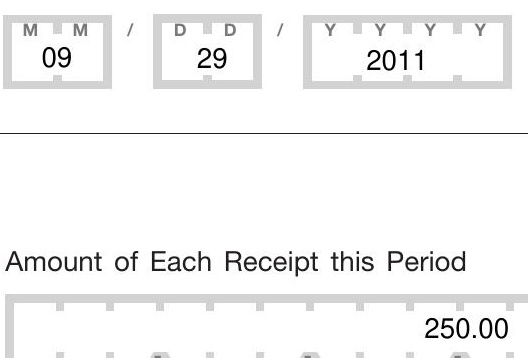

Transaction ID : A33C2E57951EE42B3A11 Date of Receipt

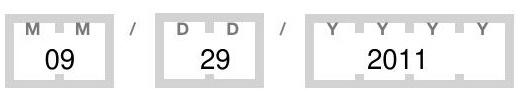

Amount of Each Receipt this Period

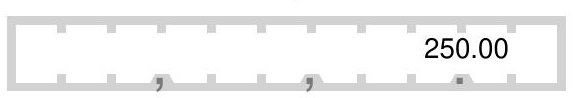

Subtotal Of Receipts This Page (optional)

600.00

Total This Period (last page this line number only) 


\section{SCHEDULE A-P} ITEMIZED RECEIPTS
Use separate schedule(s) for each category of the Detailed Summary Page

\begin{tabular}{|c|c|c|c|c|c|}
\hline \multicolumn{3}{|c|}{$\begin{array}{l}\text { FOR LINE NUMBER: } \\
\text { (check only one) }\end{array}$} & \multicolumn{3}{|c|}{ PAGE 1040 / 1572} \\
\hline 16 & $X$ 17a & $17 b$ & $17 \mathrm{c}$ & $17 d$ & 18 \\
\hline $19 a$ & $19 \mathrm{~b}$ & $20 a$ & $20 \mathrm{~b}$ & $20 c$ & 21 \\
\hline
\end{tabular}

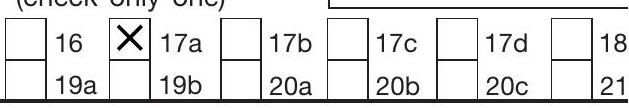

Any information copied from such Reports and Statements may not be sold or used by any person for the purpose of soliciting contributions or for commercial purposes, other than using the name and address of any political committee to solicit contributions from such committee.

NAME OF COMMITTEE (In Full)

\section{Friends of Herman Cain}

A. Full Name (Last, First, Middle Initial)

Margaret Vonder Hoya

Mailing Address 4401 Bordeaux Ave

\begin{tabular}{lcc}
\hline City & State & Zip Code \\
Dallas & TX & $75205-3620$ \\
\hline
\end{tabular}

FEC ID number of contributing federal political committee.

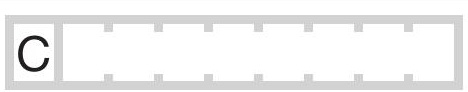

Name of Employer
Information Requested
Receipt For: 2012
X Primary
Other (specify) General

Occupation Information Requested

Election Cycle-to-Date 250.00

B. Full Name (Last, First, Middle Initial) Edward Davis

Mailing Address 8506 Crowley PI

\begin{tabular}{lcc}
\hline City & State & Zip Code \\
Alexandria & VA & $22308-1822$ \\
\hline
\end{tabular}

FEC ID number of contributing

federal political committee.

C

Name of Employer
Information Requested
Receipt For: 2012
Primary
Other (specify)

Occupation

Information Requested

Election Cycle-to-Date

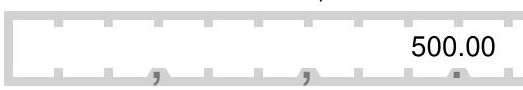

C. Full Name (Last, First, Middle Initial)

Daniel Forsyth

Mailing Address 4320 Deep Springs Ct

\begin{tabular}{lcc}
\hline City & State & Zip Code \\
Kennesaw & GA & $30144-5130$
\end{tabular}

FEC ID number of contributing federal political committee.

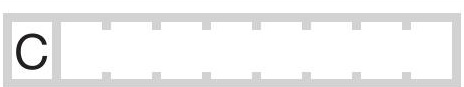

Name of Employer

Deep Springs Enterprises

Receipt For: 2012

Х $\begin{aligned} & \text { Primary } \\ & \text { Other (specify) }\end{aligned}$

\section{Occupation}

Consulting

Election Cycle-to-Date
Transaction ID : A39FDB8C941224D56984

Date of Receipt

Amount of Each Receipt this Period

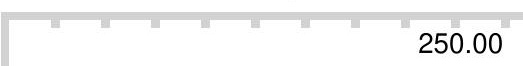

250.00

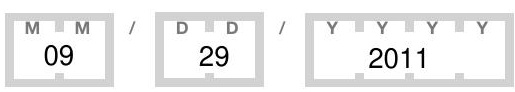

Amount of Each Receipt this Period

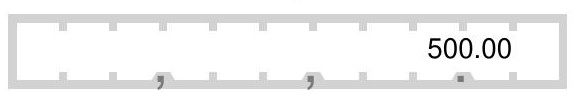

Transaction ID : A74B6E33EB8A64743ADB Date of Receipt

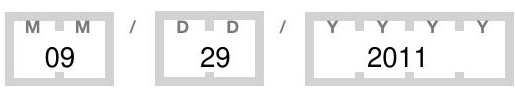

Amount of Each Receipt this Period

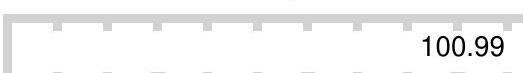

100.99

Subtotal Of Receipts This Page (optional).

Total This Period (last page this line number only) 


\section{SCHEDULE A-P} ITEMIZED RECEIPTS
Use separate schedule(s) for each category of the Detailed Summary Page

\begin{tabular}{|c|c|c|c|c|c|}
\hline \multicolumn{3}{|c|}{$\begin{array}{l}\text { FOR LINE NUMBER: } \\
\text { (check only one) }\end{array}$} & \multicolumn{3}{|c|}{ PAGE 1041 / 1572} \\
\hline 16 & $X$ 17a & $17 b$ & $17 \mathrm{c}$ & $17 d$ & 18 \\
\hline $19 a$ & $19 \mathrm{~b}$ & $20 a$ & $20 \mathrm{~b}$ & $20 c$ & 21 \\
\hline
\end{tabular}

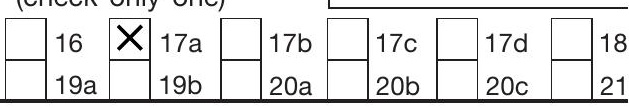

Any information copied from such Reports and Statements may not be sold or used by any person for the purpose of soliciting contributions or for commercial purposes, other than using the name and address of any political committee to solicit contributions from such committee.

NAME OF COMMITTEE (In Full)

\section{Friends of Herman Cain}

A. Full Name (Last, First, Middle Initial)

Michael Martin

Mailing Address 4266 Green Valley Dr

\begin{tabular}{lcc}
\hline City & State & Zip Code \\
Gainesville & GA & $30506-4600$
\end{tabular}

FEC ID number of contributing federal political committee.

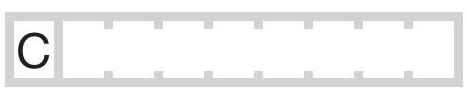

Name of Employer
Information Requested
Receipt For: 2012
X Primary
$\square$ Other (specify)

Occupation Information Requested

Election Cycle-to-Date 250.00

B. Full Name (Last, First, Middle Initial) Tazwell Butler

Mailing Address 410 Cardigan Cir SW

\begin{tabular}{lcc}
\hline City & State & Zip Code \\
Lilburn & GA & $30047-2114$
\end{tabular}

FEC ID number of contributing

federal political committee.

C

\begin{tabular}{l} 
Name of Employer \\
Powerhouse Electric Service \\
Receipt For: 2012 \\
Primary \\
\hline Other (specify)
\end{tabular}

Occupation

Electrical Technician

Election Cycle-to-Date

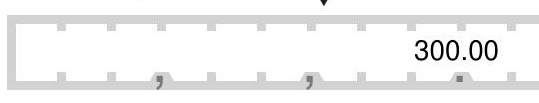

C. Full Name (Last, First, Middle Initial)

Jeff Van Dyke

Mailing Address 10001 San Bernardino Dr NE

\begin{tabular}{lcc}
\hline City & State & Zip Code \\
Albuquerque & NM & $87122-3210$
\end{tabular}

FEC ID number of contributing federal political committee.

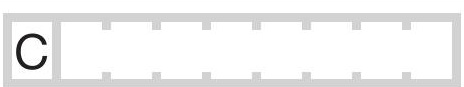

Name of Employer
Information Requested
Receipt For: 2012
Primary
Other (specify) General

Transaction ID : A8B1FAF4CCEE74C11A5A

Date of Receipt

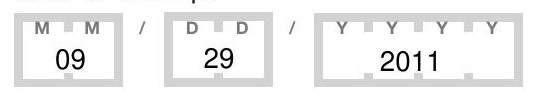

Amount of Each Receipt this Period

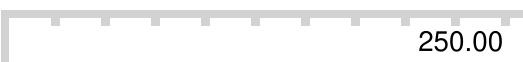

250.00
Amount of Each Receipt this Period

Transaction ID : AE8966C84DA3F4954AC7 Date of Receipt
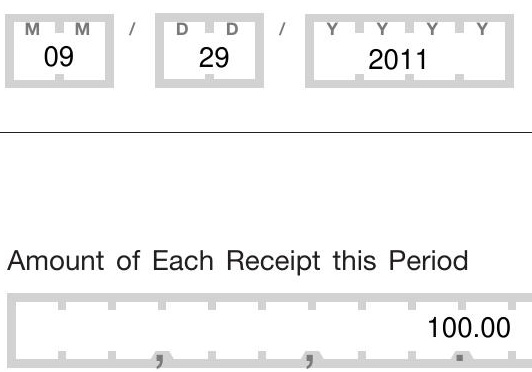

Transaction ID : AF039B85B18364FC5B5D Date of Receipt

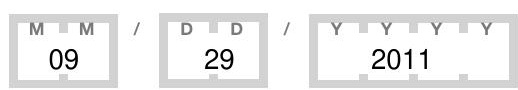

Amount of Each Receipt this Period

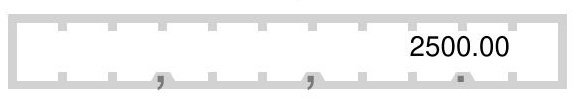

$$
\begin{aligned}
& \begin{array}{l}
\text { Occupation } \\
\text { Information Requested }
\end{array} \\
& \text { Election Cycle-to-Date }
\end{aligned}
$$

\section{Subtotal Of Receipts This Page (optional)}

Total This Period (last page this line number only) 


\section{SCHEDULE A-P} ITEMIZED RECEIPTS
Use separate schedule(s)

for each category of the

Detailed Summary Page
FOR LINE NUMBER: (check only one)

Any information or for commercial purposes, other than using the name and address of any political committee to solicit contributions from such committee.

NAME OF COMMITTEE (In Full)

Friends of Herman Cain

A. Full Name (Last, First, Middle Initial)

Nancy McKee

Mailing Address 339 Springhill Road

\begin{tabular}{lcc}
\hline City & State & Zip Code \\
Huntsville & AL & $35806-1735$
\end{tabular}

FEC ID number of contributing

federal political committee.

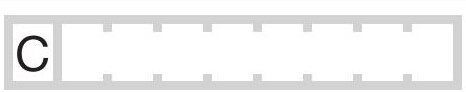

Name of Employer

The Aussie Pouch Company Inc.

Occupation

BUSINESS OWNER

Receipt For: 2012

X Primary $\square$ General Other (specify)

Election Cycle-to-Date

900.00

B. Full Name (Last, First, Middle Initial) susan wolfe

Mailing Address 2605 chimney springs drive

\begin{tabular}{lcc}
\hline City & State & Zip Code \\
Marietta & GA & $30062-6318$
\end{tabular}

FEC ID number of contributing

federal political committee.

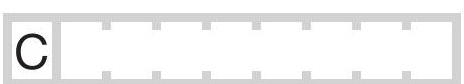

Name of Employer
n/a
Receipt For: 2012
X Primary
Other (specify)

\section{Occupation}

N/A

Election Cycle-to-Date

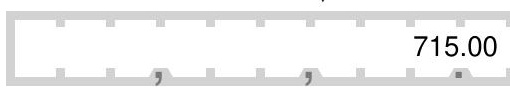

Transaction ID : A243C02425640484DA9D

Date of Receipt

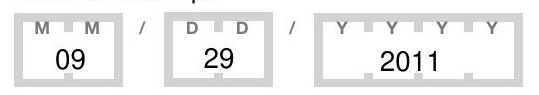

Amount of Each Receipt this Period

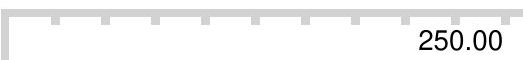

Transaction ID : AB51FF628B37847FDBF3

Date of Receipt

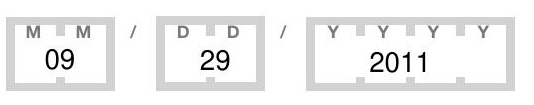

Amount of Each Receipt this Period

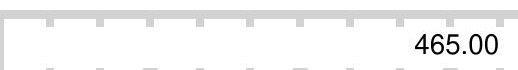

Transaction ID : A3E52F904DCC047AFB59 Date of Receipt

Lord Henry

Mailing Address 5903 Port Anadarko Trl

\begin{tabular}{lcc}
\hline City & State & Zip Code \\
Hermitage & TN & $37076-3234$
\end{tabular}

FEC ID number of contributing federal political committee.

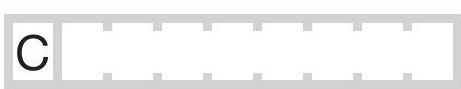

Name of Employer

Information Requested

Occupation

Information Requested

Receipt For: 2012

Х $\begin{aligned} & \text { Primary } \square \text { General } \\ & \text { Other (specify) }\end{aligned}$

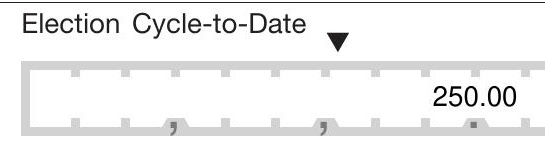

Amount of Each Receipt this Period

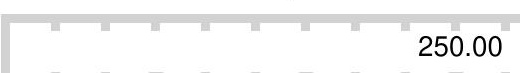

250.00

Subtotal Of Receipts This Page (optional)

965.00

Total This Period (last page this line number only) 
SCHEDULE A-P ITEMIZED RECEIPTS
Use separate schedule(s) for each category of the Detailed Summary Page
FOR LINE NUMBER: (check only one)

Any information or for commercial purposes, other than using the name and address of any political committee to solicit contributions from such committee.

NAME OF COMMITTEE (In Full)

Friends of Herman Cain

A. Full Name (Last, First, Middle Initial)

Susan Walter

Mailing Address P.O. Box 690

\begin{tabular}{lcc}
\hline City & State & Zip Code \\
Sautee Nacoochee & GA & $30571-0690$
\end{tabular}

FEC ID number of contributing federal political committee.

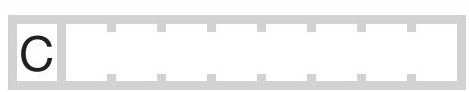

Name of Employer
None
Receipt For: 2012
X Primary $\quad$ General
Other (specify)

Occupation

Retired

Election Cycle-to-Date

2697.00

B. Full Name (Last, First, Middle Initial)

Kandy Clements

Mailing Address 325 General Cavazos Blvd

\begin{tabular}{lcc}
\hline City & State & Zip Code \\
Kingsville & TX & $78363-7203$ \\
\hline
\end{tabular}

FEC ID number of contributing

federal political committee.

C

Name of Employer
Information Requested
Receipt For: 2012
X Primary
Other (specify)

Occupation

Information Requested

Election Cycle-to-Date

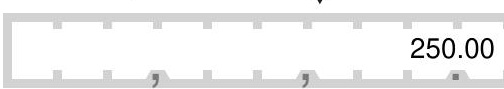

Transaction ID : A7E457030819B4EA2AAF

Date of Receipt

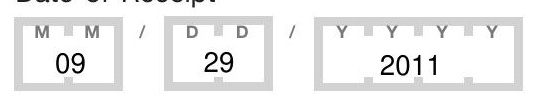

Amount of Each Receipt this Period

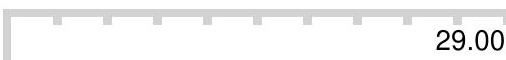

29.00

C. Full Name (Last, First, Middle Initial)

Brian Tolefree

Mailing Address 1136 E 1284 Rd

\begin{tabular}{lcc}
\hline City & State & Zip Code \\
Lawrence & KS & $66047-9200$
\end{tabular}

FEC ID number of contributing federal political committee.

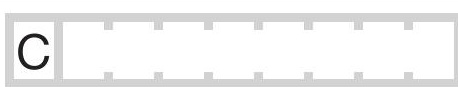

Name of Employer

Information Requested

\section{Occupation}

Information Requested

Receipt For: 2012

Х $\begin{aligned} & \text { Primary } \square \text { General } \\ & \text { Other (specify) }\end{aligned}$

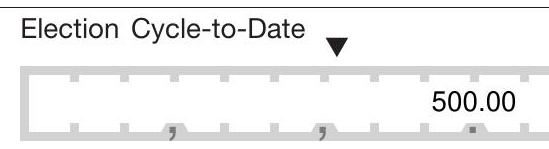

Amount of Each Receipt this Period

Transaction ID : A23D4DAF4A83548E89FC

Date of Receipt
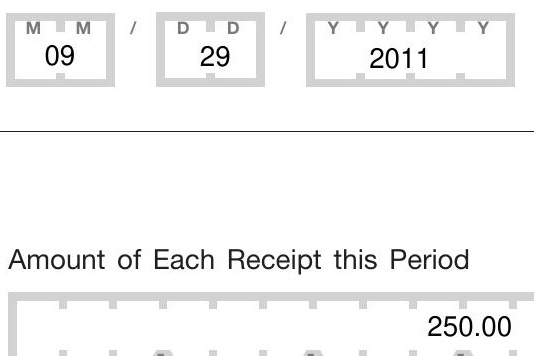

Transaction ID : A50D131184DCA41FFA96 Date of Receipt

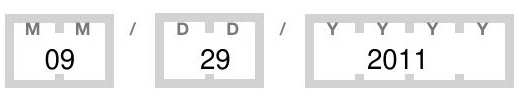

Amount of Each Receipt this Period

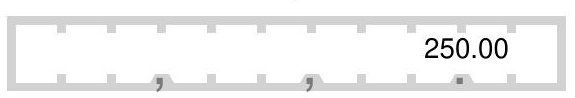

Subtotal Of Receipts This Page (optional)

529.00

Total This Period (last page this line number only) 


\section{SCHEDULE A-P} ITEMIZED RECEIPTS
Use separate schedule(s)

for each category of the

Detailed Summary Page
FOR LINE NUMBER: (check only one)

Any information or for commercial purposes, other than using the name and address of any political committee to solicit contributions from such committee.

NAME OF COMMITTEE (In Full)

Friends of Herman Cain

A. Full Name (Last, First, Middle Initial)

Jurdon Lewis

Mailing Address 20 Calabria Ave Apt 303

\begin{tabular}{lcc}
\hline City & State & Zip Code \\
Coral Gables & FL & $33134-3106$
\end{tabular}

FEC ID number of contributing

federal political committee.

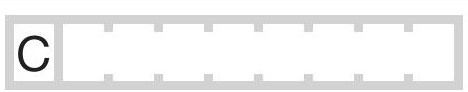

Name of Employer
Information Requested
Receipt For: 2012
X Primary $\quad \square$ General
Other (specify)

Occupation

Information Requested

Election Cycle-to-Date

250.00

B. Full Name (Last, First, Middle Initial)

John Fierke

Mailing Address 10 Wildlife $\mathrm{Dr}$

\begin{tabular}{lcc}
\hline City & State & Zip Code \\
Hopkinton & MA & $01748-2649$ \\
\hline
\end{tabular}

FEC ID number of contributing

federal political committee.

C

Name of Employer
Information Requested
Receipt For: 2012
X Primary
Other (specify)

Occupation

Information Requested

Election Cycle-to-Date

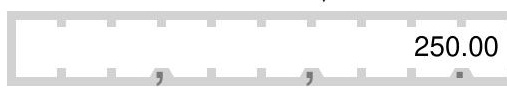

Transaction ID : ADE413953224C456C9C5

Date of Receipt

Amount of Each Receipt this Period
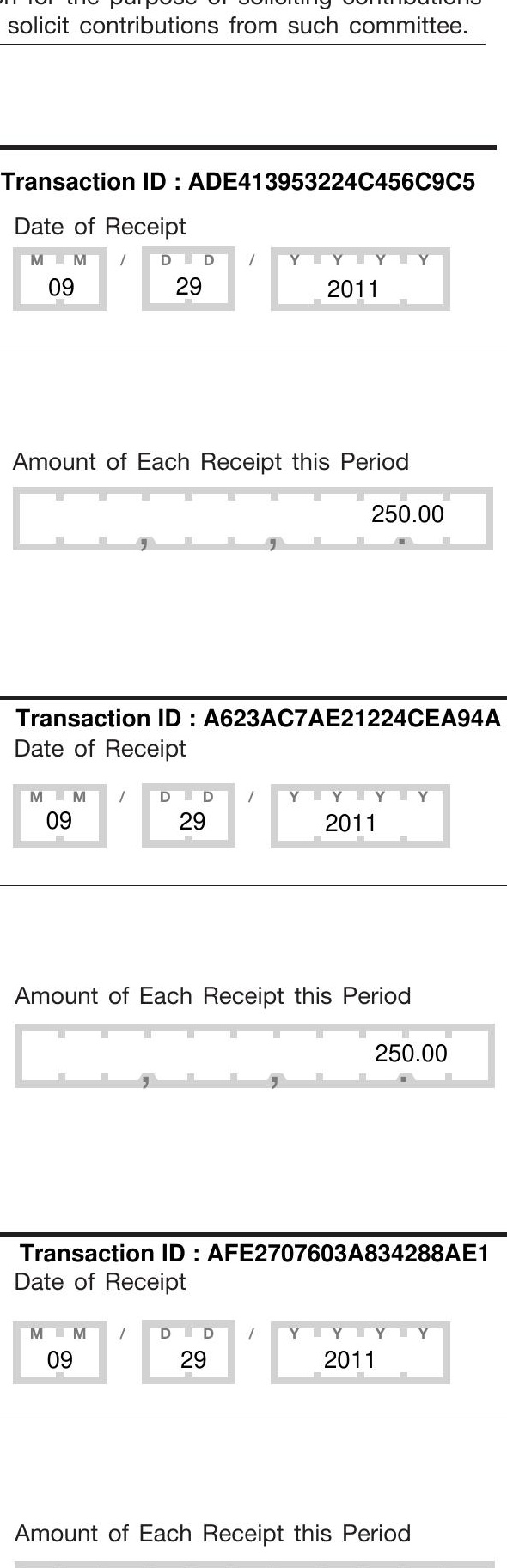

Amount of Each Receipt this Period

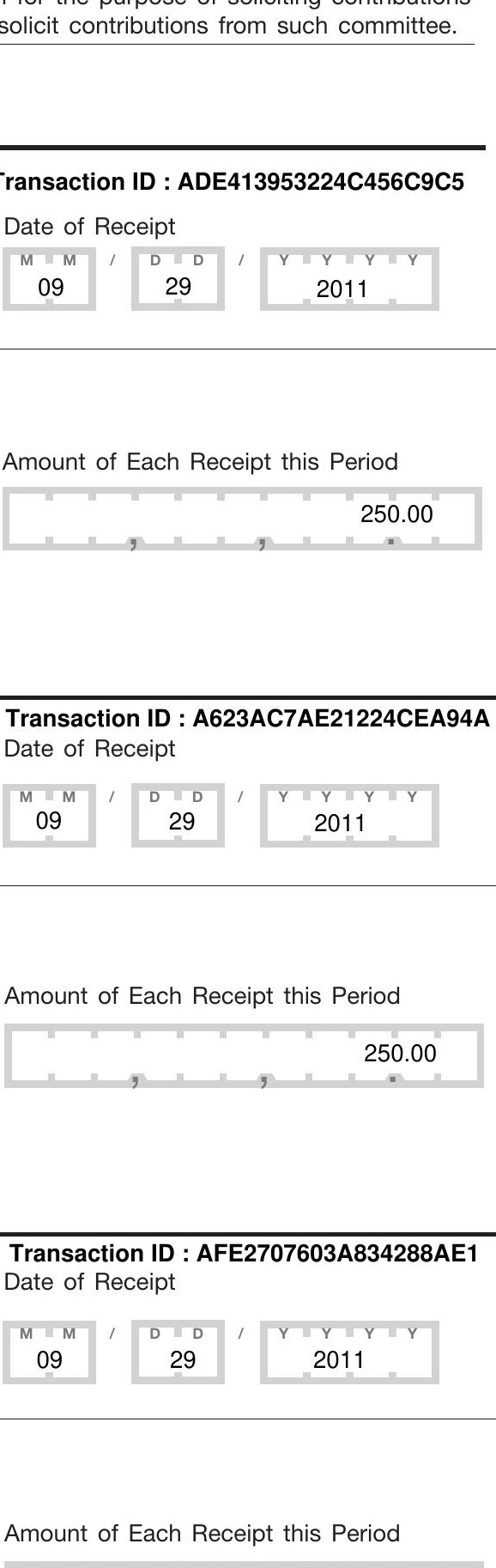

C. Full Name (Last, First, Middle Initial)

Michael Kimball

Mailing Address 937 Mount Vernon Place

\begin{tabular}{lcc}
\hline City & State & Zip Code \\
Manteca & CA & $95336-3779$
\end{tabular}

FEC ID number of contributing

federal political committee.

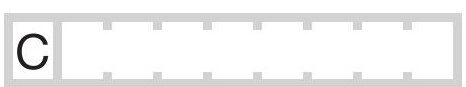

Name of Employer

Information Requested

Occupation

Information Requested

Receipt For: 2012

X Primary $\square$ General

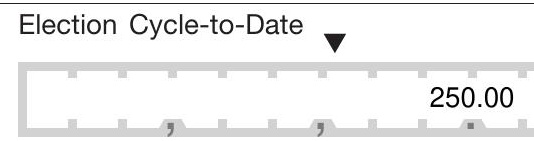

Amount of Each Receipt this Period

Transaction ID : A623AC7AE21224CEA94A

Date of Receipt
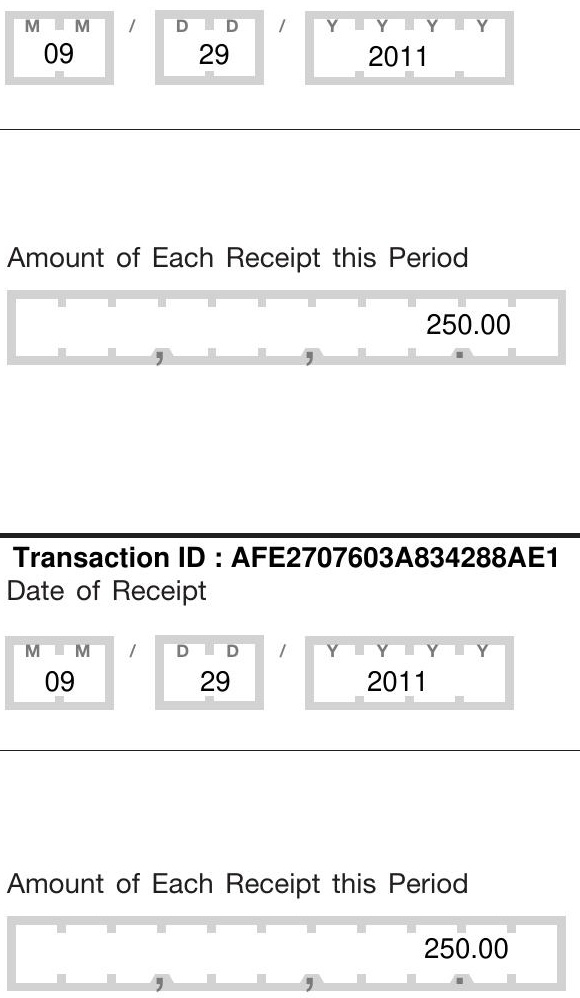

Subtotal Of Receipts This Page (optional).

750.00

Total This Period (last page this line number only) 


\section{SCHEDULE A-P} ITEMIZED RECEIPTS
Use separate schedule(s) for each category of the Detailed Summary Page
FOR LINE NUMBER: (check only one)

Any information or for commercial purposes, other than using the name and address of any political committee to solicit contributions from such committee.

NAME OF COMMITTEE (In Full)

Friends of Herman Cain

A. Full Name (Last, First, Middle Initial)

Lawrence MacCormack

Mailing Address 1020 Bixby Dr. \#136

City $\quad$ State $\quad$ Zip Code

Saint Augustine

$\mathrm{FL} \quad 32084$

FEC ID number of contributing

federal political committee.

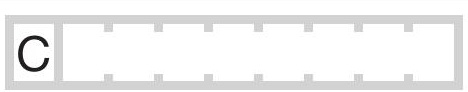

Name of Employer
Information Requested
Receipt For: 2012
X Primary $\quad \square$ General
Other (specify)

Occupation

Information Requested

Election Cycle-to-Date

300.00

B. Full Name (Last, First, Middle Initial)

Judith Gallagher

Mailing Address 2414 Westmoreland

\begin{tabular}{lcc}
\hline City & State & Zip Code \\
Red Oak & TX & $75154-5816$
\end{tabular}

FEC ID number of contributing

federal political committee.

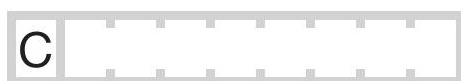

\begin{tabular}{l} 
Name of Employer \\
Information Requested \\
Receipt For: 2012 \\
X Primary \\
\hline Other (specify)
\end{tabular}

Occupation

Information Requested

Election Cycle-to-Date

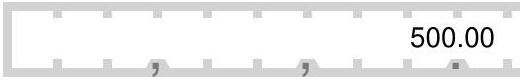

C. Full Name (Last, First, Middle Initial)

Walter Gleba

Mailing Address 225 Moir Avenue

\begin{tabular}{lcc}
\hline City & State & Zip Code \\
Conshohocken & PA & $19428-2845$
\end{tabular}

FEC ID number of contributing federal political committee.

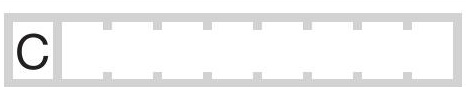

Name of Employer

Information Requested

Occupation

Information Requested

Receipt For: 2012

Х $\begin{aligned} & \text { Primary } \square \text { General } \\ & \text { Other (specify) }\end{aligned}$

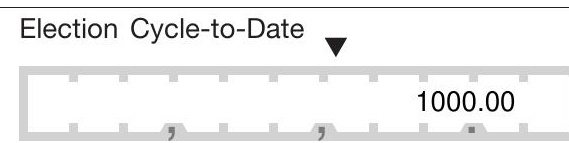

Amount of Each Receipt this Period

Transaction ID : A350B28A2F6204B99A60

Date of Receipt

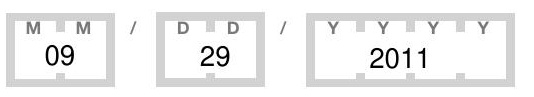

Amount of Each Receipt this Period
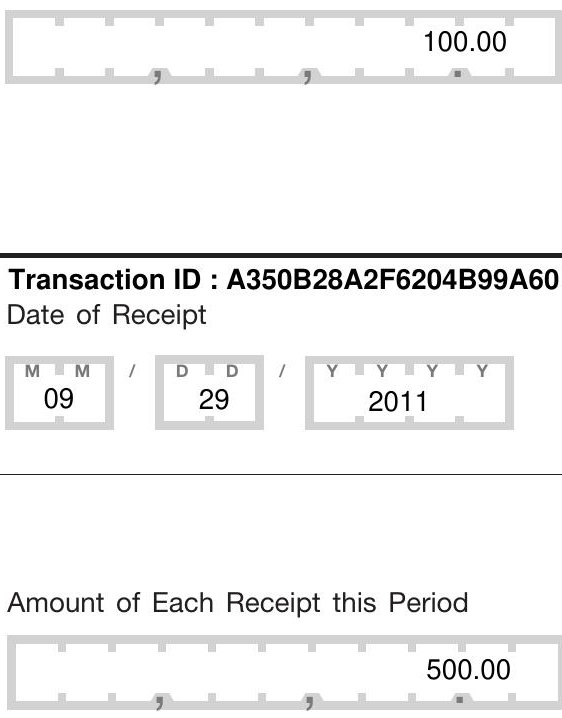

Transaction ID : A14728021C4ED43FE9F9

Date of Receipt

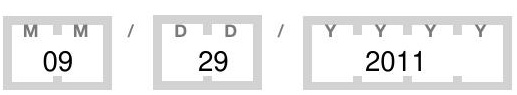

Amount of Each Receipt this Period

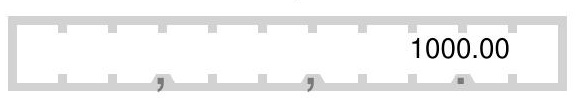

Subtotal Of Receipts This Page (optional).

1600.00

Total This Period (last page this line number only) 


\section{SCHEDULE A-P} ITEMIZED RECEIPTS
Use separate schedule(s)

for each category of the

Detailed Summary Page
FOR LINE NUMBER: (check only one)

Any information or for commercial purposes, other than using the name and address of any political committee to solicit contributions from such committee.

NAME OF COMMITTEE (In Full)

\section{Friends of Herman Cain}

A. Full Name (Last, First, Middle Initial)

Donald J Ewing

Mailing Address 13 Hawk Ridge Rd.

\begin{tabular}{lcc}
\hline City & State & Zip Code \\
Meredith & $\mathrm{NH}$ & $03253-5625$
\end{tabular}

FEC ID number of contributing

federal political committee.

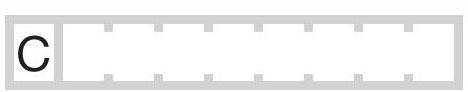

Name of Employer
Retired
Receipt For: 2012
X Primary $\square$ General
$\square$ Other (specify)

Occupation

Retired

Election Cycle-to-Date

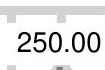

B. Full Name (Last, First, Middle Initial)

Douglas Franquemont

Mailing Address 14630 Raton Road

\begin{tabular}{lcc}
\hline City & State & Zip Code \\
Colorado Springs & CO & $80921-2926$
\end{tabular}

FEC ID number of contributing

federal political committee.

C

Name of Employer
Information Requested
Receipt For: 2012
X Primary
Other (specify)

Occupation

Information Requested

Election Cycle-to-Date

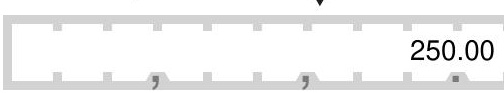

Transaction ID : AA9B25BDF185D4EA4A75

Date of Receipt

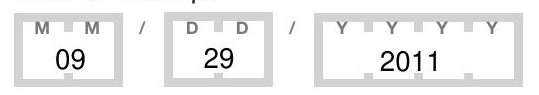

Amount of Each Receipt this Period

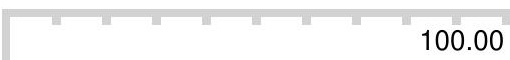

Amount of Each Receipt this Period

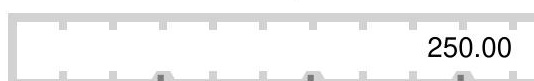

C. Full Name (Last, First, Middle Initial)

John Dobrott

Mailing Address 228 Via Orvieto johndobrott@hotmai

\begin{tabular}{lcc}
\hline City & State & Zip Code \\
Newport Beach & CA & 92663 \\
\hline
\end{tabular}

FEC ID number of contributing

federal political committee.

C

Name of Employer
Information Requested
Receipt For: 2012
X Primary
Other (specify) General

\section{Occupation}

Information Requested

Election Cycle-to-Date

Transaction ID : ACD761532FDC14C90AC9

Date of Receipt
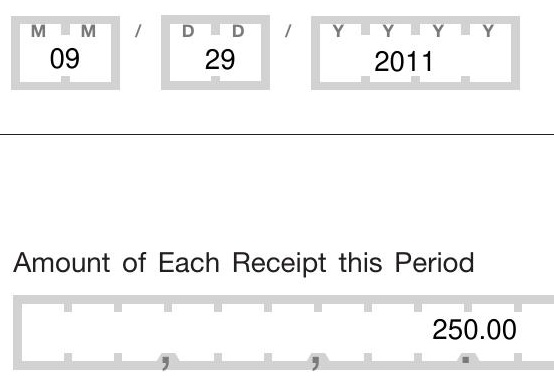

Transaction ID : AA2AB99FCC01F43EC908 Date of Receipt

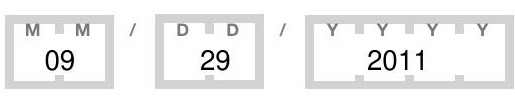

Amount of Each Receipt this Period

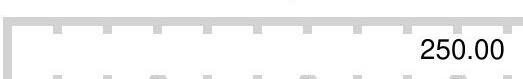

250.00

Subtotal Of Receipts This Page (optional).

600.00

ㄱ․․

Total This Period (last page this line number only)

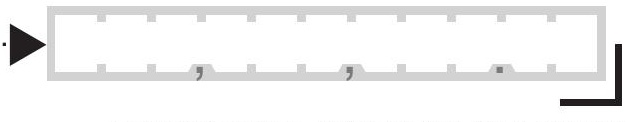

FEC Schedule A-P (Form 3P) (Rev. 03/2011) 


\section{SCHEDULE A-P} ITEMIZED RECEIPTS
Use separate schedule(s) for each category of the Detailed Summary Page
FOR LINE NUMBER: (check only one)
PAGE 1047 / 1572

\begin{tabular}{|c|c|c|c|c|c|}
\hline & & & & & \\
\hline 16 & $\begin{array}{ll}\mathbf{X} & 17 a \\
\end{array}$ & $17 \mathrm{~b}$ & $17 c$ & $17 d$ & 18 \\
\hline $19 a$ & $19 b$ & $20 \mathrm{a}$ & $20 \mathrm{~b}$ & $20 c$ & 21 \\
\hline
\end{tabular}

Any information copied from such Reports and Statements may not be sold or used by any person for the purpose of soliciting contributions or for commercial purposes, other than using the name and address of any political committee to solicit contributions from such committee.

NAME OF COMMITTEE (In Full)

Friends of Herman Cain

A. Full Name (Last, First, Middle Initial)

Lauren Schulz

Mailing Address PO Box 84

\begin{tabular}{lcc}
\hline City & State & Zip Code \\
Delta Junction & AK & $99737-0084$
\end{tabular}

FEC ID number of contributing

federal political committee.

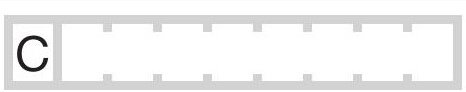

Name of Employer
Information Requested
Receipt For: 2012
X Primary $\quad \square$ General
Other (specify)

Occupation

Information Requested

Election Cycle-to-Date

250.00

B. Full Name (Last, First, Middle Initial)

larry mccoy

Mailing Address 141 indian hills dr

\begin{tabular}{lcc}
\hline City & State & Zip Code \\
Clarksville & TN & $37043-4434$ \\
\hline
\end{tabular}

FEC ID number of contributing

federal political committee.

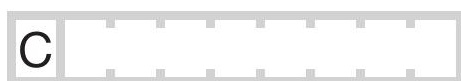

Name of Employer
Self Employed
Receipt For: 2012
X Primary
Other (specify)

Occupation

Subcontractor

Election Cycle-to-Date

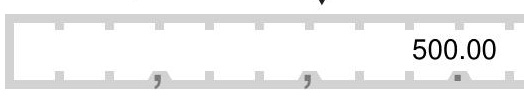

Transaction ID : A4B046D50E9D5484CA45

Date of Receipt

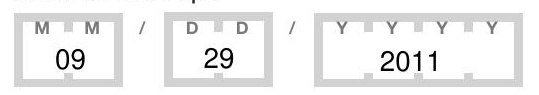

Amount of Each Receipt this Period

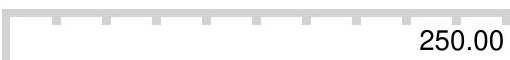

Amount of Each Receipt this Period

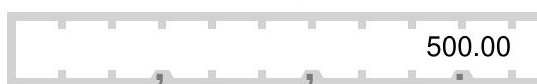

C. Full Name (Last, First, Middle Initial)

Darren Magness

Mailing Address 3938 Surfside Blvd. \#3312

\begin{tabular}{lcc}
\hline City & State & Zip Code \\
Corpus Christi & TX & $78402-1453$
\end{tabular}

FEC ID number of contributing

federal political committee.

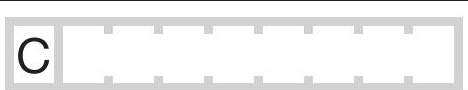

Name of Employer

Information Requested

Occupation

Information Requested

Receipt For: 2012

Х $\begin{aligned} & \text { Primary } \square \text { General } \\ & \text { Other (specify) }\end{aligned}$

Election Cycle-to-Date

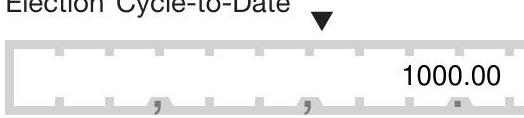

Transaction ID : ACDEBA97EF6894600971

Date of Receipt

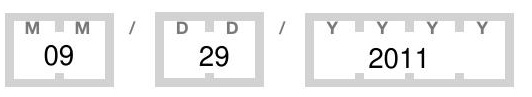

Transaction ID : AB3623A80EEB94DFD94F Date of Receipt

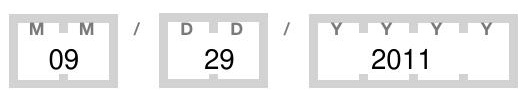

Amount of Each Receipt this Period

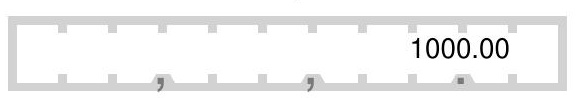

Subtotal Of Receipts This Page (optional).

1750.00

Total This Period (last page this line number only) 


\section{SCHEDULE A-P} ITEMIZED RECEIPTS
Use separate schedule(s) for each category of the Detailed Summary Page

FOR LINE NUMBER:
(check only one)

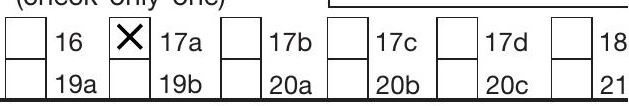

Any information copied from such Reports and Statements may not be sold or used by any person for the purpose of soliciting contributions or for commercial purposes, other than using the name and address of any political committee to solicit contributions from such committee.

NAME OF COMMITTEE (In Full)

\section{Friends of Herman Cain}

A. Full Name (Last, First, Middle Initial) Kenneth Fleming

Mailing Address 6244 Clay Hill Court

\begin{tabular}{lcc}
\hline City & State & Zip Code \\
Gainesville & VA & $20155-6627$
\end{tabular}

FEC ID number of contributing federal political committee.

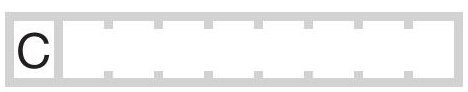

Name of Employer
Information Requested
Receipt For: 2012
X Primary
$\square$ Other (specify)

Occupation Information Requested

Election Cycle-to-Date

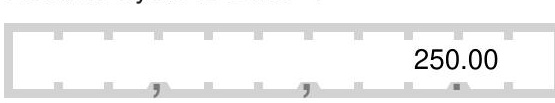

B. Full Name (Last, First, Middle Initial)

Karen Foster

Mailing Address 3179 LaVista Rd.

\begin{tabular}{lcc}
\hline City & State & Zip Code \\
Decatur & GA & $30033-1434$ \\
\hline
\end{tabular}

FEC ID number of contributing

federal political committee.

C

Name of Employer
Self-Employed
Receipt For: 2012
Xrimary
Other (specify)

Occupation medical editor

Election Cycle-to-Date

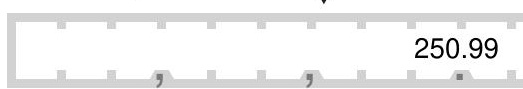

Transaction ID : A5C794B10746E4FE2A09

Date of Receipt

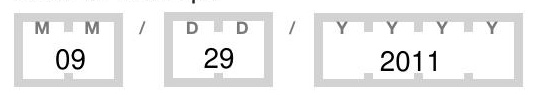

Amount of Each Receipt this Period

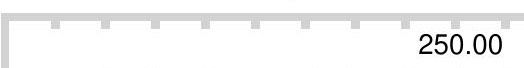

C. Full Name (Last, First, Middle Initial)

Sue Browning

Mailing Address 5017 Waple Ln

\begin{tabular}{lcc}
\hline City & State & Zip Code \\
Alexandria & VA & $22304-7727$
\end{tabular}

FEC ID number of contributing federal political committee.

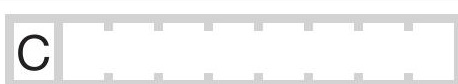

\section{Name of Employer}

Self-Employed

Receipt For: 2012

Х $\begin{aligned} & \text { Primary } \square \text { General } \\ & \text { Other (specify) }\end{aligned}$
Amount of Each Receipt this Period

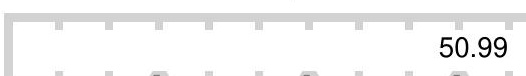

Transaction ID : AA2899C0796EE411FA96 Date of Receipt

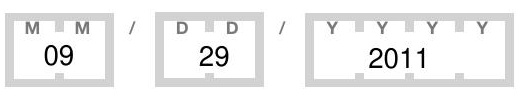

Transaction ID : A12033F4771C04524A36 Date of Receipt

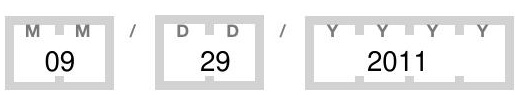

Amount of Each Receipt this Period

600.00

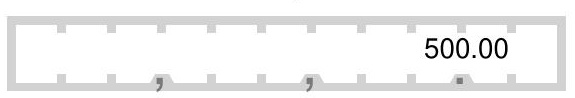

Subtotal Of Receipts This Page (optional)

800.99

a 1 ,

Total This Period (last page this line number only)

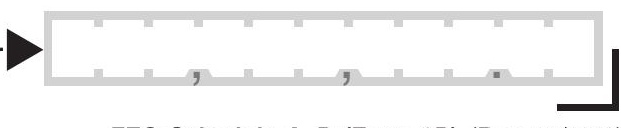

FEC Schedule A-P (Form 3P) (Rev. 03/2011) 


\section{SCHEDULE A-P} ITEMIZED RECEIPTS
Use separate schedule(s) for each category of the Detailed Summary Page

FOR LINE NUMBER:
(check only one)

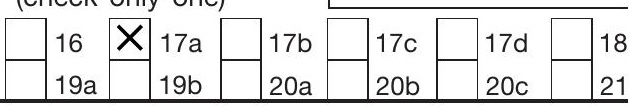

Any information copied from such Reports and Statements may not be sold or used by any person for the purpose of soliciting contributions or for commercial purposes, other than using the name and address of any political committee to solicit contributions from such committee.

NAME OF COMMITTEE (In Full)

\section{Friends of Herman Cain}

A. Full Name (Last, First, Middle Initial)

Mark Smith

Mailing Address 22952 Bolender Pontius

\begin{tabular}{lcc}
\hline City & State & Zip Code \\
Circleville & OH & $43113-9040$
\end{tabular}

FEC ID number of contributing federal political committee.

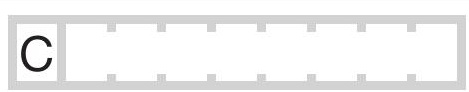

Name of Employer
Information Requested
Receipt For: 2012
X Primary
Other (specify) General

Occupation Information Requested

Election Cycle-to-Date

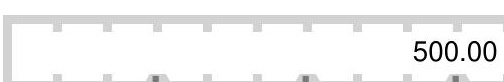

B. Full Name (Last, First, Middle Initial)

Michael R Murphy

Mailing Address 128 Beau Vista Rd

\begin{tabular}{lcc}
\hline City & State & Zip Code \\
Natchitoches & LA & $71457-1511$
\end{tabular}

FEC ID number of contributing

federal political committee.

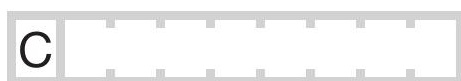

\begin{tabular}{l} 
Name of Employer \\
Information Requested \\
Receipt For: 2012 \\
X Primary \\
\hline Other (specify)
\end{tabular}

Occupation

Information Requested

Election Cycle-to-Date

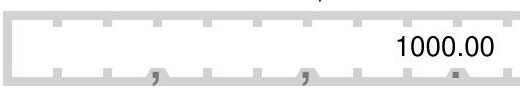

C. Full Name (Last, First, Middle Initial)

Jeffrey Stubbe

Mailing Address 902 Pintail Lane

\begin{tabular}{lcc}
\hline City & State & Zip Code \\
Wausau & WI & $54401-7141$
\end{tabular}

FEC ID number of contributing federal political committee.

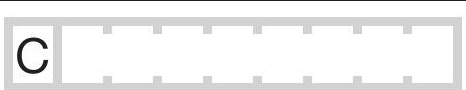

Name of Employer
WIPFLI LLP
Receipt For: 2012
Х Primary $\square$ General
Other (specify)

\section{Occupation}

CPA

Election Cycle-to-Date

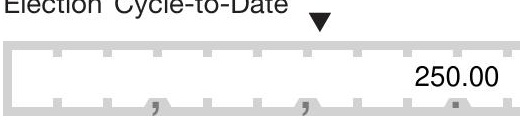

Transaction ID : A09A21FAF04AB466AB3B

Date of Receipt

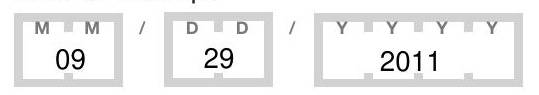

Amount of Each Receipt this Period

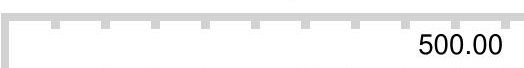

500.00

Transaction ID : AFF8FA0C53AFA44E798A

Date of Receipt

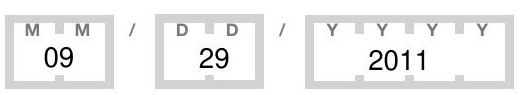

Amount of Each Receipt this Period

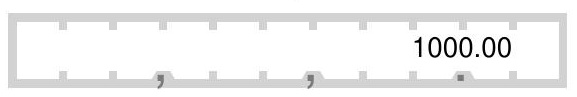

Transaction ID : A5F1B5C6501D040FCB32 Date of Receipt

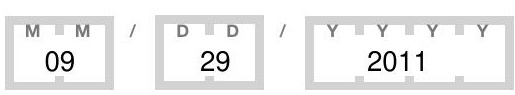

Amount of Each Receipt this Period

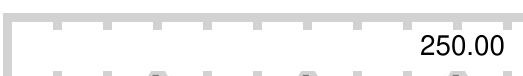

\section{Subtotal Of Receipts This Page (optional).}

Total This Period (last page this line number only) 


\section{SCHEDULE A-P} ITEMIZED RECEIPTS
Use separate schedule(s)

for each category of the

Detailed Summary Page
FOR LINE NUMBER: (check only one)

Any information copion the purpose of soliciting contributions or for commercial purposes, other than using the name and address of any political committee to solicit contributions from such committee.

NAME OF COMMITTEE (In Full)

Friends of Herman Cain

A. Full Name (Last, First, Middle Initial)

Christopher Hylen

Mailing Address 1254 Lachman Lane

\begin{tabular}{lcc}
\hline City & State & Zip Code \\
Pacific Palisades & CA & $90272-2257$
\end{tabular}

FEC ID number of contributing

federal political committee.

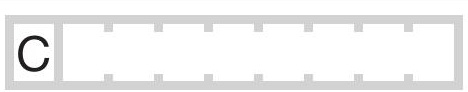

Name of Employer
Information Requested
Receipt For: 2012
X Primary $\quad \square$ General
Other (specify)

Occupation

Information Requested

Election Cycle-to-Date

250.00

B. Full Name (Last, First, Middle Initial)

John Fuller

Mailing Address 14023 Bently Cir

\begin{tabular}{lcc}
\hline City & State & Zip Code \\
Fort Myers & FL & $33912-1990$ \\
\hline
\end{tabular}

FEC ID number of contributing

federal political committee.

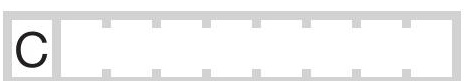

Name of Employer
Naples Air Inc
Receipt For: 2012
X Primary
Other (specify)

\section{Occupation}

Pilot

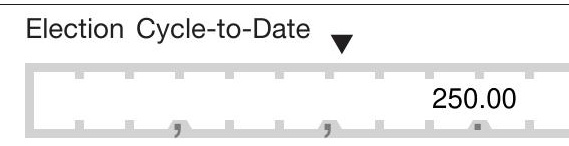

C. Full Name (Last, First, Middle Initial)

Edward Sasser

Mailing Address 608 Pilots Ridge Road

\begin{tabular}{lcc}
\hline City & State & Zip Code \\
Atkinson & NC & 28421 \\
\hline
\end{tabular}

FEC ID number of contributing

federal political committee.

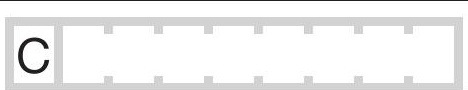

Name of Employer

Information Requested

Occupation

Information Requested

Receipt For: 2012

Х $\begin{aligned} & \text { Primary } \\ & \text { Other (specify) }\end{aligned}$

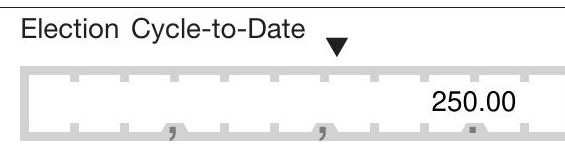

Transaction ID : AE3C4DB133FCE431F9DE

Date of Receipt

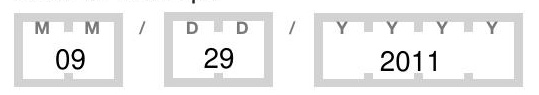

Amount of Each Receipt this Period

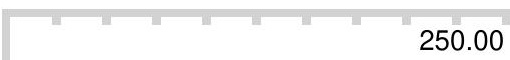

250.00

Transaction ID : A6FA824D9B0C44790B92

Date of Receipt

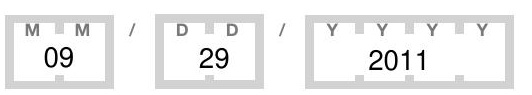

Amount of Each Receipt this Period

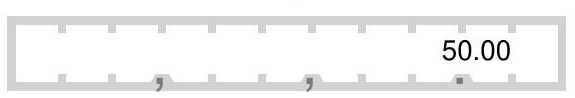

Transaction ID : A535CED4375A74953B12

Date of Receipt

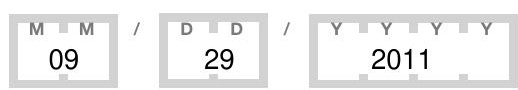

Amount of Each Receipt this Period

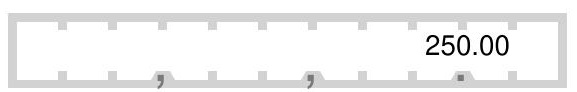

550.00

Subtotal Of Receipts This Page (optional)

anc

Total This Period (last page this line number only) 


\section{SCHEDULE A-P} ITEMIZED RECEIPTS
Use separate schedule(s)

for each category of the

Detailed Summary Page
FOR LINE NUMBER: (check only one)

Any information or for commercial purposes, other than using the name and address of any political committee to solicit contributions from such committee.

NAME OF COMMITTEE (In Full)

Friends of Herman Cain

A. Full Name (Last, First, Middle Initial)

Robert Johnson

Mailing Address 6450 Ellenwood Avenue

\begin{tabular}{lcc}
\hline City & State & Zip Code \\
Saint Louis & MO & $63105-2229$ \\
\hline
\end{tabular}

FEC ID number of contributing

federal political committee.

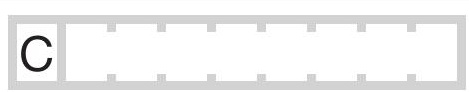

Name of Employer
Information Requested
Receipt For: 2012
X Primary $\quad \square$ General
Other (specify)

Occupation

Information Requested

Election Cycle-to-Date

500.00

B. Full Name (Last, First, Middle Initial)

Billy Hale

Mailing Address 11823 Wilcrest

\begin{tabular}{lcc}
\hline City & State & Zip Code \\
Houston & TX & $77031-1919$ \\
\hline
\end{tabular}

FEC ID number of contributing

federal political committee.

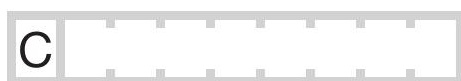

Name of Employer
None
Receipt For: 2012
X Primary $\quad$ General
Other (specify)

Occupation

Retired

Election Cycle-to-Date

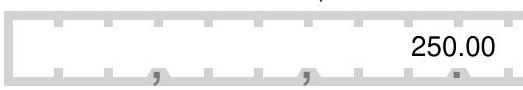

C. Full Name (Last, First, Middle Initial)

Daniel Baldwin

Mailing Address 3527 Lone Hill Lane

\begin{tabular}{lcc}
\hline City & State & Zip Code \\
Encinitas & CA & $92024-7276$
\end{tabular}

FEC ID number of contributing federal political committee.

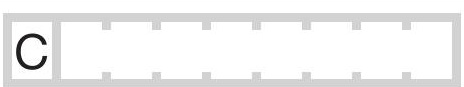

Name of Employer

Information Requested

\section{Occupation}

Information Requested

Receipt For: 2012

Х $\begin{aligned} & \text { Primary } \square \text { General } \\ & \text { Other (specify) }\end{aligned}$

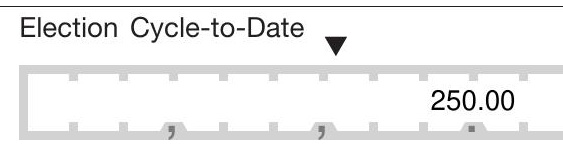

Amount of Each Receipt this Period

Transaction ID : AAA82AB16CCA743D89E9

Date of Receipt

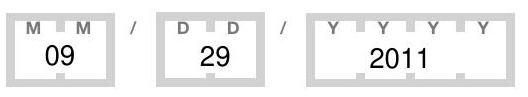

Amount of Each Receipt this Period
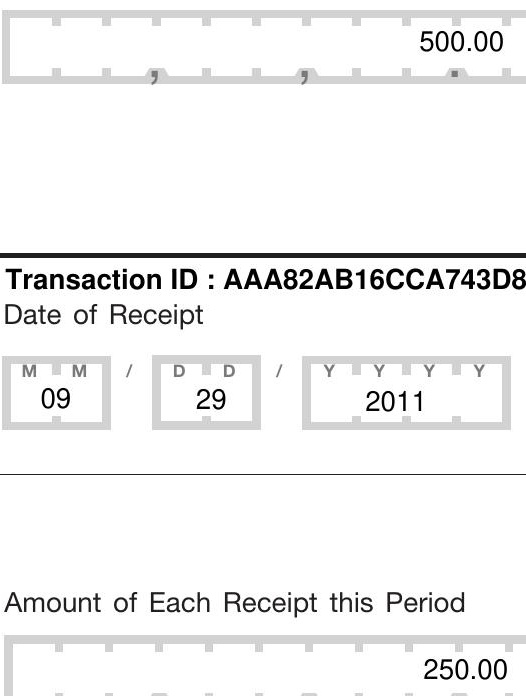

Transaction ID : A141852945AF44973BFC

Date of Receipt

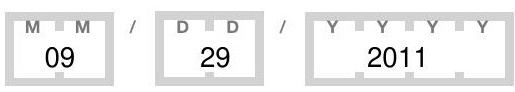

Amount of Each Receipt this Period

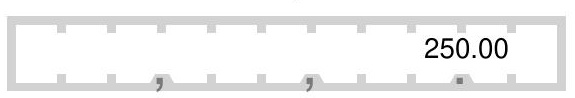

Subtotal Of Receipts This Page (optional).

1000.00

Total This Period (last page this line number only) 


\section{SCHEDULE A-P} ITEMIZED RECEIPTS
Use separate schedule(s)

for each category of the

Detailed Summary Page
FOR LINE NUMBER: (check only one)

Any information or for commercial purposes, other than using the name and address of any political committee to solicit contributions from such committee.

NAME OF COMMITTEE (In Full)

Friends of Herman Cain

A. Full Name (Last, First, Middle Initial)

Michael Connelly

Mailing Address 47517 th St Ste 980

\begin{tabular}{lcc}
\hline City & State & Zip Code \\
Denver & CO & $80202-4019$
\end{tabular}

FEC ID number of contributing

federal political committee.

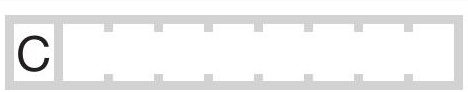

Name of Employer
Information Requested
Receipt For: 2012
X Primary $\quad \square$ General
Other (specify)

Occupation

Information Requested

Election Cycle-to-Date

250.00

B. Full Name (Last, First, Middle Initial)

Lawrence Silva

Mailing Address 1424 Kiner Ave

\begin{tabular}{lcc}
\hline City & State & Zip Code \\
San Jose & CA & $95125-4051$
\end{tabular}

FEC ID number of contributing

federal political committee.

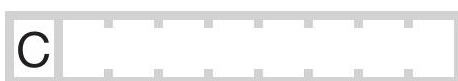

\begin{tabular}{l} 
Name of Employer \\
Information Requested \\
Receipt For: 2012 \\
X Primary \\
\hline Other (specify)
\end{tabular}

Occupation

Information Requested

Election Cycle-to-Date

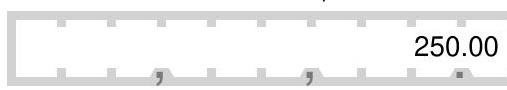

C. Full Name (Last, First, Middle Initial)

annette ryan

Mailing Address 155 johnson ferry rd

\begin{tabular}{l|ll}
\hline $\begin{array}{l}\text { City } \\
\text { Marietta }\end{array}$ & $\begin{array}{c}\text { State } \\
\text { GA }\end{array}$ & $\begin{array}{c}\text { Zip Code } \\
30068-4923\end{array}$ \\
\hline $\begin{array}{l}\text { FEC ID number of contributing } \\
\text { federal political committee. }\end{array}$ & C & \\
\hline $\begin{array}{l}\text { Name of Employer } \\
\text { Retired }\end{array}$ & $\begin{array}{l}\text { Occupation } \\
\text { Retired }\end{array}$ \\
\hline $\begin{array}{l}\text { Receipt For: } 2012 \\
\text { X }\end{array}$ & Election Cycle-to-Date \\
Other (specify)
\end{tabular}

Transaction ID : AF84B43F6E7B645DFB69

Date of Receipt

Amount of Each Receipt this Period

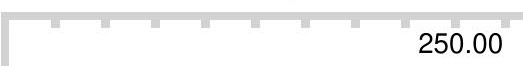

Date of Receipt
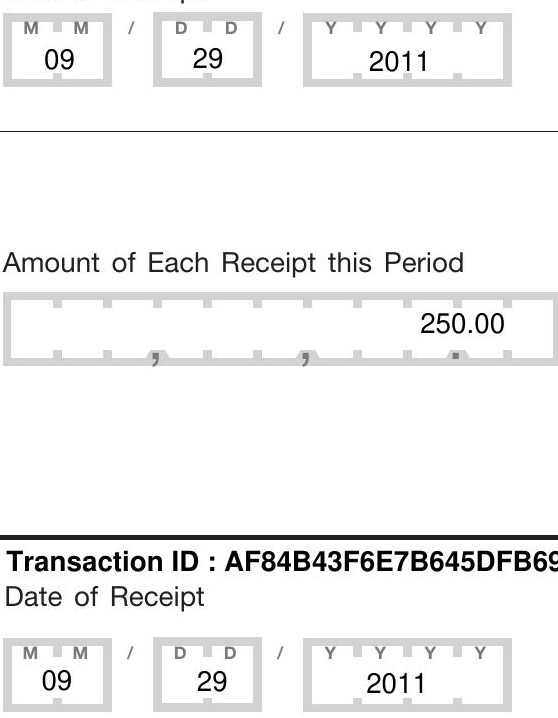

Amount of Each Receipt this Period

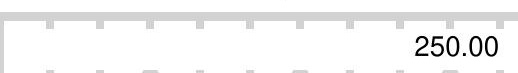

Amount of Each Receipt this Period

Transaction ID : ABA04B28528ED44EDA68 Date of Receipt
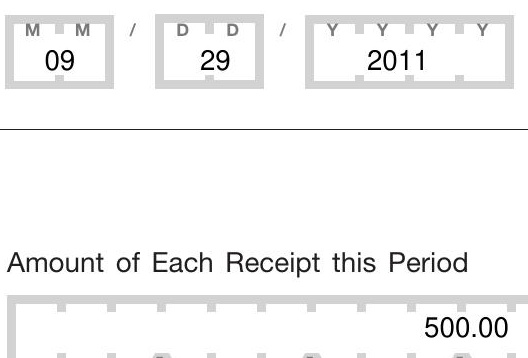

Subtotal Of Receipts This Page (optional)

1000.00

Total This Period (last page this line number only) 
SCHEDULE A-P ITEMIZED RECEIPTS
Use separate schedule(s) for each category of the Detailed Summary Page
FOR LINE NUMBER: (check only one)

Any information or for commercial purposes, other than using the name and address of any political committee to solicit contributions from such committee.

NAME OF COMMITTEE (In Full)

Friends of Herman Cain

A. Full Name (Last, First, Middle Initial)

\section{Elise Curotto}

Mailing Address 8416 Littleleaf Ct

\begin{tabular}{lcc}
\hline City & State & Zip Code \\
Orlando & FL & $32835-2559$
\end{tabular}

FEC ID number of contributing federal political committee.

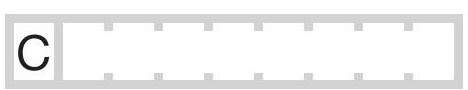

Name of Employer
Self Employed
Receipt For: 2012
X Primary $\quad$ General
Other (specify)

Occupation Attorney

Election Cycle-to-Date

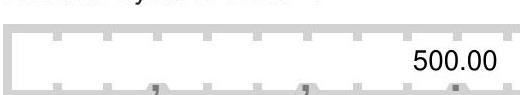

B. Full Name (Last, First, Middle Initial) John Gallagher

Mailing Address 3678 Janiero Rd

\begin{tabular}{lcc}
\hline City & State & Zip Code \\
Arapahoe & NC & $28510-9532$ \\
\hline
\end{tabular}

FEC ID number of contributing

federal political committee.

C

Name of Employer
Pamlico Community College
Receipt For: 2012
X Primary
Other (specify)

Occupation

Teacher

Election Cycle-to-Date

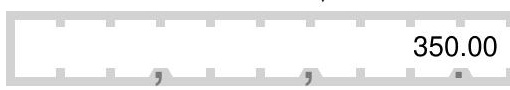

Transaction ID : A47CA5D4DC4004971BAB

Date of Receipt

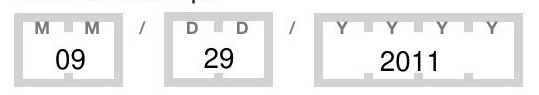

Amount of Each Receipt this Period

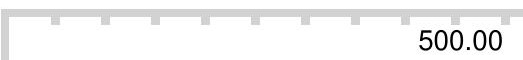

C. Full Name (Last, First, Middle Initial)

Harold Colburn

Mailing Address 1410 John B White Blvd Suite A

\begin{tabular}{lcc}
\hline City & State & Zip Code \\
Spartanburg & SC & $29306-3927$
\end{tabular}

FEC ID number of contributing federal political committee.

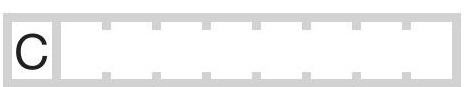

Name of Employer

Information Requested

\section{Occupation}

Information Requested

Receipt For: 2012

Х $\begin{aligned} & \text { Primary } \\ & \text { Other (specify) }\end{aligned}$

Transaction ID : ADE651ADB0A8A4280969

Date of Receipt

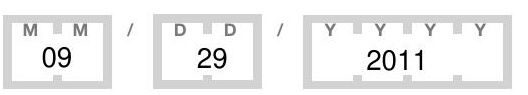

Amount of Each Receipt this Period

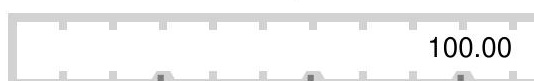

Transaction ID : AF0F4E5571CCD4C2085F Date of Receipt

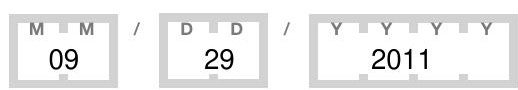

Amount of Each Receipt this Period

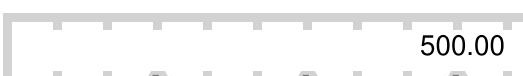

\section{Subtotal Of Receipts This Page (optional)}

Total This Period (last page this line number only) 
SCHEDULE A-P ITEMIZED RECEIPTS
Use separate schedule(s) for each category of the Detailed Summary Page
FOR LINE NUMBER: (check only one)

PAGE 1054 / 1572

\begin{tabular}{|c|c|c|c|c|c|}
\hline & & & & & \\
\hline 16 & $\begin{array}{lll}X & 17 a \\
\end{array}$ & $17 \mathrm{~b}$ & $17 c$ & $17 d$ & 18 \\
\hline $19 a$ & $19 b$ & $20 a$ & $20 \mathrm{~b}$ & $20 c$ & 21 \\
\hline
\end{tabular}

Any information copied from such Reports and Statements may not be sold or used by any person for the purpose of soliciting contributions or for commercial purposes, other than using the name and address of any political committee to solicit contributions from such committee.

NAME OF COMMITTEE (In Full)

\section{Friends of Herman Cain}

A. Full Name (Last, First, Middle Initial)

\section{Glenn Cordua}

Mailing Address Box 93056

\begin{tabular}{lcc}
\hline City & State & Zip Code \\
Sioux Falls & SD & $57186-0001$
\end{tabular}

FEC ID number of contributing federal political committee.

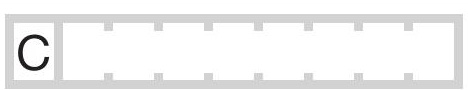

Name of Employer
Information Requested
Receipt For: 2012
X Primary
Other (specify) General

Occupation Information Requested

Election Cycle-to-Date

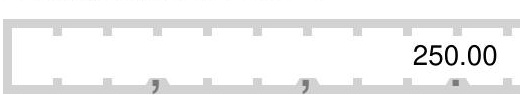

B. Full Name (Last, First, Middle Initial)

MaryAnn Ridder

Mailing Address 1025 Collingwood Dr

\begin{tabular}{lcc}
\hline City & State & Zip Code \\
Indianapolis & IN & $46228-1968$ \\
\hline
\end{tabular}

FEC ID number of contributing

federal political committee.

C

Name of Employer
Spectrum Underwriting
Receipt For: 2012
X Primary
Other (specify)

Occupation

Executive

Election Cycle-to-Date

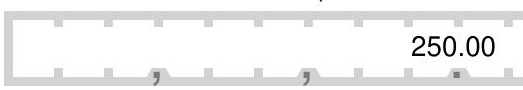

Transaction ID : A176CB55B87E145C3835

Date of Receipt

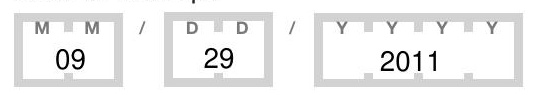

Amount of Each Receipt this Period

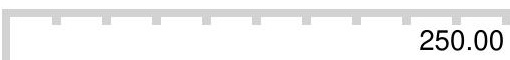

Transaction ID : ABB3564402E0F4A56B0C

Date of Receipt

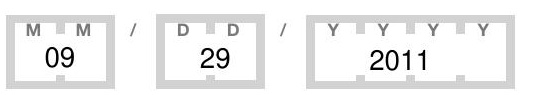

Amount of Each Receipt this Period

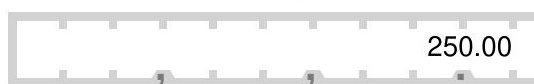

Transaction ID : AC2E08D529C38483B9F0 Date of Receipt

\section{Peter Goodell}

Mailing Address 3003 NE Quayside Lane

\begin{tabular}{lcc}
\hline City & State & Zip Code \\
Miami & FL & $33138-2258$
\end{tabular}

FEC ID number of contributing federal political committee.

C

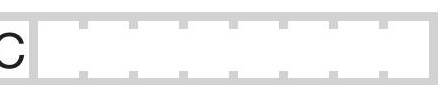

Name of Employer

Retired

Receipt For: 2012

Х $\begin{aligned} & \text { Primary } \\ & \text { Other (specify) }\end{aligned}$

Occupation

Information Requested

Election Cycle-to-Date

Subtotal Of Receipts This Page (optional).

Amount of Each Receipt this Period

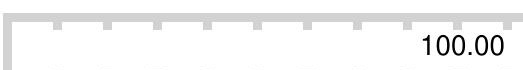

Total This Period (last page this line number only)

600.00

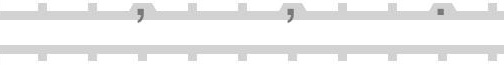

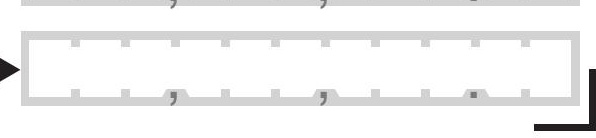

FEC Schedule A-P (Form 3P) (Rev. 03/2011) 


\section{SCHEDULE A-P} ITEMIZED RECEIPTS
Use separate schedule(s)

for each category of the

Detailed Summary Page
FOR LINE NUMBER: (check only one)

Any information or for commercial purposes, other than using the name and address of any political committee to solicit contributions from such committee.

NAME OF COMMITTEE (In Full)

Friends of Herman Cain

A. Full Name (Last, First, Middle Initial) Jeanna Carley

Mailing Address 425 E Pennsylvania Ave

\begin{tabular}{lcc}
\hline City & State & Zip Code \\
Deland & FL & $32724-3573$ \\
\hline
\end{tabular}

FEC ID number of contributing federal political committee.

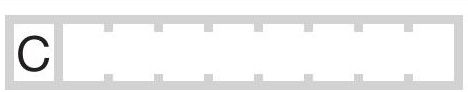

Name of Employer
Self Employed
Receipt For: 2012
X Primary $\quad$ General
Other (specify)

Occupation Aviation

Election Cycle-to-Date

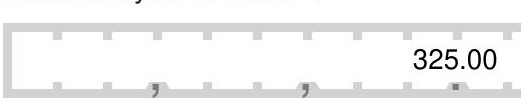

B. Full Name (Last, First, Middle Initial)

Pricie Hanna

Mailing Address 603 Fairway Drive

\begin{tabular}{lcc}
\hline City & State & Zip Code \\
West Chester & PA & $19382-2013$ \\
\hline
\end{tabular}

FEC ID number of contributing

federal political committee.

C

Name of Employer
Price Hanna Consultants LLC
Receipt For: 2012
X Primary
Other (specify)

\section{Occupation}

Consultant

Election Cycle-to-Date

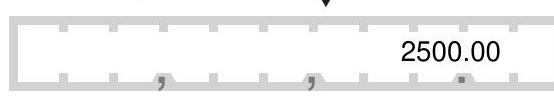

Transaction ID : ACF47A414D75C484599E

Date of Receipt

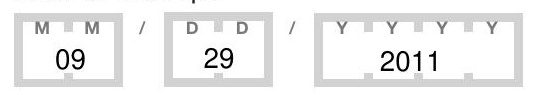

Amount of Each Receipt this Period

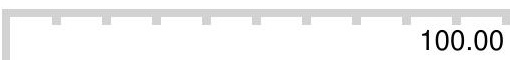

Transaction ID : A2BE43913127D4BD9B6B

Date of Receipt

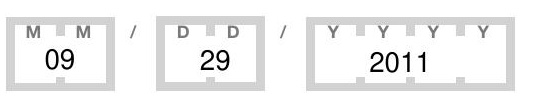

Amount of Each Receipt this Period

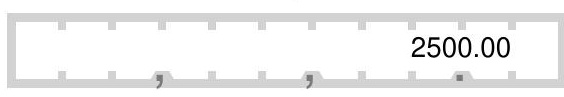

Transaction ID : ADD14E21C422641DF829

Date of Receipt

\section{LARRY WADE}

Mailing Address 3060 Valley Creek Dr Ste C

\begin{tabular}{lcc}
\hline City & State & Zip Code \\
Baton Rouge & LA & $70808-3169$
\end{tabular}

FEC ID number of contributing federal political committee.

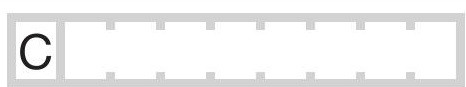

Name of Employer
Self Employed
Receipt For: 2012
X Primary $\quad \square$ General
Other (specify)

\section{Occupation} psychiatrist

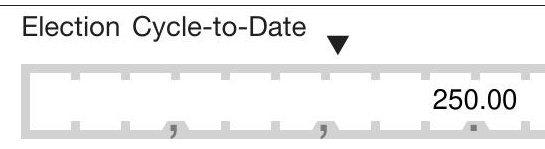

Amount of Each Receipt this Period

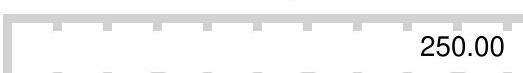

Subtotal Of Receipts This Page (optional).

2850.00

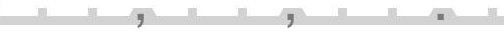

Total This Period (last page this line number only)

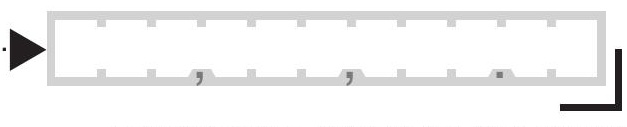

FEC Schedule A-P (Form 3P) (Rev. 03/2011) 


\section{SCHEDULE A-P} ITEMIZED RECEIPTS
Use separate schedule(s) for each category of the Detailed Summary Page

\begin{tabular}{|c|c|c|c|c|c|}
\hline \multicolumn{3}{|c|}{$\begin{array}{l}\text { FOR LINE NUMBER: } \\
\text { (check only one) }\end{array}$} & \multicolumn{3}{|c|}{ PAGE 1056 / 1572} \\
\hline 16 & $X$ 17a & $17 b$ & $17 c$ & $17 d$ & 18 \\
\hline $19 a$ & $19 \mathrm{~b}$ & $20 a$ & $20 \mathrm{~b}$ & $20 c$ & 21 \\
\hline
\end{tabular}

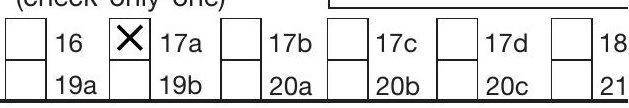

Any information copied from such Reports and Statements may not be sold or used by any person for the purpose of soliciting contributions or for commercial purposes, other than using the name and address of any political committee to solicit contributions from such committee.

NAME OF COMMITTEE (In Full)

\section{Friends of Herman Cain}

A. Full Name (Last, First, Middle Initial)

Barry Minter

Mailing Address 3035 Hwy 52 Alt

\begin{tabular}{lcc}
\hline City & State & Zip Code \\
Chatsworth & GA & $30705-5843$ \\
\hline
\end{tabular}

FEC ID number of contributing federal political committee.

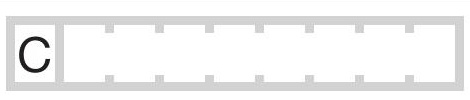

Name of Employer
Information Requested
Receipt For: 2012
X Primary
Other (specify) General

Occupation Information Requested

Election Cycle-to-Date 500.00

B. Full Name (Last, First, Middle Initial) Thomas Bairnson

\section{Mailing Address 6725 Virginia Crossing}

\begin{tabular}{lcc}
\hline City & State & Zip Code \\
University Park & FL & $34201-2321$
\end{tabular}

FEC ID number of contributing

federal political committee.

C

Name of Employer
Information Requested
Receipt For: 2012
Primary
Other (specify)

Occupation

Information Requested

Election Cycle-to-Date

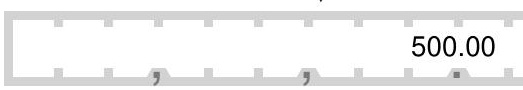

C. Full Name (Last, First, Middle Initial)

Dave Haskell

Mailing Address 798 Bradford Ct SW

\begin{tabular}{lcc}
\hline City & State & Zip Code \\
Lilburn & GA & $30047-3112$
\end{tabular}

FEC ID number of contributing federal political committee.

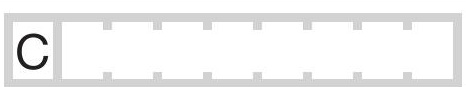

$\begin{aligned} & \text { Name of Employer } \\ & \text { self }\end{aligned}$
Receipt For: 2012
Primary
Other (specify) General

\section{Occupation}

contractor

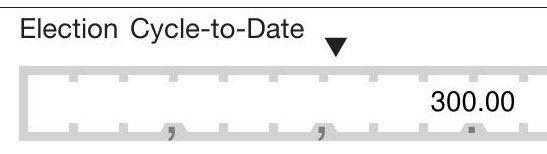

Transaction ID : A78FCB81424CA4B71BEB

Date of Receipt

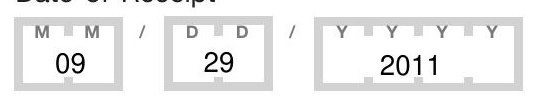

Amount of Each Receipt this Period

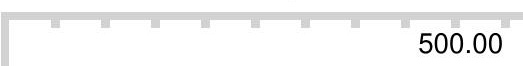

Amount of Each Receipt this Period

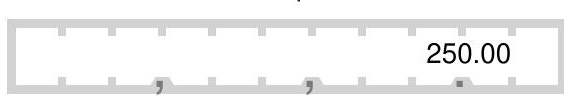

Transaction ID : AE18E0F9BE0FE4873812 Date of Receipt

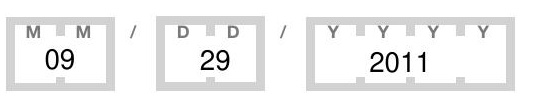

Transaction ID : AC72DBD725D0741CEB1E Date of Receipt

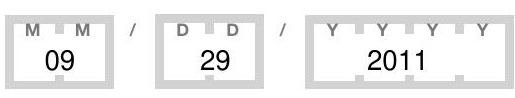

Amount of Each Receipt this Period

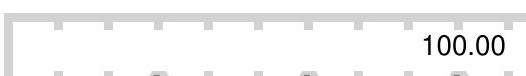

\section{Subtotal Of Receipts This Page (optional)}

850.00

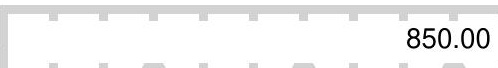

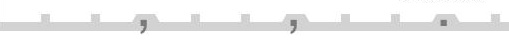

Total This Period (last page this line number only)

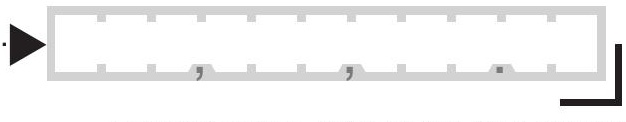

FEC Schedule A-P (Form 3P) (Rev. 03/2011) 


\section{SCHEDULE A-P} ITEMIZED RECEIPTS
Use separate schedule(s)

for each category of the

Detailed Summary Page
FOR LINE NUMBER: (check only one)

Any information or for commercial purposes, other than using the name and address of any political committee to solicit contributions from such committee.

NAME OF COMMITTEE (In Full)

Friends of Herman Cain

A. Full Name (Last, First, Middle Initial)

DANIEL GUILD

Mailing Address 406 COURT RD EXT

\begin{tabular}{lcc}
\hline City & State & Zip Code \\
Vanderbilt & PA & $15486-1177$
\end{tabular}

FEC ID number of contributing

federal political committee.

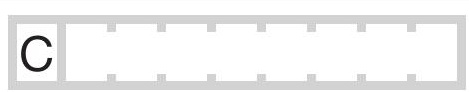

Name of Employer
SKC GULF COAST INC.
Receipt For: 2012
X Primary
$\square$ Other (specify)

Occupation

Manager

Election Cycle-to-Date

2250.00

B. Full Name (Last, First, Middle Initial)

Susan Tonne

Mailing Address 203 Towhee Dr

\begin{tabular}{lcc}
\hline City & State & Zip Code \\
Buda & TX & $78610-2648$ \\
\hline
\end{tabular}

FEC ID number of contributing

federal political committee.

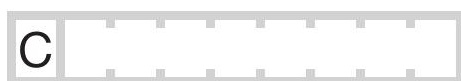

Name of Employer
None
Receipt For: 2012
X Primary
Other (specify)

Occupation

Retired

Election Cycle-to-Date

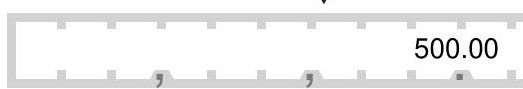

C. Full Name (Last, First, Middle Initial)

Mr Ken Wade

Mailing Address 1704 Hidden Hills Rd Suite 206

\begin{tabular}{lcc}
\hline City & State & Zip Code \\
Gatlinburg & TN & $37738-5827$
\end{tabular}

FEC ID number of contributing

federal political committee.

$\mathrm{C}$

Name of Employer

Retired

Receipt For: 2012

Х $\begin{aligned} & \text { Primary } \square \text { General } \\ & \text { Other (specify) }\end{aligned}$

\section{Occupation}

Retired

Election Cycle-to-Date

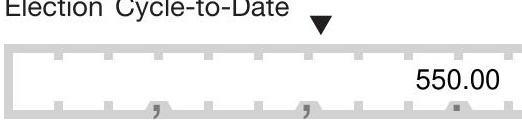

Transaction ID : A8A6EA90207A548BD93B

Date of Receipt

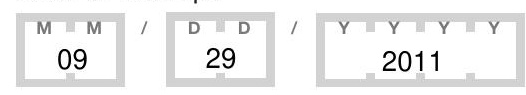

Amount of Each Receipt this Period

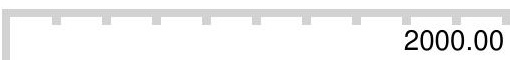

2000.00

Amount of Each Receipt this Period

Transaction ID : A821399BB2A0749F48E6

Date of Receipt
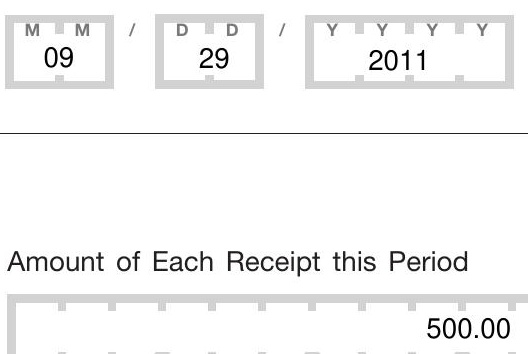

Transaction ID : AB2599AC9ECC2498193B Date of Receipt

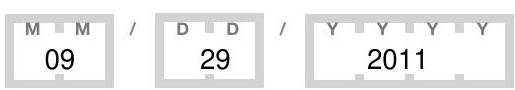

Amount of Each Receipt this Period

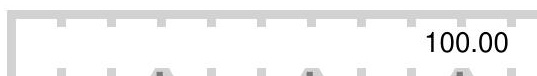

2600.00

Subtotal Of Receipts This Page (optional)

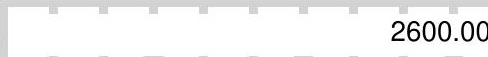

Total This Period (last page this line number only) 


\section{SCHEDULE A-P} ITEMIZED RECEIPTS
Use separate schedule(s)

for each category of the

Detailed Summary Page
FOR LINE NUMBER: (check only one)

Any information or for commercial purposes, other than using the name and address of any political committee to solicit contributions from such committee.

NAME OF COMMITTEE (In Full)

Friends of Herman Cain

A. Full Name (Last, First, Middle Initial)

Andrew Wallace

Mailing Address 505 Westwood Circle

\begin{tabular}{lcc}
\hline City & State & Zip Code \\
Waynesville & NC & $28786-1991$
\end{tabular}

FEC ID number of contributing

federal political committee.

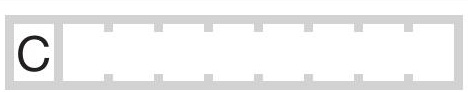

Name of Employer
Information Requested
Receipt For: 2012
X Primary $\quad \square$ General
Other (specify)

Occupation

Information Requested

Election Cycle-to-Date

300.00

B. Full Name (Last, First, Middle Initial)

Lawrence Brodie

Mailing Address 6721 S. E. Harbor Circle

\begin{tabular}{lcc}
\hline City & State & Zip Code \\
Stuart & FL & $34996-1964$
\end{tabular}

FEC ID number of contributing

federal political committee.

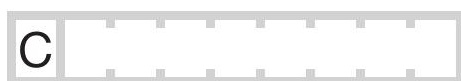

Name of Employer
Information Requested
Receipt For: 2012
X Primary
Other (specify)

Occupation

Information Requested

Election Cycle-to-Date

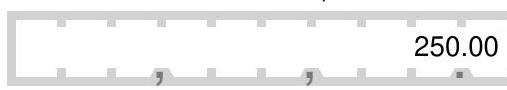

Transaction ID : A0F2B6E0D8E994720833

Date of Receipt

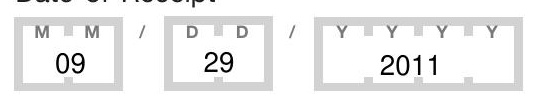

Amount of Each Receipt this Period

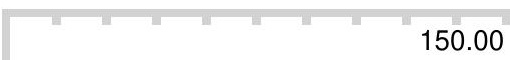

150.00

C. Full Name (Last, First, Middle Initial)

James Martin

Mailing Address 1355 Peachtree St Suite 750

\begin{tabular}{lcc}
\hline City & State & Zip Code \\
Atlanta & GA & $30309-3265$
\end{tabular}

FEC ID number of contributing

federal political committee.

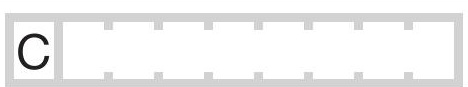

Name of Employer

Sterling Investment Management Inc

Receipt For: 2012

Х $\begin{aligned} & \text { Primary } \square \text { General } \\ & \text { Other (specify) }\end{aligned}$

\section{Occupation}

investment advisor

Election Cycle-to-Date
Transaction ID : A85B826354C4B4833870

Date of Receipt

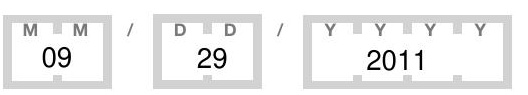

Amount of Each Receipt this Period

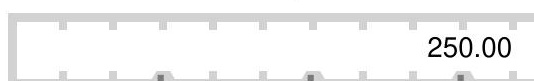

Transaction ID : AB4E7C7B9AA0A4DFDA06 Date of Receipt

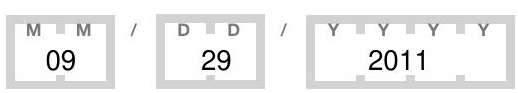

Amount of Each Receipt this Period

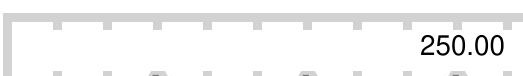

\section{Subtotal Of Receipts This Page (optional)}

650.00

a

Total This Period (last page this line number only)

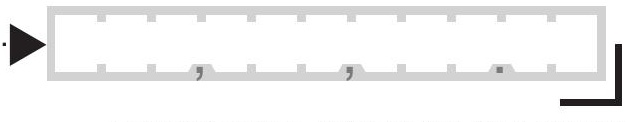

FEC Schedule A-P (Form 3P) (Rev. 03/2011) 


\section{SCHEDULE A-P} ITEMIZED RECEIPTS
Use separate schedule(s)

for each category of the

Detailed Summary Page
FOR LINE NUMBER: (check only one)

Any information or for commercial purposes, other than using the name and address of any political committee to solicit contributions from such committee.

NAME OF COMMITTEE (In Full)

Friends of Herman Cain

A. Full Name (Last, First, Middle Initial)

Michael Dreyer

Mailing Address 21731 County Road 38 S

\begin{tabular}{lcc}
\hline City & State & Zip Code \\
Summerdale & AL & $36580-3170$
\end{tabular}

FEC ID number of contributing

federal political committee.

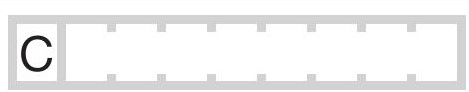

Name of Employer
Information Requested
Receipt For: 2012
X Primary $\quad \square$ General
Other (specify)

Occupation

Information Requested

Election Cycle-to-Date

250.00

B. Full Name (Last, First, Middle Initial)

william hoffman

Mailing Address 11155 dunn rd. suite $211 \mathrm{n}$

\begin{tabular}{llc}
\hline City & State & Zip Code \\
Saint Louis & MO & $63136-6166$
\end{tabular}

FEC ID number of contributing

federal political committee.

C

\begin{tabular}{l} 
Name of Employer \\
Information Requested \\
Receipt For: 2012 \\
X Primary \\
\hline Other (specify)
\end{tabular}

Occupation

Information Requested

Election Cycle-to-Date

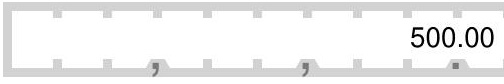

Transaction ID : A06F65FB51E204D529A8

Date of Receipt

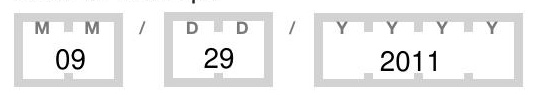

Amount of Each Receipt this Period

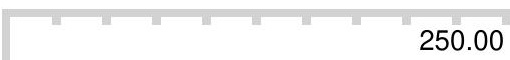

Transaction ID : A8A0B20FA1BCE4FC0812

Date of Receipt

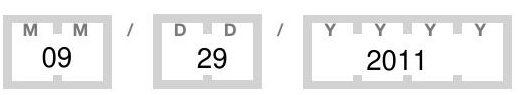

Amount of Each Receipt this Period

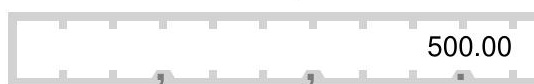

Transaction ID : A515A908C02444C4297A

Date of Receipt

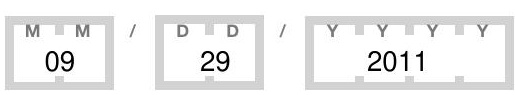

Amount of Each Receipt this Period

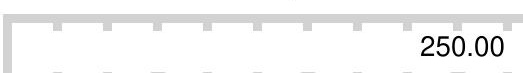

$\begin{array}{cc}\text { State } & \text { Zip Code } \\ \mathrm{OH} & 44333-1300\end{array}$

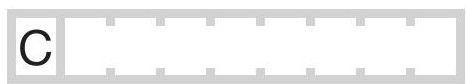

\section{Occupation}

Owner

Election Cycle-to-Date

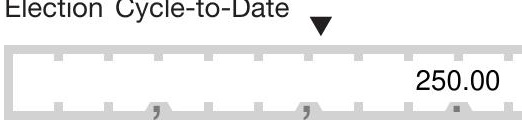

Subtotal Of Receipts This Page (optional)...

1000.00

ㄱ․․

Total This Period (last page this line number only)

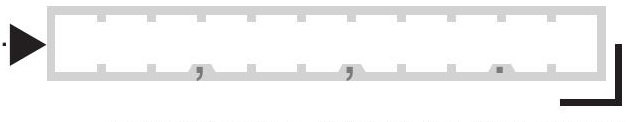

FEC Schedule A-P (Form 3P) (Rev. 03/2011) 


\section{SCHEDULE A-P} ITEMIZED RECEIPTS
Use separate schedule(s) for each category of the Detailed Summary Page

\begin{tabular}{|c|c|c|c|c|c|}
\hline \multicolumn{3}{|c|}{$\begin{array}{l}\text { FOR LINE NUMBER: } \\
\text { (check only one) }\end{array}$} & \multicolumn{3}{|c|}{ PAGE 1060 / 1572} \\
\hline 16 & $X$ 17a & $17 b$ & $17 c$ & $17 d$ & 18 \\
\hline $19 a$ & $19 \mathrm{~b}$ & $20 a$ & $20 \mathrm{~b}$ & $20 c$ & 21 \\
\hline
\end{tabular}

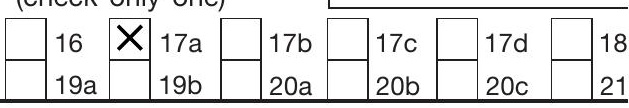

Any information copied from such Reports and Statements may not be sold or used by any person for the purpose of soliciting contributions or for commercial purposes, other than using the name and address of any political committee to solicit contributions from such committee.

NAME OF COMMITTEE (In Full)

\section{Friends of Herman Cain}

A. Full Name (Last, First, Middle Initial) Karen Cervantes

Mailing Address 54 Bank St.

\begin{tabular}{lcc}
\hline City & State & Zip Code \\
Lebanon & NH & $03766-1727$
\end{tabular}

FEC ID number of contributing federal political committee.

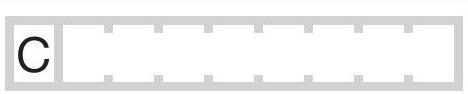

Name of Employer
Harrison Ins. agencylnc.
Receipt For: 2012
X Primary
Other (specify)

Occupation Insurance Executive

Election Cycle-to-Date 225.00

B. Full Name (Last, First, Middle Initial)

Dennis Bradley

Mailing Address 3146 River Branch Circle

\begin{tabular}{lcc}
\hline City & State & Zip Code \\
Kissimmee & FL & $34741-7601$
\end{tabular}

FEC ID number of contributing

federal political committee.

C

Name of Employer
Information Requested
Receipt For: 2012
X Primary
Other (specify)

Occupation

Information Requested

Election Cycle-to-Date

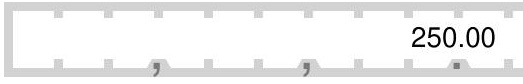

Transaction ID : A15062108F99D4C5EB2D

Date of Receipt

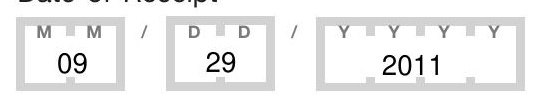

Amount of Each Receipt this Period

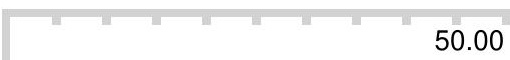

50.00
Amount of Each Receipt this Period

Transaction ID : A9F2EEDCA80B24023935

Date of Receipt
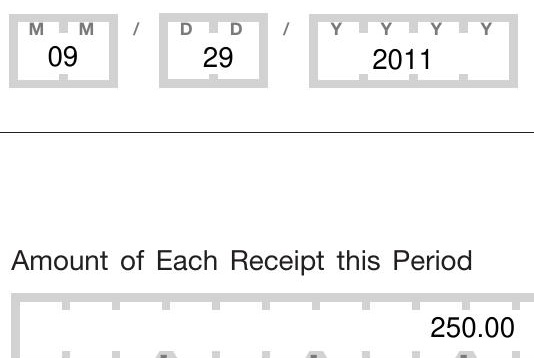

C. Full Name (Last, First, Middle Initial)

Karen Davis

Mailing Address 3120 Van Buren Ave

\begin{tabular}{lcc}
\hline City & State & Zip Code \\
Costa Mesa & CA & $92626-271$
\end{tabular}

FEC ID number of contributing federal political committee.

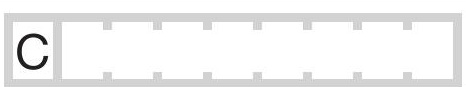

Name of Employer

Information Requested

\section{Occupation}

Information Requested

Receipt For: 2012

Х $\begin{aligned} & \text { Primary } \square \text { General } \\ & \text { Other (specify) }\end{aligned}$

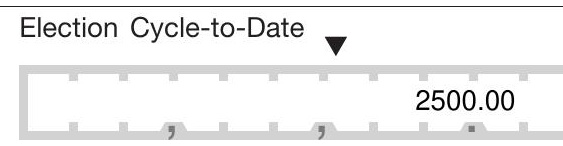

Transaction ID : A0C55769720334C8CBE7

Date of Receipt

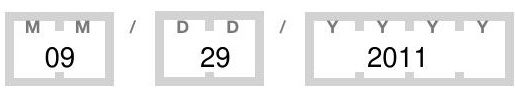

Amount of Each Receipt this Period

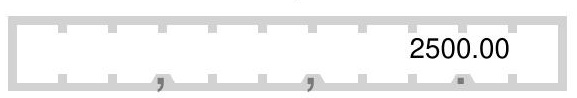

Subtotal Of Receipts This Page (optional).

2800.00

Total This Period (last page this line number only) 


\section{SCHEDULE A-P} ITEMIZED RECEIPTS
Use separate schedule(s)

for each category of the

Detailed Summary Page
FOR LINE NUMBER: (check only one)

Any information copion or for commercial purposes, other than using the name and address of any political committee to solicit contributions from such committee.

NAME OF COMMITTEE (In Full)

Friends of Herman Cain

A. Full Name (Last, First, Middle Initial)

James Hill

Mailing Address 320 Windsor Falls Drive

\begin{tabular}{lcc}
\hline City & State & Zip Code \\
Canton & GA & $30114-6831$ \\
\hline
\end{tabular}

FEC ID number of contributing

federal political committee.

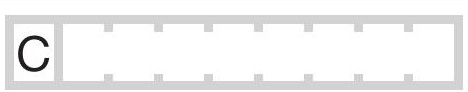

Name of Employer
Information Requested
Receipt For: 2012
X Primary $\quad \square$ General
Other (specify)

Occupation

Information Requested

Election Cycle-to-Date

250.00

B. Full Name (Last, First, Middle Initial)

Becky Plummer

Mailing Address 1042 Camellia Blvd. \#5110

\begin{tabular}{lcc}
\hline City & State & Zip Code \\
Lafayette & LA & $70508-6680$ \\
\hline
\end{tabular}

FEC ID number of contributing

federal political committee.

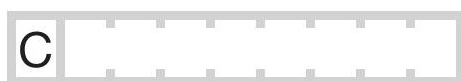

Name of Employer
None
Receipt For: 2012
X Primary
Other (specify)

\section{Occupation}

Homemaker

Election Cycle-to-Date

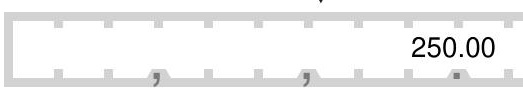

C. Full Name (Last, First, Middle Initial)

James Paton

Mailing Address 42 Bumblebee PL

\begin{tabular}{lcc}
\hline City & State & Zip Code \\
Lopez Island & WA & $98261-8485$
\end{tabular}

FEC ID number of contributing

federal political committee.

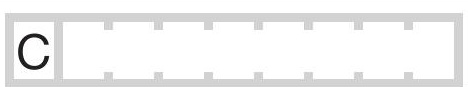

Name of Employer

Information Requested

Occupation

Information Requested

Receipt For: 2012

Х $\begin{aligned} & \text { Primary } \\ & \text { Other (specify) }\end{aligned}$

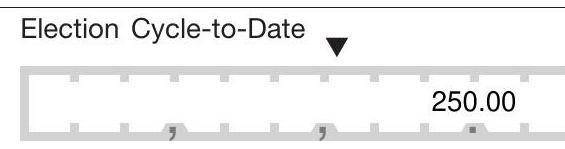

Amount of Each Receipt this Period

Transaction ID : ABA70F8829E4F41E8840

Date of Receipt

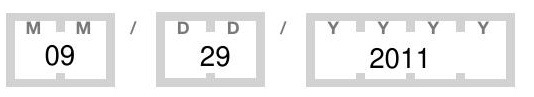

Amount of Each Receipt this Period

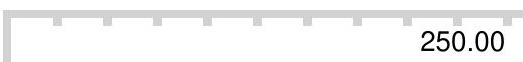

250.00

Date of Receipt

$M-M, D-D$

09

2011

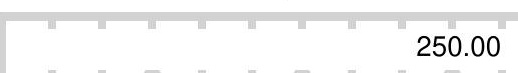

Transaction ID : A4C803CD3D9CB47DC97C Date of Receipt

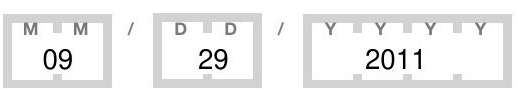

Amount of Each Receipt this Period

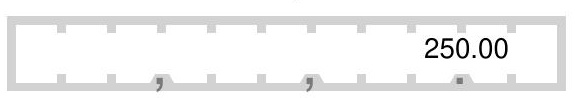

Subtotal Of Receipts This Page (optional).

750.00

Total This Period (last page this line number only) 


\section{SCHEDULE A-P} ITEMIZED RECEIPTS
Use separate schedule(s)

for each category of the

Detailed Summary Page
FOR LINE NUMBER: (check only one)

Any information or for commercial purposes, other than using the name and address of any political committee to solicit contributions from such committee.

NAME OF COMMITTEE (In Full)

Friends of Herman Cain

A. Full Name (Last, First, Middle Initial)

Sanders Walker

Mailing Address PO Box 155

\begin{tabular}{lcc}
\hline City & State & Zip Code \\
Malvern & AR & $72104-0155$ \\
\hline
\end{tabular}

FEC ID number of contributing

federal political committee.

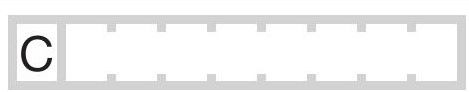

Name of Employer
Information Requested
Receipt For: 2012
X Primary $\quad \square$ General
Other (specify)

Occupation

Information Requested

Election Cycle-to-Date

500.00

B. Full Name (Last, First, Middle Initial)

Victoria Bloomfield

Mailing Address 815 N. Alamo Cir

\begin{tabular}{lcc}
\hline City & State & Zip Code \\
Mesa & AZ & $85213-5929$
\end{tabular}

FEC ID number of contributing

federal political committee.

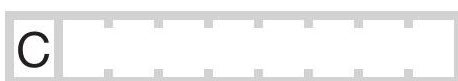

\begin{tabular}{l} 
Name of Employer \\
Information Requested \\
Receipt For: 2012 \\
X Primary \\
\hline Other (specify)
\end{tabular}

Occupation

Information Requested

Election Cycle-to-Date

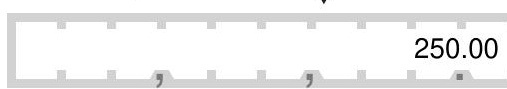

Transaction ID : AF59C99C655694F3CB52

Date of Receipt

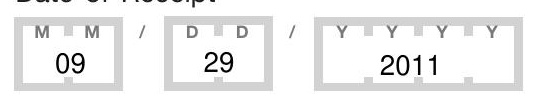

Amount of Each Receipt this Period

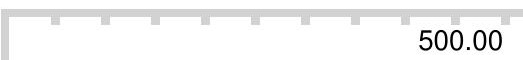

Amount of Each Receipt this Period

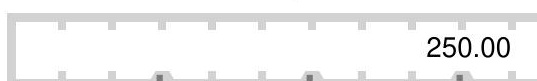

C. Full Name (Last, First, Middle Initial)

Scott McEachin

Mailing Address 7032 East 100th Street

\begin{tabular}{lcc}
\hline City & State & Zip Code \\
Tulsa & OK & $74133-6235$
\end{tabular}

FEC ID number of contributing

federal political committee.

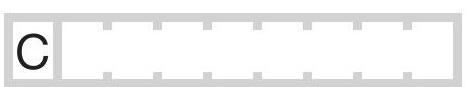

Name of Employer

Scott William McEachin PC

Receipt For: 2012

Х $\begin{aligned} & \text { Primary } \square \text { General } \\ & \text { Other (specify) }\end{aligned}$

\section{Occupation}

Attorney

Election Cycle-to-Date

Transaction ID : A6438E2CE2D394067BC9

Date of Receipt

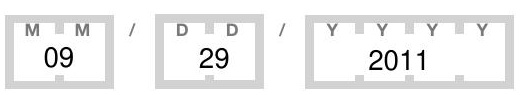

Transaction ID : A3E57A8020D034EB08D4

Date of Receipt

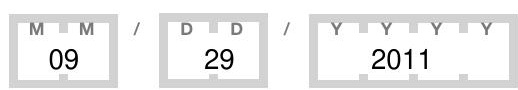

Amount of Each Receipt this Period

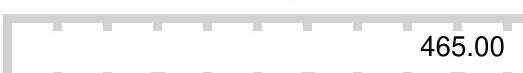

1952.00

\section{Subtotal Of Receipts This Page (optional)}

Total This Period (last page this line number only) 
SCHEDULE A-P ITEMIZED RECEIPTS
Use separate schedule(s) for each category of the Detailed Summary Page
FOR LINE NUMBER: (check only one)

Any information or for commercial purposes, other than using the name and address of any political committee to solicit contributions from such committee.

NAME OF COMMITTEE (In Full)

\section{Friends of Herman Cain}

A. Full Name (Last, First, Middle Initial)

\section{Gary Brown}

Mailing Address 19621 Michigan Ave

\begin{tabular}{lcc}
\hline City & State & Zip Code \\
Odessa & FL & $33556-4235$
\end{tabular}

FEC ID number of contributing federal political committee.

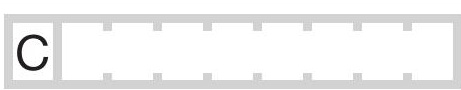

Name of Employer
Information Requested
Receipt For: 2012
X Primary
Other (specify) General

Occupation Information Requested

Election Cycle-to-Date

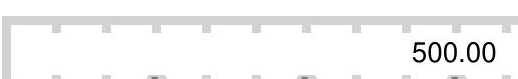

B. Full Name (Last, First, Middle Initial)

Thomas Johnson

Mailing Address 2534 Angel Court

\begin{tabular}{lcc}
\hline City & State & Zip Code \\
Gulf Breeze & FL & $32563-5551$
\end{tabular}

FEC ID number of contributing

federal political committee.

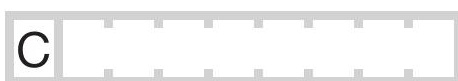

Name of Employer

Sacred Heart Medical Oncology Group

Occupation

Receipt For: 2012

X Primary $\square$ General

$\triangle$ Other (specify)

Physician

Election Cycle-to-Date

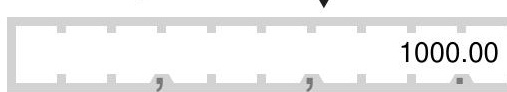

C. Full Name (Last, First, Middle Initial)

michael melio

Mailing Address 207 mcLeod court

\begin{tabular}{lcc}
\hline City & State & Zip Code \\
Waxhaw & NC & $28173-1700$
\end{tabular}

FEC ID number of contributing federal political committee.

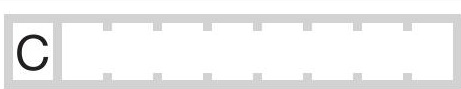

Name of Employer

Information Requested

Occupation

Information Requested

Receipt For: 2012

X Primary $\square$ General

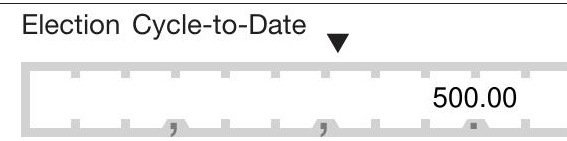

Amount of Each Receipt this Period

Transaction ID : A44E8C2CA5A7A49F6A9D Date of Receipt

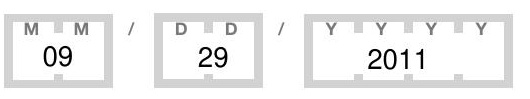

Amount of Each Receipt this Period
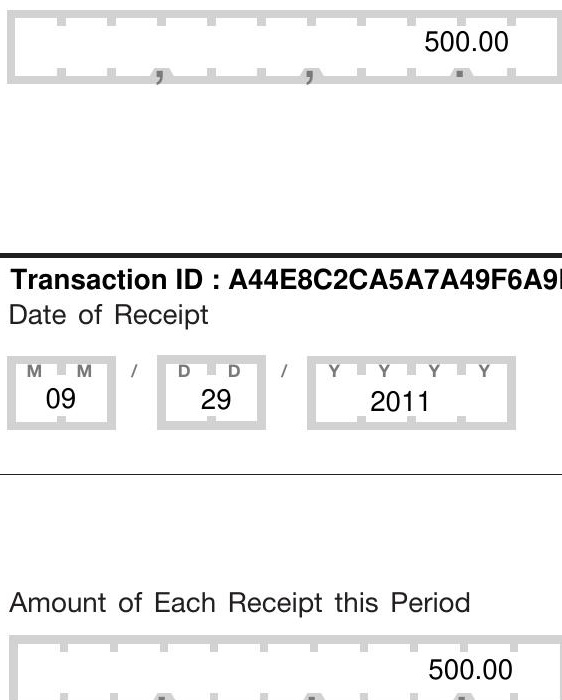

Transaction ID : A49560F1917D54F0DBA1 Date of Receipt

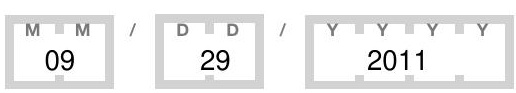

Amount of Each Receipt this Period

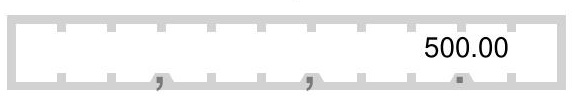

Subtotal Of Receipts This Page (optional)

1500.00

Total This Period (last page this line number only) 


\section{SCHEDULE A-P} ITEMIZED RECEIPTS
Use separate schedule(s)

for each category of the

Detailed Summary Page
FOR LINE NUMBER: (check only one)

Any information or for commercial purposes, other than using the name and address of any political committee to solicit contributions from such committee.

NAME OF COMMITTEE (In Full)

Friends of Herman Cain

A. Full Name (Last, First, Middle Initial)

tom ahlborn

Mailing Address 9808 old camp lane

\begin{tabular}{lcc}
\hline City & State & Zip Code \\
Windsor & CA & $95492-8587$
\end{tabular}

FEC ID number of contributing

federal political committee.

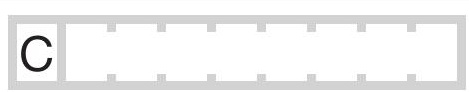

Name of Employer
Information Requested
Receipt For: 2012
X Primary $\quad \square$ General
Other (specify)

Occupation

Information Requested

Election Cycle-to-Date

300.00

B. Full Name (Last, First, Middle Initial)

Grant Hegranes

Mailing Address POB 835

\begin{tabular}{lcc}
\hline $\begin{array}{l}\text { City } \\
\text { Denton }\end{array}$ & State & Zip Code \\
FEC ID number of contributing & TX & $76202-0835$ \\
federal political committee. & C & \\
\hline
\end{tabular}

\begin{tabular}{l} 
Name of Employer \\
Information Requested \\
\hline Receipt For: 2012 \\
Primary \\
Other (specify)
\end{tabular}

\section{Occupation}

Information Requested

Election Cycle-to-Date

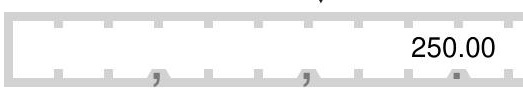

C. Full Name (Last, First, Middle Initial)

John Diggins

Mailing Address PO Box 6107

\begin{tabular}{lcc}
\hline City & State & Zip Code \\
Sheridan & WY & $82801-1507$
\end{tabular}

FEC ID number of contributing federal political committee.

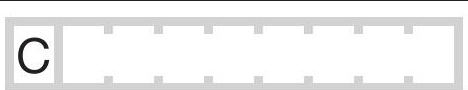

Name of Employer
Information Requested
Receipt For: 2012
X Primary
Other (specify) General

\section{Occupation}

Information Requested

Election Cycle-to-Date

Transaction ID : A39CFDF9971534ACBA18

Date of Receipt

Amount of Each Receipt this Period
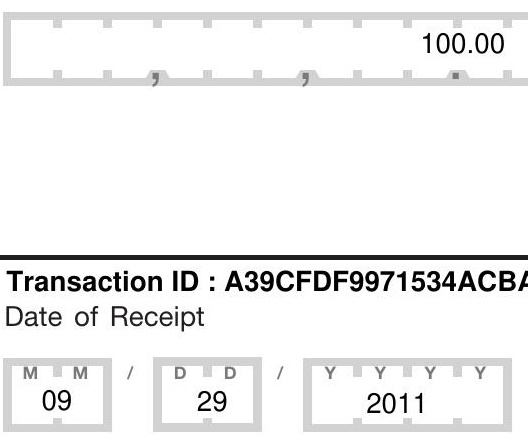

Amount of Each Receipt this Period

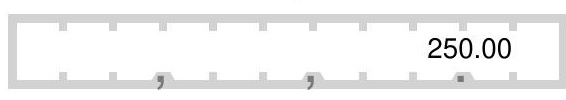

Transaction ID : A66127CB04F9B43FF979

Date of Receipt

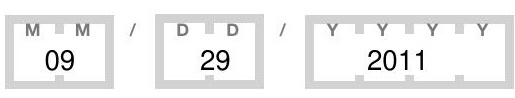

Amount of Each Receipt this Period

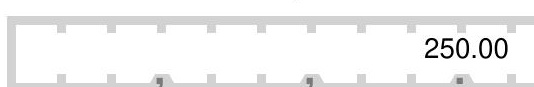

250.00

Subtotal Of Receipts This Page (optional).

600.00

ㄱ․․

Total This Period (last page this line number only)

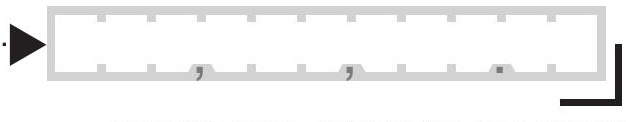

FEC Schedule A-P (Form 3P) (Rev. 03/2011) 


\section{SCHEDULE A-P} ITEMIZED RECEIPTS
Use separate schedule(s) for each category of the Detailed Summary Page
FOR LINE NUMBER: (check only one)
PAGE 1065 / 1572

\begin{tabular}{|c|c|c|c|c|c|}
\hline & & & & & \\
\hline 16 & $\begin{array}{ll}\mathbf{X} & 17 a \\
\end{array}$ & $17 \mathrm{~b}$ & $17 c$ & $17 d$ & 18 \\
\hline $19 a$ & $19 b$ & $20 \mathrm{a}$ & $20 \mathrm{~b}$ & $20 c$ & 21 \\
\hline
\end{tabular}

Any information copied from such Reports and Statements may not be sold or used by any person for the purpose of soliciting contributions or for commercial purposes, other than using the name and address of any political committee to solicit contributions from such committee.

NAME OF COMMITTEE (In Full)

\section{Friends of Herman Cain}

A. Full Name (Last, First, Middle Initial) Jeffrey Staab

Mailing Address 24735 Vantage Point Ter.

\begin{tabular}{lcc}
\hline City & State & Zip Code \\
Malibu & CA & $90265-4739$
\end{tabular}

FEC ID number of contributing federal political committee.

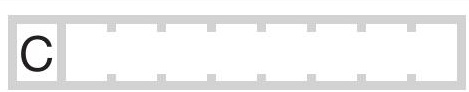

Name of Employer
Information Requested
Receipt For: 2012
X Primary
$\square$ Other (specify)

Occupation Information Requested

Election Cycle-to-Date

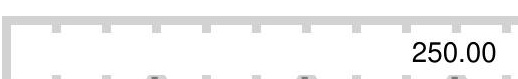

B. Full Name (Last, First, Middle Initial) EDWARD MURPHY

Mailing Address 214 CAMINO VISTA REAL

\begin{tabular}{lcc}
\hline City & State & Zip Code \\
Chula Vista & CA & $91910-6326$
\end{tabular}

FEC ID number of contributing

federal political committee.

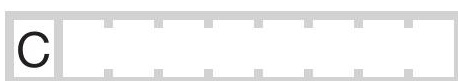

Name of Employer
navy exchange
Receipt For: 2012
Primary
Other (specify)

\section{Occupation}

Retired

Election Cycle-to-Date

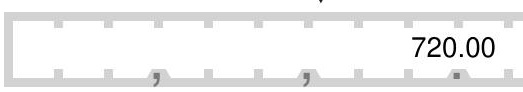

C. Full Name (Last, First, Middle Initial)

jack griffin

Mailing Address 1472 fahim dr

\begin{tabular}{lcc}
\hline City & State & Zip Code \\
Gardnerville & NV & $89410-6629$
\end{tabular}

FEC ID number of contributing federal political committee.

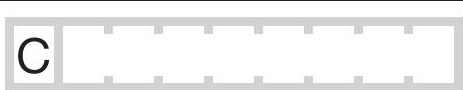

Name of Employer Information Requested

\section{Occupation}

Receipt For: 2012

Х $\begin{aligned} & \text { Primary } \square \text { General } \\ & \text { Other (specify) }\end{aligned}$

Information Requested

Election Cycle-to-Date

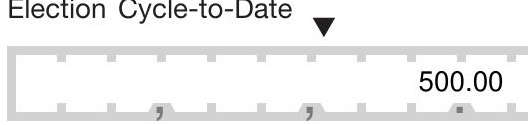

Transaction ID : AAFC7A08120B3495AB3B Date of Receipt

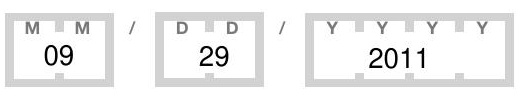

Amount of Each Receipt this Period

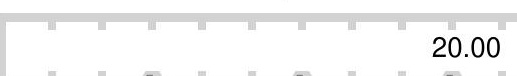

Transaction ID : A78DA4EEE34CB478F9AE Date of Receipt

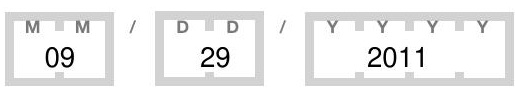

Amount of Each Receipt this Period

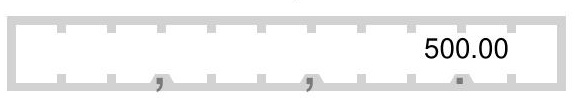

\section{Subtotal Of Receipts This Page (optional)}

Total This Period (last page this line number only) 


\section{SCHEDULE A-P} ITEMIZED RECEIPTS
Use separate schedule(s)

for each category of the

Detailed Summary Page
FOR LINE NUMBER: (check only one)

Any information or for commercial purposes, other than using the name and address of any political committee to solicit contributions from such committee.

NAME OF COMMITTEE (In Full)

Friends of Herman Cain

A. Full Name (Last, First, Middle Initial)

Condon Hughes

Mailing Address 1216 56th St

\begin{tabular}{lcc}
\hline City & State & Zip Code \\
Meridian & MS & $39305-1400$
\end{tabular}

FEC ID number of contributing

federal political committee.

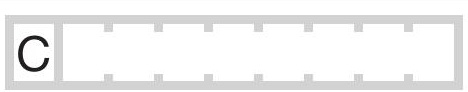

Name of Employer
Information Requested
Receipt For: 2012
X Primary $\quad \square$ General
Other (specify)

Occupation

Information Requested

Election Cycle-to-Date

500.00

B. Full Name (Last, First, Middle Initial)

Mike Sternberg

Mailing Address 804 Quail Ridge Ln

\begin{tabular}{lcc}
\hline City & State & Zip Code \\
Perry & GA & $31069-4534$ \\
\hline
\end{tabular}

FEC ID number of contributing

federal political committee.

C

Name of Employer
Information Requested
Receipt For: 2012
X Primary
Other (specify)

Occupation

Information Requested

Election Cycle-to-Date

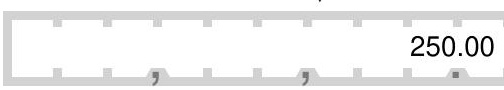

Transaction ID : A64D80D5A5D1B4F4698D

Date of Receipt

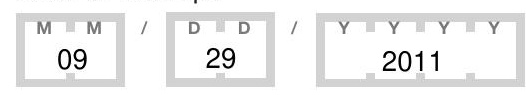

Amount of Each Receipt this Period

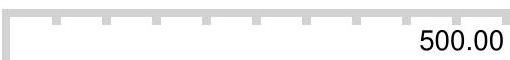

Transaction ID : AAE61C242F0C242D3875

Date of Receipt

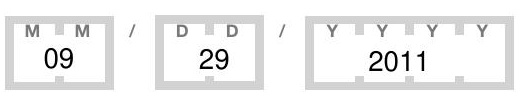

Amount of Each Receipt this Period

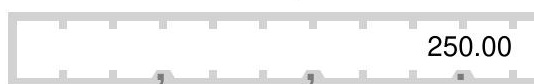

Transaction ID : AE6586F5882004D5F8A0

Date of Receipt

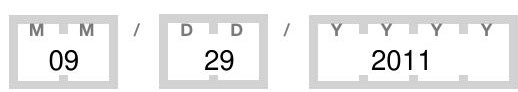

Amount of Each Receipt this Period

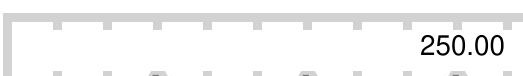

$\begin{array}{cc}\text { State } & \text { Zip Code } \\ \text { GA } & 30342-4019\end{array}$

C

Occupation

Information Requested

Election Cycle-to-Date

Receipt For: 2012

Х $\begin{aligned} & \text { Primary } \square \text { General } \\ & \text { Other (specify) }\end{aligned}$

250.00

Subtotal Of Receipts This Page (optional).

1000.00

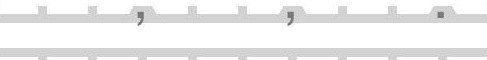

Total This Period (last page this line number only) 


\section{SCHEDULE A-P} ITEMIZED RECEIPTS
Use separate schedule(s)

for each category of the

Detailed Summary Page
FOR LINE NUMBER: (check only one)

Any information or for commercial purposes, other than using the name and address of any political committee to solicit contributions from such committee.

NAME OF COMMITTEE (In Full)

Friends of Herman Cain

A. Full Name (Last, First, Middle Initial)

\section{Edward McKee}

Mailing Address 110 Hartford Road

\begin{tabular}{lcc}
\hline City & State & Zip Code \\
Owens Cross Roads & AL & $35763-9738$
\end{tabular}

FEC ID number of contributing

federal political committee.

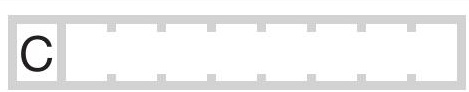

Name of Employer
self
Receipt For: 2012
X Primary $\quad$ General
Other (specify)

Occupation

Attorney

Election Cycle-to-Date

1100.00

B. Full Name (Last, First, Middle Initial)

Laura Hammontree

Mailing Address 45 Hawk Dr

\begin{tabular}{lcc}
\hline City & State & Zip Code \\
Hiram & GA & $30141-5145$ \\
\hline
\end{tabular}

FEC ID number of contributing

federal political committee.

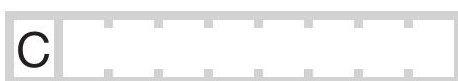

Name of Employer
WS Pharr \& Co
Receipt For: 2012
X Primary
Other (specify)

Occupation

Insurance Agent

Election Cycle-to-Date

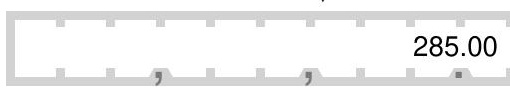

Transaction ID : A174F7AA659C34277B66

Date of Receipt

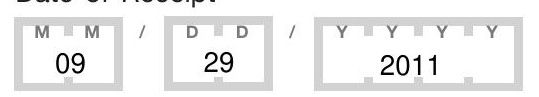

Amount of Each Receipt this Period

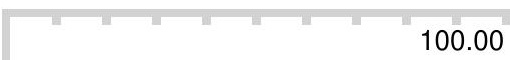

Amount of Each Receipt this Period

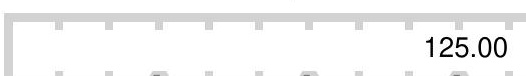

C. Full Name (Last, First, Middle Initial)

Richard Moore

Mailing Address 30 Fieldstone Trail

\begin{tabular}{lcc}
\hline City & State & Zip Code \\
Saint Louis & MO & $63124-1287$
\end{tabular}

FEC ID number of contributing

federal political committee.

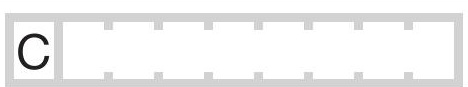

Name of Employer

The Lifestyle Center

Occupation

Receipt For: 2012

Х $\begin{aligned} & \text { Primary } \square \text { General } \\ & \text { Other (specify) }\end{aligned}$

Executive

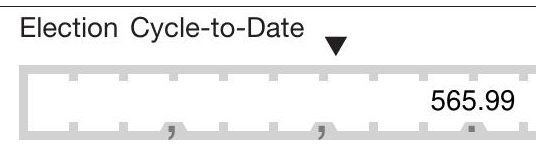

Amount of Each Receipt this Period

Transaction ID : AACBB21249695497797B

Date of Receipt
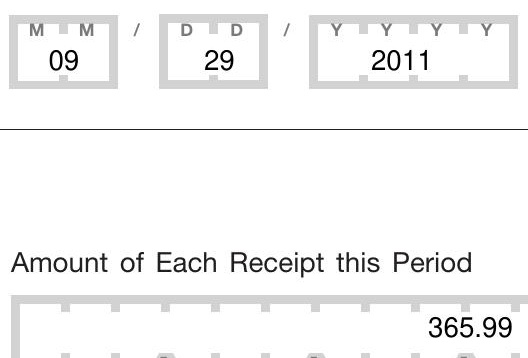

365.99

Subtotal Of Receipts This Page (optional)

590.99

Total This Period (last page this line number only) 


\section{SCHEDULE A-P} ITEMIZED RECEIPTS
Use separate schedule(s) for each category of the Detailed Summary Page
FOR LINE NUMBER: (check only one)

Any information copion or for commercial purposes, other than using the name and address of any political committee to solicit contributions from such committee.

NAME OF COMMITTEE (In Full)

Friends of Herman Cain

A. Full Name (Last, First, Middle Initial)

John Harman

Mailing Address 1001 Huron Road East \#308

\begin{tabular}{lcc}
\hline City & State & Zip Code \\
Cleveland & OH & $44115-1755$
\end{tabular}

FEC ID number of contributing

federal political committee.

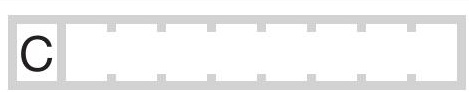

Name of Employer
Preductive Service, LLC
Receipt For: 2012
X Primary $\quad \square$ General
Other (specify)

Occupation

Executive

Election Cycle-to-Date

465.00

B. Full Name (Last, First, Middle Initial)

Thomas Woolston

Mailing Address 9124 Potomac Ridge rd

\begin{tabular}{lcc}
\hline City & State & Zip Code \\
Great Falls & VA & $22066-4106$
\end{tabular}

FEC ID number of contributing

federal political committee.

C

Name of Employer
Information Requested
Receipt For: 2012
X Primary
Other (specify)

Occupation

Information Requested

Election Cycle-to-Date

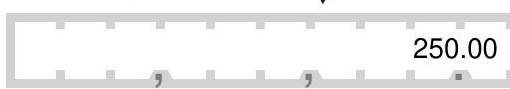

Transaction ID : A224F784F1E6B421D98F

Date of Receipt

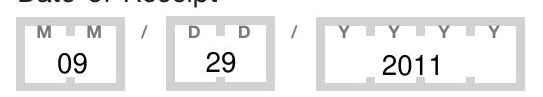

Amount of Each Receipt this Period

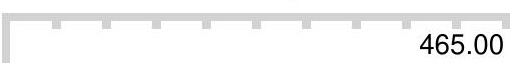

465.00

C. Full Name (Last, First, Middle Initial)

Judith Stone

Mailing Address 1021 Westbridge Ln

\begin{tabular}{lcc}
\hline City & State & Zip Code \\
Chattanooga & TN & $37405-4274$
\end{tabular}

FEC ID number of contributing

federal political committee.

C

Name of Employer

Information Requested

Occupation

Information Requested

Receipt For: 2012

Х $\begin{aligned} & \text { Primary } \square \text { General } \\ & \text { Other (specify) }\end{aligned}$

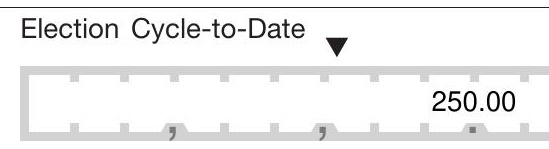

Amount of Each Receipt this Period

Transaction ID : A2C5CA71E14F84BA39D1

Date of Receipt
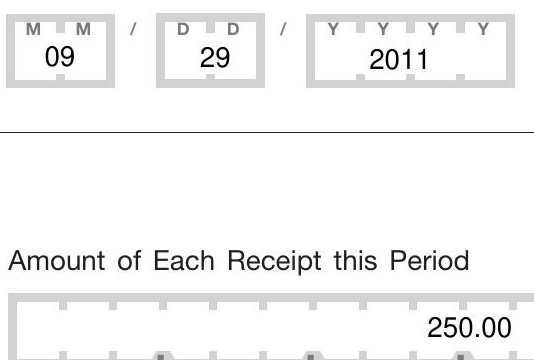

Transaction ID : AF62D71A3BC5F456EB38

Date of Receipt

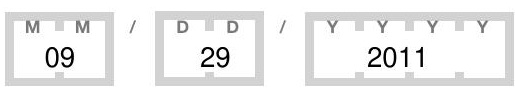

Amount of Each Receipt this Period

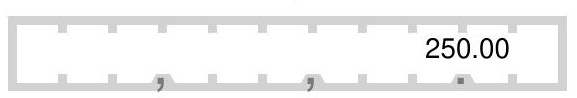

Subtotal Of Receipts This Page (optional).

965.00

Total This Period (last page this line number only) 
SCHEDULE A-P ITEMIZED RECEIPTS
Use separate schedule(s) for each category of the Detailed Summary Page
FOR LINE NUMBER: (check only one)

Any information or for commercial purposes, other than using the name and address of any political committee to solicit contributions from such committee.

NAME OF COMMITTEE (In Full)

Friends of Herman Cain

A. Full Name (Last, First, Middle Initial) Joseph Dannenmaier

Mailing Address 5612 Williamstown Road

\begin{tabular}{lcc}
\hline City & State & Zip Code \\
Dallas & TX & $75230-2130$ \\
\hline
\end{tabular}

FEC ID number of contributing federal political committee.

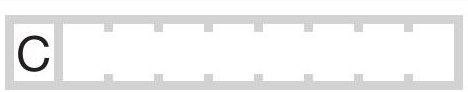

Name of Employer
Information Requested
Receipt For: 2012
X Primary
Other (specify) General

Occupation Information Requested

Election Cycle-to-Date

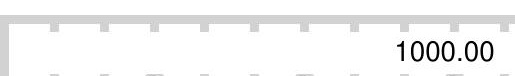

B. Full Name (Last, First, Middle Initial)

Virginia Johnson

Mailing Address 17157 Palisades Circle

\begin{tabular}{lcc}
\hline City & State & Zip Code \\
Pacific Palisades & CA & $90272-2145$
\end{tabular}

FEC ID number of contributing

federal political committee.

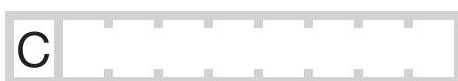

Name of Employer
Self Employed
Receipt For: 2012
X Primary
Other (specify) General

Occupation

Physician

Election Cycle-to-Date

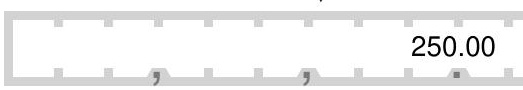

C. Full Name (Last, First, Middle Initial)

Mark Thompson

Mailing Address 1315 Mistletoe Ridge Place NW

\begin{tabular}{lcc}
\hline City & State & Zip Code \\
Concord & NC & $28027-7877$ \\
\hline
\end{tabular}

FEC ID number of contributing

federal political committee.

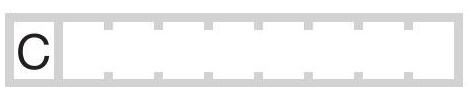

Name of Employer

Self Employed

Receipt For: 2012

Х $\begin{aligned} & \text { Primary } \\ & \text { Other (specify) }\end{aligned}$

\section{Occupation}

CPA

Election Cycle-to-Date

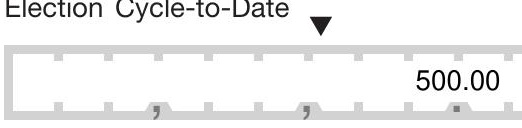

Transaction ID : A7A5FB2B387644770910

Date of Receipt

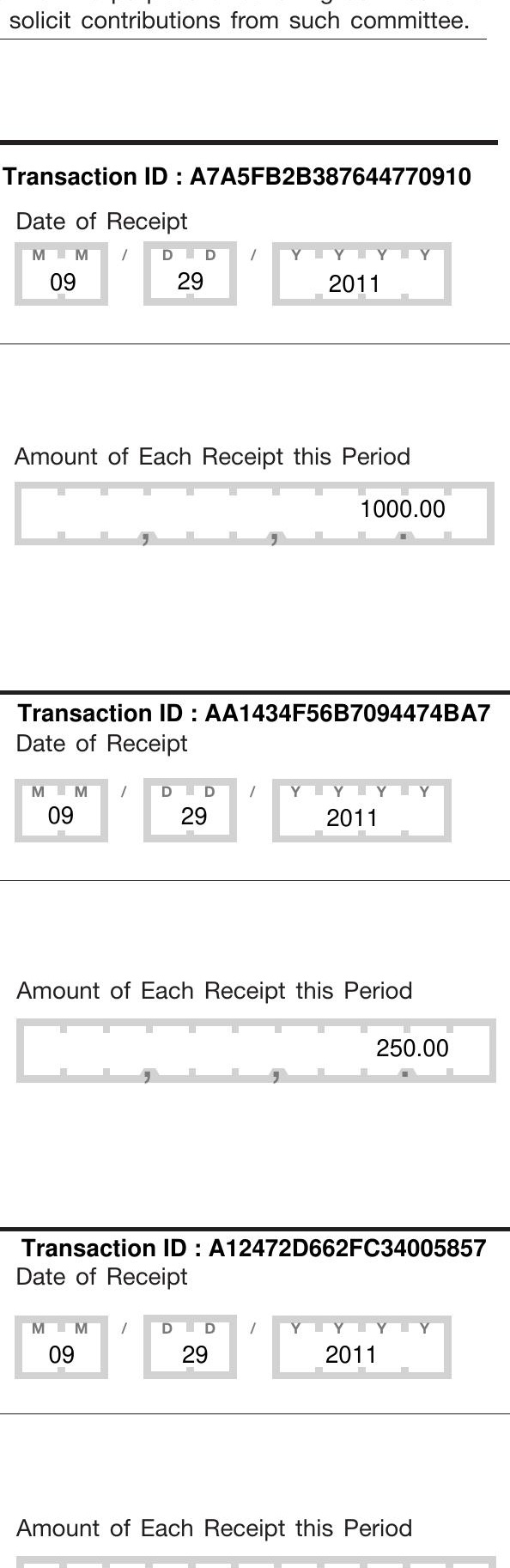

Amount of Each Receipt this Period

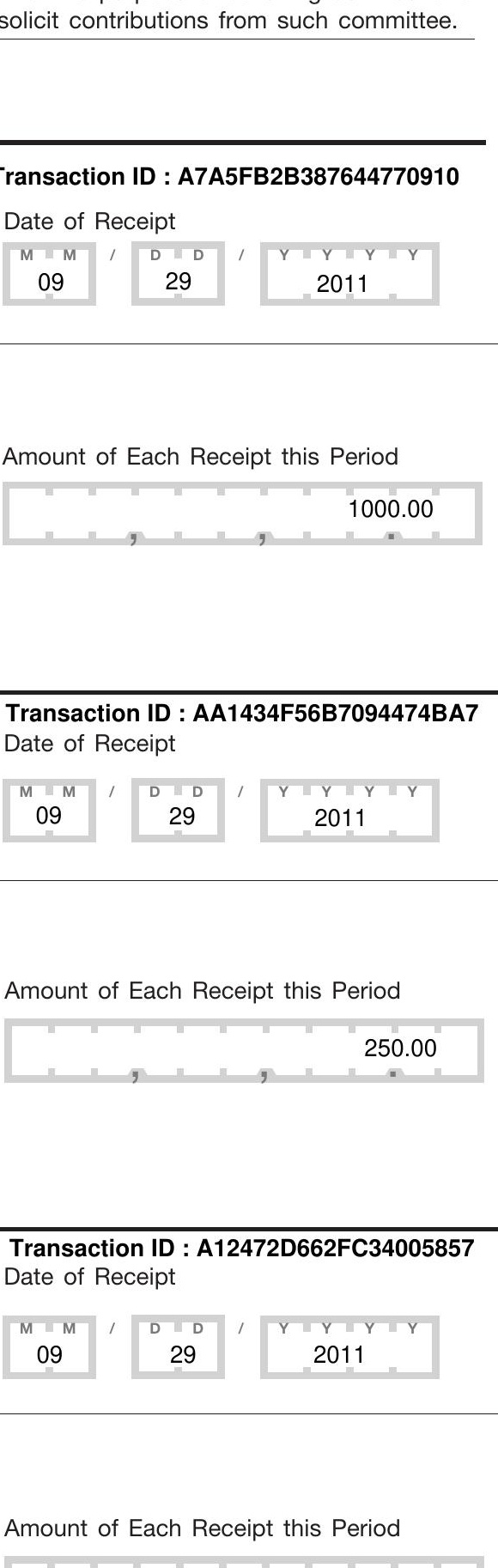

1000.00

Transaction ID : AA1434F56B7094474BA7

Date of Receipt

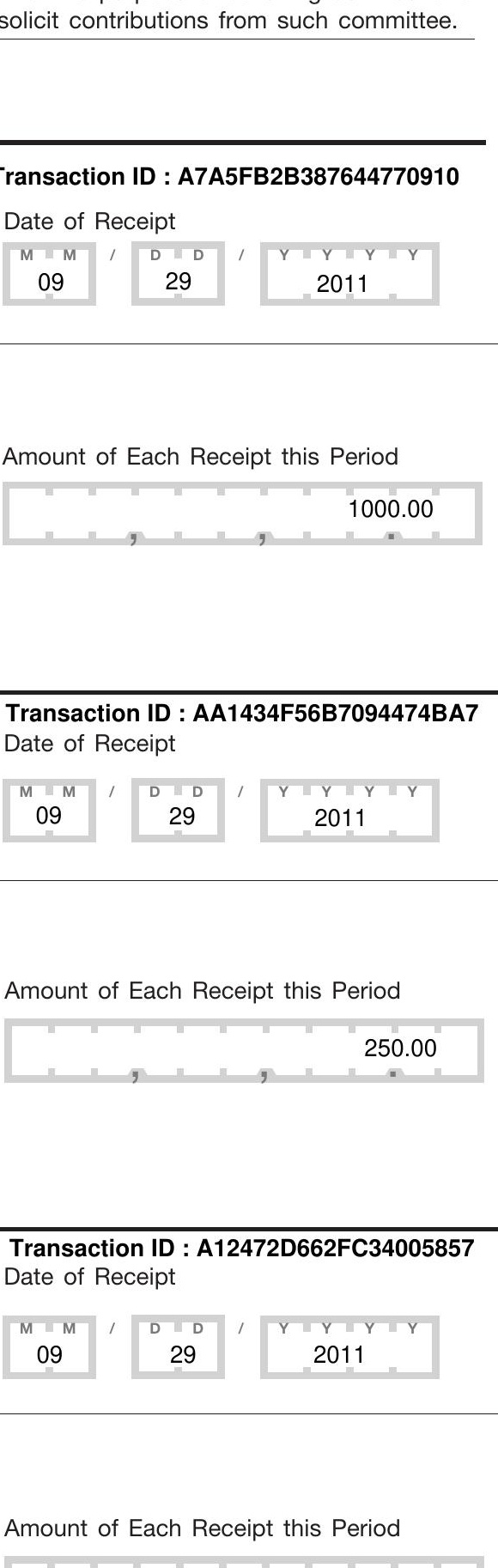

Amount of Each Receipt this Period

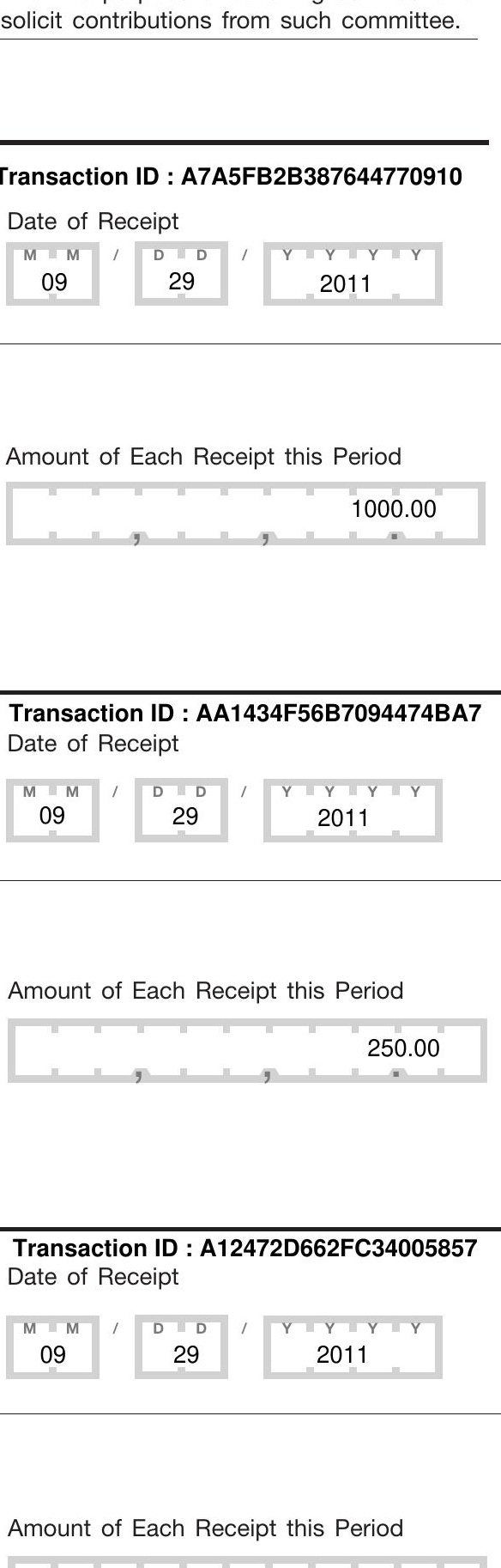

Transaction ID : A12472D662FC34005857

Date of Receipt

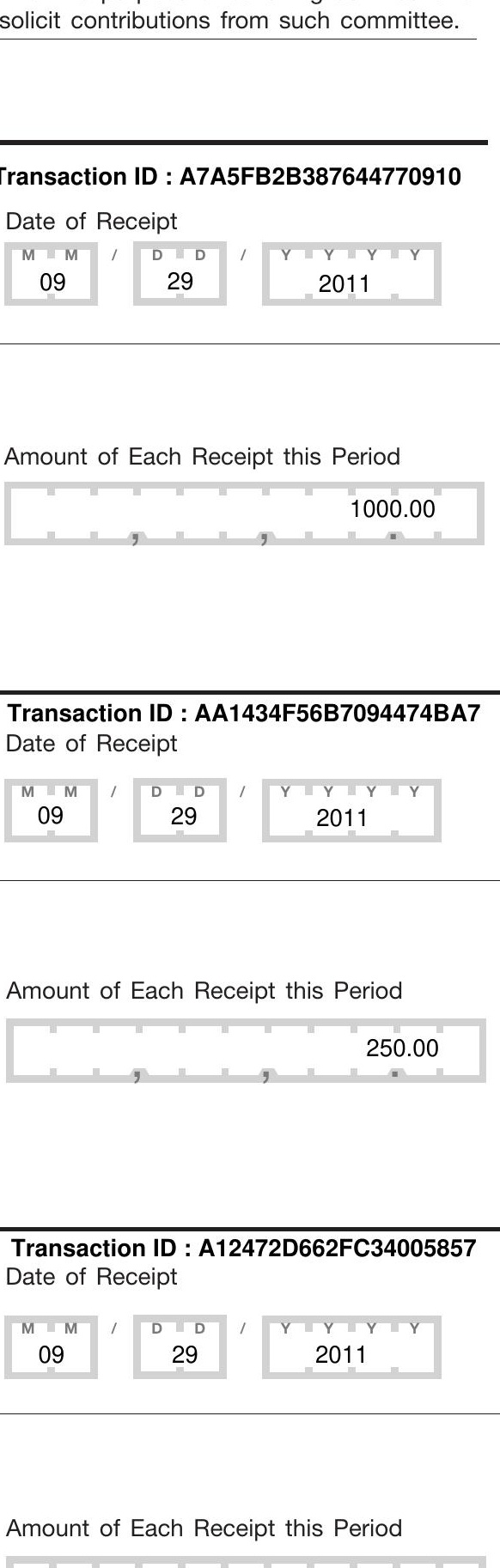

Amount of Each Receipt this Period

Subtotal Of Receipts This Page (optional).

Total This Period (last page this line number only) 


\section{SCHEDULE A-P} ITEMIZED RECEIPTS
Use separate schedule(s) for each category of the Detailed Summary Page

\begin{tabular}{|c|c|c|c|c|c|}
\hline \multicolumn{3}{|c|}{$\begin{array}{l}\text { FOR LINE NUMBER: } \\
\text { (check only one) }\end{array}$} & \multicolumn{3}{|c|}{ PAGE 1070 / 1572} \\
\hline 16 & $X$ 17a & $17 b$ & $17 \mathrm{c}$ & $17 d$ & 18 \\
\hline $19 a$ & $19 \mathrm{~b}$ & $20 a$ & $20 \mathrm{~b}$ & $20 c$ & 21 \\
\hline
\end{tabular}

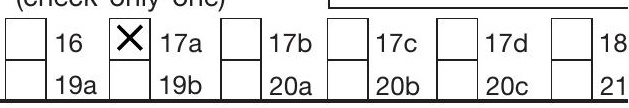

Any information copied from such Reports and Statements may not be sold or used by any person for the purpose of soliciting contributions or for commercial purposes, other than using the name and address of any political committee to solicit contributions from such committee.

NAME OF COMMITTEE (In Full)

\section{Friends of Herman Cain}

A. Full Name (Last, First, Middle Initial)

\section{David Sodamann}

Mailing Address 512 NW 56th St

\begin{tabular}{lcc}
\hline City & State & Zip Code \\
Topeka & KS & $66617-1311$ \\
\hline
\end{tabular}

FEC ID number of contributing federal political committee.

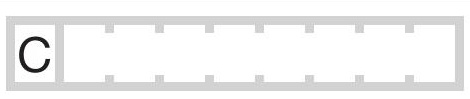

Name of Employer
US ARMY
Receipt For: 2012
X Primary
Other (specify) General

Occupation Retired Election Cycle-to-Date

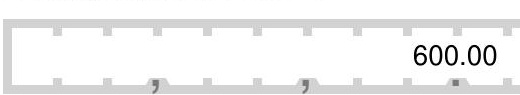

B. Full Name (Last, First, Middle Initial) raymond pasquale

Mailing Address 82 noons quarry rd

\begin{tabular}{lcc}
\hline City & State & Zip Code \\
Milford & $\mathrm{NH}$ & $03055-3445$ \\
\hline
\end{tabular}

FEC ID number of contributing

federal political committee.

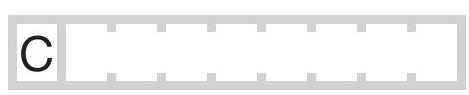

\begin{tabular}{l} 
Name of Employer \\
n/a \\
Receipt For: 2012 \\
X Primary $\quad$ General \\
\hline Other (specify)
\end{tabular}

\section{Occupation}

$\mathrm{n} / \mathrm{a}$

Election Cycle-to-Date

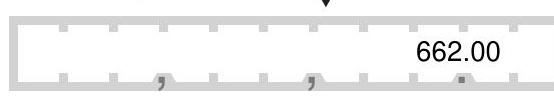

Transaction ID : A6B522EFEF2B54CF48A7

Date of Receipt

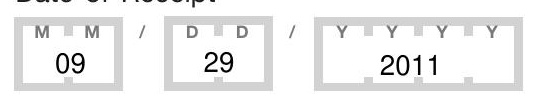

Amount of Each Receipt this Period

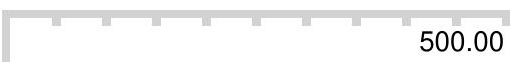

Amount of Each Receipt this Period

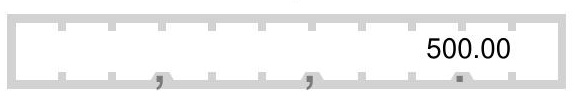

C. Full Name (Last, First, Middle Initial)

Andrew Ramsey

Mailing Address 740 West Main Street

\begin{tabular}{l|ll}
\hline $\begin{array}{l}\text { City } \\
\text { Bruceville }\end{array}$ & $\begin{array}{c}\text { State } \\
\text { IN }\end{array}$ & $\begin{array}{c}\text { Zip Code } \\
47516-6207\end{array}$ \\
\hline $\begin{array}{l}\text { FEC ID number of contributing } \\
\text { federal political committee. }\end{array}$ & C \\
\hline $\begin{array}{l}\text { Name of Employer } \\
\text { Standard Labs }\end{array}$ & $\begin{array}{l}\text { Occupation } \\
\text { coalsampler }\end{array}$ \\
\hline $\begin{array}{l}\text { Receipt For: } 2012 \\
\text { X } \begin{array}{l}\text { Primary } \\
\text { Other (specify) }\end{array}\end{array}$ & Election Cycle-to-Date & \\
\hline General & & 370.00
\end{tabular}

Transaction ID : AEA94D92521A24D3C943

Date of Receipt

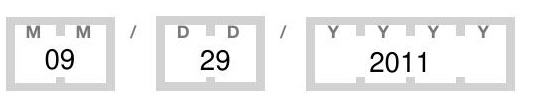

Transaction ID : ABE8AABCA2CC74DF5851 Date of Receipt

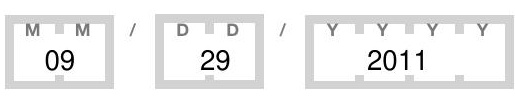

Amount of Each Receipt this Period

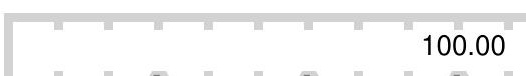

100.00

1100.00

Subtotal Of Receipts This Page (optional)

Total This Period (last page this line number only) 


\section{SCHEDULE A-P} ITEMIZED RECEIPTS
Use separate schedule(s) for each category of the Detailed Summary Page

FOR LINE NUMBER:
(check only one)

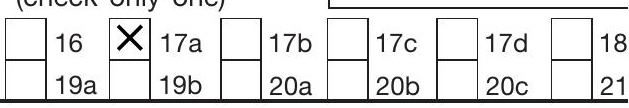

Any information copied from such Reports and Statements may not be sold or used by any person for the purpose of soliciting contributions or for commercial purposes, other than using the name and address of any political committee to solicit contributions from such committee.

NAME OF COMMITTEE (In Full)

\section{Friends of Herman Cain}

A. Full Name (Last, First, Middle Initial)

\section{Brian Parramore}

Mailing Address 619 Carvell dr

\begin{tabular}{lcc}
\hline City & State & Zip Code \\
Winter Park & FL & $32792-2715$
\end{tabular}

FEC ID number of contributing federal political committee.

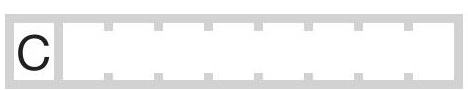

Name of Employer
Information Requested
Receipt For: 2012
X Primary
$\square$ Other (specify)

Occupation Information Requested

Election Cycle-to-Date

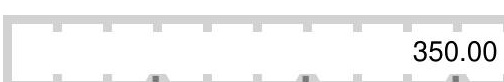

B. Full Name (Last, First, Middle Initial)

Charles Berry

Mailing Address 1050 Calle Milagro Dr.

\begin{tabular}{lcc}
\hline City & State & Zip Code \\
El Paso & TX & $79912-7521$
\end{tabular}

FEC ID number of contributing

federal political committee.

C

Name of Employer
Information Requested
Receipt For: 2012
X Primary
Other (specify)

\section{Occupation}

Information Requested

Election Cycle-to-Date

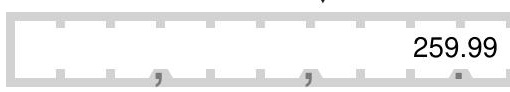

Transaction ID : AC6442BB1F1954B3FB20

Date of Receipt

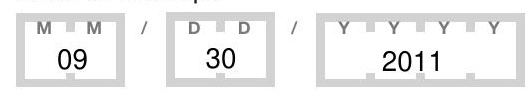

Amount of Each Receipt this Period

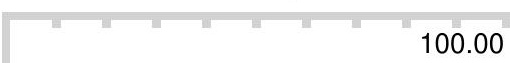

Amount of Each Receipt this Period

Transaction ID : A1D0A08CB40C4451FA73

Date of Receipt
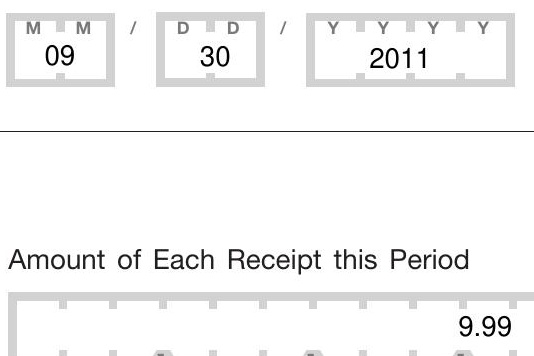

Transaction ID : A788A87E42DAB49CE8BC Date of Receipt

Keith Oulson

Mailing Address 5425 Ripple Creek Dr

\begin{tabular}{lcc}
\hline City & State & Zip Code \\
Tampa & FL & $33625-6416$
\end{tabular}

FEC ID number of contributing federal political committee.

C

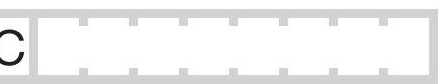

Name of Employer

Tampa General Hospital

Occupation

Receipt For: 2012

Х $\begin{aligned} & \text { Primary } \square \text { General } \\ & \text { Other (specify) }\end{aligned}$

Interface Analyst

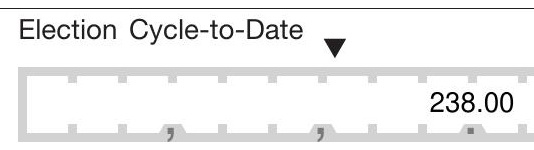

Amount of Each Receipt this Period

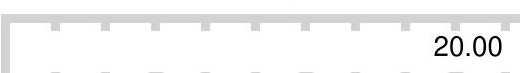

Subtotal Of Receipts This Page (optional)

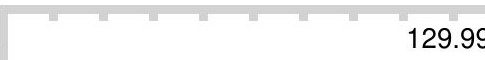

Total This Period (last page this line number only) 


\section{SCHEDULE A-P} ITEMIZED RECEIPTS
Use separate schedule(s)

for each category of the

Detailed Summary Page
FOR LINE NUMBER: (check only one)

Any information or for commercial purposes, other than using the name and address of any political committee to solicit contributions from such committee.

NAME OF COMMITTEE (In Full)

Friends of Herman Cain

A. Full Name (Last, First, Middle Initial)

Michael McGraw

Mailing Address 2621 Darlington Ct.

\begin{tabular}{lcc}
\hline City & State & Zip Code \\
Conyers & GA & $30013-4916$ \\
\hline
\end{tabular}

FEC ID number of contributing

federal political committee.

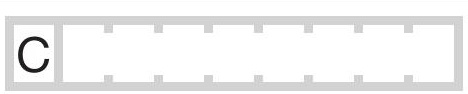

Name of Employer
n/a
Receipt For: 2012
X Primary $\quad$ General
Other (specify)

Occupation

Retired

Election Cycle-to-Date

\subsection{0}

B. Full Name (Last, First, Middle Initial)

Mary Daniel

Mailing Address 131 South End Street

\begin{tabular}{lcc}
\hline City & State & Zip Code \\
Saint Augustine & FL & $32095-6821$
\end{tabular}

FEC ID number of contributing

federal political committee.

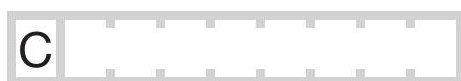

Name of Employer
The Shannon Group
Receipt For: 2012
X Primary
Other (specify)

Occupation

medical management

Election Cycle-to-Date

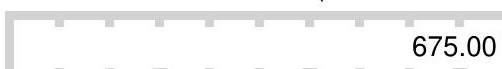

Transaction ID : A64C43D59A4A14B5DB54

Date of Receipt

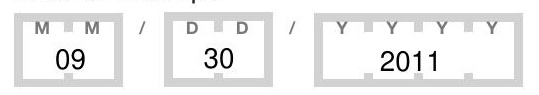

Amount of Each Receipt this Period

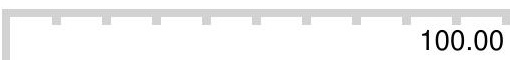

C. Full Name (Last, First, Middle Initial)

Jenny Galloway

Mailing Address 2178 Vinings North Lane

\begin{tabular}{lcc}
\hline City & State & Zip Code \\
Smyrna & GA & $30080-5977$
\end{tabular}

FEC ID number of contributing

federal political committee.

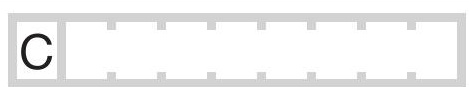

Name of Employer

Information Requested

Occupation

Information Requested

Receipt For: 2012

Х $\begin{aligned} & \text { Primary } \square \text { General } \\ & \text { Other (specify) }\end{aligned}$

Amount of Each Receipt this Period

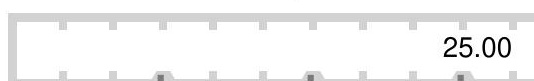

Transaction ID : AF21AF0EF7931411AAAC

Date of Receipt

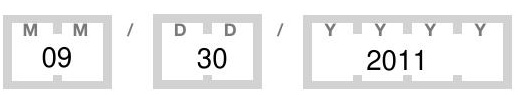

Transaction ID : A4084475FFF5A40F2BA8

Date of Receipt

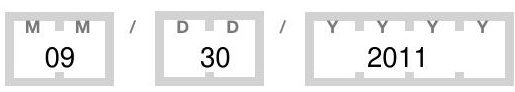

Amount of Each Receipt this Period

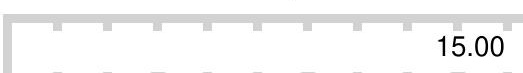

\section{Subtotal Of Receipts This Page (optional)}

140.00

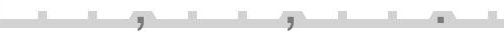

Total This Period (last page this line number only)

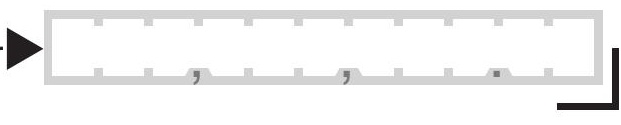

FEC Schedule A-P (Form 3P) (Rev. 03/2011) 
SCHEDULE A-P ITEMIZED RECEIPTS
Use separate schedule(s) for each category of the Detailed Summary Page
FOR LINE NUMBER: (check only one)

PAGE 1073 / 1572

\begin{tabular}{|c|c|c|c|c|c|}
\hline & & & & & \\
\hline 16 & $\begin{array}{lll}X & 17 a \\
\end{array}$ & $17 \mathrm{~b}$ & $17 c$ & $17 d$ & 18 \\
\hline $19 a$ & $19 b$ & $20 a$ & $20 \mathrm{~b}$ & $20 c$ & 21 \\
\hline
\end{tabular}

Any information copied from such Reports and Statements may not be sold or used by any person for the purpose of soliciting contributions or for commercial purposes, other than using the name and address of any political committee to solicit contributions from such committee.

NAME OF COMMITTEE (In Full)

Friends of Herman Cain

A. Full Name (Last, First, Middle Initial)

Jenny Galloway

Mailing Address 2178 Vinings North Lane

\begin{tabular}{lcc}
\hline City & State & Zip Code \\
Smyrna & GA & $30080-5977$ \\
\hline
\end{tabular}

FEC ID number of contributing

federal political committee.

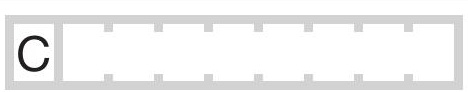

Name of Employer
Information Requested
Receipt For: 2012
X Primary $\quad \square$ General
Other (specify)

Occupation

Information Requested

Election Cycle-to-Date

220.00

B. Full Name (Last, First, Middle Initial)

Brian Dekle

Mailing Address 1177 Landings Rd

\begin{tabular}{lcc}
\hline City & State & Zip Code \\
Daphne & AL & $36526-4027$
\end{tabular}

FEC ID number of contributing

federal political committee.

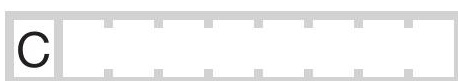

Name of Employer
Comlab Vehicle Division
Receipt For: 2012
X Primary
Other (specify)

Occupation

President

Election Cycle-to-Date

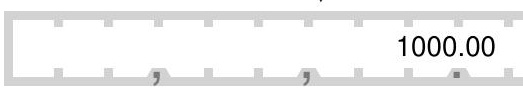

C. Full Name (Last, First, Middle Initial)

steven graham

Mailing Address 1633 e. ivyglen st.

\begin{tabular}{lcc}
\hline City & State & Zip Code \\
Mesa & AZ & 85203-2834
\end{tabular}

FEC ID number of contributing

federal political committee.

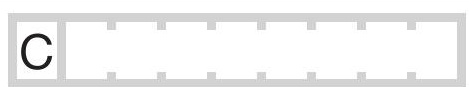

Name of Employer
Unemployed
Receipt For: 2012
X Primary
Other (specify) General

\section{Occupation}

Designer

Election Cycle-to-Date

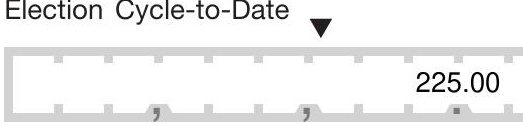

Transaction ID : A25766D710BF64EDE87C

Date of Receipt

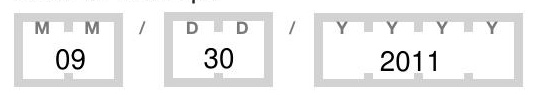

Amount of Each Receipt this Period

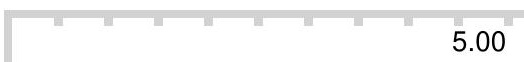

Amount of Each Receipt this Period

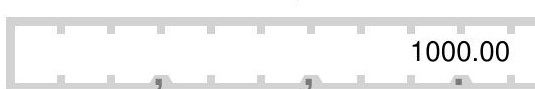

Transaction ID : A9D82B30793D943D5A9B Date of Receipt

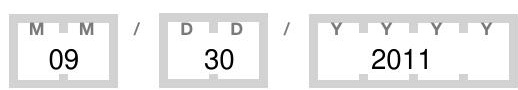

Amount of Each Receipt this Period

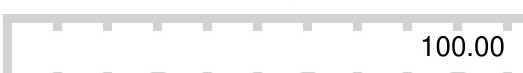

Transaction ID : AFA717AA0D8C0442E985

Date of Receipt
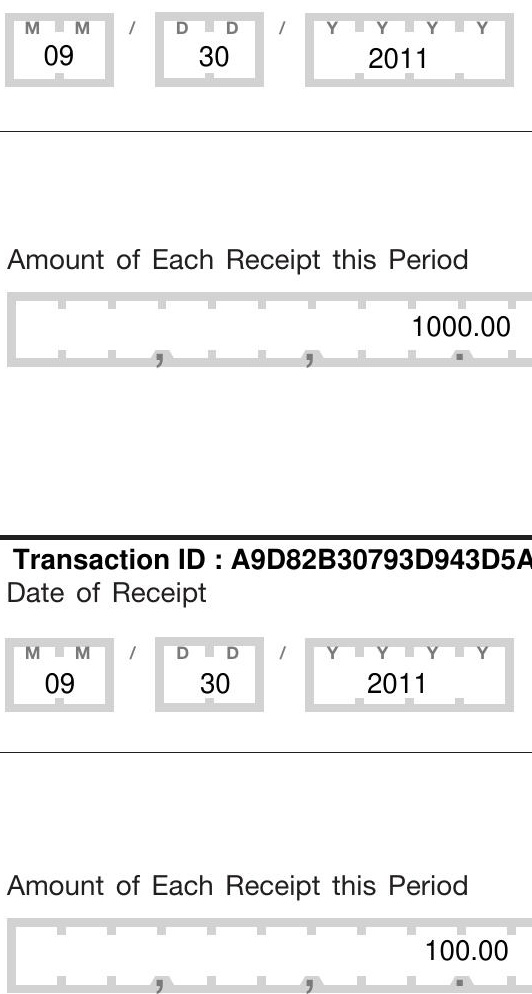

Subtotal Of Receipts This Page (optional).

1105.00

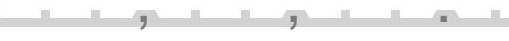

Total This Period (last page this line number only)

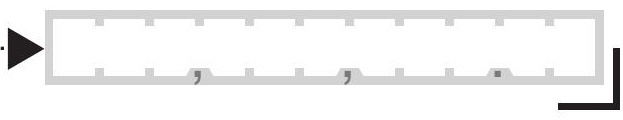




\section{SCHEDULE A-P} ITEMIZED RECEIPTS
Use separate schedule(s) for each category of the Detailed Summary Page
FOR LINE NUMBER: (check only one)

PAGE 1074 / 1572

\begin{tabular}{|c|c|c|c|c|c|}
\hline & & & & & \\
\hline 16 & $\begin{array}{l}\mathbf{X} \\
17 a\end{array}$ & $17 b$ & $17 c$ & $17 d$ & 18 \\
\hline $19 a$ & $19 \mathrm{~b}$ & $20 \mathrm{a}$ & $20 \mathrm{~b}$ & $20 \mathrm{c}$ & 21 \\
\hline
\end{tabular}

Any information copied from such Reports and Statements may not be sold or used by any person for the purpose of soliciting contributions or for commercial purposes, other than using the name and address of any political committee to solicit contributions from such committee.

NAME OF COMMITTEE (In Full)

Friends of Herman Cain

A. Full Name (Last, First, Middle Initial)

Kathy Siders

Mailing Address 6254 W 200 North

\begin{tabular}{lcc}
\hline City & State & Zip Code \\
Rochester & IN & $46975-8876$
\end{tabular}

FEC ID number of contributing federal political committee.

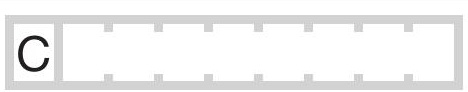

Name of Employer
self
Receipt For: 2012
X Primary $\quad$ General
Other (specify)

Occupation

farmer

Election Cycle-to-Date

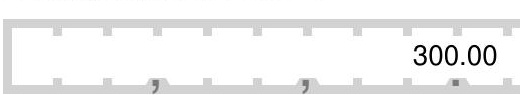

B. Full Name (Last, First, Middle Initial) James Cassell

Mailing Address P.O. Box 321

\begin{tabular}{lcc}
\hline City & State & Zip Code \\
North Webster & IN & $46555-0321$
\end{tabular}

FEC ID number of contributing

federal political committee.

C

Name of Employer
Self Employed
Receipt For: 2012
X Primary
Other (specify)

Occupation

Direct Marketing

Election Cycle-to-Date

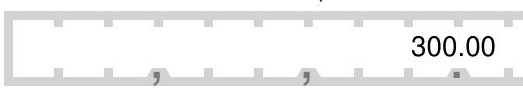

Transaction ID : AE76495C04A0E46EF99C

Date of Receipt

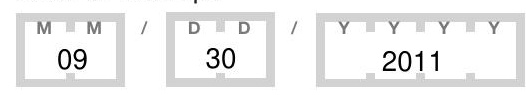

Amount of Each Receipt this Period

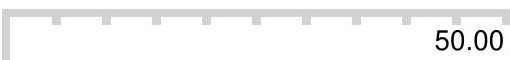

C. Full Name (Last, First, Middle Initial)

Cliff Beveridge

Mailing Address 1216 Gotier Trace Rd.

\begin{tabular}{lcc}
\hline City & State & Zip Code \\
Paige & TX & $78659-4400$
\end{tabular}

FEC ID number of contributing

federal political committee.

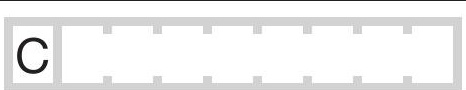

Name of Employer

Ultra Electronics-ATS

Occupation

Receipt For: 2012

Х $\begin{aligned} & \text { Primary } \square \text { General } \\ & \text { Other (specify) }\end{aligned}$

Senior Software Engineer

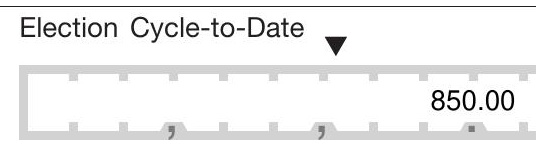

Amount of Each Receipt this Period

Transaction ID : A640D4D0F1F1C4BE68B4

Date of Receipt
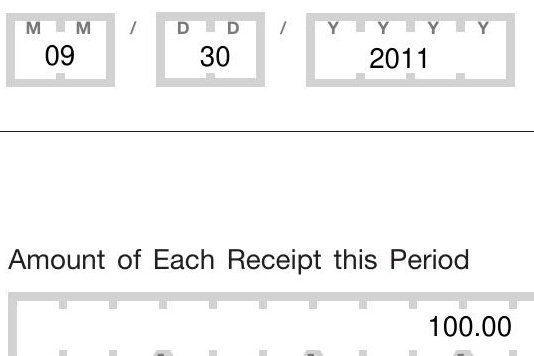

Transaction ID : A7A8F317699B245EFB39

Date of Receipt

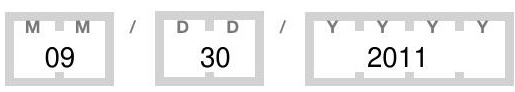

Amount of Each Receipt this Period

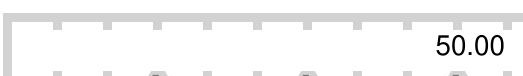

50.00

200.00

Subtotal Of Receipts This Page (optional)

Total This Period (last page this line number only) 


\section{SCHEDULE A-P} ITEMIZED RECEIPTS
Use separate schedule(s) for each category of the Detailed Summary Page

FOR LINE NUMBER:
(check only one)

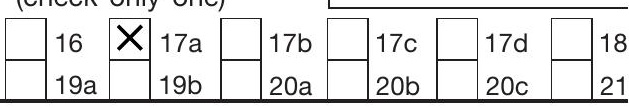

Any information copied from such Reports and Statements may not be sold or used by any person for the purpose of soliciting contributions or for commercial purposes, other than using the name and address of any political committee to solicit contributions from such committee.

NAME OF COMMITTEE (In Full)

\section{Friends of Herman Cain}

A. Full Name (Last, First, Middle Initial) Scott Burnett

Mailing Address 55 Bowen Dr

\begin{tabular}{lcc}
\hline City & State & Zip Code \\
Belmont & NC & $28012-9528$
\end{tabular}

FEC ID number of contributing federal political committee.

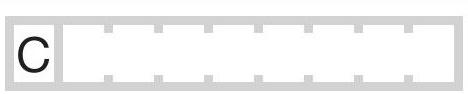

Name of Employer
Information Requested
Receipt For: 2012
X Primary
$\square$ Other (specify)

Occupation Information Requested Election Cycle-to-Date 580.00

B. Full Name (Last, First, Middle Initial) Jacquelin Post

Mailing Address 418 Triple Crown Lane

\begin{tabular}{lcc}
\hline City & State & Zip Code \\
Saint Johns & FL & $32259-8874$ \\
\hline
\end{tabular}

FEC ID number of contributing

federal political committee.

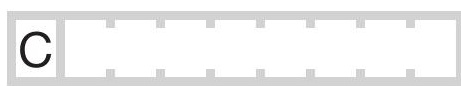

\begin{tabular}{l} 
Name of Employer \\
None \\
Receipt For: 2012 \\
X Primary $\quad$ General \\
\hline Other (specify)
\end{tabular}

\section{Occupation} Homemaker

Election Cycle-to-Date

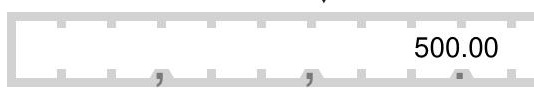

C. Full Name (Last, First, Middle Initial)

Kari Phillips

Mailing Address 3402 Blue Spruce Trail

\begin{tabular}{l|ll}
\hline $\begin{array}{l}\text { City } \\
\text { Pearland }\end{array}$ & $\begin{array}{c}\text { State } \\
\text { TX }\end{array}$ & $\begin{array}{c}\text { Zip Code } \\
77581-7562\end{array}$ \\
\hline $\begin{array}{l}\text { FEC ID number of contributing } \\
\text { federal political committee. }\end{array}$ & C \\
\hline $\begin{array}{l}\text { Name of Employer } \\
\text { Information Requested }\end{array}$ & $\begin{array}{l}\text { Occupation } \\
\text { Information Requested }\end{array}$ \\
\hline $\begin{array}{l}\text { Receipt For: } 2012 \\
\text { X } \begin{array}{l}\text { Primary } \\
\text { Other (specify) }\end{array}\end{array}$ & Election Cycle-to-Date \\
\hline
\end{tabular}

Transaction ID : A1CE73C645AC64CD3940 Date of Receipt

Amount of Each Receipt this Period

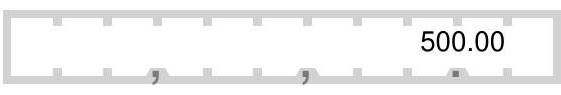

Date of Receipt
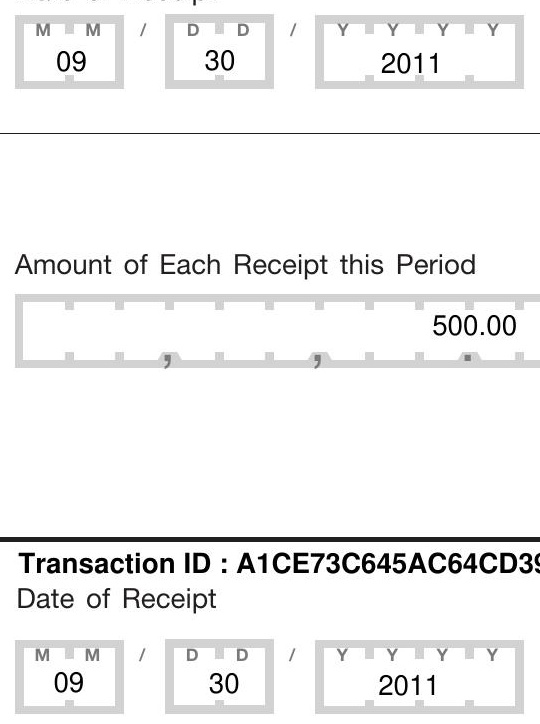

Amount of Each Receipt this Period

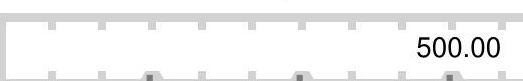

Amount of Each Receipt this Period

Transaction ID : AA7951083A21A46F1801

Date of Receipt
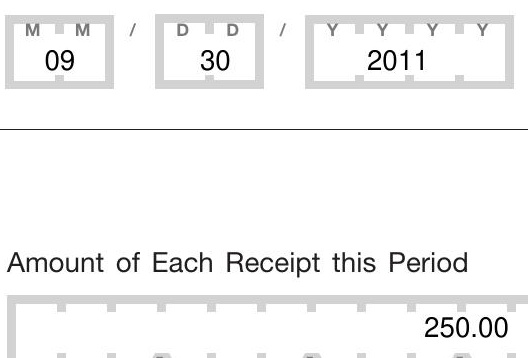

Subtotal Of Receipts This Page (optional).

Total This Period (last page this line number only) 


\section{SCHEDULE A-P} ITEMIZED RECEIPTS
Use separate schedule(s) for each category of the Detailed Summary Page

FOR LINE NUMBER:
(check only one)

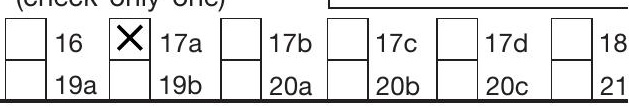

Any information copied from such Reports and Statements may not be sold or used by any person for the purpose of soliciting contributions or for commercial purposes, other than using the name and address of any political committee to solicit contributions from such committee.

NAME OF COMMITTEE (In Full)

\section{Friends of Herman Cain}

A. Full Name (Last, First, Middle Initial)

Michael Baroli

Mailing Address 101 Grosse Pines Dr.

\begin{tabular}{lcc}
\hline City & State & Zip Code \\
Rochester Hills & MI & $48309-1829$
\end{tabular}

FEC ID number of contributing federal political committee.

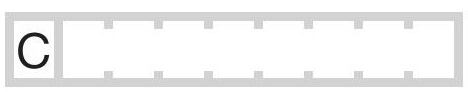

Name of Employer
None
Receipt For: 2012
X Primary $\quad \square$ General
$\square$ Other (specify)

Occupation

Retired

Election Cycle-to-Date

500.00

B. Full Name (Last, First, Middle Initial)

Van P Cunningham

Mailing Address 111 Barkwood Dr

\begin{tabular}{lcc}
\hline City & State & Zip Code \\
Dahlonega & GA & $30533-4641$
\end{tabular}

FEC ID number of contributing

federal political committee.

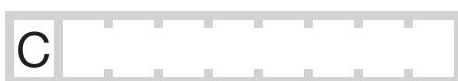

Name of Employer
None
Receipt For: 2012
X Primary
Other (specify)

\section{Occupation}

Retired

Election Cycle-to-Date

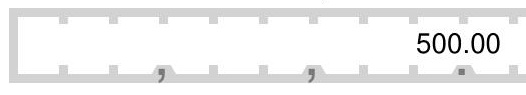

C. Full Name (Last, First, Middle Initial)

Jim Eure Jr.

Mailing Address PO Box 156

\begin{tabular}{lcc}
\hline City & State & Zip Code \\
Dahlonega & GA & $30533-0003$ \\
\hline
\end{tabular}

FEC ID number of contributing federal political committee.

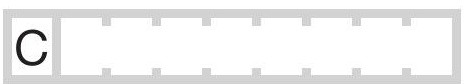

Name of Employer

Protex Security Systems

Receipt For: 2012

Х $\begin{aligned} & \text { Primary } \\ & \text { Other (specify) }\end{aligned}$
Transaction ID : A00FFBCD2A7DE4DF4AC4

Date of Receipt

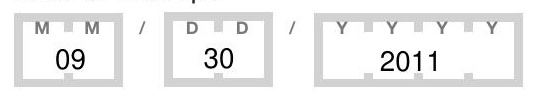

Amount of Each Receipt this Period

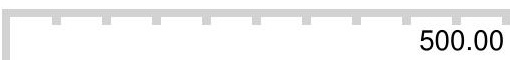

500.00
Transaction ID : A713C4897E59B4CD7A6C

Date of Receipt

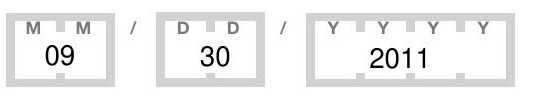

Amount of Each Receipt this Period

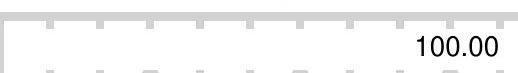

Transaction ID : A70ADED1B035844188A8 Date of Receipt

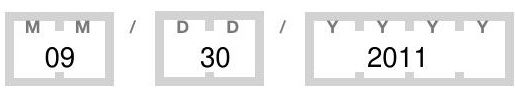

Amount of Each Receipt this Period

Occupation
Owner
Election Cycle-to-Date

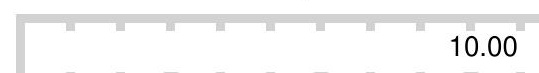

10.00
Subtotal Of Receipts This Page (optional).

610.00

a

Total This Period (last page this line number only) 


\section{SCHEDULE A-P} ITEMIZED RECEIPTS
Use separate schedule(s)

for each category of the

Detailed Summary Page
FOR LINE NUMBER: (check only one)

Any information or for commercial purposes, other than using the name and address of any political committee to solicit contributions from such committee.

NAME OF COMMITTEE (In Full)

Friends of Herman Cain

A. Full Name (Last, First, Middle Initial)

lynn newhart

Mailing Address 7095 bottle bay rd

\begin{tabular}{lcc}
\hline City & State & Zip Code \\
Sagle & ID & $83860-9041$
\end{tabular}

FEC ID number of contributing federal political committee.

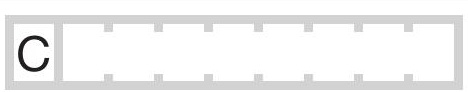

Name of Employer
Self Employed
Receipt For: 2012
X Primary
$\square$ Other (specify) General

Occupation

Owner

Election Cycle-to-Date

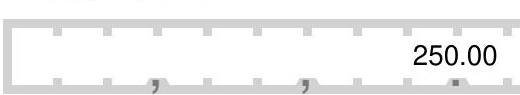

B. Full Name (Last, First, Middle Initial)

John Salak

Mailing Address 3316 Harbour Place

\begin{tabular}{lcc}
\hline City & State & Zip Code \\
Panama City & FL & $32405-1638$ \\
\hline
\end{tabular}

FEC ID number of contributing

federal political committee.

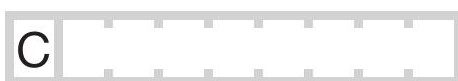

\begin{tabular}{l} 
Name of Employer \\
L3 Communications \\
Receipt For: 2012 \\
X Primary \\
\hline Other (specify) General
\end{tabular}

Occupation

Director

Election Cycle-to-Date

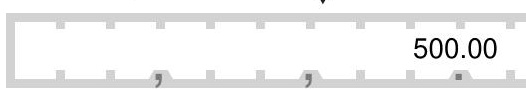

C. Full Name (Last, First, Middle Initial)

Martha W Pierce

Mailing Address 610 Society St

\begin{tabular}{lcc}
\hline City & State & Zip Code \\
Alpharetta & GA & $30022-1588$
\end{tabular}

FEC ID number of contributing federal political committee.

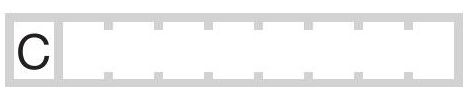

Name of Employer
None
Receipt For: 2012
Х Primary $\quad \square$ General
Other (specify)

\section{Occupation}

Homemaker

Election Cycle-to-Date

Transaction ID : ACC71F2FEE61743DBA58

Date of Receipt

Amount of Each Receipt this Period

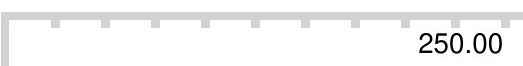

250.00

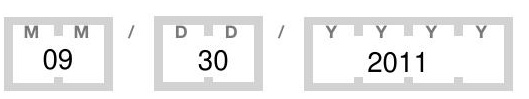

Amount of Each Receipt this Period

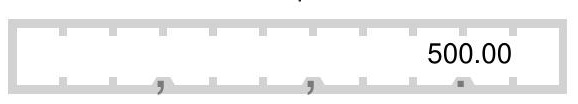

Transaction ID : A28B4F7CE2C304FF6A7F Date of Receipt

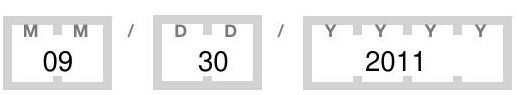

Amount of Each Receipt this Period

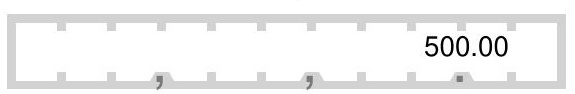

1000.00

\section{Subtotal Of Receipts This Page (optional)}

Total This Period (last page this line number only) 


\section{SCHEDULE A-P} ITEMIZED RECEIPTS
Use separate schedule(s)

for each category of the

Detailed Summary Page
FOR LINE NUMBER: (check only one)

Any information or for commercial purposes, other than using the name and address of any political committee to solicit contributions from such committee.

NAME OF COMMITTEE (In Full)

Friends of Herman Cain

A. Full Name (Last, First, Middle Initial)

Vishwa Varma

Mailing Address 2274 Astoria Circle Apt \# 305

\begin{tabular}{lcc}
\hline City & State & Zip Code \\
Herndon & VA & $20170-6103$
\end{tabular}

FEC ID number of contributing

federal political committee.

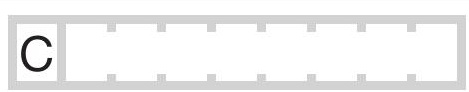

Name of Employer
CACI International Inc.
Receipt For: 2012
X Primary
$\square$ Other (specify)

Occupation

management

Election Cycle-to-Date

\subsection{0}

B. Full Name (Last, First, Middle Initial)

David Williams

\section{Mailing Address 21060 Bonanza Blvd}

\begin{tabular}{lcc}
\hline City & State & Zip Code \\
Elkhorn & NE & $68022-1801$
\end{tabular}

FEC ID number of contributing

federal political committee.

C

Name of Employer
Drake-Williams Steel
Receipt For: 2012
X Primary
Other (specify)

Occupation

Business Owner

Election Cycle-to-Date

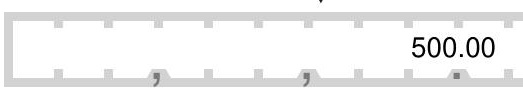

Transaction ID : AF9AAEF303AAB4428A5D

Date of Receipt

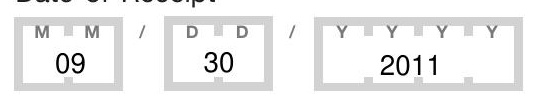

Amount of Each Receipt this Period

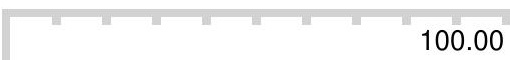

100.00

C. Full Name (Last, First, Middle Initial)

Amy Shull

Mailing Address 595 Gray Girls Road

\begin{tabular}{lcc}
\hline City & State & Zip Code \\
Senoia & GA & $30276-2844$ \\
\hline
\end{tabular}

FEC ID number of contributing federal political committee.

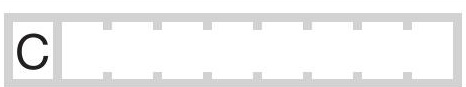

Name of Employer

Information Requested

\section{Occupation}

Information Requested

Receipt For: 2012

Х $\begin{aligned} & \text { Primary } \\ & \text { Other (specify) }\end{aligned}$

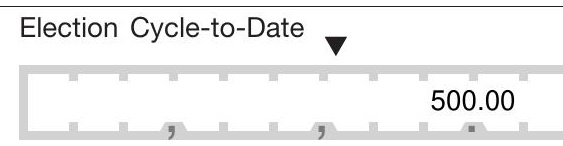

Amount of Each Receipt this Period

Transaction ID : A90CB77F332164F8BA7D

Date of Receipt
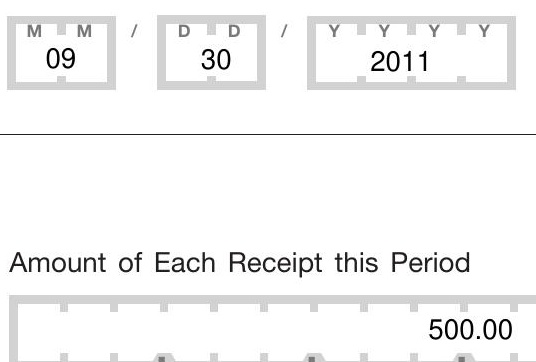

Transaction ID : A1EAE8513DC7646BC91C Date of Receipt

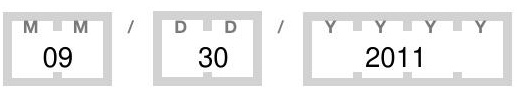

Amount of Each Receipt this Period

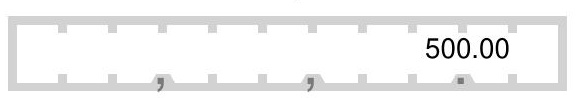

Subtotal Of Receipts This Page (optional).

1100.00

Total This Period (last page this line number only) 


\section{SCHEDULE A-P} ITEMIZED RECEIPTS
Use separate schedule(s)

for each category of the

Detailed Summary Page
FOR LINE NUMBER: (check only one)

Any information or for commercial purposes, other than using the name and address of any political committee to solicit contributions from such committee.

NAME OF COMMITTEE (In Full)

Friends of Herman Cain

A. Full Name (Last, First, Middle Initial)

Mr. John R Morris

Mailing Address 762 Acorn St

\begin{tabular}{lcc}
\hline City & State & Zip Code \\
Giddings & TX & $78942-4440$ \\
\hline
\end{tabular}

FEC ID number of contributing federal political committee.

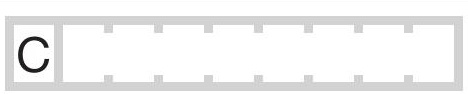

\begin{tabular}{l} 
Name of Employer \\
None \\
Receipt For: 2012 \\
X Primary $\quad \square$ General \\
\hline Other (specify)
\end{tabular}

Occupation

Retired

Election Cycle-to-Date

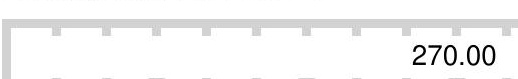

B. Full Name (Last, First, Middle Initial)

Mr. John R Morris

Mailing Address 762 Acorn St

\begin{tabular}{lcc}
\hline City & State & Zip Code \\
Giddings & TX & $78942-4440$ \\
\hline
\end{tabular}

FEC ID number of contributing

federal political committee.

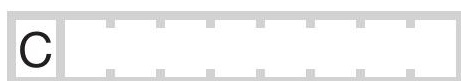

Name of Employer
None
Receipt For: 2012
X Primary
Other (specify)

Occupation

Retired

Election Cycle-to-Date

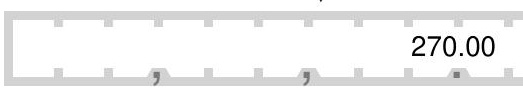

Transaction ID : A84E7DC07EA704788ACE

Date of Receipt

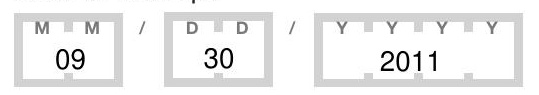

Amount of Each Receipt this Period

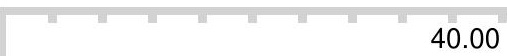

40.00

C. Full Name (Last, First, Middle Initial)

Pas Boza

Mailing Address PO Box 49

\begin{tabular}{lcc}
\hline City & State & Zip Code \\
Kilauea & HI & $96754-0049$
\end{tabular}

FEC ID number of contributing federal political committee.

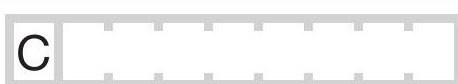

Name of Employer

Information Requested

\section{Occupation}

Information Requested

Receipt For: 2012

Х $\begin{aligned} & \text { Primary } \square \text { General } \\ & \text { Other (specify) }\end{aligned}$

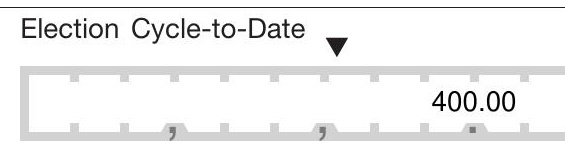

Amount of Each Receipt this Period

Transaction ID : ADF4B22CEC8994781852

Date of Receipt
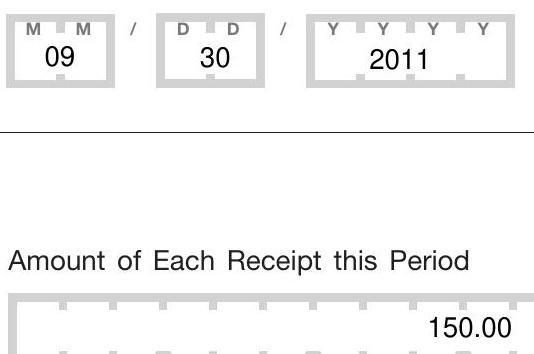

Transaction ID : A430310425661416DAB7

Date of Receipt

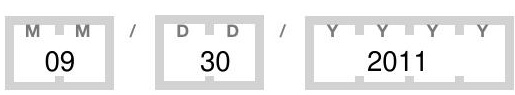

Amount of Each Receipt this Period

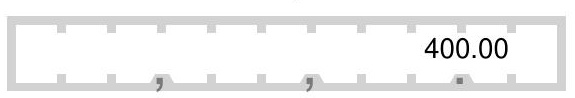

Subtotal Of Receipts This Page (optional).

590.00

Total This Period (last page this line number only) 


\section{SCHEDULE A-P} ITEMIZED RECEIPTS
Use separate schedule(s)

for each category of the

Detailed Summary Page
FOR LINE NUMBER: (check only one)

Any information or for commercial purposes, other than using the name and address of any political committee to solicit contributions from such committee.

NAME OF COMMITTEE (In Full)

Friends of Herman Cain

A. Full Name (Last, First, Middle Initial)

Randy Brown

Mailing Address 2190 Andromeda Way

\begin{tabular}{lcc}
\hline City & State & Zip Code \\
Reno & NV & $89509-3801$
\end{tabular}

FEC ID number of contributing federal political committee.

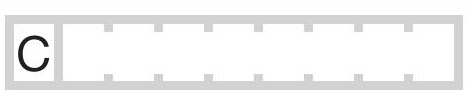

Name of Employer
Brumby Consulting
Receipt For: 2012
X Primary
Other (specify) General

Occupation Manager

Election Cycle-to-Date

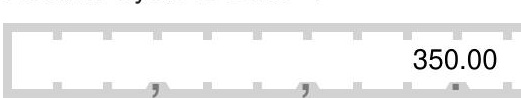

B. Full Name (Last, First, Middle Initial)

M. Clark

Mailing Address 7533 Kings Mountain Rd.

\begin{tabular}{lcc}
\hline City & State & Zip Code \\
Vestavia & AL & $35242-2589$ \\
\hline
\end{tabular}

FEC ID number of contributing

federal political committee.

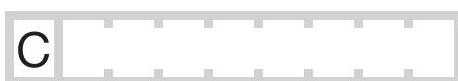

Name of Employer
Clark Financial
Receipt For: 2012
X Primary
Other (specify)

Occupation

Financial Planner

Election Cycle-to-Date

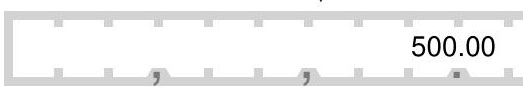

Transaction ID : AADE52B3ECF2746C0BD4

Date of Receipt

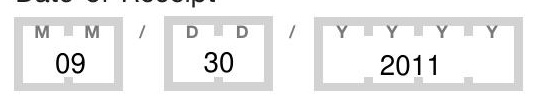

Amount of Each Receipt this Period

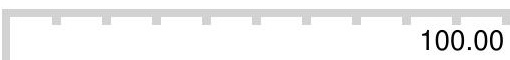

C. Full Name (Last, First, Middle Initial)

ELANE SHERIDAN

Mailing Address 5550 NW 40th TERRACE

\begin{tabular}{lcc}
\hline City & State & Zip Code \\
Coconut Creek & FL & $33073-4016$
\end{tabular}

FEC ID number of contributing

federal political committee.

C

Name of Employer

Broward Sheriff's Office

Receipt For: 2012

Х $\begin{aligned} & \text { Primary } \square \text { General } \\ & \text { Other (specify) }\end{aligned}$

\section{Occupation}

Community Service Aide

Election Cycle-to-Date

Transaction ID : A495A81DA113144898DE

Date of Receipt

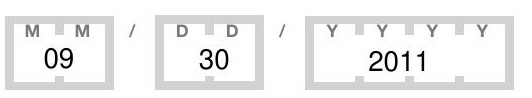

Amount of Each Receipt this Period

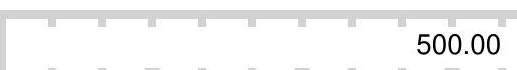

Transaction ID : A52983427B9E549C89FE

Date of Receipt

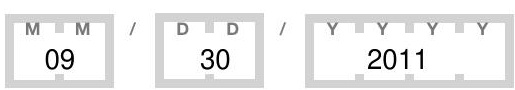

Amount of Each Receipt this Period

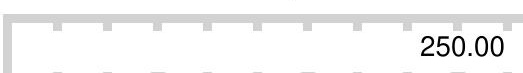

350.00

Subtotal Of Receipts This Page (optional).

850.00

a

Total This Period (last page this line number only)

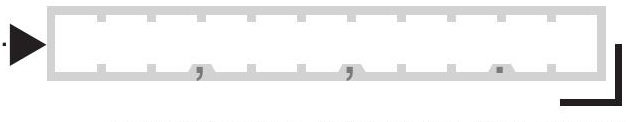

FEC Schedule A-P (Form 3P) (Rev. 03/2011) 


\section{SCHEDULE A-P} ITEMIZED RECEIPTS
Use separate schedule(s) for each category of the Detailed Summary Page

FOR LINE NUMBER:
(check only one)

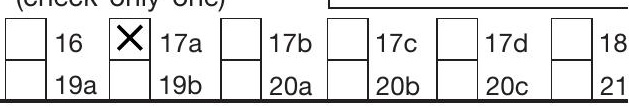

Any information copied from such Reports and Statements may not be sold or used by any person for the purpose of soliciting contributions or for commercial purposes, other than using the name and address of any political committee to solicit contributions from such committee.

NAME OF COMMITTEE (In Full)

\section{Friends of Herman Cain}

A. Full Name (Last, First, Middle Initial)

Christopher Wakeman

Mailing Address 4679 Telescope Ave.

\begin{tabular}{lcc}
\hline City & State & Zip Code \\
Carlsbad & CA & $92008-3766$
\end{tabular}

FEC ID number of contributing federal political committee.

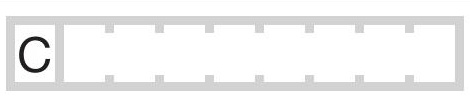

Name of Employer
Information Requested
Receipt For: 2012
X Primary
Other (specify) General

Occupation Information Requested

Election Cycle-to-Date 500.00

B. Full Name (Last, First, Middle Initial)

Mr. Michael Slocum

Mailing Address 4303 O'Brien Rd.

\begin{tabular}{lcc}
\hline City & State & Zip Code \\
Vassar & MI & $48768-8929$ \\
\hline
\end{tabular}

FEC ID number of contributing

federal political committee.

C

Name of Employer
None
Receipt For: 2012
Primary
Other (specify)

Occupation

Retired

Election Cycle-to-Date

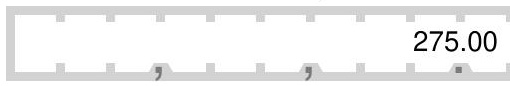

Transaction ID : AE663C786EDB749718A7

Date of Receipt

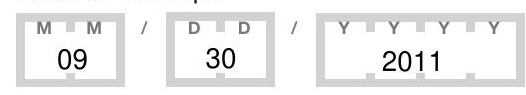

Amount of Each Receipt this Period

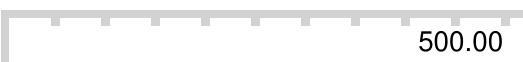

C. Full Name (Last, First, Middle Initial)

Mr. David W. Clark

Mailing Address 56 Riverview Dr

\begin{tabular}{lcc}
\hline City & State & Zip Code \\
Dawsonville & GA & $30534-9527$
\end{tabular}

FEC ID number of contributing federal political committee.

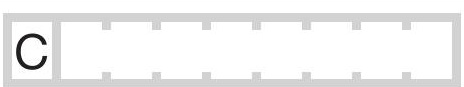

Name of Employer

Information Requested

\section{Occupation}

Information Requested

Receipt For: 2012

Х $\begin{aligned} & \text { Primary } \square \text { General } \\ & \text { Other (specify) }\end{aligned}$

Transaction ID : AC8CE107919A14D5FB2F

Date of Receipt

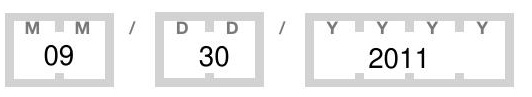

Amount of Each Receipt this Period

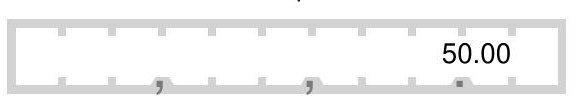

Transaction ID : A2ECD0F91D0E34EBC868 Date of Receipt

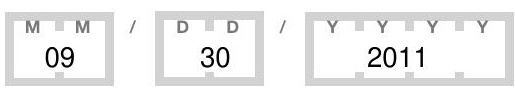

Amount of Each Receipt this Period

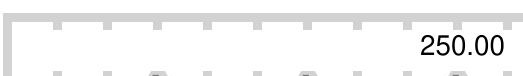

\section{Subtotal Of Receipts This Page (optional)}

800.00

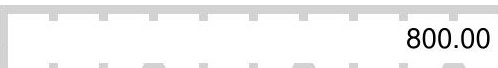

ㄱ․․

Total This Period (last page this line number only)

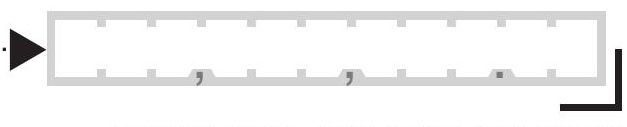

FEC Schedule A-P (Form 3P) (Rev. 03/2011) 


\section{SCHEDULE A-P} ITEMIZED RECEIPTS
Use separate schedule(s)

for each category of the

Detailed Summary Page
FOR LINE NUMBER: (check only one)

Any information or for commercial purposes, other than using the name and address of any political committee to solicit contributions from such committee.

NAME OF COMMITTEE (In Full)

Friends of Herman Cain

A. Full Name (Last, First, Middle Initial)

Kathleen Sallah

Mailing Address 5421 Westcastle Dr. \#4

\begin{tabular}{lcc}
\hline City & State & Zip Code \\
Toledo & OH & $43615-2047$
\end{tabular}

FEC ID number of contributing

federal political committee.

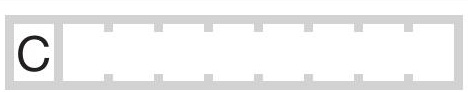

Name of Employer
sallah rentals
Receipt For: 2012
X Primary
$\square$ Other (specify) General

Occupation OWNER

Election Cycle-to-Date

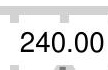

B. Full Name (Last, First, Middle Initial)

Sharon Allen

Mailing Address 6 Via Goleta

\begin{tabular}{lcc}
\hline City & State & Zip Code \\
San Clemente & CA & $92673-2736$ \\
\hline
\end{tabular}

FEC ID number of contributing

federal political committee.

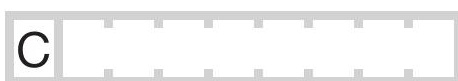

Name of Employer
Information Requested
Receipt For: 2012
X Primary
Other (specify)

Occupation

Information Requested

Election Cycle-to-Date

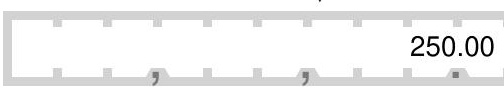

Transaction ID : AF884D231A0EA444A8A8

Date of Receipt

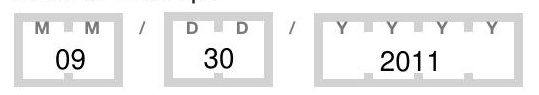

Amount of Each Receipt this Period

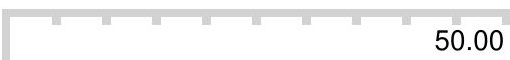

50.00

C. Full Name (Last, First, Middle Initial)

Caryn Huizen

Mailing Address 15327 Lost Channel

\begin{tabular}{lcc}
\hline City & State & Zip Code \\
Grand Haven & MI & $49417-9516$
\end{tabular}

FEC ID number of contributing

federal political committee.

C

Name of Employer

Self Employed

Occupation

Receipt For: 2012

Х $\begin{aligned} & \text { Primary } \square \text { General } \\ & \text { Other (specify) }\end{aligned}$

Property Development

Election Cycle-to-Date

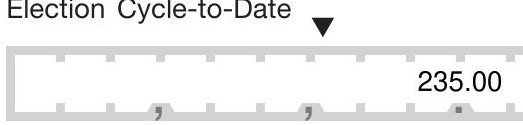

Amount of Each Receipt this Period

Transaction ID : A065A01D6569C4D1B8C0 Date of Receipt
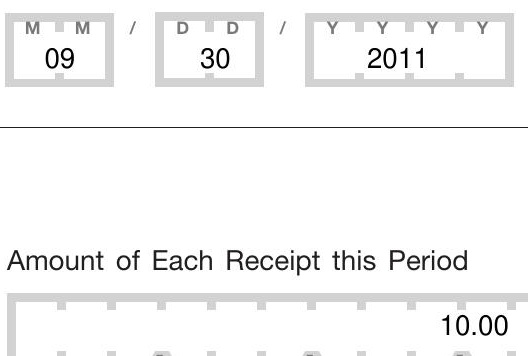

Subtotal Of Receipts This Page (optional).

Total This Period (last page this line number only) 
SCHEDULE A-P ITEMIZED RECEIPTS
Use separate schedule(s) for each category of the Detailed Summary Page
FOR LINE NUMBER: (check only one)

Any information or for commercial purposes, other than using the name and address of any political committee to solicit contributions from such committee.

NAME OF COMMITTEE (In Full)

Friends of Herman Cain

A. Full Name (Last, First, Middle Initial)

John Neal

Mailing Address 6500 Riverview Blvd

\begin{tabular}{lcc}
\hline City & State & Zip Code \\
Bradenton & FL & $34209-1351$
\end{tabular}

FEC ID number of contributing

federal political committee.

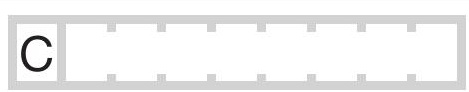

Name of Employer
John Neal Homes
Receipt For: 2012
X Primary
Other (specify) General

Occupation

Real Estate

Election Cycle-to-Date

250.00

B. Full Name (Last, First, Middle Initial)

Candy Anderson

Mailing Address 602 Lewis St

\begin{tabular}{lcc}
\hline City & State & Zip Code \\
Dekalb & IL & $60115-3479$
\end{tabular}

FEC ID number of contributing

federal political committee.

C

Name of Employer
Information Requested
Receipt For: 2012
X Primary
Other (specify)

Occupation

Information Requested

Election Cycle-to-Date

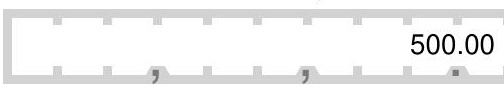

Transaction ID : AOD978298FD094DAFAE6

Date of Receipt

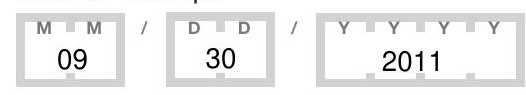

Amount of Each Receipt this Period

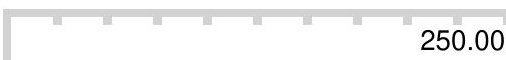

Transaction ID : A0256F21B1F80454591C

Date of Receipt

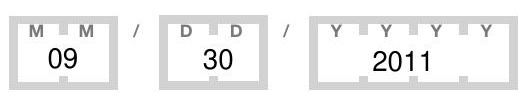

Amount of Each Receipt this Period

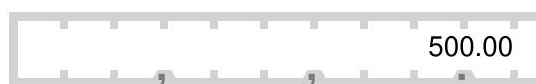

Transaction ID : A3AB5F42527034C8CB90 Date of Receipt

\section{Sean Leuba}

Mailing Address 5617 N. Prospect Rd.

\begin{tabular}{l|ll}
\hline $\begin{array}{l}\text { City } \\
\text { Peoria }\end{array}$ & $\begin{array}{c}\text { State } \\
\text { IL }\end{array}$ & $\begin{array}{c}\text { Zip Code } \\
61614-4323\end{array}$ \\
\hline $\begin{array}{l}\text { FEC ID number of contributing } \\
\text { federal political committee. }\end{array}$ & C \\
$\begin{array}{l}\text { Name of Employer } \\
\text { Information Requested }\end{array}$ & $\begin{array}{l}\text { Occupation } \\
\text { Information Requested }\end{array}$ \\
\hline $\begin{array}{l}\text { Receipt For: } 2012 \\
\text { Xrimary } \\
\text { Other (specify) }\end{array}$ & Election Cycle-to-Date & \\
\hline
\end{tabular}

Amount of Each Receipt this Period

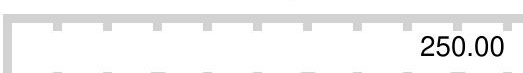

250.00

Subtotal Of Receipts This Page (optional)

1000.00

Total This Period (last page this line number only) 


\section{SCHEDULE A-P} ITEMIZED RECEIPTS
Use separate schedule(s) for each category of the Detailed Summary Page

\begin{tabular}{|c|c|c|c|c|c|}
\hline \multicolumn{3}{|c|}{$\begin{array}{l}\text { FOR LINE NUMBER: } \\
\text { (check only one) }\end{array}$} & \multicolumn{3}{|c|}{ PAGE 1084 / 1572} \\
\hline 16 & $X$ 17a & $17 b$ & $17 \mathrm{c}$ & $17 d$ & 18 \\
\hline $19 a$ & $19 \mathrm{~b}$ & $20 a$ & $20 \mathrm{~b}$ & $20 c$ & 21 \\
\hline
\end{tabular}

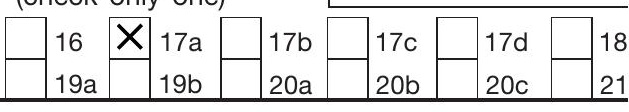

Any information copied from such Reports and Statements may not be sold or used by any person for the purpose of soliciting contributions or for commercial purposes, other than using the name and address of any political committee to solicit contributions from such committee.

NAME OF COMMITTEE (In Full)

\section{Friends of Herman Cain}

A. Full Name (Last, First, Middle Initial)

Barry Portnoy

Mailing Address 16 Drinking Brook rd

\begin{tabular}{lcc}
\hline City & State & Zip Code \\
Monmouth Junction & NJ & $08852-2800$ \\
\hline
\end{tabular}

FEC ID number of contributing federal political committee.

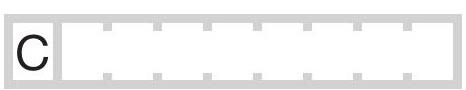

Name of Employer
Aaron \& Company, Inc.
Receipt For: 2012
X Primary
Other (specify)

\section{Occupation}

Wholesale Distribution

Election Cycle-to-Date

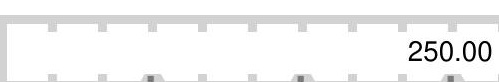

B. Full Name (Last, First, Middle Initial)

Patti Gettinger

Mailing Address 5194 Lupine Lane

\begin{tabular}{lcc}
\hline City & State & Zip Code \\
Acworth & GA & $30102-6940$
\end{tabular}

FEC ID number of contributing

federal political committee.

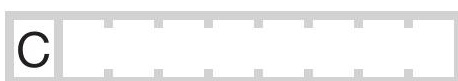

Name of Employer
Graphic Packaging
Receipt For: 2012
Primary
Other (specify)

\section{Occupation}

Marketing Manager

Election Cycle-to-Date

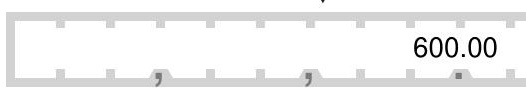

Transaction ID : A49848C2B5ECE49D89D2

Date of Receipt

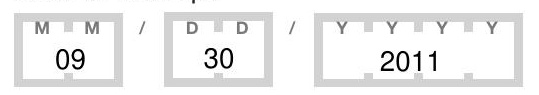

Amount of Each Receipt this Period

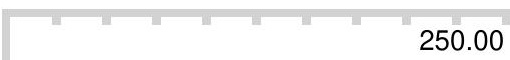

250.00
Amount of Each Receipt this Period

Transaction ID : A6EF6958B23474338898

Date of Receipt
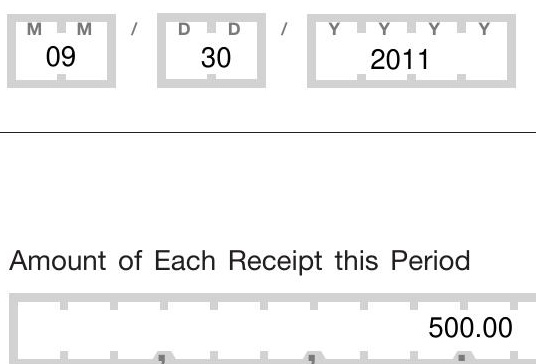

C. Full Name (Last, First, Middle Initial)

Terry Pisel

Mailing Address 8300 Carmel Ave NE Suite 202

\begin{tabular}{lcc}
\hline City & State & Zip Code \\
Albuquerque & NM & $87122-3147$
\end{tabular}

FEC ID number of contributing federal political committee.

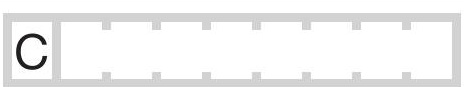

Name of Employer

Terry L. Pisel CPA LLC

\section{Occupation}

CPA

Receipt For: 2012

Х $\begin{aligned} & \text { Primary } \\ & \text { Other (specify) }\end{aligned}$

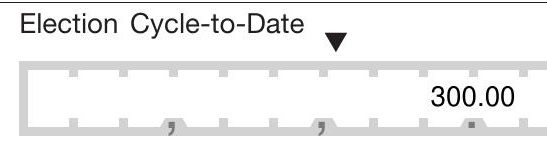

Transaction ID : A60E25E55C2EB4D2F9AB Date of Receipt

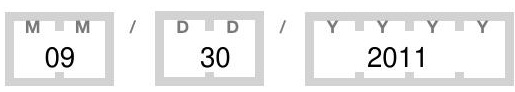

Amount of Each Receipt this Period

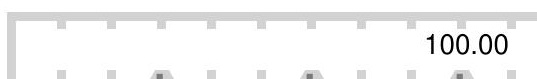

850.00

Subtotal Of Receipts This Page (optional)

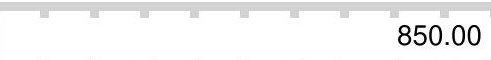

Total This Period (last page this line number only) 
SCHEDULE A-P ITEMIZED RECEIPTS
Use separate schedule(s) for each category of the Detailed Summary Page
FOR LINE NUMBER: (check only one)

Any information copied from such Repor or for commercial purposes, other than using the name and address of any political committee to solicit contributions from such committee.

NAME OF COMMITTEE (In Full)

\section{Friends of Herman Cain}

A. Full Name (Last, First, Middle Initial)

Larry Garriott

Mailing Address 1111 Double S Mountain Rd

City State Zip Code

Baileyton

AL $\quad 35019$

FEC ID number of contributing federal political committee.

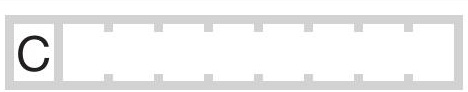

Name of Employer
n/a
Receipt For: 2012
X Primary $\quad$ General
Other (specify)

\section{Occupation}

$\mathrm{N} / \mathrm{A}$

Election Cycle-to-Date

1500.00

B. Full Name (Last, First, Middle Initial)

Michael Truman

Mailing Address $207 \mathrm{n}$ jasmine

\begin{tabular}{lcc}
\hline City & State & Zip Code \\
Republic & MO & $65738-1769$ \\
\hline
\end{tabular}

FEC ID number of contributing

federal political committee.

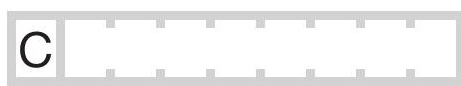

Name of Employer
self
Receipt For: 2012
X Primary
Other (specify)

Occupation

retirement planner

Election Cycle-to-Date

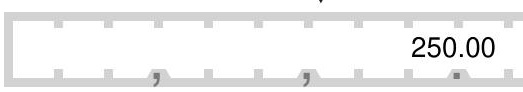

C. Full Name (Last, First, Middle Initial)

MYRLE DAVIS

Mailing Address 23830 N 113TH PL

\begin{tabular}{l|ll}
\hline $\begin{array}{l}\text { City } \\
\text { Scottsdale }\end{array}$ & $\begin{array}{c}\text { State } \\
\text { AZ }\end{array}$ & $\begin{array}{c}\text { Zip Code } \\
85255-5636\end{array}$ \\
\hline $\begin{array}{l}\text { FEC ID number of contributing } \\
\text { federal political committee. }\end{array}$ & C & \\
\hline $\begin{array}{l}\text { Name of Employer } \\
\text { self }\end{array}$ & $\begin{array}{l}\text { Occupation } \\
\text { Lawyer }\end{array}$ \\
$\begin{array}{l}\text { Receipt For: } 2012 \\
\text { Xrimary } \\
\text { Other (specify) }\end{array}$ & Election Cycle-to-Date & \\
\hline
\end{tabular}

Transaction ID : AD0083C0719CE40ABAE8 Date of Receipt

Amount of Each Receipt this Period

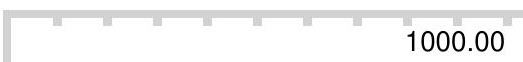

Date of Receipt

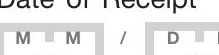

09

30

2011

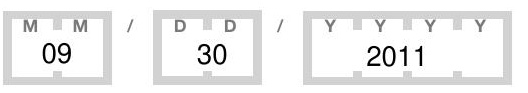

Amount of Each Receipt this Period

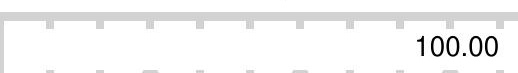

Amount of Each Receipt this Period

Transaction ID : A2A85C10C04D9439EBC8 Date of Receipt
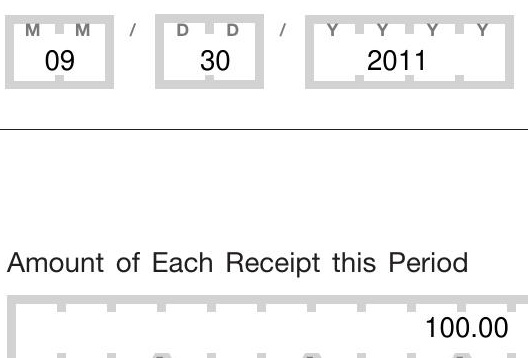

1200.00

Subtotal Of Receipts This Page (optional)

Total This Period (last page this line number only) 


\section{SCHEDULE A-P} ITEMIZED RECEIPTS
Use separate schedule(s) for each category of the Detailed Summary Page

\begin{tabular}{|c|c|c|c|c|c|}
\hline \multicolumn{3}{|c|}{$\begin{array}{l}\text { FOR LINE NUMBER: } \\
\text { (check only one) }\end{array}$} & \multicolumn{3}{|c|}{ PAGE 1086 / 1572} \\
\hline 16 & $X$ 17a & $17 b$ & $17 c$ & $17 d$ & 18 \\
\hline $19 a$ & $19 \mathrm{~b}$ & $20 a$ & $20 \mathrm{~b}$ & $20 c$ & 21 \\
\hline
\end{tabular}

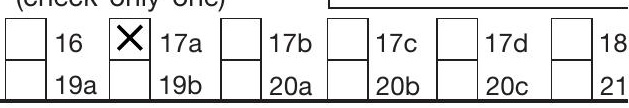

Any information copied from such Reports and Statements may not be sold or used by any person for the purpose of soliciting contributions or for commercial purposes, other than using the name and address of any political committee to solicit contributions from such committee.

NAME OF COMMITTEE (In Full)

\section{Friends of Herman Cain}

A. Full Name (Last, First, Middle Initial)

Christopher Barron

Mailing Address 2449 P St NW \# 3

\begin{tabular}{lcc}
\hline City & State & Zip Code \\
Washington & DC & $20007-3021$
\end{tabular}

FEC ID number of contributing federal political committee.

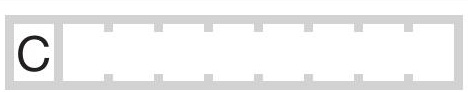

Name of Employer
CapSouth Consulting
Receipt For: 2012
X Primary
$\square$ Other (specify)

Occupation Media Consultant

Election Cycle-to-Date 400.00

B. Full Name (Last, First, Middle Initial) john graves

Mailing Address 10790 encino dr

\begin{tabular}{lcc}
\hline City & State & Zip Code \\
Ventura & CA & 93001 \\
\hline
\end{tabular}

FEC ID number of contributing

federal political committee.

C

Name of Employer
Information Requested
Receipt For: 2012
X Primary
Other (specify)

Occupation

Information Requested

Election Cycle-to-Date

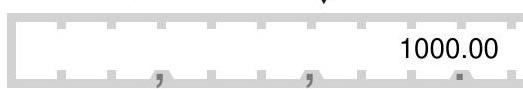

C. Full Name (Last, First, Middle Initial)

Fernande Silvers

Mailing Address 5850 Birch Ridge $\mathrm{Tr}$

\begin{tabular}{lcc}
\hline City & State & Zip Code \\
Cumming & GA & $30028-3410$
\end{tabular}

FEC ID number of contributing federal political committee.

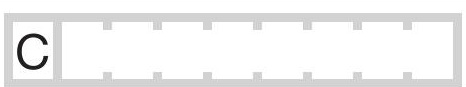

Name of Employer
Spielman \& Hicks. LLC
Receipt For: 2012
X Primary
Other (specify)

Occupation

Paralegal

Election Cycle-to-Date
Transaction ID : A2FF95FC10978494588E

Date of Receipt

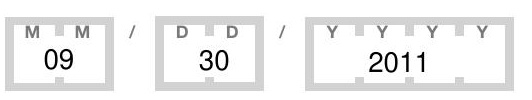

Amount of Each Receipt this Period

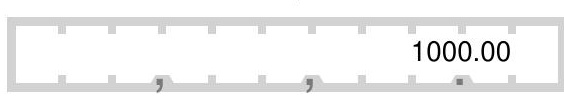

Transaction ID : A574F979296534701B5C Date of Receipt

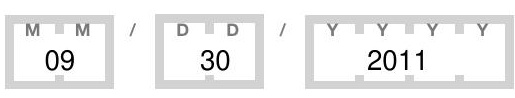

Amount of Each Receipt this Period

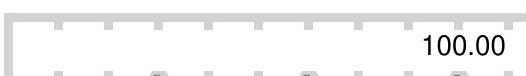

Subtotal Of Receipts This Page (optional).

Total This Period (last page this line number only) 


\section{SCHEDULE A-P} ITEMIZED RECEIPTS
Use separate schedule(s)

for each category of the

Detailed Summary Page
FOR LINE NUMBER: (check only one)

Any information or for commercial purposes, other than using the name and address of any political committee to solicit contributions from such committee.

NAME OF COMMITTEE (In Full)

Friends of Herman Cain

A. Full Name (Last, First, Middle Initial)

Robert Wilke

Mailing Address 765 Plantation Ln

\begin{tabular}{lcc}
\hline City & State & Zip Code \\
Dayton & OH & $45419-1117$ \\
\hline
\end{tabular}

FEC ID number of contributing federal political committee.

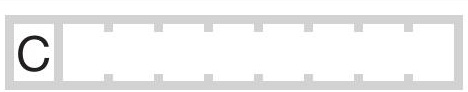

Name of Employer
Information Requested
Receipt For: 2012
X Primary
Other (specify) General

Occupation

Information Requested

Election Cycle-to-Date

250.00

B. Full Name (Last, First, Middle Initial)

Richard Robinson

Mailing Address 4832 Williams Creek Dr

\begin{tabular}{lcc}
\hline City & State & Zip Code \\
College Station & TX & $77845-3887$ \\
\hline
\end{tabular}

FEC ID number of contributing

federal political committee.

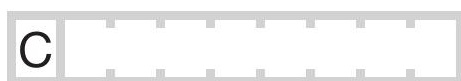

\begin{tabular}{l} 
Name of Employer \\
Texas A\&M COM \\
Receipt For: 2012 \\
X Primary \\
\hline Other (specify) General
\end{tabular}

\section{Occupation}

md

Election Cycle-to-Date

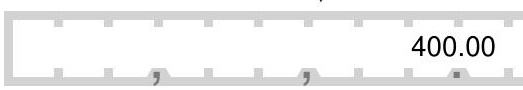

Transaction ID : A1F811BC2836046ECA56

Date of Receipt

Amount of Each Receipt this Period
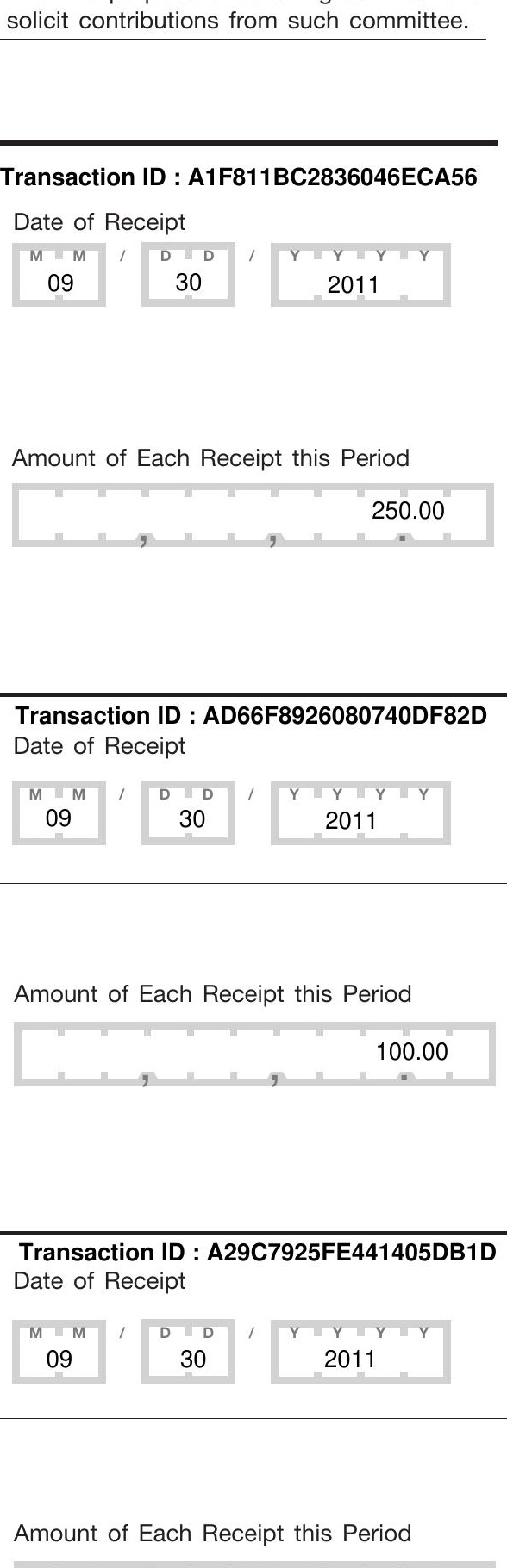

Amount of Each Receipt this Period

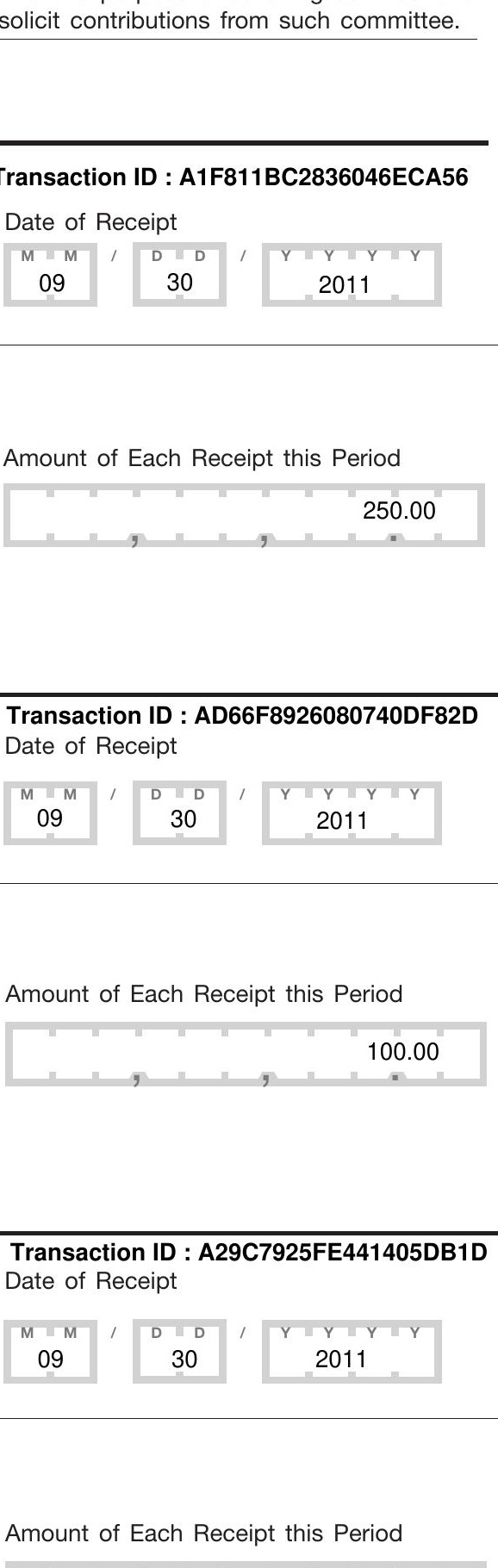

C. Full Name (Last, First, Middle Initial)

MARVIN EIDECKER

Mailing Address 4785 HEMLOCK DR

\begin{tabular}{lcc}
\hline City & State & Zip Code \\
Austell & GA & $30106-2021$
\end{tabular}

FEC ID number of contributing

federal political committee.

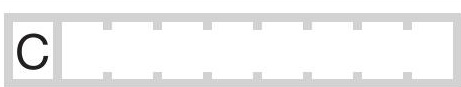

Name of Employer

ACME SECURITY INC.

Occupation

locksmith

Transaction ID : AD66F8926080740DF82D

Date of Receipt

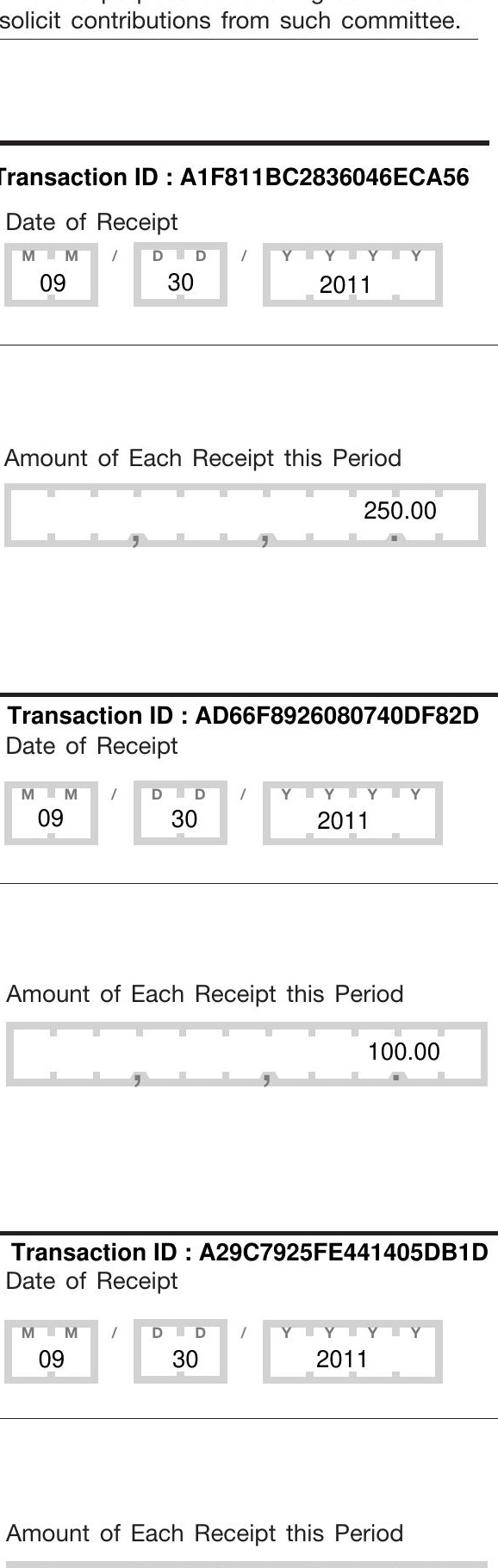

Receipt For: 2012

Х $\begin{aligned} & \text { Primary } \square \text { General } \\ & \text { Other (specify) }\end{aligned}$

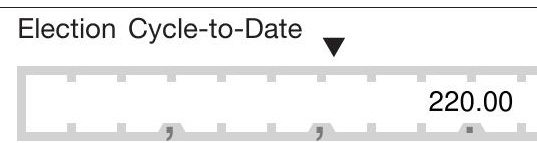

Amount of Each Receipt this Period

Transaction ID : A29C7925FE441405DB1D Date of Receipt

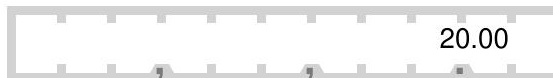

Subtotal Of Receipts This Page (optional).

370.00

Total This Period (last page this line number only) 


\section{SCHEDULE A-P} ITEMIZED RECEIPTS
Use separate schedule(s) for each category of the Detailed Summary Page

\begin{tabular}{|c|c|c|c|c|c|}
\hline \multicolumn{3}{|c|}{$\begin{array}{l}\text { FOR LINE NUMBER: } \\
\text { (check only one) }\end{array}$} & \multicolumn{3}{|c|}{ PAGE 1088 / 1572} \\
\hline 16 & $X$ 17a & $17 b$ & $17 c$ & $17 d$ & 18 \\
\hline $19 a$ & $19 \mathrm{~b}$ & $20 a$ & $20 \mathrm{~b}$ & $20 c$ & 21 \\
\hline
\end{tabular}

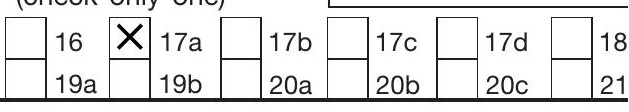

Any information copied from such Reports and Statements may not be sold or used by any person for the purpose of soliciting contributions or for commercial purposes, other than using the name and address of any political committee to solicit contributions from such committee.

NAME OF COMMITTEE (In Full)

\section{Friends of Herman Cain}

A. Full Name (Last, First, Middle Initial)

Allen Field

Mailing Address P O Box 5706

\begin{tabular}{lcc}
\hline City & State & Zip Code \\
Atlanta & GA & $31107-0706$
\end{tabular}

FEC ID number of contributing federal political committee.

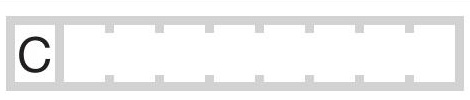

Name of Employer
Pomeroy IT
Receipt For: 2012
X Primary
Other (specify) General

\section{Occupation}

Area Manager

Election Cycle-to-Date

877.84

B. Full Name (Last, First, Middle Initial)

Allen Field

Mailing Address P O Box 5706

\begin{tabular}{lcc}
\hline City & State & Zip Code \\
Atlanta & GA & $31107-0706$ \\
\hline
\end{tabular}

FEC ID number of contributing

federal political committee.

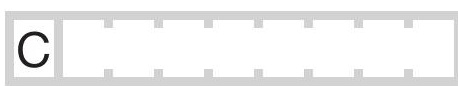

Name of Employer
Pomeroy IT
Receipt For: 2012
X Primary
Other (specify)

\section{Occupation}

Area Manager

Election Cycle-to-Date

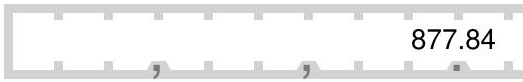

Transaction ID : A174AF71456434E3DBA9

Date of Receipt

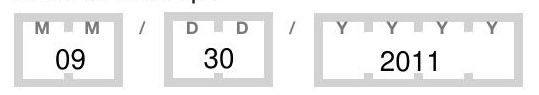

Amount of Each Receipt this Period

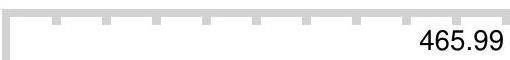

465.99
Amount of Each Receipt this Period

Transaction ID : A9333AF3C26A54F16B99

Date of Receipt
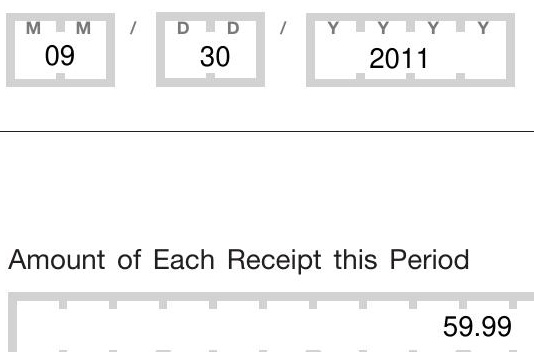

C. Full Name (Last, First, Middle Initial)

Mr. John Furbush

Mailing Address 45 Orrills Hill Rd

\begin{tabular}{lcc}
\hline City & State & Zip Code \\
Lebanon & ME & $04027-3910$
\end{tabular}

FEC ID number of contributing federal political committee.

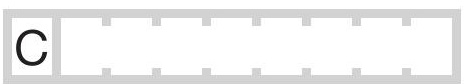

Name of Employer

Global Tecnology Talent

\section{Occupation}

Receipt For: 2012

Х $\begin{aligned} & \text { Primary } \\ & \text { Other (specify) }\end{aligned}$

Project Manager

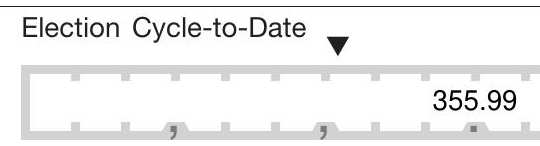

Transaction ID : A7FB37D063CD24D03A92 Date of Receipt

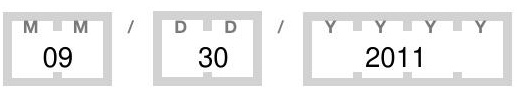

Amount of Each Receipt this Period

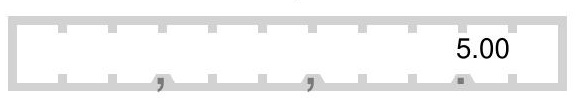

Subtotal Of Receipts This Page (optional).

530.98

Total This Period (last page this line number only) 


\section{SCHEDULE A-P} ITEMIZED RECEIPTS
Use separate schedule(s) for each category of the Detailed Summary Page

\begin{tabular}{|c|c|c|c|c|c|}
\hline \multicolumn{3}{|c|}{$\begin{array}{l}\text { FOR LINE NUMBER: } \\
\text { (check only one) }\end{array}$} & \multicolumn{3}{|c|}{ PAGE 1089 / 1572} \\
\hline 16 & $X$ 17a & $17 b$ & $17 c$ & $17 d$ & 18 \\
\hline $19 a$ & $19 \mathrm{~b}$ & $20 a$ & $20 \mathrm{~b}$ & $20 c$ & 21 \\
\hline
\end{tabular}

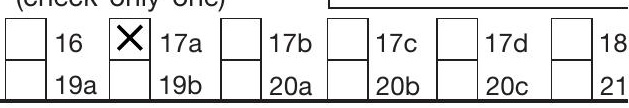

Any information copied from such Reports and Statements may not be sold or used by any person for the purpose of soliciting contributions or for commercial purposes, other than using the name and address of any political committee to solicit contributions from such committee.

NAME OF COMMITTEE (In Full)

\section{Friends of Herman Cain}

A. Full Name (Last, First, Middle Initial)

\section{Dick Hamilton}

Mailing Address RR 1, Box 25

\begin{tabular}{lcc}
\hline City & State & Zip Code \\
Arnett & OK & $73832-9701$
\end{tabular}

FEC ID number of contributing federal political committee.

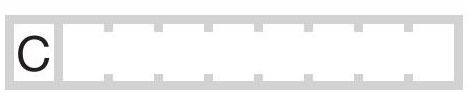

Name of Employer
Information Requested
Receipt For: 2012
X Primary
$\square$ Other (specify)

Occupation Information Requested

Election Cycle-to-Date 1000.00

B. Full Name (Last, First, Middle Initial) Janet Burman

Mailing Address 1646 James Street

\begin{tabular}{lcc}
\hline City & State & Zip Code \\
Syracuse & NY & $13203-2816$
\end{tabular}

FEC ID number of contributing

federal political committee.

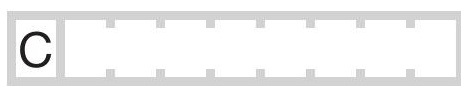

Name of Employer
Self-Employed
Receipt For: 2012
X Primary
Other (specify)

\section{Occupation}

Economist

Election Cycle-to-Date

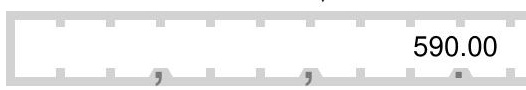

Transaction ID : A4C30ACB2A9E34063818

Date of Receipt

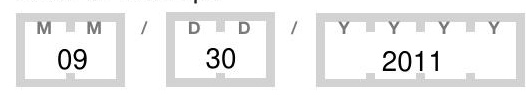

Amount of Each Receipt this Period

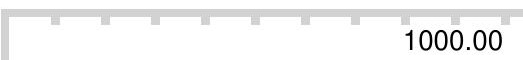

1000.00
Transaction ID : AB36FA1E5033B402E867

Date of Receipt

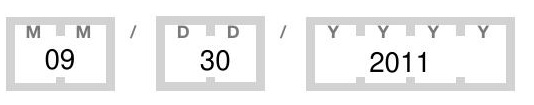

Amount of Each Receipt this Period

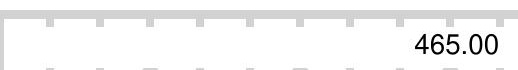

C. Full Name (Last, First, Middle Initial)

Thomas Griffith

Mailing Address 12460 Crabapple Rd Suite 202-414

\begin{tabular}{lcc}
\hline City & State & Zip Code \\
Alpharetta & GA & $30004-6602$ \\
\hline
\end{tabular}

FEC ID number of contributing federal political committee.

C

Name of Employer
Information Requested
Receipt For: 2012
Primary
Other (specify) General

Occupation

Information Requested

Election Cycle-to-Date

Transaction ID : A6C47B1D64FF74C1D85E Date of Receipt

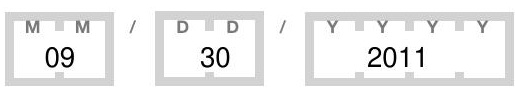

Amount of Each Receipt this Period

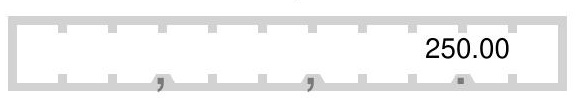

250.00

\section{Subtotal Of Receipts This Page (optional)}

1715.00

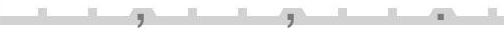

Total This Period (last page this line number only)

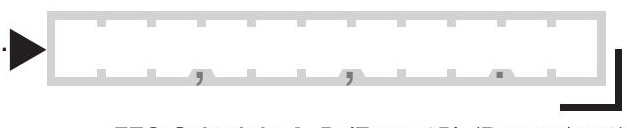

FEC Schedule A-P (Form 3P) (Rev. 03/2011) 


\section{SCHEDULE A-P} ITEMIZED RECEIPTS
Use separate schedule(s)

for each category of the

Detailed Summary Page
FOR LINE NUMBER: (check only one)

Any information or for commercial purposes, other than using the name and address of any political committee to solicit contributions from such committee.

NAME OF COMMITTEE (In Full)

Friends of Herman Cain

A. Full Name (Last, First, Middle Initial)

Mr. Warren Galkin

Mailing Address 29 Sage Dr

\begin{tabular}{lcc}
\hline City & State & Zip Code \\
Warwick & RI & $02886-6826$
\end{tabular}

FEC ID number of contributing

federal political committee.

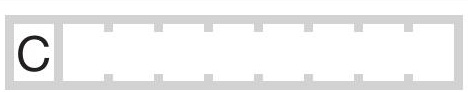

Name of Employer
Nater Products Corp
Receipt For: 2012
X Primary $\quad \square$ General
Other (specify)

Occupation

Executive

Election Cycle-to-Date

2000.00

B. Full Name (Last, First, Middle Initial)

Eric Fairbanks

Mailing Address PO Box 10

\begin{tabular}{lll}
\hline City & State & Zip Code \\
Boulder & WY & 82923-0010 \\
\hline
\end{tabular}

FEC ID number of contributing

federal political committee.

C

\begin{tabular}{l} 
Name of Employer \\
Information Requested \\
Receipt For: 2012 \\
X Primary \\
\hline Other (specify)
\end{tabular}

Occupation

Information Requested

Election Cycle-to-Date

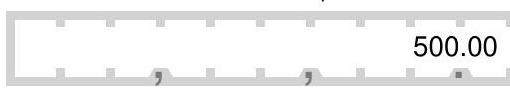

Transaction ID : ABDBAB5E29A7D40588B5

Date of Receipt

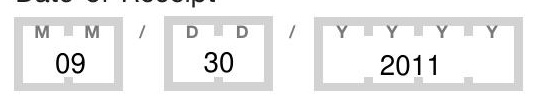

Amount of Each Receipt this Period

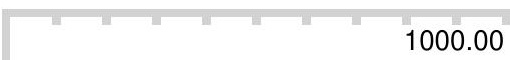

1000.00

C. Full Name (Last, First, Middle Initial)

James Poff

Mailing Address 682 Lee Highway South Suite 102

\begin{tabular}{lcc}
\hline City & State & Zip Code \\
Roanoke & VA & $24019-8678$ \\
\hline
\end{tabular}

FEC ID number of contributing federal political committee.

C

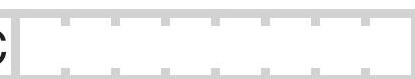

Name of Employer

Occupation

Information Requested

Information Requested

Receipt For: 2012

Х $\begin{aligned} & \text { Primary } \\ & \text { Other (specify) }\end{aligned}$

Election Cycle-to-Date

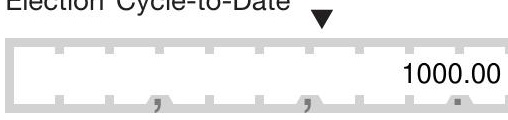

Amount of Each Receipt this Period

Transaction ID : A686B095149944075906

Date of Receipt
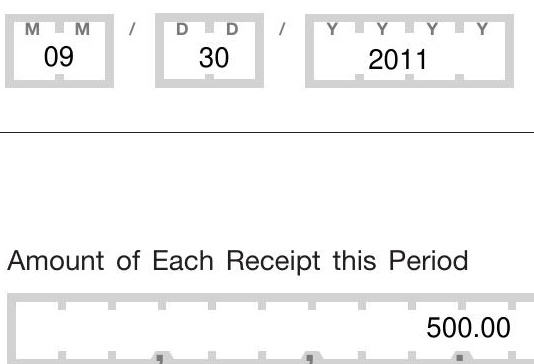

Transaction ID : A1C4785EBE1B5430EBCB Date of Receipt

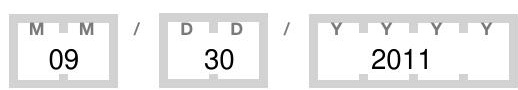

Amount of Each Receipt this Period

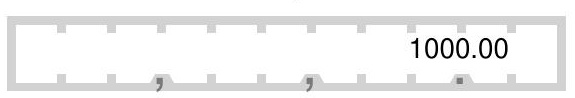

Subtotal Of Receipts This Page (optional)

Total This Period (last page this line number only) 


\section{SCHEDULE A-P} ITEMIZED RECEIPTS
Use separate schedule(s) for each category of the Detailed Summary Page

FOR LINE NUMBER:
(check only one)

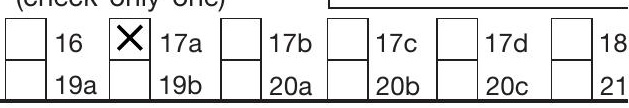

Any information copied from such Reports and Statements may not be sold or used by any person for the purpose of soliciting contributions or for commercial purposes, other than using the name and address of any political committee to solicit contributions from such committee.

NAME OF COMMITTEE (In Full)

\section{Friends of Herman Cain}

A. Full Name (Last, First, Middle Initial)

Seth Rye

Mailing Address 2315 Ridge Road

\begin{tabular}{lcc}
\hline City & State & Zip Code \\
Lincoln & NE & $68512-2410$
\end{tabular}

FEC ID number of contributing federal political committee.

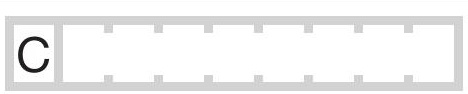

Name of Employer
Hemophilia One
Receipt For: 2012
X Primary
$\square$ Other (specify) General

Occupation

President

Election Cycle-to-Date

235.00

B. Full Name (Last, First, Middle Initial)

Randal Kirk

Mailing Address 1881 Grove Ave.

\begin{tabular}{lcc}
\hline City & State & Zip Code \\
Radford & VA & $24141-1628$ \\
\hline
\end{tabular}

FEC ID number of contributing

federal political committee.

C

\begin{tabular}{l} 
Name of Employer \\
Information Requested \\
\hline Receipt For: 2012 \\
$\square$ Primary $\quad$ Other (specify)
\end{tabular}

Occupation

Information Requested

Election Cycle-to-Date

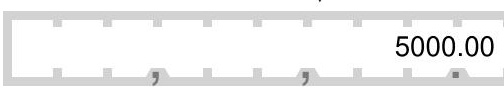

C. Full Name (Last, First, Middle Initial)

Barry Funt

Mailing Address 6 Post Lane

\begin{tabular}{lcc}
\hline City & State & Zip Code \\
Livingston & NJ & $07039-4905$
\end{tabular}

FEC ID number of contributing federal political committee.

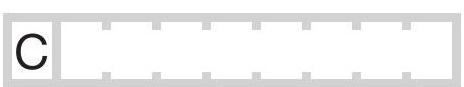

Name of Employer

Information Requested

\section{Occupation}

Information Requested

Receipt For: 2012

Х $\begin{aligned} & \text { Primary } \square \text { General } \\ & \text { Other (specify) }\end{aligned}$

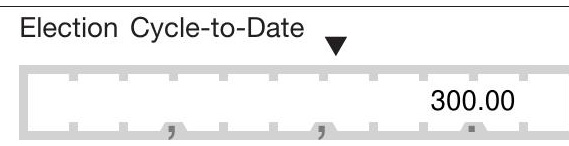

Amount of Each Receipt this Period

Amount of Each Receipt this Period

Transaction ID : A107C946C612F408FB92

Date of Receipt
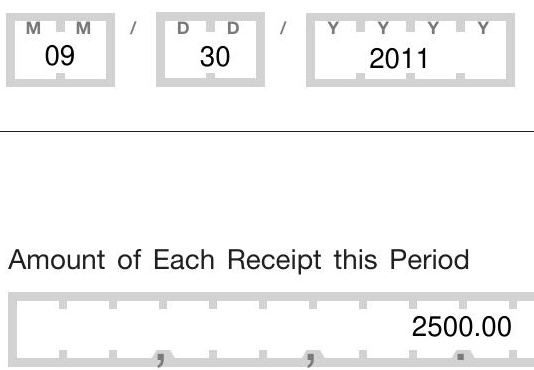

Transaction ID : A49181B4789284DCE9FD Date of Receipt
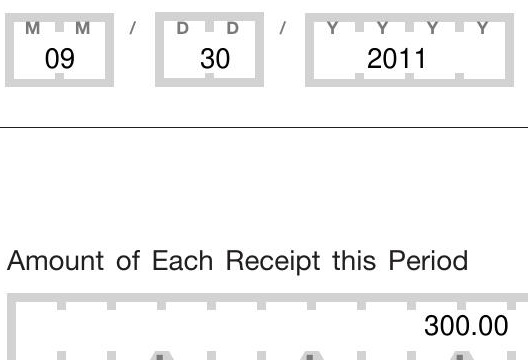

2900.00

Subtotal Of Receipts This Page (optional)

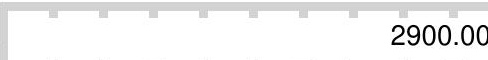

Total This Period (last page this line number only) 


\section{SCHEDULE A-P} ITEMIZED RECEIPTS
Use separate schedule(s)

for each category of the

Detailed Summary Page
FOR LINE NUMBER: (check only one)

Any information or for commercial purposes, other than using the name and address of any political committee to solicit contributions from such committee.

NAME OF COMMITTEE (In Full)

Friends of Herman Cain

A. Full Name (Last, First, Middle Initial)

ROBERT CARRUTH

Mailing Address 7201 MONTEREY LN

\begin{tabular}{lcc}
\hline City & State & Zip Code \\
La Palma & CA & $90623-1143$
\end{tabular}

FEC ID number of contributing

federal political committee.

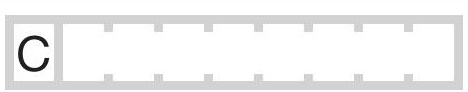

Name of Employer
Information Requested
Receipt For: 2012
X Primary $\quad \square$ General
Other (specify)

Occupation

Information Requested

Election Cycle-to-Date

250.00

B. Full Name (Last, First, Middle Initial)

Dianne Sula

Mailing Address 6 E. Walker Ave.

\begin{tabular}{lcc}
\hline City & State & Zip Code \\
Temple & TX & $76501-1724$ \\
\hline
\end{tabular}

FEC ID number of contributing

federal political committee.

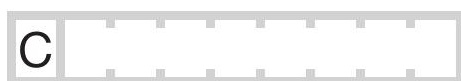

Name of Employer
US Postal Service
Receipt For: 2012
X Primary
Other (specify)

Occupation

mail processor

Election Cycle-to-Date

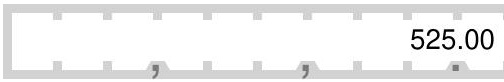

C. Full Name (Last, First, Middle Initial)

James Brown

Mailing Address 7511 N 117th Cir

\begin{tabular}{lcc}
\hline City & State & Zip Code \\
Omaha & NE & $68142-1615$
\end{tabular}

FEC ID number of contributing

federal political committee.

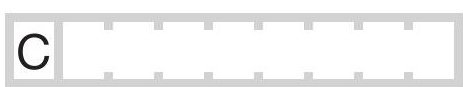

Name of Employer

Information Requested

Occupation

Information Requested

Receipt For: 2012

Х $\begin{aligned} & \text { Primary } \square \text { General } \\ & \text { Other (specify) }\end{aligned}$

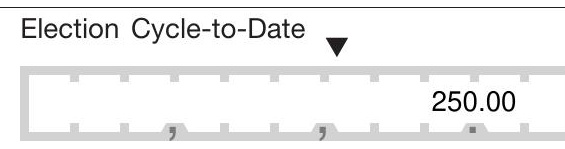

Amount of Each Receipt this Period

Transaction ID : A29711637771C4D469DE

Date of Receipt

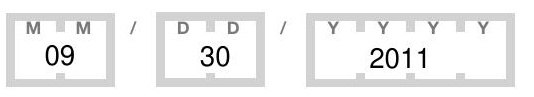

Amount of Each Receipt this Period

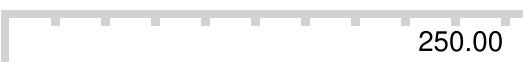

250.00

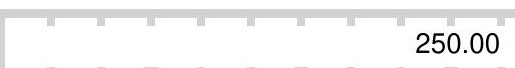

Transaction ID : A949EE8F801914CBD950

Date of Receipt

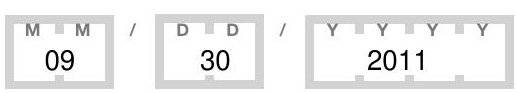

Amount of Each Receipt this Period

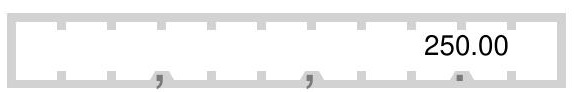

Subtotal Of Receipts This Page (optional)

750.00

Total This Period (last page this line number only) 
SCHEDULE A-P ITEMIZED RECEIPTS
Use separate schedule(s) for each category of the Detailed Summary Page
FOR LINE NUMBER: (check only one)
PAGE $1093 / 1572$

\begin{tabular}{|c|c|c|c|c|c|}
\hline & & & & & \\
\hline 16 & $\begin{array}{lll}X & 17 a \\
\end{array}$ & $17 \mathrm{~b}$ & $17 c$ & $17 d$ & 18 \\
\hline $19 a$ & $19 b$ & $20 a$ & $20 \mathrm{~b}$ & $20 c$ & 21 \\
\hline
\end{tabular}

Any information copied from such Reports and Statements may not be sold or used by any person for the purpose of soliciting contributions or for commercial purposes, other than using the name and address of any political committee to solicit contributions from such committee.

NAME OF COMMITTEE (In Full)

\section{Friends of Herman Cain}

A. Full Name (Last, First, Middle Initial)

Ben Ganther

Mailing Address 6030 County Road A

\begin{tabular}{lcc}
\hline City & State & Zip Code \\
Oshkosh & WI & $54901-9783$
\end{tabular}

FEC ID number of contributing federal political committee.

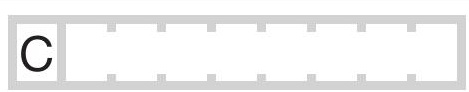

Name of Employer
Information Requested
Receipt For: 2012
X Primary
Other (specify) General

Occupation Information Requested

Election Cycle-to-Date

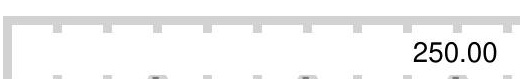

B. Full Name (Last, First, Middle Initial)

\section{Robert Stone}

Mailing Address 9127 Arbor Glen Lane

\begin{tabular}{lcc}
\hline City & State & Zip Code \\
Charlotte & NC & $28210-7988$ \\
\hline
\end{tabular}

FEC ID number of contributing

federal political committee.

C

Name of Employer

Piedmont Technical Services, Inc.

Receipt For: 2012

Х Primary $\square$ General Other (specify)

\section{Occupation}

small business owner

Election Cycle-to-Date

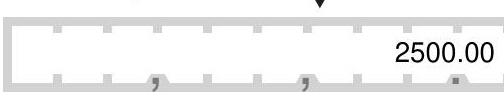

Transaction ID : A186066585B7B4F8CBF9

Date of Receipt

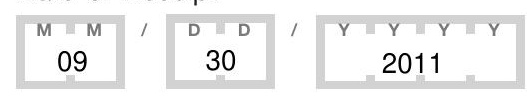

Amount of Each Receipt this Period

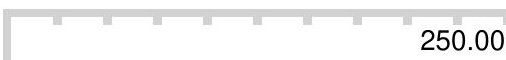

250.00

C. Full Name (Last, First, Middle Initial)

Larry Larson

Mailing Address 2172 Center St.

\begin{tabular}{lcc}
\hline City & State & Zip Code \\
Marquette & MI & $49855-1302$
\end{tabular}

FEC ID number of contributing federal political committee.

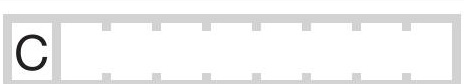

Name of Employer

Information Requested

Occupation

Receipt For: 2012

Х $\begin{aligned} & \text { Primary } \square \text { General } \\ & \text { Other (specify) }\end{aligned}$

Information Requested

Election Cycle-to-Date

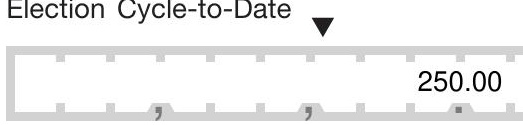

Amount of Each Receipt this Period

Transaction ID : A126639FE16F949869A3

Date of Receipt
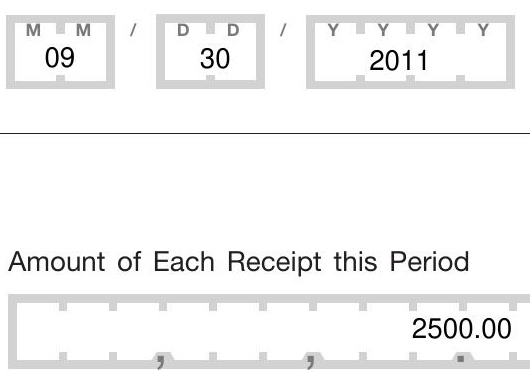

Transaction ID : A17050B8578264F34901

Date of Receipt

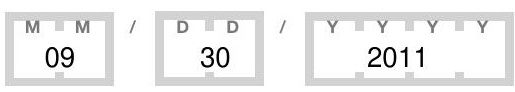

Amount of Each Receipt this Period

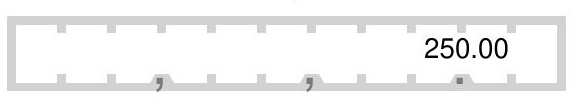

Subtotal Of Receipts This Page (optional)

3000.00

Total This Period (last page this line number only) 


\section{SCHEDULE A-P} ITEMIZED RECEIPTS
Use separate schedule(s) for each category of the Detailed Summary Page

\begin{tabular}{|c|c|c|c|c|c|}
\hline \multicolumn{3}{|c|}{$\begin{array}{l}\text { FOR LINE NUMBER: } \\
\text { (check only one) }\end{array}$} & \multicolumn{3}{|c|}{ PAGE 1094 / 1572} \\
\hline 16 & $X$ 17a & $17 b$ & $17 \mathrm{c}$ & $17 d$ & 18 \\
\hline $19 a$ & $19 \mathrm{~b}$ & $20 a$ & $20 \mathrm{~b}$ & $20 c$ & 21 \\
\hline
\end{tabular}

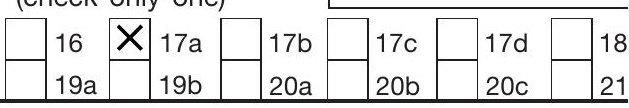

Any information copied from such Reports and Statements may not be sold or used by any person for the purpose of soliciting contributions or for commercial purposes, other than using the name and address of any political committee to solicit contributions from such committee.

NAME OF COMMITTEE (In Full)

\section{Friends of Herman Cain}

A. Full Name (Last, First, Middle Initial) KURT HOGAN

Mailing Address 3156 DOCKSIDE DR

\begin{tabular}{lcc}
\hline City & State & Zip Code \\
Gainesville & GA & $30501-1470$ \\
\hline
\end{tabular}

FEC ID number of contributing federal political committee.

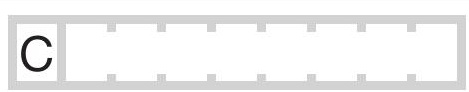

Name of Employer
BOLT EXPO LLC
Receipt For: 2012
X Primary $\quad \square$ General
$\square$ Other (specify)

Occupation FASTENER DISTRIBUTOR

Election Cycle-to-Date $\boldsymbol{\nabla}$
Transaction ID : A863A21CF8C09442B9C0

Date of Receipt

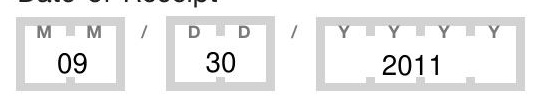

Amount of Each Receipt this Period

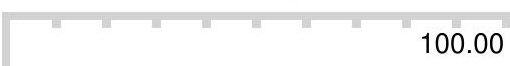
350.00

B. Full Name (Last, First, Middle Initial)

John Hays

Mailing Address 807 Brazos St. Ste. 500

\begin{tabular}{lcc}
\hline City & State & Zip Code \\
Austin & TX & $78701-2521$
\end{tabular}

FEC ID number of contributing

federal political committee.

C

Name of Employer
Information Requested
Receipt For: 2012
X Primary
Other (specify)

Occupation

Information Requested

Election Cycle-to-Date

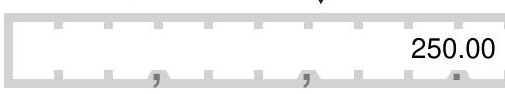

C. Full Name (Last, First, Middle Initial)

Jean Henzel

Mailing Address 2443 E Fremont Rd

\begin{tabular}{lcc}
\hline City & State & Zip Code \\
Phoenix & AZ & $85042-5928$ \\
\hline
\end{tabular}

FEC ID number of contributing federal political committee.

C

Transaction ID : A59C9C93AE2D548C78CC Date of Receipt

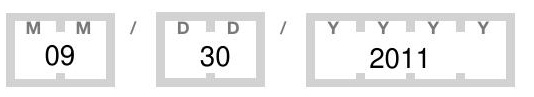

Amount of Each Receipt this Period

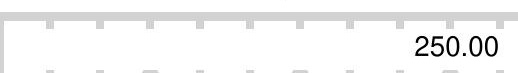

Transaction ID : A23FFCD2A1F0E486FBF4 Date of Receipt

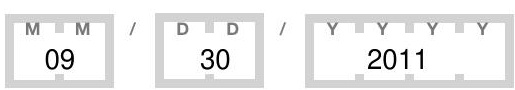

Name of Employer
Information Requested
Receipt For: 2012
X Primary
Other (specify) General

Occupation

Information Requested

Election Cycle-to-Date

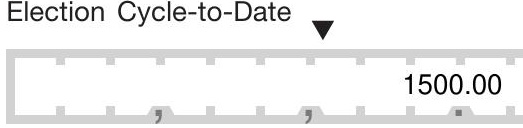

Subtotal Of Receipts This Page (optional)

850.00

Amount of Each Receipt this Period

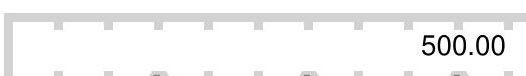

Total This Period (last page this line number only) 


\section{SCHEDULE A-P} ITEMIZED RECEIPTS
Use separate schedule(s) for each category of the Detailed Summary Page

FOR LINE NUMBER:
(check only one)

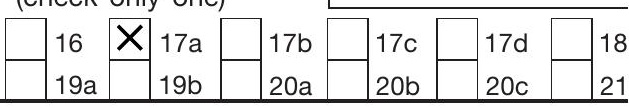

Any information copied from such Reports and Statements may not be sold or used by any person for the purpose of soliciting contributions or for commercial purposes, other than using the name and address of any political committee to solicit contributions from such committee.

NAME OF COMMITTEE (In Full)

\section{Friends of Herman Cain}

A. Full Name (Last, First, Middle Initial) Jan Achey

Mailing Address 6806 View Ln.

\begin{tabular}{lcc}
\hline City & State & Zip Code \\
Nampa & ID & $83687-8730$ \\
\hline
\end{tabular}

FEC ID number of contributing federal political committee.

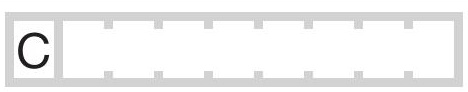

Name of Employer
Information Requested
Receipt For: 2012
X Primary
$\square$ Other (specify)

Occupation Information Requested

Election Cycle-to-Date

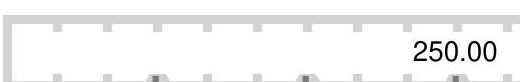

B. Full Name (Last, First, Middle Initial)

Charles Berry

Mailing Address 1050 Calle Milagro Dr.

\begin{tabular}{lcc}
\hline City & State & Zip Code \\
El Paso & TX & $79912-7521$
\end{tabular}

FEC ID number of contributing

federal political committee.

C

Name of Employer
Information Requested
Receipt For: 2012
X Primary
Other (specify)

Occupation

Information Requested

Election Cycle-to-Date

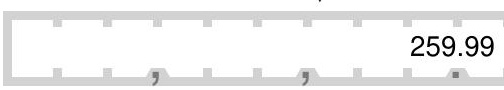

C. Full Name (Last, First, Middle Initial)

Vern Goding

Mailing Address 648 Acacia Avenue

\begin{tabular}{lcc}
\hline City & State & Zip Code \\
Melbourne & FL & $32904-2302$
\end{tabular}

FEC ID number of contributing federal political committee.

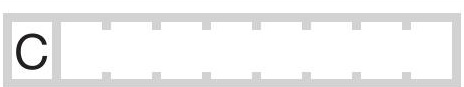

Name of Employer
None
Receipt For: 2012
Х Primary $\quad \square$ General
Other (specify)

\section{Occupation}

Retired

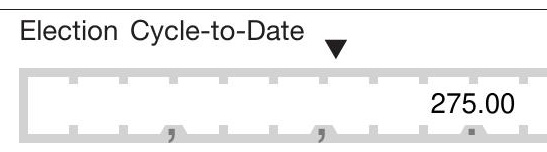

Transaction ID : A26A0C5DAF4584E1AAF9

Date of Receipt

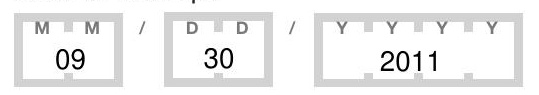

Amount of Each Receipt this Period

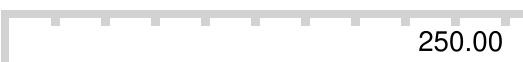

Amount of Each Receipt this Period

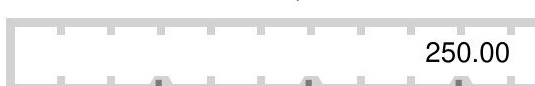

Transaction ID : AC8D77E5ECB01493F89E Date of Receipt

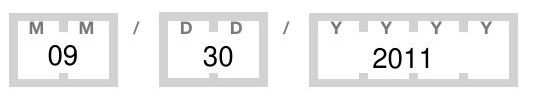

Transaction ID : ABFE65A81CF334C18BF9 Date of Receipt

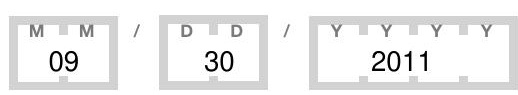

Amount of Each Receipt this Period

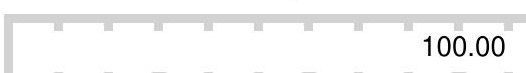

\section{Subtotal Of Receipts This Page (optional)}

600.00

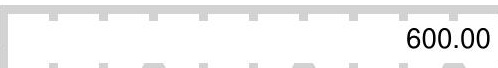

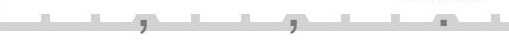

Total This Period (last page this line number only)

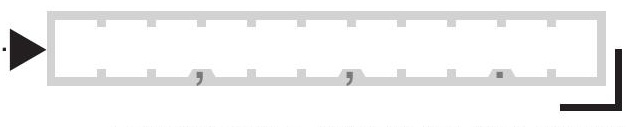

FEC Schedule A-P (Form 3P) (Rev. 03/2011) 


\section{SCHEDULE A-P} ITEMIZED RECEIPTS
Use separate schedule(s)

for each category of the

Detailed Summary Page
FOR LINE NUMBER: (check only one)

Any information or for commercial purposes, other than using the name and address of any political committee to solicit contributions from such committee.

NAME OF COMMITTEE (In Full)

Friends of Herman Cain

A. Full Name (Last, First, Middle Initial)

Scott Allen

Mailing Address PO Box 2265

\begin{tabular}{lcc}
\hline City & State & Zip Code \\
Monument & CO & $80132-2265$
\end{tabular}

FEC ID number of contributing

federal political committee.

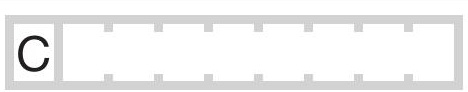

Name of Employer
Information Requested
Receipt For: 2012
X Primary $\quad \square$ General
Other (specify)

Occupation

Information Requested

Election Cycle-to-Date

250.00

B. Full Name (Last, First, Middle Initial)

Lance Howard

Mailing Address 2036 Kinridge Court

\begin{tabular}{lcc}
\hline City & State & Zip Code \\
Marietta & GA & $30062-1804$
\end{tabular}

FEC ID number of contributing

federal political committee.

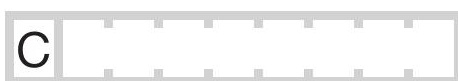

Name of Employer
Information Requested
Receipt For: 2012
X Primary
Other (specify)

Occupation

Information Requested

Election Cycle-to-Date

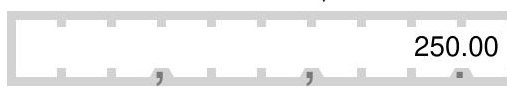

C. Full Name (Last, First, Middle Initial)

David Sapp

Mailing Address 2404 DE Short Rd

\begin{tabular}{lcc}
\hline City & State & Zip Code \\
Sasser & GA & 39885 \\
\hline
\end{tabular}

FEC ID number of contributing

federal political committee.

C

Name of Employer
Raymar Supply Inc.
Receipt For: 2012
X Primary
Other (specify) General

Occupation

Salesman

Election Cycle-to-Date
Transaction ID : A98FB55DD9C2543F9A7A

Date of Receipt

Amount of Each Receipt this Period

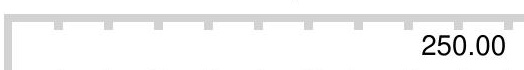

Transaction ID : A6E9BCB7779A845418E0

Date of Receipt
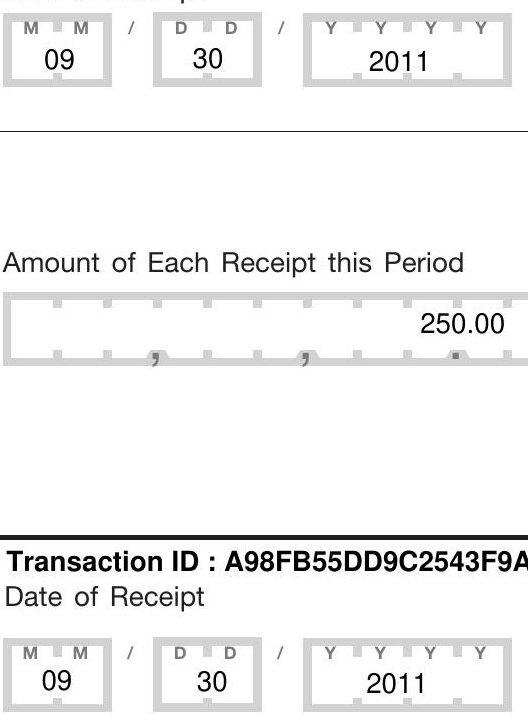

Amount of Each Receipt this Period

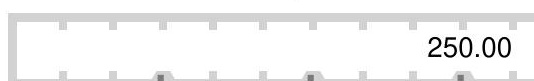

Transaction ID : A04588C7ED3DD4BADAA4 Date of Receipt

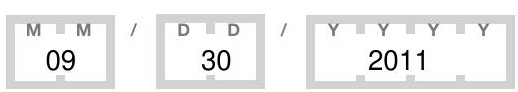

Amount of Each Receipt this Period

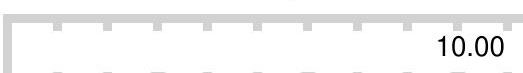

\section{Subtotal Of Receipts This Page (optional)}

Total This Period (last page this line number only) 


\section{SCHEDULE A-P} ITEMIZED RECEIPTS
Use separate schedule(s) for each category of the Detailed Summary Page

FOR LINE NUMBER:
(check only one)

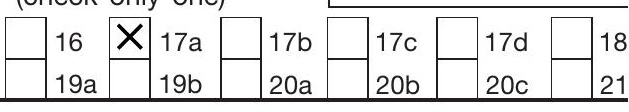

Any information copied from such Reports and Statements may not be sold or used by any person for the purpose of soliciting contributions or for commercial purposes, other than using the name and address of any political committee to solicit contributions from such committee.

NAME OF COMMITTEE (In Full)

\section{Friends of Herman Cain}

A. Full Name (Last, First, Middle Initial) JOhn Berggreen

Mailing Address 101 Timmons Ranch Rd.

\begin{tabular}{lcc}
\hline City & State & Zip Code \\
Etna & CA & $96027-9774$ \\
\hline
\end{tabular}

FEC ID number of contributing federal political committee.

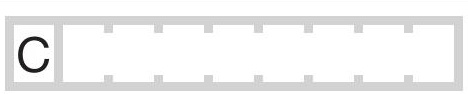

Name of Employer
PERS
Receipt For: 2012
X Primary $\quad \square$ General
$\square$ Other (specify)

Occupation Retired

Election Cycle-to-Date 550.00

B. Full Name (Last, First, Middle Initial)

William Holloway

Mailing Address 10222 Old Stagecoach Rd

\begin{tabular}{lcc}
\hline City & State & Zip Code \\
Chappell Hill & TX & $77426-6032$ \\
\hline
\end{tabular}

FEC ID number of contributing

federal political committee.

C

Name of Employer
self
Receipt For: 2012
Primary
Other (specify)

Occupation

plumbing contractor

Election Cycle-to-Date

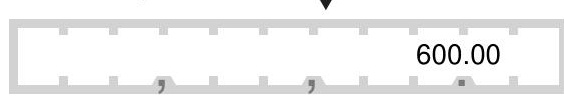

C. Full Name (Last, First, Middle Initial)

Colin Campbell

Mailing Address 5909 Yarmouth Dr.

\begin{tabular}{lcc}
\hline City & State & Zip Code \\
Dayton & $\mathrm{OH}$ & $45459-1449$
\end{tabular}

FEC ID number of contributing federal political committee.

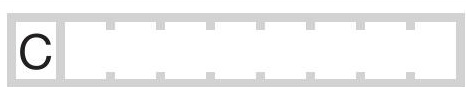

Name of Employer

Prundential One Realtors

Receipt For: 2012

Х $\begin{aligned} & \text { Primary } \\ & \text { Other (specify) }\end{aligned}$
Transaction ID : A94B763E8449E401D953

Date of Receipt

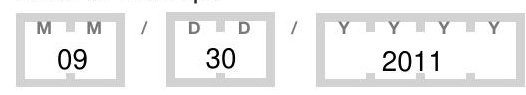

Amount of Each Receipt this Period

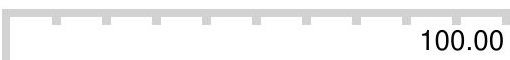

100.00
Transaction ID : A55D99BE507EF47FD9D4 Date of Receipt

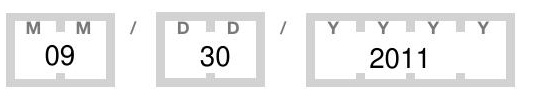

Amount of Each Receipt this Period

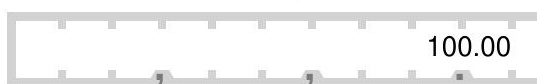

Transaction ID : AAODFAEBA81254EDB9BD Date of Receipt

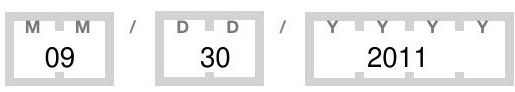

Amount of Each Receipt this Period

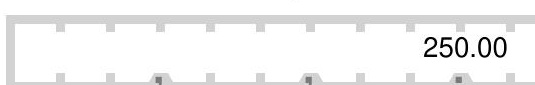

\section{Subtotal Of Receipts This Page (optional)}

Total This Period (last page this line number only) 


\section{SCHEDULE A-P} ITEMIZED RECEIPTS
Use separate schedule(s) for each category of the Detailed Summary Page

FOR LINE NUMBER:
(check only one)

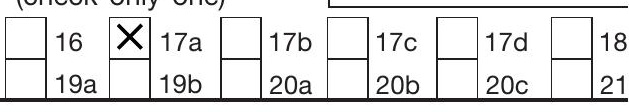

Any information copied from such Reports and Statements may not be sold or used by any person for the purpose of soliciting contributions or for commercial purposes, other than using the name and address of any political committee to solicit contributions from such committee.

NAME OF COMMITTEE (In Full)

\section{Friends of Herman Cain}

A. Full Name (Last, First, Middle Initial)

Ann Aldrich

Mailing Address 5253 E. Broad Street

Apt. 126

\begin{tabular}{lcc}
\hline City & State & Zip Code \\
Columbus & $\mathrm{OH}$ & $43213-3849$
\end{tabular}

FEC ID number of contributing federal political committee.

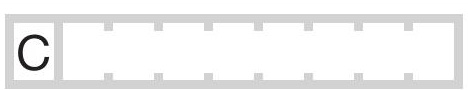

Name of Employer
Information Requested
Receipt For: 2012
X Primary
$\square$ Other (specify)

Occupation Information Requested

Election Cycle-to-Date

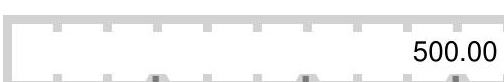

B. Full Name (Last, First, Middle Initial)

Rebecca Bianco

Mailing Address 8902 Eagle Point Loop Rd SW

\begin{tabular}{llc}
\hline City & State & Zip Code \\
Lakewood & WA & $98498-1054$
\end{tabular}

FEC ID number of contributing

federal political committee.

C

Name of Employer
Information Requested
Receipt For: 2012
X Primary
Other (specify)

Occupation

Information Requested

Election Cycle-to-Date

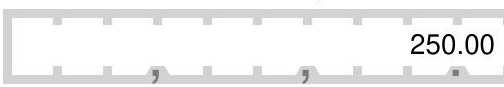

Transaction ID : A35B33F755F0246FEBB9

Date of Receipt

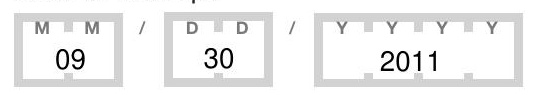

Amount of Each Receipt this Period

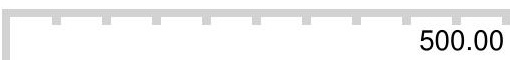

Transaction ID : A41E16887F7EF4157921

Date of Receipt

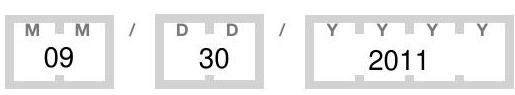

Amount of Each Receipt this Period

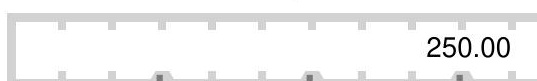

Transaction ID : A028DBE0A1C77454D830 Date of Receipt

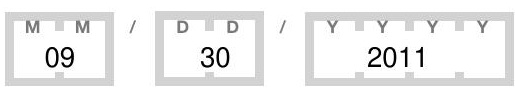

Amount of Each Receipt this Period

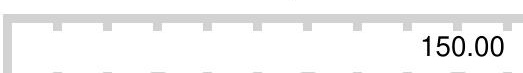

$\begin{array}{cc}\text { State } & \text { Zip Code } \\ \text { NY } & 14510-1519\end{array}$

C

Occupation

Retired

Election Cycle-to-Date

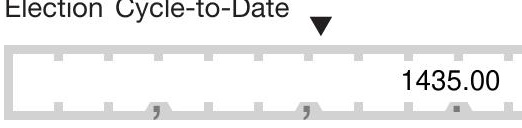

Subtotal Of Receipts This Page (optional)

900.00

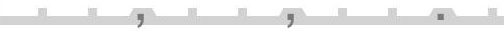

Total This Period (last page this line number only)

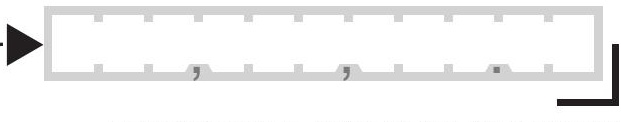

FEC Schedule A-P (Form 3P) (Rev. 03/2011) 


\section{SCHEDULE A-P} ITEMIZED RECEIPTS
Use separate schedule(s)

for each category of the

Detailed Summary Page
FOR LINE NUMBER: (check only one)

Any information or for commercial purposes, other than using the name and address of any political committee to solicit contributions from such committee.

NAME OF COMMITTEE (In Full)

Friends of Herman Cain

A. Full Name (Last, First, Middle Initial)

chris rodrigues

Mailing Address 1286 colchester drive e

\begin{tabular}{lcc}
\hline City & State & Zip Code \\
Port Orchard & WA & $98366-8519$
\end{tabular}

FEC ID number of contributing

federal political committee.

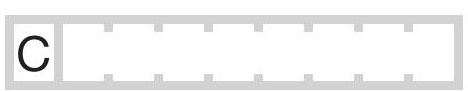

Name of Employer
Information Requested
Receipt For: 2012
X Primary $\square$ General
$\square$ Other (specify)

Occupation

Information Requested

Election Cycle-to-Date

250.00

B. Full Name (Last, First, Middle Initial)

THOMAS MCPETERS

Mailing Address 6451 N. SILVERSMITH PLACE

\begin{tabular}{lcc}
\hline City & State & Zip Code \\
Tucson & AZ & $85750-1086$ \\
\hline
\end{tabular}

FEC ID number of contributing

federal political committee.

C

Name of Employer
McPETRS MCALEARNEY SHIMOFF \&
HATT
Receipt For: 2012
X Primary
Other (specify)

Occupation

Attorney

Election Cycle-to-Date

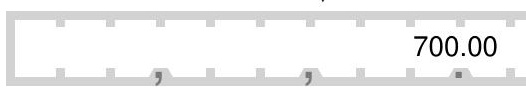

C. Full Name (Last, First, Middle Initial)

Darin Kohles

Mailing Address 21410 SE Hwy 224

\begin{tabular}{lcc}
\hline City & State & Zip Code \\
Damascus & OR & $97089-7825$
\end{tabular}

FEC ID number of contributing federal political committee.

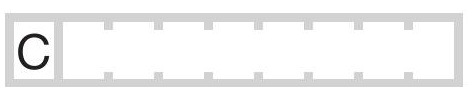

Name of Employer
Information Requested
Receipt For: 2012
X Primary $\quad \square$ General
Other (specify)

Occupation

Information Requested

Election Cycle-to-Date

Transaction ID : A6C356F8FD8EE41A0993

Date of Receipt

Amount of Each Receipt this Period

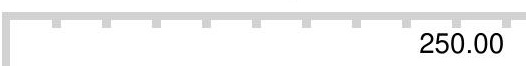

250.00

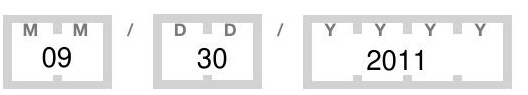

Amount of Each Receipt this Period

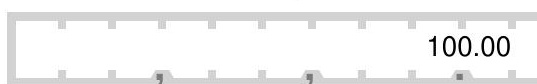

Transaction ID : AD2E2736976FA48D5B34 Date of Receipt

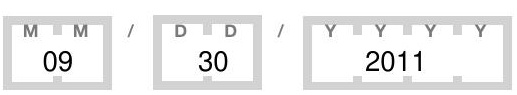

Amount of Each Receipt this Period

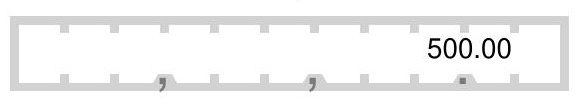

1265.00

\section{Subtotal Of Receipts This Page (optional)}

850.00

a

Total This Period (last page this line number only) 


\section{SCHEDULE A-P} ITEMIZED RECEIPTS
Use separate schedule(s)

for each category of the

Detailed Summary Page
FOR LINE NUMBER: (check only one)

Any information copion the purpose of soliciting contributions or for commercial purposes, other than using the name and address of any political committee to solicit contributions from such committee.

NAME OF COMMITTEE (In Full)

Friends of Herman Cain

A. Full Name (Last, First, Middle Initial)

Patricia Mellon

Mailing Address PO Box 1500

\begin{tabular}{lcc}
\hline City & State & Zip Code \\
Saratoga & WY & $82331-1500$
\end{tabular}

FEC ID number of contributing federal political committee.

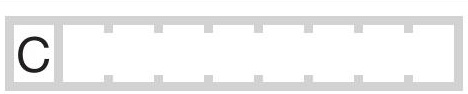

Name of Employer
None
Receipt For: 2012
X Primary $\quad \square$ General
$\square$ Other (specify)

Occupation Homemaker

Election Cycle-to-Date 500.00

B. Full Name (Last, First, Middle Initial)

Kenneth Middleton

Mailing Address 6935 Kenwood Rd.

\begin{tabular}{lcc}
\hline City & State & Zip Code \\
Cincinnati & OH & $45243-2327$ \\
\hline
\end{tabular}

FEC ID number of contributing

federal political committee.

C

Name of Employer
Information Requested
Receipt For: 2012
Primary
Other (specify)

Occupation

Information Requested

Election Cycle-to-Date

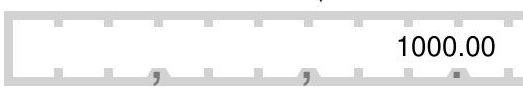

C. Full Name (Last, First, Middle Initial)

Andy Kult

Mailing Address 14 Todd Terrace

\begin{tabular}{lcc}
\hline City & State & Zip Code \\
Danville & IN & $46122-1043$
\end{tabular}

FEC ID number of contributing

federal political committee.

C

Name of Employer

The Abstract \& Title Guaranty Co. Inc.

\section{Occupation}

Attorney

Receipt For: 2012

Х $\begin{aligned} & \text { Primary } \\ & \text { Other (specify) }\end{aligned}$
Transaction ID : A624C24195CF545C9AF2

Date of Receipt

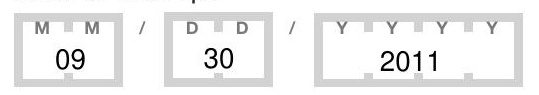

Amount of Each Receipt this Period

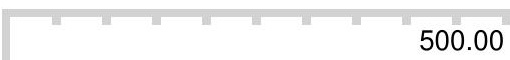

Transaction ID : AE02EEBA332B14B4EA62 Date of Receipt

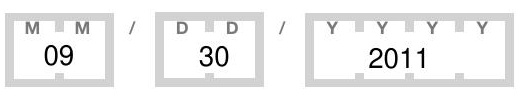

Amount of Each Receipt this Period

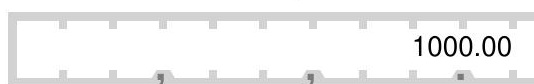

Transaction ID : A2CEFC21C44454286961

Date of Receipt

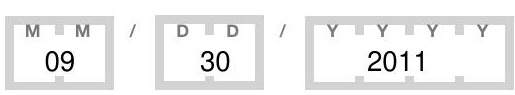

Amount of Each Receipt this Period

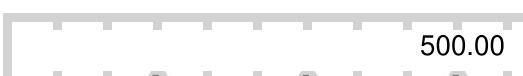

Subtotal Of Receipts This Page (optional).

Total This Period (last page this line number only) 


\section{SCHEDULE A-P} ITEMIZED RECEIPTS
Use separate schedule(s) for each category of the Detailed Summary Page

FOR LINE NUMBER:
(check only one)

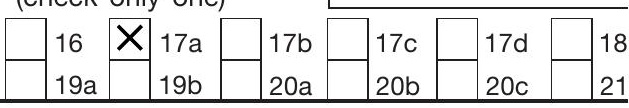

Any information copied from such Reports and Statements may not be sold or used by any person for the purpose of soliciting contributions or for commercial purposes, other than using the name and address of any political committee to solicit contributions from such committee.

NAME OF COMMITTEE (In Full)

\section{Friends of Herman Cain}

A. Full Name (Last, First, Middle Initial)

William Perez

Mailing Address 1320 N State Parkway 14 A

\begin{tabular}{lcc}
\hline City & State & Zip Code \\
Chicago & IL & $60610-2455$ \\
\hline
\end{tabular}

FEC ID number of contributing federal political committee.

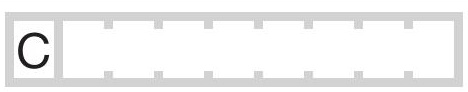

\begin{tabular}{l} 
Name of Employer \\
Greenhul \\
Receipt For: 2012 \\
$\square$ Primary $\$ General \\
\hline Other (specify)
\end{tabular}

\section{Occupation}

Senior Advisor

Election Cycle-to-Date

5000.00

B. Full Name (Last, First, Middle Initial)

Paul Blevins

Mailing Address 2901 Oak Ct

\begin{tabular}{lcc}
\hline City & State & Zip Code \\
Granbury & TX & $76048-6804$ \\
\hline
\end{tabular}

FEC ID number of contributing

federal political committee.

C

\begin{tabular}{l} 
Name of Employer \\
Huguley Memorial Med Ctr \\
Receipt For: 2012 \\
Xrimary \\
\hline Other (specify)
\end{tabular}

\section{Occupation}

Medicine

Election Cycle-to-Date

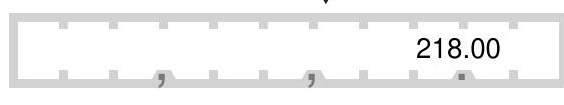

C. Full Name (Last, First, Middle Initial)

Marshall Solomon

Mailing Address 12458 Montego Plaza

\begin{tabular}{l|ll}
\hline $\begin{array}{l}\text { City } \\
\text { Dallas }\end{array}$ & $\begin{array}{c}\text { State } \\
\text { TX }\end{array}$ & $\begin{array}{c}\text { Zip Code } \\
75230-1724\end{array}$ \\
\hline $\begin{array}{l}\text { FEC ID number of contributing } \\
\text { federal political committee. }\end{array}$ & C \\
\hline $\begin{array}{l}\text { Name of Employer } \\
\text { Self Employed }\end{array}$ & $\begin{array}{l}\text { Occupation } \\
\text { Sales }\end{array}$ \\
$\begin{array}{l}\text { Receipt For: } 2012 \\
\text { X Primary } \\
\text { Other (specify) }\end{array}$ & Election Cycle-to-Date & \\
\hline
\end{tabular}

Subtotal Of Receipts This Page (optional)

Total This Period (last page this line number only)
Transaction ID : A06EB4A7F226843EC85E

Date of Receipt

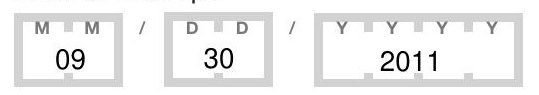

Amount of Each Receipt this Period

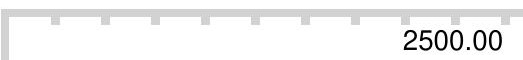

2500.00

Amount of Each Receipt this Period

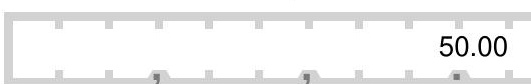

Transaction ID : A383CEC2A53A04055931

Date of Receipt

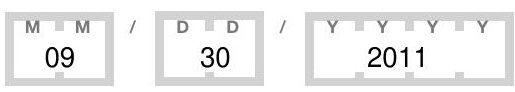

Amount of Each Receipt this Period

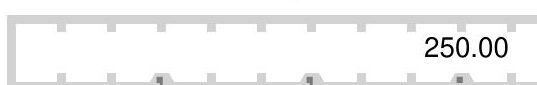

$-\quad 2800.00$

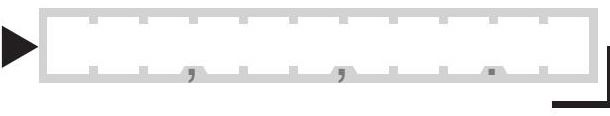

FEC Schedule A-P (Form 3P) (Rev. 03/2011) 


\section{SCHEDULE A-P} ITEMIZED RECEIPTS
Use separate schedule(s) for each category of the Detailed Summary Page

FOR LINE NUMBER:
(check only one)

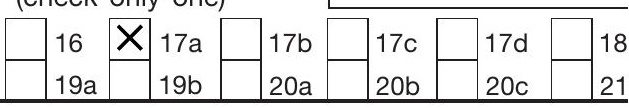

Any information copied from such Reports and Statements may not be sold or used by any person for the purpose of soliciting contributions or for commercial purposes, other than using the name and address of any political committee to solicit contributions from such committee.

NAME OF COMMITTEE (In Full)

\section{Friends of Herman Cain}

A. Full Name (Last, First, Middle Initial) jonnie jacobs

Mailing Address 36 bonita ave

\begin{tabular}{lcc}
\hline City & State & Zip Code \\
Piedmont & CA & $94611-3917$
\end{tabular}

FEC ID number of contributing federal political committee.

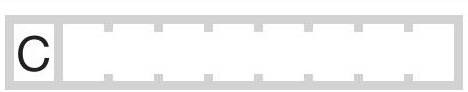

Name of Employer
Information Requested
Receipt For: 2012
X Primary
$\square$ Other (specify)

Occupation Information Requested Election Cycle-to-Date 1000.00

B. Full Name (Last, First, Middle Initial) Robert Ward

Mailing Address PO Box 464935

\begin{tabular}{lcc}
\hline City & State & Zip Code \\
Lawrenceville & GA & $30042-4935$
\end{tabular}

FEC ID number of contributing

federal political committee.

C

Name of Employer
Carter \& Sloope, Inc.
Receipt For: 2012
X Primary
Other (specify)

Occupation

Professional Engineer

Election Cycle-to-Date

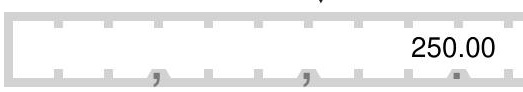

Transaction ID : A7A6158512C3843AAA93

Date of Receipt

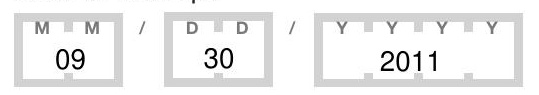

Amount of Each Receipt this Period

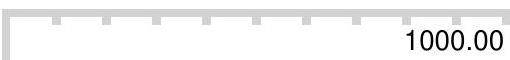

1000.00
Transaction ID : A357EB6E14EBF45359E0

Date of Receipt

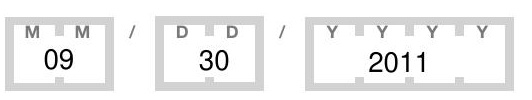

Amount of Each Receipt this Period

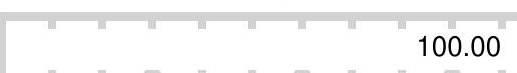

C. Full Name (Last, First, Middle Initial)

Andrew Ramsey

Mailing Address 740 West Main Street

\begin{tabular}{lcc}
\hline City & State & Zip Code \\
Bruceville & IN & $47516-6207$
\end{tabular}

FEC ID number of contributing federal political committee.

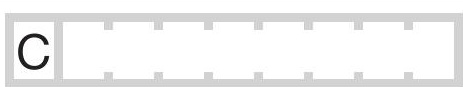

Name of Employer
Standard Labs
Receipt For: 2012
X Primary
Other (specify) General

\section{Occupation} coalsampler

Election Cycle-to-Date

Transaction ID : ABF5B2629990B41FF8F8 Date of Receipt

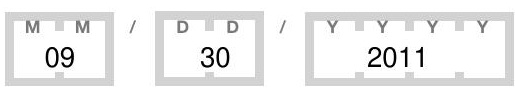

Amount of Each Receipt this Period

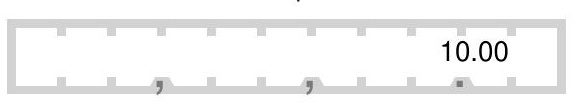

380.00

\section{Subtotal Of Receipts This Page (optional)}

Total This Period (last page this line number only) 
SCHEDULE A-P ITEMIZED RECEIPTS
Use separate schedule(s) for each category of the Detailed Summary Page
FOR LINE NUMBER: (check only one)

Any information copion or for commercial purposes, other than using the name and address of any political committee to solicit contributions from such committee.

NAME OF COMMITTEE (In Full)

\section{Friends of Herman Cain}

A. Full Name (Last, First, Middle Initial)

Hilary Gray

Mailing Address 310 Grant Park Place

\begin{tabular}{lcc}
\hline City & State & Zip Code \\
Atlanta & GA & $30315-1428$ \\
\hline
\end{tabular}

FEC ID number of contributing federal political committee.

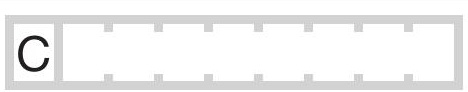

Name of Employer
Ferry Hayes and Allen
Receipt For: 2012
X Primary
Other (specify) General

Occupation Interior Designer

Election Cycle-to-Date

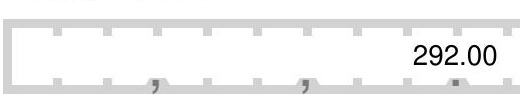

B. Full Name (Last, First, Middle Initial)

Jenny Galloway

Mailing Address 2178 Vinings North Lane

\begin{tabular}{lcc}
\hline City & State & Zip Code \\
Smyrna & GA & $30080-5977$
\end{tabular}

FEC ID number of contributing

federal political committee.

C

Name of Employer
Information Requested
Receipt For: 2012
X Primary
Other (specify)

Occupation

Information Requested

Election Cycle-to-Date

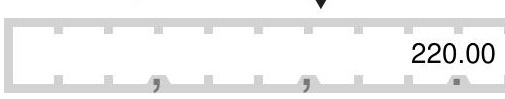

Transaction ID : A5308E7A4F33F4853A76

Date of Receipt

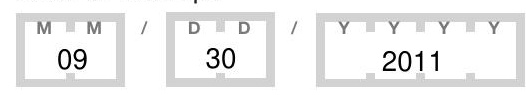

Amount of Each Receipt this Period

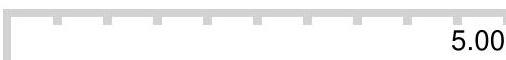

C. Full Name (Last, First, Middle Initial)

John Dorminy

Mailing Address PO Box 638

\begin{tabular}{lcc}
\hline City & State & Zip Code \\
McDonough & GA & $30253-0638$
\end{tabular}

FEC ID number of contributing federal political committee.

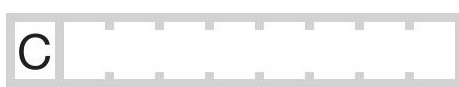

Name of Employer

Information Requested

Occupation

Information Requested

Receipt For: 2012

Х $\begin{aligned} & \text { Primary } \\ & \text { Other (specify) }\end{aligned}$

Amount of Each Receipt this Period

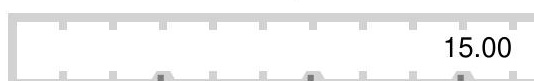

Transaction ID : AF5A063BE227A420AAFC Date of Receipt

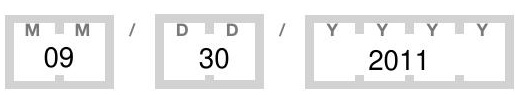

Transaction ID : A227DB58FBAB74B9980D Date of Receipt

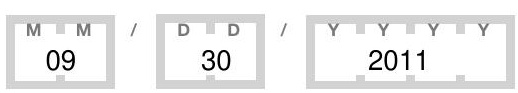

Amount of Each Receipt this Period

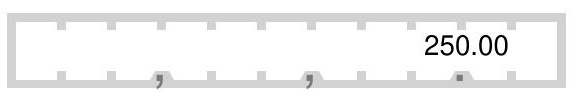

250.00
Subtotal Of Receipts This Page (optional)

270.00

ar.

Total This Period (last page this line number only)

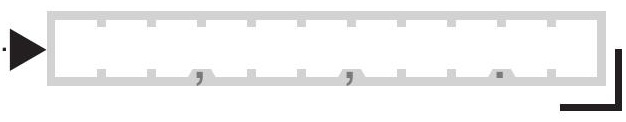

FEC Schedule A-P (Form 3P) (Rev. 03/2011) 


\section{SCHEDULE A-P} ITEMIZED RECEIPTS
Use separate schedule(s)

for each category of the

Detailed Summary Page
FOR LINE NUMBER: (check only one)

Any information or for commercial purposes, other than using the name and address of any political committee to solicit contributions from such committee.

NAME OF COMMITTEE (In Full)

Friends of Herman Cain

A. Full Name (Last, First, Middle Initial)

Stephen Ray

Mailing Address 1611 Cameron Landing Drive

\begin{tabular}{lcc}
\hline City & State & Zip Code \\
Stockbridge & GA & $30281-6863$ \\
\hline
\end{tabular}

FEC ID number of contributing

federal political committee.

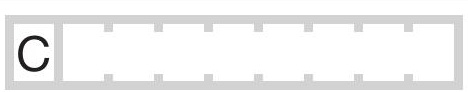

Name of Employer
Delat Air Lines
Receipt For: 2012
X Primary
$\square$ Other (specify) General

Occupation

Maintenance Coodinator

Election Cycle-to-Date $\boldsymbol{\nabla}$

300.00

B. Full Name (Last, First, Middle Initial)

Jay Tonne

Mailing Address $1801 \mathrm{~N}$ Elizabeth

\begin{tabular}{lcc}
\hline City & State & Zip Code \\
Pueblo & CO & $81003-4054$
\end{tabular}

FEC ID number of contributing

federal political committee.

C

Name of Employer
Information Requested
Receipt For: 2012
Primary
Other (specify)

Occupation

Information Requested

Election Cycle-to-Date

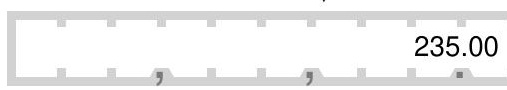

Transaction ID : AC6FC9991801748D59BA

Date of Receipt

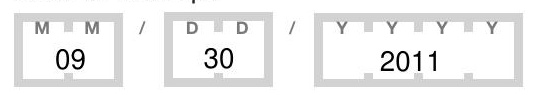

Amount of Each Receipt this Period

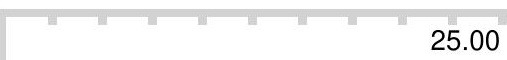

25.00

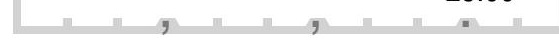

Transaction ID : AD29A288555E34893A58

Date of Receipt

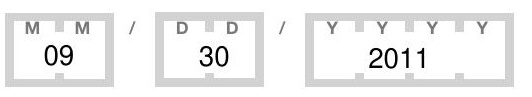

Amount of Each Receipt this Period

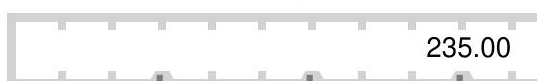

Transaction ID : AE866F7FA6E814388929

Date of Receipt

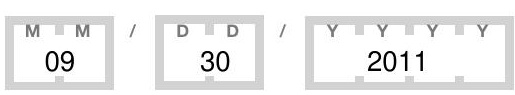

Amount of Each Receipt this Period

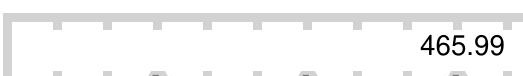

465.99

$\begin{array}{cc}\text { State } & \text { Zip Code } \\ \text { CA } & 93105-3570\end{array}$

C

Occupation

Information Requested

Election Cycle-to-Date

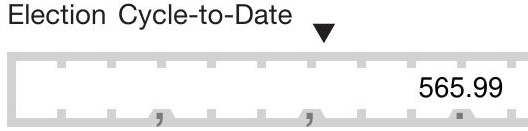

Subtotal Of Receipts This Page (optional).

725.99

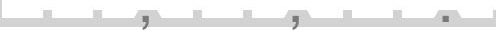

Total This Period (last page this line number only)

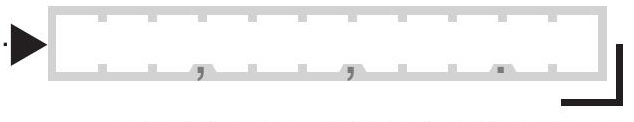

FEC Schedule A-P (Form 3P) (Rev. 03/2011) 


\section{SCHEDULE A-P} ITEMIZED RECEIPTS
Use separate schedule(s) for each category of the Detailed Summary Page

\begin{tabular}{|c|c|c|c|c|c|}
\hline \multicolumn{3}{|c|}{$\begin{array}{l}\text { FOR LINE NUMBER: } \\
\text { (check only one) }\end{array}$} & \multicolumn{3}{|c|}{ PAGE 1105 / 1572} \\
\hline 16 & $X$ 17a & $17 b$ & $17 c$ & $17 d$ & 18 \\
\hline $19 a$ & $19 \mathrm{~b}$ & $20 a$ & $20 \mathrm{~b}$ & $20 c$ & 21 \\
\hline
\end{tabular}

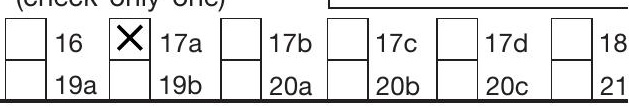

Any information copied from such Reports and Statements may not be sold or used by any person for the purpose of soliciting contributions or for commercial purposes, other than using the name and address of any political committee to solicit contributions from such committee.

NAME OF COMMITTEE (In Full)

\section{Friends of Herman Cain}

A. Full Name (Last, First, Middle Initial) JoAnne Cobasko

Mailing Address 1654 fordham Ave.

\begin{tabular}{lcc}
\hline City & State & Zip Code \\
Thousand Oaks & CA & $91360-2031$ \\
\hline
\end{tabular}

FEC ID number of contributing federal political committee.

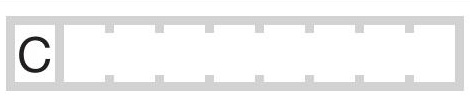

Name of Employer
Information Requested
Receipt For: 2012
X Primary $\quad \square$ General
Other (specify)

Occupation Information Requested Election Cycle-to-Date 250.00

B. Full Name (Last, First, Middle Initial) jerry massey

Mailing Address 17026 virginia avenue

\begin{tabular}{lcc}
\hline City & State & Zip Code \\
Williamsport & MD & $21795-1310$
\end{tabular}

FEC ID number of contributing

federal political committee.

C

Name of Employer
Massey Inc.
Receipt For: 2012
Xrimary
Other (specify)

\section{Occupation}

Massey Hyundai Dealer

Election Cycle-to-Date

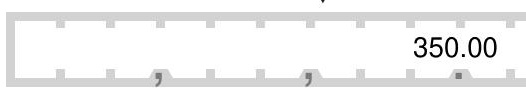

Transaction ID : A430E30B7666C4BBB8EE

Date of Receipt

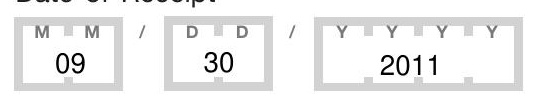

Amount of Each Receipt this Period

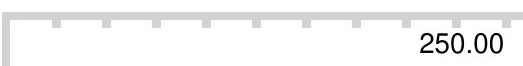

C. Full Name (Last, First, Middle Initial)

Edward J Phelan

Mailing Address 1049 Pecan Grive Place

\begin{tabular}{lcc}
\hline City & State & Zip Code \\
Lawrenceville & GA & $30046-5517$
\end{tabular}

FEC ID number of contributing federal political committee.

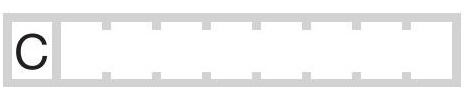

Name of Employer
None
Receipt For: 2012
Х Primary $\quad \square$ General
Other (specify)

\section{Occupation}

Retired

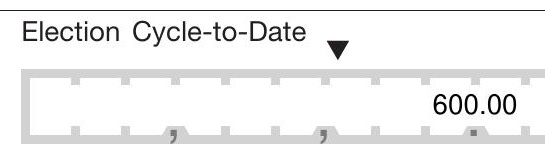

Transaction ID : A57F0B675CCD74D9CAC4 Date of Receipt

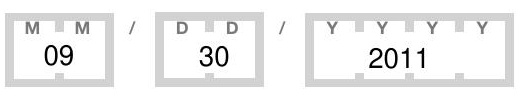

Amount of Each Receipt this Period

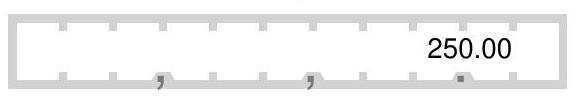

Transaction ID : AA8A55ED1165941DD9E6 Date of Receipt

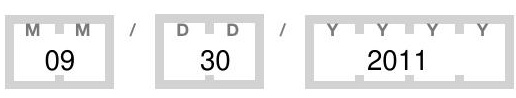

Amount of Each Receipt this Period

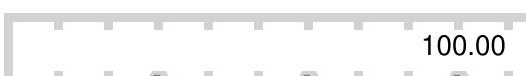

100.00

\section{Subtotal Of Receipts This Page (optional).}

600.00

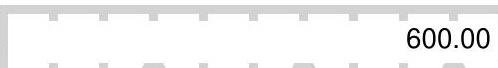

ㄱ․․

Total This Period (last page this line number only)

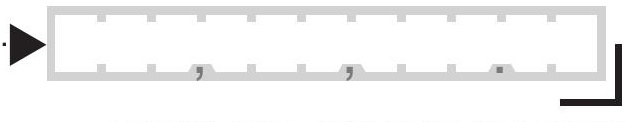

FEC Schedule A-P (Form 3P) (Rev. 03/2011) 


\section{SCHEDULE A-P} ITEMIZED RECEIPTS
Use separate schedule(s) for each category of the Detailed Summary Page

FOR LINE NUMBER:
(check only one)

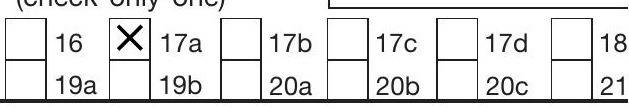

Any information copied from such Reports and Statements may not be sold or used by any person for the purpose of soliciting contributions or for commercial purposes, other than using the name and address of any political committee to solicit contributions from such committee.

NAME OF COMMITTEE (In Full)

\section{Friends of Herman Cain}

A. Full Name (Last, First, Middle Initial)

Thomas Riiser

Mailing Address 3315 Christian Avenue

\begin{tabular}{lcc}
\hline City & State & Zip Code \\
Wausau & WI & $54401-4018$
\end{tabular}

FEC ID number of contributing federal political committee.

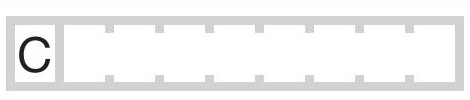

\begin{tabular}{l} 
Name of Employer \\
None \\
Receipt For: 2012 \\
X Primary $\quad$ General \\
\hline Other (specify)
\end{tabular}

Occupation

Retired

Election Cycle-to-Date

2400.00

B. Full Name (Last, First, Middle Initial)

Alan Proia

Mailing Address 4118 Deep Wood Circle

\begin{tabular}{lcc}
\hline City & State & Zip Code \\
Durham & NC & $27707-3522$ \\
\hline
\end{tabular}

FEC ID number of contributing

federal political committee.

C

Name of Employer
Information Requested
Receipt For: 2012
X Primary
Other (specify)

Occupation

Information Requested

Election Cycle-to-Date

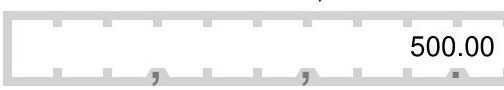

Transaction ID : AEEF0440323734187860

Date of Receipt

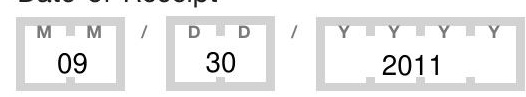

Amount of Each Receipt this Period

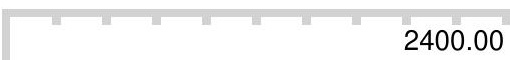

C. Full Name (Last, First, Middle Initial)

Philip Parker

Mailing Address 5428 Avenida Maravillas

\begin{tabular}{lcc}
\hline City & State & Zip Code \\
Rancho Santa Fe & CA & 92067
\end{tabular}

FEC ID number of contributing federal political committee.

C

Name of Employer
Information Requested
Receipt For: 2012
X Primary
Other (specify) General

\section{Occupation}

Information Requested

Election Cycle-to-Date
Transaction ID : A208951B2E94F4AE7ABD

Date of Receipt

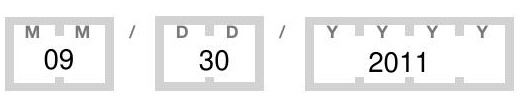

Amount of Each Receipt this Period

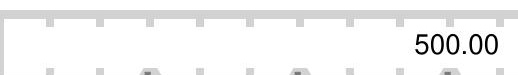

Transaction ID : AD49DE9993079406083B

Date of Receipt

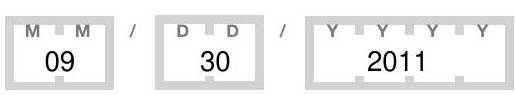

Amount of Each Receipt this Period

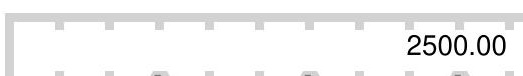

2500.00

\section{Subtotal Of Receipts This Page (optional)}

Total This Period (last page this line number only) 


\section{SCHEDULE A-P} ITEMIZED RECEIPTS
Use separate schedule(s)

for each category of the

Detailed Summary Page
FOR LINE NUMBER: (check only one)

Any information or for commercial purposes, other than using the name and address of any political committee to solicit contributions from such committee.

NAME OF COMMITTEE (In Full)

Friends of Herman Cain

A. Full Name (Last, First, Middle Initial)

Matthew McKinley

Mailing Address 1917 Green View Lane

\begin{tabular}{lcc}
\hline City & State & Zip Code \\
La Verne & CA & $91750-1330$
\end{tabular}

FEC ID number of contributing federal political committee.

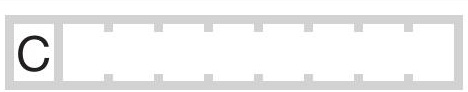

Name of Employer
Covina Valley Unified School Distic
Receipt For: 2012
X Primary $\quad \square$ General
Other (specify)

Occupation

Teacher

Election Cycle-to-Date

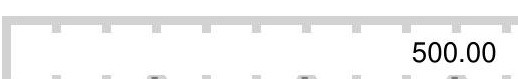

B. Full Name (Last, First, Middle Initial)

Timothy McGrath

Mailing Address 6439 Pine St. NE

\begin{tabular}{lcc}
\hline City & State & Zip Code \\
St Petersburg & FL & $33702-7660$
\end{tabular}

FEC ID number of contributing

federal political committee.

C

Name of Employer
Information Requested
Receipt For: 2012
Primary
Other (specify)

Occupation

Information Requested

Election Cycle-to-Date

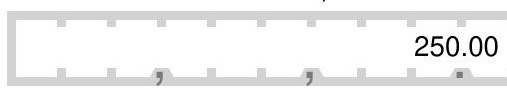

Transaction ID : ACB3925A0B63340C4987

Date of Receipt

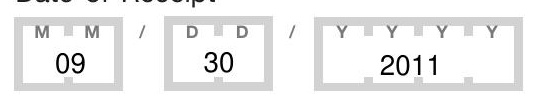

Amount of Each Receipt this Period

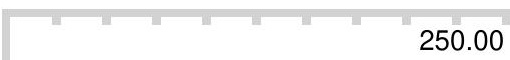

Transaction ID : A9F6C8F7C86914877A14

Date of Receipt

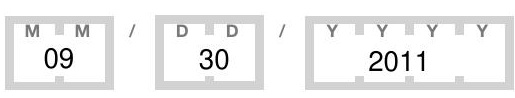

Amount of Each Receipt this Period

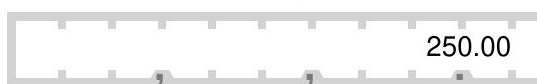

Transaction ID : AF49D49AB7DE34869A27 Date of Receipt

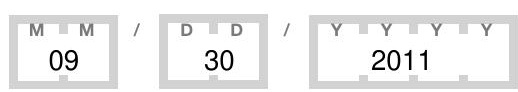

Amount of Each Receipt this Period

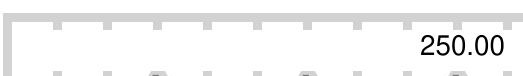

Name of Employer

Verplank Enterprises, Inc.

Receipt For: 2012

X Primary $\square$ General

$\begin{array}{cc}\text { State } & \text { Zip Code } \\ \text { AL } & \text { 35633-1615 }\end{array}$

C

\section{Occupation}

President

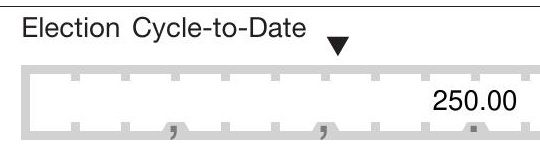

Subtotal Of Receipts This Page (optional)

750.00

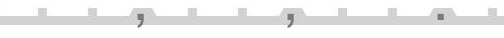

Total This Period (last page this line number only)

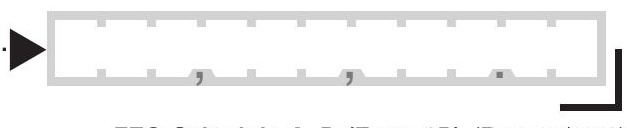

FEC Schedule A-P (Form 3P) (Rev. 03/2011) 


\section{SCHEDULE A-P} ITEMIZED RECEIPTS
Use separate schedule(s)

for each category of the

Detailed Summary Page
FOR LINE NUMBER: (check only one)

Any information copion the purpose of soliciting contributions or for commercial purposes, other than using the name and address of any political committee to solicit contributions from such committee.

NAME OF COMMITTEE (In Full)

\section{Friends of Herman Cain}

A. Full Name (Last, First, Middle Initial)

William Murphy

Mailing Address 10985 105th St N

\begin{tabular}{lcc}
\hline City & State & Zip Code \\
Stillwater & MN & $55082-9574$
\end{tabular}

FEC ID number of contributing federal political committee.

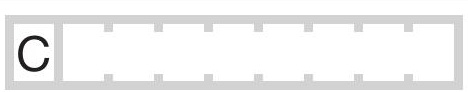

Name of Employer
Information Requested
Receipt For: 2012
X Primary
Other (specify) General

Occupation Information Requested

Election Cycle-to-Date

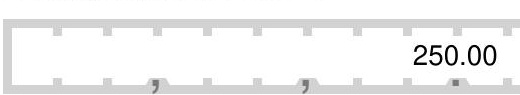

B. Full Name (Last, First, Middle Initial)

David Dearing

Mailing Address 135 Mansell PI. Ste. 505

\begin{tabular}{lcc}
\hline City & State & Zip Code \\
Roswell & GA & $30076-5686$
\end{tabular}

FEC ID number of contributing

federal political committee.

C

Name of Employer
Information Requested
Receipt For: 2012
Primary
Other (specify)

Occupation

Information Requested

Election Cycle-to-Date

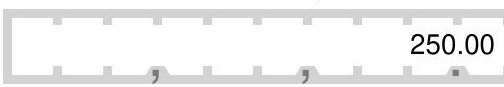

Transaction ID : ACD10820F85D94C7D92C

Date of Receipt

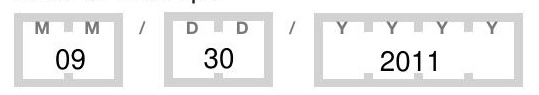

Amount of Each Receipt this Period

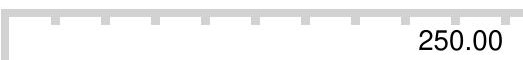

C. Full Name (Last, First, Middle Initial)

Randal Kirk

Mailing Address 1881 Grove Ave.

\begin{tabular}{lcc}
\hline City & State & Zip Code \\
Radford & VA & $24141-1628$
\end{tabular}

FEC ID number of contributing federal political committee.

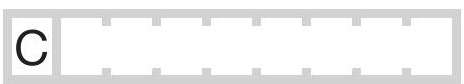

Name of Employer

Information Requested

\section{Occupation}

Information Requested

Receipt For: 2012

Х $\begin{aligned} & \text { Primary } \square \text { General } \\ & \text { Other (specify) }\end{aligned}$

Amount of Each Receipt this Period

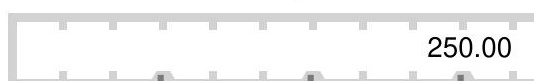

Transaction ID : A14E52350F3834A4C9AE Date of Receipt

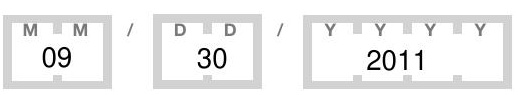

Transaction ID : A145D620F6DBB432EAA8 Date of Receipt

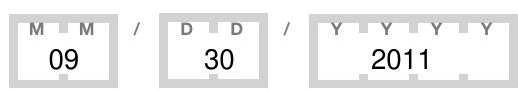

Amount of Each Receipt this Period

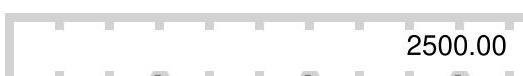

2500.00

\section{Subtotal Of Receipts This Page (optional)}

Total This Period (last page this line number only) 


\section{SCHEDULE A-P} ITEMIZED RECEIPTS
Use separate schedule(s)

for each category of the

Detailed Summary Page
FOR LINE NUMBER: (check only one)

Any information or for commercial purposes, other than using the name and address of any political committee to solicit contributions from such committee.

NAME OF COMMITTEE (In Full)

Friends of Herman Cain

A. Full Name (Last, First, Middle Initial)

Steven Sadler

Mailing Address 7855 Berkshire Lane

\begin{tabular}{lcc}
\hline City & State & Zip Code \\
Gloucester & VA & $23061-5305$
\end{tabular}

FEC ID number of contributing

federal political committee.

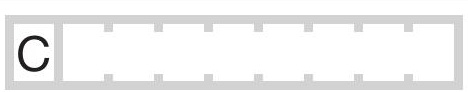

Name of Employer
Information Requested
Receipt For: 2012
X Primary $\quad \square$ General
Other (specify)

Occupation

Information Requested

Election Cycle-to-Date

250.00

B. Full Name (Last, First, Middle Initial)

Anna Howell

Mailing Address 1299 N. Tamiami Tr. \#124

\begin{tabular}{lcc}
\hline City & State & Zip Code \\
Sarasota & FL & $34236-2465$ \\
\hline
\end{tabular}

FEC ID number of contributing

federal political committee.

C

Name of Employer
Information Requested
Receipt For: 2012
X Primary
Other (specify)

Occupation

Information Requested

Election Cycle-to-Date

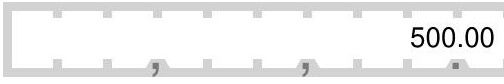

C. Full Name (Last, First, Middle Initial)

Mark Pecheck

Mailing Address 14265 Greenleaf Street

\begin{tabular}{lcc}
\hline City & State & Zip Code \\
Sherman Oaks & CA & $91423-4011$
\end{tabular}

FEC ID number of contributing

federal political committee.

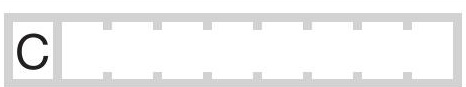

Name of Employer

Information Requested

Occupation

Information Requested

Receipt For: 2012

Х $\begin{aligned} & \text { Primary } \square \text { General } \\ & \text { Other (specify) }\end{aligned}$

Election Cycle-to-Date

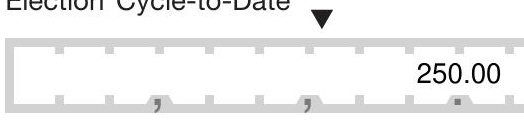

Transaction ID : A0A54F0F051EC4BFCA32

Date of Receipt

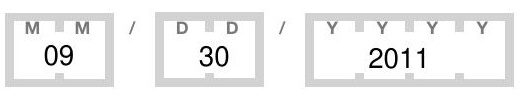

Amount of Each Receipt this Period

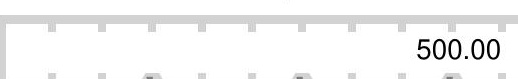

Transaction ID : AD0385A23E10D448CBBD Date of Receipt

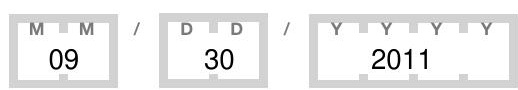

Amount of Each Receipt this Period

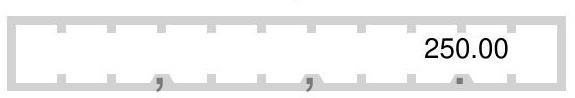

Subtotal Of Receipts This Page (optional).

1000.00

Total This Period (last page this line number only) 


\section{SCHEDULE A-P} ITEMIZED RECEIPTS
Use separate schedule(s)

for each category of the

Detailed Summary Page
FOR LINE NUMBER: (check only one)

Any information or for commercial purposes, other than using the name and address of any political committee to solicit contributions from such committee.

NAME OF COMMITTEE (In Full)

\section{Friends of Herman Cain}

A. Full Name (Last, First, Middle Initial)

Mike Trainor

Mailing Address 3506 Ehrlich Rd.

\begin{tabular}{lcc}
\hline City & State & Zip Code \\
Tampa & FL & $33618-2142$
\end{tabular}

FEC ID number of contributing federal political committee.

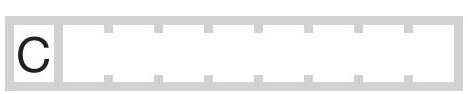

Name of Employer
Information Requested
Receipt For: 2012
X Primary
$\square$ Other (specify)

Occupation Information Requested

Election Cycle-to-Date

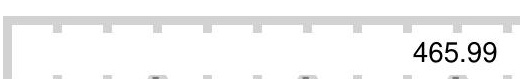

B. Full Name (Last, First, Middle Initial)

Allen Turner

Mailing Address 50 Irvin Enzor Rd. S.

\begin{tabular}{lcc}
\hline City & State & Zip Code \\
Fair Bluff & NC & $28439-9582$ \\
\hline
\end{tabular}

FEC ID number of contributing

federal political committee.

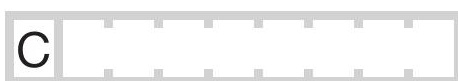

\begin{tabular}{l} 
Name of Employer \\
n/a \\
Receipt For: 2012 \\
X Primary $\quad$ General \\
\hline Other (specify)
\end{tabular}

Occupation

Retired

Election Cycle-to-Date

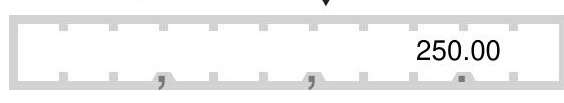

Transaction ID : ABE93D3953C124B17845

Date of Receipt

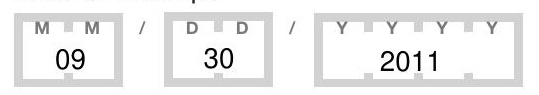

Amount of Each Receipt this Period

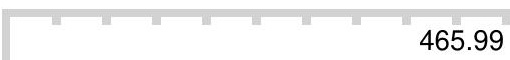

465.99

C. Full Name (Last, First, Middle Initial)

Stephen Koch

Mailing Address 344 West Azalea Dr

\begin{tabular}{lcc}
\hline City & State & Zip Code \\
Chandler & AZ & $85248-3903$
\end{tabular}

FEC ID number of contributing federal political committee.

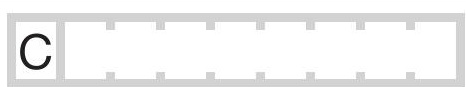

Name of Employer

\section{Occupation}

Arizone State University

Receipt For: 2012

Х $\begin{aligned} & \text { Primary } \square \text { General } \\ & \text { Other (specify) }\end{aligned}$

IT

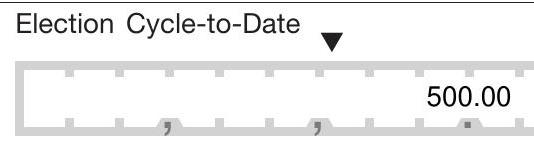

Amount of Each Receipt this Period

Transaction ID : A66AB2FF446384D529BA

Date of Receipt
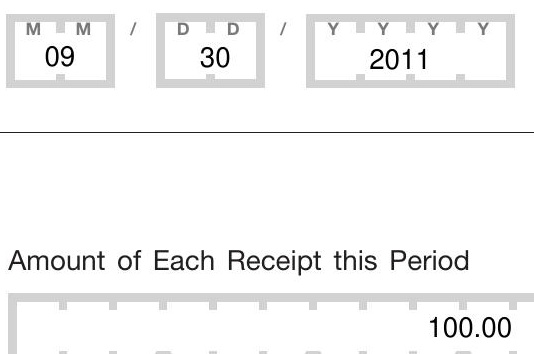

Transaction ID : AC1DE2A8BD3A84B8FB51 Date of Receipt

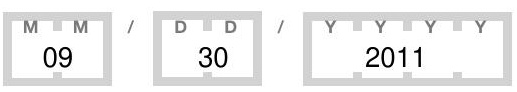

Amount of Each Receipt this Period

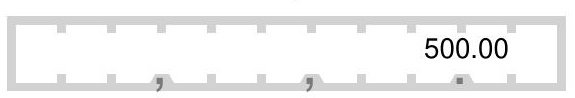

Subtotal Of Receipts This Page (optional)

1065.99

Total This Period (last page this line number only) 


\section{SCHEDULE A-P} ITEMIZED RECEIPTS
Use separate schedule(s)

for each category of the

Detailed Summary Page
FOR LINE NUMBER: (check only one)

Any information or for commercial purposes, other than using the name and address of any political committee to solicit contributions from such committee.

NAME OF COMMITTEE (In Full)

Friends of Herman Cain

A. Full Name (Last, First, Middle Initial)

George Sexton

Mailing Address 9270 Bayhill Dr

\begin{tabular}{lcc}
\hline City & State & Zip Code \\
Gainesville & GA & $30506-6737$
\end{tabular}

FEC ID number of contributing federal political committee.

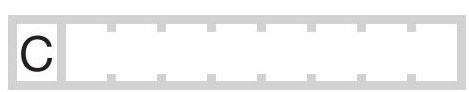

Name of Employer
U S Treasury
Receipt For: 2012
X Primary
$\square$ Other (specify) General

Occupation

Special Agent

Election Cycle-to-Date

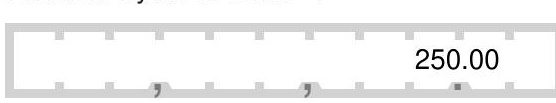

B. Full Name (Last, First, Middle Initial)

Molly Smithfield

Mailing Address 1844 W San Angelo St

\begin{tabular}{lcc}
\hline City & State & Zip Code \\
Gilbert & AZ & 85233-2925 \\
\hline
\end{tabular}

FEC ID number of contributing

federal political committee.

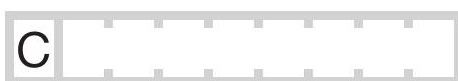

Name of Employer
None
Receipt For: 2012
X Primary $\quad$ General
Other (specify)

\section{Occupation}

Homemaker

Election Cycle-to-Date

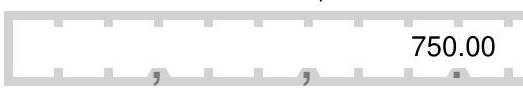

C. Full Name (Last, First, Middle Initial) marilyn Sensney

Mailing Address 19528 Creekside Ct

\begin{tabular}{lcc}
\hline City & State & Zip Code \\
Salinas & CA & $93908-1245$
\end{tabular}

FEC ID number of contributing federal political committee.

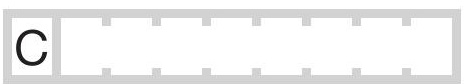

Name of Employer

Occupation

Monerey School District

Teacher

Receipt For: 2012

Х $\begin{aligned} & \text { Primary } \square \text { General } \\ & \text { Other (specify) }\end{aligned}$

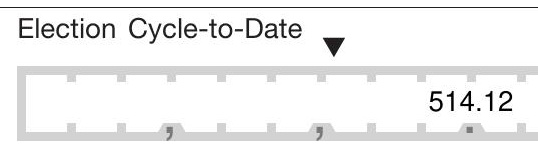

Amount of Each Receipt this Period

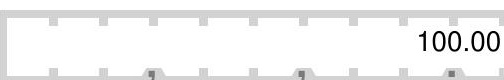

Date of Receipt

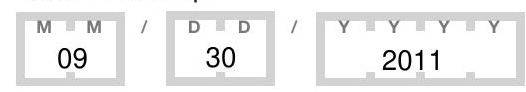

Transaction ID : AF7D1574A422B475C92C

Date of Receipt

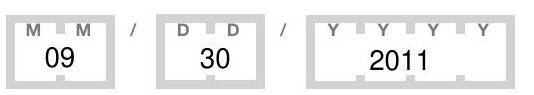

Amount of Each Receipt this Period

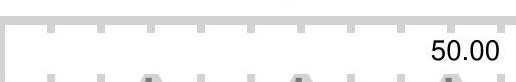

Transaction ID : A7815DA742AA24D378E8 Date of Receipt

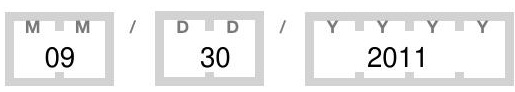

Amount of Each Receipt this Period

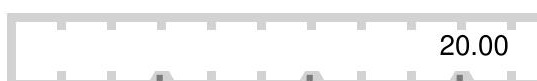

170.00

Subtotal Of Receipts This Page (optional)

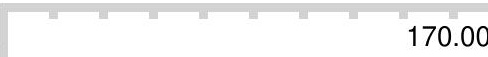

Total This Period (last page this line number only) 


\section{SCHEDULE A-P} ITEMIZED RECEIPTS
Use separate schedule(s)

for each category of the

Detailed Summary Page
FOR LINE NUMBER: (check only one)

Any information or for commercial purposes, other than using the name and address of any political committee to solicit contributions from such committee.

NAME OF COMMITTEE (In Full)

Friends of Herman Cain

A. Full Name (Last, First, Middle Initial)

Frank Duncan

Mailing Address 5964 Lockhart Hwy

\begin{tabular}{lcc}
\hline City & State & Zip Code \\
Sharon & SC & $29742-7749$
\end{tabular}

FEC ID number of contributing federal political committee.

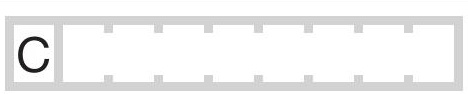

Name of Employer
Retired
Receipt For: 2012
X Primary $\quad$ General
Other (specify)

Occupation

Retired

Election Cycle-to-Date

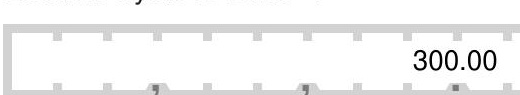

B. Full Name (Last, First, Middle Initial)

Elin Carlson

Mailing Address 17553 Lanark St.

\begin{tabular}{lcc}
\hline City & State & Zip Code \\
Northridge & CA & $91325-4317$
\end{tabular}

FEC ID number of contributing

federal political committee.

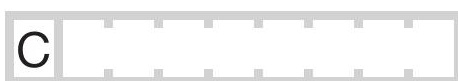

Name of Employer
self
Receipt For: 2012
Primary
Other (specify)

Occupation

professional singer

Election Cycle-to-Date

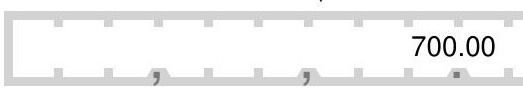

C. Full Name (Last, First, Middle Initial)

Tom Hamilton

Mailing Address 338 Nelson Ferry Road

\begin{tabular}{lcc}
\hline City & State & Zip Code \\
Decatur & GA & $30030-2320$
\end{tabular}

FEC ID number of contributing

federal political committee.

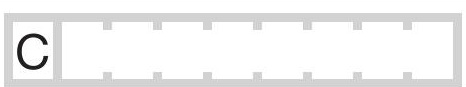

Name of Employer

Information Requested

Occupation

Information Requested

Receipt For: 2012

Х $\begin{aligned} & \text { Primary } \\ & \text { Other (specify) }\end{aligned}$

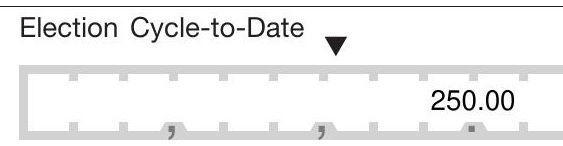

Amount of Each Receipt this Period

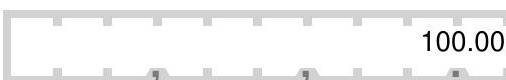

Date of Receipt

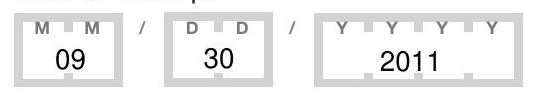

Transaction ID : AB3390D4CAEAA42F9AE1

Date of Receipt

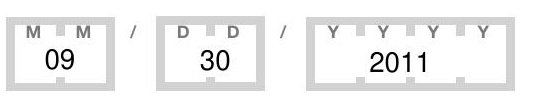

Amount of Each Receipt this Period

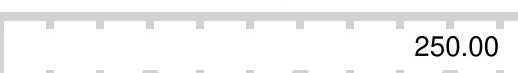

Transaction ID : A1E5F24CF3AB64054990

Date of Receipt

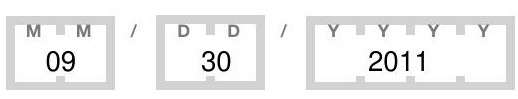

Amount of Each Receipt this Period

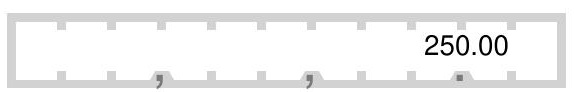

Subtotal Of Receipts This Page (optional).

600.00

Total This Period (last page this line number only) 
SCHEDULE A-P ITEMIZED RECEIPTS
Use separate schedule(s) for each category of the Detailed Summary Page
FOR LINE NUMBER: (check only one)

PAGE $1113 / 1572$

\begin{tabular}{|c|c|c|c|c|c|}
\hline & & & & & \\
\hline 16 & $\mathbf{X} 17 a$ & $17 b$ & $17 c$ & $17 d$ & 18 \\
\hline $19 a$ & $19 b$ & $20 \mathrm{a}$ & $20 \mathrm{~b}$ & $20 \mathrm{c}$ & 21 \\
\hline
\end{tabular}

Any information copied from such Reports and Statements may not be sold or used by any person for the purpose of soliciting contributions or for commercial purposes, other than using the name and address of any political committee to solicit contributions from such committee.

NAME OF COMMITTEE (In Full)

\section{Friends of Herman Cain}

A. Full Name (Last, First, Middle Initial)

Timothy Graney

Mailing Address 26223 Rustic Ranch Ln

\begin{tabular}{lcc}
\hline City & State & Zip Code \\
Katy & TX & $77494-5360$ \\
\hline
\end{tabular}

FEC ID number of contributing federal political committee.

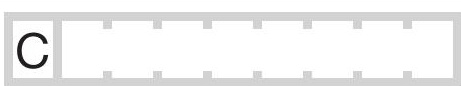

Name of Employer
self
Receipt For: 2012
X Primary $\quad$ General
Other (specify)

Occupation Consultant

Election Cycle-to-Date

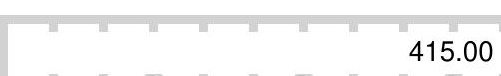

B. Full Name (Last, First, Middle Initial)

Sylvia Hodges

Mailing Address 2000 South McColl Suite B-166

\begin{tabular}{lcc}
\hline City & State & Zip Code \\
McAllen & TX & 78503-1501
\end{tabular}

FEC ID number of contributing

federal political committee.

C

Name of Employer
HCA Corporation
Receipt For: 2012
X Primary
Other (specify)

Occupation

Pharmacist

Election Cycle-to-Date

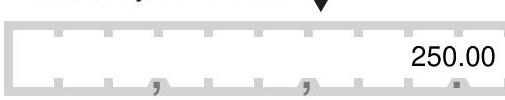

Transaction ID : A1F80B6E375B648E9960

Date of Receipt

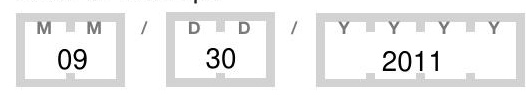

Amount of Each Receipt this Period

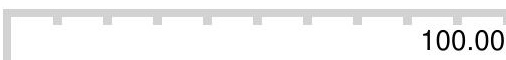

Transaction ID : A06FD1724B3E64B0E852

Date of Receipt

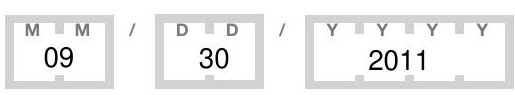

Amount of Each Receipt this Period

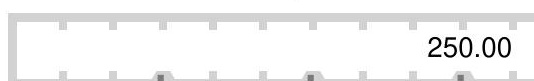

Transaction ID : A38B14536DFD3477F9AB Date of Receipt

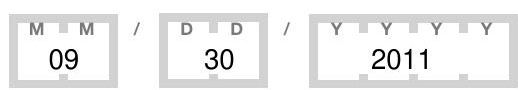

Amount of Each Receipt this Period

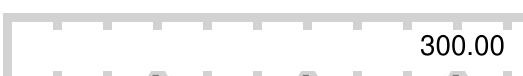

$\begin{array}{ll}\text { State } & \text { Zip Code } \\ \text { ID } & 83814-5491\end{array}$

C

\section{Occupation \\ Community Futures Tropper}

Election Cycle-to-Date

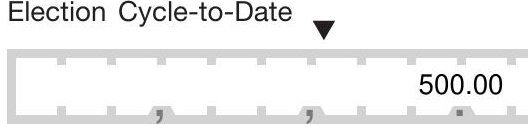

Subtotal Of Receipts This Page (optional)

650.00

a

Total This Period (last page this line number only)

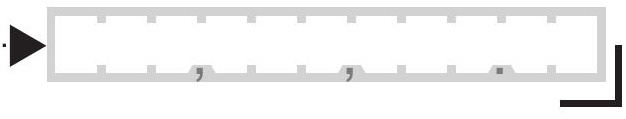

FEC Schedule A-P (Form 3P) (Rev. 03/2011) 


\section{SCHEDULE A-P} ITEMIZED RECEIPTS
Use separate schedule(s) for each category of the Detailed Summary Page

FOR LINE NUMBER:
(check only one)

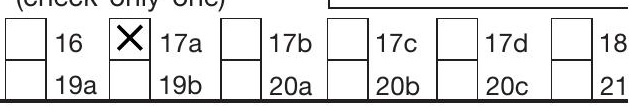

Any information copied from such Reports and Statements may not be sold or used by any person for the purpose of soliciting contributions or for commercial purposes, other than using the name and address of any political committee to solicit contributions from such committee.

NAME OF COMMITTEE (In Full)

\section{Friends of Herman Cain}

A. Full Name (Last, First, Middle Initial)

\section{Gary Martin}

Mailing Address 143 Aaronvale Circle

\begin{tabular}{lcc}
\hline City & State & Zip Code \\
Birmingham & AL & $35242-7354$
\end{tabular}

FEC ID number of contributing federal political committee.

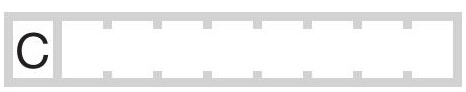

Name of Employer
Information Requested
Receipt For: 2012
X Primary
$\square$ Other (specify)

Occupation Information Requested

Election Cycle-to-Date

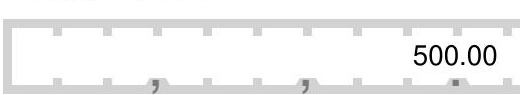

B. Full Name (Last, First, Middle Initial) John Hoffert

Mailing Address 2412 N 161st St

\begin{tabular}{lcc}
\hline City & State & Zip Code \\
Omaha & NE & $68116-2083$
\end{tabular}

FEC ID number of contributing

federal political committee.

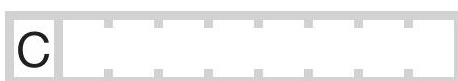

Name of Employer
None
Receipt For: 2012
X Primary
Other (specify)

\section{Occupation}

Retired

Election Cycle-to-Date

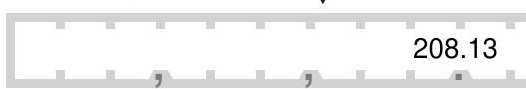

Transaction ID : A8A7784AF7790480DB4F

Date of Receipt

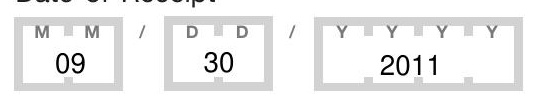

Amount of Each Receipt this Period

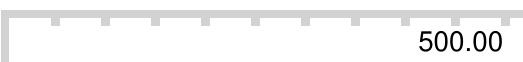

Amount of Each Receipt this Period

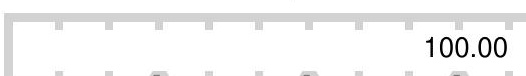

C. Full Name (Last, First, Middle Initial)

Edgar Chapman

Mailing Address 5112 Mimosa

\begin{tabular}{lcc}
\hline City & State & Zip Code \\
Bellaire & TX & $77401-4941$
\end{tabular}

FEC ID number of contributing federal political committee.

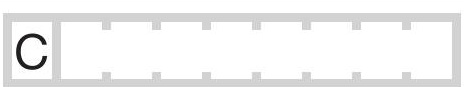

Name of Employer Information Requested

\section{Occupation}

Information Requested

Receipt For: 2012

Х $\begin{aligned} & \text { Primary } \square \text { General } \\ & \text { Other (specify) }\end{aligned}$

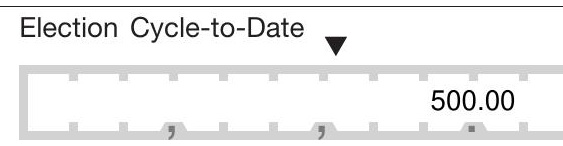

Amount of Each Receipt this Period

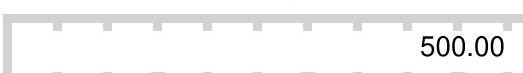

Transaction ID : AE6E71024EE714B80A5B

Date of Receipt

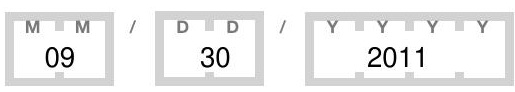

Subtotal Of Receipts This Page (optional)

1100.00

Total This Period (last page this line number only) 


\section{SCHEDULE A-P} ITEMIZED RECEIPTS
Use separate schedule(s)

for each category of the

Detailed Summary Page
FOR LINE NUMBER: (check only one)

Any information or for commercial purposes, other than using the name and address of any political committee to solicit contributions from such committee.

NAME OF COMMITTEE (In Full)

Friends of Herman Cain

A. Full Name (Last, First, Middle Initial)

Thomas George

Mailing Address 5035 E Lake Country Rd.

\begin{tabular}{lcc}
\hline City & State & Zip Code \\
Flagstaff & AZ & $86004-7835$ \\
\hline
\end{tabular}

FEC ID number of contributing federal political committee.

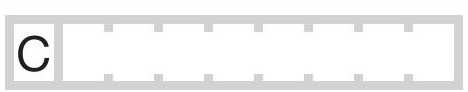

\begin{tabular}{l} 
Name of Employer \\
None \\
Receipt For: 2012 \\
X Primary $\quad$ General \\
\hline Other (specify)
\end{tabular}

Occupation

Retired

Election Cycle-to-Date

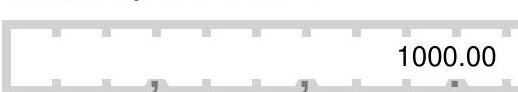

B. Full Name (Last, First, Middle Initial)

Mr George Christopoulos

Mailing Address 2301 Avenue F

\begin{tabular}{lcc}
\hline $\begin{array}{l}\text { City } \\
\text { Rosenberg }\end{array}$ & $\begin{array}{c}\text { State } \\
\text { TX }\end{array}$ & $\begin{array}{c}\text { Zip Code } \\
77471-2529\end{array}$ \\
\hline $\begin{array}{l}\text { FEC ID number of contributing } \\
\text { federal political committee. }\end{array}$ & C & \\
\hline
\end{tabular}

\begin{tabular}{l} 
Name of Employer \\
Information Requested \\
\hline Receipt For: 2012 \\
Primary \\
Other (specify)
\end{tabular}

\section{Occupation}

Information Requested

Election Cycle-to-Date

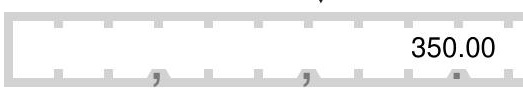

C. Full Name (Last, First, Middle Initial)

Glen Ebbing

Mailing Address 1400 Huntleigh Rd

\begin{tabular}{lcc}
\hline City & State & Zip Code \\
Quincy & IL & $62305-6017$
\end{tabular}

FEC ID number of contributing

federal political committee.

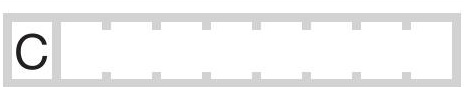

Name of Employer
ColorMaster Pain Inc
Receipt For: 2012
X Primary
Other (specify) General

\section{Occupation}

sales representative

Election Cycle-to-Date
Transaction ID : ABB616A7D6421427EB25

Date of Receipt

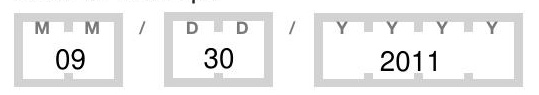

Amount of Each Receipt this Period

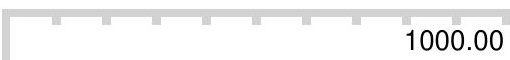

1000.00
Amount of Each Receipt this Period

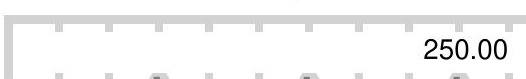

Transaction ID : A5301128C8B544F719F0

Date of Receipt

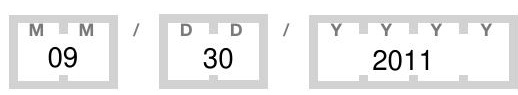

Transaction ID : A206DDA2C05E743E6951 Date of Receipt

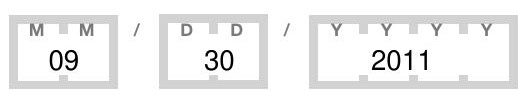

Amount of Each Receipt this Period

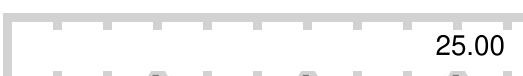

503.00

\section{Subtotal Of Receipts This Page (optional)}

Total This Period (last page this line number only) 


\section{SCHEDULE A-P} ITEMIZED RECEIPTS
Use separate schedule(s)

for each category of the

Detailed Summary Page
FOR LINE NUMBER: (check only one)

Any information or for commercial purposes, other than using the name and address of any political committee to solicit contributions from such committee.

NAME OF COMMITTEE (In Full)

\section{Friends of Herman Cain}

A. Full Name (Last, First, Middle Initial)

K Hall

Mailing Address 2520 Silver Lane NE Apt 305

\begin{tabular}{lcc}
\hline City & State & Zip Code \\
Minneapolis & MN & $55421-3421$
\end{tabular}

FEC ID number of contributing

federal political committee.

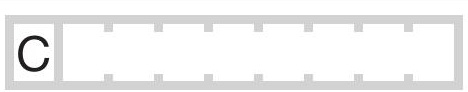

Name of Employer
Information Requested
Receipt For: 2012
X Primary $\quad \square$ General
Other (specify)

Occupation

Information Requested

Election Cycle-to-Date

250.00

B. Full Name (Last, First, Middle Initial)

William Miller

Mailing Address 2026 Black Fox Drive

\begin{tabular}{lcc}
\hline City & State & Zip Code \\
Atlanta & GA & $30345-4151$ \\
\hline
\end{tabular}

FEC ID number of contributing

federal political committee.

C

Name of Employer
Information Requested
Receipt For: 2012
X Primary
Other (specify)

Occupation

Information Requested

Election Cycle-to-Date

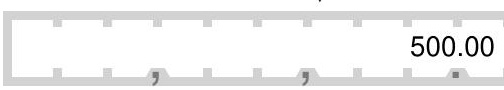

Transaction ID : A4C2EF1B64A7747AD9F0

Date of Receipt

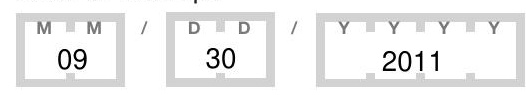

Amount of Each Receipt this Period

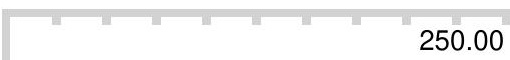

C. Full Name (Last, First, Middle Initial)

John Place

Mailing Address 34 Pond Lane

\begin{tabular}{lcc}
\hline City & State & Zip Code \\
Bryn Mawr & PA & $19010-1772$
\end{tabular}

FEC ID number of contributing federal political committee.

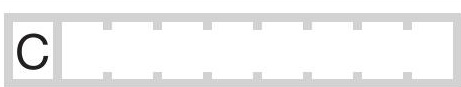

Name of Employer
None
Receipt For: 2012
X Primary $\quad \square$ General
Other (specify)

Occupation

Retired

Election Cycle-to-Date

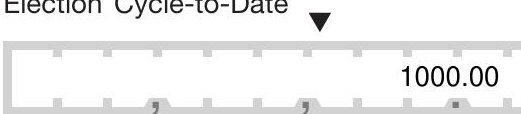

Amount of Each Receipt this Period

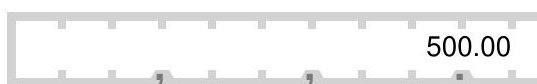

Transaction ID : AA99B0611528D40B4B1D Date of Receipt

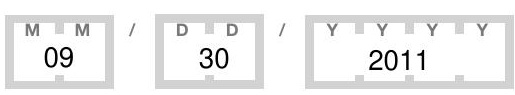

Transaction ID : A1A376053B366486D833 Date of Receipt

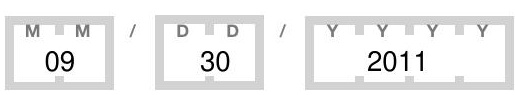

Amount of Each Receipt this Period

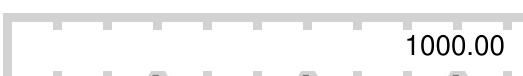

\section{Subtotal Of Receipts This Page (optional)}

Total This Period (last page this line number only) 


\section{SCHEDULE A-P} ITEMIZED RECEIPTS
Use separate schedule(s) for each category of the Detailed Summary Page

\begin{tabular}{|c|c|c|c|c|c|}
\hline \multicolumn{3}{|c|}{$\begin{array}{l}\text { FOR LINE NUMBER: } \\
\text { (check only one) }\end{array}$} & \multicolumn{3}{|c|}{ PAGE 1117 / 1572} \\
\hline 16 & $X$ 17a & $17 b$ & $17 c$ & $17 d$ & 18 \\
\hline $19 a$ & $19 \mathrm{~b}$ & $20 a$ & $20 \mathrm{~b}$ & $20 c$ & 21 \\
\hline
\end{tabular}

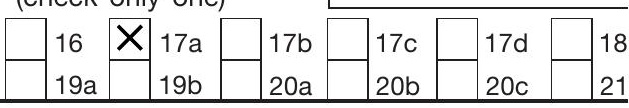

Any information copied from such Reports and Statements may not be sold or used by any person for the purpose of soliciting contributions or for commercial purposes, other than using the name and address of any political committee to solicit contributions from such committee.

NAME OF COMMITTEE (In Full)

\section{Friends of Herman Cain}

A. Full Name (Last, First, Middle Initial)

Sunny Hull

Mailing Address 5231 Santa Elena Cir.

\begin{tabular}{lcc}
\hline City & State & Zip Code \\
El Paso & TX & $79932-2535$
\end{tabular}

FEC ID number of contributing federal political committee.

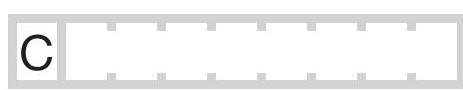

Name of Employer
Information Requested
Receipt For: 2012
X Primary
Other (specify) General

Occupation Information Requested

Election Cycle-to-Date 500.00

B. Full Name (Last, First, Middle Initial)

Donald LaRoche Jr

Mailing Address 6010 SR 39

\begin{tabular}{lcc}
\hline City & State & Zip Code \\
Martinsville & IN & $46151-9533$ \\
\hline
\end{tabular}

FEC ID number of contributing

federal political committee.

C

Name of Employer
Information Requested
Receipt For: 2012
X Primary
Other (specify)

\section{Occupation}

Information Requested

Election Cycle-to-Date

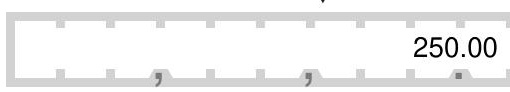

Transaction ID : A12BA8D9EB84C4278858

Date of Receipt

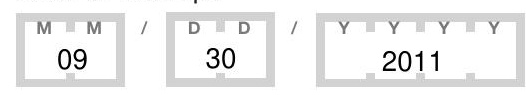

Amount of Each Receipt this Period

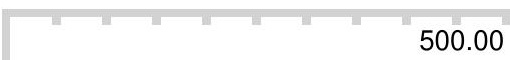

Amount of Each Receipt this Period

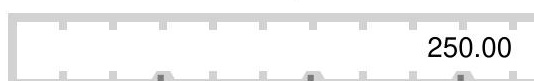

C. Full Name (Last, First, Middle Initial)

Stephen McCants

Mailing Address 4400 Cumbria Ln.

\begin{tabular}{lcc}
\hline City & State & Zip Code \\
Austin & TX & $78727-5207$
\end{tabular}

FEC ID number of contributing federal political committee.

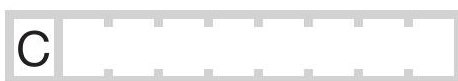

Name of Employer

Information Requested

Occupation

Information Requested

Receipt For: 2012

Х $\begin{aligned} & \text { Primary } \square \text { General } \\ & \text { Other (specify) }\end{aligned}$

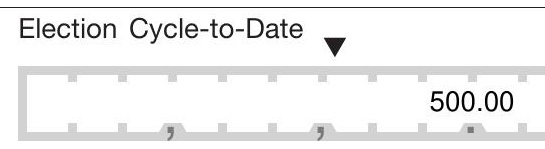

Amount of Each Receipt this Period

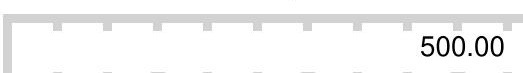

Transaction ID : A3EAA9C4DDAE046BBA84 Date of Receipt

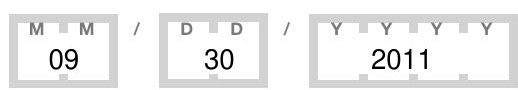

Subtotal Of Receipts This Page (optional)

Total This Period (last page this line number only) 


\section{SCHEDULE A-P} ITEMIZED RECEIPTS
Use separate schedule(s)

for each category of the

Detailed Summary Page
FOR LINE NUMBER: (check only one)

Any information or for commercial purposes, other than using the name and address of any political committee to solicit contributions from such committee.

NAME OF COMMITTEE (In Full)

Friends of Herman Cain

A. Full Name (Last, First, Middle Initial)

Jerry Ward

Mailing Address 2605 Hopewell Plantation Drive

\begin{tabular}{lcc}
\hline City & State & Zip Code \\
Alpharetta & GA & $30004-3657$
\end{tabular}

FEC ID number of contributing

federal political committee.

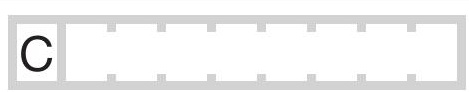

Name of Employer
Metacom, Inc.
Receipt For: 2012
X Primary $\quad \square$ General
Other (specify)

Occupation

Executive

Election Cycle-to-Date

250.00

B. Full Name (Last, First, Middle Initial)

Richard Daum MD

Mailing Address 12016 North Radio Station Road

\begin{tabular}{lcc}
\hline City & State & Zip Code \\
Seneca & SC & $29678-1143$
\end{tabular}

FEC ID number of contributing

federal political committee.

C

\begin{tabular}{l} 
Name of Employer \\
Oconee Physician Practices \\
Receipt For: 2012 \\
X Primary \\
\hline Other (specify)
\end{tabular}

Occupation

Physician

Election Cycle-to-Date

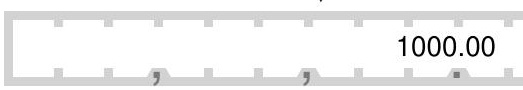

C. Full Name (Last, First, Middle Initial)

Ricky Nelson

Mailing Address 7181 Rd. 16

\begin{tabular}{lcc}
\hline City & State & Zip Code \\
Potter & NE & $69156-6607$
\end{tabular}

FEC ID number of contributing federal political committee.

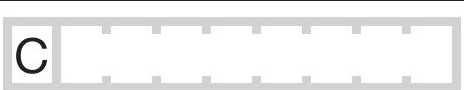

Name of Employer

Information Requested

Occupation

Information Requested

Receipt For: 2012

Х $\begin{aligned} & \text { Primary } \square \text { General } \\ & \text { Other (specify) }\end{aligned}$

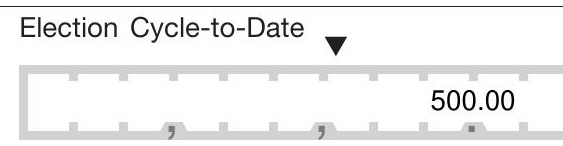

Amount of Each Receipt this Period

Transaction ID : A727717705DE54676B07

Date of Receipt

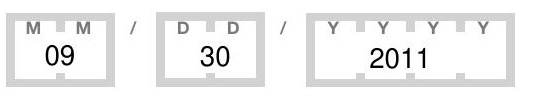

Amount of Each Receipt this Period
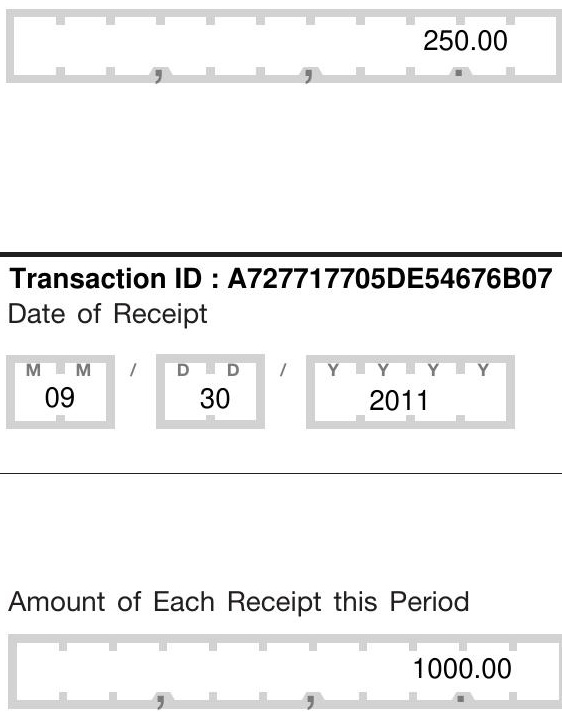

Transaction ID : ABBC4D63C3211467A9B2 Date of Receipt

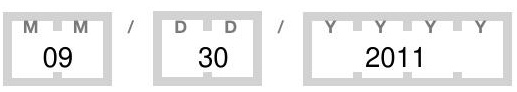

Amount of Each Receipt this Period

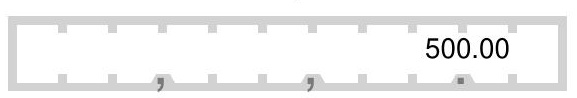

Subtotal Of Receipts This Page (optional).

1750.00

Total This Period (last page this line number only) 


\section{SCHEDULE A-P} ITEMIZED RECEIPTS
Use separate schedule(s)

for each category of the

Detailed Summary Page
FOR LINE NUMBER: (check only one)

Any information or for commercial purposes, other than using the name and address of any political committee to solicit contributions from such committee.

NAME OF COMMITTEE (In Full)

\section{Friends of Herman Cain}

A. Full Name (Last, First, Middle Initial) Jack Dean

Mailing Address 4294 Highborne Dr

\begin{tabular}{lcc}
\hline City & State & Zip Code \\
Marietta & GA & $30066-2426$
\end{tabular}

FEC ID number of contributing federal political committee.

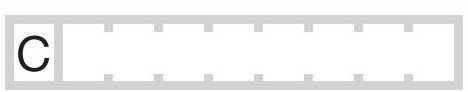

Name of Employer
Wells Fargo Bank NA
Receipt For: 2012
X Primary
Other (specify) General

Occupation

Systems Engineer

Election Cycle-to-Date

Transaction ID : A012F32D29CB9449E831

Date of Receipt

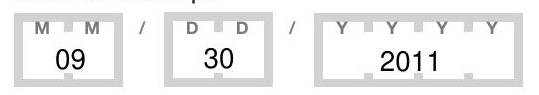

Amount of Each Receipt this Period

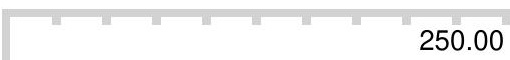

250.00

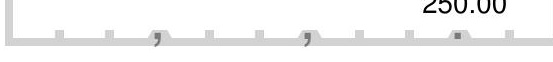

670.00

B. Full Name (Last, First, Middle Initial)

D. Curtis

Mailing Address 5135 Preston Sheffield Rd.

\begin{tabular}{lcc}
\hline City & State & Zip Code \\
Perry & FL & $32347-6829$ \\
\hline
\end{tabular}

FEC ID number of contributing

federal political committee.

C

Name of Employer
The Forestry Company
Receipt For: 2012
X Primary
Other (specify) General

Occupation

Forester

Election Cycle-to-Date

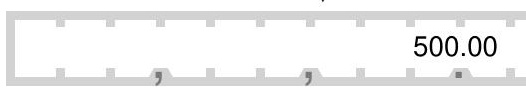

C. Full Name (Last, First, Middle Initial)

James Thomas

Mailing Address 2035 Glenhurst Drive

\begin{tabular}{lcc}
\hline City & State & Zip Code \\
Snellville & GA & $30078-6780$
\end{tabular}

FEC ID number of contributing federal political committee.

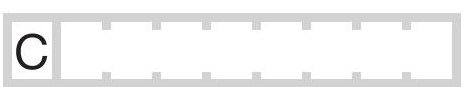

Name of Employer
None
Receipt For: 2012
Х Primary $\quad \square$ General
Other (specify)

Occupation

Retired

Election Cycle-to-Date
Transaction ID : A06C4067519A44159823

Date of Receipt

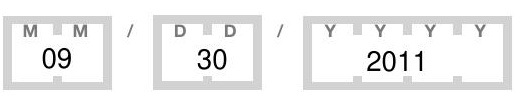

Amount of Each Receipt this Period

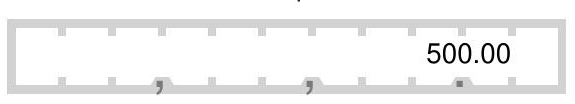

Transaction ID : A7AFBF64424EE48EDAF8 Date of Receipt

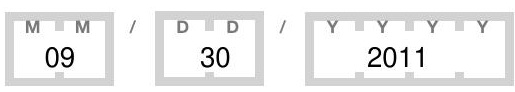

Amount of Each Receipt this Period

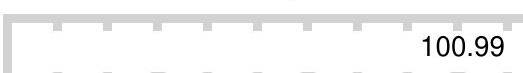

\section{Subtotal Of Receipts This Page (optional)}

Total This Period (last page this line number only) 


\section{SCHEDULE A-P} ITEMIZED RECEIPTS
Use separate schedule(s)

for each category of the

Detailed Summary Page
FOR LINE NUMBER: (check only one)

Any information or for commercial purposes, other than using the name and address of any political committee to solicit contributions from such committee.

NAME OF COMMITTEE (In Full)

Friends of Herman Cain

A. Full Name (Last, First, Middle Initial)

sarah laughon

Mailing Address 4657 ivygate $\mathrm{cr}$

\begin{tabular}{lcc}
\hline City & State & Zip Code \\
Smyrna & GA & $30080-6632$ \\
\hline
\end{tabular}

FEC ID number of contributing federal political committee.

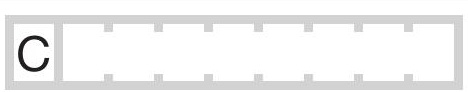

Name of Employer
Brandmovers
Receipt For: 2012
X Primary
$\square$ Other (specify) General

Occupation promotion adminstrator

Election Cycle-to-Date 210.00

B. Full Name (Last, First, Middle Initial) James Crawford

Mailing Address 8 Pine Fork Dr

\begin{tabular}{lcc}
\hline City & State & Zip Code \\
Toms River & NJ & $08755-5121$
\end{tabular}

FEC ID number of contributing

federal political committee.

C

Name of Employer
Information Requested
Receipt For: 2012
X Primary
Other (specify)

Occupation

Information Requested

Election Cycle-to-Date

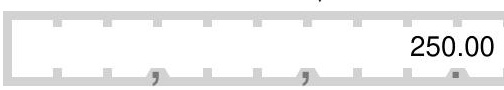

Transaction ID : A6AC5EA022F7840E485E

Date of Receipt

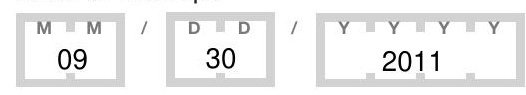

Amount of Each Receipt this Period

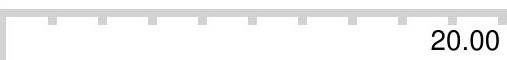

20.00

C. Full Name (Last, First, Middle Initial)

Dale Springer

Mailing Address 2326 W 15th St S

\begin{tabular}{lcc}
\hline City & State & Zip Code \\
Newton & IA & $50208-5359$
\end{tabular}

FEC ID number of contributing federal political committee.

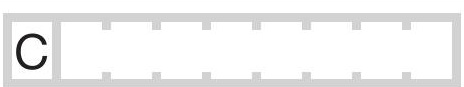

Name of Employer
Information Requested
Receipt For: 2012
X Primary $\quad \square$ General
Other (specify)

\section{Occupation}

Information Requested

Election Cycle-to-Date
Transaction ID : A52F5034E2C9341B2981

Date of Receipt

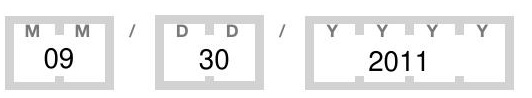

Amount of Each Receipt this Period

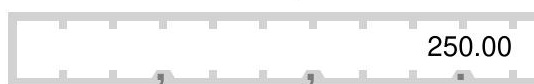

Transaction ID : A44E28637959B4B758B9

Date of Receipt

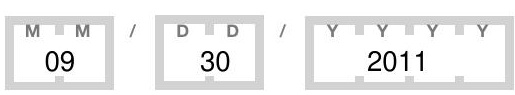

Amount of Each Receipt this Period

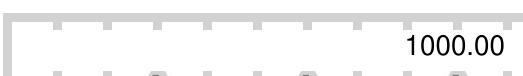

\section{Subtotal Of Receipts This Page (optional)}

Total This Period (last page this line number only) 


\section{SCHEDULE A-P} ITEMIZED RECEIPTS
Use separate schedule(s)

for each category of the

Detailed Summary Page
FOR LINE NUMBER: (check only one)

Any information or for commercial purposes, other than using the name and address of any political committee to solicit contributions from such committee.

NAME OF COMMITTEE (In Full)

Friends of Herman Cain

A. Full Name (Last, First, Middle Initial)

Arnold Chase

Mailing Address 3115 Albany Ave

\begin{tabular}{lcc}
\hline City & State & Zip Code \\
West Hartford & CT & $06117-1858$
\end{tabular}

FEC ID number of contributing

federal political committee.

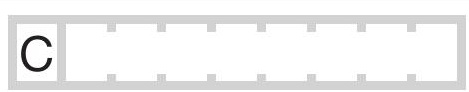

Name of Employer
Information Requested
Receipt For: 2012
X Primary
$\square$ Other (specify)

Occupation

Information Requested

Election Cycle-to-Date

1000.00

Transaction ID : A5B04CA7BBB364BC59A4

Date of Receipt

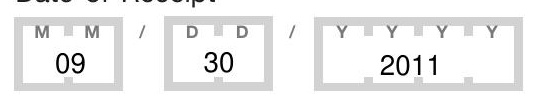

Amount of Each Receipt this Period

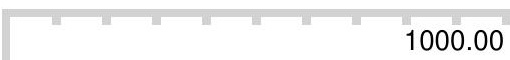

1000.00
B. Full Name (Last, First, Middle Initial)

ROBERT SCARBOROUGH

Mailing Address 109 CLARKSVILLE CT

\begin{tabular}{lcc}
\hline City & State & Zip Code \\
Macon & GA & $31210-9006$ \\
\hline
\end{tabular}

FEC ID number of contributing

federal political committee.

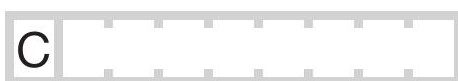

Name of Employer
Smith Barney
Receipt For: 2012
X Primary
Other (specify)

Occupation

Retired

Election Cycle-to-Date

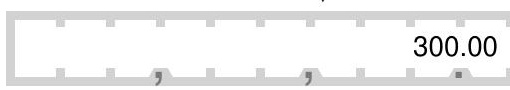

C. Full Name (Last, First, Middle Initial)

HARRY BEARDSLEY

Mailing Address PO BOX 8457

\begin{tabular}{lcc}
\hline City & State & Zip Code \\
Warner Robins & GA & $31095-8457$
\end{tabular}

FEC ID number of contributing federal political committee.

C

Name of Employer
Information Requested
Receipt For: 2012
X Primary $\quad \square$ General
Other (specify)

Occupation

Information Requested

Election Cycle-to-Date

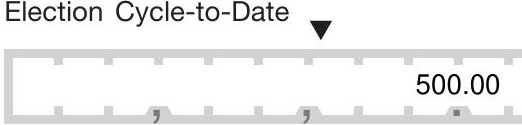

Transaction ID : A3EA6BEAFA1104E2EB77 Date of Receipt

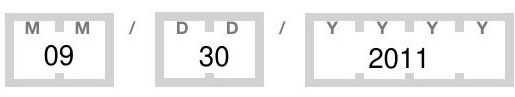

Amount of Each Receipt this Period

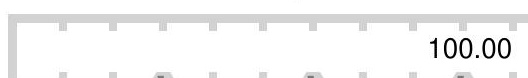

Transaction ID : AEC655C90385B4E308A5 Date of Receipt

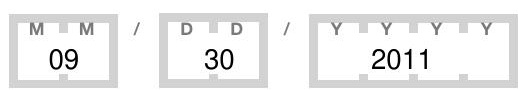

Amount of Each Receipt this Period

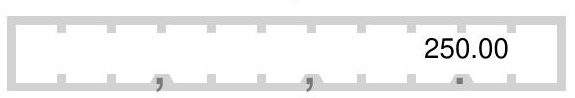

1350.00

(1)

Total This Period (last page this line number only)

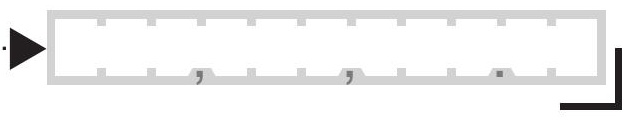

FEC Schedule A-P (Form 3P) (Rev. 03/2011) 


\section{SCHEDULE A-P} ITEMIZED RECEIPTS
Use separate schedule(s)

for each category of the

Detailed Summary Page
FOR LINE NUMBER: (check only one)

Any information or for commercial purposes, other than using the name and address of any political committee to solicit contributions from such committee.

NAME OF COMMITTEE (In Full)

Friends of Herman Cain

A. Full Name (Last, First, Middle Initial)

Lynn Teahan

Mailing Address 3432 Micah Perry Point

\begin{tabular}{lcc}
\hline City & State & Zip Code \\
Dacula & GA & $30019-5097$
\end{tabular}

FEC ID number of contributing

federal political committee.

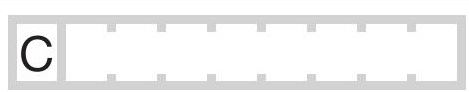

Name of Employer
Information Requested
Receipt For: 2012
X Primary $\quad \square$ General
Other (specify)

Occupation

Information Requested

Election Cycle-to-Date

500.00

B. Full Name (Last, First, Middle Initial)

david shefrin

Mailing Address 29200 sw town center loop east

\begin{tabular}{lcc}
\hline City & State & Zip Code \\
Wilsonville & OR & $97070-9464$
\end{tabular}

FEC ID number of contributing

federal political committee.

C

Name of Employer
Information Requested
Receipt For: 2012
X Primary
Other (specify)

Occupation

Information Requested

Election Cycle-to-Date

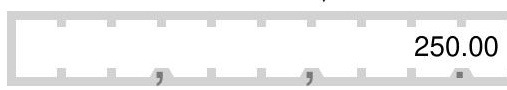

Transaction ID : A9326751EEBD647F8AFA

Date of Receipt

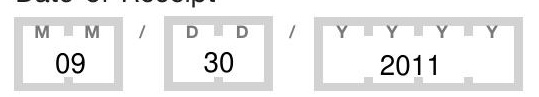

Amount of Each Receipt this Period

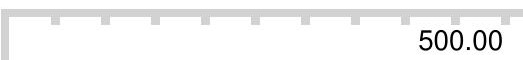

C. Full Name (Last, First, Middle Initial)

William Moretz

Mailing Address 818 St. Sebastian Way Suite 204

\begin{tabular}{lcc}
\hline City & State & Zip Code \\
Augusta & GA & $30901-2652$ \\
\hline
\end{tabular}

FEC ID number of contributing

federal political committee.

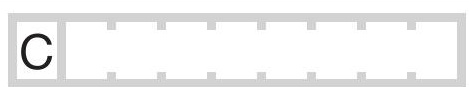

Name of Employer

Information Requested

Occupation

Information Requested

Receipt For: 2012

Х $\begin{aligned} & \text { Primary } \square \text { General } \\ & \text { Other (specify) }\end{aligned}$

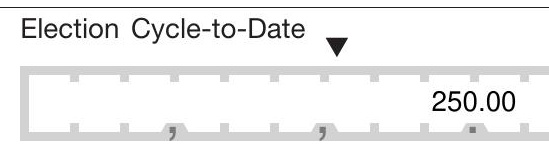

Amount of Each Receipt this Period

Transaction ID : ACC8B0C7561144D2E976

Date of Receipt
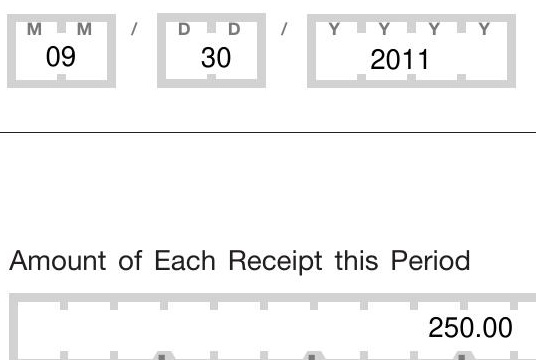

Transaction ID : AFD118434206A47858DA

Date of Receipt

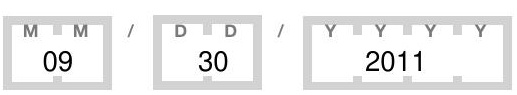

Amount of Each Receipt this Period

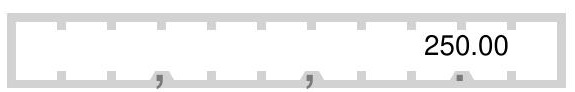

Subtotal Of Receipts This Page (optional).

1000.00

Total This Period (last page this line number only) 
SCHEDULE A-P ITEMIZED RECEIPTS
Use separate schedule(s) for each category of the Detailed Summary Page
FOR LINE NUMBER: (check only one)

Any information or for commercial purposes, other than using the name and address of any political committee to solicit contributions from such committee.

NAME OF COMMITTEE (In Full)

\section{Friends of Herman Cain}

A. Full Name (Last, First, Middle Initial)

David Tate

Mailing Address 19130 Valley View Ln

\begin{tabular}{lcc}
\hline City & State & Zip Code \\
Catoosa & OK & $74015-2239$
\end{tabular}

FEC ID number of contributing federal political committee.

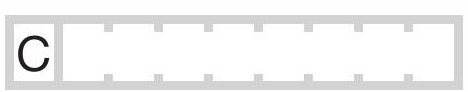

Name of Employer
Rogers Co OK
Receipt For: 2012
X Primary $\quad$ General
Other (specify)

Occupation Deputy Sheriff

Election Cycle-to-Date

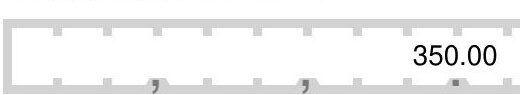

B. Full Name (Last, First, Middle Initial)

CLJ Lancaster

Mailing Address 2 Fernwood Drive

\begin{tabular}{lcc}
\hline City & State & Zip Code \\
Barrington & IL & $60010-9675$ \\
\hline
\end{tabular}

FEC ID number of contributing

federal political committee.

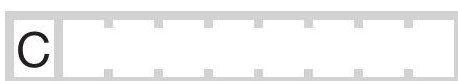

Name of Employer
Self Employed
Receipt For: 2012
X Primary $\quad$ General
Other (specify)

\section{Occupation}

Artist

Election Cycle-to-Date

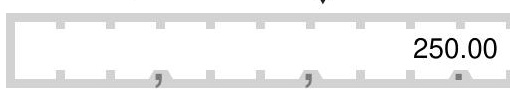

C. Full Name (Last, First, Middle Initial)

Mr Patrick D Alexander

Mailing Address 16540 Grays Bay Blvd

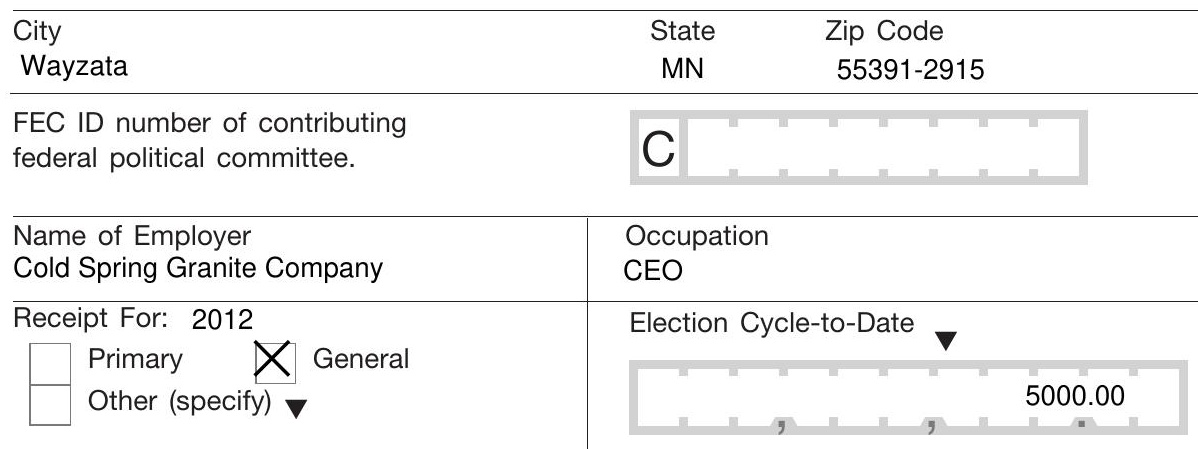

Transaction ID : AE8DC09651B2549B0A28

Date of Receipt

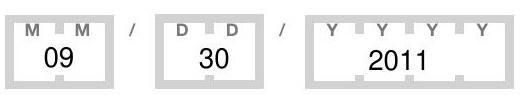

Amount of Each Receipt this Period

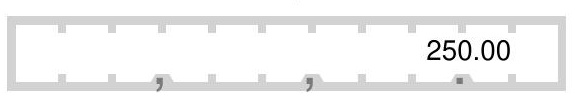

\section{Subtotal Of Receipts This Page (optional)}

3000.00

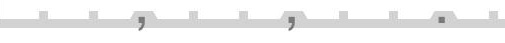

Total This Period (last page this line number only)
Amount of Each Receipt this Period

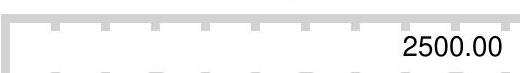

2500.00

Transaction ID : A7624B8D461A84B668E7 Date of Receipt
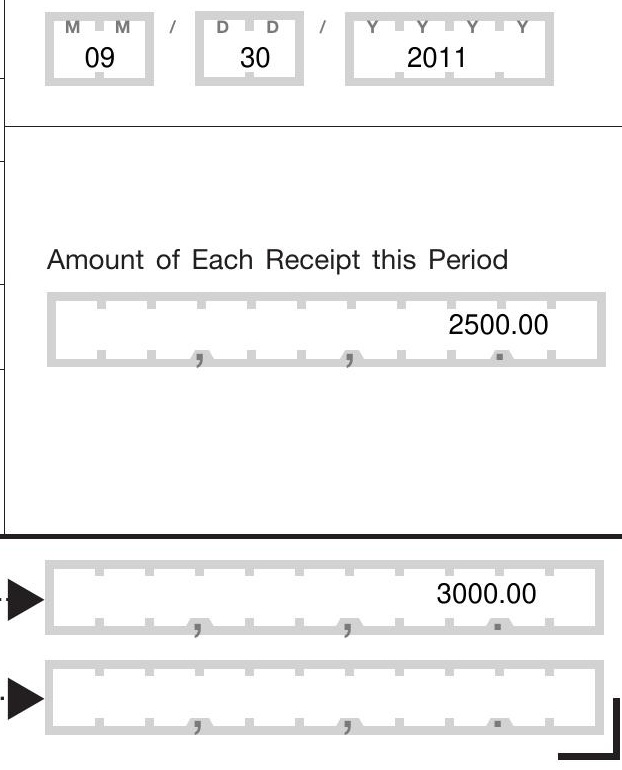

FEC Schedule A-P (Form 3P) (Rev. 03/2011) 


\section{SCHEDULE A-P} ITEMIZED RECEIPTS
Use separate schedule(s) for each category of the Detailed Summary Page

\begin{tabular}{|c|c|c|c|c|c|}
\hline \multicolumn{3}{|c|}{$\begin{array}{l}\text { FOR LINE NUMBER: } \\
\text { (check only one) }\end{array}$} & \multicolumn{3}{|c|}{ PAGE 1124 / 1572} \\
\hline 16 & $X$ 17a & $17 b$ & $17 \mathrm{c}$ & $17 d$ & 18 \\
\hline $19 a$ & $19 \mathrm{~b}$ & $20 a$ & $20 \mathrm{~b}$ & $20 c$ & 21 \\
\hline
\end{tabular}

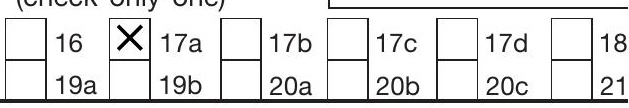

Any information copied from such Reports and Statements may not be sold or used by any person for the purpose of soliciting contributions or for commercial purposes, other than using the name and address of any political committee to solicit contributions from such committee.

NAME OF COMMITTEE (In Full)

\section{Friends of Herman Cain}

A. Full Name (Last, First, Middle Initial) Jenny Galloway

Mailing Address 2178 Vinings North Lane

\begin{tabular}{lcc}
\hline City & State & Zip Code \\
Smyrna & GA & $30080-5977$ \\
\hline
\end{tabular}

FEC ID number of contributing federal political committee.

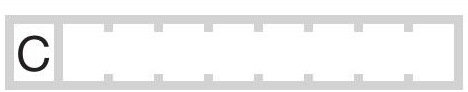

Name of Employer
Information Requested
Receipt For: 2012
X Primary
$\square$ Other (specify)

Occupation Information Requested Election Cycle-to-Date 220.00

B. Full Name (Last, First, Middle Initial) Jenny Galloway

Mailing Address 2178 Vinings North Lane

\begin{tabular}{lcc}
\hline City & State & Zip Code \\
Smyrna & GA & $30080-5977$
\end{tabular}

FEC ID number of contributing

federal political committee.

C

Name of Employer
Information Requested
Receipt For: 2012
X Primary
Other (specify)

Occupation

Information Requested

Election Cycle-to-Date

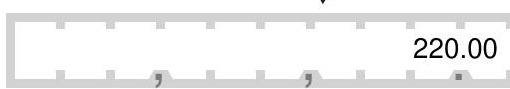

Transaction ID : A77F5590D06B148CF96C

Date of Receipt

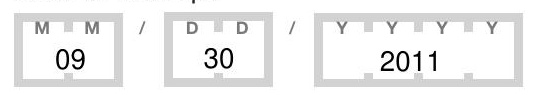

Amount of Each Receipt this Period

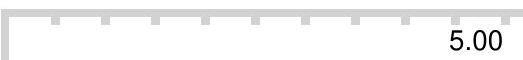

C. Full Name (Last, First, Middle Initial)

lisa jones

Mailing Address 13071 old dayton road

\begin{tabular}{lcc}
\hline City & State & Zip Code \\
New Lebanon & OH & $45345-9710$
\end{tabular}

FEC ID number of contributing federal political committee.

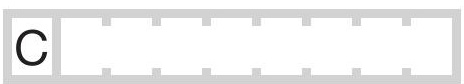

Name of Employer

Self Employed

Occupation

Receipt For: 2012

Х $\begin{aligned} & \text { Primary } \\ & \text { Other (specify) }\end{aligned}$

Property Manager

Election Cycle-to-Date

500.00

Transaction ID : AC331660EDC3B47088F3

Date of Receipt

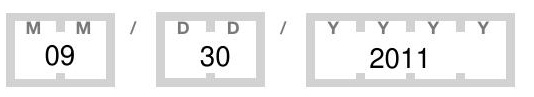

Amount of Each Receipt this Period

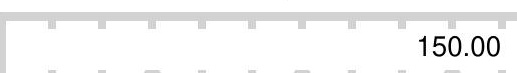

Transaction ID : AFF416A216C374A6AA14 Date of Receipt

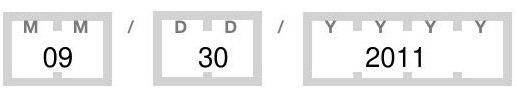

Amount of Each Receipt this Period

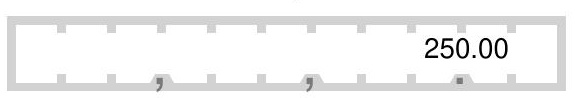

Subtotal Of Receipts This Page (optional).

405.00

Total This Period (last page this line number only) 


\section{SCHEDULE A-P} ITEMIZED RECEIPTS
Use separate schedule(s)

for each category of the

Detailed Summary Page
FOR LINE NUMBER: (check only one)

Any information or for commercial purposes, other than using the name and address of any political committee to solicit contributions from such committee.

NAME OF COMMITTEE (In Full)

\section{Friends of Herman Cain}

A. Full Name (Last, First, Middle Initial) Jack Cassell

Mailing Address 717 N. Donnelly St

\begin{tabular}{lcc}
\hline City & State & Zip Code \\
Mount Dora & FL & $32757-4833$
\end{tabular}

FEC ID number of contributing federal political committee.

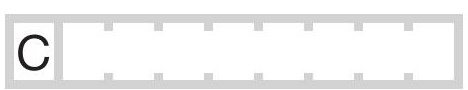

Name of Employer
Information Requested
Receipt For: 2012
X Primary
Other (specify) General

Occupation Information Requested

Election Cycle-to-Date

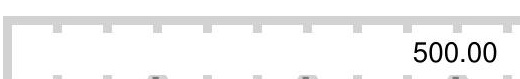

B. Full Name (Last, First, Middle Initial)

Reita King

Mailing Address 3870 Streamside Dr SE

\begin{tabular}{lcc}
\hline City & State & Zip Code \\
Marietta & GA & $30067-4700$ \\
\hline
\end{tabular}

FEC ID number of contributing

federal political committee.

C

Name of Employer
Information Requested
Receipt For: 2012
X Primary
Other (specify)

Occupation

Information Requested

Election Cycle-to-Date

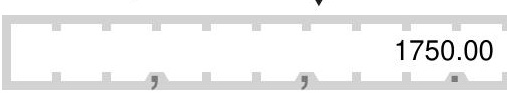

Transaction ID : AD0481B45733A4906BBE

Date of Receipt

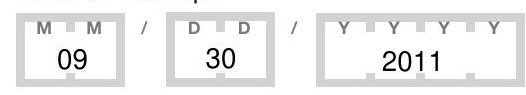

Amount of Each Receipt this Period

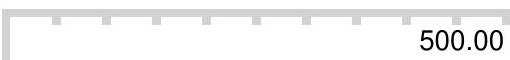

C. Full Name (Last, First, Middle Initial)

Linda Martin

Mailing Address 205 Murfield Ct.

\begin{tabular}{lcc}
\hline City & State & Zip Code \\
Dayton & NV & 89403-8757
\end{tabular}

FEC ID number of contributing federal political committee.

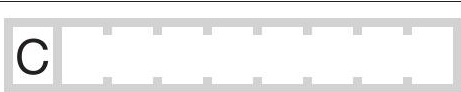

Name of Employer

Information Requested

Occupation

Information Requested

Receipt For: 2012

Х $\begin{aligned} & \text { Primary } \square \text { General } \\ & \text { Other (specify) }\end{aligned}$

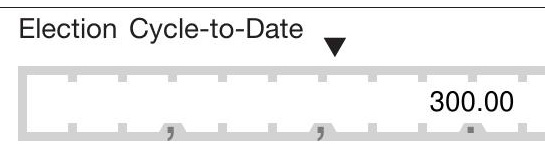

Amount of Each Receipt this Period

Transaction ID : AEFCC49CF2D424FC7A67 Date of Receipt
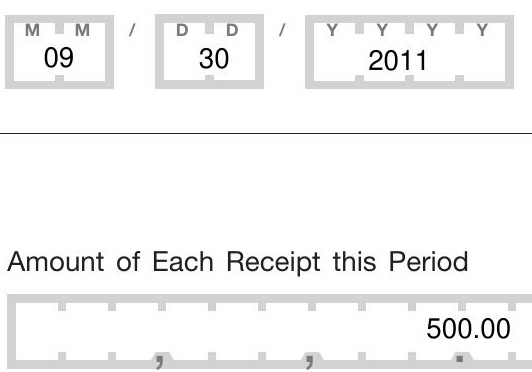

Transaction ID : AFB28756E185842B78E2

Date of Receipt

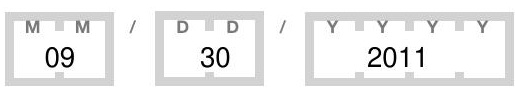

Amount of Each Receipt this Period

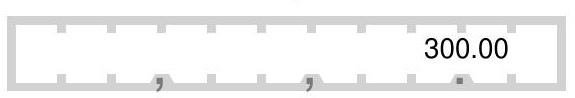

Subtotal Of Receipts This Page (optional).

1300.00

Total This Period (last page this line number only) 
SCHEDULE A-P ITEMIZED RECEIPTS
Use separate schedule(s) for each category of the Detailed Summary Page
FOR LINE NUMBER: (check only one)

PAGE $1126 / 1572$

\begin{tabular}{|c|c|c|c|c|c|}
\hline & & & & & \\
\hline 16 & $\mathbf{X} 17 a$ & $17 b$ & $17 c$ & $17 d$ & 18 \\
\hline $19 a$ & $19 b$ & $20 \mathrm{a}$ & $20 \mathrm{~b}$ & $20 \mathrm{c}$ & 21 \\
\hline
\end{tabular}

Any information copied from such Reports and Statements may not be sold or used by any person for the purpose of soliciting contributions or for commercial purposes, other than using the name and address of any political committee to solicit contributions from such committee.

NAME OF COMMITTEE (In Full)

\section{Friends of Herman Cain}

A. Full Name (Last, First, Middle Initial)

Kevin George

Mailing Address PO Box 88

\begin{tabular}{lcc}
\hline City & State & Zip Code \\
Burleson & TX & $76097-0088$
\end{tabular}

FEC ID number of contributing federal political committee.

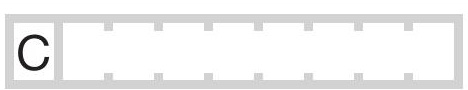

Name of Employer
Expro
Receipt For: 2012
X Primary $\quad$ General
Other (specify)

Occupation

Enginnering Manager

Election Cycle-to-Date

500.00

B. Full Name (Last, First, Middle Initial)

David Morris

Mailing Address 7921 E 46th Street

\begin{tabular}{lcc}
\hline City & State & Zip Code \\
Indianapolis & IN & $46226-3931$ \\
\hline
\end{tabular}

FEC ID number of contributing

federal political committee.

C

Name of Employer
Precision Dry Wall Inc.
Receipt For: 2012
X Primary
Other (specify)

Occupation

Construction

Election Cycle-to-Date

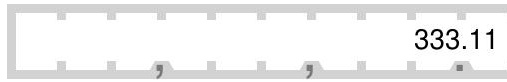

C. Full Name (Last, First, Middle Initial)

Hilary Gray

Mailing Address 310 Grant Park Place

\begin{tabular}{lcc}
\hline City & State & Zip Code \\
Atlanta & GA & $30315-1428$
\end{tabular}

FEC ID number of contributing

federal political committee.

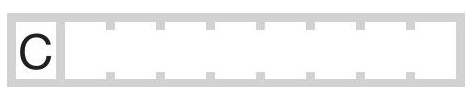

Name of Employer

Ferry Hayes and Allen

Occupation

Receipt For: 2012

Х $\begin{aligned} & \text { Primary } \square \text { General } \\ & \text { Other (specify) }\end{aligned}$

Interior Designer

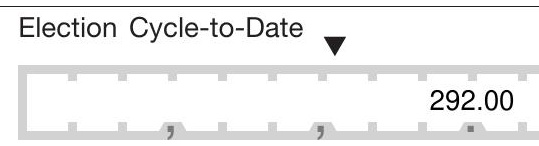

Amount of Each Receipt this Period

Transaction ID : A266727943957472D83F

Date of Receipt

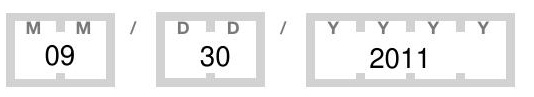

Amount of Each Receipt this Period
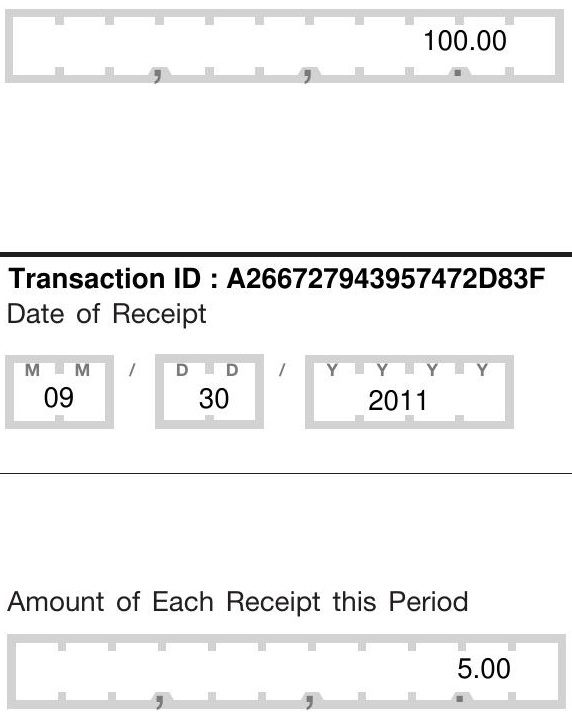

Transaction ID : A3E20501088FA4F078E0

Date of Receipt

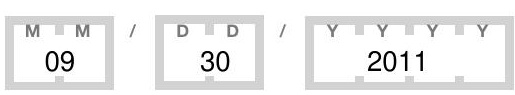

Amount of Each Receipt this Period

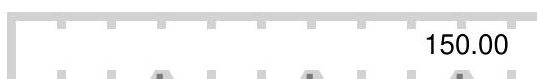

255.00

Subtotal Of Receipts This Page (optional)

Total This Period (last page this line number only) 


\section{SCHEDULE A-P} ITEMIZED RECEIPTS
Use separate schedule(s)

for each category of the

Detailed Summary Page
FOR LINE NUMBER: (check only one)

Any information or for commercial purposes, other than using the name and address of any political committee to solicit contributions from such committee.

NAME OF COMMITTEE (In Full)

Friends of Herman Cain

A. Full Name (Last, First, Middle Initial)

Renee Brown

Mailing Address 170 Sutallee Ridge Way

\begin{tabular}{lcc}
\hline City & State & Zip Code \\
White & GA & $30184-3236$
\end{tabular}

FEC ID number of contributing federal political committee.

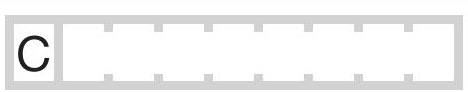

Name of Employer
Cherokee Co. Bd. of Ed.
Receipt For: 2012
X Primary $\quad \square$ General
Other (specify)

Occupation

Bus Driver

Election Cycle-to-Date

\subsection{0}

B. Full Name (Last, First, Middle Initial)

Brian Parramore

Mailing Address 619 Carvell dr

\begin{tabular}{lcc}
\hline City & State & Zip Code \\
Winter Park & FL & $32792-2715$ \\
\hline
\end{tabular}

FEC ID number of contributing

federal political committee.

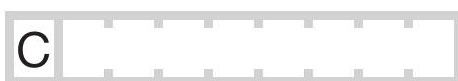

\begin{tabular}{l} 
Name of Employer \\
Information Requested \\
Receipt For: 2012 \\
X Primary \\
\hline Other (specify)
\end{tabular}

Occupation

Information Requested

Election Cycle-to-Date

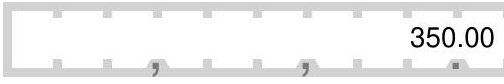

C. Full Name (Last, First, Middle Initial)

Robin Andrews

Mailing Address 5880 Huddersfield Rd

\begin{tabular}{lcc}
\hline City & State & Zip Code \\
Macon & GA & $31210-2061$
\end{tabular}

FEC ID number of contributing

federal political committee.

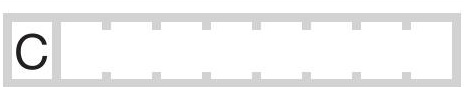

Name of Employer

Occupation

Ear Dynamics

Audiologist

Receipt For: 2012

Х $\begin{aligned} & \text { Primary } \\ & \text { Other (specify) }\end{aligned}$

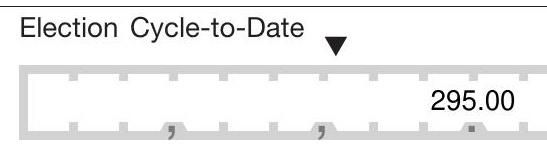

Amount of Each Receipt this Period

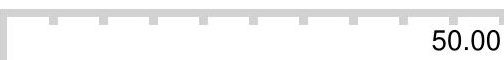

Date of Receipt
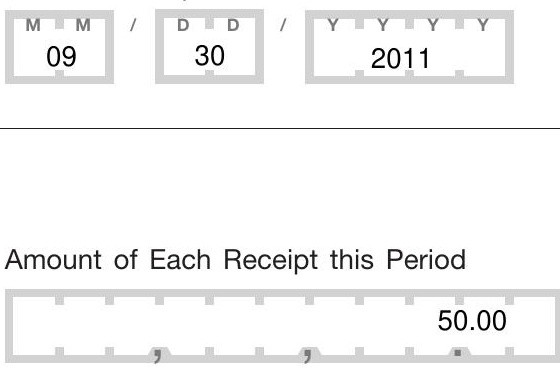

Transaction ID : AA1C3826CD449408C9EA

Date of Receipt

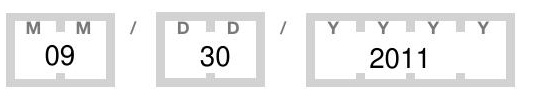

Amount of Each Receipt this Period

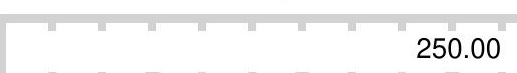

Transaction ID : A32A7FD554D934B6CB60 Date of Receipt

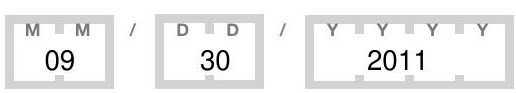

Amount of Each Receipt this Period

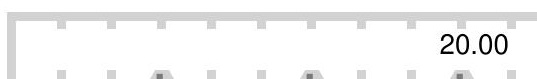

320.00

Subtotal Of Receipts This Page (optional)

Total This Period (last page this line number only) 


\section{SCHEDULE A-P} ITEMIZED RECEIPTS
Use separate schedule(s) for each category of the Detailed Summary Page

FOR LINE NUMBER:
(check only one)

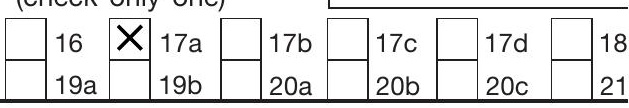

Any information copied from such Reports and Statements may not be sold or used by any person for the purpose of soliciting contributions or for commercial purposes, other than using the name and address of any political committee to solicit contributions from such committee.

NAME OF COMMITTEE (In Full)

\section{Friends of Herman Cain}

A. Full Name (Last, First, Middle Initial) Jacqueline Lopez

Mailing Address 1596 West 78 Terrace

\begin{tabular}{lcc}
\hline City & State & Zip Code \\
Hialeah & FL & $33014-3350$ \\
\hline
\end{tabular}

FEC ID number of contributing federal political committee.

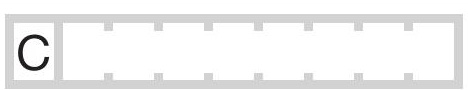

Name of Employer
US Postal Service
Receipt For: 2012
X Primary
$\square$ Other (specify) General

Occupation Letter Carrier Election Cycle-to-Date

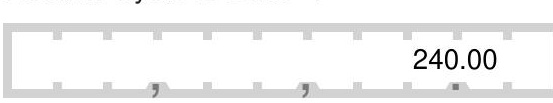

B. Full Name (Last, First, Middle Initial) robert daidone

Mailing Address 490 baldwin \#11

\begin{tabular}{lcc}
\hline City & State & Zip Code \\
Rochester & MI & $48307-2144$ \\
\hline
\end{tabular}

FEC ID number of contributing

federal political committee.

C

Name of Employer
IBM
Receipt For: 2012
X Primary
Other (specify)

Occupation

Recruiter

Election Cycle-to-Date

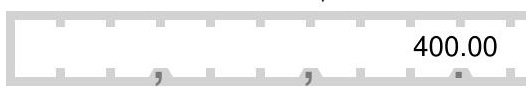

Transaction ID : AD8D14A937C33491D818

Date of Receipt

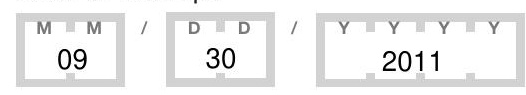

Amount of Each Receipt this Period

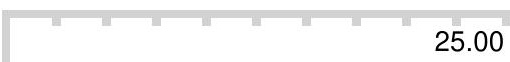

25.00

C. Full Name (Last, First, Middle Initial)

Nancy Wallace

Mailing Address 4225 Green Ct

\begin{tabular}{lcc}
\hline City & State & Zip Code \\
Villa Rica & GA & $30180-9770$
\end{tabular}

FEC ID number of contributing federal political committee.

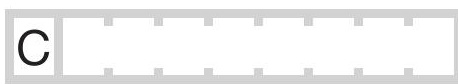

Name of Employer

do not wish to divulge

Occupation

Information Requested

Receipt For: 2012

Х $\begin{aligned} & \text { Primary } \square \text { General } \\ & \text { Other (specify) }\end{aligned}$

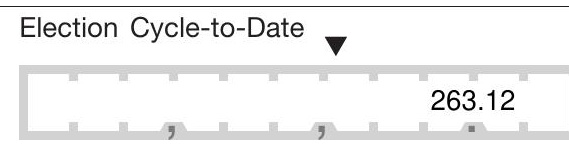

Amount of Each Receipt this Period

Transaction ID : A42BC76B4669B4B11BA8 Date of Receipt
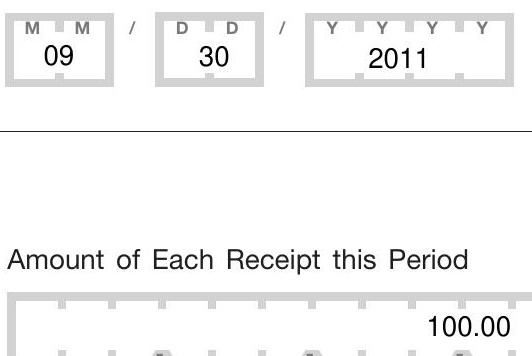

Transaction ID : AB25819602CBF4D4DB9F Date of Receipt

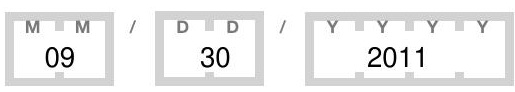

Amount of Each Receipt this Period

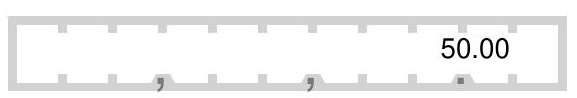

Subtotal Of Receipts This Page (optional)

175.00

Total This Period (last page this line number only) 
SCHEDULE A-P ITEMIZED RECEIPTS
Use separate schedule(s) for each category of the Detailed Summary Page
FOR LINE NUMBER: (check only one)

Any information or for commercial purposes, other than using the name and address of any political committee to solicit contributions from such committee.

NAME OF COMMITTEE (In Full)

\section{Friends of Herman Cain}

A. Full Name (Last, First, Middle Initial) Joseph Gaetani

Mailing Address 15 Lennox Drive

\begin{tabular}{lcc}
\hline City & State & Zip Code \\
Binghamton & NY & $13903-1313$
\end{tabular}

FEC ID number of contributing federal political committee.

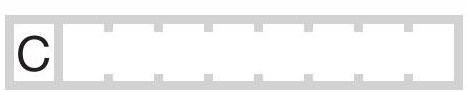

Name of Employer
self
Receipt For: 2012
X Primary $\quad$ General
Other (specify)

Occupation Insurance Agent

Election Cycle-to-Date

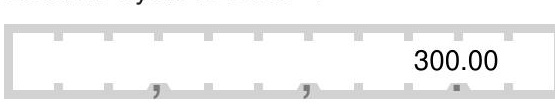

B. Full Name (Last, First, Middle Initial)

Matthew Young

Mailing Address 2561 Sunflower St.

\begin{tabular}{lcc}
\hline City & State & Zip Code \\
Fullerton & CA & $92835-3594$
\end{tabular}

FEC ID number of contributing

federal political committee.

C

Name of Employer

Sony Pictures Entertainment

Occupation

Receipt For: 2012

$\chi \begin{aligned} & \text { Primary } \\ & \text { Other (specify) }\end{aligned}$

Photo Editor/Publicist

Election Cycle-to-Date

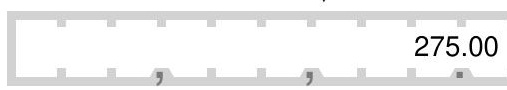

C. Full Name (Last, First, Middle Initial)

Scott Burnett

Mailing Address 55 Bowen Dr

\begin{tabular}{lcc}
\hline City & State & Zip Code \\
Belmont & NC & $28012-9528$ \\
\hline
\end{tabular}

FEC ID number of contributing federal political committee.

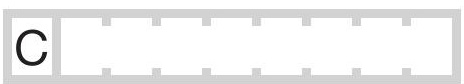

Name of Employer

Information Requested

Occupation

Information Requested

Receipt For: 2012

Х $\begin{aligned} & \text { Primary } \\ & \text { Other (specify) }\end{aligned}$

Transaction ID : ADB6CF2A0A12A49659D1

Date of Receipt

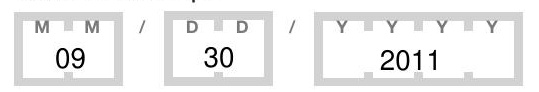

Amount of Each Receipt this Period

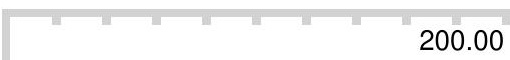

200.00
Transaction ID : AA2B9A83D54F8479390F

Date of Receipt

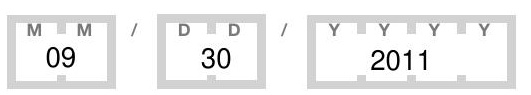

Amount of Each Receipt this Period

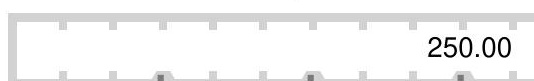

Transaction ID : A10618AB7523E4D228FE

Date of Receipt

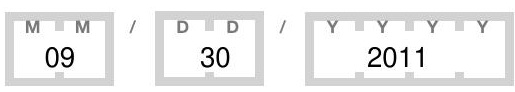

Amount of Each Receipt this Period

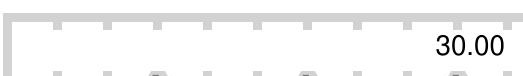

\section{Subtotal Of Receipts This Page (optional)}

Total This Period (last page this line number only) 


\section{SCHEDULE A-P} ITEMIZED RECEIPTS
Use separate schedule(s)

for each category of the

Detailed Summary Page
FOR LINE NUMBER: (check only one)

Any information or for commercial purposes, other than using the name and address of any political committee to solicit contributions from such committee.

NAME OF COMMITTEE (In Full)

Friends of Herman Cain

A. Full Name (Last, First, Middle Initial)

\section{Dean Nelson}

Mailing Address 10 Pershing Ave

\begin{tabular}{lcc}
\hline City & State & Zip Code \\
North East & PA & $16428-1312$
\end{tabular}

FEC ID number of contributing federal political committee.

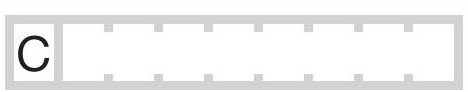

Name of Employer
Information Requested
Receipt For: 2012
X Primary
$\square$ Other (specify)

Occupation Information Requested

Election Cycle-to-Date

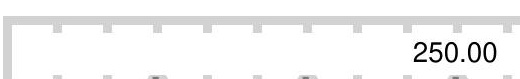

B. Full Name (Last, First, Middle Initial)

bev jaeger

Mailing Address p o box 906

\begin{tabular}{lcc}
\hline City & State & Zip Code \\
Bellevue & ID & $83313-0906$ \\
\hline
\end{tabular}

FEC ID number of contributing

federal political committee.

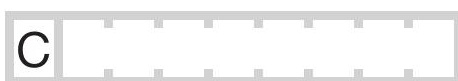

Name of Employer
None
Receipt For: 2012
X Primary
Other (specify)

Occupation

Retired

Election Cycle-to-Date

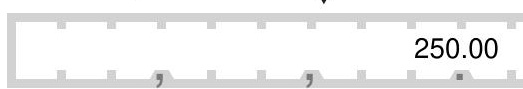

C. Full Name (Last, First, Middle Initial)

Allen Milam

Mailing Address 18001 SW 55th Street

\begin{tabular}{lcc}
\hline City & State & Zip Code \\
Southwest Ranches & FL & $33331-2215$
\end{tabular}

FEC ID number of contributing federal political committee.

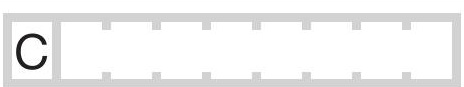

Name of Employer

Information Requested

\section{Occupation}

Information Requested

Receipt For: 2012

Х $\begin{aligned} & \text { Primary } \square \text { General } \\ & \text { Other (specify) }\end{aligned}$

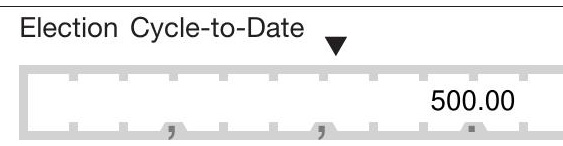

Amount of Each Receipt this Period

Transaction ID : A41FF51A2A06D470C95B

Date of Receipt

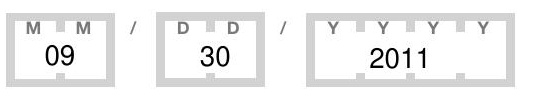

Amount of Each Receipt this Period
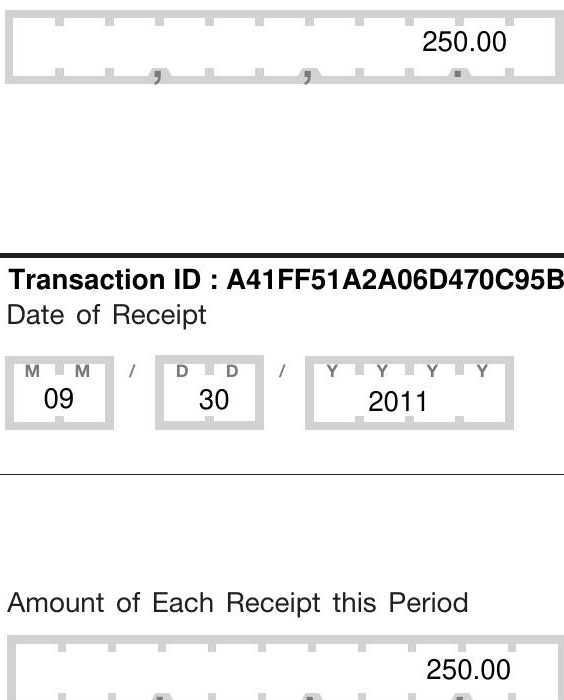

Transaction ID : A3EF845B3A0BD4B8E952 Date of Receipt

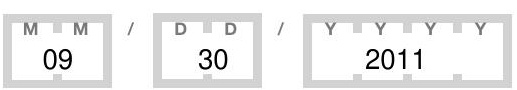

Amount of Each Receipt this Period

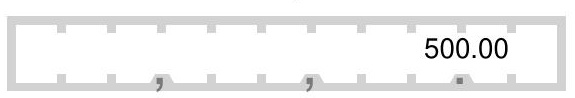

Subtotal Of Receipts This Page (optional).

1000.00

Total This Period (last page this line number only) 


\section{SCHEDULE A-P} ITEMIZED RECEIPTS
Use separate schedule(s)

for each category of the

Detailed Summary Page
FOR LINE NUMBER: (check only one)

Any information or for commercial purposes, other than using the name and address of any political committee to solicit contributions from such committee.

NAME OF COMMITTEE (In Full)

Friends of Herman Cain

A. Full Name (Last, First, Middle Initial)

Victor Williams

Mailing Address 375 Vineyard DR

\begin{tabular}{lcc}
\hline City & State & Zip Code \\
Marietta & GA & $30064-1049$
\end{tabular}

FEC ID number of contributing federal political committee.

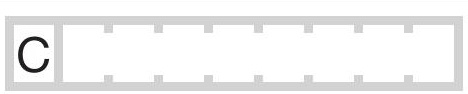

\section{Name of Employer}

Byers Engineering Company

Receipt For: 2012

Х Primary $\square$ General

Occupation

Support Specialist

Election Cycle-to-Date

300.00

B. Full Name (Last, First, Middle Initial)

Jeanne Downer

Mailing Address $6007 \mathrm{~N}$ Kansas AVe

\begin{tabular}{llc}
\hline City & State & Zip Code \\
Kansas City & MO & $64119-2115$ \\
\hline
\end{tabular}

FEC ID number of contributing

federal political committee.

C

\begin{tabular}{l} 
Name of Employer \\
WNB Architects \\
Receipt For: 2012 \\
X Primary \\
\hline Other (specify) General
\end{tabular}

Occupation

Office Manager

Election Cycle-to-Date

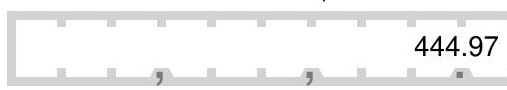

Transaction ID : A4901D801DA6A460D9EA

Date of Receipt

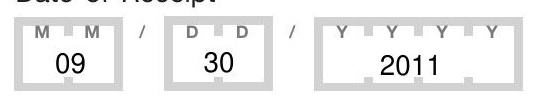

Amount of Each Receipt this Period

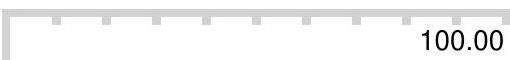

Transaction ID : AC8557148225A447B983

Date of Receipt

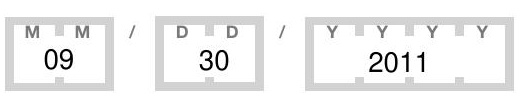

Amount of Each Receipt this Period

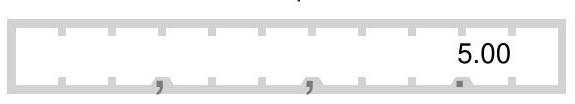

Transaction ID : ABA45741476844AA8A66 Date of Receipt

Pierce Koslosky Jr

Mailing Address 12908 Binney Street

\begin{tabular}{lcc}
\hline City & State & Zip Code \\
Omaha & NE & $68164-4246$
\end{tabular}

FEC ID number of contributing federal political committee.

C

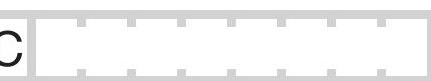

Name of Employer

Magnolia Metal Corporation

Receipt For: 2012

Х $\begin{aligned} & \text { Primary } \square \text { General } \\ & \text { Other (specify) }\end{aligned}$

\section{Occupation}

Executive

\section{Election Cycle-to-Date}

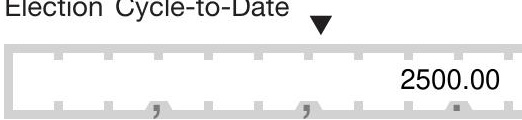

Subtotal Of Receipts This Page (optional)

2605.00

Amount of Each Receipt this Period

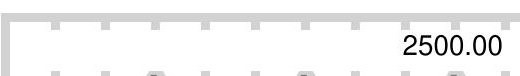

Total This Period (last page this line number only) 


\section{SCHEDULE A-P} ITEMIZED RECEIPTS
Use separate schedule(s) for each category of the Detailed Summary Page

\begin{tabular}{|c|c|c|c|c|c|}
\hline \multicolumn{3}{|c|}{$\begin{array}{l}\text { FOR LINE NUMBER: } \\
\text { (check only one) }\end{array}$} & \multicolumn{3}{|c|}{ PAGE 1132 / 1572} \\
\hline 16 & $X$ 17a & $17 b$ & $17 c$ & $17 d$ & 18 \\
\hline $19 a$ & $19 \mathrm{~b}$ & $20 a$ & $20 \mathrm{~b}$ & $20 c$ & 21 \\
\hline
\end{tabular}

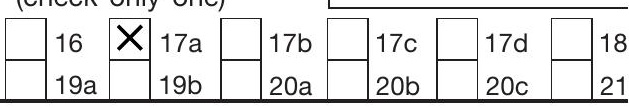

Any information copied from such Reports and Statements may not be sold or used by any person for the purpose of soliciting contributions or for commercial purposes, other than using the name and address of any political committee to solicit contributions from such committee.

NAME OF COMMITTEE (In Full)

\section{Friends of Herman Cain}

A. Full Name (Last, First, Middle Initial)

\section{David Cabell}

Mailing Address Box 7173

\begin{tabular}{lcc}
\hline City & State & Zip Code \\
Beaumont & TX & $77726-7173$ \\
\hline
\end{tabular}

FEC ID number of contributing federal political committee.

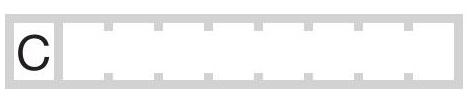

Name of Employer
Information Requested
Receipt For: 2012
X Primary
$\square$ Other (specify)

\section{Occupation} Information Requested

Election Cycle-to-Date

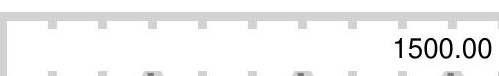

B. Full Name (Last, First, Middle Initial)

Michael Ward Jr.

Mailing Address 1331 Lost Mountain Rd.

\begin{tabular}{lcc}
\hline City & State & Zip Code \\
Powder Springs & GA & $30127-1068$ \\
\hline
\end{tabular}

FEC ID number of contributing

federal political committee.

C

Name of Employer
Information Requested
Receipt For: 2012
Primary
Other (specify)

Occupation

Information Requested

Election Cycle-to-Date

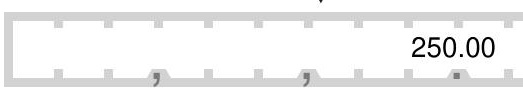

C. Full Name (Last, First, Middle Initial)

Oliver Schreiber

Mailing Address 121 Spartan Rd.

\begin{tabular}{lcc}
\hline City & State & Zip Code \\
Wilmington & NC & $28405-3707$
\end{tabular}

FEC ID number of contributing federal political committee.

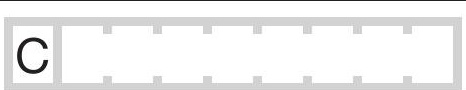

Name of Employer
n/a
Receipt For: 2012
X Primary $\quad \square$ General
Other (specify)

\section{Occupation}

Ret.FDN Y / Vet.Affairs

Election Cycle-to-Date
Transaction ID : AA6D14AE4DBB24619BBF

Date of Receipt

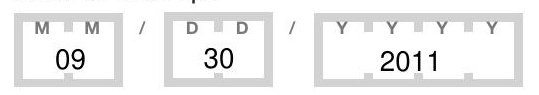

Amount of Each Receipt this Period

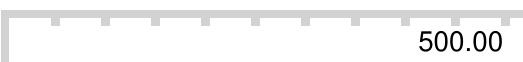

Amount of Each Receipt this Period

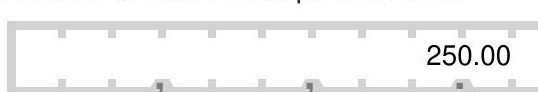

Transaction ID : AFC9DCEEB95754FAE870 Date of Receipt

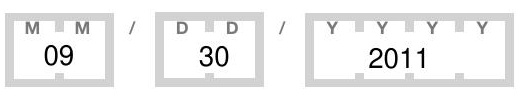

Transaction ID : AAC39AE85D8E84CF2846 Date of Receipt

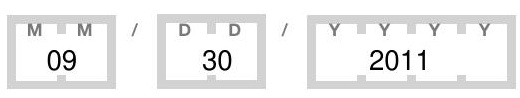

Amount of Each Receipt this Period

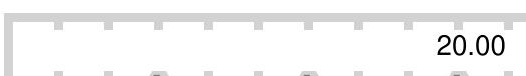

Subtotal Of Receipts This Page (optional).

$+\quad 770.00$

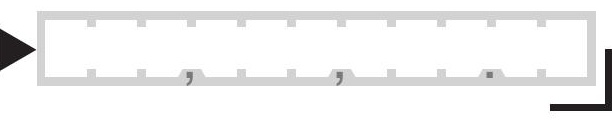

FEC Schedule A-P (Form 3P) (Rev. 03/2011)

Total This Period (last page this line number only) 
SCHEDULE A-P ITEMIZED RECEIPTS
Use separate schedule(s) for each category of the Detailed Summary Page
FOR LINE NUMBER: (check only one)
PAGE $1133 / 1572$

\begin{tabular}{|c|c|c|c|c|c|}
\hline & & & & & \\
\hline 16 & $\begin{array}{lll}X & 17 a \\
\end{array}$ & $17 \mathrm{~b}$ & $17 c$ & $17 d$ & 18 \\
\hline $19 a$ & $19 b$ & $20 a$ & $20 \mathrm{~b}$ & $20 c$ & 21 \\
\hline
\end{tabular}

Any information copied from such Reports and Statements may not be sold or used by any person for the purpose of soliciting contributions or for commercial purposes, other than using the name and address of any political committee to solicit contributions from such committee.

NAME OF COMMITTEE (In Full)

\section{Friends of Herman Cain}

A. Full Name (Last, First, Middle Initial)

Cathy Brunicardi

Mailing Address PO Box 300

\begin{tabular}{lcc}
\hline City & State & Zip Code \\
Weesatche & TX & $77993-0300$ \\
\hline
\end{tabular}

FEC ID number of contributing federal political committee.

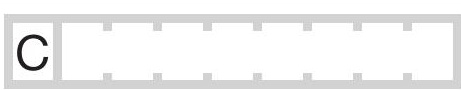

Name of Employer
None
Receipt For: 2012
X Primary $\quad$ General
Other (specify)

B. Full Name (Last, First, Middle Initial) Barbara Lago

Mailing Address 59-055 Olomana Rd

\begin{tabular}{lcc}
\hline City & State & Zip Code \\
Kamuela & HI & $96743-8515$
\end{tabular}

FEC ID number of contributing

federal political committee.

C

Name of Employer
None
Receipt For: 2012
X Primary
Other (specify)

C. Full Name (Last, First, Middle Initial)

Colette Anderson

Mailing Address 1454 Forest Drive SE

\section{City}

Smyrna

FEC ID number of contributing federal political committee.

Name of Employer

Anderson Plus Assoc Inc

Receipt For: 2012

Х $\begin{aligned} & \text { Primary } \\ & \text { Other (specify) }\end{aligned}$
Occupation

Retired

Election Cycle-to-Date

315.00
Occupation

Retired

Election Cycle-to-Date

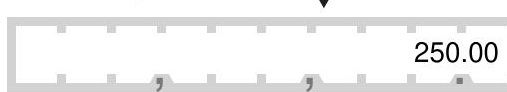

\section{Occupation}

Interior Design

Election Cycle-to-Date
Transaction ID : A47F3A4561FC6428685B

Date of Receipt

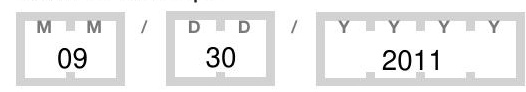

Amount of Each Receipt this Period

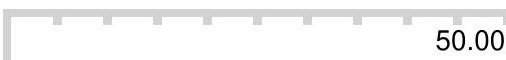

50.00
Amount of Each Receipt this Period

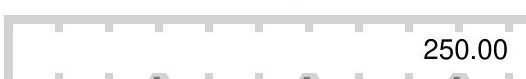

Transaction ID : ADF281C77687246D2A63

Date of Receipt

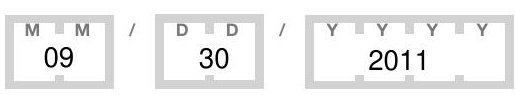

Transaction ID : A8905CA6695594A239C6 Date of Receipt

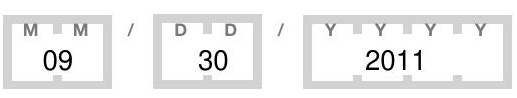

Amount of Each Receipt this Period

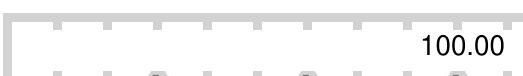

215.00

Subtotal Of Receipts This Page (optional)

400.00

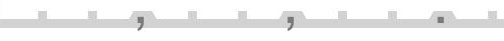

Total This Period (last page this line number only)

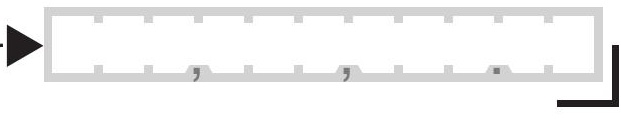

FEC Schedule A-P (Form 3P) (Rev. 03/2011) 


\section{SCHEDULE A-P} ITEMIZED RECEIPTS
Use separate schedule(s)

for each category of the

Detailed Summary Page
FOR LINE NUMBER: (check only one)

Any information or for commercial purposes, other than using the name and address of any political committee to solicit contributions from such committee.

NAME OF COMMITTEE (In Full)

Friends of Herman Cain

A. Full Name (Last, First, Middle Initial)

John Gresham

Mailing Address 4 Bogey Dr.

\begin{tabular}{lcc}
\hline City & State & Zip Code \\
Winter Haven & FL & $33881-9221$
\end{tabular}

FEC ID number of contributing

federal political committee.

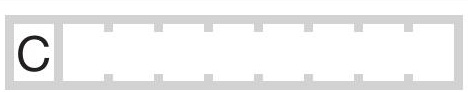

Name of Employer
Self Employed
Receipt For: 2012
X Primary
$\square$ Other (specify) General

Occupation

Marketing Consultant

Election Cycle-to-Date

250.00

B. Full Name (Last, First, Middle Initial)

Keith Myers

Mailing Address 3471 Windisch Ave.

\begin{tabular}{lcc}
\hline City & State & Zip Code \\
Cincinnati & OH & $45208-4217$ \\
\hline
\end{tabular}

FEC ID number of contributing

federal political committee.

C

Name of Employer
Information Requested
Receipt For: 2012
X Primary
Other (specify)

Occupation

Information Requested

Election Cycle-to-Date

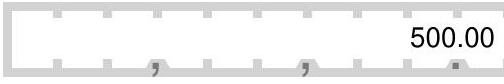

C. Full Name (Last, First, Middle Initial)

Jim Thomas

Mailing Address 895 Foxhollow Run

\begin{tabular}{lcc}
\hline City & State & Zip Code \\
Alpharetta & GA & $30004-0953$
\end{tabular}

FEC ID number of contributing

federal political committee.

C

Name of Employer

Information Requested

Occupation

Information Requested

Receipt For: 2012

Х $\begin{aligned} & \text { Primary } \square \text { General } \\ & \text { Other (specify) }\end{aligned}$

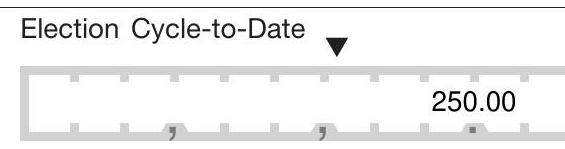

Amount of Each Receipt this Period

Transaction ID : A4A3F8660EBF148F98C1

Date of Receipt

Amount of Each Receipt this Period
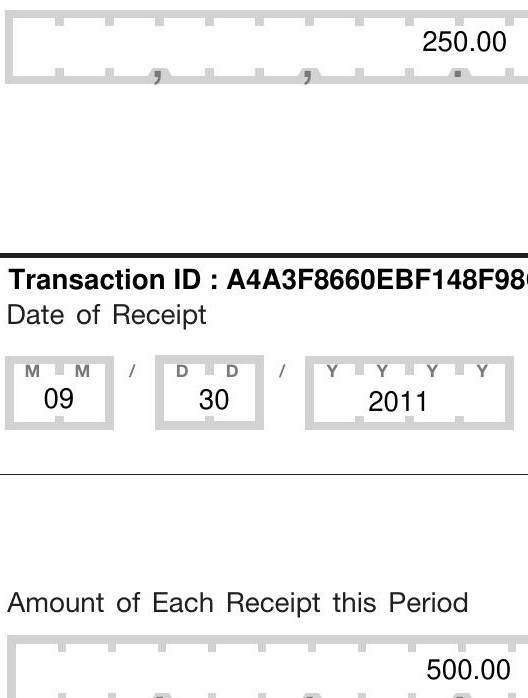

Transaction ID : AAECED2B69A574AF58B7 Date of Receipt

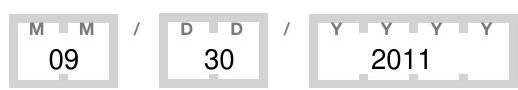

Amount of Each Receipt this Period

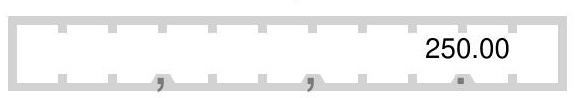

Subtotal Of Receipts This Page (optional).

1000.00

Total This Period (last page this line number only) 


\section{SCHEDULE A-P} ITEMIZED RECEIPTS
Use separate schedule(s) for each category of the Detailed Summary Page

FOR LINE NUMBER:
(check only one)

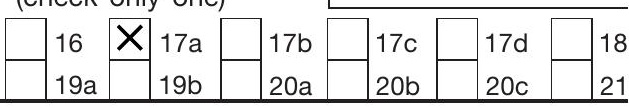

Any information copied from such Reports and Statements may not be sold or used by any person for the purpose of soliciting contributions or for commercial purposes, other than using the name and address of any political committee to solicit contributions from such committee.

NAME OF COMMITTEE (In Full)

\section{Friends of Herman Cain}

A. Full Name (Last, First, Middle Initial)

William Wilson

Mailing Address 5690 Columbine Dr.

\begin{tabular}{lcc}
\hline City & State & Zip Code \\
Johnston & IA & $50131-1547$
\end{tabular}

FEC ID number of contributing federal political committee.

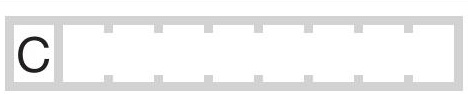

Name of Employer
Information Requested
Receipt For: 2012
X Primary
$\square$ Other (specify)

Occupation Information Requested

Election Cycle-to-Date 500.00

B. Full Name (Last, First, Middle Initial)

Patricia Dabbs

Mailing Address 1406 Reidsboro Rd

\begin{tabular}{lcc}
\hline City & State & Zip Code \\
Williamson & GA & $30292-3463$
\end{tabular}

FEC ID number of contributing

federal political committee.

C

Name of Employer
Information Requested
Receipt For: 2012
Primary
Other (specify)

Occupation

Information Requested

Election Cycle-to-Date

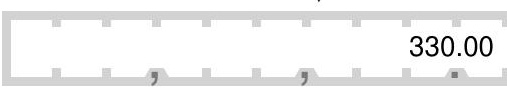

Transaction ID : A9D470033680A4EE9A05

Date of Receipt

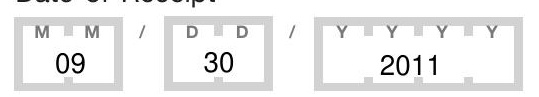

Amount of Each Receipt this Period

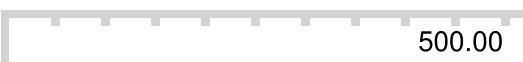

Amount of Each Receipt this Period

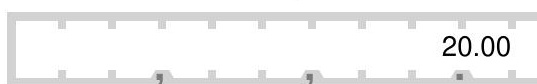

C. Full Name (Last, First, Middle Initial)

David McCleary

Mailing Address PO box 923

\begin{tabular}{lcc}
\hline City & State & Zip Code \\
Roswell & GA & $30077-0923$
\end{tabular}

FEC ID number of contributing federal political committee.

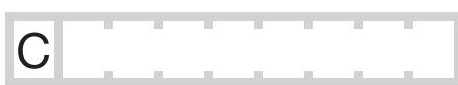

Name of Employer

Facility Maintenance Source Inc.

\section{Occupation}

Maintenance

Transaction ID : ADE8FD7D7045F4812928

Date of Receipt

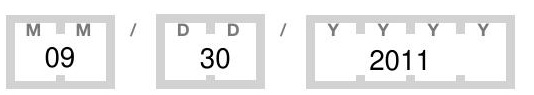

Receipt For: 2012

Х $\begin{aligned} & \text { Primary } \square \text { General } \\ & \text { Other (specify) }\end{aligned}$

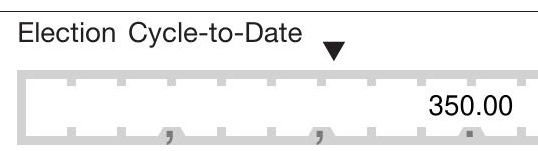

Amount of Each Receipt this Period

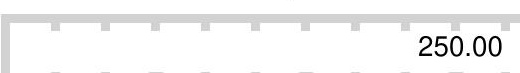

Transaction ID : AB269295B16AA46E2ACF Date of Receipt

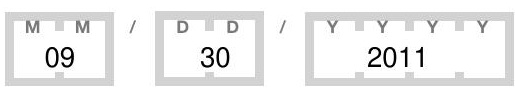

Subtotal Of Receipts This Page (optional)

Total This Period (last page this line number only) 


\section{SCHEDULE A-P} ITEMIZED RECEIPTS
Use separate schedule(s)

for each category of the

Detailed Summary Page
FOR LINE NUMBER: (check only one)

Any information or for commercial purposes, other than using the name and address of any political committee to solicit contributions from such committee.

NAME OF COMMITTEE (In Full)

Friends of Herman Cain

A. Full Name (Last, First, Middle Initial)

James Black

Mailing Address 8301 Black Brothers Court

\begin{tabular}{lcc}
\hline City & State & Zip Code \\
Las Vegas & NV & $89117-1846$ \\
\hline
\end{tabular}

FEC ID number of contributing

federal political committee.

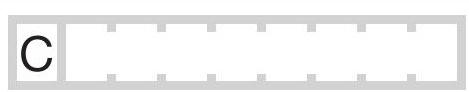

Name of Employer
Information Requested
Receipt For: 2012
X Primary $\quad \square$ General
Other (specify)

Occupation

Information Requested

Election Cycle-to-Date

1000.00

B. Full Name (Last, First, Middle Initial)

Donald Russell

Mailing Address 61 Woodbine Road

\begin{tabular}{lcc}
\hline City & State & Zip Code \\
Shelburne & VT & $05482-6702$ \\
\hline
\end{tabular}

FEC ID number of contributing

federal political committee.

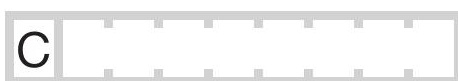

Name of Employer
Retired
Receipt For: 2012
X Primary $\quad$ General
Other (specify)

Occupation

Retired

Election Cycle-to-Date

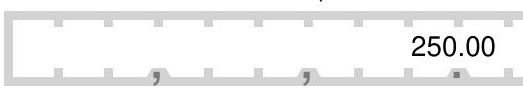

Transaction ID : A9967460A258E4E978C3

Date of Receipt

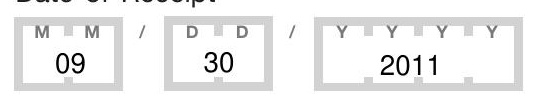

Amount of Each Receipt this Period

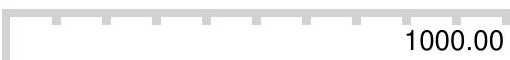

Transaction ID : A335E5059B1EF411CBC5

Date of Receipt

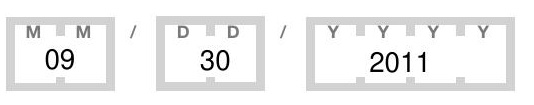

Amount of Each Receipt this Period

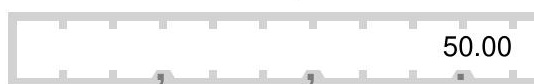

Transaction ID : A80E11323B1A8472BB22

Date of Receipt

Debra Gilliam

Mailing Address 1807 Rockybranch Pass

\begin{tabular}{lcc}
\hline City & State & Zip Code \\
Marietta & GA & $30066-8014$
\end{tabular}

FEC ID number of contributing

federal political committee.

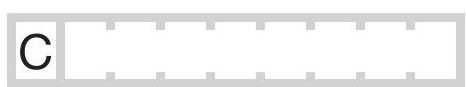

Name of Employer

Information Requested

Occupation

Information Requested

Receipt For: 2012

Х $\begin{aligned} & \text { Primary } \square \text { General } \\ & \text { Other (specify) }\end{aligned}$

Subtotal Of Receipts This Page (optional).

Amount of Each Receipt this Period

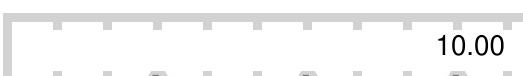

Total This Period (last page this line number only)

1060.00

a

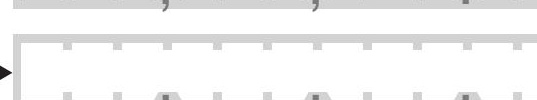

FEC Schedule A-P (Form 3P) (Rev. 03/2011) 
SCHEDULE A-P ITEMIZED RECEIPTS
Use separate schedule(s) for each category of the Detailed Summary Page
FOR LINE NUMBER: (check only one)

PAGE 1137 / 1572

\begin{tabular}{|c|c|c|c|c|c|}
\hline & & & & & \\
\hline 16 & $\mathbf{X} 17 a$ & $17 b$ & $17 c$ & $17 d$ & 18 \\
\hline $19 a$ & $19 b$ & $20 \mathrm{a}$ & $20 \mathrm{~b}$ & $20 \mathrm{c}$ & 21 \\
\hline
\end{tabular}

Any information copied from such Reports and Statements may not be sold or used by any person for the purpose of soliciting contributions or for commercial purposes, other than using the name and address of any political committee to solicit contributions from such committee.

NAME OF COMMITTEE (In Full)

\section{Friends of Herman Cain}

A. Full Name (Last, First, Middle Initial)

\section{Elaine Powers}

Mailing Address 200 tiger way

\begin{tabular}{lcc}
\hline City & State & Zip Code \\
Peachtree City & GA & $30269-1679$ \\
\hline
\end{tabular}

FEC ID number of contributing federal political committee.

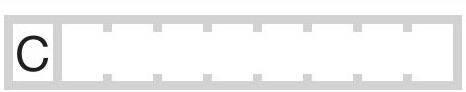

Name of Employer
Powers Heating \& Air
Receipt For: 2012
X Primary $\quad \square$ General
Other (specify)

Occupation HVAC

Election Cycle-to-Date

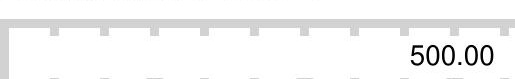

B. Full Name (Last, First, Middle Initial)

Arlene Rouse

Mailing Address 4655 E 58th St

\begin{tabular}{lcc}
\hline City & State & Zip Code \\
Tulsa & OK & $74135-4319$
\end{tabular}

FEC ID number of contributing

federal political committee.

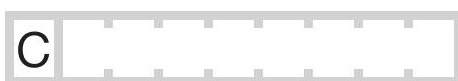

Name of Employer
Dillards
Receipt For: 2012
X Primary
Other (specify)

\section{Occupation}

Sales

Election Cycle-to-Date

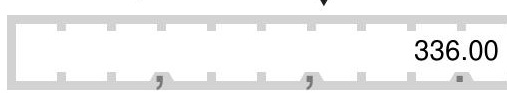

Transaction ID : A9A5C148FC2A24BA1BB1

Date of Receipt

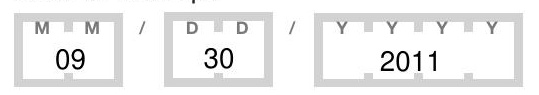

Amount of Each Receipt this Period

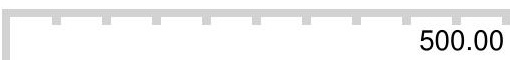

C. Full Name (Last, First, Middle Initial)

William Porter

Mailing Address 6040 Fox Creek Dr

\begin{tabular}{lcc}
\hline City & State & Zip Code \\
Cumming & GA & $30040-8720$
\end{tabular}

FEC ID number of contributing federal political committee.

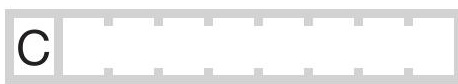

Name of Employer
NA
Receipt For: 2012
X Primary

Other (specify) General

Occupation

Information Requested

Election Cycle-to-Date

Transaction ID : A6388DBC631AE4DC8A5A Date of Receipt

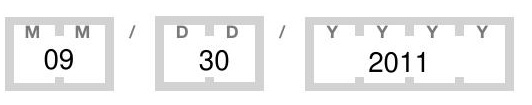

Amount of Each Receipt this Period

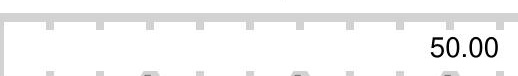

Transaction ID : ACE0C7F29D7714B20BCA Date of Receipt

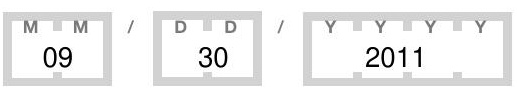

Amount of Each Receipt this Period

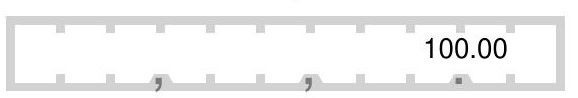

293.00

\section{Subtotal Of Receipts This Page (optional)}

Total This Period (last page this line number only) 


\section{SCHEDULE A-P} ITEMIZED RECEIPTS
Use separate schedule(s)

for each category of the

Detailed Summary Page
FOR LINE NUMBER: (check only one)

Any information or for commercial purposes, other than using the name and address of any political committee to solicit contributions from such committee.

NAME OF COMMITTEE (In Full)

Friends of Herman Cain

A. Full Name (Last, First, Middle Initial)

Michael Root

Mailing Address 9961 Essex Drive

\begin{tabular}{lcc}
\hline City & State & Zip Code \\
Omaha & NE & $68114-3873$
\end{tabular}

FEC ID number of contributing

federal political committee.

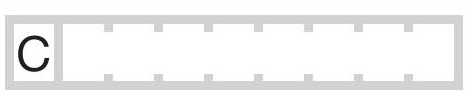

Name of Employer
Information Requested
Receipt For: 2012
X Primary $\quad \square$ General
Other (specify)

Occupation

Information Requested

Election Cycle-to-Date

500.00

B. Full Name (Last, First, Middle Initial)

Jody Harshman

Mailing Address 5908 THistledown Dr

\begin{tabular}{llc}
\hline City & State & Zip Code \\
Pasco & WA & $99301-3118$
\end{tabular}

FEC ID number of contributing

federal political committee.

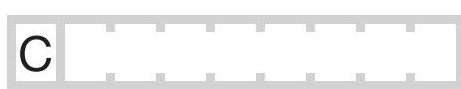

Name of Employer
Independent Contractor
Receipt For: 2012
X Primary
Other (specify) General

Occupation

technician

Election Cycle-to-Date

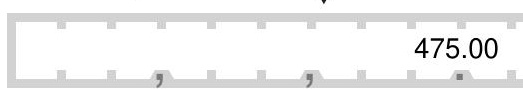

C. Full Name (Last, First, Middle Initial)

Daniel Batchelor

Mailing Address 285 Shore Lane

\begin{tabular}{lcc}
\hline City & State & Zip Code \\
Lexington & NC & $27292-7867$
\end{tabular}

FEC ID number of contributing federal political committee.

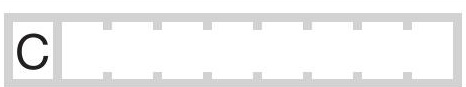

Name of Employer

Information Requested

Occupation

Information Requested

Receipt For: 2012

Х $\begin{aligned} & \text { Primary } \square \text { General } \\ & \text { Other (specify) }\end{aligned}$

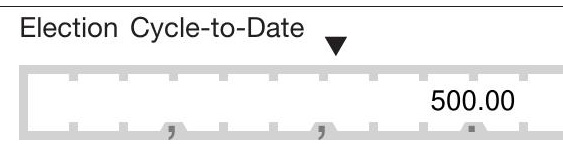

Amount of Each Receipt this Period

Transaction ID : A82823482118845FABBO

Date of Receipt

Amount of Each Receipt this Period
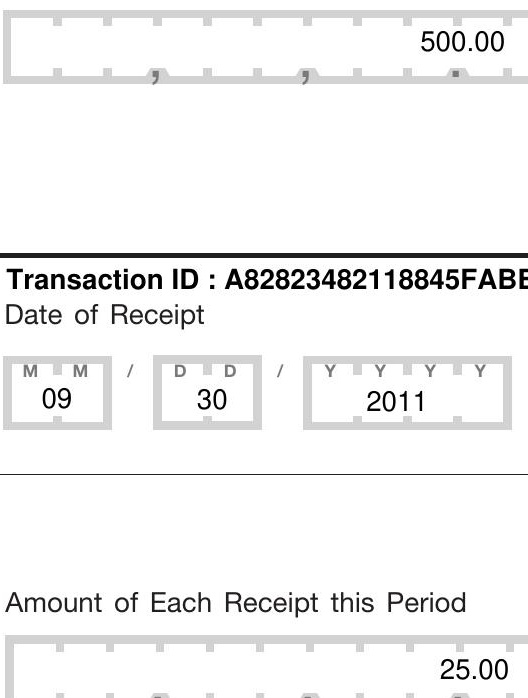

Transaction ID : A56741BA276664CD6862

Date of Receipt

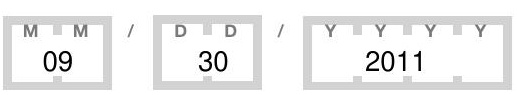

Amount of Each Receipt this Period

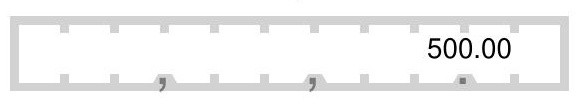

Subtotal Of Receipts This Page (optional).

1025.00

Total This Period (last page this line number only) 


\section{SCHEDULE A-P} ITEMIZED RECEIPTS
Use separate schedule(s)

for each category of the

Detailed Summary Page
FOR LINE NUMBER: (check only one)

Any information or for commercial purposes, other than using the name and address of any political committee to solicit contributions from such committee.

NAME OF COMMITTEE (In Full)

\section{Friends of Herman Cain}

A. Full Name (Last, First, Middle Initial)

Nona Long

Mailing Address 1501 N State Pkwy, Apt. 17A

\begin{tabular}{lcc}
\hline City & State & Zip Code \\
Chicago & IL & $60610-5742$ \\
\hline
\end{tabular}

FEC ID number of contributing

federal political committee.

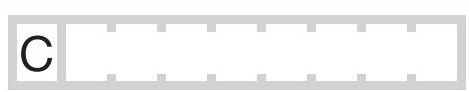

Name of Employer
None
Receipt For: 2012
X Primary $\quad$ General
Other (specify)

Occupation

homemaker

Election Cycle-to-Date

500.00

B. Full Name (Last, First, Middle Initial)

Anne Sislik

Mailing Address 8356 Delaware Drive

\begin{tabular}{lcc}
\hline City & State & Zip Code \\
Weeki Wachee & FL & $34607-2214$
\end{tabular}

FEC ID number of contributing

federal political committee.

C

Name of Employer
Information Requested
Receipt For: 2012
X Primary
Other (specify)

Occupation

Information Requested

Election Cycle-to-Date

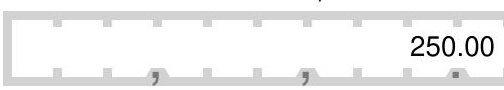

Transaction ID : A3D36C6BD5CBB48D3A64

Date of Receipt

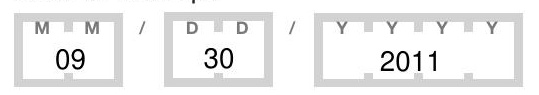

Amount of Each Receipt this Period

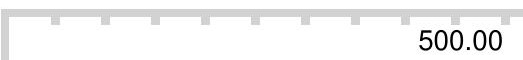

C. Full Name (Last, First, Middle Initial)

Marc Shapiro

Mailing Address 609 Atlantic St

\begin{tabular}{lcc}
\hline City & State & Zip Code \\
Melbourne Beach & FL & $32951-2013$
\end{tabular}

FEC ID number of contributing federal political committee.

C

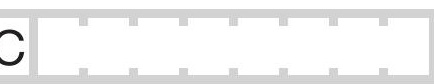

Name of Employer

Occupation

Information Requested

Information Requested

Receipt For: 2012

Х $\begin{aligned} & \text { Primary } \\ & \text { Other (specify) }\end{aligned}$

Election Cycle-to-Date

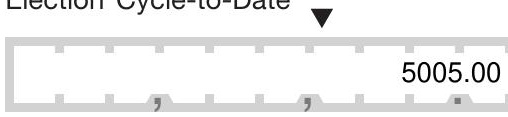

Amount of Each Receipt this Period

Transaction ID : AB20D63C3C0044157B8A

Date of Receipt
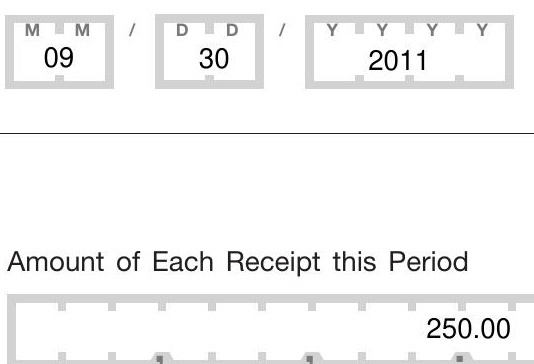

Transaction ID : A10DA4F481F6349F887D

Date of Receipt

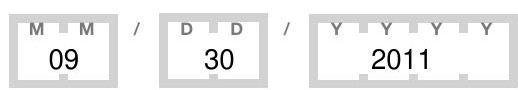

Amount of Each Receipt this Period

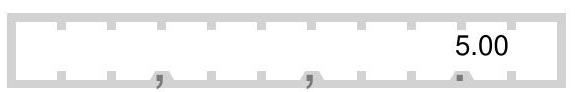

Subtotal Of Receipts This Page (optional)

755.00

Total This Period (last page this line number only) 


\section{SCHEDULE A-P} ITEMIZED RECEIPTS
Use separate schedule(s)

for each category of the

Detailed Summary Page
FOR LINE NUMBER: (check only one)

Any information or for commercial purposes, other than using the name and address of any political committee to solicit contributions from such committee.

NAME OF COMMITTEE (In Full)

Friends of Herman Cain

A. Full Name (Last, First, Middle Initial)

Linda Pellegrino

Mailing Address 1120 Brookhaven Commons Dr. NE

\begin{tabular}{lcc}
\hline City & State & Zip Code \\
Atlanta & GA & $30319-2968$ \\
\hline
\end{tabular}

FEC ID number of contributing

federal political committee.

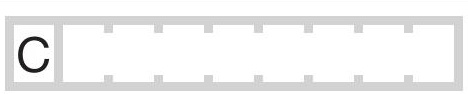

Name of Employer
Self Employed
Receipt For: 2012
X Primary
$\square$ Other (specify) General

Occupation

Consulting

Election Cycle-to-Date

500.00

B. Full Name (Last, First, Middle Initial)

Michael Witcher

Mailing Address 819 Thompson Bridge Rd

\begin{tabular}{lcc}
\hline City & State & Zip Code \\
Gainesville & GA & $30501-1774$
\end{tabular}

FEC ID number of contributing

federal political committee.

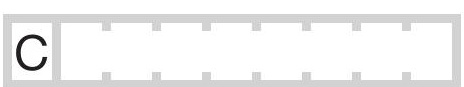

\begin{tabular}{l} 
Name of Employer \\
self \\
Receipt For: 2012 \\
X Primary $\square$ General \\
\hline Other (specify)
\end{tabular}

Occupation

Dentist

Election Cycle-to-Date

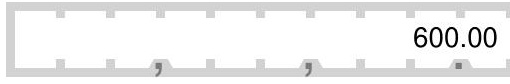

C. Full Name (Last, First, Middle Initial)

Alan Ware

Mailing Address 209 Gleneagle Point

\begin{tabular}{l|ll}
\hline $\begin{array}{l}\text { City } \\
\text { Peachtree City }\end{array}$ & $\begin{array}{c}\text { State } \\
\text { GA }\end{array}$ & $\begin{array}{c}\text { Zip Code } \\
30269-3503\end{array}$ \\
\hline $\begin{array}{l}\text { FEC ID number of contributing } \\
\text { federal political committee. }\end{array}$ & C & \\
\hline $\begin{array}{l}\text { Name of Employer } \\
\text { FedEx Kinkos }\end{array}$ & $\begin{array}{l}\text { Occupation } \\
\text { Pilot }\end{array}$ \\
\hline $\begin{array}{l}\text { Receipt For: } 2012 \\
\text { Xrimary } \\
\text { Other (specify) }\end{array}$ & Election Cycle-to-Date & \\
\hline
\end{tabular}

Transaction ID : A6D00231F52274922A3E

Date of Receipt

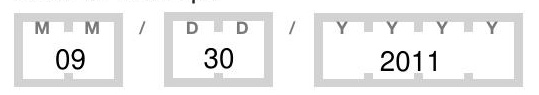

Amount of Each Receipt this Period

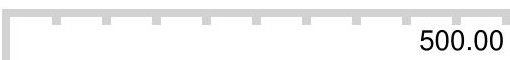

Amount of Each Receipt this Period

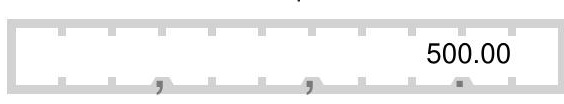

Amount of Each Receipt this Period

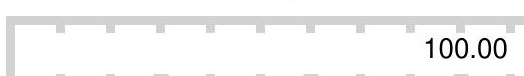

Subtotal Of Receipts This Page (optional).

$+\quad 1100.00$

Total This Period (last page this line number only)
Transaction ID : A04B5727BBD8B4C2FB65 Date of Receipt

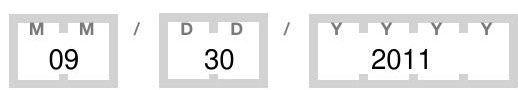




\section{SCHEDULE A-P} ITEMIZED RECEIPTS
Use separate schedule(s) for each category of the Detailed Summary Page

FOR LINE NUMBER:
(check only one)

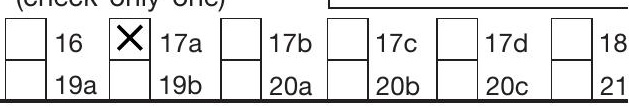

Any information copied from such Reports and Statements may not be sold or used by any person for the purpose of soliciting contributions or for commercial purposes, other than using the name and address of any political committee to solicit contributions from such committee.

NAME OF COMMITTEE (In Full)

\section{Friends of Herman Cain}

A. Full Name (Last, First, Middle Initial)

Marilyn Falkenhagen

Mailing Address 5635 Victor Street

\begin{tabular}{lcc}
\hline City & State & Zip Code \\
Dallas & TX & $75214-4734$ \\
\hline
\end{tabular}

FEC ID number of contributing federal political committee.

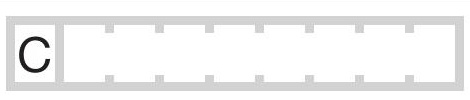

Name of Employer
Deloitte Tax LLP
Receipt For: 2012
X Primary
Other (specify) General

\section{Occupation} CPA

Election Cycle-to-Date

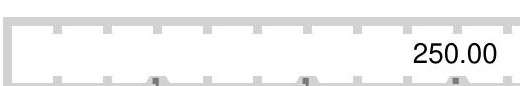

B. Full Name (Last, First, Middle Initial)

Patty Morton

Mailing Address 909 N. Maize Rd. \#736

\begin{tabular}{lcc}
\hline City & State & Zip Code \\
Wichita & KS & $67212-4557$ \\
\hline
\end{tabular}

FEC ID number of contributing

federal political committee.

C

Name of Employer
Internal Medicine Specialists PA
Receipt For: 2012
X Primary
Other (specify)

\section{Occupation}

Transcriptionist

Election Cycle-to-Date

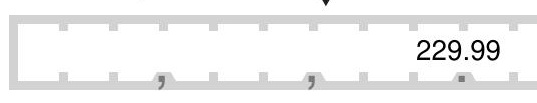

C. Full Name (Last, First, Middle Initial)

Frank Hearne

Mailing Address 18400 Timberlan Drive

\begin{tabular}{l|ll}
\hline $\begin{array}{l}\text { City } \\
\text { Lutz }\end{array}$ & $\begin{array}{c}\text { State } \\
\text { FL }\end{array}$ & $\begin{array}{c}\text { Zip Code } \\
33549-5829\end{array}$ \\
\hline $\begin{array}{l}\text { FEC ID number of contributing } \\
\text { federal political committee. }\end{array}$ & C \\
\hline $\begin{array}{l}\text { Name of Employer } \\
\text { Information Requested }\end{array}$ & $\begin{array}{l}\text { Occupation } \\
\text { Information Requested }\end{array}$ \\
$\begin{array}{l}\text { Receipt For: } 2012 \\
\text { Xrimary } \\
\text { Other (specify) }\end{array}$ & Election Cycle-to-Date & \\
\end{tabular}

Subtotal Of Receipts This Page (optional).

Total This Period (last page this line number only)
Date of Receipt

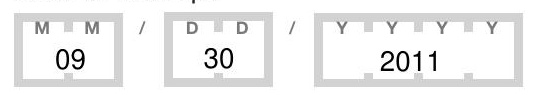

Amount of Each Receipt this Period

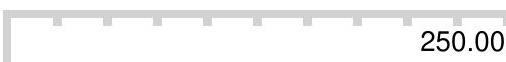

250.00
Transaction ID : AC1173E9316FE45258F8
Amount of Each Receipt this Period

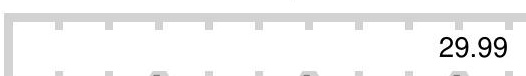

Amount of Each Receipt this Period

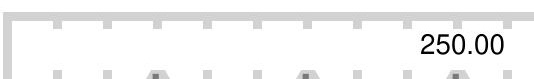
Date of Receipt

\begin{tabular}{|c|c|c|c|c|}
\hline 09 & 1 & 30 & I & $\begin{array}{c}Y \\
2011\end{array}$ \\
\hline
\end{tabular}

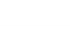

Transaction ID : A3A8E6A9671754F22AAC

Transaction ID : A2AAFAEA0A3294510A2D Date of Receipt
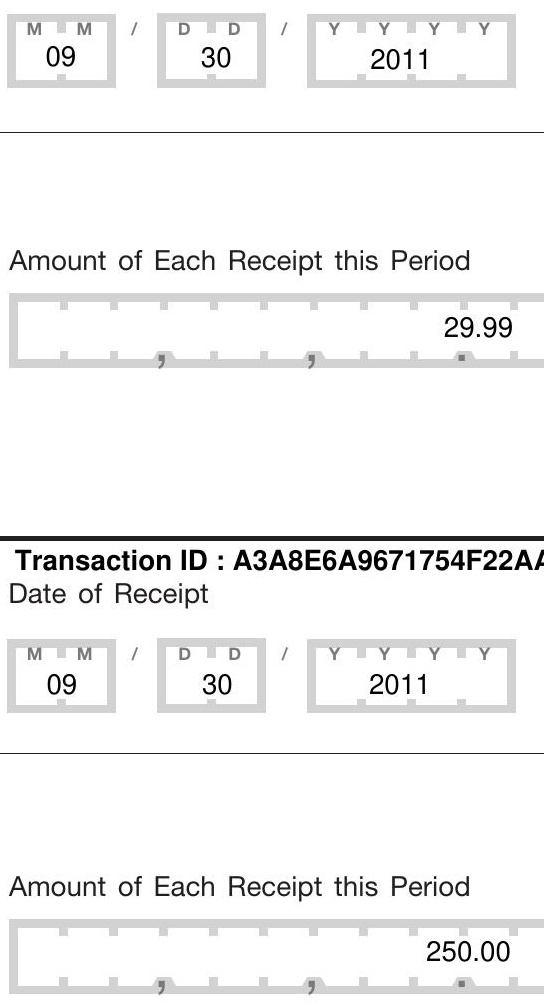

529.99

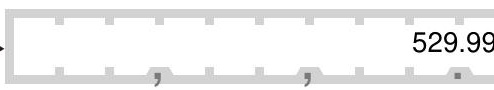

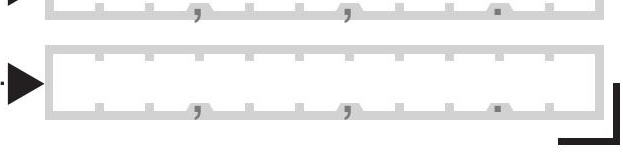

FEC Schedule A-P (Form 3P) (Rev. 03/2011) 


\section{SCHEDULE A-P} ITEMIZED RECEIPTS
Use separate schedule(s) for each category of the Detailed Summary Page

FOR LINE NUMBER:
(check only one)

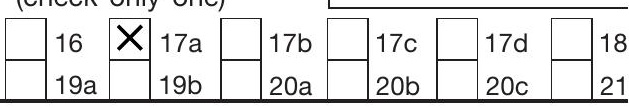

Any information copied from such Reports and Statements may not be sold or used by any person for the purpose of soliciting contributions or for commercial purposes, other than using the name and address of any political committee to solicit contributions from such committee.

NAME OF COMMITTEE (In Full)

\section{Friends of Herman Cain}

A. Full Name (Last, First, Middle Initial)

Neil Hobart

Mailing Address 219 N Barry Avenue

\begin{tabular}{lcc}
\hline City & State & Zip Code \\
Mamaroneck & NY & $10543-2827$
\end{tabular}

FEC ID number of contributing federal political committee.

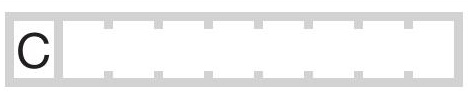

Name of Employer
None
Receipt For: 2012
X Primary $\quad \square$ General
$\square$ Other (specify)

Occupation unemployed

Election Cycle-to-Date 499.97

B. Full Name (Last, First, Middle Initial)

Patricia Duvall

Mailing Address 19 Lullwater Estate Road

\begin{tabular}{lcc}
\hline City & State & Zip Code \\
Atlanta & GA & 30307 \\
\hline
\end{tabular}

FEC ID number of contributing

federal political committee.

C

Name of Employer
American Settlement Corp.
Receipt For: 2012
$X$ Primary
Other (specify)

Occupation

Case Manager

Election Cycle-to-Date

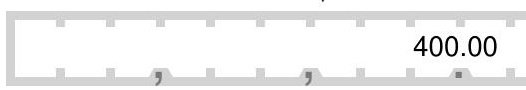

C. Full Name (Last, First, Middle Initial)

Blas Padrino

Mailing Address 1440A Circle Dr

\begin{tabular}{l|ll}
\hline $\begin{array}{l}\text { City } \\
\text { Fort Campbell }\end{array}$ & $\begin{array}{c}\text { State } \\
\text { KY }\end{array}$ & $\begin{array}{c}\text { Zip Code } \\
42223-3552\end{array}$ \\
\hline $\begin{array}{l}\text { FEC ID number of contributing } \\
\text { federal political committee. }\end{array}$ & C \\
\hline $\begin{array}{l}\text { Name of Employer } \\
\text { US ARMY }\end{array}$ & $\begin{array}{l}\text { Occupation } \\
\text { soldier }\end{array}$ \\
\hline $\begin{array}{l}\text { Receipt For: } 2012 \\
\text { X } \begin{array}{l}\text { Primary } \\
\text { Other (specify) }\end{array}\end{array}$ & Election Cycle-to-Date & \\
\hline
\end{tabular}

Transaction ID : AA337CB0DBE304CD6BAC Date of Receipt

Amount of Each Receipt this Period
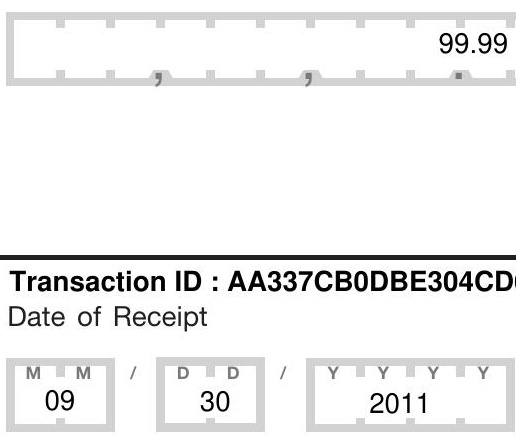

Amount of Each Receipt this Period

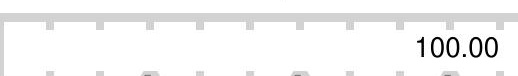

Amount of Each Receipt this Period

Transaction ID : AF4047A947E104C7F980

Date of Receipt
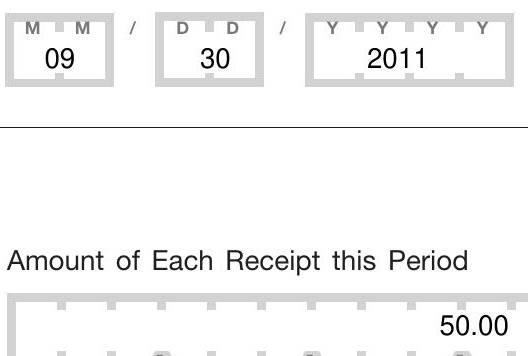

Subtotal Of Receipts This Page (optional)

Total This Period (last page this line number only) 
SCHEDULE A-P ITEMIZED RECEIPTS
Use separate schedule(s) for each category of the Detailed Summary Page
FOR LINE NUMBER: (check only one)

PAGE 1143 / 1572

\begin{tabular}{|c|c|c|c|c|c|}
\hline & & & & & \\
\hline 16 & $\mathbf{X} 17 a$ & $17 b$ & $17 c$ & $17 d$ & 18 \\
\hline $19 a$ & $19 b$ & $20 \mathrm{a}$ & $20 \mathrm{~b}$ & $20 \mathrm{c}$ & 21 \\
\hline
\end{tabular}

Any information copied from such Reports and Statements may not be sold or used by any person for the purpose of soliciting contributions or for commercial purposes, other than using the name and address of any political committee to solicit contributions from such committee.

NAME OF COMMITTEE (In Full)

\section{Friends of Herman Cain}

A. Full Name (Last, First, Middle Initial)

Annette Wade

Mailing Address 1877 Bruce Road, NE

\begin{tabular}{lcc}
\hline City & State & Zip Code \\
Atlanta & GA & $30329-2508$ \\
\hline
\end{tabular}

FEC ID number of contributing federal political committee.

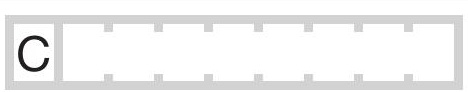

Name of Employer
BellSouth
Receipt For: 2012
X Primary $\quad$ General
Other (specify)

Occupation Retired

Election Cycle-to-Date

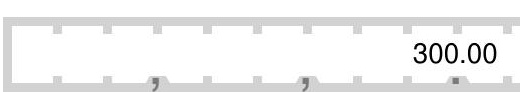

B. Full Name (Last, First, Middle Initial)

Daniel Thomas

Mailing Address 8167 SE 202 Ct

\begin{tabular}{lcc}
\hline City & State & Zip Code \\
Lake Butler & FL & $32054-5837$
\end{tabular}

FEC ID number of contributing

federal political committee.

C

Name of Employer
Information Requested
Receipt For: 2012
Xrimary
Other (specify)

Occupation

Information Requested

Election Cycle-to-Date

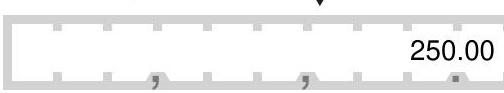

Transaction ID : AE468DE951FEB4AE7AOD

Date of Receipt

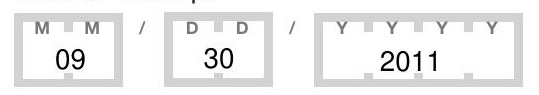

Amount of Each Receipt this Period

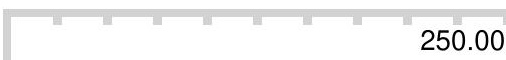

Amount of Each Receipt this Period

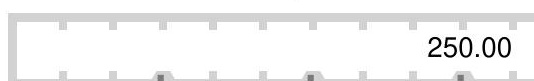

C. Full Name (Last, First, Middle Initial)

Sheryl Roberts

Mailing Address 170 Camino Rayo del Sol

\begin{tabular}{lcc}
\hline City & State & Zip Code \\
Corrales & NM & $87048-6805$
\end{tabular}

FEC ID number of contributing federal political committee.

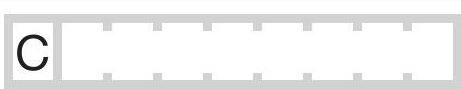

Name of Employer

Information Requested

Occupation

Information Requested

Receipt For: 2012

Х $\begin{aligned} & \text { Primary } \\ & \text { Other (specify) }\end{aligned}$

Election Cycle-to-Date

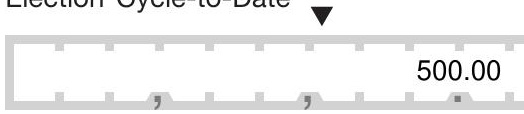

Transaction ID : A2F91FF44F2204FABBC3

Date of Receipt

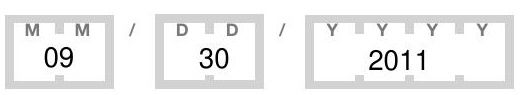

Transaction ID : A0022EBF9F70643C59BE

Date of Receipt

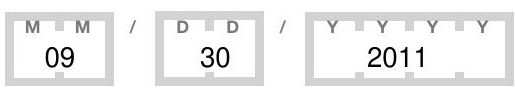

Amount of Each Receipt this Period

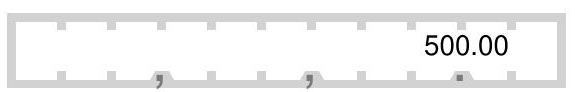

Subtotal Of Receipts This Page (optional)

1000.00

Total This Period (last page this line number only) 


\section{SCHEDULE A-P} ITEMIZED RECEIPTS
Use separate schedule(s)

for each category of the

Detailed Summary Page
FOR LINE NUMBER: (check only one)

Any information or for commercial purposes, other than using the name and address of any political committee to solicit contributions from such committee.

NAME OF COMMITTEE (In Full)

Friends of Herman Cain

A. Full Name (Last, First, Middle Initial)

Robert Van Meet

Mailing Address Box 199

\begin{tabular}{lcc}
\hline City & State & Zip Code \\
Sidney & NE & $69162-0199$ \\
\hline
\end{tabular}

FEC ID number of contributing

federal political committee.

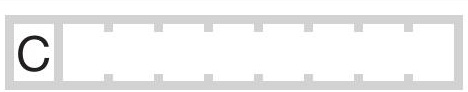

Name of Employer
Information Requested
Receipt For: 2012
X Primary $\quad \square$ General
Other (specify)

Occupation

Information Requested

Election Cycle-to-Date

465.00

B. Full Name (Last, First, Middle Initial)

Stephen Dallas

Mailing Address 11565 Laurel Lake Drive

\begin{tabular}{lcc}
\hline City & State & Zip Code \\
Roswell & GA & $30075-2175$
\end{tabular}

FEC ID number of contributing

federal political committee.

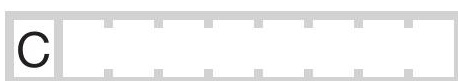

Name of Employer
Roswell Infiniti
Receipt For: 2012
X Primary
Other (specify)

Occupation

Auto Mechanic

Election Cycle-to-Date

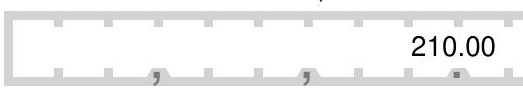

Transaction ID : A6B07F6136E2D4D1AB33

Date of Receipt

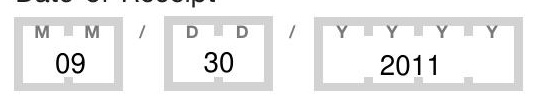

Amount of Each Receipt this Period

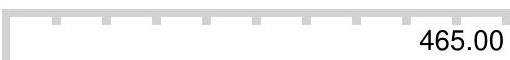

C. Full Name (Last, First, Middle Initial)

Anita Taulbee

Mailing Address 2434 Mount Vernon Dr

\begin{tabular}{lcc}
\hline City & State & Zip Code \\
Fairfield & $\mathrm{OH}$ & $45014-3906$
\end{tabular}

FEC ID number of contributing

federal political committee.

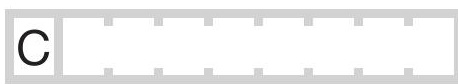

Name of Employer

Information Requested

Occupation

Information Requested

Receipt For: 2012

X Primary $\square$ General

Amount of Each Receipt this Period

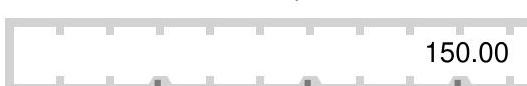

Transaction ID : AEE2B6CDC6492402E947

Date of Receipt

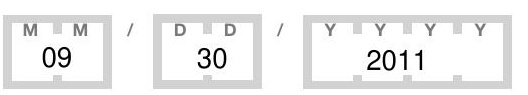

Transaction ID : A71019B4302D748CFA94

Date of Receipt

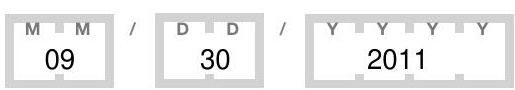

Amount of Each Receipt this Period

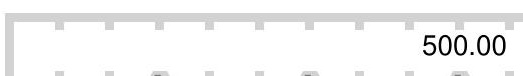

\section{Subtotal Of Receipts This Page (optional)}

Total This Period (last page this line number only) 


\section{SCHEDULE A-P} ITEMIZED RECEIPTS
Use separate schedule(s) for each category of the Detailed Summary Page

FOR LINE NUMBER:
(check only one)

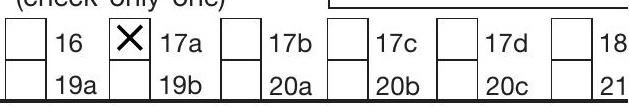

Any information copied from such Reports and Statements may not be sold or used by any person for the purpose of soliciting contributions or for commercial purposes, other than using the name and address of any political committee to solicit contributions from such committee.

NAME OF COMMITTEE (In Full)

\section{Friends of Herman Cain}

A. Full Name (Last, First, Middle Initial) John Kerber

Mailing Address 6900 NorthGlenn Way

\begin{tabular}{lcc}
\hline City & State & Zip Code \\
Johnston & IA & $50131-1234$
\end{tabular}

FEC ID number of contributing federal political committee.

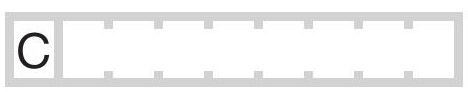

Name of Employer
Information Requested
Receipt For: 2012
X Primary
$\square$ Other (specify)

Occupation Information Requested

Election Cycle-to-Date 350.00

B. Full Name (Last, First, Middle Initial) Tony DiLascio

Mailing Address 309 Sweet Bay Rd

\begin{tabular}{lcc}
\hline City & State & Zip Code \\
Kathleen & GA & $31047-2108$
\end{tabular}

FEC ID number of contributing

federal political committee.

C

Name of Employer
Information Requested
Receipt For: 2012
Primary
Other (specify)

Occupation

Information Requested

Election Cycle-to-Date

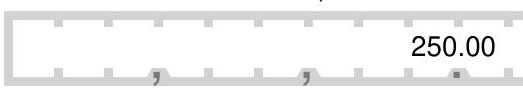

C. Full Name (Last, First, Middle Initial)

Donna Calhoun

Mailing Address 9151 Lambeth Ct

\begin{tabular}{l|ll}
\hline $\begin{array}{l}\text { City } \\
\text { Indianapolis }\end{array}$ & $\begin{array}{c}\text { State } \\
\text { IN }\end{array}$ & $\begin{array}{c}\text { Zip Code } \\
46278-5043\end{array}$ \\
\hline $\begin{array}{l}\text { FEC ID number of contributing } \\
\text { federal political committee. }\end{array}$ & C \\
\hline $\begin{array}{l}\text { Name of Employer } \\
\text { Retired }\end{array}$ & $\begin{array}{l}\text { Occupation } \\
\text { Retired }\end{array}$ \\
\hline $\begin{array}{l}\text { Receipt For: } 2012 \\
\text { X } \\
\text { Other (specify) }\end{array}$ & Election Cycle-to-Date \\
\hline
\end{tabular}

Transaction ID : AE29614AF4FA24BC4AA8 Date of Receipt

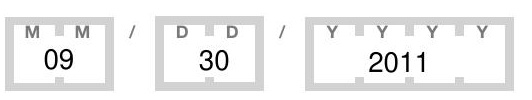

Amount of Each Receipt this Period

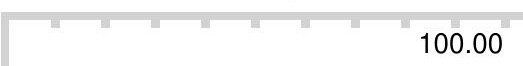

Date of Receipt
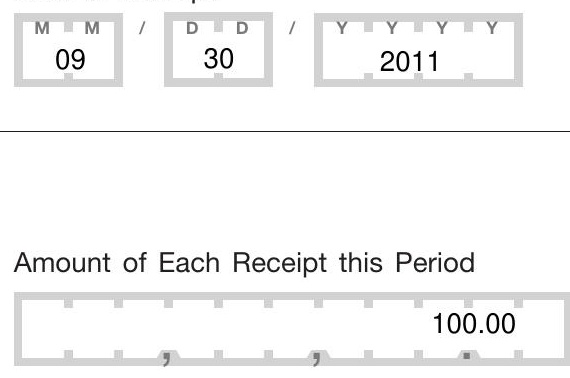

Amount of Each Receipt this Period

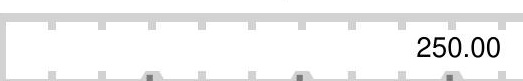

Amount of Each Receipt this Period

Transaction ID : AD91EC14D44EC43929D9 Date of Receipt
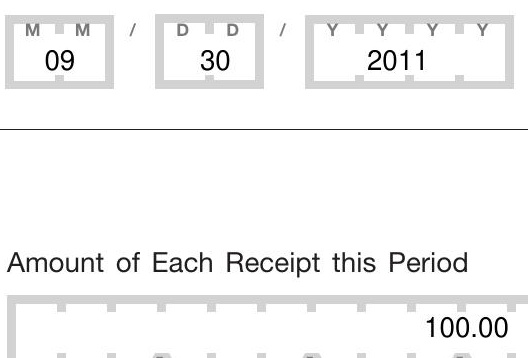

Subtotal Of Receipts This Page (optional)

Total This Period (last page this line number only) 


\section{SCHEDULE A-P} ITEMIZED RECEIPTS
Use separate schedule(s) for each category of the Detailed Summary Page

\begin{tabular}{|c|c|c|c|c|c|}
\hline \multicolumn{3}{|c|}{$\begin{array}{l}\text { FOR LINE NUMBER: } \\
\text { (check only one) }\end{array}$} & \multicolumn{3}{|c|}{ PAGE 1146 / 1572} \\
\hline 16 & $X$ 17a & $17 b$ & $17 c$ & $17 d$ & 18 \\
\hline $19 a$ & $19 \mathrm{~b}$ & $20 a$ & $20 \mathrm{~b}$ & $20 c$ & 21 \\
\hline
\end{tabular}

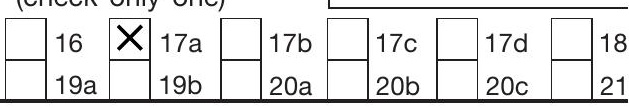

Any information copied from such Reports and Statements may not be sold or used by any person for the purpose of soliciting contributions or for commercial purposes, other than using the name and address of any political committee to solicit contributions from such committee.

NAME OF COMMITTEE (In Full)

\section{Friends of Herman Cain}

A. Full Name (Last, First, Middle Initial)

David Northrup

Mailing Address P.O. Box 82

\begin{tabular}{lcc}
\hline City & State & Zip Code \\
New UIm & TX & $78950-0082$
\end{tabular}

FEC ID number of contributing federal political committee.

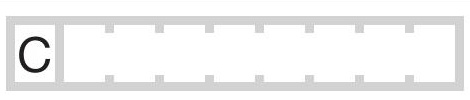

Name of Employer
Richardson \& Dunn Inc.
Receipt For: 2012
X Primary
$\square$ Other (specify)

Occupation

Superintendent

Election Cycle-to-Date

500.00

B. Full Name (Last, First, Middle Initial)

Joseph Nicholson

Mailing Address 1952 Huntington Hall Ct

\begin{tabular}{lcc}
\hline City & State & Zip Code \\
Atlanta & GA & $30338-5713$ \\
\hline
\end{tabular}

FEC ID number of contributing

federal political committee.

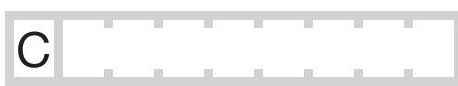

Name of Employer
n/a
Receipt For: 2012
X Primary
Other (specify)

\section{Occupation}

Retired

Election Cycle-to-Date

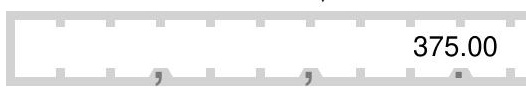

Transaction ID : AEF261D091A344F18A9B

Date of Receipt

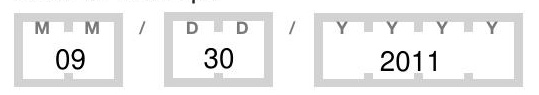

Amount of Each Receipt this Period

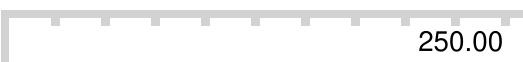

Amount of Each Receipt this Period

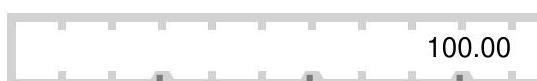

Transaction ID : AF3EE573828B147E784F

Date of Receipt

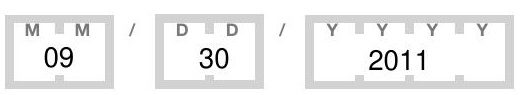

C. Full Name (Last, First, Middle Initial)

Barbara Farmer

Mailing Address 3410 Galt Ocean Drive \#1601N

\begin{tabular}{lcc}
\hline City & State & Zip Code \\
Fort Lauderdale & FL & $33308-7034$
\end{tabular}

FEC ID number of contributing federal political committee.

C

33308-7034

Name of Employer
Information Requested
Receipt For: 2012
X Primary
Other (specify) General

Occupation

Information Requested

Election Cycle-to-Date

Transaction ID : A6015739985B844BEA04 Date of Receipt

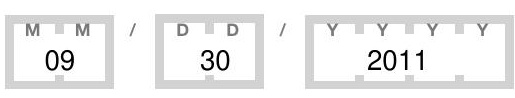

Amount of Each Receipt this Period

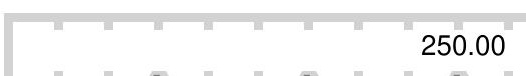

250.00

Subtotal Of Receipts This Page (optional).

600.00

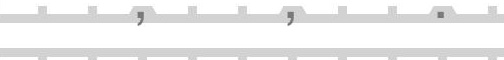

Total This Period (last page this line number only) 


\section{SCHEDULE A-P} ITEMIZED RECEIPTS
Use separate schedule(s)

for each category of the

Detailed Summary Page
FOR LINE NUMBER: (check only one)

Any information or for commercial purposes, other than using the name and address of any political committee to solicit contributions from such committee.

NAME OF COMMITTEE (In Full)

\section{Friends of Herman Cain}

A. Full Name (Last, First, Middle Initial)

Frank P Sproule

Mailing Address 135 Broadmeadow Cv

\begin{tabular}{lcc}
\hline City & State & Zip Code \\
Roswell & GA & $30075-2974$
\end{tabular}

FEC ID number of contributing

federal political committee.

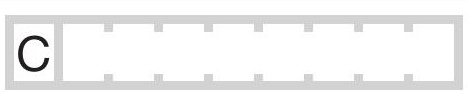

Name of Employer
Information Requested
Receipt For: 2012
X Primary $\quad \square$ General
Other (specify)

Occupation

Information Requested

Election Cycle-to-Date

350.00

Transaction ID : AA7249307B0DE4611948

Date of Receipt

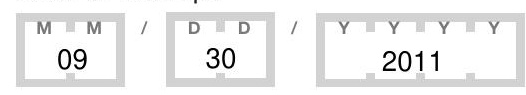

Amount of Each Receipt this Period

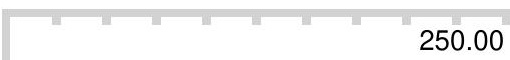

B. Full Name (Last, First, Middle Initial)

cathey parsons

Mailing Address 6115 santa rita rd

\begin{tabular}{lcc}
\hline City & State & Zip Code \\
Templeton & CA & $93465-9071$ \\
\hline
\end{tabular}

FEC ID number of contributing

federal political committee.

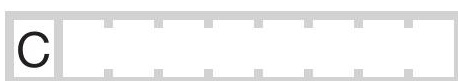

Name of Employer
Information Requested
Receipt For: 2012
X Primary
Other (specify)

\section{Occupation}

Information Requested

Election Cycle-to-Date

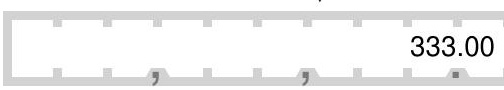

Amount of Each Receipt this Period

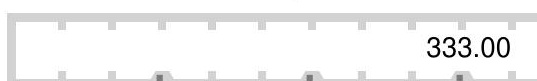

C. Full Name (Last, First, Middle Initial)

Paul Reams

Mailing Address 151 Hubbard Road

\begin{tabular}{lcc}
\hline City & State & Zip Code \\
Woodstock & GA & $30188-5036$
\end{tabular}

FEC ID number of contributing

federal political committee.

C

Name of Employer

Dynamix Group, Inc.

Occupation

Receipt For: 2012

Х $\begin{aligned} & \text { Primary } \square \text { General } \\ & \text { Other (specify) }\end{aligned}$

Director of Sales Support

Election Cycle-to-Date

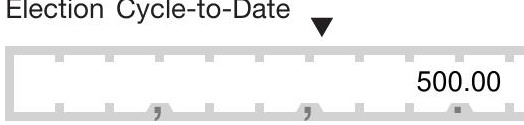

Transaction ID : A1619CBA621364563AED

Date of Receipt

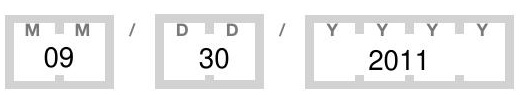

Transaction ID : A1C9B856600064B2F818 Date of Receipt

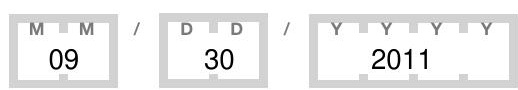

Amount of Each Receipt this Period

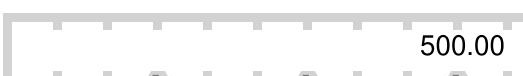

1083.00

Subtotal Of Receipts This Page (optional)

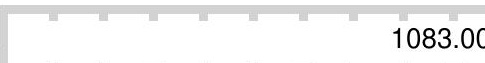

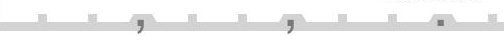

Total This Period (last page this line number only) 


\section{SCHEDULE A-P} ITEMIZED RECEIPTS
Use separate schedule(s) for each category of the Detailed Summary Page

FOR LINE NUMBER:
(check only one)

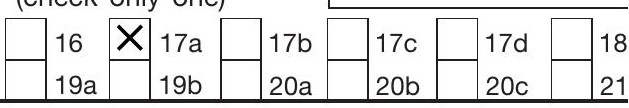

Any information copied from such Reports and Statements may not be sold or used by any person for the purpose of soliciting contributions or for commercial purposes, other than using the name and address of any political committee to solicit contributions from such committee.

NAME OF COMMITTEE (In Full)

\section{Friends of Herman Cain}

A. Full Name (Last, First, Middle Initial)

Ryan Colburn

Mailing Address 1410-A John B White Blvd

\begin{tabular}{lcc}
\hline City & State & Zip Code \\
Spartanburg & SC & 29306 \\
\hline
\end{tabular}

FEC ID number of contributing federal political committee.

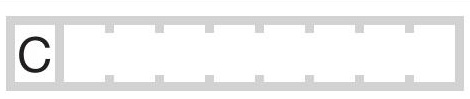

Name of Employer
Colburn and Colburn
Receipt For: 2012
Xrimary $\quad \square$ General
Other (specify)

Occupation Dentist

Election Cycle-to-Date 1000.00

B. Full Name (Last, First, Middle Initial)

Melvin England

Mailing Address 13 Revival St.

\begin{tabular}{llc}
\hline $\begin{array}{l}\text { City } \\
\text { Roswell }\end{array}$ & $\begin{array}{c}\text { State } \\
\text { GA }\end{array}$ & $\begin{array}{c}\text { Zip Code } \\
30075-4801\end{array}$ \\
\hline $\begin{array}{l}\text { FEC ID number of contributing } \\
\text { federal political committee. }\end{array}$ & C & \\
\hline
\end{tabular}

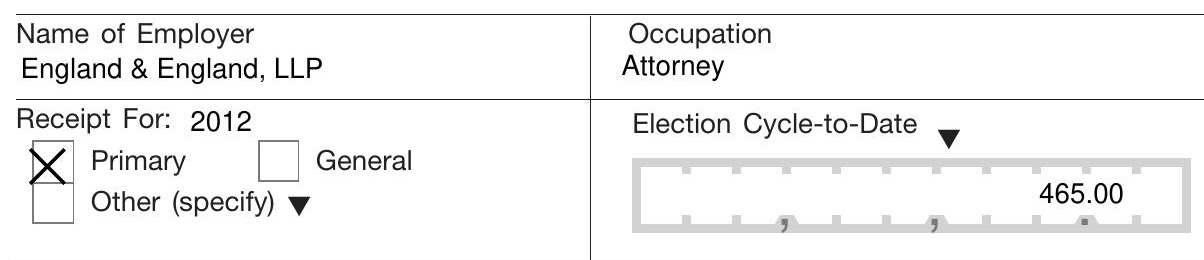

C. Full Name (Last, First, Middle Initial)

Gary R Miller

Mailing Address 3123 Millbank Ln

\begin{tabular}{l|ll}
\hline $\begin{array}{l}\text { City } \\
\text { Franklin }\end{array}$ & $\begin{array}{c}\text { State } \\
\text { TN }\end{array}$ & $\begin{array}{c}\text { Zip Code } \\
37064-4223\end{array}$ \\
\hline $\begin{array}{l}\text { FEC ID number of contributing } \\
\text { federal political committee. }\end{array}$ & C & \\
\hline $\begin{array}{l}\text { Name of Employer } \\
\text { Provident Music Group }\end{array}$ & $\begin{array}{l}\text { Occupation } \\
\text { IT }\end{array}$ \\
\hline $\begin{array}{l}\text { Receipt For: } 2012 \\
\text { Primary } \\
\text { Other (specify) }\end{array}$ & Election Cycle-to-Date & \\
\hline
\end{tabular}

Transaction ID : AC3F0F067A5FA4EF388D

Date of Receipt

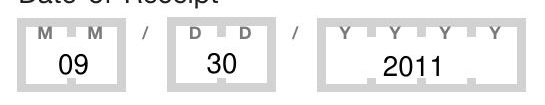

Amount of Each Receipt this Period

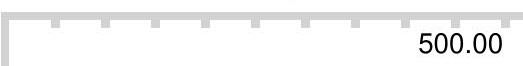

500.00
Amount of Each Receipt this Period

Transaction ID : A0B1A2880BAA54D2886B

Date of Receipt
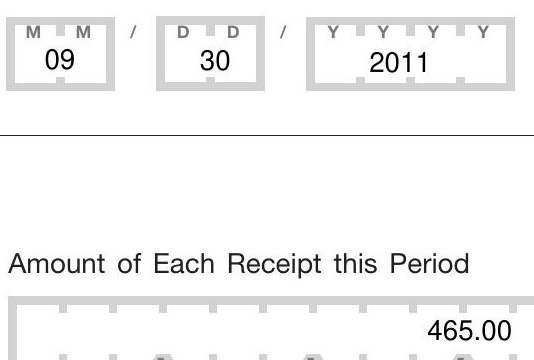

Amount of Each Receipt this Period

Transaction ID : A983625B6A9B74676BF3 Date of Receipt
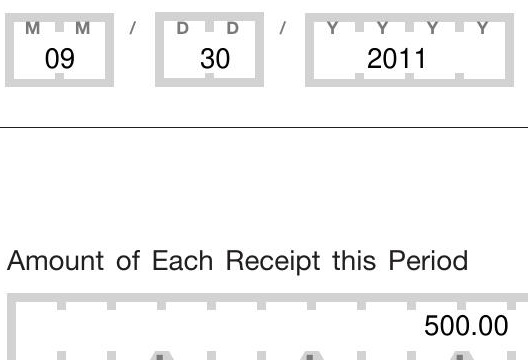

1465.00

Subtotal Of Receipts This Page (optional)

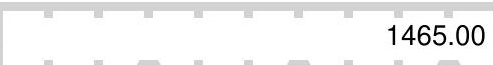

Total This Period (last page this line number only) 


\section{SCHEDULE A-P} ITEMIZED RECEIPTS
Use separate schedule(s)

for each category of the

Detailed Summary Page
FOR LINE NUMBER: (check only one)

Any information or for commercial purposes, other than using the name and address of any political committee to solicit contributions from such committee.

NAME OF COMMITTEE (In Full)

Friends of Herman Cain

A. Full Name (Last, First, Middle Initial)

Richard B Brookfield

Mailing Address 1050 Riverside Dr

\begin{tabular}{lcc}
\hline City & State & Zip Code \\
Lagrange & GA & $30240-9154$ \\
\hline
\end{tabular}

FEC ID number of contributing federal political committee.

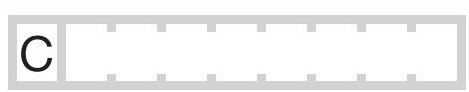

Name of Employer
VWC Construction Company
Receipt For: 2012
X Primary
Other (specify)

Occupation

Construction

Election Cycle-to-Date

550.00

B. Full Name (Last, First, Middle Initial)

Joanna Stinnett

Mailing Address 9637 N 15th Ave

\begin{tabular}{lcc}
\hline City & State & Zip Code \\
Phoenix & AZ & $85021-2103$ \\
\hline
\end{tabular}

FEC ID number of contributing

federal political committee.

C

Name of Employer
Information Requested
Receipt For: 2012
Primary
Other (specify)

Occupation

Information Requested

Election Cycle-to-Date

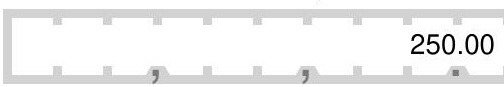

Transaction ID : A2095D5341EC64437856

Date of Receipt

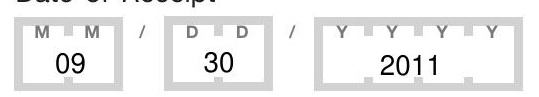

Amount of Each Receipt this Period

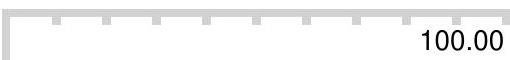

Transaction ID : AE26EACF4040542D49D5

Date of Receipt

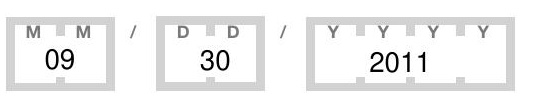

Amount of Each Receipt this Period

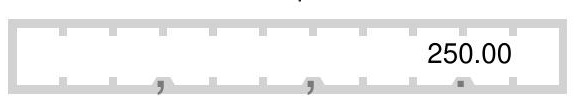

Transaction ID : A3BE1B929C24A4B1FBB8 Date of Receipt

\section{Charles Scott}

Mailing Address 1409 S. W. 135th

\begin{tabular}{lcc}
\hline City & State & Zip Code \\
Oklahoma City & OK & $73170-5115$
\end{tabular}

FEC ID number of contributing federal political committee.

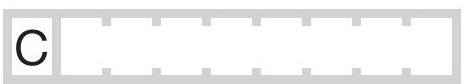

Name of Employer
CGM LLC
Receipt For: 2012
Х Primary $\quad \square$ General
Other (specify)

\section{Occupation}

OWNER

\section{Election Cycle-to-Date}

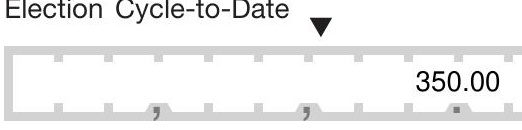

Subtotal Of Receipts This Page (optional)

Amount of Each Receipt this Period

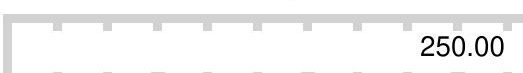

Total This Period (last page this line number only)

600.00

a

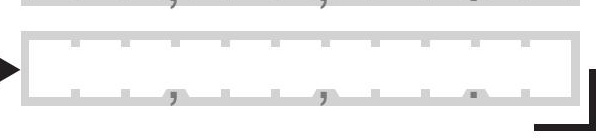

FEC Schedule A-P (Form 3P) (Rev. 03/2011) 


\section{SCHEDULE A-P} ITEMIZED RECEIPTS
Use separate schedule(s)

for each category of the

Detailed Summary Page
FOR LINE NUMBER: (check only one)

Any information or for commercial purposes, other than using the name and address of any political committee to solicit contributions from such committee.

NAME OF COMMITTEE (In Full)

Friends of Herman Cain

A. Full Name (Last, First, Middle Initial)

Jacqueline Lopez

Mailing Address 1596 West 78 Terrace

\begin{tabular}{lcc}
\hline City & State & Zip Code \\
Hialeah & FL & $33014-3350$ \\
\hline
\end{tabular}

FEC ID number of contributing

federal political committee.

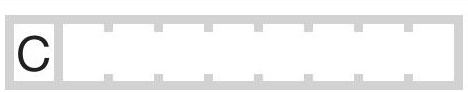

Name of Employer
US Postal Service
Receipt For: 2012
X Primary
$\square$ Other (specify) General

Occupation

Letter Carrier

Election Cycle-to-Date

240.00

B. Full Name (Last, First, Middle Initial)

James Ditto

Mailing Address 5986 Randy Ln

\begin{tabular}{lcc}
\hline City & State & Zip Code \\
Ellenwood & GA & $30294-4016$
\end{tabular}

FEC ID number of contributing

federal political committee.

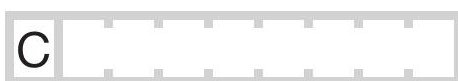

Name of Employer
Symcor
Receipt For: 2012
X Primary
Other (specify)

Occupation

Data Entry Clerk

Election Cycle-to-Date

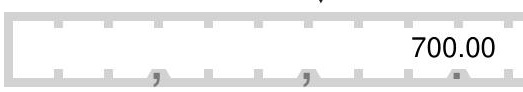

C. Full Name (Last, First, Middle Initial)

Jody Noland

Mailing Address 625 Willow Knoll Drive SE

\begin{tabular}{lcc}
\hline City & State & Zip Code \\
Marietta & GA & $30067-4649$ \\
\hline
\end{tabular}

FEC ID number of contributing

federal political committee.

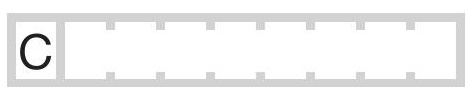

Name of Employer
None
Receipt For: 2012
Х Primary $\quad \square$ General
Other (specify)

Occupation

Homemaker

Election Cycle-to-Date

Transaction ID : A32A97A4DE8934D09988

Date of Receipt

Amount of Each Receipt this Period

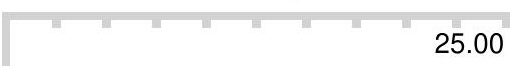

25.00

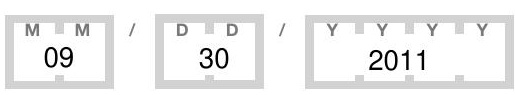

Amount of Each Receipt this Period

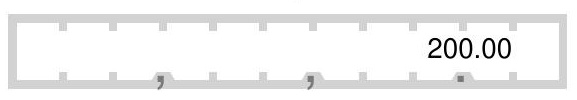

Transaction ID : A2DCC9B1EB9E0483FB58 Date of Receipt

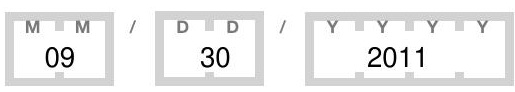

Amount of Each Receipt this Period

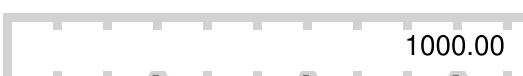

1000.00

\section{Subtotal Of Receipts This Page (optional)}

Total This Period (last page this line number only) 


\section{SCHEDULE A-P} ITEMIZED RECEIPTS
Use separate schedule(s)

for each category of the

Detailed Summary Page
FOR LINE NUMBER: (check only one)

Any information or for commercial purposes, other than using the name and address of any political committee to solicit contributions from such committee.

NAME OF COMMITTEE (In Full)

\section{Friends of Herman Cain}

A. Full Name (Last, First, Middle Initial)

\section{Elizabeth Reh}

Mailing Address 15483 Clayton Rd.

\begin{tabular}{lcc}
\hline City & State & Zip Code \\
Saint Louis & MO & 63128
\end{tabular}

FEC ID number of contributing federal political committee.

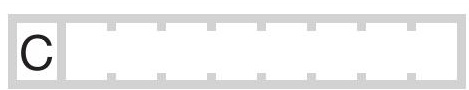

\section{Name of Employer}

Fortel's of Creve Coeur Inc.

Occupation

Elizabeth Reh

Receipt For: 2012 Х Primary $\square$ General
Election Cycle-to-Date $\boldsymbol{V}$

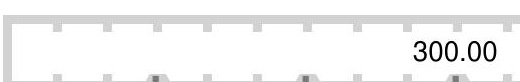

B. Full Name (Last, First, Middle Initial)

Robert Sheldon

Mailing Address 1485 Rucker Circle

\begin{tabular}{lcc}
\hline City & State & Zip Code \\
Woodstock & GA & $30188-2133$ \\
\hline
\end{tabular}

FEC ID number of contributing

federal political committee.

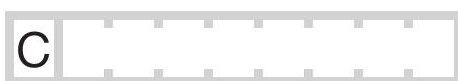

Name of Employer
None
Receipt For: 2012
X Primary
Other (specify)

\section{Occupation}

Retired

Election Cycle-to-Date

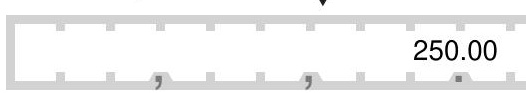

Transaction ID : ADFEC434B87004C3DA85

Date of Receipt

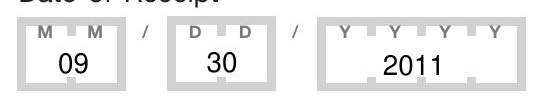

Amount of Each Receipt this Period

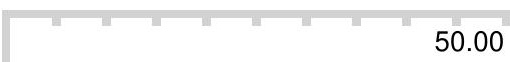

50.00

C. Full Name (Last, First, Middle Initial)

Erica Coyle

Mailing Address 205 Scottsdale Blvd

\begin{tabular}{lcc}
\hline City & State & Zip Code \\
Louisville & KY & $40214-4742$
\end{tabular}

FEC ID number of contributing federal political committee.

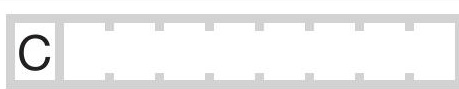

Name of Employer

St Mary's \& Elizabeth Hospital

Receipt For: 2012

Х $\begin{aligned} & \text { Primary } \square \text { General } \\ & \text { Other (specify) }\end{aligned}$

\section{Occupation}

Registered Nurse

Election Cycle-to-Date

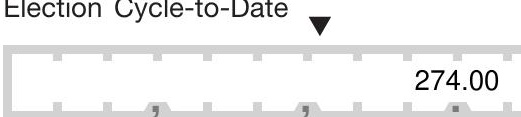

Transaction ID : A8E6DA8E4BA234A01B17 Date of Receipt

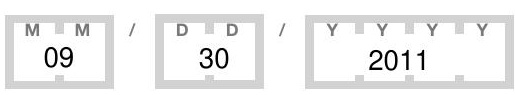

Amount of Each Receipt this Period

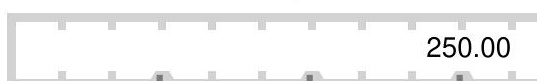

Transaction ID : A858D39AB0E464DC6A8A Date of Receipt

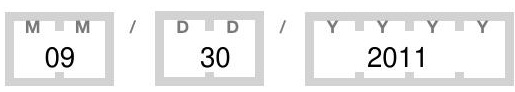

Amount of Each Receipt this Period

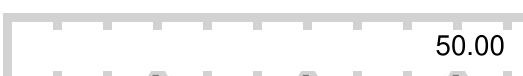

\section{Subtotal Of Receipts This Page (optional)}

Total This Period (last page this line number only) 
SCHEDULE A-P ITEMIZED RECEIPTS
Use separate schedule(s) for each category of the Detailed Summary Page
FOR LINE NUMBER: (check only one)

Any information copied from such Repors or for commercial purposes, other than using the name and address of any political committee to solicit contributions from such committee.

NAME OF COMMITTEE (In Full)

\section{Friends of Herman Cain}

A. Full Name (Last, First, Middle Initial)

Pat Peek

Mailing Address 1829 Hwy. 36 W, PO Box 5

\begin{tabular}{lcc}
\hline City & State & Zip Code \\
Jackson & GA & $30233-0001$
\end{tabular}

FEC ID number of contributing

federal political committee.

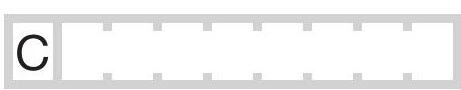

Name of Employer
PEP Inc.
Receipt For: 2012
X Primary $\quad \square$ General
Other (specify)

Occupation

Business Owner

Election Cycle-to-Date

350.00

B. Full Name (Last, First, Middle Initial)

EDWARD MURPHY

Mailing Address 214 CAMINO VISTA REAL

\begin{tabular}{lcc}
\hline City & State & Zip Code \\
Chula Vista & CA & $91910-6326$
\end{tabular}

FEC ID number of contributing

federal political committee.

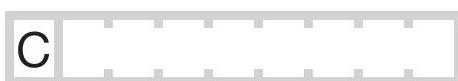

Name of Employer
navy exchange
Receipt For: 2012
Primary
Other (specify)

Occupation

Retired

Election Cycle-to-Date

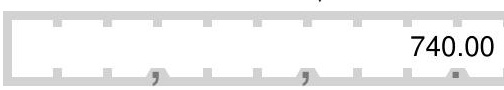

Transaction ID : AD4A4516C3EFF4559B97

Date of Receipt

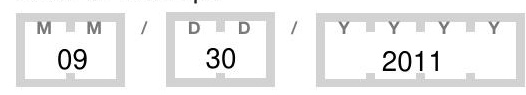

Amount of Each Receipt this Period

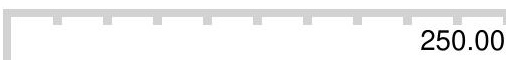

C. Full Name (Last, First, Middle Initial)

Nels Nelson

Mailing Address 302 Canton St. P.O.B. 123

\begin{tabular}{lcc}
\hline City & State & Zip Code \\
Woosung & IL & $61091-0123$
\end{tabular}

FEC ID number of contributing federal political committee.

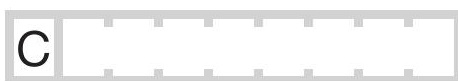

$\begin{aligned} & \text { Name of Employer } \\ & \text { self }\end{aligned}$
Receipt For: 2012
X Primary $\square$ General
Other (specify)

Occupation

Retired

Election Cycle-to-Date

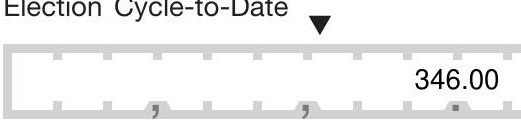

Amount of Each Receipt this Period

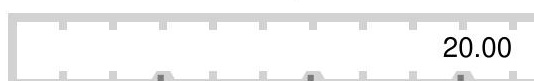

Transaction ID : AFF63CC27148B4BD1A45

Date of Receipt

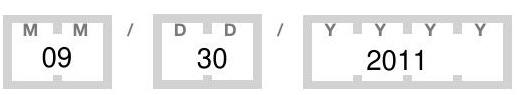

Transaction ID : AACCF3CF5D9B049D3A4B Date of Receipt

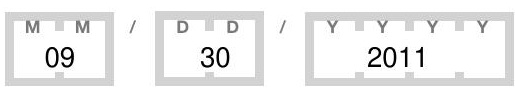

Amount of Each Receipt this Period

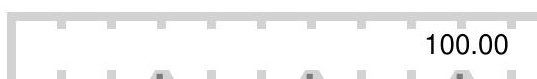

\section{Subtotal Of Receipts This Page (optional)}

Total This Period (last page this line number only) $+\quad 370.00$

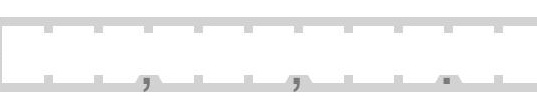

FEC Schedule A-P (Form 3P) (Rev. 03/2011) 
SCHEDULE A-P ITEMIZED RECEIPTS
Use separate schedule(s) for each category of the Detailed Summary Page
FOR LINE NUMBER: (check only one)
PAGE $1153 / 1572$

\begin{tabular}{|c|c|c|c|c|c|}
\hline & & & & & \\
\hline 16 & $\begin{array}{lll}X & 17 a \\
\end{array}$ & $17 \mathrm{~b}$ & $17 c$ & $17 d$ & 18 \\
\hline $19 a$ & $19 b$ & $20 a$ & $20 \mathrm{~b}$ & $20 c$ & 21 \\
\hline
\end{tabular}

Any information copied from such Reports and Statements may not be sold or used by any person for the purpose of soliciting contributions or for commercial purposes, other than using the name and address of any political committee to solicit contributions from such committee.

NAME OF COMMITTEE (In Full)

\section{Friends of Herman Cain}

A. Full Name (Last, First, Middle Initial)

Mr. John R Morris

Mailing Address 762 Acorn St

\begin{tabular}{lcc}
\hline City & State & Zip Code \\
Giddings & TX & $78942-4440$ \\
\hline
\end{tabular}

FEC ID number of contributing federal political committee.

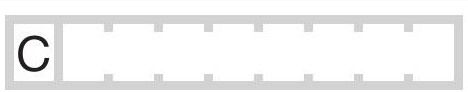

Name of Employer
None
Receipt For: 2012
X Primary $\quad$ General
Other (specify)

Occupation

Retired

Election Cycle-to-Date

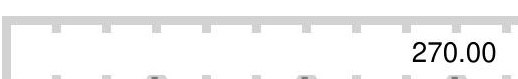

B. Full Name (Last, First, Middle Initial)

K. Kotter

Mailing Address 1680 Moliton Rd.

\begin{tabular}{lcc}
\hline City & State & Zip Code \\
Belmont & CA & $94002-3716$
\end{tabular}

FEC ID number of contributing

federal political committee.

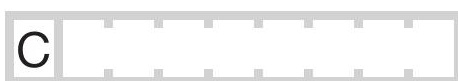

Name of Employer
Not Employed
Receipt For: 2012
X Primary
Other (specify)

\section{Occupation}

Not Employed

Election Cycle-to-Date

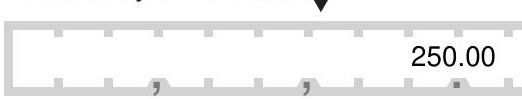

C. Full Name (Last, First, Middle Initial)

Blanche McFarland

Mailing Address 1403 Moores Mill Rd.

\begin{tabular}{lcc}
\hline City & State & Zip Code \\
Rougemont & NC & $27572-9648$
\end{tabular}

FEC ID number of contributing

federal political committee.

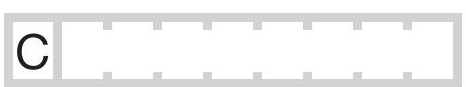

Name of Employer

Self Employed

Occupation

Receipt For: 2012

Х $\begin{aligned} & \text { Primary } \square \text { General } \\ & \text { Other (specify) }\end{aligned}$

farmer

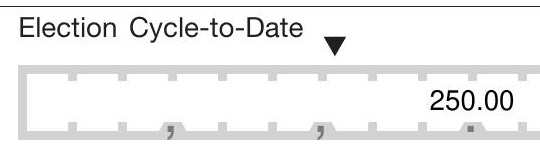

Amount of Each Receipt this Period

Transaction ID : A6FDEB23C49904F1A97F

Date of Receipt

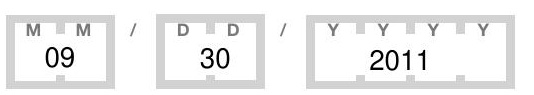

Amount of Each Receipt this Period
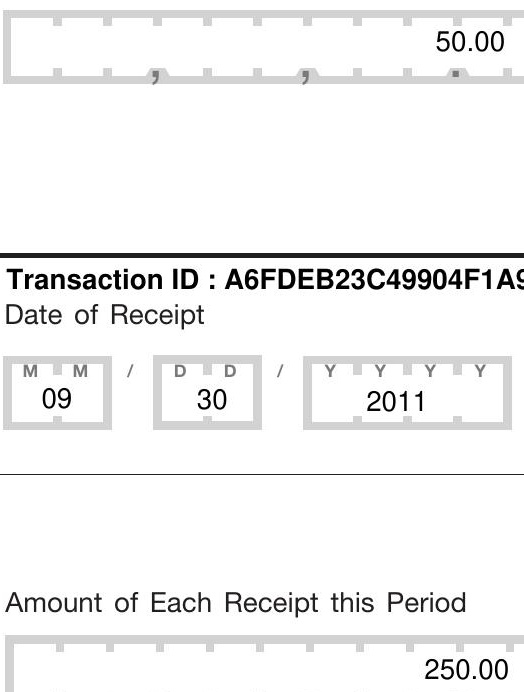

Transaction ID : A1E62F9899B33452F8B3

Date of Receipt

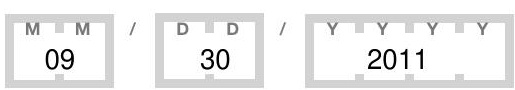

Amount of Each Receipt this Period

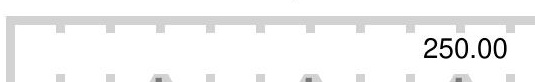

550.00

Subtotal Of Receipts This Page (optional)

Total This Period (last page this line number only) 
SCHEDULE A-P ITEMIZED RECEIPTS
Use separate schedule(s) for each category of the Detailed Summary Page
FOR LINE NUMBER: (check only one)

Any information or for commercial purposes, other than using the name and address of any political committee to solicit contributions from such committee.

NAME OF COMMITTEE (In Full)

\section{Friends of Herman Cain}

A. Full Name (Last, First, Middle Initial)

frederick fox

Mailing Address 261 Kenwood Rd

\begin{tabular}{lcc}
\hline City & State & Zip Code \\
Chambersburg & PA & $17201-1259$
\end{tabular}

FEC ID number of contributing federal political committee.

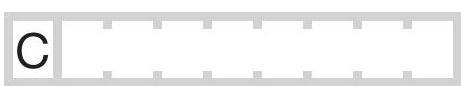

Name of Employer
Information Requested
Receipt For: 2012
X Primary
Other (specify) General

Occupation Information Requested

Election Cycle-to-Date

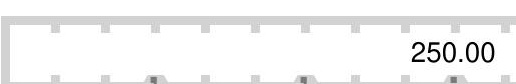

B. Full Name (Last, First, Middle Initial) James Cremins

Mailing Address 170 Marcellus Way

\begin{tabular}{lcc}
\hline City & State & Zip Code \\
Clayton & NC & $27527-5501$
\end{tabular}

FEC ID number of contributing

federal political committee.

C

Name of Employer
Information Requested
Receipt For: 2012
X Primary
Other (specify)

\section{Occupation}

Information Requested

Election Cycle-to-Date

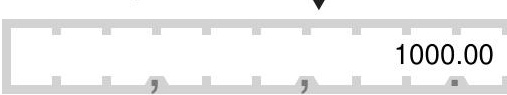

Transaction ID : AC4ECF4A9DBE04C6C9DC

Date of Receipt

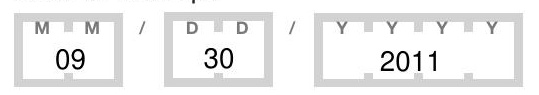

Amount of Each Receipt this Period

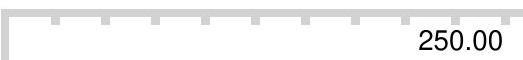

Amount of Each Receipt this Period

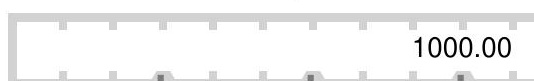

C. Full Name (Last, First, Middle Initial)

William Blanton

Mailing Address 2951 Jefferson Davis Hwy

\begin{tabular}{lcc}
\hline City & State & Zip Code \\
Stafford & VA & $22554-1729$
\end{tabular}

FEC ID number of contributing federal political committee.

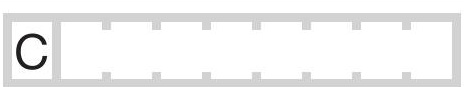

Name of Employer

Information Requested

Occupation

Receipt For: 2012

Х $\begin{aligned} & \text { Primary } \square \text { General } \\ & \text { Other (specify) }\end{aligned}$

Information Requested

Election Cycle-to-Date

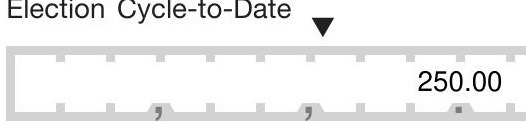

Transaction ID : ACCB94AED244E45D5A52 Date of Receipt

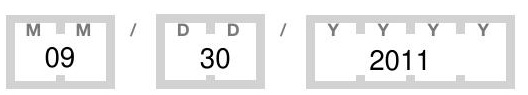

Transaction ID : A99F8094D2CB34353ABF Date of Receipt

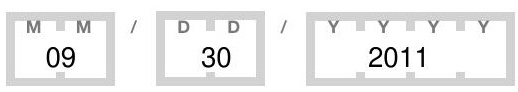

Amount of Each Receipt this Period

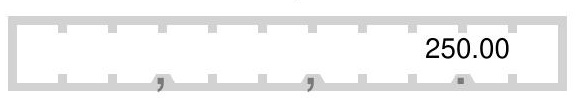

Subtotal Of Receipts This Page (optional).

1500.00

Total This Period (last page this line number only) 
SCHEDULE A-P ITEMIZED RECEIPTS
Use separate schedule(s) for each category of the Detailed Summary Page
FOR LINE NUMBER: (check only one)

Any information or for commercial purposes, other than using the name and address of any political committee to solicit contributions from such committee.

NAME OF COMMITTEE (In Full)

\section{Friends of Herman Cain}

A. Full Name (Last, First, Middle Initial)

Collin King

Mailing Address 901 Persimmon Place

\begin{tabular}{lcc}
\hline City & State & Zip Code \\
Birmingham & AL & $35226-5101$
\end{tabular}

FEC ID number of contributing

federal political committee.

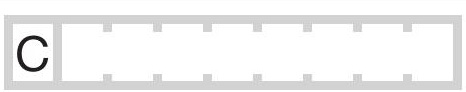

Name of Employer
Information Requested
Receipt For: 2012
X Primary $\quad \square$ General
Other (specify)

Occupation

Information Requested

Election Cycle-to-Date

250.00

B. Full Name (Last, First, Middle Initial)

Reginald Strickland

Mailing Address 3020 Queens Ct.

\begin{tabular}{lcc}
\hline City & State & Zip Code \\
Norcross & GA & $30071-2061$ \\
\hline
\end{tabular}

FEC ID number of contributing

federal political committee.

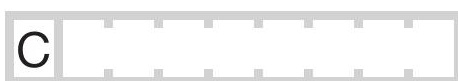

Name of Employer

Strickland General Agency Inc.

Occupation

Receipt For: 2012

Х Primary $\square$ General

Insurance

Election Cycle-to-Date

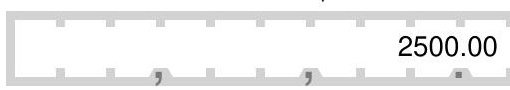

C. Full Name (Last, First, Middle Initial)

Earl Williams

Mailing Address 13505 Peseta Ct

\begin{tabular}{lcc}
\hline City & State & Zip Code \\
Corpus Christi & TX & $78418-6932$ \\
\hline
\end{tabular}

FEC ID number of contributing

federal political committee.

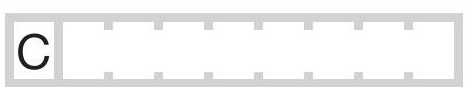

Name of Employer

Retired

Receipt For: 2012

Х $\begin{aligned} & \text { Primary } \square \text { General } \\ & \text { Other (specify) }\end{aligned}$

\section{Occupation}

Information Requested

Election Cycle-to-Date

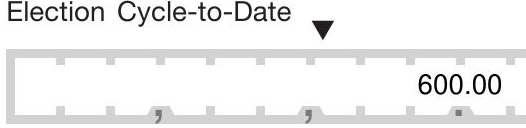

Transaction ID : A552EC0CCC1544300B32

Date of Receipt

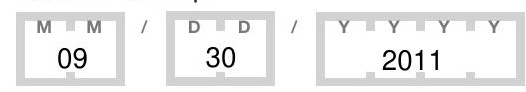

Amount of Each Receipt this Period

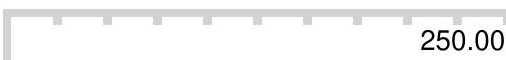

250.00

Transaction ID : AA7045BC40C4A49B8B46

Date of Receipt

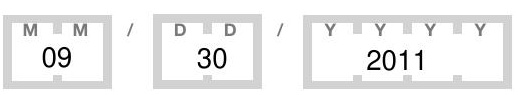

Amount of Each Receipt this Period

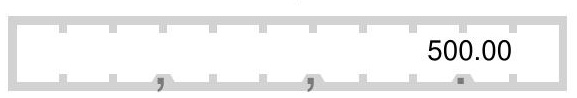

Transaction ID : AD071E3A78E9B4BCBBE9 Date of Receipt

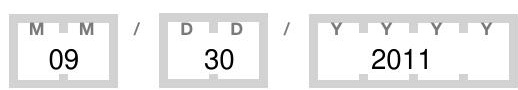

Amount of Each Receipt this Period

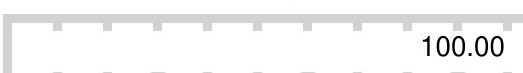

100.00

\section{Subtotal Of Receipts This Page (optional)}

Total This Period (last page this line number only) 
SCHEDULE A-P ITEMIZED RECEIPTS
Use separate schedule(s) for each category of the Detailed Summary Page
FOR LINE NUMBER: (check only one)
PAGE $1156 / 1572$

\begin{tabular}{|c|c|c|c|c|c|}
\hline & & & & & \\
\hline 16 & $\begin{array}{ll}\mathbf{X} & 17 a \\
\end{array}$ & $17 \mathrm{~b}$ & $17 c$ & $17 d$ & 18 \\
\hline $19 a$ & $19 b$ & $20 \mathrm{a}$ & $20 \mathrm{~b}$ & $20 c$ & 21 \\
\hline
\end{tabular}

Any information copied from such Reports and Statements may not be sold or used by any person for the purpose of soliciting contributions or for commercial purposes, other than using the name and address of any political committee to solicit contributions from such committee.

NAME OF COMMITTEE (In Full)

\section{Friends of Herman Cain}

A. Full Name (Last, First, Middle Initial)

\section{B.P. Niblack \\ Mailing Address 14311 Perkins Rd.}

\begin{tabular}{lcc}
\hline City & State & Zip Code \\
Woodstock & IL & $60098-7368$
\end{tabular}

FEC ID number of contributing federal political committee.

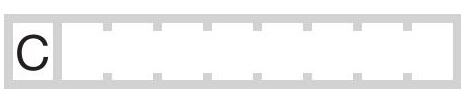

Name of Employer
Information Requested
Receipt For: 2012
X Primary $\quad \square$ General
Other (specify)

B. Full Name (Last, First, Middle Initial)

Matthew Wills

Mailing Address PO Box 67474

\begin{tabular}{lcc}
\hline City & State & Zip Code \\
Topeka & KS & $66667-0474$ \\
\hline
\end{tabular}

FEC ID number of contributing

federal political committee.

C

Name of Employer
Information Requested
Receipt For: 2012
X Primary
Other (specify)

Occupation Information Requested

Election Cycle-to-Date

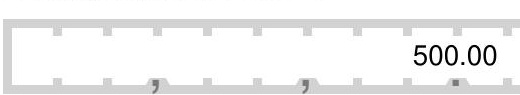

Transaction ID : A066CA1D12BB344F0853

Date of Receipt

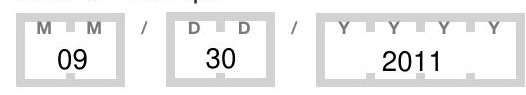

Amount of Each Receipt this Period

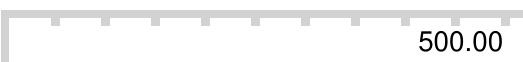

Amount of Each Receipt this Period

Occupation
Information Requested
Election Cycle-to-Date

Transaction ID : A12522D1C5F8C4F2E857 Date of Receipt

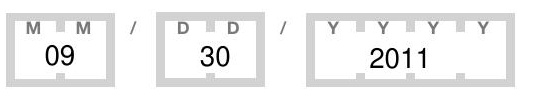

C. Full Name (Last, First, Middle Initial)

Derrick Herbst

Mailing Address 417 Old Carrington Pkwy

\begin{tabular}{lcc}
\hline City & State & Zip Code \\
Lexington & SC & $29072-7176$
\end{tabular}

FEC ID number of contributing federal political committee.

C

Name of Employer
Vendavo, Inc.
Receipt For: 2012
Primary
Other (specify) General

Occupation

Software Sales

Election Cycle-to-Date

Transaction ID : A67B63AC5E5BD4663AAA Date of Receipt

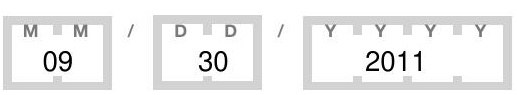

Amount of Each Receipt this Period

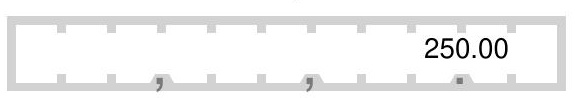

Subtotal Of Receipts This Page (optional).

1000.00

Total This Period (last page this line number only) 


\section{SCHEDULE A-P} ITEMIZED RECEIPTS
Use separate schedule(s) for each category of the Detailed Summary Page

FOR LINE NUMBER:
(check only one)

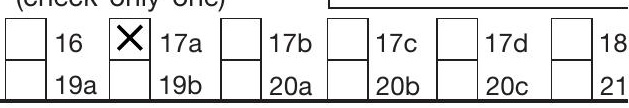

Any information copied from such Reports and Statements may not be sold or used by any person for the purpose of soliciting contributions or for commercial purposes, other than using the name and address of any political committee to solicit contributions from such committee.

NAME OF COMMITTEE (In Full)

\section{Friends of Herman Cain}

A. Full Name (Last, First, Middle Initial)

Andrey Makarevich

Mailing Address 8031 Dartmouth Rd

\begin{tabular}{lcc}
\hline City & State & Zip Code \\
Indianapolis & IN & $46260-2820$
\end{tabular}

FEC ID number of contributing federal political committee.

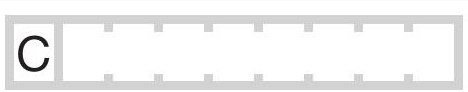

Name of Employer
capital city container
Receipt For: 2012
X Primary
Other (specify) General

Occupation machine operator

Election Cycle-to-Date 250.00

B. Full Name (Last, First, Middle Initial) Carol Peterson

Mailing Address 44 School St

\begin{tabular}{lcc}
\hline City & State & Zip Code \\
Old Orchard Beach & ME & 04064-2214
\end{tabular}

FEC ID number of contributing

federal political committee.

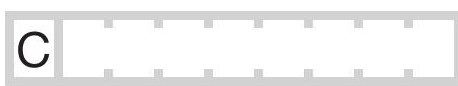

Name of Employer
Retired
Receipt For: 2012
X Primary
Other (specify)

\section{Occupation}

Retired

Election Cycle-to-Date

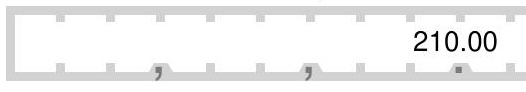

C. Full Name (Last, First, Middle Initial)

Timothy Mellon

Mailing Address PO Box 1500

\begin{tabular}{lcc}
\hline City & State & Zip Code \\
Saratoga & WY & $82331-1500$
\end{tabular}

FEC ID number of contributing federal political committee.

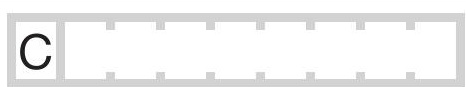

Name of Employer
Information Requested
Receipt For: 2012
X Primary
Other (specify) General

Transaction ID : A8510692A15184A08B5B

Date of Receipt

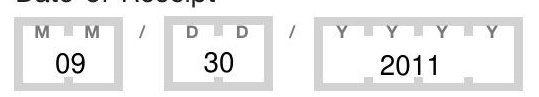

Amount of Each Receipt this Period

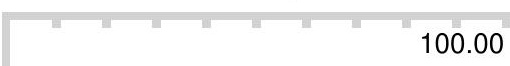

100.00
Amount of Each Receipt this Period

Transaction ID : ABF78F1D4DD4E4D18B5C Date of Receipt
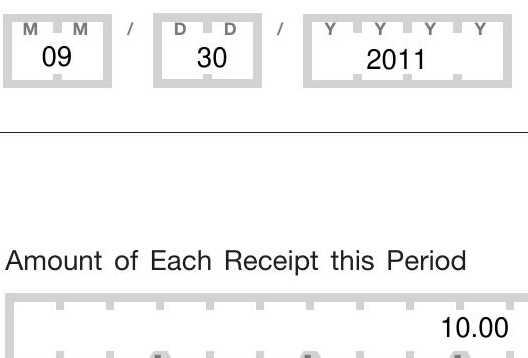

Transaction ID : A7F214BF92AF145A8821

Date of Receipt

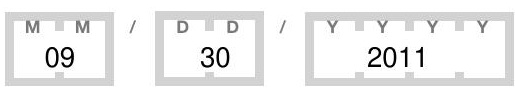

Amount of Each Receipt this Period

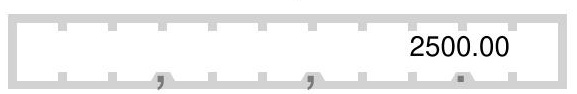

$$
\begin{aligned}
& \begin{array}{l}
\text { Occupation } \\
\text { Information Requested }
\end{array} \\
& \text { Election Cycle-to-Date } \\
&
\end{aligned}
$$

\section{Subtotal Of Receipts This Page (optional)}

2610.00

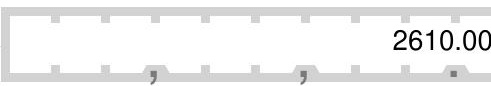

Total This Period (last page this line number only)

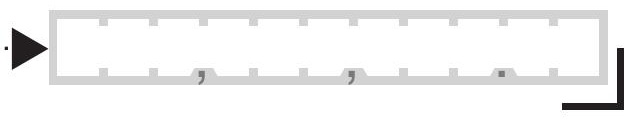

FEC Schedule A-P (Form 3P) (Rev. 03/2011) 


\section{SCHEDULE A-P} ITEMIZED RECEIPTS
Use separate schedule(s)

for each category of the

Detailed Summary Page
FOR LINE NUMBER: (check only one)

Any information or for commercial purposes, other than using the name and address of any political committee to solicit contributions from such committee.

NAME OF COMMITTEE (In Full)

\section{Friends of Herman Cain}

A. Full Name (Last, First, Middle Initial)

Robert Stern

Mailing Address 2639 Lochleven Way

\begin{tabular}{lcc}
\hline City & State & Zip Code \\
Henderson & NV & $89044-4409$
\end{tabular}

FEC ID number of contributing

federal political committee.

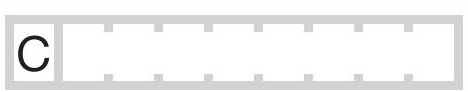

Name of Employer
Information Requested
Receipt For: 2012
X Primary $\quad \square$ General
Other (specify)

Occupation

Information Requested

Election Cycle-to-Date

250.00

B. Full Name (Last, First, Middle Initial)

Wayne Thomas

Mailing Address 1533 Clark Avenue

\begin{tabular}{lcc}
\hline City & State & Zip Code \\
Cottage Grove & OR & $97424-1891$
\end{tabular}

FEC ID number of contributing

federal political committee.

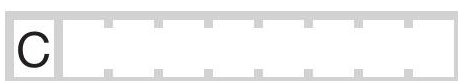

Name of Employer
PeaceHealth Laboratories
Receipt For: 2012
X Primary
Other (specify)

\section{Occupation}

courier

Election Cycle-to-Date

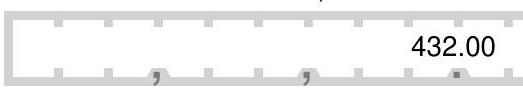

Transaction ID : A1D734CB8DEAD4250B54

Date of Receipt

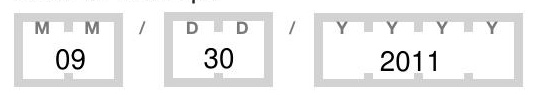

Amount of Each Receipt this Period

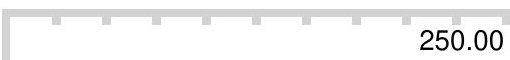

Amount of Each Receipt this Period

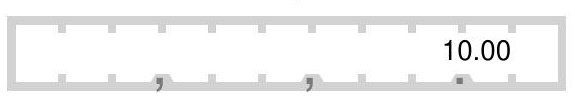

C. Full Name (Last, First, Middle Initial)

Jane Siebels

Mailing Address 139 Sunrise Ave. Apt. 408

\begin{tabular}{lcc}
\hline City & State & Zip Code \\
Palm Beach & FL & $33480-3936$
\end{tabular}

FEC ID number of contributing

federal political committee.

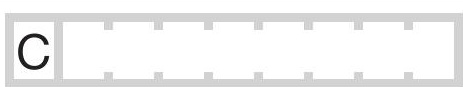

Name of Employer

Information Requested

Occupation

Information Requested

Receipt For: 2012

Х $\begin{aligned} & \text { Primary } \square \text { General } \\ & \text { Other (specify) }\end{aligned}$

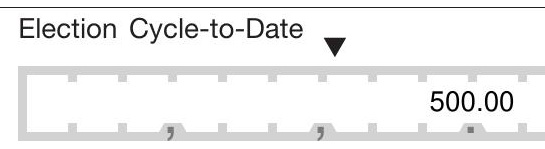

Amount of Each Receipt this Period

Transaction ID : A8E2A19068DB54D21BD5 Date of Receipt
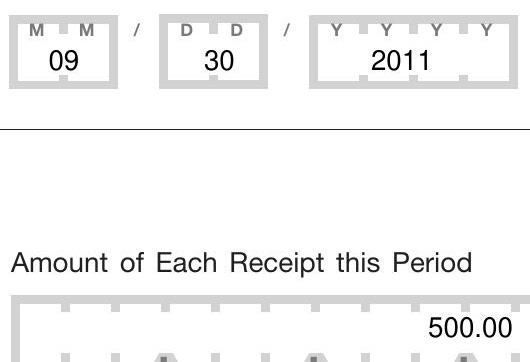

760.00

Subtotal Of Receipts This Page (optional)

Total This Period (last page this line number only) 


\section{SCHEDULE A-P} ITEMIZED RECEIPTS
Use separate schedule(s) for each category of the Detailed Summary Page
FOR LINE NUMBER: (check only one)
PAGE $1159 / 1572$

\begin{tabular}{|c|c|c|c|c|c|}
\hline & & & & & \\
\hline 16 & $\mathbf{X} 17 a$ & $17 b$ & $17 c$ & $17 d$ & 18 \\
\hline $19 a$ & $19 b$ & $20 \mathrm{a}$ & $20 \mathrm{~b}$ & $20 \mathrm{c}$ & 21 \\
\hline
\end{tabular}

Any information copied from such Reports and Statements may not be sold or used by any person for the purpose of soliciting contributions or for commercial purposes, other than using the name and address of any political committee to solicit contributions from such committee.

NAME OF COMMITTEE (In Full)

Friends of Herman Cain

A. Full Name (Last, First, Middle Initial)

Cornell Sinclair

Mailing Address 17206 Huntington Circle

\begin{tabular}{lcc}
\hline City & State & Zip Code \\
Grayslake & IL & $60030-3000$ \\
\hline
\end{tabular}

FEC ID number of contributing

federal political committee.

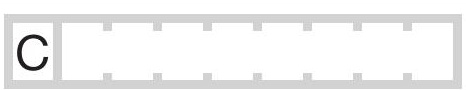

Name of Employer

Primerica Financial Services

Occupation

Receipt For: 2012

X Primary $\square$ General

Other (specify)

Financial Service Representative

Transaction ID : A2D0A419EED3F4C9D8F0

Date of Receipt

$\begin{array}{ccc}M-M & -1\end{array}$

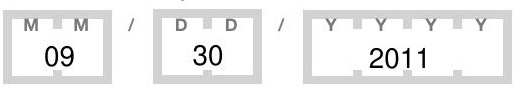

Election Cycle-to-Date $\boldsymbol{\nabla}$

\subsection{0}

B. Full Name (Last, First, Middle Initial)

George Mckerrow

Mailing Address 3915 The Highlands NW

\begin{tabular}{lcc}
\hline City & State & Zip Code \\
Atlanta & GA & $30327-3620$ \\
\hline
\end{tabular}

FEC ID number of contributing

federal political committee.

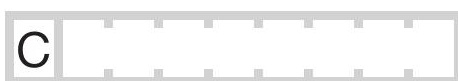

Name of Employer
Information Requested
Receipt For: 2012
X Primary
Other (specify)

Occupation

Information Requested

Election Cycle-to-Date

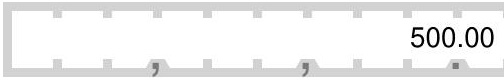

C. Full Name (Last, First, Middle Initial)

Fred Baker

Mailing Address 629 Driftwood Dr

\begin{tabular}{lcc}
\hline City & State & Zip Code \\
Woodstock & GA & $30189-5405$
\end{tabular}

FEC ID number of contributing

federal political committee.

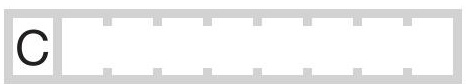

Name of Employer
AT\&T
Receipt For: 2012
X Primary

Other (specify) General

\section{Occupation}

contractor

Election Cycle-to-Date

Transaction ID : AC22790DC5AEE41B0B44

Date of Receipt

Amount of Each Receipt this Period

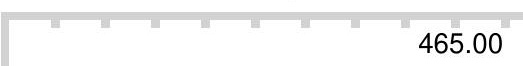

465.00

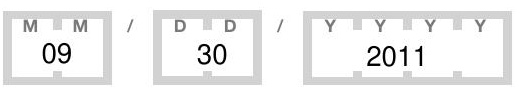

Amount of Each Receipt this Period

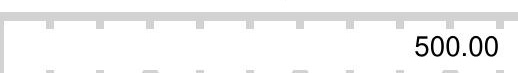

Transaction ID : AB668988639AE4510AEF

Date of Receipt

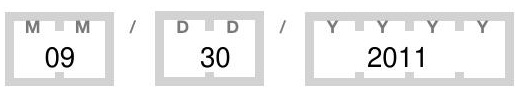

Amount of Each Receipt this Period

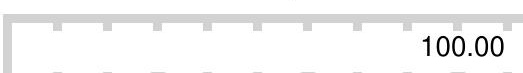

450.00

\section{Subtotal Of Receipts This Page (optional)}

1065.00

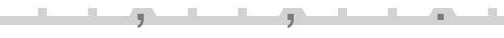

Total This Period (last page this line number only)

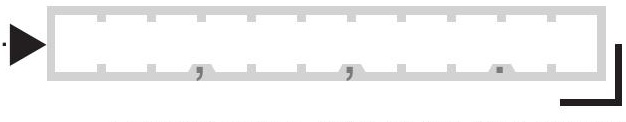

FEC Schedule A-P (Form 3P) (Rev. 03/2011) 


\section{SCHEDULE A-P} ITEMIZED RECEIPTS
Use separate schedule(s)

for each category of the

Detailed Summary Page
FOR LINE NUMBER: (check only one)

Any information or for commercial purposes, other than using the name and address of any political committee to solicit contributions from such committee.

NAME OF COMMITTEE (In Full)

Friends of Herman Cain

A. Full Name (Last, First, Middle Initial)

Timothy Egly

Mailing Address 3294 St Rt W

\begin{tabular}{lcc}
\hline City & State & Zip Code \\
Mountain View & MO & 65548 \\
\hline
\end{tabular}

FEC ID number of contributing

federal political committee.

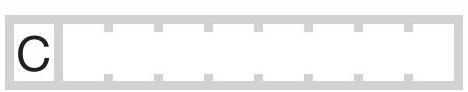

Name of Employer
Information Requested
Receipt For: 2012
X Primary $\quad \square$ General
Other (specify)

Occupation

Information Requested

Election Cycle-to-Date

465.00

B. Full Name (Last, First, Middle Initial)

James Childress

Mailing Address 911 Bandera Ct

\begin{tabular}{lcc}
\hline City & State & Zip Code \\
Allen & TX & $75013-1135$ \\
\hline
\end{tabular}

FEC ID number of contributing

federal political committee.

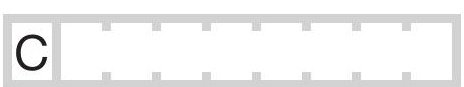

Name of Employer

James M CHildress Consulting, LLC

Occupation

Receipt For: 2012

$\chi \begin{aligned} & \text { Primary } \\ & \text { Other (specify) }\end{aligned}$

Owner

Election Cycle-to-Date

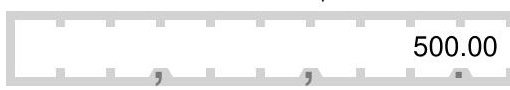

C. Full Name (Last, First, Middle Initial)

donna hester

Mailing Address 481 gray road

\begin{tabular}{lcc}
\hline City & State & Zip Code \\
Ward & AR & $72176-8997$
\end{tabular}

FEC ID number of contributing

federal political committee.

C

Name of Employer

Information Requested

Occupation

Information Requested

Receipt For: 2012

Х $\begin{aligned} & \text { Primary } \square \text { General } \\ & \text { Other (specify) }\end{aligned}$

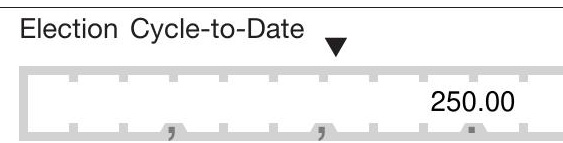

Transaction ID : A598CA8CF7153461DB38

Date of Receipt

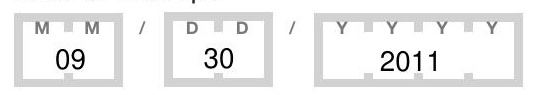

Amount of Each Receipt this Period

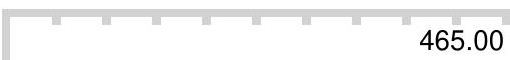

465.00

Transaction ID : A9B6C0923355D4D2993C

Date of Receipt

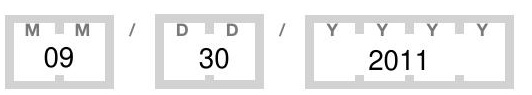

Amount of Each Receipt this Period

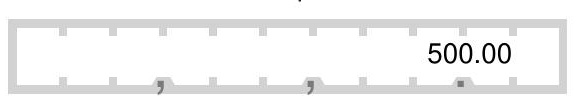

Transaction ID : A9F43F478A6EF45BD874

Date of Receipt

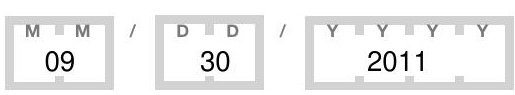

Amount of Each Receipt this Period

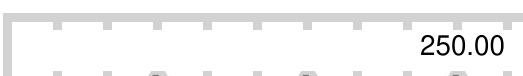

250.00

Subtotal Of Receipts This Page (optional).

1215.00

Total This Period (last page this line number only) 


\section{SCHEDULE A-P} ITEMIZED RECEIPTS
Use separate schedule(s)

for each category of the

Detailed Summary Page
FOR LINE NUMBER: (check only one)

Any information or for commercial purposes, other than using the name and address of any political committee to solicit contributions from such committee.

NAME OF COMMITTEE (In Full)

Friends of Herman Cain

A. Full Name (Last, First, Middle Initial)

Leigh Sanderson

Mailing Address 23002 Rosewood Trail

\begin{tabular}{lcc}
\hline City & State & Zip Code \\
Tomball & TX & $77377-3549$
\end{tabular}

FEC ID number of contributing

federal political committee.

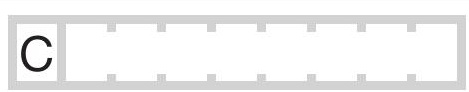

Name of Employer
Cutting Tools Inc.
Receipt For: 2012
X Primary
Other (specify) General

Occupation

VP-HR

Election Cycle-to-Date

350.00

B. Full Name (Last, First, Middle Initial)

Jennifer Cooper

Mailing Address 1080 Abingdon Ln.

\begin{tabular}{lcc}
\hline City & State & Zip Code \\
Alpharetta & GA & $30022-6270$ \\
\hline
\end{tabular}

FEC ID number of contributing

federal political committee.

C

\begin{tabular}{l} 
Name of Employer \\
K-Jen Properties I, LLC \\
Receipt For: 2012 \\
X Primary \\
\hline Other (specify)
\end{tabular}

Occupation

Real Estate

Election Cycle-to-Date

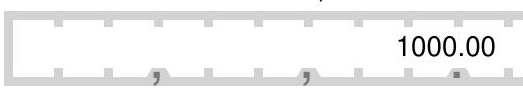

C. Full Name (Last, First, Middle Initial)

Calvin Lindsey

Mailing Address 225 Woodcrest Ct

\begin{tabular}{lcc}
\hline City & State & Zip Code \\
Jacksonville & NC & $28540-9129$
\end{tabular}

FEC ID number of contributing

federal political committee.

$\mathrm{C}$

Name of Employer

Camp Lejeune Dependent's Schools (DoDE

Occupation

Receipt For: 2012

Х $\begin{aligned} & \text { Primary } \\ & \text { Other (specify) }\end{aligned}$

Teacher

Election Cycle-to-Date

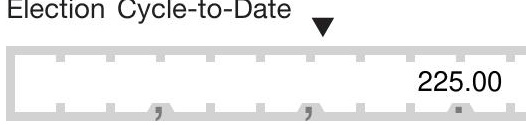

Transaction ID : A3CFA5274654F4212AB6

Date of Receipt

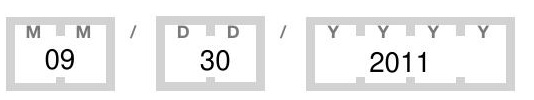

Amount of Each Receipt this Period

Amount of Each Receipt this Period
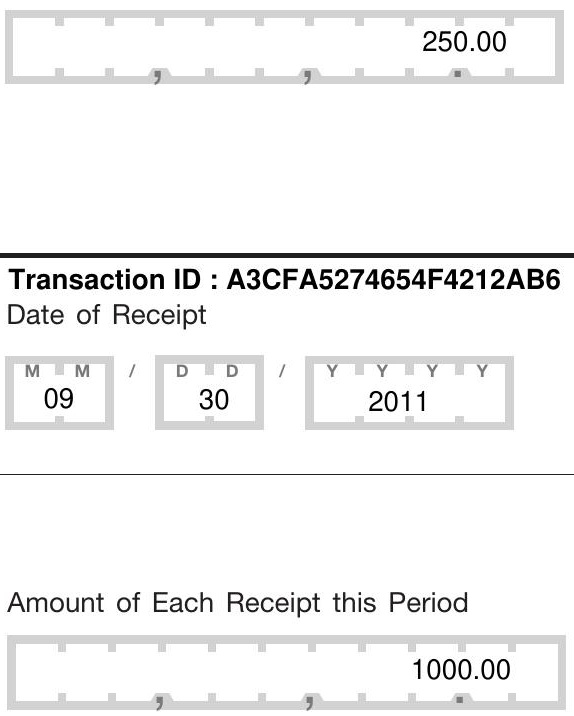

Transaction ID : AB6188AFDC7854F139E6 Date of Receipt

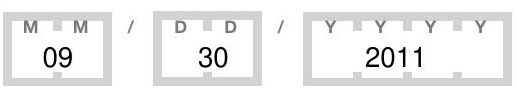

Amount of Each Receipt this Period

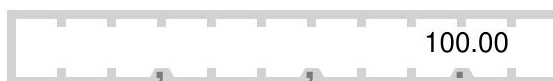

1350.00

Subtotal Of Receipts This Page (optional).

Total This Period (last page this line number only) 


\section{SCHEDULE A-P} ITEMIZED RECEIPTS
Use separate schedule(s) for each category of the Detailed Summary Page

FOR LINE NUMBER:
(check only one)

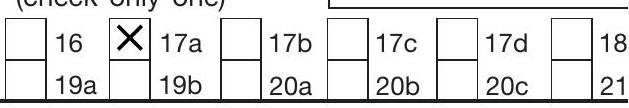

Any information copied from such Reports and Statements may not be sold or used by any person for the purpose of soliciting contributions or for commercial purposes, other than using the name and address of any political committee to solicit contributions from such committee.

NAME OF COMMITTEE (In Full)

\section{Friends of Herman Cain}

A. Full Name (Last, First, Middle Initial) Joseph Canon

Mailing Address 102 Tiquewood Circle

\begin{tabular}{lcc}
\hline City & State & Zip Code \\
Abilene & TX & $79605-4937$
\end{tabular}

FEC ID number of contributing federal political committee.

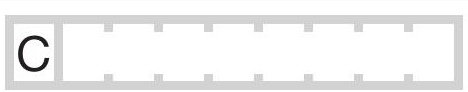

Name of Employer
Tejon Exploration Company
Receipt For: 2012
X Primary
Other (specify)

Occupation Investor

Election Cycle-to-Date
Transaction ID : A39CDE4B326174DE2B13

Date of Receipt

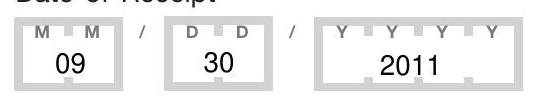

Amount of Each Receipt this Period

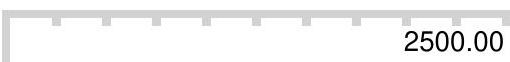

B. Full Name (Last, First, Middle Initial)

Joyce Howard

Mailing Address PO Box 423

\begin{tabular}{lcc}
\hline City & State & Zip Code \\
Simsbury & CT & $06070-0423$
\end{tabular}

FEC ID number of contributing

federal political committee.

C

\begin{tabular}{l} 
Name of Employer \\
Information Requested \\
Receipt For: 2012 \\
X Primary \\
\hline Other (specify)
\end{tabular}

Occupation

Information Requested

Election Cycle-to-Date

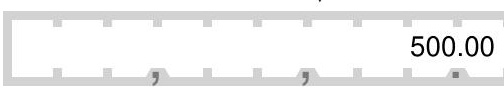

C. Full Name (Last, First, Middle Initial)

Margaret McMillen

Mailing Address 1005 Commerce Drive

\begin{tabular}{lcc}
\hline City & State & Zip Code \\
Grafton & OH & $44044-1278$ \\
\hline
\end{tabular}

FEC ID number of contributing federal political committee.

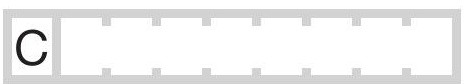

Name of Employer

Power \& Grounding Solutions

Receipt For: 2012

Х $\begin{aligned} & \text { Primary } \square \text { General } \\ & \text { Other (specify) }\end{aligned}$

\section{Occupation}

Sales

Election Cycle-to-Date

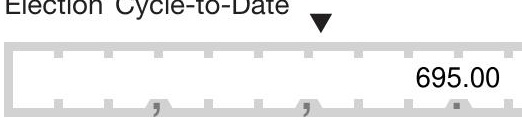

Transaction ID : AC279D20012FE4346BAF Date of Receipt

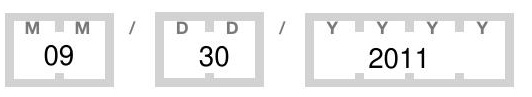

Amount of Each Receipt this Period

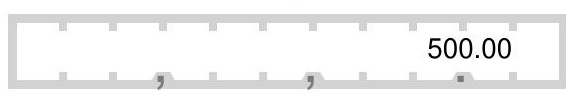

Transaction ID : AE80DADC159304D4CA1A Date of Receipt

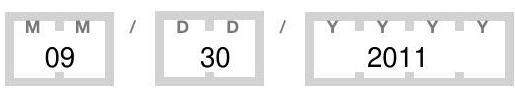

Amount of Each Receipt this Period

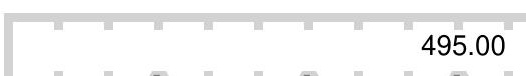

495.00

\section{Subtotal Of Receipts This Page (optional)}

Total This Period (last page this line number only) 
SCHEDULE A-P ITEMIZED RECEIPTS
Use separate schedule(s) for each category of the Detailed Summary Page
FOR LINE NUMBER: (check only one)

Any information or for commercial purposes, other than using the name and address of any political committee to solicit contributions from such committee.

NAME OF COMMITTEE (In Full)

Friends of Herman Cain

A. Full Name (Last, First, Middle Initial)

Jennie Gallastegui

Mailing Address 2233 Donato Dr.

\begin{tabular}{lcc}
\hline City & State & Zip Code \\
Belleair Beach & FL & $33786-3400$
\end{tabular}

FEC ID number of contributing

federal political committee.

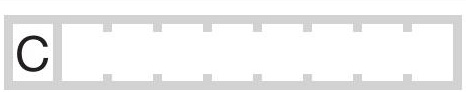

Name of Employer
Morton Plant Mease
Receipt For: 2012
X Primary
$\square$ Other (specify) General

Occupation

Registerd Nurse

Election Cycle-to-Date

300.00

B. Full Name (Last, First, Middle Initial)

MARK LOPEZ

Mailing Address 1830 BREA BLVD \#3

\begin{tabular}{lcc}
\hline City & State & Zip Code \\
Fullerton & CA & $92835-3944$
\end{tabular}

FEC ID number of contributing

federal political committee.

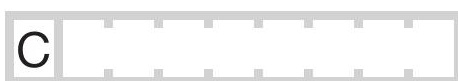

Name of Employer
BECKMAN COULTER INC
Receipt For: 2012
X Primary
Other (specify)

Occupation

SW Engineer

Election Cycle-to-Date

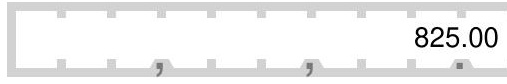

C. Full Name (Last, First, Middle Initial)

W. Patterson

Mailing Address 1407 Rotherwood Dr.

\begin{tabular}{lcc}
\hline City & State & Zip Code \\
Johnson City & TN & $37601-3226$
\end{tabular}

FEC ID number of contributing federal political committee.

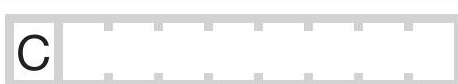

Name of Employer

Information Requested

Occupation

Information Requested

Receipt For: 2012

Х $\begin{aligned} & \text { Primary } \square \text { General } \\ & \text { Other (specify) }\end{aligned}$

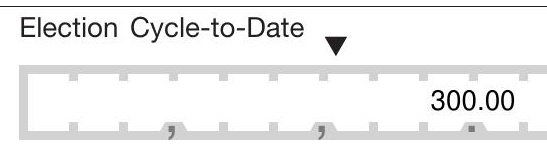

Amount of Each Receipt this Period

Transaction ID : A8FF872762360489AABC

Date of Receipt

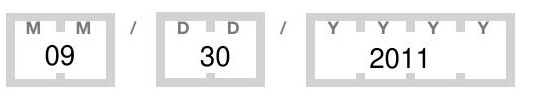

Amount of Each Receipt this Period
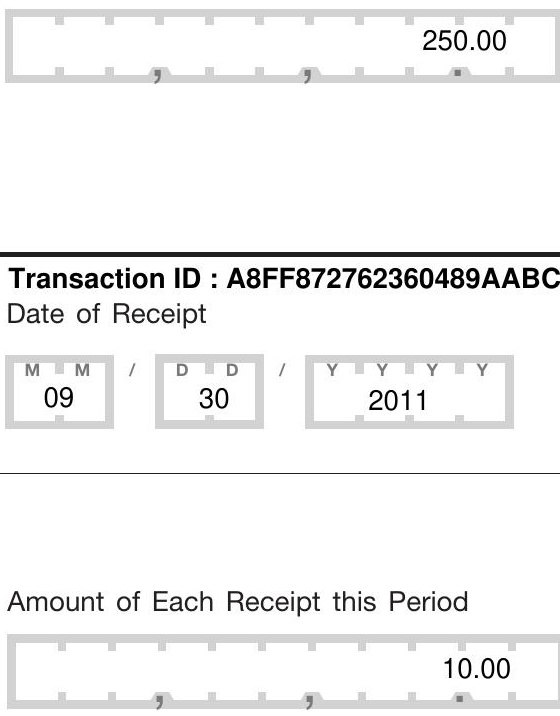

Transaction ID : AB58A90C457714751A22

Date of Receipt

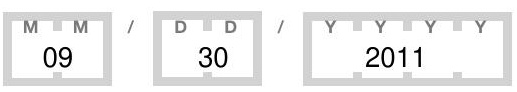

Amount of Each Receipt this Period

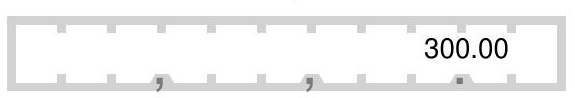

Subtotal Of Receipts This Page (optional).

560.00

Total This Period (last page this line number only) 
SCHEDULE A-P ITEMIZED RECEIPTS
Use separate schedule(s) for each category of the Detailed Summary Page
FOR LINE NUMBER: (check only one)

Any information or for commercial purposes, other than using the name and address of any political committee to solicit contributions from such committee.

NAME OF COMMITTEE (In Full)

\section{Friends of Herman Cain}

A. Full Name (Last, First, Middle Initial)

\section{Lawrence Bollinger}

Mailing Address 122 Seminole Lane

\begin{tabular}{lcc}
\hline City & State & Zip Code \\
Loudon & TN & $37774-2112$
\end{tabular}

FEC ID number of contributing federal political committee.

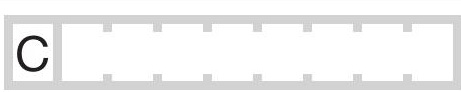

Name of Employer
Retired
Receipt For: 2012
X Primary $\quad$ General
Other (specify)

B. Full Name (Last, First, Middle Initial)

Donna Kreitzberg

Mailing Address PO Box 3242

\begin{tabular}{lcc}
\hline City & State & Zip Code \\
Tualatin & OR & $97062-3242$ \\
\hline
\end{tabular}

FEC ID number of contributing

federal political committee.

C

Name of Employer
Information Requested
Receipt For: 2012
X Primary
Other (specify)

Occupation Retired

Election Cycle-to-Date

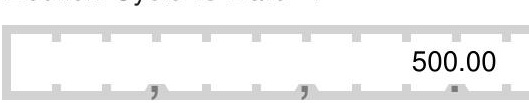

Transaction ID : AAD9AFDEC9A604BE5A81

Date of Receipt

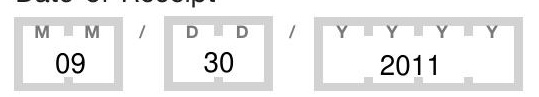

Amount of Each Receipt this Period

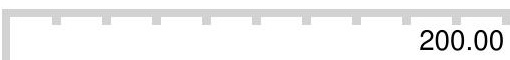

Amount of Each Receipt this Period

Occupation
Information Requested
Election Cycle-to-Date

Transaction ID : AB03A52BA207A4F53AA8 Date of Receipt

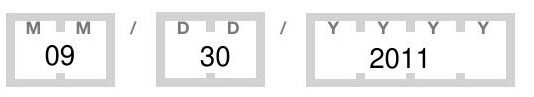

C. Full Name (Last, First, Middle Initial) John Schmidt

Mailing Address 705 Sandberg Drive

\begin{tabular}{lcc}
\hline City & State & Zip Code \\
Sycamore & IL & $60178-4401$
\end{tabular}

FEC ID number of contributing federal political committee.

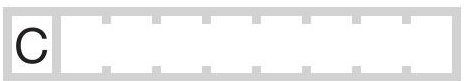

Name of Employer
self
Receipt For: 2012
X Primary $\square$ General
Other (specify)

Occupation

Dentist

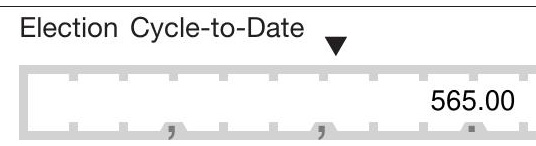

Transaction ID : A8664331D41614681A09 Date of Receipt

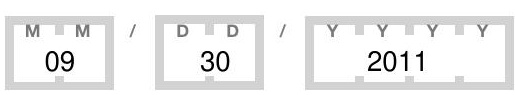

Amount of Each Receipt this Period

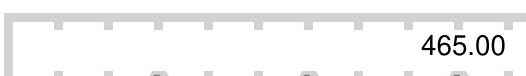

\section{Subtotal Of Receipts This Page (optional)}

Total This Period (last page this line number only) 
SCHEDULE A-P ITEMIZED RECEIPTS
Use separate schedule(s) for each category of the Detailed Summary Page
FOR LINE NUMBER: (check only one)

Any information or for commercial purposes, other than using the name and address of any political committee to solicit contributions from such committee.

NAME OF COMMITTEE (In Full)

Friends of Herman Cain

A. Full Name (Last, First, Middle Initial)

Susan Jorgensen

Mailing Address 7072 Eldorado Ct

\begin{tabular}{lcc}
\hline City & State & Zip Code \\
Cannon Falls & MN & $55009-5255$
\end{tabular}

FEC ID number of contributing federal political committee.

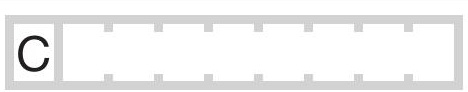

Name of Employer
Self Employed
Receipt For: 2012
X Primary $\quad$ General
Other (specify)

Occupation

Sales

Election Cycle-to-Date

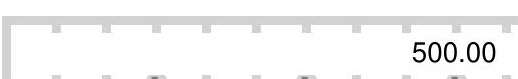

B. Full Name (Last, First, Middle Initial)

Mr. David M. Crenshaw

Mailing Address 216 Kings Hwy

\begin{tabular}{lcc}
\hline City & State & Zip Code \\
Decatur & GA & $30030-5226$ \\
\hline
\end{tabular}

FEC ID number of contributing

federal political committee.

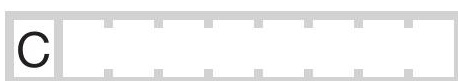

Name of Employer
None
Receipt For: 2012
X Primary
Other (specify)

Occupation

Retired

Election Cycle-to-Date

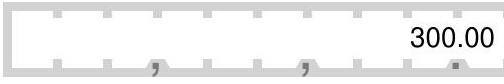

C. Full Name (Last, First, Middle Initial) Jeffrey Marler

Mailing Address 218 W Fountain Ave

\begin{tabular}{lcc}
\hline City & State & Zip Code \\
Delaware & OH & $43015-1656$
\end{tabular}

FEC ID number of contributing federal political committee.

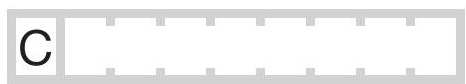

Name of Employer
Information Requested
Receipt For: 2012
Primary
Other (specify) General

\section{Occupation}

Information Requested

Election Cycle-to-Date

Transaction ID : AFFDD9A96A7404D0C9E8

Date of Receipt

Amount of Each Receipt this Period

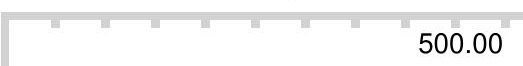

500.00

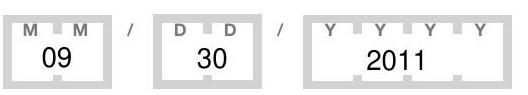

Amount of Each Receipt this Period

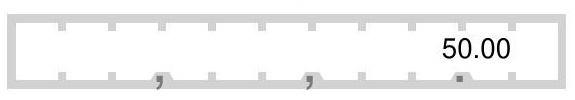

Transaction ID : A26D77CE5CB2F41D9BEE Date of Receipt

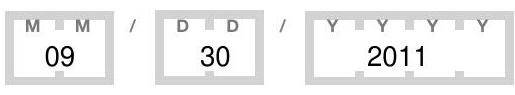

Amount of Each Receipt this Period

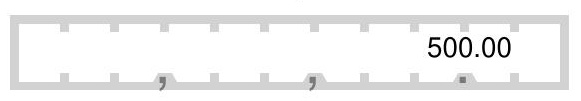

500.00

\section{Subtotal Of Receipts This Page (optional)}

Total This Period (last page this line number only) 


\section{SCHEDULE A-P} ITEMIZED RECEIPTS
Use separate schedule(s) for each category of the Detailed Summary Page

\begin{tabular}{|c|c|c|c|c|c|}
\hline \multicolumn{3}{|c|}{$\begin{array}{l}\text { FOR LINE NUMBER: } \\
\text { (check only one) }\end{array}$} & \multicolumn{3}{|c|}{ PAGE 1166 / 1572} \\
\hline 16 & $X$ 17a & $17 b$ & $17 c$ & $17 d$ & 18 \\
\hline $19 a$ & $19 \mathrm{~b}$ & $20 a$ & $20 \mathrm{~b}$ & $20 c$ & 21 \\
\hline
\end{tabular}

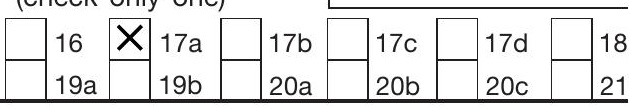

Any information copied from such Reports and Statements may not be sold or used by any person for the purpose of soliciting contributions or for commercial purposes, other than using the name and address of any political committee to solicit contributions from such committee.

NAME OF COMMITTEE (In Full)

\section{Friends of Herman Cain}

A. Full Name (Last, First, Middle Initial)

\section{David Hood}

Mailing Address 274 wehapa Lake Cir

\begin{tabular}{lcc}
\hline City & State & Zip Code \\
Leeds & AL & $35094-6424$
\end{tabular}

FEC ID number of contributing federal political committee.

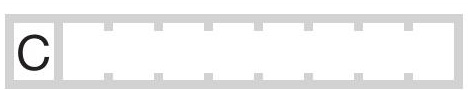

Name of Employer
Information Requested
Receipt For: 2012
X Primary
$\square$ Other (specify)

\section{Occupation} Information Requested

Election Cycle-to-Date

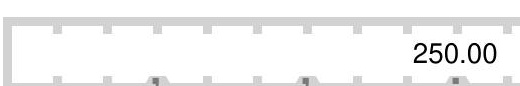

B. Full Name (Last, First, Middle Initial)

SusieJo Clouse

Mailing Address 8001 Ravenrock Road

\begin{tabular}{lcc}
\hline City & State & Zip Code \\
Rockford & MN & $55373-9394$ \\
\hline
\end{tabular}

FEC ID number of contributing

federal political committee.

C

Name of Employer
Wells Fargo/Accountemps
Receipt For: 2012
X Primary
Other (specify)

Occupation

staff accountant

Election Cycle-to-Date

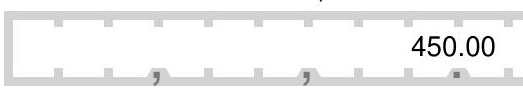

C. Full Name (Last, First, Middle Initial)

Ben W. Keeler

Mailing Address 4160 Summit Dr.

\begin{tabular}{lcc}
\hline City & State & Zip Code \\
Marietta & GA & $30068-4150$
\end{tabular}

FEC ID number of contributing federal political committee.

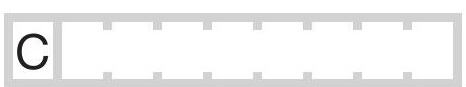

Name of Employer

Information Requested

\section{Occupation}

Information Requested

Receipt For: 2012

Х $\begin{aligned} & \text { Primary } \\ & \text { Other (specify) }\end{aligned}$

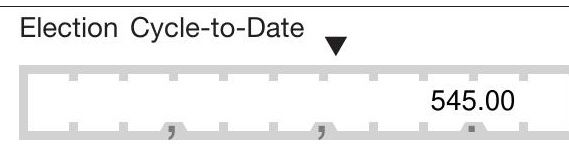

Transaction ID : AF4A081AEAB0742549BB

Date of Receipt

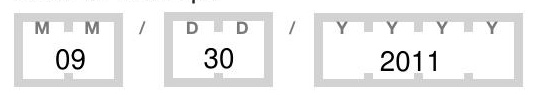

Amount of Each Receipt this Period

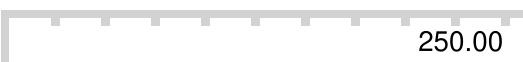

250.00

Transaction ID : AE005D4261B964F7393E

Date of Receipt

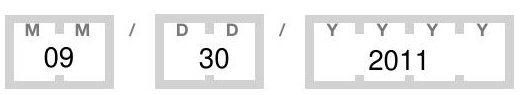

Amount of Each Receipt this Period

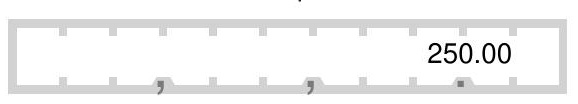

Transaction ID : A95D53CD2ED494A078CE Date of Receipt

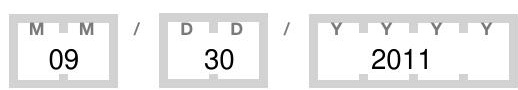

Amount of Each Receipt this Period

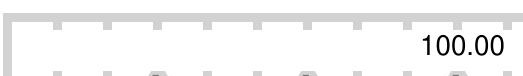

100.00

Subtotal Of Receipts This Page (optional)

600.00

Total This Period (last page this line number only) 


\section{SCHEDULE A-P} ITEMIZED RECEIPTS
Use separate schedule(s)

for each category of the

Detailed Summary Page
FOR LINE NUMBER: (check only one)

Any information or for commercial purposes, other than using the name and address of any political committee to solicit contributions from such committee.

NAME OF COMMITTEE (In Full)

Friends of Herman Cain

A. Full Name (Last, First, Middle Initial)

Michael Kilgore

Mailing Address 2303 Shaylene Way

\begin{tabular}{lcc}
\hline City & State & Zip Code \\
Alpine & CA & $91901-3174$ \\
\hline
\end{tabular}

FEC ID number of contributing

federal political committee.

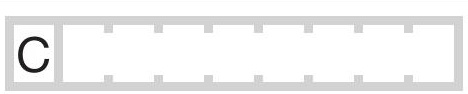

Name of Employer
Information Requested
Receipt For: 2012
X Primary $\quad \square$ General
Other (specify)

Occupation

Information Requested

Election Cycle-to-Date

250.00

B. Full Name (Last, First, Middle Initial)

Mr. John R Morris

Mailing Address 762 Acorn St

\begin{tabular}{lcc}
\hline City & State & Zip Code \\
Giddings & TX & $78942-4440$
\end{tabular}

FEC ID number of contributing

federal political committee.

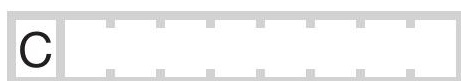

Name of Employer
None
Receipt For: 2012
X Primary
Other (specify)

Occupation

Retired

Election Cycle-to-Date

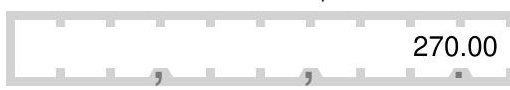

Transaction ID : AF90FB122560C412CB39

Date of Receipt

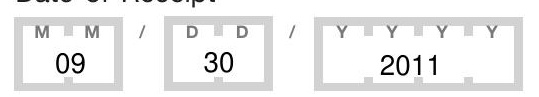

Amount of Each Receipt this Period

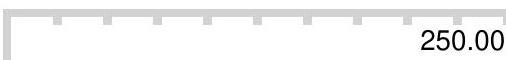

C. Full Name (Last, First, Middle Initial)

Lori Stone

Mailing Address 9127 Arbor Glen Lane

\begin{tabular}{lcc}
\hline City & State & Zip Code \\
Charlotte & NC & $28210-7988$
\end{tabular}

FEC ID number of contributing

federal political committee.

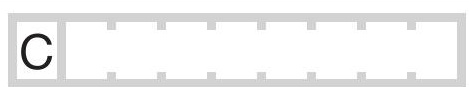

Name of Employer
None
Receipt For: 2012
X Primary $\quad$ General
Other (specify)

Occupation

Retired

Election Cycle-to-Date

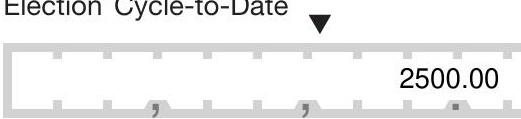

Amount of Each Receipt this Period

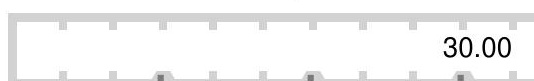

Transaction ID : A0061645797AB46C1A36

Date of Receipt

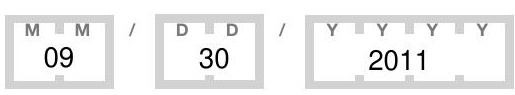

Transaction ID : AD973EAEE0D4A4C57B35 Date of Receipt

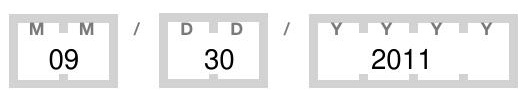

Amount of Each Receipt this Period

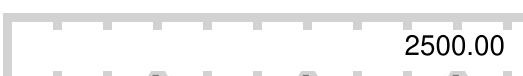

2500.00

\section{Subtotal Of Receipts This Page (optional)}

2780.00

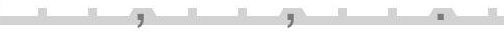

Total This Period (last page this line number only)

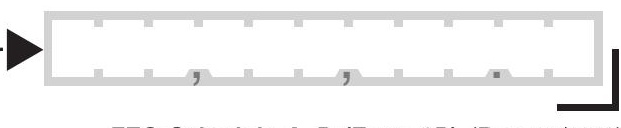

FEC Schedule A-P (Form 3P) (Rev. 03/2011) 


\section{SCHEDULE A-P} ITEMIZED RECEIPTS
Use separate schedule(s)

for each category of the

Detailed Summary Page
FOR LINE NUMBER: (check only one)

Any information or for commercial purposes, other than using the name and address of any political committee to solicit contributions from such committee.

NAME OF COMMITTEE (In Full)

Friends of Herman Cain

A. Full Name (Last, First, Middle Initial)

Leigh Hood

Mailing Address 274 Wehapa Lake Cir

\begin{tabular}{lcc}
\hline City & State & Zip Code \\
Leeds & AL & $35094-6424$
\end{tabular}

FEC ID number of contributing federal political committee.

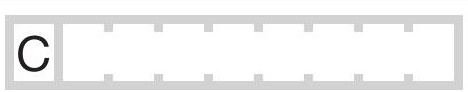

Name of Employer
Information Requested
Receipt For: 2012
X Primary
$\square$ Other (specify)

Occupation Information Requested

Election Cycle-to-Date 250.00

B. Full Name (Last, First, Middle Initial)

Danise Martinez

Mailing Address 16065 SandHill Road

\begin{tabular}{lcc}
\hline City & State & Zip Code \\
Winter Garden & FL & $34787-9765$ \\
\hline
\end{tabular}

FEC ID number of contributing

federal political committee.

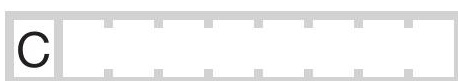

Name of Employer
self
Receipt For: 2012
X Primary
Other (specify)

Occupation

Veterinarian

Election Cycle-to-Date

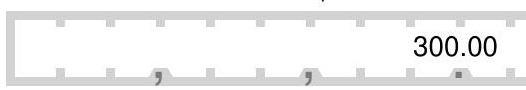

C. Full Name (Last, First, Middle Initial)

Stacie Curtis

Mailing Address 267 Stardust Cir

\begin{tabular}{lcc}
\hline City & State & Zip Code \\
Toney & AL & $35773-9396$
\end{tabular}

FEC ID number of contributing federal political committee.

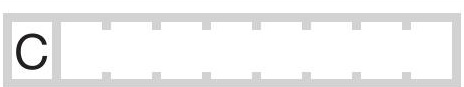

Name of Employer
The A/C Doctor
Receipt For: 2012
X Primary
Other (specify) General

\section{Occupation}

Office Manager

Election Cycle-to-Date

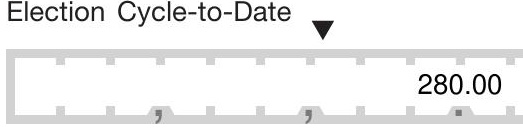

Transaction ID : A5DA54D7BC93B4A7DB92

Date of Receipt

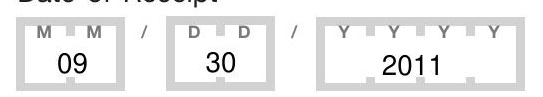

Amount of Each Receipt this Period

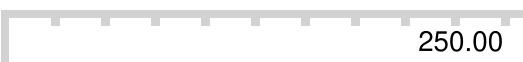

Amount of Each Receipt this Period

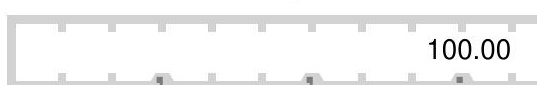

Transaction ID : A706115C579554811BA4 Date of Receipt

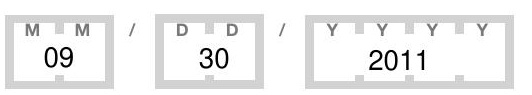

Transaction ID : A7F34A2B1F47341EB9DA Date of Receipt

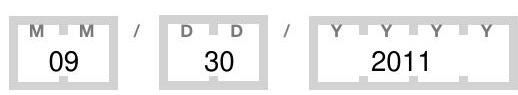

Amount of Each Receipt this Period

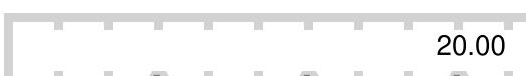

\section{Subtotal Of Receipts This Page (optional)}

370.00

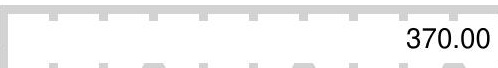

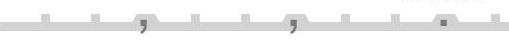

Total This Period (last page this line number only)

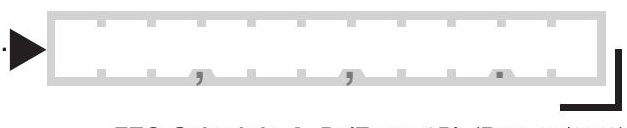

FEC Schedule A-P (Form 3P) (Rev. 03/2011) 
SCHEDULE A-P ITEMIZED RECEIPTS
Use separate schedule(s) for each category of the Detailed Summary Page
FOR LINE NUMBER: (check only one)

PAGE 1169 / 1572

\begin{tabular}{|c|c|c|c|c|c|}
\hline & & & & & \\
\hline 16 & $\mathbf{X} 17 a$ & $17 b$ & $17 c$ & $17 d$ & 18 \\
\hline $19 a$ & $19 b$ & $20 \mathrm{a}$ & $20 \mathrm{~b}$ & $20 \mathrm{c}$ & 21 \\
\hline
\end{tabular}

Any information copied from such Reports and Statements may not be sold or used by any person for the purpose of soliciting contributions or for commercial purposes, other than using the name and address of any political committee to solicit contributions from such committee.

NAME OF COMMITTEE (In Full)

\section{Friends of Herman Cain}

A. Full Name (Last, First, Middle Initial)

Timothy Graney

Mailing Address 26223 Rustic Ranch Ln

\begin{tabular}{lcc}
\hline City & State & Zip Code \\
Katy & TX & $77494-5360$ \\
\hline
\end{tabular}

FEC ID number of contributing federal political committee.

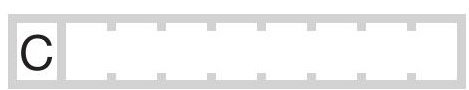

Name of Employer
self
Receipt For: 2012
X Primary $\quad$ General
Other (specify)

Occupation Consultant

Election Cycle-to-Date

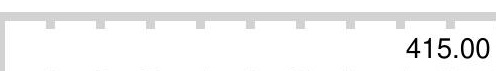

B. Full Name (Last, First, Middle Initial)

John B. Battin

Mailing Address 343 Mauldin PI

\begin{tabular}{lcc}
\hline City & State & Zip Code \\
The Villages & FL & $32162-8670$
\end{tabular}

FEC ID number of contributing

federal political committee.

C

Name of Employer
Information Requested
Receipt For: 2012
X Primary
Other (specify)

Occupation

Information Requested

Election Cycle-to-Date

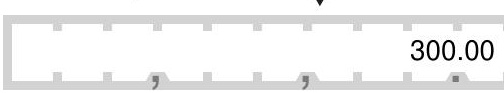

Transaction ID : A1F863A0817604490B37

Date of Receipt

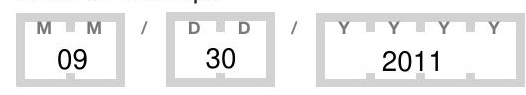

Amount of Each Receipt this Period

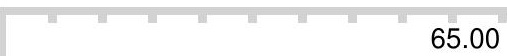

65.00

C. Full Name (Last, First, Middle Initial)

Allen Hord

Mailing Address 1662 Montcliff Court

\begin{tabular}{lcc}
\hline City & State & Zip Code \\
Decatur & GA & $30033-1313$
\end{tabular}

FEC ID number of contributing

federal political committee.

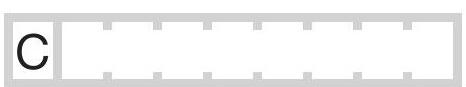

Name of Employer
ISPM
Receipt For: 2012
X Primary $\square$ General
Other (specify)

Occupation

Physician

Election Cycle-to-Date

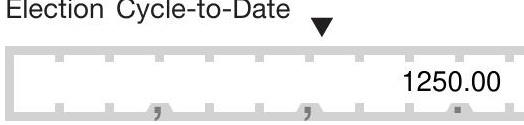

Transaction ID : A84CAE14712024FC7B2B

Date of Receipt

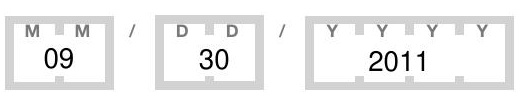

Amount of Each Receipt this Period

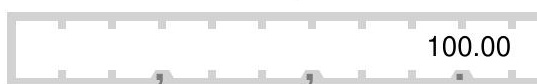

Transaction ID : A7C5226A5EDE7425A8C3 Date of Receipt

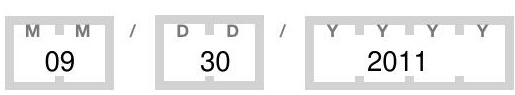

Amount of Each Receipt this Period

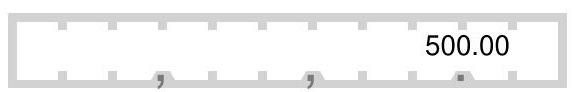

Subtotal Of Receipts This Page (optional)

665.00

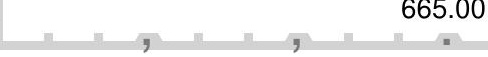

Total This Period (last page this line number only)

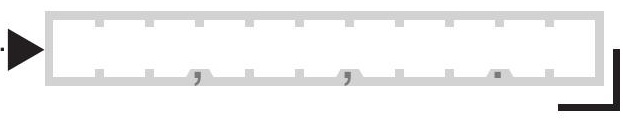

FEC Schedule A-P (Form 3P) (Rev. 03/2011) 


\section{SCHEDULE A-P} ITEMIZED RECEIPTS
Use separate schedule(s) for each category of the Detailed Summary Page

\begin{tabular}{|c|c|c|c|c|c|}
\hline \multicolumn{3}{|c|}{$\begin{array}{l}\text { FOR LINE NUMBER: } \\
\text { (check only one) }\end{array}$} & \multicolumn{3}{|c|}{ PAGE 1170 / 1572} \\
\hline 16 & $X$ 17a & $17 b$ & $17 c$ & $17 d$ & 18 \\
\hline $19 a$ & $19 \mathrm{~b}$ & $20 a$ & $20 \mathrm{~b}$ & $20 c$ & 21 \\
\hline
\end{tabular}

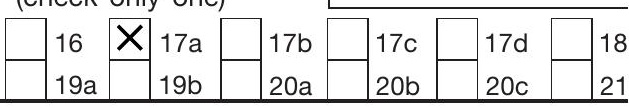

Any information copied from such Reports and Statements may not be sold or used by any person for the purpose of soliciting contributions or for commercial purposes, other than using the name and address of any political committee to solicit contributions from such committee.

NAME OF COMMITTEE (In Full)

\section{Friends of Herman Cain}

A. Full Name (Last, First, Middle Initial)

Kristine A Schroeder

Mailing Address W 4136 Raaschs Hill Rd

\begin{tabular}{lcc}
\hline City & State & Zip Code \\
Horicon & WI & 53032 \\
\hline
\end{tabular}

FEC ID number of contributing federal political committee.

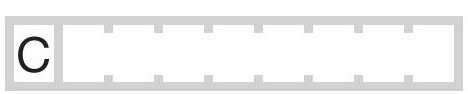

Name of Employer
self
Receipt For: 2012
X Primary $\quad \square$ General
Other (specify)

Occupation Consultant

Election Cycle-to-Date 665.00

B. Full Name (Last, First, Middle Initial) James Stewart

Mailing Address 3560 E. Via Colonia del Sol

\begin{tabular}{lcc}
\hline City & State & Zip Code \\
Tucson & AZ & $85718-6065$ \\
\hline
\end{tabular}

FEC ID number of contributing

federal political committee.

C

Name of Employer
Information Requested
Receipt For: 2012
X Primary
Other (specify)

\section{Occupation}

Information Requested

Election Cycle-to-Date

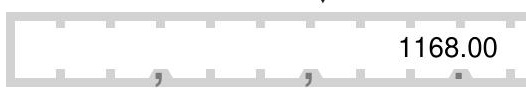

C. Full Name (Last, First, Middle Initial)

Simon Halff

Mailing Address 1103 Lachman Lane

\section{City}

Pacific Palisades

FEC ID number of contributing

federal political committee.

Name of Employer
Self Employed
Receipt For: 2012
X Primary
Other (specify) General

Transaction ID : A6FBD55F24DEA4084B65

Date of Receipt

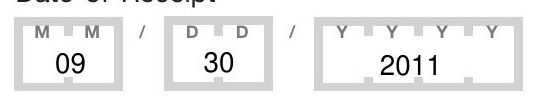

Amount of Each Receipt this Period

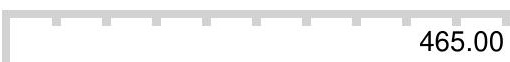

465.00
Amount of Each Receipt this Period

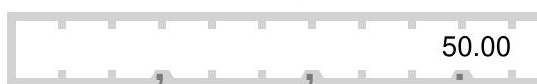

Transaction ID : AC1C64891D60D4136B22 Date of Receipt

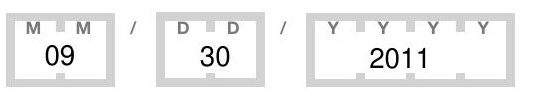

Transaction ID : AA1953D0B5976424B9F3 Date of Receipt

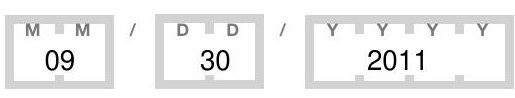

Amount of Each Receipt this Period

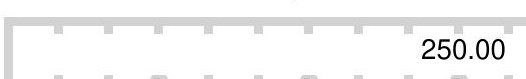

\section{Occupation}

Real Estate

Election Cycle-to-Date

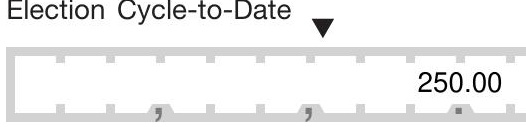

Subtotal Of Receipts This Page (optional).

765.00

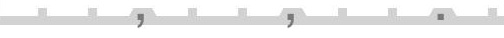

Total This Period (last page this line number only)

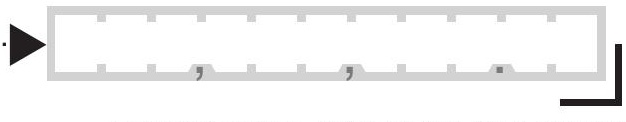

FEC Schedule A-P (Form 3P) (Rev. 03/2011) 


\section{SCHEDULE A-P} ITEMIZED RECEIPTS
Use separate schedule(s)

for each category of the

Detailed Summary Page
FOR LINE NUMBER: (check only one)

Any information copion the purpose of soliciting contributions or for commercial purposes, other than using the name and address of any political committee to solicit contributions from such committee.

NAME OF COMMITTEE (In Full)

Friends of Herman Cain

A. Full Name (Last, First, Middle Initial)

Madhu Chalasani

Mailing Address 6936 Southampton Lane

\begin{tabular}{lcc}
\hline City & State & Zip Code \\
West Chester & OH & $45069-8567$
\end{tabular}

FEC ID number of contributing

federal political committee.

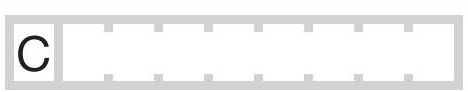

Name of Employer
Information Requested
Receipt For: 2012
X Primary $\quad \square$ General
Other (specify)

Occupation

Information Requested

Election Cycle-to-Date

250.00

B. Full Name (Last, First, Middle Initial)

Mr. Richard E. Pepper

Mailing Address 511 Navan Lane

\begin{tabular}{lcc}
\hline City & State & Zip Code \\
Statham & GA & $30666-2552$ \\
\hline
\end{tabular}

FEC ID number of contributing

federal political committee.

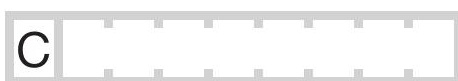

Name of Employer
None
Receipt For: 2012
X Primary $\quad$ General
Other (specify)

Occupation

Retired

Election Cycle-to-Date

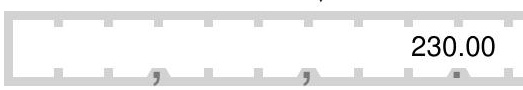

Transaction ID : A205A10BD3D9E402CAD8

Date of Receipt

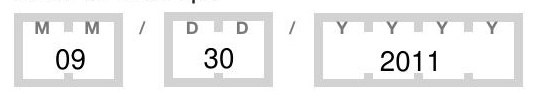

Amount of Each Receipt this Period

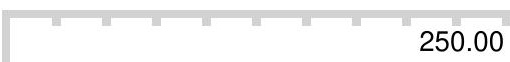

C. Full Name (Last, First, Middle Initial)

Laura Gutman

Mailing Address 310 Watts St.

\begin{tabular}{lcc}
\hline City & State & Zip Code \\
Durham & NC & $27701-2039$
\end{tabular}

FEC ID number of contributing federal political committee.

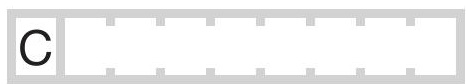

Name of Employer

Information Requested

\section{Occupation}

Information Requested

Receipt For: 2012

Х $\begin{aligned} & \text { Primary } \square \text { General } \\ & \text { Other (specify) }\end{aligned}$

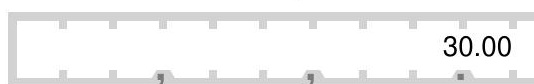

Amount of Each Receipt this Period

Transaction ID : A973923C1CA8E45AF83F

Date of Receipt

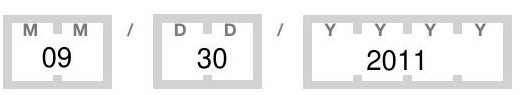

Transaction ID : A6E71D2C9EA0541E6A87 Date of Receipt

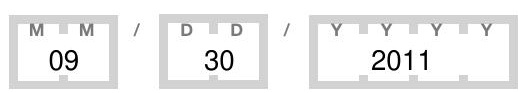

Amount of Each Receipt this Period

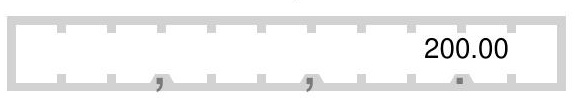

400.00
Subtotal Of Receipts This Page (optional)

480.00

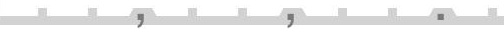

Total This Period (last page this line number only)

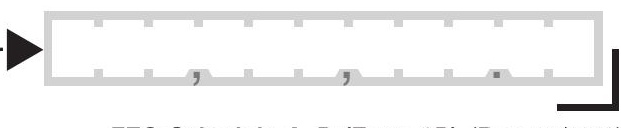

FEC Schedule A-P (Form 3P) (Rev. 03/2011) 


\section{SCHEDULE A-P} ITEMIZED RECEIPTS
Use separate schedule(s) for each category of the Detailed Summary Page
FOR LINE NUMBER: (check only one)
PAGE 1172 / 1572

\begin{tabular}{|c|c|c|c|c|c|}
\hline & & & & & \\
\hline 16 & $\mathbf{X} 17 a$ & $17 b$ & $17 c$ & $17 d$ & 18 \\
\hline $19 a$ & $19 b$ & $20 \mathrm{a}$ & $20 \mathrm{~b}$ & $20 \mathrm{c}$ & 21 \\
\hline
\end{tabular}

Any information copied from such Reports and Statements may not be sold or used by any person for the purpose of soliciting contributions or for commercial purposes, other than using the name and address of any political committee to solicit contributions from such committee.

NAME OF COMMITTEE (In Full)

Friends of Herman Cain

A. Full Name (Last, First, Middle Initial)

Richard Harper

Mailing Address 176 Rainbow Dr \#7626

\begin{tabular}{lcc}
\hline City & State & Zip Code \\
Livingston & TX & $77399-1076$ \\
\hline
\end{tabular}

FEC ID number of contributing

federal political committee.

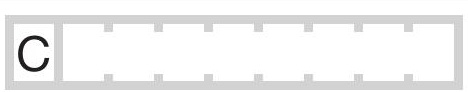

Name of Employer
Not Employed
Receipt For: 2012
X Primary
$\square$ Other (specify) General

Occupation

Retired

Election Cycle-to-Date

600.00

B. Full Name (Last, First, Middle Initial)

Carol Freund

Mailing Address 125 Cannon Gate Cir

\begin{tabular}{lcc}
\hline City & State & Zip Code \\
Sharpsburg & GA & $30277-1718$
\end{tabular}

FEC ID number of contributing

federal political committee.

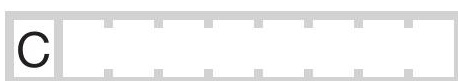

Name of Employer
Information Requested
Receipt For: 2012
X Primary
Other (specify)

Occupation

Information Requested

Election Cycle-to-Date

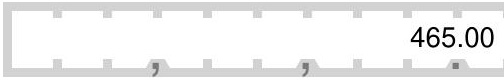

C. Full Name (Last, First, Middle Initial)

Sherry McPherson

Mailing Address 919 River Rd

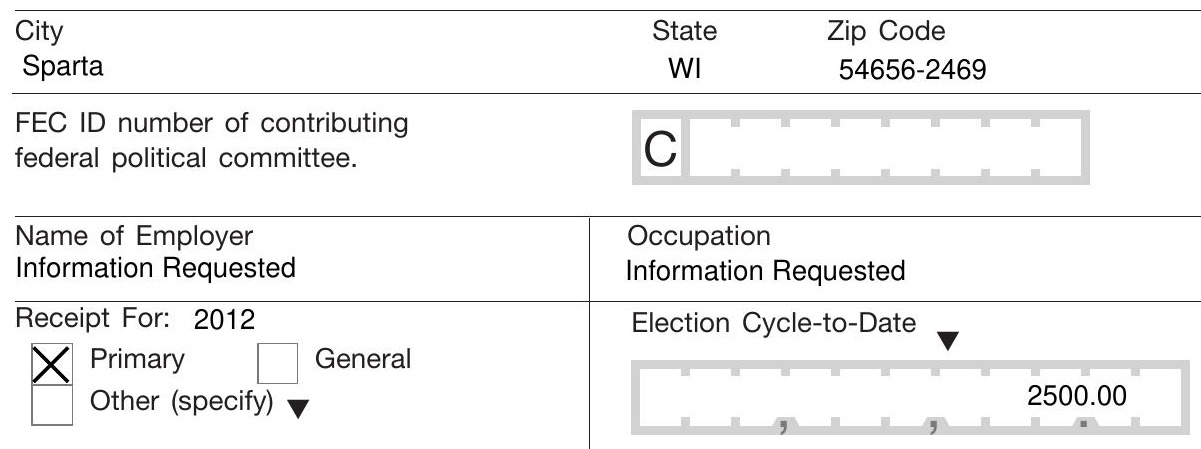

Transaction ID : ADCFFD3C90140496185B

Date of Receipt

Amount of Each Receipt this Period

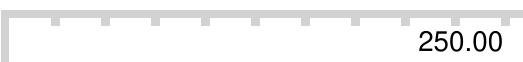

Date of Receipt

M M / D

09

30

2011

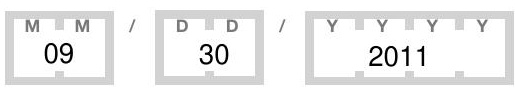

Amount of Each Receipt this Period

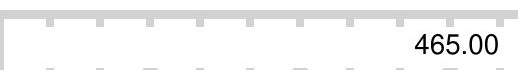

Amount of Each Receipt this Period

Transaction ID : AC652ECAF2D5942D9B6C Date of Receipt
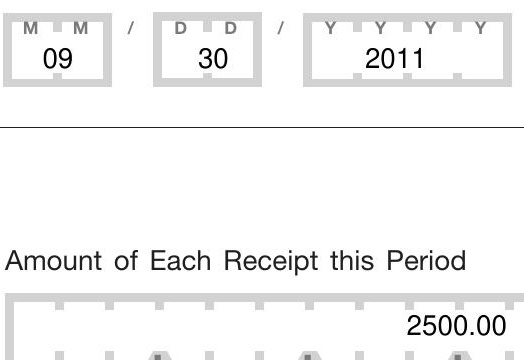

Subtotal Of Receipts This Page (optional)

3215.00

Total This Period (last page this line number only)

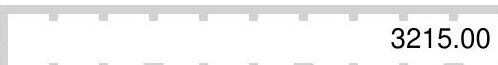

a L

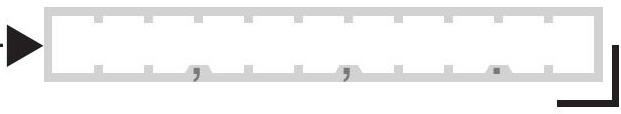


SCHEDULE A-P ITEMIZED RECEIPTS
Use separate schedule(s) for each category of the Detailed Summary Page
FOR LINE NUMBER: (check only one)

Any information or for commercial purposes, other than using the name and address of any political committee to solicit contributions from such committee.

NAME OF COMMITTEE (In Full)

Friends of Herman Cain

A. Full Name (Last, First, Middle Initial) James Gordon

Mailing Address 3824 Pershing Drive

\begin{tabular}{lcc}
\hline City & State & Zip Code \\
Lafayette & IN & $47905-7603$ \\
\hline
\end{tabular}

FEC ID number of contributing federal political committee.

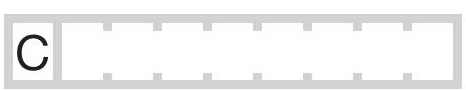

Name of Employer
Information Requested
Receipt For: 2012
X Primary
$\square$ Other (specify)

Occupation Information Requested

Election Cycle-to-Date

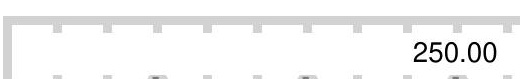

B. Full Name (Last, First, Middle Initial)

Donna Coghlan

Mailing Address 173 Massey Rd

\begin{tabular}{lcc}
\hline City & State & Zip Code \\
Homer & GA & $30547-1646$ \\
\hline
\end{tabular}

FEC ID number of contributing

federal political committee.

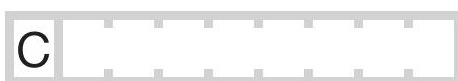

Name of Employer
n/a
Receipt For: 2012
X Primary
Other (specify)

Occupation

Retired

Election Cycle-to-Date

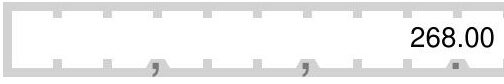

C. Full Name (Last, First, Middle Initial)

Mrs. Brenda C. Jinkins

Mailing Address 7550 Kelly Cove

\begin{tabular}{lcc}
\hline City & State & Zip Code \\
Olive Branch & MS & $38654-8250$
\end{tabular}

FEC ID number of contributing federal political committee.

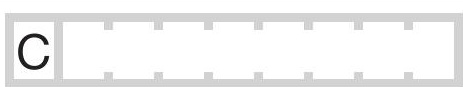

Name of Employer
Information Requested
Receipt For: 2012
X Primary $\quad \square$ General
Other (specify)

Occupation

Information Requested

Election Cycle-to-Date

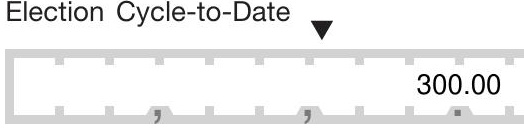

Transaction ID : A5F28CE0BDC6E456892C

Date of Receipt

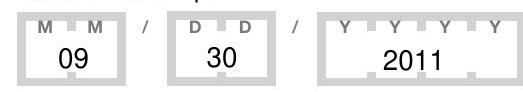

Amount of Each Receipt this Period

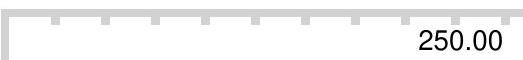

Transaction ID : AA90B4F7050D54300BBD

Date of Receipt

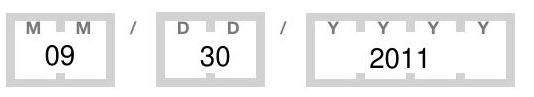

Amount of Each Receipt this Period

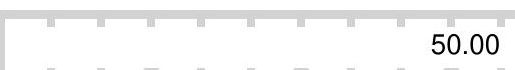

Transaction ID : ABC3665DED78F4ADBB3B Date of Receipt

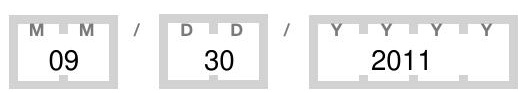

Amount of Each Receipt this Period

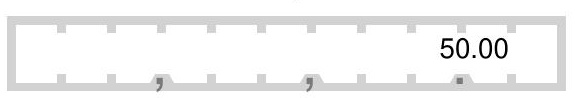

Subtotal Of Receipts This Page (optional)

350.00

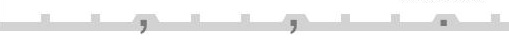

Total This Period (last page this line number only) 
SCHEDULE A-P ITEMIZED RECEIPTS
Use separate schedule(s) for each category of the Detailed Summary Page
FOR LINE NUMBER: (check only one)

Any information copied from or for commercial purposes, other than using the name and address of any political committee to solicit contributions from such committee.

NAME OF COMMITTEE (In Full)

\section{Friends of Herman Cain}

A. Full Name (Last, First, Middle Initial)

Brian Wannan

Mailing Address 14934 Webb Chapel Rd. suite 26

\begin{tabular}{lcc}
\hline City & State & Zip Code \\
Dallas & TX & $75234-2301$
\end{tabular}

FEC ID number of contributing federal political committee.

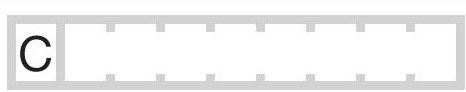

Name of Employer

Retail Autonation Systems, Inc.

Occupation

President

Receipt For: 2012

X Primary $\square$ General Other (specify)

Election Cycle-to-Date 1000.00

B. Full Name (Last, First, Middle Initial)

William Thornton

Mailing Address 3010 Saddle Creek Rd.

\begin{tabular}{lcc}
\hline City & State & Zip Code \\
Winter Haven & FL & 33884 \\
\hline
\end{tabular}

FEC ID number of contributing

federal political committee.

C

\begin{tabular}{l} 
Name of Employer \\
Information Requested \\
Receipt For: 2012 \\
X Primary \\
\hline Other (specify)
\end{tabular}

Occupation

Information Requested

Election Cycle-to-Date

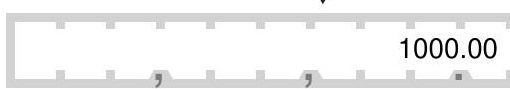

Transaction ID : AEC1537D5D1C9407CB24

Date of Receipt

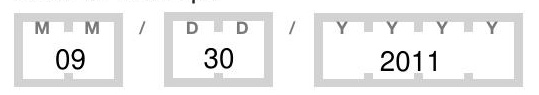

Amount of Each Receipt this Period

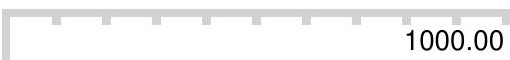

1000.00

C. Full Name (Last, First, Middle Initial)

steven kimball

Mailing Address 2224spininngwheel lane

\begin{tabular}{lcc}
\hline City & State & Zip Code \\
Cincinnati & $\mathrm{OH}$ & 45244 \\
\hline
\end{tabular}

FEC ID number of contributing federal political committee.

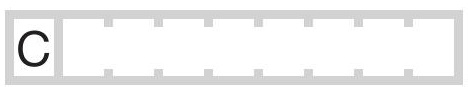

Name of Employer
Emersion Design
Receipt For: 2012
X Primary
Other (specify) General

\section{Occupation}

CEO

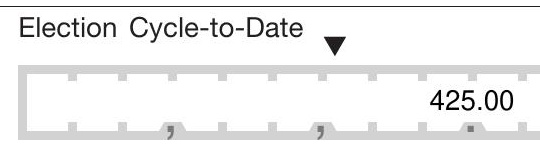

Transaction ID : AA04C6B72AEDD4BCDBAC Date of Receipt

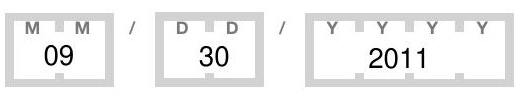

Amount of Each Receipt this Period

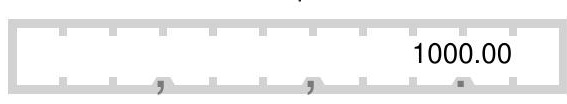

Transaction ID : A05D6292F5D784E0FBC6 Date of Receipt

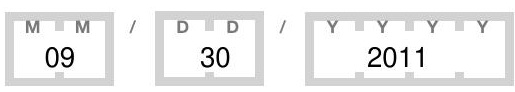

Amount of Each Receipt this Period

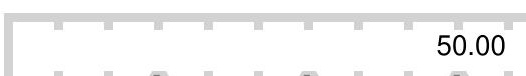

\section{Subtotal Of Receipts This Page (optional)}

2050.00

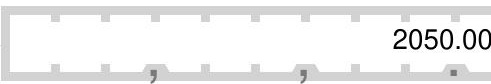

Total This Period (last page this line number only)

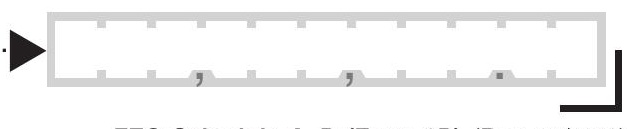

FEC Schedule A-P (Form 3P) (Rev. 03/2011) 


\section{SCHEDULE A-P} ITEMIZED RECEIPTS
Use separate schedule(s)

for each category of the

Detailed Summary Page
FOR LINE NUMBER: (check only one)

Any information copion the purpose of soliciting contributions or for commercial purposes, other than using the name and address of any political committee to solicit contributions from such committee.

NAME OF COMMITTEE (In Full)

Friends of Herman Cain

A. Full Name (Last, First, Middle Initial) Jason Capozzoli

Mailing Address 638 East College Avenue

\begin{tabular}{lcc}
\hline City & State & Zip Code \\
Tallahassee & FL & $32301-2511$
\end{tabular}

FEC ID number of contributing federal political committee.

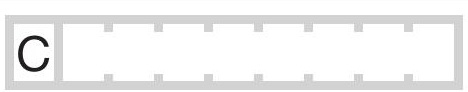

Name of Employer
Information Requested
Receipt For: 2012
X Primary
$\square$ Other (specify)

Occupation Information Requested

Election Cycle-to-Date

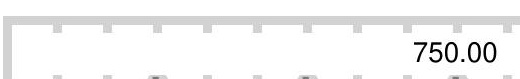

B. Full Name (Last, First, Middle Initial)

\section{Barbara Baskin-Bowen}

Mailing Address 331 Mystic Street

\begin{tabular}{lcc}
\hline City & State & Zip Code \\
Arlington & MA & $02474-1121$
\end{tabular}

FEC ID number of contributing

federal political committee.

C

Name of Employer
Information Requested
Receipt For: 2012
X Primary
Other (specify)

C. Full Name (Last, First, Middle Initial)

Vern Goding

Mailing Address 648 Acacia Avenue

\begin{tabular}{lcc}
\hline City & State & Zip Code \\
Melbourne & FL & $32904-2302$
\end{tabular}

FEC ID number of contributing federal political committee.

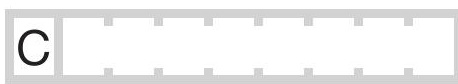

Name of Employer
None
Receipt For: 2012
X Primary $\quad \square$ General
Other (specify)

\section{Occupation}

Information Requested

Election Cycle-to-Date

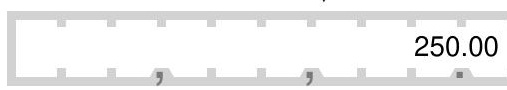

Transaction ID : AAA74C7B510A64779A54

Date of Receipt

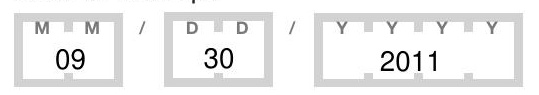

Amount of Each Receipt this Period

$\begin{aligned} & \text { Occupation } \\ & \text { Retired }\end{aligned}$
Election Cycle-to-Date

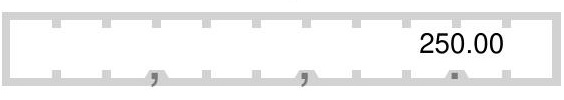

Amount of Each Receipt this Period

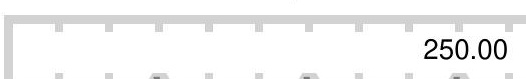

Transaction ID : A2B3B209F4D3F4715926 Date of Receipt

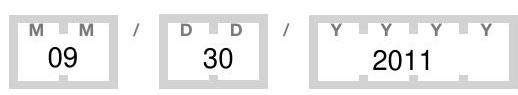

Transaction ID : A79F48D3B0BD048F3A39 Date of Receipt

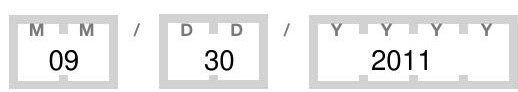

Amount of Each Receipt this Period

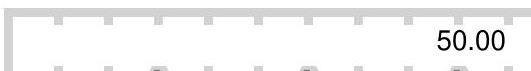

Subtotal Of Receipts This Page (optional).

Total This Period (last page this line number only) 


\section{SCHEDULE A-P} ITEMIZED RECEIPTS
Use separate schedule(s)

for each category of the

Detailed Summary Page
FOR LINE NUMBER: (check only one)

Any information or for commercial purposes, other than using the name and address of any political committee to solicit contributions from such committee.

NAME OF COMMITTEE (In Full)

Friends of Herman Cain

A. Full Name (Last, First, Middle Initial)

Richard Knoch

Mailing Address P.O. Box 2041

\begin{tabular}{lcc}
\hline City & State & Zip Code \\
Lake Ozark & MO & $65049-2041$
\end{tabular}

FEC ID number of contributing federal political committee.

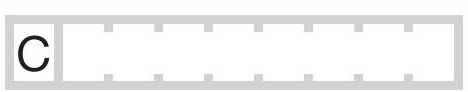

Name of Employer
CompuLink Ltd.
Receipt For: 2012
X Primary
Other (specify) General

Occupation

Software Developer

Election Cycle-to-Date

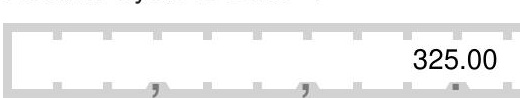

B. Full Name (Last, First, Middle Initial)

William A Hein

Mailing Address 148 Little Deer Path Ln

\begin{tabular}{lcc}
\hline City & State & Zip Code \\
La Follette & TN & $37766-6668$ \\
\hline
\end{tabular}

FEC ID number of contributing

federal political committee.

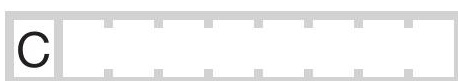

Name of Employer
None
Receipt For: 2012
X Primary
Other (specify)

Occupation

Retired

Election Cycle-to-Date

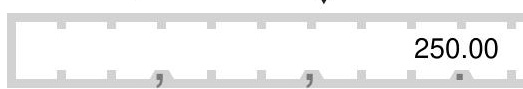

C. Full Name (Last, First, Middle Initial)

Jeffrey Johnson

Mailing Address 17817 Coit Rd \#4301

\begin{tabular}{lcc}
\hline City & State & Zip Code \\
Dallas & TX & $75252-6479$
\end{tabular}

FEC ID number of contributing

federal political committee.

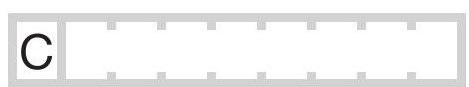

Name of Employer

Information Requested

Occupation

Information Requested

Receipt For: 2012

Х $\begin{aligned} & \text { Primary } \square \text { General } \\ & \text { Other (specify) }\end{aligned}$

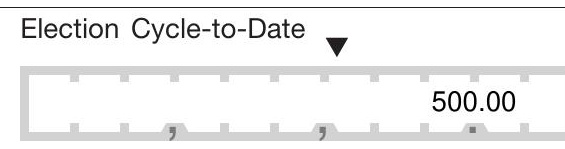

Amount of Each Receipt this Period

Transaction ID : A584CD87E952A41DF982

Date of Receipt

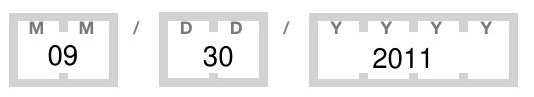

Amount of Each Receipt this Period
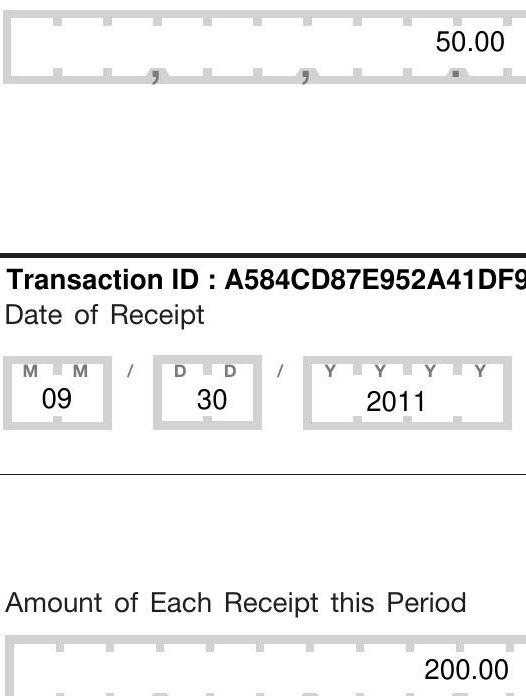

Transaction ID : A98981AC86293441A9A5

Date of Receipt

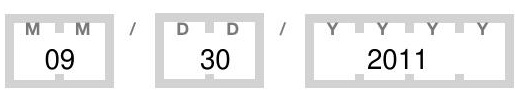

Amount of Each Receipt this Period

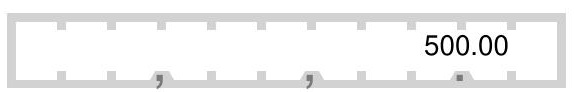

Subtotal Of Receipts This Page (optional).

750.00

Total This Period (last page this line number only) 
SCHEDULE A-P ITEMIZED RECEIPTS
Use separate schedule(s) for each category of the Detailed Summary Page
FOR LINE NUMBER: (check only one)

PAGE 1177 / 1572

\begin{tabular}{|c|c|c|c|c|c|}
\hline & & & & & \\
\hline 16 & $\begin{array}{l}\mathbf{X} \\
17 a\end{array}$ & $17 b$ & $17 c$ & $17 d$ & 18 \\
\hline $19 a$ & $19 \mathrm{~b}$ & $20 \mathrm{a}$ & $20 \mathrm{~b}$ & $20 \mathrm{c}$ & 21 \\
\hline
\end{tabular}

Any information copied from such Reports and Statements may not be sold or used by any person for the purpose of soliciting contributions or for commercial purposes, other than using the name and address of any political committee to solicit contributions from such committee.

NAME OF COMMITTEE (In Full)

\section{Friends of Herman Cain}

A. Full Name (Last, First, Middle Initial)

kim smith

Mailing Address 3832 w market st

\begin{tabular}{lcc}
\hline City & State & Zip Code \\
Johnson City & TN & $37604-9304$ \\
\hline
\end{tabular}

FEC ID number of contributing

federal political committee.

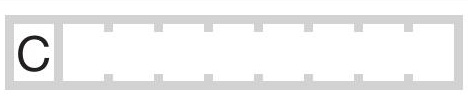

Name of Employer
Century 21 Home Team
Receipt For: 2012
X Primary $\quad \square$ General
Other (specify)

Occupation

Real Estate Agent

Election Cycle-to-Date

1000.00

B. Full Name (Last, First, Middle Initial)

Drew Gregory

Mailing Address 2438 Fernleaf Ct

\begin{tabular}{lcc}
\hline City & State & Zip Code \\
Atlanta & GA & $30318-1420$ \\
\hline
\end{tabular}

FEC ID number of contributing

federal political committee.

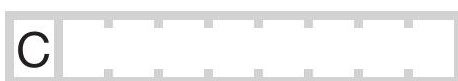

Name of Employer
PDS
Receipt For: 2012
X Primary $\quad$ General
Other (specify)

\section{Occupation}

Sales

Election Cycle-to-Date

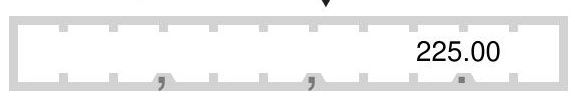

C. Full Name (Last, First, Middle Initial)

Terri Pearce

Mailing Address PO Box 1577

\begin{tabular}{lcc}
\hline City & State & Zip Code \\
Mableton & GA & $30126-1009$
\end{tabular}

FEC ID number of contributing federal political committee.

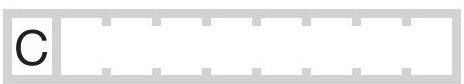

Name of Employer
Information Requested
Receipt For: 2012
X Primary $\quad \square$ General
Other (specify)

\section{Occupation}

Information Requested

Election Cycle-to-Date
Transaction ID : A6591F5C74D2D4549BE6

Date of Receipt

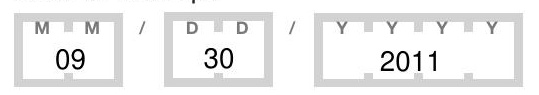

Amount of Each Receipt this Period

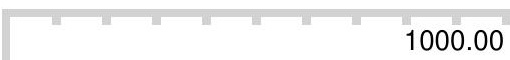

1000.00

Amount of Each Receipt this Period

Transaction ID : AF7A29658DF4940168BA

Date of Receipt
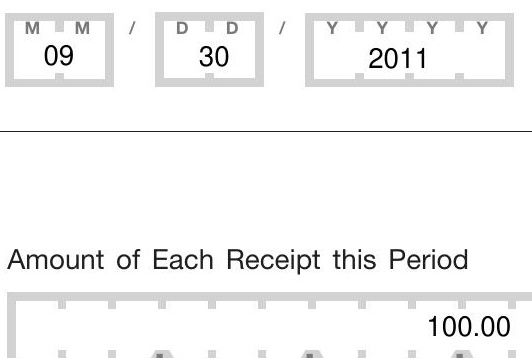

Transaction ID : AA5DF52051487408A9BE

Date of Receipt

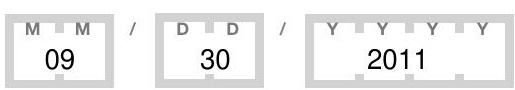

Amount of Each Receipt this Period

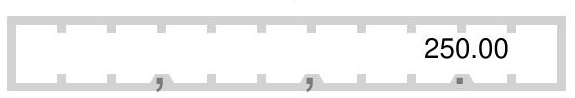

250.00

\section{Subtotal Of Receipts This Page (optional)}

Total This Period (last page this line number only) 


\section{SCHEDULE A-P} ITEMIZED RECEIPTS
Use separate schedule(s) for each category of the Detailed Summary Page

\begin{tabular}{|c|c|c|c|c|c|}
\hline \multicolumn{3}{|c|}{$\begin{array}{l}\text { FOR LINE NUMBER: } \\
\text { (check only one) }\end{array}$} & \multicolumn{3}{|c|}{ PAGE 1178 / 1572} \\
\hline 16 & $X$ 17a & $17 b$ & $17 c$ & $17 d$ & 18 \\
\hline $19 a$ & $19 \mathrm{~b}$ & $20 a$ & $20 \mathrm{~b}$ & $20 c$ & 21 \\
\hline
\end{tabular}

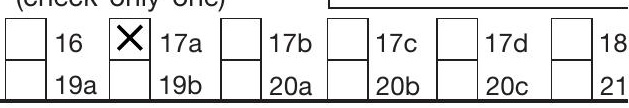

Any information copied from such Reports and Statements may not be sold or used by any person for the purpose of soliciting contributions or for commercial purposes, other than using the name and address of any political committee to solicit contributions from such committee.

NAME OF COMMITTEE (In Full)

\section{Friends of Herman Cain}

A. Full Name (Last, First, Middle Initial) Rick Skinner

Mailing Address 21710 Quail Valley Ct.

\begin{tabular}{lcc}
\hline City & State & Zip Code \\
Leander & TX & $78641-8114$
\end{tabular}

FEC ID number of contributing federal political committee.

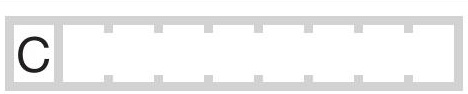

\section{Name of Employer}

Excel Electric Service, Inc.

Receipt For: 2012 Х Primary $\square$ General

Occupation

Electrician

Election Cycle-to-Date

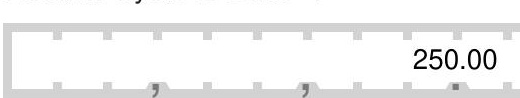

B. Full Name (Last, First, Middle Initial)

Kelvin Fisher

Mailing Address 5427 Basswood Circle

\begin{tabular}{lcc}
\hline City & State & Zip Code \\
Midland & TX & $79707-1501$
\end{tabular}

FEC ID number of contributing

federal political committee.

C

Name of Employer
Information Requested
Receipt For: 2012
X Primary
Other (specify)

Occupation

Information Requested

Election Cycle-to-Date

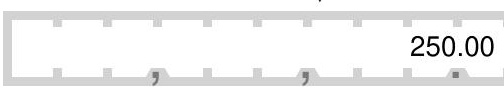

C. Full Name (Last, First, Middle Initial)

MaryBeth White

Mailing Address 16801 Fishmarket Road

\begin{tabular}{lcc}
\hline City & State & Zip Code \\
McLoud & OK & $74851-9372$
\end{tabular}

FEC ID number of contributing federal political committee.

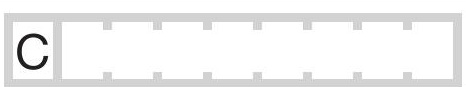

Name of Employer

Information Requested

\section{Occupation}

Information Requested

Receipt For: 2012

Х $\begin{aligned} & \text { Primary } \square \text { General } \\ & \text { Other (specify) }\end{aligned}$

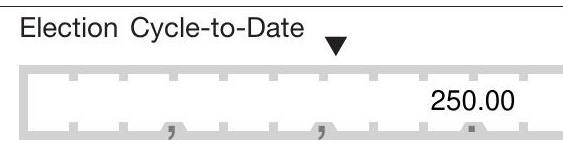

Amount of Each Receipt this Period

Transaction ID : AC03A1689013D4FF9AD3

Date of Receipt

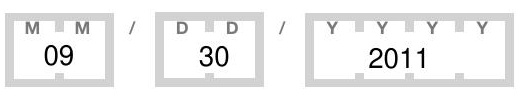

Amount of Each Receipt this Period
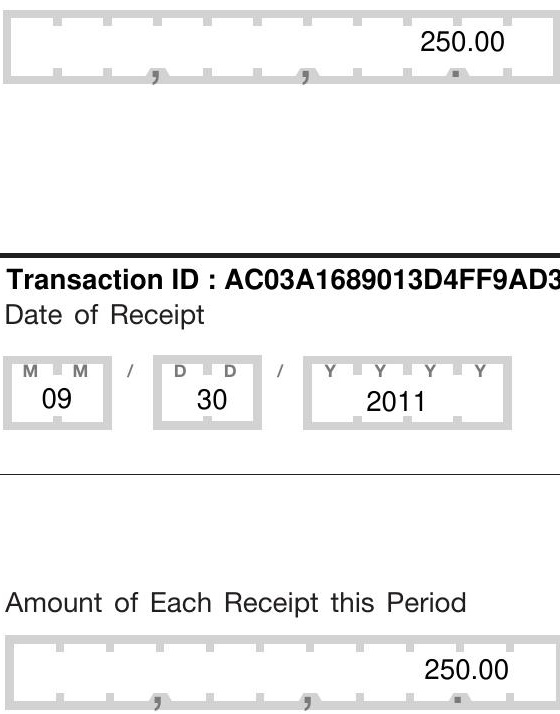

Transaction ID : AAF0448326A634391BAF

Date of Receipt

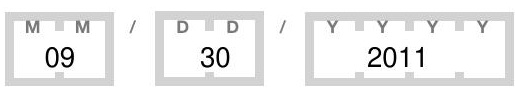

Amount of Each Receipt this Period

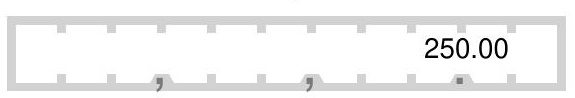

Subtotal Of Receipts This Page (optional).

750.00

Total This Period (last page this line number only) 


\section{SCHEDULE A-P} ITEMIZED RECEIPTS
Use separate schedule(s)

for each category of the

Detailed Summary Page
FOR LINE NUMBER: (check only one)

Any information or for commercial purposes, other than using the name and address of any political committee to solicit contributions from such committee.

NAME OF COMMITTEE (In Full)

Friends of Herman Cain

A. Full Name (Last, First, Middle Initial)

William Ginnetti

Mailing Address 62 Hemingway Ave.

\begin{tabular}{lcc}
\hline City & State & Zip Code \\
East Haven & CT & $06512-3404$
\end{tabular}

FEC ID number of contributing

federal political committee.

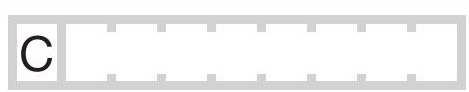

Name of Employer
Information Requested
Receipt For: 2012
X Primary $\quad \square$ General
Other (specify)

Occupation

Information Requested

Election Cycle-to-Date

250.00

Transaction ID : ABC5BF486A2BB4E2E8AF

Date of Receipt

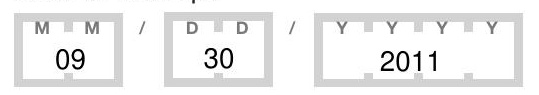

Amount of Each Receipt this Period

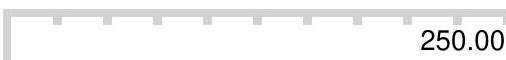

B. Full Name (Last, First, Middle Initial)

Joseph T. Freitas III

Mailing Address PO Box 677

\begin{tabular}{lcc}
\hline City & State & Zip Code \\
La Pine & OR & $97739-0677$
\end{tabular}

FEC ID number of contributing

federal political committee.

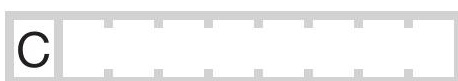

Name of Employer
None
Receipt For: 2012
X Primary
Other (specify)

Occupation

Retired

Election Cycle-to-Date

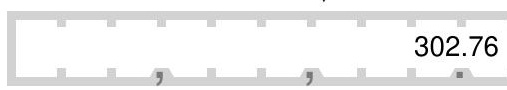

Amount of Each Receipt this Period

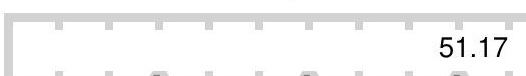

C. Full Name (Last, First, Middle Initial)

EDDY BIEHL

Mailing Address 1101 BLENNERHASSETT AVE

\begin{tabular}{lcc}
\hline City & State & Zip Code \\
Belpre & $\mathrm{OH}$ & $45714-2209$
\end{tabular}

FEC ID number of contributing

federal political committee.

C

Name of Employer

self

Occupation

small business owner

Receipt For: 2012

Х $\begin{aligned} & \text { Primary } \square \text { General } \\ & \text { Other (specify) }\end{aligned}$

Election Cycle-to-Date

1500.00

Transaction ID : A144CFA4FBF594ADFA37 Date of Receipt

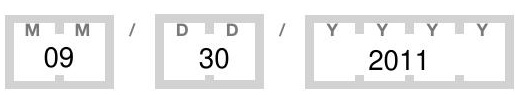

Transaction ID : A27D6DD3E2F4149DD985 Date of Receipt

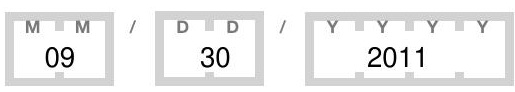

Amount of Each Receipt this Period

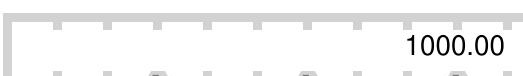

1301.17

Subtotal Of Receipts This Page (optional)

,

Total This Period (last page this line number only)

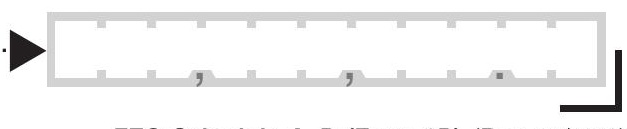

FEC Schedule A-P (Form 3P) (Rev. 03/2011) 


\section{SCHEDULE A-P} ITEMIZED RECEIPTS
Use separate schedule(s) for each category of the Detailed Summary Page

\begin{tabular}{|c|c|c|c|c|c|}
\hline \multicolumn{3}{|c|}{$\begin{array}{l}\text { FOR LINE NUMBER: } \\
\text { (check only one) }\end{array}$} & \multicolumn{3}{|c|}{ PAGE 1180 / 1572} \\
\hline 16 & $X$ 17a & $17 b$ & $17 c$ & $17 d$ & 18 \\
\hline $19 a$ & $19 \mathrm{~b}$ & $20 a$ & $20 \mathrm{~b}$ & $20 c$ & 21 \\
\hline
\end{tabular}

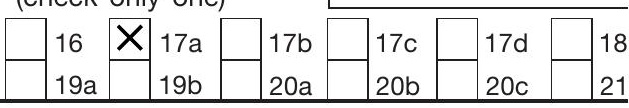

Any information copied from such Reports and Statements may not be sold or used by any person for the purpose of soliciting contributions or for commercial purposes, other than using the name and address of any political committee to solicit contributions from such committee.

NAME OF COMMITTEE (In Full)

\section{Friends of Herman Cain}

A. Full Name (Last, First, Middle Initial) James Stevens

Mailing Address 26 Brinker Road

\begin{tabular}{lcc}
\hline City & State & Zip Code \\
Barrington & IL & $60010-4008$
\end{tabular}

FEC ID number of contributing federal political committee.

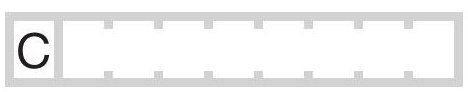

Name of Employer
Information Requested
Receipt For: 2012
X Primary
Other (specify)

Occupation Information Requested

Election Cycle-to-Date 250.00

B. Full Name (Last, First, Middle Initial) Randolph Robertson

Mailing Address 1735 Snead Drive

\begin{tabular}{lcc}
\hline City & State & Zip Code \\
Kokomo & IN & $46902-9416$
\end{tabular}

FEC ID number of contributing

federal political committee.

C

Name of Employer
Information Requested
Receipt For: 2012
Primary
Other (specify)

\section{Occupation}

Information Requested

Election Cycle-to-Date

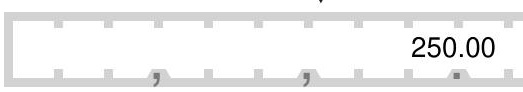

Transaction ID : A3FA4ADCF1A6D4A0AA1E

Date of Receipt

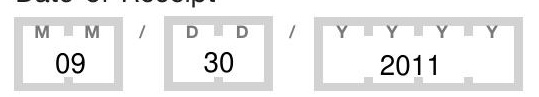

Amount of Each Receipt this Period

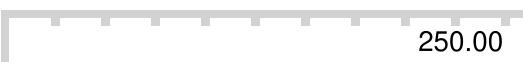

Amount of Each Receipt this Period

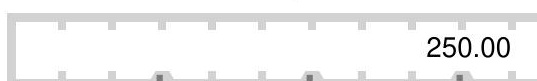

C. Full Name (Last, First, Middle Initial)

Peter Larson

Mailing Address 1619 Beaver Creek Lane

\begin{tabular}{lcc}
\hline City & State & Zip Code \\
Snellville & GA & $30078-6679$
\end{tabular}

FEC ID number of contributing federal political committee.

C

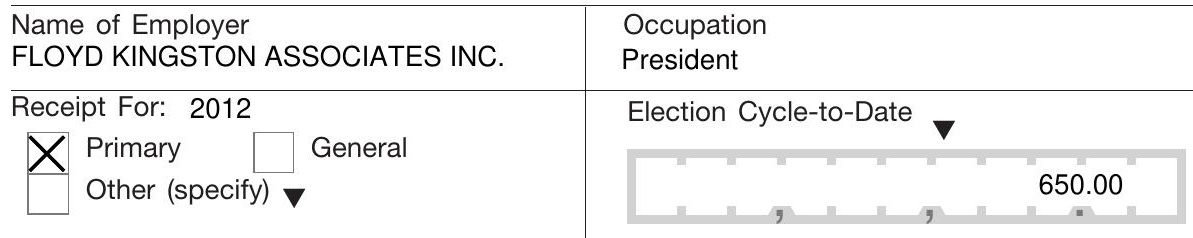

Amount of Each Receipt this Period

Transaction ID : AB48F45A984E34A7CB53 Date of Receipt
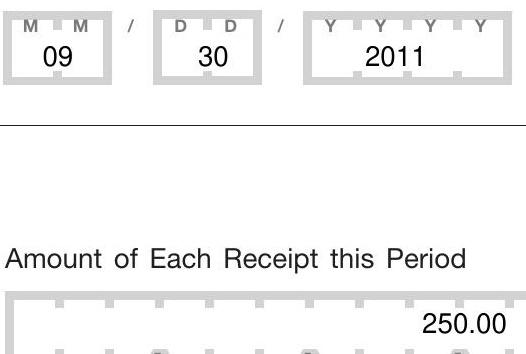

Subtotal Of Receipts This Page (optional).

Total This Period (last page this line number only) 


\section{SCHEDULE A-P} ITEMIZED RECEIPTS
Use separate schedule(s) for each category of the Detailed Summary Page

FOR LINE NUMBER:
(check only one)

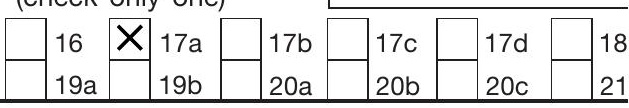

Any information copied from such Reports and Statements may not be sold or used by any person for the purpose of soliciting contributions or for commercial purposes, other than using the name and address of any political committee to solicit contributions from such committee.

NAME OF COMMITTEE (In Full)

\section{Friends of Herman Cain}

A. Full Name (Last, First, Middle Initial)

Richard Wetzel

Mailing Address 17 Waldon Road

\begin{tabular}{lcc}
\hline City & State & Zip Code \\
Califon & NJ & $07830-3506$
\end{tabular}

FEC ID number of contributing federal political committee.

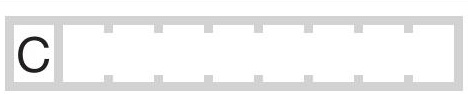

Name of Employer
Information Requested
Receipt For: 2012
X Primary
$\square$ Other (specify)

Occupation Information Requested

Election Cycle-to-Date 375.00

B. Full Name (Last, First, Middle Initial) Patrick Gale

Mailing Address 1027 Glendora PI.

\begin{tabular}{lcc}
\hline City & State & Zip Code \\
Bridge City & LA & $70094-3046$ \\
\hline
\end{tabular}

FEC ID number of contributing

federal political committee.

C

Name of Employer
Information Requested
Receipt For: 2012
Primary
Other (specify)

Occupation

Information Requested

Election Cycle-to-Date

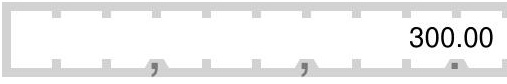

Transaction ID : A362DC65A4B944737AA4

Date of Receipt

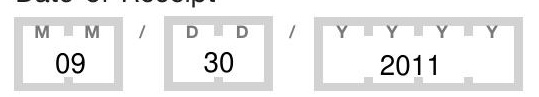

Amount of Each Receipt this Period

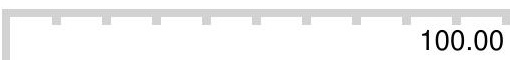

100.00

C. Full Name (Last, First, Middle Initial)

Barbara Nye

Mailing Address 7239 Lyndsey Way

\begin{tabular}{lcc}
\hline City & State & Zip Code \\
Elkridge & MD & $21075-6805$ \\
\hline
\end{tabular}

FEC ID number of contributing federal political committee.

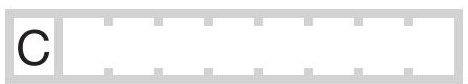

Name of Employer

Information Requested

\section{Occupation}

Information Requested

Receipt For: 2012

Х $\begin{aligned} & \text { Primary } \square \text { General } \\ & \text { Other (specify) }\end{aligned}$

Transaction ID : A354905778A764EB3A92

Date of Receipt

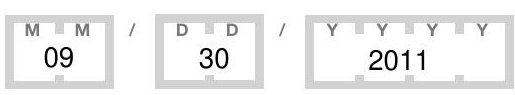

Amount of Each Receipt this Period

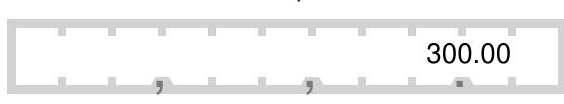

Transaction ID : A4EEEB699F18C410B83B Date of Receipt

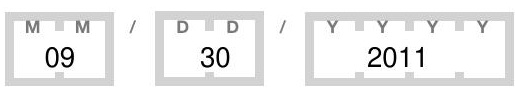

Amount of Each Receipt this Period

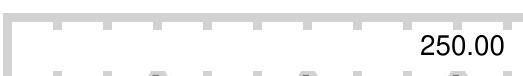

\section{Subtotal Of Receipts This Page (optional)}

Total This Period (last page this line number only) 


\section{SCHEDULE A-P} ITEMIZED RECEIPTS
Use separate schedule(s)

for each category of the

Detailed Summary Page
FOR LINE NUMBER: (check only one)

Any information or for commercial purposes, other than using the name and address of any political committee to solicit contributions from such committee.

NAME OF COMMITTEE (In Full)

Friends of Herman Cain

A. Full Name (Last, First, Middle Initial)

Susan Walter

Mailing Address P.O. Box 690

\begin{tabular}{lcc}
\hline City & State & Zip Code \\
Sautee Nacoochee & GA & $30571-0690$
\end{tabular}

FEC ID number of contributing

federal political committee.

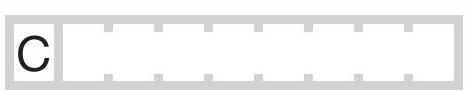

\begin{tabular}{l} 
Name of Employer \\
None \\
Receipt For: 2012 \\
X Primary $\quad$ General \\
\hline Other (specify)
\end{tabular}

Occupation

Retired

Election Cycle-to-Date

2727.00

B. Full Name (Last, First, Middle Initial)

John Jarrell

Mailing Address 3809 Brockton Loop

\begin{tabular}{lcc}
\hline City & State & Zip Code \\
Jefferson & GA & $30549-3934$ \\
\hline
\end{tabular}

FEC ID number of contributing

federal political committee.

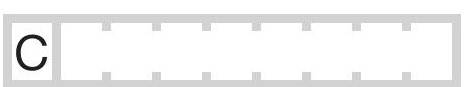

\begin{tabular}{l} 
Name of Employer \\
n/a \\
Receipt For: 2012 \\
X Primary $\quad$ General \\
\hline Other (specify)
\end{tabular}

\section{Occupation}

N/A

Election Cycle-to-Date

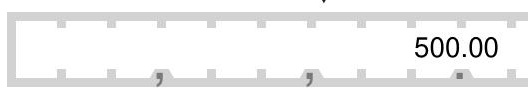

C. Full Name (Last, First, Middle Initial)

George Lilly

Mailing Address 18748 Park Grove Lane

\begin{tabular}{lcc}
\hline City & State & Zip Code \\
Jupiter & FL & 33458 \\
\hline
\end{tabular}

FEC ID number of contributing

federal political committee.

C

Name of Employer
Information Requested
Receipt For: 2012
Primary
Other (specify) General

Occupation

Information Requested

Election Cycle-to-Date
Transaction ID : AD05E6079BD5948799C7

Date of Receipt

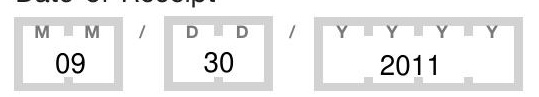

Amount of Each Receipt this Period

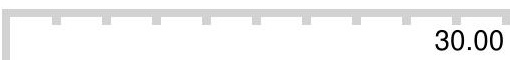

30.00

Amount of Each Receipt this Period

Transaction ID : A3A51657986A14F7D896

Date of Receipt
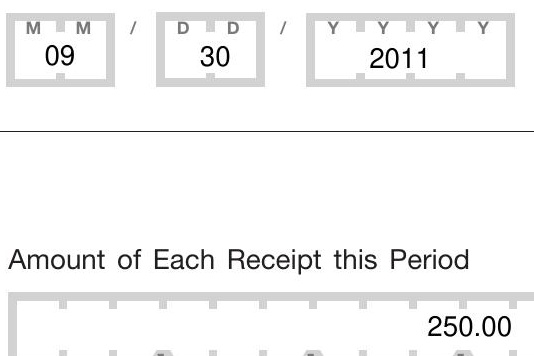

Transaction ID : A262C72DF0EEF46FF9A0 Date of Receipt

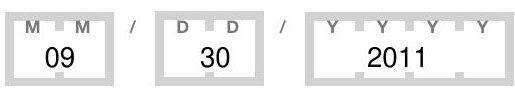

Amount of Each Receipt this Period

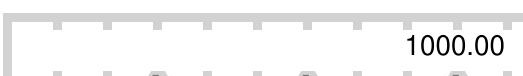

1000.00

Subtotal Of Receipts This Page (optional).

Total This Period (last page this line number only) 
SCHEDULE A-P ITEMIZED RECEIPTS
Use separate schedule(s) for each category of the Detailed Summary Page
FOR LINE NUMBER: (check only one)

PAGE 1183 / 1572

\begin{tabular}{|c|c|c|c|c|c|}
\hline & & & & & \\
\hline 16 & $\mathbf{X} 17 a$ & $17 b$ & $17 c$ & $17 d$ & 18 \\
\hline $19 a$ & $19 b$ & $20 \mathrm{a}$ & $20 \mathrm{~b}$ & $20 \mathrm{c}$ & 21 \\
\hline
\end{tabular}

Any information copied from such Reports and Statements may not be sold or used by any person for the purpose of soliciting contributions or for commercial purposes, other than using the name and address of any political committee to solicit contributions from such committee.

NAME OF COMMITTEE (In Full)

\section{Friends of Herman Cain}

A. Full Name (Last, First, Middle Initial)

Ronald Sautter

Mailing Address 4512 Stockbridge NW

\begin{tabular}{lcc}
\hline City & State & Zip Code \\
Albuquerque & NM & $87120-5406$
\end{tabular}

FEC ID number of contributing

federal political committee.

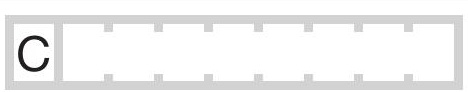

Name of Employer
Information Requested
Receipt For: 2012
X Primary $\quad \square$ General
Other (specify)

Occupation

Information Requested

Election Cycle-to-Date

250.00

B. Full Name (Last, First, Middle Initial)

Rodney Stark

Mailing Address 170 Camino Rayo del Sol

\begin{tabular}{lcc}
\hline City & State & Zip Code \\
Corrales & NM & $87048-6805$ \\
\hline
\end{tabular}

FEC ID number of contributing

federal political committee.

C

Name of Employer
Information Requested
Receipt For: 2012
X Primary
Other (specify)

Occupation

Information Requested

Election Cycle-to-Date

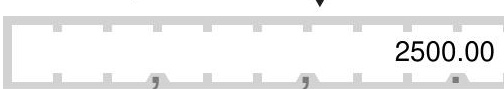

Transaction ID : AA661067D0C584E97B55

Date of Receipt

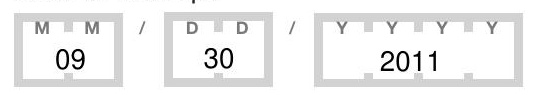

Amount of Each Receipt this Period

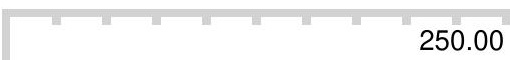

250.00

C. Full Name (Last, First, Middle Initial)

Stephen H Perry

Mailing Address 517 Carilion Ln

\begin{tabular}{lcc}
\hline City & State & Zip Code \\
Greenville & SC & $29617-7914$
\end{tabular}

FEC ID number of contributing federal political committee.

C

29617-7914

Name of Employer

Information Requested

Occupation

Receipt For: 2012

Х $\begin{aligned} & \text { Primary } \square \text { General } \\ & \text { Other (specify) }\end{aligned}$

Information Requested

Election Cycle-to-Date

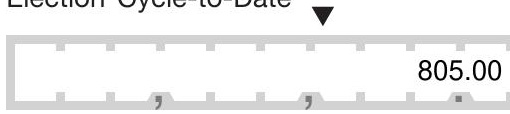

Transaction ID : A78F52BF55FCB4BE8993

Date of Receipt

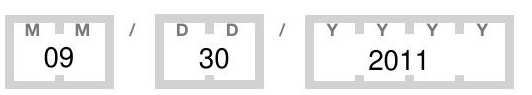

Amount of Each Receipt this Period

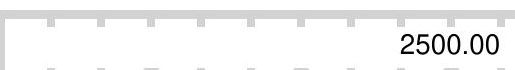

Transaction ID : A088A953E4FAA480E985

Date of Receipt

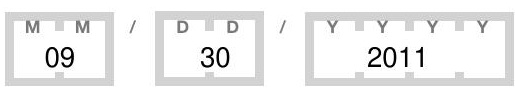

Amount of Each Receipt this Period

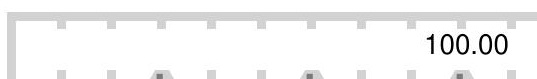

2850.00

Subtotal Of Receipts This Page (optional)

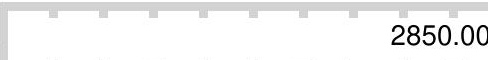

Total This Period (last page this line number only) 
SCHEDULE A-P ITEMIZED RECEIPTS
Use separate schedule(s) for each category of the Detailed Summary Page
FOR LINE NUMBER: (check only one)

PAGE 1184 / 1572

\begin{tabular}{|c|c|c|c|c|c|}
\hline & & & & & \\
\hline 16 & $\begin{array}{ll}\mathbf{X} & 17 a \\
\end{array}$ & $17 \mathrm{~b}$ & $17 c$ & $17 d$ & 18 \\
\hline $19 a$ & $19 b$ & $20 \mathrm{a}$ & $20 \mathrm{~b}$ & $20 c$ & 21 \\
\hline
\end{tabular}

Any information copied from such Reports and Statements may not be sold or used by any person for the purpose of soliciting contributions or for commercial purposes, other than using the name and address of any political committee to solicit contributions from such committee.

NAME OF COMMITTEE (In Full)

\section{Friends of Herman Cain}

A. Full Name (Last, First, Middle Initial)

Michael Reed

Mailing Address PO Box 20003698 Dean Rd., SE

\begin{tabular}{lcc}
\hline City & State & Zip Code \\
Cartersville & GA & $30120-9001$
\end{tabular}

FEC ID number of contributing federal political committee.

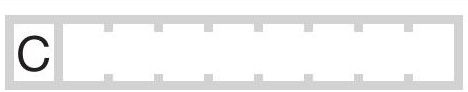

Name of Employer
self
Receipt For: 2012
X Primary $\quad$ General
Other (specify)

Occupation Physician

Election Cycle-to-Date

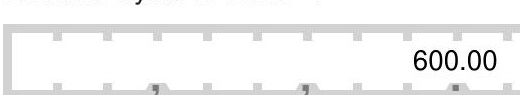

B. Full Name (Last, First, Middle Initial) mary miller

Mailing Address 234 Hudson Cir

\begin{tabular}{lcc}
\hline City & State & Zip Code \\
Douglasville & GA & $30134-5850$
\end{tabular}

FEC ID number of contributing

federal political committee.

C

Name of Employer
City of Atlanta
Receipt For: 2012
X Primary
Other (specify) General

Occupation

Project Manager

Election Cycle-to-Date

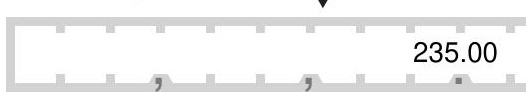

Transaction ID : A89C6D447B7AC47CEA8C

Date of Receipt

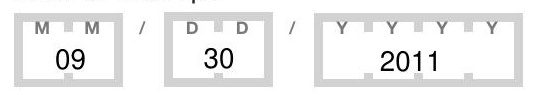

Amount of Each Receipt this Period

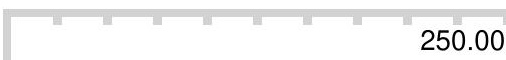

C. Full Name (Last, First, Middle Initial)

Mr Orman Whichard

Mailing Address 106 Cardinal Dr

\begin{tabular}{lcc}
\hline City & State & Zip Code \\
Greenville & NC & $27858-8908$
\end{tabular}

FEC ID number of contributing federal political committee.

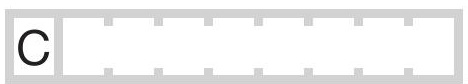

Name of Employer
self
Receipt For: 2012
X Primary
Other (specify) General

Occupation Insurance Agent

Election Cycle-to-Date

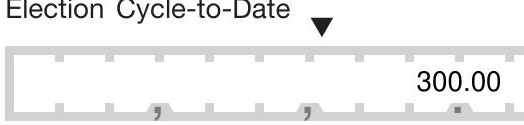

Transaction ID : A133E1DB7639E4E07B66

Date of Receipt

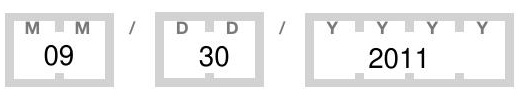

Amount of Each Receipt this Period

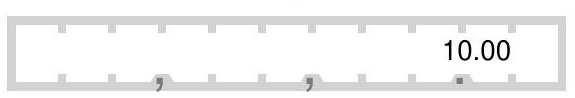

Transaction ID : AA177E7F516C5456C880 Date of Receipt

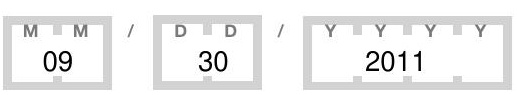

Amount of Each Receipt this Period

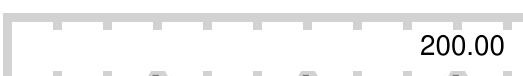

\section{Subtotal Of Receipts This Page (optional)}

Total This Period (last page this line number only) 


\section{SCHEDULE A-P} ITEMIZED RECEIPTS
Use separate schedule(s) for each category of the Detailed Summary Page

FOR LINE NUMBER:
(check only one)

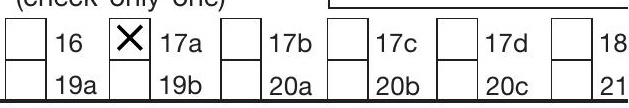

Any information copied from such Reports and Statements may not be sold or used by any person for the purpose of soliciting contributions or for commercial purposes, other than using the name and address of any political committee to solicit contributions from such committee.

NAME OF COMMITTEE (In Full)

\section{Friends of Herman Cain}

A. Full Name (Last, First, Middle Initial)

\section{Peggy Crowl \\ Mailing Address 215 Heather Lane}

\begin{tabular}{lcc}
\hline City & State & Zip Code \\
Livingston & TX & $77351-9278$ \\
\hline
\end{tabular}

FEC ID number of contributing federal political committee.

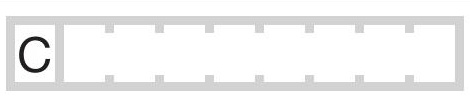

Name of Employer
Citimortgage
Receipt For: 2012
X Primary $\square$ General
Other (specify)

Occupation mortgage underwriter Election Cycle-to-Date 300.00

B. Full Name (Last, First, Middle Initial) Doanld Weber

Mailing Address 525 Old Cobblestone Drive

\begin{tabular}{lcc}
\hline City & State & Zip Code \\
Atlanta & GA & $30350-5430$ \\
\hline
\end{tabular}

FEC ID number of contributing

federal political committee.

C

Name of Employer
Information Requested
Receipt For: 2012
Primary
Other (specify)

Occupation

Information Requested

Election Cycle-to-Date

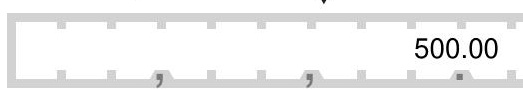

Transaction ID : A7B166DE7940845DCAEE

Date of Receipt

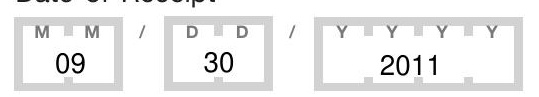

Amount of Each Receipt this Period

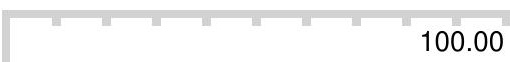

Amount of Each Receipt this Period

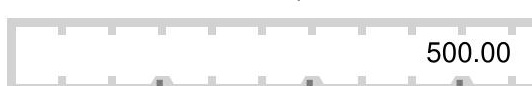

C. Full Name (Last, First, Middle Initial)

Richard Eubanks

Mailing Address 8787 Sienna Springs Blvd Apt 122

\begin{tabular}{lcc}
\hline City & State & Zip Code \\
Missouri City & TX & $77459-6065$
\end{tabular}

FEC ID number of contributing federal political committee.

C

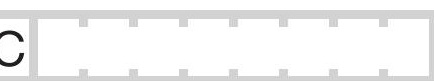

Transaction ID : AF3ADA6B92DDD47F4ADF Date of Receipt

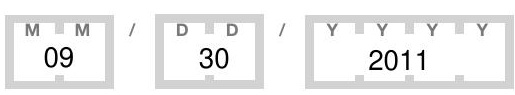

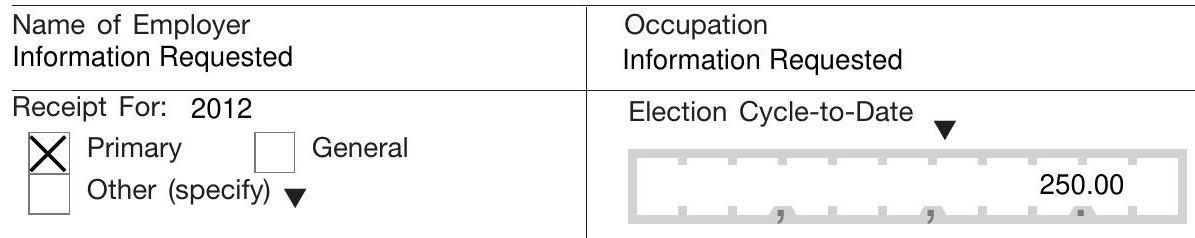

Transaction ID : A4247F3EABED34AD9A90 Date of Receipt

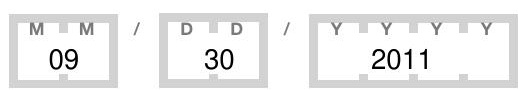

Amount of Each Receipt this Period

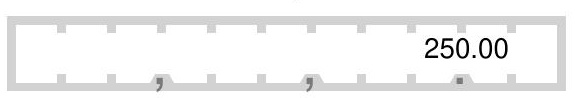

Subtotal Of Receipts This Page (optional).

850.00

Total This Period (last page this line number only) 


\section{SCHEDULE A-P} ITEMIZED RECEIPTS
Use separate schedule(s) for each category of the Detailed Summary Page

\begin{tabular}{|c|c|c|c|c|c|}
\hline \multicolumn{3}{|c|}{$\begin{array}{l}\text { FOR LINE NUMBER: } \\
\text { (check only one) }\end{array}$} & \multicolumn{3}{|c|}{ PAGE 1186 / 1572} \\
\hline 16 & $X$ 17a & $17 b$ & $17 c$ & $17 d$ & 18 \\
\hline $19 a$ & $19 \mathrm{~b}$ & $20 a$ & $20 \mathrm{~b}$ & $20 c$ & 21 \\
\hline
\end{tabular}

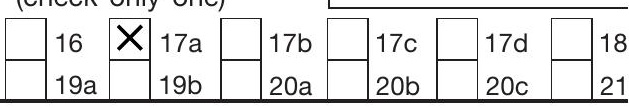

Any information copied from such Reports and Statements may not be sold or used by any person for the purpose of soliciting contributions or for commercial purposes, other than using the name and address of any political committee to solicit contributions from such committee.

NAME OF COMMITTEE (In Full)

\section{Friends of Herman Cain}

A. Full Name (Last, First, Middle Initial)

Frederick Vahlsing

Mailing Address 1014 Cherry Hill Rd.

\begin{tabular}{lcc}
\hline City & State & Zip Code \\
Princeton & NJ & $08540-7722$ \\
\hline
\end{tabular}

FEC ID number of contributing federal political committee.

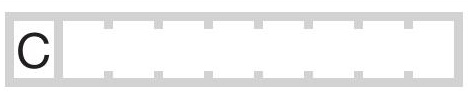

Name of Employer
Information Requested
Receipt For: 2012
X Primary
$\square$ Other (specify)

Occupation Information Requested

Election Cycle-to-Date 2500.00

B. Full Name (Last, First, Middle Initial) James Nelson

Mailing Address 1077 Country Lake Circle

\begin{tabular}{lcc}
\hline City & State & Zip Code \\
Lake Wales & FL & $33898-8704$
\end{tabular}

FEC ID number of contributing

federal political committee.

C

\begin{tabular}{l} 
Name of Employer \\
Self Employed \\
Receipt For: 2012 \\
Xrimary \\
\hline Other (specify) General
\end{tabular}

Occupation

Physician

Election Cycle-to-Date

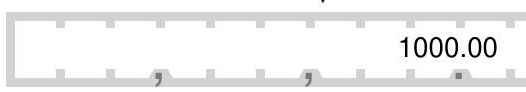

Transaction ID : A51211018D0954B6C96C

Date of Receipt

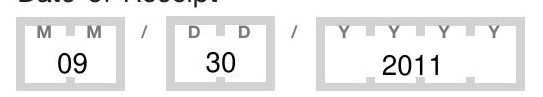

Amount of Each Receipt this Period

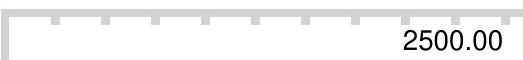

2500.00

Transaction ID : A4776F008FA9748BCBB4

Date of Receipt

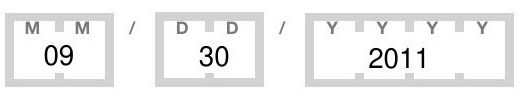

Amount of Each Receipt this Period

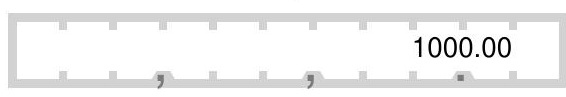

Transaction ID : A74798D0387D04F71BDA Date of Receipt

James Remington

Mailing Address 3713 Barrington Bridge Place

\begin{tabular}{lcc}
\hline City & State & Zip Code \\
Richmond & VA & $23233-1721$
\end{tabular}

FEC ID number of contributing federal political committee.

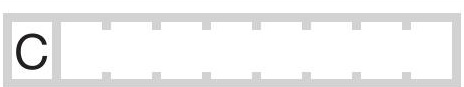

Name of Employer

Occupation

Self Employed

Timber Management

Receipt For: 2012

Х $\begin{aligned} & \text { Primary } \\ & \text { Other (specify) }\end{aligned}$
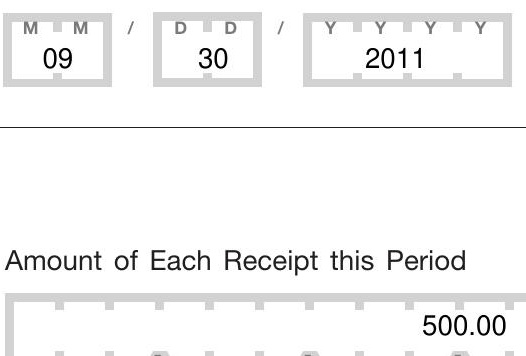

Amount of Each Receipt this Period

\section{Subtotal Of Receipts This Page (optional)}

Total This Period (last page this line number only) 
SCHEDULE A-P ITEMIZED RECEIPTS
Use separate schedule(s) for each category of the Detailed Summary Page
FOR LINE NUMBER: (check only one)

Any information or for commercial purposes, other than using the name and address of any political committee to solicit contributions from such committee.

NAME OF COMMITTEE (In Full)

\section{Friends of Herman Cain}

A. Full Name (Last, First, Middle Initial)

Mr. John Furbush

Mailing Address 45 Orrills Hill Rd

\begin{tabular}{lcc}
\hline City & State & Zip Code \\
Lebanon & ME & $04027-3910$
\end{tabular}

FEC ID number of contributing federal political committee.

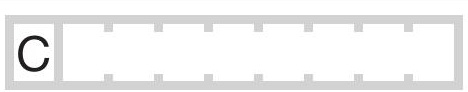

Name of Employer
Global Tecnology Talent
Receipt For: 2012
X Primary $\quad \square$ General
Other (specify)

Occupation

Project Manager

Election Cycle-to-Date

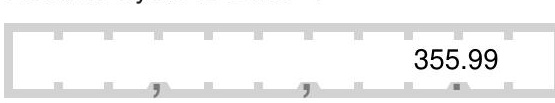

B. Full Name (Last, First, Middle Initial)

Mary Ann Snow

Mailing Address 1321 Ragley Hall Rd. NE

\begin{tabular}{lcc}
\hline City & State & Zip Code \\
Atlanta & GA & $30319-2515$ \\
\hline
\end{tabular}

FEC ID number of contributing

federal political committee.

C

Name of Employer
Information Requested
Receipt For: 2012
X Primary
Other (specify)

Occupation

Information Requested

Election Cycle-to-Date

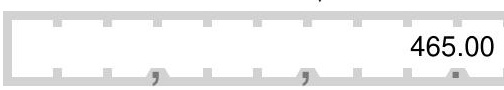

Transaction ID : AA6E35BED05BA47AA994

Date of Receipt

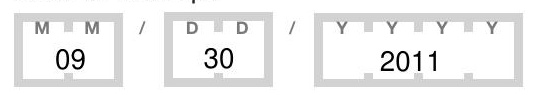

Amount of Each Receipt this Period

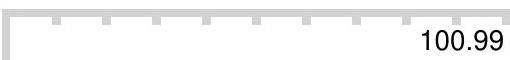

Transaction ID : A3CCFEBAC64D14798AC7 Date of Receipt

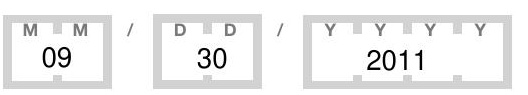

Amount of Each Receipt this Period

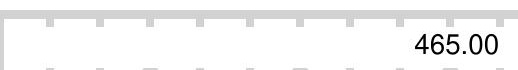

Transaction ID : A8DAA6240723F417A8C0 Date of Receipt

\section{Lawrence Feast}

C. Full Name (Last, First, Middle Initial)

Mailing Address 11025 Melissa Ct

\begin{tabular}{lcc}
\hline City & State & Zip Code \\
Fairfax & VA & $22030-5342$ \\
\hline
\end{tabular}

FEC ID number of contributing federal political committee.

C

Name of Employer
Scitor Corporation
Receipt For: 2012
X Primary $\quad \square$ General
Other (specify)

Occupation

Spectrum Team Lead

Election Cycle-to-Date

Subtotal Of Receipts This Page (optional)

Amount of Each Receipt this Period

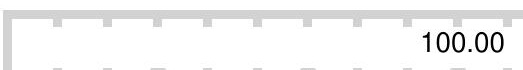

Total This Period (last page this line number only)

665.99

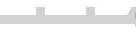




\section{SCHEDULE A-P} ITEMIZED RECEIPTS
Use separate schedule(s)

for each category of the

Detailed Summary Page
FOR LINE NUMBER: (check only one)

Any information or for commercial purposes, other than using the name and address of any political committee to solicit contributions from such committee.

NAME OF COMMITTEE (In Full)

Friends of Herman Cain

A. Full Name (Last, First, Middle Initial)

Wade Harrison

Mailing Address 1368 Mar Del Dr

\begin{tabular}{lcc}
\hline City & State & Zip Code \\
Greenville & OH & $45331-2412$
\end{tabular}

FEC ID number of contributing federal political committee.

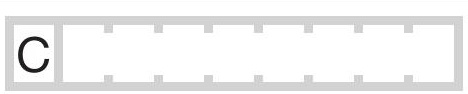

Name of Employer
Whirlpool
Receipt For: 2012
Х Primary $\square$ General
$\square$ Other (specify)

Occupation

Engineer

Election Cycle-to-Date

270.00

B. Full Name (Last, First, Middle Initial)

Karan Bumann

Mailing Address 301 Hughes Road Painted Lake Farm

\begin{tabular}{lcc}
\hline City & State & Zip Code \\
Newborn & GA & 30056
\end{tabular}

FEC ID number of contributing

federal political committee.

C

\begin{tabular}{l} 
Name of Employer \\
Information Requested \\
\hline Receipt For: 2012 \\
$X$ Primary \\
Other (specify)
\end{tabular}

Occupation

Information Requested

Election Cycle-to-Date

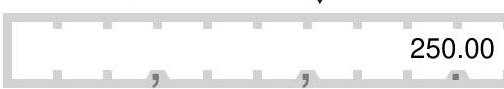

Transaction ID : A553C53A1200A4F80A63

Date of Receipt

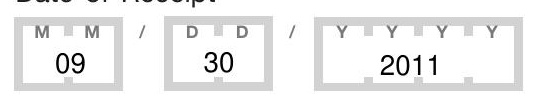

Amount of Each Receipt this Period

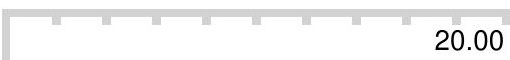

20.00

C. Full Name (Last, First, Middle Initial)

Peaches Kavanaugh

Mailing Address 216 Monty Manor

\begin{tabular}{lcc}
\hline City & State & Zip Code \\
Yorktown & VA & $23693-4414$
\end{tabular}

FEC ID number of contributing

federal political committee.

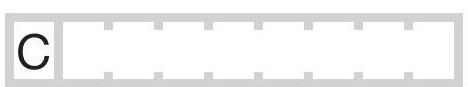

Name of Employer

Air Force

Receipt For: 2012

Х $\begin{aligned} & \text { Primary } \square \text { General } \\ & \text { Other (specify) }\end{aligned}$

\section{Occupation}

Retired

Election Cycle-to-Date

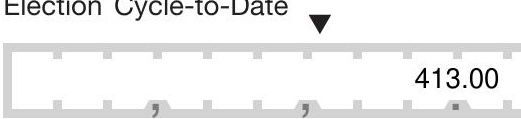

Transaction ID : AEFDC30962E674C3599B

Date of Receipt

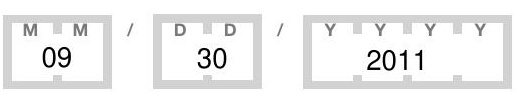

Amount of Each Receipt this Period

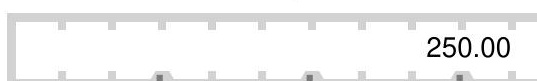

Transaction ID : AC473C61D6BE64F5ABB2 Date of Receipt

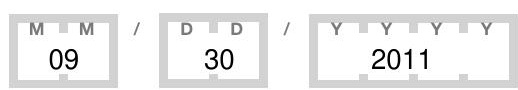

Amount of Each Receipt this Period

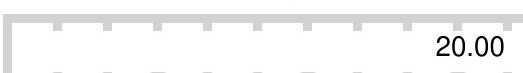

\section{Subtotal Of Receipts This Page (optional)}

Total This Period (last page this line number only) 
SCHEDULE A-P ITEMIZED RECEIPTS
Use separate schedule(s) for each category of the Detailed Summary Page
FOR LINE NUMBER: (check only one)

Any information or for commercial purposes, other than using the name and address of any political committee to solicit contributions from such committee.

NAME OF COMMITTEE (In Full)

\section{Friends of Herman Cain}

A. Full Name (Last, First, Middle Initial)

Richard Lifton

Mailing Address 4975 S 72nd East Ave Apt B

\begin{tabular}{lcc}
\hline City & State & Zip Code \\
Tulsa & OK & $74145-6750$
\end{tabular}

FEC ID number of contributing federal political committee.

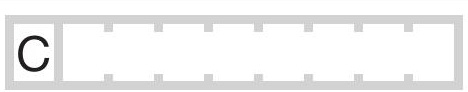

Name of Employer
EDKO
Receipt For: 2012
X Primary $\quad \square$ General
$\square$ Other (specify)

Occupation

Herbicide applicator

Election Cycle-to-Date

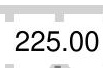

B. Full Name (Last, First, Middle Initial)

James Reynolds

Mailing Address 7910 E. Arlington Rd. Unit 7

\begin{tabular}{lcc}
\hline City & State & Zip Code \\
Scottsdale & AZ & $85250-6550$
\end{tabular}

FEC ID number of contributing

federal political committee.

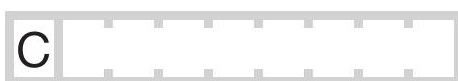

Name of Employer
None
Receipt For: 2012
X Primary
Other (specify)

\section{Occupation}

Retired

Election Cycle-to-Date

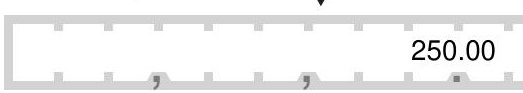

Transaction ID : A9C4A762BCED9410B9FF

Date of Receipt

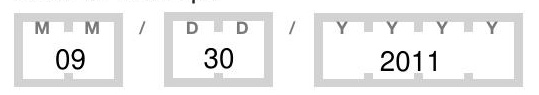

Amount of Each Receipt this Period

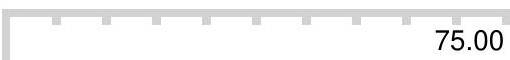

C. Full Name (Last, First, Middle Initial)

Margaret McMillen

Mailing Address 1005 Commerce Drive

\begin{tabular}{lcc}
\hline City & State & Zip Code \\
Grafton & OH & $44044-1278$
\end{tabular}

FEC ID number of contributing federal political committee.

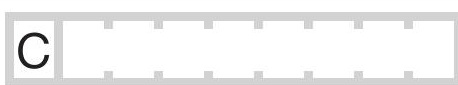

Name of Employer

Power \& Grounding Solutions

Receipt For: 2012

Х $\begin{aligned} & \text { Primary } \square \text { General } \\ & \text { Other (specify) }\end{aligned}$

\section{Occupation}

Sales

Election Cycle-to-Date

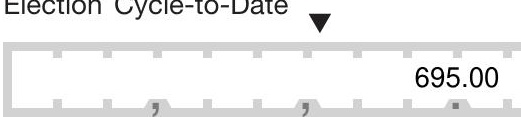

Amount of Each Receipt this Period

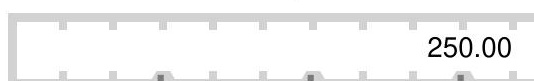

Transaction ID : AE2E251EDCEB948BCB7B Date of Receipt

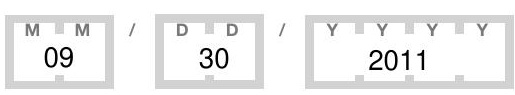

Transaction ID : A82CBD2D43F6E480F879 Date of Receipt

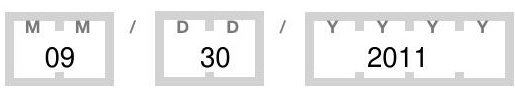

Amount of Each Receipt this Period

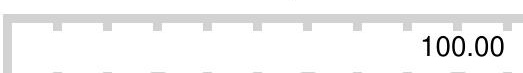

\section{Subtotal Of Receipts This Page (optional)}

Total This Period (last page this line number only) 


\section{SCHEDULE A-P} ITEMIZED RECEIPTS
Use separate schedule(s)

for each category of the

Detailed Summary Page
FOR LINE NUMBER: (check only one)

Any information or for commercial purposes, other than using the name and address of any political committee to solicit contributions from such committee.

NAME OF COMMITTEE (In Full)

\section{Friends of Herman Cain}

A. Full Name (Last, First, Middle Initial)

Nancy Wood

Mailing Address 622 Vance Drive

\begin{tabular}{lcc}
\hline City & State & Zip Code \\
Bristol & TN & $37620-4537$
\end{tabular}

FEC ID number of contributing federal political committee.

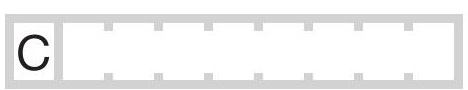

Name of Employer
n/a
Receipt For: 2012
X Primary $\quad$ General
Other (specify)

\section{Occupation} $\mathrm{N} / \mathrm{A}$

Election Cycle-to-Date

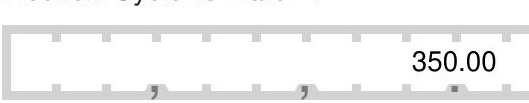

B. Full Name (Last, First, Middle Initial)

Thomas Schrade

Mailing Address 17 Via Visione \# 101

\begin{tabular}{lcc}
\hline City & State & Zip Code \\
Henderson & NV & 89011-3752 \\
\hline
\end{tabular}

FEC ID number of contributing

federal political committee.

C

Name of Employer
Information Requested
Receipt For: 2012
X Primary
Other (specify)

Occupation

Information Requested

Election Cycle-to-Date

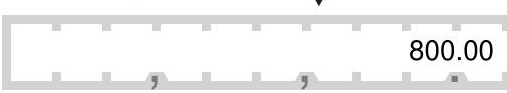

Transaction ID : AE2744E97CB3940498E2

Date of Receipt

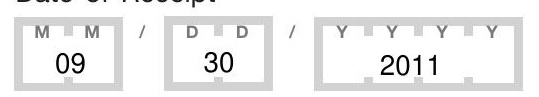

Amount of Each Receipt this Period

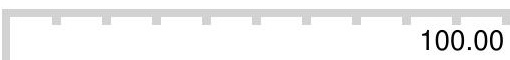

C. Full Name (Last, First, Middle Initial)

Jackie Jenkins

Mailing Address 4700 Balley Shannon Drive

\begin{tabular}{lcc}
\hline City & State & Zip Code \\
Mableton & GA & $30126-1752$
\end{tabular}

FEC ID number of contributing

federal political committee.

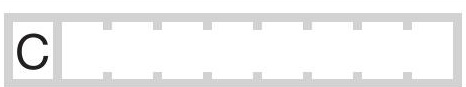

Name of Employer

MedSolutions

Receipt For: 2012

Х $\begin{aligned} & \text { Primary } \square \text { General } \\ & \text { Other (specify) }\end{aligned}$

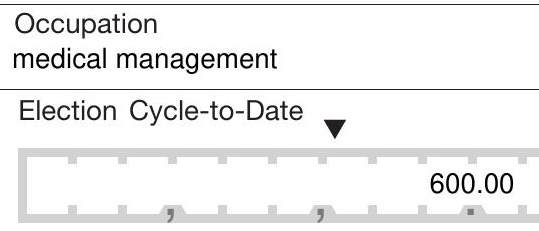

Amount of Each Receipt this Period

Transaction ID : AA0DBFCFCEE644F75BD6 Date of Receipt
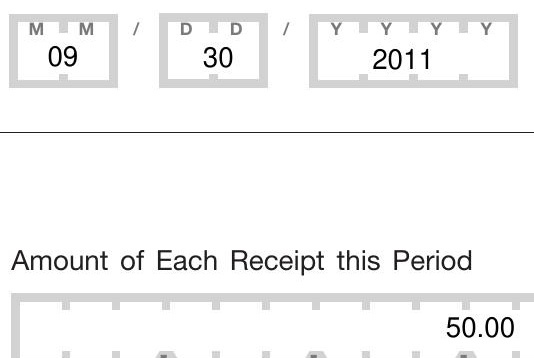

Transaction ID : A7D58E479DA564667A88

Date of Receipt

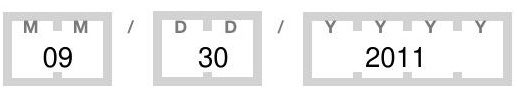

Amount of Each Receipt this Period

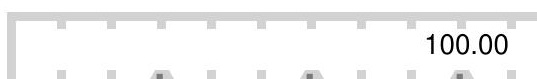

250.00

Subtotal Of Receipts This Page (optional)

Total This Period (last page this line number only) 


\section{SCHEDULE A-P} ITEMIZED RECEIPTS
Use separate schedule(s) for each category of the Detailed Summary Page

FOR LINE NUMBER:
(check only one)

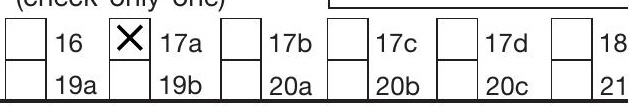

Any information copied from such Reports and Statements may not be sold or used by any person for the purpose of soliciting contributions or for commercial purposes, other than using the name and address of any political committee to solicit contributions from such committee.

NAME OF COMMITTEE (In Full)

\section{Friends of Herman Cain}

A. Full Name (Last, First, Middle Initial)

Mary Carol Gregory

Mailing Address 6927 E. Caballo Dr.

\begin{tabular}{lcc}
\hline City & State & Zip Code \\
Paradise Valley & AZ & $85253-2710$ \\
\hline
\end{tabular}

FEC ID number of contributing federal political committee.

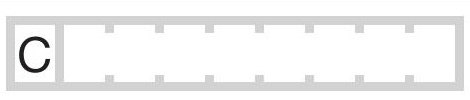

Name of Employer
Information Requested
Receipt For: 2012
X Primary
$\square$ Other (specify)

Occupation Information Requested

Election Cycle-to-Date 2000.00

B. Full Name (Last, First, Middle Initial)

Victoria Kuohung

Mailing Address 660 Washington St Apt 12-O

\begin{tabular}{lcc}
\hline City & State & Zip Code \\
Boston & MA & $02111-3226$ \\
\hline
\end{tabular}

FEC ID number of contributing

federal political committee.

C

Name of Employer
Information Requested
Receipt For: 2012
X Primary
Other (specify)

Occupation

Information Requested

Election Cycle-to-Date

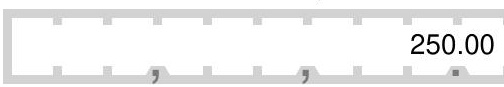

Transaction ID : AFB4B4E742ABF4277937

Date of Receipt

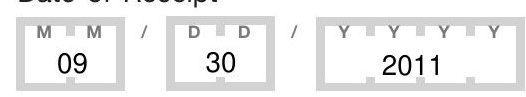

Amount of Each Receipt this Period

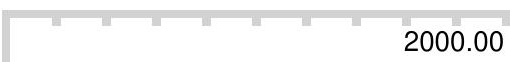

Amount of Each Receipt this Period

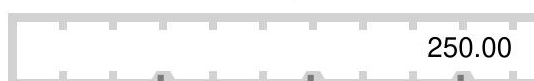

C. Full Name (Last, First, Middle Initial)

Richard Spaide

Mailing Address 530 E. 72nd St.

\begin{tabular}{lcc}
\hline City & State & Zip Code \\
New York & NY & $10021-4855$
\end{tabular}

FEC ID number of contributing federal political committee.

C

Name of Employer
Information Requested
Receipt For: 2012
X Primary
Other (specify) General

Occupation

Information Requested

Election Cycle-to-Date
Transaction ID : A357E897A73EE4AF4AEC Date of Receipt

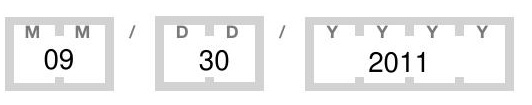

Transaction ID : A78A22E154BC84C51B5C Date of Receipt

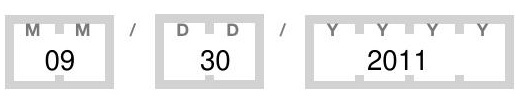

Amount of Each Receipt this Period

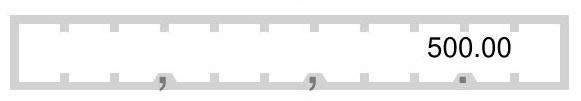

500.00

\section{Subtotal Of Receipts This Page (optional)}

Total This Period (last page this line number only) 


\section{SCHEDULE A-P} ITEMIZED RECEIPTS
Use separate schedule(s) for each category of the Detailed Summary Page

FOR LINE NUMBER:
(check only one)

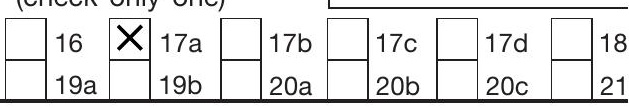

Any information copied from such Reports and Statements may not be sold or used by any person for the purpose of soliciting contributions or for commercial purposes, other than using the name and address of any political committee to solicit contributions from such committee.

NAME OF COMMITTEE (In Full)

\section{Friends of Herman Cain}

A. Full Name (Last, First, Middle Initial)

Lynn Vannier

Mailing Address 8107 Laurel Tree Dr.

\begin{tabular}{lcc}
\hline City & State & Zip Code \\
Orlando & FL & $32819-6923$
\end{tabular}

FEC ID number of contributing federal political committee.

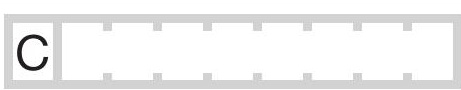

Name of Employer
Information Requested
Receipt For: 2012
X Primary
Other (specify) General

Occupation Information Requested

Election Cycle-to-Date 500.00

B. Full Name (Last, First, Middle Initial)

Gary Webb

Mailing Address 302 Riverford Way

\begin{tabular}{lcc}
\hline City & State & Zip Code \\
Lawrenceville & GA & $30043-6416$ \\
\hline
\end{tabular}

FEC ID number of contributing

federal political committee.

C

Name of Employer
Information Requested
Receipt For: 2012
Primary
Other (specify)

Occupation

Information Requested

Election Cycle-to-Date

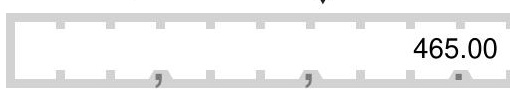

Transaction ID : A093A3BEB96074742A05

Date of Receipt

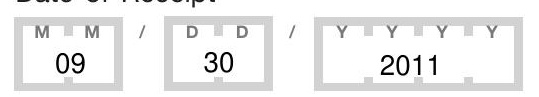

Amount of Each Receipt this Period

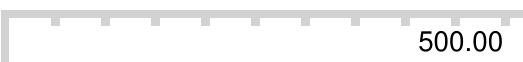

Amount of Each Receipt this Period

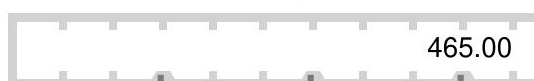

C. Full Name (Last, First, Middle Initial)

Robert Keeler

Mailing Address 18120 Southern Cross Ln.

\begin{tabular}{lcc}
\hline City & State & Zip Code \\
Beaverdam & VA & $23015-1446$
\end{tabular}

FEC ID number of contributing federal political committee.

C

Name of Employer
Information Requested
Receipt For: 2012
X Primary
Other (specify) General

\section{Occupation}

Information Requested

Election Cycle-to-Date
Transaction ID : A2DAE1815764D46DB9D6 Date of Receipt

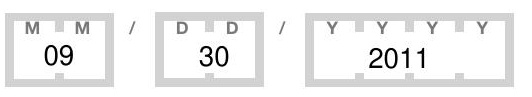

Transaction ID : ACD8D2E34FFE14949BAA Date of Receipt

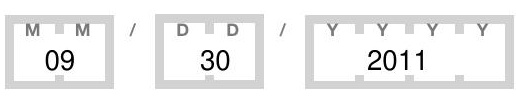

Amount of Each Receipt this Period

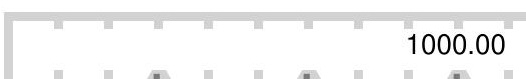

1000.00
Subtotal Of Receipts This Page (optional).

1965.00

ㄱ․․

Total This Period (last page this line number only)

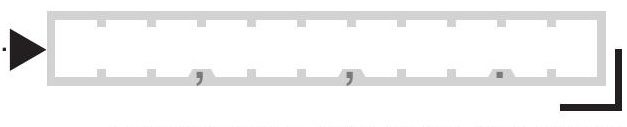

FEC Schedule A-P (Form 3P) (Rev. 03/2011) 
SCHEDULE A-P ITEMIZED RECEIPTS
Use separate schedule(s) for each category of the Detailed Summary Page
FOR LINE NUMBER: (check only one)
PAGE $1193 / 1572$

\begin{tabular}{|c|c|c|c|c|c|}
\hline & & & & & \\
\hline 16 & $\begin{array}{lll}X & 17 a \\
\end{array}$ & $17 \mathrm{~b}$ & $17 c$ & $17 d$ & 18 \\
\hline $19 a$ & $19 b$ & $20 a$ & $20 \mathrm{~b}$ & $20 c$ & 21 \\
\hline
\end{tabular}

Any information copied from such Reports and Statements may not be sold or used by any person for the purpose of soliciting contributions or for commercial purposes, other than using the name and address of any political committee to solicit contributions from such committee.

NAME OF COMMITTEE (In Full)

Friends of Herman Cain

A. Full Name (Last, First, Middle Initial)

Matt McPherson

Mailing Address 919 River Rd

\begin{tabular}{lcc}
\hline City & State & Zip Code \\
Sparta & WI & $54656-2469$
\end{tabular}

FEC ID number of contributing federal political committee.

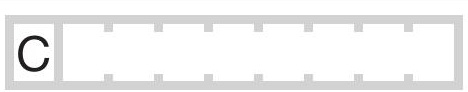

Name of Employer
Information Requested
Receipt For: 2012
X Primary
$\square$ Other (specify)

Occupation

Information Requested

Election Cycle-to-Date

2500.00

B. Full Name (Last, First, Middle Initial)

Marie Ring

Mailing Address 311 Birch Field

\begin{tabular}{lcc}
\hline City & State & Zip Code \\
Jefferson & GA & $30549-8310$ \\
\hline
\end{tabular}

FEC ID number of contributing

federal political committee.

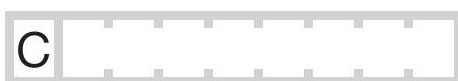

Name of Employer
Rescare Homecare
Receipt For: 2012
X Primary
Other (specify)

\section{Occupation}

$\mathrm{RN}$

Election Cycle-to-Date

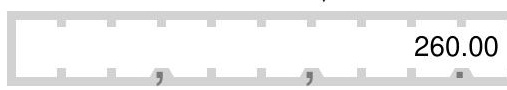

Transaction ID : ADF46C1F74BEE47149AF

Date of Receipt

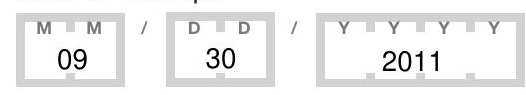

Amount of Each Receipt this Period

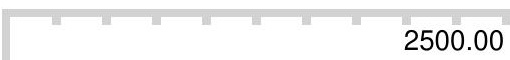

2500.00

C. Full Name (Last, First, Middle Initial)

Edward Baumgartner

Mailing Address 9115 Marlboro Pike \#51

\begin{tabular}{lcc}
\hline City & State & Zip Code \\
Upper Marlboro & MD & $20772-3660$
\end{tabular}

FEC ID number of contributing federal political committee.

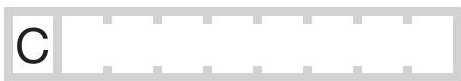

Name of Employer
$\mathrm{n} / \mathrm{a}$
Receipt For: 2012
X Primary

\section{Occupation}

Radiologic Technologist

Election Cycle-to-Date

Transaction ID : A29D2E5DACB0D4A2FAE7 Date of Receipt

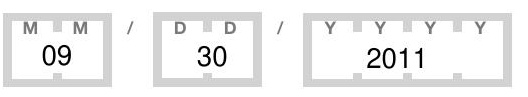

Amount of Each Receipt this Period

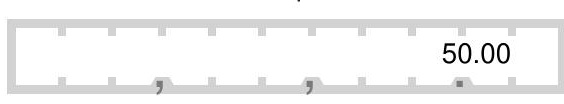

Transaction ID : ABAEB5279F52F4797864 Date of Receipt

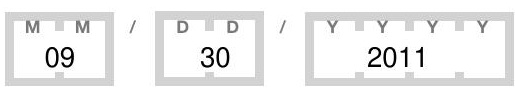

Amount of Each Receipt this Period

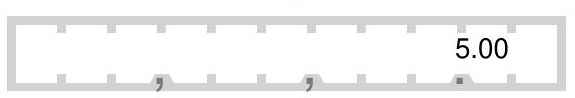

247.00

Subtotal Of Receipts This Page (optional)

2555.00

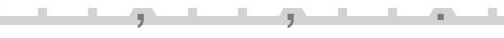

Total This Period (last page this line number only)

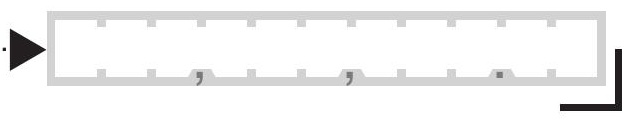

FEC Schedule A-P (Form 3P) (Rev. 03/2011) 


\section{SCHEDULE A-P} ITEMIZED RECEIPTS
Use separate schedule(s)

for each category of the

Detailed Summary Page
FOR LINE NUMBER: (check only one)

Any information or for commercial purposes, other than using the name and address of any political committee to solicit contributions from such committee.

NAME OF COMMITTEE (In Full)

\section{Friends of Herman Cain}

A. Full Name (Last, First, Middle Initial)

Ruth Allen

Mailing Address 8514 Tranquil Park

\begin{tabular}{lcc}
\hline City & State & Zip Code \\
Spring & TX & $77379-6876$ \\
\hline
\end{tabular}

FEC ID number of contributing federal political committee.

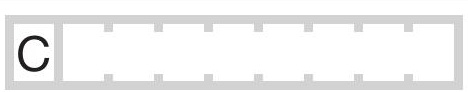

Name of Employer
Information Requested
Receipt For: 2012
X Primary
Other (specify) General

Occupation Information Requested

Election Cycle-to-Date

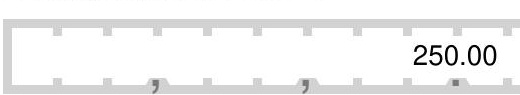

B. Full Name (Last, First, Middle Initial)

Emmett Blevins

Mailing Address 2325 whitesburg dr

\begin{tabular}{lcc}
\hline City & State & Zip Code \\
Huntsville & AL & $35801-3819$
\end{tabular}

FEC ID number of contributing

federal political committee.

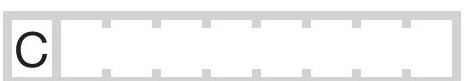

Name of Employer

Emmett Blevins Jewelers, Inc.

Occupation

Receipt For: 2012

$\chi \begin{aligned} & \text { Primary } \\ & \text { Other (specify) }\end{aligned}$

Owner

Election Cycle-to-Date

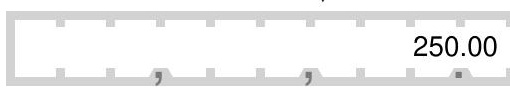

C. Full Name (Last, First, Middle Initial)

Joshua Morris

Mailing Address 830 Revere Way East

\begin{tabular}{lcc}
\hline City & State & Zip Code \\
Bartlesville & OK & $74006-8870$
\end{tabular}

FEC ID number of contributing

federal political committee.

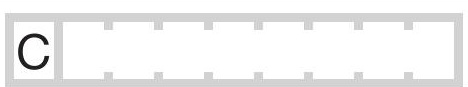

Name of Employer

Information Requested

Occupation

Information Requested

Receipt For: 2012

Х $\begin{aligned} & \text { Primary } \square \text { General } \\ & \text { Other (specify) }\end{aligned}$

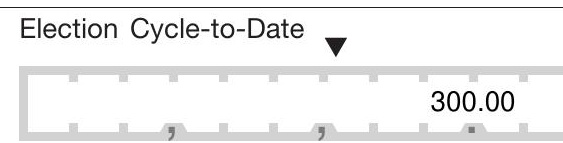

Transaction ID : AC1B0898E94CA4274BBF

Date of Receipt

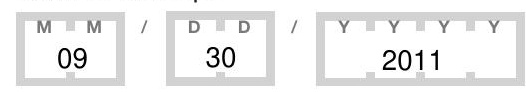

Amount of Each Receipt this Period

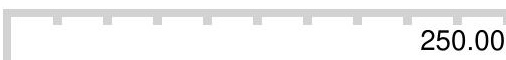

250.00

Transaction ID : AA2F5ECA42CEA4E959D3

Date of Receipt

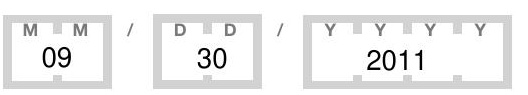

Amount of Each Receipt this Period

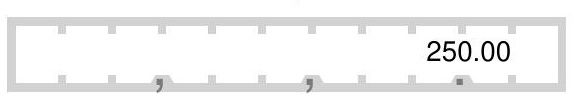

Transaction ID : AEFD18717195441CBB7E Date of Receipt

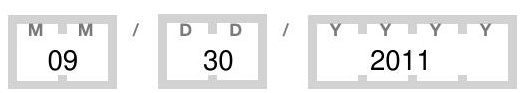

Amount of Each Receipt this Period

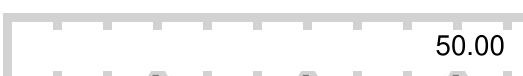

50.00

Subtotal Of Receipts This Page (optional)

550.00

Total This Period (last page this line number only) 


\section{SCHEDULE A-P} ITEMIZED RECEIPTS
Use separate schedule(s)

for each category of the

Detailed Summary Page
FOR LINE NUMBER: (check only one)

Any information or for commercial purposes, other than using the name and address of any political committee to solicit contributions from such committee.

NAME OF COMMITTEE (In Full)

\section{Friends of Herman Cain}

A. Full Name (Last, First, Middle Initial)

Robert Dillon

Mailing Address 30 Heather Lane

\begin{tabular}{lcc}
\hline City & State & Zip Code \\
Fairview & NC & $28730-8762$ \\
\hline
\end{tabular}

FEC ID number of contributing federal political committee.

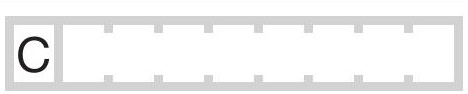

Name of Employer
n/a
Receipt For: 2012
X Primary $\quad$ General
Other (specify)

Occupation

Retired

Election Cycle-to-Date

640.99
Transaction ID : A9A7AD774196F4471814

Date of Receipt

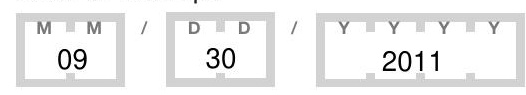

Amount of Each Receipt this Period

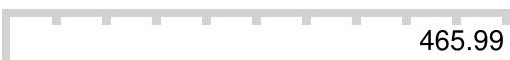

B. Full Name (Last, First, Middle Initial)

jack rettig

Mailing Address 316 Royal Plaza Dr

\begin{tabular}{lcc}
\hline City & State & Zip Code \\
Fort Lauderdale & FL & $33301-2514$
\end{tabular}

FEC ID number of contributing

federal political committee.

C

Name of Employer
Information Requested
Receipt For: 2012
X Primary
Other (specify)

Occupation

Information Requested

Election Cycle-to-Date

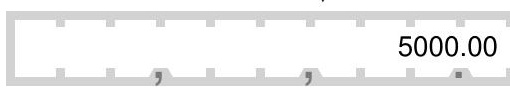

C. Full Name (Last, First, Middle Initial)

Charles Haight

Mailing Address 20 Leeward Psge

\begin{tabular}{lcc}
\hline City & State & Zip Code \\
North Yarmouth & ME & $04097-6955$
\end{tabular}

FEC ID number of contributing federal political committee.

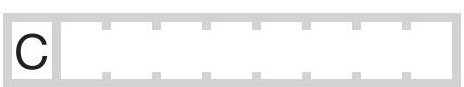

Name of Employer

Information Requested

\section{Occupation}

Information Requested

Receipt For: 2012

Х $\begin{aligned} & \text { Primary } \square \text { General } \\ & \text { Other (specify) }\end{aligned}$

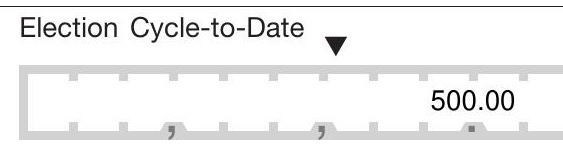

Amount of Each Receipt this Period

Transaction ID : ACE94CBFDD1A34ED880B Date of Receipt
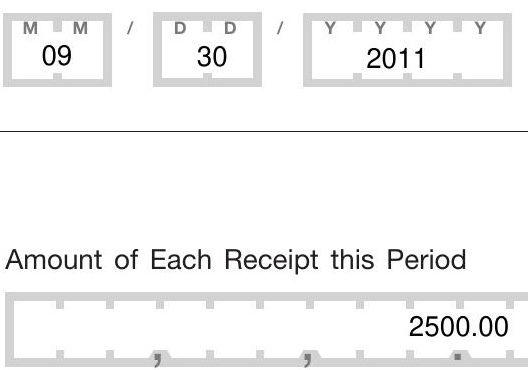

Transaction ID : AB7319308E68B4076952

Date of Receipt

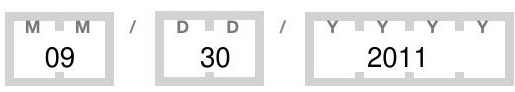

Amount of Each Receipt this Period

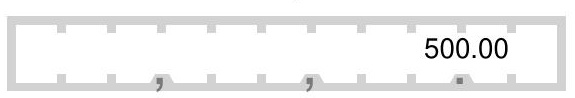

Subtotal Of Receipts This Page (optional)

3465.99

Total This Period (last page this line number only) 


\section{SCHEDULE A-P} ITEMIZED RECEIPTS
Use separate schedule(s)

for each category of the

Detailed Summary Page
FOR LINE NUMBER: (check only one)

Any information or for commercial purposes, other than using the name and address of any political committee to solicit contributions from such committee.

NAME OF COMMITTEE (In Full)

Friends of Herman Cain

A. Full Name (Last, First, Middle Initial)

Arlana St. Clair

Mailing Address 3401 Wible Rd.

\begin{tabular}{lcc}
\hline City & State & Zip Code \\
Bakersfield & CA & $93309-6509$
\end{tabular}

FEC ID number of contributing

federal political committee.

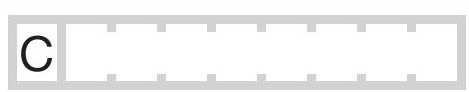

Name of Employer
Self Employed
Receipt For: 2012
X Primary
$\square$ Other (specify) General

Occupation

Real Estate

Election Cycle-to-Date

300.00

B. Full Name (Last, First, Middle Initial)

Kathleen Stassen

Mailing Address 5000 France Ave S Unit 43

\begin{tabular}{lcc}
\hline City & State & Zip Code \\
Edina & MN & $55410-2062$ \\
\hline
\end{tabular}

FEC ID number of contributing

federal political committee.

C

Name of Employer
Information Requested
Receipt For: 2012
X Primary
Other (specify)

Occupation

Information Requested

Election Cycle-to-Date

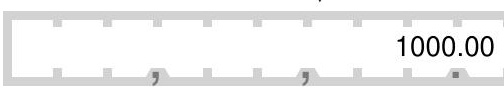

C. Full Name (Last, First, Middle Initial)

Diana Walter

Mailing Address 15323 Key Lime Blvd

\begin{tabular}{lcc}
\hline City & State & Zip Code \\
Loxahatchee & FL & $33470-3109$
\end{tabular}

FEC ID number of contributing

federal political committee.

C

Name of Employer
All-Sale
Receipt For: 2012
X Primary
Other (specify) General

\section{Occupation}

Bookkeeper

Election Cycle-to-Date
Transaction ID : AF6A66F98459F432980F

Date of Receipt

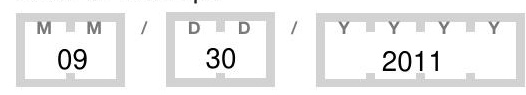

Amount of Each Receipt this Period

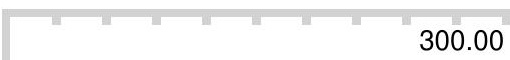

300.00
Amount of Each Receipt this Period

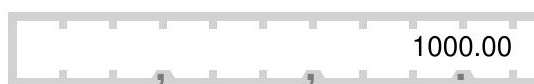

Transaction ID : A49B127608C9E4827BCB Date of Receipt

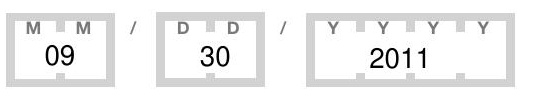

Transaction ID : A6B33F8EE4430425A974 Date of Receipt

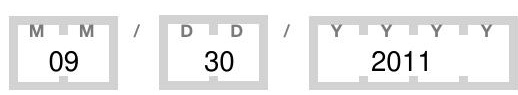

Amount of Each Receipt this Period

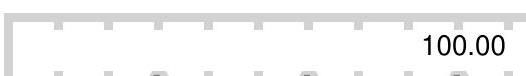

\section{Subtotal Of Receipts This Page (optional)}

Total This Period (last page this line number only) 


\section{SCHEDULE A-P} ITEMIZED RECEIPTS
Use separate schedule(s)

for each category of the

Detailed Summary Page
FOR LINE NUMBER: (check only one)

Any information coping or for commercial purposes, other than using the name and address of any political committee to solicit contributions from such committee.

NAME OF COMMITTEE (In Full)

\section{Friends of Herman Cain}

A. Full Name (Last, First, Middle Initial)

Kevin Shea

Mailing Address 1505 Kelly Blvd

\begin{tabular}{lcc}
\hline City & State & Zip Code \\
Carrollton & TX & $75006-5524$
\end{tabular}

FEC ID number of contributing federal political committee.

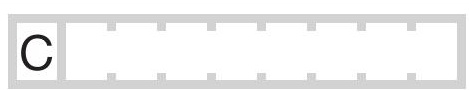

Name of Employer
Information Requested
Receipt For: 2012
X Primary
$\square$ Other (specify)

Occupation Information Requested

Election Cycle-to-Date

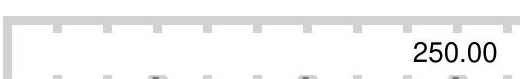

B. Full Name (Last, First, Middle Initial) john clements

Mailing Address 10570 turner road

\begin{tabular}{lcc}
\hline City & State & Zip Code \\
Roswell & GA & $30076-2497$ \\
\hline
\end{tabular}

FEC ID number of contributing

federal political committee.

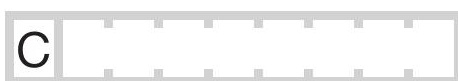

Name of Employer

TRG Inc.

Occupation

Receipt For: 2012

Х $\begin{aligned} & \text { Primary } \\ & \text { Other (specify) }\end{aligned}$

President

Transaction ID : A1C24291105FB47C69FD

Date of Receipt

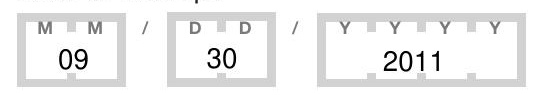

Amount of Each Receipt this Period

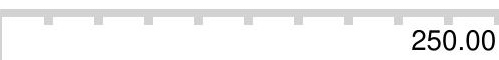

250.00

Transaction ID : A9F55A58C589E4611A52

Date of Receipt

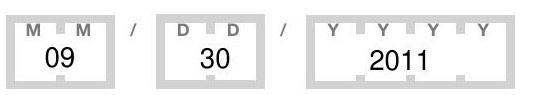

Amount of Each Receipt this Period

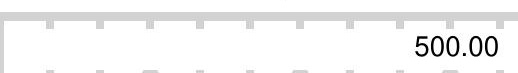

Election Cycle-to-Date

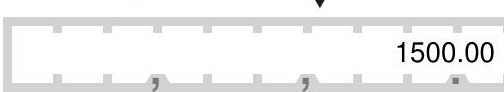

C. Full Name (Last, First, Middle Initial)

Jenny Galloway

Mailing Address 2178 Vinings North Lane

\begin{tabular}{lcc}
\hline City & State & Zip Code \\
Smyrna & GA & $30080-5977$
\end{tabular}

FEC ID number of contributing

federal political committee.

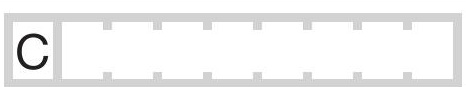

Name of Employer

Occupation

Information Requested

Information Requested

Receipt For: 2012

Х $\begin{aligned} & \text { Primary } \\ & \text { Other (specify) }\end{aligned}$

Election Cycle-to-Date

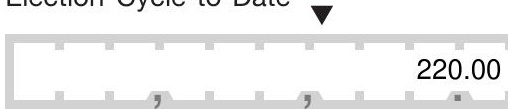

Amount of Each Receipt this Period

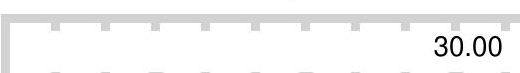

Transaction ID : A3453E16BFA15426B9CD

Date of Receipt

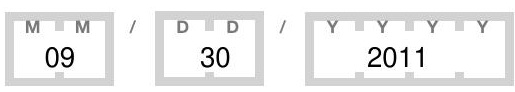

Subtotal Of Receipts This Page (optional)

780.00

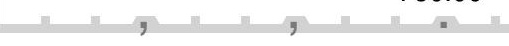

Total This Period (last page this line number only) 


\section{SCHEDULE A-P} ITEMIZED RECEIPTS
Use separate schedule(s) for each category of the Detailed Summary Page

\begin{tabular}{|c|c|c|c|c|c|}
\hline \multicolumn{3}{|c|}{$\begin{array}{l}\text { FOR LINE NUMBER: } \\
\text { (check only one) }\end{array}$} & \multicolumn{3}{|c|}{ PAGE 1198 / 1572} \\
\hline 16 & $X$ 17a & $17 b$ & $17 c$ & $17 d$ & 18 \\
\hline $19 a$ & $19 \mathrm{~b}$ & $20 a$ & $20 \mathrm{~b}$ & $20 c$ & 21 \\
\hline
\end{tabular}

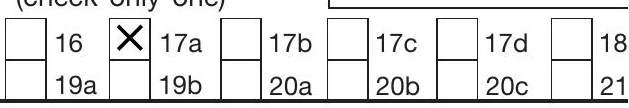

Any information copied from such Reports and Statements may not be sold or used by any person for the purpose of soliciting contributions or for commercial purposes, other than using the name and address of any political committee to solicit contributions from such committee.

NAME OF COMMITTEE (In Full)

\section{Friends of Herman Cain}

A. Full Name (Last, First, Middle Initial)

Edith Marler

Mailing Address 218 W Fountain Ave

\begin{tabular}{lcc}
\hline City & State & Zip Code \\
Delaware & OH & $43015-1656$
\end{tabular}

FEC ID number of contributing federal political committee.

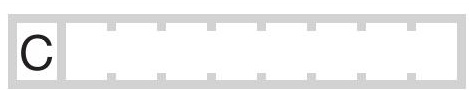

Name of Employer
OSU Education Center
Receipt For: 2012
X Primary
$\square$ Other (specify)

Occupation research scientist

Election Cycle-to-Date 550.00

B. Full Name (Last, First, Middle Initial) Jacqueline Lopez

Mailing Address 1596 West 78 Terrace

\begin{tabular}{lcc}
\hline City & State & Zip Code \\
Hialeah & FL & $33014-3350$ \\
\hline
\end{tabular}

FEC ID number of contributing

federal political committee.

C

Name of Employer
US Postal Service
Receipt For: 2012
X Primary
Other (specify)

Occupation Letter Carrier

Election Cycle-to-Date

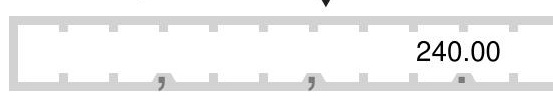

Transaction ID : A2270C6A47BBB4965AEF

Date of Receipt

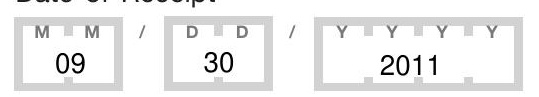

Amount of Each Receipt this Period

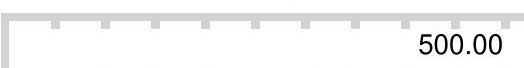

Amount of Each Receipt this Period

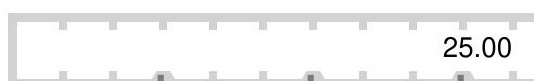

C. Full Name (Last, First, Middle Initial)

James Hogsed

Mailing Address 6750 Saint Ives Ct.

\begin{tabular}{lcc}
\hline City & State & Zip Code \\
Fort Myers & FL & $33966-1590$
\end{tabular}

FEC ID number of contributing federal political committee.

C

$33966-1590$

Name of Employer
self
Receipt For: 2012
X Primary
Other (specify) General

Occupation

Physician

Election Cycle-to-Date
Transaction ID : AEF3F3BA1F18547B7BF8 Date of Receipt

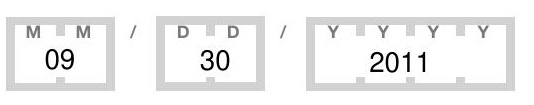

Transaction ID : AB73931CD840846C695B Date of Receipt

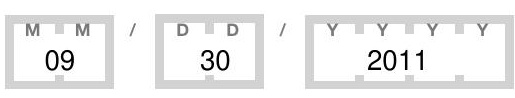

Amount of Each Receipt this Period

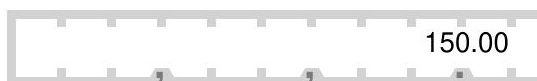

500.00

\section{Subtotal Of Receipts This Page (optional)}

675.00

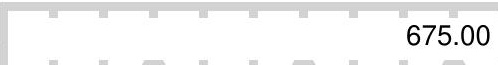

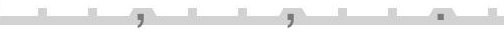

Total This Period (last page this line number only)

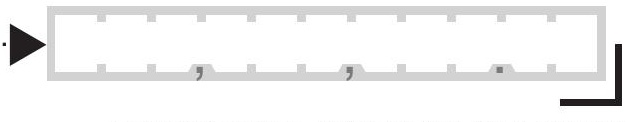

FEC Schedule A-P (Form 3P) (Rev. 03/2011) 


\section{SCHEDULE A-P} ITEMIZED RECEIPTS
Use separate schedule(s) for each category of the Detailed Summary Page

\begin{tabular}{|c|c|c|c|c|c|}
\hline \multicolumn{3}{|c|}{$\begin{array}{l}\text { FOR LINE NUMBER: } \\
\text { (check only one) }\end{array}$} & \multicolumn{3}{|c|}{ PAGE 1199 / 1572} \\
\hline 16 & $X$ 17a & $17 b$ & $17 c$ & $17 d$ & 18 \\
\hline $19 a$ & $19 \mathrm{~b}$ & $20 a$ & $20 \mathrm{~b}$ & $20 c$ & 21 \\
\hline
\end{tabular}

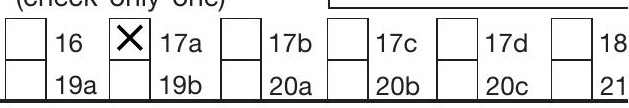

Any information copied from such Reports and Statements may not be sold or used by any person for the purpose of soliciting contributions or for commercial purposes, other than using the name and address of any political committee to solicit contributions from such committee.

NAME OF COMMITTEE (In Full)

\section{Friends of Herman Cain}

A. Full Name (Last, First, Middle Initial)

Kathleen Lopez

Mailing Address 509 Island Court

\begin{tabular}{lcc}
\hline City & State & Zip Code \\
Indian Harbour Beach & FL & $32937-4345$ \\
\hline
\end{tabular}

FEC ID number of contributing federal political committee.

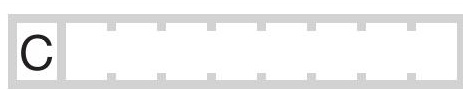

Name of Employer
Information Requested
Receipt For: 2012
X Primary
Other (specify) General

Occupation Information Requested

Election Cycle-to-Date 400.00

B. Full Name (Last, First, Middle Initial) James Robinson

Mailing Address 308 Grants Trail

\begin{tabular}{lcc}
\hline City & State & Zip Code \\
Dayton & OH & $45459-3116$
\end{tabular}

FEC ID number of contributing

federal political committee.

C

Name of Employer
None
Receipt For: 2012
Primary
Other (specify)

Occupation

Retired

Election Cycle-to-Date

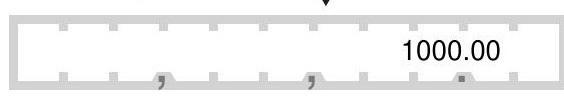

C. Full Name (Last, First, Middle Initial)

Timothy Teslow

Mailing Address 1275 sadler Way, ste 102

\begin{tabular}{lcc}
\hline City & State & Zip Code \\
Fairbanks & AK & $99701-3175$
\end{tabular}

FEC ID number of contributing federal political committee.

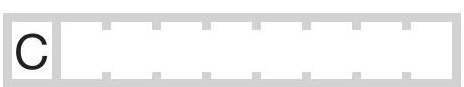

Name of Employer

Information Requested

Receipt For: 2012

Х $\begin{aligned} & \text { Primary } \square \text { General } \\ & \text { Other (specify) }\end{aligned}$
Transaction ID : A8CF6EB32E82844C18A3

Date of Receipt

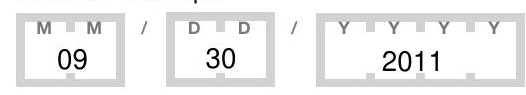

Amount of Each Receipt this Period

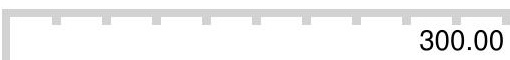

300.00
Amount of Each Receipt this Period

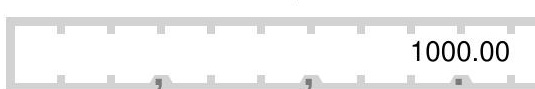

Transaction ID : A82772EB787384042937

Date of Receipt

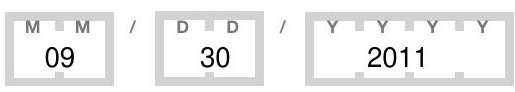

Amount of Each Receipt this Period

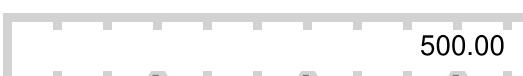

\section{Subtotal Of Receipts This Page (optional)}

Total This Period (last page this line number only) 


\section{SCHEDULE A-P} ITEMIZED RECEIPTS
Use separate schedule(s)

for each category of the

Detailed Summary Page
FOR LINE NUMBER: (check only one)

Any information or for commercial purposes, other than using the name and address of any political committee to solicit contributions from such committee.

NAME OF COMMITTEE (In Full)

Friends of Herman Cain

A. Full Name (Last, First, Middle Initial)

Karen Humeniuk

Mailing Address 145 Jervey Road

\begin{tabular}{lcc}
\hline City & State & Zip Code \\
Greenville & SC & $29609-1341$
\end{tabular}

FEC ID number of contributing federal political committee.

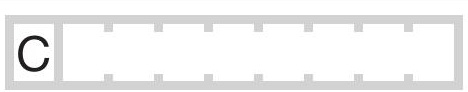

Name of Employer
self
Receipt For: 2012
X Primary $\quad$ General
Other (specify)

Occupation property management

Election Cycle-to-Date 1500.00

B. Full Name (Last, First, Middle Initial) Peter Jensen

Mailing Address W5202 Larson Road

\begin{tabular}{lcc}
\hline City & State & Zip Code \\
Rio & WI & $53960-9575$ \\
\hline
\end{tabular}

FEC ID number of contributing

federal political committee.

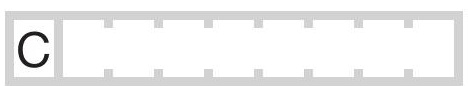

Name of Employer
Self Employed
Receipt For: 2012
X Primary
$\square$ Other (specify) General

\section{Occupation} farmer

Election Cycle-to-Date

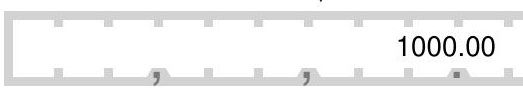

C. Full Name (Last, First, Middle Initial)

John Brett

Mailing Address 913 N. Allen Street

\begin{tabular}{l|ll}
\hline $\begin{array}{l}\text { City } \\
\text { Rockport }\end{array}$ & $\begin{array}{c}\text { State } \\
\text { TX }\end{array}$ & $\begin{array}{c}\text { Zip Code } \\
\text { 78382-3101 }\end{array}$ \\
\hline $\begin{array}{l}\text { FEC ID number of contributing } \\
\text { federal political committee. }\end{array}$ & C \\
\hline $\begin{array}{l}\text { Name of Employer } \\
\text { None }\end{array}$ & $\begin{array}{l}\text { Occupation } \\
\text { Retired }\end{array}$ \\
\hline $\begin{array}{l}\text { Receipt For: } 2012 \\
\text { X }\end{array}$ & Election Cycle-to-Date \\
Other (specify)
\end{tabular}

Transaction ID : A35D095BA99954E8284B

Date of Receipt

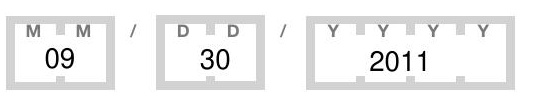

Amount of Each Receipt this Period

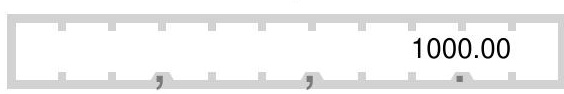

Amount of Each Receipt this Period

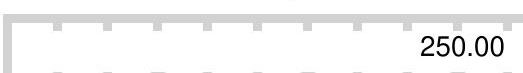

Subtotal Of Receipts This Page (optional).

$+\quad 1750.00$

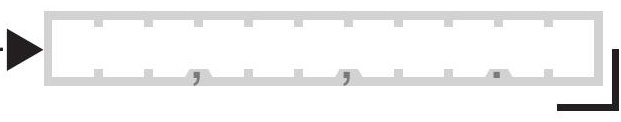

FEC Schedule A-P (Form 3P) (Rev. 03/2011)

Total This Period (last page this line number only) 


\section{SCHEDULE A-P} ITEMIZED RECEIPTS
Use separate schedule(s)

for each category of the

Detailed Summary Page
FOR LINE NUMBER: (check only one)

Any information or for commercial purposes, other than using the name and address of any political committee to solicit contributions from such committee.

NAME OF COMMITTEE (In Full)

Friends of Herman Cain

A. Full Name (Last, First, Middle Initial)

Brian Whitlow

Mailing Address 4310 Shillham Court

\begin{tabular}{lcc}
\hline City & State & Zip Code \\
Cumming & GA & $30040-1553$ \\
\hline
\end{tabular}

FEC ID number of contributing

federal political committee.

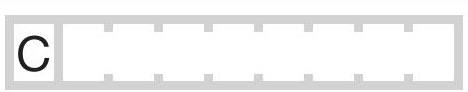

Name of Employer
FleetCor Technologies
Receipt For: 2012
X Primary $\square$ General
Other (specify)

Occupation

IT Analyst

Election Cycle-to-Date

630.00

B. Full Name (Last, First, Middle Initial)

Bruce Kiely

Mailing Address 1299 Pennsylvania Ave. NW.

\begin{tabular}{lcc}
\hline City & State & Zip Code \\
Alexandria & VA & 22314 \\
\hline
\end{tabular}

FEC ID number of contributing

federal political committee.

C

Name of Employer
Information Requested
Receipt For: 2012
X Primary
Other (specify)

Occupation

Information Requested

Election Cycle-to-Date

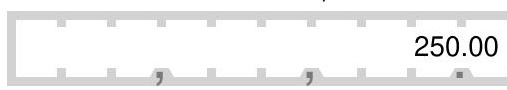

Transaction ID : AC7FD7058222443EFB67

Date of Receipt

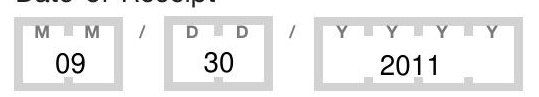

Amount of Each Receipt this Period

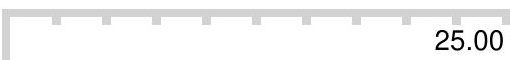

25.00

C. Full Name (Last, First, Middle Initial)

Colleen V Wynne

Mailing Address 221 Woodland Rd

\begin{tabular}{lcc}
\hline City & State & Zip Code \\
Gatlinburg & TN & $37738-5886$
\end{tabular}

FEC ID number of contributing

federal political committee.

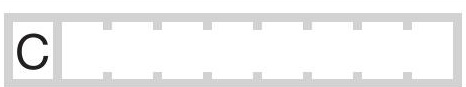

Name of Employer
Park Liquor
Receipt For: 2012
X Primary
Other (specify) General

\section{Occupation}

clerk

Election Cycle-to-Date

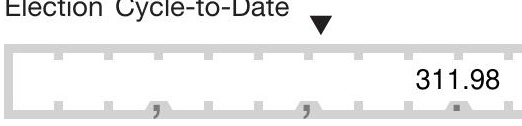

Transaction ID : ADC360CD2B8934AEF8F6

Date of Receipt

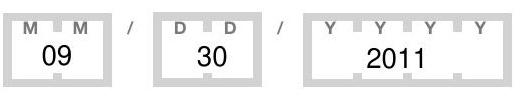

Amount of Each Receipt this Period

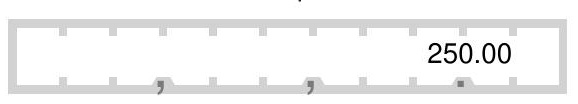

Transaction ID : A07C200CC6112406FAAB Date of Receipt

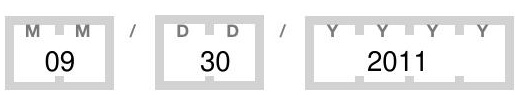

Amount of Each Receipt this Period

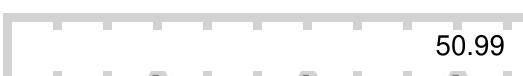

\section{Subtotal Of Receipts This Page (optional)}

Total This Period (last page this line number only) 


\section{SCHEDULE A-P} ITEMIZED RECEIPTS
Use separate schedule(s)

for each category of the

Detailed Summary Page
FOR LINE NUMBER: (check only one)

Any information or for commercial purposes, other than using the name and address of any political committee to solicit contributions from such committee.

NAME OF COMMITTEE (In Full)

Friends of Herman Cain

A. Full Name (Last, First, Middle Initial) robert watkins

Mailing Address 348 st rt 20 spur

\begin{tabular}{lcc}
\hline City & State & Zip Code \\
Cartersville & GA & $30121-5268$
\end{tabular}

FEC ID number of contributing federal political committee.

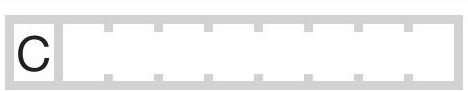

Name of Employer
Information Requested
Receipt For: 2012
X Primary
$\square$ Other (specify)

Occupation Information Requested

Election Cycle-to-Date

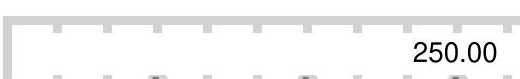

B. Full Name (Last, First, Middle Initial)

Thomas Graves

Mailing Address 6513 Sugar Creek Place

\begin{tabular}{lcc}
\hline City & State & Zip Code \\
Mobile & AL & $36695-2737$
\end{tabular}

FEC ID number of contributing

federal political committee.

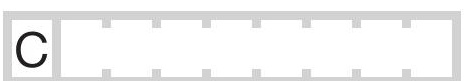

Name of Employer
Self Employed
Receipt For: 2012
Primary
Other (specify)

Occupation

Attorney

Election Cycle-to-Date

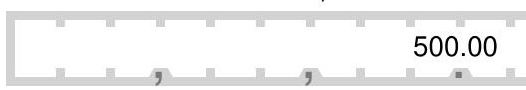

C. Full Name (Last, First, Middle Initial)

Rick Cooksey

Mailing Address 1321 benbrooke In

\begin{tabular}{lcc}
\hline City & State & Zip Code \\
Acworth & GA & $30101-8492$ \\
\hline
\end{tabular}

FEC ID number of contributing federal political committee.

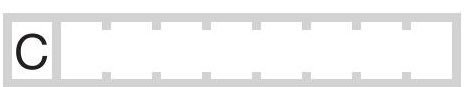

Name of Employer
FedEx Kinkos
Receipt For: 2012
X Primary $\quad \square$ General
Other (specify)

\section{Occupation}

Pilot

Election Cycle-to-Date

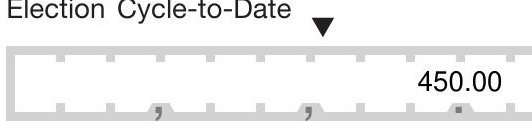

Transaction ID : A3EE4C7BC660F40D5A04

Date of Receipt

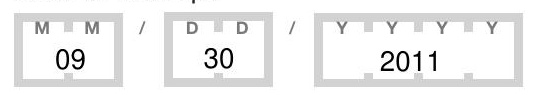

Amount of Each Receipt this Period

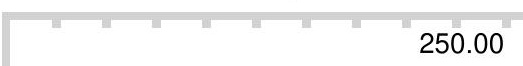

250.00
Transaction ID : A3B3545115BCC4A66AC2 Date of Receipt

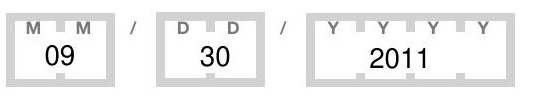

Amount of Each Receipt this Period

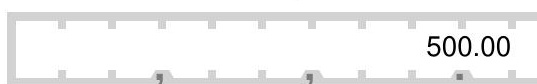

Transaction ID : AC6B07903C9DE4B81994 Date of Receipt

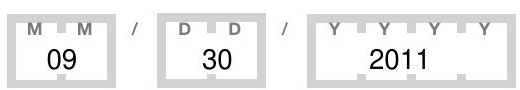

Amount of Each Receipt this Period

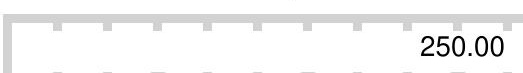

Subtotal Of Receipts This Page (optional).

1000.00

a 1 ,

Total This Period (last page this line number only)

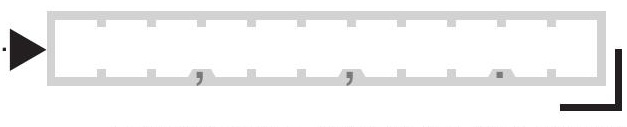

FEC Schedule A-P (Form 3P) (Rev. 03/2011) 
SCHEDULE A-P ITEMIZED RECEIPTS
Use separate schedule(s) for each category of the Detailed Summary Page
FOR LINE NUMBER: (check only one)

Any information or for commercial purposes, other than using the name and address of any political committee to solicit contributions from such committee.

NAME OF COMMITTEE (In Full)

Friends of Herman Cain

A. Full Name (Last, First, Middle Initial)

Russell Bella

Mailing Address 12870 SW 9 Place

\begin{tabular}{lcc}
\hline City & State & Zip Code \\
Davie & FL & $33325-5517$
\end{tabular}

FEC ID number of contributing federal political committee.

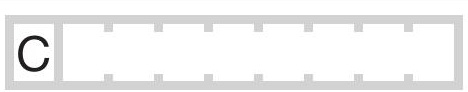

Name of Employer
Information Requested
Receipt For: 2012
X Primary
$\square$ Other (specify)

Occupation

Information Requested

Election Cycle-to-Date

250.00

B. Full Name (Last, First, Middle Initial)

Terry Varner

Mailing Address 8925 Tower Rd

\begin{tabular}{lcc}
\hline City & State & Zip Code \\
Sainte Genevieve & MO & $63670-8272$ \\
\hline
\end{tabular}

FEC ID number of contributing

federal political committee.

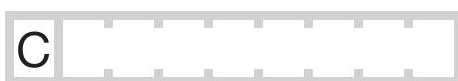

Name of Employer
Retired
Receipt For: 2012
X Primary $\quad$ General
Other (specify)

Occupation

Retired

Election Cycle-to-Date

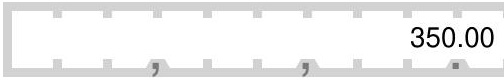

C. Full Name (Last, First, Middle Initial)

Thomas Seth Belcher

Mailing Address 4415 Chisholm Rd Apt C5

\begin{tabular}{lcc}
\hline City & State & Zip Code \\
Florence & AL & $35630-7333$
\end{tabular}

FEC ID number of contributing

federal political committee.

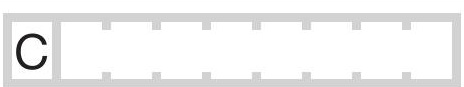

Name of Employer

Information Requested

Occupation

Information Requested

Receipt For: 2012

Х $\begin{aligned} & \text { Primary } \square \text { General } \\ & \text { Other (specify) }\end{aligned}$

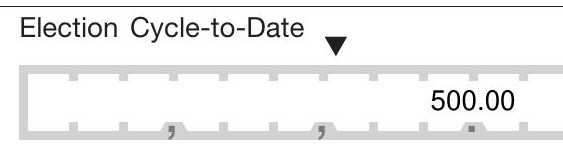

Amount of Each Receipt this Period

Transaction ID : AE840EF876E0A4621ACF

Date of Receipt

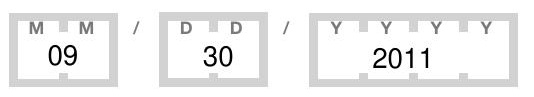

Amount of Each Receipt this Period

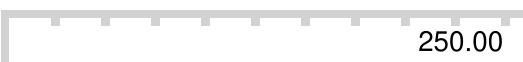

250.00

Date of Receipt
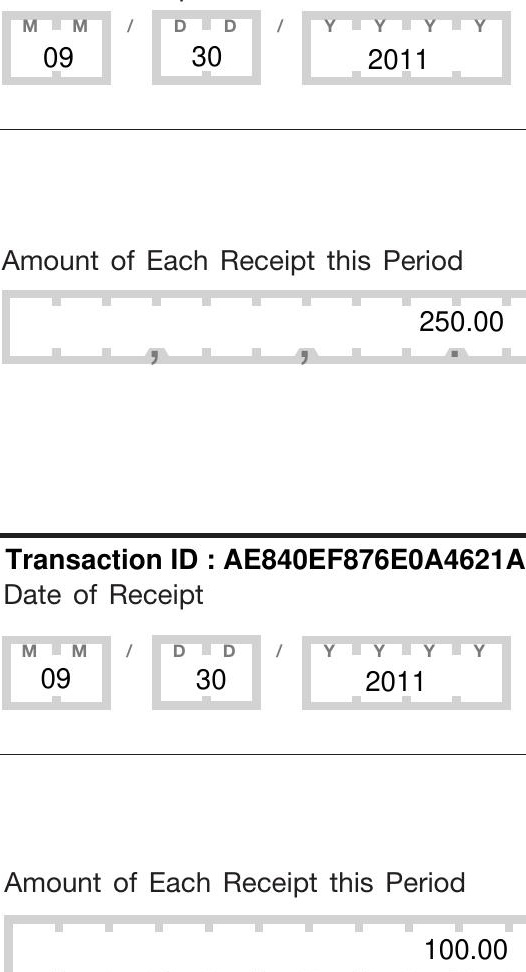

Transaction ID : A487039DB209340FC841

Date of Receipt

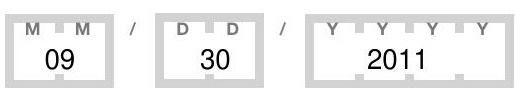

Amount of Each Receipt this Period

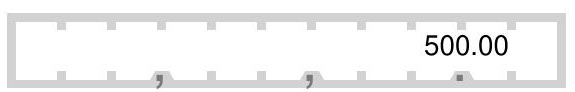

Subtotal Of Receipts This Page (optional)

850.00

Total This Period (last page this line number only) 
SCHEDULE A-P ITEMIZED RECEIPTS
Use separate schedule(s) for each category of the Detailed Summary Page
FOR LINE NUMBER: (check only one)

PAGE 1204 / 1572

\begin{tabular}{|c|c|c|c|c|c|}
\hline & & & & & \\
\hline 16 & $\begin{array}{lll}X & 17 a \\
\end{array}$ & $17 \mathrm{~b}$ & $17 c$ & $17 d$ & 18 \\
\hline $19 a$ & $19 b$ & $20 a$ & $20 \mathrm{~b}$ & $20 c$ & 21 \\
\hline
\end{tabular}

Any information copied from such Reports and Statements may not be sold or used by any person for the purpose of soliciting contributions or for commercial purposes, other than using the name and address of any political committee to solicit contributions from such committee.

NAME OF COMMITTEE (In Full)

\section{Friends of Herman Cain}

A. Full Name (Last, First, Middle Initial)

Horace Tory

Mailing Address 4970 Greentree Trail

\begin{tabular}{lcc}
\hline City & State & Zip Code \\
Atlanta & GA & $30349-1734$
\end{tabular}

FEC ID number of contributing federal political committee.

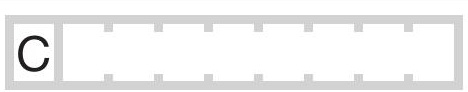

Name of Employer
Atlanta Int'l RMI Inc.
Receipt For: 2012
X Primary
Other (specify) General

Occupation Insurance \& Finance

Election Cycle-to-Date

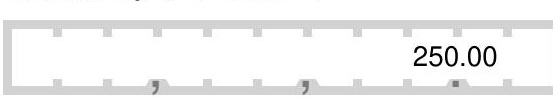

B. Full Name (Last, First, Middle Initial)

Robert Hoig

Mailing Address 11721 Shirley St.

\begin{tabular}{lcc}
\hline City & State & Zip Code \\
Omaha & NE & $68144-2913$ \\
\hline
\end{tabular}

FEC ID number of contributing

federal political committee.

C

Name of Employer
Information Requested
Receipt For: 2012
X Primary
Other (specify)

Occupation

Information Requested

Election Cycle-to-Date

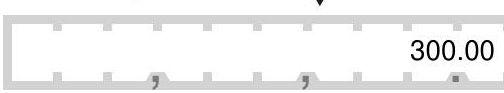

Transaction ID : AF0486074814747C1860

Date of Receipt

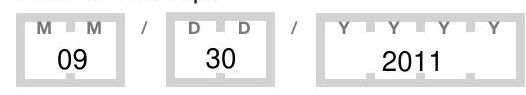

Amount of Each Receipt this Period

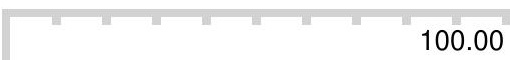

100.00

C. Full Name (Last, First, Middle Initial)

klaus schoening Sr.

Mailing Address 205 Waverly Hall Ln

\begin{tabular}{lcc}
\hline City & State & Zip Code \\
Simpsonville & SC & $29681-5287$
\end{tabular}

FEC ID number of contributing federal political committee.

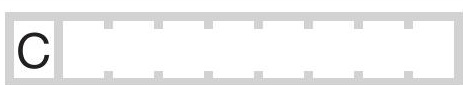

$\begin{aligned} & \text { Name of Employer } \\ & \text { self }\end{aligned}$
Receipt For: 2012
X Primary $\square$ General
Other (specify)

\section{Occupation}

Financial Advisor

Election Cycle-to-Date

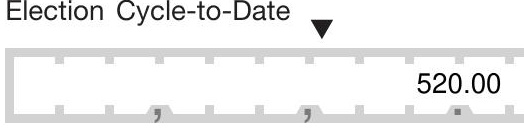

Transaction ID : AD8A4EC1CD57146D2890

Date of Receipt

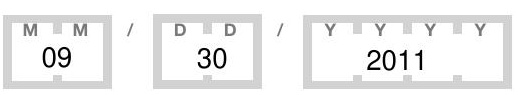

Amount of Each Receipt this Period

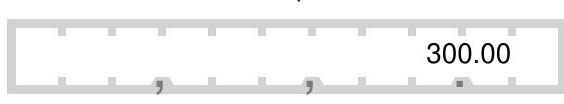

Transaction ID : A9613DD4519FE4DCE993 Date of Receipt

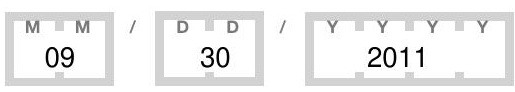

Amount of Each Receipt this Period

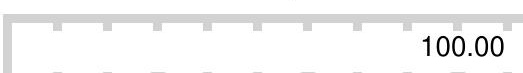

\section{Subtotal Of Receipts This Page (optional)}

Total This Period (last page this line number only) 


\section{SCHEDULE A-P} ITEMIZED RECEIPTS
Use separate schedule(s)

for each category of the

Detailed Summary Page
FOR LINE NUMBER: (check only one)

Any information or for commercial purposes, other than using the name and address of any political committee to solicit contributions from such committee.

NAME OF COMMITTEE (In Full)

Friends of Herman Cain

A. Full Name (Last, First, Middle Initial)

mark townsend

Mailing Address 350 shadow In

\begin{tabular}{lcc}
\hline City & State & Zip Code \\
Lyman & SC & $29365-9549$ \\
\hline
\end{tabular}

FEC ID number of contributing federal political committee.

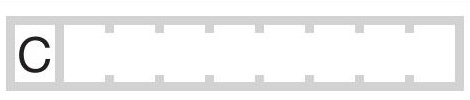

Name of Employer
Information Requested
Receipt For: 2012
X Primary $\quad \square$ General
$\square$ Other (specify)

Occupation

Information Requested

Election Cycle-to-Date

250.00

B. Full Name (Last, First, Middle Initial)

Clark Madden

Mailing Address 5614 Chaucer Dr.

\begin{tabular}{lcc}
\hline City & State & Zip Code \\
Houston & TX & $77005-2634$ \\
\hline
\end{tabular}

FEC ID number of contributing

federal political committee.

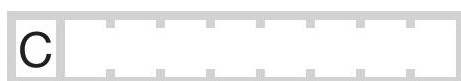

Name of Employer
Self Employed
Receipt For: 2012
X Primary
$\square$ Other (specify) General

Occupation

Dentist

Election Cycle-to-Date

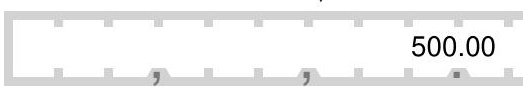

C. Full Name (Last, First, Middle Initial)

James Tharpe

Mailing Address 723 Denmead Mill

\begin{tabular}{lcc}
\hline City & State & Zip Code \\
Marietta & GA & $30067-5176$
\end{tabular}

FEC ID number of contributing

federal political committee.

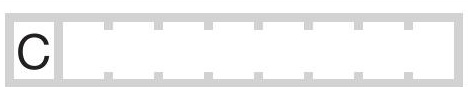

Name of Employer

Information Requested

Occupation

Information Requested

Receipt For: 2012

Х $\begin{aligned} & \text { Primary } \square \text { General } \\ & \text { Other (specify) }\end{aligned}$

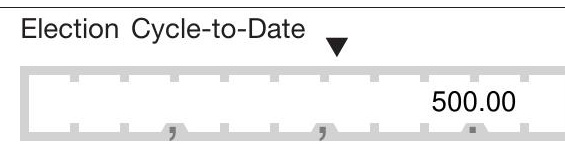

Amount of Each Receipt this Period

Transaction ID : A94D35EB578834D47B93

Date of Receipt

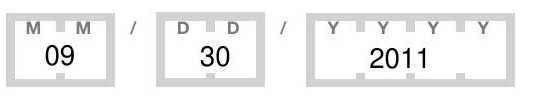

Amount of Each Receipt this Period

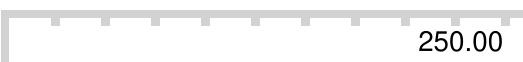

250.00

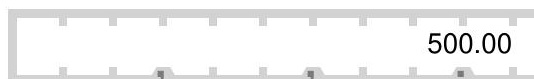

Transaction ID : AAE4B777BFF744C90BFC Date of Receipt

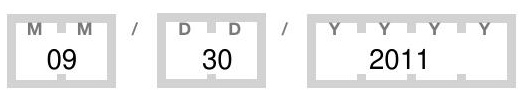

Amount of Each Receipt this Period

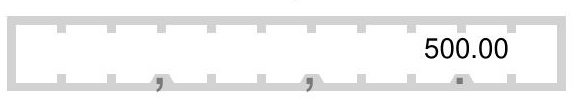

Subtotal Of Receipts This Page (optional).

1250.00

Total This Period (last page this line number only) 


\section{SCHEDULE A-P} ITEMIZED RECEIPTS
Use separate schedule(s)

for each category of the

Detailed Summary Page
FOR LINE NUMBER: (check only one)

Any information or for commercial purposes, other than using the name and address of any political committee to solicit contributions from such committee.

NAME OF COMMITTEE (In Full)

Friends of Herman Cain

A. Full Name (Last, First, Middle Initial)

Fred Eppright

Mailing Address 3215 Steck Ave., Ste. 101

\begin{tabular}{lcc}
\hline City & State & Zip Code \\
Austin & TX & $78757-8060$
\end{tabular}

FEC ID number of contributing

federal political committee.

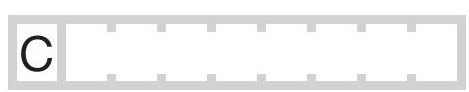

Name of Employer
Information Requested
Receipt For: 2012
X Primary $\quad \square$ General
Other (specify)

Occupation

Information Requested

Election Cycle-to-Date

500.00

B. Full Name (Last, First, Middle Initial)

Christine O'Donnell

Mailing Address 1242 Presidential Drive

\begin{tabular}{lcc}
\hline City & State & Zip Code \\
Wilmington & DE & $19807-3260$ \\
\hline
\end{tabular}

FEC ID number of contributing

federal political committee.

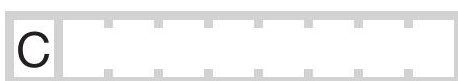

Name of Employer
Information Requested
Receipt For: 2012
X Primary
Other (specify)

Occupation

Information Requested

Election Cycle-to-Date

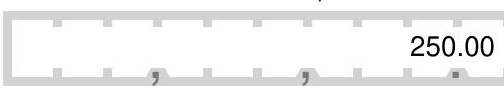

Transaction ID : A1C4F42671392488F9F2

Date of Receipt

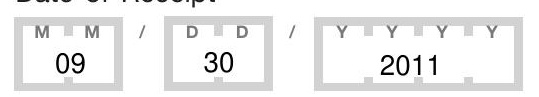

Amount of Each Receipt this Period

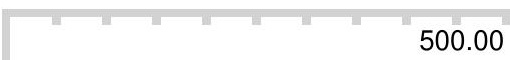

Transaction ID : A19E3A40D19D9449B937

Date of Receipt

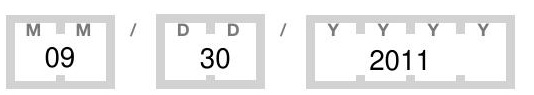

Amount of Each Receipt this Period

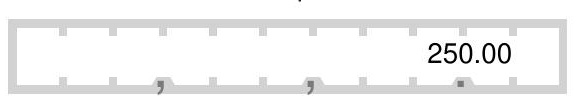

Transaction ID : AEA66CA9FB86F4BE69EF Date of Receipt

HOWARD SEIDLER

Mailing Address 6860 NW 101ST TERR

\begin{tabular}{lcc}
\hline City & State & Zip Code \\
Parkland & FL & $33076-2921$ \\
\hline
\end{tabular}

FEC ID number of contributing federal political committee.

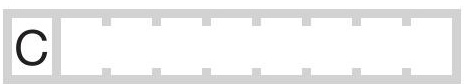

Name of Employer

Information Requested

\section{Occupation}

Information Requested

Receipt For: 2012

Х $\begin{aligned} & \text { Primary } \square \text { General } \\ & \text { Other (specify) }\end{aligned}$

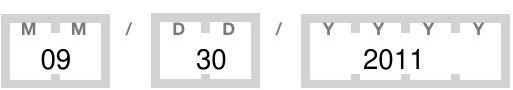

Amount of Each Receipt this Period

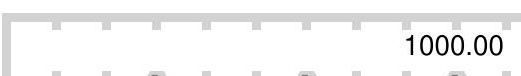

Subtotal Of Receipts This Page (optional).

1750.00

a 1 ,

Total This Period (last page this line number only) 


\section{SCHEDULE A-P} ITEMIZED RECEIPTS
Use separate schedule(s) for each category of the Detailed Summary Page
FOR LINE NUMBER: (check only one)
PAGE 1207 / 1572

\begin{tabular}{|c|c|c|c|c|c|}
\hline & & & & & \\
\hline 16 & $\begin{array}{ll}\mathbf{X} & 17 a \\
\end{array}$ & $17 \mathrm{~b}$ & $17 c$ & $17 d$ & 18 \\
\hline $19 a$ & $19 b$ & $20 \mathrm{a}$ & $20 \mathrm{~b}$ & $20 c$ & 21 \\
\hline
\end{tabular}

Any information copied from such Reports and Statements may not be sold or used by any person for the purpose of soliciting contributions or for commercial purposes, other than using the name and address of any political committee to solicit contributions from such committee.

NAME OF COMMITTEE (In Full)

Friends of Herman Cain

A. Full Name (Last, First, Middle Initial)

michael Curley

Mailing Address 4110 triana BLVD, 198

\begin{tabular}{lcc}
\hline City & State & Zip Code \\
Huntsville & AL & $35805-5447$ \\
\hline
\end{tabular}

FEC ID number of contributing

federal political committee.

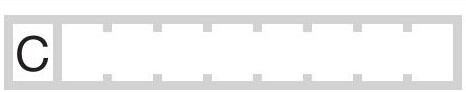

Name of Employer
alabama A\&amp;M university
Receipt For: 2012
X Primary $\square$ General
Other (specify)

Occupation

researcher

Election Cycle-to-Date

210.00

B. Full Name (Last, First, Middle Initial)

D Dodson

Mailing Address 10 S Briar Hollow Ln., \#32

\begin{tabular}{lcc}
\hline City & State & Zip Code \\
Houston & TX & $77027-2894$ \\
\hline
\end{tabular}

FEC ID number of contributing

federal political committee.

C

Name of Employer
Information Requested
Receipt For: 2012
X Primary
Other (specify)

Occupation

Information Requested

Election Cycle-to-Date

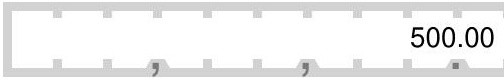

Transaction ID : AF884A53CC1404289880

Date of Receipt

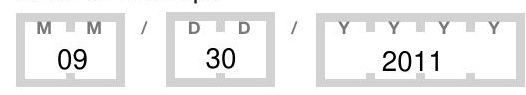

Amount of Each Receipt this Period

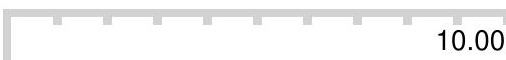

10.00

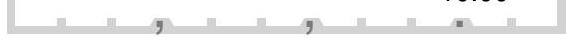

Transaction ID : A3D4A35833D6846F8AEF

Date of Receipt

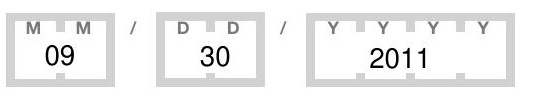

Amount of Each Receipt this Period

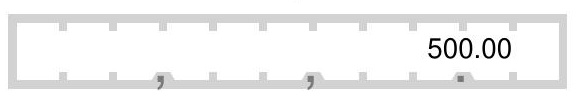

Transaction ID : A823C95BCE58B4620A7A Date of Receipt

\section{Patricia Maclean Patten}

Mailing Address Po Box 532

\begin{tabular}{lcc}
\hline City & State & Zip Code \\
Braselton & GA & $30517-0009$
\end{tabular}

FEC ID number of contributing federal political committee.

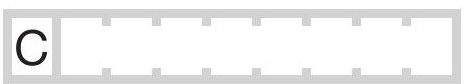

Name of Employer
Gainesville City Schools
Receipt For: 2012
X Primary $\quad \square$ General
Other (specify)

\section{Occupation}

Teacher

Election Cycle-to-Date

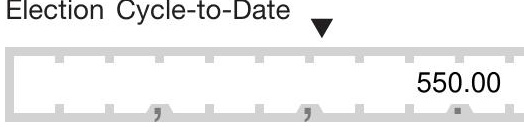

Subtotal Of Receipts This Page (optional)

760.00

Amount of Each Receipt this Period

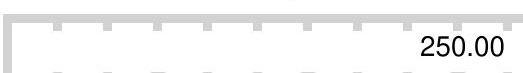

Total This Period (last page this line number only) 


\section{SCHEDULE A-P} ITEMIZED RECEIPTS
Use separate schedule(s) for each category of the Detailed Summary Page

FOR LINE NUMBER:
(check only one)

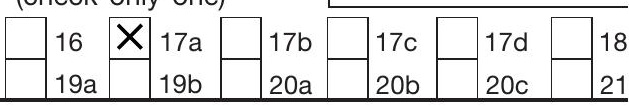

Any information copied from such Reports and Statements may not be sold or used by any person for the purpose of soliciting contributions or for commercial purposes, other than using the name and address of any political committee to solicit contributions from such committee.

NAME OF COMMITTEE (In Full)

\section{Friends of Herman Cain}

A. Full Name (Last, First, Middle Initial)

\section{Carol Burke}

Mailing Address 180 W Benton Ave Unit 303

\begin{tabular}{lcc}
\hline City & State & Zip Code \\
Naperville & IL & $60540-4587$
\end{tabular}

FEC ID number of contributing federal political committee.

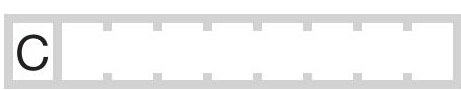

Name of Employer
None
Receipt For: 2012
X Primary $\quad \square$ General
$\square$ Other (specify)

Occupation Homemaker

Election Cycle-to-Date 450.00

B. Full Name (Last, First, Middle Initial) Judy Benishek

Mailing Address 802 Pentoga Tr.

\begin{tabular}{lcc}
\hline City & State & Zip Code \\
Crystal Falls & MI & $49920-8518$ \\
\hline
\end{tabular}

FEC ID number of contributing

federal political committee.

C

Name of Employer
Information Requested
Receipt For: 2012
Primary
Other (specify)

Occupation

Information Requested

Election Cycle-to-Date

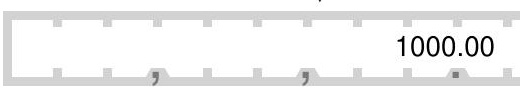

C. Full Name (Last, First, Middle Initial)

Arlene Rouse

Mailing Address $4655 \mathrm{E}$ 58th St

\begin{tabular}{lcc}
\hline City & State & Zip Code \\
Tulsa & OK & $74135-4319$
\end{tabular}

FEC ID number of contributing federal political committee.

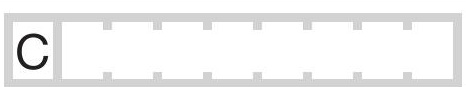

Name of Employer
Dillards
Receipt For: 2012
X Primary $\square$ General
Other (specify)

\section{Occupation}

Sales

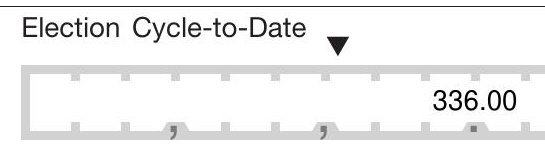

Transaction ID : A84A6C1D48C0947EB974

Date of Receipt

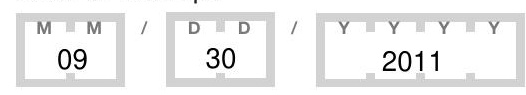

Amount of Each Receipt this Period

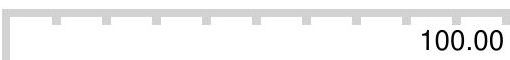

100.00

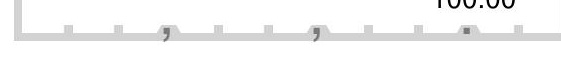

Transaction ID : A3249603AC9934BF8943

Date of Receipt

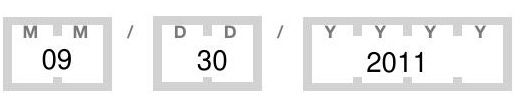

Amount of Each Receipt this Period

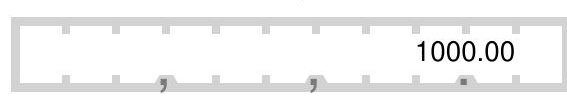

Transaction ID : A00E57E7478C64F4F873

Date of Receipt

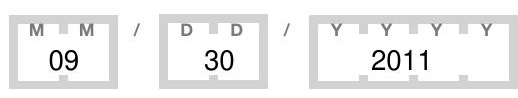

Amount of Each Receipt this Period

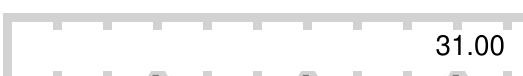

\section{Subtotal Of Receipts This Page (optional)}

Total This Period (last page this line number only) 


\section{SCHEDULE A-P} ITEMIZED RECEIPTS
Use separate schedule(s)

for each category of the

Detailed Summary Page
FOR LINE NUMBER: (check only one)

Any information or for commercial purposes, other than using the name and address of any political committee to solicit contributions from such committee.

NAME OF COMMITTEE (In Full)

Friends of Herman Cain

A. Full Name (Last, First, Middle Initial)

Mrs. Susan K. McLaurine

Mailing Address 114 La Encinal Court

\begin{tabular}{lcc}
\hline City & State & Zip Code \\
Clayton & CA & $94517-1750$ \\
\hline
\end{tabular}

FEC ID number of contributing federal political committee.

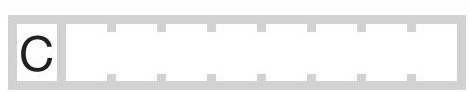

Name of Employer
Vantage Consulting LLC
Receipt For: 2012
X Primary $\quad \square$ General
Other (specify)

Occupation

Business Consul

Election Cycle-to-Date

650.00

B. Full Name (Last, First, Middle Initial)

Barbara Griffith

Mailing Address 6228 Northaven Rd.

\begin{tabular}{lcc}
\hline City & State & Zip Code \\
Dallas & TX & $75230-3013$ \\
\hline
\end{tabular}

FEC ID number of contributing

federal political committee.

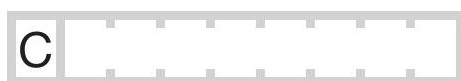

Name of Employer
Key Management Corp.
Receipt For: 2012
X Primary
Other (specify)

Occupation

Executive

Transaction ID : A4F6FBDABB581426D8ED

Date of Receipt

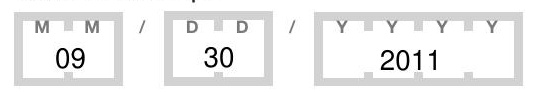

Amount of Each Receipt this Period

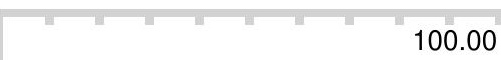

100.00

Transaction ID : AD93A7E0A5877401EAD5

Date of Receipt

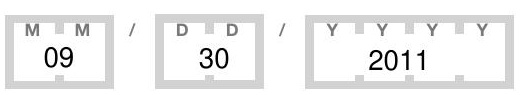

Amount of Each Receipt this Period

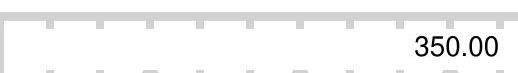

Election Cycle-to-Date

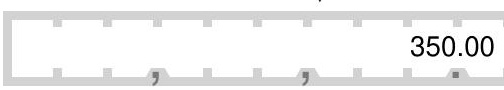

C. Full Name (Last, First, Middle Initial)

Michelle Joanou

Mailing Address 5663 Bramblewood Rd.

\begin{tabular}{lcc}
\hline City & State & Zip Code \\
La Canada Flintridge & CA & $91011-1822$
\end{tabular}

FEC ID number of contributing

federal political committee.

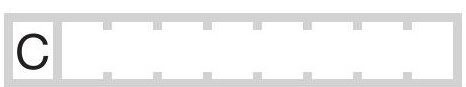

Name of Employer
n/a
Receipt For: 2012
X Primary $\square$ General
Other (specify)

\section{Occupation}

$\mathrm{N} / \mathrm{A}$

Election Cycle-to-Date

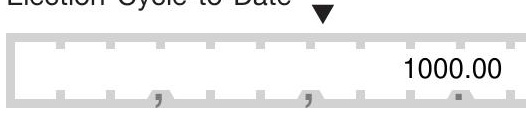

Amount of Each Receipt this Period

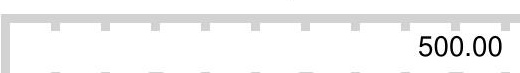

Transaction ID : A9AB7A9DF252C4B8FBB9 Date of Receipt

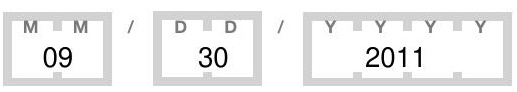

\section{Subtotal Of Receipts This Page (optional)}

Total This Period (last page this line number only) 


\section{SCHEDULE A-P} ITEMIZED RECEIPTS
Use separate schedule(s)

for each category of the

Detailed Summary Page
FOR LINE NUMBER: (check only one)

Any information or for commercial purposes, other than using the name and address of any political committee to solicit contributions from such committee.

NAME OF COMMITTEE (In Full)

\section{Friends of Herman Cain}

A. Full Name (Last, First, Middle Initial)

\section{Karen Hatke}

Mailing Address 75 Hibiscus Court

\begin{tabular}{lcc}
\hline City & State & Zip Code \\
Lafayette & IN & $47909-6302$ \\
\hline
\end{tabular}

FEC ID number of contributing federal political committee.

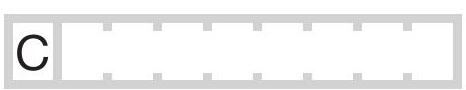

Name of Employer
self
Receipt For: 2012
X Primary $\quad$ General
Other (specify)

Occupation

Freelance Writer

Election Cycle-to-Date

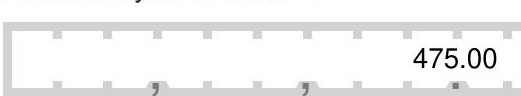

B. Full Name (Last, First, Middle Initial)

Brandon Walker

Mailing Address 728 Quincy Ave

\begin{tabular}{lcc}
\hline City & State & Zip Code \\
Clovis & CA & $93619-7667$
\end{tabular}

FEC ID number of contributing

federal political committee.

C

Name of Employer
Information Requested
Receipt For: 2012
Primary
Other (specify)

Occupation

Information Requested

Election Cycle-to-Date

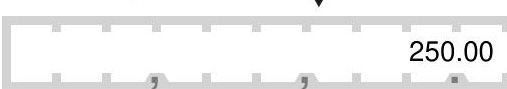

Transaction ID : AD7AF1E7619A24D479A9

Date of Receipt

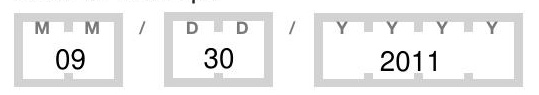

Amount of Each Receipt this Period

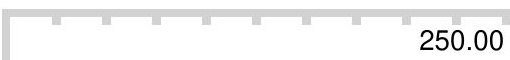

250.00

C. Full Name (Last, First, Middle Initial)

Harold Bowen

Mailing Address 2550 Woodward Way NW

\begin{tabular}{lcc}
\hline City & State & Zip Code \\
Atlanta & GA & $30305-3562$ \\
\hline
\end{tabular}

FEC ID number of contributing federal political committee.

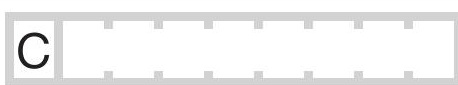

Name of Employer

Bowen, Hanes and Co. Inc.

Receipt For: 2012

Х $\begin{aligned} & \text { Primary } \square \text { General } \\ & \text { Other (specify) }\end{aligned}$

Occupation

Investment Counsel

Election Cycle-to-Date
Transaction ID : A26A555157CF94A6DB4A

Date of Receipt

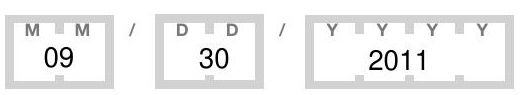

Amount of Each Receipt this Period

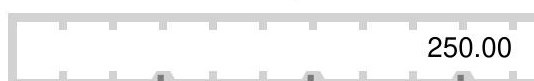

Amount of Each Receipt this Period

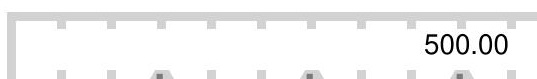

Transaction ID : AB3CEAC7DC64E44749C0 Date of Receipt

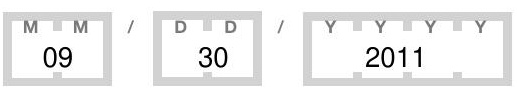

\section{Subtotal Of Receipts This Page (optional)}

Total This Period (last page this line number only)

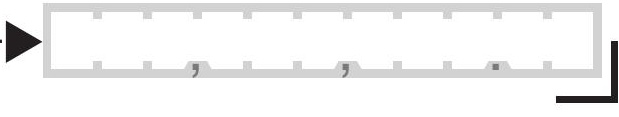




\section{SCHEDULE A-P} ITEMIZED RECEIPTS
Use separate schedule(s)

for each category of the

Detailed Summary Page
FOR LINE NUMBER: (check only one)

Any information or for commercial purposes, other than using the name and address of any political committee to solicit contributions from such committee.

NAME OF COMMITTEE (In Full)

Friends of Herman Cain

A. Full Name (Last, First, Middle Initial) Joseph Grubbs

Mailing Address 90 Kimberwick Tr.

\begin{tabular}{lcc}
\hline City & State & Zip Code \\
Newnan & GA & $30263-7102$ \\
\hline
\end{tabular}

FEC ID number of contributing federal political committee.

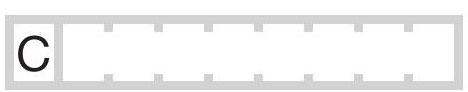

Name of Employer
Self Employed
Receipt For: 2012
X Primary
$\square$ Other (specify) General

Occupation freight broker

Election Cycle-to-Date

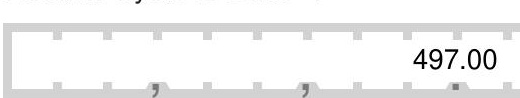

B. Full Name (Last, First, Middle Initial) Elizabeth wickham

Mailing Address po box 15

\begin{tabular}{lcc}
\hline City & State & Zip Code \\
Palm Springs & CA & $92263-0015$ \\
\hline
\end{tabular}

FEC ID number of contributing

federal political committee.

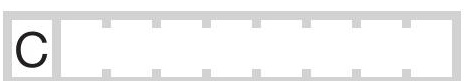

Name of Employer
Merrill Lynch
Receipt For: 2012
X Primary
Other (specify)

Occupation

Financial Advisor

Election Cycle-to-Date

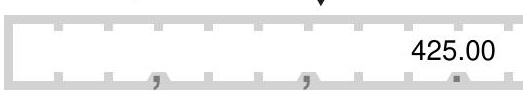

Transaction ID : AC6168C7054E14AA981D

Date of Receipt

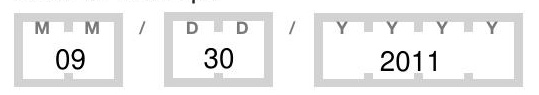

Amount of Each Receipt this Period

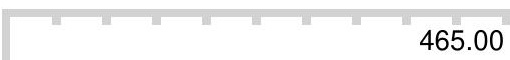

Amount of Each Receipt this Period

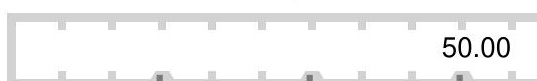

C. Full Name (Last, First, Middle Initial)

William Vaught

Mailing Address 11770 Haynes Bridge Rd. STE 205 \#5

\begin{tabular}{lcc}
\hline City & State & Zip Code \\
Alpharetta & GA & $30009-1970$
\end{tabular}

FEC ID number of contributing federal political committee.

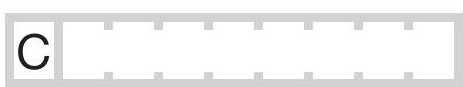

Name of Employer

Information Requested

Occupation

Receipt For: 2012

Х $\begin{aligned} & \text { Primary } \square \text { General } \\ & \text { Other (specify) }\end{aligned}$

Information Requested

Election Cycle-to-Date

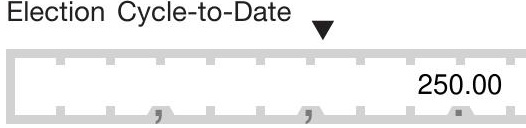

Transaction ID : A5C3A407AB9B24C1E952

Date of Receipt

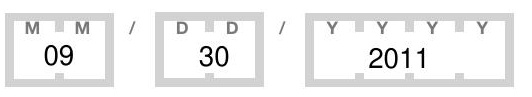

Transaction ID : AB1303A3E8B10405EBC0 Date of Receipt

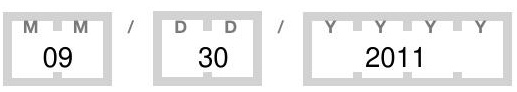

Amount of Each Receipt this Period

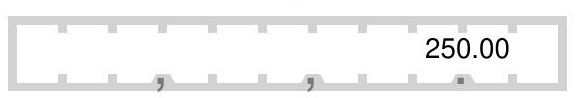

Subtotal Of Receipts This Page (optional).

765.00

Total This Period (last page this line number only) 


\section{SCHEDULE A-P} ITEMIZED RECEIPTS
Use separate schedule(s)

for each category of the

Detailed Summary Page
FOR LINE NUMBER: (check only one)

Any information or for commercial purposes, other than using the name and address of any political committee to solicit contributions from such committee.

NAME OF COMMITTEE (In Full)

Friends of Herman Cain

A. Full Name (Last, First, Middle Initial)

Roland Smith

Mailing Address 55090 Shoal Creek

\begin{tabular}{lcc}
\hline City & State & Zip Code \\
La Quinta & CA & $92253-4727$
\end{tabular}

FEC ID number of contributing federal political committee.

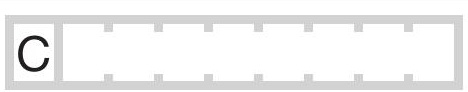

Name of Employer
None
Receipt For: 2012
X Primary $\quad$ General
Other (specify)

Occupation

Retired

Election Cycle-to-Date

500.00

B. Full Name (Last, First, Middle Initial)

Jim Nechtman Sr.

Mailing Address 3754 Lindwood Way

\begin{tabular}{lcc}
\hline City & State & Zip Code \\
Snellville & GA & $30039-8019$ \\
\hline
\end{tabular}

FEC ID number of contributing

federal political committee.

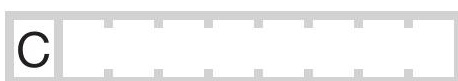

Name of Employer
None
Receipt For: 2012
X Primary
Other (specify)

Occupation

Retired

Election Cycle-to-Date

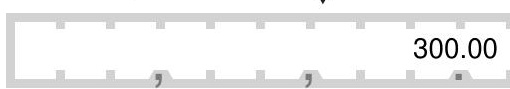

Transaction ID : A5EDD75D9846A435EB13

Date of Receipt

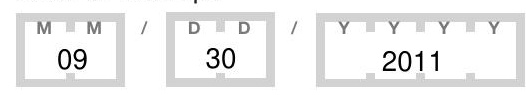

Amount of Each Receipt this Period

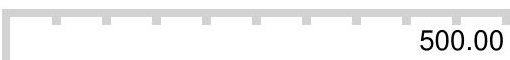

C. Full Name (Last, First, Middle Initial)

Henry Graham

Mailing Address 3700 Indian Springs Trl.

\begin{tabular}{lcc}
\hline City & State & Zip Code \\
Arlington & TX & $76016-313$
\end{tabular}

FEC ID number of contributing

federal political committee.

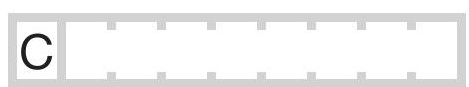

Name of Employer

Graham Financial Group LLC

Receipt For: 2012

Х $\begin{aligned} & \text { Primary } \square \text { General } \\ & \text { Other (specify) }\end{aligned}$

Occupation

Financial Advisor

Election Cycle-to-Date

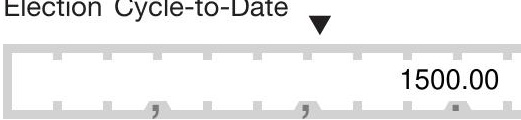

Transaction ID : ABF3FEC4D6A9B4B6A889 Date of Receipt

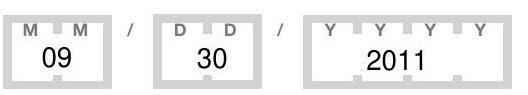

Amount of Each Receipt this Period

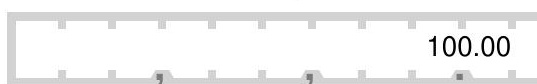

Transaction ID : A12A1182F5DD34A8D91A Date of Receipt

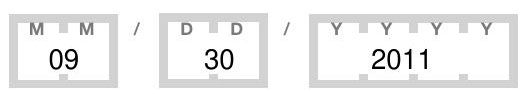

Amount of Each Receipt this Period

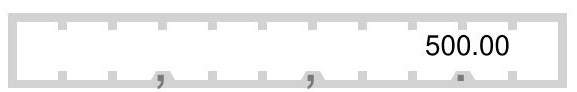

\section{Subtotal Of Receipts This Page (optional)}

Total This Period (last page this line number only) 
SCHEDULE A-P ITEMIZED RECEIPTS
Use separate schedule(s) for each category of the Detailed Summary Page
FOR LINE NUMBER: (check only one)

PAGE $1213 / 1572$

\begin{tabular}{|c|c|c|c|c|c|}
\hline & & & & & \\
\hline 16 & $\begin{array}{lll}X & 17 a \\
\end{array}$ & $17 \mathrm{~b}$ & $17 c$ & $17 d$ & 18 \\
\hline $19 a$ & $19 b$ & $20 a$ & $20 \mathrm{~b}$ & $20 c$ & 21 \\
\hline
\end{tabular}

Any information copied from such Reports and Statements may not be sold or used by any person for the purpose of soliciting contributions or for commercial purposes, other than using the name and address of any political committee to solicit contributions from such committee.

NAME OF COMMITTEE (In Full)

\section{Friends of Herman Cain}

A. Full Name (Last, First, Middle Initial)

Kathryn Collier

Mailing Address 1075 Byrnwyck Trail

\begin{tabular}{lcc}
\hline City & State & Zip Code \\
Atlanta & GA & $30319-1670$
\end{tabular}

FEC ID number of contributing

federal political committee.

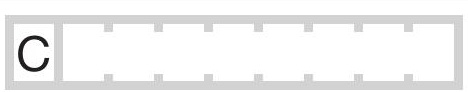

Name of Employer
Information Requested
Receipt For: 2012
X Primary
Other (specify) General

Occupation

Information Requested

Election Cycle-to-Date

1500.00

B. Full Name (Last, First, Middle Initial)

Bernetta L. Gresko

Mailing Address 159 Santa Ana Ave.

\begin{tabular}{lcc}
\hline City & State & Zip Code \\
Long Beach & CA & $90803-3461$
\end{tabular}

FEC ID number of contributing

federal political committee.

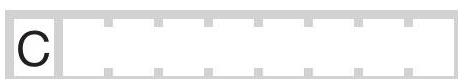

Name of Employer
None
Receipt For: 2012
X Primary
Other (specify)

\section{Occupation}

Retired

Election Cycle-to-Date

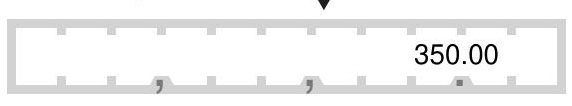

C. Full Name (Last, First, Middle Initial)

Henriette Boyle

Mailing Address 5825 SW 88th PL

\begin{tabular}{lcc}
\hline City & State & Zip Code \\
Ocala & FL & $34476-4018$
\end{tabular}

FEC ID number of contributing

federal political committee.

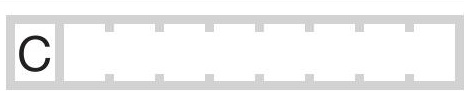

Name of Employer
No employer
Receipt For: 2012
X Primary $\quad \square$ General
Other (specify)

Occupation

Retired

Election Cycle-to-Date

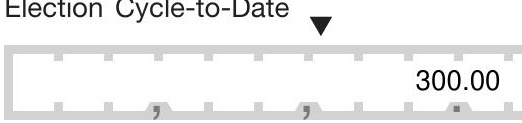

Transaction ID : AB3031713137140618D2

Date of Receipt

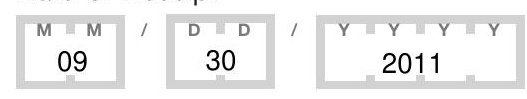

Amount of Each Receipt this Period

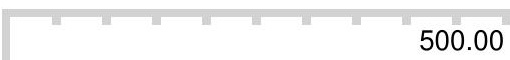

500.00

Transaction ID : A75DCAE644063485C917

Date of Receipt

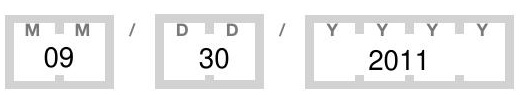

Amount of Each Receipt this Period

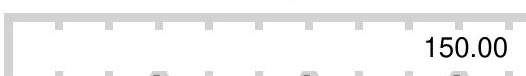

Transaction ID : A755618ECA850469DA0E Date of Receipt

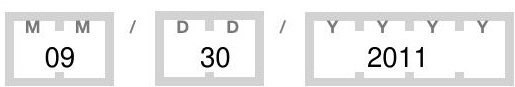

Amount of Each Receipt this Period

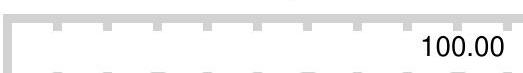

100.00
Subtotal Of Receipts This Page (optional)

750.00

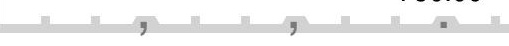

Total This Period (last page this line number only)

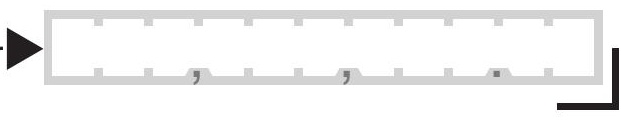

FEC Schedule A-P (Form 3P) (Rev. 03/2011) 


\section{SCHEDULE A-P} ITEMIZED RECEIPTS
Use separate schedule(s) for each category of the Detailed Summary Page
FOR LINE NUMBER: (check only one)

PAGE 1214 / 1572

\begin{tabular}{|c|c|c|c|c|c|}
\hline & & & & & \\
\hline 16 & $\begin{array}{l}\mathbf{X} \\
17 a\end{array}$ & $17 b$ & $17 c$ & $17 d$ & 18 \\
\hline $19 a$ & $19 \mathrm{~b}$ & $20 \mathrm{a}$ & $20 \mathrm{~b}$ & $20 \mathrm{c}$ & 21 \\
\hline
\end{tabular}

Any information copied from such Reports and Statements may not be sold or used by any person for the purpose of soliciting contributions or for commercial purposes, other than using the name and address of any political committee to solicit contributions from such committee.

NAME OF COMMITTEE (In Full)

Friends of Herman Cain

A. Full Name (Last, First, Middle Initial)

Tawnya Brown

Mailing Address 350 Red Bridge Road

\begin{tabular}{lcc}
\hline City & State & Zip Code \\
Ozark & MO & $65721-6381$ \\
\hline
\end{tabular}

FEC ID number of contributing federal political committee.

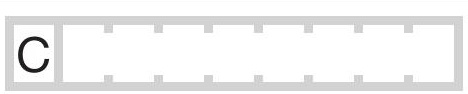

Name of Employer
Cox Health
Receipt For: 2012
X Primary
$\square$ Other (specify) General

Occupation

Pharmacist

Election Cycle-to-Date

545.12

B. Full Name (Last, First, Middle Initial)

Jack Copeland

Mailing Address 105 E Bedford St

\begin{tabular}{lcc}
\hline City & State & Zip Code \\
Dimmitt & TX & $79027-2623$
\end{tabular}

FEC ID number of contributing

federal political committee.

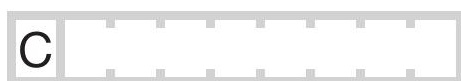

Name of Employer
Information Requested
Receipt For: 2012
X Primary
Other (specify)

Occupation

Information Requested

Election Cycle-to-Date

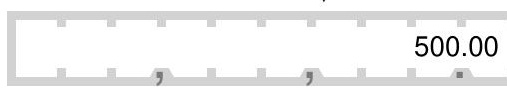

Transaction ID : A753C013FD30242CC974

Date of Receipt

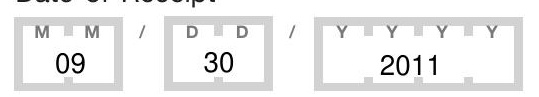

Amount of Each Receipt this Period

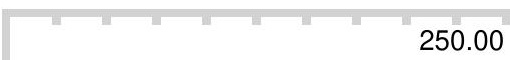

250.00

C. Full Name (Last, First, Middle Initial)

Kelly Holloway

Mailing Address 3610 31st Street

\begin{tabular}{lcc}
\hline City & State & Zip Code \\
Lubbock & TX & $79410-2735$
\end{tabular}

FEC ID number of contributing federal political committee.

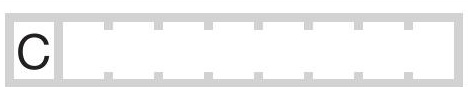

Name of Employer
Hawkeye Road Boring
Receipt For: 2012
Х Primary $\quad \square$ General
Other (specify)

\section{Occupation}

Construction

Election Cycle-to-Date
Transaction ID : AB71771991D5944C2864

Date of Receipt

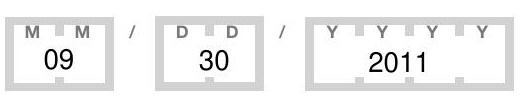

Amount of Each Receipt this Period

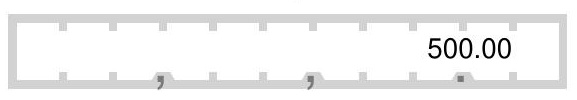

Transaction ID : A8AD25EA6307C4DE8BEC Date of Receipt

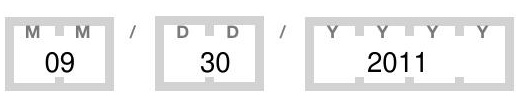

Amount of Each Receipt this Period

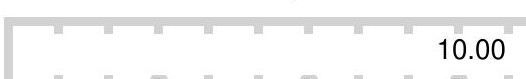

\section{Subtotal Of Receipts This Page (optional).}

Total This Period (last page this line number only) 


\section{SCHEDULE A-P} ITEMIZED RECEIPTS
Use separate schedule(s) for each category of the Detailed Summary Page
FOR LINE NUMBER: (check only one)
PAGE $1215 / 1572$

\begin{tabular}{|c|c|c|c|c|c|}
\hline & & & & & \\
\hline 16 & $\begin{array}{ll}\mathbf{X} & 17 a \\
\end{array}$ & $17 \mathrm{~b}$ & $17 c$ & $17 d$ & 18 \\
\hline $19 a$ & $19 b$ & $20 \mathrm{a}$ & $20 \mathrm{~b}$ & $20 c$ & 21 \\
\hline
\end{tabular}

Any information copied from such Reports and Statements may not be sold or used by any person for the purpose of soliciting contributions or for commercial purposes, other than using the name and address of any political committee to solicit contributions from such committee.

NAME OF COMMITTEE (In Full)

Friends of Herman Cain

A. Full Name (Last, First, Middle Initial)

Carlton Faulk

Mailing Address 260 Keetor Road

\begin{tabular}{lcc}
\hline City & State & Zip Code \\
Talking Rock & GA & $30175-2510$ \\
\hline
\end{tabular}

FEC ID number of contributing

federal political committee.

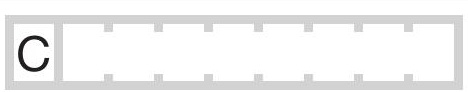

Name of Employer
Information Requested
Receipt For: 2012
X Primary $\quad \square$ General
Other (specify)

Occupation

Information Requested

Election Cycle-to-Date

500.00

B. Full Name (Last, First, Middle Initial)

Glenn Randall

Mailing Address 8 Salermo

\begin{tabular}{lcc}
\hline City & State & Zip Code \\
Laguna Niguel & CA & $92677-9032$ \\
\hline
\end{tabular}

FEC ID number of contributing

federal political committee.

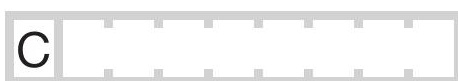

Name of Employer
Information Requested
Receipt For: 2012
X Primary
Other (specify)

Occupation

Information Requested

Election Cycle-to-Date

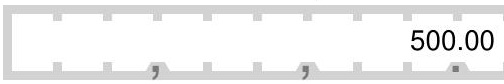

C. Full Name (Last, First, Middle Initial)

Michael Friedberg

Mailing Address 7712 Shadow Box Court

\begin{tabular}{lcc}
\hline City & State & Zip Code \\
Orlando & FL & $32819-4930$ \\
\hline
\end{tabular}

FEC ID number of contributing

federal political committee.

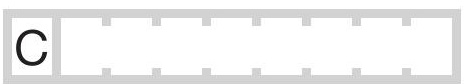

Name of Employer

Information Requested

Occupation

Information Requested

Receipt For: 2012

Х $\begin{aligned} & \text { Primary } \\ & \text { Other (specify) }\end{aligned}$

Election Cycle-to-Date

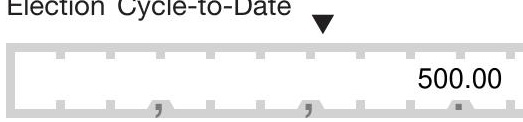

Amount of Each Receipt this Period

Transaction ID : AEB90E7246F0D4E78864

Date of Receipt

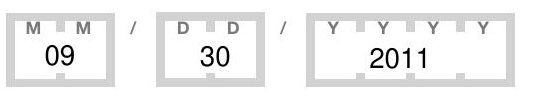

Amount of Each Receipt this Period
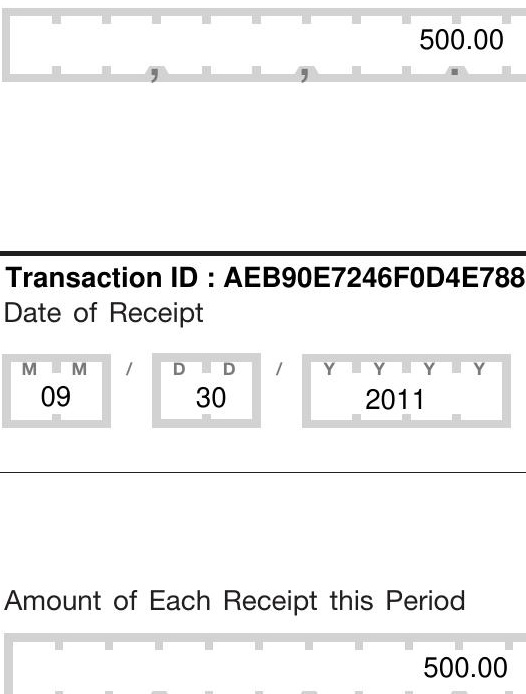

Transaction ID : AAC6BE1F75B1147D9949

Date of Receipt

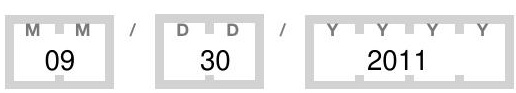

Amount of Each Receipt this Period

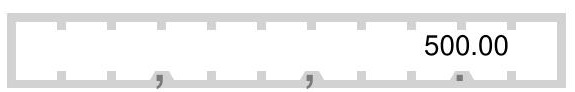

Subtotal Of Receipts This Page (optional)

1500.00

Total This Period (last page this line number only) 


\section{SCHEDULE A-P} ITEMIZED RECEIPTS
Use separate schedule(s) for each category of the Detailed Summary Page
FOR LINE NUMBER: (check only one)

PAGE 1216 / 1572

\begin{tabular}{|c|c|c|c|c|c|}
\hline & & & & & \\
\hline 16 & $\mathbf{X} 17 a$ & $17 b$ & $17 c$ & $17 d$ & 18 \\
\hline $19 a$ & $19 b$ & $20 \mathrm{a}$ & $20 \mathrm{~b}$ & $20 \mathrm{c}$ & 21 \\
\hline
\end{tabular}

Any information copied from such Reports and Statements may not be sold or used by any person for the purpose of soliciting contributions or for commercial purposes, other than using the name and address of any political committee to solicit contributions from such committee.

NAME OF COMMITTEE (In Full)

\section{Friends of Herman Cain}

A. Full Name (Last, First, Middle Initial)

Billy Lillard

Mailing Address 10941 E. 28th PI

\begin{tabular}{lcc}
\hline City & State & Zip Code \\
Tulsa & OK & $74129-7663$
\end{tabular}

FEC ID number of contributing federal political committee.

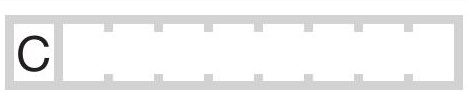

Name of Employer
OTL
Receipt For: 2012
X Primary $\square$ General
$\square$ Other (specify)

Occupation truck driver

Election Cycle-to-Date

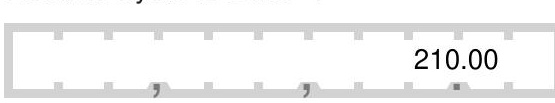

B. Full Name (Last, First, Middle Initial)

Cathy Brunicardi

Mailing Address PO Box 300

\begin{tabular}{lcc}
\hline City & State & Zip Code \\
Weesatche & TX & $77993-0300$
\end{tabular}

FEC ID number of contributing

federal political committee.

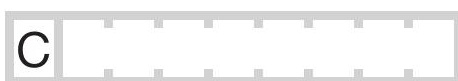

Name of Employer
None
Receipt For: 2012
X Primary
Other (specify)

Occupation

Retired

Election Cycle-to-Date

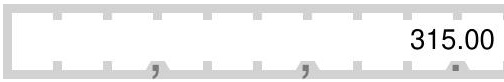

Transaction ID : A85D7D4D520C449CEB9E

Date of Receipt

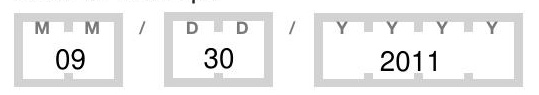

Amount of Each Receipt this Period

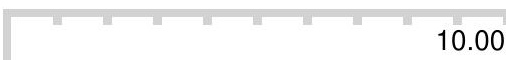

10.00

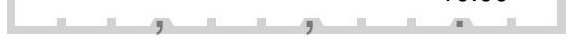

Transaction ID : AE983C3300F394F40889

Date of Receipt

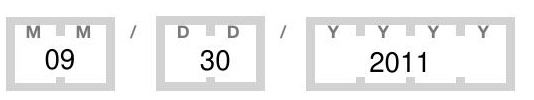

Amount of Each Receipt this Period

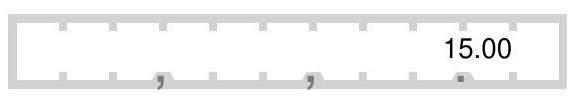

Transaction ID : AFD543076CE9F4F7AB0D Date of Receipt

Jeanne Downer

Mailing Address $6007 \mathrm{~N}$ Kansas AVe

\begin{tabular}{lcc}
\hline City & State & Zip Code \\
Kansas City & MO & $64119-2115$
\end{tabular}

FEC ID number of contributing federal political committee.

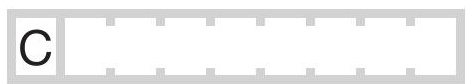

\section{Name of Employer}

WNB Architects

\section{Occupation}

Office Manager

Receipt For: 2012

Х $\begin{aligned} & \text { Primary } \square \text { General } \\ & \text { Other (specify) }\end{aligned}$

\section{Subtotal Of Receipts This Page (optional)}

Total This Period (last page this line number only)

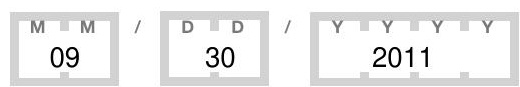

Amount of Each Receipt this Period

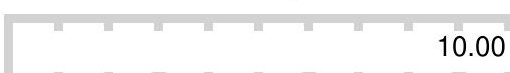

35.00

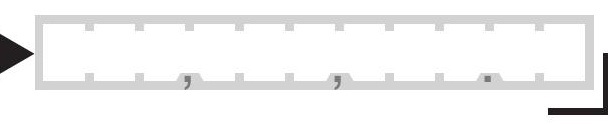

FEC Schedule A-P (Form 3P) (Rev. 03/2011) 


\section{SCHEDULE A-P} ITEMIZED RECEIPTS
Use separate schedule(s)

for each category of the

Detailed Summary Page
FOR LINE NUMBER: (check only one)

Any information or for commercial purposes, other than using the name and address of any political committee to solicit contributions from such committee.

NAME OF COMMITTEE (In Full)

Friends of Herman Cain

A. Full Name (Last, First, Middle Initial)

Wilfred Olschewski

Mailing Address 1732 S. Congree Ave. \#265

\begin{tabular}{lcc}
\hline City & State & Zip Code \\
Lake Worth & FL & 34461 \\
\hline
\end{tabular}

FEC ID number of contributing

federal political committee.

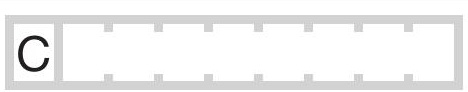

Name of Employer
Information Requested
Receipt For: 2012
X Primary $\quad \square$ General
Other (specify)

Occupation

Information Requested

Election Cycle-to-Date

2500.00

B. Full Name (Last, First, Middle Initial)

Sue Hull

Mailing Address PO Box 357

\begin{tabular}{lcc}
\hline City & State & Zip Code \\
Craig & AK & $99921-0357$
\end{tabular}

FEC ID number of contributing

federal political committee.

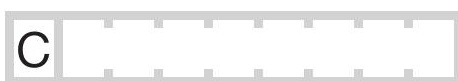

Name of Employer
Peace Health
Receipt For: 2012
X Primary
Other (specify)

Occupation

Registered Nurse

Election Cycle-to-Date

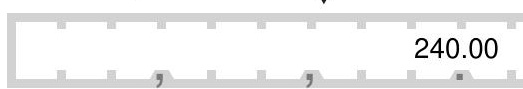

C. Full Name (Last, First, Middle Initial)

N. Kathleen Everett

Mailing Address 220 Tabor Road

\begin{tabular}{lcc}
\hline City & State & Zip Code \\
Greeneville & TN & $37743-6220$
\end{tabular}

FEC ID number of contributing

federal political committee.

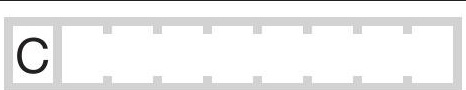

Name of Employer
None
Receipt For: 2012
Х Primary $\quad \square$ General
Other (specify)

Occupation

Retired

Election Cycle-to-Date

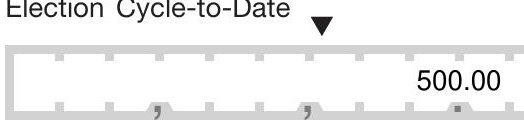

Transaction ID : AF61D997CC72A49B09F3

Date of Receipt

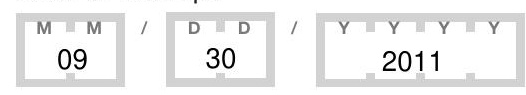

Amount of Each Receipt this Period

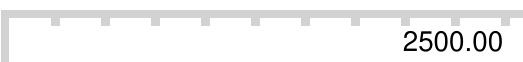

2500.00

Transaction ID : ACD5CC022263A4CFE9D6

Date of Receipt

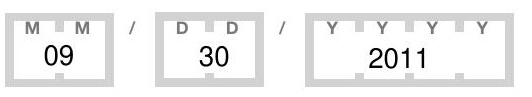

Amount of Each Receipt this Period

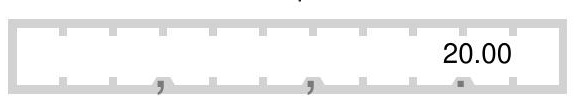

Transaction ID : A94069FA6C97C45D6B11

Date of Receipt

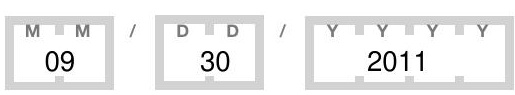

Amount of Each Receipt this Period

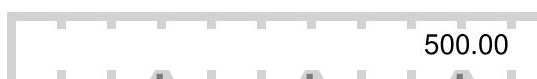

Subtotal Of Receipts This Page (optional).

3020.00

a

Total This Period (last page this line number only)

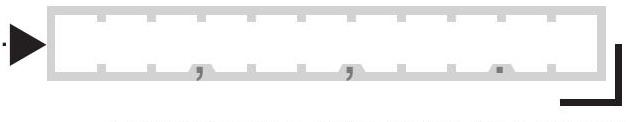

FEC Schedule A-P (Form 3P) (Rev. 03/2011) 


\section{SCHEDULE A-P} ITEMIZED RECEIPTS
Use separate schedule(s) for each category of the Detailed Summary Page

FOR LINE NUMBER:
(check only one)

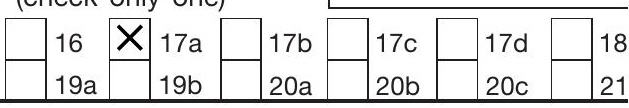

Any information copied from such Reports and Statements may not be sold or used by any person for the purpose of soliciting contributions or for commercial purposes, other than using the name and address of any political committee to solicit contributions from such committee.

NAME OF COMMITTEE (In Full)

\section{Friends of Herman Cain}

A. Full Name (Last, First, Middle Initial)

David Brumbeloe

Mailing Address 34 Centerport Drive

\begin{tabular}{lcc}
\hline City & State & Zip Code \\
White & GA & $30184-2763$ \\
\hline
\end{tabular}

FEC ID number of contributing federal political committee.

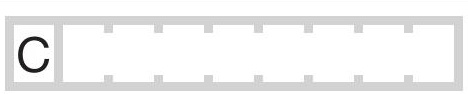

Name of Employer
PowerPlan Consultants Inc.
Receipt For: 2012
X Primary
$\square$ Other (specify)

Occupation

Consultant

Election Cycle-to-Date

\subsection{0}

B. Full Name (Last, First, Middle Initial)

James Gillespie

Mailing Address 965 Windsor Place Circle

\begin{tabular}{lcc}
\hline City & State & Zip Code \\
Grayson & GA & $30017-4914$
\end{tabular}

FEC ID number of contributing

federal political committee.

C

Name of Employer
Retired
Receipt For: 2012
Primary
$\square$ Other (specify)

Occupation

Retired

Election Cycle-to-Date

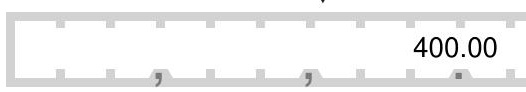

Transaction ID : A7C2242AF84A2422BBBB

Date of Receipt

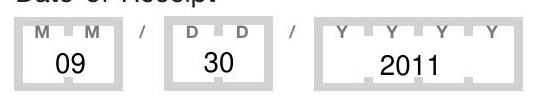

Amount of Each Receipt this Period

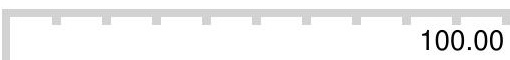

Amount of Each Receipt this Period

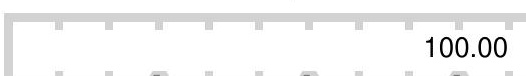

C. Full Name (Last, First, Middle Initial)

Jacqueline Lopez

Mailing Address 1596 West 78 Terrace

\begin{tabular}{lcc}
\hline City & State & Zip Code \\
Hialeah & FL & $33014-3350$
\end{tabular}

FEC ID number of contributing

federal political committee.

C

3350

Name of Employer
US Postal Service
Receipt For: 2012
X Primary
Other (specify) General

Occupation

Letter Carrier

Election Cycle-to-Date

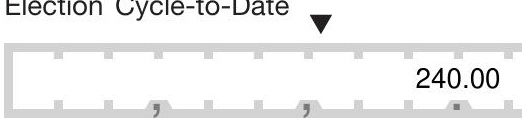

Transaction ID : A2F0EFA94484E4CAC8CC Date of Receipt

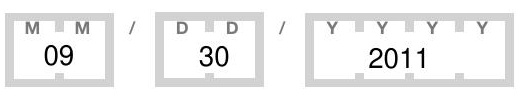

Transaction ID : AD1843CB713994B3EA61 Date of Receipt

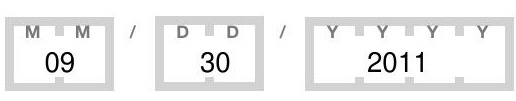

Amount of Each Receipt this Period

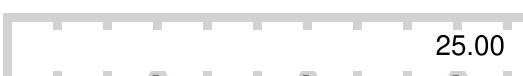

\section{Subtotal Of Receipts This Page (optional)}

Total This Period (last page this line number only) 


\section{SCHEDULE A-P} ITEMIZED RECEIPTS
Use separate schedule(s) for each category of the Detailed Summary Page
FOR LINE NUMBER: (check only one)

PAGE 1219 / 1572

\begin{tabular}{|c|c|c|c|c|c|}
\hline & & & & & \\
\hline 16 & $\begin{array}{l}\mathbf{X} \\
17 a\end{array}$ & $17 b$ & $17 c$ & $17 d$ & 18 \\
\hline $19 a$ & $19 \mathrm{~b}$ & $20 \mathrm{a}$ & $20 \mathrm{~b}$ & $20 \mathrm{c}$ & 21 \\
\hline
\end{tabular}

Any information copied from such Reports and Statements may not be sold or used by any person for the purpose of soliciting contributions or for commercial purposes, other than using the name and address of any political committee to solicit contributions from such committee.

NAME OF COMMITTEE (In Full)

\section{Friends of Herman Cain}

A. Full Name (Last, First, Middle Initial) philip averbuck

Mailing Address 5910 strickland ave.

\begin{tabular}{lcc}
\hline City & State & Zip Code \\
Lakeland & FL & $33812-4196$ \\
\hline
\end{tabular}

FEC ID number of contributing federal political committee.

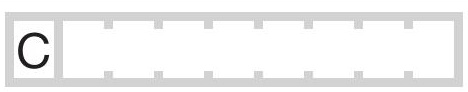

Name of Employer
self
Receipt For: 2012
X Primary $\quad$ General
Other (specify)

Occupation Attorney

Election Cycle-to-Date

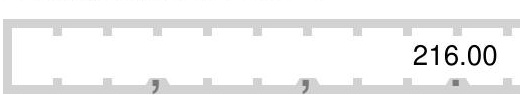

B. Full Name (Last, First, Middle Initial)

Donald Long

Mailing Address 317 Riveredge Blvd

\begin{tabular}{lcc}
\hline City & State & Zip Code \\
Cocoa & FL & $32922-7988$
\end{tabular}

FEC ID number of contributing

federal political committee.

C

Name of Employer
Centennial Development Group
Receipt For: 2012
Primary
Other (specify)

Occupation

Executive

Election Cycle-to-Date

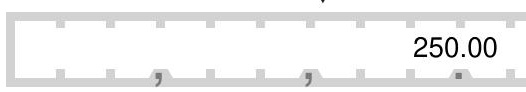

C. Full Name (Last, First, Middle Initial)

Jean Ann Herian

Mailing Address 1117 Carriage Road

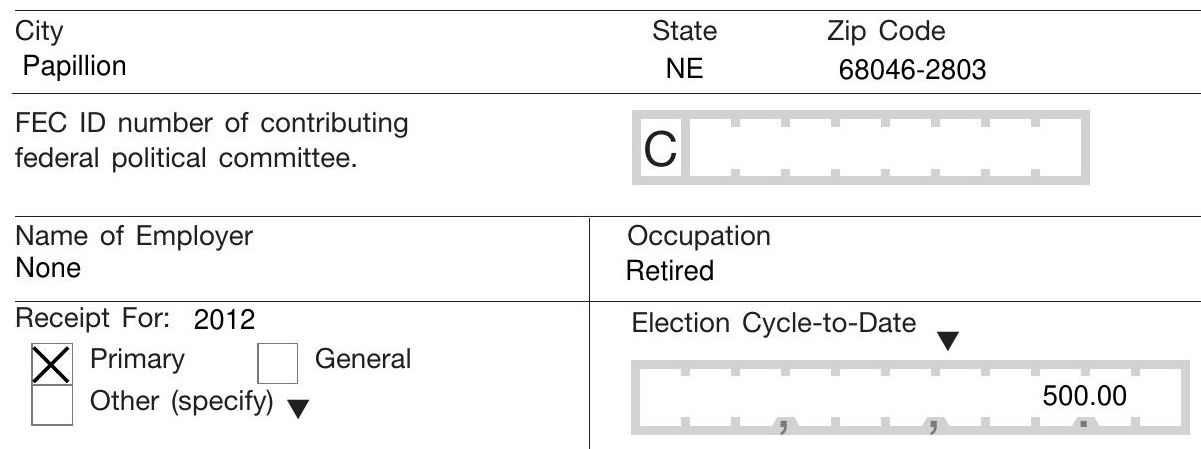

Transaction ID : AA45E190BBE0C475F8A5 Date of Receipt

Amount of Each Receipt this Period

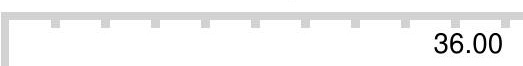

Date of Receipt
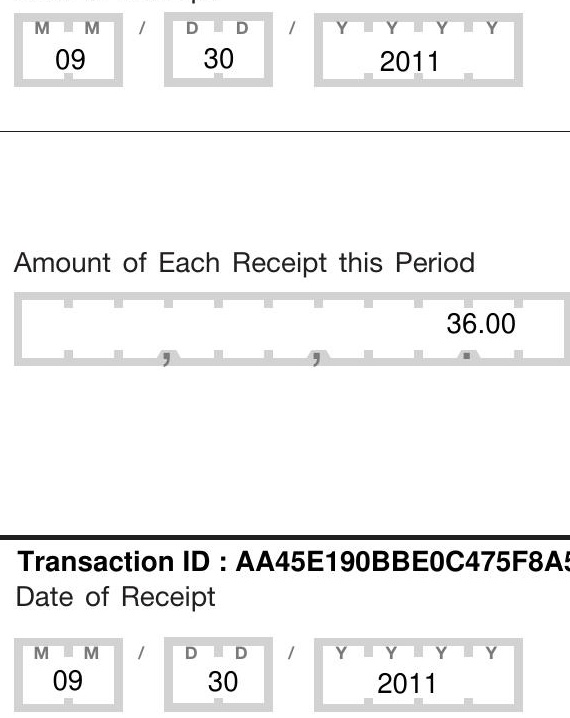

Amount of Each Receipt this Period

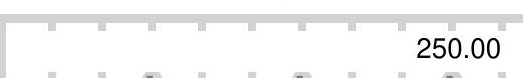

Amount of Each Receipt this Period

Transaction ID : A4309CEDEA6AE458288E Date of Receipt
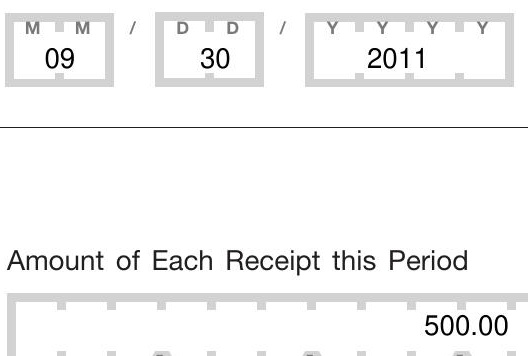

Subtotal Of Receipts This Page (optional)

Total This Period (last page this line number only) 


\section{SCHEDULE A-P} ITEMIZED RECEIPTS
Use separate schedule(s)

for each category of the

Detailed Summary Page
FOR LINE NUMBER: (check only one)

Any information or for commercial purposes, other than using the name and address of any political committee to solicit contributions from such committee.

NAME OF COMMITTEE (In Full)

Friends of Herman Cain

A. Full Name (Last, First, Middle Initial)

sam burton

Mailing Address 7960 banyan blvd

\begin{tabular}{lcc}
\hline City & State & Zip Code \\
Loxahatchee & FL & $33470-3030$
\end{tabular}

FEC ID number of contributing federal political committee.

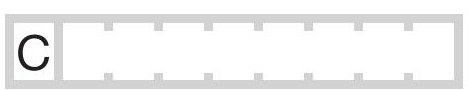

Name of Employer
self
Receipt For: 2012
X Primary $\quad$ General
Other (specify)

Occupation Designer

Election Cycle-to-Date 600.00

B. Full Name (Last, First, Middle Initial) Frances Rees

Mailing Address PO Box 223

\begin{tabular}{lcc}
\hline City & State & Zip Code \\
Braselton & GA & $30517-0004$ \\
\hline
\end{tabular}

FEC ID number of contributing

federal political committee.

C

Name of Employer
Information Requested
Receipt For: 2012
X Primary
Other (specify)

Occupation

Information Requested

Election Cycle-to-Date

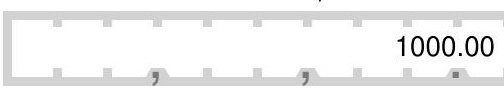

C. Full Name (Last, First, Middle Initial)

Mr. Gary Coombs

Mailing Address 21481 Via Floresta

\begin{tabular}{lcc}
\hline City & State & Zip Code \\
Lake Forest & CA & $92630-2015$
\end{tabular}

FEC ID number of contributing federal political committee.

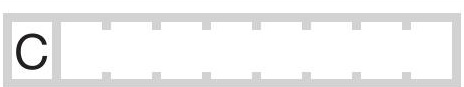

Name of Employer
None
Receipt For: 2012
Х Primary $\quad \square$ General
Other (specify)

Occupation

Retired

Election Cycle-to-Date

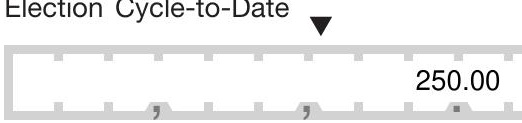

Transaction ID : ACC1F5BA66DB14BAE83E

Date of Receipt

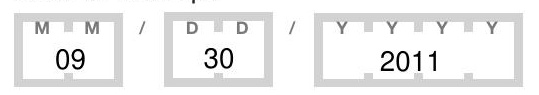

Amount of Each Receipt this Period

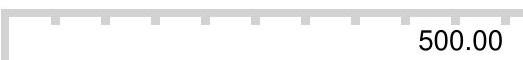

Amount of Each Receipt this Period

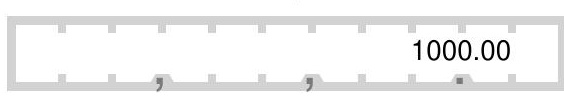

Transaction ID : AD05B86CA1B774331A0F Date of Receipt

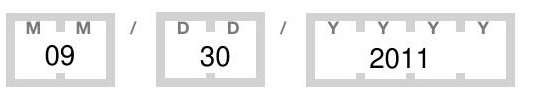

Transaction ID : A92B445DBCF0D48469DC Date of Receipt

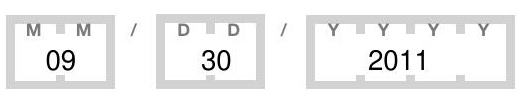

Amount of Each Receipt this Period

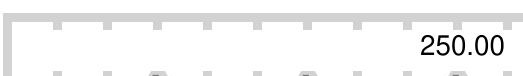

\section{Subtotal Of Receipts This Page (optional)}

Total This Period (last page this line number only) 


\section{SCHEDULE A-P} ITEMIZED RECEIPTS
Use separate schedule(s)

for each category of the

Detailed Summary Page
FOR LINE NUMBER: (check only one)

Any information or for commercial purposes, other than using the name and address of any political committee to solicit contributions from such committee.

NAME OF COMMITTEE (In Full)

Friends of Herman Cain

A. Full Name (Last, First, Middle Initial)

Shirley Mingledorff

Mailing Address PO Box 2608

\begin{tabular}{lcc}
\hline City & State & Zip Code \\
Norcross & GA & $30091-2608$
\end{tabular}

FEC ID number of contributing

federal political committee.

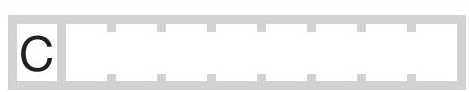

Name of Employer
None
Receipt For: 2012
X Primary $\quad \square$ General
$\square$ Other (specify)

Occupation

Homemaker

Election Cycle-to-Date

2500.00

B. Full Name (Last, First, Middle Initial)

Lynanne Rales

Mailing Address 6800 Hillmead Road

\begin{tabular}{lcc}
\hline City & State & Zip Code \\
Bethesda & MD & 20817-3026 \\
\hline
\end{tabular}

FEC ID number of contributing

federal political committee.

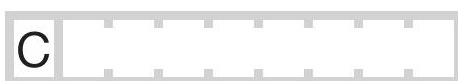

Name of Employer
None
Receipt For: 2012
X Primary $\quad$ General
Other (specify)

Occupation

Retired

Election Cycle-to-Date

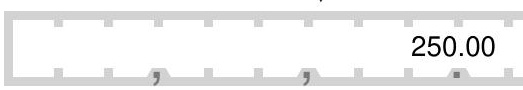

C. Full Name (Last, First, Middle Initial)

Clayton Huber

Mailing Address PO Box 298

\begin{tabular}{lcc}
\hline City & State & Zip Code \\
Sandston & VA & $23150-0298$ \\
\hline
\end{tabular}

FEC ID number of contributing

federal political committee.

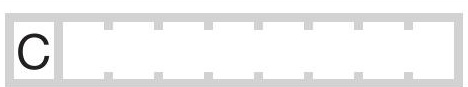

Name of Employer

Dominion Resources

Occupation

Engineer

Receipt For: 2012

Х $\begin{aligned} & \text { Primary } \square \text { General } \\ & \text { Other (specify) }\end{aligned}$

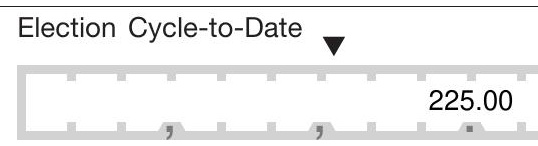

Amount of Each Receipt this Period

Transaction ID : A06D5DDECF97345C9A33

Date of Receipt

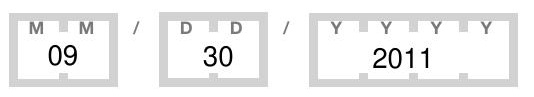

Amount of Each Receipt this Period
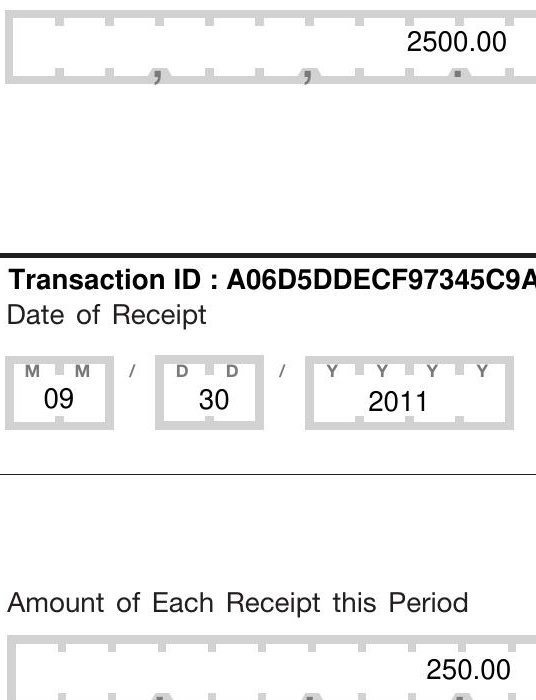

Amount of Each Receipt this Period

Transaction ID : AD63A9E37E1204ADA8C1 Date of Receipt
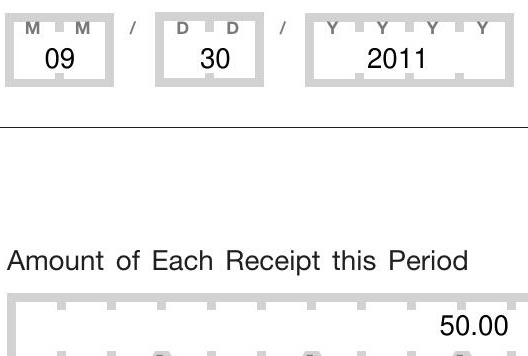

Subtotal Of Receipts This Page (optional)

Total This Period (last page this line number only) 
SCHEDULE A-P ITEMIZED RECEIPTS
Use separate schedule(s) for each category of the Detailed Summary Page
FOR LINE NUMBER: (check only one)
PAGE 1222 / 1572

\begin{tabular}{|c|c|c|c|c|c|}
\hline & & & & & \\
\hline 16 & $\begin{array}{lll}X & 17 a \\
\end{array}$ & $17 \mathrm{~b}$ & $17 c$ & $17 d$ & 18 \\
\hline $19 a$ & $19 b$ & $20 a$ & $20 \mathrm{~b}$ & $20 c$ & 21 \\
\hline
\end{tabular}

Any information copied from such Reports and Statements may not be sold or used by any person for the purpose of soliciting contributions or for commercial purposes, other than using the name and address of any political committee to solicit contributions from such committee.

NAME OF COMMITTEE (In Full)

\section{Friends of Herman Cain}

A. Full Name (Last, First, Middle Initial)

jack rettig

Mailing Address 316 Royal Plaza Dr

\begin{tabular}{lcc}
\hline City & State & Zip Code \\
Fort Lauderdale & FL & $33301-2514$ \\
\hline
\end{tabular}

FEC ID number of contributing

federal political committee.

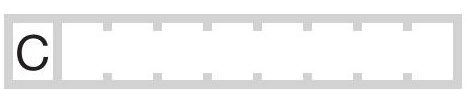

\begin{tabular}{l} 
Name of Employer \\
Information Requested \\
Receipt For: 2012 \\
$\square$ Primary \\
\hline Other (specify)
\end{tabular}

Occupation

Information Requested

Election Cycle-to-Date

5000.00

B. Full Name (Last, First, Middle Initial)

Timothy Hicks

Mailing Address 1145 Hawthorne Ridge Dr

\begin{tabular}{lcc}
\hline City & State & Zip Code \\
Brookfield & WI & $53045-4514$ \\
\hline
\end{tabular}

FEC ID number of contributing

federal political committee.

C

Name of Employer
Ardur LLC
Receipt For: 2012
Primary
Other (specify)

\section{Occupation}

Manager

Election Cycle-to-Date

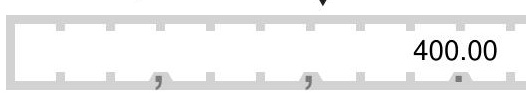

Transaction ID : A6B21866FA41840B6B45

Date of Receipt

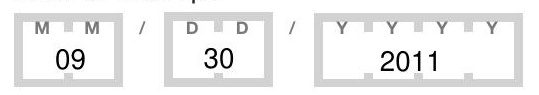

Amount of Each Receipt this Period

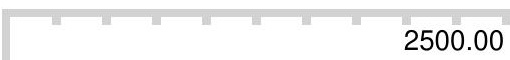

C. Full Name (Last, First, Middle Initial)

Hib Halverson

Mailing Address 228 San Napoli Dr.

\begin{tabular}{lcc}
\hline City & State & Zip Code \\
Goleta & CA & $93117-1010$
\end{tabular}

FEC ID number of contributing federal political committee.

C

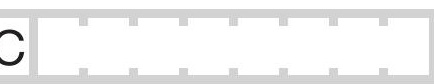

Transaction ID : A7E6869A4C55F406083B

Date of Receipt

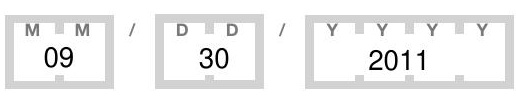

Amount of Each Receipt this Period

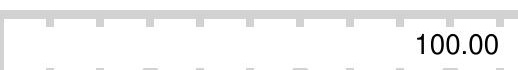

Transaction ID : A012E43762F2C4D9CA17 Date of Receipt

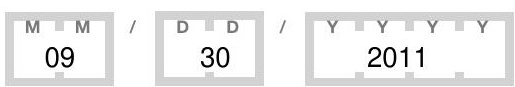

Name of Employer

Information Requested

Occupation

Information Requested

Receipt For: 2012

Х $\begin{aligned} & \text { Primary } \\ & \text { Other (specify) }\end{aligned}$

Election Cycle-to-Date

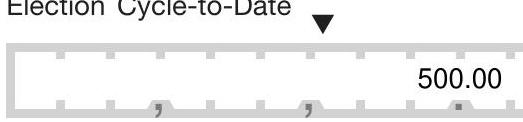

Amount of Each Receipt this Period

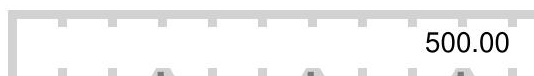

3100.00

Subtotal Of Receipts This Page (optional)

(I)

Total This Period (last page this line number only)

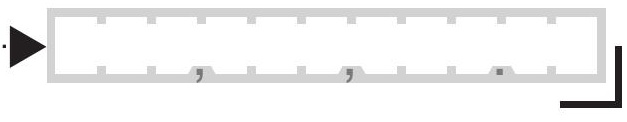

FEC Schedule A-P (Form 3P) (Rev. 03/2011) 
SCHEDULE A-P ITEMIZED RECEIPTS
Use separate schedule(s) for each category of the Detailed Summary Page
FOR LINE NUMBER: (check only one)
PAGE 1223 / 1572

\begin{tabular}{|c|c|c|c|c|c|}
\hline & & & & & \\
\hline 16 & $\begin{array}{lll}X & 17 a \\
\end{array}$ & $17 \mathrm{~b}$ & $17 c$ & $17 d$ & 18 \\
\hline $19 a$ & $19 b$ & $20 a$ & $20 \mathrm{~b}$ & $20 c$ & 21 \\
\hline
\end{tabular}

Any information copied from such Reports and Statements may not be sold or used by any person for the purpose of soliciting contributions or for commercial purposes, other than using the name and address of any political committee to solicit contributions from such committee.

NAME OF COMMITTEE (In Full)

Friends of Herman Cain

A. Full Name (Last, First, Middle Initial)

Mr James McCown

Mailing Address PO Box 8872

\begin{tabular}{lcc}
\hline City & State & Zip Code \\
Amarillo & TX & $79114-8872$ \\
\hline
\end{tabular}

FEC ID number of contributing

federal political committee.

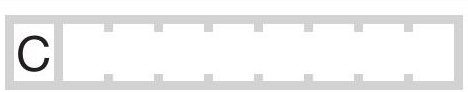

Name of Employer
Benson-McCown \& Co.
Receipt For: 2012
X Primary
$\square$ Other (specify)

Occupation

Owner

Election Cycle-to-Date

600.00

B. Full Name (Last, First, Middle Initial)

J.D. Rice

Mailing Address 3445 Laurel Dr.

\begin{tabular}{lcc}
\hline City & State & Zip Code \\
Mount Dora & FL & $32757-4634$ \\
\hline
\end{tabular}

FEC ID number of contributing

federal political committee.

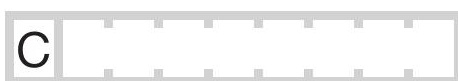

Name of Employer
None
Receipt For: 2012
X Primary
Other (specify)

Occupation

Retired

Election Cycle-to-Date

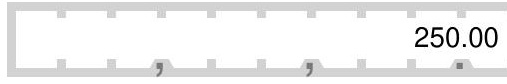

C. Full Name (Last, First, Middle Initial)

Ellen Weigant

Mailing Address 116 E 145th St

\begin{tabular}{lcc}
\hline City & State & Zip Code \\
Pawhuska & OK & 74056 \\
\hline
\end{tabular}

FEC ID number of contributing federal political committee.

C

Name of Employer
Information Requested
Receipt For: 2012
X Primary
Other (specify) General

\section{Occupation}

Information Requested

Election Cycle-to-Date

Transaction ID : A59C1AA94DDA94055B2C Date of Receipt

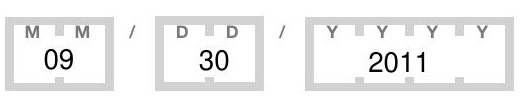

Amount of Each Receipt this Period

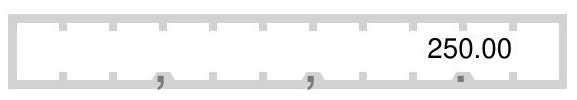

Amount of Each Receipt this Period

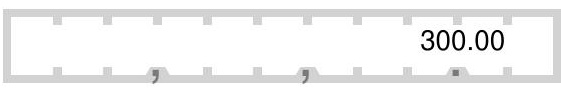

Date of Receipt

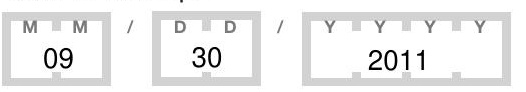

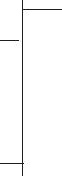

Transaction ID : A3AD0C45101AD4CBAB5B

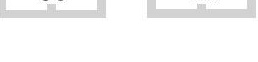

2011

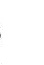
. 
SCHEDULE A-P ITEMIZED RECEIPTS
Use separate schedule(s) for each category of the Detailed Summary Page
FOR LINE NUMBER: (check only one)

Any information copied from such Repor or for commercial purposes, other than using the name and address of any political committee to solicit contributions from such committee.

NAME OF COMMITTEE (In Full)

Friends of Herman Cain

A. Full Name (Last, First, Middle Initial)

Joseph Frankovitch

Mailing Address 2112 North Forest Trail

\begin{tabular}{lcc}
\hline City & State & Zip Code \\
Atlanta & GA & $30338-5835$ \\
\hline
\end{tabular}

FEC ID number of contributing

federal political committee.

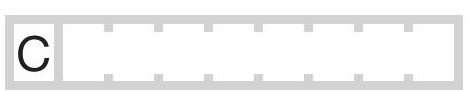

Name of Employer
Kingsley Associates
Receipt For: 2012
X Primary
Other (specify) General

Occupation

Database Administrator

Election Cycle-to-Date

1070.00

B. Full Name (Last, First, Middle Initial)

William Towles Jr

Mailing Address 4577 Rebel Valley View

\begin{tabular}{lcc}
\hline City & State & Zip Code \\
Atlanta & GA & $30339-5349$ \\
\hline
\end{tabular}

FEC ID number of contributing

federal political committee.

C

Name of Employer
self
Receipt For: 2012
X Primary
Other (specify)

\section{Occupation}

Real Estate

Election Cycle-to-Date

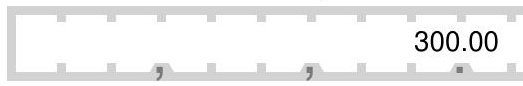

C. Full Name (Last, First, Middle Initial)

Carolyn Fairchild

Mailing Address 1109 Loop Drive

\begin{tabular}{lcc}
\hline City & State & Zip Code \\
Woodland Park & CO & $80863-9210$
\end{tabular}

FEC ID number of contributing federal political committee.

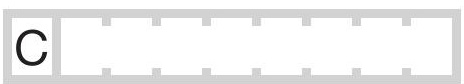

Name of Employer

Information Requested

\section{Occupation}

Information Requested

Receipt For: 2012

Х $\begin{aligned} & \text { Primary } \square \text { General } \\ & \text { Other (specify) }\end{aligned}$

Transaction ID : A07073399BE3A4C52B3C

Date of Receipt

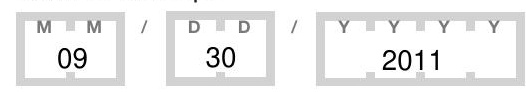

Amount of Each Receipt this Period

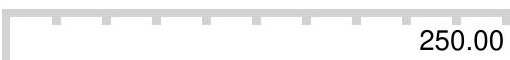

250.00
Amount of Each Receipt this Period

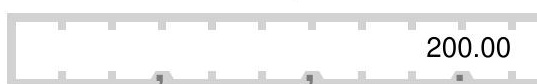

Transaction ID : A4D260F4B8E1449C1A7F Date of Receipt

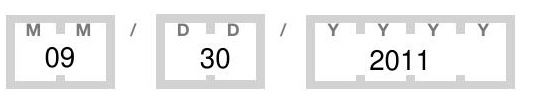

Transaction ID : AA4BE53E15A2F4032A4A Date of Receipt

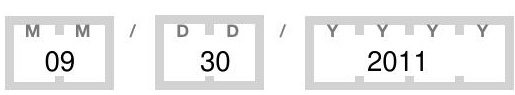

Amount of Each Receipt this Period

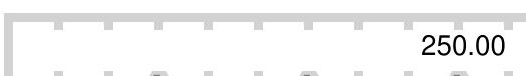

\section{Subtotal Of Receipts This Page (optional)}

Total This Period (last page this line number only) 
SCHEDULE A-P ITEMIZED RECEIPTS
Use separate schedule(s) for each category of the Detailed Summary Page
FOR LINE NUMBER: (check only one)
PAGE $1225 / 1572$

\begin{tabular}{|c|c|c|c|c|c|}
\hline & & & & & \\
\hline 16 & $\begin{array}{lll}X & 17 a \\
\end{array}$ & $17 \mathrm{~b}$ & $17 c$ & $17 d$ & 18 \\
\hline $19 a$ & $19 b$ & $20 a$ & $20 \mathrm{~b}$ & $20 c$ & 21 \\
\hline
\end{tabular}

Any information copied from such Reports and Statements may not be sold or used by any person for the purpose of soliciting contributions or for commercial purposes, other than using the name and address of any political committee to solicit contributions from such committee.

NAME OF COMMITTEE (In Full)

Friends of Herman Cain

A. Full Name (Last, First, Middle Initial)

Edward Smalley

Mailing Address PO Box 16092

\begin{tabular}{lcc}
\hline City & State & Zip Code \\
Two Rivers & AK & $99716-0092$
\end{tabular}

FEC ID number of contributing

federal political committee.

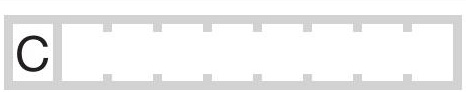

Name of Employer
AT\&T
Receipt For: 2012
X Primary $\quad \square$ General
$\square$ Other (specify)

Occupation technician

Election Cycle-to-Date

708.99

B. Full Name (Last, First, Middle Initial)

howard chapman

Mailing Address 399 crestbend

\begin{tabular}{lcc}
\hline City & State & Zip Code \\
Houston & TX & $77042-2114$
\end{tabular}

FEC ID number of contributing

federal political committee.

C

\begin{tabular}{l} 
Name of Employer \\
Information Requested \\
Receipt For: 2012 \\
X Primary \\
\hline Other (specify)
\end{tabular}

Occupation

Information Requested

Election Cycle-to-Date

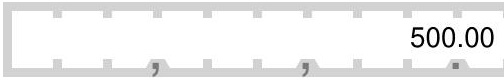

C. Full Name (Last, First, Middle Initial)

Edwin Groover

Mailing Address 1306 Bimini Place

\begin{tabular}{lcc}
\hline City & State & Zip Code \\
Augusta & GA & $30909-2610$ \\
\hline
\end{tabular}

FEC ID number of contributing federal political committee.

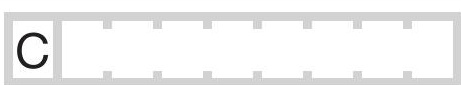

Name of Employer
Not Employed
Receipt For: 2012
X Primary
Other (specify) General

Occupation

Not Employed

Election Cycle-to-Date

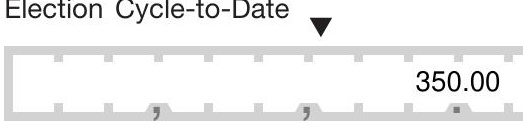

Transaction ID : ABE49440BF0A44BEEA66

Date of Receipt

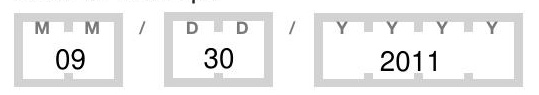

Amount of Each Receipt this Period

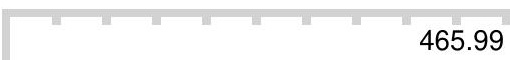

465.99
Transaction ID : A69B62574C9154870951

Date of Receipt

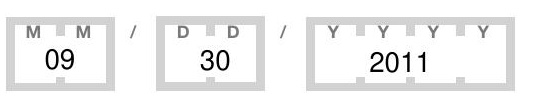

Amount of Each Receipt this Period

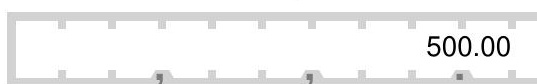

Transaction ID : A40CF828741904E4DB06 Date of Receipt

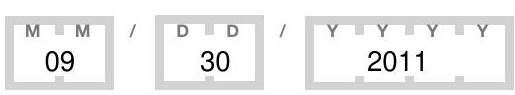

Amount of Each Receipt this Period

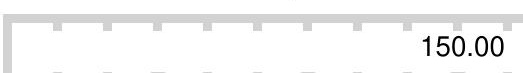

Subtotal Of Receipts This Page (optional).

1115.99

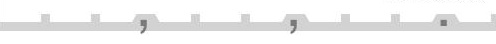

Total This Period (last page this line number only)

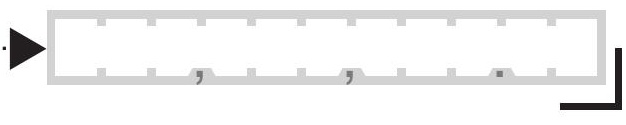

FEC Schedule A-P (Form 3P) (Rev. 03/2011) 


\section{SCHEDULE A-P} ITEMIZED RECEIPTS
Use separate schedule(s)

for each category of the

Detailed Summary Page
FOR LINE NUMBER: (check only one)

Any information copion the purpose of soliciting contributions or for commercial purposes, other than using the name and address of any political committee to solicit contributions from such committee.

NAME OF COMMITTEE (In Full)

Friends of Herman Cain

A. Full Name (Last, First, Middle Initial)

Matthew Wilson

Mailing Address 188 Flintridge Place

\begin{tabular}{lcc}
\hline City & State & Zip Code \\
Mountain Home & AR & $72653-6354$
\end{tabular}

FEC ID number of contributing

federal political committee.

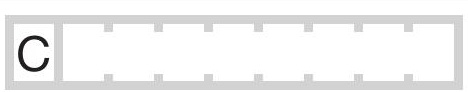

Name of Employer
Information Requested
Receipt For: 2012
X Primary $\quad \square$ General
$\square$ Other (specify)

Occupation

Information Requested

Election Cycle-to-Date

250.00

B. Full Name (Last, First, Middle Initial)

Gerhard Moeller

Mailing Address HC-65 Box 32

\begin{tabular}{lcc}
\hline City & State & Zip Code \\
Alpine & TX & $79830-9715$ \\
\hline
\end{tabular}

FEC ID number of contributing

federal political committee.

C

\begin{tabular}{l} 
Name of Employer \\
Information Requested \\
Receipt For: 2012 \\
X Primary \\
\hline Other (specify)
\end{tabular}

Occupation

Information Requested

Election Cycle-to-Date

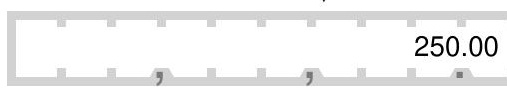

Transaction ID : AD91DD0AAF32B4B18878

Date of Receipt

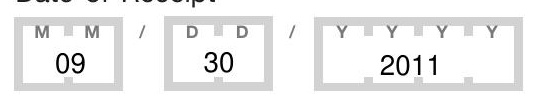

Amount of Each Receipt this Period

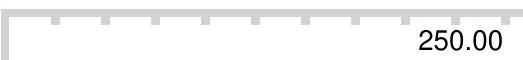

Transaction ID : A5236D25CE8364981B9B

Date of Receipt

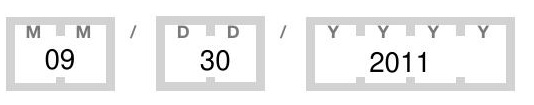

Amount of Each Receipt this Period

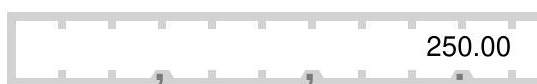

Transaction ID : A4833B9A32011421699C

Date of Receipt

John E Phillips

Mailing Address $940 \mathrm{E}$ Ellis St

\begin{tabular}{lcc}
\hline City & State & Zip Code \\
Jefferson City & TN & $37760-2648$
\end{tabular}

FEC ID number of contributing

federal political committee.

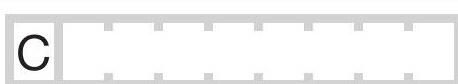

Name of Employer

State of lowa

Receipt For: 2012

Х $\begin{aligned} & \text { Primary } \\ & \text { Other (specify) }\end{aligned}$

\section{Occupation}

Retired

Election Cycle-to-Date

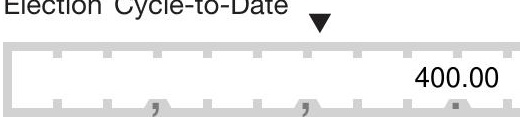

Subtotal Of Receipts This Page (optional)

Amount of Each Receipt this Period

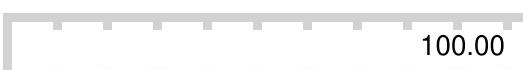

Total This Period (last page this line number only)

600.00

a

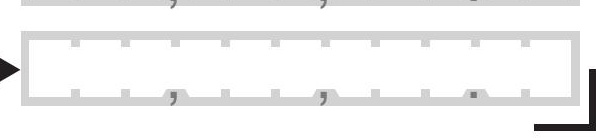

FEC Schedule A-P (Form 3P) (Rev. 03/2011) 
SCHEDULE A-P ITEMIZED RECEIPTS
Use separate schedule(s) for each category of the Detailed Summary Page
FOR LINE NUMBER: (check only one)
PAGE 1227 / 1572

\begin{tabular}{|c|c|c|c|c|c|}
\hline & & & & & \\
\hline 16 & $\begin{array}{lll}X & 17 a \\
\end{array}$ & $17 \mathrm{~b}$ & $17 c$ & $17 d$ & 18 \\
\hline $19 a$ & $19 b$ & $20 a$ & $20 \mathrm{~b}$ & $20 c$ & 21 \\
\hline
\end{tabular}

Any information copied from such Reports and Statements may not be sold or used by any person for the purpose of soliciting contributions or for commercial purposes, other than using the name and address of any political committee to solicit contributions from such committee.

NAME OF COMMITTEE (In Full)

\section{Friends of Herman Cain}

A. Full Name (Last, First, Middle Initial)

Phyllis Fine

Mailing Address 266 Trailwood Lane

\begin{tabular}{lcc}
\hline City & State & Zip Code \\
Northbrook & IL & $60062-1031$
\end{tabular}

FEC ID number of contributing

federal political committee.

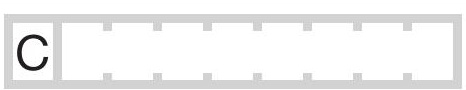

Name of Employer
homemaker
Receipt For: 2012
X Primary $\quad$ General
Other (specify)

Occupation

Homemaker

Election Cycle-to-Date

357.98

B. Full Name (Last, First, Middle Initial)

Mark Fangman

Mailing Address 4080 Beachview ct.

\begin{tabular}{lcc}
\hline City & State & Zip Code \\
Martinsville & IN & $46151-6140$
\end{tabular}

FEC ID number of contributing

federal political committee.

C

Name of Employer
Information Requested
Receipt For: 2012
Xrimary
Other (specify)

Occupation

Information Requested

Election Cycle-to-Date

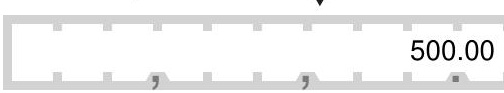

Transaction ID : A9470AF8302CC474F82F

Date of Receipt

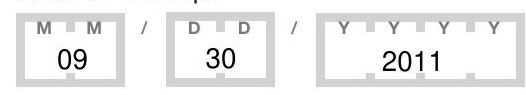

Amount of Each Receipt this Period

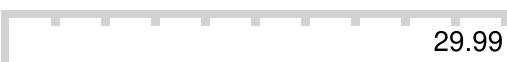

29.99

C. Full Name (Last, First, Middle Initial)

Lisa Poole

Mailing Address 217 Cotton Mill Drive

\begin{tabular}{lcc}
\hline City & State & Zip Code \\
Hiram & GA & $30141-3936$
\end{tabular}

FEC ID number of contributing

federal political committee.

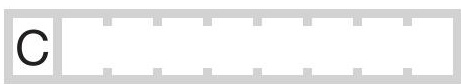

Name of Employer

Simmons Bedding Company

Receipt For: 2012

Х $\begin{aligned} & \text { Primary } \\ & \text { Other (specify) }\end{aligned}$

Occupation

Payroll Manager

Election Cycle-to-Date

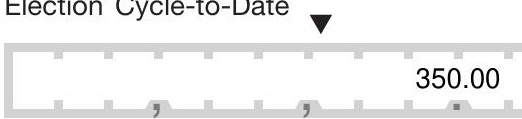

Transaction ID : A37D271E7CB5C4C65B40

Date of Receipt

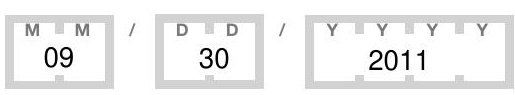

Amount of Each Receipt this Period

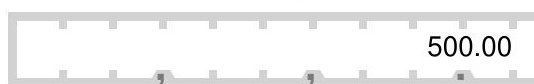

Transaction ID : ABC2B7A82E3AE4431B1B Date of Receipt

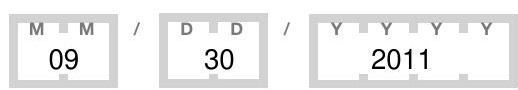

Amount of Each Receipt this Period

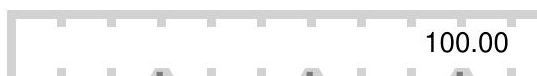

\section{Subtotal Of Receipts This Page (optional)}

629.99

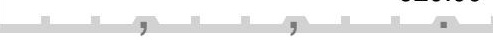

Total This Period (last page this line number only)

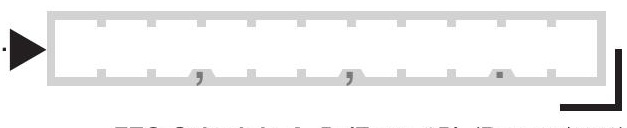

FEC Schedule A-P (Form 3P) (Rev. 03/2011) 
SCHEDULE A-P ITEMIZED RECEIPTS
Use separate schedule(s) for each category of the Detailed Summary Page
FOR LINE NUMBER: (check only one)

PAGE 1228 / 1572

\begin{tabular}{|c|c|c|c|c|c|}
\hline & & & & & \\
\hline 16 & $\begin{array}{lll}X & 17 a \\
\end{array}$ & $17 \mathrm{~b}$ & $17 c$ & $17 d$ & 18 \\
\hline $19 a$ & $19 b$ & $20 a$ & $20 \mathrm{~b}$ & $20 c$ & 21 \\
\hline
\end{tabular}

Any information copied from such Reports and Statements may not be sold or used by any person for the purpose of soliciting contributions or for commercial purposes, other than using the name and address of any political committee to solicit contributions from such committee.

NAME OF COMMITTEE (In Full)

\section{Friends of Herman Cain}

A. Full Name (Last, First, Middle Initial)

Mark Maynard

Mailing Address 5966 Paradise Point Dr

\begin{tabular}{lcc}
\hline City & State & Zip Code \\
Palmetto Bay & FL & $33157-2633$
\end{tabular}

FEC ID number of contributing federal political committee.

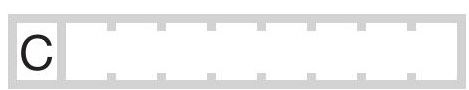

Name of Employer
Information Requested
Receipt For: 2012
X Primary
Other (specify) General

Occupation Information Requested

Election Cycle-to-Date

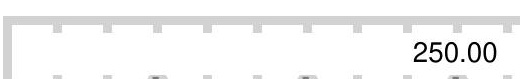

B. Full Name (Last, First, Middle Initial)

Mr. Thomas A Sweat II

Mailing Address 3080 Dowry Dr

\begin{tabular}{lcc}
\hline City & State & Zip Code \\
Lawrenceville & GA & $30044-2672$ \\
\hline
\end{tabular}

FEC ID number of contributing

federal political committee.

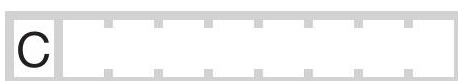

Name of Employer
None
Receipt For: 2012
X Primary
Other (specify)

Occupation

Retired

Election Cycle-to-Date

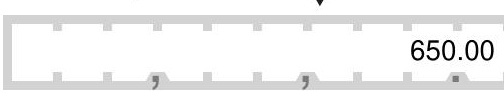

Transaction ID : AF4548A28AC974BFBB01

Date of Receipt

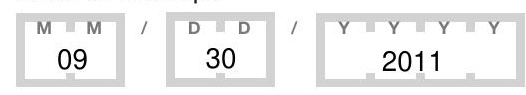

Amount of Each Receipt this Period

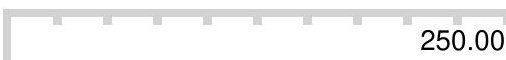

Transaction ID : A7C636AA7DBF64693962

Date of Receipt

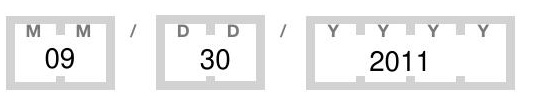

Amount of Each Receipt this Period

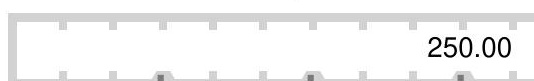

Transaction ID : A21E86287EE76450EBAD Date of Receipt

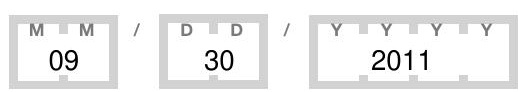

Amount of Each Receipt this Period

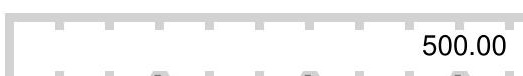

$\begin{array}{cc}\text { State } & \text { Zip Code } \\ \text { KS } & 66053-6110\end{array}$

C

Occupation

Information Requested

Election Cycle-to-Date

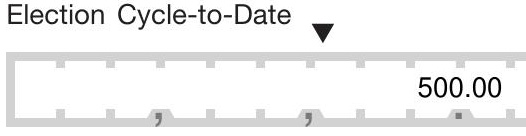

Subtotal Of Receipts This Page (optional)

1000.00

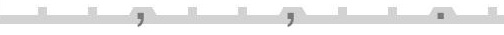

Total This Period (last page this line number only)

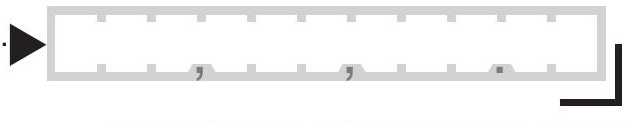

FEC Schedule A-P (Form 3P) (Rev. 03/2011) 
SCHEDULE A-P ITEMIZED RECEIPTS
Use separate schedule(s) for each category of the Detailed Summary Page
FOR LINE NUMBER: (check only one)

PAGE 1229 / 1572

\begin{tabular}{|c|c|c|c|c|c|}
\hline & & & & & \\
\hline 16 & $\mathbf{X} 17 a$ & $17 b$ & $17 c$ & $17 d$ & 18 \\
\hline $19 a$ & $19 b$ & $20 \mathrm{a}$ & $20 \mathrm{~b}$ & $20 \mathrm{c}$ & 21 \\
\hline
\end{tabular}

Any information copied from such Reports and Statements may not be sold or used by any person for the purpose of soliciting contributions or for commercial purposes, other than using the name and address of any political committee to solicit contributions from such committee.

NAME OF COMMITTEE (In Full)

\section{Friends of Herman Cain}

A. Full Name (Last, First, Middle Initial)

Herbert Brown

Mailing Address 11504 Baldy Ewell Way

\begin{tabular}{lcc}
\hline City & State & Zip Code \\
Spotsylvania & VA & $22551-4681$ \\
\hline
\end{tabular}

FEC ID number of contributing federal political committee.

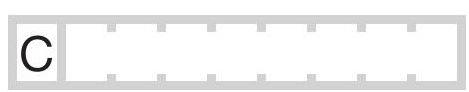

Name of Employer
Information Requested
Receipt For: 2012
X Primary
Other (specify) General

Occupation Information Requested

Election Cycle-to-Date

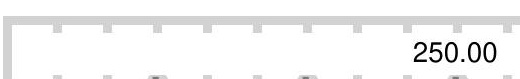

B. Full Name (Last, First, Middle Initial)

Ernest Swible Jr. Jr.

Mailing Address PO Box 561108

\begin{tabular}{lcc}
\hline City & State & Zip Code \\
Orlando & FL & $32856-1108$
\end{tabular}

FEC ID number of contributing

federal political committee.

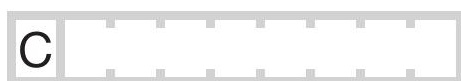

Name of Employer
Charles Rutenberg Realty
Receipt For: 2012
X Primary
Other (specify)

\section{Occupation}

Realtor

Election Cycle-to-Date

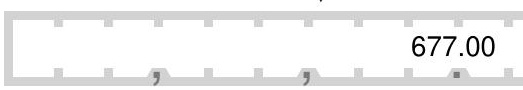

Transaction ID : A11ACD365DA064BC384E

Date of Receipt

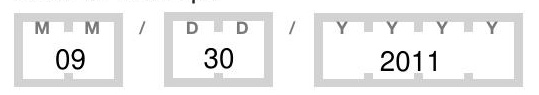

Amount of Each Receipt this Period

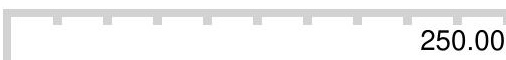

C. Full Name (Last, First, Middle Initial)

Carl Hixon 111

Mailing Address 3230 Braxton cir

\begin{tabular}{lcc}
\hline City & State & Zip Code \\
Pensacola & FL & $32504-4856$
\end{tabular}

FEC ID number of contributing federal political committee.

C

Name of Employer
Georgio's Pizza
Receipt For: 2012
Х Primary $\square$ General
Other (specify)

Occupation

President

Election Cycle-to-Date

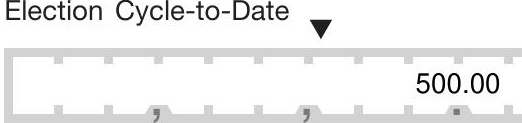

Amount of Each Receipt this Period

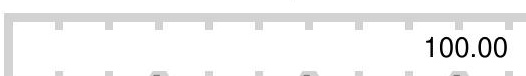

Transaction ID : A7922FB437A624A17869

Date of Receipt

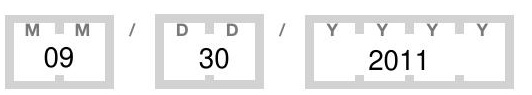

Transaction ID : A5D82625CF01E4F7DB6E Date of Receipt

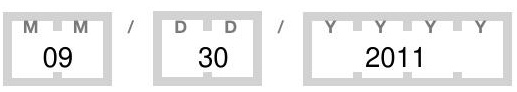

Amount of Each Receipt this Period

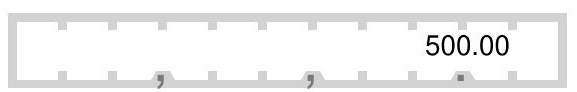

\section{Subtotal Of Receipts This Page (optional)}

Total This Period (last page this line number only) 
SCHEDULE A-P ITEMIZED RECEIPTS
Use separate schedule(s) for each category of the Detailed Summary Page
FOR LINE NUMBER: (check only one)

PAGE $1230 / 1572$

\begin{tabular}{|c|c|c|c|c|c|}
\hline & & & & & \\
\hline 16 & $\begin{array}{lll}X & 17 a \\
\end{array}$ & $17 \mathrm{~b}$ & $17 c$ & $17 d$ & 18 \\
\hline $19 a$ & $19 b$ & $20 a$ & $20 \mathrm{~b}$ & $20 c$ & 21 \\
\hline
\end{tabular}

Any information copied from such Reports and Statements may not be sold or used by any person for the purpose of soliciting contributions or for commercial purposes, other than using the name and address of any political committee to solicit contributions from such committee.

NAME OF COMMITTEE (In Full)

\section{Friends of Herman Cain}

A. Full Name (Last, First, Middle Initial) w williams

Mailing Address $1100 \mathrm{n}$ lindgergh bl

\begin{tabular}{lcc}
\hline City & State & Zip Code \\
Saint Louis & MO & $63132-2914$
\end{tabular}

FEC ID number of contributing federal political committee.

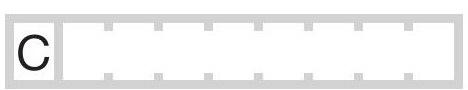

Name of Employer
Information Requested
Receipt For: 2012
X Primary
Other (specify) General

Occupation Information Requested Election Cycle-to-Date

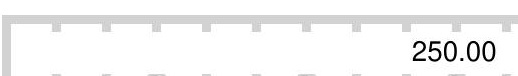

B. Full Name (Last, First, Middle Initial) Jacqueline Lopez

Mailing Address 1596 West 78 Terrace

\begin{tabular}{lcc}
\hline City & State & Zip Code \\
Hialeah & FL & $33014-3350$
\end{tabular}

FEC ID number of contributing

federal political committee.

C

Name of Employer
US Postal Service
Receipt For: 2012
X Primary
Other (specify)

\section{Occupation} Letter Carrier

Election Cycle-to-Date

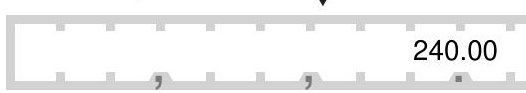

Transaction ID : AB7DE1C0E6F56470A975

Date of Receipt

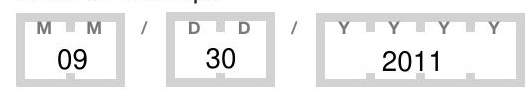

Amount of Each Receipt this Period

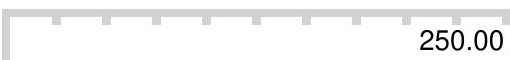

C. Full Name (Last, First, Middle Initial) Joseph Tomanelli

Mailing Address 3540 Chapel Hill Blvd

\begin{tabular}{lcc}
\hline City & State & Zip Code \\
Clermont & FL & $34711-5731$ \\
\hline
\end{tabular}

FEC ID number of contributing federal political committee.

C

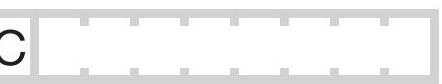

Name of Employer Information Requested

\section{Occupation}

Information Requested

Receipt For: 2012

Х $\begin{aligned} & \text { Primary } \\ & \text { Other (specify) }\end{aligned}$

Amount of Each Receipt this Period

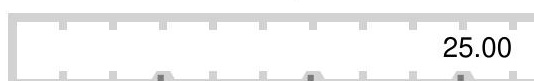

Transaction ID : A19D17A7F555C4417A42

Date of Receipt

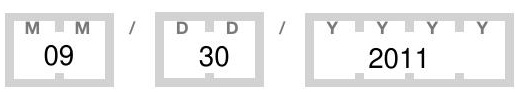

Transaction ID : A19E274482A4F419DBC8 Date of Receipt

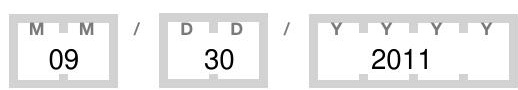

Amount of Each Receipt this Period

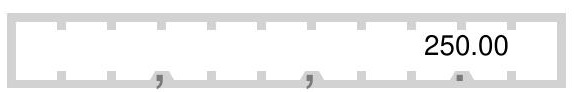

250.00
Subtotal Of Receipts This Page (optional).

525.00

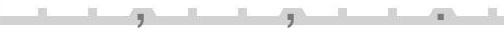

Total This Period (last page this line number only)

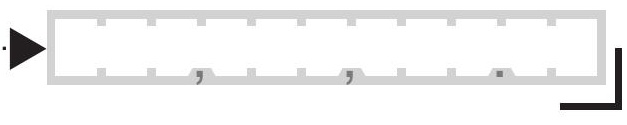

FEC Schedule A-P (Form 3P) (Rev. 03/2011) 


\section{SCHEDULE A-P} ITEMIZED RECEIPTS
Use separate schedule(s) for each category of the Detailed Summary Page
FOR LINE NUMBER: (check only one)
PAGE $1231 / 1572$

\begin{tabular}{|c|c|c|c|c|c|}
\hline & & & & & \\
\hline 16 & $\begin{array}{ll}\mathbf{X} & 17 a \\
\end{array}$ & $17 \mathrm{~b}$ & $17 c$ & $17 d$ & 18 \\
\hline $19 a$ & $19 b$ & $20 \mathrm{a}$ & $20 \mathrm{~b}$ & $20 c$ & 21 \\
\hline
\end{tabular}

Any information copied from such Reports and Statements may not be sold or used by any person for the purpose of soliciting contributions or for commercial purposes, other than using the name and address of any political committee to solicit contributions from such committee.

NAME OF COMMITTEE (In Full)

Friends of Herman Cain

A. Full Name (Last, First, Middle Initial)

Nancy Pihera

Mailing Address 2452 Kings Ct

\begin{tabular}{lcc}
\hline City & State & Zip Code \\
Atlanta & GA & $30345-2120$
\end{tabular}

FEC ID number of contributing federal political committee.

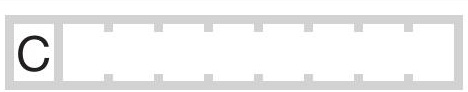

Name of Employer
self
Receipt For: 2012
X Primary $\quad$ General
Other (specify)

Occupation Designer

Election Cycle-to-Date

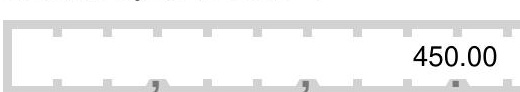

B. Full Name (Last, First, Middle Initial)

Bill Perkins

Mailing Address 15696 C.R. 614

\begin{tabular}{lll}
\hline City & State & Zip Code \\
Dexter & MO & $63841-8965$
\end{tabular}

FEC ID number of contributing

federal political committee.

C

Name of Employer
Self Employed
Receipt For: 2012
Primary
Other (specify)

C. Full Name (Last, First, Middle Initial)

Charlynn Muehle

Mailing Address 282 Etherton Ln.

\section{City}

Springfield

FEC ID number of contributing federal political committee.

Name of Employer

Information Requested

Receipt For: 2012

Х $\begin{aligned} & \text { Primary } \square \text { General } \\ & \text { Other (specify) }\end{aligned}$

\section{Occupation}

Nutritionist

Election Cycle-to-Date

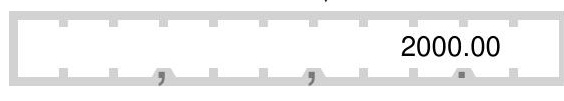

Transaction ID : ADE533EAC4CDE448FB20

Date of Receipt

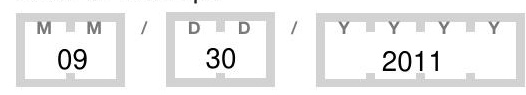

Amount of Each Receipt this Period

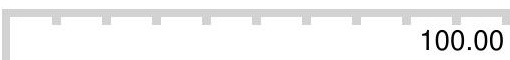

Amount of Each Receipt this Period

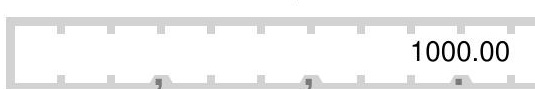

Transaction ID : A69A72CAE677D40FD8E8 Date of Receipt

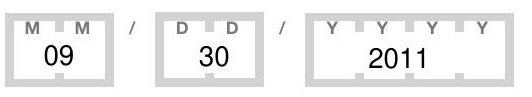

Transaction ID : A4036E9E3A82D45DBA3F Date of Receipt

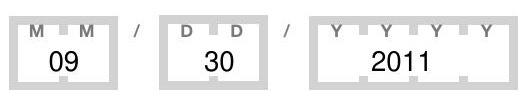

Amount of Each Receipt this Period

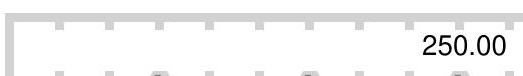

\section{Subtotal Of Receipts This Page (optional)}

Total This Period (last page this line number only) 


\section{SCHEDULE A-P} ITEMIZED RECEIPTS
Use separate schedule(s)

for each category of the

Detailed Summary Page
FOR LINE NUMBER: (check only one)

Any information or for commercial purposes, other than using the name and address of any political committee to solicit contributions from such committee.

NAME OF COMMITTEE (In Full)

\section{Friends of Herman Cain}

A. Full Name (Last, First, Middle Initial)

Kem Jones

Mailing Address 550 Highbrook Dr

\begin{tabular}{lcc}
\hline City & State & Zip Code \\
Atlanta & GA & $30342-2319$
\end{tabular}

FEC ID number of contributing federal political committee.

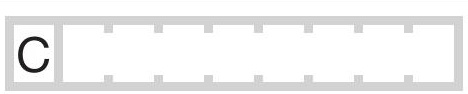

Name of Employer
SAP
Receipt For: 2012
X Primary $\quad$ General
Other (specify)

Occupation

Director of Engineerings

Election Cycle-to-Date

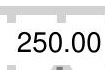

B. Full Name (Last, First, Middle Initial)

David Rohleder

Mailing Address 11503 Lakeside Place Dr.

\begin{tabular}{lcc}
\hline City & State & Zip Code \\
Houston & TX & $77077-3238$
\end{tabular}

FEC ID number of contributing

federal political committee.

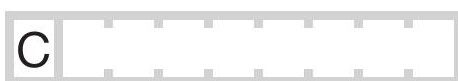

Name of Employer
Information Requested
Receipt For: 2012
X Primary
Other (specify)

\section{Occupation}

Information Requested

Election Cycle-to-Date

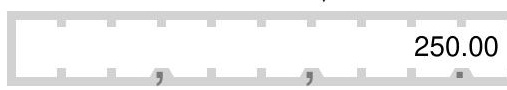

Transaction ID : A23B0626D52A2435A90A

Date of Receipt

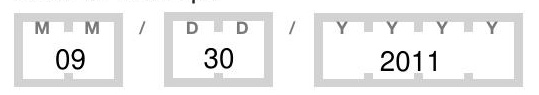

Amount of Each Receipt this Period

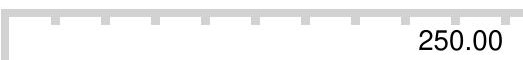

Amount of Each Receipt this Period

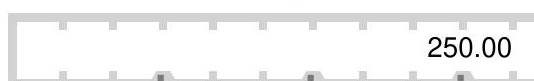

C. Full Name (Last, First, Middle Initial)

M. Scott Sayer

Mailing Address 1730 Meadowwoods Trail

\begin{tabular}{lcc}
\hline City & State & Zip Code \\
Long Lake & MN & $55356-9311$
\end{tabular}

FEC ID number of contributing

federal political committee.

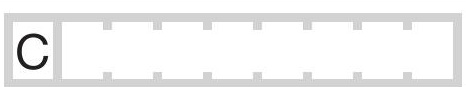

Name of Employer

Information Requested

Occupation

Information Requested

Receipt For: 2012

Х $\begin{aligned} & \text { Primary } \\ & \text { Other (specify) }\end{aligned}$

Election Cycle-to-Date

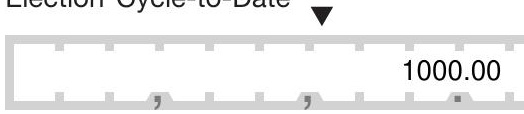

Transaction ID : A3E195A9CB9AC48EFB98

Date of Receipt

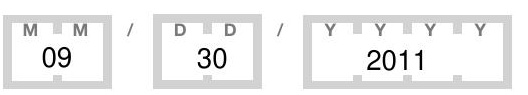

Transaction ID : ABB576F0B3E3B499FADB

Date of Receipt

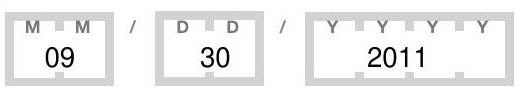

Amount of Each Receipt this Period

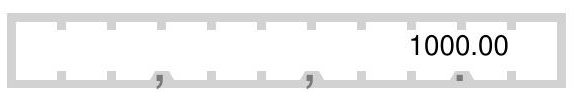

Subtotal Of Receipts This Page (optional).

1500.00

Total This Period (last page this line number only) 
SCHEDULE A-P ITEMIZED RECEIPTS
Use separate schedule(s) for each category of the Detailed Summary Page
FOR LINE NUMBER: (check only one)
PAGE 1233 / 1572

\begin{tabular}{|c|c|c|c|c|c|}
\hline & & & & & \\
\hline 16 & $\begin{array}{lll}X & 17 a \\
\end{array}$ & $17 \mathrm{~b}$ & $17 c$ & $17 d$ & 18 \\
\hline $19 a$ & $19 b$ & $20 a$ & $20 \mathrm{~b}$ & $20 c$ & 21 \\
\hline
\end{tabular}

Any information copied from such Reports and Statements may not be sold or used by any person for the purpose of soliciting contributions or for commercial purposes, other than using the name and address of any political committee to solicit contributions from such committee.

NAME OF COMMITTEE (In Full)

\section{Friends of Herman Cain}

A. Full Name (Last, First, Middle Initial)

William Wieger

Mailing Address 112 Gayven Drive

\begin{tabular}{lcc}
\hline City & State & Zip Code \\
Ball & LA & $71405-4903$
\end{tabular}

FEC ID number of contributing federal political committee.

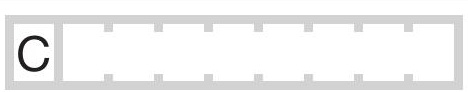

Name of Employer
Information Requested
Receipt For: 2012
X Primary
Other (specify) General

Occupation Information Requested

Election Cycle-to-Date

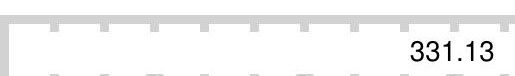

B. Full Name (Last, First, Middle Initial)

David Hemphill

Mailing Address 3020 S. Freeman Rd.

\begin{tabular}{lcc}
\hline City & State & Zip Code \\
Williamsburg & VA & $23185-7661$
\end{tabular}

FEC ID number of contributing

federal political committee.

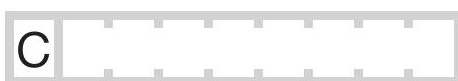

Name of Employer
None
Receipt For: 2012
X Primary
Other (specify)

\section{Occupation}

Retired

Election Cycle-to-Date

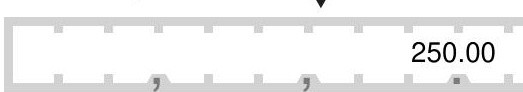

Transaction ID : AEE6C60C7CCDB4EBF960

Date of Receipt

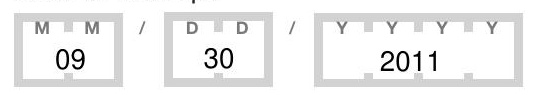

Amount of Each Receipt this Period

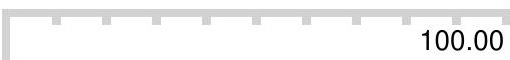

Transaction ID : A80F0C520C327446D9A2

Date of Receipt

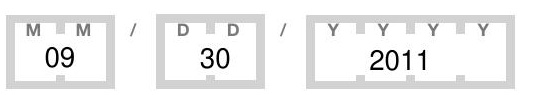

Amount of Each Receipt this Period

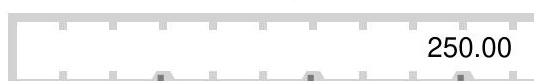

Transaction ID : A9075100F821D4066B0B

Date of Receipt

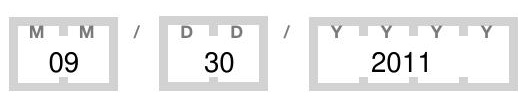

Amount of Each Receipt this Period

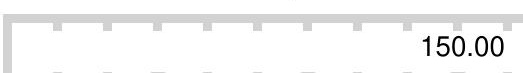

Name of Employer
Information Requested
Receipt For: 2012
X Primary $\quad \square$ General
Other (specify)

$\begin{array}{cc}\text { State } & \text { Zip Code } \\ \text { LA } & 70433-1062\end{array}$

C

Occupation

Information Requested

Election Cycle-to-Date

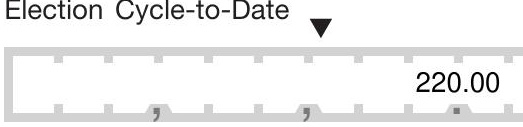

Subtotal Of Receipts This Page (optional).

500.00

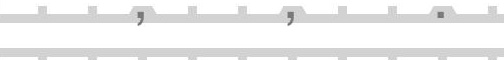

Total This Period (last page this line number only) 


\section{SCHEDULE A-P} ITEMIZED RECEIPTS
Use separate schedule(s)

for each category of the

Detailed Summary Page
FOR LINE NUMBER: (check only one)

Any information or for commercial purposes, other than using the name and address of any political committee to solicit contributions from such committee.

NAME OF COMMITTEE (In Full)

Friends of Herman Cain

A. Full Name (Last, First, Middle Initial)

Gerald Gordon

Mailing Address 4809 N. Shirley Dr.

\begin{tabular}{lcc}
\hline City & State & Zip Code \\
Tampa & FL & $33603-1723$ \\
\hline
\end{tabular}

FEC ID number of contributing

federal political committee.

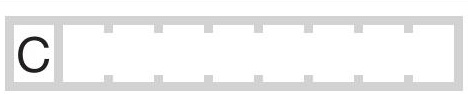

Name of Employer
None
Receipt For: 2012
X Primary $\square$ General
$\square$ Other (specify)

Occupation

Retired

Election Cycle-to-Date

500.00

B. Full Name (Last, First, Middle Initial)

JAMES FAIX

Mailing Address 2026 SAND HILL ROAD

\begin{tabular}{lcc}
\hline City & State & Zip Code \\
Menlo Park & CA & $94025-6322$ \\
\hline
\end{tabular}

FEC ID number of contributing

federal political committee.

C

Name of Employer
Information Requested
Receipt For: 2012
X Primary
Other (specify)

Occupation

Information Requested

Election Cycle-to-Date

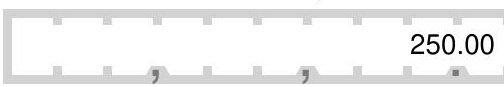

Transaction ID : A624231DC9CA4462F84E

Date of Receipt

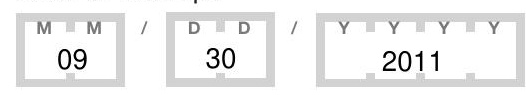

Amount of Each Receipt this Period

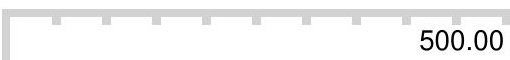

C. Full Name (Last, First, Middle Initial)

sara skersick

Mailing Address 820 snapdragon circle

\begin{tabular}{lcc}
\hline City & State & Zip Code \\
Palm Springs & CA & $92264-9660$
\end{tabular}

FEC ID number of contributing

federal political committee.

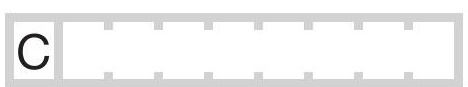

Name of Employer

Information Requested

Occupation

Information Requested

Receipt For: 2012

Х $\begin{aligned} & \text { Primary } \square \text { General } \\ & \text { Other (specify) }\end{aligned}$

Amount of Each Receipt this Period

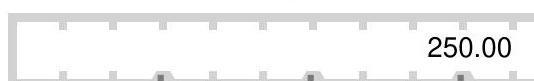

Transaction ID : AA4F7BFB10978424D856

Date of Receipt

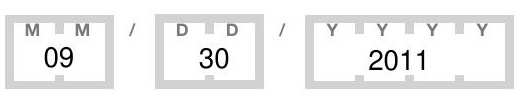

Transaction ID : AD9670B7F4FA44DEE8E9 Date of Receipt

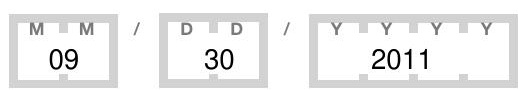

Amount of Each Receipt this Period

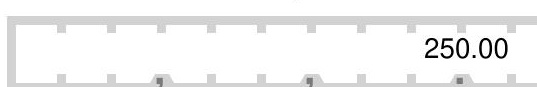

\section{Subtotal Of Receipts This Page (optional)}

1000.00

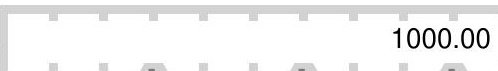

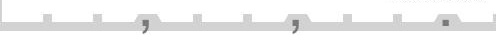

Total This Period (last page this line number only)

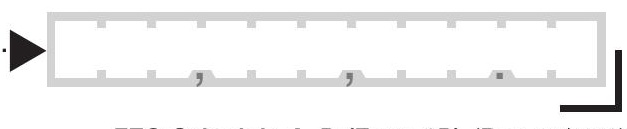

FEC Schedule A-P (Form 3P) (Rev. 03/2011) 


\section{SCHEDULE A-P} ITEMIZED RECEIPTS
Use separate schedule(s) for each category of the Detailed Summary Page

FOR LINE NUMBER:
(check only one)

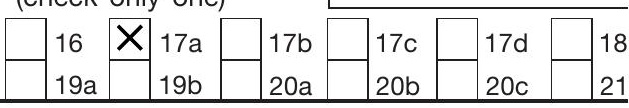

Any information copied from such Reports and Statements may not be sold or used by any person for the purpose of soliciting contributions or for commercial purposes, other than using the name and address of any political committee to solicit contributions from such committee.

NAME OF COMMITTEE (In Full)

\section{Friends of Herman Cain}

A. Full Name (Last, First, Middle Initial) Susan Balfour

Mailing Address 471 Glen Street

\begin{tabular}{lcc}
\hline City & State & Zip Code \\
Glens Falls & NY & $12801-2906$
\end{tabular}

FEC ID number of contributing federal political committee.

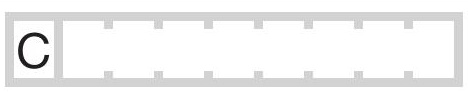

Name of Employer
Information Requested
Receipt For: 2012
X Primary
Other (specify) General

Occupation Information Requested Election Cycle-to-Date 250.00

B. Full Name (Last, First, Middle Initial) Carolyn Ann Haynes

Mailing Address 570 El Camino Real Blvd 2302

\begin{tabular}{lcc}
\hline City & State & Zip Code \\
Naples & FL & $34119-4790$ \\
\hline
\end{tabular}

FEC ID number of contributing

federal political committee.

C

Name of Employer
None
Receipt For: 2012
X Primary
Other (specify)

Occupation Retired Election Cycle-to-Date $\quad 500.00$
Transaction ID : A8D13269483D84CF6A94

Date of Receipt

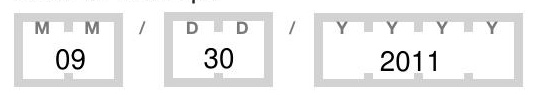

Amount of Each Receipt this Period

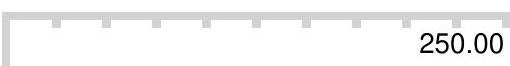

Amount of Each Receipt this Period

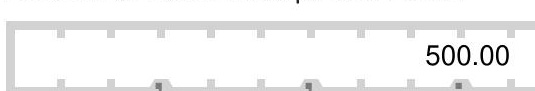

Transaction ID : ADDB4D5A58E6A4AEEBEB Date of Receipt

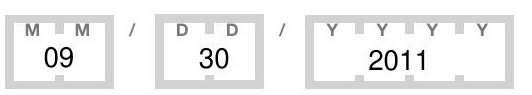

C. Full Name (Last, First, Middle Initial)

Kenneth Meloon

Mailing Address 3018 Lee Shore Loop

\begin{tabular}{lcc}
\hline City & State & Zip Code \\
Orlando & FL & $32820-1948$
\end{tabular}

FEC ID number of contributing federal political committee.

C

Name of Employer
Correct Craft
Receipt For: 2012
X Primary
Other (specify) General

\section{Occupation}

Board Director

Election Cycle-to-Date

Transaction ID : AODDBD421C2914C46891 Date of Receipt

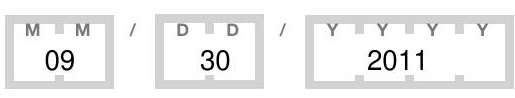

Amount of Each Receipt this Period

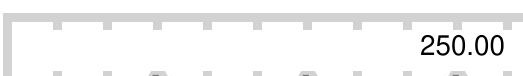

250.00

Subtotal Of Receipts This Page (optional)

1000.00

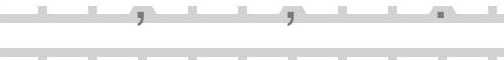

Total This Period (last page this line number only) 


\section{SCHEDULE A-P} ITEMIZED RECEIPTS
Use separate schedule(s) for each category of the Detailed Summary Page
FOR LINE NUMBER: (check only one)
PAGE $1236 / 1572$

\begin{tabular}{|c|c|c|c|c|c|}
\hline & & & & & \\
\hline 16 & $\begin{array}{ll}\mathbf{X} & 17 a \\
\end{array}$ & $17 \mathrm{~b}$ & $17 c$ & $17 d$ & 18 \\
\hline $19 a$ & $19 b$ & $20 \mathrm{a}$ & $20 \mathrm{~b}$ & $20 c$ & 21 \\
\hline
\end{tabular}

Any information copied from such Reports and Statements may not be sold or used by any person for the purpose of soliciting contributions or for commercial purposes, other than using the name and address of any political committee to solicit contributions from such committee.

NAME OF COMMITTEE (In Full)

Friends of Herman Cain

A. Full Name (Last, First, Middle Initial)

Marc Shapiro

Mailing Address 609 Atlantic St

\begin{tabular}{lcc}
\hline City & State & Zip Code \\
Melbourne Beach & FL & $32951-2013$
\end{tabular}

FEC ID number of contributing

federal political committee.

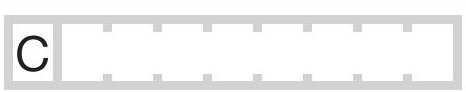

Name of Employer
Information Requested
Receipt For: 2012
X Primary $\quad \square$ General
Other (specify)

Occupation

Information Requested

Election Cycle-to-Date

5005.00

B. Full Name (Last, First, Middle Initial)

James Meadows

Mailing Address 1081 summerwind drive

\begin{tabular}{lcc}
\hline City & State & Zip Code \\
Greensboro & GA & $30642-7022$ \\
\hline
\end{tabular}

FEC ID number of contributing

federal political committee.

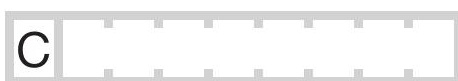

Name of Employer
Information Requested
Receipt For: 2012
X Primary
Other (specify)

Occupation

Information Requested

Election Cycle-to-Date

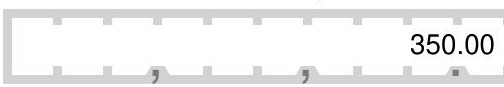

Transaction ID : A93C56284F9B342B3B2F

Date of Receipt

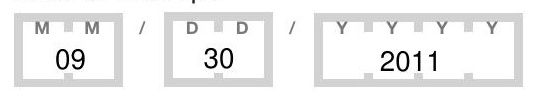

Amount of Each Receipt this Period

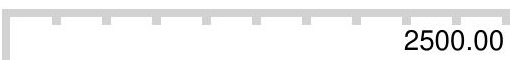

C. Full Name (Last, First, Middle Initial)

Thomas McMullan

Mailing Address 13278 Country Ridge Road

\begin{tabular}{lcc}
\hline City & State & Zip Code \\
Germantown & MD & 20874-1145
\end{tabular}

FEC ID number of contributing

federal political committee.

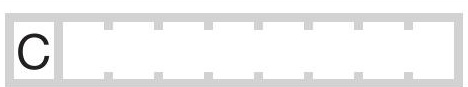

Name of Employer

Think Tank Inc.

\section{Occupation}

PC Technician

Transaction ID : A2D08B69F075C4EAD852

Date of Receipt

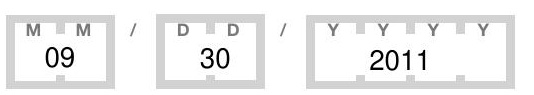

Amount of Each Receipt this Period

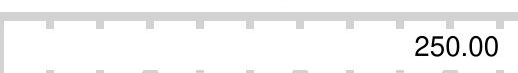

Transaction ID : A9181451BC8DB4352B52

Date of Receipt

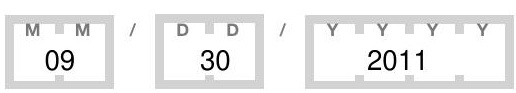

Amount of Each Receipt this Period

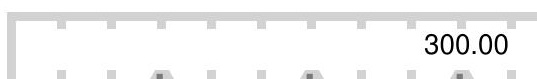

Receipt For: 2012
X Primary
Other (specify)

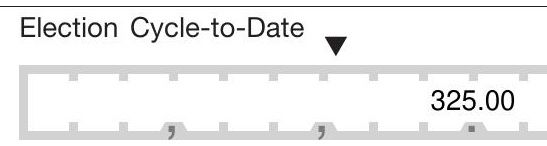

Subtotal Of Receipts This Page (optional)

3050.00

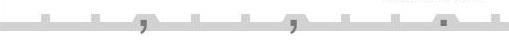

Total This Period (last page this line number only)

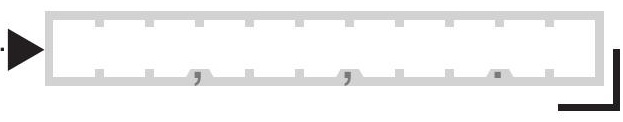

FEC Schedule A-P (Form 3P) (Rev. 03/2011) 


\section{SCHEDULE A-P} ITEMIZED RECEIPTS
Use separate schedule(s)

for each category of the

Detailed Summary Page
FOR LINE NUMBER: (check only one)

Any information or for commercial purposes, other than using the name and address of any political committee to solicit contributions from such committee.

NAME OF COMMITTEE (In Full)

Friends of Herman Cain

A. Full Name (Last, First, Middle Initial)

Karen Haught

Mailing Address PO Box 903

\begin{tabular}{lcc}
\hline City & State & Zip Code \\
Cypress & TX & $77410-0903$ \\
\hline
\end{tabular}

FEC ID number of contributing

federal political committee.

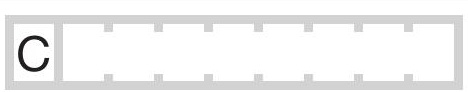

Name of Employer
Information Requested
Receipt For: 2012
X Primary $\quad \square$ General
Other (specify)

Occupation

Information Requested

Election Cycle-to-Date

2500.00

B. Full Name (Last, First, Middle Initial)

Lauren Finley

Mailing Address 757 Ginger Springs Road

\begin{tabular}{lcc}
\hline City & State & Zip Code \\
Soperton & GA & $30457-7403$ \\
\hline
\end{tabular}

FEC ID number of contributing

federal political committee.

C

Name of Employer
Information Requested
Receipt For: 2012
X Primary
Other (specify)

Occupation

Information Requested

Election Cycle-to-Date

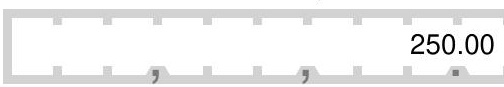

Transaction ID : A033D7FF79FE040F8A7D

Date of Receipt

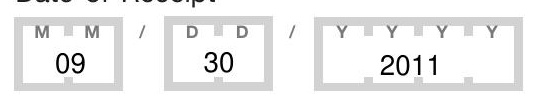

Amount of Each Receipt this Period

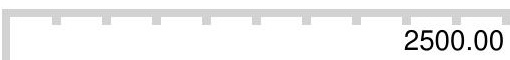

Amount of Each Receipt this Period

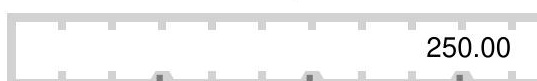

C. Full Name (Last, First, Middle Initial)

Tommy Hancock

Mailing Address 601 W. 4th Street

\begin{tabular}{lcc}
\hline City & State & Zip Code \\
Roseville & CA & 95747 \\
\hline
\end{tabular}

FEC ID number of contributing

federal political committee.

C

Name of Employer
Information Requested
Receipt For: 2012
X Primary
Other (specify) General

Occupation

Information Requested

Election Cycle-to-Date

Transaction ID : AF12D5C2746AC4CEFBFE Date of Receipt

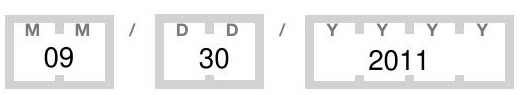

Transaction ID : A182C7872C69F4799A5B Date of Receipt

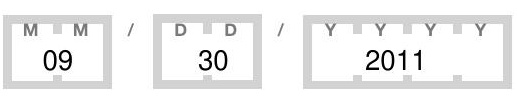

Amount of Each Receipt this Period

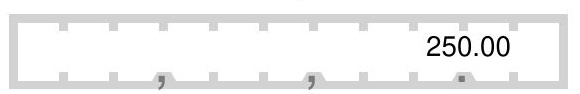

250.00

Subtotal Of Receipts This Page (optional).

3000.00

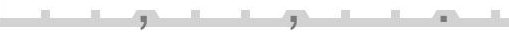

Total This Period (last page this line number only)

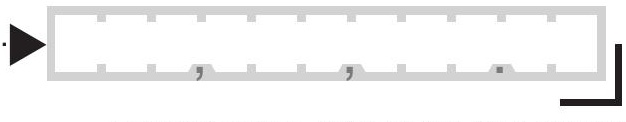

FEC Schedule A-P (Form 3P) (Rev. 03/2011) 
SCHEDULE A-P ITEMIZED RECEIPTS
Use separate schedule(s) for each category of the Detailed Summary Page
FOR LINE NUMBER: (check only one)

Any information or for commercial purposes, other than using the name and address of any political committee to solicit contributions from such committee.

NAME OF COMMITTEE (In Full)

Friends of Herman Cain

A. Full Name (Last, First, Middle Initial)

Loren Lanter

Mailing Address 58 Zanmi Rd

\begin{tabular}{lcc}
\hline City & State & Zip Code \\
Swannanoa & NC & $28778-2263$
\end{tabular}

FEC ID number of contributing federal political committee.

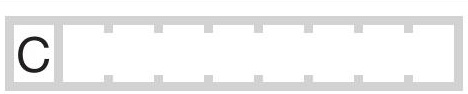

Name of Employer
Brisco Inc.
Receipt For: 2012
X Primary
Other (specify) General

Occupation

Engineer

Election Cycle-to-Date

500.00

B. Full Name (Last, First, Middle Initial)

CHARLES SWART

Mailing Address 28 WALNUT AVE

\begin{tabular}{lcc}
\hline City & State & Zip Code \\
Wheeling & WV & $26003-5727$ \\
\hline
\end{tabular}

FEC ID number of contributing

federal political committee.

C

Name of Employer
Information Requested
Receipt For: 2012
Primary
Other (specify)

Occupation

Information Requested

Election Cycle-to-Date

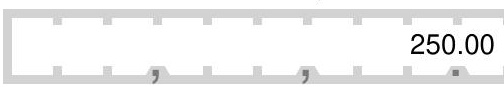

Transaction ID : AD0D75EDA96754C71BB3

Date of Receipt

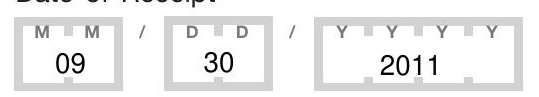

Amount of Each Receipt this Period

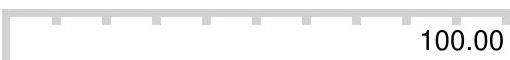

C. Full Name (Last, First, Middle Initial)

Mark Galvin

Mailing Address P.O. Box 22001

\begin{tabular}{lcc}
\hline City & State & Zip Code \\
Rye & $\mathrm{NH}$ & 03870
\end{tabular}

FEC ID number of contributing federal political committee.

C

Name of Employer
Information Requested
Receipt For: 2012
X Primary
Other (specify) General

\section{Occupation}

Information Requested

Election Cycle-to-Date
Transaction ID : AFACE24F4FAC9424791A

Date of Receipt

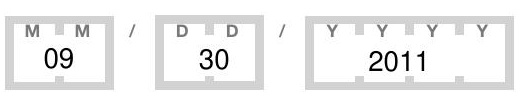

Amount of Each Receipt this Period

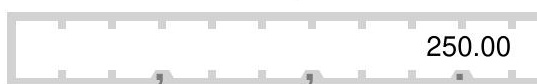

Transaction ID : A274A7017151B45BFB69

Date of Receipt

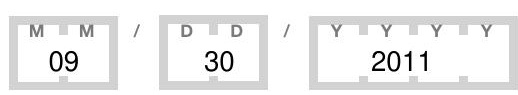

Amount of Each Receipt this Period

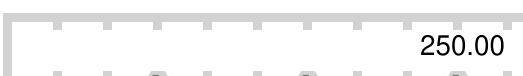

Subtotal Of Receipts This Page (optional).

600.00

a 1 ,

Total This Period (last page this line number only)

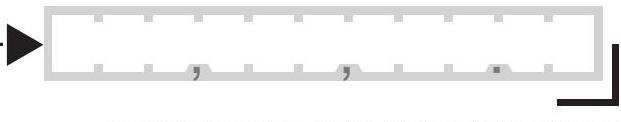

FEC Schedule A-P (Form 3P) (Rev. 03/2011) 


\section{SCHEDULE A-P} ITEMIZED RECEIPTS
Use separate schedule(s) for each category of the Detailed Summary Page

FOR LINE NUMBER:
(check only one)

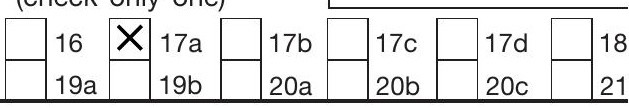

Any information copied from such Reports and Statements may not be sold or used by any person for the purpose of soliciting contributions or for commercial purposes, other than using the name and address of any political committee to solicit contributions from such committee.

NAME OF COMMITTEE (In Full)

\section{Friends of Herman Cain}

A. Full Name (Last, First, Middle Initial)

\section{David Schuitema}

Mailing Address 225 Macadamia court

\begin{tabular}{lcc}
\hline City & State & Zip Code \\
Covington & GA & $30016-5574$ \\
\hline
\end{tabular}

FEC ID number of contributing federal political committee.

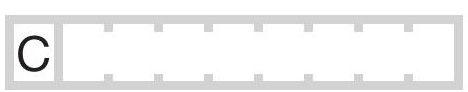

Name of Employer
Delta Airlines
Receipt For: 2012
X Primary
$\square$ Other (specify) General

Occupation

Aircraft maintenance technician

Election Cycle-to-Date

\subsection{0}

B. Full Name (Last, First, Middle Initial)

Hardy Hurdle

Mailing Address PO Box 9

\begin{tabular}{lcc}
\hline City & State & Zip Code \\
Loganville & GA & $30052-0009$ \\
\hline
\end{tabular}

FEC ID number of contributing

federal political committee.

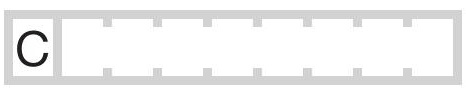

\begin{tabular}{l} 
Name of Employer \\
Information Requested \\
Receipt For: 2012 \\
X Primary \\
\hline Other (specify)
\end{tabular}

Occupation

Information Requested

Election Cycle-to-Date

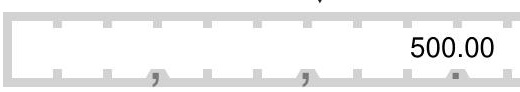

C. Full Name (Last, First, Middle Initial)

John Wilson

Mailing Address 48-46 41st St. Apt. 3R

\begin{tabular}{lcc}
\hline City & State & Zip Code \\
Sunnyside & NY & $11104-3114$
\end{tabular}

FEC ID number of contributing federal political committee.

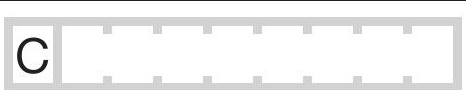

Name of Employer

Information Requested

\section{Occupation}

Information Requested

Receipt For: 2012

Х $\begin{aligned} & \text { Primary } \\ & \text { Other (specify) }\end{aligned}$

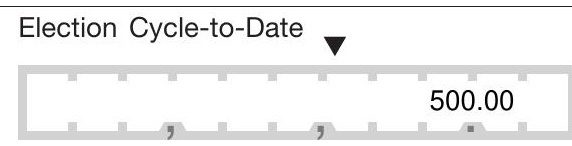

Amount of Each Receipt this Period

Transaction ID : AC112BF7BF6BA4B48A41 Date of Receipt

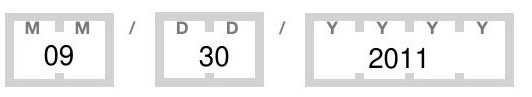

Amount of Each Receipt this Period
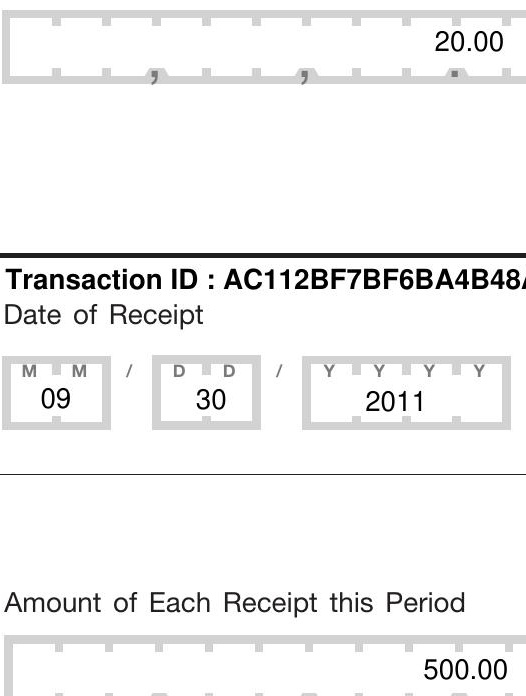

Transaction ID : A4EAB546A3DBD4D3F9CB Date of Receipt

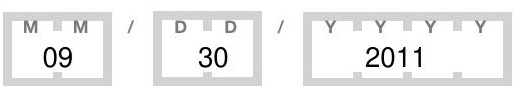

Amount of Each Receipt this Period

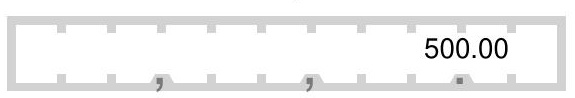

Subtotal Of Receipts This Page (optional).

Total This Period (last page this line number only) 


\section{SCHEDULE A-P} ITEMIZED RECEIPTS
Use separate schedule(s) for each category of the Detailed Summary Page
FOR LINE NUMBER: (check only one)
PAGE $1240 / 1572$

\begin{tabular}{|c|c|c|c|c|c|}
\hline & & & & & \\
\hline 16 & $\begin{array}{ll}\mathbf{X} & 17 a \\
\end{array}$ & $17 \mathrm{~b}$ & $17 c$ & $17 d$ & 18 \\
\hline $19 a$ & $19 b$ & $20 \mathrm{a}$ & $20 \mathrm{~b}$ & $20 c$ & 21 \\
\hline
\end{tabular}

Any information copied from such Reports and Statements may not be sold or used by any person for the purpose of soliciting contributions or for commercial purposes, other than using the name and address of any political committee to solicit contributions from such committee.

NAME OF COMMITTEE (In Full)

Friends of Herman Cain

A. Full Name (Last, First, Middle Initial)

Michael Shipman

Mailing Address 8914 Woodland Pass

\begin{tabular}{lcc}
\hline City & State & Zip Code \\
Boerne & TX & $78006-6546$
\end{tabular}

FEC ID number of contributing

federal political committee.

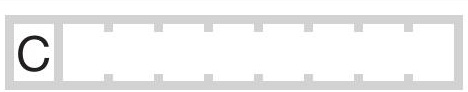

Name of Employer
Self Employed
Receipt For: 2012
X Primary
$\square$ Other (specify) General

Occupation

Financial Advisor

Election Cycle-to-Date

2000.99

B. Full Name (Last, First, Middle Initial)

terry fohey

Mailing Address 1150 Grey Drive

\begin{tabular}{lcc}
\hline City & State & Zip Code \\
Bogart & GA & $30622-2477$ \\
\hline
\end{tabular}

FEC ID number of contributing

federal political committee.

C

Name of Employer
Information Requested
Receipt For: 2012
Primary
Other (specify)

Occupation

Information Requested

Election Cycle-to-Date

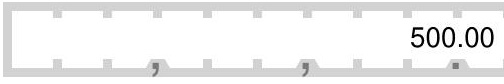

C. Full Name (Last, First, Middle Initial)

Linda Joyce-Menk

Mailing Address 70 White Oak Drive

\begin{tabular}{lcc}
\hline City & State & Zip Code \\
Newnan & GA & $30265-1267$
\end{tabular}

FEC ID number of contributing

federal political committee.

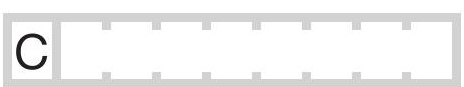

Name of Employer

Bellwether Real Estate Capital LLC

Receipt For: 2012

Х $\begin{aligned} & \text { Primary } \square \text { General } \\ & \text { Other (specify) }\end{aligned}$
Occupation

Mortgage Banker

Election Cycle-to-Date

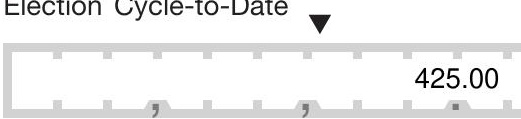

Transaction ID : AF8256D56C1124D10BF3

Date of Receipt

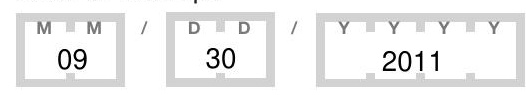

Amount of Each Receipt this Period

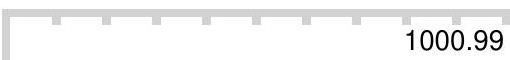

1000.99

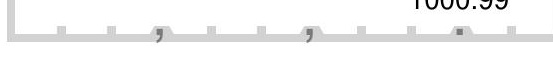

Transaction ID : ABD466CEC88764DAB900

Date of Receipt

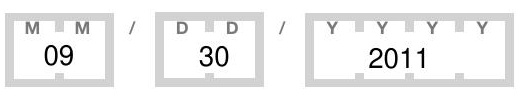

Amount of Each Receipt this Period

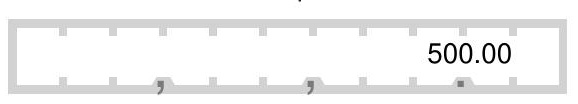

Transaction ID : A19CCD932969347AAA1E Date of Receipt

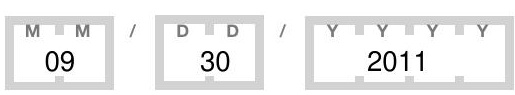

Amount of Each Receipt this Period

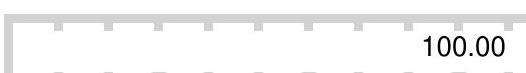

1600.99

Subtotal Of Receipts This Page (optional)

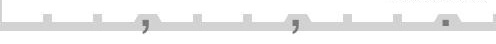

Total This Period (last page this line number only) 


\section{SCHEDULE A-P} ITEMIZED RECEIPTS
Use separate schedule(s)

for each category of the

Detailed Summary Page
FOR LINE NUMBER: (check only one)

Any information or for commercial purposes, other than using the name and address of any political committee to solicit contributions from such committee.

NAME OF COMMITTEE (In Full)

Friends of Herman Cain

A. Full Name (Last, First, Middle Initial)

Randi Helgeson

Mailing Address 16485 Ellerdale Lane

\begin{tabular}{lcc}
\hline City & State & Zip Code \\
Eden Prairie & MN & $55346-1431$
\end{tabular}

FEC ID number of contributing

federal political committee.

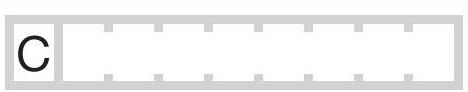

Name of Employer
Retired
Receipt For: 2012
X Primary $\square$ General
$\square$ Other (specify)

Occupation

CPA

Election Cycle-to-Date

950.00

B. Full Name (Last, First, Middle Initial)

Jodie Pessolano

Mailing Address 1003 1st Street

\begin{tabular}{lcc}
\hline City & State & Zip Code \\
Douglas & AK & $99824-5405$
\end{tabular}

FEC ID number of contributing

federal political committee.

C

Name of Employer
Information Requested
Receipt For: 2012
Primary
Other (specify)

Occupation

Information Requested

Election Cycle-to-Date

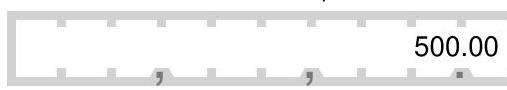

Transaction ID : AF30D73F7C06941DBA39

Date of Receipt

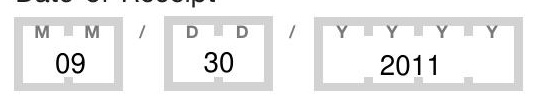

Amount of Each Receipt this Period

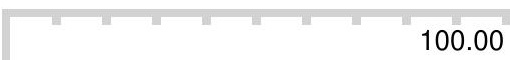

C. Full Name (Last, First, Middle Initial)

E Daniell

Mailing Address 3316A S Cobb Dr SE \# Pmb136

\begin{tabular}{lcc}
\hline City & State & Zip Code \\
Smyrna & GA & $30080-4118$
\end{tabular}

FEC ID number of contributing

federal political committee.

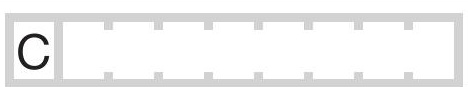

Name of Employer
Retired
Receipt For: 2012
X Primary
Other (specify) General

\section{Occupation}

Retired

Election Cycle-to-Date

Transaction ID : A1D076A01FD5F40EB968

Date of Receipt

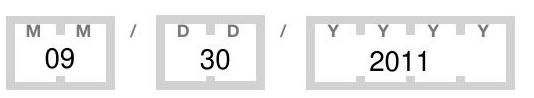

Amount of Each Receipt this Period

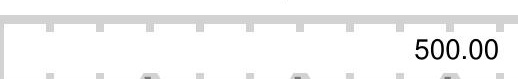

Transaction ID : AE3573A1FEB25494CB2F Date of Receipt

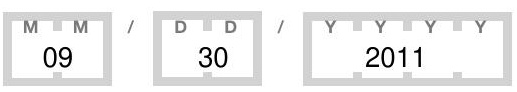

Amount of Each Receipt this Period

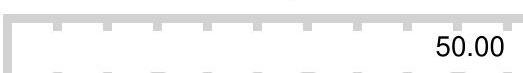

205.00

Subtotal Of Receipts This Page (optional).

650.00

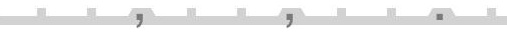

Total This Period (last page this line number only)

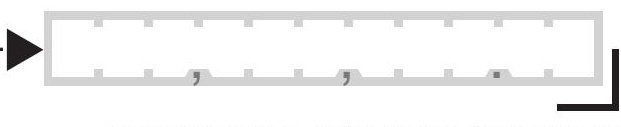

FEC Schedule A-P (Form 3P) (Rev. 03/2011) 


\section{SCHEDULE A-P} ITEMIZED RECEIPTS
Use separate schedule(s) for each category of the Detailed Summary Page
FOR LINE NUMBER: (check only one)
PAGE 1242 / 1572

\begin{tabular}{|c|c|c|c|c|c|}
\hline & & & & & \\
\hline 16 & $\begin{array}{ll}\mathbf{X} & 17 a \\
\end{array}$ & $17 \mathrm{~b}$ & $17 c$ & $17 d$ & 18 \\
\hline $19 a$ & $19 b$ & $20 \mathrm{a}$ & $20 \mathrm{~b}$ & $20 c$ & 21 \\
\hline
\end{tabular}

Any information copied from such Reports and Statements may not be sold or used by any person for the purpose of soliciting contributions or for commercial purposes, other than using the name and address of any political committee to solicit contributions from such committee.

NAME OF COMMITTEE (In Full)

Friends of Herman Cain

A. Full Name (Last, First, Middle Initial)

BARBARA MCKNIGHT

Mailing Address 135 DRIFTWOOD CIRCLE

\begin{tabular}{lcc}
\hline City & State & Zip Code \\
Aiken & SC & $29801-7275$
\end{tabular}

FEC ID number of contributing federal political committee.

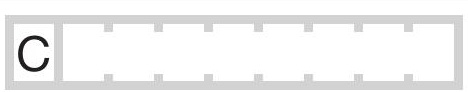

Name of Employer
Information Requested
Receipt For: 2012
X Primary
$\square$ Other (specify)

Occupation

Information Requested

Election Cycle-to-Date

250.00

B. Full Name (Last, First, Middle Initial)

Jerilyn Haid

Mailing Address P.O. Box 713

\begin{tabular}{lcc}
\hline City & State & Zip Code \\
Jasper & GA & $30143-0713$
\end{tabular}

FEC ID number of contributing

federal political committee.

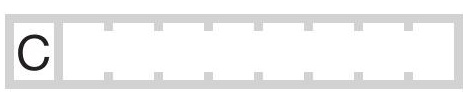

Name of Employer
Standard Coffee
Receipt For: 2012
X Primary
Other (specify)

\section{Occupation}

Sales

Election Cycle-to-Date

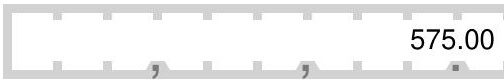

Transaction ID : A48A6BE762EAE404399B

Date of Receipt

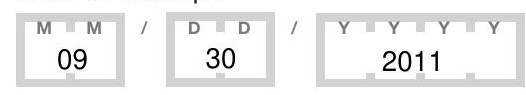

Amount of Each Receipt this Period

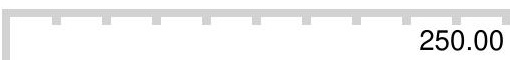

Transaction ID : A57C6D260EB214EDA874 Date of Receipt

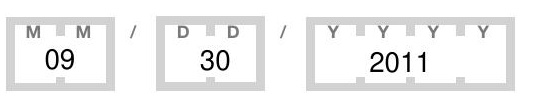

Amount of Each Receipt this Period

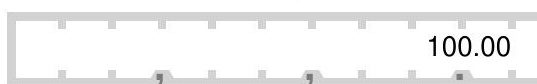

Transaction ID : A4EEA67A89065439EA02 Date of Receipt

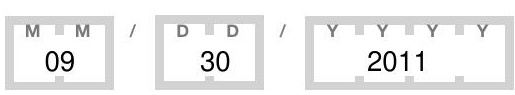

Amount of Each Receipt this Period

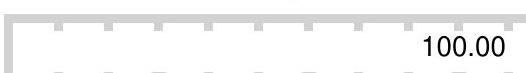

Name of Employer

KAR Recycling Center

Receipt For: 2012

Х $\begin{aligned} & \text { Primary } \square \text { General } \\ & \text { Other (specify) }\end{aligned}$

$\begin{array}{cc}\text { State } & \text { Zip Code } \\ \text { AZ } & 86402-6711\end{array}$

C

\section{Occupation}

Recycling GM

Election Cycle-to-Date

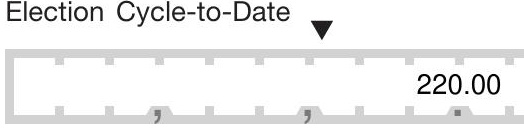

Subtotal Of Receipts This Page (optional).

450.00

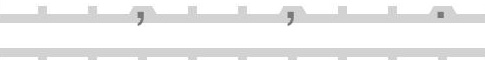

Total This Period (last page this line number only)

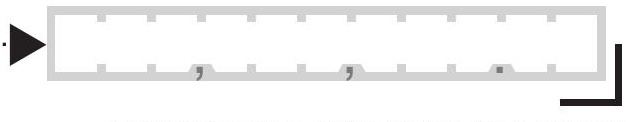

FEC Schedule A-P (Form 3P) (Rev. 03/2011) 
SCHEDULE A-P ITEMIZED RECEIPTS
Use separate schedule(s) for each category of the Detailed Summary Page
FOR LINE NUMBER: (check only one)

PAGE 1243 / 1572

\begin{tabular}{|c|c|c|c|c|c|}
\hline & & & & & \\
\hline 16 & $\begin{array}{lll}X & 17 a \\
\end{array}$ & $17 \mathrm{~b}$ & $17 c$ & $17 d$ & 18 \\
\hline $19 a$ & $19 b$ & $20 a$ & $20 \mathrm{~b}$ & $20 c$ & 21 \\
\hline
\end{tabular}

Any information copied from such Reports and Statements may not be sold or used by any person for the purpose of soliciting contributions or for commercial purposes, other than using the name and address of any political committee to solicit contributions from such committee.

NAME OF COMMITTEE (In Full)

\section{Friends of Herman Cain}

A. Full Name (Last, First, Middle Initial)

Tavia Hudi

Mailing Address 4703 Main Hwy

\begin{tabular}{lcc}
\hline City & State & Zip Code \\
Saint Martinville & LA & $70582-6002$
\end{tabular}

FEC ID number of contributing federal political committee.

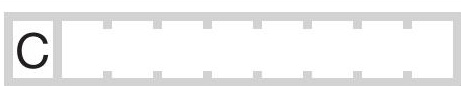

Name of Employer
GAI-Tronics Corp.
Receipt For: 2012
X Primary $\quad$ General
Other (specify)

\section{Occupation}

sales representative

Election Cycle-to-Date

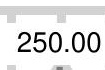

B. Full Name (Last, First, Middle Initial)

Lucy Kinnaird

Mailing Address 1131 Goodwin Road

\begin{tabular}{lcc}
\hline City & State & Zip Code \\
Atlanta & GA & $30324-2715$ \\
\hline
\end{tabular}

FEC ID number of contributing

federal political committee.

C

Name of Employer
Atlanta Communities
Receipt For: 2012
X Primary
Other (specify) General

Occupation

real estate sales

Election Cycle-to-Date

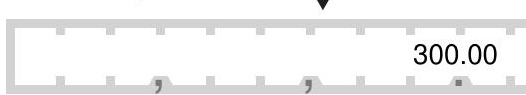

Transaction ID : AF842D1C96737408DAC8

Date of Receipt

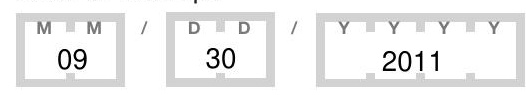

Amount of Each Receipt this Period

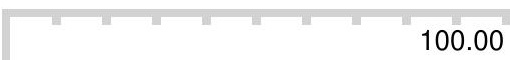

Transaction ID : A417DCCFD444E4AA49DD Date of Receipt

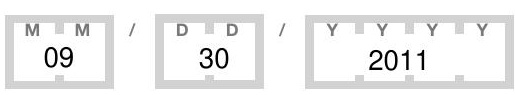

Amount of Each Receipt this Period

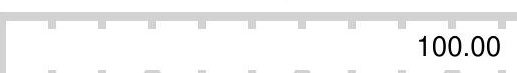

Transaction ID : A43ED7632880F42E49A1

Date of Receipt

Jean Smith

Mailing Address 16465 Hwy 12 W

\begin{tabular}{lcc}
\hline City & State & Zip Code \\
Roundup & MT & $59072-6910$
\end{tabular}

FEC ID number of contributing federal political committee.

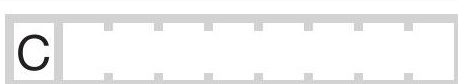

Name of Employer
Self Employed
Receipt For: 2012
X Primary $\quad \square$ General
Other (specify)

\section{Occupation}

Rancher

Election Cycle-to-Date

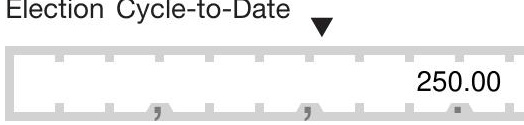

Subtotal Of Receipts This Page (optional)

Amount of Each Receipt this Period

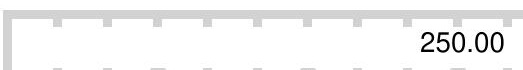

Total This Period (last page this line number only)

450.00

a

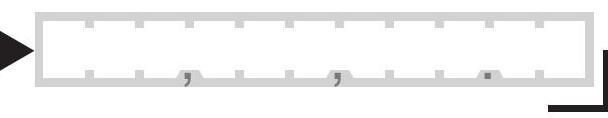

FEC Schedule A-P (Form 3P) (Rev. 03/2011) 
SCHEDULE A-P ITEMIZED RECEIPTS
Use separate schedule(s) for each category of the Detailed Summary Page
FOR LINE NUMBER: (check only one)

Any information or for commercial purposes, other than using the name and address of any political committee to solicit contributions from such committee.

NAME OF COMMITTEE (In Full)

\section{Friends of Herman Cain}

A. Full Name (Last, First, Middle Initial)

WILLIAM SHEPARD

Mailing Address 141 W. JACKSON SUITE 2270

\begin{tabular}{lcc}
\hline City & State & Zip Code \\
Lemont & IL & 60439 \\
\hline
\end{tabular}

FEC ID number of contributing federal political committee.

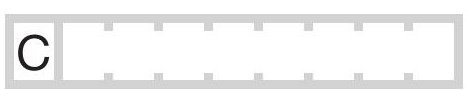

Name of Employer
Information Requested
Receipt For: 2012
X Primary
Other (specify) General

Occupation Information Requested

Election Cycle-to-Date

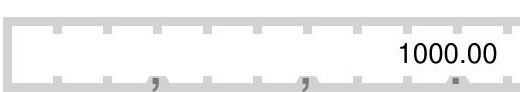

B. Full Name (Last, First, Middle Initial)

Melissa Burton

Mailing Address 1707 Championship Blvd

\begin{tabular}{lcc}
\hline City & State & Zip Code \\
Franklin & TN & $37064-8632$ \\
\hline
\end{tabular}

FEC ID number of contributing

federal political committee.

C

Name of Employer
Information Requested
Receipt For: 2012
X Primary
Other (specify)

Occupation

Information Requested

Election Cycle-to-Date

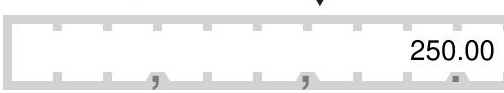

Transaction ID : AE34C45706CBD45E283A

Date of Receipt

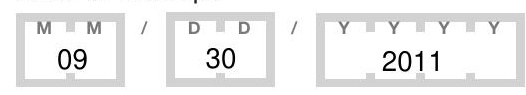

Amount of Each Receipt this Period

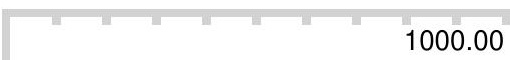

1000.00

C. Full Name (Last, First, Middle Initial)

Robert Eads

Mailing Address 264 Oak Point Landing Drive

\begin{tabular}{lcc}
\hline City & State & Zip Code \\
Mount Pleasant & SC & $29464-6283$
\end{tabular}

FEC ID number of contributing federal political committee.

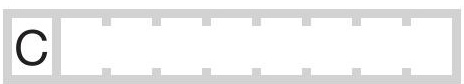

Name of Employer
Roper Hospital
Receipt For: 2012
X Primary $\quad \square$ General
Other (specify)

\section{Occupation}

Physician

Transaction ID : A727955AEEE444A4192C

Date of Receipt

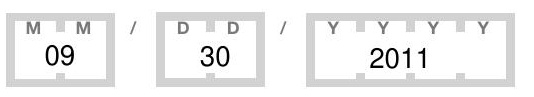

Amount of Each Receipt this Period

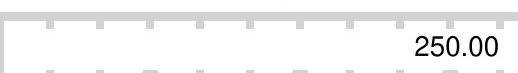

Transaction ID : A6E971A98723940A2BBC Date of Receipt

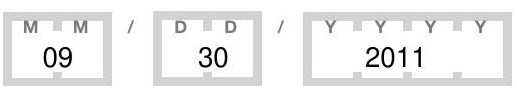

Amount of Each Receipt this Period

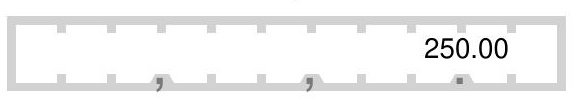

Subtotal Of Receipts This Page (optional)

1500.00

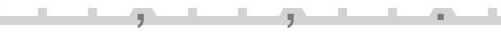

Total This Period (last page this line number only)

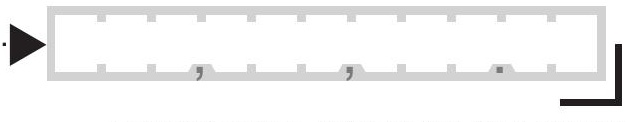

FEC Schedule A-P (Form 3P) (Rev. 03/2011) 


\section{SCHEDULE A-P} ITEMIZED RECEIPTS
Use separate schedule(s) for each category of the Detailed Summary Page
FOR LINE NUMBER: (check only one)
PAGE $1245 / 1572$

\begin{tabular}{|c|c|c|c|c|c|}
\hline & & & & & \\
\hline 16 & $\begin{array}{ll}\mathbf{X} & 17 a \\
\end{array}$ & $17 \mathrm{~b}$ & $17 c$ & $17 d$ & 18 \\
\hline $19 a$ & $19 b$ & $20 \mathrm{a}$ & $20 \mathrm{~b}$ & $20 c$ & 21 \\
\hline
\end{tabular}

Any information copied from such Reports and Statements may not be sold or used by any person for the purpose of soliciting contributions or for commercial purposes, other than using the name and address of any political committee to solicit contributions from such committee.

NAME OF COMMITTEE (In Full)

\section{Friends of Herman Cain}

A. Full Name (Last, First, Middle Initial)

Kathy Yarbrough

Mailing Address 45 Lake Haven Dr

\begin{tabular}{lcc}
\hline City & State & Zip Code \\
Cartersville & GA & $30120-8468$
\end{tabular}

FEC ID number of contributing federal political committee.

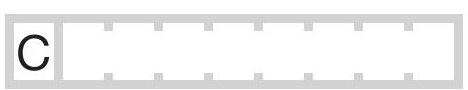

Name of Employer
Information Requested
Receipt For: 2012
X Primary
Other (specify) General

Occupation Information Requested

Election Cycle-to-Date

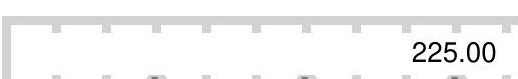

B. Full Name (Last, First, Middle Initial) James Coyle

Mailing Address 11765 Highland Colony Dr

\begin{tabular}{lcc}
\hline City & State & Zip Code \\
Roswell & GA & $30075-2149$ \\
\hline
\end{tabular}

FEC ID number of contributing

federal political committee.

C

Name of Employer
Information Requested
Receipt For: 2012
X Primary
Other (specify)

Occupation

Information Requested

Election Cycle-to-Date

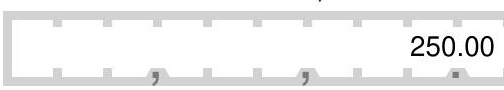

Transaction ID : AABA4C2DD352444E2B40

Date of Receipt

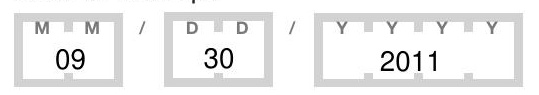

Amount of Each Receipt this Period

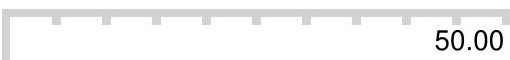

50.00

C. Full Name (Last, First, Middle Initial)

John Mandler

Mailing Address 8 Undercliff Terrace

\begin{tabular}{lcc}
\hline City & State & Zip Code \\
West Orange & NJ & $07052-3930$
\end{tabular}

FEC ID number of contributing federal political committee.

C

Name of Employer
Information Requested
Receipt For: 2012
X Primary
Other (specify) General

Occupation

Information Requested

Election Cycle-to-Date

Transaction ID : A169C758A8D744405ACB

Date of Receipt

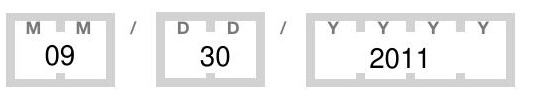

Amount of Each Receipt this Period

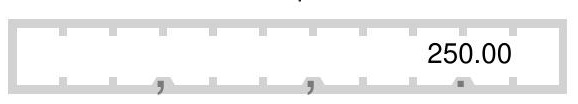

Transaction ID : AAC23EA5C97AD456E922 Date of Receipt

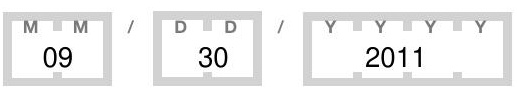

Amount of Each Receipt this Period

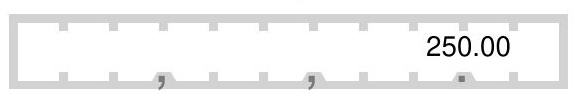

250.00

\section{Subtotal Of Receipts This Page (optional)}

Total This Period (last page this line number only) 


\section{SCHEDULE A-P} ITEMIZED RECEIPTS
Use separate schedule(s)

for each category of the

Detailed Summary Page
FOR LINE NUMBER: (check only one)

Any information or for commercial purposes, other than using the name and address of any political committee to solicit contributions from such committee.

NAME OF COMMITTEE (In Full)

\section{Friends of Herman Cain}

A. Full Name (Last, First, Middle Initial)

Jim Hibbs

Mailing Address 4659 Foothill Rd.

\begin{tabular}{lcc}
\hline City & State & Zip Code \\
Ventura & CA & $93003-1903$
\end{tabular}

FEC ID number of contributing federal political committee.

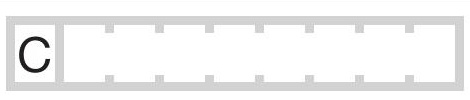

Name of Employer
Instant Baseball
Receipt For: 2012
X Primary
$\square$ Other (specify) General

Occupation

Executive

Election Cycle-to-Date

350.00

B. Full Name (Last, First, Middle Initial)

Ken Scoville

Mailing Address 244 Gunter Dr

\begin{tabular}{lcc}
\hline City & State & Zip Code \\
Colbert & GA & $30628-3589$ \\
\hline
\end{tabular}

FEC ID number of contributing

federal political committee.

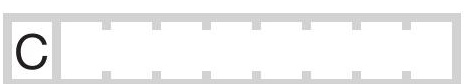

Name of Employer
Duplicating Systems
Receipt For: 2012
X Primary
Other (specify)

\section{Occupation}

Admin

Election Cycle-to-Date

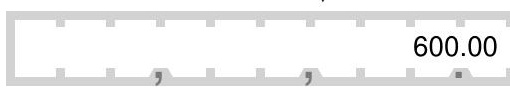

C. Full Name (Last, First, Middle Initial)

Margolyn Andrews

Mailing Address 6307 Waterford Blvd po box 226

\begin{tabular}{lcc}
\hline City & State & Zip Code \\
Bridgewater Corners & VT & $05035-0226$
\end{tabular}

FEC ID number of contributing federal political committee.

C

Name of Employer
Information Requested
Receipt For: 2012
X Primary
Other (specify) General

\section{Occupation}

Information Requested

Election Cycle-to-Date
Transaction ID : AE761FB6AF8BB4763A14

Date of Receipt

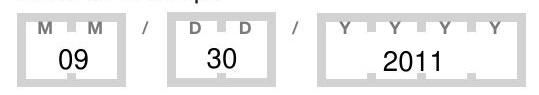

Amount of Each Receipt this Period

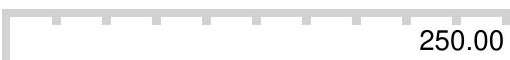

Amount of Each Receipt this Period

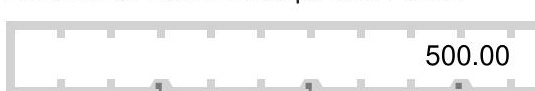

Transaction ID : A945AC146E95241759F2

Date of Receipt

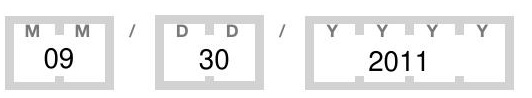

Transaction ID : A389FD965948D465DABE Date of Receipt

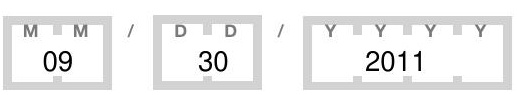

Amount of Each Receipt this Period

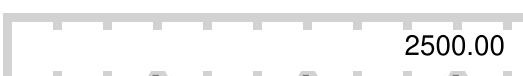

2500.00

\section{Subtotal Of Receipts This Page (optional)}

Total This Period (last page this line number only) 


\section{SCHEDULE A-P} ITEMIZED RECEIPTS
Use separate schedule(s) for each category of the Detailed Summary Page
FOR LINE NUMBER: (check only one)
PAGE 1247 / 1572

\begin{tabular}{|c|c|c|c|c|c|}
\hline & & & & & \\
\hline 16 & $\begin{array}{ll}\mathbf{X} & 17 a \\
\end{array}$ & $17 \mathrm{~b}$ & $17 c$ & $17 d$ & 18 \\
\hline $19 a$ & $19 b$ & $20 \mathrm{a}$ & $20 \mathrm{~b}$ & $20 c$ & 21 \\
\hline
\end{tabular}

Any information copied from such Reports and Statements may not be sold or used by any person for the purpose of soliciting contributions or for commercial purposes, other than using the name and address of any political committee to solicit contributions from such committee.

NAME OF COMMITTEE (In Full)

\section{Friends of Herman Cain}

A. Full Name (Last, First, Middle Initial)

Ms. Deborah Schmalshof

Mailing Address 519 Bill Anderson Rd.

\begin{tabular}{lcc}
\hline City & State & Zip Code \\
Dahlonega & GA & $30533-4045$ \\
\hline
\end{tabular}

FEC ID number of contributing federal political committee.

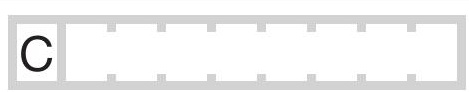

Name of Employer
Information Requested
Receipt For: 2012
X Primary
$\square$ Other (specify)

Occupation

Information Requested

Election Cycle-to-Date

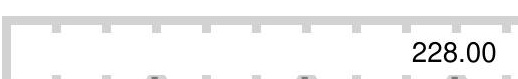

B. Full Name (Last, First, Middle Initial)

Brian Harnett

Mailing Address 188 Crowell Rd

\begin{tabular}{lcc}
\hline City & State & Zip Code \\
Contoocook & $\mathrm{NH}$ & $03229-2615$ \\
\hline
\end{tabular}

FEC ID number of contributing

federal political committee.

C

Name of Employer
Information Requested
Receipt For: 2012
Primary
Other (specify)

Occupation

Information Requested

Election Cycle-to-Date

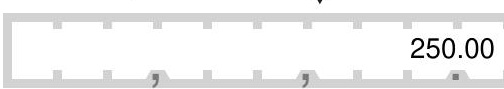

Transaction ID : A024571A7A48A4C29853

Date of Receipt

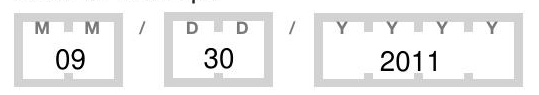

Amount of Each Receipt this Period

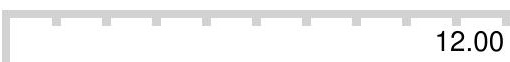

Transaction ID : A6E6A3CA816C34B4DBB2 Date of Receipt

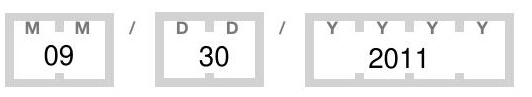

Amount of Each Receipt this Period

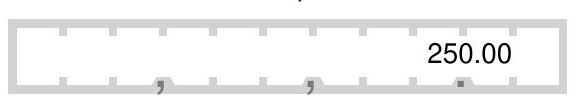

Transaction ID : AAF5F8E6E02AF45DDA08 Date of Receipt

Embree Pearson

Mailing Address P.O. Box 2275

\begin{tabular}{lcc}
\hline City & State & Zip Code \\
Winter Haven & FL & $33883-2275$
\end{tabular}

FEC ID number of contributing federal political committee.

C

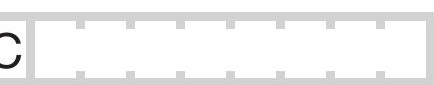

Name of Employer

Information Requested

\section{Occupation}

Information Requested

Receipt For: 2012

Х $\begin{aligned} & \text { Primary } \square \text { General } \\ & \text { Other (specify) }\end{aligned}$

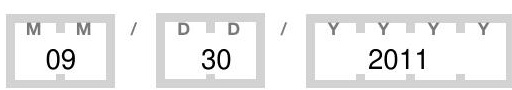

Amount of Each Receipt this Period

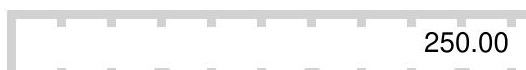

\section{Subtotal Of Receipts This Page (optional)}

Total This Period (last page this line number only) 


\section{SCHEDULE A-P} ITEMIZED RECEIPTS
Use separate schedule(s)

for each category of the

Detailed Summary Page
FOR LINE NUMBER: (check only one)

Any information or for commercial purposes, other than using the name and address of any political committee to solicit contributions from such committee.

NAME OF COMMITTEE (In Full)

Friends of Herman Cain

A. Full Name (Last, First, Middle Initial)

\section{Gretchen Roberts}

Mailing Address 1040 E Osborn Rd, 1001

\begin{tabular}{lcc}
\hline City & State & Zip Code \\
Phoenix & AZ & $85014-5251$ \\
\hline
\end{tabular}

FEC ID number of contributing federal political committee.

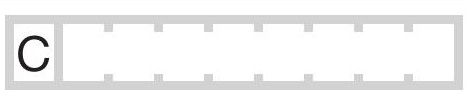

Name of Employer
Self Employed
Receipt For: 2012
X Primary $\quad \square$ General
Other (specify)

Occupation

Writer

Election Cycle-to-Date
Transaction ID : A1EA40661D8AA4357861

Date of Receipt

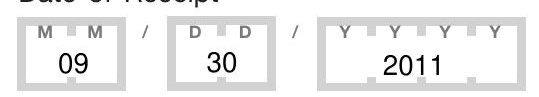

Amount of Each Receipt this Period

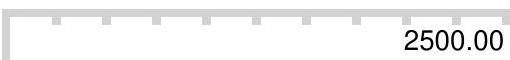

B. Full Name (Last, First, Middle Initial)

jeffrey keller

Mailing Address 3663 w. tower rd.

\begin{tabular}{lcc}
\hline City & State & Zip Code \\
Live Oak & FL & $32060-7967$
\end{tabular}

FEC ID number of contributing

federal political committee.

C

Name of Employer
Information Requested
Receipt For: 2012
X Primary
Other (specify)

Occupation

Information Requested

Election Cycle-to-Date

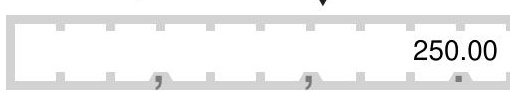

C. Full Name (Last, First, Middle Initial)

Joanna Dickens

Mailing Address 3321 Missouri Ave

\begin{tabular}{lcc}
\hline City & State & Zip Code \\
Bryan & TX & $77803-0712$
\end{tabular}

FEC ID number of contributing

federal political committee.

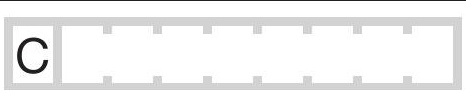

Name of Employer

Texas Transportation Institute

Receipt For: 2012

Х $\begin{aligned} & \text { Primary } \square \text { General } \\ & \text { Other (specify) }\end{aligned}$

\section{Occupation}

editor

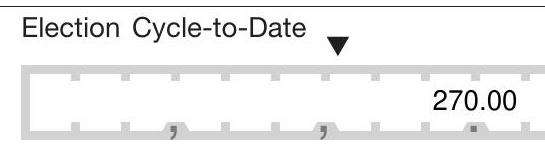

Transaction ID : A6DEC7CDA96DF444382A

Date of Receipt

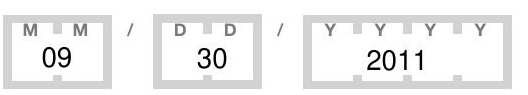

Amount of Each Receipt this Period

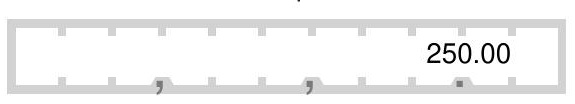

Transaction ID : AA29CDFD1D3704D588DF Date of Receipt

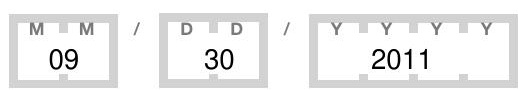

Amount of Each Receipt this Period

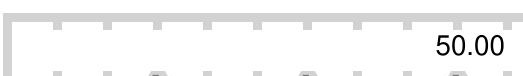

50.00

\section{Subtotal Of Receipts This Page (optional)}

2800.00

a

Total This Period (last page this line number only)

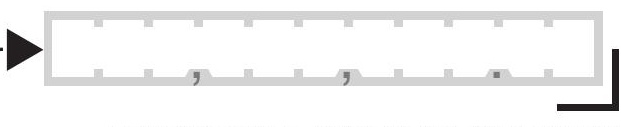

FEC Schedule A-P (Form 3P) (Rev. 03/2011) 
SCHEDULE A-P ITEMIZED RECEIPTS
Use separate schedule(s) for each category of the Detailed Summary Page
FOR LINE NUMBER: (check only one)

Any information copied from such Repor or for commercial purposes, other than using the name and address of any political committee to solicit contributions from such committee.

NAME OF COMMITTEE (In Full)

\section{Friends of Herman Cain}

A. Full Name (Last, First, Middle Initial)

\section{Brian Collins}

Mailing Address 2405 Hunter Hills Ln

\begin{tabular}{lcc}
\hline City & State & Zip Code \\
Cookeville & TN & $38506-3428$
\end{tabular}

FEC ID number of contributing federal political committee.

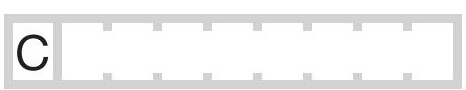

Name of Employer
Self Employed
Receipt For: 2012
X Primary $\quad$ General
Other (specify)

Occupation courier

Election Cycle-to-Date

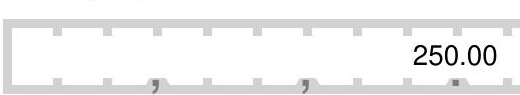

B. Full Name (Last, First, Middle Initial)

Charles Ray

Mailing Address PO Box 51608

\begin{tabular}{lcc}
\hline City & State & Zip Code \\
Midland & TX & $79710-1608$ \\
\hline
\end{tabular}

FEC ID number of contributing

federal political committee.

C

Name of Employer
Information Requested
Receipt For: 2012
X Primary
Other (specify)

Occupation

Information Requested

Election Cycle-to-Date

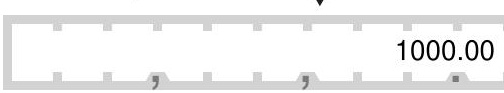

C. Full Name (Last, First, Middle Initial)

Mr Patrick D Alexander

Mailing Address 16540 Grays Bay Blvd

\begin{tabular}{lll}
\hline $\begin{array}{l}\text { City } \\
\text { Wayzata }\end{array}$ & $\begin{array}{c}\text { State } \\
\text { MN }\end{array}$ & $\begin{array}{c}\text { Zip Code } \\
55391-2915\end{array}$ \\
\hline $\begin{array}{l}\text { FEC ID number of contributing } \\
\text { federal political committee. }\end{array}$ & C & \\
\hline $\begin{array}{l}\text { Name of Employer } \\
\text { Cold Spring Granite Company }\end{array}$ & $\begin{array}{l}\text { Occupation } \\
\text { CEO }\end{array}$ \\
\hline $\begin{array}{l}\text { Receipt For: } 2012 \\
\text { Primary } \\
\text { Other (specify) }\end{array}$ & Election Cycle-to-Date & \\
\hline
\end{tabular}

Transaction ID : A65259C244751470CB0F

Date of Receipt

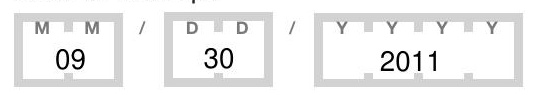

Amount of Each Receipt this Period

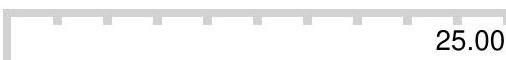

25.00

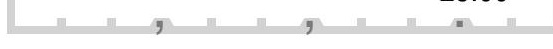

Transaction ID : A6465094E75744BFE948

Date of Receipt

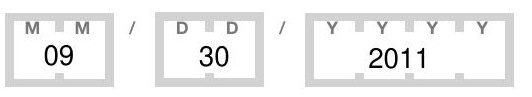

Amount of Each Receipt this Period

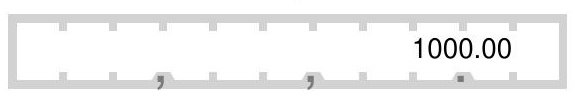

Amount of Each Receipt this Period

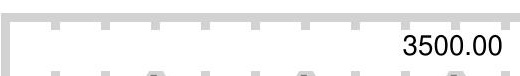

3500.00

\section{Subtotal Of Receipts This Page (optional)}

Total This Period (last page this line number only) 
SCHEDULE A-P ITEMIZED RECEIPTS
Use separate schedule(s) for each category of the Detailed Summary Page
FOR LINE NUMBER: (check only one)

Any information copied from such Repor or for commercial purposes, other than using the name and address of any political committee to solicit contributions from such committee.

NAME OF COMMITTEE (In Full)

Friends of Herman Cain

A. Full Name (Last, First, Middle Initial)

Scott Knight

Mailing Address PO BOX 816

\begin{tabular}{lcc}
\hline City & State & Zip Code \\
Woodstock & GA & $30188-0816$
\end{tabular}

FEC ID number of contributing federal political committee.

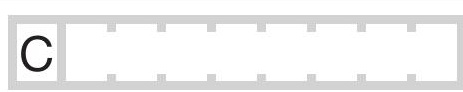

Name of Employer
ACG PIZZA PARTNERS LLC
Receipt For: 2012
X Primary $\quad \square$ General
Other (specify)

Occupation FOOD SERVICE

Election Cycle-to-Date 700.00

B. Full Name (Last, First, Middle Initial) Cathie Serrano

Mailing Address 5641 Shadow View Dr

\begin{tabular}{lcc}
\hline City & State & Zip Code \\
Stone Mountain & GA & $30087-2953$ \\
\hline
\end{tabular}

FEC ID number of contributing

federal political committee.

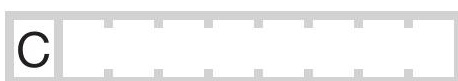

Name of Employer
n/a
Receipt For: 2012
X Primary
Other (specify)

Occupation

Retired

Election Cycle-to-Date

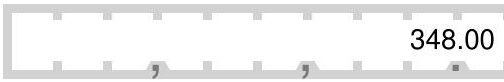

C. Full Name (Last, First, Middle Initial)

Ryan Colburn

Mailing Address 1410-A John B White Blvd

\begin{tabular}{lcc}
\hline City & State & Zip Code \\
Spartanburg & SC & 29306 \\
\hline
\end{tabular}

FEC ID number of contributing federal political committee.

C

Name of Employer
Colburn and Colburn
Receipt For: 2012
X Primary
Other (specify) General

Occupation

Dentist

Election Cycle-to-Date

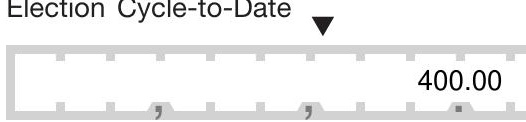

Transaction ID : AA3C0B85B52534524A7F

Date of Receipt

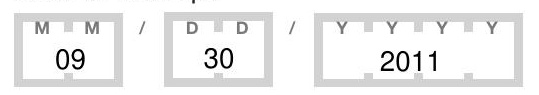

Amount of Each Receipt this Period

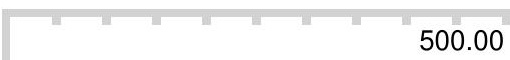

500.00
Amount of Each Receipt this Period

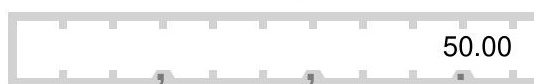

Amount of Each Receipt this Period

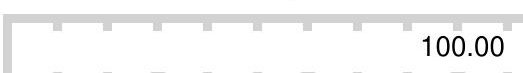

[MEMO ITEM]

Partnership: Ryan Colburn, DDS, LLC

Subtotal Of Receipts This Page (optional)

Total This Period (last page this line number only) 


\section{SCHEDULE A-P} ITEMIZED RECEIPTS
Use separate schedule(s) for each category of the Detailed Summary Page

FOR LINE NUMBER:
(check only one)

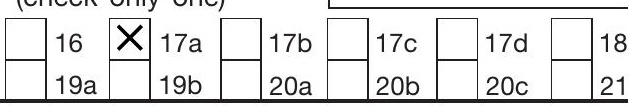

Any information copied from such Reports and Statements may not be sold or used by any person for the purpose of soliciting contributions or for commercial purposes, other than using the name and address of any political committee to solicit contributions from such committee.

NAME OF COMMITTEE (In Full)

\section{Friends of Herman Cain}

A. Full Name (Last, First, Middle Initial)

\section{PTR Truck Center LLC}

Mailing Address 1270 North Ave.

\begin{tabular}{lcc}
\hline City & State & Zip Code \\
West Chicago & IL & 60185
\end{tabular}

FEC ID number of contributing federal political committee.

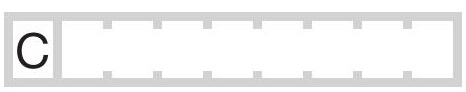

Name of Employer
Receipt For: 2012
X Primary
$\square$ Other (specify)

Occupation

Election Cycle-to-Date

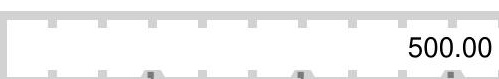

B. Full Name (Last, First, Middle Initial)

John Kraus

Mailing Address 1270 North Avenue

\begin{tabular}{lcc}
\hline City & State & Zip Code \\
West Chicago & IL & $60185-1087$
\end{tabular}

FEC ID number of contributing

federal political committee.

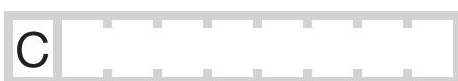

Name of Employer
PTR Truck Center LLC
Receipt For: 2012
X Primary
Other (specify)

\section{Occupation}

Partner

Election Cycle-to-Date

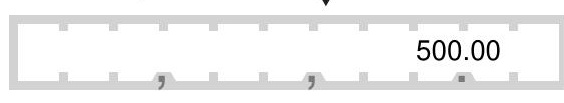

Transaction ID : A8382AC9E07BA4E8DA9F

Date of Receipt

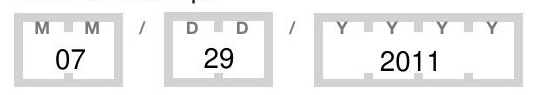

Amount of Each Receipt this Period

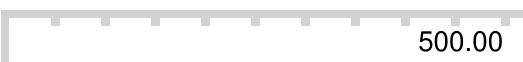

Amount of Each Receipt this Period

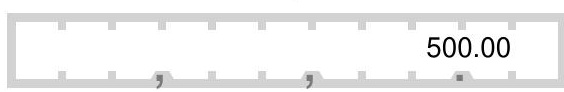

\section{[MEMO ITEM]}

Partnership: PTR Truck Center LLC

Transaction ID : AD68CB2BFE0384A58920 Date of Receipt

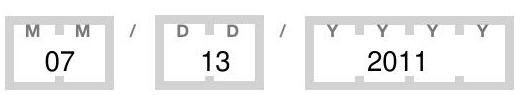

Amount of Each Receipt this Period

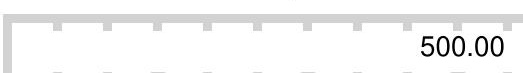

\section{State Zip Code \\ GA $\quad 30281$}

FEC ID number of contributing federal political committee.

C Occupation Election Cycle-to-Date

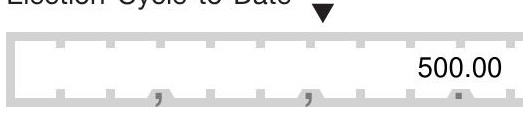

Subtotal Of Receipts This Page (optional)

1000.00

a

Total This Period (last page this line number only) 


\section{SCHEDULE A-P} ITEMIZED RECEIPTS
Use separate schedule(s)

for each category of the

Detailed Summary Page
FOR LINE NUMBER: (check only one)

\begin{tabular}{|c|c|c|c|c|c|c|}
\hline & & & & & & \\
\hline 16 & $\times 1$ & $17 a$ & $17 b$ & $17 c$ & $17 d$ & 18 \\
\hline $19 a$ & & $19 b$ & $20 \mathrm{a}$ & $20 \mathrm{~b}$ & $20 \mathrm{c}$ & 21 \\
\hline
\end{tabular}

Any information copied from such Reports and Statements may not be sold or used by any person for the purpose of soliciting contributions or for commercial purposes, other than using the name and address of any political committee to solicit contributions from such committee.

NAME OF COMMITTEE (In Full)

\section{Friends of Herman Cain}

A. Full Name (Last, First, Middle Initial)

\section{Dr. Dave Wayne}

Mailing Address 8430 Marina Bay Ct. Bay View

\begin{tabular}{lcc}
\hline City & State & Zip Code \\
Jonesboro & GA & 30236
\end{tabular}

FEC ID number of contributing

federal political committee.

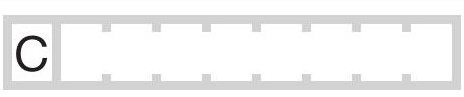

Name of Employer
Medical Systems
Receipt For: 2012
X Primary
$\square$ Other (specify) General

Occupation

Engineer

Election Cycle-to-Date

\subsection{0}

Transaction ID : A0DE8B5F23A324D238FE

Date of Receipt

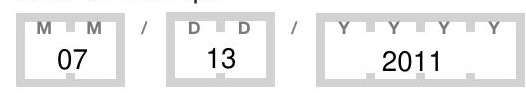

B. Full Name (Last, First, Middle Initial)

\section{Mailing Address}

\begin{tabular}{lll}
\hline City & State & Zip Code
\end{tabular}

FEC ID number of contributing

federal political committee.

C

Name of Employer
Receipt For:
\begin{tabular}{l}
$\square$ Primary $\square$ General \\
\hline
\end{tabular}

Occupation

Election Cycle-to-Date

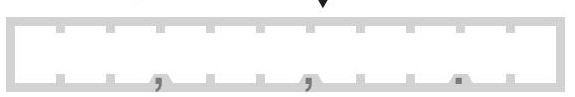

C. Full Name (Last, First, Middle Initial)

Mailing Address

City $\quad$ State Zip Code

FEC ID number of contributing federal political committee.

C

\begin{tabular}{l} 
Name of Employer \\
Receipt For: \\
$\square$ Primary $\square$ General \\
\hline Other (specify)
\end{tabular}

Occupation

Election Cycle-to-Date

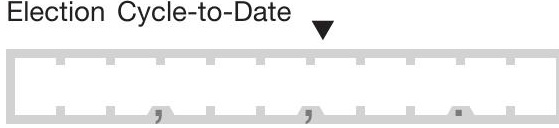

Amount of Each Receipt this Period

Amount of Each Receipt this Period

Amount of Each Receipt this Period

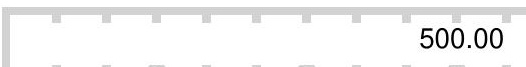

\section{[MEMO ITEM]}

Partnership: SE Medical Systems, LLC

Date of Receipt
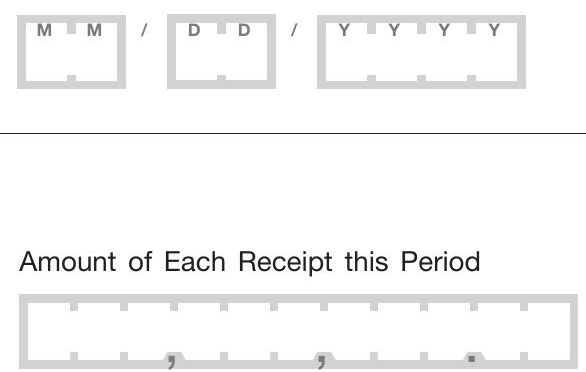

Date of Receipt

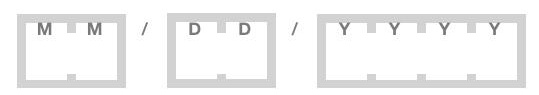

Subtotal Of Receipts This Page (optional)

Total This Period (last page this line number only)

1127652.98

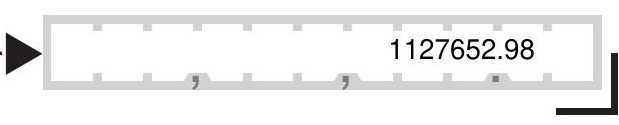

FEC Schedule A-P (Form 3P) (Rev. 03/2011) 
SCHEDULE A-P ITEMIZED RECEIPTS
Use separate schedule(s) for each category of the Detailed Summary Page
FOR LINE NUMBER: (check only one)

Any information copied from such Repors and or for commercial purposes, other than using the name and address of any political committee to solicit contributions from such committee.

NAME OF COMMITTEE (In Full)

\section{Friends of Herman Cain}

A. Full Name (Last, First, Middle Initial) Republican Party of Sauk County

Mailing Address 58161 Kassner Road \#1

\begin{tabular}{lcc}
\hline City & State & Zip Code \\
Merrimac & WI & 53561
\end{tabular}

FEC ID number of contributing federal political committee.

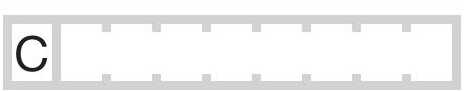

Name of Employer
Receipt For: 2012
X Primary $\quad$ General
Other (specify)

Occupation Election Cycle-to-Date

B. Full Name (Last, First, Middle Initial)

Alabama Minority GOP

Mailing Address P.O. Box 59009

\begin{tabular}{lcc}
\hline City & State & Zip Code \\
Homewood & AL & 35259 \\
\hline
\end{tabular}

FEC ID number of contributing

federal political committee.

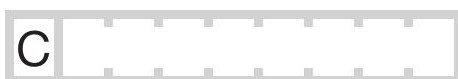

Name of Employer
Receipt For: 2012
X Primary
Other (specify)

\section{Occupation}

Election Cycle-to-Date

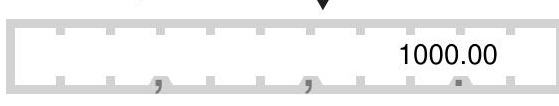

C. Full Name (Last, First, Middle Initial)

Tennessee Tea Party

Mailing Address 3800 Flewellyn Road

\begin{tabular}{lcc}
\hline City & State & Zip Code \\
Springfield & TN & $37172-5556$
\end{tabular}

FEC ID number of contributing federal political committee.

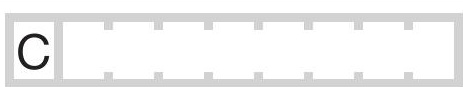

Name of Employer
Receipt For: 2012
Х Primary $\quad \square$ General
Other (specify)

Occupation

Election Cycle-to-Date

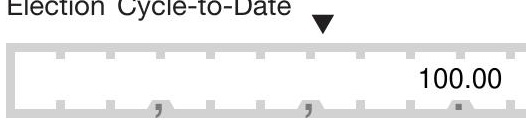

Transaction ID : A21D211505D5C44A9878

Date of Receipt

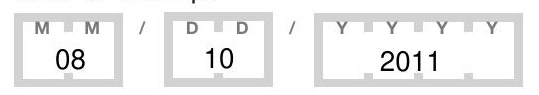

Amount of Each Receipt this Period

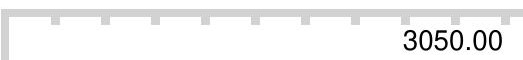

Amount of Each Receipt this Period

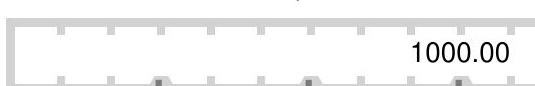

Transaction ID : A5F59CFDEEB294884BCE Date of Receipt

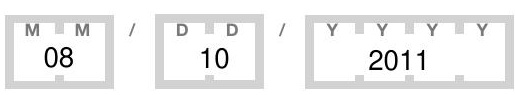

Transaction ID : AFFB0C51FD0614820ABE Date of Receipt

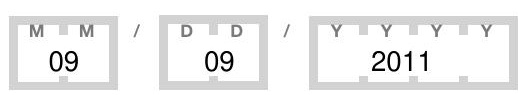

Amount of Each Receipt this Period

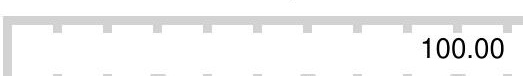

\section{Subtotal Of Receipts This Page (optional)}

4150.00

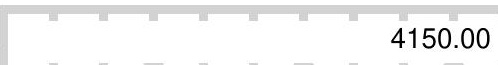

Total This Period (last page this line number only)
4150.00

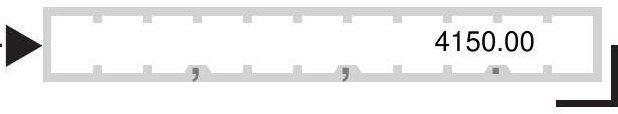

FEC Schedule A-P (Form 3P) (Rev. 03/2011) 


\section{SCHEDULE A-P} ITEMIZED RECEIPTS
Use separate schedule(s)

for each category of the

Detailed Summary Page
FOR LINE NUMBER: (check only one)

Any information copion the purpose of soliciting contributions or for commercial purposes, other than using the name and address of any political committee to solicit contributions from such committee.

NAME OF COMMITTEE (In Full)

Friends of Herman Cain

A. Full Name (Last, First, Middle Initial) Committee to Elect Andy Welch

Mailing Address PO Box 2871

\begin{tabular}{lcc}
\hline City & State & Zip Code \\
McDonough & GA & 30253 \\
\hline
\end{tabular}

FEC ID number of contributing federal political committee.

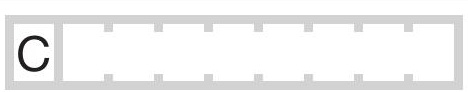

Name of Employer
Receipt For: 2012
Xrimary $\quad \square$ General
Other (specify)

Occupation

Election Cycle-to-Date

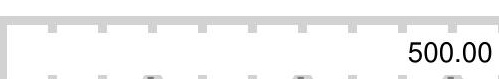

B. Full Name (Last, First, Middle Initial)

MedCath Inc. Comm. for the Improvement of Cardiac Care

Mailing Address 10720 Sikes PI. Ste. 300

\begin{tabular}{lcc}
\hline City & State & Zip Code \\
Charlotte & NC & 28277 \\
\hline
\end{tabular}

FEC ID number of contributing

federal political committee.

C $\quad 00380204$

\begin{tabular}{l|l}
\hline Name of Employer & Occupation \\
\hline Receipt For: 2012 & Election Cycle-to-Date \\
$\searrow \quad \begin{array}{l}\text { Primary } \\
\text { Other (specify) } \mathbf{\nabla}\end{array}$ & \\
\hline
\end{tabular}

C. Full Name (Last, First, Middle Initial)

Mailing Address

City $\quad$ State Zip Code

FEC ID number of contributing federal political committee.

C

\begin{tabular}{l} 
Name of Employer \\
Receipt For: \\
$\square$ Primary $\square$ General \\
\hline Other (specify)
\end{tabular}

Occupation

Election Cycle-to-Date

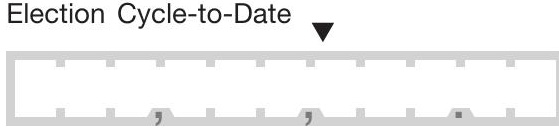

Amount of Each Receipt this Period

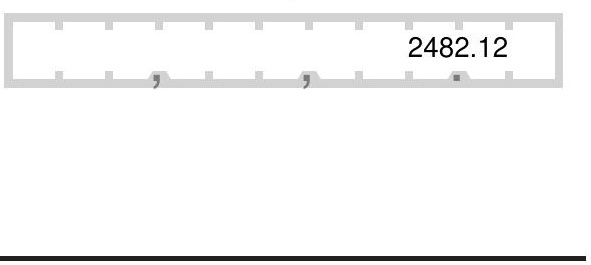

Date of Receipt

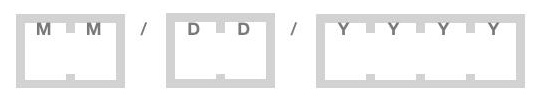

Amount of Each Receipt this Period

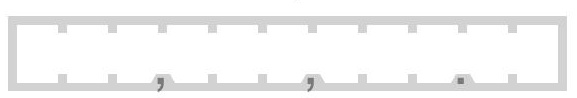

Transaction ID : AA1A967F0447B4782834

Date of Receipt

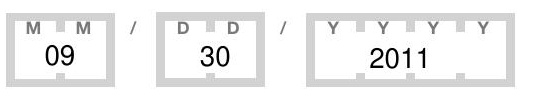

Amount of Each Receipt this Period

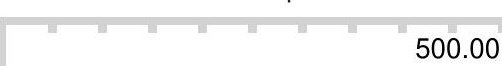

500.00

Date of Receipt
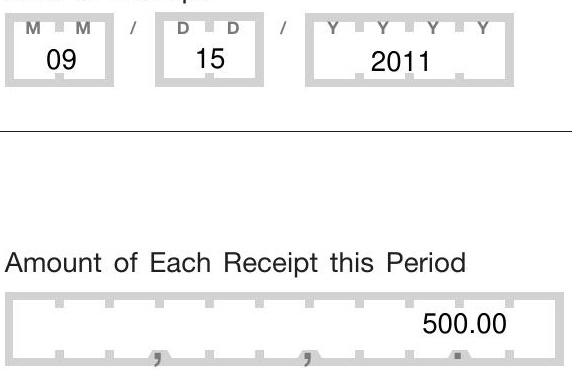
SCHEDULE A-P ITEMIZED RECEIPTS
Use separate schedule(s) for each category of the Detailed Summary Page
FOR LINE NUMBER: (check only one)

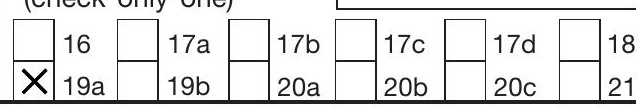

Any information copied from such Reports and Statements may not be sold or used by any person for the purpose of soliciting contributions or for commercial purposes, other than using the name and address of any political committee to solicit contributions from such committee.

NAME OF COMMITTEE (In Full)

\section{Friends of Herman Cain}

A. Full Name (Last, First, Middle Initial)

Herman Cain

Mailing Address PO Box 2158

\begin{tabular}{lcc}
\hline City & State & Zip Code \\
Stockbridge & GA & $30281-8909$ \\
\hline
\end{tabular}

FEC ID number of contributing federal political committee.

C $\quad P 0003608$

Name of Employer
Receipt For: 2012
Primary $\quad$ General
Other (specify)

Occupation

Election Cycle-to-Date

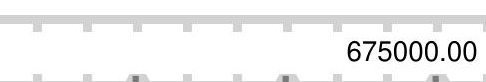

B. Full Name (Last, First, Middle Initial)

Herman Cain

Mailing Address PO Box 2158

\begin{tabular}{lcc}
\hline City & State & Zip Code \\
Stockbridge & GA & $30281-8909$ \\
\hline
\end{tabular}

FEC ID number of contributing

federal political committee.

C P00003608

\begin{tabular}{l|l}
\hline Name of Employer & Occupation \\
\hline Receipt For: 2012 & Election Cycle-to-Date \\
$\searrow \quad \begin{array}{l}\text { Primary } \\
\text { Other (specify) }\end{array}$ &
\end{tabular}

C. Full Name (Last, First, Middle Initial)

Herman Cain

Mailing Address PO Box 2158

\begin{tabular}{lcc}
\hline City & State & Zip Code \\
Stockbridge & GA & $30281-8909$
\end{tabular}

FEC ID number of contributing federal political committee.

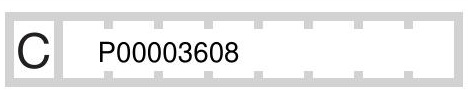

Name of Employer
Receipt For: 2012
X Primary
Other (specify)

Occupation

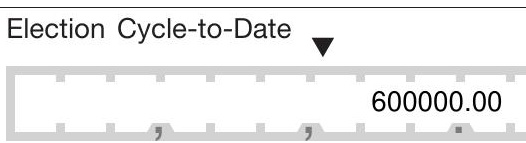

Subtotal Of Receipts This Page (optional)

125000.00

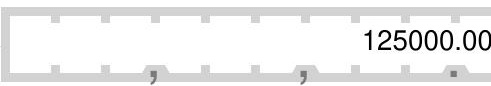

Total This Period (last page this line number only)
Transaction ID : A469804CCED1A45C48F6

Date of Receipt

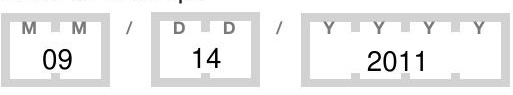

PERSONAL FUNDS

Amount of Each Receipt this Period

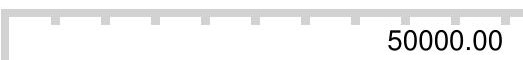

Transaction ID : A5177272DB8BD4D328B6

Date of Receipt

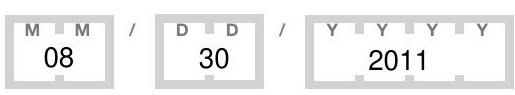

PERSONAL FUNDS

Amount of Each Receipt this Period

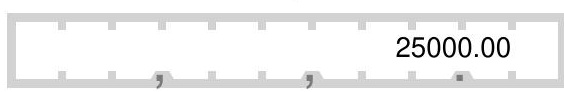

Transaction ID : AAE297F88E529458E8D6

Date of Receipt

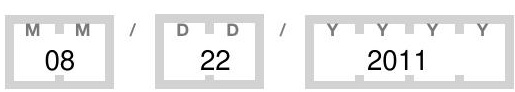

PERSONAL FUNDS

Amount of Each Receipt this Period

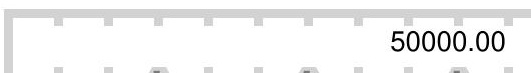




\section{SCHEDULE A-P} ITEMIZED RECEIPTS
Use separate schedule(s)

for each category of the

Detailed Summary Page
FOR LINE NUMBER: (check only one)

\begin{tabular}{|c|c|c|c|c|c|}
\hline & & & & & \\
\hline $\mathbf{X}_{19 a}$ & $19 b$ & $20 a$ & $20 b$ & $20 c$ & 21 \\
\hline
\end{tabular}

Any information copied from such Reports and Statements may not be sold or used by any person for the purpose of soliciting contributions or for commercial purposes, other than using the name and address of any political committee to solicit contributions from such committee.

NAME OF COMMITTEE (In Full)

\section{Friends of Herman Cain}

A. Full Name (Last, First, Middle Initial)

Herman Cain

Mailing Address PO Box 2158

\begin{tabular}{lcc}
\hline City & State & Zip Code \\
Stockbridge & GA & $30281-8909$ \\
\hline
\end{tabular}

FEC ID number of contributing federal political committee.

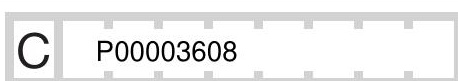

Name of Employer
Receipt For: 2012
X Primary $\quad \square$ General
Other (specify)

Occupation

Election Cycle-to-Date $\boldsymbol{\nabla}$

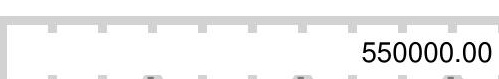

B. Full Name (Last, First, Middle Initial)

\section{Mailing Address}

\begin{tabular}{lll}
\hline City & State & Zip Code
\end{tabular}

FEC ID number of contributing

federal political committee.

C

Name of Employer
Receipt For:
$\begin{aligned} & \text { Primary } \square \text { General } \\ & \square\end{aligned}$

Occupation

Election Cycle-to-Date

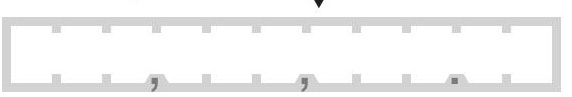

C. Full Name (Last, First, Middle Initial)

Mailing Address

City $\quad$ State Zip Code

FEC ID number of contributing federal political committee.

C

\begin{tabular}{l} 
Name of Employer \\
Receipt For: \\
$\square$ Primary $\square$ General \\
\hline Other (specify)
\end{tabular}

Occupation

Election Cycle-to-Date

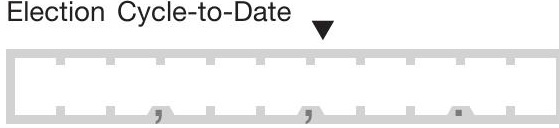

Amount of Each Receipt this Period

Amount of Each Receipt this Period

Date of Receipt
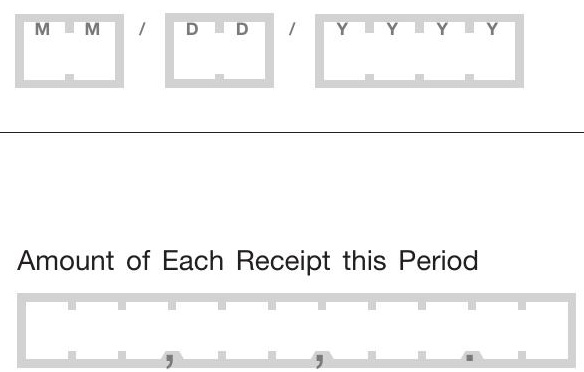

Date of Receipt

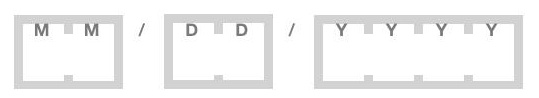

Subtotal Of Receipts This Page (optional)

50000.00

Total This Period (last page this line number only)

175000.00

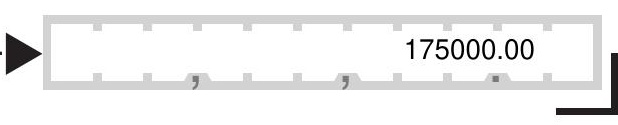

FEC Schedule A-P (Form 3P) (Rev. 03/2011) 


\section{SCHEDULE A-P} ITEMIZED RECEIPTS
Use separate schedule(s) for each category of the Detailed Summary Page

\begin{tabular}{|c|c|c|c|c|c|c|}
\hline \multicolumn{4}{|c|}{$\begin{array}{l}\text { FOR LINE NUMBER: } \\
\text { (check only one) }\end{array}$} & \multicolumn{3}{|c|}{ PAGE 1257 / 1572} \\
\hline 16 & $17 a$ & & $17 \mathrm{~b}$ & $17 \mathrm{c}$ & $17 d$ & 18 \\
\hline $19 a$ & $19 b$ & $x$ & $20 a$ & $20 \mathrm{~b}$ & $20 c$ & 21 \\
\hline
\end{tabular}

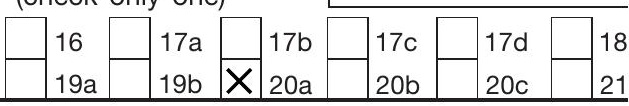

Any information copied from such Reports and Statements may not be sold or used by any person for the purpose of soliciting contributions or for commercial purposes, other than using the name and address of any political committee to solicit contributions from such committee.

NAME OF COMMITTEE (In Full)

\section{Friends of Herman Cain}

A. Full Name (Last, First, Middle Initial) James Brazil

Mailing Address 6 Baldasarri Drive

\begin{tabular}{lcc}
\hline City & State & Zip Code \\
Dunmore & PA & 18505
\end{tabular}

FEC ID number of contributing federal political committee.

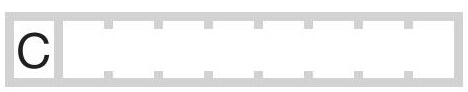

Name of Employer
Information Requested
Receipt For: 2012
X Primary $\quad \square$ General
Other (specify)

Occupation Information Requested

Election Cycle-to-Date 10000.00

B. Full Name (Last, First, Middle Initial) Tri-Net Payroll Services

Mailing Address 1100 San Leandro Boulevard
Suite

\begin{tabular}{lcc}
\hline City & State & Zip Code \\
San Leandro & CA & 94577
\end{tabular}

FEC ID number of contributing

federal political committee.

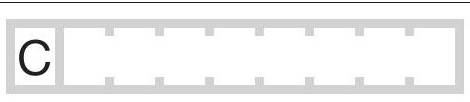

Name of Employer
Receipt For: 2012
$\triangle$ Primary
Other (specify)

Occupation

Election Cycle-to-Date

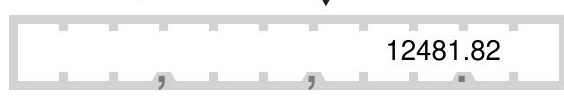

C. Full Name (Last, First, Middle Initial)

Delta Airlines

Mailing Address Post Office Box 20980

Department 980

\begin{tabular}{lcc}
\hline City & State & Zip Code \\
Atlanta & GA & $30320-2980$
\end{tabular}

FEC ID number of contributing federal political committee.

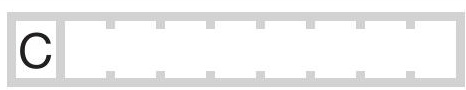

Name of Employer
Receipt For: 2012
X Primary
Other (specify)

Transaction ID : A6D1409181778455A9D3

Date of Receipt

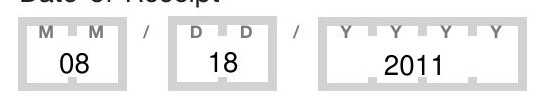

Refund

Amount of Each Receipt this Period

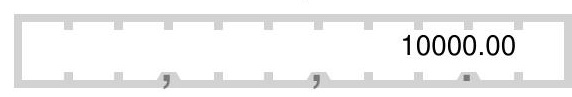

Transaction ID : A6D50BEA83B5443999DB

Date of Receipt

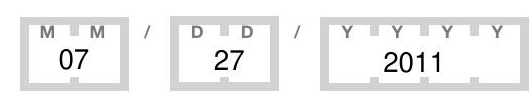

Refund

Amount of Each Receipt this Period

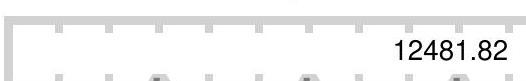

Transaction ID : A1C85C6AE7EE54D6E922 Date of Receipt

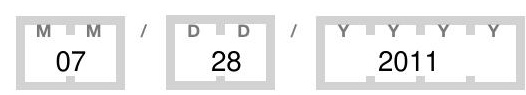

Refund

Amount of Each Receipt this Period

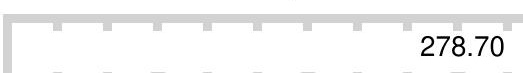

\section{Subtotal Of Receipts This Page (optional)}

Total This Period (last page this line number only) 


\section{SCHEDULE A-P} ITEMIZED RECEIPTS
Use separate schedule(s) for each category of the Detailed Summary Page

\begin{tabular}{|c|c|c|c|c|c|c|}
\hline \multicolumn{4}{|c|}{$\begin{array}{l}\text { FOR LINE NUMBER: } \\
\text { (check only one) }\end{array}$} & \multicolumn{3}{|c|}{ PAGE 1258 / 1572} \\
\hline 16 & $17 a$ & & $17 \mathrm{~b}$ & $17 c$ & $17 d$ & 18 \\
\hline $19 a$ & $19 b$ & $x$ & $20 a$ & $20 \mathrm{~b}$ & $20 c$ & 21 \\
\hline
\end{tabular}

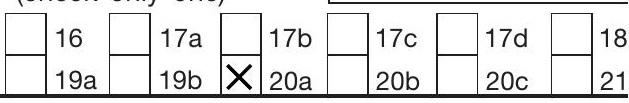

Any information copied from such Reports and Statements may not be sold or used by any person for the purpose of soliciting contributions or for commercial purposes, other than using the name and address of any political committee to solicit contributions from such committee.

NAME OF COMMITTEE (In Full)

\section{Friends of Herman Cain}

A. Full Name (Last, First, Middle Initial)

Hawkeye Stages

Mailing Address 703 Dudley Street

\begin{tabular}{lcc}
\hline City & State & Zip Code \\
Decorah & IA & 52101 \\
\hline
\end{tabular}

FEC ID number of contributing federal political committee.

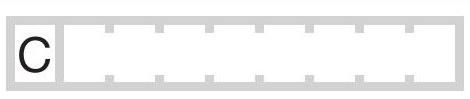

Name of Employer
Receipt For: 2012
X Primary $\quad$ General
Other (specify)

Occupation

Election Cycle-to-Date

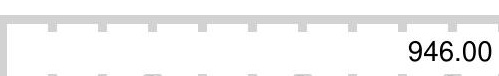

B. Full Name (Last, First, Middle Initial)

Tri-Net Payroll Services

Mailing Address 1100 San Leandro Boulevard Suite

\begin{tabular}{lcc}
\hline City & State & Zip Code \\
San Leandro & CA & 94577
\end{tabular}

FEC ID number of contributing

federal political committee.

C

Name of Employer
Receipt For: 2012
$\times$ Primary $\quad$ General
Other (specify)

Occupation

Election Cycle-to-Date

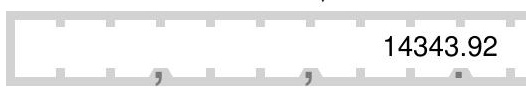

C. Full Name (Last, First, Middle Initial)

Delta Airlines

Mailing Address Post Office Box 20980

Department 980

\begin{tabular}{lcc}
\hline City & State & Zip Code \\
Atlanta & GA & $30320-2980$
\end{tabular}

FEC ID number of contributing federal political committee.

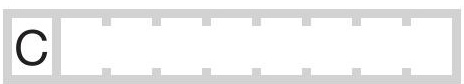

Name of Employer
Receipt For: 2012
Х Primary $\quad \square$ General
Other (specify)

Transaction ID : AA429DA7399394760AEE

Date of Receipt

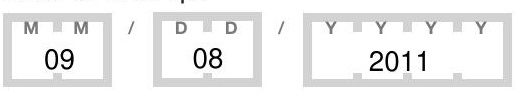

Refund

Amount of Each Receipt this Period

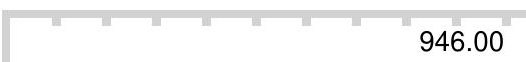

Transaction ID : A099819BBD88348B2B49

Date of Receipt

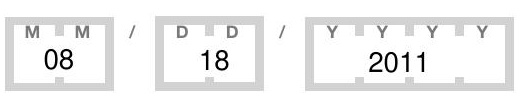

Refund

Amount of Each Receipt this Period

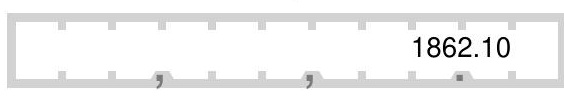

Transaction ID : A5EFD338F07C14850877

Date of Receipt

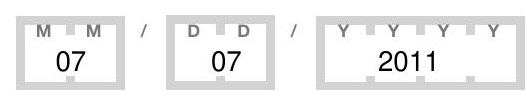

Refund

Amount of Each Receipt this Period

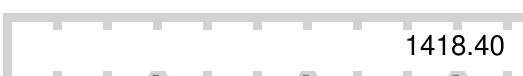

1418.40

Subtotal Of Receipts This Page (optional).

$-\quad 4226.50$

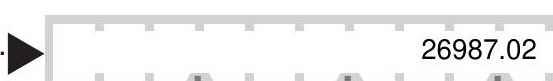

FEC Schedule A-P (Form 3P) (Rev. 03/2011)
26987.02

Total This Period (last page this line number only) 


\section{SCHEDULE B-P}

\section{ITEMIZED DISBURSEMENTS}

Use separate schedule(s)

for each category of the

Detailed Summary Page
FOR LINE NUMBER: (check only one)

\begin{tabular}{|c|c|c|c|}
\hline $\mathrm{X} 23$ & 24 & 25 & 26 \\
\hline $27 \mathrm{~b}$ & $28 a$ & $28 b$ & $28 \mathrm{c}$ \\
\hline
\end{tabular}

Any information copied from such Reports and Statements may not be sold or used by any person for the purpose of soliciting contributions or for commercial purposes, other than using the name and address of any political committee to solicit contributions from such committee.

NAME OF COMMITTEE (In Full)

\section{Friends of Herman Cain}

Full Name (Last, First, Middle Initial)

A. Andrew Roeska

Mailing Address W55N193 Woodmere Ct. \#3

Date of Disbursement

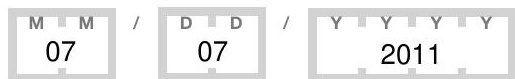

Transaction ID : B25D8AE1813144F92A93

\begin{tabular}{lcc}
\hline City & State & Zip Code \\
Cedarburg & WI & $53012-2833$
\end{tabular}

Purpose of Disbursement

In-kind:Graphic Design

Candidate Name

\begin{tabular}{l|l|l}
\hline Office Sought: & House & Disbursement For: 2012
\end{tabular} X Primary $\square$ General

State:

$$
\begin{aligned}
& \text { Senate } \\
& \text { President }
\end{aligned}
$$

District:

Full Name (Last, First, Middle Initial)

B. James Saleska

Mailing Address 1777 Valley Road

\begin{tabular}{lcc}
\hline City & State & Zip Code \\
West Bend & WI & $53090-8929$
\end{tabular}

Purpose of Disbursement

In-kind:Graphic Design

Candidate Name

Office Sought:

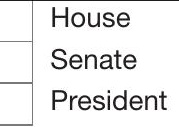

State:

District:

Full Name (Last, First, Middle Initial)

c. Tim Freeman

Mailing Address 22911 Bland Circle

\begin{tabular}{lcc}
\hline City & State & Zip Code \\
West Linn & OR & $97068-9217$
\end{tabular}

Purpose of Disbursement

In-kind:Event Catering

Candidate Name

Disbursement For: 2012

Primary $\square$ General
Other (specify)

\begin{tabular}{l|l|l}
\hline Office Sought: & House
\end{tabular}

\begin{tabular}{|l|l}
\hline & House \\
\hline & Senate \\
& President \\
District:
\end{tabular}

Disbursement For: 2012

Х $\begin{aligned} & \text { Primary } \\ & \text { Other (specify) }\end{aligned}$

State:

District:

Subtotal Of Receipts This Page (optional)

\begin{tabular}{|c|c|c|c|c|}
\hline $08^{M}$ & I & D $04^{\mathrm{D}}$ & 1 & 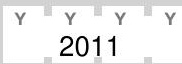 \\
\hline
\end{tabular}

Date of Disbursement

Transaction ID : B6988C2CF32704C9E9FE

Amount of Each Disbursement this Period

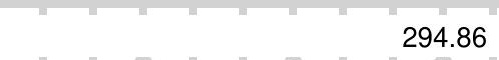

294.86

\begin{tabular}{|c|c|c|c|c|}
\hline $07^{M}$ & / & $07^{\mathrm{D}}$ & 1 & $\begin{array}{llll}Y & Y & Y & Y \\
& 2011\end{array}$ \\
\hline
\end{tabular}

Date of Disbursement

Transaction ID : BF39C56AD2B5646FB988

Amount of Each Disbursement this Period

2400.00

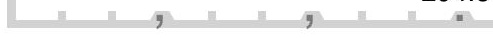
(1)

Total This Period (last page this line number only)) 


\section{SCHEDULE B-P}

\section{ITEMIZED DISBURSEMENTS}

Use separate schedule(s)

for each category of the

Detailed Summary Page
FOR LINE NUMBER: (check only one)

\begin{tabular}{|c|c|c|c|}
\hline $\mathrm{X} 23$ & 24 & 25 & 26 \\
\hline $27 \mathrm{~b}$ & $28 a$ & $28 b$ & $28 \mathrm{c}$ \\
\hline
\end{tabular}

Any information copied from such Reports and Statements may not be sold or used by any person for the purpose of soliciting contributions or for commercial purposes, other than using the name and address of any political committee to solicit contributions from such committee.

NAME OF COMMITTEE (In Full)

\section{Friends of Herman Cain}

Full Name (Last, First, Middle Initial)

A. Rachel Little

Mailing Address 3945 Beaver Road

Date of Disbursement

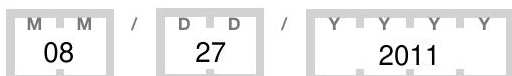

\begin{tabular}{lll}
\hline City & State & Zip Code \\
Loganville & GA & $30052-7554$
\end{tabular}

Purpose of Disbursement

In-kind:Event Bus Rental

Candidate Name

$$
\begin{array}{|l|l}
\text { House } \\
\text { Senate } \\
\text { Presiden }
\end{array}
$$
District:

State:

Full Name (Last, First, Middle Initial)

B. Josh McKoon

Mailing Address PO Box 2565

\begin{tabular}{lcc}
\hline City & State & Zip Code \\
Columbus & GA & $31902-2565$
\end{tabular}

Purpose of Disbursement

In-kind:Event Catering

Candidate Name

Office Sought:

House
Senate
President

State:

District:

Full Name (Last, First, Middle Initial)

\section{c. Hilton Hotels}

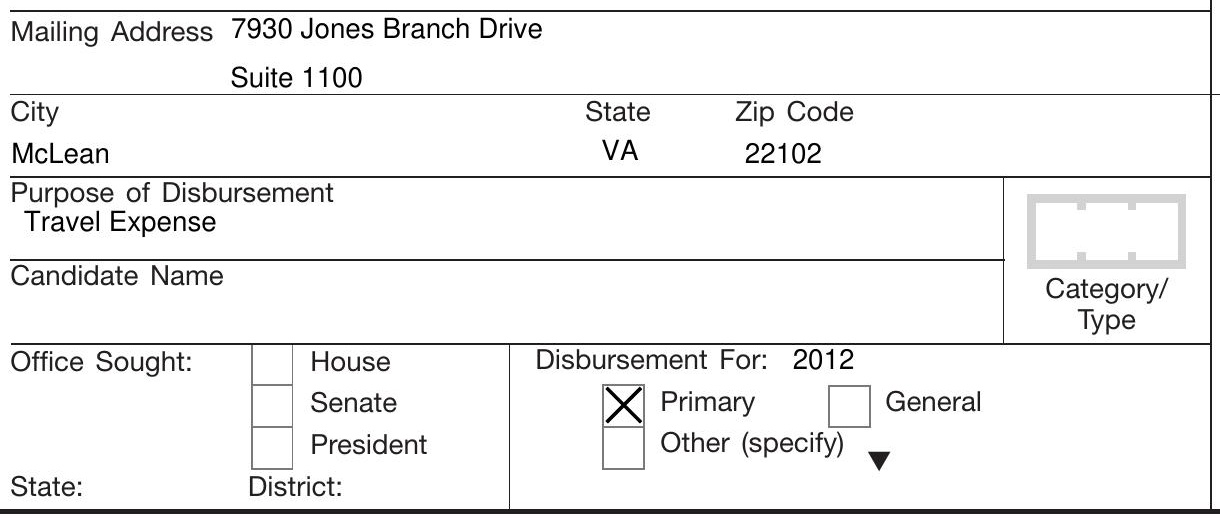

Subtotal Of Receipts This Page (optional).

Date of Disbursement

\begin{tabular}{|c|c|c|c|c|c|}
\hline M M / & D & Y & Y & Y & Y \\
07 & & 01 & & 2011 & \\
\hline
\end{tabular}

Transaction ID : B0CA2B6D001F84A64A5F

Amount of Each Disbursement this Period

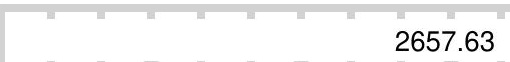

2657.63

Total This Period (last page this line number only))

5141.92

C.

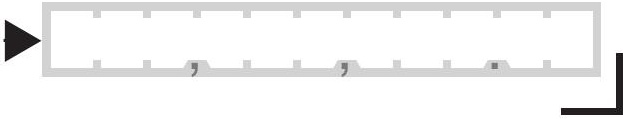

FEC Schedule B-P (Form 3P) (Rev. 03/2011) 


\section{SCHEDULE B-P}

\section{ITEMIZED DISBURSEMENTS}

\section{Use separate schedule(s) \\ for each category of the}

Detailed Summary Page
FOR LINE NUMBER: (check only one)

\begin{tabular}{|c|c|c|c|}
\hline$\times{ }_{23}$ & 24 & 25 & 26 \\
\hline $27 b$ & $28 a$ & $28 \mathrm{~b}$ & $28 \mathrm{c}$ \\
\hline
\end{tabular}

Any information copied from such Reports and Statements may not be sold or used by any person for the purpose of soliciting contributions or for commercial purposes, other than using the name and address of any political committee to solicit contributions from such committee.

NAME OF COMMITTEE (In Full)

\section{Friends of Herman Cain}

Full Name (Last, First, Middle Initial)

A. Event Rentals, Inc.

Mailing Address 225 West Main Street

Date of Disbursement

\begin{tabular}{lcc}
\hline City & State & Zip Code \\
Spartanburg & SC & 29306 \\
\hline
\end{tabular}

Purpose of Disbursement

Event Supplies

Candidate Name

$M-M, D-D$

07

01

2011

Transaction ID : BA1EE62B4B6C842D1BF6

Office Sought:

House

House
Senate
President

District:

State:

irst, Middle Initial)

B. Hawkeye Stages

Mailing Address 703 Dudley Street

\begin{tabular}{lcc}
\hline City & State & Zip Code \\
Decorah & IA & 52101
\end{tabular}

Purpose of Disbursement

Travel Expense

Candidate Name

Disbursement For: 2012 X Primary $\square$ General

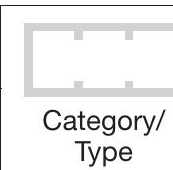

Amount of Each Disbursement this Period

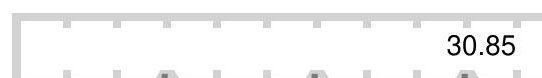

Date of Disbursement

\begin{tabular}{|c|c|c|c|c|}
\hline $07^{M}$ & & $01^{\mathrm{D}}$ & & $\begin{array}{llll} & Y & Y & Y \\
& 2011 & Y\end{array}$ \\
\hline
\end{tabular}

Transaction ID : B0584A97832864D39862

Amount of Each Disbursement this Period

1185.00
Office Sought:

State: c. A \& S Properties Inc.

Mailing Address 255 Racetrack Road

\begin{tabular}{lcc}
\hline City & State & Zip Code \\
McDonough & GA & 30252 \\
\hline
\end{tabular}

Purpose of Disbursement Office Rent Expense

Candidate Name

Office Sought:

State:
Disbursement For: 2012

Xrimary $\square$ General

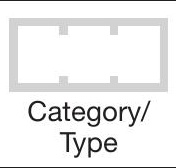

Type

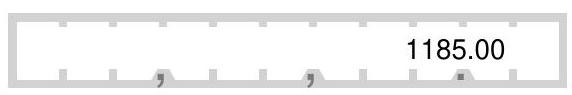

Date of Disbursement

\begin{tabular}{|c|c|c|c|c|c|}
\hline M M / & D & Y & Y Y Y \\
07 & & 01 \\
\hline
\end{tabular}

Transaction ID : BD6D96287CA2A4052AC0

Amount of Each Disbursement this Period

4750.00

Subtotal Of Receipts This Page (optional).

Total This Period (last page this line number only))

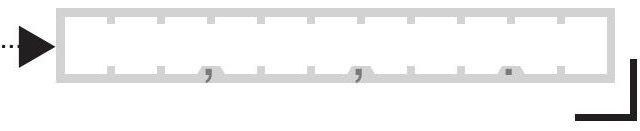




\section{SCHEDULE B-P}

\section{ITEMIZED DISBURSEMENTS}

Use separate schedule(s)

for each category of the

Detailed Summary Page
FOR LINE NUMBER: (check only one)

PAGE 1262 / 1572

\begin{tabular}{|c|c|c|c|}
\hline$X_{23}$ & 24 & 25 & 26 \\
\hline $27 \mathrm{~b}$ & $28 a$ & $28 \mathrm{~b}$ & $28 \mathrm{c}$ \\
\hline
\end{tabular}

Any information copied from such Reports and Statements may not be sold or used by any person for the purpose of soliciting contributions or for commercial purposes, other than using the name and address of any political committee to solicit contributions from such committee.

NAME OF COMMITTEE (In Full)

\section{Friends of Herman Cain}

Full Name (Last, First, Middle Initial)

A. FedEx Kinkos

Mailing Address 942 S. Shady Grove Road

Date of Disbursement

\begin{tabular}{|c|c|c|c|c|c|c|c|}
$M$ & M & Y \\
07 & 01 & 2011
\end{tabular}

Transaction ID : B5704EE280AD8433892D

\begin{tabular}{lll}
\hline City & State & Zip Code \\
Memphis & TN & 38120
\end{tabular}

Purpose of Disbursement

Shipping

Candidate Name

\begin{tabular}{l|l|l}
\hline Office Sought: & House & Disbursement For: 2012
\end{tabular} X Primary $\square$ General

State:

\section{Senate}

President

District:

Full Name (Last, First, Middle Initial)

\section{B. Delta Airlines}

\begin{tabular}{ll}
\hline Mailing Address & Post Office Box 20980 \\
& Department 980 \\
\hline City &
\end{tabular}

Atlanta

$\mathrm{GA}$

Zip Code
$30320-2980$

Purpose of Disbursement

Travel Expense

Candidate Name

Office Sought:

House
Senate
President

State:

District:

Full Name (Last, First, Middle Initial)

\section{c. RMA Chaffeured Transportation}

Mailing Address 6010 Executive Boulevard

\begin{tabular}{lcc}
\multicolumn{3}{c}{ Suite 101} \\
City & State & Zip Code \\
Rockville & MD & 20852
\end{tabular}

Purpose of Disbursement

Travel Expense

Candidate Name

Disbursement For: 2012

Xrimary $\square$ General

\begin{tabular}{|c|c|c|c|}
\hline \multirow[t]{2}{*}{ Office Sought: } & House & \multicolumn{2}{|l|}{ Disbursement For: 2012} \\
\hline & Senate & X Primary & Genera \\
\hline State: & strict: & & $\nabla$ \\
\hline
\end{tabular}

Subtotal Of Receipts This Page (optional).

Date of Disbursement

\begin{tabular}{|c|c|c|c|c|c|c|}
\hline M M / & D & Y & Y & Y \\
07 & & 01 & & 2011 & \\
\hline
\end{tabular}

Transaction ID : BCFB0C131F2214586971

Amount of Each Disbursement this Period

486.39

Date of Disbursement

\begin{tabular}{|c|c|c|c|c|}
\hline $07^{M}$ & I & $01^{\mathrm{D}}$ & 1 & 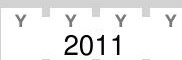 \\
\hline
\end{tabular}

Transaction ID : B86F3F580BAAE4127B73

Amount of Each Disbursement this Period

542.40
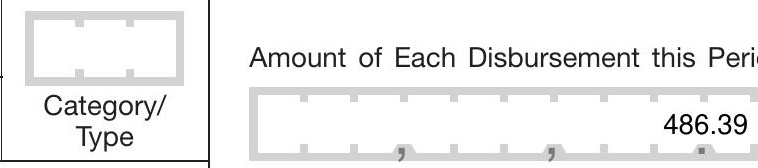

Total This Period (last page this line number only)) 


\section{SCHEDULE B-P}

\section{ITEMIZED DISBURSEMENTS}

\section{Use separate schedule(s) \\ for each category of the}

Detailed Summary Page
FOR LINE NUMBER: (check only one)

\begin{tabular}{|c|c|c|c|}
\hline$\times{ }_{23}$ & 24 & 25 & 26 \\
\hline $27 b$ & $28 a$ & $28 \mathrm{~b}$ & $28 \mathrm{c}$ \\
\hline
\end{tabular}

Any information copied from such Reports and Statements may not be sold or used by any person for the purpose of soliciting contributions or for commercial purposes, other than using the name and address of any political committee to solicit contributions from such committee.

NAME OF COMMITTEE (In Full)

\section{Friends of Herman Cain}

Full Name (Last, First, Middle Initial)

A. Fast Signs

Mailing Address 541 Haywood Road

Date of Disbursement

\begin{tabular}{lll}
\hline City & State & Zip Code \\
Greenville & SC & 29607 \\
\hline Purpose of Disbursement & &
\end{tabular}

Signs

Candidate Name

\begin{tabular}{l|l|l|l}
\hline Office Sought: & House & Disbursement For: 2012
\end{tabular} X Primary $\square$ General

State:

Senate
President
District:

Full Name (Last, First, Middle Initial)

B. The Savoury Corner

Mailing Address 99 Cleveland Street

\begin{tabular}{lcc}
\hline City & State & Zip Code \\
Greenville & SC & 29601
\end{tabular}

Purpose of Disbursement

Event Catering

Candidate Name

Office Sought:

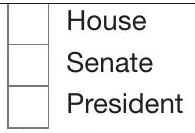

State:

District:

\begin{tabular}{|c|c|} 
& \\
Category/ \\
Type
\end{tabular}

Amount of Each Disbursement this Period

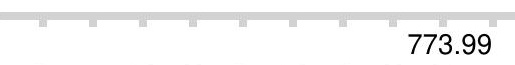

Date of Disbursement

\begin{tabular}{|c|c|c|c|c|}
\hline $07^{\mathrm{M}}$ & 1 & ${ }^{\mathrm{D}}{ }^{\mathrm{D}}$ & 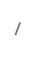 & $\begin{array}{llll}Y & Y & Y & Y \\
& 2011\end{array}$ \\
\hline
\end{tabular}

Transaction ID : BB877ABFEC07E439DA57

Full Name (Last, First, Middle Initial)

c. Mobilization Labs LLC

Mailing Address Attention: Susan Alou

\begin{tabular}{lcc|}
\multicolumn{3}{c}{3384 Peachtree Road NE } \\
\hline City & State & Zip Code \\
Atlanta & GA & 30326 \\
\hline
\end{tabular}

Date of Disbursement

\begin{tabular}{|c|c|c|c|c|c|}
\hline M M / & D & Y & Y & Y & Y \\
07 & & 01 & \\
\hline
\end{tabular}

Purpose of Disbursement

Web Services

Candidate Name

Disbursement For: 2012

Xrimary $\square$ General

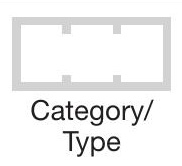

Amount of Each Disbursement this Period

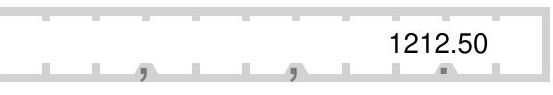

\section{Transaction ID : BF923A8275C8D47E8BC7}

Amount of Each Disbursement this Period

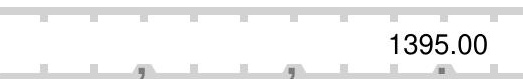

\begin{tabular}{l|l|l}
\hline Office Sought: & $\begin{array}{l}\text { House } \\
\text { Senate }\end{array}$ \\
& $\begin{array}{l}\text { President } \\
\text { State: }\end{array}$ & District:
\end{tabular}

Disbursement For: 2012
$X$ Primary
Other (specify)

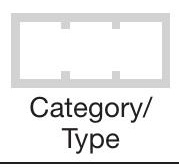

Subtotal Of Receipts This Page (optional).

Total This Period (last page this line number only)) 


\section{SCHEDULE B-P}

\section{ITEMIZED DISBURSEMENTS}

\section{Use separate schedule(s) \\ for each category of the}

Detailed Summary Page
FOR LINE NUMBER: (check only one)

\begin{tabular}{|c|c|c|c|}
\hline$X_{23}$ & 24 & 25 & 26 \\
\hline $27 \mathrm{~b}$ & $28 a$ & $28 b$ & $28 \mathrm{c}$ \\
\hline
\end{tabular}

Any information copied from such Reports and Statements may not be sold or used by any person for the purpose of soliciting contributions or for commercial purposes, other than using the name and address of any political committee to solicit contributions from such committee.

NAME OF COMMITTEE (In Full)

\section{Friends of Herman Cain}

Full Name (Last, First, Middle Initial)

A. Ellen Carmichael

Mailing Address 1007 Oak Hills Parkway

Date of Disbursement

\begin{tabular}{lcc}
\hline City & State & Zip Code \\
Baton Rouge & LA & $70810-4705$ \\
\hline
\end{tabular}

Purpose of Disbursement

Airfare, Lodging and Transportation

Candidate Name

Office Sought:

\begin{tabular}{|l|l} 
& House \\
& Senate \\
President
\end{tabular}

State:

District:

Full Name (Last, First, Middle Initial)

B. James Zeiler

Mailing Address 24059 Borg Road

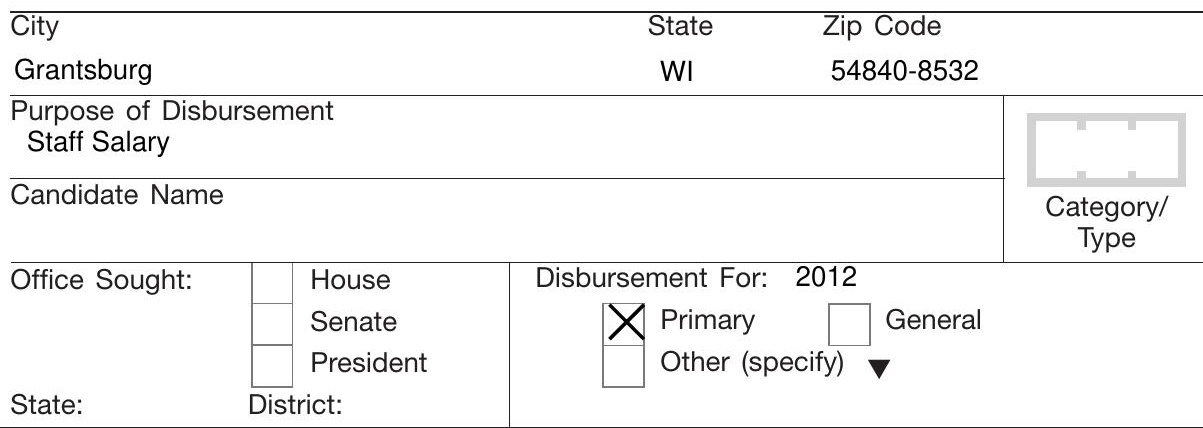

Date of Disbursement

Full Name (Last, First, Middle Initial)

c. Doulos Productions, Inc.

Mailing Address 1450 Corporate Pointe
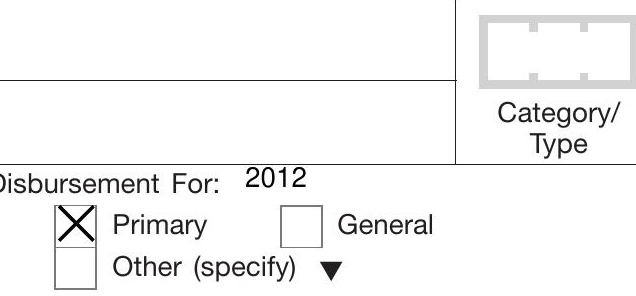

Amount of Each Disbursement this Period

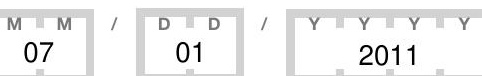

Transaction ID : B8F8F9101C0794DBDB80

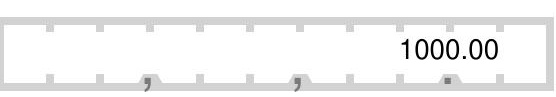

\begin{tabular}{|c|c|c|c|c|}
\hline $07^{\mathrm{M}}$ & 1 & ${ }^{\mathrm{D}}{ }^{\mathrm{D}}$ & & $\begin{array}{llll}Y & Y & Y & Y \\
& 2011 & \end{array}$ \\
\hline
\end{tabular}

Transaction ID : BEACB2F0BE9DD4C1C924

Amount of Each Disbursement this Period

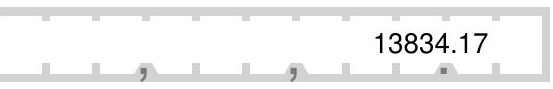

Date of Disbursement

\begin{tabular}{|c|c|c|c|c|c|}
\hline M M / & D & Y & Y Y Y \\
07 & & 05 \\
\hline
\end{tabular}

\begin{tabular}{lcc}
\hline City & State & Zip Code \\
Warner Robins & GA & 31088
\end{tabular}

Purpose of Disbursement

Office Equipment Rental

Candidate Name

(2)

\begin{tabular}{l|l|l}
\hline Office Sought: & & $\begin{array}{l}\text { House } \\
\text { Senate } \\
\end{array}$ \\
& $\begin{array}{l}\text { President } \\
\text { State: }\end{array}$ & District:
\end{tabular}

Disbursement For: 2012
$X$ Primary
Other (specify)

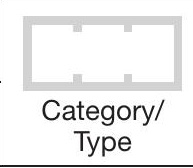

Transaction ID : B4FEEAF4B146E4D9FA11

Amount of Each Disbursement this Period

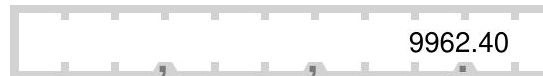

9962.40
Subtotal Of Receipts This Page (optional).

24796.57

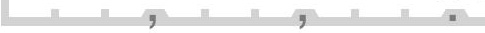

Total This Period (last page this line number only))

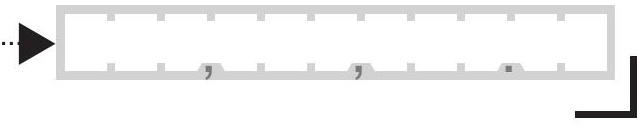

FEC Schedule B-P (Form 3P) (Rev. 03/2011) 


\section{SCHEDULE B-P}

\section{ITEMIZED DISBURSEMENTS}

\section{Use separate schedule(s) \\ for each category of the}

Detailed Summary Page
FOR LINE NUMBER: (check only one)

\begin{tabular}{|c|c|c|c|}
\hline$\times{ }_{23}$ & 24 & 25 & 26 \\
\hline $27 b$ & $28 a$ & $28 \mathrm{~b}$ & $28 \mathrm{c}$ \\
\hline
\end{tabular}

Any information copied from such Reports and Statements may not be sold or used by any person for the purpose of soliciting contributions or for commercial purposes, other than using the name and address of any political committee to solicit contributions from such committee.

NAME OF COMMITTEE (In Full)

\section{Friends of Herman Cain}

Full Name (Last, First, Middle Initial)

\section{A. Air Tran}

Mailing Address 9955 Air Tran Boulevard

Date of Disbursement

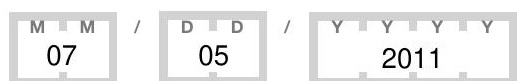

Transaction ID : BADB469FD625D4B81879

\begin{tabular}{lcc}
\hline City & State & Zip Code \\
Orlando & FL & 32827
\end{tabular}

Purpose of Disbursement

Travel Expense

Candidate Name

Office Sought:

$$
\begin{array}{|l|l}
\hline \text { House } \\
\text { Senate } \\
\cline { 1 - 2 } \text { President }
\end{array}
$$

State: District:

Full Name (Last, First, Middle Initial)

B. Inkhead Inc.

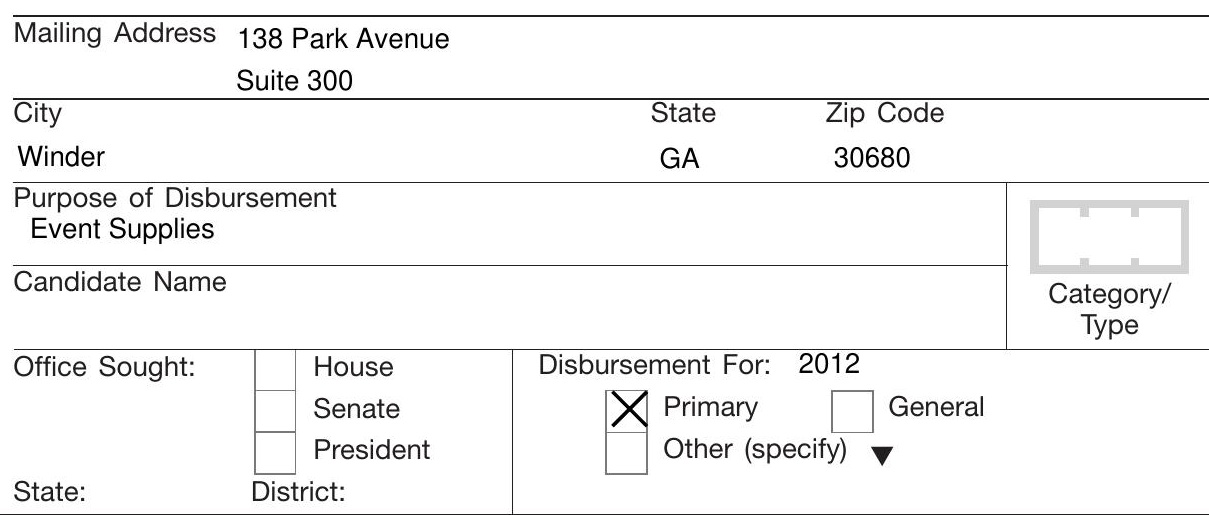

Full Name (Last, First, Middle Initial)

\section{c. RMA Chaffeured Transportation}

Mailing Address 6010 Executive Boulevard

\begin{tabular}{lcc}
\multicolumn{3}{c}{ Suite 101} \\
City & State & Zip Code \\
Rockville & MD & 20852
\end{tabular}

Purpose of Disbursement

Travel Expense

Candidate Name

Office Sought:

\begin{tabular}{|l|l|}
\hline & House \\
& Senate \\
& President \\
& District:
\end{tabular}

\begin{tabular}{|c|c|c|c|c|}
\hline${ }^{\mathrm{M}} 07^{\mathrm{M}}$ & & $05^{\mathrm{D}}$ & & 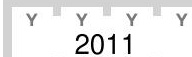 \\
\hline
\end{tabular}

Disbursement For: 2012

X $\begin{aligned} & \text { Primary } \\ & \text { Other (specify) }\end{aligned}$
Transaction ID : B4DA0DB64718A4E1E843

Amount of Each Disbursement this Period

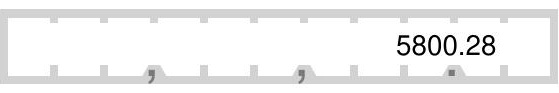

Date of Disbursement

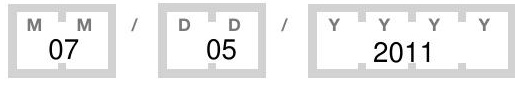

Transaction ID : BB3309836C1B14DD7941

Amount of Each Disbursement this Period

1312.48
Date of Disbursement

State:

District:

Subtotal Of Receipts This Page (optional).

Total This Period (last page this line number only))

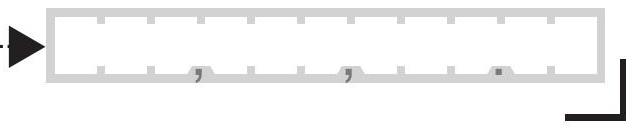




\section{SCHEDULE B-P}

\section{ITEMIZED DISBURSEMENTS}

\section{Use separate schedule(s) \\ for each category of the}

Detailed Summary Page
FOR LINE NUMBER: (check only one)

\begin{tabular}{|c|c|c|c|}
\hline$\times{ }_{23}$ & 24 & 25 & 26 \\
\hline $27 b$ & $28 a$ & $28 \mathrm{~b}$ & $28 \mathrm{c}$ \\
\hline
\end{tabular}

Any information copied from such Reports and Statements may not be sold or used by any person for the purpose of soliciting contributions or for commercial purposes, other than using the name and address of any political committee to solicit contributions from such committee.

NAME OF COMMITTEE (In Full)

\section{Friends of Herman Cain}

Full Name (Last, First, Middle Initial)

A. United Airlines

Mailing Address 1200 E Algonquin Road

Post Office Box 66100

\begin{tabular}{lcl}
\hline City & State & Zip Code \\
Elk Grove Township & IL & 60007 \\
\hline
\end{tabular}

Purpose of Disbursement

Travel Expense

Candidate Name

Office Sought:

House
Senate
President
District:

Disbursement For: 2012 X Primary $\square$ General

B. Gateway Billing

\begin{tabular}{ll}
\hline Mailing Address & authorize.net \\
& Post Office Box 8999
\end{tabular}

San Francisco

Purpose of Disbursement

CC Transaction Fees

Candidate Name

Office Sought:

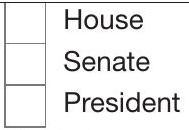

State:

District:
Date of Disbursement

\begin{tabular}{|c|c|c|c|c|c|}
\hline M M & Y \\
07 & 05 & 2011 \\
\hline
\end{tabular}

Transaction ID : B62B9DA05002D4753B5F

Amount of Each Disbursement this Period 499.20

Date of Disbursement

\begin{tabular}{|c|c|c|c|c|}
\hline $07^{M}$ & 1 & $05^{\mathrm{D}}$ & I & $\begin{array}{llll} & Y & Y & Y \\
& 2011 & Y\end{array}$ \\
\hline
\end{tabular}

Transaction ID : B105B9E92DAA54B79A02

Amount of Each Disbursement this Period

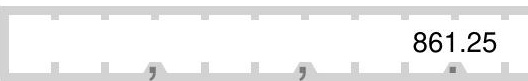

Date of Disbursement

\begin{tabular}{|c|c|c|c|c|c|c|}
\hline M M / & D & Y & Y & Y & Y \\
07 & & 05 & & 2011 & \\
\hline
\end{tabular}

Transaction ID : BCA5E52FC5506494AB43

Amount of Each Disbursement this Period

678.68 Type

\begin{tabular}{|c|c|c|c|}
\hline \multirow[t]{3}{*}{ Office Sought: } & House & \multicolumn{2}{|l|}{ Disbursement For: 2012} \\
\hline & Senate & Х Primary & General \\
\hline & President & Other (specify) & \\
\hline
\end{tabular}

Subtotal Of Receipts This Page (optional).

Total This Period (last page this line number only)) 


\section{SCHEDULE B-P}

\section{ITEMIZED DISBURSEMENTS}

\section{Use separate schedule(s)}

for each category of the

Detailed Summary Page
FOR LINE NUMBER: (check only one)

\begin{tabular}{|c|c|c|c|}
\hline$\times{ }_{23}$ & 24 & 25 & 26 \\
\hline $27 b$ & $28 a$ & $28 \mathrm{~b}$ & $28 \mathrm{c}$ \\
\hline
\end{tabular}

Any information copied from such Reports and Statements may not be sold or used by any person for the purpose of soliciting contributions or for commercial purposes, other than using the name and address of any political committee to solicit contributions from such committee.

NAME OF COMMITTEE (In Full)

\section{Friends of Herman Cain}

Full Name (Last, First, Middle Initial)

A. Crowne Plaza Hotel \& Resorts

Mailing Address 2 Somerset Parkway

Date of Disbursement

\begin{tabular}{lll}
\hline City & State & Zip Code \\
Nashua & $\mathrm{NH}$ & 03063 \\
\hline
\end{tabular}

Purpose of Disbursement

Travel Expense

Candidate Name

\begin{tabular}{l|l|l}
\hline Office Sought: & House & Disbursement For: 2012
\end{tabular} X Primary $\square$ General

State:

\section{Senate}

President

Full Name (Last, First, Middle Initial)

\section{B. FedEx Kinkos}

Mailing Address 942 S. Shady Grove Road

\begin{tabular}{|c|c|c|c|c|}
\hline \multicolumn{2}{|l|}{ City } & \multicolumn{3}{|c|}{ Zip Code } \\
\hline \multicolumn{2}{|l|}{ Memphis } & \multicolumn{3}{|c|}{38120} \\
\hline \multicolumn{4}{|c|}{$\begin{array}{l}\text { Purpose of Disbursement } \\
\text { Shipping }\end{array}$} & \\
\hline \multicolumn{4}{|c|}{ Candidate Name } & $\begin{array}{l}\text { Category/ } \\
\text { Type }\end{array}$ \\
\hline \multirow[t]{3}{*}{ Office Sought: } & House & \multirow{3}{*}{\multicolumn{3}{|c|}{$\begin{array}{l}\text { Disbursement For: } 2012 \\
\text { Xrimary } \\
\text { Other (specify) }\end{array}$}} \\
\hline & \multirow{2}{*}{$\begin{array}{l}\text { Senate } \\
\text { President }\end{array}$} & & & \\
\hline & & & & \\
\hline State: & ict: & & \multicolumn{2}{|l|}{$\nabla$} \\
\hline
\end{tabular}

Date of Disbursement

Full Name (Last, First, Middle Initial)

\section{SunTrust Bank}

Mailing Address 980 Eagles Landing Parkway

\begin{tabular}{lcc}
\hline City & State & Zip Code \\
Stockbridge & GA & 30281
\end{tabular}

Purpose of Disbursement

Bank Fees

Candidate Name

Office Sought: $\quad$ House

\begin{tabular}{l|l} 
& House \\
& Senate \\
& President \\
& \\
District:
\end{tabular}

State:

District:

Disbursement For: 2012
$X$ Primary
Other (specify)

Date of Disbursement

\begin{tabular}{|c|c|c|c|c|c|c|}
\hline M & M & D & Y & Y & Y & Y \\
07 & & 05 & & 2011 & \\
\hline
\end{tabular}

Transaction ID : BC5C14779B7754B6788E

Amount of Each Disbursement this Period

36.00

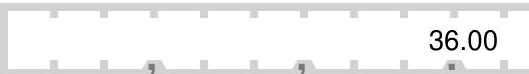

Transaction ID : BF2BBD9A134DC42009B3

Amount of Each Disbursement this Period

371.50

566.28

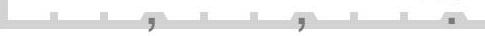

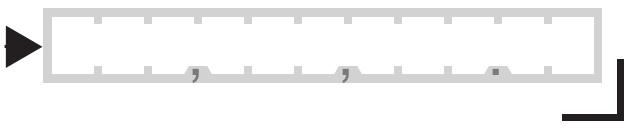

FEC Schedule B-P (Form 3P) (Rev. 03/2011) 


\section{SCHEDULE B-P}

\section{ITEMIZED DISBURSEMENTS}

Use separate schedule(s)

for each category of the

Detailed Summary Page
FOR LINE NUMBER: (check only one)

\begin{tabular}{|c|c|c|c|}
\hline$\times{ }_{23}$ & 24 & 25 & 26 \\
\hline $27 b$ & $28 a$ & $28 \mathrm{~b}$ & $28 \mathrm{c}$ \\
\hline
\end{tabular}

Any information copied from such Reports and Statements may not be sold or used by any person for the purpose of soliciting contributions or for commercial purposes, other than using the name and address of any political committee to solicit contributions from such committee.

NAME OF COMMITTEE (In Full)

\section{Friends of Herman Cain}

Full Name (Last, First, Middle Initial)

A. Amtrak

Mailing Address 60 Massacheusetts Avenue

Date of Disbursement

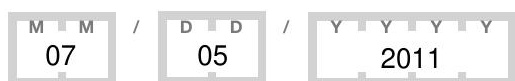

Transaction ID : B86A5508FBBAD47A1BD7

\begin{tabular}{lll}
\hline City & State & Zip Code \\
Washington & DC & $20002-4225$
\end{tabular}

Purpose of Disbursement

Travel Expense

Candidate Name

Office Sought:

\begin{tabular}{l|l} 
& $\begin{array}{l}\text { House } \\
\text { Senate } \\
\text { President }\end{array}$ \\
\\
District:
\end{tabular}

Disbursement For: 2012 X Primary $\square$ General

State:

District:

Full Name (Last, First, Middle Initial)

B. Delta Airlines

Mailing Address Post Office Box 20980

City Department 980

Atlanta

GA $\quad$ 30320-2980

Purpose of Disbursement

Travel Expense

Candidate Name

Office Sought:

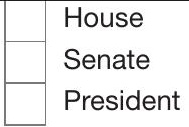

State:

District:

Full Name (Last, First, Middle Initial)

\section{c. Avis Rent A Car}

Mailing Address 900 Old Country Garden Road

\begin{tabular}{lcc}
\hline City & State & Zip Code \\
Garden City & NY & 11530
\end{tabular}

Purpose of Disbursement

Travel Expense

Candidate Name

Disbursement For: 2012

Primary
Other (specify)

Office Sought:

\begin{tabular}{|c|}
\hline House \\
\hline Senate \\
\hline President \\
\hline
\end{tabular}

Disbursement For: 2012

Х $\begin{aligned} & \text { Primary } \\ & \text { Other (specify) }\end{aligned}$

State:

District:
Date of Disbursement

\begin{tabular}{|c|c|c|c|c|}
\hline $07^{M}$ & 1 & $05^{\mathrm{D}}$ & I & 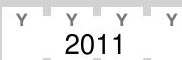 \\
\hline
\end{tabular}

Transaction ID : B39B088847F9D4527B3F

Amount of Each Disbursement this Period

2035.80

Date of Disbursement

\begin{tabular}{|c|c|c|c|c|c|c|}
\hline M M / & D & Y & Y & Y & Y \\
07 & & 05 & & 2011 & \\
\hline
\end{tabular}

Transaction ID : BF0D2FEF2A9A742D9AA5

Amount of Each Disbursement this Period

159.25 Type

Subtotal Of Receipts This Page (optional).

Total This Period (last page this line number only))

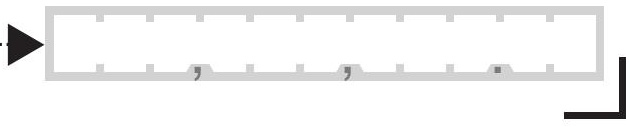




\section{SCHEDULE B-P}

\section{ITEMIZED DISBURSEMENTS}

\section{Use separate schedule(s) \\ for each category of the}

Detailed Summary Page
FOR LINE NUMBER: (check only one)

\begin{tabular}{|c|c|c|c|}
\hline$X_{23}$ & 24 & 25 & 26 \\
\hline $27 \mathrm{~b}$ & $28 a$ & $28 b$ & $28 \mathrm{c}$ \\
\hline
\end{tabular}

Any information copied from such Reports and Statements may not be sold or used by any person for the purpose of soliciting contributions or for commercial purposes, other than using the name and address of any political committee to solicit contributions from such committee.

NAME OF COMMITTEE (In Full)

\section{Friends of Herman Cain}

Full Name (Last, First, Middle Initial)

A. Tri-Net Payroll Services

Mailing Address 1100 San Leandro Boulevard

Suite

\begin{tabular}{lll}
\hline City & State & Zip Code \\
San Leandro & CA & 94577
\end{tabular}

Purpose of Disbursement

Payroll Service Fee

Candidate Name

Office Sought:

District:

Full Name (Last, First, Middle Initial)

B. Atlanta Perimeter Hotel \& Suites

Mailing Address 111 Perimeter Center West

\begin{tabular}{lcc}
\hline City & State & Zip Code \\
Atlanta & GA & 30346
\end{tabular}

Purpose of Disbursement

Travel Expense

Candidate Name

Office Sought:

$$
\begin{aligned}
& \text { House } \\
& \text { Senate } \\
& \text { President }
\end{aligned}
$$

State:

District:

Full Name (Last, First, Middle Initial)

c. Ethridge and Associates, LLC

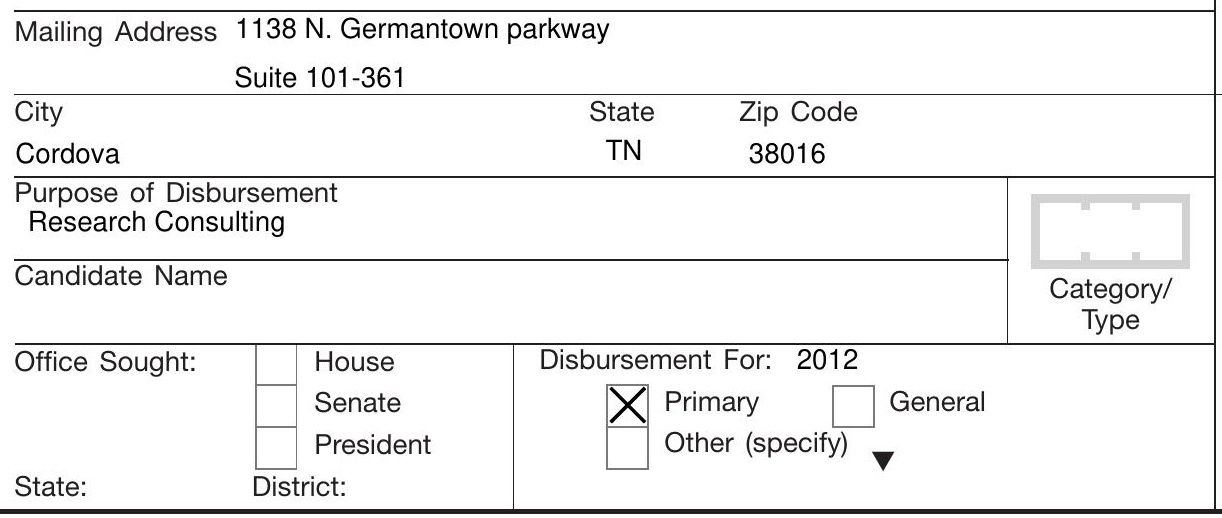

Subtotal Of Receipts This Page (optional). X Primary $\square$ General
Date of Disbursement

\begin{tabular}{|c|c|c|c|c|c|c|}
\hline$M$ & M & Y \\
07 & 05 & 2011 \\
\hline
\end{tabular}

Transaction ID : B4FC5F73DD7654B448D6

Amount of Each Disbursement this Period

\begin{tabular}{|c|c|c|c|c|}
\hline $07^{\mathrm{M}}$ & & $05^{\mathrm{D}}$ & & $\begin{array}{lll}Y & Y & Y \\
2011 & Y\end{array}$ \\
\hline
\end{tabular}

47.00

Date of Disbursement

Transaction ID : B3523219FBA7B4165915

Amount of Each Disbursement this Period

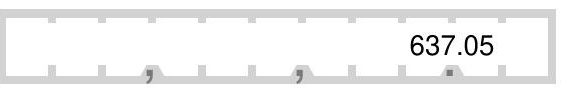

Date of Disbursement

\begin{tabular}{|c|c|c|c|c|c|c|}
\hline M M & I & D & Y & Y & Y \\
07 & & 05 & & 2011 & \\
\hline
\end{tabular}

Transaction ID : BF88DB1F58AFA4224B4A

Amount of Each Disbursement this Period

10000.00

Total This Period (last page this line number only))...

10684.05
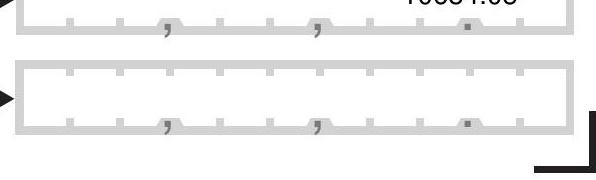

FEC Schedule B-P (Form 3P) (Rev. 03/2011) 


\section{SCHEDULE B-P}

\section{ITEMIZED DISBURSEMENTS}

Use separate schedule(s)

for each category of the

Detailed Summary Page
FOR LINE NUMBER: (check only one)

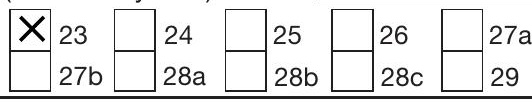

Any information copied from such Reports and Statements may not be sold or used by any person for the purpose of soliciting contributions or for commercial purposes, other than using the name and address of any political committee to solicit contributions from such committee.

NAME OF COMMITTEE (In Full)

\section{Friends of Herman Cain}

Full Name (Last, First, Middle Initial)

A. US Postal Service

Mailing Address 110 Walter Way

Date of Disbursement

\begin{tabular}{lcc}
\hline City & State & Zip Code \\
Stockbridge & GA & 30281 \\
\hline Purpose of Disbursement & &
\end{tabular}

Pisbursement

Postage

Candidate Name

\begin{tabular}{l|l|l}
\hline Office Sought: & House & Disbursement For: 2012
\end{tabular} Xrimary $\square$ General

State:

\section{Senate}

President

District:

Full Name (Last, First, Middle Initial)

B. Orbitz (ORB)

Mailing Address 500 W. Madison Street

\begin{tabular}{lcc}
\hline City & State & Zip Code \\
Chicago & IL & 60661
\end{tabular}

Purpose of Disbursement

Travel Expense

Candidate Name

Office Sought:

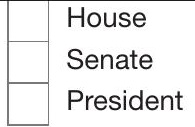

State:

District:
IL 60661
Date of Disbursement

\begin{tabular}{|c|c|c|c|c|}
\hline${ }^{\mathrm{M}} 07^{\mathrm{M}}$ & & $05^{\mathrm{D}}$ & & 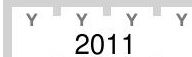 \\
\hline
\end{tabular}

Transaction ID : BB00DCF8BC7D94E5E85D

Amount of Each Disbursement this Period

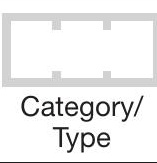

\section{Disbursement For: 2012 \\ Primary
Other (specify)}

Full Name (Last, First, Middle Initial)

\section{c. Hilton Hotels}

\begin{tabular}{|c|c|c|c|c|c|}
\hline \multicolumn{6}{|c|}{ Mailing Address 7930 Jones Branch Drive } \\
\hline \multicolumn{6}{|c|}{ Zip Code } \\
\hline \multicolumn{2}{|l|}{ McLean } & VA & 22102 & & \\
\hline \multicolumn{5}{|c|}{$\begin{array}{l}\text { Purpose of Disbursement } \\
\text { Travel Expense }\end{array}$} & \\
\hline \multicolumn{5}{|l|}{ Candidate Name } & $\begin{array}{l}\text { Category/ } \\
\text { Type }\end{array}$ \\
\hline \multirow[t]{3}{*}{ Office Sought: } & House & \multicolumn{4}{|c|}{ Disbursement For: 2012} \\
\hline & Senate & $y$ & ary & General & \\
\hline & President & & (specify) & $\nabla$ & \\
\hline State: & rict: & & & & \\
\hline
\end{tabular}

Subtotal Of Receipts This Page (optional).

Date of Disbursement

\begin{tabular}{|c|c|c|c|c|c|c|}
\hline M M & I & D & Y & Y & Y \\
07 & & 05 & & 2011 & \\
\hline
\end{tabular}

Transaction ID : B9AC0F3E20CDC4C98A59

Amount of Each Disbursement this Period

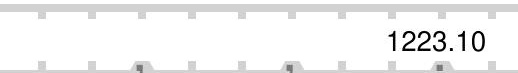

1223.10

Total This Period (last page this line number only)) 


\section{SCHEDULE B-P}

\section{ITEMIZED DISBURSEMENTS}

Use separate schedule(s)

for each category of the

Detailed Summary Page
FOR LINE NUMBER: (check only one)

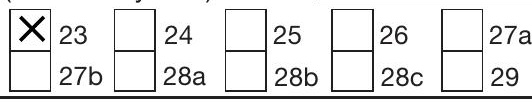

Any information copied from such Reports and Statements may not be sold or used by any person for the purpose of soliciting contributions or for commercial purposes, other than using the name and address of any political committee to solicit contributions from such committee.

NAME OF COMMITTEE (In Full)

\section{Friends of Herman Cain}

Full Name (Last, First, Middle Initial)

A. Tri-Net Payroll Services

Mailing Address 1100 San Leandro Boulevard

Suite

Date of Disbursement

\begin{tabular}{lll}
\multicolumn{2}{c}{ Suite } \\
\hline City & State & Zip Code \\
San Leandro & CA & 94577 \\
\hline Purpose of Disbursement & &
\end{tabular}

Purpose of Disbursement

Payroll Withholding

Candidate Name

Office Sought:

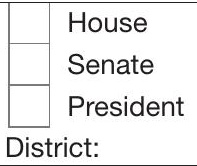

Disbursement For: 2012 X Primary $\square$ General

State: District:

Full Name (Last, First, Middle Initial)

B. Omni Hotels \& Resorts

\begin{tabular}{|c|c|c|c|c|}
\hline \multicolumn{5}{|c|}{ Mailing Address 100 CNN Center } \\
\hline \multicolumn{2}{|l|}{ City } & \multicolumn{3}{|c|}{ Zip Code } \\
\hline \multicolumn{2}{|l|}{ Atlanta } & \multicolumn{3}{|c|}{30303} \\
\hline \multicolumn{4}{|c|}{$\begin{array}{l}\text { Purpose of Disbursement } \\
\text { Travel Expense }\end{array}$} & \\
\hline \multicolumn{4}{|l|}{ Candidate Name } & $\begin{array}{l}\text { Category/ } \\
\text { Type }\end{array}$ \\
\hline \multirow[t]{3}{*}{ Office Sought: } & House & \multirow{3}{*}{\multicolumn{3}{|c|}{$\begin{array}{l}\text { Disbursement For: } 2012 \\
\text { X Primary } \\
\text { Other (specify) }\end{array}$}} \\
\hline & \multirow{2}{*}{$\begin{array}{l}\text { Senate } \\
\text { President }\end{array}$} & & & \\
\hline & & & & \\
\hline State: & rict: & & & \\
\hline
\end{tabular}

Date of Disbursement

\begin{tabular}{|c|c|c|c|c|}
\hline $07^{\mathrm{M}}$ & 1 & $06^{\mathrm{D}}$ & 1 & $\begin{array}{llll}Y & Y & Y & Y \\
& & Y & \\
& & \end{array}$ \\
\hline
\end{tabular}

Transaction ID : BEF17E902298E418B9A5

Full Name (Last, First, Middle Initial)

\section{c. US Postal Service}

\begin{tabular}{|c|c|c|c|c|c|}
\hline \multicolumn{6}{|c|}{ Mailing Address 110 Walter Way } \\
\hline \multicolumn{2}{|l|}{ City } & State & \multicolumn{3}{|l|}{ Zip Code } \\
\hline \multicolumn{2}{|l|}{ Stockbridge } & GA & \multicolumn{3}{|l|}{30281} \\
\hline \multicolumn{5}{|c|}{$\begin{array}{l}\text { Purpose of Disbursement } \\
\text { Postage }\end{array}$} & \\
\hline \multicolumn{5}{|c|}{ Candidate Name } & $\begin{array}{l}\text { Category/ } \\
\text { Type }\end{array}$ \\
\hline \multirow[t]{3}{*}{ Office Sought: } & House & \multicolumn{4}{|c|}{ Disbursement For: 2012} \\
\hline & Senate & \multirow{3}{*}{\multicolumn{2}{|c|}{$\begin{array}{l}\text { Primary } \\
\text { Other (specify) }\end{array}$}} & \multirow{2}{*}{\multicolumn{2}{|c|}{ General }} \\
\hline & President & & & & \\
\hline State: & District: & & & & \\
\hline
\end{tabular}

Subtotal Of Receipts This Page (optional).

Date of Disbursement

\begin{tabular}{|c|c|c|c|c|}
\hline M $07^{\mathrm{M}}$ & I & D 06 & 1 & $\begin{array}{cccc}Y & Y & Y & Y \\
& 2011 & \end{array}$ \\
\hline
\end{tabular}

Transaction ID : B779671A771094BA0A93

Amount of Each Disbursement this Period

Amount of Each Disbursement this Period
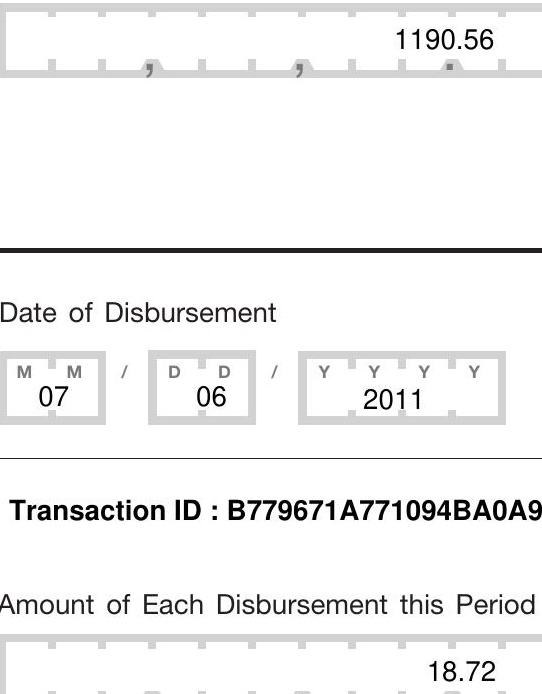

18.72

Total This Period (last page this line number only)) 


\section{SCHEDULE B-P}

\section{ITEMIZED DISBURSEMENTS}

\section{Use separate schedule(s) \\ for each category of the}

Detailed Summary Page
FOR LINE NUMBER: (check only one)

\begin{tabular}{|c|c|c|c|}
\hline$\times{ }_{23}$ & 24 & 25 & 26 \\
\hline $27 b$ & $28 a$ & $28 \mathrm{~b}$ & $28 \mathrm{c}$ \\
\hline
\end{tabular}

Any information copied from such Reports and Statements may not be sold or used by any person for the purpose of soliciting contributions or for commercial purposes, other than using the name and address of any political committee to solicit contributions from such committee.

NAME OF COMMITTEE (In Full)

\section{Friends of Herman Cain}

Full Name (Last, First, Middle Initial)

A. Hyatt Hotels

\begin{tabular}{|c|c|c|c|c|}
\hline \multicolumn{5}{|c|}{$\begin{array}{ll}\text { Mailing Address } & 71 \mathrm{~S} . \text { Wacker Dr. } \\
& \text { 12th Floor } \\
\end{array}$} \\
\hline \multicolumn{2}{|l|}{ City } & \multicolumn{3}{|c|}{ Zip Code } \\
\hline \multicolumn{2}{|l|}{ Chicago } & \multicolumn{3}{|c|}{60606} \\
\hline \multicolumn{4}{|c|}{$\begin{array}{l}\text { Purpose of Disbursement } \\
\text { Travel Expense }\end{array}$} & \\
\hline \multicolumn{4}{|l|}{ Candidate Name } & $\begin{array}{l}\text { Category/ } \\
\text { Type }\end{array}$ \\
\hline \multirow[t]{3}{*}{ Office Sought: } & House & \multirow{3}{*}{\multicolumn{3}{|c|}{$\begin{array}{l}\text { Disbursement For: } 2012 \\
\text { X } \begin{array}{l}\text { Primary } \\
\text { Other (specify) }\end{array}\end{array}$}} \\
\hline & Senate & & & \\
\hline & President & & & \\
\hline State: & District: & & & \\
\hline
\end{tabular}

Date of Disbursement

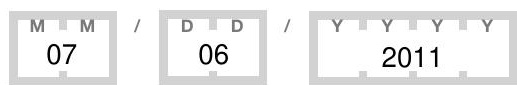

Transaction ID : B8E0DC28E93374ACA8A2

Amount of Each Disbursement this Period

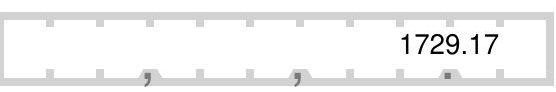

\section{Full Name (Last, First, Middle Initial)}

B. Hampton Inn Hotels

Mailing Address 7930 Jones Branch Drive

\begin{tabular}{lcc}
\hline City & State & Zip Code \\
McLean & VA & 22102
\end{tabular}

Purpose of Disbursement

Travel Expense

Candidate Name

Office Sought:

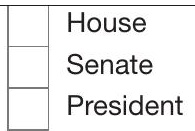

State:

District:

VA

$(2102$

Full Name (Last, First, Middle Initial)

\section{c. Michael Branch}

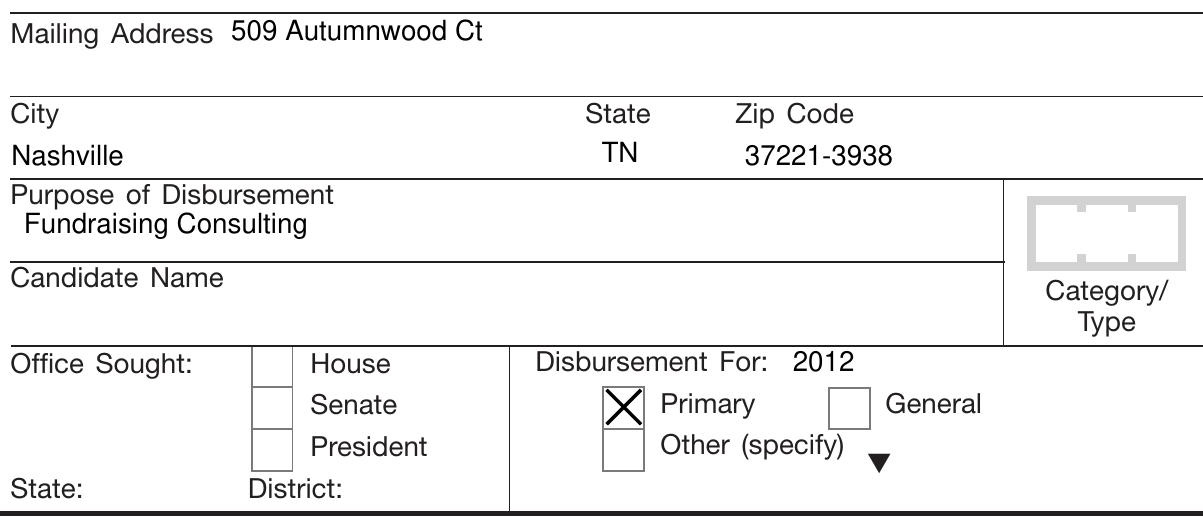

Subtotal Of Receipts This Page (optional).

Date of Disbursement

\begin{tabular}{|c|c|c|c|c|c|}
\hline M M / & D & Y & Y & Y & Y \\
07 & & 06 & & 2011 & \\
\hline
\end{tabular}

Transaction ID : B3A78F10DA4DD4095BB8

Amount of Each Disbursement this Period

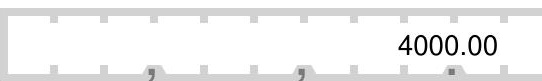

Date of Disbursement

\begin{tabular}{|c|c|c|c|c|}
\hline${ }^{\mathrm{M}} 7^{\mathrm{M}}$ & & ${ }^{\mathrm{D}} 6^{\mathrm{D}}$ & 1 & $\begin{array}{llll}Y & Y & Y & Y \\
& 2011\end{array}$ \\
\hline
\end{tabular}

Transaction ID : B383991C344924FD495F

Amount of Each Disbursement this Period

648.63

$$
\begin{aligned}
& \text { Primary } \\
& \text { Other (specify) General }
\end{aligned}
$$

Total This Period (last page this line number only)) 


\section{SCHEDULE B-P}

\section{ITEMIZED DISBURSEMENTS}

\section{Use separate schedule(s) \\ for each category of the}

Detailed Summary Page
FOR LINE NUMBER: (check only one)

\begin{tabular}{|c|c|c|c|c|}
\hline $\mathrm{X}_{23}$ & 24 & 25 & 26 & \\
\hline $27 \mathrm{~b}$ & $28 a$ & $28 b$ & $28 \mathrm{c}$ & 2 \\
\hline
\end{tabular}

Any information copied from such Reports and Statements may not be sold or used by any person for the purpose of soliciting contributions or for commercial purposes, other than using the name and address of any political committee to solicit contributions from such committee.

NAME OF COMMITTEE (In Full)

\section{Friends of Herman Cain}

Full Name (Last, First, Middle Initial)

A. John Chauhan

Mailing Address 3810 Jamaica Drive

Date of Disbursement

\begin{tabular}{lcc}
\hline City & State & Zip Code \\
Jonesboro & GA & $30236-5427$ \\
\hline Purpose of Disbursement & &
\end{tabular}

Purpose of Disbursement

Staff Housing

Candidate Name

Office Sought: $\quad$ House

\section{House
Senate}

President

State:

District:

Full Name (Last, First, Middle Initial)

B. New Hampshire Fisher Cats

Disbursement For: 2012 X Primary $\square$ General

Mailing Address 1 Line Drive

\begin{tabular}{lcc}
\hline City & State & Zip Code \\
Manchester & $\mathrm{NH}$ & 03101
\end{tabular}

Purpose of Disbursement

Event Tickets

Candidate Name

Office Sought:

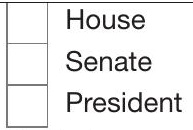

State:

District:

Full Name (Last, First, Middle Initial)

c. Frontier Airlines Inc.

Mailing Address 7001 Tower Road

Disbursement For: 2012

X Primary $\square$ General

Date of Disbursement

\begin{tabular}{|c|c|c|c|c|}
\hline${ }^{M}{ }^{\mathrm{M}} / 7^{\mathrm{D}}$ & $\mathrm{P}^{\mathrm{D}}$ & $\mathrm{Y}^{\mathrm{Y}} \mathrm{Y}$ \\
\hline
\end{tabular}

Transaction ID : BD33ED41A4C7F46AF86A

Amount of Each Disbursement this Period

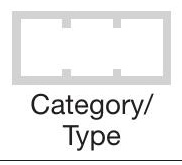

Amount of Each Disbursement this Period

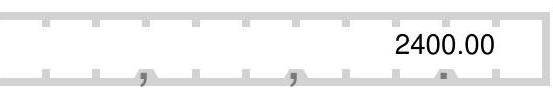

Type

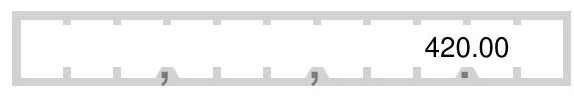

Date of Disbursement

\begin{tabular}{|c|c|c|c|c|c|}
\hline M M / & D & Y & Y & Y \\
07 & & 07 & & \\
\hline & & 2011 & \\
\hline
\end{tabular}

\begin{tabular}{lcc}
\hline City & State & Zip Code \\
Denver & CO & $80249-7312$
\end{tabular}

Purpose of Disbursement

Travel Expense

Candidate Name

(1)

\begin{tabular}{l|l|l}
\hline Office Sought: & & $\begin{array}{l}\text { House } \\
\text { Senate } \\
\end{array}$ \\
& $\begin{array}{l}\text { President } \\
\text { State: }\end{array}$ & District:
\end{tabular}

Disbursement For: 2012
$X$ Primary
Other (specify)

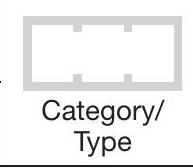

Transaction ID : B5C0AF098E8284DF6B7C

Amount of Each Disbursement this Period

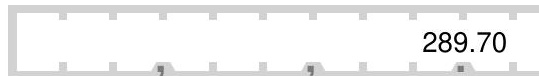

289.70

Subtotal Of Receipts This Page (optional).

Total This Period (last page this line number only)) 


\section{SCHEDULE B-P}

\section{ITEMIZED DISBURSEMENTS}

Use separate schedule(s)

for each category of the

Detailed Summary Page
FOR LINE NUMBER: (check only one)

\begin{tabular}{|c|c|c|c|}
\hline$\times \quad 23$ & 24 & 25 & 26 \\
\hline $27 \mathrm{~b}$ & $28 \mathrm{a}$ & $28 b$ & $28 \mathrm{c}$ \\
\hline
\end{tabular}

Any information copied from such Reports and Statements may not be sold or used by any person for the purpose of soliciting contributions or for commercial purposes, other than using the name and address of any political committee to solicit contributions from such committee.

NAME OF COMMITTEE (In Full)

\section{Friends of Herman Cain}

Full Name (Last, First, Middle Initial)

\section{A. Livestream}

Mailing Address 111 8th Avenue

Date of Disbursement

\begin{tabular}{lcc}
\hline City & State & Zip Code \\
New York & NY & 10011 \\
\hline Purpose of Disbursement & &
\end{tabular}

Purpose of Disbursement

Web Services

Candidate Name

Office Sought:

\begin{tabular}{|l|l} 
& House \\
Senate \\
President
\end{tabular}

Disbursement For: 2012 X Primary $\square$ General

State: District:

Full Name (Last, First, Middle Initial)

\section{B. Walmart}

Mailing Address 702 SW 8th Street

\begin{tabular}{lcc}
\hline City & State & Zip Code \\
Bentonville & AK & $72716-861$ \\
\hline $\begin{array}{l}\text { Purpose of Disbursement } \\
\text { Office Supplies }\end{array}$ & & \\
\hline
\end{tabular}

Candidate Name

Office Sought:

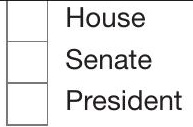

State:

District:
Disbursement For: 2012

$$
\text { X Primary } \square \text { General }
$$

c. S \& U Real Estate, LLC

Mailing Address 8530 New York Avenue

\begin{tabular}{lcc}
\hline City & State & Zip Code \\
Urbandale & IA & 50322
\end{tabular}

Purpose of Disbursement Office Rent Expense

Candidate Name

Office Sought:

State:

\begin{tabular}{|l|l|} 
& House \\
& Senate \\
& President \\
District:
\end{tabular}

Date of Disbursement

\begin{tabular}{|c|c|c|c|c|}
\hline $07^{\mathrm{M}}$ & & ${ }^{\mathrm{D}}{ }^{\mathrm{D}}$ & & $\begin{array}{llll} & Y & Y & Y \\
& 2011 & Y\end{array}$ \\
\hline
\end{tabular}

Transaction ID : BCD4A3D3732554B5F962

Amount of Each Disbursement this Period

Date of Disbursement

\begin{tabular}{|c|c|c|c|c|}
\hline $07^{M}$ & I & D 07 & I & $\begin{array}{cccc} & Y & Y & Y \\
& 2011 & \end{array}$ \\
\hline
\end{tabular}

Transaction ID : B859336A5C079486EBCC

Amount of Each Disbursement this Period

2200.00

Subtotal Of Receipts This Page (optional).

Total This Period (last page this line number only))

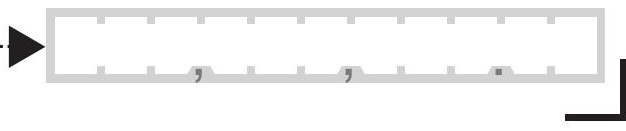




\section{SCHEDULE B-P}

\section{ITEMIZED DISBURSEMENTS}

Use separate schedule(s)

for each category of the

Detailed Summary Page
FOR LINE NUMBER: (check only one)

\begin{tabular}{|c|c|c|c|}
\hline$\times{ }_{23}$ & 24 & 25 & 26 \\
\hline $27 b$ & $28 a$ & $28 \mathrm{~b}$ & $28 \mathrm{c}$ \\
\hline
\end{tabular}

Any information copied from such Reports and Statements may not be sold or used by any person for the purpose of soliciting contributions or for commercial purposes, other than using the name and address of any political committee to solicit contributions from such committee.

NAME OF COMMITTEE (In Full)

\section{Friends of Herman Cain}

Full Name (Last, First, Middle Initial)

A. FedEx Kinkos

Mailing Address 942 S. Shady Grove Road

Date of Disbursement

\begin{tabular}{|c|c|c|c|c|c|c|}
\hline M M / & Y \\
07 & 07 & 2011 \\
\hline
\end{tabular}

Transaction ID : BDB19013C53A34ABFA95

\begin{tabular}{lll}
\hline City & State & Zip Code \\
Memphis & TN & 38120
\end{tabular}

Purpose of Disbursement

Shipping

Candidate Name

\begin{tabular}{l|l|l}
\hline Office Sought: & House & Disbursement For: 2012
\end{tabular} X Primary $\square$ General

State:

\section{Senate}

President

District:

Full Name (Last, First, Middle Initial)

B. FedEx Kinkos

Mailing Address 942 S. Shady Grove Road

\begin{tabular}{lcc}
\hline City & State & Zip Code \\
Memphis & TN & 38120
\end{tabular}

Purpose of Disbursement

Shipping

Candidate Name

Office Sought:

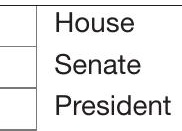

State:

District:

Full Name (Last, First, Middle Initial)

\section{c. US Airways}

Mailing Address 4000 E Sky Harbor Boulevard

\begin{tabular}{lcc}
\hline City & State & Zip Code \\
Phoenix & AZ & 85034
\end{tabular}

Purpose of Disbursement

Travel Expense

Candidate Name

Office Sought:

\begin{tabular}{|c|}
\hline House \\
\hline Senate \\
\hline President \\
\hline
\end{tabular}

Disbursement For: 2012

Х $\begin{aligned} & \text { Primary } \\ & \text { Other (specify) }\end{aligned}$

State:

District:

Subtotal Of Receipts This Page (optional).

Date of Disbursement

\begin{tabular}{|c|c|c|c|c|}
\hline $07^{\mathrm{M}}$ & 1 & D $08^{\mathrm{D}}$ & I & $\begin{array}{cccc}Y & Y & Y & Y \\
& 2011 & \end{array}$ \\
\hline
\end{tabular}

Transaction ID : B902A48F8A7414D1EA83

Amount of Each Disbursement this Period

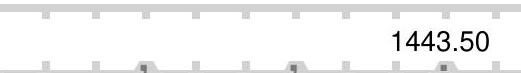

1443.50

Date of Disbursement

\begin{tabular}{|c|c|c|c|c|}
\hline $07^{M}$ & I & $08^{\mathrm{D}}$ & 1 & $\begin{array}{llll}Y & Y & Y & Y \\
& 2011 & \end{array}$ \\
\hline
\end{tabular}

Transaction ID : B95DF575AC5EB485D9B5

Amount of Each Disbursement this Period
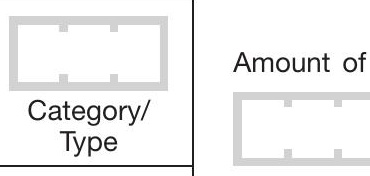

Total This Period (last page this line number only))

1653.20

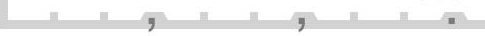

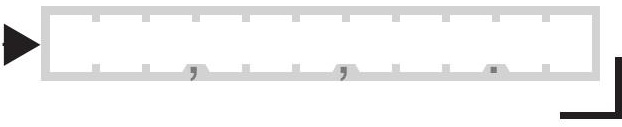

FEC Schedule B-P (Form 3P) (Rev. 03/2011) 


\section{SCHEDULE B-P}

\section{ITEMIZED DISBURSEMENTS}

\section{Use separate schedule(s)}

for each category of the

Detailed Summary Page
FOR LINE NUMBER: (check only one)

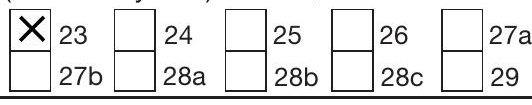

Any information copied from such Reports and Statements may not be sold or used by any person for the purpose of soliciting contributions or for commercial purposes, other than using the name and address of any political committee to solicit contributions from such committee.

NAME OF COMMITTEE (In Full)

\section{Friends of Herman Cain}

Full Name (Last, First, Middle Initial)

A. Delta Airlines

Mailing Address Post Office Box 20980

Department 980

\begin{tabular}{lll}
\hline City & State & Zip Code \\
Atlanta & GA & $30320-2980$
\end{tabular}

Purpose of Disbursement

Travel Expense

Candidate Name

Office Sought:

District:

Full Name (Last, First, Middle Initial)

\section{B. RMA Chaffeured Transportation}

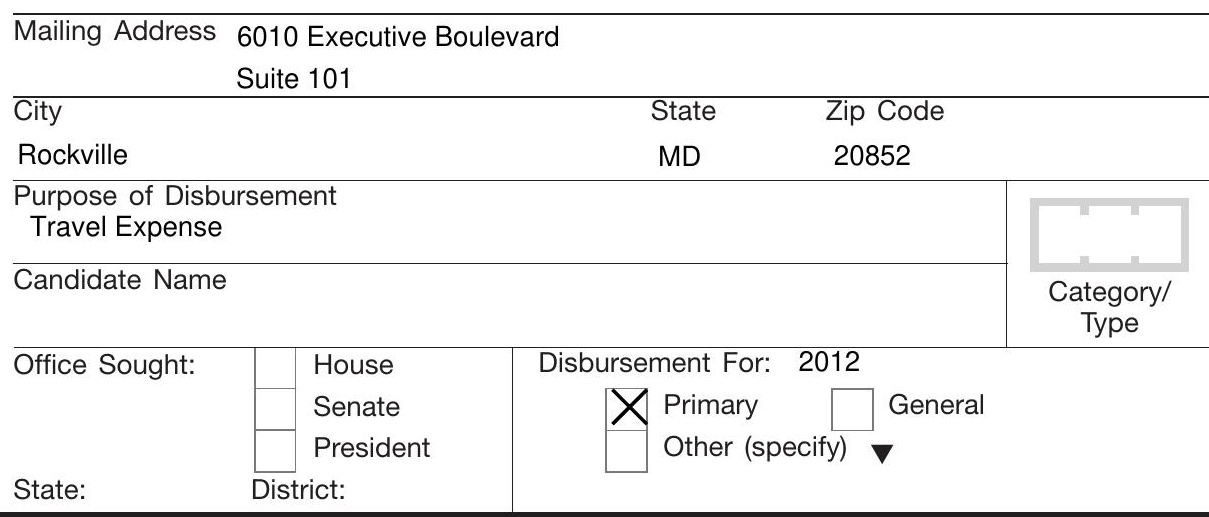

Full Name (Last, First, Middle Initial)

c. Eros Tour and Travel

Mailing Address 117 E 9th Street

\begin{tabular}{lcc}
\hline City & State & Zip Code \\
Los Angeles & CA & 90015
\end{tabular}

Purpose of Disbursement

Travel Expense

Candidate Name

Office Sought:

State:

\begin{tabular}{|l|l|}
\hline & House \\
& Senate \\
& President \\
\cline { 1 - 1 } & District:
\end{tabular}

Date of Disbursement

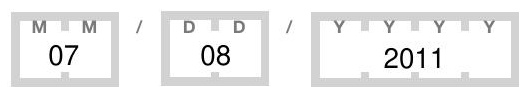

Transaction ID : B6539DD948A7044879BD

Amount of Each Disbursement this Period 460.80

Date of Disbursement

\begin{tabular}{|c|c|c|c|c|}
\hline $07^{\mathrm{M}}$ & 1 & ${ }^{\mathrm{D}} 08^{\mathrm{D}}$ & 1 & $\begin{array}{llll} & Y & Y & Y \\
& Y & Y \\
2011 & \end{array}$ \\
\hline
\end{tabular}

Transaction ID : BF4C71594E80A4077AE2

Amount of Each Disbursement this Period

835.37

Date of Disbursement

\begin{tabular}{|c|c|c|c|c|c|c|}
\hline M M & I & D & Y & Y & Y & Y \\
\hline & & 08 & & 2011 & \\
\hline
\end{tabular}

Transaction ID : B8B2A9159B1C944D98CB

Amount of Each Disbursement this Period

1116.99

Subtotal Of Receipts This Page (optional).

Total This Period (last page this line number only))

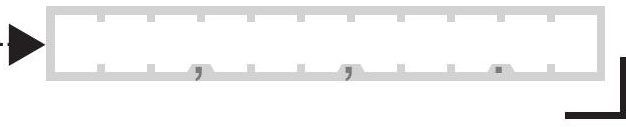

FEC Schedule B-P (Form 3P) (Rev. 03/2011) 


\section{SCHEDULE B-P}

\section{ITEMIZED DISBURSEMENTS}

\section{Use separate schedule(s) \\ for each category of the}

Detailed Summary Page
FOR LINE NUMBER: (check only one)

\begin{tabular}{|c|c|c|c|}
\hline$X_{23}$ & 24 & 25 & 26 \\
\hline $27 \mathrm{~b}$ & $28 a$ & $28 b$ & $28 \mathrm{c}$ \\
\hline
\end{tabular}

Any information copied from such Reports and Statements may not be sold or used by any person for the purpose of soliciting contributions or for commercial purposes, other than using the name and address of any political committee to solicit contributions from such committee.

NAME OF COMMITTEE (In Full)

\section{Friends of Herman Cain}

Full Name (Last, First, Middle Initial)

\section{A. Avis Rent A Car}

Mailing Address 900 Old Country Garden Road

Date of Disbursement

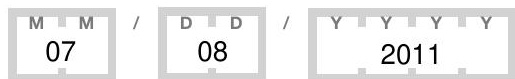

Transaction ID : B89FB6B6A39DD4D6CA4B

\begin{tabular}{lcc}
\hline City & State & Zip Code \\
Garden City & NY & 11530
\end{tabular}

Purpose of Disbursement

Travel Expense

Candidate Name

Office Sought:

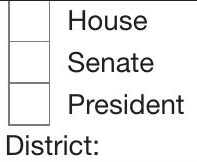
Х Primary $\square$ General

State: District:

Full Name (Last, First, Middle Initial)

\section{B. Southwest Airlines}

Mailing Address PO Box 36647

\begin{tabular}{lcc}
\hline City & State & Zip Code \\
Dallas & TX & 75235
\end{tabular}

Purpose of Disbursement

Travel Expense

Candidate Name

Office Sought:

\begin{tabular}{|l|l|l}
\hline & House \\
Senate \\
\cline { 1 - 2 } & President
\end{tabular}

State:

District:

Full Name (Last, First, Middle Initial)

\section{c. The Soarin' Group}

Mailing Address Post Office Box 14160

\begin{tabular}{lcc}
\hline City & State & Zip Code \\
Chicago & IL & $60614-0160$
\end{tabular}

Purpose of Disbursement

Campaign Strategy Consulting

Candidate Name

Office Sought: $\quad$ House

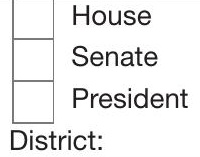

Disbursement For: 2012

Primary $\square$ General
Other (specify)

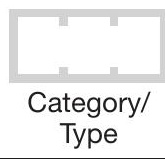

Date of Disbursement

\begin{tabular}{|c|c|c|c|c|}
\hline${ }^{\mathrm{M}} 7^{\mathrm{M}}$ & & ${ }^{\mathrm{D}} 08^{\mathrm{D}}$ & 1 & $\begin{array}{llll}Y & Y & Y & Y \\
& 2011\end{array}$ \\
\hline
\end{tabular}

Transaction ID : B6899D298E93B4E5395A

Amount of Each Disbursement this Period

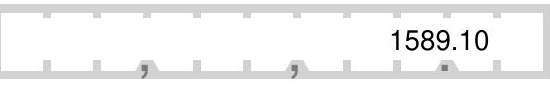

Date of Disbursement

\begin{tabular}{|c|c|c|c|c|}
\hline $07^{\mathrm{M}}$ & l & $\begin{array}{ll}\mathrm{D} & \mathrm{D} \\
& \end{array}$ & 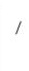 & $\begin{array}{cccc}Y & Y & Y & Y \\
& 2011 & \end{array}$ \\
\hline
\end{tabular}

Transaction ID : B3F1B4188A88547C4B62

Amount of Each Disbursement this Period

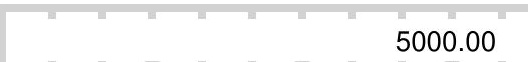

5000.00

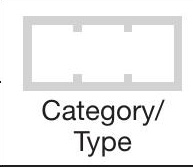

ype
State:

District:

X $\begin{aligned} & \text { Primary } \\ & \text { Other (specify) }\end{aligned}$

Subtotal Of Receipts This Page (optional)

6657.48

C.

Total This Period (last page this line number only))

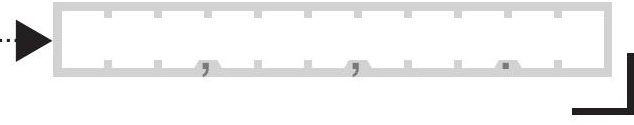

FEC Schedule B-P (Form 3P) (Rev. 03/2011) 


\section{SCHEDULE B-P}

\section{ITEMIZED DISBURSEMENTS}

\section{Use separate schedule(s) \\ for each category of the}

Detailed Summary Page
FOR LINE NUMBER: (check only one)

\begin{tabular}{|c|c|c|c|}
\hline$\times{ }_{23}$ & 24 & 25 & 26 \\
\hline $27 b$ & $28 a$ & $28 \mathrm{~b}$ & $28 \mathrm{c}$ \\
\hline
\end{tabular}

Any information copied from such Reports and Statements may not be sold or used by any person for the purpose of soliciting contributions or for commercial purposes, other than using the name and address of any political committee to solicit contributions from such committee.

NAME OF COMMITTEE (In Full)

\section{Friends of Herman Cain}

Full Name (Last, First, Middle Initial)

\section{A. Little Bonanza Productions LLC}

Mailing Address 34729 Petersen Road

Date of Disbursement

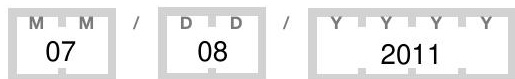

Transaction ID : BC76E7710E1DF4408B63

\begin{tabular}{lcc}
\hline City & State & Zip Code \\
Agua Dulce & CA & 91390
\end{tabular}

Purpose of Disbursement

Media Production

Candidate Name

$$
\begin{aligned}
& \text { House } \\
& \text { Senate } \\
& \text { President }
\end{aligned}
$$

State: District:

Full Name (Last, First, Middle Initial)

\section{B. Air Tran}

Mailing Address 9955 Air Tran Boulevard

\begin{tabular}{lcc}
\hline City & State & Zip Code \\
Orlando & FL & 32827 \\
\hline
\end{tabular}

Purpose of Disbursement

Travel Expense

Candidate Name

Office Sought:

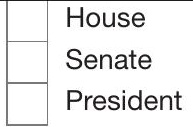

State:

District:

Full Name (Last, First, Middle Initial)

c. Nathan Naidu

Mailing Address 3601 canton rd \#131

Disbursement For: 2012

Primary
Other (specify)

$$
\text { X Primary } \square \text { General }
$$

\begin{tabular}{|c|c|c|c|c|}
\hline $07^{\mathrm{M}}$ & 1 & $08^{\mathrm{D}}$ & I & $\begin{array}{llll}Y & Y & Y & Y \\
& 2011\end{array}$ \\
\hline
\end{tabular}

Amount of Each Disbursement this Period 10000.00
Date of Disbursement

Transaction ID : B25E6F8AAFEB24DD9888

Amount of Each Disbursement this Period

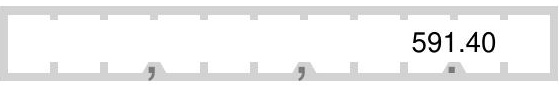

\begin{tabular}{lcc}
\hline City & State & Zip Code \\
Marietta & GA & $30066-2892$
\end{tabular}

Purpose of Disbursement

Transportation/Airfare/Internet/Meals

Candidate Name

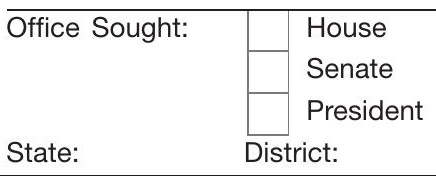

Date of Disbursement

\begin{tabular}{|c|c|c|c|c|c|}
\hline M M / & D & Y & Y & Y & Y \\
07 & & 08 & & 2011 & \\
\hline
\end{tabular}

\section{Transaction ID : B29D5B3326B4A49C3808}

Amount of Each Disbursement this Period

2179.53

Subtotal Of Receipts This Page (optional).

Total This Period (last page this line number only))

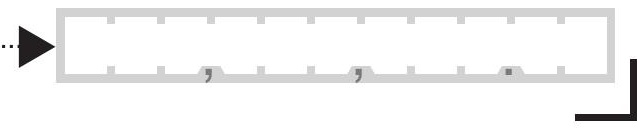




\section{SCHEDULE B-P}

\section{ITEMIZED DISBURSEMENTS}

Use separate schedule(s)

for each category of the

Detailed Summary Page
FOR LINE NUMBER: (check only one)

\begin{tabular}{|c|c|c|c|}
\hline $\mathrm{X} 23$ & 24 & 25 & 26 \\
\hline $27 \mathrm{~b}$ & $28 a$ & $28 b$ & $28 \mathrm{c}$ \\
\hline
\end{tabular}

Any information copied from such Reports and Statements may not be sold or used by any person for the purpose of soliciting contributions or for commercial purposes, other than using the name and address of any political committee to solicit contributions from such committee.

NAME OF COMMITTEE (In Full)

\section{Friends of Herman Cain}

Full Name (Last, First, Middle Initial)

A. Larry Tuel

Mailing Address 5129 Welker Ave.

Date of Disbursement

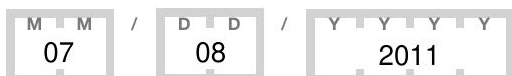

Transaction ID : B66762C1186DA4025AA2

$\begin{array}{lcc}\text { City } & \text { State } & \text { Zip Code } \\ \text { Des Moines } & \text { IA } & 50312-2159\end{array}$

Purpose of Disbursement

Postage, Event Tickets, Office Maintenan

Candidate Name

$$
\begin{array}{|l|l|l} 
& \begin{array}{l}
\text { House } \\
\text { Senate } \\
\\
\text { President }
\end{array} \\
\text { District: }
\end{array}
$$

State:

IA

50312-2159

Full Name (Last, First, Middle Initial)

B. Larry Tuel

Mailing Address 5129 Welker Ave.

\begin{tabular}{lcc}
\hline City & State & Zip Code \\
Des Moines & IA & $50312-2159$
\end{tabular}

Purpose of Disbursement

Lodging, Airfare, Office Supplies

Candidate Name

Office Sought:

\begin{tabular}{|l|l} 
House & Senate \\
President
\end{tabular}

State:

District:

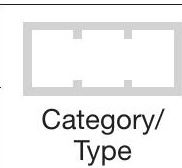

Amount of Each Disbursement this Period

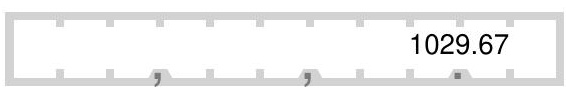

Full Name (Last, First, Middle Initial)

\section{c. Southwest Airlines}

Mailing Address PO Box 36647

\begin{tabular}{lcc}
\hline City & State & Zip Code \\
Dallas & TX & 75235
\end{tabular}

Purpose of Disbursement

Travel Expense

Candidate Name

\begin{tabular}{|c|c|c|c|c|}
\hline $07^{\mathrm{M}}$ & & ${ }^{\mathrm{D}}{ }^{\mathrm{D}}$ & & $\begin{array}{llll} & Y & Y & Y \\
& 2011 & Y\end{array}$ \\
\hline
\end{tabular}

Office Sought:

State:
Date of Disbursement

Transaction ID : B85FBCC1D06DA43C5BA1

\begin{tabular}{|c|c|c|c|c|}
\hline $07^{\mathrm{M}}$ & & $\begin{array}{ll}\mathrm{D} & \mathrm{D} \\
& 11\end{array}$ & & 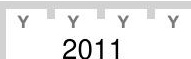 \\
\hline
\end{tabular}

Amount of Each Disbursement this Period

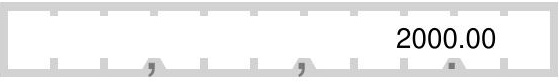

Date of Disbursement

Transaction ID : BCFE3F34005794590AB3

Amount of Each Disbursement this Period

405.40

Subtotal Of Receipts This Page (optional)......

Total This Period (last page this line number only))

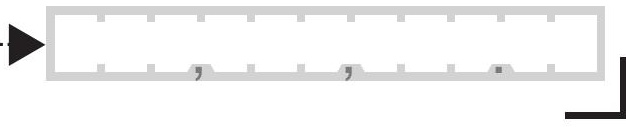




\section{SCHEDULE B-P}

\section{ITEMIZED DISBURSEMENTS}

\section{Use separate schedule(s)}

for each category of the

Detailed Summary Page
FOR LINE NUMBER: (check only one)

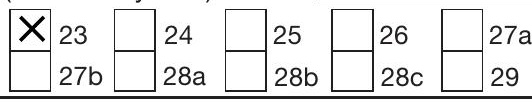

Any information copied from such Reports and Statements may not be sold or used by any person for the purpose of soliciting contributions or for commercial purposes, other than using the name and address of any political committee to solicit contributions from such committee.

NAME OF COMMITTEE (In Full)

\section{Friends of Herman Cain}

Full Name (Last, First, Middle Initial)

A. Nextiva

Mailing Address 8125 North 86th Place

Date of Disbursement

\begin{tabular}{lcc}
\hline City & State & Zip Code \\
Scottsdale & AZ & 85258
\end{tabular}

Purpose of Disbursement

Telephone

Candidate Name

\begin{tabular}{l|l|l|l}
\hline Office Sought: & & House & Disbursement For: 2012
\end{tabular} X Primary $\square$ General

State:

Senate
President
District:

Full Name (Last, First, Middle Initial)

B. American Airlines

Mailing Address Post Office Box 619612 MD 2400

\begin{tabular}{lcc}
\hline City & State & Zip Code \\
DFW Airport & TX & 75261-9612
\end{tabular}

Purpose of Disbursement

Travel Expense

Candidate Name

Office Sought:

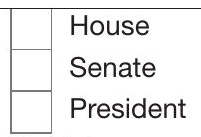

State:

District:

Full Name (Last, First, Middle Initial)

\section{Maggianos}

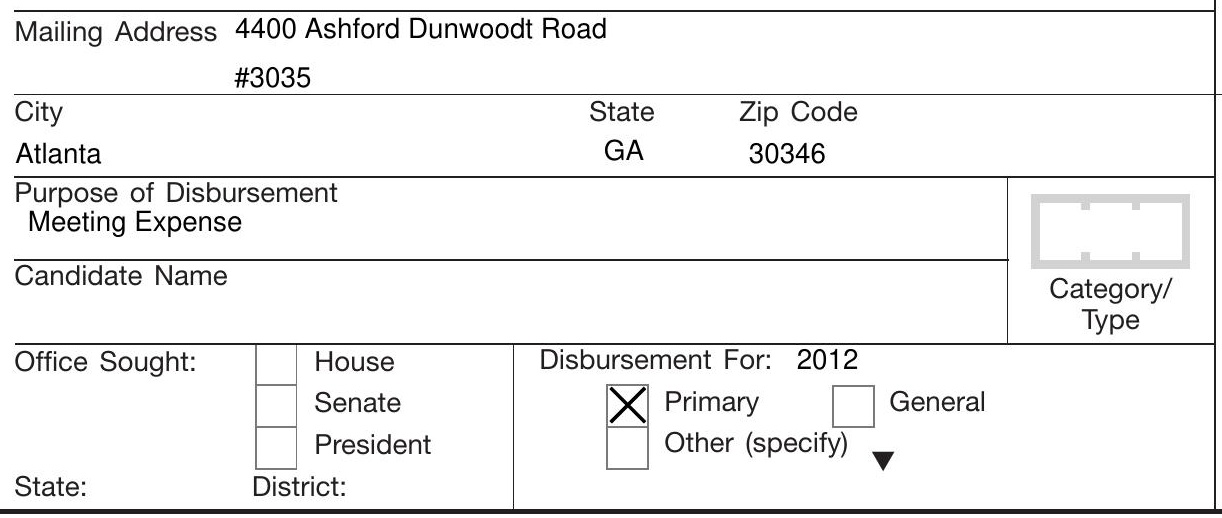

Subtotal Of Receipts This Page (optional).

Date of Disbursement

\begin{tabular}{|c|c|c|c|c|c|c|}
\hline M & M & D & Y & Y \\
07 & & 11 & \\
& & 2011 & \\
\hline
\end{tabular}

Transaction ID : B1FA8FA5E6CBC4C30A3D

Amount of Each Disbursement this Period

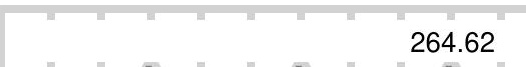

Total This Period (last page this line number only))

1115.43

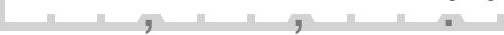

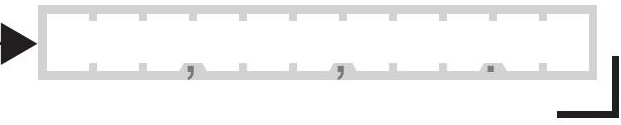

FEC Schedule B-P (Form 3P) (Rev. 03/2011) 


\section{SCHEDULE B-P}

\section{ITEMIZED DISBURSEMENTS}

Use separate schedule(s)

for each category of the

Detailed Summary Page
FOR LINE NUMBER: (check only one)

\begin{tabular}{|c|c|c|c|}
\hline$X_{23}$ & 24 & 25 & 26 \\
\hline $27 \mathrm{~b}$ & $28 a$ & $28 b$ & $28 \mathrm{c}$ \\
\hline
\end{tabular}

Any information copied from such Reports and Statements may not be sold or used by any person for the purpose of soliciting contributions or for commercial purposes, other than using the name and address of any political committee to solicit contributions from such committee.

NAME OF COMMITTEE (In Full)

\section{Friends of Herman Cain}

Full Name (Last, First, Middle Initial)

A. Wynn Las Vegas Hotel

Mailing Address 3131 Las Vegas Boulevard

Date of Disbursement

\begin{tabular}{l|c|c|c|c|c|c|c|}
$M$ & M & Y \\
07 & 11 & 2011
\end{tabular}

Transaction ID : BC928A7F41B53430885B

\begin{tabular}{lll}
\hline City & State & Zip Code \\
Las Vegas & NV & $89109-1967$
\end{tabular}

Purpose of Disbursement

Event Facility Rental and Catering

Candidate Name

Office Sought:

$$
\begin{array}{|l|l}
\text { House } \\
\text { Senate } \\
\text { Presiden }
\end{array}
$$
District:

State:

Full Name (Last, First, Middle Initial)

\section{B. RMA Chaffeured Transportation}

\begin{tabular}{ll}
\hline Mailing Address & $\begin{array}{l}6010 \\
\text { Suite } 101\end{array}$ \\
\hline City &
\end{tabular}

Rockville

State Zip Code

Purpose of Disbursement

Travel Expense

Candidate Name

MD 20852

Office Sought:

House
Senate
President

State:

District:

Full Name (Last, First, Middle Initial)

c. Delta Airlines

\begin{tabular}{llcc}
\hline Mailing Address & Post Office Box 20980 & & \\
& Department 980 & & \\
\hline City & State & Zip Code \\
Atlanta & GA & $30320-2980$
\end{tabular}

Purpose of Disbursement

Travel Expense

Candidate Name

Disbursement For: 2012

$$
\begin{aligned}
& \text { Primary } \square \text { General } \\
& \text { Other (specify) } \nabla
\end{aligned}
$$

\begin{tabular}{|c|c|c|c|c|}
\hline $07^{\mathrm{M}}$ & & ${ }_{11}^{\mathrm{D}}$ & & 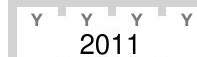 \\
\hline
\end{tabular}

Date of Disbursement

\section{Transaction ID : BBBE2596F785C4227989}

Amount of Each Disbursement this Period

420.75
Date of Disbursement

\begin{tabular}{|c|c|c|c|c|c|}
\hline M M & I & D & Y & Y & Y \\
07 & & 11 & & 2011 & \\
\hline
\end{tabular}

Transaction ID : B8F2AD37D21C84405862

Amount of Each Disbursement this Period

\begin{tabular}{|c|c|c|c|}
\hline \multirow[t]{3}{*}{ Office Sought: } & House & \multicolumn{2}{|l|}{ Disbursement For: 2012} \\
\hline & Senate & Primary & General \\
\hline & President & Other (specify) & \\
\hline
\end{tabular}

492.70

Subtotal Of Receipts This Page (optional).

Total This Period (last page this line number only))

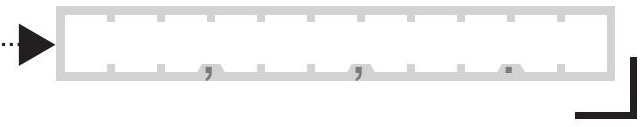




\section{SCHEDULE B-P}

\section{ITEMIZED DISBURSEMENTS}

Use separate schedule(s)

for each category of the

Detailed Summary Page
FOR LINE NUMBER: (check only one)

PAGE 1282 / 1572

\begin{tabular}{|c|c|c|c|}
\hline$X_{23}$ & 24 & 25 & 26 \\
\hline $27 \mathrm{~b}$ & $28 a$ & $28 \mathrm{~b}$ & $28 \mathrm{c}$ \\
\hline
\end{tabular}

Any information copied from such Reports and Statements may not be sold or used by any person for the purpose of soliciting contributions or for commercial purposes, other than using the name and address of any political committee to solicit contributions from such committee.

NAME OF COMMITTEE (In Full)

\section{Friends of Herman Cain}

Full Name (Last, First, Middle Initial)

\section{A. US Airways}

Mailing Address 4000 E Sky Harbor Boulevard

Date of Disbursement

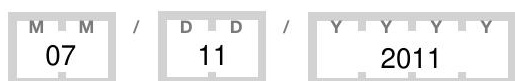

\begin{tabular}{lcc}
\hline City & State & Zip Code \\
Phoenix & AZ & 85034 \\
\hline
\end{tabular}

Purpose of Disbursement

Travel Expense

Candidate Name

\begin{tabular}{l|l|l}
\hline Office Sought: & House & Disbursement For: 2012
\end{tabular} X Primary $\square$ General

State:

\section{Senate}

President

District:

Full Name (Last, First, Middle Initial)

\section{B. FedEx Kinkos}

Mailing Address 942 S. Shady Grove Road

\begin{tabular}{lcc}
\hline City & State & Zip Code \\
Memphis & TN & 38120
\end{tabular}

Purpose of Disbursement

Shipping

Candidate Name

Office Sought:

House
Senate
President

State:

District:

Full Name (Last, First, Middle Initial)

\section{c. Office Depot Corporate}

Mailing Address 2500 Mill Center Parkway

\begin{tabular}{lcc}
\hline City & State & Zip Code \\
Buford & GA & 30518
\end{tabular}

Purpose of Disbursement

Office Supplies

Candidate Name

Disbursement For: 2012

Primary $\square$ General
Other (specify)

Office Sought:

\begin{tabular}{|l|l|}
\hline & House \\
& Senate \\
& President \\
\cline { 1 - 1 } & District:
\end{tabular}

Disbursement For: 2012

Х $\begin{aligned} & \text { Primary } \\ & \text { Other (specify) }\end{aligned}$

State:

District:

Subtotal Of Receipts This Page (optional)

Date of Disbursement

\begin{tabular}{|c|c|c|c|c|c|}
\hline M M / & D & Y & Y & Y & Y \\
07 & & 11 & & 2011 & \\
\hline
\end{tabular}

Transaction ID : B8815B4E9C6D74B6C8C1

Amount of Each Disbursement this Period

64.82

Date of Disbursement

\begin{tabular}{|c|c|c|c|c|}
\hline $07^{M}$ & 1 & ${ }_{11}^{\mathrm{D}}$ & 1 & $\begin{array}{llll}Y & Y & Y & Y \\
& 2011 & \end{array}$ \\
\hline
\end{tabular}

Transaction ID : BFFCBF0CB45D44E0CA24

Amount of Each Disbursement this Period
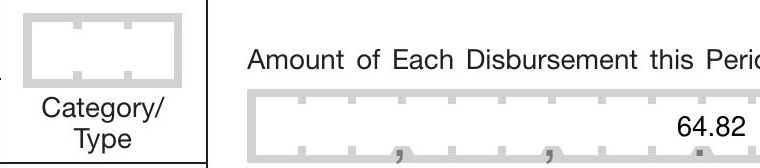

Total This Period (last page this line number only))

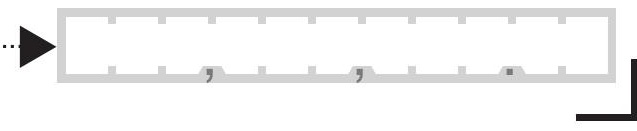




\section{SCHEDULE B-P}

\section{ITEMIZED DISBURSEMENTS}

\section{Use separate schedule(s) \\ for each category of the}

Detailed Summary Page
FOR LINE NUMBER: (check only one)

\begin{tabular}{|c|c|c|c|}
\hline$\times{ }_{23}$ & 24 & 25 & 26 \\
\hline $27 b$ & $28 a$ & $28 \mathrm{~b}$ & $28 \mathrm{c}$ \\
\hline
\end{tabular}

Any information copied from such Reports and Statements may not be sold or used by any person for the purpose of soliciting contributions
or for commercial purposes, other than using the name and address of any political committee to solicit contributions from such committee.

NAME OF COMMITTEE (In Full)

\section{Friends of Herman Cain}

Full Name (Last, First, Middle Initial)

A. SunTrust Bank

Mailing Address 980 Eagles Landing Parkway

Date of Disbursement

\begin{tabular}{lcc}
\hline City & State & Zip Code \\
Stockbridge & GA & 30281 \\
\hline Purpose of Disbursement & &
\end{tabular}

Candidate Name

Office Sought:

\begin{tabular}{|l|l|} 
& House \\
& Senate \\
President
\end{tabular}
X Primary $\square$ General

State: District:

Full Name (Last, First, Middle Initial)

в. NEW HAMPSHIRE REPUBLICAN STATE COMMITTEE

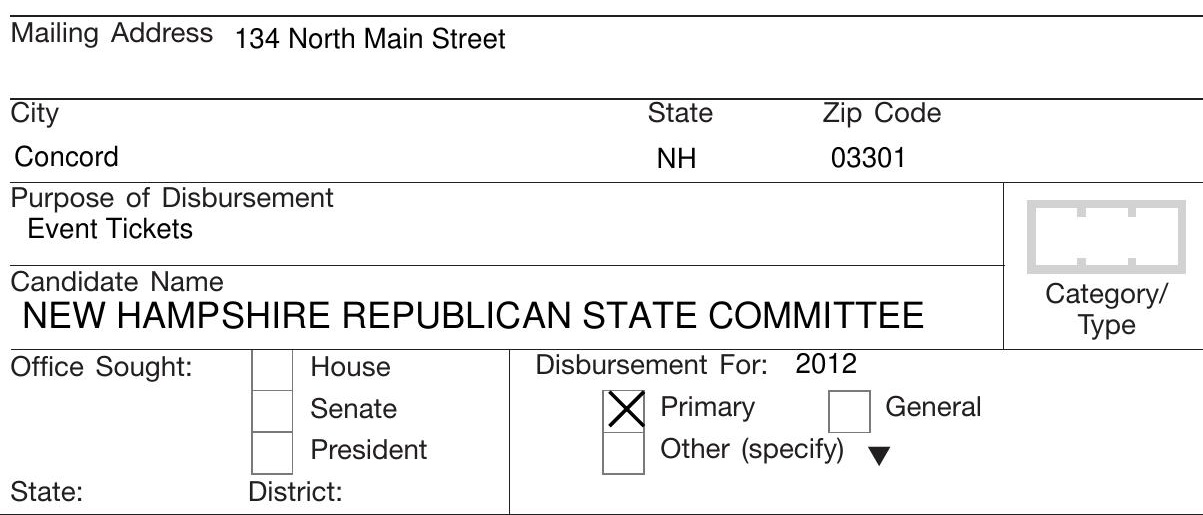

Date of Disbursement

\begin{tabular}{|c|c|c|c|c|}
\hline $07^{\mathrm{M}}$ & 1 & ${ }_{11}^{\mathrm{D}}$ & l & 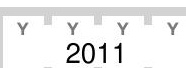 \\
\hline
\end{tabular}

Transaction ID : B618FC367ED1F470E9E5

Full Name (Last, First, Middle Initial)

\section{c. Tri-Net Payroll Services}

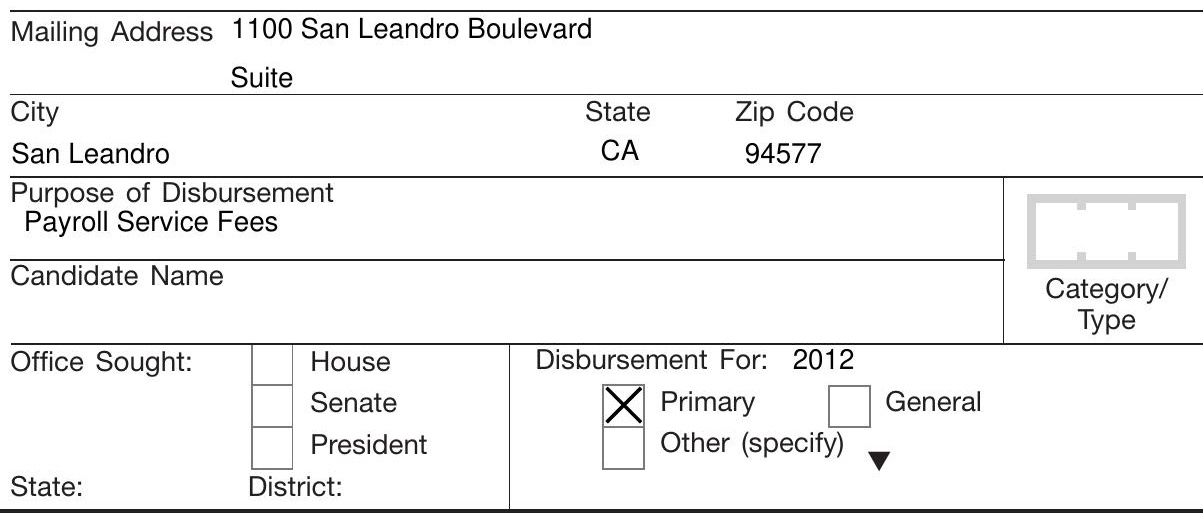

Subtotal Of Receipts This Page (optional).

Date of Disbursement

\begin{tabular}{|c|c|c|c|c|c|}
\hline M M & I & D & Y & Y & Y \\
07 & & 12 & \\
\hline
\end{tabular}

\section{Transaction ID : B637925200BB84D75B97}

Amount of Each Disbursement this Period

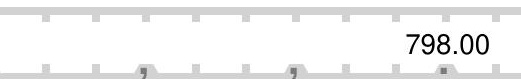

798.00

Total This Period (last page this line number only)) 


\section{SCHEDULE B-P}

\section{ITEMIZED DISBURSEMENTS}

\section{Use separate schedule(s) \\ for each category of the}

Detailed Summary Page
FOR LINE NUMBER: (check only one)

\begin{tabular}{|c|c|c|c|}
\hline$\times{ }_{23}$ & 24 & 25 & 26 \\
\hline $27 b$ & $28 a$ & $28 \mathrm{~b}$ & $28 \mathrm{c}$ \\
\hline
\end{tabular}

Any information copied from such Reports and Statements may not be sold or used by any person for the purpose of soliciting contributions or for commercial purposes, other than using the name and address of any political committee to solicit contributions from such committee.

NAME OF COMMITTEE (In Full)

\section{Friends of Herman Cain}

Full Name (Last, First, Middle Initial)

A. Lutz and Company P.C.

Mailing Address 13616 California Street

Suite 300

Date of Disbursement

\begin{tabular}{llll}
\multicolumn{3}{c}{ Suite 300} & \\
\hline City & State & Zip Code \\
Omaha & NE & $68154-5336$
\end{tabular}

Purpose of Disbursement

Accounting Services

Candidate Name

\begin{tabular}{l|l|l}
\hline Office Sought: & House & Disbursement For: 2012
\end{tabular}

State:

\section{Senate}

President

Full Name (Last, First, Middle Initial)

B. Capital Grille

Mailing Address 3200 Las Vegas Blvd S Ste. 3300

\begin{tabular}{lll}
\hline City & State & Zip Code \\
Las Vegas & NV & 89109
\end{tabular}

Purpose of Disbursement

Meeting Expense

Candidate Name

Office Sought:

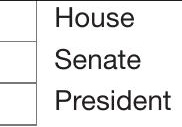

State:

District:

Full Name (Last, First, Middle Initial)

\section{c. Jason's Deli}

Mailing Address 3755 Carmia Dr

Ste. 1210

\begin{tabular}{lcc}
\hline City & State & Zip Code \\
Atlanta & GA & 30331
\end{tabular}

Purpose of Disbursement

Event Catering

Candidate Name

Office Sought:

State:

Subtotal Of Receipts This Page (optional).

\begin{tabular}{|c|c|c|}
\hline House & Disbursement For: 2012 & \\
\hline Senate & Х Primary & General \\
\hline President & Other (sp & \\
\hline
\end{tabular}
X Primary $\square$ General

Date of Disbursement

\begin{tabular}{|c|c|c|c|c|}
\hline $07^{\mathrm{M}}$ & 1 & ${ }^{\mathrm{D}} 12^{\mathrm{D}}$ & 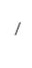 & $\begin{array}{llll}Y & Y & Y & Y \\
& 2011\end{array}$ \\
\hline
\end{tabular}

Transaction ID : B875F4ED87E4C4780AC1

Amount of Each Disbursement this Period

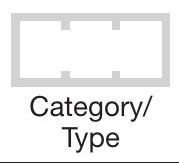

$$
\begin{aligned}
& \text { Disbursement For: } 2012 \\
& \text { X Primary } \\
& \text { Other (specify) }
\end{aligned}
$$

Category/ Type

Amount of Each Disbursement this Period 3238.50

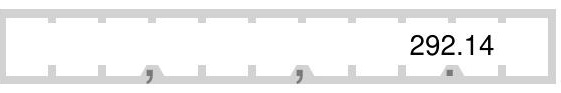

Date of Disbursement

\begin{tabular}{|c|c|c|c|c|c|c|}
\hline M & M & D & Y & Y & Y \\
07 & & 12 & & 2011 & \\
\hline
\end{tabular}

Transaction ID : B076F6C8A71804783AED

Amount of Each Disbursement this Period

461.10

Total This Period (last page this line number only))

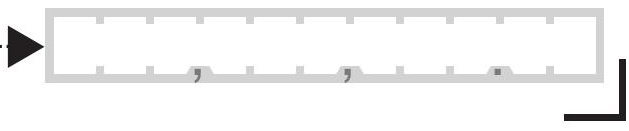




\section{SCHEDULE B-P}

\section{ITEMIZED DISBURSEMENTS}

Use separate schedule(s)

for each category of the

Detailed Summary Page
FOR LINE NUMBER: (check only one)

\begin{tabular}{|c|c|c|c|}
\hline$\times{ }_{23}$ & 24 & 25 & 26 \\
\hline $27 b$ & $28 a$ & $28 \mathrm{~b}$ & $28 \mathrm{c}$ \\
\hline
\end{tabular}

Any information copied from such Reports and Statements may not be sold or used by any person for the purpose of soliciting contributions or for commercial purposes, other than using the name and address of any political committee to solicit contributions from such committee.

NAME OF COMMITTEE (In Full)

\section{Friends of Herman Cain}

Full Name (Last, First, Middle Initial)

A. Office Depot Corporate

Mailing Address 2500 Mill Center Parkway

City

Buford

Purpose of Disbursement

Office Supplies

Candidate Name

Office Sought:

State:

House
Senate
President
District:

Disbursement For: 2012

Х Primary

$\begin{array}{ll}\text { State } & \text { Zip Code } \\ \text { GA } & 30518\end{array}$

B. FedEx Kinkos

Mailing Address 942 S. Shady Grove Road

\begin{tabular}{lcc}
\hline City & State & Zip Code \\
Memphis & TN & 38120
\end{tabular}

Purpose of Disbursement

Shipping

Candidate Name

Office Sought:

House
Senate
President

State:

District:

Full Name (Last, First, Middle Initial)

c. LexisNexis

Mailing Address Post Office Box 2314

\begin{tabular}{lcc}
\hline City & State & Zip Code \\
Carol Stream & IL & $60132-2314$
\end{tabular}

Purpose of Disbursement

Subscription Fee

Candidate Name

Office Sought:

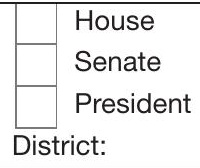

Disbursement For: 2012

Х $\begin{aligned} & \text { Primary } \\ & \text { Other (specify) }\end{aligned}$

District:
Date of Disbursement

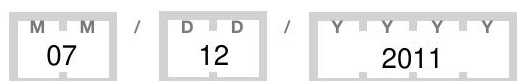

Transaction ID : BB5AE06398925472D92B

Amount of Each Disbursement this Period 556.48

Date of Disbursement

\begin{tabular}{|c|c|c|c|c|}
\hline $07^{\mathrm{M}}$ & 1 & ${ }^{\mathrm{D}} 2^{\mathrm{D}}$ & 1 & $\begin{array}{llll}Y & Y & Y & Y \\
& 2011 & \end{array}$ \\
\hline
\end{tabular}

Transaction ID : B81E46104DAF64B038B8

Amount of Each Disbursement this Period

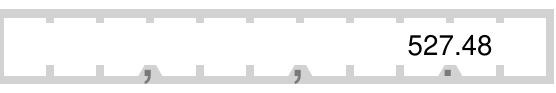

Date of Disbursement

\begin{tabular}{|c|c|c|c|c|}
\hline $07^{M}$ & I & D 12 & I & $\begin{array}{cccc} & Y & Y & Y \\
& 2011 & \end{array}$ \\
\hline
\end{tabular}

Transaction ID : BEB36A5AF8A6F452CBF7

Amount of Each Disbursement this Period

300.00 Type

Subtotal Of Receipts This Page (optional)

Total This Period (last page this line number only))

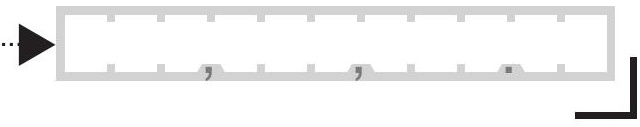




\section{SCHEDULE B-P}

\section{ITEMIZED DISBURSEMENTS}

\section{Use separate schedule(s) \\ for each category of the}

Detailed Summary Page
FOR LINE NUMBER: (check only one)

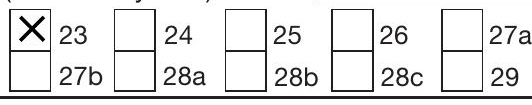

Any information copied from such Reports and Statements may not be sold or used by any person for the purpose of soliciting contributions or for commercial purposes, other than using the name and address of any political committee to solicit contributions from such committee.

NAME OF COMMITTEE (In Full)

\section{Friends of Herman Cain}

Full Name (Last, First, Middle Initial)

A. Delta Airlines

Mailing Address Post Office Box 20980

Department 980

\begin{tabular}{lcc}
\hline City & State & Zip Code \\
Atlanta & GA & $30320-2980$
\end{tabular}

Purpose of Disbursement

Travel Expense

Candidate Name

Office Sought:

House
Senate
President
District:

Disbursement For: 2012

X Primary $\square$ General
Date of Disbursement

\begin{tabular}{|c|c|c|c|c|c|}
\hline M M & D \\
07 & 12 & 2011 \\
\hline
\end{tabular}

Transaction ID : BE2E41DF7765C4DC7824

Amount of Each Disbursement this Period 4961.90

\section{B. Washington Political Group}

Mailing Address 5061 Hodgkins Place

\begin{tabular}{lcc}
\hline City & State & Zip Code \\
Lilburn & GA & 30047
\end{tabular}

Purpose of Disbursement

Website Maintenance

Candidate Name

Office Sought:

House
Senate
President

State:

District:
Date of Disbursement

\begin{tabular}{|c|c|c|c|c|}
\hline $07^{\mathrm{M}}$ & & ${ }^{\mathrm{D}} 2^{\mathrm{D}}$ & & 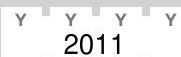 \\
\hline
\end{tabular}

Transaction ID : BABD853CE0CFF441F889

Amount of Each Disbursement this Period

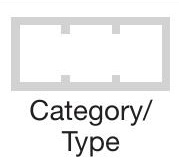
Disbursement For: 2012
\[ \begin{array}{l}\text { Primary } \\ \text { Other (specify) }\end{array} \]

\section{c. RMA Chaffeured Transportation}

Mailing Address 6010 Executive Boulevard

\begin{tabular}{lcc}
\multicolumn{3}{c}{ Suite 101} \\
City & State & Zip Code \\
Rockville & MD & 20852
\end{tabular}

Purpose of Disbursement

Travel Expense

Candidate Name

\begin{tabular}{|c|c|}
\hline \multirow[t]{3}{*}{ Office Sought: } & House \\
\hline & Senate \\
\hline & President \\
\hline ate: & rict: \\
\hline
\end{tabular}

Date of Disbursement

\begin{tabular}{|c|c|c|c|c|c|}
\hline M M / & D & D & Y & Y & Y \\
07 & & 12 & & 2011 & \\
\hline
\end{tabular}

Transaction ID : BF520361B213A4F6C937

Amount of Each Disbursement this Period

116.64

Subtotal Of Receipts This Page (optional).

13078.54

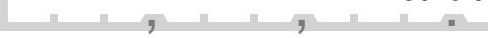

Total This Period (last page this line number only))

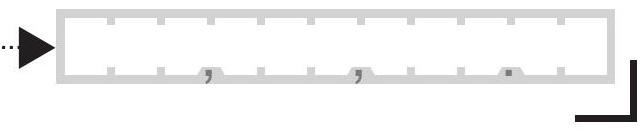




\section{SCHEDULE B-P}

\section{ITEMIZED DISBURSEMENTS}

\section{Use separate schedule(s) \\ for each category of the}

Detailed Summary Page
FOR LINE NUMBER: (check only one)

\begin{tabular}{|c|c|c|c|}
\hline$\times{ }_{23}$ & 24 & 25 & 26 \\
\hline $27 b$ & $28 a$ & $28 \mathrm{~b}$ & $28 \mathrm{c}$ \\
\hline
\end{tabular}

Any information copied from such Reports and Statements may not be sold or used by any person for the purpose of soliciting contributions or for commercial purposes, other than using the name and address of any political committee to solicit contributions from such committee.

NAME OF COMMITTEE (In Full)

\section{Friends of Herman Cain}

Full Name (Last, First, Middle Initial)

A. Wynn Las Vegas Hotel

Mailing Address 3131 Las Vegas Boulevard

Date of Disbursement

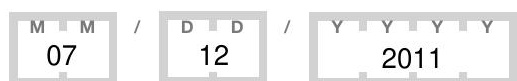

\section{Transaction ID : B8C8500211C494F2F9CC}

$\begin{array}{lll}\text { City } & \text { State } & \text { Zip Code } \\ \text { Las Vegas } & \text { NV } & 89109-1967\end{array}$

Purpose of Disbursement

Travel Expense

Candidate Name

$$
\begin{array}{|l|l} 
& \text { House } \\
& \text { Senate } \\
\cline { 1 - 2 } & \text { President }
\end{array}
$$

State: District:

\begin{tabular}{|c|c|c|c|c|}
\hline \multicolumn{5}{|c|}{ Mailing Address 22 Sylvan Way } \\
\hline \multicolumn{2}{|l|}{ City } & \multicolumn{3}{|c|}{ Zip Code } \\
\hline \multicolumn{2}{|l|}{ Parsippany } & \multicolumn{3}{|c|}{07054} \\
\hline \multicolumn{4}{|c|}{$\begin{array}{l}\text { Purpose of Disbursement } \\
\text { Travel Expense }\end{array}$} & \\
\hline \multicolumn{4}{|l|}{ Candidate Name } & $\begin{array}{l}\text { Category/ } \\
\text { Type }\end{array}$ \\
\hline \multirow[t]{3}{*}{ Office Sought: } & House & \multirow{3}{*}{\multicolumn{3}{|c|}{$\begin{array}{l}\text { Disbursement For: } 2012 \\
\text { X Primary } \\
\text { Other (specify) }\end{array}$}} \\
\hline & Senate & & & \\
\hline & President & & & \\
\hline State: & \multicolumn{4}{|c|}{ District: } \\
\hline
\end{tabular}

Full Name (Last, First, Middle Initial)

B. Microtel Inn and Suites

Full Name (Last, First, Middle Initial)

\section{c. Italian Oven Stockbridge GA}

Mailing Address 938 Eagles Landing Parkway

\begin{tabular}{lcc}
\hline City & State & Zip Code \\
Stockbridge & GA & 30281
\end{tabular}

Purpose of Disbursement

Meeting Expense

Candidate Name

\section{sbursement For: 2012

\begin{tabular}{|c|c|c|c|c|}
\hline $07^{\mathrm{M}}$ & 1 & ${ }^{\mathrm{D}} 2^{\mathrm{D}}$ & 1 & $\begin{array}{llll}Y & Y & Y & Y \\
& 2011 & \end{array}$ \\
\hline
\end{tabular} \\ Х $\begin{aligned} & \text { Primary } \square \text { General } \\ & \text { Other (specify) }\end{aligned}$}

Date of Disbursement

\section{Transaction ID : B60DA4B5F77704D96906}

Amount of Each Disbursement this Period

\begin{tabular}{|c|c|c|c|c|}
\hline M $07^{M}$ & I & ${ }^{\mathrm{D}}{ }^{\mathrm{D}}$ & I & 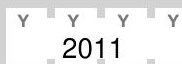 \\
\hline
\end{tabular}

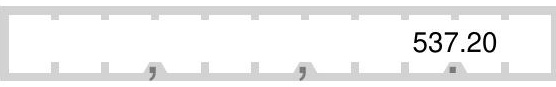

Date of Disbursement

Transaction ID : B894EB18449C44C2CB0A

Amount of Each Disbursement this Period

68.75

\begin{tabular}{l|l|c|}
\hline Office Sought: & $\begin{array}{l}\text { House } \\
\text { Senate } \\
\text { President } \\
\text { State: }\end{array}$ & $\begin{array}{r}\text { Disbursement For: } 2012 \\
\text { District: }\end{array}$ \\
\cline { 2 - 3 }
\end{tabular}

Subtotal Of Receipts This Page (optional).

Total This Period (last page this line number only)) 


\section{SCHEDULE B-P}

\section{ITEMIZED DISBURSEMENTS}

\section{Use separate schedule(s) \\ for each category of the}

Detailed Summary Page
FOR LINE NUMBER: (check only one)

\begin{tabular}{|c|c|c|c|}
\hline$X_{23}$ & 24 & 25 & 26 \\
\hline $27 \mathrm{~b}$ & $28 a$ & $28 b$ & $28 \mathrm{c}$ \\
\hline
\end{tabular}

Any information copied from such Reports and Statements may not be sold or used by any person for the purpose of soliciting contributions or for commercial purposes, other than using the name and address of any political committee to solicit contributions from such committee.

NAME OF COMMITTEE (In Full)

\section{Friends of Herman Cain}

Full Name (Last, First, Middle Initial)

A. Tri-Net Payroll Services

Mailing Address 1100 San Leandro Boulevard

Suite

\begin{tabular}{lll}
\hline City & State & Zip Code \\
San Leandro & CA & 94577
\end{tabular}

Purpose of Disbursement

Payroll Benefits

Candidate Name

Office Sought:

House
Senate
President
District:

Disbursement For: 2012

X Primary $\square$ General
Date of Disbursement

\begin{tabular}{|c|c|c|c|c|c|}
\hline M M & P \\
07 & 12 & 2011 \\
\hline
\end{tabular}

Transaction ID : B465600CC55364BF5B81

Amount of Each Disbursement this Period 3048.42

\section{B. Tri-Net Payroll Services}

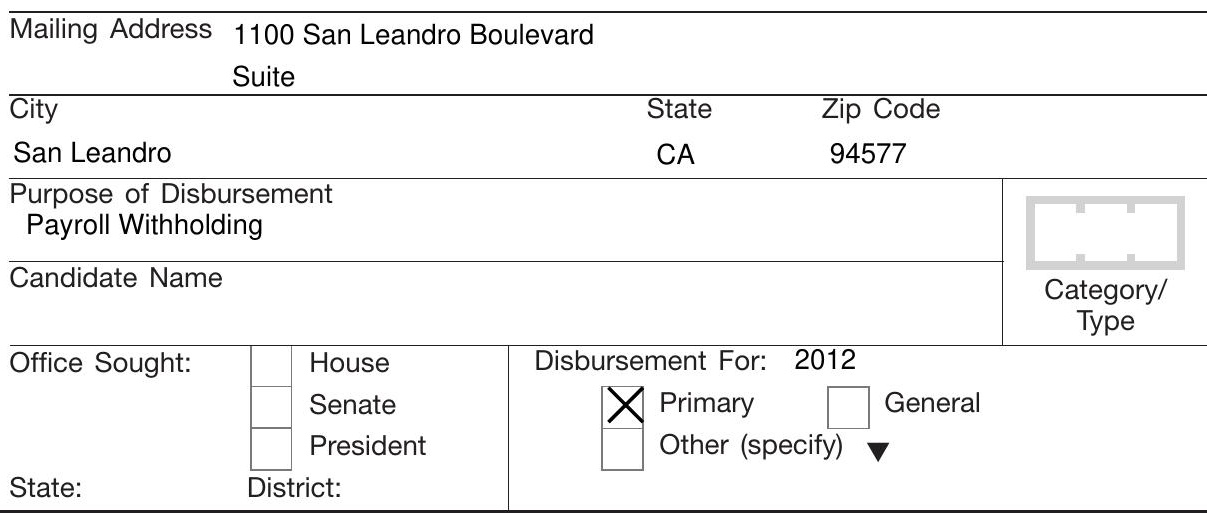

Date of Disbursement

\begin{tabular}{|c|c|c|c|c|}
\hline${ }^{M}{ }^{\mathrm{M}}$ & $/$ & ${ }^{\mathrm{D}}$ & $\mathrm{P}^{\mathrm{D}}$ & $\mathrm{Y}^{\mathrm{Y}} \mathrm{Y}$ \\
\hline
\end{tabular}

\section{Transaction ID : BFF2C3EC4C73840BE918}

Amount of Each Disbursement this Period

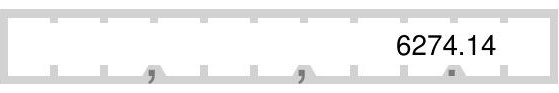

Full Name (Last, First, Middle Initial)

\section{c. Avis Rent A Car}

Mailing Address 900 Old Country Garden Road

Date of Disbursement

\begin{tabular}{|c|c|c|c|c|c|}
\hline M M / & D & Y & Y & Y & Y \\
07 & & 12 & & 2011 & \\
\hline
\end{tabular}

\begin{tabular}{lcc}
\hline City & State & Zip Code \\
Garden City & NY & 11530
\end{tabular}

Purpose of Disbursement

Travel Expense

Candidate Name

Office Sought: $\quad$ House

\begin{tabular}{|l|l|l|} 
& House \\
& Senate \\
& President \\
District:
\end{tabular}

Disbursement For: 2012

X $\begin{aligned} & \text { Primary } \\ & \text { Other (specify) }\end{aligned}$

State:

Subtotal Of Receipts This Page (optional).

9818.56

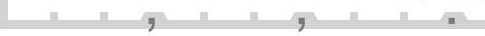

Total This Period (last page this line number only))
Transaction ID : BFE6FC679B4884764A17

Amount of Each Disbursement this Period

496.00 


\section{SCHEDULE B-P}

\section{ITEMIZED DISBURSEMENTS}

Use separate schedule(s)

for each category of the

Detailed Summary Page
FOR LINE NUMBER: (check only one)

PAGE 1289 / 1572

\begin{tabular}{|c|c|c|c|}
\hline$X_{23}$ & 24 & 25 & 26 \\
\hline $27 \mathrm{~b}$ & $28 a$ & $28 \mathrm{~b}$ & $28 \mathrm{c}$ \\
\hline
\end{tabular}

Any information copied from such Reports and Statements may not be sold or used by any person for the purpose of soliciting contributions or for commercial purposes, other than using the name and address of any political committee to solicit contributions from such committee.

NAME OF COMMITTEE (In Full)

\section{Friends of Herman Cain}

A. Okada Restaurant

Mailing Address 3131 Las Vegas Blvd S

\begin{tabular}{lll}
\hline City & State & Zip Code \\
Las Vegas & NV & 89109 \\
\hline
\end{tabular}

Purpose of Disbursement

Meeting Expense

Candidate Name

Office Sought:

House
Senate
President
District:
X Primary $\square$ General
Date of Disbursement

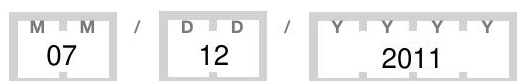

Transaction ID : B6892BB7B232E481CB1A

Amount of Each Disbursement this Period

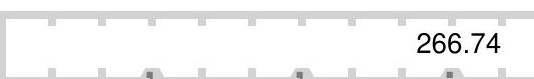

\section{B. Ashley Frasca}

Mailing Address 601 Springharbor Drive

\begin{tabular}{lcc}
\hline City & State & Zip Code \\
Woodstock & GA & $30188-604$
\end{tabular}

Purpose of Disbursement

Staff Salary

Candidate Name

Office Sought:

House
Senate
President

Disbursement For: 2012

Primary
Other (specify) General

State:

District:

Full Name (Last, First, Middle Initial)

c. Hertz Rent A Car

Mailing Address 225 Brae Boulevard

\begin{tabular}{|c|c|c|c|c|c|}
\hline M M / & D & Y & Y & Y & Y \\
07 & & 12 & & 2011 & \\
\hline
\end{tabular}

\begin{tabular}{lcc}
\hline City & State & Zip Code \\
Park Ridge & NJ & 07656
\end{tabular}

Purpose of Disbursement

Travel Expense

Candidate Name

Date of Disbursement

\begin{tabular}{|c|c|}
\hline $07^{\mathrm{M}}$ & 1 \\
\hline
\end{tabular}

Transaction ID : B61D21667D7EA45A4BA9

Amount of Each Disbursement this Period

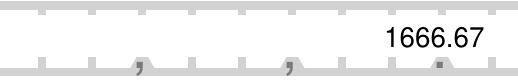

Transaction ID : B066C85D3D6E74E47AE8

Amount of Each Disbursement this Period

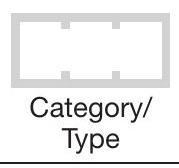

Office Sought:

\begin{tabular}{|l|l|}
\hline & House \\
& Senate \\
& President \\
& District:
\end{tabular}

Disbursement For: 2012

X $\begin{aligned} & \text { Primary } \\ & \text { Other (specify) }\end{aligned}$

State:

District:

Subtotal Of Receipts This Page (optional)

Total This Period (last page this line number only))

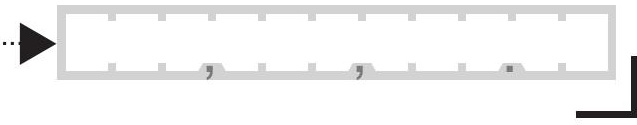




\section{SCHEDULE B-P}

\section{ITEMIZED DISBURSEMENTS}

\section{Use separate schedule(s)}

for each category of the

Detailed Summary Page
FOR LINE NUMBER: (check only one)

\begin{tabular}{|c|c|c|c|}
\hline$X_{23}$ & 24 & 25 & 26 \\
\hline $27 \mathrm{~b}$ & $28 a$ & $28 b$ & $28 \mathrm{c}$ \\
\hline
\end{tabular}

Any information copied from such Reports and Statements may not be sold or used by any person for the purpose of soliciting contributions or for commercial purposes, other than using the name and address of any political committee to solicit contributions from such committee.

NAME OF COMMITTEE (In Full)

\section{Friends of Herman Cain}

Full Name (Last, First, Middle Initial)

A. UPS

Mailing Address Post Office Box 7247-0244

Date of Disbursement

\begin{tabular}{lcc}
\hline City & State & Zip Code \\
Philadelphia & PA & $19170-0001$
\end{tabular}

Purpose of Disbursement

Shipping

Candidate Name

Office Sought:

$$
\begin{array}{|l|l}
\text { House } \\
\text { Senate } \\
\cline { 1 - 2 } \text { President }
\end{array}
$$

State: District:

Full Name (Last, First, Middle Initial)

\section{B. Schindler Elevator Corporation}

Mailing Address 6600 Highlands Parkway SE

\begin{tabular}{lcc}
\hline City & State & Zip Code \\
Smyrna & GA & 30082
\end{tabular}

Purpose of Disbursement

Office Maintenance

Candidate Name

Office Sought:

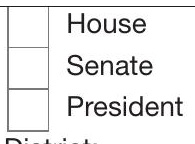

Disbursement For: 2012

Xrimary $\square$ General

State:

District:

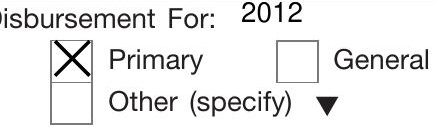

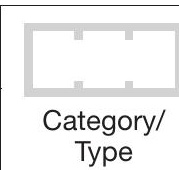
Type
Amount of Each Disbursement this Period

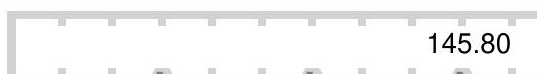

Full Name (Last, First, Middle Initial)

c. Larry Tuel

Mailing Address 5129 Welker Ave.

\begin{tabular}{|c|c|c|c|c|}
\hline $07^{\mathrm{M}}$ & 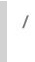 & D 12 & & $\begin{array}{cccc}Y & Y & Y & Y \\
& 2011 & \end{array}$ \\
\hline
\end{tabular}

Date of Disbursement

\begin{tabular}{lcc|} 
& & \\
\hline City & State & Zip Code \\
Des Moines & IA & $50312-2159$ \\
\hline
\end{tabular}

Purpose of Disbursement

Staff Salary

Candidate Name

t

\begin{tabular}{c|c} 
Category/ \\
Type
\end{tabular}

\section{Transaction ID : B34A3394832FC4FC2B55}

\begin{tabular}{l|l|r|}
\hline \multirow{2}{*}{ Office Sought: } & $\begin{array}{l}\text { House } \\
\text { Senate } \\
\text { President }\end{array}$ & $\begin{array}{r}\text { Disbursement For: } 2012 \\
\text { State: }\end{array}$ \\
\cline { 2 - 3 } & District: & X Primary \\
Other (specify)
\end{tabular}

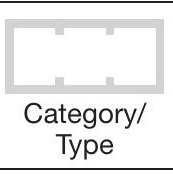

Amount of Each Disbursement this Period

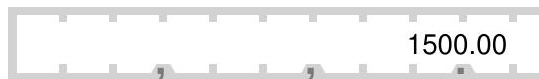

Subtotal Of Receipts This Page (optional).

Total This Period (last page this line number only)) 


\section{SCHEDULE B-P}

\section{ITEMIZED DISBURSEMENTS}

Use separate schedule(s)

for each category of the

Detailed Summary Page
FOR LINE NUMBER: (check only one)

\begin{tabular}{|c|c|c|c|c|}
\hline$X_{23}$ & 24 & 25 & 26 & \\
\hline $27 \mathrm{~b}$ & $28 a$ & $28 b$ & $28 \mathrm{c}$ & 2 \\
\hline
\end{tabular}

Any information copied from such Reports and Statements may not be sold or used by any person for the purpose of soliciting contributions or for commercial purposes, other than using the name and address of any political committee to solicit contributions from such committee.

NAME OF COMMITTEE (In Full)

\section{Friends of Herman Cain}

Full Name (Last, First, Middle Initial)

A. Scott Toomey

Mailing Address 3738 North Wilton Ave \#6

Date of Disbursement

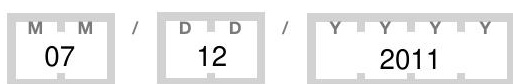

Transaction ID : BCEB390DFBCAA419A909

\begin{tabular}{lcc}
\hline City & State & Zip Code \\
Chicago & IL & $60613-3966$
\end{tabular}

Purpose of Disbursement

Staff Salary

Candidate Name

\begin{tabular}{l|l|l}
\hline Office Sought: & House & Disbursement For: 2012
\end{tabular} X Primary $\square$ General

State:

\section{Senate}

President

District:

Full Name (Last, First, Middle Initial)

\section{B. Scott Sidney}

Mailing Address N40 W6522 Jackson Street

\begin{tabular}{lcc}
\hline City & State & Zip Code \\
Cedarburg & WI & $53012-2317$
\end{tabular}

Purpose of Disbursement

Staff Salary

Candidate Name

Office Sought:

House
Senate
President

State:

District:

Full Name (Last, First, Middle Initial)

c. Kyle Maichle

Mailing Address 617 N 23rd Street Apt 305

\begin{tabular}{lcc}
\hline City & State & Zip Code \\
Milwaukee & WI & $53233-1976$
\end{tabular}

Purpose of Disbursement

Research

Candidate Name

Disbursement For: 2012

Primary $\square$ General
Other (specify)

Office Sought: $\quad$ House

\begin{tabular}{|l|l|} 
& House \\
Senate \\
President
\end{tabular}

Disbursement For: 2012

X $\begin{aligned} & \text { Primary } \\ & \text { Other (specify) }\end{aligned}$

State:
Date of Disbursement

\begin{tabular}{|c|c|c|c|c|}
\hline${ }^{\mathrm{M}} 7^{\mathrm{M}}$ & & ${ }^{\mathrm{D}} 12^{\mathrm{D}}$ & 1 & 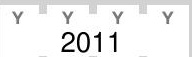 \\
\hline
\end{tabular}

Transaction ID : B7E2ACC55589F42A7BC3

Amount of Each Disbursement this Period

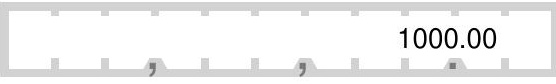

Date of Disbursement

\begin{tabular}{|c|c|c|c|c|c|}
\hline M M / & D & Y & Y & Y & Y \\
07 & & 12 & & 2011 & \\
\hline
\end{tabular}

Transaction ID : B646367771A664238BF4

Amount of Each Disbursement this Period

1000.00

Subtotal Of Receipts This Page (optional).

Total This Period (last page this line number only))

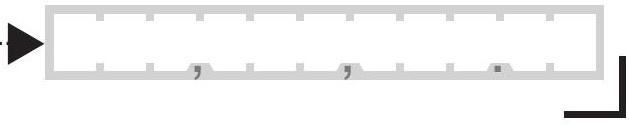




\section{SCHEDULE B-P}

\section{ITEMIZED DISBURSEMENTS}

Use separate schedule(s)

for each category of the

Detailed Summary Page
FOR LINE NUMBER: (check only one)

\begin{tabular}{|c|c|c|c|}
\hline$\times{ }_{23}$ & 24 & 25 & 26 \\
\hline $27 b$ & $28 a$ & $28 \mathrm{~b}$ & $28 \mathrm{c}$ \\
\hline
\end{tabular}

Any information copied from such Reports and Statements may not be sold or used by any person for the purpose of soliciting contributions or for commercial purposes, other than using the name and address of any political committee to solicit contributions from such committee.

NAME OF COMMITTEE (In Full)

\section{Friends of Herman Cain}

Full Name (Last, First, Middle Initial)

A. Scott F. Bieniek

Mailing Address 1782 Schooling Road

Date of Disbursement

\begin{tabular}{lcc}
\hline City & State & Zip Code \\
Spencer & IN & $47460-7528$
\end{tabular}

Purpose of Disbursement

Staff Salary

Candidate Name

Office Sought:

\section{House} \begin{tabular}{|l|l} 
House \\
Senate \\
President
\end{tabular} District:

State:

Full Name (Last, First, Middle Initial)

B. Mark Block

Mailing Address 18125 West Plateau Lane

\begin{tabular}{lcc}
\hline City & State & Zip Code \\
New Berlin & WI & $53146-5116$
\end{tabular}

Purpose of Disbursement

Staff Salary

Candidate Name X Primary $\square$ General

Office Sought:

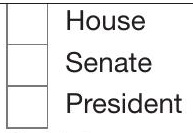

Disbursement For: 2012 Xrimary $\square$ General

State:

District:

Full Name (Last, First, Middle Initial)

c. Stephanie Latham

Mailing Address 827 Cog Hill

\begin{tabular}{lcc}
\hline City & State & Zip Code \\
McDonough & GA & $30253-4027$
\end{tabular}

Purpose of Disbursement Staff Salary

Candidate Name

Office Sought:

State:

\begin{tabular}{|l|l|l}
\hline & House \\
& Senate \\
& President \\
& Pistrict:
\end{tabular}

Disbursement For: 2012

X $\begin{aligned} & \text { Primary } \\ & \text { Other (specify) }\end{aligned}$
Date of Disbursement

\begin{tabular}{|c|c|c|c|c|}
\hline $07^{\mathrm{M}}$ & & ${ }^{\mathrm{D}} 2^{\mathrm{D}}$ & & 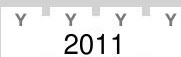 \\
\hline
\end{tabular}

Transaction ID : B4A84D78363B14AF48A9

Amount of Each Disbursement this Period

5005.28
Date of Disbursement

\begin{tabular}{|c|c|c|c|c|}
\hline${ }^{\mathrm{M}}{ }^{\mathrm{M}}$ & 1 & $\begin{array}{ll}\text { D } \\
12\end{array}$ & 1 & $\begin{array}{cccc}Y & Y & Y & Y \\
& 2011 & \end{array}$ \\
\hline
\end{tabular}

Transaction ID : B08B5AAB7E2204FCAA19

Amount of Each Disbursement this Period

2708.33

Subtotal Of Receipts This Page (optional).

Total This Period (last page this line number only))

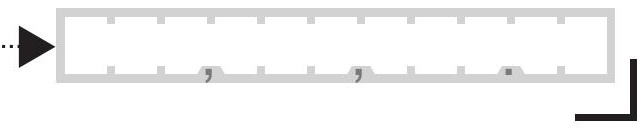




\section{SCHEDULE B-P}

\section{ITEMIZED DISBURSEMENTS}

\section{Use separate schedule(s) \\ for each category of the}

Detailed Summary Page
FOR LINE NUMBER: (check only one)

\begin{tabular}{|c|c|c|c|}
\hline$\times{ }_{23}$ & 24 & 25 & 26 \\
\hline $27 b$ & $28 a$ & $28 \mathrm{~b}$ & $28 \mathrm{c}$ \\
\hline
\end{tabular}

Any information copied from such Reports and Statements may not be sold or used by any person for the purpose of soliciting contributions or for commercial purposes, other than using the name and address of any political committee to solicit contributions from such committee.

NAME OF COMMITTEE (In Full)

\section{Friends of Herman Cain}

Full Name (Last, First, Middle Initial)

A. Ellen Carmichael

Mailing Address 1007 Oak Hills Parkway

\begin{tabular}{lcc}
\hline City & State & Zip Code \\
Baton Rouge & LA & $70810-4705$
\end{tabular}

Purpose of Disbursement

Airfare and Telephone

Candidate Name

Office Sought: $\quad$ House

\section{Senate}

President

State:

District:

Full Name (Last, First, Middle Initial)

B. Raquel Rhada Hirsch

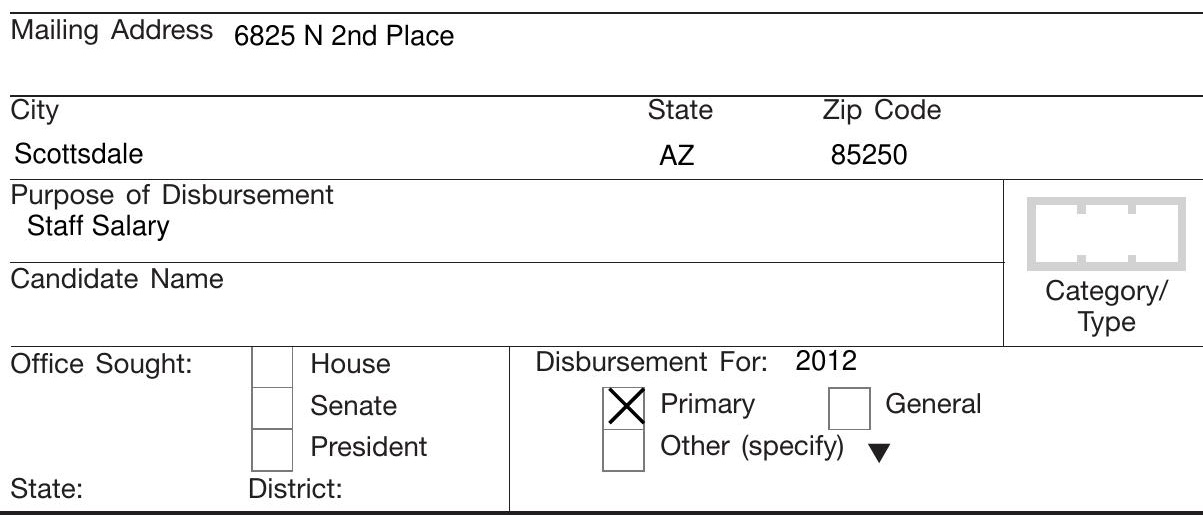

Full Name (Last, First, Middle Initial)

c. Karleen Smith

Mailing Address 105 Marilyn Drive E

\begin{tabular}{lcc}
\hline City & State & Zip Code \\
Fayetteville & GA & 30214 \\
\hline
\end{tabular}

Purpose of Disbursement

Staff Salary

Candidate Name

\begin{tabular}{l|l}
\hline Office Sought: & House \\
& $\begin{array}{l}\text { Senate } \\
\text { Senatent } \\
\text { President }\end{array}$ \\
State: & District:
\end{tabular}

Date of Disbursement

\begin{tabular}{|c|c|c|c|c|}
\hline $07^{\mathrm{M}}$ & 1 & ${ }_{12}^{\mathrm{D}}$ & l & 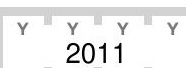 \\
\hline
\end{tabular}

Transaction ID : B0B341D040B8E4945853

Date of Disbursement

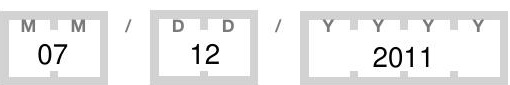

Transaction ID : B08B59E94AAD1435B80E

Amount of Each Disbursement this Period 597.38

Amount of Each Disbursement this Period

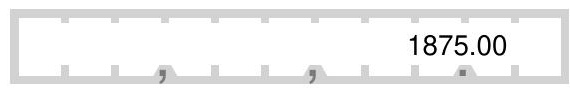

Date of Disbursement

\begin{tabular}{|c|c|c|c|c|}
\hline $07^{\mathrm{M}}$ & 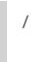 & D 12 & & $\begin{array}{cccc}Y & Y & Y & Y \\
& 2011 & \end{array}$ \\
\hline
\end{tabular}

Transaction ID : B8FF4226FBF0D4B92885

Amount of Each Disbursement this Period 3000.00

Subtotal Of Receipts This Page (optional).

Total This Period (last page this line number only)).

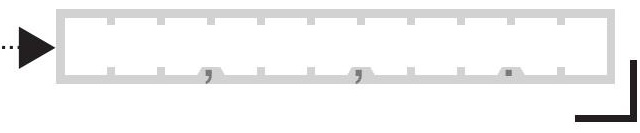




\section{SCHEDULE B-P}

\section{ITEMIZED DISBURSEMENTS}

Use separate schedule(s)

for each category of the

Detailed Summary Page
FOR LINE NUMBER: (check only one)

\begin{tabular}{|c|c|c|c|}
\hline$\times{ }_{23}$ & 24 & 25 & 26 \\
\hline $27 b$ & $28 a$ & $28 \mathrm{~b}$ & $28 \mathrm{c}$ \\
\hline
\end{tabular}

Any information copied from such Reports and Statements may not be sold or used by any person for the purpose of soliciting contributions or for commercial purposes, other than using the name and address of any political committee to solicit contributions from such committee.

NAME OF COMMITTEE (In Full)

\section{Friends of Herman Cain}

Full Name (Last, First, Middle Initial)

A. Michelle Gwaltney

\begin{tabular}{lcc}
\hline City & State & Zip Code \\
McDonough & GA & $30253-4229$ \\
\hline
\end{tabular}

Purpose of Disbursement

Staff Salary

Candidate Name

Office Sought:

House
Senate
President
District:
X Primary $\square$ General
Mailing Address 123 Glen Eagle Way

Disbursement For: 2012

Date of Disbursement

\begin{tabular}{|c|c|c|c|c|c|}
\hline M M / & Y \\
07 & 12 & 2011 \\
\hline
\end{tabular}

Transaction ID : BC6CE179362484371AC4

Amount of Each Disbursement this Period 8750.00

Date of Disbursement

\begin{tabular}{|c|c|c|c|c|}
\hline $07^{\mathrm{M}}$ & 1 & ${ }^{\mathrm{D}} 2^{\mathrm{D}}$ & 1 & $\begin{array}{llll}Y & Y & Y & Y \\
& 2011 & \end{array}$ \\
\hline
\end{tabular}

Transaction ID : B9913245403A442C9919

Amount of Each Disbursement this Period

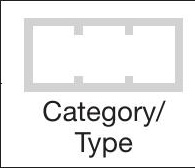
Zip Code
50125-8931

Purpose of Disbursement

Staff Salary

Candidate Name

IA

\begin{tabular}{c|c} 
& \\
Category/ \\
Type
\end{tabular}

Office Sought:

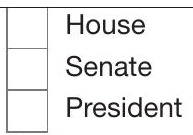

Disbursement For: 2012

Xrimary $\square$ General

State:

District:

Full Name (Last, First, Middle Initial)

\section{c. Sandra Poehler}

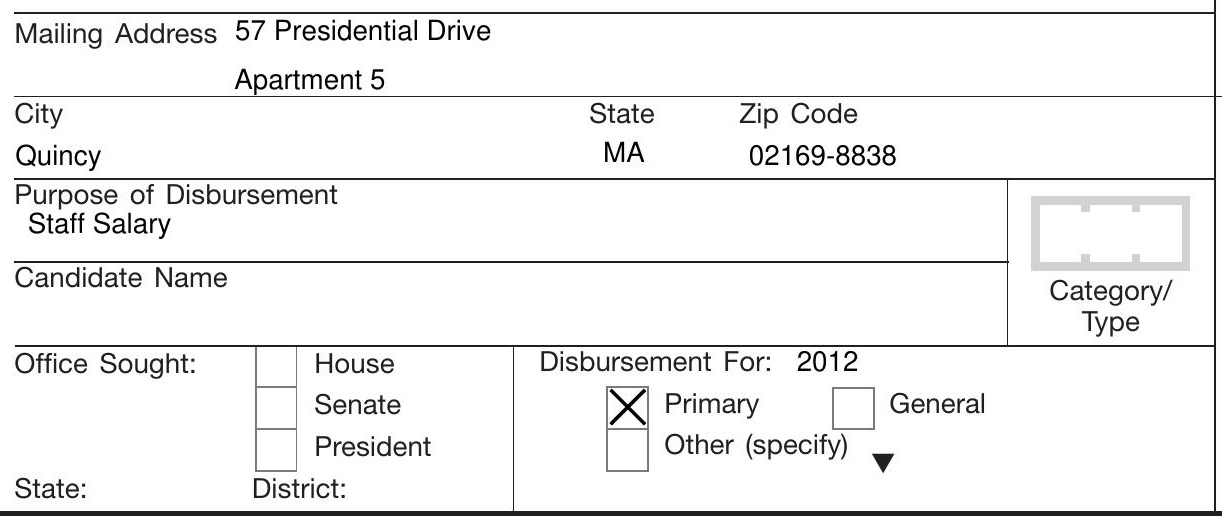

Subtotal Of Receipts This Page (optional)...

11125.00

Total This Period (last page this line number only))
Date of Disbursement

\begin{tabular}{|c|c|c|c|c|c|c|}
\hline M & M & D & Y & Y & Y \\
07 & & 12 & & 2011 & \\
\hline
\end{tabular}

Transaction ID : B3B24EA3DFD4D4AC3837

Amount of Each Disbursement this Period

1000.00 


\section{SCHEDULE B-P}

\section{ITEMIZED DISBURSEMENTS}

Use separate schedule(s)

for each category of the

Detailed Summary Page
FOR LINE NUMBER: (check only one)

\begin{tabular}{|c|c|c|c|}
\hline$\times{ }_{23}$ & 24 & 25 & 26 \\
\hline $27 b$ & $28 a$ & $28 \mathrm{~b}$ & $28 \mathrm{c}$ \\
\hline
\end{tabular}

Any information copied from such Reports and Statements may not be sold or used by any person for the purpose of soliciting contributions or for commercial purposes, other than using the name and address of any political committee to solicit contributions from such committee.

NAME OF COMMITTEE (In Full)

\section{Friends of Herman Cain}

Full Name (Last, First, Middle Initial)

A. Ellen Carmichael

Mailing Address 1007 Oak Hills Parkway

Date of Disbursement

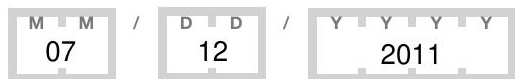

Transaction ID : B5609C06E72D94A3BA36

\begin{tabular}{lll}
\hline City & State & Zip Code \\
Baton Rouge & LA & $70810-4705$
\end{tabular}

Purpose of Disbursement

Staff Salary

Candidate Name

\begin{tabular}{l|l|l}
\hline Office Sought: & House & Disbursement For: 2012
\end{tabular} X Primary $\square$ General

State:

\section{Senate}

President

District:

Full Name (Last, First, Middle Initial)

\section{B. Lisa Shiflett}

Mailing Address 157 Stokes Drive

\begin{tabular}{lcc}
\hline City & State & Zip Code \\
Stockbridge & GA & $30281-1376$
\end{tabular}

Purpose of Disbursement

Staff Salary

Candidate Name

Office Sought:

House
Senate
President

State:

District:

Full Name (Last, First, Middle Initial)

c. Karis McKinney

Mailing Address 5017 N. 50th Street

\begin{tabular}{lcc}
\hline City & State & Zip Code \\
Milwaukee & WI & $53218-4326$
\end{tabular}

Purpose of Disbursement

Staff Salary

Candidate Name

Disbursement For: 2012

Primary
Other (specify)

Office Sought:

\begin{tabular}{|l|l|} 
& House \\
& Senate \\
President
\end{tabular}

Disbursement For: 2012

Х $\begin{aligned} & \text { Primary } \\ & \text { Other (specify) }\end{aligned}$

State:
Date of Disbursement

\begin{tabular}{|c|c|c|c|c|}
\hline${ }^{\mathrm{M}} 7^{\mathrm{M}}$ & & ${ }^{\mathrm{D}} 12^{\mathrm{D}}$ & 1 & 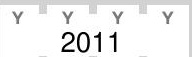 \\
\hline
\end{tabular}

\section{Transaction ID : B920B83E0DD2940D8BC9}

Amount of Each Disbursement this Period

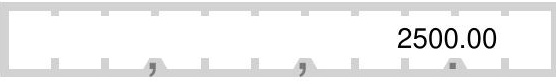

Date of Disbursement

\begin{tabular}{|c|c|c|c|c|}
\hline $07^{M}$ & I & $12^{\mathrm{D}}$ & I & 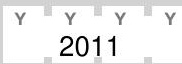 \\
\hline
\end{tabular}

Transaction ID : BB18750C187A84DE0946

Amount of Each Disbursement this Period

1875.00

Subtotal Of Receipts This Page (optional).

Total This Period (last page this line number only))

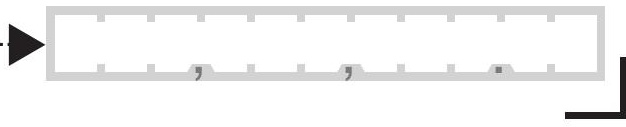




\section{SCHEDULE B-P}

\section{ITEMIZED DISBURSEMENTS}

\section{Use separate schedule(s)}

for each category of the

Detailed Summary Page
FOR LINE NUMBER: (check only one)

\begin{tabular}{|c|c|c|c|}
\hline$\times{ }_{23}$ & 24 & 25 & 26 \\
\hline $27 b$ & $28 a$ & $28 \mathrm{~b}$ & $28 \mathrm{c}$ \\
\hline
\end{tabular}

Any information copied from such Reports and Statements may not be sold or used by any person for the purpose of soliciting contributions or for commercial purposes, other than using the name and address of any political committee to solicit contributions from such committee.

NAME OF COMMITTEE (In Full)

\section{Friends of Herman Cain}

Full Name (Last, First, Middle Initial)

A. Linda Hansen

Mailing Address PO Box 371312

Date of Disbursement

\begin{tabular}{lcc}
\hline City & State & Zip Code \\
Milwaukee & WI & $53237-2412$ \\
\hline
\end{tabular}

Purpose of Disbursement

Staff Salary

Candidate Name

\begin{tabular}{l|l|l}
\hline Office Sought: & House & Disbursement For: 2012
\end{tabular} X Primary $\square$ General

State:

\section{House President} District:

Full Name (Last, First, Middle Initial)

\section{B. Elicia Huffaker}

\section{Mailing Address 7317 Alta Drive}

\begin{tabular}{lcc}
\hline City & State & Zip Code \\
Las Vegas & NV & $89145-5238$
\end{tabular}

Purpose of Disbursement

Staff Salary

Candidate Name

Office Sought:

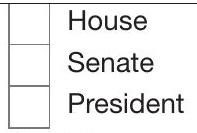

State:

District:

Full Name (Last, First, Middle Initial)

\section{Michael Johnson}

Mailing Address 8225 W. Center St. Apt. 3

\begin{tabular}{lcc}
\hline City & State & Zip Code \\
Milwaukee & WI & $53222-4861$
\end{tabular}

Purpose of Disbursement

Staff Salary

Candidate Name

\begin{tabular}{l|l}
\hline Office Sought: & House \\
& $\begin{array}{l}\text { Senate } \\
\text { Senatent } \\
\text { President }\end{array}$ \\
State: & District:
\end{tabular}

\section{Disbursement For: 2012 \\ Х $\begin{aligned} & \text { Primary } \\ & \text { Other (specify) }\end{aligned}$}

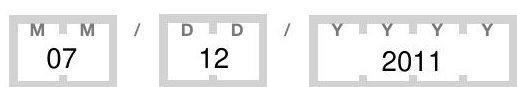

Transaction ID : BE0BFC4C8C0CE4E7AA96

Amount of Each Disbursement this Period

2916.67
Date of Disbursement

\begin{tabular}{|c|c|c|c|c|}
\hline $07^{\mathrm{M}}$ & & ${ }^{\mathrm{D}} 2^{\mathrm{D}}$ & & 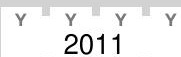 \\
\hline
\end{tabular}

Transaction ID : B3DBEE088BD8B48C090B

Amount of Each Disbursement this Period
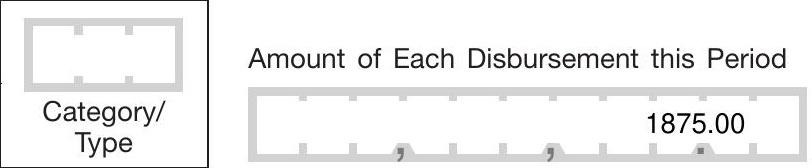

Date of Disbursement

\begin{tabular}{|c|c|c|c|c|}
\hline $07^{M}$ & I & D 12 & I & 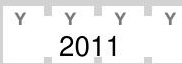 \\
\hline
\end{tabular}

Transaction ID : BA89B9A07352E4B8E9CD

Amount of Each Disbursement this Period

2000.00

Subtotal Of Receipts This Page (optional).

Total This Period (last page this line number only))

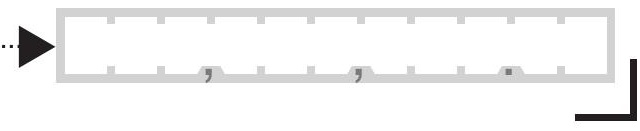




\section{SCHEDULE B-P}

\section{ITEMIZED DISBURSEMENTS}

Use separate schedule(s)

for each category of the

Detailed Summary Page
FOR LINE NUMBER: (check only one)

\begin{tabular}{|c|c|c|c|}
\hline$\times{ }_{23}$ & 24 & 25 & 26 \\
\hline $27 b$ & $28 a$ & $28 \mathrm{~b}$ & $28 \mathrm{c}$ \\
\hline
\end{tabular}

Any information copied from such Reports and Statements may not be sold or used by any person for the purpose of soliciting contributions or for commercial purposes, other than using the name and address of any political committee to solicit contributions from such committee.

NAME OF COMMITTEE (In Full)

\section{Friends of Herman Cain}

Full Name (Last, First, Middle Initial)

A. Francis Boustany, III

Mailing Address 126 Westfield Drive

Date of Disbursement

\begin{tabular}{lcc}
\hline City & State & Zip Code \\
Lafayette & LA & $70503-5484$
\end{tabular}

Purpose of Disbursement

Staff Salary

Candidate Name

Office Sought: $\quad$ House

Senate

President

State:

District:

Full Name (Last, First, Middle Initial)

B. Zachary Dalluge

Mailing Address 506 3rd Street

\begin{tabular}{lcc}
\hline City & State & Zip Code \\
Grafton & IA & $50440-7570$
\end{tabular}

Purpose of Disbursement

Staff Salary

Candidate Name

Disbursement For: 2012

Xrimary $\square$ General

Office Sought:

House
Senate
President

Disbursement For: 2012

Xrimary $\square$ General

State:

District:

Full Name (Last, First, Middle Initial)

\section{c. Stacy DeJarnette}

\begin{tabular}{|c|c|c|c|c|c|}
\hline \multicolumn{6}{|c|}{ Mailing Address 207 Robin Street } \\
\hline \multicolumn{2}{|l|}{ City } & State & \multicolumn{3}{|l|}{ Zip Code } \\
\hline \multicolumn{2}{|l|}{ White Hall } & AR & \multicolumn{3}{|c|}{$71602-5418$} \\
\hline \multicolumn{5}{|c|}{$\begin{array}{l}\text { Purpose of Disbursement } \\
\text { Staff Salary }\end{array}$} & \\
\hline \multicolumn{5}{|c|}{ Candidate Name } & $\begin{array}{l}\text { Category/ } \\
\text { Type }\end{array}$ \\
\hline \multirow[t]{3}{*}{ Office Sought: } & House & \multirow{3}{*}{\multicolumn{4}{|c|}{$\begin{array}{l}\text { Disbursement For: } 2012 \\
\text { Х Primary } \\
\text { Other (specify) }\end{array}$}} \\
\hline & Senate & & & & \\
\hline & President & & & & \\
\hline State: & \multicolumn{5}{|c|}{ District: } \\
\hline
\end{tabular}

Subtotal Of Receipts This Page (optional).

Date of Disbursement

\begin{tabular}{|c|c|c|c|c|}
\hline $07^{\mathrm{M}}$ & 1 & ${ }^{\mathrm{D}} 2^{\mathrm{D}}$ & I & 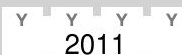 \\
\hline
\end{tabular}

Transaction ID : B5082F06C46B94F97A00

Amount of Each Disbursement this Period

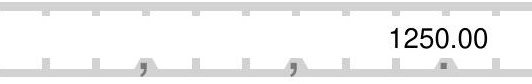

Date of Disbursement

\begin{tabular}{|c|c|c|c|c|c|c|}
\hline${ }^{M}$ & M & D & Y & Y & Y \\
07 & 12 & 2011 & \\
\hline
\end{tabular}

Transaction ID : B423D8219299344E7B62

Amount of Each Disbursement this Period

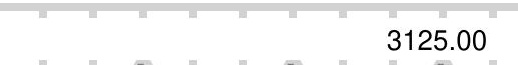

3125.00

Total This Period (last page this line number only)) 


\section{SCHEDULE B-P}

\section{ITEMIZED DISBURSEMENTS}

Use separate schedule(s)

for each category of the

Detailed Summary Page
FOR LINE NUMBER: (check only one)

\begin{tabular}{|c|c|c|c|}
\hline$\times{ }_{23}$ & 24 & 25 & 26 \\
\hline $27 b$ & $28 a$ & $28 \mathrm{~b}$ & $28 \mathrm{c}$ \\
\hline
\end{tabular}

Any information copied from such Reports and Statements may not be sold or used by any person for the purpose of soliciting contributions or for commercial purposes, other than using the name and address of any political committee to solicit contributions from such committee.

NAME OF COMMITTEE (In Full)

\section{Friends of Herman Cain}

Full Name (Last, First, Middle Initial)

A. Brenda Hicks

Mailing Address 3653 S 75th Street

Date of Disbursement

\begin{tabular}{lcc}
\hline City & State & Zip Code \\
Milwaukee & WI & $53220-1139$
\end{tabular}

Purpose of Disbursement

Staff Salary

Candidate Name

\begin{tabular}{l|l|l}
\hline Office Sought: & House & Disbursement For: 2012
\end{tabular} X Primary $\square$ General

State:

\section{Senate}

President

District:

Full Name (Last, First, Middle Initial)

B. Michael Johnson

Mailing Address 8225 W. Center St. Apt. 3

\begin{tabular}{lcc}
\hline City & State & Zip Code \\
Milwaukee & WI & $53222-4861$
\end{tabular}

Purpose of Disbursement

Staff Salary

Candidate Name

Office Sought:

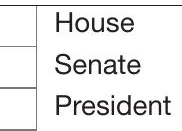

State:

District:

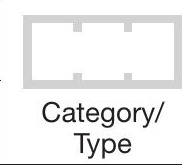

Amount of Each Disbursement this Period

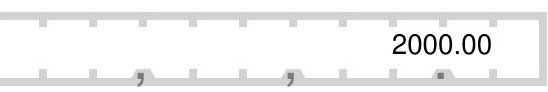

Full Name (Last, First, Middle Initial)

\section{c. Daniel Tripp}

Mailing Address 300 Hickory Lane

\begin{tabular}{lcc}
\hline City & State & Zip Code \\
Mauldin & SC & $29662-2238$
\end{tabular}

Purpose of Disbursement

Staff Salary

Candidate Name

Office Sought:

State:

Subtotal Of Receipts This Page (optional).

\begin{tabular}{|c|c|c|}
\hline House & Disbursement For: 2012 & \\
\hline Senate & Х Primary & General \\
\hline President & Other (sp & \\
\hline
\end{tabular}

Date of Disbursement

\begin{tabular}{|c|c|c|c|c|}
\hline $07^{\mathrm{M}}$ & 1 & ${ }^{\mathrm{D}} 4^{\mathrm{D}}$ & I & $\begin{array}{llll} & Y & Y & Y \\
& 2011 & \end{array}$ \\
\hline
\end{tabular}

Transaction ID : BAEC81C2F2F9848458B1

Amount of Each Disbursement this Period

985.83

Date of Disbursement

\begin{tabular}{|c|c|c|c|c|c|}
\hline M & M & D & Y & Y & Y \\
07 & & 14 & & 2011 & \\
\hline
\end{tabular}

Transaction ID : B8F35D792E6E84712902

Amount of Each Disbursement this Period

985.83 Type

Total This Period (last page this line number only)) 


\section{SCHEDULE B-P}

\section{ITEMIZED DISBURSEMENTS}

Use separate schedule(s)

for each category of the

Detailed Summary Page
FOR LINE NUMBER: (check only one)

\begin{tabular}{|c|c|c|c|c|}
\hline$X_{23}$ & 24 & 25 & 26 & \\
\hline $27 \mathrm{~b}$ & $28 a$ & $28 b$ & $28 \mathrm{c}$ & 2 \\
\hline
\end{tabular}

Any information copied from such Reports and Statements may not be sold or used by any person for the purpose of soliciting contributions or for commercial purposes, other than using the name and address of any political committee to solicit contributions from such committee.

NAME OF COMMITTEE (In Full)

\section{Friends of Herman Cain}

Full Name (Last, First, Middle Initial)

A. Karis McKinney

Mailing Address 5017 N. 50th Street

Date of Disbursement

\begin{tabular}{lcc}
\hline City & State & Zip Code \\
Milwaukee & WI & $53218-4326$
\end{tabular}

Purpose of Disbursement

Staff Salary

Candidate Name

\begin{tabular}{l|l|l|l}
\hline Office Sought: & House & Disbursement For: 2012
\end{tabular} X Primary $\square$ General

State:

\section{Senate}

President

District:

Full Name (Last, First, Middle Initial)

B. Raquel Rhada Hirsch

Mailing Address 6825 N 2nd Place

\begin{tabular}{lcc}
\hline City & State & Zip Code \\
Scottsdale & AZ & 85250
\end{tabular}

Purpose of Disbursement

Staff Salary

Candidate Name

Office Sought:

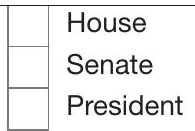

State:

District:

Full Name (Last, First, Middle Initial)

c. Frontier Airlines Inc.

Mailing Address 7001 Tower Road

Disbursement For: 2012

X Primary $\square$ General

City State Zip Code

Denver

CO 80249-7312

Purpose of Disbursement

Travel Expense

Candidate Name

Office Sought: $\quad$ House

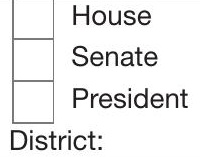

Disbursement For: 2012

X $\begin{aligned} & \text { Primary } \\ & \text { Other (specify) }\end{aligned}$

State:

District:

Subtotal Of Receipts This Page (optional).

Date of Disbursement

\begin{tabular}{|c|c|c|c|c|}
\hline $07^{\mathrm{M}}$ & 1 & D 14 & 1 & 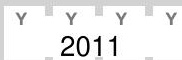 \\
\hline
\end{tabular}

Transaction ID : BA90241AA00444EA9910

Amount of Each Disbursement this Period

446.40

Total This Period (last page this line number only)) 


\section{SCHEDULE B-P}

\section{ITEMIZED DISBURSEMENTS}

Use separate schedule(s)

for each category of the

Detailed Summary Page
FOR LINE NUMBER: (check only one)

\begin{tabular}{|c|c|c|c|}
\hline$\times{ }_{23}$ & 24 & 25 & 26 \\
\hline $27 b$ & $28 a$ & $28 \mathrm{~b}$ & $28 \mathrm{c}$ \\
\hline
\end{tabular}

Any information copied from such Reports and Statements may not be sold or used by any person for the purpose of soliciting contributions or for commercial purposes, other than using the name and address of any political committee to solicit contributions from such committee.

NAME OF COMMITTEE (In Full)

\section{Friends of Herman Cain}

Full Name (Last, First, Middle Initial)

\section{A. AWG Charter Service}

Mailing Address 4676 Wynn Road

Date of Disbursement

\begin{tabular}{|c|c|c|c|c|c|c|}
\hline M M / & D D \\
07 & 14 & 2011 \\
\hline
\end{tabular}

Transaction ID : B64A6B920265D48DA8D8

\begin{tabular}{lll}
\hline City & State & Zip Code \\
Las Vegas & NV & 89103
\end{tabular}

Purpose of Disbursement

Travel Expense

Candidate Name

Office Sought:

$$
\begin{aligned}
& \text { House } \\
& \text { Senate } \\
& \text { Presiden }
\end{aligned}
$$
District:

State:

Full Name (Last, First, Middle Initial)

B. Hotels.com

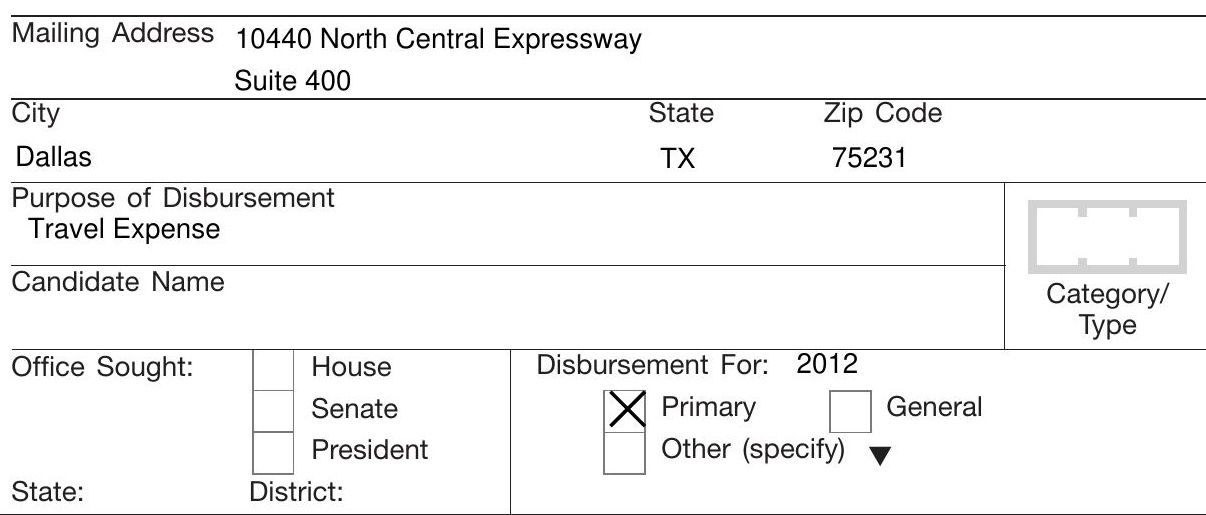

Full Name (Last, First, Middle Initial)

c. Inkhead Inc.

\begin{tabular}{|c|c|c|c|c|c|}
\hline \multicolumn{6}{|c|}{$\begin{aligned} \text { Mailing Address } & 138 \text { Park Avenue } \\
& \text { Suite } 300\end{aligned}$} \\
\hline \multicolumn{2}{|l|}{ City } & State & \multicolumn{3}{|l|}{ Zip Code } \\
\hline \multicolumn{2}{|l|}{ Winder } & GA & \multicolumn{3}{|l|}{30680} \\
\hline \multicolumn{5}{|c|}{$\begin{array}{l}\text { Purpose of Disbursement } \\
\text { Event Supplies }\end{array}$} & \\
\hline \multicolumn{5}{|l|}{ Candidate Name } & $\begin{array}{l}\text { Category/ } \\
\text { Type }\end{array}$ \\
\hline \multirow[t]{3}{*}{ Office Sought: } & House & \\
\hline & Senate & \multirow{3}{*}{\multicolumn{2}{|c|}{ Х $\begin{array}{l}\text { Primary } \\
\text { Other (specify) }\end{array}$}} & \multirow{2}{*}{\multicolumn{2}{|c|}{ General }} \\
\hline & President & & & & \\
\hline State: & District: & & & & \\
\hline
\end{tabular}

Subtotal Of Receipts This Page (optional).

Date of Disbursement

\begin{tabular}{|c|c|c|c|c|c|}
\hline M M & I & D & Y & Y & Y \\
07 & & 14 & & 2011 & \\
\hline
\end{tabular}

Transaction ID : BE99A76886B744DCF985

Amount of Each Disbursement this Period

Date of Disbursement

Amount of Each Disbursement this Period
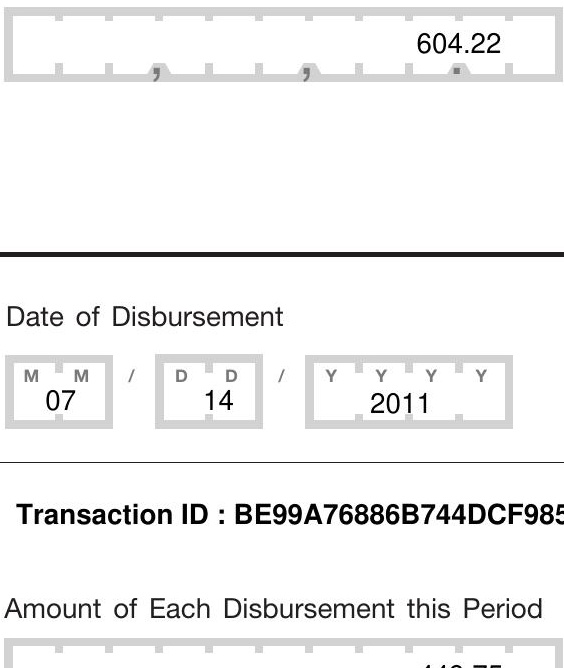

449.75

Total This Period (last page this line number only))

1263.97
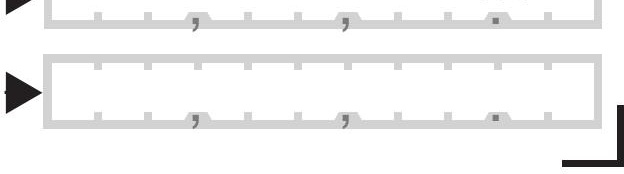

FEC Schedule B-P (Form 3P) (Rev. 03/2011) 


\section{SCHEDULE B-P}

\section{ITEMIZED DISBURSEMENTS}

Use separate schedule(s)

for each category of the

Detailed Summary Page
FOR LINE NUMBER: (check only one)

\begin{tabular}{|c|c|c|c|}
\hline$X_{23}$ & 24 & 25 & 26 \\
\hline $27 \mathrm{~b}$ & $28 a$ & $28 b$ & $28 \mathrm{c}$ \\
\hline
\end{tabular}

Any information copied from such Reports and Statements may not be sold or used by any person for the purpose of soliciting contributions or for commercial purposes, other than using the name and address of any political committee to solicit contributions from such committee.

NAME OF COMMITTEE (In Full)

\section{Friends of Herman Cain}

Full Name (Last, First, Middle Initial)

A. Tri-Net Payroll Services

Mailing Address 1100 San Leandro Boulevard

Suite

\begin{tabular}{lll}
\hline City & State & Zip Code \\
San Leandro & CA & 94577
\end{tabular}

Purpose of Disbursement

Payroll Benefits

Candidate Name

Office Sought:

House
Senate
President
District:

Disbursement For: 2012

X Primary $\square$ General
Date of Disbursement

\begin{tabular}{|c|c|c|c|c|}
\hline M M & D \\
07 & 14 & 2011 \\
\hline
\end{tabular}

Transaction ID : B949B6841A24A4CF88CF

Amount of Each Disbursement this Period 388.07

\section{B. Tri-Net Payroll Services}

\begin{tabular}{|c|c|c|c|c|}
\hline Mailing Address & \multicolumn{4}{|c|}{1100 San Leandro Boulevard } \\
\hline \multicolumn{2}{|l|}{ City } & \multicolumn{3}{|c|}{ Zip Code } \\
\hline \multicolumn{2}{|l|}{ San Leandro } & \multicolumn{3}{|c|}{94577} \\
\hline \multicolumn{4}{|c|}{$\begin{array}{l}\text { Purpose of Disbursement } \\
\text { Payroll Withholding }\end{array}$} & \\
\hline \multicolumn{4}{|l|}{ Candidate Name } & $\begin{array}{l}\text { Category/ } \\
\text { Type }\end{array}$ \\
\hline \multirow[t]{3}{*}{ Office Sought: } & House & \multirow{3}{*}{\multicolumn{3}{|c|}{ Disbursement For: 2012}} \\
\hline & Senate & & & \\
\hline & President & & & \\
\hline State: & \multicolumn{4}{|c|}{ District: } \\
\hline
\end{tabular}

Date of Disbursement

\begin{tabular}{|c|c|c|c|c|}
\hline $07^{\mathrm{M}}$ & 1 & ${ }_{14}^{\mathrm{D}}$ & 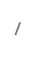 & $\begin{array}{llll}Y & Y & Y & Y \\
& 2011\end{array}$ \\
\hline
\end{tabular}

Transaction ID : B3B1DAA8DEF5045F79EF

Full Name (Last, First, Middle Initial)

\section{c. Wynn Las Vegas Hotel}

Mailing Address 3131 Las Vegas Boulevard

Date of Disbursement

\begin{tabular}{lcc} 
& \\
\hline City & State & Zip Code \\
Las Vegas & NV & $89109-1967$
\end{tabular}

Purpose of Disbursement

Travel Expense

Candidate Name

\begin{tabular}{|c|c|c|c|c|}
\hline $07^{\mathrm{M}}$ & & $\begin{array}{ll}D \\
14\end{array}$ & & $\begin{array}{ccc}Y & Y & Y \\
& & \\
2011\end{array}$ \\
\hline
\end{tabular}

Transaction ID : B3B9F1258FF21455296B

Amount of Each Disbursement this Period

\begin{tabular}{l|l|c|}
\hline Office Sought: & $\begin{array}{l}\text { House } \\
\text { Senate } \\
\text { President } \\
\text { State: }\end{array}$ & $\begin{array}{r}\text { Disbursement For: } 2012 \\
\text { District: }\end{array}$
\end{tabular}

Amount of Each Disbursement this Period

303.34

District:

Subtotal Of Receipts This Page (optional)

Total This Period (last page this line number only))

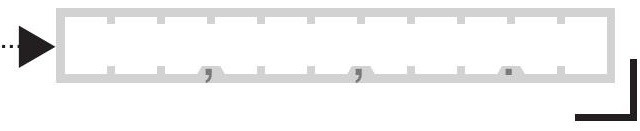




\section{SCHEDULE B-P}

\section{ITEMIZED DISBURSEMENTS}

Use separate schedule(s)

for each category of the

Detailed Summary Page
FOR LINE NUMBER: (check only one)

\begin{tabular}{|c|c|c|c|}
\hline$\times \quad 23$ & 24 & 25 & 26 \\
\hline $27 \mathrm{~b}$ & $28 \mathrm{a}$ & $28 b$ & $28 \mathrm{c}$ \\
\hline
\end{tabular}

Any information copied from such Reports and Statements may not be sold or used by any person for the purpose of soliciting contributions or for commercial purposes, other than using the name and address of any political committee to solicit contributions from such committee.

NAME OF COMMITTEE (In Full)

\section{Friends of Herman Cain}

Full Name (Last, First, Middle Initial)

A. United Airlines

Mailing Address 1200 E Algonquin Road

Post Office Box 66100

City

Elk Grove Township

Purpose of Disbursement

Travel Expense

Candidate Name

Office Sought:

State:

Full Name (Last, First, Middle Initial)

\section{B. Delta Airlines}

\begin{tabular}{ll}
\hline Mailing Address & Post Office Box 20980 \\
& Department 980 \\
\hline City &
\end{tabular}

Atlanta

Purpose of Disbursement

Travel Expense

Candidate Name

Office Sought:

\begin{tabular}{|l|l} 
& House \\
Senate \\
\cline { 1 - 2 } & President
\end{tabular}

State:

District:

\section{c. Tri-Net Payroll Services}

Mailing Address 1100 San Leandro Boulevard

Suite

\begin{tabular}{lcc}
\multicolumn{2}{c}{ Suite } & \\
\hline City & State & Zip Code \\
San Leandro & CA & 94577 \\
\hline
\end{tabular}

Purpose of Disbursement

Payroll Service Fees

Candidate Name

Office Sought:

State:

\begin{tabular}{|l|l|}
\hline & House \\
& Senate \\
& President \\
& President
\end{tabular}

State Zip Code

IL $\quad 60007$

60007




\section{SCHEDULE B-P}

\section{ITEMIZED DISBURSEMENTS}

\section{Use separate schedule(s) \\ for each category of the}

Detailed Summary Page
FOR LINE NUMBER: (check only one)

\begin{tabular}{|c|c|c|c|c|}
\hline $\mathrm{X}_{23}$ & 24 & 25 & 26 & \\
\hline $27 \mathrm{~b}$ & $28 a$ & $28 b$ & $28 \mathrm{c}$ & 2 \\
\hline
\end{tabular}

Any information copied from such Reports and Statements may not be sold or used by any person for the purpose of soliciting contributions or for commercial purposes, other than using the name and address of any political committee to solicit contributions from such committee.

NAME OF COMMITTEE (In Full)

\section{Friends of Herman Cain}

Full Name (Last, First, Middle Initial)

\section{A. Action Limousines \& Luxury Buses}

Mailing Address 1797 Rugby Avenue

Date of Disbursement

\begin{tabular}{|c|c|c|c|c|c|c|}
\hline M M & Y \\
07 & 15 & 2011 \\
\hline
\end{tabular}

Transaction ID : B4BF04BE5F3C942C9855

\begin{tabular}{lcc}
\hline City & State & Zip Code \\
Atlanta & GA & 30337 \\
\hline Purpose of Disbursement & &
\end{tabular}

Purpose of Disbursement

Travel Expense

Candidate Name

\begin{tabular}{l|l|l}
\hline Office Sought: & House & Disbursement For: 2012
\end{tabular} X Primary $\square$ General

State:

\section{Senate}

President

District:

Full Name (Last, First, Middle Initial)

B. Wynn Las Vegas Hotel

Mailing Address 3131 Las Vegas Boulevard

\begin{tabular}{lcc}
\hline City & State & Zip Code \\
Las Vegas & NV & $89109-1967$
\end{tabular}

Purpose of Disbursement

Travel Expense

Candidate Name

Office Sought:

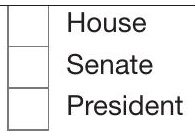

State:

District:

Full Name (Last, First, Middle Initial)

\section{c. Concert Production}

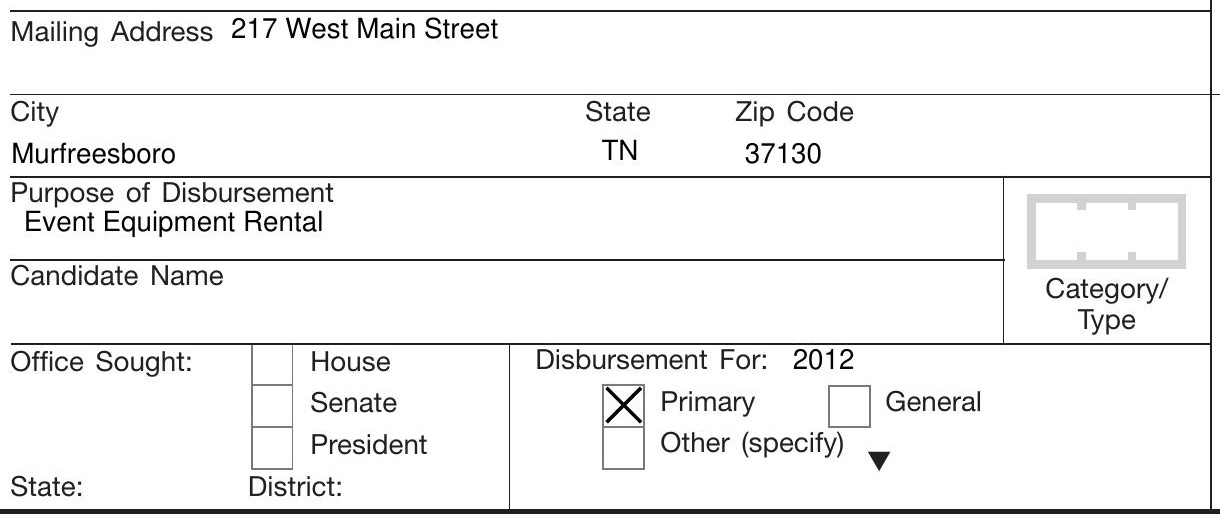

Subtotal Of Receipts This Page (optional)......

Date of Disbursement

\begin{tabular}{|c|c|c|c|c|c|c|}
\hline M M & I & D & Y & Y & Y \\
07 & & 15 & & 2011 & \\
\hline
\end{tabular}

\section{Transaction ID : B8F55C41D214641FE8C6}

Amount of Each Disbursement this Period

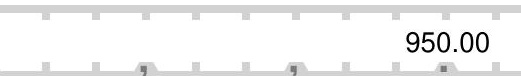

950.00

Total This Period (last page this line number only))

2933.63

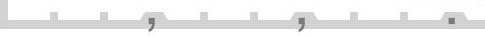

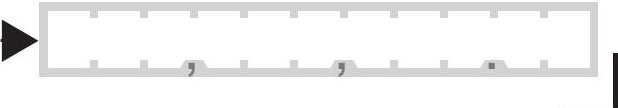




\section{SCHEDULE B-P}

\section{ITEMIZED DISBURSEMENTS}

\section{Use separate schedule(s) \\ for each category of the}

Detailed Summary Page
FOR LINE NUMBER: (check only one)

\begin{tabular}{|c|c|c|c|}
\hline$\times{ }_{23}$ & 24 & 25 & 26 \\
\hline $27 b$ & $28 a$ & $28 \mathrm{~b}$ & $28 \mathrm{c}$ \\
\hline
\end{tabular}

Any information copied from such Reports and Statements may not be sold or used by any person for the purpose of soliciting contributions or for commercial purposes, other than using the name and address of any political committee to solicit contributions from such committee.

NAME OF COMMITTEE (In Full)

\section{Friends of Herman Cain}

Full Name (Last, First, Middle Initial)

A. Inkhead Inc.

Mailing Address 138 Park Avenue

Suite 300

Date of Disbursement

\begin{tabular}{lll}
\multicolumn{2}{r}{ Suite 300} & \\
\hline City & State & Zip Code \\
Winder & GA & 30680 \\
\hline Purpose of & Disbursement
\end{tabular}

Purpose of Disbursement

Event Supplies

Candidate Name

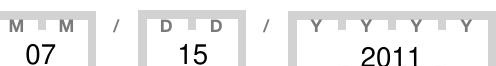

2011

Transaction ID : B825B93B3B8CB4CD7AF6

Amount of Each Disbursement this Period

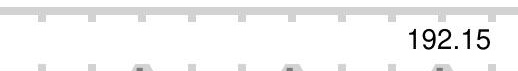

\begin{tabular}{l|l|c|}
\hline Office Sought: & $\begin{array}{l}\text { House } \\
\text { Senate } \\
\text { President }\end{array}$ & $\begin{array}{r}\text { Disbursement For: } 2012 \\
\text { X Primary } \\
\text { Other (specify) }\end{array}$
\end{tabular}

Full Name (Last, First, Middle Initial)

B. Del Friscos

Mailing Address 1221 Avenue of the America's

\begin{tabular}{lcc}
\hline City & State & Zip Code \\
New York & NY & 10020
\end{tabular}

Purpose of Disbursement

Meeting Expense

Candidate Name

Office Sought:

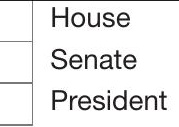

State:

District:
Date of Disbursement

\begin{tabular}{|c|c|c|c|c|}
\hline $07^{\mathrm{M}}$ & 1 & ${ }_{15}^{D}$ & 1 & $\begin{array}{llll} & Y & Y & Y \\
& & Y & Y\end{array}$ \\
\hline
\end{tabular}

Transaction ID : B5EB6C493900B48309FE

Amount of Each Disbursement this Period

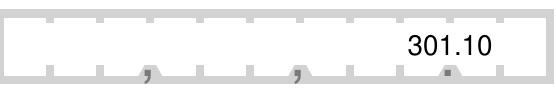

Date of Disbursement

\begin{tabular}{|c|c|c|c|c|}
\hline $07^{\mathrm{M}}$ & 1 & $\begin{array}{ll}\text { D } \\
15\end{array}$ & 1 & 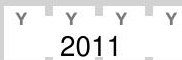 \\
\hline
\end{tabular}

Transaction ID : BA345D324A85844378FB

Amount of Each Disbursement this Period

344.90 Type Disbursement For: 2012
$X \begin{aligned} & \text { Primary } \\ & \text { Other (specify) General }\end{aligned}$

\begin{tabular}{|c|c|c|c|}
\hline \multirow[t]{3}{*}{ Office Sought: } & House & \multicolumn{2}{|l|}{ Disbursement For: 2012} \\
\hline & Senate & X Primary & General \\
\hline & $\begin{array}{l}\text { President } \\
\text { trict: }\end{array}$ & Other (specıty) & \\
\hline
\end{tabular}

Subtotal Of Receipts This Page (optional).

Total This Period (last page this line number only))

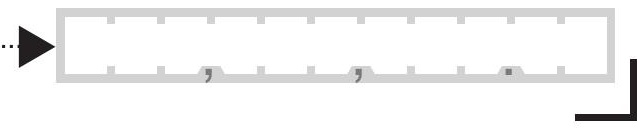




\section{SCHEDULE B-P}

\section{ITEMIZED DISBURSEMENTS}

Use separate schedule(s)

for each category of the

Detailed Summary Page
FOR LINE NUMBER: (check only one)

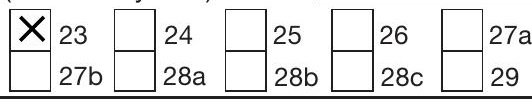

Any information copied from such Reports and Statements may not be sold or used by any person for the purpose of soliciting contributions or for commercial purposes, other than using the name and address of any political committee to solicit contributions from such committee.

NAME OF COMMITTEE (In Full)

\section{Friends of Herman Cain}

Full Name (Last, First, Middle Initial)

A. Stephanie Latham

Mailing Address 827 Cog Hill

Date of Disbursement

\begin{tabular}{lcc}
\hline City & State & Zip Code \\
McDonough & GA & $30253-4027$
\end{tabular}

Purpose of Disbursement

Fundraising Consulting

Candidate Name

Office Sought: $\quad$ House

Senate

President

State:

District:

Full Name (Last, First, Middle Initial)

\section{B. Stephanie Latham}

\section{Mailing Address 827 Cog Hill}

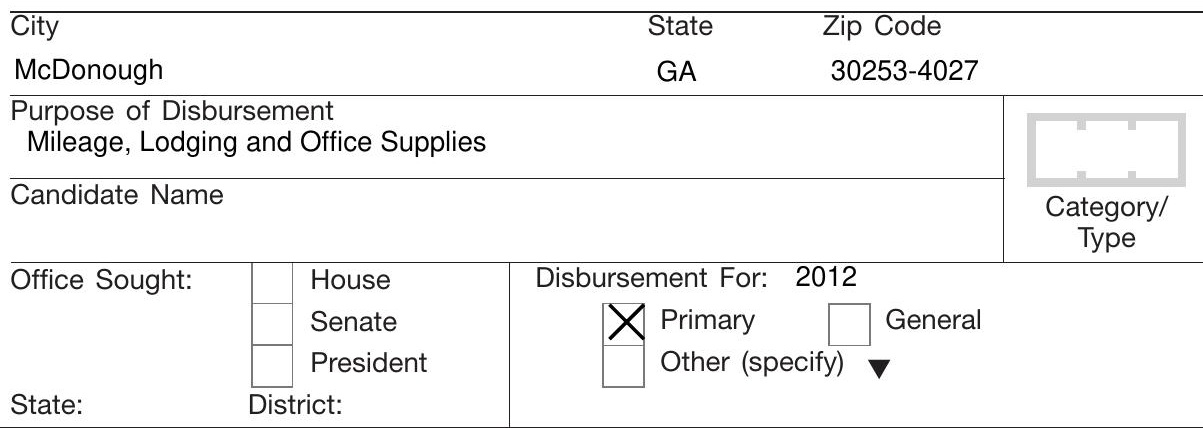

Full Name (Last, First, Middle Initial)

c. Ashley Frasca

Mailing Address 601 Springharbor Drive

\begin{tabular}{lcc}
\hline City & State & Zip Code \\
Woodstock & GA & $30188-6044$
\end{tabular}

Purpose of Disbursement

Postage and Mileage

Candidate Name

Office Sought: $\quad$ House

$\begin{aligned} & \text { House } \\ & \text { Senate } \\ & \text { President }\end{aligned}$
District:

State: Type

\section{Disbursement For: 2012 \\ X Primary $\square$ General}

\section{$M M$, D D}

07

15

2011

Transaction ID : B27282A5043A8447496D

Amount of Each Disbursement this Period

\section{Category/} Type
Date of Disbursement

\begin{tabular}{|c|c|c|c|c|}
\hline $07^{M}$ & & ${ }_{15}^{\mathrm{D}}$ & & $\begin{array}{llll} & Y & Y & Y \\
& & Y & Y\end{array}$ \\
\hline
\end{tabular}

\section{Transaction ID : B6BE21C0430494355A1E}

Amount of Each Disbursement this Period

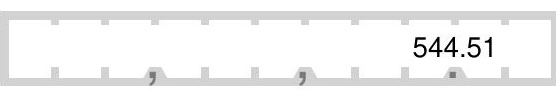

Date of Disbursement

\begin{tabular}{|c|c|c|c|c|c|c|}
\hline M M & I & D & Y & Y & Y & Y \\
07 & & 18 & & 2011 & \\
\hline
\end{tabular}

Transaction ID : B2E4FAAAE3EA94E36833

Amount of Each Disbursement this Period

Subtotal Of Receipts This Page (optional)

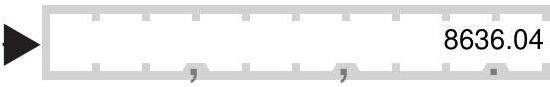

Total This Period (last page this line number only))

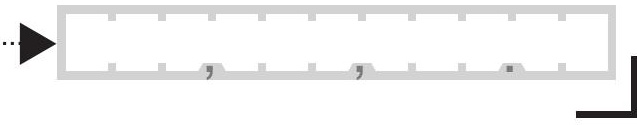




\section{SCHEDULE B-P}

\section{ITEMIZED DISBURSEMENTS}

\section{Use separate schedule(s) \\ for each category of the}

Detailed Summary Page
FOR LINE NUMBER: (check only one)

\begin{tabular}{|c|c|c|c|}
\hline$\times{ }_{23}$ & 24 & 25 & 26 \\
\hline $27 b$ & $28 a$ & $28 \mathrm{~b}$ & $28 \mathrm{c}$ \\
\hline
\end{tabular}

Any information copied from such Reports and Statements may not be sold or used by any person for the purpose of soliciting contributions or for commercial purposes, other than using the name and address of any political committee to solicit contributions from such committee.

NAME OF COMMITTEE (In Full)

\section{Friends of Herman Cain}

Full Name (Last, First, Middle Initial)

A. Steven Hensler

Mailing Address 401 Woodview Drive

Date of Disbursement

\begin{tabular}{lcc}
\hline City & State & Zip Code \\
Sun Prairie & WI & $53590-2353$
\end{tabular}

Purpose of Disbursement

Mileage

WI 53590-2353

Candidate Name

\begin{tabular}{l|l|l|l}
\hline Office Sought: & House & Disbursement For: 2012
\end{tabular} X Primary $\square$ General

State:

\section{Senate}

President

District:

Full Name (Last, First, Middle Initial)

B. Nathan Naidu

Mailing Address 3601 canton rd \#131

\begin{tabular}{lcc}
\hline City & State & Zip Code \\
Marietta & GA & $30066-2892$
\end{tabular}

Purpose of Disbursement

Lodging and Meeting Expenses

Candidate Name

Office Sought:

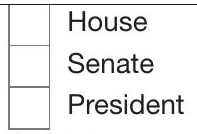

State:

District:

GA

Full Name (Last, First, Middle Initial)

\section{c. Sandra Poehler}

\begin{tabular}{ll}
\hline Mailing Address 57 Presidential Drive \\
\\
Apartment 5
\end{tabular}

Quincy

Purpose of Disbursement

Transportation, Meeting Expenses, Office

Candidate Name

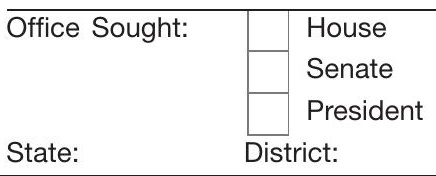

Disbursement For: 2012

$$
\text { Xrimary } \square \text { General }
$$

Date of Disbursement

\begin{tabular}{|c|c|c|c|c|}
\hline $07^{\mathrm{M}}$ & 1 & $18^{\mathrm{D}}$ & 1 & 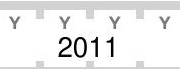 \\
\hline
\end{tabular}

Transaction ID : B50D28BDA88854AE69C6

Amount of Each Disbursement this Period

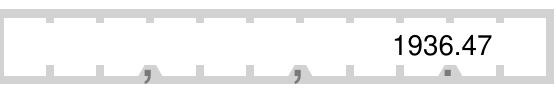

Date of Disbursement

\begin{tabular}{|c|c|c|c|c|c|}
\hline M M & I & D & Y & Y & Y \\
07 & & 18 & & 2011 & \\
\hline
\end{tabular}

Transaction ID : B8F1BB581DD4043DD85B

Amount of Each Disbursement this Period

429.67

Subtotal Of Receipts This Page (optional).

Total This Period (last page this line number only))

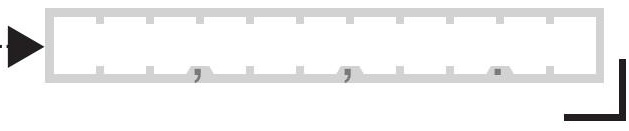




\section{SCHEDULE B-P}

\section{ITEMIZED DISBURSEMENTS}

\section{Use separate schedule(s)}

for each category of the

Detailed Summary Page
FOR LINE NUMBER: (check only one)

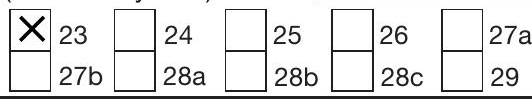

Any information copied from such Reports and Statements may not be sold or used by any person for the purpose of soliciting contributions or for commercial purposes, other than using the name and address of any political committee to solicit contributions from such committee.

NAME OF COMMITTEE (In Full)

\section{Friends of Herman Cain}

Full Name (Last, First, Middle Initial)

\section{A. Chris Burgard}

Mailing Address 34729 Petersen Road

Date of Disbursement

\begin{tabular}{lcc}
\hline City & State & Zip Code \\
Santa Clarita & CA & $91390-2809$
\end{tabular}

Purpose of Disbursement

Transportation/Meeting Expenses/Postage

Candidate Name

\begin{tabular}{l|l|l}
\hline Office Sought: & House & Disbursement For: 2012
\end{tabular} X Primary $\square$ General

State:

\section{Senate}

President

District:

Full Name (Last, First, Middle Initial)

B. Kevin Hanratty

Mailing Address 35-45 78th Street Apt. 03

\begin{tabular}{lcc}
\hline City & State & Zip Code \\
Jackson Heights & NY & $11372-4728$
\end{tabular}

Purpose of Disbursement

Event Catering

Candidate Name

Office Sought:

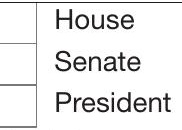

State:

District:

Full Name (Last, First, Middle Initial)

c. Jake Dagel

Mailing Address 717 10th Street

\begin{tabular}{lcc}
\hline City & State & Zip Code \\
Sheldon & IA & $51201-2034$
\end{tabular}

Purpose of Disbursement

Mileage

Candidate Name

Office Sought:

State:

Subtotal Of Receipts This Page (optional).

\begin{tabular}{|c|c|c|}
\hline House & Disbursement For: 2012 & \\
\hline Senate & Х Primary & General \\
\hline President & Other (sp & \\
\hline
\end{tabular}

Disbursement For: 2012

Primary
Other (specify) General
Date of Disbursement

\begin{tabular}{|c|c|c|c|c|}
\hline${ }^{\mathrm{M}} 07^{\mathrm{M}}$ & & $18^{\mathrm{D}}$ & & 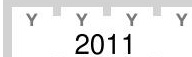 \\
\hline
\end{tabular}

Transaction ID : BE420115E1B244ABDBD5

Amount of Each Disbursement this Period

538.64

Date of Disbursement

\begin{tabular}{|c|c|c|c|c|c|c|}
\hline M & M & D & Y & Y & Y \\
07 & & 18 & & 2011 & \\
\hline
\end{tabular}

Transaction ID : BDA28D0ED89784569B56

Amount of Each Disbursement this Period

355.17

Total This Period (last page this line number only)) 


\section{SCHEDULE B-P}

\section{ITEMIZED DISBURSEMENTS}

\section{Use separate schedule(s)}

for each category of the

Detailed Summary Page
FOR LINE NUMBER: (check only one)

\begin{tabular}{|c|c|c|c|}
\hline$X_{23}$ & 24 & 25 & 26 \\
\hline $27 \mathrm{~b}$ & $28 a$ & $28 b$ & $28 \mathrm{c}$ \\
\hline
\end{tabular}

Any information copied from such Reports and Statements may not be sold or used by any person for the purpose of soliciting contributions or for commercial purposes, other than using the name and address of any political committee to solicit contributions from such committee.

NAME OF COMMITTEE (In Full)

\section{Friends of Herman Cain}

Full Name (Last, First, Middle Initial)

A. Elicia Huffaker

Mailing Address 7317 Alta Drive

Date of Disbursement

\begin{tabular}{lll}
\hline City & State & Zip Code \\
Las Vegas & NV & $89145-5238$
\end{tabular}

Purpose of Disbursement

Meeting Expenses and Mileage

Candidate Name

Office Sought: $\quad$ House $\quad$ Disbursement For: 2012 Xrimary $\square$ General

State:

Senate
President
District:

Full Name (Last, First, Middle Initial)

B. Scott F. Bieniek

Mailing Address 1782 Schooling Road

\begin{tabular}{lcc}
\hline City & State & Zip Code \\
Spencer & IN & $47460-7528$
\end{tabular}

Purpose of Disbursement

Airfare

Candidate Name

Office Sought:

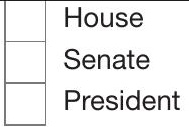

Disbursement For: 2012

Primary
Other (specify) General

State:

District:

Full Name (Last, First, Middle Initial)

c. Kyle Maichle

Mailing Address 617 N 23rd Street Apt 305

\begin{tabular}{lcc}
\hline City & State & Zip Code \\
Milwaukee & WI & $53233-1976$
\end{tabular}

Purpose of Disbursement

Research

Candidate Name

Office Sought: $\quad$ House

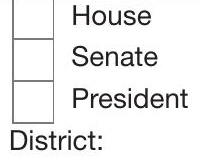

Disbursement For: 2012

X $\begin{aligned} & \text { Primary } \\ & \text { Other (specify) }\end{aligned}$

State:

District:

Subtotal Of Receipts This Page (optional).

Date of Disbursement

\begin{tabular}{|c|c|c|c|c|c|}
\hline M M & M & D & Y & Y & Y \\
07 & & 18 & & 2011 & \\
\hline
\end{tabular}

Transaction ID : BDD11126FE18240A1A21

Amount of Each Disbursement this Period

Date of Disbursement

\begin{tabular}{|c|c|c|c|c|}
\hline $07^{M}$ & I & $18^{\mathrm{D}}$ & 1 & $\begin{array}{llll}Y & Y & Y & Y \\
& 2011 & \end{array}$ \\
\hline
\end{tabular}

Transaction ID : B3BDFBBDA2A9140C7BCB

Amount of Each Disbursement this Period
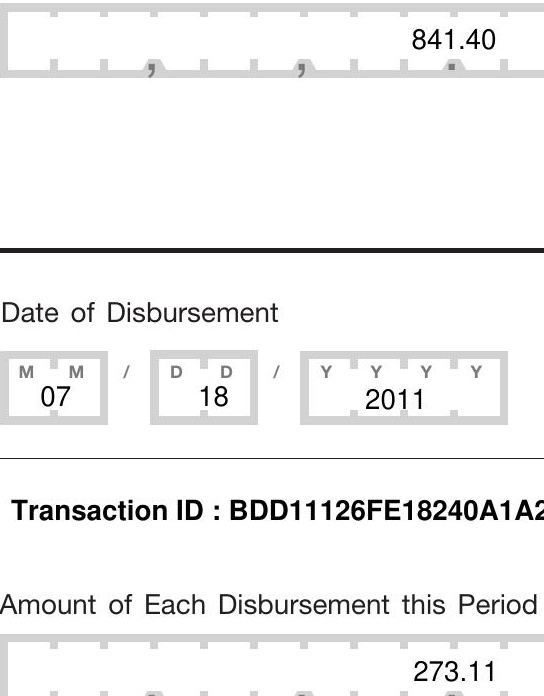

273.11

Total This Period (last page this line number only)) 


\section{SCHEDULE B-P}

\section{ITEMIZED DISBURSEMENTS}

Use separate schedule(s)

for each category of the

Detailed Summary Page

FOR LINE NUMBER: (check only one)

\begin{tabular}{|c|c|c|c|}
\hline $\mathrm{X} 23$ & 24 & 25 & 26 \\
\hline $27 \mathrm{~b}$ & $28 a$ & $28 b$ & $28 \mathrm{c}$ \\
\hline
\end{tabular}

Any information copied from such Reports and Statements may not be sold or used by any person for the purpose of soliciting contributions or for commercial purposes, other than using the name and address of any political committee to solicit contributions from such committee.

NAME OF COMMITTEE (In Full)

\section{Friends of Herman Cain}

Full Name (Last, First, Middle Initial)

A. James Zeiler

Mailing Address 24059 Borg Road

Date of Disbursement

\begin{tabular}{|c|c|c|c|c|c|c|c|}
$M$ & M & Y \\
07 & 18 & 2011
\end{tabular}

Transaction ID : B09F9292BA1EA49A7846

\begin{tabular}{lll}
\hline City & State & Zip Code \\
Grantsburg & WI & $54840-8532$
\end{tabular}

Purpose of Disbursement

Lodging and Meeting Expenses

Candidate Name

Office Sought:

$$
\begin{array}{|l|l}
\text { House } \\
\text { Senate } \\
\text { Presiden }
\end{array}
$$
District:

State:

Full Name (Last, First, Middle Initial)

\section{B. Scott Sidney}

Mailing Address N40 W6522 Jackson Street

\begin{tabular}{lcc}
\hline City & State & Zip Code \\
Cedarburg & WI & $53012-2317$
\end{tabular}

Purpose of Disbursement

Transportation and Meeting Expenses

Candidate Name

$$
\begin{aligned}
& \text { Disbursement For: } 2012 \\
& \qquad \begin{array}{l}
\text { Primary } \\
\text { Other (specify) General }
\end{array}
\end{aligned}
$$

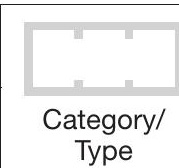

Amount of Each Disbursement this Period

134.41
Date of Disbursement

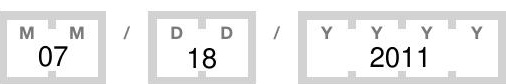

\section{Transaction ID : B519190AF8D5C48F3A77}

Amount of Each Disbursement this Period

\begin{tabular}{|c|c|c|c|c|}
\hline $07^{\mathrm{M}}$ & 1 & $\begin{array}{l}\text { D } \\
18\end{array}$ & I & $\begin{array}{cccc}Y & Y & Y & Y \\
& 2011 & \end{array}$ \\
\hline
\end{tabular}

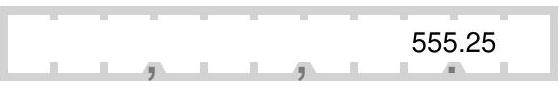

Date of Disbursement

Transaction ID : BDE953431819A477180C

Amount of Each Disbursement this Period

5590.00

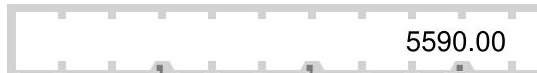

Mailing Address 44084 Riverside Parkway

Ste. 350

City
Lansdowne

Purpose of Disbursement

Direct Mail Production

Candidate Name

Office Sought:

State:

State Zip Code

VA $\quad 20176$

Disbursement For: 2012

Х $\begin{aligned} & \text { Primary } \\ & \text { Other (specify) }\end{aligned}$

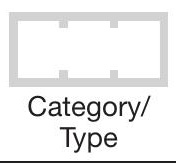

ype
Subtotal Of Receipts This Page (optional).

6279.66

Can

Total This Period (last page this line number only))

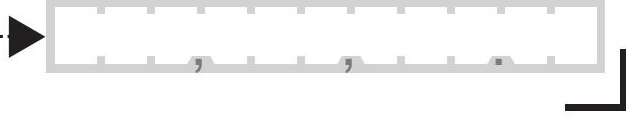

FEC Schedule B-P (Form 3P) (Rev. 03/2011) 


\section{SCHEDULE B-P}

\section{ITEMIZED DISBURSEMENTS}

Use separate schedule(s)

for each category of the

Detailed Summary Page
FOR LINE NUMBER: (check only one)

\begin{tabular}{|c|c|c|c|}
\hline$\times{ }_{23}$ & 24 & 25 & 26 \\
\hline $27 b$ & $28 a$ & $28 \mathrm{~b}$ & $28 \mathrm{c}$ \\
\hline
\end{tabular}

Any information copied from such Reports and Statements may not be sold or used by any person for the purpose of soliciting contributions or for commercial purposes, other than using the name and address of any political committee to solicit contributions from such committee.

NAME OF COMMITTEE (In Full)

\section{Friends of Herman Cain}

Full Name (Last, First, Middle Initial)

A. Nashville Security Agency

Mailing Address 4441 Stoneview Drive

Date of Disbursement

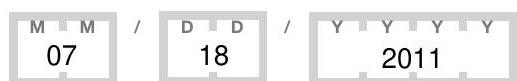

Transaction ID : B9988768A080E4F2E89D

\begin{tabular}{lll}
\hline City & State & Zip Code \\
Antioch & TN & 37013 \\
\hline
\end{tabular}

Purpose of Disbursement

Event Security

Candidate Name Xrimary $\square$ General

State:

\section{Senate}

President

District:

Full Name (Last, First, Middle Initial)

B. Air Expedite Inc.

Mailing Address Post Office Box 331

\begin{tabular}{lcc}
\hline City & State & Zip Code \\
Hampton & GA & 30228
\end{tabular}

Purpose of Disbursement

Travel Expense

Candidate Name

Office Sought:

House
Senate
President

State:

District:

Full Name (Last, First, Middle Initial)

\section{c. Mobilization Labs LLC}

Mailing Address

City

Atlanta

State Zip Code

Purpose of Disbursement

Web Services

Candidate Name

GA 30326

\section{Primary $\square$ General
Other (specify)}

Amount of Each Disbursement this Period 600.00
Date of Disbursement

\begin{tabular}{|c|c|c|c|c|}
\hline${ }^{\mathrm{M}} 07^{\mathrm{M}}$ & & $18^{\mathrm{D}}$ & & 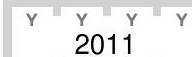 \\
\hline
\end{tabular}

Transaction ID : B503155E53EEA43C48B9

Amount of Each Disbursement this Period

$$
53177.57
$$

Date of Disbursement

\begin{tabular}{|c|c|c|c|c|c|}
\hline M & M & D & Y & Y & Y \\
07 & & 18 & & 2011 & \\
\hline
\end{tabular}

Transaction ID : B49148300A23B4D22955

Amount of Each Disbursement this Period

300.00

\begin{tabular}{l|l|c|}
\hline Office Sought: & House & Disbursement For: 2012 \\
& $\begin{array}{l}\text { Senate } \\
\text { President } \\
\text { State: }\end{array}$ &
\end{tabular}

Subtotal Of Receipts This Page (optional).

Total This Period (last page this line number only))

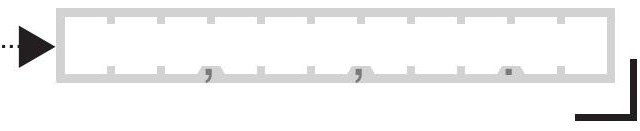




\section{SCHEDULE B-P}

\section{ITEMIZED DISBURSEMENTS}

\section{Use separate schedule(s) \\ for each category of the}

Detailed Summary Page
FOR LINE NUMBER: (check only one)

\begin{tabular}{|c|c|c|c|}
\hline$\times{ }_{23}$ & 24 & 25 & 26 \\
\hline $27 b$ & $28 a$ & $28 \mathrm{~b}$ & $28 \mathrm{c}$ \\
\hline
\end{tabular}

Any information copied from such Reports and Statements may not be sold or used by any person for the purpose of soliciting contributions or for commercial purposes, other than using the name and address of any political committee to solicit contributions from such committee.

NAME OF COMMITTEE (In Full)

\section{Friends of Herman Cain}

Full Name (Last, First, Middle Initial)

A. Patriot Data Services

Mailing Address 44084 Riverside Parkway

Ste. 350

\begin{tabular}{lll}
\hline City & State & Zip Code \\
Lansdowne & VA & 20176 \\
\hline
\end{tabular}

Purpose of Disbursement

Direct Mail Production

Candidate Name

Office Sought:

House
Senate
President
District:

Disbursement For: 2012

X Primary $\square$ General
Date of Disbursement

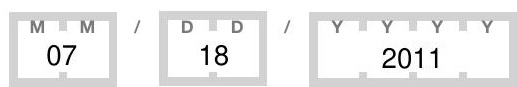

Transaction ID : BEE44714C66BA4899949

Amount of Each Disbursement this Period 522.07

\section{B. Party Time Rental}

Mailing Address 30 S 3rd Street

\begin{tabular}{lcc}
\hline City & State & Zip Code \\
Ames & IA & 50010
\end{tabular}

Purpose of Disbursement

Event Equipment Rental

Candidate Name

Office Sought:

House
Senate
President

Disbursement For: 2012

Xrimary $\square$ General

State:

District:

Full Name (Last, First, Middle Initial)

c. Chick-Fil-A

Mailing Address 5200 Buffington Road

\begin{tabular}{lcc}
\hline City & State & Zip Code \\
Atlanta & GA & 30349
\end{tabular}

Purpose of Disbursement

Meeting Expense

Candidate Name

Office Sought: $\quad$ House

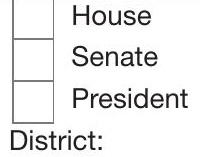

Disbursement For: 2012

X $\begin{aligned} & \text { Primary } \\ & \text { Other (specify) }\end{aligned}$

State:

District:

Subtotal Of Receipts This Page (optional).

Date of Disbursement

\begin{tabular}{|c|c|c|c|c|}
\hline $07^{\mathrm{M}}$ & 1 & ${ }^{\mathrm{D}} 18^{\mathrm{D}}$ & & $\begin{array}{llll}Y & Y & Y & Y \\
& 2011 & \end{array}$ \\
\hline
\end{tabular}

Transaction ID : BA0264FA60D0B4FCEBD2

Amount of Each Disbursement this Period
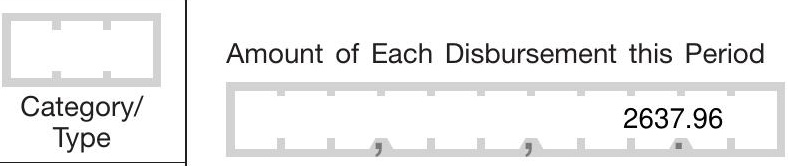

Date of Disbursement

\begin{tabular}{|c|c|c|c|c|}
\hline $07^{\mathrm{M}}$ & I & D 18 & I & 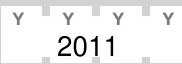 \\
\hline
\end{tabular}

Transaction ID : B0D4456A9A7004FBC9B9

Amount of Each Disbursement this Period

58.56

Total This Period (last page this line number only)) 


\section{SCHEDULE B-P}

\section{ITEMIZED DISBURSEMENTS}

Use separate schedule(s)

for each category of the

Detailed Summary Page
FOR LINE NUMBER: (check only one)

\begin{tabular}{|c|c|c|c|}
\hline$X_{23}$ & 24 & 25 & 26 \\
\hline $27 \mathrm{~b}$ & $28 a$ & $28 b$ & $28 \mathrm{c}$ \\
\hline
\end{tabular}

Any information copied from such Reports and Statements may not be sold or used by any person for the purpose of soliciting contributions or for commercial purposes, other than using the name and address of any political committee to solicit contributions from such committee.

NAME OF COMMITTEE (In Full)

\section{Friends of Herman Cain}

Full Name (Last, First, Middle Initial)

A. Stephanie Zeiler

Mailing Address 175 W 87th Street

Apt 20B

Date of Disbursement

\begin{tabular}{llc}
\multicolumn{3}{c}{ Apt 20B } \\
\hline City & State & Zip Code \\
New York & NY & 10024 \\
\hline
\end{tabular}

Purpose of Disbursement

Airfare and Transportation

Candidate Name

Office Sought: $\quad$ House

House
Senate

President

State:

District:

Full Name (Last, First, Middle Initial)

B. Hawkeye Stages

Mailing Address 703 Dudley Street

\begin{tabular}{lcc}
\hline City & State & Zip Code \\
Decorah & IA & 52101
\end{tabular}

Purpose of Disbursement

Travel Expense

Candidate Name

Disbursement For: 2012

X Primary $\square$ General

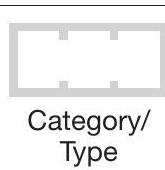

Type
Amount of Each Disbursement this Period

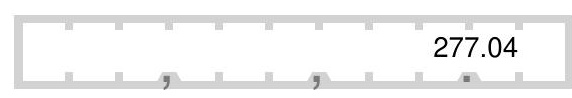

Office Sought:

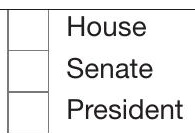

State:

District:
IA

Full Name (Last, First, Middle Initial)

c. Wynn Las Vegas Hotel

Mailing Address 3131 Las Vegas Boulevard

Disbursement For: 2012

X Primary $\square$ General

\section{Mailing Address 3131 Las Vegas Boulevard}

\begin{tabular}{lcc}
\hline City & State & Zip Code \\
Las Vegas & NV & $89109-1967$
\end{tabular}

Purpose of Disbursement

Travel Expense

Candidate Name

\begin{tabular}{l|l|l}
\hline Office Sought: & & $\begin{array}{l}\text { House } \\
\text { Senate } \\
\end{array}$ \\
\cline { 2 - 2 } & $\begin{array}{l}\text { President } \\
\text { State: }\end{array}$ & District:
\end{tabular}

Disbursement For: 2012
$\square$ Primary
Other (specify)

Date of Disbursement

\begin{tabular}{|c|c|c|c|c|}
\hline $07^{\mathrm{M}}$ & 1 & $18^{\mathrm{D}}$ & 1 & 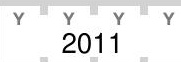 \\
\hline
\end{tabular}

Transaction ID : B5E2ED4576CCD40319D0

Amount of Each Disbursement this Period

3545.00

Date of Disbursement

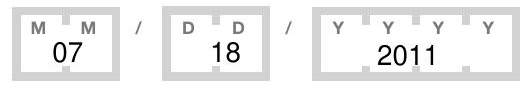

Transaction ID : B14498BF5BAA84C4E8CD

Amount of Each Disbursement this Period

67.20

Subtotal Of Receipts This Page (optional).

Total This Period (last page this line number only))

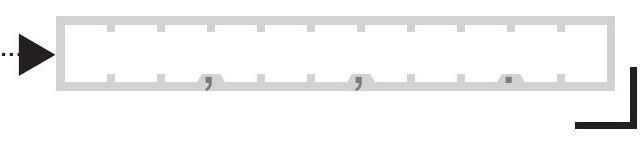




\section{SCHEDULE B-P}

\section{ITEMIZED DISBURSEMENTS}

\section{Use separate schedule(s) \\ for each category of the}

Detailed Summary Page
FOR LINE NUMBER: (check only one)

\begin{tabular}{|c|c|c|c|}
\hline$\times{ }_{23}$ & 24 & 25 & 26 \\
\hline $27 b$ & $28 a$ & $28 \mathrm{~b}$ & $28 \mathrm{c}$ \\
\hline
\end{tabular}

Any information copied from such Reports and Statements may not be sold or used by any person for the purpose of soliciting contributions or for commercial purposes, other than using the name and address of any political committee to solicit contributions from such committee.

NAME OF COMMITTEE (In Full)

\section{Friends of Herman Cain}

Full Name (Last, First, Middle Initial)

A. MDI Imaging \& Mail

Mailing Address 21955 Cascades Parkway

Date of Disbursement

\begin{tabular}{lll}
\hline City & State & Zip Code \\
Dulles & VA & 20166 \\
\hline
\end{tabular}

Purpose of Disbursement

Direct Mail Production

Candidate Name

Office Sought: $\quad$ House

House

President

State:

District:

Full Name (Last, First, Middle Initial)

B. MDI Imaging \& Mail

Mailing Address 21955 Cascades Parkway

\begin{tabular}{lll}
\hline City & State & Zip Code \\
Dulles & VA & 20166
\end{tabular}

Purpose of Disbursement

Direct Mail Production

Candidate Name

Disbursement For: 2012

X Primary $\square$ General

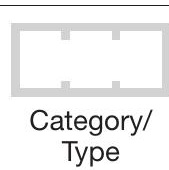

Type
Amount of Each Disbursement this Period

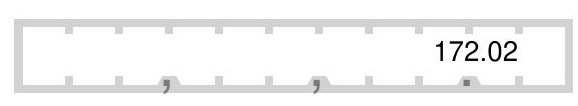

Office Sought:

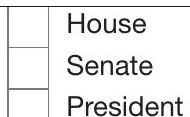

State:

District:
Date of Disbursement

\begin{tabular}{|c|c|c|c|c|}
\hline $07^{M}$ & & ${ }^{\mathrm{D}} 18^{\mathrm{D}}$ & & $\begin{array}{llll}Y & Y & Y & Y \\
& 2011\end{array}$ \\
\hline
\end{tabular}

Transaction ID : BB3B0783DCC7C4374A57

Amount of Each Disbursement this Period

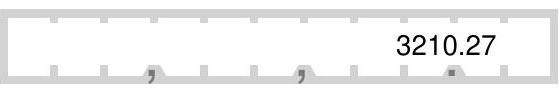

Date of Disbursement

\begin{tabular}{|c|c|c|c|c|}
\hline $07^{\mathrm{M}}$ & 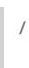 & $\begin{array}{r}\text { D } \\
\quad 18\end{array}$ & I & $\begin{array}{cccc}Y & Y & Y & Y \\
& 2011 & \end{array}$ \\
\hline
\end{tabular}

Transaction ID : B39020E851A794ACDB9D

Amount of Each Disbursement this Period

12496.47

c. Integram

Mailing Address 22695 Commerce Center Court

\begin{tabular}{lcc}
\hline City & State & Zip Code \\
Dulles & VA & 20166 \\
\hline
\end{tabular}

Purpose of Disbursement

Direct Mail Production

Candidate Name

Xrimary $\square$ General

Category/ Type

Office Sought:

\begin{tabular}{|l|l|}
\hline & House \\
& Senate \\
& President \\
\hline & District:
\end{tabular}

Disbursement For: 2012

Х $\begin{aligned} & \text { Primary } \\ & \text { Other (specify) }\end{aligned}$

State:

District:

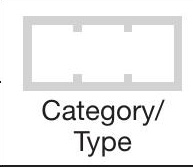

ype
Subtotal Of Receipts This Page (optional).

15878.76

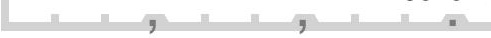

Total This Period (last page this line number only))

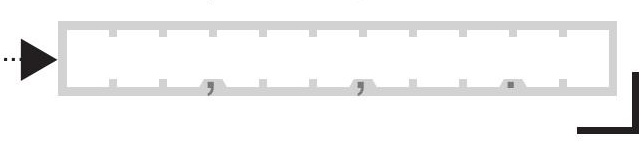

FEC Schedule B-P (Form 3P) (Rev. 03/2011) 


\section{SCHEDULE B-P}

\section{ITEMIZED DISBURSEMENTS}

\section{Use separate schedule(s) \\ for each category of the}

Detailed Summary Page
FOR LINE NUMBER: (check only one)

\begin{tabular}{|c|c|c|c|}
\hline$\times{ }_{23}$ & 24 & 25 & 26 \\
\hline $27 b$ & $28 a$ & $28 \mathrm{~b}$ & $28 \mathrm{c}$ \\
\hline
\end{tabular}

Any information copied from such Reports and Statements may not be sold or used by any person for the purpose of soliciting contributions or for commercial purposes, other than using the name and address of any political committee to solicit contributions from such committee.

NAME OF COMMITTEE (In Full)

\section{Friends of Herman Cain}

Full Name (Last, First, Middle Initial)

A. RMA Chaffeured Transportation

Mailing Address 6010 Executive Boulevard

Suite 101

\begin{tabular}{lll}
\hline City & State & Zip Code \\
Rockville & MD & 20852 \\
\hline
\end{tabular}

Purpose of Disbursement

Travel Expense

Candidate Name

20852

Office

State: District:

Full Name (Last, First, Middle Initial)

B. Narrow Path Productions Inc.

Mailing Address 250 Jarvis Street

\begin{tabular}{lcc}
\hline City & State & Zip Code \\
Canton & GA & 30114
\end{tabular}

Purpose of Disbursement

Media Production

Candidate Name

Date of Disbursement

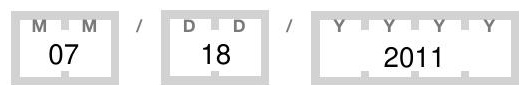

Transaction ID : B51CAEF63D967450B8B8

Amount of Each Disbursement this Period

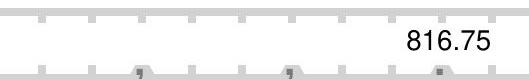

Office Sought:

State:

\section{c. Delta Airlines}

\begin{tabular}{ll}
\hline Mailing Address & Post Office Box 20980 \\
& Department 980
\end{tabular}

Atlanta

Purpose of Disbursement

Travel Expense

Candidate Name

Office Sought:

State:

$$
\begin{aligned}
& \text { House } \\
& \text { Senate } \\
& \text { President }
\end{aligned}
$$

\begin{tabular}{|c|c|c|c|c|}
\hline $07^{\mathrm{M}}$ & 1 & $18^{\mathrm{D}}$ & 1 & 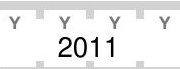 \\
\hline
\end{tabular}

District:
Date of Disbursement

\section{Transaction ID : BCC290FC1E5D84848989}

Amount of Each Disbursement this Period

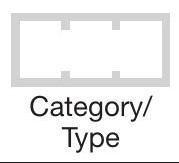

$$
\begin{aligned}
& \text { Disbursement For: } 2012 \\
& X \text { Primary } \\
& \text { Other (specify) }
\end{aligned}
$$

900.00
Date of Disbursement

\begin{tabular}{|c|c|c|c|c|c|}
\hline M & M & D & Y & Y & Y \\
07 & & 18 & & 2011 & \\
\hline
\end{tabular}

Transaction ID : BA5760F09E0E143B9B82

Amount of Each Disbursement this Period

822.30

Subtotal Of Receipts This Page (optional).

Total This Period (last page this line number only))

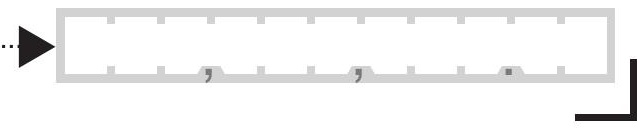




\section{SCHEDULE B-P}

\section{ITEMIZED DISBURSEMENTS}

Use separate schedule(s)

for each category of the

Detailed Summary Page
FOR LINE NUMBER: (check only one)

\begin{tabular}{|c|c|c|c|}
\hline$\times{ }_{23}$ & 24 & 25 & 26 \\
\hline $27 b$ & $28 a$ & $28 \mathrm{~b}$ & $28 \mathrm{c}$ \\
\hline
\end{tabular}

Any information copied from such Reports and Statements may not be sold or used by any person for the purpose of soliciting contributions or for commercial purposes, other than using the name and address of any political committee to solicit contributions from such committee.

NAME OF COMMITTEE (In Full)

\section{Friends of Herman Cain}

Full Name (Last, First, Middle Initial)

A. Amtrak

Mailing Address 60 Massacheusetts Avenue

Date of Disbursement

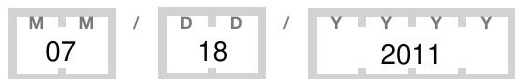

Transaction ID : BC8BA37C327F640219A6

$\begin{array}{lll}\text { City } & \text { State } & \text { Zip Code } \\ \text { Washington } & \text { DC } & 20002-4225\end{array}$

Purpose of Disbursement

Travel Expense

Candidate Name

Office Sought:

$$
\begin{aligned}
& \text { House } \\
& \text { Senate } \\
& \text { President }
\end{aligned}
$$

State: District:

Full Name (Last, First, Middle Initial)

\begin{tabular}{|c|c|c|c|c|}
\hline \multicolumn{2}{|l|}{ City } & \multicolumn{3}{|c|}{ Zip Code } \\
\hline \multicolumn{2}{|l|}{ Buford } & \multicolumn{3}{|c|}{30518} \\
\hline \multicolumn{4}{|c|}{$\begin{array}{l}\text { Purpose of Disbursement } \\
\text { Office Supplies }\end{array}$} & \\
\hline \multicolumn{4}{|c|}{ Candidate Name } & $\begin{array}{l}\text { Category/ } \\
\text { Type }\end{array}$ \\
\hline \multirow[t]{3}{*}{ Office Sought: } & House & \multirow{3}{*}{\multicolumn{3}{|c|}{$\begin{array}{l}\text { Disbursement For: } 2012 \\
\text { Xrimary } \\
\text { Other (specify) }\end{array}$}} \\
\hline & \multirow{2}{*}{$\begin{array}{l}\text { Senate } \\
\text { President }\end{array}$} & & & \\
\hline & & & & \\
\hline State: & rict: & & \multicolumn{2}{|l|}{$\nabla$} \\
\hline
\end{tabular}

\section{B. Office Depot Corporate}

Mailing Address 2500 Mill Center Parkway

Full Name (Last, First, Middle Initial)

\section{c. US Airways}

Mailing Address 4000 E Sky Harbor Boulevard

\begin{tabular}{lcc}
\hline City & State & Zip Code \\
Phoenix & AZ & 85034
\end{tabular}

Purpose of Disbursement

Travel Expense

Candidate Name

\begin{tabular}{l|l}
\hline Office Sought: & House \\
& $\begin{array}{l}\text { Senate } \\
\text { Senatent } \\
\text { President }\end{array}$ \\
State: & District:
\end{tabular}

\begin{tabular}{|c|c|c|c|c|}
\hline${ }^{\mathrm{M}} 07^{\mathrm{M}}$ & & $18^{\mathrm{D}}$ & & 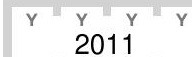 \\
\hline
\end{tabular}

Disbursement For: 2012
$\searrow$ Primary $\quad \square$ General
Other (specify)

Date of Disbursement

Transaction ID : BDB84F6C0DE9F495F819

Amount of Each Disbursement this Period

\begin{tabular}{|c|c|c|c|c|}
\hline $07^{\mathrm{M}}$ & 1 & D 19 & 1 & 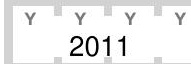 \\
\hline
\end{tabular}

Date of Disbursement

Transaction ID : B374A6E2A14184ED6AB2

Amount of Each Disbursement this Period

675.70

Subtotal Of Receipts This Page (optional).

Total This Period (last page this line number only))

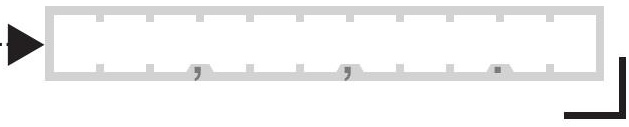




\section{SCHEDULE B-P}

\section{ITEMIZED DISBURSEMENTS}

\section{Use separate schedule(s) \\ for each category of the}

Detailed Summary Page
FOR LINE NUMBER: (check only one)

\begin{tabular}{|c|c|c|c|}
\hline$\times{ }_{23}$ & 24 & 25 & 26 \\
\hline $27 b$ & $28 a$ & $28 \mathrm{~b}$ & $28 \mathrm{c}$ \\
\hline
\end{tabular}

Any information copied from such Reports and Statements may not be sold or used by any person for the purpose of soliciting contributions or for commercial purposes, other than using the name and address of any political committee to solicit contributions from such committee.

NAME OF COMMITTEE (In Full)

\section{Friends of Herman Cain}

Full Name (Last, First, Middle Initial)

A. Bally's Hotel Banquets

Mailing Address 3645 Las Vegas Blvd S

Date of Disbursement

\begin{tabular}{lll}
\hline City & State & Zip Code \\
Las Vega & NV & 89109 \\
\hline
\end{tabular}

Purpose of Disbursement

Event Catering

Candidate Name

\begin{tabular}{l|l|l}
\hline Office Sought: & House & Disbursement For: 2012
\end{tabular} X Primary $\square$ General

State:

$$
\begin{aligned}
& \text { Senate } \\
& \text { President }
\end{aligned}
$$

Full Name (Last, First, Middle Initial)

\begin{tabular}{|c|c|c|c|c|}
\hline Mailing Address & \multicolumn{2}{|c|}{3 Ravinia Drive } & \multicolumn{2}{|c|}{ Ste. 100} \\
\hline \multicolumn{2}{|l|}{ City } & \multicolumn{3}{|c|}{ Zip Code } \\
\hline \multicolumn{2}{|l|}{ Atlanta } & \multicolumn{3}{|c|}{30346} \\
\hline \multicolumn{4}{|c|}{$\begin{array}{l}\text { Purpose of Disbursement } \\
\text { Travel Expense }\end{array}$} & \\
\hline \multicolumn{4}{|l|}{ Candidate Name } & $\begin{array}{l}\text { Category/ } \\
\text { Type }\end{array}$ \\
\hline \multirow[t]{3}{*}{ Office Sought: } & House & \multirow{3}{*}{\multicolumn{3}{|c|}{$\begin{array}{l}\text { Disbursement For: } 2012 \\
\text { Primary } \\
\text { Other (specify) }\end{array}$}} \\
\hline & Senate & & & \\
\hline & President & & & \\
\hline State: & \multicolumn{4}{|c|}{ District: } \\
\hline
\end{tabular}

\section{B. Holiday Inn Hotels}

Date of Disbursement

Full Name (Last, First, Middle Initial)

c. Frontier Airlines Inc.

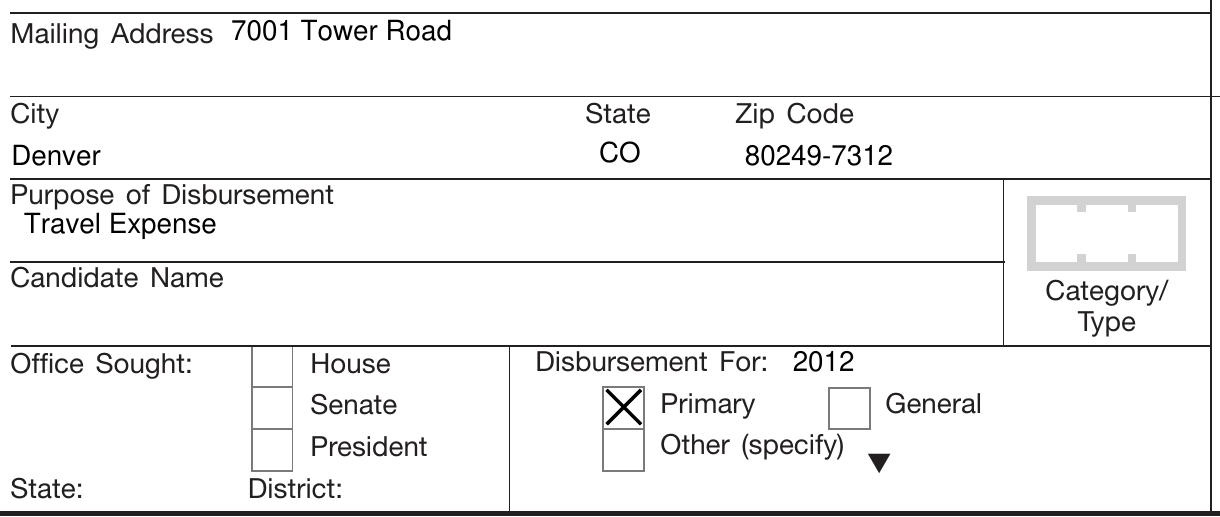

Subtotal Of Receipts This Page (optional).

Date of Disbursement

\begin{tabular}{|c|c|c|c|c|c|c|}
\hline M M & I & D & Y & Y & Y \\
07 & & 19 & & 2011 & \\
\hline
\end{tabular}

\section{Transaction ID : B2D09011FF0F144A48DD}

Amount of Each Disbursement this Period

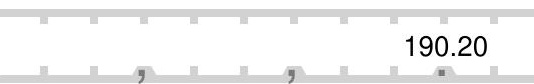

Total This Period (last page this line number only)) 


\section{SCHEDULE B-P}

\section{ITEMIZED DISBURSEMENTS}

\section{Use separate schedule(s) \\ for each category of the}

Detailed Summary Page
FOR LINE NUMBER: (check only one)

\begin{tabular}{|c|c|c|c|}
\hline$\times{ }_{23}$ & 24 & 25 & 26 \\
\hline $27 b$ & $28 a$ & $28 \mathrm{~b}$ & $28 \mathrm{c}$ \\
\hline
\end{tabular}

Any information copied from such Reports and Statements may not be sold or used by any person for the purpose of soliciting contributions or for commercial purposes, other than using the name and address of any political committee to solicit contributions from such committee.

NAME OF COMMITTEE (In Full)

\section{Friends of Herman Cain}

Full Name (Last, First, Middle Initial)

A. Air Tran

Mailing Address 9955 Air Tran Boulevard

Date of Disbursement

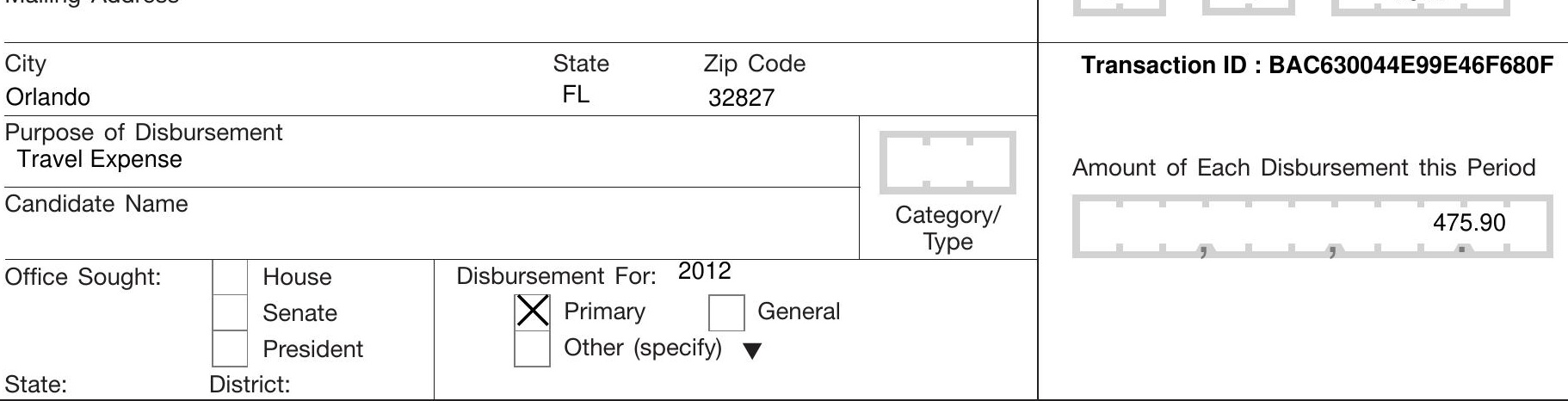

Full Name (Last, First, Middle Initial)

B. Greg West

Mailing Address 3905 Stratmore Drive

\begin{tabular}{lcc}
\hline City & State & Zip Code \\
Montgomery & AL & $36116-4615$
\end{tabular}

Purpose of Disbursement

Pilot Services

Candidate Name

Office Sought:

House
Senate
President

Disbursement For: 2012

Primary $\square$ General
Other (specify)

State:

District:

Date of Disbursement

\begin{tabular}{|c|c|c|c|c|}
\hline $07^{M}$ & & ${ }_{19}^{\mathrm{D}}$ & & $\begin{array}{llll}Y & Y & Y & Y \\
& 2011^{-}\end{array}$ \\
\hline
\end{tabular}

Full Name (Last, First, Middle Initial)

\section{c. Bilal Soodoo}

Mailing Address 3414 Lucius St.

\begin{tabular}{lcc}
\hline City & State & Zip Code \\
Tuskegee & AL & $36083-3001$
\end{tabular}

Purpose of Disbursement

Pilot Services

Candidate Name

Office Sought:

State:

Subtotal Of Receipts This Page (optional).

\begin{tabular}{l|l|l|}
\hline $\begin{array}{l}\text { House } \\
\text { Senate } \\
\text { President }\end{array}$ & Disbursement For: 2012 \\
\hline District: & $\square$ & $\begin{array}{l}\text { Primary } \\
\text { Other (specify) }\end{array}$
\end{tabular}

Date of Disbursement

\begin{tabular}{|c|c|c|c|c|c|}
\hline M M & Y & Y Y Y Y \\
07 & & 19 \\
\hline
\end{tabular}

Transaction ID : B58C5F75446334BA5B73

Amount of Each Disbursement this Period

1425.00

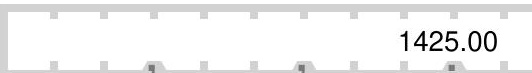

Total This Period (last page this line number only))

5022.70

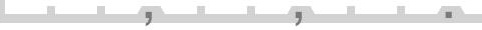

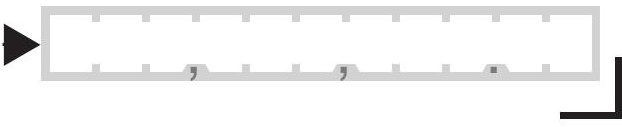

FEC Schedule B-P (Form 3P) (Rev. 03/2011) 


\section{SCHEDULE B-P}

\section{ITEMIZED DISBURSEMENTS}

\section{Use separate schedule(s)}

for each category of the

Detailed Summary Page
FOR LINE NUMBER: (check only one)

\begin{tabular}{|c|c|c|c|}
\hline$X_{23}$ & 24 & 25 & 26 \\
\hline $27 \mathrm{~b}$ & $28 a$ & $28 b$ & $28 \mathrm{c}$ \\
\hline
\end{tabular}

Any information copied from such Reports and Statements may not be sold or used by any person for the purpose of soliciting contributions or for commercial purposes, other than using the name and address of any political committee to solicit contributions from such committee.

NAME OF COMMITTEE (In Full)

\section{Friends of Herman Cain}

Full Name (Last, First, Middle Initial)

A. James Brazil

Mailing Address 6 Baldasarri Drive

Date of Disbursement

\begin{tabular}{lcc}
\hline City & State & Zip Code \\
Dunmore & PA & 18505 \\
\hline
\end{tabular}

Purpose of Disbursement

Lodging/Trasportation/Meeting Expense

Candidate Name

Office Sought: $\quad$ House

Senate

President

State:

District:

Full Name (Last, First, Middle Initial)

\section{B. Stacy DeJarnette}

Mailing Address 207 Robin Street

\begin{tabular}{lcc}
\hline City & State & Zip Code \\
White Hall & AR & $71602-5418$
\end{tabular}

Purpose of Disbursement

Lodging/Transportation/Office Equipment

Candidate Name

Office Sought:

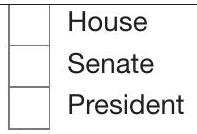

State:

District:

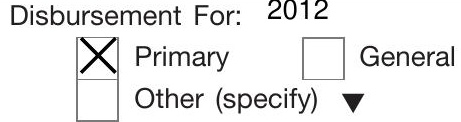

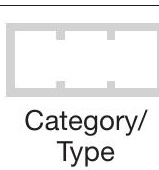

Type
Amount of Each Disbursement this Period

762.32

Full Name (Last, First, Middle Initial)

C. Ian Nichols

Mailing Address 4023 Laura Court

Disbursement For: 2012

Xrimary $\square$ General

Date of Disbursement

\begin{tabular}{|c|c|c|c|c|}
\hline $07^{M}$ & 1 & 20 & I & 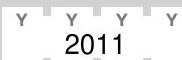 \\
\hline
\end{tabular}

Transaction ID : BB521F1F30B0046CDB77

Amount of Each Disbursement this Period
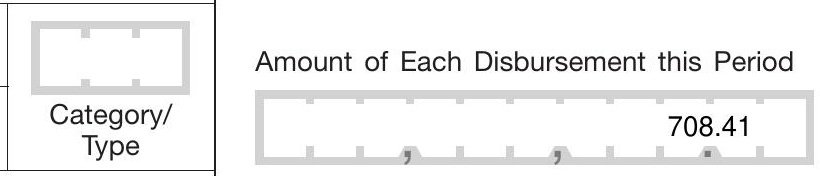

Date of Disbursement

\begin{tabular}{|c|c|c|c|c|}
\hline $07^{\mathrm{M}}$ & I & D 20 & 1 & $\begin{array}{cccc}Y & Y & Y & Y \\
& 2011 & \end{array}$ \\
\hline
\end{tabular}

\begin{tabular}{lcc}
\hline City & State & Zip Code \\
Ames & IA & $50010-4185$
\end{tabular}

Purpose of Disbursement

Mileage

Candidate Name

(2)

Office Sought:

\begin{tabular}{l|l|l}
\hline Office Sought: & $\begin{array}{l}\text { House } \\
\text { Senate }\end{array}$ \\
& $\begin{array}{l}\text { President } \\
\text { State: }\end{array}$ & District:
\end{tabular}

Disbursement For: 2012
$\searrow$ Primary
Other (specify)

\section{Transaction ID : B3D4B2AE163014C1B937}

Amount of Each Disbursement this Period

201.81

Subtotal Of Receipts This Page (optional).

Total This Period (last page this line number only))

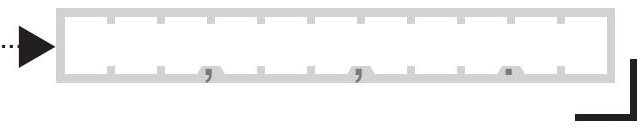




\section{SCHEDULE B-P}

\section{ITEMIZED DISBURSEMENTS}

Use separate schedule(s)

for each category of the

Detailed Summary Page
FOR LINE NUMBER: (check only one)

\begin{tabular}{|c|c|c|c|}
\hline $\mathrm{X} 23$ & 24 & 25 & 26 \\
\hline $27 \mathrm{~b}$ & $28 a$ & $28 b$ & $28 \mathrm{c}$ \\
\hline
\end{tabular}

Any information copied from such Reports and Statements may not be sold or used by any person for the purpose of soliciting contributions or for commercial purposes, other than using the name and address of any political committee to solicit contributions from such committee.

NAME OF COMMITTEE (In Full)

\section{Friends of Herman Cain}

Full Name (Last, First, Middle Initial)

A. Lisa Shiflett

Mailing Address 157 Stokes Drive

Date of Disbursement

\begin{tabular}{lcc}
\hline City & State & Zip Code \\
Stockbridge & GA & $30281-1376$
\end{tabular}

Purpose of Disbursement

Mileage and Telephone

Candidate Name

Office Sought:

$$
\begin{array}{|l|l}
\text { House } \\
\text { Senate } \\
\cline { 1 - 2 } \text { Presiden }
\end{array}
$$
District:

State:

Full Name (Last, First, Middle Initial)

\section{B. Lisa Lockwood}

Mailing Address 12746 Ford Trail South

\begin{tabular}{lcc}
\hline City & State & Zip Code \\
Indianola & IA & $50125-8931$
\end{tabular}

Purpose of Disbursement

Mileage/Meeting Exp/Phone/Office Supp.

Candidate Name

Disbursement For: 2012 X Primary $\square$ General

Office Sought:

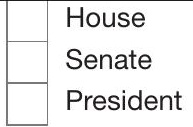

State:

District:

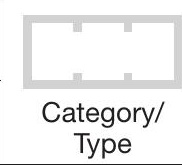

Amount of Each Disbursement this Period

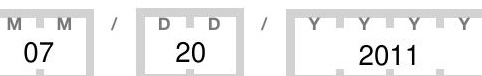

\section{Transaction ID : B0008C9F606F44E5780C}

Full Name (Last, First, Middle Initial)

C. Joel Ricks

Mailing Address 3073 Meadowlark Lane

Disbursement For: 2012

Xrimary $\square$ General

Date of Disbursement

\begin{tabular}{|c|c|c|c|c|}
\hline $07^{\mathrm{M}}$ & 1 & $20^{\mathrm{D}}$ & I & $\begin{array}{llll}Y & Y & Y & Y \\
& 2011 & \end{array}$ \\
\hline
\end{tabular}

Transaction ID : B9ADD80E90DB84A3786A

Amount of Each Disbursement this Period
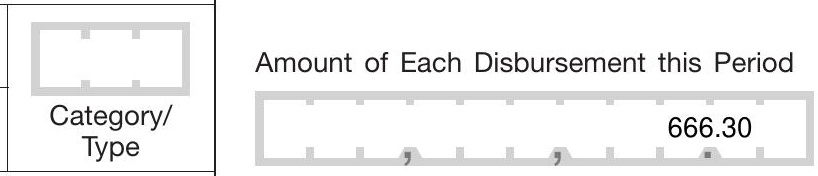

Date of Disbursement

\begin{tabular}{|c|c|c|c|c|}
\hline $07^{\mathrm{M}}$ & I & D 20 & 1 & $\begin{array}{cccc}Y & Y & Y & Y \\
& 2011 & \end{array}$ \\
\hline
\end{tabular}

\begin{tabular}{lcc}
\hline City & State & Zip Code \\
East Point & GA & 30344
\end{tabular}

Purpose of Disbursement

Office Maintenance

Candidate Name

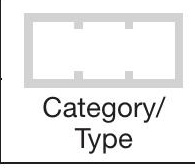

\begin{tabular}{l|l}
\hline Office Sought: & $\begin{array}{l}\text { House } \\
\text { Senate }\end{array}$ \\
\cline { 2 - 2 } & \\
State: & $\begin{array}{l}\text { President } \\
\text { Sistrict: }\end{array}$
\end{tabular}

Disbursement For: 2012
\[ \begin{array}{l}\text { Primary } \\ \text { Other (specify) }\end{array} \]

Transaction ID : BA05592B004AB4E6B98B

Amount of Each Disbursement this Period

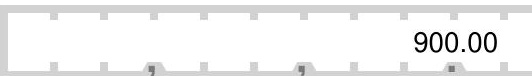

Subtotal Of Receipts This Page (optional).

Total This Period (last page this line number only))

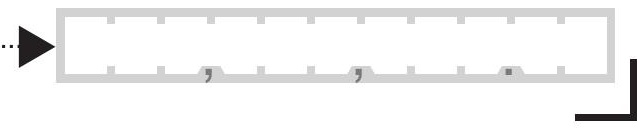




\section{SCHEDULE B-P}

\section{ITEMIZED DISBURSEMENTS}

Use separate schedule(s)

for each category of the

Detailed Summary Page
FOR LINE NUMBER: (check only one)

\begin{tabular}{|c|c|c|c|}
\hline$\times \quad 23$ & 24 & 25 & 26 \\
\hline $27 \mathrm{~b}$ & $28 \mathrm{a}$ & $28 b$ & $28 \mathrm{c}$ \\
\hline
\end{tabular}

Any information copied from such Reports and Statements may not be sold or used by any person for the purpose of soliciting contributions or for commercial purposes, other than using the name and address of any political committee to solicit contributions from such committee.

NAME OF COMMITTEE (In Full)

\section{Friends of Herman Cain}

Full Name (Last, First, Middle Initial)

A. David Burrell

Mailing Address 5061 Hodgins Plae

Date of Disbursement

\begin{tabular}{lcc}
\hline City & State & Zip Code \\
Lilburn & GA & 30047
\end{tabular}

Purpose of Disbursement

Lodging

GA $\quad 30047$

Candidate Name

\begin{tabular}{l|l|l|l}
\hline Office Sought: & House & Disbursement For: 2012
\end{tabular} Xrimary $\square$ General

State:

\section{Senate}

President

District:

Full Name (Last, First, Middle Initial)

B. Zachary Dalluge

Mailing Address 506 3rd Street

\begin{tabular}{lcc}
\hline City & State & Zip Code \\
Grafton & IA & $50440-7570$
\end{tabular}

Purpose of Disbursement

Mileage and Telephone

Candidate Name

.

Office Sought:

House
Senate
President

Disbursement For: 2012

X Primary $\square$ General

State:

District:

Full Name (Last, First, Middle Initial)

c. Air Tran

Mailing Address 9955 Air Tran Boulevard

\begin{tabular}{lcc|} 
& & \\
City & State & Zip Code \\
Orlando & FL & 32827 \\
\hline
\end{tabular}

\begin{tabular}{|c|c|c|c|c|}
\hline $07^{\mathrm{M}}$ & 1 & $\begin{array}{l}\mathrm{D} \\
20\end{array}$ & 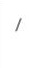 & $\begin{array}{cccc}Y & Y & Y & Y \\
& 2011 & \end{array}$ \\
\hline
\end{tabular}

Purpose of Disbursement

Travel Expense

Candidate Name

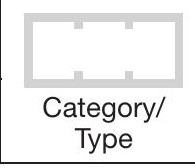

Transaction ID : B17B5543588844A6096D

Amount of Each Disbursement this Period

\begin{tabular}{l|l|c|}
\hline Office Sought: & $\begin{array}{l}\text { House } \\
\text { Senate } \\
\text { President } \\
\text { State: }\end{array}$ & $\begin{array}{r}\text { Disbursement For: } 2012 \\
\text { District: }\end{array}$
\end{tabular}

Subtotal Of Receipts This Page (optional).

Total This Period (last page this line number only)) 


\section{SCHEDULE B-P}

\section{ITEMIZED DISBURSEMENTS}

Use separate schedule(s)

for each category of the

Detailed Summary Page
FOR LINE NUMBER: (check only one)

\begin{tabular}{|c|c|c|c|}
\hline $\mathrm{X} 23$ & 24 & 25 & 26 \\
\hline $27 \mathrm{~b}$ & $28 a$ & $28 b$ & $28 \mathrm{c}$ \\
\hline
\end{tabular}

Any information copied from such Reports and Statements may not be sold or used by any person for the purpose of soliciting contributions or for commercial purposes, other than using the name and address of any political committee to solicit contributions from such committee.

NAME OF COMMITTEE (In Full)

\section{Friends of Herman Cain}

Full Name (Last, First, Middle Initial)

A. UPS

Mailing Address Post Office Box 7247-0244

Date of Disbursement

\begin{tabular}{lcc}
\hline City & State & Zip Code \\
Philadelphia & PA & $19170-0001$
\end{tabular}

Purpose of Disbursement

Shipping

Candidate Name

Office Sought:

\begin{tabular}{|l|l} 
& House \\
& Senate \\
& President \\
\hline District:
\end{tabular}

Disbursement For: 2012 Xrimary $\square$ General

State: District:

Full Name (Last, First, Middle Initial)

B. Little Bonanza Productions LLC

Mailing Address 34729 Petersen Road

\begin{tabular}{lcc}
\hline City & State & Zip Code \\
Agua Dulce & CA & 91390
\end{tabular}

Purpose of Disbursement

Media Production

Candidate Name

Office Sought:

House
Senate
President

Disbursement For: 2012

Xrimary $\square$ General

State:

District:

Full Name (Last, First, Middle Initial)

c. Holiday Inn Hotels

Mailing Address 3 Ravinia Drive

Ste. 100

\begin{tabular}{lcc}
\hline City & State & Zip Code \\
Atlanta & GA & 30346 \\
\hline
\end{tabular}

Purpose of Disbursement

Travel Expense

Candidate Name

Office Sought:

State:

\begin{tabular}{|l|l|}
\hline & House \\
& Senate \\
& President \\
\cline { 1 - 1 } & District:
\end{tabular}

Disbursement For: 2012

X $\begin{aligned} & \text { Primary } \\ & \text { Other (specify) }\end{aligned}$
Date of Disbursement

\begin{tabular}{|c|c|c|c|c|}
\hline $07^{M}$ & & ${ }^{\mathrm{D}} 0^{\mathrm{D}}$ & & 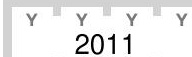 \\
\hline
\end{tabular}

Transaction ID : B9DC020FA63F04259971

Amount of Each Disbursement this Period

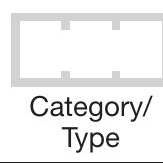

Category/ Type
Date of Disbursement

\begin{tabular}{|c|c|c|c|c|c|}
\hline M M / & D & Y & Y & Y \\
07 & & 20 & & 2011 & \\
\hline
\end{tabular}

Transaction ID : B337DC40CE2254658996

Amount of Each Disbursement this Period

371.50

Subtotal Of Receipts This Page (optional).

Total This Period (last page this line number only))

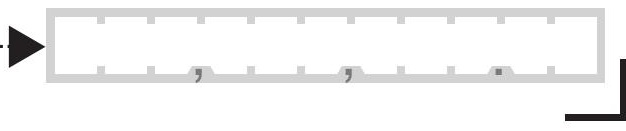




\section{SCHEDULE B-P}

\section{ITEMIZED DISBURSEMENTS}

Use separate schedule(s)

for each category of the

Detailed Summary Page

FOR LINE NUMBER: (check only one)

PAGE 1322 / 1572

\begin{tabular}{|c|c|c|c|}
\hline$X_{23}$ & 24 & 25 & 26 \\
\hline $27 \mathrm{~b}$ & $28 a$ & $28 \mathrm{~b}$ & $28 \mathrm{c}$ \\
\hline
\end{tabular}

Any information copied from such Reports and Statements may not be sold or used by any person for the purpose of soliciting contributions or for commercial purposes, other than using the name and address of any political committee to solicit contributions from such committee.

NAME OF COMMITTEE (In Full)

\section{Friends of Herman Cain}

Full Name (Last, First, Middle Initial)

A. Homewood Suites

Mailing Address 7930 Jones Branch Dr.

Ste. 1100

\begin{tabular}{lll}
\hline City & State & Zip Code \\
McLean & VA & 22102 \\
\hline
\end{tabular}

Purpose of Disbursement

Travel Expense

Candidate Name

\begin{tabular}{l|l|l|l}
\hline Office Sought: & House & Disbursement For: 2012
\end{tabular} Xrimary $\square$ General

State: Senate President District:

Full Name (Last, First, Middle Initial)

\section{B. Charter Business}

Mailing Address P.O. Box 742615

\begin{tabular}{lcc}
\hline City & State & Zip Code \\
Cincinnati & OH & $45274-2615$
\end{tabular}

Purpose of Disbursement Internet/Phone/Cable

Candidate Name

Office Sought:

House
Senate
President

State: District:

Full Name (Last, First, Middle Initial)

c. Marriott International

Mailing Address 10400 Fernwood Road

Disbursement For: 2012

Primary
Other (specify) General

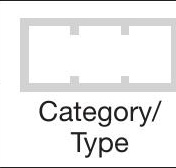

Date of Disbursement

\begin{tabular}{|c|c|c|c|c|}
\hline${ }^{\mathrm{M}} 7^{\mathrm{M}}$ & & ${ }^{\mathrm{D}} 20^{\mathrm{D}}$ & 1 & $\begin{array}{llll}Y & Y & Y & Y \\
& 2011\end{array}$ \\
\hline
\end{tabular}

Transaction ID : B867AD68E98944E0A91F

Amount of Each Disbursement this Period

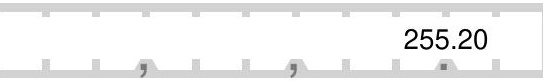

Date of Disbursement

\begin{tabular}{|c|c|c|c|c|}
\hline $07^{\mathrm{M}}$ & 1 & $20^{\mathrm{D}}$ & 1 & $\begin{array}{cccc}Y & Y & Y & Y \\
& 2011 & \end{array}$ \\
\hline
\end{tabular}

\begin{tabular}{lcc}
\hline City & State & Zip Code \\
Bethesda & MD & 20817
\end{tabular}

Purpose of Disbursement

Travel Expense

Candidate Name

Office Sought: $\quad$ House

\begin{tabular}{|l|l|l|} 
& House \\
& Senate \\
& President \\
District:
\end{tabular}

Disbursement For: 2012

X $\begin{aligned} & \text { Primary } \\ & \text { Other (specify) }\end{aligned}$

State:

Subtotal Of Receipts This Page (optional).

Total This Period (last page this line number only))

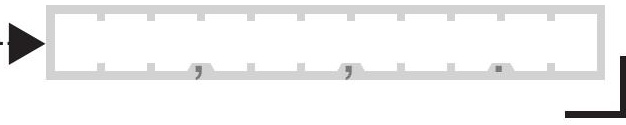




\section{SCHEDULE B-P}

\section{ITEMIZED DISBURSEMENTS}

\section{Use separate schedule(s) \\ for each category of the}

Detailed Summary Page
FOR LINE NUMBER: (check only one)

\begin{tabular}{|c|c|c|c|c|}
\hline $\mathrm{X}_{23}$ & 24 & 25 & 26 & \\
\hline $27 \mathrm{~b}$ & $28 a$ & $28 b$ & $28 \mathrm{c}$ & 2 \\
\hline
\end{tabular}

Any information copied from such Reports and Statements may not be sold or used by any person for the purpose of soliciting contributions or for commercial purposes, other than using the name and address of any political committee to solicit contributions from such committee.

NAME OF COMMITTEE (In Full)

\section{Friends of Herman Cain}

Full Name (Last, First, Middle Initial)

A. The Soarin' Group

Mailing Address Post Office Box 14160

Date of Disbursement

\begin{tabular}{lcc}
\hline City & State & Zip Code \\
Chicago & IL & $60614-0160$
\end{tabular}

Purpose of Disbursement

Lodging, Airfare and Meeting Expenses

\section{Candidate Name}

Office Sought:

\begin{tabular}{l|l} 
& $\begin{array}{l}\text { House } \\
\text { Senate } \\
\text { President }\end{array}$ \\
\hline & District:
\end{tabular}

State: District:

Full Name (Last, First, Middle Initial)

\section{B. The Soarin' Group}

\section{Mailing Address Post Office Box 14160}

\begin{tabular}{lcc}
\hline City & State & Zip Code \\
Chicago & IL & $60614-0160$
\end{tabular}

Purpose of Disbursement

Campaign Strategy Consulting

Candidate Name

Office Sought:

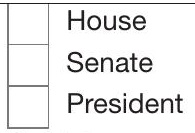

State:

District:

Full Name (Last, First, Middle Initial)

\section{c. Victory Enterprises}

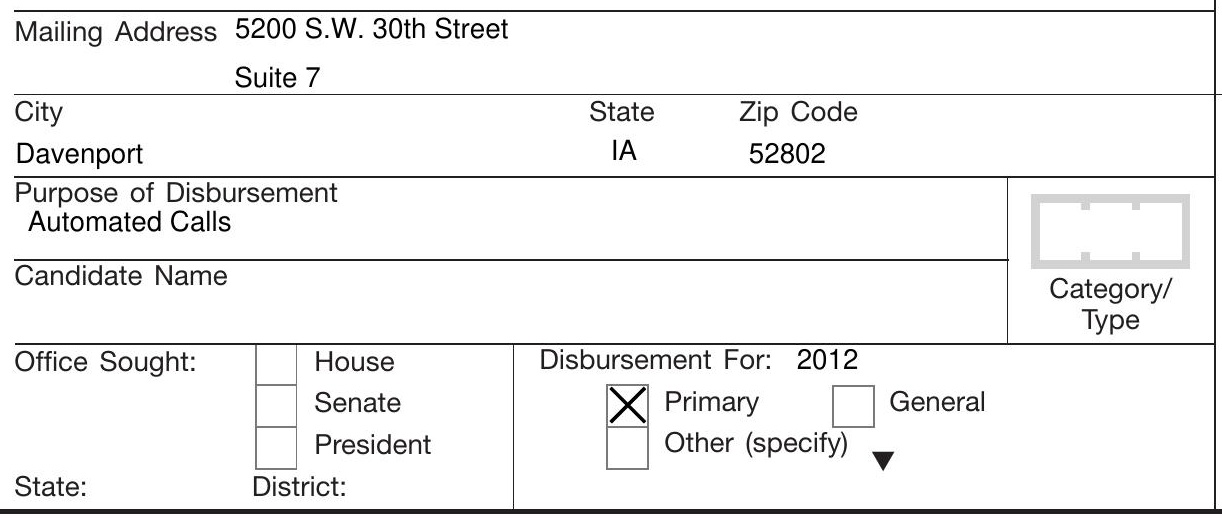

Subtotal Of Receipts This Page (optional)......

Date of Disbursement

\begin{tabular}{|c|c|c|c|c|c|c|}
\hline M & M & D & Y & Y & Y \\
07 & & 20 & & 2011 & \\
\hline
\end{tabular}

Transaction ID : B97C50203BDB94259A52

Amount of Each Disbursement this Period

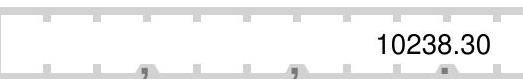

Total This Period (last page this line number only))

17563.11
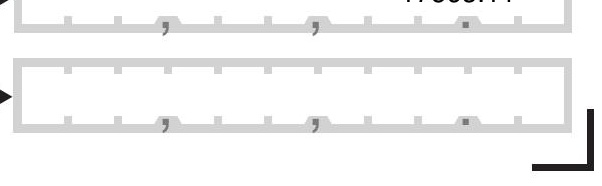


\section{SCHEDULE B-P}

\section{ITEMIZED DISBURSEMENTS}

\section{Use separate schedule(s) \\ for each category of the}

Detailed Summary Page
FOR LINE NUMBER: (check only one)

\begin{tabular}{|c|c|c|c|}
\hline$\times{ }_{23}$ & 24 & 25 & 26 \\
\hline $27 b$ & $28 a$ & $28 \mathrm{~b}$ & $28 \mathrm{c}$ \\
\hline
\end{tabular}

Any information copied from such Reports and Statements may not be sold or used by any person for the purpose of soliciting contributions or for commercial purposes, other than using the name and address of any political committee to solicit contributions from such committee.

NAME OF COMMITTEE (In Full)

\section{Friends of Herman Cain}

Full Name (Last, First, Middle Initial)

A. Eagle Printing \& Graphics Inc.

Mailing Address 16660 W National Avenue

\begin{tabular}{lcc}
\hline City & State & Zip Code \\
New Berlin & WI & 53151 \\
\hline Purpose of Disbursement
\end{tabular}

Purpose of Disbursement

Printing

Candidate Name

Office Sought:

\begin{tabular}{|l} 
House \\
Senate \\
President \\
District:
\end{tabular}

Disbursement For: 2012 X Primary $\square$ General
Date of Disbursement

\begin{tabular}{|c|c|c|c|c|c|}
\hline M M / & D D \\
07 & 20 & 2011 \\
\hline
\end{tabular}

Transaction ID : B495C7EB8F8154B118D9

Amount of Each Disbursement this Period 531.00

Date of Disbursement

\begin{tabular}{|c|c|c|c|c|}
\hline${ }^{\mathrm{M}} 7^{\mathrm{M}}$ & & ${ }^{\mathrm{D}} 20^{\mathrm{D}}$ & 1 & $\begin{array}{llll}Y & Y & Y & Y \\
& 2011\end{array}$ \\
\hline
\end{tabular}

Transaction ID : BCA505FCD84C74A04A86

Amount of Each Disbursement this Period

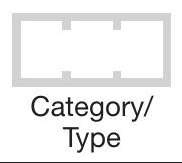

Office Sought:

c/o Brad Marston

City

State

Zip Code

MA 02108

Purpose of Disbursement

Fundraising Consulting

Candidate Name

Disbursement For: 2012

State:

House
Senate
President
Ptrict:

Xrimary $\square$ General

Full Name (Last, First, Middle Initial)

c. Troupis Law Office LLC

Mailing Address 7609 Elmwood Avenue

Suite 102

\begin{tabular}{lcc}
\hline City & State & Zip Code \\
Middleton & WI & 53562 \\
\hline
\end{tabular}

Purpose of Disbursement

Legal Fees

Candidate Name

Office Sought:

State:

\begin{tabular}{|c|}
\hline House \\
\hline Senate \\
\hline President \\
\hline
\end{tabular}

Disbursement For: 2012

X $\begin{aligned} & \text { Primary } \\ & \text { Other (specify) }\end{aligned}$
Date of Disbursement

\begin{tabular}{|c|c|c|c|c|}
\hline${ }^{\mathrm{M}} 07^{\mathrm{M}}$ & I & 20 & 1 & $\begin{array}{llll}Y & Y & Y & Y \\
& 2011 & \end{array}$ \\
\hline
\end{tabular}

Transaction ID : BB38F64E3AF594058B32

Amount of Each Disbursement this Period

7197.50
Subtotal Of Receipts This Page (optional).

21100.62

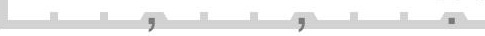

Total This Period (last page this line number only))

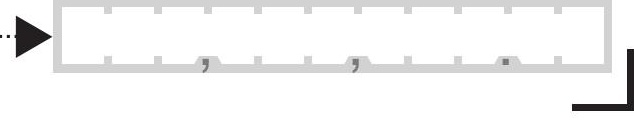

FEC Schedule B-P (Form 3P) (Rev. 03/2011) 


\section{SCHEDULE B-P}

\section{ITEMIZED DISBURSEMENTS}

\section{Use separate schedule(s)}

for each category of the

Detailed Summary Page
FOR LINE NUMBER: (check only one)

\begin{tabular}{|c|c|c|c|}
\hline$\times{ }_{23}$ & 24 & 25 & 26 \\
\hline $27 b$ & $28 a$ & $28 \mathrm{~b}$ & $28 \mathrm{c}$ \\
\hline
\end{tabular}

Any information copied from such Reports and Statements may not be sold or used by any person for the purpose of soliciting contributions or for commercial purposes, other than using the name and address of any political committee to solicit contributions from such committee.

NAME OF COMMITTEE (In Full)

\section{Friends of Herman Cain}

Full Name (Last, First, Middle Initial)

A. Concert Production

Mailing Address 217 West Main Street

\begin{tabular}{lcc}
\hline City & State & Zip Code \\
Murfreesboro & TN & 37130 \\
\hline
\end{tabular}

Purpose of Disbursement

Event Equipment Rental

Candidate Name

Office Sought:

House
Senate
President
District:

Disbursement For: 2012

X Primary $\square$ General
Date of Disbursement

\begin{tabular}{|c|c|c|c|c|c|c|}
\hline M M / & D \\
07 & 20 & 2011 \\
\hline
\end{tabular}

Transaction ID : B068CC18055BF41B8994

Amount of Each Disbursement this Period 950.00

\section{B. Publix Supermarkets}

Mailing Address 3300 Publix Corporate Pkwy

\begin{tabular}{lcc}
\hline City & State & Zip Code \\
Lakeland & FL & 33811
\end{tabular}

Purpose of Disbursement

Meeting Expense

Candidate Name

Office Sought:

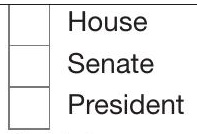

State:

District:

FL

3381

Full Name (Last, First, Middle Initial)

c. Collins Digital Imaging Inc.

Mailing Address 1218 B Old Chattahoochee Avenue

\begin{tabular}{lcc}
\hline City & State & Zip Code \\
Atlanta & GA & 30318
\end{tabular}

Purpose of Disbursement

Office Supplies

Candidate Name

Office Sought:

State:
Disbursement For: 2012

X Primary $\square$ General
Date of Disbursement

\begin{tabular}{|c|c|c|c|c|}
\hline $07^{\mathrm{M}}$ & 1 & $20^{\mathrm{D}}$ & I & $\begin{array}{llll} & Y & Y & Y \\
& 2011 & \end{array}$ \\
\hline
\end{tabular}

Transaction ID : B7DE0DCBB6FBD4CEAB52

Amount of Each Disbursement this Period

4.11

Date of Disbursement

\begin{tabular}{|c|c|c|c|c|c|}
\hline M M & I & D & Y & Y & Y \\
07 & & 20 & & 2011 & \\
\hline
\end{tabular}

Transaction ID : B32263089979F4CAA8F5

Amount of Each Disbursement this Period

171.91

Subtotal Of Receipts This Page (optional).

Total This Period (last page this line number only))

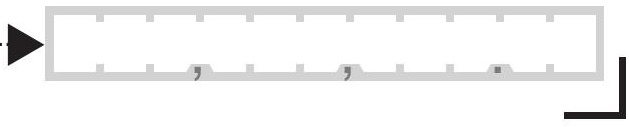




\section{SCHEDULE B-P}

\section{ITEMIZED DISBURSEMENTS}

\section{Use separate schedule(s) \\ for each category of the}

Detailed Summary Page
FOR LINE NUMBER: (check only one)

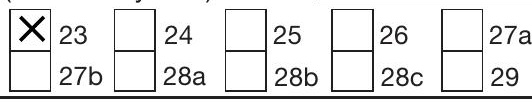

Any information copied from such Reports and Statements may not be sold or used by any person for the purpose of soliciting contributions or for commercial purposes, other than using the name and address of any political committee to solicit contributions from such committee.

NAME OF COMMITTEE (In Full)

\section{Friends of Herman Cain}

Full Name (Last, First, Middle Initial)

A. RMA Chaffeured Transportation

Mailing Address 6010 Executive Boulevard Suite 101

\begin{tabular}{lll}
\hline City & State & Zip Code \\
Rockville & MD & 20852 \\
\hline
\end{tabular}

Purpose of Disbursement

Travel Expense

Candidate Name

\begin{tabular}{l|l|c|}
\hline Office Sought: & $\begin{array}{l}\text { House } \\
\text { Senate } \\
\text { President }\end{array}$ & $\begin{array}{r}\text { Disbursement For: } 2012 \\
\text { X Primary } \\
\text { Other (specify) }\end{array}$
\end{tabular}

\section{Full Name (Last, First, Middle Initial)}

\section{B. Publix Supermarkets}

Mailing Address 3300 Publix Corporate Pkwy

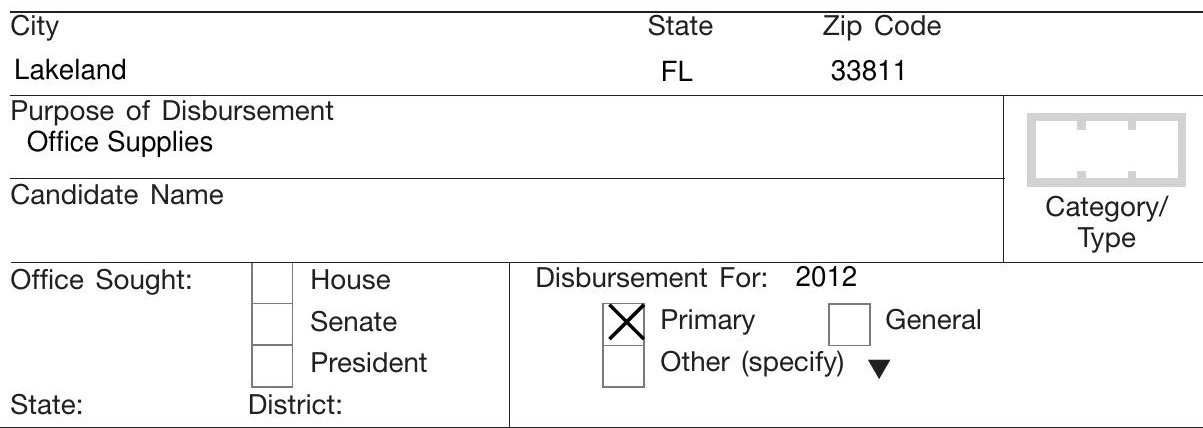

Full Name (Last, First, Middle Initial)

\section{c. FedEx Kinkos}

\begin{tabular}{|c|c|c|c|c|c|}
\hline \multicolumn{6}{|c|}{ Mailing Address 942 S. Shady Grove Road } \\
\hline \multicolumn{2}{|l|}{ City } & State & \multicolumn{3}{|l|}{ Zip Code } \\
\hline \multicolumn{2}{|l|}{ Memphis } & $\mathrm{TN}$ & \multicolumn{3}{|l|}{38120} \\
\hline \multicolumn{5}{|c|}{$\begin{array}{l}\text { Purpose of Disbursement } \\
\text { Office Supplies }\end{array}$} & \\
\hline \multicolumn{5}{|c|}{ Candidate Name } & $\begin{array}{l}\text { Category/ } \\
\text { Type }\end{array}$ \\
\hline \multirow[t]{3}{*}{ Office Sought: } & House & \multicolumn{4}{|c|}{ Disbursement For: 2012} \\
\hline & Senate & \multirow{3}{*}{\multicolumn{2}{|c|}{$\begin{array}{l}\text { Primary } \\
\text { Other (specify) }\end{array}$}} & \multirow{2}{*}{\multicolumn{2}{|c|}{ General }} \\
\hline & President & & & & \\
\hline State: & District: & & & & \\
\hline
\end{tabular}

Subtotal Of Receipts This Page (optional)...

Date of Disbursement

\begin{tabular}{|c|c|c|c|c|c|c|}
\hline M M & I & D & Y & Y & Y \\
07 & & 21 & & 2011 & \\
\hline
\end{tabular}

Transaction ID : B8D56E854C72F4903854

Amount of Each Disbursement this Period

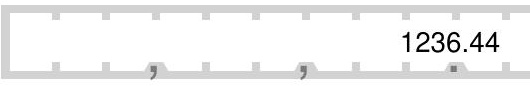

Date of Disbursement

Amount of Each Disbursement this Period

Transaction ID : BDE2369A0317E42BBA9D

Total This Period (last page this line number only)) 


\section{SCHEDULE B-P}

\section{ITEMIZED DISBURSEMENTS}

Use separate schedule(s)

for each category of the

Detailed Summary Page
FOR LINE NUMBER: (check only one)

\begin{tabular}{|c|c|c|c|}
\hline$\times{ }_{23}$ & 24 & 25 & 26 \\
\hline $27 b$ & $28 a$ & $28 \mathrm{~b}$ & $28 \mathrm{c}$ \\
\hline
\end{tabular}

Any information copied from such Reports and Statements may not be sold or used by any person for the purpose of soliciting contributions or for commercial purposes, other than using the name and address of any political committee to solicit contributions from such committee.

NAME OF COMMITTEE (In Full)

\section{Friends of Herman Cain}

Full Name (Last, First, Middle Initial)

A. Capital Grille

Mailing Address 3200 Las Vegas Blvd S Ste. 3300

\begin{tabular}{lll}
\hline City & State & Zip Code \\
Las Vegas & NV & 89109
\end{tabular}

Purpose of Disbursement

Meeting Expense

Candidate Name

\begin{tabular}{l|l|l}
\hline Office Sought: & House & Disbursement For: 2012
\end{tabular} X Primary $\square$ General

State:

\section{Senate}

President

District:

Full Name (Last, First, Middle Initial)

B. SunTrust Bank

Mailing Address 980 Eagles Landing Parkway

\begin{tabular}{lcc}
\hline City & State & Zip Code \\
Stockbridge & GA & 30281
\end{tabular}

Purpose of Disbursement

Bank Fees

Candidate Name

Office Sought:

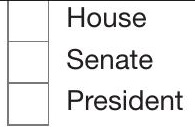

State:

District:

\begin{tabular}{c|c} 
Category/ \\
Type
\end{tabular}

Date of Disbursement

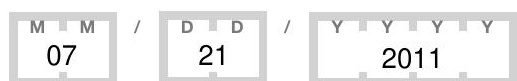

Transaction ID : B098AEDDA2C144CAC98F

Amount of Each Disbursement this Period

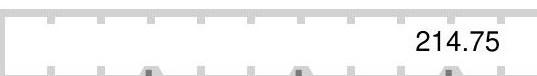

Full Name (Last, First, Middle Initial)

\section{SunTrust Bank}

Mailing Address 980 Eagles Landing Parkway

Date of Disbursement

\begin{tabular}{lcc} 
& & \\
\hline City & State & Zip Code \\
Stockbridge & GA & 30281 \\
\hline
\end{tabular}

\section{Purpose of Disbursement \\ Bank Fees}

Candidate Name

\section{Disbursement For: 2012 \\ Xrimary $\square$ General}

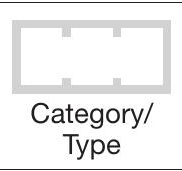

Date of Disbursement

\begin{tabular}{|c|c|c|c|c|}
\hline $07^{M}$ & & ${ }^{\mathrm{D}} 21^{\mathrm{D}}$ & & $\begin{array}{llll}Y & Y & Y & Y \\
& 2011\end{array}$ \\
\hline
\end{tabular}

Transaction ID : BE5B6914611474D34B3E

Amount of Each Disbursement this Period

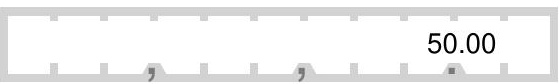

\begin{tabular}{c|c} 
Category/ \\
Type
\end{tabular}

\begin{tabular}{|c|c|c|c|c|c|}
\hline M M / & D & Y & Y & Y \\
07 & & 21 & \\
\hline
\end{tabular}

Transaction ID : BA40CAAFB22034CAA876

Amount of Each Disbursement this Period

\begin{tabular}{l|l|l|l}
\hline \multirow{2}{*}{ Office Sought: } & $\begin{array}{l}\text { House } \\
\text { Senate } \\
\text { President }\end{array}$ & $\begin{array}{r}\text { Disbursement For: } 2012 \\
\text { State: }\end{array}$ & X Primary \\
District: & $\square$ General (specify)
\end{tabular}

Subtotal Of Receipts This Page (optional).

Total This Period (last page this line number only)) 


\section{SCHEDULE B-P}

\section{ITEMIZED DISBURSEMENTS}

\section{Use separate schedule(s)}

for each category of the

Detailed Summary Page
FOR LINE NUMBER: (check only one)

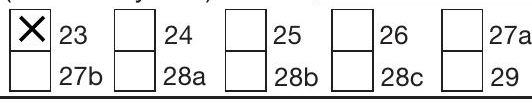

Any information copied from such Reports and Statements may not be sold or used by any person for the purpose of soliciting contributions or for commercial purposes, other than using the name and address of any political committee to solicit contributions from such committee.

NAME OF COMMITTEE (In Full)

\section{Friends of Herman Cain}

Full Name (Last, First, Middle Initial)

A. SunTrust Bank

Mailing Address 980 Eagles Landing Parkway

Date of Disbursement

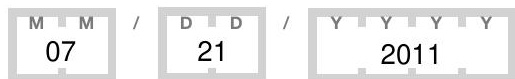

Transaction ID : B8541433EC5504DC3A7B

$\begin{array}{lcc}\text { City } & \text { State } & \text { Zip Code } \\ \text { Stockbridge } & \text { GA } & 30281\end{array}$

Purpose of Disbursement

Bank Fees

Candidate Name Xrimary $\square$ General

State:

Senate
District:

Full Name (Last, First, Middle Initial)

\section{B. SunTrust Bank}

Mailing Address 980 Eagles Landing Parkway

\begin{tabular}{lcc}
\hline City & State & Zip Code \\
Stockbridge & GA & 30281
\end{tabular}

Purpose of Disbursement

Bank Fees

Candidate Name

Office Sought:

House
Senate
President

Disbursement For: 2012

Primary
Other (specify)

State:

District:

Full Name (Last, First, Middle Initial)

c. RST MARKETING INC

Mailing Address 1272 Corporate Park Road

\begin{tabular}{lcc}
\hline City & State & Zip Code \\
Forest & VA & 24551
\end{tabular}

Purpose of Disbursement

Postage

Candidate Name

Office Sought: $\quad$ House

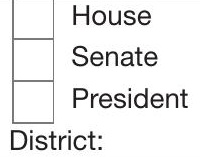

Disbursement For: 2012

X $\begin{aligned} & \text { Primary } \\ & \text { Other (specify) }\end{aligned}$

State:
Date of Disbursement

\begin{tabular}{|c|c|c|c|c|}
\hline${ }^{\mathrm{M}} 7^{\mathrm{M}}$ & & ${ }^{\mathrm{D}} 21^{\mathrm{D}}$ & 1 & $\begin{array}{llll}Y & Y & Y & Y \\
& 2011\end{array}$ \\
\hline
\end{tabular}

Transaction ID : B8FB6BDBF84D24589934

Amount of Each Disbursement this Period

199.40

Date of Disbursement

\begin{tabular}{|c|c|c|c|c|c|}
\hline M M / & D & Y & Y & Y & Y \\
07 & & 21 & & 2011 & \\
\hline
\end{tabular}

Transaction ID : B600F3EACCC874869AAB

Amount of Each Disbursement this Period

1881.39

Subtotal Of Receipts This Page (optional).

Total This Period (last page this line number only))

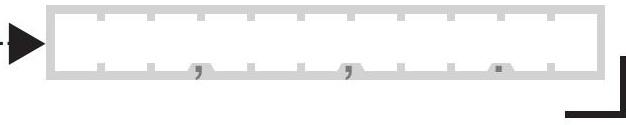




\section{SCHEDULE B-P}

\section{ITEMIZED DISBURSEMENTS}

Use separate schedule(s)

for each category of the

Detailed Summary Page
FOR LINE NUMBER: (check only one)

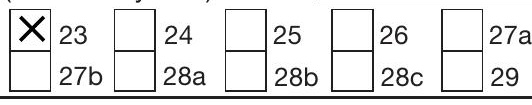

Any information copied from such Reports and Statements may not be sold or used by any person for the purpose of soliciting contributions or for commercial purposes, other than using the name and address of any political committee to solicit contributions from such committee.

NAME OF COMMITTEE (In Full)

\section{Friends of Herman Cain}

Full Name (Last, First, Middle Initial)

A. Marriott International

Mailing Address 10400 Fernwood Road

Date of Disbursement

\begin{tabular}{lll}
\hline City & State & Zip Code \\
Bethesda & MD & 20817 \\
\hline
\end{tabular}

Purpose of Disbursement

Travel Expense

Candidate Name

$M-M, D M$

07

21

2011

Transaction ID : B9C7EBBE1636149F3B22

Office Sought:

House

House
Senate

President

State:

District:

Full Name (Last, First, Middle Initial)

B. Air Expedite Inc.

Mailing Address Post Office Box 331

\begin{tabular}{lcc}
\hline City & State & Zip Code \\
Hampton & GA & 30228
\end{tabular}

Purpose of Disbursement

Travel Expense

Candidate Name

X Primary $\square$ General

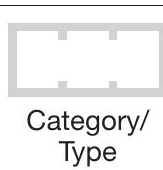

Type
Amount of Each Disbursement this Period

400.44
Date of Disbursement

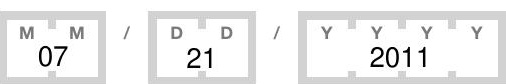

Transaction ID : B6D69EB3F7EEB45F6935

Amount of Each Disbursement this Period

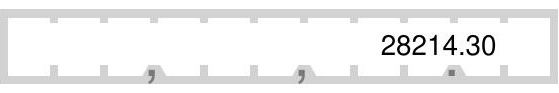

Office Sought:

State: c. Air Expedite Inc.

Mailing Address Post Office Box 331

\begin{tabular}{lcc}
\hline City & State & Zip Code \\
Hampton & GA & 30228
\end{tabular}

Purpose of Disbursement

Travel Expense

Candidate Name

Office Sought:

State:
Disbursement For: 2012

Xrimary $\square$ General

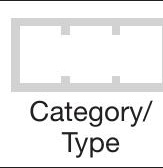

ype
Date of Disbursement

\begin{tabular}{|c|c|c|c|c|c|}
\hline M M & I & D & Y & Y & Y \\
07 & & 21 & & 2011 & \\
\hline
\end{tabular}

Transaction ID : B13F23AC9D7614F67B41

Amount of Each Disbursement this Period

9692.50
Subtotal Of Receipts This Page (optional).

38307.24

C.

Total This Period (last page this line number only))

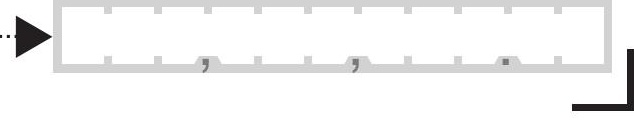

FEC Schedule B-P (Form 3P) (Rev. 03/2011) 


\section{SCHEDULE B-P}

\section{ITEMIZED DISBURSEMENTS}

Use separate schedule(s)

for each category of the

Detailed Summary Page
FOR LINE NUMBER: (check only one)

\begin{tabular}{|c|c|c|c|}
\hline $\mathrm{X} 23$ & 24 & 25 & 26 \\
\hline $27 \mathrm{~b}$ & $28 a$ & $28 b$ & $28 \mathrm{c}$ \\
\hline
\end{tabular}

Any information copied from such Reports and Statements may not be sold or used by any person for the purpose of soliciting contributions or for commercial purposes, other than using the name and address of any political committee to solicit contributions from such committee.

NAME OF COMMITTEE (In Full)

\section{Friends of Herman Cain}

Full Name (Last, First, Middle Initial)

A. Air Tran

Mailing Address 9955 Air Tran Boulevard

Date of Disbursement

City $\quad$ State Zip Code

Orlando

FL $\quad 32827$

Purpose of Disbursement

Travel Expense

Candidate Name

\begin{tabular}{l|l|l}
\hline Office Sought: & House & Disbursement For: 2012
\end{tabular} Xrimary $\square$ General

State:

\section{Senate}

President

District:

Full Name (Last, First, Middle Initial)

B. Michael Branch

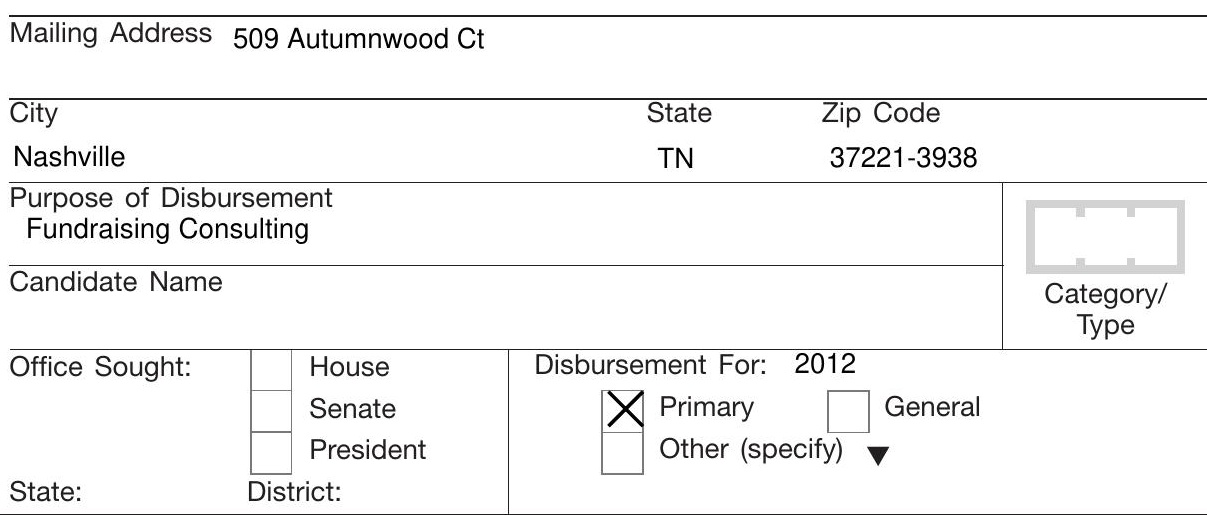

Date of Disbursement

\begin{tabular}{|c|c|c|c|c|}
\hline${ }^{\mathrm{M}} 7^{\mathrm{M}}$ & & ${ }^{\mathrm{D}} 21^{\mathrm{D}}$ & 1 & $\begin{array}{llll}Y & Y & Y & Y \\
& 2011\end{array}$ \\
\hline
\end{tabular}

Transaction ID : BB5AD0DE10E774A1E965

Full Name (Last, First, Middle Initial)

c. Marriott International

Mailing Address 10400 Fernwood Road

Date of Disbursement

\begin{tabular}{lcc} 
& & \\
\hline City & State & Zip Code \\
Bethesda & MD & 20817
\end{tabular}

Purpose of Disbursement

Travel Expense

Candidate Name

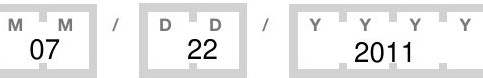

Transaction ID : BB4813DADE9D244D19D9

\begin{tabular}{c|c} 
Category \\
Type
\end{tabular}

Amount of Each Disbursement this Period

\begin{tabular}{l|l|c|}
\hline Office Sought: & $\begin{array}{l}\text { House } \\
\text { Senate } \\
\text { President } \\
\text { State: }\end{array}$ & $\begin{array}{r}\text { Disbursement For: } 2012 \\
\text { District: }\end{array}$
\end{tabular}

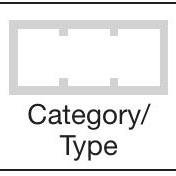

pe
Amount of Each Disbursement this Period

1361.65
Subtotal Of Receipts This Page (optional).

3354.10

C.

Total This Period (last page this line number only))
1740.45

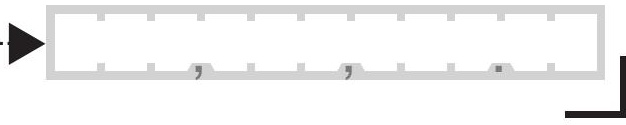

FEC Schedule B-P (Form 3P) (Rev. 03/2011) 


\section{SCHEDULE B-P}

\section{ITEMIZED DISBURSEMENTS}

Use separate schedule(s)

for each category of the

Detailed Summary Page
FOR LINE NUMBER: (check only one)

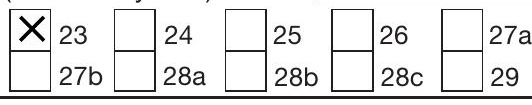

Any information copied from such Reports and Statements may not be sold or used by any person for the purpose of soliciting contributions or for commercial purposes, other than using the name and address of any political committee to solicit contributions from such committee.

NAME OF COMMITTEE (In Full)

\section{Friends of Herman Cain}

Full Name (Last, First, Middle Initial)

A. Facebook, Inc.

Mailing Address 1601 S. California Ave.

Date of Disbursement

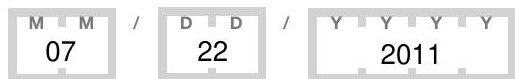

Transaction ID : BC6857A61609848D581C

\begin{tabular}{lcc}
\hline City & State & Zip Code \\
Palo Alto & CA & 94304
\end{tabular}

Purpose of Disbursement

Advertising Expense

Candidate Name

Office Sought:

$$
\begin{aligned}
& \text { House } \\
& \text { Senate } \\
& \text { Presiden }
\end{aligned}
$$
District:

State:

Full Name (Last, First, Middle Initial)

\section{B. Italian Oven Stockbridge GA}

\section{Mailing Address 938 Eagles Landing Parkway}

\begin{tabular}{lcc}
\hline City & State & Zip Code \\
Stockbridge & GA & 30281
\end{tabular}

Purpose of Disbursement

Meeting Expense

Candidate Name

Office Sought:

$$
\begin{array}{|l}
\text { House } \\
\text { Senate } \\
\text { President }
\end{array}
$$

State:

District:

Full Name (Last, First, Middle Initial)

\section{c. FedEx Kinkos}

Mailing Address 942 S. Shady Grove Road

\begin{tabular}{lcc}
\hline City & State & Zip Code \\
Memphis & TN & 38120
\end{tabular}

Purpose of Disbursement

Shipping

Candidate Name

Disbursement For: 2012

Xrimary $\square$ General

$$
\text { X Primary } \square \text { General }
$$

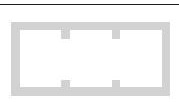

Category/

\begin{tabular}{|c|c|c|c|c|}
\hline $07^{M}$ & & $22^{D}$ & 1 & 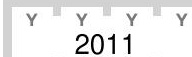 \\
\hline
\end{tabular}
Type
Amount of Each Disbursement this Period

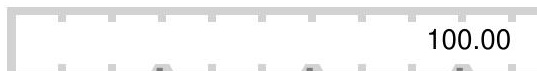

Date of Disbursement

Transaction ID : B3B0A152C7B4A4EF9AAE

Amount of Each Disbursement this Period

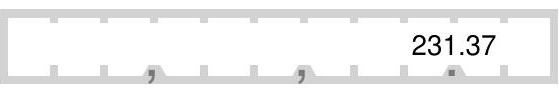

Date of Disbursement

\begin{tabular}{|c|c|c|c|c|c|}
\hline M M / & D & Y & Y & Y & Y \\
07 & & 22 & & 2011 & \\
\hline
\end{tabular}

Transaction ID : B442CBCCBC84840FBB08

Amount of Each Disbursement this Period

127.74

\begin{tabular}{l|l|c|}
\hline Office Sought: & $\begin{array}{l}\text { House } \\
\text { Senate } \\
\text { President } \\
\text { State: }\end{array}$ & $\begin{array}{r}\text { Disbursement For: } 2012 \\
\text { District: }\end{array}$ \\
\cline { 2 - 3 }
\end{tabular}

Subtotal Of Receipts This Page (optional).

Total This Period (last page this line number only))

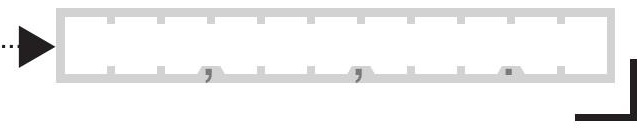




\section{SCHEDULE B-P}

\section{ITEMIZED DISBURSEMENTS}

\section{Use separate schedule(s) \\ for each category of the}

Detailed Summary Page
FOR LINE NUMBER: (check only one)

\begin{tabular}{|c|c|c|c|}
\hline$X_{23}$ & 24 & 25 & 26 \\
\hline $27 \mathrm{~b}$ & $28 a$ & $28 b$ & $28 \mathrm{c}$ \\
\hline
\end{tabular}

Any information copied from such Reports and Statements may not be sold or used by any person for the purpose of soliciting contributions or for commercial purposes, other than using the name and address of any political committee to solicit contributions from such committee.

NAME OF COMMITTEE (In Full)

\section{Friends of Herman Cain}

Full Name (Last, First, Middle Initial)

A. RMA Chaffeured Transportation

Mailing Address 6010 Executive Boulevard

Suite 101

\begin{tabular}{lll}
\hline City & State & Zip Code \\
Rockville & MD & 20852 \\
\hline
\end{tabular}

Purpose of Disbursement

Travel Expense

Candidate Name

$$
\begin{array}{|l|l}
\text { House } \\
\text { Senate } \\
\text { President }
\end{array}
$$

State: District:

Full Name (Last, First, Middle Initial)

\section{B. American Express}

Mailing Address Post Office Box 53852

\begin{tabular}{lcc}
\hline City & State & Zip Code \\
Phoenix & AZ & $85072-3852$
\end{tabular}

Purpose of Disbursement

CC Transaction Fees

Candidate Name

Disbursement For: 2012 Xrimary $\square$ General

Office Sought:

State:

Full Name (Last, First, Middle Initial)

\section{c. Atlanta Perimeter Hotel \& Suites}

Mailing Address 111 Perimeter Center West

\begin{tabular}{lcc}
\hline City & State & Zip Code \\
Atlanta & GA & 30346
\end{tabular}

Purpose of Disbursement

Travel Expense

Candidate Name

Office Sought:

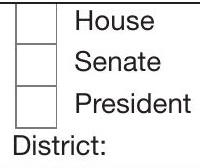

State:

District:
Date of Disbursement

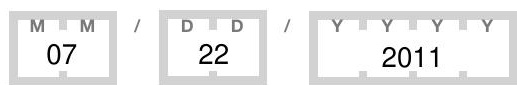

Transaction ID : BEE630F244B45452A8B2

Amount of Each Disbursement this Period

\begin{tabular}{|c|c|c|c|c|}
\hline $07^{\mathrm{M}}$ & 1 & 24 & 1 & 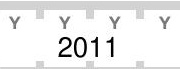 \\
\hline
\end{tabular}
920.00
Date of Disbursement

Transaction ID : B7D4F784290584C6D8BA

Amount of Each Disbursement this Period 2133.76
Date of Disbursement

\begin{tabular}{|c|c|c|c|c|c|}
\hline M M & I & D & Y & Y & Y \\
07 & & 25 & & 2011 & \\
\hline
\end{tabular}

Transaction ID : BF6B292A8153D411C8F2

Amount of Each Disbursement this Period

406.26

Subtotal Of Receipts This Page (optional)

Total This Period (last page this line number only))

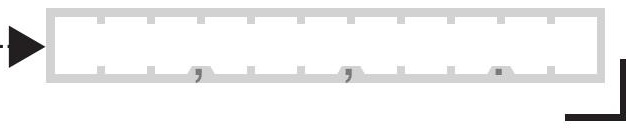




\section{SCHEDULE B-P}

\section{ITEMIZED DISBURSEMENTS}

\section{Use separate schedule(s) \\ for each category of the}

Detailed Summary Page
FOR LINE NUMBER: (check only one)

\begin{tabular}{|c|c|c|c|}
\hline$\times{ }_{23}$ & 24 & 25 & 26 \\
\hline $27 b$ & $28 a$ & $28 \mathrm{~b}$ & $28 \mathrm{c}$ \\
\hline
\end{tabular}

Any information copied from such Reports and Statements may not be sold or used by any person for the purpose of soliciting contributions or for commercial purposes, other than using the name and address of any political committee to solicit contributions from such committee.

NAME OF COMMITTEE (In Full)

\section{Friends of Herman Cain}

Full Name (Last, First, Middle Initial)

A. Delta Airlines

\begin{tabular}{c} 
Mailing Address $\begin{array}{c}\text { Post Office Box } 20980 \\
\text { Department } 980\end{array}$ \\
\hline
\end{tabular}

\begin{tabular}{lcc}
\hline City & State & Zip Code \\
Atlanta & GA & $30320-2980$ \\
\hline
\end{tabular}

Purpose of Disbursement

Travel Expense

Candidate Name

Office Sought:

State: District:

\begin{tabular}{l|l|l|}
\hline Office Sought: & $\begin{array}{l}\text { House } \\
\text { Senate } \\
\text { President }\end{array}$ & $\begin{array}{c}\text { Disbursement For: } 2012 \\
\text { State: }\end{array}$ \\
\cline { 2 - 3 } & District: & $\square$ Primary \\
Other (specify)
\end{tabular}

Full Name (Last, First, Middle Initial)

\section{B. Crowne Plaza Hotel \& Resorts}

\begin{tabular}{|c|c|c|c|c|}
\hline \multicolumn{5}{|c|}{ Mailing Address 2 Somerset Parkway } \\
\hline \multicolumn{2}{|l|}{$\overline{\text { City }}$} & \multicolumn{3}{|c|}{ Zip Code } \\
\hline \multicolumn{2}{|l|}{ Nashua } & \multicolumn{3}{|c|}{03063} \\
\hline \multicolumn{4}{|c|}{$\begin{array}{l}\text { Purpose of Disbursement } \\
\text { Travel Expense }\end{array}$} & \\
\hline \multicolumn{4}{|l|}{ Candidate Name } & $\begin{array}{l}\text { Category/ } \\
\text { Type }\end{array}$ \\
\hline \multirow[t]{3}{*}{ Office Sought: } & \multirow{3}{*}{$\begin{array}{l}\text { House } \\
\text { Senate } \\
\text { President }\end{array}$} & \multirow{3}{*}{\multicolumn{3}{|c|}{ Disbursement For: 2012}} \\
\hline & & & & \\
\hline & & & & \\
\hline State: & rict: & & & \\
\hline
\end{tabular}

Date of Disbursement

Full Name (Last, First, Middle Initial)

\section{c. Oriental Trading Company}

\begin{tabular}{|c|c|c|c|c|c|}
\hline \multicolumn{6}{|c|}{ Mailing Address Post Office Box 2308} \\
\hline \multicolumn{2}{|l|}{ City } & State & \multicolumn{3}{|l|}{ Zip Code } \\
\hline \multicolumn{2}{|l|}{ Omaha } & NE & \multicolumn{3}{|c|}{ 68103-2308 } \\
\hline \multicolumn{5}{|c|}{$\begin{array}{l}\text { Purpose of Disbursement } \\
\text { Event Supplies }\end{array}$} & \\
\hline \multicolumn{5}{|c|}{ Candidate Name } & $\begin{array}{l}\text { Category/ } \\
\text { Type }\end{array}$ \\
\hline \multirow[t]{3}{*}{ Office Sought: } & House & \multicolumn{4}{|c|}{ Disbursement For: 2012} \\
\hline & Senate & \multirow{3}{*}{\multicolumn{2}{|c|}{$\begin{array}{l}\text { Primary } \\
\text { Other (specify) }\end{array}$}} & \multirow{2}{*}{\multicolumn{2}{|c|}{ General }} \\
\hline & President & & & & \\
\hline State: & \multicolumn{3}{|c|}{ District: } & & \\
\hline
\end{tabular}

Subtotal Of Receipts This Page (optional).

Date of Disbursement

\begin{tabular}{|c|c|c|c|c|c|}
\hline M & M & D & Y & Y & Y \\
07 & & 25 & & 2011 \\
\hline
\end{tabular}

\section{Transaction ID : BA53AAFFFD42944EF887}

Amount of Each Disbursement this Period

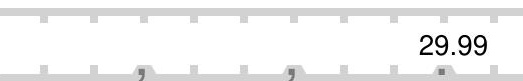

Total This Period (last page this line number only))... 


\section{SCHEDULE B-P}

\section{ITEMIZED DISBURSEMENTS}

Use separate schedule(s)

for each category of the

Detailed Summary Page
FOR LINE NUMBER: (check only one)

\begin{tabular}{|c|c|c|c|}
\hline$\times{ }_{23}$ & 24 & 25 & 26 \\
\hline $27 b$ & $28 a$ & $28 \mathrm{~b}$ & $28 \mathrm{c}$ \\
\hline
\end{tabular}

Any information copied from such Reports and Statements may not be sold or used by any person for the purpose of soliciting contributions or for commercial purposes, other than using the name and address of any political committee to solicit contributions from such committee.

NAME OF COMMITTEE (In Full)

\section{Friends of Herman Cain}

Full Name (Last, First, Middle Initial)

A. Office Depot Corporate

Mailing Address 2500 Mill Center Parkway

Date of Disbursement

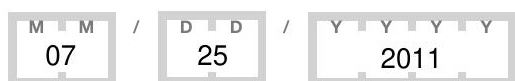

Transaction ID : BA1903BF4F9FE4E79B2B

\begin{tabular}{lll}
\hline City & State & Zip Code \\
Buford & GA & 30518
\end{tabular}

Purpose of Disbursement

Office Supplies

Candidate Name

$$
\begin{array}{|l|l}
\text { House } \\
\text { Senate } \\
\text { President }
\end{array}
$$

State: District:

Full Name (Last, First, Middle Initial)

B. Facebook, Inc.

c. Air Tran

$$
\text { Xrimary } \square \text { General }
$$

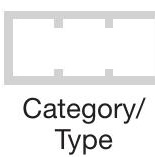

Amount of Each Disbursement this Period

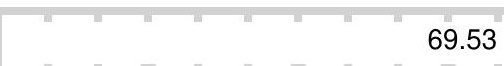

Mailing Address 1601 S. California Ave.

\begin{tabular}{lcc}
\hline City & State & Zip Code \\
Palo Alto & CA & 94304
\end{tabular}

Purpose of Disbursement

Advertising Expense

Candidate Name

Office Sought:

House
Senate
President

State:

District:

Full Name (Last, First, Middle Initial)

Mailing Address 9955 Air Tran Boulevard

\begin{tabular}{|c|c|c|c|c|}
\hline $07^{\mathrm{M}}$ & 1 & $25^{\mathrm{D}}$ & 1 & 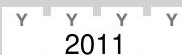 \\
\hline
\end{tabular}

Disbursement For: 2012

Xrimary $\square$ General

Date of Disbursement

Transaction ID : B2BD977054F2C422CBFB

Amount of Each Disbursement this Period
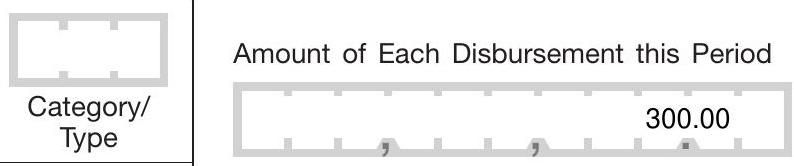

Date of Disbursement

\begin{tabular}{|c|c|c|c|c|c|}
\hline M M & M & Y & Y & Y & Y \\
07 & & 25 & & 2011 & \\
\hline
\end{tabular}

Transaction ID : B30B3E5EFCB8445A4BF0

Orlando

State Zip Code

Purpose of Disbursement

FL $\quad 32827$

Travel Expense

Candidate Name

Office Sought: $\quad$ House

\begin{tabular}{|l|l} 
& House \\
& Senate \\
& President
\end{tabular}

Disbursement For: 2012

X $\begin{aligned} & \text { Primary } \\ & \text { Other (specify) }\end{aligned}$

State:
Subtotal Of Receipts This Page (optional).

389.53

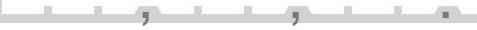

Total This Period (last page this line number only))

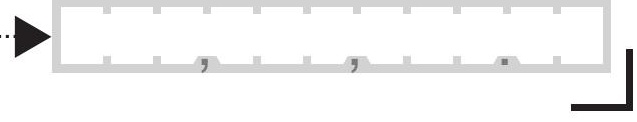

FEC Schedule B-P (Form 3P) (Rev. 03/2011) 


\section{SCHEDULE B-P}

\section{ITEMIZED DISBURSEMENTS}

\section{Use separate schedule(s)}

for each category of the

Detailed Summary Page
FOR LINE NUMBER: (check only one)

\begin{tabular}{|c|c|c|c|}
\hline$\times{ }_{23}$ & 24 & 25 & 26 \\
\hline $27 b$ & $28 a$ & $28 \mathrm{~b}$ & $28 \mathrm{c}$ \\
\hline
\end{tabular}

Any information copied from such Reports and Statements may not be sold or used by any person for the purpose of soliciting contributions or for commercial purposes, other than using the name and address of any political committee to solicit contributions from such committee.

NAME OF COMMITTEE (In Full)

\section{Friends of Herman Cain}

Full Name (Last, First, Middle Initial)

A. Michael Branch

Mailing Address 509 Autumnwood Ct

Date of Disbursement

\begin{tabular}{lcc}
\hline City & State & Zip Code \\
Nashville & TN & $37221-3938$
\end{tabular}

Purpose of Disbursement

Fundraising Consulting

Candidate Name

Office Sought: $\quad$ House

Senate

President

State:

District:

Full Name (Last, First, Middle Initial)

B. James Zeiler

Mailing Address 24059 Borg Road

\begin{tabular}{lcc}
\hline City & State & Zip Code \\
Grantsburg & WI & $54840-8532$
\end{tabular}

Purpose of Disbursement

Mileage

Candidate Name

X Primary $\square$ General

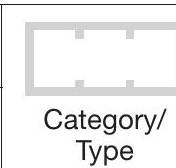

Amount of Each Disbursement this Period 2000.00
Date of Disbursement

\begin{tabular}{|c|c|c|c|c|}
\hline $07^{M}$ & 1 & $25^{\mathrm{D}}$ & 1 & 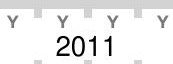 \\
\hline
\end{tabular}

Transaction ID : B77F6E070A95740E087B

Amount of Each Disbursement this Period

586.50
Office Sought:

\begin{tabular}{|l|l} 
House \\
Senate \\
\cline { 1 - 2 } President
\end{tabular}

State:

District:
Disbursement For: 2012

Primary
Other (specify) General

Full Name (Last, First, Middle Initial)

\section{c. Beacon Hotel}

\section{Mailing Address 1615 Rhode Island Ave. NW}

\begin{tabular}{lcc}
\hline City & State & Zip Code \\
Washington & DC & 20036
\end{tabular}

Purpose of Disbursement

Travel Expense

Candidate Name

Office Sought:

State:

\begin{tabular}{|c|}
\hline House \\
\hline Senate \\
\hline President \\
\hline
\end{tabular}

Disbursement For: 2012

X $\begin{aligned} & \text { Primary } \\ & \text { Other (specify) }\end{aligned}$
Date of Disbursement

\begin{tabular}{|c|c|c|c|c|c|}
\hline M M / & D & I & Y & Y & Y \\
07 & & 26 & & 2011 & \\
\hline
\end{tabular}

Transaction ID : B70D981A134DD4FFBBF9

Amount of Each Disbursement this Period

387.02

Subtotal Of Receipts This Page (optional).

Total This Period (last page this line number only))

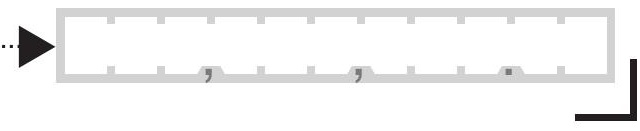




\section{SCHEDULE B-P}

\section{ITEMIZED DISBURSEMENTS}

\section{Use separate schedule(s) \\ for each category of the}

Detailed Summary Page
FOR LINE NUMBER: (check only one)

\begin{tabular}{|c|c|c|c|}
\hline$\times{ }_{23}$ & 24 & 25 & 26 \\
\hline $27 b$ & $28 a$ & $28 \mathrm{~b}$ & $28 \mathrm{c}$ \\
\hline
\end{tabular}

Any information copied from such Reports and Statements may not be sold or used by any person for the purpose of soliciting contributions or for commercial purposes, other than using the name and address of any political committee to solicit contributions from such committee.

NAME OF COMMITTEE (In Full)

\section{Friends of Herman Cain}

Full Name (Last, First, Middle Initial)

A. Facebook, Inc.

Mailing Address 1601 S. California Ave.

Date of Disbursement

\begin{tabular}{|c|c|c|c|c|c|c|}
\hline M M / & D \\
07 & 26 & 2011 \\
\hline
\end{tabular}

Transaction ID : B5B9EAA80E911425EA39

\begin{tabular}{lcc}
\hline City & State & Zip Code \\
Palo Alto & CA & 94304
\end{tabular}

Purpose of Disbursement

Advertising Expense

Candidate Name

\begin{tabular}{l|l|l}
\hline Office Sought: & House & Disbursement For: 2012
\end{tabular} X Primary $\square$ General

State:

\section{Senate}

President

District:

Full Name (Last, First, Middle Initial)

\section{B. Office Depot Corporate}

Mailing Address 2500 Mill Center Parkway

\begin{tabular}{lcc}
\hline City & State & Zip Code \\
Buford & GA & 30518
\end{tabular}

Purpose of Disbursement

Office Supplies

Candidate Name

Office Sought:

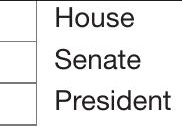

State:

District:

Full Name (Last, First, Middle Initial)

\section{c. Delta Airlines}

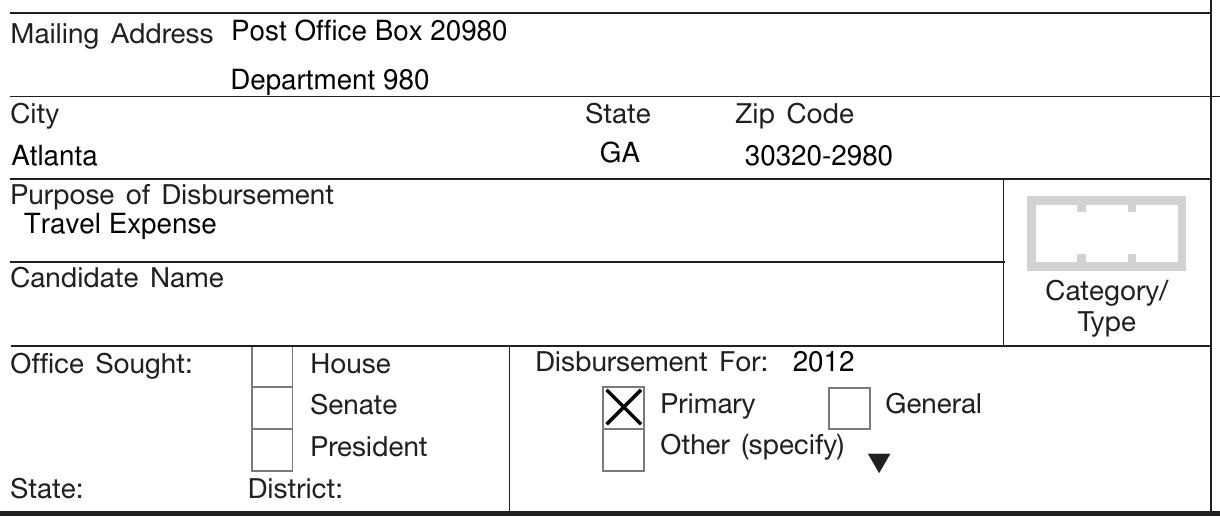

Subtotal Of Receipts This Page (optional).

Date of Disbursement

\begin{tabular}{|c|c|c|c|c|c|}
\hline M M & I & D & Y & Y & Y \\
07 & & 26 & & 2011 & \\
\hline
\end{tabular}

Transaction ID : B2CC3878A6DC54613AB8

Amount of Each Disbursement this Period

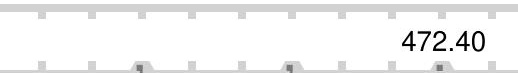

472.40

Total This Period (last page this line number only)) 


\section{SCHEDULE B-P}

\section{ITEMIZED DISBURSEMENTS}

\section{Use separate schedule(s) \\ for each category of the}

Detailed Summary Page
FOR LINE NUMBER: (check only one)

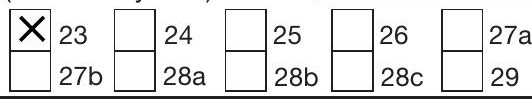

Any information copied from such Reports and Statements may not be sold or used by any person for the purpose of soliciting contributions or for commercial purposes, other than using the name and address of any political committee to solicit contributions from such committee.

NAME OF COMMITTEE (In Full)

\section{Friends of Herman Cain}

Full Name (Last, First, Middle Initial)

A. Crowne Plaza Hotel \& Resorts

Mailing Address 2 Somerset Parkway

Date of Disbursement

\begin{tabular}{lll}
\hline City & State & Zip Code \\
Nashua & $\mathrm{NH}$ & 03063 \\
\hline
\end{tabular}

Purpose of Disbursement

Travel Expense

Candidate Name

\begin{tabular}{l|l|l}
\hline Office Sought: & House & Disbursement For: 2012
\end{tabular} X Primary $\square$ General

State:

\section{Senate} President

Full Name (Last, First, Middle Initial)

\section{B. Tri-State Travel}

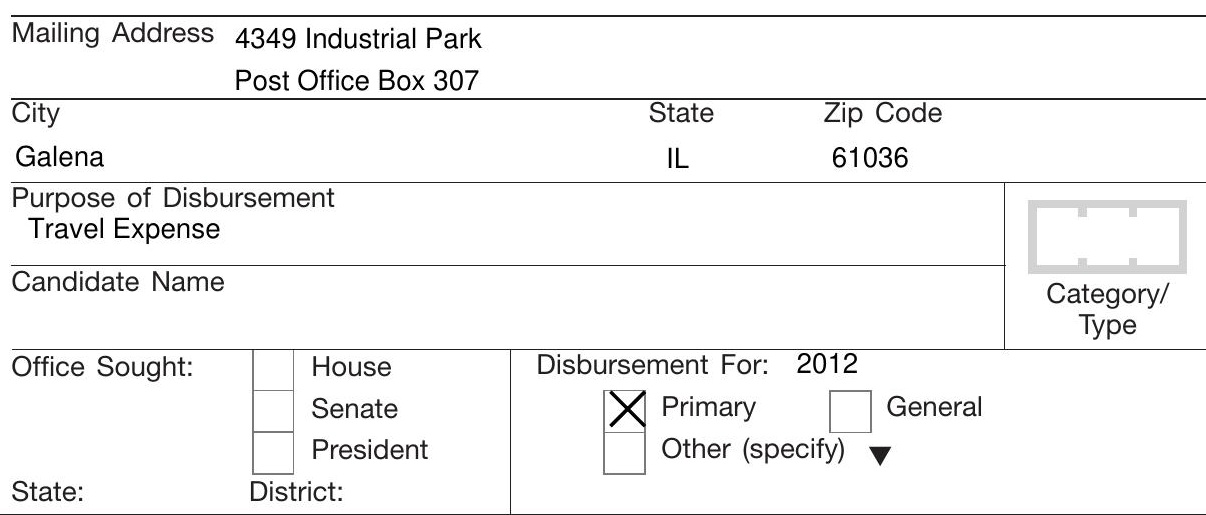

Date of Disbursement

Full Name (Last, First, Middle Initial)

\section{c. Tri-Net Payroll Services}

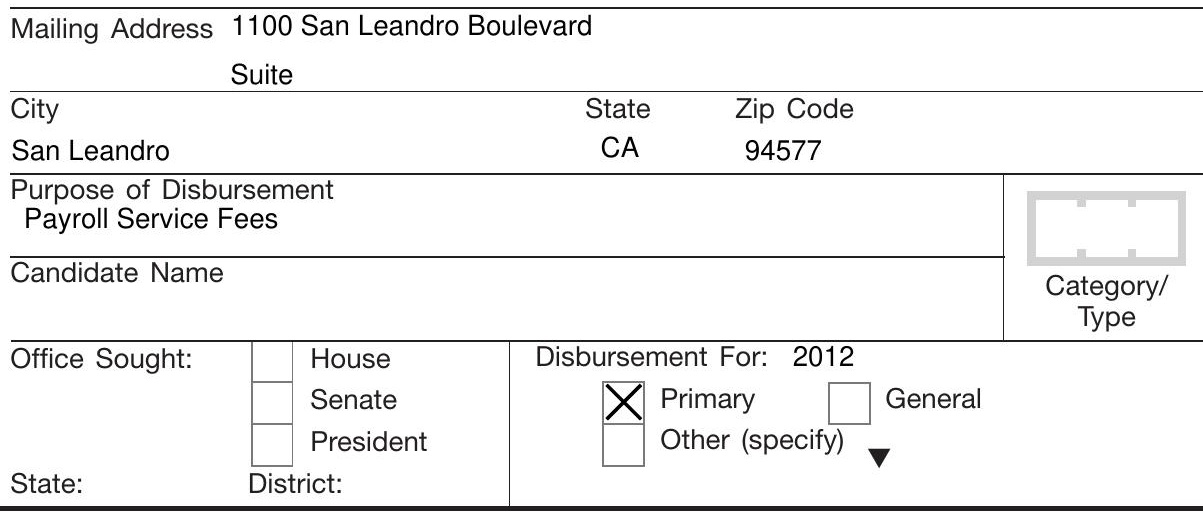

Subtotal Of Receipts This Page (optional)......

Date of Disbursement

\begin{tabular}{|c|c|c|c|c|c|}
\hline M M & I & D & Y & Y & Y \\
07 & & 27 & & 2011 & \\
\hline
\end{tabular}

Transaction ID : BBF255054962F4A218CD

Amount of Each Disbursement this Period

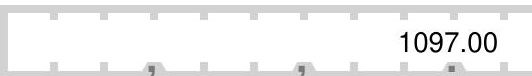

1097.00

Total This Period (last page this line number only)) 


\section{SCHEDULE B-P}

\section{ITEMIZED DISBURSEMENTS}

\section{Use separate schedule(s) \\ for each category of the}

Detailed Summary Page
FOR LINE NUMBER: (check only one)

\begin{tabular}{|c|c|c|c|}
\hline$X_{23}$ & 24 & 25 & 26 \\
\hline $27 \mathrm{~b}$ & $28 a$ & $28 b$ & $28 \mathrm{c}$ \\
\hline
\end{tabular}

Any information copied from such Reports and Statements may not be sold or used by any person for the purpose of soliciting contributions or for commercial purposes, other than using the name and address of any political committee to solicit contributions from such committee.

NAME OF COMMITTEE (In Full)

\section{Friends of Herman Cain}

Full Name (Last, First, Middle Initial)

A. Tri-Net Payroll Services

Mailing Address 1100 San Leandro Boulevard

Suite

\begin{tabular}{lll}
\hline City & State & Zip Code \\
San Leandro & CA & 94577
\end{tabular}

Purpose of Disbursement

Payroll Benefits

Candidate Name

Office Sought:

House
Senate
President
District:

Disbursement For: 2012

Xrimary $\square$ General

State:

First, Middle Initial)

B. Tri-Net Payroll Services

\begin{tabular}{|c|c|}
\hline Mailing Address & $\begin{array}{l}1100 \text { San Leandro Boulevard } \\
\text { Suite }\end{array}$ \\
\hline
\end{tabular}

San Leandro CA Zip Code

Purpose of Disbursement

Payroll Withholding

Candidate Name

Office Sought:

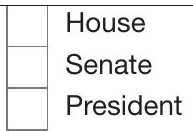

State:

District:

Full Name (Last, First, Middle Initial)

\section{c. Soundmind Productions}

\begin{tabular}{|c|c|c|c|c|c|}
\hline \multicolumn{6}{|c|}{ Mailing Address 509 Autumnwood Court } \\
\hline \multicolumn{2}{|l|}{ City } & State & Zip Code & & \\
\hline \multicolumn{2}{|l|}{ Nashville } & $\mathrm{TN}$ & 37221 & & \\
\hline \multicolumn{5}{|c|}{$\begin{array}{l}\text { Purpose of Disbursement } \\
\text { Event Entertainment }\end{array}$} & \\
\hline \multicolumn{5}{|c|}{ Candidate Name } & $\begin{array}{l}\text { Category/ } \\
\text { Type }\end{array}$ \\
\hline \multirow[t]{3}{*}{ Office Sought: } & House & \multicolumn{4}{|c|}{ Disbursement For: 2012} \\
\hline & Senate & \multirow{3}{*}{\multicolumn{2}{|c|}{$\begin{array}{l}\text { Primary } \\
\text { Other (specify) }\end{array}$}} & \multirow{2}{*}{\multicolumn{2}{|c|}{ General }} \\
\hline & President & & & & \\
\hline State: & District: & & & & \\
\hline
\end{tabular}

Subtotal Of Receipts This Page (optional).
Date of Disbursement

\begin{tabular}{|c|c|c|c|c|c|}
\hline M M & D \\
07 & 27 & 2011 \\
\hline
\end{tabular}

Transaction ID : BAF06009A554A43909E9

Amount of Each Disbursement this Period

4341.58

Date of Disbursement

\begin{tabular}{|c|c|c|c|c|}
\hline $07^{\mathrm{M}}$ & 1 & 27 & l & 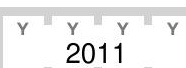 \\
\hline
\end{tabular}

Transaction ID : BC7374B16DF034026ACC

Amount of Each Disbursement this Period

7687.15

Date of Disbursement

\begin{tabular}{|c|c|c|c|c|}
\hline $07^{M}$ & I & D 27 & I & 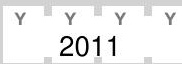 \\
\hline
\end{tabular}

Transaction ID : BF3DAC6C0C9C247DF826

Amount of Each Disbursement this Period

1550.00

Total This Period (last page this line number only))

13578.73

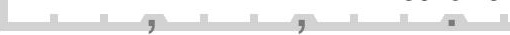




\section{SCHEDULE B-P}

\section{ITEMIZED DISBURSEMENTS}

Use separate schedule(s)

for each category of the

Detailed Summary Page
FOR LINE NUMBER: (check only one)

\begin{tabular}{|c|c|c|c|c|}
\hline$X_{23}$ & 24 & 25 & 26 & \\
\hline $27 \mathrm{~b}$ & $28 a$ & $28 b$ & $28 \mathrm{c}$ & 2 \\
\hline
\end{tabular}

Any information copied from such Reports and Statements may not be sold or used by any person for the purpose of soliciting contributions or for commercial purposes, other than using the name and address of any political committee to solicit contributions from such committee.

NAME OF COMMITTEE (In Full)

\section{Friends of Herman Cain}

Full Name (Last, First, Middle Initial)

A. Microtel Inn and Suites

Mailing Address 22 Sylvan Way

Date of Disbursement

\begin{tabular}{lll}
\hline City & State & Zip Code \\
Parsippany & NJ & 07054 \\
\hline
\end{tabular}

Purpose of Disbursement

Travel Expense

Candidate Name

Office Sought:

\begin{tabular}{|l} 
House \\
Senate \\
President \\
District:
\end{tabular}

Disbursement For: 2012 X Primary $\square$ General

State: District:

Full Name (Last, First, Middle Initial)

B. SunTrust Bank

Mailing Address 980 Eagles Landing Parkway

\begin{tabular}{lcc}
\hline City & State & Zip Code \\
Stockbridge & GA & 30281
\end{tabular}

Purpose of Disbursement

Bank Fees

Candidate Name

Office Sought:

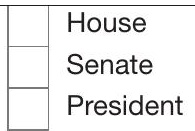

State:

District:

Full Name (Last, First, Middle Initial)

c. Facebook, Inc.

Mailing Address 1601 S. California Ave.

Disbursement For: 2012

Xrimary $\square$ General

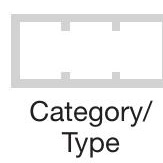

Amount of Each Disbursement this Period

\begin{tabular}{|c|c|}
\hline 07 & $27^{\mathrm{D}}$ \\
\hline
\end{tabular}

Transaction ID : B675A51DAF2F34B7B868 Type 402.90

Date of Disbursement

\begin{tabular}{|c|c|c|c|c|}
\hline $07^{\mathrm{M}}$ & 1 & 27 & 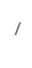 & $\begin{array}{llll}Y & Y & Y & Y \\
& 2011\end{array}$ \\
\hline
\end{tabular}

Transaction ID : BE901C625CF33462A95E

Amount of Each Disbursement this Period

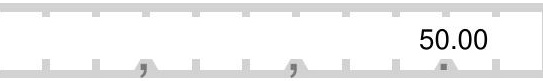

Date of Disbursement

\begin{tabular}{|c|c|c|c|c|c|}
\hline${ }^{M}$ & M & D & Y & Y Y Y \\
07 & 27 & 2011 \\
\hline
\end{tabular}

\begin{tabular}{lcc}
\hline City & State & Zip Code \\
Palo Alto & CA & 94304
\end{tabular}

Purpose of Disbursement Advertising Expense

Candidate Name

\begin{tabular}{l|l|c|}
\hline Office Sought: & $\begin{array}{l}\text { House } \\
\text { Senate } \\
\text { President }\end{array}$ & $\begin{array}{r}\text { Disbursement For: } 2012 \\
\text { State: }\end{array}$ \\
\cline { 2 - 3 } & District: & X $\begin{array}{l}\text { Primary } \\
\text { Other (specify) }\end{array}$
\end{tabular}

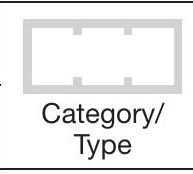
ype
Transaction ID : B759E185A1CA34D58A1D

Amount of Each Disbursement this Period 100.00

Subtotal Of Receipts This Page (optional).

Total This Period (last page this line number only))

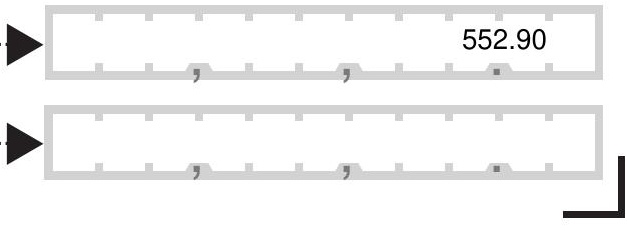




\section{SCHEDULE B-P}

\section{ITEMIZED DISBURSEMENTS}

\section{Use separate schedule(s) \\ for each category of the}

Detailed Summary Page
FOR LINE NUMBER: (check only one)

\begin{tabular}{|c|c|c|c|}
\hline$X_{23}$ & 24 & 25 & 26 \\
\hline $27 \mathrm{~b}$ & $28 a$ & $28 b$ & $28 \mathrm{c}$ \\
\hline
\end{tabular}

Any information copied from such Reports and Statements may not be sold or used by any person for the purpose of soliciting contributions or for commercial purposes, other than using the name and address of any political committee to solicit contributions from such committee.

NAME OF COMMITTEE (In Full)

\section{Friends of Herman Cain}

Full Name (Last, First, Middle Initial)

A. Navigator Motorcoaches Inc.

Mailing Address 84605 North US Highway 81

Post Office Box 2244

Date of Disbursement

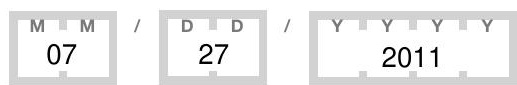

Transaction ID : BE764CEBDB6C7481A8F9

\begin{tabular}{lll}
\hline City & State & Zip Code \\
Norfolk & NE & 68702
\end{tabular}

Purpose of Disbursement

Travel Expense

Candidate Name

\begin{tabular}{l|l|l|l}
\hline Office Sought: & House & Disbursement For: 2012
\end{tabular} X Primary $\square$ General

State:

\section{Senate}

President

District:

Full Name (Last, First, Middle Initial)

B. Michelle Gwaltney

Mailing Address 123 Glen Eagle Way

\begin{tabular}{lcc}
\hline City & State & Zip Code \\
McDonough & GA & $30253-4229$
\end{tabular}

Purpose of Disbursement

Staff Salary

Candidate Name

Office Sought:

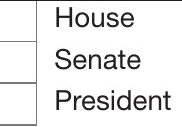

State:

District:

Full Name (Last, First, Middle Initial)

\section{Scott Sidney}

Mailing Address N40 W6522 Jackson Street

\begin{tabular}{lcc}
\hline City & State & Zip Code \\
Cedarburg & WI & $53012-2317$
\end{tabular}

Purpose of Disbursement

Staff Salary

Candidate Name

Disbursement For: 2012

Primary $\square$ General
Other (specify)

Office Sought:

\begin{tabular}{|c|}
\hline House \\
\hline Senate \\
\hline President \\
\hline
\end{tabular}

Disbursement For: 2012

Х $\begin{aligned} & \text { Primary } \\ & \text { Other (specify) }\end{aligned}$

State:
Date of Disbursement

\begin{tabular}{|c|c|c|c|c|}
\hline${ }^{\mathrm{M}} 7^{\mathrm{M}}$ & & ${ }^{\mathrm{D}} 27^{\mathrm{D}}$ & 1 & $\begin{array}{lll}Y & Y & Y \\
& 2011 & Y\end{array}$ \\
\hline
\end{tabular}

Transaction ID : BA1FD49C59597494E9B6

Amount of Each Disbursement this Period

2916.67

Date of Disbursement

\begin{tabular}{|c|c|c|c|c|c|}
\hline M M / & D & Y & Y & Y & Y \\
07 & & 27 & & 2011 & \\
\hline
\end{tabular}

Transaction ID : B1EFF058164FD444BA85

Amount of Each Disbursement this Period

1000.00

Subtotal Of Receipts This Page (optional).

Total This Period (last page this line number only))

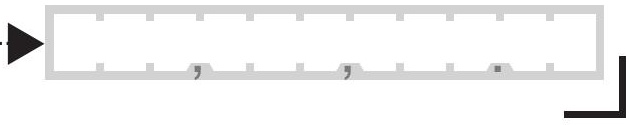




\section{SCHEDULE B-P}

\section{ITEMIZED DISBURSEMENTS}

Use separate schedule(s)

for each category of the

Detailed Summary Page
FOR LINE NUMBER: (check only one)

\begin{tabular}{|c|c|c|c|}
\hline$\times{ }_{23}$ & 24 & 25 & 26 \\
\hline $27 b$ & $28 a$ & $28 \mathrm{~b}$ & $28 \mathrm{c}$ \\
\hline
\end{tabular}

Any information copied from such Reports and Statements may not be sold or used by any person for the purpose of soliciting contributions or for commercial purposes, other than using the name and address of any political committee to solicit contributions from such committee.

NAME OF COMMITTEE (In Full)

\section{Friends of Herman Cain}

Full Name (Last, First, Middle Initial)

A. Michael Branch

Mailing Address 509 Autumnwood Ct

Date of Disbursement

\begin{tabular}{lcc}
\hline City & State & Zip Code \\
Nashville & TN & $37221-3938$
\end{tabular}

Purpose of Disbursement

Staff Salary

Candidate Name

\begin{tabular}{l|l|l}
\hline Office Sought: & House & Disbursement For: 2012
\end{tabular} X Primary $\square$ General

State:

\section{Senate}

President

District:

Full Name (Last, First, Middle Initial)

B. Larry Tuel

Mailing Address 5129 Welker Ave.

\begin{tabular}{lcc}
\hline City & State & Zip Code \\
Des Moines & IA & $50312-2159$
\end{tabular}

Purpose of Disbursement

Staff Salary

Candidate Name

Office Sought:

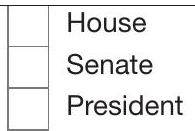

State:

District:

IA

Full Name (Last, First, Middle Initial)

c. Mark Block

Mailing Address 18125 West Plateau Lane

\begin{tabular}{lcc}
\hline City & State & Zip Code \\
New Berlin & WI & $53146-5116$
\end{tabular}

Purpose of Disbursement

Staff Salary

Candidate Name

Office Sought: $\quad$ House

\begin{tabular}{|l|l|} 
& House \\
& Senate \\
& President
\end{tabular}

State:

District:
Disbursement For: 2012

Xrimary $\square$ General
Date of Disbursement

\begin{tabular}{|c|c|c|c|c|}
\hline $07^{\mathrm{M}}$ & & ${ }^{\mathrm{D}} 27^{\mathrm{D}}$ & 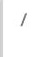 & $\begin{array}{llll}Y & Y & Y & Y \\
& 2011^{\prime}\end{array}$ \\
\hline
\end{tabular}

Transaction ID : B2F21468C09904C9A9F2

Amount of Each Disbursement this Period

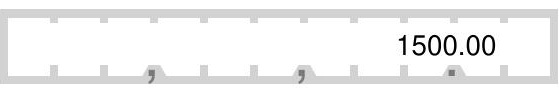

Date of Disbursement

\begin{tabular}{|c|c|c|c|c|c|}
\hline M M & D & Y & Y & Y \\
07 & & 27 & & 2011 & \\
\hline
\end{tabular}

Transaction ID : B2663C1163FD240509B2

Amount of Each Disbursement this Period

5000.00

Subtotal Of Receipts This Page (optional).

Total This Period (last page this line number only))

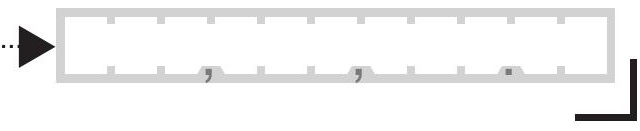




\section{SCHEDULE B-P}

\section{ITEMIZED DISBURSEMENTS}

\section{Use separate schedule(s)}

for each category of the

Detailed Summary Page
FOR LINE NUMBER: (check only one)

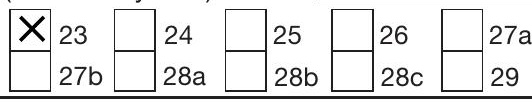

Any information copied from such Reports and Statements may not be sold or used by any person for the purpose of soliciting contributions or for commercial purposes, other than using the name and address of any political committee to solicit contributions from such committee.

NAME OF COMMITTEE (In Full)

\section{Friends of Herman Cain}

Full Name (Last, First, Middle Initial)

A. Scott F. Bieniek

Mailing Address 1782 Schooling Road

Date of Disbursement

\begin{tabular}{lcc}
\hline City & State & Zip Code \\
Spencer & IN & $47460-7528$
\end{tabular}

Purpose of Disbursement

Staff Salary

Candidate Name

\begin{tabular}{l|l|l|l}
\hline Office Sought: & House & Disbursement For: 2012
\end{tabular} X Primary $\square$ General

State:

\section{Senate}

President

District:

Full Name (Last, First, Middle Initial)

B. Stephanie Latham

Mailing Address 827 Cog Hill

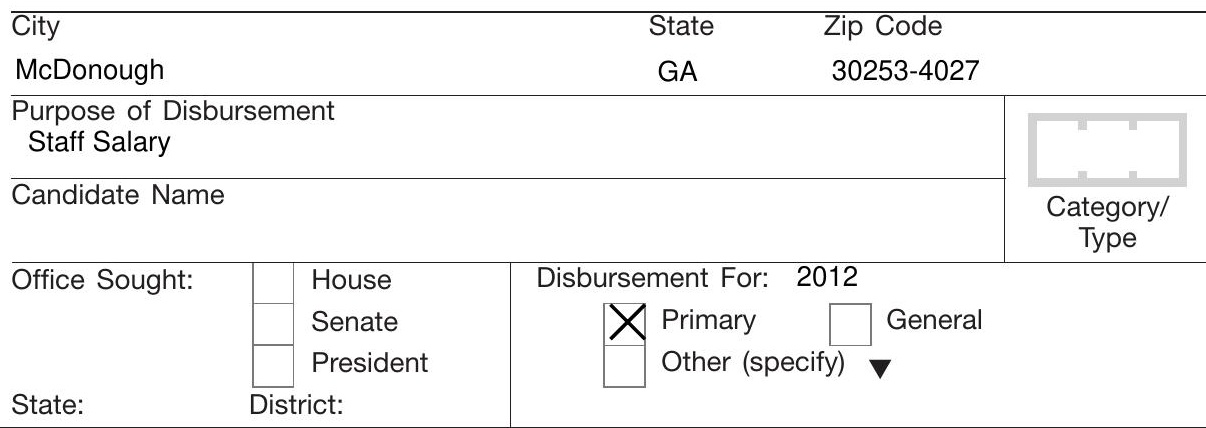

Full Name (Last, First, Middle Initial)

\section{c. Lisa Shiflett}

Mailing Address 157 Stokes Drive

\begin{tabular}{lcc}
\hline City & State & Zip Code \\
Stockbridge & GA & $30281-1376$
\end{tabular}

Purpose of Disbursement

Staff Salary

Candidate Name

Office Sought:

State:
Disbursement For: 2012

X $\begin{aligned} & \text { Primary } \\ & \text { Other (specify) }\end{aligned}$
Date of Disbursement

\begin{tabular}{|c|c|c|c|c|}
\hline $07^{\mathrm{M}}$ & & $27^{\mathrm{D}}$ & & $\begin{array}{llll} & Y & Y & Y \\
& 2011 & Y\end{array}$ \\
\hline
\end{tabular}

Transaction ID : B34FF8557A2244DC991D

Amount of Each Disbursement this Period

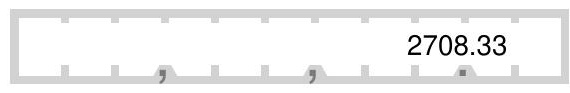

Date of Disbursement

\begin{tabular}{|c|c|c|c|c|c|}
\hline M M / & D & Y & Y & Y & Y \\
07 & & 27 & & 2011 & \\
\hline
\end{tabular}

Transaction ID : B7AC782C6C248462B9EC

Amount of Each Disbursement this Period

2500.00

Subtotal Of Receipts This Page (optional).

Total This Period (last page this line number only))

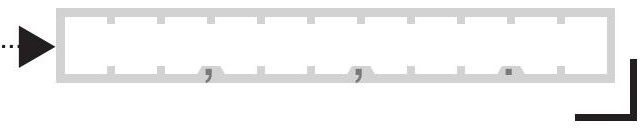




\section{SCHEDULE B-P}

\section{ITEMIZED DISBURSEMENTS}

\section{Use separate schedule(s) \\ for each category of the}

Detailed Summary Page
FOR LINE NUMBER: (check only one)

\begin{tabular}{|c|c|c|c|}
\hline$\times{ }_{23}$ & 24 & 25 & 26 \\
\hline $27 b$ & $28 a$ & $28 \mathrm{~b}$ & $28 \mathrm{c}$ \\
\hline
\end{tabular}

Any information copied from such Reports and Statements may not be sold or used by any person for the purpose of soliciting contributions or for commercial purposes, other than using the name and address of any political committee to solicit contributions from such committee.

NAME OF COMMITTEE (In Full)

\section{Friends of Herman Cain}

Full Name (Last, First, Middle Initial)

A. Karleen Smith

Mailing Address 105 Marilyn Drive E

Date of Disbursement

\begin{tabular}{lcc}
\hline City & State & Zip Code \\
Fayetteville & GA & 30214 \\
\hline Purpose of Disbursement & &
\end{tabular}

bursement

Candidate Name

|.

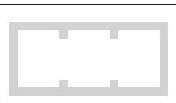

Category/ Type
Amount of Each Disbursement this Period 3000.00

\begin{tabular}{l|l|l|l|}
\hline Office Sought: & \begin{tabular}{l} 
House \\
Senate \\
President \\
\cline { 2 - 3 }
\end{tabular} & $\begin{array}{c}\text { Disbursement For: } 2012 \\
\text { State: }\end{array}$ & Primary \\
Other (specify)
\end{tabular}

Full Name (Last, First, Middle Initial)

B. Tina Spratling

Mailing Address PO Box 2158

\begin{tabular}{lcc}
\hline City & State & Zip Code \\
Stockbridge & GA & $30281-8909$
\end{tabular}

Purpose of Disbursement

Staff Salary

Candidate Name

Office Sought:

House
Senate
President

State:

District:

Full Name (Last, First, Middle Initial)

\section{c. Brenda Hicks}

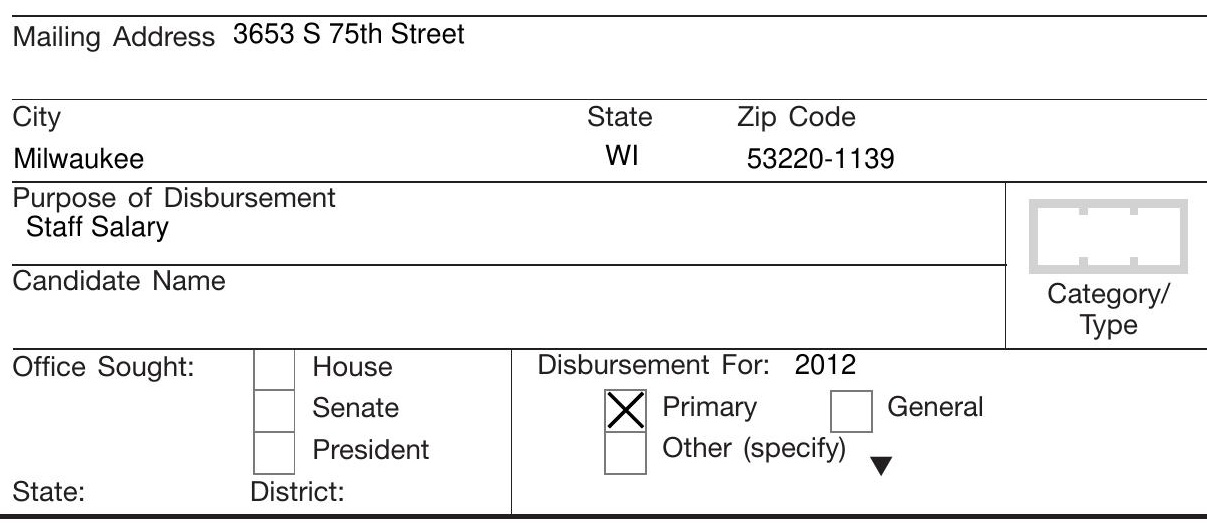

Subtotal Of Receipts This Page (optional).

Date of Disbursement

\begin{tabular}{|c|c|c|c|c|c|}
\hline M M / & D & Y & Y & Y & Y \\
07 & & 27 & \\
\hline
\end{tabular}

Transaction ID : BA6CAB581E5C144DC9EB

Amount of Each Disbursement this Period

Date of Disbursement

\begin{tabular}{|c|c|c|c|c|}
\hline $07^{M}$ & I & $27^{\mathrm{D}}$ & 1 & 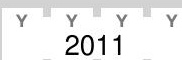 \\
\hline
\end{tabular}

Transaction ID : BA23280BA499445149ED

Amount of Each Disbursement this Period
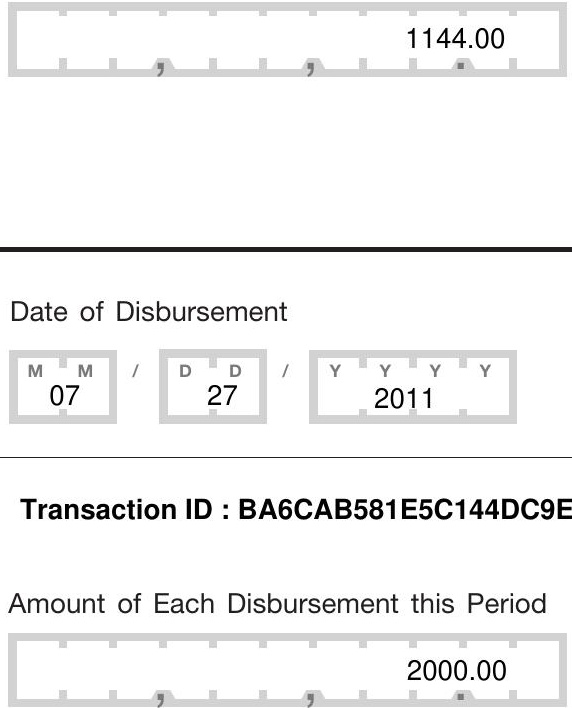

Total This Period (last page this line number only)) 


\section{SCHEDULE B-P}

\section{ITEMIZED DISBURSEMENTS}

\section{Use separate schedule(s) \\ for each category of the}

Detailed Summary Page
FOR LINE NUMBER: (check only one)

\begin{tabular}{|c|c|c|c|}
\hline$\times{ }_{23}$ & 24 & 25 & 26 \\
\hline $27 b$ & $28 a$ & $28 \mathrm{~b}$ & $28 \mathrm{c}$ \\
\hline
\end{tabular}

Any information copied from such Reports and Statements may not be sold or used by any person for the purpose of soliciting contributions or for commercial purposes, other than using the name and address of any political committee to solicit contributions from such committee.

NAME OF COMMITTEE (In Full)

\section{Friends of Herman Cain}

Full Name (Last, First, Middle Initial)

A. Lisa Lockwood

Mailing Address 12746 Ford Trail South

Date of Disbursement

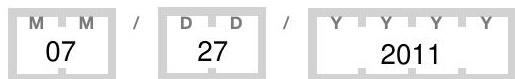

Transaction ID : B71F7D06E37204291848

\begin{tabular}{lcc}
\hline City & State & Zip Code \\
Indianola & IA & $50125-8931$
\end{tabular}

Purpose of Disbursement

Staff Salary

Candidate Name

\begin{tabular}{l|l|l}
\hline Office Sought: & House & Disbursement For: 2012
\end{tabular} Xrimary $\square$ General

State: Senate President District:

Full Name (Last, First, Middle Initial)

B. Raquel Rhada Hirsch

Mailing Address 6825 N 2nd Place

\begin{tabular}{lcc}
\hline City & State & Zip Code \\
Scottsdale & AZ & 85250
\end{tabular}

Purpose of Disbursement

Staff Salary

Candidate Name

Office Sought:

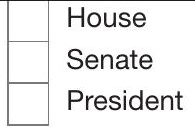

State:

District:

Full Name (Last, First, Middle Initial)

\section{c. Stacy DeJarnette}

Mailing Address 207 Robin Street

\begin{tabular}{lcc}
\hline City & State & Zip Code \\
White Hall & AR & $71602-5418$
\end{tabular}

Purpose of Disbursement Staff Salary

Candidate Name

Disbursement For: 2012

Primary
Other (specify)
Date of Disbursement

\begin{tabular}{|c|c|c|c|c|}
\hline $07^{\mathrm{M}}$ & & ${ }^{\mathrm{D}} 27^{\mathrm{D}}$ & 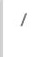 & $\begin{array}{llll}Y & Y & Y & Y \\
& 2011^{\prime}\end{array}$ \\
\hline
\end{tabular}

Transaction ID : B24B61F62390D4815B4A

Amount of Each Disbursement this Period

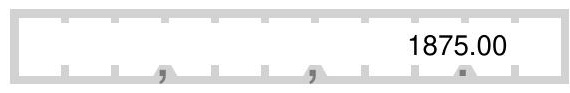

Date of Disbursement

\begin{tabular}{|c|c|c|c|c|c|}
\hline M M / & D & Y & $Y$ & $Y$ & $Y$ \\
07 & & 27 & & 2011 & \\
\hline
\end{tabular}

Transaction ID : B4F5A6DDF79F6418E85B

Amount of Each Disbursement this Period

3125.00

Office Sought:

\begin{tabular}{|l|l|}
\hline & House \\
& Senate \\
& President \\
District:
\end{tabular}

Disbursement For: 2012

X $\begin{aligned} & \text { Primary } \\ & \text { Other (specify) }\end{aligned}$

State:

District:

Subtotal Of Receipts This Page (optional).

Total This Period (last page this line number only))

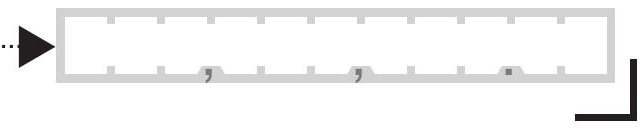




\section{SCHEDULE B-P}

\section{ITEMIZED DISBURSEMENTS}

\section{Use separate schedule(s)}

for each category of the

Detailed Summary Page
FOR LINE NUMBER: (check only one)

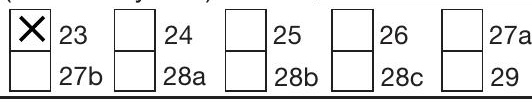

Any information copied from such Reports and Statements may not be sold or used by any person for the purpose of soliciting contributions or for commercial purposes, other than using the name and address of any political committee to solicit contributions from such committee.

NAME OF COMMITTEE (In Full)

\section{Friends of Herman Cain}

Full Name (Last, First, Middle Initial)

A. Ellen Carmichael

Mailing Address 1007 Oak Hills Parkway

Date of Disbursement

\begin{tabular}{lcc}
\hline City & State & Zip Code \\
Baton Rouge & LA & $70810-4705$
\end{tabular}

Purpose of Disbursement

Staff Salary

Candidate Name

\begin{tabular}{l|l|l|l}
\hline Office Sought: & House & Disbursement For: 2012
\end{tabular} Xrimary $\square$ General

State:

\section{Senate}

President

District:

Full Name (Last, First, Middle Initial)

B. Linda Hansen

Mailing Address PO Box 371312

\begin{tabular}{lcc}
\hline City & State & Zip Code \\
Milwaukee & WI & $53237-2412$
\end{tabular}

Purpose of Disbursement

Staff Salary

Candidate Name

Office Sought:

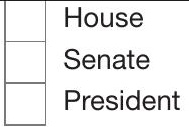

Disbursement For: 2012

Xrimary $\square$ General

State:

District:

Full Name (Last, First, Middle Initial)

c. Elicia Huffaker

Mailing Address 7317 Alta Drive

\begin{tabular}{lcc}
\hline City & State & Zip Code \\
Las Vegas & NV & $89145-5238$
\end{tabular}

Purpose of Disbursement

Staff Salary

Candidate Name

Office Sought: $\quad$ House

$\begin{aligned} & \text { House } \\ & \text { Senate } \\ & \text { President }\end{aligned}$
District:

State:
Date of Disbursement

\begin{tabular}{|c|c|c|c|c|}
\hline${ }^{\mathrm{M}} 7^{\mathrm{M}}$ & & ${ }^{\mathrm{D}} 27^{\mathrm{D}}$ & 1 & $\begin{array}{lll}Y & Y & Y \\
& 2011 & Y\end{array}$ \\
\hline
\end{tabular}

Transaction ID : B48E69FE85CBC4DF59CF

Amount of Each Disbursement this Period

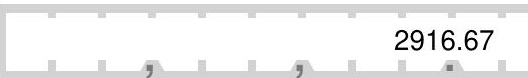

Date of Disbursement

\begin{tabular}{|c|c|c|c|c|c|}
\hline M M / & D & Y & Y & Y & Y \\
07 & & 27 & & 2011 & \\
\hline
\end{tabular}

Transaction ID : B6CC3E1CB8B734B57B36

Amount of Each Disbursement this Period

1875.00

Subtotal Of Receipts This Page (optional).

Total This Period (last page this line number only))

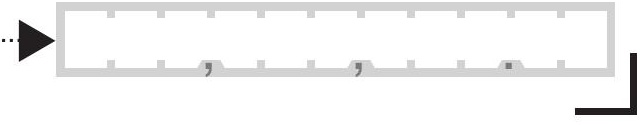




\section{SCHEDULE B-P}

\section{ITEMIZED DISBURSEMENTS}

\section{Use separate schedule(s)}

for each category of the

Detailed Summary Page
FOR LINE NUMBER: (check only one)

\begin{tabular}{|c|c|c|c|}
\hline$\times{ }_{23}$ & 24 & 25 & 26 \\
\hline $27 b$ & $28 a$ & $28 \mathrm{~b}$ & $28 \mathrm{c}$ \\
\hline
\end{tabular}

Any information copied from such Reports and Statements may not be sold or used by any person for the purpose of soliciting contributions or for commercial purposes, other than using the name and address of any political committee to solicit contributions from such committee.

NAME OF COMMITTEE (In Full)

\section{Friends of Herman Cain}

Full Name (Last, First, Middle Initial)

A. Karis McKinney

Mailing Address 5017 N. 50th Street

Date of Disbursement

\begin{tabular}{lcc}
\hline City & State & Zip Code \\
Milwaukee & WI & $53218-4326$
\end{tabular}

Purpose of Disbursement

Staff Salary

Candidate Name

\begin{tabular}{l|l|l|l}
\hline Office Sought: & House & Disbursement For: 2012
\end{tabular} Xrimary $\square$ General

State:

\section{Senate}

President

District:

Full Name (Last, First, Middle Initial)

B. Michael Johnson

Mailing Address 8225 W. Center St. Apt. 3

\begin{tabular}{lcc}
\hline City & State & Zip Code \\
Milwaukee & WI & $53222-4861$
\end{tabular}

Purpose of Disbursement

Staff Salary

Candidate Name

Office Sought:

House
Senate
President

Disbursement For: 2012

Xrimary $\square$ General

State:

District:

Full Name (Last, First, Middle Initial)

c. Ashley Frasca

Mailing Address 601 Springharbor Drive

\begin{tabular}{lcc}
\hline City & State & Zip Code \\
Woodstock & GA & $30188-6044$
\end{tabular}

Purpose of Disbursement

Staff Salary

Candidate Name

Office Sought:

State:
Date of Disbursement

\begin{tabular}{|c|c|c|c|c|}
\hline $07^{\mathrm{M}}$ & & $27^{\mathrm{D}}$ & & $\begin{array}{llll} & Y & Y & Y \\
& 2011 & Y\end{array}$ \\
\hline
\end{tabular}

Transaction ID : BD037185AB3654CCA938

Amount of Each Disbursement this Period

2000.00
Date of Disbursement

\begin{tabular}{|c|c|c|c|c|c|}
\hline M M / & D & Y & Y & Y & Y \\
07 & & 27 & & 2011 & \\
\hline
\end{tabular}

Transaction ID : B0B0196D3E37E4B57BE1

Amount of Each Disbursement this Period

1666.67

Subtotal Of Receipts This Page (optional).

Total This Period (last page this line number only))

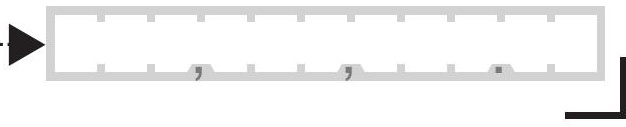




\section{SCHEDULE B-P}

\section{ITEMIZED DISBURSEMENTS}

\section{Use separate schedule(s) \\ for each category of the}

Detailed Summary Page
FOR LINE NUMBER: (check only one)

\begin{tabular}{|c|c|c|c|}
\hline$\times{ }_{23}$ & 24 & 25 & 26 \\
\hline $27 b$ & $28 a$ & $28 \mathrm{~b}$ & $28 \mathrm{c}$ \\
\hline
\end{tabular}

Any information copied from such Reports and Statements may not be sold or used by any person for the purpose of soliciting contributions or for commercial purposes, other than using the name and address of any political committee to solicit contributions from such committee.

NAME OF COMMITTEE (In Full)

\section{Friends of Herman Cain}

Full Name (Last, First, Middle Initial)

A. Steven Hensler

Mailing Address 401 Woodview Drive

\begin{tabular}{lll}
\hline City & State & Zip Code \\
Sun Prairie & WI & $53590-2353$
\end{tabular}

Purpose of Disbursement

Staff Salary

Candidate Name

Office Sought:

\begin{tabular}{l|l} 
House \\
Senate \\
President \\
District:
\end{tabular}

Disbursement For: 2012 X Primary $\square$ General
Date of Disbursement

\begin{tabular}{|c|c|c|c|c|c|}
\hline M M / & D D \\
07 & 27 & 2011 \\
\hline
\end{tabular}

Transaction ID : B6A9EA2C626CD4972ADB

Amount of Each Disbursement this Period 3000.00

Date of Disbursement

\begin{tabular}{|c|c|c|c|c|}
\hline${ }^{\mathrm{M}} 7^{\mathrm{M}}$ & & ${ }^{\mathrm{D}} 27^{\mathrm{D}}$ & 1 & $\begin{array}{lll}Y & Y & Y \\
& 2011 & Y\end{array}$ \\
\hline
\end{tabular}

Transaction ID : B99E956A343AE49FDB7E

Amount of Each Disbursement this Period

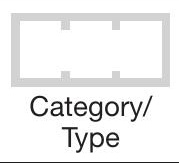

Office Sought:

\begin{tabular}{l|l} 
House \\
Senate \\
President
\end{tabular}

Disbursement For: 2012

Xrimary $\square$ General

State:

District:

$\begin{array}{cc}\text { State } & \text { Zip Code } \\ \text { PA } & 18505\end{array}$

Purpose of Disbursement

Staff Salary

Full Name (Last, First, Middle Initial)

c. Francis Boustany, III

Mailing Address 126 Westfield Drive

\begin{tabular}{lcc}
\hline City & State & Zip Code \\
Lafayette & LA & $70503-5484$
\end{tabular}

Purpose of Disbursement

Staff Salary

Candidate Name

Office Sought: $\quad$ House

\begin{tabular}{|l|l|} 
& House \\
& Senate \\
& President
\end{tabular}

Disbursement For: 2012

Х $\begin{aligned} & \text { Primary } \\ & \text { Other (specify) }\end{aligned}$
Date of Disbursement

\begin{tabular}{|c|c|c|c|c|c|}
\hline M M / & D & Y & Y & Y & Y \\
07 & & 27 & & 2011 & \\
\hline
\end{tabular}

\section{Transaction ID : B4ED653FE59D945F1BDF}

Amount of Each Disbursement this Period

1500.00
State:

District:
Subtotal Of Receipts This Page (optional)

14500.00

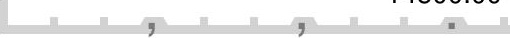

Total This Period (last page this line number only))

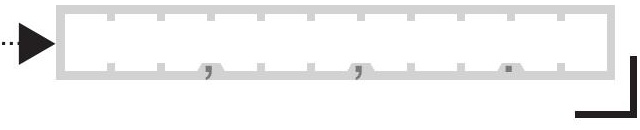

FEC Schedule B-P (Form 3P) (Rev. 03/2011) 


\section{SCHEDULE B-P}

\section{ITEMIZED DISBURSEMENTS}

\section{Use separate schedule(s) \\ for each category of the}

Detailed Summary Page
FOR LINE NUMBER: (check only one)

\begin{tabular}{|c|c|c|c|}
\hline$\times{ }_{23}$ & 24 & 25 & 26 \\
\hline $27 b$ & $28 a$ & $28 \mathrm{~b}$ & $28 \mathrm{c}$ \\
\hline
\end{tabular}

Any information copied from such Reports and Statements may not be sold or used by any person for the purpose of soliciting contributions or for commercial purposes, other than using the name and address of any political committee to solicit contributions from such committee.

NAME OF COMMITTEE (In Full)

\section{Friends of Herman Cain}

Full Name (Last, First, Middle Initial)

A. Sandra Poehler

Mailing Address 57 Presidential Drive

Apartment 5

Date of Disbursement

\begin{tabular}{lll}
\multicolumn{3}{c}{ Apartment 5} \\
City & State & Zip Code \\
Quincy & MA & $02169-8838$
\end{tabular}

Purpose of Disbursement

Staff Salary

Candidate Name

Office Sought: $\quad$ House

\section{Senate}

President

State:

District:

Full Name (Last, First, Middle Initial)

B. Zachary Dalluge

Mailing Address 506 3rd Street

\begin{tabular}{lcc}
\hline City & State & Zip Code \\
Grafton & IA & $50440-7570$
\end{tabular}

Purpose of Disbursement

Staff Salary

Candidate Name

Office Sought:

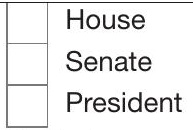

Disbursement For: 2012

Xrimary $\square$ General

State:

District:

Disbursement For: 2012

X Primary $\square$ General

Full Name (Last, First, Middle Initial)

c. Nathan Naidu

Mailing Address 3601 canton rd \#131

\begin{tabular}{lcc}
\hline City & State & Zip Code \\
Marietta & GA & $30066-2892$
\end{tabular}

Purpose of Disbursement

Staff Salary

Candidate Name

Office Sought: $\quad$ House

\begin{tabular}{|l|l|} 
& House \\
& Senate \\
& President
\end{tabular}

Disbursement For: 2012

Х $\begin{aligned} & \text { Primary } \\ & \text { Other (specify) }\end{aligned}$

Date of Disbursement

\begin{tabular}{|c|c|c|c|c|}
\hline${ }^{M}{ }^{\mathrm{M}}$ & $/$ & $\mathrm{D}$ & $7^{\mathrm{D}}$ & $\mathrm{Y}^{\mathrm{Y}} \mathrm{Y}^{\mathrm{Y}}$ \\
\hline
\end{tabular}

Transaction ID : B76C5811890E34F90B70

Amount of Each Disbursement this Period
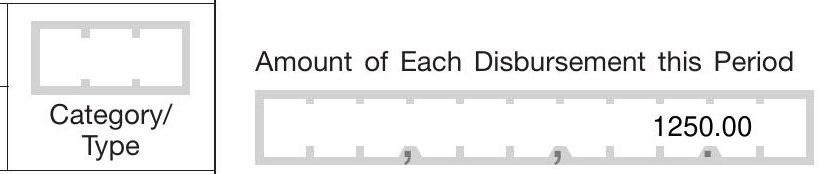

State:

District:

Subtotal Of Receipts This Page (optional).

Date of Disbursement

\begin{tabular}{|c|c|c|c|c|c|}
\hline M M & D & Y & Y & Y \\
07 & & 27 & & 2011 & \\
\hline
\end{tabular}

\section{Transaction ID : BFA09F6F592C34B8C8B5}

Amount of Each Disbursement this Period

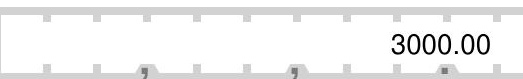

Total This Period (last page this line number only)) 


\section{SCHEDULE B-P}

\section{ITEMIZED DISBURSEMENTS}

Use separate schedule(s)

for each category of the

Detailed Summary Page
FOR LINE NUMBER: (check only one)

\begin{tabular}{|c|c|c|c|}
\hline $\mathrm{X} 23$ & 24 & 25 & 26 \\
\hline $27 \mathrm{~b}$ & $28 a$ & $28 b$ & $28 \mathrm{c}$ \\
\hline
\end{tabular}

Any information copied from such Reports and Statements may not be sold or used by any person for the purpose of soliciting contributions or for commercial purposes, other than using the name and address of any political committee to solicit contributions from such committee.

NAME OF COMMITTEE (In Full)

\section{Friends of Herman Cain}

Full Name (Last, First, Middle Initial)

A. Shelley Rogers

Mailing Address 4215 Shady Springs Dr.

Date of Disbursement

\begin{tabular}{|c|c|c|c|c|c|}
\hline$M$ & M & P & Y \\
07 & 28 & 2011 \\
\hline
\end{tabular}

Transaction ID : B26404F50949344628ED

\begin{tabular}{lcc}
\hline City & State & Zip Code \\
Seabrook & TX & $77586-5022$
\end{tabular}

Purpose of Disbursement

Fundraising Consulting

Candidate Name X Primary $\square$ General

State:

$$
\begin{aligned}
& \text { Senate } \\
& \text { President }
\end{aligned}
$$

District:

Full Name (Last, First, Middle Initial)

B. Facebook, Inc.

Mailing Address 1601 S. California Ave.

\begin{tabular}{lcc}
\hline City & State & Zip Code \\
Palo Alto & CA & 94304
\end{tabular}

Purpose of Disbursement

Advertising Expense

Candidate Name

Office Sought:

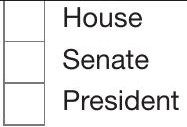

Disbursement For: 2012

Primary
Other (specify) General

State:

District:

Full Name (Last, First, Middle Initial)

\section{c. Avis Rent A Car}

Mailing Address 900 Old Country Garden Road

\begin{tabular}{lcc}
\hline City & State & Zip Code \\
Garden City & NY & 11530
\end{tabular}

Purpose of Disbursement

Travel Expense

Candidate Name

Office Sought:

\begin{tabular}{|l|l|} 
& House \\
& Senate \\
& President \\
\hline & District:
\end{tabular}

Disbursement For: 2012

X $\begin{aligned} & \text { Primary } \\ & \text { Other (specify) }\end{aligned}$

\begin{tabular}{|c|c|c|c|c|}
\hline $07^{\mathrm{M}}$ & & $28^{D}$ & & $\begin{array}{llll} & Y & Y & Y \\
& 2011 & Y\end{array}$ \\
\hline
\end{tabular}

Date of Disbursement

Transaction ID : BB7FAD4B6C290477F885

Amount of Each Disbursement this Period
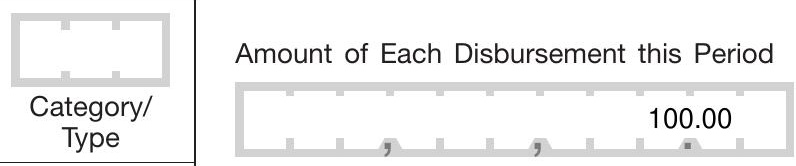

Date of Disbursement

\begin{tabular}{|c|c|c|c|c|c|}
\hline M M & M & D & Y & Y & Y \\
07 & & 28 & & 2011 & \\
\hline
\end{tabular}

Transaction ID : B7CFAC2491BE34064B39

Amount of Each Disbursement this Period

25.30
State:

District:

Subtotal Of Receipts This Page (optional)

Total This Period (last page this line number only))

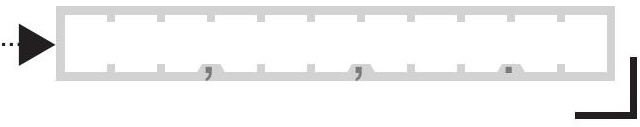




\section{SCHEDULE B-P}

\section{ITEMIZED DISBURSEMENTS}

\section{Use separate schedule(s) \\ for each category of the}

Detailed Summary Page
FOR LINE NUMBER: (check only one)

\begin{tabular}{|c|c|c|c|}
\hline$X_{23}$ & 24 & 25 & 26 \\
\hline $27 \mathrm{~b}$ & $28 a$ & $28 b$ & $28 \mathrm{c}$ \\
\hline
\end{tabular}

Any information copied from such Reports and Statements may not be sold or used by any person for the purpose of soliciting contributions or for commercial purposes, other than using the name and address of any political committee to solicit contributions from such committee.

NAME OF COMMITTEE (In Full)

\section{Friends of Herman Cain}

Full Name (Last, First, Middle Initial)

A. US Postal Service

Mailing Address 110 Walter Way

Date of Disbursement

\begin{tabular}{lcc}
\hline City & State & Zip Code \\
Stockbridge & GA & 30281 \\
\hline Purpose of Disbursement & &
\end{tabular}

Purpose of Disbursement

Postage

Candidate Name

\begin{tabular}{|c|c|c|c|}
\hline \multirow[t]{3}{*}{ Office Sought: } & House & \multicolumn{2}{|l|}{ Disbursement For: 2012} \\
\hline & Senate & Primary & \\
\hline & President & Other (specify) & $\nabla$ \\
\hline
\end{tabular}

Full Name (Last, First, Middle Initial)

\section{B. RMA Chaffeured Transportation}

\begin{tabular}{|c|c|c|c|c|}
\hline Mailing Address & \multicolumn{4}{|c|}{6010 Executive Boulevard } \\
\hline \multicolumn{2}{|l|}{ City } & \multicolumn{3}{|c|}{ Zip Code } \\
\hline \multicolumn{2}{|l|}{ Rockville } & \multicolumn{3}{|c|}{20852} \\
\hline \multicolumn{4}{|c|}{$\begin{array}{l}\text { Purpose of Disbursement } \\
\text { Travel Expense }\end{array}$} & \\
\hline \multicolumn{4}{|l|}{ Candidate Name } & $\begin{array}{l}\text { Category/ } \\
\text { Type }\end{array}$ \\
\hline \multirow[t]{3}{*}{ Office Sought: } & House & \multirow{3}{*}{\multicolumn{3}{|c|}{ Disbursement For: 2012}} \\
\hline & Senate & & & \\
\hline & President & & & \\
\hline State: & \multicolumn{4}{|c|}{ District: } \\
\hline
\end{tabular}

Date of Disbursement

\begin{tabular}{|c|c|c|c|c|}
\hline${ }^{\mathrm{M}}{ }^{\mathrm{M}}$ & I & $28^{D}$ & 1 & $\begin{array}{llll} & Y & Y & Y \\
& 2011 & \end{array}$ \\
\hline
\end{tabular}

Transaction ID : BA266F6D9263F4777BAF

Full Name (Last, First, Middle Initial)

\section{c. Delta Airlines}

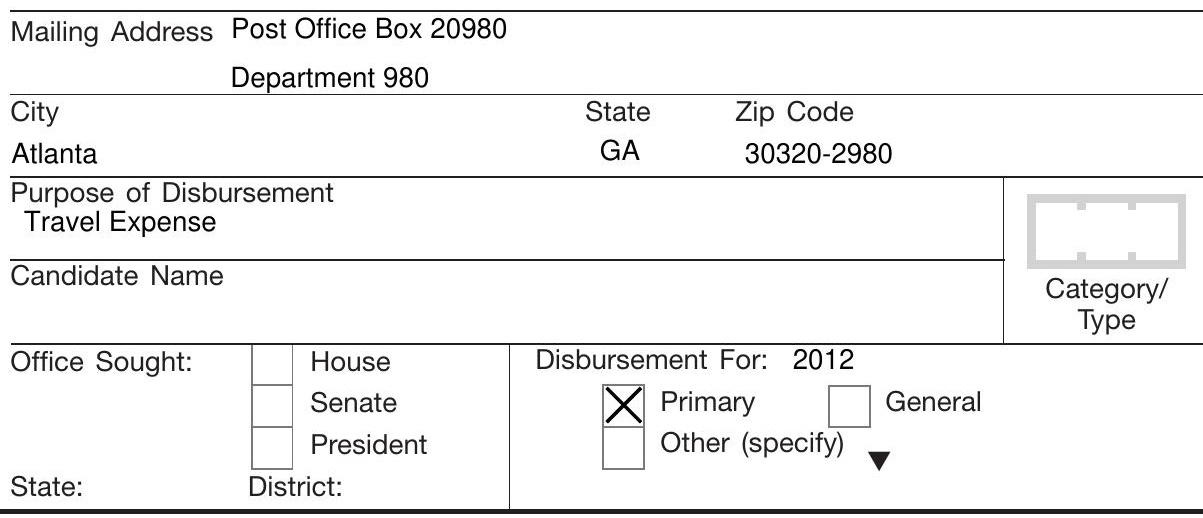

Subtotal Of Receipts This Page (optional).

Date of Disbursement

\begin{tabular}{|c|c|c|c|c|c|c|}
\hline M M & I & D & Y & Y & Y \\
07 & & 29 & & 2011 & \\
\hline
\end{tabular}

Transaction ID : B8B05B7192CCD4C29964

Amount of Each Disbursement this Period

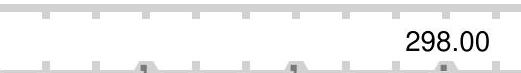

298.00

Total This Period (last page this line number only)) 


\section{SCHEDULE B-P}

\section{ITEMIZED DISBURSEMENTS}

\section{Use separate schedule(s) \\ for each category of the}

Detailed Summary Page
FOR LINE NUMBER: (check only one)

\begin{tabular}{|c|c|c|c|}
\hline$\times{ }_{23}$ & 24 & 25 & 26 \\
\hline $27 b$ & $28 a$ & $28 \mathrm{~b}$ & $28 \mathrm{c}$ \\
\hline
\end{tabular}

Any information copied from such Reports and Statements may not be sold or used by any person for the purpose of soliciting contributions or for commercial purposes, other than using the name and address of any political committee to solicit contributions from such committee.

NAME OF COMMITTEE (In Full)

\section{Friends of Herman Cain}

Full Name (Last, First, Middle Initial)

A. Office Depot Corporate

Mailing Address 2500 Mill Center Parkway

Date of Disbursement

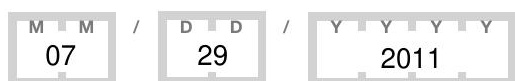

Transaction ID : BFABA2F1CCF2F406981D

\begin{tabular}{lll}
\hline City & State & Zip Code \\
Buford & GA & 30518
\end{tabular}

Purpose of Disbursement

Office Supplies

Candidate Name Xrimary $\square$ General

State: Senate President District:

Full Name (Last, First, Middle Initial)

B. Mayfair Rent A Car Inc.

Mailing Address 1750 N. Mayfair Road

\begin{tabular}{lcc}
\hline City & State & Zip Code \\
Milwaukee & WI & 53226
\end{tabular}

Purpose of Disbursement

Travel Expense

Candidate Name

Office Sought:

House
Senate
President

State:

District:

Full Name (Last, First, Middle Initial)

\section{c. SunTrust Bank}

Mailing Address 980 Eagles Landing Parkway

\begin{tabular}{lcc}
\hline City & State & Zip Code \\
Stockbridge & GA & 30281
\end{tabular}

Purpose of Disbursement

Bank Fees

Candidate Name

Office Sought: $\quad$ House

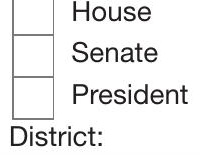

Disbursement For: 2012

Primary $\square$ General
Other (specify)
Date of Disbursement

\begin{tabular}{|c|c|c|c|c|}
\hline${ }^{M}{ }^{M}$ & D & $7^{\mathrm{D}}$ & $\mathrm{Y}^{\mathrm{Y}} \mathrm{Y}$ \\
\hline
\end{tabular}

Transaction ID : B6A0D8276A39646DD85B

Amount of Each Disbursement this Period

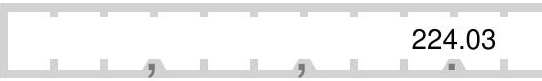

Date of Disbursement

\begin{tabular}{|c|c|c|c|c|c|}
\hline M M & M & D & Y & Y & Y \\
07 & & 29 & & 2011 & \\
\hline
\end{tabular}

Transaction ID : BD1942A861FD14161B34

Amount of Each Disbursement this Period

280.70
District:

Disbursement For: 2012

X $\begin{aligned} & \text { Primary } \square \text { General } \\ & \text { Other (specify) }\end{aligned}$

Subtotal Of Receipts This Page (optional)

Total This Period (last page this line number only))

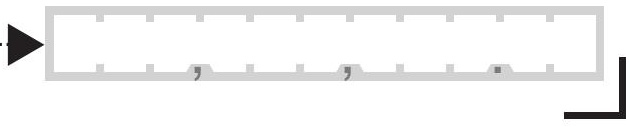




\section{SCHEDULE B-P}

\section{ITEMIZED DISBURSEMENTS}

Use separate schedule(s)

for each category of the

Detailed Summary Page
FOR LINE NUMBER: (check only one)

\begin{tabular}{|c|c|c|c|}
\hline $\mathrm{X} 23$ & 24 & 25 & 26 \\
\hline $27 \mathrm{~b}$ & $28 a$ & $28 b$ & $28 \mathrm{c}$ \\
\hline
\end{tabular}

Any information copied from such Reports and Statements may not be sold or used by any person for the purpose of soliciting contributions or for commercial purposes, other than using the name and address of any political committee to solicit contributions from such committee.

NAME OF COMMITTEE (In Full)

\section{Friends of Herman Cain}

Full Name (Last, First, Middle Initial)

A. SunTrust Bank

Mailing Address 980 Eagles Landing Parkway

Date of Disbursement

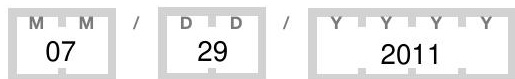

Transaction ID : B6F77525CEC28437A968

$\begin{array}{lcc}\text { City } & \text { State } & \text { Zip Code } \\ \text { Stockbridge } & \text { GA } & 30281\end{array}$

Purpose of Disbursement

Bank Fees

Candidate Name X Primary $\square$ General

State:

Senate
President
District:

Full Name (Last, First, Middle Initial)

\section{B. SunTrust Bank}

Mailing Address 980 Eagles Landing Parkway

\begin{tabular}{lcc}
\hline City & State & Zip Code \\
Stockbridge & GA & 30281
\end{tabular}

Purpose of Disbursement

Bank Fees

Candidate Name

Office Sought:

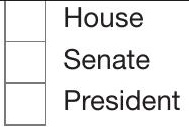

Disbursement For: 2012

Xrimary $\square$ General

State:

District:

Full Name (Last, First, Middle Initial)

c. Facebook, Inc.

Mailing Address 1601 S. California Ave.

\begin{tabular}{lcc}
\hline City & State & Zip Code \\
Palo Alto & CA & 94304
\end{tabular}

Purpose of Disbursement

Advertising Expense

Candidate Name

Office Sought: $\quad$ House

\begin{tabular}{|l|l|} 
& House \\
Senate \\
President
\end{tabular}

Disbursement For: 2012

Х $\begin{aligned} & \text { Primary } \\ & \text { Other (specify) }\end{aligned}$

State:
Date of Disbursement

\begin{tabular}{|c|c|c|c|c|}
\hline $07^{\mathrm{M}}$ & I & $29^{D}$ & 1 & $\begin{array}{llll} & Y & Y & Y \\
& 2011 & \end{array}$ \\
\hline
\end{tabular}

Transaction ID : B41D9F5FE44504387B06

Amount of Each Disbursement this Period
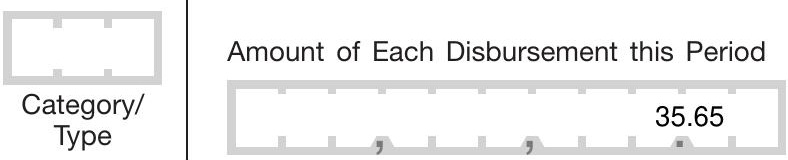

Date of Disbursement

\begin{tabular}{|c|c|c|c|c|c|}
\hline M M & M & D & Y & Y & Y \\
07 & & 29 & & 2011 & \\
\hline
\end{tabular}

Transaction ID : B496B450B69D142A4979

Amount of Each Disbursement this Period

100.00

Subtotal Of Receipts This Page (optional).

Total This Period (last page this line number only))

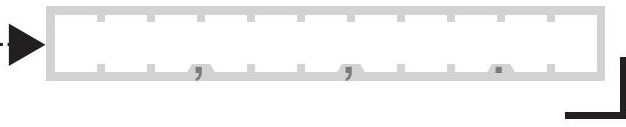




\section{SCHEDULE B-P}

\section{ITEMIZED DISBURSEMENTS}

\section{Use separate schedule(s) \\ for each category of the}

Detailed Summary Page
FOR LINE NUMBER: (check only one)

\begin{tabular}{|c|c|c|c|}
\hline$\times{ }_{23}$ & 24 & 25 & 26 \\
\hline $27 b$ & $28 a$ & $28 \mathrm{~b}$ & $28 \mathrm{c}$ \\
\hline
\end{tabular}

Any information copied from such Reports and Statements may not be sold or used by any person for the purpose of soliciting contributions or for commercial purposes, other than using the name and address of any political committee to solicit contributions from such committee.

NAME OF COMMITTEE (In Full)

\section{Friends of Herman Cain}

Full Name (Last, First, Middle Initial)

A. Inkhead Inc.

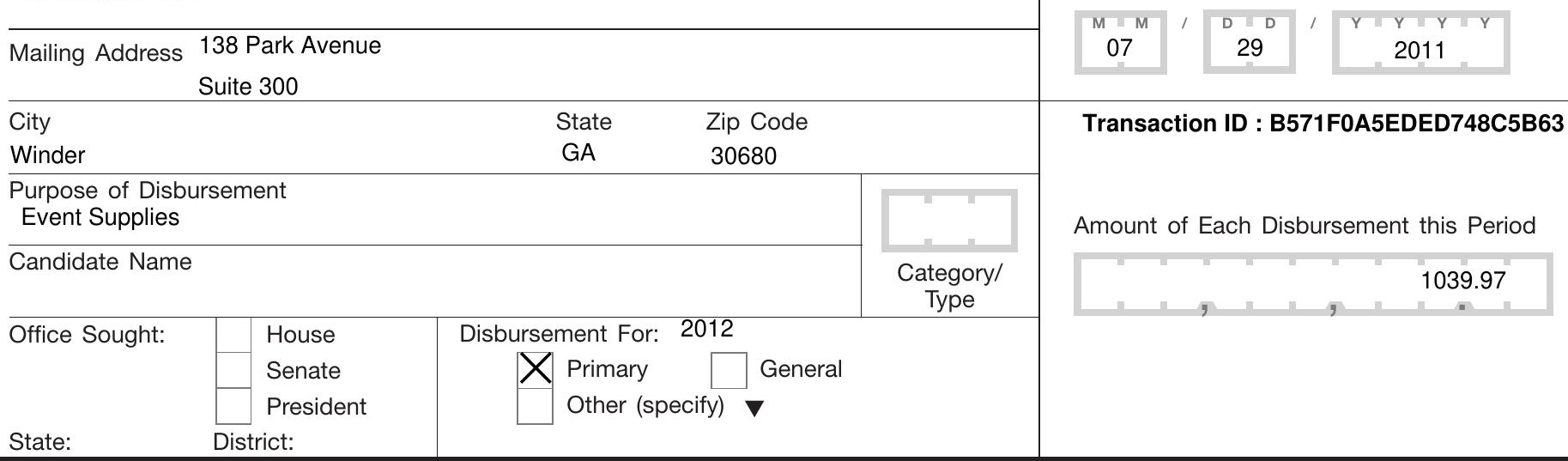

Full Name (Last, First, Middle Initial)

B. Inkhead Inc.

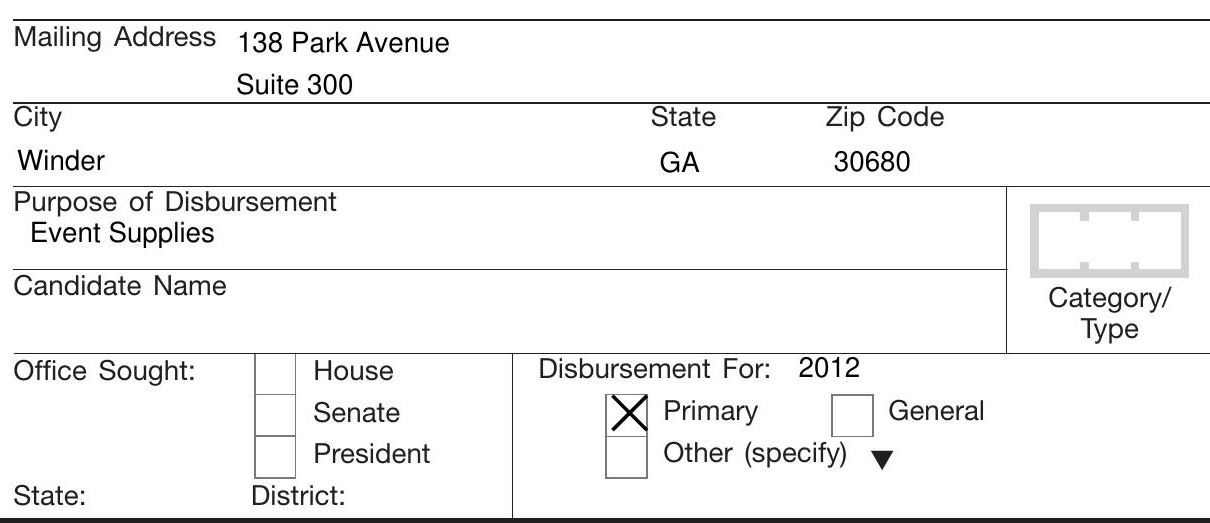

Date of Disbursement

\begin{tabular}{|c|c|c|c|c|}
\hline $07^{M}$ & & $30^{\mathrm{D}}$ & 1 & $\begin{array}{llll} & Y & Y & Y \\
& 2011 & Y\end{array}$ \\
\hline
\end{tabular}

\section{Transaction ID : B64087888CE0749AFA04}

Amount of Each Disbursement this Period

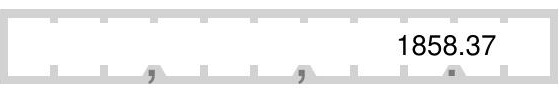

Full Name (Last, First, Middle Initial)

c. Tina Goff

Mailing Address 7640 NW 54th Avenue

\begin{tabular}{lcc}
\hline City & State & Zip Code \\
Johnston & IA & $50131-1783$
\end{tabular}

Purpose of Disbursement

Mileage/Meeting Expense/Phone

Candidate Name

Office Sought: $\quad$ House

\begin{tabular}{l|l} 
& House \\
& Senate \\
& President \\
\hline & District:
\end{tabular}

State:

District:
Disbursement For: 2012

X $\begin{aligned} & \text { Primary } \\ & \text { Other (specify) }\end{aligned}$
Date of Disbursement

\begin{tabular}{|c|c|c|c|c|}
\hline $07^{\mathrm{M}}$ & 1 & $30^{\mathrm{D}}$ & I & $\begin{array}{cccc}Y & Y & Y & Y \\
& 2011 & \end{array}$ \\
\hline
\end{tabular}

Transaction ID : BA431A4DF43C1464290C

Amount of Each Disbursement this Period

2231.06

Subtotal Of Receipts This Page (optional).

Total This Period (last page this line number only))

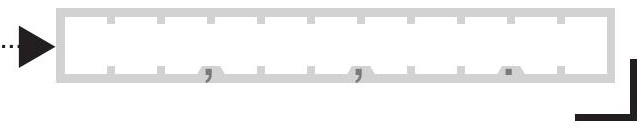




\section{SCHEDULE B-P}

\section{ITEMIZED DISBURSEMENTS}

\section{Use separate schedule(s) \\ for each category of the}

Detailed Summary Page
FOR LINE NUMBER: (check only one)

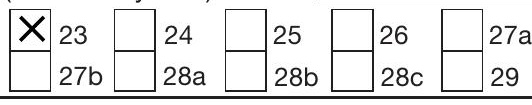

Any information copied from such Reports and Statements may not be sold or used by any person for the purpose of soliciting contributions or for commercial purposes, other than using the name and address of any political committee to solicit contributions from such committee.

NAME OF COMMITTEE (In Full)

\section{Friends of Herman Cain}

Full Name (Last, First, Middle Initial)

A. Christopher Kenworthy

Mailing Address PO Box 2158

City

Stockbridge

Purpose of Disbursement

Staff Salary

Candidate Name

Office Sought:

House
Senate
President
istrict:

Disbursement For: 2012

X Primary $\square$ General

GA 30281-8909

\begin{tabular}{c|c} 
& \\
Category/ \\
Type
\end{tabular}

\section{B. Stephen Morrison}

Mailing Address PO Box 2158

\begin{tabular}{lcc}
\hline City & State & Zip Code \\
Stockbridge & GA & $30281-8909$
\end{tabular}

Purpose of Disbursement

Staff Salary

Candidate Name

Office Sought:

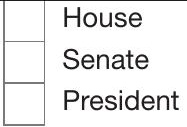

State:

District:

Full Name (Last, First, Middle Initial)

c. Facebook, Inc.

Mailing Address 1601 S. California Ave.

\begin{tabular}{lcc}
\hline City & State & Zip Code \\
Palo Alto & CA & 94304
\end{tabular}

Purpose of Disbursement

Advertising Expense

Candidate Name

Office Sought: $\quad$ House

\begin{tabular}{|l|l} 
& House \\
Senate \\
President
\end{tabular}

Disbursement For: 2012

Х $\begin{aligned} & \text { Primary } \\ & \text { Other (specify) }\end{aligned}$ Type

District:
Date of Disbursement

\begin{tabular}{|c|c|c|c|c|}
\hline $08^{M}$ & & 01 & & 2011 \\
\hline
\end{tabular}

Transaction ID : BBE3CEC5A1E0D4A96B3D

Amount of Each Disbursement this Period 456.50

Date of Disbursement

\begin{tabular}{|c|c|c|c|c|}
\hline${ }^{M}{ }^{\mathrm{M}} / 8^{\mathrm{D}}$ & ${ }^{\mathrm{D}} / 1^{\mathrm{Y}}$ & $\mathrm{Y}^{\mathrm{Y}}$ & $\mathrm{Y}$ \\
\hline
\end{tabular}

Transaction ID : B89217F09A8344026868

Amount of Each Disbursement this Period

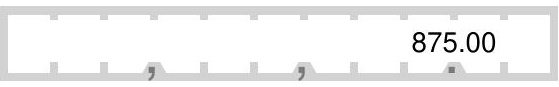

Date of Disbursement

\begin{tabular}{|c|c|c|c|c|c|}
\hline M M / & D & Y & Y & Y & Y \\
08 & & 01 & & 2011 & \\
\hline
\end{tabular}

Transaction ID : B2C2A9428239E402EAD6

Amount of Each Disbursement this Period

100.00

Subtotal Of Receipts This Page (optional).

Total This Period (last page this line number only))

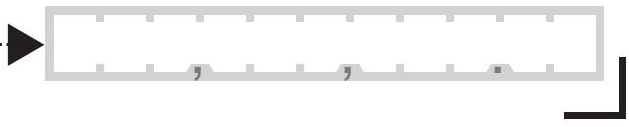




\section{SCHEDULE B-P}

\section{ITEMIZED DISBURSEMENTS}

\section{Use separate schedule(s) \\ for each category of the}

Detailed Summary Page
FOR LINE NUMBER: (check only one)

\begin{tabular}{|c|c|c|c|}
\hline$X_{23}$ & 24 & 25 & 26 \\
\hline $27 \mathrm{~b}$ & $28 a$ & $28 b$ & $28 \mathrm{c}$ \\
\hline
\end{tabular}

Any information copied from such Reports and Statements may not be sold or used by any person for the purpose of soliciting contributions or for commercial purposes, other than using the name and address of any political committee to solicit contributions from such committee.

NAME OF COMMITTEE (In Full)

\section{Friends of Herman Cain}

Full Name (Last, First, Middle Initial)

A. Tri-Net Payroll Services

Mailing Address 1100 San Leandro Boulevard

Suite

\begin{tabular}{lll}
\hline City & State & Zip Code \\
San Leandro & CA & 94577
\end{tabular}

Purpose of Disbursement

Payroll Withholding

Candidate Name

Office Sought:

House
Senate
President
District:

Disbursement For: 2012

X Primary $\square$ General

State:

First, Middle Initial)

\section{B. Tri-Net Payroll Services}

\begin{tabular}{ll}
\hline Mailing Address & $\begin{array}{l}1100 \text { San Leandro Boulevard } \\
\text { Suite }\end{array}$ \\
\hline City
\end{tabular}

San Leandro CA Zip Code

Purpose of Disbursement

Payroll Service Fee

Candidate Name

Office Sought:

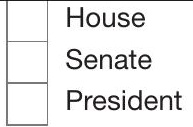

State:

District:

Full Name (Last, First, Middle Initial)

\section{c. Office Depot Corporate}

\begin{tabular}{|c|c|c|c|c|c|}
\hline \multicolumn{6}{|c|}{ Mailing Address 2500 Mill Center Parkway } \\
\hline \multicolumn{2}{|l|}{ City } & State & Zip Code & & \\
\hline \multicolumn{2}{|l|}{ Buford } & GA & 30518 & & \\
\hline \multicolumn{5}{|c|}{$\begin{array}{l}\text { Purpose of Disbursement } \\
\text { Office Supplies }\end{array}$} & \\
\hline \multicolumn{5}{|c|}{ Candidate Name } & $\begin{array}{l}\text { Category/ } \\
\text { Type }\end{array}$ \\
\hline \multirow[t]{3}{*}{ Office Sought: } & House & \multicolumn{4}{|c|}{ Disbursement For: 2012} \\
\hline & Senate & \multirow{3}{*}{\multicolumn{2}{|c|}{$\begin{array}{l}\text { Primary } \\
\text { Other (specify) }\end{array}$}} & \multirow{2}{*}{\multicolumn{2}{|c|}{ General }} \\
\hline & President & & & & \\
\hline State: & District: & & & & \\
\hline
\end{tabular}

Subtotal Of Receipts This Page (optional).

Total This Period (last page this line number only))
Date of Disbursement

\begin{tabular}{|c|c|c|c|c|c|}
\hline M M / & Y \\
08 & 01 & 2011 \\
\hline
\end{tabular}

Transaction ID : B47A24EA83D484614B8C

Amount of Each Disbursement this Period 209.02

Date of Disbursement

\begin{tabular}{|c|c|c|c|c|}
\hline $08^{M}$ & 1 & ${ }^{\mathrm{D}}{ }^{\mathrm{D}}$ & 1 & $\begin{array}{llll} & Y & Y & Y \\
& & Y & Y\end{array}$ \\
\hline
\end{tabular}

Transaction ID : B49B03E87329146DCB3E

Amount of Each Disbursement this Period

Date of Disbursement

\begin{tabular}{|c|c|c|c|c|c|c|}
\hline M & M & D & Y & Y & Y & Y \\
\hline & & 01 & & 2011 & \\
\hline
\end{tabular}

Transaction ID : BCE097C16D3154BB4A4D

Amount of Each Disbursement this Period

57.39

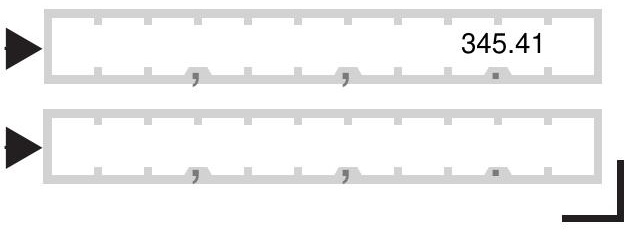

FEC Schedule B-P (Form 3P) (Rev. 03/2011) 


\section{SCHEDULE B-P}

\section{ITEMIZED DISBURSEMENTS}

\section{Use separate schedule(s) \\ for each category of the}

Detailed Summary Page
FOR LINE NUMBER: (check only one)

\begin{tabular}{|c|c|c|c|}
\hline$\times{ }_{23}$ & 24 & 25 & 26 \\
\hline $27 b$ & $28 a$ & $28 \mathrm{~b}$ & $28 \mathrm{c}$ \\
\hline
\end{tabular}

Any information copied from such Reports and Statements may not be sold or used by any person for the purpose of soliciting contributions or for commercial purposes, other than using the name and address of any political committee to solicit contributions from such committee.

NAME OF COMMITTEE (In Full)

\section{Friends of Herman Cain}

Full Name (Last, First, Middle Initial)

A. Delta Airlines

\begin{tabular}{c} 
Mailing Address $\begin{array}{c}\text { Post Office Box } 20980 \\
\text { Department } 980\end{array}$ \\
\hline
\end{tabular}

\begin{tabular}{lll}
\hline City & State & Zip Code \\
Atlanta & GA & $30320-2980$
\end{tabular}

Purpose of Disbursement

Travel Expense

Candidate Name

\begin{tabular}{l|l|c|}
\hline Office Sought: & $\begin{array}{l}\text { House } \\
\text { Senate } \\
\text { President }\end{array}$ & $\begin{array}{r}\text { Disbursement For: } 2012 \\
\text { X Primary } \\
\text { Other (specify) }\end{array}$
\end{tabular}

Full Name (Last, First, Middle Initial)

\section{B. US Airways}

Mailing Address 4000 E Sky Harbor Boulevard

\begin{tabular}{|c|c|c|c|c|}
\hline \multicolumn{2}{|l|}{ City } & \multicolumn{3}{|c|}{ Zip Code } \\
\hline \multicolumn{2}{|l|}{ Phoenix } & \multicolumn{3}{|c|}{85034} \\
\hline \multicolumn{4}{|c|}{$\begin{array}{l}\text { Purpose of Disbursement } \\
\text { Travel Expense }\end{array}$} & \\
\hline \multicolumn{4}{|c|}{ Candidate Name } & $\begin{array}{l}\text { Category/ } \\
\text { Type }\end{array}$ \\
\hline \multirow[t]{3}{*}{ Office Sought: } & House & \multirow{3}{*}{\multicolumn{3}{|c|}{$\begin{array}{l}\text { Disbursement For: } 2012 \\
\text { Xrimary } \\
\text { Other (specify) }\end{array}$}} \\
\hline & \multirow{2}{*}{$\begin{array}{l}\text { Senate } \\
\text { President }\end{array}$} & & & \\
\hline & & & & \\
\hline State: & rict: & & \multicolumn{2}{|l|}{$\nabla$} \\
\hline
\end{tabular}

Date of Disbursement

Full Name (Last, First, Middle Initial)

\section{c. United Airlines}

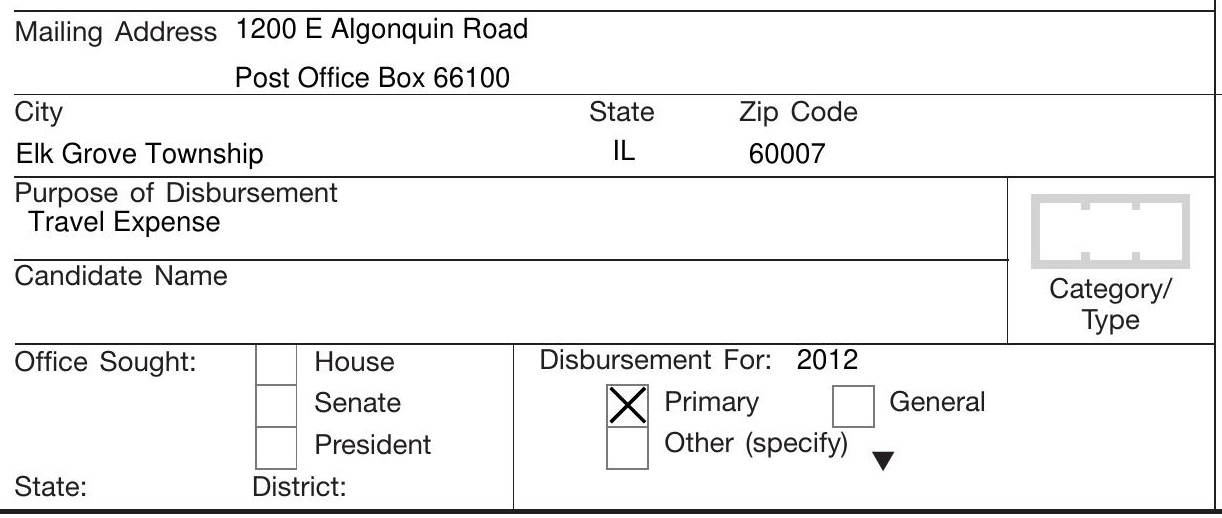

Subtotal Of Receipts This Page (optional).

Date of Disbursement

\begin{tabular}{|c|c|c|c|c|}
\hline $08^{M}$ & I & D 01 & I & $\begin{array}{cccc}Y & Y & Y & Y \\
& 2011 & \end{array}$ \\
\hline
\end{tabular}

Transaction ID : B10A453CE72134BC49F7

Amount of Each Disbursement this Period

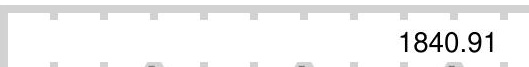

1840.91

Total This Period (last page this line number only)) 


\section{SCHEDULE B-P}

\section{ITEMIZED DISBURSEMENTS}

\section{Use separate schedule(s)}

for each category of the

Detailed Summary Page
FOR LINE NUMBER: (check only one)

\begin{tabular}{|c|c|c|c|}
\hline$\times{ }_{23}$ & 24 & 25 & 26 \\
\hline $27 b$ & $28 a$ & $28 \mathrm{~b}$ & $28 \mathrm{c}$ \\
\hline
\end{tabular}

Any information copied from such Reports and Statements may not be sold or used by any person for the purpose of soliciting contributions or for commercial purposes, other than using the name and address of any political committee to solicit contributions from such committee.

NAME OF COMMITTEE (In Full)

\section{Friends of Herman Cain}

Full Name (Last, First, Middle Initial)

\section{A. United States Patent \& Trademark Office}

Mailing Address Post Office Box 1451

Date of Disbursement

\begin{tabular}{lll}
\hline City & State & Zip Code \\
Alexandria & VA & 22313-1451
\end{tabular}

Purpose of Disbursement

Copyright Fees

Candidate Name

Office Sought:

\begin{tabular}{|l|l|l} 
& House \\
Senate \\
President
\end{tabular}

Disbursement For: 2012 X Primary $\square$ General

State: District:

Full Name (Last, First, Middle Initial)

\section{B. Gateway Billing}

\section{Mailing Address authorize.net \\ Post Office Box 8999}

San Francisco

Purpose of Disbursement

CC Transaction Fees

Candidate Name

Office Sought:

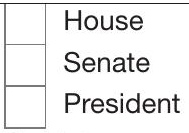

State:

District:

(1)

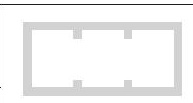

Category/ Type
Amount of Each Disbursement this Period 100.00
Full Name (Last, First, Middle Initial)

c. United Airlines

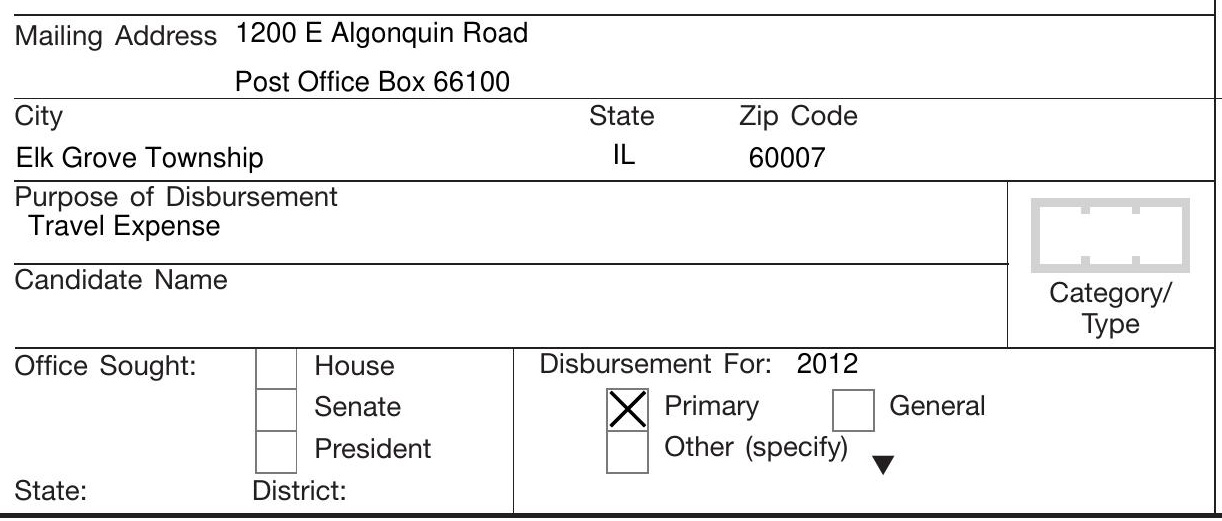

Subtotal Of Receipts This Page (optional).

Date of Disbursement

\begin{tabular}{|c|c|c|c|c|c|}
\hline M & M & D & Y & Y & Y \\
08 & & 02 & & 2011 & \\
\hline
\end{tabular}

Transaction ID : B3CF32F93F4D1428A9ED

Amount of Each Disbursement this Period

Date of Disbursement

\begin{tabular}{|c|c|c|c|c|}
\hline $08^{M}$ & 1 & $02^{\mathrm{D}}$ & I & $\begin{array}{llll} & Y & Y & Y \\
& 2011 & \end{array}$ \\
\hline
\end{tabular}

Transaction ID : B18302FC23EA643D7A66

Amount of Each Disbursement this Period

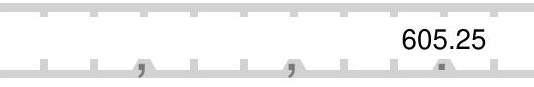

Total This Period (last page this line number only))

1038.25

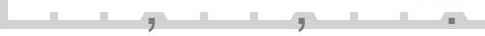

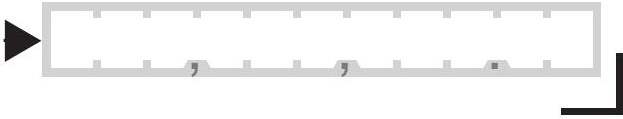

FEC Schedule B-P (Form 3P) (Rev. 03/2011) 


\section{SCHEDULE B-P}

\section{ITEMIZED DISBURSEMENTS}

Use separate schedule(s)

for each category of the

Detailed Summary Page
FOR LINE NUMBER: (check only one)

\begin{tabular}{|c|c|c|c|}
\hline$\times{ }_{23}$ & 24 & 25 & 26 \\
\hline $27 b$ & $28 a$ & $28 \mathrm{~b}$ & $28 \mathrm{c}$ \\
\hline
\end{tabular}

Any information copied from such Reports and Statements may not be sold or used by any person for the purpose of soliciting contributions or for commercial purposes, other than using the name and address of any political committee to solicit contributions from such committee.

NAME OF COMMITTEE (In Full)

\section{Friends of Herman Cain}

Full Name (Last, First, Middle Initial)

\section{A. US Airways}

Mailing Address 4000 E Sky Harbor Boulevard

Date of Disbursement

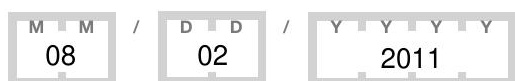

Transaction ID : B18FDD0CE24F045DD9F4

\begin{tabular}{lcc}
\hline City & State & Zip Code \\
Phoenix & AZ & 85034
\end{tabular}

Purpose of Disbursement

Travel Expense

Candidate Name

Office Sought:

\begin{tabular}{l|l} 
& $\begin{array}{l}\text { House } \\
\text { Senate } \\
\text { President }\end{array}$ \\
\\
District:
\end{tabular}

Disbursement For: 2012 X Primary $\square$ General

State: District:

Full Name (Last, First, Middle Initial)

\section{B. Delta Airlines}

\begin{tabular}{ll}
\hline Mailing Address & Post Office Box 20980 \\
& Department 980 \\
\hline City &
\end{tabular}

Atlanta

$\mathrm{GA}$

$\begin{array}{ll}\text { State } & \text { Zip Code } \\ \text { GA } & 30320-2980\end{array}$

Purpose of Disbursement

Travel Expense

Candidate Name

Office Sought:

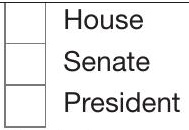

State:

District:

Full Name (Last, First, Middle Initial)

\section{c. LexisNexis}

Mailing Address Post Office Box 2314

\begin{tabular}{lcc}
\hline City & State & Zip Code \\
Carol Stream & IL & $60132-2314$
\end{tabular}

Purpose of Disbursement

Subscription Fee

Candidate Name

Office Sought:

\begin{tabular}{|l|l|l} 
& House \\
Senate \\
& President \\
\hline & Pistrict:
\end{tabular}

Disbursement For: 2012

Х $\begin{aligned} & \text { Primary } \\ & \text { Other (specify) }\end{aligned}$
Disbursement For: 2012

Xrimary $\square$ General

\begin{tabular}{|c|c|c|c|c|}
\hline${ }^{M}$ & ${ }^{M}$ & $8^{\mathrm{D}}$ & $\mathrm{P}^{\mathrm{D}}$ & $\mathrm{Y}^{\mathrm{Y}} \mathrm{Y}$ \\
\hline
\end{tabular}

Transaction ID : BCD84BFBA01F44296BA9

Amount of Each Disbursement this Period 385.00
Date of Disbursement
Date of Disbursement

\begin{tabular}{|c|c|c|c|c|}
\hline $08^{M}$ & 1 & D 02 & I & $\begin{array}{cccc}Y & Y & Y & Y \\
& 2011 & \end{array}$ \\
\hline
\end{tabular}

Transaction ID : BBA92B6D955E246D6884

Amount of Each Disbursement this Period

300.00
State:

District:

Subtotal Of Receipts This Page (optional).

Total This Period (last page this line number only))

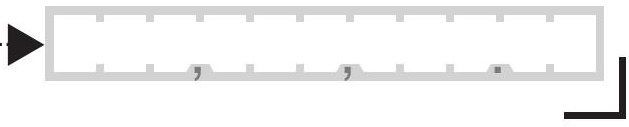




\section{SCHEDULE B-P}

\section{ITEMIZED DISBURSEMENTS}

\section{Use separate schedule(s) \\ for each category of the}

Detailed Summary Page
FOR LINE NUMBER: (check only one)

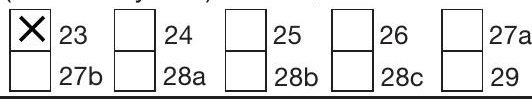

Any information copied from such Reports and Statements may not be sold or used by any person for the purpose of soliciting contributions or for commercial purposes, other than using the name and address of any political committee to solicit contributions from such committee.

NAME OF COMMITTEE (In Full)

\section{Friends of Herman Cain}

Full Name (Last, First, Middle Initial)

\section{A. New Hampshire Young Republicans}

Mailing Address 10 Water Street

Date of Disbursement

\begin{tabular}{lll}
\hline City & State & Zip Code \\
Concord & NH & 03301 \\
\hline
\end{tabular}

Purpose of Disbursement

Event Tickets

Candidate Name

Office Sought:

\begin{tabular}{|l|l} 
& House \\
& Senate \\
President
\end{tabular}

Disbursement For: 2012 X Primary $\square$ General

State: District:

Full Name (Last, First, Middle Initial)

\section{B. 3rd Coast Digital Films}

Mailing Address PO Box 80517

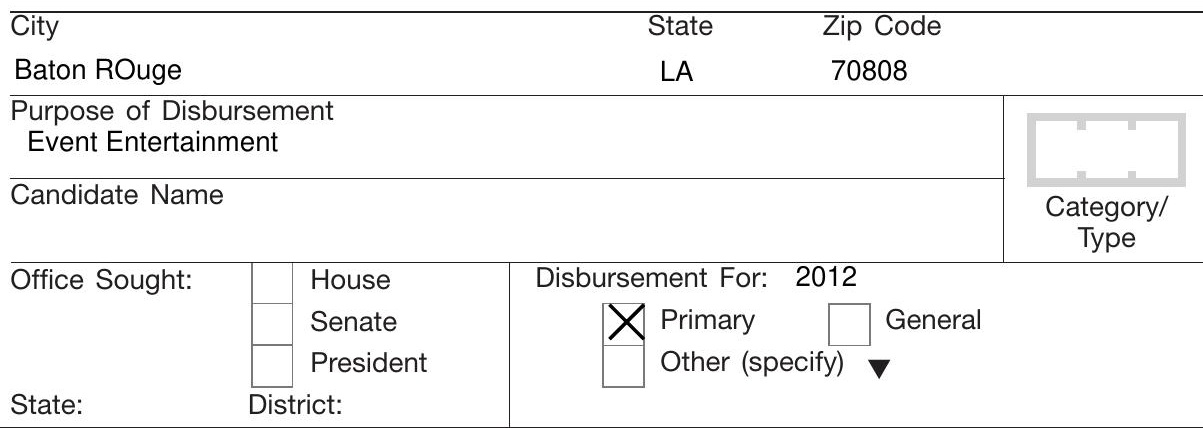

Date of Disbursement

\begin{tabular}{|c|c|c|c|c|}
\hline${ }^{M}$ & ${ }^{M}$ & $8^{\mathrm{D}}$ & $\mathrm{P}^{\mathrm{D}}$ & $\mathrm{Y}^{\mathrm{Y}} \mathrm{Y}$ \\
\hline
\end{tabular}

Transaction ID : B7B508A1DC4C64F7F98E

Full Name (Last, First, Middle Initial)

c. TomJohn Design

Mailing Address 700 W. Highland Road

\begin{tabular}{lcc}
\hline City & State & Zip Code \\
Mequon & WI & 53092
\end{tabular}

Purpose of Disbursement

Printing

Candidate Name

Office Sought:

State:
Date of Disbursement

\begin{tabular}{|c|c|c|c|c|c|c|}
\hline M & M & D & D & Y & Y & Y \\
\hline & & 02 & & 2011 & \\
\hline
\end{tabular}

Transaction ID : B75D32E0B71344B699E1

Amount of Each Disbursement this Period

450.00

Subtotal Of Receipts This Page (optional).....

Total This Period (last page this line number only))

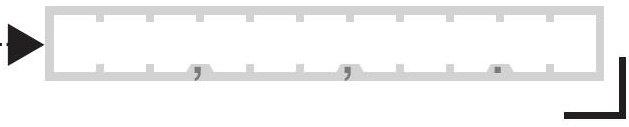




\section{SCHEDULE B-P}

\section{ITEMIZED DISBURSEMENTS}

\section{Use separate schedule(s) \\ for each category of the}

Detailed Summary Page
FOR LINE NUMBER: (check only one)

\begin{tabular}{|c|c|c|c|}
\hline$X_{23}$ & 24 & 25 & 26 \\
\hline $27 \mathrm{~b}$ & $28 a$ & $28 b$ & $28 \mathrm{c}$ \\
\hline
\end{tabular}

Any information copied from such Reports and Statements may not be sold or used by any person for the purpose of soliciting contributions or for commercial purposes, other than using the name and address of any political committee to solicit contributions from such committee.

NAME OF COMMITTEE (In Full)

\section{Friends of Herman Cain}

Full Name (Last, First, Middle Initial)

\section{A. Stonewall Strategies}

$$
\text { Mailing Address PO Box } 2896
$$

\begin{tabular}{lcc}
\hline City & State & Zip Code \\
West Columbia & SC & 29171 \\
\hline Purpose of Disbursement
\end{tabular}

Purpose of Disbursement

Airfare

Candidate Name

Office Sought: $\quad$ House

House
Senate
President

District:

State:

rst, Middle Initial)

B. Facebook, Inc.

Mailing Address 1601 S. California Ave.

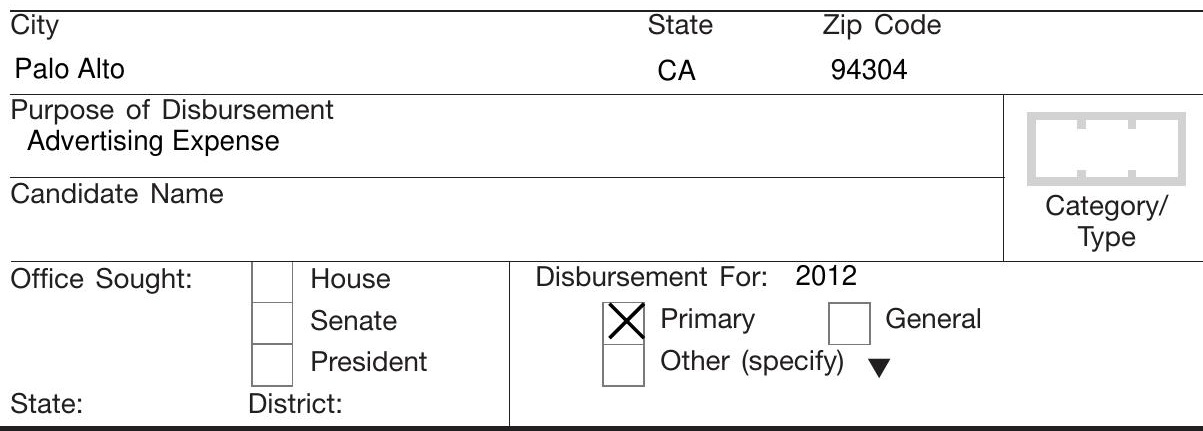

Date of Disbursement

\begin{tabular}{|c|c|c|c|c|}
\hline $08^{\mathrm{M}}$ & 1 & $02^{\mathrm{D}}$ & 1 & 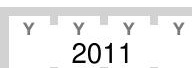 \\
\hline
\end{tabular}

Transaction ID : B70D11045DC4B49D2898

Full Name (Last, First, Middle Initial)

\section{c. Ruth's Chris Steak House}

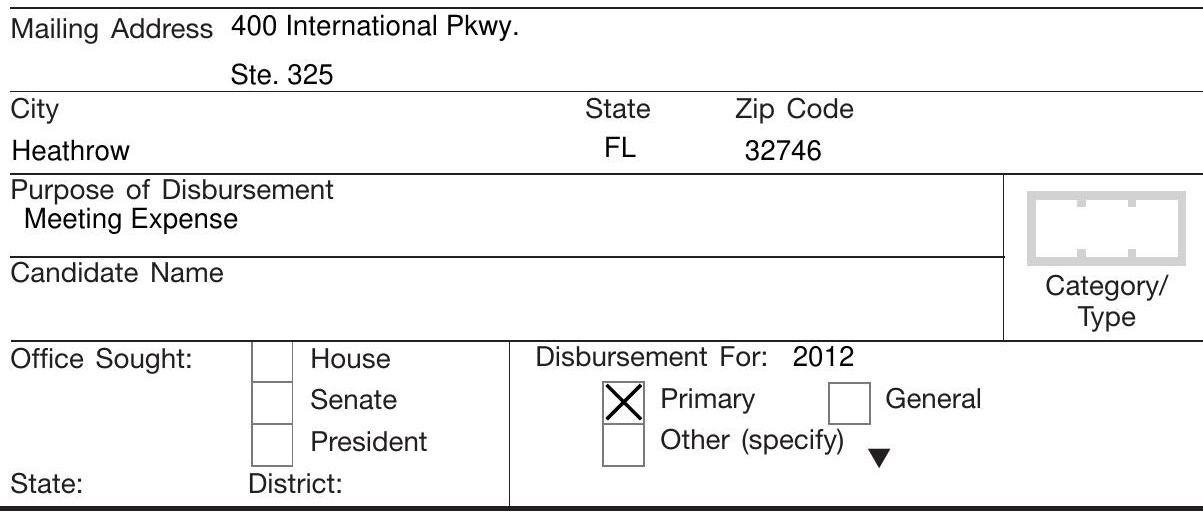

Subtotal Of Receipts This Page (optional).

Date of Disbursement

\begin{tabular}{|c|c|c|c|c|}
\hline $08^{M}$ & I & D 02 & I & 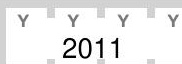 \\
\hline
\end{tabular}

Transaction ID : B087A63169C5746ABAF7

Amount of Each Disbursement this Period

Amount of Each Disbursement this Period
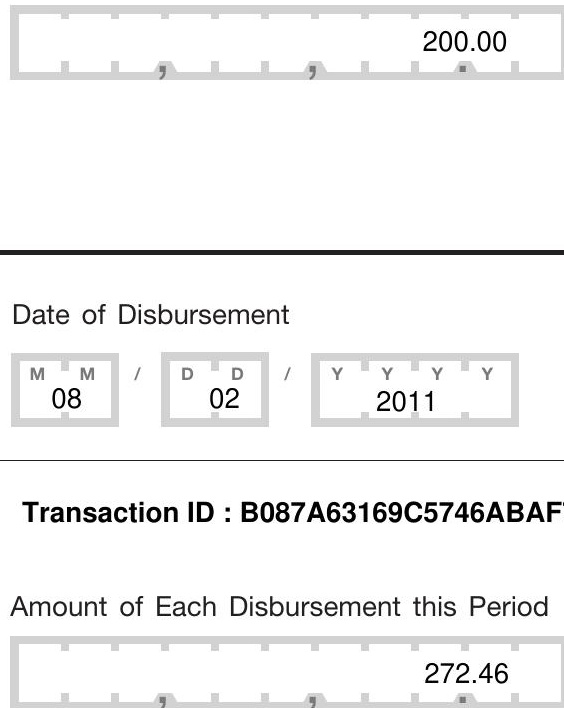

Total This Period (last page this line number only)) 


\section{SCHEDULE B-P}

\section{ITEMIZED DISBURSEMENTS}

\section{Use separate schedule(s) \\ for each category of the}

Detailed Summary Page
FOR LINE NUMBER: (check only one)

\begin{tabular}{|c|c|c|c|}
\hline$X_{23}$ & 24 & 25 & 26 \\
\hline $27 \mathrm{~b}$ & $28 a$ & $28 b$ & $28 \mathrm{c}$ \\
\hline
\end{tabular}

Any information copied from such Reports and Statements may not be sold or used by any person for the purpose of soliciting contributions or for commercial purposes, other than using the name and address of any political committee to solicit contributions from such committee.

NAME OF COMMITTEE (In Full)

\section{Friends of Herman Cain}

Full Name (Last, First, Middle Initial)

A. Raquel Rhada Hirsch

Mailing Address $6825 \mathrm{~N}$ 2nd Place

\begin{tabular}{lcc}
\hline City & State & Zip Code \\
Scottsdale & AZ & 85250 \\
\hline
\end{tabular}

Purpose of Disbursement

Mileage, Airfare, Telephone and Meeting

Candidate Name

Office Sought:

State:

House
Senate
President
istrict:

Disbursement For: 2012 X Primary $\square$ General

B. Celerity Services

Mailing Address 3057 99th St.

\begin{tabular}{lcc}
\hline City & State & Zip Code \\
Urbandale & IA & 50322 \\
\hline $\begin{array}{l}\text { Purpose of Disbursement } \\
\text { Office Maintenance }\end{array}$ & & \\
\hline
\end{tabular}

Candidate Name

Office Sought:

House
Senate
President

State:

District:

Full Name (Last, First, Middle Initial)

\section{c. Ellen Carmichael}

Mailing Address 1007 Oak Hills Parkway

\begin{tabular}{lcc}
\hline City & State & Zip Code \\
Baton Rouge & LA & $70810-4705$
\end{tabular}

Purpose of Disbursement

Airfare and Transportation

Candidate Name

Office Sought: $\quad$ House

\begin{tabular}{|l|l} 
& House \\
Senate \\
President
\end{tabular}

State:

District:
Disbursement For: 2012

Primary
Other (specify) General
Date of Disbursement

\begin{tabular}{|c|c|c|c|}
\hline 08 & & $02^{\mathrm{D}}$ & \\
\hline
\end{tabular}

Transaction ID : BB2D074F8B8E14978B16

Amount of Each Disbursement this Period 669.29
Date of Disbursement

\begin{tabular}{|c|c|c|c|c|}
\hline $08^{M}$ & 1 & $02^{\mathrm{D}}$ & 1 & 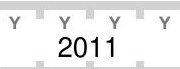 \\
\hline
\end{tabular}

Transaction ID : B5400824276A14A55B94

Amount of Each Disbursement this Period
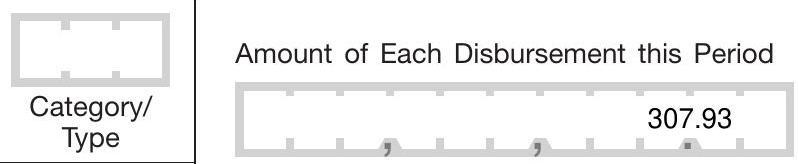

Subtotal Of Receipts This Page (optional).

Date of Disbursement

\begin{tabular}{|c|c|c|c|c|c|c|}
\hline M & M & D & I & Y & Y & Y \\
\hline & & 03 & & 2011 & \\
\hline
\end{tabular}

Transaction ID : B9654D8B18387459999F

Amount of Each Disbursement this Period

458.91

Total This Period (last page this line number only)) 


\section{SCHEDULE B-P}

\section{ITEMIZED DISBURSEMENTS}

\section{Use separate schedule(s) \\ for each category of the}

Detailed Summary Page
FOR LINE NUMBER: (check only one)

\begin{tabular}{|c|c|c|c|}
\hline$X_{23}$ & 24 & 25 & 26 \\
\hline $27 \mathrm{~b}$ & $28 a$ & $28 b$ & $28 \mathrm{c}$ \\
\hline
\end{tabular}

Any information copied from such Reports and Statements may not be sold or used by any person for the purpose of soliciting contributions or for commercial purposes, other than using the name and address of any political committee to solicit contributions from such committee.

NAME OF COMMITTEE (In Full)

\section{Friends of Herman Cain}

Full Name (Last, First, Middle Initial)

A. Stephen Morrison

Mailing Address PO Box 2158

Date of Disbursement

\begin{tabular}{lcc}
\hline City & State & Zip Code \\
Stockbridge & GA & $30281-8909$
\end{tabular}

Purpose of Disbursement

Staff Salary

Candidate Name

\begin{tabular}{l|l|l|l}
\hline Office Sought: & House & Disbursement For: 2012
\end{tabular} X Primary $\square$ General

State:

\section{Senate}

President

District:

Full Name (Last, First, Middle Initial)

B. PowerPay, LLC

\begin{tabular}{|c|c|c|c|c|}
\hline \multicolumn{5}{|c|}{ Mailing Address 320 Cumberland Ave } \\
\hline \multicolumn{2}{|l|}{ City } & \multicolumn{3}{|c|}{ Zip Code } \\
\hline \multicolumn{2}{|l|}{ Portland } & \multicolumn{3}{|c|}{04101} \\
\hline \multicolumn{4}{|c|}{$\begin{array}{l}\text { Purpose of Disbursement } \\
\text { CC Transaction Fees }\end{array}$} & \\
\hline \multicolumn{4}{|l|}{ Candidate Name } & $\begin{array}{l}\text { Category/ } \\
\text { Type }\end{array}$ \\
\hline \multirow[t]{3}{*}{ Office Sought: } & House & \multirow{3}{*}{\multicolumn{3}{|c|}{$\begin{array}{l}\text { Disbursement For: } 2012 \\
\text { X Primary } \\
\text { Other (specify) }\end{array}$}} \\
\hline & Senate & & & \\
\hline & President & & & \\
\hline State: & \multicolumn{4}{|c|}{ District: } \\
\hline
\end{tabular}

Date of Disbursement

\begin{tabular}{|c|c|c|c|c|}
\hline${ }^{M} 8^{M}$ & & $03^{\mathrm{D}}$ & 1 & $\begin{array}{lll}Y & Y & Y \\
& 2011 & Y\end{array}$ \\
\hline
\end{tabular}

Transaction ID : B7870364C758E4E44B1D

Full Name (Last, First, Middle Initial)

c. Facebook, Inc.

Mailing Address 1601 S. California Ave.

Date of Disbursement

\begin{tabular}{lcc|} 
& & \\
City & State & Zip Code \\
Palo Alto & CA & 94304 \\
\hline
\end{tabular}

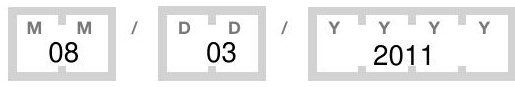

Purpose of Disbursement

Advertising Expense

Candidate Name

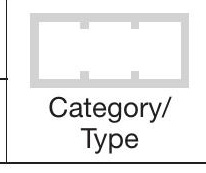

Transaction ID : B2D94DA6099DF4705894

\begin{tabular}{l|l} 
Cype & Typegor
\end{tabular}

Amount of Each Disbursement this Period

\begin{tabular}{l|l|r|}
\hline \multirow{2}{*}{ Office Sought: } & $\begin{array}{l}\text { House } \\
\text { Senate } \\
\text { President }\end{array}$ & $\begin{array}{r}\text { Disbursement For: } 2012 \\
\text { State: }\end{array}$ \\
\cline { 2 - 3 } & District: & X Primary \\
Other (specify)
\end{tabular}

Amount of Each Disbursement this Period

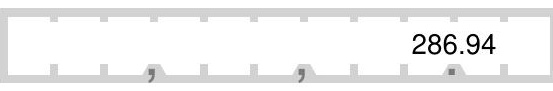

Subtotal Of Receipts This Page (optional)

Total This Period (last page this line number only))

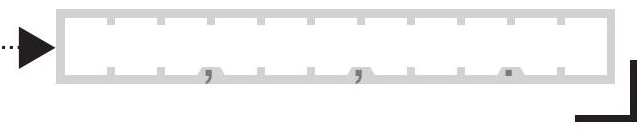




\section{SCHEDULE B-P}

\section{ITEMIZED DISBURSEMENTS}

\section{Use separate schedule(s) \\ for each category of the}

Detailed Summary Page
FOR LINE NUMBER: (check only one)

\begin{tabular}{|c|c|c|c|}
\hline$\times{ }_{23}$ & 24 & 25 & 26 \\
\hline $27 b$ & $28 a$ & $28 \mathrm{~b}$ & $28 \mathrm{c}$ \\
\hline
\end{tabular}

Any information copied from such Reports and Statements may not be sold or used by any person for the purpose of soliciting contributions or for commercial purposes, other than using the name and address of any political committee to solicit contributions from such committee.

NAME OF COMMITTEE (In Full)

\section{Friends of Herman Cain}

Full Name (Last, First, Middle Initial)

A. Inkhead Inc.

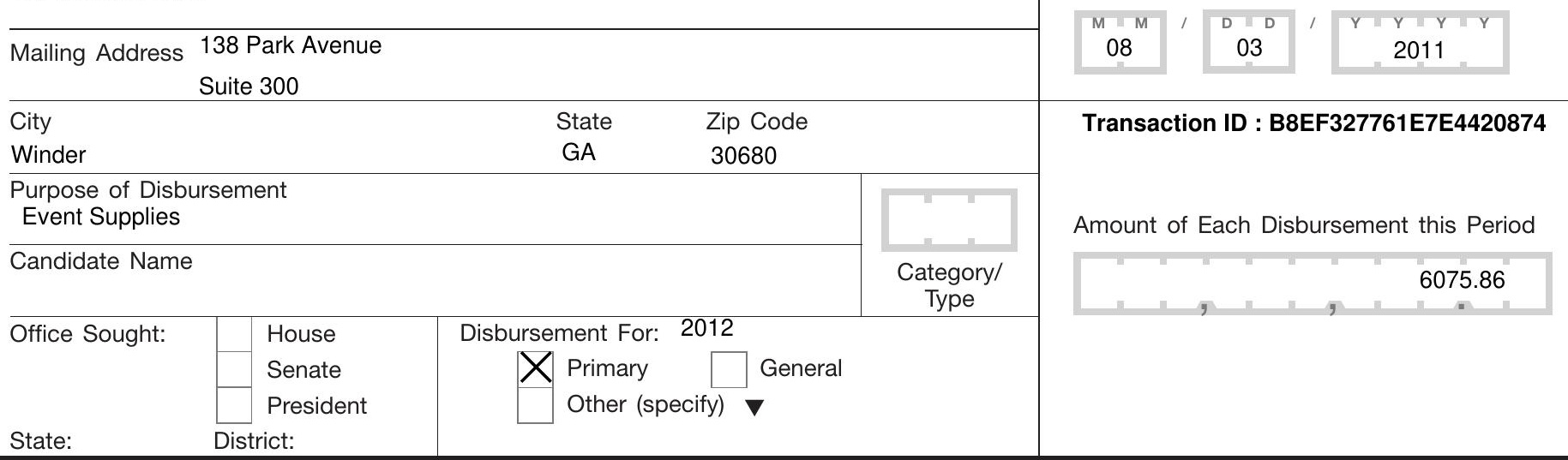

\section{Full Name (Last, First, Middle Initial)}

\section{B. Tri-Net Payroll Services}

\begin{tabular}{|c|c|}
\hline Mailing Address & $\begin{array}{l}1100 \text { San Leandro Boulevard } \\
\text { Suite }\end{array}$ \\
\hline
\end{tabular}

San Leandro

Purpose of Disbursement

Payroll Withholding

Candidate Name

Office Sought:

State:

Full Name (Last, First, Middle Initial)

\section{c. Tri-Net Payroll Services}

Mailing Address 1100 San Leandro Boulevard

Suite

\begin{tabular}{lcc}
\multicolumn{2}{c}{ Suite } & \\
\hline City & State & Zip Code \\
San Leandro & CA & 94577 \\
\hline
\end{tabular}

Purpose of Disbursement

Payroll Service Fees

Candidate Name

Office Sought: $\quad$ House

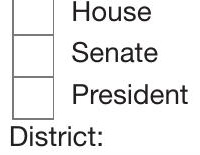

State:

District:

State Zip Code

CA $\quad 94577$

Disbursement For: 2012

Xrimary $\square$ General
Date of Disbursement

\begin{tabular}{|c|c|c|c|c|}
\hline${ }^{M} 8^{M}$ & 1 & $03^{\mathrm{D}}$ & 1 & $\begin{array}{llll}Y & Y & Y & Y \\
& 2011 & \end{array}$ \\
\hline
\end{tabular}

Transaction ID : B0F12BBF7D88446A380C

Amount of Each Disbursement this Period
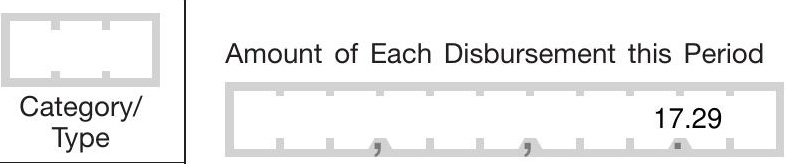

Date of Disbursement

\begin{tabular}{|c|c|c|c|c|c|c|}
\hline M & M & D & I & Y & Y & Y \\
\hline & & 03 & & 2011 & \\
\hline
\end{tabular}

Transaction ID : B33106FCF903A4C2BA53

Amount of Each Disbursement this Period
77.00 Type
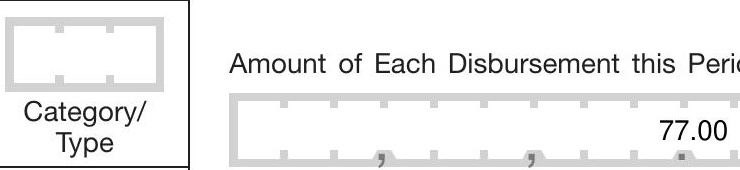
Disbursement For: 2012
$\searrow$ Primary
Other (specify)

Subtotal Of Receipts This Page (optional)

6170.15

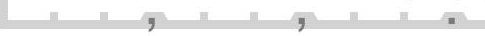

Total This Period (last page this line number only))

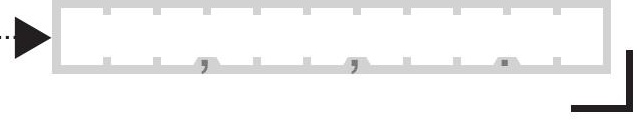

FEC Schedule B-P (Form 3P) (Rev. 03/2011) 


\section{SCHEDULE B-P}

\section{ITEMIZED DISBURSEMENTS}

\section{Use separate schedule(s) \\ for each category of the}

Detailed Summary Page
FOR LINE NUMBER: (check only one)

\begin{tabular}{|c|c|c|c|}
\hline$X_{23}$ & 24 & 25 & 26 \\
\hline $27 \mathrm{~b}$ & $28 a$ & $28 b$ & $28 \mathrm{c}$ \\
\hline
\end{tabular}

Any information copied from such Reports and Statements may not be sold or used by any person for the purpose of soliciting contributions or for commercial purposes, other than using the name and address of any political committee to solicit contributions from such committee.

NAME OF COMMITTEE (In Full)

\section{Friends of Herman Cain}

Full Name (Last, First, Middle Initial)

A. Delta Airlines

\begin{tabular}{c} 
Mailing Address $\begin{array}{c}\text { Post Office Box } 20980 \\
\text { Department } 980\end{array}$ \\
\hline
\end{tabular}

\begin{tabular}{lll}
\hline City & State & Zip Code \\
Atlanta & GA & $30320-2980$
\end{tabular}

Purpose of Disbursement

Travel Expense

Candidate Name

\begin{tabular}{l|l|c|}
\hline Office Sought: & $\begin{array}{l}\text { House } \\
\text { Senate } \\
\text { President }\end{array}$ & $\begin{array}{r}\text { Disbursement For: } 2012 \\
\text { X Primary } \\
\text { Other (specify) }\end{array}$
\end{tabular}

Full Name (Last, First, Middle Initial)

B. United Airlines

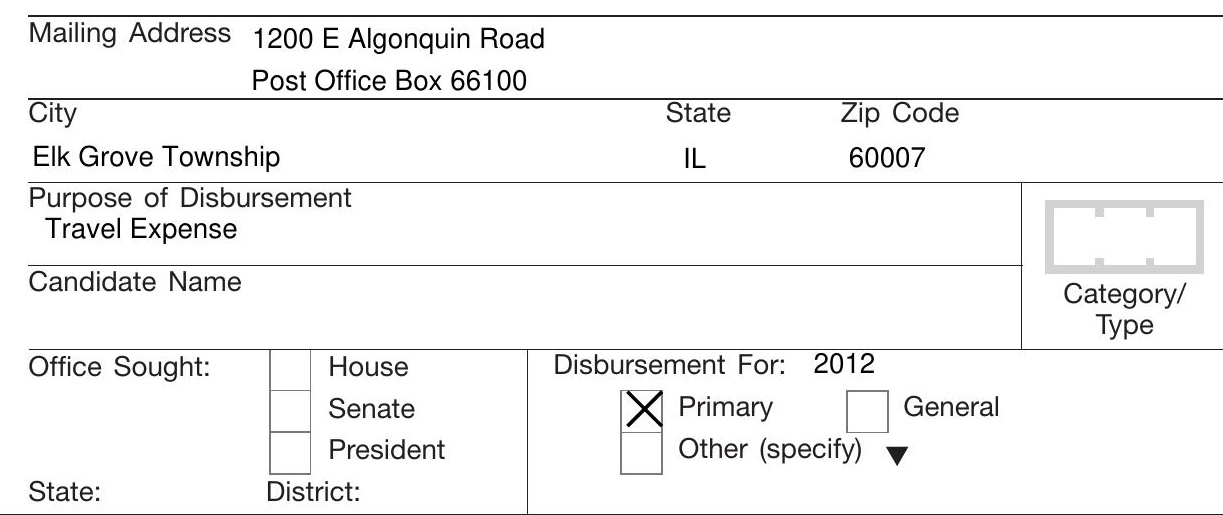

Date of Disbursement

Full Name (Last, First, Middle Initial)

\section{c. RMA Chaffeured Transportation}

\begin{tabular}{|c|c|c|c|c|c|}
\hline \multicolumn{6}{|c|}{$\begin{array}{c}\text { Mailing Address } 6010 \text { Executive Boulevard } \\
\text { Suite } 101\end{array}$} \\
\hline \multicolumn{2}{|l|}{ City } & State & Zip Code & & \\
\hline \multicolumn{2}{|l|}{ Rockville } & MD & 20852 & & \\
\hline \multicolumn{5}{|c|}{$\begin{array}{l}\text { Purpose of Disbursement } \\
\text { Travel Expense }\end{array}$} & \\
\hline \multicolumn{5}{|l|}{ Candidate Name } & $\begin{array}{l}\text { Category/ } \\
\text { Type }\end{array}$ \\
\hline \multirow[t]{3}{*}{ Office Sought: } & House & \multirow{4}{*}{\multicolumn{4}{|c|}{ Disbursement For: 2012}} \\
\hline & Senate & & & & \\
\hline & President & & & & \\
\hline State: & rict: & & & & \\
\hline
\end{tabular}

Subtotal Of Receipts This Page (optional).

Date of Disbursement

\begin{tabular}{|c|c|c|c|c|c|c|}
\hline M & M & D & Y & Y & Y \\
\hline & 04 & & 2011 & \\
\hline
\end{tabular}

Transaction ID : BCOECBBD0A3824EFDAA3

Amount of Each Disbursement this Period

\section{Transaction ID : B6AD3D3C587354FE28C0}

Amount of Each Disbursement this Period
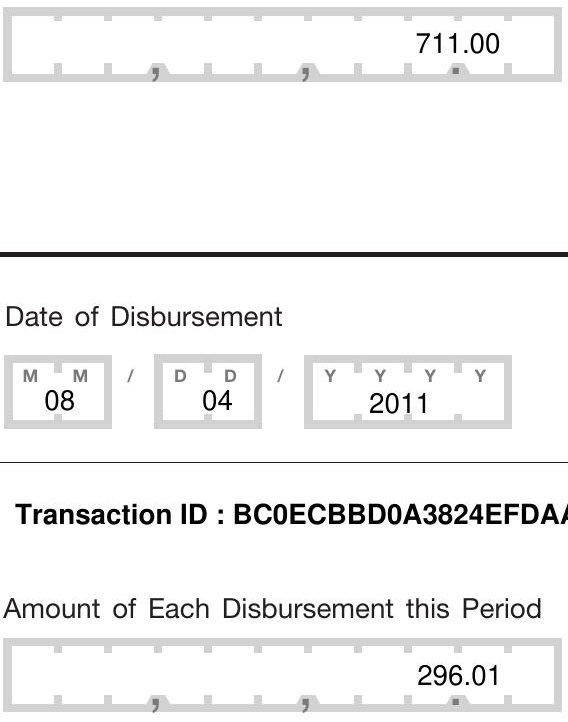

Total This Period (last page this line number only)) 


\section{SCHEDULE B-P}

\section{ITEMIZED DISBURSEMENTS}

\section{Use separate schedule(s) \\ for each category of the}

Detailed Summary Page
FOR LINE NUMBER: (check only one)

\begin{tabular}{|c|c|c|c|}
\hline$X_{23}$ & 24 & 25 & 26 \\
\hline $27 \mathrm{~b}$ & $28 a$ & $28 b$ & $28 \mathrm{c}$ \\
\hline
\end{tabular}

Any information copied from such Reports and Statements may not be sold or used by any person for the purpose of soliciting contributions or for commercial purposes, other than using the name and address of any political committee to solicit contributions from such committee.

NAME OF COMMITTEE (In Full)

\section{Friends of Herman Cain}

Full Name (Last, First, Middle Initial)

A. Delta Airlines

Mailing Address Post Office Box 20980 Department 980

\begin{tabular}{lll}
\hline City & State & Zip Code \\
Atlanta & GA & $30320-2980$
\end{tabular}

Purpose of Disbursement

Travel Expense

Candidate Name

Office Sought:
Date of Disbursement

\begin{tabular}{|c|c|c|c|c|}
\hline M M & D & Y Y Y Y \\
\hline & 04 & 2011 \\
\hline
\end{tabular}

Transaction ID : B017B1A4A4C2D42ACA3D

Amount of Each Disbursement this Period 435.60

\section{B. Crystal Clear Bottled Water}

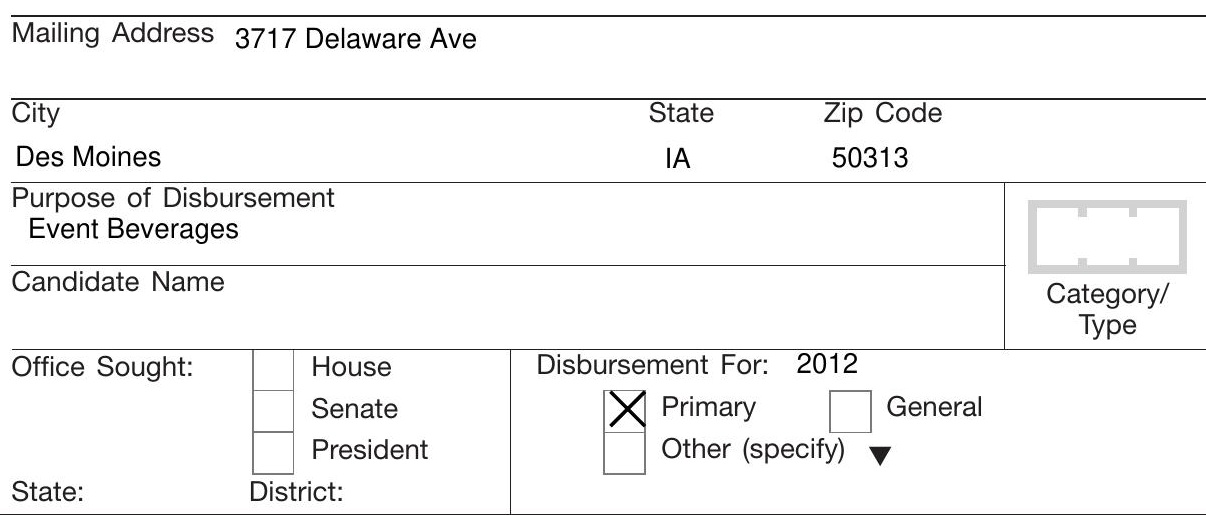

Date of Disbursement

\begin{tabular}{|c|c|c|c|c|}
\hline $08^{M}$ & 1 & $04^{\mathrm{D}}$ & 1 & $\begin{array}{llll}Y & Y & Y & Y \\
& 2011 & \end{array}$ \\
\hline
\end{tabular}

Transaction ID : BF3C06702DF404E2BB28

Full Name (Last, First, Middle Initial)

c. Facebook, Inc.

Mailing Address 1601 S. California Ave.

Date of Disbursement

\begin{tabular}{lcc|} 
& & \\
\hline City & State & Zip Code \\
Palo Alto & CA & 94304 \\
\hline
\end{tabular}

\begin{tabular}{|c|c|c|c|c|}
\hline $08^{M}$ & I & D 04 & I & $\begin{array}{cccc}Y & Y & Y & Y \\
2011 & \end{array}$ \\
\hline
\end{tabular}

Transaction ID : BC7B4C04231994954926

Purpose of Disbursement Advertising Expense

Candidate Name

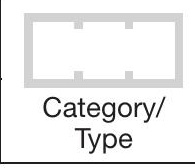

\begin{tabular}{l|l|l}
\hline Office Sought: & & $\begin{array}{l}\text { House } \\
\text { Senate } \\
\end{array}$ \\
\cline { 2 - 2 } & $\begin{array}{l}\text { President } \\
\text { State: }\end{array}$ & District:
\end{tabular}

Disbursement For: 2012
\[ \begin{array}{l}\text { Primary } \\ \text { Other (specify) }\end{array} \]

Amount of Each Disbursement this Period

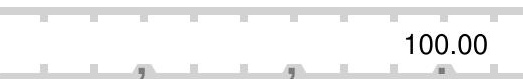

Subtotal Of Receipts This Page (optional).

Total This Period (last page this line number only))

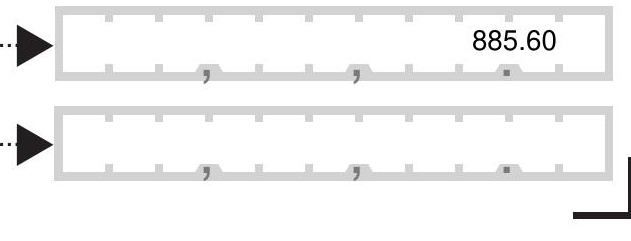




\section{SCHEDULE B-P}

\section{ITEMIZED DISBURSEMENTS}

\section{Use separate schedule(s) \\ for each category of the}

Detailed Summary Page
FOR LINE NUMBER: (check only one)

\begin{tabular}{|c|c|c|c|}
\hline$\times{ }_{23}$ & 24 & 25 & 26 \\
\hline $27 b$ & $28 a$ & $28 \mathrm{~b}$ & $28 \mathrm{c}$ \\
\hline
\end{tabular}

Any information copied from such Reports and Statements may not be sold or used by any person for the purpose of soliciting contributions or for commercial purposes, other than using the name and address of any political committee to solicit contributions from such committee.

NAME OF COMMITTEE (In Full)

\section{Friends of Herman Cain}

Full Name (Last, First, Middle Initial)

A. Target Stores

Mailing Address 1000 Nicollet Mall

Date of Disbursement

\begin{tabular}{lll}
\hline City & State & Zip Code \\
Minneapolis & MN & 55403 \\
\hline
\end{tabular}

Purpose of Disbursement

Office Supplies

Candidate Name

\begin{tabular}{l|l|l}
\hline Office Sought: & House & Disbursement For: 2012
\end{tabular} X Primary $\square$ General

State:

\section{Senate}

President

District:

Full Name (Last, First, Middle Initial)

B. Air Tran

Mailing Address 9955 Air Tran Boulevard

\begin{tabular}{lcc}
\hline City & State & Zip Code \\
Orlando & FL & 32827
\end{tabular}

Purpose of Disbursement

Travel Expense

Candidate Name

Office Sought:

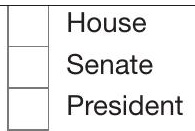

State:

District:

FL 32827

Full Name (Last, First, Middle Initial)

\section{Air Tran}

Mailing Address 9955 Air Tran Boulevard

\begin{tabular}{lcc}
\hline City & State & Zip Code \\
Orlando & FL & 32827
\end{tabular}

Purpose of Disbursement

Travel Expense

Candidate Name

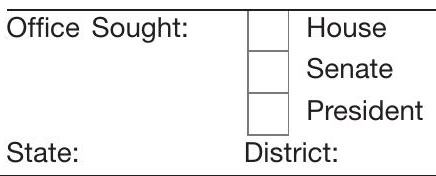

\section{Disbursement For: 2012 \\ Primary $\square$ General
Other (specify)}

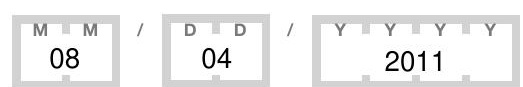

Transaction ID : B8CFF5BD309C34562928

Amount of Each Disbursement this Period

Date of Disbursement

\begin{tabular}{|c|c|c|c|c|}
\hline $08^{M}$ & 1 & ${ }^{\mathrm{D}} 4^{\mathrm{D}}$ & l & $\begin{array}{llll}Y & Y & Y & Y \\
2011 & Y\end{array}$ \\
\hline
\end{tabular}

Transaction ID : B8D23A6599D2B4256BB4

Amount of Each Disbursement this Period

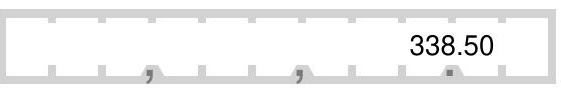

Date of Disbursement

\begin{tabular}{|c|c|c|c|c|c|c|}
\hline M & M & D & I & Y & Y & Y \\
\hline & & 05 & & 2011 & \\
\hline
\end{tabular}

Transaction ID : B04971486DA1D4F12B10

Amount of Each Disbursement this Period

300.50

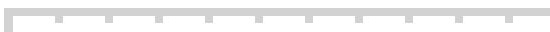
Disbursement For: 2012
\[ \begin{array}{l}\text { Primary } \\ \text { Other (specify) }\end{array} \] Type

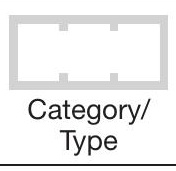

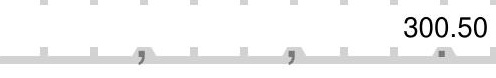

Subtotal Of Receipts This Page (optional).

Total This Period (last page this line number only))

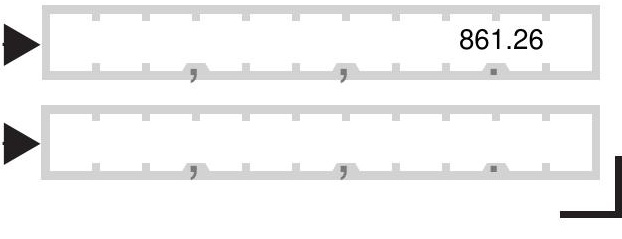




\section{SCHEDULE B-P}

\section{ITEMIZED DISBURSEMENTS}

\section{Use separate schedule(s)}

for each category of the

Detailed Summary Page
FOR LINE NUMBER: (check only one)

\begin{tabular}{|c|c|c|c|}
\hline$\times{ }_{23}$ & 24 & 25 & 26 \\
\hline $27 b$ & $28 a$ & $28 \mathrm{~b}$ & $28 \mathrm{c}$ \\
\hline
\end{tabular}

Any information copied from such Reports and Statements may not be sold or used by any person for the purpose of soliciting contributions or for commercial purposes, other than using the name and address of any political committee to solicit contributions from such committee.

NAME OF COMMITTEE (In Full)

\section{Friends of Herman Cain}

Full Name (Last, First, Middle Initial)

A. Party Time Rental

Mailing Address 30 S 3rd Street

Date of Disbursement

\begin{tabular}{lcc}
\hline City & State & Zip Code \\
Ames & IA & 50010 \\
\hline
\end{tabular}

Purpose of Disbursement

Event Equipment Rental

Candidate Name X Primary $\square$ General

State:

\section{House
Senate President} District:

Full Name (Last, First, Middle Initial)

B. Facebook, Inc.

Mailing Address 1601 S. California Ave.

\begin{tabular}{lcc}
\hline City & State & Zip Code \\
Palo Alto & CA & 94304
\end{tabular}

Purpose of Disbursement

Advertising Expense

Candidate Name

Office Sought:

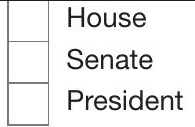

State:

District:

Full Name (Last, First, Middle Initial)

\section{c. Marriott International}

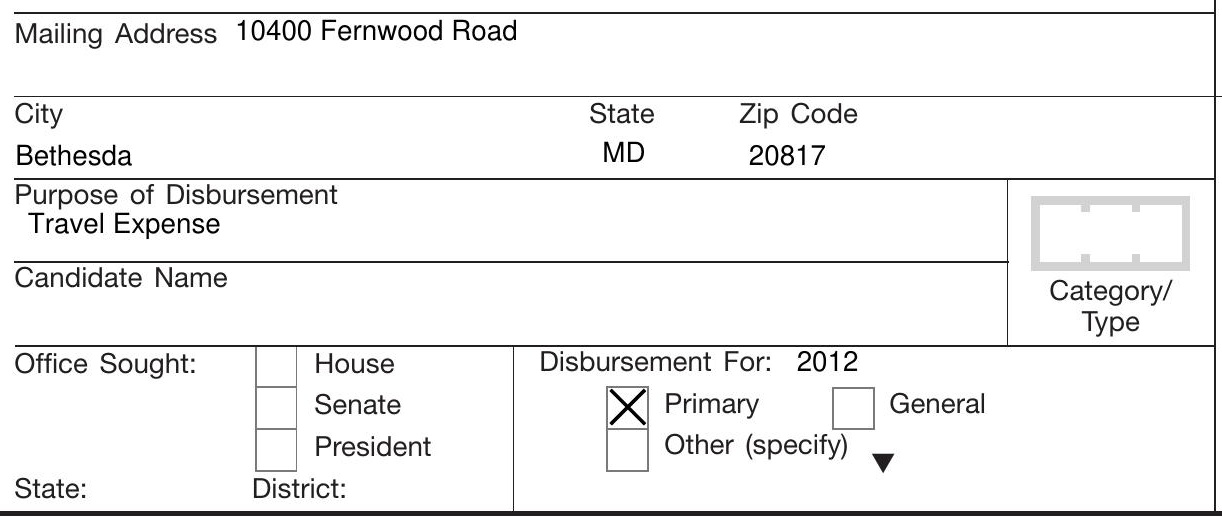

Subtotal Of Receipts This Page (optional)...

Date of Disbursement

\begin{tabular}{|c|c|c|c|c|c|c|}
\hline M & M & D & Y & Y & Y \\
08 & & 05 & & 2011 & \\
\hline
\end{tabular}

Transaction ID : BCD6FD198B91C47ADBD4

Amount of Each Disbursement this Period

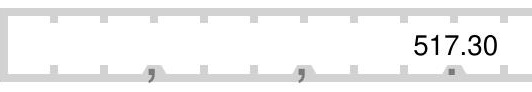

Date of Disbursement

\begin{tabular}{|c|c|c|c|c|}
\hline $08^{\mathrm{M}}$ & & ${ }^{\mathrm{D}} 5^{\mathrm{D}}$ & , & $\begin{array}{llll}Y & Y & Y & Y \\
& 2011^{-}\end{array}$ \\
\hline
\end{tabular}

Transaction ID : BDDD60983F6034474967

Amount of Each Disbursement this Period

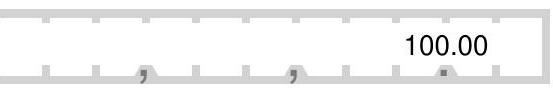

Total This Period (last page this line number only))...

2758.69

C.

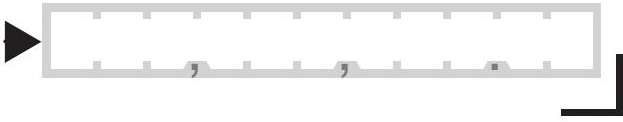

FEC Schedule B-P (Form 3P) (Rev. 03/2011) 


\section{SCHEDULE B-P}

\section{ITEMIZED DISBURSEMENTS}

\section{Use separate schedule(s) \\ for each category of the}

Detailed Summary Page
FOR LINE NUMBER: (check only one)

\begin{tabular}{|c|c|c|c|}
\hline$\times{ }_{23}$ & 24 & 25 & 26 \\
\hline $27 b$ & $28 a$ & $28 \mathrm{~b}$ & $28 \mathrm{c}$ \\
\hline
\end{tabular}

Any information copied from such Reports and Statements may not be sold or used by any person for the purpose of soliciting contributions or for commercial purposes, other than using the name and address of any political committee to solicit contributions from such committee.

NAME OF COMMITTEE (In Full)

\section{Friends of Herman Cain}

Full Name (Last, First, Middle Initial)

A. James Brazil

Mailing Address 6 Baldasarri Drive

Date of Disbursement

\begin{tabular}{lcc}
\hline City & State & Zip Code \\
Dunmore & PA & 18505 \\
\hline Purpose of Disbursement & &
\end{tabular}

Purpose of Disbursement

Field Consulting

Candidate Name

Office Sought:

\begin{tabular}{|l} 
Souse \\
Senate \\
President \\
District:
\end{tabular}

Disbursement For: 2012 X Primary $\square$ General

State: District:

Full Name (Last, First, Middle Initial)

B. James Brazil

Mailing Address 6 Baldasarri Drive

\begin{tabular}{lcc}
\hline City & State & Zip Code \\
Dunmore & PA & 18505
\end{tabular}

Purpose of Disbursement

Field Consulting

Candidate Name

Office Sought:

\begin{tabular}{|l|l} 
& House \\
& Senate \\
\cline { 1 - 2 } & President
\end{tabular}

State:

District:

\begin{tabular}{|c|c|} 
& \\
Category/ \\
Type
\end{tabular}

Amount of Each Disbursement this Period

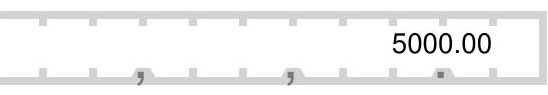

Full Name (Last, First, Middle Initial)

c. Adventure Advertising, LLC

Mailing Address 554 W. Main Street

$$
\text { Ste. } 202
$$

\begin{tabular}{lcc}
\hline City & State & Zip Code \\
Buford & GA & 30518 \\
\hline
\end{tabular}

Purpose of Disbursement

Advertising Expense

Candidate Name

Office Sought:

State:

\begin{tabular}{|l|l|} 
& House \\
& Senate \\
& President \\
District:
\end{tabular}

Disbursement For: 2012

X Primary $\square$ General
Date of Disbursement

\begin{tabular}{|c|c|c|c|c|}
\hline $08^{M}$ & 1 & $05^{\mathrm{D}}$ & 1 & 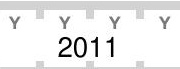 \\
\hline
\end{tabular}

Transaction ID : BC248F3FEE3F74243A16

Amount of Each Disbursement this Period

5000.00
Date of Disbursement

\begin{tabular}{|c|c|c|c|c|c|c|}
\hline M & M & D & Y & Y & Y \\
08 & & 05 & & 2011 & \\
\hline
\end{tabular}

Transaction ID : B116E0A090C4A4922959

Amount of Each Disbursement this Period

15700.00

Subtotal Of Receipts This Page (optional).

Total This Period (last page this line number only))

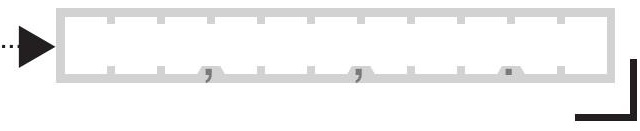




\section{SCHEDULE B-P}

\section{ITEMIZED DISBURSEMENTS}

Use separate schedule(s)

for each category of the

Detailed Summary Page
FOR LINE NUMBER: (check only one)

PAGE 1369 / 1572

\begin{tabular}{|c|c|c|c|}
\hline $\mathrm{X} 23$ & 24 & 25 & 26 \\
\hline $27 \mathrm{~b}$ & $28 a$ & $28 b$ & $28 \mathrm{c}$ \\
\hline
\end{tabular}

Any information copied from such Reports and Statements may not be sold or used by any person for the purpose of soliciting contributions or for commercial purposes, other than using the name and address of any political committee to solicit contributions from such committee.

NAME OF COMMITTEE (In Full)

\section{Friends of Herman Cain}

Full Name (Last, First, Middle Initial)

A. Walmart

Mailing Address 702 SW 8th Street

\begin{tabular}{lll}
\hline City & State & Zip Code \\
Bentonville & AK & $72716-8611$
\end{tabular}

Purpose of Disbursement

Event Supplies

Candidate Name

Office Sought:

\begin{tabular}{|l|l|l} 
& House \\
& Senate \\
& President
\end{tabular}

Disbursement For: 2012 X Primary $\square$ General

State:

District:

Full Name (Last, First, Middle Initial)

\section{B. Delta Airlines}

\begin{tabular}{ll}
\hline Mailing Address & Post Office Box 20980 \\
& Department 980 \\
\hline City &
\end{tabular}

Atlanta

$\mathrm{GA}$

State Zip Code

Purpose of Disbursement

Travel Expense

Candidate Name

Office Sought:

House
Senate
President

State:

District:

Full Name (Last, First, Middle Initial)

\section{c. Publix Supermarkets}

Mailing Address 3300 Publix Corporate Pkwy

\begin{tabular}{lcc}
\hline City & State & Zip Code \\
Lakeland & FL & 33811
\end{tabular}

Purpose of Disbursement

Travel Expense

Candidate Name

Office Sought:

\begin{tabular}{|l|l|}
\hline & House \\
& Senate \\
& President \\
& District:
\end{tabular}

Disbursement For: 2012

X $\begin{aligned} & \text { Primary } \\ & \text { Other (specify) }\end{aligned}$
Date of Disbursement

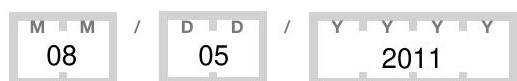

Transaction ID : B94B37E4E6BED462991A

Amount of Each Disbursement this Period

1481.04

Date of Disbursement

\begin{tabular}{|c|c|c|c|c|}
\hline${ }^{M}{ }^{\mathrm{M}} / 8^{\mathrm{D}}$ & 05 & $\mathrm{P}^{\mathrm{D}}$ & $\mathrm{Y}^{\mathrm{Y}}$ & $\mathrm{Y}$ \\
\hline
\end{tabular}

Transaction ID : B4296FE01AD0641AE93E

Amount of Each Disbursement this Period

5406.51

Date of Disbursement

\begin{tabular}{|c|c|c|c|c|}
\hline $08^{M}$ & I & D 05 & 1 & 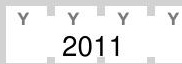 \\
\hline
\end{tabular}

Transaction ID : B953AA431BDBF40DFA46

Amount of Each Disbursement this Period

1059.50
State:

District:

Subtotal Of Receipts This Page (optional).

Total This Period (last page this line number only))

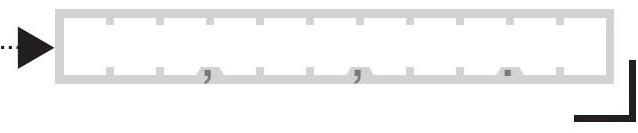




\section{SCHEDULE B-P}

\section{ITEMIZED DISBURSEMENTS}

\section{Use separate schedule(s) \\ for each category of the}

Detailed Summary Page
FOR LINE NUMBER: (check only one)

\begin{tabular}{|c|c|c|c|}
\hline$X_{23}$ & 24 & 25 & 26 \\
\hline $27 \mathrm{~b}$ & $28 a$ & $28 b$ & $28 \mathrm{c}$ \\
\hline
\end{tabular}

Any information copied from such Reports and Statements may not be sold or used by any person for the purpose of soliciting contributions or for commercial purposes, other than using the name and address of any political committee to solicit contributions from such committee.

NAME OF COMMITTEE (In Full)

\section{Friends of Herman Cain}

Full Name (Last, First, Middle Initial)

\section{A. SunTrust Bank}

Mailing Address 980 Eagles Landing Parkway

Date of Disbursement

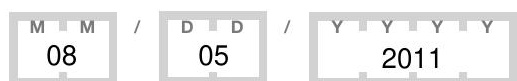

Transaction ID : BDE4D8FF6A192463C9B5

\begin{tabular}{lcc}
\hline City & State & Zip Code \\
Stockbridge & GA & 30281 \\
\hline Purpose of Disbursement & &
\end{tabular}

Purpose of Disbursement

Bank Fees

Candidate Name

\begin{tabular}{l|l|l}
\hline Office Sought: & House & Disbursement For: 2012
\end{tabular} X Primary $\square$ General

State:

Senate
President
trict:

Full Name (Last, First, Middle Initial)

B. Office Depot Corporate

Mailing Address 2500 Mill Center Parkway

\begin{tabular}{lcc}
\hline City & State & Zip Code \\
Buford & GA & 30518
\end{tabular}

Purpose of Disbursement

Office Supplies

Candidate Name

Office Sought:

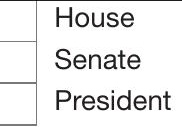

State:

District:

Full Name (Last, First, Middle Initial)

\section{c. FedEx Kinkos}

Mailing Address 942 S. Shady Grove Road

\begin{tabular}{lcc}
\hline City & State & Zip Code \\
Memphis & TN & 38120
\end{tabular}

Purpose of Disbursement

Event Supplies

Candidate Name

\begin{tabular}{l|l|l}
\hline Office Sought: & & $\begin{array}{l}\text { House } \\
\text { Senate } \\
\end{array}$ \\
& $\begin{array}{l}\text { President } \\
\text { State: }\end{array}$ & District:
\end{tabular}

Disbursement For: 2012

Xrimary $\square$ General

General

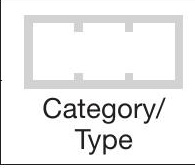

Date of Disbursement

Amount of Each Disbursement this Period

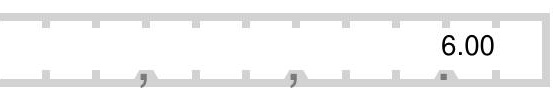

Transaction ID : B3E8BFE6AAD324C618B1

Amount of Each Disbursement this Period

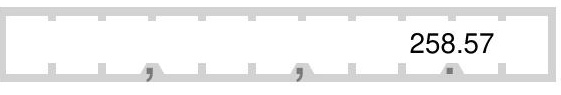

Date of Disbursement

\begin{tabular}{|c|c|c|c|c|}
\hline $08^{\mathrm{M}}$ & 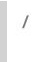 & $\begin{array}{l}\mathrm{D} \\
08\end{array}$ & & $\begin{array}{cccc}Y & Y & Y & Y \\
& 2011 & \end{array}$ \\
\hline
\end{tabular}

Transaction ID : B0DE0E2A40F95499A9B4

Amount of Each Disbursement this Period

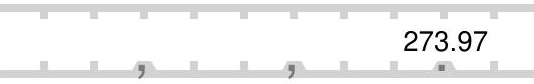

Subtotal Of Receipts This Page (optional).

Total This Period (last page this line number only))

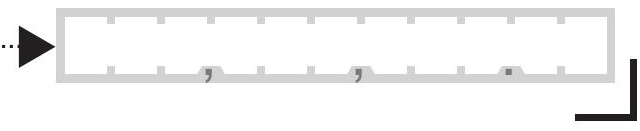




\section{SCHEDULE B-P}

\section{ITEMIZED DISBURSEMENTS}

\section{Use separate schedule(s) \\ for each category of the}

Detailed Summary Page
FOR LINE NUMBER: (check only one)

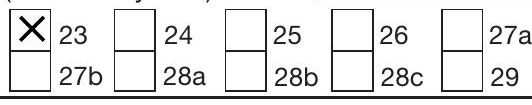

Any information copied from such Reports and Statements may not be sold or used by any person for the purpose of soliciting contributions or for commercial purposes, other than using the name and address of any political committee to solicit contributions from such committee.

NAME OF COMMITTEE (In Full)

\section{Friends of Herman Cain}

Full Name (Last, First, Middle Initial)

A. Delta Airlines

Mailing Address Post Office Box 20980

Department 980

\begin{tabular}{lcc}
\hline City & State & Zip Code \\
Atlanta & GA & $30320-2980$ \\
\hline
\end{tabular}

Purpose of Disbursement

Travel Expense

Candidate Name

Office Sought:

State:

Full Name (Last, First, Middle Initial)

B. United Airlines

\begin{tabular}{ll}
\hline Mailing Address & 1200 E Algonquin Road \\
& Post Office Box 66100 \\
\hline City &
\end{tabular}

Elk Grove Township

Purpose of Disbursement

Travel Expense

Candidate Name

Office Sought:

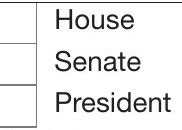

State:

District:

Full Name (Last, First, Middle Initial)

c. Orbitz (ORB)

Mailing Address 500 W. Madison Street

Disbursement For: 2012

State Zip Code

IL 60007

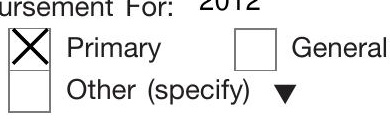

Date of Disbursement

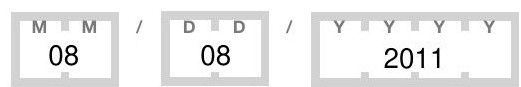

Transaction ID : B63C1BF155B684E5196E

Amount of Each Disbursement this Period 3549.20

Date of Disbursement

\begin{tabular}{|c|c|c|c|c|}
\hline $08^{M}$ & 1 & $08^{\mathrm{D}}$ & 1 & $\begin{array}{llll}Y & Y & Y & Y \\
& 2011 & \end{array}$ \\
\hline
\end{tabular}

Transaction ID : B8B2FFE978DC54C7B8AF

Amount of Each Disbursement this Period

453.00

Date of Disbursement

\begin{tabular}{|c|c|c|c|c|c|c|}
\hline M & M & D & I & Y & Y & Y \\
\hline & & 08 & & 2011 & \\
\hline
\end{tabular}

Transaction ID : BAEBA7C720AC548A0A5F

Chicago

State Zip Code

Purpose of Disbursement

IL $\quad 60661$

Travel Expense

Candidate Name

Office Sought: $\quad$ House

\begin{tabular}{l|l} 
& House \\
& Senate \\
& President \\
\hline & District:
\end{tabular}

Disbursement For: 2012

X $\begin{aligned} & \text { Primary } \\ & \text { Other (specify) }\end{aligned}$

State:

District:

Subtotal Of Receipts This Page (optional).

4188.53

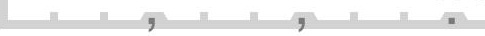

Total This Period (last page this line number only))

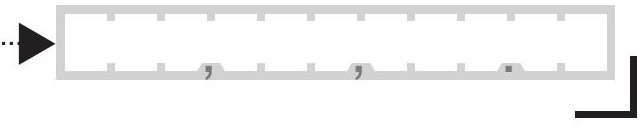

FEC Schedule B-P (Form 3P) (Rev. 03/2011) 


\section{SCHEDULE B-P}

\section{ITEMIZED DISBURSEMENTS}

\section{Use separate schedule(s) \\ for each category of the}

Detailed Summary Page
FOR LINE NUMBER: (check only one)

\begin{tabular}{|c|c|c|c|}
\hline$X_{23}$ & 24 & 25 & 26 \\
\hline $27 \mathrm{~b}$ & $28 a$ & $28 b$ & $28 \mathrm{c}$ \\
\hline
\end{tabular}

Any information copied from such Reports and Statements may not be sold or used by any person for the purpose of soliciting contributions or for commercial purposes, other than using the name and address of any political committee to solicit contributions from such committee.

NAME OF COMMITTEE (In Full)

\section{Friends of Herman Cain}

Full Name (Last, First, Middle Initial)

\section{A. Avis Rent A Car}

Mailing Address 900 Old Country Garden Road

Date of Disbursement

\begin{tabular}{|c|c|c|c|}
\hline 08 & 1 & $08^{\mathrm{D}}$ & 1 \\
\hline
\end{tabular}

Transaction ID : BD9C4C3EA719C47B788D

\begin{tabular}{lll}
\hline City & State & Zip Code \\
Garden City & NY & 11530 \\
\hline
\end{tabular}

Purpose of Disbursement

Travel Expense

Candidate Name

Office Sought:

$$
\begin{array}{|l|l}
\text { House } \\
\text { Senate } \\
\cline { 1 - 2 } \text { President }
\end{array}
$$

State: District:

Full Name (Last, First, Middle Initial)

\section{B. Microtel Inn and Suites}

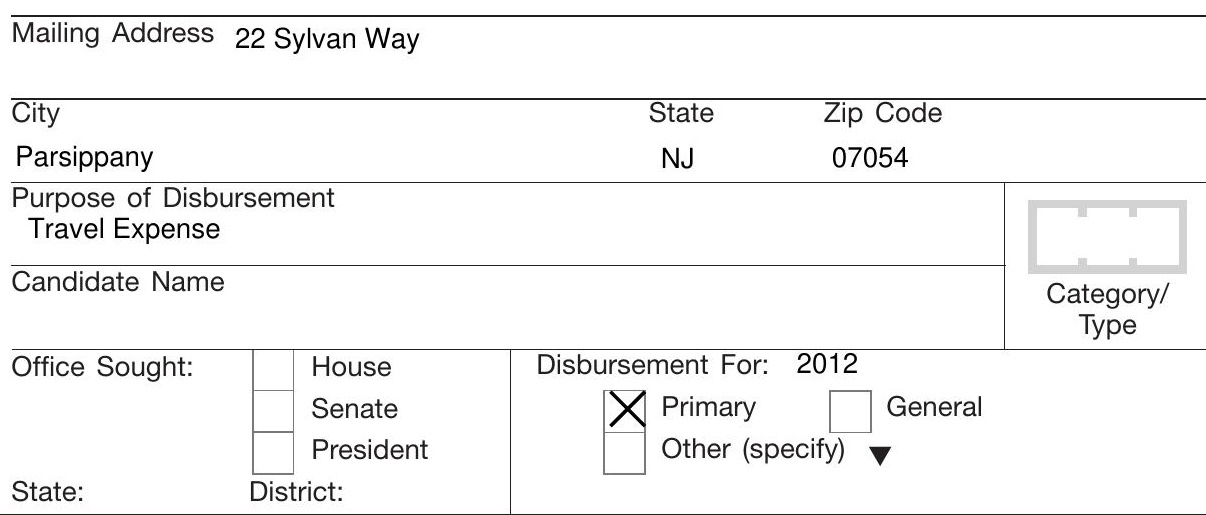

Full Name (Last, First, Middle Initial)

\section{c. Italian Oven Stockbridge GA}

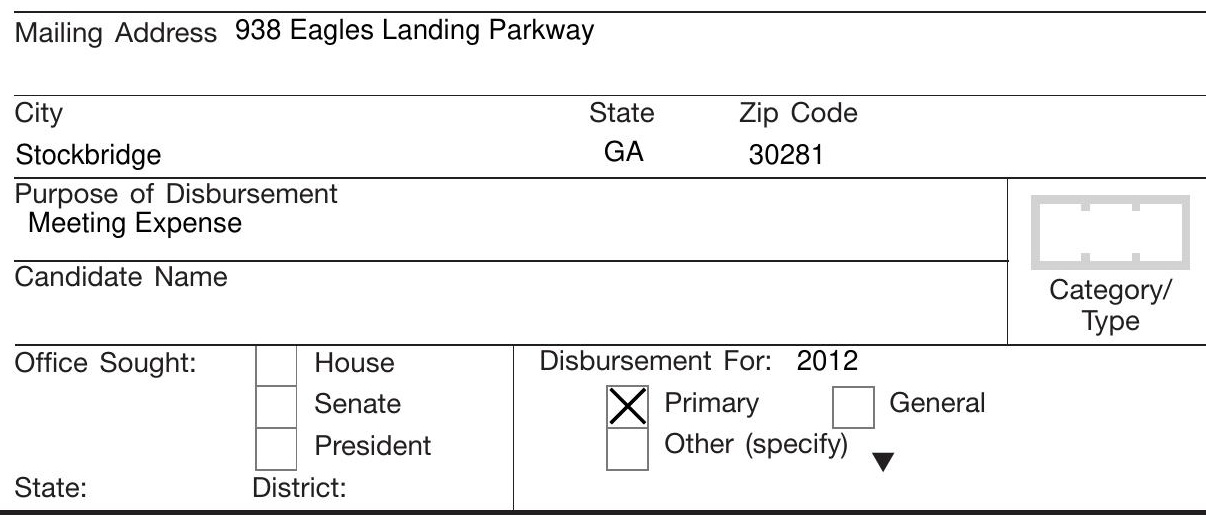

Subtotal Of Receipts This Page (optional).

Date of Disbursement

\begin{tabular}{|c|c|c|c|c|c|c|}
\hline M & M & D & D & Y & Y & Y \\
\hline & & 08 & & 2011 & \\
\hline
\end{tabular}

Transaction ID : BCAA8F0D0E74A4495813

Amount of Each Disbursement this Period

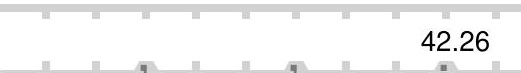

Total This Period (last page this line number only))

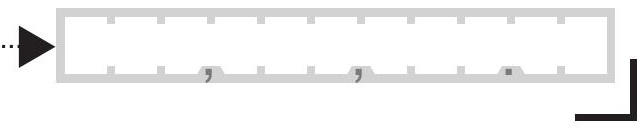




\section{SCHEDULE B-P}

\section{ITEMIZED DISBURSEMENTS}

\section{Use separate schedule(s) \\ for each category of the}

Detailed Summary Page
FOR LINE NUMBER: (check only one)

\begin{tabular}{|c|c|c|c|c|}
\hline $\mathrm{X}_{23}$ & 24 & 25 & 26 & \\
\hline $27 \mathrm{~b}$ & $28 a$ & $28 b$ & $28 \mathrm{c}$ & 2 \\
\hline
\end{tabular}

Any information copied from such Reports and Statements may not be sold or used by any person for the purpose of soliciting contributions or for commercial purposes, other than using the name and address of any political committee to solicit contributions from such committee.

NAME OF COMMITTEE (In Full)

\section{Friends of Herman Cain}

Full Name (Last, First, Middle Initial)

\section{A. Central Lighting and Equipment}

Mailing Address 675 NE 45th Place

Date of Disbursement

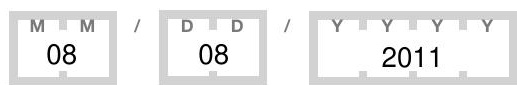

Transaction ID : B172F419357BC4749B99

\begin{tabular}{lcc}
\hline City & State & Zip Code \\
Des Moines & IA & 50313
\end{tabular}

Purpose of Disbursement

Event Production

Candidate Name X Primary $\square$ General

State:

\section{Senate}

President

District:

Full Name (Last, First, Middle Initial)

B. AT\&T

Mailing Address 208 S Akard Street

\begin{tabular}{lcc}
\hline City & State & Zip Code \\
Dallas & TX & 75202
\end{tabular}

Purpose of Disbursement

Telephone

Candidate Name

Office Sought:

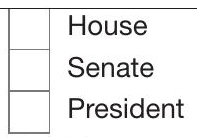

State:

District:

Full Name (Last, First, Middle Initial)

c. Facebook, Inc.

Mailing Address 1601 S. California Ave.

Disbursement For: 2012

Xrimary $\square$ General

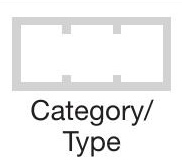

Date of Disbursement

\begin{tabular}{|c|c|c|c|c|}
\hline${ }^{M}{ }^{\mathrm{M}} / 8^{\mathrm{D}}$ & $08^{\mathrm{D}} / \mathrm{Y}^{\mathrm{Y}} \mathrm{Y}^{\mathrm{Y}}$ \\
\hline
\end{tabular}

Transaction ID : BA666F408733941BE9C4

Amount of Each Disbursement this Period

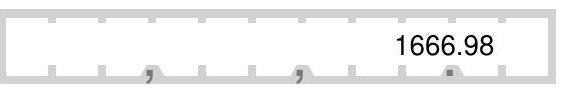

Date of Disbursement

\begin{tabular}{|c|c|c|c|c|}
\hline $08^{M}$ & 1 & D 08 & I & $\begin{array}{cccc}Y & Y & Y & Y \\
& 2011 & \end{array}$ \\
\hline
\end{tabular}

\begin{tabular}{lcc}
\hline City & State & Zip Code \\
Palo Alto & CA & 94304
\end{tabular}

Purpose of Disbursement

Advertising Expense

Candidate Name

Office Sought: $\quad$ House

\begin{tabular}{|l|l|} 
& House \\
& Senate \\
& President
\end{tabular}

Disbursement For: 2012

X $\begin{aligned} & \text { Primary } \\ & \text { Other (specify) }\end{aligned}$

State:

District:

Subtotal Of Receipts This Page (optional)

Total This Period (last page this line number only))

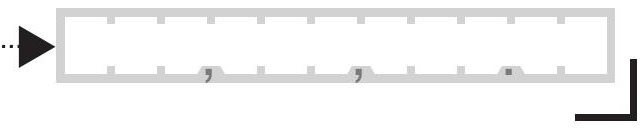

FEC Schedule B-P (Form 3P) (Rev. 03/2011) 


\section{SCHEDULE B-P}

\section{ITEMIZED DISBURSEMENTS}

Use separate schedule(s)

for each category of the

Detailed Summary Page
FOR LINE NUMBER: (check only one)

\begin{tabular}{|c|c|c|c|}
\hline $\mathrm{X} 23$ & 24 & 25 & 26 \\
\hline $27 \mathrm{~b}$ & $28 a$ & $28 b$ & $28 \mathrm{c}$ \\
\hline
\end{tabular}

Any information copied from such Reports and Statements may not be sold or used by any person for the purpose of soliciting contributions or for commercial purposes, other than using the name and address of any political committee to solicit contributions from such committee.

NAME OF COMMITTEE (In Full)

\section{Friends of Herman Cain}

Full Name (Last, First, Middle Initial)

A. Hotels.com

Mailing Address 10440 North Central Expressway

Suite 400

Date of Disbursement

\begin{tabular}{lccc}
\multicolumn{3}{c}{ Suite 400} & \\
\hline City & State & Zip Code \\
Dallas & TX & 75231 \\
\hline
\end{tabular}

Purpose of Disbursement

Travel Expense

TX 75231

Candidate Name

\begin{tabular}{l|l|l}
\hline Office Sought: & House & Disbursement For: 2012
\end{tabular} X Primary $\square$ General

State:

\section{Senate}

President

District:

Full Name (Last, First, Middle Initial)

B. Livestream

Mailing Address 111 8th Avenue

\begin{tabular}{lcc}
\hline City & State & Zip Code \\
New York & NY & 10011
\end{tabular}

Purpose of Disbursement

Web Services

Candidate Name

Office Sought:

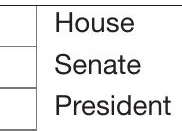

State:

District:

\begin{tabular}{c|c} 
Category/ \\
Type
\end{tabular}

Amount of Each Disbursement this Period

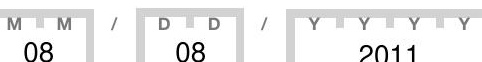

08

08

2011

Transaction ID : B66B8C2F5396F4D2F8A4 Type

Date of Disbursement

\begin{tabular}{|c|c|c|c|c|}
\hline $08^{M}$ & & ${ }^{\mathrm{D}}{ }^{\mathrm{D}}$ & & $\begin{array}{llll} & Y & Y & Y \\
& 2011 & Y\end{array}$ \\
\hline
\end{tabular}

Transaction ID : B67511006150B4C928B6

Full Name (Last, First, Middle Initial)

c. Air Tran

Mailing Address 9955 Air Tran Boulevard

Disbursement For: 2012

Xrimary $\square$ General

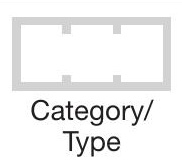

Amount of Each Disbursement this Period

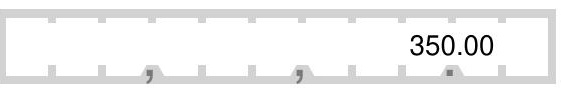

\begin{tabular}{lcc} 
& & \\
\hline City & State & Zip Code \\
Orlando & FL & 32827
\end{tabular}

Purpose of Disbursement

Travel Expense

Candidate Name

Date of Disbursement

\begin{tabular}{|c|c|c|c|c|c|c|}
\hline M & M & D & I & Y & Y & Y \\
\hline & & 08 & & 2011 & \\
\hline
\end{tabular}

Transaction ID : B630EBDC3E80E4BE995E

\begin{tabular}{c|c} 
Category/ \\
Type
\end{tabular}

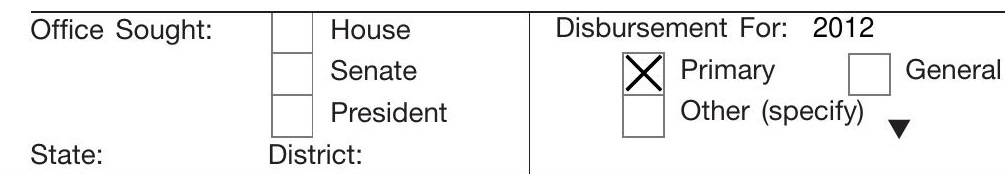

Subtotal Of Receipts This Page (optional).

Total This Period (last page this line number only)) 


\section{SCHEDULE B-P}

\section{ITEMIZED DISBURSEMENTS}

\section{Use separate schedule(s)}

for each category of the

Detailed Summary Page
FOR LINE NUMBER: (check only one)

\begin{tabular}{|c|c|c|c|}
\hline$\times{ }_{23}$ & 24 & 25 & 26 \\
\hline $27 b$ & $28 a$ & $28 \mathrm{~b}$ & $28 \mathrm{c}$ \\
\hline
\end{tabular}

Any information copied from such Reports and Statements may not be sold or used by any person for the purpose of soliciting contributions or for commercial purposes, other than using the name and address of any political committee to solicit contributions from such committee.

NAME OF COMMITTEE (In Full)

\section{Friends of Herman Cain}

Full Name (Last, First, Middle Initial)

A. Town Hall Liquors

Mailing Address 8135 Baltimore Ave.

Date of Disbursement

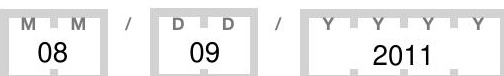

Transaction ID : B70BF40C8C5FE44D7BB6

\begin{tabular}{lll}
\hline City & State & Zip Code \\
College Park & MD & 20740
\end{tabular}

Purpose of Disbursement

Event Beverages

Candidate Name

Office Sought:

$$
\begin{aligned}
& \text { House } \\
& \text { Senate } \\
& \text { Presiden }
\end{aligned}
$$
District:

State:

Full Name (Last, First, Middle Initial)

B. Facebook, Inc.

Mailing Address 1601 S. California Ave.

\begin{tabular}{lcc}
\hline City & State & Zip Code \\
Palo Alto & CA & 94304
\end{tabular}

Purpose of Disbursement

Advertising Expense

Candidate Name

Office Sought:

House
Senate
President

State:

District:

Full Name (Last, First, Middle Initial)

\section{c. Holiday Inn Hotels}

\begin{tabular}{|c|c|c|c|c|c|}
\hline \multicolumn{6}{|c|}{ Mailing Address 3 Ravinia Drive } \\
\hline \multicolumn{2}{|l|}{ City } & State & \multicolumn{3}{|l|}{ Zip Code } \\
\hline \multicolumn{2}{|l|}{ Atlanta } & GA & \multicolumn{3}{|l|}{30346} \\
\hline \multicolumn{5}{|c|}{$\begin{array}{l}\text { Purpose of Disbursement } \\
\text { Travel Expense }\end{array}$} & \\
\hline \multicolumn{5}{|l|}{ Candidate Name } & $\begin{array}{l}\text { Category/ } \\
\text { Type }\end{array}$ \\
\hline \multirow[t]{3}{*}{ Office Sought: } & House & \multicolumn{4}{|c|}{ Disbursement For: 2012} \\
\hline & Senate & X & hary & General & \\
\hline & President & & er (specify) & & \\
\hline State: & rict: & & & & \\
\hline
\end{tabular}

Subtotal Of Receipts This Page (optional).

Total This Period (last page this line number only))
Date of Disbursement

\begin{tabular}{|c|c|c|c|c|}
\hline $08^{M}$ & 1 & $09^{\mathrm{D}}$ & 1 & 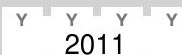 \\
\hline
\end{tabular}

\section{Transaction ID : B4F7952927E9A4A60ADA}

Amount of Each Disbursement this Period

Date of Disbursement

\begin{tabular}{|c|c|c|c|c|c|}
\hline M & M & D & Y & Y & Y \\
08 & & 09 & & 2011 & \\
\hline
\end{tabular}

Transaction ID : BC29944FA576B4640879

Amount of Each Disbursement this Period

2875.36 


\section{SCHEDULE B-P}

\section{ITEMIZED DISBURSEMENTS}

\section{Use separate schedule(s) \\ for each category of the}

Detailed Summary Page
FOR LINE NUMBER: (check only one)

\begin{tabular}{|c|c|c|c|}
\hline$\times{ }_{23}$ & 24 & 25 & 26 \\
\hline $27 b$ & $28 a$ & $28 \mathrm{~b}$ & $28 \mathrm{c}$ \\
\hline
\end{tabular}

Any information copied from such Reports and Statements may not be sold or used by any person for the purpose of soliciting contributions or for commercial purposes, other than using the name and address of any political committee to solicit contributions from such committee.

NAME OF COMMITTEE (In Full)

\section{Friends of Herman Cain}

Full Name (Last, First, Middle Initial)

A. Premiere Transportation

Mailing Address 109 International Dr. Ste. 300

\begin{tabular}{|c|c|c|}
\hline City & State & Zip Code \\
\hline Franklin & $\mathrm{TN}$ & 37067 \\
\hline
\end{tabular}

Purpose of Disbursement

Event Transportation Rental

Candidate Name

Office Sought: $\quad$ House

House
Senate

President

State:

District:

Full Name (Last, First, Middle Initial)

B. Walmart

\begin{tabular}{|c|c|c|c|c|}
\hline \multicolumn{5}{|c|}{ Mailing Address 702 SW 8th Street } \\
\hline \multicolumn{2}{|l|}{ City } & \multicolumn{3}{|c|}{ Zip Code } \\
\hline \multicolumn{2}{|l|}{ Bentonville } & \multicolumn{3}{|c|}{$72716-8611$} \\
\hline \multicolumn{4}{|c|}{$\begin{array}{l}\text { Purpose of Disbursement } \\
\text { Event Supplies }\end{array}$} & \\
\hline \multicolumn{4}{|l|}{ Candidate Name } & $\begin{array}{l}\text { Category/ } \\
\text { Type }\end{array}$ \\
\hline \multirow[t]{3}{*}{ Office Sought: } & House & \multirow{3}{*}{\multicolumn{3}{|c|}{$\begin{array}{l}\text { Disbursement For: } 2012 \\
\text { X Primary } \\
\text { Other (specify) }\end{array}$}} \\
\hline & Senate & & & \\
\hline & President & & & \\
\hline State: & rict: & & & \\
\hline
\end{tabular}

Date of Disbursement

\begin{tabular}{|c|c|c|c|c|}
\hline${ }^{M}$ & ${ }^{M}$ & ${ }^{\mathrm{D}}$ & $\mathrm{Y}^{\mathrm{D}}$ & $\mathrm{Y}^{\mathrm{Y}} \mathrm{Y}^{\mathrm{Y}}$ \\
\hline
\end{tabular}

Transaction ID : BF8412E5F74EF4A37B50

Full Name (Last, First, Middle Initial)

\section{c. United Airlines}

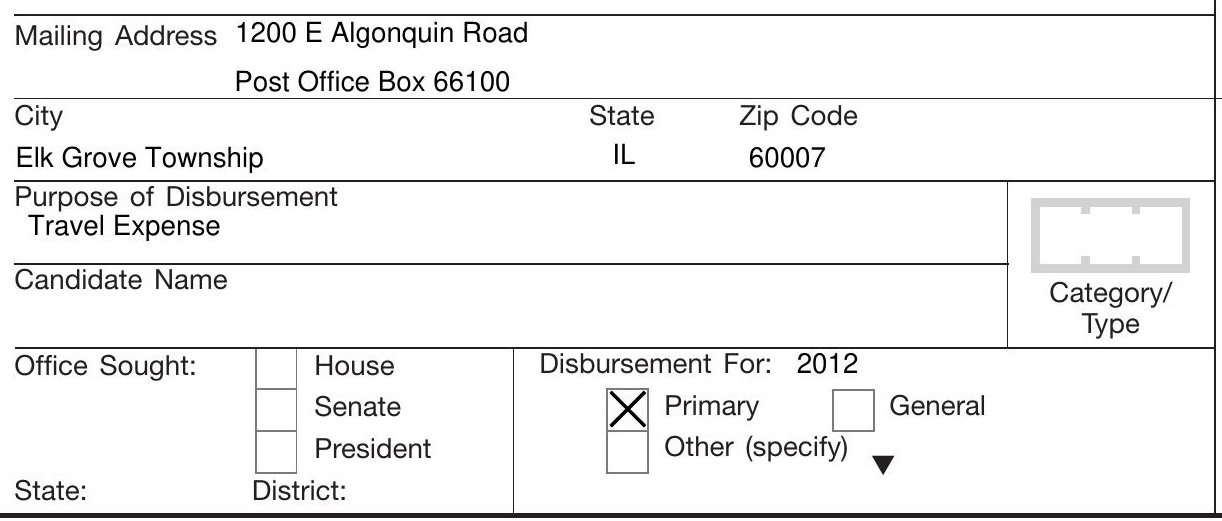

Subtotal Of Receipts This Page (optional)...

Date of Disbursement

\begin{tabular}{|c|c|c|c|c|}
\hline $08^{M}$ & 1 & D 09 & 1 & $\begin{array}{cccc}Y & Y & Y & Y \\
& 2011 & \end{array}$ \\
\hline
\end{tabular}

Transaction ID : B8E7EB3DBBABF4C95BEC

Amount of Each Disbursement this Period

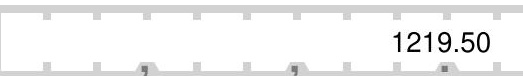

1219.50

Total This Period (last page this line number only))

17906.98

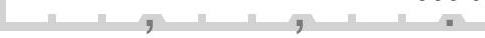

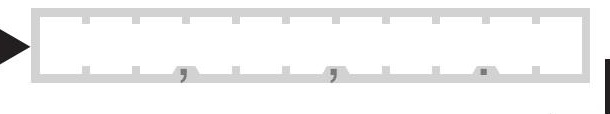




\section{SCHEDULE B-P}

\section{ITEMIZED DISBURSEMENTS}

\section{Use separate schedule(s) \\ for each category of the}

Detailed Summary Page
FOR LINE NUMBER: (check only one)

\begin{tabular}{|c|c|c|c|}
\hline$\times{ }_{23}$ & 24 & 25 & 26 \\
\hline $27 b$ & $28 a$ & $28 \mathrm{~b}$ & $28 \mathrm{c}$ \\
\hline
\end{tabular}

Any information copied from such Reports and Statements may not be sold or used by any person for the purpose of soliciting contributions or for commercial purposes, other than using the name and address of any political committee to solicit contributions from such committee.

NAME OF COMMITTEE (In Full)

\section{Friends of Herman Cain}

Full Name (Last, First, Middle Initial)

A. RMA Chaffeured Transportation

Mailing Address 6010 Executive Boulevard Suite 101

\begin{tabular}{lll}
\hline City & State & Zip Code \\
Rockville & MD & 20852 \\
\hline
\end{tabular}

Purpose of Disbursement

Travel Expense

Candidate Name

\begin{tabular}{l|l|l}
\hline Office Sought: & House & Disbursement For: 2012
\end{tabular} X Primary $\square$ General

State:

\section{Senate} President

Full Name (Last, First, Middle Initial)

\section{B. Delta Airlines}

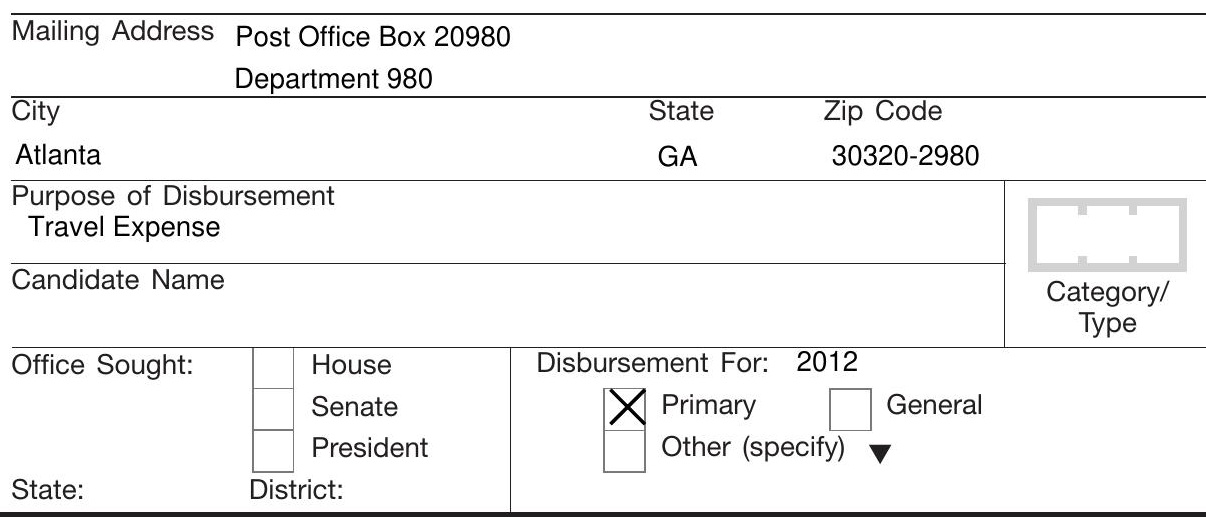

Date of Disbursement

Full Name (Last, First, Middle Initial)

\section{c. Staples}

\begin{tabular}{|c|c|c|c|c|c|}
\hline \multicolumn{6}{|c|}{ Mailing Address 500 Staples Drive } \\
\hline \multicolumn{2}{|l|}{ City } & State & \multicolumn{3}{|l|}{ Zip Code } \\
\hline \multicolumn{2}{|l|}{ Framingham } & MA & \multicolumn{3}{|l|}{01702} \\
\hline \multicolumn{5}{|c|}{$\begin{array}{l}\text { Purpose of Disbursement } \\
\text { Office Supplies }\end{array}$} & \\
\hline \multicolumn{5}{|c|}{ Candidate Name } & $\begin{array}{l}\text { Category/ } \\
\text { Type }\end{array}$ \\
\hline \multirow[t]{3}{*}{ Office Sought: } & House & \multicolumn{4}{|c|}{ Disbursement For: 2012} \\
\hline & Senate & \multirow{3}{*}{\multicolumn{2}{|c|}{$\begin{array}{l}\text { Primary } \\
\text { Other (specify) }\end{array}$}} & \multirow{2}{*}{\multicolumn{2}{|c|}{ General }} \\
\hline & President & & & & \\
\hline State: & \multicolumn{3}{|c|}{ District: } & & \\
\hline
\end{tabular}

Subtotal Of Receipts This Page (optional)......

Date of Disbursement

\begin{tabular}{|c|c|c|c|c|c|c|}
\hline M & M & D & Y & Y & Y \\
08 & & 09 & & 2011 & \\
\hline
\end{tabular}

\section{Transaction ID : B51BA086A13F944B3B89}

Amount of Each Disbursement this Period

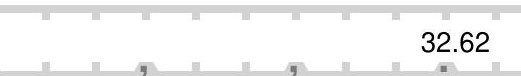

Total This Period (last page this line number only)) 


\section{SCHEDULE B-P}

\section{ITEMIZED DISBURSEMENTS}

\section{Use separate schedule(s) \\ for each category of the}

Detailed Summary Page
FOR LINE NUMBER: (check only one)

\begin{tabular}{|c|c|c|c|}
\hline$X_{23}$ & 24 & 25 & 26 \\
\hline $27 \mathrm{~b}$ & $28 a$ & $28 b$ & $28 \mathrm{c}$ \\
\hline
\end{tabular}

Any information copied from such Reports and Statements may not be sold or used by any person for the purpose of soliciting contributions or for commercial purposes, other than using the name and address of any political committee to solicit contributions from such committee.

NAME OF COMMITTEE (In Full)

\section{Friends of Herman Cain}

Full Name (Last, First, Middle Initial)

\section{A. US Airways}

Mailing Address 4000 E Sky Harbor Boulevard

Date of Disbursement

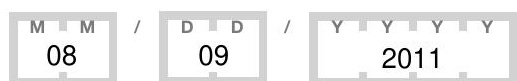

Transaction ID : BEB734AB2541F44058B4

\begin{tabular}{lcc}
\hline City & State & Zip Code \\
Phoenix & AZ & 85034
\end{tabular}

Purpose of Disbursement

Travel Expense

Candidate Name

Office Sought:

$$
\begin{array}{|l|l}
\text { House } \\
\text { Senate } \\
\text { President }
\end{array}
$$

State: District:
Full Name (Last, First, Middle Initial)

\section{B. Eberle Communications Group}

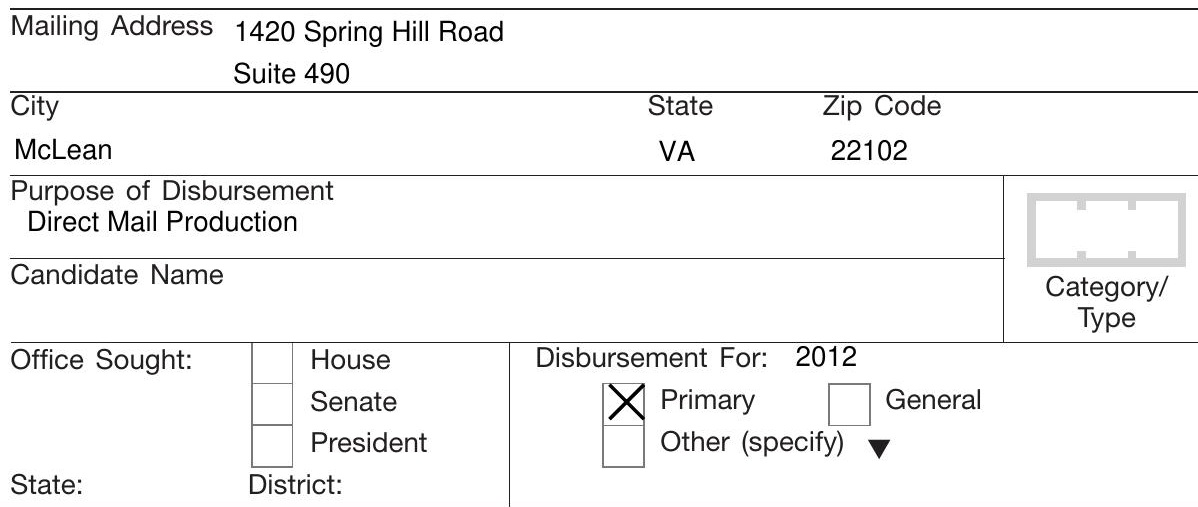

Full Name (Last, First, Middle Initial)

\section{c. SunTrust Bank}

Mailing Address 980 Eagles Landing Parkway

\begin{tabular}{lcc}
\hline City & State & Zip Code \\
Stockbridge & GA & 30281
\end{tabular}

Purpose of Disbursement CC Transaction Fees

Candidate Name

Office Sought:

\begin{tabular}{|l|l|}
\hline & House \\
& Senate \\
& President \\
& District:
\end{tabular}

Disbursement For: 2012 X $\begin{aligned} & \text { Primary } \\ & \text { Other (specify) }\end{aligned}$

State:

District:
Date of Disbursement

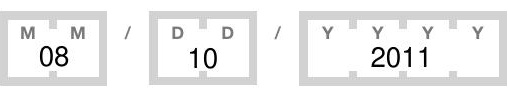

\section{Transaction ID : BE213F55615624ADAA07}

Amount of Each Disbursement this Period

\begin{tabular}{|c|c|c|c|c|}
\hline $08^{M}$ & t & D 10 & & $\begin{array}{lll}Y & Y & Y \\
2011 & Y\end{array}$ \\
\hline
\end{tabular}

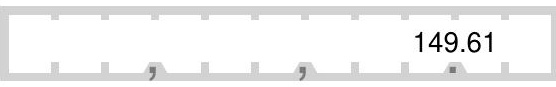

Date of Disbursement

Transaction ID : BCE318FFD08374B6FAA9

Amount of Each Disbursement this Period

13523.80

Subtotal Of Receipts This Page (optional).

Total This Period (last page this line number only))

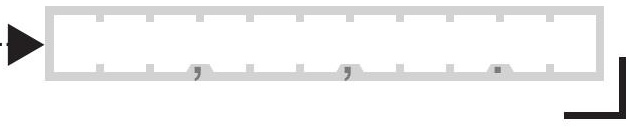




\section{SCHEDULE B-P}

\section{ITEMIZED DISBURSEMENTS}

Use separate schedule(s)

for each category of the

Detailed Summary Page
FOR LINE NUMBER: (check only one)

\begin{tabular}{|c|c|c|c|}
\hline$X_{23}$ & 24 & 25 & 26 \\
\hline $27 \mathrm{~b}$ & $28 a$ & $28 b$ & $28 \mathrm{c}$ \\
\hline
\end{tabular}

Any information copied from such Reports and Statements may not be sold or used by any person for the purpose of soliciting contributions or for commercial purposes, other than using the name and address of any political committee to solicit contributions from such committee.

NAME OF COMMITTEE (In Full)

\section{Friends of Herman Cain}

Full Name (Last, First, Middle Initial)

A. Holiday Inn Hotels

Mailing Address 3 Ravinia Drive

Ste. 100

\begin{tabular}{lll}
\hline City & State & Zip Code \\
Atlanta & GA & 30346 \\
\hline Purpose of Disbursement & &
\end{tabular}

Purpose of Disbursement

Travel Expense

Candidate Name

Office Sought:

State:

Full Name (Last, First, Middle Initial)

B. Facebook, Inc.

Mailing Address 1601 S. California Ave.

\begin{tabular}{lcc}
\hline City & State & Zip Code \\
Palo Alto & CA & 94304
\end{tabular}

Purpose of Disbursement

Advertising Expense

Candidate Name

Office Sought:

House
Senate
President

State:

District:

Full Name (Last, First, Middle Initial)

c. The Soarin' Group

Mailing Address Post Office Box 14160

\begin{tabular}{lcc}
\hline City & State & Zip Code \\
Chicago & IL & $60614-0160$
\end{tabular}

Purpose of Disbursement

Campaign Strategy Consulting

Candidate Name

Office Sought: $\quad$ House

\begin{tabular}{|l|l|} 
& House \\
& Senate \\
& President \\
\hline & District:
\end{tabular}

State:

District:

Subtotal Of Receipts This Page (optional).

Disbursement For: 2012

Х $\begin{aligned} & \text { Primary } \\ & \text { Other (specify) }\end{aligned}$
Date of Disbursement

\begin{tabular}{|c|c|c|c|c|c|}
\hline${ }^{M}$ & M & D & Y \\
\hline & 10 & 2011 \\
\hline
\end{tabular}

Transaction ID : B351DC4A341DE429C98A

Amount of Each Disbursement this Period

557.76

Date of Disbursement

\begin{tabular}{|c|c|c|c|c|}
\hline $08^{M}$ & & ${ }^{D} 0^{D}$ & & 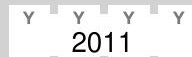 \\
\hline
\end{tabular}

Transaction ID : B1524C8EODEE14A86817

Amount of Each Disbursement this Period
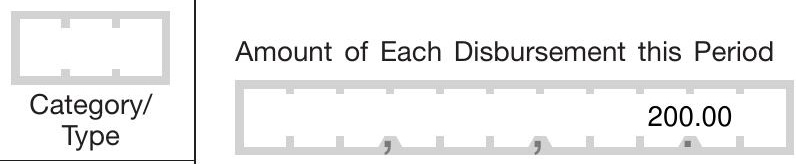

Date of Disbursement

\begin{tabular}{|c|c|c|c|c|}
\hline $08^{M}$ & 1 & D $10^{\mathrm{D}}$ & I & 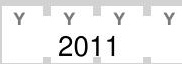 \\
\hline
\end{tabular}

Transaction ID : B1BEBB255D4634367A87

Amount of Each Disbursement this Period

5000.00

Total This Period (last page this line number only)) 


\section{SCHEDULE B-P}

\section{ITEMIZED DISBURSEMENTS}

\section{Use separate schedule(s) \\ for each category of the}

Detailed Summary Page
FOR LINE NUMBER: (check only one)

\begin{tabular}{|c|c|c|c|}
\hline$\times{ }_{23}$ & 24 & 25 & 26 \\
\hline $27 b$ & $28 a$ & $28 \mathrm{~b}$ & $28 \mathrm{c}$ \\
\hline
\end{tabular}

Any information copied from such Reports and Statements may not be sold or used by any person for the purpose of soliciting contributions or for commercial purposes, other than using the name and address of any political committee to solicit contributions from such committee.

NAME OF COMMITTEE (In Full)

\section{Friends of Herman Cain}

Full Name (Last, First, Middle Initial)

A. Omega List Company Inc.

Mailing Address 1420 Spring Hill Road

Suite 490

\begin{tabular}{lll}
\hline City & State & Zip Code \\
McLean & VA & 22102
\end{tabular}

Purpose of Disbursement

Direct Mail Production

Candidate Name

Office Sought:

Full Name (Last, First, Middle Initial)

B. Air Tran

Mailing Address 9955 Air Tran Boulevard

\begin{tabular}{lcc}
\hline City & State & Zip Code \\
Orlando & FL & 32827
\end{tabular}

Purpose of Disbursement

Travel Expense

Candidate Name

Office Sought:

$$
\begin{array}{|l}
\text { House } \\
\text { Senate } \\
\text { President }
\end{array}
$$

State:

District:

\begin{tabular}{|c|c|c|c|c|c|}
\hline \multicolumn{6}{|c|}{ Mailing Address 34729 Petersen Road } \\
\hline \multicolumn{2}{|l|}{ City } & State & Zip Code & & \\
\hline \multicolumn{2}{|l|}{ Agua Dulce } & $\mathrm{CA}$ & 91390 & & \\
\hline \multicolumn{5}{|c|}{$\begin{array}{l}\text { Purpose of Disbursement } \\
\text { Media Production }\end{array}$} & \\
\hline \multicolumn{5}{|c|}{ Candidate Name } & $\begin{array}{l}\text { Category/ } \\
\text { Type }\end{array}$ \\
\hline \multirow[t]{3}{*}{ Office Sought: } & House & \multicolumn{4}{|c|}{ Disbursement For: 2012} \\
\hline & Senate & \multirow{3}{*}{\multicolumn{2}{|c|}{$\begin{array}{l}\text { Primary } \\
\text { Other (specify) }\end{array}$}} & \multirow{2}{*}{\multicolumn{2}{|c|}{ General }} \\
\hline & President & & & & \\
\hline State: & District: & & & & \\
\hline
\end{tabular}

Full Name (Last, First, Middle Initial)

\section{c. Little Bonanza Productions LLC}

\begin{tabular}{|c|c|c|c|c|}
\hline $08^{M}$ & I & D $10^{\mathrm{D}}$ & I & $\begin{array}{cccc} & Y & Y & Y \\
& 2011 & \end{array}$ \\
\hline
\end{tabular}

Subtotal Of Receipts This Page (optional).

Date of Disbursement

Transaction ID : B178DBCC483A0473AB79

\begin{tabular}{|c|c|c|c|c|}
\hline $08^{M}$ & 1 & $10^{\mathrm{D}}$ & I & 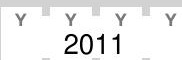 \\
\hline
\end{tabular}

Amount of Each Disbursement this Period

Date of Disbursement

Transaction ID : B0249A8860D864E5A833

Amount of Each Disbursement this Period

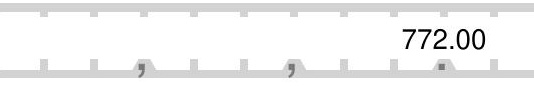

Total This Period (last page this line number only)) 


\section{SCHEDULE B-P}

\section{ITEMIZED DISBURSEMENTS}

\section{Use separate schedule(s) \\ for each category of the}

Detailed Summary Page
FOR LINE NUMBER: (check only one)

\begin{tabular}{|c|c|c|c|}
\hline$\times{ }_{23}$ & 24 & 25 & 26 \\
\hline $27 b$ & $28 a$ & $28 \mathrm{~b}$ & $28 \mathrm{c}$ \\
\hline
\end{tabular}

Any information copied from such Reports and Statements may not be sold or used by any person for the purpose of soliciting contributions or for commercial purposes, other than using the name and address of any political committee to solicit contributions from such committee.

NAME OF COMMITTEE (In Full)

\section{Friends of Herman Cain}

Full Name (Last, First, Middle Initial)

A. Air Tran

Mailing Address 9955 Air Tran Boulevard

Date of Disbursement

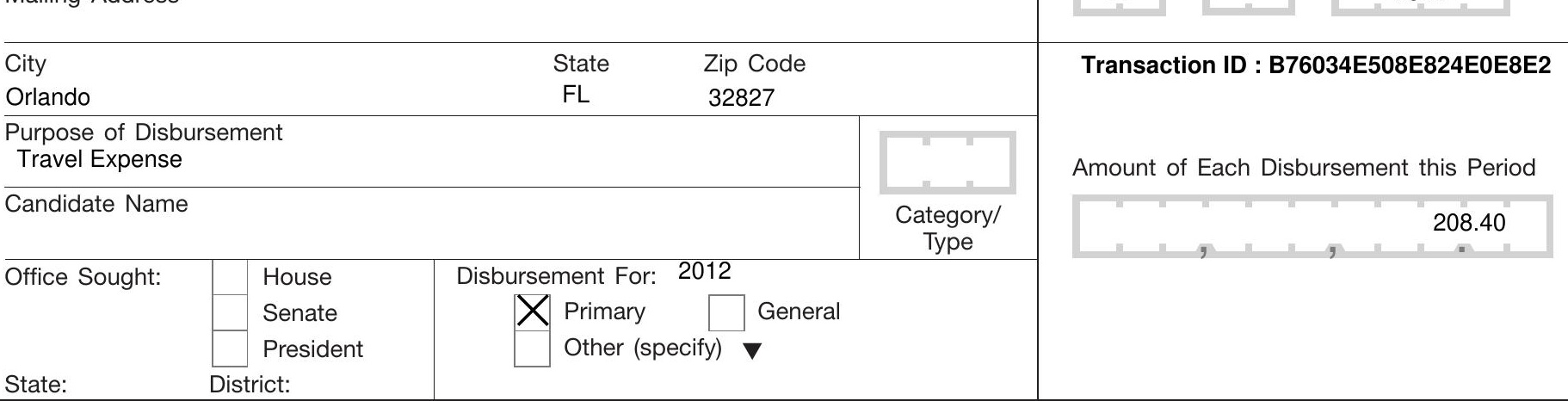

Full Name (Last, First, Middle Initial)

B. Inkit Printing \& Consulting LLC

Mailing Address 321 Oriole Lane

Date of Disbursement

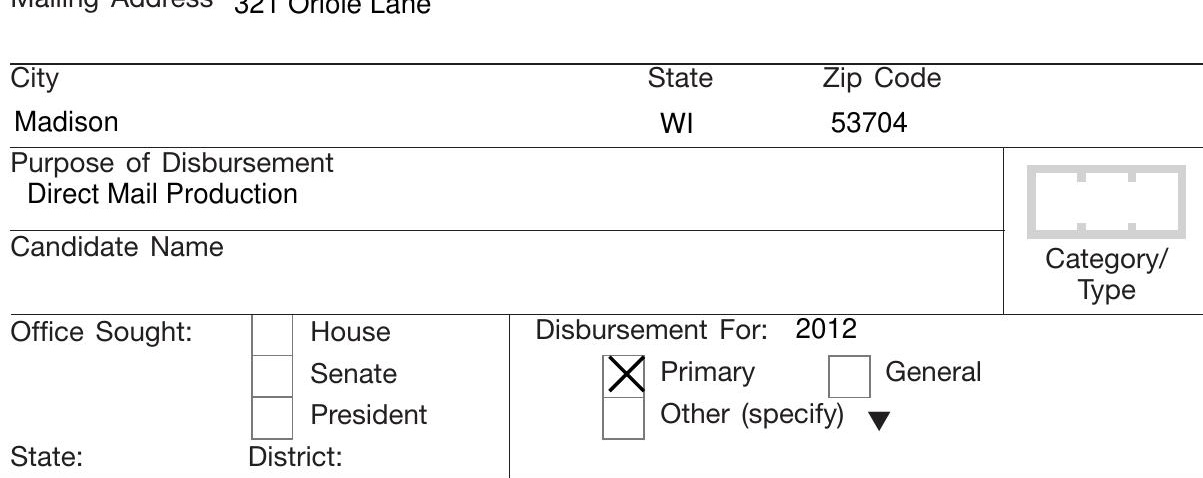

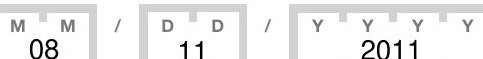

11

Transaction ID : B2E3BFAB70779462D9E1

Amount of Each Disbursement this Period

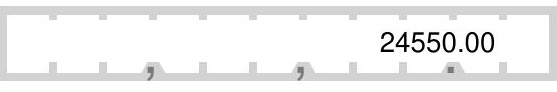

Full Name (Last, First, Middle Initial)

c. William Head

Mailing Address PO Box 2158

\begin{tabular}{lcc}
\hline City & State & Zip Code \\
Stockbridge & GA & $30281-8909$
\end{tabular}

Purpose of Disbursement

Staff Salary

Candidate Name

Office Sought: $\quad$ House

$\begin{aligned} & \text { House } \\ & \text { Senate } \\ & \text { President }\end{aligned}$
District:

State:
Date of Disbursement

\begin{tabular}{|c|c|c|c|c|}
\hline $08^{M}$ & I & D $11^{\mathrm{D}}$ & 1 & $\begin{array}{cccc}Y & Y & Y & Y \\
& 2011 & \end{array}$ \\
\hline
\end{tabular}

Transaction ID : B83191FC3539A45EBAA6

Amount of Each Disbursement this Period

1250.00

Subtotal Of Receipts This Page (optional).

Total This Period (last page this line number only))

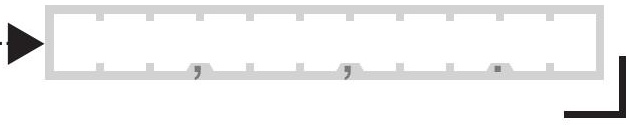




\section{SCHEDULE B-P}

\section{ITEMIZED DISBURSEMENTS}

Use separate schedule(s)

for each category of the

Detailed Summary Page
FOR LINE NUMBER: (check only one)

\begin{tabular}{|c|c|c|c|}
\hline $\mathrm{X} 23$ & 24 & 25 & 26 \\
\hline $27 \mathrm{~b}$ & $28 a$ & $28 b$ & $28 \mathrm{c}$ \\
\hline
\end{tabular}

Any information copied from such Reports and Statements may not be sold or used by any person for the purpose of soliciting contributions or for commercial purposes, other than using the name and address of any political committee to solicit contributions from such committee.

NAME OF COMMITTEE (In Full)

\section{Friends of Herman Cain}

Full Name (Last, First, Middle Initial)

A. Nathan Naidu

Mailing Address 3601 canton rd \#131

Date of Disbursement

\begin{tabular}{lcc}
\hline City & State & Zip Code \\
Marietta & GA & $30066-2892$ \\
\hline
\end{tabular}

Purpose of Disbursement

Staff Salary

Candidate Name

\begin{tabular}{l|l|l}
\hline Office Sought: & House & Disbursement For: 2012
\end{tabular} Xrimary $\square$ General

State:

\section{Senate}

President

District:

Full Name (Last, First, Middle Initial)

B. Francis Boustany, III

\begin{tabular}{|c|c|c|c|c|}
\hline \multicolumn{5}{|c|}{ Mailing Address 126 Westfield Drive } \\
\hline \multicolumn{2}{|l|}{ City } & \multicolumn{3}{|c|}{ Zip Code } \\
\hline \multicolumn{2}{|l|}{ Lafayette } & \multicolumn{3}{|c|}{$70503-5484$} \\
\hline \multicolumn{4}{|c|}{$\begin{array}{l}\text { Purpose of Disbursement } \\
\text { Staff Salary }\end{array}$} & \\
\hline \multicolumn{4}{|l|}{ Candidate Name } & $\begin{array}{l}\text { Category/ } \\
\text { Type }\end{array}$ \\
\hline \multirow[t]{3}{*}{ Office Sought: } & House & \multirow{3}{*}{\multicolumn{3}{|c|}{$\begin{array}{l}\text { Disbursement For: } 2012 \\
\text { X Primary } \\
\text { Other (specify) }\end{array}$}} \\
\hline & Senate & & & \\
\hline & President & & & \\
\hline State: & \multicolumn{4}{|c|}{ District: } \\
\hline
\end{tabular}

Date of Disbursement

\begin{tabular}{|c|c|c|c|c|}
\hline $08^{M}$ & 1 & ${ }^{D} 1^{\mathrm{D}}$ & 1 & $\begin{array}{llll}Y & Y & Y & Y \\
& 2011 & \end{array}$ \\
\hline
\end{tabular}

Transaction ID : B182176244B7D4E6386F

Full Name (Last, First, Middle Initial)

\section{c. Brenda Hicks}

\begin{tabular}{|c|c|c|c|c|c|}
\hline \multicolumn{6}{|c|}{ Mailing Address 3653 S 75th Street } \\
\hline \multicolumn{2}{|l|}{ City } & State & \multicolumn{3}{|l|}{ Zip Code } \\
\hline \multicolumn{2}{|l|}{ Milwaukee } & WI & \multicolumn{3}{|c|}{$53220-1139$} \\
\hline \multicolumn{5}{|c|}{$\begin{array}{l}\text { Purpose of Disbursement } \\
\text { Staff Salary }\end{array}$} & \\
\hline \multicolumn{5}{|c|}{ Candidate Name } & $\begin{array}{l}\text { Category/ } \\
\text { Type }\end{array}$ \\
\hline \multirow[t]{3}{*}{ Office Sought: } & House & \multicolumn{4}{|c|}{ Disbursement For: 2012} \\
\hline & Senate & \multirow{3}{*}{\multicolumn{2}{|c|}{$\begin{array}{l}\text { Primary } \\
\text { Other (specify) }\end{array}$}} & \multirow{2}{*}{\multicolumn{2}{|c|}{ General }} \\
\hline & President & & & & \\
\hline State: & District: & & & & \\
\hline
\end{tabular}

Subtotal Of Receipts This Page (optional)...

Date of Disbursement

\begin{tabular}{|c|c|c|c|c|}
\hline $08^{M}$ & 1 & D ${ }_{11}^{\mathrm{D}}$ & 1 & 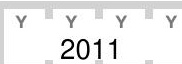 \\
\hline
\end{tabular}

Transaction ID : B7A4ADEC3F5FC49648CD

Amount of Each Disbursement this Period

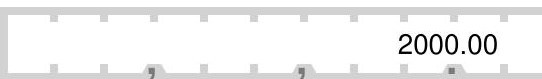

Amount of Each Disbursement this Period

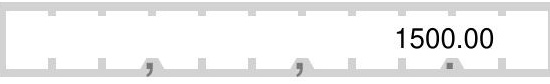

Total This Period (last page this line number only)) 


\section{SCHEDULE B-P}

\section{ITEMIZED DISBURSEMENTS}

\section{Use separate schedule(s) \\ for each category of the}

Detailed Summary Page
FOR LINE NUMBER: (check only one)

\begin{tabular}{|c|c|c|c|}
\hline$\times{ }_{23}$ & 24 & 25 & 26 \\
\hline $27 b$ & $28 a$ & $28 \mathrm{~b}$ & $28 \mathrm{c}$ \\
\hline
\end{tabular}

Any information copied from such Reports and Statements may not be sold or used by any person for the purpose of soliciting contributions or for commercial purposes, other than using the name and address of any political committee to solicit contributions from such committee.

NAME OF COMMITTEE (In Full)

\section{Friends of Herman Cain}

Full Name (Last, First, Middle Initial)

\section{A. Ashley Frasca}

Mailing Address 601 Springharbor Drive

Date of Disbursement

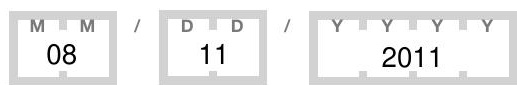

Transaction ID : B398FA7297CBC43BCACC

\begin{tabular}{lll}
\hline City & State & Zip Code \\
Woodstock & GA & $30188-6044$ \\
\hline
\end{tabular}

Purpose of Disbursement

Staff Salary

Candidate Name

\begin{tabular}{l|l|l}
\hline Office Sought: & House & Disbursement For: 2012
\end{tabular} Xrimary $\square$ General

State:

\section{Senate}

President

District:

Full Name (Last, First, Middle Initial)

B. Tina Spratling

Mailing Address PO Box 2158

\begin{tabular}{lcc}
\hline City & State & Zip Code \\
Stockbridge & GA & $30281-8909$
\end{tabular}

Purpose of Disbursement

Staff Salary

Candidate Name

Office Sought:

\begin{tabular}{l|l} 
House \\
Senate \\
President
\end{tabular}

State:

District:

Full Name (Last, First, Middle Initial)

\section{c. Lisa Lockwood}

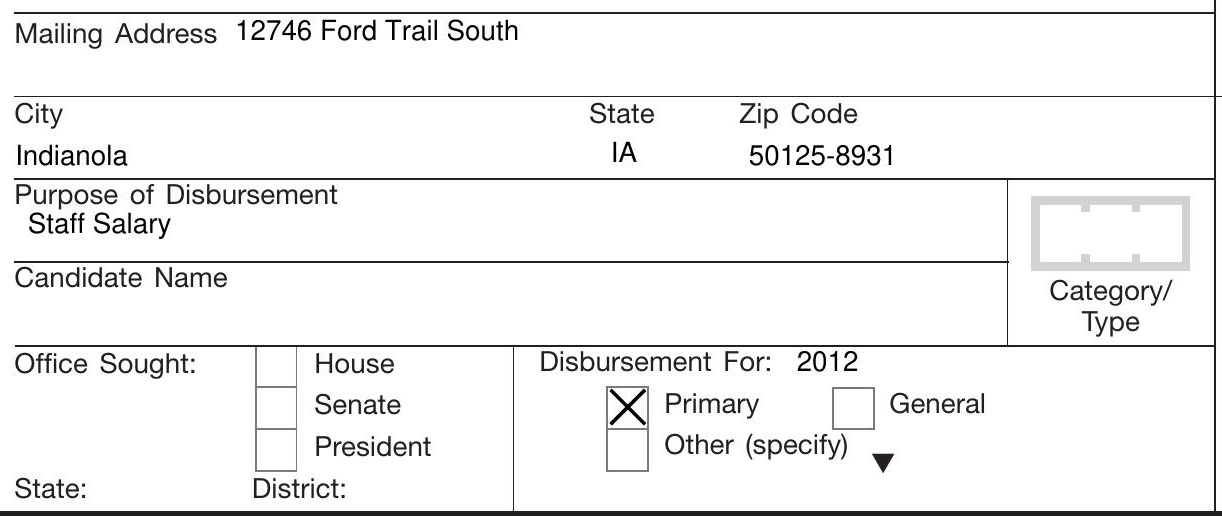

Subtotal Of Receipts This Page (optional)...

Date of Disbursement

\begin{tabular}{|c|c|c|c|c|c|}
\hline${ }^{M}$ & $/$ & $\mathrm{D}$ & $\mathrm{Y}$ & $\mathrm{Y}$ & $\mathrm{Y}$ \\
\hline & 11 & & 2011 & \\
\hline
\end{tabular}

Transaction ID : B3CBD511070D149D3A5D

Amount of Each Disbursement this Period

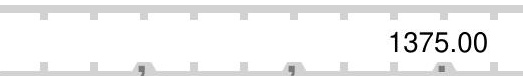

1375.00

Total This Period (last page this line number only))..

4009.67

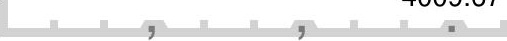

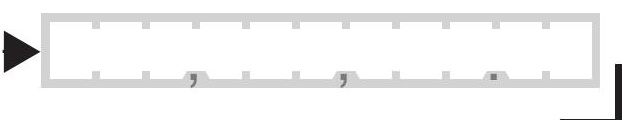




\section{SCHEDULE B-P}

\section{ITEMIZED DISBURSEMENTS}

\section{Use separate schedule(s) \\ for each category of the}

Detailed Summary Page
FOR LINE NUMBER: (check only one)

\begin{tabular}{|c|c|c|c|}
\hline$\times{ }_{23}$ & 24 & 25 & 26 \\
\hline $27 b$ & $28 a$ & $28 \mathrm{~b}$ & $28 \mathrm{c}$ \\
\hline
\end{tabular}

Any information copied from such Reports and Statements may not be sold or used by any person for the purpose of soliciting contributions or for commercial purposes, other than using the name and address of any political committee to solicit contributions from such committee.

NAME OF COMMITTEE (In Full)

\section{Friends of Herman Cain}

Full Name (Last, First, Middle Initial)

A. Stacy DeJarnette

Mailing Address 207 Robin Street

Date of Disbursement

\begin{tabular}{lcc}
\hline City & State & Zip Code \\
White Hall & AR & $71602-5418$
\end{tabular}

Purpose of Disbursement

Staff Salary

Candidate Name

\begin{tabular}{l|l|l}
\hline Office Sought: & House & Disbursement For: 2012
\end{tabular} X Primary $\square$ General

State:

\section{Senate}

President

District:

Full Name (Last, First, Middle Initial)

B. Raquel Rhada Hirsch

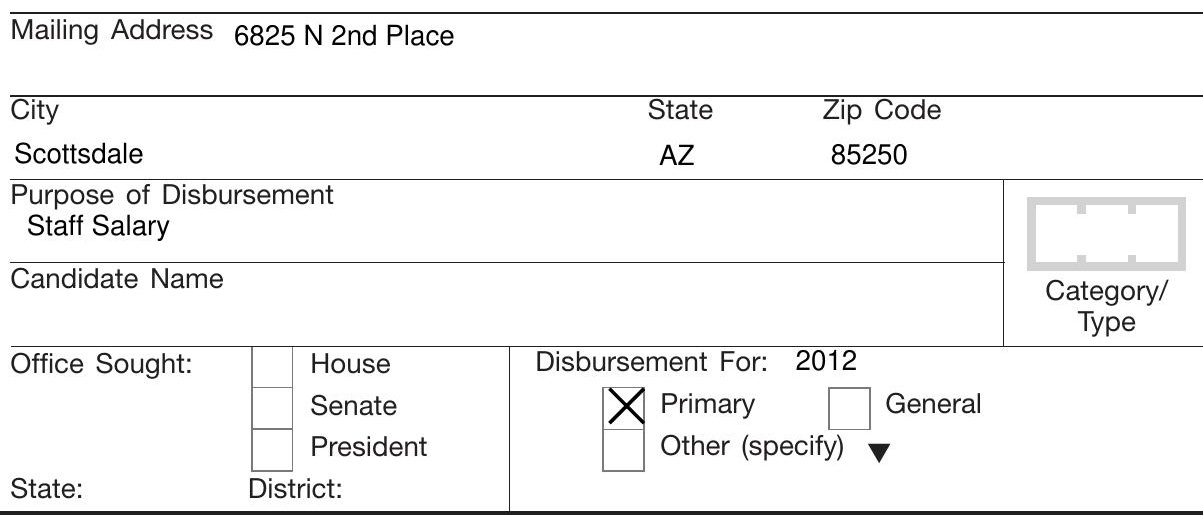

Date of Disbursement

\begin{tabular}{|c|c|c|c|c|}
\hline${ }^{M}$ & ${ }^{M}$ & $8^{\mathrm{D}}$ & ${ }^{\mathrm{D}}$ & $\mathrm{Y}^{\mathrm{Y}} \mathrm{Y}^{\mathrm{Y}}$ \\
\hline
\end{tabular}

Transaction ID : B6EFA168FE4C0452FB64

Full Name (Last, First, Middle Initial)

\section{c. Steven Hensler}

Mailing Address 401 Woodview Drive

\begin{tabular}{lcc}
\hline City & State & Zip Code \\
Sun Prairie & WI & $53590-2353$
\end{tabular}

Purpose of Disbursement

Staff Salary

Candidate Name

Office Sought: $\quad$ House

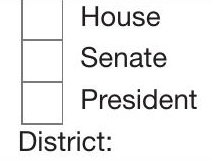

Disbursement For: 2012

X $\begin{aligned} & \text { Primary } \\ & \text { Other (specify) }\end{aligned}$

\begin{tabular}{|c|c|c|c|c|}
\hline $08^{M}$ & 1 & D 11 & 1 & $\begin{array}{llll}Y & Y & Y & Y \\
& 2011 & \end{array}$ \\
\hline
\end{tabular}

Date of Disbursement

State:

Subtotal Of Receipts This Page (optional).

Total This Period (last page this line number only))

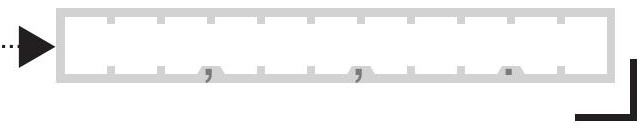




\section{SCHEDULE B-P}

\section{ITEMIZED DISBURSEMENTS}

\section{Use separate schedule(s) \\ for each category of the}

Detailed Summary Page
FOR LINE NUMBER: (check only one)

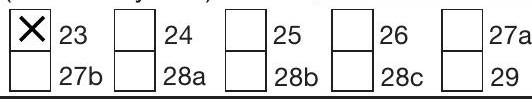

Any information copied from such Reports and Statements may not be sold or used by any person for the purpose of soliciting contributions or for commercial purposes, other than using the name and address of any political committee to solicit contributions from such committee.

NAME OF COMMITTEE (In Full)

\section{Friends of Herman Cain}

Full Name (Last, First, Middle Initial)

A. Sandra Poehler

Mailing Address 57 Presidential Drive

Apartment 5

Date of Disbursement

\begin{tabular}{lll}
\multicolumn{3}{c}{ Apartment 5} \\
City & State & Zip Code \\
Quincy & MA & $02169-8838$
\end{tabular}

Purpose of Disbursement

Staff Salary

Candidate Name

Office Sought: $\quad$ House

\section{Senate}

President

State:

District:

Full Name (Last, First, Middle Initial)

\section{B. Lisa Shiflett}

Date of Disbursement

Mailing Address 157 Stokes Drive

\begin{tabular}{lcc}
\hline City & State & Zip Code \\
Stockbridge & GA & $30281-1376$
\end{tabular}

Purpose of Disbursement

Staff Salary

Candidate Name

Office Sought:

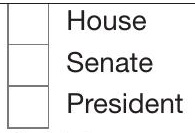

State:

District:

Disbursement For: 2012
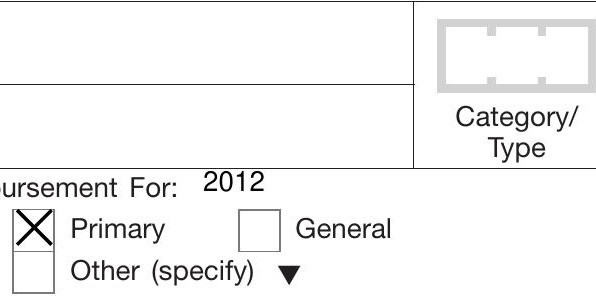

Amount of Each Disbursement this Period

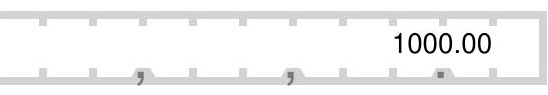

Full Name (Last, First, Middle Initial)

c. Karleen Smith

Mailing Address 105 Marilyn Drive E

\begin{tabular}{lcc}
\hline City & State & Zip Code \\
Fayetteville & GA & 30214 \\
\hline
\end{tabular}

Purpose of Disbursement

Staff Salary

Candidate Name

\begin{tabular}{|c|c|}
\hline Office Sought: & House \\
\hline & Senate \\
\hline & President \\
\hline ate & trict: \\
\hline
\end{tabular}

Disbursement For: 2012

Primary
Other (specify) General

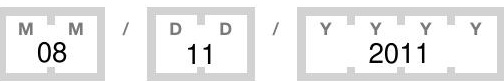

Transaction ID : BB3A3F8F7257F4B0E993

Amount of Each Disbursement this Period

2500.00

Date of Disbursement

\begin{tabular}{|c|c|c|c|c|c|}
\hline M M / & D & Y & Y & Y & Y \\
08 & & 11 & & 2011 & \\
\hline
\end{tabular}

Transaction ID : B1457CBD1CF554639BB3

Amount of Each Disbursement this Period

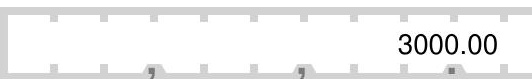

3000.00

Subtotal Of Receipts This Page (optional).

Total This Period (last page this line number only)). 


\section{SCHEDULE B-P}

\section{ITEMIZED DISBURSEMENTS}

\section{Use separate schedule(s) \\ for each category of the}

Detailed Summary Page
FOR LINE NUMBER: (check only one)

\begin{tabular}{|c|c|c|c|}
\hline$\times{ }_{23}$ & 24 & 25 & 26 \\
\hline $27 b$ & $28 a$ & $28 \mathrm{~b}$ & $28 \mathrm{c}$ \\
\hline
\end{tabular}

Any information copied from such Reports and Statements may not be sold or used by any person for the purpose of soliciting contributions or for commercial purposes, other than using the name and address of any political committee to solicit contributions from such committee.

NAME OF COMMITTEE (In Full)

\section{Friends of Herman Cain}

Full Name (Last, First, Middle Initial)

A. Elicia Huffaker

Mailing Address 7317 Alta Drive

Date of Disbursement

\begin{tabular}{lll}
\hline City & State & Zip Code \\
Las Vegas & NV & $89145-5238$
\end{tabular}

Purpose of Disbursement

Staff Salary

Candidate Name

\begin{tabular}{l|l|l}
\hline Office Sought: & House & Disbursement For: 2012
\end{tabular} X Primary $\square$ General

State:

\section{Senate}

President

District:

Full Name (Last, First, Middle Initial)

\section{B. Charles Spano}

Mailing Address PO Box 2158

\begin{tabular}{lcc}
\hline City & State & Zip Code \\
Stockbridge & GA & $30281-8909$
\end{tabular}

Purpose of Disbursement

Staff Salary

Candidate Name

Office Sought:

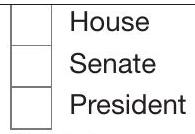

State:

District:

Full Name (Last, First, Middle Initial)

\section{c. Ellen Carmichael}

Mailing Address 1007 Oak Hills Parkway

\begin{tabular}{lcc}
\hline City & State & Zip Code \\
Baton Rouge & LA & $70810-4705$
\end{tabular}

Purpose of Disbursement

Staff Salary

Candidate Name

Office Sought:

State:

\begin{tabular}{|l|l|}
\hline & House \\
Senate \\
President \\
Pistrict:
\end{tabular}

Disbursement For: 2012

Х $\begin{aligned} & \text { Primary } \\ & \text { Other (specify) }\end{aligned}$
GA

Date of Disbursement

\begin{tabular}{|c|c|c|c|c|}
\hline${ }^{M}$ & ${ }^{M}$ & $8^{\mathrm{D}}$ & ${ }^{\mathrm{D}}$ & $\mathrm{Y}^{\mathrm{Y}} \mathrm{Y}^{\mathrm{Y}}$ \\
\hline
\end{tabular}

Transaction ID : B3E1256446C394F39897

Amount of Each Disbursement this Period

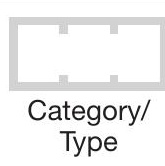

\section{Disbursement For: 2012 \\ X Primary $\square$ General}

Date of Disbursement

\begin{tabular}{|c|c|c|c|c|c|c|}
\hline M & M & D & Y & Y & Y & Y \\
\hline & 11 & & 2011 & \\
\hline
\end{tabular}

Transaction ID : B0D107A29660F4B0EB27

Amount of Each Disbursement this Period

2250.00

Subtotal Of Receipts This Page (optional)

Total This Period (last page this line number only)) 


\section{SCHEDULE B-P}

\section{ITEMIZED DISBURSEMENTS}

\section{Use separate schedule(s) \\ for each category of the}

Detailed Summary Page
FOR LINE NUMBER: (check only one)

\begin{tabular}{|c|c|c|c|}
\hline$\times{ }_{23}$ & 24 & 25 & 26 \\
\hline $27 b$ & $28 a$ & $28 \mathrm{~b}$ & $28 \mathrm{c}$ \\
\hline
\end{tabular}

Any information copied from such Reports and Statements may not be sold or used by any person for the purpose of soliciting contributions or for commercial purposes, other than using the name and address of any political committee to solicit contributions from such committee.

NAME OF COMMITTEE (In Full)

\section{Friends of Herman Cain}

Full Name (Last, First, Middle Initial)

A. Michelle Gwaltney

Mailing Address 123 Glen Eagle Way

\begin{tabular}{lcc}
\hline City & State & Zip Code \\
McDonough & GA & $30253-4229$ \\
\hline
\end{tabular}

Purpose of Disbursement

Staff Salary

Candidate Name

Office Sought:

House
Senate
President
istrict:

Disbursement For: 2012

X Primary $\square$ General
Date of Disbursement

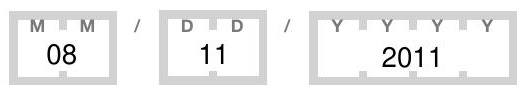

Transaction ID : BB2480A12E0104D838F1

Amount of Each Disbursement this Period

2916.67

Date of Disbursement

\begin{tabular}{|c|c|c|c|c|}
\hline $08^{M}$ & 1 & ${ }^{D} 1^{\mathrm{D}}$ & 1 & $\begin{array}{llll}Y & Y & Y & Y \\
& 2011 & \end{array}$ \\
\hline
\end{tabular}

Transaction ID : B9108AA186F7A4E05BB8

Amount of Each Disbursement this Period

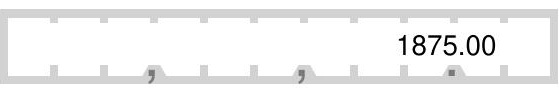

Date of Disbursement

\begin{tabular}{|c|c|c|c|c|}
\hline $08^{M}$ & & $\begin{array}{ll}\text { D } & \text { D } \\
& 11\end{array}$ & & $\begin{array}{llll}Y & Y & Y & Y \\
& 2011 & \end{array}$ \\
\hline
\end{tabular}

Transaction ID : B9D49BFA23C0C40CDBF4

Amount of Each Disbursement this Period

379.50

\begin{tabular}{l|l|r|}
\hline Office Sought: & House & Disbursement For: 2012 \\
& & $\begin{array}{l}\text { Senate } \\
\text { President } \\
\text { State: }\end{array}$
\end{tabular}

Subtotal Of Receipts This Page (optional)...

Total This Period (last page this line number only))

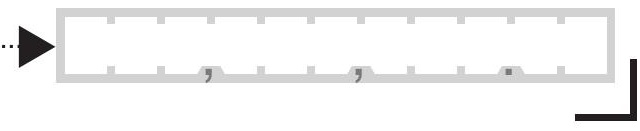




\section{SCHEDULE B-P}

\section{ITEMIZED DISBURSEMENTS}

\section{Use separate schedule(s) \\ for each category of the}

Detailed Summary Page
FOR LINE NUMBER: (check only one)

\begin{tabular}{|c|c|c|c|}
\hline$\times{ }_{23}$ & 24 & 25 & 26 \\
\hline $27 b$ & $28 a$ & $28 \mathrm{~b}$ & $28 \mathrm{c}$ \\
\hline
\end{tabular}

Any information copied from such Reports and Statements may not be sold or used by any person for the purpose of soliciting contributions or for commercial purposes, other than using the name and address of any political committee to solicit contributions from such committee.

NAME OF COMMITTEE (In Full)

\section{Friends of Herman Cain}

Full Name (Last, First, Middle Initial)

A. Michael Johnson

Mailing Address 8225 W. Center St. Apt. 3

Date of Disbursement

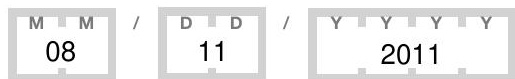

Transaction ID : BE74F1E2F7F3A411A9C5

\begin{tabular}{lcc}
\hline City & State & Zip Code \\
Milwaukee & WI & $53222-4861$
\end{tabular}

Purpose of Disbursement

Staff Salary

Candidate Name

\begin{tabular}{l|l|l}
\hline Office Sought: & House & Disbursement For: 2012
\end{tabular} X Primary $\square$ General

State:

\section{Senate}

President

District:

Full Name (Last, First, Middle Initial)

B. J Ryan Hudson

Mailing Address 418 Landing Pointe

\begin{tabular}{lcc}
\hline City & State & Zip Code \\
Stockbridge & GA & 30281
\end{tabular}

Purpose of Disbursement

Staff Salary

Candidate Name

Office Sought:

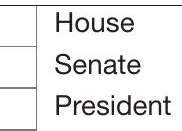

State:

District:

Full Name (Last, First, Middle Initial)

c. Linda Hansen

Mailing Address PO Box 371312

\begin{tabular}{lcc}
\hline City & State & Zip Code \\
Milwaukee & WI & $53237-2412$
\end{tabular}

Purpose of Disbursement

Staff Salary

Candidate Name

Disbursement For: 2012

Primary
Other (specify)

Date of Disbursement

\begin{tabular}{|c|c|c|c|c|}
\hline $08^{M}$ & 1 & ${ }^{\mathrm{D}} 1^{\mathrm{D}}$ & I & 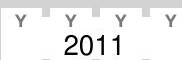 \\
\hline
\end{tabular}

Transaction ID : B449A2DDA542F4F67B12

Amount of Each Disbursement this Period

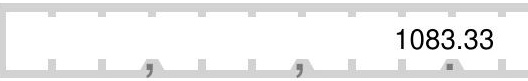

Date of Disbursement

\begin{tabular}{|c|c|c|c|c|}
\hline $08^{M}$ & I & D ${ }^{\mathrm{D}}$ & 1 & 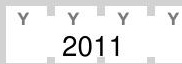 \\
\hline
\end{tabular}

Transaction ID : BCA349E6AEF1C448EAD7

Amount of Each Disbursement this Period

2916.67

\begin{tabular}{l|l|c|}
\hline Office Sought: & $\begin{array}{l}\text { House } \\
\text { Senate } \\
\text { President }\end{array}$ & $\begin{array}{c}\text { Disbursement For: } 2012 \\
\text { State: }\end{array}$ \\
\cline { 2 - 3 } & & Xrimary \\
Other (specify)
\end{tabular}

District:

Subtotal Of Receipts This Page (optional).

Total This Period (last page this line number only))

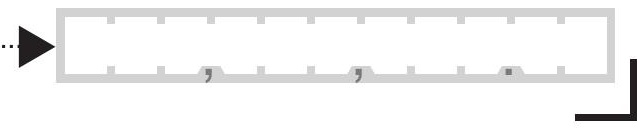




\section{SCHEDULE B-P}

\section{ITEMIZED DISBURSEMENTS}

Use separate schedule(s)

for each category of the

Detailed Summary Page
FOR LINE NUMBER: (check only one)

\begin{tabular}{|c|c|c|c|}
\hline$\times{ }_{23}$ & 24 & 25 & 26 \\
\hline $27 b$ & $28 a$ & $28 \mathrm{~b}$ & $28 \mathrm{c}$ \\
\hline
\end{tabular}

Any information copied from such Reports and Statements may not be sold or used by any person for the purpose of soliciting contributions or for commercial purposes, other than using the name and address of any political committee to solicit contributions from such committee.

NAME OF COMMITTEE (In Full)

\section{Friends of Herman Cain}

Full Name (Last, First, Middle Initial)

A. Zachary Dalluge

Mailing Address 506 3rd Street

Date of Disbursement

\begin{tabular}{lcc}
\hline City & State & Zip Code \\
Grafton & IA & $50440-7570$
\end{tabular}

Purpose of Disbursement

Staff Salary

Candidate Name

Office Sought: $\quad$ House

Senate

President

State:

District:

Full Name (Last, First, Middle Initial)

B. Scott F. Bieniek

Mailing Address 1782 Schooling Road

Disbursement For: 2012

X Primary $\square$ General

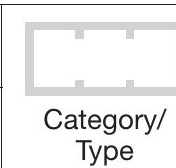

Type
Amount of Each Disbursement this Period

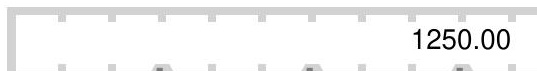

Date of Disbursement

\begin{tabular}{|c|c|c|c|c|}
\hline $08^{M}$ & 1 & ${ }_{11}^{\mathrm{D}}$ & 1 & 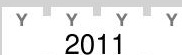 \\
\hline
\end{tabular}

Transaction ID : BCE1C204651AB4921A7C

Amount of Each Disbursement this Period 6250.00

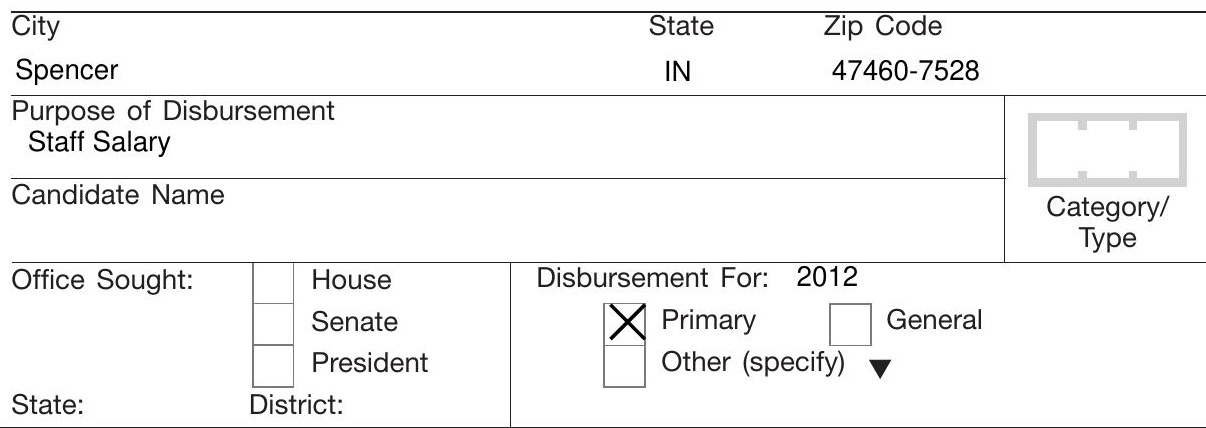

Full Name (Last, First, Middle Initial)

c. Mark Block

Mailing Address 18125 West Plateau Lane

\begin{tabular}{lcc}
\hline City & State & Zip Code \\
New Berlin & WI & $53146-5116$
\end{tabular}

Purpose of Disbursement

Staff Salary

Candidate Name

Office Sought: $\quad$ House

\begin{tabular}{l|l} 
& House \\
& Senate \\
& President \\
& \\
District:
\end{tabular}

Disbursement For: 2012

X $\begin{aligned} & \text { Primary } \\ & \text { Other (specify) }\end{aligned}$

State:

District:

Subtotal Of Receipts This Page (optional).

Date of Disbursement

\begin{tabular}{|c|c|c|c|c|}
\hline $08^{M}$ & 1 & D 11 & 1 & 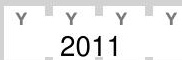 \\
\hline
\end{tabular}

Transaction ID : BA8746DE8F97E45A9AF0

Amount of Each Disbursement this Period

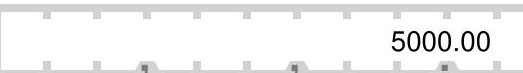

Total This Period (last page this line number only)) 


\section{SCHEDULE B-P}

\section{ITEMIZED DISBURSEMENTS}

Use separate schedule(s)

for each category of the

Detailed Summary Page
FOR LINE NUMBER: (check only one)

\begin{tabular}{|c|c|c|c|}
\hline$\times{ }_{23}$ & 24 & 25 & 26 \\
\hline $27 b$ & $28 a$ & $28 \mathrm{~b}$ & $28 \mathrm{c}$ \\
\hline
\end{tabular}

Any information copied from such Reports and Statements may not be sold or used by any person for the purpose of soliciting contributions or for commercial purposes, other than using the name and address of any political committee to solicit contributions from such committee.

NAME OF COMMITTEE (In Full)

\section{Friends of Herman Cain}

Full Name (Last, First, Middle Initial)

A. Larry Tuel

Mailing Address 5129 Welker Ave.

Date of Disbursement

\begin{tabular}{lcc}
\hline City & State & Zip Code \\
Des Moines & IA & $50312-2159$
\end{tabular}

Purpose of Disbursement

Staff Salary

Candidate Name

\begin{tabular}{l|l|l|l}
\hline Office Sought: & House & Disbursement For: 2012
\end{tabular} X Primary $\square$ General

State:

\section{Senate}

President

District:

Full Name (Last, First, Middle Initial)

B. Scott Sidney

Mailing Address N40 W6522 Jackson Street

\begin{tabular}{lcc}
\hline City & State & Zip Code \\
Cedarburg & WI & $53012-2317$
\end{tabular}

Purpose of Disbursement

Staff Salary

Candidate Name

Office Sought:

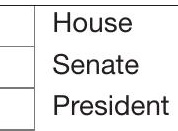

State:

District:

Full Name (Last, First, Middle Initial)

\section{c. Michael Branch}

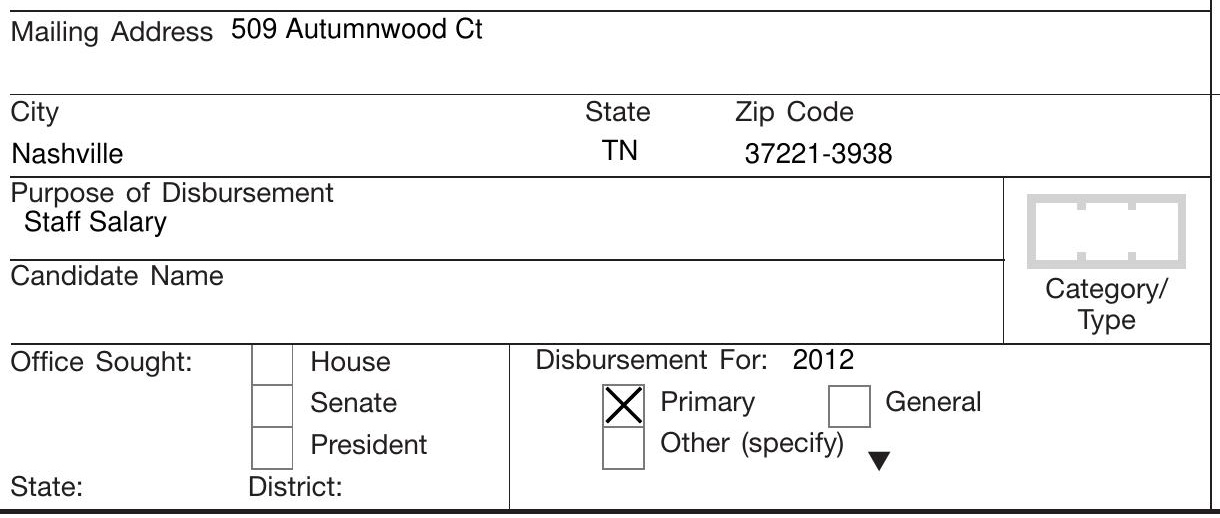

Subtotal Of Receipts This Page (optional)......

Date of Disbursement

\begin{tabular}{|c|c|c|c|c|}
\hline $08^{M}$ & 1 & ${ }^{\mathrm{D}}{ }^{\mathrm{D}}$ & I & 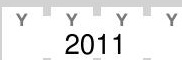 \\
\hline
\end{tabular}

Transaction ID : B8352344C64C94D2CB50

Amount of Each Disbursement this Period
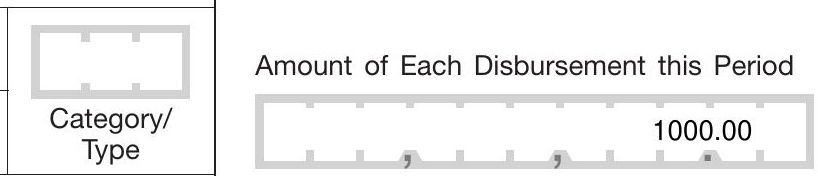

Date of Disbursement

\begin{tabular}{|c|c|c|c|c|c|}
\hline${ }^{M}{ }^{M}$ & Y & Y & Y \\
\hline & 11 & 2011 \\
\hline
\end{tabular}

\section{Transaction ID : BE7892705050E48628C6}

Amount of Each Disbursement this Period

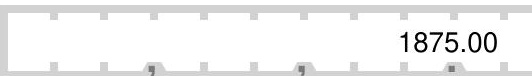

1875.00

Total This Period (last page this line number only)) 


\section{SCHEDULE B-P}

\section{ITEMIZED DISBURSEMENTS}

\section{Use separate schedule(s) \\ for each category of the}

Detailed Summary Page
FOR LINE NUMBER: (check only one)

\begin{tabular}{|c|c|c|c|}
\hline$\times{ }_{23}$ & 24 & 25 & 26 \\
\hline $27 b$ & $28 a$ & $28 \mathrm{~b}$ & $28 \mathrm{c}$ \\
\hline
\end{tabular}

Any information copied from such Reports and Statements may not be sold or used by any person for the purpose of soliciting contributions or for commercial purposes, other than using the name and address of any political committee to solicit contributions from such committee.

NAME OF COMMITTEE (In Full)

\section{Friends of Herman Cain}

Full Name (Last, First, Middle Initial)

A. Radisson Hotel

Mailing Address 11340 Blondo St.

\begin{tabular}{lll}
\hline City & State & Zip Code \\
Omaha & NE & 68164 \\
\hline Purpose of Disbursement & &
\end{tabular}

Purpose of Disbursement

Travel Expense

Candidate Name

Office Sought:

House
Senate
President
istrict:

Disbursement For: 2012

X Primary $\square$ General

State:

First, Middle Initial)

B. Tri-Net Payroll Services

\begin{tabular}{|c|c|}
\hline Mailing Address & $\begin{array}{l}1100 \text { San Leandro Boulevard } \\
\text { Suite }\end{array}$ \\
\hline
\end{tabular}

San Leandro CA Zip Code

Purpose of Disbursement

Payroll Service Fee

Candidate Name

Office Sought:

House
Senate
President

State:

District:

Full Name (Last, First, Middle Initial)

\section{c. Tri-Net Payroll Services}

Mailing Address 1100 San Leandro Boulevard

Suite

\begin{tabular}{lcc}
\multicolumn{3}{c}{ Suite } \\
City & State & Zip Code \\
San Leandro & CA & 94577 \\
\hline
\end{tabular}

Purpose of Disbursement

Payroll Withholding

Candidate Name

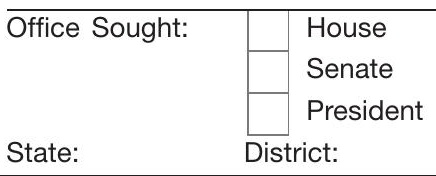

Date of Disbursement

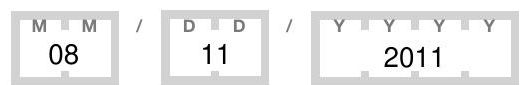

Transaction ID : BF0FC878AA8C3414686D

Amount of Each Disbursement this Period 2698.72

Date of Disbursement

\begin{tabular}{|c|c|c|c|c|}
\hline $08^{M}$ & & ${ }_{11}^{\mathrm{D}}$ & & $\begin{array}{llll} & Y & Y & Y \\
& 2011 & Y\end{array}$ \\
\hline
\end{tabular}

Transaction ID : B3551CB509BD446B7BD0

Amount of Each Disbursement this Period
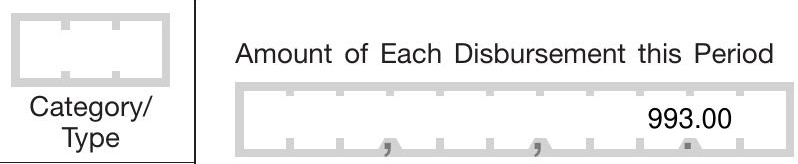

Date of Disbursement

\begin{tabular}{|c|c|c|c|c|c|}
\hline M M / & D & D & Y & Y & Y \\
\hline & & 11 & & 2011 & \\
\hline
\end{tabular}

Transaction ID : B71367A35D0DD442AB96

Amount of Each Disbursement this Period

6152.80

Subtotal Of Receipts This Page (optional).

Total This Period (last page this line number only))

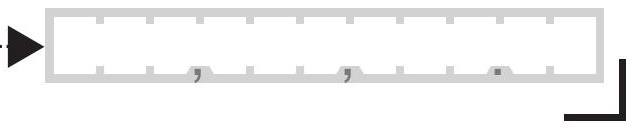




\section{SCHEDULE B-P}

\section{ITEMIZED DISBURSEMENTS}

\section{Use separate schedule(s) \\ for each category of the}

Detailed Summary Page
FOR LINE NUMBER: (check only one)

\begin{tabular}{|c|c|c|c|}
\hline$X_{23}$ & 24 & 25 & 26 \\
\hline $27 \mathrm{~b}$ & $28 a$ & $28 b$ & $28 \mathrm{c}$ \\
\hline
\end{tabular}

Any information copied from such Reports and Statements may not be sold or used by any person for the purpose of soliciting contributions or for commercial purposes, other than using the name and address of any political committee to solicit contributions from such committee.

NAME OF COMMITTEE (In Full)

\section{Friends of Herman Cain}

Full Name (Last, First, Middle Initial)

A. Tri-Net Payroll Services
Mailing Address 1100 San Leandro Boulevard

Suite

Purpose of Disbursement

Payroll Benefits

Candidate Name

Office Sought:

House
Senate
President
District:

Disbursement For: 2012 X Primary $\square$ General

\begin{tabular}{lll}
\hline City & State & Zip Code \\
San Leandro & CA & 94577
\end{tabular}

\section{B. Famous Dave's (Corporate)}

\begin{tabular}{ll}
\hline Mailing Address & 12701 Whitewater Dr \\
& Ste 200 \\
\hline
\end{tabular}

\begin{tabular}{lcc}
\hline City & State & Zip Code \\
Minnetonka & MN & 55343 \\
\hline $\begin{array}{l}\text { Purpose of Disbursement } \\
\text { Meeting Expense }\end{array}$ & & \\
\hline Candidate Name & &
\end{tabular}

Office Sought:

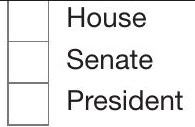

State:

District:
Date of Disbursement

\begin{tabular}{|c|c|c|c|c|}
\hline M M & D \\
08 & 11 & 2011 \\
\hline
\end{tabular}

Transaction ID : B641EA345D9D149D8B9C

Amount of Each Disbursement this Period 2877.01

Date of Disbursement

\begin{tabular}{|c|c|c|c|c|}
\hline $08^{M}$ & & ${ }^{\mathrm{D}}{ }^{\mathrm{D}}$ & & 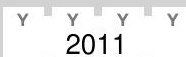 \\
\hline
\end{tabular}

Transaction ID : B2794709D992B46F495E

Amount of Each Disbursement this Period

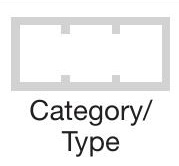
Disbursement For: 2012
\[ \begin{array}{l}\text { Primary } \\ \text { Other (specify) }\end{array} \]

Date of Disbursement

c. Delta Airlines

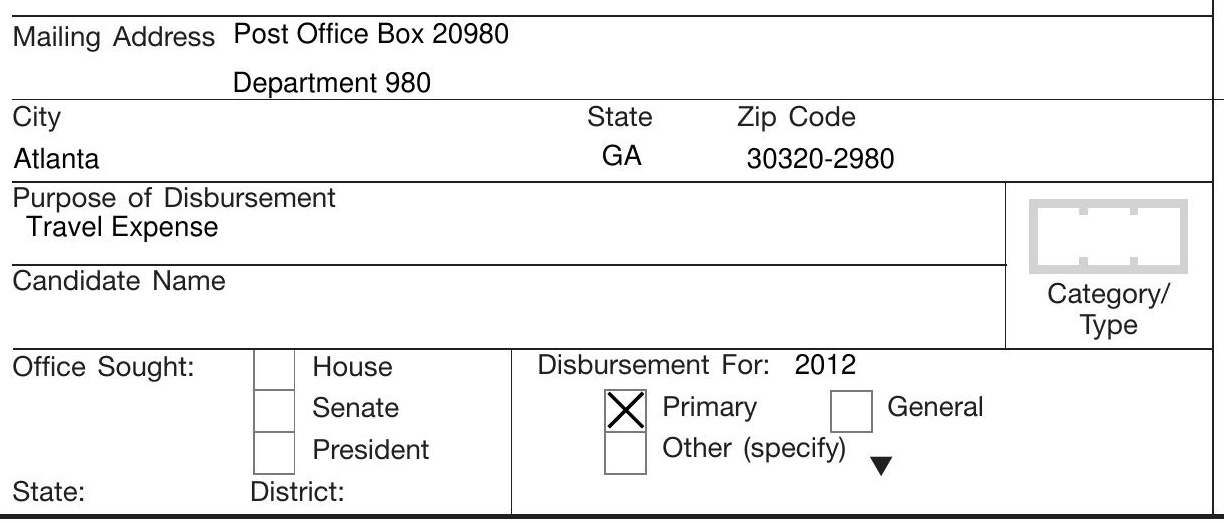

Subtotal Of Receipts This Page (optional).

Total This Period (last page this line number only))

\section{Transaction ID : B23C7B32584FF4781BA1}

Amount of Each Disbursement this Period

698.01 .

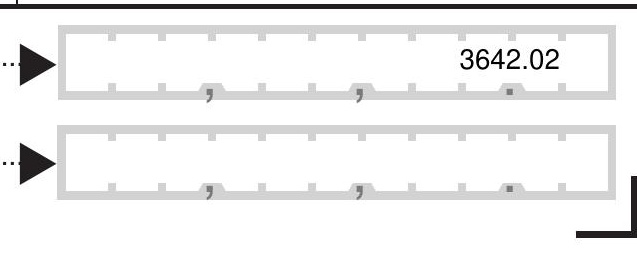




\section{SCHEDULE B-P}

\section{ITEMIZED DISBURSEMENTS}

\section{Use separate schedule(s) \\ for each category of the}

Detailed Summary Page
FOR LINE NUMBER: (check only one)

\begin{tabular}{|c|c|c|c|}
\hline$\times{ }_{23}$ & 24 & 25 & 26 \\
\hline $27 b$ & $28 a$ & $28 \mathrm{~b}$ & $28 \mathrm{c}$ \\
\hline
\end{tabular}

Any information copied from such Reports and Statements may not be sold or used by any person for the purpose of soliciting contributions or for commercial purposes, other than using the name and address of any political committee to solicit contributions from such committee.

NAME OF COMMITTEE (In Full)

\section{Friends of Herman Cain}

Full Name (Last, First, Middle Initial)

A. Delta Airlines

\begin{tabular}{c} 
Mailing Address $\begin{array}{c}\text { Post Office Box } 20980 \\
\text { Department } 980\end{array}$ \\
\hline
\end{tabular}

\begin{tabular}{lll}
\hline City & State & Zip Code \\
Atlanta & GA & $30320-2980$
\end{tabular}

Purpose of Disbursement

Travel Expense

Candidate Name

\begin{tabular}{l|l|l|l}
\hline Office Sought: & $\begin{array}{l}\text { House } \\
\text { Senate } \\
\text { President }\end{array}$ & $\begin{array}{c}\text { Disbursement For: } 2012 \\
\text { State: }\end{array}$
\end{tabular}

\section{Full Name (Last, First, Middle Initial)}

\section{B. Office Depot Corporate}

Mailing Address 2500 Mill Center Parkway

\begin{tabular}{|c|c|c|c|c|}
\hline \multicolumn{2}{|l|}{ City } & \multicolumn{3}{|c|}{ Zip Code } \\
\hline \multicolumn{2}{|l|}{ Buford } & \multicolumn{3}{|c|}{30518} \\
\hline \multicolumn{4}{|c|}{$\begin{array}{l}\text { Purpose of Disbursement } \\
\text { Office Supplies }\end{array}$} & \\
\hline \multicolumn{4}{|c|}{ Candidate Name } & $\begin{array}{l}\text { Category/ } \\
\text { Type }\end{array}$ \\
\hline \multirow[t]{3}{*}{ Office Sought: } & House & \multirow{3}{*}{\multicolumn{3}{|c|}{$\begin{array}{l}\text { Disbursement For: } 2012 \\
\text { Xrimary } \\
\text { Other (specify) }\end{array}$}} \\
\hline & \multirow{2}{*}{$\begin{array}{l}\text { Senate } \\
\text { President }\end{array}$} & & & \\
\hline & & & & \\
\hline State: & rict: & & \multicolumn{2}{|l|}{$\nabla$} \\
\hline
\end{tabular}

Full Name (Last, First, Middle Initial)

c. Nextiva

Mailing Address 8125 North 86th Place

\begin{tabular}{lcc}
\hline City & State & Zip Code \\
Scottsdale & AZ & 85258
\end{tabular}

Purpose of Disbursement

Telephone

Candidate Name

\begin{tabular}{|c|c|}
\hline \multirow[t]{3}{*}{ Office Sought: } & House \\
\hline & Senate \\
\hline & President \\
\hline ate: & rict: \\
\hline
\end{tabular}

Date of Disbursement

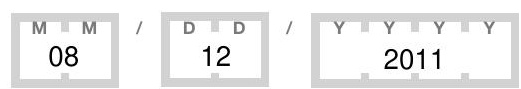

\section{Transaction ID : BC278BF1FB9C44D3690D}

Amount of Each Disbursement this Period

Date of Disbursement

\begin{tabular}{|c|c|c|c|c|}
\hline${ }^{M}$ & ${ }^{M}$ & $8^{\mathrm{D}}$ & ${ }^{\mathrm{D}}$ & $\mathrm{Y}^{\mathrm{Y}} \mathrm{P}^{\mathrm{Y}}$ \\
\hline
\end{tabular}

Transaction ID : BDE530E7BFD3F4F3D9E4

Amount of Each Disbursement this Period

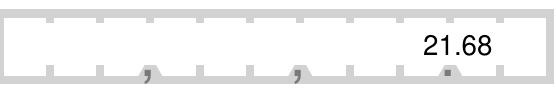

Date of Disbursement

\begin{tabular}{|c|c|c|c|c|c|}
\hline M M & I & D & Y & Y & Y \\
\hline & 12 & & 2011 & \\
\hline
\end{tabular}

Transaction ID : B1948E50B8DA147979E8

Amount of Each Disbursement this Period

302.41

Subtotal Of Receipts This Page (optional).

Total This Period (last page this line number only))

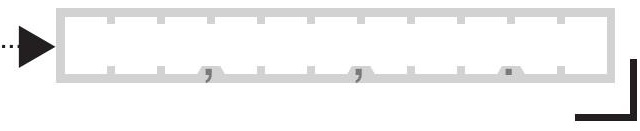




\section{SCHEDULE B-P}

\section{ITEMIZED DISBURSEMENTS}

\section{Use separate schedule(s) \\ for each category of the}

Detailed Summary Page
FOR LINE NUMBER: (check only one)

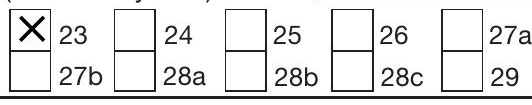

Any information copied from such Reports and Statements may not be sold or used by any person for the purpose of soliciting contributions or for commercial purposes, other than using the name and address of any political committee to solicit contributions from such committee.

NAME OF COMMITTEE (In Full)

\section{Friends of Herman Cain}

Full Name (Last, First, Middle Initial)

A. Facebook, Inc.

Mailing Address 1601 S. California Ave.

Date of Disbursement

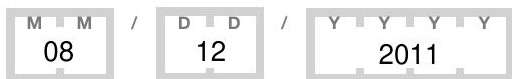

Transaction ID : B9857656F22BD4C04A35

\begin{tabular}{lll}
\hline City & State & Zip Code \\
Palo Alto & CA & 94304 \\
\hline
\end{tabular}

Purpose of Disbursement

Advertising Expense

Candidate Name Xrimary $\square$ General

State:

$$
\begin{aligned}
& \text { Senate } \\
& \text { President }
\end{aligned}
$$

District:

Full Name (Last, First, Middle Initial)

B. Facebook, Inc.

Mailing Address 1601 S. California Ave.

\begin{tabular}{lcc}
\hline City & State & Zip Code \\
Palo Alto & CA & 94304
\end{tabular}

Purpose of Disbursement

Advertising Expense

Candidate Name

Office Sought:

House
Senate
President

Disbursement For: 2012

Primary
Other (specify)

State:

District:

Full Name (Last, First, Middle Initial)

\section{c. Fast Signs}

Mailing Address 541 Haywood Road

\begin{tabular}{lcc}
\hline City & State & Zip Code \\
Greenville & SC & 29607
\end{tabular}

Purpose of Disbursement

Signs

Candidate Name

Office Sought: $\quad$ House

\begin{tabular}{l|l} 
& House \\
& Senate \\
& President \\
& \\
District:
\end{tabular}

Disbursement For: 2012

Х $\begin{aligned} & \text { Primary } \\ & \text { Other (specify) }\end{aligned}$

State:

District:

\begin{tabular}{|c|c|c|c|c|}
\hline $08^{M}$ & 1 & $15^{\mathrm{D}}$ & 1 & $\begin{array}{llll}Y & Y & Y & Y \\
& 2011 & \end{array}$ \\
\hline
\end{tabular}

Date of Disbursement

Transaction ID : B63C6006A413343B8915

Amount of Each Disbursement this Period
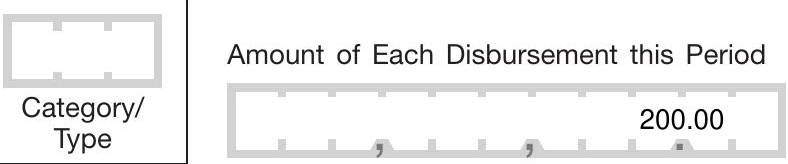

\begin{tabular}{|c|c|c|c|c|}
\hline $08^{M}$ & I & D $15^{\mathrm{D}}$ & I & $\begin{array}{cccc}Y & Y & Y & Y \\
& 2011 & \end{array}$ \\
\hline
\end{tabular}

Date of Disbursement

Transaction ID : BEED16343D1D4405BA79

Amount of Each Disbursement this Period

424.00

Subtotal Of Receipts This Page (optional).

Total This Period (last page this line number only))

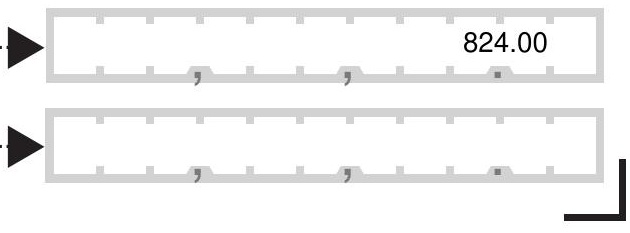




\section{SCHEDULE B-P}

\section{ITEMIZED DISBURSEMENTS}

Use separate schedule(s)

for each category of the

Detailed Summary Page
FOR LINE NUMBER: (check only one)

\begin{tabular}{|c|c|c|c|}
\hline $\mathrm{X} 23$ & 24 & 25 & 26 \\
\hline $27 \mathrm{~b}$ & $28 a$ & $28 b$ & $28 \mathrm{c}$ \\
\hline
\end{tabular}

Any information copied from such Reports and Statements may not be sold or used by any person for the purpose of soliciting contributions or for commercial purposes, other than using the name and address of any political committee to solicit contributions from such committee.

NAME OF COMMITTEE (In Full)

\section{Friends of Herman Cain}

Full Name (Last, First, Middle Initial)

A. Marina Inn

Mailing Address 4th and B Street

Date of Disbursement

\begin{tabular}{lll}
\hline City & State & Zip Code \\
South Souix City & NE & 68776 \\
\hline Purpose
\end{tabular}

Purpose of Disbursement

Travel Expense

Candidate Name

08

Transaction ID : B0A5A7091FB074671ACA

Office Sought:

State:

District:

Full Name (Last, First, Middle Initial)

B. Larry Tuel

Date of Disbursement

Mailing Address 5129 Welker Ave.

\begin{tabular}{lcc}
\hline City & State & Zip Code \\
Des Moines & IA & $50312-2159$
\end{tabular}

Purpose of Disbursement

Staff Salary

Candidate Name

Disbursement For: 2012

Amount of Each Disbursement this Period

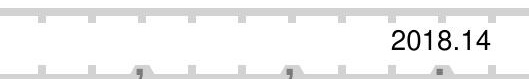

\subsection{4}

Office Sought:

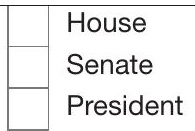

State:

District:

Full Name (Last, First, Middle Initial)

\section{c. Donald Henry}

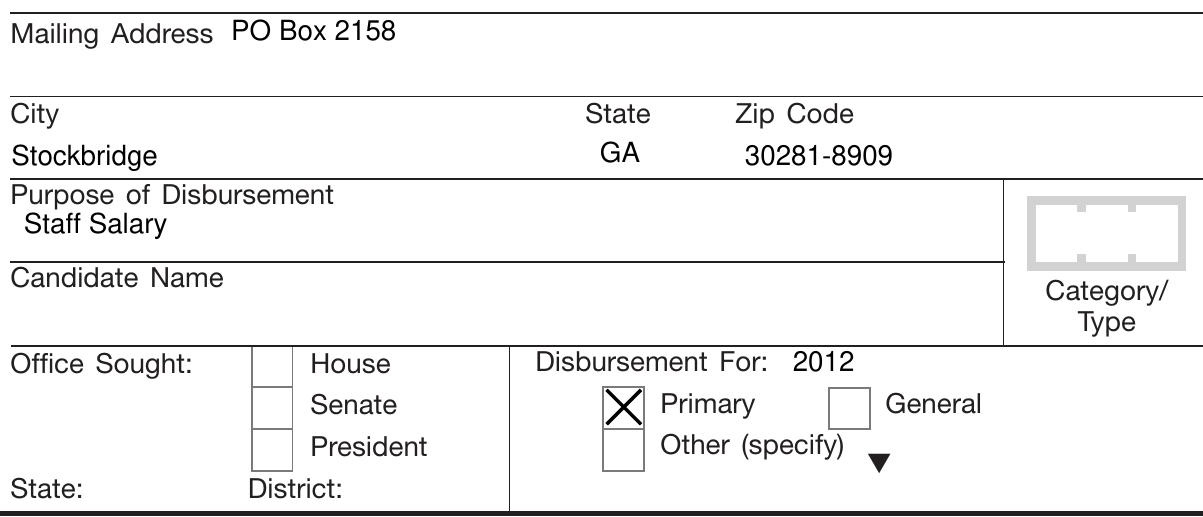

Subtotal Of Receipts This Page (optional).

Total This Period (last page this line number only))
Date of Disbursement

\begin{tabular}{|c|c|c|c|c|c|c|}
\hline M & M & D & Y & Y & Y \\
08 & & 15 & & 2011 & \\
\hline
\end{tabular}

Transaction ID : BA591F55EF1B24C2997C

Amount of Each Disbursement this Period

2083.33 


\section{SCHEDULE B-P}

\section{ITEMIZED DISBURSEMENTS}

\section{Use separate schedule(s)}

for each category of the

Detailed Summary Page
FOR LINE NUMBER: (check only one)

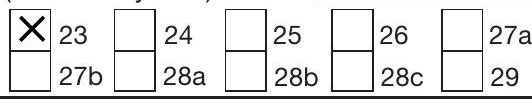

Any information copied from such Reports and Statements may not be sold or used by any person for the purpose of soliciting contributions or for commercial purposes, other than using the name and address of any political committee to solicit contributions from such committee.

NAME OF COMMITTEE (In Full)

\section{Friends of Herman Cain}

Full Name (Last, First, Middle Initial)

A. Lisa Shiflett

Mailing Address 157 Stokes Drive

Date of Disbursement

\begin{tabular}{lcc}
\hline City & State & Zip Code \\
Stockbridge & GA & $30281-1376$
\end{tabular}

Purpose of Disbursement

Staff Salary

Candidate Name

\begin{tabular}{l|l|l}
\hline Office Sought: & House & Disbursement For: 2012
\end{tabular} X Primary $\square$ General

State:

\section{Senate}

President

Full Name (Last, First, Middle Initial)

B. Karis McKinney

\begin{tabular}{|c|c|c|c|c|}
\hline \multicolumn{5}{|c|}{ Mailing Address 5017 N. 50th Street } \\
\hline \multicolumn{2}{|l|}{ City } & \multicolumn{3}{|c|}{ Zip Code } \\
\hline \multicolumn{2}{|l|}{ Milwaukee } & \multicolumn{3}{|c|}{$53218-4326$} \\
\hline \multicolumn{4}{|c|}{$\begin{array}{l}\text { Purpose of Disbursement } \\
\text { Staff Salary }\end{array}$} & \\
\hline \multicolumn{4}{|l|}{ Candidate Name } & $\begin{array}{l}\text { Category/ } \\
\text { Type }\end{array}$ \\
\hline \multirow[t]{3}{*}{ Office Sought: } & \multirow{3}{*}{$\begin{array}{l}\text { House } \\
\text { Senate } \\
\text { President }\end{array}$} & \multirow{3}{*}{\multicolumn{3}{|c|}{$\begin{array}{l}\text { Disbursement For: } 2012 \\
\text { X Primary } \\
\text { Other (specify) }\end{array}$}} \\
\hline & & & & \\
\hline & & & & \\
\hline State: & rict: & & & \\
\hline
\end{tabular}

Date of Disbursement

\begin{tabular}{|c|c|c|c|c|}
\hline${ }^{M}$ & ${ }^{M}$ & $8^{\mathrm{D}}$ & ${ }^{\mathrm{D}}$ & $\mathrm{Y}^{\mathrm{Y}}$ \\
\hline
\end{tabular}

Transaction ID : BCFD07A5F9D8A45F4805

Full Name (Last, First, Middle Initial)

\section{Almost Always Open}

Mailing Address 419 Lincoln Way

\begin{tabular}{lcc}
\hline City & State & Zip Code \\
Ames & IA & 50010
\end{tabular}

Purpose of Disbursement

Event Supplies and Catering

Candidate Name

Office Sought: $\quad$ House

\begin{tabular}{|l|l|} 
& House \\
& Senate \\
& President
\end{tabular}

State:

District:
Disbursement For: 2012

X $\begin{aligned} & \text { Primary } \\ & \text { Other (specify) }\end{aligned}$
Date of Disbursement

\begin{tabular}{|c|c|c|c|c|c|c|}
\hline M & M & D & I & Y & Y & Y \\
\hline & 15 & & 2011 & \\
\hline
\end{tabular}

Transaction ID : B873243BBF59442B0849

Amount of Each Disbursement this Period

4629.36 Type

Subtotal Of Receipts This Page (optional).

Total This Period (last page this line number only))

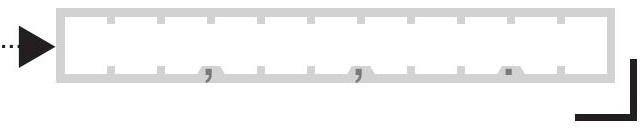




\section{SCHEDULE B-P}

\section{ITEMIZED DISBURSEMENTS}

\section{Use separate schedule(s) \\ for each category of the}

Detailed Summary Page
FOR LINE NUMBER: (check only one)

\begin{tabular}{|c|c|c|c|}
\hline$\times{ }_{23}$ & 24 & 25 & 26 \\
\hline $27 b$ & $28 a$ & $28 \mathrm{~b}$ & $28 \mathrm{c}$ \\
\hline
\end{tabular}

Any information copied from such Reports and Statements may not be sold or used by any person for the purpose of soliciting contributions or for commercial purposes, other than using the name and address of any political committee to solicit contributions from such committee.

NAME OF COMMITTEE (In Full)

\section{Friends of Herman Cain}

Full Name (Last, First, Middle Initial)

\section{A. Almost Always Open}

Mailing Address 419 Lincoln Way

Date of Disbursement

\begin{tabular}{lcc}
\hline City & State & Zip Code \\
Ames & IA & 50010 \\
\hline
\end{tabular}

Purpose of Disbursement

Event Catering

Candidate Name

\begin{tabular}{l|l|c|}
\hline Office Sought: & $\begin{array}{l}\text { House } \\
\text { Senate } \\
\text { President }\end{array}$ & $\begin{array}{r}\text { Disbursement For: } 2012 \\
\text { X Primary } \\
\text { Other (specify) }\end{array}$ \\
\cline { 2 - 3 }
\end{tabular}

Full Name (Last, First, Middle Initial)

\section{B. Tri-Net Payroll Services}

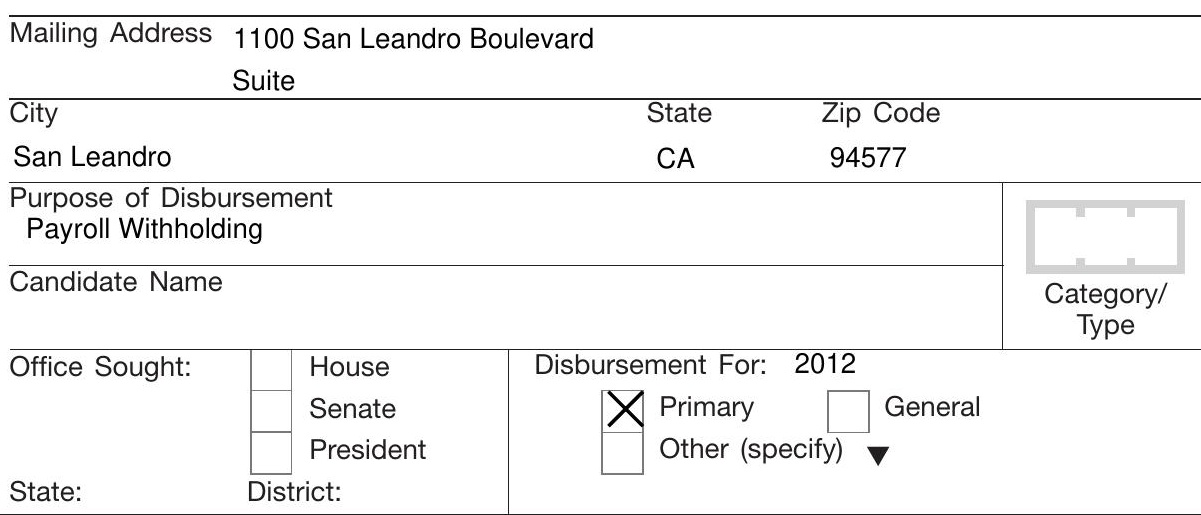

Date of Disbursement

\begin{tabular}{|c|c|c|c|c|}
\hline${ }^{\mathrm{M}} 08^{\mathrm{M}}$ & 1 & ${ }_{15}{ }^{\mathrm{D}}$ & 1 & $\begin{array}{llll} & Y & Y & Y \\
& 2011 & \end{array}$ \\
\hline
\end{tabular}

Transaction ID : B704A58A80EA44E3EBA5

Full Name (Last, First, Middle Initial)

\section{c. Hawkeye Stages}

\begin{tabular}{|c|c|c|c|c|c|}
\hline \multicolumn{6}{|c|}{ Mailing Address 703 Dudley Street } \\
\hline \multicolumn{2}{|l|}{ City } & State & Zip Code & & \\
\hline \multicolumn{2}{|l|}{ Decorah } & IA & 52101 & & \\
\hline \multicolumn{5}{|c|}{$\begin{array}{l}\text { Purpose of Disbursement } \\
\text { Travel Expense }\end{array}$} & \\
\hline \multicolumn{5}{|c|}{ Candidate Name } & $\begin{array}{l}\text { Category/ } \\
\text { Type }\end{array}$ \\
\hline \multirow[t]{3}{*}{ Office Sought: } & House & \multicolumn{4}{|c|}{ Disbursement For: 2012} \\
\hline & Senate & \multirow{3}{*}{\multicolumn{2}{|c|}{ X $\begin{array}{l}\text { Primary } \\
\text { Other (specify) }\end{array}$}} & \multirow{2}{*}{\multicolumn{2}{|c|}{ General }} \\
\hline & President & & & & \\
\hline State: & District: & & & & \\
\hline
\end{tabular}

Subtotal Of Receipts This Page (optional)...

Date of Disbursement

\begin{tabular}{|c|c|c|c|c|c|}
\hline M M & I & D & Y & Y & Y \\
\hline & 15 & & 2011 & \\
\hline
\end{tabular}

\section{Transaction ID : B0F233B529217494489C}

Amount of Each Disbursement this Period

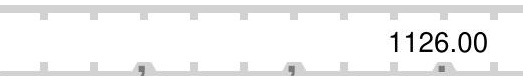

Total This Period (last page this line number only)) 


\section{SCHEDULE B-P}

\section{ITEMIZED DISBURSEMENTS}

Use separate schedule(s)

for each category of the

Detailed Summary Page
FOR LINE NUMBER: (check only one)

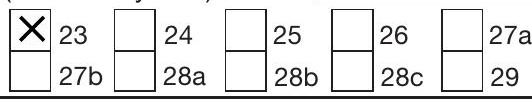

Any information copied from such Reports and Statements may not be sold or used by any person for the purpose of soliciting contributions or for commercial purposes, other than using the name and address of any political committee to solicit contributions from such committee.

NAME OF COMMITTEE (In Full)

\section{Friends of Herman Cain}

Full Name (Last, First, Middle Initial)

A. La Chiesa Italian Restaurant

Mailing Address 24 West Park Street

Date of Disbursement

\begin{tabular}{lcc}
\hline City & State & Zip Code \\
Spencer & IA & 51301
\end{tabular}

Purpose of Disbursement

Event Catering

Candidate Name

IA $\quad 51301$

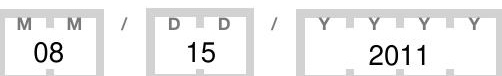

Transaction ID : BB4A24EF26AB946A8892

Category/
Type

Full Name (Last, First, Middle Initial)

B. Orbitz (ORB)

Mailing Address 500 W. Madison Street

Х Primary $\square$ General

\section{Senate}

President

12 General

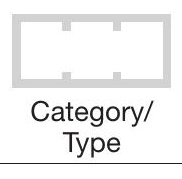

Amount of Each Disbursement this Period

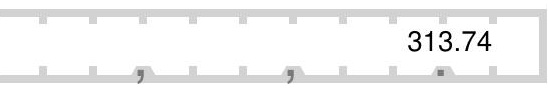

\begin{tabular}{lcc}
\hline City & State & Zip Code \\
Chicago & IL & 60661
\end{tabular}

Purpose of Disbursement

Travel Expense

Candidate Name

Office Sought:

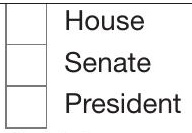

Disbursement For: 2012

X Primary $\square$ General

State:

District:

Full Name (Last, First, Middle Initial)

\section{c. FedEx Kinkos}

Mailing Address 942 S. Shady Grove Road

\begin{tabular}{lcc}
\hline City & State & Zip Code \\
Memphis & TN & 38120
\end{tabular}

Purpose of Disbursement

Office Supplies

Candidate Name

\begin{tabular}{l|l}
\hline Office Sought: & House \\
& $\begin{array}{l}\text { Senate } \\
\text { Senatent } \\
\text { President }\end{array}$ \\
State: & District:
\end{tabular}

Disbursement For: 2012
$\searrow$ Primary
Other (specify)

Date of Disbursement

\begin{tabular}{|c|c|c|c|c|}
\hline${ }^{M}$ & ${ }^{M}$ & $8^{\mathrm{D}}$ & ${ }^{\mathrm{D}}$ & $\mathrm{Y}^{\mathrm{Y}}$ \\
\hline
\end{tabular}

Transaction ID : BEAA76A76939E48CCB7B

Amount of Each Disbursement this Period
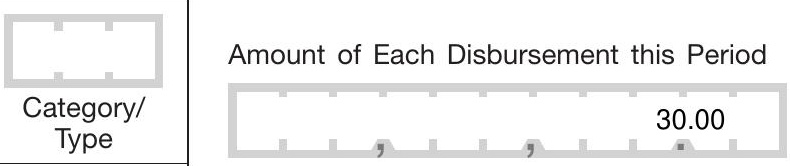

Date of Disbursement

\begin{tabular}{|c|c|c|c|c|c|c|}
\hline M & M & D & I & Y & Y & Y \\
\hline & & 15 & & 2011 & \\
\hline
\end{tabular}

Transaction ID : BAF0BD96F55964A51988

Amount of Each Disbursement this Period

661.44

Subtotal Of Receipts This Page (optional).

Total This Period (last page this line number only))

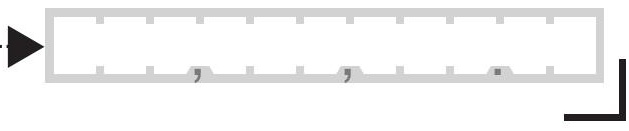




\section{SCHEDULE B-P}

\section{ITEMIZED DISBURSEMENTS}

Use separate schedule(s)

for each category of the

Detailed Summary Page
FOR LINE NUMBER: (check only one)

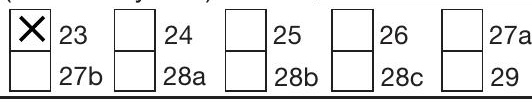

Any information copied from such Reports and Statements may not be sold or used by any person for the purpose of soliciting contributions or for commercial purposes, other than using the name and address of any political committee to solicit contributions from such committee.

NAME OF COMMITTEE (In Full)

\section{Friends of Herman Cain}

Full Name (Last, First, Middle Initial)

A. Office Depot Corporate

Mailing Address 2500 Mill Center Parkway

Date of Disbursement

\begin{tabular}{lcc}
\hline City & State & Zip Code \\
Buford & GA & 30518 \\
\hline
\end{tabular}

Purpose of Disbursement

Office Supplies

Candidate Name

08

15 2011

Transaction ID : BE95C366F6EF94340BED

\begin{tabular}{l|l|l|l}
\hline Office Sought: & $\begin{array}{l}\text { House } \\
\text { Senate } \\
\text { President }\end{array}$ & $\begin{array}{r}\text { Disbursement For: } 2012 \\
\text { X Primary } \\
\text { Other (specify) }\end{array}$
\end{tabular}

Full Name (Last, First, Middle Initial)

B. Delta Airlines

Mailing Address Post Office Box 20980

Department 980

\begin{tabular}{lcc}
\hline City & State & Zip Code \\
Atlanta & GA & $30320-2980$
\end{tabular}

Purpose of Disbursement

Travel Expense

Candidate Name

Office Sought:

House
Senate
President

State:

District:

Full Name (Last, First, Middle Initial)

\section{c. Best Western}

\begin{tabular}{|c|c|c|c|c|c|}
\hline \multicolumn{6}{|c|}{ Mailing Address 100 W 76th St } \\
\hline \multicolumn{2}{|l|}{ City } & State & \multicolumn{3}{|l|}{ Zip Code } \\
\hline \multicolumn{2}{|l|}{ Davenport } & IA & \multicolumn{3}{|l|}{52806} \\
\hline \multicolumn{5}{|c|}{$\begin{array}{l}\text { Purpose of Disbursement } \\
\text { Travel Expense }\end{array}$} & \\
\hline \multicolumn{5}{|c|}{ Candidate Name } & $\begin{array}{l}\text { Category/ } \\
\text { Type }\end{array}$ \\
\hline \multirow[t]{3}{*}{ Office Sought: } & House & \multicolumn{4}{|c|}{ Disbursement For: 2012} \\
\hline & Senate & \multirow{3}{*}{\multicolumn{2}{|c|}{$\begin{array}{l}\text { Primary } \\
\text { Other (specify) }\end{array}$}} & \multirow{2}{*}{\multicolumn{2}{|c|}{ General }} \\
\hline & President & & & & \\
\hline State: & District: & & & & \\
\hline
\end{tabular}

Subtotal Of Receipts This Page (optional).

Date of Disbursement

\begin{tabular}{|c|c|c|c|c|c|c|c|}
\hline M & M & D & Y & Y & Y \\
08 & & 15 & & 2011 & \\
\hline
\end{tabular}

Transaction ID : BFDEB317D91474996910

Amount of Each Disbursement this Period

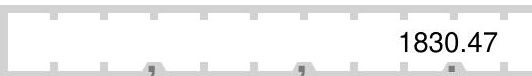

Date of Disbursement

\begin{tabular}{|c|c|c|c|c|}
\hline${ }^{\mathrm{M}} 08^{\mathrm{M}}$ & & ${ }_{15}^{\mathrm{D}}$ & 1 & $\begin{array}{cc}Y & Y \\
2011\end{array}$ \\
\hline
\end{tabular}

Transaction ID : B4BEFBAA3FBCD425D89B

Amount of Each Disbursement this Period

2011.00

\section{Primary $\square$ Genera
Other (specify) $\boldsymbol{\nabla}$}

Total This Period (last page this line number only))

3873.20

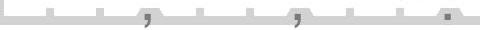

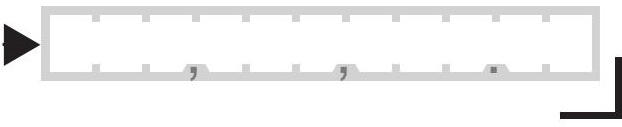

FEC Schedule B-P (Form 3P) (Rev. 03/2011) 


\section{SCHEDULE B-P}

\section{ITEMIZED DISBURSEMENTS}

\section{Use separate schedule(s) \\ for each category of the}

Detailed Summary Page
FOR LINE NUMBER: (check only one)

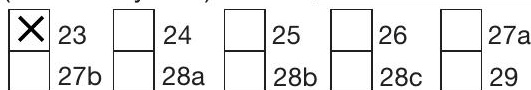

Any information copied from such Reports and Statements may not be sold or used by any person for the purpose of soliciting contributions or for commercial purposes, other than using the name and address of any political committee to solicit contributions from such committee.

NAME OF COMMITTEE (In Full)

\section{Friends of Herman Cain}

Full Name (Last, First, Middle Initial)

A. Tri-Net Payroll Services

Mailing Address 1100 San Leandro Boulevard

Suite

City

San Leandro

Purpose of Disbursement

Payroll Service Fees

Candidate Name

Office Sought:
Full Name (Last, First, Middle Initial)

\section{B. REPUBLICAN PARTY OF IOWA}

Mailing Address $621 \mathrm{E}$. Ninth Street

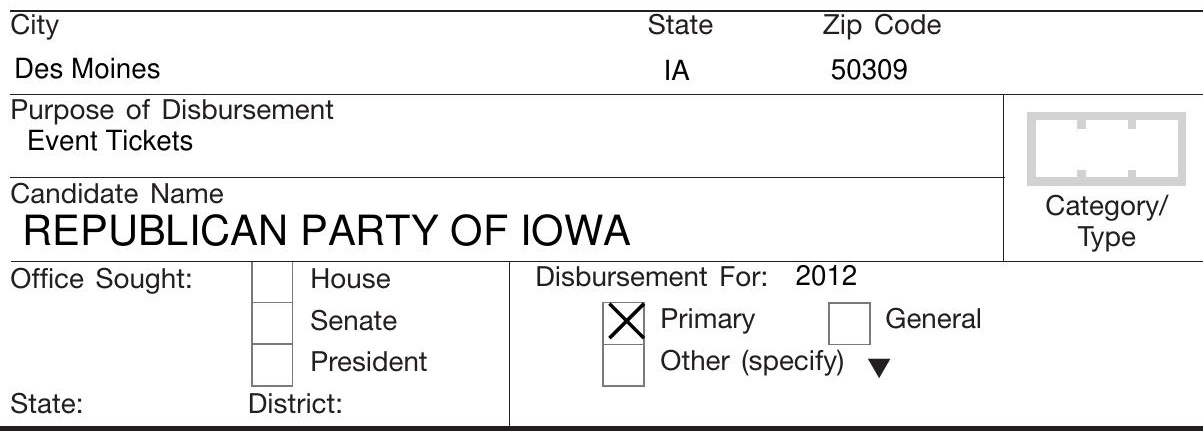

Full Name (Last, First, Middle Initial)

c. REPUBLICAN PARTY OF IOWA

Mailing Address 621 E. Ninth Street

\begin{tabular}{lcc}
\hline City & State & Zip Code \\
Des Moines & IA & 50309
\end{tabular}

Purpose of Disbursement

Event Tickets

Candidate Name

REPUBLICAN PARTY OF IOWA

Office Sought:

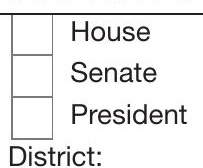

Disbursement For: 2012

Х $\begin{aligned} & \text { Primary } \\ & \text { Other (specify) }\end{aligned}$

District:

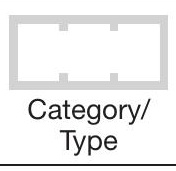

ype

$\begin{array}{cc}\text { State } & \text { Zip Code } \\ \text { CA } & 94577\end{array}$

Date of Disbursement

\begin{tabular}{|c|c|c|c|c|c|}
\hline M M & D \\
08 & 15 & 2011 \\
\hline
\end{tabular}

Transaction ID : B5F9EE82E2BB84079B62

Amount of Each Disbursement this Period

143.00
Date of Disbursement

\begin{tabular}{|c|c|c|c|}
\hline $08^{\mathrm{M}}$ & & ${ }_{15}^{\mathrm{D}}$ & 1 \\
\hline
\end{tabular}

Transaction ID : B5FE2AC06228C41D8A5B

Amount of Each Disbursement this Period 15000.00

Date of Disbursement

\begin{tabular}{|c|c|c|c|c|}
\hline $08^{M}$ & I & D $\quad 5^{\mathrm{D}}$ & 1 & $\begin{array}{cccc}Y & Y & Y & Y \\
& 2011 & \end{array}$ \\
\hline
\end{tabular}

Transaction ID : B1A5C5702D40241AB9A0

Amount of Each Disbursement this Period 9000.00
Subtotal Of Receipts This Page (optional)

24143.00

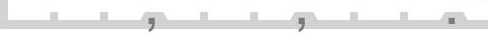

Total This Period (last page this line number only))

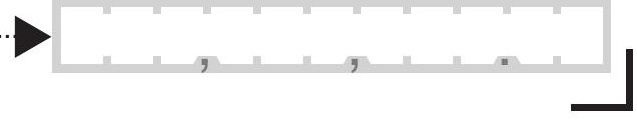

FEC Schedule B-P (Form 3P) (Rev. 03/2011) 


\section{SCHEDULE B-P}

\section{ITEMIZED DISBURSEMENTS}

\section{Use separate schedule(s) \\ for each category of the}

Detailed Summary Page
FOR LINE NUMBER: (check only one)

\begin{tabular}{|c|c|c|c|}
\hline$X_{23}$ & 24 & 25 & 26 \\
\hline $27 \mathrm{~b}$ & $28 a$ & $28 b$ & $28 \mathrm{c}$ \\
\hline
\end{tabular}

Any information copied from such Reports and Statements may not be sold or used by any person for the purpose of soliciting contributions or for commercial purposes, other than using the name and address of any political committee to solicit contributions from such committee.

NAME OF COMMITTEE (In Full)

\section{Friends of Herman Cain}

Full Name (Last, First, Middle Initial)

\section{A. REPUBLICAN PARTY OF IOWA}

Mailing Address 621 E. Ninth Street

\begin{tabular}{lcc}
\hline City & State & Zip Code \\
Des Moines & IA & 50309 \\
\hline
\end{tabular}

Purpose of Disbursement

Event Tickets

Candidate Name

REPUBLICAN PARTY OF IOWA

\begin{tabular}{l|l|l|l}
\hline Office Sought: & & House & Disbursement For: 2012
\end{tabular}

X Primary $\square$ General

State:

Senate

President

District:

Full Name (Last, First, Middle Initial)

\section{B. RMA Chaffeured Transportation}

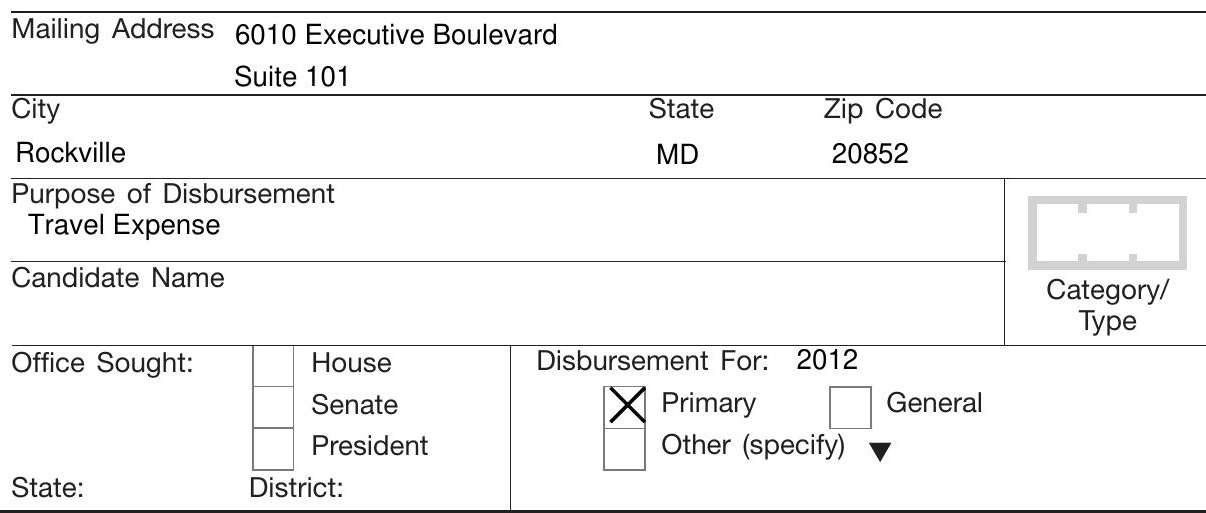

Full Name (Last, First, Middle Initial)

\section{c. US Airways}

Mailing Address 4000 E Sky Harbor Boulevard

\begin{tabular}{lcc}
\hline City & State & Zip Code \\
Phoenix & AZ & 85034
\end{tabular}

Purpose of Disbursement

Travel Expense

Candidate Name

Office Sought: $\quad$ House

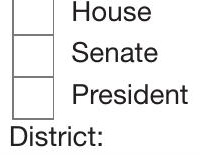

Disbursement For: 2012

Х $\begin{aligned} & \text { Primary } \\ & \text { Other (specify) }\end{aligned}$
Date of Disbursement

\begin{tabular}{|c|c|c|c|c|}
\hline $08^{M}$ & & 15 & & 2011 \\
\hline
\end{tabular}

Transaction ID : B984CCF56A5AC450CBF0

Amount of Each Disbursement this Period 3000.00

Date of Disbursement

\begin{tabular}{|c|c|c|c|c|}
\hline $08^{M}$ & 1 & ${ }^{\mathrm{D}}{ }^{\mathrm{D}}$ & & 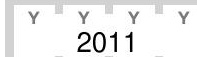 \\
\hline
\end{tabular}

Transaction ID : BC07490FE8F8045709B9

Amount of Each Disbursement this Period

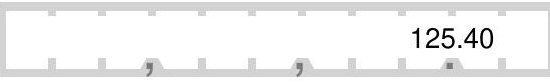

Date of Disbursement

\begin{tabular}{|c|c|c|c|c|c|c|}
\hline M & M & D & Y & Y & Y & Y \\
\hline & & 16 & & 2011 & \\
\hline
\end{tabular}

Transaction ID : B797E729FDB0048E7B34

Amount of Each Disbursement this Period

554.10

Subtotal Of Receipts This Page (optional)

Total This Period (last page this line number only))

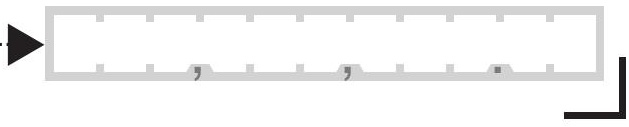




\section{SCHEDULE B-P}

\section{ITEMIZED DISBURSEMENTS}

\section{Use separate schedule(s)}

for each category of the

Detailed Summary Page
FOR LINE NUMBER: (check only one)

\begin{tabular}{|c|c|c|c|c|}
\hline$X_{23}$ & 24 & 25 & 26 & \\
\hline $27 \mathrm{~b}$ & $28 a$ & $28 b$ & $28 \mathrm{c}$ & 29 \\
\hline
\end{tabular}

Any information copied from such Reports and Statements may not be sold or used by any person for the purpose of soliciting contributions or for commercial purposes, other than using the name and address of any political committee to solicit contributions from such committee.

NAME OF COMMITTEE (In Full)

\section{Friends of Herman Cain}

Full Name (Last, First, Middle Initial)

A. Office Depot Corporate

Mailing Address 2500 Mill Center Parkway

Date of Disbursement

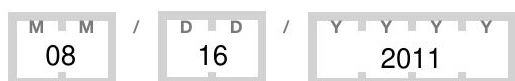

Transaction ID : BA104D00FF3074B9492C

\begin{tabular}{lll}
\hline City & State & Zip Code \\
Buford & GA & 30518
\end{tabular}

Purpose of Disbursement

Office Supplies

Candidate Name

Office Sought:

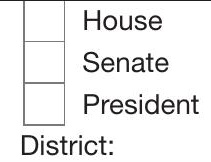

Disbursement For: 2012 Х Primary $\square$ General

State: District:

Full Name (Last, First, Middle Initial)

B. FedEx Kinkos

Mailing Address 942 S. Shady Grove Road

\begin{tabular}{lcc}
\hline City & State & Zip Code \\
Memphis & TN & 38120
\end{tabular}

Purpose of Disbursement

Shipping

Candidate Name

Office Sought:

\begin{tabular}{|l|l} 
& House \\
Senate \\
\cline { 1 - 2 } \\
\cline { 1 - 2 } President
\end{tabular}

State:

District:

Full Name (Last, First, Middle Initial)

\section{c. Hickory Park Restaurant}

Mailing Address 1404 South Duff Ave.

Disbursement For: 2012

Primary
Other (specify)

City State Zip Code

Ames

IA 50010

Purpose of Disbursement

Event Catering

Candidate Name

Office Sought:

\begin{tabular}{|l|l|}
\hline & House \\
& Senate \\
& President \\
& District:
\end{tabular}

Disbursement For: 2012

Х $\begin{aligned} & \text { Primary } \\ & \text { Other (specify) }\end{aligned}$

State:

District:
Date of Disbursement

\begin{tabular}{|c|c|c|c|c|}
\hline $08^{M}$ & 1 & $16^{\mathrm{D}}$ & 1 & 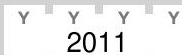 \\
\hline
\end{tabular}

Transaction ID : B7E118C9616AA4551ADF

Amount of Each Disbursement this Period

380.13

Date of Disbursement

\begin{tabular}{|c|c|c|c|c|}
\hline $08^{M}$ & I & D 16 & 1 & 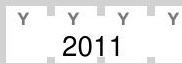 \\
\hline
\end{tabular}

Transaction ID : B65E5CA025F3A40AD998

Amount of Each Disbursement this Period

584.81

Subtotal Of Receipts This Page (optional)

Total This Period (last page this line number only))

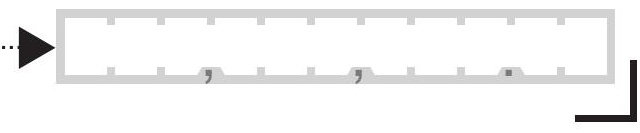




\section{SCHEDULE B-P}

\section{ITEMIZED DISBURSEMENTS}

\section{Use separate schedule(s) \\ for each category of the}

Detailed Summary Page
FOR LINE NUMBER: (check only one)

\begin{tabular}{|c|c|c|c|}
\hline$\times{ }_{23}$ & 24 & 25 & 26 \\
\hline $27 b$ & $28 a$ & $28 \mathrm{~b}$ & $28 \mathrm{c}$ \\
\hline
\end{tabular}

Any information copied from such Reports and Statements may not be sold or used by any person for the purpose of soliciting contributions
or for commercial purposes, other than using the name and address of any political committee to solicit contributions from such committee.

NAME OF COMMITTEE (In Full)

\section{Friends of Herman Cain}

Full Name (Last, First, Middle Initial)

A. A \& S Properties Inc.

Mailing Address 255 Racetrack Road

Date of Disbursement

\begin{tabular}{lcc}
\hline City & State & Zip Code \\
McDonough & GA & 30252 \\
\hline Purpose of Disbursement & &
\end{tabular}

Candidate Name

Office Sought:

nouse

(2)

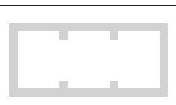

Category/ Type
Amount of Each Disbursement this Period

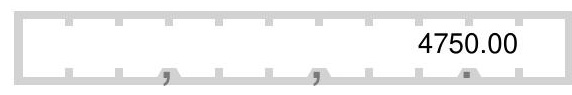

State:

Disbursement For: 2012 X Primary $\square$ General

Full Name (Last, First, Middle Initial)

B. S \& U Real Estate, LLC

Mailing Address 8530 New York Avenue

\begin{tabular}{lcc}
\hline City & State & Zip Code \\
Urbandale & IA & 50322
\end{tabular}

Purpose of Disbursement

Office Rent Expense

Candidate Name

Office Sought:

\begin{tabular}{|l|l} 
House \\
Senate \\
President
\end{tabular}

Disbursement For: 2012

Xrimary $\square$ General

State:

District:

Full Name (Last, First, Middle Initial)

\section{c. One Way Quartet}

\begin{tabular}{|c|c|c|c|c|c|}
\hline \multicolumn{6}{|c|}{ Mailing Address 2273 Kingbird Ave. } \\
\hline \multicolumn{2}{|l|}{ City } & State & Zip Code & & \\
\hline \multicolumn{2}{|l|}{ George } & IA & 51237 & & \\
\hline \multicolumn{5}{|c|}{$\begin{array}{l}\text { Purpose of Disbursement } \\
\text { Event Entertainment }\end{array}$} & \\
\hline \multicolumn{5}{|c|}{ Candidate Name } & $\begin{array}{l}\text { Category/ } \\
\text { Type }\end{array}$ \\
\hline \multirow[t]{3}{*}{ Office Sought: } & House & \multicolumn{4}{|c|}{ Disbursement For: 2012} \\
\hline & Senate & \multirow{3}{*}{\multicolumn{2}{|c|}{$\begin{array}{l}\text { Primary } \\
\text { Other (specify) }\end{array}$}} & \multirow{2}{*}{\multicolumn{2}{|c|}{ General }} \\
\hline & President & & & & \\
\hline State: & District: & & & \multicolumn{2}{|l|}{$\boldsymbol{\nabla}$} \\
\hline
\end{tabular}

Subtotal Of Receipts This Page (optional)......

Date of Disbursement

\begin{tabular}{|c|c|c|c|c|}
\hline $08^{M}$ & I & ${ }^{\mathrm{D}} \begin{array}{r}\mathrm{D} \\
\end{array}$ & 1 & 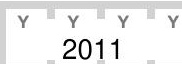 \\
\hline
\end{tabular}

Transaction ID : BD25842EEDB1F41C2BA6

Amount of Each Disbursement this Period

Date of Disbursement

\begin{tabular}{|c|c|c|c|c|}
\hline $08^{M}$ & I & $16^{\mathrm{D}}$ & 1 & $\begin{array}{llll}Y & Y & Y & Y \\
& 2011 & \end{array}$ \\
\hline
\end{tabular}

Transaction ID : B7EAEC17140FB4132A36

Amount of Each Disbursement this Period
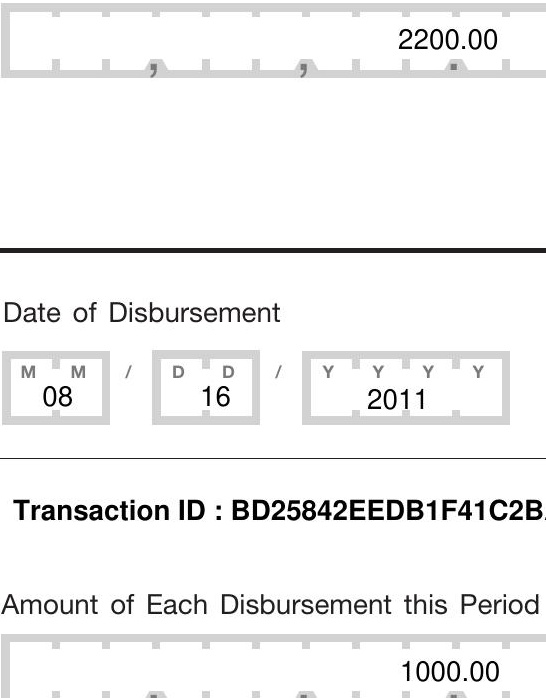

1000.00

Total This Period (last page this line number only)) 


\section{SCHEDULE B-P}

\section{ITEMIZED DISBURSEMENTS}

\section{Use separate schedule(s) \\ for each category of the}

Detailed Summary Page
FOR LINE NUMBER: (check only one)

\begin{tabular}{|c|c|c|c|}
\hline$\times{ }_{23}$ & 24 & 25 & 26 \\
\hline $27 b$ & $28 a$ & $28 \mathrm{~b}$ & $28 \mathrm{c}$ \\
\hline
\end{tabular}

Any information copied from such Reports and Statements may not be sold or used by any person for the purpose of soliciting contributions or for commercial purposes, other than using the name and address of any political committee to solicit contributions from such committee.

NAME OF COMMITTEE (In Full)

\section{Friends of Herman Cain}

Full Name (Last, First, Middle Initial)

A. Hotels.com

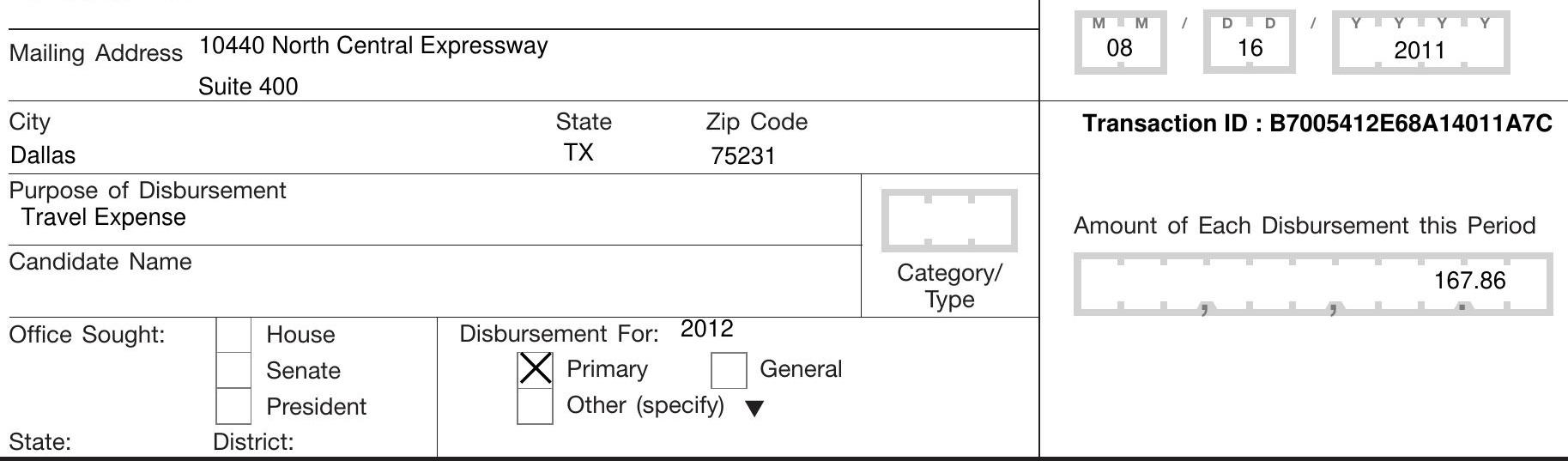

Full Name (Last, First, Middle Initial)

\section{B. St. Elmo Steakhouse}

Mailing Address 127 S Illinois St.

\begin{tabular}{lcc}
\hline City & State & Zip Code \\
Indianapolis & IN & 46225
\end{tabular}

Purpose of Disbursement

Meeting Expense

Candidate Name

Office Sought:

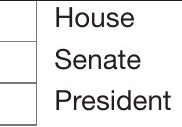

State:

District:

Date of Disbursement

\begin{tabular}{|c|c|c|c|c|}
\hline $08^{M}$ & & ${ }^{\mathrm{D}}{ }^{\mathrm{D}}$ & 1 & 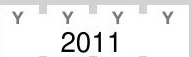 \\
\hline
\end{tabular}

Full Name (Last, First, Middle Initial)

c. Inkhead Inc.

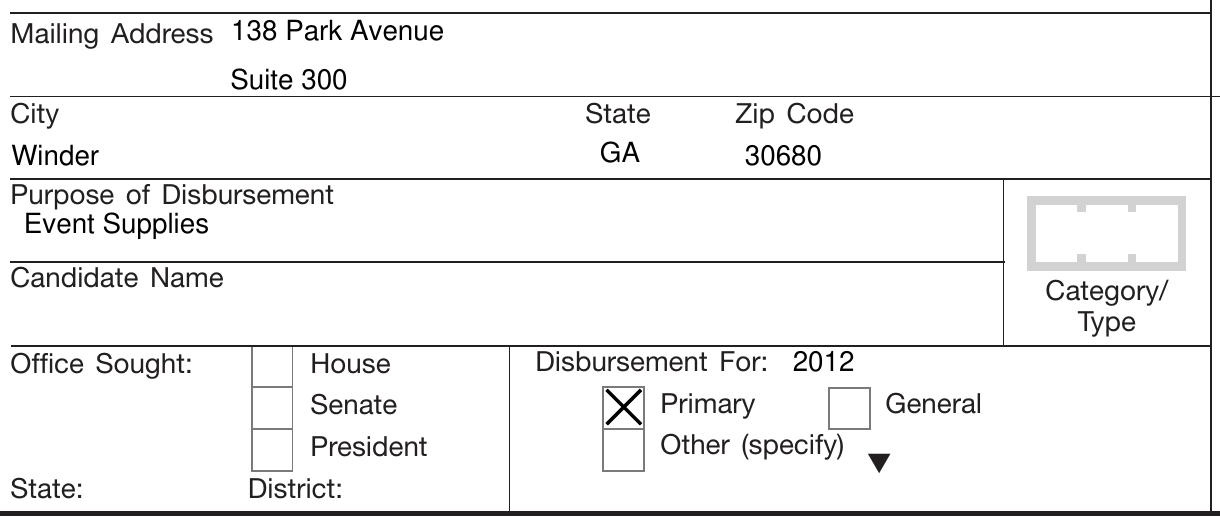

Subtotal Of Receipts This Page (optional).

Date of Disbursement

\begin{tabular}{|c|c|c|c|c|c|c|}
\hline$M$ & M & D & Y & Y & $Y$ \\
08 & & 16 & & 2011 & \\
\hline
\end{tabular}

Transaction ID : B71446CBD146C4076A31

Amount of Each Disbursement this Period

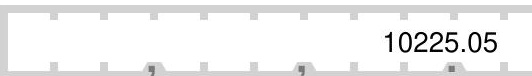

Total This Period (last page this line number only)) 


\section{SCHEDULE B-P}

\section{ITEMIZED DISBURSEMENTS}

Use separate schedule(s)

for each category of the

Detailed Summary Page
FOR LINE NUMBER: (check only one)

\begin{tabular}{|c|c|c|c|}
\hline$\times{ }_{23}$ & 24 & 25 & 26 \\
\hline $27 b$ & $28 a$ & $28 \mathrm{~b}$ & $28 \mathrm{c}$ \\
\hline
\end{tabular}

Any information copied from such Reports and Statements may not be sold or used by any person for the purpose of soliciting contributions or for commercial purposes, other than using the name and address of any political committee to solicit contributions from such committee.

NAME OF COMMITTEE (In Full)

\section{Friends of Herman Cain}

Full Name (Last, First, Middle Initial)

A. Inkhead Inc.

Mailing Address 138 Park Avenue

Suite 300

Date of Disbursement

\begin{tabular}{lll}
\multicolumn{3}{r}{ Suite 300} \\
City & State & Zip Code \\
Winder & GA & 30680 \\
\hline Purpose of Disbursement & &
\end{tabular}

Purpose of Disbursement

Event Supplies

Candidate Name
08
16
2011

Transaction ID : B762BF981943743E18A2

\begin{tabular}{c|c} 
Category/ \\
Type
\end{tabular}

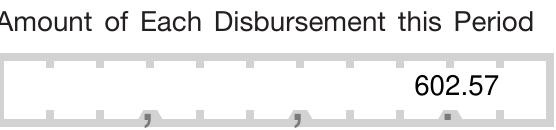

\begin{tabular}{l|l|l|l|}
\hline Office Sought: & $\begin{array}{l}\text { House } \\
\text { Senate } \\
\text { President }\end{array}$ & $\begin{array}{r}\text { Disbursement For: } 2012 \\
\text { X Primary } \\
\text { Other (specify) }\end{array}$
\end{tabular}

Full Name (Last, First, Middle Initial)

B. Facebook, Inc.

Mailing Address 1601 S. California Ave.

\begin{tabular}{lcc}
\hline City & State & Zip Code \\
Palo Alto & CA & 94304
\end{tabular}

Purpose of Disbursement

Advertising Expense

Candidate Name

Office Sought:

\begin{tabular}{|l|l} 
House \\
Senate \\
\hline
\end{tabular}

Disbursement For: 2012

Primary
Other (specify) General

State:

District:

Full Name (Last, First, Middle Initial)

\section{c. Ground Floor LLC}

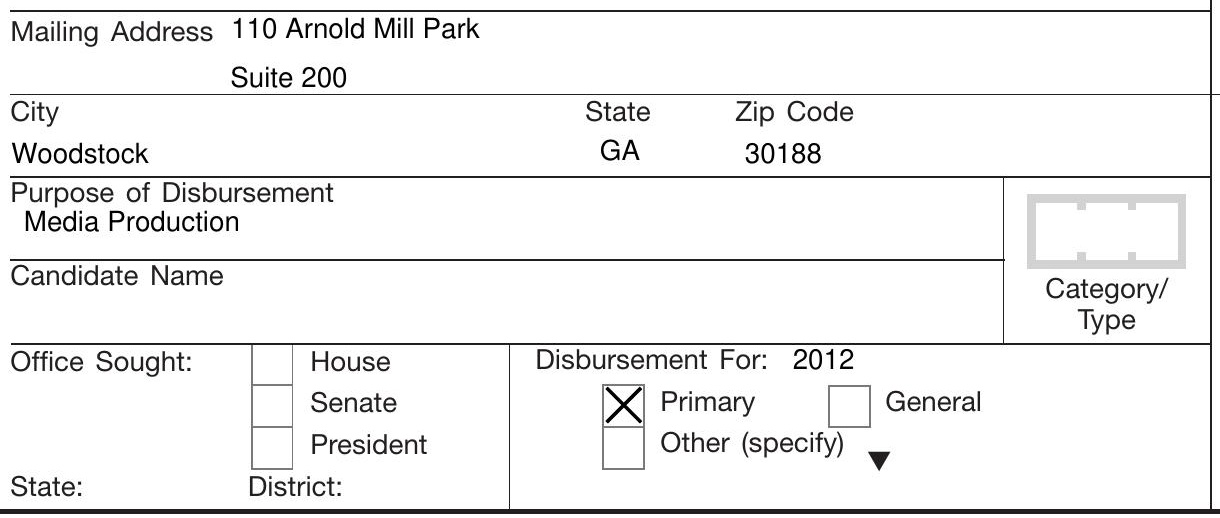

Subtotal Of Receipts This Page (optional).

Date of Disbursement

\begin{tabular}{|c|c|c|c|c|c|c|}
\hline M & M & D & Y & $Y$ & $Y$ \\
08 & & 16 & & 2011 & \\
\hline
\end{tabular}

Transaction ID : B5C2C04D8220C443B8DA

Amount of Each Disbursement this Period

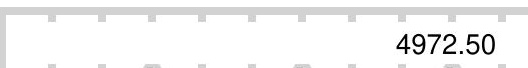

4972.50

Total This Period (last page this line number only)) 


\section{SCHEDULE B-P}

\section{ITEMIZED DISBURSEMENTS}

\section{Use separate schedule(s) \\ for each category of the}

Detailed Summary Page
FOR LINE NUMBER: (check only one)

\begin{tabular}{|c|c|c|c|}
\hline$\times{ }_{23}$ & 24 & 25 & 26 \\
\hline $27 b$ & $28 a$ & $28 \mathrm{~b}$ & $28 \mathrm{c}$ \\
\hline
\end{tabular}

Any information copied from such Reports and Statements may not be sold or used by any person for the purpose of soliciting contributions or for commercial purposes, other than using the name and address of any political committee to solicit contributions from such committee.

NAME OF COMMITTEE (In Full)

\section{Friends of Herman Cain}

Full Name (Last, First, Middle Initial)

A. Doulos Productions, Inc.

Mailing Address 1450 Corporate Pointe

Date of Disbursement

\begin{tabular}{lcc}
\hline City & State & Zip Code \\
Warner Robins & GA & 31088 \\
\hline Purpose of Disbursement & &
\end{tabular}

Purpose of Disbursement

Candidate Name

Office Sought: $\quad$ House

$\begin{array}{ll} & \text { Senate } \\ \text { President } \\ \text { District: }\end{array}$

Disbursement For: 2012 Х Primary $\square$ General

State: District:

\section{Full Name (Last, First, Middle Initial)}

\section{B. Mobilization Labs LLC}

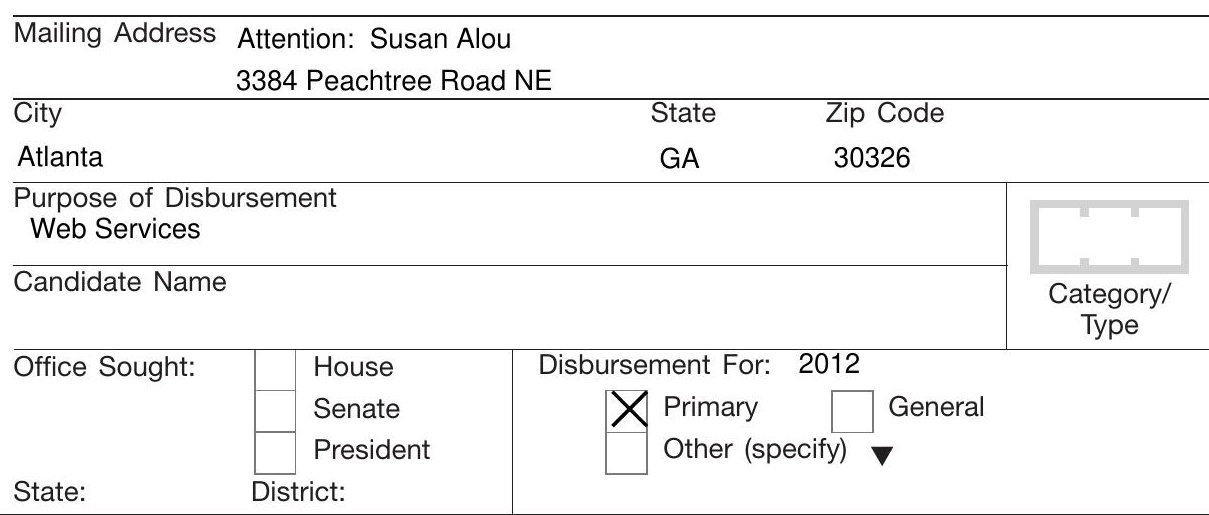

Date of Disbursement

Full Name (Last, First, Middle Initial)

\section{c. Catch the Glory, LLC}

\begin{tabular}{|c|c|c|c|c|c|}
\hline \multicolumn{6}{|c|}{ Mailing Address 16 Lowell Street } \\
\hline \multicolumn{2}{|l|}{ City } & State & \multicolumn{3}{|l|}{ Zip Code } \\
\hline \multicolumn{2}{|l|}{ Manchester } & $\mathrm{NH}$ & \multicolumn{3}{|l|}{03101} \\
\hline \multicolumn{5}{|c|}{$\begin{array}{l}\text { Purpose of Disbursement } \\
\text { Office Rent Expense }\end{array}$} & \\
\hline \multicolumn{5}{|c|}{ Candidate Name } & $\begin{array}{l}\text { Category/ } \\
\text { Type }\end{array}$ \\
\hline \multirow[t]{3}{*}{ Office Sought: } & House & \multicolumn{4}{|c|}{ Disbursement For: 2012} \\
\hline & Senate & \multirow{3}{*}{\multicolumn{2}{|c|}{$\begin{array}{l}\text { Primary } \\
\text { Other (specify) }\end{array}$}} & \multirow{2}{*}{\multicolumn{2}{|c|}{ General }} \\
\hline & President & & & & \\
\hline State: & District: & & & & \\
\hline
\end{tabular}

Subtotal Of Receipts This Page (optional).

Date of Disbursement

\begin{tabular}{|c|c|c|c|c|}
\hline $08^{M}$ & I & $\begin{array}{ll}\mathrm{D} \\
17\end{array}$ & 1 & 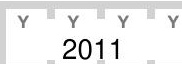 \\
\hline
\end{tabular}

\section{Transaction ID : B4B1B04130382483AA80}

Amount of Each Disbursement this Period

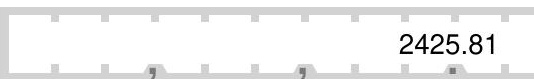

Total This Period (last page this line number only)) 


\section{SCHEDULE B-P}

\section{ITEMIZED DISBURSEMENTS}

\section{Use separate schedule(s)}

for each category of the

Detailed Summary Page
FOR LINE NUMBER: (check only one)

\begin{tabular}{|c|c|c|c|}
\hline$\times{ }_{23}$ & 24 & 25 & 26 \\
\hline $27 b$ & $28 a$ & $28 \mathrm{~b}$ & $28 \mathrm{c}$ \\
\hline
\end{tabular}

Any information copied from such Reports and Statements may not be sold or used by any person for the purpose of soliciting contributions or for commercial purposes, other than using the name and address of any political committee to solicit contributions from such committee.

NAME OF COMMITTEE (In Full)

\section{Friends of Herman Cain}

Full Name (Last, First, Middle Initial)

A. Facebook, Inc.

Mailing Address 1601 S. California Ave.

Date of Disbursement

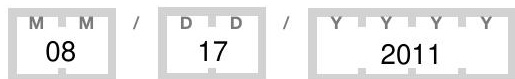

Transaction ID : BA4E23D1EF47D460CB82

\begin{tabular}{lll} 
City & State & Zip Code \\
Palo Alto & CA & 94304 \\
\hline
\end{tabular}

Purpose of Disbursement

Advertising Expense

Candidate Name

Office Sought:

$$
\begin{array}{|l}
\text { House } \\
\text { Senate } \\
\text { President }
\end{array}
$$

State:

District:

Full Name (Last, First, Middle Initial)

B. Paypal

Mailing Address P.O. Box 45950

\begin{tabular}{lll}
\hline City & State & Zip Code \\
Omaha & NE & 68145
\end{tabular}

Purpose of Disbursement

CC Transaction Fees

Candidate Name

Office Sought:

House
Senate
President

State:

District:

Full Name (Last, First, Middle Initial)

c. Michael Branch

Mailing Address 509 Autumnwood Ct

\begin{tabular}{lcc}
\hline City & State & Zip Code \\
Nashville & TN & $37221-3938$
\end{tabular}

Purpose of Disbursement

Mileage

Candidate Name

Office Sought:

\begin{tabular}{|l|l|l|} 
& House \\
Senate \\
President \\
District:
\end{tabular}

Disbursement For: 2012

Xrimary $\square$ General

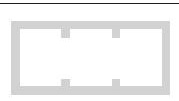

Category/ Type
Amount of Each Disbursement this Period

\begin{tabular}{|c|c|c|c|c|}
\hline $08^{M}$ & I & ${ }^{\mathrm{D}} 7^{\mathrm{D}}$ & 1 & 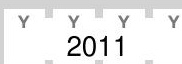 \\
\hline
\end{tabular}

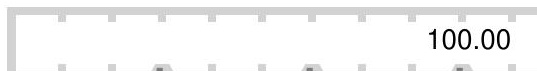

Date of Disbursement

Transaction ID : B941A608DF6894C47859

Amount of Each Disbursement this Period

Date of Disbursement

\begin{tabular}{|c|c|c|c|c|c|}
\hline M & M & D & Y & Y & Y \\
08 & & 17 & & 2011 & \\
\hline
\end{tabular}

Transaction ID : B3353ECDF7A954C2B835

Amount of Each Disbursement this Period

1432.58
State:

District:

Disbursement For: 2012
$\times \quad \begin{aligned} & \text { Primary } \\ & \text { Other (specify) }\end{aligned}$

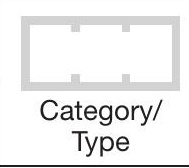

ype
Subtotal Of Receipts This Page (optional).

1533.57

and

Total This Period (last page this line number only))

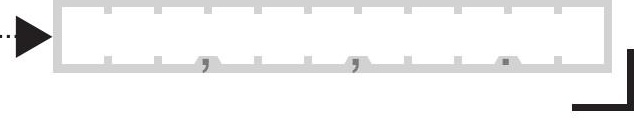

FEC Schedule B-P (Form 3P) (Rev. 03/2011) 


\section{SCHEDULE B-P}

\section{ITEMIZED DISBURSEMENTS}

\section{Use separate schedule(s)}

for each category of the

Detailed Summary Page
FOR LINE NUMBER: (check only one)

\begin{tabular}{|c|c|c|c|}
\hline$\times{ }_{23}$ & 24 & 25 & 26 \\
\hline $27 b$ & $28 a$ & $28 \mathrm{~b}$ & $28 \mathrm{c}$ \\
\hline
\end{tabular}

Any information copied from such Reports and Statements may not be sold or used by any person for the purpose of soliciting contributions or for commercial purposes, other than using the name and address of any political committee to solicit contributions from such committee.

NAME OF COMMITTEE (In Full)

\section{Friends of Herman Cain}

Full Name (Last, First, Middle Initial)

A. Comfort Inn Hotels

Mailing Address 10750 Columbia Pike

Date of Disbursement

\begin{tabular}{lll}
\hline City & State & Zip Code \\
Silver Spring & MD & 20901 \\
\hline
\end{tabular}

Purpose of Disbursement

Travel Expense

Candidate Name

\begin{tabular}{l|l|l}
\hline Office Sought: & House & Disbursement For: 2012
\end{tabular} X Primary $\square$ General

State:

\section{Senate}

President

District:

Full Name (Last, First, Middle Initial)

B. SunTrust Bank

Mailing Address 980 Eagles Landing Parkway

\begin{tabular}{lcc}
\hline City & State & Zip Code \\
Stockbridge & GA & 30281
\end{tabular}

Purpose of Disbursement

Bank Fees

Candidate Name

Office Sought:

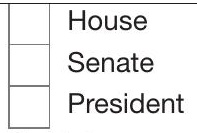

State:

District:

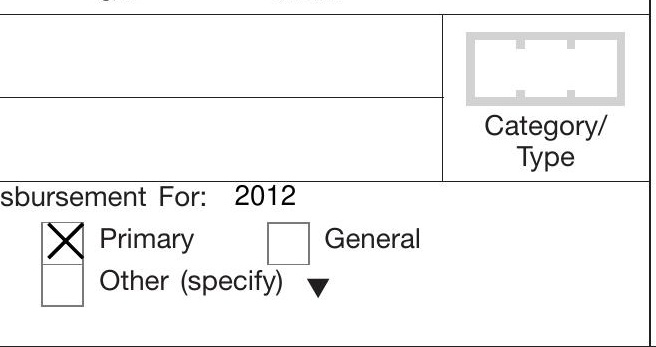

Date of Disbursement

\begin{tabular}{|c|c|c|c|c|}
\hline $08^{M}$ & 1 & ${ }^{\mathrm{D}} 17^{\mathrm{D}}$ & l & $\begin{array}{llll}Y & Y & Y & Y \\
2011 & Y\end{array}$ \\
\hline
\end{tabular}

Transaction ID : B737D9221FBB04501AB2

Amount of Each Disbursement this Period

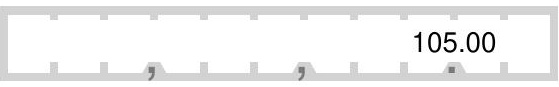

Full Name (Last, First, Middle Initial)

c. Strawn \& Co. Insurance

Mailing Address 16 Hampton Street

Date of Disbursement

\begin{tabular}{lcc|} 
& & \\
\hline City & State & Zip Code \\
McDonough & GA & 30253
\end{tabular}

\begin{tabular}{|c|c|c|c|c|c|}
\hline${ }^{M}$ & M & D & Y Y Y Y \\
\hline & & 17 & 2011 \\
\hline
\end{tabular}

Purpose of Disbursement

Insurance

Candidate Name

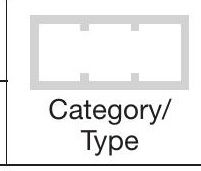

Transaction ID : B27528747262E46A3965

\begin{tabular}{|c|c|c|c|}
\hline \multirow{3}{*}{ Office Sought: } & House & \multicolumn{2}{|l|}{ Disbursement For: 2012} \\
\hline & Senate & X Primary & Gene \\
\hline & President & Other (specif & \\
\hline
\end{tabular}

Amount of Each Disbursement this Period

Subtotal Of Receipts This Page (optional)......

Total This Period (last page this line number only)).

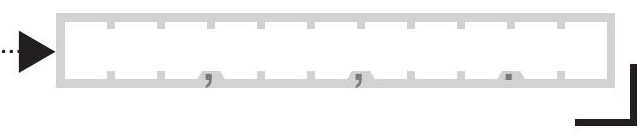




\section{SCHEDULE B-P}

\section{ITEMIZED DISBURSEMENTS}

Use separate schedule(s)

for each category of the

Detailed Summary Page
FOR LINE NUMBER: (check only one)

\begin{tabular}{|c|c|c|c|}
\hline$\times{ }_{23}$ & 24 & 25 & 26 \\
\hline $27 b$ & $28 a$ & $28 \mathrm{~b}$ & $28 \mathrm{c}$ \\
\hline
\end{tabular}

Any information copied from such Reports and Statements may not be sold or used by any person for the purpose of soliciting contributions or for commercial purposes, other than using the name and address of any political committee to solicit contributions from such committee.

NAME OF COMMITTEE (In Full)

\section{Friends of Herman Cain}

Full Name (Last, First, Middle Initial)

A. Runde Suzuki

Mailing Address 138 Route 35

Date of Disbursement

\begin{tabular}{lll}
\hline City & State & Zip Code \\
Hazel Green & WI & 53811
\end{tabular}

Purpose of Disbursement

Travel Expense

Candidate Name

Office Sought:

\begin{tabular}{|l|l} 
& $\begin{array}{l}\text { House } \\
\text { Senate } \\
\text { President }\end{array}$ \\
\hline District:
\end{tabular}

State:

District:

Full Name (Last, First, Middle Initial)

B. Delta Airlines

Mailing Address Post Office Box 20980

Department 980

\begin{tabular}{lcc}
\hline City & State & Zip Code \\
Atlanta & GA & $30320-2980$ \\
\hline Purpose of Disbursement & &
\end{tabular}

Travel Expense

Candidate Name

Office Sought:

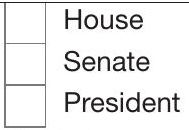

State:

District:
Disbursement For: 2012 X Primary $\square$ General

M M I D D

08

17

2011

Transaction ID : BE2F4B543A2624025992

Amount of Each Disbursement this Period

2168.24

Date of Disbursement

\begin{tabular}{|c|c|c|c|c|}
\hline $08^{M}$ & 1 & ${ }^{\mathrm{D}}{ }^{\mathrm{D}}$ & 1 & 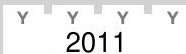 \\
\hline
\end{tabular}

Transaction ID : B4A943ECF76184445819

Amount of Each Disbursement this Period

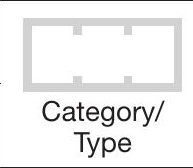
Disbursement For: 2012
Primary
Other (specify)

Date of Disbursement

c. Integram

Mailing Address 22695 Commerce Center Court

\begin{tabular}{|c|c|c|c|c|c|}
\hline M & M & P & Y & Y & Y \\
08 & 17 & & 2011 & \\
\hline
\end{tabular}

\begin{tabular}{lcc}
\hline City & State & Zip Code \\
Dulles & VA & 20166 \\
\hline
\end{tabular}

Purpose of Disbursement

Direct Mail Production

Candidate Name

Office Sought: $\quad$ House

\begin{tabular}{|l|l|} 
& House \\
& Senate \\
& President
\end{tabular}

Disbursement For: 2012

X $\begin{aligned} & \text { Primary } \\ & \text { Other (specify) }\end{aligned}$

State:

Subtotal Of Receipts This Page (optional).

Total This Period (last page this line number only))

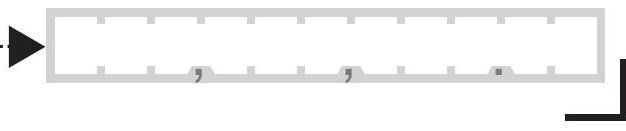

FEC Schedule B-P (Form 3P) (Rev. 03/2011) 


\section{SCHEDULE B-P}

\section{ITEMIZED DISBURSEMENTS}

\section{Use separate schedule(s) \\ for each category of the}

Detailed Summary Page
FOR LINE NUMBER: (check only one)

\begin{tabular}{|c|c|c|c|}
\hline$\times{ }_{23}$ & 24 & 25 & 26 \\
\hline $27 b$ & $28 a$ & $28 \mathrm{~b}$ & $28 \mathrm{c}$ \\
\hline
\end{tabular}

Any information copied from such Reports and Statements may not be sold or used by any person for the purpose of soliciting contributions or for commercial purposes, other than using the name and address of any political committee to solicit contributions from such committee.

NAME OF COMMITTEE (In Full)

\section{Friends of Herman Cain}

Full Name (Last, First, Middle Initial)

A. United Airlines

\begin{tabular}{cc}
\hline Mailing Address & 1200 E Algonquin Road \\
& Post Office Box 66100
\end{tabular}

\begin{tabular}{lll}
\hline City & State & Zip Code \\
Elk Grove Township & IL & 60007
\end{tabular}

Purpose of Disbursement

Travel Expense

Candidate Name

\begin{tabular}{l|l|l|l}
\hline Office Sought: & $\begin{array}{l}\text { House } \\
\text { Senate } \\
\text { President }\end{array}$ & $\begin{array}{r}\text { Disbursement For: } 2012 \\
\text { X Primary } \\
\text { Other (specify) }\end{array}$
\end{tabular}

Full Name (Last, First, Middle Initial)

B. The Standard Restaurant and Club

Mailing Address 167 Rosa L. Parks Blvd.

\begin{tabular}{|c|c|c|c|c|}
\hline \multicolumn{2}{|l|}{$\overline{\text { City }}$} & \multicolumn{3}{|c|}{ Zip Code } \\
\hline \multicolumn{2}{|l|}{ Nashville } & \multicolumn{3}{|c|}{37203} \\
\hline \multicolumn{4}{|c|}{$\begin{array}{l}\text { Purpose of Disbursement } \\
\text { Event Catering }\end{array}$} & \\
\hline \multicolumn{4}{|c|}{ Candidate Name } & $\begin{array}{l}\text { Category/ } \\
\text { Type }\end{array}$ \\
\hline \multirow[t]{3}{*}{ Office Sought: } & House & \multirow{3}{*}{\multicolumn{3}{|c|}{$\begin{array}{l}\text { Disbursement For: } 2012 \\
\text { Xrimary } \\
\text { Other (specify) }\end{array}$}} \\
\hline & \multirow{2}{*}{$\begin{array}{l}\text { Senate } \\
\text { President }\end{array}$} & & & \\
\hline & & & & \\
\hline State: & rict: & & \multicolumn{2}{|l|}{$\nabla$} \\
\hline
\end{tabular}

Date of Disbursement

Full Name (Last, First, Middle Initial)

\section{c. Delta Airlines}

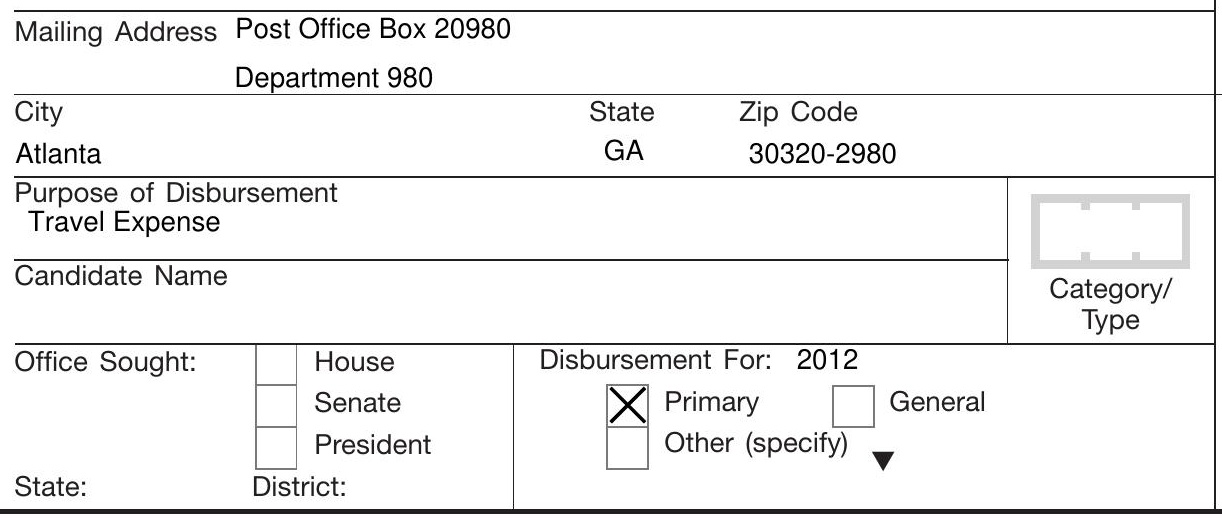

Subtotal Of Receipts This Page (optional).....

Date of Disbursement

\begin{tabular}{|c|c|c|c|c|c|}
\hline M & M & D & Y & Y & Y \\
0 & & 18 & & 2011 & \\
\hline
\end{tabular}

\section{Transaction ID : BB119732752F540F6960}

Amount of Each Disbursement this Period

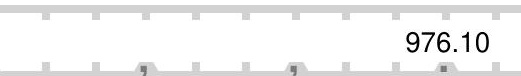

976.10

Total This Period (last page this line number only)) 


\section{SCHEDULE B-P}

\section{ITEMIZED DISBURSEMENTS}

\section{Use separate schedule(s) \\ for each category of the}

Detailed Summary Page
FOR LINE NUMBER: (check only one)

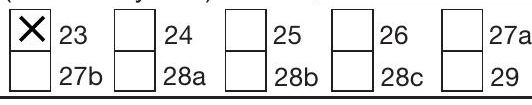

Any information copied from such Reports and Statements may not be sold or used by any person for the purpose of soliciting contributions or for commercial purposes, other than using the name and address of any political committee to solicit contributions from such committee.

NAME OF COMMITTEE (In Full)

\section{Friends of Herman Cain}

Full Name (Last, First, Middle Initial)

A. SunTrust Bank

Mailing Address 980 Eagles Landing Parkway

Date of Disbursement

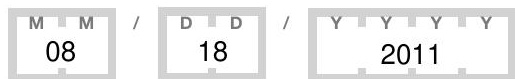

Transaction ID : B37B9984B09D74DB7B05

\begin{tabular}{lll}
\hline City & State & Zip Code \\
Stockbridge & GA & 30281
\end{tabular}

Purpose of Disbursement

Bank Fees

Candidate Name

\begin{tabular}{l|l|l}
\hline Office Sought: & House & Disbursement For: 2012
\end{tabular} X Primary $\square$ General

State:

\section{Senate}

President

District:

Full Name (Last, First, Middle Initial)

B. Mo's A Place for Steak

Mailing Address 47 S. Pennsylvania St.

\begin{tabular}{|c|c|c|c|c|}
\hline \multicolumn{2}{|l|}{ City } & \multicolumn{3}{|c|}{ Zip Code } \\
\hline \multicolumn{2}{|l|}{ Indianapolis } & \multicolumn{3}{|c|}{46204} \\
\hline \multicolumn{4}{|c|}{$\begin{array}{l}\text { Purpose of Disbursement } \\
\text { Event Catering }\end{array}$} & \\
\hline \multicolumn{4}{|c|}{ Candidate Name } & $\begin{array}{l}\text { Category/ } \\
\text { Type }\end{array}$ \\
\hline \multirow[t]{3}{*}{ Office Sought: } & House & \multirow{3}{*}{\multicolumn{3}{|c|}{$\begin{array}{l}\text { Disbursement For: } 2012 \\
\text { Xrimary } \\
\text { Other (specify) }\end{array}$}} \\
\hline & \multirow{2}{*}{$\begin{array}{l}\text { Senate } \\
\text { President }\end{array}$} & & & \\
\hline & & & & \\
\hline State: & rict: & & \multicolumn{2}{|l|}{$\nabla$} \\
\hline
\end{tabular}

Full Name (Last, First, Middle Initial)

c. SunTrust Bank

Mailing Address 980 Eagles Landing Parkway

\begin{tabular}{lcc}
\hline City & State & Zip Code \\
Stockbridge & GA & 30281
\end{tabular}

Purpose of Disbursement

Bank Fees

Candidate Name

Office Sought: $\quad$ House

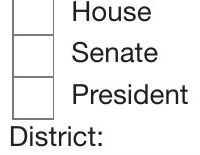

Disbursement For: 2012

Х $\begin{aligned} & \text { Primary } \\ & \text { Other (specify) }\end{aligned}$

State:
Date of Disbursement

\begin{tabular}{|c|c|c|c|c|}
\hline${ }^{M} 8^{M}$ & & ${ }^{\mathrm{D}}{ }^{\mathrm{D}}$ & 1 & 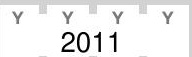 \\
\hline
\end{tabular}

Transaction ID : B4A0D305736334BF8A38

Amount of Each Disbursement this Period

586.88

Date of Disbursement

\begin{tabular}{|c|c|c|c|c|c|}
\hline M M & M & D & Y & Y & Y \\
\hline & 18 & & 2011 & \\
\hline
\end{tabular}

Transaction ID : BD8272BD2FE824852B78

Amount of Each Disbursement this Period

108.00

Subtotal Of Receipts This Page (optional).....

Total This Period (last page this line number only))

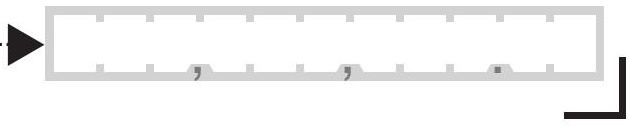




\section{SCHEDULE B-P}

\section{ITEMIZED DISBURSEMENTS}

\section{Use separate schedule(s) \\ for each category of the}

Detailed Summary Page
FOR LINE NUMBER: (check only one)

\begin{tabular}{|c|c|c|c|}
\hline$\times{ }_{23}$ & 24 & 25 & 26 \\
\hline $27 b$ & $28 a$ & $28 \mathrm{~b}$ & $28 \mathrm{c}$ \\
\hline
\end{tabular}

Any information copied from such Reports and Statements may not be sold or used by any person for the purpose of soliciting contributions or for commercial purposes, other than using the name and address of any political committee to solicit contributions from such committee.

NAME OF COMMITTEE (In Full)

\section{Friends of Herman Cain}

Full Name (Last, First, Middle Initial)

\section{A. Avis Rent A Car}

Mailing Address 900 Old Country Garden Road

Date of Disbursement

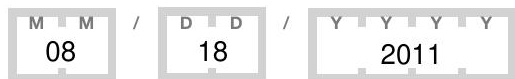

Transaction ID : B2F62D187AC4B4643969

\begin{tabular}{lcc}
\hline City & State & Zip Code \\
Garden City & NY & 11530
\end{tabular}

Purpose of Disbursement

Travel Expense

Candidate Name

Office Sought:

$$
\begin{array}{|l|l}
\text { House } \\
\text { Senate } \\
\text { President }
\end{array}
$$

State: District:

Full Name (Last, First, Middle Initial)

B. Facebook, Inc.

Mailing Address 1601 S. California Ave.

\begin{tabular}{lcc}
\hline City & State & Zip Code \\
Palo Alto & CA & 94304
\end{tabular}

Purpose of Disbursement Advertising Expense

Candidate Name

Office Sought:

\begin{tabular}{|l|l|l}
\hline & House \\
Senate \\
\cline { 1 - 2 } & President
\end{tabular}

State: District:

Full Name (Last, First, Middle Initial)

c. Air Expedite Inc.

Mailing Address Post Office Box 331

\begin{tabular}{lcc}
\hline City & State & Zip Code \\
Hampton & GA & 30228
\end{tabular}

Purpose of Disbursement

Travel Expense

Candidate Name

Disbursement For: 2012

Xrimary $\square$ General

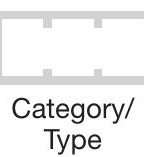

Amount of Each Disbursement this Period

25.30
Date of Disbursement

\begin{tabular}{|c|c|c|c|c|}
\hline${ }^{M}$ & ${ }^{M}$ & $8^{\mathrm{D}}$ & ${ }^{\mathrm{D}}$ & $\mathrm{Y}^{\mathrm{Y}}$ \\
\hline
\end{tabular}

Transaction ID : BC21AA32149614D278DB

Amount of Each Disbursement this Period

\begin{tabular}{|c|c|c|c|c|}
\hline $08^{M}$ & I & D 18 & 1 & $\begin{array}{cccc}Y & Y & Y & Y \\
& 2011 & \end{array}$ \\
\hline
\end{tabular}

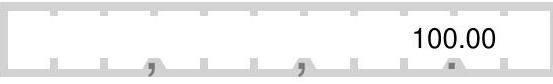

Date of Disbursement

Transaction ID : BF8790B96DC7F45AFA59

Amount of Each Disbursement this Period

38140.86

\begin{tabular}{l|l|l|l}
\hline Office Sought: & House & $\begin{array}{c}\text { Disbursement For: } 2012 \\
\text { Senate } \\
\text { President } \\
\text { State: }\end{array}$ & X Primary \\
Other (specify)
\end{tabular}

Subtotal Of Receipts This Page (optional).

Total This Period (last page this line number only))

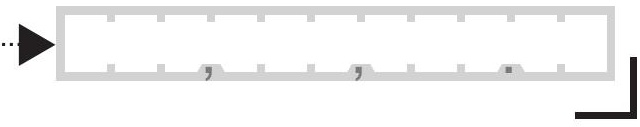




\section{SCHEDULE B-P}

\section{ITEMIZED DISBURSEMENTS}

\section{Use separate schedule(s) \\ for each category of the}

Detailed Summary Page
FOR LINE NUMBER: (check only one)

\begin{tabular}{|c|c|c|c|}
\hline$\times{ }_{23}$ & 24 & 25 & 26 \\
\hline $27 b$ & $28 a$ & $28 \mathrm{~b}$ & $28 \mathrm{c}$ \\
\hline
\end{tabular}

Any information copied from such Reports and Statements may not be sold or used by any person for the purpose of soliciting contributions or for commercial purposes, other than using the name and address of any political committee to solicit contributions from such committee.

NAME OF COMMITTEE (In Full)

\section{Friends of Herman Cain}

Full Name (Last, First, Middle Initial)

\section{A. Hampton Inn Hotels}

Mailing Address 7930 Jones Branch Drive

Date of Disbursement

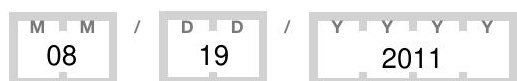

Transaction ID : B9627E3B3ED8743CB83B

\begin{tabular}{lll}
\hline City & State & Zip Code \\
McLean & VA & 22102 \\
\hline
\end{tabular}

Purpose of Disbursement

Travel Expense

Candidate Name

Office Sought:

$$
\begin{array}{|l|l} 
& \text { House } \\
& \text { Senate } \\
\cline { 1 - 2 } & \text { President }
\end{array}
$$

State: District:

Full Name (Last, First, Middle Initial)

\section{B. Aristotle International Inc.}

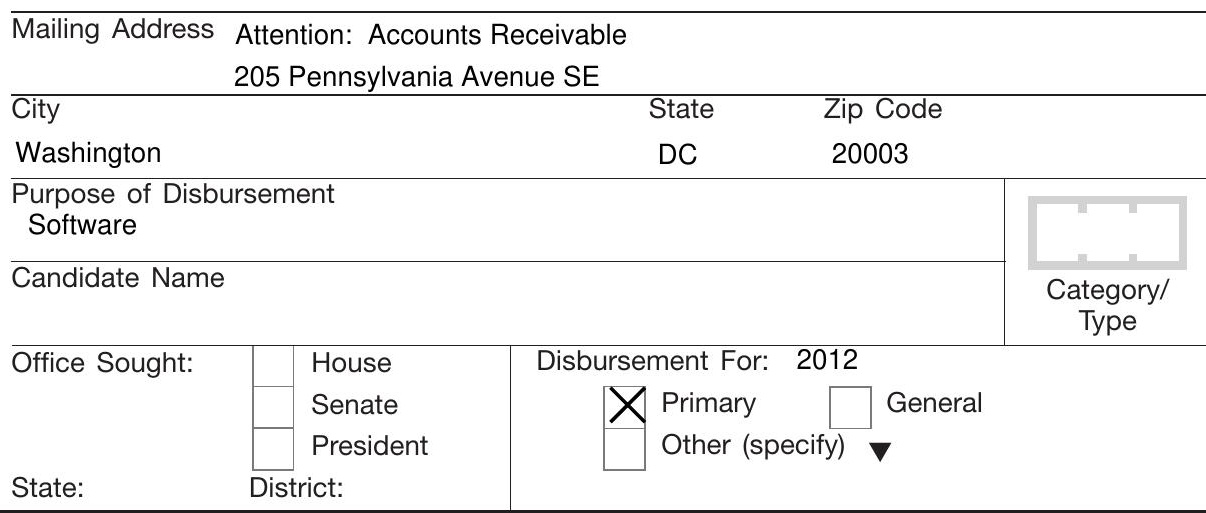

Full Name (Last, First, Middle Initial)

c. Facebook, Inc.

Mailing Address 1601 S. California Ave.

\begin{tabular}{lcc}
\hline City & State & Zip Code \\
Palo Alto & CA & 94304 \\
\hline
\end{tabular}

Purpose of Disbursement Advertising Expense

Candidate Name

\begin{tabular}{l|l}
\hline Office Sought: & House \\
& $\begin{array}{l}\text { Senate } \\
\text { Senatent } \\
\text { President }\end{array}$ \\
State: & District:
\end{tabular}
Disbursement For: 2012
\[ \begin{array}{l}\text { Primary } \\ \text { Other (specify) }\end{array} \]

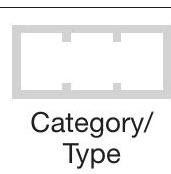

Amount of Each Disbursement this Period

\begin{tabular}{|c|c|c|c|c|}
\hline $08^{M}$ & 1 & $19^{\mathrm{D}}$ & 1 & $\begin{array}{llll}Y & Y & Y & Y \\
& 2011\end{array}$ \\
\hline
\end{tabular}

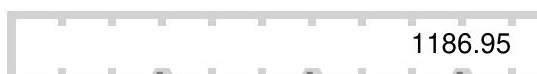

Date of Disbursement

Transaction ID : BBA68E900C3A54489A51

Amount of Each Disbursement this Period

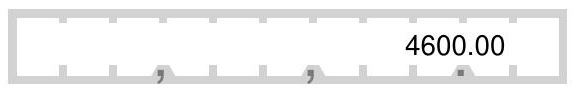

Date of Disbursement

\begin{tabular}{|c|c|c|c|c|c|}
\hline M M & I & P & Y Y Y \\
\hline & & 19 \\
\hline
\end{tabular}

Transaction ID : B53F99930D6AC428DBAF

Amount of Each Disbursement this Period 100.00

Subtotal Of Receipts This Page (optional).

Total This Period (last page this line number only))

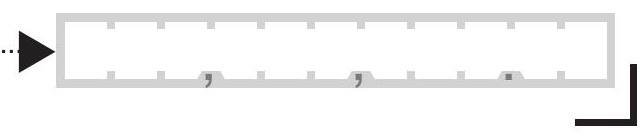




\section{SCHEDULE B-P}

\section{ITEMIZED DISBURSEMENTS}

\section{Use separate schedule(s) \\ for each category of the}

Detailed Summary Page
FOR LINE NUMBER: (check only one)

\begin{tabular}{|c|c|c|c|}
\hline$\times{ }_{23}$ & 24 & 25 & 26 \\
\hline $27 b$ & $28 a$ & $28 \mathrm{~b}$ & $28 \mathrm{c}$ \\
\hline
\end{tabular}

Any information copied from such Reports and Statements may not be sold or used by any person for the purpose of soliciting contributions or for commercial purposes, other than using the name and address of any political committee to solicit contributions from such committee.

NAME OF COMMITTEE (In Full)

\section{Friends of Herman Cain}

Full Name (Last, First, Middle Initial)

A. Hotels.com

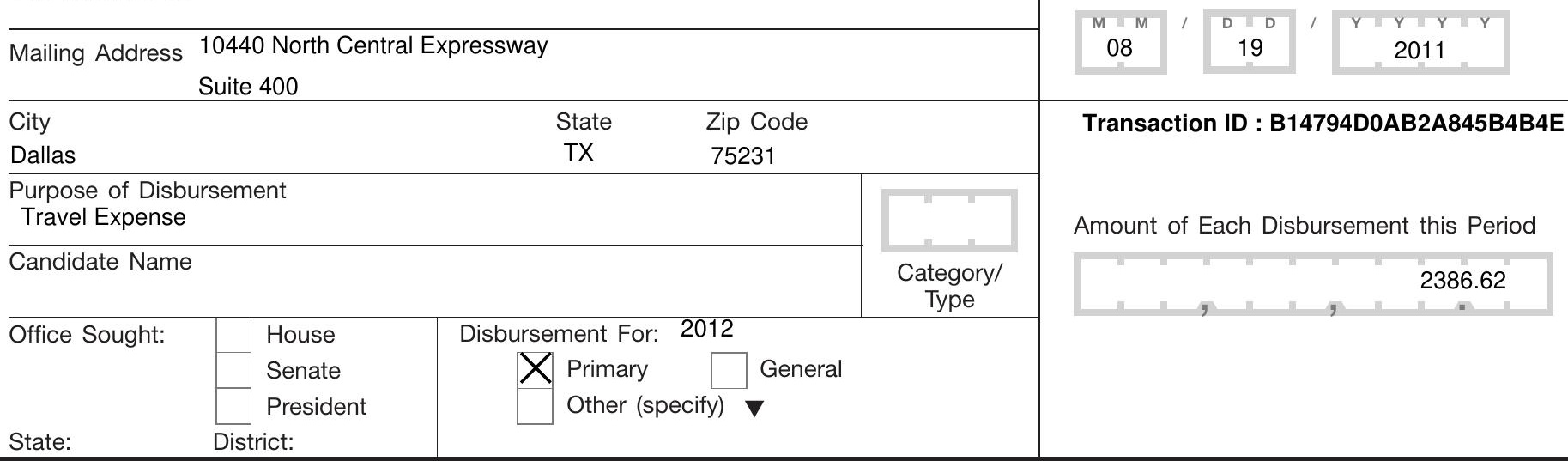

Full Name (Last, First, Middle Initial)

B. Holiday Inn Hotels

\begin{tabular}{|c|c|c|c|c|}
\hline Mailing Address & \multicolumn{4}{|c|}{3 Ravinia Drive } \\
\hline \multicolumn{2}{|l|}{ City } & \multicolumn{3}{|c|}{ Zip Code } \\
\hline \multicolumn{2}{|l|}{ Atlanta } & \multicolumn{3}{|c|}{30346} \\
\hline \multicolumn{4}{|c|}{$\begin{array}{l}\text { Purpose of Disbursement } \\
\text { Travel Expense }\end{array}$} & \\
\hline \multicolumn{4}{|l|}{ Candidate Name } & $\begin{array}{l}\text { Category/ } \\
\text { Type }\end{array}$ \\
\hline \multirow[t]{3}{*}{ Office Sought: } & \multirow{4}{*}{$\begin{array}{l}\text { House } \\
\text { Senate } \\
\text { President } \\
\end{array}$} & \multirow{3}{*}{\multicolumn{3}{|c|}{ Disbursement For: 2012}} \\
\hline & & & & \\
\hline & & & & \\
\hline State: & & \multicolumn{3}{|c|}{ District: } \\
\hline
\end{tabular}

Date of Disbursement

\begin{tabular}{|c|c|c|c|c|}
\hline${ }^{\mathrm{M}}{ }^{\mathrm{M}}$ & 1 & 19 & 1 & $\begin{array}{llll}Y & Y & Y & Y \\
2011 & Y\end{array}$ \\
\hline
\end{tabular}

Transaction ID : B91C229C14D0C468D976

Full Name (Last, First, Middle Initial)

c. Nathan Naidu

Mailing Address 3601 canton rd \#131

Date of Disbursement

\begin{tabular}{lcc|} 
& & \\
City & State & Zip Code \\
Marietta & GA & $30066-2892$
\end{tabular}

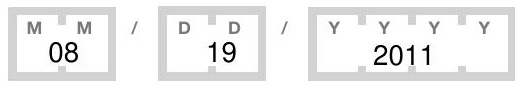

Purpose of Disbursement

Airfare, Lodging and Transportation

Candidate Name

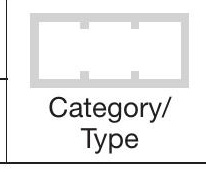

Transaction ID : B4F9F004F034146F18A1

\begin{tabular}{r|r} 
Type & $\begin{array}{c}\text { Tategory/ } \\
\text { Ong }\end{array}$ \\
\hline
\end{tabular}

Amount of Each Disbursement this Period

Amount of Each Disbursement this Period

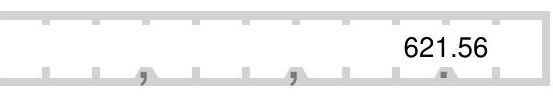

\begin{tabular}{l|l|l|}
\hline Office Sought: & House & $\begin{array}{c}\text { Disbursement For: } 2012 \\
\text { Senate } \\
\text { President }\end{array}$ \\
\cline { 2 - 3 } & & X Primary \\
State: & & $\square$ Other (specify) General
\end{tabular}

Subtotal Of Receipts This Page (optional).

Total This Period (last page this line number only)) 


\section{SCHEDULE B-P}

\section{ITEMIZED DISBURSEMENTS}

\section{Use separate schedule(s) \\ for each category of the}

Detailed Summary Page
FOR LINE NUMBER: (check only one)

\begin{tabular}{|c|c|c|c|}
\hline$\times{ }_{23}$ & 24 & 25 & 26 \\
\hline $27 b$ & $28 a$ & $28 \mathrm{~b}$ & $28 \mathrm{c}$ \\
\hline
\end{tabular}

Any information copied from such Reports and Statements may not be sold or used by any person for the purpose of soliciting contributions or for commercial purposes, other than using the name and address of any political committee to solicit contributions from such committee.

NAME OF COMMITTEE (In Full)

\section{Friends of Herman Cain}

Full Name (Last, First, Middle Initial)

\section{A. Nathan Naidu}

Mailing Address 3601 canton rd \#131

Date of Disbursement

\begin{tabular}{lcc}
\hline City & State & Zip Code \\
Marietta & GA & $30066-2892$
\end{tabular}

Purpose of Disbursement

Office Equipment

Candidate Name

\begin{tabular}{l|l|c|}
\hline Office Sought: & $\begin{array}{l}\text { House } \\
\text { Senate } \\
\text { President }\end{array}$ & $\begin{array}{c}\text { Disbursement For: } 2012 \\
\text { X Primary } \\
\text { Other (specify) }\end{array}$ \\
\cline { 2 - 3 } &
\end{tabular}

Full Name (Last, First, Middle Initial)

\section{B. Delta Airlines}

\section{Mailing Address Post Office Box 20980 \\ Department 980}

\begin{tabular}{lcc}
\hline City & State & Zip Code \\
Atlanta & GA & $30320-2980$
\end{tabular}

Purpose of Disbursement

Travel Expense

Candidate Name

Office Sought:

State:

Full Name (Last, First, Middle Initial)

\section{c. RMA Chaffeured Transportation}

Mailing Address 6010 Executive Boulevard

\begin{tabular}{lcc}
\multicolumn{3}{c}{ Suite 101} \\
City & State & Zip Code \\
Rockville & MD & 20852
\end{tabular}

Purpose of Disbursement

Travel Expense

Candidate Name

Office Sought:

State:
Date of Disbursement

\begin{tabular}{|c|c|c|c|c|}
\hline $08^{M}$ & 1 & $19^{\mathrm{D}}$ & 1 & $\begin{array}{llll}Y & Y & Y & Y \\
& 2011\end{array}$ \\
\hline
\end{tabular}

\section{Transaction ID : B7BE4517803EF437EB87}

Amount of Each Disbursement this Period

419.70
Date of Disbursement

\begin{tabular}{|c|c|c|c|c|c|c|}
\hline M & M & D & Y & Y & Y & Y \\
\hline & & 19 & & 2011 & \\
\hline
\end{tabular}

Transaction ID : BFB492804AF0E47B1B98

Amount of Each Disbursement this Period

174.96

Subtotal Of Receipts This Page (optional).

Total This Period (last page this line number only))

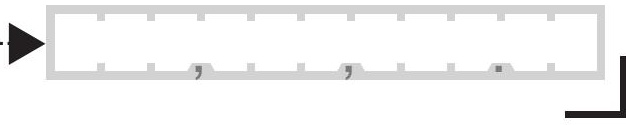




\section{SCHEDULE B-P}

\section{ITEMIZED DISBURSEMENTS}

\section{Use separate schedule(s) \\ for each category of the}

Detailed Summary Page
FOR LINE NUMBER: (check only one)

\begin{tabular}{|c|c|c|c|}
\hline$X_{23}$ & 24 & 25 & 26 \\
\hline $27 \mathrm{~b}$ & $28 a$ & $28 b$ & $28 \mathrm{c}$ \\
\hline
\end{tabular}

Any information copied from such Reports and Statements may not be sold or used by any person for the purpose of soliciting contributions or for commercial purposes, other than using the name and address of any political committee to solicit contributions from such committee.

NAME OF COMMITTEE (In Full)

\section{Friends of Herman Cain}

Full Name (Last, First, Middle Initial)

\section{A. RMA Chaffeured Transportation}

Mailing Address 6010 Executive Boulevard Suite 101

\begin{tabular}{lll}
\hline City & State & Zip Code \\
Rockville & MD & 20852 \\
\hline
\end{tabular}

Purpose of Disbursement

Travel Expense

Candidate Name

\begin{tabular}{l|l|l}
\hline Office Sought: & House & Disbursement For: 2012
\end{tabular} X Primary $\square$ General

State:

\section{Senate} President

Full Name (Last, First, Middle Initial)

B. United Airlines

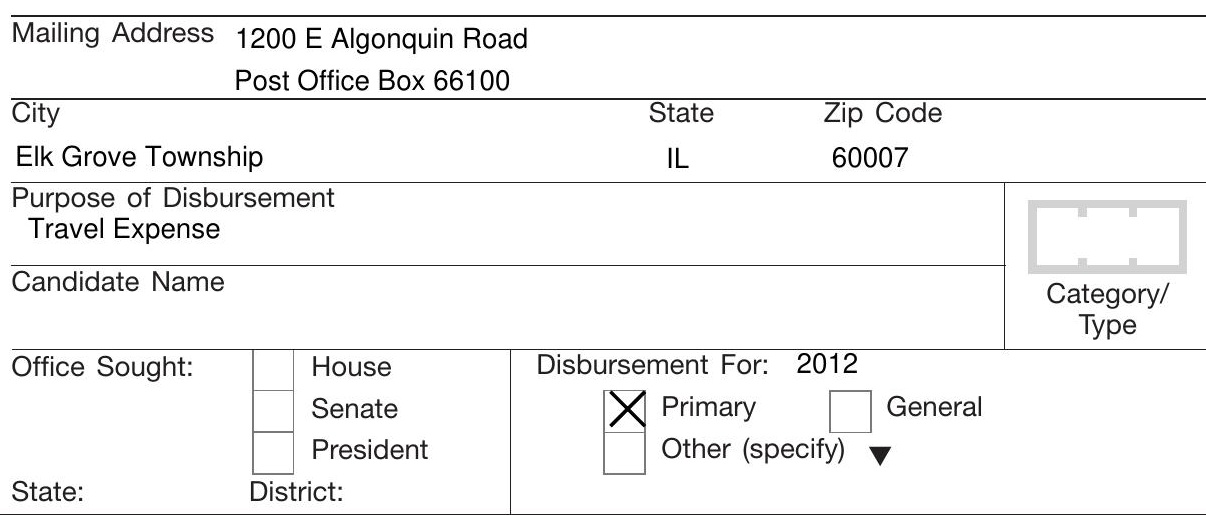

Date of Disbursement

Full Name (Last, First, Middle Initial)

\section{c. Delta Airlines}

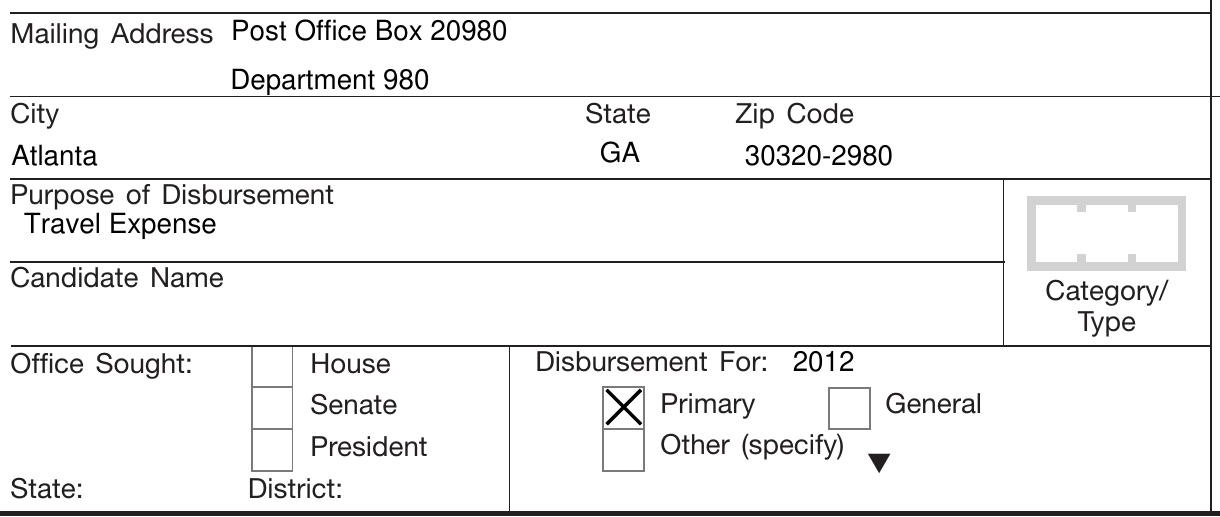

Subtotal Of Receipts This Page (optional).

Date of Disbursement

\begin{tabular}{|c|c|c|c|c|}
\hline $08^{M}$ & I & $\begin{array}{ll}\text { D } & \text { D } \\
22\end{array}$ & I & $\begin{array}{cccc}Y & Y & Y & Y \\
& 2011 & \end{array}$ \\
\hline
\end{tabular}

\section{Transaction ID : B8D116612B3C940FE84E}

Amount of Each Disbursement this Period

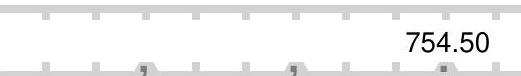

754.50

Total This Period (last page this line number only)) 


\section{SCHEDULE B-P}

\section{ITEMIZED DISBURSEMENTS}

\section{Use separate schedule(s) \\ for each category of the}

Detailed Summary Page
FOR LINE NUMBER: (check only one)

\begin{tabular}{|c|c|c|c|}
\hline$\times{ }_{23}$ & 24 & 25 & 26 \\
\hline $27 b$ & $28 a$ & $28 \mathrm{~b}$ & $28 \mathrm{c}$ \\
\hline
\end{tabular}

Any information copied from such Reports and Statements may not be sold or used by any person for the purpose of soliciting contributions or for commercial purposes, other than using the name and address of any political committee to solicit contributions from such committee.

NAME OF COMMITTEE (In Full)

\section{Friends of Herman Cain}

Full Name (Last, First, Middle Initial)

\section{A. US Airways}

Mailing Address 4000 E Sky Harbor Boulevard

Date of Disbursement

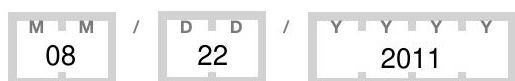

Transaction ID : B9B84458944224DE085B

\begin{tabular}{lcc}
\hline City & State & Zip Code \\
Phoenix & AZ & 85034 \\
\hline
\end{tabular}

Purpose of Disbursement

Travel Expense

Candidate Name

Office Sought:

\begin{tabular}{l|l} 
& $\begin{array}{l}\text { House } \\
\text { Senate } \\
\text { President }\end{array}$ \\
\\
District:
\end{tabular}
X Primary $\square$ General

State: District:

Full Name (Last, First, Middle Initial)

\section{B. FedEx Kinkos}

Mailing Address 942 S. Shady Grove Road

\begin{tabular}{|c|c|c|c|c|}
\hline \multicolumn{2}{|l|}{ City } & \multicolumn{3}{|c|}{ Zip Code } \\
\hline \multicolumn{2}{|l|}{ Memphis } & \multicolumn{3}{|c|}{38120} \\
\hline \multicolumn{4}{|c|}{$\begin{array}{l}\text { Purpose of Disbursement } \\
\text { Printing }\end{array}$} & \\
\hline \multicolumn{4}{|c|}{ Candidate Name } & $\begin{array}{l}\text { Category/ } \\
\text { Type }\end{array}$ \\
\hline \multirow[t]{3}{*}{ Office Sought: } & House & \multirow{3}{*}{\multicolumn{3}{|c|}{$\begin{array}{l}\text { Disbursement For: } 2012 \\
\text { Xrimary } \\
\text { Other (specify) }\end{array}$}} \\
\hline & \multirow{2}{*}{$\begin{array}{l}\text { Senate } \\
\text { President }\end{array}$} & & & \\
\hline & & & & \\
\hline State: & rict: & & \multicolumn{2}{|l|}{$\nabla$} \\
\hline
\end{tabular}

Full Name (Last, First, Middle Initial)

c. Celebrations of Columbia

Mailing Address 830 Sunset Blvd.

\begin{tabular}{lcc}
\hline City & State & Zip Code \\
West Columbia & SC & 29169
\end{tabular}

Purpose of Disbursement

Event Supplies

Candidate Name

Office Sought:

\begin{tabular}{|l|l|} 
& House \\
& Senate \\
& President \\
\hline & District:
\end{tabular}

Disbursement For: 2012

Х $\begin{aligned} & \text { Primary } \\ & \text { Other (specify) }\end{aligned}$

\begin{tabular}{|c|c|c|c|c|}
\hline${ }^{\mathrm{M}} 08^{\mathrm{M}}$ & 1 & $22^{D}$ & 1 & 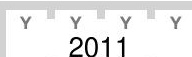 \\
\hline
\end{tabular}

Transaction ID : B7312FC00822A4FD9802

Amount of Each Disbursement this Period

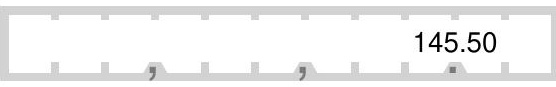

Date of Disbursement

\begin{tabular}{|c|c|c|c|c|}
\hline $08^{M}$ & I & D 22 & 1 & $\begin{array}{cccc}Y & Y & Y & Y \\
& 2011 & \end{array}$ \\
\hline
\end{tabular}

Transaction ID : B425A2C0F090F43D1A8C

Amount of Each Disbursement this Period

257.65
Date of Disbursement Type

State:

Subtotal Of Receipts This Page (optional).

Total This Period (last page this line number only))

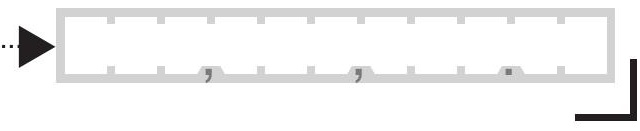




\section{SCHEDULE B-P}

\section{ITEMIZED DISBURSEMENTS}

\section{Use separate schedule(s)}

for each category of the

Detailed Summary Page
FOR LINE NUMBER: (check only one)

\begin{tabular}{|c|c|c|c|}
\hline$X_{23}$ & 24 & 25 & 26 \\
\hline $27 \mathrm{~b}$ & $28 a$ & $28 b$ & $28 \mathrm{c}$ \\
\hline
\end{tabular}

Any information copied from such Reports and Statements may not be sold or used by any person for the purpose of soliciting contributions or for commercial purposes, other than using the name and address of any political committee to solicit contributions from such committee.

NAME OF COMMITTEE (In Full)

\section{Friends of Herman Cain}

Full Name (Last, First, Middle Initial)

A. Chick-Fil-A

Mailing Address 5200 Buffington Road

Date of Disbursement

City

Atlanta

Purpose of Disbursement

Meeting Expense

Candidate Name

Office Sought:

State:

Full Name (Last, First, Middle Initial)

B. Facebook, Inc.

Mailing Address 1601 S. California Ave.

\begin{tabular}{lcc}
\hline City & State & Zip Code \\
Palo Alto & CA & 94304
\end{tabular}

Purpose of Disbursement

Advertising Expense

Candidate Name

Office Sought:

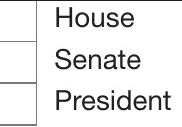

State:

District:

Full Name (Last, First, Middle Initial)

c. Air Tran

Mailing Address 9955 Air Tran Boulevard

\begin{tabular}{lcc}
\hline City & State & Zip Code \\
Orlando & FL & 32827
\end{tabular}

Purpose of Disbursement

Travel Expense

Candidate Name

Office Sought:

State:

\begin{tabular}{|c|}
\hline House \\
\hline Senate \\
\hline President \\
\hline
\end{tabular}

Disbursement For: 2012

Х $\begin{aligned} & \text { Primary } \\ & \text { Other (specify) }\end{aligned}$
Zip Code

GA $\quad 30349$

Primary $\square$ General
Other (specify) $\quad \nabla$

Date of Disbursement

\begin{tabular}{|c|c|c|c|c|}
\hline $08^{M}$ & 1 & $22^{\mathrm{D}}$ & 1 & $\begin{array}{llll}Y & Y & Y & Y \\
& 2011 & \end{array}$ \\
\hline
\end{tabular}

Transaction ID : B86CE6328AC4D49558C1

Amount of Each Disbursement this Period

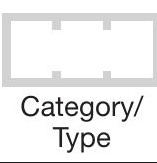

Disbursement For: 2012

Xrimary $\square$ General

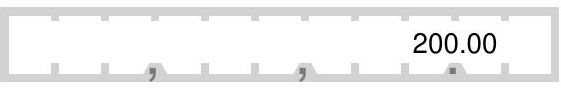

Type

19.86

Date of Disbursement

\begin{tabular}{|c|c|c|c|c|}
\hline $08^{M}$ & I & 22 & 1 & $\begin{array}{cccc}Y & Y & Y & Y \\
& 2011 & \end{array}$ \\
\hline
\end{tabular}

Transaction ID : B3752A74880934B6EAF9

Amount of Each Disbursement this Period

224.70

Subtotal Of Receipts This Page (optional).

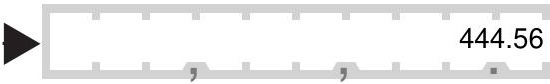

Total This Period (last page this line number only))

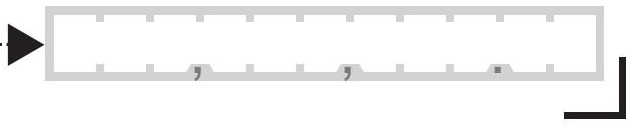




\section{SCHEDULE B-P}

\section{ITEMIZED DISBURSEMENTS}

\section{Use separate schedule(s)}

for each category of the

Detailed Summary Page
FOR LINE NUMBER: (check only one)

\begin{tabular}{|c|c|c|c|}
\hline$X_{23}$ & 24 & 25 & 26 \\
\hline $27 \mathrm{~b}$ & $28 a$ & $28 b$ & $28 \mathrm{c}$ \\
\hline
\end{tabular}

Any information copied from such Reports and Statements may not be sold or used by any person for the purpose of soliciting contributions or for commercial purposes, other than using the name and address of any political committee to solicit contributions from such committee.

NAME OF COMMITTEE (In Full)

\section{Friends of Herman Cain}

Full Name (Last, First, Middle Initial)

A. Little Bonanza Productions LLC

Mailing Address 34729 Petersen Road

Date of Disbursement

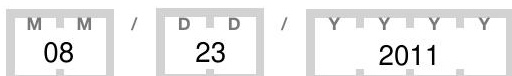

Transaction ID : BBADC5E81B8B644D0855

\begin{tabular}{lcc}
\hline City & State & Zip Code \\
Agua Dulce & CA & 91390 \\
\hline Purpose of Disbursement & &
\end{tabular}

Purpose of Disbursement

Media Production

Candidate Name X Primary $\square$ General

State:

$$
\begin{aligned}
& \text { Senate } \\
& \text { President }
\end{aligned}
$$
District:

Full Name (Last, First, Middle Initial)

B. Facebook, Inc.

Mailing Address 1601 S. California Ave.

\begin{tabular}{lcc}
\hline City & State & Zip Code \\
Palo Alto & CA & 94304
\end{tabular}

Purpose of Disbursement

Advertising Expense

Candidate Name

Office Sought:

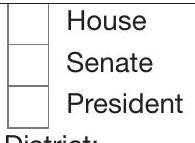

Disbursement For: 2012

Xrimary $\square$ General

State:

District:

Full Name (Last, First, Middle Initial)

c. The Soarin' Group

Mailing Address Post Office Box 14160

\begin{tabular}{lcc}
\hline City & State & Zip Code \\
Chicago & IL & $60614-0160$
\end{tabular}

Purpose of Disbursement

Campaign Strategy Consulting

Candidate Name

\begin{tabular}{l|l|l}
\hline Office Sought: & House
\end{tabular}

$\begin{aligned} & \text { House } \\ & \text { Senate } \\ & \text { President }\end{aligned}$
District:

Disbursement For: 2012

X $\begin{aligned} & \text { Primary } \\ & \text { Other (specify) }\end{aligned}$

State:

\begin{tabular}{|c|c|c|c|c|}
\hline $08^{M}$ & & $23^{\mathrm{D}}$ & & $\begin{array}{llll} & Y & Y & Y \\
& 2011 & Y\end{array}$ \\
\hline
\end{tabular}

Date of Disbursement

Transaction ID : B4B49A9EB1E9646D5A2D

Amount of Each Disbursement this Period
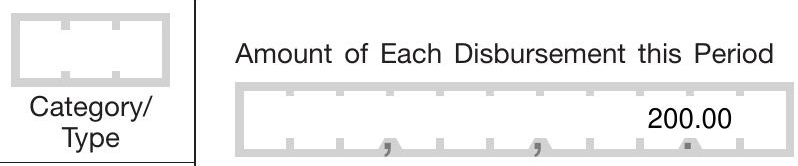

\begin{tabular}{|c|c|c|c|c|}
\hline $08^{M}$ & I & $23^{\mathrm{D}}$ & 1 & 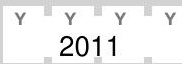 \\
\hline
\end{tabular}

Date of Disbursement

Transaction ID : B7300CB321A574D1A858

Amount of Each Disbursement this Period 5000.00

Subtotal Of Receipts This Page (optional)

Total This Period (last page this line number only))

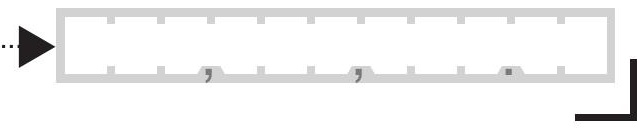




\section{SCHEDULE B-P}

\section{ITEMIZED DISBURSEMENTS}

Use separate schedule(s)

for each category of the

Detailed Summary Page
FOR LINE NUMBER: (check only one)

\begin{tabular}{|c|c|c|c|}
\hline$\times{ }_{23}$ & 24 & 25 & 26 \\
\hline $27 b$ & $28 a$ & $28 \mathrm{~b}$ & $28 \mathrm{c}$ \\
\hline
\end{tabular}

Any information copied from such Reports and Statements may not be sold or used by any person for the purpose of soliciting contributions or for commercial purposes, other than using the name and address of any political committee to solicit contributions from such committee.

NAME OF COMMITTEE (In Full)

\section{Friends of Herman Cain}

Full Name (Last, First, Middle Initial)

A. Brenda Hicks

Mailing Address 3653 S 75th Street

Date of Disbursement

\begin{tabular}{lcc}
\hline City & State & Zip Code \\
Milwaukee & WI & $53220-1139$
\end{tabular}

Purpose of Disbursement

Airfare/Phone/Printing/Postage

Candidate Name

Office Sought: $\quad$ House

Senate

President

State:

District:

Full Name (Last, First, Middle Initial)

B. James Coughlin

\begin{tabular}{|c|c|c|c|c|}
\hline \multicolumn{5}{|c|}{ Mailing Address 16 South Hills Drive } \\
\hline \multicolumn{2}{|l|}{ City } & \multicolumn{3}{|c|}{ Zip Code } \\
\hline \multicolumn{2}{|l|}{ Bedford } & \multicolumn{3}{|c|}{$03110-4920$} \\
\hline \multicolumn{4}{|c|}{$\begin{array}{l}\text { Purpose of Disbursement } \\
\text { Field Consulting }\end{array}$} & \\
\hline \multicolumn{4}{|l|}{ Candidate Name } & $\begin{array}{l}\text { Category/ } \\
\text { Type }\end{array}$ \\
\hline \multirow[t]{3}{*}{ Office Sought: } & House & \multirow{3}{*}{\multicolumn{3}{|c|}{$\begin{array}{l}\text { Disbursement For: } 2012 \\
\text { X Primary } \\
\text { Other (specify) }\end{array}$}} \\
\hline & Senate & & & \\
\hline & President & & & \\
\hline State: & \multicolumn{4}{|c|}{ District: } \\
\hline
\end{tabular}

Date of Disbursement

\begin{tabular}{|c|c|c|c|c|}
\hline${ }^{\mathrm{M}} 08^{\mathrm{M}}$ & 1 & $23^{D}$ & 1 & 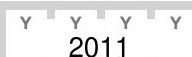 \\
\hline
\end{tabular}

Transaction ID : B7610FF49CDF34B66AB3

Full Name (Last, First, Middle Initial)

c. Linda Hansen

Mailing Address PO Box 371312

\begin{tabular}{lcc}
\hline City & State & Zip Code \\
Milwaukee & WI & $53237-2412$
\end{tabular}

Purpose of Disbursement

Transportation/Airfare/Lodging/Mtg Exp

Candidate Name

Office Sought:

State:

\begin{tabular}{|l|l|}
\hline & House \\
& Senate \\
& President \\
District:
\end{tabular}

\section{Disbursement For: 2012 \\ Х Primary $\square$ General}

Amount of Each Disbursement this Period

842.98
Amount of Each Disbursement this Period

1625.00
Date of Disbursement

\begin{tabular}{|c|c|c|c|c|}
\hline $08^{M}$ & I & D 23 & 1 & $\begin{array}{cccc}Y & Y & Y & Y \\
& 2011 & \end{array}$ \\
\hline
\end{tabular}

Transaction ID : B27CC50D143774DABBE8

Amount of Each Disbursement this Period

2400.66

Subtotal Of Receipts This Page (optional).

Total This Period (last page this line number only))

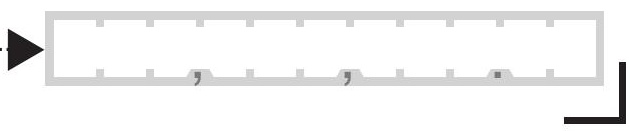




\section{SCHEDULE B-P}

\section{ITEMIZED DISBURSEMENTS}

Use separate schedule(s)

for each category of the

Detailed Summary Page
FOR LINE NUMBER: (check only one)

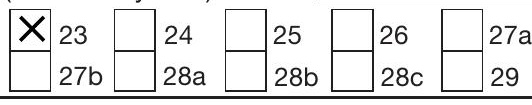

Any information copied from such Reports and Statements may not be sold or used by any person for the purpose of soliciting contributions or for commercial purposes, other than using the name and address of any political committee to solicit contributions from such committee.

NAME OF COMMITTEE (In Full)

\section{Friends of Herman Cain}

Full Name (Last, First, Middle Initial)

A. James Brazil

Mailing Address 6 Baldasarri Drive

Date of Disbursement

\begin{tabular}{lcc}
\hline City & State & Zip Code \\
Dunmore & PA & 18505 \\
\hline Purpose
\end{tabular}

Purpose of Disbursement

Field Consulting

Candidate Name

Office Sought:

\begin{tabular}{|l|l|l} 
& House \\
Senate \\
President
\end{tabular}

Disbursement For: 2012 X Primary $\square$ General

State: District:

Full Name (Last, First, Middle Initial)

\section{B. Continental Airlines}

Mailing Address Post Office Box 4607

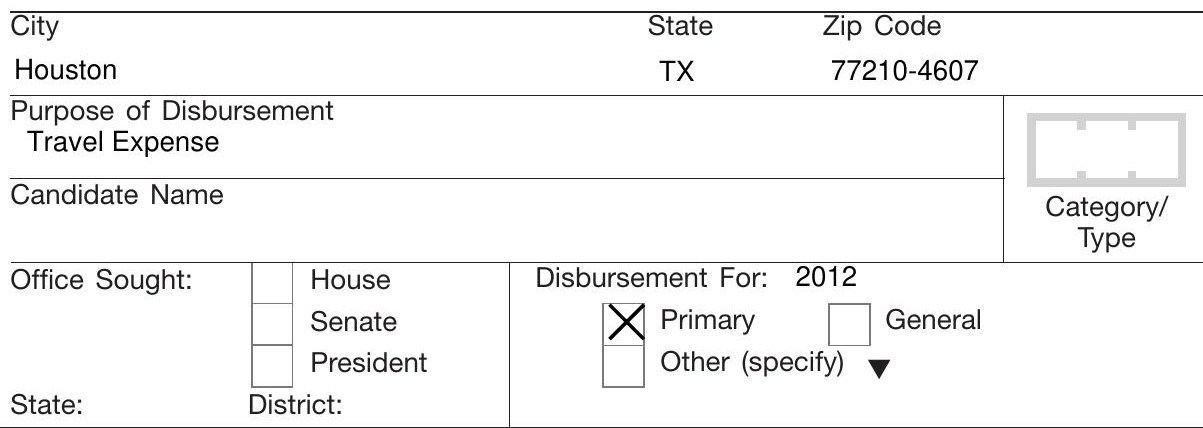

Date of Disbursement

Full Name (Last, First, Middle Initial)

\section{c. RMA Chaffeured Transportation}

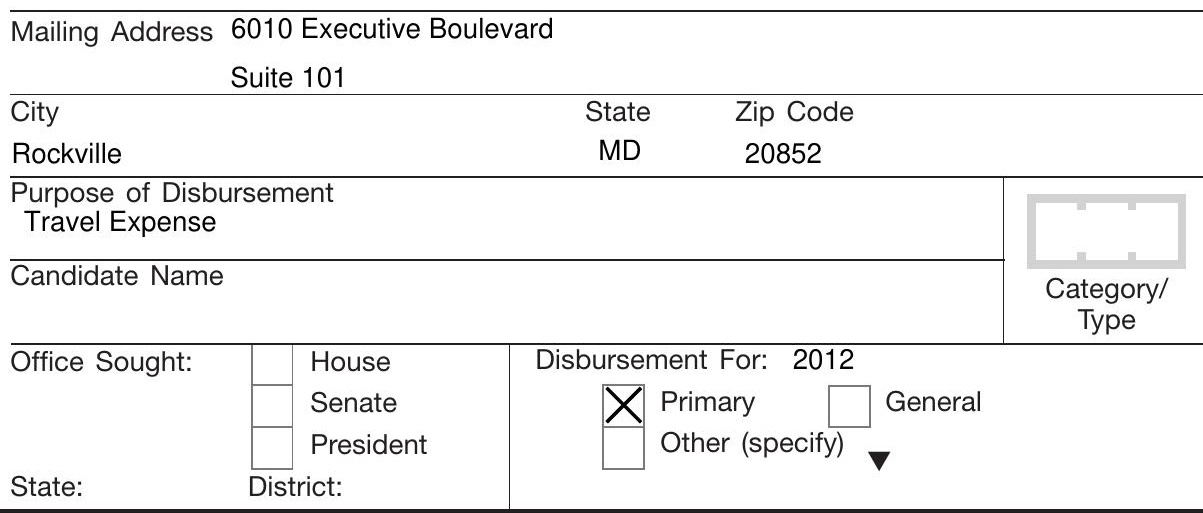

Subtotal Of Receipts This Page (optional).

Date of Disbursement

\begin{tabular}{|c|c|c|c|c|c|c|}
\hline M & M & D & Y & Y & $Y$ \\
0 & & 23 & & 2011 & \\
\hline
\end{tabular}

Transaction ID : B1A7A58EEBCD84516B70

Amount of Each Disbursement this Period

\section{Transaction ID : B531A320E50404B2A922}

Amount of Each Disbursement this Period
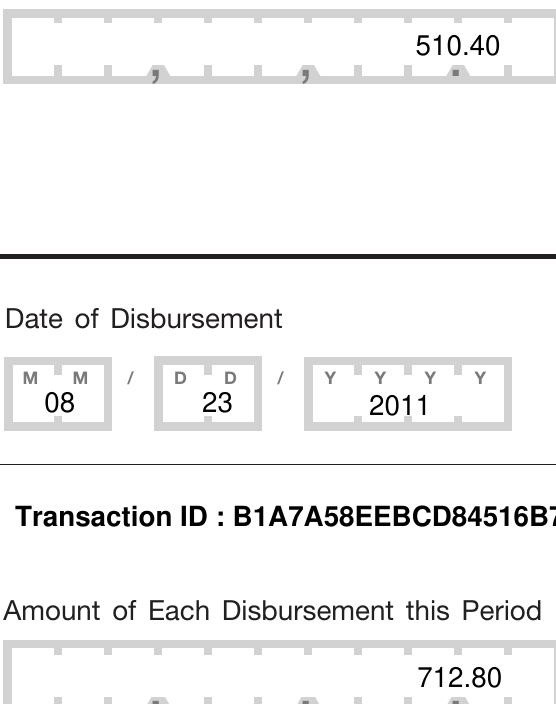

712.80

Total This Period (last page this line number only)) 


\section{SCHEDULE B-P}

\section{ITEMIZED DISBURSEMENTS}

\section{Use separate schedule(s)}

for each category of the

Detailed Summary Page
FOR LINE NUMBER: (check only one)

\begin{tabular}{|c|c|c|c|}
\hline$\times{ }_{23}$ & 24 & 25 & 26 \\
\hline $27 b$ & $28 a$ & $28 \mathrm{~b}$ & $28 \mathrm{c}$ \\
\hline
\end{tabular}

Any information copied from such Reports and Statements may not be sold or used by any person for the purpose of soliciting contributions or for commercial purposes, other than using the name and address of any political committee to solicit contributions from such committee.

NAME OF COMMITTEE (In Full)

\section{Friends of Herman Cain}

Full Name (Last, First, Middle Initial)

A. Hilton Hotels

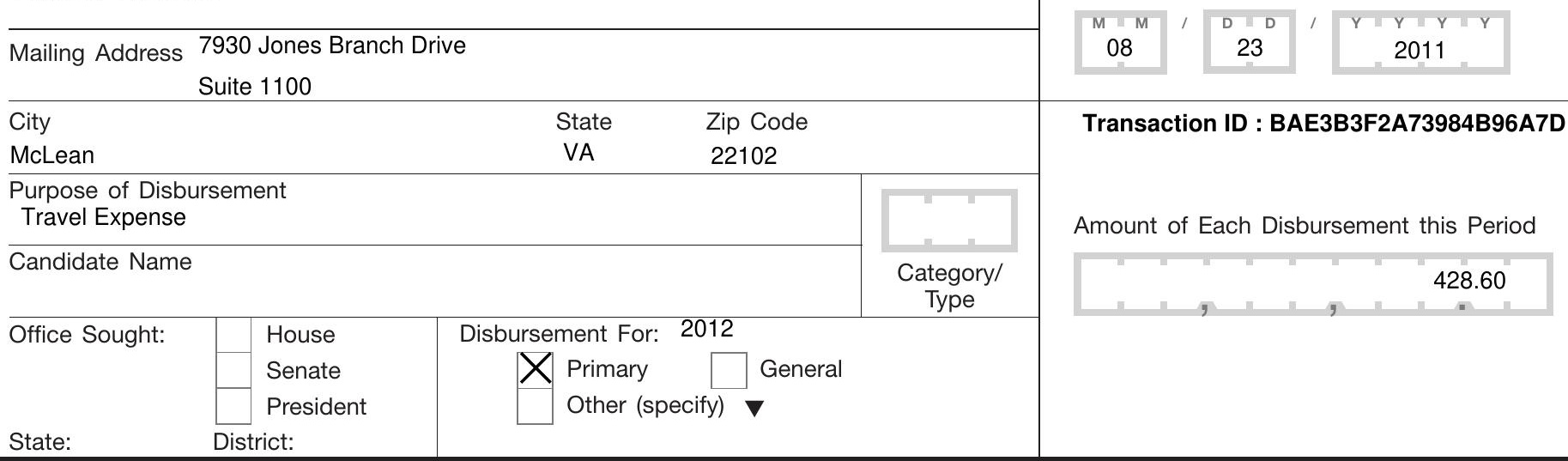

Full Name (Last, First, Middle Initial)

B. Hilton Hotels

Date of Disbursement

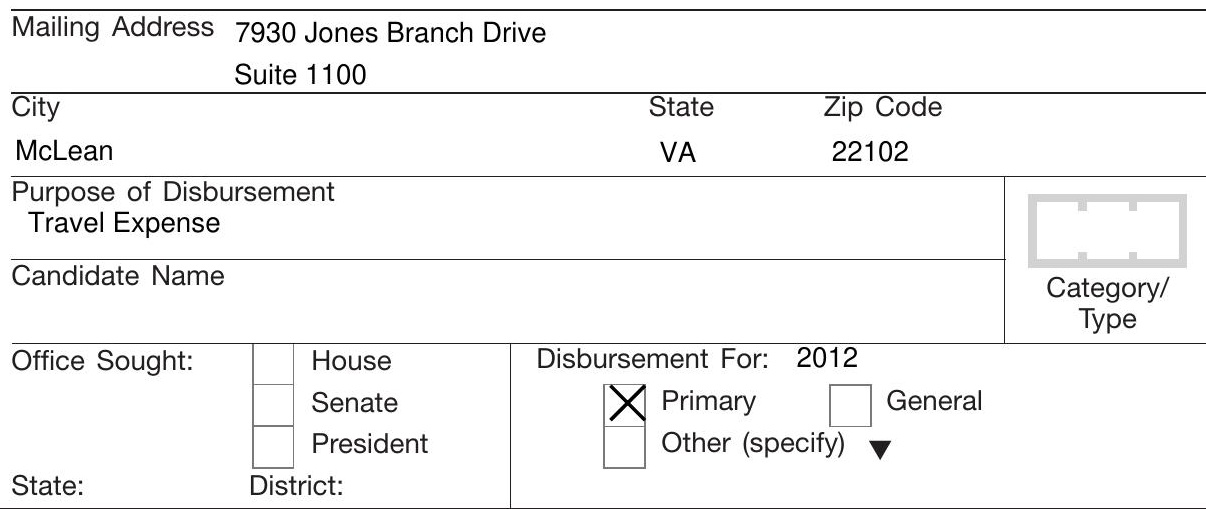

\begin{tabular}{|c|c|c|c|c|}
\hline${ }^{\mathrm{M}} 08^{\mathrm{M}}$ & 1 & $24^{\mathrm{D}}$ & 1 & 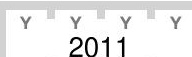 \\
\hline
\end{tabular}

Transaction ID : B512BF28344E94DCEA77

Full Name (Last, First, Middle Initial)

\section{Avis Rent A Car}

Mailing Address 900 Old Country Garden Road

Date of Disbursement

$\begin{array}{lcc} & & \\ \text { City } & \text { State } & \text { Zip Code } \\ \text { Garden City } & \text { NY } & 11530\end{array}$

Purpose of Disbursement

Travel Expense

Candidate Name

\begin{tabular}{|c|c|c|c|c|}
\hline $08^{M}$ & 1 & $\begin{array}{ll}D \\
24\end{array}$ & 1 & $\begin{array}{cccc}Y & Y & Y & Y \\
& 2011 & \end{array}$ \\
\hline
\end{tabular}

Transaction ID : BF6FCCCA358EA4F9ABE8

\begin{tabular}{c|c} 
Category/ \\
Type
\end{tabular}

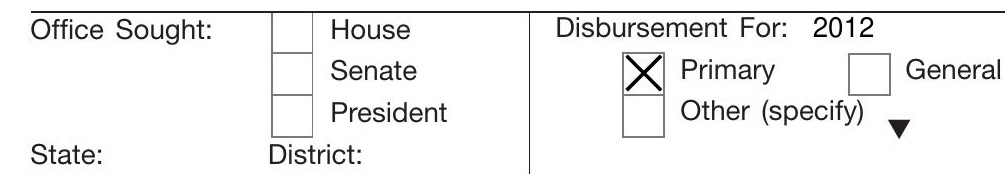

Subtotal Of Receipts This Page (optional).

Total This Period (last page this line number only))

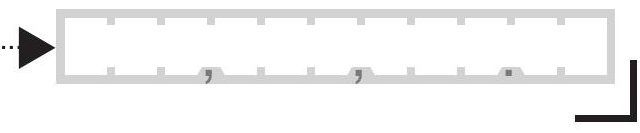




\section{SCHEDULE B-P}

\section{ITEMIZED DISBURSEMENTS}

\section{Use separate schedule(s) \\ for each category of the}

Detailed Summary Page
FOR LINE NUMBER: (check only one)

\begin{tabular}{|c|c|c|c|c|}
\hline $\mathrm{X}_{23}$ & 24 & 25 & 26 & \\
\hline $27 \mathrm{~b}$ & $28 a$ & $28 b$ & $28 \mathrm{c}$ & 2 \\
\hline
\end{tabular}

Any information copied from such Reports and Statements may not be sold or used by any person for the purpose of soliciting contributions or for commercial purposes, other than using the name and address of any political committee to solicit contributions from such committee.

NAME OF COMMITTEE (In Full)

\section{Friends of Herman Cain}

Full Name (Last, First, Middle Initial)

A. Facebook, Inc.

Mailing Address 1601 S. California Ave.

Date of Disbursement

\begin{tabular}{lll}
\hline City & State & Zip Code \\
Palo Alto & CA & 94304 \\
\hline
\end{tabular}

Purpose of Disbursement

Advertising Expense

Candidate Name

Office Sought: $\quad$ House

$\begin{array}{ll} & \text { Senate } \\ \text { President } \\ \text { District: }\end{array}$
X Primary $\square$ General

State: District:

Full Name (Last, First, Middle Initial)

B. Inkhead Inc.

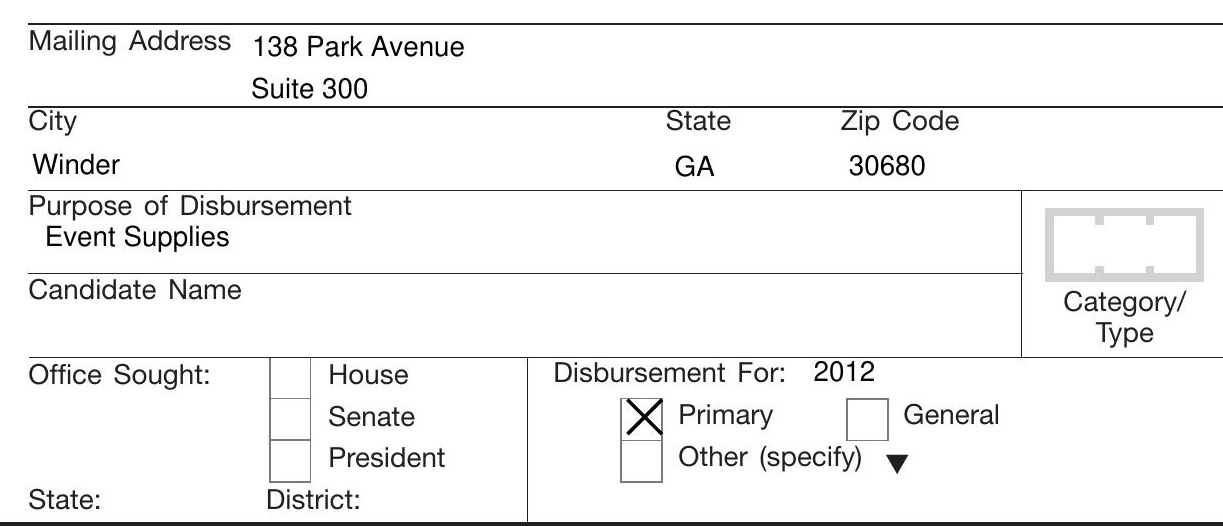

Date of Disbursement

\begin{tabular}{|c|c|c|c|c|}
\hline${ }^{\mathrm{M}} 08^{\mathrm{M}}$ & & $24{ }^{D}$ & & $\begin{array}{llll} & Y & Y & Y \\
2011 & Y\end{array}$ \\
\hline
\end{tabular}

Transaction ID : B038184A4F9C342D69FC

Full Name (Last, First, Middle Initial)

c. Enterprise Rent-A-Car

Mailing Address 600 Corporate Park Drive

Date of Disbursement

\begin{tabular}{lcc|} 
& & \\
\hline City & State & Zip Code \\
St. Louis & MO & 63105 \\
\hline
\end{tabular}

\begin{tabular}{|c|c|c|c|c|}
\hline $08^{M}$ & I & $\begin{array}{l}\text { D } \\
24\end{array}$ & I & $\begin{array}{cccc}Y & Y & Y & Y \\
& 2011 & \end{array}$ \\
\hline
\end{tabular}

Purpose of Disbursement

Travel Expense

Candidate Name

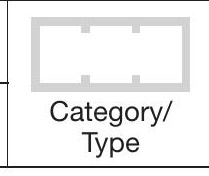

Transaction ID : B752406761F22411F8E6

Amount of Each Disbursement this Period

\begin{tabular}{l|l|l|}
\hline Office Sought: & $\begin{array}{l}\text { House } \\
\text { Senate } \\
\text { President } \\
\text { State: }\end{array}$ & $\begin{array}{r}\text { Disbursement For: } 2012 \\
\text { District: }\end{array}$ \\
\cline { 2 - 3 } & &
\end{tabular}

Subtotal Of Receipts This Page (optional).

Total This Period (last page this line number only))

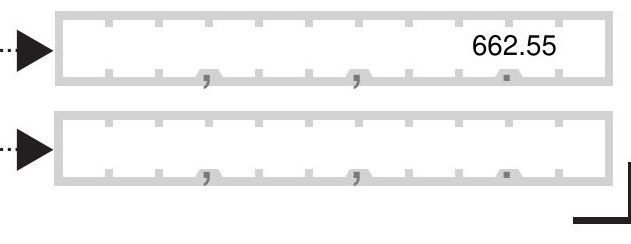




\section{SCHEDULE B-P}

\section{ITEMIZED DISBURSEMENTS}

\section{Use separate schedule(s) \\ for each category of the}

Detailed Summary Page
FOR LINE NUMBER: (check only one)

\begin{tabular}{|c|c|c|c|}
\hline$\times{ }_{23}$ & 24 & 25 & 26 \\
\hline $27 b$ & $28 a$ & $28 \mathrm{~b}$ & $28 \mathrm{c}$ \\
\hline
\end{tabular}

Any information copied from such Reports and Statements may not be sold or used by any person for the purpose of soliciting contributions or for commercial purposes, other than using the name and address of any political committee to solicit contributions from such committee.

NAME OF COMMITTEE (In Full)

\section{Friends of Herman Cain}

Full Name (Last, First, Middle Initial)

A. Air Expedite Inc.

Mailing Address Post Office Box 331

Date of Disbursement

\begin{tabular}{lcc}
\hline City & State & Zip Code \\
Hampton & GA & 30228 \\
\hline Purpose
\end{tabular}

Purpose of Disbursement

Travel Expense

Candidate Name

\begin{tabular}{l|l|l}
\hline Office Sought: & House & Disbursement For: 2012
\end{tabular} X Primary $\square$ General

State:

\section{Senate}

President

District:

Full Name (Last, First, Middle Initial)

B. Air Tran

Mailing Address 9955 Air Tran Boulevard

\begin{tabular}{lcc}
\hline City & State & Zip Code \\
Orlando & FL & 32827
\end{tabular}

Purpose of Disbursement

Travel Expense

Candidate Name

Office Sought:

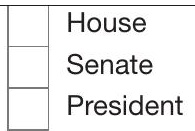

State:

District:

$\mathrm{FL}$ 32827

Full Name (Last, First, Middle Initial)

\section{Scott Sidney}

Mailing Address N40 W6522 Jackson Street

\begin{tabular}{lcc}
\hline City & State & Zip Code \\
Cedarburg & WI & $53012-2317$
\end{tabular}

Purpose of Disbursement

Lodging and Transportation Rental

Candidate Name

Office Sought: $\quad$ House

$\begin{aligned} & \text { House } \\ & \text { Senate } \\ & \text { President }\end{aligned}$
District:

State:

District:
Disbursement For: 2012

Primary
Other (specify) General
Date of Disbursement

\begin{tabular}{|c|c|c|c|c|}
\hline${ }^{\mathrm{M}} 08^{\mathrm{M}}$ & & $24{ }^{D}$ & & $\begin{array}{llll}Y & Y & Y & Y \\
& 2011\end{array}$ \\
\hline
\end{tabular}

Transaction ID : BBB26D198E46E448DA28

Amount of Each Disbursement this Period

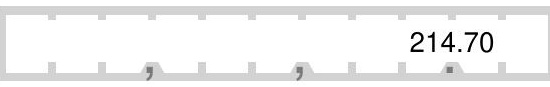

Date of Disbursement

\begin{tabular}{|c|c|c|c|c|}
\hline $08^{M}$ & I & D 25 & 1 & $\begin{array}{cccc}Y & Y & Y & Y \\
& 2011 & \end{array}$ \\
\hline
\end{tabular}

Transaction ID : BDE5114602C844755834

Amount of Each Disbursement this Period

1641.35
Subtotal Of Receipts This Page (optional).

17356.05

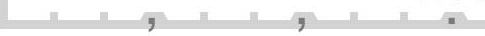

Total This Period (last page this line number only))

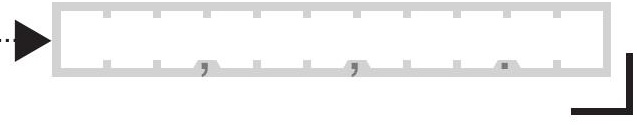

FEC Schedule B-P (Form 3P) (Rev. 03/2011) 


\section{SCHEDULE B-P}

\section{ITEMIZED DISBURSEMENTS}

\section{Use separate schedule(s) \\ for each category of the}

Detailed Summary Page
FOR LINE NUMBER: (check only one)

\begin{tabular}{|c|c|c|c|}
\hline$\times{ }_{23}$ & 24 & 25 & 26 \\
\hline $27 b$ & $28 a$ & $28 \mathrm{~b}$ & $28 \mathrm{c}$ \\
\hline
\end{tabular}

Any information copied from such Reports and Statements may not be sold or used by any person for the purpose of soliciting contributions or for commercial purposes, other than using the name and address of any political committee to solicit contributions from such committee.

NAME OF COMMITTEE (In Full)

\section{Friends of Herman Cain}

Full Name (Last, First, Middle Initial)

\section{A. Avis Rent A Car}

Mailing Address 900 Old Country Garden Road

Date of Disbursement

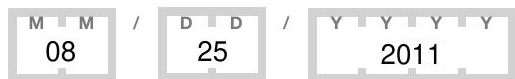

Transaction ID : B608277CADDD04855935

\begin{tabular}{lcc}
\hline City & State & Zip Code \\
Garden City & NY & 11530
\end{tabular}

Purpose of Disbursement

Travel Expense

Candidate Name

Office Sought:

\begin{tabular}{l|l} 
& $\begin{array}{l}\text { House } \\
\text { Senate } \\
\text { President }\end{array}$ \\
\\
District:
\end{tabular}

Disbursement For: 2012 X Primary $\square$ General

State: District:

Full Name (Last, First, Middle Initial)

\section{B. Delta Airlines}

\begin{tabular}{ll}
\hline Mailing Address & $\begin{array}{l}\text { Post Office Box } 20980 \\
\text { Department } 980\end{array}$ \\
\hline City &
\end{tabular}

Atlanta

$\mathrm{GA}$

State Zip Code

Purpose of Disbursement

Travel Expense

Candidate Name

Office Sought:

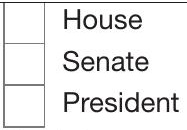

State:

District:

Full Name (Last, First, Middle Initial)

\section{SunTrust Bank}

Mailing Address 980 Eagles Landing Parkway

\begin{tabular}{lcc}
\hline City & State & Zip Code \\
Stockbridge & GA & 30281
\end{tabular}

Purpose of Disbursement

Bank Fees

Candidate Name

Office Sought:

\begin{tabular}{|l|l|}
\hline & House \\
& Senate \\
& President \\
& District:
\end{tabular}

Disbursement For: 2012

X $\begin{aligned} & \text { Primary } \\ & \text { Other (specify) }\end{aligned}$

\section{Disbursement For: 2012 \\ X Primary $\square$ General}

Date of Disbursement

\begin{tabular}{|c|c|c|c|c|}
\hline $08^{M}$ & 1 & $25^{\mathrm{D}}$ & 1 & 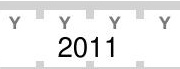 \\
\hline
\end{tabular}

Transaction ID : BCF06A438638B4823AF7

Amount of Each Disbursement this Period 230.40

Date of Disbursement

\begin{tabular}{|c|c|c|c|c|}
\hline $08^{M}$ & 1 & D 25 & 1 & 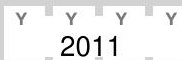 \\
\hline
\end{tabular}

Transaction ID : B6467811922A045CBBAC

Amount of Each Disbursement this Period

50.00 Type

Subtotal Of Receipts This Page (optional).

Total This Period (last page this line number only))

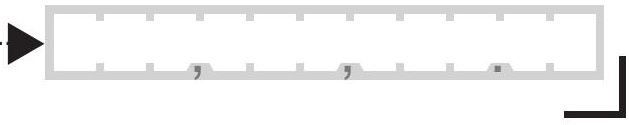




\section{SCHEDULE B-P}

\section{ITEMIZED DISBURSEMENTS}

\section{Use separate schedule(s) \\ for each category of the}

Detailed Summary Page
FOR LINE NUMBER: (check only one)

\begin{tabular}{|c|c|c|c|}
\hline$\times{ }_{23}$ & 24 & 25 & 26 \\
\hline $27 b$ & $28 a$ & $28 \mathrm{~b}$ & $28 \mathrm{c}$ \\
\hline
\end{tabular}

Any information copied from such Reports and Statements may not be sold or used by any person for the purpose of soliciting contributions
or for commercial purposes, other than using the name and address of any political committee to solicit contributions from such committee.

NAME OF COMMITTEE (In Full)

\section{Friends of Herman Cain}

Full Name (Last, First, Middle Initial)

A. RMA Chaffeured Transportation

Mailing Address 6010 Executive Boulevard Suite 101

\begin{tabular}{lll}
\hline City & State & Zip Code \\
Rockville & MD & 20852 \\
\hline
\end{tabular}

Purpose of Disbursement

Travel Expense

Candidate Name

\begin{tabular}{l|l|l}
\hline Office Sought: & House & Disbursement For: 2012
\end{tabular} X Primary $\square$ General

State:

\section{Senate} President

Full Name (Last, First, Middle Initial)

\section{B. Premiere Transportation}

\begin{tabular}{|c|c|c|c|c|}
\hline \multicolumn{5}{|c|}{$\begin{array}{ll}\text { Mailing Address } & 109 \text { International Dr. } \\
& \text { Ste. } 300\end{array}$} \\
\hline \multicolumn{2}{|c|}{ City } & \multicolumn{3}{|c|}{ Zip Code } \\
\hline \multicolumn{2}{|l|}{ Franklin } & \multicolumn{3}{|c|}{37067} \\
\hline \multicolumn{4}{|c|}{$\begin{array}{l}\text { Purpose of Disbursement } \\
\text { Event Transportation Rental }\end{array}$} & \\
\hline \multicolumn{4}{|l|}{ Candidate Name } & $\begin{array}{l}\text { Category/ } \\
\text { Type }\end{array}$ \\
\hline \multirow[t]{3}{*}{ Office Sought: } & House & \multirow{3}{*}{\multicolumn{3}{|c|}{$\begin{array}{l}\text { Disbursement For: } 2012 \\
\qquad \begin{array}{l}\text { Primary } \\
\text { Other (specify) }\end{array}\end{array}$}} \\
\hline & Senate & & & \\
\hline & President & & & \\
\hline State: & \multicolumn{4}{|c|}{ District: } \\
\hline
\end{tabular}

Date of Disbursement

\begin{tabular}{|c|c|c|c|c|}
\hline${ }^{M}{ }^{\mathrm{M}}$ & $/$ & $\mathrm{D}$ & ${ }^{\mathrm{D}}$ & $\mathrm{Y}^{\mathrm{Y}} \mathrm{Y}^{\mathrm{Y}}$ \\
\hline
\end{tabular}

Full Name (Last, First, Middle Initial)

\section{c. Omni Hotels \& Resorts}

\begin{tabular}{|c|c|c|c|c|c|}
\hline \multicolumn{6}{|c|}{ Mailing Address 100 CNN Center } \\
\hline \multicolumn{2}{|l|}{ City } & State & \multicolumn{3}{|l|}{ Zip Code } \\
\hline \multicolumn{2}{|l|}{ Atlanta } & $\mathrm{GA}$ & \multicolumn{3}{|l|}{30303} \\
\hline \multicolumn{5}{|c|}{$\begin{array}{l}\text { Purpose of Disbursement } \\
\text { Travel Expense }\end{array}$} & \\
\hline \multicolumn{5}{|c|}{ Candidate Name } & $\begin{array}{l}\text { Category/ } \\
\text { Type }\end{array}$ \\
\hline \multirow[t]{3}{*}{ Office Sought: } & House & \multicolumn{4}{|c|}{ Disbursement For: 2012} \\
\hline & Senate & \multirow{3}{*}{\multicolumn{2}{|c|}{$\begin{array}{l}\text { Primary } \\
\text { Other (specify) }\end{array}$}} & \multirow{2}{*}{\multicolumn{2}{|c|}{ General }} \\
\hline & President & & & & \\
\hline State: & District: & & & \multicolumn{2}{|l|}{$\nabla$} \\
\hline
\end{tabular}

Subtotal Of Receipts This Page (optional)...

Date of Disbursement

\begin{tabular}{|c|c|c|c|c|c|}
\hline M & M & D & Y & Y & Y \\
08 & & 26 & & 2011 & \\
\hline
\end{tabular}

Transaction ID : B04CD76B8F56C492BBC8

Amount of Each Disbursement this Period

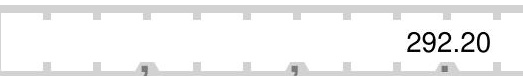

Total This Period (last page this line number only)) 


\section{SCHEDULE B-P}

\section{ITEMIZED DISBURSEMENTS}

\section{Use separate schedule(s) \\ for each category of the}

Detailed Summary Page
FOR LINE NUMBER: (check only one)

\begin{tabular}{|c|c|c|c|}
\hline$\times{ }_{23}$ & 24 & 25 & 26 \\
\hline $27 b$ & $28 a$ & $28 \mathrm{~b}$ & $28 \mathrm{c}$ \\
\hline
\end{tabular}

Any information copied from such Reports and Statements may not be sold or used by any person for the purpose of soliciting contributions or for commercial purposes, other than using the name and address of any political committee to solicit contributions from such committee.

NAME OF COMMITTEE (In Full)

\section{Friends of Herman Cain}

Full Name (Last, First, Middle Initial)

\section{A. American Express}

Mailing Address Post Office Box 53852

Date of Disbursement

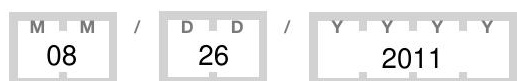

Transaction ID : BC46030BCFF264A388B5

\begin{tabular}{lll}
\hline City & State & Zip Code \\
Phoenix & AZ & $85072-3852$
\end{tabular}

Purpose of Disbursement

CC Transaction Fees

Candidate Name

\begin{tabular}{l|l|l}
\hline Office Sought: & House & Disbursement For: 2012
\end{tabular} X Primary $\square$ General

State:

\section{Senate}

President

District:

Full Name (Last, First, Middle Initial)

B. SunTrust Bank

Mailing Address 980 Eagles Landing Parkway

\begin{tabular}{lcc}
\hline City & State & Zip Code \\
Stockbridge & GA & 30281
\end{tabular}

Purpose of Disbursement

Bank Fees

Candidate Name

Office Sought:

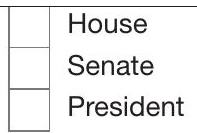

State:

District:

Full Name (Last, First, Middle Initial)

\section{c. Gerald Strober}

Mailing Address 52 East End Ave.

\begin{tabular}{lcc}
\hline City & State & Zip Code \\
New York & NY & $10028-8096$
\end{tabular}

Purpose of Disbursement

Media Production

Candidate Name

Office Sought: $\quad$ House

\begin{tabular}{|l|l} 
& House \\
Senate \\
President
\end{tabular}

Disbursement For: 2012

Primary $\square$ General
Other (specify)
Amount of Each Disbursement this Period

1128.22
Date of Disbursement

\begin{tabular}{|c|c|c|c|c|}
\hline $08^{M}$ & & ${ }^{\mathrm{D}} 26^{\mathrm{D}}$ & & 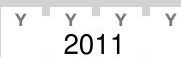 \\
\hline
\end{tabular}

Transaction ID : BA06F737A40EB4B65A59

Amount of Each Disbursement this Period

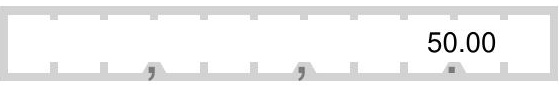

Date of Disbursement

\begin{tabular}{|c|c|c|c|c|}
\hline $08^{M}$ & I & D 26 & 1 & $\begin{array}{cccc}Y & Y & Y & Y \\
& 2011 & \end{array}$ \\
\hline
\end{tabular}

Transaction ID : BAF8B028A0D9A4D12BFD

Amount of Each Disbursement this Period

1000.00
State:

District:

Disbursement For: 2012
$\times \quad \begin{aligned} & \text { Primary } \\ & \text { Other (specify) }\end{aligned}$

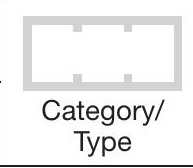

ype

Subtotal Of Receipts This Page (optional)

Total This Period (last page this line number only))

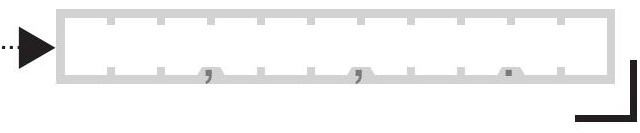




\section{SCHEDULE B-P}

\section{ITEMIZED DISBURSEMENTS}

\section{Use separate schedule(s) \\ for each category of the}

Detailed Summary Page
FOR LINE NUMBER: (check only one)

\begin{tabular}{|c|c|c|c|}
\hline$\times{ }_{23}$ & 24 & 25 & 26 \\
\hline $27 b$ & $28 a$ & $28 \mathrm{~b}$ & $28 \mathrm{c}$ \\
\hline
\end{tabular}

Any information copied from such Reports and Statements may not be sold or used by any person for the purpose of soliciting contributions or for commercial purposes, other than using the name and address of any political committee to solicit contributions from such committee.

NAME OF COMMITTEE (In Full)

\section{Friends of Herman Cain}

Full Name (Last, First, Middle Initial)

A. Facebook, Inc.

Mailing Address 1601 S. California Ave.

Date of Disbursement

\begin{tabular}{|c|c|c|c|c|c|}
\hline \multicolumn{2}{|l|}{$\begin{array}{l}\text { City } \\
\text { Palo Alto }\end{array}$} & \multicolumn{3}{|c|}{$\begin{array}{l}\text { Zip Code } \\
94304\end{array}$} & \multirow{2}{*}{$\begin{array}{l}\text { Transaction ID : B78A5A4C310474F9082F } \\
\text { Amount of Each Disbursement this Period }\end{array}$} \\
\hline \multicolumn{4}{|c|}{$\begin{array}{l}\text { Purpose of Disbursement } \\
\text { Advertising Expense }\end{array}$} & & \\
\hline \multicolumn{4}{|c|}{ Candidate Name } & $\begin{array}{l}\text { Category/ } \\
\text { Type }\end{array}$ & 200.00 \\
\hline & President & \multicolumn{3}{|c|}{ Disbursement For: 2012} & \\
\hline State: & \multicolumn{4}{|c|}{ District: } & \\
\hline
\end{tabular}

Full Name (Last, First, Middle Initial)

B. Facebook, Inc.

Mailing Address 1601 S. California Ave.

Date of Disbursement

\begin{tabular}{|c|c|c|c|c|}
\hline \multicolumn{2}{|l|}{ City } & \multicolumn{3}{|c|}{ Zip Code } \\
\hline \multicolumn{2}{|l|}{ Palo Alto } & $\mathrm{CA}$ & \multicolumn{2}{|c|}{94304} \\
\hline \multicolumn{4}{|c|}{$\begin{array}{l}\text { Purpose of Disbursement } \\
\text { Advertising Expense }\end{array}$} & \\
\hline \multicolumn{4}{|c|}{ Candidate Name } & $\begin{array}{l}\text { Category/ } \\
\text { Type }\end{array}$ \\
\hline \multirow[t]{3}{*}{ Office Sought: } & House & \multirow{3}{*}{\multicolumn{3}{|c|}{ Disbursement For: 2012}} \\
\hline & Senate & & & \\
\hline & President & & & \\
\hline
\end{tabular}

\begin{tabular}{|c|c|c|c|c|}
\hline${ }^{\mathrm{M}} 08^{\mathrm{M}}$ & I & $29^{\mathrm{D}}$ & 1 & 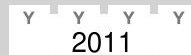 \\
\hline
\end{tabular}

Transaction ID : B7031C3351B7745D29B4

Full Name (Last, First, Middle Initial)

c. Tina Spratling

\begin{tabular}{|c|c|c|c|c|c|}
\hline \multicolumn{6}{|c|}{ Mailing Address PO Box 2158} \\
\hline \multicolumn{2}{|l|}{ City } & State & \multicolumn{3}{|l|}{ Zip Code } \\
\hline \multicolumn{2}{|l|}{ Stockbridge } & GA & \multicolumn{3}{|c|}{$30281-8909$} \\
\hline \multicolumn{5}{|c|}{$\begin{array}{l}\text { Purpose of Disbursement } \\
\text { Staff Salary }\end{array}$} & \\
\hline \multicolumn{5}{|c|}{ Candidate Name } & $\begin{array}{l}\text { Category/ } \\
\text { Type }\end{array}$ \\
\hline \multirow[t]{3}{*}{ Office Sought: } & House & \multicolumn{4}{|c|}{ Disbursement For: 2012} \\
\hline & Senate & \multirow{3}{*}{\multicolumn{2}{|c|}{$\begin{array}{l}\text { Primary } \\
\text { Other (specify) }\end{array}$}} & \multirow{2}{*}{\multicolumn{2}{|c|}{ General }} \\
\hline & President & & & & \\
\hline State: & District: & & & \multicolumn{2}{|c|}{$\nabla$} \\
\hline
\end{tabular}

Subtotal Of Receipts This Page (optional).

Date of Disbursement

\begin{tabular}{|c|c|c|c|c|}
\hline $08^{M}$ & I & 29 & 1 & $\begin{array}{cccc}Y & Y & Y & Y \\
& 2011 & \end{array}$ \\
\hline
\end{tabular}

\section{Transaction ID : B193F0B1F5885405BAE3}

Amount of Each Disbursement this Period

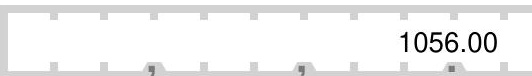

1056.00

Total This Period (last page this line number only)) 


\section{SCHEDULE B-P}

\section{ITEMIZED DISBURSEMENTS}

\section{Use separate schedule(s) \\ for each category of the}

Detailed Summary Page
FOR LINE NUMBER: (check only one)

\begin{tabular}{|c|c|c|c|}
\hline$\times{ }_{23}$ & 24 & 25 & 26 \\
\hline $27 b$ & $28 a$ & $28 \mathrm{~b}$ & $28 \mathrm{c}$ \\
\hline
\end{tabular}

Any information copied from such Reports and Statements may not be sold or used by any person for the purpose of soliciting contributions or for commercial purposes, other than using the name and address of any political committee to solicit contributions from such committee.

NAME OF COMMITTEE (In Full)

\section{Friends of Herman Cain}

Full Name (Last, First, Middle Initial)

A. Christopher Kenworthy

Mailing Address PO Box 2158

Date of Disbursement

\begin{tabular}{lcc}
\hline City & State & Zip Code \\
Stockbridge & GA & $30281-8909$
\end{tabular}

Purpose of Disbursement

Staff Salary

Candidate Name

Office Sought: $\quad$ House

Senate

President

State:

District:

Full Name (Last, First, Middle Initial)

B. William Head

Mailing Address PO Box 2158

\begin{tabular}{lcc}
\hline City & State & Zip Code \\
Stockbridge & GA & $30281-8909$
\end{tabular}

Disbursement For: 2012

X Primary $\square$ General

Purpose of Disbursement

Staff Salary

Candidate Name

Office Sought:

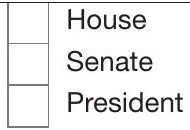

State:

District:

GA

Full Name (Last, First, Middle Initial)

c. J Ryan Hudson

Mailing Address 418 Landing Pointe

\begin{tabular}{lcc}
\hline City & State & Zip Code \\
Stockbridge & GA & 30281
\end{tabular}

Purpose of Disbursement

Staff Salary

Candidate Name

Office Sought: $\quad$ House

\begin{tabular}{|l|l|} 
& House \\
& Senate \\
& President
\end{tabular}

State:

District:
Disbursement For: 2012

Xrimary $\square$ General
Date of Disbursement

\begin{tabular}{|c|c|c|c|c|}
\hline${ }^{M}$ & ${ }^{M}$ & $8^{\mathrm{D}}$ & $\mathrm{P}^{\mathrm{D}}$ & $\mathrm{Y}^{\mathrm{Y}} \mathrm{Y}$ \\
\hline
\end{tabular}

Transaction ID : B26F17BB693D14FC8AA1

Amount of Each Disbursement this Period

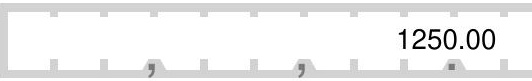

Date of Disbursement

\begin{tabular}{|c|c|c|c|c|}
\hline $08^{M}$ & I & D 29 & 1 & $\begin{array}{cccc}Y & Y & Y & Y \\
& 2011 & \end{array}$ \\
\hline
\end{tabular}

Transaction ID : BF15F52E6D9E5419E8FF

Amount of Each Disbursement this Period

171.67 Type

Subtotal Of Receipts This Page (optional).

Total This Period (last page this line number only))

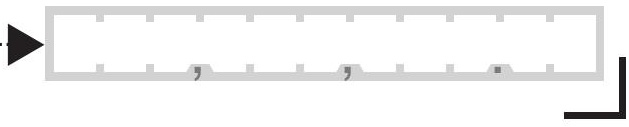




\section{SCHEDULE B-P}

\section{ITEMIZED DISBURSEMENTS}

\section{Use separate schedule(s) \\ for each category of the}

Detailed Summary Page
FOR LINE NUMBER: (check only one)

\begin{tabular}{|c|c|c|c|}
\hline$\times{ }_{23}$ & 24 & 25 & 26 \\
\hline $27 b$ & $28 a$ & $28 \mathrm{~b}$ & $28 \mathrm{c}$ \\
\hline
\end{tabular}

Any information copied from such Reports and Statements may not be sold or used by any person for the purpose of soliciting contributions or for commercial purposes, other than using the name and address of any political committee to solicit contributions from such committee.

NAME OF COMMITTEE (In Full)

\section{Friends of Herman Cain}

Full Name (Last, First, Middle Initial)

A. Charles Levin

Mailing Address PO Box 7834 Jerusalem

\begin{tabular}{lll}
\hline City & State & Zip Code \\
Israel
\end{tabular}

Purpose of Disbursement

Media Production

Candidate Name

Office Sought:

State:

Full Name (Last, First, Middle Initial)

\section{B. Tri-Net Payroll Services}

\begin{tabular}{ll}
\hline Mailing Address & 1100 San Leandro Boulevard \\
& Suite
\end{tabular}

San Leandro

Purpose of Disbursement

Payroll Service Fee

Candidate Name

Office Sought:

House
Senate
President

State:

District:
Disbursement For: 2012

Xrimary $\square$ General
Date of Disbursement

\begin{tabular}{|c|c|c|c|c|}
\hline $08^{M}$ & 1 & $29^{D}$ & & $\begin{array}{lll}Y & Y & Y \\
2011 & Y\end{array}$ \\
\hline
\end{tabular}

Transaction ID : B4A490F0E15B44348BF1

Amount of Each Disbursement this Period 3000.00

Full Name (Last, First, Middle Initial)

\section{c. Tri-Net Payroll Services}

Mailing Address 1100 San Leandro Boulevard

Suite

\begin{tabular}{lcc}
\multicolumn{2}{c}{ Suite } & \\
\hline City & State & Zip Code \\
San Leandro & CA & 94577
\end{tabular}

Purpose of Disbursement

Payroll Withholding

Candidate Name

Office Sought: $\quad$ House

$\begin{aligned} & \text { House } \\ & \text { Senate } \\ & \text { President }\end{aligned}$
District:

State:

District:
Date of Disbursement

\begin{tabular}{|c|c|c|c|c|}
\hline $08^{M}$ & 1 & $29^{\mathrm{D}}$ & 1 & 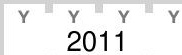 \\
\hline
\end{tabular}

Transaction ID : B2E1913DC53D14B70AE9

Amount of Each Disbursement this Period
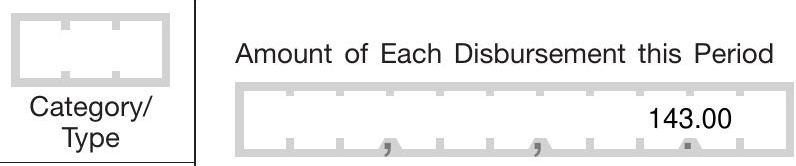

Date of Disbursement

\begin{tabular}{|c|c|c|c|c|c|}
\hline M M & I & D & Y & Y & Y \\
08 & & 29 & & 2011 & \\
\hline
\end{tabular}

Transaction ID : B3D0BA9FD56A04566B75

Amount of Each Disbursement this Period

428.76

Subtotal Of Receipts This Page (optional).

Total This Period (last page this line number only))

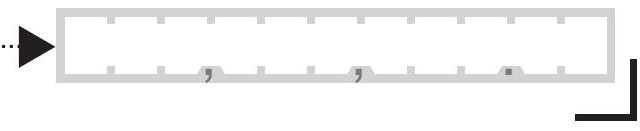




\section{SCHEDULE B-P}

\section{ITEMIZED DISBURSEMENTS}

\section{Use separate schedule(s) \\ for each category of the}

Detailed Summary Page
FOR LINE NUMBER: (check only one)

\begin{tabular}{|c|c|c|c|}
\hline$\times{ }_{23}$ & 24 & 25 & 26 \\
\hline $27 b$ & $28 a$ & $28 \mathrm{~b}$ & $28 \mathrm{c}$ \\
\hline
\end{tabular}

Any information copied from such Reports and Statements may not be sold or used by any person for the purpose of soliciting contributions or for commercial purposes, other than using the name and address of any political committee to solicit contributions from such committee.

NAME OF COMMITTEE (In Full)

\section{Friends of Herman Cain}

Full Name (Last, First, Middle Initial)

A. Hyatt Hotels

\begin{tabular}{|c|c|c|c|c|c|c|c|}
\hline \multirow{3}{*}{\multicolumn{5}{|c|}{$\begin{array}{ll}\text { Mailing Address } & 71 \text { S. Wacker Dr. } \\
& \text { 12th Floor }\end{array}$}} & \multirow{3}{*}{08} & \multirow{3}{*}{29} & \multirow{3}{*}{$\begin{array}{c}\text { / } \\
2011\end{array}$} \\
\hline & & & & & & & \\
\hline & & & & & & & \\
\hline \multicolumn{2}{|l|}{$\begin{array}{l}\text { City } \\
\text { Chicago }\end{array}$} & State & Code & & \multicolumn{3}{|c|}{ Transaction ID : B75ED4CF880A548A58DB } \\
\hline \multicolumn{4}{|c|}{$\begin{array}{l}\text { Purpose of Disbursement } \\
\text { Travel Expense }\end{array}$} & & \multicolumn{3}{|c|}{ Amount of Each Disbursement this Period } \\
\hline \multicolumn{4}{|l|}{ Candidate Name } & $\begin{array}{l}\text { Category/ } \\
\text { Type }\end{array}$ & \multirow{4}{*}{\multicolumn{3}{|c|}{, $\quad 639.36$}} \\
\hline \multirow[t]{3}{*}{ Office Sought: } & House & \multirow{3}{*}{\multicolumn{3}{|c|}{ Disbursement For: 2012}} & & & \\
\hline & Senate & & & & & & \\
\hline & President & & & & & & \\
\hline
\end{tabular}

Full Name (Last, First, Middle Initial)

\section{B. RMA Chaffeured Transportation}

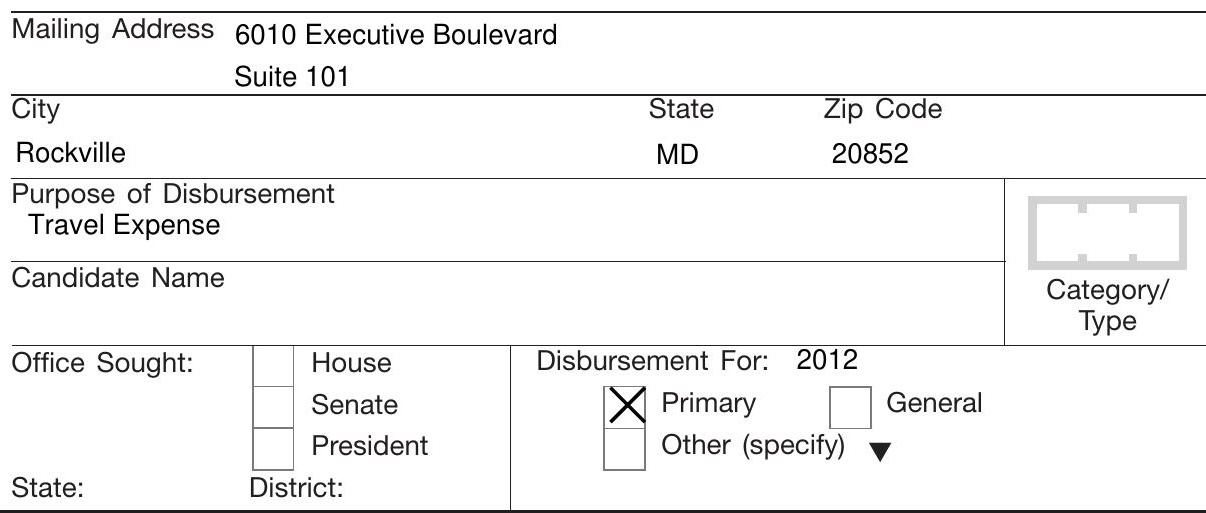

Date of Disbursement

\begin{tabular}{|c|c|c|c|c|}
\hline${ }^{M}$ & ${ }^{M}$ & $8^{\mathrm{D}}$ & $\mathrm{P}^{\mathrm{D}}$ & $\mathrm{Y}^{\mathrm{Y}} \mathrm{Y}$ \\
\hline
\end{tabular}

Transaction ID : BE1E24CF0BD63422D860

Full Name (Last, First, Middle Initial)

\section{SunTrust Bank}

Mailing Address 980 Eagles Landing Parkway

\begin{tabular}{lcc}
\hline City & State & Zip Code \\
Stockbridge & GA & 30281
\end{tabular}

Purpose of Disbursement

Bank Fees

Candidate Name

Office Sought:

State:

Subtotal Of Receipts This Page (optional).

Total This Period (last page this line number only))
Date of Disbursement

\begin{tabular}{|c|c|c|c|c|}
\hline $08^{M}$ & I & 29 & 1 & 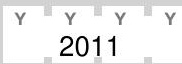 \\
\hline
\end{tabular}

Transaction ID : B4009592B6F364288845

Amount of Each Disbursement this Period

60.00 


\section{SCHEDULE B-P}

\section{ITEMIZED DISBURSEMENTS}

\section{Use separate schedule(s) \\ for each category of the}

Detailed Summary Page
FOR LINE NUMBER: (check only one)

\begin{tabular}{|c|c|c|c|}
\hline$X_{23}$ & 24 & 25 & 26 \\
\hline $27 \mathrm{~b}$ & $28 a$ & $28 b$ & $28 \mathrm{c}$ \\
\hline
\end{tabular}

Any information copied from such Reports and Statements may not be sold or used by any person for the purpose of soliciting contributions or for commercial purposes, other than using the name and address of any political committee to solicit contributions from such committee.

NAME OF COMMITTEE (In Full)

\section{Friends of Herman Cain}

Full Name (Last, First, Middle Initial)

A. Delta Airlines

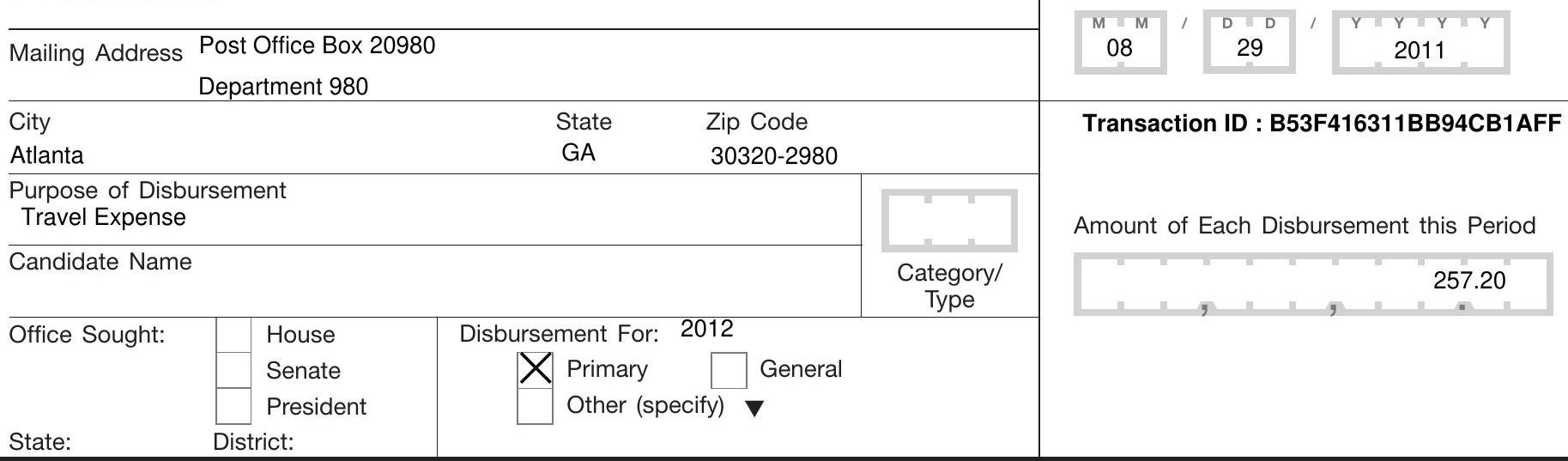

Full Name (Last, First, Middle Initial)

B. Accuconference

\begin{tabular}{|c|c|c|c|c|}
\hline Mailing Address & \multicolumn{4}{|c|}{2360 Corporate Circle } \\
\hline \multicolumn{2}{|l|}{ City } & \multicolumn{3}{|c|}{ Zip Code } \\
\hline \multicolumn{2}{|l|}{ Henderson } & \multicolumn{3}{|c|}{89074} \\
\hline \multicolumn{4}{|c|}{$\begin{array}{l}\text { Purpose of Disbursement } \\
\text { Automated Calls }\end{array}$} & \\
\hline \multicolumn{4}{|l|}{ Candidate Name } & $\begin{array}{l}\text { Category/ } \\
\text { Type }\end{array}$ \\
\hline \multirow[t]{3}{*}{ Office Sought: } & House & \multirow{3}{*}{\multicolumn{3}{|c|}{ Disbursement For: 2012}} \\
\hline & Senate & & & \\
\hline & President & & & \\
\hline State: & \multicolumn{4}{|c|}{ District: } \\
\hline
\end{tabular}

Date of Disbursement

\begin{tabular}{|c|c|c|c|c|}
\hline $08^{M}$ & 1 & $29^{\mathrm{D}}$ & 1 & $\begin{array}{llll}Y & Y & Y & Y \\
& 2011 & \end{array}$ \\
\hline
\end{tabular}

Transaction ID : B9DD04BFE13894688B57

Full Name (Last, First, Middle Initial)

c. Georgia Republican Party

Mailing Address PO Box 550008

\begin{tabular}{lcc}
\hline City & State & Zip Code \\
Atlanta & GA & 30355
\end{tabular}

Purpose of Disbursement

Event Tickets

Candidate Name

Georgia Republican Party

Office Sought:

\begin{tabular}{|l|l|} 
& House \\
& Senate \\
& President \\
District: &
\end{tabular}

State:

District:
Disbursement For: 2012

Х $\begin{aligned} & \text { Primary } \\ & \text { Other (specify) }\end{aligned}$
Date of Disbursement

\begin{tabular}{|c|c|c|c|c|}
\hline $08^{M}$ & I & $\begin{array}{l}\text { D } \\
29\end{array}$ & 1 & $\begin{array}{cccc}Y & Y & Y & Y \\
& 2011 & \end{array}$ \\
\hline
\end{tabular}

Transaction ID : B31401BA0D4B843F7A0A

Amount of Each Disbursement this Period

150.00

Subtotal Of Receipts This Page (optional)

Total This Period (last page this line number only))

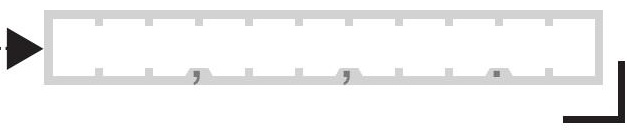

FEC Schedule B-P (Form 3P) (Rev. 03/2011) 


\section{SCHEDULE B-P}

\section{ITEMIZED DISBURSEMENTS}

\section{Use separate schedule(s) \\ for each category of the}

Detailed Summary Page
FOR LINE NUMBER: (check only one)

\begin{tabular}{|c|c|c|c|}
\hline$\times{ }_{23}$ & 24 & 25 & 26 \\
\hline $27 b$ & $28 a$ & $28 \mathrm{~b}$ & $28 \mathrm{c}$ \\
\hline
\end{tabular}

Any information copied from such Reports and Statements may not be sold or used by any person for the purpose of soliciting contributions or for commercial purposes, other than using the name and address of any political committee to solicit contributions from such committee.

NAME OF COMMITTEE (In Full)

\section{Friends of Herman Cain}

Full Name (Last, First, Middle Initial)

A. Tri-Net Payroll Services

Mailing Address 1100 San Leandro Boulevard Suite

\begin{tabular}{lll}
\hline City & State & Zip Code \\
San Leandro & CA & 94577
\end{tabular}

Purpose of Disbursement

Payroll Withholding

Candidate Name

Office Sought:

State:

Full Name (Last, First, Middle Initial)

\section{B. Tri-Net Payroll Services}

\begin{tabular}{ll}
\hline Mailing Address & 1100 San Leandro Boulevard \\
Suite
\end{tabular}

San Leandro

Purpose of Disbursement

Payroll Service Fees

Candidate Name

Office Sought:

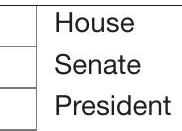

State:

District:

\section{c. Delta Airlines}

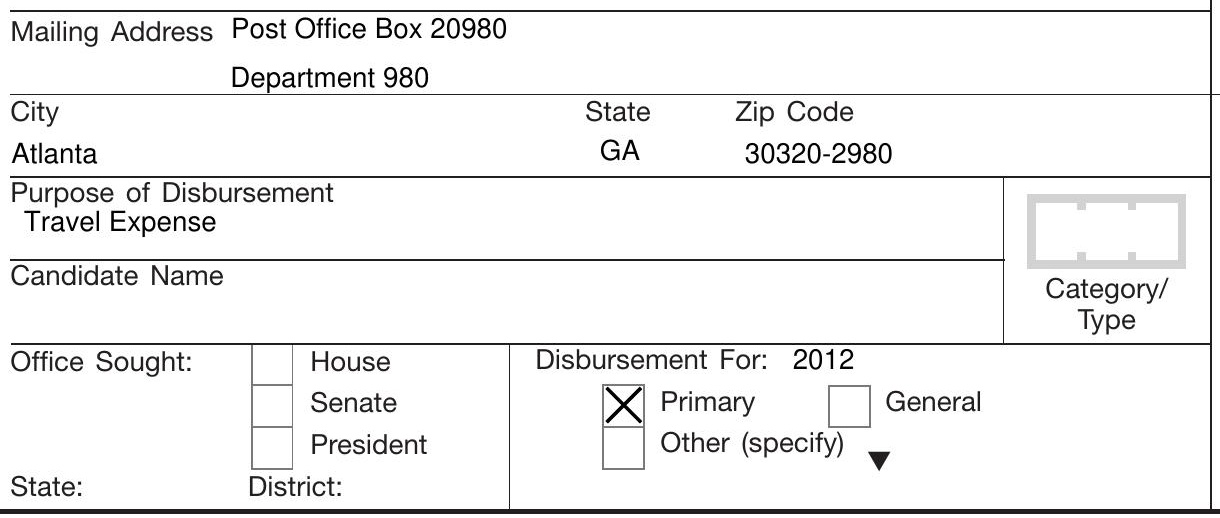

Subtotal Of Receipts This Page (optional).

Total This Period (last page this line number only))
Date of Disbursement

\begin{tabular}{|c|c|c|c|c|c|}
\hline${ }^{M}$ & M & D & Y \\
\hline & 30 & 2011 \\
\hline
\end{tabular}

Transaction ID : BA24F22245269439E8C3

Amount of Each Disbursement this Period 5925.41

Date of Disbursement

\begin{tabular}{|c|c|c|c|c|}
\hline $08^{\mathrm{M}}$ & 1 & $30^{D}$ & 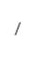 & 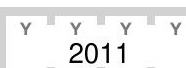 \\
\hline
\end{tabular}

Transaction ID : B11C0AF1EC41F49DD88A

Amount of Each Disbursement this Period

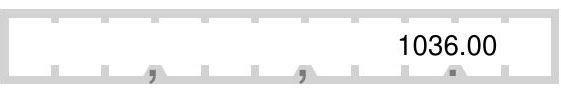

Date of Disbursement

\begin{tabular}{|c|c|c|c|c|c|c|}
\hline M & M & D & Y & Y & Y \\
08 & & 30 & & 2011 & \\
\hline
\end{tabular}

Transaction ID : BAA99F8353B274E7C916

Amount of Each Disbursement this Period

258.70 


\section{SCHEDULE B-P}

\section{ITEMIZED DISBURSEMENTS}

\section{Use separate schedule(s) \\ for each category of the}

Detailed Summary Page
FOR LINE NUMBER: (check only one)

\begin{tabular}{|c|c|c|c|}
\hline$\times{ }_{23}$ & 24 & 25 & 26 \\
\hline $27 b$ & $28 a$ & $28 \mathrm{~b}$ & $28 \mathrm{c}$ \\
\hline
\end{tabular}

Any information copied from such Reports and Statements may not be sold or used by any person for the purpose of soliciting contributions or for commercial purposes, other than using the name and address of any political committee to solicit contributions from such committee.

NAME OF COMMITTEE (In Full)

\section{Friends of Herman Cain}

Full Name (Last, First, Middle Initial)

A. Tri-Net Payroll Services

Mailing Address 1100 San Leandro Boulevard Suite

Date of Disbursement

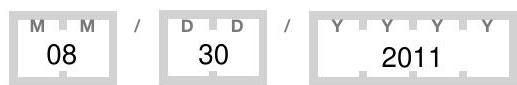

Transaction ID : B3323E5A586C946EC870

\begin{tabular}{lll}
\hline City & State & Zip Code \\
San Leandro & CA & 94577
\end{tabular}

Purpose of Disbursement

Payroll Benefits

Candidate Name

Office Sought:

\begin{tabular}{|l|l} 
& $\begin{array}{l}\text { House } \\
\text { Senate } \\
\text { President }\end{array}$ \\
\hline District:
\end{tabular}

Disbursement For: 2012 X Primary $\square$ General

State: District:

Full Name (Last, First, Middle Initial)

B. Domino's

Mailing Address 202 Main Street

\begin{tabular}{lcc}
\hline City & State & Zip Code \\
Concord & $\mathrm{NH}$ & 03301
\end{tabular}

Purpose of Disbursement

Meeting Expense

Candidate Name

Office Sought:

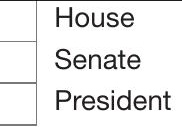

State:

District:

Full Name (Last, First, Middle Initial)

c. Nathan Naidu

Mailing Address 3601 canton rd \#131

Disbursement For: 2012

Xrimary $\square$ General

Primary
Other (specify) G

City

Marietta

Purpose of Disbursement

Staff Salary

Candidate Name

Office Sought:

State:

Subtotal Of Receipts This Page (optional).

State Zip Code

GA 30066-2892

(1)

(n)

House

Disbursement For: 2012
$X$ Primary
Other (specify)

Date of Disbursement

\begin{tabular}{|c|c|c|c|c|}
\hline $08^{M}$ & & ${ }^{\mathrm{D}}{ }^{\mathrm{D}}$ & & 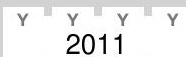 \\
\hline
\end{tabular}

Transaction ID : B6EADD0A7E2904A56BBD

Amount of Each Disbursement this Period
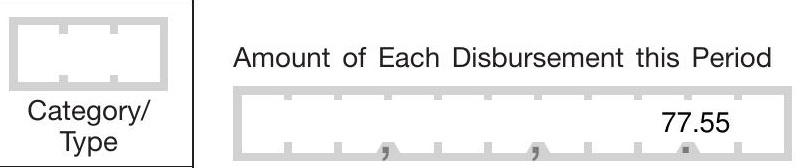

Date of Disbursement

\begin{tabular}{|c|c|c|c|c|}
\hline $08^{M}$ & & $30^{\mathrm{D}}$ & 1 & $\begin{array}{cccc}Y & Y & Y & Y \\
& 2011 & \end{array}$ \\
\hline
\end{tabular}

Transaction ID : B2F59C02AD6764B7B945

Amount of Each Disbursement this Period

1500.00

Total This Period (last page this line number only))

6571.00

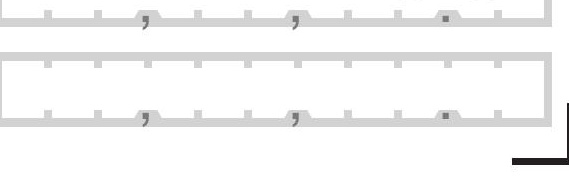




\section{SCHEDULE B-P}

\section{ITEMIZED DISBURSEMENTS}

\section{Use separate schedule(s)}

for each category of the

Detailed Summary Page
FOR LINE NUMBER: (check only one)

\begin{tabular}{|c|c|c|c|}
\hline$\times{ }_{23}$ & 24 & 25 & 26 \\
\hline $27 b$ & $28 a$ & $28 \mathrm{~b}$ & $28 \mathrm{c}$ \\
\hline
\end{tabular}

Any information copied from such Reports and Statements may not be sold or used by any person for the purpose of soliciting contributions or for commercial purposes, other than using the name and address of any political committee to solicit contributions from such committee.

NAME OF COMMITTEE (In Full)

\section{Friends of Herman Cain}

Full Name (Last, First, Middle Initial)

A. Lisa Shiflett

Mailing Address 157 Stokes Drive

Date of Disbursement

\begin{tabular}{lcc}
\hline City & State & Zip Code \\
Stockbridge & GA & $30281-1376$
\end{tabular}

Purpose of Disbursement

Staff Salary

Candidate Name

Office Sought: $\quad$ House

Senate

President

State:

District:

Full Name (Last, First, Middle Initial)

B. J Ryan Hudson

Mailing Address 418 Landing Pointe

\begin{tabular}{lcc}
\hline City & State & Zip Code \\
Stockbridge & GA & 30281
\end{tabular}

Disbursement For: 2012

X Primary $\square$ General

Purpose of Disbursement

Staff Salary

Candidate Name

Office Sought:

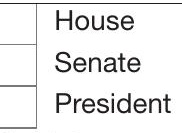

State:

District:

GA 30281

Full Name (Last, First, Middle Initial)

\section{c. Steven Hensler}

Mailing Address 401 Woodview Drive

\begin{tabular}{lcc}
\hline City & State & Zip Code \\
Sun Prairie & WI & $53590-2353$
\end{tabular}

Purpose of Disbursement

Staff Salary

Candidate Name

\begin{tabular}{l|l}
\hline Office Sought: & House \\
& $\begin{array}{l}\text { Senate } \\
\text { Senatent } \\
\text { President }\end{array}$ \\
State: & District:
\end{tabular}

Date of Disbursement

\begin{tabular}{|c|c|c|c|c|}
\hline $08^{M}$ & & ${ }^{\mathrm{D}}{ }^{\mathrm{D}}$ & & 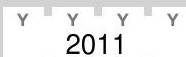 \\
\hline
\end{tabular}

Transaction ID : B02582F15F31B4AB7A8B

Amount of Each Disbursement this Period

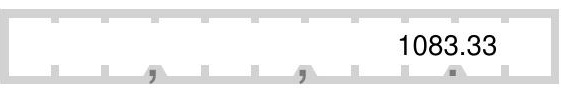

Date of Disbursement

\begin{tabular}{|c|c|c|c|c|}
\hline $08^{M}$ & I & 30 & 1 & $\begin{array}{cccc}Y & Y & Y & Y \\
& 2011 & \end{array}$ \\
\hline
\end{tabular}

Transaction ID : BBA9E30FAA526409E857

Amount of Each Disbursement this Period

1500.00

Subtotal Of Receipts This Page (optional).

Total This Period (last page this line number only))

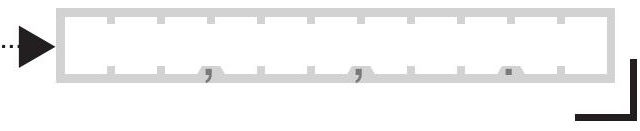




\section{SCHEDULE B-P}

\section{ITEMIZED DISBURSEMENTS}

\section{Use separate schedule(s) \\ for each category of the}

Detailed Summary Page
FOR LINE NUMBER: (check only one)

\begin{tabular}{|c|c|c|c|}
\hline$\times{ }_{23}$ & 24 & 25 & 26 \\
\hline $27 b$ & $28 a$ & $28 \mathrm{~b}$ & $28 \mathrm{c}$ \\
\hline
\end{tabular}

Any information copied from such Reports and Statements may not be sold or used by any person for the purpose of soliciting contributions or for commercial purposes, other than using the name and address of any political committee to solicit contributions from such committee.

NAME OF COMMITTEE (In Full)

\section{Friends of Herman Cain}

Full Name (Last, First, Middle Initial)

A. Michael Branch

Mailing Address 509 Autumnwood Ct

Date of Disbursement

\begin{tabular}{lcc}
\hline City & State & Zip Code \\
Nashville & TN & $37221-3938$
\end{tabular}

Purpose of Disbursement

Staff Salary

Candidate Name

Office Sought:

\begin{tabular}{|l|l|l} 
& House \\
Senate \\
President
\end{tabular}

Disbursement For: 2012 X Primary $\square$ General

State: District:

Full Name (Last, First, Middle Initial)

B. Larry Tuel

Mailing Address 5129 Welker Ave.

\begin{tabular}{lcc}
\hline City & State & Zip Code \\
Des Moines & IA & $50312-2159$
\end{tabular}

Purpose of Disbursement

Staff Salary

Candidate Name

Office Sought:

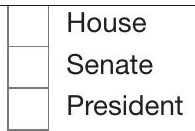

State:

District:

IA

Full Name (Last, First, Middle Initial)

\section{c. Scott Sidney}

Mailing Address N40 W6522 Jackson Street

\begin{tabular}{lcc}
\hline City & State & Zip Code \\
Cedarburg & WI & $53012-2317$
\end{tabular}

Purpose of Disbursement

Staff Salary

Candidate Name

Office Sought:

State:

\begin{tabular}{|c|}
\hline House \\
\hline Senate \\
\hline President \\
\hline
\end{tabular}

Disbursement For: 2012

Х $\begin{aligned} & \text { Primary } \\ & \text { Other (specify) }\end{aligned}$
Date of Disbursement

\begin{tabular}{|c|c|c|c|c|}
\hline $08^{\mathrm{M}}$ & 1 & $30^{D}$ & 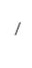 & 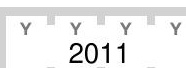 \\
\hline
\end{tabular}

Transaction ID : B93B67E9E8A4D4F61A4F

Amount of Each Disbursement this Period

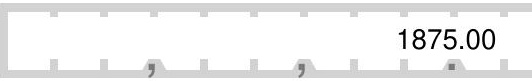

Date of Disbursement

\begin{tabular}{|c|c|c|c|c|}
\hline $08^{M}$ & I & 30 & 1 & $\begin{array}{cccc}Y & Y & Y & Y \\
& 2011 & \end{array}$ \\
\hline
\end{tabular}

Transaction ID : B7E944B90D306488FB03

Amount of Each Disbursement this Period

1000.00

Subtotal Of Receipts This Page (optional).

Total This Period (last page this line number only))

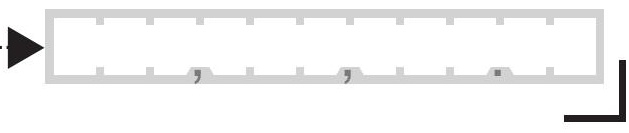




\section{SCHEDULE B-P}

\section{ITEMIZED DISBURSEMENTS}

Use separate schedule(s)

for each category of the

Detailed Summary Page
FOR LINE NUMBER: (check only one)

\begin{tabular}{|c|c|c|c|}
\hline$\times{ }_{23}$ & 24 & 25 & 26 \\
\hline $27 b$ & $28 a$ & $28 \mathrm{~b}$ & $28 \mathrm{c}$ \\
\hline
\end{tabular}

Any information copied from such Reports and Statements may not be sold or used by any person for the purpose of soliciting contributions or for commercial purposes, other than using the name and address of any political committee to solicit contributions from such committee.

NAME OF COMMITTEE (In Full)

\section{Friends of Herman Cain}

Full Name (Last, First, Middle Initial)

A. Mark Block

Mailing Address 18125 West Plateau Lane

Date of Disbursement

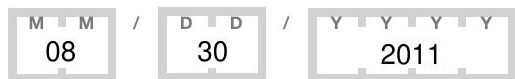

Transaction ID : B4A4ECA14FF58474FBFD

\begin{tabular}{lll}
\hline City & State & Zip Code \\
New Berlin & WI & $53146-5116$
\end{tabular}

Purpose of Disbursement

Staff Salary

Candidate Name

\begin{tabular}{l|l|l}
\hline Office Sought: & House & Disbursement For: 2012
\end{tabular} X Primary $\square$ General

State:

\section{Senate}

President

District:

Full Name (Last, First, Middle Initial)

B. Scott F. Bieniek

Mailing Address 1782 Schooling Road

\begin{tabular}{lcc}
\hline City & State & Zip Code \\
Spencer & IN & $47460-7528$
\end{tabular}

Purpose of Disbursement

Staff Salary

Candidate Name

Office Sought:

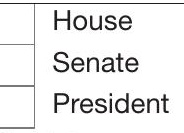

State:

District:

Full Name (Last, First, Middle Initial)

c. Ashley Frasca

Mailing Address 601 Springharbor Drive

Disbursement For: 2012

Primary
Other (specify)

Primary
Other (specify)

\section{Category/ \\ Category/ Type}

Amount of Each Disbursement this Period

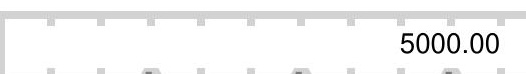

5000.00

Date of Disbursement

\begin{tabular}{|c|c|c|c|c|}
\hline $08^{M}$ & & ${ }^{\mathrm{D}}{ }^{\mathrm{D}}$ & & $\begin{array}{llll} & Y & Y & Y \\
& 2011 & Y\end{array}$ \\
\hline
\end{tabular}

Transaction ID : B959F9055959444FAB18

Amount of Each Disbursement this Period
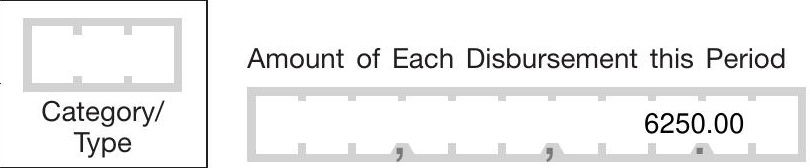

Date of Disbursement

\begin{tabular}{|c|c|c|c|c|}
\hline $08^{M}$ & I & 30 & 1 & $\begin{array}{cccc}Y & Y & Y & Y \\
& 2011 & \end{array}$ \\
\hline
\end{tabular}

\begin{tabular}{lcc}
\hline City & State & Zip Code \\
Woodstock & GA & $30188-6044$
\end{tabular}

Purpose of Disbursement

Staff Salary

Candidate Name

(2)

Candidate Name

Office Sought:

\begin{tabular}{|l|l|} 
& House \\
& Senate \\
& President \\
& District:
\end{tabular}

Disbursement For: 2012
\[ \begin{array}{l}\text { Primary } \\ \text { Other (specify) }\end{array} \]

\section{Transaction ID : BF01263E4FD8A48D3B7A}

Amount of Each Disbursement this Period

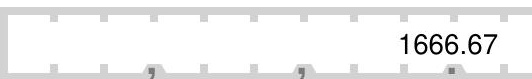

1666.67
State:

District:
Subtotal Of Receipts This Page (optional).

12916.67

C.

Total This Period (last page this line number only)) 


\section{SCHEDULE B-P}

\section{ITEMIZED DISBURSEMENTS}

\section{Use separate schedule(s) \\ for each category of the}

Detailed Summary Page
FOR LINE NUMBER: (check only one)

\begin{tabular}{|c|c|c|c|}
\hline$\times{ }_{23}$ & 24 & 25 & 26 \\
\hline $27 b$ & $28 a$ & $28 \mathrm{~b}$ & $28 \mathrm{c}$ \\
\hline
\end{tabular}

Any information copied from such Reports and Statements may not be sold or used by any person for the purpose of soliciting contributions or for commercial purposes, other than using the name and address of any political committee to solicit contributions from such committee.

NAME OF COMMITTEE (In Full)

\section{Friends of Herman Cain}

Full Name (Last, First, Middle Initial)

A. Raquel Rhada Hirsch

Mailing Address $6825 \mathrm{~N}$ 2nd Place

\begin{tabular}{lll}
\hline City & State & Zip Code \\
Scottsdale & AZ & 85250
\end{tabular}

Pcoursement

Staff Salary

Candidate Name

Office Sought:

Full Name (Last, First, Middle Initial)

\section{B. Charles Spano}

Mailing Address PO Box 2158

\begin{tabular}{|c|c|c|c|c|}
\hline \multicolumn{2}{|l|}{ City } & \multicolumn{3}{|c|}{ Zip Code } \\
\hline \multicolumn{2}{|l|}{ Stockbridge } & \multicolumn{3}{|c|}{$30281-8909$} \\
\hline \multicolumn{4}{|c|}{$\begin{array}{l}\text { Purpose of Disbursement } \\
\text { Staff Salary }\end{array}$} & \\
\hline \multicolumn{4}{|c|}{ Candidate Name } & $\begin{array}{l}\text { Category/ } \\
\text { Type }\end{array}$ \\
\hline \multirow[t]{3}{*}{ Office Sought: } & House & \multirow{3}{*}{\multicolumn{3}{|c|}{$\begin{array}{l}\text { Disbursement For: } 2012 \\
\text { Xrimary } \\
\text { Other (specify) }\end{array}$}} \\
\hline & Senate & & & \\
\hline & President & & & \\
\hline State: & rict: & & & \\
\hline
\end{tabular}

Full Name (Last, First, Middle Initial)

c. William Head

Mailing Address PO Box 2158

\begin{tabular}{lcc}
\hline City & State & Zip Code \\
Stockbridge & GA & $30281-8909$
\end{tabular}

Purpose of Disbursement

Staff Salary

Candidate Name

Office Sought: $\quad$ House

$\begin{aligned} & \text { House } \\ & \text { Senate } \\ & \text { President }\end{aligned}$
District:

State:

\section{Disbursement For: 2012 \\ X Primary $\square$ General}

Date of Disbursement

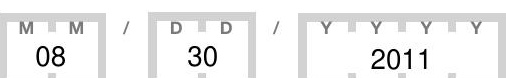

Transaction ID : BD759F8E689A747BD80E

Amount of Each Disbursement this Period

1875.00

Date of Disbursement

\begin{tabular}{|c|c|c|c|c|}
\hline $08^{\mathrm{M}}$ & & $30^{D}$ & & 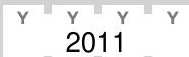 \\
\hline
\end{tabular}

Transaction ID : BE053E5A4B0654F2EB49

Amount of Each Disbursement this Period

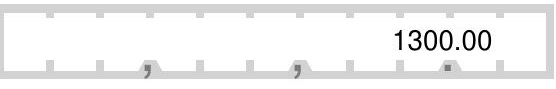

Date of Disbursement

\begin{tabular}{|c|c|c|c|c|}
\hline $08^{M}$ & I & $30^{\mathrm{D}}$ & I & $\begin{array}{cccc}Y & Y & Y & Y \\
& 2011 & \end{array}$ \\
\hline
\end{tabular}

Transaction ID : B78D09F6374034A70858

Amount of Each Disbursement this Period

1250.00

Subtotal Of Receipts This Page (optional).

Total This Period (last page this line number only))

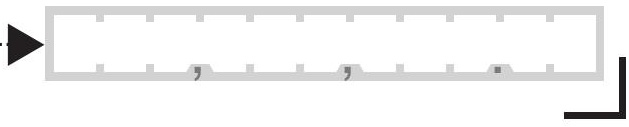




\section{SCHEDULE B-P}

\section{ITEMIZED DISBURSEMENTS}

Use separate schedule(s)

for each category of the

Detailed Summary Page
FOR LINE NUMBER: (check only one)

\begin{tabular}{|c|c|c|c|}
\hline$\times \quad 23$ & 24 & 25 & 26 \\
\hline $27 \mathrm{~b}$ & $28 \mathrm{a}$ & $28 b$ & $28 \mathrm{c}$ \\
\hline
\end{tabular}

Any information copied from such Reports and Statements may not be sold or used by any person for the purpose of soliciting contributions or for commercial purposes, other than using the name and address of any political committee to solicit contributions from such committee.

NAME OF COMMITTEE (In Full)

\section{Friends of Herman Cain}

Full Name (Last, First, Middle Initial)

A. Brenda Hicks

Mailing Address 3653 S 75th Street

Date of Disbursement

\begin{tabular}{lcc}
\hline City & State & Zip Code \\
Milwaukee & WI & $53220-1139$
\end{tabular}

Purpose of Disbursement

Staff Salary

Candidate Name

\begin{tabular}{l|l|l}
\hline Office Sought: & House & Disbursement For: 2012
\end{tabular} Xrimary $\square$ General

State:

\section{Senate}

President

District:

Full Name (Last, First, Middle Initial)

B. Elicia Huffaker

Mailing Address 7317 Alta Drive

\begin{tabular}{lcc}
\hline City & State & Zip Code \\
Las Vegas & NV & 89145-5238
\end{tabular}

Purpose of Disbursement

Staff Salary

Candidate Name

Office Sought:

House
Senate
President

Disbursement For: 2012

Primary
Other (specify) General

State:

District:

Full Name (Last, First, Middle Initial)

c. Francis Boustany, III

Mailing Address 126 Westfield Drive

\begin{tabular}{lcc}
\hline City & State & Zip Code \\
Lafayette & LA & $70503-5484$
\end{tabular}

Purpose of Disbursement

Staff Salary

Candidate Name

Office Sought: $\quad$ House

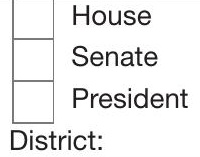

Disbursement For: 2012

X $\begin{aligned} & \text { Primary } \\ & \text { Other (specify) }\end{aligned}$

State:

District:

Subtotal Of Receipts This Page (optional)

Date of Disbursement

\begin{tabular}{|c|c|c|c|c|}
\hline $08^{M}$ & I & $30^{\mathrm{D}}$ & I & $\begin{array}{cccc}Y & Y & Y & Y \\
& 2011 & \end{array}$ \\
\hline
\end{tabular}

Transaction ID : BCAE1CDAC49C14465813

Amount of Each Disbursement this Period

Date of Disbursement

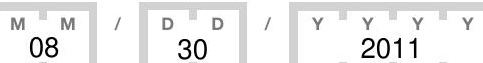

Transaction ID : B30CE4630BCAE436C8B5

Amount of Each Disbursement this Period
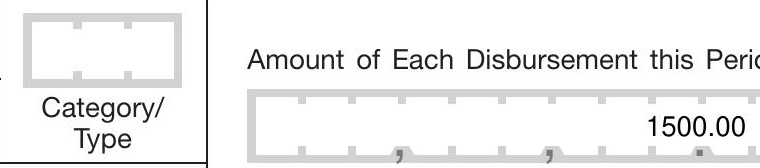

1500.00

Total This Period (last page this line number only)) 


\section{SCHEDULE B-P}

\section{ITEMIZED DISBURSEMENTS}

\section{Use separate schedule(s) \\ for each category of the}

Detailed Summary Page
FOR LINE NUMBER: (check only one)

\begin{tabular}{|c|c|c|c|}
\hline$\times{ }_{23}$ & 24 & 25 & 26 \\
\hline $27 b$ & $28 a$ & $28 \mathrm{~b}$ & $28 \mathrm{c}$ \\
\hline
\end{tabular}

Any information copied from such Reports and Statements may not be sold or used by any person for the purpose of soliciting contributions or for commercial purposes, other than using the name and address of any political committee to solicit contributions from such committee.

NAME OF COMMITTEE (In Full)

\section{Friends of Herman Cain}

Full Name (Last, First, Middle Initial)

A. Karleen Smith

Mailing Address 105 Marilyn Drive E

Date of Disbursement

\begin{tabular}{lcc}
\hline City & State & Zip Code \\
Fayetteville & GA & 30214 \\
\hline
\end{tabular}

Purpose of Disbursement

Staff Salary

Candidate Name

\begin{tabular}{l|l|l}
\hline Office Sought: & House & Disbursement For: 2012
\end{tabular} X Primary $\square$ General

State:

\section{Senate}

President

District:

Full Name (Last, First, Middle Initial)

B. Michael Johnson

Mailing Address 8225 W. Center St. Apt. 3

\begin{tabular}{|c|c|c|c|c|}
\hline \multicolumn{2}{|l|}{ City } & \multicolumn{3}{|c|}{ Zip Code } \\
\hline \multicolumn{2}{|l|}{ Milwaukee } & WI & \multicolumn{2}{|c|}{$53222-4861$} \\
\hline \multicolumn{4}{|c|}{$\begin{array}{l}\text { Purpose of Disbursement } \\
\text { Staff Salary }\end{array}$} & \\
\hline \multicolumn{4}{|c|}{ Candidate Name } & $\begin{array}{l}\text { Category/ } \\
\text { Type }\end{array}$ \\
\hline \multirow[t]{3}{*}{ Office Sought: } & House & \multicolumn{3}{|c|}{ Disbursement For: 2012} \\
\hline & Senate & X Prim & General & \\
\hline & President & \multicolumn{3}{|c|}{ Other (specify) $\nabla$} \\
\hline State: & rict: & & & \\
\hline
\end{tabular}

Date of Disbursement

\begin{tabular}{|c|c|c|c|c|}
\hline${ }^{M} 8^{M}$ & & ${ }^{\mathrm{D}}{ }^{\mathrm{D}}$ & & 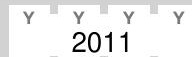 \\
\hline
\end{tabular}

Transaction ID : BC538026FA45242B581F

Full Name (Last, First, Middle Initial)

\section{c. Sandra Poehler}

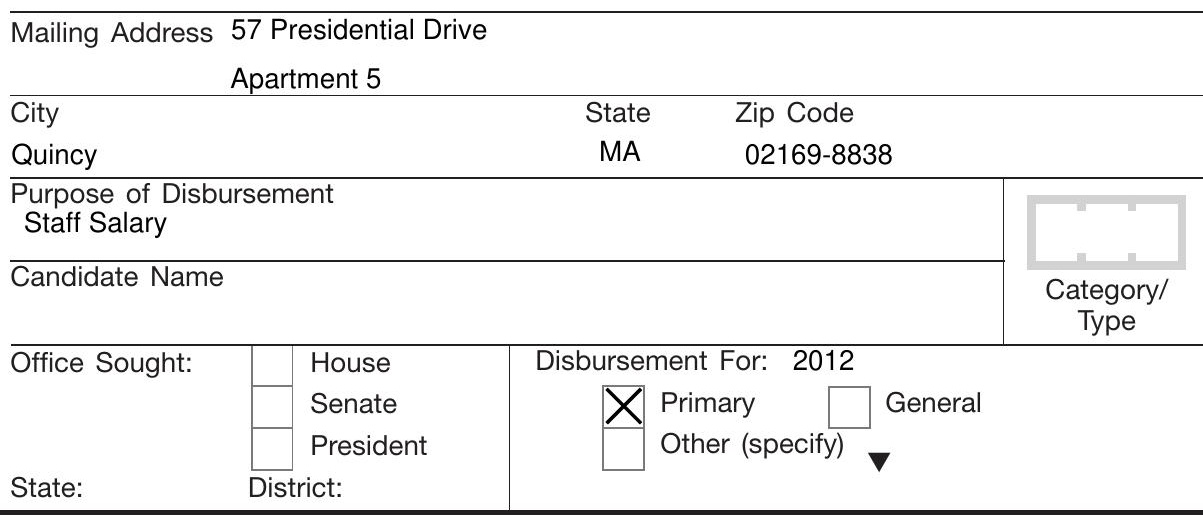

Subtotal Of Receipts This Page (optional).

Date of Disbursement

\begin{tabular}{|c|c|c|c|c|c|c|}
\hline M & M & D & Y & Y & Y \\
08 & & 30 & & 2011 & \\
\hline
\end{tabular}

Transaction ID : BFABB7C725C1A4BC4872

Amount of Each Disbursement this Period

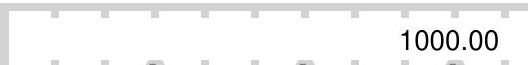

1000.00

Total This Period (last page this line number only)) 


\section{SCHEDULE B-P}

\section{ITEMIZED DISBURSEMENTS}

\section{Use separate schedule(s) \\ for each category of the}

Detailed Summary Page
FOR LINE NUMBER: (check only one)

\begin{tabular}{|c|c|c|c|}
\hline$\times{ }_{23}$ & 24 & 25 & 26 \\
\hline $27 b$ & $28 a$ & $28 \mathrm{~b}$ & $28 \mathrm{c}$ \\
\hline
\end{tabular}

Any information copied from such Reports and Statements may not be sold or used by any person for the purpose of soliciting contributions or for commercial purposes, other than using the name and address of any political committee to solicit contributions from such committee.

NAME OF COMMITTEE (In Full)

\section{Friends of Herman Cain}

Full Name (Last, First, Middle Initial)

A. Linda Hansen

Mailing Address PO Box 371312

Date of Disbursement

\begin{tabular}{lcc}
\hline City & State & Zip Code \\
Milwaukee & WI & $53237-2412$ \\
\hline
\end{tabular}

Purpose of Disbursement

Staff Salary

Candidate Name

\begin{tabular}{l|l|l|l}
\hline Office Sought: & House & Disbursement For: 2012
\end{tabular} X Primary $\square$ General

State:

\section{Senate}

President

District:

Full Name (Last, First, Middle Initial)

B. Michelle Gwaltney

Mailing Address 123 Glen Eagle Way

\begin{tabular}{lcc}
\hline City & State & Zip Code \\
McDonough & GA & $30253-4229$
\end{tabular}

Purpose of Disbursement

Staff Salary

Candidate Name

Office Sought:

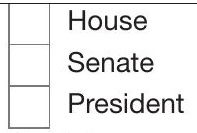

State:

District:

GA

Full Name (Last, First, Middle Initial)

\section{c. Lisa Lockwood}

Mailing Address 12746 Ford Trail South

\begin{tabular}{lcc}
\hline City & State & Zip Code \\
Indianola & IA & $50125-8931$
\end{tabular}

Purpose of Disbursement

Staff Salary

Candidate Name

Office Sought:

State:

\begin{tabular}{|c|}
\hline House \\
\hline Senate \\
\hline President \\
\hline
\end{tabular}

Disbursement For: 2012

Х $\begin{aligned} & \text { Primary } \\ & \text { Other (specify) }\end{aligned}$
Date of Disbursement

\begin{tabular}{|c|c|c|c|c|}
\hline $08^{\mathrm{M}}$ & 1 & $30^{D}$ & 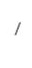 & 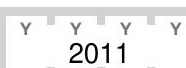 \\
\hline
\end{tabular}

Transaction ID : B303CADE98B884E6A88D

Amount of Each Disbursement this Period

2916.67

Date of Disbursement

\begin{tabular}{|c|c|c|c|c|}
\hline $08^{M}$ & I & 30 & 1 & $\begin{array}{cccc}Y & Y & Y & Y \\
& 2011 & \end{array}$ \\
\hline
\end{tabular}

Transaction ID : BF53BFAD3727F4D64B7B

Amount of Each Disbursement this Period

1375.00 Type

Subtotal Of Receipts This Page (optional).

Total This Period (last page this line number only))

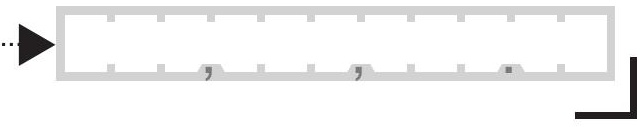




\section{SCHEDULE B-P}

\section{ITEMIZED DISBURSEMENTS}

Use separate schedule(s)

for each category of the

Detailed Summary Page
FOR LINE NUMBER: (check only one)

PAGE 1442 / 1572

\begin{tabular}{|c|c|c|c|}
\hline$X_{23}$ & 24 & 25 & 26 \\
\hline $27 \mathrm{~b}$ & $28 a$ & $28 \mathrm{~b}$ & $28 \mathrm{c}$ \\
\hline
\end{tabular}

Any information copied from such Reports and Statements may not be sold or used by any person for the purpose of soliciting contributions or for commercial purposes, other than using the name and address of any political committee to solicit contributions from such committee.

NAME OF COMMITTEE (In Full)

\section{Friends of Herman Cain}

Full Name (Last, First, Middle Initial)

A. Zachary Dalluge

Mailing Address 506 3rd Street

Date of Disbursement

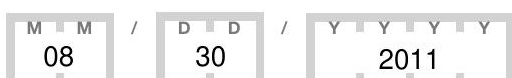

\begin{tabular}{lcc}
\hline City & State & Zip Code \\
Grafton & IA & $50440-7570$
\end{tabular}

Purpose of Disbursement

Staff Salary

Candidate Name

\begin{tabular}{l|l|l}
\hline Office Sought: & House & Disbursement For: 2012
\end{tabular} X Primary $\square$ General

State:

\section{Senate}

President

District:

Full Name (Last, First, Middle Initial)

B. Donald Henry

Mailing Address PO Box 2158

\begin{tabular}{lcc}
\hline City & State & Zip Code \\
Stockbridge & GA & $30281-8909$
\end{tabular}

Purpose of Disbursement

Staff Salary

Candidate Name

Office Sought:

House
Senate
President

Disbursement For: 2012

Primary $\square$ General
Other (specify)

State:

District:

Full Name (Last, First, Middle Initial)

c. Karis McKinney

Mailing Address 5017 N. 50th Street

\begin{tabular}{lcc}
\hline City & State & Zip Code \\
Milwaukee & WI & $53218-4326$
\end{tabular}

Purpose of Disbursement

Staff Salary

Candidate Name

Office Sought: $\quad$ House

\begin{tabular}{|l|l|} 
& House \\
Senate \\
President
\end{tabular}

Disbursement For: 2012

Х $\begin{aligned} & \text { Primary } \\ & \text { Other (specify) }\end{aligned}$

State:
Date of Disbursement

\begin{tabular}{|c|c|c|c|c|}
\hline${ }^{M} 8^{M}$ & & ${ }^{\mathrm{D}}{ }^{\mathrm{D}}$ & & 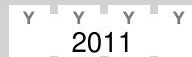 \\
\hline
\end{tabular}

Transaction ID : B2DA4D86D629F4C18B3D

Amount of Each Disbursement this Period

2083.33

Date of Disbursement

\begin{tabular}{|c|c|c|c|c|}
\hline $08^{M}$ & I & $30^{\mathrm{D}}$ & I & $\begin{array}{cccc}Y & Y & Y & Y \\
& 2011 & \end{array}$ \\
\hline
\end{tabular}

Transaction ID : B86123AD171F14A8F9C1

Amount of Each Disbursement this Period

1875.00

Subtotal Of Receipts This Page (optional).

Total This Period (last page this line number only))

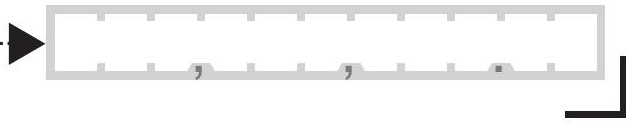




\section{SCHEDULE B-P}

\section{ITEMIZED DISBURSEMENTS}

\section{Use separate schedule(s) \\ for each category of the}

Detailed Summary Page
FOR LINE NUMBER: (check only one)

\begin{tabular}{|c|c|c|c|}
\hline$\times{ }_{23}$ & 24 & 25 & 26 \\
\hline $27 b$ & $28 a$ & $28 \mathrm{~b}$ & $28 \mathrm{c}$ \\
\hline
\end{tabular}

Any information copied from such Reports and Statements may not be sold or used by any person for the purpose of soliciting contributions or for commercial purposes, other than using the name and address of any political committee to solicit contributions from such committee.

NAME OF COMMITTEE (In Full)

\section{Friends of Herman Cain}

Full Name (Last, First, Middle Initial)

A. Facebook, Inc.

Mailing Address 1601 S. California Ave.

Date of Disbursement

\begin{tabular}{lcc}
\hline City & State & Zip Code \\
Palo Alto & CA & 94304 \\
\hline Purpose of Disbursement & &
\end{tabular}

Purpose of Disbursement

Advertising Expense

Candidate Name

\begin{tabular}{l|l|l}
\hline Office Sought: & House & Disbursement For: 2012
\end{tabular} X Primary $\square$ General

State:

Senate

District:

Full Name (Last, First, Middle Initial)

\section{B. Ellen Carmichael}

Mailing Address 1007 Oak Hills Parkway

\begin{tabular}{lcc}
\hline City & State & Zip Code \\
Baton Rouge & LA & $70810-4705$
\end{tabular}

Purpose of Disbursement

Staff Salary

Candidate Name

Office Sought:

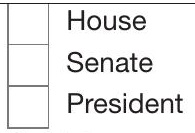

State:

District:

LA

Full Name (Last, First, Middle Initial)

\section{c. Stacy DeJarnette}

\begin{tabular}{|c|c|c|c|c|c|}
\hline \multicolumn{6}{|c|}{ Mailing Address 207 Robin Street } \\
\hline \multicolumn{2}{|l|}{ City } & State & \multicolumn{3}{|l|}{ Zip Code } \\
\hline \multicolumn{2}{|l|}{ White Hall } & AR & \multicolumn{3}{|c|}{$71602-5418$} \\
\hline \multicolumn{5}{|c|}{$\begin{array}{l}\text { Purpose of Disbursement } \\
\text { Staff Salary }\end{array}$} & \\
\hline \multicolumn{5}{|c|}{ Candidate Name } & $\begin{array}{l}\text { Category/ } \\
\text { Type }\end{array}$ \\
\hline \multirow[t]{3}{*}{ Office Sought: } & House & \multicolumn{4}{|c|}{ Disbursement For: 2012} \\
\hline & Senate & \multirow{3}{*}{\multicolumn{2}{|c|}{$\begin{array}{l}\text { Primary } \\
\text { Other (specify) }\end{array}$}} & \multirow{2}{*}{\multicolumn{2}{|c|}{ General }} \\
\hline & President & & & & \\
\hline State: & District: & & & & \\
\hline
\end{tabular}

Subtotal Of Receipts This Page (optional).

Date of Disbursement

\begin{tabular}{|c|c|c|c|c|}
\hline $08^{M}$ & I & $30^{D}$ & 1 & 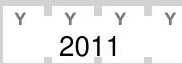 \\
\hline
\end{tabular}

Transaction ID : B3FAEC9939A0C4C02B6F

Amount of Each Disbursement this Period

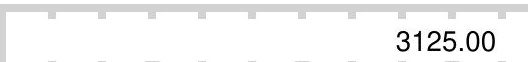

3125.00

Total This Period (last page this line number only)) 


\section{SCHEDULE B-P}

\section{ITEMIZED DISBURSEMENTS}

\section{Use separate schedule(s)}

for each category of the

Detailed Summary Page
FOR LINE NUMBER: (check only one)

\begin{tabular}{|c|c|c|c|}
\hline$\times{ }_{23}$ & 24 & 25 & 26 \\
\hline $27 b$ & $28 a$ & $28 \mathrm{~b}$ & $28 \mathrm{c}$ \\
\hline
\end{tabular}

Any information copied from such Reports and Statements may not be sold or used by any person for the purpose of soliciting contributions or for commercial purposes, other than using the name and address of any political committee to solicit contributions from such committee.

NAME OF COMMITTEE (In Full)

\section{Friends of Herman Cain}

Full Name (Last, First, Middle Initial)

\section{A. Air Tran}

Mailing Address 9955 Air Tran Boulevard

Date of Disbursement

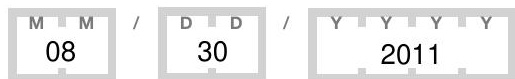

\section{Transaction ID : B73CC68CA56CB407FBBC}

\begin{tabular}{lcc}
\hline City & State & Zip Code \\
Orlando & FL & 32827
\end{tabular}

Purpose of Disbursement

Travel Expense

Candidate Name

Office Sought:

$$
\begin{aligned}
& \text { House } \\
& \text { Senate } \\
& \text { Presiden }
\end{aligned}
$$$$
\text { District: }
$$

FL $\quad 32827$

State: District:

Full Name (Last, First, Middle Initial)

B. Air Tran

Mailing Address 9955 Air Tran Boulevard

\begin{tabular}{lcc}
\hline City & State & Zip Code \\
Orlando & FL & 32827
\end{tabular}

Purpose of Disbursement

Travel Expense

Candidate Name

Office Sought:

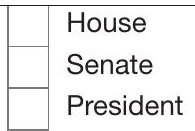

State:

District:

Full Name (Last, First, Middle Initial)

\section{c. UPS}

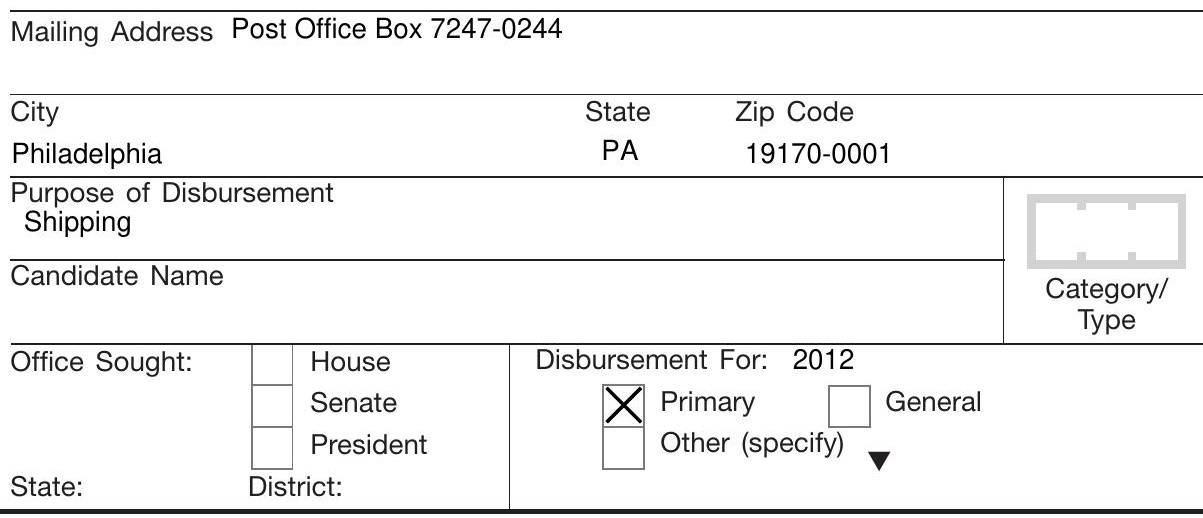

Subtotal Of Receipts This Page (optional).

Date of Disbursement

\begin{tabular}{|c|c|c|c|c|}
\hline $08^{M}$ & 1 & $\begin{array}{ll}\mathrm{D} \\
& \\
& \end{array}$ & I & $\begin{array}{cccc}Y & Y & Y & Y \\
& 2011 & \end{array}$ \\
\hline
\end{tabular}

Transaction ID : BC91F7A9EF7F2455C816

Amount of Each Disbursement this Period

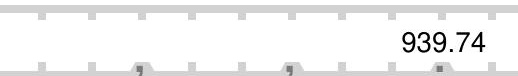

939.74

Total This Period (last page this line number only))

1638.54
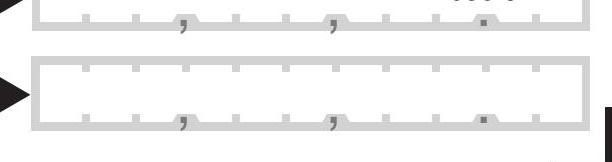


\section{SCHEDULE B-P}

\section{ITEMIZED DISBURSEMENTS}

\section{Use separate schedule(s)}

for each category of the

Detailed Summary Page
FOR LINE NUMBER: (check only one)

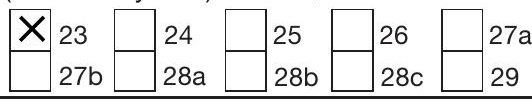

Any information copied from such Reports and Statements may not be sold or used by any person for the purpose of soliciting contributions or for commercial purposes, other than using the name and address of any political committee to solicit contributions from such committee.

NAME OF COMMITTEE (In Full)

\section{Friends of Herman Cain}

Full Name (Last, First, Middle Initial)

A. Hotels.com

Mailing Address 10440 North Central Expressway

Suite 400

Date of Disbursement

\begin{tabular}{lccc}
\multicolumn{3}{c}{ Suite 400} & \\
\hline City & State & Zip Code \\
Dallas & TX & 75231 \\
\hline
\end{tabular}

Purpose of Disbursement

Travel Expense

Candidate Name

\begin{tabular}{|c|c|c|c|}
\hline $08^{M}$ & 1 & 31 & 1 \\
\hline
\end{tabular}

Transaction ID : BD39D66733EFC4D8A933

Office Sought:

House

President

State:

District:

Full Name (Last, First, Middle Initial)

B. Facebook, Inc.

Mailing Address 1601 S. California Ave.

\begin{tabular}{lcc}
\hline City & State & Zip Code \\
Palo Alto & CA & 94304
\end{tabular}

Purpose of Disbursement

Advertising Expense

Candidate Name

Disbursement For: 2012
X Primary
Other (specify)

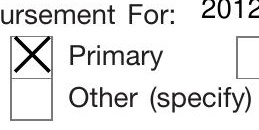

Amount of Each Disbursement this Period

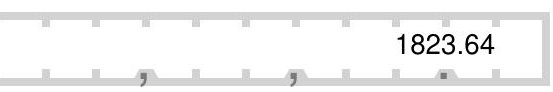

Type

1823.64

Date of Disbursement

\begin{tabular}{|c|c|c|c|c|}
\hline $08^{M}$ & & ${ }^{\mathrm{D}}{ }^{\mathrm{D}}$ & & $\begin{array}{lll}Y & Y & Y \\
2011 & Y\end{array}$ \\
\hline
\end{tabular}

Office Sought:

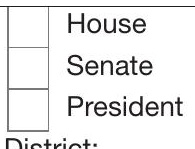

Disbursement For: 2012

Xrimary $\square$ General

State:

District:

Full Name (Last, First, Middle Initial)

c. J Ryan Hudson

Mailing Address 418 Landing Pointe

Date of Disbursement

\begin{tabular}{lcc} 
& & \\
City & State & Zip Code \\
Stockbridge & GA & 30281 \\
\hline
\end{tabular}

Purpose of Disbursement

Mileage/Transportation/Airfare/Lodging

Candidate Name

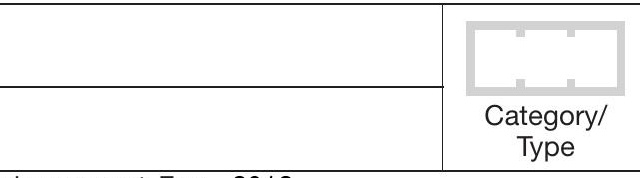

\begin{tabular}{|c|c|c|c|}
\hline \multirow[t]{3}{*}{ Office Sought: } & House & \multicolumn{2}{|l|}{ Disbursement For: 2012} \\
\hline & Senate & Х Primary & General \\
\hline & President & Other (specify) & \\
\hline
\end{tabular}

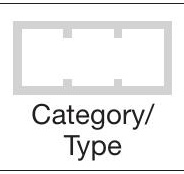

Transaction ID : BAC347B02A1DB428B976

Amount of Each Disbursement this Period

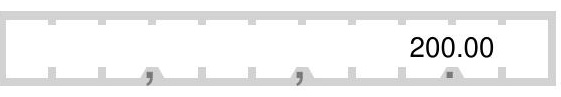

Subtotal Of Receipts This Page (optional).

Total This Period (last page this line number only))

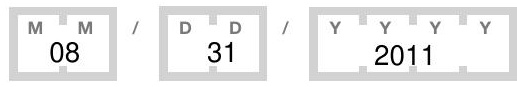

Transaction ID : B492BC15BE8B94A098B2

Amount of Each Disbursement this Period

3289.48 


\section{SCHEDULE B-P}

\section{ITEMIZED DISBURSEMENTS}

\section{Use separate schedule(s) \\ for each category of the}

Detailed Summary Page
FOR LINE NUMBER: (check only one)

\begin{tabular}{|c|c|c|c|}
\hline$\times{ }_{23}$ & 24 & 25 & 26 \\
\hline $27 b$ & $28 a$ & $28 \mathrm{~b}$ & $28 \mathrm{c}$ \\
\hline
\end{tabular}

Any information copied from such Reports and Statements may not be sold or used by any person for the purpose of soliciting contributions or for commercial purposes, other than using the name and address of any political committee to solicit contributions from such committee.

NAME OF COMMITTEE (In Full)

\section{Friends of Herman Cain}

Full Name (Last, First, Middle Initial)

A. Greg West

Mailing Address 3905 Stratmore Drive

Date of Disbursement

\begin{tabular}{lcc}
\hline City & State & Zip Code \\
Montgomery & AL & $36116-4615$ \\
\hline
\end{tabular}

Purpose of Disbursement

Pilot Services

Candidate Name

Office Sought: $\quad$ House

Senate

President

State:

District:

Full Name (Last, First, Middle Initial)

B. Kyle Maichle

Mailing Address 617 N 23rd Street Apt 305

\begin{tabular}{lcc}
\hline City & State & Zip Code \\
Milwaukee & WI & 53233-1976
\end{tabular}

Purpose of Disbursement

Research

Candidate Name

Office Sought:

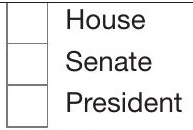

Disbursement For: 2012

Xrimary $\square$ General

State:

District:

Disbursement For: 2012

X Primary $\square$ General

Full Name (Last, First, Middle Initial)

\section{c. Derrick Barker}

\begin{tabular}{|c|c|c|c|c|c|}
\hline \multicolumn{6}{|c|}{ Mailing Address 705 Birchberry } \\
\hline \multicolumn{2}{|l|}{ City } & State & \multicolumn{3}{|l|}{ Zip Code } \\
\hline \multicolumn{2}{|l|}{ Atlanta } & GA & \multicolumn{3}{|c|}{$30331-8486$} \\
\hline \multicolumn{5}{|c|}{$\begin{array}{l}\text { Purpose of Disbursement } \\
\text { Pilot Services }\end{array}$} & \\
\hline \multicolumn{5}{|c|}{ Candidate Name } & $\begin{array}{l}\text { Category/ } \\
\text { Type }\end{array}$ \\
\hline \multirow[t]{3}{*}{ Office Sought: } & House & \multicolumn{4}{|c|}{ Disbursement For: 2012} \\
\hline & Senate & \multirow{3}{*}{\multicolumn{2}{|c|}{$\begin{array}{l}\text { Primary } \\
\text { Other (specify) }\end{array}$}} & \multirow{2}{*}{\multicolumn{2}{|c|}{ General }} \\
\hline & President & & & & \\
\hline State: & District: & & & \multicolumn{2}{|c|}{$\boldsymbol{\nabla}$} \\
\hline
\end{tabular}

Subtotal Of Receipts This Page (optional)...

Date of Disbursement

\begin{tabular}{|c|c|c|c|c|}
\hline $08^{M}$ & 1 & $31^{\mathrm{D}}$ & I & 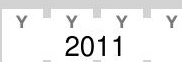 \\
\hline
\end{tabular}

Transaction ID : BE4C42BF92F854902BD7

Amount of Each Disbursement this Period

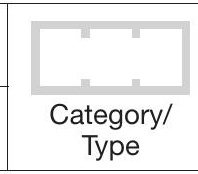

Amount of Each Disbursement this Period
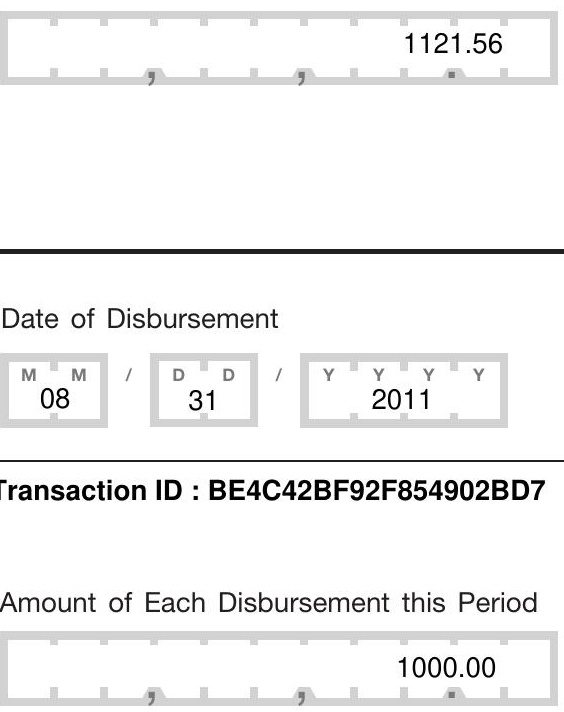

Date of Disbursement

\begin{tabular}{|c|c|c|c|c|}
\hline $08^{\mathrm{M}}$ & 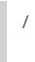 & D 31 & & 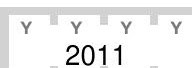 \\
\hline
\end{tabular}

Transaction ID : BD2D9F1A515E84F66BE2

Amount of Each Disbursement this Period

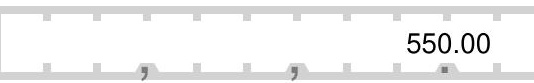

Total This Period (last page this line number only)) 


\section{SCHEDULE B-P}

\section{ITEMIZED DISBURSEMENTS}

\section{Use separate schedule(s) \\ for each category of the}

Detailed Summary Page
FOR LINE NUMBER: (check only one)

\begin{tabular}{|c|c|c|c|}
\hline$\times{ }_{23}$ & 24 & 25 & 26 \\
\hline $27 b$ & $28 a$ & $28 \mathrm{~b}$ & $28 \mathrm{c}$ \\
\hline
\end{tabular}

Any information copied from such Reports and Statements may not be sold or used by any person for the purpose of soliciting contributions or for commercial purposes, other than using the name and address of any political committee to solicit contributions from such committee.

NAME OF COMMITTEE (In Full)

\section{Friends of Herman Cain}

Full Name (Last, First, Middle Initial)

A. Premiere Transportation

Mailing Address 109 International Dr. Ste. 300

\begin{tabular}{lcc}
\hline City & State & Zip Code \\
Franklin & TN & 37067 \\
\hline Purpose of Disbursement &
\end{tabular}

Purpose of Disbursement

Event Tranportation Rental

Candidate Name

B. Petty Cash

Mailing Address PO Box 2158

\begin{tabular}{lcc}
\hline City & State & Zip Code \\
Stockbridge & GA & 30281
\end{tabular}

Purpose of Disbursement

Office Furniture

Candidate Name

Office Sought:

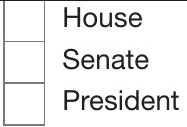

State:

District:

Full Name (Last, First, Middle Initial)

\section{c. SunTrust Bank}

Mailing Address 980 Eagles Landing Parkway

\begin{tabular}{lcc}
\hline City & State & Zip Code \\
Stockbridge & GA & 30281
\end{tabular}

Purpose of Disbursement

Bank Fees

Candidate Name

Office Sought:

\begin{tabular}{|l|l|l} 
& House \\
Senate \\
President \\
District:
\end{tabular}

State:

District:

Subtotal Of Receipts This Page (optional) Disbursement For: 2012 X $\begin{aligned} & \text { Primary } \\ & \text { Other (specify) }\end{aligned}$
Date of Disbursement

\begin{tabular}{|c|c|c|c|c|c|}
\hline M M & D \\
08 & 31 & 2011 \\
\hline
\end{tabular}

Transaction ID : BF08FAD2B19544B21B92

Amount of Each Disbursement this Period 10769.07

Date of Disbursement

\begin{tabular}{|c|c|c|c|c|}
\hline $08^{M}$ & 1 & $31^{\mathrm{D}}$ & I & $\begin{array}{llll} & Y & Y & Y \\
& 2011 & Y\end{array}$ \\
\hline
\end{tabular}

Transaction ID : B31B8452ACA004765977

Amount of Each Disbursement this Period
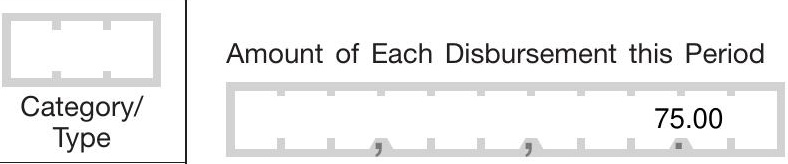

Date of Disbursement

\begin{tabular}{|c|c|c|c|c|c|}
\hline M M / & D & D & Y & Y & Y \\
\hline & & 31 & & 2011 & \\
\hline
\end{tabular}

Transaction ID : BF287E88D6D6042D1803

Amount of Each Disbursement this Period

106.40 Type

Total This Period (last page this line number only)) 


\section{SCHEDULE B-P}

\section{ITEMIZED DISBURSEMENTS}

\section{Use separate schedule(s) \\ for each category of the}

Detailed Summary Page
FOR LINE NUMBER: (check only one)

\begin{tabular}{|c|c|c|c|}
\hline$\times{ }_{23}$ & 24 & 25 & 26 \\
\hline $27 b$ & $28 a$ & $28 \mathrm{~b}$ & $28 \mathrm{c}$ \\
\hline
\end{tabular}

Any information copied from such Reports and Statements may not be sold or used by any person for the purpose of soliciting contributions or for commercial purposes, other than using the name and address of any political committee to solicit contributions from such committee.

NAME OF COMMITTEE (In Full)

\section{Friends of Herman Cain}

Full Name (Last, First, Middle Initial)

A. SunTrust Bank

Mailing Address 980 Eagles Landing Parkway

Date of Disbursement

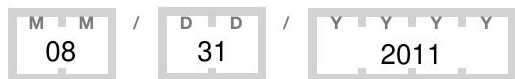

Transaction ID : BF2F12872FA884EB68DA

\begin{tabular}{lcc}
\hline City & State & Zip Code \\
Stockbridge & GA & 30281
\end{tabular}

Purpose of Disbursement

Bank Fees

Candidate Name

Office Sought:

\begin{tabular}{|l|l} 
House \\
Senate \\
President
\end{tabular}

District:

State:

(n)

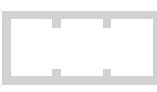

Category/ Type
Amount of Each Disbursement this Period

74.90

$$
\begin{aligned}
& \text { Disbursement For: } 2012 \\
& \qquad \begin{array}{l}
\text { Primary } \\
\text { Other (specify) }
\end{array}
\end{aligned}
$$

Full Name (Last, First, Middle Initial)

B. Microtel Inn and Suites

Mailing Address 22 Sylvan Way

\begin{tabular}{lcc}
\hline City & State & Zip Code \\
Parsippany & NJ & 07054
\end{tabular}

Purpose of Disbursement

Travel Expense

Candidate Name

Office Sought:

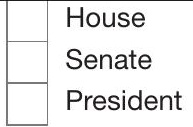

Disbursement For: 2012

Xrimary $\square$ General

State:

District:

Full Name (Last, First, Middle Initial)

\section{c. Delta Airlines}

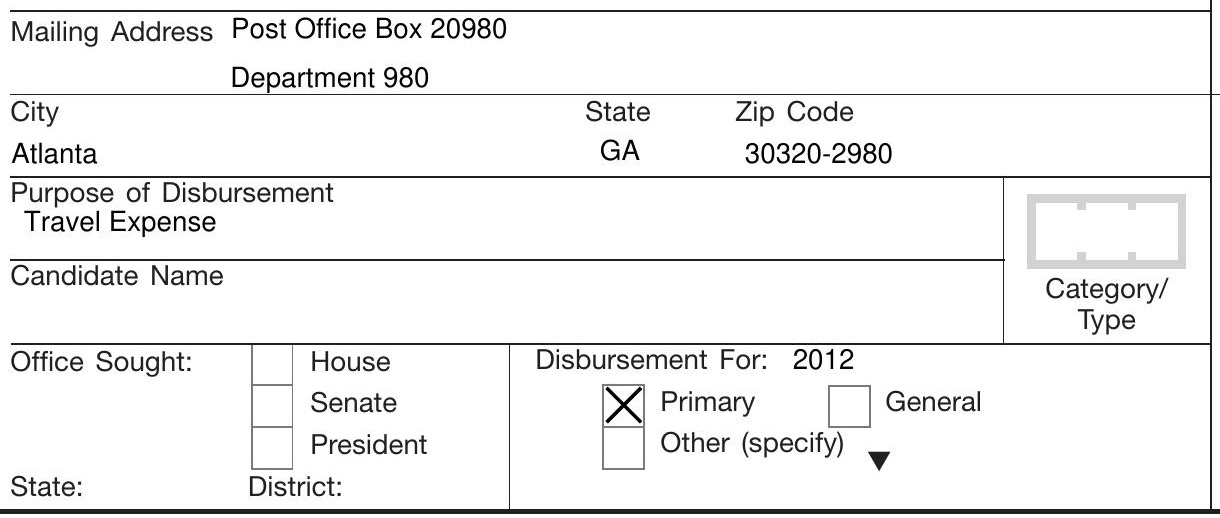

Subtotal Of Receipts This Page (optional).

Date of Disbursement

\begin{tabular}{|c|c|c|c|c|c|}
\hline M M & I & D & Y & $Y$ & $Y$ \\
08 & & 31 & & 2011 & \\
\hline
\end{tabular}

Transaction ID : BF078811C3B4D41BCBDC

Amount of Each Disbursement this Period

\begin{tabular}{|c|c|c|c|c|}
\hline $08^{M}$ & 1 & $31^{\mathrm{D}}$ & 1 & $\begin{array}{llll}Y & Y & Y & Y \\
& 2011 & \end{array}$ \\
\hline
\end{tabular}

Date of Disbursement

Transaction ID : B8F738CA75B4E403D93E

Amount of Each Disbursement this Period
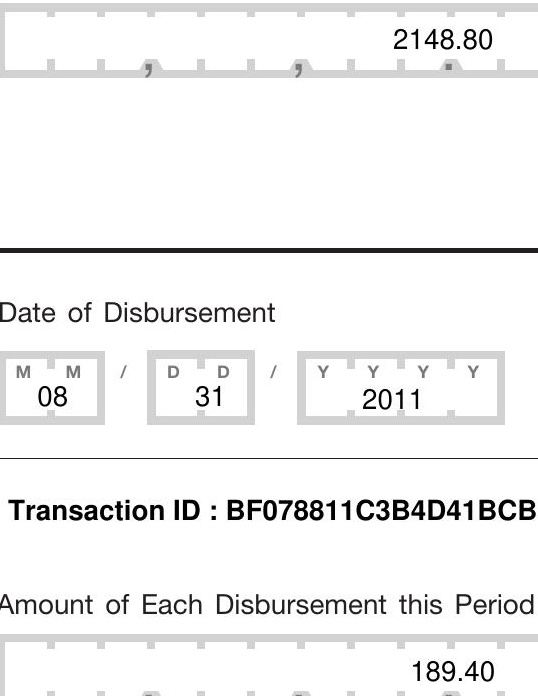

189.40

Total This Period (last page this line number only)) 


\section{SCHEDULE B-P}

\section{ITEMIZED DISBURSEMENTS}

Use separate schedule(s)

for each category of the

Detailed Summary Page
FOR LINE NUMBER: (check only one)

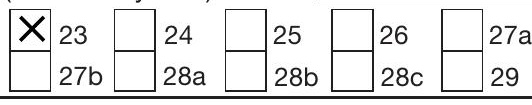

Any information copied from such Reports and Statements may not be sold or used by any person for the purpose of soliciting contributions or for commercial purposes, other than using the name and address of any political committee to solicit contributions from such committee.

NAME OF COMMITTEE (In Full)

\section{Friends of Herman Cain}

Full Name (Last, First, Middle Initial)

A. SunTrust Bank

Mailing Address 980 Eagles Landing Parkway

Date of Disbursement

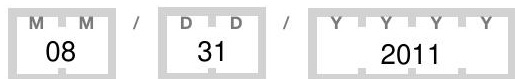

Transaction ID : B99C4C523A1EF4738983

\begin{tabular}{lcc}
\hline City & State & Zip Code \\
Stockbridge & GA & 30281
\end{tabular}

Purpose of Disbursement

Bank Fees

Candidate Name

\begin{tabular}{l|l|l}
\hline Office Sought: & House & Disbursement For: 2012
\end{tabular} Xrimary $\square$ General

State:

\section{Senate}

President

District:

Full Name (Last, First, Middle Initial)

\section{B. FedEx Kinkos}

Mailing Address 942 S. Shady Grove Road

\begin{tabular}{lcc}
\hline City & State & Zip Code \\
Memphis & TN & 38120
\end{tabular}

Purpose of Disbursement

Shipping

Candidate Name

Office Sought:

House
Senate
President

State:

District:

Full Name (Last, First, Middle Initial)

\section{c. Office Depot Corporate}

Mailing Address 2500 Mill Center Parkway

\begin{tabular}{lcc}
\hline City & State & Zip Code \\
Buford & GA & 30518
\end{tabular}

Purpose of Disbursement

Office Supplies

Candidate Name

Disbursement For: 2012

Primary $\square$ General
Other (specify)

Office Sought:

\begin{tabular}{|l|l|} 
& House \\
& Senate \\
& President \\
& District:
\end{tabular}

Disbursement For: 2012

Х $\begin{aligned} & \text { Primary } \\ & \text { Other (specify) }\end{aligned}$

State:

District:

Subtotal Of Receipts This Page (optional).

Date of Disbursement

\begin{tabular}{|c|c|c|c|c|}
\hline $08^{M}$ & 1 & D 31 & 1 & 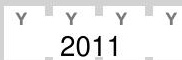 \\
\hline
\end{tabular}

Transaction ID : B98B27FF1A1B74EEA91E

Amount of Each Disbursement this Period

79.45
Amount of Each Disbursement this Period

133.00
Date of Disbursement

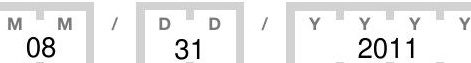

Transaction ID : BE0E53FD8EC7B46718A9

Amount of Each Disbursement this Period

715.82
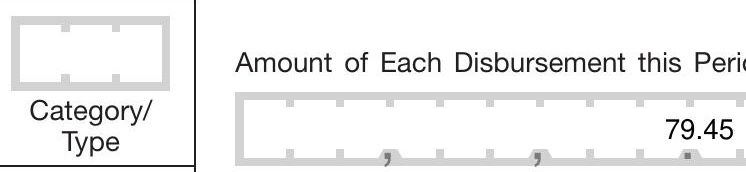

Total This Period (last page this line number only)) 


\section{SCHEDULE B-P}

\section{ITEMIZED DISBURSEMENTS}

\section{Use separate schedule(s) \\ for each category of the}

Detailed Summary Page
FOR LINE NUMBER: (check only one)

\begin{tabular}{|c|c|c|c|}
\hline$X_{23}$ & 24 & 25 & 26 \\
\hline $27 \mathrm{~b}$ & $28 a$ & $28 b$ & $28 \mathrm{c}$ \\
\hline
\end{tabular}

Any information copied from such Reports and Statements may not be sold or used by any person for the purpose of soliciting contributions or for commercial purposes, other than using the name and address of any political committee to solicit contributions from such committee.

NAME OF COMMITTEE (In Full)

\section{Friends of Herman Cain}

Full Name (Last, First, Middle Initial)

A. Strawn \& Co. Insurance

Mailing Address 16 Hampton Street

Date of Disbursement

\begin{tabular}{lcc}
\hline City & State & Zip Code \\
McDonough & GA & 30253 \\
\hline
\end{tabular}

Purpose of Disbursement

Insurance

Candidate Name

\begin{tabular}{l|l|l}
\hline Office Sought: & House & Disbursement For: 2012
\end{tabular} X Primary $\square$ General

State:

$$
\begin{aligned}
& \text { Senate } \\
& \text { President }
\end{aligned}
$$

Full Name (Last, First, Middle Initial)

\section{B. Tri-Net Payroll Services}

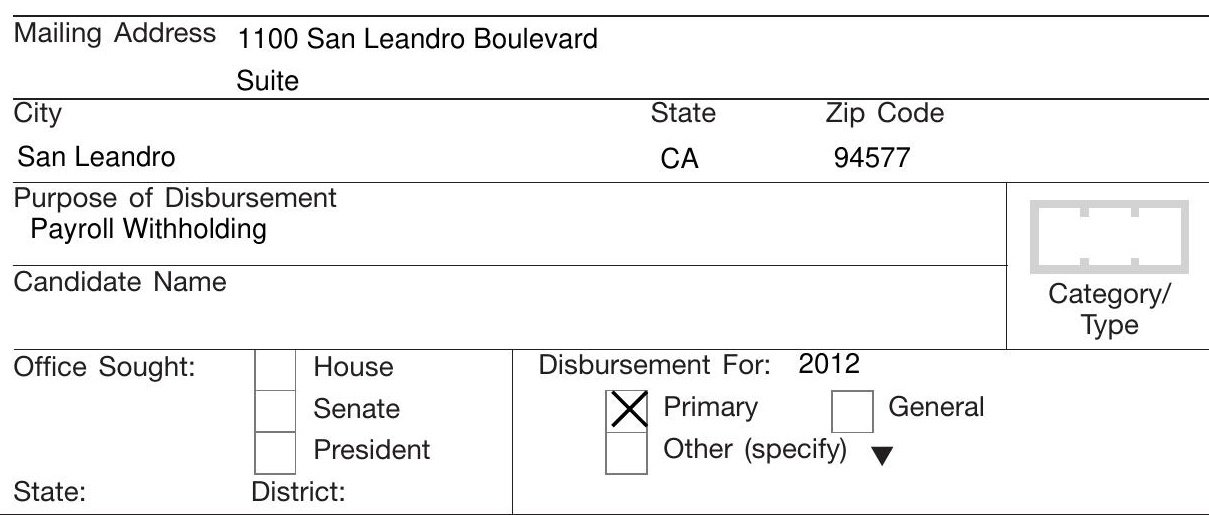

\begin{tabular}{|c|c|c|c|c|}
\hline $09^{\mathrm{M}}$ & 1 & $01^{\mathrm{D}}$ & I & $\begin{array}{lll}Y & Y & Y \\
& & Y \\
& & Y\end{array}$ \\
\hline
\end{tabular}

Date of Disbursement

Full Name (Last, First, Middle Initial)

\section{c. Tri-Net Payroll Services}

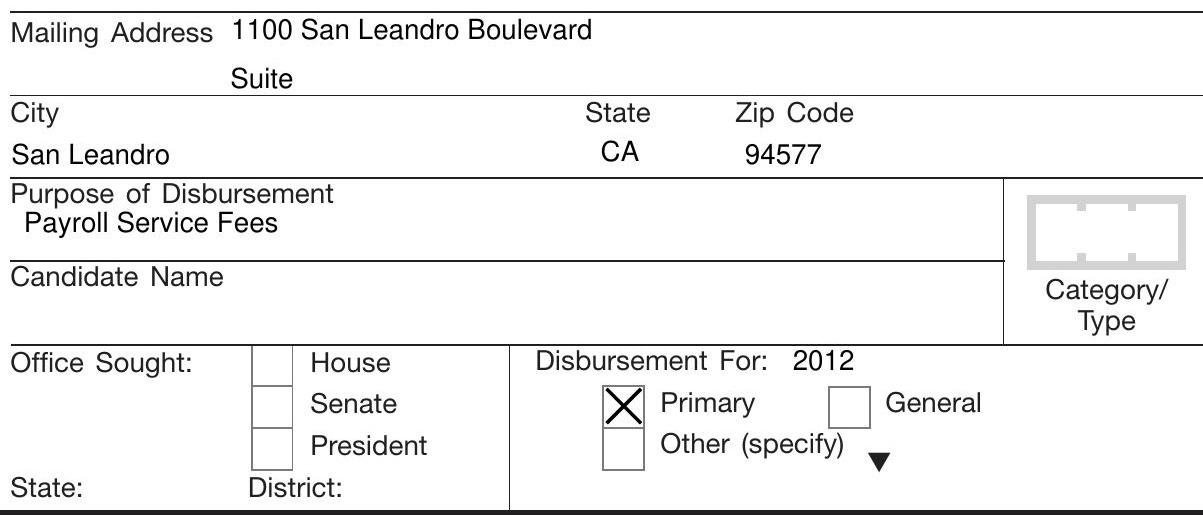

Subtotal Of Receipts This Page (optional).

Date of Disbursement

\begin{tabular}{|c|c|c|c|c|c|c|}
\hline M M / & D & Y & Y & Y & Y \\
09 & & 01 & 2011 & \\
\hline
\end{tabular}

\section{Transaction ID : B68903221D53A485E912}

Amount of Each Disbursement this Period

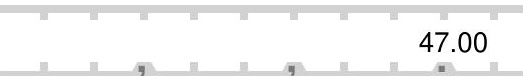

47.00

Total This Period (last page this line number only)) 


\section{SCHEDULE B-P}

\section{ITEMIZED DISBURSEMENTS}

\section{Use separate schedule(s)}

for each category of the

Detailed Summary Page
FOR LINE NUMBER: (check only one)

\begin{tabular}{|c|c|c|c|}
\hline$\times{ }_{23}$ & 24 & 25 & 26 \\
\hline $27 b$ & $28 a$ & $28 \mathrm{~b}$ & $28 \mathrm{c}$ \\
\hline
\end{tabular}

Any information copied from such Reports and Statements may not be sold or used by any person for the purpose of soliciting contributions or for commercial purposes, other than using the name and address of any political committee to solicit contributions from such committee.

NAME OF COMMITTEE (In Full)

\section{Friends of Herman Cain}

Full Name (Last, First, Middle Initial)

\section{A. J Ryan Hudson}

Mailing Address 418 Landing Pointe

Date of Disbursement

\begin{tabular}{lcc}
\hline City & State & Zip Code \\
Stockbridge & GA & 30281 \\
\hline Purpose of
\end{tabular}

Purpose of Disbursement

Staff Salary

Candidate Name

09

01

2011

Transaction ID : BD94E4D54126A4275A0E

Office Sought:

\section{House} House
Senate
President District:

State:

Full Name (Last, First, Middle Initial)

B. Facebook, Inc.

Mailing Address 1601 S. California Ave.

\begin{tabular}{lcc}
\hline City & State & Zip Code \\
Palo Alto & CA & 94304
\end{tabular}

Purpose of Disbursement

Advertising Expense

Candidate Name

Office Sought:

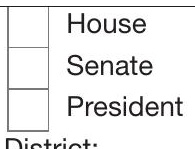

Disbursement For: 2012

Xrimary $\square$ General

State:

District:

Disbursement For: 2012

X Primary $\square$ General

Full Name (Last, First, Middle Initial)

C. Air Tran

Mailing Address 9955 Air Tran Boulevard

Date of Disbursement

\begin{tabular}{lcc|} 
& & \\
\hline City & State & Zip Code \\
Orlando & FL & 32827
\end{tabular}

\begin{tabular}{|c|c|c|c|c|}
\hline${ }^{\mathrm{M}} 09^{\mathrm{M}}$ & I & $\begin{array}{ll}\mathrm{D} \\
01\end{array}$ & 1 & 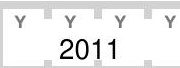 \\
\hline
\end{tabular}

Purpose of Disbursement

Travel Expense

Candidate Name

Transaction ID : B0E14486ADF874B9D9FD

\begin{tabular}{l|l|c|}
\hline Office Sought: & $\begin{array}{l}\text { House } \\
\text { Senate } \\
\text { President } \\
\text { State: }\end{array}$ & $\begin{array}{r}\text { Disbursement For: } 2012 \\
\text { District: }\end{array}$
\end{tabular}

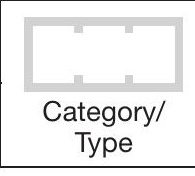
Type
Date of Disbursement

\begin{tabular}{|c|c|c|c|c|}
\hline $09^{M}$ & 1 & 01 & 1 & $\begin{array}{llll}Y & Y & Y & Y \\
& 2011\end{array}$ \\
\hline
\end{tabular}

Transaction ID : B50E85C9DE0F24AA0A0C

Amount of Each Disbursement this Period

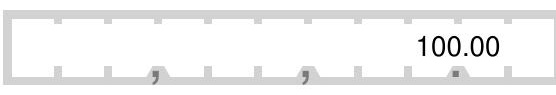

Amount of Each Disbursement this Period

124.20

Subtotal Of Receipts This Page (optional).

Total This Period (last page this line number only))

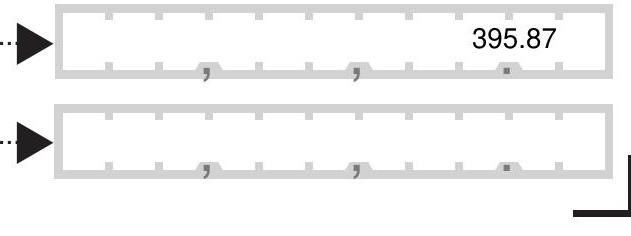

FEC Schedule B-P (Form 3P) (Rev. 03/2011) 


\section{SCHEDULE B-P}

\section{ITEMIZED DISBURSEMENTS}

Use separate schedule(s)

for each category of the

Detailed Summary Page
FOR LINE NUMBER: (check only one)

\begin{tabular}{|c|c|c|c|}
\hline$\times{ }_{23}$ & 24 & 25 & 26 \\
\hline $27 b$ & $28 a$ & $28 \mathrm{~b}$ & $28 \mathrm{c}$ \\
\hline
\end{tabular}

Any information copied from such Reports and Statements may not be sold or used by any person for the purpose of soliciting contributions or for commercial purposes, other than using the name and address of any political committee to solicit contributions from such committee.

NAME OF COMMITTEE (In Full)

\section{Friends of Herman Cain}

Full Name (Last, First, Middle Initial)

A. Facebook, Inc.

Mailing Address 1601 S. California Ave.

Date of Disbursement

\begin{tabular}{lll}
\hline City & State & Zip Code \\
Palo Alto & CA & 94304 \\
\hline
\end{tabular}

Purpose of Disbursement

Advertising Expense

Candidate Name

\begin{tabular}{l|l|l}
\hline Office Sought: & House & Disbursement For: 2012
\end{tabular} X Primary $\square$ General

State:

Senate
President
District:

Full Name (Last, First, Middle Initial)

B. James Brazil

Mailing Address 6 Baldasarri Drive

\begin{tabular}{lcc}
\hline City & State & Zip Code \\
Dunmore & PA & 18505
\end{tabular}

Purpose of Disbursement

Field Consulting

Candidate Name

Office Sought:

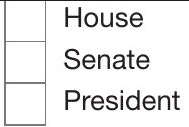

Disbursement For: 2012

Xrimary $\square$ General

State:

District:

Full Name (Last, First, Middle Initial)

c. James Coughlin

Mailing Address 16 South Hills Drive

\begin{tabular}{lcc}
\hline City & State & Zip Code \\
Bedford & $\mathrm{NH}$ & $03110-4920$
\end{tabular}

Purpose of Disbursement

Field Consulting

Candidate Name

\begin{tabular}{l|l}
\hline Office Sought: & House \\
& $\begin{array}{l}\text { Senate } \\
\text { Senatent } \\
\text { President }\end{array}$ \\
State: & District:
\end{tabular}

Disbursement For: 2012
$\searrow \begin{aligned} & \text { Primary } \\ & \text { Other (specify) }\end{aligned}$

Date of Disbursement

\begin{tabular}{|c|c|c|c|c|}
\hline $09^{M}$ & & ${ }^{\mathrm{D}} 02^{\mathrm{D}}$ & 1 & $\begin{array}{llll}Y & Y & Y & Y \\
& 2011\end{array}$ \\
\hline
\end{tabular}

Transaction ID : BDE094414C4EE439194D

Amount of Each Disbursement this Period

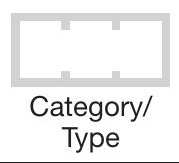

Amount of Each Disbursement this Period
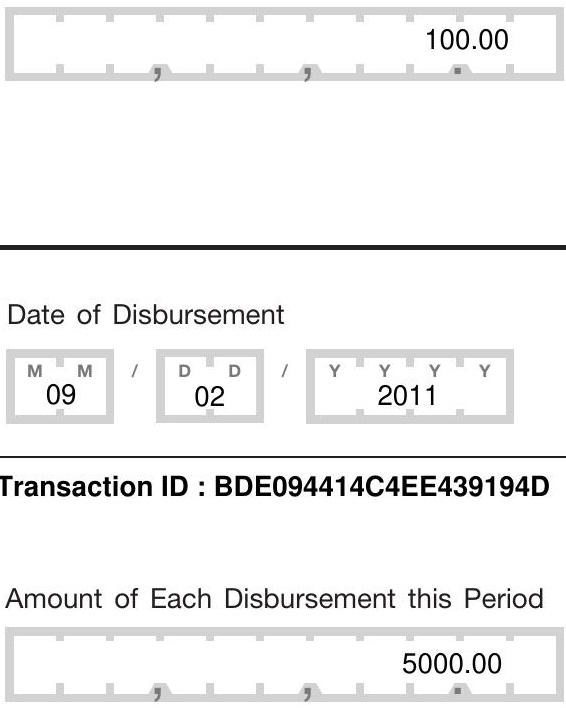

Date of Disbursement

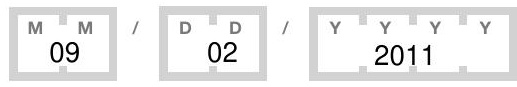

\section{Transaction ID : B9088B4C7E31C4BFAB17}

Amount of Each Disbursement this Period

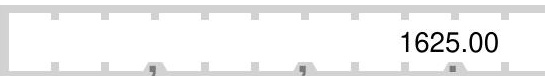

1625.00

Subtotal Of Receipts This Page (optional).

Total This Period (last page this line number only))

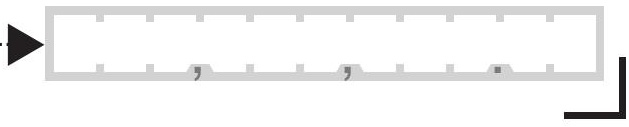


Image\# 12951402701

\section{SCHEDULE B-P}

\section{ITEMIZED DISBURSEMENTS}

\section{Use separate schedule(s)}

for each category of the

Detailed Summary Page
FOR LINE NUMBER: (check only one)

\begin{tabular}{|c|c|c|c|}
\hline$\times{ }_{23}$ & 24 & 25 & 26 \\
\hline $27 b$ & $28 a$ & $28 \mathrm{~b}$ & $28 \mathrm{c}$ \\
\hline
\end{tabular}

Any information copied from such Reports and Statements may not be sold or used by any person for the purpose of soliciting contributions or for commercial purposes, other than using the name and address of any political committee to solicit contributions from such committee.

NAME OF COMMITTEE (In Full)

\section{Friends of Herman Cain}

Full Name (Last, First, Middle Initial)

A. SunTrust Bank

Mailing Address 980 Eagles Landing Parkway

Date of Disbursement

\begin{tabular}{lcc}
\hline City & State & Zip Code \\
Stockbridge & GA & 30281 \\
\hline Purpose of Disbursement & &
\end{tabular}

Purpose of Disbursement

CC Transaction Fees

Candidate Name

Office Sought: $\quad$ House

House

President

State:

District:

Full Name (Last, First, Middle Initial)

B. Delta Airlines

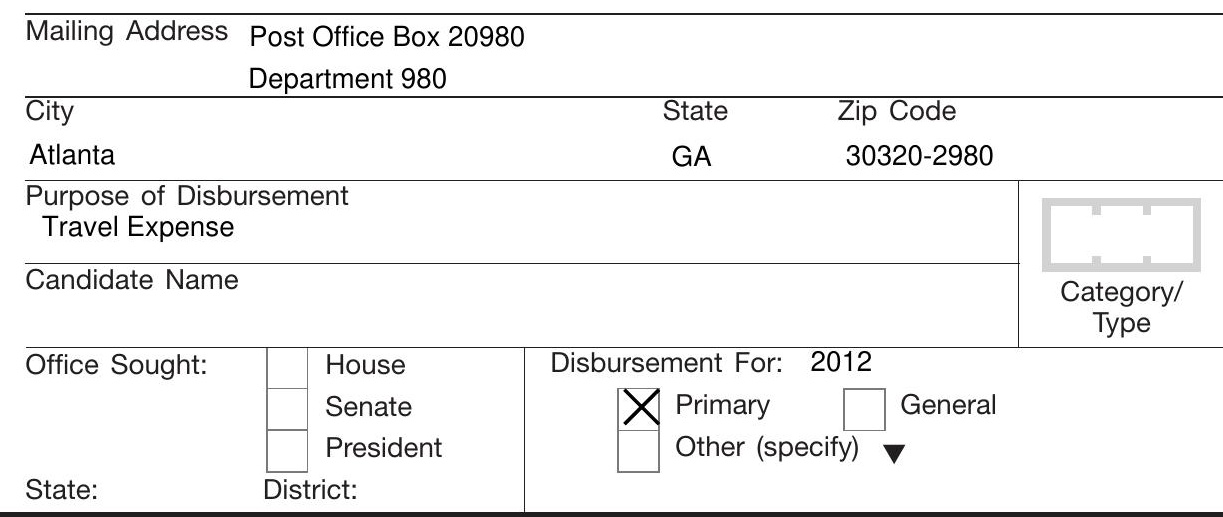

Date of Disbursement

\begin{tabular}{|c|c|c|c|c|}
\hline $09^{M}$ & 1 & $02^{\mathrm{D}}$ & 1 & $\begin{array}{llll} & Y & Y & Y \\
& 2011 & \end{array}$ \\
\hline
\end{tabular}

Transaction ID : B3E947EBF9010440AA20

Full Name (Last, First, Middle Initial)

c. Gateway Billing

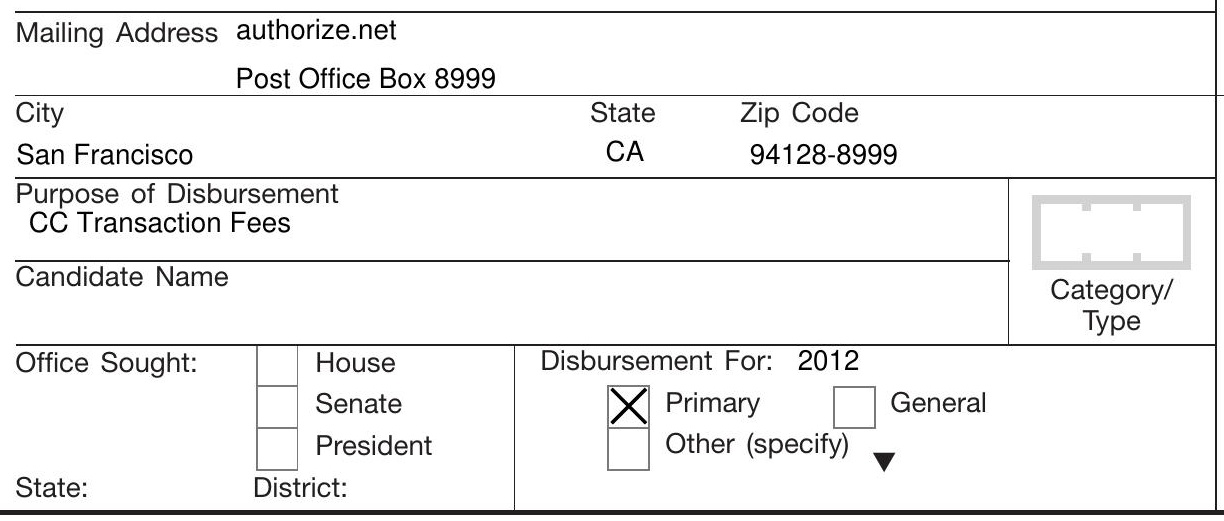

Subtotal Of Receipts This Page (optional).

Date of Disbursement

\begin{tabular}{|c|c|c|c|c|}
\hline $09^{M}$ & I & D 02 & I & 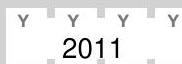 \\
\hline
\end{tabular}

\section{Transaction ID : B4844B102754F4A9692A}

Amount of Each Disbursement this Period

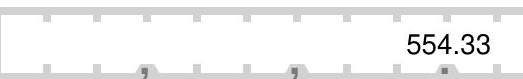

554.33

Total This Period (last page this line number only)) 


\section{SCHEDULE B-P}

\section{ITEMIZED DISBURSEMENTS}

Use separate schedule(s)

for each category of the

Detailed Summary Page
FOR LINE NUMBER: (check only one)

\begin{tabular}{|c|c|c|c|}
\hline$\times{ }_{23}$ & 24 & 25 & 26 \\
\hline $27 b$ & $28 a$ & $28 \mathrm{~b}$ & $28 \mathrm{c}$ \\
\hline
\end{tabular}

Any information copied from such Reports and Statements may not be sold or used by any person for the purpose of soliciting contributions or for commercial purposes, other than using the name and address of any political committee to solicit contributions from such committee.

NAME OF COMMITTEE (In Full)

\section{Friends of Herman Cain}

Full Name (Last, First, Middle Initial)

A. Campaigner

Mailing Address 2379 Holly Lane

Suite 210

Date of Disbursement

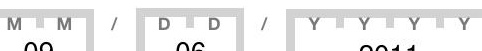

09

2011

\begin{tabular}{lll}
\hline City & State & $\begin{array}{l}\text { Zip Code } \\
\text { K1V7P }\end{array}$ \\
Ottawa & & Kurpose
\end{tabular}

Purpose of Disbursement

E-Marketing

Candidate Name

\begin{tabular}{l|l|l}
\hline Office Sought: & House & Disbursement For: 2012
\end{tabular} Xrimary $\square$ General

State:

\section{Senate}

President

District:

Full Name (Last, First, Middle Initial)

\section{B. Delta Airlines}

\section{Mailing Address Post Office Box 20980 \\ Department 980}

\begin{tabular}{lcc}
\hline City & State & Zip Code \\
Atlanta & GA & $30320-2980$
\end{tabular}

Purpose of Disbursement

Travel Expense

Candidate Name

Office Sought:

State:

Full Name (Last, First, Middle Initial)

\section{c. US Airways}

Mailing Address 4000 E Sky Harbor Boulevard

\begin{tabular}{lcc}
\hline City & State & Zip Code \\
Phoenix & AZ & 85034
\end{tabular}

Purpose of Disbursement

Travel Expense

Candidate Name

Office Sought:

State:

Subtotal Of Receipts This Page (optional).

Total This Period (last page this line number only))
Date of Disbursement

\begin{tabular}{|c|c|c|c|c|}
\hline $09^{M}$ & 1 & $06^{\mathrm{D}}$ & 1 & 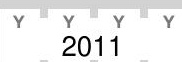 \\
\hline
\end{tabular}

\section{Transaction ID : BFC9F56A2FC1F466FBC7}

Amount of Each Disbursement this Period

5057.90

Date of Disbursement

\begin{tabular}{|c|c|c|c|c|c|c|}
\hline M M & I & D & Y & Y & Y & Y \\
09 & & 06 & & 2011 & \\
\hline
\end{tabular}

Transaction ID : B14CBE84803BF479ABA6

Amount of Each Disbursement this Period

317.70 


\section{SCHEDULE B-P}

\section{ITEMIZED DISBURSEMENTS}

\section{Use separate schedule(s)}

for each category of the

Detailed Summary Page
FOR LINE NUMBER: (check only one)

\begin{tabular}{|c|c|c|c|}
\hline$\times{ }_{23}$ & 24 & 25 & 26 \\
\hline $27 b$ & $28 a$ & $28 \mathrm{~b}$ & $28 \mathrm{c}$ \\
\hline
\end{tabular}

Any information copied from such Reports and Statements may not be sold or used by any person for the purpose of soliciting contributions or for commercial purposes, other than using the name and address of any political committee to solicit contributions from such committee.

NAME OF COMMITTEE (In Full)

\section{Friends of Herman Cain}

Full Name (Last, First, Middle Initial)

\section{A. Avis Rent A Car}

Mailing Address 900 Old Country Garden Road

Date of Disbursement

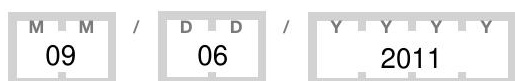

Transaction ID : BC5BA4024C635439BB01

\begin{tabular}{lll}
\hline City & State & Zip Code \\
Garden City & NY & 11530 \\
\hline Purpose of Disbursement
\end{tabular}

Purpose of Disbursement

Travel Expense

Candidate Name

Office Sought:

$$
\begin{array}{|l|l}
\text { House } \\
\text { Senate } \\
\text { President }
\end{array}
$$

State: District:

Full Name (Last, First, Middle Initial)

\section{B. Ellen Carmichael}

Mailing Address 1007 Oak Hills Parkway

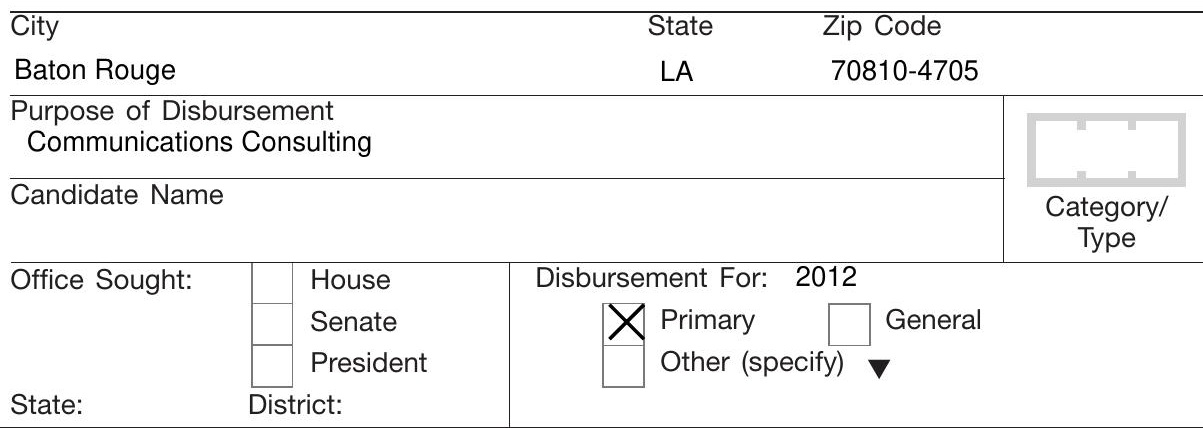

Full Name (Last, First, Middle Initial)

c. Facebook, Inc.

Mailing Address 1601 S. California Ave.

\begin{tabular}{lcc}
\hline City & State & Zip Code \\
Palo Alto & CA & 94304
\end{tabular}

Purpose of Disbursement Advertising Expense

Candidate Name

\begin{tabular}{l|l}
\hline Office Sought: & House \\
& $\begin{array}{l}\text { Senate } \\
\text { Senatent } \\
\text { President }\end{array}$ \\
State: & District:
\end{tabular}
Disbursement For: 2012
$\searrow$ Primary
Other (specify)

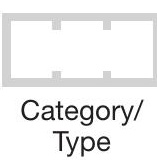

\begin{tabular}{|c|c|c|c|c|}
\hline $09^{M}$ & & ${ }^{\mathrm{D}}{ }^{\mathrm{D}}$ & & 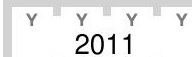 \\
\hline
\end{tabular}

Amount of Each Disbursement this Period

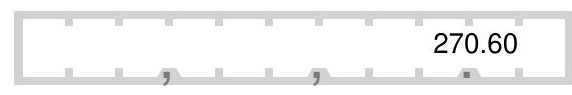

Transaction ID : B13DDDC8E235F4BCD901

Amount of Each Disbursement this Period

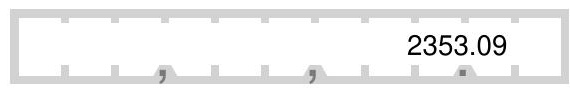

Date of Disbursement

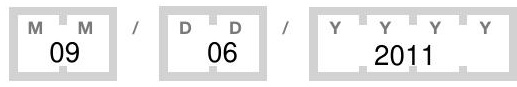

Transaction ID : BB7C5FBC9C59D4335BF6

Amount of Each Disbursement this Period

399.96
Date of Disbursement

Subtotal Of Receipts This Page (optional).

Total This Period (last page this line number only))

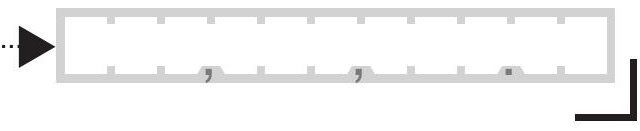




\section{SCHEDULE B-P}

\section{ITEMIZED DISBURSEMENTS}

\section{Use separate schedule(s)}

for each category of the

Detailed Summary Page
FOR LINE NUMBER: (check only one)

\begin{tabular}{|c|c|c|c|}
\hline$\times{ }_{23}$ & 24 & 25 & 26 \\
\hline $27 b$ & $28 a$ & $28 \mathrm{~b}$ & $28 \mathrm{c}$ \\
\hline
\end{tabular}

Any information copied from such Reports and Statements may not be sold or used by any person for the purpose of soliciting contributions or for commercial purposes, other than using the name and address of any political committee to solicit contributions from such committee.

NAME OF COMMITTEE (In Full)

\section{Friends of Herman Cain}

Full Name (Last, First, Middle Initial)

A. Wyndham Worldwide

Mailing Address 22 Sylvan Way

\begin{tabular}{lll}
\hline City & State & Zip Code \\
Parsippany & NJ & 07054 \\
\hline
\end{tabular}

Purpose of Disbursement

Travel Expense

Candidate Name

Office Sought:

Full Name (Last, First, Middle Initial)

B. Air Tran

Mailing Address 9955 Air Tran Boulevard

\begin{tabular}{lcc}
\hline City & State & Zip Code \\
Orlando & FL & 32827
\end{tabular}

Purpose of Disbursement

Travel Expense

Candidate Name

Office Sought:

$$
\begin{array}{ll}
\text { House } \\
\text { Senate } \\
\text { President }
\end{array}
$$

State:

District:

Full Name (Last, First, Middle Initial)

\section{c. Wyndham Worldwide}

Mailing Address 22 Sylvan Way

\begin{tabular}{lcc}
\hline City & State & Zip Code \\
Parsippany & NJ & 07054 \\
\hline
\end{tabular}

Purpose of Disbursement

Travel Expense

Candidate Name

\begin{tabular}{|c|}
\hline House \\
\hline Senate \\
\hline President \\
\hline
\end{tabular}

Office Sought:

State:

Disbursement For: 2012

Х $\begin{aligned} & \text { Primary } \\ & \text { Other (specify) }\end{aligned}$
Date of Disbursement

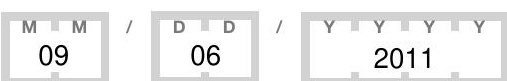

Transaction ID : B26086FDA5D0C47BCA69

Amount of Each Disbursement this Period

\begin{tabular}{|c|c|c|c|c|}
\hline $09^{M}$ & & ${ }^{\mathrm{D}} 6^{\mathrm{D}}$ & 1 & $\begin{array}{llll}Y & Y & Y & Y \\
& 2011\end{array}$ \\
\hline
\end{tabular}
399.84

Date of Disbursement

Transaction ID : BAC917346D4B34F9691F

Amount of Each Disbursement this Period

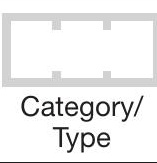
Disbursement For: 2012
\[ \begin{array}{l}\text { Primary } \\ \text { Other (specify) }\end{array} \]

\begin{tabular}{|c|c|c|c|c|}
\hline $09^{M}$ & 1 & D 07 & 1 & $\begin{array}{cccc}Y & Y & Y & Y \\
& 2011 & \end{array}$ \\
\hline
\end{tabular}
Type

Date of Disbursement

Transaction ID : BD32F8486DBB24A9CB3F

Amount of Each Disbursement this Period

99.96

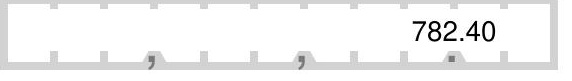

Subtotal Of Receipts This Page (optional)

Total This Period (last page this line number only))

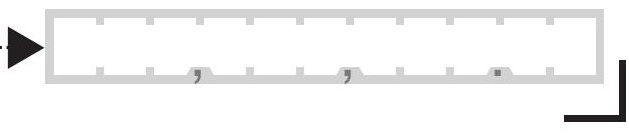




\section{SCHEDULE B-P}

\section{ITEMIZED DISBURSEMENTS}

\section{Use separate schedule(s) \\ for each category of the}

Detailed Summary Page
FOR LINE NUMBER: (check only one)

\begin{tabular}{|c|c|c|c|}
\hline$\times{ }_{23}$ & 24 & 25 & 26 \\
\hline $27 b$ & $28 a$ & $28 \mathrm{~b}$ & $28 \mathrm{c}$ \\
\hline
\end{tabular}

Any information copied from such Reports and Statements may not be sold or used by any person for the purpose of soliciting contributions or for commercial purposes, other than using the name and address of any political committee to solicit contributions from such committee.

NAME OF COMMITTEE (In Full)

\section{Friends of Herman Cain}

Full Name (Last, First, Middle Initial)

A. Facebook, Inc.

Mailing Address 1601 S. California Ave.

Date of Disbursement

\begin{tabular}{|c|c|c|c|c|c|c|c|}
\hline M M / & Y \\
09 & 07 & 2011 \\
\hline
\end{tabular}

Transaction ID : B97F9BBBE75E9497EB11

\begin{tabular}{lcc}
\hline City & State & Zip Code \\
Palo Alto & CA & 94304
\end{tabular}

Purpose of Disbursement

Advertising Expense

Candidate Name

Office Sought:

$$
\begin{array}{ll}
\text { House } \\
\text { Senate } \\
\text { President }
\end{array}
$$

State: District:

Full Name (Last, First, Middle Initial)

\section{B. City of Warner Robins}

Mailing Address 700 Watson Blvd.

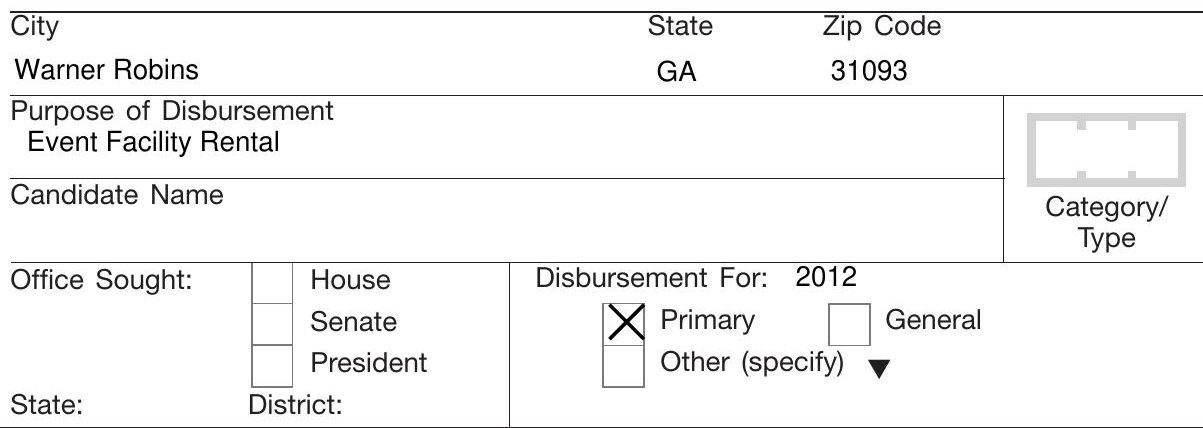

Full Name (Last, First, Middle Initial)

c. Adventure Advertising, LLC

Mailing Address 554 W. Main Street

$$
\text { Ste. } 202
$$

\begin{tabular}{lcc}
\hline City & State & Zip Code \\
Buford & GA & 30518 \\
\hline
\end{tabular}

Purpose of Disbursement
Photography

Candidate Name

\begin{tabular}{|c|c|c|c|c|}
\hline $09^{M}$ & & ${ }^{\mathrm{D}}{ }^{\mathrm{D}}$ & & 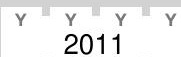 \\
\hline
\end{tabular}

\begin{tabular}{l|l|l}
\hline Office Sought: & & $\begin{array}{l}\text { House } \\
\text { Senate } \\
\end{array}$ \\
& $\begin{array}{l}\text { President } \\
\text { State: }\end{array}$ & District:
\end{tabular}

Disbursement For: 2012
$X$ Primary
Other (specify)

Date of Disbursement

Transaction ID : B498B98C063824784BCC

Amount of Each Disbursement this Period

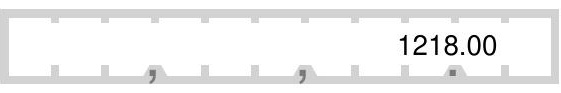

Date of Disbursement

\begin{tabular}{|c|c|c|c|c|c|c|}
\hline M & M & D & Y & Y & Y \\
09 & & 08 & & 2011 & \\
\hline
\end{tabular}

\section{Transaction ID : BE0C67A120D0544678FF}

Amount of Each Disbursement this Period

1350.00

Subtotal Of Receipts This Page (optional).

Total This Period (last page this line number only))

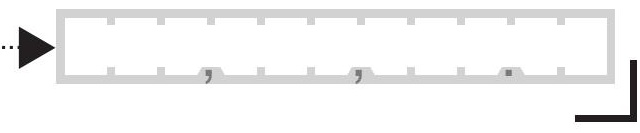




\section{SCHEDULE B-P}

\section{ITEMIZED DISBURSEMENTS}

\section{Use separate schedule(s) \\ for each category of the}

Detailed Summary Page
FOR LINE NUMBER: (check only one)

\begin{tabular}{|c|c|c|c|}
\hline$X_{23}$ & 24 & 25 & 26 \\
\hline $27 \mathrm{~b}$ & $28 a$ & $28 b$ & $28 \mathrm{c}$ \\
\hline
\end{tabular}

Any information copied from such Reports and Statements may not be sold or used by any person for the purpose of soliciting contributions or for commercial purposes, other than using the name and address of any political committee to solicit contributions from such committee.

NAME OF COMMITTEE (In Full)

\section{Friends of Herman Cain}

Full Name (Last, First, Middle Initial)

A. Ruth's Chris Steak House

Mailing Address 400 International Pkwy.

Ste. 325

\begin{tabular}{lcc}
\hline City & State & Zip Code \\
Heathrow & FL & 32746 \\
\hline
\end{tabular}

Purpose of Disbursement

Meeting Expense

Candidate Name

\begin{tabular}{l|l|l}
\hline Office Sought: & House & Disbursement For: 2012
\end{tabular} Xrimary $\square$ General

State:

\section{Senate}

President

Full Name (Last, First, Middle Initial)

B. Hotels.com

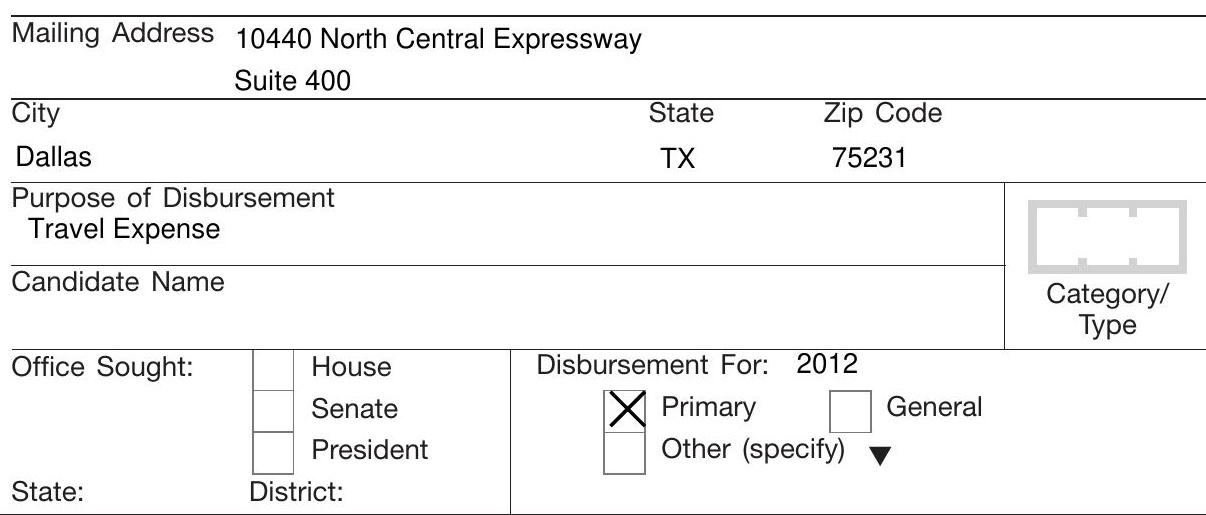

Date of Disbursement

\begin{tabular}{|c|c|c|c|c|}
\hline${ }^{M}$ & ${ }^{M}$ & $9^{\mathrm{D}}$ & $\mathrm{Y}^{\mathrm{D}}$ & $\mathrm{Y}^{\mathrm{Y}}$ \\
\hline
\end{tabular}

Transaction ID : BD254AACF4681438B855

Full Name (Last, First, Middle Initial)

\section{c. Fins Seafood}

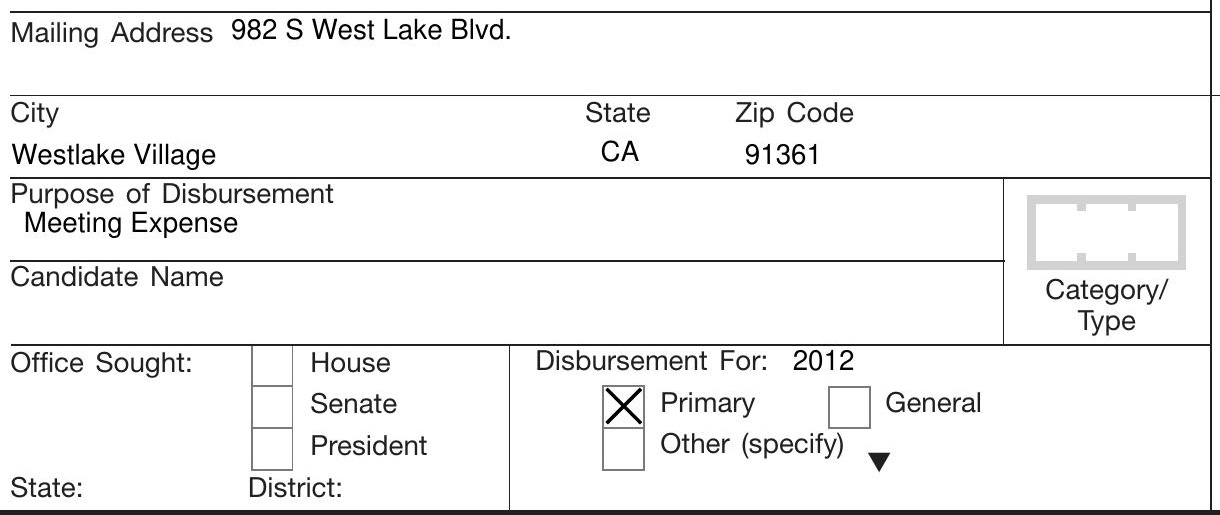

Subtotal Of Receipts This Page (optional)......

Date of Disbursement

\begin{tabular}{|c|c|c|c|c|c|}
\hline M M / & D & Y & Y & Y & Y \\
09 & & 09 & & 2011 & \\
\hline
\end{tabular}

\section{Transaction ID : B2B221C31C6F4436EA80}

Amount of Each Disbursement this Period

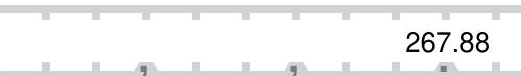

267.88

Total This Period (last page this line number only)) 


\section{SCHEDULE B-P}

\section{ITEMIZED DISBURSEMENTS}

\section{Use separate schedule(s)}

for each category of the

Detailed Summary Page
FOR LINE NUMBER: (check only one)

\begin{tabular}{|c|c|c|c|}
\hline$\times{ }_{23}$ & 24 & 25 & 26 \\
\hline $27 b$ & $28 a$ & $28 \mathrm{~b}$ & $28 \mathrm{c}$ \\
\hline
\end{tabular}

Any information copied from such Reports and Statements may not be sold or used by any person for the purpose of soliciting contributions or for commercial purposes, other than using the name and address of any political committee to solicit contributions from such committee.

NAME OF COMMITTEE (In Full)

\section{Friends of Herman Cain}

Full Name (Last, First, Middle Initial)

A. Facebook, Inc.

Mailing Address 1601 S. California Ave.

Date of Disbursement

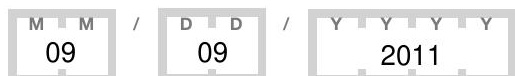

Transaction ID : B417BB99BC1FF46F8A43

\begin{tabular}{lcc}
\hline City & State & Zip Code \\
Palo Alto & CA & 94304
\end{tabular}

Purpose of Disbursement

Advertising Expense

Candidate Name

Office Sought:

$$
\begin{aligned}
& \text { House } \\
& \text { Senate } \\
& \text { President }
\end{aligned}
$$

State: District:

Full Name (Last, First, Middle Initial)

B. Nextiva

Mailing Address 8125 North 86th Place

\begin{tabular}{lcc}
\hline City & State & Zip Code \\
Scottsdale & AZ & 85258
\end{tabular}

Purpose of Disbursement

Telephone

Candidate Name

Office Sought:

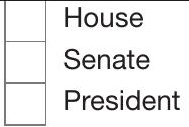

Disbursement For: 2012

Xrimary $\square$ General

State:

District:

Full Name (Last, First, Middle Initial)

\section{c. Delta Airlines}

\begin{tabular}{ll}
\hline Mailing Address & Post Office Box 20980 \\
& Department 980
\end{tabular}

Atlanta

Purpose of Disbursement

Travel Expense

Candidate Name

\begin{tabular}{|c|c|c|c|c|}
\hline $09^{M}$ & & ${ }^{\mathrm{D}} 9^{\mathrm{D}}$ & & $\begin{array}{llll}Y & Y & Y & Y \\
& 2011\end{array}$ \\
\hline
\end{tabular}

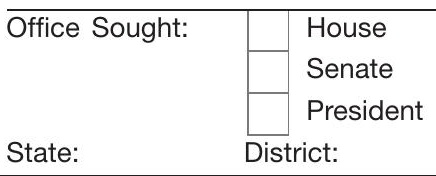

Date of Disbursement

Transaction ID : BC7718AEA3AE14161B46

Amount of Each Disbursement this Period

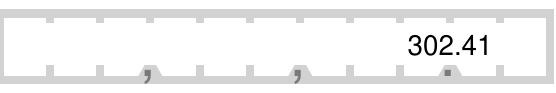

Date of Disbursement

\begin{tabular}{|c|c|c|c|c|c|c|}
\hline$M$ & M & I & Y & Y & Y \\
09 & & 09 & & 2011 & \\
\hline
\end{tabular}

Transaction ID : B79482A7EB6094584BC0

Amount of Each Disbursement this Period

150.00

Subtotal Of Receipts This Page (optional).

Total This Period (last page this line number only))

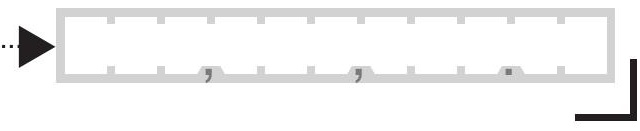




\section{SCHEDULE B-P}

\section{ITEMIZED DISBURSEMENTS}

\section{Use separate schedule(s) \\ for each category of the}

Detailed Summary Page
FOR LINE NUMBER: (check only one)

\begin{tabular}{|c|c|c|c|}
\hline$\times{ }_{23}$ & 24 & 25 & 26 \\
\hline $27 b$ & $28 a$ & $28 \mathrm{~b}$ & $28 \mathrm{c}$ \\
\hline
\end{tabular}

Any information copied from such Reports and Statements may not be sold or used by any person for the purpose of soliciting contributions or for commercial purposes, other than using the name and address of any political committee to solicit contributions from such committee.

NAME OF COMMITTEE (In Full)

\section{Friends of Herman Cain}

Full Name (Last, First, Middle Initial)

A. Delta Airlines

Mailing Address Post Office Box 20980 Department 980

\begin{tabular}{lll}
\hline City & State & Zip Code \\
Atlanta & GA & $30320-2980$
\end{tabular}

Purpose of Disbursement

Travel Expense

Candidate Name

Office Sought:

State:

\begin{tabular}{|l|l|l} 
& $\begin{array}{l}\text { House } \\
\text { Senate }\end{array}$ \\
& President \\
\hline & District:
\end{tabular}

B. SunTrust Bank

Mailing Address 980 Eagles Landing Parkway

\begin{tabular}{lcc}
\hline City & State & Zip Code \\
Stockbridge & GA & 30281
\end{tabular}

Purpose of Disbursement

Bank Fees

Candidate Name

Office Sought:

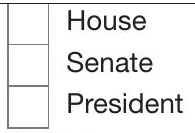

State:

District:

Full Name (Last, First, Middle Initial)

\section{c. US Airways}

Mailing Address 4000 E Sky Harbor Boulevard

\begin{tabular}{lcc}
\hline City & State & Zip Code \\
Phoenix & AZ & 85034
\end{tabular}

Purpose of Disbursement

Travel Expense

Candidate Name

Office Sought:

State:

\begin{tabular}{|c|}
\hline House \\
\hline Senate \\
\hline President \\
\hline
\end{tabular}

Disbursement For: 2012

Х $\begin{aligned} & \text { Primary } \\ & \text { Other (specify) }\end{aligned}$
Date of Disbursement

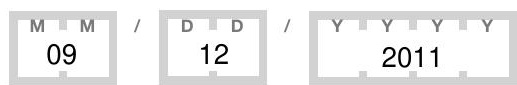

Transaction ID : BD3AC7A3E97764588B6F

Amount of Each Disbursement this Period

3357.86

Date of Disbursement

\begin{tabular}{|c|c|c|c|c|}
\hline${ }^{M}$ & ${ }^{M}$ & $9^{\mathrm{D}}$ & ${ }^{\mathrm{D}}$ & $\mathrm{Y}^{\mathrm{Y}} \mathrm{Y}^{\mathrm{Y}}$ \\
\hline
\end{tabular}

Transaction ID : B2841FF9DB40C4FF1808

Amount of Each Disbursement this Period

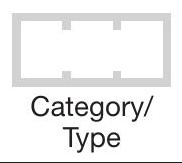
Disbursement For: 2012
Xrimary
Other (specify) Type

Date of Disbursement

\begin{tabular}{|c|c|c|c|c|}
\hline $09^{\mathrm{M}}$ & I & D 12 & 1 & $\begin{array}{cccc}Y & Y & Y & Y \\
& 2011 & \end{array}$ \\
\hline
\end{tabular}

\section{Transaction ID : B30FE490D7425437F980}

Amount of Each Disbursement this Period

1770.70

Subtotal Of Receipts This Page (optional).

Total This Period (last page this line number only))

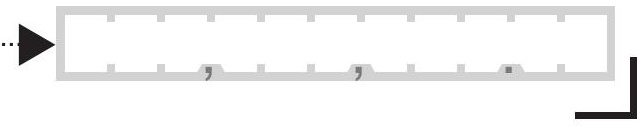




\section{SCHEDULE B-P}

\section{ITEMIZED DISBURSEMENTS}

\section{Use separate schedule(s) \\ for each category of the}

Detailed Summary Page
FOR LINE NUMBER: (check only one)

\begin{tabular}{|c|c|c|c|c|}
\hline $\mathrm{X}_{23}$ & 24 & 25 & 26 & \\
\hline $27 \mathrm{~b}$ & $28 a$ & $28 b$ & $28 \mathrm{c}$ & 2 \\
\hline
\end{tabular}

Any information copied from such Reports and Statements may not be sold or used by any person for the purpose of soliciting contributions or for commercial purposes, other than using the name and address of any political committee to solicit contributions from such committee.

NAME OF COMMITTEE (In Full)

\section{Friends of Herman Cain}

Full Name (Last, First, Middle Initial)

A. SunTrust Bank

Mailing Address 980 Eagles Landing Parkway

Date of Disbursement

\begin{tabular}{lcc}
\hline City & State & Zip Code \\
Stockbridge & GA & 30281 \\
\hline Purpose of Disbursement & &
\end{tabular}

Purpose of Disbursement

CC Transaction Fees

Candidate Name

Office Sought: $\quad$ House

House

President

State:

District:

Full Name (Last, First, Middle Initial)

Disbursement For: 2012

X Primary $\square$ General

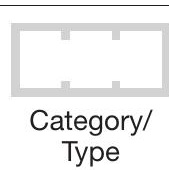

Type
Amount of Each Disbursement this Period

8686.09
B. Hartsfield Jackson International Airport

Mailing Address Post Office Box 20786

\begin{tabular}{lcc}
\hline City & State & Zip Code \\
Atlanta & GA & 30320
\end{tabular}

Purpose of Disbursement

Parking

Candidate Name

Date of Disbursement

\begin{tabular}{|c|c|}
\hline $09^{M}$ & \\
\hline
\end{tabular}

Transaction ID : B7E9956AE4ECE4C84955

Amount of Each Disbursement this Period

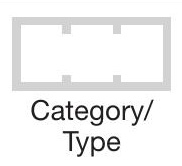

Office Sought:

House
Senate
President

Disbursement For: 2012

Х Primary $\square$ General

District:

Full Name (Last, First, Middle Initial)

c. Petty Cash

Mailing Address PO Box 2158

\begin{tabular}{lcc}
\hline City & State & Zip Code \\
Stockbridge & GA & 30281 \\
\hline
\end{tabular}

Purpose of Disbursement

Event Change

Candidate Name

Office Sought:

\begin{tabular}{|l|l|l} 
& House \\
Senate \\
& $\begin{array}{l}\text { President } \\
\text { District: }\end{array}$
\end{tabular}

Disbursement For: 2012

Х $\begin{aligned} & \text { Primary } \\ & \text { Other (specify) }\end{aligned}$

State:

District:

Subtotal Of Receipts This Page (optional).

9010.09

Total This Period (last page this line number only))
Date of Disbursement

\begin{tabular}{|c|c|c|c|c|}
\hline $09^{\mathrm{M}}$ & I & 12 & 1 & $\begin{array}{cccc}Y & Y & Y & Y \\
& 2011 & \end{array}$ \\
\hline
\end{tabular}

Transaction ID : B6B5E7E3BBC4C4BC598E

Amount of Each Disbursement this Period

300.00 Type 


\section{SCHEDULE B-P}

\section{ITEMIZED DISBURSEMENTS}

\section{Use separate schedule(s) \\ for each category of the}

Detailed Summary Page
FOR LINE NUMBER: (check only one)

\begin{tabular}{|c|c|c|c|}
\hline$\times{ }_{23}$ & 24 & 25 & 26 \\
\hline $27 b$ & $28 a$ & $28 \mathrm{~b}$ & $28 \mathrm{c}$ \\
\hline
\end{tabular}

Any information copied from such Reports and Statements may not be sold or used by any person for the purpose of soliciting contributions or for commercial purposes, other than using the name and address of any political committee to solicit contributions from such committee.

NAME OF COMMITTEE (In Full)

\section{Friends of Herman Cain}

Full Name (Last, First, Middle Initial)

A. Hotels.com

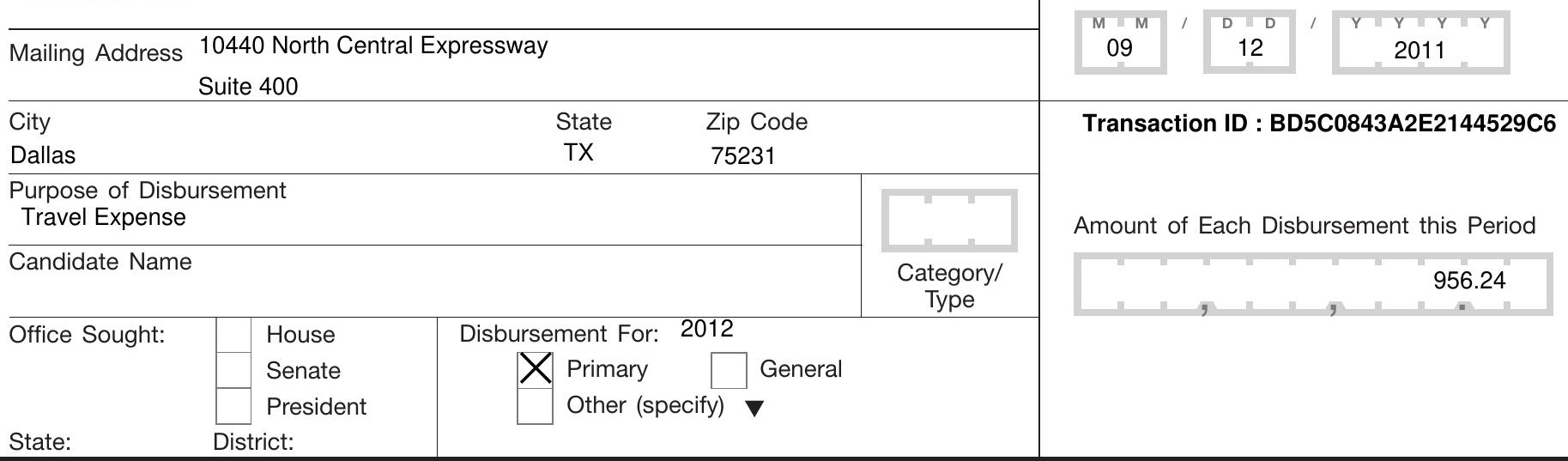

Full Name (Last, First, Middle Initial)

B. Wyndham Worldwide

\begin{tabular}{|c|c|c|c|c|}
\hline \multicolumn{5}{|c|}{ Mailing Address 22 Sylvan Way } \\
\hline \multicolumn{2}{|l|}{ City } & \multicolumn{3}{|c|}{ Zip Code } \\
\hline \multicolumn{2}{|l|}{ Parsippany } & \multicolumn{3}{|c|}{07054} \\
\hline \multicolumn{4}{|c|}{$\begin{array}{l}\text { Purpose of Disbursement } \\
\text { Travel Expense }\end{array}$} & \\
\hline \multicolumn{4}{|l|}{ Candidate Name } & $\begin{array}{l}\text { Category/ } \\
\text { Type }\end{array}$ \\
\hline \multirow[t]{3}{*}{ Office Sought: } & House & \multirow{3}{*}{\multicolumn{3}{|c|}{$\begin{array}{l}\text { Disbursement For: } 2012 \\
\text { X Primary } \\
\text { Other (specify) }\end{array}$}} \\
\hline & Senate & & & \\
\hline & President & & & \\
\hline State: & \multicolumn{4}{|c|}{ District: } \\
\hline
\end{tabular}

Date of Disbursement

\begin{tabular}{|c|c|c|c|c|}
\hline $09^{M}$ & & ${ }^{\mathrm{D}} 2^{\mathrm{D}}$ & 1 & $\begin{array}{llll} & Y & Y & Y \\
& 2011 & Y\end{array}$ \\
\hline
\end{tabular}

Transaction ID : BF04E31240AF74587A3B

Full Name (Last, First, Middle Initial)

\section{c. QueueWay.com}

Mailing Address 1485 North Clinton Ave

\begin{tabular}{lcc}
\hline City & State & Zip Code \\
Bayshore & NY & 11706
\end{tabular}

Purpose of Disbursement

Event Supplies

Candidate Name

Office Sought:

State:
Disbursement For: 2012

X $\begin{aligned} & \text { Primary } \\ & \text { Other (specify) }\end{aligned}$
Date of Disbursement

\begin{tabular}{|c|c|c|c|c|}
\hline $09^{\mathrm{M}}$ & I & D 12 & 1 & $\begin{array}{cccc}Y & Y & Y & Y \\
& 2011 & \end{array}$ \\
\hline
\end{tabular}

Transaction ID : B50F3D78CEC3D4688951

Amount of Each Disbursement this Period

204.61

Subtotal Of Receipts This Page (optional).

Total This Period (last page this line number only))

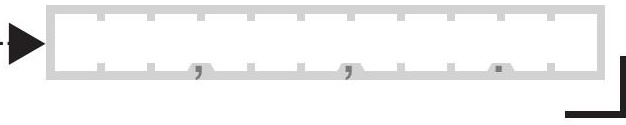




\section{SCHEDULE B-P}

\section{ITEMIZED DISBURSEMENTS}

\section{Use separate schedule(s) \\ for each category of the}

Detailed Summary Page
FOR LINE NUMBER: (check only one)

\begin{tabular}{|c|c|c|c|}
\hline$\times{ }_{23}$ & 24 & 25 & 26 \\
\hline $27 b$ & $28 a$ & $28 \mathrm{~b}$ & $28 \mathrm{c}$ \\
\hline
\end{tabular}

Any information copied from such Reports and Statements may not be sold or used by any person for the purpose of soliciting contributions or for commercial purposes, other than using the name and address of any political committee to solicit contributions from such committee.

NAME OF COMMITTEE (In Full)

\section{Friends of Herman Cain}

Full Name (Last, First, Middle Initial)

A. Air Tran Mailing Address 9955 Air Tran Boulevard

Date of Disbursement

City

\begin{tabular}{lcc}
\hline City & State & Zip Code \\
Orlando & FL & 32827 \\
\hline Purpose of Disbursement & &
\end{tabular}

Purpose of Disbursement

Travel Expense

Candidate Name

\begin{tabular}{l|l|l}
\hline Office Sought: & House & Disbursement For: 2012
\end{tabular} X Primary $\square$ General

State:

\section{Senate}

President

Full Name (Last, First, Middle Initial)

B. Scott Sidney

Mailing Address N40 W6522 Jackson Street

\begin{tabular}{lcc}
\hline City & State & Zip Code \\
Cedarburg & WI & $53012-2317$
\end{tabular}

Purpose of Disbursement

Car Rental

Candidate Name

Office Sought:

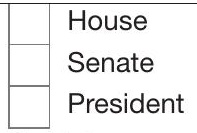

State:

District:

Full Name (Last, First, Middle Initial)

\section{c. Gerald Strober}

\begin{tabular}{|c|c|c|c|c|c|}
\hline \multicolumn{6}{|c|}{ Mailing Address 52 East End Ave. } \\
\hline \multicolumn{2}{|l|}{ City } & State & \multicolumn{3}{|l|}{ Zip Code } \\
\hline \multicolumn{2}{|l|}{ New York } & NY & \multicolumn{3}{|c|}{$10028-8096$} \\
\hline \multicolumn{5}{|c|}{$\begin{array}{l}\text { Purpose of Disbursement } \\
\text { Media Production }\end{array}$} & \\
\hline \multicolumn{5}{|c|}{ Candidate Name } & $\begin{array}{l}\text { Category/ } \\
\text { Type }\end{array}$ \\
\hline \multirow[t]{3}{*}{ Office Sought: } & House & \multicolumn{4}{|c|}{ Disbursement For: 2012} \\
\hline & Senate & \multirow{3}{*}{\multicolumn{2}{|c|}{$\begin{array}{l}\text { Primary } \\
\text { Other (specify) }\end{array}$}} & \multirow{2}{*}{\multicolumn{2}{|c|}{ General }} \\
\hline & President & & & & \\
\hline State: & District: & & & \multicolumn{2}{|c|}{$\boldsymbol{\nabla}$} \\
\hline
\end{tabular}

Subtotal Of Receipts This Page (optional)......

Date of Disbursement

\begin{tabular}{|c|c|c|c|c|}
\hline${ }^{M}{ }^{\mathrm{M}}$ & $/$ & ${ }^{\mathrm{D}}$ & $\mathrm{P}^{\mathrm{Y}}$ & $\mathrm{Y}^{\mathrm{Y}} \mathrm{Y}$ \\
\hline
\end{tabular}

Transaction ID : B2E996055556D4EFF8CB

Amount of Each Disbursement this Period

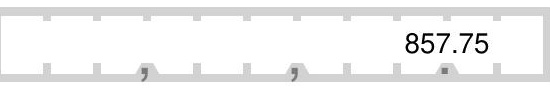

Date of Disbursement

\begin{tabular}{|c|c|c|c|c|}
\hline $09^{\mathrm{M}}$ & I & D 13 & 1 & $\begin{array}{cccc}Y & Y & Y & Y \\
& 2011 & \end{array}$ \\
\hline
\end{tabular}

Transaction ID : B85D0C59AD42046A0BE6

Amount of Each Disbursement this Period

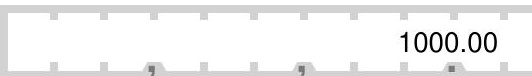

1000.00

Total This Period (last page this line number only)) 


\section{SCHEDULE B-P}

\section{ITEMIZED DISBURSEMENTS}

\section{Use separate schedule(s) \\ for each category of the}

Detailed Summary Page
FOR LINE NUMBER: (check only one)

\begin{tabular}{|c|c|c|c|}
\hline$\times{ }_{23}$ & 24 & 25 & 26 \\
\hline $27 b$ & $28 a$ & $28 \mathrm{~b}$ & $28 \mathrm{c}$ \\
\hline
\end{tabular}

Any information copied from such Reports and Statements may not be sold or used by any person for the purpose of soliciting contributions or for commercial purposes, other than using the name and address of any political committee to solicit contributions from such committee.

NAME OF COMMITTEE (In Full)

\section{Friends of Herman Cain}

Full Name (Last, First, Middle Initial)

A. Facebook, Inc.

Mailing Address 1601 S. California Ave.

Date of Disbursement

\begin{tabular}{lll}
\hline City & State & Zip Code \\
Palo Alto & CA & 94304 \\
\hline
\end{tabular}

Purpose of Disbursement

Advertising Expense

Candidate Name

\begin{tabular}{l|l|c|}
\hline Office Sought: & $\begin{array}{l}\text { House } \\
\text { Senate } \\
\text { President }\end{array}$ & $\begin{array}{c}\text { Disbursement For: } 2012 \\
\text { X Primary } \\
\text { Other (specify) }\end{array}$
\end{tabular}

Full Name (Last, First, Middle Initial)

B. Delta Airlines

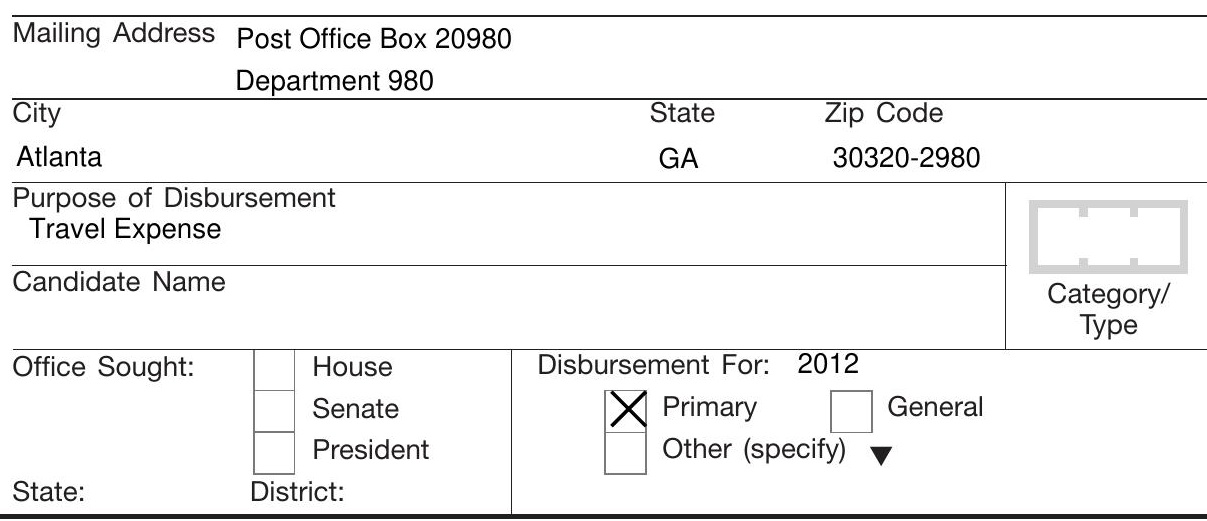

Date of Disbursement

\begin{tabular}{|c|c|c|c|c|}
\hline${ }^{\mathrm{M}} 09^{\mathrm{M}}$ & 1 & $13^{\mathrm{D}}$ & 1 & $\begin{array}{llll}Y & Y & Y & Y \\
& 2011\end{array}$ \\
\hline
\end{tabular}

\section{Transaction ID : B78EBF707B8FF4893984}

Amount of Each Disbursement this Period

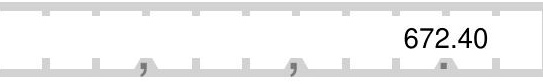

Full Name (Last, First, Middle Initial)

\section{c. SunTrust Bank}

Mailing Address 980 Eagles Landing Parkway

\begin{tabular}{lcc}
\hline City & State & Zip Code \\
Stockbridge & GA & 30281
\end{tabular}

Purpose of Disbursement

Office Supplies

Candidate Name

Date of Disbursement

\begin{tabular}{|c|c|c|c|c|c|c|}
\hline M & M & D & Y & Y & Y & Y \\
09 & & 14 & & 2011 & \\
\hline
\end{tabular}

Transaction ID : B2AB52D1288FD48A2BF1

\begin{tabular}{c|c} 
Category/ \\
Type
\end{tabular}

Amount of Each Disbursement this Period

\begin{tabular}{l|l|c|}
\hline Office Sought: & $\begin{array}{l}\text { House } \\
\text { Senate } \\
\text { President } \\
\text { State: }\end{array}$ & $\begin{array}{r}\text { Disbursement For: } 2012 \\
\text { District: }\end{array}$
\end{tabular}

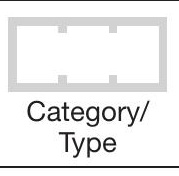

e

Subtotal Of Receipts This Page (optional).

Total This Period (last page this line number only))

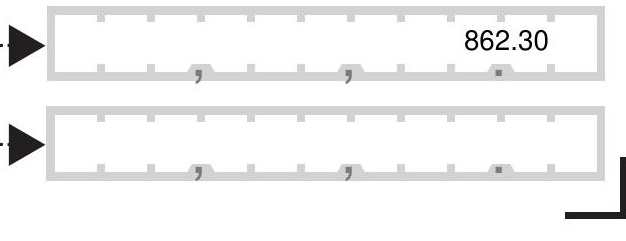




\section{SCHEDULE B-P}

\section{ITEMIZED DISBURSEMENTS}

\section{Use separate schedule(s) \\ for each category of the}

Detailed Summary Page
FOR LINE NUMBER: (check only one)

\begin{tabular}{|c|c|c|c|}
\hline$\times{ }_{23}$ & 24 & 25 & 26 \\
\hline $27 b$ & $28 a$ & $28 \mathrm{~b}$ & $28 \mathrm{c}$ \\
\hline
\end{tabular}

Any information copied from such Reports and Statements may not be sold or used by any person for the purpose of soliciting contributions or for commercial purposes, other than using the name and address of any political committee to solicit contributions from such committee.

NAME OF COMMITTEE (In Full)

\section{Friends of Herman Cain}

Full Name (Last, First, Middle Initial)

A. FedEx Kinkos

Mailing Address 942 S. Shady Grove Road

Date of Disbursement

\begin{tabular}{lcc}
\hline City & State & Zip Code \\
Memphis & TN & 38120 \\
\hline Purpose of Disbursement & &
\end{tabular}

Shipping

Candidate Name

\begin{tabular}{l|l|l}
\hline Office Sought: & House & Disbursement For: 2012
\end{tabular} X Primary $\square$ General

State:

\section{Senate}

President

Full Name (Last, First, Middle Initial)

\section{B. Delta Airlines}

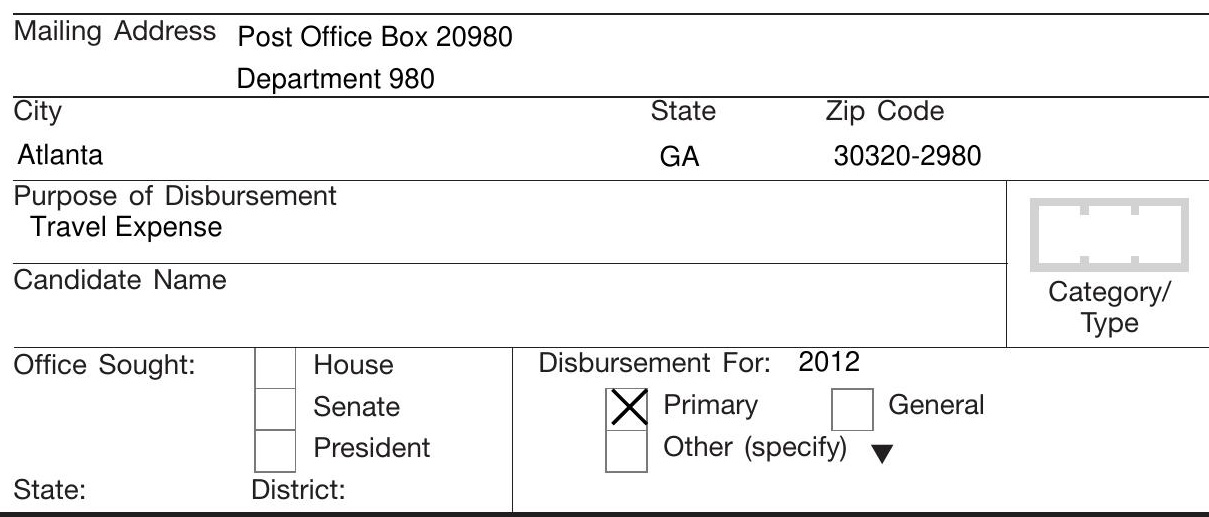

Date of Disbursement

Full Name (Last, First, Middle Initial)

\section{c. Washington Political Group}

Mailing Address 5061 Hodgkins Place

\begin{tabular}{lcc}
\hline City & State & Zip Code \\
Lilburn & GA & 30047
\end{tabular}

Purpose of Disbursement

Website Maintenance

Candidate Name

Office Sought: $\quad$ House

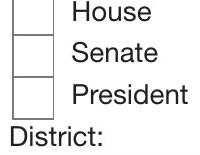

State:

District:

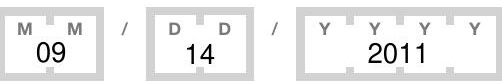

Transaction ID : BAE5F01A452024A4AABD

Amount of Each Disbursement this Period

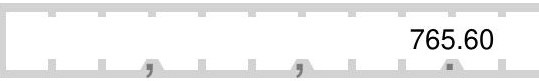

Date of Disbursement

\begin{tabular}{|c|c|c|c|c|c|}
\hline M & M & D & Y & Y & Y \\
09 & & 14 & & \\
\hline
\end{tabular}

Transaction ID : BB64F54E4B7914D4F8F6

Amount of Each Disbursement this Period

16600.24

Subtotal Of Receipts This Page (optional).

Total This Period (last page this line number only))

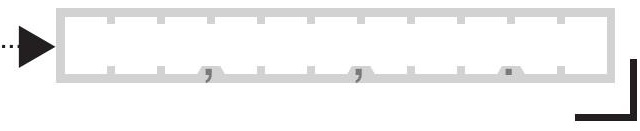




\section{SCHEDULE B-P}

\section{ITEMIZED DISBURSEMENTS}

Use separate schedule(s)

for each category of the

Detailed Summary Page
FOR LINE NUMBER: (check only one)

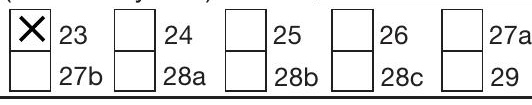

Any information copied from such Reports and Statements may not be sold or used by any person for the purpose of soliciting contributions or for commercial purposes, other than using the name and address of any political committee to solicit contributions from such committee.

NAME OF COMMITTEE (In Full)

\section{Friends of Herman Cain}

Full Name (Last, First, Middle Initial)

A. Campaigner

Mailing Address 2379 Holly Lane

Suite 210

Date of Disbursement

$M M$, D D , Y Y Y Y Y Y Y

\begin{tabular}{l|l|l|}
09 & 14 & 2011
\end{tabular}

\begin{tabular}{lll}
\hline City & State & $\begin{array}{l}\text { Zip Code } \\
\text { K1V7P }\end{array}$ \\
Ottawa & & Kurpose
\end{tabular}

Purpose of Disbursement

E-Marketing

Candidate Name

\begin{tabular}{l|l|l}
\hline Office Sought: & House & Disbursement For: 2012
\end{tabular} X Primary $\square$ General

State:

\section{Senate}

President

District:

Full Name (Last, First, Middle Initial)

B. Response Catalysts, Inc.

Mailing Address 14953 L Street

\begin{tabular}{lcc}
\hline City & State & Zip Code \\
Omaha & NE & 68137
\end{tabular}

Purpose of Disbursement

Automated Calls

Candidate Name

Office Sought:

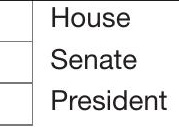

State:

District:

\begin{tabular}{|c} 
Category/ \\
Type
\end{tabular}

Transaction ID : BBD92D790B3734893849

Amount of Each Disbursement this Period

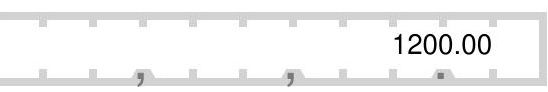

Date of Disbursement

\begin{tabular}{|c|c|c|c|c|}
\hline $09^{M}$ & & ${ }^{\mathrm{D}} 14^{\mathrm{D}}$ & 1 & $\begin{array}{lll}Y & Y & Y \\
& 2011 & Y\end{array}$ \\
\hline
\end{tabular}

Transaction ID : B5B2BF480DB0348028EA

Full Name (Last, First, Middle Initial)

c. iPROMOTEU

Mailing Address Department $\mathrm{CH} 17195$

\begin{tabular}{lcc}
\hline City & State & Zip Code \\
Palatine & IL & $60055-7195$
\end{tabular}

Purpose of Disbursement

Event Supplies

Candidate Name

Office Sought: $\quad$ House

\begin{tabular}{l|l} 
& House \\
& Senate \\
& President \\
& \\
District:
\end{tabular}

State:
Disbursement For: 2012

Primary $\square$ General
Other (specify)
Amount of Each Disbursement this Period

1593.94
Date of Disbursement

\begin{tabular}{|c|c|c|c|c|c|}
\hline M & M & D & Y & Y & Y \\
\hline & & 14 & & 2011 & \\
\hline
\end{tabular}

Transaction ID : B1745D3CB00FB49259AE

Amount of Each Disbursement this Period

155.12

Subtotal Of Receipts This Page (optional)

Total This Period (last page this line number only))

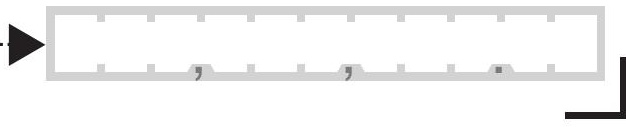




\section{SCHEDULE B-P}

\section{ITEMIZED DISBURSEMENTS}

\section{Use separate schedule(s) \\ for each category of the}

Detailed Summary Page
FOR LINE NUMBER: (check only one)

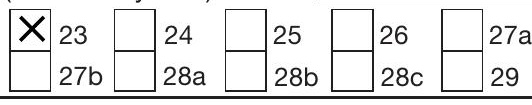

Any information copied from such Reports and Statements may not be sold or used by any person for the purpose of soliciting contributions or for commercial purposes, other than using the name and address of any political committee to solicit contributions from such committee.

NAME OF COMMITTEE (In Full)

\section{Friends of Herman Cain}

Full Name (Last, First, Middle Initial)

A. Washington Political Group

Mailing Address 5061 Hodgkins Place

City

Lilburn

Purpose of Disbursement

Website Maintenance

Candidate Name

Office Sought:

House
Senate
President
District:

Disbursement For: 2012 X Primary $\square$ General

Full Name (Last, First, Middle Initial)

B. Tri-C

\section{Mailing Address 5169 Southridge Pkwy}

Ste. 120

\begin{tabular}{lcc}
\hline City & State & Zip Code \\
College Park & GA & 30349 \\
\hline $\begin{array}{l}\text { Purpose of Disbursement } \\
\text { Postage }\end{array}$ & & \\
\hline
\end{tabular}

Candidate Name

Office Sought:

$$
\begin{array}{|l|l|} 
& \text { House } \\
\text { Senate } \\
\cline { 1 - 2 } \text { President }
\end{array}
$$

State:

District:
Date of Disbursement

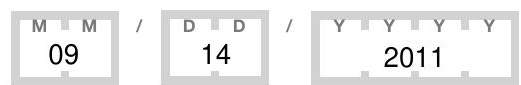

Transaction ID : BE170AC9398CE422B908

Amount of Each Disbursement this Period 3000.00

\section{Full Name (Last, First, Middle Initial)}

\section{c. Premiere Transportation}

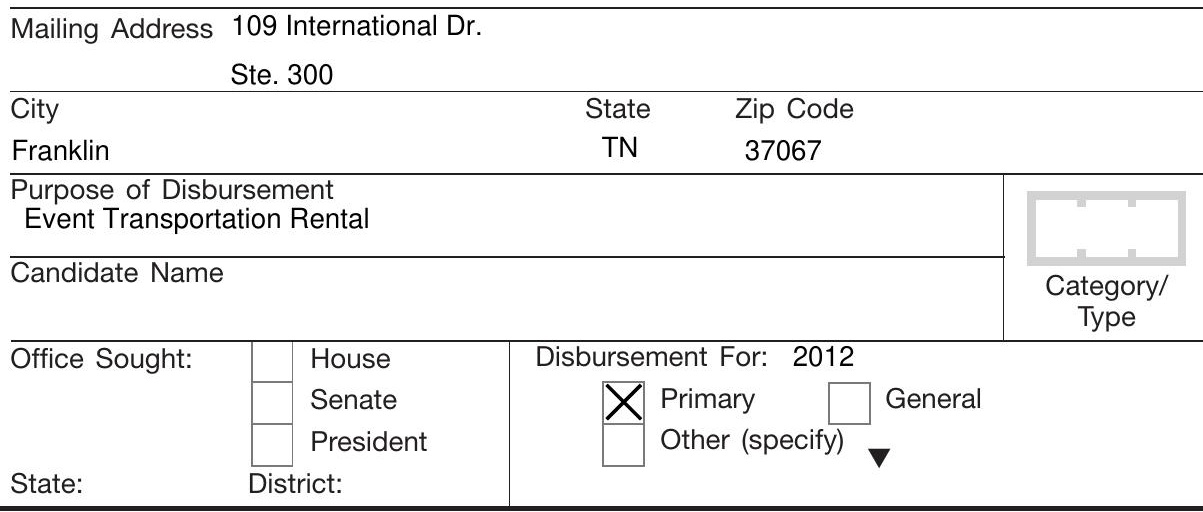

\begin{tabular}{|c|c|c|c|c|}
\hline $09^{M}$ & I & $\begin{array}{ll}\text { D } & \text { D } \\
14\end{array}$ & I & $\begin{array}{cccc}Y & Y & Y & Y \\
& 2011 & \end{array}$ \\
\hline
\end{tabular}

Subtotal Of Receipts This Page (optional).

Date of Disbursement

Transaction ID : B67ECAB58C82141D8807

\begin{tabular}{|c|c|c|c|c|}
\hline $09^{M}$ & I & $14^{\mathrm{D}}$ & 1 & $\begin{array}{llll}Y & Y & Y & Y \\
& 2011 & \end{array}$ \\
\hline
\end{tabular}

Amount of Each Disbursement this Period

Date of Disbursement

Transaction ID : BC966035EAA3E400C800

Amount of Each Disbursement this Period
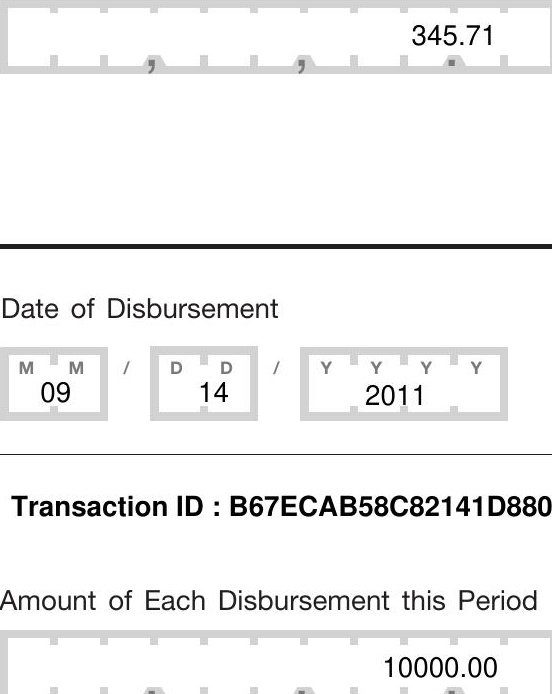

10000.00

Total This Period (last page this line number only)) 


\section{SCHEDULE B-P}

\section{ITEMIZED DISBURSEMENTS}

Use separate schedule(s)

for each category of the

Detailed Summary Page
FOR LINE NUMBER: (check only one)

\begin{tabular}{|c|c|c|c|}
\hline$\times{ }_{23}$ & 24 & 25 & 26 \\
\hline $27 b$ & $28 a$ & $28 \mathrm{~b}$ & $28 \mathrm{c}$ \\
\hline
\end{tabular}

Any information copied from such Reports and Statements may not be sold or used by any person for the purpose of soliciting contributions or for commercial purposes, other than using the name and address of any political committee to solicit contributions from such committee.

NAME OF COMMITTEE (In Full)

\section{Friends of Herman Cain}

Full Name (Last, First, Middle Initial)

A. Facebook, Inc.

Mailing Address 1601 S. California Ave.

Date of Disbursement

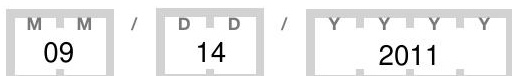

Transaction ID : BC32EC51663524C349F3

\begin{tabular}{lll}
\hline City & State & Zip Code \\
Palo Alto & CA & 94304
\end{tabular}

Purpose of Disbursement

Advertising Expense

Candidate Name

\begin{tabular}{l|l|l}
\hline Office Sought: & House & Disbursement For: 2012
\end{tabular} X Primary $\square$ General

State:

\section{Senate \\ President}

District:

Full Name (Last, First, Middle Initial)

\section{B. Charter Business}

Mailing Address P.O. Box 742615

\begin{tabular}{lcc}
\hline City & State & Zip Code \\
Cincinnati & OH & $45274-2615$
\end{tabular}

Purpose of Disbursement

Internet/Phone/Cable

Candidate Name

Office Sought:

House
Senate
President

State:

District:

Full Name (Last, First, Middle Initial)

c. UPS

Mailing Address Post Office Box 7247-0244

\begin{tabular}{lcc}
\hline City & State & Zip Code \\
Philadelphia & PA & $19170-0001$
\end{tabular}

Purpose of Disbursement

Shipping

Candidate Name

Disbursement For: 2012

Primary $\square$ General
Other (specify)

Office Sought: $\quad$ House

\begin{tabular}{|l|l|} 
& House \\
Senate \\
President
\end{tabular}

Disbursement For: 2012

Х $\begin{aligned} & \text { Primary } \\ & \text { Other (specify) }\end{aligned}$

State:

District:

Subtotal Of Receipts This Page (optional)

Date of Disbursement

\begin{tabular}{|c|c|c|c|c|}
\hline $09^{M}$ & I & D 14 & I & 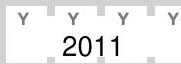 \\
\hline
\end{tabular}

Transaction ID : BEF31DDCB5C2B469B9CB

Amount of Each Disbursement this Period

191.23
Amount of Each Disbursement this Period 200.00
Date of Disbursement

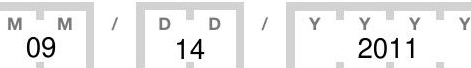

Transaction ID : BEACC41EE940F4137A70

Amount of Each Disbursement this Period 256.09

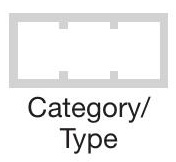

Total This Period (last page this line number only))

647.32

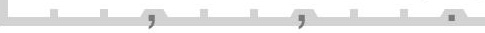

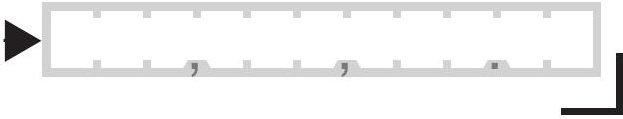

FEC Schedule B-P (Form 3P) (Rev. 03/2011) 


\section{SCHEDULE B-P}

\section{ITEMIZED DISBURSEMENTS}

\section{Use separate schedule(s) \\ for each category of the}

Detailed Summary Page
FOR LINE NUMBER: (check only one)

\begin{tabular}{|c|c|c|c|}
\hline$X_{23}$ & 24 & 25 & 26 \\
\hline $27 \mathrm{~b}$ & $28 a$ & $28 b$ & $28 \mathrm{c}$ \\
\hline
\end{tabular}

Any information copied from such Reports and Statements may not be sold or used by any person for the purpose of soliciting contributions or for commercial purposes, other than using the name and address of any political committee to solicit contributions from such committee.

NAME OF COMMITTEE (In Full)

\section{Friends of Herman Cain}

Full Name (Last, First, Middle Initial)

\section{A. Consolidated Copier Services}

Mailing Address 1303 Parker Road

Suite G

\begin{tabular}{lcc}
\hline City & State & Zip Code \\
Conyers & GA & 30094 \\
\hline
\end{tabular}

Purpose of Disbursement

Office Equipment Rental

Candidate Name

Office Sought:

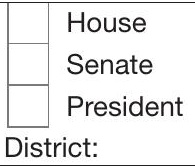

Disbursement For: 2012 X Primary $\square$ General

State: District:

Full Name (Last, First, Middle Initial)

B. James Coughlin

\begin{tabular}{|c|c|c|c|c|}
\hline \multicolumn{5}{|c|}{ Mailing Address 16 South Hills Drive } \\
\hline \multicolumn{2}{|l|}{ City } & \multicolumn{3}{|c|}{ Zip Code } \\
\hline \multicolumn{2}{|l|}{ Bedford } & \multicolumn{3}{|c|}{$03110-4920$} \\
\hline \multicolumn{4}{|c|}{$\begin{array}{l}\text { Purpose of Disbursement } \\
\text { Field Consulting }\end{array}$} & \\
\hline \multicolumn{4}{|l|}{ Candidate Name } & $\begin{array}{l}\text { Category/ } \\
\text { Type }\end{array}$ \\
\hline \multirow[t]{3}{*}{ Office Sought: } & House & \multirow{3}{*}{\multicolumn{3}{|c|}{$\begin{array}{l}\text { Disbursement For: } 2012 \\
\text { X Primary } \\
\text { Other (specify) }\end{array}$}} \\
\hline & Senate & & & \\
\hline & President & & & \\
\hline State: & \multicolumn{4}{|c|}{ District: } \\
\hline
\end{tabular}

Date of Disbursement

\begin{tabular}{|c|c|c|c|c|}
\hline $09^{M}$ & 1 & ${ }^{\mathrm{D}} 14^{\mathrm{D}}$ & 1 & 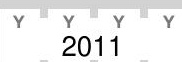 \\
\hline
\end{tabular}

Full Name (Last, First, Middle Initial)

\section{c. Aaron T. Manaigo}

\begin{tabular}{|c|c|c|c|c|c|}
\hline \multicolumn{6}{|c|}{$\begin{array}{c}\text { Mailing Address } 6723 \mathrm{~W} . \text { Wakefield Drive } \\
\text { Suite A2 }\end{array}$} \\
\hline \multicolumn{2}{|c|}{ City } & State & Zip Code & & \\
\hline \multicolumn{2}{|l|}{ Alexandria } & VA & 22307 & & \\
\hline \multicolumn{5}{|c|}{$\begin{array}{l}\text { Purpose of Disbursement } \\
\text { Transportation/Mtg Exp/Office Supplies }\end{array}$} & \\
\hline \multicolumn{5}{|l|}{ Candidate Name } & $\begin{array}{l}\text { Category/ } \\
\text { Type }\end{array}$ \\
\hline \multirow[t]{3}{*}{ Office Sought: } & House & \multirow{4}{*}{\multicolumn{4}{|c|}{ Disbursement For: 2012}} \\
\hline & Senate & & & & \\
\hline & President & & & & \\
\hline State: & rict: & & & & \\
\hline
\end{tabular}

Subtotal Of Receipts This Page (optional).

Date of Disbursement

\begin{tabular}{|c|c|c|c|c|}
\hline $09^{M}$ & I & D 14 & 1 & 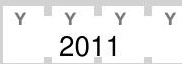 \\
\hline
\end{tabular}

Transaction ID : BF2568223DD8A4C98B1F

Amount of Each Disbursement this Period

\section{Transaction ID : B3290547D5AB94A90823}

Amount of Each Disbursement this Period
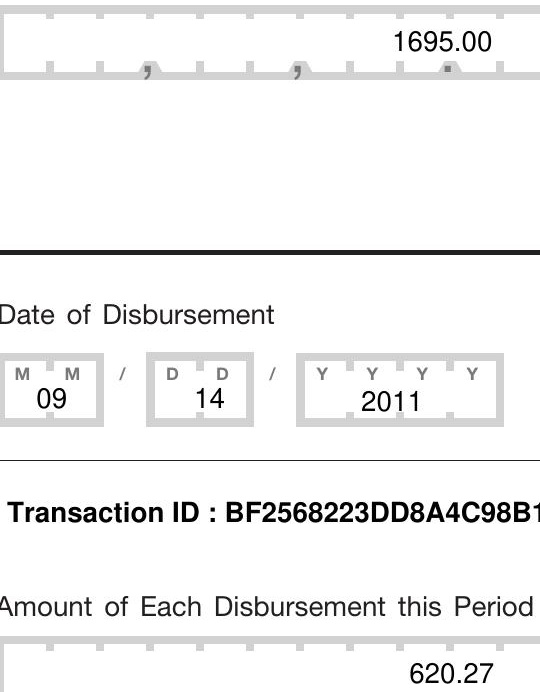

620.27

Total This Period (last page this line number only)) 


\section{SCHEDULE B-P}

\section{ITEMIZED DISBURSEMENTS}

\section{Use separate schedule(s) \\ for each category of the}

Detailed Summary Page
FOR LINE NUMBER: (check only one)

\begin{tabular}{|c|c|c|c|}
\hline$\times{ }_{23}$ & 24 & 25 & 26 \\
\hline $27 b$ & $28 a$ & $28 \mathrm{~b}$ & $28 \mathrm{c}$ \\
\hline
\end{tabular}

Any information copied from such Reports and Statements may not be sold or used by any person for the purpose of soliciting contributions or for commercial purposes, other than using the name and address of any political committee to solicit contributions from such committee.

NAME OF COMMITTEE (In Full)

\section{Friends of Herman Cain}

Full Name (Last, First, Middle Initial)

A. James Brazil

Mailing Address 6 Baldasarri Drive

Date of Disbursement

\begin{tabular}{lcc}
\hline City & State & Zip Code \\
Dunmore & PA & 18505 \\
\hline Purpose of Disbursement & &
\end{tabular}

Purpose of Disbursement

Field Consulting

Candidate Name

\begin{tabular}{l|l|l}
\hline Office Sought: & House & Disbursement For: 2012
\end{tabular} X Primary $\square$ General

State:

\section{Senate}

President

District:

Full Name (Last, First, Middle Initial)

B. Facebook, Inc.

Mailing Address 1601 S. California Ave.

\begin{tabular}{lcc}
\hline City & State & Zip Code \\
Palo Alto & CA & 94304
\end{tabular}

Purpose of Disbursement

Advertising Expense

Candidate Name

Office Sought:

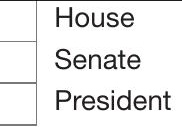

State:

District:

CA 94304

Full Name (Last, First, Middle Initial)

c. Hotels.com

Mailing Address 10440 North Central Expressway Suite 400

\begin{tabular}{lcc}
\hline City & State & Zip Code \\
Dallas & TX & 75231 \\
\hline
\end{tabular}

Purpose of Disbursement

Travel Expense

Candidate Name

Office Sought:

State:
Disbursement For: 2012

Xrimary $\square$ General
Date of Disbursement

\begin{tabular}{|c|c|c|c|c|}
\hline${ }^{M}$ & ${ }^{M}$ & $9^{\mathrm{D}}$ & ${ }^{\mathrm{D}}$ & $\mathrm{Y}^{\mathrm{Y}}$ \\
\hline
\end{tabular}

Transaction ID : B7CC9B4498C8047608EB

Amount of Each Disbursement this Period
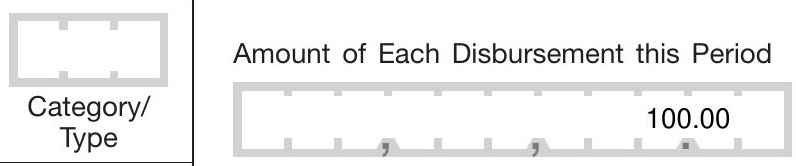

Date of Disbursement

\begin{tabular}{|c|c|c|c|c|c|c|c|}
\hline M & M & D & Y & Y & Y \\
09 & & 15 & & 2011 & \\
\hline
\end{tabular}

Transaction ID : BF9DCF03BAC0948FB87F

Amount of Each Disbursement this Period

377.73

Subtotal Of Receipts This Page (optional).

Total This Period (last page this line number only))

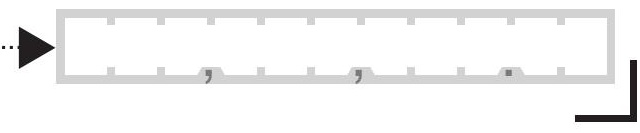




\section{SCHEDULE B-P}

\section{ITEMIZED DISBURSEMENTS}

\section{Use separate schedule(s) \\ for each category of the}

Detailed Summary Page
FOR LINE NUMBER: (check only one)

\begin{tabular}{|c|c|c|c|}
\hline$\times{ }_{23}$ & 24 & 25 & 26 \\
\hline $27 b$ & $28 a$ & $28 \mathrm{~b}$ & $28 \mathrm{c}$ \\
\hline
\end{tabular}

Any information copied from such Reports and Statements may not be sold or used by any person for the purpose of soliciting contributions or for commercial purposes, other than using the name and address of any political committee to solicit contributions from such committee.

NAME OF COMMITTEE (In Full)

\section{Friends of Herman Cain}

Full Name (Last, First, Middle Initial)

A. Campaign Now!

Mailing Address 1126 S. 70th Street Suite $S 420$

City

Milwaukee

Purpose of Disbursement

Telemarketing

Candidate Name

Office Sought:

State:

House
Senate
President
ict:
X Primary $\square$ General
Date of Disbursement

\begin{tabular}{|c|c|c|c|c|}
\hline M M & D \\
09 & 15 & 2011 \\
\hline
\end{tabular}

Transaction ID : B8A63003F15EC426A96A

Amount of Each Disbursement this Period 10000.00

\section{B. Delta Airlines}

\section{Mailing Address Post Office Box 20980 Department 980}

City

Atlanta

Purpose of Disbursement

Travel Expense

Candidate Name

Office Sought:

State:

Full Name (Last, First, Middle Initial)

\section{c. Eberle Communications Group}

\begin{tabular}{llcc}
\hline Mailing Address & \begin{tabular}{l} 
1420 Spring Hill Road \\
\multicolumn{3}{c}{ Suite 490}
\end{tabular} & & \\
\hline City & & State & Zip Code \\
McLean & & VA & 22102 \\
\hline
\end{tabular}

\section{Purpose of Disbursement Direct Mail Production}

Candidate Name

Office Sought:

State:

\begin{tabular}{|l|l|} 
& House \\
& Senate \\
& President \\
\hline District:
\end{tabular}

Disbursement For: 2012

$$
\text { Xrimary } \square \text { General }
$$

$\begin{array}{cc}\text { State } & \text { Zip Code } \\ \text { GA } & 30320-2980\end{array}$

Category/ Type
Date of Disbursement

\begin{tabular}{|c|c|c|c|c|}
\hline${ }^{M}{ }^{\mathrm{M}}$ & $/$ & ${ }^{\mathrm{D}}{ }^{\mathrm{D}}$ & $\mathrm{Y}^{\mathrm{Y}} \mathrm{Y}^{\mathrm{Y}}$ \\
\hline
\end{tabular}

Transaction ID : B013D2D6830F54856A2A

Amount of Each Disbursement this Period 336.70

Date of Disbursement

\begin{tabular}{|c|c|c|c|c|c|}
\hline M & M & D & Y & $Y$ & $Y$ \\
09 & & 16 & & 2011 & \\
\hline
\end{tabular}

Transaction ID : BAC8D26AF28404FDCB2B

Amount of Each Disbursement this Period

3363.56

Subtotal Of Receipts This Page (optional).

Total This Period (last page this line number only))

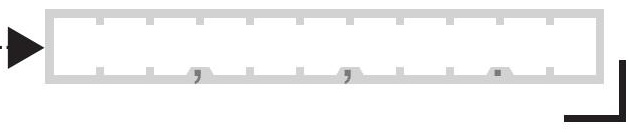




\section{SCHEDULE B-P}

\section{ITEMIZED DISBURSEMENTS}

Use separate schedule(s)

for each category of the

Detailed Summary Page
FOR LINE NUMBER: (check only one)

\begin{tabular}{|c|c|c|c|}
\hline $\mathrm{X} 23$ & 24 & 25 & 26 \\
\hline $27 \mathrm{~b}$ & $28 a$ & $28 b$ & $28 \mathrm{c}$ \\
\hline
\end{tabular}

Any information copied from such Reports and Statements may not be sold or used by any person for the purpose of soliciting contributions or for commercial purposes, other than using the name and address of any political committee to solicit contributions from such committee.

NAME OF COMMITTEE (In Full)

\section{Friends of Herman Cain}

Full Name (Last, First, Middle Initial)

A. Delta Airlines

Mailing Address Post Office Box 20980

Department 980

\begin{tabular}{lcc}
\hline City & State & Zip Code \\
Atlanta & GA & $30320-2980$
\end{tabular}

Purpose of Disbursement

Travel Expense

Candidate Name

Office Sought:
Date of Disbursement

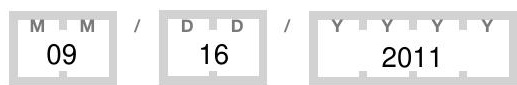

Transaction ID : BB2D244E75325493892F

Amount of Each Disbursement this Period 419.70

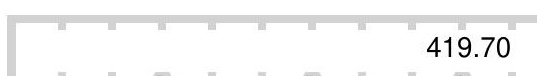

\section{B. Eagle Printing \& Graphics Inc.}

Mailing Address 16660 W National Avenue

\begin{tabular}{lcc}
\hline City & State & Zip Code \\
New Berlin & WI & 53151
\end{tabular}

Purpose of Disbursement

Printing

Candidate Name

\begin{tabular}{l|c} 
House & Disbursement For: 2012 \\
Senate & Primary \\
President & $\square$ General \\
Other (specify)
\end{tabular}

Category/ Type

Date of Disbursement

\begin{tabular}{|c|c|c|c|c|}
\hline $09^{M}$ & & ${ }^{\mathrm{D}}{ }^{\mathrm{D}}$ & 1 & 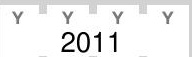 \\
\hline
\end{tabular}

Office Sought:

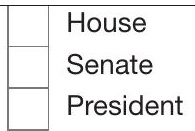

Disbursement For: 2012

Primary
Other (specify) General

State:

District:

Full Name (Last, First, Middle Initial)

c. S \& U Real Estate, LLC

Mailing Address 8530 New York Avenue

\begin{tabular}{lcc} 
& & \\
\hline City & State & Zip Code \\
Urbandale & IA & 50322
\end{tabular}

Purpose of Disbursement

Office Rent Expense

Candidate Name

Office Sought: $\quad$ House

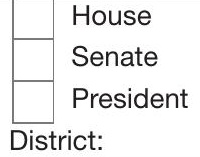

Disbursement For: 2012

X $\begin{aligned} & \text { Primary } \\ & \text { Other (specify) }\end{aligned}$

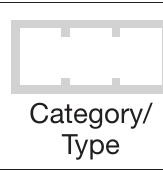

ype
Transaction ID : B5E8CB912C8C94E21AD0

Amount of Each Disbursement this Period

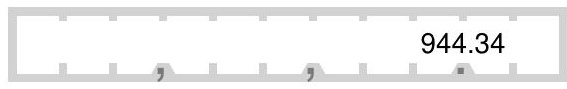

State:

District:

Subtotal Of Receipts This Page (optional).

Total This Period (last page this line number only))

\begin{tabular}{|c|c|c|c|c|c|c|}
\hline$M$ & M & D & Y & Y & Y \\
09 & & 16 & & 2011 & \\
\hline
\end{tabular}

Transaction ID : BF155CBAFDE2947B0A5E

Amount of Each Disbursement this Period 


\section{SCHEDULE B-P}

\section{ITEMIZED DISBURSEMENTS}

\section{Use separate schedule(s) \\ for each category of the}

Detailed Summary Page
FOR LINE NUMBER: (check only one)

\begin{tabular}{|c|c|c|c|}
\hline$X_{23}$ & 24 & 25 & 26 \\
\hline $27 \mathrm{~b}$ & $28 a$ & $28 b$ & $28 \mathrm{c}$ \\
\hline
\end{tabular}

Any information copied from such Reports and Statements may not be sold or used by any person for the purpose of soliciting contributions or for commercial purposes, other than using the name and address of any political committee to solicit contributions from such committee.

NAME OF COMMITTEE (In Full)

\section{Friends of Herman Cain}

Full Name (Last, First, Middle Initial)

A. Tri-C

Mailing Address 5169 Southridge Pkwy

Ste. 120

\begin{tabular}{lll}
\hline City & State & Zip Code \\
College Park & GA & 30349 \\
\hline
\end{tabular}

Purpose of Disbursement

Event Supplies

Candidate Name

Office Sought:

Full Name (Last, First, Middle Initial)

\section{B. Italian Oven Stockbridge GA}

Mailing Address 938 Eagles Landing Parkway

\begin{tabular}{lcc}
\hline City & State & Zip Code \\
Stockbridge & GA & 30281
\end{tabular}

Purpose of Disbursement

Meeting Expense

Candidate Name

Office Sought:

House
Senate
President

State:

District:
Date of Disbursement

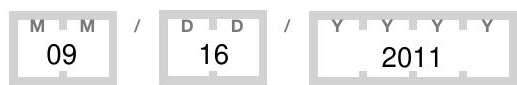

Transaction ID : B9976297EBA78489D945

Amount of Each Disbursement this Period 798.71
Date of Disbursement

\begin{tabular}{|c|c|c|c|c|}
\hline $09^{M}$ & 1 & $16^{\mathrm{D}}$ & 1 & 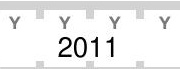 \\
\hline
\end{tabular}

Transaction ID : B392C0931EC4C49B3906

Amount of Each Disbursement this Period

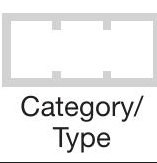
Disbursement For: 2012
Other (specify)
$\square$

Full Name (Last, First, Middle Initial)

c. Microtel Inn and Suites

Mailing Address 22 Sylvan Way

\begin{tabular}{lcc}
\hline City & State & Zip Code \\
Parsippany & NJ & 07054
\end{tabular}

Purpose of Disbursement

Travel Expense

Candidate Name

Office Sought:

State:
Date of Disbursement

\begin{tabular}{|c|c|c|c|c|c|c|}
\hline M & M & D & Y & Y & Y & Y \\
\hline & 16 & & 2011 & \\
\hline
\end{tabular}

Transaction ID : B568E9DB158834228B5C

Amount of Each Disbursement this Period

738.65

Subtotal Of Receipts This Page (optional).

Total This Period (last page this line number only))

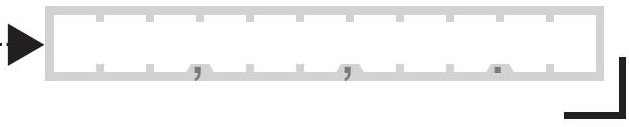




\section{SCHEDULE B-P}

\section{ITEMIZED DISBURSEMENTS}

\section{Use separate schedule(s)}

for each category of the

Detailed Summary Page
FOR LINE NUMBER: (check only one)

\begin{tabular}{|c|c|c|c|c|}
\hline$X_{23}$ & 24 & 25 & 26 & \\
\hline $27 \mathrm{~b}$ & $28 a$ & $28 b$ & $28 \mathrm{c}$ & 29 \\
\hline
\end{tabular}

Any information copied from such Reports and Statements may not be sold or used by any person for the purpose of soliciting contributions or for commercial purposes, other than using the name and address of any political committee to solicit contributions from such committee.

NAME OF COMMITTEE (In Full)

\section{Friends of Herman Cain}

Full Name (Last, First, Middle Initial)

A. Campaign Funding Direct, Inc.

Mailing Address 1420 Spring Hill Road

Suite 490

\begin{tabular}{lll} 
& & \\
\hline City & State & Zip Code \\
McLean & VA & 22102
\end{tabular}

Purpose of Disbursement

Direct Mail Production

Candidate Name

Office Sought:

\begin{tabular}{|l|l}
\hline & $\begin{array}{l}\text { House } \\
\text { Senate }\end{array}$ \\
& President \\
\hline & District:
\end{tabular}

Disbursement For: 2012 X Primary $\square$ General

State: District:

Full Name (Last, First, Middle Initial)

B. A \& S Properties Inc.

Mailing Address 255 Racetrack Road

\begin{tabular}{lcc}
\hline City & State & Zip Code \\
McDonough & GA & 30252
\end{tabular}

Purpose of Disbursement

Office Rent Expense

Candidate Name

Office Sought:

\begin{tabular}{|l|l} 
& House \\
& Senate \\
\cline { 1 - 2 } & President
\end{tabular}

Disbursement For: 2012

Primary
Other (specify) General

State:

District:

Full Name (Last, First, Middle Initial)

c. Direct Mail Processors Inc.

Mailing Address 1150 conrad Court

\begin{tabular}{lcc}
\hline City & State & Zip Code \\
Hagerstown & MD & 21740
\end{tabular}

Purpose of Disbursement

Direct Mail Production

Candidate Name

Office Sought: $\quad$ House

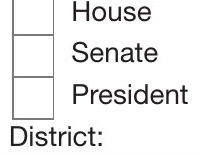

Disbursement For: 2012

X $\begin{aligned} & \text { Primary } \\ & \text { Other (specify) }\end{aligned}$

State:

District:

Subtotal Of Receipts This Page (optional)

Date of Disbursement

\begin{tabular}{|c|c|c|c|c|}
\hline $09^{M}$ & I & D $16^{\mathrm{D}}$ & I & 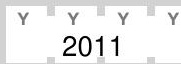 \\
\hline
\end{tabular}

Transaction ID : B592242160CFE44EDA36

Amount of Each Disbursement this Period

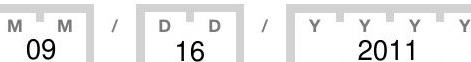

Transaction ID : B52CEC748B32C4F42BE9

Amount of Each Disbursement this Period

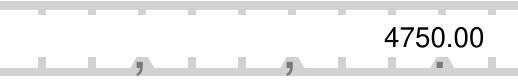

Date of Disbursement

Amount of Each Disbursement this Period 17999.01 


\section{SCHEDULE B-P}

\section{ITEMIZED DISBURSEMENTS}

\section{Use separate schedule(s) \\ for each category of the}

Detailed Summary Page
FOR LINE NUMBER: (check only one)

\begin{tabular}{|c|c|c|c|}
\hline$X_{23}$ & 24 & 25 & 26 \\
\hline $27 \mathrm{~b}$ & $28 a$ & $28 b$ & $28 \mathrm{c}$ \\
\hline
\end{tabular}

Any information copied from such Reports and Statements may not be sold or used by any person for the purpose of soliciting contributions or for commercial purposes, other than using the name and address of any political committee to solicit contributions from such committee.

NAME OF COMMITTEE (In Full)

\section{Friends of Herman Cain}

Full Name (Last, First, Middle Initial)

A. Tri-Net Payroll Services

Mailing Address 1100 San Leandro Boulevard

Suite

\begin{tabular}{lll}
\hline City & State & Zip Code \\
San Leandro & CA & 94577
\end{tabular}

Purpose of Disbursement

Payroll Service Fees

Candidate Name

Office Sought:

House
Senate
President
District:

Disbursement For: 2012

X Primary $\square$ General

State:

irst, Middle Initial)

\section{B. Tri-Net Payroll Services}

\begin{tabular}{ll}
\hline Mailing Address & $\begin{array}{l}1100 \text { San Leandro Boulevard } \\
\text { Suite }\end{array}$ \\
\hline City
\end{tabular}

San Leandro CA Zip Code

Purpose of Disbursement

Payroll Withholding

Candidate Name

Office Sought:

$$
\begin{array}{|l|l}
\text { House } \\
\text { Senate } \\
\text { President }
\end{array}
$$

State:

District:

\section{Primary $\square$ General
Other (specify) $\boldsymbol{\nabla}$}

Full Name (Last, First, Middle Initial)

c. Omega List Company Inc.

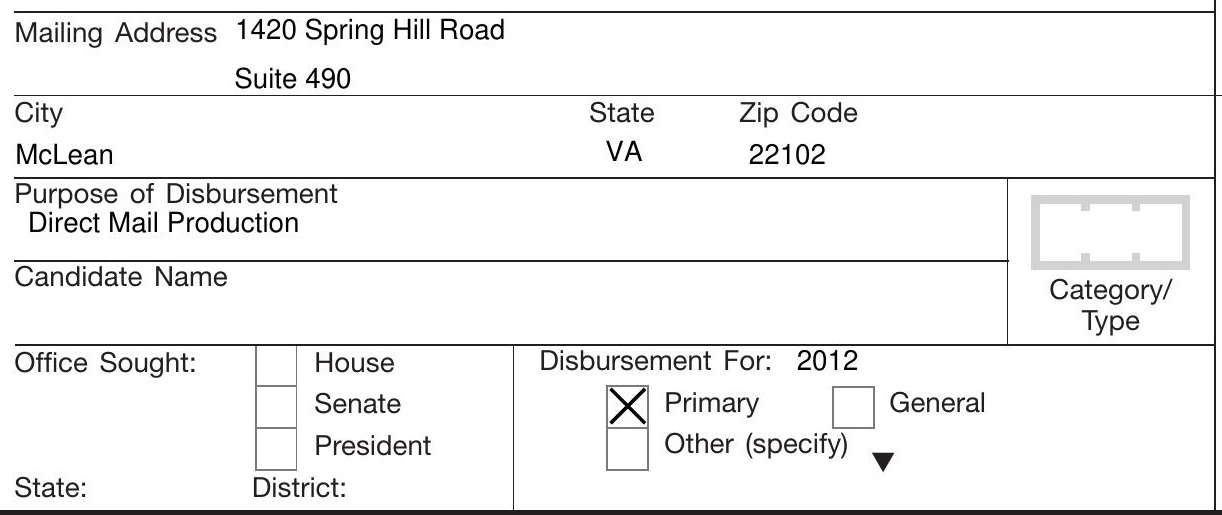

Subtotal Of Receipts This Page (optional).

Total This Period (last page this line number only))
Date of Disbursement

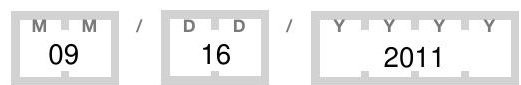

\section{Transaction ID : BD4E31798458B4F8190B}

Amount of Each Disbursement this Period

\begin{tabular}{|c|c|c|c|c|}
\hline${ }^{M} 9^{M}$ & 1 & ${ }^{D} 6^{\mathrm{D}}$ & 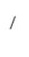 & 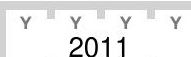 \\
\hline
\end{tabular}

3843.00

Date of Disbursement

Transaction ID : B0B4903819ACD40B7907

Amount of Each Disbursement this Period

5615.08

Date of Disbursement

\begin{tabular}{|c|c|c|c|c|c|c|}
\hline M & M & D & Y & Y & Y & Y \\
\hline & 16 & & 2011 & \\
\hline
\end{tabular}

Transaction ID : BC24310325C514BDD800

Amount of Each Disbursement this Period

18879.07

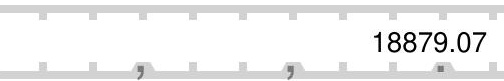

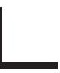

28337.15

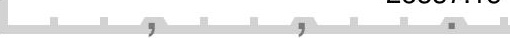

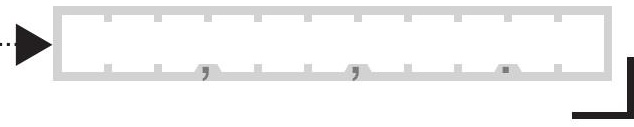

FEC Schedule B-P (Form 3P) (Rev. 03/2011) 


\section{SCHEDULE B-P}

\section{ITEMIZED DISBURSEMENTS}

Use separate schedule(s)

for each category of the

Detailed Summary Page
FOR LINE NUMBER: (check only one)

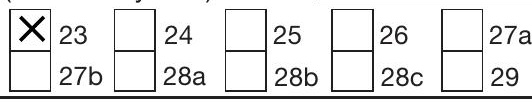

Any information copied from such Reports and Statements may not be sold or used by any person for the purpose of soliciting contributions or for commercial purposes, other than using the name and address of any political committee to solicit contributions from such committee.

NAME OF COMMITTEE (In Full)

\section{Friends of Herman Cain}

Full Name (Last, First, Middle Initial)

A. DirectMail.com

Mailing Address 201 Skipjack Road

Date of Disbursement

\begin{tabular}{lll}
\hline City & State & Zip Code \\
Prince Frederick & MD & 20678 \\
\hline Purpose of Disbursement & &
\end{tabular}

Direct Mail Productionent

Candidate Name

Office Sought:

\begin{tabular}{|l|l} 
& $\begin{array}{l}\text { House } \\
\text { Senate } \\
\text { President }\end{array}$ \\
\hline District:
\end{tabular}

Disbursement For: 2012 X Primary $\square$ General

State: District:

Full Name (Last, First, Middle Initial)

B. Inkhead Inc.

\begin{tabular}{|c|c|c|c|c|}
\hline \multicolumn{5}{|c|}{$\begin{array}{ll}\text { Mailing Address } & 138 \text { Park Avenue } \\
& \text { Suite } 300\end{array}$} \\
\hline \multicolumn{2}{|c|}{ City } & \multicolumn{2}{|c|}{ Zip Code } & \\
\hline \multicolumn{2}{|l|}{ Winder } & \multicolumn{3}{|c|}{30680} \\
\hline \multicolumn{4}{|c|}{$\begin{array}{l}\text { Purpose of Disbursement } \\
\text { Event Supplies }\end{array}$} & \\
\hline \multicolumn{4}{|l|}{ Candidate Name } & $\begin{array}{l}\text { Category/ } \\
\text { Type }\end{array}$ \\
\hline \multirow[t]{3}{*}{ Office Sought: } & House & \multirow{4}{*}{\multicolumn{3}{|c|}{ Disbursement For: 2012}} \\
\hline & Senate & & & \\
\hline & President & & & \\
\hline State: & District: & & & \\
\hline
\end{tabular}

Date of Disbursement

\begin{tabular}{|c|c|c|c|c|}
\hline $09^{M}$ & 1 & ${ }^{\mathrm{D}}{ }^{\mathrm{D}}$ & 1 & 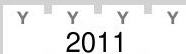 \\
\hline
\end{tabular}

Transaction ID : B89F3472B4C874A64BDA

Full Name (Last, First, Middle Initial)

\section{c. Mobilization Labs LLC}

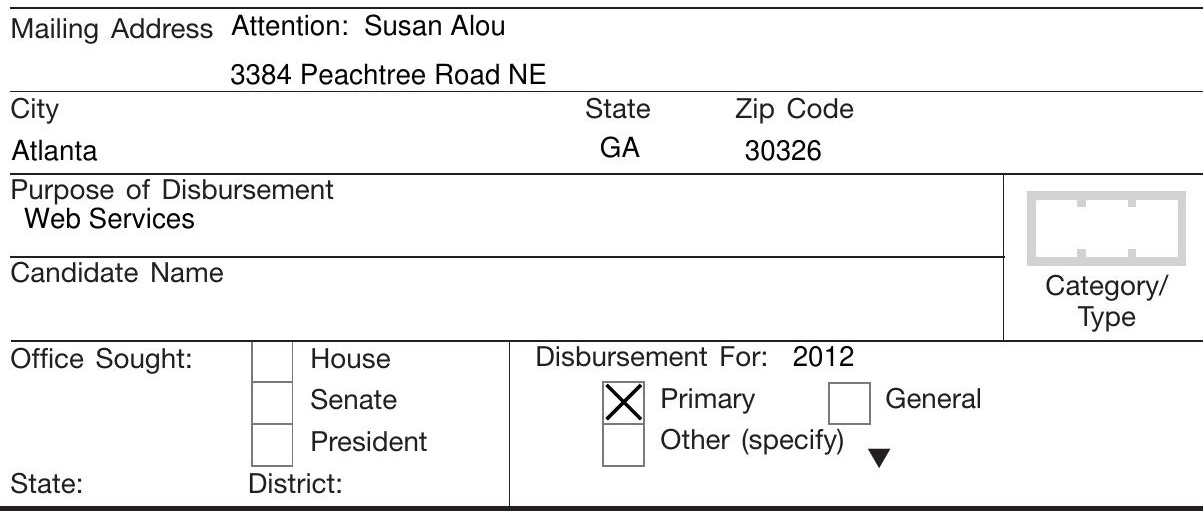

Subtotal Of Receipts This Page (optional).

Date of Disbursement

\begin{tabular}{|c|c|c|c|c|}
\hline $09^{M}$ & I & D $16^{\mathrm{D}}$ & 1 & 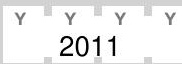 \\
\hline
\end{tabular}

\section{Transaction ID : B93B24774504340AB91E}

Amount of Each Disbursement this Period

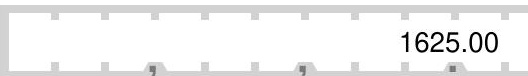

Total This Period (last page this line number only)) 


\section{SCHEDULE B-P}

\section{ITEMIZED DISBURSEMENTS}

Use separate schedule(s)

for each category of the

Detailed Summary Page
FOR LINE NUMBER: (check only one)

\begin{tabular}{|c|c|c|c|}
\hline$\times{ }_{23}$ & 24 & 25 & 26 \\
\hline $27 b$ & $28 a$ & $28 \mathrm{~b}$ & $28 \mathrm{c}$ \\
\hline
\end{tabular}

Any information copied from such Reports and Statements may not be sold or used by any person for the purpose of soliciting contributions or for commercial purposes, other than using the name and address of any political committee to solicit contributions from such committee.

NAME OF COMMITTEE (In Full)

\section{Friends of Herman Cain}

Full Name (Last, First, Middle Initial)

A. Catch the Glory, LLC

Mailing Address 16 Lowell Street

Date of Disbursement

\begin{tabular}{lll}
\hline City & State & Zip Code \\
Manchester & NH & 03101
\end{tabular}

Purpose of Disbursement

Office Rent Expense

Candidate Name

Office Sought:

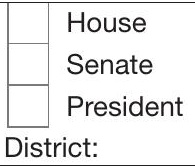

Disbursement For: 2012 X Primary $\square$ General

State:

District:

Full Name (Last, First, Middle Initial)

B. Air Tran

Mailing Address 9955 Air Tran Boulevard

\begin{tabular}{lcc}
\hline City & State & Zip Code \\
Orlando & FL & 32827
\end{tabular}

Purpose of Disbursement

Travel Expense

Candidate Name

Office Sought:

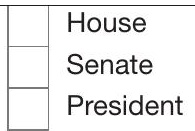

State:

District:

Full Name (Last, First, Middle Initial)

c. Michelle Gwaltney

Mailing Address 123 Glen Eagle Way

\begin{tabular}{lcc}
\hline City & State & Zip Code \\
McDonough & GA & $30253-4229$
\end{tabular}

Purpose of Disbursement

Staff Salary

Candidate Name

Office Sought: $\quad$ House

\begin{tabular}{|l|l|} 
& House \\
& Senate \\
& President
\end{tabular}

State:

District:

Subtotal Of Receipts This Page (optional).

Disbursement For: 2012

Х $\begin{aligned} & \text { Primary } \\ & \text { Other (specify) }\end{aligned}$

$\mathrm{FL}$ 32827
Date of Disbursement

\begin{tabular}{|c|c|c|c|c|}
\hline $09^{M}$ & 1 & ${ }^{\mathrm{D}}{ }^{\mathrm{D}}$ & 1 & 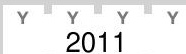 \\
\hline
\end{tabular}

Transaction ID : BB3B8EE3723804DA794E

Amount of Each Disbursement this Period

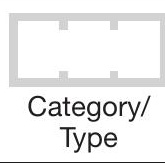
Disbursement For: 2012
$X$ Primary
Other (specify) Type

Date of Disbursement

\begin{tabular}{|c|c|c|c|c|c|c|}
\hline M & M & D & Y & Y & Y & Y \\
\hline & 16 & & 2011 & \\
\hline
\end{tabular}

Transaction ID : BB71D3440E0064351A99

Amount of Each Disbursement this Period

2916.67

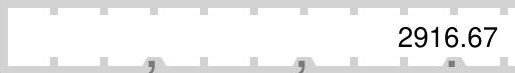

Total This Period (last page this line number only)) 


\section{SCHEDULE B-P}

\section{ITEMIZED DISBURSEMENTS}

Use separate schedule(s)

for each category of the

Detailed Summary Page
FOR LINE NUMBER: (check only one)

\begin{tabular}{|c|c|c|c|}
\hline$\times{ }_{23}$ & 24 & 25 & 26 \\
\hline $27 b$ & $28 a$ & $28 \mathrm{~b}$ & $28 \mathrm{c}$ \\
\hline
\end{tabular}

Any information copied from such Reports and Statements may not be sold or used by any person for the purpose of soliciting contributions or for commercial purposes, other than using the name and address of any political committee to solicit contributions from such committee.

NAME OF COMMITTEE (In Full)

\section{Friends of Herman Cain}

Full Name (Last, First, Middle Initial)

A. Lisa Lockwood

Mailing Address 12746 Ford Trail South

Date of Disbursement

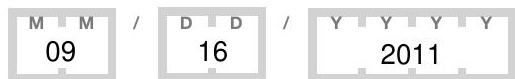

Transaction ID : B60C34B2062454DFEA8B

$\begin{array}{lcc}\text { City } & \text { State } & \text { Zip Code } \\ \text { Indianola } & \text { IA } & 50125-8931\end{array}$

Purpose of Disbursement

Staff Salary

Candidate Name

\begin{tabular}{l|l|l}
\hline Office Sought: & House & Disbursement For: 2012
\end{tabular} X Primary $\square$ General

State: District:

Full Name (Last, First, Middle Initial)

\section{B. Lisa Shiflett}

Mailing Address 157 Stokes Drive

\begin{tabular}{lcc}
\hline City & State & Zip Code \\
Stockbridge & GA & $30281-1376$
\end{tabular}

Purpose of Disbursement

Staff Salary

Candidate Name

Office Sought:

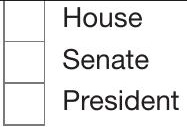

Disbursement For: 2012

Primary
Other (specify) General

State:

District:

Full Name (Last, First, Middle Initial)

c. Sandra Poehler

Mailing Address 57 Presidential Drive

Apartment 5

\begin{tabular}{lcc}
\hline City & State & Zip Code \\
Quincy & MA & $02169-8838$
\end{tabular}

Purpose of Disbursement

Staff Salary

Candidate Name

Office Sought: $\quad$ House

\begin{tabular}{|l|l|} 
& House \\
Senate \\
President
\end{tabular}

Disbursement For: 2012

Х $\begin{aligned} & \text { Primary } \\ & \text { Other (specify) }\end{aligned}$

State:

District:
Date of Disbursement

\begin{tabular}{|c|c|c|c|c|}
\hline $09^{\mathrm{M}}$ & & ${ }^{D}{ }^{\mathrm{D}}$ & 1 & $\begin{array}{llll}Y & Y & Y & Y \\
& 2011\end{array}$ \\
\hline
\end{tabular}

Transaction ID : B9C8D3E73FD8F4F6A944

Amount of Each Disbursement this Period

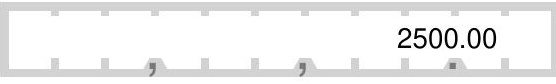

Date of Disbursement

\begin{tabular}{|c|c|c|c|c|}
\hline $09^{M}$ & 1 & D 16 & I & 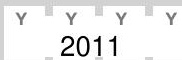 \\
\hline
\end{tabular}

Transaction ID : B95C3D102AFCF40EFB99

Amount of Each Disbursement this Period

1000.00

Subtotal Of Receipts This Page (optional)

Total This Period (last page this line number only))

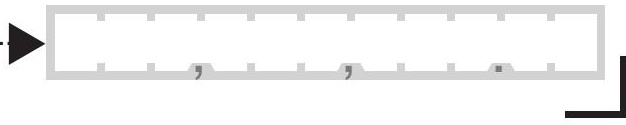




\section{SCHEDULE B-P}

\section{ITEMIZED DISBURSEMENTS}

Use separate schedule(s)

for each category of the

Detailed Summary Page
FOR LINE NUMBER: (check only one)

\begin{tabular}{|c|c|c|c|}
\hline$\times \quad 23$ & 24 & 25 & 26 \\
\hline $27 \mathrm{~b}$ & $28 \mathrm{a}$ & $28 b$ & $28 \mathrm{c}$ \\
\hline
\end{tabular}

Any information copied from such Reports and Statements may not be sold or used by any person for the purpose of soliciting contributions or for commercial purposes, other than using the name and address of any political committee to solicit contributions from such committee.

NAME OF COMMITTEE (In Full)

\section{Friends of Herman Cain}

Full Name (Last, First, Middle Initial)

A. Michael Johnson

Mailing Address 8225 W. Center St. Apt. 3

Date of Disbursement

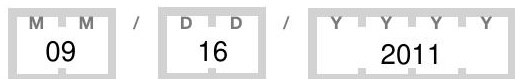

Transaction ID : BD5E95609734848F6ABF

\begin{tabular}{lcc}
\hline City & State & Zip Code \\
Milwaukee & WI & $53222-4861$
\end{tabular}

Purpose of Disbursement

Staff Salary

Candidate Name

\begin{tabular}{l|l|l}
\hline Office Sought: & House & Disbursement For: 2012
\end{tabular} X Primary $\square$ General

State: Senate President District:

Full Name (Last, First, Middle Initial)

B. Raquel Rhada Hirsch

Mailing Address 6825 N 2nd Place

\begin{tabular}{lcc}
\hline City & State & Zip Code \\
Scottsdale & AZ & 85250
\end{tabular}

Purpose of Disbursement

Staff Salary

Candidate Name

Office Sought:

House
Senate
President

State:

District:

Full Name (Last, First, Middle Initial)

c. Karis McKinney

Mailing Address 5017 N. 50th Street

\begin{tabular}{lcc}
\hline City & State & Zip Code \\
Milwaukee & WI & $53218-4326$
\end{tabular}

Purpose of Disbursement

Staff Salary

Candidate Name

Disbursement For: 2012

Primary
Other (specify)

Office Sought:

\begin{tabular}{|l|l|}
\hline & House \\
& Senate \\
& President \\
& District:
\end{tabular}

Disbursement For: 2012

Х $\begin{aligned} & \text { Primary } \\ & \text { Other (specify) }\end{aligned}$
Date of Disbursement

\begin{tabular}{|c|c|c|c|c|}
\hline $09^{M}$ & 1 & ${ }^{\mathrm{D}} 16^{\mathrm{D}}$ & I & 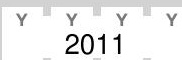 \\
\hline
\end{tabular}

Transaction ID : BFD701BC66FEF4C7F91A

Amount of Each Disbursement this Period
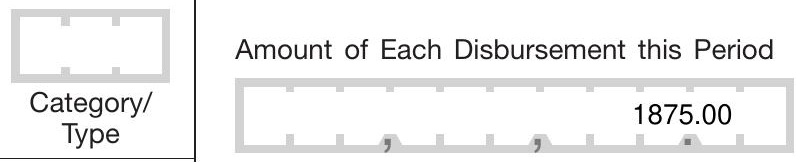

Date of Disbursement

\begin{tabular}{|c|c|c|c|c|}
\hline $09^{M}$ & I & D $16^{\mathrm{D}}$ & I & 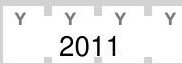 \\
\hline
\end{tabular}

Transaction ID : B62EDA2C2BC164D6E913

Amount of Each Disbursement this Period

1875.00 Type

State:

Subtotal Of Receipts This Page (optional).

Total This Period (last page this line number only))

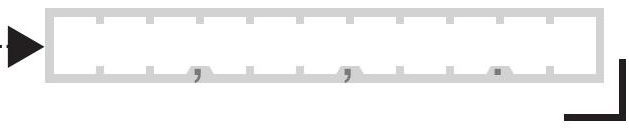




\section{SCHEDULE B-P}

\section{ITEMIZED DISBURSEMENTS}

\section{Use separate schedule(s) \\ for each category of the}

Detailed Summary Page
FOR LINE NUMBER: (check only one)

\begin{tabular}{|c|c|c|c|}
\hline$\times{ }_{23}$ & 24 & 25 & 26 \\
\hline $27 b$ & $28 a$ & $28 \mathrm{~b}$ & $28 \mathrm{c}$ \\
\hline
\end{tabular}

Any information copied from such Reports and Statements may not be sold or used by any person for the purpose of soliciting contributions or for commercial purposes, other than using the name and address of any political committee to solicit contributions from such committee.

NAME OF COMMITTEE (In Full)

\section{Friends of Herman Cain}

Full Name (Last, First, Middle Initial)

A. Donald Henry

Mailing Address PO Box 2158

Date of Disbursement

\begin{tabular}{lcc}
\hline City & State & Zip Code \\
Stockbridge & GA & $30281-8909$
\end{tabular}

Purpose of Disbursement

Staff Salary

Candidate Name

Office Sought: $\quad$ House

Senate

President

State:

District:

Full Name (Last, First, Middle Initial)

B. William Head

Mailing Address PO Box 2158

\begin{tabular}{lcc}
\hline City & State & Zip Code \\
Stockbridge & GA & $30281-8909$
\end{tabular}

Disbursement For: 2012

X Primary $\square$ General

Purpose of Disbursement

Staff Salary

Candidate Name

Office Sought:

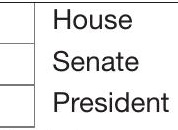

State:

District:

GA

Full Name (Last, First, Middle Initial)

c. Joel Ricks

Mailing Address 3073 Meadowlark Lane

\begin{tabular}{lcc}
\hline City & State & Zip Code \\
East Point & GA & 30344 \\
\hline
\end{tabular}

Purpose of Disbursement

Office Maintenance

Candidate Name

\begin{tabular}{l|l|l}
\hline Office Sought: & House
\end{tabular}

\begin{tabular}{l|l} 
& House \\
& Senate \\
& President \\
\hline & District:
\end{tabular}

State:

District:
Disbursement For: 2012

Xrimary $\square$ General
Date of Disbursement

\begin{tabular}{|c|c|c|c|c|}
\hline $09^{M}$ & 1 & ${ }_{16}^{\mathrm{D}}$ & 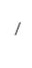 & $\begin{array}{llll}Y & Y & Y & Y \\
& 2011\end{array}$ \\
\hline
\end{tabular}

Transaction ID : BAA84B4A4856F4093819

Amount of Each Disbursement this Period

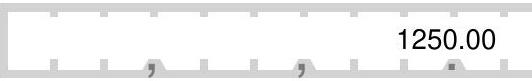

Date of Disbursement

\begin{tabular}{|c|c|c|c|c|}
\hline $09^{M}$ & I & $16^{\mathrm{D}}$ & I & $\begin{array}{cccc} & Y & Y & Y \\
& 2011 & \end{array}$ \\
\hline
\end{tabular}

Transaction ID : B36CEE2D118FE492E9B4

Amount of Each Disbursement this Period

900.00

Subtotal Of Receipts This Page (optional).

Total This Period (last page this line number only))

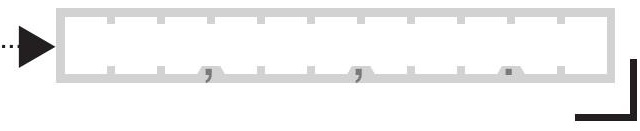




\section{SCHEDULE B-P}

\section{ITEMIZED DISBURSEMENTS}

\section{Use separate schedule(s) \\ for each category of the}

Detailed Summary Page
FOR LINE NUMBER: (check only one)

\begin{tabular}{|c|c|c|c|}
\hline$\times{ }_{23}$ & 24 & 25 & 26 \\
\hline $27 b$ & $28 a$ & $28 \mathrm{~b}$ & $28 \mathrm{c}$ \\
\hline
\end{tabular}

Any information copied from such Reports and Statements may not be sold or used by any person for the purpose of soliciting contributions or for commercial purposes, other than using the name and address of any political committee to solicit contributions from such committee.

NAME OF COMMITTEE (In Full)

\section{Friends of Herman Cain}

Full Name (Last, First, Middle Initial)

A. Stacy DeJarnette

Mailing Address 207 Robin Street

Date of Disbursement

\begin{tabular}{lcc}
\hline City & State & Zip Code \\
White Hall & AR & $71602-5418$
\end{tabular}

Purpose of Disbursement

Staff Salary

Candidate Name

\begin{tabular}{l|l|l}
\hline Office Sought: & House & Disbursement For: 2012
\end{tabular} X Primary $\square$ General

State:

\section{Senate}

President

District:

Full Name (Last, First, Middle Initial)

B. Nathan Naidu

Mailing Address 3601 canton rd \#131

\begin{tabular}{lcc}
\hline City & State & Zip Code \\
Marietta & GA & $30066-2892$
\end{tabular}

Purpose of Disbursement

Staff Salary

Candidate Name

Office Sought:

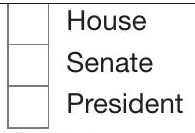

State:

District:

GA

Full Name (Last, First, Middle Initial)

c. Ellen Carmichael

Mailing Address 1007 Oak Hills Parkway

\begin{tabular}{lcc}
\hline City & State & Zip Code \\
Baton Rouge & LA & $70810-4705$
\end{tabular}

Purpose of Disbursement

Staff Salary

Candidate Name

Office Sought:

State:

\begin{tabular}{|c|}
\hline House \\
\hline Senate \\
\hline President \\
\hline
\end{tabular}

Disbursement For: 2012

Х $\begin{aligned} & \text { Primary } \\ & \text { Other (specify) }\end{aligned}$
Date of Disbursement

\begin{tabular}{|c|c|c|c|c|}
\hline $09^{M}$ & 1 & ${ }_{16}^{\mathrm{D}}$ & 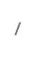 & $\begin{array}{llll}Y & Y & Y & Y \\
& 2011\end{array}$ \\
\hline
\end{tabular}

Transaction ID : B82DD389F04C84D6B8EC

Amount of Each Disbursement this Period

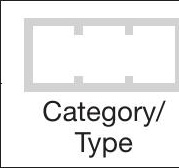
Disbursement For: 2012
Primary
Other (specify) Type

Date of Disbursement

\begin{tabular}{|c|c|c|c|c|c|c|}
\hline M & M & D & Y & $Y$ & $Y$ \\
09 & 16 & & 2011 & \\
\hline
\end{tabular}

Transaction ID : B026BA02CB4A847D3884

Amount of Each Disbursement this Period

2250.00

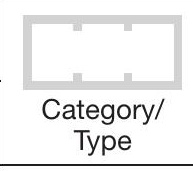

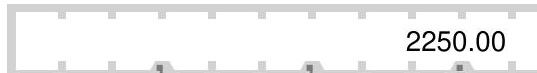

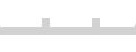




\section{ITEMIZED DISBURSEMENTS}

\section{SCHEDULE B-P}

Use separate schedule(s)

for each category of the

Detailed Summary Page
FOR LINE NUMBER: (check only one)

PAGE 1485 / 1572

\begin{tabular}{|c|c|c|c|}
\hline$X_{23}$ & 24 & 25 & 26 \\
\hline $27 \mathrm{~b}$ & $28 a$ & $28 \mathrm{~b}$ & $28 \mathrm{c}$ \\
\hline
\end{tabular}

Any information copied from such Reports and Statements may not be sold or used by any person for the purpose of soliciting contributions or for commercial purposes, other than using the name and address of any political committee to solicit contributions from such committee.

NAME OF COMMITTEE (In Full)

\section{Friends of Herman Cain}

Full Name (Last, First, Middle Initial)

A. Karleen Smith

Mailing Address 105 Marilyn Drive E

\begin{tabular}{lcc}
\hline City & State & Zip Code \\
Fayetteville & GA & 30214 \\
\hline Purpose of Disbursement & &
\end{tabular}

Purpose of Disbursement

Staff Salary

Candidate Name

\begin{tabular}{l|l|l}
\hline Office Sought: & House & Disbursement For: 2012
\end{tabular} X Primary $\square$ General

State:

\section{Senate}

President

District:

Full Name (Last, First, Middle Initial)

B. Ashley Frasca

Mailing Address 601 Springharbor Drive

\begin{tabular}{lcc}
\hline City & State & Zip Code \\
Woodstock & GA & $30188-6044$
\end{tabular}

Purpose of Disbursement

Staff Salary

Candidate Name

Office Sought:

House
Senate
President

State:

District:

Full Name (Last, First, Middle Initial)

c. Zachary Dalluge

Mailing Address 506 3rd Street

\begin{tabular}{lcc}
\hline City & State & Zip Code \\
Grafton & IA & $50440-7570$
\end{tabular}

Purpose of Disbursement

Staff Salary

Candidate Name

Disbursement For: 2012

Xrimary $\square$ General

Office Sought:

\begin{tabular}{|l|l|} 
& House \\
& Senate \\
& President \\
& \\
District:
\end{tabular}

Disbursement For: 2012

Х $\begin{aligned} & \text { Primary } \\ & \text { Other (specify) }\end{aligned}$
Date of Disbursement

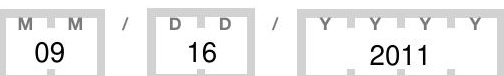

Transaction ID : BEA7F4C426B3A461CA80

Amount of Each Disbursement this Period 3000.00

Date of Disbursement

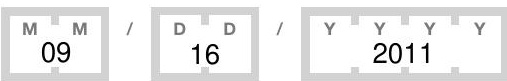

Transaction ID : BA1C2A5DC098C4E66AD3

Amount of Each Disbursement this Period

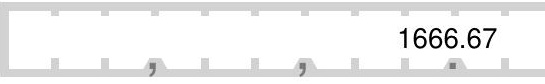

Date of Disbursement

\begin{tabular}{|c|c|c|c|c|c|c|}
\hline M & M & D & Y & Y & Y & Y \\
09 & & 16 & & 2011 & \\
\hline
\end{tabular}

Transaction ID : BA08DEE80D0ED407F803

Amount of Each Disbursement this Period

1250.00
State:

District:

Subtotal Of Receipts This Page (optional).

Total This Period (last page this line number only))

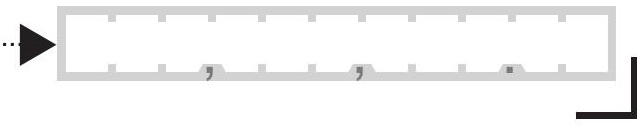




\section{SCHEDULE B-P}

\section{ITEMIZED DISBURSEMENTS}

Use separate schedule(s)

for each category of the

Detailed Summary Page
FOR LINE NUMBER: (check only one)

\begin{tabular}{|c|c|c|c|}
\hline$\times{ }_{23}$ & 24 & 25 & 26 \\
\hline $27 b$ & $28 a$ & $28 \mathrm{~b}$ & $28 \mathrm{c}$ \\
\hline
\end{tabular}

Any information copied from such Reports and Statements may not be sold or used by any person for the purpose of soliciting contributions or for commercial purposes, other than using the name and address of any political committee to solicit contributions from such committee.

NAME OF COMMITTEE (In Full)

\section{Friends of Herman Cain}

Full Name (Last, First, Middle Initial)

A. J Ryan Hudson

Mailing Address 418 Landing Pointe

Date of Disbursement

\begin{tabular}{lcc}
\hline City & State & Zip Code \\
Stockbridge & GA & 30281 \\
\hline Purpose of
\end{tabular}

Purpose of Disbursement

Staff Salary

Candidate Name

Office Sought: $\quad$ House

Senate

President

State:

District:

Full Name (Last, First, Middle Initial)

\section{B. Charles Spano}

Mailing Address PO Box 2158

\begin{tabular}{lcc}
\hline City & State & Zip Code \\
Stockbridge & GA & $30281-8909$
\end{tabular}

Disbursement For: 2012

X Primary $\square$ General

Purpose of Disbursement

Staff Salary

Candidate Name

Office Sought:

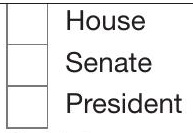

State:

District:

GA

Full Name (Last, First, Middle Initial)

\section{c. Brenda Hicks}

Mailing Address 3653 S 75th Street

\begin{tabular}{lcc}
\hline City & State & Zip Code \\
Milwaukee & WI & $53220-1139$
\end{tabular}

Purpose of Disbursement

Staff Salary

Candidate Name

Office Sought:

State:

\begin{tabular}{|l|l|}
\hline & House \\
& Senate \\
& President \\
\hline District:
\end{tabular}

Disbursement For: 2012

Х $\begin{aligned} & \text { Primary } \\ & \text { Other (specify) }\end{aligned}$
Date of Disbursement

\begin{tabular}{|c|c|c|c|c|}
\hline $09^{M}$ & 1 & ${ }^{\mathrm{D}}{ }^{\mathrm{D}}$ & 1 & 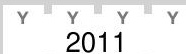 \\
\hline
\end{tabular}

Transaction ID : BED2E1CCCC1154898920

Amount of Each Disbursement this Period

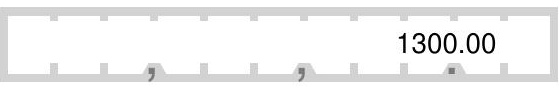

Date of Disbursement

\begin{tabular}{|c|c|c|c|c|}
\hline $09^{M}$ & 1 & D 16 & 1 & 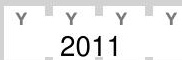 \\
\hline
\end{tabular}

Transaction ID : B13967A09F1584F19AB1

Amount of Each Disbursement this Period

2000.00

Subtotal Of Receipts This Page (optional).

Total This Period (last page this line number only)) 


\section{SCHEDULE B-P}

\section{ITEMIZED DISBURSEMENTS}

\section{Use separate schedule(s)}

for each category of the

Detailed Summary Page
FOR LINE NUMBER: (check only one)

\begin{tabular}{|c|c|c|c|}
\hline$\times{ }_{23}$ & 24 & 25 & 26 \\
\hline $27 b$ & $28 a$ & $28 \mathrm{~b}$ & $28 \mathrm{c}$ \\
\hline
\end{tabular}

Any information copied from such Reports and Statements may not be sold or used by any person for the purpose of soliciting contributions or for commercial purposes, other than using the name and address of any political committee to solicit contributions from such committee.

NAME OF COMMITTEE (In Full)

\section{Friends of Herman Cain}

Full Name (Last, First, Middle Initial)

\section{A. Scott Sidney}

Mailing Address N40 W6522 Jackson Street

Date of Disbursement

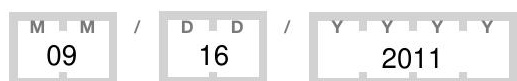

Transaction ID : B97576CF270CA4072BBA

\begin{tabular}{lcc}
\hline City & State & Zip Code \\
Cedarburg & WI & $53012-2317$
\end{tabular}

Purpose of Disbursement

Staff Salary

Candidate Name

\begin{tabular}{l|l|l}
\hline Office Sought: & House & Disbursement For: 2012
\end{tabular} Xrimary $\square$ General

State:

\section{Senate}

President

District:

Full Name (Last, First, Middle Initial)

B. Larry Tuel

Mailing Address 5129 Welker Ave.

\begin{tabular}{lcc}
\hline City & State & Zip Code \\
Des Moines & IA & $50312-2159$
\end{tabular}

Purpose of Disbursement

Staff Salary

Candidate Name

Office Sought:

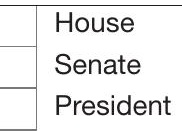

State:

District:

Full Name (Last, First, Middle Initial)

C. Michael Branch

Mailing Address 509 Autumnwood Ct

\begin{tabular}{lcc}
\hline City & State & Zip Code \\
Nashville & TN & $37221-3938$
\end{tabular}

Purpose of Disbursement

Staff Salary

Candidate Name

Disbursement For: 2012

Primary $\square$ General
Other (specify)

Office Sought:

\begin{tabular}{|c|}
\hline House \\
\hline Senate \\
\hline President \\
\hline
\end{tabular}

Disbursement For: 2012

Х $\begin{aligned} & \text { Primary } \\ & \text { Other (specify) }\end{aligned}$
Date of Disbursement

\begin{tabular}{|c|c|c|c|c|}
\hline${ }^{M}$ & ${ }^{M}$ & $9^{\mathrm{D}}$ & ${ }^{\mathrm{D}}$ & $\mathrm{Y}^{\mathrm{Y}}$ \\
\hline
\end{tabular}

Transaction ID : B1ECE7C52D58046EAB59

Amount of Each Disbursement this Period
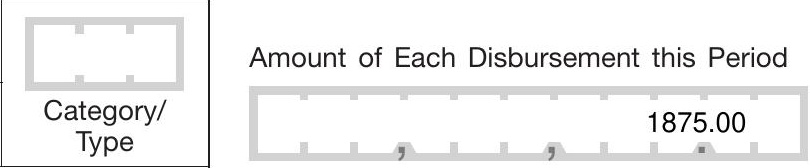

Date of Disbursement

\begin{tabular}{|c|c|c|c|c|}
\hline $09^{M}$ & I & D $16^{\mathrm{D}}$ & I & 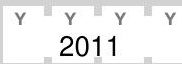 \\
\hline
\end{tabular}

Transaction ID : B6A976F60AABC45B895D

Amount of Each Disbursement this Period

1875.00
State:

District:

Subtotal Of Receipts This Page (optional)

Total This Period (last page this line number only))

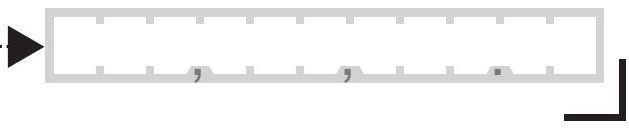




\section{SCHEDULE B-P}

\section{ITEMIZED DISBURSEMENTS}

\section{Use separate schedule(s) \\ for each category of the}

Detailed Summary Page
FOR LINE NUMBER: (check only one)

\begin{tabular}{|c|c|c|c|}
\hline$\times{ }_{23}$ & 24 & 25 & 26 \\
\hline $27 b$ & $28 a$ & $28 \mathrm{~b}$ & $28 \mathrm{c}$ \\
\hline
\end{tabular}

Any information copied from such Reports and Statements may not be sold or used by any person for the purpose of soliciting contributions or for commercial purposes, other than using the name and address of any political committee to solicit contributions from such committee.

NAME OF COMMITTEE (In Full)

\section{Friends of Herman Cain}

Full Name (Last, First, Middle Initial)

A. Scott F. Bieniek

Mailing Address 1782 Schooling Road

Date of Disbursement

\begin{tabular}{lcc}
\hline City & State & Zip Code \\
Spencer & IN & $47460-7528$
\end{tabular}

Purpose of Disbursement

Staff Salary

Candidate Name

\begin{tabular}{l|l|l}
\hline Office Sought: & House & Disbursement For: 2012
\end{tabular} X Primary $\square$ General

State:

\section{Senate}

President

District:

Full Name (Last, First, Middle Initial)

B. Mark Block

Mailing Address 18125 West Plateau Lane

\begin{tabular}{lcc}
\hline City & State & Zip Code \\
New Berlin & WI & $53146-5116$
\end{tabular}

Purpose of Disbursement

Staff Salary

Candidate Name

Office Sought:

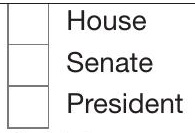

State:

District:

Full Name (Last, First, Middle Initial)

\section{c. Steven Hensler}

Mailing Address 401 Woodview Drive

\begin{tabular}{lcc}
\hline City & State & Zip Code \\
Sun Prairie & WI & $53590-2353$
\end{tabular}

Purpose of Disbursement

Staff Salary

Candidate Name

Disbursement For: 2012

Xrimary $\square$ General

Office Sought:

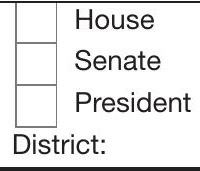

Disbursement For: 2012

Х $\begin{aligned} & \text { Primary } \\ & \text { Other (specify) }\end{aligned}$

State:

District:

Subtotal Of Receipts This Page (optional)

Date of Disbursement

\begin{tabular}{|c|c|c|c|c|}
\hline $09^{M}$ & 1 & ${ }^{\mathrm{D}} 16^{\mathrm{D}}$ & I & 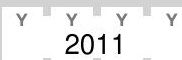 \\
\hline
\end{tabular}

Transaction ID : BD16BD1323C11450F9E4

Amount of Each Disbursement this Period
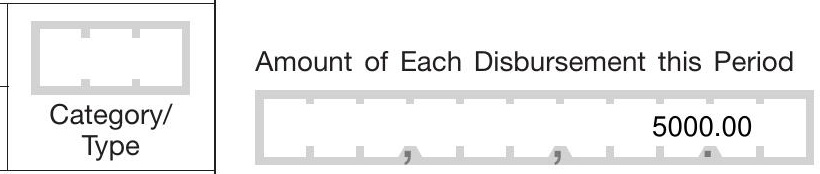

Date of Disbursement

\begin{tabular}{|c|c|c|c|c|c|}
\hline$M^{M}$ & $/$ & $\mathrm{D}$ & $\mathrm{Y}$ & $\mathrm{Y}$ & $\mathrm{Y}$ \\
09 & & 16 & & 2011 & \\
\hline
\end{tabular}

Transaction ID : B92DCE8C6BC674A7BA61

Amount of Each Disbursement this Period

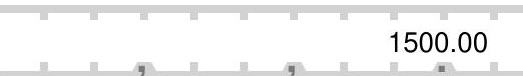

1500.00

Total This Period (last page this line number only)) 


\section{SCHEDULE B-P}

\section{ITEMIZED DISBURSEMENTS}

Use separate schedule(s)

for each category of the

Detailed Summary Page
FOR LINE NUMBER: (check only one)

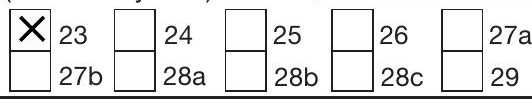

Any information copied from such Reports and Statements may not be sold or used by any person for the purpose of soliciting contributions or for commercial purposes, other than using the name and address of any political committee to solicit contributions from such committee.

NAME OF COMMITTEE (In Full)

\section{Friends of Herman Cain}

Full Name (Last, First, Middle Initial)

A. Tina Spratling

Mailing Address PO Box 2158

Date of Disbursement

\begin{tabular}{lcc}
\hline City & State & Zip Code \\
Stockbridge & GA & $30281-8909$
\end{tabular}

Purpose of Disbursement

Staff Salary

Candidate Name

\begin{tabular}{l|l|l}
\hline Office Sought: & House & Disbursement For: 2012
\end{tabular} Xrimary $\square$ General

State:

\section{Senate}

President

District:

Full Name (Last, First, Middle Initial)

B. Francis Boustany, III

Mailing Address 126 Westfield Drive

\begin{tabular}{lcc}
\hline City & State & Zip Code \\
Lafayette & LA & $70503-5484$
\end{tabular}

Purpose of Disbursement

Staff Salary

Candidate Name

Office Sought:

House
Senate
President

State:

District:

LA

Full Name (Last, First, Middle Initial)

c. Christopher Kenworthy

Mailing Address PO Box 2158

\begin{tabular}{lcc}
\hline City & State & Zip Code \\
Stockbridge & GA & $30281-8909$
\end{tabular}

Purpose of Disbursement

Staff Salary

Candidate Name

Office Sought: $\quad$ House

$\begin{aligned} & \text { House } \\ & \text { Senate } \\ & \text { President }\end{aligned}$
District:

State:

District:
Disbursement For: 2012

Xrimary $\square$ General
Date of Disbursement

\begin{tabular}{|c|c|c|c|c|}
\hline $09^{M}$ & & ${ }^{\mathrm{D}}{ }^{\mathrm{D}}$ & & $\begin{array}{llll} & Y & Y & Y \\
& & Y & Y\end{array}$ \\
\hline
\end{tabular}

Transaction ID : BE5023E50DDB14EE2BF8

Amount of Each Disbursement this Period

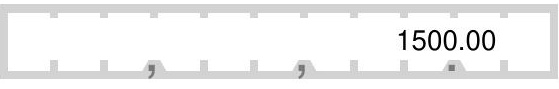

Date of Disbursement

\begin{tabular}{|c|c|c|c|c|}
\hline $09^{M}$ & I & D $16^{\mathrm{D}}$ & I & 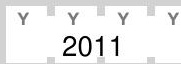 \\
\hline
\end{tabular}

Transaction ID : BFBFF705B19854737AE3

Amount of Each Disbursement this Period

209.00

Subtotal Of Receipts This Page (optional)

Total This Period (last page this line number only))

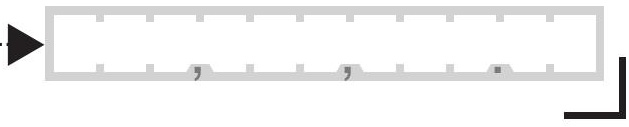




\section{SCHEDULE B-P}

\section{ITEMIZED DISBURSEMENTS}

Use separate schedule(s)

for each category of the

Detailed Summary Page
FOR LINE NUMBER: (check only one)

\begin{tabular}{|c|c|c|c|}
\hline$\times{ }_{23}$ & 24 & 25 & 26 \\
\hline $27 b$ & $28 a$ & $28 \mathrm{~b}$ & $28 \mathrm{c}$ \\
\hline
\end{tabular}

Any information copied from such Reports and Statements may not be sold or used by any person for the purpose of soliciting contributions or for commercial purposes, other than using the name and address of any political committee to solicit contributions from such committee.

NAME OF COMMITTEE (In Full)

\section{Friends of Herman Cain}

Full Name (Last, First, Middle Initial)

A. Elicia Huffaker

Mailing Address 7317 Alta Drive

Date of Disbursement

\begin{tabular}{lll}
\hline City & State & Zip Code \\
Las Vegas & NV & $89145-5238$
\end{tabular}

Purpose of Disbursement

Staff Salary

Candidate Name

\begin{tabular}{l|l|l}
\hline Office Sought: & House & Disbursement For: 2012
\end{tabular} Xrimary $\square$ General

State:

\section{Senate}

President

District:

Full Name (Last, First, Middle Initial)

B. Linda Hansen

Mailing Address PO Box 371312

\begin{tabular}{lcc}
\hline City & State & Zip Code \\
Milwaukee & WI & $53237-2412$
\end{tabular}

Purpose of Disbursement

Staff Salary

Candidate Name

Office Sought:

House
Senate
President

State:

District:

Full Name (Last, First, Middle Initial)

\section{c. Tri-Net Payroll Services}

Mailing Address 1100 San Leandro Boulevard

Suite

\begin{tabular}{lcc}
\multicolumn{3}{c}{ Suite } \\
\hline City & State & Zip Code \\
San Leandro & CA & 94577
\end{tabular}

Purpose of Disbursement

Payroll Benefits

Candidate Name

Office Sought:

State:

Subtotal Of Receipts This Page (optional).

\begin{tabular}{l|c|} 
House & $\begin{array}{r}\text { Disbursement For: } 2012 \\
\text { Senate } \\
\text { President }\end{array}$ \\
District: & Xrimary \\
Other (specify)
\end{tabular}

Date of Disbursement

\begin{tabular}{|c|c|c|c|c|}
\hline${ }^{M}$ & ${ }^{M}$ & $9^{\mathrm{D}}$ & ${ }^{\mathrm{D}}$ & $\mathrm{Y}^{\mathrm{Y}}$ \\
\hline
\end{tabular}

Transaction ID : BBD02F8561F934DEB866

Amount of Each Disbursement this Period

2916.67

Date of Disbursement

\begin{tabular}{|c|c|c|c|c|c|c|}
\hline M & M & D & Y & $Y$ & $Y$ \\
09 & 16 & & 2011 & \\
\hline
\end{tabular}

Transaction ID : B7013FC108DF64DF6AA7

Amount of Each Disbursement this Period

4688.23

Total This Period (last page this line number only))

9479.90

C.

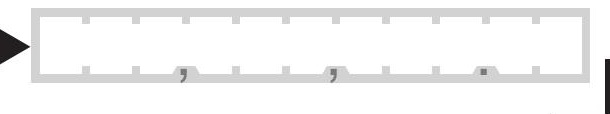




\section{SCHEDULE B-P}

\section{ITEMIZED DISBURSEMENTS}

Use separate schedule(s)

for each category of the

Detailed Summary Page
FOR LINE NUMBER: (check only one)

\begin{tabular}{|c|c|c|c|}
\hline$\times{ }_{23}$ & 24 & 25 & 26 \\
\hline $27 b$ & $28 a$ & $28 \mathrm{~b}$ & $28 \mathrm{c}$ \\
\hline
\end{tabular}

Any information copied from such Reports and Statements may not be sold or used by any person for the purpose of soliciting contributions or for commercial purposes, other than using the name and address of any political committee to solicit contributions from such committee.

NAME OF COMMITTEE (In Full)

\section{Friends of Herman Cain}

Full Name (Last, First, Middle Initial)

A. Andrew Roeska

Mailing Address W55N193 Woodmere Ct. \#3

Date of Disbursement

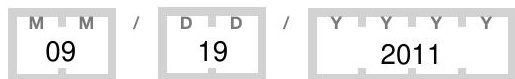

Transaction ID : BF8A29D24B82E488586E

\begin{tabular}{lcc}
\hline City & State & Zip Code \\
Cedarburg & WI & $53012-2833$
\end{tabular}

Purpose of Disbursement

Marketing Consulting

Candidate Name X Primary $\square$ General

State:

$$
\begin{aligned}
& \text { Senate } \\
& \text { President }
\end{aligned}
$$
District:

Full Name (Last, First, Middle Initial)

B. James Saleska

Mailing Address 1777 Valley Road

\begin{tabular}{lcc}
\hline City & State & Zip Code \\
West Bend & WI & $53090-8929$
\end{tabular}

Purpose of Disbursement

Marketing Consulting

Candidate Name

Office Sought:

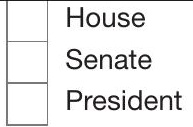

State:

District:

Full Name (Last, First, Middle Initial)

c. Ashley Frasca

Mailing Address 601 Springharbor Drive

Disbursement For: 2012

Xrimary $\square$ General

General

Amount of Each Disbursement this Period 5600.00

\begin{tabular}{|c|c|c|c|c|}
\hline $09^{M}$ & 1 & $19^{\mathrm{D}}$ & 1 & 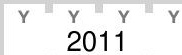 \\
\hline
\end{tabular}

Date of Disbursement

Transaction ID : B79A19FF2E1694B98AB0

Amount of Each Disbursement this Period
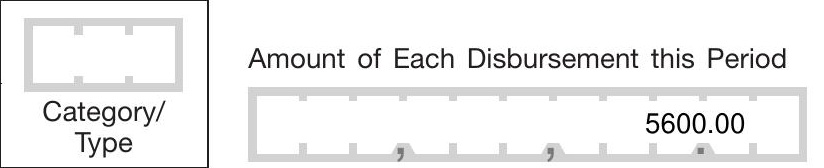

Date of Disbursement

\begin{tabular}{|c|c|c|c|c|c|}
\hline M & M & D & Y & Y & Y \\
09 & & 19 & & 2011 & \\
\hline
\end{tabular}

\begin{tabular}{lcc}
\hline City & State & Zip Code \\
Woodstock & GA & $30188-6044$
\end{tabular}

Purpose of Disbursement

Mileage and Postage

Candidate Name

(2)

Office Sought:

\begin{tabular}{l|l|l}
\hline Office Sought: & & $\begin{array}{l}\text { House } \\
\text { Senate } \\
\end{array}$ \\
& $\begin{array}{l}\text { President } \\
\text { State: }\end{array}$ & District:
\end{tabular}

Disbursement For: 2012

Х $\begin{aligned} & \text { Primary } \\ & \text { Other (specify) }\end{aligned}$

\section{Transaction ID : BCF8592E379324E748DC}

Amount of Each Disbursement this Period

61.26

Subtotal Of Receipts This Page (optional).

Total This Period (last page this line number only))

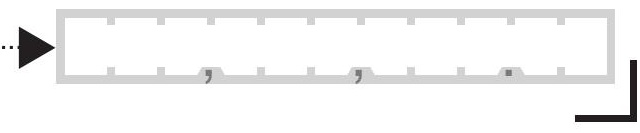




\section{SCHEDULE B-P}

\section{ITEMIZED DISBURSEMENTS}

Use separate schedule(s)

for each category of the

Detailed Summary Page
FOR LINE NUMBER: (check only one)

\begin{tabular}{|c|c|c|c|}
\hline$\times{ }_{23}$ & 24 & 25 & 26 \\
\hline $27 b$ & $28 a$ & $28 \mathrm{~b}$ & $28 \mathrm{c}$ \\
\hline
\end{tabular}

Any information copied from such Reports and Statements may not be sold or used by any person for the purpose of soliciting contributions or for commercial purposes, other than using the name and address of any political committee to solicit contributions from such committee.

NAME OF COMMITTEE (In Full)

\section{Friends of Herman Cain}

Full Name (Last, First, Middle Initial)

A. Rosen Centre Hotel

Mailing Address 9840 International Drive

Date of Disbursement

\begin{tabular}{lcc}
\hline City & State & Zip Code \\
Orlando & FL & 32819 \\
\hline
\end{tabular}

Purpose of Disbursement

Event Catering

Candidate Name

Office Sought: $\quad$ House

House

President

State:

District:

Full Name (Last, First, Middle Initial)

B. Great American Grille

\begin{tabular}{|c|c|c|c|c|}
\hline \multicolumn{5}{|c|}{ Mailing Address 207 Willie Lee Parkway } \\
\hline \multicolumn{2}{|l|}{ City } & \multicolumn{3}{|c|}{ Zip Code } \\
\hline \multicolumn{2}{|l|}{ Warner Robins } & \multicolumn{3}{|c|}{31093} \\
\hline \multicolumn{4}{|c|}{$\begin{array}{l}\text { Purpose of Disbursement } \\
\text { Event Catering }\end{array}$} & \\
\hline \multicolumn{4}{|l|}{ Candidate Name } & $\begin{array}{l}\text { Category/ } \\
\text { Type }\end{array}$ \\
\hline \multirow[t]{3}{*}{ Office Sought: } & \multirow{3}{*}{$\begin{array}{l}\text { House } \\
\text { Senate } \\
\text { President }\end{array}$} & \multicolumn{3}{|c|}{ Disbursement For: 2012} \\
\hline & & Prim & \multicolumn{2}{|c|}{ General } \\
\hline & & \multicolumn{3}{|c|}{ Other (specify) $\boldsymbol{\nabla}$} \\
\hline State: & \multicolumn{4}{|c|}{ District: } \\
\hline
\end{tabular}

Date of Disbursement

\begin{tabular}{|c|c|c|c|c|}
\hline $09^{M}$ & 1 & $19^{\mathrm{D}}$ & I & 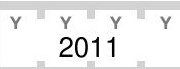 \\
\hline
\end{tabular}

Transaction ID : BF6E91844F5C94BA9853

Full Name (Last, First, Middle Initial)

\section{c. Target Stores}

\begin{tabular}{|c|c|c|c|c|c|}
\hline \multicolumn{6}{|c|}{ Mailing Address 1000 Nicollet Mall } \\
\hline \multicolumn{2}{|l|}{ City } & State & \multicolumn{3}{|l|}{ Zip Code } \\
\hline \multicolumn{2}{|l|}{ Minneapolis } & MN & \multicolumn{3}{|l|}{55403} \\
\hline \multicolumn{5}{|c|}{$\begin{array}{l}\text { Purpose of Disbursement } \\
\text { Office Supplies }\end{array}$} & \\
\hline \multicolumn{5}{|c|}{ Candidate Name } & $\begin{array}{l}\text { Category/ } \\
\text { Type }\end{array}$ \\
\hline \multirow[t]{3}{*}{ Office Sought: } & House & \multicolumn{4}{|c|}{ Disbursement For: 2012} \\
\hline & Senate & \multirow{3}{*}{\multicolumn{2}{|c|}{$\begin{array}{l}\text { Primary } \\
\text { Other (specify) }\end{array}$}} & \multirow{2}{*}{\multicolumn{2}{|c|}{ General }} \\
\hline & President & & & & \\
\hline State: & District: & & & & \\
\hline
\end{tabular}

Subtotal Of Receipts This Page (optional)...

Date of Disbursement

\begin{tabular}{|c|c|c|c|c|c|c|}
\hline M & M & D & Y & Y & Y & Y \\
09 & & 19 & 2011 & \\
\hline
\end{tabular}

Transaction ID : B73F1C0AD35CE4A16B55

Amount of Each Disbursement this Period

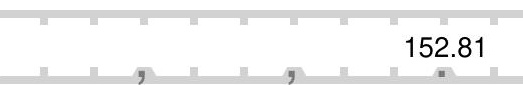

152.81

Total This Period (last page this line number only)) 


\section{SCHEDULE B-P}

\section{ITEMIZED DISBURSEMENTS}

\section{Use separate schedule(s) \\ for each category of the}

Detailed Summary Page
FOR LINE NUMBER: (check only one)

\begin{tabular}{|c|c|c|c|}
\hline$\times{ }_{23}$ & 24 & 25 & 26 \\
\hline $27 b$ & $28 a$ & $28 \mathrm{~b}$ & $28 \mathrm{c}$ \\
\hline
\end{tabular}

Any information copied from such Reports and Statements may not be sold or used by any person for the purpose of soliciting contributions or for commercial purposes, other than using the name and address of any political committee to solicit contributions from such committee.

NAME OF COMMITTEE (In Full)

\section{Friends of Herman Cain}

Full Name (Last, First, Middle Initial)

A. Facebook, Inc.

Mailing Address 1601 S. California Ave.

Date of Disbursement

\begin{tabular}{lcc}
\hline City & State & Zip Code \\
Palo Alto & CA & 94304 \\
\hline
\end{tabular}

Purpose of Disbursement

Advertising Expense

Candidate Name

\begin{tabular}{l|l|c|}
\hline Office Sought: & $\begin{array}{l}\text { House } \\
\text { Senate } \\
\text { President }\end{array}$ & $\begin{array}{r}\text { Disbursement For: } 2012 \\
\text { X Primary } \\
\text { Other (specify) }\end{array}$ \\
\cline { 2 - 3 }
\end{tabular}

Full Name (Last, First, Middle Initial)

B. Hotels.com

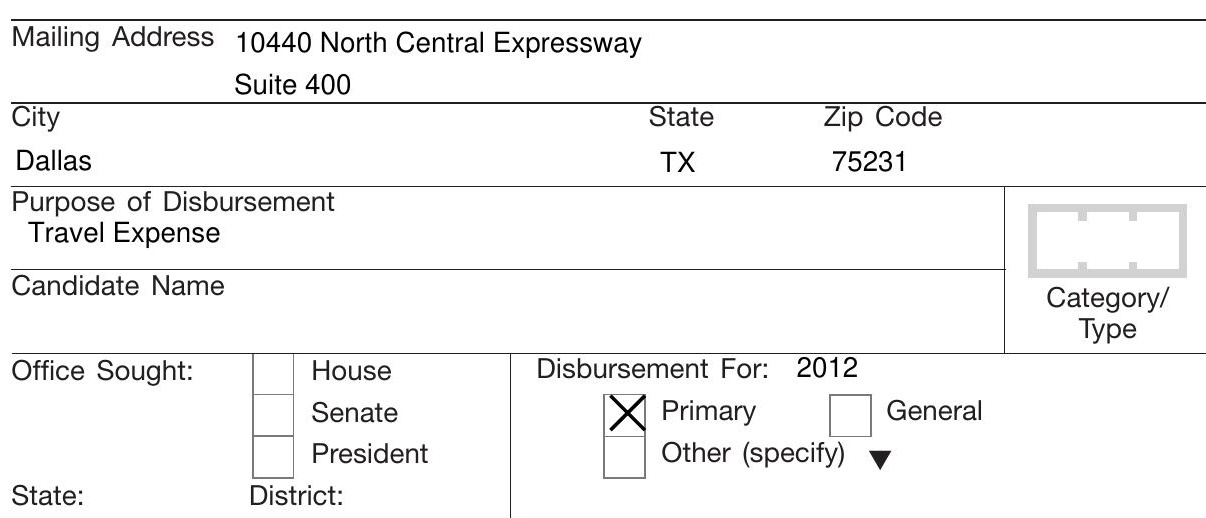

Date of Disbursement

\begin{tabular}{|c|c|c|c|c|}
\hline $09^{M}$ & & $19^{\mathrm{D}}$ & & $\begin{array}{llll} & Y & Y & Y \\
& 2011 & \end{array}$ \\
\hline
\end{tabular}

Transaction ID : BDD625C62E3E14CFEBA3

Full Name (Last, First, Middle Initial)

c. FourTier Strategies, LLC

Mailing Address c/o Brad Marston

90 Beacon Street \#2

\begin{tabular}{lcc}
\hline City & State & Zip Code \\
Boston & MA & 02108
\end{tabular}

Purpose of Disbursement

Fundraising Consulting

Candidate Name

\begin{tabular}{|c|c|}
\hline \multirow[t]{3}{*}{ Office Sought: } & House \\
\hline & Senate \\
\hline & President \\
\hline ate: & rict: \\
\hline
\end{tabular}

Date of Disbursement

\begin{tabular}{|c|c|c|c|c|c|}
\hline M M & M & Y \\
09 & & 19 \\
\hline
\end{tabular}

Transaction ID : B30EEBD3443E744E6889

Amount of Each Disbursement this Period 4000.00

Subtotal Of Receipts This Page (optional).

Total This Period (last page this line number only))

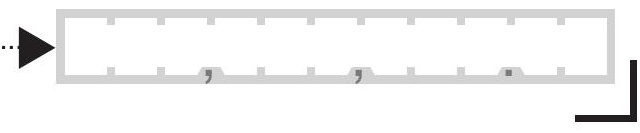




\section{SCHEDULE B-P}

\section{ITEMIZED DISBURSEMENTS}

\section{Use separate schedule(s) \\ for each category of the}

Detailed Summary Page
FOR LINE NUMBER: (check only one)

\begin{tabular}{|c|c|c|c|}
\hline$\times{ }_{23}$ & 24 & 25 & 26 \\
\hline $27 b$ & $28 a$ & $28 \mathrm{~b}$ & $28 \mathrm{c}$ \\
\hline
\end{tabular}

Any information copied from such Reports and Statements may not be sold or used by any person for the purpose of soliciting contributions or for commercial purposes, other than using the name and address of any political committee to solicit contributions from such committee.

NAME OF COMMITTEE (In Full)

\section{Friends of Herman Cain}

Full Name (Last, First, Middle Initial)

A. Italian Oven Stockbridge GA

Mailing Address 938 Eagles Landing Parkway

Date of Disbursement

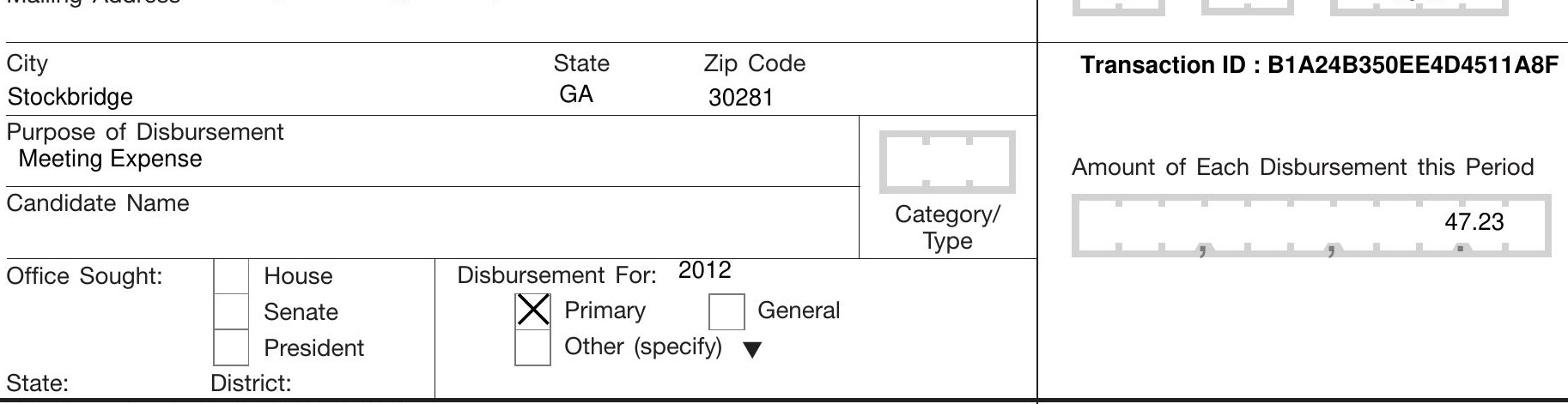

Full Name (Last, First, Middle Initial)

B. Adventure Advertising, LLC

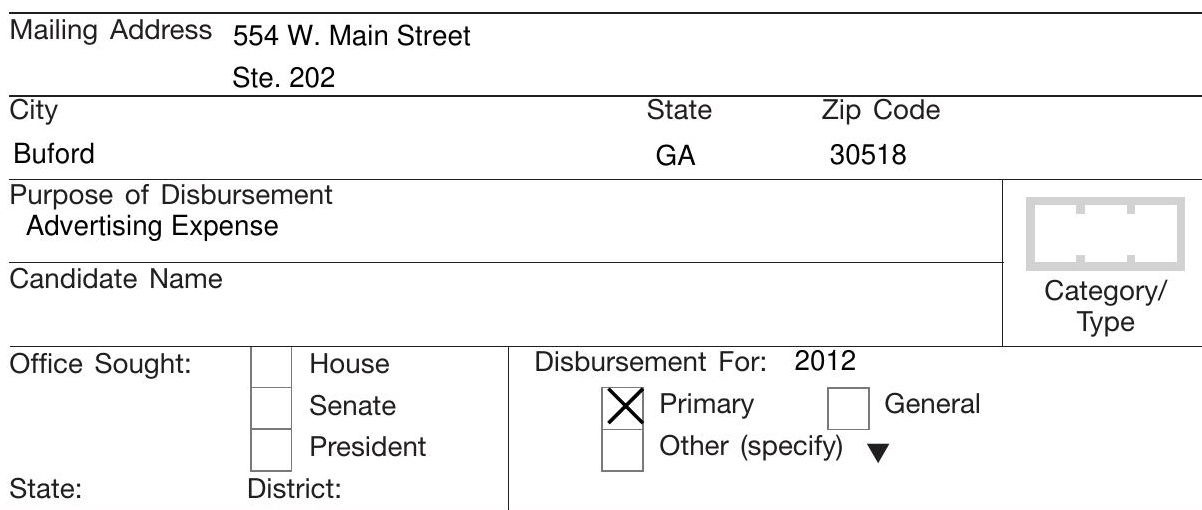

Date of Disbursement

\begin{tabular}{|c|c|c|c|c|}
\hline $09^{M}$ & 1 & $199^{\mathrm{D}}$ & 1 & 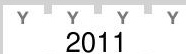 \\
\hline
\end{tabular}

Transaction ID : B00E26DCE0DBC4820B3A

Full Name (Last, First, Middle Initial)

\section{c. Professional Data Services}

Mailing Address 2470 Daniell's Bridge Road

\begin{tabular}{lcc}
\multicolumn{4}{c}{ Ste. 121} & \\
\hline City & State & Zip Code \\
Athens & GA & 30606
\end{tabular}

Purpose of Disbursement

Compliance Consulting

Candidate Name

Date of Disbursement

\begin{tabular}{|c|c|c|c|c|c|c|}
\hline M & M & D & Y & Y & Y & Y \\
\hline & & 19 & & 2011 & \\
\hline
\end{tabular}

Transaction ID : BA22A7962610A4CE0AF6

\begin{tabular}{c|c} 
Category/ \\
Type
\end{tabular}

Amount of Each Disbursement this Period

\begin{tabular}{l|l|c|}
\hline Office Sought: & $\begin{array}{l}\text { House } \\
\text { Senate } \\
\text { President }\end{array}$ & $\begin{array}{r}\text { Disbursement For: } 2012 \\
\text { State: }\end{array}$ \\
\cline { 2 - 3 } & District: & X $\begin{array}{l}\text { Primary } \\
\text { Other (specify) }\end{array}$
\end{tabular}

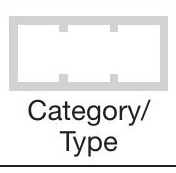

pe
Amount of Each Disbursement this Period

15820.00

\section{Subtotal Of Receipts This Page (optional).}

Total This Period (last page this line number only))

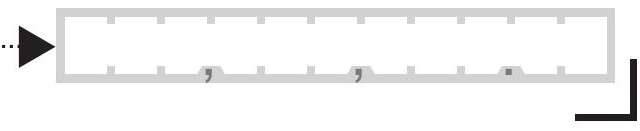




\section{SCHEDULE B-P}

\section{ITEMIZED DISBURSEMENTS}

Use separate schedule(s)

for each category of the

Detailed Summary Page
FOR LINE NUMBER: (check only one)

\begin{tabular}{|c|c|c|c|}
\hline$\times{ }_{23}$ & 24 & 25 & 26 \\
\hline $27 b$ & $28 a$ & $28 \mathrm{~b}$ & $28 \mathrm{c}$ \\
\hline
\end{tabular}

Any information copied from such Reports and Statements may not be sold or used by any person for the purpose of soliciting contributions or for commercial purposes, other than using the name and address of any political committee to solicit contributions from such committee.

NAME OF COMMITTEE (In Full)

\section{Friends of Herman Cain}

Full Name (Last, First, Middle Initial)

A. Delta Airlines

\begin{tabular}{c} 
Mailing Address $\begin{array}{c}\text { Post Office Box } 20980 \\
\text { Department } 980\end{array}$ \\
\hline
\end{tabular}

\begin{tabular}{lll}
\hline City & State & Zip Code \\
Atlanta & GA & $30320-2980$
\end{tabular}

Purpose of Disbursement

Travel Expense

Candidate Name

\begin{tabular}{l|l|c|}
\hline Office Sought: & $\begin{array}{l}\text { House } \\
\text { Senate } \\
\text { President }\end{array}$ & $\begin{array}{r}\text { Disbursement For: } 2012 \\
\text { X Primary } \\
\text { Other (specify) }\end{array}$
\end{tabular}

Full Name (Last, First, Middle Initial)

B. Delta Airlines

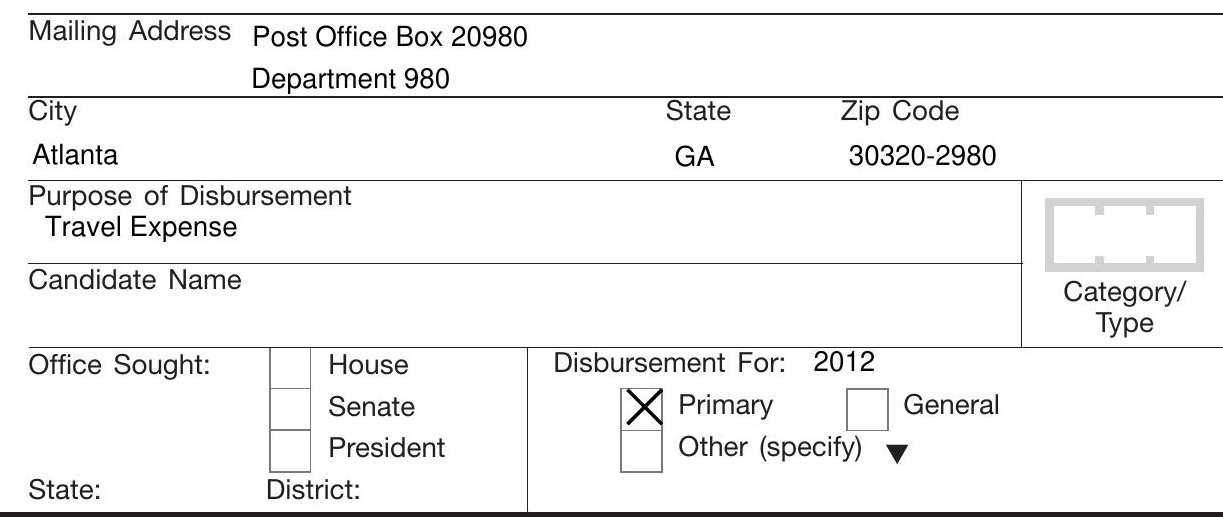

Date of Disbursement

Full Name (Last, First, Middle Initial)

\section{Avis Rent A Car}

Mailing Address 900 Old Country Garden Road

\begin{tabular}{|c|c|c|c|c|c|}
\hline \multicolumn{2}{|l|}{ City } & State & \multicolumn{3}{|l|}{ Zip Code } \\
\hline \multicolumn{2}{|l|}{ Garden City } & NY & \multicolumn{3}{|l|}{11530} \\
\hline \multicolumn{5}{|c|}{$\begin{array}{l}\text { Purpose of Disbursement } \\
\text { Travel Expense }\end{array}$} & \\
\hline \multicolumn{5}{|c|}{ Candidate Name } & $\begin{array}{l}\text { Category/ } \\
\text { Type }\end{array}$ \\
\hline \multirow[t]{3}{*}{ Office Sought: } & House & \multicolumn{4}{|c|}{ Disbursement For: 2012} \\
\hline & Senate & \multirow{3}{*}{\multicolumn{2}{|c|}{$\begin{array}{l}\text { Primary } \\
\text { Other (specify) }\end{array}$}} & \multirow{2}{*}{\multicolumn{2}{|c|}{ General }} \\
\hline & President & & & & \\
\hline State: & \multicolumn{3}{|c|}{ District: } & & \\
\hline
\end{tabular}

Subtotal Of Receipts This Page (optional).

Date of Disbursement

\begin{tabular}{|c|c|c|c|c|}
\hline $09^{\mathrm{M}}$ & I & $20^{\mathrm{D}}$ & 1 & $\begin{array}{cccc} & Y & Y & Y \\
& 2011 & \end{array}$ \\
\hline
\end{tabular}

\section{Transaction ID : B6C556DABF4594E1089C}

Amount of Each Disbursement this Period

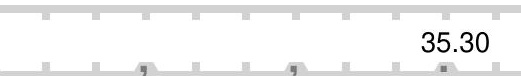

Total This Period (last page this line number only)) 


\section{SCHEDULE B-P}

\section{ITEMIZED DISBURSEMENTS}

\section{Use separate schedule(s) \\ for each category of the}

Detailed Summary Page
FOR LINE NUMBER: (check only one)

\begin{tabular}{|c|c|c|c|}
\hline$\times{ }_{23}$ & 24 & 25 & 26 \\
\hline $27 b$ & $28 a$ & $28 \mathrm{~b}$ & $28 \mathrm{c}$ \\
\hline
\end{tabular}

Any information copied from such Reports and Statements may not be sold or used by any person for the purpose of soliciting contributions or for commercial purposes, other than using the name and address of any political committee to solicit contributions from such committee.

NAME OF COMMITTEE (In Full)

\section{Friends of Herman Cain}

Full Name (Last, First, Middle Initial)

A. Hotels.com

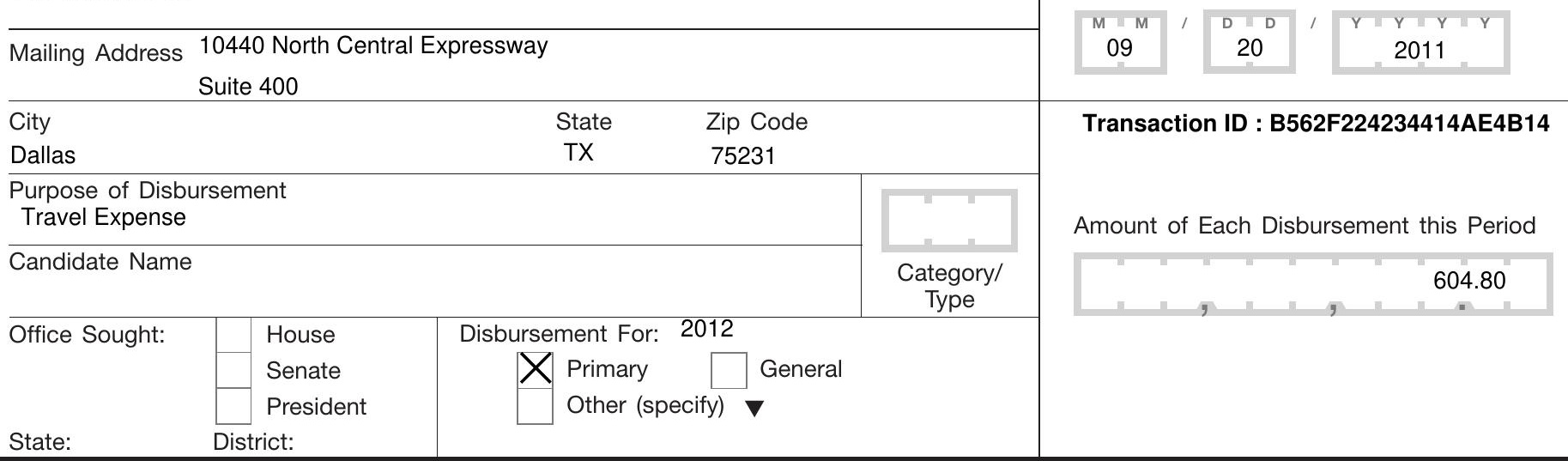

Full Name (Last, First, Middle Initial)

B. Facebook, Inc.

Mailing Address 1601 S. California Ave.

\begin{tabular}{lcc}
\hline City & State & Zip Code \\
Palo Alto & CA & 94304
\end{tabular}

Purpose of Disbursement

Advertising Expense

Candidate Name

Office Sought:

\begin{tabular}{|l|l} 
House \\
Senate \\
President
\end{tabular}

Disbursement For: 2012

Xrimary $\square$ General

State:

District:

Date of Disbursement

Full Name (Last, First, Middle Initial)

\section{c. Rosen Centre Hotel}

Mailing Address 9840 International Drive

\begin{tabular}{lcc}
\hline City & State & Zip Code \\
Orlando & FL & 32819
\end{tabular}

Purpose of Disbursement

Event Catering

Candidate Name

Office Sought:

State:
Date of Disbursement

\begin{tabular}{|c|c|c|c|c|}
\hline $09^{\mathrm{M}}$ & & $\begin{array}{l}\text { D } \\
20\end{array}$ & 1 & $\begin{array}{cccc}Y & Y & Y & Y \\
& 2011 & \end{array}$ \\
\hline
\end{tabular}

Transaction ID : BB650E4D7C6C346F6936

Amount of Each Disbursement this Period

2164.87

Subtotal Of Receipts This Page (optional).

Total This Period (last page this line number only))

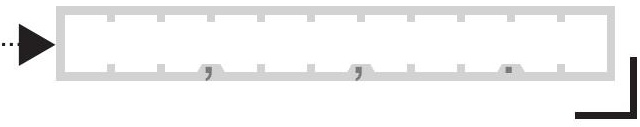




\section{SCHEDULE B-P}

\section{ITEMIZED DISBURSEMENTS}

\section{Use separate schedule(s)}

for each category of the

Detailed Summary Page
FOR LINE NUMBER: (check only one)

\begin{tabular}{|c|c|c|c|}
\hline$\times{ }_{23}$ & 24 & 25 & 26 \\
\hline $27 b$ & $28 a$ & $28 \mathrm{~b}$ & $28 \mathrm{c}$ \\
\hline
\end{tabular}

Any information copied from such Reports and Statements may not be sold or used by any person for the purpose of soliciting contributions or for commercial purposes, other than using the name and address of any political committee to solicit contributions from such committee.

NAME OF COMMITTEE (In Full)

\section{Friends of Herman Cain}

Full Name (Last, First, Middle Initial)

\section{A. Sirata Beach Resort}

Mailing Address 5300 Gulf Blvd.

Date of Disbursement

\begin{tabular}{lcc}
\hline City & State & Zip Code \\
St. Petersburg & FL & 33706 \\
\hline
\end{tabular}

Purpose of Disbursement

Travel Expense

Candidate Name

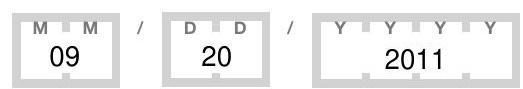

Transaction ID : B255BE1FDE3614DC4830

\begin{tabular}{l|l|c|}
\hline Office Sought: & $\begin{array}{l}\text { House } \\
\text { Senate } \\
\text { President }\end{array}$ & $\begin{array}{c}\text { Disbursement For: } 2012 \\
\text { State: }\end{array}$ \\
\cline { 2 - 3 } & District: & X Primary \\
Other (specify)
\end{tabular}

Full Name (Last, First, Middle Initial)

B. Air Tran

Mailing Address 9955 Air Tran Boulevard

\begin{tabular}{lcc}
\hline City & State & Zip Code \\
Orlando & FL & 32827
\end{tabular}

Purpose of Disbursement

Travel Expense

Candidate Name

Office Sought:

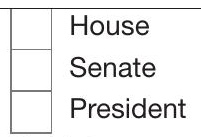

State:

District:

$\mathrm{FL}$ 32827

Full Name (Last, First, Middle Initial)

C. Air Tran

Mailing Address 9955 Air Tran Boulevard

\begin{tabular}{lcc}
\hline City & State & Zip Code \\
Orlando & FL & 32827
\end{tabular}

Purpose of Disbursement

Travel Expense

Candidate Name

Office Sought:

State:

\begin{tabular}{|l|l} 
& House \\
Senate \\
President
\end{tabular}

Disbursement For: 2012

Xrimary $\square$ General
Date of Disbursement

\begin{tabular}{|c|c|c|c|c|}
\hline $09^{M}$ & & ${ }^{\mathrm{D}} 0^{\mathrm{D}}$ & & 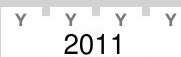 \\
\hline
\end{tabular}

Transaction ID : B3946E78B205A4D8C9CA

Amount of Each Disbursement this Period

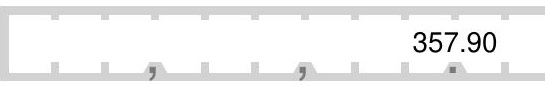

Date of Disbursement

\begin{tabular}{|c|c|c|c|c|c|}
\hline M & M & D & Y & Y & $Y$ \\
09 & & 21 & 2011 & \\
\hline
\end{tabular}

Transaction ID : B588D17DE523E4010A21

Amount of Each Disbursement this Period

49.00

Subtotal Of Receipts This Page (optional).

Total This Period (last page this line number only))

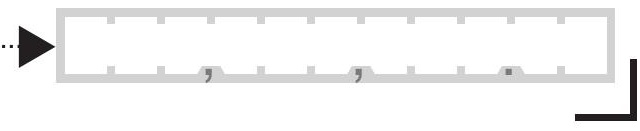




\section{SCHEDULE B-P}

\section{ITEMIZED DISBURSEMENTS}

\section{Use separate schedule(s) \\ for each category of the}

Detailed Summary Page
FOR LINE NUMBER: (check only one)

\begin{tabular}{|c|c|c|c|}
\hline$X_{23}$ & 24 & 25 & 26 \\
\hline $27 \mathrm{~b}$ & $28 a$ & $28 b$ & $28 \mathrm{c}$ \\
\hline
\end{tabular}

Any information copied from such Reports and Statements may not be sold or used by any person for the purpose of soliciting contributions or for commercial purposes, other than using the name and address of any political committee to solicit contributions from such committee.

NAME OF COMMITTEE (In Full)

\section{Friends of Herman Cain}

Full Name (Last, First, Middle Initial)

\section{A. Action Limousines \& Luxury Buses}

Mailing Address 1797 Rugby Avenue

Date of Disbursement

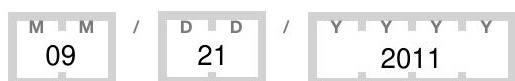

Transaction ID : B1AB83B2D128440BAA43

\begin{tabular}{lcc}
\hline City & State & Zip Code \\
Atlanta & GA & 30337 \\
\hline Purpose of Disbursement & &
\end{tabular}

Purpose of Disbursement

Travel Expense

Candidate Name

\begin{tabular}{l|l|l}
\hline Office Sought: & House & Disbursement For: 2012
\end{tabular} X Primary $\square$ General

State: District:

Full Name (Last, First, Middle Initial)

B. Inkhead Inc.

Mailing Address 138 Park Avenue

Suite 300

City
Winder

Purpose of Disbursement

Event Supplies

Candidate Name

Office Sought:

State:

\section{c. Avis Rent A Car}

Mailing Address 900 Old Country Garden Road

\begin{tabular}{lcc}
\hline City & State & Zip Code \\
Garden City & NY & 11530
\end{tabular}

Purpose of Disbursement

Travel Expense

Candidate Name

Office Sought:

State:

State Zip Code

GA $\quad 30680$

sbursement For: 2012

Xrimary $\square$ General
Date of Disbursement

\begin{tabular}{|c|c|c|c|c|}
\hline $09^{M}$ & & ${ }^{\mathrm{D}} 21^{\mathrm{D}}$ & & 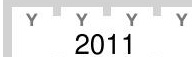 \\
\hline
\end{tabular}

Transaction ID : BEEDA57689D7D4C29B8E

Amount of Each Disbursement this Period

1170.94
Date of Disbursement

\begin{tabular}{|c|c|c|c|c|c|}
\hline M & M & D & Y & Y & Y \\
09 & & 21 & 2011 & \\
\hline
\end{tabular}

Transaction ID : B447E7FDAD1F247B2B07

Amount of Each Disbursement this Period

99.66

Subtotal Of Receipts This Page (optional).

Total This Period (last page this line number only))

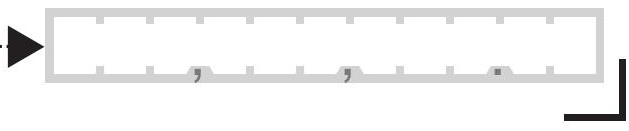




\section{SCHEDULE B-P}

\section{ITEMIZED DISBURSEMENTS}

Use separate schedule(s)

for each category of the

Detailed Summary Page
FOR LINE NUMBER: (check only one)

\begin{tabular}{|c|c|c|c|}
\hline$\times{ }_{23}$ & 24 & 25 & 26 \\
\hline $27 b$ & $28 a$ & $28 \mathrm{~b}$ & $28 \mathrm{c}$ \\
\hline
\end{tabular}

Any information copied from such Reports and Statements may not be sold or used by any person for the purpose of soliciting contributions or for commercial purposes, other than using the name and address of any political committee to solicit contributions from such committee.

NAME OF COMMITTEE (In Full)

\section{Friends of Herman Cain}

Full Name (Last, First, Middle Initial)

A. Hilton Hotels

Mailing Address 7930 Jones Branch Drive

Suite 1100

Date of Disbursement

\begin{tabular}{lll}
\multicolumn{3}{c}{ Suite 1100} \\
\hline City & State & Zip Code \\
McLean & VA & 22102 \\
\hline Purpose of Disbursement
\end{tabular}

Purpose of Disbursement

Travel Expense

Candidate Name

\begin{tabular}{l|l|l}
\hline Office Sought: & House & Disbursement For: 2012
\end{tabular} X Primary $\square$ General

State:

\section{Senate}

President

District:

Full Name (Last, First, Middle Initial)

B. SunTrust Bank

Mailing Address 980 Eagles Landing Parkway

\begin{tabular}{lcc}
\hline City & State & Zip Code \\
Stockbridge & GA & 30281
\end{tabular}

Purpose of Disbursement

Bank Fees

Candidate Name

Office Sought:

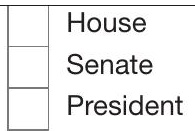

State:

District:

Full Name (Last, First, Middle Initial)

\section{SunTrust Bank}

Mailing Address 980 Eagles Landing Parkway

\begin{tabular}{lcc}
\hline City & State & Zip Code \\
Stockbridge & GA & 30281
\end{tabular}

Purpose of Disbursement

Bank Fees

Candidate Name

Office Sought:

State:

\begin{tabular}{|l|l|}
\hline & House \\
& Senate \\
& President \\
\hline District:
\end{tabular}

Disbursement For: 2012

Х $\begin{aligned} & \text { Primary } \\ & \text { Other (specify) }\end{aligned}$
GA 30281

Date of Disbursement

\begin{tabular}{|c|c|c|c|c|}
\hline $09^{M}$ & & $21^{\mathrm{D}}$ & & $\begin{array}{llll} & Y & Y & Y \\
& 2011 & Y\end{array}$ \\
\hline
\end{tabular}

Transaction ID : BEBB9A170598A43DFA5E

Amount of Each Disbursement this Period

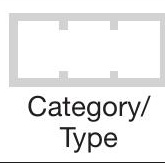

\section{Disbursement For: 2012 \\ Xrimary $\square$ General}

Date of Disbursement

\begin{tabular}{|c|c|c|c|c|}
\hline $09^{M}$ & I & D ${ }^{\mathrm{D}}$ & 1 & $\begin{array}{cccc}Y & Y & Y & Y \\
& 2011 & \end{array}$ \\
\hline
\end{tabular}

Transaction ID : B0F70AA76E39747D4B6C

Amount of Each Disbursement this Period

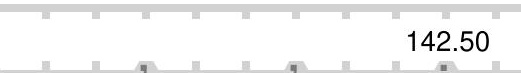

142.50

Subtotal Of Receipts This Page (optional).

Total This Period (last page this line number only)) 


\section{SCHEDULE B-P}

\section{ITEMIZED DISBURSEMENTS}

Use separate schedule(s)

for each category of the

Detailed Summary Page
FOR LINE NUMBER: (check only one)

\begin{tabular}{|c|c|c|c|}
\hline$\times{ }_{23}$ & 24 & 25 & 26 \\
\hline $27 b$ & $28 a$ & $28 \mathrm{~b}$ & $28 \mathrm{c}$ \\
\hline
\end{tabular}

Any information copied from such Reports and Statements may not be sold or used by any person for the purpose of soliciting contributions or for commercial purposes, other than using the name and address of any political committee to solicit contributions from such committee.

NAME OF COMMITTEE (In Full)

\section{Friends of Herman Cain}

Full Name (Last, First, Middle Initial)

A. Delta Airlines

Mailing Address Post Office Box 20980

Department 980

\begin{tabular}{lcc}
\hline City & State & Zip Code \\
Atlanta & GA & $30320-2980$
\end{tabular}

Purpose of Disbursement

Travel Expense

Candidate Name

Office Sought:

State:

House
Senate
President
trict:

Disbursement For: 2012 X Primary $\square$ General
Date of Disbursement

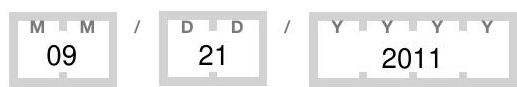

Transaction ID : BE1B69F09292E4397B13

Amount of Each Disbursement this Period 818.60

\section{B. SunTrust Bank}

Mailing Address 980 Eagles Landing Parkway

\begin{tabular}{lcc}
\hline City & State & Zip Code \\
Stockbridge & GA & 30281
\end{tabular}

Purpose of Disbursement

Bank Fees

Candidate Name

Office Sought:

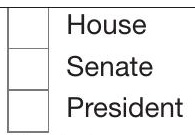

State:

District:

Full Name (Last, First, Middle Initial)

\section{c. Delta Airlines}

\begin{tabular}{|c|c|c|c|c|c|}
\hline \multicolumn{6}{|c|}{ Mailing Address Post Office Box 20980} \\
\hline \multicolumn{2}{|l|}{ City } & State & \multicolumn{3}{|l|}{ Zip Code } \\
\hline \multicolumn{2}{|l|}{ Atlanta } & GA & \multicolumn{3}{|c|}{$30320-2980$} \\
\hline \multicolumn{5}{|c|}{$\begin{array}{l}\text { Purpose of Disbursement } \\
\text { Travel Expense }\end{array}$} & \\
\hline \multicolumn{5}{|l|}{ Candidate Name } & $\begin{array}{l}\text { Category/ } \\
\text { Type }\end{array}$ \\
\hline \multirow[t]{3}{*}{ Office Sought: } & House & \multirow{4}{*}{\multicolumn{4}{|c|}{ Disbursement For: 2012}} \\
\hline & Senate & & & & \\
\hline & President & & & & \\
\hline State: & rict: & & & & \\
\hline
\end{tabular}

Subtotal Of Receipts This Page (optional)...

Date of Disbursement

\begin{tabular}{|c|c|c|c|c|}
\hline $09^{M}$ & I & D $22^{\mathrm{D}}$ & I & $\begin{array}{cccc}Y & Y & Y & Y \\
& 2011 & \end{array}$ \\
\hline
\end{tabular}

Transaction ID : BA4E758028703464F92C

Amount of Each Disbursement this Period

Date of Disbursement

\begin{tabular}{|c|c|c|c|c|}
\hline $09^{M}$ & 1 & $21^{\mathrm{D}}$ & I & 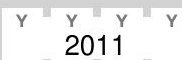 \\
\hline
\end{tabular}

Transaction ID : BA93550160D4F49ABA4F

Amount of Each Disbursement this Period
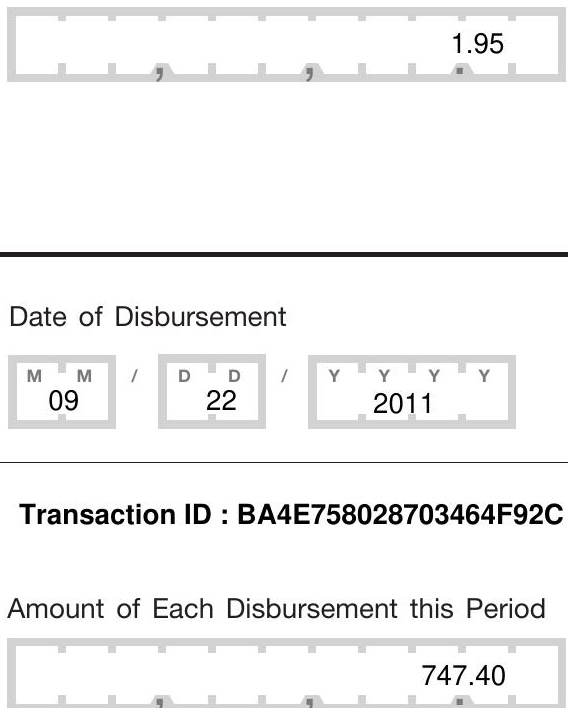

747.40

Total This Period (last page this line number only)) 


\section{SCHEDULE B-P}

\section{ITEMIZED DISBURSEMENTS}

Use separate schedule(s)

for each category of the

Detailed Summary Page
FOR LINE NUMBER: (check only one)

\begin{tabular}{|c|c|c|c|}
\hline$X_{23}$ & 24 & 25 & 26 \\
\hline $27 \mathrm{~b}$ & $28 a$ & $28 \mathrm{~b}$ & $28 \mathrm{c}$ \\
\hline
\end{tabular}

Any information copied from such Reports and Statements may not be sold or used by any person for the purpose of soliciting contributions or for commercial purposes, other than using the name and address of any political committee to solicit contributions from such committee.

NAME OF COMMITTEE (In Full)

\section{Friends of Herman Cain}

Full Name (Last, First, Middle Initial)

A. RMA Chaffeured Transportation

Mailing Address 6010 Executive Boulevard

Suite 101

\begin{tabular}{lll}
\hline City & State & Zip Code \\
Rockville & MD & 20852
\end{tabular}

Purpose of Disbursement

Travel Expense

Candidate Name

$$
\begin{array}{|l|l}
\text { House } \\
\text { Senate } \\
\text { President }
\end{array}
$$

State: District:

Full Name (Last, First, Middle Initial)

B. Facebook, Inc.

Mailing Address 1601 S. California Ave.

\begin{tabular}{lcc}
\hline City & State & Zip Code \\
Palo Alto & CA & 94304
\end{tabular}

Purpose of Disbursement

Advertising Expense

Candidate Name

Disbursement For: 2012 Xrimary $\square$ General

Office Sought:

House
Senate
President

Disbursement For: 2012

X Primary $\square$ General

State:

District:

Full Name (Last, First, Middle Initial)

c. Hotels.com

Mailing Address 10440 North Central Expressway

Suite 400

\begin{tabular}{lcc}
\hline City & State & Zip Code \\
Dallas & TX & 75231
\end{tabular}

Purpose of Disbursement

Travel Expense

Candidate Name

Office Sought:

State:
Date of Disbursement

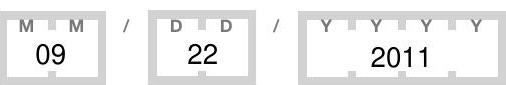

Transaction ID : B8B1EFE183CBD4FE8876

Amount of Each Disbursement this Period

\begin{tabular}{|c|c|c|c|c|}
\hline $09^{M}$ & & ${ }^{\mathrm{D}} 2^{\mathrm{D}}$ & 1 & $\begin{array}{llll}Y & Y & Y & Y \\
& 2011\end{array}$ \\
\hline
\end{tabular}

79.88
Date of Disbursement

Transaction ID : BA02EC06F412D4A41B35

Amount of Each Disbursement this Period

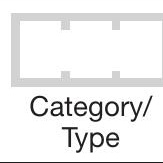

\begin{tabular}{|c|c|c|c|c|}
\hline $09^{M}$ & I & 22 & 1 & 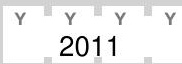 \\
\hline
\end{tabular}

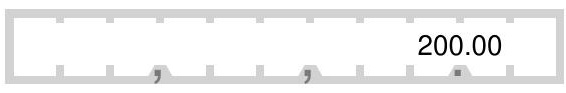

Date of Disbursement

Transaction ID : BF2759687B5674676907

Amount of Each Disbursement this Period

976.81

Subtotal Of Receipts This Page (optional).

Total This Period (last page this line number only))

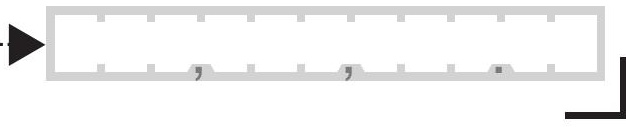


Image\# 12951402751

SCHEDULE B-P ITEMIZED DISBURSEMENTS
Use separate schedule(s)

for each category of the

Detailed Summary Page
FOR LINE NUMBER: (check only one)

\begin{tabular}{|c|c|c|c|c|}
\hline$\times 23$ & 24 & 25 & 26 & $27 a$ \\
\hline $27 \mathrm{~b}$ & $28 a$ & $28 b$ & $28 c$ & 29 \\
\hline
\end{tabular}

Any information copied from such Reports and Statements may not be sold or used by any person for the purpose of soliciting contributions
or for commercial purposes, other than using the name and address of any political committee to solicit contributions from such committee.

NAME OF COMMITTEE (In Full)

Friends of Herman Cain

Full Name (Last, First, Middle Initial)

A. DirectMail.com

Mailing Address 201 Skipjack Road

Date of Disbursement

\begin{tabular}{lll}
\hline City & State & Zip Code \\
Prince Frederick & MD & 20678 \\
\hline Purpose of Disbursement
\end{tabular}

Purpose of Disbursement

Direct Mail Production

Candidate Name

Office Sought: $\quad$ House

\section{Senate}

President

State:

District:

Full Name (Last, First, Middle Initial)

B. Inkhead Inc.

\begin{tabular}{|c|c|c|c|c|}
\hline \multicolumn{2}{|c|}{$\begin{array}{ll}\text { Mailing Address } & 138 \text { Park Avenue } \\
& \text { Suite } 300 \\
\end{array}$} & & & \\
\hline \multicolumn{2}{|l|}{ City } & \multicolumn{3}{|c|}{ Zip Code } \\
\hline \multicolumn{2}{|l|}{ Winder } & \multicolumn{3}{|c|}{30680} \\
\hline \multicolumn{4}{|c|}{$\begin{array}{l}\text { Purpose of Disbursement } \\
\text { Event Supplies }\end{array}$} & \\
\hline \multicolumn{4}{|l|}{ Candidate Name } & $\begin{array}{l}\text { Category/ } \\
\text { Type }\end{array}$ \\
\hline \multirow[t]{3}{*}{ Office Sought: } & House & \multirow{3}{*}{\multicolumn{3}{|c|}{$\begin{array}{l}\text { Disbursement For: } 2012 \\
\text { X Primary } \\
\text { Other (specify) }\end{array}$}} \\
\hline & Senate & & & \\
\hline & President & & & \\
\hline State: & rict: & & & \\
\hline
\end{tabular}

Date of Disbursement

\begin{tabular}{|c|c|c|c|c|}
\hline $09^{\mathrm{M}}$ & & $23^{\mathrm{D}}$ & & $\begin{array}{llll}Y & Y & Y & Y \\
& 2011\end{array}$ \\
\hline
\end{tabular}

Transaction ID : B65895F1C24D34DC2BFC

Full Name (Last, First, Middle Initial)

c. Aaron T. Manaigo

Mailing Address 6723 W. Wakefield Drive

Suite A2

\begin{tabular}{lcc}
\hline City & State & Zip Code \\
Alexandria & VA & 22307 \\
\hline
\end{tabular}

Purpose of Disbursement

Field Consulting

Candidate Name

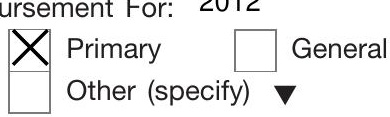

Category/ Type

Amount of Each Disbursement this Period

Amount of Each Disbursement this Period

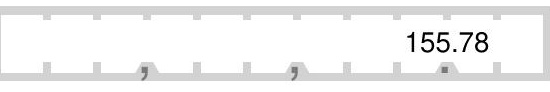

Date of Disbursement

\begin{tabular}{|c|c|c|c|c|}
\hline${ }^{M} 9^{M}$ & 1 & $\begin{array}{l}\text { D } \\
23\end{array}$ & 1 & 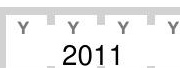 \\
\hline
\end{tabular}

Transaction ID : B34176EA1EDB54CCF99F

Amount of Each Disbursement this Period

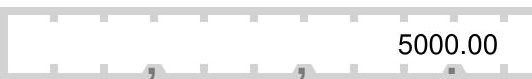

\begin{tabular}{l|l|c|}
\hline Office Sought: & $\begin{array}{l}\text { House } \\
\text { Senate } \\
\text { President } \\
\text { State: }\end{array}$ & $\begin{array}{r}\text { Disbursement For: } 2012 \\
\text { District: }\end{array}$ \\
\cline { 2 - 3 }
\end{tabular}

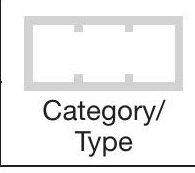

Subtotal Of Receipts This Page (optional).

15057.15

Total This Period (last page this line number only)) 


\section{SCHEDULE B-P}

\section{ITEMIZED DISBURSEMENTS}

\section{Use separate schedule(s) \\ for each category of the}

Detailed Summary Page
FOR LINE NUMBER: (check only one)

\begin{tabular}{|c|c|c|c|}
\hline$\times{ }_{23}$ & 24 & 25 & 26 \\
\hline $27 b$ & $28 a$ & $28 \mathrm{~b}$ & $28 \mathrm{c}$ \\
\hline
\end{tabular}

Any information copied from such Reports and Statements may not be sold or used by any person for the purpose of soliciting contributions or for commercial purposes, other than using the name and address of any political committee to solicit contributions from such committee.

NAME OF COMMITTEE (In Full)

\section{Friends of Herman Cain}

Full Name (Last, First, Middle Initial)

A. John Chauhan

Mailing Address 3810 Jamaica Drive

Date of Disbursement

\begin{tabular}{|c|c|c|c|}
\hline $09^{M}$ & 1 & $23^{\mathrm{D}}$ & \\
\hline
\end{tabular}

Transaction ID : B916BE68C0EA54095A28

\begin{tabular}{lll}
\hline City & State & Zip Code \\
Jonesboro & GA & $30236-5427$
\end{tabular}

Purpose of Disbursement

Staff Housing

Candidate Name

\begin{tabular}{l|l|l}
\hline Office Sought: & House & Disbursement For: 2012
\end{tabular} X Primary $\square$ General

State:

\section{Senate}

President

District:

Full Name (Last, First, Middle Initial)

\section{B. David McCleary}

Mailing Address PO box 923

\begin{tabular}{lcc}
\hline City & State & Zip Code \\
Roswell & GA & $30077-0923$
\end{tabular}

Purpose of Disbursement

Event Supplies

Candidate Name

Office Sought:

House
Senate
President

State:

District:

Full Name (Last, First, Middle Initial)

\section{c. Soundmind Productions}

Mailing Address 509 Autumnwood Court

\begin{tabular}{lcc}
\hline City & State & Zip Code \\
Nashville & TN & 37221
\end{tabular}

Purpose of Disbursement

Event Entertainment

Candidate Name

Office Sought: $\quad$ House

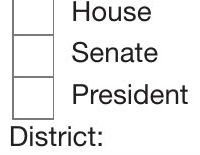

Disbursement For: 2012

Primary $\square$ General
Other (specify)

Date of Disbursement

\begin{tabular}{|c|c|c|c|c|}
\hline $09^{M}$ & 1 & $23^{\mathrm{D}}$ & 1 & $\begin{array}{llll}Y & Y & Y & Y \\
& 2011 & \end{array}$ \\
\hline
\end{tabular}

Transaction ID : B24AD59B688BD48C4849

Amount of Each Disbursement this Period

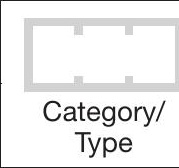

Amount of Each Disbursement this Period
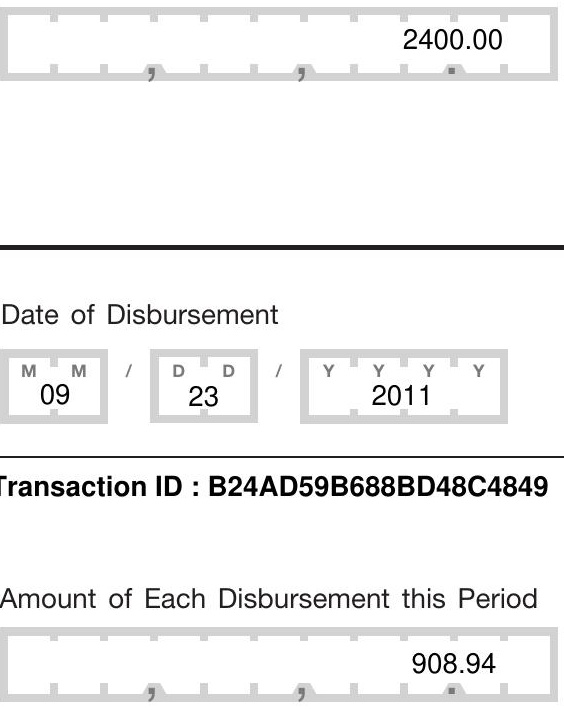

Date of Disbursement

\begin{tabular}{|c|c|c|c|c|}
\hline $09^{\mathrm{M}}$ & I & D 23 & 1 & $\begin{array}{cccc}Y & Y & Y & Y \\
& 2011 & \end{array}$ \\
\hline
\end{tabular}

Transaction ID : BDDC1BA6FD7D44CB893C

Amount of Each Disbursement this Period

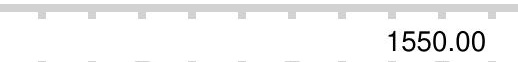

1550.00

Disbursement For: 2012
$X \begin{aligned} & \text { Primary } \\ & \text { Other (specify) }\end{aligned} \quad$ General

State:

District:

Subtotal Of Receipts This Page (optional).

Total This Period (last page this line number only)) 


\section{SCHEDULE B-P}

\section{ITEMIZED DISBURSEMENTS}

Use separate schedule(s)

for each category of the

Detailed Summary Page
FOR LINE NUMBER: (check only one)

\begin{tabular}{|c|c|c|c|}
\hline$\times{ }_{23}$ & 24 & 25 & 26 \\
\hline $27 b$ & $28 a$ & $28 \mathrm{~b}$ & $28 \mathrm{c}$ \\
\hline
\end{tabular}

Any information copied from such Reports and Statements may not be sold or used by any person for the purpose of soliciting contributions or for commercial purposes, other than using the name and address of any political committee to solicit contributions from such committee.

NAME OF COMMITTEE (In Full)

\section{Friends of Herman Cain}

Full Name (Last, First, Middle Initial)

A. Direct Mail Processors Inc.

Mailing Address 1150 conrad Court

\begin{tabular}{lll}
\hline City & State & Zip Code \\
Hagerstown & MD & 21740 \\
\hline
\end{tabular}

Purpose of Disbursement

Direct Mail Production

Candidate Name

Office Sought:

\begin{tabular}{|l|l|l} 
& House \\
Senate \\
President
\end{tabular}

Disbursement For: 2012

Х Primary $\square$ General

State:

District:

Full Name (Last, First, Middle Initial)

\section{B. Eberle Communications Group}

\begin{tabular}{|c|c|c|c|c|}
\hline \multicolumn{5}{|c|}{$\begin{array}{ll}\text { Mailing Address } & 1420 \text { Spring Hill Road } \\
& \text { Suite } 490\end{array}$} \\
\hline \multicolumn{2}{|l|}{ City } & \multicolumn{3}{|c|}{ Zip Code } \\
\hline \multicolumn{2}{|l|}{ McLean } & \multicolumn{3}{|c|}{22102} \\
\hline \multicolumn{4}{|c|}{$\begin{array}{l}\text { Purpose of Disbursement } \\
\text { Direct Mail Production }\end{array}$} & \\
\hline \multicolumn{4}{|l|}{ Candidate Name } & $\begin{array}{l}\text { Category/ } \\
\text { Type }\end{array}$ \\
\hline \multirow[t]{3}{*}{ Office Sought: } & House & \multirow{3}{*}{\multicolumn{3}{|c|}{$\begin{array}{l}\text { Disbursement For: } 2012 \\
\qquad \begin{array}{l}\text { Primary } \\
\text { Other (specify) }\end{array}\end{array}$}} \\
\hline & Senate & & & \\
\hline & President & & & \\
\hline State: & \multicolumn{4}{|c|}{ District: } \\
\hline
\end{tabular}

Date of Disbursement

\begin{tabular}{|c|c|c|c|c|}
\hline${ }^{\mathrm{M}}{ }^{\mathrm{M}}$ & 1 & $23^{D}$ & 1 & 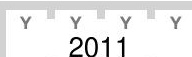 \\
\hline
\end{tabular}

Transaction ID : B4B59CB7ADFC44378854

Full Name (Last, First, Middle Initial)

c. Collins Digital Imaging Inc.

Mailing Address 1218 B Old Chattahoochee Avenue

Date of Disbursement

\begin{tabular}{lcc} 
& & \\
City & State & Zip Code \\
Atlanta & GA & 30318 \\
\hline
\end{tabular}

Purpose of Disbursement

Event Supplies

Candidate Name

\begin{tabular}{|c|c|c|c|}
\hline \multirow[t]{3}{*}{ Office Sought: } & House & \multicolumn{2}{|l|}{ Disbursement For: 2012} \\
\hline & Senate & X Primary & Gener \\
\hline & $\begin{array}{l}\text { President } \\
\text { rict: }\end{array}$ & Ot & $\nabla$ \\
\hline
\end{tabular}

Subtotal Of Receipts This Page (optional).

Total This Period (last page this line number only))

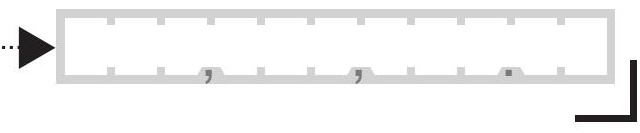




\section{SCHEDULE B-P}

\section{ITEMIZED DISBURSEMENTS}

Use separate schedule(s)

for each category of the

Detailed Summary Page
FOR LINE NUMBER: (check only one)

\begin{tabular}{|c|c|c|c|}
\hline$\times{ }_{23}$ & 24 & 25 & 26 \\
\hline $27 b$ & $28 a$ & $28 \mathrm{~b}$ & $28 \mathrm{c}$ \\
\hline
\end{tabular}

Any information copied from such Reports and Statements may not be sold or used by any person for the purpose of soliciting contributions or for commercial purposes, other than using the name and address of any political committee to solicit contributions from such committee.

NAME OF COMMITTEE (In Full)

\section{Friends of Herman Cain}

Full Name (Last, First, Middle Initial)

A. Delta Airlines

Mailing Address Post Office Box 20980

Department 980

\begin{tabular}{lll}
\hline City & State & Zip Code \\
Atlanta & GA & $30320-2980$
\end{tabular}

Purpose of Disbursement

Travel Expense

Candidate Name

Office Sought:

\section{B. Delta Airlines}

\begin{tabular}{ll}
\hline Mailing Address & $\begin{array}{l}\text { Post Office Box } 20980 \\
\text { Department } 980\end{array}$ \\
\hline City &
\end{tabular}

Atlanta

Purpose of Disbursement

Travel Expense

Candidate Name

Office Sought:

House
Senate
President

State:

District:

\section{Categor \\ Category/ Type}

Date of Disbursement

\begin{tabular}{|c|c|c|c|}
\hline $09^{M}$ & 1 & 23 & I \\
\hline
\end{tabular}

Transaction ID : B3D544D2089504A15AC2

Amount of Each Disbursement this Period 954.30

Full Name (Last, First, Middle Initial)

\section{c. Hyatt Hotels}

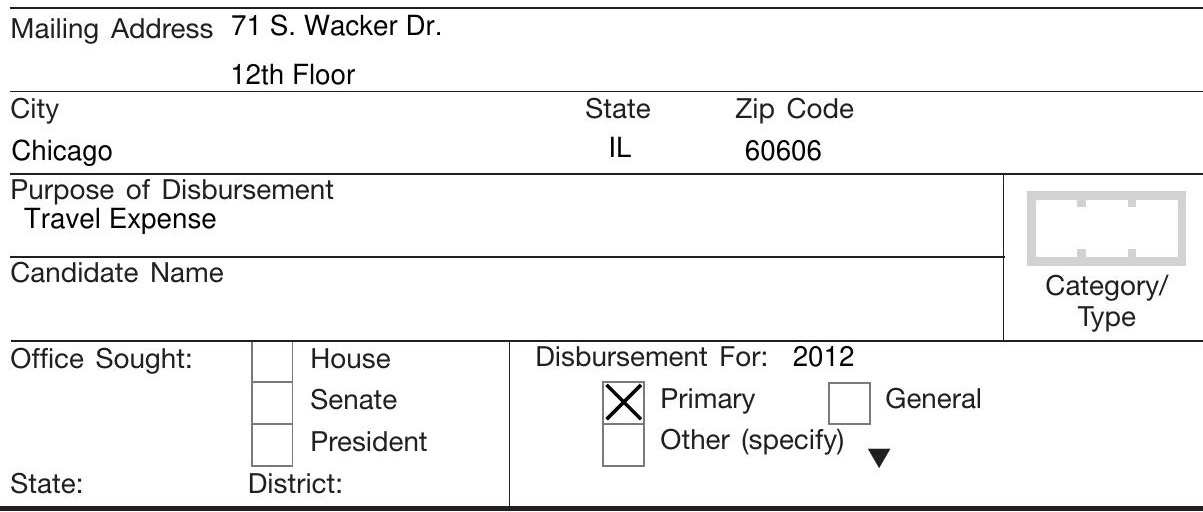

Subtotal Of Receipts This Page (optional).

Date of Disbursement

\begin{tabular}{|c|c|c|c|c|}
\hline $09^{M}$ & 1 & $26{ }^{\mathrm{D}}$ & I & 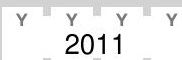 \\
\hline
\end{tabular}

Transaction ID : BA532F1BD8C1C4E44965

Amount of Each Disbursement this Period

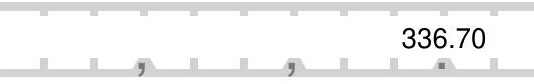

Date of Disbursement

\begin{tabular}{|c|c|c|c|c|c|}
\hline M & M & D & Y & Y & $Y$ \\
09 & & 26 & & 2011 & \\
\hline
\end{tabular}

Transaction ID : BBD301266311B45439AA

Amount of Each Disbursement this Period

266.60

Total This Period (last page this line number only))

1557.60

C. ㄱ.

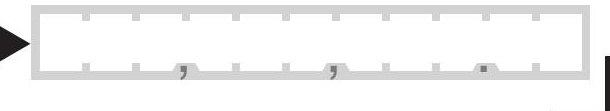




\section{SCHEDULE B-P}

\section{ITEMIZED DISBURSEMENTS}

\section{Use separate schedule(s) \\ for each category of the}

Detailed Summary Page
FOR LINE NUMBER: (check only one)

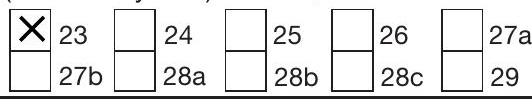

Any information copied from such Reports and Statements may not be sold or used by any person for the purpose of soliciting contributions or for commercial purposes, other than using the name and address of any political committee to solicit contributions from such committee.

NAME OF COMMITTEE (In Full)

\section{Friends of Herman Cain}

Full Name (Last, First, Middle Initial)

A. Sheraton Hotels

Mailing Address 1111 Westchester Ave.

Date of Disbursement

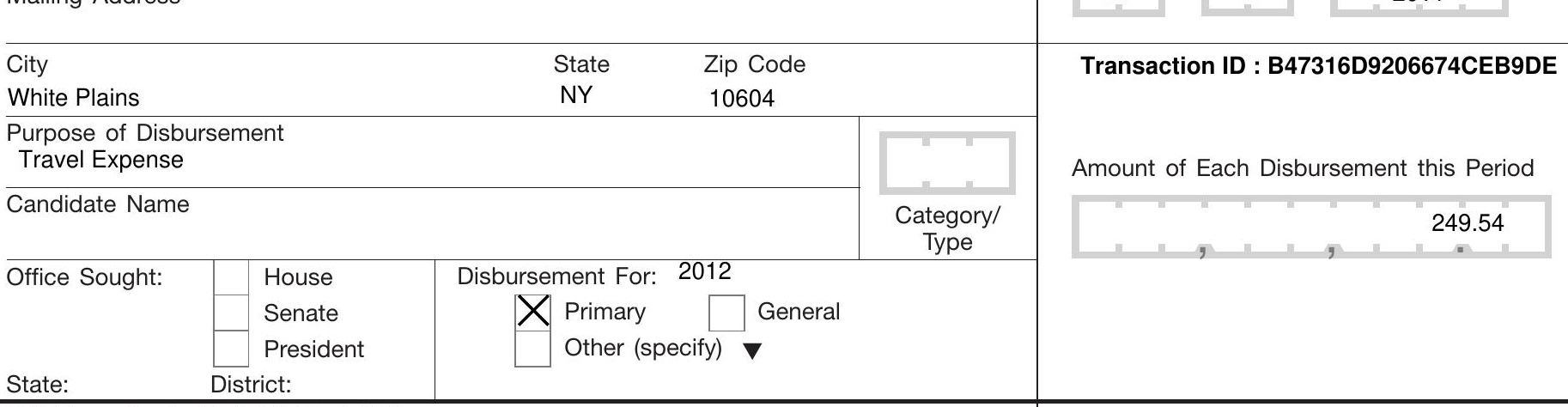

Full Name (Last, First, Middle Initial)

\section{B. American Express}

Mailing Address Post Office Box 53852

\begin{tabular}{lcc}
\hline City & State & Zip Code \\
Phoenix & AZ & $85072-3852$
\end{tabular}

Purpose of Disbursement

CC Transaction Fees

Candidate Name

Office Sought:

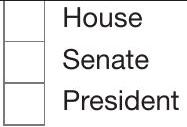

Disbursement For: 2012

Primary
Other (specify) General

State:

District:

Date of Disbursement

\begin{tabular}{|c|c|}
\hline${ }^{\mathrm{M}} 09^{\mathrm{M}}$ & 1 \\
\hline
\end{tabular}

Transaction ID : B6873AD0BD36D43648AC

Full Name (Last, First, Middle Initial)

c. Facebook, Inc.

Mailing Address 1601 S. California Ave.

Date of Disbursement

$\begin{array}{lcc} & & \\ \text { City } & \text { State } & \text { Zip Code } \\ \text { Palo Alto } & \text { CA } & 94304\end{array}$

Purpose of Disbursement

Advertising Expense

Candidate Name

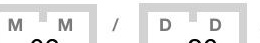

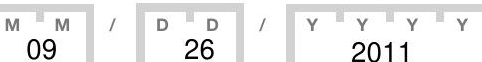

$26 \quad 2011$

Transaction ID : BFD3EA0ED887849FAB71

\begin{tabular}{c|c} 
Category/ \\
Type
\end{tabular}

\begin{tabular}{l|l|l|l}
\hline Office Sought: & House & $\begin{array}{c}\text { Disbursement For: } 2012 \\
\text { Senate } \\
\text { President } \\
\text { State: }\end{array}$ & X Primary \\
Other (specify)
\end{tabular}

Subtotal Of Receipts This Page (optional).

Total This Period (last page this line number only))

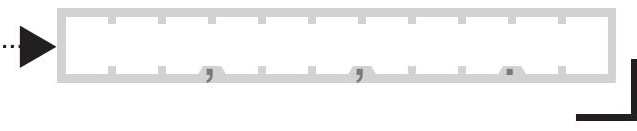




\section{SCHEDULE B-P}

\section{ITEMIZED DISBURSEMENTS}

\section{Use separate schedule(s)}

for each category of the

Detailed Summary Page
FOR LINE NUMBER: (check only one)

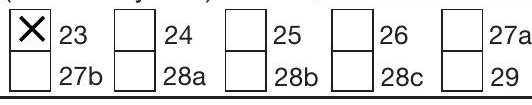

Any information copied from such Reports and Statements may not be sold or used by any person for the purpose of soliciting contributions or for commercial purposes, other than using the name and address of any political committee to solicit contributions from such committee.

NAME OF COMMITTEE (In Full)

\section{Friends of Herman Cain}

Full Name (Last, First, Middle Initial)

A. Frontier Airlines Inc.

Mailing Address 7001 Tower Road

Date of Disbursement

\begin{tabular}{lll}
\hline City & State & Zip Code \\
Denver & CO & $80249-7312$ \\
\hline
\end{tabular}

Purpose of Disbursement

Travel Expense

Candidate Name

Office Sought:

\begin{tabular}{|l|l} 
& House \\
& Senate \\
President
\end{tabular}

Disbursement For: 2012 X Primary $\square$ General

State: District:

Full Name (Last, First, Middle Initial)

B. Party Time Rental

\begin{tabular}{|c|c|c|c|c|}
\hline \multicolumn{5}{|c|}{ Mailing Address $30 \mathrm{~S}$ 3rd Street } \\
\hline \multicolumn{2}{|l|}{ City } & \multicolumn{3}{|c|}{ Zip Code } \\
\hline \multicolumn{2}{|l|}{ Ames } & \multicolumn{3}{|c|}{50010} \\
\hline \multicolumn{4}{|c|}{$\begin{array}{l}\text { Purpose of Disbursement } \\
\text { Event Equipment Rental }\end{array}$} & \\
\hline \multicolumn{4}{|l|}{ Candidate Name } & $\begin{array}{l}\text { Category/ } \\
\text { Type }\end{array}$ \\
\hline \multirow[t]{3}{*}{ Office Sought: } & \multirow{3}{*}{$\begin{array}{l}\text { House } \\
\text { Senate } \\
\text { President }\end{array}$} & \multirow{3}{*}{\multicolumn{3}{|c|}{$\begin{array}{l}\text { Disbursement For: } 2012 \\
\text { Primary } \\
\text { Other (specify) }\end{array}$}} \\
\hline & & & & \\
\hline & & & & \\
\hline State: & rict: & & & \\
\hline
\end{tabular}

Date of Disbursement

\begin{tabular}{|c|c|c|c|c|}
\hline${ }^{M}$ & ${ }^{M}$ & $9^{\mathrm{D}}$ & ${ }^{\mathrm{D}}$ & $\mathrm{Y}^{\mathrm{Y}} \mathrm{Y}^{\mathrm{Y}}$ \\
\hline
\end{tabular}

Transaction ID : BB4DF47EA475C42DBAD2

Full Name (Last, First, Middle Initial)

\section{c. Qwest Communications}

\begin{tabular}{|c|c|c|c|c|c|}
\hline \multicolumn{6}{|c|}{ Mailing Address 20 Ferry Street } \\
\hline \multicolumn{2}{|l|}{ City } & State & \multicolumn{3}{|l|}{ Zip Code } \\
\hline \multicolumn{2}{|l|}{ St. Louis } & MO & \multicolumn{3}{|l|}{63147} \\
\hline \multicolumn{5}{|c|}{$\begin{array}{l}\text { Purpose of Disbursement } \\
\text { Telephone }\end{array}$} & \\
\hline \multicolumn{5}{|c|}{ Candidate Name } & $\begin{array}{l}\text { Category/ } \\
\text { Type }\end{array}$ \\
\hline \multirow[t]{3}{*}{ Office Sought: } & House & \multicolumn{4}{|c|}{ Disbursement For: 2012} \\
\hline & Senate & \multirow{3}{*}{\multicolumn{2}{|c|}{ Х $\begin{array}{l}\text { Primary } \\
\text { Other (specify) }\end{array}$}} & \multirow{2}{*}{\multicolumn{2}{|c|}{ General }} \\
\hline & President & & & & \\
\hline State: & District: & & & & \\
\hline
\end{tabular}

Subtotal Of Receipts This Page (optional)...

Date of Disbursement

\begin{tabular}{|c|c|c|c|c|c|}
\hline M M / & D & D & Y & Y & Y \\
09 & & 27 & \\
\hline
\end{tabular}

\section{Transaction ID : B3E91365E50C240E6BCC}

Amount of Each Disbursement this Period

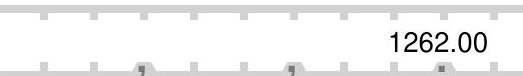

\subsection{0}

Total This Period (last page this line number only)) 


\section{SCHEDULE B-P}

\section{ITEMIZED DISBURSEMENTS}

Use separate schedule(s)

for each category of the

Detailed Summary Page
FOR LINE NUMBER: (check only one)

\begin{tabular}{|c|c|c|c|}
\hline$X_{23}$ & 24 & 25 & 26 \\
\hline $27 \mathrm{~b}$ & $28 a$ & $28 b$ & $28 \mathrm{c}$ \\
\hline
\end{tabular}

Any information copied from such Reports and Statements may not be sold or used by any person for the purpose of soliciting contributions or for commercial purposes, other than using the name and address of any political committee to solicit contributions from such committee.

NAME OF COMMITTEE (In Full)

\section{Friends of Herman Cain}

Full Name (Last, First, Middle Initial)

A. UPS

Mailing Address Post Office Box 7247-0244

Date of Disbursement

\begin{tabular}{lcc}
\hline City & State & Zip Code \\
Philadelphia & PA & $19170-0001$
\end{tabular}

Purpose of Disbursement

Shipping

Candidate Name

Office Sought:

\begin{tabular}{|l|l} 
& House \\
Senate \\
President
\end{tabular}

Disbursement For: 2012 X Primary $\square$ General

State: District:

Full Name (Last, First, Middle Initial)

\section{B. Newsmax Media}

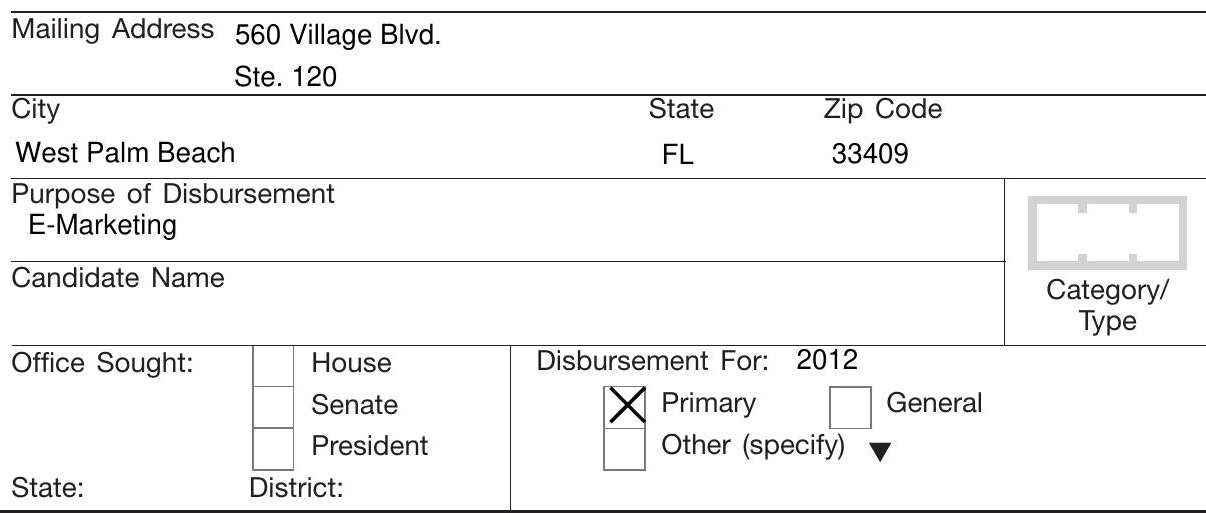

Date of Disbursement

Full Name (Last, First, Middle Initial)

c. Facebook, Inc.

Mailing Address 1601 S. California Ave.

Date of Disbursement

\begin{tabular}{lcc|} 
& & \\
\hline City & State & Zip Code \\
Palo Alto & CA & 94304 \\
\hline
\end{tabular}

\begin{tabular}{|c|c|c|c|c|}
\hline $09^{M}$ & I & $27^{\mathrm{D}}$ & I & $\begin{array}{llll} & Y & Y & Y \\
& 2011 & \end{array}$ \\
\hline
\end{tabular}

Transaction ID : B87BDAE0A542644F5BEF

Purpose of Disbursement

Advertising Expense

Candidate Name

\begin{tabular}{|c|c|c|c|c|c|}
\hline M M & M / & D \\
\hline & 27 & $Y$ & $Y$ & $Y$ \\
\hline
\end{tabular}

Transaction ID : BDE108AA1D2E447A7975

\begin{tabular}{c|c} 
Category/ \\
Type
\end{tabular}

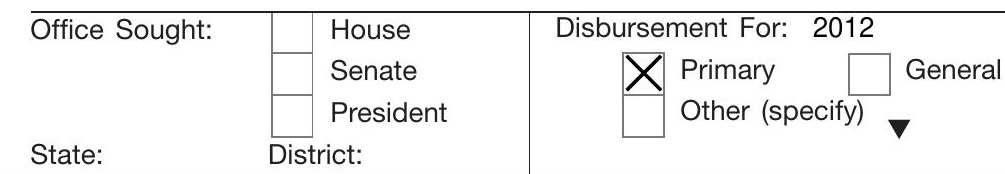

Subtotal Of Receipts This Page (optional).

Total This Period (last page this line number only))

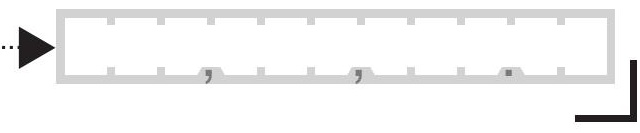




\section{SCHEDULE B-P}

\section{ITEMIZED DISBURSEMENTS}

Use separate schedule(s)

for each category of the

Detailed Summary Page
FOR LINE NUMBER: (check only one)

\begin{tabular}{|c|c|c|c|}
\hline$\times{ }_{23}$ & 24 & 25 & 26 \\
\hline $27 b$ & $28 a$ & $28 \mathrm{~b}$ & $28 \mathrm{c}$ \\
\hline
\end{tabular}

Any information copied from such Reports and Statements may not be sold or used by any person for the purpose of soliciting contributions or for commercial purposes, other than using the name and address of any political committee to solicit contributions from such committee.

NAME OF COMMITTEE (In Full)

\section{Friends of Herman Cain}

Full Name (Last, First, Middle Initial)

A. Inkhead Inc.

Mailing Address 138 Park Avenue

Suite 300

Date of Disbursement

\begin{tabular}{lll}
\multicolumn{3}{r}{ Suite 300} \\
City & State & Zip Code \\
Winder & GA & 30680
\end{tabular}

Purpose of Disbursement

Event Supplies

Candidate Name

\begin{tabular}{l|l|l}
\hline Office Sought: & House & Disbursement For: 2012
\end{tabular} X Primary $\square$ General

State:

\section{Senate}

President

District:

Full Name (Last, First, Middle Initial)

B. The Peabody

Mailing Address 9801 International Drive

\begin{tabular}{lcc}
\hline City & State & Zip Code \\
Orlando & FL & 32819
\end{tabular}

Purpose of Disbursement

Travel Expense

Candidate Name

Office Sought:

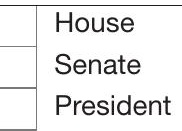

State:

District:

FL 32819

Full Name (Last, First, Middle Initial)

\section{c. Charter Business}

Mailing Address P.O. Box 742615

\begin{tabular}{lcc}
\hline City & State & Zip Code \\
Cincinnati & OH & $45274-2615$
\end{tabular}

Purpose of Disbursement

Internet/Phone/Cable

Candidate Name

Office Sought: $\quad$ House

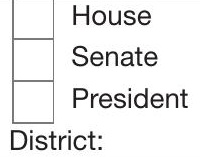

Disbursement For: 2012

Xrimary $\square$ General

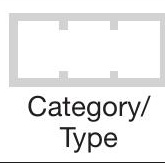

Date of Disbursement

\begin{tabular}{|c|c|c|c|c|c|}
\hline${ }^{M}{ }^{M}$ & $/$ & $9^{\mathrm{D}}$ & $\mathrm{Y}^{\mathrm{Y}}$ & $\mathrm{Y}^{\mathrm{Y}}$ & $\mathrm{Y}$ \\
\hline
\end{tabular}

Transaction ID : BBE32B04BD15D4F13A1B

Amount of Each Disbursement this Period

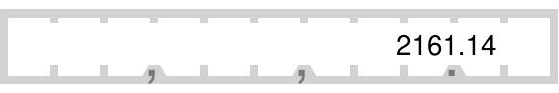

Date of Disbursement

\begin{tabular}{|c|c|c|c|c|}
\hline $09^{\mathrm{M}}$ & I & D 27 & 1 & $\begin{array}{cccc}Y & Y & Y & Y \\
& 2011 & \end{array}$ \\
\hline
\end{tabular}

Transaction ID : B1CE64D0F8D5241AA9A1

Amount of Each Disbursement this Period

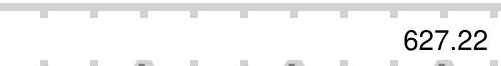

627.22

Subtotal Of Receipts This Page (optional).

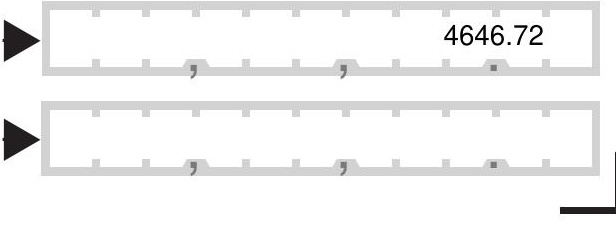

Total This Period (last page this line number only)) 


\section{SCHEDULE B-P}

\section{ITEMIZED DISBURSEMENTS}

Use separate schedule(s)

for each category of the

Detailed Summary Page
FOR LINE NUMBER: (check only one)

\begin{tabular}{|c|c|c|c|}
\hline$\times{ }_{23}$ & 24 & 25 & 26 \\
\hline $27 b$ & $28 a$ & $28 \mathrm{~b}$ & $28 \mathrm{c}$ \\
\hline
\end{tabular}

Any information copied from such Reports and Statements may not be sold or used by any person for the purpose of soliciting contributions or for commercial purposes, other than using the name and address of any political committee to solicit contributions from such committee.

NAME OF COMMITTEE (In Full)

\section{Friends of Herman Cain}

Full Name (Last, First, Middle Initial)

A. William Head

Mailing Address PO Box 2158

Date of Disbursement

\begin{tabular}{lcc}
\hline City & State & Zip Code \\
Stockbridge & GA & $30281-8909$
\end{tabular}

Purpose of Disbursement

Staff Salary

Candidate Name

Office Sought: $\quad$ House

Senate

President

State:

District:

Full Name (Last, First, Middle Initial)

B. Ellen Carmichael

Mailing Address 1007 Oak Hills Parkway

\begin{tabular}{lcc}
\hline City & State & Zip Code \\
Baton Rouge & LA & $70810-4705$
\end{tabular}

Purpose of Disbursement

Staff Salary

Candidate Name

Disbursement For: 2012

X Primary $\square$ General

Office Sought:

\begin{tabular}{|l|l} 
House \\
Senate \\
President
\end{tabular}

Disbursement For: 2012

Xrimary $\square$ General

State:

District:

Full Name (Last, First, Middle Initial)

\section{c. Scott F. Bieniek}

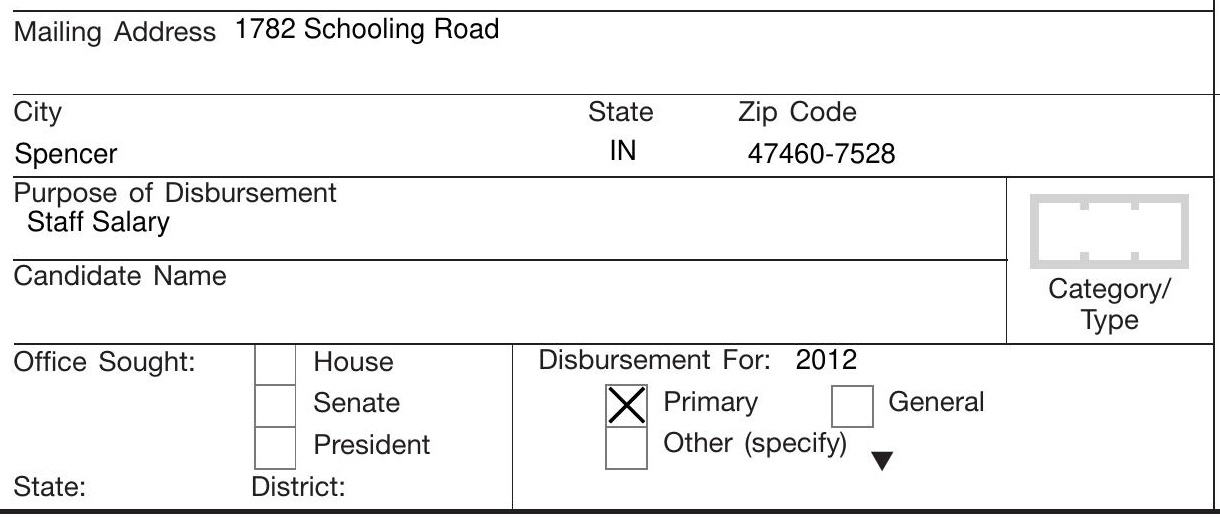

Subtotal Of Receipts This Page (optional).

Total This Period (last page this line number only))
Date of Disbursement

\begin{tabular}{|c|c|c|c|c|}
\hline $09^{M}$ & 1 & $27^{\mathrm{D}}$ & 1 & 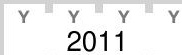 \\
\hline
\end{tabular}

Transaction ID : B5DFB7148F0044722853

Amount of Each Disbursement this Period

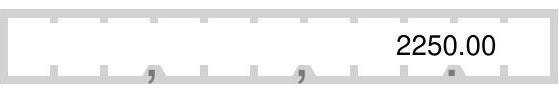

Date of Disbursement

\begin{tabular}{|c|c|c|c|c|}
\hline $09^{M}$ & 1 & D 27 & I & $\begin{array}{cccc}Y & Y & Y & Y \\
& 2011 & \end{array}$ \\
\hline
\end{tabular}

Transaction ID : BA61126F38FE544D8B99

Amount of Each Disbursement this Period

5000.00 


\section{SCHEDULE B-P}

\section{ITEMIZED DISBURSEMENTS}

\section{Use separate schedule(s)}

for each category of the

Detailed Summary Page
FOR LINE NUMBER: (check only one)

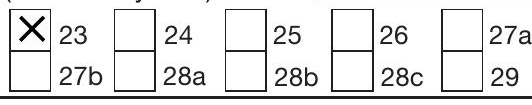

Any information copied from such Reports and Statements may not be sold or used by any person for the purpose of soliciting contributions or for commercial purposes, other than using the name and address of any political committee to solicit contributions from such committee.

NAME OF COMMITTEE (In Full)

\section{Friends of Herman Cain}

Full Name (Last, First, Middle Initial)

A. Scott F. Bieniek

Mailing Address 1782 Schooling Road

Date of Disbursement

\begin{tabular}{lcc}
\hline City & State & Zip Code \\
Spencer & IN & $47460-7528$
\end{tabular}

Purpose of Disbursement

Mileage/Transportation/Meeting Expense

Candidate Name

\begin{tabular}{l|l|l}
\hline Office Sought: & House & Disbursement For: 2012
\end{tabular} X Primary $\square$ General

State:

Senate
President
District:

Full Name (Last, First, Middle Initial)

B. Mark Block

Mailing Address 18125 West Plateau Lane

\begin{tabular}{lcc}
\hline City & State & Zip Code \\
New Berlin & WI & $53146-5116$
\end{tabular}

Purpose of Disbursement

Staff Salary

Candidate Name

Office Sought:

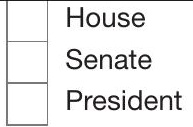

Disbursement For: 2012

Xrimary $\square$ General

State:

District:

Full Name (Last, First, Middle Initial)

c. Michael Branch

Mailing Address 509 Autumnwood Ct

\begin{tabular}{lcc}
\hline City & State & Zip Code \\
Nashville & TN & $37221-3938$
\end{tabular}

Purpose of Disbursement

Staff Salary

Candidate Name

Office Sought: $\quad$ House

$\begin{aligned} & \text { House } \\ & \text { Senate } \\ & \text { President }\end{aligned}$
District:

State:

Disbursement For: 2012

X $\begin{aligned} & \text { Primary } \\ & \text { Other (specify) }\end{aligned}$
Date of Disbursement

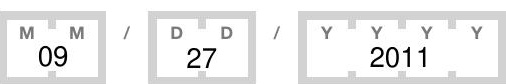

Transaction ID : B0CE153D9D0384FA2A42

Amount of Each Disbursement this Period

5000.00

Date of Disbursement

\begin{tabular}{|c|c|c|c|c|}
\hline $09^{M}$ & I & D 27 & I & 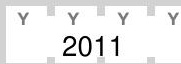 \\
\hline
\end{tabular}

Transaction ID : B78A3C610F0A94523B10

Amount of Each Disbursement this Period

1875.00
Subtotal Of Receipts This Page (optional).

7704.94

C.

Total This Period (last page this line number only))

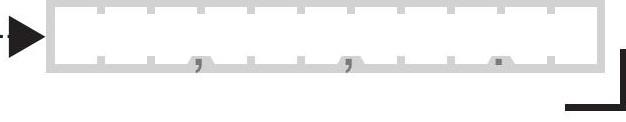

FEC Schedule B-P (Form 3P) (Rev. 03/2011) 


\section{SCHEDULE B-P}

\section{ITEMIZED DISBURSEMENTS}

\section{Use separate schedule(s) \\ for each category of the}

Detailed Summary Page
FOR LINE NUMBER: (check only one)

\begin{tabular}{|c|c|c|c|}
\hline$\times{ }_{23}$ & 24 & 25 & 26 \\
\hline $27 b$ & $28 a$ & $28 \mathrm{~b}$ & $28 \mathrm{c}$ \\
\hline
\end{tabular}

Any information copied from such Reports and Statements may not be sold or used by any person for the purpose of soliciting contributions or for commercial purposes, other than using the name and address of any political committee to solicit contributions from such committee.

NAME OF COMMITTEE (In Full)

\section{Friends of Herman Cain}

Full Name (Last, First, Middle Initial)

A. Larry Tuel

Mailing Address 5129 Welker Ave.

Date of Disbursement

\begin{tabular}{lcc}
\hline City & State & Zip Code \\
Des Moines & IA & $50312-2159$
\end{tabular}

Purpose of Disbursement

Mileage/Event Supplies/Transportation

Candidate Name

\begin{tabular}{l|l|l}
\hline Office Sought: & House & Disbursement For: 2012
\end{tabular} X Primary $\square$ General

State:

\section{Senate}

President

District:

Full Name (Last, First, Middle Initial)

B. Larry Tuel

Mailing Address 5129 Welker Ave.

\begin{tabular}{lcc}
\hline City & State & Zip Code \\
Des Moines & IA & $50312-2159$
\end{tabular}

Purpose of Disbursement

Staff Salary

Candidate Name

Office Sought:

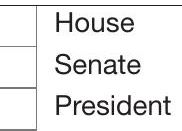

State:

District:

Full Name (Last, First, Middle Initial)

\section{c. Scott Sidney}

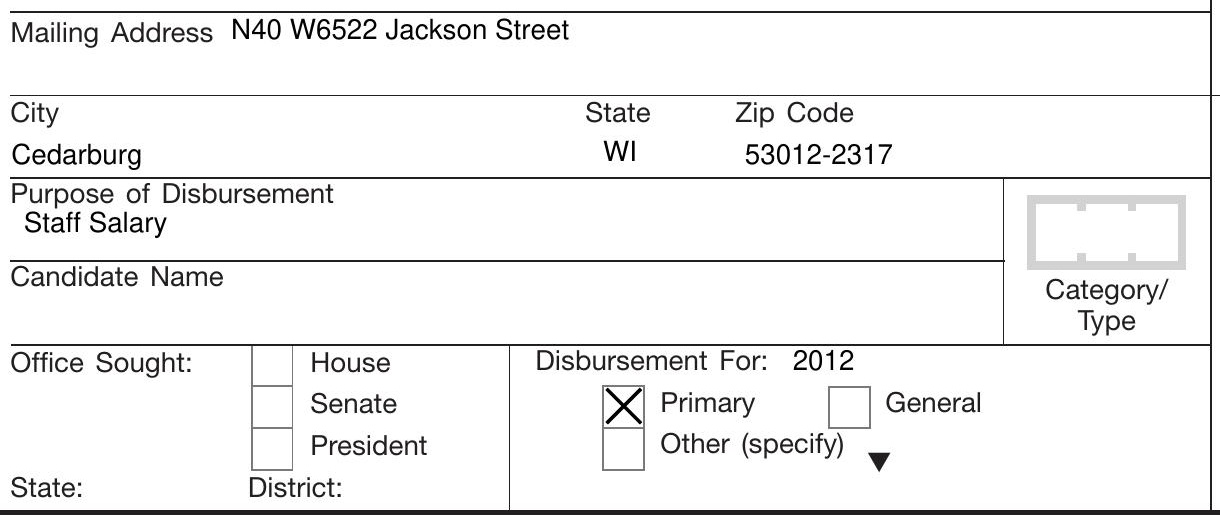

Subtotal Of Receipts This Page (optional)...

Date of Disbursement

\begin{tabular}{|c|c|c|c|c|}
\hline${ }^{M}$ & ${ }^{M}$ & $9^{\mathrm{D}}$ & ${ }^{\mathrm{D}}$ & $\mathrm{Y}^{\mathrm{Y}} \mathrm{Y}^{\mathrm{Y}}$ \\
\hline
\end{tabular}

Transaction ID : B286A791B39AF45FEAE3

Amount of Each Disbursement this Period

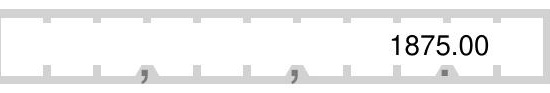

Date of Disbursement

\begin{tabular}{|c|c|c|c|c|}
\hline $09^{\mathrm{M}}$ & I & D 27 & 1 & $\begin{array}{cccc}Y & Y & Y & Y \\
& 2011 & \end{array}$ \\
\hline
\end{tabular}

\section{Transaction ID : BC192A24B778440E0BED}

Amount of Each Disbursement this Period

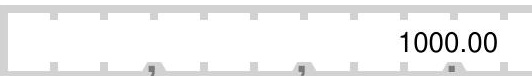

1000.00

Total This Period (last page this line number only)) 


\section{SCHEDULE B-P}

\section{ITEMIZED DISBURSEMENTS}

\section{Use separate schedule(s) \\ for each category of the}

Detailed Summary Page
FOR LINE NUMBER: (check only one)

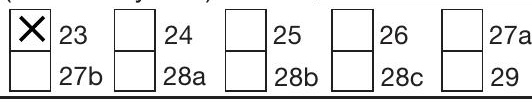

Any information copied from such Reports and Statements may not be sold or used by any person for the purpose of soliciting contributions or for commercial purposes, other than using the name and address of any political committee to solicit contributions from such committee.

NAME OF COMMITTEE (In Full)

\section{Friends of Herman Cain}

Full Name (Last, First, Middle Initial)

\section{A. Scott Sidney}

Mailing Address N40 W6522 Jackson Street

Date of Disbursement

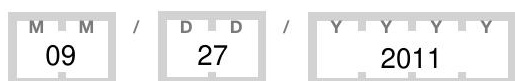

Transaction ID : B736CCDE7A1854FE184F

\begin{tabular}{lll}
\hline City & State & Zip Code \\
Cedarburg & WI & $53012-2317$
\end{tabular}

Purpose of Disbursement

Transportation/Office Supplies/Mtg Exp

Candidate Name

Office Sought:

$$
\begin{array}{|l|l}
\text { House } \\
\text { Senate } \\
\text { President }
\end{array}
$$$$
\text { District: }
$$

State:

Full Name (Last, First, Middle Initial)

B. Kyle Maichle

Mailing Address 617 N 23rd Street Apt 305

\begin{tabular}{lcc}
\hline City & State & Zip Code \\
Milwaukee & WI & 53233-1976
\end{tabular}

Purpose of Disbursement

Research

Candidate Name

Office Sought:

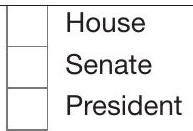

Disbursement For: 2012

Xrimary $\square$ General

State:

District:

Full Name (Last, First, Middle Initial)

\section{c. Lisa Lockwood}

Mailing Address 12746 Ford Trail South

\begin{tabular}{lcc}
\hline City & State & Zip Code \\
Indianola & IA & $50125-8931$
\end{tabular}

Purpose of Disbursement

Staff Salary

Candidate Name

Office Sought: $\quad$ House

\begin{tabular}{|l|l|} 
& House \\
& Senate \\
& President
\end{tabular}

Disbursement For: 2012

X $\begin{aligned} & \text { Primary } \\ & \text { Other (specify) }\end{aligned}$

\begin{tabular}{|c|c|c|c|c|}
\hline${ }^{M}$ & ${ }^{M}$ & $9^{\mathrm{D}}$ & $\mathrm{P}^{\mathrm{D}}$ & $\mathrm{Y}^{\mathrm{Y}} \mathrm{Y}$ \\
\hline
\end{tabular}

Transaction ID : BB0A55D2E9B2D4E58864

Amount of Each Disbursement this Period

1117.19

\begin{tabular}{|c|c|c|c|c|}
\hline $09^{\mathrm{M}}$ & I & D 27 & 1 & $\begin{array}{cccc}Y & Y & Y & Y \\
& 2011 & \end{array}$ \\
\hline
\end{tabular}

Date of Disbursement

Transaction ID : B8D38C10665D6497D910

Amount of Each Disbursement this Period

1375.00
Date of Disbursement

State:

District:

Subtotal Of Receipts This Page (optional).

Total This Period (last page this line number only))

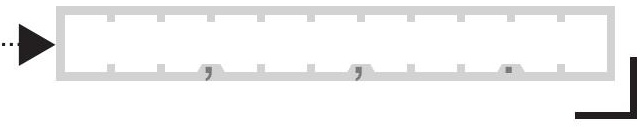




\section{SCHEDULE B-P}

\section{ITEMIZED DISBURSEMENTS}

Use separate schedule(s)

for each category of the

Detailed Summary Page
FOR LINE NUMBER: (check only one)

\begin{tabular}{|c|c|c|c|}
\hline$\times \quad 23$ & 24 & 25 & 26 \\
\hline $27 \mathrm{~b}$ & $28 \mathrm{a}$ & $28 b$ & $28 \mathrm{c}$ \\
\hline
\end{tabular}

Any information copied from such Reports and Statements may not be sold or used by any person for the purpose of soliciting contributions or for commercial purposes, other than using the name and address of any political committee to solicit contributions from such committee.

NAME OF COMMITTEE (In Full)

\section{Friends of Herman Cain}

Full Name (Last, First, Middle Initial)

A. Charles Spano

Mailing Address PO Box 2158

Date of Disbursement

\begin{tabular}{lll}
\hline City & State & Zip Code \\
Stockbridge & GA & $30281-8909$
\end{tabular}

Purpose of Disbursement

Lodging/Transportation/Office Supplies

Candidate Name

Office Sought:

$$
\begin{array}{|l|l}
\text { House } \\
\text { Senate } \\
\text { President }
\end{array}
$$
District:

State:

Full Name (Last, First, Middle Initial)

B. James Coughlin

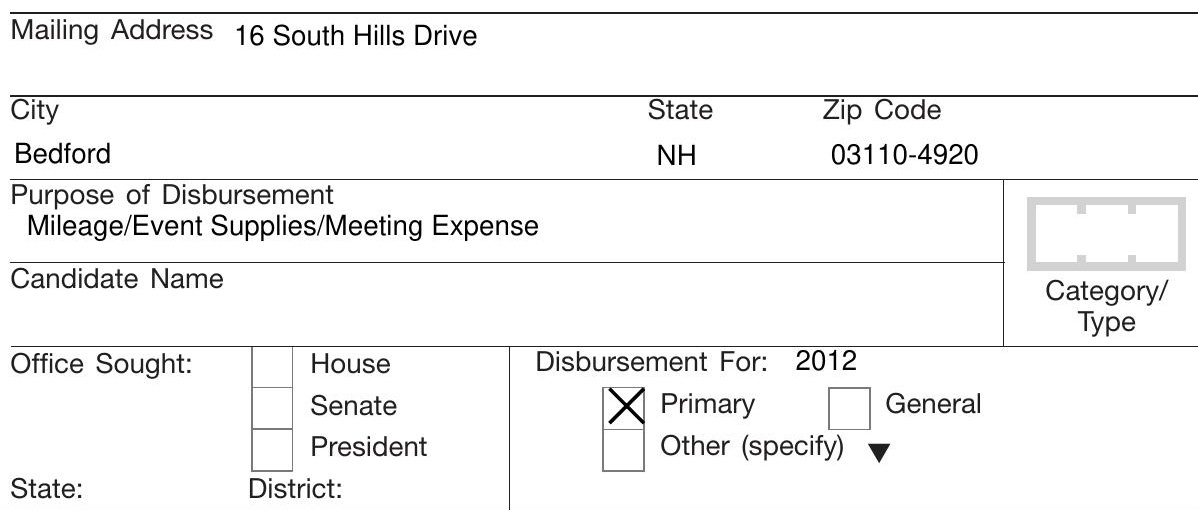

Date of Disbursement

\begin{tabular}{|c|c|c|c|c|}
\hline${ }^{M}$ & ${ }^{M}$ & $9^{\mathrm{D}}$ & ${ }^{\mathrm{D}}$ & $\mathrm{Y}^{\mathrm{Y}} \mathrm{Y}^{\mathrm{Y}}$ \\
\hline
\end{tabular}

Transaction ID : B5442DBDC34424A37953

Full Name (Last, First, Middle Initial)

c. Francis Boustany, III

Mailing Address 126 Westfield Drive

Date of Disbursement

$\begin{array}{lcc} & & \\ \text { City } & \text { State } & \text { Zip Code } \\ \text { Lafayette } & \text { LA } & 70503-5484\end{array}$

Purpose of Disbursement

Staff Salary

Candidate Name

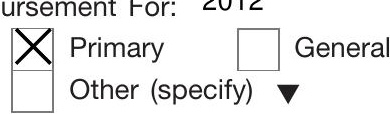

Amount of Each Disbursement this Period

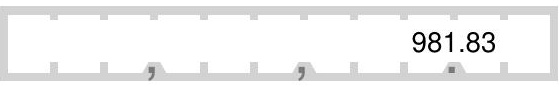

\begin{tabular}{|c|c|}
\hline $09^{M}$ & 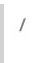 \\
\hline
\end{tabular}

\begin{tabular}{l|l|c|}
\hline Office Sought: & $\begin{array}{l}\text { House } \\
\text { Senate } \\
\text { President }\end{array}$ & $\begin{array}{c}\text { Disbursement For: } 2012 \\
\text { State: }\end{array}$ \\
\cline { 2 - 3 } & District:
\end{tabular}

Transaction ID : B5EAAD9961ECE402F947

Amount of Each Disbursement this Period

1500.00

Subtotal Of Receipts This Page (optional).

Total This Period (last page this line number only))

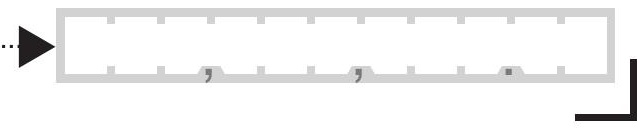




\section{SCHEDULE B-P}

\section{ITEMIZED DISBURSEMENTS}

\section{Use separate schedule(s)}

for each category of the

Detailed Summary Page
FOR LINE NUMBER: (check only one)

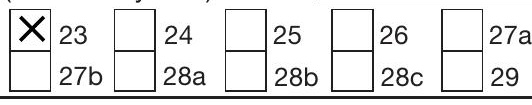

Any information copied from such Reports and Statements may not be sold or used by any person for the purpose of soliciting contributions or for commercial purposes, other than using the name and address of any political committee to solicit contributions from such committee.

NAME OF COMMITTEE (In Full)

\section{Friends of Herman Cain}

Full Name (Last, First, Middle Initial)

A. J Ryan Hudson

Mailing Address 418 Landing Pointe

Date of Disbursement

\begin{tabular}{lcc}
\hline City & State & Zip Code \\
Stockbridge & GA & 30281
\end{tabular}

Purpose of Disbursement

Staff Salary

Candidate Name

Office Sought: $\quad$ House

Senate

President

State:

District:

Full Name (Last, First, Middle Initial)

B. Michael Johnson

Mailing Address 8225 W. Center St. Apt. 3

\begin{tabular}{lcc}
\hline City & State & Zip Code \\
Milwaukee & WI & $53222-486$
\end{tabular}

Purpose of Disbursement

Staff Salary

Candidate Name

Disbursement For: 2012

X Primary $\square$ General

Office Sought:

House
Senate
President

Disbursement For: 2012

Xrimary $\square$ General

State:

District:

Full Name (Last, First, Middle Initial)

\section{c. Stacy DeJarnette}

\begin{tabular}{|c|c|c|c|c|c|}
\hline \multicolumn{6}{|c|}{ Mailing Address 207 Robin Street } \\
\hline \multicolumn{2}{|l|}{ City } & State & \multicolumn{3}{|l|}{ Zip Code } \\
\hline \multicolumn{2}{|l|}{ White Hall } & AR & \multicolumn{3}{|c|}{$71602-5418$} \\
\hline \multicolumn{5}{|c|}{$\begin{array}{l}\text { Purpose of Disbursement } \\
\text { Staff Salary }\end{array}$} & \\
\hline \multicolumn{5}{|c|}{ Candidate Name } & $\begin{array}{l}\text { Category/ } \\
\text { Type }\end{array}$ \\
\hline \multirow[t]{3}{*}{ Office Sought: } & House & \multirow{3}{*}{\multicolumn{4}{|c|}{$\begin{array}{l}\text { Disbursement For: } 2012 \\
\text { Х Primary } \\
\text { Other (specify) }\end{array}$}} \\
\hline & Senate & & & & \\
\hline & President & & & & \\
\hline State: & \multicolumn{5}{|c|}{ District: } \\
\hline
\end{tabular}

Subtotal Of Receipts This Page (optional)......

Date of Disbursement

\begin{tabular}{|c|c|c|c|c|}
\hline $09^{M}$ & 1 & $27^{\mathrm{D}}$ & I & 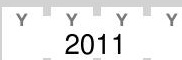 \\
\hline
\end{tabular}

Transaction ID : B48F888AEA447448C9D6

Amount of Each Disbursement this Period

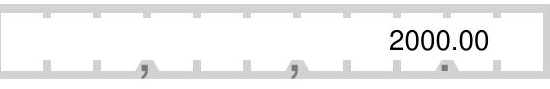

Date of Disbursement

\begin{tabular}{|c|c|c|c|c|}
\hline $09^{M}$ & 1 & D 27 & I & $\begin{array}{cccc}Y & Y & Y & Y \\
& 2011 & \end{array}$ \\
\hline
\end{tabular}

Transaction ID : B199AEE3CA7D04775B00

Amount of Each Disbursement this Period

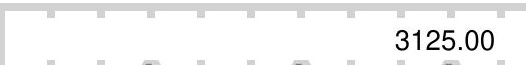

3125.00

Total This Period (last page this line number only)) 


\section{SCHEDULE B-P}

\section{ITEMIZED DISBURSEMENTS}

\section{Use separate schedule(s)}

for each category of the

Detailed Summary Page
FOR LINE NUMBER: (check only one)

\begin{tabular}{|c|c|c|c|}
\hline$\times{ }_{23}$ & 24 & 25 & 26 \\
\hline $27 b$ & $28 a$ & $28 \mathrm{~b}$ & $28 \mathrm{c}$ \\
\hline
\end{tabular}

Any information copied from such Reports and Statements may not be sold or used by any person for the purpose of soliciting contributions or for commercial purposes, other than using the name and address of any political committee to solicit contributions from such committee.

NAME OF COMMITTEE (In Full)

\section{Friends of Herman Cain}

Full Name (Last, First, Middle Initial)

\section{A. Nathan Naidu}

Mailing Address 3601 canton rd \#131

Date of Disbursement

\begin{tabular}{lcc}
\hline City & State & Zip Code \\
Marietta & GA & $30066-2892$ \\
\hline
\end{tabular}

Purpose of Disbursement

Lodging, Airfare and Meeting Expenses

Candidate Name

Office Sought:

\begin{tabular}{|l|l} 
& House \\
Senate \\
President
\end{tabular}

Disbursement For: 2012 X Primary $\square$ General

State: District:

Full Name (Last, First, Middle Initial)

B. Raquel Rhada Hirsch

\begin{tabular}{|c|c|c|c|c|}
\hline \multicolumn{5}{|c|}{ Mailing Address 6825 N 2nd Place } \\
\hline \multicolumn{2}{|l|}{ City } & \multicolumn{3}{|c|}{ Zip Code } \\
\hline \multicolumn{2}{|l|}{ Scottsdale } & \multicolumn{3}{|c|}{85250} \\
\hline \multicolumn{4}{|c|}{$\begin{array}{l}\text { Purpose of Disbursement } \\
\text { Staff Salary }\end{array}$} & \\
\hline \multicolumn{4}{|l|}{ Candidate Name } & $\begin{array}{l}\text { Category/ } \\
\text { Type }\end{array}$ \\
\hline \multirow[t]{3}{*}{ Office Sought: } & House & \multirow{3}{*}{\multicolumn{3}{|c|}{$\begin{array}{l}\text { Disbursement For: } 2012 \\
\text { X Primary } \\
\text { Other (specify) }\end{array}$}} \\
\hline & Senate & & & \\
\hline & President & & & \\
\hline State: & \multicolumn{4}{|c|}{ District: } \\
\hline
\end{tabular}

Date of Disbursement

\begin{tabular}{|c|c|c|c|c|}
\hline${ }^{M}$ & ${ }^{M}$ & $9^{\mathrm{D}}$ & $\mathrm{P}^{\mathrm{D}}$ & $\mathrm{Y}^{\mathrm{Y}} \mathrm{Y}$ \\
\hline
\end{tabular}

Transaction ID : BF11957CED9514528BCC

Full Name (Last, First, Middle Initial)

c. Nathan Naidu

Mailing Address 3601 canton rd \#131

\begin{tabular}{lcc}
\hline City & State & Zip Code \\
Marietta & GA & $30066-2892$
\end{tabular}

Purpose of Disbursement Staff Salary

Candidate Name

\begin{tabular}{|c|c|}
\hline \multirow[t]{3}{*}{ Office Sought: } & House \\
\hline & Senate \\
\hline & President \\
\hline ate: & rict: \\
\hline
\end{tabular}

Date of Disbursement

\begin{tabular}{|c|c|c|c|c|c|}
\hline M & M & D & Y & Y & Y \\
09 & & 27 & & 2011 & \\
\hline
\end{tabular}

Transaction ID : BCAD8FE5E784A4925837

Amount of Each Disbursement this Period 1500.00

Subtotal Of Receipts This Page (optional).

10752.72

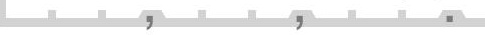

Total This Period (last page this line number only)) 


\section{SCHEDULE B-P}

\section{ITEMIZED DISBURSEMENTS}

\section{Use separate schedule(s)}

for each category of the

Detailed Summary Page
FOR LINE NUMBER: (check only one)

\begin{tabular}{|c|c|c|c|}
\hline$\times{ }_{23}$ & 24 & 25 & 26 \\
\hline $27 b$ & $28 a$ & $28 \mathrm{~b}$ & $28 \mathrm{c}$ \\
\hline
\end{tabular}

Any information copied from such Reports and Statements may not be sold or used by any person for the purpose of soliciting contributions or for commercial purposes, other than using the name and address of any political committee to solicit contributions from such committee.

NAME OF COMMITTEE (In Full)

\section{Friends of Herman Cain}

Full Name (Last, First, Middle Initial)

A. Lisa Lockwood

Mailing Address 12746 Ford Trail South

Date of Disbursement

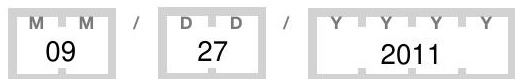

Transaction ID : BEFD20FC316864948920

\begin{tabular}{lcc}
\hline City & State & Zip Code \\
Indianola & IA & $50125-8931$
\end{tabular}

Purpose of Disbursement

Phones/Mileage/Event Supplies/Postage

Candidate Name

Office Sought:

$$
\begin{array}{|l|l}
\text { House } \\
\text { Senate } \\
\cline { 1 - 2 } \text { President }
\end{array}
$$
District:

State:

Full Name (Last, First, Middle Initial)

\section{B. Steven Hensler}

\section{Mailing Address 401 Woodview Drive}

\begin{tabular}{lcc}
\hline City & State & Zip Code \\
Sun Prairie & WI & $53590-2353$
\end{tabular}

Purpose of Disbursement

Staff Salary

Candidate Name

Office Sought:

House
Senate
President

Disbursement For: 2012

Xrimary $\square$ General

State:

District:

Full Name (Last, First, Middle Initial)

c. Joel Ricks

Mailing Address 3073 Meadowlark Lane

\begin{tabular}{lcc}
\hline City & State & Zip Code \\
East Point & GA & 30344
\end{tabular}

Purpose of Disbursement

Office Maintenance

Candidate Name

Office Sought: $\quad$ House

\begin{tabular}{|l|l|} 
& House \\
Senate \\
President
\end{tabular}

Disbursement For: 2012

Х $\begin{aligned} & \text { Primary } \\ & \text { Other (specify) }\end{aligned}$

District:

$$
\text { X Primary } \square \text { General }
$$

Amount of Each Disbursement this Period

5557.49

\begin{tabular}{|c|c|c|c|c|}
\hline $09^{M}$ & 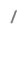 & ${ }^{\mathrm{D}} 27^{\mathrm{D}}$ & & $\begin{array}{llll}Y & Y & Y & Y \\
& 2011 & \end{array}$ \\
\hline
\end{tabular}

Date of Disbursement

Transaction ID : B3F289B5F44A74513988

Amount of Each Disbursement this Period

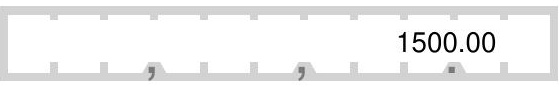

\begin{tabular}{|c|c|c|c|c|}
\hline $09^{\mathrm{M}}$ & I & D 27 & 1 & $\begin{array}{cccc}Y & Y & Y & Y \\
& 2011 & \end{array}$ \\
\hline
\end{tabular}

Date of Disbursement

Transaction ID : BEFB6F55C3E984D41A0C

Amount of Each Disbursement this Period

800.00

Subtotal Of Receipts This Page (optional)......

Total This Period (last page this line number only))

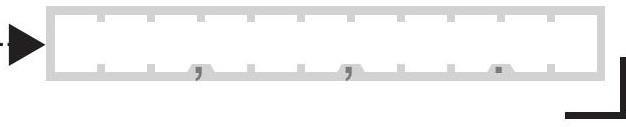




\section{SCHEDULE B-P}

\section{ITEMIZED DISBURSEMENTS}

Use separate schedule(s)

for each category of the

Detailed Summary Page
FOR LINE NUMBER: (check only one)

\begin{tabular}{|c|c|c|c|}
\hline $\mathrm{X} 23$ & 24 & 25 & 26 \\
\hline $27 \mathrm{~b}$ & $28 a$ & $28 b$ & $28 \mathrm{c}$ \\
\hline
\end{tabular}

Any information copied from such Reports and Statements may not be sold or used by any person for the purpose of soliciting contributions or for commercial purposes, other than using the name and address of any political committee to solicit contributions from such committee.

NAME OF COMMITTEE (In Full)

\section{Friends of Herman Cain}

\section{A. Chris Burgard}

Mailing Address 34729 Petersen Road

\begin{tabular}{lcc}
\hline City & State & Zip Code \\
Santa Clarita & CA & $91390-2809$
\end{tabular}

Purpose of Disbursement

Event Supplies and Catering

Candidate Name

Office Sought:

House
Senate
President
District:

Disbursement For: 2012 X Primary $\square$ General
Date of Disbursement

\begin{tabular}{|c|c|c|c|c|c|}
\hline M M / & D D \\
09 & 27 & 2011 \\
\hline
\end{tabular}

Transaction ID : BDC3307E8DF38424A96D

Amount of Each Disbursement this Period 365.85

Date of Disbursement

\begin{tabular}{|c|c|c|c|c|}
\hline${ }^{\mathrm{M}} 09^{\mathrm{M}}$ & 1 & $27^{\mathrm{D}}$ & 1 & $\begin{array}{llll} & Y & Y & Y \\
& 2011 & Y\end{array}$ \\
\hline
\end{tabular}

Transaction ID : B61805648618A4DFAA25

Grafton

State Zip Code

IA 50440-7570

Purpose of Disbursement

Mileage/Transportation/Meeting Expense

Candidate Name

Office Sought:

House
Senate
President

Disbursement For: 2012

Xrimary $\square$ General

State:

District:

Full Name (Last, First, Middle Initial)

c. Francis Boustany, III

Mailing Address 126 Westfield Drive

\begin{tabular}{lcc}
\hline City & State & Zip Code \\
Lafayette & LA & $70503-5484$
\end{tabular}

Purpose of Disbursement

Mileage

Candidate Name

Office Sought: $\quad$ House

\begin{tabular}{|l|l|} 
& House \\
& Senate \\
& President \\
& District:
\end{tabular}

Disbursement For: 2012

Х $\begin{aligned} & \text { Primary } \\ & \text { Other (specify) }\end{aligned}$
Date of Disbursement

\begin{tabular}{|c|c|c|c|c|}
\hline $09^{\mathrm{M}}$ & I & D 27 & 1 & $\begin{array}{cccc}Y & Y & Y & Y \\
& 2011 & \end{array}$ \\
\hline
\end{tabular}

Transaction ID : BED5BD55874A04E82806

Amount of Each Disbursement this Period

127.65
State:

District:

Subtotal Of Receipts This Page (optional)

Total This Period (last page this line number only))

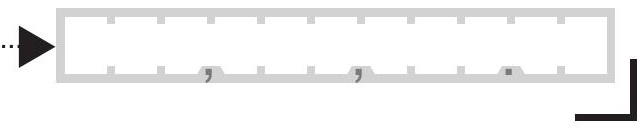




\section{SCHEDULE B-P}

\section{ITEMIZED DISBURSEMENTS}

Use separate schedule(s)

for each category of the

Detailed Summary Page
FOR LINE NUMBER: (check only one)

\begin{tabular}{|c|c|c|c|}
\hline $\mathrm{X} 23$ & 24 & 25 & 26 \\
\hline $27 \mathrm{~b}$ & $28 a$ & $28 b$ & $28 \mathrm{c}$ \\
\hline
\end{tabular}

Any information copied from such Reports and Statements may not be sold or used by any person for the purpose of soliciting contributions or for commercial purposes, other than using the name and address of any political committee to solicit contributions from such committee.

NAME OF COMMITTEE (In Full)

\section{Friends of Herman Cain}

Full Name (Last, First, Middle Initial)

A. Zachary Dalluge

Mailing Address 506 3rd Street

Date of Disbursement

\begin{tabular}{lcc}
\hline City & State & Zip Code \\
Grafton & IA & $50440-7570$
\end{tabular}

Purpose of Disbursement

Staff Salary

Candidate Name

Office Sought: $\quad$ House

Senate

President

State:

District:

Full Name (Last, First, Middle Initial)

B. Jacob Luneau

Mailing Address PO Box 80052

\begin{tabular}{lcc}
\hline City & State & Zip Code \\
Baton Rouge & LA & $70898-0052$
\end{tabular}

Purpose of Disbursement

Fundraising Consulting

Candidate Name

Disbursement For: 2012

Xrimary $\square$ General

Office Sought:

(1)

Disbursement For: 2012

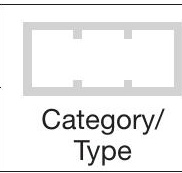

Amount of Each Disbursement this Period

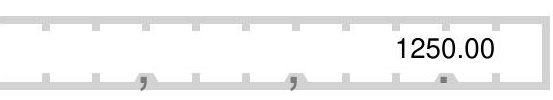

Transaction ID : BF4F407B288AE42399F8

\begin{tabular}{l|l|r|} 
& $\begin{array}{l}\text { House } \\
\text { Senate } \\
\text { President }\end{array}$ & $\begin{array}{r}\text { Disbursement For: } 2012 \\
\text { State: }\end{array}$ \\
\cline { 2 - 3 } & District: & Xrimary \\
Other (specify)
\end{tabular}

Full Name (Last, First, Middle Initial)

\section{c. Christopher Kenworthy}

\begin{tabular}{|c|c|c|c|c|c|}
\hline \multicolumn{6}{|c|}{ Mailing Address PO Box 2158} \\
\hline \multicolumn{2}{|l|}{ City } & State & \multicolumn{3}{|l|}{ Zip Code } \\
\hline \multicolumn{2}{|l|}{ Stockbridge } & $\mathrm{GA}$ & \multicolumn{3}{|c|}{$30281-8909$} \\
\hline \multicolumn{5}{|c|}{$\begin{array}{l}\text { Purpose of Disbursement } \\
\text { Staff Salary }\end{array}$} & \\
\hline \multicolumn{5}{|c|}{ Candidate Name } & $\begin{array}{l}\text { Category/ } \\
\text { Type }\end{array}$ \\
\hline \multirow[t]{3}{*}{ Office Sought: } & House & \multicolumn{4}{|c|}{ Disbursement For: 2012} \\
\hline & Senate & \multirow{3}{*}{\multicolumn{2}{|c|}{$\begin{array}{l}\text { Primary } \\
\text { Other (specify) }\end{array}$}} & \multirow{2}{*}{\multicolumn{2}{|c|}{ General }} \\
\hline & President & & & & \\
\hline State: & District: & & & \multicolumn{2}{|l|}{$\nabla$} \\
\hline
\end{tabular}

Subtotal Of Receipts This Page (optional).

Date of Disbursement

\begin{tabular}{|c|c|c|c|c|}
\hline $09^{M}$ & I & $\begin{array}{ll} & \text { D } \\
27\end{array}$ & I & $\begin{array}{cccc}Y & Y & Y & Y \\
& 2011 & \end{array}$ \\
\hline
\end{tabular}

\section{Transaction ID : B19F1B22D484D4785AD1}

Amount of Each Disbursement this Period

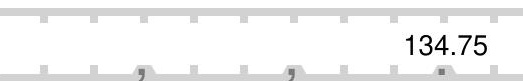

Date of Disbursement

\begin{tabular}{|c|c|c|c|c|}
\hline $09^{\mathrm{M}}$ & 1 & ${ }^{\mathrm{D}} 27^{\mathrm{D}}$ & l & $\begin{array}{llll}Y & Y & Y & Y \\
2011 & Y\end{array}$ \\
\hline
\end{tabular}

Transaction ID : B614A194A09494DF4A2F

Amount of Each Disbursement this Period

Total This Period (last page this line number only)) 


\section{SCHEDULE B-P}

\section{ITEMIZED DISBURSEMENTS}

Use separate schedule(s)

for each category of the

Detailed Summary Page
FOR LINE NUMBER: (check only one)

\begin{tabular}{|c|c|c|c|}
\hline$X_{23}$ & 24 & 25 & 26 \\
\hline $27 \mathrm{~b}$ & $28 a$ & $28 b$ & $28 \mathrm{c}$ \\
\hline
\end{tabular}

Any information copied from such Reports and Statements may not be sold or used by any person for the purpose of soliciting contributions or for commercial purposes, other than using the name and address of any political committee to solicit contributions from such committee.

NAME OF COMMITTEE (In Full)

\section{Friends of Herman Cain}

Full Name (Last, First, Middle Initial)

A. Sandra Poehler

Mailing Address 57 Presidential Drive

Apartment 5

Date of Disbursement

\begin{tabular}{lll}
\multicolumn{3}{c}{ Apartment 5 } \\
City & State & Zip Code \\
Quincy & MA & 02169-8838
\end{tabular}

Purpose of Disbursement

Staff Salary

Candidate Name

Office Sought: $\quad$ House

Senate

President

State:

District:

Full Name (Last, First, Middle Initial)

B. Brenda Hicks

Mailing Address 3653 S 75th Street

\begin{tabular}{lcc}
\hline City & State & Zip Code \\
Milwaukee & WI & $53220-1139$
\end{tabular}

Purpose of Disbursement

Staff Salary

Candidate Name

Disbursement For: 2012

X Primary $\square$ General

Office Sought:

House
Senate
President

Disbursement For: 2012

Xrimary $\square$ General

State:

District:

Full Name (Last, First, Middle Initial)

\section{c. Steven Hensler}

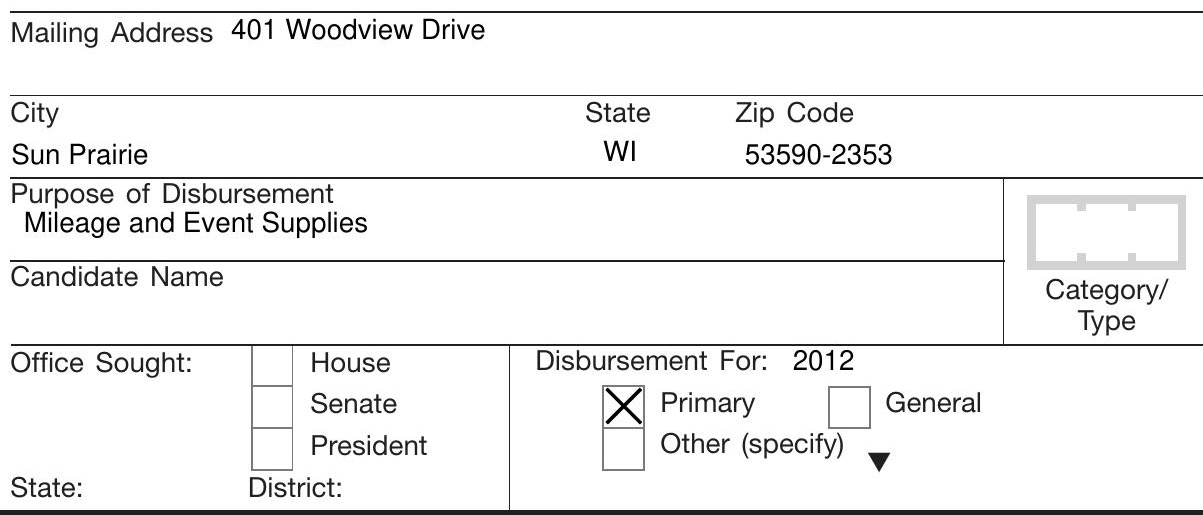

Subtotal Of Receipts This Page (optional).....

Date of Disbursement

\begin{tabular}{|c|c|c|c|c|c|}
\hline M & M & D & Y & Y & Y \\
09 & & 27 & & 2011 & \\
\hline
\end{tabular}

Transaction ID : B1D4ADEC297A74A0BBF0

Amount of Each Disbursement this Period

Date of Disbursement

\begin{tabular}{|c|c|c|c|c|}
\hline $09^{M}$ & I & $27^{\mathrm{D}}$ & I & $\begin{array}{llll}Y & Y & Y & Y \\
& 2011\end{array}$ \\
\hline
\end{tabular}

Transaction ID : B8BEA3329C21245A8BAE

Amount of Each Disbursement this Period
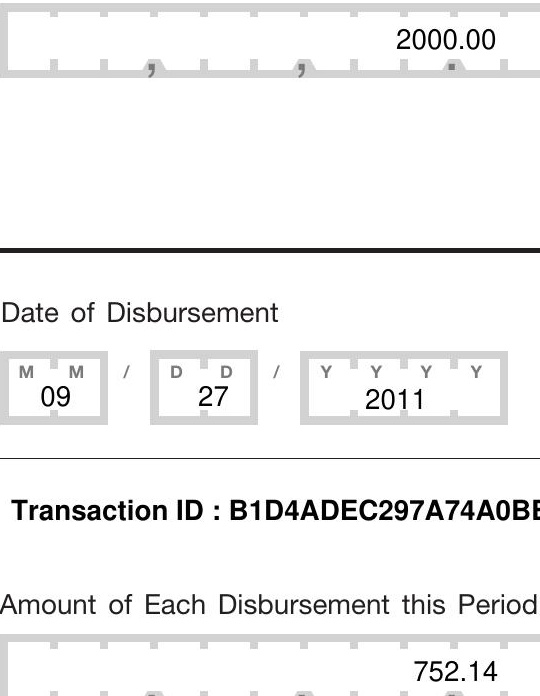

752.14

Total This Period (last page this line number only)) 


\section{SCHEDULE B-P}

\section{ITEMIZED DISBURSEMENTS}

Use separate schedule(s)

for each category of the

Detailed Summary Page
FOR LINE NUMBER: (check only one)

\begin{tabular}{|c|c|c|c|}
\hline $\mathrm{X} 23$ & 24 & 25 & 26 \\
\hline $27 \mathrm{~b}$ & $28 a$ & $28 b$ & $28 \mathrm{c}$ \\
\hline
\end{tabular}

Any information copied from such Reports and Statements may not be sold or used by any person for the purpose of soliciting contributions or for commercial purposes, other than using the name and address of any political committee to solicit contributions from such committee.

NAME OF COMMITTEE (In Full)

\section{Friends of Herman Cain}

Full Name (Last, First, Middle Initial)

A. Sandra Poehler

Mailing Address 57 Presidential Drive

Apartment 5

Date of Disbursement

\begin{tabular}{lll}
\multicolumn{3}{c}{ Apartment 5 } \\
City & State & Zip Code \\
Quincy & MA & $02169-8838$
\end{tabular}

Purpose of Disbursement

Postage and Mileage

Candidate Name

\begin{tabular}{l|l|l|l}
\hline Office Sought: & House & Disbursement For: 2012
\end{tabular} X Primary $\square$ General

State:

\section{Senate}

President

District:

Full Name (Last, First, Middle Initial)

B. James Harmon

Mailing Address 65 Beckett Avenue

\begin{tabular}{lcc}
\hline City & State & Zip Code \\
Branford & CT & $06405-4807$
\end{tabular}

Purpose of Disbursement

Automated Calls

Candidate Name

Office Sought:

House
Senate
President

Disbursement For: 2012

Xrimary $\square$ General

State:

District:

Full Name (Last, First, Middle Initial)

c. Michael Johnson

Mailing Address 8225 W. Center St. Apt. 3

\begin{tabular}{lcc} 
& & \\
\hline City & State & Zip Code \\
Milwaukee & WI & $53222-4861$
\end{tabular}

Purpose of Disbursement

Office Equip/Phone/Airfare/Transport.

Candidate Name

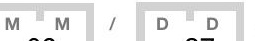

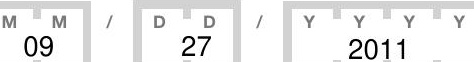

Date of Disbursement

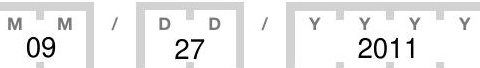

ransaction ID : B76770AB584E64FDD8B9

Amount of Each Disbursement this Period

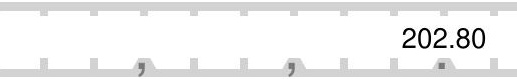

Transaction ID : B98623D2B696F4AEEBD2

\begin{tabular}{c|c} 
Category/ \\
Type
\end{tabular}

Amount of Each Disbursement this Period

\begin{tabular}{l|l|c|}
\hline Office Sought: & $\begin{array}{l}\text { House } \\
\text { Senate } \\
\text { President }\end{array}$ & $\begin{array}{r}\text { Disbursement For: } 2012 \\
\text { State: }\end{array}$ \\
\cline { 2 - 3 } & District: & X $\begin{array}{l}\text { Primary } \\
\text { Other (specify) }\end{array}$
\end{tabular}

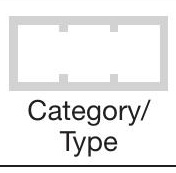

Subtotal Of Receipts This Page (optional).

Total This Period (last page this line number only)) 
Image\# 12951402771

\section{SCHEDULE B-P}

\section{ITEMIZED DISBURSEMENTS}

\section{Use separate schedule(s) \\ for each category of the}

Detailed Summary Page
FOR LINE NUMBER: (check only one)

\begin{tabular}{|c|c|c|c|}
\hline$\times{ }_{23}$ & 24 & 25 & 26 \\
\hline $27 b$ & $28 a$ & $28 \mathrm{~b}$ & $28 \mathrm{c}$ \\
\hline
\end{tabular}

Any information copied from such Reports and Statements may not be sold or used by any person for the purpose of soliciting contributions or for commercial purposes, other than using the name and address of any political committee to solicit contributions from such committee.

NAME OF COMMITTEE (In Full)

\section{Friends of Herman Cain}

Full Name (Last, First, Middle Initial)

A. Elicia Huffaker

Mailing Address 7317 Alta Drive

Date of Disbursement

\begin{tabular}{lll}
\hline City & State & Zip Code \\
Las Vegas & NV & $89145-5238$
\end{tabular}

Purpose of Disbursement

Event Supplies/Transportation/Airfare

Candidate Name

\begin{tabular}{l|l|l}
\hline Office Sought: & House & Disbursement For: 2012
\end{tabular} X Primary $\square$ General

State:

\section{Senate}

President

District:

Full Name (Last, First, Middle Initial)

B. Lisa Shiflett

Mailing Address 157 Stokes Drive

\begin{tabular}{lcc}
\hline City & State & Zip Code \\
Stockbridge & GA & $30281-1376$
\end{tabular}

Purpose of Disbursement

Staff Salary

Candidate Name

Office Sought:

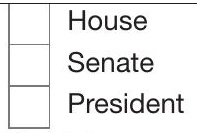

State:

District:

GA

Full Name (Last, First, Middle Initial)

c. Elicia Huffaker

Mailing Address 7317 Alta Drive

\begin{tabular}{lcc}
\hline City & State & Zip Code \\
Las Vegas & NV & $89145-5238$
\end{tabular}

Purpose of Disbursement

Staff Salary

Candidate Name

Office Sought:

State:

\begin{tabular}{|c|}
\hline House \\
\hline Senate \\
\hline President \\
\hline
\end{tabular}

Disbursement For: 2012

Х $\begin{aligned} & \text { Primary } \\ & \text { Other (specify) }\end{aligned}$
Date of Disbursement

\begin{tabular}{|c|c|c|c|c|}
\hline${ }^{M}$ & ${ }^{M}$ & $9^{\mathrm{D}}$ & ${ }^{\mathrm{D}}$ & $\mathrm{Y}^{\mathrm{Y}} \mathrm{Y}^{\mathrm{Y}}$ \\
\hline
\end{tabular}

Transaction ID : BD007185FFC3C41858B7

Amount of Each Disbursement this Period

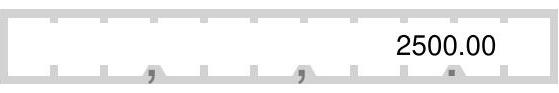

Date of Disbursement

\begin{tabular}{|c|c|c|c|c|c|}
\hline M & M & D & Y & Y & Y \\
09 & & 27 & & 2011 & \\
\hline
\end{tabular}

Transaction ID : BA7DA91F3C2544E5585C

Amount of Each Disbursement this Period

1875.00 Type

Subtotal Of Receipts This Page (optional).

Total This Period (last page this line number only))

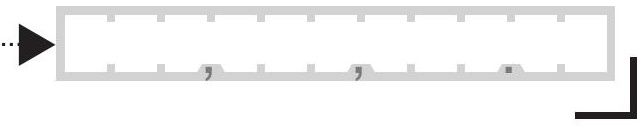




\section{SCHEDULE B-P}

\section{ITEMIZED DISBURSEMENTS}

Use separate schedule(s)

for each category of the

Detailed Summary Page
FOR LINE NUMBER: (check only one)

\begin{tabular}{|c|c|c|c|}
\hline$X_{23}$ & 24 & 25 & 26 \\
\hline $27 \mathrm{~b}$ & $28 a$ & $28 b$ & $28 \mathrm{c}$ \\
\hline
\end{tabular}

Any information copied from such Reports and Statements may not be sold or used by any person for the purpose of soliciting contributions or for commercial purposes, other than using the name and address of any political committee to solicit contributions from such committee.

NAME OF COMMITTEE (In Full)

\section{Friends of Herman Cain}

Full Name (Last, First, Middle Initial)

A. Tina Spratling

Mailing Address PO Box 2158

Date of Disbursement

\begin{tabular}{lcc}
\hline City & State & Zip Code \\
Stockbridge & GA & $30281-8909$
\end{tabular}

Purpose of Disbursement

Staff Salary

Candidate Name

Office Sought: $\quad$ House

Senate

President

State:

District:

Full Name (Last, First, Middle Initial)

B. Lisa Shiflett

Mailing Address 157 Stokes Drive

\begin{tabular}{lcc}
\hline City & State & Zip Code \\
Stockbridge & GA & $30281-1376$
\end{tabular}

Disbursement For: 2012

X Primary $\square$ General

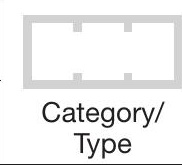

Amount of Each Disbursement this Period

\begin{tabular}{|c|c|c|}
\hline $09^{M}$ & & $27^{\mathrm{D}}$ \\
\hline
\end{tabular}

Transaction ID : B17DBF013DD624B75AEA

Purpose of Disbursement

Mileage and Telephone

Candidate Name

Office Sought:

\begin{tabular}{l|l} 
House \\
Senate \\
President
\end{tabular}

State:

District:

GA

Full Name (Last, First, Middle Initial)

\section{c. Donald Henry}

\begin{tabular}{|c|c|c|c|c|c|}
\hline \multicolumn{6}{|c|}{ Mailing Address PO Box 2158} \\
\hline \multicolumn{2}{|l|}{ City } & State & \multicolumn{3}{|l|}{ Zip Code } \\
\hline \multicolumn{2}{|l|}{ Stockbridge } & GA & \multicolumn{3}{|c|}{$30281-8909$} \\
\hline \multicolumn{5}{|c|}{$\begin{array}{l}\text { Purpose of Disbursement } \\
\text { Staff Salary }\end{array}$} & \\
\hline \multicolumn{5}{|c|}{ Candidate Name } & $\begin{array}{l}\text { Category/ } \\
\text { Type }\end{array}$ \\
\hline \multirow[t]{3}{*}{ Office Sought: } & House & \multicolumn{4}{|c|}{ Disbursement For: 2012} \\
\hline & Senate & \multirow{3}{*}{\multicolumn{2}{|c|}{$\begin{array}{l}\text { Primary } \\
\text { Other (specify) }\end{array}$}} & \multirow{2}{*}{\multicolumn{2}{|c|}{ General }} \\
\hline & President & & & & \\
\hline State: & District: & & & \multicolumn{2}{|c|}{$\boldsymbol{\nabla}$} \\
\hline
\end{tabular}

Subtotal Of Receipts This Page (optional).

Total This Period (last page this line number only))
Date of Disbursement

\begin{tabular}{|c|c|c|c|c|}
\hline $09^{M}$ & 1 & $27^{\mathrm{D}}$ & 1 & 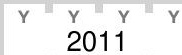 \\
\hline
\end{tabular}

Transaction ID : B71D69FE51FC843CBAB6

Amount of Each Disbursement this Period

466.66

Date of Disbursement

\begin{tabular}{|c|c|c|c|c|}
\hline $09^{\mathrm{M}}$ & I & D 27 & 1 & $\begin{array}{cccc}Y & Y & Y & Y \\
& 2011 & \end{array}$ \\
\hline
\end{tabular}

Transaction ID : B073447FBD4AE4231BA6

Amount of Each Disbursement this Period

2083.33 


\section{SCHEDULE B-P}

\section{ITEMIZED DISBURSEMENTS}

Use separate schedule(s)

for each category of the

Detailed Summary Page
FOR LINE NUMBER: (check only one)

\begin{tabular}{|c|c|c|c|}
\hline $\mathrm{X} 23$ & 24 & 25 & 26 \\
\hline $27 \mathrm{~b}$ & $28 a$ & $28 b$ & $28 \mathrm{c}$ \\
\hline
\end{tabular}

Any information copied from such Reports and Statements may not be sold or used by any person for the purpose of soliciting contributions or for commercial purposes, other than using the name and address of any political committee to solicit contributions from such committee.

NAME OF COMMITTEE (In Full)

\section{Friends of Herman Cain}

Full Name (Last, First, Middle Initial)

A. David Burrell

Mailing Address 5061 Hodgins Plae

Date of Disbursement

\begin{tabular}{lcc}
\hline City & State & Zip Code \\
GA & 30047
\end{tabular}

Lilburn

GA $\quad 30047$

Purpose of Disbursement

Lodging and Transportation

Candidate Name

Office Sought: $\quad$ House

Senate

President

State:

District:

Full Name (Last, First, Middle Initial)

B. Jeffrey Gordon

Mailing Address PO Box 2158

\begin{tabular}{lcc}
\hline City & State & Zip Code \\
Stockbridge & GA & $30281-8909$
\end{tabular}

Purpose of Disbursement

Staff Salary

Candidate Name

Xrimary $\square$ General

Office Sought:

House
Senate
President

State:

District:

Full Name (Last, First, Middle Initial)

c. Linda Hansen

Mailing Address PO Box 371312

\begin{tabular}{lcc}
\hline City & State & Zip Code \\
Milwaukee & WI & $53237-2412$
\end{tabular}

Purpose of Disbursement

Staff Salary

Candidate Name

Office Sought: $\quad$ House

\begin{tabular}{|l|l|} 
& House \\
& Senate \\
& President
\end{tabular}

State:

District:
Disbursement For: 2012

Primary
Other (specify) General
Date of Disbursement

\begin{tabular}{|c|c|c|c|c|}
\hline $09^{M}$ & 1 & $27^{\mathrm{D}}$ & 1 & $\begin{array}{llll} & Y & Y & Y \\
& 2011 & \end{array}$ \\
\hline
\end{tabular}

Transaction ID : BB2BB06327CC34B8D806

Amount of Each Disbursement this Period

5000.00
Date of Disbursement

\begin{tabular}{|c|c|c|c|c|}
\hline $09^{\mathrm{M}}$ & I & D 27 & 1 & $\begin{array}{cccc}Y & Y & Y & Y \\
& 2011 & \end{array}$ \\
\hline
\end{tabular}

Transaction ID : BB82A19A6FB354B25867

Amount of Each Disbursement this Period

2916.67

Subtotal Of Receipts This Page (optional).

Total This Period (last page this line number only))

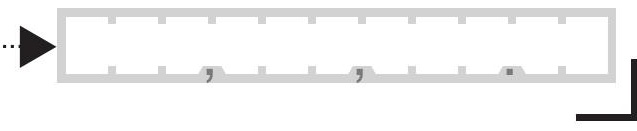




\section{SCHEDULE B-P}

\section{ITEMIZED DISBURSEMENTS}

\section{Use separate schedule(s) \\ for each category of the}

Detailed Summary Page
FOR LINE NUMBER: (check only one)

\begin{tabular}{|c|c|c|c|}
\hline$\times{ }_{23}$ & 24 & 25 & 26 \\
\hline $27 b$ & $28 a$ & $28 \mathrm{~b}$ & $28 \mathrm{c}$ \\
\hline
\end{tabular}

Any information copied from such Reports and Statements may not be sold or used by any person for the purpose of soliciting contributions or for commercial purposes, other than using the name and address of any political committee to solicit contributions from such committee.

NAME OF COMMITTEE (In Full)

\section{Friends of Herman Cain}

Full Name (Last, First, Middle Initial)

A. Charles Spano

Mailing Address PO Box 2158

Date of Disbursement

\begin{tabular}{lcc}
\hline City & State & Zip Code \\
Stockbridge & GA & $30281-8909$
\end{tabular}

Purpose of Disbursement

Staff Salary

Candidate Name

\begin{tabular}{l|l|l|l}
\hline Office Sought: & House & Disbursement For: 2012
\end{tabular} X Primary $\square$ General

State:

\section{Senate}

President

District:

Full Name (Last, First, Middle Initial)

B. William Head

Mailing Address PO Box 2158

\begin{tabular}{lcc}
\hline City & State & Zip Code \\
Stockbridge & GA & $30281-8909$
\end{tabular}

Purpose of Disbursement

Mileage/Transportation/Event Supplies

Candidate Name

Office Sought:

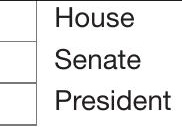

State:

District:

GA

Full Name (Last, First, Middle Initial)

c. Karis McKinney

Mailing Address 5017 N. 50th Street

\begin{tabular}{lcc}
\hline City & State & Zip Code \\
Milwaukee & WI & $53218-4326$
\end{tabular}

Purpose of Disbursement

Staff Salary

Candidate Name

Office Sought: $\quad$ House

\begin{tabular}{l|l} 
& House \\
& Senate \\
& President \\
& \\
District:
\end{tabular}

State:

District:
Disbursement For: 2012

Primary
Other (specify) General
Date of Disbursement

\begin{tabular}{|c|c|c|c|c|}
\hline $09^{M}$ & & ${ }^{\mathrm{D}} 27^{\mathrm{D}}$ & 1 & $\begin{array}{lll}Y & Y & Y \\
& 2011 & Y\end{array}$ \\
\hline
\end{tabular}

Transaction ID : B44DCE0F5FFEA4043B9A

Amount of Each Disbursement this Period

1214.31
Date of Disbursement

\begin{tabular}{|c|c|c|c|c|}
\hline $09^{\mathrm{M}}$ & I & D 27 & 1 & $\begin{array}{cccc}Y & Y & Y & Y \\
& 2011 & \end{array}$ \\
\hline
\end{tabular}

Transaction ID : B1640B12A26854826ADB

Amount of Each Disbursement this Period

1875.00

Subtotal Of Receipts This Page (optional).

Total This Period (last page this line number only))

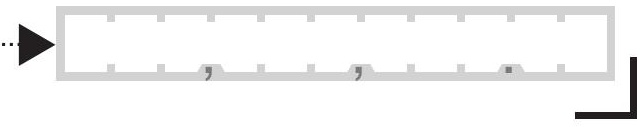




\section{SCHEDULE B-P}

\section{ITEMIZED DISBURSEMENTS}

\section{Use separate schedule(s) \\ for each category of the}

Detailed Summary Page
FOR LINE NUMBER: (check only one)

\begin{tabular}{|c|c|c|c|}
\hline$\times{ }_{23}$ & 24 & 25 & 26 \\
\hline $27 b$ & $28 a$ & $28 \mathrm{~b}$ & $28 \mathrm{c}$ \\
\hline
\end{tabular}

Any information copied from such Reports and Statements may not be sold or used by any person for the purpose of soliciting contributions or for commercial purposes, other than using the name and address of any political committee to solicit contributions from such committee.

NAME OF COMMITTEE (In Full)

\section{Friends of Herman Cain}

Full Name (Last, First, Middle Initial)

\section{A. Aaron T. Manaigo}

Mailing Address 6723 W. Wakefield Drive

Suite A2

\begin{tabular}{lll}
\hline City & State & Zip Code \\
Alexandria & VA & 22307 \\
\hline Purpose of Disbursement & &
\end{tabular}

Purpose of Disbursement

Field Consulting

Candidate Name

Office Sought:

\begin{tabular}{|l|l} 
& House \\
Senate \\
President \\
District:
\end{tabular}

Disbursement For: 2012 X Primary
Date of Disbursement

\begin{tabular}{|c|c|c|c|c|c|}
\hline M M & D \\
09 & 27 & 2011 \\
\hline
\end{tabular}

Transaction ID : B11D042FB2CF346EC99F

Amount of Each Disbursement this Period 5000.00

\section{B. Karleen Smith}

Mailing Address 105 Marilyn Drive E

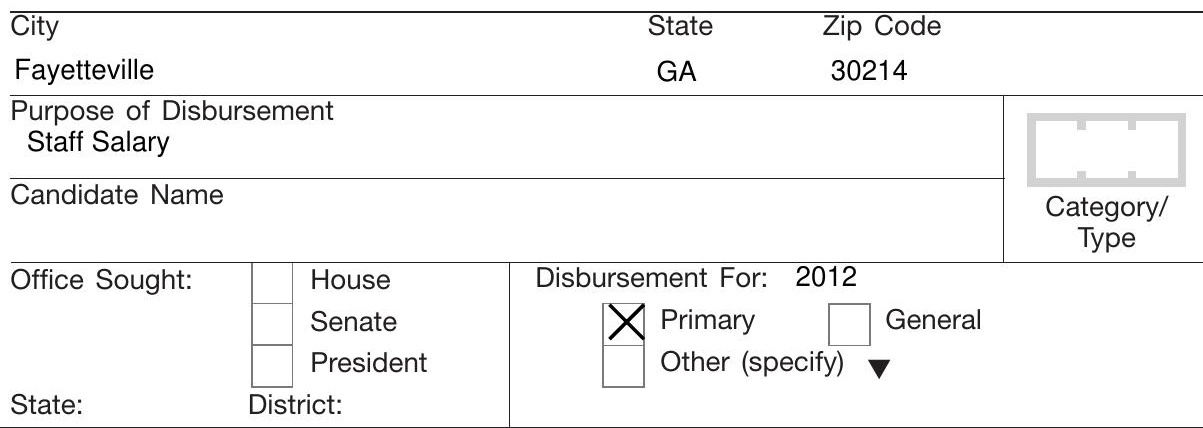

Full Name (Last, First, Middle Initial)

c. Ashley Frasca

Mailing Address 601 Springharbor Drive

\begin{tabular}{lcc}
\hline City & State & Zip Code \\
Woodstock & GA & $30188-6044$
\end{tabular}

Purpose of Disbursement

Staff Salary

Candidate Name

Office Sought:

State:
Disbursement For: 2012

Х $\begin{aligned} & \text { Primary } \\ & \text { Other (specify) }\end{aligned}$
Date of Disbursement

\begin{tabular}{|c|c|c|c|c|}
\hline $09^{M}$ & 1 & $27^{\mathrm{D}}$ & 1 & 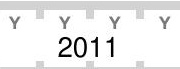 \\
\hline
\end{tabular}

Transaction ID : B4C2A83D51DF64918823

Amount of Each Disbursement this Period

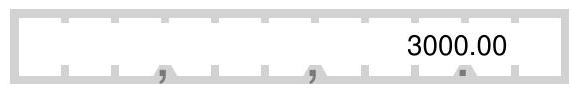

Date of Disbursement

\begin{tabular}{|c|c|c|c|c|c|}
\hline M M / & D & D & Y & Y & Y \\
09 & & 27 & \\
\hline
\end{tabular}

Transaction ID : BD356D94F1FA14969952

Amount of Each Disbursement this Period

1666.67

Subtotal Of Receipts This Page (optional).

Total This Period (last page this line number only))

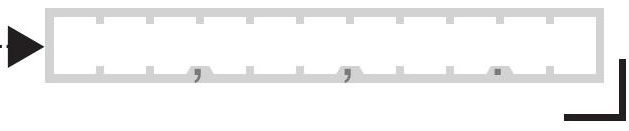




\section{SCHEDULE B-P}

\section{ITEMIZED DISBURSEMENTS}

\section{Use separate schedule(s)}

for each category of the

Detailed Summary Page
FOR LINE NUMBER: (check only one)

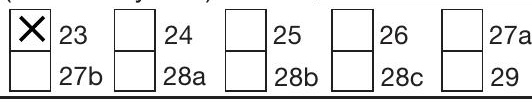

Any information copied from such Reports and Statements may not be sold or used by any person for the purpose of soliciting contributions or for commercial purposes, other than using the name and address of any political committee to solicit contributions from such committee.

NAME OF COMMITTEE (In Full)

\section{Friends of Herman Cain}

Full Name (Last, First, Middle Initial)

A. Zachary Dalluge

Mailing Address 506 3rd Street

Date of Disbursement

\begin{tabular}{lcc}
\hline City & State & Zip Code \\
Grafton & IA & $50440-7570$
\end{tabular}

Purpose of Disbursement

Mileage, Postage and Office Supplies

Candidate Name

Office Sought: $\quad$ House

\section{Senate}

President

State:

District:

Full Name (Last, First, Middle Initial)

B. Michelle Gwaltney

Mailing Address 123 Glen Eagle Way

\begin{tabular}{lcc}
\hline City & State & Zip Code \\
McDonough & GA & $30253-4229$
\end{tabular}

Purpose of Disbursement

Staff Salary

Candidate Name

X Primary $\square$ General

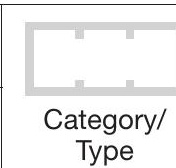
Type
Amount of Each Disbursement this Period

294.10
Date of Disbursement

\begin{tabular}{|c|c|c|c|c|}
\hline $09^{M}$ & 1 & $27^{\mathrm{D}}$ & 1 & 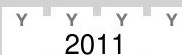 \\
\hline
\end{tabular}

Transaction ID : B4BB8F59B2A4D4866B74

Amount of Each Disbursement this Period

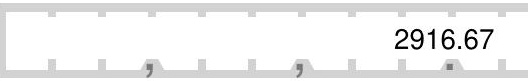

Date of Disbursement

\begin{tabular}{|c|c|c|c|c|}
\hline $09^{\mathrm{M}}$ & I & D 27 & 1 & $\begin{array}{cccc}Y & Y & Y & Y \\
& 2011 & \end{array}$ \\
\hline
\end{tabular}

Transaction ID : BC0A53E54911C45D2B4C

Amount of Each Disbursement this Period

2000.00

\begin{tabular}{|c|c|c|c|}
\hline \multirow[t]{3}{*}{ Office Sought: } & House & Disbursement For: 2012 & \multirow{3}{*}{ General } \\
\hline & Senate & Primary & \\
\hline & President & Other (specify) & \\
\hline
\end{tabular}

Subtotal Of Receipts This Page (optional).

Total This Period (last page this line number only))

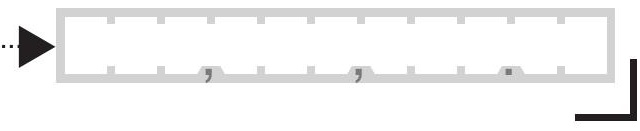




\section{SCHEDULE B-P}

\section{ITEMIZED DISBURSEMENTS}

Use separate schedule(s)

for each category of the

Detailed Summary Page
FOR LINE NUMBER: (check only one)

\begin{tabular}{|c|c|c|c|}
\hline $\mathrm{X} 23$ & 24 & 25 & 26 \\
\hline $27 \mathrm{~b}$ & $28 a$ & $28 b$ & $28 \mathrm{c}$ \\
\hline
\end{tabular}

Any information copied from such Reports and Statements may not be sold or used by any person for the purpose of soliciting contributions or for commercial purposes, other than using the name and address of any political committee to solicit contributions from such committee.

NAME OF COMMITTEE (In Full)

\section{Friends of Herman Cain}

Full Name (Last, First, Middle Initial)

A. Stacy DeJarnette

Mailing Address 207 Robin Street

Date of Disbursement

\begin{tabular}{lcc}
\hline City & State & Zip Code \\
White Hall & AR & $71602-5418$
\end{tabular}

Purpose of Disbursement

Telephone

Candidate Name

Office Sought:

\begin{tabular}{|l|l|l}
\hline & $\begin{array}{l}\text { House } \\
\text { Senate }\end{array}$ \\
& President \\
\hline & District:
\end{tabular}

Disbursement For: 2012 Xrimary $\square$ General

State: District:

Full Name (Last, First, Middle Initial)

\section{B. Dale Peterson}

Mailing Address PO Box 360717

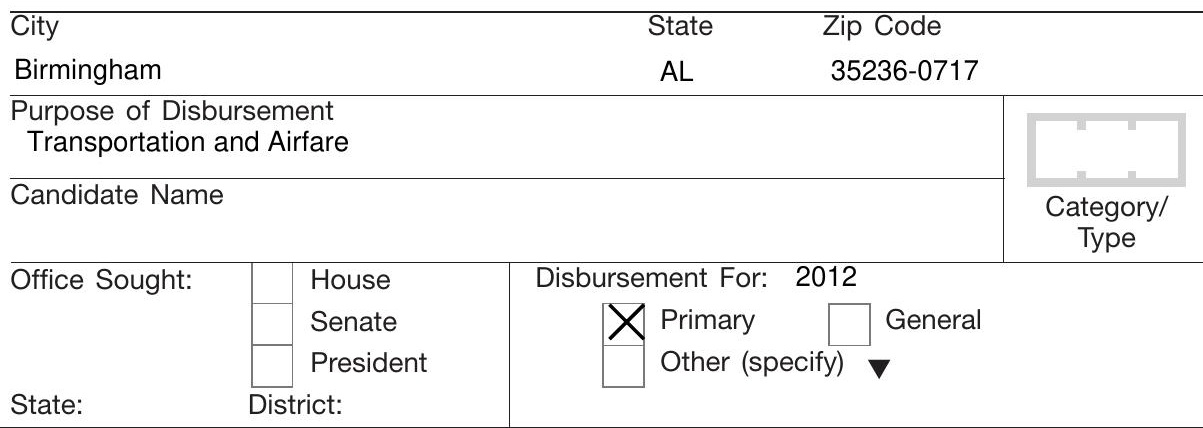

Date of Disbursement

Full Name (Last, First, Middle Initial)

c. Tri-C

Mailing Address 5169 Southridge Pkwy

Ste. 120

\begin{tabular}{lcc}
\hline City & State & Zip Code \\
College Park & GA & 30349
\end{tabular}

Purpose of Disbursement

Event Supplies

Candidate Name

Office Sought:

\begin{tabular}{|l|l|}
\hline & House \\
& Senate \\
& President \\
& District:
\end{tabular}

State:

District:
Disbursement For: 2012

$$
\text { Х } \begin{aligned}
& \text { Primary } \\
& \text { Other (specify) }
\end{aligned}
$$

Date of Disbursement

\begin{tabular}{|c|c|c|c|c|c|c|}
\hline M & M & D & Y & Y & Y \\
09 & & 27 & & 2011 & \\
\hline
\end{tabular}

Transaction ID : BA7171FECFF1B4DDE9A8

Amount of Each Disbursement this Period

456.85

Transaction ID : BFC473A2FFE284DEF9A8

Amount of Each Disbursement this Period

Subtotal Of Receipts This Page (optional).

Total This Period (last page this line number only))

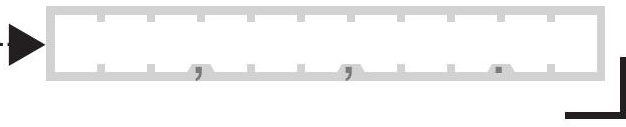




\section{SCHEDULE B-P}

\section{ITEMIZED DISBURSEMENTS}

\section{Use separate schedule(s)}

for each category of the

Detailed Summary Page
FOR LINE NUMBER: (check only one)

\begin{tabular}{|c|c|c|c|}
\hline$X_{23}$ & 24 & 25 & 26 \\
\hline $27 \mathrm{~b}$ & $28 a$ & $28 b$ & $28 \mathrm{c}$ \\
\hline
\end{tabular}

Any information copied from such Reports and Statements may not be sold or used by any person for the purpose of soliciting contributions or for commercial purposes, other than using the name and address of any political committee to solicit contributions from such committee.

NAME OF COMMITTEE (In Full)

\section{Friends of Herman Cain}

Full Name (Last, First, Middle Initial)

A. Victory Enterprises

Mailing Address 5200 S.W. 30th Street

Suite 7

Date of Disbursement

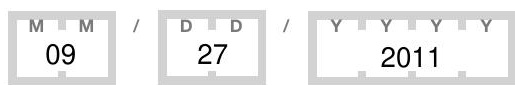

Transaction ID : BC7E53F65CC02425D935

\begin{tabular}{lcc}
\hline City & State & Zip Code \\
Davenport & IA & 52802
\end{tabular}

Purpose of Disbursement

Automated Calls

Candidate Name

Office Sought:

$$
\begin{aligned}
& \text { House } \\
& \text { Senate } \\
& \text { President }
\end{aligned}
$$

State:

District:

Amount of Each Disbursement this Period

Full Name (Last, First, Middle Initial)

\section{B. Adventure Advertising, LLC}

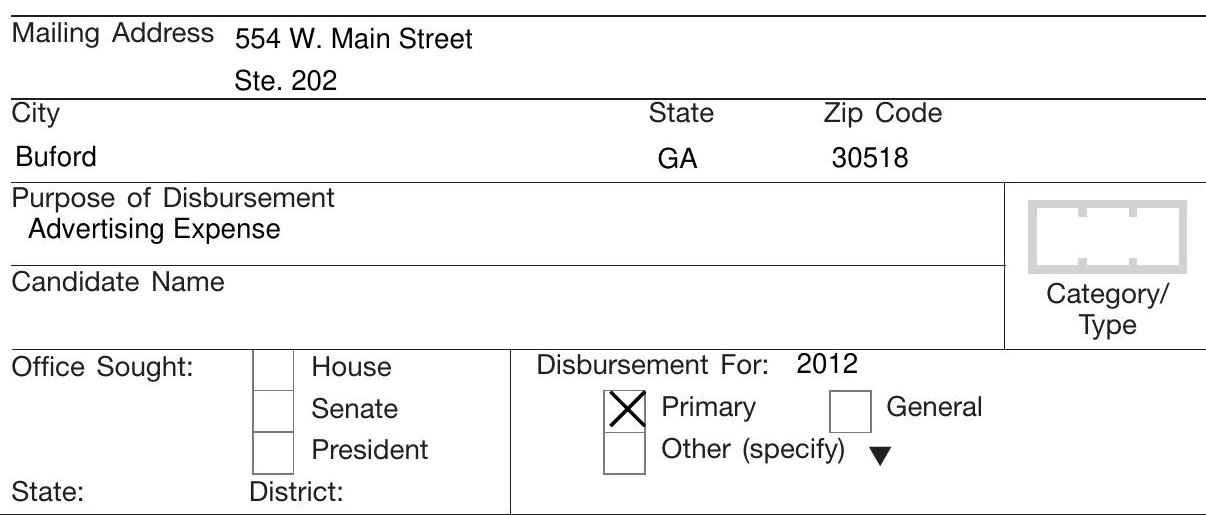

Date of Disbursement

Full Name (Last, First, Middle Initial)

\begin{tabular}{|c|c|c|c|c|c|}
\hline \multicolumn{6}{|c|}{ Mailing Address 22 Sylvan Way } \\
\hline \multicolumn{2}{|l|}{ City } & State & \multicolumn{3}{|l|}{ Zip Code } \\
\hline \multicolumn{2}{|l|}{ Parsippany } & NJ & \multicolumn{3}{|l|}{07054} \\
\hline \multicolumn{5}{|c|}{$\begin{array}{l}\text { Purpose of Disbursement } \\
\text { Travel Expense }\end{array}$} & \\
\hline \multicolumn{5}{|c|}{ Candidate Name } & $\begin{array}{l}\text { Category/ } \\
\text { Type }\end{array}$ \\
\hline \multirow[t]{3}{*}{ Office Sought: } & House & \multicolumn{4}{|c|}{ Disbursement For: 2012} \\
\hline & Senate & \multirow{3}{*}{\multicolumn{2}{|c|}{ Х $\begin{array}{l}\text { Primary } \\
\text { Other (specify) }\end{array}$}} & \multirow{2}{*}{\multicolumn{2}{|c|}{ General }} \\
\hline & President & & & & \\
\hline State: & District: & & & & \\
\hline
\end{tabular}

\section{c. Microtel Inn and Suites}

Subtotal Of Receipts This Page (optional).

Date of Disbursement

\begin{tabular}{|c|c|c|c|c|c|}
\hline M M & M & D & Y & Y & Y \\
09 & & 27 & & 2011 & \\
\hline
\end{tabular}

\section{Transaction ID : B968281959EEC42F78F8}

Amount of Each Disbursement this Period

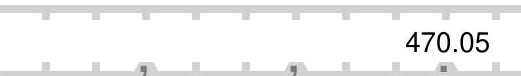

470.05

Total This Period (last page this line number only)) 


\section{SCHEDULE B-P}

\section{ITEMIZED DISBURSEMENTS}

Use separate schedule(s)

for each category of the

Detailed Summary Page
FOR LINE NUMBER: (check only one)

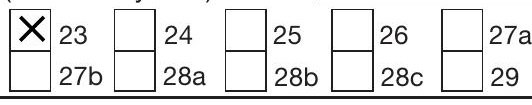

Any information copied from such Reports and Statements may not be sold or used by any person for the purpose of soliciting contributions or for commercial purposes, other than using the name and address of any political committee to solicit contributions from such committee.

NAME OF COMMITTEE (In Full)

\section{Friends of Herman Cain}

Full Name (Last, First, Middle Initial)

A. Sheraton Hotels

Mailing Address 1111 Westchester Ave.

Date of Disbursement

\begin{tabular}{llc}
\hline City & State & Zip Code \\
White Plains & NY & 10604 \\
\hline Purpose
\end{tabular}

Purpose of Disbursement

Travel Expense

Candidate Name

\begin{tabular}{l|l|l}
\hline Office Sought: & House & Disbursement For: 2012
\end{tabular} X Primary $\square$ General

State:

\section{Senate}

President

District:

Full Name (Last, First, Middle Initial)

B. Troupis Law Office LLC

\begin{tabular}{|c|c|c|c|c|}
\hline Mailing Address & \multicolumn{4}{|c|}{7609 Elmwood Avenue } \\
\hline \multicolumn{2}{|l|}{ City } & \multicolumn{3}{|c|}{ Zip Code } \\
\hline \multicolumn{2}{|l|}{ Middleton } & \multicolumn{3}{|c|}{53562} \\
\hline \multicolumn{4}{|c|}{$\begin{array}{l}\text { Purpose of Disbursement } \\
\text { Legal Fees }\end{array}$} & \\
\hline \multicolumn{4}{|l|}{ Candidate Name } & $\begin{array}{l}\text { Category/ } \\
\text { Type }\end{array}$ \\
\hline \multirow[t]{3}{*}{ Office Sought: } & House & \multirow{3}{*}{\multicolumn{3}{|c|}{ Disbursement For: 2012}} \\
\hline & Senate & & & \\
\hline & President & & & \\
\hline State: & \multicolumn{4}{|c|}{ District: } \\
\hline
\end{tabular}

Date of Disbursement

\begin{tabular}{|c|c|c|c|c|}
\hline${ }^{M}{ }^{\mathrm{M}} / 9^{\mathrm{D}}$ & ${ }^{\mathrm{D}}$ & $\mathrm{Y}^{\mathrm{Y}}$ & $\mathrm{Y}^{\mathrm{Y}}$ \\
\hline
\end{tabular}

Transaction ID : BBD574E26B683408F9F0

Full Name (Last, First, Middle Initial)

C. Fundly, Inc.

Mailing Address 70 Broadway Street

Date of Disbursement

\begin{tabular}{lcc|} 
& & \\
\hline City & State & Zip Code \\
Westford & MA & 01886
\end{tabular}

\begin{tabular}{|c|c|c|c|c|}
\hline $09^{\mathrm{M}}$ & l & $\begin{array}{l}\mathrm{D} \\
27\end{array}$ & & $\begin{array}{lll}Y & Y & Y \\
2011 & Y\end{array}$ \\
\hline
\end{tabular}

Purpose of Disbursement

CC Transaction Fees

Candidate Name

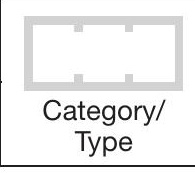

Transaction ID : B452063AA3A8D450A8D0

\begin{tabular}{l|l} 
Cype & Typandidate Name
\end{tabular}

Amount of Each Disbursement this Period

\begin{tabular}{l|l|r|}
\hline \multirow{2}{*}{ Office Sought: } & $\begin{array}{l}\text { House } \\
\text { Senate } \\
\text { President }\end{array}$ & $\begin{array}{r}\text { Disbursement For: } 2012 \\
\text { State: }\end{array}$ \\
\cline { 2 - 3 } & District: & X Primary \\
Other (specify)
\end{tabular}

Subtotal Of Receipts This Page (optional).

12131.11

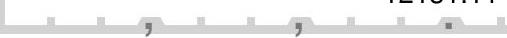

Total This Period (last page this line number only))

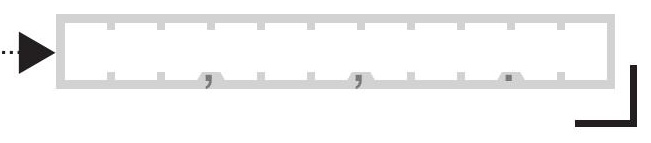

FEC Schedule B-P (Form 3P) (Rev. 03/2011) 


\section{SCHEDULE B-P}

\section{ITEMIZED DISBURSEMENTS}

\section{Use separate schedule(s) \\ for each category of the}

Detailed Summary Page
FOR LINE NUMBER: (check only one)

\begin{tabular}{|c|c|c|c|}
\hline$X_{23}$ & 24 & 25 & 26 \\
\hline $27 \mathrm{~b}$ & $28 a$ & $28 b$ & $28 \mathrm{c}$ \\
\hline
\end{tabular}

Any information copied from such Reports and Statements may not be sold or used by any person for the purpose of soliciting contributions or for commercial purposes, other than using the name and address of any political committee to solicit contributions from such committee.

NAME OF COMMITTEE (In Full)

\section{Friends of Herman Cain}

Full Name (Last, First, Middle Initial)

A. Tri-Net Payroll Services

Mailing Address 1100 San Leandro Boulevard

Suite

\begin{tabular}{lll}
\hline City & State & Zip Code \\
San Leandro & CA & 94577
\end{tabular}

Purpose of Disbursement

Payroll Fees

Candidate Name

Office Sought:

House
Senate
President
District:

Disbursement For: 2012

Xrimary $\square$ General
Date of Disbursement

\begin{tabular}{|c|c|c|c|c|c|}
\hline M M & D \\
09 & 27 & 2011 \\
\hline
\end{tabular}

Transaction ID : B53658BBAF3894DFFB1A

Amount of Each Disbursement this Period

1207.00

\section{B. Tri-Net Payroll Services}

\begin{tabular}{|c|c|c|c|c|}
\hline Mailing Address & \multicolumn{4}{|c|}{1100 San Leandro Boulevard } \\
\hline \multicolumn{2}{|l|}{ City } & \multicolumn{3}{|c|}{ Zip Code } \\
\hline \multicolumn{2}{|l|}{ San Leandro } & \multicolumn{3}{|c|}{94577} \\
\hline \multicolumn{4}{|c|}{$\begin{array}{l}\text { Purpose of Disbursement } \\
\text { Payroll Benefits }\end{array}$} & \\
\hline \multicolumn{4}{|l|}{ Candidate Name } & $\begin{array}{l}\text { Category/ } \\
\text { Type }\end{array}$ \\
\hline \multirow[t]{3}{*}{ Office Sought: } & House & \multirow{3}{*}{\multicolumn{3}{|c|}{ Disbursement For: 2012}} \\
\hline & Senate & & & \\
\hline & President & & & \\
\hline State: & \multicolumn{4}{|c|}{ District: } \\
\hline
\end{tabular}

Date of Disbursement

Full Name (Last, First, Middle Initial)

\section{c. Tri-Net Payroll Services}

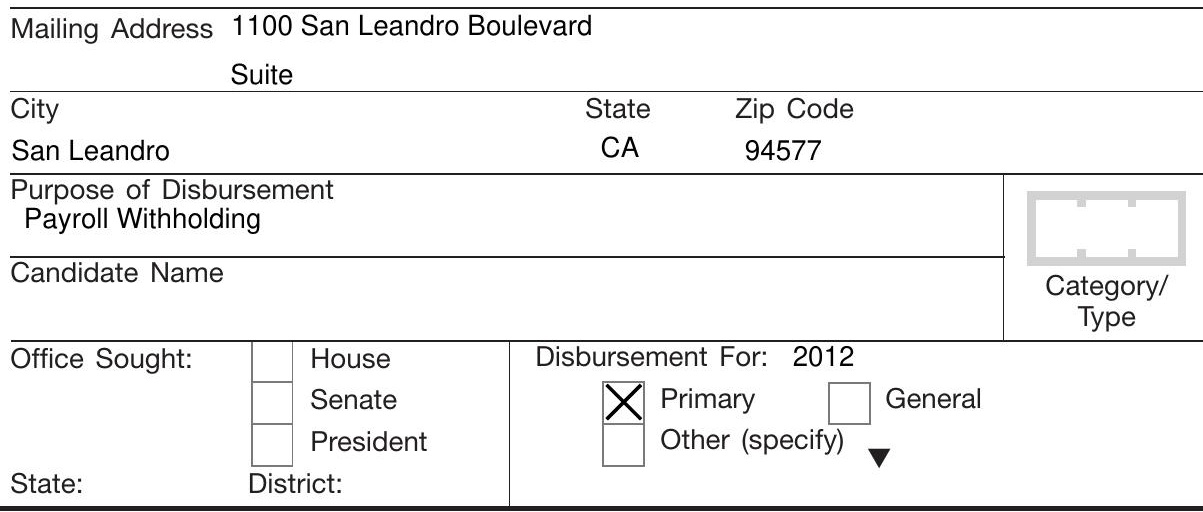

Subtotal Of Receipts This Page (optional)...

Date of Disbursement

\begin{tabular}{|c|c|c|c|c|}
\hline $09^{\mathrm{M}}$ & I & $\begin{array}{l}\text { D } \\
27\end{array}$ & 1 & 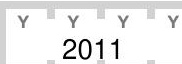 \\
\hline
\end{tabular}

Transaction ID : B11ECB17B19DF402B88D

Amount of Each Disbursement this Period

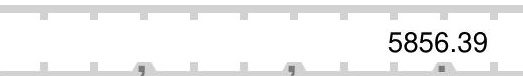

5856.39

Total This Period (last page this line number only)) 


\section{SCHEDULE B-P}

\section{ITEMIZED DISBURSEMENTS}

\section{Use separate schedule(s) \\ for each category of the}

Detailed Summary Page
FOR LINE NUMBER: (check only one)

\begin{tabular}{|c|c|c|c|}
\hline$\times{ }_{23}$ & 24 & 25 & 26 \\
\hline $27 b$ & $28 a$ & $28 \mathrm{~b}$ & $28 \mathrm{c}$ \\
\hline
\end{tabular}

Any information copied from such Reports and Statements may not be sold or used by any person for the purpose of soliciting contributions or for commercial purposes, other than using the name and address of any political committee to solicit contributions from such committee.

NAME OF COMMITTEE (In Full)

\section{Friends of Herman Cain}

Full Name (Last, First, Middle Initial)

A. Delta Airlines

\begin{tabular}{c} 
Mailing Address $\begin{array}{c}\text { Post Office Box } 20980 \\
\text { Department } 980\end{array}$ \\
\hline
\end{tabular}

\begin{tabular}{lll}
\hline City & State & Zip Code \\
Atlanta & GA & $30320-2980$
\end{tabular}

Purpose of Disbursement

Travel Expense

Candidate Name

\begin{tabular}{l|l|c|}
\hline Office Sought: & $\begin{array}{l}\text { House } \\
\text { Senate } \\
\text { President }\end{array}$ & $\begin{array}{c}\text { Disbursement For: } 2012 \\
\text { State: }\end{array}$
\end{tabular}

Full Name (Last, First, Middle Initial)

B. LexisNexis

Mailing Address Post Office Box 2314

\begin{tabular}{lcc}
\hline City & State & Zip Code \\
Carol Stream & IL & $60132-2314$
\end{tabular}

Purpose of Disbursement

Subscription Fee

Candidate Name

Office Sought:

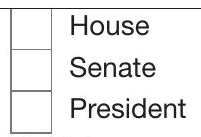

State:

District:

IL

Full Name (Last, First, Middle Initial)

\section{c. FedEx Kinkos}

\begin{tabular}{|c|c|c|c|c|c|}
\hline \multicolumn{6}{|c|}{ Mailing Address 942 S. Shady Grove Road } \\
\hline \multicolumn{2}{|l|}{ City } & State & \multicolumn{3}{|l|}{ Zip Code } \\
\hline \multicolumn{2}{|l|}{ Memphis } & $\mathrm{TN}$ & \multicolumn{3}{|l|}{38120} \\
\hline \multicolumn{5}{|c|}{$\begin{array}{l}\text { Purpose of Disbursement } \\
\text { Shipping }\end{array}$} & \\
\hline \multicolumn{5}{|c|}{ Candidate Name } & $\begin{array}{l}\text { Category/ } \\
\text { Type }\end{array}$ \\
\hline \multirow[t]{3}{*}{ Office Sought: } & House & \multicolumn{4}{|c|}{ Disbursement For: 2012} \\
\hline & Senate & \multirow{3}{*}{\multicolumn{2}{|c|}{$\begin{array}{l}\text { Primary } \\
\text { Other (specify) }\end{array}$}} & \multirow{2}{*}{\multicolumn{2}{|c|}{ General }} \\
\hline & President & & & & \\
\hline State: & District: & & & & \\
\hline
\end{tabular}

Subtotal Of Receipts This Page (optional)...

Date of Disbursement

\begin{tabular}{|c|c|c|c|c|c|c|}
\hline M & M & D & Y & Y & Y \\
09 & & 27 & & 2011 & \\
\hline
\end{tabular}

Transaction ID : B7CBBB1F6CB6D4B9C91F

Amount of Each Disbursement this Period

Date of Disbursement

\begin{tabular}{|c|c|c|c|c|}
\hline $09^{M}$ & 1 & $27^{\mathrm{D}}$ & I & $\begin{array}{llll}Y & Y & Y & Y \\
& 2011 & \end{array}$ \\
\hline
\end{tabular}

Transaction ID : B764C7C37AB6E43C1971

Amount of Each Disbursement this Period
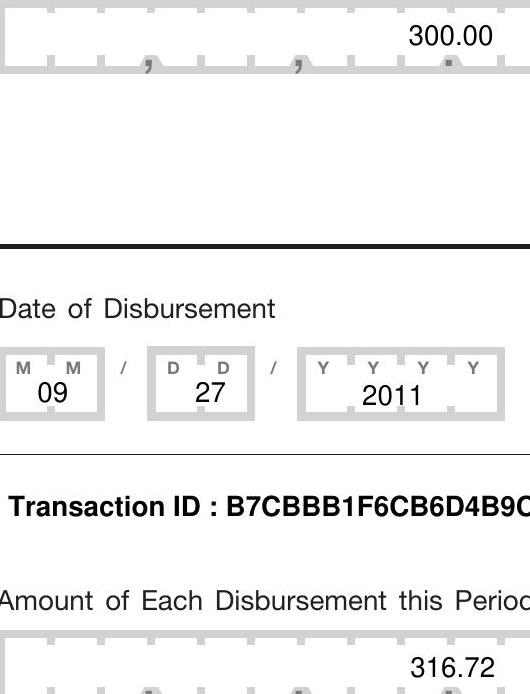

316.72

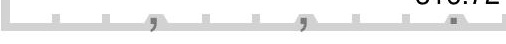

Total This Period (last page this line number only)) 


\section{SCHEDULE B-P}

\section{ITEMIZED DISBURSEMENTS}

\section{Use separate schedule(s) \\ for each category of the}

Detailed Summary Page
FOR LINE NUMBER: (check only one)

\begin{tabular}{|c|c|c|c|}
\hline$\times{ }_{23}$ & 24 & 25 & 26 \\
\hline $27 b$ & $28 a$ & $28 \mathrm{~b}$ & $28 \mathrm{c}$ \\
\hline
\end{tabular}

Any information copied from such Reports and Statements may not be sold or used by any person for the purpose of soliciting contributions or for commercial purposes, other than using the name and address of any political committee to solicit contributions from such committee.

NAME OF COMMITTEE (In Full)

\section{Friends of Herman Cain}

Full Name (Last, First, Middle Initial)

A. Collins Digital Imaging Inc.

Mailing Address 1218 B Old Chattahoochee Avenue

Date of Disbursement

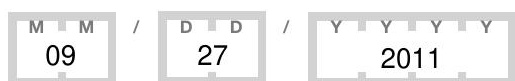

Transaction ID : BD7733E6BD44C40AAB6D

\begin{tabular}{lll}
\hline City & State & Zip Code \\
Atlanta & GA & 30318
\end{tabular}

Purpose of Disbursement

Event Supplies

Candidate Name

\begin{tabular}{l|l|l}
\hline Office Sought: & House & Disbursement For: 2012
\end{tabular} X Primary $\square$ General

State:

\section{Senate}

President

District:

Full Name (Last, First, Middle Initial)

\section{B. GOP Lounge}

Mailing Address PO Box 93931

\begin{tabular}{lcc}
\hline City & State & Zip Code \\
Des Moines & IA & 50393
\end{tabular}

Purpose of Disbursement

Membership Dues

Candidate Name

Office Sought:

House
Senate
President

State:

District:

Full Name (Last, First, Middle Initial)

\section{c. Washington Political Group}

Mailing Address 5061 Hodgkins Place

\begin{tabular}{lcc}
\hline City & State & Zip Code \\
Lilburn & GA & 30047
\end{tabular}

Purpose of Disbursement

Website Maintenance

Candidate Name

Office Sought: $\quad$ House

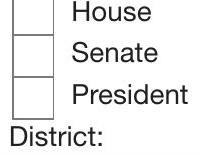

Disbursement For: 2012

Primary $\square$ General
Other (specify)

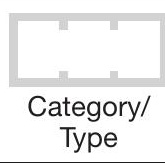

Date of Disbursement

\begin{tabular}{|c|c|c|c|c|}
\hline${ }^{M}$ & ${ }^{M}$ & $9^{\mathrm{D}}$ & $\mathrm{P}^{\mathrm{D}}$ & $\mathrm{Y}^{\mathrm{Y}} \mathrm{Y}$ \\
\hline
\end{tabular}

Transaction ID : B33B43745C73E4A318CA

Amount of Each Disbursement this Period

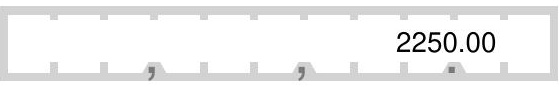

Date of Disbursement

\begin{tabular}{|c|c|c|c|c|}
\hline $09^{\mathrm{M}}$ & I & D 27 & 1 & $\begin{array}{cccc}Y & Y & Y & Y \\
& 2011 & \end{array}$ \\
\hline
\end{tabular}

Transaction ID : B0F3C55066F02468C872

Amount of Each Disbursement this Period

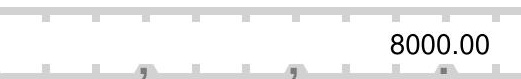

8000.00

Subtotal Of Receipts This Page (optional).

Total This Period (last page this line number only))

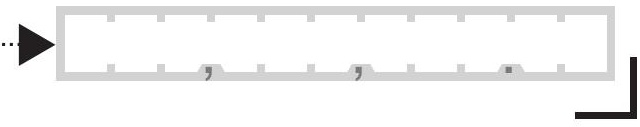




\section{SCHEDULE B-P}

\section{ITEMIZED DISBURSEMENTS}

\section{Use separate schedule(s)}

for each category of the

Detailed Summary Page
FOR LINE NUMBER: (check only one)

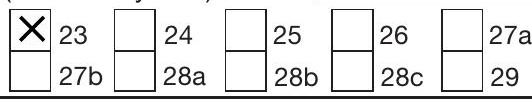

Any information copied from such Reports and Statements may not be sold or used by any person for the purpose of soliciting contributions or for commercial purposes, other than using the name and address of any political committee to solicit contributions from such committee.

NAME OF COMMITTEE (In Full)

\section{Friends of Herman Cain}

Full Name (Last, First, Middle Initial)

A. Washington Political Group

Mailing Address 5061 Hodgkins Place

Date of Disbursement

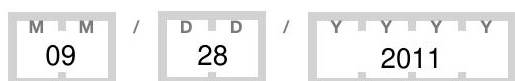

Transaction ID : B448BB1079B24406BBAE

\begin{tabular}{lll}
\hline City & State & Zip Code \\
Lilburn & GA & 30047
\end{tabular}

Purpose of Disbursement

Website Maintenance

Candidate Name

Office Sought:

$$
\begin{aligned}
& \text { House } \\
& \text { Senate } \\
& \text { Presiden }
\end{aligned}
$$
District:

State:

Full Name (Last, First, Middle Initial)

\section{B. Campaign Now!}

\begin{tabular}{ll}
\hline Mailing Address & $\begin{array}{l}1126 \text { S. 70th Street } \\
\text { Suite S420 }\end{array}$ \\
\hline City &
\end{tabular}

Milwaukee

State

Zip Code

Purpose of Disbursement

Telemarketing

Candidate Name

Office Sought:

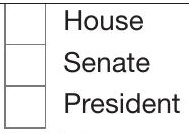

State:

District:

WI $\quad 53214$

Full Name (Last, First, Middle Initial)

\section{c. Delta Airlines}

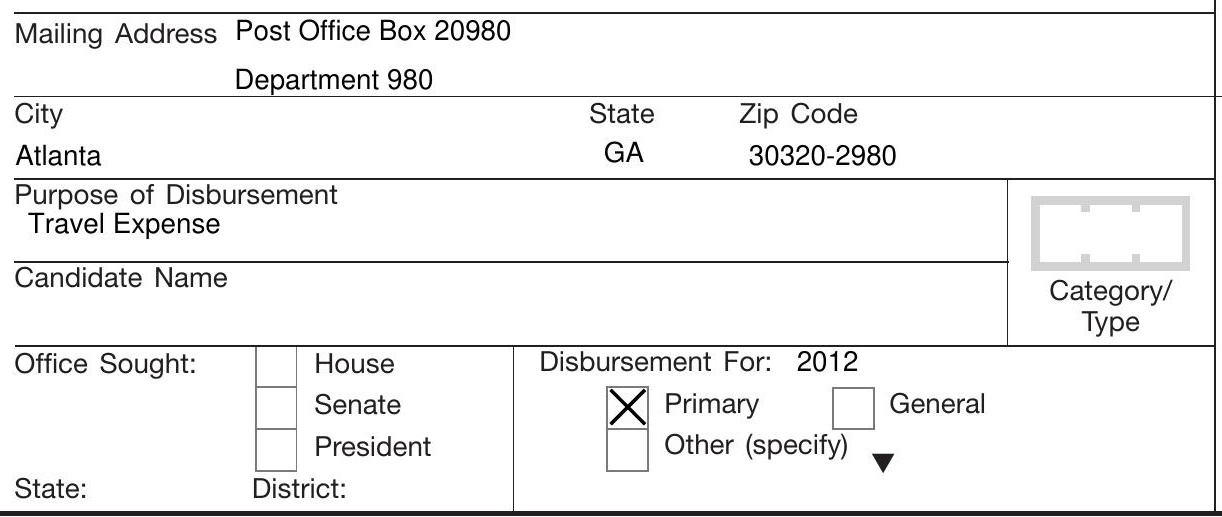

Subtotal Of Receipts This Page (optional).

Date of Disbursement

\begin{tabular}{|c|c|c|c|c|c|}
\hline M & M & D & Y & Y & $Y$ \\
09 & & 28 & & 2011 & \\
\hline
\end{tabular}

Transaction ID : BAFDAE21D94D84AC29C6

Amount of Each Disbursement this Period

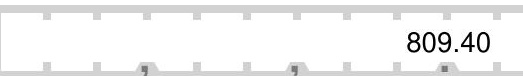

809.40

29879.54

Total This Period (last page this line number only))
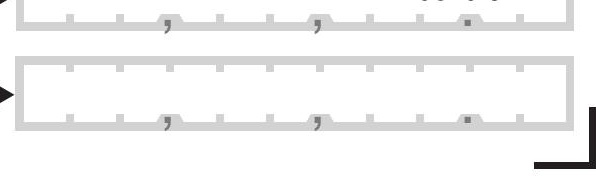

FEC Schedule B-P (Form 3P) (Rev. 03/2011) 


\section{SCHEDULE B-P}

\section{ITEMIZED DISBURSEMENTS}

\section{Use separate schedule(s) \\ for each category of the}

Detailed Summary Page
FOR LINE NUMBER: (check only one)

\begin{tabular}{|c|c|c|c|}
\hline$\times{ }_{23}$ & 24 & 25 & 26 \\
\hline $27 b$ & $28 a$ & $28 \mathrm{~b}$ & $28 \mathrm{c}$ \\
\hline
\end{tabular}

Any information copied from such Reports and Statements may not be sold or used by any person for the purpose of soliciting contributions or for commercial purposes, other than using the name and address of any political committee to solicit contributions from such committee.

NAME OF COMMITTEE (In Full)

\section{Friends of Herman Cain}

Full Name (Last, First, Middle Initial)

A. Washington Political Group

Mailing Address 5061 Hodgkins Place

Date of Disbursement

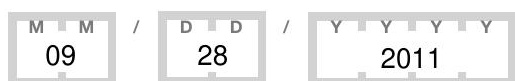

Transaction ID : B072E224AB5D94988865

\begin{tabular}{lll}
\hline City & State & Zip Code \\
Lilburn & GA & 30047
\end{tabular}

Purpose of Disbursement

Website Maintenance

Candidate Name

\begin{tabular}{l|l|l}
\hline Office Sought: & House & Disbursement For: 2012
\end{tabular} X Primary $\square$ General

State: Senate President District:

Full Name (Last, First, Middle Initial)

B. Lutz and Company P.C.

\begin{tabular}{ll}
\hline Mailing Address & 13616 California Street \\
& Suite 300 \\
\hline City &
\end{tabular}

Omaha State Zip Code

Purpose of Disbursement Accounting Services

Candidate Name

Office Sought:

\begin{tabular}{|l|l} 
& House \\
& Senate \\
\cline { 1 - 2 } & President
\end{tabular}

State:

District:

Full Name (Last, First, Middle Initial)

c. TechCMO

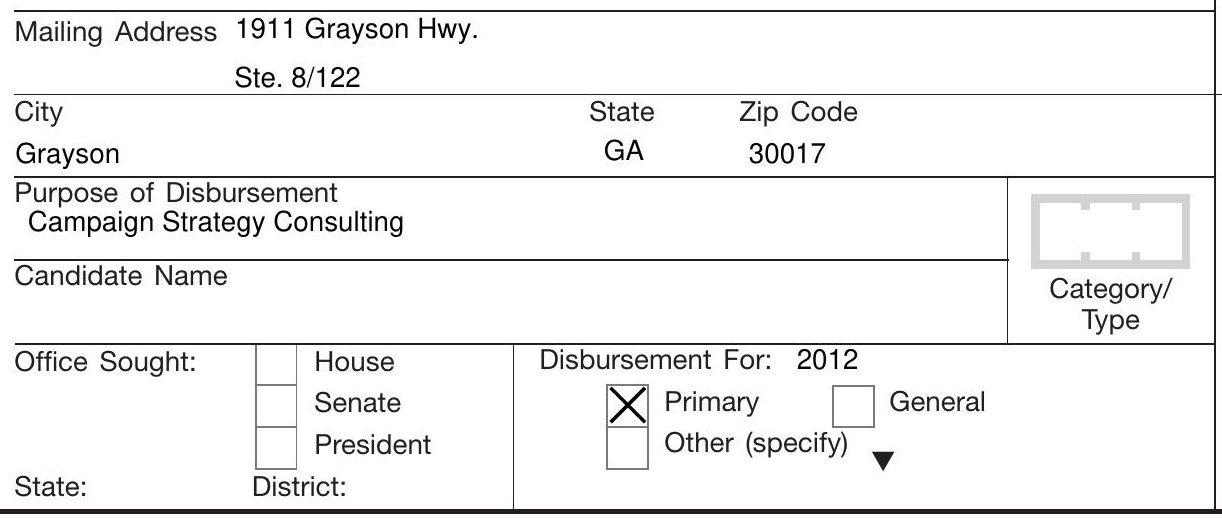

Subtotal Of Receipts This Page (optional). Primary $\square$ General
Other (specify)
Date of Disbursement

\begin{tabular}{|c|c|}
\hline $09^{M}$ & \\
\hline
\end{tabular}

Transaction ID : B71F0981727104D88B49

Amount of Each Disbursement this Period

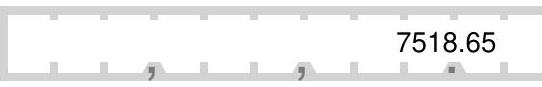

Date of Disbursement

\begin{tabular}{|c|c|c|c|c|}
\hline $09^{\mathrm{M}}$ & 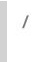 & $\begin{array}{l}\text { D } \\
28\end{array}$ & & 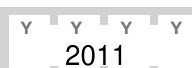 \\
\hline
\end{tabular}

Transaction ID : BD9A09E3F41854877A27

Amount of Each Disbursement this Period

1577.94

Total This Period (last page this line number only)) 


\section{SCHEDULE B-P}

\section{ITEMIZED DISBURSEMENTS}

\section{Use separate schedule(s) \\ for each category of the}

Detailed Summary Page
FOR LINE NUMBER: (check only one)

\begin{tabular}{|c|c|c|c|}
\hline$\times{ }_{23}$ & 24 & 25 & 26 \\
\hline $27 b$ & $28 a$ & $28 \mathrm{~b}$ & $28 \mathrm{c}$ \\
\hline
\end{tabular}

Any information copied from such Reports and Statements may not be sold or used by any person for the purpose of soliciting contributions or for commercial purposes, other than using the name and address of any political committee to solicit contributions from such committee.

NAME OF COMMITTEE (In Full)

\section{Friends of Herman Cain}

Full Name (Last, First, Middle Initial)

A. TechCMO

Mailing Address 1911 Grayson Hwy.

Ste. $8 / 122$

Date of Disbursement

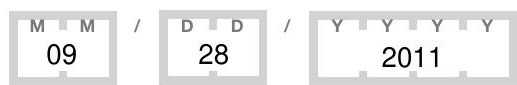

Transaction ID : B04FD60F577C74470B1A

\begin{tabular}{lll}
\hline City & State & Zip Code \\
Grayson & GA & 30017 \\
\hline
\end{tabular}

Purpose of Disbursement

Campaign Strategy Consulting

Candidate Name

Office Sought:

\begin{tabular}{|l|l} 
House \\
Senate \\
\cline { 1 - 2 } President
\end{tabular}

District:

GA $\quad 30017$

State:

Full Name (Last, First, Middle Initial)

B. Troupis Law Office LLC

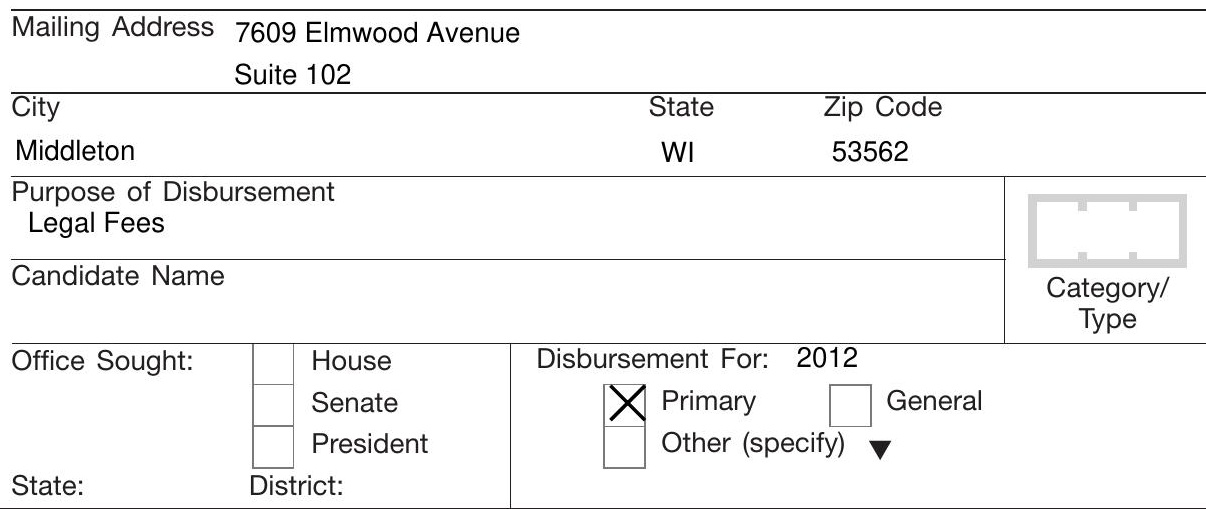

Full Name (Last, First, Middle Initial)

c. Sheraton Hotels

Mailing Address 1111 Westchester Ave.

\begin{tabular}{l} 
Disbursement For: 2012 \\
\hline Primary \\
Other (specify)
\end{tabular}
Amount of Each Disbursement this Period

13500.00
Date of Disbursement

\begin{tabular}{|c|c|c|c|c|}
\hline $09^{M}$ & & $28^{\mathrm{D}}$ & 1 & 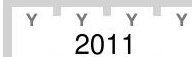 \\
\hline
\end{tabular}

Transaction ID : B3ED9C54277714E1E9EF

Amount of Each Disbursement this Period

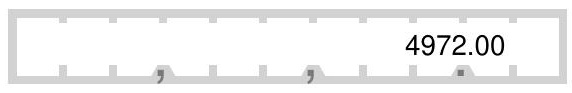

\begin{tabular}{lcc}
\hline City & State & Zip Code \\
White Plains & NY & 10604
\end{tabular}

Purpose of Disbursement

Travel Expenses

Candidate Name

Office Sought:

State:

\begin{tabular}{|l|l|}
\hline & House \\
Senate \\
President \\
\\
District:
\end{tabular}

Disbursement For: 2012

X $\begin{aligned} & \text { Primary } \\ & \text { Other (specify) }\end{aligned}$
Date of Disbursement

\begin{tabular}{|c|c|c|c|c|}
\hline $09^{\mathrm{M}}$ & I & D 28 & 1 & $\begin{array}{cccc}Y & Y & Y & Y \\
& 2011 & \end{array}$ \\
\hline
\end{tabular}

Transaction ID : B64F3E3F68C594615B0F

Amount of Each Disbursement this Period

29.97
Subtotal Of Receipts This Page (optional).

18501.97

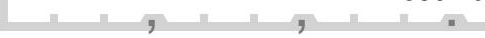

Total This Period (last page this line number only))

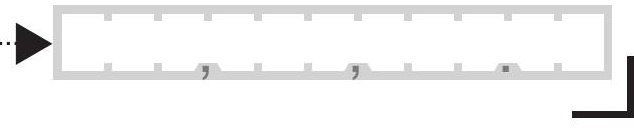

FEC Schedule B-P (Form 3P) (Rev. 03/2011) 


\section{SCHEDULE B-P}

\section{ITEMIZED DISBURSEMENTS}

\section{Use separate schedule(s) \\ for each category of the}

Detailed Summary Page
FOR LINE NUMBER: (check only one)

\begin{tabular}{|c|c|c|c|}
\hline$X_{23}$ & 24 & 25 & 26 \\
\hline $27 \mathrm{~b}$ & $28 a$ & $28 b$ & $28 \mathrm{c}$ \\
\hline
\end{tabular}

Any information copied from such Reports and Statements may not be sold or used by any person for the purpose of soliciting contributions or for commercial purposes, other than using the name and address of any political committee to solicit contributions from such committee.

NAME OF COMMITTEE (In Full)

\section{Friends of Herman Cain}

Full Name (Last, First, Middle Initial)

A. FourTier Strategies, LLC

Mailing Address c/o Brad Marston

90 Beacon Street \#2

\begin{tabular}{lll}
\hline City & State & Zip Code \\
Boston & MA & 02108
\end{tabular}

Purpose of Disbursement

Fundraising Consulting

Candidate Name

Office Sought:

$$
\begin{array}{|l|l}
\text { House } \\
\text { Senate } \\
\text { President }
\end{array}
$$

State: District:

Full Name (Last, First, Middle Initial)

B. Ethridge and Associates, LLC

\begin{tabular}{ll}
\hline Mailing Address & 1138 N. Germantown parkway \\
& Suite $101-361$ \\
\hline City &
\end{tabular}

Cordova

State Zip Code

Purpose of Disbursement

Research

Candidate Name

TN 38016

Office Sought:

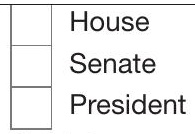

Disbursement For: 2012

$$
\text { X Primary } \square \text { General }
$$

State:

\begin{tabular}{|c|c|c|c|c|c|}
\hline \multicolumn{6}{|c|}{ Mailing Address 22 Sylvan Way } \\
\hline \multicolumn{2}{|l|}{ City } & State & \multicolumn{3}{|l|}{ Zip Code } \\
\hline \multicolumn{2}{|l|}{ Parsippany } & NJ & \multicolumn{3}{|l|}{07054} \\
\hline \multicolumn{5}{|c|}{$\begin{array}{l}\text { Purpose of Disbursement } \\
\text { Travel Expense }\end{array}$} & \\
\hline \multicolumn{5}{|c|}{ Candidate Name } & $\begin{array}{l}\text { Category/ } \\
\text { Type }\end{array}$ \\
\hline \multirow[t]{3}{*}{ Office Sought: } & House & \multicolumn{4}{|c|}{ Disbursement For: 2012} \\
\hline & Senate & \multirow{3}{*}{\multicolumn{2}{|c|}{$\begin{array}{l}\text { Primary } \\
\text { Other (specify) }\end{array}$}} & \multirow{2}{*}{\multicolumn{2}{|c|}{ General }} \\
\hline & President & & & & \\
\hline State: & District: & & & \multicolumn{2}{|l|}{$\boldsymbol{\nabla}$} \\
\hline
\end{tabular}

District:

Full Name (Last, First, Middle Initial)

c. Microtel Inn and Suites

Subtotal Of Receipts This Page (optional).

Date of Disbursement

\begin{tabular}{|c|c|c|c|c|c|}
\hline M M & I & D & Y & Y & Y \\
09 & & 28 & & 2011 & \\
\hline
\end{tabular}

\begin{tabular}{|c|c|c|c|c|}
\hline $09^{M}$ & 1 & $28^{\mathrm{D}}$ & 1 & $\begin{array}{llll} & Y & Y & Y \\
& 2011 & Y\end{array}$ \\
\hline
\end{tabular}

Transaction ID : B15799760C2BE4A8CADA

Amount of Each Disbursement this Period

Date of Disbursement

Transaction ID : B60DFE7B33EC14B37A89

Amount of Each Disbursement this Period
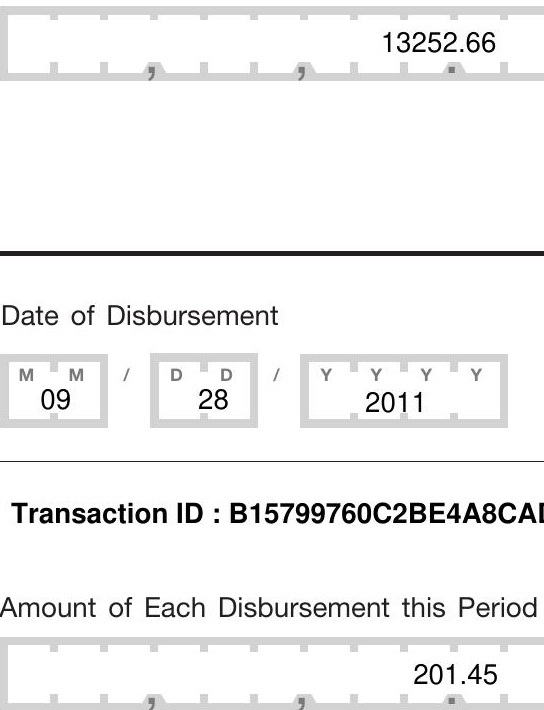

201.45

Total This Period (last page this line number only)) 


\section{SCHEDULE B-P}

\section{ITEMIZED DISBURSEMENTS}

Use separate schedule(s)

for each category of the

Detailed Summary Page
FOR LINE NUMBER: (check only one)

PAGE 1539 / 1572

\begin{tabular}{|c|c|c|c|}
\hline$X_{23}$ & 24 & 25 & 26 \\
\hline $27 \mathrm{~b}$ & $28 a$ & $28 \mathrm{~b}$ & $28 \mathrm{c}$ \\
\hline
\end{tabular}

Any information copied from such Reports and Statements may not be sold or used by any person for the purpose of soliciting contributions or for commercial purposes, other than using the name and address of any political committee to solicit contributions from such committee.

NAME OF COMMITTEE (In Full)

Friends of Herman Cain
A. Osanka Communications

Mailing Address 1742 Skyline Boulevard

\begin{tabular}{lll}
\hline City & State & Zip Code \\
Eugene & OR & 97403
\end{tabular}

Purpose of Disbursement

Communications Consulting

Candidate Name

Office Sought:

Full Name (Last, First, Middle Initial)

B. Hartsfield Jackson International Airport

Mailing Address Post Office Box 20786

\begin{tabular}{lcc}
\hline City & State & Zip Code \\
Atlanta & GA & 30320
\end{tabular}

Purpose of Disbursement

Parking

Candidate Name

Office Sought:

House
Senate
President

State:

District:

Full Name (Last, First, Middle Initial)

c. Fiscal Associates, Inc.

Mailing Address 713 Rose Square

\begin{tabular}{lcc}
\hline City & State & Zip Code \\
Alexandria & VA & 22314
\end{tabular}

Purpose of Disbursement

Economic Consulting

Candidate Name

Office Sought: $\quad$ House

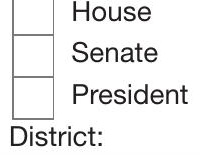

State:

District:
Disbursement For: 2012

$$
\begin{aligned}
& \text { Primary } \\
& \text { Other (specify) }
\end{aligned}
$$

Date of Disbursement

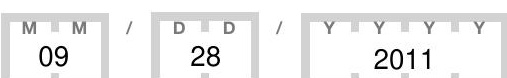

Transaction ID : BA2D0C03F95DD4BF9B72

Amount of Each Disbursement this Period 9000.00

Date of Disbursement

\begin{tabular}{|c|c|c|c|c|}
\hline $09^{\mathrm{M}}$ & & ${ }^{\mathrm{D}} 28^{\mathrm{D}}$ & 1 & $\begin{array}{llll}Y & Y & Y & Y \\
& 2011\end{array}$ \\
\hline
\end{tabular}

Transaction ID : BE29B3F35C5C74B62A50

Amount of Each Disbursement this Period

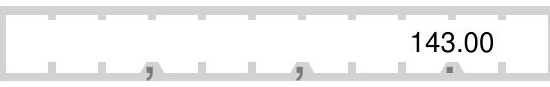

Date of Disbursement

\begin{tabular}{|c|c|c|c|c|c|}
\hline M M & M & Y & Y & Y & Y \\
09 & & 28 & & 2011 & \\
\hline
\end{tabular}

Transaction ID : B6183860A0B8E4A8F903

Amount of Each Disbursement this Period 5000.00

Subtotal Of Receipts This Page (optional)

Total This Period (last page this line number only))

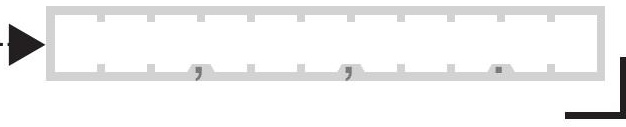




\section{SCHEDULE B-P}

\section{ITEMIZED DISBURSEMENTS}

Use separate schedule(s)

for each category of the

Detailed Summary Page
FOR LINE NUMBER: (check only one)

\begin{tabular}{|c|c|c|c|c|}
\hline$X_{23}$ & 24 & 25 & 26 & \\
\hline $27 \mathrm{~b}$ & $28 a$ & $28 b$ & $28 \mathrm{c}$ & 2 \\
\hline
\end{tabular}

Any information copied from such Reports and Statements may not be sold or used by any person for the purpose of soliciting contributions or for commercial purposes, other than using the name and address of any political committee to solicit contributions from such committee.

NAME OF COMMITTEE (In Full)

\section{Friends of Herman Cain}

Full Name (Last, First, Middle Initial)

A. LSAC Inc.

Mailing Address 10941 N. Range Line road

Date of Disbursement

\begin{tabular}{|c|c|c|c|c|c|c|c|}
$M$ & M & Y \\
09 & 28 & 2011
\end{tabular}

Transaction ID : B2A94D25AB3DC4231B75

\begin{tabular}{lcc}
\hline City & State & Zip Code \\
Mequon & WI & 53092
\end{tabular}

Purpose of Disbursement

Airfare

Candidate Name Xrimary $\square$ General

State:

\section{Senate}

President

District:

Full Name (Last, First, Middle Initial)

B. Karis McKinney

Mailing Address 5017 N. 50th Street

\begin{tabular}{lcc}
\hline City & State & Zip Code \\
Milwaukee & WI & $53218-4326$
\end{tabular}

Purpose of Disbursement

Staff Salary

Candidate Name

Office Sought:

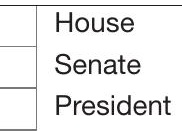

State:

District:

Full Name (Last, First, Middle Initial)

c. J Ryan Hudson

Mailing Address 418 Landing Pointe

\begin{tabular}{lcc}
\hline City & State & Zip Code \\
Stockbridge & GA & 30281
\end{tabular}

Purpose of Disbursement

Airfare/Transp./Lodging/Event Supplies

Candidate Name

Office Sought: $\quad$ House

\begin{tabular}{l|l} 
& Senate \\
\cline { 2 - 3 } & President
\end{tabular}

State:

District:
Date of Disbursement

\begin{tabular}{|c|c|c|c|c|}
\hline $09^{M}$ & & $28^{\mathrm{D}}$ & & $\begin{array}{llll} & Y & Y & Y \\
& 2011 & Y\end{array}$ \\
\hline
\end{tabular}

Transaction ID : B82C3E5F8BF0F41758B2

Amount of Each Disbursement this Period

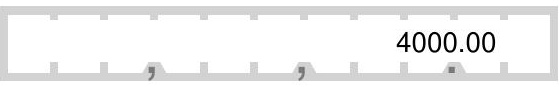

Date of Disbursement

\begin{tabular}{|c|c|c|c|c|}
\hline $09^{\mathrm{M}}$ & I & D 28 & 1 & $\begin{array}{cccc}Y & Y & Y & Y \\
& 2011 & \end{array}$ \\
\hline
\end{tabular}

Transaction ID : BC62AE067ED3A4827832

Amount of Each Disbursement this Period

5391.13
Subtotal Of Receipts This Page (optional).

15190.67

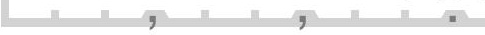

Total This Period (last page this line number only))

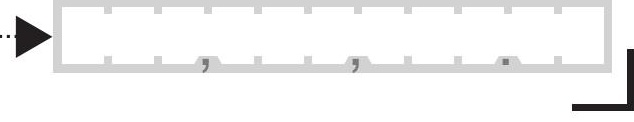

FEC Schedule B-P (Form 3P) (Rev. 03/2011) 


\section{SCHEDULE B-P}

\section{ITEMIZED DISBURSEMENTS}

Use separate schedule(s)

for each category of the

Detailed Summary Page

FOR LINE NUMBER: (check only one)

\begin{tabular}{|c|c|c|c|}
\hline$\times \quad 23$ & 24 & 25 & 26 \\
\hline $27 \mathrm{~b}$ & $28 \mathrm{a}$ & $28 b$ & $28 \mathrm{c}$ \\
\hline
\end{tabular}

Any information copied from such Reports and Statements may not be sold or used by any person for the purpose of soliciting contributions or for commercial purposes, other than using the name and address of any political committee to solicit contributions from such committee.

NAME OF COMMITTEE (In Full)

\section{Friends of Herman Cain}

Full Name (Last, First, Middle Initial)

A. James Harmon

Mailing Address 65 Beckett Avenue

Date of Disbursement

\begin{tabular}{|c|c|c|c|c|c|c|c|}
$M$ & M & Y \\
09 & 28 & 2011
\end{tabular}

\begin{tabular}{lll}
\hline City & State & Zip Code \\
Branford & CT & $06405-4807$
\end{tabular}

Purpose of Disbursement

Data Subscription

Candidate Name X Primary $\square$ General

State:

$$
\begin{aligned}
& \text { Senate } \\
& \text { President }
\end{aligned}
$$

District:

Full Name (Last, First, Middle Initial)

\section{B. Chris Burgard}

\section{Mailing Address 34729 Petersen Road}

\begin{tabular}{lcc}
\hline City & State & Zip Code \\
Santa Clarita & CA & $91390-2809$
\end{tabular}

Purpose of Disbursement

Lodging, Airfare and Meeting Expenses

Candidate Name

Office Sought:

House
Senate
President

Disbursement For: 2012

$$
\text { Xrimary } \square \text { General }
$$

State:

District:

Full Name (Last, First, Middle Initial)

c. James Brazil

Mailing Address 6 Baldasarri Drive

\begin{tabular}{lcc}
\hline City & State & Zip Code \\
Dunmore & PA & 18505
\end{tabular}

Purpose of Disbursement

Transportation, Airfare and Lodging

Candidate Name

Office Sought: $\quad$ House

\begin{tabular}{|l|l|} 
& House \\
Senate \\
President
\end{tabular}

State:

\begin{tabular}{|c|c|c|c|c|}
\hline $09^{M}$ & & $28^{\mathrm{D}}$ & & 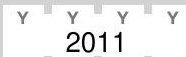 \\
\hline
\end{tabular}

District:
Date of Disbursement

\section{Transaction ID : B47107ABDCD434CD9A11}

Amount of Each Disbursement this Period
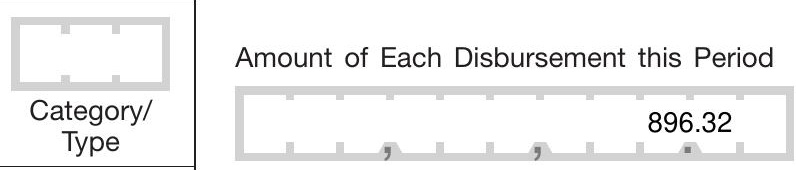

Date of Disbursement

\begin{tabular}{|c|c|c|c|c|c|}
\hline M M & M & Y & Y & Y & Y \\
09 & & 28 & & 2011 & \\
\hline
\end{tabular}

Transaction ID : B498B094014AE4FEDB2A

Amount of Each Disbursement this Period

1577.35

Subtotal Of Receipts This Page (optional)

Total This Period (last page this line number only))

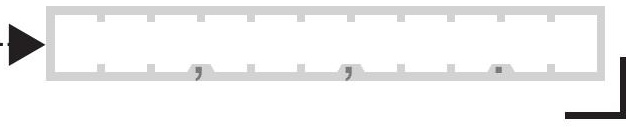




\section{SCHEDULE B-P}

\section{ITEMIZED DISBURSEMENTS}

Use separate schedule(s)

for each category of the

Detailed Summary Page
FOR LINE NUMBER: (check only one)

\begin{tabular}{|c|c|c|c|}
\hline$\times \quad 23$ & 24 & 25 & 26 \\
\hline $27 \mathrm{~b}$ & $28 \mathrm{a}$ & $28 b$ & $28 \mathrm{c}$ \\
\hline
\end{tabular}

Any information copied from such Reports and Statements may not be sold or used by any person for the purpose of soliciting contributions or for commercial purposes, other than using the name and address of any political committee to solicit contributions from such committee.

NAME OF COMMITTEE (In Full)

\section{Friends of Herman Cain}

Full Name (Last, First, Middle Initial)

A. James Brazil

Mailing Address 6 Baldasarri Drive

Date of Disbursement

\begin{tabular}{lcc}
\hline City & State & Zip Code \\
Dunmore & PA & 18505 \\
\hline
\end{tabular}

Purpose of Disbursement

Field Consulting

Candidate Name

Office Sought:

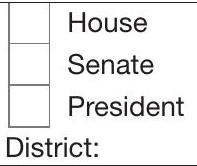

Disbursement For: 2012 X Primary $\square$ General

State: District:

Full Name (Last, First, Middle Initial)

B. James Coughlin

\begin{tabular}{|c|c|c|c|c|}
\hline \multicolumn{5}{|c|}{ Mailing Address 16 South Hills Drive } \\
\hline \multicolumn{2}{|l|}{ City } & \multicolumn{3}{|c|}{ Zip Code } \\
\hline \multicolumn{2}{|l|}{ Bedford } & \multicolumn{3}{|c|}{$03110-4920$} \\
\hline \multicolumn{4}{|c|}{$\begin{array}{l}\text { Purpose of Disbursement } \\
\text { Field Consulting }\end{array}$} & \\
\hline \multicolumn{4}{|l|}{ Candidate Name } & $\begin{array}{l}\text { Category/ } \\
\text { Type }\end{array}$ \\
\hline \multirow[t]{3}{*}{ Office Sought: } & House & \multirow{3}{*}{\multicolumn{3}{|c|}{$\begin{array}{l}\text { Disbursement For: } 2012 \\
\text { X Primary } \\
\text { Other (specify) }\end{array}$}} \\
\hline & Senate & & & \\
\hline & President & & & \\
\hline State: & \multicolumn{4}{|c|}{ District: } \\
\hline
\end{tabular}

Date of Disbursement

\begin{tabular}{|c|c|c|c|c|}
\hline $09^{M}$ & & $28^{\mathrm{D}}$ & & 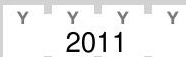 \\
\hline
\end{tabular}

Transaction ID : BA77A6434E39E48AF99A

Full Name (Last, First, Middle Initial)

c. Kyle Maichle

Mailing Address 617 N 23rd Street Apt 305

\begin{tabular}{lcc}
\hline City & State & Zip Code \\
Milwaukee & WI & $53233-1976$
\end{tabular}

Purpose of Disbursement

Research

Candidate Name

Office Sought: $\quad$ House

\begin{tabular}{|l|l|} 
& House \\
& Senate \\
& President
\end{tabular}

Disbursement For: 2012

X $\begin{aligned} & \text { Primary } \\ & \text { Other (specify) }\end{aligned}$

State:

District:

Subtotal Of Receipts This Page (optional)

Date of Disbursement

\begin{tabular}{|c|c|c|c|c|c|c|}
\hline M & M & D & Y & Y & Y & Y \\
\hline & 28 & & 2011 & \\
\hline
\end{tabular}

Transaction ID : B235F84B9C6634EC885E

Amount of Each Disbursement this Period

Amount of Each Disbursement this Period
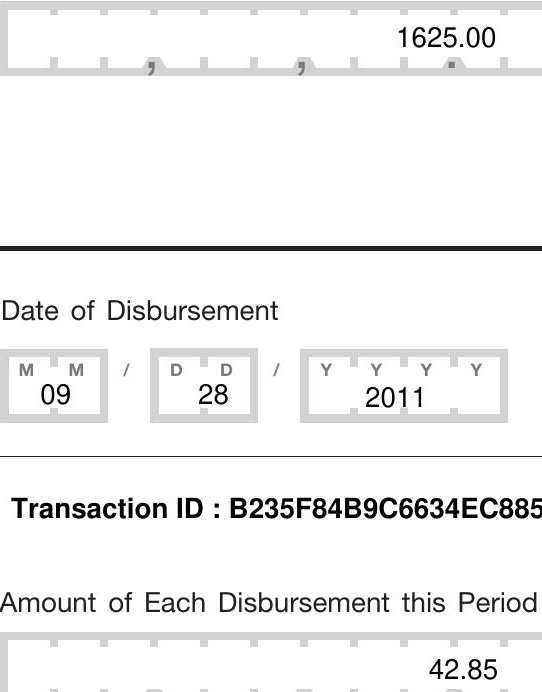

Total This Period (last page this line number only)) 
Image\# 12951402791

\section{SCHEDULE B-P}

\section{ITEMIZED DISBURSEMENTS}

\section{Use separate schedule(s) \\ for each category of the}

Detailed Summary Page
FOR LINE NUMBER: (check only one)

\begin{tabular}{|c|c|c|c|}
\hline$\times{ }_{23}$ & 24 & 25 & 26 \\
\hline $27 b$ & $28 a$ & $28 \mathrm{~b}$ & $28 \mathrm{c}$ \\
\hline
\end{tabular}

Any information copied from such Reports and Statements may not be sold or used by any person for the purpose of soliciting contributions or for commercial purposes, other than using the name and address of any political committee to solicit contributions from such committee.

NAME OF COMMITTEE (In Full)

\section{Friends of Herman Cain}

Full Name (Last, First, Middle Initial)

\section{A. Hotels.com}

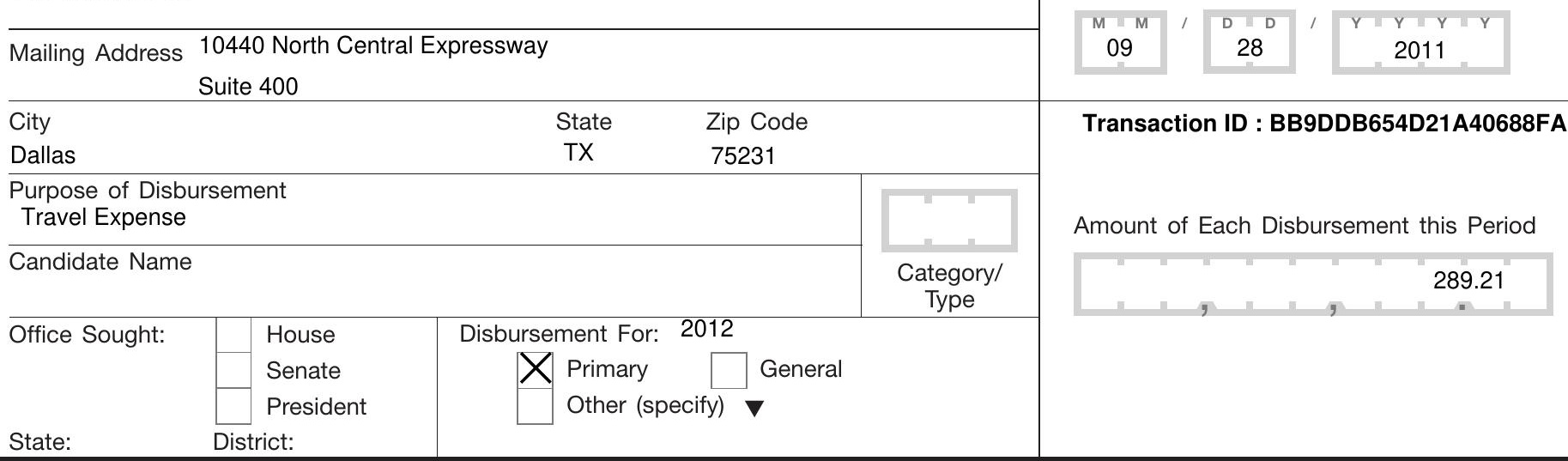

Full Name (Last, First, Middle Initial)

B. T.H.E. New Voice Inc.

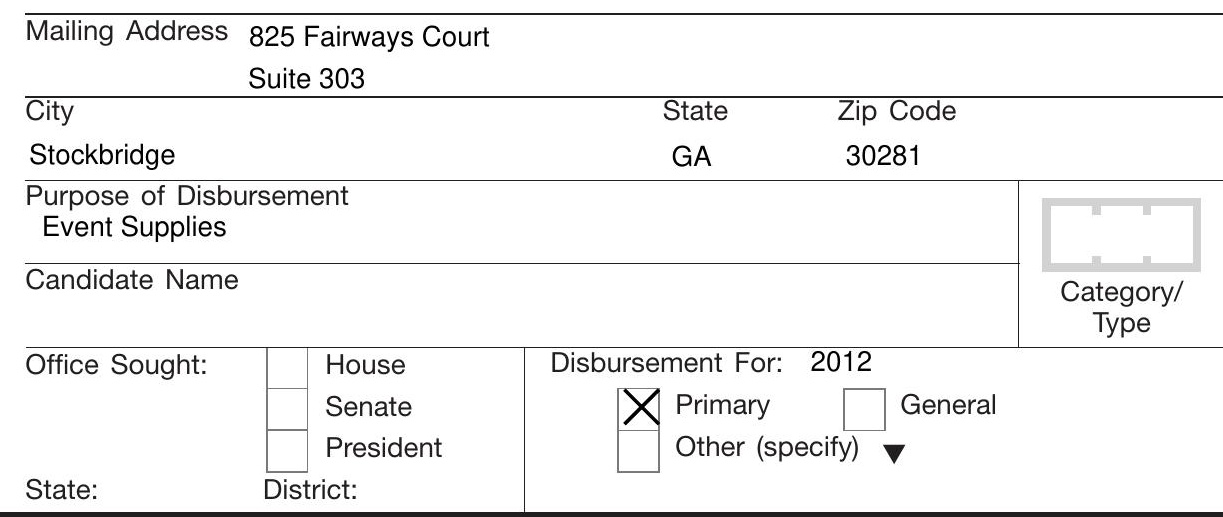

Date of Disbursement

\begin{tabular}{|c|c|c|c|c|}
\hline $09^{M}$ & 1 & $28^{D}$ & 1 & 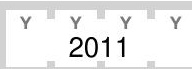 \\
\hline
\end{tabular}

Transaction ID : B3311463AF579497B9CD

Full Name (Last, First, Middle Initial)

c. Inkhead Inc.

\begin{tabular}{|c|c|c|c|c|c|}
\hline \multicolumn{6}{|c|}{ Mailing Address 138 Park Avenue } \\
\hline \multicolumn{6}{|c|}{ Suite 300} \\
\hline \multicolumn{2}{|l|}{ City } & State & Zip Code & & \\
\hline \multicolumn{2}{|l|}{ Winder } & $\mathrm{GA}$ & 30680 & & \\
\hline \multicolumn{5}{|c|}{$\begin{array}{l}\text { Purpose of Disbursement } \\
\text { Event Supplies }\end{array}$} & \\
\hline \multicolumn{5}{|l|}{ Candidate Name } & $\begin{array}{l}\text { Category/ } \\
\text { Type }\end{array}$ \\
\hline \multirow[t]{3}{*}{ Office Sought: } & House & \multicolumn{4}{|c|}{ Disbursement For: 2012} \\
\hline & Senate & \multirow{3}{*}{\multicolumn{2}{|c|}{$\begin{array}{l}\text { Primary } \\
\text { Other (specify) }\end{array}$}} & \multirow{2}{*}{\multicolumn{2}{|c|}{ General }} \\
\hline & President & & & & \\
\hline State: & District: & & & & \\
\hline
\end{tabular}

Subtotal Of Receipts This Page (optional).

Date of Disbursement

\begin{tabular}{|c|c|c|c|c|c|}
\hline M & M & D & Y & Y & Y \\
09 & & 28 & & 2011 & \\
\hline
\end{tabular}

Transaction ID : BB1B9D36ACD614625A26

Amount of Each Disbursement this Period

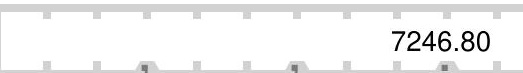

7246.80

Total This Period (last page this line number only)) 


\section{SCHEDULE B-P}

\section{ITEMIZED DISBURSEMENTS}

Use separate schedule(s)

for each category of the

Detailed Summary Page
FOR LINE NUMBER: (check only one)

\begin{tabular}{|c|c|c|c|}
\hline$\times \quad 23$ & 24 & 25 & 26 \\
\hline $27 \mathrm{~b}$ & $28 \mathrm{a}$ & $28 b$ & $28 \mathrm{c}$ \\
\hline
\end{tabular}

Any information copied from such Reports and Statements may not be sold or used by any person for the purpose of soliciting contributions or for commercial purposes, other than using the name and address of any political committee to solicit contributions from such committee.

NAME OF COMMITTEE (In Full)

\section{Friends of Herman Cain}

Full Name (Last, First, Middle Initial)

A. Facebook, Inc.

Mailing Address 1601 S. California Ave.

Date of Disbursement

\begin{tabular}{|c|c|c|c|c|c|c|c|}
$M$ & M & Y \\
09 & 28 & 2011
\end{tabular}

Transaction ID : B725FBE00450540F6829

\begin{tabular}{lcc}
\hline City & State & Zip Code \\
Palo Alto & CA & 94304
\end{tabular}

Purpose of Disbursement

Advertising Expense

Candidate Name

Office Sought:

$$
\begin{aligned}
& \text { House } \\
& \text { Senate } \\
& \text { President }
\end{aligned}
$$

State: District:

Full Name (Last, First, Middle Initial)

B. Aristotle International Inc.

Mailing Address Attention: Accounts Receivable 205 Pennsylvania Avenue SE

\begin{tabular}{lcc}
\hline City & State & Zip Code \\
Washington & DC & 20003
\end{tabular}

Purpose of Disbursement Software

Candidate Name

Office Sought:

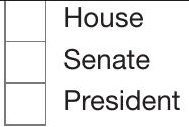

Disbursement For: 2012

$$
\text { Xrimary } \square \text { General }
$$

State:

District:

Full Name (Last, First, Middle Initial)

c. Air Tran

Mailing Address 9955 Air Tran Boulevard

\begin{tabular}{lcc}
\hline City & State & Zip Code \\
Orlando & FL & 32827
\end{tabular}

Purpose of Disbursement

Travel Expense

Candidate Name

Office Sought:

\begin{tabular}{|c|c|c|c|c|}
\hline $09^{M}$ & & $28^{\mathrm{D}}$ & 1 & 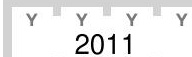 \\
\hline
\end{tabular}

$$
\begin{array}{|l|l|}
\hline & \text { House } \\
& \text { Senate } \\
& \text { President } \\
\text { District: }
\end{array}
$$

\begin{tabular}{|c|c|c|c|c|}
\hline $09^{M}$ & I & $28^{D}$ & I & $\begin{array}{cccc} & Y & Y & Y \\
& 2011 & \end{array}$ \\
\hline
\end{tabular}

State:
Date of Disbursement

\section{Transaction ID : BE84076C4E85F4F20A68}

Amount of Each Disbursement this Period

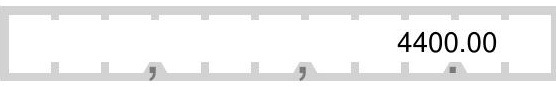

Date of Disbursement

Transaction ID : B6143AB8B9E7140F69F4

Amount of Each Disbursement this Period Type

Subtotal Of Receipts This Page (optional)

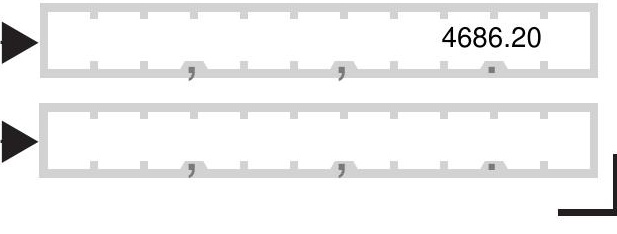




\section{SCHEDULE B-P}

\section{ITEMIZED DISBURSEMENTS}

\section{Use separate schedule(s)}

for each category of the

Detailed Summary Page
FOR LINE NUMBER: (check only one)

\begin{tabular}{|c|c|c|c|}
\hline$\times{ }_{23}$ & 24 & 25 & 26 \\
\hline $27 b$ & $28 a$ & $28 \mathrm{~b}$ & $28 \mathrm{c}$ \\
\hline
\end{tabular}

Any information copied from such Reports and Statements may not be sold or used by any person for the purpose of soliciting contributions or for commercial purposes, other than using the name and address of any political committee to solicit contributions from such committee.

NAME OF COMMITTEE (In Full)

\section{Friends of Herman Cain}

Full Name (Last, First, Middle Initial)

A. Doulos Productions, Inc.

Mailing Address 1450 Corporate Pointe

Date of Disbursement

\begin{tabular}{lcc}
\hline City & State & Zip Code \\
Warner Robins & GA & 31088
\end{tabular}

Purpose of Disbursement

Web Maint./Development/Graphic Design

Candidate Name

GA $\quad 31088$

\begin{tabular}{|c|c|c|c|c|c|c|}
\hline$M$ & M & D & Y \\
09 & 28 & 2011 \\
\hline
\end{tabular}

Office Sought:

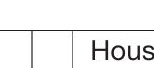

House
Senate
President

District:

State:

irst, Middle Initial)

B. Book Revue

Mailing Address 313 New York Ave.

Disbursement For: 2012

Х Primary $\square$ General

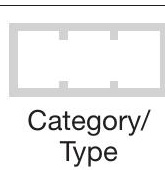

Transaction ID : B00FFB24C9E7D4DA8B26

Amount of Each Disbursement this Period 33308.02
Date of Disbursement

\begin{tabular}{|c|c|c|c|}
\hline $09^{\mathrm{M}}$ & & ${ }^{\mathrm{D}}$ & \\
\hline
\end{tabular}

Transaction ID : B8177D2BCB6DA4B9481C

Amount of Each Disbursement this Period

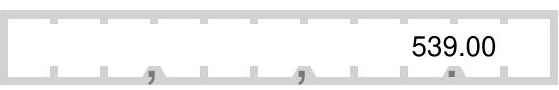

\section{Office Sought:}

City
Huntington

Purpose of Disbursement

Event Supplies

Candidate Name

State:

House
Senate
President
Prict:

Disbursement For: 2012

Primary
Other (specify) General

Full Name (Last, First, Middle Initial)

c. Little Bonanza Productions LLC

Mailing Address 34729 Petersen Road

Date of Disbursement

\begin{tabular}{lcc} 
& & \\
\hline City & State & Zip Code \\
Agua Dulce & CA & 91390
\end{tabular}

Purpose of Disbursement

Media Production

Candidate Name

\begin{tabular}{l|l|l}
\hline Office Sought: & & $\begin{array}{l}\text { House } \\
\text { Senate } \\
\end{array}$ \\
& $\begin{array}{l}\text { President } \\
\text { State: }\end{array}$ & District:
\end{tabular}

Disbursement For: 2012
X Primary
Other (specify)

\begin{tabular}{|c|c|c|c|c|}
\hline $09^{\mathrm{M}}$ & & $\begin{array}{ll} & \text { D } \\
28\end{array}$ & I & $\begin{array}{cccc}Y & Y & Y & Y \\
& 2011 & \end{array}$ \\
\hline
\end{tabular}

\section{Transaction ID : B38FBA5954F304DC1AD9}

Amount of Each Disbursement this Period

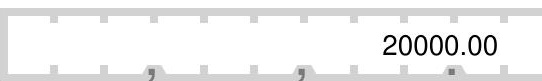

Subtotal Of Receipts This Page (optional)

Total This Period (last page this line number only)) 


\section{SCHEDULE B-P}

\section{ITEMIZED DISBURSEMENTS}

\section{Use separate schedule(s) \\ for each category of the}

Detailed Summary Page
FOR LINE NUMBER: (check only one)

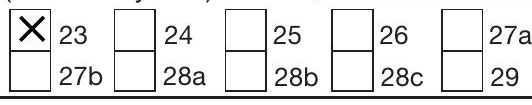

Any information copied from such Reports and Statements may not be sold or used by any person for the purpose of soliciting contributions or for commercial purposes, other than using the name and address of any political committee to solicit contributions from such committee.

NAME OF COMMITTEE (In Full)

\section{Friends of Herman Cain}

Full Name (Last, First, Middle Initial)

\section{A. Desumo Strategies}

Mailing Address 9211 Forest Hill Ave.

Ste. 207

\begin{tabular}{lll}
\hline City & State & Zip Code \\
Richmond & VA & 23235 \\
\hline Purpose of Disbursement & &
\end{tabular}

Purpose of Disbursement

Event Supplies

Candidate Name

Office Sought:

State:

Full Name (Last, First, Middle Initial)

\section{B. Premiere Marketing}

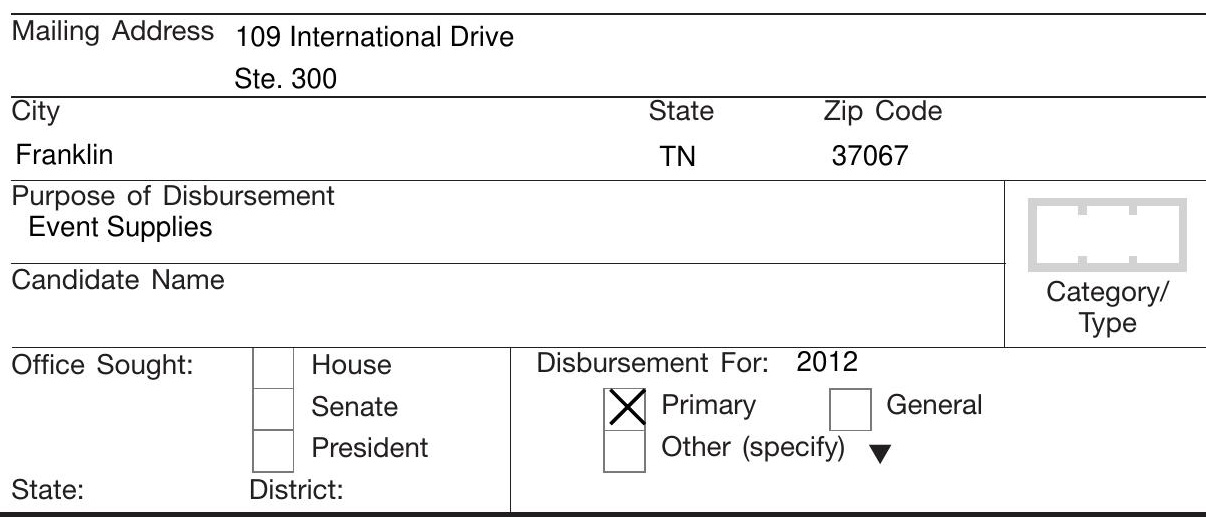

Full Name (Last, First, Middle Initial)

\section{c. Consolidated Copier Services}

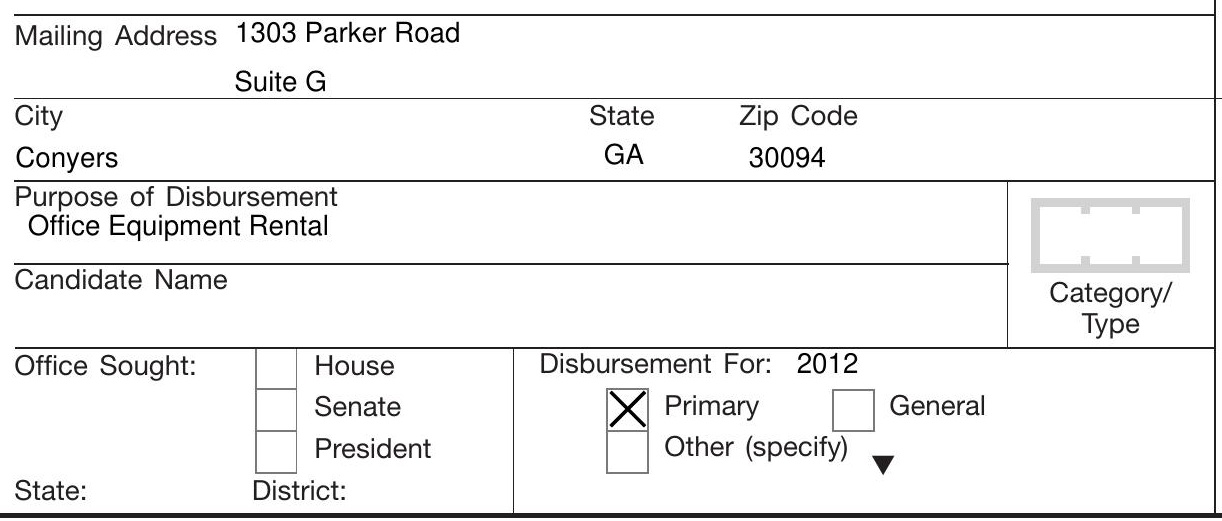

Subtotal Of Receipts This Page (optional). X Primary $\square$ General

Date of Disbursement

\begin{tabular}{|c|c|c|c|c|}
\hline${ }^{\mathrm{M}} 09^{\mathrm{M}}$ & 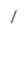 & ${ }^{\mathrm{D}} 28^{\mathrm{D}}$ & 1 & $\begin{array}{lll}Y & Y & Y \\
& 2011 & Y\end{array}$ \\
\hline
\end{tabular}

Transaction ID : B9C9A624C385E492FA8A

Amount of Each Disbursement this Period

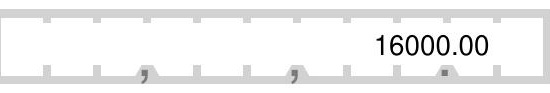

Date of Disbursement

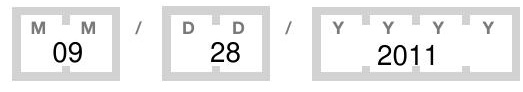

Transaction ID : BB5AB4F2D4DE646499C1

Amount of Each Disbursement this Period

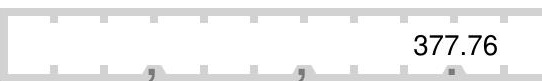

Total This Period (last page this line number only)) 


\section{SCHEDULE B-P}

\section{ITEMIZED DISBURSEMENTS}

\section{Use separate schedule(s)}

for each category of the

Detailed Summary Page
FOR LINE NUMBER: (check only one)

\begin{tabular}{|c|c|c|c|}
\hline$\times{ }_{23}$ & 24 & 25 & 26 \\
\hline $27 b$ & $28 a$ & $28 \mathrm{~b}$ & $28 \mathrm{c}$ \\
\hline
\end{tabular}

Any information copied from such Reports and Statements may not be sold or used by any person for the purpose of soliciting contributions or for commercial purposes, other than using the name and address of any political committee to solicit contributions from such committee.

NAME OF COMMITTEE (In Full)

\section{Friends of Herman Cain}

Full Name (Last, First, Middle Initial)

A. Rosen Centre Hotel

Mailing Address 9840 International Drive

Date of Disbursement

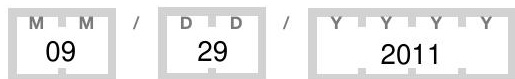

Transaction ID : B212C7B2E298E41D280B

\begin{tabular}{lcc}
\hline City & State & Zip Code \\
Orlando & FL & 32819
\end{tabular}

Purpose of Disbursement

Event Catering

Candidate Name Xrimary $\square$ General

State: Senate President District:

Full Name (Last, First, Middle Initial)

B. UPS

Mailing Address Post Office Box 7247-0244

\begin{tabular}{lcc}
\hline City & State & Zip Code \\
Philadelphia & PA & $19170-000$
\end{tabular}

Purpose of Disbursement Shipping

Candidate Name

Office Sought:

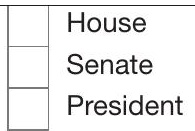

State:

District:

Full Name (Last, First, Middle Initial)

c. Facebook, Inc.

Mailing Address 1601 S. California Ave.

Disbursement For: 2012

Primary
Other (specify)
Date of Disbursement

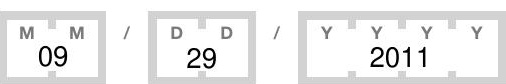

Transaction ID : BBAC977722ABC42CC88C

Amount of Each Disbursement this Period
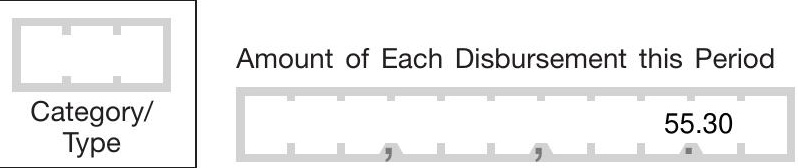

Date of Disbursement

\begin{tabular}{|c|c|c|c|c|}
\hline $09^{\mathrm{M}}$ & I & D 29 & 1 & $\begin{array}{cccc}Y & Y & Y & Y \\
& 2011 & \end{array}$ \\
\hline
\end{tabular}

Transaction ID : BD5A56CBE2154420D994

Amount of Each Disbursement this Period

100.00

\begin{tabular}{lcc}
\hline City & State & Zip Code \\
Palo Alto & CA & 94304 \\
\hline
\end{tabular}

Purpose of Disbursement Advertising Expense

Candidate Name

Office Sought:

State:

\begin{tabular}{|l|l|l}
\hline & House \\
& Senate \\
& President \\
& Pistrict:
\end{tabular}

Disbursement For: 2012

X $\begin{aligned} & \text { Primary } \\ & \text { Other (specify) }\end{aligned}$

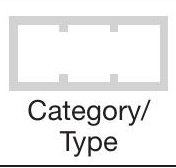

ype
Subtotal Of Receipts This Page (optional)

4828.91

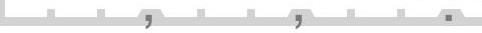

Total This Period (last page this line number only))

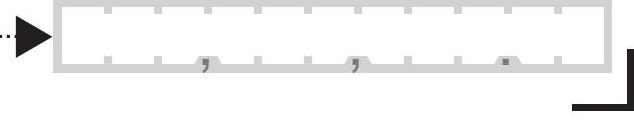

FEC Schedule B-P (Form 3P) (Rev. 03/2011) 


\section{SCHEDULE B-P}

\section{ITEMIZED DISBURSEMENTS}

\section{Use separate schedule(s) \\ for each category of the}

Detailed Summary Page
FOR LINE NUMBER: (check only one)

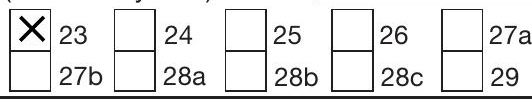

Any information copied from such Reports and Statements may not be sold or used by any person for the purpose of soliciting contributions or for commercial purposes, other than using the name and address of any political committee to solicit contributions from such committee.

NAME OF COMMITTEE (In Full)

\section{Friends of Herman Cain}

Full Name (Last, First, Middle Initial)

A. The Soarin' Group

Mailing Address Post Office Box 14160

Date of Disbursement

\begin{tabular}{lcc}
\hline City & State & Zip Code \\
Chicago & IL & $60614-0160$
\end{tabular}

Purpose of Disbursement

Airfare/Transportation/Internet Service

Candidate Name

Office Sought:

\begin{tabular}{|l|l|l} 
& House \\
Senate \\
President
\end{tabular}

Disbursement For: 2012 X Primary $\square$ General

State: District:

Full Name (Last, First, Middle Initial)

\section{B. Amtrak}

Mailing Address

City

Washington

Purpose of Disbursement

Travel Expense

Candidate Name

Office Sought:

60 Massacheusetts Avenue

\begin{abstract}
DC
\end{abstract}

(20)

\begin{tabular}{|c|c|c|c|}
\hline & $\begin{array}{cc}\text { State } & \text { Zip } \\
\text { DC } & 20\end{array}$ & $\begin{array}{l}\text { Code } \\
02-4225\end{array}$ & \\
\hline & & & \\
\hline & & & $\begin{array}{c}\text { Category/ } \\
\text { Type }\end{array}$ \\
\hline House & Disbursement For: 2012 & & \\
\hline Senate & X Primary & General & \\
\hline President & Other (specify) & $\nabla$ & \\
\hline
\end{tabular}

\begin{tabular}{|c|c|c|c|}
\hline & $\begin{array}{cc}\text { State } & \text { Zip } \\
\text { DC } & 20\end{array}$ & $\begin{array}{l}\text { Code } \\
02-4225\end{array}$ & \\
\hline & & & \\
\hline & & & $\begin{array}{c}\text { Category/ } \\
\text { Type }\end{array}$ \\
\hline House & Disbursement For: 2012 & & \\
\hline Senate & X Primary & General & \\
\hline President & Other (specify) & $\nabla$ & \\
\hline
\end{tabular}

\begin{tabular}{|c|c|c|c|}
\hline & $\begin{array}{cc}\text { State } & \text { Zip } \\
\text { DC } & 20\end{array}$ & $\begin{array}{l}\text { Code } \\
02-4225\end{array}$ & \\
\hline & & & \\
\hline & & & $\begin{array}{c}\text { Category/ } \\
\text { Type }\end{array}$ \\
\hline House & Disbursement For: 2012 & & \\
\hline Senate & X Primary & General & \\
\hline President & Other (specify) & $\nabla$ & \\
\hline
\end{tabular}

State:

\section{c. Office Depot Corporate}

Mailing Address 2500 Mill Center Parkway

\begin{tabular}{lcc}
\hline City & State & Zip Code \\
Buford & GA & 30518
\end{tabular}

Purpose of Disbursement

Office Supplies

Candidate Name

\begin{tabular}{|c|c|}
\hline \multirow[t]{3}{*}{ Office Sought: } & House \\
\hline & Senate \\
\hline & President \\
\hline ate: & rict: \\
\hline
\end{tabular}

Disbursement For: 2012
X Primary
Other (specify)

Date of Disbursement

\begin{tabular}{|c|c|c|c|c|}
\hline $09^{M}$ & & $29{ }^{D}$ & & 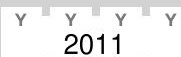 \\
\hline
\end{tabular}

Transaction ID : B5B300DB9BF85448BBA2

Amount of Each Disbursement this Period

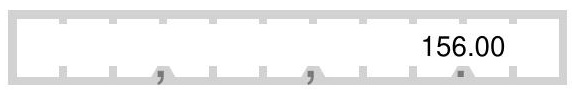

Date of Disbursement

\begin{tabular}{|c|c|c|c|c|}
\hline $09^{\mathrm{M}}$ & & $\begin{array}{l}\text { D } \quad \text { D } \\
29\end{array}$ & 1 & 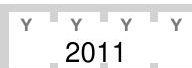 \\
\hline
\end{tabular}

Transaction ID : B4979D78E9CF8469591E

Amount of Each Disbursement this Period

56.70

Subtotal Of Receipts This Page (optional).

Total This Period (last page this line number only))

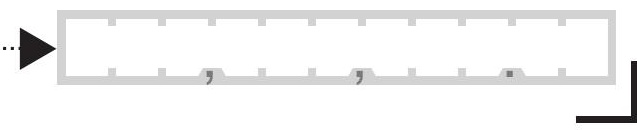




\section{SCHEDULE B-P}

\section{ITEMIZED DISBURSEMENTS}

Use separate schedule(s)

for each category of the

Detailed Summary Page
FOR LINE NUMBER: (check only one)

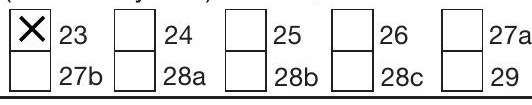

Any information copied from such Reports and Statements may not be sold or used by any person for the purpose of soliciting contributions or for commercial purposes, other than using the name and address of any political committee to solicit contributions from such committee.

NAME OF COMMITTEE (In Full)

\section{Friends of Herman Cain}

Full Name (Last, First, Middle Initial)

A. Delta Airlines

Mailing Address Post Office Box 20980

Department 980

\begin{tabular}{lcc}
\hline City & State & Zip Code \\
Atlanta & GA & $30320-2980$ \\
\hline
\end{tabular}

Purpose of Disbursement

Travel Expense

Candidate Name

Office Sought:

Full Name (Last, First, Middle Initial)

B. United Airlines

\begin{tabular}{ll}
\hline Mailing Address & 1200 E Algonquin Road \\
& Post Office Box 66100 \\
\hline City &
\end{tabular}

Elk Grove Township

Purpose of Disbursement

Travel Expense

Candidate Name

Office Sought:

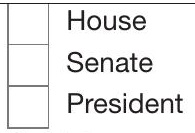

State:

District:

Disbursement For: 2012

Xrimary $\square$ General

$\begin{array}{cc}\text { State } & \text { Zip Cod } \\ \text { IL } & 60007\end{array}$

Date of Disbursement

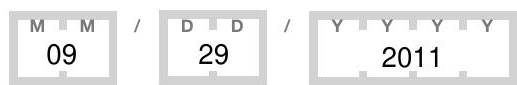

Transaction ID : BFC49A228AA714AB2BFC

Amount of Each Disbursement this Period 898.40
Date of Disbursement

\begin{tabular}{|c|c|c|c|c|}
\hline $09^{M}$ & 1 & $29^{\mathrm{D}}$ & 1 & 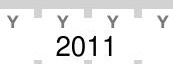 \\
\hline
\end{tabular}

Transaction ID : B3EEDA81652EA477D991

Amount of Each Disbursement this Period 565.40

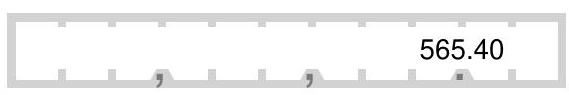

\section{Full Name (Last, First, Middle Initial)}

\section{c. 15th Street Pizza \& Pub}

Mailing Address 2130 Jodeco Road

\begin{tabular}{lcc}
\hline City & State & Zip Code \\
McDonough & GA & 30253
\end{tabular}

Purpose of Disbursement

Meeting Expense

Candidate Name

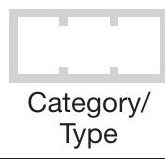

Date of Disbursement

\begin{tabular}{|c|c|c|c|c|c|c|}
\hline$M^{M}$ & $/$ & D & P & Y & Y & Y \\
09 & & 30 & & 2011 & \\
\hline
\end{tabular}

Transaction ID : B1890F599F6A84D459C8

Amount of Each Disbursement this Period

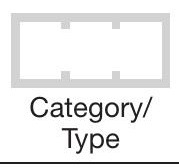

\begin{tabular}{|c|c|}
\hline Office Sought: & House \\
\hline & Senate \\
\hline & President \\
\hline ate & trict: \\
\hline
\end{tabular}

Disbursement For: 2012
\[ \begin{array}{l}\text { Primary } \\ \text { Other (specify) }\end{array} \]

Subtotal Of Receipts This Page (optional).

Total This Period (last page this line number only))

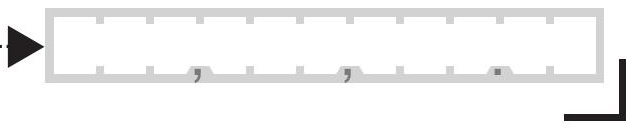




\section{SCHEDULE B-P}

\section{ITEMIZED DISBURSEMENTS}

\section{Use separate schedule(s)}

for each category of the

Detailed Summary Page
FOR LINE NUMBER: (check only one)

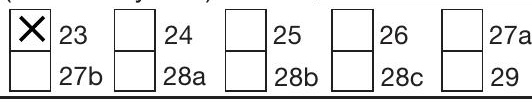

Any information copied from such Reports and Statements may not be sold or used by any person for the purpose of soliciting contributions or for commercial purposes, other than using the name and address of any political committee to solicit contributions from such committee.

NAME OF COMMITTEE (In Full)

\section{Friends of Herman Cain}

Full Name (Last, First, Middle Initial)

A. SunTrust Bank

Mailing Address 980 Eagles Landing Parkway

Date of Disbursement

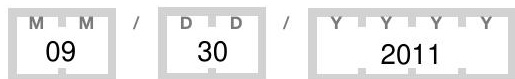

Transaction ID : B6134D5231270445DA4B

$\begin{array}{lcc}\text { City } & \text { State } & \text { Zip Code } \\ \text { Stockbridge } & \text { GA } & 30281\end{array}$

Purpose of Disbursement

Bank Fees

Candidate Name

Office Sought:

$$
\begin{array}{|l}
\text { House } \\
\text { Senate } \\
\text { President }
\end{array}
$$

State: District:

Full Name (Last, First, Middle Initial)

\begin{tabular}{|c|c|c|c|c|}
\hline \multicolumn{5}{|c|}{$\begin{array}{cl}\text { Mailing Address } & 4445 \text { Willard Ave. } \\
& \text { Ste. } 800\end{array}$} \\
\hline \multicolumn{2}{|c|}{ City } & \multicolumn{3}{|c|}{ Zip Code } \\
\hline \multicolumn{2}{|l|}{ Chevy Chase } & \multicolumn{3}{|c|}{20815} \\
\hline \multicolumn{4}{|c|}{$\begin{array}{l}\text { Purpose of Disbursement } \\
\text { Travel Expense }\end{array}$} & \\
\hline \multicolumn{4}{|l|}{ Candidate Name } & $\begin{array}{l}\text { Category/ } \\
\text { Type }\end{array}$ \\
\hline \multirow[t]{3}{*}{ Office Sought: } & House & \multirow{3}{*}{\multicolumn{3}{|c|}{$\begin{array}{l}\text { Disbursement For: } 2012 \\
\qquad \text { Primary } \\
\text { Other (specify) }\end{array}$}} \\
\hline & Senate & & & \\
\hline & President & & & \\
\hline State: & rict: & & & \\
\hline
\end{tabular}

\section{B. Ritz Carlton Hotels}

Full Name (Last, First, Middle Initial)

\section{c. SunTrust Bank}

Mailing Address 980 Eagles Landing Parkway

\begin{tabular}{lcc}
\hline City & State & Zip Code \\
Stockbridge & GA & 30281
\end{tabular}

Purpose of Disbursement

Bank Fees

Candidate Name

Office Sought: $\quad$ House

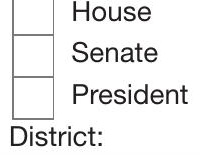

Disbursement For: 2012

X $\begin{aligned} & \text { Primary } \\ & \text { Other (specify) }\end{aligned}$

\section{Disbursement For: 2012 \\ Х Primary}

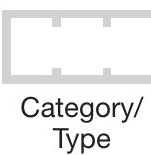

Amount of Each Disbursement this Period

51.45

\begin{tabular}{|c|c|c|c|c|}
\hline $09^{M}$ & 1 & ${ }^{\mathrm{D}}{ }^{\mathrm{D}}$ & 1 & 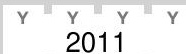 \\
\hline
\end{tabular}

Date of Disbursement

Transaction ID : BA5BF049E088A4BC4A2B

Amount of Each Disbursement this Period

285.23

\begin{tabular}{|c|c|c|c|c|}
\hline $09^{M}$ & I & $30^{D}$ & 1 & 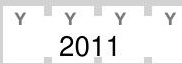 \\
\hline
\end{tabular}

Date of Disbursement

Transaction ID : B50CB552DAD7C469CAD8

Amount of Each Disbursement this Period

172.55
State:

Subtotal Of Receipts This Page (optional).

Total This Period (last page this line number only))

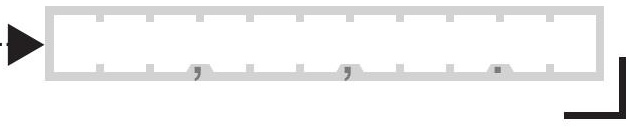




\section{SCHEDULE B-P}

\section{ITEMIZED DISBURSEMENTS}

Use separate schedule(s)

for each category of the

Detailed Summary Page
FOR LINE NUMBER: (check only one)

\begin{tabular}{|c|c|c|c|}
\hline$\times \quad 23$ & 24 & 25 & 26 \\
\hline $27 \mathrm{~b}$ & $28 \mathrm{a}$ & $28 b$ & $28 \mathrm{c}$ \\
\hline
\end{tabular}

Any information copied from such Reports and Statements may not be sold or used by any person for the purpose of soliciting contributions or for commercial purposes, other than using the name and address of any political committee to solicit contributions from such committee.

NAME OF COMMITTEE (In Full)

\section{Friends of Herman Cain}

Full Name (Last, First, Middle Initial)

A. NYC Taxi

Mailing Address 500 W Madison Street

Suite 1000

Date of Disbursement

\begin{tabular}{lcc}
\multicolumn{3}{c}{ Suite 1000} \\
City & State & Zip Code \\
Chicago & IL & 60661
\end{tabular}

Purpose of Disbursement

Travel Expense

Candidate Name

\begin{tabular}{l|l|l}
\hline Office Sought: & House & Disbursement For: 2012
\end{tabular} X Primary $\square$ General

State:

\section{Senate}

President

Full Name (Last, First, Middle Initial)

B. Delta Airlines

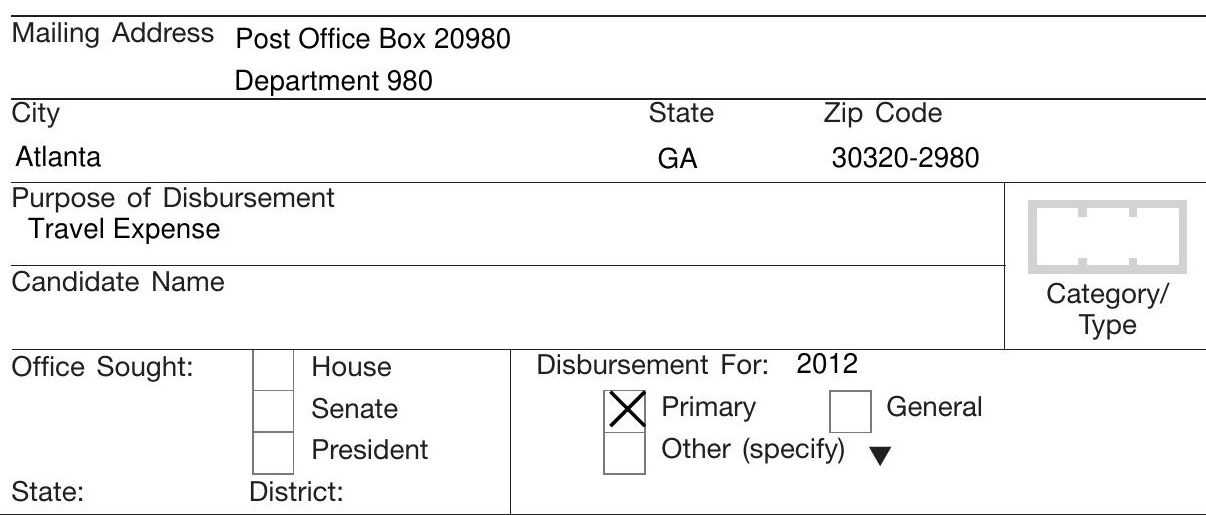

Date of Disbursement

\begin{tabular}{|c|c|c|c|c|}
\hline $09^{M}$ & 1 & ${ }^{\mathrm{D}}{ }^{\mathrm{D}}$ & 1 & 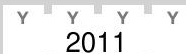 \\
\hline
\end{tabular}

Transaction ID : B6D267465876845A9A16

Full Name (Last, First, Middle Initial)

c. Continental Airlines

Mailing Address Post Office Box 4607

\begin{tabular}{lcc}
\hline City & State & Zip Code \\
Houston & TX & $77210-4607$
\end{tabular}

Purpose of Disbursement

Travel Expense

Candidate Name

Office Sought:

State:
Date of Disbursement

\begin{tabular}{|c|c|c|c|c|c|c|}
\hline$M^{M}$ & $/$ & D & Y & Y & Y & Y \\
09 & & 30 & & 2011 & \\
\hline
\end{tabular}

Transaction ID : B5D4B8EAF0DC047C782C

Amount of Each Disbursement this Period

893.40

Subtotal Of Receipts This Page (optional).

Total This Period (last page this line number only))

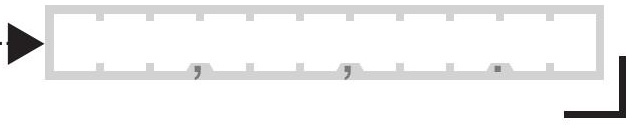




\section{SCHEDULE B-P}

\section{ITEMIZED DISBURSEMENTS}

\section{Use separate schedule(s)}

for each category of the

Detailed Summary Page
FOR LINE NUMBER: (check only one)

\begin{tabular}{|c|c|c|c|}
\hline$\times{ }_{23}$ & 24 & 25 & 26 \\
\hline $27 b$ & $28 a$ & $28 \mathrm{~b}$ & $28 \mathrm{c}$ \\
\hline
\end{tabular}

Any information copied from such Reports and Statements may not be sold or used by any person for the purpose of soliciting contributions or for commercial purposes, other than using the name and address of any political committee to solicit contributions from such committee.

NAME OF COMMITTEE (In Full)

\section{Friends of Herman Cain}

Full Name (Last, First, Middle Initial)

A. SunTrust Bank

Mailing Address 980 Eagles Landing Parkway

Date of Disbursement

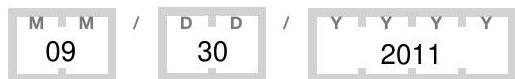

Transaction ID : BF0BE279104964FC1853

\begin{tabular}{lcc}
\hline City & State & Zip Code \\
Stockbridge & GA & 30281
\end{tabular}

Purpose of Disbursement

Bank Fees

Candidate Name Xrimary $\square$ General

State:

$$
\begin{aligned}
& \text { Senate } \\
& \text { President }
\end{aligned}
$$
District:

Full Name (Last, First, Middle Initial)

B. Facebook, Inc.

Mailing Address 1601 S. California Ave.

\begin{tabular}{lcc}
\hline City & State & Zip Code \\
Palo Alto & CA & 94304
\end{tabular}

Purpose of Disbursement Advertising Expense

Candidate Name

Office Sought:

\begin{tabular}{|l|l} 
House \\
Senate \\
\hline President
\end{tabular}

State:

District:

Full Name (Last, First, Middle Initial)

\begin{tabular}{|c|c|c|c|c|c|}
\hline \multicolumn{6}{|c|}{ Mailing Address 138 Park Avenue } \\
\hline \multicolumn{6}{|c|}{ Suite 300} \\
\hline \multicolumn{2}{|l|}{ City } & State & Zip Code & & \\
\hline \multicolumn{2}{|l|}{ Winder } & $\mathrm{GA}$ & 30680 & & \\
\hline \multicolumn{5}{|c|}{$\begin{array}{l}\text { Purpose of Disbursement } \\
\text { Event Supplies }\end{array}$} & \\
\hline \multicolumn{5}{|l|}{ Candidate Name } & $\begin{array}{l}\text { Category/ } \\
\text { Type }\end{array}$ \\
\hline \multirow[t]{3}{*}{ Office Sought: } & House & \multicolumn{4}{|c|}{ Disbursement For: 2012} \\
\hline & Senate & \multirow{3}{*}{\multicolumn{2}{|c|}{$\begin{array}{l}\text { Primary } \\
\text { Other (specify) }\end{array}$}} & \multirow{2}{*}{\multicolumn{2}{|c|}{ General }} \\
\hline & President & & & & \\
\hline State: & District: & & & & \\
\hline
\end{tabular}

c. Inkhead Inc.

Subtotal Of Receipts This Page (optional).

Date of Disbursement

\begin{tabular}{|c|c|c|c|c|c|}
\hline M & M & D & Y & Y & Y \\
09 & & 30 & & 2011 & \\
\hline
\end{tabular}

Transaction ID : BA7DEE10F3E884607B1F

Amount of Each Disbursement this Period

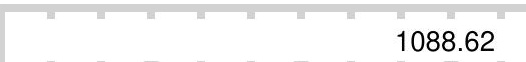

1088.62

Total This Period (last page this line number only))

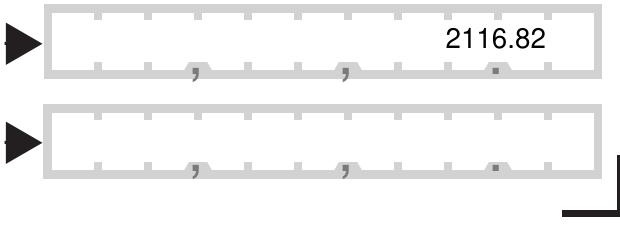




\section{SCHEDULE B-P}

\section{ITEMIZED DISBURSEMENTS}

\section{Use separate schedule(s) \\ for each category of the}

Detailed Summary Page
FOR LINE NUMBER: (check only one)

\begin{tabular}{|c|c|c|c|}
\hline$\times{ }_{23}$ & 24 & 25 & 26 \\
\hline $27 b$ & $28 a$ & $28 \mathrm{~b}$ & $28 \mathrm{c}$ \\
\hline
\end{tabular}

Any information copied from such Reports and Statements may not be sold or used by any person for the purpose of soliciting contributions or for commercial purposes, other than using the name and address of any political committee to solicit contributions from such committee.

NAME OF COMMITTEE (In Full)

\section{Friends of Herman Cain}

Full Name (Last, First, Middle Initial)

A. Jeffrey Osanka

Mailing Address 1742 Skyline Blvd.

Date of Disbursement

\begin{tabular}{lll}
\hline City & State & Zip Code \\
Eugene & OR & $97403-2146$
\end{tabular}

Purpose of Disbursement

Cabs/Meals/Event Catering

Candidate Name

Office Sought: $\quad$ House

Senate

President

State:

District:

Full Name (Last, First, Middle Initial)

B. Scott Sidney

Mailing Address N40 W6522 Jackson Street
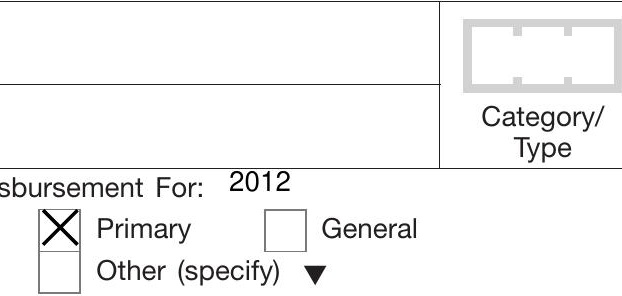

Amount of Each Disbursement this Period

\begin{tabular}{|c|c|}
\hline $09^{M}$ & 30 \\
\hline
\end{tabular}

Transaction ID : B9EDC8A4849504E849AD

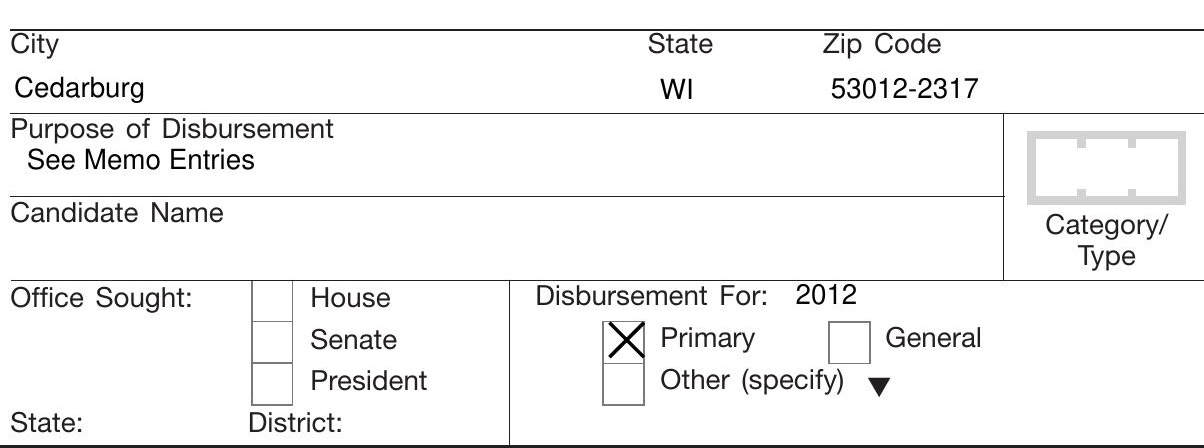

Date of Disbursement

\begin{tabular}{|c|c|c|c|c|}
\hline $07^{\mathrm{M}}$ & 1 & 27 & 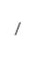 & $\begin{array}{llll}Y & Y & Y & Y \\
& 2011\end{array}$ \\
\hline
\end{tabular}

Transaction ID : B22E0042F105B4C9CB7F

Full Name (Last, First, Middle Initial)

c. Mayfair Rent A Car Inc.

Mailing Address 1750 N. Mayfair Road

Date of Disbursement

\begin{tabular}{lcc} 
& & \\
City & State & Zip Code \\
Milwaukee & WI & 53226 \\
\hline
\end{tabular}

Purpose of Disbursement

Travel Expense

Candidate Name

\begin{tabular}{|c|c|c|c|c|}
\hline $07^{\mathrm{M}}$ & 1 & $\begin{array}{l}\mathrm{D} \\
27\end{array}$ & 1 & $\begin{array}{cccc}Y & Y & Y & Y \\
2011 & \end{array}$ \\
\hline
\end{tabular}

Transaction ID : BA31FA778463841B69E9

\begin{tabular}{c|c} 
Type & Ty \\
\hline
\end{tabular}

\begin{tabular}{l|l|l|}
\hline Office Sought: & $\begin{array}{l}\text { House } \\
\text { Senate } \\
\text { President }\end{array}$ & $\begin{array}{r}\text { Disbursement For: } 2012 \\
\text { State: }\end{array}$ \\
\cline { 2 - 3 } & District: & X Primary \\
Other (specify)
\end{tabular}

Subtotal Of Receipts This Page (optional).

Total This Period (last page this line number only)) 


\section{SCHEDULE B-P}

\section{ITEMIZED DISBURSEMENTS}

\section{Use separate schedule(s) \\ for each category of the}

Detailed Summary Page
FOR LINE NUMBER: (check only one)

\begin{tabular}{|c|c|c|c|}
\hline$X_{23}$ & 24 & 25 & 26 \\
\hline $27 \mathrm{~b}$ & $28 a$ & $28 b$ & $28 \mathrm{c}$ \\
\hline
\end{tabular}

Any information copied from such Reports and Statements may not be sold or used by any person for the purpose of soliciting contributions or for commercial purposes, other than using the name and address of any political committee to solicit contributions from such committee.

NAME OF COMMITTEE (In Full)

\section{Friends of Herman Cain}

Full Name (Last, First, Middle Initial)

A. Holiday Inn Hotels

Mailing Address 3 Ravinia Drive

Ste. 100

\begin{tabular}{lll}
\hline City & State & Zip Code \\
Atlanta & GA & 30346 \\
\hline
\end{tabular}

Purpose of Disbursement

Travel Expense

Candidate Name

Office Sought:

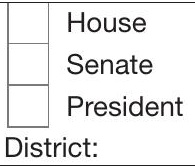

Disbursement For: 2012 X Primary $\square$ General

State: District:

Full Name (Last, First, Middle Initial)

B. Omni Hotels \& Resorts

\begin{tabular}{|c|c|c|c|c|}
\hline \multicolumn{5}{|c|}{ Mailing Address 100 CNN Center } \\
\hline \multicolumn{2}{|l|}{ City } & \multicolumn{3}{|c|}{ Zip Code } \\
\hline \multicolumn{2}{|l|}{ Atlanta } & \multicolumn{3}{|c|}{30303} \\
\hline \multicolumn{4}{|c|}{$\begin{array}{l}\text { Purpose of Disbursement } \\
\text { Meeting Expense }\end{array}$} & \\
\hline \multicolumn{4}{|l|}{ Candidate Name } & $\begin{array}{l}\text { Category/ } \\
\text { Type }\end{array}$ \\
\hline \multirow[t]{3}{*}{ Office Sought: } & House & \multirow{3}{*}{\multicolumn{3}{|c|}{$\begin{array}{l}\text { Disbursement For: } 2012 \\
\text { X Primary } \\
\text { Other (specify) }\end{array}$}} \\
\hline & \multirow{2}{*}{$\begin{array}{l}\text { Senate } \\
\text { President }\end{array}$} & & & \\
\hline & & & & \\
\hline State: & rict: & & & \\
\hline
\end{tabular}

Date of Disbursement

\begin{tabular}{|c|c|c|c|c|}
\hline $07^{\mathrm{M}}$ & & ${ }^{\mathrm{D}} 27^{\mathrm{D}}$ & 1 & $\begin{array}{llll}Y & Y & Y & Y \\
& 2011 & \end{array}$ \\
\hline
\end{tabular}

Transaction ID : BD994B8AB84C64C6C93D

Full Name (Last, First, Middle Initial)

c. Quiktrip

Mailing Address 4777 S. 129th East Ave.

Date of Disbursement

\begin{tabular}{lcc} 
& & \\
\hline City & State & Zip Code \\
Tulsa & OK & 74134 \\
\hline
\end{tabular}

Purpose of Disbursement

Travel Expense

Candidate Name

\begin{tabular}{|c|c|c|c|}
\hline \multirow[t]{3}{*}{ Office Sought: } & House & \multicolumn{2}{|l|}{ Disbursement For: 2012} \\
\hline & Senate & X Primary & Genera \\
\hline & President & Other (specify) & \\
\hline
\end{tabular}

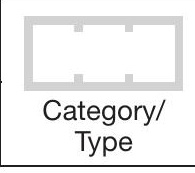

Subtotal Of Receipts This Page (optional).

Total This Period (last page this line number only))

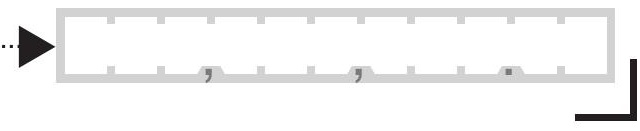




\section{SCHEDULE B-P}

\section{ITEMIZED DISBURSEMENTS}

\section{Use separate schedule(s)}

for each category of the

Detailed Summary Page
FOR LINE NUMBER: (check only one)

\begin{tabular}{|c|c|c|c|}
\hline$X_{23}$ & 24 & 25 & 26 \\
\hline $27 \mathrm{~b}$ & $28 a$ & $28 b$ & $28 \mathrm{c}$ \\
\hline
\end{tabular}

Any information copied from such Reports and Statements may not be sold or used by any person for the purpose of soliciting contributions or for commercial purposes, other than using the name and address of any political committee to solicit contributions from such committee.

NAME OF COMMITTEE (In Full)

\section{Friends of Herman Cain}

Full Name (Last, First, Middle Initial)

\section{A. Hertz Rent A Car}

Mailing Address 225 Brae Boulevard

Date of Disbursement

\begin{tabular}{|c|c|c|c|c|c|}
\hline M M / & D D \\
07 & 27 & 2011 \\
\hline
\end{tabular}

Transaction ID : BDF923DE0626C42FDA47

\begin{tabular}{lll}
\hline City & State & Zip Code \\
Park Ridge & NJ & 07656 \\
\hline Purpose of Disbursement & &
\end{tabular}

Purpose of Disbursement

Travel Expense

Candidate Name

Office Sought:

$$
\begin{array}{|l|l} 
& \text { House } \\
\text { Senate } \\
\cline { 1 - 2 } & \text { President }
\end{array}
$$

State: District:

Full Name (Last, First, Middle Initial)

\section{B. Scott F. Bieniek}

Mailing Address 1782 Schooling Road

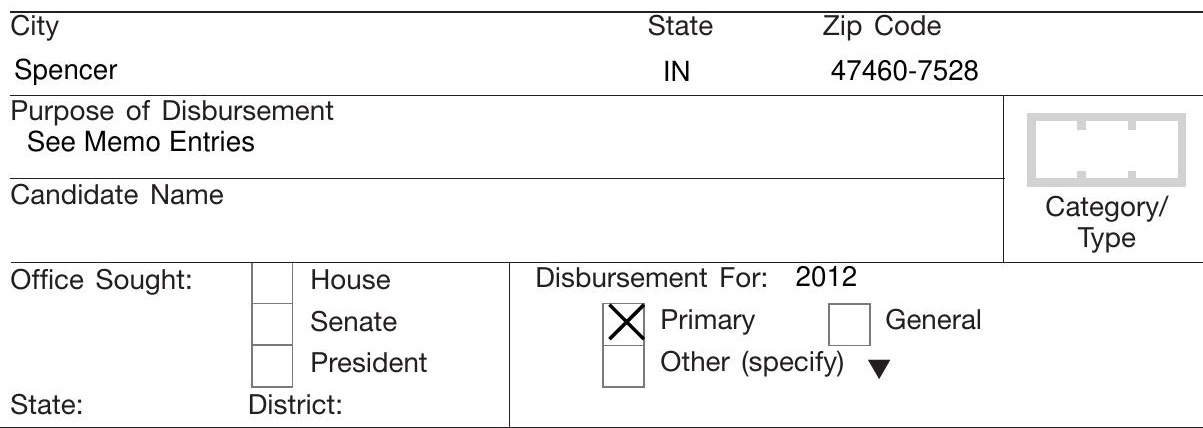

Full Name (Last, First, Middle Initial)

c. AT\&T

Mailing Address 208 S Akard Street

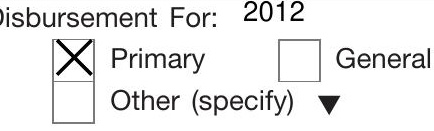

Amount of Each Disbursement this Period

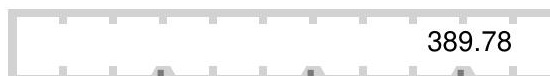

\begin{tabular}{|c|c|c|c|c|}
\hline $07^{\mathrm{M}}$ & & ${ }^{\mathrm{D}} 5^{\mathrm{D}}$ & I & $\begin{array}{llll}Y & Y & Y & Y \\
& 2011\end{array}$ \\
\hline
\end{tabular}

[MEMO ITEM]
Date of Disbursement

Transaction ID : B799D1E59F48F4160AFC

Amount of Each Disbursement this Period

\begin{tabular}{|c|c|c|c|c|}
\hline $07^{\mathrm{M}}$ & 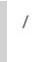 & D ${ }^{\mathrm{D}}$ & & $\begin{array}{cccc}Y & Y & Y & Y \\
2011 & \\
& & \\
2011\end{array}$ \\
\hline
\end{tabular}

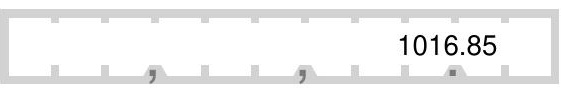

Date of Disbursement

\section{Transaction ID : B5083978A5E03484288C}

Amount of Each Disbursement this Period

\begin{tabular}{|c|}
\hline \multirow{2}{*}{$\begin{array}{l}\text { House } \\
\text { Senate }\end{array}$} \\
\hline \\
\hline President \\
\hline
\end{tabular}

\section{[MEMO ITEM]}

State:

Disbursement For: 2012
$\searrow$ Primary
Other (specify)

Subtotal Of Receipts This Page (optional).

Total This Period (last page this line number only))

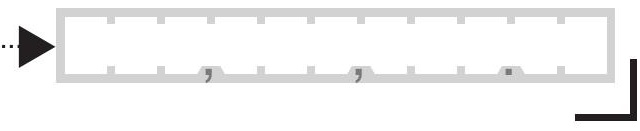




\section{SCHEDULE B-P}

\section{ITEMIZED DISBURSEMENTS}

Use separate schedule(s)

for each category of the

Detailed Summary Page
FOR LINE NUMBER: (check only one)

\begin{tabular}{|c|c|c|c|}
\hline$\times \quad 23$ & 24 & 25 & 26 \\
\hline $27 \mathrm{~b}$ & $28 \mathrm{a}$ & $28 b$ & $28 \mathrm{c}$ \\
\hline
\end{tabular}

Any information copied from such Reports and Statements may not be sold or used by any person for the purpose of soliciting contributions or for commercial purposes, other than using the name and address of any political committee to solicit contributions from such committee.

NAME OF COMMITTEE (In Full)

\section{Friends of Herman Cain}

Full Name (Last, First, Middle Initial)

A. Scott F. Bieniek

Mailing Address 1782 Schooling Road

Date of Disbursement

\begin{tabular}{lcc}
\hline City & State & Zip Code \\
Spencer & IN & $47460-7528$
\end{tabular}

Purpose of Disbursement

Mileage

Candidate Name

Office Sought:

\begin{tabular}{|l|l} 
& House \\
Senate \\
President
\end{tabular}

Disbursement For: 2012 X Primary $\square$ General

State: District:

Full Name (Last, First, Middle Initial)

\section{B. Delta Airlines}

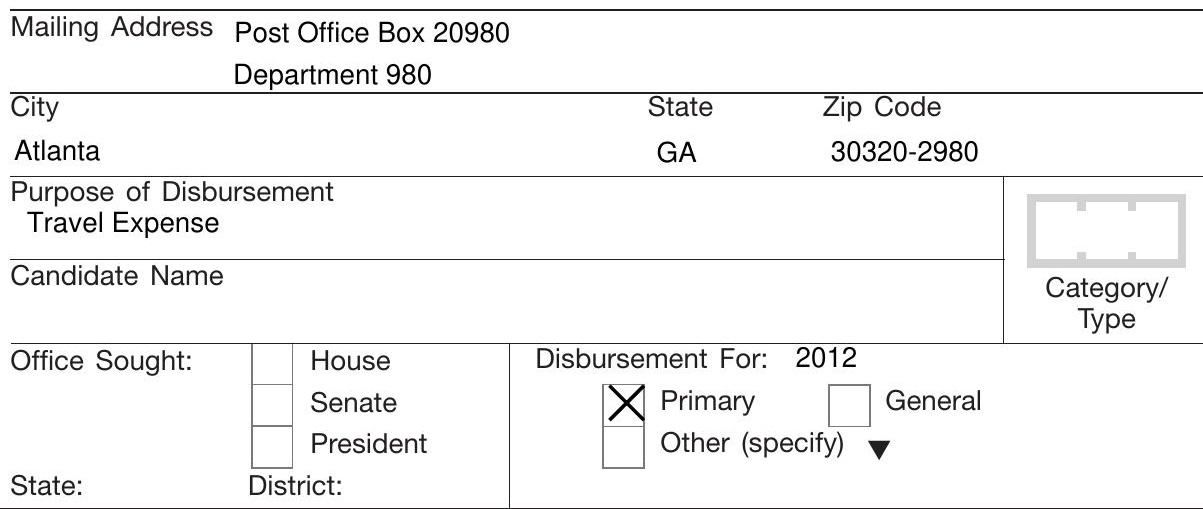

Date of Disbursement

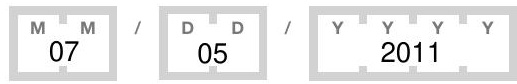

\section{Transaction ID : BC2EE12D8E7554699B95}

Amount of Each Disbursement this Period

Full Name (Last, First, Middle Initial)

C.

Mailing Address

Date of Disbursement

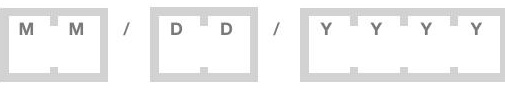

City $\quad$ State Zip Code

Purpose of Disbursement

Candidate Name

Office Sought: $\quad$ House

\begin{tabular}{|l|l|} 
& House \\
& Senate \\
& President \\
\hline District:
\end{tabular}

Disbursement For:

Primary $\square$ General
Other (specify) $\quad \nabla$

State:

Subtotal Of Receipts This Page (optional).

Total This Period (last page this line number only))

1955635.16 


\section{SCHEDULE B-P}

\section{ITEMIZED DISBURSEMENTS}

Use separate schedule(s)

for each category of the

Detailed Summary Page
FOR LINE NUMBER: (check only one)

Any information copied from such Reports and Statements may not be sold or used by any person for the purpose of soliciting contributions or for commercial purposes, other than using the name and address of any political committee to solicit contributions from such committee.

NAME OF COMMITTEE (In Full)

\section{Friends of Herman Cain}

Full Name (Last, First, Middle Initial)

A. Elizabeth Gundersen

Mailing Address $1610 \mathrm{~N}$ Cleveland Ave

Date of Disbursement

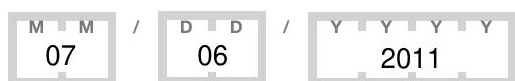

\begin{tabular}{lll}
\hline City & State & Zip Code \\
Fergus Falls & MN & $56537-1569$ \\
\hline
\end{tabular}

Purpose of Disbursement

Refund

Candidate Name

Office Sought: $\quad$ House

\begin{tabular}{l|c} 
House & Disbursement For: 2012 \\
Senate & Primary \\
President & $\square$ General \\
\hline
\end{tabular}

State:

District:

Full Name (Last, First, Middle Initial)

B. Kristie Hillhouse

Mailing Address 257 Fisk Road

\begin{tabular}{lcc}
\hline City & State & Zip Code \\
Benton Harbor & MI & $49022-6718$
\end{tabular}

Purpose of Disbursement

Refund

Candidate Name

Office Sought:

House
Senate
President

State:

District:

Full Name (Last, First, Middle Initial)

\section{c. Mr Patrick D Alexander}

Mailing Address 16540 Grays Bay Blvd

\begin{tabular}{lcc}
\hline City & State & Zip Code \\
Wayzata & MN & $55391-2915$
\end{tabular}

Purpose of Disbursement

Refund

Candidate Name

Office Sought:

State:
Date of Disbursement

\begin{tabular}{|c|c|c|c|c|}
\hline $09^{M}$ & & ${ }^{\mathrm{D}}{ }^{\mathrm{D}}$ & & 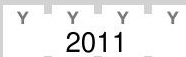 \\
\hline
\end{tabular}

Transaction ID : B23F2680A821B4A66A22

Amount of Each Disbursement this Period

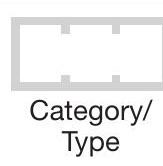

$$
\begin{aligned}
& \text { Disbursement For: } 2012 \\
& X \text { Primary } \\
& \text { Other (specify) }
\end{aligned}
$$

Date of Disbursement

\begin{tabular}{|c|c|c|c|c|c|c|}
\hline M & M & D & Y & Y & Y & Y \\
\hline & 30 & & 2011 & \\
\hline
\end{tabular}

Transaction ID : B51A42ECFB9954CE3808

Amount of Each Disbursement this Period

1000.00

Subtotal Of Receipts This Page (optional)

Total This Period (last page this line number only))

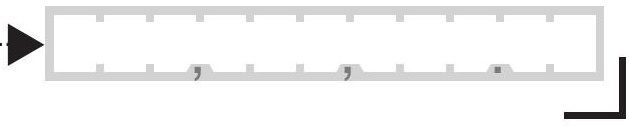




\section{SCHEDULE B-P}

\section{ITEMIZED DISBURSEMENTS}

Use separate schedule(s)

for each category of the

Detailed Summary Page
FOR LINE NUMBER: (check only one)

PAGE $1558 / 1572$

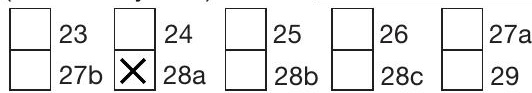

Any information copied from such Reports and Statements may not be sold or used by any person for the purpose of soliciting contributions or for commercial purposes, other than using the name and address of any political committee to solicit contributions from such committee.

NAME OF COMMITTEE (In Full)

\section{Friends of Herman Cain}

Full Name (Last, First, Middle Initial)

A. Chad Trotter

Mailing Address 182 Rebecca Street

Date of Disbursement

\begin{tabular}{lcc}
\hline City & State & Zip Code \\
Hoschton & GA & $30548-3148$
\end{tabular}

Purpose of Disbursement

Refund

Candidate Name

Office Sought: $\quad$ House

\begin{tabular}{l|c} 
House & Disbursement For: 2012 \\
Senate & Primary \\
President & $\square$ General \\
\hline
\end{tabular}

State:

District:

Full Name (Last, First, Middle Initial)

B. Robert Worms

Mailing Address 3131 Memorial Ct Unit 24114

City State Zip Code

Houston

TX

77007-6286

Purpose of Disbursement

Refund

Candidate Name

Office Sought:

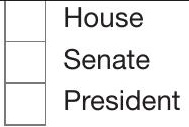

Disbursement For: 2012

Xrimary $\square$ General

State:

District:

Full Name (Last, First, Middle Initial)

c. andrews oakey

Mailing Address 4560 se 5th place \#208

\begin{tabular}{lcc}
\hline City & State & Zip Code \\
Cape Coral & FL & $33904-2516$
\end{tabular}

Purpose of Disbursement

Refund

Candidate Name

Office Sought: $\quad$ House

\begin{tabular}{|l|l|} 
& House \\
& Senate \\
& President \\
\hline District:
\end{tabular}

Disbursement For: 2012

X $\begin{aligned} & \text { Primary } \\ & \text { Other (specify) }\end{aligned}$

State:

District:

Subtotal Of Receipts This Page (optional)

7450.00

C.

Total This Period (last page this line number only))
Date of Disbursement

\begin{tabular}{|c|c|c|c|c|}
\hline $09^{\mathrm{M}}$ & 1 & $28^{\mathrm{D}}$ & 1 & 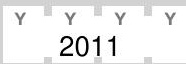 \\
\hline
\end{tabular}

Date of Disbursement

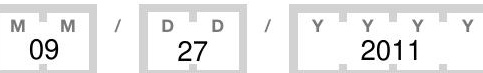

Transaction ID : B49DA1FFC886F4758AED

Amount of Each Disbursement this Period

2500.00

Transaction ID : B60A749A26CE24447A10

Amount of Each Disbursement this Period

2450.00 


\section{SCHEDULE B-P}

\section{ITEMIZED DISBURSEMENTS}

Use separate schedule(s)

for each category of the

Detailed Summary Page
FOR LINE NUMBER: (check only one)

PAGE 1559 / 1572

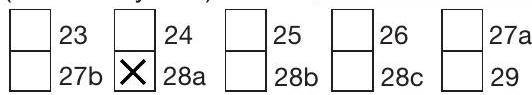

Any information copied from such Reports and Statements may not be sold or used by any person for the purpose of soliciting contributions or for commercial purposes, other than using the name and address of any political committee to solicit contributions from such committee.

NAME OF COMMITTEE (In Full)

\section{Friends of Herman Cain}

Full Name (Last, First, Middle Initial)

A. Raymond Anderson

Mailing Address 4840 Miller Rd

Date of Disbursement

\begin{tabular}{lcc}
\hline City & State & Zip Code \\
Atlanta & GA & $30349-2342$ \\
\hline
\end{tabular}

Purpose of Disbursement

Refund

Candidate Name

Office Sought: $\quad$ House

Senate

President

State:

District:

Full Name (Last, First, Middle Initial)

B. Jean Lucero

Mailing Address 205 Arrow Wood Dr

\begin{tabular}{lcc}
\hline City & State & Zip Code \\
Waleska & GA & 30183-2895
\end{tabular}

Purpose of Disbursement

Refund

Candidate Name

Disbursement For: 2012

X Primary $\square$ General

Office Sought:

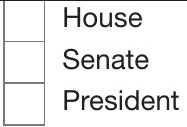

Disbursement For: 2012

Xrimary $\square$ General

State:

District:

Full Name (Last, First, Middle Initial)

C.

Mailing Address

City $\quad$ State Zip Code

Purpose of Disbursement

Candidate Name

Office Sought: $\quad$ House

\begin{tabular}{|l|l|}
\hline & House \\
& Senate \\
President & Prident \\
District:
\end{tabular}

Disbursement For:

Primary $\square$ General
Other (specify) $\boldsymbol{\nabla}$

State:

Subtotal Of Receipts This Page (optional).

Date of Disbursement
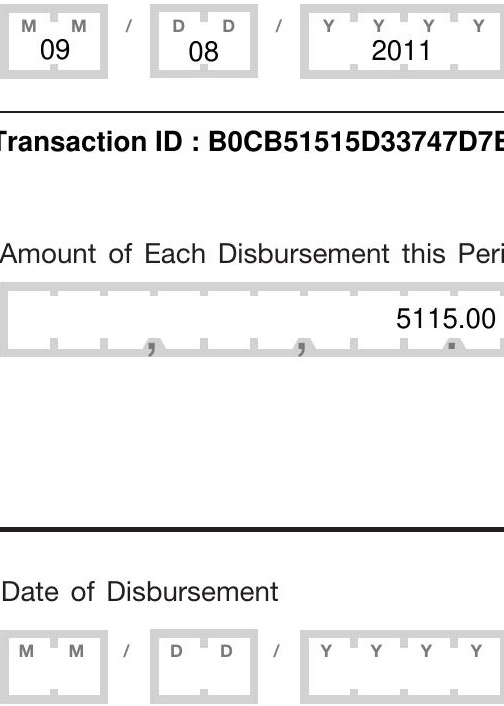

Transaction ID : B0CB51515D33747D7B37

Amount of Each Disbursement this Period

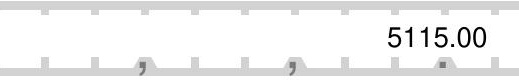

Amount of Each Disbursement this Period

Total This Period (last page this line number only)) 


\section{SCHEDULE C-P} LOANS
Use separate schedule(s) for each category of the Detailed Summary Page
PAGE $1560 / 1572$

FOR LINE NUMBER:
(check only one) $\quad \mathbf{X}_{19 a} \quad \square$ 19b

Transaction ID : C5177272DB8BD4D328B6

NAME OF COMMITTEE (In Full)

Friends of Herman Cain

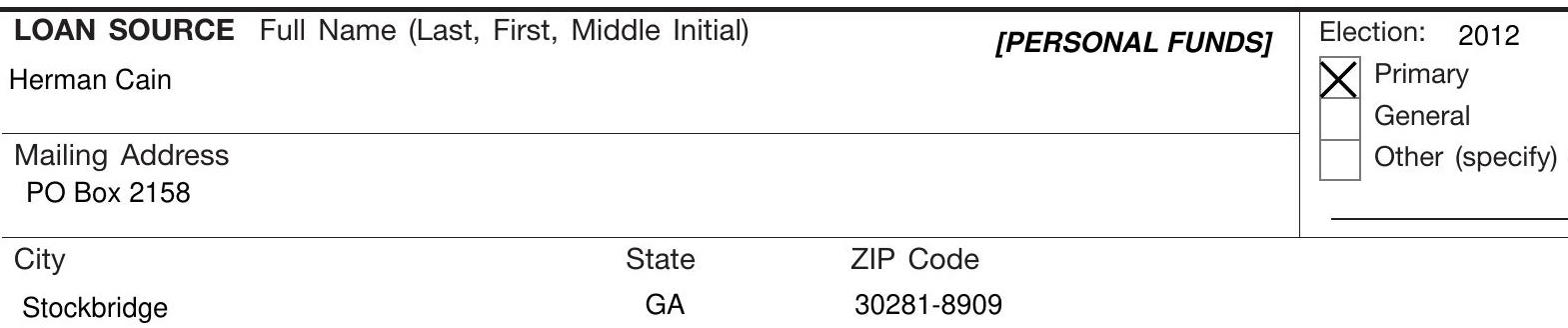

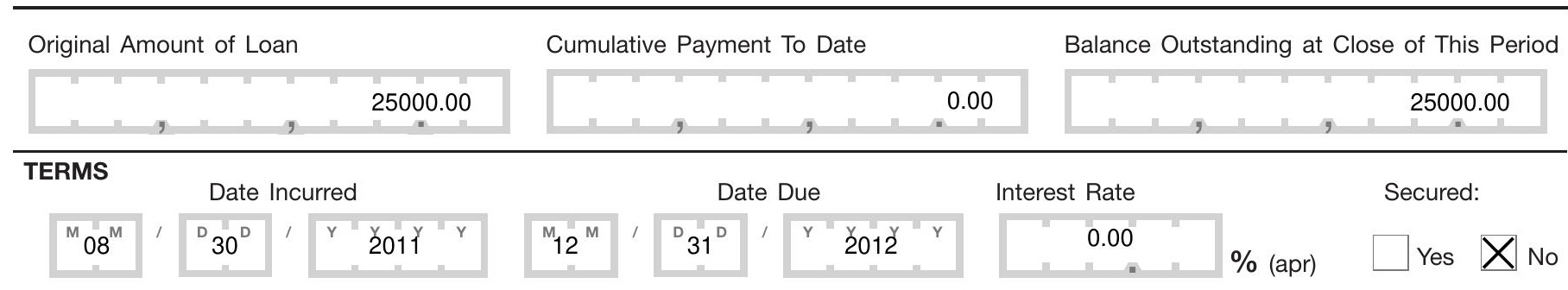

\section{List All Endorsers or Guarantors (if any) to Loan Source}

1. Full Name (Last, First, Middle Initial)

Name of Employer

Mailing Address

Occupation

City State ZIP Code

Amount

Guaranteed

Outstanding:

2. Full Name (Last, First, Middle Initial)

Name of Employer

Mailing Address

Occupation

City

State ZIP Code

Amount

Guaranteed

Outstanding:

3. Full Name (Last, First, Middle Initial)

Name of Employer

Mailing Address

Occupation

City State ZIP Code

Amount

Guaranteed

Outstanding:

4. Full Name (Last, First, Middle Initial)

Name of Employer

Mailing Address

Occupation

Amount

Guaranteed

Outstanding:

Subtotal Of Receipts This Page (optional).

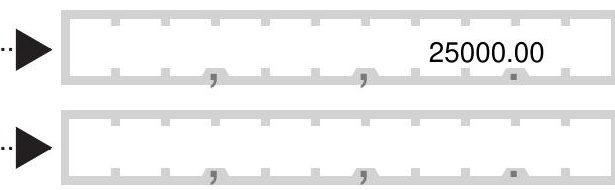

Total This Period (last page this line number only)

Carry outstanding balance only to LINE 3, Schedule D, for this line. If no Schedule D, carry forward to appropriate line of Summary.

FEC Schedule C-P (Form 3P) (Revised 03/2011) 


\section{SCHEDULE C-P} LOANS
Use separate schedule(s) for each category of the Detailed Summary Page
PAGE $1561 / 1572$

FOR LINE NUMBER:
(check only one) $\quad \mathbf{X}_{19 a} \quad \square$ 19b

Transaction ID : CAE297F88E529458E8D6

NAME OF COMMITTEE (In Full)

Friends of Herman Cain

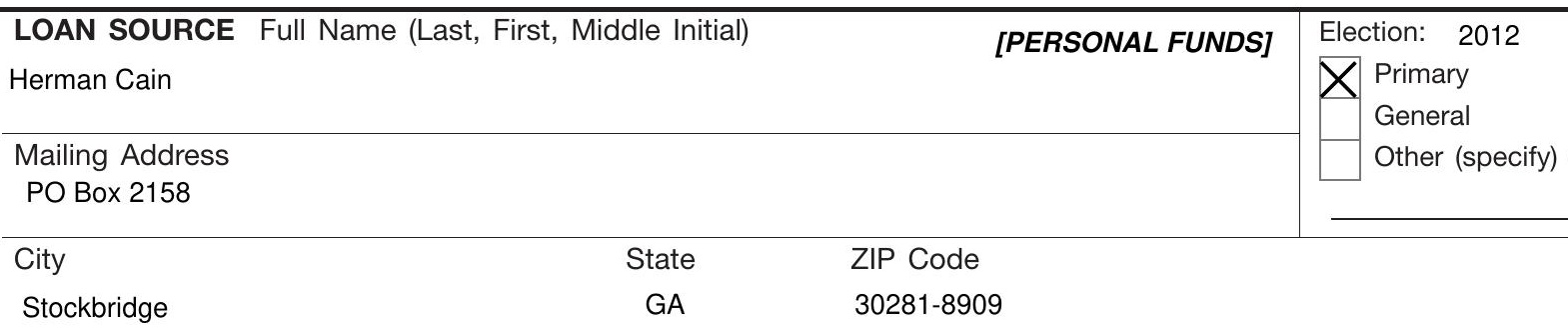

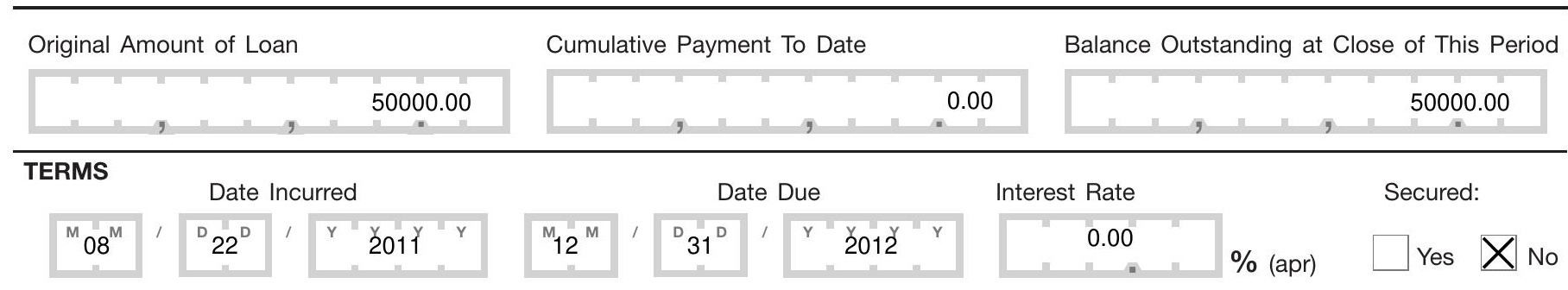

\section{List All Endorsers or Guarantors (if any) to Loan Source}

1. Full Name (Last, First, Middle Initial)

Name of Employer

Mailing Address

Occupation

City State ZIP Code

Amount

Guaranteed

Outstanding:

2. Full Name (Last, First, Middle Initial)

Name of Employer

Mailing Address

Occupation

City

State ZIP Code

Amount

Guaranteed

Outstanding:

3. Full Name (Last, First, Middle Initial)

Name of Employer

Mailing Address

Occupation

City State ZIP Code

4. Full Name (Last, First, Middle Initial)

Mailing Address

City State ZIP Code

Amount

Guaranteed

Outstanding:

\section{Amount}

Guaranteed

Outstanding:

Name of Employer

\section{Occupation}

(2)

Subtotal Of Receipts This Page (optional).

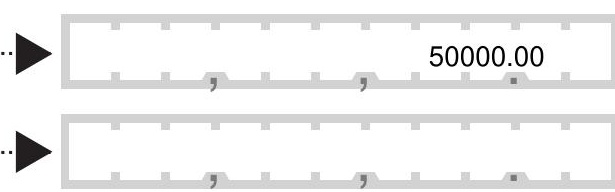

Total This Period (last page this line number only)

Carry outstanding balance only to LINE 3, Schedule D, for this line. If no Schedule D, carry forward to appropriate line of Summary.

FEC Schedule C-P (Form 3P) (Revised 03/2011) 


\section{SCHEDULE C-P} LOANS
Use separate schedule(s) for each category of the Detailed Summary Page
PAGE 1562 / 1572 $\begin{array}{r}\text { FOR LINE NUMBER: } \\ \text { (check only one) }\end{array} \quad \times{ }_{19 a} \quad \square$ 19b

NAME OF COMMITTEE (In Full)

Transaction ID : CB22B43F241EF4A89870

\section{Friends of Herman Cain}

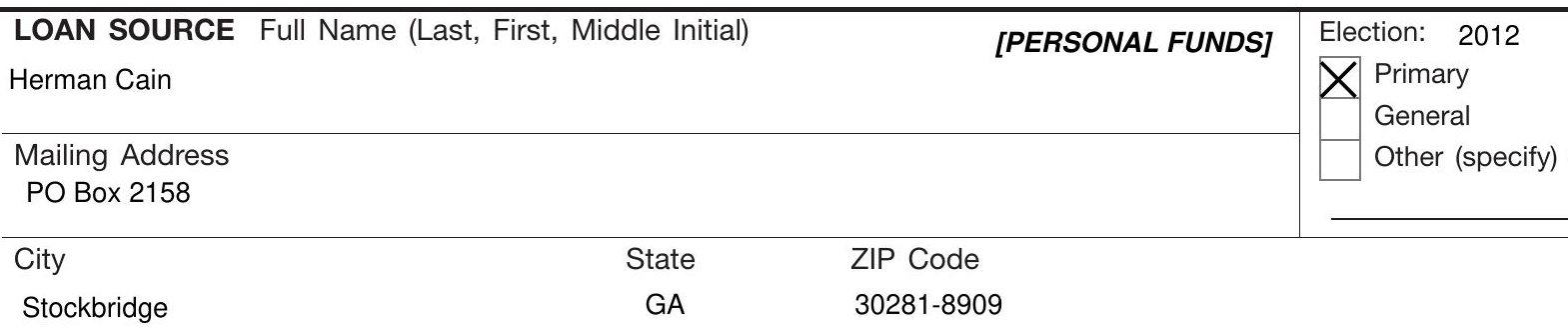

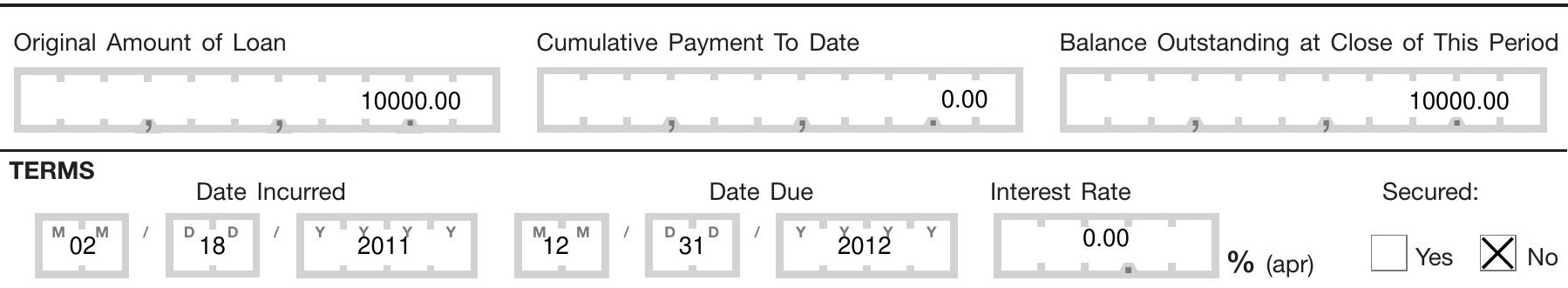

\section{List All Endorsers or Guarantors (if any) to Loan Source}

1. Full Name (Last, First, Middle Initial)

Name of Employer

Mailing Address

Occupation

City State ZIP Code

Amount

Guaranteed

Outstanding:

2. Full Name (Last, First, Middle Initial)

Name of Employer

Mailing Address

Occupation

City

State ZIP Code

Amount

Guaranteed

Outstanding:

3. Full Name (Last, First, Middle Initial)

Name of Employer

Mailing Address

Occupation

City State ZIP Code

Amount

Guaranteed

Outstanding:

4. Full Name (Last, First, Middle Initial)

Name of Employer

Mailing Address

Occupation

Amount

Guaranteed

Outstanding:

\begin{tabular}{ll|l} 
City State ZIP Code & Guaranteed \\
Outstanding:
\end{tabular}

Subtotal Of Receipts This Page (optional)

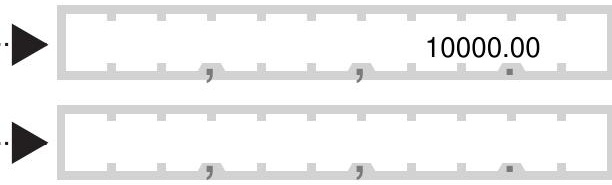

Total This Period (last page this line number only)

Carry outstanding balance only to LINE 3, Schedule D, for this line. If no Schedule D, carry forward to appropriate line of Summary

FEC Schedule C-P (Form 3P) (Revised 03/2011) 


\section{SCHEDULE C-P} LOANS
Use separate schedule(s) for each category of the Detailed Summary Page
PAGE $1563 / 1572$

FOR LINE NUMBER:
(check only one) $\quad \mathbf{X}_{19 a} \quad \square$ 19b

Transaction ID : CCF2CBF3BF963400590B

NAME OF COMMITTEE (In Full)

Friends of Herman Cain

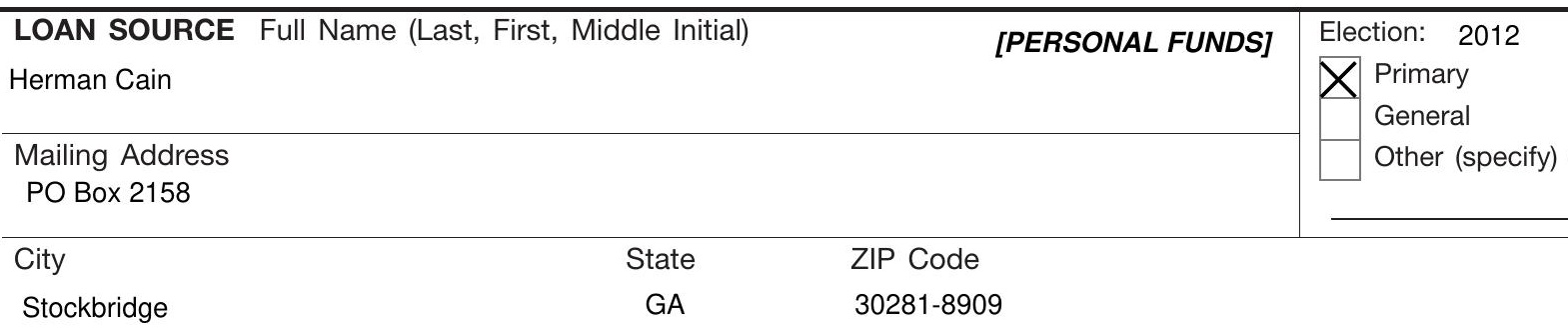

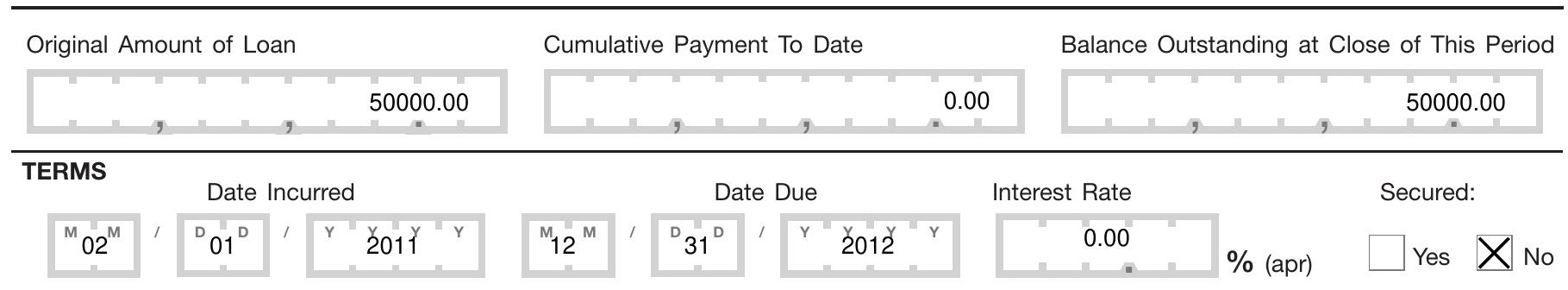

\section{List All Endorsers or Guarantors (if any) to Loan Source}

1. Full Name (Last, First, Middle Initial)

Name of Employer

Mailing Address

Occupation

City State ZIP Code

Amount

Guaranteed

Outstanding:

2. Full Name (Last, First, Middle Initial)

Name of Employer

Mailing Address

Occupation

City

State ZIP Code

Amount

Guaranteed

Outstanding:

3. Full Name (Last, First, Middle Initial)

Name of Employer

Mailing Address

Occupation

City State ZIP Code

Amount

Guaranteed

Outstanding:

4. Full Name (Last, First, Middle Initial)

Name of Employer

Mailing Address

Occupation

Amount

Guaranteed

Outstanding:

Subtotal Of Receipts This Page (optional).

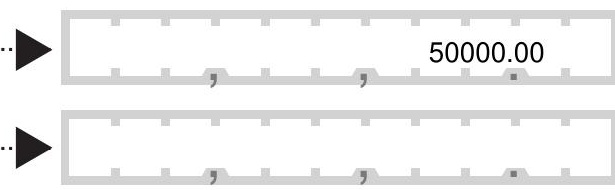

Total This Period (last page this line number only)

Carry outstanding balance only to LINE 3, Schedule D, for this line. If no Schedule D, carry forward to appropriate line of Summary.

FEC Schedule C-P (Form 3P) (Revised 03/2011) 


\section{SCHEDULE C-P} LOANS
Use separate schedule(s) for each category of the Detailed Summary Page
PAGE 1564 / 1572

FOR LINE NUMBER:
(check only one) $\mathbf{X}_{19 a} \quad \square$ 19b

Transaction ID : C4BC95735988842D0AA0

NAME OF COMMITTEE (In Full)

Friends of Herman Cain

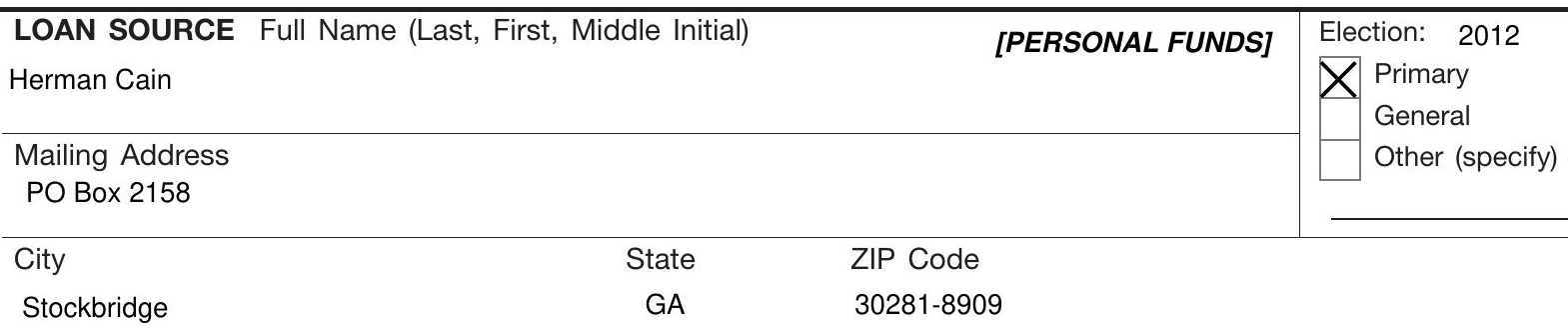

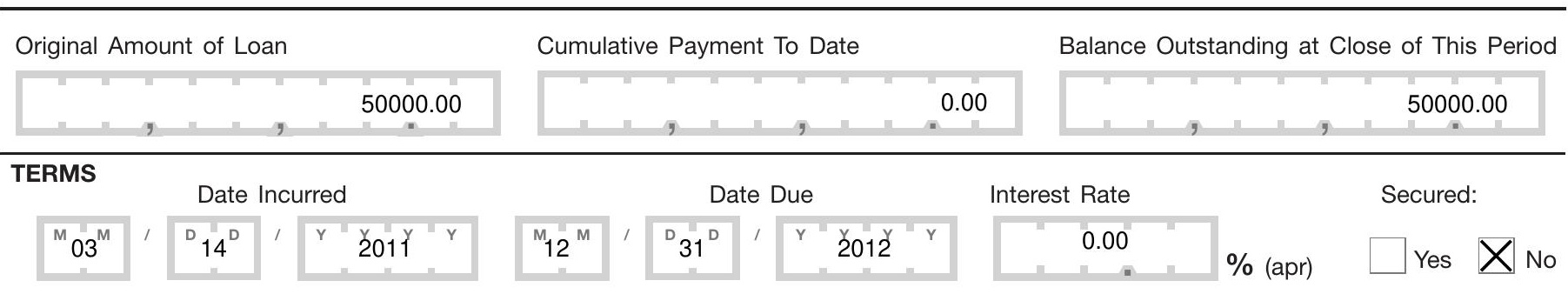

\section{List All Endorsers or Guarantors (if any) to Loan Source}

1. Full Name (Last, First, Middle Initial)

Name of Employer

Mailing Address

Occupation

City State ZIP Code

Amount

Guaranteed

Outstanding:

2. Full Name (Last, First, Middle Initial)

Name of Employer

Mailing Address

Occupation

City

State ZIP Code

Amount

Guaranteed

Outstanding:

3. Full Name (Last, First, Middle Initial)

Name of Employer

Mailing Address

Occupation

City State ZIP Code

Amount

Guaranteed

Outstanding:

4. Full Name (Last, First, Middle Initial)

Name of Employer

Mailing Address

Occupation

Amount

Guaranteed

Outstanding:

\begin{tabular}{ll|l} 
City State ZIP Code & Guaranteed \\
Outstanding:
\end{tabular}

Subtotal Of Receipts This Page (optional)

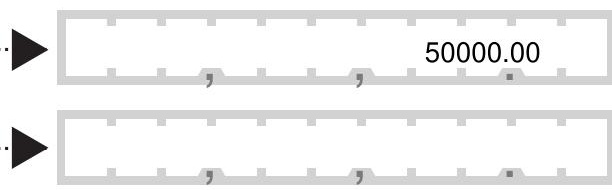

Total This Period (last page this line number only)

Carry outstanding balance only to LINE 3, Schedule D, for this line. If no Schedule D, carry forward to appropriate line of Summary.

FEC Schedule C-P (Form 3P) (Revised 03/2011) 


\section{SCHEDULE C-P} LOANS
Use separate schedule(s) for each category of the Detailed Summary Page
PAGE $1565 / 1572$

FOR LINE NUMBER:
(check only one) $\quad \mathbf{X}_{19 a} \quad \square$ 19

Transaction ID : CEB87A3CD25EA433EAD4

NAME OF COMMITTEE (In Full)

Friends of Herman Cain

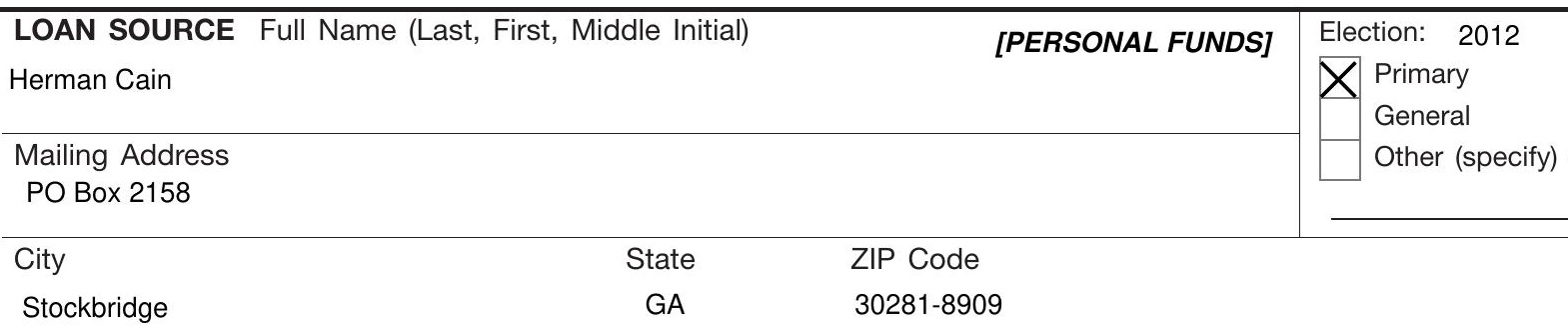

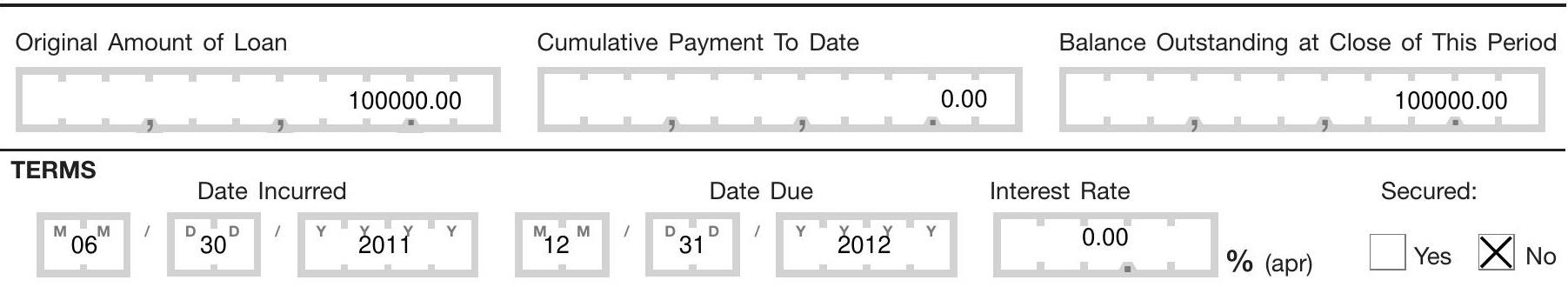

\section{List All Endorsers or Guarantors (if any) to Loan Source}

1. Full Name (Last, First, Middle Initial)

Name of Employer

Mailing Address

Occupation

City State ZIP Code

Amount

Guaranteed

Outstanding:

2. Full Name (Last, First, Middle Initial)

Name of Employer

Mailing Address

Occupation

City

State ZIP Code

Amount

Guaranteed

Outstanding:

3. Full Name (Last, First, Middle Initial)

Name of Employer

Mailing Address

Occupation

City State ZIP Code

Amount

Guaranteed

Outstanding:

4. Full Name (Last, First, Middle Initial)

Name of Employer

Mailing Address

Occupation

Amount

Guaranteed

Outstanding:

\begin{tabular}{ll|l} 
City State ZIP Code & Guaranteed \\
Outstanding:
\end{tabular}

Subtotal Of Receipts This Page (optional)

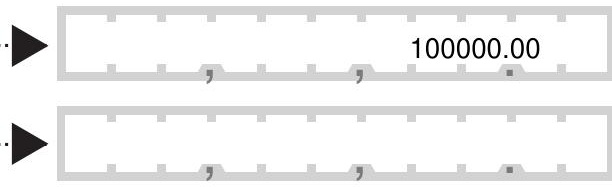

Total This Period (last page this line number only)

Carry outstanding balance only to LINE 3, Schedule D, for this line. If no Schedule D, carry forward to appropriate line of Summary.

FEC Schedule C-P (Form 3P) (Revised 03/2011) 


\section{SCHEDULE C-P} LOANS
Use separate schedule(s) for each category of the Detailed Summary Page
PAGE $1566 / 1572$

FOR LINE NUMBER:
(check only one) $\quad \mathbf{X}_{19 a} \quad \square$ 19b

Transaction ID : C557ACC2C96204B23B26

NAME OF COMMITTEE (In Full)

Friends of Herman Cain

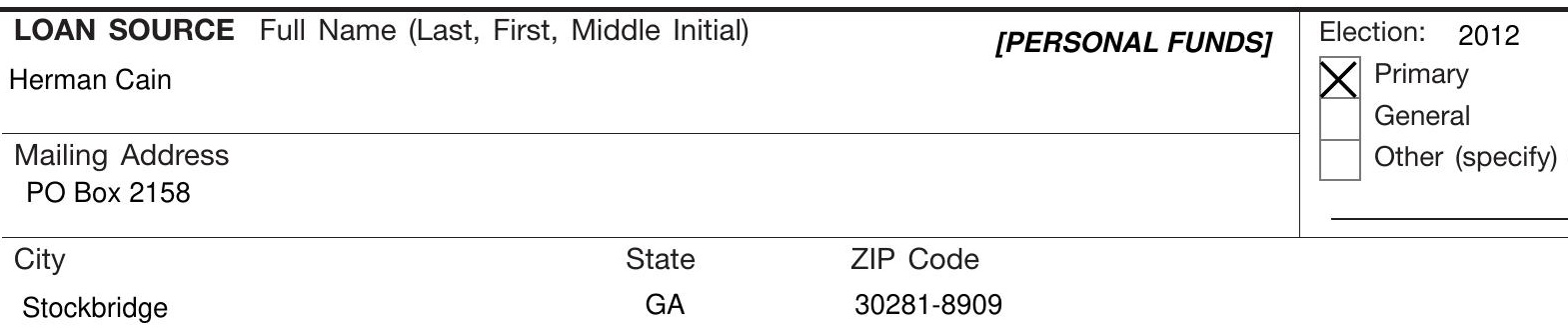

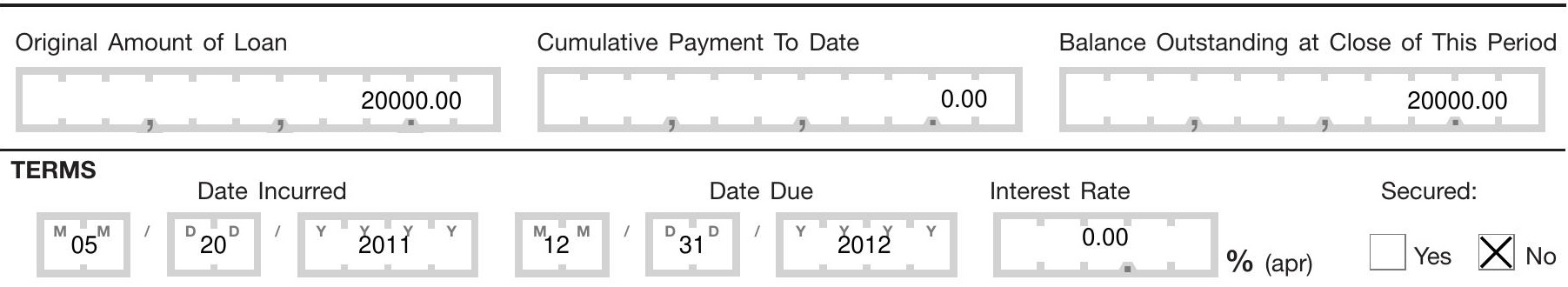

\section{List All Endorsers or Guarantors (if any) to Loan Source}

1. Full Name (Last, First, Middle Initial)

Name of Employer

Mailing Address

Occupation

City State ZIP Code

Amount

Guaranteed

Outstanding:

2. Full Name (Last, First, Middle Initial)

Name of Employer

Mailing Address

Occupation

City

State ZIP Code

Amount

Guaranteed

Outstanding:

3. Full Name (Last, First, Middle Initial)

Name of Employer

Mailing Address

Occupation

City State ZIP Code

Amount

Guaranteed

Outstanding:

4. Full Name (Last, First, Middle Initial)

Name of Employer

Mailing Address

Occupation

Amount

Guaranteed

Outstanding:

Subtotal Of Receipts This Page (optional).

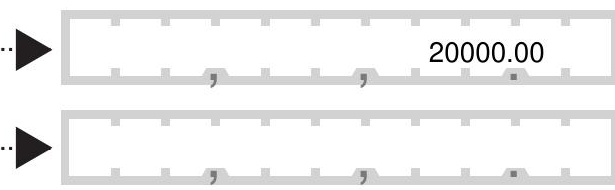

Total This Period (last page this line number only)

Carry outstanding balance only to LINE 3, Schedule D, for this line. If no Schedule D, carry forward to appropriate line of Summary

FEC Schedule C-P (Form 3P) (Revised 03/2011) 


\section{SCHEDULE C-P} LOANS
Use separate schedule(s) for each category of the Detailed Summary Page
PAGE 1567 / 1572

FOR LINE NUMBER:
(check only one) $\quad \mathbf{X}_{19 a} \quad \square$ 19b

Transaction ID : C4B872B03A1C04059B2F

NAME OF COMMITTEE (In Full)

Friends of Herman Cain

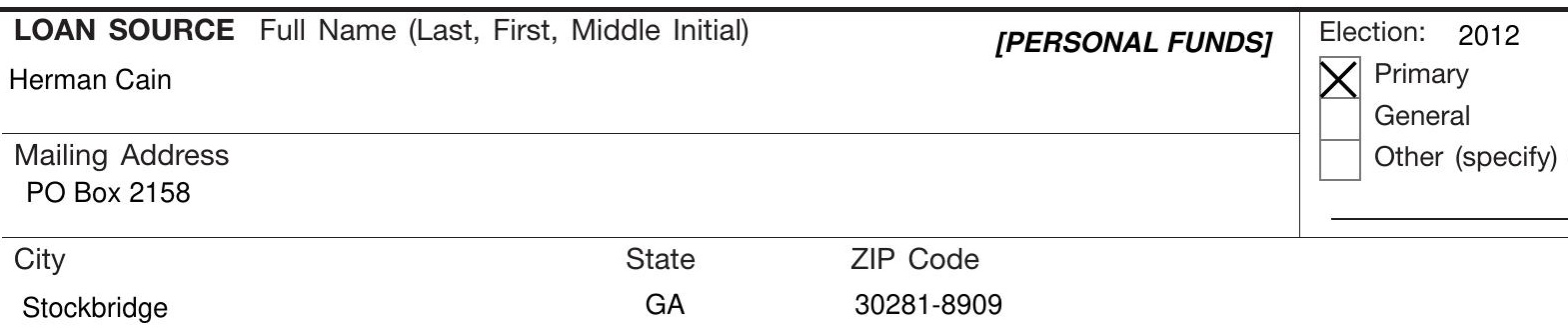

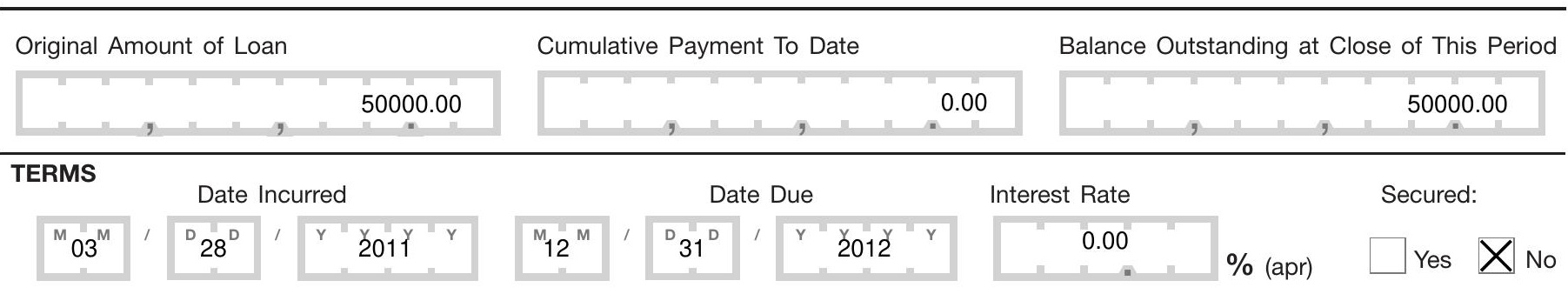

\section{List All Endorsers or Guarantors (if any) to Loan Source}

1. Full Name (Last, First, Middle Initial)

Name of Employer

Mailing Address

Occupation

City State ZIP Code

Amount

Guaranteed

Outstanding:

2. Full Name (Last, First, Middle Initial)

Name of Employer

Mailing Address

Occupation

City

State ZIP Code

Amount

Guaranteed

Outstanding:

3. Full Name (Last, First, Middle Initial)

Name of Employer

Mailing Address

Occupation

City State ZIP Code

Amount

Guaranteed

Outstanding:

4. Full Name (Last, First, Middle Initial)

Name of Employer

Mailing Address

Occupation

Amount

Guaranteed

Outstanding:

Subtotal Of Receipts This Page (optional)

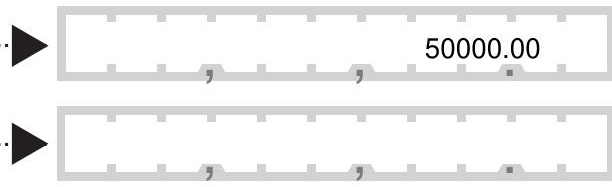

Total This Period (last page this line number only)

Carry outstanding balance only to LINE 3, Schedule D, for this line. If no Schedule D, carry forward to appropriate line of Summary.

FEC Schedule C-P (Form 3P) (Revised 03/2011) 


\section{SCHEDULE C-P} LOANS
Use separate schedule(s) for each category of the Detailed Summary Page
PAGE 1568 / 1572

FOR LINE NUMBER:
(check only one) $\quad \mathrm{X}_{19 a} \quad \square$ 19

Transaction ID : C469804CCED1A45C48F6

NAME OF COMMITTEE (In Full)

Friends of Herman Cain

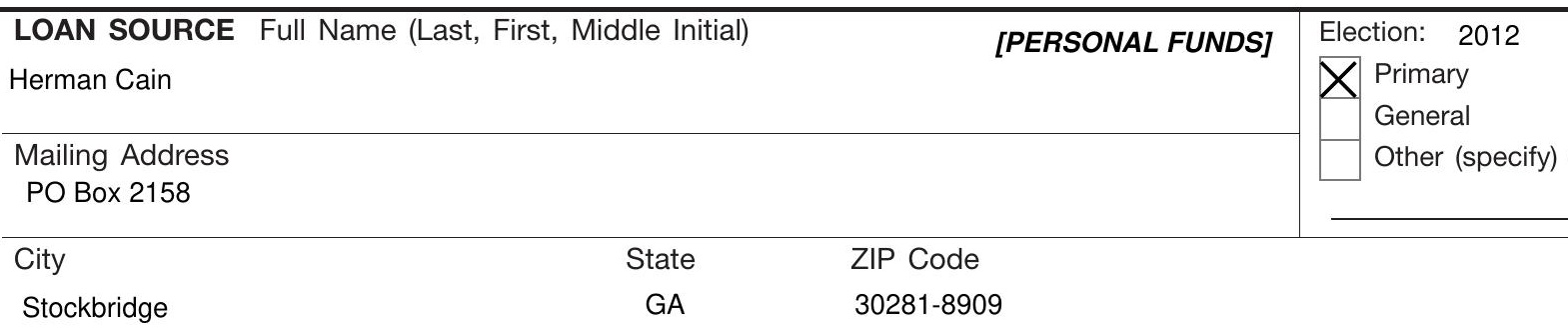

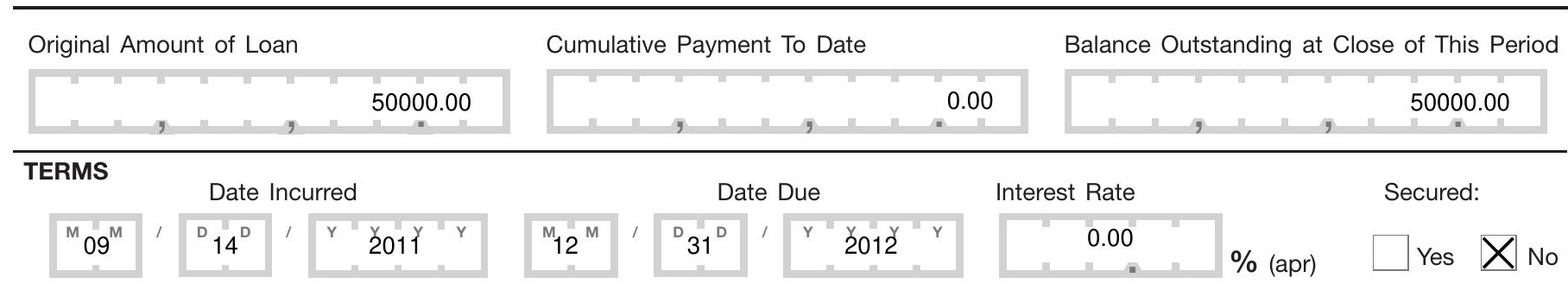

\section{List All Endorsers or Guarantors (if any) to Loan Source}

1. Full Name (Last, First, Middle Initial)

Name of Employer

Mailing Address

Occupation

City State ZIP Code

Amount

Guaranteed

Outstanding:

2. Full Name (Last, First, Middle Initial)

Name of Employer

Mailing Address

Occupation

City

State ZIP Code

Amount

Guaranteed

Outstanding:

3. Full Name (Last, First, Middle Initial)

Name of Employer

Mailing Address

Occupation

City State ZIP Code

Amount

Guaranteed

Outstanding:

4. Full Name (Last, First, Middle Initial)

Name of Employer

Mailing Address

Occupation

Amount

Guaranteed

Outstanding:

Subtotal Of Receipts This Page (optional).

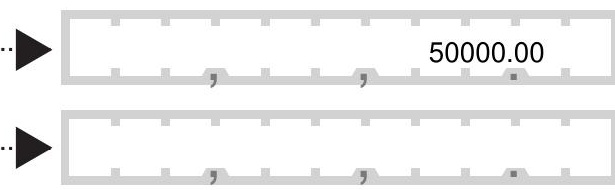

Total This Period (last page this line number only)

Carry outstanding balance only to LINE 3, Schedule D, for this line. If no Schedule D, carry forward to appropriate line of Summary.

FEC Schedule C-P (Form 3P) (Revised 03/2011) 


\section{SCHEDULE C-P} LOANS
Use separate schedule(s) for each category of the Detailed Summary Page
PAGE 1569 / 1572 $\begin{array}{r}\text { FOR LINE NUMBER: } \\ \text { (check only one) }\end{array} \quad \times$ 19a $\quad \square$ 19b

NAME OF COMMITTEE (In Full)

Transaction ID : C1002A1AB78E7419CB70

\section{Friends of Herman Cain}

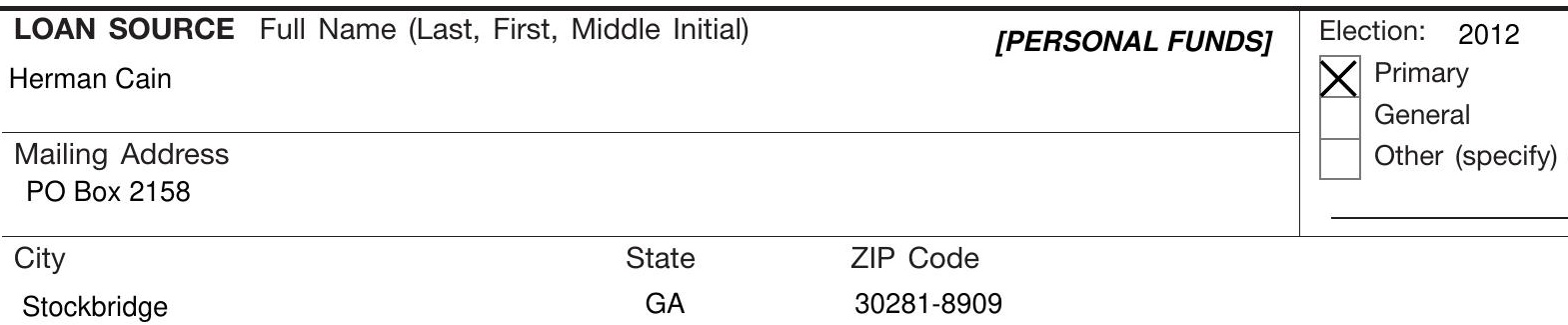

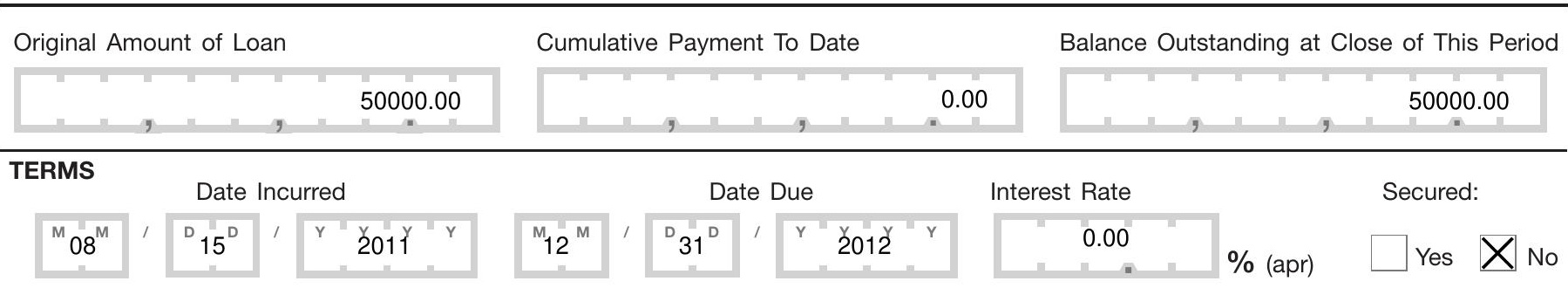

\section{List All Endorsers or Guarantors (if any) to Loan Source}

1. Full Name (Last, First, Middle Initial)

Name of Employer

Mailing Address

Occupation

City State ZIP Code

Amount

Guaranteed

Outstanding:

2. Full Name (Last, First, Middle Initial)

Name of Employer

Mailing Address

Occupation

City

State ZIP Code

Amount

Guaranteed

Outstanding:

3. Full Name (Last, First, Middle Initial)

Name of Employer

Mailing Address

Occupation

City State ZIP Code

Amount

Guaranteed

Outstanding:

4. Full Name (Last, First, Middle Initial)

Name of Employer

Mailing Address

Occupation

Amount

Guaranteed

Outstanding:

Subtotal Of Receipts This Page (optional)

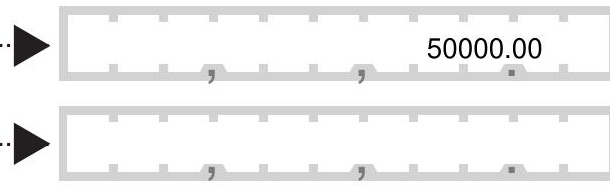

Total This Period (last page this line number only)

Carry outstanding balance only to LINE 3, Schedule D, for this line. If no Schedule D, carry forward to appropriate line of Summary.

FEC Schedule C-P (Form 3P) (Revised 03/2011) 


\section{SCHEDULE C-P} LOANS
Use separate schedule(s) for each category of the Detailed Summary Page
PAGE $1570 / 1572$

FOR LINE NUMBER:
(check only one) $\quad \mathbf{X}_{19 \mathrm{a}} \quad \square$ 19b

Transaction ID : C25A50473FF6F4374935

NAME OF COMMITTEE (In Full)

Friends of Herman Cain

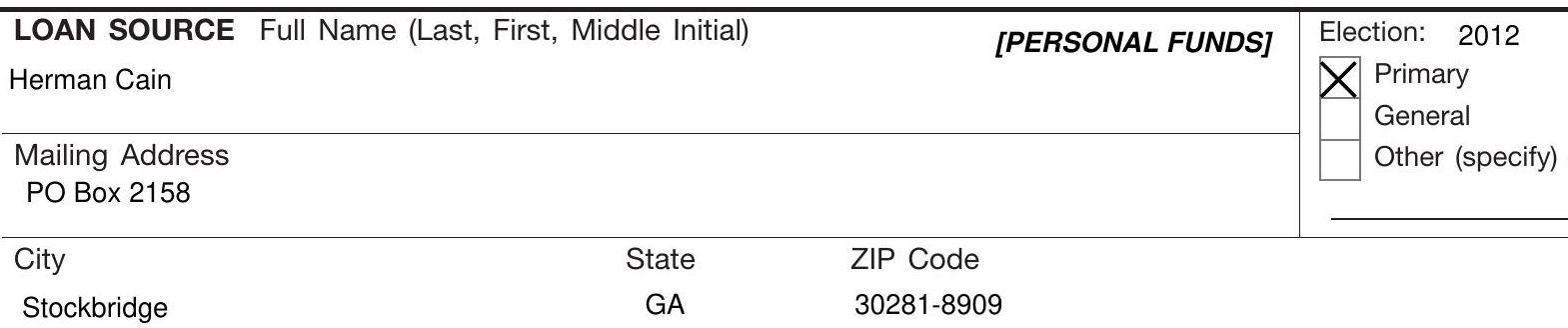

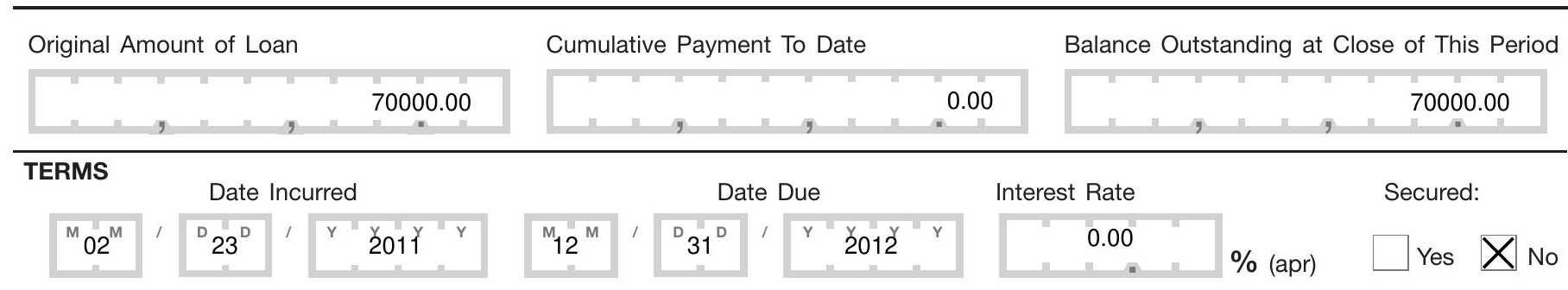

\section{List All Endorsers or Guarantors (if any) to Loan Source}

1. Full Name (Last, First, Middle Initial)

Name of Employer

Mailing Address

Occupation

City State ZIP Code

Amount

Guaranteed

Outstanding:

2. Full Name (Last, First, Middle Initial)

Name of Employer

Mailing Address

Occupation

City

State ZIP Code

Amount

Guaranteed

Outstanding:

3. Full Name (Last, First, Middle Initial)

Name of Employer

Mailing Address

Occupation

City State ZIP Code

4. Full Name (Last, First, Middle Initial)

Mailing Address

City State ZIP Code

Amount

Guaranteed

Outstanding:

\section{Amount}

Guaranteed

Outstanding:

Name of Employer

\section{Occupation}

(20)

Subtotal Of Receipts This Page (optional).

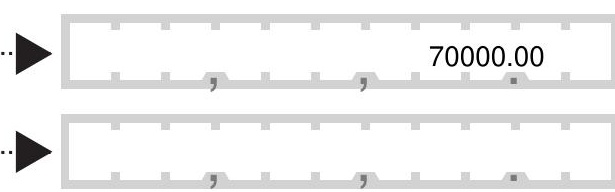

Total This Period (last page this line number only)

Carry outstanding balance only to LINE 3, Schedule D, for this line. If no Schedule D, carry forward to appropriate line of Summary.

FEC Schedule C-P (Form 3P) (Revised 03/2011) 


\section{SCHEDULE C-P} LOANS
Use separate schedule(s) for each category of the Detailed Summary Page
PAGE $1571 / 1572$

FOR LINE NUMBER:
(check only one) $\quad \mathbf{X}_{19 a} \quad \square$ 19b

Transaction ID : C72ABEE6041AB4612869

NAME OF COMMITTEE (In Full)

Friends of Herman Cain

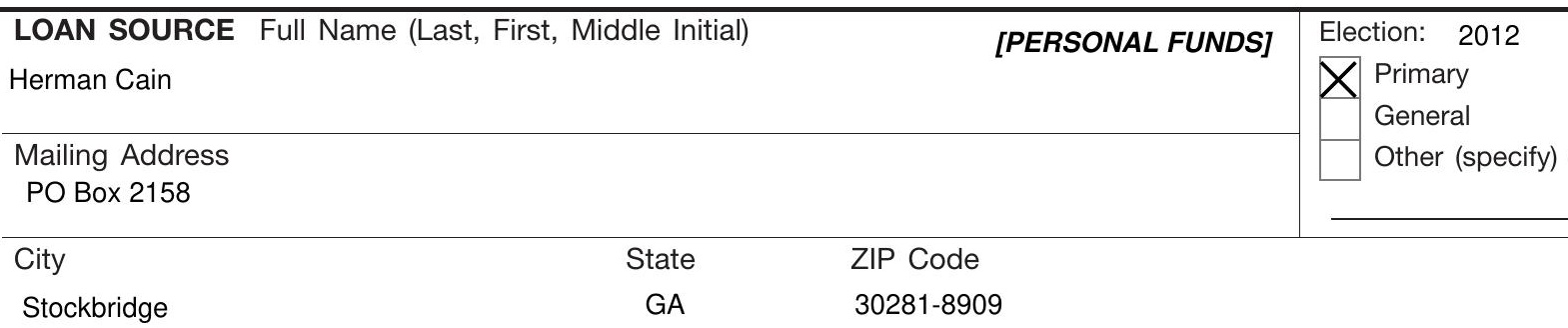

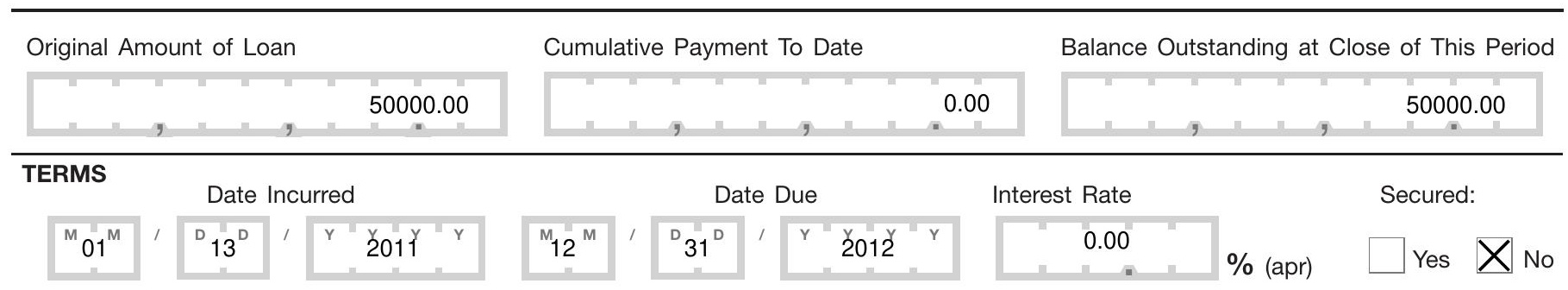

\section{List All Endorsers or Guarantors (if any) to Loan Source}

1. Full Name (Last, First, Middle Initial)

Name of Employer

Mailing Address

Occupation

City State ZIP Code

Amount

Guaranteed

Outstanding:

2. Full Name (Last, First, Middle Initial)

Name of Employer

Mailing Address

Occupation

City

State ZIP Code

Amount

Guaranteed

Outstanding:

3. Full Name (Last, First, Middle Initial)

Name of Employer

Mailing Address

Occupation

City State ZIP Code

Amount

Guaranteed

Outstanding:

4. Full Name (Last, First, Middle Initial)

Name of Employer

Mailing Address

Occupation

Amount

Guaranteed

Outstanding:

Subtotal Of Receipts This Page (optional).

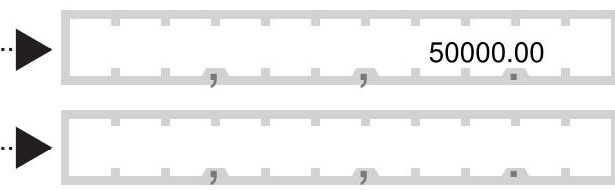

Total This Period (last page this line number only)

Carry outstanding balance only to LINE 3, Schedule D, for this line. If no Schedule D, carry forward to appropriate line of Summary.

FEC Schedule C-P (Form 3P) (Revised 03/2011) 


\section{SCHEDULE C-P} LOANS
Use separate schedule(s) for each category of the Detailed Summary Page
PAGE 1572 / 1572

FOR LINE NUMBER:
(check only one) $\quad \mathbf{X}_{19 a} \quad \square$ 19b

Transaction ID : C90F7A98623D346B6968

NAME OF COMMITTEE (In Full)

Friends of Herman Cain

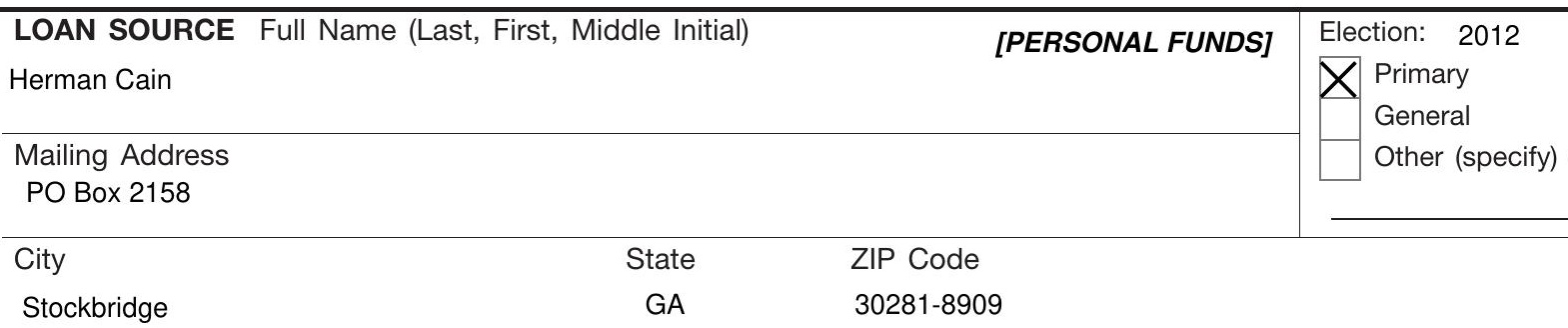

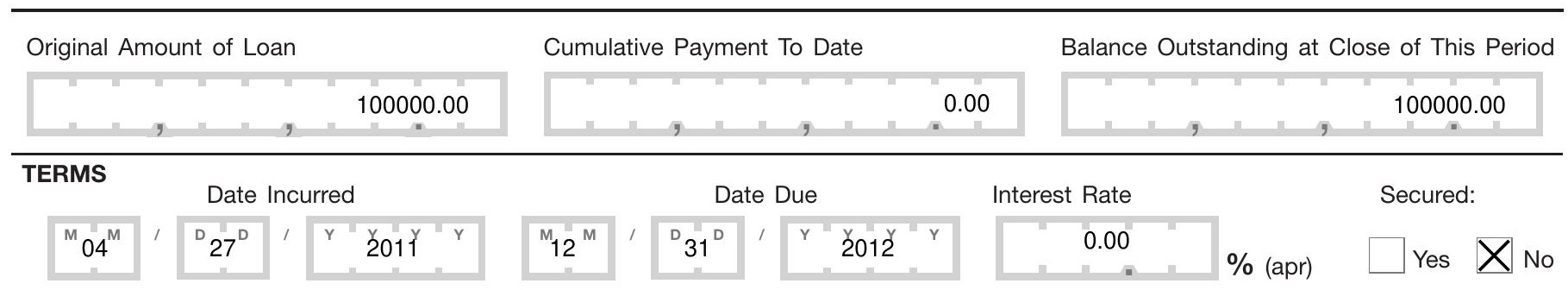

\section{List All Endorsers or Guarantors (if any) to Loan Source}

1. Full Name (Last, First, Middle Initial)

Name of Employer

Mailing Address

Occupation

City State ZIP Code

Amount

Guaranteed

Outstanding:

2. Full Name (Last, First, Middle Initial)

Name of Employer

Mailing Address

Occupation

City

State ZIP Code

Amount

Guaranteed

Outstanding:

3. Full Name (Last, First, Middle Initial)

Name of Employer

Mailing Address

Occupation

City State ZIP Code

Amount

Guaranteed

Outstanding:

4. Full Name (Last, First, Middle Initial)

Name of Employer

Mailing Address

Occupation

Amount

Guaranteed

Outstanding:

City State ZIP Code

Subtotal Of Receipts This Page (optional).

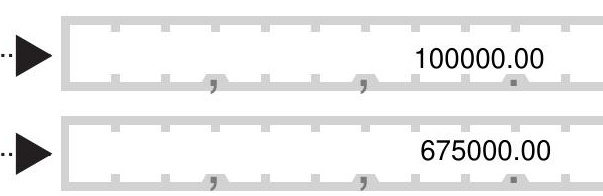

Total This Period (last page this line number only) 